

\section{MED ICAL COLLEGE KEY TABLE}

A List of Medical Colleges of the Unied States. Canada and Philippine Islands, Arranged Chronologically by States. Showing the Kiv Number by Which Each Is Designated. MEDICAL COLLEGES OF UNITED STATES
CANADA AND PHILIPPINE ISLANDS

Active colleges In black-pace type.

Colleges in llght-face tywo are extinct or merged with other colleges.

theported fraudulent or not in good standlug. For complete Informatlon, see Medical College section, pase 99.

For l'ost Graduate Colleges see juge 109. For Forelgn Itedicil Colleges, and licensin Bodles of (ireat Britaln and lrelamd, sete pages $110-111$

\section{ALABAMA}

Ala.1-Graffenburg Institute, Dadeville.

Ala.2-Univ, of Alabama School of Med., Moblle. Ala.3-Southern Univ. Med. Dept., Greensboro. Ala.4-Birmingham Medical College.

Ala.5-Med. Coll. Moutezuma Univ., Bessemer. ARKANSAS

Ark. I-Univ. of Ark.. Med. Dept., Little Rock. Ark.2-College of Pliys. and Surgs., Little Rock. Ark.3-Bethel Med. Dept., Southwestern Unlv. Little Itock.
Ark.4-Texas Healtli College, Hot Springs. Ark.5-Med. Dept. Sulphur Rock College.

\section{CALIFORNIA}

Cal. I-Cooper Nedleal College, San Franciseo. Cal. 2-University of California, M

Cal. 3-Callfornia Medical Soclety and College of I'hysleians, San Francisco.

Cal. 4-Cal. Eclectic Med. Coll., Los Angeles.

Cal. 5-Hahnemann Medical College of the Pacific. San Francisco.

Cal. 6-Unlv. of S. Cal., Coll. Med., Las Angeles. Cal. 7-Coll. of Phys. and Surgs., San Francis

Cal. 9-Coll. of Phys. and Surgs., Los Angeles.

Cal.10-Pacific Coast Regular Coll. of Medleine.t Cal.II-Leland Stanford Junior Univ., Dept. of Med., Palo Alto-San Francisco.

Cal.12-Coll. of Med. Evangelists, Loma Linda. COLORADO

Colo.1-Denver College of Medicine.

Colo.2-Univ. of Colo., School of Med., Boulder.

Colo.3-Cross Medical College, Denver.

Colo.4-Denver College of Phys. and Surgs.

Colo.5-Denver and Gross Coll. of Med., Denver. CONNECTICUT

Conn.1-Yale Univ. Med. Dept., New Haven. DISTRICT OF COLUMBIA

D.C.I-George WashIngton University, Depart ment of Medicine, Washington.
D.C.2-Georgetown University School of Medi-
cine, Washington. cine, Washington.
D.C.3-Howard University School of Medicine,
Washington.

D.C.4-Natlonal Un!v., Med. Dept., Washington. D.C.5-Washington Homeopathic Mied. Coll. FLORIDA

Fla.I-Univ. of Florlda, Med. Dept., Jacksonville. GEORGIA

Ga. I-Univ. of Georgia, Coll. of Med., Augusta Ga. 2-Southern Botanico-1led. Coll., Macol Ga. 3-Thompsonian College, Barbo

Ga. 5-Atlanta Medical College.

Ga. 6-Oglethorpe Med. Coll., Savannah. Ga. 9-Ga. Coll. Ecl. Med. and Surg., Atlanta. Ga.10-Southern Medical College, Atlanta. Ga.11-Atlanta Collego of Phys. and surgs. Ga.12-Atlanta School of Medicine.

Ga.13-Middle Georgia Med. Coll., Griffn. Ga.14-Dalton Medlcal College, Dalton. Ga.15-Clark Unlversity, Med. Dept., Atlanta. Ga.16-Woman's Med. Coll. of Georia, Atlanta. Ga.17-Internatlonal Med. Niss. Coll., Atlanta. Ga.18-Hospital Med. Coll. Eclectic, Atlanta. Ga.18-Hospital Med. Coll., Eclectic, Atlanta.
Ga.19-South. Coll. of Med. and Surg., Atlant ILLINOIS III. I-Rush Medical College, Chicago. III. S-Med. Dept., University of St. Charles. III. 4- Hahnem'n Med. Coll, and Hosp., Chicazo. III. 6-Northwestern Univ. Med. Sehool, Chicago. III. 7-Edinburg University, Chicago. $\dagger$ III. 8-Bennett Medical College, Chicago. III. 9-Northwest'n Lniv. Woman's Med. School. 111.10-Chicago Homeopathic Medical College. III.II-University of Illinois, Coll. of Medicin III. 2-Chaddock School of Medicine, Quincy. IIl.13-llarvey Atedical College, Chicago.
1II. 14-National Nedlcal Iniversity, Chicago.

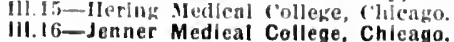
III.16-Jenner Medieal College, Chicago. III.Is-liunfiam Medieal College, Chlcamo.

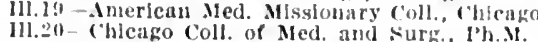
111.21- (blcago Coll. of Med. and surg, l'h. It III.22-Chicago Coll. of Med. and Surg., Chicago. III. 2i-lyearborn Medical College, Clileato. the Coper IIssissifpl, Rock Island.
the III.25-Northwestern Coll. of Mildwlf., Chlcago. 111.26-Chicago College of Scicnce.

111.27-National Univ. of Illinols, Chlcago.t

III.28-Cerman Coll. of Med. and Obs., Chleago III.29-Cierman Ilomeo. Med. Coll. Chlcago.

11..31-German Academy of l'liyslatric l'lays!clans, Chicago. $f$

I11.32-German-Americun IIomeopathle Medleal College, Chicago.t

111.33-German College of Gynecology, Pediatrles and Obstetries, Chicago.†

III.34-International Medical Misslonary Inst tute, Chlcago.

IIl.35-Illinols Health Unlversity, Chlcago.

111.36-Illinols Standard College of Medicine and Surgery, Chlcago.

III.37-Netropolltan Medical College, Chlcago.

III.38-Dutton Medical College, Chicago.

IIl.39-Rellance Medical College, Chlcago.

III.4 -Lombard College, Med. Dept., Galesburg. III.42-Chicago Hospital College of Medicine

\section{INDIANA}

Ind. 1-Indiana Medical College, Lis l'orte.

Ind. 2-Medical College of Evansville.

Ind. 3-Indlana Central Med. Coll., (ireencastle. Ind. 4-Indiana Medical College, Indianapolis. Ind. 5-1hyslo-Med. Coll. of Ind., Indianapolis. Ind. 6-Coll. of P. and S. of Ind., Indian

Ind. 8-Medical College of Indiana, Indianapolis. Ind. 9-Central Coll. of P. and S., Indianapolis. Ind.10-Fort Wayne College of Medicine.

Ind.11-Ind. Eclectle Med. Coll., Indianapolls. Ind.12-Curils Physio-Med. Institute, Marion. Ind.12-Curils Physio-Ned. Institute, Mar Ind.15-Beach Medical Inst Itute, Indianapolis Ind.15-Beach Medical Instltute, Indianapolis. Ind.1\%-Eclectlc Med. Coll. of Ind., Indianapolis Ind.18-Indlana Medical College, School of Med. of P'urdue Univ., Indianapolis.

Ind.19-American Med. Coll., Indianapolis.

Ind.20-Indiana University School of Medicine, Bloomington.Indian apolis.

Ind.21-State Coll. of $\mathrm{P}$. and $\mathrm{S}_{\text {., Indianapolls. }}$

Ind.23-University of Indiana, New Albany $t$ wifery, Indlanapolis. $f$

Ind.25-University of Indianapolls.t

Ind.26-Curtis Physio-Med. Coll., Indianapolis. IOWA

Ia. 1-College of Phys and Surgs., Keokuk.

Ia. 2-Iowa Medical College, Keokuk.

la. 3-State Univ. of la. Coll of Med.. lowa City. la. 4-Stato Univ. of
lowa City.

Ia. 6-Drake Univ. Coll. of Med., Des Moines. Ia. 7-King Eclectlc Med. Coll., Des Moines.

la. 8-Sioux City College of Medicine.

Ia. 9-keokuk Medical College.

Ia.I0-Keokuk Med. Coll., Coll. of P. and S.

Ia.11-Council Bluffs Medical College.

KANSAS

Kan.1-Kansas Medical Coll., Independence.
Kan.2-University of Kansas School of Medicine, Lawrence and Kansas City.

Kan.3-Kansas Medical College, Topeka.

Kan.4-Coll. of Phys. and Surgs., liansas City.

Kan.5-Wichita Medical Collere.

Kan.6-Kansas City College of Med. and Surg.

Kan.7-Western Eclectic College of Medicine and Surgery, Kansas City.

\section{KENTUCKY}

liy. 1-Kentucky School of Mediclne, Louisville.

Ky. 2-University of Louisville, Med. Dept.

Ky. 3-Eclectic Medical College, Louisville.

Ky. 4-Louisville Medical College.

Ky. 5-Hospital Coll. of Med., Louisville.
Ky. 6-Jefferson School of Med., Louisville.

ky. 7-Louisville National Med. College.

Ky. S-Southwestern Homeopathic Med. Coll and Hospital, Louisville.

Ky, 9-Kentucky Iniv., Med. Dept., Louisrille. Ky.10-Ifed. Dept., State Unir., Louisville.

\section{LOUISIANA}

La.I-Tulane University of Louisiana School of Medicine, New Orleans.

an.-New Orleans Sellon of Medicine.

orleans.

MAINE

Mo.I-Medical School of Maine, Portland.

Me.2-Eclectlc Med. Coll. of Mane, Lewiston. Me.3- Druldic Unir. of Maine, Lewiston.t
Ve.4-Jortland School for Med. Instruction.

\section{MARYLAND}

Md. I-Univ. of Md., School of Med., Baltimore. Ml. 2-Wasb. Univ. School of Med." Isaltmore. Md. 3-College of Phys. and Surgs., Baltimore. il. 4-Jialtimore Medleal College

Mld. 5-Waltimore Medleal College.

Vil. 6-Maltmore Universlty School of Med. Md. 7-Johns Hopkins Med. School, Baltimore. .1d. 8-Atlantlc Medical College, Baltimore. Md. 9-Marylnut Medical College, Baltimore. Md.1I-Eastern Unist's Instltution, Baltimore.

\section{MASSACHUSETTS}

Mass. 1-Harvard University, Medical School. IIass. 2-Berkshlre Medlcal College, I'ltsfleld. llass. 3-New Eng. Female Med. Coll., Boston. Mass. 5-Worcester Medlen] College, Felectlc. Miss. 6-Collen of . School of Med., Boston. Mass. 7-Tufts Collega Medical School, Boston. IIass. 8-New England University of Arts and Seiences, Boston. $†$

Mass. 9-Bellevue Med. Coll, of Mass., Boston.t IIass.10-Med. Dept., American Unlv. of Boston. Mass. 11-First Medical College of the Amerlcan Ilealth Society, Roston.t

Mass.12-Excelslor Medical College, Boston.t

Miss.13-Iteserved College of I'hys. and Surgs. Springfield.

Mass.14-Clark Univ., Med. Dept., Worcester.

\section{MICHIGAN}

Mich. I-University of Michigan, Dept, of Med. and Surg., Ann Arbor.

Mich. 2-Detroit Medical College.

IIch. 4-Micligan IIomeo. Med. Coll., Lansing.

Mich. 5-Ulicligan IIomeo. Med. Coll., Lansing.

Mich. 5- Univ. of Mich. Homeo.Coll., Ann Arbor.

Mich. 7-Detroit College of Med. and Surg.

Mllch. 8-Mich. Coll. of Med. and Surg., Detrolt.

Mich. 9-Sakinaw Valley Med. Coll., Saginaw.

Ifieh. 10-Grand Rapids Medieal College.

Mich.12-Michigan School of Homeopathy and Surrery, Detroit.

Mich.13-Michlgan Eclectic Med. Coll., Detrolt. Mich.14-Detroit University of Rational Medlcine and Surrery.

Mich.15-Detroit Lniversity of Medicine.

Mich.16-Michlgan Medical College, Lansing.

\section{MINNESOTA}

Minn.1-Winona Medical School.

Itinn.3-Minnesofa llospital Coll., Minncapolls.

Minn.4-University of Minnesota, Med. School, Minneapolis.

Minn.5-Minneapolis Coll. of Phys. and Surgs.
Minn.6-Univ. of Minn., Coll. of Homeo. Med. and Surg., Minneapolis.

\section{MISSISSIPPI}

Miss.1-Univ. of Mississippi, Med. Dept., Oxford.

Miss.2-Mississippi IIedical College, Merldan. MISSOURI

Mo. 1-Missouri Medical College, St. Louls.

Mo. 2-Washington Univ., Med. School, St. Louis.
Mo. 3-Univ. of Mo., Scliool of Ned., Columbla.

IIo. 4-Humboldt Nedical College, St. Louls.

IIo. 5- momeo Med. Coll. of Missourl, St. Lou

Mo. 7-St. Louis College of Phys. and Surgs.

Mo. S-Kansas City Medical College.

Mo. 9-IIomeopathic Med. Coll. of St. Louls.t

Mo.10-American Medical College, St. Louis.

Mo.11-Medical College of Kansas City.

Mo.12-St. Louis Hahnemann Medical College.

Mo.13-St. Louis Ecleetic Medical College.

Mo.15-College of Pliys. and Surgs., St. Joseph.

Mo.I6-Hering Medical College, St. Louis.

Mo.17-Joplin College of Phys and Surgs.
Mo.18-Northwestern Med. Coll., St. Joseph.

Io.19-Joplin Mledical College.

Mo.20-University Med. Coll. of Kansas City.

Ilo.21-Kansas City Hospital Coll. of Med. 
Mo.22-Ensworth Medical College, St Joseph. Mo.23-Woman's Medical Collece, St. Louls. Mo.s4-Beaumoni llosp. Jed. Coll. St. Louls.

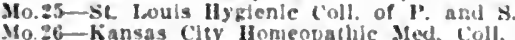
Mo. 2L-Kansas Ciry Homeopathic Med. Coll. Mo. Zi-Marion.Sims Coll. of Med.. St. Lou Mo.zo-Central Medical Collego of st. Josep! Mo.30-Woman's Mfefical Collece, hansas city. Ho.31-Hahu. Med. Coll. of Kinsas City Linls Mo.32-Mledlco-Chirurbical Coll. of Kansas Clty Mo.34-St Louis University School of Med. Mo.35-Kansas City Hahnemana Med. College Mo.35-Kansas City Hahnemans Med. Collec
Mo.36-Oceldental Coll. of $\mathrm{P}$. and S., Joplln. Mo.36-Oceidental Coll. of $\mathrm{P}^{2}$ and S., Joplln Mo.3i-Me Louts Woman's Medleal College. Mo.35-Missourt Ecl. Med. Coll. Kansas Clig. Mo.40-IIppocratean Coll. of Med.. St. Louls. Mo.40-llppocratean Coll. of Med. St. Louls. 3lo.42-Milssourt School of Mldwifery and Dis.
of Women and Children, St. Louls. $t$

\section{NEBRASKA}

Neb.1-Unltr. of Neb., Coll. of Med., Regular. Llineoln.

Neb.2-Unir. of Neb., Coll. of Mled., Eclectlc.

Lincoln.
Neb.3-inir, of Neb. Coll. of Med., Homeopathle, Lincoln.

Neb.4-Cotner University Medical College.

Neb.5-Unlv. of Neb., Coll. of Med., Lincoln and Omaha.

Neb.6-John A. Creighton Med. Coll., Omaha.

Neb.7-Nebraska College of Medlcine, Lincoln.

Nieb.8-Nebraska Medlcal College, Ecl., Lncoln.

\section{NEW HAMPSHIRE}

N.H.1-Dartmouth Medical School, Hanover.

S.H.2-Now Eutg. Enlv. of. Arss and Sclences. Manchester.

N.H.3-UnIr. of N. H., Dept. of Med., Nashua. $\uparrow$ NEW JERSEY

N.J.1-Hygelo-Therapeutic Coll. Bergen His.t N.J.2-Med and Surg. Coll. of the State of $\mathbf{N}$. N.J.3-Livingston Unirersity, lladdonfleld t’

N.J.1-Central L'nls. of Medicine and sclence. Jersey city.t

\section{NEW YORK}

N.Y. 1-Columbla University, Coll

and Surgs.. New York.

x.Y. 2-College of P'hysiclans of the Western N.Y. 3-Albany Medical College.

N.Y. - Geneva Medleal Colleze.

N.X. 5-New York Unir. Medical College.

N.Y. G-University of Buffalo, Med. Dept.

N.Y. T-New York siedical College.

N.Y. 8-Long Island College Hospital, Brooklyn.

N.Y. 2-New York Homeo. Med. Coll. and Hosp.

N. New York.

.

X.Y.II-New York Med. Coll. and Hosp. for X.Y.12-Recents of Vnlv, of State of New York N.Y.13- Eel. Sled. Coll. of the Clty of Sew York. ary for Wonets and Chlld. New York.

N.Y.13-Syracuse University Coll. of Medicine. \$.Y.10-United States Med. Coll. of New York N.Y.17-Coll. of I' and S. Ilomeo, Iturgalo.

N.Y.19-Unir. and Beilevue Hospital Med. Coll. New York.

N.Y.20-Cornell Univ. Med. College, New York N.Y.21-Wed. Faculty of Rutger'a (Queen's) Col-

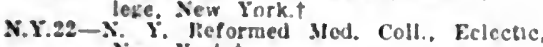
N.1.22-X. Jorkt

X.Y.23-New York School of Medlelne.

N.Y.24-Coll. of Mled.. Botanic. New York.t

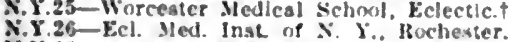

N.Y.2T-Itanilolph F.cl. Med. Inst. Itochester.

N.28-Rochester boclectic Medical college.

N.Y.30-Syracuse Med. Coll. E.Ch, Mochester. York. ${ }^{2}$

N.Y.31-R.xcelsior Med. Coll., New York.

XY3z-x. Y. Ilszeio-Therap. Coll., New Yook X.Y.32-Amer. Coll. of Med Science. New York

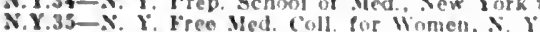
N.r.36-iturfalo coll. of ltational Mel.. IIom. N.Y.3i-Muliawk Medical colleze, Hugalo.?

Y.38-llamburg cassl finlege. Iturgal

N.Y.39-3ied and Surg. Institute and Sanlta.

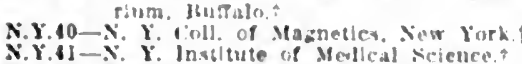

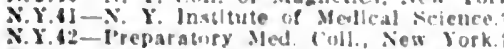
N.Y.43-Fordham Univ, School of Med.o N. Y N.Y.4-Fedwards' Med. Coll. Sew lork.

\section{NORTH CAROLINA}

N.C.I-Unir of N. C. Med. Deep. Chapel Hit

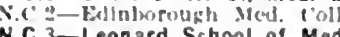
N.C.3-Leonard School of Medicina. Raleigh. N.C.4-North Carolina Med. Coll., Charlotte N.C.3-Wake Forest Scheol of Mediclne.

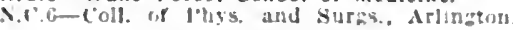
NORTH DAKOTA

N.D.1-Univ. of N. D., Coll. of Med., University. $\mathrm{OH} 1 \mathrm{O}$

3. -Medical college of (holo, Cincinnat. o. 3-starliug Medlcal college. Columbus o. 4-i'bysion-Medleal College, cincinuati. o. 5-Jlotanicn-Med. Coll. of Olifo, Clncinnal.

0. 6-Western Reserve Univ., School of Med. Cleveland.

o. F-Cleveland I'nlv. of Medlclne and surgery 3. 8-Clnclnnati College of Mel. and Sur.

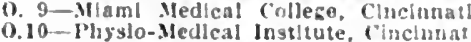
0.11-Lnir. of Wooster, Ifed. Hept. Pleveland. 0.12-Cleveland (vilege of lihy and surgs. 9.13- Tulte Medical College Ciuclunati.

O.14-Columbiss Medical Colletie.

0.15-I'hyslo-Eclecllc Med. Coll. CIncinnatl.

o.16-American Eciectic Med. "Oll. Cinclnnat

o.18-Northwestern Olito Med. Cullege, Toledo.

o.19-Toledo Medical College. Toledo.

0.20 - Woman's Medical Collese of Cincinnat.

0.21-Laura Memorial Woman's Medlcal Col gege, Clncimnatl.

0.22-National Normal Lalv., Coll. of Med., Lebanon.

0.23-Clereland Medical College, Homeopathle

0.24 -I'resbyterlan llospltal and Woman's Med. Coll. . Ancinnat

o.25-Ohto Medical I'nlrerslty, Columbus

0.26-C'leveland-1'ulte Medical Colleze.

O.2i-CInciunatl Medical College.

0.:8-Wllloughby Lnlversity, Ned. Dept.

0.30 - American Yed. Coll., Eclectle, Cincinnat.

0.3I-Ecl. Coll. of lled and Surf., CInclunat.

0.32-International Klectropathic Inst. Mentor.
0.33-Ilomeo. Med. Coll. for Women. Clevelaud.

1).3-American Health College, CIncinnati.

$0.35-Z$ anesvllle Academy of Medicine.

0.36-Toledo School of Medicine.

0.38 - Oblon Medical Lnirersity. Medicine and Mldwifery, Cincinnat.

0.39-Ilyeia Medical College, Cincinnat.t

O.40-Staring. Ohio Med. Coll. Columbus. versity of Cincinnati.

\section{OKLAHOMA}

Oxia.1-Univ. of Oxla. School of Med., Norman. oxlahoma cily.

Okla.2- Epworth College of Mcd., Okla. City.
Okla.2-Twentieth Century I'hysjo-Medical Col leze, (iuthriet

Okla.4-Oklaboma Med. Coll., Oklahoma CIty.

OREGON

(ire.1-Willamelle UnIv.. Med. Ilent. Salem.

\section{PENNSYLVANIA}

Pa.. 1-Univ. of Pa., Depl. of Med., Philadelahia.

Pa. 2-Jefferson Med. Coll. Philadelphia.

Pa. 3-Petunsylrnola Med. Coll., lietlysturg.

la. 5-Frantlin yedical collere philadelplia

Pa

Pa. 7-Woman's Med. Coll. of Pa. Philadelphia.

l'a. S-I'enn. Med. Lntversley. Plalladelplita

a. 9-Kahn. Med. Coll. and Hosp., Philadelphla. I'a.10-1.Aneoln Linir., Med. Dept. Oxford.

Pa.ll-Medico. Chirurgical Coll. of Philatelphia. Pa.12-Universify of Pitssurgh. Med. Deat. Pa.13-Temole Univ., Med. Dept., Philadelphia.

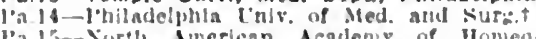
l'a.15--Xorth Ameriean Arateng of Homed pathic lleallug Art. Alsentomn.

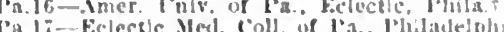

ra

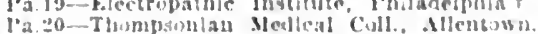

PHILIPPINE ISLANDS

P.I.I-Univ of St. Thomas. Med. Dept. Manila

P.1.2-Unir. of tt:o Philippines, Med. Dept.

\section{RHODE ISLAND}

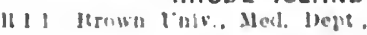

SOUTH CAROLINA

S.C.1-Med. Coll. of the State of S.C. Charleston.

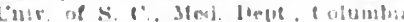

SOUTH DAKOTA

S.D.I-Unir. of S. D. Coll of Med. Vermilian.

\section{TENNESSEE \\ Tena. ! l'riv of Nablible. Med. Irepl \\ Mediral Invilute. Memplas \\ Tenn. 5-Vanderbilt Univ., Med. Dept. Nashville. Tenn. 6-Unlr. of Tenn.. Med. Dept. Memphis.

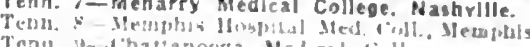 Tenn.10- Lincoln Memorial Univ.. Med. Depe. \\ Tenn.11-lnibersliy of the siuth, Med. Dept. \\ Temn.12-Kincux.lle Collere, Medieal Dept. \\ Tenn.14-Universily of West Tenn., Med. Dept. Memplis. \\ Tenn. 1:- toll. of thys and Suras. Memphas. Temn 16- Jeftersin lied Assoelation. Ilantidge.

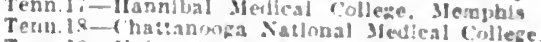 Tenn.J9- Lnireraltes if Nashrille and Tenne-
see, Med. luent. TEXAS}

Tex. I-Texas Med. Coll. and Ilosp., lialreston. Tex. 2-Unir. of Texas. Med. Dept., Gaireston. Tex. 3-Ft. Worth School of Medicine.

Tex...-Baylor Univ. Coll. of Med., Dallas. Tex. "W-l'hyslo-yled. Coll. of Teras. Mallas. Tex. T- hate Clty Med. Coll., Texarkana.Dallas. Tex. S- ioll, of mys. and surks. Dallas. rex. 2- Cuir. of San intonio, Mod. Depe

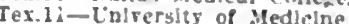

UTAH Utah 1-Unir. of Utah, School of Med. Salt
Lake.

Cah 2-Medlcal Insticution of Jlorgan City. VERMONT

ril-Castleton Medical Colleze.

Vt.2-Univ. of Vt Coll. of Med., Burlington. C.:B-Vermont Medical College. Woodstock "t. - Vermont Medlcal Colleze, hutland. Vt.5-Trinity Linls. Coll of lied aod Surs. Ve.6-inion Medical Instilute. Newberry.t

\section{VIRGINIA}

Val-Univ, of Virginia, Dept. of Med., Char. lottsville. winchester.

Va.3-Winchester Medical Colleze.

Va.4-Med. Coll. of Vircinia, Richmond. andolph-Macon Coll. Mled. Depe. I'rince Edward Court House.

V.a.5-Cniversity Coll. of Med, Richnond.

WASHINGTON

Wash 1-t'nir, of Wash.. Med. Dene. Seatuo. Wash.-W-Wash. Coll. of Blochentstry, spokane.

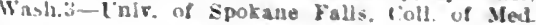
WEST VIRGINIA

W.Va.I-West Virginia Univ. Coll, of Med. Morgantown.

\section{WISCONSIN}

Wis 1-Vilwauke Coll. of lhys and surest Wis.2-Wiscut aln ('oll. of $\Gamma$. and $s$. MIIwauker. Mis.t-M.Jwanke Mculeal collece Wis. - Wireonsin Ficlecilc Mediral Schnol t Wis.5-Univ. of Wis., Coll. of Med., Madison. Wis.6-Marquelle University School of Med. Milwaukee.

CANADIAN MEDICAL COLLEGES MANITOBA

Man. I-Manitoba Medical College, Winnipeg. NOVA SCOTIA

N.S.I-Dalhousie Univ. Med. Faculty, Halifax. ONTARIO

Ont.1-Unir. of Toronto. Faculty of Med.

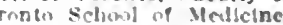
Trinity Medical iollowe. Tomnto. u: Victoria [n!T. Mel. Iept. Toronto On: 5-Med. Faculty of Oueen's Univ.. Kingston. Onf 6 -Med. Dept. Western University, Londoa.

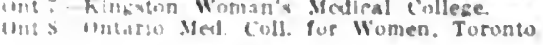
QUEBEC

Que.I-Mccill Unir.. Med. Faculty. Montreal

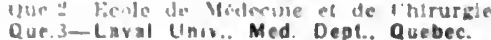
Que.d-Montreal School of Med, and Suro.

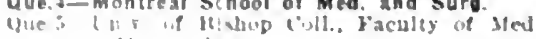




\section{5 "The House of Lea

\section{AND ITS SERVICE TO MEDICAL SCIENCE IN AMERICA}

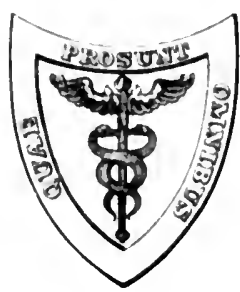

An American House in its 130th successful year proves its public value by that fact. Institutions here stand on merit only. "The House of Lea" antedates the American Constitution of 1789 by four years. It witnessed the rise and fall of Napoleon, the War of 1812, the Mexican War of 1848, the long agony of the Civil War, and the triumph over Spain in 1898. It went through the panics of 1819,1837, 1857, 1873, 1884, 1893 and 1907 with credit unimpaired. It was never stronger and more serviceable than today, and there is no reason why it should not as easily reach its third century.

Fair dealing is the essence of such permanence. In the long run the public detects, avoids, and so crushes those who do not deal fairly by it. "Let the buyer beware," says the law, a caution especially valuable to the purchaser of books. For instance, he should judge the age of a book by the date of its copyright, NOT by the date on its title page. In Lea \& Febiger's books these dates will be found to agree. Similarly the word "edition" is often misused and applied to a merc printing from unaltered or slightly altered plates to give a book a fictitious appearance of freshness. In Lea \& Febiger's books an "edition" means a revision. The difference in both cases is important to the purchaser.

The "Lea Imprint" shown above is the stamp of sterling medical literature. The motto of the imprint, "Quae Prosunt Omnibus"-_Those Things Which Benefit All"-is manifestly apt. The rod is the staff of Mercury, the god of arts and sciences, teacher of EEsculapius, the demi-god of medicine. Mercury, walking in a garden, endeavored to separate two snakes, which thereupon twined on his staff, where he fixed them. Thereafter the snakeentwined staff was Mercury's emblem. The wings of the staff typify Mercury as the messenger of the gods and the diffuser of knowledge. As a whole, the imprint denotes the universal benefits flowing from the diffusion of medical knowledge.

This hallmark is affixed to books only after careful selection. Presence in the list of books which it identifies is recognized the world over as prima facie evidence of the standing of their authors, and as a guarantee of value to their purchasers. These publications are moreover the criterion in physical form as well as literary contents. "The House of Lea," now Lea \& Febiger, can justly claim a leading share of credit for American preemnence in medical literature.

Catalogues and Descriptive Circulars mailed on request. Physicians may for the asking have their addresses filed for early information regarding new books and new editions as issued. Correspondence Invited. Remunerative and Permanent Employment for Salesmen. 


\section{The Winkley Artificial Limb Co.}

\section{LARGEST MANUFACTORY OF ARTIFICIAL LEGS IN THE WORLD}

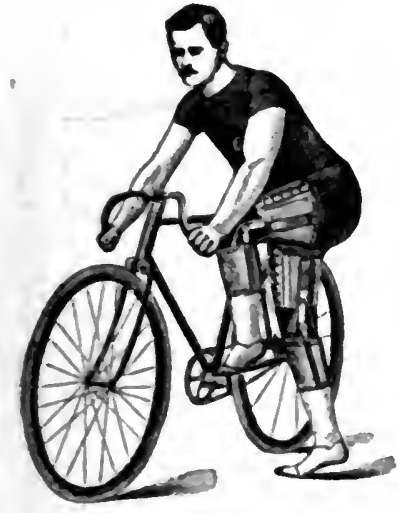

Boch lezs amputaied five inches below the kaee
ARTIFICIAL WITA

MANUFACTURERS OF THE LATEST IMIRUVED

PATENT ADJUS'TABLE DOUBLE SLH' SOCKET

\section{Sponge Rubber, Mosican Foll or FOOT}

WARRANTED NOT TO CHAFE THE STUMP

PERFECT FIT GUARANTEED; from Casts and Measurements, WITHOUT LEAVING HOME

THOUSANDS OF OUR SLIP SOCKET I.EGS NOW BEING WORN U. S. GOVERNMENT MANUFAC"TURERS

This is the Leg that is being recommended and ordered by so many of the leading physicians and surgeons

SEND FOR OUR LARLE NEW ILLUSTRATED CATALOG

\section{MINNEA POLIS, MINN., U. S. A.}

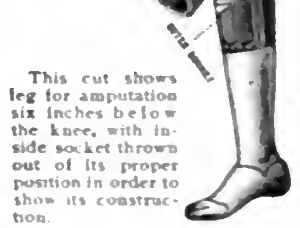

\section{WA
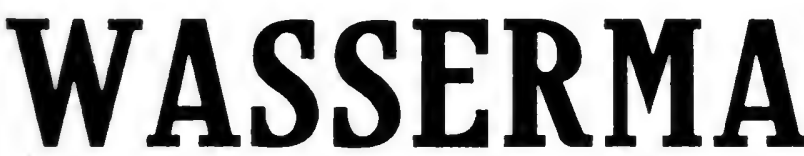

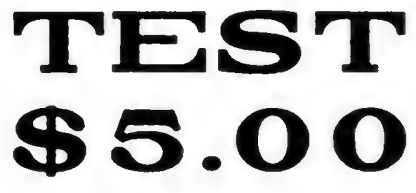

$\$ 5.00$

$\$ 5.00$

ABDERHALDEN SERODIAGNOSIS OF PREGNANCY

Experienced clinical laboratory diagnosticians analyse every specimen submitted to our laboratory for report. Our special knowledge and years of practical experience in this work is at the service of every practitioner at a reasonable fee. Sterile containers for 11 assermann Test with hypodermic needle and all attachments, ready to collect the blood, and explicit instructions as to technic, mailed frees to physicians. 
Abram Co., Abe.................. l'age 122 Addressing Service, Am. Med, Ass'n... 82 Ajax Battery Co................., 82 Albuquerque Sanatorlum

IIyglenil (13g) h Co.............Page 122 IIygela Hospltal and sanäorium....... 120 Hynson, westcott \& Co........... 128 Hynson, Westeott \& Co............ 128 indlana University, School of Medicine... 42 International Instrument Co......... 114

Johns IIopkins Unly., Med. Dept..

Johnson \& Johnson...

Kenllworth Sanitarluin............. 86

Kesselrlng $\mathrm{X}$-Ray Tube Co............. 110

killough, Chas. $11 . \ldots \ldots \ldots \ldots \ldots \ldots . . \ldots 107$

linoll \& Co....

larson, Martin................... 112

Lau-Gordon Crinics..................

Lau-Gordon clinlcs................ ${ }^{78}$

Leather Tre Goods Co............ 104

Leltz, Ernst

Leberknecht \& Fraass.

Lippincott Co., J. B.

Livermore Sanitarlum.

Login Brotliers.....

Lovett, A. E.

Macalaster-Wiggin $\mathrm{Co}$

Machlett \& Son, $E$.

Madlson Sanltanan, The............. 15

Malne Sanatorlum, "Greenwood Mount." 71

Maltine Co., The................. 48

Manhattan Eye Salve Co C........... 117
Margaret Wright Hospital..........

Marks, A. A...........

Marshall Sanitarlum.

May,

Maver. Michael.

IcCaskey Reglster ................ 123

Meclurg, A. C. \& Co .............. 123

McCready's Hosp. \& School, Dr. E.. B. 80

McDermott Surgical Instrument Co... 123

McDougall Sanit. Treat. Rooms, D. M. 81

McDougall Sanit. Treat. Rooms, D. M.
McFarland's Sanitarlum, Dr...........

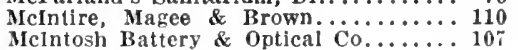

Mclntosh Battery \& Optical Co....... 107
MeIntosh Co., Jno., The........... 119

MeIntosh Co., Jno.
McNutt IIospital..

Medical Protective Co.

Medlcal Research Pamphlet............. ${ }_{74}^{3}$

Medical \& Surgical Supply Depot....... 116

Medico-Chirurgical College of Phila.... 36

Meinecke \& Co................... 115

Mercer sanitari.

Merlweather Hosp. and $T r$. Sch. for Nur. To

Nerrian Co., G. \& C................. 8

Meyrowitz, $E$. B., Inc.................. 114

Mulliken \& Co. John $\mathrm{T} \ldots \ldots \ldots \ldots \ldots \ldots \ldots$

Mllwaukee Sanitarium..Facing ihird cover

Missourl Baptlst Sanitarlum....

Mount Clemens Sanitarlum Co

Mrueller \& Co., V.

Muller \& Co.. Franklyn $\mathrm{R}$.

National Pathologleal Laboratory.

Vational Vaccine \& Antltoxin Institute 1

Nauhelm Sanitarium.

New Mexico Cottage Sanatorium........ 68

New lork Poly. Med. School and Hosp.

Norbury Sanatorium

North Chicago Hospltal.

North Louisiana Sanltarinm.

North Shore IIealth Resort

Yorthwestern Tniversity Medical School

"Norways" Sanatorlum

Nugent Sanitarium...

Nystrom \& Co., A.

Oak Lawn Sanatorum

Oak Leigh Sanitarium.

Oakwood Retreat Association...

oconomowoc Health Resort. The.

Ohlo State University, Coll. of Med...

Paciflc Wassermann Laboratories.

Pamsetgaaf Sanatorlum.

Pearson Home.

Pennock, Edward.

Pennoyer Sanitarium......................
Fa. Orth. Inst. and Sch. of Mechanother

Peoples Hospital.

Peorla Sanatnrium

Pettey \& Wallace's Sanltarium, Drs.

Pfau, H.........................

Physician's Casually Association....... 11
Polar Water Still Co............Page 82

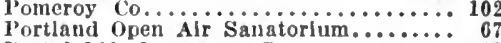
Postal Life Insurance Co... Chica...... l'ost-Graduate Mod. Sch. of Chlcago... 40 Pottenger Sanatorium, The........... 52 F'rometheus Electric Co............ 122 Punton Sanltarlum .............. 63 Randall-Falchney Co., The.......... 117

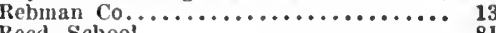
Reed School................. 81 lleinschlld themical Co........... 87 lietreat Sanitarium, The............ 68 RIchard Gundry Home, The.......... 62 Riedel \& Company........ facling third corer Itwer Crest Sanitarlum........... 73 Sacred Heart Sanitarium.............. St. Helen St. Joseph's Mat. Hosp. and Infant Asy. 81 St. Louls Univ. Sch. of Medicine..... 43 St. Luke's Hospital.............. 78

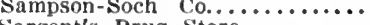
Sargent's Drug Store............ 123 Savo Manufacturing Co.............. 122 Sawyer Sanatorlum, The.......... 57 Scanlan-Morris Co................. 120 Scheidel-Western X-ray Coll Co......... 95 Schering \& Glatz.............. Schleffelln \& Co........... Inslde back cover Scholl Manufacturing Co........... 101 Sharp \& Smith $\ldots \ldots \ldots \ldots \ldots \ldots \ldots \ldots \ldots 109$ Shelton Electric Co.............. 123 Sherman, Dr. G. H..................... 107 Southworth Co., The............. 8

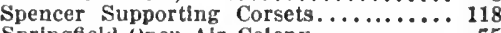
Springfield Open Air Colony ......... 75 Stanford University, Med. Dept....... 4

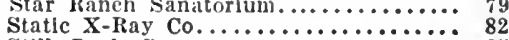
Still Rock Spa.................... 65 Storm, Dr. Katherine $\mathrm{L}_{\ldots \ldots \ldots \ldots \ldots \ldots \ldots} \ldots \ldots \ldots$ Sugar Pine Hospital............... ${ }^{81}$ Telfair Santarlum................ 80 Tonney \& Graves, Drs............... 46 Torbett Sanatorium, The .......... 80

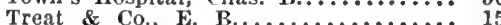
Triple Tread Manufacturing Co....... 119 Trommer Co., The $\ldots \ldots \ldots \ldots \ldots \ldots \ldots . . .65$ Turts College Medical School........ 37 Tulane Univ. of Louisiana, Med. Dept. 35 University of Alabama, Sch. of Med... 40 University of Cincinnati, College of Med. 44 Univ. of Ill. Coll. of Mediclne......... 38 Unlversity of Loulsville, Med. Dept.... 42 Unlversity of Michlgan, Dept. of M. \& S. 42 University of Nebraska, Coll. of Med... University of North Dakota, Sch. of Med. University of Oregon, Med. Dept.

Unlversity of Pennsylvania, Sch, of Med. Unirersity of Pittsburgh, Sch. of Med. University of Vermont, Coll. of Med... University of Virginla, Dept. of Med.. Useful Drugs................... 11 Van Orden Corset Co.................. 118 VIchy Celestins .................. 90 Vittel Health Resort.................. 84 Waite \& Bartlett Mfg. Co............ 120 Waldheim Park................... i2 Walker's Sanllarium............. 76 Wappler Electric MP. Co........... 114 Waukesha Health Products Co........ 89 Waukesha Springs Sanitarium ....... 59 Westey Hosp. Training Sch. for Nurses 47 Western Reserre Univ., Sch. of Med... 39 Wetmore Co., The S. H. Wch. of Med... 119 White Sulphur springs, inc............. Wilbur Home and School........... Wilgus, Sanitarium, Dr............. Willows Maternity Sanitarim........ 70 Winkley Artiffelal Limb Co.......... 1 Wolfe, H. P., Therapeutic Baths....... 106

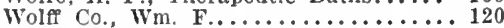
Wolff Manufaeturing Co., I $_{\ldots} \ldots \ldots \ldots \ldots \ldots . \ldots \ldots 112$ Yankee Co., The ............... 122

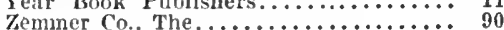
Zieman, Fred..................... 


\section{0\% BETTER}

\section{PREVENTION \\ DEFENSE}

\section{INDEMNITY}

1 All claims or suits for alleged civil malpractice, error or mistake, for which our contract holder,

2 Or his estate is sued, whether the act or omission was his own

3 Or that of any other person (not necessarily an assistant or agent)

4 All such claims arising in suits involving the collection of professional fees

5 All claims arising in autopsies, inquests, and in the prescribing and handling of drugs and medicines.

6 Defense through the court of last resort and until all legal remedies are exhausted

7 Without limit as to amount expended.

8 You have a voice in the selection of local counsel.

9 If we lose, we pay to amount specified, in addition to the unlimited defense.

10 The only contract containing all the above features and which is protection per se. A sample: poun reyuest.

\section{THE MEDICAL PROTECTIVE CO.} of FORT WAYNE, INDIANA

PROFESSIONAL PROMHCMION, EXCIUSIVELY 


\section{P. BLAKISTON'S SON \& CO.} ESTABLISHED 1843

1012 WALNUT ST.

PHILADELPHIA

(1. Publishers of Books on Medicine, Dentistry, Pharmacy, Nursing, Chemistry, Physics, Biology. Including The Physicians Visiting List (63d year) Gould's Medical Dictionaries, of which over 340,000 have been sold, and the United States Pharmacopoeia.

Catalogues, Illustrated Circulars, Sample Pages and Descriptions of Books will be sent upon Application. Correspondence Solicited.

d. The new edition of the American Medical Directory issued under the auspices of the American Medical Association contains a classified list of the principal books on medicine and allied subjects. In this list about 350 titles are followed by the name "Blakiston" or "Blak." We will gladly furnish further information concerning any of these.

\section{P. BLAKISTON'S SON \& C0., 1012 WALNUT STREET}




\section{Saunders'}

\section{Important

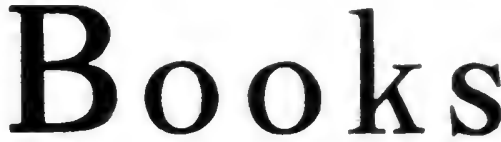

AMERICAN ILLUSTRATED MED. ICAL DICTIONARY. Seventh Edition. Octavo of 1107 pages, illustrated.

54.50 net.

AMERICAN POCKET MEDICAL DICTIONARY, Eighth Edition.

$\$ 1.00$ net.

ANDERS.-Practice of Medicine. By JaMes M. Axners, M.D. Eleventi Edition. Octavo of 1335 pages, illustrated. 85.50 net.

ANDERS and BOSTON. - TextBook of Medical Diagnosis. By JAS. M. A.NDERS, MI.D., and L. Napoteon Bostox, M.D. Octayo of 1175 pages, 443 illustrations. $\$ 6.00$ net.

ARNY.-Principles of Pharmacy. By Hexry V. ABsy, Pu.G. Octavo of II75 pages, 246 illustrations. $\$ 5.00$ net.

ASHTON.-Practice of Gynecology. By W. EAsterly Asiton. M.D. Fifth Edition. Octavo of 1100 pages, with 1058 line drawings. $\$ 6.50$ net

BANDLER. - Medical Gynecology. By S. Wrills BANDLER, M.D. Third Edition. Octavn of 790 pages, illustrated $\$ 5.00$ net.

BARNHILL and WALES.-Modern Otology. By J. F. BARNIIILL, M.D., and E. DEW. WALES, M.D. 2d Ed. Octavo, 599 pages. 314 illustrations.

$\$ 5.50$ net.

BASTED0. - Materia Medica Pharmacology, Therapeutics, and Prescription Writing. By $\mathrm{W}$. A Bastrio, M.D. Detuvo of 602 pages, illustrated. Cloth, \$3.50 net.

BERGEY.-Principles of Hygiene. By D. A. BERGEY, M.D. ith E.d

$\$ 3.00$ nit.

BICKHAM.-Operative Surgery. $13 y$ WARREX STOXE BrCKHAM. M.i) Third Edition. Octavo of 1200 pages, 854 illustrations. $\$ 6,50$ net
BÖHM and PAINTER.-Massage. By Max BÖn, Berlin, and Cnas. 1. Painter, M.1). \$1.75 net.

BÖHM, DAVIDOFF, and HUBER.Human Histology. By Dr. A. A. BOHM, Dr. M. Vox DAVidore, and G. CABl licber. M.D. Id E'd. 550 pages, 375 illustrations.

$\$ 3.50$ net.

BRILL.-Psychanalysis. By A. A. Brill, M.D. Octavo of 337 pages. $\$ 3.00$ net.

BRYAN.-Principles of Surgery. By W. A. Bryax, M.D. Oetavo of 677 pages, illustrated.

Clotlr. $\$ 4.00$ net.

BUCHANAN.-Veterinary Bacteriology. By RoBert E. BLCHANAx, PII.I. Octavo of 516 pages. with 214 illustrations. $\quad \$ 3.00$ net.

BUTLER.-Materia Medica, Therapeutics and Pharmacology. $\mathrm{By}$ fiforge T. Butler. PH.G.. M.D. Sixth Edition Octavo of 700 pages.

$\$ 4.00$ net.

CABOT.-Differential Diagnosis. By Richard C. Cabot. M.D. $2 d$ Fid. Octaro of 76.5 pages, illustrated. 85.50 net.

CAMPBELL. - Surgical Anatomy.

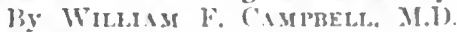
od $\mathrm{Ed}$. Oetavo of 67.5 pitges; 319 illustrations.

ริธ่.00 net.

CARTER.-Diet List of the Presbyterian Hospital of New York City. IBv 1I. S. C.IRTER, M.1). \$1.(1) ne't

CHURCH and PETERSON-Nervous and Mental Diseases. $3 y$. Archibald (urge11, M.1). ani?

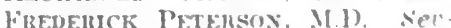
enth Edition. Oetavo of 9.2: payes: 341 illustrationa. $\quad 85.110 \mathrm{net}$

COTTON.-Dislocation and Joint

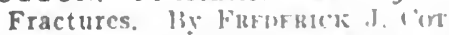

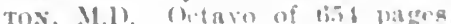
with land illustratiend solion net.
CRANDON and EHRENFRIED.Surgical After-Treatment. $B y^{*}$ I. R. G. CRIXDOx, M.D., and ALEERT Firhexfried, M.D. Octavo of 831 pages, illustrated. $\quad \$ 6.00$ net.

Dacosta (J. Chalmers).-Modern Surgery. IBy J. Culalmers DA Costa, M.D. Seventh Edition. OC. tavo, 1525 pages, 1050 illustra. tions.

$\$ 5.50$ net.

DacosTA (John C., Jr.).-Physical Diagnosis. By Johx C. D.ACosta. JR., M.D. 2d Ed. Octain of 557 pages, illustrated.

$\$ 3.50$ net.

DANNREUTHER - M in o I a nd Emergency Surgery. By WALTER T. DAXXBECTHER. M.D. l. 2.25 pages, illustrated.

Cloth, $\$ 1.25 \mathrm{nat}$

DAVIS. - Anatomy and Development of the Paranasal Cavities in Man. BY W. A. DAvis, M.D.

In Press.

DAVIS.-Operative Obstetrics. B० E. P. Divis. M.1. Octavo of 483 pages, with 204 illustrations.

$\$ 5.50$ net.

DEADERICK.-Malaria. By WM. H. De.NERICK. M.D. Octaio, 402 paces, illustrated. $\quad$ t.50 ront.

DeLEE.-Principles and Practice of

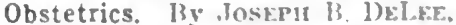
M.D. Octavo of 1000 mges, with 413 illustrations. $\$ 8.10$ net.

DERCUM. - Mental Diseases. $13 \mathrm{y}$ X. Denct3. M.1). Detarn of 4?i pagess. Cloth, $\$ 3.00$ siet.

deSCHWEINITZ.-The Eyc. 13\%. C.

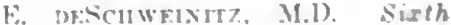
lidition. O.tavo of gt5 paurs. 351 tert.euts an!? plate's. $\$ 5.00$ net.

DREW. - Invertebrate Zoology. Br

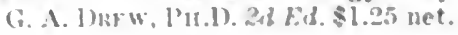

Send for Our Complete Illustrated Catalogue

\section{SEE ALSO THE NEXT TWO PAGES}




\section{Saunders' Important Books}

EISENDRATH. - Surgical Diagnosis. By D. N. Eisexiratir, M.1). 2d Ed. Oetavo of 885 pages, 574 illustrations.

$\$ 6.50$ '. st.

EYRE. - Bacteriologic Technique. By .T. W. II. EYrE, MI.D. $2 d \mathrm{Ed}$. $\$ 3.00$ net.

FAUGHT.-Blood Pressure. By It A. FAUgitT, M.D. Octavo of 281 pages, illustrated $\$ 3.00$ net.

FENGER Memorial Volumes.-Cdited by ludvig HekToes, M.D. Two octavos. of 525 pages each, illustrated.

$\$ 15.00$ net.

FOWLER.-The Operating Room and the Patient. By Russelt $S$. Fow LER, M.D. 3d Ed. $\$ 3.50$ net

FRIEDENWALD and RUHRÄH.Dict in Health and Disease. By JiLu's FrIEDExwati, M.D., and Jolis Ruirëir. M.D. 4th Ed. Octavo. 780 pages. $\$ 4.00$ net

GANT.-Constipation and Intestinal Obstruction. By SAMUel G. GaNT, MI.D. Octavo of 560 pages, illus trated.

$\$ 6.00$ net.

GANT.-Diarrhea. By SAMUel G. GaNT, M.D. Octavo of 500 pages. illustrated.

In Press.

GARRISON.-History of Medicine. By F. H. Garrisor, M.D. Octayo of 763 pages, illustrated.

Cloth, $\$ 6.00$ net.

GOEPP.-Dental State Board Questions and Answers. By R. MAx GoEFF, M.D. Octavo of 428 pages. $\$ 2.75$ net.

GOEPP.-Medical State Board Ques tions and Answers. By R. Max GoEPP, M.D. Octavo of 714 pages. $3 d \mathrm{Ed}$.

$\$ 4.00$ net.

GREENE and BROOKS.-GenitoUrinary Organs and the Kidney. By Robert H. Greene. M.D., and Harlow Brooks, M.D. Second Edition. Octaro of 560 pages, illustrated.

$\$ 5.00$ net.

GRULEE. - Infant Feeding. By Clifford G. Grulee, M.D. Octavo of 295 pages, illustrated.

$\$ 3.00$ net.
HEISLER.-Embryology. By Jo1I C. Heister, M.D. $3 d$ Ld. Octaro, 435 pages; 212 illus. $\$ 3.00$ net.

HILL.-Histology and Organography. By Cilarles Hill, M.D. $2 d E d .12$ mo of 468 pages, 337 illustrations.

$\$ 2.00$ net.

HINSDALE. - Hydrotherapy. By GuY Hirsiale, M.D. Octavo of 466 pages, illustrated. $\$ 3.50$ net.

HIRST.-Diseases of Women. By Barton Cooke Hirst, M.D. $2 d$ Ed. Octavo of 741 pares, 700 illustrations. $\$ 5.00$ net.

HIRST. - Obstetrics. By BarTov Cooke Hirst, M.D. ith Ed. Octavo of 1013 pages, 895 illustrations.

$\$ 5.00$ net.

HOLLAND.-Medical Chemistry and Toxicology. By J. IV. Horland, M.D. $3 d E d$. Octavo of 655 pages, illustrated.

$\$ 3.00$ net.

HORNSBY and SCHMIDT.-The Modern Hospital. By JoHN A. Hornsby, M.D., and R. C. Scrimdi, Architect. Octavo of 644 pages, illustrated. Cloth, $\$ 7.00$ net

HOWELL. - Physiology. By WM. H. Howell, M.D. Fifth Edition. Octavo of 1018 pages, 306 illus. $\$ 4.00$ net.

HUNT.-Diagnostic Symptoms of Nervous Diseases. By A. L. Hunt M.D. 12 mo of 229 pages, illus. $\$ 1.50$ net

IVY.-Applied Anatomy and Oral Surgery for Dental Staudents. By Robert H. IVY, M.D., D.D.S. $12 \mathrm{mo}$ of 282 pages, illustrated. $\$ 1.50$ net.

JORDAN. - General Bacteriology By E. O. Jordan, Ph.D. $s d ~ E d$. Octavo of 623 pages, illustrated.

$\$ 3.00$ net.

KAPLAN.-Serology of Nervous and Mental Diseases. By D. M. KAPLAN, M.D. Octavo of 400 pages, illustrated. In Press.
KEEN.-Surgery. Edited by W. W. KKEEN, M.D., LL.D., HoN. F. R.C.S., Eng. Axd EDIx. Six octavos of 1050 pages each, 3100 original illustrations, 157 in color's. l'er volume: $\$ 7.00$ net.

KELLY.-Cyclopedia of American Medical Biography. By Howaro A. Kelly, M.D. Two octavos of 525 pages each, illustrated.

Per set: $\$ 10.00$ net.

KELLY and NOBLE.-Gynecology and Abdominal Surgery. By. II. A. Keliy, M.D., and C. P. Noble, M.D. Two octavos of 900 pages each, 880 illustrations.

Per volume: $\$ 8.00$ net.

KEMP.-Stomach, Intestines and Pancreas. By Robert C. Kearp, M.D. Octaro of 1021 pages, illus trated.

$\$ 6.00$ net.

KERLEY.-Pediatrics. By CHÄLES Gilmore Kerley, M.D. Octavo of 850 pages, fully illustrated.

In Press.

KLIMMER and WOLFF-EISNER.Serum Diagnosis and Therapy in Veterinary Medicine. In Press.

KERR.-Diagnostics of Diseases of Children. By LeGrand KerR, M.D. Octavo, 542 pages, illustrated.

$\$ 5.00$ net.

KYLE.-Nose and Throat. By D. Bradey Krle, M.D. ith Ed. Octavo, 725 pages; 215 illustrations, 28 in colors. $\$ 4.00$ net.

LUSK.-Science of Nutrition. By GrahaM IUSK, Ph.D., F.R.S. (Edin.) 2dEd. Octavo, 402 pages. $\$ 3.00$ net.

MALLORY:-Pathologic Histology. By Frank B. Mallory, M.D. Octavo of 677 pages, with 683 illus. trations on 497 figures, 124 in colors.

$\$ 5.50$ net.

MALLORY and WRIGHT.-Pathological Technic. By Frank B. Mallory, M.D., and JAMES H. Wright, M.D. Fifth Edition. Octavo, 507 pages; 160 illustrations. $\$ 3.00$ net. 


\section{Saunders' \\ Important \\ Books}

MAYO-A Collection of Papers. (Published previous to I909.) By W. J. MAYO, M.D., and C. H. Mayo, M.D. Two octavos of 550 pages each, illustrated.

Per set: $\$ 10.00$ net.

MAYO-Clinic Papers. By W.I. J Mayo, M.D., Chas. H. MiYo, M.D., and their Associates. Papers of $1905 \cdot 09,1910,1911,1912,1913$. Each an octaro of 6.50 pages, illustrated. Fach volume, \$5.50 net.

McC O N N E L. - Pathology. By Gutirie McCorvel, M.D. Second Edition. 12mo of 523 pages, 170 illustrations. $\$ 2.50$ net.

McFARLAND. - Biology: Medical and General. By Josepil Mcliar. LAND, M.D. Octavo of 414 pages. illustrated.

$\$ 1.75$ net.

MeFARLAND-Pathology. By Jos. EPII McFarLaxd, M.D. $2 d$ Ed. $\$ 5.00$ net.

McFARLAND. - Pathogenic Bacteria and Protozoa. By JoserI McFarlasd, M.D. Seventh Edit ion. Octavo of 878 pages, illus. trated. $\$ 3.50$ net.

MORROW.-Diagnostic and Therapeutic Technic. By A. S. MorRow, M.D. Octavo of 850 pages, 815 line-drawings. $\$ 5.00$ net.

MORROW.-Immediate Care of the Injured. By A. S. Morrow, M.D. Second Edition. Octavo of 354 pages, 242 illus. $\$ 2.50$ net.

MOYNIHAN.-Duodenal Ulcer. By Sir Berkeley Moryllas, M.S. Second Fdition. Octavo of 485 pages, illustrated. $\$ 5.00$ net.

MOYNIHAN. - Gall-Stones and Their Surgical Treatment. By SIR BFRKELEY MOYNIIAN, M.S. Second Edition. Octavo of 368 pages, illustrated. $\$ 5.00$ net.

MUMFORD.-The Practice of Surgety. By JaMes G. Musforb. M.D. Octaro of 1075 pages, with 682 illustrations

$\$ 7.00$ net.
MURPHY.-Clinics of John B. Murphy, M.D. Issued every other month. Each number about 175 octavo pages, illustratel. Per cal endar year: $\$ 8.00$; cloth, $\$ 12.00$

MUSSER and KELLY.-Practical Treatment. By J. II. MUSSER, M.D., and A. O. J. KeLly, M.D Three octavos of 950 pages each, illus. I's vol.: $\$ 6.00$ net.

NORRIS.-Gonorrhea in Women. By Cinarees C. Noriss, M.D., wit! introduction by Joris G. Chark, M.D. Jarge octavo of 520 pages, illustrated.

$\$ 6.00$ net

PILCHER. - Practical Cystoscopy By Paul, M. Pilciler, M.D. OC tavo of 368 pages, illustrated.

$\$ 5.50$ net.

RUHRÄH.-Diseases of Infants and Children. By Jonæ RenR̈̈н, M.D. $3 d \mathrm{E} d$.

$\$ 2.50$ net.

SAHLI.-Diagnostic Methods. By Prof. Dr. SAllLI, of Mern. Edited by N. B. PotTer, M.D. $2 d E d$ Octavo of 1225 pages, illustraterl. $\$ 6.50$ net

SCHAMBERG. - Diseases of the Skin and the Eruptive Fevers. By JAY F. ScilaMBERG, M.D. SCC ond Edition. Octavo of 573 pages, illustrated.

$\$ 3.00$ net.

SCUDDER. - The Treatment of Fractures. By C. I. ScuDDEr, M.1). Serenth Fidition. Octavo of 703 pages; 994 illus. $\$ 6.00$ net

SCUDDER.-Tumors of the Jaws. By CialleES L. Sc(inder, M.l) Oetavo of 395 pages, illustruted. Cloth. $\$ 6.00$ net.

SHARP.-0phthalmology for Veteri narians. By WAI.TER N. NHAR", M.D. 12 mo of 205 pages.

\$. $2.00 \mathrm{net}$

SISSON.-Veterinary Anatomy. $13 y$

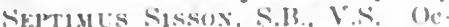
tavo of 826 jagres, 585 illustra. tions.

$\$ 7.00$ net.
SLADE,-Physical Examination and Diagnostic Anatomy. liy $1: 13$ SLAde, M.D. 12 mo of 145 pages. illustrated.

$\$ 1.25$ net.

SMITH.-What to Eat and Why. By G. Carroi.r. SutTu, M. I). I2mo of 325 pages.

s....0 net.

SOBOTTA and MCMURRICH.-Human Anatomy. By Prof. I. So BoTrA. of Wurzburg. Fitited by .I P. McMlraicil, Pil.D. Three quar tos, 750 paces each: 900 illustra. tions, mostly in colors. Per vol: $\$ 6.00$ net.

SOLLMANN. - Pharmacology. I $y^{\circ}$ Torild Solduary, M.U. Second Fdition. Getaro, 1070 pages, il. lustrated. st.00 net.

STELWAGON. - Diseases of the Skin. By Hexry W. Stelwagon M.D., PH.D. ith Ed. Oetavo, 1250 pages. 33I text-ents, 33 plates. si.00 net.

STEVENS.-Molern Materia Me1ica and Therapeutics. I3y . 1. . . Stevexs, M.I). 5th Ed. Ortaro. 690 prages.

$\$ 3.50$ net.

STEVENS. - Practice of Medicine. By A. A. STEVENS, MID. 9th Ed. I. $m o$ of 573 pages, illustrated.

$\$ 2.50$ net.

TODD.-Clinical Diagnosis. By, J C. Tonn, M.1). Second Eidition. 12 mo of 469 pages, illustratel. $\$ 2.25$ net.

TOUSEY.-Medical Electricity and Roentgen Rays. By sixcl ur TotsEY, M.I). Oetavo of 1118 pages, illus.

$\$ 7.0011 \% t$

VECKI. - Sexual Impotence. $13 \mathrm{~F}$ Viltor C. Vecki. II.D. fith Eid. l:mo of 400 pages. S2.25 net.

WARD.-Bedside Hematology. By GombN R. WARD. M.D. Cetavo of 400 pages, illustrated. In Press.

WELLS-Chemical Pathology. By II. G. Wel.LS, M.D. 549 pages. $\$ 3.25$ net 


\section{THE SOUTHWORTH COMPANY, Publishers MEDICAL WORKS

\section{ANNOUNCEMENTS.}

\section{Section XVIII Now Ready CHARLES H. MAY 0, M.D., Rochester, Minn. \\ Excision of Sigmoid with Cautery \\ Anterior Gastroenterostomy \\ W. J. MAYO, M.D., Rochester, Minn. \\ Pylorectomy and Partial Gastrec- tomy; Extirpation of Carcinoma- tous Colon. \\ (84 pages, 3 half-tones, 51 stereos) \\ The last, and certainly one of the best of the Sections of the Stereo-Clinic so far published.}

Ready January, 1914

\section{SOME AMERICAN} MEDICAL BOTANISTS

Commemorated in our Botanical

Nomenclature

BY

HOWARD A. KELLY, M.D., LL.D.

\section{Stereoroentgenography of the Alimentary Tract

JAMES T. CASE, M.D.

Lectnrer on Roentgenology, Northwestern University Medical School, Chicago; Roentgenologist to Battle Creek Sanitarium, Battle Creek, Michigan, and to St. Lake's Hospital, Chicago; Attending Roentgenologist to Cook County Hospital, Chlcago

We have now pubiisbed thirty sections devoted entirely to the illustrating, by the means of a stereogram, the stens of surgical technique. It has been thought wise to include in this series several sections devoted to X-Ray investigation. Two new sections devoted entirely to "Stereoroentgenography of the Alimentary Trat" are now in course of publication and will be ready early in January.

It is the purpose of Dr. Case to divide this-work into two sections, the first devoted to esophagus, stomach, duodeum, and the second to the intestines, both small and large.

In the two sections there will be about ninety stereoroentgenograms. In addition to these a la rge amount of descriptive text, besides line-drawings and half tone illustrations.

In the first section Dr. Case has planned to include a discussion of the normal esophagus, esophageal diverticula, carcinoma, cardiospasms and esophageal distortions due to other causes. In addition to this he will discuss and illustrate, among other things, the normal stomach, carcinoma of the stomach, gastric and duodenal nl cer and hourglass stomach. Duodenal obstruction and gall siones will come for extended consideration, The gall stones will be shown, both in relation to the stomach and to the colon.

In the second section on the colon, Dr. Case will discuss acute and chronic small intestine obstruction, Lane's kinks, ileal stasis associared with ileocecal valve incompetency, adhesions of the cecum, ileocecal region adhesions, chronic appendical dis: ease Jackson's membrane aber rant sigmoid, spastic constipation, carcinoma of the colon, fecal fistulae. etc. There are, in addition to the above named, a number of interesting conditions which the stereos illustrate. The stereoroentgenograms are exceptionally good. Many of them have been admired throughout this country and Europe, and these sections of the Clinic are well worthy of a large circulation.

The announcement of other publications on $\mathrm{X}$ Ray will appear in the near future.

For further particulars address

The Southworth Company, Publishers TROY, N. Y., U. S. A. 


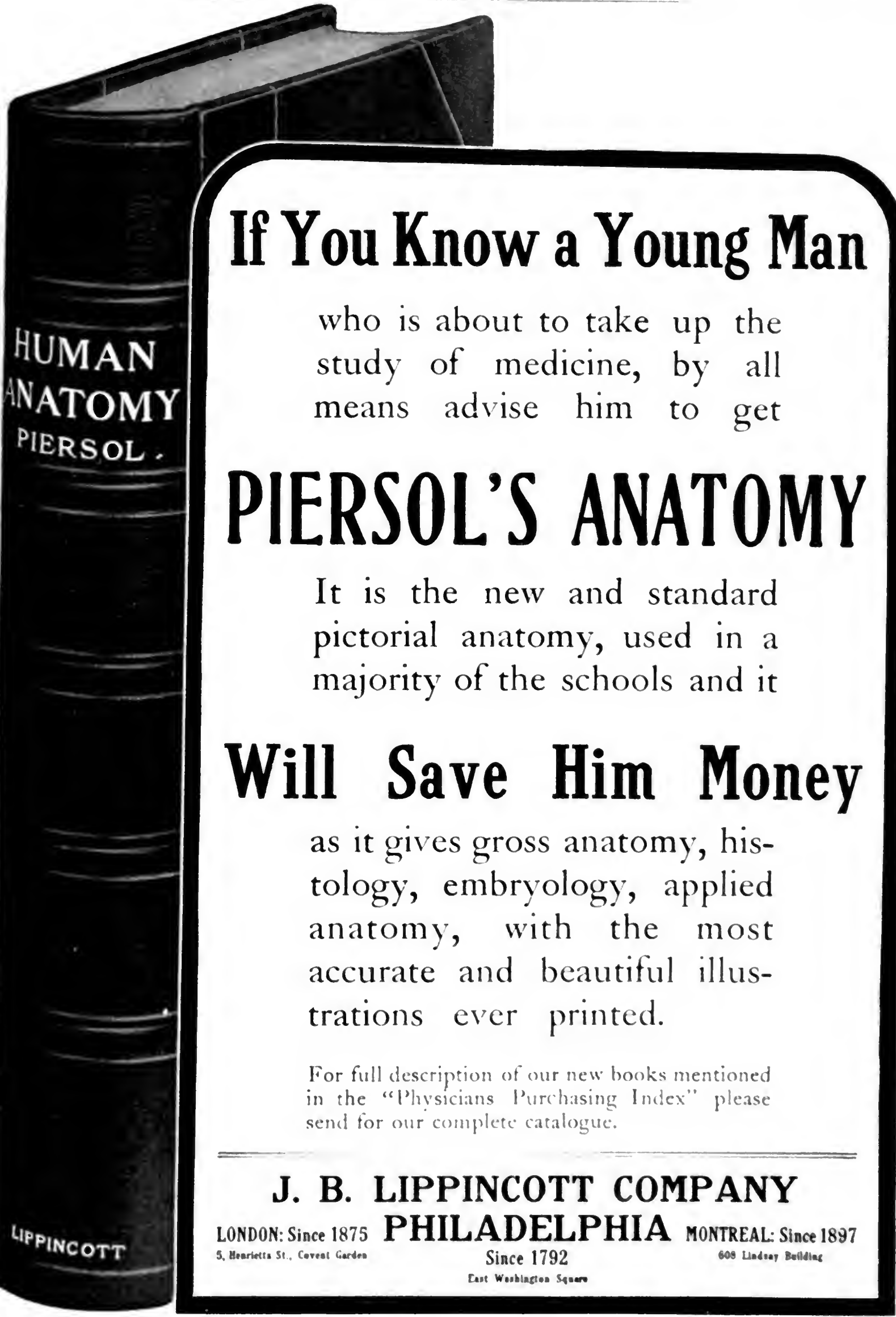




\section{MEDICAL BOOKS OF ALL THE PUBLISHERS}

One of the Most Complete Assortments in the Country

\begin{tabular}{|c|}
\hline N E W \\
B O O K S \\
R E C E I V E D \\
A S \\
I S S U E D \\
\hline
\end{tabular}

FOREIGN BOOKS

IMPORTED TO

ORDER AT

REASONABLE

R AT E S

\section{P R O M P T A T T E N T I O N \\ G I V E N T O A L L O R D E R S}

SEND FOR CATALOGUES and MONTHLY BULLETINS

\section{Chicago Medical Book Co.}

WEST SIDE

Congress and Honore Sts.

PHONES
DOWN TOWN

29 E. Madison Street. Heyworth Bldg. 


\section{The Practical Medicine Series 1914-OF YEAR BOOKS-1914}

\section{The Standard Authority on the World's Progress in Medicine and Surgery}

\section{COMPRISING TEN VOLUMES THIRTEENTH YEAR}

Whatever is new, selected and concisely arranged for reference and reading, finds its way by means of these volumes into the permanent convenience of the prac. titioner's working library, bringing it fully up to date.

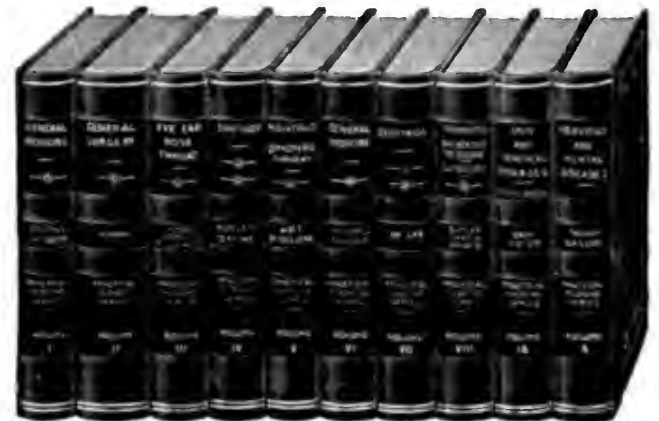

ORDER NOW ON APPROVAL

Beginnine in February, the volumes are publiahed at about equal intervals during tho year.

Represtuting, as it dues. the latest and most valuable research. nos of one man bu of all the workers in Medicise and Surgery cevery uhere, this series is nre-eminently the best literature to be found in medl cal book form.

To do the best work of which he is capable, it is essential for the physician to have a complete and ready means of access to all that is most recent in the development of his jrofession.

In the ten 12mo volumes comprising the 1914 Practical Medicine Series, the publishers offer a complete and permanent record of the recent advance in every department of Medicine and Surgery-systematized, and edited in the most able and authoritative manner.

EVERY SOURCE OF INFORMATION IS UTILIZED. The important character of the text, jts practical arrangement, with all on one subject in one place in one volume, each volume indexed, the low cost and convenient method of publication-make the Practical Medicine Series invaluable to cuery prac. titioner.

The books are printed in large, clear type on a fine quality of paper, are well illustrated, and hand somely bound in cloth. Each volume is on a different subject and brought practically up to date of publication.

The cost of the complete series of ten volumes is but $\$ \mathbf{1 0 . 0 0}$, payable $\$ 1.00$ each time a volume is delivered.

Sign the CONDITIONAL ORDER COUPON, noting terms, and mail it to us and we will be pleased to send Volume I as soou as published ON APPROVAL.

\section{SUBJECTS, EDITORS, AND ORDER OF PUBLICATION}

GEN ERAL MEDICINE (Seetion 1). By Frank Hitlings. M.S. M.I., Protessor of Medicine, Rush Medical Collexe; GENERAL 8URGERY. BY John B. Murphy. A.M. M.I). L.L.D., Yrotessor and llead of the bepartment ol Surgerys EYR, EAR. NO8E AND THROAT. The Eye, by Casey A. Woot. C.M., M 13. W.C.L., Consultimz Oshehalmol.

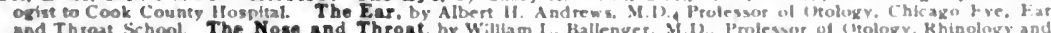

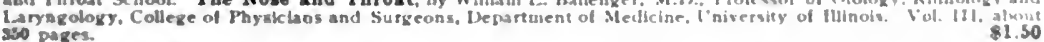

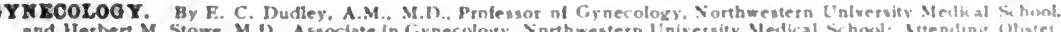

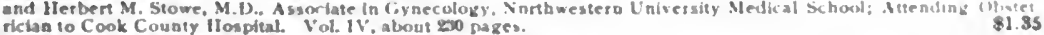
EDIATICS AND ORTHOPEDIC STROERY. Pediatri

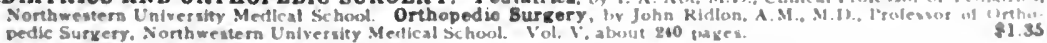

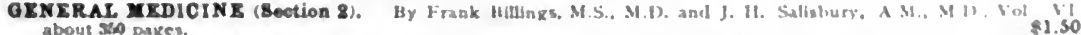

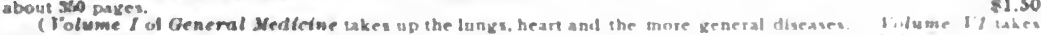

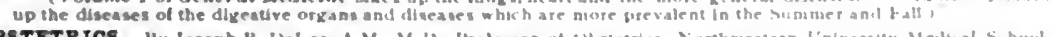

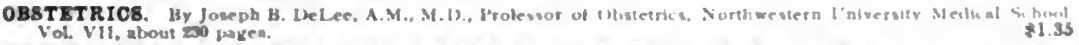
MATERIA YEDICA AND THERA PEOTICS. PREVENTIVE MEDICINE. Malerta Medica and Therapeutica.

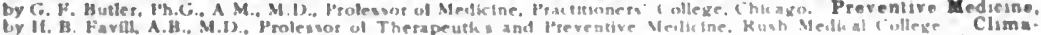

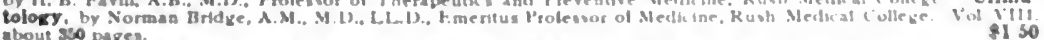

BXIN AND VENEREAL DISEABES AND KISCELLANEOUS TOPICS gkin and Venermal, by W 1 .

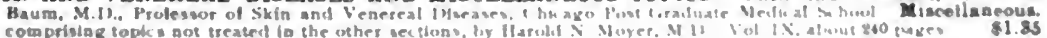

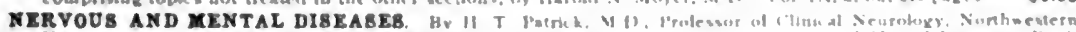

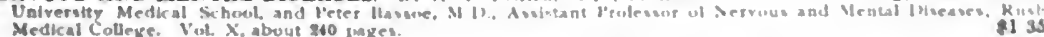
Cedicar colis 1 is

PRICE FOR COMPLETE SERIES (CARRIAGE PAID), \$10.00

The Year Book Publishers, Chicago

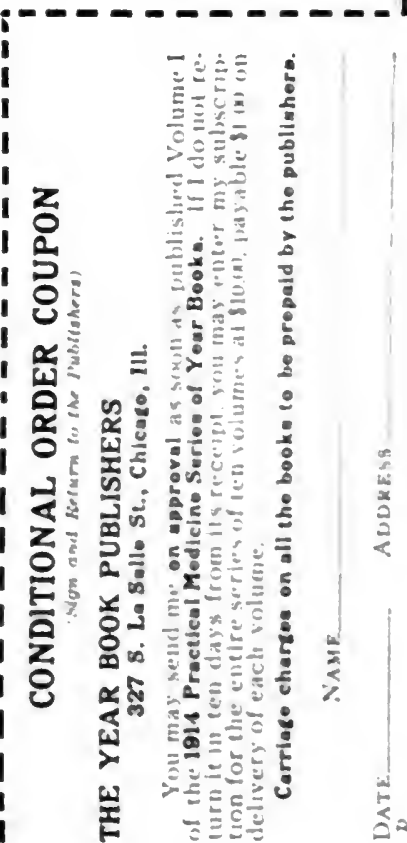




\section{PHYSICIANS'PURCHASING INDEX}

\section{ABDOMINAL SUPPORTERS}

Aloo Co., A. S..................... 122 Ambulatory Pneumatic Splnt Mtf. Co.. 9

Bolen Mig. Co.

May, Berthe.

C.m. IIs

McDermott Surgleal Instrument (o..... 123

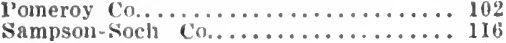

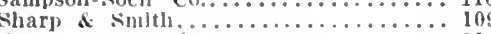

spencer supportiug Corsets............ 11

Storm, Dr. Katherine L........... 118

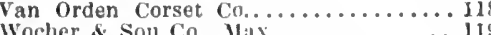

ABSORBENT COTTON

Betz Co., Frank S. .

Johnson \& Johnson...

$$
\text { ACCOUNTING SYSTEMS }
$$

McCaskey Reglster Co............ 123 ADDRESSING COMPANIES

lkupld Addressing Machine Co........ 106 ADJUSTABLE SPLINTS

Ambulatory Pneumatic splint Meg. Co.. 99 Melnecke \& $\mathrm{Co}$.

\section{ADVERTISING SERVICE}

Cooperative Medical Advertising Bureau 124 Itapld Addressing Machine Co........ 106 AIR COMPRESSORS

Jaeckh Meg. Co................. 97

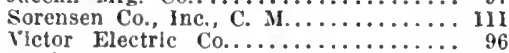

Wocher \& Son Co., Max.............. IY9 AIR MOISTENERS

Savo Mfg. Co.................. 122

\section{AMBULATORY SPLINTS}

Ambulatory Pneumatic Splint Mfg. Co.. 99 ANALYTICAL LABORATORIES

American Laboratories............ 46 Columbus Medical Jaboratory......... 45 National Pathological Laboratory...... 1

Tonney \& Graves, Drs............... 46 ANATOMICAL MANIKINS

Betz Co., Frank S............... 94

\section{ANESTHETIC APPARATUS}

Dressler-Beard Mfg. Co............. I28A

AcDermott Surgjcal Instrument Co..... 123

Sorensen Co., Inc., C. M............ III

\section{ANESTHETICS}

Powers-Weightman-Rosengarten Co.... 84
Schleffelin \& Co.......... Inside Back Cover

ANIMALS FOR INOCULATION TESTS

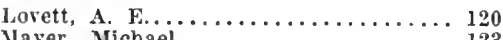

Mayer, Michael.................... 123

ANTIQUARIAN BOOK DEALERS

login \& Son, B.............. 45

\section{ANTI-SKID TREADS}

Leather Tire Goods Co............. 104

Triple Tread Mfg. Co............... 119

\section{ANTITOXIN AND SERUMS}

Fritzsche Bros. (Pollantin).

Mulford Co., II. K................. 84

National Vaccine \& Antitoxin Institute r 125

schieffelin \& Co.......... Inside Back Cover

Sherman, Dr. G. H................ I07 ARCH FITTING MACHINES

SHuIl Mfg. Co............... 101

ARTIFICIAL ARMS WITH RUBBER HANDS

\section{ARTIFICIAL EYES}

Alne Co.. \&.$\ldots \ldots \ldots \ldots \ldots \ldots \ldots \ldots 122$ ARTIFICIAL LIMBS

Aloe Co., $\downarrow$ S................... 122
Betz Co., Frank S.

Erlckson Artlficlal Ljub Co., k. î...... rel Fisk \& Amold.................. 113 Marks, A. A.................... 91

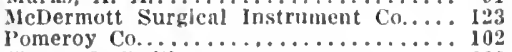

Sharp \& smith.

Wlnkley Artlficlal Limb Co............. 109 ARTIFICIAL LIMB SOCKS

Marks, A. A................. 9 I ARTIFICIAL NOSES, EARS AND MASKS Aloe Co., A. S................ I22

ASBESTONE SANITARY FLOORING

Nuller \& Co., Frankiyn H.......... 108 ATOMIZERS AND NEBULIZERS

Betz Co., Frank S.............. 94 De Vlibiss Manufacturing Co........... 122 Jaeckh Manufacturing Co.......... 97 Kiflough, Charles H. ........... I07 Wetmore Co., S. H.................. II

AUTO ACCESSORIES AND SUPPLIES

Atlas Auto Supply Co.- "Tire-Doh".... 105 Leather Tire Goods Co................ 104 AUTOMOBILE ANTI-SKID

Leather Tire Goods Co.............. 104 AUTO BATTERIES

Ajax Battery Co............... 82 AUTO TIRE PROTECTORS

Leather Tire Goods Co............ 104 Triple Tread Mfg. Co................... 119 AWNINGS AND TENTS

Cabinet Manufacturing Co.......... I15 BACTERIOLOGICAL APPARATUS

Castle Co., Wilmot............... 93

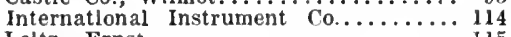
Leltz, Ernst.................. 115

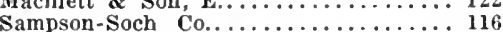

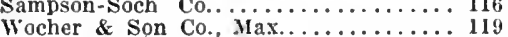
BACTERIOLOGICAL INCUBATORS

Leitz, Ernst........................

BACTERIOLOGICAL LABORATORIES

American I aboratories........... 4

Columbus Medical Laboratory........... 4

Mulf ord Co., H. K.

Natlonal Pathological Jaboratory......
Pacific Wassermann Laboratories......

Tonney \& Graves, Drs..............

BACTERIOLOGICAL PREPARATIONS

Sampson-Soch Co.............. 116

Sherman, Dr. G. HANDAGES

Johnson \& Johnson.............. 86

\section{BATH CABINETS}

Betz Co., Frank S............... 94

\section{BATH ESTABLISHMENTS}

Vittel, Vosges, France..............
Wolfe, H. P..................

Wolfe, H. P.................
BATTERIES

Ajax Battery Co...

McIntosh Battery \& Optical Co........ 107

Sharp \& Smith...............

\section{BED PANS}

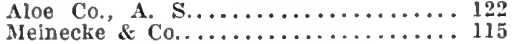

\section{BED SHEETING}

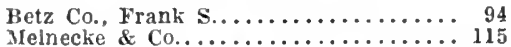

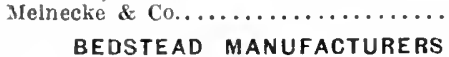

Amerlcan Bed Co................. 120 BIERS CUPPING APPLIANCES

Betz Co., Frank S............... 94 Sorensen Co., Inc., C.ii .............. III

\section{BLOOD-PRESSURE APPARATUS}

Aloe Co., A. S..................... 122

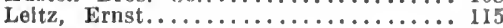
BOOKSELLERS

Blakjston's Son \& Co., P....

Chlcago Medileal Book Co.............

Forbes \& Co.................. 15

Lea \& Feblger. Ieft Hand Front Fnd Sheet

Ijpplncott Co., J. B............ 9

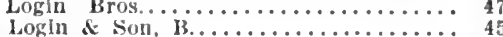

Iacmillan Co.................. I5

Rebman Co..................... 13

Saunders Co., W. H.............5, 6,7

Southworth $(0, \ldots \ldots \ldots \ldots \ldots \ldots \ldots \ldots$.

Year Book publlshers.................. I1

\section{BRACES}

Ambulatory Pneumatlc Splint Mifg. Co.. 99

IcDermott Surg. Inst. Co............ 123

Mueller \& Co., V................... I 24

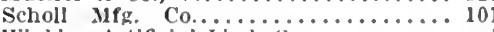
WInkley Artjflelal Limb co........... 1 BRONCHOSCOPES, GASTRO.
SCOPES, ETC.

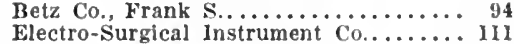
BRUSHES

Hygienic Brush Co............... 122

CASE AND ACCOUNT RECORDS

McCaskey Register Co............. 123 CASES AND BAGS

Betz Co., Frank S............... 94 CATGUT-STERILIZED

Johnson \& Johnson.............. 86 Meinecke \& Co....................... 115 Sampson-Soch Co...................... II Van Horn and Sawtell............... 92

CATHETERS AND BOUGIES

Betz Co., Frank S.............. 94 Johnson \& Johnson............... 86

\section{CAUTERY TRANSFORMERS}

Betz Co., Frank S.............. 94 Electro-Surgical Instrument Co............ III Sorensen Co., Inc., C. M............. 111 Victor Electric Co.................... 96 CENTRIFUGES

Betz Co., Frank S.............. 94 International Instrument $\mathrm{Co} . \ldots \ldots \ldots \ldots 114$

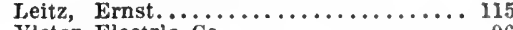

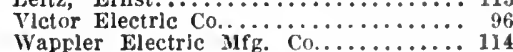
Wappler Electric ifg. Co.......................

Wetmore Co., S. IH............... 119 CESSPOOLS ELIMINATED

Archer, George F.................110 CHAIRS-INVALID AND SURGICAL

Aloe Co., A. S................. 122

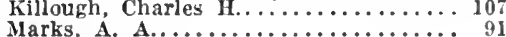
CHARTS AND MANIKINS

Betz Co., Frank S................ 94

Rebman "Co...................... I CHEMICAL APPARATUS

Machlett \& Son, E.............. 122 CHEMISTS-ANALYTICAL AND
CONSULTING

American Laboratories............. 46

American Medical Assocjation............ 98

Columbus Medical Laboratory.......... 45

Natlonal Pathological Laboratory......

Tonney \& Graves, Drs................ 46 CHEST PROTECTORS

Betz Co., Frank S................. 94

CLINICAL RECORD SYSTEMS

Chicago Medical Book Co........... II McCaskey Register Co.................. 123 


\section{REBMAN NEW YORK \\ Telephone: 619 Greeley
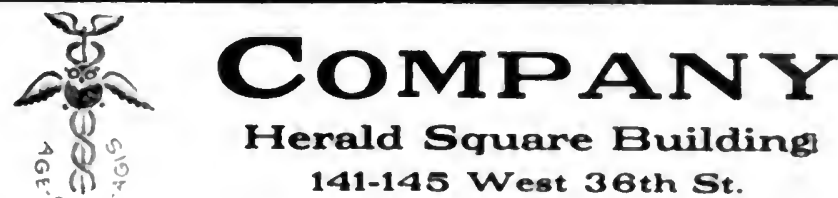 \\ Herald Square Building 141-145 West 36th St.}

Gold Medal Awarded by XVII International Congress of Medicine, London, August, 1913 ALL PREVIOUS PRICES ARE HEREWITH CANCELLED. ALL BINDINGS ARE CLOTH, UNLESS OTHERWISE STATED

\section{ANATOMY}

BARDELEBEN and HAECKEL-Applied Anatomy

\section{BLOOD}

EHRLICH-Anemia-Many colored fllustrations.........\$54.00 SCHLEIP-Hematological Atias (colored plates).......... 5.00 BRAIN

KRAUSE-Surgery of the Brain-With 199 (17 of which are in colors) lllustrations in the text, 122 flgures on 60 plates in colors and 2 halftone plates-over 1,200

pares: 3 volumes, artiflclal leather............\$20.00

TANZI $A$ A Text-Book of Mental Diseases............. 7.00

\section{DIAGNOSIS}

ABRAMS-Diagnostio Therapeutios-Illustrated.

ADAM-Oohthalmosoogic Diagnosis.

BiNG-Regional Diagnosis-lliustrated.

-One colored plate....... 4.00

\section{EAR}

BRAUN and FRIESNER-The Labyrinth .........\$4.00

KOPETSKY_Surgery of the Ear................\$ 4.00

\section{ELECTRICITY}

BRUCE-A System of Radiology.

CLEAVES-Light Energy.

FREUND-Radiography-Latest issue

GUILLEMINOT-Eleotricity in Medioine.

JUDD - X.Ray and High Frequeney.................

STRONG-High Frequency Currents.

STRONG_Modern Electro-Therapentics Ill......... 3.00

EYE

ADAM-Ophthalmosoopio Diagnosis.............\$ 6.00

GREEFF-External Diseases of the Eye.............. 10.00

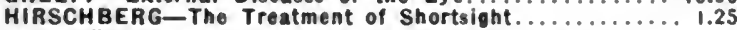

NEUSTÄTTER-Skiascopy-Phantoms and Dtagrammatical

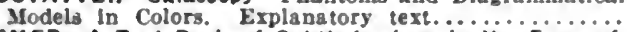

ROEMER-A Text-Book of Ophthaimology in the Form of

Clinical Leetures-186 black and white fllustrations in

the text and 58 flgures in colors; 896 pages.

\section{FOOD}

CARRINGTON-Vitality, Fastiag and Nutrition.

COMBE-Intestinal Auto-intoxioation.

GOULEY-Dining and its Amenities.

GOURAUD-What Shall I Eat?

GUELPA-Auto-Intoxioation and Disintoxication

WEGELE-Therapeutics of the Gastro-Intestinal Traet.

\section{GENITO-URINARY}

GOULEY - Surgery of Genito. Urinary Organs.

HÜHNER-Sterility in the Maie and Female and its

OPPENHEIMER - Practical Points in Gonorrhea............ 1.00

RUMPEL - Cystoscopy - 108 Illustrations-half foather.... 5.00

\section{GYNECOLOGY}

BLAND.SUTTON-Diseases of Women.

JOLLY-Misrosoople Diagnosis in Gynecology.

KISCH-The Sexual life of Woman-lllustri........

MARTIN and JUNG-Pathology and Therapy of the Dis

eases of women.

\section{HISTOLOGY}

KRAUSE (Rudolf)-Normal Histology, Including Mioro.

seopieal Anatomy. Part 1.75 oents: Part 2....... $\$ 5.00$ HYDROTHERAPY

DIEFFENBACH-Illustrated

HYGIENE

SENATOR-KAMINER-Health and Disease in Relaiton to

Marriage and the Married State. .

HYPNOTISM

FOREL-Hypnotism and Sugpestion...

\section{MICROSCOPY}

JOLLY-Miorosoopio Diagnosis in Gynecology........... 55.00 KLOPSTOCK and KOWARSKY $\rightarrow$ Clinloal Chemistry, "Mi.

\section{MISCELLANEOUS}

BIER-Hyperemia-Latest Edition..............\$\$.00 BJÖRLING-Briquettes ........................... 35

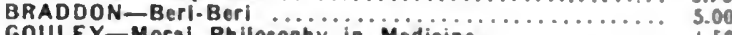

GOULEY - Morai Philosophy in Medioine.............. 1.50

KILNER-Tho Human Atmosphere. or the Aura made Visible by the Ald of Chemieal Sereens-Illustrated. Book (cloth) separate, \$2.00. Screens separate, $\$ 2.50$. 4 Casobooks separate, 50 cents. Book, Screens and i Casebooks together.

M'BRIDE-Alooholism and Drüg Narootism.......... $\$ .00$

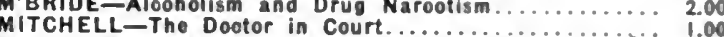

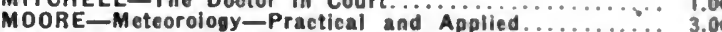

WACHENHEIM-Climatio Treatment of Children.......... 1.30

WAITE-Tho Seoret Tradition in Freemasonry and an Analysis of the inter-Relation Between the Craft and the High Grades in Respect of Their Term of Research. Expressed by the Way of Symbolism-2 rolumes, edition du luxe, 28 Pull-page plates and many IIIustratlons in the text; gllt top................... 14.00 WHITBY_Makers of Man-lllustrated............. 3.00 W00DRUFF-EXpansion of Races............... 4.00 WOODRUFF-Effects of Tropical Light on White $\ddot{M}$ en... 3.00

\section{NERVOUS SYSTEM}

BELOUSOW-Delineation of the Nervous System of the

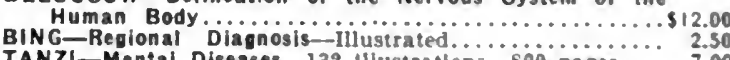
TANZI_Mental Diseases-132 Llustratlons- $\$ 00$ pages.... 7.00

\section{PERIODICALS}

Archives of the Roentgen Rays. Per annum............\$4.50

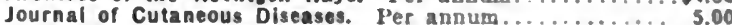
NEISSER-JACOBI-loonographia Dermatologica-Pör issue 2.50 PSYCHOLOGY

FOREL-The Sexual Question-illustrated. KISCH-The Sexual Life of WomanKRAFFT-EBING_Psyohopathia Sexualis. REED-Sex: Its Orisin and Determination............ 3.00

\section{SKIN}

BULKLEY_Skin and Internal Diseases. BULKLEY_Menstrual Funotion and Skin Disease......... 1.00

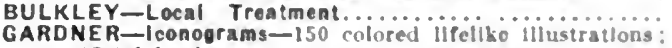
artificlal leather

KINGSBURY-Portfolio of Dermochromes-iliti leatior 3 volumes

PRINGLE-Pictoriai Atias. SABOURAUD-Rogional Dermatology-icis Edition

\section{SURGERY}

GOULEY-Surgery of Genito-Urinary Organs

KRAUSE-Surgery of the Brain-Arunclal leather ......20.00 PELS-LEUSDEN-Surgieal Operations......................... RUMPEL_Cystosoopy in Surgery-llaif leather........ 5.00

\section{SYPHILIS}

EHRLICH-Experimenta] Chemotherapy of Spiriloses ....\$\$.00 FOURNIER-Treatment and Prophylaxis of Syphilis ... $\mathbf{3 . 0 0}$ ZINSSER-Diseases of the Mouth-Syphilis and Similar Diseases

\section{THERAPEUTICS}

ABRAMS_Dlagnostic Therapeutics ............... 55.00 WEGELE-Therapeutics of the Gastro-intestinal Tract ... 3.00 THROAT AND MOUTH

BRUCK-Diseases of Nose and Throat........... $\$ 5.00$ MOURE-Larynx and Pharynx. ZINSSER-Diseases of the Mouth-52 colored slates..... 
CLINICAL THERMOMETERS

Randall-Falchney Co.............. 117 CLOTHING

Bernard, Hewltt \& Co..............116

CLOVER LEAF X-RAY TUBES

Green \& Bauer................. 109 COLLEGES

Undergraduate

Allanta Medical College.

Cornefl Unlv. Med. Coll. .

Dartmouth Medícal School.....

Georgetown Unlversity, School of Med. George Washington Univ., Med. Dept. Harvard Med. School.

IIoward University, Sch. of iled......................

Johns Hopklns University Med. School.

Stanford Unlversity Med. Dept........

stadico-Chirurersel Coll of phliadeiphia

Northwesteru Unfr.

ohio State Unirersity, Coliege of ied.

Rush Medical College.

Univ. of ClncInnatl College of ifedicine

St. Louis University, School of Mediclne

Syracuse Univ. Coll. of Med....

Tufts Coll. Nedical School.

Tulane University of La., Med. Dept.

Unlv. of Alabama, Med. Dept. .

Univ. of Buffalo, Med. Dept.

Univ, of Cincinnati, Med. Dept.

Univ, of Inimois Coll. of Medicine.

University of Louisville, Med. Dept.

Unirersity of Louisville, Med. Dept...

Univ. of Milchigan, Dept. of M. \& S
Univ. of Nebraska, Coll. of Med..

Inlv. of North Dakota, Sch. of Ned...

Univ. of Oregon, Med. Dept.

Univ. of Pennsylvania, school of Yied..

Vinis. of Pittsburgh, Sch. of Med.

Unlr. of Vermont, Coll. of Med.

Univ. of Vtrginla, Med. Dept.......

Washington University, Med. Sch.......

$$
\text { Postgraduate }
$$

Chilcago Policlinic.......................

IIarvard Graduate Sch. of Med..........

Post-Gr. Med. Sc. and Hosp. of Chicago

Post-Gr. Med. Sc. and Hosp. of Chicago
Philadelphía Pol. \& Coll. for G. in Med.

Philadelphí Pol. \& Coll. Por G in Med.
Pent. Ortho. Inst. and Sc. of Mechano. COMPOSITION FLOORS

Muller \& Co., Franklin R........... 108 COMPRESSED AIR OUTFITS

Jaeckh Mrg. Co................. 97 CORK LEGS

Betz $\mathrm{C}_{0}$, Frank $\mathrm{S} . . \ldots \ldots \ldots \ldots \ldots \ldots ., 94$ CORKS

Betz Co., Frank S....... CORRECTIVE FOOT APPLIANCES

Larson, Martin................... 112

\section{CORSETS AND SHOULDER BRACES}

Ambulatory Pneumatlc Splint Mifg. Co. 99

Betz Co., Frank S.................. 94

Betz Co., Frank
Gossard Co., H. W......................

Gossard Co., H. W.................. 100

Pomeroy Co.

Spencer supporting Corsets............. 118

Storm, Dr. Katherine L.............. 118

Yan orden Corset Co................ 118 CRUTCHES

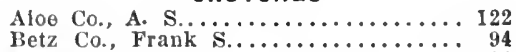
Marks, A. A..................... 91 CRUTCH RUBBERS

Marks, A. A..................
CUSPIDORS

Betz Co., Frank S.............. 94

CYSTOSCOPES, URETHROSCOPES, ETC.

Betz Co., Frank S.............. 94 Electro-Surgical Instrument Co........ III Wappler Electric Mfg. Co............. II DEFORMITY APPAR. AND APPLIANCES Aloe $C 0 .$, A. S................... 122

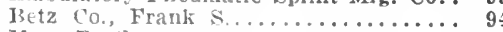
May, Berthe......................... 118

Mueller \& Co., Vi.
Pomeroy Co..

Sharp \& Smith.............

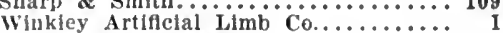

Wocher \& Son, Max................... 119

Zleman, Fred....................... I13 DENTAL SPECIALTIES

Johnson \& Johnson.............. 86 DESK LIGHTS

Wolff Co., whillam F.............. 120 DESKS

Betz Co., Frank S................ 94

DIAGNOSTIC INSTRUMENTS ELEC. TRICALLY LIGHTED

Betz Co., Frank S.

Cramer Dry plate Co. G................

Electro-Surgical Instrument $\mathrm{C} 0 . . \ldots \ldots \ldots$ III

Meyrowitz, Inc., E. IB............... 114

Wappler Electric Mig. Co............. II DICTIONARIES

Merrlam Co., G. \& C............ 82 DIETETIC PRODUCTS

Arend Drug Co., A.............. 89

Horlick's yalted yilk Co.................

Mellin's Food Co

Waukesha Health products $\mathrm{Co} \ldots \ldots \ldots \ldots$ 4

\section{DISINFECTING AND SANITARY} APPARATUS

Betz Co., Frank S.

DISINFECTORS-STEAM PRESSURE American Sterllizer Co............. 117 DISPENSING UTENSILS

Betz Co., Frank S.................. DISTILLING SYSTEMS

Polar Water Still Co.............. 82 DRYING OVENS

Castle Co., wilmot............... 93 DRAINAGE TUBES

Van Horn and Sawtell.............. 92 EAR MASSAGE PUMPS

Sorensen Co., Inc., C. M........... 111 Victor Electric Co.................. 96

ELASTIC HOSIERY AND SUPPORTERS Aloe Co., A. S.................. ${ }^{122}$ Johnson " \& John S.

.

rument Co....... 123

Pampson-Soch Co....................... $102_{116}$

Sharp \& Smith...................... 109

Wocher \& Son Co., Miax............... 119

ELASTIC WEBBING FOR SURGICAL APPLIANGES

Marks, A. A................... 91

\section{ELECTRICAL APPARATUS}

Aloe Co., A. S. . $\ldots \ldots \ldots \ldots \ldots \ldots \ldots \ldots, 122$ International Instrument $\mathrm{Co} . \ldots \ldots \ldots \ldots \ldots$ II3 Killough, Chas. H............. 107 Macalaster-Wiggin Co................ 112 McIntosh Battery \& Optical Co.......... 107 Meyrowitz, Inc., E. B................. 114 Prometheus Electric Co............... 122 Scheldel-Western X-Ray Coil Co........ 95 Scheldel-Western
Shelton Electric Co.................. 123 Sorensen Co., Inc., C. i................ 111 ELECTRIC FANS

Hamllton-Beach Mfg. Co............. 115 ELECTRIC HEATERS

Hamilton-Beach Mfg. Co............. 115 ELECTRIC MOTORS

Victor Electrlc Co......................

Hamilton-Beach MPg. CO........... 115 Shelt on Eiectric Co.................... 123

ELECTRO-CAUTERY APPLIANCES

Electro-Surgical Instrument Co....... 111

Victor Electric Co................... ${ }_{96}$
ELECTRODES

KesselrIng X-Ray Tube Co........... 110 ELECTROTHERAPEUTIC AND DIAG. NOSTIC APPLIANCES

Betz Co., Frank S................ 9 Brady \& Co., Geo. W................ 121 Carliczek \& Co., O.................. 117 Doehren Co., John V................ 112 Electro-Surglcal Instrument Co....... I11 Green \& Bauer.................. 109 Mclntosh Battery \& optical Co........... 107 McIntosh Co., John, The............. 119 Meyrowltz, Inc., E. B............. 114 Scheldel-Western X-Kay Coll Co..... 95 Sharp \& Smlth................... 109 Vharp \& Smith ....................... ${ }_{96}$ Walte \& Bartiett $\mathrm{Mif}$. Co............... 120 Wappler Electrlc Mfg. Co............. 114 ELECTRO-THERAPEUTISTS

Penna. Or. Inst. \& Sch. of Mech. Ther. 40

ENAMELED INSTRUMENT TABLES

Aloe Co., A. S.................. 122 ENDOWMENT INSURANCE

Postal Llfe Insurance Co............ 19

EYE, EAR, NOSE AND THROAT INSTRUMENTS

Aloe Co., A. S.................... 122 Hardy Co., F. A.................. 106 Pfau, H................... 84 Lleberknecht \& Fraass............. 84 Meyrowitz, Inc., E. B............. 114 EYE GLASSES

Hardy \& Co., F. A................ 106 EYE MAGNETS

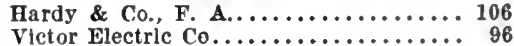
FARADIC BATTERIES

Betz Co., Frank S............... 94 FINSEN LAMPS

Betz Co., Frank S.............. 94 FIRE PROOF FLOORS

Muller \& Co., Franklyn R........... 108 FIRST AID SUPPLIES

Johnson \& Johnson................ 86 FLAT-FOOT BRACES Aloe Co., A. S................... 122

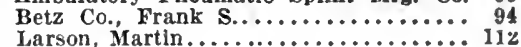
Scholl Mff. Co...................... 101

$$
\text { FLOORS }
$$

Auller \& Co., Franklyn R........... 108 FLOOR LAMPS

Wolff Co., Will lam F............. 120 FLUOROSCOPES

Kesselring X-Ray Tube Co.......... 110 FOODS

Infants and Invalids

Arend's Kumyss.................. 89 Benger's Food Co., Ltd............. 29 Heinz Co., H. J. J.............. 127 Mellin's Food Co.................. Diabetic

Waukesha Health Products Co...... 89 FURNITURE EXCHANGE

Physlclans' Furniture Exchange....... 107

GALVANIC, FARADIC AND SINUSOIDAL MACHINES

Wappler Electric Mfg. Co............ II GENITO-URINARY INSTRUMENTS

Dugan-Johnson Co............... I17 GLASS \& BRASS SIGNS

Abram Co., Abe................. 122 GRINDERS OF SURGICAL INSTRUMENTS Aloe Co., A. S.................. 122 GUINEA PIGS

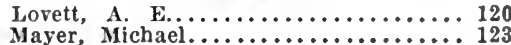




\section{The Standard Books on Sex Education}

\author{
BY DR. E. B. LOWRY
}

CONFIDENCES: Talks with Y Young Girl Concerning Heraelf. 50 cents.

TRUTHS: Talks with Boy Concerning Himself. 50 cents. HERSELF: Talks with Women Concerning Themselves. \$1.00. HIMSELF: Talks with Men Concerning Themselves. \$1.00. FALSE MODESTY: That Protects Vice by Ignorance. 50 cents.

Physicians are being consulted more thanever for books on sexual hypiene. Do you realize that the only books on the subject which have been endorsed by the entire medical press are the notable books by Dr. E. B. Lowrs Ther meet every requirement and avoid the objections made to all other books on the subject The auther is a made to allother books on the subject. will be glad to oun these books and "ou will wiu gratitude from your patients for recommending them.

"Dr. Lowry's books are excellent and can be safel recommended."-The Jowrnal of the American lledical Association.

"Every physician should read and circulate the lowry books. "-Journal of Therapeutics.

"Dr. Lowry's 'Herself" should be recommended by physiclans to all their female vatients." - The Lunct-Clinic.

For sule by all booksellers or supplied by the publishers

FORBES \& CO., 443 Dearborn St., Chicago, Ill.

\section{Practical Monographs}

Diseases and Deformities of the Foot Diseases of the Rectum

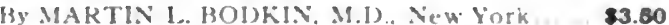

Surgical Diseases of Children

By SAMUEL W. KELLEY II D. $2 d$ Ed. $\$ 5.00$

New Aspects of Diabetes

B5: PROF. CARL, von YOORDE.', Vienna ......s1.80

The Diagnosis of Nervous Diseases By 'URVES STEW'AR'T. M.D. Ldinburgh......84.60

The Blood-Its Examination and Diagnosis of Diseases

By GUI,LAND and GOODALI..

86.00

Bacterial Food Poisoning

By PROF. DIEUDON.NE. Trans, by DR. CHAS.

F. BOL,DUAN, New York ............ $\$ 1.00$

1914 International Medical Annual Review of the world's progress for the pass year.. $\mathbf{\$ 3 . 6 0}$

See listings in Physicians Purchasing Inites. Send for neze medical cafaliog.

E. B. TREAT \& CO. 241-243 W. 23d St., New York

Publiahers of Medical Books and the Pracllcal Journal en Dlaenaes af Chindres.

\section{Macmillan's International Monographs}

Offer You in Compact Form

The Results of Late Research

By Leading Authorities

IN MEDICINE, SURGERY AND ALLIED SUBJECTS

Send for Medical Catalog of

\section{THE MACMILLAN COMPANY}

64 and 66 Fifth Ave.

NEW YORK 


\section{HAY FEVER ANTITOXIN}

Fritzseho Bros. HEALTH RESORTS AND CONVALES CENT HOMES

Arrowhead Hot Springs

Gien Springs. The.

lirandview sanatorium.

Mount Clemens Sanita

Mount Clemens Sanitarium Co...

Nauheim Sanitarium .......
North Shore Health Resort.

"Orth-the-Hill" Health Resort.

"On-the-Hill" Health Resort

Vittel Health Resort

Waldheim Park.

White Sulphur Springs

\section{HEATING PADS}

Betz Co., Frank S..

HIGH FREQUENCY APPARATUS

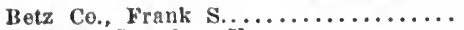

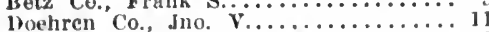

McIntosh Battery \& opticai Co.......... 107

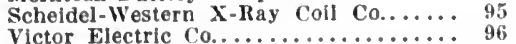

Wappler Electric iff. Co............... I1

HOMES, HOSPITALS AND SANITARIA Alouholic and Vureotic

Ariington Heights Sanitarlum, Ft. Worth Bancroft Sanitarium...

Barnes Sanitarium, Dr.

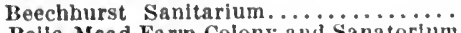

Belle Mead Farm Colony and Sanatoriun

Board's Sanatorium, Dr

Broadoaks Sanatorlum.

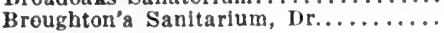

Bushhill Sanatoritwn.

Case's Sanitarium. Dr.

Corbett's Sanitarium, Dr.

Fisk Hospital. .

Grandvtew Sanitarium, Cincinnati, 0

Grandvlew Sanitarium, Kansas City,

lian.

"Green Gables"

Highland Hospitai.

Lau-Gordon Clinics.

IIcFarland's Sanitarium, Dr....

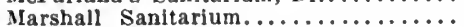

Moody's Sanitarium, Dr. George II...

North Shore Health Resort...........

"Norways" Sanatorium.

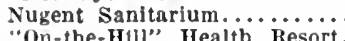

Pearson Home.

Pennoyer Sanitarium, The.

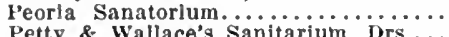

Petty \& Wallace's San

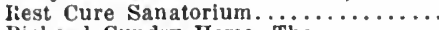

Pichard Gundry Home, The...........

River Crest Sanita

St. Mary's Hlll..........

Town's Hospital, Charles B..........
Westbrook Sanatorium............ 56

Wilgus' Santtarlum, Dr.

$$
\text { Epileptic. }
$$

"Norways" Sanatorium.

$$
\text { Nervous and Mental }
$$

Arlington Heights Sanitarium, Ft. Worth

Balley Sanaterium Co., Dr. Benj. F....

Bancroft Sanitarium.

Barnes' Sanitarium, Dr

Belle Mead Farm Colony and Sanato....... Board's Sanatorium, Dr.

Broadoaks Sanatorium.

Broughton's Sanitarium, Dr.

Bushhill Sanatorium

Creighton Sanitarium.

Falr Oaks

Falr Oaks viil

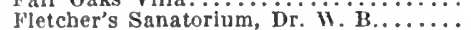

Grandview Sanitarium, Kansas City,

kan..............................

"Gruen Cables"...............

litury Santarium.

llerbert Itall hospital.

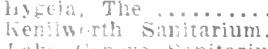

lat-cordon clinies.....

Mcroddy' IInspital-shool, ib.
Mclariand's Sanitarium, Dr....... 76

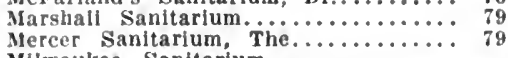
Milwaukee Sanitarium.

Facing Third Cover Page Moody's Sanitarium, Dr. George H.....6. Norbury Sanatorlum Co....

"Norways" Sanatorium.

Nugent Sanitarium.

tok Grove Hospital.

Oak Lawn Sanatorluin.

Oakwood Retreat Association.

Oconomowoc Health Resort, The.

On-the-Hill Health ltesert.

Pennoyer Sanitarlum

l'eople's Jiospltal........

Pettey \& Waliace's Sanitarlum, l)rs... 58

Punton Sanitarium, The.

Rest Cottage.

Rest Cure Sanatorlum.

Rlchard Gundry Home, The

Biver Crest Sanitarlum.

Sawyer Sauatorlum, The.

St. Mary's IIIll

Telfalr Sanitarium, The.

Waldheim Park..........

Waukesha Springs Sanitarium.

Westbrook Sanatorium

Dinbetic and Bright's Distase Still Rock Spa.

$$
\text { Nervous-Only }
$$

Corbett's Sanitarium, Dr...........

Creighton Sanitarium.

\section{Educational}

Bancroft Training School.

Belle Mead Farm Colony and Sanatorium Gary de Vabre Academy.

Herrick Home Sch. for Bkwd. Child..

Mfcready's Hospital-School, Dr.......

"Norways" Sanatorium.

"Oak Letgh" Educationai Sanitarium.

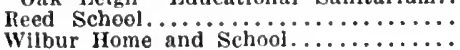

$$
\text { Gencrul }
$$

Arlington Hotel, Marlin Sanitarium and

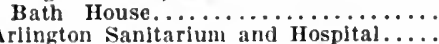

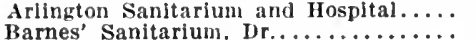

Battie Creek Santtarium............

Bushhili Sanatorlum ...................
Cincinnati General Hospital.......

Chicago Institute of Phystologic Thera-

peutics

corbett's sanitarium, $\ldots \ldots \ldots \ldots \ldots \ldots \ldots$

Davis' Infirmary, Dr. J. D. S.

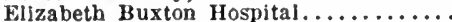

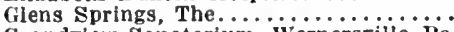

Grandview Sanatorium, Wernersville, $\mathrm{Pa}$

Grandview, The

"Green Gables"

Hygeia, The.

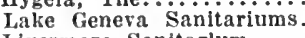

Livermore Sanitarlum.

Madison Sanitarium.

Margaret Wright Hospital.

Massachusetta General Hospital, The..

McDougall's Sanlt. Treat. Rooms.......

McNutt Hospital.

Meriweather Hosp. \& $\mathbf{T r}$. Sch. for Nur

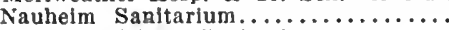

North Louisiana Sanitarium........

North Shore Health Resort.

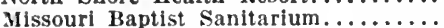

Mount Clemens Sanitarium Co.........

"Norways" Sanatorium.

Oak Lawn Sanatorium.

On-the-Hill Health Resort.

Pennoyer Sanitarium, The.

People's Hespital.

Rest Cure Sanatorium.

Sacred Heart Sanitarlum.

Scarlet Oaks Sanatorium.

St. Helena Sanitarium.

St. Luke's Hospital .......

Still Rock Spa.

Sugar Pine Hospital.......

Torbett Sanat., Majestic Hotel and $\ddot{B a t h}$ House

Vittel Health Resort.

Waldheim Park.

Walker's Sanitarium.

White Sulphur Springs.
Uateruity

Ariington Sanitarlum and IIospital.

St. Joseph's Maternity Hoapital and

Infant Asyium.................. 8

Mineral Baths aul Mlilo-Thripeutie

Arlington IIotel, Marlin Sauit. and Bath

llouse $\ldots \ldots \ldots \ldots \ldots \ldots \ldots \ldots \ldots \ldots . . . \ldots$

Bushhill Sanatorium ............ 80

Glen Springs, The

Mount Ciemens Mnerai Batis.

IIclougall's Sanit. Treat. Kooms.

Scariet Oaks Sanatorium...

Torbett Sanatorium.

Vittel Grande Source.

iphur Springs.

Suryiral and Golmerelogjical

Arlington Sanitarium and Irospital.

Davis Infirmary

Lake Geneva Sanitariums.

Madison Sanitarium, The

Margaret Wright Hospltal.......... if

Meriweather Hosp. Tr. Sch. for Nur.

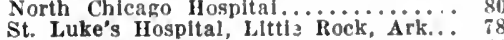

Valker's Sanitarium............. 6

$$
\text { Tulprentusis }
$$

Albuquerque Sanatorium.

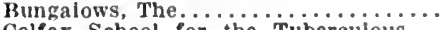

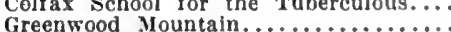

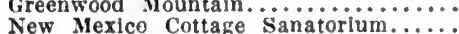

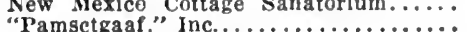

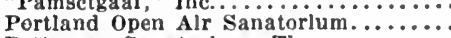

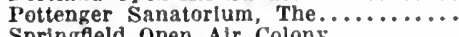

Springfleld Open Air Colony.............

Sugar Pine Hospital............... 81

Winter Resorts

Arrowhead Hot Springs..............

Horlick's Malted Milk Co............ HOSPITAL CALL SIGNALS

Chicago Signal Co.................

HOSPITAL EQUIPMENT

HOSPITAL FURNITURE

Aloe Co., A. S................. 122

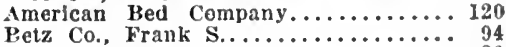

Cole \& Cole..................... 82

Killough, charles H.............. 107

MicCray Refrigerator Co............ 120

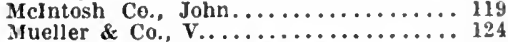

Mueller \& Co., V.............................. 107
Phystclans

Scanlan-Morris Co................. 120

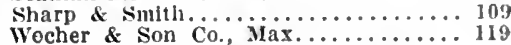
HOSPITAL SUPPLIES

Aloe Co., A. S................... 122 Ambulatory Pneumatic Splint iffg. Co. 99 American Ironing Machine Co......... 113

Brady \& Co., Geo. w...................... 121

Castle Co , Vilmot................ 93

Chicago Signal Co C. $_{\ldots} \ldots \ldots \ldots \ldots \ldots 114$

Draeger Oxygen Apparatus Co........ 91

Dressier-Beard Mfg. Co............ 128A

Huston Bros. Co.................. 108

Hyglenic Brush Co............. 122

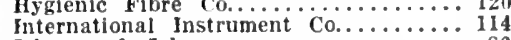

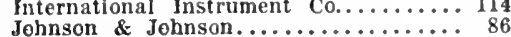

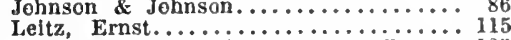

McDermott Surgicai instrument Co......

McIntosh Co., Jolu............. 119

May, Berthe ................ 118

Melnecke \& Co.............. 115

Mller Rubber Co.............. 103

Muller \& Co.. Frankiyn R.............. 108

Prometheus Electric Co............ 122

Randall-Faichney Co............ 117

Sargent's Drug Store............... I 22

Savo IIf. Co....................... 122

Scheidel-Western $\ddot{x}$ - $R$ ay Coil Co...... 95

Sharp \& Smith..................... 113

Victor Electric Co.................. 96

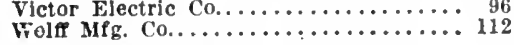
sterilizers-Disinfectors

American Sterilizer Co............117 

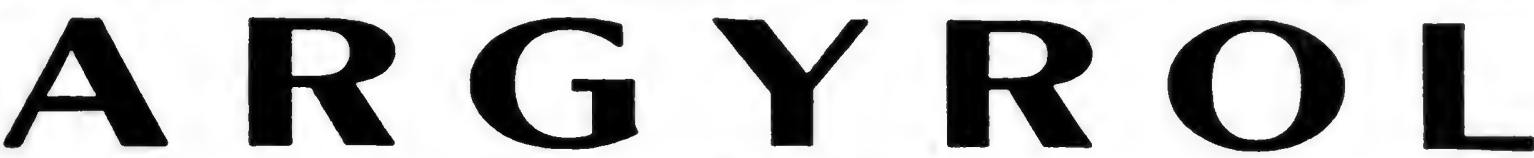

(SILVER VITELLIN)

Has the property of allaying pain and other symptoms of inflammation.

Incidentally, its effects in eradicating germ-produced diseases has been proved Clinically by authorities, in thousands of cases during the past twelve years.

These facts explain why Argyrol is considered, the world over, a superior remedy in the treatment of gonorrhea (injection of 10 per cent. solution every three hours); also in inflammations of the eye, throat, nose and ear ( 25 per cent. solution instillation or local application).

Produced by

\section{A. C. BARNES COMPANY}

LONDON

PHILADELPHIA

SYDNEY

\section{IF IRON IS INDICATED}
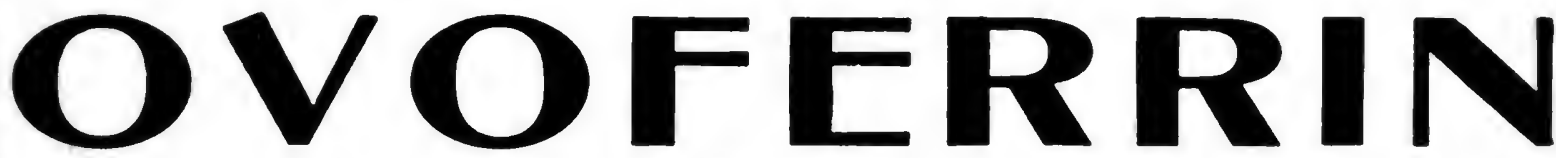

(See description "Niow and Nonoflcial Remedies.")

should be prescribed, because it has well-defined general tonic properties and does not disturb digestion or produce constipation.

Ovoferrin acts quickly in building haemoglobin and red blood cells.

Indicated in anaemia, malnutrition and nervous exhaustion.

Ovoferrin is furnished by druggists, on prescription, in twelve ounce bottles. The dosage is one tablespoonful in wine-glass of water or milk three times daily.

Produced by

\section{A. C. BARNES COMPANY}




\section{HOSPITAL UNIFORMS}

Betz Co., Frank S............... 94 HOSPITALS

(See Ilomes, IIospltals and Sanitaria.) HOUSE DRAINAGE

Archer, George F................. 110 HYDROPHOBIA-PASTEUR TREATMENT Chlcago Pasteur Instltute........... 45 Mulford Co., II. K....................
HYDROTHERAPEUTIC APPARATUS

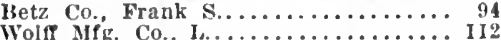
HYPODERMIC SYRINGES

Betz Co., Frank S................. 94 Johnson \& Johnson.............. 86 IRandall-Faichncy Co............... II Electro-Surgical Instrument Co....... II1 IMMUNIZING PREPARATIONS

Natlonal Vacclne and Antitoxin Institute 125 IMPORTERS MEDICAL BOOK

Rebman Company............... 13 INCANDESCENT LIGHT BATHS

Wolfe's System of Baths............ 106 INFANT FOODS

Arend's liumyss ............... 89

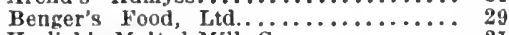

Horlick's Malted Milk Co............ 21

Mellin's Food Co................. 49 INSTRUMENT CABINETS

Wocher \& Son Co., Max............ 119 INSUFFLATION APPARATUS

Dressler-Beard Mfg. Co............ I28A INSURANCE

Physiclan's Casualty Assn. of America II3 Medical Protectlve Co.............. 3 Postal Life Insurance Co...........
INTENSIFYING SCREENS

Kesselring $\mathrm{X}$-Ray Tube Co.......... 110 INVALIO FOODS

Arend Drug Co., A...

Horlick's Mtalted Milik............... INVALID ROLLING CHAIRS

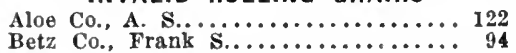

Marks, A A .............. 91

McDermott Surgical Instrument $\ddot{C o}_{0 .} \ldots{ }_{123}$

Sampson-Soch Co.................. 116

INVALID SUPPLIES

Medical and Surgical Supply Depot.... 116 KUMYSS

Arend Drug Co., A............... 89

LABELS AND PRESCRIPTION BLANKS

Medical and Surgical Supply Depot.... 116 LABORATORIES

American Laboratories............. 46

Columbus Nedical Laboratory....... 45

Pacific Wassermann Laboratorfes....... 46

Tonney \& Graves, Drs.............. 46

\section{LABORATORY APPARATUS}

Brady \& Co., Geo. W.............. 121

Cramer Dry Plate Co., G............ 121

International Instrument Co.......... 114

Leitz, Ernst........................ 115

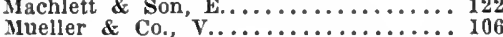

Sampson-Soch ' Co....................... 116

Wilmot Castle Co...................... 93

LAMPS, ELECTRIC, FOR DIAGNOSIS

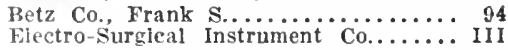
LAND DRAINAGE

Archer, George F.............. I10 LANTERN SLIDES

AUNDRY MACHINERY

an lroning Machine Co.........

LEATHER TIRE PROTECTORS

L.eather Tire Goods Co.............. 104 LEATHER GOODS

Detz Co, Frank

\section{LEDGERS}

Chicago Medical Book Co............ I1

LEGS, ARTIFICIAL ALUMINUM

Marks, A. A.................. 91

LEGS, ARTIFICIAL, WITH RUBBER FEET

Marks, A. A................... 91

\section{LIFE INSURANCE}

Postal LIfe Insurance Co........... 19

\section{LIGHT THERAPY APPLIANCES}

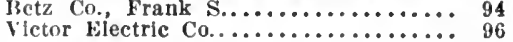

LIM!TED PAYMENT LIFE POLICIES

Postal Life Insurance Co........... 19

MACHINERY FOF DISINFECTION

Betz Co., Frank S................ 94

MAILING LISTS

Rapld Addressing Machlne Co....... 106

\section{MALT PREPARATIONS}

IIorlick's Malted Milk Co........... 2

Maltine Company....................

MALTED MILK

MANOMETERS

Dressler-Beard Mfg. Co............128A

\section{MANUFACTURING CHEMISTS}

Bayer Company................. 2

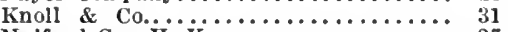
Mulford Co., H. K............... 27 Powers-Weightman-Rosengarten Co..... 92 Schering \& Giatz................. 31

\section{MANUFACTURING PHARMACISTS}

Armour \& Co..................

Barnes Co., A. C................ I7

Betz Co., Frank S................... 94

Fritzsche Bros................... 84

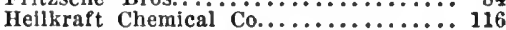

Horlick's Malted Milk Co............. 21

Hynson, Westcott \& Co................. 128

Maltine Co..

Mulf ord Co., H. K.................

Powers-Weightman-Rosengarten Co... 84

Schleffelin \& Co........... inside Bäk C Cove

Sherman, Dr. G. H............... 107

Trommer Co., The. . . . . . . . . . . . 85

\section{MASSAGE}

Pennsylvania Ortho. Inst. and Sch. of

Mechanotherapy ............... 40

Volfe's System of Baths.............. 106

\section{MATERNITY APPLIANCES}

Bolen Manufacturing Co............ 121

Gossard Co., H. W............... 100

Johnson \& Johnson............. 86

May, Berthe........................ 118

Sampson-Soch Company............... 116

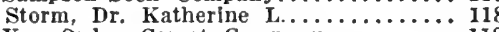

Van orden Corset Company............ 118

\section{MATERNITY OUTFITS}

Johnson \& Johnson.............. 86

\section{MATTRESSES}

Betz Co., Frank S............. 94

\section{MECHANO-THERAPEUTICS}

Pennsylvania Ortho. Inst. and Sch. of

Iechanotherapy .................

\section{MEDICAL ART PRINTS}

Rebman Co. .................. I3

MEDICAL BOOKS

Anatomy and Zoology

Ballou-Equine Anat. \& Phys. (Blak.)

Bardeleben \& Haeckel-Ap. An. (Reb.)

Barker-Anat. Nomen., (BNA) (Blak.)

Blakiston's Manikins-(Blakiston)....
Box \& Eccles-Clin. App. Anat. (Blak.) Bundy-Anat. Por Nurses (Blakiston). Buchanan-Anatomy (Chl. M. Bk. Co.) Calkins-Protozoölogy (Lea) ........... Crury-Field Zoology (Biakiston)... Davls-Anat. of Nas. Acces. Sinu. (S.) Davis-Applied Anatomy (Lipplncott). Davis-Applied Anatomy (Lipplncott)... Deaver-Surg. Anat. IId, \& Nk. (Bla.)
Deaver-Surgleal Anatomy (Blakiston) Deaver-Surgleal Anatomy (Blakiston) Delamere \& Leaf-lymph. (C.M.B.Co.)
Drew-Invertebrate Zoology (Saunders) Dwight-Cl. At. of B. of H. \& F. (Lipp.) Gerrish-Anatomy (Lea)..............

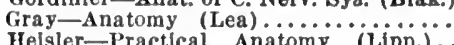
Helsler-Practleal Anatomy (Lipp.). Ifoiden-I)issector. 2 Vois. (Biaklston) Hopewell-Smith-Dental Anat. (Lea).. Iuntington-Abdominal Anatomy (Lea) Johnston-Nerv. Sys. of Vert. (Blak.) Keibel \& Mall-Human Embry. (Lipp.) Kingsley-Comp. Anatomy (Blakiston). Kingsley-Comp. Anatomy (Blakiston) Littlo-Anatomy (Lea) ................ Ifcliurrich-Embryology (Blaklston)... Minot-Embryology. Illus. (Blakiston) Morris-Text-Book of Anat. (Blak).... F'lersol-Human Anatomy (Lipplncott) Potter-Compend (Blakiston)
Rotch-X-rays in Pediatrics (Lipo.). Rockwell-Anatomy (Lea) ............... Slade-Phys. Ex. \& Diag. Anat. (\$.j. Santee-Anat. of Br. \& Sp. Cd. (Blak.) Smallwood-Blology (Lea) ............. Sobotta \& McMurrich-II. An. (Saü...) Sutton \& Drinker-Osteology (Blak.) Taylor-Applled Anatomy (Lippincott) Toldt-Human Anatomy (Rebman)... Treves-Surgical Anatomy (Lea)..... 1A Woolsey-Surgical Anatomy (Lea)....
Yutzy-Manual \& Atl. of Osteo. (Blak.) Anesthetics

Braun-Local Anesthesla (Lea)..... 1A

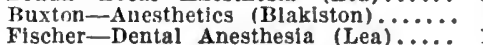
Bacteriology and Pathology

Abbott-Bacteriology (Lea) ......... 1A Adami \& McCrae-Pathology ( Adaml-Pathology (Lea) ............. Allen-Vaccine Therapy (Blakiston). Archinard-Bacteriology (Lea)........ Beattie and Dickson-Pathol. Spec. (B.) Buckmaster-Morph. of Blood. (Blak.) Burchard-Dental Pathology (Lea).... Calkins-Protozoölogy (Lea) ..........

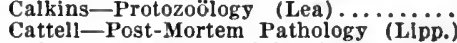
Cattins \& Mayou-P. \& B. of Eye (Blak.) Collins \& Mayou-P. \& B. of Eye (Blak.) Coplin-Manual of Pathol. (Blak.)... DaCosta-Clin. Hematology (Blak.)...

Daniels-Labor. Stud. in Tr. Med. (B.) Emery-Clin. Bact. \& Hematol. (Blak.) Ewlng-Blood (Lea) .................. Eyro-Bacteriologic Technic (Saunders) Gruner-Puncture Fluids (Blakiston).
Fox-Bacterlology for Nurses (Lea). Gaylord-Aschoff-Path. Histology (Lea)

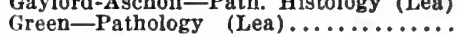

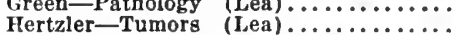
Hertzler-Tumors (Lea) ............. Herzog-Veterinary Microorganisms (L)
Hurry-Vicious Circles in Dis. (Blak.) Horry-Vicious Circles in Dis. (Blak.) Klopstock \& Kowarsky-Bact. (Reb.). Krehl-Clinical Pathology (Lipp.) … Lazarus-Barlow-G. or E. Path. (Blaik.) McConnell-Pathology (Saunders).... McFarland-Pathology (Saunders).... AcFarland-Pathogenic Bact. (Saund.) Mac Neal-Manual of Bact. (Blak.).. Mallory-Pathologlc Histology (Saund.) Mallory \& Wright-Path. (Tech. Saund.) Marshall-Microbiol, of Bact. (Blak.) Panton-Clinical Pathology (Blakiston) Panton-Clinical Pathology (Blakiston

Pitfleld-Bact., incl. An. Parasites (Blak) Richet-Anaphylaxis (C. M. B. Co.).. Richet-Anaphylaxis (C. M. B. Co.)..
Schneider-Pharm. Bact. Illus. (Blak.) Simon-Infection and Immunity (Lea) Sinith-Bacteriology (Blaklston)

Taylor-Diges. and Metabolism (Lea) Stenhouse-Pathology (Lea) . .......... Stitt-Practical Bacteriology (Biak.). Ward-Bedside Hematology (Saunders) Wells-Chemical Pathology (Saunders)
Zeit-Post Mort. Protocol (C.M.B.Co.) 


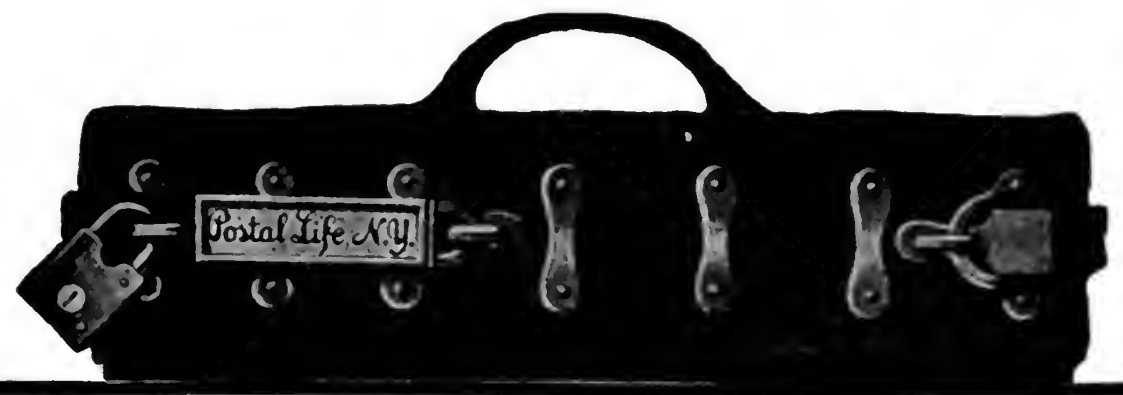

\section{The Postal Life Insurance Company pays you the Commissions that other Companies pay their agents}

7 HE POSTAL LIFE is the only Company that opens its doors to the deal directly for it, either personally or by correspondence.

Whether you call or write, you make a guaranteed saving corresponding to the agent's commission the first year, less a moderate advertising cnarge. Your first year Commission Dividend ranges up to

STRONG POSTAL POINTS

First: Sandard policy reserves now nearly $\$ 10,000,000$. Inmerance ir force nearly $\$ 50,000,000$ Second: Oldline lronl rescrle inmunance-not fraI crmal or meswent.

Third: Snndarl policy. provigion, approved by the Serte Insurance Department. Fourth: Operates under atrirt viate requarement and subject to the United Stales postal suthorities.

Fifth: $H$ igh medical arritands in the selection of risks.

Sixth: Policyholdere" Jenleh Burean provide one free modical examinution each yeas, il denred. $40 \%$ of the Premium

In subsequent years you get the Renewal Commis sion other companies pay their agents. namely $7,1 / \%$, and rou also receive an Office-Fixpeuse Saving of $2 \%$ making up the

\section{Annual \\ Dividend of

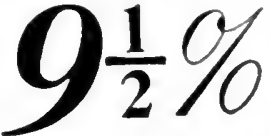

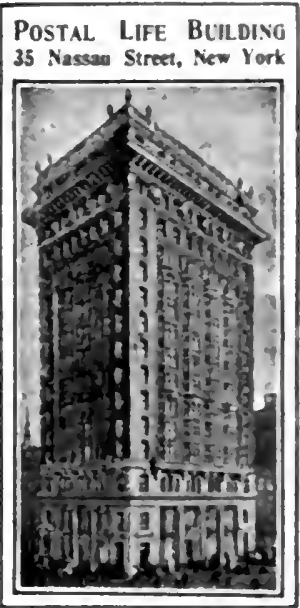

Guaranteed in the Policy

And after the first year the POSTAI pays contingent dividends besides, depend. ing on earnings as in the case of other comparies.

Such is the I'OSTA1, way: it is open to you. Call at the company's offices if convenicnt, or write now and find out the cxact sum it will ny you at your arethe first year and every other.

\section{POSTAL LIFE INSURANCE COMPANY} WM. R. MALONE, Preaident 35 Nassau Strect, New York

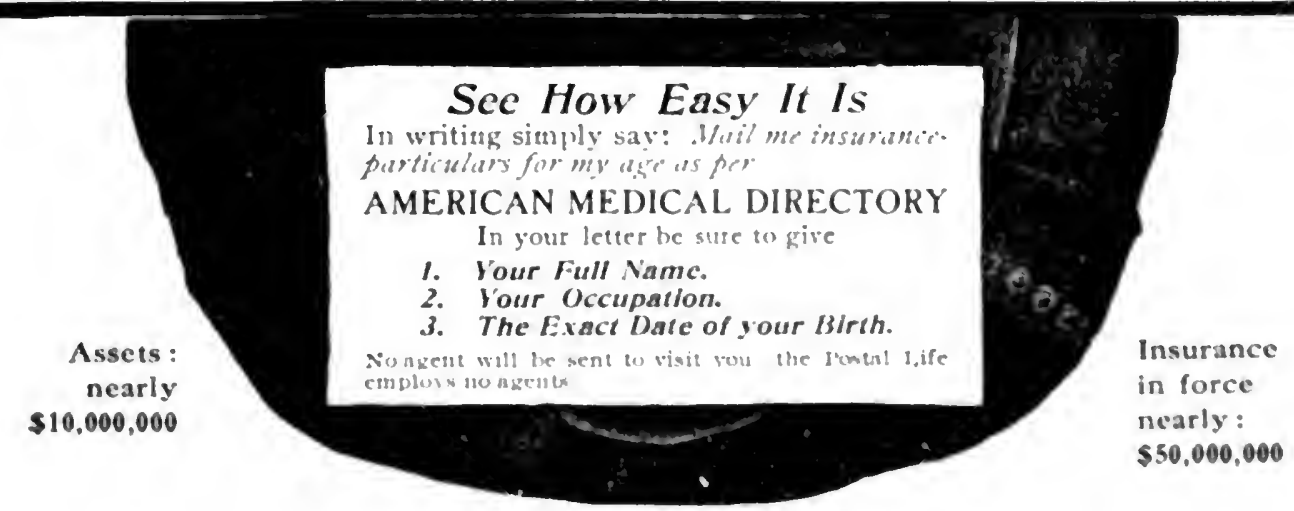


Davison-Mammal. Anat. Illus. (Blak.) Folsom-Entomology (Blaklston)..... (ialloway-Zoology (Blaklston) Galloway-Elementary Zoology (iilak.) Ilanaker-Princlples of Blology (Blak. Johnston-Nerre. Syst of Vert. (Blak) hingsley-Comp. Anatony (J3laklston) Patten-Evol. of Verteb. \& Kln (Blak.)

$$
\text { lsotan! }
$$

Green-Veget. Physiol. 189 nlus. (IBlak.)

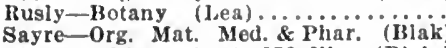
Stevens-l'lant. Anat. I52 Illus. (Blak.)

$$
\text { Brain, Nerious and Mental }
$$

Barr-Mental Defectlves (Blakiston).. Brill-Psychanalysís (Sannders)...

Chase-General Paresis (Rlakistoni... Church \& Peterson-N. \& M. (Saund.) Cralg-Psyciologlcal Med. (Blaklston) Curschmann-Handbook of N. D. (B.) Denslow-Iocomotor Ataxia (C.M.M.Co. Dercum-Mental Diseases (Saunders). Dercum-Rest Hypnot. M. Ther. (Blak.) Frenkel-Tabetlc Ataxla (Blakiston) Freud-Interp. of Drms. (Macmlllan) Gordinler-Anat, of C. N. Sys. (Blak.)
Gordon-Man. of Nerv. Dis. (Blak.).. Gordon-Man. of Nerv. Dis. (Blak.).. Gowers-Dis of Nerv. Sys. (Blak.)...
Gowers-C. I. on Dis. N. Sys. (Blak.) Gowers-Borderlands of Epllepsy (Blak.) IIunt-Diag. Sym. of Nerv. Dis. (Saund.) Jelliffe-White-Nerv. \& Men. Dls. (I,ea) Jelliffe-Paychoneuroses (Lipp.). Jolinston-N. Sys. of Vertebrates (B.)
Kaplan-Serology of Nerv. Dls. (Saund.) Krause-Surg. of the Brain (Rebman) Lewis-Mental Diseases (Blaklston)... Nagel-Nerv. and Ment. Dls. (Lea).... Osler-Modern Mcdlclne (Lea)........ Mitchell-Fat and Blood (Llppincott)

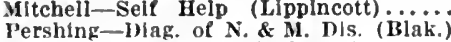
Pershing-Diag. of N. \& M. Dis. (Blak.) Potts-Nerv, and Ment. Diseases (Lea) Santeo-Anat. of Br. \& Sp. Cd. (Blak.) Starr-Nervous Diseases (Lea)....... Schofleld-The Nerve Patlent (Blak ). Stewart-Dlag. Nerv. Diseases (Treat).. Stoddard-MInd and Its Disor. (Blak.). Tanzl-Mental Dlseases (Rebman)... Turner and Stewart-Nerv. Dis. (Blak.) Turner and Stewart-Nerv. Dis. (Blak.) Walton-Those Nerves (Lippincott)... Walton-Why Worry (Lippincott)
White \& Jelliffe-Mod. Treat. of $\mathrm{N}$. and M. Dis. (Lea)

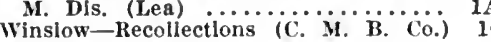

Winslow-Insantty (C. M. B. Co.).... 10

\section{Chemistry and Physics
Cheunger-insanity (C. M. B. Co.}

Allen-Com. Organ. Analysis (Blak.) Arup-Indust. Organ. Anairsis (Blak.) Attfield-Chemistry (Lea)...

Balley \& Cady-Qualit. Anal. (Biak.). Barnett-Organic Compounds (Blak.).. Bartley-Medical Chemistry (Blak.). Bartley-Physlol. \& Clin. Chem. (Blak.)
Bolton \& Revls-Fatty Foods (Blak.) Bolton \& Revis-Fatty Foods (Blak.) Brown-History of Chemistry (Blak.).

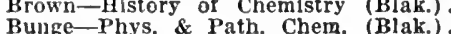
Bunge-Phys. \& Path. Chem. (Blak.).
Clowes \& Coleman-Quant. Anal. (Blak.) Clowes \& Coleman-Quant. Anal. (Blak.)
Coblentz \& Vorisek-Vol. Anal. (Blak.) Daggett-Pharm. Chemlstry (Lea).... Dutt-Text-Book of Physles (Blak.). Duff and Ewell-Phys. Meas. (Blak.)

Essig-Koenig-Dental Metallurgy (Lea) fitren-Sugar Analysis (Blakiston) II ampshire-Volumetric Anal. (Blak.). IIatschek-Ch. \& Phys, of Col. (Blak.) Hatsenek-Physics of Colloids (Blak.). IIati-prac. Phys. Chem. Illus. (Blak.) Alkaloids (Blakiston).. Alkaloids (Blakiston) Toxicology (Saund.) cont. Pois. \& Milk (B) Chem. (R.) Blakiston) Blakiston
Leftmann \& Beam-Food Anal. (Blak.) Leffmann \& LaWall-Org. Chem. (Biak. Long-I'hyslologlcal Chem. (Blaklston) loug-Ceneral Chemistry (Biaklston). Long-Analytical Chemistry (Blakiston) l.uty is Candy - M. of Chem. (C.M.B.Co.) Martin-Rockwell-Chem. \& Phy. (Lea) McGlannan-Inorgan. Ch. \& Phy. (Lea) MeGlannan-Org. \& Phys. Chem. (Lea) McClung-Cond. of Elec (Blak.) ...... Medicus-Qualitative Analysis (Lipp.) Nemninger-Quallt. Anal. Br. (13lak. Molinar-indus. Chem. Org. (Blak). Molter-Analysis (Blakiston) (Rlak). Nutting-Appled optles (Blakiston... Perkin \& Kipping-Or. Chem. (Lipp.) Rlcliter-Inorganic Chem. (Blaklston). Rlchter-Organic, 2 rols. (Blaklston). Rlley-Toxlcology (Blakiston) ...... Rockwood-Chemical Analysis (Blak.) Simon \& Bare-Chemistry (Lea) ..... Simon-Laboratory Dlagnosis (Lea)... Simon-Physlological Chemistry (Lea) Stanlslaus-Pharm. Chemlstry (Blak.) Sutton-Volumetric Analysis (Blak.) Taylor-Digestion and Metabol. (Lea) Thresh-Pres. in Food \& F. Exam. (Blak) Thresh-Exam. of Waters (Blakiston). Tower-Qual. Analysis (Blaklston)... Tower-Qual. Analysis (Blaklston).... Vaughan-Protein Products (Lea) ... Vorisek-Qualitative Analysis (Blak.) Waddell-Quant. Anal. in Prac. (Blak.) Wells-Chemical Pathology (Saunders) Whymper-Cocoa \& Chocolate (Blak.) wiley-Foods \& Adniterations (Blak.) Wurtz-Modern Chemistry (Llppincott)

$$
\text { Chest, Heart and Lungs }
$$

Colbeck-Dis. of Heart (C. M. B. Co.) Franclne-Pulmonary Tuber (Lipp.). Hirschfelder-Heart and Aorta (Lipp.) Huber-Consump. \& Clvillzation (Lipp.)

\section{('hildien}

Barr-Mental Defectives (Blaklston). Binet \& Simon-Develop. (C.M.B.Co.). Carr-Pediatrics (Lea) .............. Davis-Mother and Chlld (Lippincott). Forsyth-Child. in Hith. \& Dis. (Blak.) Grulee-Infant Feeding (Saunders)... Hatfleld-Compend of. (Blakiston) ....)
Heiman \& Feldstein-Me. Men. (Lipp.) Judson \& Gittings-Ar. F. of In?. (L.) Kerr-Diag. of Chlldren's Dis. (Saund.) Kerr-Diag. of Chlldren's Dis. (Saund. Moplik-Children (Lea) .... \# (Biä. Pfaundler-Dls. of Children (Lipp.). Rotch-Pediatrics (Llppincott) ....

Rotch-X-ray in Pediatrics (Lipp.)....
Ruhrah-Infants and Children (Saund.) Shuttleworth-Ment. Def. Chlld. (Blak.) Starr-Dis. of Digest. Org. IIIus. (Blak.) Starr-Hyglene of Nursery (Blakiston) Starr-Weight Chart (Blaklston).... Tuley-Pediatrics (Lea) ............... Tuttle-Children (Lea) .............. 1A Wachenhelm-Clim. Tr. of Chii. (Rë.)
Willard-Surg. of Childhood (Llpp.)..

\section{Willard-Surg. of Childhood
Compend}

Ballou-Equine Anat. and Phys. (Blak.) Brubaker'g Physlology (Blakiston)... Hatfleld-Children (Blakiston).

Hirsch-G.-U., Ven. Dls. \& Syp. (Biak.) Horwitz-Surgery (Blakiston).......... Horwitz-Surgery (Blakiston).

Landis-Obstetrles (Blakiston)

Landis-obstetrles (Blakiston) ........ Pitfield-Bacterlology (Blakiston)...... Potter-Anatomy (Blakiston)

Potter-Materla Med. (Blaklston)...... Radasch-Histology (Blakiston).

St. Clair-Medical Latin (Blaklston)... Stewart-Pharmacy (Blakiston)

Schamberg-Skin Dis. Illus. (Blak.).. Warren-Dental Pathology (Blakiston).

\section{Dentistry}

Barrett-Dental Surgery (Blakiston)... Berry-Hare-L. \& Cleft-Pal. (Blak.). Brophy-Oral Surgery (Blakiston).....
Brown-Oral Surgery (Lea).

Burchard-Dental Pathology (Lea).... IA

Buckley-Dent. Mat. Med. 1'. \& T. (Blak)

Essig-Koenig-Metaliurgy (Lea)...... IA

Flacher-Dental Anesthesla (Lea)..... IA

Goepp-Dent. S. B. Ques. \& Ana. (S.) 6

Gorgas-Dental Medlclne (Blakiston).

(

Guerinl-History of Dentlatry (Lea).

Irarris-l'rinclples \& P'rac. (Rtak.)

Hopewell-Smlth Anat. and Phys. (Lea)

Ivy - App. Anat. \& Oral Surg. (Saund.)

Johnson-Operative Dentlatry. (Blak).

Johnson-Success in Dental Pr. (Lipp.)

Klrk-0perative Dentlstry (Lea) .....

Ischer -0rthodontics (Lea)......... is

Long-Dental Mat. Med., etc. (Lea)... iA

Marshall-Mouth Hyglene (Lipp.) ......
Marshall-Opera. Dentlstry (Llpplncott)

Marshall-Opera. Dentlstry (Llpplncott)

Mlkell-Dental Jurisprudence (Lea).....

Noyes-Dental Histology (Lea) ........

Sturridge-Dental Elec Ther. (Lea).

Tomes-Dental Surgery (Blakiston)...

Tomes-Dental Anatomy (Blakiston)...

Turner-Prosthetlc Dentlatry (Lea)...

Wallis-Dental Extractlons (Blakiston)

Warren's Compend. (Blakiston) .......

Warren's Mech. Dent. \& Metall. (Blak.)
Wilson-Dental Prosthetics (Lea)....

\section{Diaynosis}

Abrams-Dlag. Therapeutics (Rebman) Acam-Ophth. Dlagnosls (Rebman)... I3 Anders \& Boston-Med. Dlag. (Saund.) 5 Arneill-Clinical Diagnosis (Lea) ..... 1A Beard-Ophthaimic Diag. (Blakiston). Bing-Regional Dlagnosis (Rebman). Cabot-Differentlal Dlapnosis (Saund.) Casper \& Richter-Funct. Dlag. (Blak)

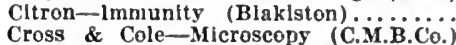
Cross \& Cole-Microscopy (C.M.B.Co.)
DaCosta-Physical Dlagnosis (Saund.) DaCosta_Physical Dlagnosis (Saund.)
Dacosta_Clinical Hematology (Blak.) Cisendrath-Surg. Diag. (Saunders). Emery-Clin. Bact. \& Hematol. (Blak.) Emerson-Clinical Dlagnosls (Lipp.). Ewing-Blood (Lea) .................. Findley-Gynecological Dlagnosla (Lea) Flint-Auscultation and Percus. (Lea) French-Med. Lab Meth. (C. M. B. Co Greene-Med Exam in Life Ins, (Blak.) Greene-Medical Dlagnosls. (Blakiston) Gultand \& Goodall-The Blood (Treat) Hare-Dlagnosis (Lea) ................... Hensel-Urine and Feces (Lea) ...... Hollis-Medical Dlagnosls (Lea) ...... Martln-Surgical Dlagnosis (Lea)... Memminger-Diag. by Urine (Blak.). Morrow-Diag. \& Thera. Tech. (Saund.) Muller-Serodiagnostic Methods (Lipp.) Musser-Medical Dlagnosts (Lea).... O'Reilly-Physical Diagnosis (Blak.). O'Reilly-Physical Diagnosis (Blak.)
Pershing-Diag. of N. \& M. Dis. (Blak) Pershing-Diag. of N.\& M. Dis. (Blak) Schmidt-Abdominal Tumors (Rebman) Schmidt_Pain (Lippincott) .......... Simon-Clinical Diagnosis (Lea)........ Slado-Phys. Ex. \& Diag. Anat. (S.)
Stitt-Dlag. \& Treat. Trop. Dis. (Blak) Stitt-Dlag. \& Treat. Trop. Dis. (Blak) Von Jaksch- Clinical Dlagnosis (Lipp.) Von Neusser-Dis. of Resp., 3 v. (Treat) Ward-Bedside Hematology (Saunders) Webster-Dlag. Methods. Illus. (Blak.)
Wilson-Medical Dlagnosis (Lipp.)...

\section{Dictionaries, Ele.}

American lllust. Med. Dlct. (Saund.) American Pocket Med. Dlct. (Saund.) Barker-Anat. Nomen. (BNA) (Blak.) Dunglison-Medical Dictlonary (Lea).. Gould's Illus. Dlc. of Med. (Blakiston) Gould's Sup. as above. H.Mfor. (Blak.) Gould's Sup. as above. H.Mtor. (Blak.) Gould's Prac. Med. Dic. Illus. (Blak.) Gould-Pocket Med. Dic. (Blakiston) Gould's Pocket Dictlonary (Blakiston) Gould \& Pyle's P. Cyclo. of Med. (Blak) Gould \& Pyle's Prac. Cyclo. (Blak). Lang-Ger.-Eng. Med. Dict. (Blaklston) Lewis-Medical Vade Mecum. (Blak). Lipplncott's New Medical Dictionary. 


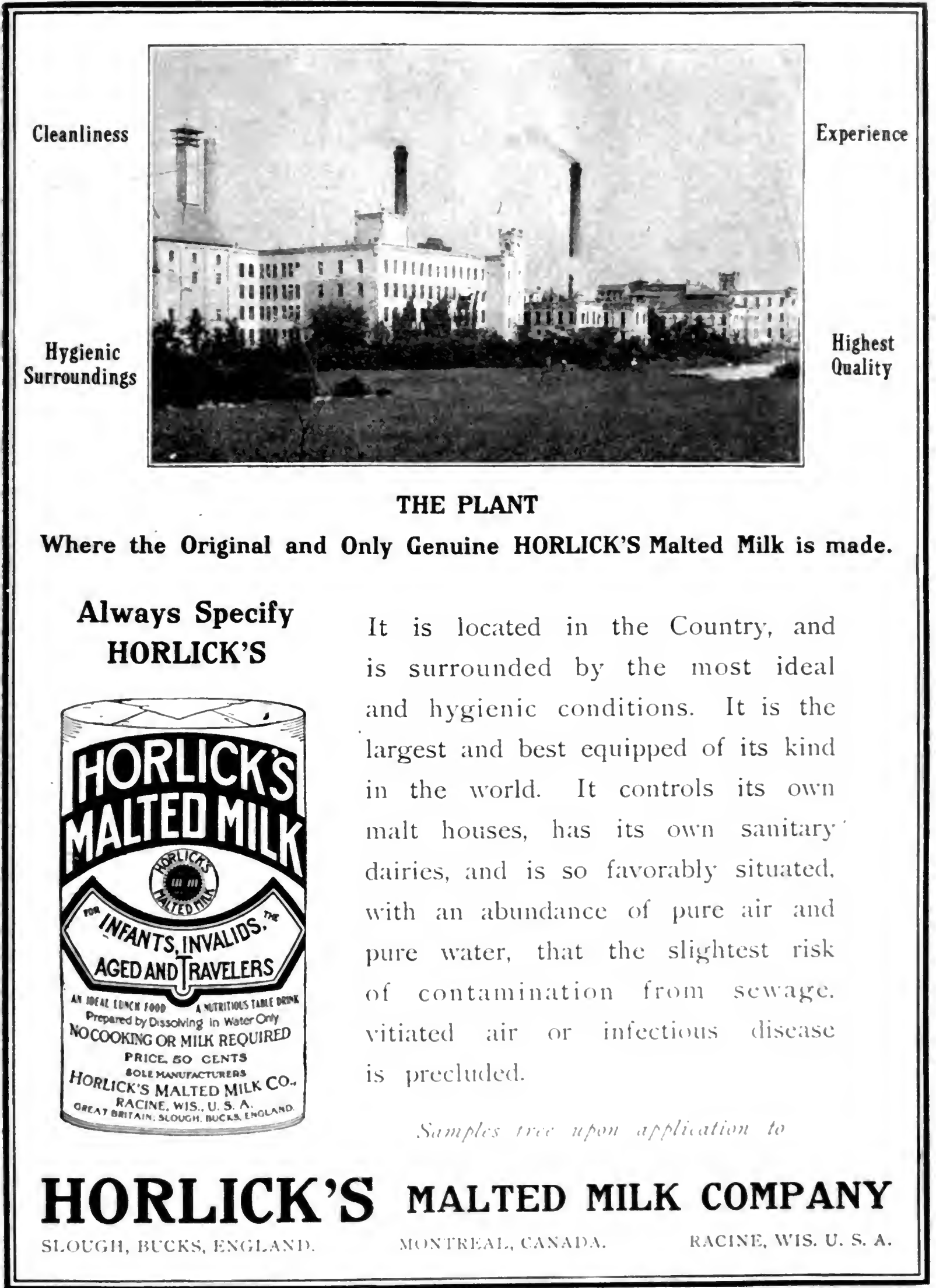


lilectrotherapeutics

Allen-Radiotherapy (Lea).

Arthur \& Muir-Pr. X-Ray Wk, (Reb.)

Christie-X-ray Technlc (Lippincott).

Cleaves-light Energy (Rebman).

Freund-Iadlotherapy (Rebman).

facoby-Electrother. 2 Vols. (Biak.)

Jones-Med Efec (Biakiston)

Jones-Ionic Medication (Biakiston). Kassablan - Electro-Therap. (Lipp.) Morton-Med. Hiec. \& Rad. (C.M.M.(O.) Potts-Eiectrictty (I,ea).

Strong-Inigh Freq. Currents (Rebman Sturridge-Dental Electro-Ther. (Lea) Tousey-Med. Elect. \& X-rays (Saund.) Turner-I'orter-Sklagraphy (C.M.B.Co.)

Embryology and Biolo!n!"

Bensiey-Anat. of Rabhit. Ilius. (Blak.) Helsler-Embryology (Saunders) .... McFarland-Biol., Med. \& Gen. (Saund.)

Smallwood-Biology (Lea) ...........

Eye, Ear, Nosc and Throat

Adam-Diseases of the Eye (Rebman) Adam-Ophth. Diagnosis (Rebman).... Alling-Grifln-Ese and Ear (Lea)....

Kacon-Ear (Lea)

Ballenger-Ear, Nose and Throat (Lea) Ballenger-Wippern-Eye, E. N \& T. (Lea)

Barnhill \& Wäes-Mod. otö. (Saund.) Barr-Dis. of the Ear (Macmillan)... Beard-Ophthalmic Surgery. (Blak.). Beard-Ophthaimic Diagnosis (Blak.) Berry-Prac. Ophthalmology (Lipp.).

Braun \& Friesner-The Labyrinth (R.) Bruck-Nose, Mouth, Pharynx. (Reb.) Coakley-Nose and Throat (Lea) Collins \& Mayou-Path. \& Bact. (Blak. Davls-Nasal Access. Sinuses (Saund.) Darler-Ophth. Ther. Reissue (B।ak DeSchweinitz-Dis, of the Eye (Saund.) Donders-Refraction (Biakiston)...... Ferguson-Nose and Throat (Lea).

Gould and Pyle-Compend. (Blakiston) fould-Bingraphic Clinics (Blakiston) Gowers-Man. \& Atlas of Ophth. (Blak.) Grayson-Nose, Throat, Ear (Lea)... Greeff-Ext. Diseases of the Eye (Reb.) Ilansell and Reber-Oc. Mus. (Blak.)

Hansell and Sweet-Tre:t. on D. (Blak.) Hartridge-Refraction (Blakiston)... Hartridge-Ophthalmoscope (Blakiston) Henderson-Les. on Eye. Illus. (Blak.) Hlrschberg $\rightarrow$ Shortsight (Rebman)..... Hollopeter-Hay Ferer (Blakiston)... Jackson-Diseases of the Eye (Saund.) Jennings-Ophthalmoscopy (Blakiston) Kerrlson-Dlseases of the Ear (Lipp.). Kopetzky-Surgery of the Ear (Reb.). Kyle J. J.-Man. of Dis. E. N. \& T. (B) Kyle-Dis. of Nose \& Throat (Saund.) Kyle J. J.-Man. of Dis. E. N. \& T. (B) Melier-Ophthalmic Surgery (Blak.)... Milligan \& Wingrare-Dls. of Ear (Mac) Morton-Refraction (Blakiston)...... Nettleshlp-Eye (Lea)

Norris \& Ollver-Dls. of the Eye (Lipp.) Nutting-Applied Optics (Biakiston).. Ohlemann-Ocular Ther. (Blakiston). Oppenhelmer-Chr. Suppuration (Blak) Parsons-Diseases of Eye (Blakiston) Packard-Nose, Throat \& Ear (Llpp.) Phillips-Spectacles and Eyegl. (Blak.) Posey-Eye (Lea)

Posey \& Spiller-Eye \& Ner. Sys. (Lipp. Richardson-Thyr. and Para. Gl. (B.) Shoemaker-Retinits Pigmen. (Lipp.) Skillern-Acces. Sin. of the Nose (Llpp.) Swanzy-Dis, of the Eye (Blakiston). Sym-Dis. and Inj. of Eye (Macmillan) Thorington-RetInoscopy (Blakiston). Thorington-Refr. and How to Refr. (B.) Thorington-The Ophthal. (Blakiston) Torok \& Grout-Surg. of the Eye (Lea) Pinster- Pleumotherapy (Bilakiston)...

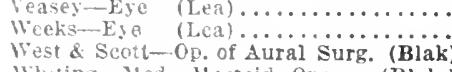
Whating-Mod. Mastoid Opera. (Blak.) Wood-Woodruft-C. D) of E. (C.M.B.Co.) Yearsley-Dis. of the Ear (C.M.B. Co.)

\section{Food and Diet}

Black- Eating to Live (Llppincott)... Bulduan-Bach Food Poison. (Treat). Bolton and Iteris-Fatty Foods (Blak.) IBurnet-Foods and ntetaries (Biak.). Carter-Diet hists (Saunders) ......... Carrington-Vital., Fast. \& Nut. (Keb.) Combe-Auto-Intoxication (Rebman)... Edelmann-Meat IIygiene (Lea).

Gautler-Dlet and Dletetics (Lippincoti) (iouraud-What Shall I Eat? (Reb.) Greenish-Mlcroscopical Exam. (Blak.) Grulee-Infant Feeding and Dis. (S.).. (ivell-Sugar Analysis (Blaklston)... IIalg-Diet and Food (Blakiston).

Lefrinann-Food Analysis (Blakiston). Letrmann-Milk and Milik Prod. (Blak.) Schreiner-Diet Charts. (Blak.)

Sinith-What to Eat and Why (Saund.) Tirresh-Food Examination (Blakiston) Tibles-Foods (C. M. B. Co.) ….̈. Wiley-Foods and Their Adulter. (Blak.)

\section{Gynecology and Obstetries}

Ashton-Prac. of Gynecology (Saund.) Bacon-obstetrics for Nurses (Iea).; Bandier-Medical Gynecology (Saund.)
Barbour \& Watson-G. Diag. \& P. (Mac) Berkeley and Bonney-D. (Blak.)....... Birubaum-Malformatlons (Blakiston) 13land-Sutton \& Giles-Women (Reb.) Buree-Gynecology (Iea) ............ Child-Gynecology (Lea)...

Clark-Gynecological Diagnosis (Lipp.) Cooke-Handbook of Obstetrics (Lipp.) Cooke-Obstetrical Technique (Lipp.) Crockett-Gynecology (Lea).

Davis-operative obstetrics (Saund.) Davis-obstetrles (Lea)...............

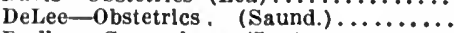

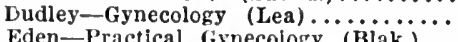
Eden-Practical Gynecology (Blak.)...

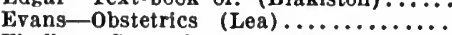
Findley-Gynecological Diagnosis (Lea) Findley-Gynecology (Lea)............

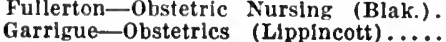
Hartmann-Gyn. Operations (Blak.). . Hirst-Diseases of Women (Saund.).... Hirat-Obstetrics (Saunders)...........

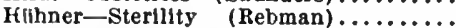
Jewett-obstetrles (Lea) .............. IA Johnstone-Text of Mldwifery (Mïa) 15 Jolly-Microscopic Gynecology (Reb.).. 13 Kelly \& Noble-Gyn. \& Abd. Surg. (\$.) King-Obstetrics (Lea)............... Kisch-Woman (Rebman) ................. 13 Landis -Compend. (Blakiston)......... Manton-Obstetrics (Lea) .............. IA Martin \& Jung-Dls. of Women (Reb.) 13 Montgomery-Text-Book of (Biakiston) Norris-Gonorrhea in Women (Saund.) Peterson-Obstetrics (Lea)............

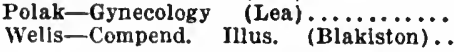

Hygiene, Exercise and Prophylaxis Bergey-Princp. of Hyglene (Saund.) Delano and McIsaac-Hygiene (Blak.) Edelmann-Meat Hygiene (Lea)...... Egbert-Hyglene and Sanltation (Lea) Forel-Sexual Question (Rebman).... Gatewood-Naval Hygiene (Blakiston). Gautier-Diet and Dietetics (Lipp.).... Gould-Righthandedness and Left (Lipp.) Harrington-Practical Hygiene (Lea) Howard-Sex Worship (C. M. B. Co.). Langfeld-Infectious Dis. (Blakiston). Kelynack-Med. Inspection (C.M.B.Co.) Krafft-Fbing-Psycho. Sexualls (Reb.) McFarland and Others-Proph. (Blak.) Newmayer-School Hygiene (Lea)... Notter-Practical Hygiene (Blakiston). Parkes-Manual of (Blakiston)........

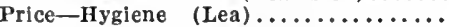
Price-Hygiene for Nurses (iea)....... 1A Savage-B. Ex. of Water Sup. (Blak.). Senator Kaminer-Marriage (Rebman) Starr-Hygiene of Nursery (Blakiston) Sterenson and Murphy-Treatise. (Blak.) Weir-Religion \& Lust (C. M. B. Co.)
Massage, Etc.

Böhm \& Painter-Masage (Saund.).. Graham-Massage (Lipplncott) ....... Gulick-I'hysical Educ. (Biakiston)... Mitchell-Nechanotherapy. (Blak.).... Ostrum-Massage (Blakiston)..........

Materia Mediea, Therapeutics and l'harmac'n

Abrams-Diag. Therapeutics (Reb.).. 13 Adan-Ophthalmic Therapeutics (Heb.) 13 Allen-liadiotherapy (Lea)........... IA Bastedo-M. M., Phar. Ther., P.W. (S.) Beasley's Formulary (Blakiston)...... Beasley's Receipt-Book (Blakiston)... Beasley-Prescriptions (Blakiston).

Buckley-D. Mat. Med. \& Ther. (Blak.) Burchard-Dental Therapeutics (Lea). Butler-Mat. Med., Therap., etc. (S.)

Citron-Immunity (Blakiston).

Casparl-Pharmacy (Lea).......... 1A Cohen-Ihys. Ther, II Vols: (Blak.). 4 Culbreth-Mat. Med. \& Pharm. (Lea).. iA Cushny-Pharmacology \& Thera. (Lea) IA Daggett-Pharmaceut.Chemistry (Lea.) IA DeLorme-Man. of P. for Phys. (Blak.) Emerson-Essentials of Medlcine (L/pp.) Eurlich-Chemotherapy (Reb.) (Llpp.) Fantus-Ess. of Pres. Writ. (C.Mi.B....) Fantus-I'r. Writ. \& Phar. (C.M.B.Co.) IO Foote-Mat. Med. for Nurses (Llpp.).. Foote-Mat. Med. \& Thera. (Lippincott) Gorgas-Dental Mat. Med. (Blakiston) Greene-Exper. Pharmacology (Blak.). Green-Vegetable Physiology (Blak.). Greentsh-Exam, of. F and Dr. (Blak.) Grotf-Mat. Med. for Nurses (Blak.).. Halsey-Pharmacology (Llppincott)...

II are-Alcoholism (Blakist

IIare-Modern Treatment (Lea)...... IA Hare-Practical Therapeutics (Lea)... IA Henry-Nur. Handbook of Med. (Lipp.) Hogan-How to Feed Children (Llpp.) Keating-Mat., Inf. \& Childhood (Lipp.) Kiepe-Materia Medica (Lea) ........ Kraemer-Botany (Lippincott)........ I.ong-Dental Mat. Med. \& Ther. (Lea) Mills-Care of Nerv. \& Insane (Lipp.) Mitchell-Doctor and Patlent (Lipp.). Morrow-Diag. \& Ther. Tech. (Saund.) Natlonal Standard Dlspensatory (Lea) O'Connor-Commercial Pharm. (Lipp.) Osborne-Materla Medica, etc. (Lea).. Potter-Compend. (Blakiston) ......... Potter-T., Mat. Med. and Phar. (Blak.)
Potter-Ther. M. M. and Ph. (Blak.) Potts-Electricity (Lea) ............... Remlngton-Practlce of Phar. (Lipp.) Ruddiman-Materia Medica (Lea)... Rusby-Botany (Lea) ............. Schleif-Materia Medica, etc. (Lea)... Sollmann-Pharmacology, etc. (Saund.) Stevens-Mat. Med. \& Tbera. (Saund.) Sterens-Pharmacy and Dispens. (Lea) Stanislaus-Pharma. Chem. (Blaklston) Sayre-Org. Mat. Med. and P. (Blak.) Scoville-Compound. of Drugs (Blak.) Schnelder-Phar. Bact. (Blakiston).. Stevens-Plant Anatomy (Blaklston).. Stewart-Compend. of Pharm. (Blak.) Tavera-Med. Pl. of the Phillpp. (B.) Thornton-Formulary (Lea) ......... IA Thornton-Materia Medica (Lea)..... 1A Tyrode-Pharmacology (Blakiston).... 4

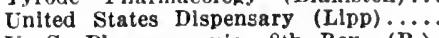
U. S. Pharmacopœia, 8th Rev. (B.). Wood-Pharmacology (Lippincott)... Wood-Tablet Manufacture (Lipp.)... Wilcox-Mat. Wilcox-Treat. of Dis. (Blakiston)... Wilson-Clinical Charts (Lipplncott). Wilson-Clinlcal Diagrams (Lippincott) Medical Jurisprudence

Culbertson-Med. Men and Law (Lea) IA Dwight-Medical Jurisprudence (Lea).. IA $\begin{array}{lll}\text { Knacker-Accldents (C. M. B. Co.).... } 10 & 10\end{array}$ Mikell-Dental Jurisprudence (Lea) ... IA Taylor-Medical Jurisprudence (Lea).. IA 


\section{ORGANOTHERAPEUTICS}

The facilities of Armour \& Company for producing the following preparations are unequalled, and the high quality of the finished articles shows that the firm's advantages are made use of.

Pituitary Liquid.................. Sol. Active Principle, post. part. Pit. body.

Pituitary Substance

Whole Gland.

Anterior Pituitary

Powder.

Posterior

Thyroids, U. S. P...................... 0.2 per cent organic iodin.

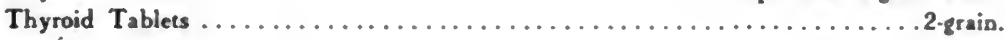

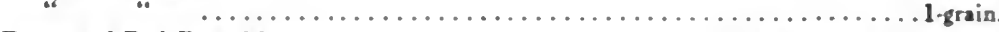

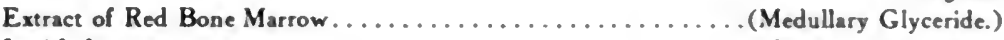

Lecithol ............................... Emulsion of lecithin.

Elixir of Enzymes.

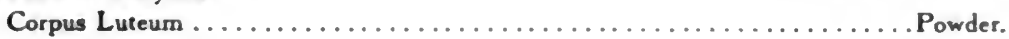

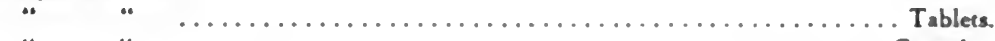

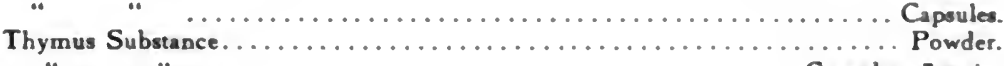
Capsules, 5-grain. Tablets. 1-grain.

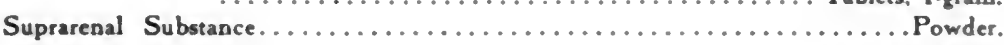

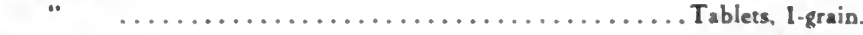

.

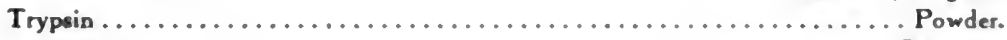

Tablets.

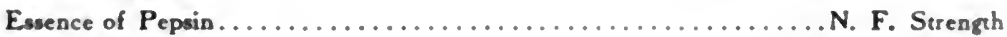

Glycerole of Pepsin........................ 10 per cent. U. S. P.

Pancreatin, U. S. P.

$$
\text { Essence. }
$$

Pancreatin, Glycerole

10 per cent., U. S. P.

Pancreatin and Soda

(Peptonizing) Tablets.

Benzoinated Lard.

Also high test, 4,000, 5,000 and 6,000 Pepsin, and glandular products whose therapeutic value has been suggested.

\section{ARMOUR ẪD COMPANY}


Hicroserom!

Carpenter-Micros. and its Revel. (Blak.) Greenish-Micro. Exam. of F. and D. (B.) Lee--Viale Vlecum (Biakiston).

\section{Niseflanculle}

Americun Red ('ross Charts (Mhak.). American Pocket Med. Dict. (Saund.) Hetousow-Delineation of Nerves (Hcb.) Birubatum- Maformations (Jlakiston). Cattell-lostmortem Pathology (Lipp.) ('omn- Malcleria in Milk (Blakinton). DeGarmo-Nech. Tr. of $\mathrm{Ab}$. Ileru. (I.) Forcl-Sexual Question (Rebmath)... Garrison-History of Mediclne (siund.) Glovnni-Clin. Commentaries (keb.) liven singar Inatysis (Mlakiston) Could - Biographic Clinics. (Blak.)... direne Med. Fx. Life lus. (Blak.) Griffith's Temp. Ch.-Pads 50 (Blak) Gultck-Physical Education (Blak.) llatg ('aus. of Mls. by Tric Acid (Blak.) llaik lic Acid Epitome (Blaktston). liaig-Iric Acid in the Ctinic (Blak.) liare-Aleoholism (Biakiston)

ICrold-Iegal Medicine (Lippincott). Hinsdale-Hydrotherapy (Saunders) Iloltand-Vr. 3. \& Connon Poís. (B.)

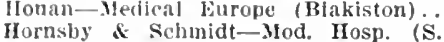

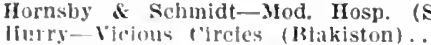
Intermat. Med. Nmuat 1914 (Treat). Jensen-Itilk liygiene (Lippincott)... lieen-outine loray. of It. body (B) Kelly-Cycio. of Am. Med. Bio. (S.) Kiliner-Iluman Atmosphere (Rebman). Krafft \& Ebing-Psycbopathia Sex. (R.)
l.effmann-Mik and Mlik Prod. (B!ak.) Leffmann-Water Anaiysis (Blakiston). Lippert \& Holmes-When sd. for Dr. (I.) lynch-Red Cross Text-book (Blak.). Maylard-Abdom. Tuber. (Blak.). Memminger-Diag. by Urine. (Blak.). Mitchell-Doctor in Court (Rebman). Mitcheli-Nech. T. \& Phys. Ed. (Blak.) Atorton-Abdomen Proper (Rebman). Nascher-bis. of old ALe (Blakistom). Osler- Hquanim, and other Add. (Blak.) Powclt \& Hartley-L. and Pleu. (Blak.) Red Cross (hiarts (Btakiston). Reed-Sex : Its Origin and Deter. (Reb.) Reilly-Building I'rofitable Prac. (L.) . liecse-Med. Juris. and Toxi. (Blak.). Richardson-Thyr. and Para. Gl. (Blak.) Ross-Ind. Cell-Rep. and Cancer (Blak.) loss-Fur. R. into Ind. C. R. \& C. (Blak.) Ross-Further Itesearch (Blakiston)... Ross-lleduc. of Dom. Mosquit. (Blak.) Saundby-Medical Ethics (Lippincott) Schieip-IIematologlcal Atlas (Reb.).

Schlcip-Hematology (Rebman)... Starr-Welght Chart (Blakiston). St. Ctair-Medical Latin (Blakiston). Straub-Med. Serv, in Camp. (Blak.). Thresh-Water and Water Sup. (Blak.) Weber and II insdale-Climatol. (Blak.) Whitby-Makers of Man (Rebman)... Winternitz-Ifydrotherapy (Blakiston) Woodruff-Tropical Light (Rebman)...

$$
\text { inrsing }
$$

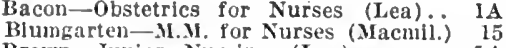
Brown-Junior Nursing (Lea) ... ̈̈̈̈̈.;) (11t1-I.ec. on Med. for Nurs. (Blak.) llavis-Bandaging. Illus. (Blakiston) Delano \& Mclsata-II. Care of Sick (B.) Demano \& Mctsac-II.C De Witt-Private Duty Nursing (Lipp.j) lomville-Mamual of Nursing (Blak.) Fux-bacteriology for Nurses (Lea). Olisteric Nursing (Biak.). cursing (Blakiston)

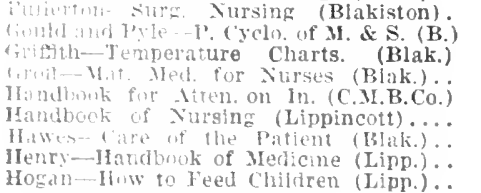

Ifumphry-Manual of Nursing. (Blak.) Keating-Mat., Ine, and Chlld. (Lipp.) L, nngfeid-Infectlous Dis. (Blakiston) Ifttle-Anat. and I'hys. (Lea) Lounsberry-Itak'g G'd on Pr. $\mathfrak{D}^{\prime} \mathrm{g}$ ( $\ddot{L}_{\text {. }}$ ) l'rlce-IIyglene for Nurses (Lea)...... ien. Hosp. (C. M. B. Co.)

Marquard-Irinal. for N. (C.Mi.B.Co.) Mills-Niur. \& Care of Insane (Lipp.). Ostrum-Nassage. Hlus. (Blakiston). l'arker \& Breckenridge-s. \& G. N. (L.) Sachse-How to Cook for the Sick (L.) Senu-Nur. F, to Op. Itin. (C.M.B.Co.) Sichreiner-Dict Lists (Btaklston). Schreiner-Dict lists (Btaklston) .... Wilcox-Fever Nursing (Blakiston) Wilson-Clinical Charts (Lipp.)... Wilson-Clinical Diagrams (Lipp.)... Wiison-Fever Nursing (Iipp.)........

l'hysiology, Histology and Metabolism

Alcock and Ellison-Ex. Phys. (Blak.)

Bohm, Davidoft and Huber-Hist. (S.).

Broomell and Fischells-A. \& H. (Blak.)

lirubaker-Compend. (Biakiston).

Brubaker-Text-Book (Blakiston).

Buckmaster-Morpl. of Blood (Biak.)

Coliins-Rockwell--Physiology (Lea)....

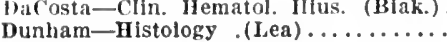

Emery-Clin. Bact. \& IJematol. (Blak.)

Fischelis-Histology (Lea) ...........

Gaylord-Aschoff-Path. Histology (Lea) IA

Guenther-Physiology (Lea)......... 1A

IIall-Experiniental Physiology (Lea)..

IIall \& Herxheimer-Mor. Hist. (Lipp.)

Hardesty-Labo. G. for Hist. (Bla:.).

Hardesty-Labo. G. Por Hist. (Blak.)

Henneter-Lab. Man. of Phys. (Blak.)

Hopewell-Smith-D. Ana. \& Phy. (Lea)

Howell-Physiology (Saunders) ........

Jones-Outlines of. Ilius. (Blak.)....

Krause-Histology (Rebman).........

Luciani-IIuman Physiol. (Macmillan) ]

Lusk-Nutrition (Saunders).......... 6

ItcGiannan-Physiological Chem. (Lea) 1A

Piersol-Normal Histology (Lippincott)

Porter-Introduction to Physiol. (Lipp.)

Porter-Introduction to Illus. (Blak.)...

Schäer-Histology (Lea) ............ 1A

Simon-Physlological Chemistry (Lea) iA

Starling-Physiology (Lea)......... IA

Stirling-Histology (Blakiston).

Stirling-Practical Phys. (Blakiston).

Stohr's Text-book of Hist. (Blak.)...

Taylar Digestion and lletabol. (Lei) I

Vaughan-Protein Products (Lea).... 1A

Von Noorden-Disord. of Met. (Treat.) I5
Wathen-Histology (Lea)........... 1A

\section{Poisons}

Autenrieth-Det. of Poisons \& St. Dr. (B.) Reese-Med. Juris. and Toxi. (Blak.).

Tanner-Memo. of Polsons (Blakiston)

\section{Practice of Mcalicine}

Aaron-Diseases of Stomach (Lea).... IA Allbutt-Dis. of Art. \& A. Pect. (Mac.) 15 Allbutt \& Rolleston-S. of M. (Mac.) 15 Auders-Practice of Medicine (Saund.) 5 Beebe-Ductless Glands (Lea) ....... IA Black-Forty Yrs in Med. Pro. (Lipp.) Brown-Tuberculosis (Lea) …........ Brown-Tuberculosis (Lea) .......... 1A Daniels-Laboratory Work (Blakiston) $\mathbf{4}$ Deaderick-Malaria (Saunders)....... 5 $\begin{array}{ll}\text { Dieffenbach-Hydrotherapy (Rebman). } & 13 \\ \text { Edwards-Practice of Ifedicine (Lea) } & 1 \mathrm{~A}\end{array}$ Ehrlich-Anaemia (Rebman).......... 13 Emerson-Essentials of Med. (Lipp.) 9 Emerson-Essentials of Med. (Lipp.) 9 Fox-Small-Pox (Lippincott) ............ 9 Goenp-Med. St. B. Ques, \& Ans. (S.) Hare-Modern Treatment (Lea)..... IA Hare-Typhold (Lea).............. IA Harvey-Lectures (Lippincott) .......... 9 Hertzler-Tumors (Lea) .............
Hinsdale-Hydrotherapy (Saunders)...
Hughes-Compend, of Practice. (Blak.) International Clinles (Lippincott)....... Jeffery and Maxwell-Dis. of China (B. Kelly-Practice of Medicine (Lea).... Lathan \& English-S. of T. (Macmilian) 1 Latham-llictionary of Treat. (Biak.) Lydston-Dis. of Society (Lippincott). Lockwood-Diseases of Stomach (Lea) Mackenzie-Symptonis (C. M. J3. Co.). Meigs-II unian Blood-Vesscls (Llpp.). Meigs-Origin of Disease (Llppincott) Iusser \& Kelly-Prac. Treat. (Saund.) Nicholson-IBlood Pressure (Lippincott) Ortner-Trea. of Inter. Dis. (Lipp.). Orter-Modern Medicine (Lea) Packard-Ilist. of Medicine (Lippincöti) Paton-Nerv. \& Chem. R. of M. (Mac.) Poynton \& Paine-Rheumatism (Mac.) Ramsey-Life Ins. Examinations (Lipp. Robin-Tr. of Tuberculosis (Macmlilan) Rolleston-Dis. of Liver, Gail, B.D. (Mac. Saundby-Digestive Giands (Lippincott) Saundby-Ifedical Ethics (Iippincott) Stevens-Practice of Mediclne (Saund. Stitt-Diag. and Tr. of Trop. Dis. (Blak.) Thompson-Glimp. of Med. Eur. (Lipp.) Thompson-Practical Mledicine (Lea). Thorne-Schott Meth. Heart Dis. (Blak.) Thorpe-Blog. Dr. Wm. Pepper (Lipp.) Tyson and Fussell-Practice. (Blak.) Tyson and Fussell-Practice. (Blak.)
Wegele-Thera. of G.-Int. Tract (Reb.) Welch-Schamberg-Ac. Con. Dis. (Lea) Whitla-Treatment (C. M. B. Co.).... I0 Wilcox-Treat. of bis. (Blakiston)

Wilson-Iled. Pock. Formulary (Lipp.)

skin, Cienito-Urinary and Venereal Diseases

Ball-Syph. and the Nerve. Sys. (Lipp.)

Brown-Eczema (IBlakiston) . \#.....

Casper-Cen-Urin. Dis. (Blakiston).

Casper and Richter-F. Kid. D. (Blak.)

Crocker-Dis, of Skin (Blakiston)...

Crocker-Dis. of Skin (Blakiston)
Deaver-Enlarge. of Prostate (Blak.)

Whrlich-Chemotherapy (Rebman)....

Engman-Treat. of Skin 1)is. (Blak.)

Fournier-Syphilis (Rebman).........

Gardner-Iconograms (Rebman)....... 13

Grindon-Skin (Lea) .............. 1A

Hardaway-Grindon-Cut. Ther. (Lea) IA

Hayden-G.U. \& Venereal Dis. (Lea) IA

Hirsch-G.-U. Ven. Dis. \& Syph. (Blak.) Hyde-Diseases of Skin (Lea) ........ Jackson-Diseases of Skin (Lea) .....

I ingsbury-Dermochromes (Rebman)

Mann-Phys. \& Path. of Urine (Lipp.) 9

Morrow-Social Dis. \& Marriage (Lea) 1A

Moullin-The I'rostate (Blakiston)....

Noguchi-Serum Dlag. of Syph. (Lipp.) Pilcher-Pract. Cystoscopy (Saund.) Reider-Atias, Urinary Sedi. (Lipp.) Sabouraud-Dermatology (Rebman)...

Schalek-Dermatology (Lea) ......... IA

Schamberg-Compend. (Biakiston)...

Schamberg-Skin \& Erup. Fev. (Saun.)
Schmidt-Gen. Ur. \& Ven. Dis. (Lea).

Schmidt-Gen. Or. \& Ven. Dis. (Blak.). Sequeira-Dis. of the Skin. (Blak.). Stelwagon-Diseases of Skin (Saund.) Taylor-Gen. Ur. \& Ven. Dis. (Lea)...
Tyson-Bright's Dis. and Diab. (Blak.) Tyson-Bright's Dis. and Diab. (Blak.)
Van Harlingen-skin Uis. Illus. (Blak.) Veckl-Sexual Impotence (Saunders). Walsh-Dis. of the Hair (C.M.B.Co.). Watson-Cunningham-G.-U. Dis. (Lea) White \& Martln-G.U.S. \& V. D. (Lipp.)

Stomach. Intestines and Liver.

Aaron-Diseases of the Stomach (Lea) IA

Cohnheim-Dis. of Stom., Intes. (Lipp.) Ccmbe-Auto-Intoxication (Rebman). Gant-Diarrhea (Saunders) ............... (uelpa-Auto-Intoxlcation (Rebman)... Habershon-Dis. of Stom. (C.M.B.Co.) Hemmeter-Dis, of Sto.; Diag. \& Tr. (B.) Hemmeter-Dis. of Intestines. (Blak.) Kemp-Stom., Intes., Pancrea (Saund.) Iane-Constipation (C. M. B. Co.)... Iane-kink of the Ileum (C. If. B. Co.) Lockwood-Diseases of Stomach (Lea). IA Morton-Abdomen Proper (Rebman).. 13 Pawlow-Dis. of Dig. Glands (Lipp.). Wegele-Gastro-Intest. Tract. (Rebman) is

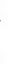

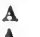
(n) 年 政 


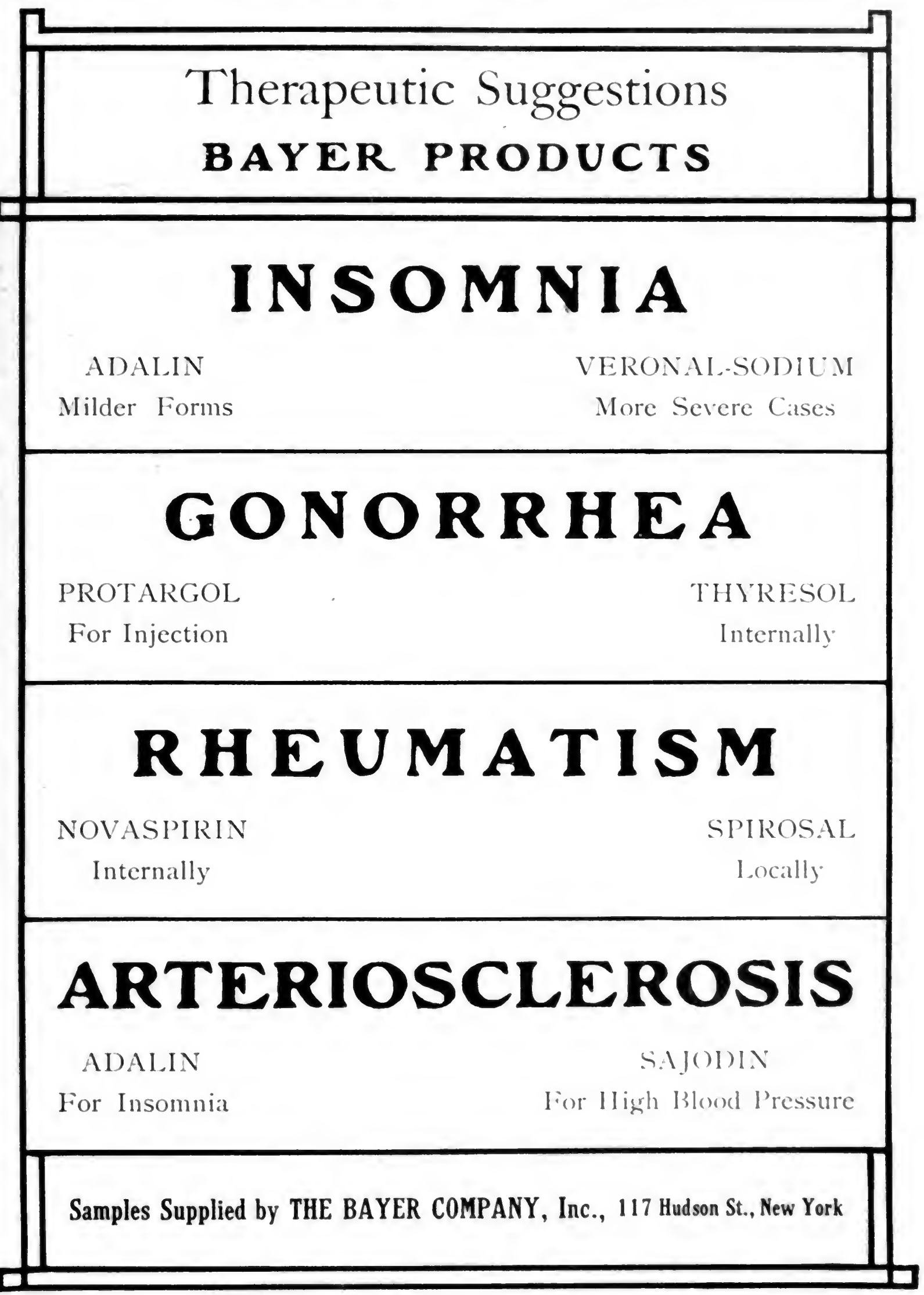


Annals of Surgent (ury

(Lippincott).

Ashhurst-Surgery (Lea).

Bardeleben \& Haeckel-Ap. Ai... (13eb.) 13

Rerg-surgical Diagnesis (Lea)..... I

Bernheim-Surgery of Vas. Sys. (iifip.)

Berry-ifare-Lip and Cleft-l'al. (Blak.)

Biekham-Operative Surgery (Saund.)

Binule-oper. Surg. IHus. (IBiakiston)

Bockenheimer-lkonograms (Bebman).

Bockenheimer-Typ. Operations (1Reb.)

Bodkin-1)iseases of Heetum (Treat).

Brewer-Surgery (Lea).

Brophy-oral surg. (Blaktston)........

Brown-Oral Surgery (Lea).

Bryan-Principles of Surgery (Saund.)

Murreil and Biake-Case T. in Surg. (13.)

Cheyne-13urghard-Surg. Treat. (Lea)

Clark-Gynecological Diag. (Lipp.).

Compton-Essen. of Surg. (C.M.B.C. Co.)

Crandon-Surg. After-treat. (Saund.

Cushing-The Pitultary Body (Lipp.)

DaCosta-Modern Surgery (Saund.).

Dannreuther-.Minor \& Emer. Surg (S.)

Davls-Bandiging. llitus. (Blakiston).

DeGarmo-Hernla (Lippineott) ........
Deaver-Surg. Anat. 3 'vols. (Blak.).

Deaver-Srg. An of Head $\&$ Neek (B.)

Deaver-Enlarre. of l'rostate (Blak.)

Deaver-Surg. of the Sto. \& D. (Blak.)

Douglas-Surg. Dis. of Abd. (Blak.)
puijes-Emergeneies (Blakistonl)

Earle-Dls. of Anus, Rec. \& Slg. (Lipp.)

Fenger Memorial Volumes (Saunders).

Fowler-operating Room (Saunders).:

Fullerton surnical Nursing (Btak.).

Gouley-Surgery of the G. U Or. (Reb.)

Hertzler-Tumors (Lea) ...............

IIopkins-Roller Bandage (Lippincott).

liorwitz-Compend (Biakiston).

Jacobsen-1Rowlands \& Turner-Operations of Surgery (Macmillan)

Jacobson-Surgical Operations (Biak.)

hanavel-Infections of Hand (Lea).

Keen-Surg.: Its Prin. \& Prac. (S.)

Kelly-Appendicitis (Lippineott) .......

Kelley-Surg. Dis. of Chi. Ap. (Lipp.)

Kopetzky - Surgery of the Ear (Teb)

hrause-Surgery of the Brain (Reb.).

Lane-Cleft 1'al. and II. L. (C.M.M.Co.)

Lane-Oper. Treat. of Frac. (C.M.B.Co.)

Lorett-Lat. Curvat, Round Shoul. (Blak

Luke-Guide to Anesthetics (Lippincott)

Lynch-Diseases of Rectum (Lea)

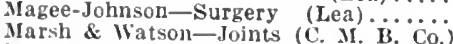

Martin-Surgical Diagnosis (Lea) ....

Mayiard-Abdominal Tuber. (Blak.).

Maylard-Pr. and Prob. in Abd. Srg. ( $\underset{B}{ }$.)

Mayo-Collected Papers (Saunders).

Mouilin-Enlarge. of the Pros. (Blak.)

Morrow-Imme. Care of the Inj. (S.)

Morton-Abdomen Proper (Rebman).

Moynihan-Duodenal Ulcer (Saund.).

Moynihan-Gallstones (Saunders).

Mumford-Practice of Surgery (Saund.)

Murphy-Clinics (Saunders)...........

Murray-Hernia (Blakiston).

Nutt-Dis. \& Def. of Foot (Treat)....

Ople-Dis. of the Pancreas (Lippincoti)

Oppenheimer-Surg. Treat. (Blak.)...

Pels-Leusden-Surgical (Lea). (Reß̈.

Richardson-Thyr. \& Para. Gl. (Blak.)

Robb-Aseptic Surg. Technique (Blipp.)

Rodman-Surg. of Breast (Blak.) (Lipp.

Rovsing-Abdominal Surgery (Lipp.)...

Rumpel-Cystoscopy (Rebman)

Sehudder-Tumors of the Jaws (Saund.)

Scudder - Treatment or Frac. (Saund.)

Siuss-Emergency Surgery (Blakiston)

Stewart-Man. of Surg. (Blak.).
Stimson-Fractures \& Dislocat.

Thorndike-Manual of Ortho. (Lea)

Thorndike-0rtho. Surg. Illus, (Blak.)

Torok \& Grout-Surgery of Eye (Lea)

Treves-Surgical Anatomy (Lea)...

Tuthy-Tieformities of $\mathbf{B}$. \& J. (iiac.) Tauhan-Pract. of Surgery (Lipp.). Wation-('unningham-G.-U. D. \& $\mathrm{S}$.

Wharton-............................. 1A Whatman-Mrthopedic and Band (Leaj is Whiting-Mastoid Operation (Blak.).
Willard-Surg. of Childhood (Lipp.) Woolsey-Surgical Anatomy (Lea).... 1A Young-Manual and Atlas (Blakiston). Veterinary

Barton-On the llorse (C. M. B. Co.) 10 Juchanan-Veterinary Bacteri. (Reb.) Buchanan-Veterinary Bacter. (Saund.) Courtenay-Vet. Medicine (C.M.B.Co.) Fleming \& Woiff-Elsner-Ser. Diag. (S.) Frledberger \& Frohner-Vet. Path. an

Herzog-Veter. Miferoörganisms (Lea) hohday-Dis. of Dog \& Cat (C.M.B.Co.) lowett-BI. S. T. for V. S. (C.M.M.C.) Jowett-Blood Ser. Ther (C i. B, Co) Kitt-Vet. Iath. (Ch?. Med. Bk. Co,) P'aton-Veterinary Plyssio. (C.MI.B.Co.) Itobertson-Agricult. (hem. (C.M.B.C.) liohertson-Herzog-iI.SF.In. (C.M.B.Co.) Sharp-ophth. for Veterin. (Saund.). Strangeway-Vet. Anat. (C. M. B. Co.) Tusgn-Vet. J'harmacy (C. M. B. Co.) 10

$$
\text { Visitin! Lists }
$$

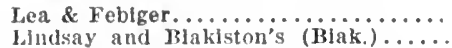

MEDICAL BOOK IMPORTERS

Macmillan Company, The............. 15

MeClurg \& Co., A. C.................. 123

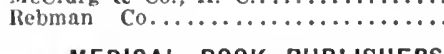

\section{MEDICAL BOOK PUBLISHERS AND DEALERS}

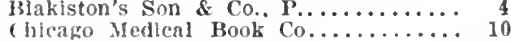

Forbes \& Co..................... 15 Lea \& Febiger...Left Hand $\ldots$ Front End Sheet Lippincott Co., J. B................ 9 Login Bros................... Macmilian Company, The............... 15 MeClurg \& Co., A. C.............. 12,

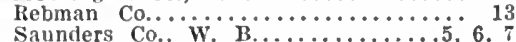

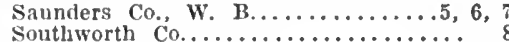
Treat \& Co.. E. B.......

Year Book Publishers................

\section{MEDICAL BOOKS-SECOND HAND}

login Bros................... 47

\section{MEDICAL CHARTS}

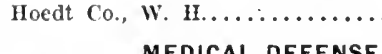

Medical Protective Co.............. 3

MEDICAL JOURNALS

American Medicat Association......... 126

$$
\text { MEDICAL SOAPS }
$$

Johnson \& Johnson............ 86 Sehieffelin \& Co........................ 31

\section{MEDICATED PLASTERS}

Johnson \& Johnson............... 86 MEDICINE CABINETS

Aloe Co., A. S.................... 122

\section{MEDICINE CASES AND BAGS}

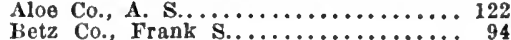
Sharp \& ${ }_{\text {Smith......................... }} 94$

\section{MICROSCOPES AND ACCESSORIES}

Aloe Co., A. S................... 122

Hynson, westcott \& Co.............. 128 Leitz, Ernst..................... 115 Nystrom \& Co., A. J.............. 11 Pennock, Edward................... 123

\section{MICROTOMES}

International Instrument Co.......... 113

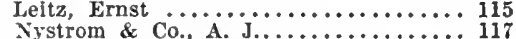
MILK MODIFIERS

Benger's Food, Ltd..................
Mellin's Food Co.................

\section{MILK PRODUCTS}

Arend Drug Co., A................ 89

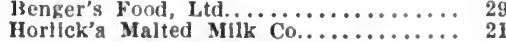
MINERAL WATERS

Arrowhead Hot Springs Co......

"Ballarilvale springs Co., The.

"Souree Salee"

Ylehy Celestins.

Vittei rirande source.

White Sulphur springs.

\section{MOTORCYCLE TREADS}

Leather Tire Goods Co............. 104

MURPHY DRIP OUTFITS

Meinecke \& Co................. 115

\section{NEBULIZERS}

Eetz Co, Frank S.............. 94

Jaeckh Mif. Co.................... NITROUS OXIDE APPARATUS

Dresster-Beard Mff. CO............128A NURSING BOTTLES

Yankee Co..................... 122 NURSES' CALL SIGNALS

Chicago Signal Co., The............ 114 NURSES' TRAINING SCHOOLS

IHinois Training School.............. 4t OBSTETRICAL SUPPLIES

Sampson-Soch Co................. 116 OCULISTS' SUPPLIES

Mclntire, Nagee \& brown Co........ 110 OFFICE COATS

Eetz Co., Frank S................ 94 OFFICE FURNITURE

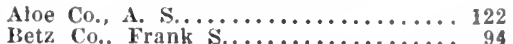

Ketz Co., Frank $\$$................... 94

Mclntosh Co., John.................. 119

Physicians' Furniture Exchange.......... 102

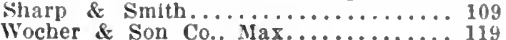

\section{OFFICE FURNITURE-ASEPTIC}

Cole $\&$ Cole.................... 82

\section{OINTMENTS}

Fritzsche Brothers................. 84

Janhattan Eye Salve Co............... 117 OLIVE OIL-MEDICINAL

Heinz Co., H. J.................. 127

OPERATING TABLE PADS

Aloe Co., A. S................ 122

Meinecke \& Co...................... 115

\section{OPERATING TABLES}

Betz Co., Frank S............... 94

OPERATION LIGHTS FOR HOSPITALS

Leitz, Ernst................... 115

\section{OPHTHALMOLOGIC APPARATUS}

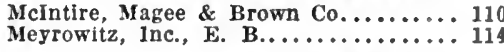

\section{OPTICAL INSTRUMENTS}

Betz Co., Frank s................. 94 Hardy \& Co., F. A.................. 106 McIntlre, Magee \& Brown $\mathrm{C}_{0} . . . \ldots \ldots \ldots$..... 110 Meyrowitz, Inc., E. B................ 114

\section{OPTICIANS}

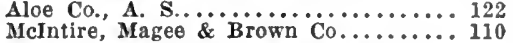
ORTHOPEDIC APPARATUS

Aloe Co., A. S................... 122 Ambulatory Pneumatic Splint Mfg. Co.. 99 Retz Co., Frank S................... ${ }^{94}$ Mueller \& Co., V.................... 124 Pomeroy Co........................... 102 Seholl $\| 19$. Co...................... 101 


\section{The Mulford}

\section{Antitoxins, Serums, Bacterins, and Pharmaceuticals are the Standard}

Physicians should bear in mind that different brands of pharmaceutical and biological products differ widely in regard to their therapeutic value. This variation accounts for many of the failures to secure results from the administration of well-known products.

The proper preparation and standardization of pharmaceuticals and biologicals requires exceptional technical skill and expert knowledge, together with unlimited facilities for scientific research.

The H. K. Mulford Company are leaders in drug standardization, and to-day the Mulford brand is recognized as a guarantee of superiority throughout the world.

Our large staff of scientists and experts and extensive connections with hospitals and other institutions enable us not only to keep in constant touch with the progress of bacteriological science but also to obtain the various strains of pathogenic microorganisms so absolutely necessary to the production of effective and polyvalent serums and bacterins.

Dependable results are assured by specifying the Mulford Brand

\section{H. K. MULFORD COMPANY, Philadelphia} Pharmaceutical and Biological Chemists

\begin{tabular}{|c|c|c|c|c|c|}
\hline New lork & Boston & Kansas City & St. I,onis & New (Orleaus & San Fraucisco \\
\hline Chicago & Atlanta & Dallas & Serttle & Minneaprolls & Turonto \\
\hline
\end{tabular}


Sharp \& smith.

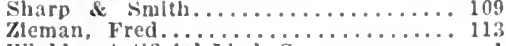
ORTHOPEDIC INSTITUTIONS

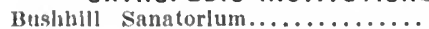
ORTHOPEDIC SHOES

Ambulatory Pneumatle Splint Mg. Co. Lietz Co., Frank S..

Larson, Martln....

............... OXYGEN APPARATUS

Draeger Oxygen Apparatus Co...

\section{PASTEUR TREATMENT}

Chlcago Pasteur Institute.

Mulford Co., II. I...............

\section{PATHOLOGICAL PERIODICALS}

Logln \& Son, B........

Marks, PEG LEGS

\section{PHARMACEUTICAL PRODUCTS}

Alleratires and Tonic

Fxtract Chlnae-Nanulug. .

Ferro-Mangan

Meinz olive oll.

Maltine
Ovoferrin

Sajodln

.

Trommer Diastasic itait Ext........... 85 dursthrtirs

Ether, P.-W.-R. Co...........

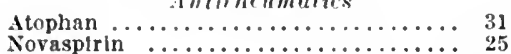

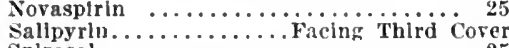
Splrosal $\ldots \ldots \ldots \ldots \ldots \ldots \ldots \ldots \ldots \ldots \ldots{ }_{25}$ Anliscpties. Disinfertants and Gonorides Argyol (sllver vitellin) . . . . . . . 17

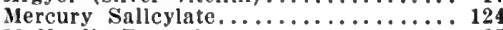
Mulf ord's Bacterin.

Protargol.

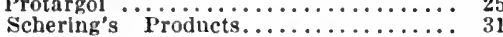

Thiol. ................ Third Cover

Thyresol ..................... 25

Tannalbin Astringents

Diglpuratum cardiants

Chemicals, Imlutiny symthetifs

Mergal................ Facing Third Cover Novatophan

Sajodln... Arend's Kumyss............... 89 Bromo-Mangan

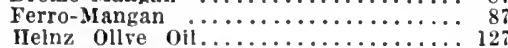

Horllck's Malted iilik.

Maltine ....

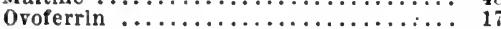

Triferrin $\ldots \ldots \ldots \ldots \ldots \ldots \ldots \ldots \ldots, 31$

\section{liuretics}

Diuretin $\ldots \ldots \ldots \ldots \ldots \ldots \ldots \ldots \ldots \ldots . . .31$

Vichy Celestins.................. Cov.

Vittel Grande Source.............. 90

Dry-or Dosage Form Preparations

Hay Fever Antitoxln Pollantin....... 84

Mllilken's Pharmaceutlcals............ 120

Pollantln ...................... 84 Schleftelin's Soluble Pills.. Inside Bk. Cov.

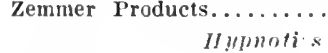

Adalín

Broniural

Vedinal Sodium

Feronal_Sodlum $\ldots \ldots \ldots \ldots \ldots \ldots \ldots \ldots . .31$ linuld Plentmateltiral Preparations. Extract Clinae-X゙anning........... 87

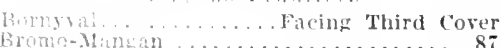
Brovalol .....

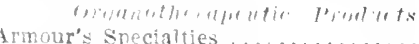

Soliil Provations for Hetenal Lis

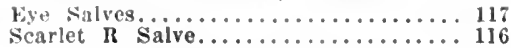
suppositurifs

Gibbs Hollow Suppositorles.Inslde Bk. Cov. Schering's Suppositorles............ 31

\section{PHARMACEUTICAL CHEMISTS}

Arend Drug Co., A............. 89 Armour \& Co.................. 23 Harnes Co.. A. C $\ldots \ldots \ldots \ldots \ldots \ldots \ldots \ldots, 17$

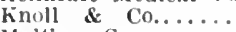

Maltine Co....

Mllikken \& $\mathrm{C} 0 .$, Jolin $\mathrm{T}$

Mtulford Co., II. K. .

Surueut's Co............ Faclng Third Coser

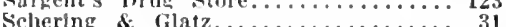

Zemner co

\section{PHOTOGRAPHIC APPARATUS}

Leltz, Ernst .................. 115 PHOTOGRAPHIC DEVELOPERS

Berline Aniline Works......... 121 Harris \& Co., Ralph................. 123

PHOTO-MICROGRAPHIC APPARATUS

Leltz, Ernst................ 115 PHOTOTHERAPY

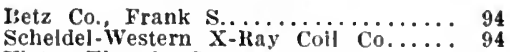
Vletor Electrlc Co .............. 96

\section{PHYSICAL CULTURE APPLIANCES}

May, Berthe................. 118

$$
\text { PHYSICIANS' ASEPTIC OFFICE }
$$
FURNISHINGS

Scanlan-Morrls Co............... 120 PHYSICIANS' DEFENSE

Medical Protective Co.............. 3

\section{PHYSICIANS' OFFICE COATS}

Betz Co., Frank S.............. 94 PHYSICIANS' RECORDS

Chlcago Medical Book Co.......... 10

McCaskey Reglster Co............ 123 Medical and Surgical Supply Depot... 116

PHYSICIANS' AND HOSPITAL SIGNS

Abram Co., Abe................ 122

\section{PHYSICIANS' SUPPLIES}

Draeger Oxygen Apparatus Co........ 91

Medical and Surgical Supply Depot.... 116 McIntosh Co., John, The........... 119

Mueller \& Co., V................ 124

Rapid Addressing Machlne Co........ 106

\section{PHYSIOLOGIC THERAPEUTICS}

Chlcago Inst. of Physiologic Thera.... 116

\section{PLASTERS}

Johnson $\mathcal{E}$ Johnson. ............... 86 Shiver's Adhesive Plaster..Inside Bk. Cov. PLUMBING

Wolff \& Co........................ 112

PLUMBING WASTES PURIFIED

Archer, George F................ 110 POWDER BLOWERS

De Vilbiss Mfg. Co............. 122 PUBLISHERS

Blaklston's Son \& Co., P........... 4 Chicago Medlcal Book Co............ 10 Forbes \& Co...................... 15 Lea \& Febiger... Left Hand, Front End Sheet Lippincott Co., J. B............. 9 Iacmillan Co.................... 15 Merriam Co., (i. \& C.............. 82 Rebman Co................... 13 Saunders Co., W. B...........5, 6, 7 Southworth Co................. 8 Treat $\&$ Co., E. B................ 15 Year Book Publishers............. 11 PULMOTOR

Draeger Oxygen Apparatus Co....... 91
REFRIGERATORS

McCray Refrlgerator Co........... 120 ROENTGEN PLATES

IBerltn Anfline Works.............. 12

\section{ROLLING CHAIRS}

Aloe Co., A. S................. 122 Betz Co., Frank...$\ldots \ldots \ldots \ldots \ldots \ldots .94$ Marks, A. A................... 91 RUBBER FEET AND HANDS

Betz Co., Frank...$\ldots \ldots \ldots \ldots \ldots \ldots 94$

Marks, A. A..................... 91 RUBBER GLOVES

Johnson \& Johnson............. 86 Mlller Rubber Company............... 103 RUBBER GOODS

Betz Co., Frank S................. 94

Johnson \& Johnson................ 89

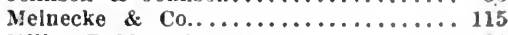

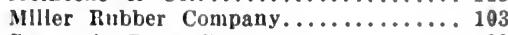

Sargent's Drug Store..............122 RUGS

Betz Co., Frank S............... 94

\section{SANITARIA}

(See Homes, Hospltals and Sanltaria.)

\section{SANITARY FLOORS}

Betz Co., Frank S.............. 94 Muller \& Co., F. R................. 108

\section{SANITARY RECEPTACLES}

Aloe Co., A. S................. 122 Betz Co., Frank S................. 94 Wolff Mfg. Co., L............... 112

\section{SCALES}

Betz Co., Frank s................ 94 SCHOLL'S FOOT EAZERS

Scholl Mff. Co..................101

SCHOOLS FOR NURSES

Chlcago Pollclinlc.............. 33

Davls' Sanltarlum, Dr. J. D. \$........ 69

Illinols TralnIng School,........... 47

SEWAGE DISPOSAL PLANTS

Archer, George F............. 110

SIGNAL SYSTEMS

Chlcago slgnal Co...............114

$$
\text { SIGNS }
$$

Betz Co., Frank S.........

\section{SOAP}

Johnson \& Johnson.............. 86 Schiefrelln \& Co. .................... Corer Page

\section{SPECIAL FORMULA PRODUCTS}

Mllliken \& Co., John T........... 120

SPECIAL SERVICE TO PHYSICIANS

Rapld Addresslng Nachine Co........ 106

SPECTACLES AND EYE GLASSES

Hardy \& Co., F. A............... 106 SPINAL APPARATUS

Ambulatory Pneumatic Splint Mfg. Co. 99 Betz Co., Frank S................. 94

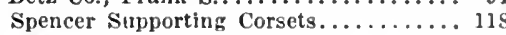
Van Orden Corset Co.............. 118

\section{SPLINTS}

Aloe Co., A. S................. 122 Ambulatory Pneumatic Splint Mfg. Co. 99 Betz Co., Frank S................. 94 Johnson \& Johnson............... 86 SPRAYING AND NEBULIZING OUTFITS Jaeckh Mfg. Co.................. 97

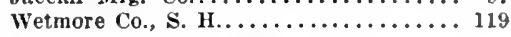
SPUTUM CUPS

Jclunson \& Johnson.............. 86 Meinecke \& Co................. 115 
TEXT BOOK REFERENCES TO THE USE OF BEN. GER'S FOOD

"Benger" Food we have found of real use in quite young infants who were going progressively backward or were stationary on other foods." - Rosunda Proctical Midwiferv.

"The Food (Benger's) is a very good one and usually agrees well." - Wosting Diseases of $\mathbf{I n}$ fants and Children.

"Partially-malted cereal foods

.. Benger's Food is somewhat similar, but the partial conversion is accomplished by pancreatic ferments." - Article on Infant Feeding, in "Encyclopedia Medica."

"The food (Benger's) is specially valuable for marasmic in. fants over six months of age, and it may be given with advantage. if cautiously watched, to much younger infants who cannot digest ordinary cow's milk." "Spatem of Diet and Dietelics."

BENGER'S FOOD IN INFECTIOOS DISEASES

\section{Children's Diet in Fevers}

-The patient may prefer Beager Food: most of the children take Benger's Food well." -Inectious Diseases. (Oxford Medical Publications.)

\section{Typhold f'ever}

"I have always found Benger's Food a most useful preparation. and employ it perhaps more frequendly thas any of the others."

"It is a valuable food in $\mathrm{Ty}$. phoid Fever." - "Sustem of Diel and Dieterics."

\section{Diphtherla}

\section{Diet in Convalescence.}

Supper.-A glass of milk. bread and milk, oat flour porridge, of Benger: Food, as preferred." - "Infectious Dis. eanes." (Orford Medical Publi. cations.)

"Among Proprietary Food. Benger"s is one of the most useful preparations, especially for casem of continued fever."-Food and Feeding in Healsh and Dineanea.

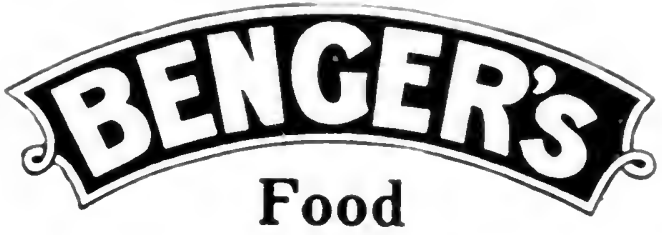

For Infants, Invalids and the Aged is quite distinct from any other food obtainable.

Benger's Food is unique in combining the two natural digestive principles, Amylopsin and Trypsin, in such a manner that these become active while the food is being prepared with fresh new milk.

\section{THE NORMAL PRESCRIPTION FOR BENGER'S FOOD IS -}

\author{
"Set aside fifteen \\ minutes for digestion."
}

If allowed to stand at one stage of its preparation, Benger's Food is self-digestive, both as regards the milk with which it is prepared and the Food itself.

$\mathrm{By}$ indicating the time of standing, 5 to 45 minutes, the physician is able to adapt Benger's Food to the physical condition of the patient.

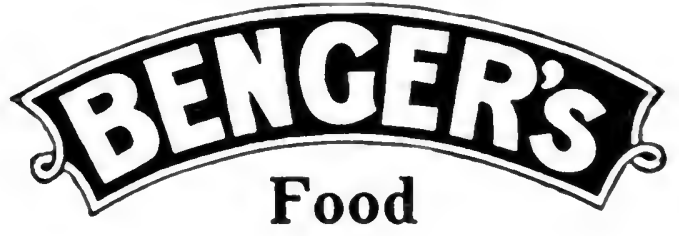

For Infants, Invalids and the

Aged is guitedistinct from any other food obtainable.

A physician's sample with analysis and report will be sent post free, upon application, to any member of the Medical Profession.

\section{BENGER'S F00D, Ltd.}

\author{
92 William Street \\ NEW YORK CITY
}

REFERENCES TO USE OF BENGER'S FOOD IN DISEASES OF THE DIGES. TIVE TRACT

ARTICLE ON ULCERS OF THE STOMACH

"If the patient gets tired of milk, or if it be not well borne. Benger's Food may be tried." Sostem of Medicine.

\section{Diet in Gastric Irritation}

"For the midday meal 12 to 1. milk and Benger's Food made quite thin. with the white of an unboiled eqg beaten up in it. a little salt being added.". Funcsional and Organic Diseases of the Siomach.

\section{Acute Enteritis}

"Thinly made Benger's is often most useful."

\section{Dilatation of the Stomach}

"Peptonized milk. Benger's Food are the most suitable, and should be given in small quantities at intervals of tour hours."

\section{Chronic Gastritis}

"Such food as is required should be of the simplest character, milk and soda water thinly prepared, Benger's Food are most suitable, and should be given in small quantitics."- Manual of Medicine.

\section{DIET IN DISEASES OF THE} STOMACB

\section{Gastric Ulcer}

Beager's Find can be given al 4:30 p.m., and at 10.00 p.m.

Chronic Ulcer past operative

$\mathrm{O}_{21}$ the third day mone carbo hydrate may be added in the form of Benger's Fond.

\section{Chronic Gastritis}

The carbo-hydrate element is best given in the form of Beager"s Food - Sustem of Dies and Dieberics.

Carcinoma of the Stomach "Benger's Find may be found usciul."

Surgical Aspect of "Iadizes tion."-Proctifioner. 
STATIC MACHINES

Betz Co., Frank S.............. 94 Statle X-Ray Co......................... 82

STEREOSCOPIC MEDICAL WORKS Southworth Co., The..............

\section{STERILIZERS}

Aloe Co., A. S.................. 122 Amerlcan Sterillzer Co............ 117 Betz Co., Frank S............... 94 Castle Co., Wilmot.............. 93 Leilz, Ernst.................. 115

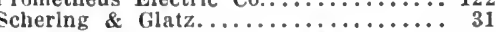
Sorensen \& Co., Inc., C. M.......... 111 Victor Electric Co................ 96

Wocher \& Son Co., Max............ 119

\section{STERILIZING APPARATUS}

Scanlan Morrls Co.............. 120 STOMACH TUBES

Betz Co., Frank S................ 94

\section{STREAM POLLUTION PREVENTED}

Archer, George F............... 110

SUPPORTERS-ABDOMINAL AND UTERINE

Aloe Co., A. S..................... 122

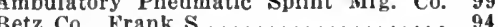
Bolen Mfg. Co.................... 121 Gossard Co., H. W.............. 100

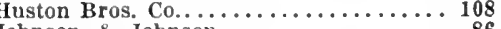
Johnson \& Johnson.

May, Bertbe..

Pomeroy Co..

. . . . . . . . . . . . 124

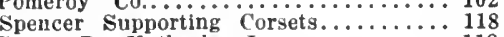

Storm, Dr. Katherine L.............. 118

Van Orden Corset Co................. 118

\section{SURGEONS' GOWNS}

Betz Co., Frank S.............. 94 SURGICAL APPLIANCES

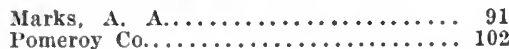

SURGICAL CHAIRS AND TABLES

Betz Co., Frank S............. 94

\section{SURGICAL DRESSINGS}

Jolnnson \& Johnson............. 86

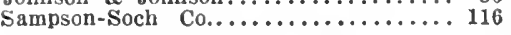
SURGICAL DRILLS

Sorensen \& Co., Inc., C. M......... 111

\section{SURGICAL INSTRUMENTS}

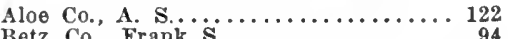

Betz Co., Frank S.................... 94

Electro-Surgical instrument Co....... 111

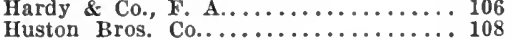

Huston Bros. Co...

Heberknecht \& Fraas.

McDermott Surglcal Instrument Co..... 123

Mey rowitz, Inc., E.B............. 114

Mueller \& Co., V...

Sampson-Soch $\mathrm{C}_{0}$

Randall-Faichney Co

Sharp \& Smith.................... 109

Wocher \& Son Co., Max............... 119

\section{SURGICAL SUPPLIES}

Castle Co., Wilmot............... 93

Draeger Oxygen Apparatus Co........ 91

Electro-Surgical Instrument Co....... 111

Huston Bros. Co............... 108

Hytenic Fibre Co............. 120

Johnson \& Johnson. ............ 86

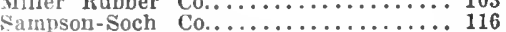

Storm. Dr. Katherine L............ 118

Vitn Horn and Sawtell.

Nterilivers-Disinfectors

Sterilizer Co............. 117 STATE BOARD QUIZ

\section{SUSPENSORY BANDAGES}

Wetmore \& Jounsin.

\section{SUTURES AND LIGATURES}

Betz Co., Frank s............... 94 Johnson \& Johnson.............. 86

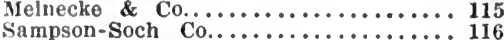

Vun Horn \& Sawtell............... 92 SYRINGES

Isetz Co., Frank S................ 94

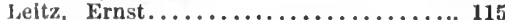

\section{"TABLOID" PRODUCTS}

Dugan-Johnson Co............... 117 TAILORING

Bernard, Hewitt \& Co............ 116

TANKLESS AIR COMPRESSORS

Sorensen \& Co., Inc., C. M........ 111

\section{THERAPEUTIC BATHS}

Chlcago Inst. of Physiologlc Ther..... 116

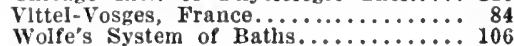

\section{THERAPEUTIC LAMPS}

Betz Co., Frank S.................. 94 Scheidel-Western X-Ray Coil Co....... 95 Víctor Electric Co...................

\section{THERMOMETERS}

Aloe Co., A. S.................. 122 Betz Co., Frank s.................. 94 Hardy \& Co., F. A.............. 106

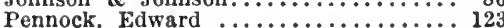

\section{TIRES FOR AUTOMOBILES}

Leather Tire Goods Co............ 104

\section{TIRE PROTECTORS}

Atlas Auto Supply Co., Tire Paint.... 105 Leather Tire Goods Co............. 104 Triple Tread Mifg. Co............... 119

\section{TIRE TREADS}

Leather Tire Goods Co............ 104 Triple Tread Mfg. Co............... 119

\section{TRAINING SCHOOL FOR NURSES}

Clncinnati General Hospital......... 44 Chlcago Policlinlc (Henrotin Memoria) Hospltal)

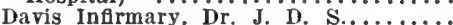

Illinols Training School.

Margaret Wright Hospital.

McNutt Hospital.

$\mathcal{N}$ Chicago Hosp. and $\mathrm{T}_{\mathrm{S}} \mathrm{S}_{\mathrm{c}} \ldots \ldots \ldots$

North Louislana Sanltarium..........

North Louislana Sanltarium........... 77

\section{TRAVELLING LAMPS}

Wolff Co., Will

\section{TREADS FOR AUTOMOBILES}

Leather Tire Goods Co............ 104

\section{TRIAL CASES}

Betz Co., Frank S.........

Ambulatory Pneumatic Spllnt Mfg. Co. 99 Betz Co., Frank- S................ 94 Johnson \& Johnson................ 86 McDermott Surgical Instrument Co.... 123

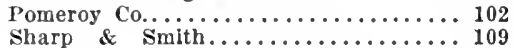

\section{TYPEWRITERS}

Sears, Roebuck \& Co.............. 113

TYPEWRITTEN ADDRESSING TO PHYSICIANS

American Medical Assoclatlon....... 82 Rapld Addressing Machine Co......... 106

\section{URINALS}

Meinecke \& Co................ 115

\section{VACCINE}

Mulford Co., H. K................ 27 National Vaceine Schieffelin \& Co......... Inside Back Cover

\section{VACUUM APPLIANCES}

Betz Co., Frank $\$ . . \ldots \ldots \ldots \ldots \ldots \ldots . . .94$ Jaeckh Mfg. Co..................

Sorensen \& Co., Inc., C. M.......... 11 VACUUM ELECTRODES

Machlett \& Son, E............... 122

\section{VIBRATORS}

Betz Co., Frank S................

IIainllton-Beach Mfg. Co............. 115

McIntosh Battery \& optlcal Co.......... 107

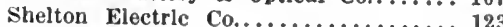

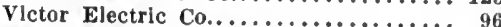

Wappler Electric Mig. Co...................... 114

\section{VISITING LISTS}

Blakiston's Son \& Co., P............ Chicago Medical Book Co.............. Lea \& Fobiger. .Left Hand, Front End Sheet WALL PLATES

Betz Co., Frank S................. Wappler Electrlc Mfg. Co............... 114

WASHING AND IRONING MACHINERY American Ironlng Machlne Co........ 113 Jaeckh Mfg. Co................. 113

WASSERMANN TESTS

Columbus Medical Laboratory........ 45

Natlonal Pathologlcal Laboratory....... 45

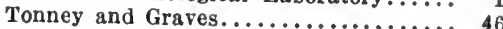
WATER ANALYSIS

Archer, George F............... 110 WATER STILLS

Yolar Water Stlll Co............. 88

WATER SUPPLY

Archer, George F............... 110 WINDOW TENTS

Cabinet Mfg. Co................. 115

\section{WOODEN LEGS}

Marks, A. A................ 91

\section{$X \cdot R A Y$ APPARATUS}

Betz Co., Frank ................. 94

Carliczek \& Co., 0........................ 117

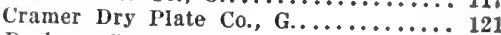

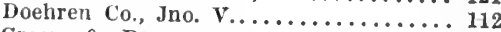

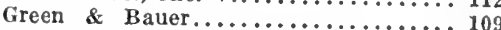

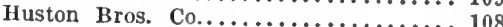

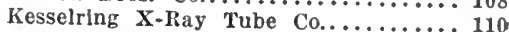

Macalaster-Wiggin Co................... 112

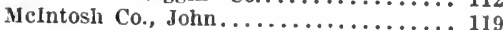

MeIntosh Battery \& Optical Co........ 107

Meyrowitz, Inc., E. B................. 114

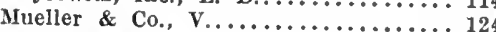

Scheldel-Western X-Ray Coil Co....... 95

Static X-Ray Co.................

Victor Electric Co..................... ${ }_{96}$

Waite \& Bartlett $\mathrm{Mfg}$. Co. ................. 120

Wappler Electric Mfg. Co............... 114

Wocher \& Son Co., Max.................. 119

\section{X-RAY PLATES}

Berllne Aniline Works..............121

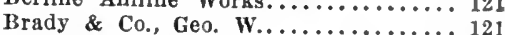

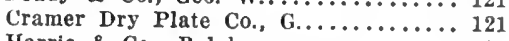
Harris \& Co., Ralph................. 12

\section{X-RAY TUBES}

Betz Co., Frank S.............. 94 Carliczek \& Co., $0 . \ldots \ldots \ldots \ldots \ldots \ldots \ldots \ldots \ldots, \ldots \ldots \ldots$

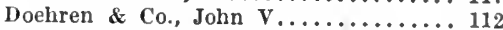

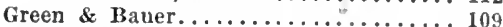

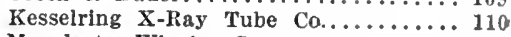
Macalaster-Wiggin Co.................... 112

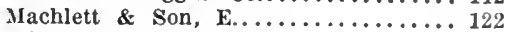
Schoidel-Western X-Ray Coll Co...... 95 Victor Electric Co................ 96

\section{$X \cdot R A Y$ TUBE REPAIRING}

Kesselring $\mathrm{X}$-Ray Tube Co..........110 


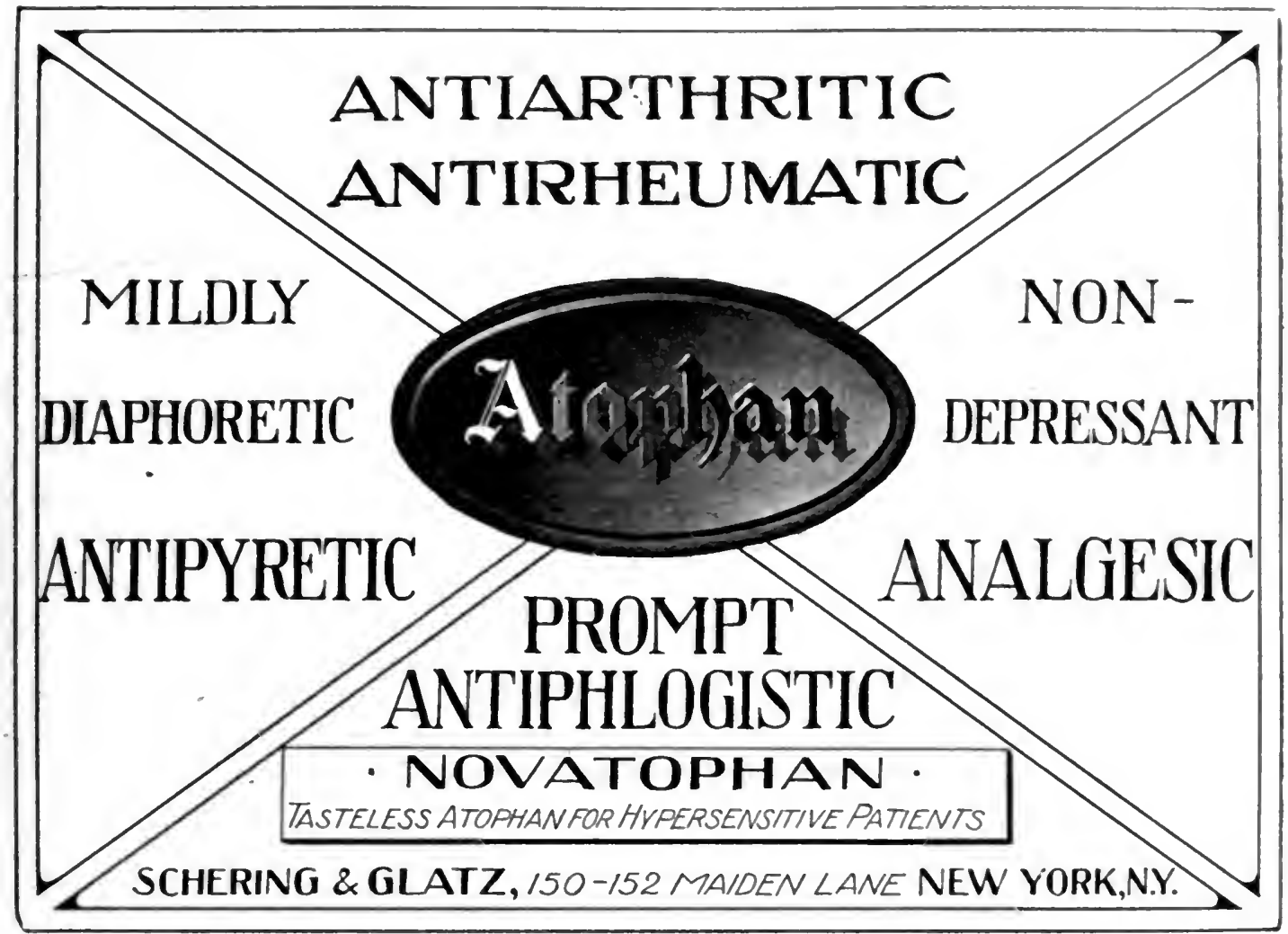

Fine Pharmaceuticals "KNOLL"

\section{DIGIPURATUM}

\section{Physiologically Standard. Digitannoid}

Reliable in Action and Uniform in Strength

\section{BROMURAL}

Nerve Sedative and Hypnotic

Pre.Anesthetic

\section{TANNALBIN}

Non-Irritating Intestinal Astringent

\section{DIURETIN \\ Powerful Diuretic \\ Vascular Remedy and Heare Tonic \\ TRIFERRIN \\ Organic Iron I'reparacion Cont. ''hosphorus}

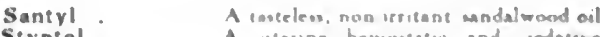

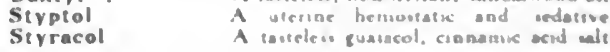

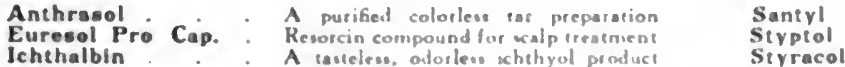
For sale by

Merck \& Co., New York and St. Louin 


\section{NEW YORK POLYCLINIC MEDICAL SCHOOL AND HOSPITAL}

\section{1-351 West 50th Street, New York, City}

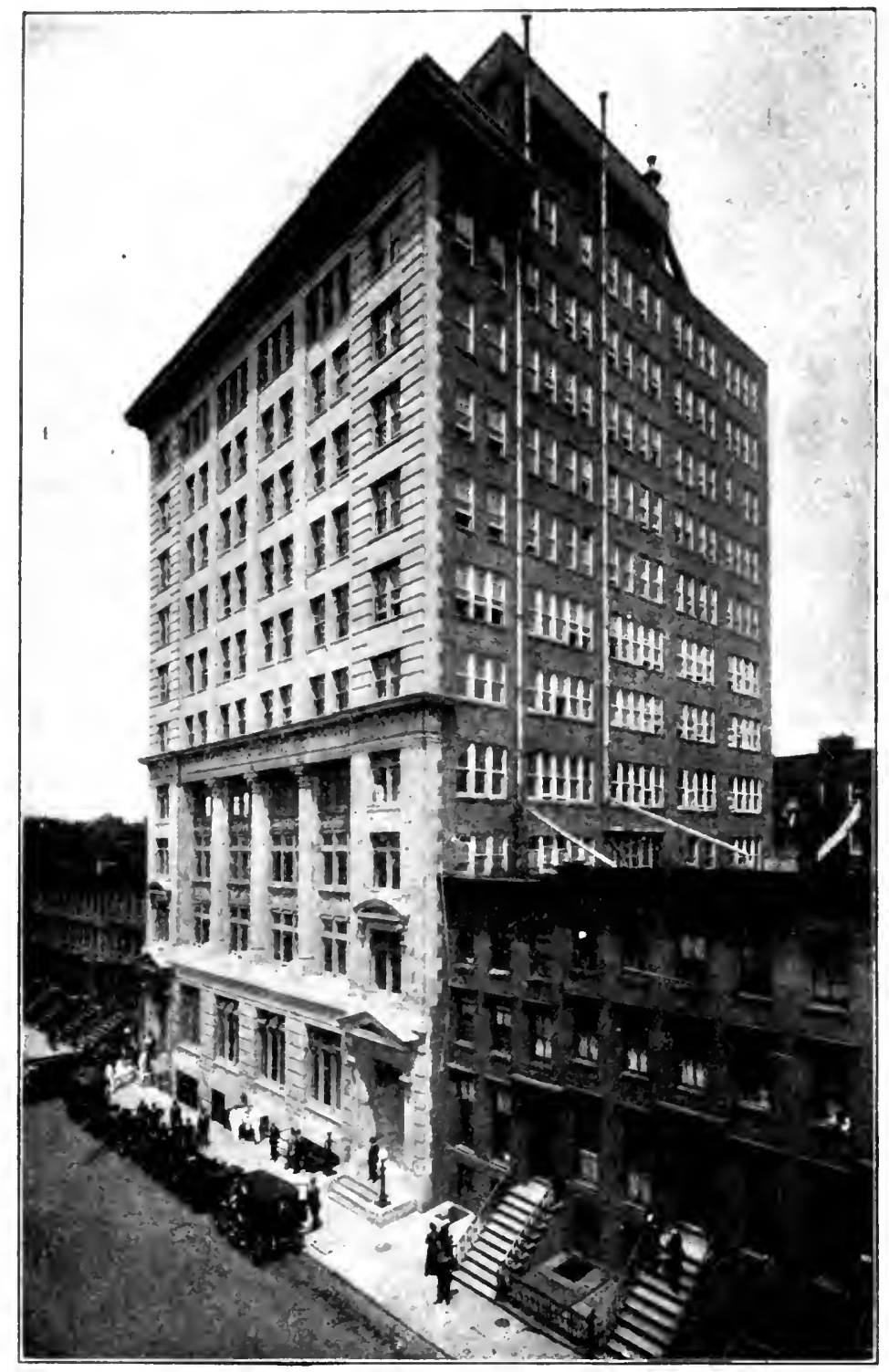

Founded in 1R\&1; the first organization for post.graduate medical instruction in Anerica.

New School and Hospital Build. ing opened May 1, I912.

A Maximum Capacity of 300 medical and surgical beds, a large Dispensary Clinic, and an Accident and Iinergency Anbulance Service, covering a district with a resident population of 360.060 , insure a clinical material equal to every demand of post-graduate teaching.

Special Laboratory Courses to limited classes in Bacteriology, Serum Therapy, Blood Reactions, and in the various analyses essential to diagnosis.

\section{Subdivisions of Study}

Surgery: Gieneral, Orthopedic, Genito-Urinary, Rectal and Neurological.

Medicine: Clinical Medicine and Physical Diagnosis, Diseases of Children, Diseases of the Digestive System, Neurology, Dermatology and Obstetrics.

Special Subjects: Diseases of the Ere, Ear. Nose, Throat, Radiography and Electro-Therapeutics.

The Faculty and Trustees have introduced a course of individual instruction which includes a special personal training in the laboratory as an aid to diagnosis, in anesthesia, in operative technic and bedside treatment. Matriculants for this course act as Assistant on the Intern Staff.

Students especially desirous of utilizing every opportunity for instruction may roon in the hospital, and be subject to call night or day.

Instruction is continuous through. out the year, and so arranged that a physician may begin study at any For announcement of special courses, see medical journals.

For catalogue and further information, address:

JOHN A. WYETH, M.D., LL.D., President of the Faculty or MR. JOHN GUNN, Superintendent 341-351 West 50th Street New York City 
JOHN H. CHEW PRESIDENT
JDWIS W. RYERSON VICL-JREIITH.XT
H1..NKY IIOOFE"R THFASCRER

\section{THE CHICAGO POLICLINIC HOSPITAL}

\section{A CLINICAL SCHOOL FOR POST-GRADUATE INSTRUCTION}

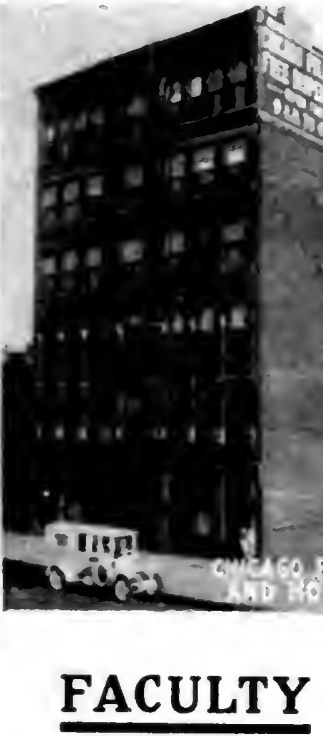

SURGERY

MAI,COLM I. HARRS

EDWIX M. SMITH

WILIIAM HESTERT

COLFman G. BI.Fort

NORMAN KFRR

D. R. MACMIARTIS

ORTHOPEDICS

EOWIN W. RYFRSON

OPERATIVE SURGERY SURGICAL ANATOMY

PAU1. GR(INAREI')

RECTAL

J. R. I'Finivgton
FACULTY
GYNECOLOGY

A. BEICHAN KEVE

CHANWISII BAKRET

PARSEY TYTER

HOWARD (I SHIHEFR

OBSTETRICS

CIAKIAE B BACOS
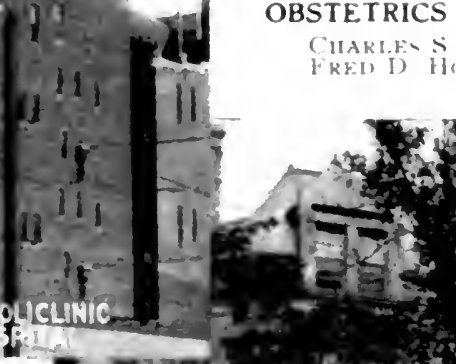
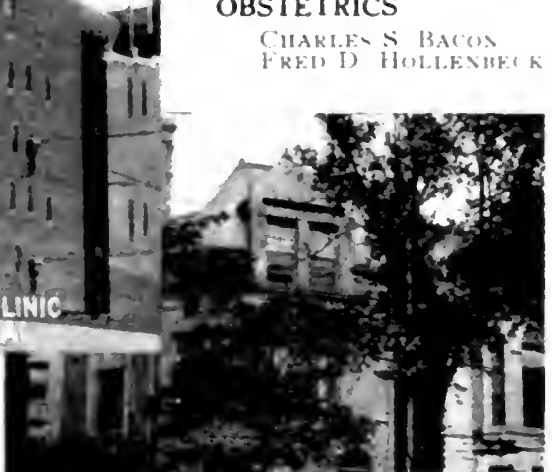

\section{PEDIATRICS}

S. WALKF

11 KIEISl'

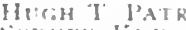

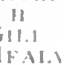

EAR, NOSE AND

THROAT

(i) F. Fisk:

$$
\begin{aligned}
& \text { PATH. BACT, and } \\
& \text { MICROSCOPY } \\
& \text { liII A rishAM }
\end{aligned}
$$

EYE

II II WRBAR

U.

O. 1 FRFER

1)Alu fink

A. 11 ANIIREN

II. (i Krake

In addition to the regular clinical connes, we offer Gencral Operative Cunses on the Cabace, and in intestinal work on dogs. Also Special Operative Couses on the Cadaver in Five, Ear, Nose and Throat. These classes afford the hest possil, medium for anatonical review, and the acepirement of molern surcical technipue. Short practical course's are given in the examination of Bloxl. P'us. Sputum, Lrine, Castric

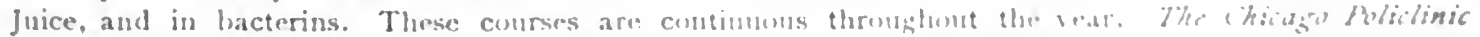

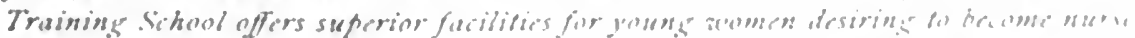

MALCOLM L. HARRIS, M.D., Secretary 


\section{Washington University Medical School}
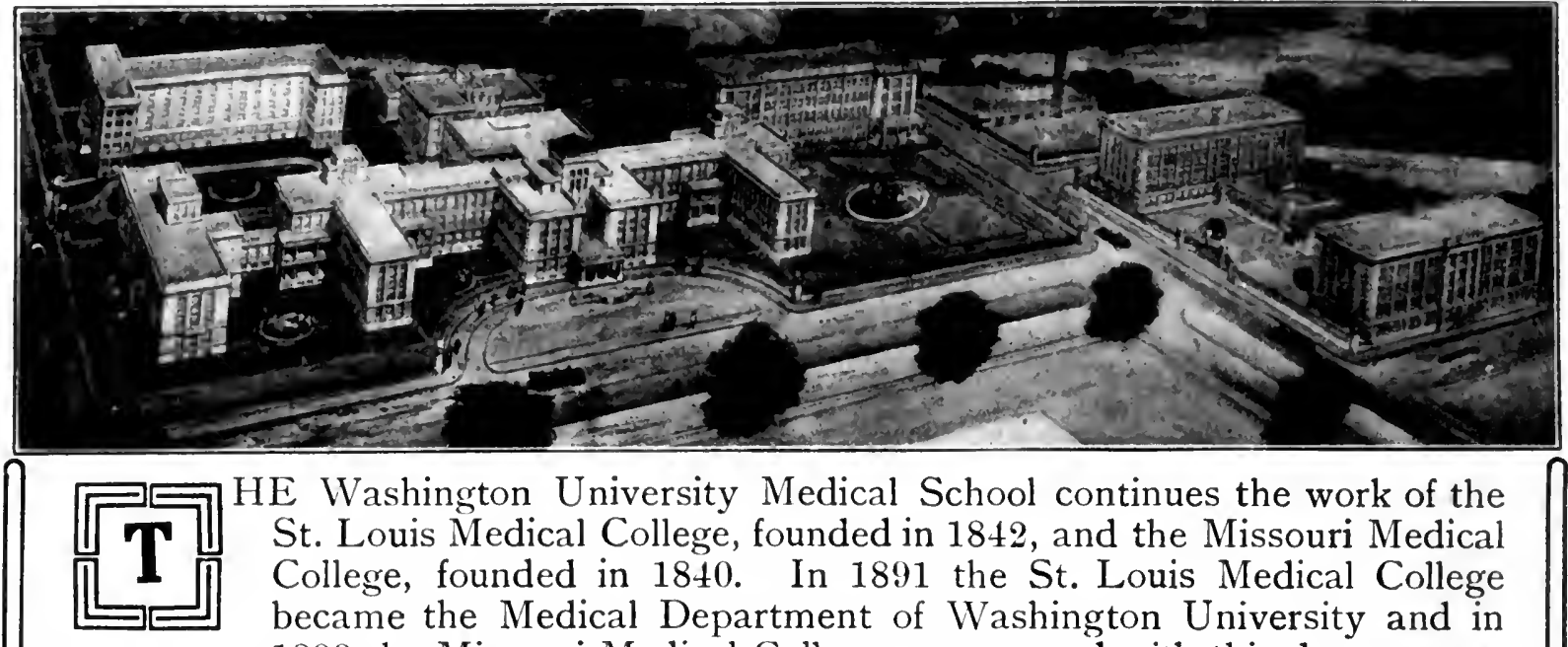

HE Washington University Medical School continues the work of the St. Louis Medical College, founded in 1842, and the Missouri Medical College, founded in 1840. In 1891 the St. Louis Medical College became the Medical Department of Washington University and in 1899 the Missouri Medical College was merged with this department.

With the aid of funds donated by philanthropic citizens of St. Louis the Medical School has been reorganized in all departments. An affiliation has been established between the Barnes Hospital and the St. Louis Children's Hospital and Washington University by which the University agrees to provide the medical staffs of the hospitals and the hospitals permit the University to use the institutions for purposes of teaching.

\section{REQUIREMENTS FOR ADMISSION}

Candidates for entrance are required to have completed at least two full years of college work, which must include English, German and instruction with laboratory work in Physics, Chemistry and Biology.

\section{INSTRUCTION}

Instruction begins on the last Thursday in September and ends on the second Thursday in June.

Clinical instruction is given in the Barnes Hospital, in the St. Louis Children's Hospital, in the Mullanphy Hospital and in the dispensaries connected with these institutions. During the session of 1914-1915 the Medical School will occupy its new buildings immediately adjacent to the Barnes Hospital and the St. Louis Children's Hospital, which are affiliated with the Medical School.

\section{COURSES LEADING TO ACADEMIC DEGREES}

Students in Washington University may pursue study in the fundamental medical sciences leading to the degree of A.M. and Ph.D.

\section{GRADUATE INSTRUCTION}

Summer courses for physicians in medicine, surgery, obstetrics, various specialties, pathology, bacteriology, physiology and pathological chemistry, are given during June.

\section{TUITION}

The tuition fee for undergraduate medical students is $\$ 150$ per annum.

The catalog of the Medical School may be obtained by application to the Dean of the Washington University Medical School, 1806 Locust St., St. Louis, Mo. 


\section{Tulane University of Louisiana THE COLLEGE OF MEDICINE}

\section{Established 1834}

\section{THE SCHOOL OF MEDICINE}

Regular Courses for M.D. Degree

ADMISSION. Graduation from four year high school with $141 / 2$ Carnegie units and one college year of Biology, Chemistry and Physics and one modern language.

Graduate courses offered for M.S. and Ph.D. OPPORTUNITY. Jnlimited anatomical material. Unexcelled clinics. Intern positions available in three hospitals in the state and a number elsewhere.

FEES. $\$ 195$ per session, including all charges of all sorts, except graduation fee in Senior year.

\section{THE SCHOOL OF HYGIENE AND} TROPICAL MEDICINE, INCLUDING PREVENTIVE MEDICINE

Degrees in Public Health and Tropical Medicine. Special opportunities in laboratory and clinic courses. Field work in Hygiene. Courses for doctors, engineers, school teachers, nurses, etc.

More tropical diseases under observation than in any other center in the United States.

\section{THE POSTGRADUATE SCHOOL OF MEDICINE}

(The New Orleans Polyclinic)

Open to all licensed practitioners of medicine. Practical clinic courses in all subjects with exceptional opportunities for special branches. Research laboratories in Operative Surgery and Gynecology, Clinical Medicine and Pathology.

FEES. Full courses for four weeks, \$75.00; six weeks, $\$ 100.00$, including all lectures and clinics in the College of Medicine. Special subjects from $\$ 20.00$.

\section{THE SCHOOL OF DENTISTRY}

Three years' course for degree of D.D.S.

ADMISSION. Three years of high school work or 12 Carnegie units.

Full courses of university grade. Unusual clinical facilities. Excellent equipment.

FEES. $\$ 150.00$ per session.

\section{THE SCHOOL OF PHARMACY}

Degrees of Ph.G. (2 years), Ph.C. (3 years), Pharm.D. ( 4 years). Three years of high school work required for entrance, or 10 Carnegie units. High standard of class work. Training the student for scientific as well as practical calling. Courses offered in Pure Food and Pure Drugs to advanced students. Homen afmabed on same ferms as men.

FEES. $\$ 100 .(0)$ per session.

SUMMER SCHOOL OF MEDICINE JUNE TO SEPTEMBER

\section{The College of Medicine,Tulane University}

P. 0. Drawer 261, New Orleans, Louisiana 


\section{The Medico-Chirurgical College of Philadelphia}

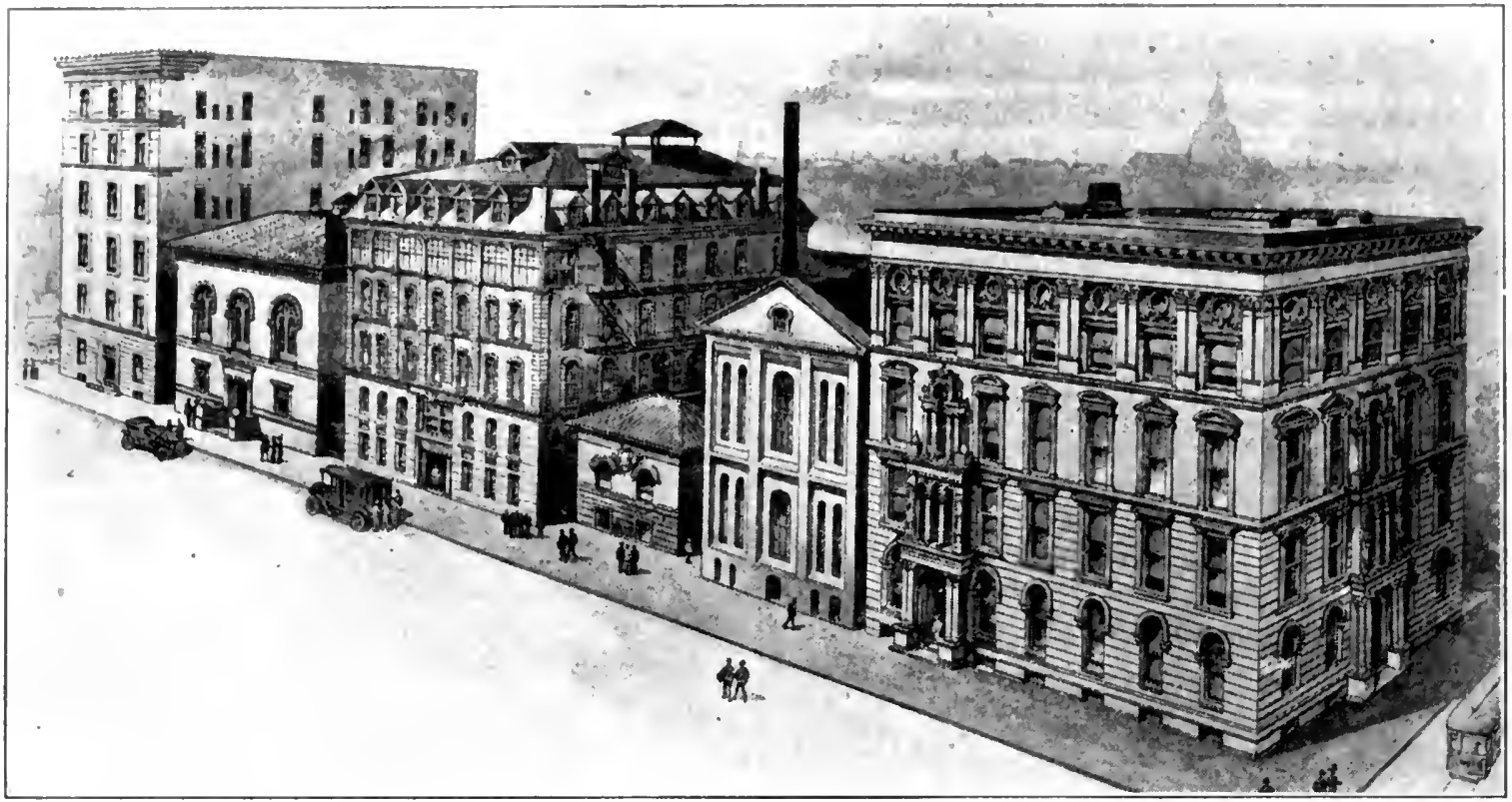

The Maternity and Children's Hospital, Clinical Amphitheater. Main Hosnital, Power House, College Hall and New Laboratory Building (in order named)

\section{The Department of Medicine}

Has carefully graded courses of eight months each. The new five-year course includes a first or pre-medical year in Physics, Chemistry, Biology and German, in lieu of which, however, satisfactory credits for equivalent work in recognized academic or scientific colleges and universities will be accepted. Thoroughly practical instruction; Free Quizzes; Limited Ward Classes; Clinical Conferences. Particular attention to laboratory work, ward work and bedside teaching. Largest and finest clinical amphitheater in the world.

\section{The Department of Dentistry}

Offers superior advantages to students. Abundance of material for practical work in the Dental Infirmary. College clinics present splendid opportunities for practical study of general and oral surgery. Dental students accorded same clinic privileges as medical students. Quizzing conducted by Professors free of charge.

\section{The Department of Pharmacy and Pharmaceutic Chemistry}

Is also an integral part of the institution, thoroughly organized and equipped to prepare graduates not only for positions in pharmacy but also for those created by the new Federal Pure Food and Drugs Act or any in which a practical knowledge of analytic chemistry is essential.

Address the Dean of the Department in which you are interested for an illustrated catalogue, describing courses in full and containing information as to courses, methods, fees, etc. 


\section{TUFTS COLLEGE MEDICAL SCHOOL BOSTON, MASS.}

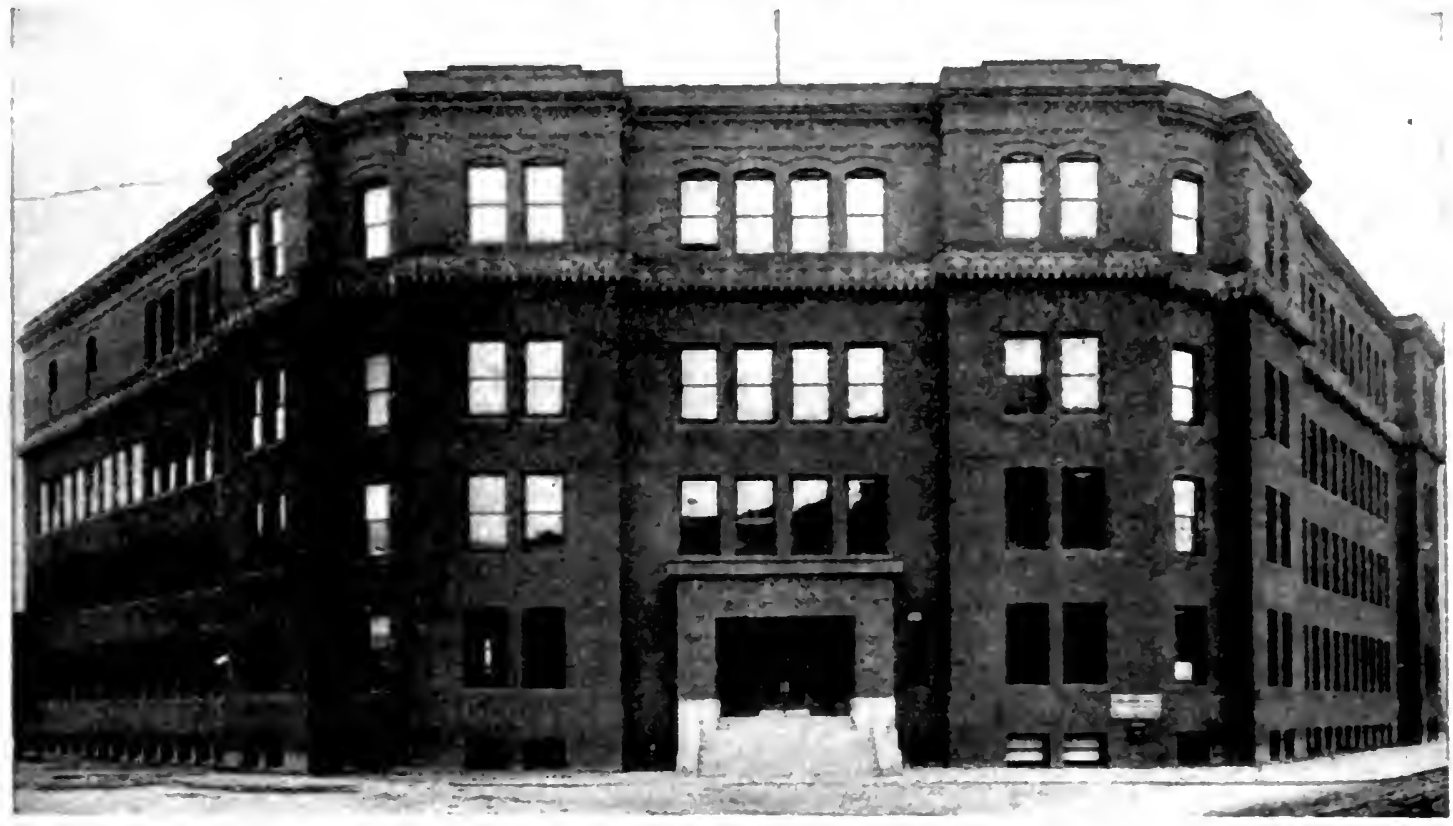

WILIIAN L. HOMPYR. A.M., PH.D.

\section{FACULTY}

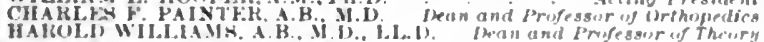

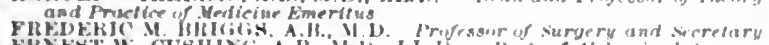

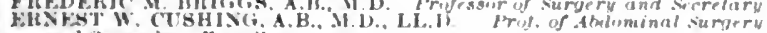

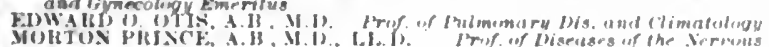
wivetem Ewerims

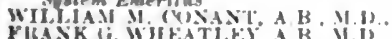

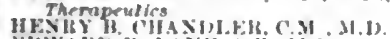

riwa

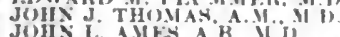

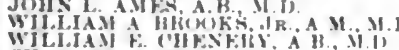

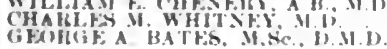

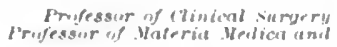

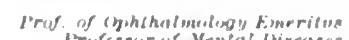

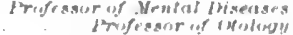

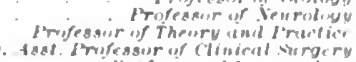

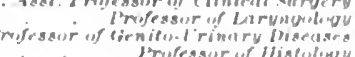

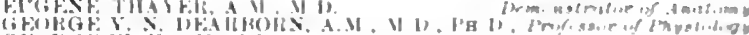

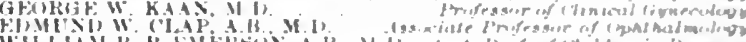

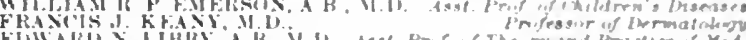

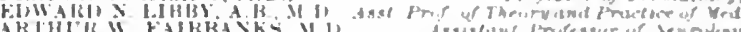

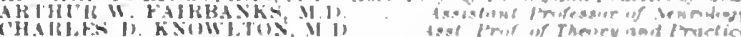

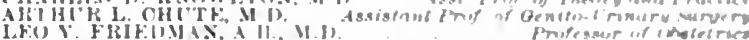

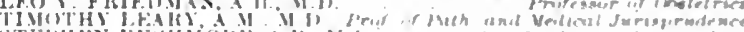

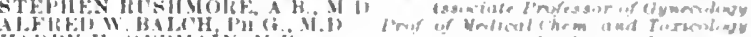

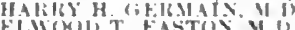

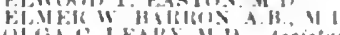
Co

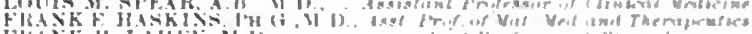

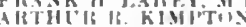

\section{OTHER INSTRUCTORS}

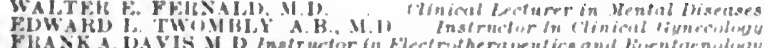

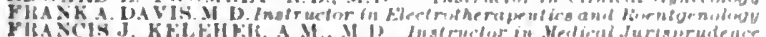

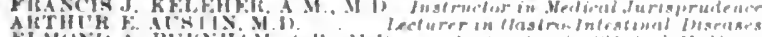

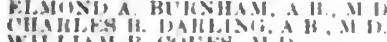

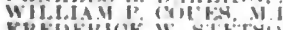

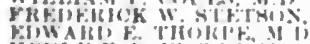

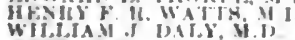

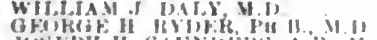

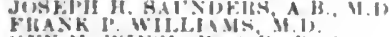

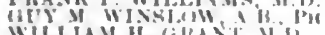

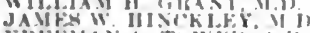

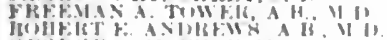

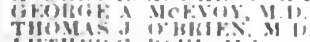

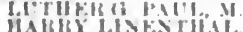

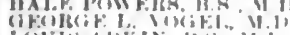

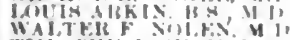

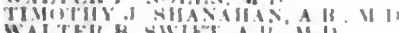

YRASKIA

i.I,IN "yi)

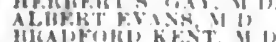

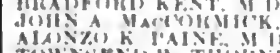

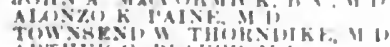

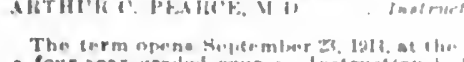

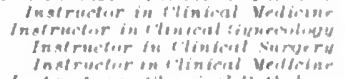

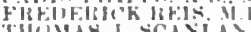

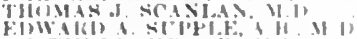

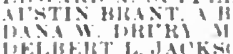

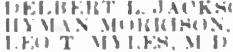

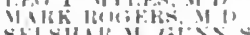

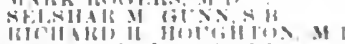

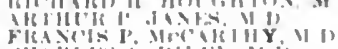

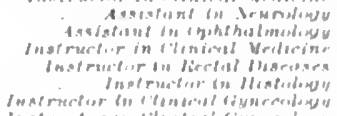

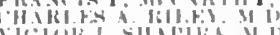

iviter creplet is y

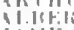

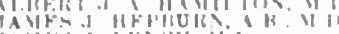

ing

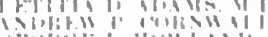

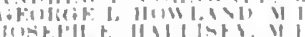

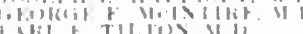

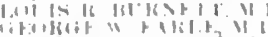

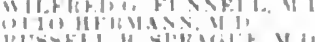

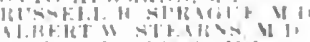

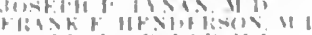

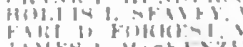

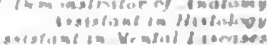

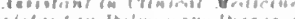

Lit 


\title{
NORTHWESTERN UNIVERSITY MEDICAL SCHOOL
}

\author{
ARTHUR R, EDWARDS, A.M., M.D., Dean
}

\author{
Requirements \\ for Admission
}

Clinical

Facilities

Tuition Fees,
1. The candidate for admission to the Medical School must be of good moral character as evidenced by certificates signed by two physicians of good standing in the state in which the candidate last resided.

11. He must have credit for two years of work in an approved college.

111. He must have completed in those two vears of college work at least nine-twentieths of the total number of hours or units repuired for gracluation from his college; and in the schedule of his work must have been included not less than a vear each in

a. Chenistry, comprising general inorganic chemistry and qualitative analısis; b. General Physics; c. Biologv; and d. A foreign langriage. These requirements will be satisfied by courses such as the following, described in the catalogue of Northwestern University in the section on the College of Liberal Arts, pages 81 to 116: Chemistry,

Course $A$ and at least the first semester of Course B; Physics, Course A; \%oology, Conrse A, German, Course AA or A; French, Course AA or A.

It is recommended that the candidate include at least two years of Latin in his preparation.

Applicants for admission to advanced standing from other medical schools must present with their official credentials, letters of honorable dismissal.

South Side IDispensary, 30,000 patients annually. IVesley Hospital, 225 beds. Mercy Hospital, 400 beds. St. Luke's Hospital, 400 beds. Michael Reese Hospital, 400 beds. Cook County Hospital, 30,000 patients annually. Calumet Avenue Dispensary. The Peoples Hospital. Provident Hospital. The L ring-in Dispensary.

$\$ 175$ annually. Laboratory fees from $\$ 15$ to $\$ 25$ annually. Combined sixyear course in science and medicine. Next scholastic year begins Tuesday, September $29,1914$.

Write for Information and Interesting Book of Courses

\section{THE REGISTRAR, - - - 243 I Dearborn Street, Chicago}

\section{T)he Hlnturerotity Iff $\mathfrak{I}$ llithtutio \\ Uallenge af Allenirine}

Minimum Admission Requirements-Two years in a recognized University or College of Liberal Arts and Sciences in addition to fifteen units completed in an accredited High School or Academy.

For course of Medical study, four years are required.

Well equipped laboratories and good hospital facilities.

Excellent location in the heart of Chicago's great medical center.

Collegiate year begins October 1st, 1914.

For full information address SECRETARY

College of Medicine University of Illinois CONGRESS and HONORE STS.

Chicago, Ill. 


\title{
WESTERN RESERVE UNIVERSITY SCHOOL OF MEDICINE
}

(Founded 1843)

\begin{abstract}
A well-endowed school for men with college preparation; its course including a large amount of individual practical work in laboratory departments and controlled hospitals.
\end{abstract}

Admits only college graduates, or seniors in absentia from standard four-year colleges, who can fulfill certain subject requirements.

Small classes assure large amount of individual opportunity.

Offers optional fifth year leading to degree of A.M. in Medicine.

Only regular medical school in Cleveland (the sixth city in the United States) with 650,000 population.

Controls all material and nominates the staffs in three hospitals with over 800 free beds, and maintains dispensaries having over 100,000 visits per year.

Every graduate has the opportunity of a hospital appointment.

Tuition \$1 50.00 per year.

For catalogue and information address the

SECRETARY, East 9th Street and St. Clair Avenue - Cleveland, Ohio

\section{School of Medicine of the University of Pennsylvania - FOUNDED 1765-}

The annual session opens the last Fridny in September and closes the third Wednesday in $J$ une.

REQUIREMENTS FOR ADMISSION: Candidates must have successfully completed work ayuivalent to that frescribu? for the Freshman and Sorhomore Clases in Colleges recognized by thi c Unipersity, which mun inclnde collesiate courses in

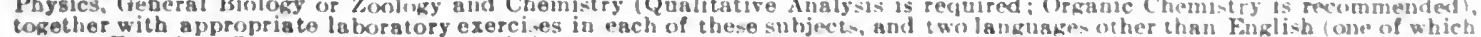

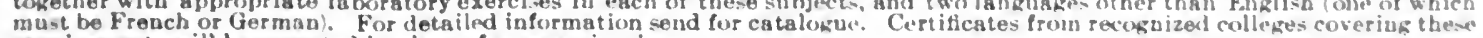
requirernents will be accroted in ulace of an exauimation

UNDERGRADUATE COURSE: The curse of instruction extendsover four annual sesions, the work so graded that the first and second yests are larkely occupied by the fundamental medical subjects. The third and fourt hy year- are larkels

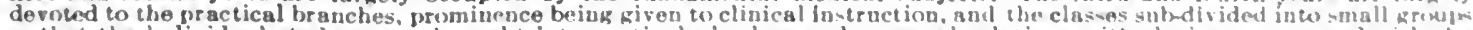

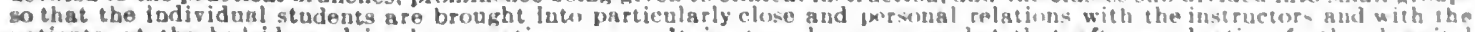

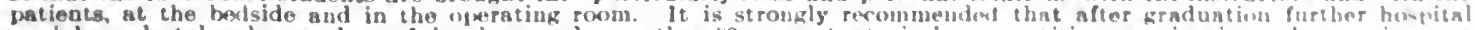
work be undertaken by members of the class a s more than

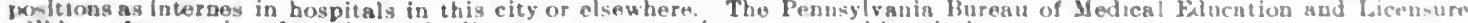
will hereafur reruire of applicants for license, a yar strent in an apgrovenl hospital.

POST-GRADUATE WORK: (1) An Rraduate posseces

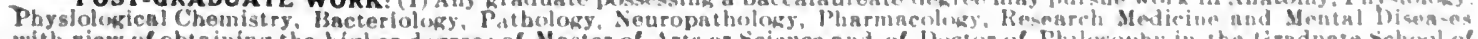

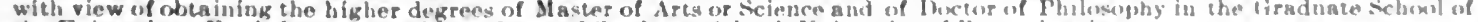

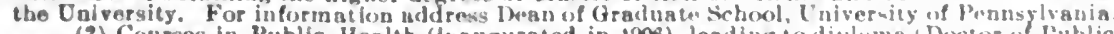

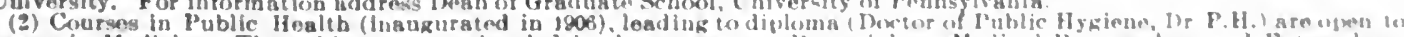

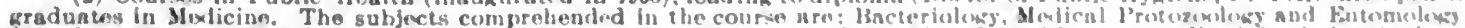

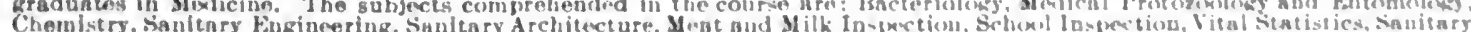
Legislation. and l'ermonal and fieneral Hygiege.

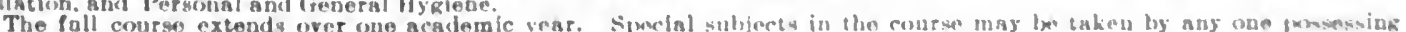

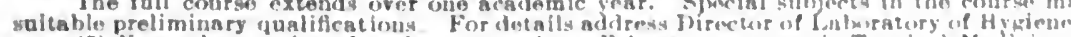

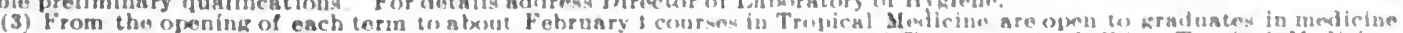

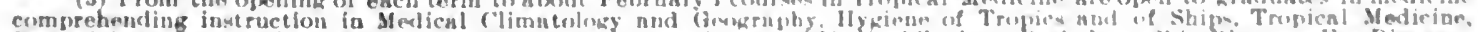

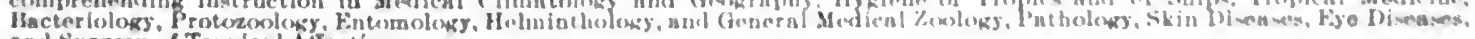
and Surgery of Trupical Aifections.

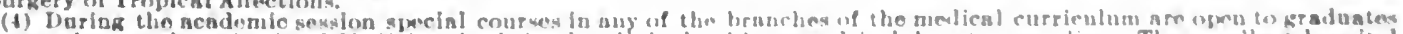

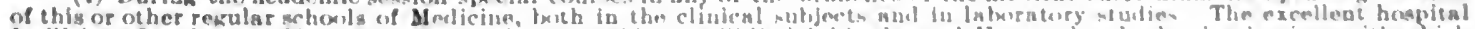

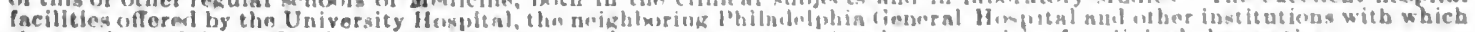

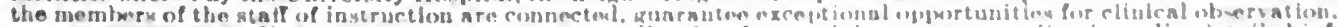

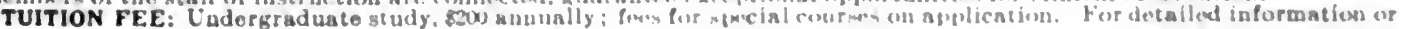
chtalokue addross

\section{Dean of School of Medicine}




\section{Harvard Medical School}

Boston Massachusetts

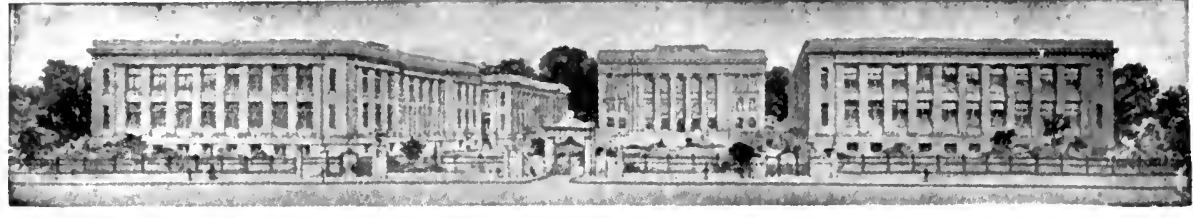

CONRSE FOR THE DEGREE OF M.D. A four years' course is

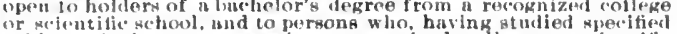
illibects during two sears in a recognized college or melentiflo wehoul, hute scood in the Hrst third of their class. The wtulies of ecte, keneral medicine and surgery and the spetcial clinieal last Wedinesday in September to the Thurslay before the last Vodntuday in June.

COURSE FOR THE DEGREe OF Dr. P.H. Graduales in mediine und other properly qualitied persons may beeome candidateg corthe degree of Doetor of Public Health.
Graduate School of Medicine Gradacte Instraction on a University Basis COURSES are given throughout the year in all cilical and laboratory subjects. Students are ndmlted at any time and for any length of atudy. insTRUCTION will be as thorough and seien
tifle an in the liedical School proper. Flement ary and advanced courwes. Kesearch courses for qualified students.

SCHOOL OF TROPICAL MEDICINE. HARVARD MEDICAL SCHOOL, Boston, Mass.

\section{THE PHILADELPHIA POLYCLINIC} and

\section{COLLEGE for GRADUATES in MEDICINE}

Open throughout the year except July and August.

For catalog of clinical, laboratory and cadaicr courses write to

R. MAX GOEPP, M.D., Dean

18th and Lombard Streets,

\section{INSTRUCTION IN MECHANO-THERAPY \\ Swedish Sostem of Masage, Medical and Orthapaedic Gumnastica Courses in Electro-Therapy and Hpdro-Therapp \\ Thorongh, practical and theoretical instruction. Mlost of the instruct. ors are assoctited with the leading medical colleges. Special short courses \\ To Hospitais and Sanitaria we offer our free service to supply them with competent graduates at sliort notice. Many linstitutions will find some of their nurses to take our courses with the purpose of later teaclilgo their own nurses and taking charge of the mechanical departments. Cor. \\ respondence is solicited.
Complete Facilities for all Forms of Physiological Thera- poutlcs - Nauheim Brine Baths; Schott Kxercises; Vapor Baths; Hot Sea Water Baths, Scotch Douches; Steam, Neenle, Sitz, Shower, Perineal Baths

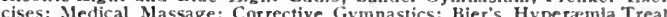 ment; Static, Galvanic, Faradic Flectricity; Sinusoidal, High-Frefueocy Currents, X-Ray Work. Illustrated Prospectur. FOR PARTICULARS ADDRESS \\ The Penasylvanis Orthopeedic Institute (Inc.) 1711 Green St., Philadelphia, Pa.}

Post-Graduate Medical School and Hospital of Chicago

HOSPITAL - Modern fireproof, newly decorated and equipped throughout. new operating depart ment. The Hospital is open to the profession.

TRAINING SCHOOL-Regular and Post-Graduate Courses for Nurses.

MEDICAL SCHOOL - Post-Graduate courses for General Practitioners. Personal courses in all departments.

2400 Dearborn Street CHICAGO, ILL.

\section{UNIVERSITY OF ALABAMA SCHOOL OF MEDICINE MOBILE, ALA.}

Requirement for admission:-One year of College work in Physics. Chemistry, Biology, and a modern foreign language, in addition to the if unit high schoo course.

Seven full time instructors. Clinical facilities ample. Senior year devoted to practical work in hospital and dispensary.

The Department of Pharmacy offers a two year course leading to the degree of Ph. G. For catalogue and information address

EUGENE D. BONDURANT, M.D., Dean School of Medicine. St. Anthony and Lawrence Sts. - - - - Mobile, Ale.

\section{SCHOOL OF MEDICINE OF HOWARD UNIVERSITY}

\section{Including Medical, Dental and Pharmaceutic Colleges}

STEPHEN M. NEWMAN, D.D., President

EDWARD A. BALlOCH, M.D., Dean

The FORTY-SEVENTH ANNUAL SESSION will begin October 1, 1914, and continue eight months. Requires for admission two years of college work including courses in inorganic and organic chemistry, qualitative analysis, physics, biology and either French or German.

Full corps of instructors, well equipped laboratories, unexcelled hospital facilities.

For further information or catalog, write

W. C. McNEILL, M.D., Sec. - - - - - Fifth and W Sts., N. W., Washington, D. C. 


\section{DARTMOUTH MEDICAL SCHOOL \\ Established in 1798 \\ Hanover, N. H.}

Entrance reguirment: two yeurs of collegr work, includine Chemistry, Biology, Physics and the lampunge

Candidates for the 13.5, esegrev in Dnrtmonth College wa substitute the work of the first two sears in the Medical Scher

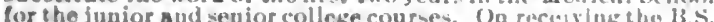

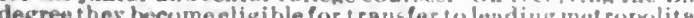
chols wich otor hos of the clinical yer hospital the A.B. degree may alect the first yeat in medicion as their senior sear in college.

Partmouth Medical school will bestow nu degrees after lgk. Fully evuipued modern laboratories are frovided for the courses of the first two years. Quiet surroundings and close supervision abd persogal in-truction by the Faculty fator ladividal work abd insure the thorough nreparation necessar wor successful specialization or nd vancerl work in any direct ion. For further informalion atures COLIN C. STEWART, sec

\section{Atlanta Medical College} ATLANTA. GA.

Sixtieth Annual Session begios Sept. 28, 1914, and ends June 1, 1915. Entrance requirements are those of Class "A" Medical Colleges. Four large buildings used exclusively for teaching purposes. Clinical work in City Hospital and College Dispensary. Laboratory facilities un. surpassed. Tuition $\$ 150$.

Registration book closes October 3, 1914. For catalogue and other information, address

\section{W. S. ELKIN, Dean}

Cor. Butler and Armstrong Sis., ATLANTA, GA.

\section{Stanford University MEDICAL DEPARTMENT}

ADMISSION

INSTRUCTION

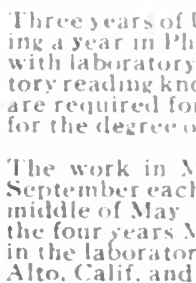

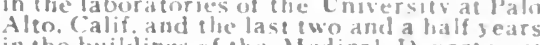
in the buildings of the Medical Departmens

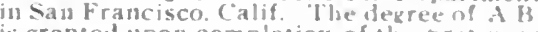
of the Medical curriculum. Studenes enter ing septemler 1011 or thereafter will be re quired to spend an addisional inserne or prac

TUITION

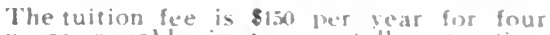
tember and lanuars.

The annualdannouncement af the . Wedical lepartment ar

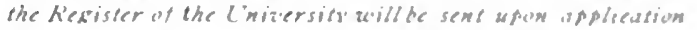

Dean of the Stanford University Medical Department Sacramento and Webater streets SAN FRANCISCO, CALIF.

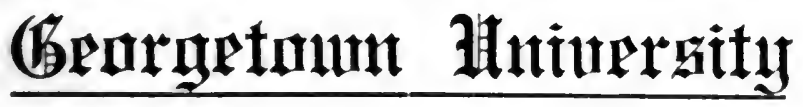 \\ SCHOOL OF MEDICINE AND DENTAL DEPARTMENT}

THE SIXTY-FOURTH SESSION begins on the $3 d$ Wednesday in September. 1 1914, and ends the 2d Wednesday in June. The Medical School requires for admission two years of college work, including chemistry, physics, biology and either French or German. Offers a six year collegiate medical course leading to degrees B.S. and M.D. Ample facilities for laboratory and clinical work. I'niversity Hospital and Dispensary with 265 beds. Additional clinics in the City and (iovernment Hospitals with over 3000 beds. Tuition, $\$ 150.00$ per annum.

For further information apply to the Dean, WH H Street, X. W.. Washington, I). C

\section{THE GEORGE WASHINGTON UNIVERSITY Department of Medicine

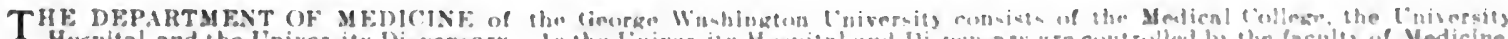

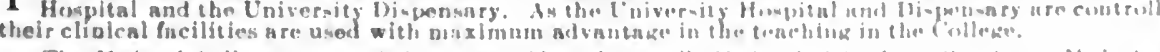

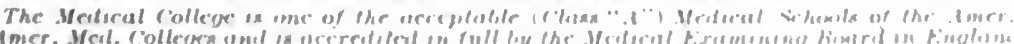

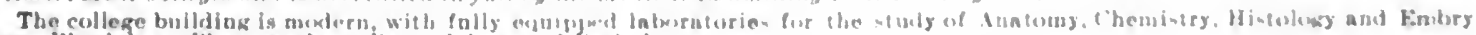

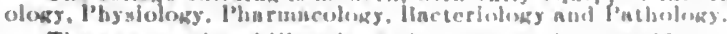

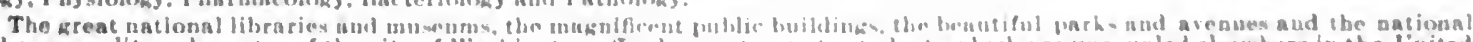

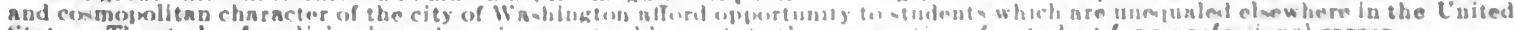

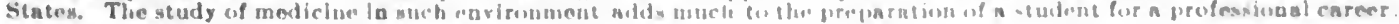

For catalongs or cother informatlon, nuldress

W. C. BORDEN, M.D., Dean

1325 H St., N. W., Washington, D. C. 


\section{RUSH MEDICAL COLLEGE IN AFFILIATION WITH THE UNIVERSITY OF CHICAGO

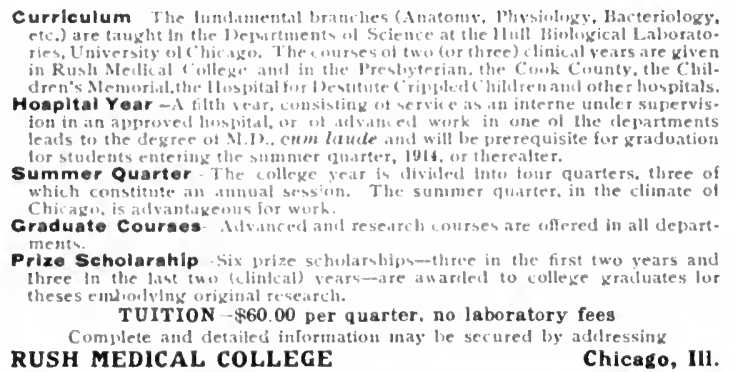 \\ RUSH MEDICAL COLLEGE \\ Chicago, IIt}

\section{THE INDIANA UNIVERSITY SCHOOL OF MEDICINE}

Bloomington and Indianapolis

CHARLES P. EMERSON, Dean.

D. B. MYERS, Bloomington, Ind.

E. D. CLARK, Indianapolis, Ind., Secretaries.

Term opens about September 25 of each year.

Clinical Facilities: Five hospitals, one of which is owned by the University. The obstetric service is ten times larger than required by State Boards. Forty-two interitships are open to graduates.

\section{university of Couisuille}

MEDICAL DEPARTMENT

The following named Medical Schooli, by mutual agreement of the respectlve Faculties, and in perfect pecord. have now united and be ferring their rood will and prestige:

THE MEDiCal DEPARTMENT OF THE UNIVERITY OF LOUISVILLE, Organized In $1 \mathrm{~s} 37$

THE KENTUCKY SchOOL OF MEDICINE. Orkanized in 1850.

THE LOUISVILLE MEDICAL COLlege. Orkanized in $1 \times 69$.

THE HOAPITAL COLLEGE OF MEDICINE. Organized in 1873. Organized in 1698

Member of the Association of American Medical Colleges. The SeventyEighth Annual Session begins October 18t, 1914 and ends Ifay 29th, 1915. For College Announcements of the Medical Dept., address the Dean

W. ED. GRANT, M.D., Louisville, Ky

\section{UNIVERSITY OF MICHIGAN}

Department of Medicine and Surgery

Two rears of college work are required for admission to this school, the same to include Physics, Biologr, Chemistry and German or French.

The laboratories are well equipped, and the Uni. versity Hospital affords ample clinical facilities.

For further information and special announcement, address

C. W. EDMUNDS, M.D., Secretary, Ann Arbor, Michigan

\section{Johns Hopkins University Medical Department}

The Medical School is an Integral Part of the University and is in Close Alliliation with the Johus Hopkius Hospital

\section{A DMISSION}

Cundidates for aduission must be graduates of approved colleges or seientifle schools with at least one year's instruc tion, including laboratory work, in physies, chemistry and biology, and with evidence of a reading knowledge of French and German.

Eacb class is limited to 90 students, men and women being odmitted on the same terms. Fxcept in unusual circumstances applications for admission will not be considerd after July tst.

If vacancies occur students from other institutions desiring advanced sianding may be admitted to the second or third sear, provided they fulfill all of our reculrements and present exceptional qualifications.

\section{INSTRUCTION}

The academie year begins the first Tuesday in October and closes the second Tuesday in June. The course of instruction occupies four years, and especial emphasis is laid upon prac tical work in the laboratories, in the wards of the Hospital and in the Dispensary.

\section{TUITION}

The charge for tuition is $\$ 240$ per annum, payable in threo instalments. There are no extra fees except for rental of microscope, certain expensive supplies, and laboratory breakage.

Summer Work For Graduates in Medicine

Beginniug June 1st, courses in Medicine, Surgery, and various specialties, as well as in several of the underlying seientific branches, will be available for graduates in Medicine. These conrses will extend over six weeks and are fally deseribed in a special circular.

The annual announcement, application blanks, and circular describing graduate courses may be obtained by addressing th

Dean of the Johns Hopkins Medical School Washington and Monuments Sts. BALTIMORE, MD.
THE UNIVERSITY OF NEBRASKA College of Medicine

OMAHA

NEBRASKA

Offers great advantages for a medical education. A new Laboratory building, with exceptionally well equipped laboratories for Anatomy, Micro. Anatomy, Pathology, Bacteriology, Chemistry, Physiology, Pharmacology and Experimental Medicine was occupied September, 1913.

Clinical work for Junior and Senior years provided in six hospitals and the University Dispensary.

Two years college preparation required for entrance to Freshman class.

Address Secretary, College of Medicine,

THE UNIVERSITY OF NEBRASKA 42d and Dewey Avenue 


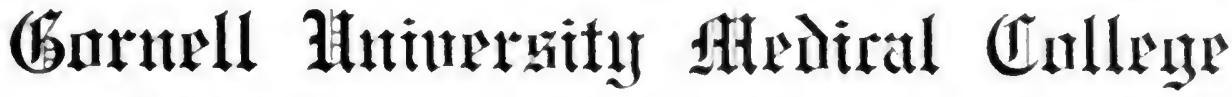

Entrence
Requiremento

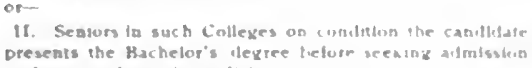

To the secoad year la wedicioe: or

aminalion.

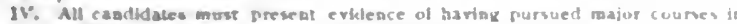

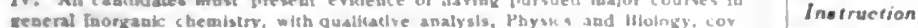

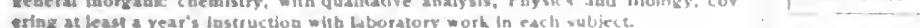

The first year in medicine may he taken either at New lork or at Ithaca, later years only at New York City. For further particulass isply to

The Dean, Cornell University Medical College,

28th Street and First Avenue, NEW YORK CITY

\section{ST. LOUIS UNIVERSITY SCHOOL OF MEDICINE}

(Formerly Marion Sims-Beaumont)

Offers Thorough, Modern, Practical Work in All Medical Branches

Regular Session, froin September to June. Summer School of six weeks follows regular term.

For Bullefin and Information. Adiress

The Dean, 1402 S. Grand Ave., St. Louis, Mo.

\section{THE COLLEGE OF MEDICINE OF SYRACUSE UNIVERSITY}

\section{Syracuse - - . - Now York}

SYRACUSE UNIVERSITY was one of the first to estabilsh modern methods of teaching medicine It is ranked in the "A Plus" group.

SYRACUSE offers laboratory instruction during the first two years in Anatomy. Plissiology. Chemistry. Bacteriology. Pathology. Clinical Miaghosis. Materia Medica and Pharmacology in trerfectiy enuipped laboratories under men who devote their entire sime to teaching and to research.

SYRACUSF glves sumerior Clinical onportunities in the uthor and senior years Themew college dispensats. the ewo general hospitals. one special hospital, the muncipal, the coutnty and the state hosptals give untramnered obsortumities for the sturly and min azement of cases under the zuldance of members uf the facule An une qualled ialurators and clinical course in Public blealth is given in the sentor your.

SYRACUSF MFN hava no difficuley in securmg anch positions as husbitalinternes as they desir.

SYRACUSt; ADMrts only those offering in furetat ation two years es college work which mont meluse language. Latin and Prawius.

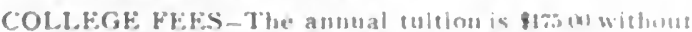

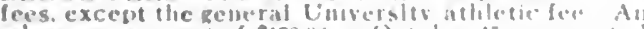

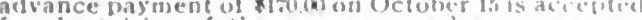
for the tuttion of the year. or an advance biabmeots of sing.00 is accented for tuition for the entire cours

For barticulars addresm the l)an,

College of Medicine, Syracuse,' N. Y.

\section{UNIVERSITY OF BUFFALO}

Medical Department

SIXTY-EIGHTH SESSION begins Soph. 22, 1914 CO-EDUCATIONAL

I.aboratory recently enlarked. remondeled and fully cquipred. Clinical facilities ample. Ward cases and bedside instruction are prominent features of the course. Only medical school in Buffato porulation. tw, (mon. Hos pital positions for all graduates.

$$
\text { Wribe for Cabalogue }
$$

SECRETARY, MEDICAL DEPARTMENT UNIVERSITY OF BUFFALO BUFFALO, N. Y.

\section{Ohio State University} DEPARTMENTS OF

Medicine-Dentistry - Pharmacy

College of Medicine

Requlrements for admission to the Merel cal Degarement aree, astudemes Medical Certificate bratsed be the thio siate (n) school "lotk and collon of

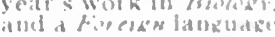

rlinical facciluties-dereetly under con trol of thic fiterth is

Protestant Haspital

St. Fruncis Hospital

Ohio Penisentiurv Hospiral

Two Oup-donr Dispensaries

Aneciated flesputals "ith cluncal

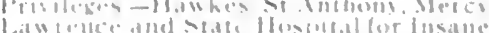

Session of 1914 begins September 23d and Continues Eight Month.

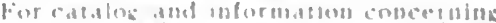

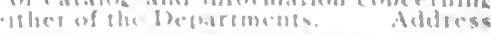

OHIO STATE UNIVERSITY COLLEGE OF MEDICINE

701716 North l'at Suret COLUMBUS, OIHO 


\section{UNIVERSITY OF CINCINNATI}

(Ohio-Miami College of Medicine)

(A partially endowed University Medical College)

ENTRANCE REQUIREMENTS: State Board certificite. First Grade High School work. 'lwo years suecincel work in l'lysies. (liemistry inomganic and organic), Biology and a modern language.

$6 \times 5$ Beds for General Disenses in the Cincinnati General Hospital.

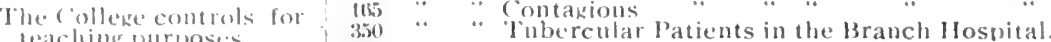

ligk rotal.

Students of the senior class will serve as clerks in the wards of the New Cincinnati General Hospital (850 beds

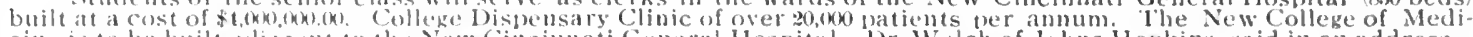
cine is to be bult aljacent to the New Cincinnati General Hospital. Dr. Welch of Johns Hopkins. said in an addressYou hav" Hospital here menualled in this comery in its possibilities for Medical Education.

Suall classes: judividual instruction. Many internships available in Cincinnati andother cities of the state. Course, four years of wa weeks each. Sessions oben in last week of September.

FOR DETAHEU INFURMATHON. ADHRESS

THE DEAN, Clifton Avenue, near Vine Street, CINCINNATI, OHIO

\section{UNIVERSITY of VIRGINIA CHARIOTTESVILIE, VIRGINIA \\ DEPARTMENT OF MEDICINE \\ EDW IN A. A L DE R M A N, D.C.L., LL.D., President}

ORGANIZED in $18 \% 5$, this department offers thorough medical instruction in the environment of an old and famous University.

THE ENTRANCE REQUIREMENTS are the completion of a four-year high-school course or its equivalent, and of good college courses in Chemistry, Biology, Physics and a reading knowledge of at least one modern language besides English, preferably German.

THE PROMINENT FEATURES of the course are extensive laboratory instruction in all the fundamental medical sciences; and abundant clinical training in the practical branches in the Dispensary and in the University Hospital, which contains accommodations for 110 patients, and is the property of the University. For catalogue and other information,

Address HOWARD WINSTON, Registrar

\section{UNIVERSITY OF PITTSBURGH}

\section{The School of Medicine}

The School of Medicine of the University of Pittsburgh offers two courses of instruction-one the regular four-vear all medical course leading to the degree of M.D., for which the entrance requirements are two years of recognized college work, including courses in Chemistry (Inorganic and Organic), Physics, Biology and German or French, in addition to a four-year high school course; the other a six-year combined collegiate and medical course leading to degrees of B.S. and M.D., for which the entrance requirements are a four-year high school course or its erjuivalent.

The School now occupies a thoroughly-equipped laboratory building on the University Campus. The Medical School is in affiliation with two general and five special hospitals, representing a combined bed capacity of over fourteen hundred beds. Clinical work is given to small sections of the class in these affiliated hospitals. The required work includes residence in a Maternity Hospital with board and room furnished.

The twenty-ninth Annual Session begins September '28th, 1914.

For bulletin and information, address

Thomas Shaw Arbuthnot, M.D., Dean Grant Boulevard, Pittsburgh, Pa.

\section{University of North Dakota}

\section{= SCHOOL OF MEDICINE}

\section{GRAND FORKS (University), NORTH DAKOTA}

Two years of college work including Chemistry, Physics, Biology and Modern Language are required for admission to the medical classes.

The University offers a combination course consistiug of two years of pre-medical college work and two years or medicine. Upon those who complete this course it confers the $\mathrm{A}$. B. degree and a certificate that is accepted for en trance to the junior year in many of the best medical schools of the United States.

Special courses are offered to advanced students and to physicians. For Bulletin and information address

H. E. FRENCH, M.D., Dean, University, No. Dakota

\section{Medical Department}

\section{University of Oregon}

A high-grade four year course in all depart. ments of Medicine and Surgery ; well equipped laboratories in Anatomy, Chemistry, Physiology, Bacteriology and Pathology ; all under the supervision of expert teachers; actual clinical experience is afforded by St. Vincent's, Good Samaritan, and Multnomah Hospitals. For catalog and particulars address The Dean, 23d and Lovejoy streets, Portland, Oregon. 
The University of Vermont COLLEGE of MEDICINE

\section{Class A}

Member Association American Medical Colleges

Ideally Located Founded in 1809 Expenses Moderate

Write for literature and information to

MAX W. ANDREWS - Registrar UNIVERSITY OF VERMONT, BURLINGTON

\section{MEDICAL JOURNALS}

We supply copies, volumes or sets of back issues, of AMERICAN and Foreign Periodicals. Let us help you complete your files. Also have a large stock of Medical Books. Catalog sent on request.

\section{B. LOGIN \& SON} 152 East 23d Street New York City

No connectlon with any other firm of same name
chicAgo pASTEUR INSTITUTE

FOR THE PREVENTIVE TREATMENT OF HYDROPHOBIA 24th Year 812 N. Dearborn St., Chicago

Astenle Lugerio. M.D. UL.D Medical Directer

G. B. Brues, A.D
Aisediote Directes

Freak A Ligorlo. M D Astisteat

\section{ANNOUNCEMENT}

Since October, 1910, this Institute has taken an advanced progressive step in abandoning the old methods now in vogue, discarding the cords treatment, and in adopting instead the use of the brain substance properly treated and attenuated and rendered safe by having its virulence destroyed.

Furthermore, in severe cases, the treatment is combined with injections of anti-rabic serum, all prepared in our laboratory.

N. B. - We have no branches, and the use of our name is unauthorized.

\section{Send Specimens for Diagnosis to \\ Columbus Medical Laboratory

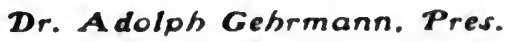

A Laboratory for Physicians' Chemic, Microscopic and Bacteriologic Examinations. Laboratory Instruction, Investigation of Sanitary and Medico-Legal ()uestions. Fee table on application. Culture Media and Staims.

Suite 1406, Columbus Memorial Building

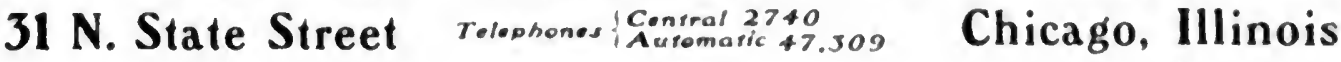




\title{
Dependable Wassermann Tests
}

High Grade Laboratory Service.

Wassermann 'le'sts. ('The Citrols cuantitative system,

which defects lhe weaker bositives, not demonstrable

by otber methods. The nineste mestiod-not drop method

of measuring reagents.)

I.ange's Colloidal Gold Test for Syphilis and other infee

tions of the Cerebrospinal system.

Gonorrheal Complement Fixation Test.

Dianosis of Rabies (Brain tissue sloould be forwarded in General Bacteriological. Chemical and Medico-Legal InGlycerince)

\author{
Abderlakden's test for l'regnancy and Cancer. \\ Autogenous Vaccines. \\ Anti-Typhoid Vaccines. \\ l'athological Tissues. \\ restigations.
}

Our methods of conducting the biologic reactions represent the last word in the technique of serum diagnosis.

Our Wassermann tests are being constantly checked under our personal observation against all types and stages of clinical syphilis, thereby reducing the possibility of error to a minimum.

Special care is exercised in the preparation of our autogenous vaccines, to preserve the maximum of potency.

In all our work we employ only the most accurate and approved methods for each test, without reference to expense for materials or time involved in doing the work. Short-cut commercial methods, which usually are inaccurate and unreliable, are avoided.

Work of an exacting character, in which careful personal attention to technique is desired, is especially solicited.

Sterile containers and complete directions for collecting blood for Wassermann and Complement Fixation Tests furnished on request. (Abderhalden's tests do not yield reliable results if specimens are sent by mail; they must be taken in our laboratory.)
F. O. Tonney, M.D.
S. S. Graves, M.D. 32 North State Street, Chicago

Send Specimens for Laboratory Diagnosis to the

\section{American Laboratories}

Our laboratories are centrally located and are well equipped to perform all kinds of examinations. We are better than ever prepared to render superior, and at all times prompt service to physicians and surgeons.

We are also prepared to give instruction to those desiring it. A full and complete course in Clinical Diagnosis including Chemistry, Toxicology, Pathology, Bacteriology and Hygiene. Physicians and Surgeons who are sending work to the laboratories will not be charged for this course. This department is conducted for the benefit of those who desire to become acquainted with the numerous laboratory methods used in diagnosis and also for the express purpose of serving as a review in pathology and bacteriology.

\section{PRICE LIST}

Wassermann Test for Syphilis Urinalysis, Chemical and Microscoplcal.

Widal Test for Typhoid.

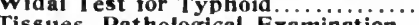

Thec Vaccines, Der dozen.

Complement Fixation Test...................... 6.00

Sputum and Smears...................... 1.00

Blood Count and Hemogiobin................... $\mathbf{3 . 0 0}$

Differential Count

Autogenous Vaccines ...................... 10.00 Migh Frequency Polyvalent Baclerins - Iraduate Course in laboratory Diagnosis Write for Porliculars.

AMERICAN LABORATORIES

Phone Randoiph 2233 1203 Masonic Temple. Chicago, Ill.
Wassermann Test $\$ 5.00$ (INCLUDING NOGUCHI CONTROL)

Serodiagnosis of Gonorrhea ............\$5.00

Serodiagnosis of Pregnancy............ 5.00

Autogenous Vaccines.................... 5.00

All other forms of laboratory work at a reasonable fee. Expert work and prompt reports assured.

Complete fee list and containers furnished on request.

\section{Pacific Wassermann Laboratories}

San Francisco.......................Pacific Bldg.

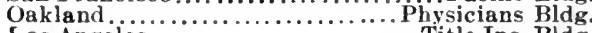

Los Angeles..................... Title Ins. Bldg.

Seattle..................... Joshua Green Bldg.

\section{THE FOMON SYSTEM}

in preparation for

State Board, Hospital, Civil Service, Army and Navy Examinations

For full particulars, address

L. P. KOZIE, Sec.,

1575 Ogden Ave., Cor. Madison St., CHICAGo, ILL. 


\section{Training School for Nurses 25th and Dearborn Sts., Chicago, III. \\ Gives a three years' course in Nurse 'Training. \\ Is accredited by the State Board. \\ High School education is a requirement for entrance. \\ Its graduates readily find official positions in other training schools. \\ Is affiliated with Northwestern University Medical School. \\ Has a Faculty of forty instructors. \\ Full particulars furnished on application to \\ BERTHA L. KNAPP, R.N. - Principal of Training School}

\section{Bancroft Training School \\ Founded 1883 by Margaret Bancrolt}

A home for the treatment and training of $\mathrm{BACK}$. WARD and MENTALLY SUBNORMAL CHIL. DREN. Winter quarters (18 acres) within

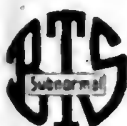

a few miles of Philadelphia; summe schools (28 acres) at Owl's Head on the Maine coast. Enrollinent limited to 50 pupils, both sexes. The school staff consists of 76 employees, including a resident physician, 10 teachers, 29 nurses and attendants, etc. Physicians who desire to retain supervision of their cases will have the full co-operation of the resident and the consulting staff. Circular on request.

E. A. FARRINGTON, M.D., Box 134, Haddonfield, N. J.

Bargains in Medical Books of All the Publishers

\section{LOCIN EROS.}

\section{New and Used Medical} Books at Cut Rates

1911 W. Harrison St.

CHICAú̃, ILL.

3 doors went of Cook Couniy Hospltal

Ask for Cataboure

Do connection with any other prom of same nom

\section{The Illinois}

\section{Training School}

\section{For Nurses}

FOUNDED 1880

A systematic course of instruction in nursing is offered, in cover a period of three years.

Information may be obtained from the

SIMHRISTENIISTT

MARY C. WHEELER, R.N. 509 Honore Street CHICAGO, ILL.

Box 2 


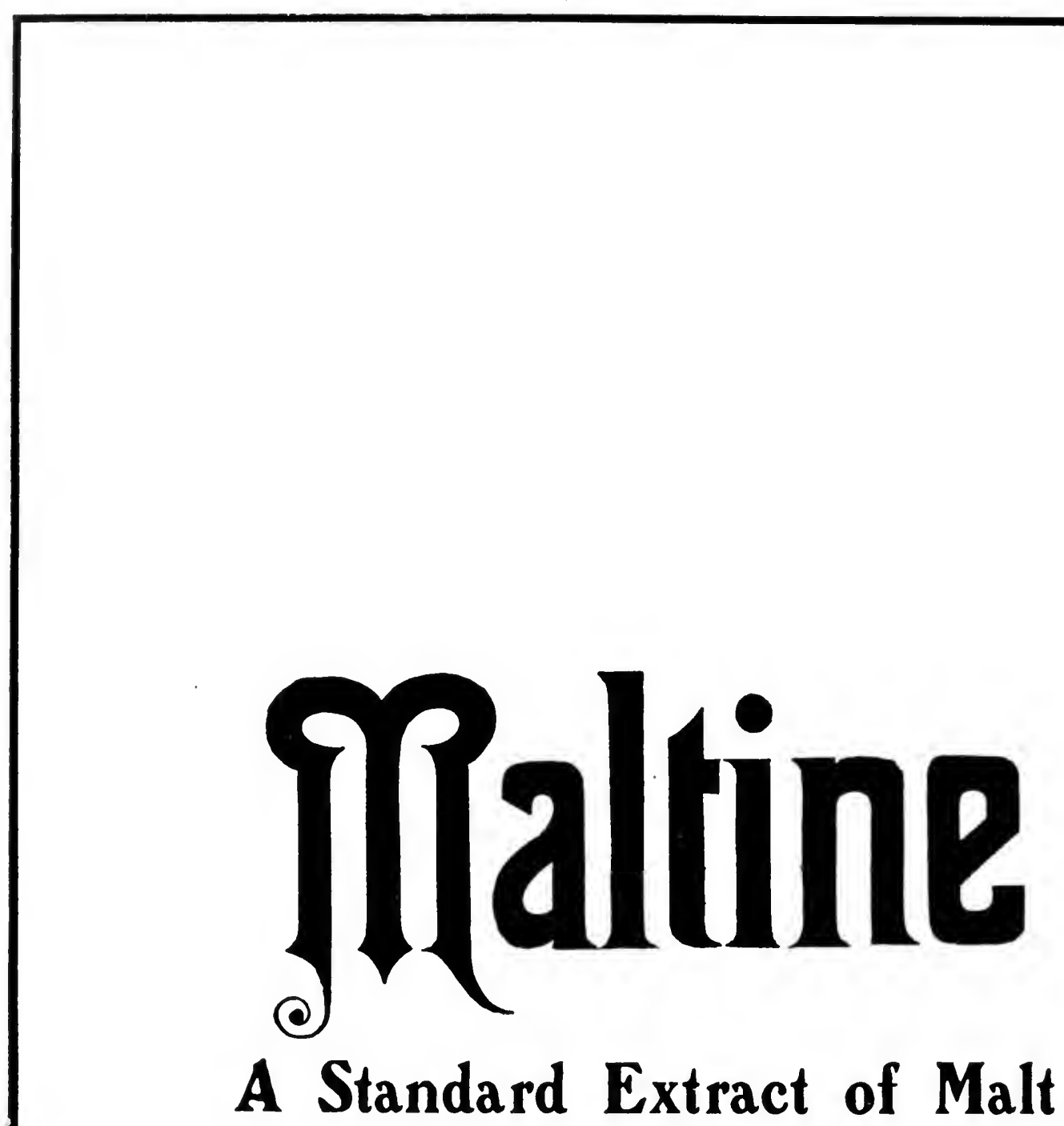


$P$

Med

A

MEDICAL DIRECTORY

I9I4

FOURTH EDITION

A REGISTER OF LEGALLY QUALIFIED PHYSICIANS

OF THE

\section{UNITED STATES}

ALASKA, CANAL ZONE, HAWAII, PORTO RICO, PHILIPPINE ISLANIS

CANADA AND NEWFOUNDLAND

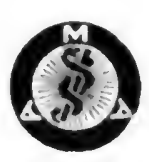

PRICE

$\$ 10.00$

$$
\frac{411253}{7.4 .43}
$$




$$
\begin{aligned}
& R \\
& 7 / 2 \\
& 19196 \\
& 1914
\end{aligned}
$$

\section{Copyright, 1.914}

BY

Amfrican Medical Association 


\section{CONTENTS}

COILEGE KEL T.IBLE.

Pige

IXDEX TO ADIERTISFMENTS.

PHYSICIANS' PLRCHASING IXIFX

Inside Frint laver

INDE TO DIR ECTORY . . .

Evell lagen 12.30

KEY TO DIRECTORY.

$3,5-56$

Symbols and Ibbreviations; special Explanatory lote $\ldots \ldots \ldots \ldots \ldots \ldots$

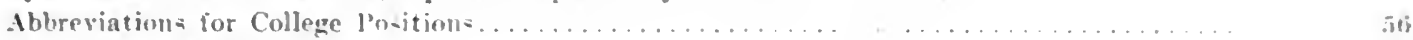

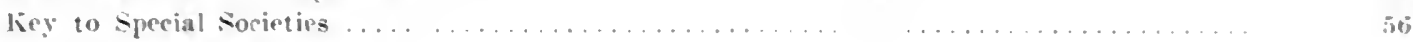

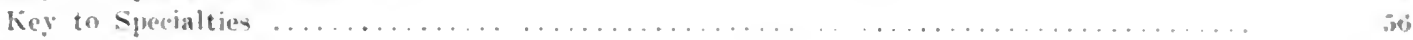

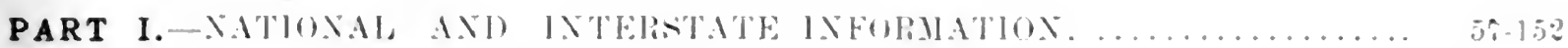

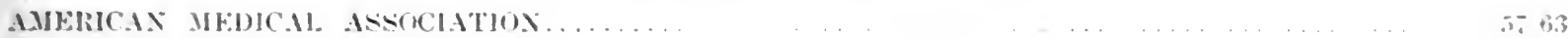

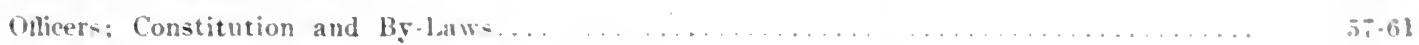

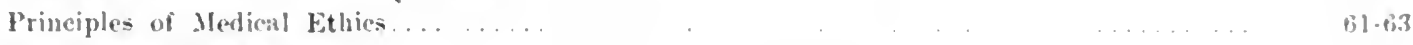

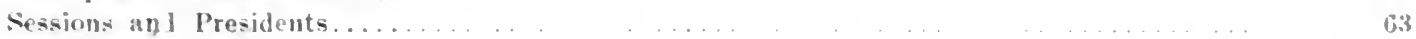

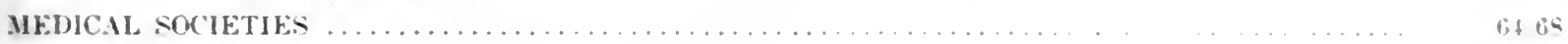

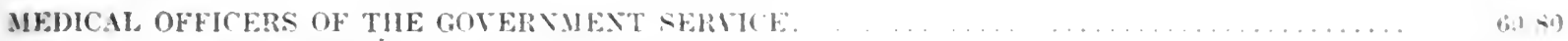

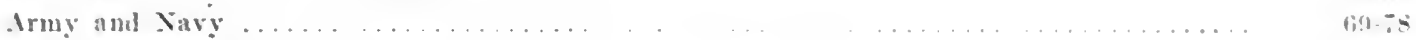

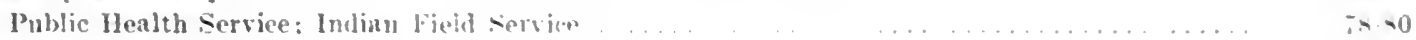

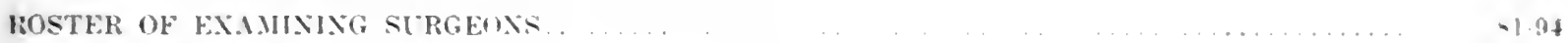

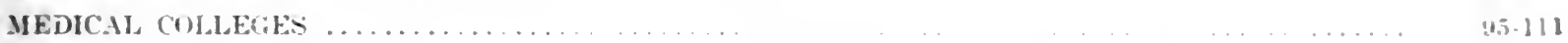

Nphabetical List $\ldots \ldots \ldots \ldots \ldots \ldots \ldots . \ldots \ldots$

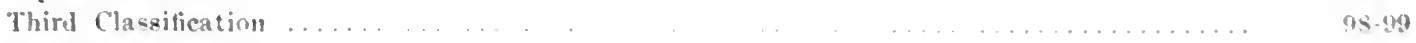

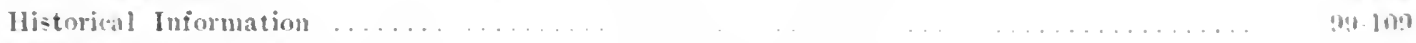

Puntgraduate Medieal Collegen...... . . . . . . . . . . . .

Foreign Melical College hey Tathe... . . . . . . . 110111

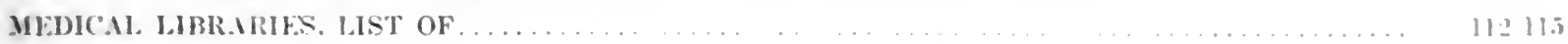

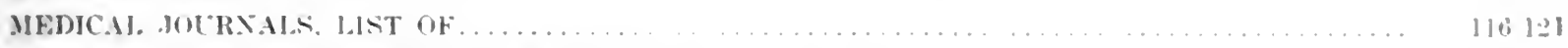

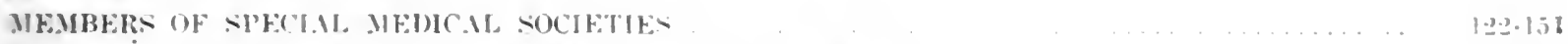

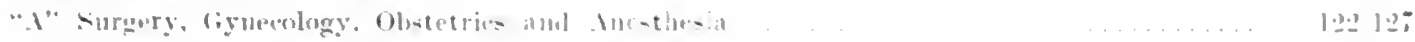

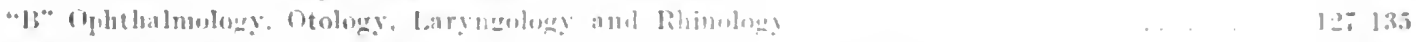

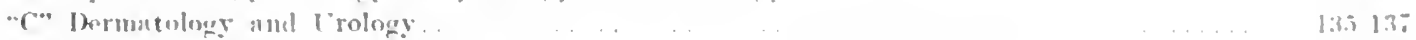

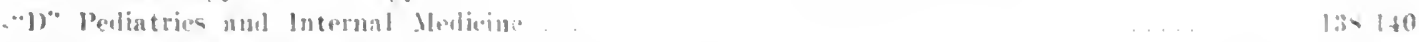

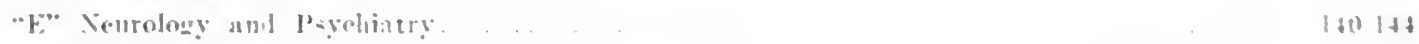

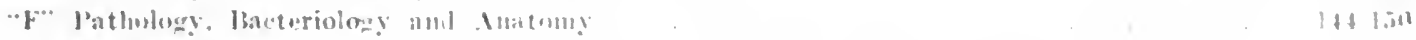

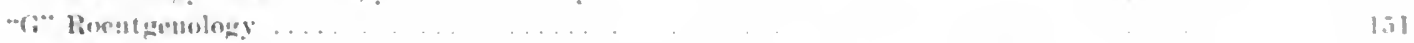

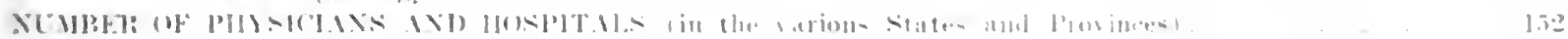

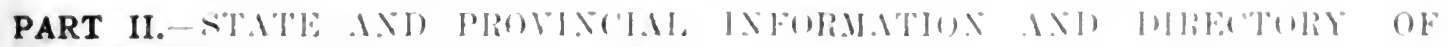

Pll

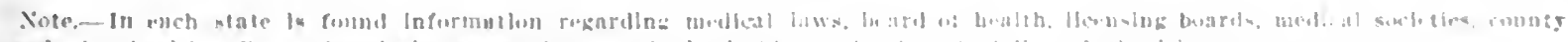

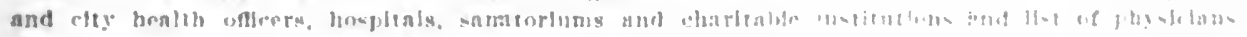

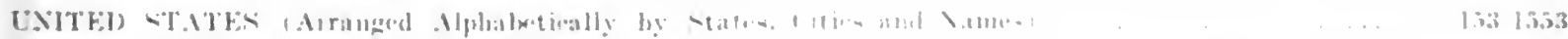

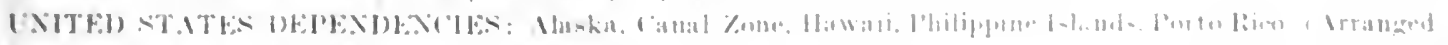

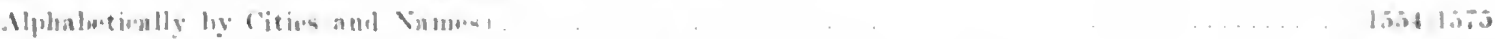

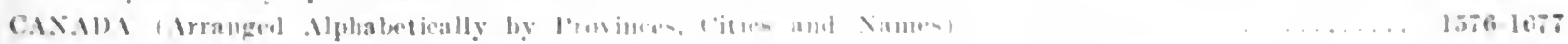

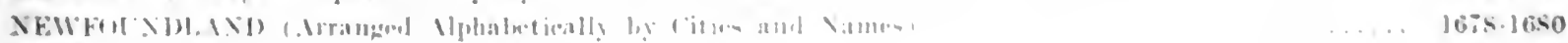

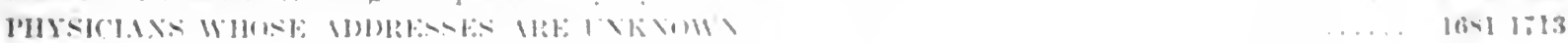

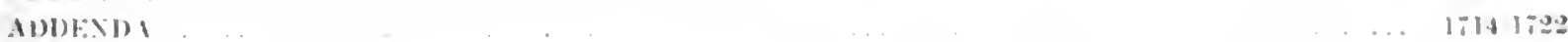

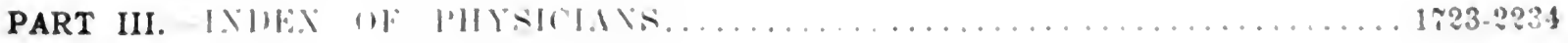




\section{INDEX TO DIRECTORY}

Abbrevintions and Symbols.

Abbreviations for College lositions

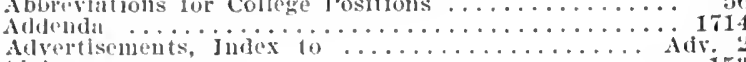

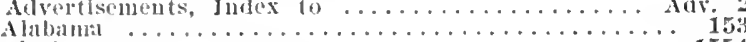

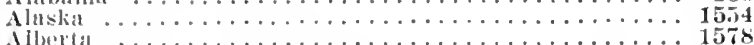

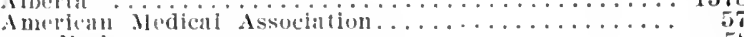

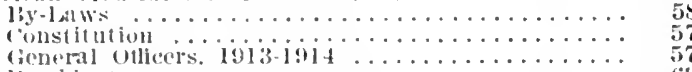

jeneralche

l'rincleles of inedical lithics.

section OHicers, 1913-1914

Sessions
Anatomical societies, Members of

Anesthetlcal suchetles, Menbers of

Anglo-Amerlean Medical Society, Continentil

Arlzona

Arkillsis

Army Medicil Oilicers, Active.

Aruy Medienl Otheers, Ietired....

Jacteriological societles, Aembers of . . . . . . . . . 14

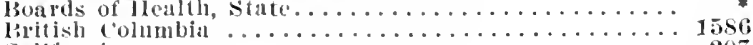

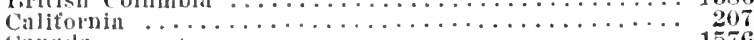

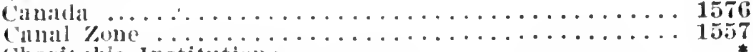

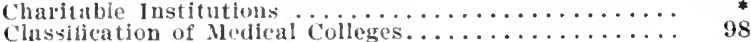

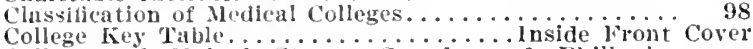

Colleges of United sitates, Canada und Fhilippine

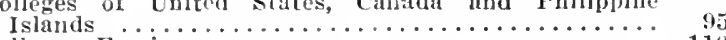

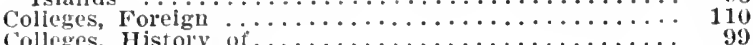

Colleges, History of ... . . . . . . . .

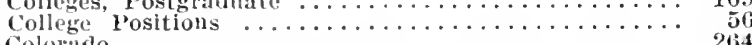

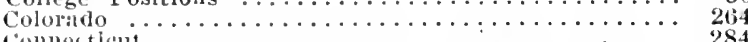

Consitution and iyy-ians of Ainerican iledical issoeiConsiltution and liy-Laws of Alnerican Medical Associ-
ation $\ldots \ldots \ldots \ldots \ldots \ldots \ldots \ldots \ldots \ldots \ldots \ldots \ldots \ldots \ldots \ldots \ldots$
Contents

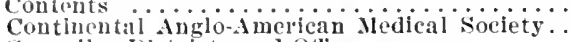

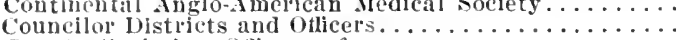

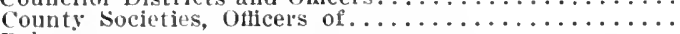

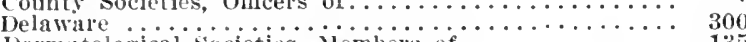

Dermatological soejeties, juembers of ..........

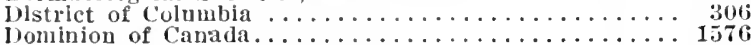

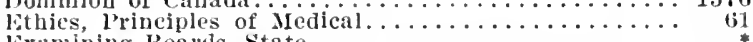

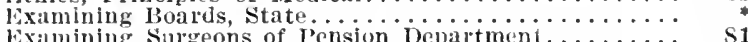

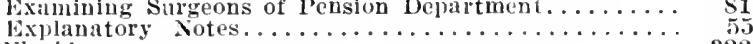

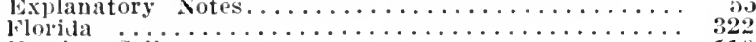

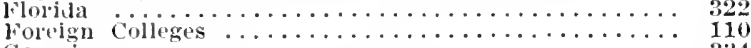

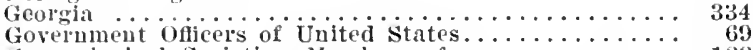

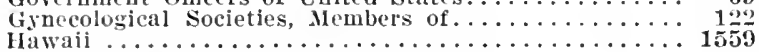

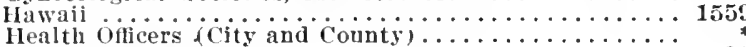

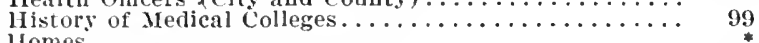

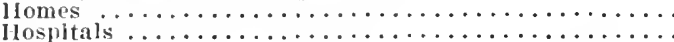

Hospitals, Number by states..............

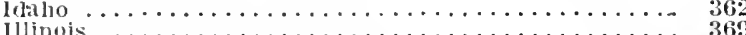

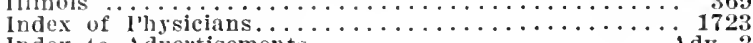

Index to Advertisements ...............

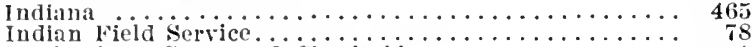

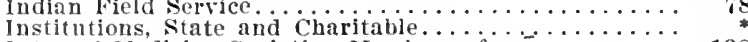

Internal Medicine Societies, Members of . . . . . . .

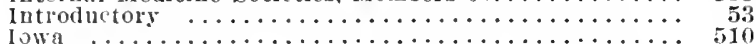

Jowa

Jonnals of lnited States, Canada and Philippine Islinds

Kinsils

Key to Directory

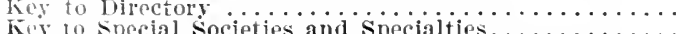

Ka to special Societies and Specialties.

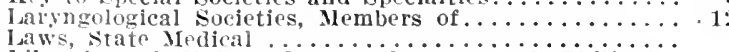

libraties of United States, Canada and Philippine

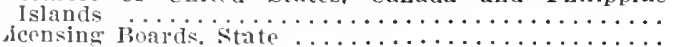

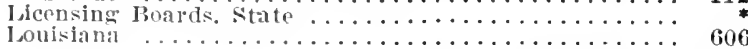

1'AGE

626
1596

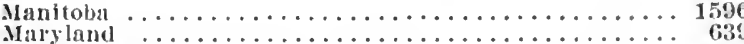

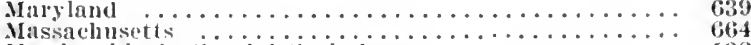

Menbership in specia $i$ socleties..................

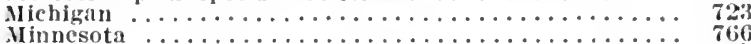

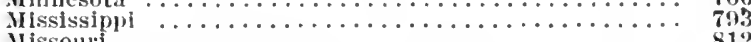

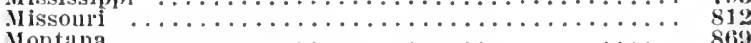

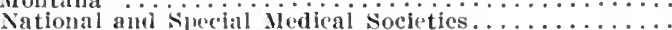

Navy Medical oflicers, Active................

Navy Medical Otlicers, Retired................... 76

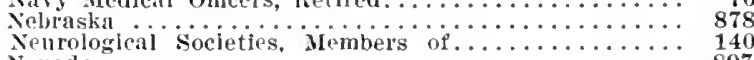

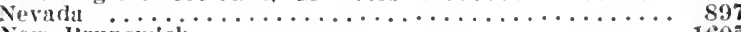

New Brunswick .................... 1605

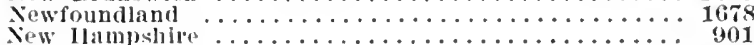

Now Jersey . . . . . . . . . .

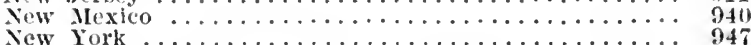

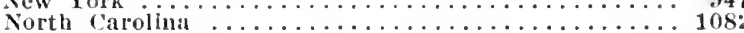

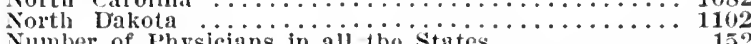

Number of Physicians in all the states........... 15

Obstetrical Societies, ifembers of...............

Officers of American Medical Association for i9i3-1914,

Grneral and Section................. 57

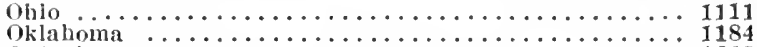

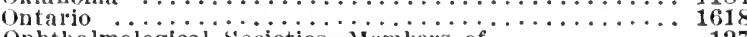

Ophthalmological societies, ilenbris of ........... 127

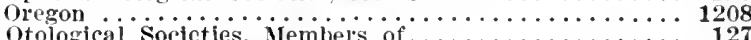

Patbologlcal Societies, Members of ...........

Pediatric Societies, Members of ........... 138

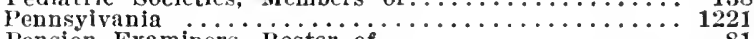

Pension Examiners, Roster of ............. 81

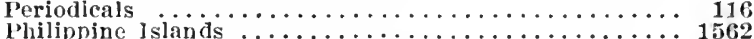

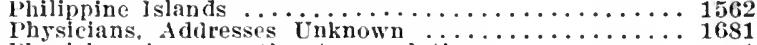

Physicians, Adoresses

Jhysicians, Number by States......................

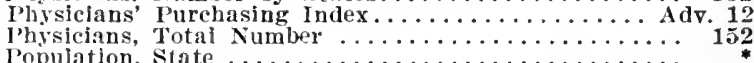

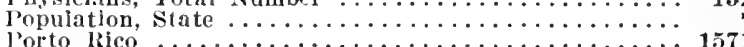

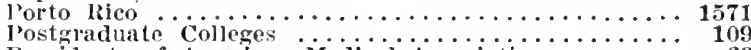

Presidents of American ifedical Association.......... 63

Prince Eciward Island ................... 1645

l'sychiatrical Societies, iembers of...............

Publications, Official ...................

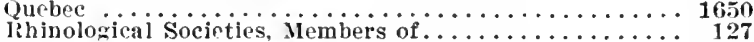

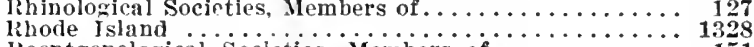

Roentgenological socleties, Members of ..........

Sanatoriums

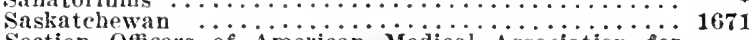

Section Officers of American Medical Association for

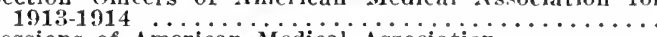

Sessions of American iedical Association .......... 63

Societies, National and Special Medical.........

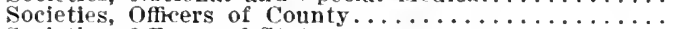

Societies, officers of State.

Society, Continental Anglo-American.............

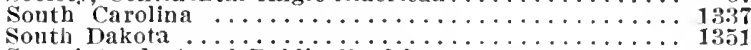

Superintendents of Public Health.

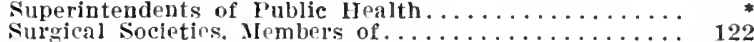

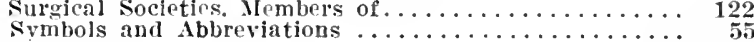

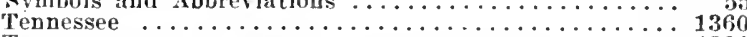

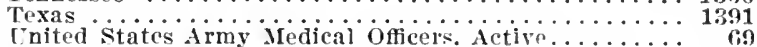

Inited States Army Medical Officers, Retired.........

United States Navy Medical Officers, Active........ 7 .

United States Public Health Service, Officers of . . . . 77

Trological Socioties, Nembers of .............. $13 \%$

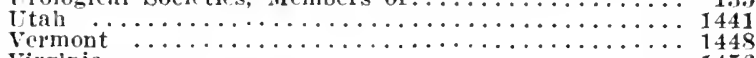

Virglnia $\ldots \ldots \ldots \ldots \ldots \ldots \ldots \ldots \ldots \ldots \ldots \ldots \ldots \ldots \ldots \ldots$

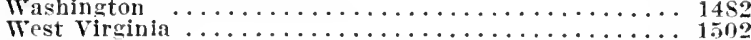

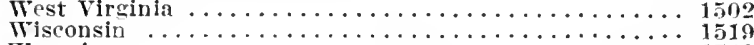

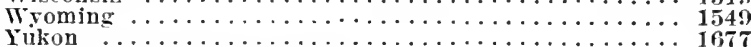

* SEE RESPECTIVE STATE-GENERAI INFORMATION. 


\section{INTRODUCTORY}

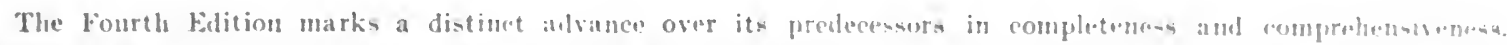

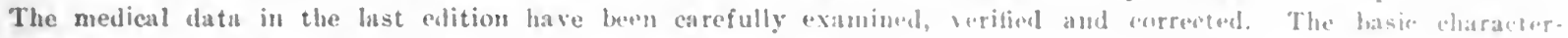
jsties have been retained and many new foutures have been addid.

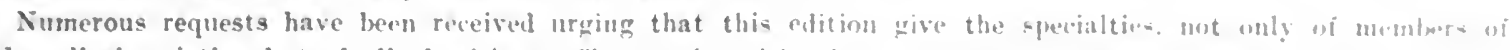

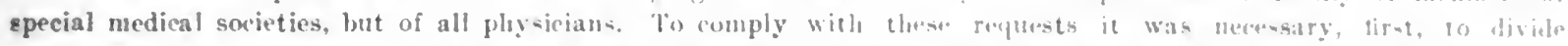

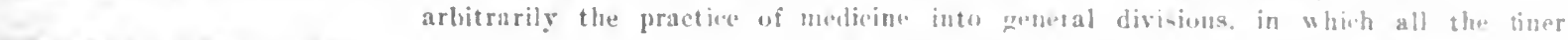

\section{SPECIALTY PRACTICED}

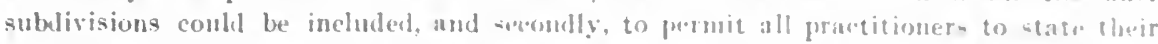

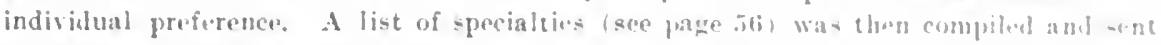

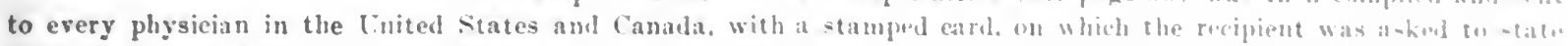
whether he was especially interested in. or limited his practice to, one of the special branohes of melirine, or was

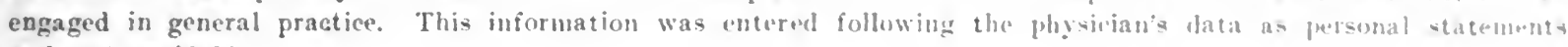
and not verifiable.

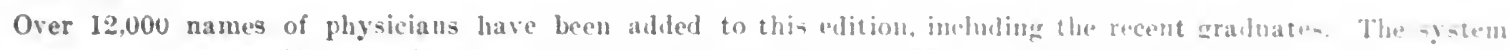
NEW NAMES of avoiding duplication used in previous editions has bers continned in the present vinlune, NEW NAMpleteness, accuracy and utility are the high ideals for which the American letical 1 - comiation stands in the proluetion of the Directory.

\section{THE DIRECTORY IS DIVIDED INTO THREE GRAND DIVISIONS}

First: Information relating to national anl interstate matters. Scconl: luformation relating (1) state and provineial matters, names of physicians whose addresses are umknown and the aldenda. Third: Names of physiciaus arranged alphabetically by name followed by their addresses.

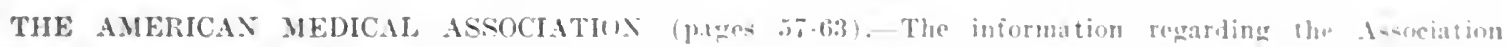
inchdes the offeers, 1913-1914; the Constitution and Ry-lan-: the Principles of Mediral Etlrics. a lizt of the

FIRST DIVISION-(Pages 57-152). National Matters, Societies, Government Officers, Colleges, Libraries, Journals and Members of Special Societies and Comparative Statements of Hospitals and Physicians. places of the annual sessions and names of those who presided at exph.

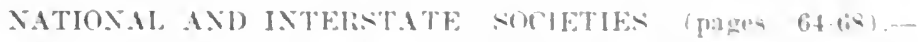
The list includes year of organization, date and flato of next meretimg and nflicers. A list of members of the Continental Inglo Imerican Monl. ical Society is given with their locations.

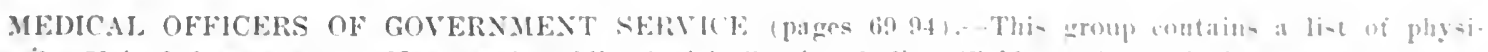

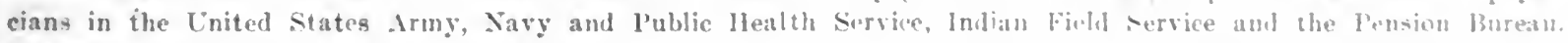

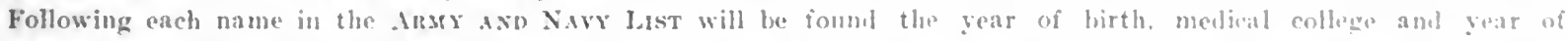

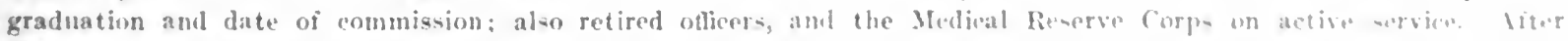

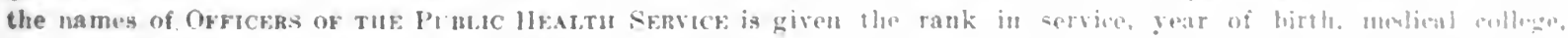
year of graduation and date of comnission and aloo date of entering service. The list of the physician of the

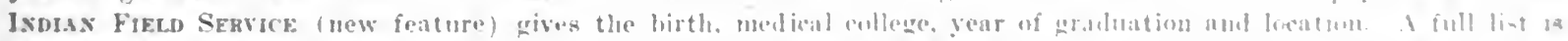

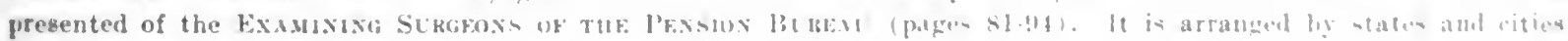
at which the various boards meet, with olliuers of eateh horat.

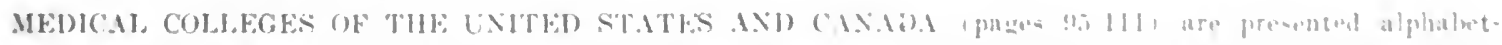

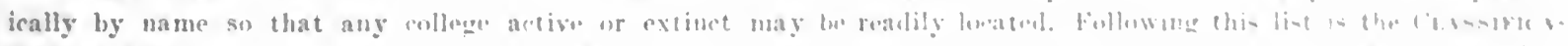

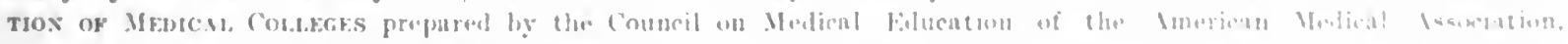

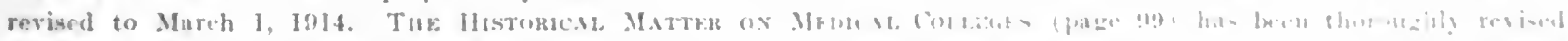

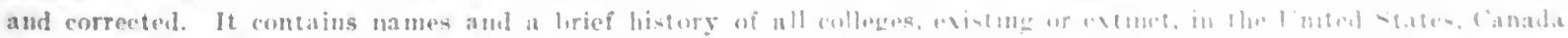

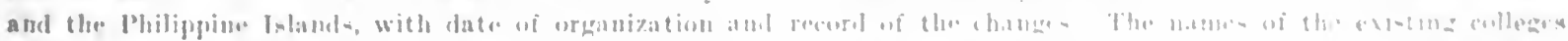

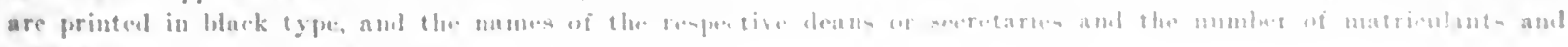
gradusters for 19]!. 19!3 are given.

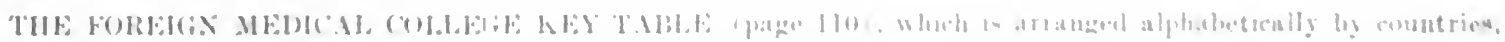

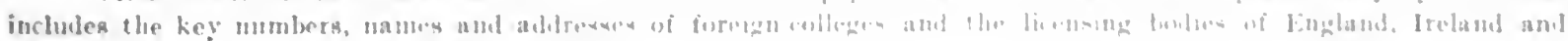
Scotlund.

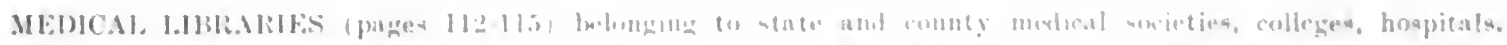

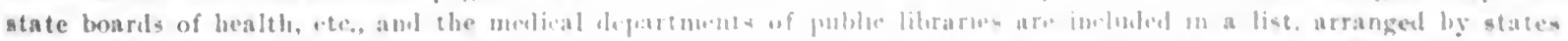

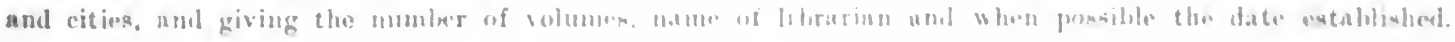




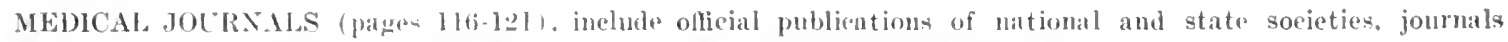
devoted to one of the serral specialtien of medieine and hyeriene, bourls of health, ulumni, ete. The information furnished inchudes guar established. publisher, editor. When imsurl and subieription rate.

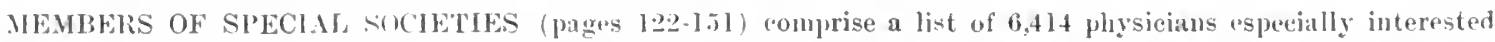
in on or more of the several branches of melinine. The societipe are arranged nuder seven general gronps designated by letters. The 1 group refer- to Surgery. Gynerology. (Hostrotries and Anesthesia, numbering l.2.29 nanes; B. Ophthalmologg, Otology, largugology and Rhinology, mumbering 1,700 names; C, Dermatology and Crology. 463 names; D. Pediatries and Internal Medicine. 591 names; L. Nenrology and Pediatries, 846 names; F, Pathology. Bacteriology and Anatomy, 1.4:3 names; and (i, Roentgenology, 16: names. In each group the names are listed by states, and each state is divided into sertions, the large eitios appearing first, followed ly the other names in the state. The names in moh portion are amanged alphabetically.

The information given muler each state ineluder laws. lieensing and health buards. societies, hospitals, sanatoriums, homus and charitable institutions and molical information eoncerning each physician.

MEDICAL PRACTICE LAWS of each state will be found preceding

SECOND DIVISION (Pages 1531722). The states in alphabetical order, dependencies of the United States, Canada, Physicians whose addresses are unknown and Addenda. the list of phrsicians. They lave been revised to date and include all amendments. For convenience the subject treated in each section is indicater in capital letters at the head of the section. Jists of Medical lixamining Boards. Boards of Health, officers of the State Medical Assopiation. president and secretary of each component society, County and City Health ollicer's lave been carefully revised.

IIOSPITALS. S.XATORIUNS, incheling state and charitable institutions having hospitals under their control, are arranged ly eities. This list has been thoronghly revised and furnishes the most eomplete and aceurate list ret published. When obtainable, the following information is given; location, date of establishment, whether public or private, number of beds, character of cases treated, name of physician in charge or superintendent. All unethical institutions so far as possible are omitted.

THE IIST OF PHYSICIANS is really a biographieal eyclopedia. The names of physicians are grouped under states and towns, names of states. towns and individnals being arranged in alphabetical order, following the plyssician's name are the medical college and year of graduation verified from oflicial alumni lists and the year of license, also verifed from reports received from state licensing authorities. In addition, whenever possible, the year of birth. membership in eounty and state societies, fellowship in the American Medical Association. membership in national and local special medical societies, professorship in medical colleges and the specialty practiced, or in which the physician is interested. are given. In towns of 10,000 and over, the residence and office address and the office hours are stated. All information is taken from official rosters except specialty information, which is furnished by the physician. Alaska. Caxal Zoxe, Hawait, Pindippine Istaxds and Porto Rico follow the states and are in turn followed by CaNADA, arranged alphabetically hy provinees, and have been revised and brought up to date.

PHYSICIANS-ADDRESS UNKNOWX (pages 1681-1713).-A list of graduates of Medieal schools with their medical data and last known addresses has been compiled. Many of these physicians have retired from practice and many have engaged in other business; a number may have died. These names appear in the alphabetical index followed by the symbol $\mathbf{8}$. Information conceming any of these physicians will be thankfully received.

ADDENDA (pages 1714-1722).-Ineludes new names. also corrections, removals and deaths received too late to classify in the Geographieal Section. The'se names are indicated in the alphabetical index with the symbol $\dagger$ for new names or corrections and $\neq$ for deaths.

INDEX OF PHYSICIANS is a list of all the physicians in the directory arranged alphabetically by name, with their loeations (state and city). Surnames are printed in capital letters. Full names are given in place of initials whenever possible. The address which follows the name indicates the portion of the geographical division where complete

THIPD DIVISION (Pages I7232234). Physicians alphabetically arranged by name. information may be found. An additional eity appearing in parenthesis indicates a residence in one city and an office in another. The full data will be found in the first-named city. The symbol s indicates that the name will be found in the list of physicians whose addresses are unknown; $\dagger$ refers to a new name or correction in the addenda; ; indicates deceaned during the printing of the book. When there are different spellings of the name, under each form of the name is given a list of the other variants as; "Cane: see Caine, Cain, Kane, Kean, Keen, Keene."

THE PAPER used in this Directory was imported from Belgium; this for the double purpose of having strong. opaque, and yet thin, paper. While much more expensive. it means not only better and more lasting quality, but also a more satisfaetory book to handle.

\section{APPRECIATION}

To the secretaries of the various medieal licensing boards in the United States and Canada, to the officers of medical colleges, county societies and state associations and the thousands of correspondents who have so cordially assisted us in making possible this edition. we extend our thanks and express our appreciation. 


\section{KEY TO DIRECTORY}

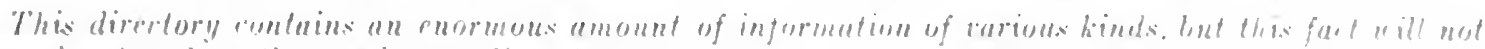

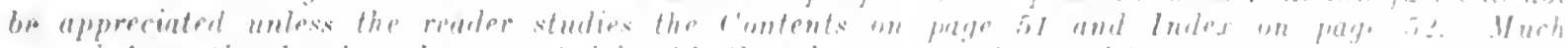

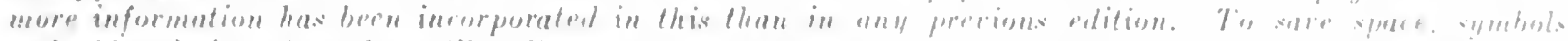

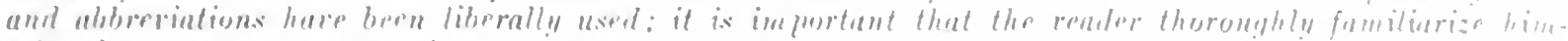

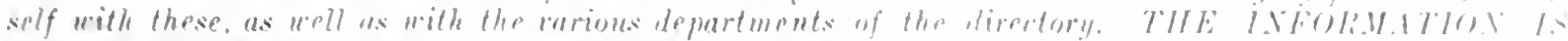

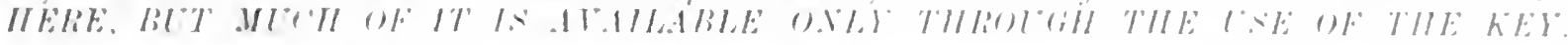

\section{Symbols and Abbreviations}

Names in expitals signify membership in the ('ounty Society and State dssociation (I) (O). I()IIN).

+ Fellowship in American Medical Asandiatim. $(1,75)$ lear of hirth.

H. Homeopathie: E. Eclertic; P.Ml, Plysiomerlic.

IId.A.0?. College und year of graduation.

(Fur key to colleges, see inside front cover parye.)

lier.l.09. College and year of gruluation.

i For key to ioreign folleges. see page 110.1

C Information receivel does not show grabluation.

(8) In practice before passage of present law and licensed by filing diploma or by years of praetice: also in Oklaboma, reregistered acemeling to det of $190 \mathrm{~s}$ : in

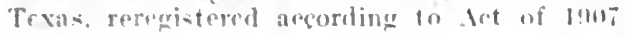

\section{Part I-National and Interstate Information (l'ages $5 \%-152$,}

Amerlean Medleal Assoclation and lts Otticers, constlutium. lif-laws, L'rluelples of Medical lithles. Sressions and l'vilenls.

Natlonal and Interstate sncletes.

Cuntimental Anglo-American Mideal Association.

Medlcal Otlleps of the Army. Navy and lublle llealth sirvine.

Physlelans in the Indlan Fy.lel service

Roster of lewsion liximminiers.

Mealcal Colleges.

Medical IAbrariso.

Medical Journals.

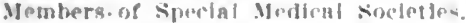

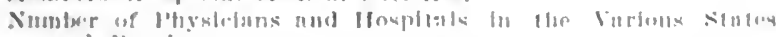
unas lempliferes

\section{Part II - Information Under Each State} Ingers lon 1720 1

Joupulutlon (19)]0 Census).

Number of Combles in stat.

Ninmber of t'bystclans.

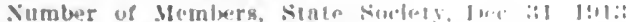

Meilleal l'ructlow Iaw.

Nembers, sian Hourd of Healsh, lixumlulur lburl.

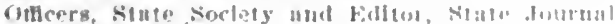

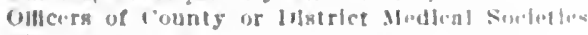

Clty, county and Illmerlet llanlih inliors.

slate Instilutions.

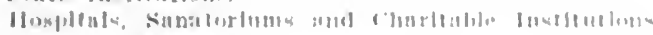

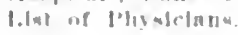

\section{Part III-Index of Physicians

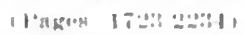

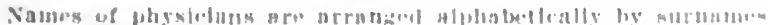

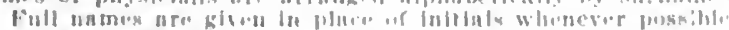

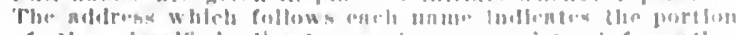

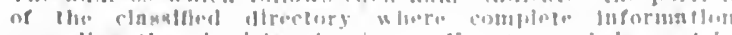

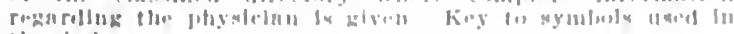
the Index

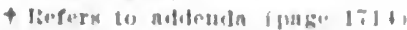

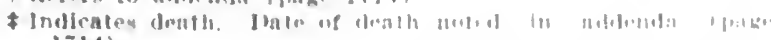
$1711)$.

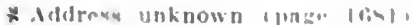

('in!) lisar of liopnas.

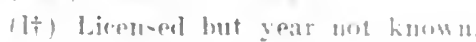

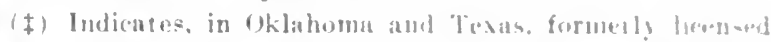
but not reregistered; in luciana, liconomb los -tate+

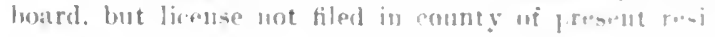
denent.

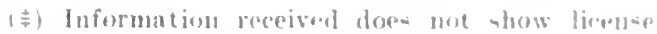

l'A.A., Jilited sititese Army.

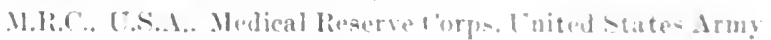
l'S.X.. Luited Sithes Sary

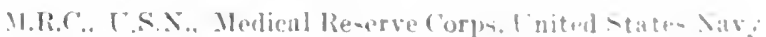

I's.l' il

\section{Special Explanatory Notes}

\section{Addenda (Page 1714)}

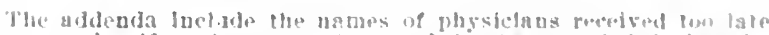

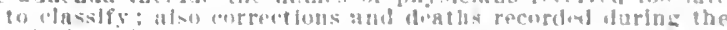
furinting of the dirtetory. These names apjerar in tha fndex.

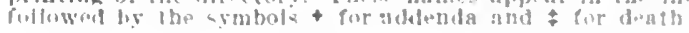

\section{Addresses Unknown (l'are 16i-1)}

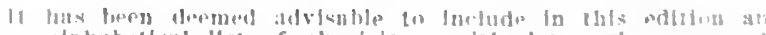

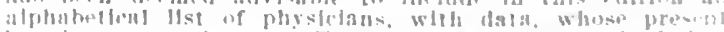

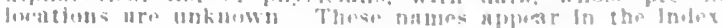

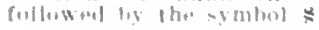

\section{Local Address and Office Hours}

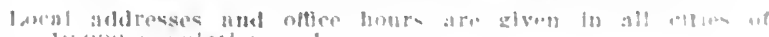

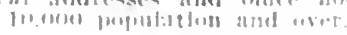

\section{Number of Physicians}

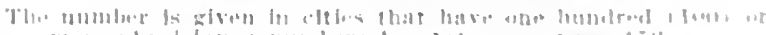

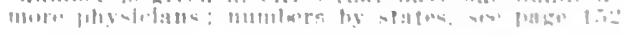

Pathologists, Bacteriologists. Dentists, Etc.

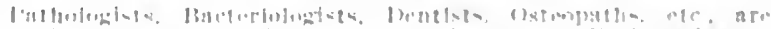

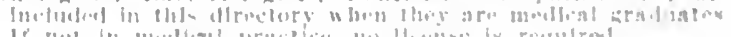

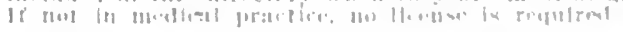

Physicians Listed Under Two Places

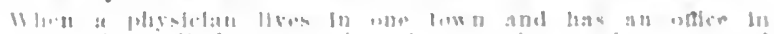

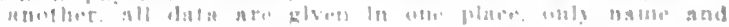

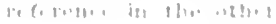

\section{Population}

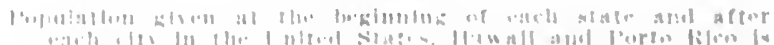

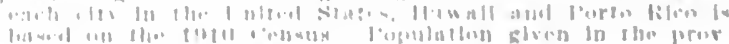

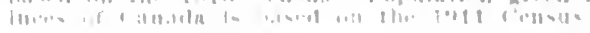

\section{R. F. D. and Neighboring P.O.}

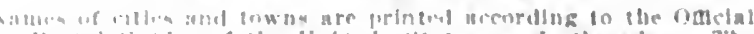

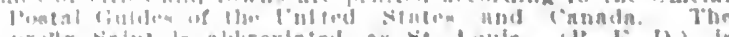

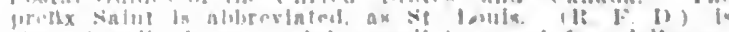

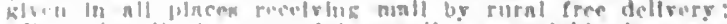

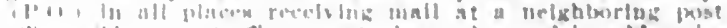

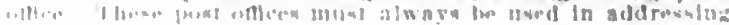

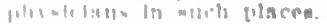




\section{Abbreviations for College Positions}

I'rof Oust, 111 6', slaplifies t'rufessor of Ohstetrles, North-

western Unfersity Medical School, Chicago.

Abd.-Abdomlnal.

Adf.-Adjunct.

Anes.-Anestlieties.

Assoc.-Issuclate.

Bact.-Baeteriology.

Chll-Children.

Cutan.-Cutaneous.

Derm.-Dermatology.

biag.-Diaguosis.

Did.-Didactic
Dis.-Diseases.
biet.-Dietetics.
bxper.-Experimental.
Gas.- Euter-Gastro-
Enterology.
Gyn.-Gynecology.
llyg.-IIyglene.
Inter.-Internal.
laryn.-laryngology.

I'rof. Otol. Ill.Gi, gignifles Professor of Otology, lilinols

lost-Graduate Medical School, Chlcago.

\author{
Ment.-Mental \\ Nerv-Nervous. \\ Neur-Neurology. \\ Obst.-Obstetrics. \\ Oper-Operatlve. \\ Ophth.-Ophthaluology. \\ Osteo.-Osteology. \\ Otol.-0tology. \\ Iatli-Pathologs.
}
Ped.-Pediatrles.
I'har.-l'harmacology.
'hilos.-1'hliosophy.
1'hyslol.-Plhysiology
'rer.-l'reventlro.
Proct.-Proctology.
Psych.-P'sychiatry.
1'ui.-Pulmonary.
laadlol.- Radiology.

\section{Special Societies}

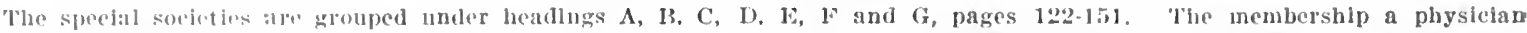

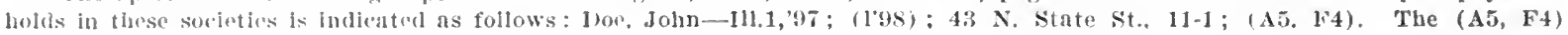
signify thit lor. Ino is a membor of the Americun Surgical Assoclation and the Chleago Inthologleal Soclety.
A - Surgery, Gynecology, Obstetrics and Anesthesia Page 122
1. American Assuciation of Obstetriclans and Gynecologlsts.
2. American fignecological Socicty.
3. Anerican Orthopedic Association.
4. Amerlean l'roetologic Society.
6. Southern surglcal and (iviecological Assoclation.
б. Western Surglcal Association.
8. Boston-Obsterleal Soclety of Boston.
9. Boston-Otsterieal Socle
10. Brooklyn Gynecologleal Society:
10. Brooklyn Gynecologleal Socicty.
12. ("hłcago Orthopedic Soclety
13. Chleago surgical soclety.
14. Cincinnatl Obstetrical Society.
15. New York Obstetrical Society.
16. New York Surgical Soclety.
17. Philadelphila Academy of Surgery.
18. Philadelphila - Obstetrleal Soclets of Philadelphla.
19. St. Joseph Surglcal Soclety.
20. St. louis-siection on obstetries and Diseases of Women.
21. American Association of Anesthetists.
2. Surgeons Club of St. Louis.
23. Surgeons (lub of St. Louis.
23. Nt. Louls Surgical Soclety. Gynecological Soeiety.
Gynecological Society.
washlngton (D.C.)- Surgleal Soclety.
25. Washlngton (D.C.)-Surglea
27. Milwankee Surgical Society.

\section{B - Ophthalmology, Otology, Laryn- gology and Rhinology-Page 127}

1. Amerlcan Academy of Ophthaimology and oto-haryngology.

3. Ameriean Latryurological Association.

3. American Laryngological, Rhinological and Otological Society.

4. American Ophthatmological Society.

5. American Otological Society.

6. Buffalo Ophthalmological Club.

. Chicago Laryngological and Otological Society.

8. Chicago Ophthalmological Society.

9. Colorado Ophthalmological Society.

10. Detrolt ophthalmological and otological Club.

11. Detroit Oto-Laryngological Society.

12. Los Angeles Co. Med. Assn., Eye, Ear, Jose and Throat Section.
13. Niiwanke Oto-Ophthalmic Club.

14. New lingland Ophthalmologlcal Soclety.

15. New England Otological and Laryngolog. ical Soclety.

16. New York Ophthalmological Society.

17. New York Otological Soclety.

18. Omaha Ophthalmological Otological so clety.

19. Pacifle Coast Oto-Ophthalmological Soclety.

20. Philadelphia Laryngologieal Society.

21. Phlladelphia Polyclinic Ophthalmic Soclety.

22. Philadelphia-Section on Ophthalmology of the College of Physicians.

23. Nhiladelphia - Section on Otology and Laryngology of the College of Physlclans.

24. Philadelphia-Wills Hospital Ophthalmic Society

25. Puget Sound Acadeny of Ophthalmology and Oto-Laryngology.

26. Rhode Island Ophthalmological and Otological Soclety.

27. St. Louis-Ophthalmic Section St. Louis Nedical Society.

28. San Francisco-Section on Eye, Ear, Nose and Throat.

29. The Minnesota Academy of Ophthalmology and Oto-Laryngology.

30. Washington (D.C.)-Society of Ophthalmologists and Otologists.

31. Northwestern Oph-Lar-Rhin-Otic Soclety.

32. South-western Michigan Triological Soclety.

33. St. Louis-Oto Laryngologica] Section St. Louls Medical Society.

\section{C-Dermatology and Urology- Page 135}

1. Amerlcan Associatlon of Genito-Urinary Surgeons.

2. American Dermatological Association.

3. American Urological Association.

4. Boston Dermatological Club.

5oston-New England Branch of the Amerlcan Urological Association.

6. Chicago Dermatological Society.

7. Chicago Urological Society.

9. New York-Dermatological Society.

10. New York-Manhattan Dermatological Society.

12. New York Society, American Urological Association.

13. Philadelphia Dermatological Society.

14. San Franciseo-Section of Urology.
D_Pediatrics and Internal Medicine Page 138

1. Ainerlcan l'ediatric Society.

2. ('hicago Pedlatric Society.

3. New England P'ediatrlc Society.

4. Philadelphla Pediatric Society.

5. St. Louls Pediatric Society.

6. Association of American P'hysicians.

\section{E-Neurology and Psychiatry} Page 140

1. Amerlcan Neurologlcal Assoclation

2. Boston Society of Psychlatry and Neurology.

3. Brooklyn Soclety of Neurology.

4 . Chicago Neurologlcal Society.

4. Detroit Society of Neurology and Psychiatry.

6. Maryland Psychiatric Society.

7. New York Neurological Society.

8 . New York Psychiatrical Society.

9. New York - Ward's Island Psychiatrle Society.

10. Philadelphia Neurologica! Soclety

11. Philadelphia I'sychiatrlc Soclety.

12. Washington (D.C.) Soclety of Nervous and Mental Dlseases.

13. American Medico-Psychological Associatlon.

\section{F_Pathology, Bacteriology and Anatomy_-Page 144}

1. American Assoclation of Anatomists.

2. American Association of Pathology and Bacteriology

3. Los Angeles-Clinical and Pathological Society.

4. Chlcago Pathological Soclety.

5. Des Moines Pathologleal Society.

5. Des Moines Pathological Society.

6. Minnesota Pathological Society. Science.

8. New York Pathological Society.

9. Omaha Pathological Association.

10. Philadelphia - Pathologlcal Soclety of Philadelphia.

\section{G_Roentgenology-Page 151}

1. American Roentgen Ray Society.

2. New York Roentgen Ray Soclety.

3. I'hiladelphia Roentgen Ray Soci

4. Chicago Roentgen Ray Society.

\section{Specialties are Indicated as Follows}

only one specialty inserted

\author{
S.-Surgeon \\ Ob.-Obstetrician. \\ ObG.-Obstetricia \\ G.-- Ginecologist. \\ Pr.--Orthopedist. \\ Op.-Ophthalmologist.
}

A.-Aurist.

LR.-Laryngologist, Rhinologlst.

ALR.- Aurist, Lary

OALR.-Ophthalmolugist. Aurist,

U.-Trologist.

\author{
D.-Dermatologlst. \\ N.-Neurologist. \\ NP.-Psychiatrist. Psychiatrist. \\ I. - Internist. \\ T.-Tuberculotherapist.
}

\author{
Anes.-Anesthetist. \\ LD.-Laboratory Diagnostician. \\ R.-Actinologist, Radiologist \\ Roentgenologlst. \\ Path.-Pathologist. \\ Bact.-Bacteriologist.
}

WHEN THE ABBREVIATION REPRESENTING A SPECIALTY IS FOLLOWED BY AN ASTERISK ( $\star$ ) IT INDICATES THAT THE PHYSICIAN CLAIMS HIS PRACTICE IS LIMITED TO THAT PARTICULAR BRANCH OF MEDICINE; WITHOUT THE ASTERISK, THAT HE IS ESPECIALLY INTERESTED IN, BUT DOES NOT LIMIT HIS PRACTICE TO, THAT BRANCH. THIS INFORMATION CONCERNING SPECIALTY IS BASED ON PERSONAL DATA FURNISHED BY THE PHYSICIAN AND IS NOT VERIFIABLE. 


\title{
AMERICAN MEDICAL ASSOCIATION
}

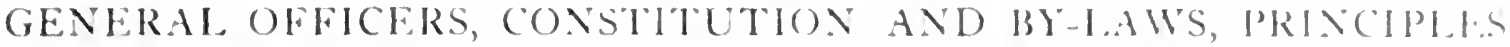 \\ OF MEIICAL WHICS, SHSSIONS A II PRLSIDHNS
}

\section{OFFICERS, 1913.14}

General omcers

John A. Wisherspoon. Presldent.... Nashrille Victor C. Viaglan, i'resident-kilect.......

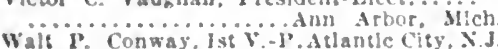

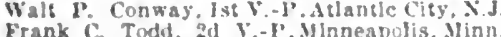

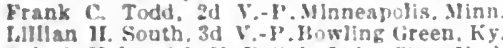
sol. 6. Kahn, th Y.-1. Salt Lake City, t'ah Georze il. slramons. Fublor and Genera Manager, 535 X. Dearborn Strcet, Chlcago Alexander R. Craig. Secreiary.

wiil.....535 $\times$. Dearborn Street, Chlcag. Willarn Allen pusey, Treasurer.... Chlcago HOAIS OE TRLSTEEs, - Philip Marvel, Atlantic City, 1919; I'hllip Mills Jones, Sal Francisco, 1914; W. T. Sarles. Sparta, wls. 1914: M. H. Wiarris, secretary, Chlcago, 1915: W. T. Councllinan. Chairman, Bnston. 1985: Thomas NeDaritt, St. I'aul, Minn. 1915: 11. Wi. Grant, Denver, 1916: Frank J. Lutze St. Louls, 1916: Oscar Dowling. Shreveport. La., 1916.

JUdicial CoUvicil--Alexander Lambert, Chalrman, New York Chty, 1914; Jame E. Moure Minneaprills, 1915; IIubert Wiork Pueblo, volo., 1916: George W: riuthrie, Wilkes-Barre, Pa., $191 \hat{i}$; A. B. Cooke. L.os Anceles, cal 1918: Secretary, 535 x. Wearborn Street, Chicago. COEXCIL ON HENLTH AND PEBLIC iNSThuction-11. M. Bracken, Minneapoils, 1914: if. C. Woodward, Washington D. C., 1915: H. B. Favill, (chalrman, Chlcago, 1916; Wialter B. l'annon, IBoston. Freterick R. Green, Secretary, $535 \mathrm{~N}$. Dearborn Street, Chlcago.

COUNCH ON MEDICAT, EDECATIOSArthur D. Beran, Chalrman, Cblcago, 1914 fenrge lowek, st. Louls, 1915: W. D. Hag gnrd, Nashrllle, Tenn 1016: James 11 Holland, fluiladelphla, illi: II. D. Arnold Boston, lu1s: $X Y$. Colwell, sectetary, 535 s. Dearborn street, Chlcago.

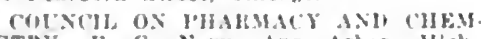
ISTRY, $r$. Nory, Ann Atbor, Mllh. 1915: Georte H. Simmons, (halrman, (hl cago, 1915; It W. Whley, Washmutun, It. C. 1915: 0. T. Osborne, Yew Ilaven, Conts., 1916; Torald Sollmann, (Cleseland, Ohle, 1918: M. I. Wilbers. Washlingtrill, I" '" 1915; Beld Ifuns, Roston, $191 ;$ J J H lomb

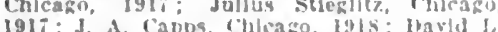

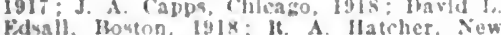
York clestois: John Howland, Baltimere. York Clty, 1918, John Howland, Baltimure 1919: Heney Kraesner, Fhlludelyhia 1919 A. I'urkner. Secretary, $53, x$ Dearhorn sircet. Chileago

OFFICERS OF SECTIONS, 1913.14 PHACTUCE OF MEDITINE-Chalrman Charles L. (ireene, st. l'aul: Vlce- ("halr

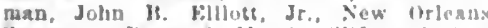

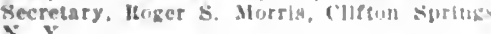
X. Y.

sctibils chatrmas, tharles H. Fra. vler. Phlladelphin: Hre-chairman. J $\mathrm{E}$

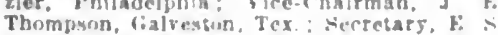
Judd lochester, MIn!n.

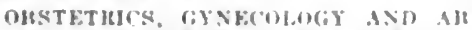

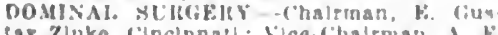
tar Zluke, cinclnnall Vice-('halmman, of to

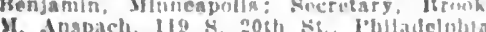
oprotich, Tudis. Minneapolis: Vico-rhalrnas, II Illan
Zentmayer, Phlladpha; Secrebry, Genree $\therefore$ Derlis.: Herefurd si Boston

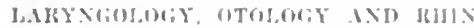

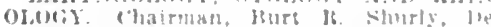

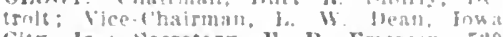
Cliy, 1a.; secretary, F. P. Emerson, 320 Commonwealth Are., Boston.

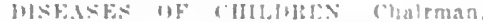

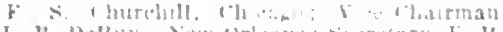

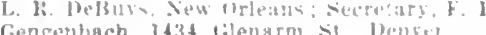
fencentach, It3t tilenarma st. Densu

PHAMMACOLOGY AND THEKAP'LTICS. ('halrman, J. F. Anderson. Washington. D. C. ; Vice-Chalrman, M. A. IIatcher, New lork: Seiretarv. M. I. Wllbers, 25th and E Ste, III, Washington, D 4

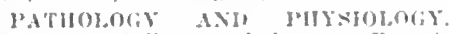
Thairman. William Uphils, san Franclsen: Vicethalrman, I. If. Wilson, lechester. Mllnn. : secretary, A. J. Carlson, Lniversity of Chlcage, chicago.

stuMstolofis thalrman, William I Flsher Yow Yurk. Hice-chairman $F$ Nooreliead, Chicago; Secretary, Eugene s. Talb t, 31 x. State St., ethicab

NHUTIS AND MEXTAL MSEASESChalrman, W. W. Grares, St. Lomis; Vice

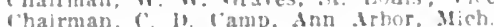

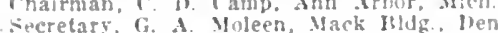
ret.

WEMMATOLOt: ... (hairnan, Bichard I. Sulton, Kansns r'ity. Min.: Vlee-thairman. J. H. hessler, lowa clly, la.; Secretary lloward Fox, 616 Madison dve., New linth

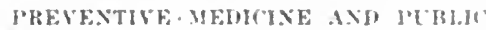
HFALTIS-Chairman M. I. Marenel. Nallisom. Wls. : Vice-chalrman. W. C. liucker. Mnohlngton. D. C.; secretary, C. Hampsisn Junes, 2.529 st. I'aul st., Baltimore.

GENTTH-IRINARY D]SEASES - Thatr math, Asthur f. Chute. Koston; Vice-that man. Granrllle Macfowan, Los Ingeles. Secretary. Lum

HOSPITILS - Chatrman, L IB BaldwIt.

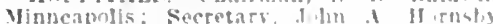
G. N. Michican Are., chicago.

ORTHuibsli siltikit thateman. leconard W. Ely, sin Erancisen: Vee Chair-

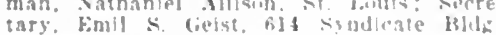
uluncapolls.

\section{CONSTITUTION AND BY.LAWS}

\section{CONSTITUTION}

Arlicle I.-Tille

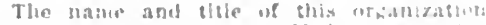

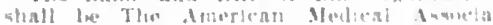
tlon Article 2.-Object

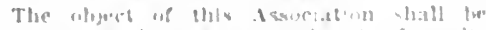

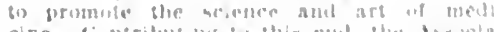

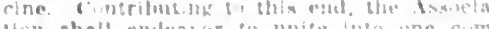

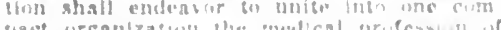

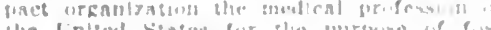

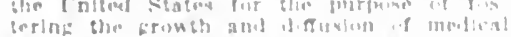

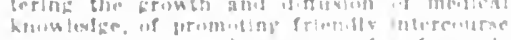

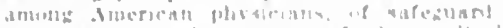

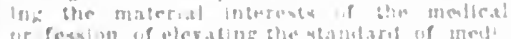

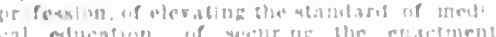

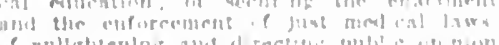

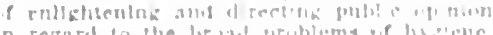

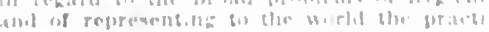

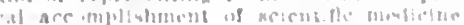

Arficle 3.- Membership

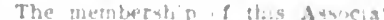

convixe of the members in e.s w giand n?

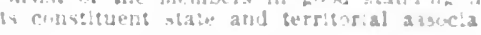

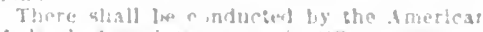

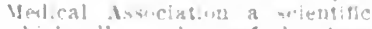
which all Tembers of gle Av. al in wh

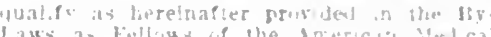

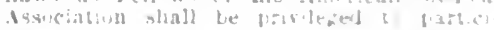
nate

Article 4-Constituent Associalions Shabe and ierriturial midicat acsira: which hate. or whirb herwafer may. tec rew what cal disiciation. and which has dectarent by rea lution theit alleciance bs the sald

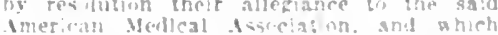
shall agree with other sia: and atr:-4.al

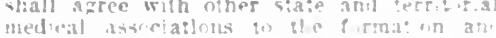

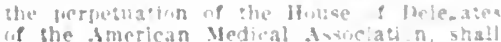
(1) the American Medical Avoctati n, sha!

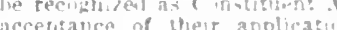

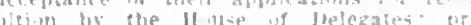
vided hiwerer. that the birm lecour at

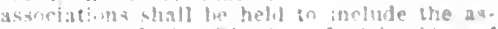

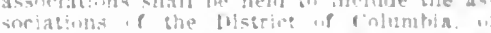
fie Canal Zorle, and no the insular proses tions of the I nited staliex

\section{Article 5-House of Delegates}

sectum 1. There shall he a loisinesa buly known as the $H$ inse of llelepates of Uhe

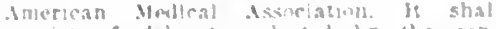
(1)nsint of delegates elected by the orn stibuept associations and by the setents

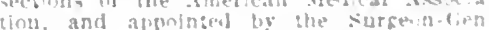
rrats from the medical devarments rif the Irmy. Nary and the [n.tent sentes Pliblic

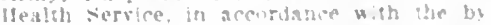
bus hereinafor providest jevided h.w

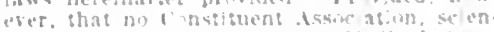
fic sectiul of the Ametican Menlcal Axo. ciastun, or medical department of the Arms Nary or the l'used states publir Mealth serrice nay the represented th the ll huse of

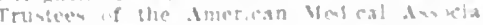
won he hall represen: the delesated jurb il Aneratine, and whil le the nat inat

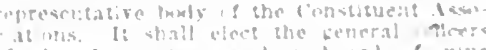

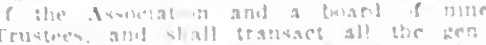

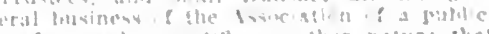

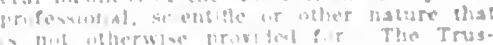

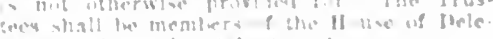

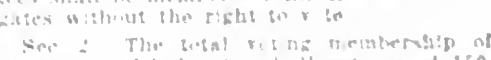

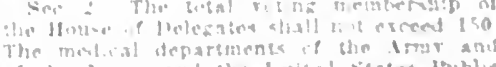

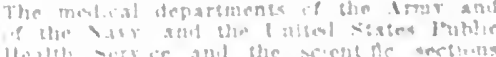

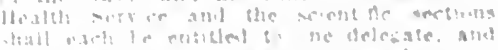

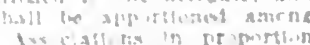

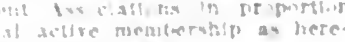
[ris] in It. I.ans

Article 6.-.Sections numbnabize the srienting iviscuatsou, there shall be carth of which ahall to

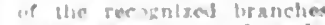
aritave alut art of mell.

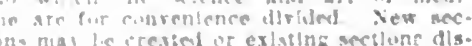
cussinuml to the Houten of Velecates 
Article 7.-Branches

'tha House of velegates may critu such lirinch organlzations as may he doement mediest profession.

\section{Article 8.-Annual Sessions}

The Assoclation shall hold an unmul ses. slon at a time and place to be tlxed by the llouse of belegates. The time and place of the sousion may, however, he changed by the unanimous atetion of the IBond of Trustees at any tlme prlor to two months of the time selected for the session. The
annmal session may be held at any place in the ionted stites.

\section{Article 9.-0ficers} section 1. The general onleers of this l'residenty, is sodretary and a Treasurer.

sice. 2. These officers shall be elected ammilly by the hlouse of lielegates, th serve for one year, or until their successors are elected and installed.

Set. 3. Xin member of the IIonse of Delerates shatl to elinible fo the offlee of I'resident or vice-presictent.

\section{Article 10.-Board of Trustees}

Section 1. The Board of Trustees shall have charge of the property and of the finaneial aftairs of the Issociation.

Sec. 2. Three Trustees shall be elected imnually by the House of Ivelegates, each to serve for a period of three years.

\section{Articie 11.-Funds}

Funds shall be laised by an eyual assessment of not more than ten flolars annuall on each of the members; from the Assomanner approred by the Board of trus tees. Funds nay be appropriated by the Board of Trustees to defray the necessary expenses of the Association; to enable standing committees to fulfl their respective duties and to conduct their correspondence; to encourage sclentific investitations by the giving of prizes and awards of merit; to carry on its publications, and for any other purpose approved by the Board of Trustes or recommended by the IIouse of velegates.

\section{Article 12.-Amendments}

The House of Delegates may amend any article of this Constitution at any annual session. provided that the proposed amenclment shall not be acted on until the rext imual session following that at which it was introduced, and providing that threeIIouse of Delegates registered at the session it which action is taken rote in faror of such change or amendment.

\section{BY-LAWS}

\section{Business and Legislation}

Chapter 1.-Qualifications, Term, Apportionment and Registration of Delegates section 1. DEIEGATES MUST HAVE BEEN FELLOWS OF THE AMERICAN IEDICAL ASSOCIATION TWO TEARS: in one shall serve as a member of the liw of the American Iedical Association for at least the two years immediately preceding the mecting of the House of velerates at which he is to serve.

Sec. 2. TERMI: Delegates and alternates from constituent associations shall be elected for two years. Constituent associations entitled to more than one representative shail elect them so that one-half, as nean as may be, shall be elected each year. tions, or delegates appointed from the Inited States Army, United States Nay and Cnited States Public Healih Service shall hold office for nne year.

SEe. 3. APPORTIONMENT OF DELEevery thirl rear thereafter, the 1903 , and belegates shall appoint a committee of fleo on

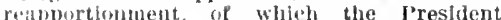
and the secretary shall be members. The comnittee shail apportlon the delegates among the constituent associations in nccordance witl Artiele 5. Section 2, of the Cunstitution, and in proportion to the mentberslip of each constltuent nssociation on Anril 1 of each year in which the apporthonment is made, as shown by the certifteates of membership submitted by the secretaries of the constluent issociations. annual session next succeding that at which it is made, and shall previll until the It is made, and shall preval until the
next trlennial apportionment. whether the next triennlal apportionment, whether the
membership of the constituent association shall increase or decrease.

Sec. 4. IEGISTLATION OF IELE (ATES: Each delegate, before being seated shall deposit with the committee on cre dentials a certiflcate signed by the secre tary under the seal of the constituent association stating that he has leen legally and regularly elected a delegate to the Ameri-
can Nedical Association. Each delegate from a section shall present credentials signed by the clatirman and the secretary of the section which he represents. Each delegate from a government serveon-General of the departinent which he represents.

Sec. 5. A DELEGATE, ONCE SEATED TO RETAIN HIS SEAT FOR THE ENTIRE
SESSION: The credentials of a delegate having been accepted by the conmittee on credentials and his name placed on the roll of the House, he shall remain the duly accredited delegate of the body which he session, and his place shall not be taken by any other delegate or alternate.

\section{Chapter 11.-Procedure of House of \\ Delegates}

Section 1. ORDER OF BUSINESS.--The following shall be the order of business, unless otherwise ordered :

I. Call to order by the l'resident.

2. Roll call

3. Reading and adonting the minutes.

4. Reports of officers.

5. Reports of committees.

6. Unfinished business

7. New business.

See. 2, JIMIT OF TIME FOR INTMO DUCTION OF NEW BUSINESS: No new business shall be introtuced into the llouse of Delegates after the second day of the annual session (third day of the House of Delegates), unless with unanimous consent and such new business, whether in the form of a motion, a resolution or a memorial. sliall require
tive vote for adoption.

Sec. RiLES Or ORDER: The House of Delegates shall be governed by Robert's Rules of Order when not in conflict with these by-laws or with the rules of the

Sec. 4. QUORUM: Twenty roting memhers of the House of Delegates shall consitute a quormm for the transaction of husiness.

\section{Chapter III.- Meetings of the House of Deiegates}

Section I. REGIlaAR SESSIONS: The llouse of Delegates shall meet annually on the day preceding the opening of, and at the same place as, the annual session of the Issociation.

Sec. 2. SPECIAL SESSIONS: Special fhe House of Delegates shall be of at least twenty-seven delegates representing a majority of the constituent associations. When a special session is called by the President, the Secretary shall mail by the President, the Secretary shall mail a notice to the last known address of each member of the last House of Delegates at sion is to be held, in which notice shall be specifled the time and place of meeting and the objects of such special session. No other business shall be transacted at the call.
Chapler IV.-Nomination and Election of lows, Installation of Officers

sectlon 1. Now11NATlONs: Nominathons for oflice shall be made orally, lint a nominating speech nust not exceed two min utes. The Treasurer shall be nombnated by the Hoard of Trustees.

Sec. 2. Nh'THOH OF HOLDING ELES TIONS: All elections shall he ly ballot. and a majority of the votes rast shall be necessary to elect. In case no nominee re celres a majority of the votes on the first ballot, the nominee recelving the lowes number of votes shall be droplued and : new ballot taken. This procedure shal le continued until one of the nominees receives a majority of all the vote
when he shall he declared elected.

sec. 3. TIME of ELECTION: The election of officers shall be the first order of business of the Hollse of Delegates after the reading of the minutes on the afternoon of the third day of the annual session.

Sec. 4. ASSOCIATE AND HONORAR FELI, ovis: Appllcations for assoclate fellowship from foreign physlclans must be approved by the Judteial Council; applications from dentists must he approved by the Section on Stomatology, from pharmaclsts by the Section on I'harmacology and clsts by the section on Pharmacology and Therapeutics, and from representative teachcine by the officers of a section.

Nominations for honorary fellowship shall be made by the sections and must be submitted to the House of Delegates not later than the second day of the annual session. These applications and nomlnations shall be referred without debate to the Comnittee on Sections and Section Work, which shall consider the scientific attalnments and professional character of the applicants and report to the House of Delegates.

The election of associate and honorary fellows shall immediately follow the election of offlcers. Not more than three honorary fellows shall be elected in any one year.

Sec. 5. INSTALLATION : The general dent. shall assunie thelr duties at the close of the last meeting of the annual session at which they are elected.

Sec. 6. INSTALLATION OF THE PRESIDENT.-The President shall be installed at the general meeting of the annual session followlng that at which he was elected.

\section{Chapter V.-Duties of Officers}

Section 1. PRESIDENT: The President shall preside at the general meeting and at the meetings of the House of Delegates, and shall perform such duties as custom and parliamentary usage require. On the mornfollowing his election he shall deliver an address at the general meeting on such matters as he may deem of importance to the Association. He may at any time make suggestions in writing to the House of Delegestions in writing to the House of Dele-
gates or to any special or standing committee.

Sec. 2. VICE-PRESIDENTS: The VicePresidents shall assist the President in the performance of his duties; during his absence, or at his request, one of them shall officiate in his place. In case of the death, vacancy shall be flled by the ranking VicePresident.

Sec. 3. SECRETARY : The Secretary shall give due notice of the time and place of all annual and special sessions of the Association and of the House of Delegates in The Journal of the American Medinotice of each annual or special session to the secretary of each constituent association and to the secretary of each section. He shall keep the minutes of the House of Delegates. He shall notify members of comDelegates. He shall notify members of commitiees of their appointment and of the duties assigned them. He shall verify the credentials of the members of the House of book in which shall be recorded the name of each delegate in attendance at each session, together with that of the association, government service or section which he represents. He shall prepare a roll of the dele- 
Lates attending each sesylun to facilitate bu ing by roll call. Ite shall prepare for mit, lication the oficlal program of each seswion. and shall perform such other lluties as may be directed by the llouse of Ilelegates. the Board of Trustes of the General Ilanaser. Sec. 4 TREASCRER: Tho Treasurer ahall be the custodlan of all moneys, securi Jes and deeds belonging to the Assoclation which may come into his possesslum, and shall bold the same subject to the direction and disposition of the Board of irustees. IIe shall glve to the Board of Trustees a suitable bond for the falthif performance ice a salary to be fixed by the Isnari of Trustees.

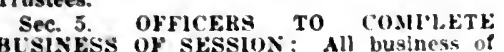
hisixess of Skssion: All business of each annual sesslon shall be completed by
the officers (Including section offlcers) why have served through the sesslou.

Chapter VI.-Board of Trustes

Sectlon 1. BOARD OF TRUSTEES: The Board of Trustees shall have charke of all propertles and of the Ananclal affalrs of the Assoclation. At the frst meeting of the Hoard after the annual session of the Axsi)-
ciation. It shall organize by electing a chalrman and secretary, and the chairinan shall appoint such commlttees as may be necessary or desirable. It shall be the duty of this Board to provide for and $w$ superintend the publlcation of The Journal of the American Medical Assoclation, and of all proceedings, transactions and memoirs eretionary power to omit from The Journal of the American Medical Assoclation, In of the American Medlcal Association, in part or in whole, any paper that may bo
referred to it by any of the sectlons. It referred to It by any of the sectlons. It editor of The Journal, which two pisitions may be heid by one person, and such assis:ants as mas be necessary, and shall determlne their salarles and the terms and condlitions of thelr employmeat. All resolutions or recommendations of the llouse of belegates pertaining to the expenditure of money must be approved by the Board of money must be approved by the Board of Trustees before the sante shall become
effectire. Durlng the annual session of effectire. During the annual session of
the Association the Board shall hold meetthe Assoclation the Board shall hold meet-
Ings as often as may be deemed necessary hy the chalrman, and all matters referrel to is by the House of Delegates shall be rep.rted on withln twenty-four hours, If 80 requested by the IIouse. The Hoard of Trustees shall have the accounts of the Treasurer and of The Journal once audited annually or of tener, If deemed necessary. and shall inake an annual report on the same $w$ the House of llelegates, which report shall also speclfy the character aul cost of all the publications of the Issocin. proverty belonging to the issoclation. In proverty belonding to the Axsoclation. In case of a racancy In the nffice of Treasurer wlse, the vacancy shall ine filted liy the Hoard of Truatees until the next annual sesslon of the IIoure of Delexates. The Hoard of Trustees shall fix the salary uf the meetings of the Board shall be helit immediately after the annual sexsion of the Ismelation, and on the flrst fridas in the month of February of each year. Sivecial month of February of each year. Sibecial meetings of the lbord may be called at any thie by the chalrman, or by fre members of the Bnard, by malling a writien or
printed notice to the last known sdotress of each trimtee, a! least llre days before vuch nseeting is to lie lield. In which stall he suecined, in general terms, the nhject wheh mpecial neeting. and no ethitr busluess whall the tranaacted thereat: providel, that If at any the a meeting of the lioard in or the procesllnga of which are approved if the procesdlnge of Which are ayproved in writing by erery memiler of the Ifoard. without any previous notice having ben iren. Five meminery of the Bumard shall constlute a yuntum. lluring the intervala
herween the seswlons of the Jonse of bele. cates the ltuard of Trustees shall super rlse the action of commlttees conatlutied in the acticil of the liouse. silis. The kiard if Truateos aliall have full eontrol it all arrangensente tor the innual seswlelss and shall provlde meeting places fur the lisuciation. House of Dele gales and the various sectons. It sliall aly have conters of all exhitits. The Ituarl of Trustes. In thelr discretion, inay appolnt a Iceat committee of arrangements. Which shall tre at all times
the liourd of trustees.

\section{Chapter VII,-Committees}

Sectlon 1. CLASSIFIF ATION or rum MITTEEs: Commltees shall be classifles as (a) standing commitues, (b) Leferelice Committees, and (c) special commitrtes I'resident anl elected by the lloure of Delegases, unless otherwise prorided for in these by-jaws. Any of these commitees acting during the interral hetween the sesacting luring the interral hetween the ses-
sings of the llouse of Delegates shall he subject to the lloard of Trusiees. In cast of racancles in enmmltees occurring dur Int the Interral between unnual sesslous. the Presldent shall hare the power to up:
pint fellows to fll the vanncies until the next annual session.

See. 2. MFMHERsHI OF COMUI TEEs : Keference Commitees shall be appolnted by the l'resldent. from among the
House of lelegates, but any fellow of the Assoriation shill be ell;ible on serre on standing or speclal committees. All memhers of commltiees who are not members if the lliuse of lielegates shall bave the riflt fo present their reports in person to the IInuse of Delegates and to Darticipate in the
debate thereon. hut shall not have the right debate thereon, hut shall not have the rlght
to vote. The Ilouse of Delegates may recall to vote. The Ilouse of Delegates may recall ment of any memlier of a conmlttee or Council at any session by a two-thlrds rote present and votlug, prorided that no motlon for recall shall be acted on till the day fol lowing that on which it is introduced.

sec. 3. S T A N b I X G CoMIITTEES

standing committees shall be the following:

(a) Judiclal councll.

(b) Council on Ilealth and Public In(c) Committee

(d) Councll on Medical Education

(e) Committee on Red Cross Iledical work.

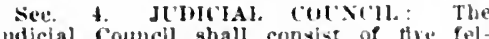
Judicial Councll shall consist of the fol
lows. who shall be nominated by the l'resi lows. who shall be nominated by the l'resi.
dent and elected by the Honse of lelegates. it the annual session in 1911 one member of the Council shall be elected to surve ent five years, one for four years. (ine for three years, one for two years and one for one year, and thereafter ont nembe

'aincll shall be elected each year ti serv for fire years. If shall select a charman from its nembershlp. The secretary of the of the Connell. Is stiall expend muney and isontract delsty only on the suthorits of th. buarl of Truatees it shall keen a perma hall be at the bealugarbers of the s clathon. It shall make an inmual tepurt of its declslons and the restllts of

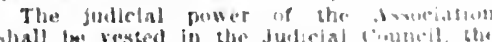

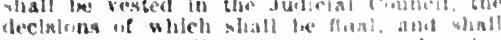

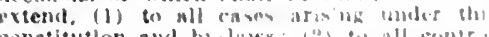
constitusion nud by-lats:

rersies to whlch the Imertian Mollical Ixw ciation is a party: (3) to combrabrsien la

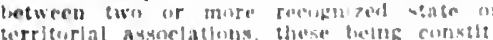
urut asanclutions within bhe meaphes of

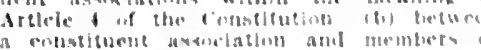

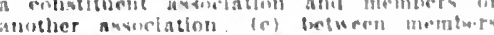

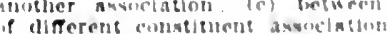

Ii all cases In which the Amerlian llat.

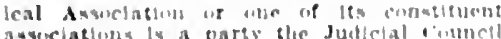

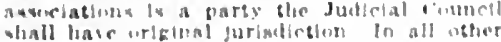

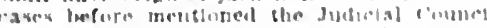
whall hare appellate furtediction. bothl an bo

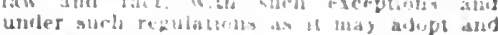
Dublisl: in The Jurnal, prosuent tha! suet

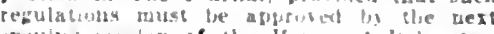
and be undally certitied is each comstiment axpoctation.

The Jubleial council taiss. at in diacre dith, insestizate reneral profesid

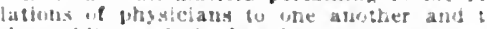
the public, and shall make sucls recommendathini to :be lloure of belegates and the

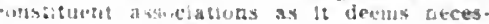

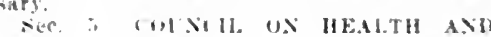

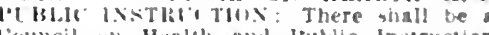
"ounci! on Hualth and l'ublis Instruction

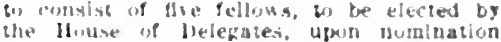

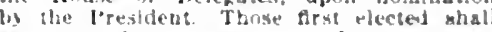
serre one fur one year. one for tho years one tor blaree geara, wre tor fout geats and terms of scrvice shail be determined by los Thereatier one member of the cisunell whall lie elected annually, on momination $\$ 15$ the le elected antually, on momination 115 the shall organize and shalj elect a chalrman from lts number. The troard of Trustees shall appuint a secretary on monastion by the council, and shall tix his salar

The council shall athor such rules and as it may deem expedicnt. It shail expend money or contrat thatedal obligabuns ouly as shall be althorked in writing by the lions if Trustees. The work of the inuncll shall embrace the fllowing subjecs:

(a) Legrislation

(i) Orianization

l'ublic lustruction

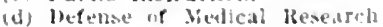

(e) Irublic Health.

It may appoint conmitiees tis carry on the respectire purposes of the council. It shall make an anaual report uf is work to cruncil shall loe at the beadiuarters of the inticiatlon.

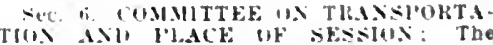

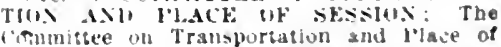
susiun shall consist of tive felluws. The charman shall be elected bo serre for three icars; the wher four metnters of the corminntee shall be appointed ly the l'resident the annual session and shall publish the same in The Journal of the Imerlean Medical Asmociatlon sufleients early on enable all who desire to attend the snnual sesslob (1) ritain necessary information. It shall

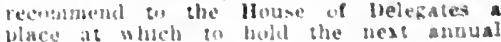
ressiun, afier due collsiderasion of the latiou and rabload rases

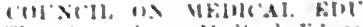

ATIIN The council un tedlcal rolues

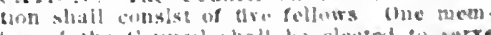

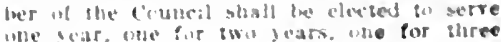
whe rour, ome fur two joars. whe tor three pars Thereafier we shit? que civebul each romaze, whall elect a cha:pran and mecre

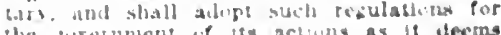

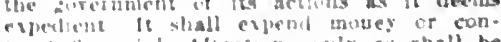
tract ibancial onfleations anly as ahall te

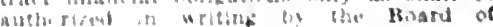
Trustoes

Feluse function shall be

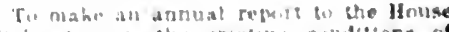

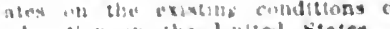

Tin niake sugagsglotus as (n) the means iif mothind bo which the dmerican Medal I wwolation mal best Infuence faror thralical elucation.

Vedical Inotsolation under Instructons of tho If inse of lieirgates in its eforts to elerate the slandart of medical esucation. See s. COMMITEF ON RED CROSS IFill il. Wuth: The Commltice on Hed 


\section{AMERICAN MEDICAL DIREC'TORY}

Cross Melleal Work shall consist of three fellows, one of whom shall be appointed liy the l'resictent upon the nomination of the Surpeon-(ieneral of the Army, one upon the nomination of the Surgeon-fieneral of the Nary, und the third member of the committee, who shall be its chairman, shall be appointed by the F'restelent nnd nominated to the lied cross as the representative of this Association on Its Relief Boart. This Commitee is anthorized to cooperate with the National feel cross and shall hare arlvisory supervision urer state and count visory supervision wer state and county
commottees having charge of the samo subcommittees having charge of the samo sub Association in matters involving medical persunnel in times of disaster, provides that it shall cxpend money or contraet thorized in writiog by the Band of 'ruse au

see. 9. IRElok'ts of STANDING roM MH'TEES: leports of standing committees so far as posslble, shall be transmitte thirty days before the anuual session to the secretary, who shall have them printed for distribution to the members of the llouse of Delezatos.

Sec. 10. SPECIAL CoMMITEFS: Special committees may be created by the House of lelerates to perform the special functions for which they are created. Tliey shall be appoInted by the offcer presidin over the meeting at which the committee is authorized.

Sec. II. REFEREYCE COMMTTEE: (a) Immediately after the organization of the House of lelegates at each annual session the Iresident shall appoint from among the members of the Ilouse such conmittees as may bo deemed expedient by the Ifouse as Delerates. Each committee shall consist of the menbers, unless otherwise provided, the the members, unless otherwise provided, the These committees shall serve during the session at which they are appointed.

(b) To the appropriate committee shal be referred resolutions, measures and propositions presented to the Iouse of Delegates before final action shall be otherwise unanimously ordered by the IIouse otherwise unani

(c) Each Reference Committee shall, as soon as possible after the adjournment of each meeting, or during the meeting, if necessary, take up and consider such business as may have been referred to it, and shall report on the same at the next meeting, or when called on to do so. Three members shall constitute a quorum.

(d) The following committees are hereby provided :

(1) A Committee on Sections and Section Work, to which shall be referred all business relating to the sections.

(2) A committee on Rules and Order of Business, to which shall be referred all matters regarding rules governing the action, methods of procedure and

(3) A Committee on Medical Education, to which slall be referred all matters relating to medical colleges and medical education. (The members of the Council on
Medical Education shall be members, exofficio, of this committee.)

(4) A Coinmittee on Legislation and Political Action, to which shall be referred all matters relating to state and national legislation, memorials to Legislatures, to the United States Congress, or to the President of the United States. (The members of the shall be members, ex-officio, of this committee.)

(5) A Committee on Hygiene and Public Ilealth, to which silall be referred all mat ters relating to hygiene and public health. (6) A Committee on Amendments to the Constitution and By-Laws, to which shall be referred all proposed a
Constitution and By-Laws.

(i) Committee on Reports of Officers, address and the Secretary's and the Trustees' l'eports.

(8) A committee on Credentials, to which shall be referred all questions regarding the registration and the credentials of delegates.
(9) $\boldsymbol{A}$ Committee on Miscellaneous Business, to which shall be referred all business not otherwise disposed of.

\section{SCIENTIFIC ASSEMBLY}

Membership and Fellowship

Chapter VIII.-Membership and Fellowship Section 1. MEMHEls: The members in food standing of the constluent state und territorial medleal associations of the $\mathrm{Am}$ erican Medical Association shall be memiers. Sec. 2. TFNITE OF MEIIIEISIHI : Membership in this Association shall contimue only so loug as the Individuat is a member in good standing of a constituent associatlon. When the secretary shall be offlelally informed by the Secretary of tho eonstltuent association througl which a
member holds membership in this Association that the member is not in good standing, the secretary shall remove the name of the Amertcan Helical Assoclation.

Sec. 3. EFFECT ON MEMIBEIRSHIP OF liE.ITYAL TO ANOTIER STATE: A mem-
ber who changes the location at whlch he practices medicine from the state through whose constituent assoclation he holds membership in the American Medical Assoclation to another state in which there is a bership in the component is eligible to memlocation upon the presentation of a transfer card and an offleial statement that his dues have been paid in full in the society in which he holds membership. IIe shall forfeit lis membership in the American Nedical Association one year after sucl change of location, unless he becomes a meniber of the constituent association of the state to which he has moved. Provlded, lowever, that if the component society into shall refuse him membership, the member shall be prlvileged to appeal to the Judicial Council of this Association to determine whether or not he be guilty of any act that warrants the enforcement of any act that of this seetion. Pending the decision of such appeal he shall retain his membership in the Amertcan Ifedical Association through his original state association. And provided further, that the term "the practice of medicine" throughout these by-laws shall be held to mean the offering of scrvice or counsel for the relief of those suffering from abnormal physical or mental conditions.

Sec. 4. FELIOWS, ASSOCIATE FELLOWS, HONORARY FELLOWS: Any member of this Association, who on the presubscribe for The Journal, paying the annual dues for the current sear, shall be a fellow.

Commissloned medical officers of the United States Army, United States Navy vice shall be fellows of this Association so vice shall be fellows of this Association so long as they are engaged actively in their respective service and thereafter if they
have been retired on account of age or have been retired on account of age or be required to pay dues and shall not re ceive The Journal of the American Medlcal Assnciation except by personal subscription. There shall be associate and honorary fellows who shall be elected and shail qualify in accordance with the provisions set forth in these By-Laws.

Members, associate members and honorary members of thls Association at the time of the adoption of this By-Law, shall be respectively fellows, associate fellows and honorary fellows; and in interpreting these By-Iaws, "membership" in the Association at the time of the adoption of thls By-Law shall be construed as fellowship.

Sec. 5. TENURE OF FELLOWSHIP Fellowship in this Association shall contimue only so long as the individual is a member. When the Secretary shall be nember, the Secletary shall remore the name of such fellow from the fellowship roll of the American Medical Assoclation und shall notify the fellow of the action taken, together with the reason therefor.

Sec. 6. DELINQUENCY: Any fellow who for one year, has falled to pay his amnua dues, shail forfeit his fellowship thirty days malled to his last known actdress.

See. 7. FELLOWSHH IRESTOR FD: Any former fellow who comnlies with Section (hapter VII, shall be relnstated upon payment of his indebtedness tncluding lis subserlption for the current calendar year.

Sec. 8. Associate FELLOWS: The following may he elected in nceordance with Section 4, (hapter IV, to assoclate fellowshlp: Physiclans who are members of the foreign countries inedical societles of foreign countrles adjacent to the United D.l.s. who are members of state or local D.l.S. who are members of state or local
lental socletles, and pharmaclsts who are active members of the American Pharmaceutical Association; and representative teachers, students of science alled to medicine, resident in the United States, and not eligtble to regular membership. Assoclate fellows shall enjoy the same privileges as regular fellows, and shall be subject to the same conditlons.

Sec. 9. HONORARY FELLOWS; Physlcians of foreign countrles may be elected honorary fellows by the House of Delegates
in accordance with Sectlon 4, Chapter IV.

Sec. 10. INVITED GUESTS: Sclentlsts, who are not engaged in the practice of
medicine, may be invited, with the consent of the secretary of the component county of the secretary of the component county side, by the general officers or by the side, by the general officers or by the sesslon and to take part in the scientlfic work. They shall be designated as invited guests and be entitled to partlclpate in the sclentific and soclal functions.

\section{Chapter IX.-Registration}

None but fellows, associate fellows, hon orary fellows and Invited guests shall be allowed to register or take part at the sclenific meetings of the Assoclation.

No fellow shall be eligible to reglster at his current indebtedness.

No fellow shall take part in the proceed ings of the Assoclation or of any of the sections until he has registered his name and address in the registration offlce.

A fellow on registerlng shall designate the section in which he wishes to be enthan one section at any annual session.

\section{Chapter X.-General Meeting}

Section 1. TIME OF GENERAL MEETING: The general meeting shall be held at $10: 20$ a. $m$. on the first day of the by the President, or in lis absence or at his request, by one of the vice-Presidents.

Sec. 2. ADDRESS AT GENERAL MEET ING: Before the general meeting shall be delivered the address by the President, whose recommendatlons shall thereupon go
to the House of Delegates for action.

Sec. 3. ORDER OF BUSINESS: The order of business of the general meeting

1. The calling of the meeting to order by the President, or, in his absence, by one of the Vice-Presldents.

\section{Prayer.}

3. Address of welcome and response.

4. The report of the Committee of Ar5 .

President-elect.

6. The annual address of the President.

7. Adjournment.

\section{Chapter XI.-Sections}

Section 1. TITLES OF SECTIONS FOR SCIENTIFIC WORK: The Amerlcan Medical Association shall be divided into the following sections:

I. Practice of Medicine.

. Surgery. 


\section{AMERICAN MEDICAL ASSOCIATION}

3. Obstetrics, (i) necology and Abiominal

sergery.

4. Ophthalmology.

5. Larynzolozy, Otology and Ithlnology.

6. Diseases of Children.

7. Pharmacology and Therapeutles.

8. Pathology and Physiology.

8. Stomatolocy.

10. Nerrous and Mental Diseases.

11. Dermatology.

12. Prerentive Medlclne and Publlc Health.

13. (ienlto-Urinary Dlseases.

14. Hospisals.

15. Orthopedic Surgery

8ec. 2. OFFICEIS OF SFCTIONS: The omcers of each section shall cunsist of a chalrman, a vice-chairman and a secretar and such other officers as the section shal deem advisable. These shail serve for one rear, or unul thelr successors are elected and quallifed: provided, that each sectlon may elect its secretary to serve a longer Ime at Its discretion. Each section shat loo elect annually one delecate and one atterase in the llouse of Delegates of aiternace to the House of Delegates of the American Medical Assoclation to serve on

Sec. 3. ELECTION OF OFFICERS: The election of omcers shall be the first order of business of the morning meeting of the section on the third day of each annual aession. To participate in the election of any section a fellow must bave indlcated on any sectlon a fellow must bave indlcated on registering that he desires to affillate with
such section, and must have recorded his such section, and must have recorded his name and address on the section regiater on Surgery and on P'rerentive Medicine and public Ilealth may each elect a fellow to dellver at the ensuing annual session the oration on practlce of medicine, the oration on surgery and the oration on state mediclne before their respective sections.

sec. 4. DUTIES OF SECTION OFFICFR8: (a) Chairman.--The chairman shail preside at the meetings of the section and shall perform such duttes as usually belong to such an offce, or as may be provided by the by-laws of the section. He shall cooperate with the secretary in arranging the program, and shall see that proper arrangements are made for his section a the annual session.

(b) Vice-Chairman.-The vice-chairman shall asslat the chairman in the perform ance of bis dutles and shall prestde in his absence, or at h/s request.

(c) Secretary.- The secretary shall keep a record of the proceedings of the sectlon in book provlded for such purpose; shall with the cooperation of the chairman, arrange the program; and shall, at least thirty days before the annual session, forwand it to the Secretary of the Association int insertion in. the oficial prograin: and shall perform such other duties pertalnin shall perform auch other duties pertaining w hls offce as may be provided by the by-
laws of the Association or of the section

sec. 5. EXECLTIVE COMMITTFE: Each section shall have an executire committee which shall conals! of the last three retiring chairmen. In case of absence of a member of the executive committee from au snnual session, the vacancy slatil be thlled by the chairman. This committee (as con by the chalrman. Thla committee (as conshall examine and pass on all papers real before the neetlon, and hall endorse for publication only those that are of scientifle or of practlcal value, and which will reflect credit on the sectlon before which they were read.

Bec. 6. MEkTiNis: Each nectlon shall hold its nrst meeting ai $2 \mathrm{p}$. In. of the flrat day of the annual sesslou, and each sul, seruent day at 0 a. m. nud at 2 p. m. untll the prosram is completed, or as the section may decide.

Sec. : WHO MAY TAKF PART IN BECTION WORK: Fellows and assoclate fellows only ahall have the richt to particl pate In the business dellberatlons of a ary fellown and inrled suests may present papers and lake part in the scientine dis. cussions.
Sec. א. HONOKARY FHILows: Each sectlon at each anumal secsion mas at the the of the clection of les omeers uenulnate for honorary fellowshly in the Amerlean Medical Assuciation a physiclan of a for. elgn country who has risen to pre-eminence II the professlon of medlelne. The secreof the Issoclation of such nomination.

sec. 9. AssocIATE FELIOW: : The ofteers of a section uny nomlnate for asiseclate fellowshlp representalve teachers and students of sriences alled to mellelne, resident in the linited states, not eliglbite to
rebulair memliershlp. The secretary shall inmediately notify the secretary of the Association of such nombations.

Sec. 10. TIME AT WHICII TITLES IILST HE IN: TItles of papers (1) be presellted to the section nust be in the hands of the secretary of the section at least annual sesslon. With the title, the writer shall submlt an abstract of the paper not less than thlrty or more than one hundred and fifly words in length and an estimate of the time required to read his paper.

Sec. II. I.RNGTH OF PAPERS AXI Hisclissioss: The time allowed for the presentation of a paper before a section shall be limited to fifteen -minutes. No one the same subject, nor for inger than fire ininutes, except with the unanimous consent of those present.

Sec. 12. NUMBER OF PAPrIS O.: PItoGram : The number of papers, including addresses, on the program of any section shall not exceed thirty.

Sec. 13. CAN JRESENT ONIY ONE PAPER AT AN ANNUAL NESSION: No fellow shall present more than one paper at any annual session. The title and abstract of the paper must be submitted to the
secretary of the section before which the paper is to be read.

Sec. 14. SECTION TO IllovidF BYfor its own section may make by-laws shall in no way contlet with the constitu. ton and $13 y$-Laws of the American Medical Association.

\section{Chapter XII.-Publication}

Section 1. PAPERS APPR(IYYD FUR IUBLICATION: No paper shall bo puhlished as havlng been read before $a$ sectlon unless it has receired the approval and the endorsement of each member of the execu. tire committee

Sec. 2. FAIPERS MLST IBE READY FOH IUBLICATION: Each nuthor shall band hls paper to the secretary of the sectlon immedlately after it is read. The secretary shall endorse thereon that it has been read and shall hand it to the chairmall of the executive committee. All pithers aptroved turned to the secretary of the seetion. whn thrned to the secretary of the section. whin The Journal.

Ser. 3. FAPEILS "REAI) IBY TITI.:" No paper shall be publlshed ss harlug been read before a section untess it has actually been read, or unless. for special reasoms. when the author bas been present and pre. pared to read the paper. the sectinl shall unanlmously rote to hare it rend by litle

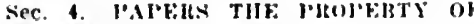
TIIF Assofiatio: : All papers and re. ports broxented on a mertion and approrm hy the exreutire commltove shall become the vleled that the Hoard of Truvieces may per.

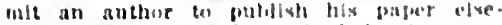
where than in The

\section{MISCELLANEOUS}

Chapter XIII.-Omcial Resolutions Approved by the House of Delesales

No memorial, resolution or oplnlon of any
Name of the American Veoliral Ansedation

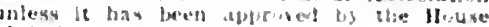
of lielezates.

Chapter XIV.-Annual Dues

The annual duey slabll be Are dublars. payalile in advance un the throt day of Jamuary of each year, of which not less subscription fir one 3 car b, The Juurral.

Chapter XV.-Articles of Incorporation

The llouse of lelegates. at any nrinual sesslon, wherever the sime may to lield may Instruc: the ltoard if Trustees in make any changes in be articies of incurgur atlon in accurdance with the lan which may appear vessable. or which may bo male necessary by any change ir amend ment to the ionstlution ard by-l.ans of

\section{Chapter XVI.-Amendnent to These} By-Laws

These liy-Jaws may be anended on wates, proviled that no amendment shall be acted on till the day following that on which it is intrutuced; except that the Board of Trustees may, by unanjmula rote. make such changes, and such changes only. is inay be regulred to adapt them to the rules and reculations of the linited siates postal authorltles.

\section{PRINCIPLES OF MEDICAL ETHICS}

CHAPTER I.-THE DUTIES OF PHYSI
CIANS TO THEIR PATIENTS

The Physician's Responsibility

Section 1. A profestion has for jes pritne objeet the service It can render to humanits reward or nnanclal fain stould te a subordinate consideration. The practice of medicine is a profession. In choosing th:

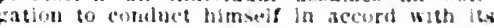
ideal.

Patience, Delicacy and Secrecy

2. Patience and delicacy should characterize all the acts of a phystcian The confldences concerning Individua! or dumestic life entrusted by a patient to Migsician, and the defects of dispositistn or thws of character oherved in liatiente durirust and shonld nerer be revesled excent when imperative! required by the laws of the state. There are oteasions. hewerer. or mot ho duty sinclety requires him to take definlte action so protert a heslihy individual from beenming inferend, thecause the physleian has knowledice, dibalued throuph the conflences entrusted of hrm as through the confledices entrused fo hom as

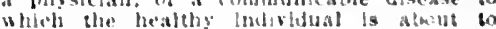
lee exposed. In sich a case, the physician lee exposed. In such a case, the physician act toward ore ot bis own tamlly under like circumstances. liofore he deformlnes his

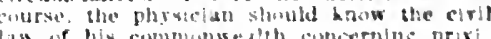
lecerd conmunications.

\section{Pregnosis}

I whyuclan vfuniul gire limely unitice of dancerums mantertations of the diacinot the trlomals ut the patient llo

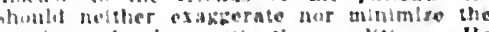

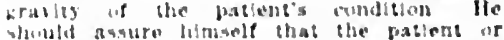

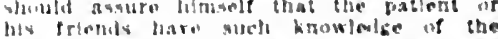
patentis condition as will verre the best linturesty of the fattent and the fambly.

\section{Patients Must Not be Nevlected}

Ses t. I thyslclan is frre to choose whom be will werre. He should, howerer, alwass rengund to any request for his avintance in all emeriency or whenerer imuprato public noinion expeces the serifre Onen bavint ublertaken a case. a patient trecause the disease is deemed in curalile: nur abould lie wlthdraw trom the 
case for any reason until a sufficient notice of a desire to be released has been given the patlent or his friencts to make it posattenditint.

\section{HAPTER II.-THE DUTIES OF PHYSI. CIANS TO EACH OTHER AND TO THE PROFESSION AT LARGE}

\section{Article 1.-Duties to the Profession Uphold Honor of Profession}

Section 1. Tha obligation atsumed on entering the profession requires the mosstclan to comport timself as a gentlemin and domands that he use erery lomorable meins to upholil the dimity and honor of his vocatom. Its sphere of usefulness. A physician stomld not hase his joratice on an exelusive dogma or sectarlan system, for "sects are implacable despots: to accept their thraldom is to takc away, all thlerty from one's actions

\section{Duty to Medical Societies}

Sec. In order that the dignity and helu its standards oxofession may be upusefulness extended, aud the advaneement of medical selence promoted a nancencent should associate himself with medical soclemeans in order that these societies may means in order that these societies
represint the Ideals of the profession.

\section{Deportment}

Sec. 3. A whysician should be "an upright man, Instructed in the art of healing." Consequentiy, he must keep himself pure in character and conform to a high and conscientlous in his studies. "He should also be modest, soler, patient, prompt to do his whole duty without anxiety, pious withhis whole duty without anxiety; pinus withbimself with propriety in his profession and in all the actions of his life." (Hippocrates.)

\section{Advertising}

Sec. 4. Solicitation of patients by circulars or advertisements, or by personal communications or interviews, not warranted by personal relations, is unprofessional. It is equally unprofessional to proeure patients by indirection through solicitors or ngents of any kind, or by indirect advertisement, or by furnishing or concerning cases in which the physician has been or is concerned. All other like selflaudations defy the traditions and lower the tone of any profession and so are intoleratile. The most worthy and effective advertisement possible, even for a young physiclan, and especially with his brother physiclans, is the establishment of a well-merited reputation for professional ability and fldelity. This cannot be forced, but must fldelity. This cannot be forced, but must be the outcome of character and conduct.
The publication or circulation of ordinary The publication or circulation of ordinary
simple business cards, being a matter of simple business cards, being a matter of times of convenlence, is not, per se, improper. As implied, it is unprofessional to ideals in publishing or eireulating such cards.

1t is unprofessional to promise radical cures; to boast of cures and secret methods of treatment or remedies; to exhibit certiflcates of skill or of success in the treatment of diseases; or to employ any methods to gain the attention of the public for the gain the attention of the pubti
purpose of obtaining patients.

\section{Patents and Perquisites}

Sec. 5. It is unprofessional to receive remuneration from patents for surgical inon prescriptions or surgical appliances, or perquisites from attendants who ald in the care of patients.

\section{Medical Laws-Secret Remedies}

Sec. 6. It is unprofessional for a physician to assist unqualified persons to evade lecal restrictions governing the practice of medicine; it is equally unethical to pre-
scribe or dispense secret medicines or other seret ramedial agents, or manufacture or promite thelr use in any way.

\section{Safeguarding the Profession}

Physfeians should expose without fwit or favor, before the proper medical or legat trifunals, corrupt or dishonest concluct of members of the profession. Every phystelan stould ald in silfeguarding the irofession ugalnst the admission to lts rank of those wio are unfit or unqualified be cause deficient either in moral character or etiucation.

Articlo II.-Professional Services of Physicians to Each Other

Physicians Dependent on Each Other

Section 1. Expericice teaches that it is unwise for in physician to treat members of his own family or himself. Consequently. a physiclun should always cheerfully and ratuitousiy respond with his professiona services to the call of any physician practloing in his vlcinity, or of the immerliate fimily dependents of physicians.

\section{Compensation for Expenses}

Sec. 2. When a physlcian from a distance is called on to advise another physiar one of his fanily dependents, an the physician to whom the services is rendered is in easy financial circumstances, a craveling expenses of the visiting physician should be proffered. When such a service requires an absence from the accustomed fleld of professional work of the visitor that might reasonably be expected to entail a pecunlary loss, such loss should, in part at offered.

\section{One Physician to Take Charge}

Sec. 3. When a physician or a nember r his family should select a physician from among his neighboring colleagues to take charge of the case. Other physicians inay be associated in the care of the patient as consultants.

\section{Article 1II.-Duties of Physicians in Consultations}

Consultations Should be Requested

Section 1. In serious lllness, especially in doubtful or diffleult conditions, the phy sician should request consultation.

Consuitation for Patient's Benefit

Sec. 2. In every consultation, the benefit to be derived by the patient is of first importance. All the physicians interested in the case should be frank and candid wit! the patient and his family. There never is neeasion for insincerity, rivalry or envy and these should never be permitted between consultants.

\section{Punetuality}

See. 3. It is the duty of a physician. particularly in the instance of a consulta. tion, to be punctual in attendance. When, however, the consultant or the physician in charge is unavoidably delayed, the one who first arrives should watt for the other for a reasonable time, after which the consultation should be considered postponed. When the consultant has come from a distance, or the consultant has come from a distance, or
when for any reason it will be difficult to meet the physician in charge at another or if it b the desire of the patient, he may examine the patient and mail lis written opinion, or see that it is delirered under seal, to the physician in charge. Under these conditions, the consultant's conduct must be especially tactful; he must remember that he is framing an opinion without the aid of the physician who has observed the course of the disease.

\section{Patient Referred to Specialist}

sec. 4. When a patient is sent to one specially skilled in the care of the condition from which he is thought to be suffering, and for any reason it is impractical for the physician in charge of the case to accomipany the patient, the physielan in charge should send to the consultant by mail, or in care of the patient under seal, a his tory of the case, together with the phrsi cian's opinion and an outline of the treat- ment, or so much of this as nay posslbly be of servlce to the consultant; and as soun as posslble after the case has been seen and studied, the consultint slisuld address the physician in charge und advise him of the resuits of the esonsuitant's investigation of the case. Both these oplaions are confldential and infsist be so regarded by the consultant and by the physician ln charge.

\section{Discussions in Consultation}

See. 5. After the physiclans ealled in gations of have completed therr investiselves to discuss conditlons and determine the esurse to be followed in the treatment of the patient. No statement or discusssion of the case should take piace before the patient or friends, except in the presence of all the physiclans attendimg, or by their common consent; and 120 oplinfons or prognostications should be delivered as a result of the dellterations of the consultants,
which have not been concurred in by the consultants at their conference.

\section{Attending Physician Responsible}

Sec. 6. The physlcian in attendance is in eharge of the case and is responslble for the treatment of the patient. Consequently, he may preseribe for the patient at any the and is privileged to vary the mode of treatment ontlined and agreed on at a con-
sultation whenever, in his opinion, such a sultation whenever, in his opinion, such a
change is warranted. However, at the next change is warranted. However, at the next consultation, he should state his reasons
for departing from the course declded on at for departing from the course declded on at
the previous conference. When an enerthe previous conference. When an enlerattending pliysician, a consultant may provide for the emergency and the subsequent care of the patient until the arrival of the physician in charge, but should do 110 more than this without the consent of the physician in charge.

\section{Conflict of Opinion}

Sec. $i$. Should the attending physician and the consultant find it impossible to agrce in their rlews of a case another consultant should be called to the conference or the first consultant should withdraw. However, since the consultant was employed by the patient in order that his opinion might be obtained, he should be permitted to state the result of his study of the case to the of the physician in charge.

\section{Consuitant and Attendant}

Sec. 8 When a physician has attended a case as a consultant, he should not become the attendant of the patient during that illness except with the consent of the physician who was in charge at the time of the consultation.

\section{Article IV.-Duties of Physicians in Cases} of Interference

\section{Criticism to be Avoided}

Section 1. The physician, in his intercourse with a patient under the care of another physician, should observe the strictest caution and reserve; should give no disengenuous hints relative to the nature and treatment of the patient's disorder; nor should the course of conduct of the physician, directly or indirectly, tend to diminish the
sician.

\section{Social Calls on Patient of Another Physician}

Sec. 2. A physician should avold making social ealls on those who are under the professional care of other physicians wlthout the knowledge and consent of the attendant. Shoutd such a friendly visit be tendant. Should such a friendly risit be made, there should be no inquiry relative upon the treatment of the case, but the conversation should be on subjects other than the physical condition of the patient. Services to Patient of Another Physician See. 3. A physician should never take charge of or preseribe for a patient who is under the care of another physician, except in an emergency, until after the other physician has relinquished the case or has been properiy dismissed. 


\section{Criticism to be Aroided}

sec. When a physlclan dnes sucrerel another physlcian in the charge of the case. he should not make comments on or insinu. ations regardiog the practice of the one who preseded him. Such comments or Inalnuations tend to lower the exteen of the patlent for the medleal prifessing and so react asainst the critlc.

\section{Emergency Cases}

Sec. 5. When a physlcian is called in an einergency and flnds that he has been sent for because the famils attendant is not at hand, or when a physlelan is asked to see another physlclan's patient because of an aggravatlon of the disease, he should pro. ride only for the patlent's Inmediate need and should withulaw from the case on the arriral of the famlly physician after he has reported the condition found and the treatment adminlstered.

Whon Several Physicians are Summoned

sec. t. When sereral physlelaus have been summoned in a case of sudden tllisess or of accident. the tirst to arrire should be consldered the physician in charge. How ever, as soon as the exlgencles of the case permit, or on the arrival of the acknowledsed famlly attendant or the physician the patient desires to serve hlm, the first physlelan should withdraw in favor of the chosen attendant: should the patient or his family wish someone other than the phystclan known to be the farrily physician to take charge of the case the patient should adrise the family physlelan of hls desire. When, because of sudden Illness or acciWent, a patlent is taken to a hospital, the dent, patlent is taken to a hospital, the
patient should be returned to the care of patient should be returned to the care of condition of the patient and the circumatances of the case warrant this transfer.

\section{A Colleague's Patient}

Sec. 7 . When a physiclan is requested by a collesgue to care for a patlent during his temporary absence, or when, because of an emergency, he is asked to see a patlent of colleague, the physlcian should treat the patlent in the same manner and with the same dellcacy as he would hare one of his own patients carerl for under be returned to the care of the attending physiclan as soon as possible.

Relinquish Pationt to Regular Attendant

Sec. 8. When a physlclan is called to the patient of another phsslcian during the enforced absence of that physlclan, the patient should be relinuluished on the return
of the latter.

\section{Substituting in Obstetric Work}

Sec. 9. Whon a physician attends it woman in labur in the absence of austher who has been engaged to atterd. such ping alclan should resign the patient to the one frut engaged, upon his arrival: the physiclan Is entitled to compensatlon for the lir.
fesslonal aerrlces he nay have renderevl.

\section{Article V.-Difierences Between Physicians} Arbitration

Sectlon 1. Wheneser there arlses between physlelans a krave difference of oplnion which cannut be pronubly adjusted. Sho ilapute should to referred in arbiration to a cominittee of impartial pliysiclans, preter. ably the buard of iensors of a componemt county soclety of the Ameriean Medical Association.

\section{Article VI.-Compensation}

\section{Limits of Gratuitous Servic}

sectson 1. The porerty of a batient ame the mutual professional obligation of phy siclans should command the sratuluus ners. ices of $\mathrm{A}$ phymiclan. But institutions $\mathrm{nn}$. dower by acleties, and organlationa for mutual beneflt, or for accident, sickness anil life Inaurauce, or for analogons purporats. whould the accoridel no anch privllege.

\section{Contract Practice}

Sec. 2. It is unprofesslonal for a phyal. clan to dispose of hls serriceg unter con. ditions that make it lemposithle to render alfumate service to his patjent or which Interfare with reasonahle competion anming the plissiclans of a community $T_{0}$ do this is detriments! to the publte and th the
individual physlelan. nnd lowers the dig. indlididual physlclan.
nity of the urofesston.

\section{Secret Divlsion of Fees Condemned}

Sec, 3. It is detrlmenta! in the public Enod and degrading to the profeusion. and therefire unjorfesalonal, to kive or to recelve $x$ eommlssion. it is nlat) unprofes slonal to divlde a fee for medical advlce or sureleal trentmen: unleas the pitlent or his next iriend is fully informel 19 to the terms of the transaction. The patlent should the made wo reallze that a proper fee should he pald the famlly physleian for the serr. loe he reulers in determining the surgieal or medical trentment sulted th the condt. tion. and in adrlalng concerning those hest pualled th render any speclal service that may be renulred by the patlent.

\section{CHAPTER III.-THE DUTIES OF THE PROFESSION TO THE PUBLIC} Physicians as Citizens

Section 1. Physlclans, as good citizens and because thelr professlonal tralning specially quallfes them to render this serv ce. should give adrlce coneerning the puh lic health of the community. They shnuld bear thelr full part In enforclng Its laws and sustaining the Institutlons that adrance the Interests of humanity. They should co. operate especlally with the proper authort. thes in the administration of sanitary law and regulations. They should be readr to cosinuel the public on subjects relating in eomnel the public on subjects relating in mantlary

\section{Physlefans Should Enlighten Public- Duties in Epidemics}

sec. 2. Phrsicians, especlalls thuse eneлем in puble health work, should on lighen the publle regarling unarantine refulations: on the locatlon, grrangement reculdions: on the locatlon, arrangement
and dietarles of hospltals, asylums, sehwols prisons nod similar Instlutions: and con cerning measures for the prevention of epldemle and contaginus disesses. When an epldemle prevalls. a mysiclan must continue his labors for the nllevlation of suffering penple. without regard in the riak to his own health or llfe ir in finanelal return. It nll times. it is the duty of the phratclan to notify the projerly constluted puh Jlc health authoritle if every case of com munleable dlsease under his care, in ac cordance with the laws, rules and regula tinns of the health authiritses of the lneally in whlch the patlent is.

\section{Public Warned}

Ser. 3. Phrsleisns whould warn the mulle agalnst the devices prarticen and the false pretenglons made hy charlatans which ma! cause infury to health nud loss of life.

\section{Pharmacists}

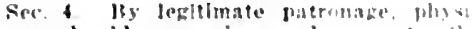
rians should recolnde and promose the profesuinn of pliarmacy : lint ats fharma.

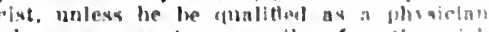
who nssumes to proserilie fur tlu, porf. Moreover. whonever a drutsiol

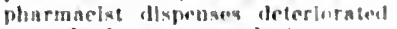
terated druge. or substimtes and rement for anothor abosignated in a prenesift. he thereby forfeits all claims th the bat

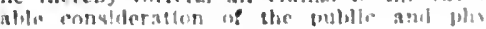
4h้ 1 iा th 4

\section{Conclusion}

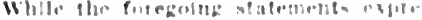
General was the dute of the pliveletal

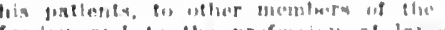

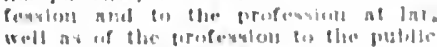

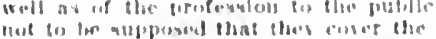
theld of modical ethlews or that the phisletas

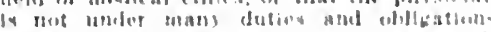

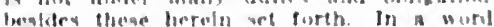

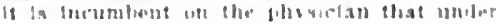

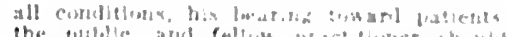

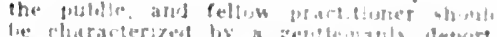

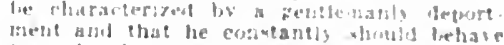

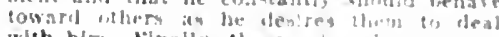

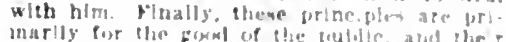

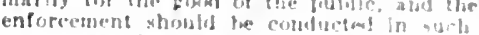
manner as whall ileseric aral

SESSIONS AND PRESIDENTS OF THE AMERICAN MEDICAL ASSOCIATION

Year and l'lace of Brellug Irentert 1847 rhlladelphis Xathaniel chaponar. I'a

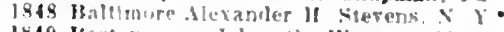

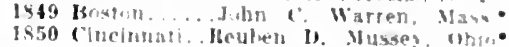

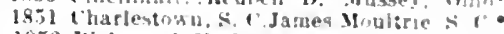
1952 lilchmona. Va Bererly th Welford. Va 1553 New York. Jonathan Knight, Can -

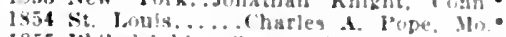
185.5 l'blladelphla..George Is. Wood. Ba 1856 lleswlt. Mleh... Zina l'ticher. Mirh. 1857 Nashvile, Tenn. l'aul F. Fire. Tenn: is5s Washingtun....IIarrey lindsly. I" 1 s60 New Ilaven. Comn.... Eli Ires, 1 nr. $1 \times 61 \mathrm{Ni}$ session held.

106: No session held.

lsb. Theagn...........lden 3arch. $x$ r

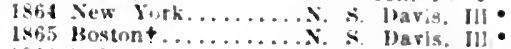
1866 Baltimore. ij. Iumphrey storer, Mas? 1867 rIncinnatl.....Henry $\mathbf{F}$. lakew. liel. 1869 New Orleans. William o balusin pa 18 o Washington.tipope Mendenhall. Whine 18:1 San Franclsco.......Alfred sille, Ira. 18:2 Philatelphia...li. W Jambll, ky:

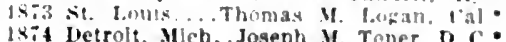

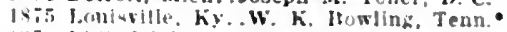

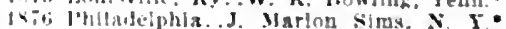
$16:-$ i high.... Henry I. Bnwditch. Mass

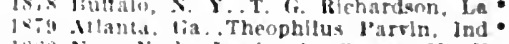
lsin Vew Vork. Lewls A. sayre. X. Y. laxl kichmonel. Wa..John T. II dean, Mo. lise st l'aul, Minn.

1883 Clereland ot Arming 1824 Wereland, Otio... Juhn L. Vilee, I'a.

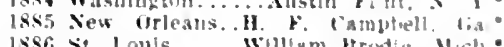

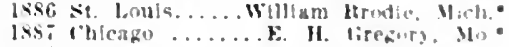
isss cincinnali. ....

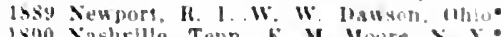

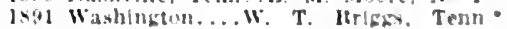
189. letront Meb....It o. Marey Masy

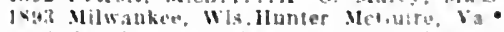

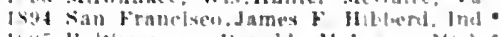

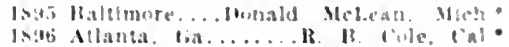

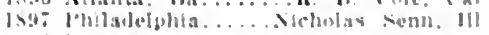

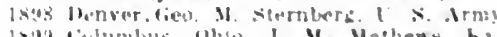

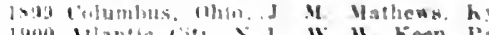
l!ou Mlantic lits. N J.. W " kem. I"

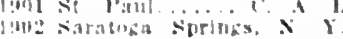

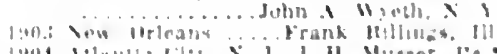

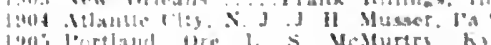

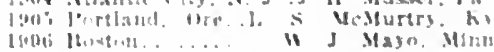

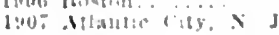

Jus "I Iirrant. N" I. Iurrell. Mass.

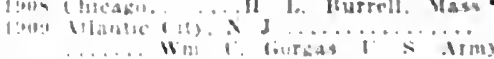

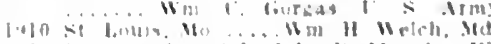

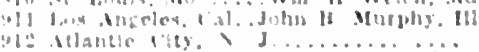

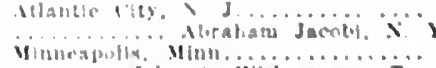
Juhn $\wedge$ Wilicropion. Tén

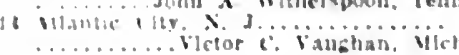

- Thir constitution havbig lwen atuended charilgh the electfon of oftcers, 10r. ilaris avideu nt Ifoston also 


\title{
NATIONAL AND INTERSTATE SOCIE'TIES
}

\author{
OF 'THE UNITED STATES AND CANADA
}

YOTE.-This list of suclelles Inclndes: year of organization, date and place of next mceting and offlcers, and 1s offclally correct to March 1, 1914. A roster of the members of the Anglo-Ameriean Medical society is given.

Alpha Omega Alpha Honorary Fraternity Organized 1902. liussell Burton-Opitz, l'resident, Colmubia Universily, N. Y. ; Car Huber, Vice-President, University of tary-Treasurer, Slaterville Springs, N. Y.

\section{American Academy of Medicine}

Organized 1876. Next meeting in Allantic City, N. J., May 29-June 1, 1914. Ray L. Wilbur, I'resident, san Franciseo; Ilorace Newhart, First V'ice-I'resident, Hinneapolis, Minn.; W. Jarvis barlow, second VicePresident, Los Angeles; C. L. Sterens, Third Vice-President, Athens, 1 'a.; $\mathbf{W}$. Blair stewart, Fourth Vice-President, Atlantic City, N. J. ; Charles icIntire, Seeretary-TreasEstes, Jr. Asslstant Secretary, South BetliEstes, Jr.,

American Academy of Ophthalmology and Oto-Laryngology

Next meeting in Boston, Oct. 19-21, 1914. J. II. Ray, Presldent, Louisrille, Ky.; First Vire-President, j. o. Meleynolds, lallas, Tex.; second Vice-l'resident, P'erry Goldsmiti, Toronto; Third Fice-I'resident, J. L. Brown, Columbus, Ohio; Lee M. Fran-
cls, Secretary, 555 Delaware Ave., Buffalo, c. Y. ; Secord H. Large, Treasurer, Cleveland, Ohlo.

American Association for Study and Prevention of Infant Mortality

Organized 1909. Next meeting in Boston, Nov, 1914. L. Emmett Ifolt, President, New York; J. Whitridge Williams, l'resident-Elect, Baltimore ; I. A. Abt, First Vice-I'resident, Chicago; Mr. A. D. Baldwin. stecond Vice-I'resident, 'leveland; Philip Fin Ingen, Secretary, 125 E. 71st St., New York; Mr. Austin McLanahan, Treasurer, Baltimore.

American Association for the Conservation of Vision

Organized 1911. Next meeting in March, 1914. F. Park Lewis, President, Buffalo, N. Y. ; Mr. Douglas C. McMurtrie, Secretary, Mletropolitan Tower, New York; Mr. H. F. J. I'oriel, 'I'reasurer, New York.

American Association for the Study of the Feeble-Minded

Organized 1876. J. K. Kutnewsky, President. Redtleld, S. I. ; II. H. Coddard, I'l. D.

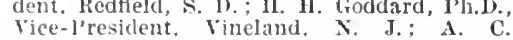
Rice-l'resident, Vineland, $N$ J.; A. C.
hogers, secretary and Treasurer, Faribault, Minn.

American Association of Anatomists Organized 18s8. Next meeting Dec. 28-30, 1914. G. Carl Huber, President, Ann Arhor, Mich.; Thomas G. Lee, Vice-Presldent, Minneapolis; Chas. R. Stockard, Secretary-Treasurer, Cornell Medical College, New liork

American Association of Anesthetists Organized 1912. Next meeting in Atlantic City in June, 1914. James Tayloe Gwathiney, I'resident, New York; Vice-Presidents, Chas. IL. Teter; F. H. Mellechan; Mr. Yandell Henderson; William Cavan Woolsey, Harold A. Sanders, Treasurer, Brooklyn.
American Association of Clinical Research Hrganized 1909. Frank H. Hlackmarr, Presidenl, chicago; Leonard heene Hlrshbert, First Vice-I'resident, Baltimore; Alice I. Conklin, Second Vice-President, Chicago; James lirauss, Secretary and Treasurer, 419 Joylston st., Boston.

\section{American Association of Genito-Urinary} Surgeons

Organlzed 1886. Next meeting in Stockbridge, Mass., May 15-16, 19I4. Hugh Cabot, P'resident, Boston; F. l.. Hagner, Vice-Presldent, Washington, D.C. ; R. F. O'Nell, Secretary-Treasurer, 379 Beacon St., IBoston.

American Association of Immunologists

Organized 1913. Next meeting in Atlantic rity, N.t., June 1, 1914. Forty-one charter members. Gerald B. Webb, Iresident, Colorado Springs, Colo.; Martin J. Synnot, orado Springs, Colo.; M. Marti
secretary, Montclair, N. J.

American Association of Medical Examiners Organized 1900. Next meeting in Atlantic City, N. J. June, 19I4. Henry Wireman Cook, President, Minneapolis; A. T. Gaillard,
First Vice-I'resident, Jhiladelphia; W. W. Tompkins, Second Vice-President, Charleston, W. Va. ; J. W. Guest, Third Vice-Presldent, Louisville. Ky.; James H. Stowell, 'Fourth Vice-Iresident, Chicago; G. Strohbach, Secretary-Treasurer, Miami Bldg., Cach, Secrinuti.

American Association of Obstetricians and Gynecologists

Organized 1888. Next meeting in Buffalo, Sept. 15-1i, 1914. Miles F. Porter, President, Ft. Wayne, Ind. Chas. N. Smith, First Vice-I'resident, Toledo, Ohio ; James E. Sadlier, Second Vice-President, Poughkeepsie, N. Y. E. Gustav Zinke, Secretary, 4, Treasurer, Buffalo, X.Y.

American Association of Pathologists and Bacteriologists

Organized 1900. Next meeting in Toronto, April 10-11, 1914. John J. Mackenzie, President, Toronto, Ont.; Leo Loeb. Vice-Presiident, St. Louis, Mio.; Harold C. Ernst, Secletary, Harrird Medical School, Boston; F. B. Mallory, Treasurer, Boston.

American Association of Physio-Medical Physicians and Surgeons

Organized 1883. Next meeting in Indianapolis, Jay 1914. T. B. Hammer, President, bes Moines, Ia.; J. I. Stephenson, ViceI'resident, Chillicothe, O.; John C. MeCandeago; I. P. Nelson, Treasurer, Chicago.

American Association of Prison Surgeons Organized 1896. Daniel Phelan, President, Kingston, Ont.; Wm. Healy, Vice-President, Chicago; Theodore Cooke, Secretary, Baltimore.

American Association of Railway Surgeons Organized 1904. Next meeting in Chicago, oct. 14-16, 1914. D. S. Fairchild, President, Clinton, Ia.; Vice-Presidents, W. J. Means, Columbus, O. J. H. Rishmiller, Minneapolis, Minn.; Wm. Battle Nalone, Nemphis, Tenn.; Louis 'J. Mitchell, Secretary, 29 E. Madison Council Bluffs, Ia.
American Climatological Association Organized I8\$3. Next neeting in Atlantic Clty, June 19-20, 1914. James M. Anders, I'resident, Philadelphia; Vice-Presidents, Lawrason Brown, Saranac Lake, N. Y.; Will H. Swan, Colorado Springs, Colo.; Guy Hinsdale, Secretary-Treasurer, Hot Springs, $\mathrm{Va}$.

\section{American Dermatological Association} Organized 18:6. Next meeting in Chicago, Nay 14-16, 1914. James IIcFarlane Winfield, President, Brooklyn, N. Y.; Slgmund Pollitzer, Vlce-President, New York; OHver S. Ormsby, Secretary-Treasurer, 32 N. State si., Chicago.

American Electro-Therapeutic Association Organlzed 1890. Next meeting in Battle Creek, Mlch., Sept. 15-17, 1914. Geo. E. Pfahler, Presldent, Philadelphia; VIce-Presldents, Albert C. Geysen, New York; Frank
13. Granger, Boston; John W. Torbett, Mar13. Granger, Boston; John W. Torbett, Marlin, Tex. Wm. L. Clark, Pliladelphia; Fredell, Secretary, 27 E. 11th St., New York; ell, Secretary, 27 E. 11th St., New York; 11. Law, Reglstrar, New York.

American Federation for Sex Hygiene

Organized 1910. Chas. W. Ellot, President, Cambridge, Mass.; Vice-Presidents, bavid Starr Jordan, Leland Stanford UniYersity, Cal.; Wm. 'T. Foster, Portland, Ore.; Mr. Felix M. Warburg, New York; Dean Walter T. Sumner, Chicago; Donald R Hooker, Secretary, Roland Park, Baltimore
Ienry L. Higginson, Treasurer, Boston.

American Gastro-Enterological Association

Next meeting in Atlantic City, N. J., June 22-23, 1914. Jacob Kaufmann, President New York; Joseph C. Bloodgood, First ViceI'resident, BaItimore; W. Li. Morgan, Second
Vice-President, Washington, I. C.; Franklin W. White, Secretary-Treasurer, 322 IIarlboro St., Boston.

American Gynecological Society

Organlzed 1876. Next meeting in Boston, May 19-21, 1914. Membership limited to 100 J. Whitridge Williams, President, Baltimore Thomas J. Watkins, First Vice-President, ('hicago; Howard c. Taylor, Second VicePresident, New York; Leroy Broun, Secretary, I48 W. Tith St., New York; J. Wesley Bovee, Treasurer, Washington, D. C.

\section{American Hospital Association}

Organlzed 1859. Next meeting in Minneapolls, 1914. Thomas Howell, President, New York: Mr. H. E. Webster, First Vicel'resident, Montreal, Que.; Miss Mary A. Baker, Second Vice-President, Jacksonville Fla.; Miss Margaret Rogers, Third VicePresident, St. Louis; H. A. Boyce, Secretary, Kingston General Hospital, Kingston, Ont. Mr. Asa Bacon, Treasurer, Chicago.

American Institute of Homeopathy

Organized 1814. Next meeting in Atlantic City, N. J., June 1914. Dewitt G. Wilcox. President, Boston; Grant S. Peck, First Vice-President, Denver; Anna D. Varner, Second Vice-President, Wilkinsburg, Pa. J. Richey Horner, Secretary, Rose' Bldg., Cleveland, 0.; T. Franklin Smith, Treasurer New York; W. o. Forbes, Registrar, Hot Springs, Ark. 


\section{American Laryngological Association}

Organized 13is. Nert meeting in Atlantic city, N. J., Jay 25-27, 1914. Thos. Ilubbard, Presldent, Toledo, $0 .: 5$. k. Hopkins. Nrrt Vlce-I'resldent, springtleld, Mass; (jeo. E. Shambaugh, Second Vlco-Presiclent, Chlcaso; Ilarmon Smith, Secretary, 4 W. $49 t h$ St. New York:
Washington, D. C.

\section{American Laryngological, Rhinological and} Otological Society

Orzanized 1895. Next meeting tn Atlantic Clty. $x$ J., June 19-20, 1914. Joseuh A. White, jresident, Richmond, Va. : Lewls A. Comn, Fce-President Eastern Section. New lork; B. IR. Shurly, Vice-I'resident ilidile Section, Detrolt, Mich. : Lorenzo B. lockard. Vice-l'resldent Western section, Denrer. Colo. F. M. Thimpen, Vlce-I'resident Southern section, Moutgomery Ala. Thos. J. Ewing W. Uay. Treasurer, I'ittsburgh, Ha.

\section{American Medical Association.}

\section{(See pp. 5i-63.)}

\section{American Medical Editor's Association}

Organlzed 1869. Nert meeting in Atlantlc City. ‥ J." June 1911. E. A. Van der Veer,

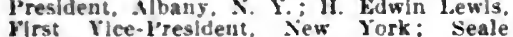
harris, Second Vice-President, Moblie, Ala.; Harris, Second Vice-President, Moblle, Ala.; 92 William St. New York.

American Medico-Psychological Association Organlzed 1844. Next meetlng in Baltimore, May 26-29, 1914. Carios F. MacDonald, Presldent, New York; S. E. Smith, VlcePresident, Hichmond, Ind. ; Charles 6 . Wag. ner, Secretary-Treasurer. Binghamton. $N$.

\section{American Neurological Association}

Organized 18i5. Wm. X. Bullard, President, Boston; Hice-l'residents, E. W. Taylor, Boston: T. M. T. Mckennan. Pittsurgh. Pa: Alfred Reginald Allen. Secretary-Treas urer, 2013 Spruce St., Phjladelphia.

American Ophthalmoiogical Society Organized 186t. Next meeting in Hot Springs. Va.. Mas 12-13, 1914. Roberi Sattler, President, CIncinnati, O.; M. H. Post. Vice-1'resldent, St. Louis, Mo.; Wm. MI. Phlladelphla : Artuld Knapu. Corresponding Secretary, New York.

\section{American Orthopedic Association}

Organized 188\%. NeIt meeting in Phtladelphia, June 18-20, 1914. G. G. Davis, President Ihlladelphia: Charles Painter, VicePresident, Boston; Ralph R. Fitch, Necretary. 365 Fast Are. Itochester, X. Y.; J. L. Porter. Treasurer, Chlcago.

\section{American Otological Society}

Organized 186 ${ }^{\circ}$. Next meetho in Atlantle City, J. May $27=28.1914$ Jimes $F$. Ic. Kernon. Presldent, New York; bugene A. Kernon, President, New York; bugene A. Rae, Secretary-Treasurer, "47 W: F0th St. New York.

\section{American Pediatric Society}

Orzanized 1888. Next meeting in Niw London, Conn. Mas 26, 1914 . Samuel il Hamill, President. Itbiladelphia: Wathas Nicoll, Ir., Vice-I'realdent, New York: Samil. S. Allams, secretary, I loupont circle. WanlInston, $D$. $C$ : Chas. II unter lounn, Treas

\section{American Physiological Society}

Orzanized 1887. Next mecting in st. President, Moston:" Jarlmon, Secretary. Cnirersity of Chicago: J. Frlanger, Treas urer, St. louls, Mo.

\section{American Prostologic Sosiety}

Organized 1899. Next meetlng In Allantis City, x. J., June 22-23, 1914. Joseph II Mathews, I'resident, Loularille, Ky, Jame Mich.: Alfred J. Zobel, serretary.Treasurer, San Francisco.

American Psychopathological Association

Ureanized 19!n. Alfrel Heglnall Allen.

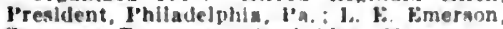
secretary-Treasurer, Cambrlige, il ass.
American Public Health Association

Organized 18\%. Next meeting in Jack. mnville, Ila., Nor. $24 \cdot 25, j y 14$. Wm. C Woodward, Iresident. Washingtua, I. C. Jun F. Inderson, First vice-1'resident Vice-President, llavana. Iuba; $C$ J. Hastings, Third Vice-Ireslient, Torndo, Ont. Sedskar M. Gunn, Secretary. is. Boylston Houlder, Colo.

\section{American Roentgen Ray Society}

Organized 1900. Next meetirg in Cleve land sept. 0-1\%, 1914 . Sldney Jange, I'res ldent, 'luclnnatl Vice-l'resfdents, G. M
steele. Oshkosh, Wls.: H. W. Van Allen. springfleld, Mass.: J. H. Flmonson, lBir mingham. Ala.; W. If, Fagar, Halifax, N s.: II. E. l'otter, Chicago: W. F. Manges. Secretary, 264 S. I6th St., l'hiladelphia Leonard Reu, Treasurer, Butalo, N.

\section{American Sanatorium Association}

(brauized 1905. Vincent $Y$. Howditch. I'restdeut, Boston: Lawrasnn Brown, VicePresident, samac Lake, $\mathbf{N}$.: Hatry Lee
Barnes, Secretary-Treasurer, Wallum Lake, 1. I.

American School Hyoiene Association Organized 1907. Darld L. Edsall, I'resldent, Boston: Wim. H. Burnham, Ih.I. Vice-President. Clark Unirersity. Worcester, Sass. : Thomas A. Storey, Secretary-Treasurer. College of the Chty of New York, New York.

American Society for Pharmacology and Experimentai Therapeutics

Organized 1908. Torald Sollmann, President, clereland; John Auer, Secretary, Loevenhart, Treasurer, Iadison, Wis.

American Society for the Study of Alcohol and Narcotics

Organized 18:0. Lewis D. Mason, Presl den:, Brooklyn: C. $\mathbf{k}$. Stewart, Vice 'resident, Baltie Creek, Mich. : T. I Crothers, secretary-Treasurer, 1t2 Fairfleld Are. Hartford, Conn.

American Society of Tropical Medicine Organized 1903. Next meeting in boston. May 29-30, 1914. Richard P'. Strong. 'resident. Biston: Viee-l'resilents. ('reighton Welimann. New (1rleans: Chas, F, cralght Learenworth. Kan,; Joh M. Swan, secre tary $45 i$ lark twe. linchester. S. I. delphia: Jos. il. Weis, Treasurer Yew orlean.

\section{American Surgical Association}

Organlzed Isso. Actire membership limited to 125 . Next meeting in New York. Apri 9-11. 1914. Wm. J. Mayo, l'resident. Roches ter, Minn.: Vice-Preslients. lieo. F. Brewer. New York: Wm. S. Halsted. Haltimore Hohert d. LeConte, secretars, 1530 lencus st. Plliladelphla: Chas, l. libson. Treas urer, Sien lork.

\section{American Therapeulic Society}

Orsanlzerl 1900. Nert meeting In Allany. X. Y.. May $29-30$, 1914. IIoward Van less selaer, l'restelent, Nuany. $X Y$ : Kobe 7

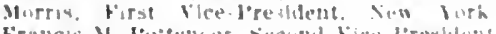
los Angeles, Cal. J. Madisurs Taslor. Thato Fice-l'resident. Hhildelphia: lewas if Tay lice-l'resident. Hhildelpha: law is Tay A Fonest tiallant. Treasurer, New lork.

American Uroiogical Association

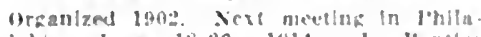

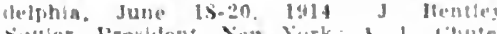

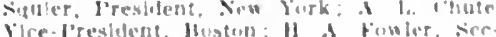

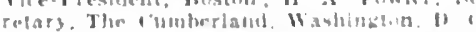

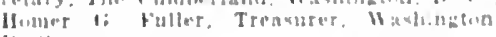
11. ${ }^{\prime}$

Association of American Medical Colleges

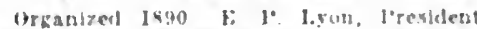

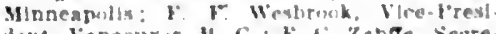

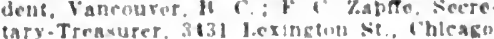

Association of American Physicians

lirganized Iss6 Xext mectum in Atlase! City. ‥ J. May 12-13.1914. Simon Flezer. l'zevident, Jew Yurk: s J Yelizer. Vice.

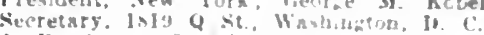
J. 1. Crozer Grimin. Treasures, inliadel. whia: Thomas lletrae, liecrader, labiladel. whas

Association of American Teachers of the Diseases of Children

Organlzed 190\%. Next nees:u: $n$ Itha

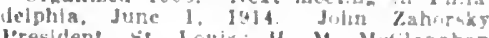

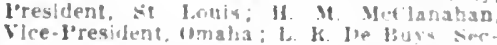
retary, New orleans: il. liroolice \$ills. Treanier, lohltadelphia.

Association of Life insurance Medical Directors

Organized lseg Harry Tolstmla. President. Harerford, Pa.; Edward K. Itnot, Fles: Vice I'revident, llarifond linnn: W' Evelyn Prir ter, second Vice-leresident, Vew Jork: Faneuil $x$ Welsue, secretary, New Jork Angustus s. Knight. Treasurer. New lork Association of Military Surgeons of the Brig. Gen. Chas. dems, lli. N r. Jefredsou Randolph Kean. Medical (Corps. Jetrersou Randolph Kean, Medical lcorps,

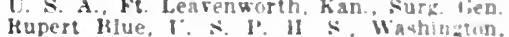

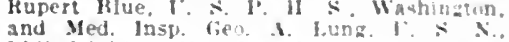

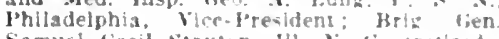

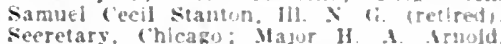

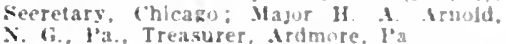

Association of Officers of Medical Services of Canada

organized 190: Tex: meeting in Or:awa. Ont, February, 1914. Lt Col. J. T. Fotheringham. Presideat. Toronto, Ont.; Majur

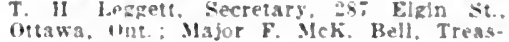
urer. livawa, ont.

Canadian Association for the Prevention of Tuberculosis

lorganized 1500. Newt meeting in Halifar.

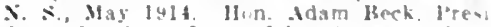
deni. iondon. Ont. John stevar: lice. lresident, lialifax, $\mathbf{x}$ s. : lien. I) Purter.

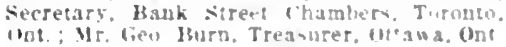
Canadian Hospital Associatioo

Iraanized 190\%. H. A. Iboyce. Iresidens.

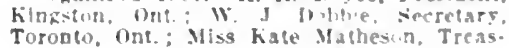
iger, Toronin.

Canadian Medieal Association () reanized lwo: Next nowing in st

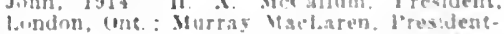

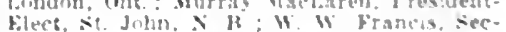

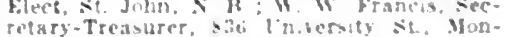
retert.

Canadian Public Health Association 1rganized 10]10. Vero meeting un liegina. sask John W $W$ Verull ugh. l'restient.

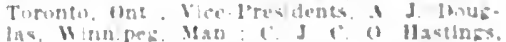

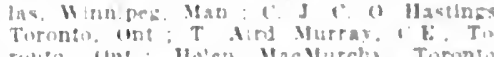
ruh:? Im! Hoven Maclturclin Torons

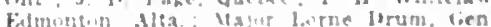

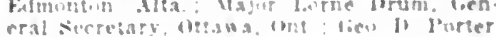

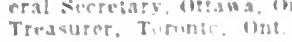

\section{Clinical Conoress of Surecons of North} Ameriea

Mrganizol Inth licotze limmonn Itrewer. Prev!dent. New lopk, W. W thipman. vice.

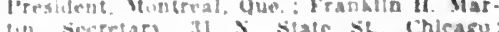
Hllell ll haibrel. Treanurer. Chicaco.

Conference of the state and Provinelal Boards of Health of North America

Drgantzel lsit Virt meeting in Wash.

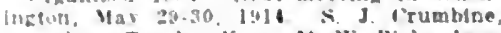
presilent. Tupekn, Kan : 3t. W klobandson. ile l'realdent, Hoston: W. S Mankln. Secretary, Haledsh. N. 
Congress of American Physicians and Surgeons

Grtanized lsss. Nort meetim in Wash ington, May 1916. Col. Wh. C. fiorgas. I. S. A., Iresident, Ancon, C. Z. ; Witter R. Steher, Secretary \& Trinity St., Ilari ford, conn.
vew york.

Medical Association of the Southwest Next meeting in tialveston, 'lex., Nos. 1914. Nembership limited to members of the

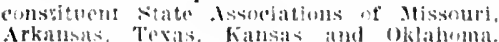
Arkntus, Tryals, Kansal and bktahma Organized lito6. K. S. Clatsserk, resident

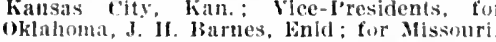
W. IB. lorsett, st. Louls; for Texas, F. II Carey, Dallas: for liansas, (C. 1'. Nessetrode liansas city, Kan.; F. H. Clark, SecretaryTreasurer, fil keno, Okla.

Medical Society of the Missouri Valley

Organized 1888. Next meeting in Lincoln March 26-27, 1914. F. B. Tiffuny, President, Kansas City, Mo.; M, L, Hildreth, Vlee-l'resldent, Lyons, Neb. : t'liarles Wood Geblurt, Treasurer, St, Josepl, Mo.

Mississippi Valley Medical Association

Orgunized 1875. Next meeting in Cin cinnati, Oct. 27-29, 1914. President, D'Orsay Hecht, Cisicago; vice-l'residents, w. w Bullerworth, New orlenns; Willard .1. Stone, Toledo; Henry Enos Tuley, Secretary, $705 \mathrm{~S}$. 3d St., Loulsville, Ky. : Samuel C. Stanton, Treasurer, Chicago.

National Association for the Study and Education of Exceptional Children

Established 1905. Next meeting in New York City, 1914. A. Enil Schmitt. President, New York; Ira S. Wile, VIce-President New York; Waldemar H. Groszmann, Secretary, Plainfleld $\mathrm{N}$. J.; A. A. D'Ancona. Board of Education, San Franciseo.

National Association for the Study and Prevention of Tuberculosis

Organized 1904. Next meeting in Washington, D. C., May 7-9, 1914. Homer Folks President, New York; Vice-Presidents, Miss Mabel T. Boardman, Washington, D. C. Theodore B. Sachs, Chicago; Henry Barton Jacobs, Sccretary, il Mt. Vernon Pl., Balti more; Mr. William H. BaIdwin, Treasurer, Washington, D. C.; Livingston Farrand, Executive Secretary, New York.

National Association for the Study of Epi lepsy and the Care and Treatment of Epileptics

Organized 1901. Next meeting in Baltimore Jay 25, 1914 Mr. W. C Graves, President, Chicago; David F. Weeks, VicePresident, Skillman, N. J.: J. F. IIunson Secretary-Treasurer, Sonyea, N. Y.

\section{National Association for the Study of} Pellagra

Organized 1909. Next meeting in 1915 Surg. C. H. Lavinder, U. S. P. H.S., President, Savannah, Ga.: Capt. J. F. Siler, M. C. U. S. A., Vice-President, Spartanburg, S. C. J. A. Hayne, Treasurer, Columbia, S.

\section{National Eclectic Medical Association}

Orcanized 1870. Next meeting in Indianapolis, June $16-19,1914$. W. S. Glenn President, State College, Pa.; Vice-Presidents, Rosa B. Gates, Waco, Tex.; W. E. Daniels, Madison, S. D.: O. S. Coffin, Indianapolis, Ind.; Wni. P. Best, Secretary, 2218 E. 10th St., Indianapolis, Ind.; E. G. Sharp, Treasurer, Guthrie, Okla.

\section{National Medical Association (Colored)}

Organized 1895. John A. Kenny, President, Tuskegee Institute. Ala.; D. A. Ferguson. D.D.S., First Vice-President, Richmond. Va.; C. II. Wilkerson, Ph.G., Alexander, Secretary, 14 Webster Pl, Orange. ऽ. J. ; J. R. Lery. Treasurer, Florence S. C.
National Volunteer Emergency Service Med-

$$
\text { lcal Corps }
$$

Organized 1900. Brig. Gen. F. Hibert Daris. President, New York; Geo, ii Muren, Vice-I'resident, Brooklyı; Adj. Gen, Jos. Ifenry Thompson, Jr. Secretary, 30 Chureh st., New York; coi. Wm. if. Robinson, St., New York; cot.

Northern Tri-State Medical Association

Organizet 1874 tien. W. Mc Mnskey, l'resident, Ft. Wayne, Ind. ; Theo. F. Wood sponu, seretiry, Elklart, Ind. ; I. A. Weltz. 'lreasurer, Inontpelier, (),

\section{Ohio Valiey Medical Association}

Organlzed 1899. Henry R. Alburger. President, Indianapolis, Ind. : A. J. Whllmoth, First Vice-l'resident, Loulsville, Ky. E. O. Smith, Second Vice-President, Cinclnnati; 1. Ii. Young, Third Vlee-Presldent bary-Treasurer, Evansville, Ind.

\section{Society of American Bacteriologists}

Next meeting in Philadelphla, Dec. 29-31, 1914. Chas. E. Marshall, President, Amlierst, Mass.; A. Parker Hitchens, Secretary, (ilenolden, P'a.

\section{Society of Clinical Surgery}

Organized 1903. Wn. J. Mayo, President. lochester yinn. L I VcArthur, vicePrestdent, Chicazo; J. F, Mumford, Secretary, Clifion Springs, $N$. Y.; C. H. Frazier, Treasurer, Philadelphia.

\section{Southern Medical Association}

Organized 1906. Next meeting in Richmond For 9-11, 1914. Membership limited to members of the state societies of Alabama, Irkansas, District of Columbia, Florida, Georria, Kentucky, Loulsiana, Maryland, Mississippi, North Carolina, Oklahoma, South Carolina, Tennessee, Texas, Virginia, West Virginia, and commissioned officers States Army, Navy and Public Health States Army, Navy and Public Health phis, Tenul. Stuart MeGuire, First Vlcephis, Tenul, S Stuart MeGuire, First Vlce-
I'resident, Richmond, Va.; J. D. Love, Second Vice-President, Jacksonville, Fla.; Seale Harris, Secretary-Treasurer, Mobile, Ala.

\section{Southern Surgical and Gynecological Association}

Organtzed 188\%. Next meeting in Asheville, $Y$. ( $\because$ Dec. $15-17,1914$. John W Long. President, Greensboro, $N$. C.; YicePresident, Wm. 1. Carr, Washington; W. D. Haghard, Secretary, 148, 8th Ave., N., Nashville, Tenn.; le (;rand Guerry, Treasurer. columbia, s. C

\section{Tri-State Medical Association of the Carolinas and Virginia}

Organized 1898. Next meeting in Wilmington, N. C., Feb. 18-19, 1914. The anuual meetings are held consecutively in the constituent states, North Carolina, South Carolina and Virginia. Southgate Leigh, President, Norfolk. Va.; Vice-Presldents, Stephen Harnsherger, Catlett, Va.; E. Reld Russell, Asheville. N. C. ; J. H. Taylor, Columbia, S. (', R. E. Hughes, SecretaryTrmbia, S. C $\because$ R. E. Hurer, Jaurens, S. C.

\section{Tri-State Medical Society-Arkansas, Louisiana and Texas}

Organized 1904. T. B. Younger, President, Fisher, La.; Vice-Presidents, for Arkansas, G. B. 'Sanders, McNeil; for Louisiana, J. L. Scales, Shreveport; for Texas, W. G. Hartt, Marshall; J. M. Bodenheimer, Sccretary-Treasurer, Shreveport, La.

\section{Tri-State Medical Society of lowa, Ilinois} and Missouri

Organized 1891. Hurbert H. Fletcher, President, Winchester, Ill.; Vice-Presidents : for lowa, Fred W. Bailey, Cedar Rapids; for Illinois, William F. Waugh, Chicago; for II. Bounds. Secretary, Hannibal, Io. Emory Lauphear, Treasurer, St. Louis.
Weslern Association for the Preservation of Medical Records

Organized 1909. Amnual meetings held in Cincinnati. rlhas. A. I. Reed, President, Cincinnati; (i. W. H. Kemper, Vice-President vuncle, Ind: Otto luettner Sacretary. Cincinnati; i. i Drury, Treasurer, Cincinnati.

\section{Western Surgical Association}

Organized 1891. Next meeting in Denver. 1)ec., 1914. Memberslip limited to $150 \mathrm{men}$ bers, Byron I3. Davis, President, Omaha, Neb.; J. Rilus Eastman, First Vice-President, Indianapolis, Ind.; Major G. Seellg, T. Mann, Secretary-Treasurer, Minneapolis, Minn.

\section{American Association of Medical Milk Commissions}

Oryanized 1907. Next annual meeting in Rocliester, $\mathrm{N}$. $\mathrm{I}$

\section{EXECUTIVE OFFICERS}

John W. lierr, I'resident, Washington 1). C. otto P. Geier, Secretary, 124 Garfield Pl., Cincinnati; Wm. I. Graf, Assistant SecSedgwiek, Treasurer, Mimeapolis, Minn.

$$
\text { COUNCLL }
$$

J. R. Williams, Chairman, Rochester, N. Y. Otto P. Geler, Secretary, Cincinnatl; Richard M. Smith, Boston, Mass, T. C. Mccleave, Berkeley, Cal.; John W. Kerr o.; Walter D. Ludlum, Brooklyn, $\mathbf{X}$. J. P. Sedgwick, Minneapolis, Minn.

Milk Commission of Mobile County (Ala.) Medical Soclety, Dan'1 T. McCall, Secretary, Yan Antwerp BIdg., Mobile, Ala.

Milk Commission of the Alameda County (Cal.) Medical Society, J. K. Hamllton, Secretary, Bay Station, Álameda, Cal.

Milk Commission of the Los Angeles County (Cal.) Medical Soclety, P. V. K. Jolinson, Secretary, Security Bldg., Los Angeles, Cal.

Milk Commission of the San Franciseo County (Cal.) Medical Society, E. C. Fleischner, Secretary, 350 Post St., San rancisco, Cal.

Ifilk Commission of the El Paso County (Colo.) Medical Socjety, C. F. Gardiner,
President, 818 N. Cascade Ave., Colorado springs, Colo.

Milk Commission of the Bridgeport Medical Association, F. L. Day, Secretary, 475 State St., Bridgeport, Conn.

Milk Commission of the Greenwich Medical Society, Edw. Parker, Secretary, Putnan Greenwich, Conn.

Milk Commission of the Hartford County (Conn.) Medical Society, Walter G. Murphy, Secretary, 75 Pratt St., Hartford, Conn.

Dural County Medical Milk Commission, Wm. Edson Ross, Secretary, 43 Ashley St. Jacksonville, Fla.

Milk Commission of the Chicago Medical Society, Robert Black, Secretary, Del Prado Hotel, Chicago.

IIik Commission of Galesburg, E. $\mathbf{x}$ Nash, Secretary, Galesburg, Ill.

Iilk Commission of the Jefferson County (Ky.) Medical Society, Ben Carlos Frazler Secretary, Atherton Bldg., Louisvllle, Ky.

Milk Commission of the Fayette County (Ky.) Medical Association, D. Woolfolk Barrow, Secretary, 148 Market St., Lexington, ky.

Y'ilk Commission of the New Orleans Pure Ifilk Society, Mr. Robt. H, Polack, Secretary, New Orleans, La.

New Bedford Milk Commission, The, Wm A. Nield, Secretary, 62 Fifth Are., New Bedford, Mass.

Hilk Commission of the Suffolk District (Mass.) Medical Society, Richard M. Smith, Secretary, 222 Marlborough St., Boston.

Ifilk Commission of the Cambridge (Mass.) Medical Improvement Society, Albert P. Norris, Secretary, 760 Massachusetts Ave., Cambridge, Mass.

Milk Commission of the Malden (Mass.) Iedical Society, E. W. Barron, Secretary, Malden, Mass. 
Medical Mllk Commission, 1:. J. Ward, Secretary, 3yi Ileasant St. Worcester. Mass.

Mlk Commlssion of the Calhoun (ounty"

(3leh.) Medical Siclety. W. H. IIaughey (3lch.) Medlcal Siclets, W.

MIlk Commisalon of the Wayne Count: (Mich.) Medlcal Society. Wm. If. I'rlce, sec retary. Wasbington Arcalle, leetrolt, Mlich.

Yllk Commission of Flint, Mlch., I. W clift. Secretary.

Milk Commission of the Kent County (Mlch.) Medlcal Soclety, c. C. Slemons, Secretary. Firand Raplds. Mlich.

Mulk Commlssion of the Hice counis (Mnn.) Medical soclety. I. Irlene lane. Secretary, 128 Central Are.. Farilault, Minn.

Mulk Conmlsylun of the llennepin County (Minn.) Medleal Sirclets, tieu. Mnggisd Secretary, 2400 ("hlcagu Are., Mumeapolls. Jinu.

Kansas Clty (Mo.) ['ure Milk Commirsion. D. E. Bmderick, Secretary, Kinsas city, Mo.

SL Louls Fure Milk Commlsslon. Mr. H. F. Mortland. Secretary, 1:26 $\mathrm{X}$. $13 \mathrm{th}$ St.. St. Louls, Mo.

Unlen County (x, J.) Medleal Milk Commlssion, Arthur Stern, Secretary, 224 b Jersey St., Elizabeth. X. J.

IIIk Commission of the IIuison counts (X. J.) Mledical Soclety S. A. Cosgrove. Secretary, 9 Virtinla ire.. Jersey ('ity, $x$. J. Milk Commlsalon of the Morrls County (X. J.) Stedleal Soclety, T. W. Rebout. Secretary, Stlrling, $\mathbf{N}$. J.

Mllk Commission of Essex County (S. J.) Flos Mckwen, Secretary, 209 Bellerille Are. Newark, N. J

Mllk Commlssion of the lassalc County (X, J.) Nedical Society, (i, Edward Tuers, Secretary, 12 Church St., Paterson, N. J.
MIk Commlsafon of linfon lounty (x J) No. 3. Harld F. Fugllsh, secretary, 309 springtheld Are., Summlt, $\therefore$ i

$311 k$ Conimittee of the Medical suclety. County of Allang (X. Y. llenry L Shaw. Secretary, Albany. $x$. y.

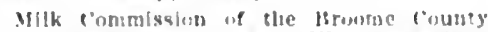
(X. Y.) Medleal Soclety, I" W" Greene, Sece retary, 16 Jay st.. Minghamun, I y

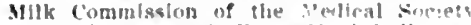
County of kings (x. Y.), Alfeed Bell. Sec retary, 37 inden sit. lirunklyn. $x$

Milk rommlssion of the chautauqua tounty (X. Y.) Medical Suclety, Melvil s core, (halrman, 504 Central Ave, Dunklrk, .). Y.

llik tommlsston of the Firle Count (X.) Vellcal Soclety, Claytion W. Greent secretary, 469 Franklin St. Butfalo, $X$. Y

Milk (o)mmlssion of the Elmira ( $X$. Y. Academy of Mediche, Buss 1:. loup. Secre. tary, 54 s. Main St. Elmira, X. I

New York Medical Milk Commlisjon. \& H liuddleston, Secretary, it5 W. Tsth st. Xew Fork.

Mllk Commlssion of the Medical soreers. County of New York, Rowlant f. Freman secretary, 2ll w. 5ith st., New Jork City

Mllk Commission of the Medical Socien: ('ounty of Jutcliess (X. Y.). Knlght Heyo

Iilk Commisaton of the Ionroe cinunt

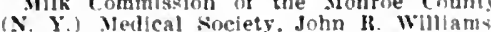
(X. Y.) Medlcal society, John B. Wllliams

The Westchester Coung (X. Y.) Milk Conntisslon, R. Condit Eddy, Secretary. I: centre Are. New kochelle, $\mathrm{x}$. $\mathrm{Y}$

Mllk Commission of the Onondaga Medical Soclety (X. Y.).

Milk Commission of the dinneombe Cuunty Vedical soclety (x. C.), 1. B. McBrayer. Secretary, Clty Hall, Isherille, X. C.

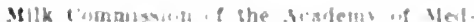

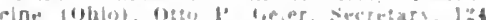
Garflelu I'l. incingat, lots

Mllk couminalon of the lits of cleveland

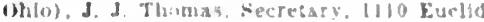
ire., C'lereland, thhlo.

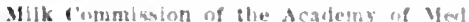

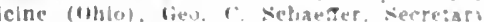

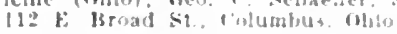

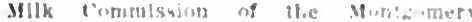

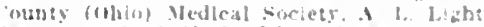

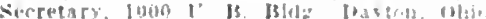
MHk tommliaion uf the Arastemy of liest

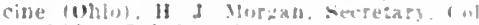
ton Mde. Tilterls, Whin

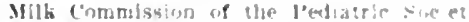

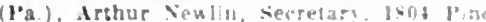
si. Ihhlladelphis

Milk foms:nasion of the Nllegherns a cunt

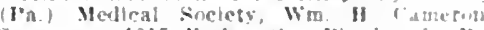

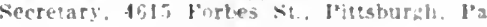

Milk rommlssion of Memphis and Shelbs (onnty Medical sucletles (Tena.), Eju i Mitchell. l69: Lawrence Are., Memphis. Tentl.

Milk Commission of the lity nf Nabtrille (Tenn.), O. H. Wilson, (hairman, 14: ith tre. Nashville. Tenn.

Mllk Commissinn of the El l'ason Count: (Tex.) Medleal siclety. Branch rraige. Mill Hlife. Fil I"ast), Texas

Yilk Commlsalon of the Santery lenart ment (Wash.) Wllliam (i. lionth Secretary. dJaska lidz., Seattle. Wash

lertifled Milh Commixion (W. Val. Writ IIty Mclain, sccetary, Wheellng, W. Va

Mtk fommlsslon of the Medical society W. W. T lic lisughton secretary, 0 stephenson Midr. Milwaukee. W/s

Whk Commlssion of the Acadenty of Med

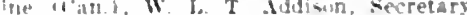
fid brondriew ire., Toronto, Ont

\section{THE CONTINENTAL ANGLO-AMERICAN MEIDCA SOCIETY}

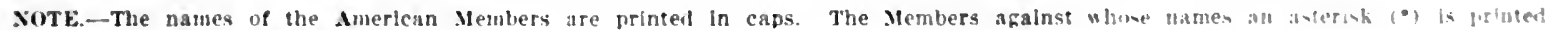
uractlce in more than one place.

\section{MEMBERS}

AIX-LES-BAINS (Savole. France) Gubb, Dr. Alfred S.. S, Place du Revard

-llort. Dr. F, A. 4, Hue des Ilalus (April to Sept. 15th)

- Kendall. I)r. Stanley, Ilotel Thermal (lu aummer) : $1: 30-3$.

ALASSIO (italy)

Boon. Wr. E. G.. VIlla Catarína ; $1: 30-3$

ALGECIRAS (So. Spaín)

Dowding, Dr. A. W. W.. Miramar (net. to June).

\section{ALGIERS}

- fubbb. Dr. Alfred s.. ("lub Anglals. Mus tapha Supsrleur (In winter); 1.3.

AROSA (Switzerland)

Morland, Dr. E. C

ASSOUAN (Egyot)

Canney, Dr. H. F. lelkh (In winter) ant 32. Harley sit, iondon. W

Saunders. Wr, F. W. (November in Marelu) and bownington llurst. Newbury (April s, (October).

BEAULIEU (Alpes-Marit. France)

-Johnston-Lavis. Ir. II. J. V'lli. L... Heaulleu (In winter).

Bellagio (lago di Como)

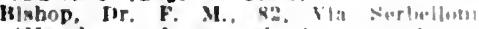
March

- vilot, D

BERLIN

lloman, Irr. A. II., Is, spejererafldume

BORDIGHERA (Italy)

bogle, Jr. J. Ionton. Villa Vanlglia. Inet Ist in June Ist) : i:30.2:30

Ifamillon. Wr. C:lulio, Villa lonzufurte: $1: 30$ $: 30$

Mübliarl, Dr. II. I.. C'ana sia Vunica

\section{BRUSSELS}

Thomson, Dr. P. J., 254, Wellue tontate

$2-4$

CADENABBIA, (Lago di Como, Italy)

- Bishop, Hr. F. M. (Marcli to dume and

Sept. 10 Dec.)

- Ellot, Dr. F. F., IIntel Relle-viue.

CAIRO (Eqypl)

Heldoe, 1)r. [D. M., 3z, Sharia hasr-el-Nil I0.12.

Gerald-Garry, Ibr. T., The fireshatn IIouse sharla sulelman jaslia.

l'hlllps, lir. l. I’. Saving thanthers: Telegf Nyllewell, Cairo

Tribe. Dr. P. C. F. Tahros Mansions, savo Itnunt loint (in wister), and Harle St.. London, W

\section{CANNES (Alpes-Marit. France)}

Hright, lir. (i. C.. Thalet Magall: $1: 30$.

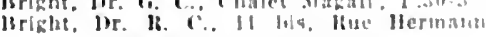
$1-3: 30$

Samders, Irr. Cincleus, Villa Martha:

CERNOBBIO (Lago di Como, Italy)

- Hellor. Iir. H. F. Ulatel Villa d'Fonte

CONTREXEVILLE (VOSGES)

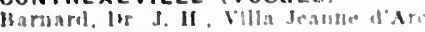

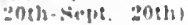

DAVOS PLATZ (SWitzeriand)

Iilli, IIS M

FLORENCE (ltaly)

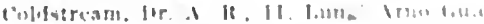

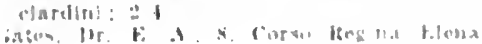

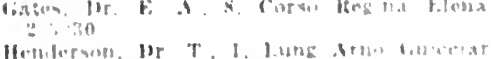

Horiderving

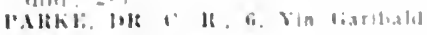

GENEVA (Switzertand)

linels, lor. IIenty

manuin: 1

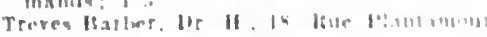

GIBRALTAR

Turner. IJ. W.. Iolonla! [I ispital:

HELOUAN (EOypt)

Hobson. Dr. 1l. Villa sakhara, (V'ne to Inrl1); a baths. $11-18:$ at bome. $1:-1: 15$ Print's Cupner. Gimalmino.

HYERES (Var, France

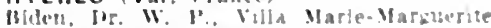

Irenue lieauregard (la winier): :-3

LANGENSCHWALBACH

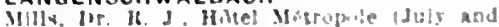
A Uanvi).

LE TOUQUET

Viale Dr $C$ sullory (n summer)

LUXOR (UPDeT EOYDI)

lounn. br II: t: $x$

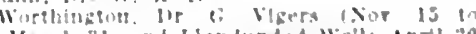

March 81 , and J.iandundind Wells Aprts:0

(1) 1300.31 . 3): $10-1$

MENAGgio (Lapo di Como. Itals)

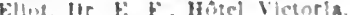

MENTONE (Alpes-Maril. France)

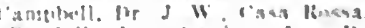

- Rendali, lir sianles bue l*almers din

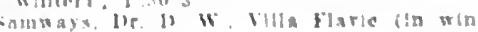

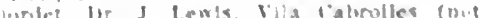
urnateing)

MONTE.CARLO (MONace)

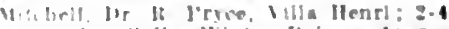

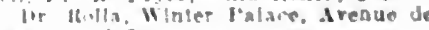
Vardutine. I $\$$.

MONTREUX (Switzeriand

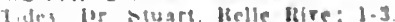

II He lir a Turher. VIlla Champond

NAIILS

- Hirci lip \& I llotel Royal des Fitrangers in winteri. Telegr biyre-Niaples.

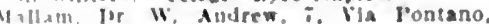
lituetre imedo. 
Molyneux, 1r. J. F., 184 Plazia Amedeo;

$$
\text { 1-3. }
$$

Ricketts, Dr. W. S. P., 7 , Via Pontano. Rlowe A medeo; 11-12, 2-3.

NAUHEIM (Germany)

IIONAN, DR. J. II., 1, Bismarckstrasso, (May ist to Oet. 1st), and Iugusta, Ga., U. S. A. (in winter).

NICE (Alpes Maritimes. France)

Any, pr. (;. J., 6, Houlevard Vietor-Hugo.

- Brandt, Dr. J. E.. 4i, llue Cotta (in winter) : $2-3$

* Gileirist, irr. A. W., 39, Boulevara Vietorliugo (in winter); $2-3$.

- IIort, Ir. F. A., Villa Majestic, Houlevard de Cimiez (in winter)

Levis, Dr. Mare de, Vilia Goiran, Place Sasserno; $2-3$

LiNs, Dk. THoMAs, Vila Goiran, Place Sasserno; 1-4.

PALLANZA (Lago Maggiore, Italy)

leask, i)r. Johm.

PARIS

AUSTIN, DR. C. K., 20, Rue Chaigrin, $16 .{ }^{\mathrm{e}}$; 2-3. DU BoUCHFT, DR. C. W., 48, Arenue du
Trocadero, $16.0^{\circ} ; 2-3$.

CHAUSsegros, 'DR. C., 236, Boulevard Raspail ; $1-3$.

Dupuy, Dr. E. 13 , rue des Saints-Peres, $\mathbf{6}^{\mathbf{e}}$ Faure Miller, Dr. Roland, 8, Rue Mlromesnll, Faure Miller. $2-4$.

GRos, DR. E. L., 23, Avenue du Bois de Boulogne, 16. e ; 2-4.

Hogg, Dr. W. D., 62, Arenue des ChampsElysees (not practicing).

Jarvis, Dr. Charles G., 81, Boulevard Malesherbes, $8 .{ }^{\mathrm{e}} ; 2-4$.
K(ENIG, DR. C. J., 65, Rue Mlromesnll, 8.e ; 2-4.

MAGNiN, DK. A. J., 121, Boulevard Haussmann, $8 e^{e} ; 2-4$.

Mumlock, Dr. II. C., 20, Rue Lesueur, 16. ;

DE IAARVILLE, DH. D. H. B., 35, Rue de DE MARVIL,LE, DH.

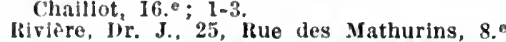
and 15, Boulevard de la Madelelne (Maison de Sante) ; $2-5$

Robinson. Dr. Leonard, 28 , Rue de Ponthleu, $8 .{ }^{\circ} ; 2-3$ 30; Teiegr. "Crusoe-1'aris."

Suzor, Ir. R., 21, Rue du Faubourg Montmartre; $2-4$.

Tucker, Dr. I. A. C., 4, Rue St.-Florentin, $1 . \mathrm{er}^{-}$1-3.

TIRNER, DR. ROBERT, Ont., 42, Rue de Villejust, $16 . e^{\mathrm{e}} ; 2-3: 30$.

Paris,"

Warden, Dr. A. A., 11, Avenue du Bois de Boulogne, 16.e ; 1-3; Telegr. "Doctoward, VHITMAN, DR. C. C., 20, Rue de Lubeck, 16. $; 1-2: 30$.

PAU (Basses-Pyrenees, France)

Brown, Dr. F. L., 4, Rue d'Orléans; 2-3.

RAPALLO (Italy)

Winslow, Dr. W., 3, Via Montebello.

ROME

Barnard, Dr. Annie T., 3, Via Gregorlana; $2-3: 30$.

Brock, Dr. G. S., 6, Corso d'Italla, Porta

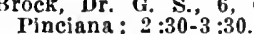

JAMESON-GAVIGAN, DR. W., care of Union Club, 23, Piazza di Spagna (not practicing).

*Welsford, Dr. A. G., 35, Piazza di Spagna $9-10,2-3$
ROYAT-IES-BAINS (Puy-de-Dome)

- Brandt, Dr. J. Egerton (in summer)

SALSOMAGGIORE (Italy)

- Fyre, Dr. J. J., Grand Hotel des Thermes (spring and autumn).

SAN REMO (Italy)

* Foster, Dr. M. G., Villa San Giovanui (Nov. to May), and Harrogate (May to Oct.).

SEVILLE (Spain)

Dalebrook, Dr. J., 36, O'Donuell ; 12-1, 5-6, 8.9.

SPA (Belgium)

Cafferata, Dr. A. M., 5, Av du Marteau; 9-11, 2-4.

TAORMINA (Sicily)

Dashwood, Dr. C. E., Vllla San Pancrazlo; $2-3: 30$.

VARENNA (Lago di Como, Italy)

Bishop, Dr. F. M., Hotel Royal (March to June and Sept. to Dec.).

VENICE (Italy)

Blaydes, Dr. W., 51, Zattere (near the Salute) : $1-3$.

VERNET LES BAINS

Vale, Dr. C. Sillery (in wlnter).

VESINET (S.-et-0)

Jennings, Dr. O., 3, Route de la Croix.

VILLARS-SUR-OLLON (Vaud, Swltzerland)

* Bishop, Dr. F. M. (Dec. to March).

VITTEL (Vosges, France)

Johnston-Lavis, Dr. H. J., Vllla Mlnima (1st June to 1st Sept.)

WIESBADEN

KNIFFLER, DR. OSCAR H., 42, wlthelmstrasse; $9-11,3-4$.

An educated man is known not only by his store of knowledge, but also by the fact that he knows where to look for the things he wants to know. If you do not readily find what you want to know in this dicectory, turn to contents, page 51 and index, page 52. 


\section{MEDICAL OFFICERS OF GOIERN- MENT SERVICE}

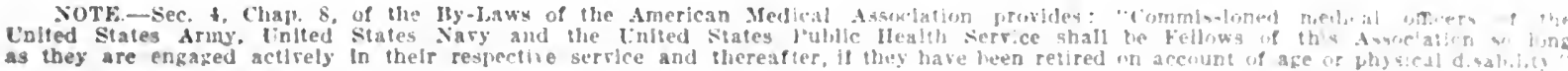

MEDICAL. OFFICLRS OF THE ARMY OF THE. UNITED STATH

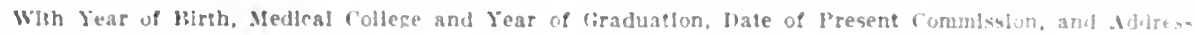

\section{ACTIVE LIST}

NuMliz of PHISICIAXs, 503.

\section{Surgeon-General}

With Rank of Brigadier-General.

GORGAS, WH.LIAM C. $\left(\mathrm{b}^{\circ} 54\right)-\mathrm{X}$ Y.10.'0; Colonels

MALS, LOUIS M. (b'51)-Md.,"it; May 10, "OF; Gorernor's Island. X.1.

AlPEL, DANIKL M. (b'st) - I'A.2,55; Dec12,08; Hawaitan Dept., Honriulu. T.H.

BRECHEMI, LOLIS (b'52) - Pa.1.76: Feb, 26,0!: Medical Supply Depot, Sew York Clts.

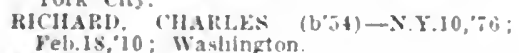

EBERT, IULDOLPII G (b.5)-YY.10,\% Dec.2:-10: San Francisco.

ARTHUR, WILLIAM H. (b'56)-Md.1, $;$;

Jan.1,11: Manila, P.I.

BUSHAELI, (iEORGE k. (b'53)-conn.1, 'So: Nay 1,'II; Fe. Mayard, N.M.

BIRMINGIIM, HENRY 1 . (b'o4)-Mtrh.l,

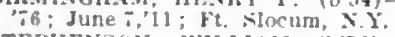

STEPHENSOS, WIIIIAM (b6) - N.Y.I.

PHILLIP's, JoHN I. $\left(b^{\prime} 59\right)-$ N.Y.1.8\%; Apr.13,'1:- Aneon, (" $\%$.

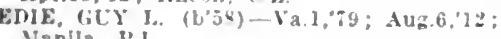
Mablla, J.I.

CROSHY, WIILJAM D. (b"5i)-X.1.1,82: Dec. $: 12 ; F t$. Sam Houston. Tex.

GANIVY, CHARLES M. (b'57)-l'a.2;79; Apr.16.'13; Waghington.

McCAW, WLTtE D. (b'63) - V'a.4,'82, X.1.1,84; May 9,13; Waslitugton.

\section{Lleutenant Colonels}

GHAX, JEFFERSOX R. (b'60)-ia.l, $x:$;

Jan.I,09; Ft. Leavenworth, Kan.

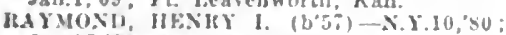

Jan.15,09; Ft. Kuley, Kan.

ILAIIIS, HENIt \&. T. (b'63)-D.c.1, 81; Feb.26,09: K. D. A. Russell, wyo.

KENUALL, WM. Y. $\left(6^{\prime} 58\right)-X .1 .1,82$; Jan.1,10: San Franclsco.

BANISTEK, WM. I3. (b'61) - Ky.5, \$3; Jan.1,10: Texas City, Tex.

MASOX, CHAHLEs E. (b'64) - Vat."8t: Jan.1, Ancon, C.\%

LENNAN, JAMES I) (b'C2)-D, (C,, 86 ;

Jan.1.10: Washlngton. (b'61)-I'a.2,8: ; Jan.28,10; Goteraor's IsIand, N.Y.

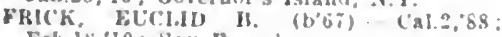
Feh.ix, 10: San Franclsco.

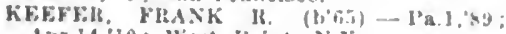
Apr.14,10; West Volnt, N.Y.

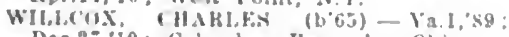
Dec.2i,"10; Columbus Jarracks, Obio

RAYM(IND, THOMAS U. $\left(6^{6} 65\right) \rightarrow$ Y Y.10,ss: Jan. 1,11: Nt. Lumls.

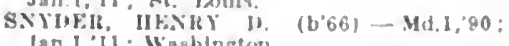
Jan. 1,']1: Washlngtoti.

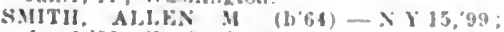
Jan.1, II: Ft. Snelling. Minn.

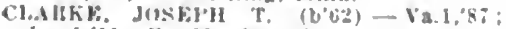
Jin. 1.11 ; . Meade, s.l.
IRFI.AND, MEIRITTE W. (li, $)$ MICh. '90: I'a.2,91; May 1,'I1: Manila, I'I. FISHER, HENRI C (l, tot) SHAW", HF. ThY A (b'66) - Mass.1, 90 ;

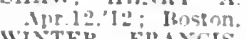

WINTER, FIAACIS A. (b'67)-\$0.2,89 Apr.13,12; Hot Springs, Ark.

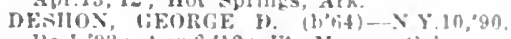
I'a 1,98; Aug.6,12: Ft. Nason, Cat.

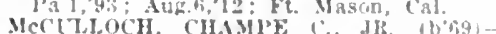

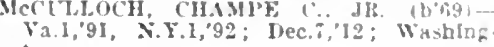

RFYNITS. FREDEHICK I". (b'6i)-Pa ? 90 ; Apr.16,13; Honoludu. T.H.

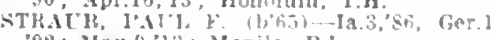

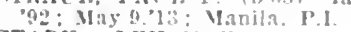

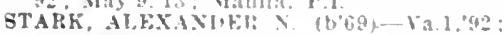
Maร.29,06; Washington.

\section{Majors}

LYYCH, ('IIARLE (b'69) - X.1.15,'9]

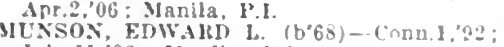
July it,06; Manila, 1.1.

KEXXEDY JAMES M. (b'65) - Md.3.92

Mar.20,07; Jefferson Barracks, Mo.

HOWAUD, DEANE C. (b"70)-D. ( 1,43 ; Apr.2t,07: Wastlugton.

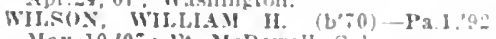
May 10,0\%; Ft. McDowell, Cal

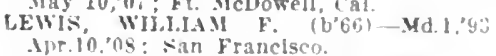

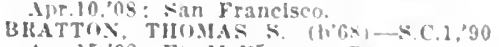

A pr.15,08: Ft Mepherson. Fa.

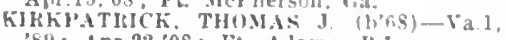
's9; Apr.22,0s; Fl. Adama. H 1

R.Ail, IItVivi" w. (bo6)-1) (.1,92: A pr.23,08; $\mathrm{kt}$. Hanenck, $\mathrm{X} . \mathrm{J}$

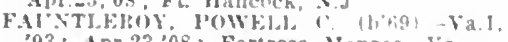
93 : Ipr.23,08: Fortress ILntoe Va.

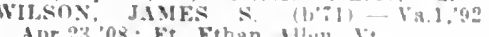

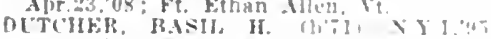

DCTCHkR. BAsll, H. H'il

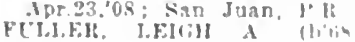

coraz

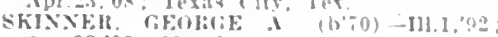

Inr.23,0s; Manila, P.I

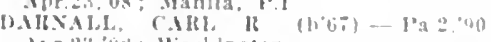

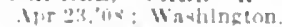

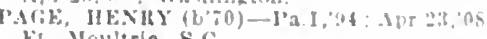

ki Mruatrie $\leq \mathrm{C}$

ASHFORI, R.IILEY K. (b':

wipr 23,08 ; Nan Juan, I"IR

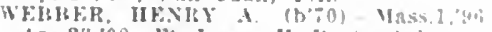

Ant.23,08; Ft. logan II. IS t. Ark

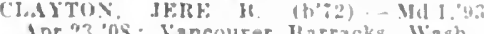

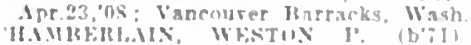

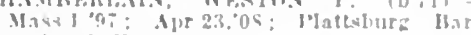

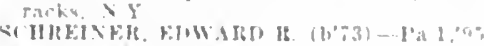

Apr 23.0, Manlla l'

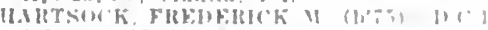

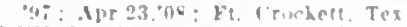

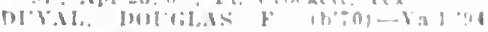

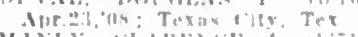

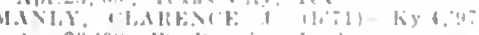

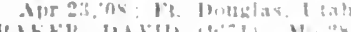

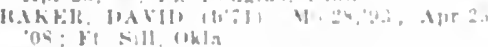

Tiliti. MIJikt

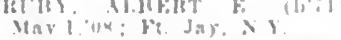

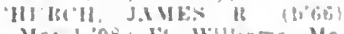

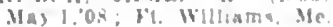

Iay a.0. (

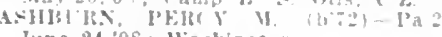

June 24,08 ; Washington

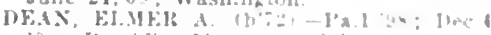

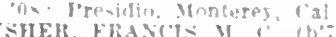

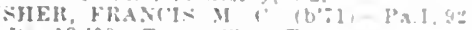

llec.12,0s: Texas ciey, Tex

TIIHY, WII.IRD F.

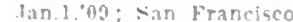

HISELLI. FHETERITK FELI.F,

X.1."03: Jan 1.09: New York Clis.

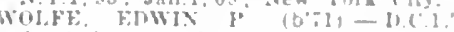

Jan 1,os: Manila PI.

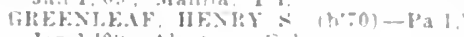

Ian d on: Aleatraz, (a)

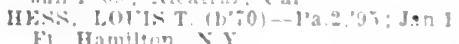

COILIX: IIISISTHUHER

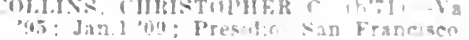

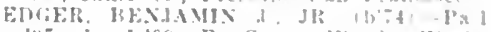

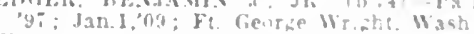

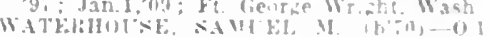

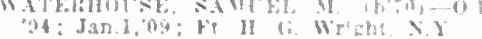

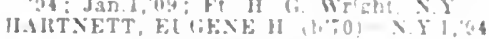
Jan.1,09; Ft. Bit, nat n, Nét

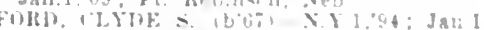

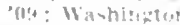

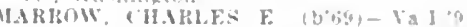
Ian 1,0!9: Fl. law!n. Wash

SHuChIEY, II I. W $(10 ; 4)-11,8,40$

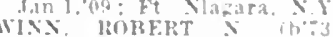

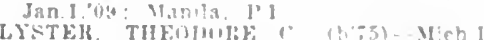

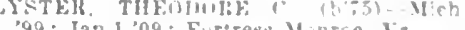

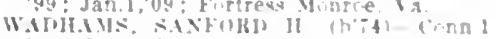
'cot: Jan $1,04:$ t'? Jneter. $\mathrm{X}$

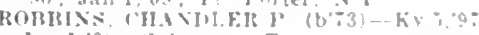

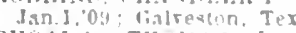

RHCilis TIIUVAs i.

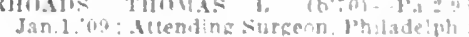

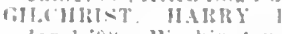

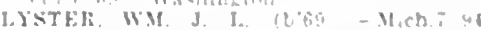

$\operatorname{lan} 1$ in: Wa-ling

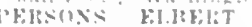

Jan 1,og. Washinge in Barracks il

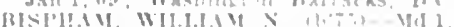

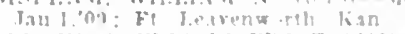

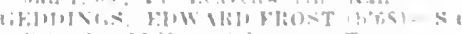

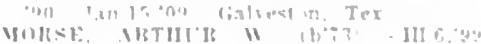

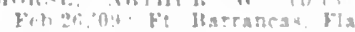

IIKFla, rlikik,

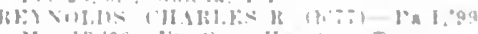

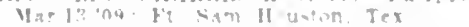

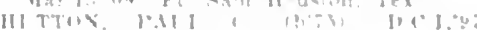

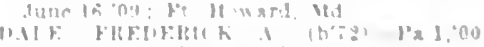

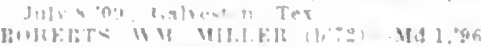

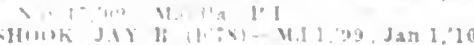

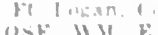

(b\%) Va 1 ; $94:$ Jan 1,'ill " 1 an 13 l. 1 .

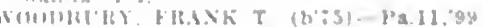
Jan l, lo, rifumbut Rarrach, cibla

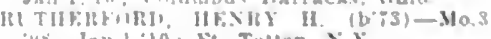

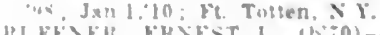

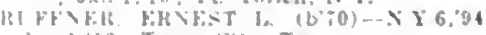
San 1: 10: Twis etty. Tex

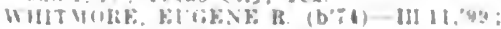
Jan 1,"10. Wasbington. 
MeAN1)KEW, PATHCK 11. (b't8) - l'a.1,'43; Jnn, '10; 'Pt. Terry, N. $\mathrm{r}_{\text {. }}$

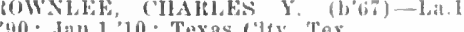
mutragil, Joln $A$ clty' Tex.

Jan. 1,$10 ; \mathrm{Ft}$. McIntosh. Tex.

ERWuly Jan.1,10; Ft. Andrews, Mass.

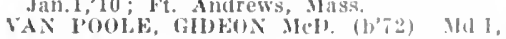
'y9 ; Jan.1,'10 ; Ilonohuln, T.11.

RENo, WHLLAN W (b't2)-YHChs, 90 Ian.1,10; Pt. 1). A. kussel, Wyo.

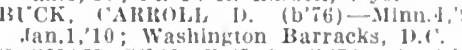

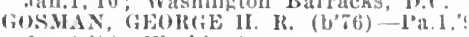

Jian.1,10: Washlngton.

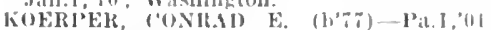

Jan.1,'10; Texas ('ity, Tex.

ALLEN, JOHN 11. (l, ;3)-b.C.1,99; Jan.1, 10: Ft. Myer, va.

PATTELSON, ROLERT U. (b'it)-Que.1 4: d:all. 1, 10; Washingt on.

'CoxNOL, RODERICK P'. (b'is)- p'i1, '110: Jau. I, 10: Ft.Ifuachuca, Ariz.

NORLE, ROHEL'T L. $\left(b^{\prime} 70\right)-N . Y .1,99$; Jan. 1,$10 ;$ Washington.

CAN DUSEN, JAMES iv (b'71)-Micli,1, 96 ; Jun.1, 10 ; Manila, P.,

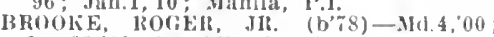
Jan.2S, 10 ; Presidio, San Francisco.

ne WITT. WALLACE (b'78)-Pa1.00 Feb.1s,'10; schofeld Barracks, Honolutu, T.11.

'HOHSBLCRGI, HOHEKT M.

'47; Apr. 7,10 ; Manila, 1.1 .

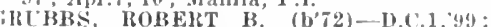
Apr.14,10; Ft. Baker, Cal.

De LANEY, MATTHEW A. (b'74)-P'A.1,98; lec. 27, I0; Waskilngton.

BLOOMISERGII, HORACE D. (b'T-T)-Mfl. 01 ; vin. 1,'11; $k^{*}$. Yellowstone, wy

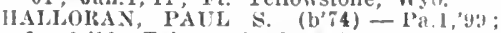

Jan.1,11; Takoma 1'ark, M/d.

NELSOX, KENT $\left(b^{\prime} 66\right)$-Minn.4, 00 ; Jan. 1, 11 ; F. l.eavenworth, kan.

FIELA, I'ETER C. $\left(\right.$ b'69) $^{\prime}$ X.Y.1,'95; Jan, 1,11 ; Manila, P.

HAW MERBERT G. (b'76)-Cal.1,98; Jan.1, 11 ; Ft. Banks, $M$ ass.

RECHI,NIN, LOUIS, JR. (b'75)-Pa.2,00 Jan.1,'11; Ft. Greble, k.1.

MIT 91; lan.1,11; 543 Greenwich st., Yew lork Clty

CARTISEE, GEORGE H. (b'70)-1'a.11,'93, Jan.1.'11; Camp Ionglas, Arlz

DAVIDSON, WILSON T. (b'68)-Tex.2,'y6 May 1.'11; Ft. Bliss, Tex.

BARTLETT, CosAM J. (b'î4)-('al.2.'98 June 7,$11 ; \mathrm{Ft}$. Worden, Wash.

UILLER, REUBEN B. (b'ish.-Mich.7, 93 June 21,'11; Washington.

BAGAN, CHARLES A. (b'33)-D.C.1,00 July $14, I 1$; Ft. Oglethorpe, Ga.

EASTMAN, WILLIAM R. (b'73)-D.C.1,01 Apr.12,12; Columbus, N.M.

HALL. JAMES FRANK (b;7)-NIass.1,99 Apr.13,'12; Ft. Strong, Mass.

METCALFE, RAYMOND F. $\left(b^{\prime}-7\right)-N . Y .6$, 00; Aug.12,'12; 1720 II St., N.W., Washington.

RICII, EDWIN W. (b'72) - Mass.1,00 Ang. 7,12 : Galreston, Tex.

OYER, PElRY 1. (b'T̃) - Md.1.99; Dec. $i, 12$; Madison Barracks, N.Y.

PHALEN, JAMES M. (b'72)-III.11, 00 ; Apr.16,13; Texas City, Tex.

EVANS, JAlIES L. (b'69) - I11.6.9?; May 9,$13 ;$ Ft. MeKinley, Me.

\section{Captains}

LITTLE, WM. L. (b'i6)-Pa.1,00; Jan.6, 07 ; Ft. Wadsworth, X.Y. WILLIAMS, ALIE W. (b; 72$)-N . Y .10,96$;
Feb.4,0i,; (falreston, Tex.

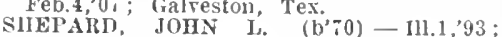
Feb. 21,07 ; Ft. Hancock, N.J.

KELLER, WILIIAM L.' (b'4)-Va.4,'99; June 2,07; West Point, N.Y,

BILLINCSIEA. CHARLES C. (b'o '00; Ime 2,'07; Chicago.

MONCR1EF, WILLIAM H. (b'76)-Ga.10, '97, Nor.30,06; Takoma Park, D.C.

G.APEN, NELSON (b'79) - D.C. 2,00 ; June 24,07 ; Ft. Rerere, Mass.

IORSE, CHARLES F. (b'i4)-Yt.2,96; June 24.07; Presidio, San Francisco.

HAXSELI, HAYWOOD S. (b'75)-Ga.11, '99; June 24,07; San Francisco.

GREGORY, JUNIUS C. (b'75)-Ya.4,00. June $24.07 ; \mathrm{Ft}$. Screven, Ga.
"NNOH. (LAHENCE H. (1,'7)-VH.1,01 ; June 2., 07 ; Washington

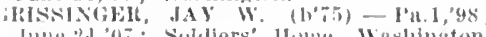

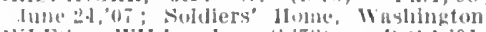
PYLEs Wili lo (b'78)

Iune 20,07 Ft. Adants, It.1. June 24,07 ; Fortress Monroe, Va.

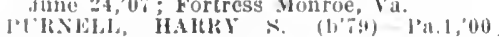
June 24,07 ; $\mathrm{Ft}$. pu pont, bei.

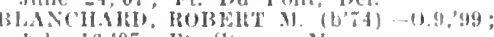
duly 16,07; Ft. Strong. Mass.

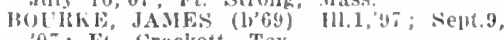
07 Ft. Crockett, Tex

(1)LOFFKL, SAMUEL M. (b'75)- 1'a.1,99 sept. 10,07; Plattsburg Barracks, Ny. MNCAX, LOUIS C. $\left(b^{\prime}\left(6^{\prime}\right)\right.$

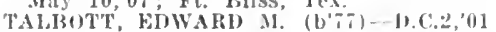
0ct. $27,0 \tau ; 1720$ II St., N.W., Washing-

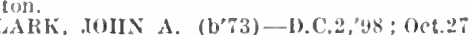
'07; Walter leed llospital, 'Takoma l'ark,

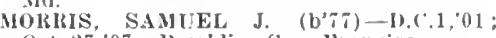
Oct. 27,07 ; P'residio, San Francisco.

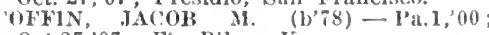
Oct.27,07: Ft. Riley, Kan.

HANER, JOIN W. (b'7̈)-Tenn.5,01 (ct. 27,$07 ;$ 1'residio, San h'ranciseo.

IATHAWAY, LEVY M. (b'7i)-Va.1,01; Oct.27,07; l'residio, Monterey, Cal.

MUKITY, ALEXANDER $\left(b^{\prime}+4\right)-D . C 1,02$.

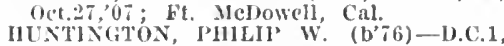
98; Oct.27,07; Ft. Totten, N.Y.

IFE, JAllES D. (b'i4)-Va,1.97; Oct.27, 07; Arnuy and Navy (ieneral llospital, Ifot syrings, Ark.

POWELL, WLLLAM A. (b'î)-Ga.11,00 Oet. 27,07 ; Presidio, San Francisco.

HALHS, JWSSE R. (b'74)-X'Y.6,01; Oet. 27,07 ; Ft. slocum, N.Y.

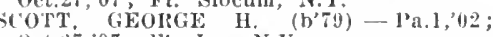
oct.27,07; Fq. Jay, N.Y.

KILBOUUNE, EDWJN D. (b'7i)-111.6,99. Oct.27,07; Ft. Oglethorpe, Ga.

ARSWELI, ROBERT L. (b'76)-Tenn.5. 00 ; Oct. $27,0 \overline{0} ; \mathbf{F t}$. Howard, IId.

RAIti, CHARLES F. (b'72)-Conn.1,94 Feb.18,08; Ft. Leavenworth, Kan.

BANTA, WM. P. (b'73) Ky.2,'94; Yeb.18, $08 ; \mathrm{Ft}$. Nicl'herson, (ia.

PIERSON. ROBERT Ḧ. (b'Tt)-N.Y.15, 98 Apr. 23,08 ; Ft. Gibbon, Alaska.

MAJBEE, JAMES I. (b'70)-0.3,94; Apr.23, 08; Letterman General Hospital, San Francisco.

PEED, GEORGE P. (b'74)-Yง.1,95: 1)ec. 30 , 03 ; Ft. Thomas, $\mathrm{Ky}$.

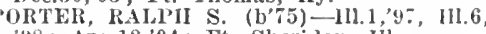
'J8; Apr.12,04; Ft. Sheridan, IIl.

HOIASON, IIENKY D. (b'58)-Pia.1,82, Ont.3,91; Mar.3,05; Ft. Sam Houston, T'ex.

JONES, PERCY L. (b'75) - Tenn.6,'yi dume 26,05 ; Texas City, Tex

PALAIK, FRED W. (b';2)-Mteh. 1, 94 Nor.14,06; Ft. IRosecrans, Cal.

Apro., 08: Army Jedical sechool, , Washingto

TPES, HENRY l'. (b'79) - D.C.1,02

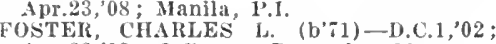

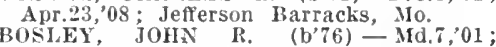
BOSLEY, JOHN R. (b'76)-Md.
Apr.23,'08; Ft. H. (i. Wright, N.Y. LOVING, KOJERT $\left(\because \quad\left(b^{\circ} \div 8\right)-\right.$ Pa.I1,02 Apr.23,'08; Ft. Bayard, N.M.

BROWN, ORVILLE (;. (b; $\tilde{4} 4)$-D.C.1, 00 ; Apr.23,08; Ft. Worden, Wash.

JEAENANA 97 ; Apr.23,08; Ft. Logan, Colo ILER, JOSEPH F. (b'5) - Va.1,98; Apr.23,08; Spartanburg, s.C.
WIALEY. ARTHUR M. (b'i2)IIALEY, ARTHUR M. (b'22)-N.Y.6,'96 Apr.23,08; Fortress Monroe, Va.

LAISON, THEODORE (b'75) - IId.7, 01 Apr.23,08; Ft. Flagler, Wash.

SNYDER, CRAIG R. (b'Ti) - Ill.6, 02 Apr.23,08; Columbus Barracks, Ohio.

N.X.6,02; Apr.23,08; Ft. Winfleld Scott, Cal.

HEYSINGER, JAMES D. (b'77)-Pa.2,01; Apr.23,08; Ft. Casey, Wash.

SMITH, LLOYD L. (b'74) - Pa.1,01; Apr. 23,08 ; Nanila, P.I.
HUGGINS. JOHN B. (b'76)-N.Y.6,02 Apr.23,'08; Ft. Robinson, Neb.

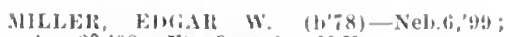
Apr.23,'0S; Ft. Ontario, N.Y

-Mich.1,?8: Mis.

DAVIS, WLIIAM R. (b'71)-Tenn.5,'98; Aug, $8,0 \%$ : Honolulu, $T .11$

OWEN, LEAKT'S J. (b'78)-V'a.1,00, Md.3,04; Apr.23,08; Ft. Shafter, IIonolulu, T.11

CULLLK, ROHERT M. (b'77) - Pat2,01 Apr.23,'0s; Schotield Barracks, Honolulu, T.II.

WEED, FHANK W. (b'81) - .1d.1,03 Apr.23,08; Manila, 1'.I.

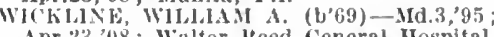
Apr.23,08; Walter leed General Hospital, Takoma l'ark, Mld.

BHOW', HENIKY 1. (b'73)-Mich.7,94 ; Apr.23, 0s; 'tt. Siocum, N.Y.

BAlLY, HOWALD 11. (b'74) - Va.1,97; Apr.23,08; Texas City, Tex.

T.MP'HLESS, HAlk1 Y G. (b'74)-Pa.1,99; Apr.23,'08; Jefferson Barracks, Mo.

FRELMAN, PAUL L. (b'7i)-D.C.1,01 ; Apr.23,0s; Manila, P.I.

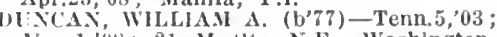
Jiay 1,08; 21 II St, N.E, Washington. ,0s: General Hospital, Ft. Bayard, N.y. GIBNElt, HERBEL'T C.' (b'79)-Conn.1,03; May 1,08; Vancouver Barracks, Wash. COLE, 'LARENCE LE R. (b' 'T)-Kan.3, , 03 : May 13,08; Ft. Sam Houston, Tex.

Love May 13,08; Ft. Sam Houston, Tex. June 30,09; Surgeon General's Office, Washington.

JONES, 11AROL1) W. (b'77)-Mass.1,01; June 30,09 ; Jackson Barracks, La.

I'INKSTON, OMAR W. (b'75)-110.8,98; June 30,09; Columbus Barracks, Ohlo. REASONER, MATHEW A. (b'75) -III.11,'99; June 30,09; Texas City, Tex.

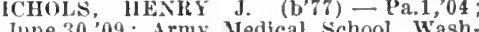
School, Washington

HANSON, LOUIS II. (b'iT) - D.C.1,04; June 30, 09 ; Manila, P'.I.
noPWO0 June 30,09; Presidio, San Francisco.

FREEMAN, CHARLES $\mathrm{E}$. (b'73)-ML.28, '9y; June 30,'09; Presldio, San Francisco. ('HMTTER, FERDINAND (b'

MACY, FREDERICK S. (b'76)-Mass.7,97; June 15,$10 ; \mathrm{Ft}$. Stcvens, Ore.

RCKKE, (iUY V. (b'67)- Ilich.1,04; June 15, 10; Jefferson Barracks, Mo.

'ILLSBU1', HENKY C. (b'81)-Mass.1, '06; June 15,'10; Jefferson Barracks, Mo. KING, EDGAR (b'84)-Ark.1,06; June 15, '10; Army II Ifical School, Washington.

CHRISTIE, ARTIUU C. $\left(b^{\prime} 79\right)-0.12,04$; June 15,'10 ; Army Medical School, Wash-

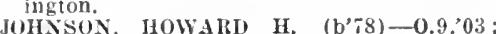
June 15,'10; Walter Reed General Hospital, Takoma, Park, Md.

BKYAN, KAY W. (蛹76)-Ky.4,97; June 15, '10; Texas City, Tex.

RICHARDSON, WLLIAN H. (b'76)-0.6, '01; June 15,'10; Ft. Miley, Cal.

BAKTLETT, WILLIAN K. (b'i8) - Pa.11, '03; June 15,10 ; Ft. Ethan Allen, Vt.

BAIBER, JOHN K. (b' 68$)-11.1,02$;

June 13,'11; Ft. IIuachuca, Ariz. (b'79) IIo.34,02; June 13,'11; Western Dept.,

San Francisco.
ASHFORD, MAHLON (b'81) - D.C.2,04 ; Jume 13, 11; Ft. D. A. Kussell, Wyo.

HUBElt, EDWALD G. (b'82)-Mich.1,05; June 13,'11; Army and Navy General Hospital, Hot springs, Ark.

LAIBIE, JOHX S., JR. (b'82)-Pa.2,06 ; June 13,'11; Haines, Alaska.

TASKER, ARTHUR NEWMAN (b'78)D.C.1, 06 ; June 13,'11; Ft. Hancock, N.J. SNYDEK, HOWARD IICC. (b'81)-1'a.2, 05 ; June 13,11 ; Ft. D. A. Russell, wyo.

COWLES, CALVIN D., JR. (b'80)-Md.7,05; June 13,11; Ft. Clark, Tex.

IICKINNEY, GARFIELD Lo, (b'81)-Pa.1, '06; June 13,'11; Ft. Caswell, N.C.

PHILLIPS, HIRA AI A, (b'83)-Ky.5,06 ; June 13,11; Ft. McIntosh, Tex.

HART, WM. L. (b'83)-Md.1,06; Sept.14, '11; Ft. Sam Houston, Tex.

COBÚRN, HENRY C., JR. (b'i8)-D.C.1,03: June 25, 12; Ft. Douglas, Utah. 


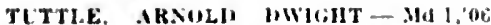
June 25,12 : Soldiers' Home Washlagun

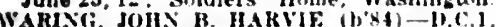
07 ; June 23,12 ; Ft. logan, Colo. DEAR. WULIAY KICHARD (b's) - l'a.1 06: June 25.'12: FT. Slocum. N.Y DOERR, CHARLES E- - 0.1,06; June 25,1 Fi. Thomas. Ky

CARD, DANIEI, PARKER (b'As)-N.Y.19, Got: June 25,12; West Polnt, N.Y. -Yass.1,06: June 25,12; F't. Hamillon. N.Y.

WBIGHT FREDERICK STARH (b'78) V.5.1,06 ; June 25,'12; Fl. Sam Houston. Tex.

HARMON. DANIEL WARWICK (b'BO) Va.1,03: June 25,12: Ft. Oglethorpe, Ga MAGES. JAMES CARRE, Pa2,05; June 25 , 12: Ft. Leavenworth. Kan.

SNow, CORYDON G.-IIIII.04; June 25. 12: Presldio, San Franclsco.

MCDIARMID, NORMAN L. (b';9)-10.1,0: June 25,12; Presidlo, San Francisco.

MCLELLAN. GEORGE HUDSON (b'8t)Ylch.1,07: June 25, 12; Ft. McDowell.

Cal. ALEX D-N.Y.19,03: June 25,12: Letterman General Hospltal, San Franclsco.

WILSON, JAMES ARTIUUR (b'80)-Mleh.1, '05: June 25,'12; Ft. Slocum. N.Y.

STAYER, MOKRISON CIAY (b'2) -Pa.2 '06: June 25,12 : Madison Barracks, $\mathbf{N}$. KERE. ROBERT W. (b'30)-Conn.1,03; June 25,'12 ; Columbus Barracks, Ohlo. June 25,12 ; $F$. Leavenworth, Kan.

GARCIA, LEON C. (b'82)-Mo.34,04: June 25,$12 ;$ Ft. Morgan, Ala

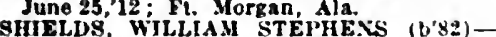
Pa.11,06; June 25,12; Texas Cily, Tex.

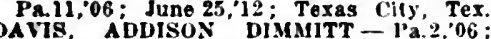
DVis, ADDISON DIMMIT
June $25,12:$ Ft. Hlley, Kan

SMTH, WILLIAM H.-Mo.2,06; lune 23, 12: Texas City, Tex.

PRONK, CLARENĆE E.-Mo.34,06 : June 25. 12: Texas Clty, Tex.

HEATII, GEORGE DAWSOS. JK.-Ky.Z, 07 : June 25,12 : chester $S \mathrm{C}$

BOWES, ALBERT S. (b'79) - Ill.6,03 ; June 15,13: Nanlla, Y.1.

(E.STRY EK.NEST R. (b'st)-hid.3,09 June 15, 13; Manla, P.

BFLEBOWER, HOY CLFELAND (b'84) D.C.1,06 : June 15,13 : Corregldor, P.I. EDWARIDS, GEORGE MARTIN (b"t) Pa.1,03: June 15,'13 ; Manlla, P.l.

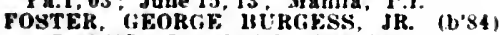
Pa.207: June 15.13; Manila, P.I

CASPER, JOSEPH-N.Y.1,06; June 15, 13; Manlla, P.I.

13; Manlia, $P$. 1 .

I. WELLES, EDWARD MCRRAY, JR. (b'8:
N.Y.20,07: June 15,13; Manlla, Pl. MeCORNACK, CONDON CAKLETON $(1,80)$ -Pa.2.04; June 15,13; Manlla, I'.l.

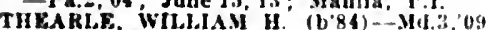
June 15,'13: Manlla, F.I.

JONES, GLEN IRVINE (b 83)-1). 1,105 June 15, 13: Manila P.I.

COOK. CEORGF W. (b's0) - I'a.1, 01 JUne 15;13: Manlla. P.l. Mich.1,06: June 15.13: Schoneld Hat racks, Innolulu, T.II.

KING. CHARIES TOMLINSOS (t,79) Pa.il:06; June 15,13; Vancourer IBat

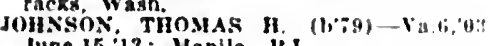
June. 15, 13 : Manlla, 1 , 1 .

AlLEN, WH,LAM HERSCHF,

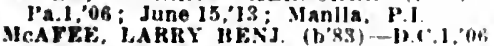
June is.13: Ft Sliafter Ilonoluh, T. II sune 15.13: Ft slarter: llonolulu, T.11 June 15,13: Pt. Shafter. Hontulu, $T$. II

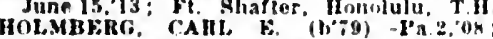
June 15,'1s; General Ilospltal. Ft. Hayast X.M.

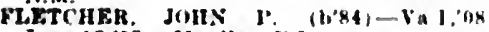
June.15.'13 Manlla, P.I

BASTION, JOSEPII E -11,2.2,06: Jun 18 13. Manlia. P.1.

WOODSON. THOMAS DUP'TYY (b'K2)-Mo.". 07 : June 15,13: Fe. learenworth, Kan COOPH. ALEXANIER TAYIOH (b's?)-

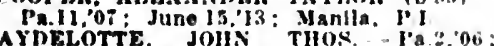
AYmELOTTE: Joll, THos
MAKIYY TAYLOR El'ABNE (l'AB) NA.1 04; June 15, I3; Manlla, 1'.1.

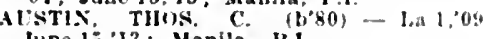
June,15,13: Manila, P.1.

WFEl) NAKK D. (b'81) I'a.2,05: June 15 13: Washington Barracks, Dic

KREMERS. FDWAKD WESTER (b'S1)Mich.1.03; June 15,'13; Ft. Shafter, Hono lulu. T.H.

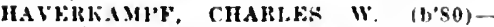
Kan:z: June 15.13; Manila, P.I.

MEEHY, HAHKY BEBEA (L'S2)-III.1.00 June 15. I3: Manlla, P.I.

NoCNT, JAMES R.-Mo.32,99; June 15,'13 Schofleld Barracks. Honolulu. T.It

HEYTOLIS, ROYAL (b'81) - I.a 1.06 Jume,15,13 ; Manlla, P.I.

Fox. JAilks s. $\left(b^{\prime}+9\right)-M d .1,05$; June $1:$ 13: Manlla, 1'.I.

H11... FEIIX R. (b'81) - La.1,08; Jume 15 1.3. Vanlla P.1.

HeYOE. MAIPII GODWIX (b's3) J'a.1, 08 June 15,13 ; Manila, 1'.1.

(CR1M. WAYXE H. (b'82) - Ky.9, 05 Iune 15.13 : Ft. D. A. Russell, Wyo.

MIJket, Joll A-Ia.3,0\%; June 15,13 Manila. P.I.

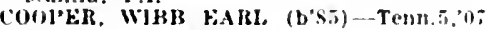
June.15,'13: Manila. P.I.

FERENRAEGH, THOMAS LIDOW (b81)Md :,09: June 15,13: F!. St. Niclael Alasina.

SHEEP', WILLIAM L.OYD (b'81)- I.C. 06 ; June 15,13; Lellerman General Hoipital. Presidio, San Francisco.

JONES. FDG.AR CLYNE (b'79)-1': 2.06 June 15,1:3; Texas Clly, Tex.

DAVIS, ARTHUR O.-Ne.1,06; June 15,'13 Manila. P.1.

KRAMER, FLOYD (b'84) - O.40,0S ; June 15, 13 : $\mathrm{Ft}$. Nckinley, Me

NAPIER EDWARI I. (b'83)-La.1,06 June 15, 13: Manila, 1 .

DAVIS, "W. COLE-Id I, 0 : IUne 15,'13 west point. N.Y.

\section{First Lieutenants}

WILLA VISOX, LIEWELIST P-Mo.1,97 Sept.2.'10: Cristobal. (C.z

CILTER, JOHN STANLEY (b'85)-l'a 09: Feb.2.'11 : Manila, P.I.

FocraR, FREUK. H.-N.Y.1,0i ; Feb.3,11 Army and Nary Hospltal, Hot springs. Ark.

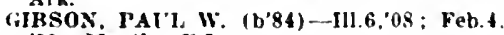
11: Manila. 1'J.

LAKE, GEOR(iE BI:RT (b's0)-111.1.02: Feb.5,'11; Manila, P.I.

CHLTON. FRANK NIFONG (bNo)-Mo.2. 09: Feb.6.'11: Manlla, P.I.

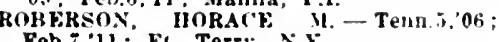
Feb.t11; Fo. Terry $N$ :

MDD, LFo $c$ (b'Ri) ${ }^{N}$. 11: Ft. Shafter. Ilonolulu. T.H.

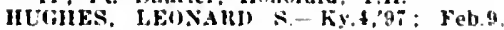
II: Manila, P.I.

WHIHAM, JAY DAsHl:L, (1).85)-Pa.1. 08: Feb.10,11: Honolulu, T.11

ARTEH. HENRY P.-Nd.1,03; Feb.11,11 Texas city, Tex

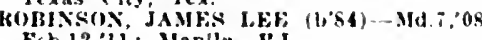
Feb.12,ii Janiln, P.I.

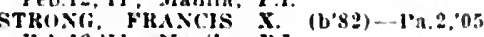
Feti 13,11; Manlla, i.I.

MClONALI, ROHERT CIARFNCE (bSI) L.a 1,09: Feb.14,'11; Fi. Kamelamelia. inonoluli, T.II

'IAAkE., HoWARD-La.1.05: Fuh 15.'11 Manlla, P.I.

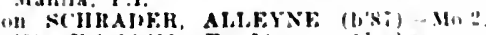
09: Fel.16,11: Fe. Liscum Mlaska.

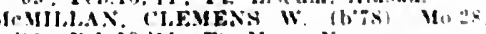

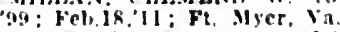

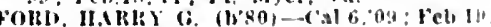
11: ('any) \%. s. olis, t'z.

Jollistor. Jines F.-Ala t.09; reb:1 11: Honolulu. T.II

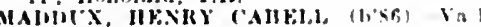
os; pei.ge, i1; Fi. Hayard, fil

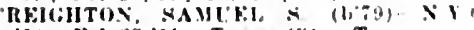

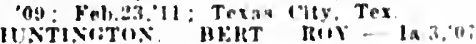

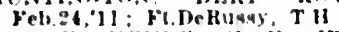

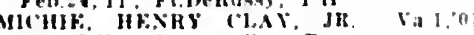
Fel 20,11: Texas 1'lly. Tex

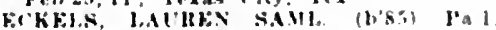
0y: Fett.26.'11: Ft tirant. Ariz.

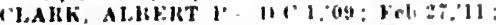

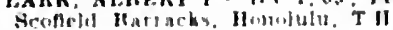

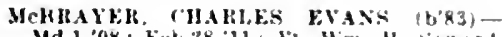

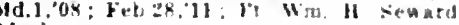
Alaska

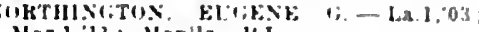
Mar.1,11; Nanlla, 1' 1

HALLETT, HARLEY JAMRS (b'RO) Da: 03: Mlar.2,11: (ialrestorn. Ter.

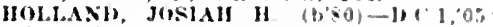
Mar 311 ; Manlla, [']

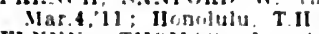

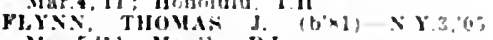
Mar.5,11: Manlla, P.I.

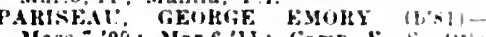
Mass.i.09: Mar.6.'1l; Camp E. s. enth

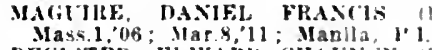

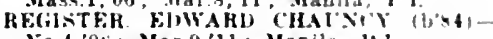
Va.4,0s; Mar.9,'11: Manila, 1'.1.

WILl.IS, JOHI M. $(1, \times 5)$ - 1101,04 Mar.10.11; Galveston, Tex.

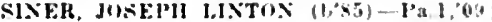
Mar.il,'ll; schofleld Barracks, Hono lulu, $T$ in

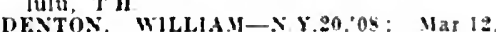
i1: Fi. Sam Irousinn. Tex

WAIKCP JOSEI'I 0 (b's5)-111.22,0s Mar.13,'11; 'ieneral Ilosutal, Ft. Mayard N.M.

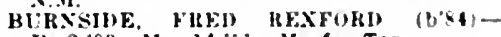
Pa.209: Mar.14.11; Marfa. Tex

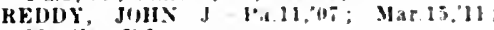
Manila, 1'.1

SHAHPE, HEHUET HEXIYY (b's3) X.Y.,06: Mar.16,11; Mt. Wintleid Scot? Cal.

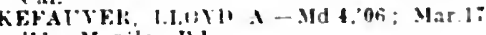

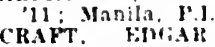

Mar.18,1l: Manlla, P.I

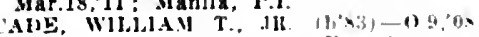
Mar.18,11; Prestelin, San Francikec.

MckNigit, JoH hor - I'a 2,06 Mar.19.'Il: Fi. Andrews, Mass.

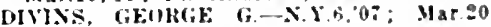
11: Sierra Blanca. Tex.

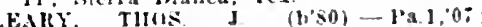
Apr.25.1: Walter Reed feneral IIosmital. Tiakma liask. Ild.

WoOn. NHAL NIRIMOKE (b's - - Nich 1 .

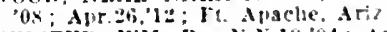

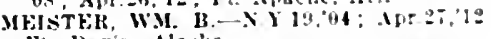
Ft. Daris, Alaska.

VCKELLAR, HALRY REX (li<t) - 1'az:10 Apr.28,12: Vancourer Bartack, Wash.

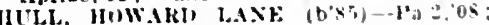
Apr.29,12: Washington.

TARLETOS, LEESOS o. (b'st)-Mass 10: Apr.30,12: Vancouter Barracks. Wast

MARIETTA, SHELALY $l$, (bS1) - 1111 wo: Hay l,1: (ieneril Hosplial, bt Hayari. $X$ is.

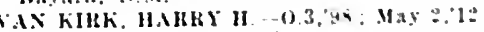
l'resuldin, Munterey, Ial.

SkEITUS, KoHT. (1,'so

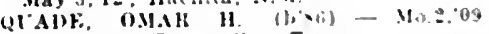

May t.1:: Texas riss. Tex

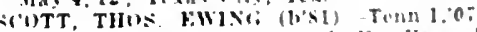
May 5,12: Cieneral llospltal ki Marand (II

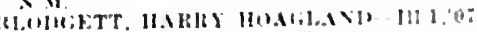
Gas i.12: Texas rity. Ter.

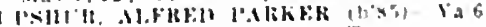
os: llas s.19: Texay rey. Tos

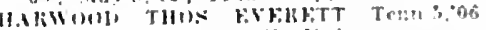

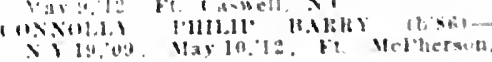

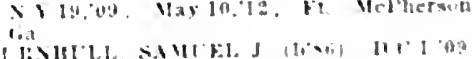

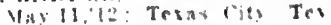

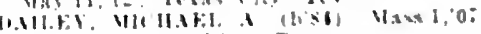
Na) 12.19: Pe Hllev. Tox

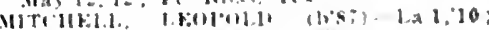

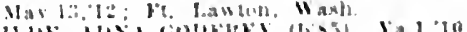

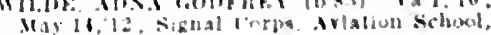
Sath lowero. in al

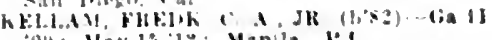

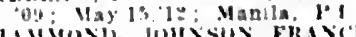

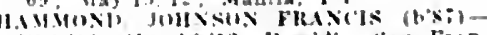
1!1 1:10, Nas 16.8:; Prealdo, san Fran

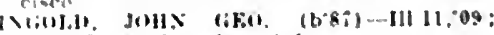

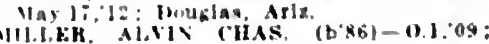
Ifyy 1s.l:; Aleatraz, Cal 
HAT; (IIESTER RAYMOND (b'83)-I'a.1, '09; May 19,'12; P'lattsburg Barracks, N. TRINLE, JOHN JOLMEA (b'81)-1'a.2,'04 May 20,12 ; Texas City, Tex.

IIII., W. E.-Wo.28,00; May 21,12; J.et terman Genoral Ifosjlal, I'resido, Sam Franciseo.

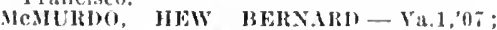
Iay 22,12 ; Ft. Jluachuea, Iriz.

BIRNHTT, TIIOS. WAlRI) (b's2)-N.Y.1, 08; May 23,12; Ft. Rosecrans, Cal.

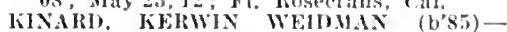
I'a.1, 08 ; May 24,12; Ft. Melntosh, Tex.

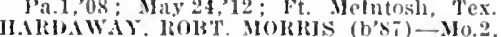
'10; May 25,12; Texas ('Ity Tex.

SIIERWOON, JOIIN WRSLF (b'S1)-D.C.1 os: May 26,12: Ft. BIiss, Tex.

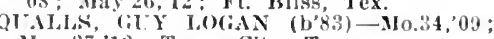
Jay 27,12; Texas City, Tex

13AYHA. JAM ES ERNEST (b's4)-1.1,10 ; May 28,12 ; Ft. Il. A. Russell, wyo.

CANTHEN (MAS. RUBY (b's6)-Mi).2,09; May 29,$12 ; \mathrm{lt}$. Columbla, Wash.

MeE.NEliY, DOV(;LAS W. (b'81)-l,C.1,09; lay 30,12; Washington.

MbEllA, JoII W. (b'84) - Nel, 6, 08 ; Ifiy 31,12; Ft. Sam IIouston, Tex.

WALSON, CIIAS. M. (b'83)-1'a.2,06; June 1,12; Texas City. Tex.

I'OT'ST, LUTHER R.AYTOND (b'85)-Pa.11, '09; June 8,'12; Ft. Bayard, N.M.

WARRivbl, BEN.I. B.-Va.6,90; May 8, 'li: Fit. Willams, Me.

IIERIBER', W.1. DEY (b'81)-I'a.2,09; May 9,'13; Ft. Sam IJouston, Tex.

SIITH, STFPIIEN IIARIRINoN (b'83)D.C.1, 'ob; May 10,13; Jresidio, San Francisco.

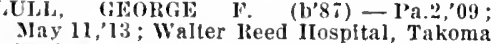
llay 11, 13 ; Walter Reed Ilospital, Takoma T'alk, Md. HLLMAN. CHAS. CIAIK (b'87)-Ill.1,11 ;
May 12,13; FL. Myer, Va.

CHAP'ELI, SIDNEY LOVETT (b'86)D.C.1,09; May 13,13; Ft. Bliss, Tex.

NeFARLAND, FlitCHER OI.IN (b'so)Ill.1,'10; Miay 14,13; - t. D. A. Russell, 115o.

AIE, ILARRY LOUIŚ (b'86)-Ill.1,'11 ; M. 13 ; Hachita, N.M

CHOENLEIBER, AIVIN W. (b's6)-III.11, '11: May 16,'13; Ft. D. A. kussell, Wyo. 0.41,10; Hay 1;,13; Ft. Riley, Kan.

CALLFXDER, GEO, RUSSEL, (b'84) Mass. T,08; May 18,13; Ft. Bayard, N.M. May 19,13; Presidio, San Francisco.

BLISS, RAYMOND W. (b'88)-Mass.7, 10

May 20,'13; Nogales, Arlz.

BLI.I. RAYMONI) ('. (b'82) - Pa.2, 09 Nay 21,'13; Texas City, Tex.

KIRK, YoRMAN TIIOS. (b'88)-IId.1,10;

May 22,'13; Texas City, Tex.

May 22,13 ; Texas City, Tex.
BORINEN,
WM. Md.1,06

BORIEN, 13 ; Soldiers' HENI. - Md.1,06;

CIMHIFG, RoYAL EDWIN (b'81)Tenn.1,03; May 24,'13; Ft. Sam Houston, Tex.

BELL, CLARENCE RALPH (b'83)-Mo.34, '04; May 25.'13; Ft. Bliss, Tex.

DUENNER, ROBT. HENRY (b'83)-D.C.1, '10: May 26,13; Ft. Oglethorpe, Ga.

DUCKWAIL, BERTRAII FOSTER (b'89) Mich.1,'11; May 27,13 ; Ft. Sill, Okla.
FIEIDEN, JoHN S. C., JR. (b'S8)-Pa.2, "10 : May 28,13; Ft. Du Pont, Del. HARRIS. HALBERT PORTER (b'82)-Va.6, '09; May. 29,'13; Ft. Apache, Ariz.

\section{MEDICAL RESERVE CORPS}

First Lieutenants

(On Active Duty.)

BROWX: IRA C. (b'61) - N.Y.6,'s8; July 7,08 ; Seattle, Wash.

HEREFORD, JOHN R.-Mo.2,'83; July 7,08 ; Manila. P.I.

EBER, ALBERT H.-Mich. $7,9 \tau$; July 7,08 ; Ilanila, I'. I.

STEMINS, CHARLES HENRY (b'69)Mo.24.'91 ; July 7,'08; Ft. Ward, Wash.
ARTAUI, FRANK EDWARD (b'69) - La.1, '84; July 7,08: Ft. Gibbon, Alaska.

TENNFY, ELMER SETH (b'70)-N.H.1,97 ; July 7,08 ; San Francisco.

KENNEDY, JAMES S. (b'57)-Pa.2,'80; July 7,os; Ft. Barrancas, Fla.
SIARRFNBERGER, FREDEIICK II. (b'72) Tenn.11,'90; July 7,08; Ft. Mackenzle Wyo.

MecokD, DONALD P.-No.27,'94; July 7 $08 ; 1$ t. Sereren, fia.

I'IIELAN, 11ENRY du 1R.-Cal.2,'93; Fra.6 '03: July 7,08; Ft. Barry, Cal.

PECK, IUKE I3. (b'66) - Mass. 7,97

Iuly $7,08:$ Ft. Mcade, S.D

IASCOE, IAMES B.-N.Y.10,94; July 7 08 : Ft. Warren, Mass

LOWE, THOMAS S.-MIL.s., 37 ; July 7,08 Manila, I'.I.

L. IIARDY JELIUS C.-Ga.1,93; July os: Benicia Arsenal. Cal.

WA'KINS, V'lCTOL E. (b'71)-D.C.2,'94 July 7,0s; key West Barracks, Fla

IIARRIS, HERBERT I. (h'74)-X.Y.6,98 Iuly is.08; Washlugton.

NEWLOVE. GEORGE-P'a.11,'98; July Mantla, r.I.

BAKEI, (IIARLES L.-Va.1,97; Iuly 7,'08 Ft. liuger, Ionolulu, T.H.

MILLS, FREDERICK IIUBBELL (b'71)J'i.2,?4; July 7,08 ; Manila, P.I.

IIOGiN, 'DAVID DURWARD - J11.1, 96 July ,os: $^{2} \mathrm{t}$. Yellowstone, Wyo.

1'ATERSON, EDWIN w. (b'70)-D.c.1,96 July $\tau, 08 ;$ Ft. IIunt, Va.

BELL, LEONARD P.-Ind.9,'92; July 7,'08 Manila. I'I.

MeColy, THOMAS B. (b'68) - Jll.6,'93 Tuly 7,08 ; Manlla, P.I.

BOWMAX, MADISON II.-AId.4,92; July 7 , os; Manila, P.I

WML, FRIXCIS M.-Ky.1,88; July 7,'08 Ft. Lawton, Wash.

GRIFFIS, FRANK C.-0.25,'96; July 7,08 Ilenry Barracks. Cayey, P.R.

STYCKEY, HARRISON W. (b'74)-Ill.15 97; July 7,'08; Manila, P.I.

ANDERSON. EVERETT A.-0.1,89; July 7

'OS; Manila, P.I.
HEWITT, JoIN MCIIA
.Tuly $\tau, 0$; Manila, P.I.

Tuly $\pi$ '0s; Ianila P.I ROBERTS, ERNES'T F. (b'78)-Mo.27,'99; July T,08; Ft. Caswell, N.C.

FARliow. EDGAR JAMES (b'71)-Cal.2,'00 July 7,08 ; Ft. Morgan, Ala.

COFFEY, ALBION MICD. - Mo.20,'97 July 7,08 ; Manila, P.I.

YEMAN', HERBERT iVM. (b'57)-MIJch.2, '78; Iuly 7,'08; Manila, P.I.

WALKER, TIIOMAS CARL (b'71)-Va.4 95: July 7,08: Ft. Rodman, IIass.

BIERBOWER, HENRY C. (b'74)-Neb.6, 00 July 7,08 ; Manila, P.I.

IIENNING, OSWALD F. (b'78)-Ill.1,04 July 7,08 ; Monterey, Cal.

HALLIDAY, CHARIES H. $\left(b^{\prime} 80\right)-M d .3$,

CULLEN, CIIARLES W. (b'76) - 0.1,00

July $\tau, 08 ;$ Ft. Constitution, N.H.

STALIMAN, GEORGE PHILIP (b'76)Ind.1S,06; July 7,'08; Manila, P.I.

BAYLEY, EDMUND' W. (b'75)-Kan.4,'98 July $:, 08 ;$ Manila, P.I.

INCOLN, HENRY F.-Mo.2,05; July $\%$, $0 \mathrm{~s}$ Ianila, P.I.

FREFI,AND, IIERBERT L. (b'76)-IIo.34 06; July i, 08; Ft. Mlott, N.J.

ARCHER, WILIIAM M., JR. (b'78)-Va.4, '04; July 7,08 ; Ft. St. Philip, La.

WESTON, HENRY REUBEN (b'78)-N.Y.19 03; July 7, 08; Manila, P.I

NEWTOX. RAIPI WALDO - N.Y.5,98 Sept. 23,08 ; Manlla, P.I.

FOLEY. TIIOMAS MADDEN (b'76)-D.C.1 '05: Sept.25,08; Manila, P.I.

HFNRY. ZIBA LINDLEY (b'72)-0.3,'96 ; Sept.30,08; Manila, P.I.

GIFFIX, ADOLPHE M. (b'76)-Md.9,03 : Apr.23,09: Marfa, Tex.

PHILIPS, HENRY FULI,ER (b'81)-Tex.2 '07; Aug. 18, 09; Washington.

SIMPSON, JAMES ASA (b'74)-Tenn.5,00 : Sept.11,09; Ft. Moultrie, S.C.

LAVANTURE, LEWIS ADOLPHUS (b'82)Ill.19,'06; Sept.11,'09; Ft. George Wright. Wash.

MILTENBERGER, VAI, F. - Mo.34,04 Sept.11,09; Ft. Omaha, Neb. BRADLEY, JOHI RUSKIN (b'79)-N.Y.20,
07; Sept.15,09; Manila, P.I.

PENROSE, THOMAS W. (b'80)-Pa.2,06 ; Sept.22,09; Ft. D. A. Russell, Wyo.

HAINES, EDGAR FREMONT-Mass. 5, 06 ; Sept.23,'09; Military Prison, Ft. Leavenworth, Kan.
CHRISTENSEN, WALDFMAI ALFItED (b'68)-Ky.1,06 ; Dec.3,09; Ft. Huachuca, Arle.

MAYNARD, EDWIN BROOKS (b'86)-Va.1, Fis Mar., 10 ; Manlla, P.I.

AIS, CIIARLES JOIIN (b'85)-D.C.2,09 Mar.27,'10; Manila, P.I.

OMiBARI, MARION SUNSAIRI-Neb.6,'10 Apr.6,'11 Manila, P.I.

SIFA, WM. E. (b'80)-D.C.1,05; Apr.21 BUIRCiIA.I, TIIOS. A.-Ia.6, 06 ; Apr.28,'11 Fit. Des Molnes, Ia

KFENE, TIIOS. B. V.-Mich.1,02; May 12 'I 1 ; Indianapolts.

NGwBERRY, NRANK H.-May 12,11; Ft. Wayne, Mlch.

WEISSTER, EVII, HENRY (b'69)-Ont.3, 90 ; May 12,11; Sault Ste. Marie, Mlch. FETTEItoLF, IANI. IV. (b'63)-Pa.1,'93 June 3,11; Medical Supply Depot, New York City.

CARJ3ONELL, ARTURO (b'87)-Pa.2,'11; Feb.13,'11; San Juan, P.R.

DI LANNEY, ENILE L. (b'72)-Neb.6, 01 Mar.25,'12 ; Ft. Crook, Neb.

IKATT, JOIIN M. (b'84) - Pa.1,08 Oet.5.'12; Army Medical School, Wash.

ington. Feb.11,'13; Army Medical School, Washington.

THODE, E. FREDK. (b'88)-N.Y.19,'11; Apr.1,13; Army Medical School, Washington.

BEAVEN, COLNRIDGE L. (b'85)-Md.4,08; Iay 30,'13; Army Medical School, Wash-

Ington. May 30,13 ; Army Medical School, Wash. ington.

ANDERSON, JOHN B. (b'86)-Tex.2,'12 ; Apr.30,13; Army Medical School, Wash: ington.

BAUER, LOUIS H. (b'88)-Mass.1,'12; Aug.25, 13; Boston.

CANNISG, AUSTIN J. (b'87)-Pa.1,11 Aug.25,'13; Army Medical School, Wash-

ington.
DAVENPORT, WALTER P. (b'88)-IIl.11, '11; Aug.25,13; Army Medical School, Washington.

DIETRICH, FREDK. H. (b'87)-N.Y.1,10 Aug. 25,'13; Army Nedical School, Washington.

GANDY, CHARLES L. (b'89)-Mich.1,'12 ; July 3,13 ; Army Medlcal School, Washington.

GUTHRIE, WM. G. (b'84)-Vt. 2,'10; Aug.25 '13; Army - Mledical School, Washington. July 3,'12; Army Medical School, Wash-

ing CONITE, RALPH M. (b'88)-D.C.2,10 : Aug. 25,'13; Army Medical School, Washington.

SCUDDER, JOHN H. H. (b'83)-Pa.2,10 Sept.19,'11; Army Medical School, Washington.

VON KESSLER, WILSON C. (b'84)-Pa.11, Washington. WEBB, LANPHEAR, W., JR. $\left(b^{\prime} 86\right)-$ Pa.1,

Washington.
WILILAIS, ALEXANDER W. (b'84)-MId.7, '12; Aug.25,'13; Army Medical School. Washington.

\section{RETIRED LIST}

NUMBER OF PHYSICIANS, 88.

\section{Brigadier-Generals}

ALEXANDER, CHARLES T. (b'33)*Apr.23,04; 1640 Connecticut Ave., Washington.

CLEARY, PETER J. A. (b'39)-Eng.14,'60 ; Aug. 7,$03 ; 2708$ McCallie Ave., Chattanooga, Tenn.

FORWOOD, WILLIAM H. (b'38)-Pa.1,61 Sept.7,02; 1425 Euclid St., N.W., Wash-

Ington.
IRWIIN, BERNARD J. D. (b'30)-*Apr.23, 04; 32 E. Division St.; Chicago.

MOSELLEY, EDWARD B.' (b'46)-Pa.1,'68; May 10,07; Hollywood, Los Angeles, Cal. STERNBERG, GEORGE II. (b'38)-N.Y.1, '60; June 8,'02; 2005 Massachusetts Ave. N.w., Washington. 
WLсох, тімотиY E. (b'40)-Apr.26,04 1841 Callfornia Se. N.W.. Washington. WOODHULL, ALFRED A. (b'37)-P'A.1,59 Apr.23.04; 16 Bayard Lane, Princeton. Ni.J. Colonels

ADAIR, GEORGE W. (b'43)-Feb.25,09; Fayeiteville, Ohlo.

FYRNE, CHARLES H. (b'46)-Pa.1,6i: Jan.28, 10: The Wyoming. Wishington. GARDNER, FININ F. (b'is)-N.Y.1,'5;

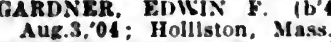

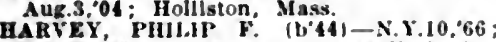
Dec. 12, 08 ; 114 E. fith St., New York Clty

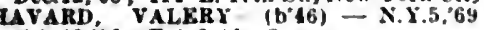
Yeb.18;10; Falrfleld, Conn.

HEIZIIANN, CIIARLYS Io, (b'46)-Pa.1,'6? Mar.31,08; 37 Presldlo Ave., San Fran elaco.

nORTON, SAMUEL M. (b'38)-*Apr.23,04

Tow Broad St, Boston. $\left(b^{\prime} 36\right)-$ N.H.1,60 ; Och.io,'96: Lancaster, N.II.

NINE, CHARLKS $K$. (b'38)-*Apr.23,04:

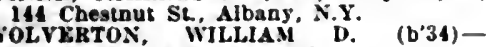
*LVRERTON, WILLIAM

GIRARD, JOSEPH B. (b'46)-Mich.1,'6i Dec.26, 10; 719 Carson St, San Antonlo, Tex.

BANISTER, JOHN M. (b'5t)-Va.1;8; Dec.31,10; Brandels Theatre Bldg.

TAYLOR, BLAIR D. (b'48)-Va.1,69: N.Y.5; 0 ; Apr.30,11; 755 Pledmont Ave. Atlenta, Ga

APPEL, AARON H. (h'56)-Pa.2,'78 June 6,11 ; 785 Cniversity St, Montreal, Que.

HOFY, JOHN VAN R. (b'48)-N.Y.3,'1 X.Y.1,74; Apr.11,12; 2112 Massacbusetts Are. Wasblngton.

DAVIS, WM, B. (b'\$3)-Va.1,70; Aug.5,'12 Baltimore.

GRAY, WM. W. (b'50)-N.Y.10,75; Dec.6。 12: stanford University. Cal.

LA GARDE. LOUIS A. $\left(b^{\prime} 49\right)-N .1 .10,72$ Apr.15,13; 2624 Woodley Pl., N.W. Washington.

\section{Liautenant Colonels}

BARTHOLF, JOHN H. (b'30)-N.Y.1,'54 Apr.23,01; Plattsburg, N.Y.

BENTLEY, EDWIN (b'2t) - N.Y.10,7 Apr.23,"04; 113 E. Capitol Are., Litle Rock. Ark

BORDEX, WILLIAM C. (b'58)-D.C.1,83 Jan.1,09; 1801 Callfornla St., Wasblag.

CORBUSIER, WILLIAM II. (b'44)-N.Y.10 '67; Apr.10, 08; 612 Park Are., Plalnfeld,

CROXKIITE, HENRY M. (b'34)-X.Y.3, $\Delta$ pr.23,04; 100 W. 80th St., New York City.

Gibsox RoBERT J (b'54)-Conn.1'79:

Jan.1;10; 152 Marshfeld St., New llaven. Jan.1,
MFAKNS, FDGAR A. (b') Jan. 1,09: The Nortbumberland, Washln: ton.

MORRIS, F.DWAKII R. (b'53)-X.Y.10,81; Yeb.26,09; 2006 Columbla Rd., Washlugton.

d'ATZskl. JULIUS H. (b'38)-Pa.2,6i: Apr.23,04: Florence Court, Washington.

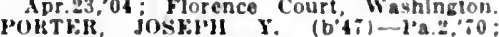
Mar.s.07; Key West, Ha.

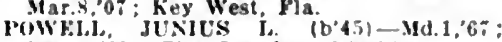
May 1,0\%: The Dresden, Washinglon

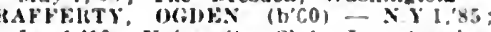
Jan.1,10; University Club, Los Angeles, Cal.

SIILIOCK, YAUl, (b'63) - N.Y.1,8i ; Jan.I, $10 ; 812$, th St.. S.K., Minneapolis.

WOOD, MARSHALI, W. (b'46)-III.1, 'T; Apr.23,04: Sunnyside. Ida.

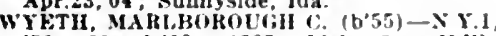
8 May 1,08; 1823, 19th St. N.W.,

PURVIATCF, WM. E. (b'65)-l'a.2,89: Aug.6,'12; 432 S. Main St., l.os Angeles.

Wol. 86; July 12.13; East Chester Kd., New Kocbelle, Ni.

BARNEY CII Majors

CHARLES $N$ ( $\left.b^{\prime} / 2\right)-\bullet$ Dec.31 Coles Bldk. El laso, Tex.

CAITER, W. FITZHIGH $\left(b^{\prime} 50\right)-V^{\prime} a .1,72$; July 8,09; Crozet, Va.

EGAN, PETER R. $\left(b^{\prime} 55\right)-* A p r .2,06 ; 2$ Chenles St. (or Gower St.), London, W.C. Eingland.

EWEN, CLARENCE (b'43)- Jan.26,'9i City Hall, New York Clty.

EWIXG, CHAKLES b. (b'58)-Mo.1, 99 Nor.16.09; 400 E. Fayette St., Baltimore.

ARIR. CHARLES W. (b'76) - Ta.2, Jan. I,'10; 20 Waller Ave., Ossinlng, \$.Y. Jan.16,09; 2717 Kenwood Are., Los Angeles, Cal.

KXFEDLER, WLLLAM L. (b'56)-Pa.2,79; July 11,06 ; Coronado, Cal.

NEWGARDEX, GEORGE J. (b'6t)-Pa.2 '89; Apr.24;07; 1633 Massachusetts Are. Washington.

OWEN, WILLIAM o. (b'54)-la.1,is washington.

QUINTU., WILLIAM W. (b'70)-N.Y.1,92; Feb.26,09: 232 Elmwood Are., Buffalo.

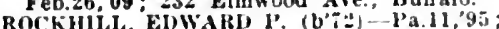
Feb.26,03: Central, N.M.

Feb.26,09: Central, N.M. ${ }^{\prime}$ (1) - 1).C.1,76 Apr.23,04; 3356. 18th St. N.W., Wash.

Ington.
SKINNER, JOHX o. (b'45) - Md.1.,66 Oct.26,"93; Columbla Hospltal, Wasbing ton. HENRY R. (b'66)-Conn.1, $\$ 8$

July 1;05: Chatham, Conn. June 20,11 : 105 i Gorernment st., Moblle, June.

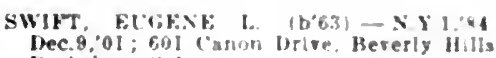
Herkeley, ("al

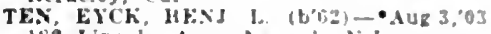
182 Lincrin Ave. Jrwark. NJ

Jan.i.09; inos Connecteut Are. Wast Ington.

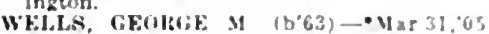
t2 26 College Ave. Indlanapolis.

wownsox, k Ave. Indlanapolis. Tenn.1, sy; Apr.7,10; 3d and Mlise ste sit. Jouls.

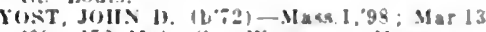
09 152 Main st. Worcester, Mass

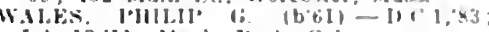
July 13,11: Menlo rark. Cal.

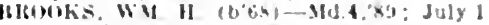
13; 600 Market st. San Franclsco.

\section{Captains}

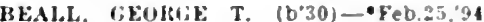

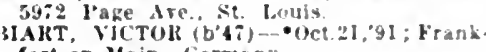

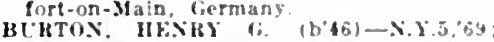
Feb.5,92; 271,231 st., Oakland. Cal

CABELL, JILAX M. (b) Mar.29,997: 1730 M St., X.W. Washing ton.

CHAPIN, A1.0NZU is. $(1,59)-111.1,33$ May $10.95 ; 381$ s. Catalina Are., l'ass dena, Cal.

CHERBOSTIEls. ANBREW b. (b'26)- Oct.12,90: 2116 St Paul st. Ballimore. CI,OLI). MARsllAl. M. (b'68)-\$o.8, 92 Nor.14,01; Grosse Bidg. Las Angeles. Cal.

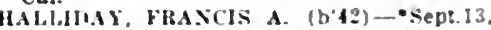
03 ; Bryant lldg., Kansay Clty. Mo.

JARVIS, NATIHAN S. $\left(b^{\prime} 60\right)-$ N.I 10,84 ; July 12,01; Manhattan Club, Madison Square New York City.

JEAN C;EORGE W. (b'it)- Nov.6,06; 122 F. 3tth St., New York City.

MINol: WILLIAM C. (b'35)-Conn.1.63: pec.15.70; Adjutant General's once. Washington

ROHFITS. WILLIAM (b\%2) - Mal.90 July 15,06; 22216 N. High St. (n)lum bus, 0 .

111L.L, F.HE ( '13: College ire. Poughkeepsle. $\mathbf{X}$

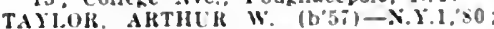
Feb.5.92; Nordhor. Cal.

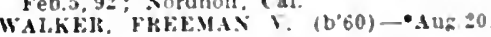
06: Butrion, SC'

WEIRICK SAYLEL T. (b'43)-•June IR 06: 1313 Lollins St, Haltimore. Md.

First Lieutenants

GFFR, CHARLES C. (b'43)-DDec $\$ 1,04$

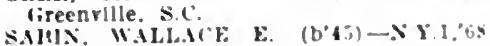
June 16,09: Anna, 111.

Fisk, OWr: C. (b:A)-0.1.0?: Feb.l.13: iisti Listun Are. Riretside, l'meinnati

\title{
MEDICAL OFFICERS OF THE NAVY OF THE UNITEIS STAKS
}

\author{
With lear of Blrth, Medlcal College and Vear of Graduatlon, and Nillewe
}

\section{ACTIVE LIST}

STMRER OF PHYSICIANS, 411

\section{Surgeon-Genera}

With rank of Rear Admlral STOKEs, CHAS. F. (b'63)-N.1.1,'94: Wash. Inston, U. C.

Medical Diroctors

With rank of Cajtaln

GIREN, BIWWALD IIARISIS (b's3)-Ya.I. 72: Waululngton.

ANIFESON, FIANK (b'52)-N.1'1,74

Washington.
Durosio, Willald R. (b'34)-Va 1,75:

Wiashington.

GATEWO()D,

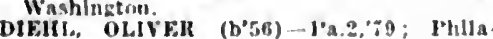

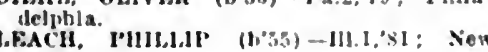
jork cliy.
CURTIs, 1.1.0YD W. (b'56)-Ia. so: New

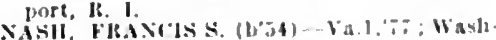
lingtion.

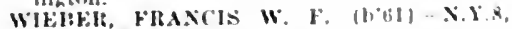
81: Hoston.

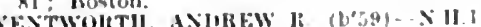

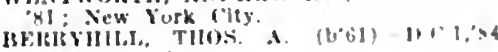

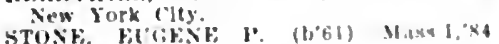
Wastingenen

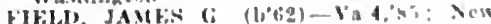
imet, It. I.

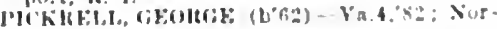
folk. lia

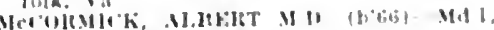

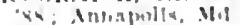

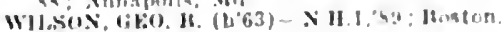
Medical Inspeciors

Will rank of cumpruameles

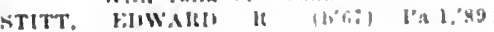
Washington. (i) TH: MANB) ह (t) Ixlandi, ial

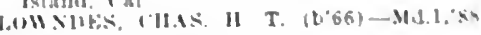
Wabling urler

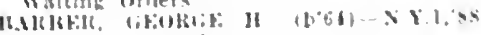

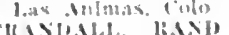

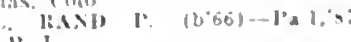

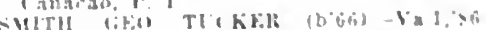

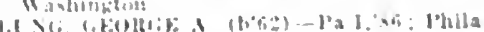

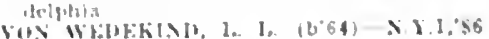
iivalingteul. Wavbingterh

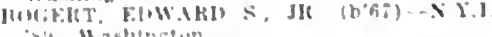

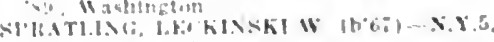
(on). Illanla. lin

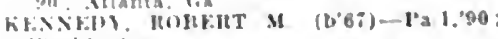
IIs.hincton.

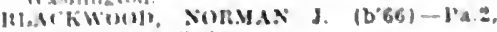

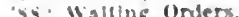

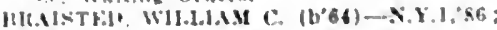
II a vhlmglon. 
FVANi, SHELDON, (i. (b'69)-Md.3,'90 ; Wushlngton.

ALFRED, ADHIAN IR. (b'64)-Mich.1, 89 Indlan liead, Md.

\section{Surgeons}

With rank of Lleutenant Commander DEVALIN, ('IIAS. M. (b'69)-I). ('.1, 41 ;

Washington.
BROWNELL, CAlRL DeW. (b'66)-N.'.5,'88; Washlugton.

WILSON, IIENRY DEIANO (b'ti)--Pa.1, 89 ; Boston.

MOHRIS, HEWIS (b'67)--Md.l,94; Washington.

SHPP, स⿴囗十 Washington.

HIGGS, ClIAs. E. (b'69)-Ia.3,92; Washington.

LEYS, JAMES F. (b'67)-I'a.1,90; Newport, 1 . 1 .

cook, FRANK C. (b'69)-Mass, 1,93; Hremerton, FANK

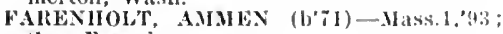
San Frauciseo.

KINDLHBEGER, CHAS. l'. (b'70)-P'a.l 94; Guam.

DUNBAk, ARTHUR W. (b'69)-Cal.2,'91 ; Washington.

RichaltDs, TILE. W. (b'70)-D.C.1,93: Washington.

JOIINON, MOELTON K. (b'69)-Ya.1,95; Newport, R. I

WHELLEIt, WM. M. (b'74)-Vit.1,95; Norfolk, $\mathrm{Va}$.

EI,IOTT, MIDDLETON $\rightarrow$. (b'72)-I), ('.1 '94; Washington.

PLEADWELL, FRANK L. (b'i2)-Mass.I, 96 : Washingtón.

CARIENTER, DUDLEY $\times$. (b'it)-Mass. 1 , 96 ; Washlington.

PRYOR, JAMES C. (b'-1)-Tenn.5,'94 Washlugton.

GROVE, WASHINGTON, B. (b'75)-Ya.1,

SPEAR, RAYMOND (b'73)-1'a.2,'95; Washington

THOMPSON, EDGAR (b’て2)-No.24,'93: Guantanamo, Cuba.

OENXIS, JOHN B. (b'74)-Pa.1,95; Washington.

GROW, EUGENE JULLU (b'73)-N.H.1,

I.ANGHORNE, CAREY D. (b'73)-Va.1,97; Wasbington.

THOMPSON, JOSEPH C. $\left.(6)^{\prime} 4\right)-$ N.Y.1,96; Washington.

BENTON, FREDERICK 1. (b'75)-N.Y.I,

'96; Norfolk, Va.
GARTON, WHL MI. (b'75)-Ia.4,'96; WashGARTON, WHLL M. $\left(\mathrm{b}^{\prime} 75\right)$-La.4,96; Wash-

McCULLOU(iH, FRANK E. (b'70)-Cal.2, 91 ; Waslington.

FURLONG. FRANCIS M. (b'73)-D.C.2,'95 ; Washington.

ORVIS, RALPH T. (b'72)-Cal.1,93; Las

ANGENY, GRANVILLE L. (b'68)-Pa.1,94; Washington.

BELL, WM. HEMPHILL (b'73)-Pa.1,'97; rhiladelphia.

CURL, HOLTON C. (b'72)-Cal.2,'97 ; Mare Island, Cal.

HOLCOMB, RICHMLND C. (b'T4)-N.Y.s, '96; Washington.

PARKER, EDWARD G. (b'70)-Mass. 1,'98;

Annapolis, IId.
WRIGHT, BARTON $\quad$ L. (b'70)-Pa.1,95; Portsmouth, N. H.
ODELL, HENRY E. (b'i1)-Mich.1,95; Mare Island, Cal.

TAYLOR, JAMES S. (b'70)-Va.1,94; Chicago.

MU15PHY, JOSEPH A. (b'76)-Pa.11,9s; san Franclsco.

KENNEDY, JOHN T. (b'73)-N.Y.5,94;

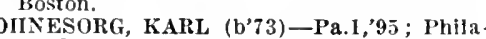
delphia.

FISliE, CHAS. NORMAN (b'76)-Mass.1, 00 ; Washington.

PLUMMER, RALPH W. (b'74)-H.1,97; Washington.

SNYDER, JOHN J. (b'69)-Md.3.'93; Philadelphia.

BLACKWELL, EDWARD M. (b'65)-Md.1, Washinirton.
BOGAN, FlRED M. (b'71)-D.C.1,93; Portsmouth, N. H

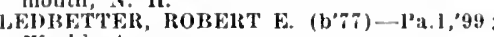
Washington.

BUTLFR, CHAS. ST. J. (b'75)-Va.l, 97 ('anacao, I'. I.

WHIIAMS, RICHARD B. $\left(b^{\prime} 75\right)$-Va.I, 98 ; Sorfolk, Va.

mODMAN, SAM'L S. (b'7 $)-K y .1,98$; BISETEK, JoliN M. (b'7z)-l'a.11.98; Washington.
Wast

Washington.
SIIIFFERT, HERBERT o. (b'72)-Ya.11, '99; Norfolk, Va.

PE(K, AILAN E. (b'73)-('al.1, 00 ; San Franclso.

SMITI, CHAs. G. (b'78)-Va. ,'99; Wash lington.

IIEN, Joll H. (b'74)-Va.I,'99; Annapolis, $.1 d$.

SFAMAN, WHLLAM (b'71)-1'a.1,92; Waslinirton.

RI(IIARl)SON, ROYAL R. (b'75)-I'a.1,99;

Wasington.

WSELlisox, FREDK. A. (b'79)-Va.1,99;

Washlngton.
DUN, 11ENRY A. (b'73)-D.C.I,'97: Washington.

STUART, ALLAN (b'64)-S.C.1,89; Wash ington.

STEPP, IACOB (b'6i)-Mass.1,98; Washlngton.

TOLFREL, HERBERT M. (b'ï)-N.Y.10, 97 ; Washington.

BHSIIOP, LOUIS W. (b'72)-N.Y.8,96; New Fork City.

NAUNTIEROY, ARCHIBALD Ir. (b'i 6$)-$ Va.1, 01 ; Washington.

WEBB, ULYYS R. (b'74)-D.C.1,00; Olang apo, P. I.

OMAN, CIIAS. M. (b'78)-Pa.l,'0I ; Washington.

BACHMANN, ROBT. A. (b'72)-111.1,00 ;

TRINE, HOWARD F. $\left(b^{\prime} 78\right)-$ N.Y.19, 02;

HOYT, RóRT. E. (b'79)-Mass.1,01 ; Wash-

ington.
TRAYNOR, JOSEPH P. (b'78)-Me.1,01, Washington.
IURPHY, JOHN F. (b'76)-Mich.1, 00 ; Washington.

BACKUS, JESSE W. (b'79)-Ill.I,'99; Bremerton, Wash.

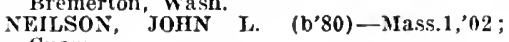
Guam.

DEAN, F. W. S. (b'74)-Tenn.11,98; Pa.2, '0I: Washington.

EFY, CLARENCE F. (b'79)-Pa.2, 02 ; Tutulia, Samoa.

DYKES, JAMES R. (b'73)-Va.I,'97 ; Washington.

GEICER, ALBERT J. (b'76)-Mich.1,02 ; Washington.

ROSSITER, PERCEVAI, S. (b'i4)-MI.1, 95: Washington.

RENNIE WESLEY H. (b'76)-Pa.9,'97; Washington.

HOEN. WAITER S. (b'77)_Va.1,02; Mare Island, Cal. GRIEVE, CHAS. C. (b'73)-Mich. 1,01; Las
Animas, Colo.

MANCIIESTER. JOHN D. (b'75)-IH.1,'99; Washington.

WOODWARD, JAMES S. (b'80)-Md.4,01 ;

Olongapo, P. I.
RANDAI, JAMES A. (b'77)-Ga.11,01; Cavite, P. I.

\section{Passed Assistant Surgeons} With rank of Lleutenant

MUNSON, FRANCIS M. (b'78)-Pa.I1,'99; Washington.

RYDER, CHAS. F. (b'74)-Mass.1,'98; Washington.

MeLEAN, ALLEN D. (b'73)-Mich.7,'95; Washington.

ABEKEN, FREDERICK G. (b'7 7$)-\mathbf{M o . 2}$,

'99; GUam. WINFIELD S., JR. (b'80) Pa.2,'01; Washington.

GHLL, JAMES E. (b'i8)-D.C.2,01; Camp Grove, Ill.

REEVES, ISAAC S. K. (b'81)-D.C.2,'03;

Washington.

ton.

JENNESS, BURT F. (b’76)-N.H.I,'99; Slck Leare.
HFINER, ROBT. G. (b'77)-Va.1,00; Guantanamo, Cuba.

STOOI's, IOOHT. EARL (b'78)-Ii.11,02; North Chleago.

DORSEY, BLNJ. It. (b'78)-Md.1,01 ; Camp Eillott, canal Zone.

HELl. HARIR F. (b'75)-N.Y.3,'99; Bremerton, Wash.

WICKE, GFO. I. (b'74) -N.Y.5,96; New York city.

BROWN, IIARRY LEE (b'75)-D.C.I, 01 ;

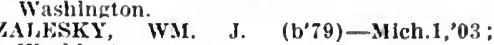
Washington.

WHFELER, LEWIS H. (b'76)-Conn.I,'97; l'ortsmouth, $\mathrm{N}$. H.

MAY, HENRY A. (b'74)-D.C.1,99; Wash. ington.

OWENS, WM. 1). (b'79)-D.C.2,01; Manacua, Nlcaraugua.

ANGWIN, WM. A. (b'79)-Ca3.7,03; Norfolk, Va.

MINK, OWEN J. (b'79)-Mich.1,04; Wash-

PORTER, FREDERICK, E. (b'75)-Tenn.5, '01: Aslatle Station. Washington.

ICLEAN, NORMAN T. (b'75)-Mass.7,'00 ; Washington.

GRAYSON, CARY T. (b' ('78)-Tenn.11,o3; Washington.

FARWELL, WREY G. (b'82)-Pa.1,04; (ATHER, DAVID G. (b'79)-Pa.1,03; Phil-

McDoNNELL, WM. NEIL (b'76)-Minn.4, '03: Annapolis, Md. SMITH, HAROLD
Waiting Orders.

CIFFORD, ADDISON B. (b'75)-Mich.1, 04: Washington. VICKERY, EUGENE A. (b'79)-Mass.1, 03 ;
New York City.

WARNER, RICHARD A. (b'78)-D.C.2,'01; Washington.

STALNAKER, PAUL R. (b'80)-Tex.2,04; New York City.

EYTINGE, ERNEST O. J. (b'80)-N.Y.I,'04

Unassigned May 22, , $_{13}$.

IUUNGER, CURTIS B. (b'78)-Cal.1, 03 ; Washington.

BROOKS, FLETCHER H. (b'75)-Md.4,'02 ; Washington.

MEARS, JOIrN BOWDOIN (b'79)-Va.1,'01 ; Washington. GEO. S. (b'81)-Mass.I,'02;
Newport, R. I.

SFLLERS, FRANK E. (b'75)-Va.I,'0I;

('harleston, S. C.
OLD, EDWARD H. H. $\quad\left(b^{\prime} 76\right)-V a .1,99$;

OLD, EDWARD H. H. $\quad\left(b^{\prime} 76\right)-$ Va.1,'99
Washington.

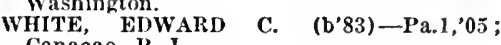
Canacao, P. I.
EED, THURLOW, W. (b'79)-N.Y.Y0,'03; San Francisco. REED, EDWARD U. (b'84)-Pa.1,'05; Las
Animas, Colo.

STRITE, CLARENCE E. (b'77)-Md.4,'02 ; Washington.

COLE, HOWSON WHITE, JR. (b'78)-Va.1,

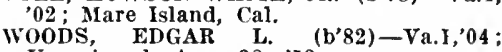
Unassigned, Aug. 28, 'I3.
ANSDELL, ROBERT C. (b'80)-D.C.I,'02 RANSDFLL, R
Washington.

Washington.
JONES, EDWIN L. (b'76)-T'ex.2,'03; 0longapo, P. I. apo, P. I.
FoSTER, THos. G. (b'75)-Va.1,'99; Port
Royal, S. C.

WINN, CONDIE K. (b'79)-Pa.1,04; Washington.

KAUFMAN, JOHN BROOKS (b'78)-Pa.I,

'03; Philadelphla.
AMES, MATTHEWS H. (b'81)-Pa.I,'05; Boston.

ROBNETT, AUSEY H. (b'79)-D.C.I,'05;

Washington.
HAYNES, JAMES P. (b's0)-Tenn.5,'0I ; Washington.

ALLEN, ABRAHAM H. (b'81)-Pa.11,'03 ; Philadelphia.

LEE, ANDRE E. (b'80)-IId.7,'06; Pekin, China.

BUTTS, HEBER E. (b'77)-D.C.1,04; Washington.

GARRISON, PHILIP E. (b'77)-D.C.1,06 ; Washington.

RAISON, THOMAS W. (b'83)-D.C.1,05 Washington. 
DOWNEY, JOHN 0. (b'83)-1'a.1,06; Alaska. (Special Duty.)

IINER, JAMYS M. (b'82)-TeUn.11,03 Newport, R. I.

HIGGIS, SPENCER L. $\left(\mathrm{U}^{\prime} \mathrm{T} 6\right)-\mathrm{N}, \mathrm{Y} .1,03$ :

Washlngton.
8TKAETEN. RFNIER J. (b'84)-Veb.6,03: Washington.

WTIBBENS, FRANK H. (b'78)-('al.1,03; Washincton.

COHN, ISIDORE FHANKLIN (b:83)-Pa.I, $05:$ Jiremerton. Wash.

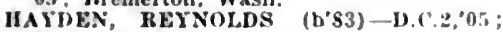
Washlugton.

VAl.z, ElWARD V. (b'78)-Va.1,0s; Wastington.

UART, MONTGOMERY A. (b'81) - Mlch. 7 .

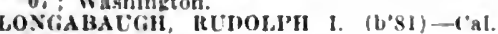
2.03: Guam.

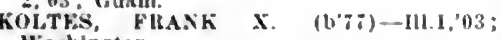
Washlngton.

SHORT, WM, H. (b'31)-D.6.2,04: WastIngton.

KELLEY, HERBERT L. $\left(b^{\prime} 80\right)-U d .7,0 \%$; Washington.

MILLER, JULIAN TAYLOR (b'il)-Va.I, '92: Charleston. S. C.

TRIBLE, GEO. BAR.NET (b'83)-M0.2,'06 ; Washington.

Washlngton.
GARFISON, HARRY A. (b'78)-Pa.I,06: Washington.
OLLARD, IIFXRY J. (b's0)-X.Y.1.'02 : OLlLARD, IIFXRY J. (b's0)-N.Y.1.'02
Washlngton.

UÜF, EARLF, MHINEAS $\left(\right.$ b' $\left.^{\prime} 9\right)-\mathrm{X} Y .1$, 03 : Washington.

HERM FSCH, IIAItR IR, (u'is)-D.C.2,0\%: Canacao, I. I.

SMITH, HARRY LUTHEl: (b'83)-Pa.1,06 ; Washington.

STKADMAN, WILIARD G., JR $\left.(1)^{\prime 81}\right)-\mathrm{X}$.

19,06: Detrolt.
DONELSON, MARTIN (b'82)-Ya.1,06:

DONELSON.

Washington.
HAKER, MYRON C. (b'79)-Mass.7, 06 ; Washington.

CCRTIS, ELMER E. (b'7i)-No.34,05: Guam.

CasTo, Dow H. (b'81)-Va.I,06; Wash

Ington.
BUNKER, CHAS. W, O. (b'82)-N.Y.20,05; Wishington.

IAWRENCE, HOWARD F. (b'82)-N.Y.I9, 04: Washington.

HOLEMAN, chas. J. (b'80)-1'a. 1,07 ; Jas HOLFMAN, CHA
AnLmas, Colo.

HALE, GORDOX D. (b'77)-N.Y.1,04: Washington.

HAYWARD, ALFXANDER R. (b'82)-Pa.I, 04: Phlladelphla.

HGGiNs, MONTGOMERY k. (b'79)-D.C.I. 04: Washington.

SHEPARD, GEO. WANZER (b'78)-0.6, 03 ; Washlngton.

RHOWN, ERNEST W. (b'78)-D.C.,06

Special Duty, submarines.

Special Duty, submarines.
suTToN, DaI, Washington.

SCHMIIT, IAWRENCE MAUTICE (b'83)111.11,06: Washlugtón.

MORAN, CHAS. L. (b,79)-Mass. 1,05 Mare island, Cal.

Cliambirs, W.I. (b'84)-l'a.2,07: Nor folk Ya.

BACON. SANKEY (b'81)-Neb.4,05:

Charleston. S. C.

noUGH, FHANk P. W (h'84)-Va.t,0i Canacan. I'. 1.

MHLHORX, KExT c. (b'83)-I'a I,06 Washlngton.

MeGUIIE, LK: W, (b'8\$)-(1.1,06: Wusl, ington.

IIHLLO, JOSE.PI A. (b'80)-1'a.s, 05 Washington.

HOADES, GEORGE C. (b'8I)-Ya.I, '06; Washington.
TOUTOX, AIFIED J. (b'82)-1'a 11,08:

Washlnuton.
ANE, HARRY Ht, (b'80)-I'a $20^{\prime} 04$; AuนapI.NF: HA

Mciowri.l, RAIIII W. (b'83)-l'a.2.05 Annapolls. Md.

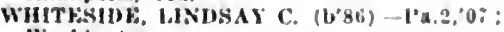
Wahlokton.

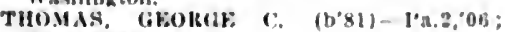

Mare island, Cal.
Bol.ANi), MICAJAll (b'7i)-Va.1,05: San Dlego, Cal.

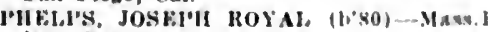
'0:b: Moston.
ClOUW (iFi) Washington.

CLIFTON, ALFRFI) I. (b's:)-l'n. I,06:

New York City.

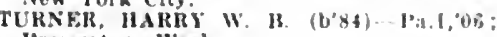

Itremerton. Wash.

IENRY, RFGINAII, B. (b'Q1)-Va.1,0\%

Wiashington

(il)TXER, HAKRY A. (1)":

Norfolk: Va.

Jollssos, I,UCIUS W. (1,82) l'a $1,0 \overrightarrow{0}$

Washlington

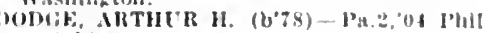
dulelphia.

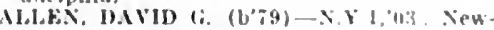
port, M.I.

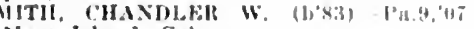

Mare lsland, Cal.

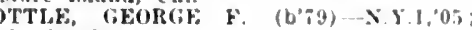

Norlh (hlcago.

MANX, WM. L., JIt. (b'84)-Mass. I, Ox

Dallas, Tex.

('UTHBHTSON, ROY (b'st)-Mich. I, 08
New York Clly.

WHITORE, GEORGF; BYKOX (1):80)-

l'a.2,03; Bremerton, Wash.

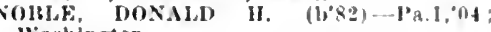

Washington.

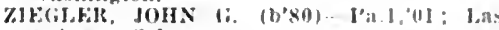
Inimas, Colo.

('IARK, GIFNMORE F, (b's0)-1'a.11:0R Washingtan.

KF:1k16, Wal. M. tb'soj-N.Y $20,0 \%$ IIono tulu, II. T.

POLLARD, JOHN B. (b's0)-ba.1, 0 :

Atlanta, Fa.

RIKkil, GEORGE A. (b'79)-1'a.2,05

Washington.

HARIAN, THAROS (b'90)-11.1'1,05: Nur rolk, $\mathrm{a}$

MVIDSON, ANDREW BIAINE (b's4)- l'a 2.09: Annapolls, Md.

RVINE, WM. L. (b'81)-Conn. 1,'06; Y Yew port, IR. I.

IIILIIPS, FARLE W. (b'83)-N.Y.20,05 Chattanooga, Tenn.

I.ASA, JAMES A. (b'84)-Md.7,09; An napolis, Md

WIITON, pt:cas, (․ (b's6)-Md.:,09 New York Clity.

THOMAS, GIRFYITH EDWARDS (b'82)Mlill.5,08; Portsmouth, N. H.

IHOEDORS, WALTER A. (b'S6)-Neb.6,

09: Washington.

('MERKR, CLYDE BRADLEY (b'82)-Mo. 34,09; Mare lsland, Cal.

IOOHERTSON, GARDNER E. (b'83)-N.Y.6 uf: I'hlladelphla.

cOBBINs, IRVING w. (b'83)-C'al.1.08 San Franclsco.

FiNkixs, JAIRI F. (b'80)-Md.1,05:

Porl Itoyal. S.

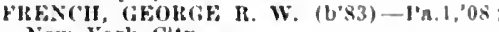
New Vork City.

HART, STANLEY D. (6'81)-N.Y.19,06

Washlucton.

('ONNOH, Wil. Il. (b'80)-Mass. 1,06; Hos ton.

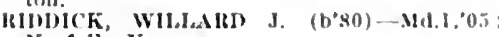
Norfolk. Va.

McMULLIN, Jos. J. A. (b+8.5)-1'1.2, (18 Washluztou.

1AlTON, HDW, P. (b'82)-C'oun.1,05; Newport, R.I.

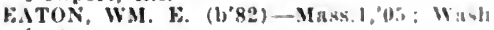
Ington.

HALSFY, WM. H. (b'84)-11t.1,'06: l'nas

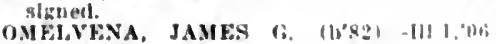
Cavite, I'. 1

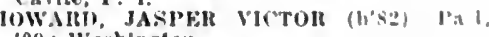
09 : Washlngtor.

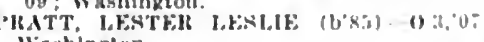

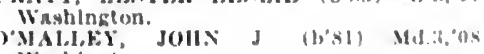
Wantington.

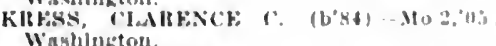

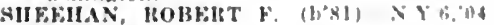
Wavlifugton.

\section{Assistant Surgeons}

Wilh rank of Jeutenaut. Junlor firate

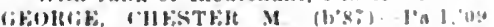
Washlngtor

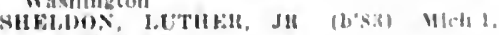
oy: Wavblugtur

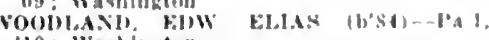
10 : Waspilington

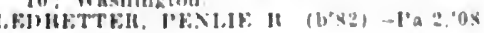
i)totatom, i' 1 .

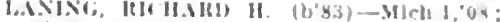
Wastingten.

I'AKII.M. J11.

Tutulla, Samoa

Jiskis, BOIERT

Washington.

ington.

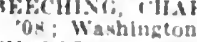

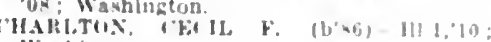
Washingion.

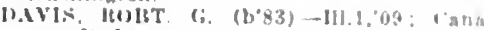
cao, I. I.

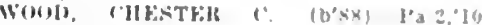
Wishlugetor.

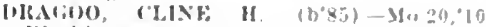
Wustilizton.

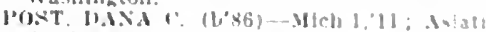
stablon.

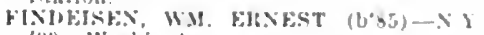
'0! Wawhingten.

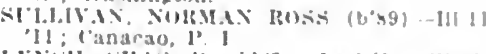

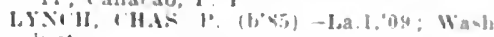
lingersin.

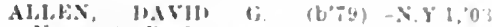
Newtrest, 16. 1

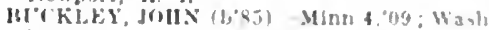

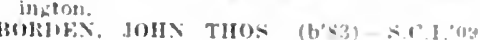
Phlladelnhia.

\section{Acting Assistant Surgeons}

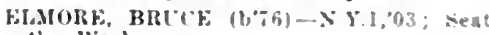
tle. Wash.

MCHELS, ROHERT I1. (b\%9)-1 1,0 Chicago.

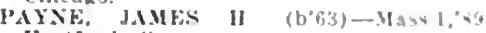
Harfford. Conn.

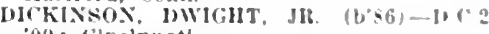
09: c'Inelnnatt.

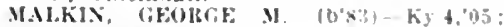

New orleans.
scllier, ANTOx, R. (b':2)-Coln 3.93 St. I'anl and Minneapolls.

BARKER, ZACHALIAII A (6's)-rope 1 . os; sin Franclsco.

latrila. Joll $\mathrm{C}$ (b.85)-041,10: salt lake City.

DCIIICi, JAMES T. (b'82)-111 I1, 0 : cleveland.

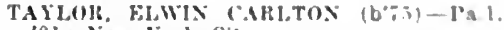
'01: New york rity.

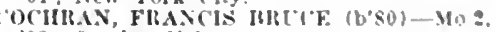
03; Omaha, Neb.

RFFil. JFWFTT Vild.ilor (b'is)-Mase z,ot: Indlanapolls.

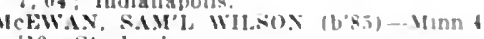
10 St. Louls.

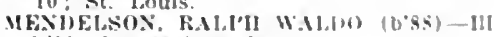
6,11 : Des Molnes, la

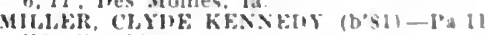
os; lirooklyn.

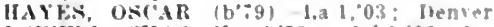

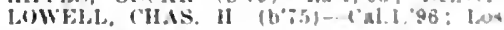
Inceles, Cal.

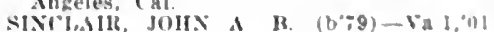
lortlund, ore

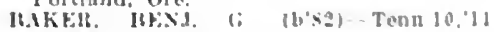

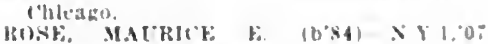
Kansas Clty. Mo.

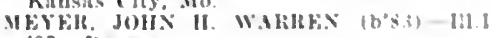
$0 \%$ : Denver

\section{MEDICAL RESERVE CORPS}

\section{Assistant Surseon}

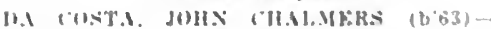

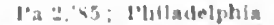

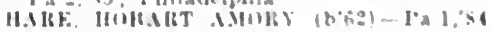
fhiladelphia

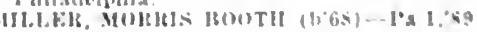
Iniltadelphta

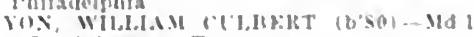
Bi: linfreston. Tes

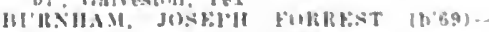
Mave i,"0i ; lawroner. Mass

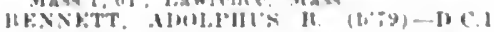
ol. Washlacton

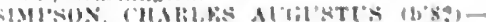
in. 1,0et: Wamlitroton.

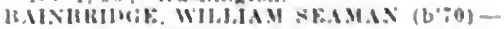
yil. 83 : New Vork ing

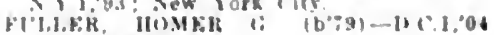




\section{AMERICAN. MEDICAL DIRECTORY}

MOItGAN, WHLLAM GELIR (b'68)-l'a.1 93: Washington.

VAUGHAX, GBOHGE TULLY (b'59)-V'a.1, '79: N.Y.10,80: Washington.

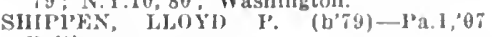
Baltimore.

TOWNSEND, WHLIAM GUY (b'64) - Md.1 '88; Baitlmore, Nd.

TOMI'KINS, JOHN A. (b'71)-MU.7,'98; Buffalo, N.Y.

GALLANT, AIBERT ERNFST

N.Y.I,90; New York ('ity.

ADAMS, SAMUEL SIIUGERT

(b'61)-

II.C.2, 99 ; Washington.

THOMAS, WILLIAM STUIKGIS (b'TI) 1). 4 , !n ; New Vork City.

HEF'FITAN, WAVII) ALOYSIUS (b'81) Mass. 1,02; Dorchester, Mass.

MEEKEIR, HAROLD DENMAN (b75)-

N.Y.1,02; New York City.

WILKINSON, WAITER WATKINS (b'76)D.C.1,05: Washington.

FIINK, ChaUIH AUGUSTINE (b'i6)$N$ Y.1, 02 ; New York Clty.

FOOTE, EDWA ItD MILTON (b'66)-Mass.1, 90 : New York City.

SHUtisy, BUtT ik. (b'il)_Mlch. 7,95 Detroit.

GOULD, EVERETT W. (b'73)-N.Y.1,'99; New York Cíty

RUSSELL, WORTIINGTON SEATON (b'T0) -N.Y.5,'93; New York Clty.

LeCONTE, ROBERT GHLE (b'65)-I'a.1, 88 : l'htladelphlu.

DALAND, JUDSON (b'60)-1'a.1,'82; I'hiladelphita.

MORGAX. JAMES DUDLEY (b'62)-H.C.2, 85: Washington

ROSENAU, MILTON JOSEPH (b'69)-Pa.1, 89 : Boston.

NOLAND, LLOYD (b'80)-Md.4,03; B/rmingham, Ala.

LA FEETE, ALFREI DANIEL (b'86) - - ', 10 ; Detroit.

ESSUP DAVID STUART DODGE (b'70)N.Y.I,94; New York Clty.

CORNET, HORACE VICTOR (b'8i)-Va.1, '11; Norfolk, Va.

MACA'TEE, HENRY C. (b'T8)-D.C.1,'00 Washington.

POUNDS, THOMAS C. (b'76)-Cal.6,'03 ;

San Diego, Cal.
HELM, JESSE BUNDREN (b'85) - Ky.2,'11 White Pine, Tenn.

BOVEE, JOHN WESLEY (b'61) - D.C.1,'85 Washington.

GRIFFITH, CHARLES I. (b'T7)-D,C.2,'05; Washington.

WESTON, ALBERT THEODORE (b'60)X.Y.5,82 : New York City.

IDEN, BENJAMIN FRANKLIN, JR. (b'83)Ya, ${ }^{\circ} 09$ : Manassas, Va

SCIIUMANY, EDWARD ARMIN (b'79)Pa.l,01 ; Philadelphla.

PAYNE, BOBERT LEE, JR. (b'82)-Pa.1 05 ; Norfolk, va

AMMERMAN, CIIARLES CLARK (b'68)D.C.1,06; '1'ttsburgh.

HETFIELA), WILLIAM BRAWNER (b'88)Md. i,'Il; Newport, R. I

HAIGIER, FRANK HALDANE (b'82)Vo.20,11. Уew York City.

CALYAR, GEORGE WEHNES (b'8i)-D.C.1, '12; Washington.

SAURMAN, JOIN S. (b'85)-Pa.13,'09 1'hiladelyhla.

HARGRAVE, WM. W. (b'si)-Va.4,'12, Washington.

W'ILIIS, BYRI) C. (b`80)-Va.4,09; Rich-

mond, Va. .96: San Diego, Cal. CLARK, FRANCIS C. (b’tS)-S.C.I, 03 Rosebank, N. X.

MASSEY, WILLIAM HINKLE (b*6)Cal.1,'12; Mare Island, Cal.

IIHLIS. IONYD SWEENEY (b'-3)-IIt.6, ?

Washington.

(ber

F. (b'80)-Ya.1,02,

FORTESCLE. THOMAS A. (b'84)-Pa.2,'08 Philadelphia.

MAN10N, JAMES L. (b'83)-Pa.2,'10 ; Port land, Ore.

ANE, JOHN DAVID (b'S0)-III.s,09 Benuington, it

HOLLOWAY. TIONAS B. (b'72) -Pa.1,97; l'hiladelphia.
LEHITHELD, LOUIS (b'90)-1'a.11,12 ; OS'TEJt, HOHERT HEATI (b'85)-La.1, os: Iforillan Mlss.

('FIt F, FItEUEHICK, (b'90) - Pa.1,'13; Washinaton.

CHAWFORD, ROBERT ILEE (b'89) - TenH.5, 12: Washington.

ICCONNELL, GUTHRJE (b'75)-Pa.1,96; I'hiladelpla.

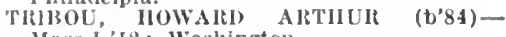
Milss. I, '12: Washington.

YoINIE, AITHUI ELNEST (b'87)-0re.2, I. : Portland Ore

W'AC'II, WALTEI C. $\left(b^{\prime} 87\right)-0.26,11$; Washington.

IONES, JOIIN FItANCIS $\mathrm{X}$. (b'81)-Pa.1, '07. P'a.2,'10; I'hiladelyhla.

CRAWFORi, STANLEY ERNEST (b'87)l'a.1.11; Waslington.

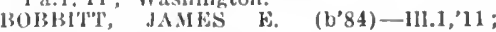
Washlngton.

Fo('l'k2, OY'11) $\because$ (b'89)-Idd.7,'12; Washinctou.

P'RIEST, HOW:NIV (b'84)-Ky.9,06; Wash-

Ington.
BELP)OE, AltTUUR E. (b'85)-Pa.1,'10 ; Washington.

BAKEI, CAIROLI R. (b'85)-1'a,2,09; Washington.

STEIIIENSON, CHARLES S. (b'87) Teun.5,'12; Washington.

WENTZEL, WM. S. (b'89) - Pa.11,'12; l'hiladelphla.

WATEIHOUSE, ROSCOE M. (b'86) -Mass.i, 11 ; Newton, Mass.

BHOWX, ItEAWALD), (b'78) - Ill.6,'03; Santa Barbara, Cal. A. (b'86)-Ya.1,'11; ItATLIFF, The

IIIXT, I)ANILI, (b'89)-Pa.2,'12; Washington.

IIAWOH'TI, WALTER L. (b'85) - Ind.20,'10; Washington.

BRADBUIR, WAIREN E. (b'89) - Ill.22, 12 ; Neillsvllle, Wls.

BOS'TIIK, JOIN BENTON (b'75)-Cal.7,

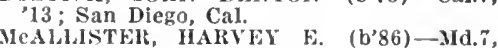
I2; Washlington.

IIORDAN, JOHN F. (b'88)-Mo.34,'12; Washington.

COSTELIO, CHAS. A. (b'78)-111.1,01 ; Chicago.

IAVENEX, JOSEPII J. (b'80)-D.C.2,04; CARR, ClAUDE W. (b'86)-III.1,'12; Washlngton.

RODDIS, LOUIS II. (b'86) - Minn.4,'13; Washington.

GREENE, JOSEPH B. (b'69)-Va.1,93; Ashevile, N.C

BASSIN, JOHN N. (b'74) - N.Y.8,'03; Poughkeepsle, N.Y.

WILSON, CLIFF C. (b'87)-Tex.2,'12; Washlngton.

MANY, ALBERT E. (b'89)-MId.3,'12; Nantlonke, r'a.

HOLLIIAY, GRAY G. (b'70)-X.Y.10,95; Portsmouth, Va.

OWEN, IIUBLEY R. (b'83) - Pa.1,'05; Washington.

JOWMAN, FOSTER H. (b'86)-Ta.1,13 ; Redford' Park, N.Y.

TYNCI, CHARLES I. (b'85)-IA.1,'99; Washington.

ICCLEILAND, N. M. (b'\$8)-Tenn.8,'13. IIemphis, Tenn.

\section{U. S. NAVY RETIRED}

NUMBER OF PHYSICIANS, 104.

Surgeons-General

With rank of Rear Admiral

VAN REYPEN, WILIJAM K. (b'40)-N.Y.5,

62 ; Jan.25,02. Leare abroad.

RIXFY, PRESLEY MARJON (b'52) - Va.1,

73; Feb.4,'10; Washington.

\section{Medical Directors}

With rank of Rear Admiral

TNXELL, FRAXCIS M. (b'27)-D.C.1,'46; Yor.27, 89 ; Washington

COUES, SAMIUEL FRANKLIN (b'25)-Pa.2, 49 ; Sept. $17,8 \pi$; Cambridge, Mass.

INDLEBERGER, DAVID (b'34)-Y'a.2,'58 : Sept.2,96; leave abroad.
ClaIKK, JOHN HOWE (b'37)-Mass.1,62 HOEHLING, ADOLPH AUGUST (b'39)1'a.1,60: June 14,95; Chery Chase, Md. WHTE, CHAS. HENRY (b'38)-Mass.1,'62 Nov. 19,00; Center Sandwich, N. II

COKE, GEO. HENItY (b'36)-Pa.4,57 Dec.12,'98; Rldley Park, I'a.

FLINT, JAMES MIITON (b'38)-Mass.1,"60 Feb. T,00; Washington.

WJASLOW, GLOR(iE FREDK. (b'42)-

Mass.1,'fi ; Jan.19,03; New Bedford, Mass.

PARKER, JOSEYII BENSON (b'41)-N.Y.10, '66: June 20,03; P'hlladelphla.

AYERS, JOSEIII GEItIISII (b'39)-Vt.2 ' 64 ; Nov. 3,01 ; Yort Jervls, N. Y.

DRENNAN, MICHAEL COYLE (b'38)-Pa.1. 63: Oct.24,'99: Easton, Pa.

\section{Medical Directors}

With rank of Commodore

PRICl, ABEL, FITZWATER (b'47)-Pa.1, '68: Dec.13,'09; Sandwich, Mass.

DICKINSON, DWIGHT (b'47) - N.Y.6, 69 Oct. $3 \mathrm{I}, 09$; leavo abroad.

WISE, JOHN CROPPER ( $\left.\mathrm{b}^{\circ} 48\right)$-Md.2,'69; Oct.7,10; Warrenton, $\mathrm{Va}$.

PEISONS, ItEMUS CHARLES (b'50)-

N.Y.5,'72; Jec. 28,12 ; Opellka, Ala.

\section{Medical Directors}

With rank of Captain

RHOADES, ARCIIBALD CRAIG (b'36)N.Y.1,'59; Sept.14,'88; Stamford, N.Y.

OBERLY, AALON SHIMER ( $\left.\mathrm{b}^{\prime} 37\right)$-Jan.24, '89; Eáston, $\mathrm{Pa}$.

FAITWELL, WM. GIIMORE (b'43)-Que.1, 68; April 5,05; New York City.

BRADLEY, GEORGE PERLEY (b'49)N.Y.l,'T0; June 15,'07; South Lancaster. Mass.

GRAVATT, CHAS. URQUHART (b'49)Md.3,'70; June 8,'03; Port Royal, Va.
ITZSIMONS, PAUL, (b'49) - Ga.1,'69 Feb.27,'11; Washington.

DIXON, WMi. SUEL (b'4i)-D.C.2,68; Jan.5 '09; Washington.

FEREBEE, NELSON McP, (b'49)-Md.1, STREETS, THOS. HALE' (b'47)-Pa.1, '76 Nov.20,'09; Wyncote, Pa.

ROSS, JOIIN WALTON (b'43)-I,a.1,'68 : Jan.11,'05; Pasadena, Cal.

SIMONS, MANLY HALE (b'49)-MICh.1,7I ; July $11, ' 11$; St. Helena, Cal.

BOYD, JOHX́ CALVERT' (b'50)-N.Y.5,'72 June 1,11 ; leave abroad.

WELLS, HOWARD (b'49) - Pa.2,'70; Sept.17,11; Philadelphia.

DERR, EZRA ZACHARIAS (b'51)-Va.1 '70; N.X.5,'72; June 10,'11; Decatur, Ga. Sept.1,08; Washington.

DICKSON, SAMIUEL HENRY (b'49)-Pa.2, '90; July 10,'11; Nantucket, Mass.

AMES, HOWARD EMERSON (b'50)-Md.1, '74; Aug.7,'12; Washington.

BEYER, HENRY GUSTAVE (b'50)-N.Y.10 'T6; Oct.28,'12 ; leare abroad. GARDNER, JAMES EDWIN (b'50)-La.1

BERTOLETTE, DANIEL NICHOLAS (b'51) Pa.2,'72; Jan.22,'13; Reading, Pa

HENEBERGER, LUCIÁN GUY (b'51) - Va.1 '72: Oct.20,'13 ; Washington.

LOVERING, PHJLLIPS ADAMS ( $\left.b^{\prime} 51\right)$ Mass. 1,75 ; Sept. 29,13 ; St. Helena, Cal. HIBBETT, CIIAS. T. (b'51) - Va.1,'74; Nov.20,13; Nashville, Tenn

BYRNES JAMES CARROLL (b'51)-D.C.2 , $70 ;$ Jan.12.'13;Phlladelphia.

EDGAR, JOHN MARION (b'58)-Pa.1,'80 Sept.1,12; leave abroad.

NORTON, OLIVER D. (b'59) - 0.9,'83 Nov.13,13: New York City.

\section{Medical Inspectors}

With rank of Commander

PAYNE, EDWARD DUGAN (b'36)-Pa.2 '57; Apr.13,'66; Philadelphia.

ECKSTEIN, HENRY CLAY (b'36)-Pa.1, '62; May 10,93; Philadelphia.

ROGERS, FRANKLIN $\left(\mathrm{b}^{\prime} 50\right)-$ N.Y.10,72 Oct.28,01 : Winchester, Va.

STEPHENSON, FRANKLIN BACHE (b'48) Pa.1, '73; Jan.3,'03; Pittsfleld, Mass.

KERSĆHNER, EDWARD (b'39) -N.Y.5, 61 Apr.2,'02 ; Hagerstown, 3id.

STEELE JOHN MURRAY (b'53)-Pa.1, '̇3

Sept.18,'08; 0wings Nills, Md. 
LUMSOEN, GEORGE PEEMIES (b'53)Va.4, it: feb.:11; Riehmond, Va. RUSSELL, AVERY CIACUE HOLMES (b'3)-Va.1, is: June 30,09; leavo abroad. BIDDLE, CLFMENT (b'5t) - Pa 2,78: Oct.10,08: P'hlladelphla.,

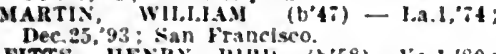

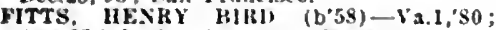
Aug.23,'10; 1'rovlncetown. Mass.

\section{Surgeons}

With rank of Lleutenant Commander

MAGRUDER, ALEX. FITZHYCH $\left(6^{\prime} 49\right)-$ D.C.4.1: Nov.14:96; Washington.

BALDWIN, LloYD BYROS (ut5)-1'a.1. 'it: Sept 18,99: loulswille, hy.

MARSTELIAR, EVITY HARRISON (b'51) Ya.1, 'T2; Sept.15,08: Brooklyn.

RUSI, WILLIM HEVRY (b"5:)-Pa.1,'73: OeL 31,'00: Ardmore, 1'a.

MEANS, VICTOR CLAY BARRINGER (b'60) Y.Y.5.82 Peb.22.08; Phlladelphla.

CORDEIRO FREDERICK JOAQUIN BAR. BOSA (b'59) - Mass.1,'84; Mar.23,06 Newton Center, Mass.

KITE, ISAAC WALTER (b'61)-Va.4, 85 ; Mar. 23,10 ; Washlugton.

Aug.31,07: Vloeland, $N$. J.

AlE, JOHI FRANCIS (b

Apr.19,04; Bowllng Green. $\mathrm{Ky}$.

Apr.19,04; Bowllng Green, Ky.

OTHGANGER, GEORGE (b'6t)-Cal.1,'s8

Dec.10,'08: San Franclsco.

UEST, MIDDLETON SEMMIES (b'69) Pa.1,90; Jan.6.'11; Annapolls, IId.

BAGG, CHARLES PERKY (b'66)-Cal.6,'s8; Novi, 16,11 : Los Anzeles, Cal.

BUCHER, WILIAM HENRY (D'TA)-PA.II, '96; June 11,09; Kingman, Ariz.
ILNTINGTON, kHON OBED (b'69)-N.Y.1, "96: Jan 29 , 10 ; Newburgh $x . y$.

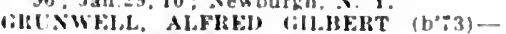

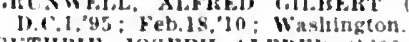
GTTHKIE, JOSEPH ALFHEI) (b'6)- $\mathrm{V}_{1} 1$ '90; Nay 9,06; Portsmouth, Ya

PALE, JOHN ENELYS (b'6i) Md 1,89 Apr.3.'0s : Berryville, $\mathrm{Pa}$

MOLLOWAY JAMES HILAYH (b'T3) X.Y.10,97; Xor.I4,'12; Asherlle, N.'.

\section{Surgeons}

With rank of Lleutenant

STEWART, HE.XRY (b'4i)--l.a.2, 8 ; ; Apr 10,'st; Canandalgua, $x$.

C.ANES, JAMES HENKY (b'48)-1'a:-, :0 Mar. I8,'91: leare abroad.

GUITERAS, DANYEL M. (b'53)-l'all'it Oct 13.96 : Frisco, Tiat

CRaIt, THOMas CaNIsY (b'55)-P'a.1,90 Mar.2.,9i; Brooklyn.

BAKEII, JOHN WA.TER (b'60)-Mass.1, '81; Nov.5,97; Newton, Mlass.

\section{Passed Assistant Surgeons}

Will rank of Lleutenant

MYERS, TALIYRANI DESAIX (b'46)81; Nor.5,97; Philadelphla.

MEFFENGEI, ARTHER COWTON (b52)

IIPPIXCOTT, GEORGE COOTE (b'50)

Pa.z, 5 ; Dec. 17,86 ; Salem, $x, 3$

MORGAX, DANIEL HENKY (b'io)-Md.1. 91; Mar.9,04; Amella Court House, $Y$ a. BELL, WILLIAI LISLE (b'75)-Cal.2,"98; June 20,05: Santa Cruz, Cal

DeLANCE, CHAS. HERMANCE (b'66)-

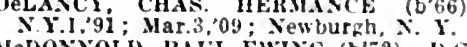

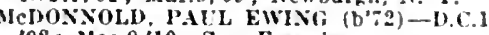
"98; Mar.9; 10 ; San Francisco.

BROW, EARLE MASON (b'6)-Illch.1,

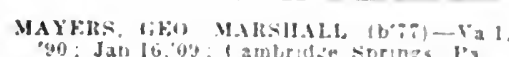

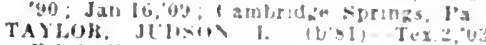
Feb.19.12: II

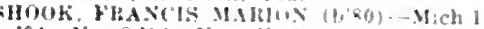
of Nor 8 ; 12 : New lork rieg.

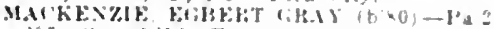
ats sebe 1: Trant in $x$

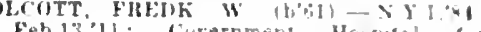
Insane.

\section{Passed Assistant Surgeons}

With rank of Lleutenant, Jutiur lirste

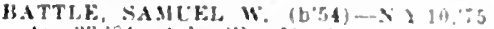
Apr 23,54 atherlle, $X$.

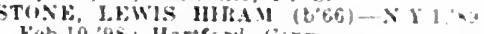
Fetheras; Harteort. (com

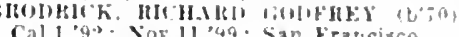

al.1,92; Yor 11, 49 ; San Francisco.

$$
\text { Assistant Surgeons }
$$

With rank of Lueutenan:, Junder ciracle

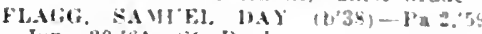

June 20, 'ti : st. raul.

PAGE, JEREMHAH JOHN (b'ti)-Me 1. June 30,79: sawlelle, Cal.

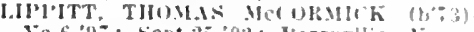

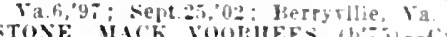
'96; Jan.26i.04: Healdsturg ral.

SITTOS RICHAL Llintul

No.20,01; Iune $30,05:$ Kansas city yo OLOQ.0, ViEne 30.05 Kansas City, Mra Minn 4.04: Dec 2.'10; Ieare abroad.

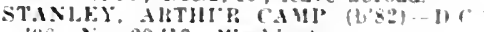
. 05 ; Xiv. 23,10 ; Washington.

\section{Assistant Surgeons \\ With rank of Eusian}

HEXRY, CIIIILE 1'HILIP $\left(\mathrm{b}^{\circ} 60\right)-\mathrm{P}^{\circ} 1$. '82: Irec.en.sg: l'hllsdelphla.

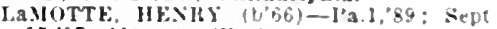
15,97 ; Manette, Wash.

\section{MEDICAL OFFICERS OF UNITED STATES PUBLIC HFAITH SERVICE} Wlth Year of Blrth, College and Year of Graduatlon, Dafe of commission, Date of Entering serrice, and Aldress.

NCMBER OF PIISICIANS, IGI.

\section{Surgeon-Generai}

BLUE. RUPERT (b'68)-Md.1,92; May 1 , 09; Mar.3,'93; Washington, D. $\mathrm{C}$.

\section{Assistant Surgeon-Generals}

GLENXAN, AKTHLR H.-X.Y.5,82; Dec.28 98 ; Apr.29,'82. In charge of Personnel and Accounts; Washington. D.

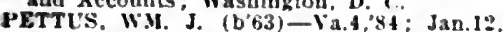
00: Yeb.5.86. Jiarine llosplials and Rellef: Washington, $\mathrm{D}$. C.

COFER, LELASD E. VA.4.89; Dec.1\%:00: Nov.21,90. Voreling and insular Quaran. une: Washinkton. I. a

KERK JOHS W- W. C. Jan 12,04: Wec 23,"98. Sclentifc Revearch and Sanltatlon: Washington, $b$.

ReCKFH, WHLIAM COLBY-HI.1.9: : Aug. 3,07: July 21,02 . Domestic (Inier-State) quarantine: Washlngton. II. ¿

ThAsk. JOHX w-Mleh. I, '01: Dec.19,0: Auz.16.02. Sanitary Reports and statisUlea: Washington. D. C.

\section{Senior Surgeons}

ALSTIX, HIIAM W-Mlch.1, 75 : Feb.21, "89: Feb. 23,"76, Detrolt

CASSAWAY, JAMks M. P'a.2,82; Feb.21, 89 Apr.15\%66: "airo, III.

STONER, CEOHCF W. N 10,;A: Feb:1 89: Oct.28,76; New York

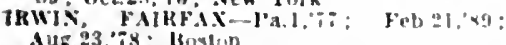

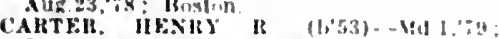
Jan. $28,92:$ May 5.99 : Haltimere

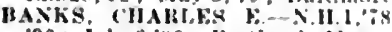

96 : July $6 . \times 0$; Portiand, Ne.

96 : Jnly fi.k0; Portland, Me.

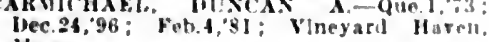

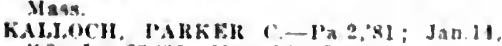
"g8: Jan 23,"82; Memphis, Trun

GLENNAN, ARTUI'K II.-N Y.5's?: Pec.9k, 998: Apr.29,'s2: Wastilngton, ii i

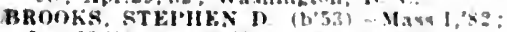
Dec.23:9s: Mar.9.83; los ingeles.

\section{Surgeons}

BAIHIIATIF, JBESTOX II. (b.3.5)-Pa.3 5:; Feb.21,'s9; Aug.20,'73; Stapleton, s.y.

SAWTELLE, HENRY W-D.C. 268 ; Feb. 21 '89; Aug, 20,73: Walting Orders.

WIITE, JOSEPII H.-Md.3,83; Dec. 23,98 octz'st: New Orleans.

CAnINGTON PAYl M (10,2)-Mld.3.9: Jan.23.99; Jan.16,'8: : Sin Diego, Ca!

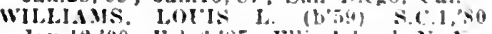
Jan la: $(10$; Feb, 6.95 ; Ellis laland $x 1$. MCISTOSH WILLAM YMUE (b'55)-Nd.3

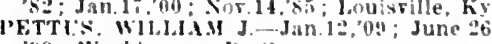

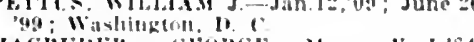
Magiclith, Gorker M. - va.l,s Jan $23,00:$ Anr.24'st: Pertland, Ore.

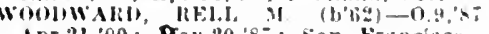
Anr.21.00 9ay 20.8\% san Frucisen. conk jlits $0 .$.

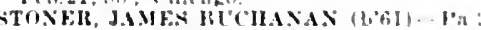
\$5: Oct.16,02; Yeh.21, \$s: Pittsturph

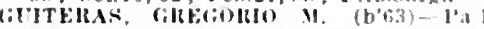

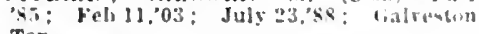
Tex

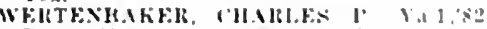
Fel, 16.04: Alug 18." Norfolk Va

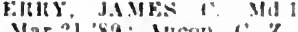

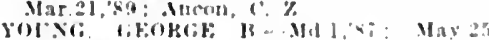

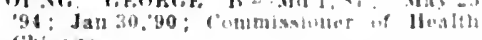
('hleagt)

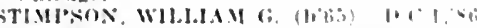

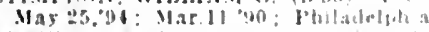

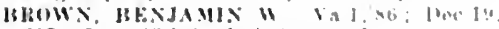

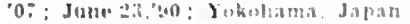

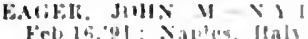

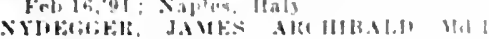

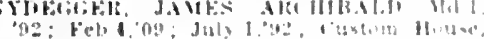
Hali:merto"

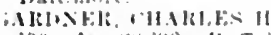

og: Jan jow

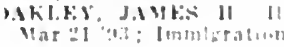

ter int $x$ J
SPlluil E, E.7RA $K$ (b66)-Mass bi 40 May 1.09 Apr.10,'s3 Immaration sert.

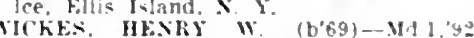
Aug $810 ;$ ADr -4.93; Boston

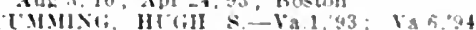

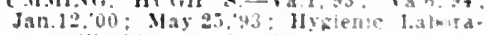
tory Washingto: "l $"$.

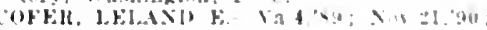
Washingant, 1).

MATHEWSUS. HROR SUTI XY1,93: Feb 23,12; Ape 1:905: quaran ine. Pertland, ve

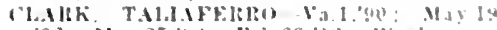

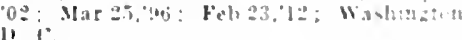

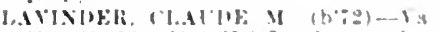

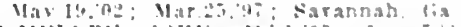

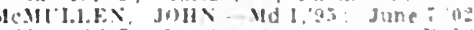

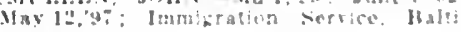
more.

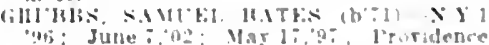

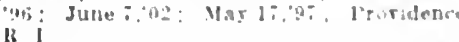

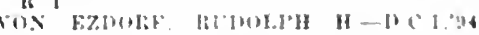

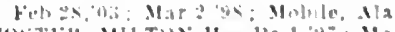

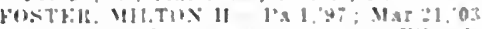

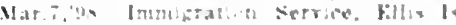

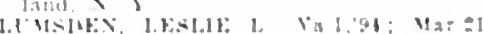

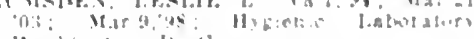

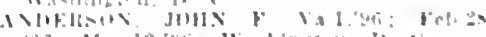

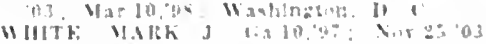

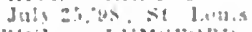

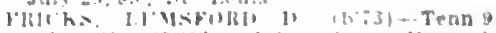

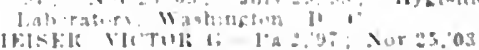

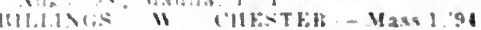

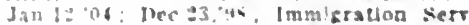

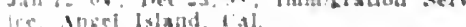

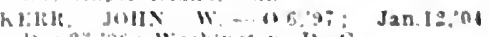

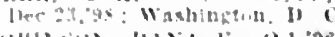

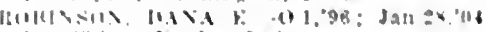

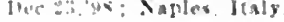




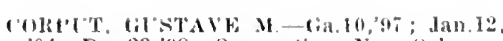
04; Dec.23,98; Quarantine, New orleans. KING, WALTEIS W-La.1,97; Apr.2l,04 Mar 4,'99; Sin Juan, $P^{\prime}$, it.

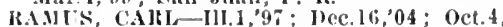
97 ; Inmigration Service, Eilis Islani, IOORE.

OORE, DUNLOI - I'a.1,93; Dec.19,04 Mat 31,99: Ellls Island, N, Y. Yoc 19,04 July 25, 99 ; Washington, D.

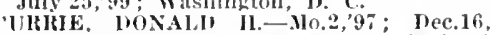
04; July 25,94; Epliemle buty', Federal laboratory. Sian Franelson

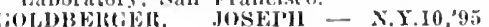
hec.19.04: July 25,99; Hygienle Labolatory lWashlugton.

liolis, WHLIAM A.-Conn.1.92; Dec.17, 04: July 25,49; Manila, I'. I

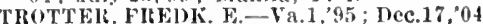
July of,'y9: Quarantine, IIonolułu. T.il.

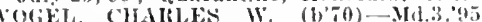
llec 17.04 ; July 25,99 ; Jillis Istand, $\mathbf{x}$.

:WYN, MATTHEW K.-Md.6.97; Dec.17 04; Aug.3,'98; Immigration Service, Ellis Island. $N$. Y

S'HEIESCINWSKY, JOSEIII W.-X.11. '99; bec.16,04; Nov.2,'y9; Hrgienic Labmatory, Washington, D. C.

WILA CLARENCE W. (d,73)-I'a.I.97 llec.19.04; Nov.22,99; Cleveland.

IClAIGIILAN, ALIAY I. - Mich. T,96; Dec. 19.05; Mar.5.00; on leave.

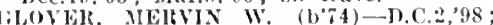
July 26,05; Nar.9,00; Angel Island, Cal

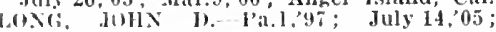
Mar.11,00; 111 Sew Montgomery st., San Francisco.

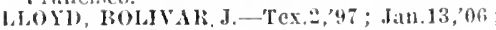
Apr., 00; Seattle Wash.

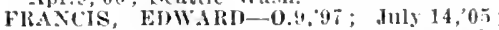
June 22,00; Hyglente Laboratory, Washington. D. C

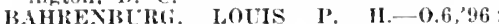
lan.13,'06; June 22,00 ; Immigration Serv ice Gialreston, Tex.

Mocis GEO. WAITER (b'76)-Pa.1,98; July i4,05; June 22,'00; Kalawao, T.H.

PIBRCE. CLAUDE C. (b'78)-Tenn.9? 98 July 21,05; Jume 22,00; Cristobal, C. Z IAIREN, BENJAMIN S.-La.1,91; July 11 . 05; June 22,00; Washington, D. C

BOGGESS, JOHN SAMUEL (b'r3)-0.9,98 ; Jan.12.07; June 22, 00 ; Mobile Quarantine, Fort Morgan, Ala.

\section{Passed Assistant Surgeons}

PARKEL, IIERMAN B.-Pa.1,96; Mar.5, 03; Feb. 26,'98; Guasaquil, Ecuador.

HOLT, JOHN it-X.Y.S,95; Dec. 17,04 July 25,99; Station "Ml," San Francisco. VIISON, ROBT. L.-Tex.2.'98; Dec.17,04 Nov.22,99; Quarantine, Charleston, s. i" FARIE, BAYLIS, H.-S.C. 1,92 ; July 26 05; Apr.9,00; Quarantine, Port 'Townsend. Wash.

BLIKHALTER, JOIN T.-Md.9,99; Jan.13, 06 ; June 22,00 ; Ballimore.

STIMSON, ARTHUR M.-N.Y.8,98; Aug.5, 07; July 16,02; Hygienic Laboratory, Washington, D.C.

RECKER, WILLIA C.-Ill.1,97; Aug.5, 07: July 2I.03; Washington, D.'C. (REEL, IIICIIARD II-MIO.20,00; Sept.17, 07 ; July 21,02; San Juan, P.ß.

EBERSOLE, RUEL E.-Va.1,00; Sept.17, 07 ; Aug.18.00; Immleration Service. Ellis Island, $\mathbf{N}$.

TRASK. JOH.N W.-T"t.2,04; Aug.5,07 : Mar.24.02; Washington, D.
Fos'TKK, ALISERT D.-Mlleh.1,99; Dec.19, 07 ; June 2.'00; New Orleans.

IROBERTSON, HOI.COMBE MeG.-Ya.1,00 ; Dec.19,07: Nov.17,02; State Quarantlue Station, Marcus llook, Pa.

H(iBEkTS, NORMAN (b'76)-Pa.1,07

July 0,08 ; July 25, 03; Phlladelphia.

Colliss. GEolteE I. (b'52)-llass. 1,00 duly 9,08 ; July 25,03; On leave; Vienna, Austrla.

EBERT, HAIYEY G.-Va.1,0I; July 9,08 July 25,03 ; San Franciseo.

MANNING. IIEIHBEIT II. - D.C. 1,00 July 9,08; July 25,03 ; Key West, Fla.

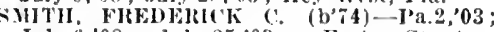
July 9,'08; duly 25,03; Fort Stanton, N. Mex.

TlJ0.MAS W.-N.Y.3:99; July 9, 08 ; July 25, 03 : New York

cKEON. FRANCIS H.-11.C.2.'02; Sov.27, '08; May 2,'04; San Franeisco.

WTYYJOHN, JOSEPH-Tenn.11,97; Oct.20 '08: Itay 2,04: walting orders.

SWEET, EliNEST A.-N.Y.3,00; July 28

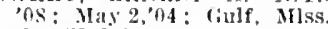

s'ItATT, ROBElit D.-La.1,02; July 28,08 May 2,04: Immigration Service, Fllis Islind. N. Y.

Flios't, WADE II-Va.1.03; Feb.3,09; Ian. Io, 05 ; 13:2 E. Mevillan st., Ciuclnnatl.

MIULAN, ELGENE II-MI.1,03; Feb.2 '0!) ; Jan. 13,05; Immigration Serrice, vili Islund, N. Y.

ASHFORD, FRANCIS A.-D.C.2,01; Aug.11 09; Oct.29,03; Immigration Service. Iontral, Que.

DeVAIIN, HUGH - Pa.1,99; Dec.19,05; Sept.21,09: Aug.30,05; Roanoke. Ya.

GITHIRIE, HARSHAL C-NC.1,04; lec. 19 11:-: Sept.9,09: Aug.30,05: Ouarantine verice cane Fear $\mathbf{N}$.

SIMISON, FRIENCH Tex.2,03; Oct.6,'10. bec.13,'06 ; Neattle, Wash.

HEItRING, ROB'T, A.-La.1,05; Oct.5.'10 Dec.13,'06; San Franciseo

HURIEY, JAMES RAYVIOND (b's0)Cal.2,03; May 4,07: San Franeiser.

BILAN, WM. M.-Va.1,06; May 4,07; Stipleton. N. Y.

HAl'IN, CHAS. W.-N.Y.20,03; Jan.27, '12 ; San Juan, P. R

ARSIIALI, EDWARD R. - Mich.1,05 Jan.2-,12; Honolulu, T. II.

KRLLISH, EMIT-D.C.1,05 ; Dec.20.'11 Duty in Mlaska.

YARNER. IIARRY J.D.C.I.'0\% ; Apr.3,'08 Ft. De Soto, Fla.

OLESEN, ROBERT-D.C.2,'05; Apr.1,08; Sall Francisco.

LANZA. ANTHONY J. (b'S4)-D.C.1,06 May 4.07; Fort Stanton, $N$. Mex.

PREBIA, PAUL-Md. 7,07 ; Dec. 22, 08 Oct.20, 08 : Washington, D, C

GRIMM. RÁNDOLPII M. (b's2)-NId.7,08; Dec. 22,$08 ;$ Oct. 20,08 ; Savannah, Ga.

RIDLON, JOSEPH R.-He.1,06; Dec.22,08 Sept.30,08; State Quarantine Station Marcus Hook, Pa.

FAL'NTLELOY, CHARLES M.-Ya.1,06; Apr. 1,08; Honolulu, T. H.

HASSELTINE, H. E.-Md.4,'04; July 21,'09 July 21,'09; Hygienic Laboratory, Washington, $D$. C.

LEAKE, JAMES P.-Ia.1,01; Mass. 1,07 July 21,09; July 21,09; Hygienic Laboratory, Washinaton, D. C:

KOLIB. LAWRENCE-Ild.1, 08 ; July 21,09 July 21,09; Ellis Island, N. Y.
Assistant Surgeons

TURNIPSEED, IAVID C,-La.1,04; Mar.12. 10 ; Mar.12,10; Ilollo, 1'.I.

KNIGHT, CARLISI.E $\Gamma^{\prime}$ (b'80)-D.C.1,04: Mar.16,10; Mar.16,10; Stapleton, N. Y MEAR 16, 10 ; Mar.16,10; Stapleton, N. Y: EARNEY, RICHARU A. (b'83)-La.1, 05 ;
July 12, 10 ; July 12,'10; Washington, D. C. July 12,10 ; July 12,10 ; Washington, D. C.
DItAPEI?. WARREN FALFS (b'83)-Mass.1. '10; July 12,'10; July 12,'10; Colonial Beach, Va.

GILIESI'IE, JULIAN MASON (b'82)-Md.1 '09; July' 12,'10; July 12,'10; Hongkong, China.

DUFFY, BENEDICT JAMES (b'85)-N.Y.6 I0 ; Aug.5, 10 ; Marlveles, P. I.

TIIONIPSON, L. It.-Ky.4,05; Sept.6,'10 ; Sept.6,10; Chlcago

PAICHEIR, GEOHGE-Mass 1,10; Mar.22, 11; Mar.22,'11; Immigration Service, Ellts Island, $\mathrm{N}$. ' $\mathrm{X}$.

SCHIVARTZ, LOUIS-Pa.2,05; Mar.22,'11 Mar.22,11; Cebu, P. I.

IITERICK, ROBERT H.-0.1,06; $0.2,11$ Manlla. P. I.

WATKINS, JoHN A.-La.1,'10; 0ct.2,11 San Franclsco.

WILLIAMS, CHARLES I.-Va.1,11; May 13,12; Apr.30,12; U.S.R.C. "Tahoma."” May 13,'12; Apr.29,'12; Immigration Service. Ellis Island, N. Y

KEMPF, GROVER ANDREW-Ind.20,'10 Ellis Island, N. $\mathbf{Y}$.

SUNIWWAL, JOHN-MI.7,'12; On leave.

NEILL, MATIER HUMPHIEY-Mass.1, 09 ; Cincinnati.

SWEEXEY, ALVIN 1.-Pa.2,08; Ellls Island, N. Y.

GLANVILLE, WILLIA.M EAHL-N.Y.20,'11;

WIITE, HARRY F.-Va.6,'08; Ells Island,

S.IITH, JOHN H., JR.-IId.1,05; Ells Island, N. Y

CARMELIA, FRANCIS A.-Pa.2,'11; May 12 J13; May 12,13; Ellis Island, N.Y. '13; May 12,'13; Angel Island, Cal.

PAINE, LISTON-Pa.1,10; May 12,'13; May 12,13; Boston.

HOOPER, LIONEI E.-D.C.2,11; May 12 , '13; Nay $12, ' 13$; U.S.R.C. Thetls.

SAFFORD, M. VICTOR-Me. 1,93; May 12, '13: June 1,'00 ; May 12,'13; Boston.

ScoTT, ERNEST W.-Va.1,04; May 12,'13; May 12,13; Ellls Island, N.X.

BALCHMIN; D. S.-Ill.22,11; July 12,'13; July 12,$13 ;$ Chicago.

LALGHLiN, J. B.-Va.1,'12; July 12,13; July 12,'13; Quarantine, Ft. Morgan, Ala. TIONETZ. HARRY MCHAEL ROBERT.Ill.1,11; July 12.'13; July 12,'13; Chlcago IOLTEN, JOSEPH-Pa.11,11; July 22,13 July 25,13 ; Detroit.

UERI A UX, IHOBEIT'T C.....IO.2,'11; July 22 , 13: July 25,'13: Nobile Ala.

ItUOFF, J. S.-La.1,11; July 22,'13; July 25 , '13; Quarantine, New Orleans.

IIDDELL. T. J.-La.1,12 ; July 22,13 ; July 25,13: New Orleans.

CODY, II. C.-Que.1,'09; July 22,'13; July 25,13; Immigration Service, Eliis Island,

TREADWAY, W. I.-Mo.28,'07; July 22,'13 July 25,'13; Immigration Service, Ellis Island. N. Y

SMITII, HOWARD F.-Md.4,'09; Sept. 5,'13 Manila. P.I.

WELDON, LON 0.-Ky.11,08; Sept.5,'13; San Francisco, Cal.

\section{MEDICAL OFFICERS OF INDIAN FIELD SERVICE}

With Year of Birth, Medical college and Year of Graduation, and Address

NEMBER OF IHYSICIANS, ISS.

Field Service

Murphy, Jos. A.-D.C.1.'05; (Medical superrisor at Large); Indian Office, Washington.

Shomaker. Ferdinand (b'68) - D.C.2. 91; (Tuberculosis and Trachoma Expert at Large); Indian Office, Washington.
Daugherty, John E. $\left(b^{\prime} ; 6\right)-$ Wo.28,02; Chief Health Section, Washington.

Harrison, Wm. H. (b'70)-Ky.1,98; Indian Offece, Washington.

Richards, Polk-Ind.1S,06; Indian Office.

Wan Cleave. W. Edgar (b'i)-Ky.9,05;

an Cleave. W. Edgar (b'

Indian Office, Washington. querque, $\mathrm{x} . \mathrm{M}$

l)wey. Christian Henry (b'80)-D.C.1,07 ; Indian Office, washington.

\section{Indian Field Service}

Doyle, Guy P.-Ill.1,94; Bishop School, Bishop, Cal

Fisher, Albert M. (b’75)-Ill.6,'04; Bismarck School, Bismarck, N. D.

Phillips, Orlyn S. (b'83)-D.C.1,'07 ; Black-

feet School, Browning, Mont.
Boyd, Carl B. (b'73)-D.C.2,98; Campo School, Campo, Cal.

Hughes, Coit Inge (b'82)—Ky.2,'09; Camp Yerde School, Camp Verde, Ariz. 
Eumwer. Herry Reld (b'79)-D.C.2,98: Cancon Asrlum sebool, Canton. B. i D. Cart Ifar E.-Mo. P'96; Cantonment Sechool, Cantonment, Okla.

lile. Aberteus R. (b'62)-Pa.1.8: ; Carlialo school, Carllale. Pa. Carion Clty, Theodore (b'75)-Cal.7.03: Walle. Cuifoind Eillson (b'86)-D.C.1,'10;

smare, Albert H. (6'68)-Mo.7,97; Cheyenoe and Arapaho School, Darlington, Otla.

rrwanen, Corwin A. (b'30)-N.Y.8, '76 : Hobart. Otta.

stalbere, lano 2. (b'82)-Mo.i.05: Cheycase Hiver School, Chesenne Agency, S. I reamer, Frank Harrison (b'86)-Ma,3,08 Crogenno River School, Cheyeneo Agency. 8. D.

Banden. Geo. A.-Cheyenne River School Cbejenne Azency, s. D.

stokes, Fredk. A. (b'73)-Ind.8,'98; Cheyeane River School, Cheyenne Agencs. S. D mile, Lawrence W. $(b, 72)-D, C, 4,02$ : Chiloceo sehool. Chiloceo, Okla.

(b'66)-Pa.2.91;; Desmet. Id:

Nettle, Yary A. (b'81)-D.C.3,05; Colorado River School, Parker. Arlz.

Kelly. lsanc N. (b'83)-Ky.i,0i: Nespelem

MeEac, Roderick D. $\rightarrow$ : Hunter, Wash.

Lane. Cornellus Wilson-Ill.4;03: Onak,

Oberlander, Hertman L-C.Y.Y.15.87; Cruw Scbool, Crow Azency, Mont.

Heurance, Edward (b't9)-Nu. 32, '03 ; Crow School, Crow Agency. Mont.

Eilia, Frant G. Mo.28,06; Crox Schnot. Crow Arency. Mont.

Alley. Amency. Mont. (b'it)-Vt.2, 29 ; Crow Creek Behool. Crow Creek, S.'D.

Tinmear, Claude H. (b'68)-Pa.2,'89! Cushman 8chool. Tacoma. Wash.

Gartaer. Geo. H. (b'i4)-Cal.1,'96; Fallon Bebool, Fallon. Ner.

nuscell, J. A-Mo.1,98; Fallon School, Lorelocks. Nier.

Bpatrord, Fred A. (b'35) -N.R.1,'80 : Flandreau School, Flandreau. S. D.

Geldelman, John H. (b'66)-0.8,91; Flathead 8chool, Jocko, Mont.

vyoulat, Jacob E. (b'-3)-MInn.t,05: Fond du Lae School, Cloquet. Minn

Fralle, Harrs B. (b'81)-Pa.11,0.; Apacha sehool, Wbiteriver, Arlz.

Van KIrk, Asber W. (b'81)-Md.3, 0i : L.amont, wash.

Mekee Mary H. (b'65)-Pajz'sQ: it Berthold School, Elbowoods. N. It.

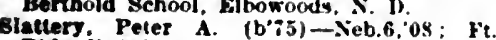
Bldwell School, Ft. Bidwell, Cal.

Tinsman, Chis. U. (b'66)-Ia.1,98; Adin Cal.

Wheeler, Henry R. (b'63)-Mo.20,96; Ft. Hall School, Rossfork. Ida.

clley. John N. (b'72)-Pa.2,96; Ft. Lap:xal sehool, Lapwal. Ida.

Gabel. Wm. P. H. (b'84)-D.C.1,09: $r$ Lnowal Schnol, Lapwal, Ida.

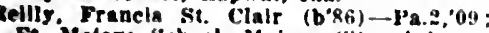
Ft. Mojaro school, Mojare Clty Arlz.

Atkinson, James $\mathrm{L}_{4}\left(\mathrm{~b}^{\prime} 56\right)$ - Mo. $\mathrm{i}, 79$ :

Peek Sehool. Poptex, Mont.

Huber. Levl Huuston (b'al)-D.C.1,06; rit

Peek School. Poplar. Siont.

Wamer, Albert Kowlind (b'i5) - Pa.1,98 ni. Totien school. Vh. Totten. N. I).

Jacobs, Leon (b'78)-II1.1.03; yt. luma Behool. Yuma, Ariz.

Davis. Homer (b'68)-Neb.5.00; lienna sctiool, (ienon. Neb.

Hekn. Frank 18, (6.01)-III.1,9!) : lirand Portage school. firand Portake, il inn.

Wilson, E. E.-Cal.7.01: Greenrille school. (ireentille. Cal.

Yeager. Yan Glenn (b.83)-L.a.1;00: Has ward sehool, IIayward. Wis.

Ariterson, Carl A. (b-79) - Minn 4,0: Hoopa valley School. Iloupa, Cal

Wrekon, Feo Lewts (6,7)-1a.3.95; Jicar ills Sehowl. Mulce. $\mathbf{x}$. II

Ragan. Win Frarik (b'86) - Wis.3.08 Kevtena school. Neoplt, Wils.

runk. Jlalph $t$. (b'79)-Kan.1,01: Kich apoo sichrol. R.F.I). No. H. Horton, Kan.

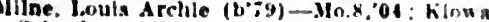
sehool. Anadarke, Wkia.
Vosles, Virsit A-Ky.144; Klowa school.

Anadarko Okla
Rendtorn, Walter (b'79)-culo.5,03: Kiowa Bchool, Anadarko, Okla.

Johnson, Alfred (b'is)-Ia.t.09: Klamath School. Klamath Agency, Ore.

Hemenway, Stacy $\left(b^{\circ} 36\right)-111.6,62$; Yalnax, Ore.

Pinch. J. W.-Mleh.8,"91 : Lac du Flambeau School, lac du Vlambeau, K's.

Sincock, Henry arthur (b'86)-III.6.'11: Olanah. Wha.

Caatell. Loula Bernard (b'83)-IJ)1,1,12: Leech Lake School. Onlgum. Minn.

House, Zacherlah $\mathrm{E}$ ( $\left.\mathrm{b}^{\prime} 5\right)-\mathrm{D} . \mathrm{C} .1,03$ : Leech Lake Schoot. Onigum. Milnn.

child. Hownrd Tennyson (b'84)-1'a 2,09: Franklln,

Read. Boyd Rlehard (b'89)-D.c.1,12: Lower Brule School, Lower Brule, s. b. hussell, Holt. L.-D.C.I,01: Sac and Fox Sanatorium, Toledo, Ia.

King. John ic: (b'53)-Tenn.1, it; Malki scbool, Banning, Cal.

Cotrman, Harry L. (b'66)-1'a.11,01 : 1'alm springs, Cal.

Erans, J. II.-Malkl School, Bamming, (al.

Calaway, John R. (b'ii)-\$lo.7,06: Mes-

calero School. Nescalero, $\$$. $M$.

heeler. Arthur Jos. (b's2)-D.c.1,0s

Moutul school. Kcams Canon. Ariz

Herman, Maxwell (b'88)-1'a.2,09; Sall Carlos. Ariz.

Farour, Hiehmond, Jr. (0'06)-M(1.1.04 Moqul school, keams Canon. Ariz.

Brondstetter, Michael Fredk. (b'85) - Mich.1. 11 ; Mt. Pleasant Scbool, Mt. Pleasani. Mich.

Murtaukh, Edward G. (b'68) - Mo.20.'s Moapa River School, Moapa, Nev.

wigglesworth, Albert Mathew (bra) Colo.2.96; Narajo School, Ft. Deflance. Ariz.

Barton. Wm. C.-Mo.2s,11; Narajo School, Fi. Heflance, Artz

Chambers claude $\mathrm{s}$. - Tenn.6,'13; Tohatchi, N.M.

Elltott. Lee Louls (b'88)-D.C.1.10; (herohee, N.c.

Calkins, Hoyal $w$. (b;0)-1a.4.93; Navajo springs scluool, Narajo springs. Colo.

Woods, Chas. It. $\left(b^{\prime} 60\right)$-Ind.10.94: Neah Bay School, Neah Bay, Wash.

Capps. Paul Gilbert (b'84)-Mo.2s,08

Lake, Albert b. (b'46)-0.15.68; (juwanda. N. Y.

Walker. Harry (b'61)-...Y.10'st; Osage School, l'ay luuska, Okla.

Lovelady, Otis Eimer (b'69)-Mlo. 28,99: otoe S'chool, Otoe, Okla

Mckinles, Frank J. (b't)-S.C.1.03; Pala School, l'ala, Cal.

Phillips, (ieo. llarrison $\left(b^{\circ} 58\right)-0.9,80$ : Pawnee School, Pawnet, Okla

Marden Augustus Erdman (b63)-Mass.5 89: Phoenlx School, Phoenix, Ariz.

Hollister. Chas. If. (b'6 $\left.{ }^{\prime}\right)-1$ 'a.1, 45 ; P'lerre School, lierre. S. D.

Slms. Claude Edison (b'79)-1nd.18,06: Phoenix, Ariz.

Rlchards, i. il.-l'Ima sichuel, Saraton. Arlz.

Delcher, Hazlett Austin MU.1,0耳: L'ma School, Sacaton, Ariz

Rnsa. Balph II. (b'bi)-D.C.2.91: Pine Hidec Scluool, i'ine kidge. s. i)

Linclley, John s. (b'60)-ky 2,'ss: l'ne

nidge school, l'ine Bldre s. lo.

Walker, Janies R. (b'49)-111.6.73: Pine

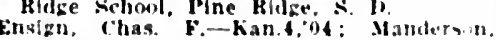
s.. 10

Jenckes, Herbert D $(1,50)$ III.11, st Pipestone schurl, l'ipestane, Mimin

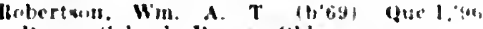
Pene: schonl, lonea, okla.

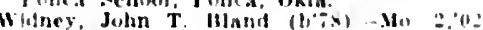
Penea Schmel, Whitende, Okia

lia) lewis clinicon (bia) reat

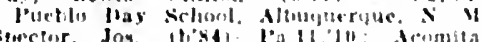

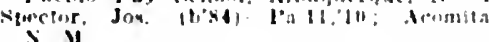

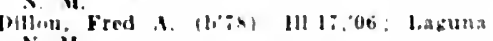
$x$ is.

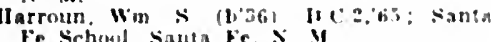

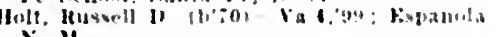

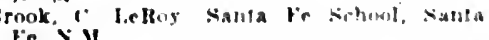

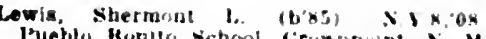

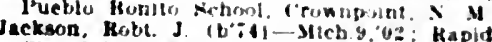
clity School, Hapid cliy. \& II

Hannum. Henry (b's5)-ill.1.' 1 ; Ked cll school, Basteld, Wis.

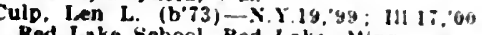
Red Lako school, Red Lake. Btinn

LInton, Edmund $c_{\text {. }}\left(b^{\circ 84}\right)$ N.Y.19;05: Hed Lake School, Red Lake, sinin.

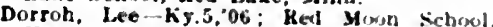
Hammon, Okla.

Perkins. James \&. (b'65)-La 1,93; Hice Station school, Bice, Ariz.

Befout, Win. It. (b79)-0.3.05: Hinetrus srlicul, Rosebud, S. I

Smith, Arthur C. (b.sx)-10.1.11: Itse bud schimil, Hosetud s. li.

Zitnmernan, Mas. F, Mosebud schoms hicsetud. S. It

Miller, James $L-1 a$ 6,01; Winner, S.D).

'ralk, Harrs 2 . (b.84-Mo 2.'10; Shiprek

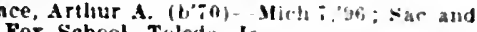
Fox School. Toledo. I

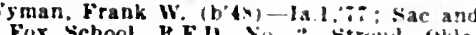

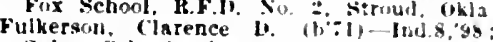
Salem Schronl Chemawa, "tre

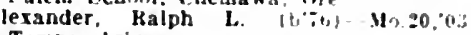
Tempe, Ariz.

Taylor. jos. J. (b'66) -Mo.:04: M० [0,' 3

San Carlos School. San Carlus. Ariz

Brcdt. Chas. E.-San Juan Schinil, shoprock. x. is.

llart. Edward S. $\left(b^{\prime} 30\right)-0, ;,: 3$; Santee schiol, Santee, Nicb.

Quinton. Chas. Byron (b'is)-No.10.12:

sall Xarier school, Tucson, triz

servin, fuillermo $k$. (b'bl - Mer $3 \cdots$

Xarler school, Tueson, Ariz.

narnell. klmer E. (b'sl)-ohla 1.11: sezar school Coluny, Okla

l'oints. Blals (b)t1-okla.1,11: seneca school, Wyandotte "Wla.

Bradford, Walter claudius (bi-is)-30.90 'ol: shawnee Schoml. Shawnee, Ohla

Hoblee. Wm. Wallace (b'72)-Cal.1.95

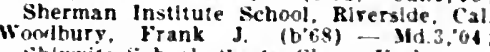
shtrwits schonl. Santa Clara letah.

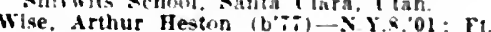
Washakie, Wyo.

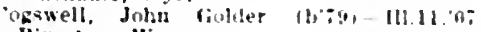
Biverton. Wy.

Clauslus, Maximllian $F$ (t'5e)-111s.so YY.6,91: siletz schow siletz Ore.

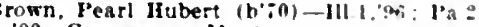
'00: Girassrange. Mont.

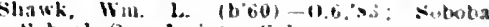

School. San Jacinıo, Cal

Arnold. Chadwick Erans (b:5)-C:al 1,01 Solota schoml. San Jacinzo, Cal.

Hiodes. Thos if -..spokane schoul, Lin

coln. Wash.

Bennett, Willis S.-Ia 10:08: stadine leock Schom. Ft. Yates, $\mathbf{x}$ 11

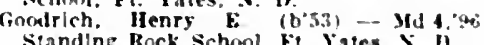
Standing Rnck Schml, Fi Yates, NII

in.

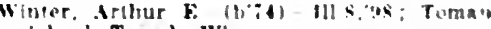
sichool. Tomah, wis.

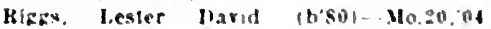
Truxton Caston schow? Valentine, Ariz

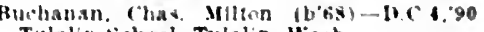
Tulalip scluoni. Tulalip. Wash

lialley, Alfred kohb-Tenn.1:ss; Tulallp scheul. Tulalis, Wash

Murrow, Wim. lingd l'a g.'gl: Toneue Hirer school, lame beer, Jiont

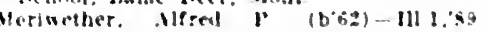

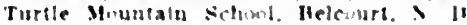

1. Word llenry Baluin (b69)-Tenn 10.99: bi buchesne, litah.

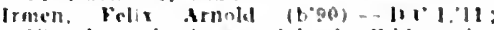
fibtal, and diuray school, Whlterucks. I'tmh

Ilomirpan. Thes Martin (to:?2)-Ky 2,93 ; l'mathlla Schomt, lendleton, Ire

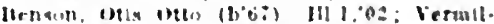
tuil lake sirbirel, Tuwer, Minn. andall. lauret in (b'6i)-111.10.95 Mirh:iez: Meqa lirande, Cal

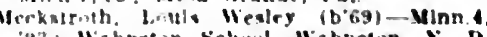
97: Wahpeton sctumil. Wahyewn, X. D Hallman. Hutert ictur loci:07: Walker Hirer scherl. Schurz, Ver

(Chas James (b'6:) -... Y Y.3.93 Warmepring Sicheril, Warmepring, Ore. 
Wilson, Henry Kirke (b'74)-Ill.6,00; Westeris Navajo School. Tuba, Arlz.

Townsend, Benj. Ira (b'84)-Kan.2,08 Narah, Sprlngs, Colo.

Rodwell, Thos, F. $\left(b^{\prime} 60\right)$ - Wleh.7'86; white

Earth School, White Earth Minm.

Janney, James finrfleld (b'82) - Mo.22,'10

White Earth School, White Farth, Iinn.

Guittard, Vhigll 1).-0.25,07; Whito Earth School, White Earth, Minn.

Ballou, James larkin (b'73)-Tenn.1, 01 Pa.2,'07; Ponsford, Minn.

Aseher, Alfred (b'st)-Mo.34,'12; White Eartl School, White Farth. Minn

Young, Clifton E. (b'81)-D.C.1,10; Winne-

bago School, VImnebago, Neb.

Rothmun, Jewis (b'61)-111.1,81; Wltten -

berg Schwol, Wittenberg, wis.
Duncall, Cleveland Reuben $(1,84)-I a .3,09$; Yaklma School, Ft. Slmcoe, Wash. Dunn, II. M.-Yakima School, Ft. Slmcoe, Wash.

WImberly, Geo. WV. $\left(b^{\prime} 75\right)-D . C .1,02$; Yaklma Sehool, Ft. Slineoe, Wash.

Collier, Ieland H. (b'80)-Mo.20,10; Yankollier, leland H, (b'80)-Mo.20,

Davis, Edward I. Jaekson (b'70)-Mass.1, 99; Zunl School, Zunl, N. M.

llerman, Marguerite Balley (b'88)-Pa.7,'11; San Carlos School, San Carlos, Arlz.

Five Civilized Tribes Schools

Works, Walter scott (b'i2)-Ky,4,07; Armstrong School, Academy, Okla.

Ellls, Geo. H. (b'71)-Tenn.8,03; Bloomfleld School, Hendrlx, Okla.
Duckworth, John Frank (b'76)-Ind.8,'00; Cherokee School, Park Hill, Okla.

Truax, Geo. II.-Tex.7,'04; Collins School Frlsco, Okla.

Longmire, Wm. Polk (b'81)-Ky.5,04: Euchee School, Sapulpa, Okla.

Tolleson Y'm A (b'69)-Mo.1,95: Eufaula

School, Eufaula, Okla.

Sames, Wm. Walter (b'61) - Mo.1,'96; Hartshorne, Okla.

Harber, Jasper Newton $\left(b^{\prime} 79\right)-M o .28,05$; Mekusukey School, Mekusukey, Okla.

Culp, Amos II. (b'60)-Ky.4,'88; Beggs Okla.

Renegar. James Frank (b'73)-Ky.2,'06 :

Tuskahoma School, Tuskahoma, Okla.

Denison, James S.-Tenn.6,04; Wheelock School, Garvin, Otrla.

Much more information has been incorporated in this than in any previous edition. To save space, symbols and abbreviations have been liberally used; it is important that the reader thoroughly familiarize himself with these, as well as with the various departments of the directory.

The information is here, but much of it is available only through the use of the keys. Have you become familiar with them? See pages $55-56$. 


\section{ROSTER OF EXAMINING SURGEONS}

Inuninted under authority of the

COMMISSIONFR ()F PFNSIONS

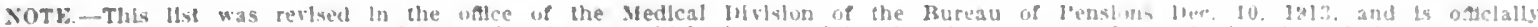
correct to that date. The city glien denotes lhe place at which the exanlning loard convenes and nut the lucation if the surgess.

OFFICERS OF THE MEDICAL DIVISION. BUREAU OF PENSIONS

Thomas Featherstonhaugh, Medical Ref eree: (ieo, I". Wu Bose, Axalatant Mledlca] Wondman, uuallfied surgeons.

\section{Alabama}

Axvistos, Calmun Co-J. B. kelly. Pres, T. J. Brothers, Sec. ; H. M. Martin. Jros Treas:

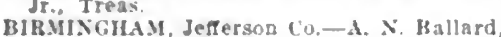

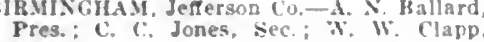

Tres:

CLLldlat, Cullman Co.-J. H. Walling l'res.: Golbob llarlumg, sec.; 5 . M. Wil hise, Treas.

DECATCu, Morgan Co._C. \& " chenaul, I'res.; W. F. Sterrs, siec.; It. T. Fineralse, Trens.

FLOREvCk, Lauderdale Co _ P. S. Boyll.

IIETSVILLF. Madlson ("n-H. F. Scruggs, I'res.: U. J Brooks, sec : II. I). Hest moreland, Treas.

MOHIL. Moblle Co.m. I. Crampton. Pres.: T. J M. Acker, sec.: \$. \$. Pugh. Treas.

MONTGOMERY, Montgomery ('o.-J. L. Gaston. I'res.: C. I. Marks. Sec.; Hohert Goldhwalte. Treas.

ScotTsBoro, Jackson (1.-... X. Mlake. more, Pres.; W. C. Map!es. Sec.; IJugh Boyd, Treas.

Srissi, Jallas Co.--J. T. Chamman, I'res. B. B. Ward, Sec. H. B. Kogan, Treas.

\section{Arizona}

PHoEvix, Marlcopa Co._J. W. Fuss, I'res. w. il. Sartent sec. 0. E. Plath. Treas. PREscrot, Yavajal Co.-W. E. Way. TCCsoN, PJms (o,-H. H. Jllling.

\section{Arkansas}

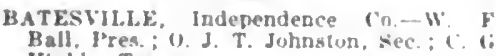
Hinkle. Treas

BLACK ROCK, Lawrence Co. (i. I Whren.

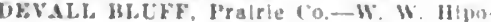
like, Pres.; James I'arker, Sec. : F. Illpollie, Treas

ELBRik SIBINGis, lartoll ('o.-Is. (; Floyd. l'res. : 12 r. Ellls, Treas.

FAYFTTEIILE. Washlngton ('),- \&

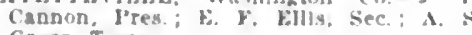
firegg. Treas.

FORT s.IITH, sehastian Co W W urney, Treas: J. A koliz, Ster in

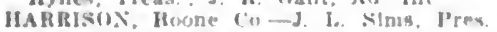
J J. Johrian, sec, $k$ it kirhy, Treas.

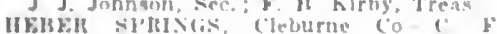
Croshy.

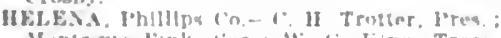
Monlague Fink. Sec ; if i king. Treas.

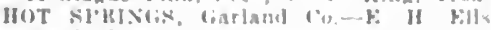

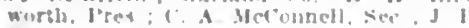
Handolpti. Treas.

ILNTsind, Madian in $\rightarrow$ krefertek Younctileres

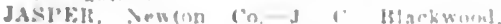

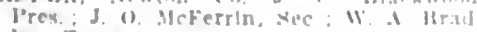
ley. Treas

JOxksunhe, Cralgheal I o liracey llal

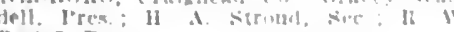
Ratint Treas.

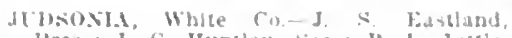
l'res.; J. C. Huntley, sec.; i. l. lotitle Treas.

I.ITTLE ROCK, rulaski ro, - bilw in Mentley pres. S. L'. Klgg. sec. J J. It. Burell,

M.ABSIEALL, Searcy, ('0.-S, (;, Janlel, lres.; E. W. Woud, sec : J. i) cotrin, Treas

MrLbolilise, Izard ('o... E A. Harter

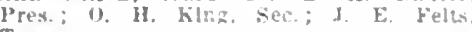
Treas

MF.N. l'olk Cn.-W. P. Parks. l'res ; k. I lee, Sec.: P. R. Watkins. Treas.

MOt NTAI HOME. Baxter lo- R. S Wlison, I'res.: J. It. Simpson, Ser.: J. T. Tinton. Tress.

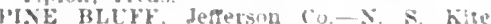
I'res: J. S. Smith, Sec. A iv. Troupe, Treas

Muikis, kenton ("o. W. If. Mller, l'res: b. F. Plekens, see : K. S. Hice, Treas.

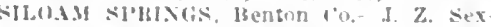
son, Pres. J. T. Clest. Sec, j. W. Wel. ster. Treas.

Tk:IKkANA. Mller Co.-James McMahon Pres.: II. K. Welster, Sec.; I. I. IVII. lians, Treas.

WYNXE. Cross Co.-W. B. Barner.

\section{California}

CHICO. Butte Co.-1'. I. Hamilton

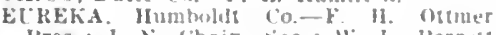
I'res.; j. X. Chain, sec, ; W. L. Lerruts, Treas

FIsEs.jo, Fresno Co,-. (; H. Aiken, l'res. II. St. (ieo. Ifoyklns, sec. : 1 . X. Itussell, Treas. : W. T. Barr, Al lint.

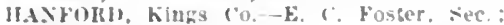
I. k. Felion. Treas.

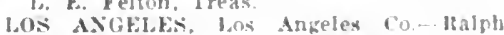
Hagan, I'res: : W. C. Harrlson, Sec. A. W. Monre, Treas.; j. A. Mcharry, Id Int.

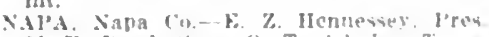
M. 13. I'pnd, sec, 0. T. seliulze. Treiss. S. M. Wuberty, Ad. Ine.

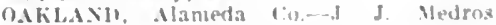
l'res, II j. Lackey, Sece: A 5 hilly Trens. : Bulley smlih, Ad in

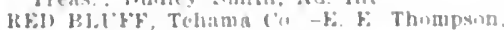
Ires. H. H. Zummernan, sec. : S. T white, Treas

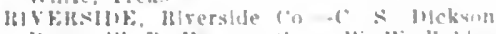

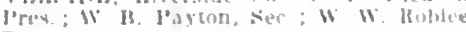
Treasy

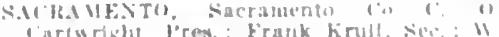

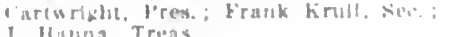

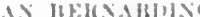

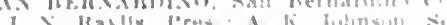

1: li llwern. Trean

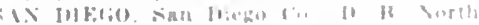
ruy. l'res: T. I.

IBemundinu, Trome

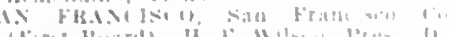

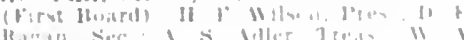

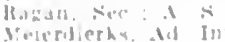

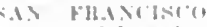

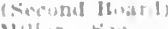

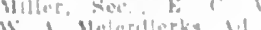

il jost santa ilar.

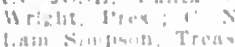

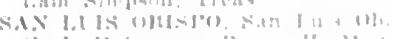

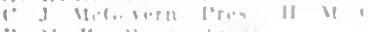

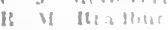

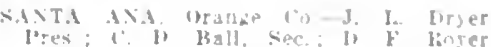
pres
Treas.

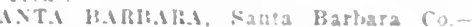
1'larlea Anderatn, I'rus: IV. T. Marrs.

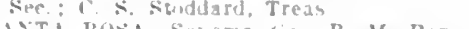

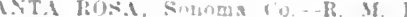
l'res: J. IV Clne, Sec.: J. II. Mileod.

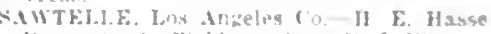
l'res: 1. .l. Fielding. sec : k. J. Waztie: Treas. I. H. Case, Ad Ins.

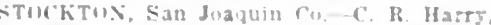

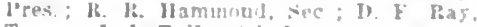
Treas: J. J. Tully, Ad. int

TLIAAKE, Tulare (O.- T. 1). Blotaen

\section{Colorado}

A.PF. J'itkin ('v.-C. W. Judkins.

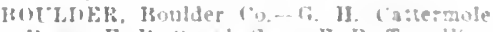
Trea. ;

HRECKFIRITIE, Summit (No,-J, F Cont tonl

INON FTY, Fremon: Cn.- W. T Lalle. l'res.; It. E. Holmes, sec. : C. H dirares. Treas.

COLORAM) SPRINCE, FI Paw ro.-r, F rardiner, l'res.: H C. Moses, Sec; H $\mathbf{W}$ H.)agland, Treas.

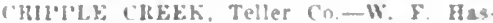
senplug. I'res. : T. A. Mantyre, sec ; A J. Campleell, Treaz.

WEXIFR. Wenver Co.-W. W. Rulerson. l'res.: (; C. Stemen, see : C. k: Anoper. Treas

MKAxi(1. La Plats $10-W$. W. Mckwen, lires: L. S. Barres. Sece: 1. C. Hund, Treas.

FukT (OILIS, Larlmer is s $T$ idulek. lres: : $k$ i. Sadler. Treas

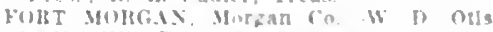

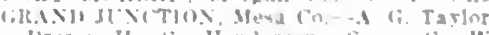

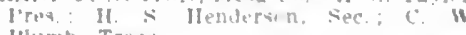
l'Jumb. Treas

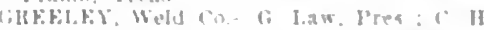
Ilulford sec : 15 f liralism. Trezs

I.AVIR. P'powers co. - $k$ M. Frend

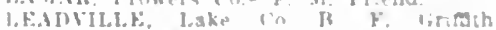

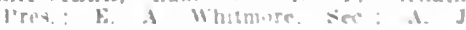
Velonnale. Tress

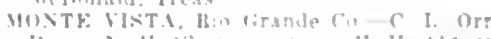

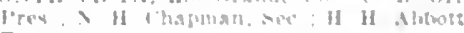
Tro:atis

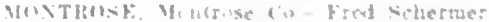

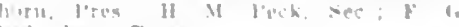

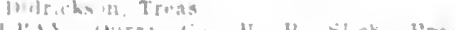

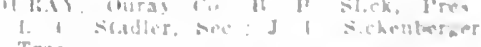

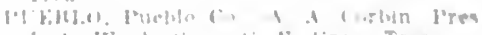

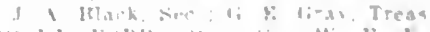

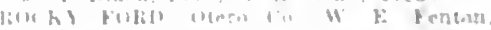

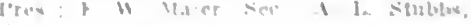

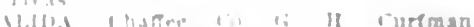

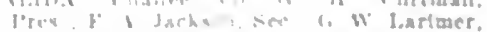

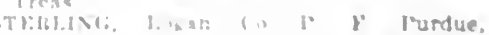

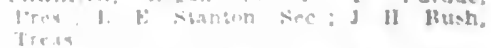

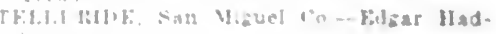

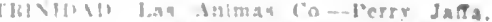

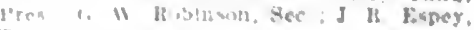

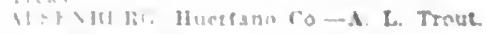




\section{Connecticut}

BRIDGEPORT, Fairfleld Co.-C. C. Godfrey, I'res.; W. C. Bowers, sec.; (;. W. Osborn, Treas.; F. M. Tukey, Ad. Int.

HARTFORD, Hartford Co.-J. B. McCook, l'ves.; T. F, Welch, Treas.

MIIDLTown, Mlddlesex co.-J. F. Calef Ires. ; J. E. Loveland, Sec.; A. J. Campbell, Treas.

NEW HAVEx, New Haren Co.-W. H Crowe, l'res.; T. M. C'alitll, Treas.

NEW JONDON, New Jondon ro,- A. IY Nelson, I'res.; H. K. Thoms, Sec.

NoflWir, New London ('o.-N. iv. Smith, l'res. : I. E. Walker, sce.; C. F, Congdon, Treas.

ROCKVILLF, Tolland Co.-F, I, Smith, I'res. : T. F. Hockwell, sec.; $\mathbf{F}$. II. lolckinsou Treas.

Waterbury, New havell co.-B. A O'llara, Pres.; D. 13. Deming, sec.; c. W S. Frost, Treas.

WILIMAXTIC, Windham Co.-W. W. Adans, Ires.; E. F. I'erry, Sec.; T. $\mathbf{K}$ l'arker, Treas.

WINSTEI, Litchfield Co.-E. R, Kelsey. I'res. ; S. G. Howd, Sec.; I. L. Hamant, Treas.

\section{Delaware}

Dover, Kent Co.-l. S. Conwell, Pres. J. II. Whlson, sec.; I. A. II. Bishop,

GEORGETOWN, Sussex Co.-O. D. RoblnSon, Pres.; J. H. Chlpman, Sec.; W. R. Messlck, Treas.

Wil.MINGTON, New Castle Co.-J. P. Wales, spruance, Treas.

\section{District of Columbia}

WASHINGTON, D. C. (First Board)-John Tan lensselaer, Pres.; J. L. Thompson, Sec. ; J. A. Gannon, Treas.; R. M. Ellyson, Ad. Int

WASHINGTON, D. C. (Second Board)-S. C. ('ox, Pres.; J. R. Blggs, Sec.; M. J.

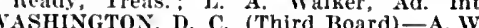
valentine, Pres.; T. B. Dixon, Sec. Howard Fisher, Treas.; C. H. Bowker, Ad. Int.

\section{Flerida}

BARTOW, Polk Co.-F. M. Wllson, Pres. ; J. N. Smith, Sec.; J. M. Oglesby, Treas. CRYSTAL RIVER, Citrus Co.-J. D. Bennett. GAINES LILE, Alacbua Co.-J. H. Colson. Pres. ; J. M. Dell, Jr., Sec, ; J. F. McKinstry, Jr. Treas.

JAChsoxillLE, Duval Co,-Claude Joyner, Pres.; J. H. Durkee, Sec.

orLANio, orange Co.-G. H. Edwards, Pres. ; Washington Kilmer, Sec.; J. D. Rush, Treas.

PENSACOLA, Escambia Co.-J. H. Pierpont, Pres.; W. A. Mills, Sec.; W. A. J. Pollock, Treas.

ST. CLOUD, Osceola Co.-E. G. Farrls, Pres.; J. D. Cliunn, Sec.; C. S. Cooper, Treas.

TALLAHASSEe, Leon Co.-H. E. Palmer, Pres.; E. MI. Brevard, Sec.; W. J. Gunn, Treas.

TAMPA, Hillsboro Co.-.J. C. Dickinson, Pres.; E. W. Bitzer, Sec. ; J. J. Saxton, Tres.;
Treas.

\section{TITLSVILLE, Brevard Co}

ATLANTA, Fulton Co.-C. M. Paine, Pres. R. E. Hinman, Sec.; R. R. Klme, Treas. AUGUSTA, Richmond Co.-W. S. Wilkinson. BRLXSWICK, Glynn Co.-J. A. Butts. DALTON, Whitield Co-J G McAfee, Pres.; H. L. Erwin, Sec.; J. F. Harris,

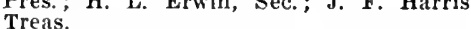

ELIIJAY, Gilmer Co.-J. S. Darnell, Pres.; J. S. Tankersley, Sec.; J. B. Chastain, Treas.

HITZGERALD, Ben Hill Co.-J. C. Fussell, Pres.; L. S. Osborne, Sec. ; 'T. E. White, Treas.

GAINESTILLE, Hall Co.-J. B. Rudolph, Ires.; W. A. Palmour, Sec.; J. H. Dowmey, Treas.

MACON, Bibb Co.-I. H. Adams, Pres.; 0. II. Wearer, Sec.; F. L. Webb, Treas.

ROME, Floyd Co.-L. P. Hammond, Pres. W. L. Funkhouser, sec.; W. J. Shaw, SATAXXAH, Chatham Co.-T. P. Waring.
THOMASVILLE, Thomas Co.-Ilarry Ainsworth.

\section{Idaho}

BOISF, Ada Co.-L. P. McCalla, Pres. C. Bowers, Sec.: S. M. C. Reynolds, Treas. F. E. Maxer, $A d$. Int. CAllifil, Canyon Co-W. C. Maxey.

GRANGEVIILE, Idalo Co.-G. S. Stockton. IFLLOGG. Shoshone Co.-G. S. Lesher.

LEWISTON, Nez Ferce Co.-C. W. Shaff, Pres. ; L. J. I'erklis, Sec.; J. F. IIurlbut, Treas.

Moscow, Latah Co.-

POCATELLO, Iannock Co-II. A. Castle, I'res.; W. F. Howard, sec. ; O. B. Steely, Treas.

THis Kootenat Co.-Frank Wen Clouchek, Pres.; II. W. Wilson, sec.; W. F. Pike, Treas.

\section{llinois}

AlBIOx, Edwards Co.-J. II. Iacey, Pres. C. S. Brannon, Sec.; J. L. McCormack, Treas

AITOX, Madison Co.-Frank Worden, Pres. Isaac Moore, See.; C. If. Merritt, Treas.; J. II. Fiegenbaum, $A d$. Int.

ANXI, Union Co.-J. F. Morse, Pres.; F. A. Sabin, Sec.; J. C. Stewart, Treas.

A ulokA, Kane Co.-o. S, I'arker, Pres. ; A. H. Mclaughlin, Sec.; C. W. Geyer, Treas.

BeARDSTow: Cass Co.C. E. Soule, Pres. T. G. Charles, Sec.; J. A. IlcGee, Treas.

BELLEVILLE, st. Clatr co. - B. E, Twitchell, Ires, ; B, H. Portuondo, Sec.; E. M. Irwin, Treas.

BELVIDERE, Boone Co.-A. W. Swift I'res.; H. E. Delavergne, Sec.; Alden

Alguire, Treas.
BENTON, Franklin Co.-J. P. Brown, Pres. ; F. O. Harrison, Sec. ; R. E. Poindexter, Treas.

BLoomington, Melean Co.-A. W. Meyer, Pres.; John Little, Sec.; L. B. Cavins, Treas.

BUSHNELI, McDonough Co.-B. E. Le Master, Sec.

CAIIO, Alexander Co.-W. C. Clarke, Pres. W. H. Fields, Sec.; S. B. Cary, Treas. CARLINVILLE, Macoupin Co.-J. S. Collins,
Pres.; J. P. Matthews, Sec. ; J. P. Denby, Treas.

CARLYLE, Clinton Co.-J. Q. Roane, Sec.; J. W. Ducomb, Treas.

CARMI, White Co.-J. N. Hopkins, Pres. ; IV. F. Stokes, Sec.; P. C. Giltner, Treas. CARRolltoN, Greene Co.-G. W. Ross, Pres.; S. F. March, Sec.; Howard Burns,

Treas.
CARTHAGE, Hancock Co.-J. H. Callahan, Pres. ; C. L. Ferris, Sec.; William Blender, Treas.

CHAMPAIGN, Champaign Co.-J. M. Bartholow, Pres.; C. B. Johnson, Sec.; E. A. Kratz, Treas.

CHARLESTON, Coles Co.-Nathan Starr, Pres. ; C. E. Greer, Sec.; P. O. Carrico, Treas.

CHICAGO, Cook Co. (First Board)-J. B. Armstrong, Pres.; A. W. Gray, Sec.; S. W. Cox, Treas.; W. H. Daley, Ad. Int. Murray, Pres. : H. M. Stowe, Sec. : Ernst Jentzsch, Treas.; W. H. Daley, Ad. Int. CHICAGO, Cook Co. (Third Board)-W. F. Bernart, Pres.; John McKlnlock, Sec.;
F. H. Schembs, Treas.; W. H. Daley, Ad. F. Int.

ClINTON, DeWitt Co.-J. M. Wilcox, Pres.; G. S. Edmonson, Sec.; A. E. Campbell, Treas.

DANVILLE, Yermilion Co.-F. W. Boston, Pres.; D. C. Hinshaw, Sec.; L. B. Rus SECÁTUR Macon Co-B I Yalenthal, Pres.; H. C. Jomes, Sec.; C. M. Wood, Treas.

DIXON, Lee Co.-W. C. Smith, Pres.; G. P. Powell, Sec.; A. F. Moore, Treas.

DLQUOIN, Perry Co.-F. M. Ward, Pres. R. D. Pope, Sec.; G. F. Mead, Treas

EAST ST. LOIIS, St. Clair Co.-H. C. Fairbrother, Pres.; C. W. Lillie, Sec.; J. E. Wiggins, Treas.

EFFIXGHA I, Effingham Co.-F. W. Godell, Pres. ; T. J. Dunn, Sec.; G. M. Baker, Treas.

EILZABETHTOW:, Hardin Co.-R. H Wlllinghain, Sec.; W. G. Gregory, Treas. EUItEKA, Woodford Co-F. H. Henderson, l'res.; C. 13. IIIgby, Sec.; F. E. Briggs,

AltFIEL, Wayne Co.-Francls Bean, Pres.; W. H. Davls, sec. ; I3. E. Garrison, Treas.

FuorA, Clay Co.-W. F. Falrehlla, Sec.

FREFPoRT, Stephenson Co.-J. F. Fair, Pres. : C. I'. Leltzell, sec.; Ailen Salter. Treas. GALENA, Jo Daviess Co.-W. A. Smith,
Pres.; E. M. Bench, Sec.; J. F. Dolamore, Treas.

GAlHSibUG, Knox Co.-G. A. Longbrake, Pres.; F. G. IIall, Sec.; J. F. Corbln, Treas.

GOLCONDA, I'ope Co.-Daniel Iawrence, I'res.; II. W. Ilccoy, Sec.; J. A. Fisher, Treas.

GRENUP, Cumberland Co.-N. J. Haughton, I'res.; J. C. Brookhart, Sec.; W. I. Simith, Treas.

GIEENVILLF, Bond Co.-W. 'T. Easley Ires. ; I. It. WilkIns, Sec. ; H. D. Cartmell, Treas.

HA ItISSBURG, Saline Co.-S. J. Blackman, Pres.; G. B. Rawlings, Sec.; W. S. Swan, Treas.

JACKSONVILLE, Morgan Co.-C. M. Vertrees, I'res.;

JOLIFT Will Co. Alpred Nash, Pros.

JOLIET, Will Co.-Alfred Nash, Pres. ; G.
M. Ieairs, Sec.; L. M. Strusynsk, Treas

KANKAKEE, Kankakee Co.-C. K. Smith, Sec. : W. II. Wilson, Treas.

LAWREYCEVIILE, Iawrence Co.-B. F Iockman, I'res.; J. E. Connett, Sec.; R. R. Trueblood, 'Treas.

LEVISTOWN, Fulton Co.-A. I. McCumber Pres.: W. S. Strode, Sec.; C. $\mathbf{X}$. McCum-

ColN, Logan Co.-H. B. Brown, Pres. F. M. Ewing, Sec. ; W. C. Paine, Treas.

ITCHFIELD, Montgomery Co.-P. M. Kelly Pres.; II. F.

McLEA SSBORO, Hamilton Co.-w. W. Hall,

Pres.; P. M. Nation, Sec.; 1. M. Asbury Treas.

MARION, Williamson Co.-L. B. Casey Pres ; L. L. Fowler, Sec.; G. J. Baker, Treas.

MARSHALL, Clark Co.-E. M. Dunean Pres.; Edward I'earce, sec. ; R. H. Brad ley, Treas.

MATtoon, Coles Co.-F. E. Bell, Pres. F. M. Beals, Sec. ; O. W. Ferguson, Treas. METRopolis, Massac Co.-J. A. Orr ETRopolis, Massac Co.-J. A. Orr,
Pres.; A. E. Miller, Sec.; J. T. Willis, Treas.

MONSIOUTH, Warren Co.-J. F. MeCutchan Pres.; W. H. Wells, Sec.; H. L. Kampen Treas.

MONTICELIO, Piatt Co.-W. B. Caldwell, Pres. ; B. M. Barker, Sec.; J. ir. Holmes, MOUNT CARMEL, Wabash Co.-L. J. Lescher, Pres.; S. W. Schneck, Sec. ; P. G. Manley, Treas.

MOUNT STERLING, Brown Co.-S. J. WHI-

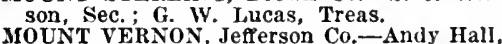

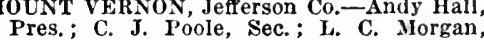
Treas.; J. H. Watson, $A d$. Int.

MURPHÝsBoRo, Jackson Co.-0. B. Orms by, Pres.; John Bennett, Sec.; H. G Horstman, Treas.

NASHVILLE, Washington Co.-W. D. Carter Pres.; S. P. Schroeder, Sec.; James Mcllwain, Treas.

NEWTON, Jasper Co.-J. H. Maxwell, Pres. ; H. S. Hinman, Sec. ; J. P. Prestley, Treas. E. H. Horner, Sec.; W. E. Fritschle,
W. Treas. Horner, Sec.; W. E. Fritschle, OREGON, Ógle Co.-J. F. Van Voorhis, Pres.; J. B. Roe, Sec.; W. W. Hanes, Treas.

OTTAWA, Lasalle Co.-E. W. Weis, Pres. E. P. Hatheway, Sec.; W. A. Pike, Treas. A. J. Roberts, Ad. Int.

PANA, Christian Co.-G. T, Meacham, Pres.; J. H. Miller, Sec.; F. J. Eberspacher, Treas.; L. H. Miller, Ad. Int. PARIS, Edgar Co.-J. G. KIlgore, Pres. : T. C. McCord, Sec.; F. D. Lydick, Treas. PEKIN, Tazewell Co.-iwliam Niergarth, Pres.; F. C. Gale, Sec.; J. M. Coleman, Treas. 
PEORIA, Peoria Co. $\rightarrow$ J. J. L. Finnell, Pres.; J. J. Toalson, Sec.; E. E. Barber

PETERSBLRG, Menard Co.-A. L. Brittin, Pres ; B. D. Epling, Sec.; 11. P. Moulton, Treas.

PIzTgnizln, PIke Co.-C. H. Doss, Pres. : T. X. Wells, Sec.: W. E. Shastid, Tress.

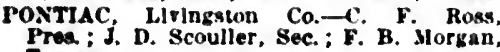
Treas:

PRINCETOX, Bureau Co.-C. c. scots Pres.: A. G. Downer, Sec.; M. A. Nix, Treas.

QUINC:, Adaros Co-C. A. Wells, Pres.

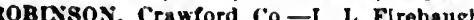

Pres.: A. G. Meserve, Sec.; II. F. Jones,

OCkYORD. WInnehago Co.-s. C. Andrus Pres.: Danlel Lichty, Sec.; F. J. Clark,

ROCK ISLANI), Rock Island (o.-M. J. O'Herm, Pres.: Ralph Dart, Sec.; M. F Dondenville, Treas.

Ri:sHVILLE. Schuyler Co.-T. W. Scott, Pres: A. W. Ball, Sec.; w. P. Harvey, Treas.: $\mathbf{F}$. D. Culberson, Ad. Int.

8ALEM, Marion Co.-J. J. Frke, Pres. G. 8. Ralney, Sec.; H. A. Cunningham, Treas.

8AVANiNa, carroll Co.-G. W. Johnson, Pres.: R. B. Rice, Sec.; F. E. Melugin. Treas.

SHAWNEETOWN, Gallatin Co. - J. w Bowling. Pres.; J. C. Harrell, Sec.; W. H. Rlley, Treas.

SPARTA, Randolph Co.-II. L. Gault, Pres. J. W. Weir, Sec.; G. E. Hendrickson, Treas.

SPRIXGFIEI.D, Sangamon co.-J. L. Whcox, Pres. : H. R. Riddle, sec.; G. $r$ sterlcker, Treas.

sTERLING; Whiteside Co.-J. F. Keefer. Pres.; W. H. Perry, Sec.; J. L. Snavely,

SULLIVAN, Moultrie Co.J. D. Donotan. Pres.; J. F. Lawsou. Sec.; S. W. Johnson, Treas

TOLLox, Stark Co.-W. T. Hall, I'res. C75de Berfeld, Sec.; W. D. Chrisman. Treas.

TUSCOLA, Douglas Co. - C. W. Rutherford, Pres.; John Ewing, Sec.; J. M. Mlller, Tress.

TANDALIA, Fajette Co.-I. I. Morey. Prea.; C. W. Durst, Sec.; G. R. Van Vranken. Tress.

VIENNA, Johnson Co. $-A$. I. Brown, Pres. W. J. Tern, Sec, : H. W. Walker, Treas. WATELKA, Iroquols Co.-A. I. Green, Pres.; G. W. Ross, sec.; D. W. Miller, Treas.

WAUKEGAN, Lake Co.-r. C. KnIght, Pres.; A. L. Brown, Sec.; L. H. Tombaukh, Treas.

WIXCHESTER, Scutt Co.-t;. C. Brengle Pres.; C. 's. Bowman, Sec.: G. M. Fres. : C. S.

WOODstoCK. McIlenry Co.-E. V. Anderson. Pres.: J. W. (iroesbeck, Sec. : W. A Nason, Treas.

\section{Indlana}

ANDERSON, Madison Co.-8. W. Rdwing, Pree.; B. H. Perce, Sec.; F. G. Keller, Trean.

AxGOLA. Steuten Co.-H. L. Cunningham Pres.: F. N. Sutherland, Sec.; W. II. Waller, Treas.

AtBURN. Dekalb Co.-H. W. Bowman, Pres.: A. H. Darby, Sec.; v. C. Brunson, Treas.

BDPORD, Lawrence Co.-A. J. McDonald, Pres.; J. B. Duncan, Sec.; F. E. Mitchell Treas:

BLoomitiln, fireene Co.-J. W. Gray, Pres: B. A. Rose, sec: H. R. Jowder, Treas.

Bloomingtox, Monroe (o.-R. C' Itogers. Pres.: R. A. Akin, Sec.; D. J. Ilollani, Treas.

BLurtios, Wells Cn.-M. N. Newman, Prex: L. A. Spaulding. Sec.; J. W. McKinney, Treas.

Boovitit. W. Warrlck Co.-D. A. De borest Pres.: Wesiey Wilson, Sec. : J. (i. Honver. Treas.

BRAzIL, Clay Co.-olluer James, I'rea. W. H. Orr, Sec.: W. II. Van sandt.
BROOKVILLE, Franklin Co-C. H. MayGeld, Pres.: J. M. Linezar, Sec.; J. F. West, Treas.

CIIARI.FSTOWN, Clark Co.-

Columaia city. Whitley Co.-X. I. Kithcart, Pres.; D. S. Linvlli, Sec. ; t. li.

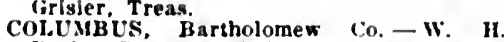
Hutler, Pres.; f. E. Reynolds, Sec.; s. II Vorls. Treas.

coNfersvilit. Fayetle Co.-s. N. Hamllton, Fres.: I. D. Dillman, Sec.; R. W. Sipe, Treas.

corfion, Harrison Co.-B. F. Forbls, Treas.

covifitos, Fountaln Co.-C. J. Finnes, l'res. : George Rowland, Sec.; $A . \quad L$.

RAWFORDSVILLE, Montgomery (o..S. L. Finsminger, Pres.: E. 1I. Cowan, c. W. Keegan, Treas.

ANVill, Hendricks Co.-Ernest Co per Pres.; J. T. Barker, Sec.; D. M. Reynolds. Treas.

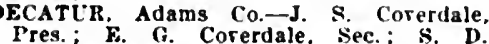
Beavers, Treas.

DEI.PIII, Carroll Co.-I. N. Cochran, J'res. : W. F. Sharrar, Sec.; C. E. Scholl, Treas. EVANSVILLE, Vanderburg co. $-w$ s. I'ollard, l'res.: D. G. Tweedall, Sec. : FoRT WAYNe, Allen Co.-k. A. Crull, Pres. : A. L. Schnelder, Sec.; Garrett Van Sweringen, Treas.

OWLER. Benton Co.-D. E. Marlty, Pres. Clark Cook, Sec.; Arthur I,e Sage, Treas.
MANKForT, Clinton Co.-W. T. Cooper, Pres. : G. W. Brown, Sec.; J. A. Kent, Treas.

FRANKILI, Johnson Co.-R. S. Byers, Pres.; J. W. Dixon. Sec,; R. B. McAlpln, Treas.

CoSHFX, Elkhart Co.-A. L. Fisher, Pres. : GREFCASTLE, putman Co. w. W. Tucker, Pres.; w. M. Mckaughey, Sec. Logan Stanley, Treas.

GREENFIELD, Hancock Co.-W. A. Justice, Pres.; J. I. Allen, Sec. J. I. Rlack, Treas.

GREENSBLRG. Decatur Co.-William Hause, Pres.; F. T. Riley, Sec.; C. M. Beall, Treas.

HA.MOND, Lake Co.-J. T. Clark. Pres. : H. E. Sharrer, Sec.: E. M. Shanklin,

HARTFonD cITy. Blackford co.-J. A. Taylor, Pres. ; Samuel IIollis, Sec.; J. R. liarrold, Treas.

IUNTINGR Rt;, Dubols Co.-Victor Knapp, Pres. ; L. C. Lukemeyer, Sec. : J. F. Casper. Trens.

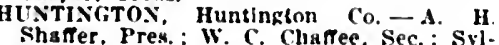
ranis hoontz. Treas.

INIAXAPOLIS, Marlon Co. (Flrst Boaril) -F. A. Rose. Pres.: T. I. sullivan, Sec.: 8. A. Petersdorf, Treas.; J. J. Irrlgas, Al. Int

INMiAarolis, Marlon Co.(Second Joard) T. J. Dugan, Treas. : J. J. Freelaud. Sec.

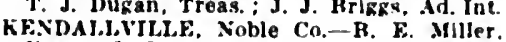
I'res.; J. I. Gillbert. Sec. : J. W. Hays. Treas.

K.jox, Starke Co.-J. R. Alner, Pres

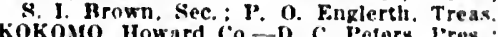
J. W. Wright ('n-D. C. Peters. Press. LA FAYETTE, TIppecanoe Bride Pres, : J. S. Morrison, Sec. : 1. : Throekmorton. Treas.

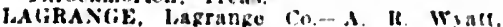
l'res: D. W. Dryer, sec.; $k$. $($. Wadr.

l.A IORTE, Ja lorte (o.-1) a. Huck. Ires.: E. I.. Aubls. Sec.: II. 3. Thomb son. Treas.

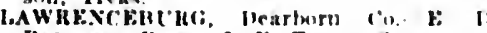
Hateman, I'rex, J. J. Tremon, Sec.

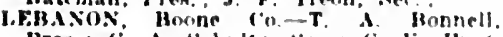
Pres.: f. A. Schultz. Sre. : f k. Ilurt. Treas.

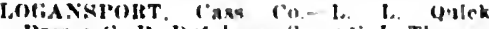

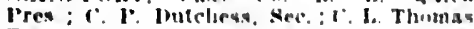
Treas.

Malisox. Jeferann I'o,-- It Auseln. Ires, :F. rook, sec: W: It Mathews.
Mardox, Grant Co.-G. W. Danlels. Sr. I'res.: J. C. Knlght, sec.: J. W. Patterson. Trea.

MAkTINSviLLE. Morkan Co W. J. Sandy. l'res.; O. A. Sweet, sec.: F R. Maxwell, Treas.

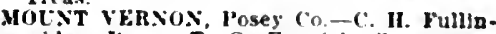
wliler, Ires.; T. C. Frmick, Sec. : Amo Klein. Treas.

MLCiE, Delaware Co.-G. W. II. Kemper, Irex.; F. G. Jackson, Sec.; s. G. Jump.

NAsHvill, Hrown to.-K. M. Tulon, Pres.; J. A. Turner, Sec.; A. J. Raiphy, Treas.

NEW ALBANY Floyd Co.-E. J. Taslor, Treas.

NEWiasti, Henry Co.-B. O. Post. Pres. II. H. Koons, Sec.; O. II. Hees, Treas.

NFWPoht, Vermilinn (o,-F. E. Sanders. Pres.: M. R. Iollom. Sec. ; I. M. Casebeet

Hershey, Pres. ; W. $\mathbf{W}$. Graham. Sec.
Hamilon Hershey, Pres. : W. H.
C. H. Tomlinson. Treas.

NORTH VEKNON, Jennings Co.-W. A Wildman, Ires, : W. H. RIchardson, Sec.: W. W. Case Treas.

oscioot, Ripley Co.--J. C. IIlcks, Pres. E. I, Freeman, Sec.: K. T. Olmsted,

PAtli, orange Co.-

'E.It: Miami Co.-J. W. Wsreham, Pres.

f. Rldenour. Sec. ; F. A. MIlls, Treas. PET E.R.SR LIRG, Plke Co.-J. T. KIme, Pres.
T. W. Bassinger, Sec.; J. R. Burger, Treas. rLYMOLTH, Marshall Co.-s. W. Gould, I'res.; 1. C. Knots, Sec.; H. P. Preston. Treas.

Porthind, Jay Co.-J. T. Dlckes, Pres. II. T, Jay, sec.

PHiferto.; Gibson Co.-w. w. Blalr. Pres.; A. R. Burton, Sec.: W. G. Hopkins, Treas.

REIIIFTOX, Jasper Co.-Emll Besser, I'res.: Hanntbal Landon, Sec.; J. A. Richuivin is

I'res.; S. E. Bond, Sec.; w. M. Helm.

ROCKPORT, Spencer Co-C, D Ebrman, 'res. : J.' C. Jolly, Sec; (i. B. De Tar. Treas.

Rocklillf, Parke Co.-Alonzo Marta. Pres.; K. F. Swope, Sec.; W. II. Glllum, Treas.

RISIIVIJ.LE, Rush Co.-F. G. Hackleman, Pres.; F. H. Green, Sec.; E. I. Wooden,

SAlbil, Wasbington Co.-L. W. Pagnter, P'res.; K. J. Wllson, Sec, F. A. May.

SCOTTSBIRG, Scott $\mathrm{Co}-\mathrm{J}$. P. Wilson,

Pres.; W. I. Melain, Sec.; H. R. Cases, Treas.

EYMoLr, Jaclison Co.-Albert May, Pres. J. K. Hitser, Sec: IIndley Ruddlek. Treas.

SHELBYVILLE, Shelby Co.-T. R. Rubush Pres.; W. W. Tindall, sec. ; H. F. Phares.
Treas.

SIIOAls. Mariln Co.-G. F. Freman. Fres. : C. Ftone, sec: J. W. Strange, Treas sofTI IE:Nin, st. Joseph Co.J. H. Greene, l'res. : J II. Cannon, Sec. W. A. Wickham. Treas, : $F$. I. Fastman. A. Int

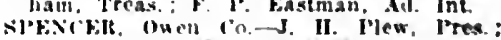
siten, Jierwon. Siec : F, V. Stucks, Treas. IIIIVAX, sulliran io-j. T Ollphent.

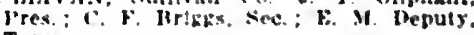
Treas

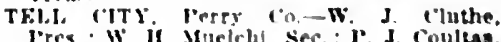
Ires: W. if. Ifueleht, sec.: Ir. J. Coulas.

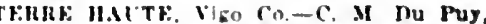
I'rey: i. 7. lireake, sec: M. II. Waters. Truas

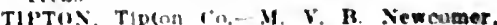

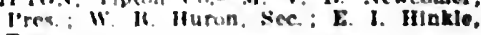
Treas

Vilitillalio, burter co-n. D. Rose. Ires: fi H. lbuslas, Sre ; A. P. Letherman. Treas

VHol. Swiferland Co.-R. M. Copeland, Jrem $J$ W Ward, Sec.: H. $\mathbf{N}$. Seares, Treas

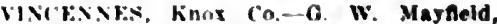
l'res. : F. if. Frigae, Sec : W. B. Sprinkle, 
WABASII, Wabash Co.-C. I. Dicken, I'res, ; B. A. Houser, sec.; L. W. Simith Treas.

WARSAW, Koselusko Co-J, S. Smith, Pres.; C. C. bu Bols, Sec.; F. J. Young, Treas.

WASHINGTON, Daviess (o.-Vance May, Pres.; Henry IIerr, Sec.; U. H. IIolder Treas.

WIIIIA.MSPORT, Warren Co.-G. s. I'orter, Pres.; F. H. Pugh, Sec. ; S. S. De Lancey Treas.

WINAMAC, Pulaski (co. A. J. Kelsey, Pres. : $i$, W. Thompson, Sec.; J. C

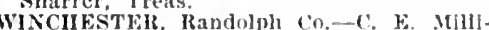
gan, Pres.; C. M. helley, sec.; J. II Moroney, Treas.

lowa

ALBIA. Monroe Co.C. B. Iowell, I'res.; C. N. Hyatt, Sec.; II. C. Eschbach, Treas. Pres.; C. II. Cretzmeyer, sec. : II. Kennefick, Treas.

ALLERTON, Wayne Co.-B, S. Ererett, Pres, ; D. E. Williams, sec.; G. W. Hinkle, Treas.

ANAliosA, Jones Co.-II. W. Sigworth, Pres.; J.' E. King, Sec.; T. C. Gorman,

Treas.
ATLANTIC, Cass Co.-U. S. Mullins, Pres. C. L. Campbell, Sec.; T. B. Morris, Treas. BEDFORD, Taylor Co.-C. M. Paschal Pres. : J. P. Standiey, Sec.; T. W. Bhoompiend, Davis Co.- T, B, Jennings, I'res.; II. C. Young, Sec.; C. C. Heady Treas.

Boone, Boone Co.-J. H. Noyes, Pres. ; G. H. Stanger, Sec.; G. D. Rowe, Treas. G. H. Stanger, Sec.;

BURLINGTON, Des Moines Co.-(;. B. Little Pres.; Carl Stutsman, Sec.; J. C. Fieming, Treas.

CARROLl, Carroll Co.-J. A. Downs, P'res. A. S. Gockley, Sec.; L. G. Patty, Treas CEDAR RAIIDS, Linn Co.-Ward Wood bridge, Pres. ; G. E. Crawford, Sec. ; J. W La Grange, Treas.

CENTERVILLE, Appanoose Co. - W. M. Scott, Pres.; C. P. Tilimont, Sec.; E. E.

Bamford, Treas.
CHARIToN, Jucas Co.-A. I. Yocum. Pres. HARITON, Jucas Co. -A. I. Yocum, Pres.
T. M. Throckmorton, Sec.; T. P. Stanton, Treas.

CHEROKEE, Cherokee Co.-R. L. Cleaves, Pres.; L. A. Westcott, Sec.; (ieorge Hadden, Treas.

ClARINIA, Page Co.-D. H. Killingsworth Pres.; W. C. Phlllips, Sec. ; F. H. Clark,
Treas.

CLINTON, Clinton Co.-J. S. Lowell, Pres. ; J. C. Langan, Sec. ; H. K. Reynolds, Treas. Pres. Adams Co.-J. H. Wallahan Pres.

COUNCIL BLUFFs, Pottawattamie Co.J. H. Clearer, Pres. ; V. L. Treynor. Sec. ; A. V. Hennessy, Treas.

CRESTON, Union Co.J.J. W. Lauder, Pres. W. K. Keith, Sec.; M. B. Reed, Treas.

DAVENPORT, Scott Co.-H. U. Braunitich, Pres.; E. S. Bowman, sec.; J. D. Cantwell, Treas.

DECORAH, Winneshiek Co.-A. J. Swezey, Pres. ; P. M. Jewell, Sec. ; F. A. Hennessy, Treas.

DENison, Crawford Co.-H. A. Boyle, Pres.; J. J. Jeehan, Sec.; I. I. Bond, Treas.

DES MOINES, Polk Co.-R. U. Chapman, Pres.; A. S. Price, Sec.; W. S. Conkling, Treas.

DUBUQUE, Dubuque Co.-I. S. Bigelow, Pres.; Bernard Michel, Sec.; M. I. Moes, Treas.

ELDORA, Hardin Co.-W. E. Whitney, Pres.; E. O. Koeneman, Sec. ; N. C. Morse Treas.

Emmetsbing, Palo Aito Co.-Gilbert Baldwin. Pres.; J. L. Vau Gorden, Sec. ; J. L. Walker. Treas.

FAIRFIELD, Jefferson Co.-M. C. Carpenter Pres.; J. †. Bean, Sec.; I. D. James,

FORT DonGE, Wehster Co.-J. II. Garrett Pres.; A. H. McCrelght, Sec.; C. H. Mulroney. Treas.

GLENTYOD, Mills Co.-S. A. Campbell, Pres.; G. M. Agan, Sec.; R. A. Moore, Treas.
GIRFENFIELD, Adair Co.-C. D. Knapp, I'res.; J. A. II arper, Sec.; it. G. Lyuch, Treas.

GRINELL, Poweshiek Co.-F. B. Wiley, RINNELL, Poweshiek Co.-F. B. Wiley,
I'res.; F. C. Bliss, Sec.; E. E. Marris, Treas.

(ITHHE rENTER, liuthrie Co.-C. O. Sones, I'res. : J. W. Ilarrison, Sec.; F. I. Bower, Treas.

HAMI'TON, Frankin Co.-I. E. Haecker, Pres. : W. F. Hoxle, Sec.; J. C. Howers, Treas.

HARLAN, Shelly Co.-E. A. Cobb, Pres. F. I. Cook sec. V. J. Heyer, Treas.

INDEPENDENCE, 'Buchanan Co.-Emery Sherman, Pres.; J. II. HeGready, Sec. II. II. IIunt, Treas.

INIIANOLA, Warren Co.-W. M. Park, 'res.; J.' I. Mc(leary, Sec.; M. L, IIoover, Treas.

IOWA CITY, Johnson ('o.-J. B. Kessier I'res.; J. A. Valenta, Sec.; A. J. Burge, T: 2as.

JEFFFRSOx, Greene co.-.T. H. Shlpley, I'res.; Charles Entield, Sec.; F. M. Dean, Treas.

KEOKUK, Lee Co.-W, W, Holmes, Pres. H. A. Kinneman, Sec.; J. M. Casey, Treas. KEOSAUQUA, Van Buren Co.-W. T. Harris, Pres. ; R. L. Boon, Sec.; E. F, Sherman, Treas.

KNoxVille, Marion Co.-J. W. Finarty, Pres.; C. W. Cornell, Sec. ; E. C. Mcclure, Treas.

LE MARS, Plymouth Co.-G, H. Nammen, Pres.; W. T. Shepard, Sec.; F. S. Clarke, Treas.

LEON, Decatur Co.-H. R. Layton, Pres. F. A. Bowman, Sec.; J. W. Walles, Treas. LOGAN, Harrison Co. - David Willams, I'res.; C. S. Kennedy, Sec. ; Hans Hanson, Treas.

McGREGor, Clayton Co.-H. H. Ciark, Pres.; C. W. I Uuffn, Sec.; W. II. Thomas, Treas.

MANCHESTER, Delaware Co.-J. J. Lindsay, Pres.; H. M. Bradies, Sec.; E. J. Winterbury, Treas.

MANSON, Calhoun Co.- Ilenry Young, Pres.; W. T. Speaker, Sec.; D. T. Martin, Treas.

MAQUOKETA, Jackson Co.-A. B. Bowen, Pres.; A. M. Avery, Sec. ; Hugh Jenkins, Treas.

MARENGo, Iowa Co.-William Noershel, Pres.; E. N. Brown, see. ; J. L. Angustine Treas.

IARSHALLTOWN, Marshall Co.-W. C Payne, Pres.; W. S. Devine, Sec.; F. H. Boucher, Treas.

MASON ĆrTY, Cerro Gordo Co.-B. F. Weston, Pres.; W. E. Long, Sec. ; C. M. Swale, Treas.

MOUNT AYR, Ringgoid Co.-M. F. Hannelly, Pres.; Samuel Bailey, Sec.; C. T. Lesan, Treas.

HOUNT PLEASANT, Henry Co.-G. T. Mason, Pres.: I. B. Allen, Sec.; W. S. Lesseger, Treas.

MUSCATINE, Muscatine Co.-F. H. Little, Pres.; E. H. King, Sec.; H. M. Dean, Treas.

NEVADA, Story Co.-J. I. Hostetter, Pres. : H. D. Chamberlin, Sec. ; F. H. Conner. Treas.

NEW HAMPTOX, Chickasaw Co.-J. K. Gardner, Pres.; P. F. Gardner, Sec. Gardner, Pres.; P. H.

NEWTON, Jasper Co.-J. R. Gorrell, Pres. : Perry Engle, Sec. ; E. F. Besser, Treas. NoRTIwO01, Worth Co.-C. A. Hurd, Pres. ; L. G. Hewitt, Sec. ; H. B. Graeser,
Treas.

ONAWA, Monona Co.-H. E. Douglass, Pres.; R. R. Gingles, Sec.; A. L. Allison, Treas.

OSAGE, Mitchell Co.-H. T. Walker, Pres.; Louis Savre. Sec.; F. I. Anderson, Treas. osCEOLA, Clarke Co.-T. M. Wai, Pres.; H. L. Hollenbeck, Sec.; W. o. Parrish, Treas.; W. R. Bolibaugh, Ad. Int.

oSkALOOSA, MIahaska Co.-W. L. Crowder, Pres. ; J. C. Barringer, Sec.; L. A. Rogers, Treas.

OTTUMIVA, Wapello Co.-A. O. Williams, Pres.; E. T. Edgerly, See.; E. A. Sheafe,

Treas.
PERRY, Dallas Co.-A. W. Trout, Pres.; W. P. Mowrer, Sec.; 1. ․ Paul. Treas.
RED OAK. Montgomery Co.-J. A. J. Martin, Pres.; H. S. Iingers, Sec.; W. S. Relley, Treas.

ROCK RAPIDS, Lyon Co-J F North, Pres.; I. I. Corcoran, Sec. ; J. M. Crowley

RolFF, Pocaliontas co.-w. W. Beam, Ires.; E. W. Wilson, Sec.; J. 1). Wallace, Treas.

SAC CITY, Sac Co.-W. H. Townsend, I'res. J. II. Stalford. Sec. : w. J. Findley, Treas. SHFLDON, O'Brien "Co.-W, R. Brock, Pres.; H. J. Brackney, Sec. ; F. W. Horton

SIDNEY, Fremont Co.-T, G, Stephens, Ires.; A. E. Nelson, Sec.; J. M. Iovelady,

SIGOURNFY, Keokuk Co.-J. F. Richardson, I'res.; I. B. Oliver, Sec.; W. W. Eastburn, Treas.

SIOUX CITY, Woodbury Co,-J. P. Savage, Pres. ; G. J. Ross, Sec.; E. D. Frear, Treas.

SPEXCER, Clay Co.-Charies McAllister Pres. ; E. E. II Iunger, Sec. ; F. J. Coleman, Treas:

N, Cedar Co.-P. M. Hoffinan, Pres. I. A. Peters, Sec. ; A. B. Hender, Treas. H. W. Boynton, Sec.: E. R. Smlth, Treas. VINTON, Benton Co.-C. C. Griffn, Pres. J. E. Luckey, Sec.; J. F. Whitney, Treas WAPELLO, Louisa Co.-D. J. Higley, Pres. W. S. Grimes, Sec.; S. J. Lewis, Treas. WASHINGTON, Washington Co.-J. H. IIull, Pres.; C. W. Stewart, Sec.; E. T. Wlckham, Treas.

WATERLOO, Blackhawk Co.-F. H. Cutler, 'res.; E. I. Dunkelberg, Sec.; C. A. Waterbury, Treas

WAUKOX. Allamakee Co. - J. W. Cain, Pres.; J. C. Crawford, Sec. ; J. W. Davis, Treas.

WAYERIY, Bremer Co.-D. S. Bradford, Pres.; J. F. Auner, Sec.; W. A. Rohle, Treas.

WEBSTER CITY, Hamilton Co.-T. F. Desmond, Pres.; G. T. IIcCauliff, Sec.; W. W. Wyatt, Treas.

WEST UNION, Fayette Co.-G. D. Darnal! Pres.; J. W. McLean, Sec. ; H. S. Hadsel, Treas.

WINTERSET, Madison Co.-R. R. Davisson Pres.; Ed. Embree, Sec.; F. D. Davenport, Treas.

\section{Kansas}

ABILFNE, Dickinson Co.-P. B, Witmer, Pres.; N. W. Hayes, Sec.; A. S. Gish Treas.

ANTHONY, Harper Co.-C. J. Callender, Pres. ; H. I..

ASHIAND, Clark Co.-W. F. Taylor.

ATCHISON, Atehison Co.- D. W. Campbell, Pres.; Virgil Morrison, Sec. ; W. F. Smith, Treas.

BELLEVILLE, Republic Co.-J. S. Billings ley, Pres.; C. M. Arbuthnot, Sec.; W. G. Hanring, Treas.

BELOIT, Mitchell Co.-D. S. O'Brien, Pres. F. B. Home, Sec.; W. H. Cook, Treas.

BURLINGTON, Coffee Co.-A. K. Berry, Pres.; G. R. Norris, Sec.; M. L. Stockton, Treas.

CLAY CENTER, Clay Co,-G, A Tul! Pres.; D. P. Cook, Sec.; Xenophon Olsen Treas.

COLBY, Thomas Co.-W. M. Bearer, Pres. W. J. Lowis, Sec.; V. C. Eddy, Treas. Colunib US, Cherokee Co.-H. A. Browne Pres.; W. N. Johnson, Sec. ; L. W. Baxter, Treas.; R. B. McKinney, Ad. Int.

CONCORDIA, Cloud Co.-T. E. Raines, Pres.; S. C. Plgman, Sec. ; Alfred Johnson, Treas.

COTTONIVOOD FALLS, Chase Co,-Jacob Hinden, Pres.; F. T. Johnson, Sec.; J. F Shelley, Treas.

DODGE CITY, Ford Co.-James Hawkins, Pres.; Herbert Whitworth, Sec.; W. F. Pine, Treas.

ELDORADO, Butler Co.-M. L. Fullinwider. Pres.; J. B. Carlile, Sec.; W. O. Bennett, Treas.

EMPORIA, Lyon Co.-T. F, Foncannon, Pres.; J. II. Parrington, Sec. ; F. A. Fckdall, Treas.

EHIE, Neosho Co.-M. E. Lake, Pres.; R. J. Harlin, Sec.; R. C. Henderson, Treas. 
FORT SCOTT, Bourion Co.-Hobert Alkman, Pres.: J. B. Carver, sec.; A. E. currler, Treas.

PlFDONIA, Wilison Co.-A. C. Ylack, I'res.: F. M. Wiles. sec.; k. C. Duncan. Treas. GARNETT, Anderson Co-T. A. Hood. I'res.; Thunas kirkpatrlek, Sec.; G. A. Blasdel, Treas.

GIRARI), Crawford Co.-(i. F. Cole. Pres. L. P. Adammon, Sec; : 1 . Ilewelt, Treas Als. Flls Co.G. B. Snvider, 1'res.; J. II Middlekaur. Sec.; J. W. Catudal, Treas.
nIAWATHA, Brown Co.-E. J. Lelgh, I'res. nIAWATHA, Brown Co.-E. J. Lelgh, Pres. nL. W. Nise. Sec. S. H. Blakels, Treas. Prea,; I. B. Parker, Sec.; A. H. Van Duyn, Treas.

noLto., Jackson Co.-C. M. Slever, Pres. J. C. Shaw, Sec.: E. W. Reed, Treas. HowARD Eik co.-w. F. Flack, I'res. : J. L Hays. Sec.; J. W. Farrow Treas. Pres. H. J. Duvall, Sec.; C. S. Erans. Tres.:

INIEPENDENCE. Montromery Co.-C. C. Surber, Pres.: G. C. Chanes, Sec.; (.. II. Meacat; Treas.

IOLA, Allen Co.-J. E. Jewell, Pres. : R. 0 Christlan. Sec.; John Willson. Treas.

JNCTION CITY' (Geary Co. - C. E. Steadman, Pres.: W. S. Yates. Sec.; L. R. King. Treas.

KANSAS CITY. Wyandotte Co-D. I. Marrison. Pres.: W. T. McDougall, Sec.; S. S. Glasscock, Treas.

KINGMAN. Kingman Co.-H. E. Hasking, Pres.: C. W. Longenecker. Sec.; W. I"

Callahan, Treas.
LA CRosse. Rush Co.-s. W. Dutton, Pres.: Lewis Attwood, Sec. : N. W. Robl-

mawi Treas. Douglas Co.-E. R. Keith. Pres.; $\boldsymbol{r}$. D. Yorse, Sec,; H. L. Chambers: Treas.

LBAVENwoRTR, Learenworth Co.-Russell Phlllips, Pres.; J. L. Fiverhardy, Sec. Stewart McKee, Treas.

LEOTI. Wichita Co.-W. D. Kunkel.

LIBFral, Seward Co.-G. S. Smlth

LIBERAL; Seward Co. - G. Alfred Hulener. Wres.: H. M. Hall, Sec.: G. M. Anderson,
Prong Tres.

LYONS, Rlce Co.-I. E. Vermllilon. Pres.: E. C. Fisher, Sec.; H. M. Bentley. Treas. MePHERSON. McPherson Co.-H. L. Salthouse, Pres.: H. S. Simpson, Sec.: Andrew Enzberk. Treas.

YANHATTAN, Riley Co-L. J. Jyman. Pres.; C. F. Lattle, Sec.: E. J. Momtt,

Treas.
MANkAto, Jewell Co.-E. I. Raynolds, Pres: A. B. Peters, Sec.; Jullus WesselPres: A. B. Preas.

MARakg. Treas. Marshall Co.-M. A. Brawley. Prea: Robert Hawkins, Sec.; J. I. Hausman, Treas.

MEDICINE LODGE, Barber Co.-J. S. Fulton, Pres.; Hardin Glibert. Sec.; J. A. Clinger. Treas.

MINXEAPOLIS, Ottawa Co.-C. D. Clark. Pres.; J. F. Brewer, Sec.; B. K. kil. bourne. Treas.

Newto:, IIartey Co.-Max Muler. Pres. Gaston Royd, Sec.; A. E. Smolt, Treas. Nontox, Norton Co. - R. M. Tinney. Pres.; oprelis, becalur Co. - Selien intner. Pres.: L. C. Tulden, Sec, : W. E. Knox. Treas.

oLArize Johnaon Co.-J. B. Arnistrong. Pres.: F. F. Grecne, Ser. : S. G. W. ster: ens. Treas.

OsAGE CITY, Osage Co.--D. M. Moore Pres.: E. B. Packer, Sec. : F. F. Schenek. Treas.

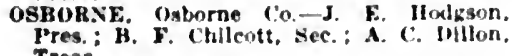
Treas.

oskaloosa, Jeferson ( $n$, A. G smuth. Irrea.: M. S

otTAWA. Pranklln Co-J. R. Thrrulury, Pres.; F. C. Hert, Sec.; M. L. Fobes,

PAOLI. Mlaml Co-L. A. Van Peli. I'res.: J. D. Walthall, sec.: S. C. Speer. Tress. Jarsoxs, Labelte co. -1 . H. Hackley. Ires.: J. Is. Anderson. Trea

PEABODY, Marlon Co. - l. W Wazar, I'res. C. J. Sesbold, sec.; U. is. Majer, Treas.

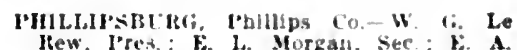
lew. l'res.

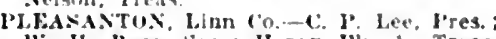

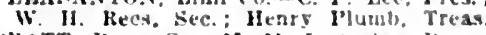
l'k.ITT, I'rat Co.-M. M. Lottr.4be, I'res. J. I. Bouthart, sec. : C. F. Bucklin, Trens.

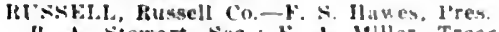
st. Jontewart. Nec. f. 1. Willer Treas. pres. : J. T. Scote, Sec.: G. "W. Akers. Tres.

SAlisi. Saline Co-J. K. Crawfird, Pres. 3. J Brown, Sec.: W. E. Fowler, Treas. SEDs. Chautaugua wriklit, Pres.

stikcd, Nemaha co.-Noah Hayes, I'res. V. (i. Hes. Sec, J. II. Brown, Treas.

sllakos siprixgs, Wallace fo.-W. J

SMitil CENTER. Smlth Co.- L. A Golden. Pres.; D. W. Helihan, Sec.; is. W. Slagle, Treas

SYRACLSE. Hamllen Co.

TOl'kkd. Shawnee Co.-s. G. Stewart, I'res.; 1. A. Ryder, Sec.; M. i. Mitchell Treas.

WAMEgo, Pottawatomie Co.-F. L. Simonton Pres.; Benjamln J. Brunuer. Sec.; J. W. Wilholt, Treas.

WAsHivgtoN, Washington Co.-M. $\mathrm{M}$. Gardner. Pres.; W. M. Earnest, Sec.; I. H. Horn, Treas.

WELLiNGTON, sumner Co.-R. H. DownShelbr. Treas.

wichiti, Sedgwick Co.-J. Z. Hoffman Pres.; A. W. McCoy, Sec.; L. W. Minick Treas.

WINFIELD, Cowley Co.-H. W. Marsh Pres.: F. M. Plckens, Sec.: Charles YATES CENTER, Woodson Co. - b. W. Maxson, Pres.; E. D. Jones, Sec.; II. W. West, Treas.

\section{Kentucky}

ALBANY, Clinton Co.-D. I. Cook, Pres. S. F. Stephenson, Sec.; F. W. Huddleston. Treas.

ASHLAND, Boyd Co.

ALGUSTA, Bracken Co.-T. S. Bradford, Pres.; J. L. Yelton, Sec.; M. A. Aullek.

RARBOURVILLE, Knox Co.-w. B. Dozler. Pres. William Burnside Sec: T. W. Jones, Treas.

BEATtYill.E, Lee Co.-C. B. Cann Pres. ; J. H. Evans. Sec.; A. B. Hoskins, Treas.

BLAINE, Lawrence Co. - J. J. Gamblll, Pres.: N. T. Rlce, Sec.; H. II. Gamblli, Treas.

TrVille, Owsley Co.-J. A. Mahaffey, Pres. : A. M. Glass, Sec. ; C. M. Anderson. Treas.

BOWLING GREEN, Warren Co. - J. F Meredith, P'res.; J. F. Rodgers, sec. J. W. Grubbs, Treas

BURkesvilLE, Cumberland Cu.-W. Sharp, Treas

CARIJSLE. Nicholas Co. A. H. Durrum. Yres.; if. il. Buntin, Sec.; L. il. Holmes, Treas.

Carkolltox, Carroll Co.-s. E. llampton, I'res.; F. M. Gaines, Sec. ; J. Y. Wheeler.

CENTAlil IITy, Muhlenberg Co,-ll. kennerly, I'res.; J. P. Walkn. sec. ; W. I MeDowell, Treas.

Col.LMBA. Adair Co-W. It Grlswom Miller. Treas.

coveritox kenton Con

cretillasa. llarrison co. I H. Van Deren, l'res.: Marahall Melunell, Sice.

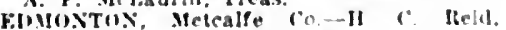
Pres:; II. IR. Vanzant, sec.: J A. Vates Treas.

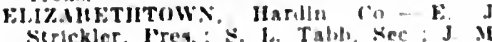
Sirickler, Fres.
Fingxllah, Treas

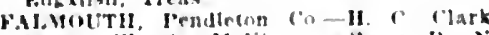
Pres.: W. A. Mikinney. Ser. I. N

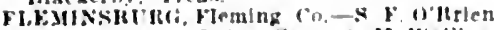
I'res, : J. S Hrice, Sec, A M Wallng pord. Jr., Treas.

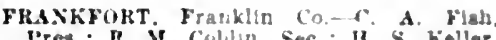
I'res, : R. M. Collhn, Sec, H. S. heller,

Gl.Ascow, Barren Co.-C W. Froedze, Y'res.: S. J. Smuek, Ste : 1. L. I'almore

GREkNUP, Gireenus Co-H. T. Sorris, Pres.: A. S. Rrady, sece; r. Ih. Fisch,

ILADINSBUBG, Breckinridge Co-... M Kincheloe, r're4; W. L. Mintis, sec. A. A. Slmons. Treas.

MAlTFOHL, Ohlo Co...S. S. Wedding. Ires.; J. W. Taylor, Sec.: S. D. Taybre.

HAZAAn, lerry Cn-C. A. rversule, I'res. II. E. Crombs sec.; J. C. Sumner, Treas. Sr.. I'res.: A. J. Lleter, Sec.: J. H.

IINDJI- Knot Co-M. $\boldsymbol{F}$. Kelley.

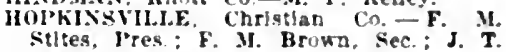
v'ernister. Treas.

IRVine, Estill co - Comelius Marcum Pres.; G. A. Embry. Sec.; Tracy Wallace.

Treas.
JACKsox, Breathltt Co-W. Y'. Hogg. Pres.; A. M. Arnold, Sec, ; J. S. Redwlne, Treas P'res.: W. G, D. Flanagan, Sec; J. E

KtTTAWA. Lyon Co.-W. G. Kinsolving. Pres.; A. D. Purdy, Sec.; D. J. Travls, Treas.

LA GRANGE, oldham Co.-J. E. L. Harbold, Pres.; R. B. Cassady, Sec.; J. W. Ozlesby. Treas.

LAXCASTER. Garrard Co.-jelson Mays, Pres.: J. A. Amon, Sec; J. M. Elllot, Treas.

LAWRESCERLRG, Anderson Co.-J. W. Gllbert. Pres. : C. W

LFBAXON, Jarion Co.-R. T. Hodgen, Pres.; C. H. Bateman, Sec.; T. F. Clearer, Treas.

LEITCliFIELD, Grasson Co.- $\boldsymbol{N}$. S. Clark, Pres.; W. H. Conklin, Sec.; 8. L. Givan, Treas.

LEXIsGtos, Fayette Co.-E. M. Whey, Pres.: P. D.

LIBERTY. Casey Co.-W. J. Sweeney, Pres. I. S. Wesley, Sec.: J. M. Haney, Treas. LoNnos, Laurel Co.-H. S. Pitman, Pres. J. B. Mason, Sec, ; G. S. Brock, Treas. Pres. : s. C. Hrankel, Sec.

MANCHESTER, Clas Co.-G. P. Webb. Pres.; J. R. Burchell, Sec.; J. L. Anderson. Treas.

MARION, Crittenden Co.-A. J. Driskill. Y'res.: T. A. Frazer, Sec; B. B. Fox,

MAYFIELD, Graves Co.-S. H. Slauchter. Ires.: B. F. Green, Sec.

MaYsille, Mason Co.-Irsin Berty. Mres. ings. Treas.

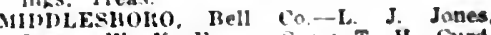
I'res. : W. K. kivans, see.; T. Ul. Curd, Treas.

Mostickllo. Wasne co.-M. J. Kelly. Pres.: J. F. Young, Sce: A. S. Cook.

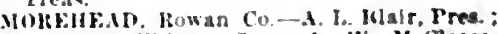
Jeremiah Wilsun. Sec.: I. W. Macleese, Trens,

WorgintuWs, Butler ro._W. r, West erfelit. Pres.; I'. E. Jaruea, Sec.; J. H Auntin, Treas

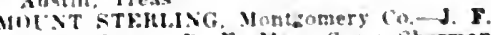
Jonies, Pres.; R. K. May, Sec.; Sherman sice. Treas

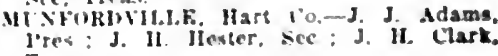
WESsilluko Darieas co-Jacob Glahn. Press: 1. II Tuld, sec.; C. M. Hearria, Tres.

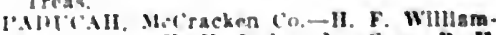
won. I'res.; II. II. Inuley. Jr., Sec, ; R B starhs. Treas.

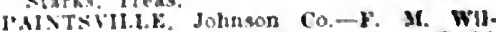
liams. Yreq, j. II. Holbrook, Sec; $\mathbf{T} . \mathbf{X}$

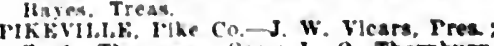
Z.A. Thompson, See; L. Q. Thorabury, 
PRestonibure. Floyd Co.-I. M. Burke, Pres.; W. R. Callihan, See. ; Frank Ramer, 'Treas.

RUSSEILVILLE, Logau Co.-C. H. Haberer. 'res.; Walter lByrne, sec; w. 1R. Bur. Treas.

SALYEISVILI, Magofin ('o- - D) R. Skages, Pres.

SANDY HOOK, Fillott Co.-s. (;. IIunter, Pres.; A. M. Isyon, See.; W. W. Jolnson, Treas.

SCOTTSVILLE, Allen Co.t. 1. Mlxon, Pres, ; II. M. Meredith, Sec.; C. W II Iolland, Treas.

SOMFRSET, Pulask] Co.-J. A. IBolln, Pres.; A. W. Cain, See.; f. W. lsaacs Treas.

TOMPKINSVILLE, Monroe Co. - $\mathrm{G}$ Bushong, Pres.; w. Sympson, sec. II. I3. Ray, Treas. ; E. E. Palmore, Ad. lut.

VANCEBURG, Lewis Co.-I. A. (irimes, Pres. ; J. D. lilles, Sec.; J. F. Irvine, Treas.

WELCHBURG, Jaekson Co.-J. M. Morris, Pres.; G. C. Goodman, See.; R. W. King, Treas.

WEST LIBERTY, Morgan Co.-B. F. Carter, Pres.; H. V. Nickell, Sec.; W. H. Wheeler. Treas.

WILLIAMSBURG, Whitley Co.-C. G. Ellison, Pres.; J. D. Adkins, Sec.; A. A Richarison, Treas.

WiLliAMSTowN, Grant Co.-A. v. Menefee, Pres.; C. D. O'Hara, Sec.; N. S. Iatthews, Treas.

WINCHESTER, Clark Co.-M. S. Browne Pres.; J. H. Uolmes, See. ; D. H. Meliniey, Treas.

\section{Louisiana}

BATON ROUfE, East Baton Rouge Co.LAKE H. Jones. F. R. Bernard.

NEW orLEANS, orleans Co.-1st BoardJ. T. Seott, Pres.; J. II. Lamb, See. ; NEW ORLEANS, Orleans Co.-2d BoardL. F. Salomon, Pres.; J. J. D'Aquin, Sec. : OPELOUSAS, St. Landry Co.-F. C. Shute. SHREVEPORT, Caddo Co.-G. C. Chandler, Pres.; F. J. Frater, Sec.; F. S. Furman, Treas.

\section{Maine}

ALFRED, York Co.-E. L. Burnham, Pres. C. E. Lander, See.; F. H. Hobbs, Trcas. AUgusTA, Kennebec Co.-C. W. Taggart, Pres.; W. S. Hill, Sec.; F. C. Thayer, Treas.; F. R. Campbell, Ad. Int.

BANGOR, Penobscot Co.-C. B. Porter, Pres.; H. H. Crane, Sec. ; J. B. Thompson, Treas.

BAR HARBOR, Hancoek Co.-G. A. Phillips, Pres.; G. R. Hagerty, Sec.; E. I. Morrison, Treas.

BATH, Sagadaloc Co.-I. C. Jrish, Pres. : E. M. Fuller, Jr., Sec. ; J. B. Weseott, Treas.

BELFAST, Waldo Co.-E. L. Stevens, Pres. S. W. Johnson, Sec.; Adelbert MIllett, Treas.

BUClisPORT, Hancock Co.-G. H. Emerson, Pres.; H. E. Snow, Sec.; C. W. Brown, Treas.

CALAIS, Washington Co.-J. R. N. Smith, Pres.; S. E. Webber, Sec.; W. N. Miner,

CARIBOU, Aroostock Co.-S. W. Boone, Pres.; G. C. Upham, Sec.; C. F. Thomas, Treas.

DAMARISCOTTA, Lincoln Co.-W. H Parsons, Pres.; J. T. Sanborn, Sec.; J. E. Odiorne, Treas.

DANFORTH, Washington Co.-R. J. Love Pres.; II. L. Porter, Sec.; B. F. Porter, Treas.

DOVER, Piscataquis Co.-C. W. Ray, Tres.; R. H. Marsh, Sec.; W. R. L. Hathaway, Treas.

ELLSWORTII, Haneoek Co.-N. C. King, Pres.; T. T. McDonald, Sec. ; Lewis Hodgkins, Treas.

FARMINGTON, Franklin Co.-J. w. Nichols, Pres.; W. J. Trefethen, See.; C. W. Bell, Treas.

FRYEBURG, Oxford Co.-H. F. Fitch, Pres. : A. J. Lougee, Sec.; C. M. Coolidge, Treas.
HOU1.TON, Aroostook CO.-C. E. Wllliams, Pres.; II. 1. P'utnam, Sec. ; T. S. Dickison, Treas

LEWISTON, Androseoggin Co.-(;. B. O'Conllell, I'res. : II. W. Ga reelon, sec.; B. $\mathbf{6}$ : W. I'uslinian, Treas.

MACHIAS, Washington ('o.-A. I. Smith, Pres.; J. W. Longfellow, sec.; $\mathbf{E}$. A. White, 'Treas.

PATTFS, Penrbseot Co.-F F. Bigelow, Pres.; F. J. Farnham, sec. ; (i. F. Woodbury, Treas.

poRTLANib, cumberland co.-N. W. R. Straw, Pres. ; C. lk. Burr, Sec. ; J. I. Sturgis, Treas.

Ito'KIAAD, Knox Co.-J. E. Walker, Pres. : W. M. Spear, ser.; J. K. Hooper, Treas; SICO, York Co.-J. Ji. Coehrane, l'res.; I. S. IIlll, Sec.; L. II. O'Neill, Treas.

Sliow IIGAN, som e r set Co-I. A l) ascombe, Pres.
Andrews. Treas.

SOUTH PAIIS, oxford Co.-H. IR. Farris, Pres.; J. G. Littlefield, See.; B. F. Bradliury, Treas.

INN, Penobscot Co.-G. F. Way, Jr. Treas.

\section{Maryland}

BALTIMORE, 1st Board-C. T. Seudder, Pres. ; H. S. Jarrett, See. ; F. R. Owings,

BALTIMLIRE, 2d Board-C. M. Dodson Pres.; G. L. Taneylill, Sec. ; J. T. Avery, Treas.

CIMBERIAND, Allegany Co.-J. M. Spear, Pres.; W. F. Twigg, Sec.; F. W. Fochtman, Treas.

EASTON, Talbot Co.-S. D. Willson.

ELKTON, Cecil Co.-S. T. Roman, Pres.; J. H. Jamar, Sec.; W. T. Morrison, Treas. Kinney, Pres.: J. M. Goodman, Sec.; C. F. Goodell, Treas.

HACERSTOWN, Washington Co. - W. M. Nihiser, Pres.; W. B. Morrison, Sec.; C. R. Scheller, Treas LoNACo.iING, Allegany Co.-J. O. Bullock,
Pres.; J. D. Skilling, Sec.; J. H. Carpenter, Treas.

PoCoMole CITY, Worcester Co.-S. S. Quinn, Pres.; R. L. Hall, Sec.; 1. T Costen, Treas.

SALISBURY, Wleomico Co.-J. McF. Dick, Pres.; H. C. Tull, Sec. ; D. B. Potter, Treas.

WFSTIINSTER, Carroll Co.-C. H. Diller, Pres. ; M. L. Bott, Sec. ; L. K. Woodward, Treas.

\section{Massachusetts}

BARNSTABLE, Barnstable Co.-S. H. Sears, Pres.; C. W. Milliken, Sec.; C. E. Harris, Treas.

BOSTON, Suffolk Co.-1st Board-G. B. Fenwlek, Pres.; E. M. Harding, Sec.; J. F. McCarthy, Treas.; J. B. Thornton, Ad. Int.

BOSTON, Suffolk Co.-2d Board-G. B. Stevens, Pres.; E. M. Bowker, Sec.; F. L. Bogan, Treas.; J. B. Thornton, Ad. Int.

BROCKTON, Plymouth Co.-A. L. Chase, Pres.; W. C. Keith, Sec.; F. G. Wheatley, Treas.

CAMBridiE, Middlesex Co.-A. J. Norris, Pres.; E. L. White, Sec.; Leo T. Myles, Treas.

FALL RIYER. Bristol Co.-A. C. Dedrick, Pres.; G. E. Butler, Sec.; John Gilbert, Treas.

FITCHBURG, Worcester Co.-A. O. Hitchcoek, Pres.; D. S. Woodworth, Sec.; E.P. Miller, Treas.

GREENFIELD, Franklin Co.-N. P. Wood, Pres. ; E. G. Best, Sec. ; S. J. Ten Broeck, Treas.

HAVERHILL, Essex Co.-C. E. Durant, Pres.; F. H. Coffn, Sec.; Hugh Donahue, Treas.

IAWRENCE, Essex Co.-W. J. Sullivan, Pres.; G. B. Sargent, Sec.; G. W. Dow, Treas.

LOWELL, Middlesex Co.-J. E. Lamoureux, Pres. ; C. B. Sanders, Sec.; J. F. Loughran, Treas.

LYNN, Essex Co.-G. W. Gale, Pres.; J. A Bedard, Sec.; F. T. Lougee, Treas.

MARLBORO, Middlesex Co. - R. E. Stevens, Pres.; E. H. Ellis, Sec.; T. F. IIcCarthy, Treas.
NANTLCKET, Nantucket Co.-S. M. Roberts, Pres.; C. (i. S. Austiu, Sec.; E. B. Coleman, Treas.

NEW HFilfOID, Bristol Co.-W. J. Nlekerson, l'res.; G. F. Lewis, sec.; S. W. IIayes, Treas.

NolTHAMPTON, Hampshire Co. - J. Mt. Woods, Treas.

PITTSFIFLl), Berkshire Co.-D. M. Whlcox, Pres, ; W. A. Mlllet, See. ; A. K. Boom,

Treas.
SAIEMI, Essex Co.-G. A. Stlckney, Pres. ; F. S. Atwnod, Sec.; G. K. Blair, Treas. SPliNGFIELD, II ampden Co-David Clark, l'res.; I. J. Gibbs, Sec. : E. A. Gates, TAlNToN, Bristol Co.-A. S. Deane, Pres. W. Y. Fox, Sec.; T. J. Robinson, Treas. WALTHAM, Mlddlesex Co.-W. S. Inoyt. Pres.; o. L. Dascombe, Sec. ; Rlchart Collins, Treas.

WORCFSTER, Worcester Co.-J. R. Lincoln. Pres.; W. R. Gilman, Sec. ; G. o. Ward Treas.

\section{Mexico}

TAMIPICO-A. W. Parsons.

Michigan

ADRIAN, Lenawee Co.-Danlel Todd, Pres. F. E. Andrews, Sec.; Clifford Kirkpatrick. Treas.

AILLEAN, Allegan Co.-W. H. Bills, Pres. N. E. Leighton, Sec.; A. L. Van Horn, ALMA, Gratiot Co.-G. W. Pettey, Pres. E. 'T. Lamb, Sec.; E. H. Foust, Treas. ALPENA, Alpena Co.-D. A. Cameron. Pres.; C. M. Williams, Sec.; S. T. Bell, Treas.

ANN ARBOR, Washtenaw Co.-Samuel Chapln, Pres.; W. F. Breakey, Sec. ;H. B. Britton, Treas.; G. M. Hull, Ad. Int.

BAD AXE, Huron Co.-J. W. Jackman Pres.; Daniel Conboy, Sec.; iv. J. Herrington, Treas.

BAY CITY, Bay Co.-Willam Kerr, Pres. G. F. Andrews, Sec.; N. R. Gilbert, Treas. : A. T. Stevenson, Ad. Int. BENZONIA, Benzle Co. - H. J. Kinne, Pres.
E. J. C. Ellis, Sec.; E. I. Covey, Treas. CHARLEvoIX, Charlevolx Co.-R. B. Armstrong, Pres.; L. B. Bartlett, Sec.; A. M. Wilkinson, Treas.

CHARLOTTE, Faton Co.-A. R. Stealy, Pres.; W. H. Kand, Sec.; C. A. Stlmsol,,

CHEBOYGAN, Cheboygan Co. -A. M. Gerow, Pres.; W. F. Reed, Sec.; W. E. Chapman, Treas.

COLDWATER, Branch Co.D. H wood, Pres. ; E. F. Gamble, Sec.; E. E. Hancock, Treas.

DETRoIT, Wayne Co.-lst Board-W. P. Melody, Pres.; W. E. Keane, Sec.; W. S. Grimes, Treas.

DETROIT, Wayne Co. (Second Board)F. H. Slevin, Pres.; R. T. Mason, Sec.; Int.

EAST TAWAS, Iosco Co.-F. C. Thompson, Pres.; C. V. Crane, Sec.; Albert Stealy, Treas.

FLINT, Genesee Co. - Joseph Scheidler, Pres.; G. V. Chamberlain, Sec.; B. E Burnell, Treas.

GAYLORD, Otsego Co.-G. G. Richards, Pres.; J. P. Fox, Sec.; H. W. Knapp, Treas.

GRAND RAPIDS, Kent Co.-J. B. Griswold Pres.; John Brady, Sec.; M. C. Sinclair. Treas.

HART, Oeeana Co.-H. B. Hatch. Pres. ; J. H. Nicholson, Sec.; J. D. Buskirk, Treas. 0

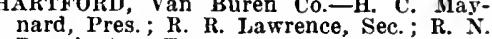
nard, Pres.; R. R.

Dunnington, Treas.
HASTINGS, Barry Co._Amos Hanlon, Pres. ; G. R. Hyde, See.; G. W. Lowry, Treas. HILLSDALE, Hillsdále Co.-W. H. Ditmars, Pres.; W. H. Sawyer, Sec.; W. H. Atterbury, Treas.

HLAND, Ottawa Co.-C. P. Brown, Pres. HOUGHTON, Houghton Co.-G. A. Conrad. HOWELL, Livingston Co.-W. H. Erwin, Pres.; w. C. Huntington, Sec.; R. H. Baird, Treas.

IONIA, Ionia Co.-G. D. Allen, Pres. ; J. J. Defendorf, Sec.; F. M. MIarsh, Treas. 
JACKsux, Jackson Co,-W. A. Gibson, Pres.: i. J. llarris, Sec.; E. C. Taylor, Treas.

KAldiszoo, Kalanazoo Co.-J. W. Bosman, Pres. : A. II. liockwell, Sec.; Eilwaril Ames, Treay.

KALKishA, Kalkaska Co, -F. B. Balirock, Pres. : P. W. I'earsall. Sec.; S. F. Neihardi. Treas.

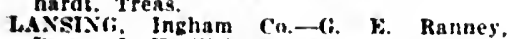
I'res.; j. H. Wellings, Sec, ; J. A. L'ost, Treas.

LAPELR, Iapeer (')-D. J. OBRien. I'res. : William Blake, sec. : (c. i). Chavin. Treas.

LEIIXGTox, Mason co.-W. II. Taylor, Pres. W. C. Martin, sec. ; H. F. Ilofiman, Treas.

MANiste. Manlstee (o.- E. s. Ellis. Pres, H. D. Roblnson. Sec.: A. S. Payne, Treas.

MaNistiqid, Schoolcraft $1 \%$ - dndrew Nelson. J'res.: W. J. Saunders, Sec.; D. W: Roos, Treas.

MARsHALL, Calhoun Co.-A. W. Alrorl, Pres.; E. J. Marshall, Sec.; W. C. Marsli, Treas.

MENOMIXEE, Menominee $(\mathrm{n},-$ B. T. Phll. Ilps. Pres.: H. A. Vennema, Sec.; J. F. IIlcks, Treas.

MinLA.in. Midland Co-F. A. Torsley, Pres.: J. H. Johnson, Sec. : C. Y. Hlgh,

Treas.

IOXRoE, Monroe Co.-P. S. Root. Pres. ; C. T. Southworth, Sec.: G. W. Hichardson. Treas.

MOUXT PLEASAAT, Isabelia Co,-H. v: Abbott. Pres. : S. F. Gar.

MTSkEGo. Muskegon Co.-I. R. Marvin, Pres.: B. F. Black, Sec.; G. S, Williams, Treas.

Nefaline. Marquette Co.-H. W. Sheldon, Pres.: J. Il. Andrus, sec.: (i, f.

Barnete, Treas.
NII.ES. Berrien ro.-R. C. Allen, Pres. Orrlile Curtls. Sec.; J. H. Jones, Treas. ; W. I. Trler. Ad. Int

NoRTHVille, Wayne Ca.-J. M. Burgess. Pres.; T. B. Henry, Sec.; T. H. Turner, Treas.

owosso. Shlawassee Co.-H. P. Halsted, Pres, : S. S. C. Phippen. Sec.: A. M Hume, Treas.

PETOSKE. Fimmet Co.-l. W. (jardnet. Pres.: (i. W. Nihare, Sec.: I. is. Crotser, Treas.

Poxtic. Oakland (o.-.J. I. raniphell. Pres. II. S. Chapman. Sec.; S. F. Galbralth. Treas.

PORT HERON, st. clalr co.-s. s. Hanson. Pres.; W. j. Dun, sec.; $w$. $l$. berck.

Pres CITY, Osceola Co.- W. A. Whitney, Treas.

SAGINAW, Saginaw Co.-.S. C. I. Ogtrum, Pres.: C. W. Stewart, Sec.: $F$ w Frlel.

mann. Treas. Pres.; C. F. Knapp, Sec.; W. ll. (iale, Treas.

Batit STE. MaRIf, rhlppesa Co,-clay. ton Willson. Pres.; it. C. Winslow, Sec. F. II. Webster. Treas.

staxplsh, Arenac co.-J, R. l'elty, Ires. F. F. Abbott. Bec. $\&$ b. Howiver Treis.

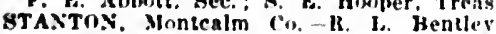
Pres.: 5 . F. Hachman. Sec. : F. M. II Highfleld. Truas.

THRFE RiveRs. St. Joseph Co.-Ernevt

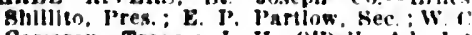
Canceon. Treas.; J. H. O'beli. Ad. Int TRAYERSF: CITY, Cirand Traverse co. F. P. lawton, jires. Frank lloldsworth. Sec. O. r. Chase, Treas.

rissir. Tuscola Co. S. F. Chane. l'rex.: T. A. Cullix. Sec.; H. I. Morrls, Treas. whitह chocid, Newaygo (o. w. A

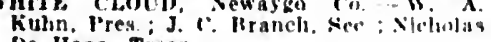
De IIass, Treas.

\section{Minnesota}

ALHERT LEA, Freebro I\%, d. It. Nan nestad.

ANOKA, Anoka C'o. A. T, ralng, I'rex: A. W. Cilddings. sec.; $F$, Fo. Vroman,

Treas.

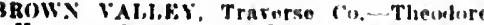
Harcum, l'res.:
Taplin, Treas. W. Fogarty, Sec : $\mathbf{A}, \mathbf{b}$.
Itrkite. Wright in. Vietor Kousteau. I'res. : J. J. Catlin, Sec.; $A$. M. Wooster, Treas.

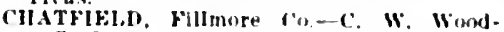

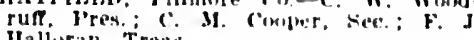
cleotheteis polk

Cl(o)kstos, Polk Co.-A. A. Just, l'res. I I Impler sice : J. S. Kjellami, Trua

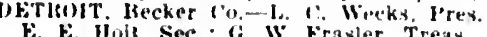

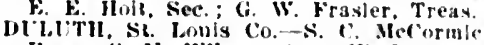

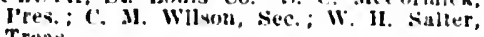

Followox, Martin Co.-A. F. Hunte, l'rey is. J. Rlchartson, sec. : I. I'. Mastliud

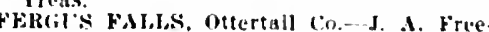
born, l'res. : W. W. Drought, Scee,; A. B. cole, Treas.

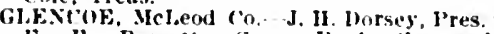
E. b. Barrett, Sec.; Fred shempard, Treas.

II. AstiNgs, Dakota Co.-A. M. Adsit, Ires.

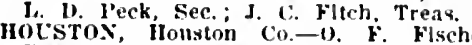
IOLSTox, Ilouston Co.-1; F. Flscher,
I'res.; L. K. Onsgard, Sec.; w. E. Browning. Treas.

ITCHFikil), Meeker co.-W. E. Chapman, I'res.: J. w.

LITTLE FALLS. Jiorrlson to. - L. II. Koberts, l'res.; J. G. Mlllspaugh, Sec, ; Noe Trens.

LONG l'RAIRIE, Todd Co.-G. R. Christie. Pres.: B. F. Van Valkenturs. Sec. W. W. Parrott, Treas.

MA.ikATo, Blue Earth Co.-J. S. Ilolbrook Pres. I. A. Hielscher, Sec.; R. : Andrews. Treas.

MARsilali., lyon Co.-C. F. Persons.

MINNFAlolis, Hennepin lo.-lst Bourl-

C. H. Norred, Pres.; W. J. Byrnes. Sec.

T. Qulnby, Treas.

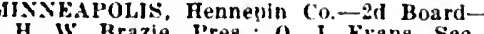
H. W. Brazie, I'res. :
J. W. Rutledge, Treas.

MoxtEviDEo, Chippewa (o.-R. De Wit Zimbeck, I'res.; R. S. Bacon, Sec.; W. II. stratton, Treas.

MORRIS, stevens ('o.-H. L. Ilulburd, I'res. Amos leuty, sec.; C. F. Caine, Trens.

Nonthrleli, Rlce Co.-J. R. Phillips, Pres.; Warren Wlison, sec.; W. A. Ilnnt,

ofToxill,k. Bigstone Co.-Jacol harn Pres.; licorge Mic Wurphey, Sec.; ( harles IBolsta. Treas.

ow.AToxi.t, Steele Co.-J. H. Adair, l'res.

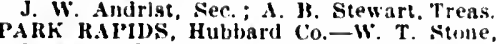
Ires.; I. D. Winshlp, sec.; C. A. Uutuston Treas.

Pll'stoxt, Pipestone Co.-A. E. snaldlug, I'res. : II. I). Jenckes, Sec.; Tliomas
lowwe, Treas.

PRESTN, Filimore $(0 .-W$. R. lirinnell.

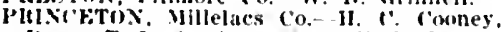

Ires.: T. I. Irmitage, soc. : it. i. lacon. Treas.

IEEl) WIXG. Gomblhe ('o.-A. W. Jones. I'res.: 1i. (C. Winter, see, J. V. Mul ersoli, Treas

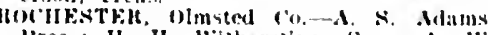
l'res. II. II. Witherviline, sec; $d . W$ Finfinteli, Treas.

Iuskill. Ilusean Co.- F. I. Xiurin

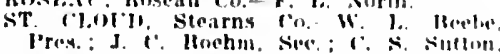
Treas.

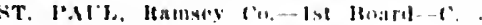

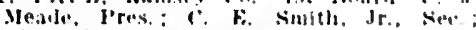
Mesinder Inimalis. Treas.

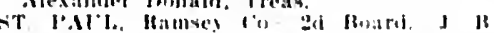

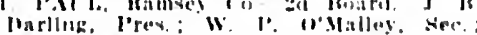

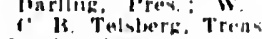

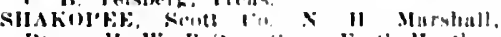

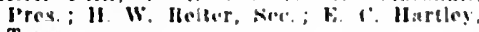
Treas.

SI.FEI ESE, Hruwn in, J W. II IVmleritur:

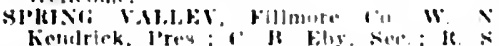
Mlechill, Treis.

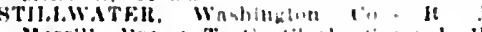
Merrlli, l'res: 1 1. 19ath, sine; J il II:Iine, Treas

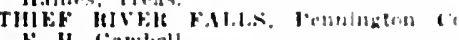
1. II liambell

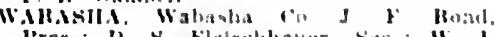

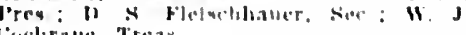
conelirillo, Trear

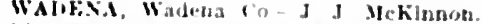

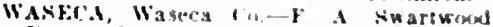
Pres. II. I; Hlanchiard. Siec.; A. J willitite hatid

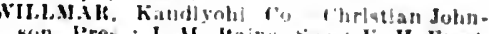
son, I'res.; J. MI. Itains. Sice : $\mathbf{k}$. II. Fresst, Treas.

Wison. Winna ro-G; l. Gaies, lres: If. I NeGaughes, sec: K. I. Keys:

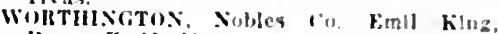
l'res,; F. M. Manon, sec.; r. H. Weiser. Mississipoi

comisti, Aleorn ('n-Theslore Borroum, Pres.: J. S. Voyles, Sec.; W. A. John, Treas

GLostek, Amite (v,- W. IR. Brunfleld. Pres.: il. T. Cuming, sec.; $c$ 1. Field. Treas.

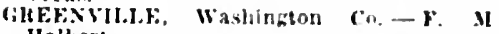
IInlhert.

Arkill. Ilinels ('o. . C. C. Womack, Ires.

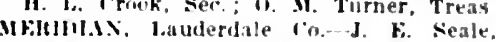
Tres: T. J. Butrdeaux, sec.; i. F Tatum. Treas.

Nitclifz Ndams Co. Phllip Heekman. Pres.: Marcus

WhKBLRf;, Warren Co.-Hichard o'jeary. Pres.; G. Y. Illcks, Sec.: B. B. Martin.

WEST 1'OIST. rlay Co.-W. D. lluhbard, Pres. : $I^{2}$ is. Brown, sec.: T, 6 , Iry Treas.

\section{Missourl}

ALRANY, Gentry To-C. $x$ WHllamson. Pres.; i. W. Whiteley, sec.; A. L. Wiolls, atTo:, Oregan Co.-calvin Hhea. Pres $T$. Piles. Sec.: 1. Eblen, Treas. APILFTos CiTy, Si. ('lair (co.-J. I. Niller, Pres. : r. l'. Buwden, sec.: Wilburn (lline, Treas.

ETIANY. Harrison ('o.-J. W'. Karanaugh. Pres.: Jackson Walker, Sec.; r. H. Brovlex. Treas.

HIsCH TilF, Nhamnon co.-C. A. Wright. l'res.: F. D. lium. Sec.: Frank IIsde. Treas

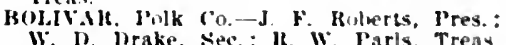
BI'F

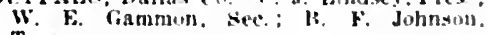
Treas.

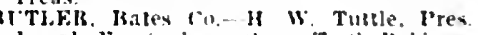
Joseph Ereringliam, sec, : T. ('. Kobinson.

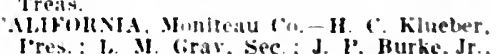
I'ress:
rreas

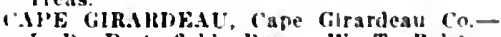
I. D. Portertleld. Pres. : W. T. Rolston.

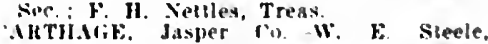
I'res: C. II. Ketcham, sec: W. B. Posi. Treas

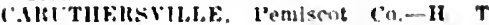

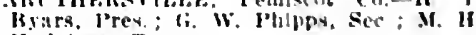
IIndginks, Treas

AsSVll.I.E. Barry to.-J. S. Fostor. leres. J. I. Lawhouser, sec. $W$. $l^{2}$. Searey. Treas

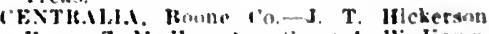

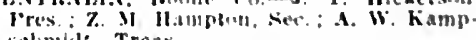
selimide. Treas.

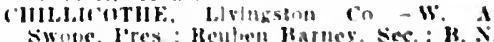
Swove. I're's : Hen

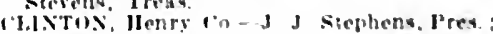
W. M. Slianklame, see : F. F. Netherton. Trento

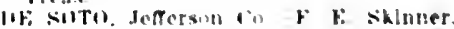

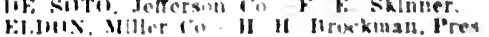

J W: Temple. Sce: W \& Hliee. Treas

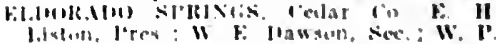

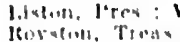

H. If:Tt: II

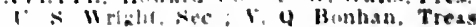

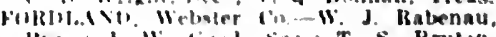

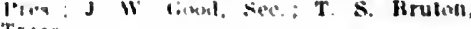
Tronas

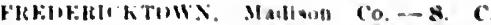
slahelitor, l'req, I. loarls. Sec.; W. W liale. Truas

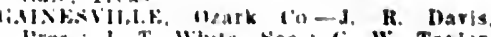
lres: J. T. White. Sec.: 6. W. Taylor. Trivas 
GALENA, Stone Co.-T. J. MeCord, fres.; Lafayette Ilenson, Ser.; If. W. Simart, Treas

(ALATIN, Davless (o.-l, k. boolin Ires. ; M. A. smbth, sec. ; J. A. Burteh, Treas.

GiNA' CITY, Worth ('o,- John Andrews,

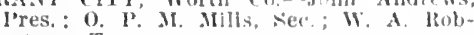
ertson. Tress.

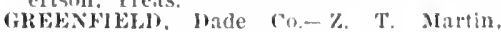
l'res.; R. (. Thomas, sec.; B. K. Kirly, Treas.

MANNIBN, Marlon Co.- I. I. Hoturn, l'res. E. 11. 13ommis. Sec, I. li, Hill, Treas.

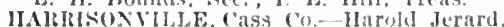

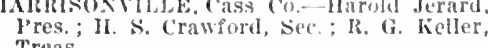

molestox. Texas ('n--H. L. Johnston, l'res, : i. W. Illemister, sec, IV I Covert, Treas.

IBkRIA, Miller in.-W. A. Von Gremp, I'res.; j. L. Renige, Sec.; (i. R. Mace, Treas.

JHFERSON CITY, Cole Co.-.I. I. Forth, Ires.; J. A. Hill, See. ; C. F. Enloe, Treas. JOI'LIX, Jasper Co.-M. Is. Kincheloe, J'res. ; (; W. Miller. Sec. ; M. M. Marutum, Treas. Filoki, Clark (o,-R. G. Callhan, Pres. H. W. IIarris, Treas.

KAXSAS CITY, Jackson Co,-D, R. Porter,

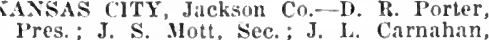
Pres. :

kHRKSille, Adair Co.-E. A. (irim, Pres. ; J. W. Martin, sec.; E. C. Callison, Treas. LACIFEE, Linn Co.-J. L. Rurke, Pres. ; F. W. Burke, Sec.; H. H. Iratt, Treas. I.AMAR, Barton Co.-J. L. IIcComb, Pres. G. D. Allee; Sec.; C. A. Smith, Treas.

LAXCAsTER, Schuyler Co-B. B. Potter, Pres.; F. I. IItchell, Sec.; W. F. Iustlce, Treas.

IEBANON, Laclede Co.-James McComb Pres, ; J. M. Billings, Sec.; T. B. Herbert,

LEXINGTON, Lafayette Co,-A. J. Chalkley, Pres.; C. T. Ryland, Sec.; M. G. Roberts. Treas

LoUISIANA, Pike Co.-S. B. Ayres, Pres.; T. G. Hetherlin, Sec.; D. II. Pearson, Treas.

IACON, Macon Co.-J. I'. Foster, Pres.; E. B. Clements, Sec.; W. P. Rowland,

MALDEX, Dunklin Co.-J. A. Shivers, Pres. G. T. Van Clere, Sec.; S. E. Mitchell, G. T.

MANSFIELD, Wright Co.-R. M. Rogers, Pres.; J. A. Fuson, Sec.; B. E. Latimer, Treas.

MARBLE IIILL, Bollinger Co.C. M. WItmer, Pres.: C. A. Sander, Sec.; J. J. Chandler, Treas.

MARSHALL, Saline Co.-F. F. H. Sulliran, Pres.; A. C. I'utnam, Sec.; G. C. Emerson, Treas.

IARYVille, Nodaway Co.-A. B. Allen, I'res, ; D. C. Wilson, Sec. ; J. II. Todd, Treas.

MEMPHIS, Scotland Co.-A. F. Platter, Pres.; I. A. Baker, Sec.; A. I. Daris, Treas.

MIllAN, Sullivan Co.-E. S. Porter, Treas,

IOBERLY, Randolpl Co.-C. F. Burkhalter, Pres.; Thomas Irwln, Sec.; G. O. Cuppaidge, Treas.

MOUNT VERNON, Lawrence Co.-C. W. Slielton, I'res. ; G.

NEOSHO, Newion Co.-H. F. Foster, Pres. ; A. W. Benton, Sec.; H. S. Bowers, Treas.

NEVADA. Vernon Co.-G. C. Willson, Pres.; E. A. Dulln, Sec. ; I. W. Anerman, Treas. OREGON, Holt Co.-F. E. Bullock, I'res. C. I. Evans, Sec.; J. T. Thatcher, Treas, OZARK, Christian 'Co.-J. A. Robertson, I'res.; J. W. Bruton, Sec. ; D. F. Hedgpeth. Treas.

PERRYVILLE, Perry Co.-J. P. Clark, Pres. ; Fiti ressells, Sec. ; C. B. Bowman. Treas. Pres.; I. E. Toney, Sec. J. E. G. Gilmer tinn, Treas.

PIERCE CITY, Lawrence Co.-E. B. Wright, Pres.; W. W. Rodman, sec.; W. S. Loveland. Treas.

PINETILLE, MePonald Co.-E. T. Doty, Pres. : Oakley St. John, Sec.; J. G. Webster. Treas.

OLO Caldwell Co.-R. L. Mount, Pres. r. B. Cowley, sec, H. A. Schroeder,
Treas.
IOPlaAR BI.TFE, Buller Co.-C, W. Williamson, I'res.; B. L. Ellls, siee; .I. T. Redwine, Treas.

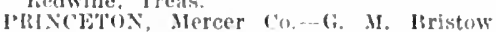
l'jes.; W. F. Buren, sec.; E. W. Stacy

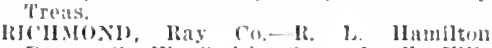
Pres, ; (i. W. Smith, sec. : 1. F. Ells Treitis

Itolla, Pluelps ro, C. If, Julbright, pres.

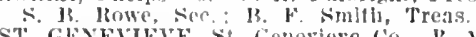
ST. GLXEVIFVE. St. Cenerieve Co.-K. W Lanning. I'res.; $C$. llertich, Sec. : A.

ST. JosEPH, Buchanan ('b.-Iacol) Ge!ger. Pres, I. M. IBoll, Sce. G. I. Sherman, Treas.

ST. IAOLIS, North loard-J. B. l'richard, l'res.; T.'s. liawley, sec.; J. J. Ingram. Treas.

ST, Lotis, South lioarl-F. W. Wesseler I'res, : II. N. Chapman, sec.; J. I. Isoelum, Treas.

SHLEN, Dent Co.-I. ' Welch. Pres. T. F Rudd, sec ; R. H. Conaway. Treas E. A. Abers. See.-A. H. Heaten, Pres. sot AIt ST, Jos Sec.; F. R. Morley, Treas. siemens, Ires, ; Herbert lee, Sec.; I. I. byrme, Treas.

SPRINGFIELD, (ireene ("o. C. F. Woody, I'res.; W. M. Smith, Sec.; F. W. Diemer, Treas.

TAlklo, Atchison Co.-I. W. Holliday, Ires.; C. E. Ben!am, Sec.; C. W. lott, Treas.

TKENTON, Grundy Co.-J. A. Asher, Pres. ; W. D. Fulkerson. Sec. J. F. Fair, Treas. TROY, Lincoln Co.-J. I. Duwelins, Pres. C. D. Avery, sec. ; W. I. Smith, Treas UNioNyllLE, I'uinam Co.-L. L. Gray, Pres.; A. C. Berry, Sec.; J. Il. Holman, Tres.

VERSAIlles, Morgan Co.-J. A. Braden, Pres.; II. N. Lutman, Sec.; H. F Blacksten, Treas

WARRENSB URG, Johnson Co.-L. J. Scho-
fleld, Pres, ; If. P. Gilkeson, Sec. Gllbert, Tréas.

WAsIINGTON, Franklin Co-W C Miller, Pres.; O. L. Muench, Sec.; D. A. Selbert, Treas.

WELLSVILLE, Montgomery Co. - D. 0 Hudson, Pres.; S. S. Cox, Sec.; C. F Iikins, Treas.

WESTPLAINS. Howell Co.-H. .T. Rowe, I'res.; I' J. Nichols, Sec.; J. Mc B.

\section{Montana}

BITTF, Silverbow Co.-T. A. Frigg. Pres. R. S. Freund, Sec.; S. E. Schwartz, Treas.

HAMILTON, Rarall Co.-F. E. Buchen.

IIELENA, Lewis and Clarke Co.-P. G. Cole, Ires.; w. C. Rlddell, Treas.

KALISPELL, Flathead Co.-W. H. Campbell, Pres.; Arthur Ilorrow, Sec.; A. D Macdonald, Treas.

IIINGSTON. Park Co.-R. D. Alton, Pres. S. E. Leard, Sec. : H. L. Pampel, Treas. MiLes CITY, Custer Co.-W. W. Andrus. MILES CITY, Custer Co.-W. W. Andrus.

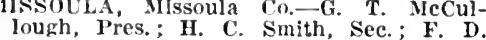
Pease, Treas.

PHILIPsBuRG, Granite Co.-W. I. Power.

Nebraska

AINSWoRTII, Brown Co.-G. W. Lambley, Pres.; W. B. Ely, Sec.; J. J. Evans, Treas.

ALBION, Hoone Co.-.I. H. Smith, Pres.; J. H. Thompson, sec.; F. J. McRae, ALLINCE, Boxbutte Co.-C. H. Churchill Pres.; C. E. Slagle, Sec. ; H. H. Bellwood Treas.

AUBURN, Nemaba Co.-E. M. Tyler, Pres. B. F. Lorance, Sec.; I. W. Irvin, Treas AURORA, Hamilton Co.-C. D. Hustead Pres.; J. M. Woodard, Sec, ; F. A Thomas, Treas.

BEATRICE, Gage Co.-J. L. Webb, Pres. C. W. Walden, Sec.; C. S. Curry, Treas. BEAVER CITY, Furnas Co.-C. C. Green, Pres.; J. R. Cameron, Sec.; C. C. Copeland, Treas.

BENKELMAN, Dundy Co.-J. F. Walthall.

BLArR, Washington Co.-lR. J. Murdoch, Pres.; E. R. Stewart, Sec.; A. W. Fees, Treas.
BROKEx BOW, Custer (O,-G, F. Fenulngton. Pres, ; (i. I. Selion, Siec.; w. H. Taltut. Treas.

CENTRAl, CITY, Merrlek Co.-S. I. IIull, Ires, ; F. F. Boyel, Sec.; (C. C. laaxton, Treas.

'llAmBon, llawes ('o, - C. W. Deemer, l'res.; L. I. Vernon, See.; M. B. Me-

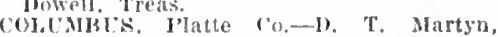
I'res.; F. II. Morrow, See; C. I) Evaus, Treas.

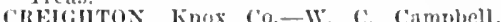
I'res.; W. H. Britt, siee.; R. 11. Burrell, Treas.

"AVIU CITY. Butler Co.-I, E, Burdick. pres.: s. C. Heede, See.; K. Ii. Rlch, Treas:

FakBuky, tefferson Co.- (;. I. Pritchett, I'res.; Warren lerry, Sec.; G. A. Heath, Treas.

FAllFIELD, Clay Co-A. R. llay. I'res, Anthony keller, Sec.; C. T,

Geverar, Filmore Co. - Joseph Bixby, Pres.: F. L. Ieck, Sec.; Royal Woods, Treas.

GRAND ISLAND, Hall Co-George Roeder, Pres.; G. W. Weeter, Sec.; w. B. Hoge, Treas.

HASTINGS, Adams Co.-Winfield Ackley, Pres.; S. E. Bamford, Sec. ; J. Y. Beghtol,

Treas.
HEBRON, Thayer Co. - Charles Henry, Pres.; C. II. Laston, Sec. ; U. H. Squires,
Treas.

HOLDREDGE, Phelps Co.-S. F. Sanders, Pres.; W. D. Shields, Sec.; P. A. Sundbury, Treas.

NDIANOLA, Redwillow Co.-W. D. Mackechnie, I'res.; J. E. Hathorn, Sec.; II. J. Arbogast, Treas.

KEARNEY, Buffalo Co.-C. Fan D. Basten, Pres. ; M. A. Hoover, Sec. ; J. J. Cameron, Treas.

I.EXINGTON, Dawson Co.-F. J. Rosenberg, Treas.

LINCOLN, Lancaster Co.-E. I. Holyoke Pres. ; C. H. Rush, Sec.; J. R. Haggard, Treas.; E. B. Finney, Ad. Int.

NEBRASKA CITY, Otoe Co.-Claude Watson, Pres.; M. L. Koser, Sec. ; A. P. Ginn, Treas.

NELIGH, Antelope Co.-.W. F. Conwell Pres.; G. H. Hildebrand, Sec.; G. A. Medillan, Treas.

NORFOLK, Madison Co.-A. L. Macomber, Pres.; E. L. Brush, Sec.; W. H. Pllger, Treas.

NORTH PlatTE, Lincoln Co.-G. B. Dent, Pres.; A. J. Ames, Sec.; T. J. Kerr, Treas. OGALIALA, Keith Co.-A. Hollingsworth. OMAHA, Douglas Co.-S. $\mathbf{K}$. Spalding, Pres.; Charles Rosewater, Sec.; J. B. Ralph, Treas. ; A. S. Pierce, Ad. Int. Nert, Holt Co.-J. P. Giligan, Pres. oRD, Valley Co. - F. D. Haldeman, Pres. C. J. Miller, Sec.; I. M. Newbecker, Treas.

ORLEANS, Harlan Co.-D. R. Waggoner Pres.; J. O. IIoffman, Sec. ; S. MI. Baker, Treas.

OSCEOLA, Polk Co.-S. O. Whaley, Pres, C. L. Le Mar, Sec.; L. M. Shaw, Treas. AWNEE CITY, Pawnee Co.-G. W. ColBoyer Treas.

PLATTSiIOUTH, Cass Co.-E. W. Cook, Pres.; J. H. Hall, Sec.; E. D. Cummins, Treas.

RED CLOUD, Webster Co,-J. W. Moranville, Pres.; R. P. Ioxsey, Sec. ; E. A. Creighton. 'Treas.

ST. PAUL, Howard Co.-Ole Grothan, Pres. F. S. Nicholson, Sec.; P. M. Pederson, Treas.

SEWARD, Seward Co.-G. W. Brandon, Pres.; Joseph Morrow, Sec.; H. B. Cummins, Treas.

SIDNEY, Cheyenne Co.-L. G. Simon, Pres.; H. E. Mantor, Sec.; $\mathbf{X}$. T. Owen, Treas. SPEXCER, Boyd Co.-E. B. Bradley.

SUPERIOR, Nuckolls Co.-J. w. IItchell, Pres.; W. F. Mitchell, Sec.; J. S. Butler, Pres.;

TECUMSEH, Johnson Co.-Malcolm Stewart, Pres.; C. R. Snell, Sec.; G. J. Rubelman, Treas. 

TEkAMall, Burt Co-A. D. Nesblt. Pres. Treas.

TREXTOS, uttchcock Co,-J. It Bell.

Valextive. Cherry Co.-. Mle red Lewis. WAYNE, Wayne Co-Andrew Texley. Pres. E. S. Blalt, sec : J. J. Whllams, Treas WEEPING WATER, Cass Co.-M. M M Butler. Pres.

wiLely. Treas. Sallne co.-F. F. Dodson

Yokk. York Co.J. B. Conawas, Pres. Robert McConaughy, Sec; J. N. Ylumb, Treas.

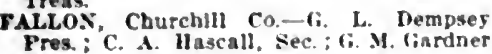
Treas.

\section{Nevada}

RENO. Washoe Co-B. F. Cunnlugham Pres: Fi. B. IIamilton, Sec.; 3. A Ascher, Treas.

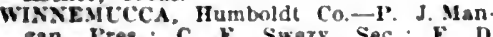
gan, Yres: C

\section{New Hampshire}

BERLIN. Con Co,-J. J. Cobb, P'res. Arsine Lavallee, Sec.: Henry Marble, Treas.

coxcoRb, Merrimack Co.-... K. Das. Prea: F. A.

KERSE. Cheshire Co.-F. M. Dinsmoor. Pres. : I. J. Prouty, Sec.; C. S. Walker,

Treas Pres.; A. W. Abbott, Sec.; J. G. Qutinby, Treass.

Livcaster. Cons Co.-R. F. Webb, Pres. E. F. stockirell, Sec.; W. 11. Lelth, Treas IACHESTER, Hilsboro $\mathrm{Co}-W$, H. A. Lyons, Pres.: A. G. Straw, Sec.: J. E. Lemaltre, Treas.

NASHUA, Hillsboro Co.-B. f. Moran, Pres, ; C. E. Congdon, Sec; s. s. Drearhom, Treas.

NEWPORT. Sulliran Co.-E. C. Fisher, Pres.: F. 1'. Claggett, Sec.; H. I. Hanaford. Treas.

PLYMoUTh, Grafton Co-b. I. Bell. Pres. ; W. R. Garland, sec. : A. A. Wearer, Treas. PoRTsMotTH, Rockingam Co. - A. C. Hefenzer, Pres.; J. R. May, Sec. : i. F Smith. Treas.

RocuEster. Straftord Co.-F. L. Keay. Pres.: C. A. Faltbanks, Sec.; C. C. Rogers. Treas.

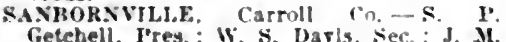
Getchell. I'res.; W. S. Darls, sec.; J. M. learlts. Treas.

\section{New Jersey}

ASBLRY PARK. Monmouth (o. - J. F. Ackerman, l'res.; (i. F. Wilbur, sec.: Bdwin Field, Treas.

ATLANTiC CiTY, Allantic Co. J. T. Beckwlih.

BRIDGETOS, Cumberland Co.-.M. R. Faulk. ner. Pres.: J. Hi. Moore, sec.; s. M. wilson, Treas.

CaMIJES camden Co-W. H. Iszard, I'res. 11. F, Halm, Sec. in. W. Hlake, Treas.

JERSEY CITY, IILilson CH, llenty Illers. Pres.: T. J. Mclaughlln, Sec.; Alfred A. Mutter. Treas.

MtLbUl,LE, Cumberland Co.- Fuzene Way. Pres.: C. H. Neal, sec.; H. if. Mlller,

NEWARK, Fasex co.-1. C. Inugherty. Pres: i w. luneker, sec. ; 1 . C. l'otter, Treas.

Pitbiksos l'aksale to.r. H. McFadden. Pres.; J. W Wlltiams, Sec. : 1. . Harris. Treas: II II Luras. Al. Itit. II. Cornell, l'rew:; f. Buopo. See.; J. J. IIctivite Treas.

WAshisgtos, Warten ro.-C, k. Stmlth.

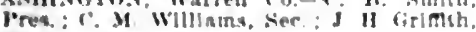
Treas.

\section{New Mexico}

ALRQTERQUE, Bernallli Co -. W Elder, Treas.

E.AST IAS VEGAS, San MIguel co,-W W Tipton, I'res.; H. M. $\mathbf{H m i h}$, sice, ; $\boldsymbol{E}$. II

Shaw. Treas.

MOGOL QuS Socotro M. Thnmpsn.

vara visa, quay co.-J. T. Ciaines
RaTos, colfax Co-T. Is fyon, Pros Roswri.l. Chares (i) 11 . i. Inóalls

SANTA FE. Santa fo (o.- W s. Harroun I'rey : F'. Fo. Mers. Ser ; J. I Massle, Treas:

Tilbs. Tans co-T. P. Marbin

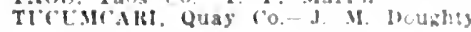

\section{New York}

M.M.NY, Albany Co.-llerman Lendell, Pres, ti. A. Bartete, sec. W. 1 .

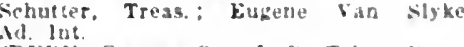

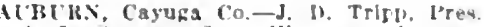
A. It. Stewark, Sec.; W. A. Strohmenger. Treas.

Hathid, denese con W. Skinner pres, is. M. Andrews, sec, i. F. Miller

BaTH. Steuben Co-H J. Wynking, Mres.

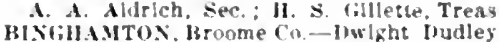
pres.: C. W. Gireene, sec.: D. 1'. Balley. Treas.

HRookity, kings Co.-d. G. Meyersburz. Pres.: S. h. Taslor, Sec.; it. E. Turner. Treas.

Biffilo, Erie Co.-J. E. Culbert, Pres. J. J. Bowen, Sec.: C. II. W. Auel, Treas.

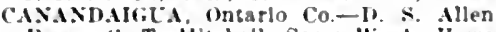
ires.: C. T. Mitchell, Sec.; W. A. Howe Treas.

Colbkskll, Schoharle Co-C. S. Best. P'res.; David Norwood, Sec.; L. 6. White Treas

CoRTLaND, Cortland Co.-6, D. Bradford. Pres. : E. A. IVifama, Sec.; M. C. Barket. Treas.

DELHI, Delaware $\mathrm{Co}, \mathrm{H}$. A. Ciates. Pres. Williaru ormlston, sec.; W. D. Heimet Treas.

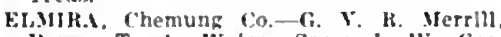
Ires.: T. A. Wales, Sec.; J. W. Gee.

coNibs. Montzonery Co...W. I. Peddle, Pres.; G. Meyer, sec: $C$. . Timmerman, Treas.

FREDONIA. Chautaqua Co.-W. J. Irish rres.; $:$. G. Richmond, Sec.; $i$ W. Nods Treas.

GLENS F.Alls, Warren Co.-E*. S. Mullis, Irres. J. E. Goodman, Jr., Sec.; Kugar Blrdsall, Treas.

GLOVERSilliti, Fulton Co-_.J. 11. ledder Pres.; C. E. pannacl, sec.; Telson Everest. Treas.

horseli. Steuben co..J. di. Kelly, Pres. C. R. I'hlllips, sec. : II. I. Jack. Treas.

Hedsos. Columbla co. -. A. M. Tracy. pres.: G. E. Swift, Sec. : J. E. Cochrane Treas.

ITHACA, Torankins (Co-W. IL. Lockerby, Pres.: E. K. $k$

Mumici, queens Co-n. M. Wool, I'res M. M. kitsell, sec.; $\mathbf{F}$. S. Senjor, Treas AMrstow. chautauqua in. - w M jemus, l'res.: laban Itazeftine. Sec. J. "I. Hrooks, Treas. : I. W. Selson kingstos, l'later ron-ll. Yan lfoevenherg, l'res: F. II. Loughran, Sec.; Frank heator, Treas.

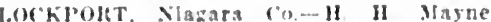
lires maker, Treas

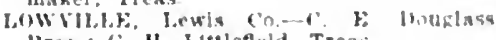
l'res: 6. Il Buttlefleld, Treas

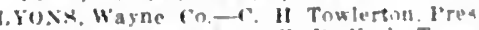
IV. I. Jennessy, ser.; (i. I) Vork, Treay II. E. Carmer. Ad. Int

MAloNk, Franklin ro-G. Il mirer. Fres

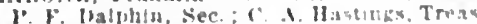

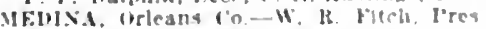
II A Magnapd. Sec

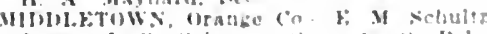

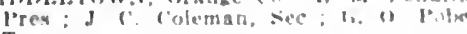
Tress:

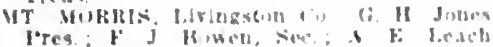

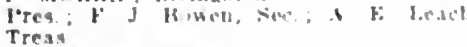

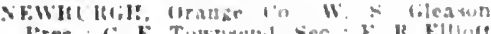

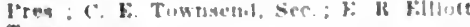

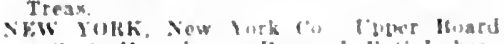

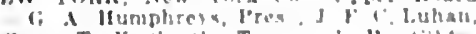

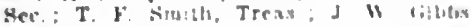
in int

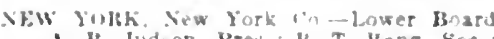
1. II Judan, Prey It T Kanz, Seec. EW rollk, New line in feneral Boar

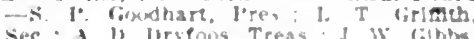
id. Int

NEW YOHk, New York Co,- Bronx Boand

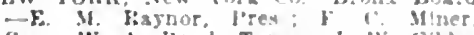
Sec. : W. A. Bosd, Treas.; J. W. Gibben. Ad. Int

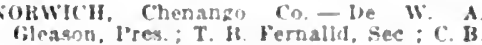
Palmatler. Treas.

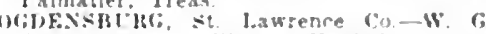
Cipoter, Prea iN. It. Hanbidge. Sec.

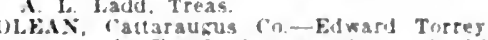
rres.: J k. $k$. Morrls, Fee: 1: W

OXEIDA, Madison Co. - Wllliam Taybr. l'res; (;. W. Milex, Sec.; II. C. Rearses. Treas.

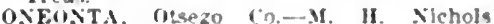
ires.: J. C. smish, sec.; R. W. Ford, Treas.

aswbio. Oswego Co-L. K. Stockwell. l'res.: I. D. P'ulsifer, sec, W. H. Acker,

owEGo. Tioga Co.-R. D. Eastman, l'res. W. L. Ayer, Sec; G. M. Cady, Treas.

PFix YAX Yates Co-E M. Scherer. Treas.

PLATTSBLRf, Clinton Co.- W. E. Clough. I'res.; J. II. La kocque, sec-: J. II Hackett. Treas

PORT HFxR Essex ro.-W. E. Patison Pres.: W. T. Sberman, sec, C. B Warner. Treas.

POEGHKEFrsis, Dutcheaq $\mathrm{Co}-\mathrm{J}$. w Poucher. I'res.; W. J. Conklin, Sec.; C. E Lane, Treas.

ROCHESTER. Monroe Co-porter Farley, lres: J. K. Culkin, Sec.: s. W. Llitle. Treas.

none, Oneida co.-C. H. Glldden, Pres. B. Illen. Sec : $\mathbf{X}$ C. Scudder. Treas 'res.; I. H. Bourne, Sec.; M. E. Fisher. Tress.

SARATOGA spmisg, Saratoga Co._. J Ressegule, Pres.; C. B. Small, Sec; E. H hinf. Treas.

SCHEXECTAliY. Schenectady Co-G. E. Mclonald, Prez.: W. W, Goddard, sec. f. W. Mates, Treas.

S.NECI F.llis, Seneca Co-D. F. F.rers. Pres.: J. E. Medden, Sec.: A. J. Frantz. Treas.

SolTH FALSBLRG, sulliran Co-W: H II. Hoar. l'res, : W. H. De Kay, Sec,

SPRISGrTil.E, Eirlo co-0. C. stronz. Pres.: F. hl. Stanbro, sec, : W A Mc. Farlane, Treas. $y$. $x$. Brooks, Ad Int

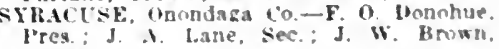
Treas.

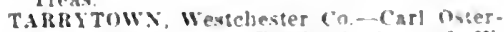
held, l'res.: $x$ II Freeland, sec, : II Ealrehild. Treas.

ThoY, Rensselaet i'n.- kmmett How l'res. Wiliana hirk. Jr. Soc: : E W. Hacket,

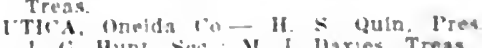

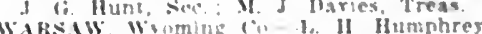

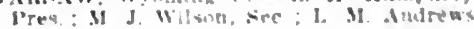
Tress

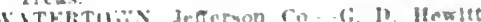
leres: II il leaste, ser: J. E. Mran. remas

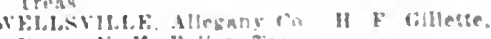

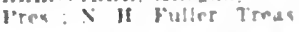

\section{North Carolin}

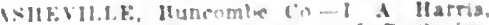

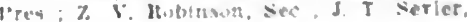

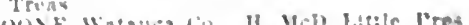

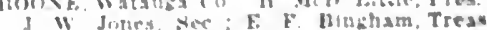

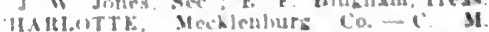
sirun:

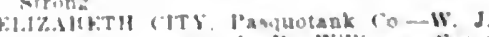

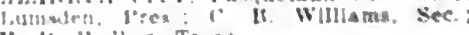
il 11. "Isalher. Trean

FIETTEVILLE, rumberland co-d. W Ucxilli

Puskitix, Macon $\mathrm{Co}$ \& II. Lyle, Pres. J. II Finuts. Sere.: P. L. Sller, Treas 1.11.bstukn, Wasne en Johu spleer. 
GHEFXSBORO, (i u I I f o r ll Co.- F. R. Atichaux, Jres: A R. Wilson, Sec : is Is. Wllliams, Treas.

IFXIDESONVIILE, Hendersun Co, - T.

illen, I'res.; J. L. Egertun, Sec

I.Fxoll, Caldwell Co.c. B. McNairy, l'res.; A. A. Kent, Ser, G. II, Carter, Treas.

IAISHALl, Itadison ('o,-Frank Itwerts, l'res.; W. J. Weatrer, Sec. ; J. C. Tilsou, Treas.

MLIFII, Cherokep (o,-N, H. Alams.

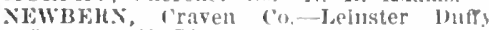
Pres.; J. F. Rlem, Sec. ; li. S. Primrose, Treas.

HALEIGII, Wake Co.-I, It Mogers.

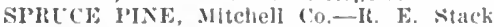
P'res, C. $d$. Peterson, Sec. ; 1. W. Brad shaw, Treas.

WASHINGTON, Beaufort Co.-F. M. Brown

W.I NESV]LI, Haywood Co. - Thomas sitringtleld, Pres.; J. R. MrCracken, Sec. J. F. Abel, Treas.

WILKESHOHO, Wilkes ('o.-I. I'. Sinmers, I'res.; J. W: White, Sec.; W. P. Hortou, Treas.

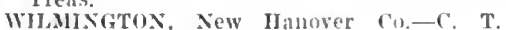
II arper.

\section{North Dakota}

Bismarck, Burlelgh Co.-W. I1. Bodenstab, l'res.; A. II. Fisher, sec.; F. R. Simyth, Treas.

ELI,ENDALE, Iickey ('o.-Roy Lyude.

FARGo Cass Co.-li. J llowe l'res: : J Kaess, siec.; Ii. F. Weible, Treas.

JAMESTOWX, Stutsman (o.-R. G. We I'us, Pres.; Francls I'eake, Sec.; $A$. W. Guest, Treas.

LlsBON, Ransom Co.-F. E. Wands, Pres. : T. C. Jatterson, Sec.; A. (i. Jatterson,

WAHPETON, Richland ('o--IR. H. Devine.

\section{Ohio}

AKROX, Sumnit Co.-A. E. Foltz, Jres. H. C. Theiss, Sec.; F. M. Hughes, Treals. ASHLAVl, Ashland Co-E. V. Kendig, Pres.; W. M. IJcCle

ASHTABUIA, Ashtabula Co.-F, E. Perry, Pres.; W. R. Flower, Sec.; H. J. Austin,

Treas.
ATHFN, Athens Co.-V. G. Imanford, Ires. ;

D. H. Biddle, Sec.; K. T. Crossen, Treas.

BATAVi Clermont Co.-F, C. Jreton, Pres, G. S. Van Itorn, Sec.; W. B. Woan, Tres, ;

BELI.AIRE, Belmont Co.-W. L. Judkins, Pres.; J. S. Mcclellan, Sec. ; A. (" Beetham, Treas.

BELLEFONTAINE, Logan Co.-L. C. Pratt, I'res.; R. W. Chalfant, Sec.; J. H. Wilson, Treas.

Bowhlig GREEN, Wood Co.-M. A. ICKendree, Pres.; C. S. St. John, Sec. R. J. Simon, Treas.

BHTAX, Willams (o.-J. Y. Iesnet, pres.; T. E. Schrider, Sec.; Calvin Hathaway,

Treas. l'res.; C. A. Clmer, Sec.; W. L. Yeomans, Treas.

CADIZ, Harrison Co.-W. H. Lemmon, Pres. ; S. B. IIcGarran, Sec. ; J. S. Campbell, Treas.

CALDWELL, Noble Co.-J. W. Beebout, Treas.

CAMBRIDGE, Guernsey Co,--(i. W. Hixson, Pres.; F. W. Lane, Sec.; J. F. Robins, Treas.

CANTON, stark Co.-S. S. P. Barnes, Pres.;

H. A. March, Sec.; W. D. Davis, Treas.

CARRolitoN, Carroll Co.-C. S. Clark, ARrolitos. Carroll Co.-C. S. Clark,
Pres.; A. H. Hise, Sec.; B. B. Buck,

Treas.
CELINA, Mercer Co.-J. A. Shirack, Pres.; H. J. Cordier, Sec.; M. I. Downing. Treas. CHARDON, Geauga Co.-A. D. Warner, Pres.; P. M. Cowles, Sec.; O. A. Hopkins, Treas.

CIICA Inumbaugh, Pres.; G. C. McCreight, Sec.; R. II. Reynolds, Treas.

CHILLICOTHE, Ross Co.-G. E. Robbins, l'ves.; H. R. Brown, Sec.; Charles Miesse, Treas : R. W. Holmes, Ad. Int.

CINCINATI, IJamilton Co.-Ist BoardA. I. Carson. Pres.; 0. I. Cameron, Sec. H. II. IIines, Treas.
CINCINATt, Hamflton Co,-2d Board(i. F. Ilermanu, I'res, J. II. Adans, See. A. W' Nelsoll, Treas.

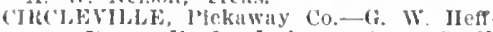
ner, J'res.; H. 1). Jackson, sec.; (i. H. (olville. Treas.

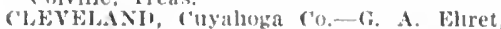
I'res.; H. E. luedy, see, ; $x$. F. Herlure Treas.

coliml31's, Franklin ro.-I'. (1) (iordon, Pres.; Frank Ileculterty, Sec.; 16. (: Noble, Treas.

cosiloctox, coshocton Co.-F. II. Yarnall, Pres.; 1). F. Cone, See.; W. 16. litten Treas.

TiYTOX, dontgomery Co.-H. E. Ciardiner. l'res.; F. lk. Bakel", Sec.; W. H. Allaman, Trias.

J)HA $\mathrm{CH}$, beflunce ("o.-H. ('. Jindersinitl, I'res.; W. W. Westrick, Sec.

OELA WARE, Delaware Co.-C. W: Chidester, I'res.; 0. W. Bonner, Sec.; G. W. More house. Treas.

EATON, Yreble Co.-C. A. IIawley, J'res. F. F. Welsl, Sec.; A. C Hunter, Treas. Elitid, Lorain Co.-W. E. Jart, Jres. P. I" Keefy, Sec.; Frank Young, Treas. Fivillis, Hancock ("o.-M. S. Whiltamson, l'res.; W. N. lost, See.; W. J. Zoufl, Treas

FostoriA, Seneca co.-C. A. Henry, Pres. G. J. Hoege, Sec.; li. W. Hales, Treas. Flf Kenney, Pres.; J. M. Stewart, Sec.; M. 0. l'hillips, Treas.

(AIJIIIOLIS, Gallia Co.- (i. k. Ewing, Pres.; C. W. Ely, sec.; (s. A. Mack, Treas, (HEOHGETOWN. Brown Co.-R. I3. Hanna Jres.; H. I. Shelton, Sec. ; II. S. Guthrie, Treas.

GREFYLLE. Darke Co. - Wm. Isnch, I'res. ; J. E. Nonger, Sec. ; J. M. Inderson, Treas.

HAMILTON, Butler Co.-F. G. Hornung, I'res.; J.' H. Roll, Sec.; W. F. Weikal,

Treas,
HARRISON, Hamilton Co-Charles Huber, Pres.; Thomas Bowels, Sec.; C. W. Caley,
Promilton Co.-Clarles Huber, 'Treas.

HILLSBORO, IIighland Co.-W. W. Glenn, Pres.; H. A. Russ, Sec.; C. H. Beain, Treas.

IRONTON, Iawrence Co.-F. E. Wells, Pres. : o. U. O'Neill, Sec. ; N. K. Moxley, Treas. JACKSON, Jackson Co.-G. W. Darling, Pres.; E. H. Morgan, Scc.; U. I. Kinnison, Treas.

KENTON, Hardin Co.-B. L. Johnson, Pres. WT. A. Belt, Sec.; C. C. McJaughlin, Treas.

LANCASTER, Fairfleld Co.-G. A. Harman, Pres, : H. I. Ilazelton, Sec.; C. A Kefauver, Treas.

IEBANON, Warren Co.-C. A. Hough, Pres.; E. C. Thompson, Sec.; N. A Hamilton, Treas.

I.IMA, Allén Co.-J. B. Vail, Pres. ; S. A. ISteheock, Sec.; .I. I. Johnston, Treas J'res.; W. C. Nevin, Sec.; W. R. Clark. Treas.

LOGAN, Hocking Co.-J. D. Lyon, Pres. C. F. Aplin, sec.; W. S. Rhodes, Treas. LONDON. Iadison Co.-A. J. Strain, I'res.; II. C. Sprague, Sec.

MCARTHLR, V'inton Co.-

ICCONNELIASILIE, Jorgan Co.-L. S. Holcomb, Pres.; J.' E. Brown, Sec.; J. B. Naslor, Treas.

MADISONVILIE, Hamilton Co.-W. G. Hier, Pres.; I. s. Dunhan, Sec.; G. A. Pierret. Treas.

MAYSFIELD, Richland Co.-B. F. Harding, Pres.; G. P. Sattler, Sec.; S. E. Findley,

Treas.
MARIETTA, Washington Co.-S. F. Adair, Pres.; E. I. Cooke, See.; F. G. Mitchell, Treas.

MARION, Marion Co.-G. T. Harding, Pres. ; G. H. Masters, Sec.; Robert Ramroth, MARYSVILLE, Cnion Co-_A, B. Swisher Pres.; C. D. Mills, See.; J. J. McCloud, Treas.

MIDDLEPORT, Meigs Co.-J. R. Plilson, Pres.; D. S. Hartinger, Sec.; C. W. ltowley, Treas.

MLLERŚBLRG, Holmes Co.-F, D. Carson,

ILLERSBLRG, Holmes Co.-F. D. Carson,
Pres.: D. S. Olsmtead, Sec. ; A. T. Cole, Treas.
MIIXT GIIASI, Morrow Co.-D. 13. Virtuel'res.; J. I. Mctormick, Sec.; F. F. Thompson, Treas.

MOUNT VERNON, Knox Co.-1\%, (1. Philllps, Pres.; F. C. Larimore, Sec.; II. W. Jilair, Treas.

NAPOLLON, Menry Co.-0, L. Norris, l'res.; John J Bloomfleld, Sec.; H. F. Itohrs, Treas.

NATIXA], MIITARY HOME, Montgomery 1'0.-J. M. IIowell, I'res.; C. J. Olto, See. W'. A. T. Hyan, Treas.

SEWAlK, Jicking Co.-J. N. Wright, l'res.; A. T. Speer, Sec.; D. O. Roberts, Treas. NEW J.EXINGTON, Perry Co.-J. II. Wright, l'res.; J. (i. Ncibugal, Sec.; Alsa Itichl'res. ; J. (:
ards, Treas.

XEW PHLAHFLIJIA, Tuscarawas Co.(i. I. Coolrich, Pres.; T. J. W. IRichards, sec.; ( ;. T. IIaverfleld, Treas.

Nolk AJ, Huron Co.-D. H. Young, I'res. J. A. Sipher, sec.; M. L. IIndley, Treas. OTTAWA, I'utnam Co.-F. J. Reed, Pres. ; Treas.

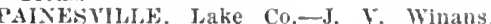
I'res.; II. N. Amidon, sec.; C. II. Tanner, Treats.

I'AULINiNG, Paulding Co.-C. E. I3urgett, pres.; R. A. Dillery, sec.; E. D. Murpliy, Treas.

PoltsinotTil, Scloto Co.-J. S. Frizell, I'res.; I. J. Kline, Sec.; W. G. Cheney, Treas.

IA VEXNA, Portage Co.-E. B. Dyson, Pres.; (i. J. Waggoner, Sec.; W. B. Andrews, Treas.

SANDUSKY, Erie Co.-J. T. Haynes, Pres. If. C. Schoepfle, Sec.; Wllliam Storey, 'Treas.

SIDNEY, Shelby Co.-

SPRIN(ifIFI, ], Clark Co.-E. C. Harris, 1'res.; J. I'. Dugan, Sec.; J. H. Neese, Treas.

STEUBExVILLE, Jefferson Co.-De Marr Erskine, Pres.; $s .0$. Barkhurst, Sec.

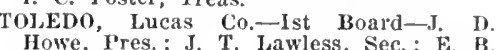
Barlow, Treas.

TOJEDO, Lucas Co.-2d Board-William Watts, Pres.; W. A. Wlckey, Sec.; J. G. Cullen, Treas.

TRoY, Mami Co.-W, R. Thompson, Pres. J. S. Shinn, Sec.; J. W. Means, Treas. UPPER SANDUSKY, Wyandot Co.-G. W. Sampson, Pres.; $V . K$. Knapp, Sec.; W. A. Crum, Treas.

URBANA, Champaign Co.-J. D. O'Gara, I'res.; Ir. T

VAN WEIT, Van Wert Co.-M, s. Cramer, J'res.; F. P. Kreider, Sec.; David Davis, Treas.

WAPAKONETA, Auglaize Co.-F, C. Hunter, Pres.; E. F. Heffner, Sec.; I. J. Longsworth, Treas.

WARIEN, Trumbull Co.-J, S. Brown, Pres.; ir. I. Williams, Sec.; F. C. Hunt,

WASHINGTON CoURT HoUsE, Fayette Co. -J. L. Brock, Pres. ; A. A. Hyer, Sec. :

VAUSEON, Fulton Co.-F. A. Jurbach, Pres.; W. H. Maddox, Sec.; P. S. Bishop, Treas.

WAVERLY, Pike Co.-C. H. Willson, Pres.; J. I. Caldwell, Sec.; R. C. Bingaman, Treas.

WEST UNIOX, Adams Co.-O. B. Kirkpatrick, Pres.; J. W. Irwin, Sec.; O. E. McHenry, Treas.

WILMINGTON, Clinton, Co.-W. T. Scott, Pres.; L. (i, Il Iurrell, Sec.; T. E. Craig, Treas.

WoODsFibl, Monroe Co.-J. W. Reed, Pres.; J. R. Parry, Sec.; F. C. Huth, Treas.

WoOSTER, Wayne $\mathrm{Co}-\mathrm{H}$ A. Hart, Pres. II. B. Bertolette, Sec.; J. D. Beer, Treas. XENIA, Greene (o.-C. M. Galloway, Pres. A. D. De Haven, Sec.; J. P. Dice, Treas. GoUNGSTow, Mahoning Co.-W. L. Carroll, Pres.; J. J. Thomas, Sec.; Daniel Campbell, Treas.

ZANESVILIE, Iuskingum Co.-J. G. F. Holston, Pres. ; E. C. Logsdon, Sec.; J. F. Dorsey, Treas. 


\section{Oklahoma}

aNADARKo. Caddo Co.-C. R. Hume, l'res. G. C. Campbell. Sec.: W. W. Kerley, Treas.

ARDMORE. Carter Co-F. I. Von helles, Pres.: $\mathbb{R}$. II. Henry, Sec.; J. F, Son, Treas. ARNETT. EIII Co - i. W. II Ubbelf. Pres. Pollard. Ires.: : II. C, Weber, sec.; W. L: Rammel, Treas.

BEATER. Beater Co.-1

L. Long. Pres.

BLFrilo. Harper $(\%$. Hardín Walker. Pres.: E. E. Heads, Sec.; $\mathbf{E}$. M. MIller, Treas.

CHANDLER, Lincoln ro,-H, M. Fagalnes, Pres.: A. M. Marshall, Sec.; J. J. Erans, Treas.

CHEROKEE. Alfalfa co. - S. B. Crowdoll, Fres.: J. S. Hibbard, Sec.; H. B. Ames,

CHickisma, Grady Co.-S. O. Marrs. Pres. Walter Penquite. Sec.: T. B.

Coulter. Treas.

Pres.; P. A. Anderson, Sec.; E. Y. Bass. Trees. :

CLEvElind, Pawnee Co.-G. W. Sutton. Pres.; C. W. Ballaine, Sec.; E. T. RobInson. Treas.

Dücax, Btephens Co.-J. O. Wharton, Pres.: s. H. Williamson, Sec.; Dock I.ong. Treas.

ELK CITY, Beckham Co.-A. G. Low, l'res.: J. M. MeComas, Sec.; II. O. Jones, Treas. 3L REvo. Canadian Co.-A. H. Jackson. Pres.; F. H. Clark, Sec.; w. J. Mluzzy. Treas.

NID, Garteld Co. - J. W. Baker. Pres. w. A. Altken, Sec.; S. F. Scote. Treas. PAJRVIEW, Major Co,-J. S. Lindley. Pres. W. J. Taylor, Sec; B. I. Townsend, Treas. GUTHRIR, Logan Co.-David Sterens, Pres. C. $\boldsymbol{F}$. Cotteral. Sec.; F. O. Barker, Treas gurion, teras Co-L. W. Palmer, pres. W. H. Langston, Sec; : R. B. Hases, Treas A. L. Wasoner, Sec.: J. M. Bonham, Treas.

KINGFigh ER, kingesher Co-J. A Orerstreet, Pres: C. W. Fisk, Sec. A. I Bhare. Treas.

LAWTOS, Comanche Co.-Jackson Broshears, Pres.; L. A. Milne, Sec.; F. W Hammond. Treas.

McALESTER, PIttsburs Co.-H. E. Willlams, Pres.: A. J. Welch, Sec.; G. E. Harts-

Morne, Treas Pres.; W. E. Floyd, Sec.; B. I. Sorrell Treas.

Niwkink, Kay Co.-J. W. Werner. Pres. I. O. Gowey, Bec.; A. V. Decker, Treas. Nonxis, Clereland Co-D. W. Grimn Pres.: S. T. Burch, Sec.; c. s. Boho, Treas

OKLAROMA, Oklahoma Co.-A. W. White. Pres.: R. D. Long, Sec.; J. r. Messenbaveh. Treas

PONDCREEK, Grant Co.-H. A. Stalker. Pres. : R. F. O'Rear, Sec.; c. R. Hulen. Trean

SHAwNEE. Pottamatomle Co.-G. H. Sanborn, Pres.: W. C. Bradford, Sec; B. F Hamilion. Treas.

stillwater, Pajne Co.-C. E. Sexton, Pres.: L. A. cleverdon. Sec. : R. W. Hol Proski Treas.

TAFLEQTA, Cheroke Co.-E. W. Blake TALOGA, Dewey Co. - E. J. Jlughes, P'res. v. M. Gore. Sec. : F. II. Loyd. Treas.

F. 8. Clinton, Bes.: N. W. Masginnes. Trean.

ViNita, Cralg Co.-F, L. Jughson. pres I. R. Chapman, Sec. : C. Neer. Treas Prea: J. B. Lelsuse. Sec, : W. R. Kelly, Treas.

weATuERFonn, ruster co.-Abraham Ieleh. Pres.: J. M. Gordon. Ser.: J. J. Wililama. Treas.

WELEETKA. Okfuskee Co.-Beuton tore lady. Treas.

WooriwaRD. Wondwam (n,-S. M. Work

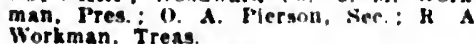
Oregon

ALBAXY, IInn (o. - II. II. Fills, I'res. J. C. Booth, sec.; T. I. Marks, Treas.
AstoRla, Clatsop ('o.-O. IB. Estes.

IITRNS. Harney Co.

Cofvalis. Henton Co.-Edward Rennet, I'res: H. S. Permot, ser.: 1'. H. Newth Treas:

F.NtERI'kisk. Wallowa ro.-C. A. Ault.

HILLARORO, Washington ("o-W. W. Word, Pres. J. I. Tamlesle. See : C. I. I.arge.

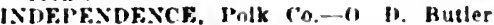
l'res. : I. L. Hewlu, Sec.; b. L. Ketchum. Treas.

I.A GRANDF. Inlon Co.-A. I. Richarifon I'res.: (;. L. Blgkers. See.: M. K. Hall Treas.

LAKEIEW. Lake Co.-Bernard Daly.

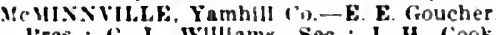
l'res.: C. L. Wllllams, Sec.: J. H. Cook, Treas.

MFPORD, Jackson Co.-J. K. Reader, i'res.; E. R. Seely, Sec, ; W. W. P. Ifoll Treas.

OkPGo: (1TY, Clackamas Co. - J. w Norris, Pres.; C. H. Melssner. Sec. : II. A Dedman. Treas.

PENDLETON, Cimatilla Co.-F. W. vincene, Ires.: F. b. Hogden. Sec.; i. C. Temple. Treas.

PORTLAND. Multumah Co.-William Roys Pres.: E. H. Thornton, Sec.; C. C. Moore, Treas. ; J. I) Fenton, Ad. Int

ROSERLRf, Douglas Co.-K. I. Miller. OSER C RC. Douglas Co.-K. I. Miller.
Pres.: F. H. Vincll, Sec.: E. V. Honer, Treas.

ST. HFLEX, Columbia Co-A. P. McLaren Pres.; A. J. Peel, Sec.; Edwin Ross, Treas. SALEM, Marion Co.-J. N. Sinth. Fres. J. H. Fairchild, Sec.: w. H. Byrd, Treas THE INLLES. Wasco Co.-willam Shackleford. Pres.: o. D. Doane, Sec.; Hugh Logan, Treas.

\section{Pennsyivania}

ALI.FGHEYY, Allegheny Co.-W. J. I,angfitt Pres.' $\mathbf{N}$. Grallam, Sec: $H . K$ Beatty. Treas.

ALLENTow: Lehigh Co.-A. S. Mller Pres. : F. H. Mckenshied, sec.; F. $R$ Bausch, Treas.

APOLLO, Armstrong Co.-R. P. IIunter. I'res. W. W. I.eech, Sec.; A. H. Townsend. Treas.

ATHESS, Bradfond Co.-J. T. Holcomb Pres.: C. L. Sterens, Sec. ; I. B. Denison, Treas.

BRAVER FAILIS, Rearer Co.-J. H. Wilson I'res.; T. P. Simnson, Sec.; S. H. Peirsol, Treas.

BEDFORn, Bedford Co.-S. H. Gump. I. A. Clark, Sec. : A. Enfleld, Treas. BELLEFONTE, renter (C.-.I. A. Thompson Pres.; R. G. H. Hayes, Sec.; M. J. locke

hof. Pres. : Ash. Treas.

BRISTOL. Burks. Co.-J. F. Gron, Pres. Howard Pursell. Sec. : A. F. Fretz. Treas. BUTLFR, Butler io-ii. $P$. st. Clals. Pres. w. B. Clark. See.: A. V. Cunningham. Treas.

CARIJSI.F. rumberland co.-A H. Allen, Pres.: $j$ C. Darls. Sec.: S. L. Diren Trex.

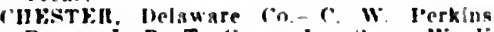
Prew. J. R. T Ciray. Jr., Sec. : $\mathbf{W}$ h brans. Treas.

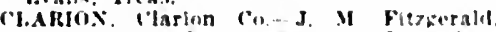
Fres: J T. llimer. sec.: J B Viller.

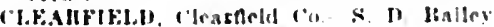

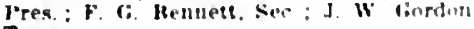
Treas.

(o) 11 Rochwell see: 1; A Elsun, Treav

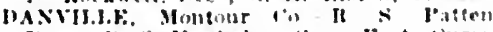
j'res. : "Newhake. See ; E. I iurry Treas.

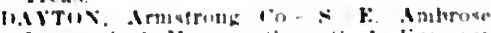

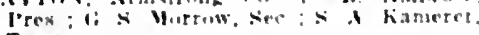
Treas

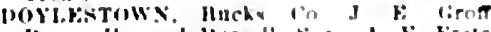

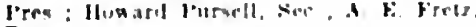
Treas

lithos, clearnell $r$ o $l$ sulliran,

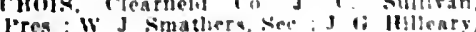
Treas

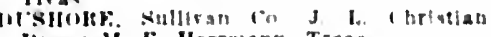
ires: if $f$ Herrmann. Treas
EAsToN. Northanthon ton - Mraham Stous, l'res.: 0. M. Hichards, sec : E. W. Erans, Treas.

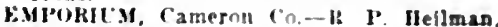
l'res: W. H. Bubb, Sec.; H. K. Corbett.

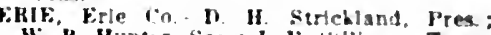
W. $\boldsymbol{h}$ Ilumer, sec. : J. F. Sillimar, Treas.

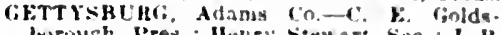
burmigh. Pres.; llolisy sten art. sec. : J. P. balbery. Treas.

GRFFitist.F., Frankin Co.-1.

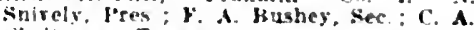
Chrilzman. Treas.

GRFi:sibthi, Westmreland Co-b T Amirose, Ires.; J. J. Singer. sec.; L. I. R. Smith, Treas.

I.I RH:sulki, liaphin ro.-w. C. Baker,

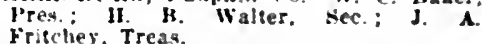

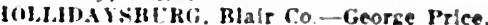
Pres: II. II. Brotherlín, Sec.; s. L. Siccarthy. Treas.

HoNksD.l.k, Warne Co.-F. W. Bums, Pres. : K. W. Brady, Sec, : F. W. Powell,

IINTINGDON, Huntingdon Co.-A. J. Hamilton, Pres. : L. L. Schum, Sec.: Samuel Grezory. Treas.

INDIANA, Indiana Co-William Hosack. Pres. ; T. D. Stephens, sec. : W. L. Shields. JoHXstow. Cambra Co-l, w. Jones. Pres.; J. S. Koontz, Sec.; A. F. Dunsmine, Treas.

KITTANiNig. Armatrong Co.-S. A. B. Jesson. I'res.: F. C. Monks, Sec.: $\mathbf{S}$ P. Heliman. Treas.

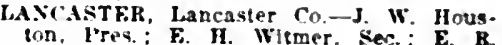
Milier. Treas.: G. I. Cassel, Ad. Int

LERANON. I.ebanon Co.-John Walter, Pres.: i. R. I.Ight. Sec. S. A. Light,

I. Evis Bithi, Inion Co.-u. I. Focht. Pres.: T. C. Thornton. Sec.: Willam l.eiser. Ir.. Treas.

Lrwistow. Miffin (o.-A. S. Harsh. lerger. Pres. J. A. C. Clarkson, Sec: ock refrer. Treas.

Pres. If Hollowas (-.J. II Hases. inaker. Treas.

ICCONEEI.sBLRG, Fulton Co._J w Mosser. Pres.; A. D. Nalbey, Sec; iv. F. Sappington. Treas.

MAIVER. inester Co.-C. E. Woodwand, Pres.: A. W. Baugh, Nec.; J. K. Erans, Treas.

MAl'CII CHLNk. Garlwn Co - J R hasten. Treas.

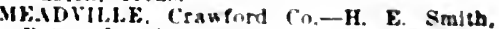
Pres; K. W. Clark, Sec: I. K. Rnberts.

MEDIA, Pelauare in. Trimble Prate. l'res.: E II. llarves, sec.: C. H. Schot.

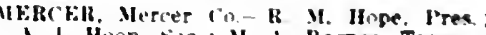
A. I Hoon, sic : 1 .I Rames. Treas.

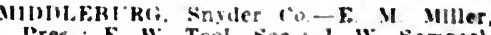
I'res: F. W. Trol. sec. J W. Sampsel.

Mrplistows. Juniata $\because,-R$ Y. Qule lerex: 1.11

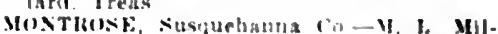
ler. I'rev": f: I'. Ilines, sec: F.

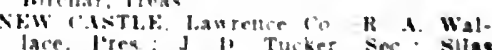
sicuseng, Treas

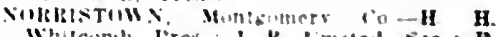
Whitromb. I'res: J $\mathrm{K}$ Imstad. Sere: I Y Eiveruters. Treas

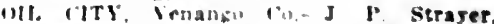

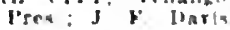
Treas

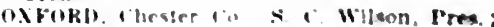
liarly Viaches sec : il. J" Kettew, Treas:

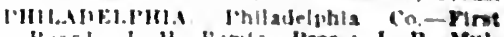

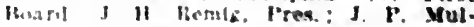
reman. Ser : II II llute. Treas

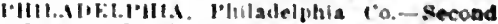
livari J r.. schechle. Pres.: Samuel Metsier. Sier: Iichard Murray. Treas

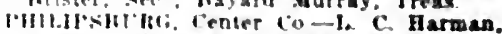
I'res : J W Iburiwidule. Sec.; F. H. Resd. Trras 
PITTSHIRGH, Allegheny Co.-First Board. -D. (\%. Huffnan, I'res.; T'. D. Davis, Sec. ; John Porter, Treas.

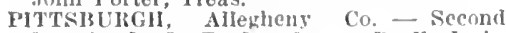
Board.- It. L. Taylor, ires.; iv. F, Jackson. Sce.: E. S. Dickey". Treas.

I'ITTSBURGH, Nllegheny ('o.-Third Board. -J. J. Crawford, l'res.; A. M. I'ierce, Sec. ; W. W. Stelyy, Treas.

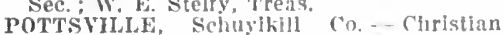
lenker. Pres. : C. D. Mlller, Sec.; It. 13. Gray, Treas.

PUNXSUTAWNEY, Jefperson Co._. S Hamliton, l'res.; W. F. Beyer, Sec.; J. F. Grube, Treas.

READING, Berks Co.-J. F. Felck, I'res. D. W. B. Kupp, Sec.; O. J. Thonipson, Treas

RIDGWAY, Elk Co.-M. M. Rankin, I'res. : W. It. Whllims, Sec.; S. G. Logtn, Treas. Fetter Pr, "estmoreland Co.-W. H. Iorner, Treas.; J. P. Strickler, Ad. Int. SCRANTOX, Lackawama Co. - Herman Bessey, Pres.; James Steln, See. ; J. C. Reifsnyder, Treas.

sombRSET, Somerset Co.-J. H. Gitrdner, Pres.; H. S. Kimmel!, Sec.; W. S. Mountain, Treas.

STRot'DSBUik, Monroe Co.-L. R. Sinith, P'res.; W. E. Gregory, Sec.; C. S. Logan, Treas suNBURY, Northumberland Co.-J. II.
Mlles, Pres.; B. L. Kerchner, Sec.; W. H. Lewls, Treas.

SUSQUEHANNA, Susquehanna Co.-M. I. Mlller, I'res.; E. P. Hines, Sec.; F. S Blrchard, Treas.

TIONESTA, Forest Co. - F J Bovard Pres.; W. G. Morrow, Sec.; J. C. Dunn, Treas.

TOWANDA, Bradford Co.-Charles Reed, Pres.; D. L. Pratt, Sec.; C. W. Woodburn, Treas

TROY, Bradford Co.-J. W. Phillips, Pres. M. B. Ballard, Sec.; A. E. Dann, 'Treas. Sturdevant, Pres.; F. J. Bardwell, Sec.; v. C. Decker, Treas.

UNIONTOWN, Fayette Co.-J. II. Hazlett, Pres.; A. S. Hagan, Sec.; S. H. Baum, Treas. WAHREN, Warren Co.
J. C. Russell, Treas.

WASHINGTON, Waslington Co,-.J. Y. Scott, Pres.; J. A. Patterson, Sec. ; D. H. Lewls, Treas.

WAYNESTLRG, Greene Co.-C. W. Spragg, Pres.; II. C. Scott, Sec.; H. C. Rice Treas.

WELLSBORo, Tloga Co.-N. W. Mastin. Pres.; S. P. Hakes, Sec.; C. W. Irazlett, Treas.

WILKES-BARRE, Luzerne Co. - E. I. Meyers, Pres.; $R$. A. Clark, Treas.

WILIIAMSPORT, lycoming Co.-A. P
Hull, Pres.; A. F. Fleming, Sec.; W. E Glosser, Treas.

YORK, York Co.-S. K. Pfaltzgraff, Pres. C. W. Elsenhower, Sec.; E. S. Mam,

\section{Rhode Island}

PROVIDExCE, Providence Co.-F. H. Peck ham, Pres.; J. W. Mitelell, Sec.; A. E. Ham, Treas.

WOONSOCKET, Providence Co,-F, II Jenckes, Pres.; J. A. King. Sec. ; Kober Wilcox, Treas.; G. W. Jenckes, Ad. Int.

\section{South Carolina}

BEAUFORT, Beaufort Co.-C. M. Guffin Pres. ; N. J. Kennedy, Sec. ; i. G. Elliott,

CHARLESTON, Charleston Co.- $\mathbb{W}$. H COLUMBIA, Richland Co.-H. W. Rice, Pres.; D. S. Pope, Sec.; A. E. Bnozer,

FLORENCE, Florence Co.-L, Y. King

GREENVILLE, Greenrille Co.-C. B. Earle, Pres, ; G, T. Swandale, Sec.; W. II.
Burnett, Treas.

\section{South Dakota}

ABERDEEN, Brown Co.-G. F. Countryman, Pres. ; H. J. Rock, Sec. ; II. C. Johnson, Treas.

Pres. Treas.
C.NTON, Lincoln Co- -1. t. Wendt, Pres. bil Lewison, sec. S. A. Young, Treas.
CENTEKVILL, Turner Co. - Hicliard Finlay.

1DluAs, Gregory Co.-M. M. lifoler.

DEAIWón, Lawrence Co.-F. S. Howe, I'res, ; H. E. Holvey, sec.; F. H. Asheroft, Treas.

FAULKTON, Faulk ("O-W. M. Edgerton. FiANIDREAU, Mody (b.-F. A. Spaftord, Pres.; A. S. Kider, Sec.; W. J. Erans,

GEDUL, Charles Mix ("o.-F. T. Anderson, l'res.; F. E. liyle, Sec.; J. A. Seapy, Treas.

GiTTYSBUHG, Potter Co-S. E. IIurley.
HOT SPRANG, Fill River Co.-E.

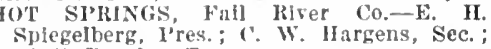
W. S. Bentley, Treas

muno: Beadle Co.-F. L. Mass, pres. T. J. Wood, Sec.; I. l. Fuxton, Treas. LEMMON, Perkins $\mathrm{CO}_{\mathrm{O}}-$

MADISON, Lake Co.-A. E. Clough, Pres. k. W. Goldman, Sec ; J. M. Duff, Treas.

MDLAivd. Stanley Co-A. A. I Ielnemann,

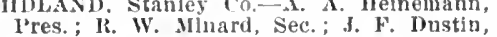
Treas.

MILIBANK, Grant ('o-W. J. Ferguson, I'res.; Charles Flett, Sec.; J. A. Jacotel,

Treas.
MTCILLL, Davison Co.-R. C. Warne,
Pres.: W, R. Ball, Sec.; B. A. Bobb, Treas.

PARKER, Turner Co.-... L. Peterman, P'res.: D. S. Kalayjian, sec.; H. s. Graves, Treas.

PIERRE, Hughes Co.-C. M. Hollister, Pres.; A. H. Youngs, Sec.; II. T. Kenney,

Treas.
REDFIEL, Splnk Co.- (i. W. Potter, Pres.; F. M. Crain, Sec.; J. G. (chichester, Treas. SALEM, McCook Co. R. T. Dott, Pres. Guy Ransey, Sec; ;. H. Hoyne, Treas. SCOTJaND, Bonhomme Co, - Malcolm
Munn, Pres.; H. J. G. Koobs, Sec.; A. H. Mluun, Pres.; H.
Steffens, Treas.

SIOUX FALLS, Minnehaha Co.-S. A. Brown, Pres.; C. F. Culver, Sec.; A. H. Tufts, Treas,

WATERTOWN, Codington Co,-R. F. Campbell, Pres.; H. A. Tarbeli, Sec.; H. II. Finnerud, Treas.

WEBSTER, Day Co.-J. L. Harris, Pres. ; M. C. Schenecker, Sec.; r. 1). Peabody, WINNER. Tripp Co-I. S. Hooker.

WOONSOCKET, Sanborn Co. Templeton.

YANKTON, Yankton Co.-E. M. Doyle, Pres.; II. F. Livingston, Sec.; James Roane, Treas.

\section{Tennessee}

ATHEXS, McMinn Co.-G. W. Stanton, Pres.; Gustavus Shipley, Sec.; J. L. Basinger, Treas.

BHISTOL, Sulliran Co.-C. W. Fleenor, Pres.; M. M. Pearson, Sec.; W. B. St. John, Treas.

BYRDSTOWN, Pickett Co.-W. C. Groce, Pres.; L. F. Zachry, Sec.; H. V. Craig,

Treas.
CHATTANOOGA, Hamilton Co. - F. T. Smith, Pres.; w. A. Dietrich, Sec.; S. W. Jenkins, Treas.

CLARKESVILIE, Nontgomery Co.-E. C. Humes, Tres.

CLEVEI ÁND, Bradiey Co.-R. O. Kibler, Pres.; R. L. Bean, Sec.; R. I'. Sullivan, Treas

CLINTON, Anderson Co.-S. B. Hall, Pres. H. D. Hicks, Sec.; E. M. Beasley, Treas Coldibia, Mraury Co.-J. L. Woorhies,
Pres.; P. D. Biddle, Sec.; J. W. Wilkes, Treas. DANDRIDGE, Jefferson Co.-B. M. Titts-
worth, Pres.; T. R. French, Sec.; J. C. Anderson, Treas.

DAYTON, Rhea Co.-J. C. Wasson, Pres.; J. W. Kammack, Sec.; Sam Donaldson, Treas.

ELIZABETHTON, Carter Co.-S. E. Reyholds, Pres.; R. A. Range, Sec.; A. R. Collins, Treas.

ERWIX, Unicol Co.-L. S. Tilson, Pres.; T. C.' Hensley, Sec.; W. T. Woodward, Treas.

GREENYTLLE, Greene Co.-G. S. Hays, Pres.; S. W. Woodyard, Sec.; F. P. Robinson, Treas.
HUNTINGDoN, carroll Co.-J. W. MeCall Pres.; J. 13. Cox, Scc.; J. J. Lancaster. Treas.

Jouxsox rITY, Washington Co.-H. L. P'alton, P'res.; J. W. Cox, Sec.; N. N Warliek, Treas.

KXNAVILLE, finox ('n.-J. S. Mebonough, l'res, ; II. 1'. Colle, sec, 'T. N. Kllis,

LAFAYTTTE, Macon ('o._Patterson Fast, 'res. ; C. K. Hanes, Sec. ; W. W. Tucker, Treas.

LAFOLIETTE, Canubell Co._-B. B. Brown, Pres.; A. L. Lawson, Sec.; J. 1). Mel'hetridge, Treas.

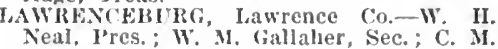
Womack, Treas.

LEXIXGTON, Henderson Co.-.J. M. Arnold, I'res.; W.' W. IIutstinann, Sec.; S. T, Parker, Treas.

LIBERTY, Dekalb Co.-T. J. ১lackson, Pres. ; T. J. Bratten, Sec.; S. C. Robinson, Treas.

W II Loudon Co.-J. (i. Eblen, Pres. Treas. Ilarrison, Sec.; J. .. Harrison, Jr. MeMINUILLE, Warren Co.-T. O. Burger, Pres.; Albert Seitz, Sec.; A. J. Trall,

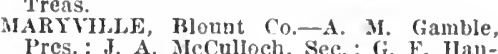
nah. Treas.

MAYNAHDVILAE, Union Co.-M. T. Colvin, Pres; A. II. Longmire, Sec.; II. A. C. MENIIIIS, Shetb

Pres.; H. S. Wolff, Sec.; H. 'Z. Landis, Trea

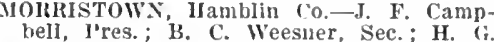
bangle, Treas.
Pangl

MOUNTAIN CITY, Johnson Co.-J. G. Butler, Pres.; J. S. Donnelly, Sec.; J. 13. D. Robinson, Treas. NASHVILLE, Davidson Co. - R. Q. Lillard,
Pres.; J. W. Handly, Sec.; Hillard Wood, Treas.; W. B. Lee, Ad. Int.

ONEIDA, Scott Co-J. Q. Dick, Pres.; A. R. W'est, Sec.; W. W. Foust, Treas.

PUlASKI, Giles Co.-G. D. Butler.

ROCKWOOD, Roane Co.-T. L. Bowers, Pres.; J. E. Nelson, Sec.; „. E. George, Treas.

ROGERSVILLE, Hawkins Co.-L. F. Brown, Pres.; W. H. Armstrong, Sec.; J. K WaIters, Treas.

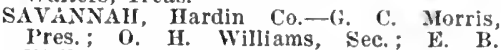
Walker, Treas.

SELMER, McNairy Co.-W. T. Beil, Pres. SEVIERVILLE, Sevier. H. Hodges, Treas Pres.; S. W. Flanagin, Sec.; T. A. Campbell. Treas.

SHELI3YVILLE, Bedford Co.-F. B. Reagor, Pres.; J. L. Morton, Sec.; J. H. Dyer, Treas.

SNEEDVILLE, Hancock Co.-J. B. Mitchell, Pres.; W. J. Seal, Sec.; B. F. Campell, Treas.

SOUTH PITTSBURG, Marlon Co.-J. P. Gillen, Pres.; C. 1. Hackworth, Sec.

SPARTA, White Co.-A. F. Richards, Pres. : S. F. Gaines, Sec.; li. E. L. Smith, Treas. TAZEWELI, Claiborne Co,-S. W. Stone, Pres.; J. C. Carr, Sec.; B. I. Waris, Treas.

UNION CITY, Obion Co.-D. M. Pearce, Pres.; W. A. Nailling, Sec.; L. D. Boaz, Treas.

Texas

ABHLENE, Taylor Co.-W. H. Barnett, Pres.; A. J. Pope, Sec.; S. M. Alexander,

Treas.
AMARILL, Potter Co.-G. T. Yinyard, Pres.; Isaac Rasco, Sec.; C. F. Randall Treas.

AUSTIN, Travls Co.-W. H. Way, Pres.; N. O. Brenizer, Sec.; H. C. Horrow,

AlllaS, Dallas Co.-J. R. Bragg, Pres. Rufus Whitis, Sec.; F. H. Anthony, Treas.; B. S. Bruce, Ad. Int. Anthony, DENISON, Grayson Co. - w. T. Booth, Pres.; ir. M. Morrison, Sec.; L. C. Ellls, Treas.

EL PASO, EI Paso Co.-H. E. Stevenson, Treas. 
FoRt wortil. Tarrant Co, J L. Cooper, Pres.; O. $\boldsymbol{F}$. Carison, sec, i W. A. Cook. Treas.

GaI.Vistox, Galveston Co.-L. S. Downs.

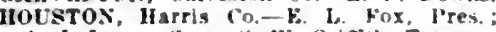
A. J. James, sec. : 6 . Gimin, Treas. LAREDO, Webb Co-H. J. Hatnition.

PARIS, lamar Co-G. F. Long. Pres. L. $i$. Meculston. Sec,; W. II. Moore. Treas.

SAN ANGglo, Tom Green Co._s. I. S. Smith.

SAN ANToxto, Bexar Co.-B. F. Kingley, Pres. : (i. J. Starnes. Sec.; L. M. Weln. teld. Treas.

SEGUix, (iuadalupe Co.-Willam Mgers.

SHERWAX, Grayson Co, - U. A Allers. Fres.; E. D. Neer. Sec.; E. J. Neathery, Treas.

WACo. Mclennan Co.-N. A. Olive, J'res. W. 0 . Wilkes. Sec; J. B. Farrell, Treas wichita FAlLs, Wlehita Co.-l. Coons.

\section{Utah}

MANTI. Sanpere Co.-W. H. Olsten

OGDEs, Weber co-t. S Condon, l'res. 6. A. Dickson, Sec. R. S. Josce, Treas. C. A. Coulter, Ad. Int

SALT LAKE CiTy, Salt lake co-s Ewing, Pres: T. C. Gibson, Sec, i. S. Вожеr, Treas.

\section{Vermont}

BrLlows Falls, Windham Co.J. S IIIL, pres.: Edward kirkland, sec.; $\mathfrak{C}, 11$. Hay Treas.

BExisctox, Bennington Co.- L. II. IRoss. P'res.; J. H. Wllson, Sec.; W. E. I'utnam, Treas.

BRATTLFBoRo, Winutham $\mathrm{Co}_{-}-\mathrm{r}, \mathrm{r}$ White, Pres.; H. L. Waterman, sec.; C. A.

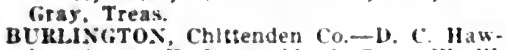
ley, Pres.; F. K. Stoddard, Sec.; W. W. sisles, Treas.

FAIR IIAEN, Rutland Co.-E. B. Clark, sec; (. D. Parkiurit, Treas.

MIDDLEHURY, Addison Co,E S Weston, 'rres.: W. J. White, Sec.; D. J. Carroll, Treas.

MONTPELIER, Washington Co.-F. E. Steele, l'res.; J. W. Jachison, sec. ; P. I. Templeton, Treas.

MOkRISTILLE, Lamollle Co.-J. C. MorEan, Pres,; (G. L. Bates, Sec.; (i. H. Newron. Treas.

NEwPoltr, orleans Co,-J, F, Wright, l'res.; J. F. Hlanchard, sec.; ‥ L. Dow, Treas.

MANióly, Orange Co.-r. c. Angell, I'res.; U. H. Hajward, Sec.; 0. V. Greene, Treas.

REThAND, Rutand co.-C. B. Boss, b'res, ; Georfe kustedt, sec: C A. Ciale, Treas.

ST. ALBANS, Franklin Co,-11. E. Welch, Pres.; C. k. Allen. Sece.; F. M. Mrokn. Treas.: J. 1; I'ersault, Ad. Int.

ST, JoHssutu, caledrula co- - E. II. Boss, I'rex.; J. M. Allen, Siec. : 5. Jones, Treas.; 11. It. Bruwn, Ad. Int.

WELLS HVER, Orange Cis,-presterlek Fletcher, l'res.; s. S. Eastman, sec.; 11. 11. Lee, Treas.

WHitE HIER Jusctos, Whdsot Co.R. J. Ginas, l'res.: II. I'. Stanles. Sec.;
C. W, Worthen, Treas.

\section{Virginia}

COEBLRs, Whe (o..... W. stallard, Pres.: W. B. Culbertson, sec,; J is

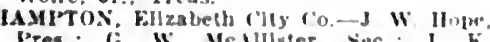
Pres.: G. W. Medulster, sec, : J. K Cons. Treas.

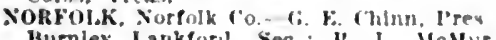
lsurnley Lankford, Sec.; is. L. Mellus ran. Treas.

petrasmigr, Dinwiddie ro.-It. A Map Iln, l'res, ; k. L. Mctill, sec. : W.

RichMoxil, Henrice ('o,-H. W. Darls, I'res.: Cieorge tiay, sec, : 1. W: statu,

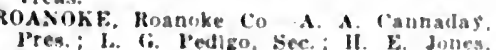

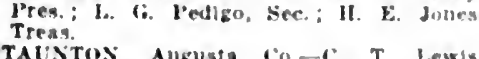

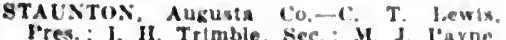
Pres.: 1. II. Trimble. see, : il. J. layne

\section{Washington}

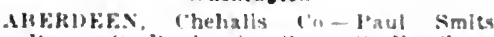

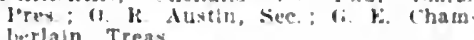

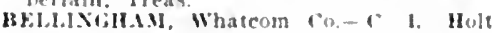
I'res: s. N. Kells, see, ; I. E. Bigrs Tress.

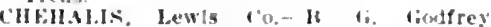
I'reצ. ; 1. H. Duw, See, ; b. I. hinskern Treas.

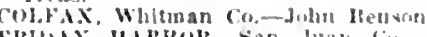

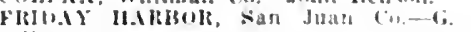
Wright.

K.I..MI, Cowlltz Co - Chas (; Mecallum l'res.: I.. M. sims, sec.; J. C llarnell, Treas

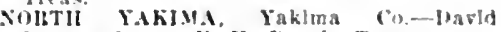
Honser, l'res.: $\mathbf{k}$. II. Brush. Treas.

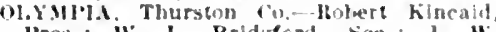
I'res.: W. L. Bridhford. See.: J. W 3 Irwell, Treas.

ontsig, plerce (o.-D. A. liove.

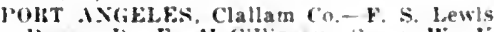
Ires.; II. F. McGlllirray. See.; W. h mont Ther. Treas.

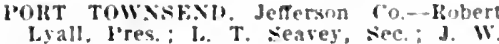
Edwards. Treas.

SFitT l.E., king Co._C. I. Snith, pres. s. J. Holmes, Sec; $\forall$ it Carroll, Treas SPOKiNE. Spokane Co.-18. It. yreeman. Pres.; r. 1). Olmsted, Sec. : (i. W. Libly Treas. T.Acowd, Plerce Co.-J. J, Rsming, Pres.
(i. D. Shaver, Sec. F. S. Stewart, Treats

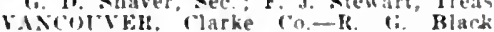
'res.; k. $r$. Mron, sec.; II. $\because$ Leser Treas.: R. D. Wiswall. Mi. Int

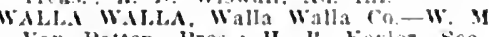
Yan Patten, fres.; H. li. heylor, see. I. C. Mack, Treas

WIT Hirll..F. Houglas in.

WFistchke, Chelan io. 1!. T. Congdon Pres.; II. A. Saunders, sec.; F. k. Culs. Treas.

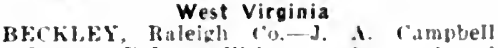
Pres.: Mohert Wriston. Sec.: A Ahshire. Treas

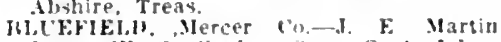
Pres.: W. C. Slusher, sec.; C. I. Johnstun. Treas

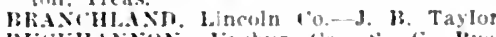

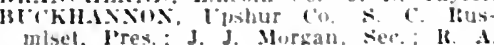
mhet. Pres.; J. J. Murzan, Ser, : K. A
leger. Treas.

CaMEIos, Marshall Co- $-C$. k. Hutchin son, Pres.: J. k. comper, sec.; W. F.
lirim, Treas.

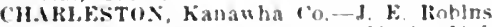

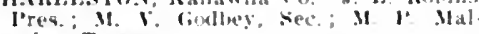

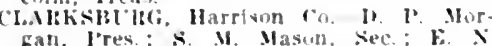
Ean. I'res,
flowers, Treas.

Elkiss, Handolph 10.-W. W. doblen, I’res.: 0. 1. Jerry. seer.; i. W. Bamiels Treas.

Fallemost Marion la W II. Kunst. Pres, "1. Henry, Seco : 6. II Hrown Held, Treas

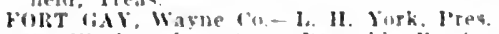
1. W. Bromley, sere, Restulds rrester.

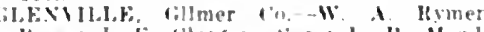
I'res. J. Fo. Claytom, sec. ; 1.. IS Mean

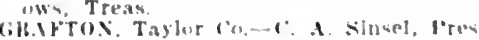

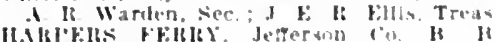

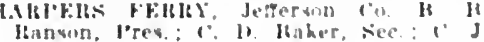
kimere. Truat

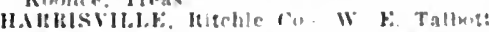

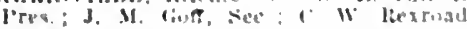
Treas:

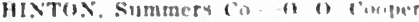

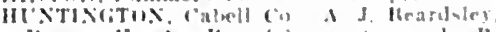

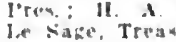

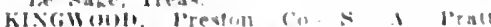

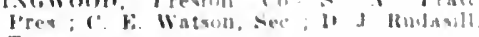
Treasingtos, Varten a 11 r a 11

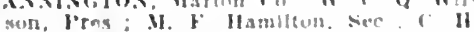
son, leras

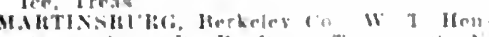

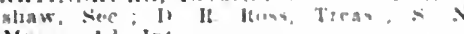
Mers. Wi int

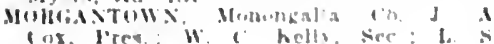
IIrnek. Treas

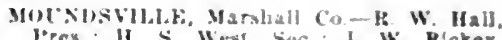
l'pes. H. S. West, sec.; J W Bickey. Parkensbluk; Woud con-W J. Dapld-

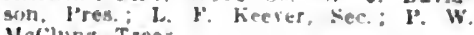
Mccilune. Treas

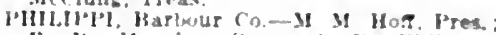

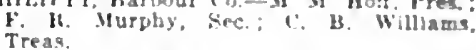

I'I H.MONT, Mineral Co.-C. S Hueman l'res, ; Z. T. Kaltaugh, sec; K. II, l'ar: PolNT PlLASANT, Mason Co.-n. J

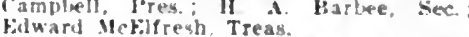

miltir, Jachon Cu- B. E Harrison, r'pes.; $V$. L. Canon, sec.; J. E. Barrows, Treas.

ST M.MYs, l'beasants co-J. R. Mccollum, l'res.; II. Q steere, sec, A. S. Grimm, Treas.

StSTELSVIILE, Tyler Co-J, M. Boice, Ires.; r. H. IJje, Sec, i H. H. Boice,

SPENCrH. Hane (n,-J. B. Thompson, Pres.; k. s. Gioz. Sec.; J. E. Mcquala. frtos, Braston co-W. H. Mecauley, l'res.; M. M squites. Sec. : M. T. Mor rison. Treas

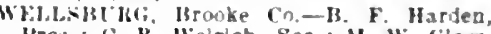
Pres, c. H. Weirich, Sec.; M. W. Glass.

WEstor, Lew ls Co.-J. I. Wander, Pres.

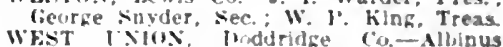
P'xole, l'res.; w. L. Iclane, sec; w. Innes, Treas.

Whblisis, ohin Co.-I. R. Best, Pres.

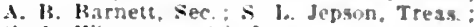
C. N. Wingerter, sd. Int.

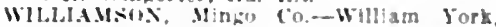
I'res; J. H. Millard, Sec; Tunis Nune-

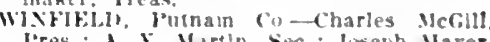
I'res. A. I. Marthn, Sec.; Jinseph Mayer.
Treas.

\section{Wisconsin}

INTICio, Langiate co, I l) sieffen

AlPletux, outagamie Co-H. E. Ells. Worth. Pres; 6. A kutchie, Sec.; A. M.

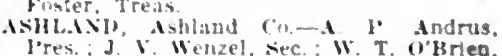
Treav

Mritst. Fanu claire in-G. F. Ilamilon.

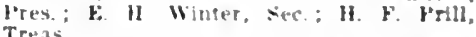

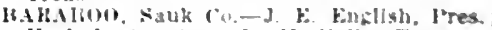
If I Irwin. Sec : II M. helly, Treas.

MFillals. Tireen latke (co. J. S. Walbridse,

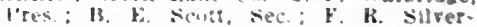
thorn, Treas

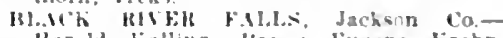

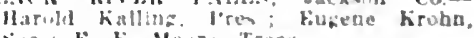

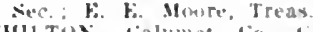

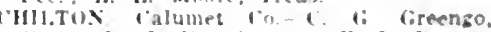
peres: X. J. hratut sece; E. L. Holton,

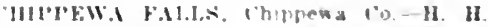

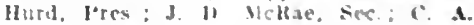
Haver, Treas.

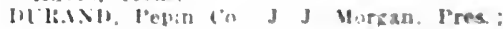
1. Huleate. Sers. W. II iasady.

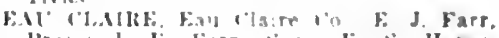

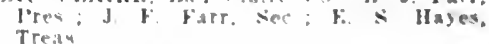
bitkilokx. Waluoreh f's W II Hurltut.

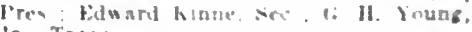
Ir. Treas

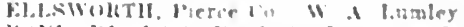

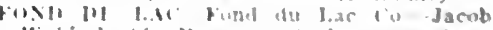
Waldoclimitle. lires 1 hrumme. Ser.;

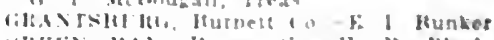

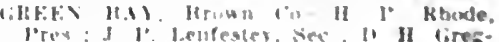
"ris Trea"

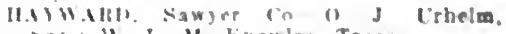

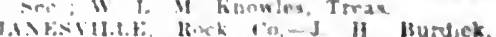
lorm of it liurkmsstep, sec. J James IIIIn. Truas

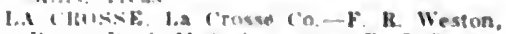
I'res: It s Mesthur, see: F. C Sulter, Treas.

LAliss WITH, Rusk $10-W$ F. O'Connot. l'res: WV L stepherson, sec: : H. II T. 


\section{AMERICAN MEDICAL DIRECTORY}

MAdison, Dane Co.-T. W. Fvans, Pres. ; E. A. Brown, Sec.; J. W, Kester, Treas. : 1. R. Head, Ad. Int.

MANITowoc, Manitowoc Co. - J. F. Prltchard, Pres. : Full Christensen, Sec.; Pritchard, Pres. ; Ent

MARiNETTE, Marinette Co.-II. E. Mann, Pres. ; T. A. Lld, Sec.; S. I'. Jones, Treas. : G. F. Colter, Ad. Int.

MAJSTON, Juneau Co.-E. H. Townsend, Pres.; W. T. O'brien, Sec.; A. T. Gregory, Treas.

MEDFORD, Taylor Co.-Eugene te sage, Pres.; C. E. Nystrum, Sec.; G. H. Meclúre, Treas.

MENoMINEE, Dunn Co.-A. F. IJeising, Pres.; F. H. Grannls, Sec.; N. L. Howison, Treas.

MILWAUKEE, Mllwauke Co.-First Board -D. J. Hayes, Pres.; F. C. Glllen, Sec.; A. F. Young, Treas.

MHWAUkEe, Milwauke Co. - Second Board.-R. Elmergreen. Pres.; J. J. McGovern, Sec.; 0 . F. Krueger, Treas.

MILWAUKEE, Mllwaukee Co.-Third Board. -IV. J. Cronyn, Pres. ; It. F. Mehl, Sec.; W. T Lochemes, Treas.

MONDovi, Bufralo Co.-Charles IIebard, Pres.; G. M. Smith, Sec.; P. B. Amunson, Treas.

MONROE, Green Co.-C. C. Gratiot, Pres. F. W. Byers, Sec.; S. R. Moyer, Treas.

NEILISVILLE, Clark Co.-J. H. Frank, Pres.; Arne Matheson, Sec.; C. F. Bachman, Treas.
NEW I.ONDON, Waupaca Co.-A. C. Borchardt, P'res.; J. Y. Potter, Sec.; J. W. Monsted, Treas.

NEW RICllMoND, St. Crolx Co.-W, H I'ark, I'res. : F. S. Wade, Sec.; II F I'errin, Treas.

osCkOLA, Polk Co.-F. W. Walker, Pres.; H. F. Combacker, Sec. ; H. G. Murdock, Treas.

osiliosH, Winnebago Co.-T. F. Kussell, Pres. Frank Brockway, Sec.; J. M. Conley, Treas.

PlatTEYhle, Grant Co.-Herman Gasser, Pres.; James Oettiker, Sec.; f. C. Buck, Treas. : Wlison Cunningham, Ad. Int.

PortaGe, Columbla Co.-F. T. Gorton, Pres.; C. E. Wintermute, Sec.; J. R. Kellogg, Treas.

IPRAIRE DU CHIEN, Crawford Co.-Emll Stelger, Pres.; W. A. IIall, Sec.; H. L. Watrous, Treas.

RACINE, Racine Co.-W. S. Flaven, Pres.; A. J. Wllliams, Sec.; Soren Sorenson, Treas.

RICE LAKE, Barron Co.-O. M. Sattre, Pres.; B. N. Webster, Sec. ; T. A. Charron, Treas.

RICHLAND CENTER, Richland Co.-A. D. Campbell, Pres.; H. J. Wall, Sec. ; F. W. Mckee, Treas.

SHAWANo, Shawano Co.-IV. H. Cantwell, Pres.; J. B. Gordon, Sec.; Edward Puchner, Treas.
SHEBOYGAN, Sheboygan Co. - w. H. Gunther, Pres.; O. B. Bock, Sec. ; O. J. Gutsch, Treas.

SPARTA, Monroe Co.-F. P. Stites, Pres.: iv. T. Sarles, Sec. : If. H. WiHlams, Treas. : V. W. Stlles, Ad. Int.

STEVENS PoINT, Portage Co-F A Southwlch, Pres.; M. G. Rood, Sec.; C. vou Neupert. Jr., Treas.

von Neupert, Jr., Treas.
SUPERIOR, Douglas Co.-E. T. Gauvreau, Pres. ; H. A. Russell, Sec. ; J. C. Adams, Treas.

VIROQUA, Vernon Co.-W. M. Trowbrldge Pres.; C. II. Trowbridge, Sec.; A. J. Dake, Treas.

WAUPACA. Waupaca Co.-E. H. Jones, Ires.; O. N. Mortensen, Sec. ; T. E. loope, Treas.

WAUSAW, Marathon Co.-D. T. Jones, Sec. A. T. Koch. Treas.

WAUTOMA, ivaushara Co-E, M. Wllson Pres.; H. B. B. loppe, Sec.; L. A. Vanderlinde, Treas.

Wyoming

CASPER, Natrona Co.- - Go. P. Johnston, Pres.; G. A. Fox, Sec. ; A. W. Barber, Treas.

DOUGLAS, Converse Co.-J. R. Hylton.

EVANSTON, Uinta Co.-C. H. Soller.

LANDEH, Fremont Co.-T. G. Maghee.

LARAMIE, Albany Co.-H. E. McCollum.

RIVERTON, Fremont Co.-C. G. Cogswell.

RIVERTON, Fremont Co.-C. G. Cogswell.
SHERIDAN, Sherldan Co.-F. A. Hodson

SHERIDAN, Sheridan Co.-F. A. Hodson,
Pres. : T. E. Marshall, Sec.; C. E. Prevenson, Treas.

Pharmaceutical preparations advertised in the American Medical Directory have been passed on and accepted by the Council on Pharmacy and Chemistry of the American Medical Association. Refer to Physicians' Purchasing Index, page 12. 


\section{MEDICAL COLLEGES}

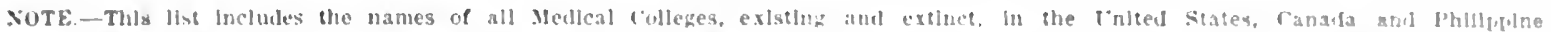

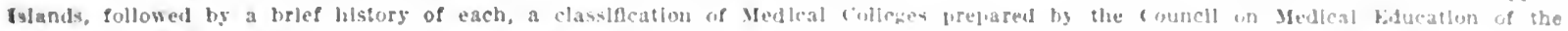

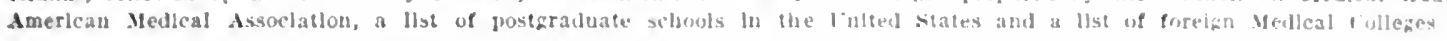

\section{ALPHABETICAL LIST OF AMERICAN COLLEGES}

Alabama, Jedical College of, Moblle.-. Na.2. Alabama, Enlr. of, School of Med.-Mla.. Albany itelical College. Albang.-X.... Amerlcan inthropologlcal indrersity of $s$ Louls. - 110.39

American College of Arts and Sciences. Butalo. $\rightarrow$ X.1.39

American College of Medical sclence, New lork Clty.-N.Y.33.

Amerlcan College of Medlcine in Vennsylramla -1 . 14 .

Amerlcan College of Med. and Surg.-Ill.22 American Eclectle Medical College-0.16.

Amerlcan Health College, Cincinnatl.-0.34

American Healtb Soclety, Flrst Medical College of, Boston.-Mass. 11.

Amerlcan Medical College, Éclectlc-0.30.

Amer. Med. Coll., Eclectlc, St. Louls.-Mo.10.

American Med. Coll. Indianapolls.-Ind.19.

American Medical Coll., St. Louls. Mo.10.

American Medlcal Misslonary Coll.-1ll.19.

American Soclety of Arts and Sciences, Bur ralo. - X.Y.39.

Amerlcan Soclety of Literature and Art. Buffalo.-X.Y.39.

American Unirersity of Boston, Medical Department of the, Boston.-Mass.10.

American Cnirersity of Pennsylranla, Eclectic. Whlladelphla.-1'a.I6.

Arkansas Industrlal Lniversty, Medical Ilepartment. Little Rock.-Ark.i.

Arkansas, Lnirersliy of, Med. Dent., Lltile kock-Ark. 1 .

Ashury Cnlrerslly, Med. Dept.-Ind.3.

Atlanta College of Phys. and Surgs-Ga.11.

Atlanta Medical College. Ga.5.

Allanta School of Medicine.-Ga.12.

Atlantlc Medical College, Ballimore.-Md.s.

Isaltimore Medical College.-Md.t.

Baltimore Linltersity School of Med-Md.h. Barnes Medical College, Si. Louls- Mo.28 Baylor Linlversity College of Med.-Tex.t.

Beach Medieal College, Indianapolls,-Ind.is.

Beach Med. Instltute, Indlanapolis. Ind.15.

Heaumont II osplial Medical College. Mo.24

Hell Medlcal College, Dallas - Ter. 8 .

Bellerue Hospltal Medical College.-Y.Y.10

Belleve Medlcal College of Massachusetts. $\rightarrow$ Mass.9.

Bennet College of Eelectic Mediche and

Surgers, ('bicago,-Ill.8.

Bentuet Medlcal College.-III.8.

Berkshlre Medical Coll.. I'ltsfleld-Mass.2.

Berhel Jedlcal Department of Suuthsestern

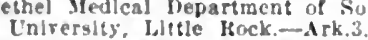

Blrminghan Medical College. Nal

IBoston I"niversity. School of Med.-Mass

Rotanje Medical College, Memphls - Toun 3

Itotanlen-Medlcal College of (Ohlo 0.5.

llowdoln (vlleze, Med. lient of-Me.1.

Brooklyn Academ of Medlcine-1.Y. I?

Hrown Tulv.. Merl. Dept., J'roridence. - II I I.

Itutralo College of Ihational Med.-N.1.36.

Iiuralo, Inlrerslty of. Med. Ilepr- N.Y.6.

Rutler Inirersity, Med. Irepartment-Ind.s

Callfornla Eclectle Medical College-ral t. Callfornla Med. Coll., san Vranclaces - Cal.t Callenrnla Medical boclety and rillege of

l'hyslclans, San Franclseo, - r al.'t

Callfornla, Conlversity of, Med. Irept. Cal." (astleton Medlcal Icademy (Colleze). - Vit. Central college of I'bys. and surs-lud?

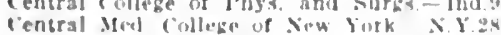
Central Medical coll. of St. Joveph -Most Central Tenn. College, Med. Mebt. Tena. Ceutral Intrerslty of Kentucky - Ky... Central Unlv of Ifed and sclence yst Chadulock school of Med., Qulncy.-- III.12.
Charity Hosp. Med. Coll. Cleveland-0.11. Charity Hosp. Med. Coll. New urleans La.3 Charleston Medllcal School - S.('3. Chattanma Medical college.-Tenn.y. 'hateanowgat Xational Med. Coll-Tenn 18 Chastanonga, l'uiv, of, Med. Dept-Tenn. Chlciliro College of Jed. and surg.-111.2.2. Chlcaro College of Medicine and Surgery l'hyslo- Medlcal-Ill.2i).

chleato cullege of sclence--111.26.

'hicago kiclectlc Medlcal Cullege.-111.2.?.

'hlcago IIomeopathic Med. College--1ll.10.

(hicago Hospital College of Med.-IH.4:.

Chicago Medlcal College.-Ill.6.

(hlcago Northwestern College.-Ill.

Chlcago Physto-Medical College.-Ill.

Chicazo Physlo-Medical Institute.-II).j

inicazo. Untrerslty of Med. Dept-Ill. .

(inclunall College of Med. and surg.-0.8

Cluclnnati Medica! College.-0.2-

Clncinnatl Physlo-sledical College.--0.t

'lark l'nlrerslty, Med. Dent-Gra.15.

Clark Lntrersity, Med. Nept-Mass. it

Clereland College of Phys. and surgs.-0.12.

Cleveland II omeopathlc Med. Coll.-0.26.

Clereland Medical College. -0.6 .

cleveland Med. Coll., IIomeopathlc-0.23.

'lereland-I'ulte Medical College-0.26.

Cleveland Lniversity of Med. and Surg.-0.i

Clintcal School of Med!clne.-Vit.3.

College of Anerlcan Med. and surg-Ga.2.

(ollete of Inmernathlc Medicine and sur

cullege of Medlcal Frangelists, Lona Linda

college of Medicine, Botanlc. New York (1t)-5.1.24.

college of Medlcine and surgery, PhysioMedical. ihlcago.-Ill.j.

coll. of Med. of Maryland, Italtimore.-Md.1.

college of I'hiladelphla, Dept. of Med.- Pa 1 .

college of Physlclans and surgeons, Lltile Rock.-Irk:i.

college of l'hisicians and surgeons, Los Ingeles - ial. 9 .

rollege of Plyystcians and surgeons, san Francisco. Cal.:

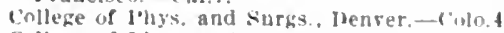

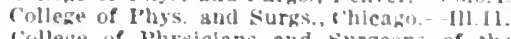
College of Ihysiclans and surgeons of the liper Mlssissippl, Hoek Island.-Ill.2t.

loll. of l'hys. and surgs. of Indiana.-Ind.6. college of Phys. and Surgs., Keokuk, Ia.1. 'ollege of I'hysiclans and Surgeons, Kansas 1to-kan $t$

(t)ll. of Phys. and surgs., Baltumare....M. M. idll of l'hys. and surgs. IBoston. -Mass.6. 'ollege of I'hyslrlans and Surgeons, Mlane. apolis. - Mrint.

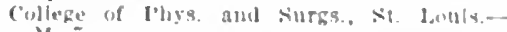
I11.

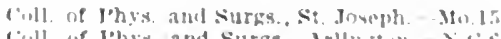
coll. of l'hy and surgs. Irllugton Xin "ulleg" of I'hyslclans and
'lly of vew York.

college of l'liyslicianu and surgeonv of the Wratern IDstrles of New York Faleflelds X I. 1.

college of Ihyedefans sul surgons, Honten-

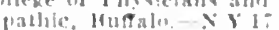

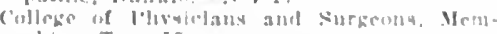
phls Tamitit.

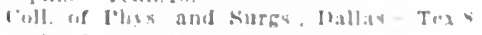

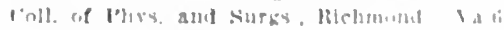
coloratu, lobreralty of. Sichool of Med. cine. liomlder rolu.

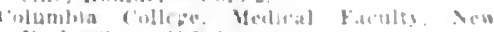
Jork I'li Y. I

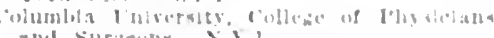
and surigroma $\mathrm{Xl}$

columblan lime Coll, Kangay l'ay Voll

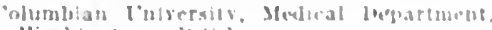
Washlingtin. II t
Columinus Medtcal college - o It

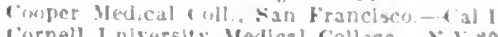
inrnell I. niversity Merlical College - $\mathrm{x}$ i $\geq 0$ cutner Culsersily, Mod Ibept-Neb.

council bluts Vialical cosllege.-Ia.11.

Crelghoon Mediral cullen-Neb.

curt:s l'hystro-Medlcal colloze. Itullanajolis -Ind: 2 -

rurtis l'hyslo-Med. Inst. Marlon-lud.L.

lallowsie Inir., Med. Faculty of - N S I.

Dalhotisie Inly Med. Faculiy. - S S.I.

Hallas Meilleal college - Tex.10.

lialion Metlcal college, Inalon-Ga.lt

lbartianuth Medlcal schinol, Hanorer. Nul

lorldien school of Medicine._.C.C.

Daytun Medical Inlrerslts. - 0.3\%.

learturn Medical College, chlcago-nll 23

Denver and Gross coll. of Med-Colo.5.

Denver Pollege of Medicine.-Colo.1.

lenter Inllege of Phys. and Surgs.-colot

linver Inmeupathle Colleze.-Culon

lenver, Intrersity of. Med. Dept-rolo.

Inetroit cinllege of Medlelne.-IIlch.

Detrolt Homenpathle College-Mlch it

Wetrult Homenpathlc Medical coll-Mich.3.

letroit Medical College. Mllch. I

letroit Universlty of Medlelne-Mich.15

Detrolt I"nirerslty of Ratlonal Medlcine and Surgery, Detroit -Mlch.it

Drake Inireraity College of Medicine-Ia.6.

Druidic Banchorelon, Butalo... Y Y.39

Iruidic I"nis of Maine. Lew]ston-Me.s

bunhan Medlial Colleze. Chicazo-lli. is

Dutton Medical rolleze, Chlcagn.-111.38

Eastern Inlx. School of Med. HaltimureMil 11

Felectic Colleze of l'hys. and surgs.-Ind its. Erlectic ('ollege of Med and Surg - O.3I.

Eelectir Medical college of Imulans. - Ind It.

Eclectic Medical College, Lujwrille - Kr.3

Eclectle Medloal college, Clneinnati-1).

Erlectli Metlical ('nlleze of the l'ly of New York-Nis 13

Fuleoplc Medical college of Maine. Lewiston.

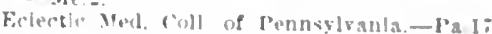

Eelevt: Verl coll of Philadelphia - Pa 14

Eclectio Merlical Institupe. (Inetonat - O ?

Folectic Vedical Instrute. Inallas-Tex?.

Eclectie Medt Inatiture. Memphis-Tern 3

Eclectic Medica! fustiture of New Inr.

Itwhester - Y y 26

Folootic Mal. Intr. Kandas Clty - Mn 33

Ecole de Mindetar et de l"hirurate - que :

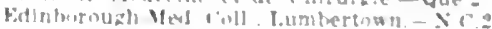

fithourg l'ubervity, Chlogan 111.-

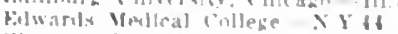

kilectropathie Invt!tute. I'hiladelphia - ra 18

Ensworth. Contral Meil. Cull. St. JosephM11 $: 2,3$

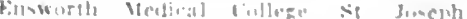
Vhe.2.2

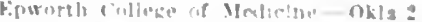

fixcelvior Mmfiral follege li istom - Masa 12

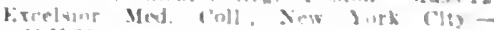
X) 131

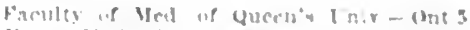

birat llellcal frollege of the American

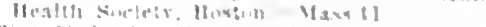

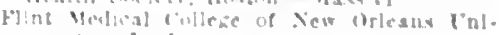
o.t.

Fluriale l'nibersity of. Meal Depe-Fls

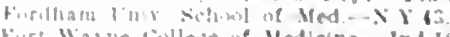
Firt Wasme college of Sediene. Ind 10

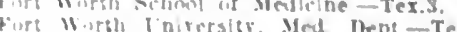
Franklat Viol coll. Dhiladelphla-pas.

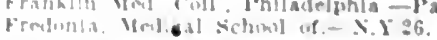

1.alrention VInlical college - Tex 1

lote I 11 . Mel. Cullegr, Texarkana - Tex.i.

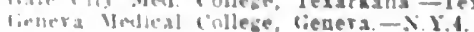


George Washington Unls., Deyt. of Med.D.C.1

Georgetow'il Unle. School of Med-b.C.2. Georta Coll. of Eclec. Mcd. and Surg.-Cia.9. (ieorgla Felcetic Med. Coll., Atlanta.-lia.9. ficorgla, Unlversity of, Medical Dept-Cia.1. ferman Acad. of I'hyslatrle P'hys.-111.31. German-Amerlcan Homeo. Med. Coll. - III.32. German college of Gynecology, l'ediatrics and obstetrles, Chleago.-11l.33.

German College of Medieine and Obstetrles, Chleago-IIl:ox.

German Homeopathic Medleal College, chicago.-111.29.

German Medical College, Chieago.-111.30.

Graffenburg Institute.-Ala.1.

Grama Rapids Medical College.-Midi.10.

Grant Lniverslty, lled. Dept.-Tenn.:'.

Gross Medical College, Wenver.-Colo.3.

Hahnemann Hospital College of Sam Frin("iseo.-Cal.5.

Hahmemann Yed. ('oll. and IIospital.-Ill.4. IIahnemamn Med. Coll. and IIospital.-Da.9. Hahnemann Ifedical College of the Kansas city Iniversity--Mo.31.

Hahnemann Med. Coll. of the Pacifie-Cal.5.

Iabnemann Med. Coll. of l'hlladelphia.lia.?.

Jahnemann Med. Coll., San Francisco.fal.5.

Halifix Medical College._X.s.1.

Hamburg Canal College. Buffalo.-N.Y.38

Hamline Lniversity, Medieal Dept.-Minn.5.

II ampden Syuney College, Med. Dept.-Va.4.

Jannlbal Medical College.-Tenn.IT.

IIarrard Medical Sehool, Boston.-Mass.I.

IIarrey Medleal College, Chicago.-Ill.13.

Hering Iledical College, Chicago.-111.15.

Hering Medieal College, St. Iouis.-Mo.16.

Hippocratean Coll. of Med., st. Louls. Mo.40.

Honterlathic College of 1'hysicians and Surgeons.-XY.IT.

Ifomeopathic Coll., Univ. of Mich.-Mieh.5.

Iomeopathic Hospital Coll Cleveland-o.7.

Honeopathie Hospital Coll.. Cleveland.-O.7.

Homeolathic Medical College of Pennsylvania.-Pa.6.

IIomeopathic Med. Coll. of St. Louis.-Mo.9. Jfomeopathle Medical collegre of the State of New York, New York City.-N.Y.9.

IIomeopathic Med. Coll. for Women.-0.33.

Hospital College of Med., Iouisville. - Ky.5.

Jospital Med. Coll., Eelec., Atlanta.-Ga.18.

Hospital Med. Coll. of Eransville-Ind.13.

IFoward Inlversity School of Med.-D.C.3.

Iludson Medical College.-0.6.

IIumboldt Institute, St. Louis.-Mo.f

IIumboldt Medieal College, St. Louls,-Mo.4.

Hygela Medical College, Cincinnati.-0.39

Hygeio-Tlerapeutic College, Bergen Hgts.ז.J.1.

Hygeio-Therapeutic College.-N.Y.32.

Illinois Coll., Med. Dept., Jacksonville.-1ll.2.

Illinois Health University, Chicago.-111.35.

Illinois Medical College, Chicago.-Ill.17.

fllinols standard Coll. of Med. and Surg.J11.36.

Illinois, University of, Med. Dept.-Ill.I1.

Independent Medieal Coll., Chicago.-Ill.21.

Indiana Central Medical College.-Ind.3.

Indiana rollege of Medicine and Miswifery. Ind. 24

Indiana Eelectic Medical College, Indianapolis.-Ind.11

Indiana Eelectic Medical College, Dept. of Obstetries, Indianapolis, -Ind. 22 .

Indiana Medica] Coll., Indianapolis.-Ind.4.

Indiana Medical Coll., La Porte--Ind.1.

Indiana Medical college, School of Medicine of Purdue Lnicersity - Ind.18.

Indianapolis, University of.-Ind.25.

Indiana, Lnirersity of, New Albany.-Ind. 23.

Indiana Unlversity School of Medicine, Bloomington-Indianapolis.-Ind.20.

International Electropathic Institution.O.:32.

International Medical Missionary Coll. and Training School for Nurses, Atlanta.-

International Med. Missionary Inst.-Ill.34. lowa roll. of Phys, and Surg.-1a.6.

Iowa Electic Med. Coll., Des Moines-Ia.6. Iowa Med. Coll, Eeleetic, Des Moines.-Ia.6. Iowal Medical College, Keokuk.-Ia.2. lown, State Unlverslty of, College of Homeopathle Mediclne, lowa Clty.-Ia.4.

lowa, state F"nlverslty of, College of Modlclice, lowa city.-Ja.3.

leffersou lonlege, Medical Dept.-1'a.2. Jefterson Medieal Association.-Tenn. I6. Itefterson Medlcal Coll., I'hiladelphla.-1'a.2. Jetterson School of Med., Loulsville-Ky.6. denner Melleal rollege.-1ll.16.

Joln A. Creighton Medieal Coll._Keb.6.

Johns Hopkins Med. Scliool, Baltimore. Mat.

Joplin College of I'hys. and Surgs.-Mo.I\%.

Joplin Medieal College, Joplln.-Mo.19.

kansas ('ity ('oll. of Mea. and surg.-Kan.6. Kinnsas Clty Jahnemann Med. Coll.-Mo.35. liansas rity Homeopatile Medical College.M1). 26

Kansas (ity IIospital Coll. of Med.-Mo.21 Kansas city Medieal College.-Mo.s.

Kansas City, Medleal College of.-Mo.11.

Kausas City Cnlversity, IIa]nemann Medical college of -110.31

Kinsas (jity, Univ of, Med. Dept.-MI 0.20 . Kansas City Lniversity College of Homeo pathle Mediclne and Surgery.-Mo.31. liansas Medical Coll., Independenee--Kan. Kansas Melleal College, Topeka.-Kan.3. Kansas, I'niversity of, School of Medicine, kitnsas city and Lawrenee.--lian.2. Kemper College, Medieal Dept.-Mo.1 Kentueky Seliool of Medicine.-Ky.1

Kentucky University, Medical Dept.-Ky.9. lieokuk Medical College.-la.9.

Keokuk Medieal College, College of I'hysicians and surgeons.-Ia.I0.

Iing Eelectic Metl. Coll., Des Molnes.-Ia.7. King's College, Medical Faculty,_..N. Y.1

King's College, Medical Faculty of - Ont.1. Kingston Woman's Medleal College.-Ont.7. Knoxville College, Medical Dept.-Tenn.12. Finoxville Medieal College.-Tenn. I3.

Ia I'orte University, Medieal Dept.-Ind.1. Laura Memorial Woman's Medleal College, Cincinnati. -0.21

Laval University, Med. Dept.-Que.3.

Leland Stanford Junior Lniversity, Dept. of Medicine.-Cal.11.

I.eonard Medieal Sehool.-N.C.3.

Lincoln Medieal College.-Neb.

Lincoln University, Med. Dept.-Pa.I0.

Llneoln Memorlal Unlversity, Medieal Dept. Tenn.10.

Lind Unlversity, Med. Dept. of--Ill.6.

Livingston Unirersity, Haddonfield.- - N.J.3.

Lonbard College, Med. Dept.-III.41.

Long Island College Hospital- - Y. Y.

Louisiana, Medical College of, New Orleans. -La.1.

Louisiana, University of, Med. Dept.-La.1.

Louisvilie and Hospital Med. Coll.-Ky.5.

Louisville Med. Coll., Louisville.-Ky.4.

Louisville Medical Institute.-Ky.2.

Louisville National Medical Colleye.-Ky.

loyola University, Med. Dept.--I]I.8.

McDowell Medical College.-Mo.1.

Mefill Cnlversity, Med. Faculty of-Que.I.

Maine, Medical School of Portland-Me.I.

Manitoba Medical College.-Man.I.

Manitoba, University of, Med. Dept.-Man.1

Marlon-Sims Beaumont Med. Coll.-Mo.34.

Marion-Sims Coll. of Med., St. Louls. Mo.27.

Marquette University School of Med.-Wis.6. Maryland Meslical Coll., Baltimore.-Md.9.

Maryland, Iniv. of, School of Med.-Md.i.

Medieal Aeademy of Gerrgia, Augusta.-Ga.1

Medical College of Eransville.-Ind.2.

Medical College of Georgia, Augusta.-Ga.I

Medical College of Fort Wayne-Ind. 7 .

Iedical College of Indiana.-Ind. 8 .

Medical College of ohio.-o.1.

Medical College of the Pacific.-Cal.1.

Medical and Surgical College of the state of New sersey.-N.J.2.

Nedieal Department of the American [n]versity of Boston.-Mass.I0.

Medical Department of the Lincoln Memoria! Iniversity.-Tenn.10.

Medical Department of the University of west Tennessee.-.Tenn.14.

Medical Faculty of Rutger's (Queen's) Colledge, New York Cit. - N.Y.21.

Medical Instltution of Geneva.- N.Y.4.

Medieal Institution of Morgan City.- Ltah 2.
Medicai School of Fredonla.-N. Y.26.

Medical Sehool of Harvard Unjv.-Mass.1.

dedical school of the valley of Virginda Winchester.-Va.2

Medical und surgieal Instlute and Samltarimm, Butfalo.-N. Y.39.

Medieal Univ. of Ohlo, Cineinnat.-0.17. vedieo-Chlrurgleal and Theological ('ollege of Clirlst's Institution, Baltimore.-Mfl.10. Medico-Chlrurgleal College, Kansas Clty.Mo.32.

Medieo-('htrurgleal College of I'llladelphia. - J'a.11

Meharry Medleal Coll., Nashvll]e.-Tenn. $i$.

Memphis IIospital Med. Coll.-Tenn.8.

Memphls Medical College, Memphls.-Tenn.2.

Metropolltan Ned. Coll., Chlcago.-Ill.37.

Metropolitan Med. Coll., Felectlc.-N.Y.30.

Mllaml Medical College. - 0.9 .

Mlchigan Coliege of Medicine.-Mich.6.

Mlehigan Coll, of Med. and Surg.-Mich.8.

Mlehigan Eclectic Med. Coll-Mich.13.

Mlehlgan IIomeopathic Med. Coll.-Mich.4.

Mleligan Med. Coll., Lansing-Mlch.I6.

Michlgan School of Homeopathy and Surgery.-Mlich. 12

Mlehlgan, University of Department of Medlclne and surgery.-Mich. I.

Mlchigan, UnJversity of, Homeopathic College.-Mich.5.

Middle Georgia Medical College-Ga.13.

Milwaukee Coll. of Phys. and Surgs. - Wis.1

Milwaukee Medlcal College.-Wis.3.

Minneapolis College of Physicians and Surgeons.-Minn.5.

MInnesota College Hospital.-MInn.3.

Minnesota Homeopathic Med. Coll.-Minn.6.

Minnesota Hospital College.-Minn.3.

Minnesota. Enirersity of, College of llomeopathic Medieine and Surgery.-Minn.6.

Minnesota, University of, School of Medleine. -Minn. 4

Mississippi Medical Coll., Meridlan.-Miss.2.

Mississippi, Univ. of, Med. Dept.-Miss.1.

Mssouri Eclectic Medical College-Mo.38

Missourl Medleal College, St. Louls.-Mo.I.

Missouri Sehool of Midwifery and Diseases of Women and Children, St. Louls.-Mo.42. Missouri, University of, Med. School-Mo.3 Mohawk Medlcal College, Buffalo.-N.Y.3. Montezuma University Med. College.-Ala.5. Montreal Medical Institution.-Que.I.

IIontreal School of Med. and Surg.-Que.4

Morgan Clty, Med. Institution of.-Utah 2.

Nashville Medleal College.-Tenn.6.

Nashville, University of Med. Dept.-Tenn.1.

National Homeopathic iled. College.-Ill.14.

National Homeopathic Med. College.-D.C.5.

National Medical College, Chicago.-Ill.14.

National Medical Coll., Washington.-D.C.1.

National Medical Univ., Chicago,-Ill.I4.

National Normal Univ., Coll. of Med.-0.22

National Un!rersity, Medical Dept.-D.C.4.

National University of Illinois.-11l.27.

Nebraska College of Med., Lincoln.-Neb. 7 .

Nebraska Medical College, Eclectic, Lincol -Neb.8.

Nebraska School of Med., Omaha.-Neb.5.

Nebraska, University of, College of Medlcine, Eeleetie Dept.-Neb.2.

Nehraska, University of, College of Medieine. Homeopathic Dept. - Neb.3.

Nebraska, University of, College of Medlcine, Jineoln and omaha.-Neb.5.

Nebraska, University of, College of Medieine. Regular Jept., Lineoln.-Neb.l.

New England Botanjco-Nedical College.Mass.4.

New England Female Medical College, Boston.-Mass, 3

New England Univ. of Arts and Selenees.N.H. 2.

New Fngland Lniv. of Arts and Selences.1:ass.8.

New Hamushire, Lniv. of, Dept. of Med.N.H.3.

New Jersey, Medical and Surgical College of the State of.-X.J.2.

New Medical Institution, New York Clty. N. . 21.

New Orleans School of Medicine.-La.2.

New Orleans Iniv, Med. College.-La.4

New York College of Magneties, New York City- Y.Y.40.

ew York, Eelectic 
New York Free Medical College for Women. New York City -.X.X.35.

New York Howeopathic Nedlcal College and Hospltal. - X.Y.9.

Now York Hsgeio-Therapeutlc Colleze, New York Clty.-N.Y.32.

NeT York institute of Medical science.S.Y.ti.

New York Yedical College.-...Y.i.

New York Medical College and Hospital for Women.-X.Y.11.

New York Preparatory School of Mediclne. New York Clty.-S.Y.34.

New York Reformed Jledical Colleze, Eclec te, New York Cliy.-N.T.22.

New Yort school of Medicine.-N.Y.23.

New Yort Unitersity Medical Coll.-NiY.s

Niagara Unlrersity, Med. Dept.-Y.Y.18.

Sorth Amerlcan Academy of the llomeopathlc Healling Art, Allentown.-Pa.15.

North Carollna Miedical Colleze.-N.C.4.

North Carolina. Unir. of, Med. Dept.-..C..1.

North Dakota, iniverslty of, College of MedIetine, Enireralty.-...D.1.

Sorthreatern College of Blochemistry.Tresh.2.

Nortbreetern College of Midwifery.-III.25.

Nortbwestern college of Ms Joseph.-Mo.18

Northwestern Ohio Medical Collese.-0.18.

Nortbwestern University Med. School.-IIl.6.

Northwostern Unlrersliy Woman's Jiedical Bchool, Chicaso.-III.9.

Oakland College of Med. and Surg-Cal.8. Doeldental Coll. of Phsa. and Surgs.- Mo.3fi. Ozlethorpo Medical Coli., Sarannah.-Gia.6. Yidwifers, Cincinnall - - 38 .

Oblo, Medical Lnir. of, Cincinnatl.-0.17. Oblo Medical Vulverslty, Columbus. - 0.25

Ohlo-Miaml Med. Coll., Cincinnati.-0.41.

Oblo Wesles an Univ.. Med. Dept.-0.12.

Oxlaboma Medlcal College, Oklahoma City. Oriabous.

Otlahome, Inir. of, Med. School.-Okla.1. Omahe Medical Collese, Omaha.-Xeb.5. Omnha University, Jedical Dept.-Neb.5.

Ontario Medical College for Women.-Ont.8. Oregon, Enireralty of, Medical Dept.--Ore.2.

Pacife Coast Beeular Coll. of Med.-Cal.10. Penn Medical University. Pa.8

Pensylrania Modical College. Philadejphia. Pa.3.

Pennasiranie, University of. Department of Medicine, Philladelphia.-1'a.1

Philadelphia Coll. of Med. and Surg.-Pa.4.

Phlledelphla Vnitersity of Medicine and surzers.-Pa.14.

Phillpoine Medical College. Manila.--P.I.2. Parsio-Eclectuc Medical College -..-15. Physlo-Medical College, Cincinnati.-0.t. Phyolo-Medical College of Indiana.--Ind.5 Phymo-Yredical Colleze of Texas.-Tex.j.

Physio- Medical Institute. Cincinnati.--0.10.

Pope Medical 8chool. - jio.2.

Portland School of Mied. Instructlon.-Me.4. Preparatory Medical College. New York City and youghkeepsie.-N.X.t2.

Presbrterlan Rosplial and Woman's Mledical Colleze. -0.24

Pulte Medical College, Clncinnatl.-0.13.

Quebec School of Mediclne.-Que. 3 .

Queen's College (New Jersej). Faculty of

Medicine, New York Cliy.-X.Y.21.

Queen's t'olreralty. Hed. Faculty of.-Ont.5.

qulocy Collese of Medicine.--IIt.12.

Randolph Eclectlc Hed. Instlute - X.Y.zi Randolph Hacon College, Med. Irept.- Va. Reform sedical College of Gesriata lin". Rerenis of Vnir.. State of X. Y - .Y. IY. Bellance Medical College, Chicaso.-..III.39.

Beserved Coll. of Phys and Surga.-. Mays.1: Rochester Eclectle siedical folleze N. Y.28 Rocky Mountain Cnlv., Med. Dept. - iolo.3. Rolph' (Medical) 8chuol.-.ont.4.

Royal Colleze of Phys. and Surgs Ons.;

Rush Yedical College, Chicazo..-111.

futger's racults of Geneta collese. N.Y 21

Saginaw Valles Medical College. Saginax. Hich.9.

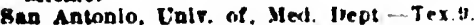

8t Charlea, University of. Med. Jept Ili.3.

82. Jomeph Hoopltal Menlical Colleke.--Mo. Mt

Bt. Jomeph Medical inllege.-Mo,22.

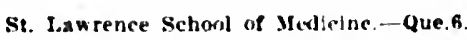
St. Louls College of Homenpathic l'hysicians and surterons. Mo.6.

st. Louls College of Medical and Natural sclences, St. Louls -.-Mo.t.

St. Louls college of Phys. and surts. Mor. $i$ St. Louls Eclectic Medical College. Mto.13.

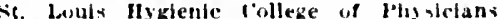
and surkeons.- Mo.25.

st. Louls Medtcal College. - Mo.:

st. Louls inirersity Med. Lept-No.34

St. Louls Iniversity Sch of of Med.-Ni, 34

st. Louis Womnn's Medical iollege -...Mn.37.

5 . P'aul Mellcal College.-Minn.?

St. Thomas. Liniverglty of, Medical Depi., Manlla - P.I.1.

Sarannah Medical College.-1;a.t.

scientific Medical Collece.-Jil. in

Sewnee Medical Collese.-Tenn.il

Shis l'nirersity, Med. Deps. of - S C .3

Shelby Medical College. Nashville.-Tenn.

sloux cits College of Medicine-la.8.

South Carolina, Medical College of the state

of. Charleston.-S.C.l.

South Carolina, Enlr. of, Med. Lept.-S.C.2. South Dakota, Iniversity of. College of

Medicine, Vermillon.-S.D.1.

Southern Botanico-Medical College-Ca.2.

Southern Callfornia, University of, College of Medicine, Los Angeles.-Cal.6.

Southern College of Sledicine and Surgery, Atlan:a-Ga.19.

southern Homeodathic Medical Coll._-Mdd.8. Southern Medical college.--Ga.10.

Southern Jethodist Iniversity Medical Collexe-Tex.6.

Southern Lnirerslty, Medical Dept.-Ala.3.

Southwestern Homeopathic Medical College and Hospltal, Loulsville.-Ky.8.

outhwestern Methodist Lniversity, Medical Department.-Tex.6.

Southwestern I'ntrersity. Bethel Medical Department of, Little Rock.-Ark. 3.

Spokane Falls. inirersity of, College of Medicine.-Wash.3.

Starling Medlcal College, Columbus.-0.3

Starllng-Ohlo Med. Coll., Columbus.-0.40.

State College of Phys. and Surgs.-Ind.2i

State tiniverstty, Mledical Dept. of.-Ky.jo

Sulphur Rock Coll., Med. Dept. of.-Ark.3.

Syracuse Medical College, Eclectic, Roches-

ter.-.Y.Y.

Syracuse Iniversity Coll. of Med.-N.Y.15.

Syracuse cutversity, College of Physician and Surgeons of, Syracuse. - N.x.ij.

Tallahassee College of Medicine and Surgery.-rla.1.

Temple Cniversity, Med. Dept.-Pa.13.

Tennessee Medical College.-Tenn.10.

Tennessee, Inlv. of, Med. Dept.-Tenn.6.

Texas Christian University Medical Department, Fort Worth - Tex.3.

Texas Health college, Hot Springs.-Ark.4.

Texas Medical College and Hospltal.-Tex.1.

Texas, Luirerslty of, Medical Dept.-Tex.2.

Thompsonian College, Harbourville-Cia.3.

Thompsonian Med. Coll., Allentown.- Pa.20.

Toland Medical Coll., San Franciscu.-Cal.2.

Toledo Medical College.-0.19.

Toledo School of Medicine. Toledo--0.36.

Toronto School of Medicine.--Ont.

Turonto, Enir. of, Faculty of Med-Ont.1

Translyvania inirersity. Med. Dept.-Ky.1

Trinlty Medlcal College, Toronto,--ont.t.

Trinlty Inlversity College of Medlcine and

Surgery of the State of vernont. - its.

Trinlty Intversity. Medical Dept. Tex.10

Tufts College Med. Schoul. Boston -.-Masa..

Tulane l'niversity of Loulstana sichoof of Medicine.-La.1.

Twentech century Pliysio. Medicat college. Okla.3.

Union Medical Institute. Sewlunry - Vt.6.

Inton teniveralts, Medical lept. I Y.3.

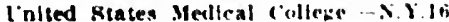

l'ntreralty and Rellerue llingital Irdicat college- S.Y.Is.

inlrersits Coll. of Med, Rirhmund. - Vas

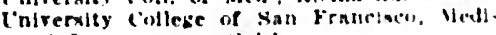

cal Departument.-.-(al 1

linlrersity

Iniversity of Alabama sibuel of Vieds. cine Ain?:

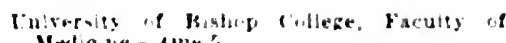
Methenie- Yur.

Iniversity of Cinclunati rollege of Med. cine - 11

Iniversty of Dallas, Meslcal Dewt - Tex 4. Tniversity of Gesra!n cill. of Med-Tia 1. iniverslts of Illinois Coll. of Med-1ll.11.

inirersity of Indianapolts, Medical Depart. ment-Ind.8.

Iniversity of Med.. Indianapolls - Ind:ai

iniversity of Mediclne and surg. Tex il

liniversity of Jemphls, SIed. Jept-Tenuls

[intrersity of Munuesita Jedical schiolMinn.t.

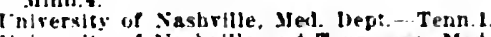

inirerslly of Nashrille and Tennessee, Medieal lepariment - Tenn.

lintersity of Pittaburgh, Sedical lepartment. - l'a.12.

Tnurersts of the I'acinc. Ned. Dept-Cal.1.

lniversity of the l'hilippines, Medical loepartment, Manilia - P.I.2.

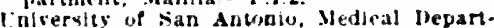
ment.-Tex.9.

Lniversity of Southern california colleze of Medicine.-Cal.6.

Inirerstsy of spokane Falls collece of Jed. icine.-Wash. 3 .

tiniversity of Tennessee, Med. Dept. - Teun.6.

iniverstry of the South, Siedical Department.-Tenn.11.

Cnirersity of Toronto, Fac. of Med.-Ont.]. liniversity of Wonster, Medical Dedt-o.11. loper Canada school of Medirine.-Ont 3 . 'tah. Iniverslty of, School of Med.- Cuh 1. valey of Virginia. Mledical Schoul of the. Winchester.-Va.z.

Valparaiso Cnirersity. Medical Dept. - III.2. Vanderbilt Lniversity, Med. Dept.-Tenn.j. Vermons Acadeny of Medicine.-Vt.1. Yernont Medical College, Kutand-Vit. Vermont Medical College, Wodstuck - it.3. vermont, Lniversits of Coll. of Med.-unt.4.

Victorta Lntversits,

Virginia, University of, Dept. of Med-Va.s.

Wake Forest School of Metlicine.-X.C.J.

Walden Cutrersits, Ned. Dept. - Tenn.i.

Washington Bichemic Med. Coll.-Wissit.

Washington Collece. Med. INept.-Md.

Washingon Homeopathic Med. Coll.-D C.5.

Washingion iniversity. Med. Dept-Mo.s.

Washington Lniversity Scbuol of Medicine. Baltimore.- Id.

Washington, Inis of Med. Dept-Wash.1.

West Coass Medical colleze, Can Francisco. - Cal.10

Western College of Homeopsthic Med.--o.i Western Eclectic College of Medicine and surkery, Kansas City. - Kan. í

Western Homeopathic Coll. . Cleveland - - O.:

Western Pennsylrania iredical college. Pittshurgh.-Pa.12.

Western Reserve iniversliy School of Medl. cine. Cleveland - 0.6 .

Western Iniversity, ifed. Dept-Dont. $t$

Western Liversity, Nied. Dept.- Ont. Medl. cine - colo 4 .

West Tennestee. Intrerslity of. Medical Departinent. - Tenn.14.

Wist Virgina I niv. Coll. of Med-W.Mal. Wichita Medical Coillege. Wichita - Kans.

Willamette iniversity, Medical Dept- - i)re.1. Willoughby Initerstits. Medical Dept.-0.2s

W!nchester Modical College.-Ma.3.

Winons tedical school.-Minn.1.

Wisconsin coll. of Phys and surss.-Wis:

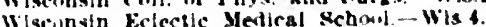

Wisconsin inir. of ioll. of Med-Wis.s.

Woman's Hospital viedieal Collere. - III.9.

Womat. Mod. Foll. Ilomerpathic - Mo -3

Womm's Med. Collese of Naltimore - Mdd.s

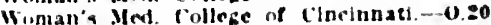

Wiumans Hal colleze Kanssa city - Vo.30. Wuman'. Med college Kingston-oni.:

Womnn a Med colleger Kingston-omi. and

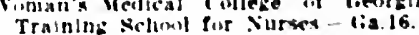

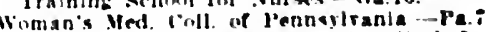

Wonan's Med colleze of the Yew York In

nemary tor Wimen and ihildren.-.... 16. Wimeser. Inlseralty of. Med Dept. 0.11 .

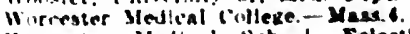

"irester Mediral School. Eeiectle, New Jirk eits.-. Y r.es

Wurth nicton Mellcal Collere. Eclectle, - 0.2 lule college Medical Inutstution, New

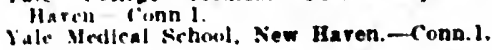

Zaneurillin Academs of Medicine-0.35. 


\section{THIRD CLASSIFICATION OF MEDICAL COLLEGHS}

lrepared by the Councll on Medteal Fincation of the American Melleal Association. Itevised 10 March 1 , 1914 . Colleges omitled have ceased to exlst ly merger or otherwlse.

CLASS A PLUS-ACCEPTABLE MEDICAL COLLEGES

1. Giving an Accentable Four-Year Course:

C.MLIFURIA

Leland Stanford Jumior, Unir., bept.

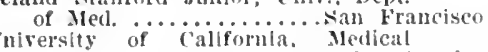

Dept. ....... San Francison-Las Angeles CONingtel't

Vale Medieal School........... New Haven 1L.LINOIS

Northwestern I"niv. Med. School....Chicago ltush Medical follege (Lniversity of

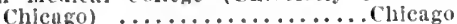
INDIANA

Indiana Lniversity Sclrool of Medicine

........... Bloomington-Indlanapolis 10W'A

Stute Cnir. of Iowa, Coll. of Med. Iowa Clty LOUISIAN

Tulane Iniversity of Louisiana, Med.

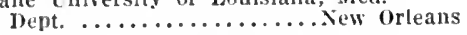
MAMYLAND

Johns Hopklns Inlv. Med. Dept..Baltimore MASSACIILSETTS

Harvard Medical School...........Boston MICHIGAN

University of Michigan, Dept. of Med. and surg. ................n Arbor MINNESOTA

University of Minnesota, College of

Med. and Surg............. Minneapolis MISSOURI

Wasluington Unir. Med. School.... St. Louis NEW YORK

Columbia University College of Plyys. and surgs. ............... York City Cornell Lniv. Med. College.... New York City University and Bellevue Hospital Medical College........... New York City syracuse Lnir., Coll. of iled.......syracuse OHIO

Ohio-Mlianl Medical College of the Luiv of Cincinnati........... ('incinnati Starling-olnfo Medical College ${ }^{i}$......columbus Western Reserve Lniv. Med. Dept. .Cleveland PENNSYLYNIA

Jefferson Medical College ${ }^{1}$...... Philadelphia Universlty of Pennsylvania, Dept. of Mediclne ............. I'hiladelphia cinversity of Pittsurgh, School of

Iedicine ${ }^{1} \ldots \ldots \ldots \ldots \ldots \ldots \ldots$. Pittsburgh TEXAS

Lnir. of Texas, Dept. of Med.... Galveston VIRGINiA

Eniversity of Virginia, Department of

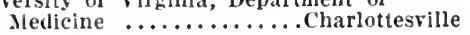

2. Giving a Two-Year Course Acceptably: MIISSOURl

Univ. of Mo., School of Medicine. . Columbia WXSCONSIN

Lniv. of Wiscousin, Coll. of Med...Madison Total 27

\section{CLASS A.-COLLEGES ALSO ACCEPT ABLE WHICH COULD MAKE CER TAIN IMPROVEMENTS TO ADVANTAGE \\ 1. Giving a Complete Four-Year Course: ALABAMA}

Cniv. of Alabama, School of Med....Mobile

\section{COLORADO}

Lniversity of Colorado, school of Nedicine .............Boulder-nenver

\section{IISTIRT OF COLUMBLA}

fieorgetown Uiniversity School of Med-

lcine ................ Washington

Ceorge Washington University, Dept.

of Medlcina............ Washington Iloward Iniv., school of Med... Washington

\section{GEOIRGIA}

Atlinta Medlcal College ${ }^{2} \ldots . . . .$. Atlanta Lniv. of Georgla, Coll. of Med....Augusta

\section{ILLINOIS}

College of rhys. and Surgs........ Chicago IOWA

State Universlty of lowa, IIomeopathic College ................ lowa City

KANSAS

Unlversity of liansas, School of Med-

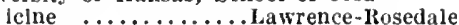
KENTUCKY

Lniv. of Louisrille, Med. Dept.... Louisville MAINE

Med. School of Maine..Brunswick-Portland

MARYLAND

College of Plyss. and Surgeons...Baltimore University of Maryland, School of

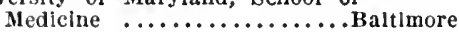

\section{MASSACHUSETTS}

Boston Lniv. School of Medicine....Boston Tufts College Medical School..........Boston

\section{MICHIGAN}

Unicersity of Michigan, Homeopathic College ..................nn Arbor MISSOURI

St. Louis Iniv. School of Med.....St. Louis

\section{YEBRASLA}

Universlty of Nebraska, College of Medicine .............Lincoln-Omaha

NEW HAMPSHIRE

Dartmouth Medical School........Hanover

\section{NEW YORK}

Albany Medical College............Albany

Fordham Lniversity, School of Medicine $\ldots \ldots \ldots \ldots \ldots \ldots$. Wew York city New York Homeopathic Ned. Coll. and Flower Hospital.... New York City Lniversity of Buffalo, Med. Dept.....Buffalo OREGON

University of Oregon, Med. Dept...Portland

\section{PEXNSYLYANIA}

Halnemann Medical College and Hospital ................Philadelphia Medico-Chirurgical College of Philadelphia ............... Philadelphia Woman's Iedical College of Pennsylvania ......................... TENNESSEE

Vanderbilt Univ., Med. Dept...... Sashville VERMONT

Eniv. of Velmont, Coll. of Med..Burlington VIRGINIA

Medical College of Virginia......Richmond

\section{Giving a Two-Year Course:} MSSISAIPII

rulv. of Mississippl, Med. Dept......oxford NoItTH CAROLINA

Iniversity of Nortl Carolina, School

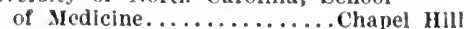
Wake Forest College, School of Medleine ................Wake porest NORTII DAKOTA

Iniversity of North Dakota, College of Medieine ............ Cniversity SOLTII DAKOTA

Iniversity of Soutli Dakota, Collese of Nedicine ............. Vermllion U'TAII

Lniv, of Ltah, School of Med.Salt Lake City Total 37

\section{CLASS B.-COLLEGES NEEDING GEN- ERAL IMPROVEMENTS TO BE MADE ACCEPTABLE}

\section{i. Giving a Complete Four-Year Course:}

\section{ALABAMA}

Birminghan Medical College ${ }^{5}$..Blrminglam ARKANSAS

Lniv. of Arkansas, Med. Dept... Little Rock CAlifOKNIA

College of Phys and Surgs..... Los Angeles Hahnemann IIedical College of the

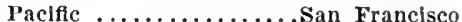
Oakland College of Mled. and Surg. .Oakland IILINOIS

Hahmewann Med. Coll. and Hosp...Chicago MICHIGAN

Detroit College of Med. and Surg...Detroit NEBRASKA

Jolnu A. Creighton Medlcal College... Omaha NEW YORK

Long Island College Hospltal......Brooklyn OHIO

Eclectic Medical College.........Clnclnnati OKL.AIIOMLA

State University of Oklahoma, School of Medicine.....Norman-Oklahoma City PENNSYLVANIA

Temple Lnir., Dept. of Med....Philadelphia SOUTH CAROLINA

Medical College of the State of South Carolina.............. Charleston TENNESSEE

Meharry Medical College ${ }^{6} \ldots . .$. ... Nashrille Unir. of Tennessee, Med. Dept......Memphis TEXAS

Baylor University College of Med....Dallas WISCONSIX

Marquette Lniversity, School of Medicine ................... Mllwaukee

2. Giving a Two-Year Course: WEST VIRGINIA

West Virginia Lniversity College of

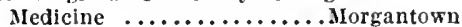
Total 18 


\section{CLASS C.-COLLEGES REQUIRING A COMPLETE REORGANIZATION TO \\ MAKE THEM ACCEPTABLE}

CAIJFORNIA

Callfornla Eclectle Mod. Coll... Los Angeles Collese of l'hys. and Surks...San branclsco College of Sledical Evangelistx. . Loma Linda GEORGIA

Georgla College of Eclectic Medicine and surgery $\ldots . . . . . . . . . . .$. Allanta Southern Colleso of Med. and surs. . Atlanta II.LISOLS

Rennett Medleal College....... Chicago Chlcazo college of Med and surg. ". Chlcago Chleago Hoaplial Coll. of Med...... Chicago marylaxid

Bastern Linlr. Scbool of Med.... Baltimore MASSACHLSETTS

College of Phys. and Surgs. ${ }^{20} \ldots . .$. Boston MISSOLH

American Medical Collece....... Lt. Louls Eelectic Medical Lniversity ${ }^{12} \ldots$........ knsworth Medleal tollege'......... Joseph Kanvas Clty llahucmana Medical College.................... Kansas clty St. Louls College of Ihysiclans and Surgeons ................... Louls
NERRASKR

Cotner Lniversity Mled Coll NEW YU\}K

New York Medlcal Collece and Hos pltal for Women........ \ew york ciey

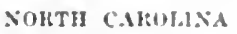

Leonard Medlcal Sichool...........Ralelgh Forth Carolina Medical College... Charlute ollo

Clereland-lsulte Medlcal College. cleveland Toledo Medica! Collece. TENDESSER

If́ncoln Memorlal Universty;, Medical

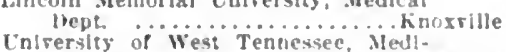

\section{cal liept. $\begin{array}{r}\cdots \\ \text { Tr.x. }\end{array}$}

Fort Worth School of Medicine. Fort Winth Southern Methodlst Lniv. Med. Dept, ballas Total 26

Note.-Offclal statements from the followtag state llcensing boards indicate that as a rule the colleges rated In fiass $C$ are not recognlzed: Mlabama; Arkansas (Reg.) Colorado. Connectlcui (Ileg.); Delaware: Indlana: lowa: Kentucky; Louislana (Reg.); Maryland (Reg.): Mtichlgan; Minne-
Mola: Mlasisslppl: New liampahlse; Ne Jersey: New Mexieo: Nirth Uakots; Ohlo fennsylranla: Khode luband: Teras; Vermont; Virainia: West Viritria: Wisconsin.

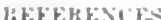

I llating changet to class $A+$ leby. 191 1911

3. Kating changed to Ciass A keb. It

t. Kating changed to Class a Feb. at

1914. When the senlor class now enrolled has araduated. Uits colleze will ozer ouls a post-graduate medlcal course.

6. Rating changed to Class B Feb. 24 1914

1914

Rating changed to Class C Feb. - 6 ,

8. leported not fulls recoznized by wenty-nlue diferent state IIcenslog boards. 9. Meported not la good standing by the Marsla

10. Heported not reengnlzed by the Massa. chusets Medical Soclety.

11. Reported not in gool standing by the Mlssouri State Board of Healih.

12. Will close when the senfer class now enrolled hav been graduated.

\section{HISTORICAL MATTER ON MEDICAL COLLEGES}

Number of Colleges Fxlsting. 148; Extlnct, 335. Tilles of Exlsting Colleges are In Black Letters.

\section{MEDICAL COLLEGES OF THE UNITED STATES AND CANADA.}

\section{ALABAMA}

Ala. 1.-Graftenburg Instltute. Chartered 1852. First class graduated in 1836. ExHnct 1862

Ala. 2.-University of Alabama. School of Medicine, Moblle. Organlzed 1859 as the graduated 1861 , and a class graduated each subsequent year except 1862-68, inclusive : reorganlzed as Medlcal llepartment of the Unlversity of Alabama in $159 z^{2}$, and assumed University of Alabama In $1597^{\circ}$ and assumed Bondurant. Tolal rezlstratlon. 1912.13, 115 ; graduates, 15.

See sforcial Announrement Adt. page 40

Ala. 3.-Southern Lnlversity, Medlcal Department, Greenstoro Organlzed $182^{2}$, extinet 1880 .

Ala 4.-Birmingham Medical College, Bir. minchm class graduated in 1995 in 1913 became the Graduate School of Iledlcine of the Enirersity of Alabama. There are 25 profesors and 15 assistants, loial 40. The braces two segmions of elght months ench. Only junlors aud senlurs will be enrolled. When then two clases hare graduated. the collezo $w i l l$ cease to do undergraduate teach. ins. The secretary is lir. b. lP. Huzan Remstration, 1912.13, 102: graduates, Ala. 3.-Medical College Monteruma [n]. reraliy, Heswemer. Wrganjzed 1s96. IIrst class craltuated $159 \%$ secund class 1898. Foxtince septenter, 1898

\section{ARKANSAS}

Ark. 1.-Universily of Arkansas, Medical Department. IItLe Hock. Drianlyod Is:9 frat class graduated In 1580 and a class sraduated each subseguent year. [irlginal tlite of Arkansas Imluxirlal Iniveraity changed to present tille in 1949 by tealslatire enaciment. In July. 1911. it nimsed with the College of lhyslclant and Surberong; and the school became an lutecral part uf ir. Morgan Smith. Total reciatra: na lill:13. 110 : erahlualev. $3=$

13. I10: Erailuatev 3: Invelelana and sur Ark 2 - Tollece of Physlclans and surcanlsed in 1900 . Classes were gradisated from 1907 to 1911. Inciuslre, when it was merged with the L
Medical Department.

Ark. 3.-Bethel Medical Department, Southwestern L'niversliy, Little Bock. Exinct about 1890 .

Ark. 4-Texas Healih College, Hot Springs. Organlzed 1893. Extinct.

Ark. 5.-Medlcal Department of Sulphur Rock Colleze, Sulphur liock. Organlzed isos Colles Texarkana and under new charter became the Gate City Medical College. (See Tex. :.)

\section{CALIFORNIA}

Cal. 1.-Cooper Medical Collece, San Francisco. Organlzed 1858 as Medical bepartment of viversty of the lacific. lliscal lhepartment Ciniversity iollege of san Franclsco 18:t. Pille of Medical Pollege of the Paclflc p'resent tile assumed in iss: Firat clasa pratuated 1860 and a class Frat clasa krattuated erarluaterl each sulsequent year except 1 s. pord Juntor linlrervity. It resalned the tifle of Conper Medlcal College, howerer, until the class of 1912 was graduablul. ISec ('al. 11.)

Cal. 2. -University of Caliteraia. Medical Depariment, Iterkeles, I.os Anvoles and sian feoariment, herkeles, 208 Angoles and San cal collece Firat class graduated in lvos. and a class graduated each subseduent year. and a class rralduated each subseduent jear. in lit: becamo Medical liepartment. Cm.

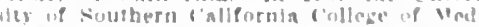
clae merzed as the lon Angeles Medical fropartmone The nret iwo vears work gelven at lierkeley The last two prark wrork can in taken plther at sin franciso Moni, Sam Framolseo. Total Pegletrablul Pur 191:-13, 104: Leaduatea. The 1.4

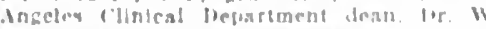
Jarria liarlew. Total reidatratuon lor 1919 13. : : cracluatea, I

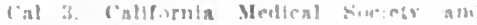

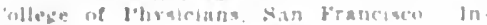

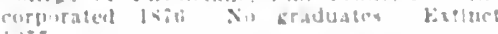

Cal. 4.-Califoenia Eclectic Medical Col

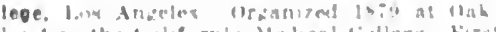

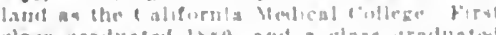

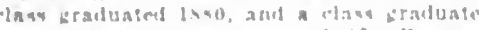

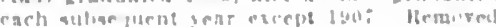

to San Francisco in 15Si, Suspended In 1906. Reorganized at Los sngeles in 1907 with present title. The dean is Dr. J. A Mlunk, S21 Securlis Bldg. Toial remlstration for 1912-13, ะ0; graduates, 4 .

Cal. 5.-Hahnemann Medical College of the Paciffe, San Franclsco. Homeopatble urganlzed issi as Habnemann Medical Col. lege. First class graduated 1884, and a class araduated each subseyuent gear. Name changed in 1388 to llahnemann liospltal College of San Francisco. In 190: assuraed present name. The dean ls lir. James W IVard, 391 sutter sit. San Francisco. Total recistration for $1912-13,35$; graduaies. Le.

('al. 6. - l'ntrersity of Southern callomla. college of Medicine. Las Angeies bounded 1455. First class graduated In 14,8s, and ciass graduated each subseguent gear. Farly In 1909 it merged with the l'nirersity of
califurnia as bie Los Angeles Medieal doepartment.

Cal. 7.-College of Physicians and Sur.

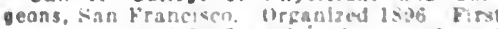
clabs graduated $15 \%$. and in class kraduated

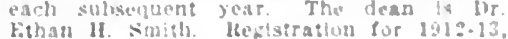
10: graduaser, 3

Cal. 8.-Oakland Colfege of Medicine and Surgeey, llahlami (1romired bout openet

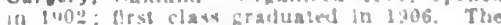
regleirar is lit. Holward $x$ buer Total

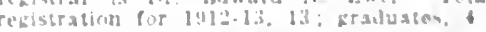

Cal. 9.-Callege of Physicians and Sur.

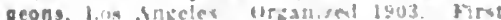
class opaduated byis. In lyos at berame the

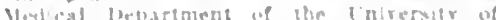

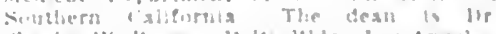

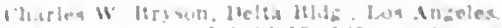

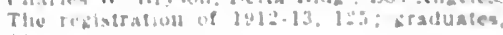

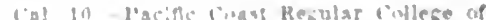

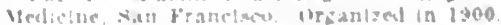

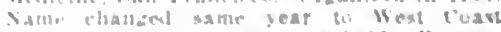

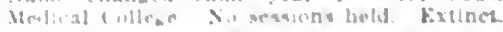
Cal. M1, - Leland Stanford Junier Uaiver. sity, Department of Medicias, J'slus Allo and

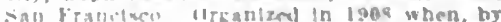

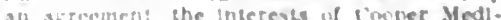

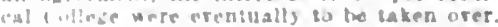
The lasier constuvel beching untll 191:. The dean is lor li l. Wubur. Sacramento alui Whlower siss. San liranclseo. Total

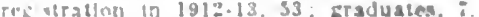

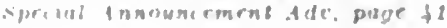


Cal. 12.-College of Medical Evangelists, Loma I.nda. Organlzed 1909. Gives a flve-sear eourse including theological work. Total reglstratlon for 1912-13, 62; no uraduates.

\section{COLORADO}

Colo. 1-Denver College of Mediche. Organized 1881. First elass graduated 1s82, and a class graduated each sulsenuent year college to form the benrer and (iross (ollege of Medicina.

Colo. 2.-University of Colorado Sehool of Medicine (Colorado scliool of Medicine). Boulder and benver. opened 1883 . First
class graduated 18s5, and a elass gratuated each subsequent year except 1898-9. on Jan. 1, 1911, through the umlon with the lenver and Gross college of Mtedleine, provlslon was made for conducting the two clincal years of the conrse in terter. tration for 1912-13, 90; graduates, 50 .

Colo 3-Gross ifedical college, Dencer Organlzed in 18,8 as Nedleal Department Rocky Mountain Cniversity; a elass graduated 1888, and each subsequent year until 1902. When it consolldated with the Denver College of Medicine, to

(olo. 4.- Denser College of Physlelans and surreous, Denver organized 1894 as the Denver Ilomeopathic College. Flrst class traduated 1895 , and a class graduated each subsequent year. In 1907 it became nonsectarlan as the Westminster University College of Medicine. Took present name in 1908 . Extinet in 1909.

Colo. 5.-Denrer and Gross College of Medicine, Medieal Department, Enirersity of Denver. Formed ln 1902 by unfon of (iross Medienl College with the Denrer College of Medlelne. First class graduated 1903. On of Colorado, Scliool of Medieine.

\section{CONNECTICUT}

Conn. 1.- Yale University Medical Department (Yale yedical School) New Haren, charterel In 1810, organlzed 1813, as Mledieal Institution of Yale College. First class graduated 1814, and a class graduated eaeh subsequent year. In 1879 a new charter changed Its name to the Medical Departbecame Yale Unirersity. In I884 the Connecticut ledical Society surrendered its authority to the University. The dean is 1). Georte Blumer, New IIaven. The total reglstration for 1912-13, was 42; graduates, 9.

\section{DISTRICT OF COLUMBIA}

D. C. -George Washington University, Department of Medicine. Organized 1825 as the Mledical Department of Columbian College, it was also subsequently authorized to use the name National Mledical College. First class graduated 1826, and classes graduated all subsequent rears except 1834-38 and 1861-63. It absorbed the vational and 1861-63. It absorbed the National $1904, b y$ an act of Congress, it became the Department of Mledicine of George Washington University. The dean is Dr. William C. Borden. The total registration of student for the session of $1912-13$ was 103 ; graduates, 11

Ner Apcral Announcement Adr. page 41 Medicine, Waslington. Organized 1851 First class graduated 1852, and a class graduated each subsequent year. The dean is Dr. Ceorge M. Kober, 1600 Tha registration for 1912-13 was 126; graduates,

Sief sperial Announcement Adv. page 41 D. C. 3.-Howard University School of Organized in 1869 . Chartered in 18aduated 1871 , and a class graduated each subsecuent year. Colored students compose a majority of those in attendanee. The dean is Dr. Edward A. Balloeh. Registration for 1912-13 was 122; graduates, 21 . See sinccial Annuncement Adr. page 40
D. C. 4. Natlonal Unlversity Mledical Department, Washington. Orkanlzed 1884, first class fraduated I885, and a class graduated cach subsequent year. Merged Into the in 1903 .

11. C. 5.-Washington Homeopathie Medlcal College. Orianlyed 1893 as the National IIomeopathic Medical college. F'irst class iraduated 1894 and classes graduated all sraduated 1894 and classes graduated all title. Last class, numberimg 10 students. title. Latst class, mimberimg 10 stidents,

\section{FLORIDA}

Fla. 1.-Tallahassee College of Medlelne and Surgers, Medical lepartment of the l'nlversity of Florida. Organlyed at Talla-
hassee 1883, removed to Jacksonville 1885. hinsee 1883 ,

\section{GEORGIA}

Ga. I.-University of Geargia. College of Medicine, Augusta. Medical Academy of Georgia, organized 1828, present title in 18:9. First class graduated in 1833, suspended 1861-65. Became integral part of the Unlversity of (ieorgia in 1911. The dean is lor. William Il. Doughty. Total enGa. 2.-Southern Botanieo-Medical College. Chartered 1839. First located at elass graduated 1841. A class graduated each year until 1854. Name then changed each year until 1854. Name then changed to Reform tasses graduated to 1861 . Suspended durin Clvil War. Resumed 1867. Classes graduated 1868 to 1874 , when name of college of American lledieine and surgery was assumed. No classes graduated 1877 to 1881. Removed to Atlanta in 1881. In lege of Eclectic Nedicine and Surgery.

Ga. 3.-Thompsonian College, Barbourille. Organized 1850. Extinet.

Ga. 4.-Sarannah Medical College. Inamended 1857, suspended 1861-66.' Extincr 1880.

Ga. 5.-Atlanta Medical College, Atlanta. Organized 1855 . Classes graduated 1855 to 1861, inclusive. Suspended 1861. Reorganized 1865. United with Southern Medi. cal College I898 to form Atlanta College of
Physicians and Surgeons. In 1913 the AtPhysicians and Surgeons. In 1913 the At-
lanta College of Physicians and Surgeons merged with the Atlanta school of lledicine, reassuming the present name. The dean is two colleges in $1912-13$ was 560 ; graduates, 121.

special dmouncement tro page 4 Ga. 6. - Oglethorpe MIedical College,
rannah. Organized 1856. Extinct 1861.

Ga. 9.-Geargia College of Eelectic Medi. cine and Surgery, Atlanta. Organized 1877 as Geortia Eclectic Medical College. Acquired charter College of Ameriean Medicine and Surgery 1884. Assumed present name 1886. First elass 1878, and a class each B. Thomas. Total registration for 1912-13 was $70 ;$ graduates, 42 .

Ga. 10.-Southern MLedical College, Atlanta. organized 1878. First class graduated 1880 , and a class graduated each year until 1898, when it united with Atlanta Physieians and Surgeons.

(ra. 11.-Atlanta College of Physicians and Surgeons. Formed in 1898 by union of Atlanta Medical College and Southern Nedieal College. In 1913 merged with the
Atlanta Scliool of Iedicine to form the Atlanta Medical College.

Ga. 12.-Atlanta School of Medicine. Orcanized 1905. First class graduated 1906. In 1913 it merged with the Atlanta College of Physicians and Surgeons under the name of Atlanta Medical College.

Ga. 13.-Middle Georgia NIedical College, Griffin.

Ga. 14.-Dalton Medical College, Dalton. Incorporated Narch 2, 1866. Extinct.

Ga. 15.-Clark Unirersity, Medical Department, Atlanta. Chartered in 1886. No graduates. Extinct.
Ga. 16. - Woman's Medlcal College of Georgla and Training School for Nurses Atlanta. Organlzed In 1889 and graduated a class the following year. In 1890-91 graduated seven out of ten matriculants. Extinet.

Ga. 17.-Internatlonal Medlcal Mlsslonary College and Tralning School for viurses, At lantil. Organized in 1904. Classes were graduated in 1906, 1907 and 1908, when it suspended.

Ga. 18.-Ilospital Medical College, Eelecgraduated in 1909 . In 1911 it became extlnct.

Ga. 19.-Southern College of Medicine and Surgery, Atlanta. Organized 1911. The dean is Dr. W' Bernard Lingo. Total regls-
tratlon for 19i2-13 w'as 53; graduates. 15 .

\section{ILLINOIS}

III. I.-Rush Medical College, Chicago. graduated 1844, organized 1843, first class subsequcint year. Became iledical Department lake Forest Universlty 1887. Affiliated with University of Chicago 1898. The dean is Dr. John N. Dodson, 34 Washington dean is Dr. John N. Dodson, 34 Washington
st. Total registration. 1912-13 was 422, graduates, $\$ \overline{0}$.

sec specill Annourcement Adv. page 42

III. 2.-NIedical Department of Illinols College, Jacksonvllle. Organized 1843. Suspended 1848. llad 37 graduates.

III. 3.-Medical Department of the University of st. Charles, St. Charles. Orcanized 1844. Extinct in 1845.

III. 4.- Hahnemann Medical College and Homeopathic. Orand a class graduated each subsequent year. In 1904 this college absorbed the Chicago Homeopathic Medical College. The registrar Homeopathic Nedical College. The registrar
ls Ipr. W. Henry Wilson. Total reglstration, $1912-13$ was 66 ; graduates, 31 .

IIl. 5.-College of NIedicine and Surgery (1hysiomedical). Organized in 1885 as the chicago Physionedical Institute. The first class graduated in 1886. In 1891 the name was changed to the Chlcago Physiomedical College. IIedical) (IIl, 20), and assunzed the above title. In 1911 it was absorbed by the Chicago College of Medicine and Surgery. (III. 22.)

III. 6.- Northwestern University Medical Sehool. Organized 1859 as Medical Department lind University. First class graduated 1860 and a elass graduated each subsequent
year. In 1864 became Chicago Medical College. In 1905 it became an integral part of Norhwestern University, with which it had been affllated since, 1869. Present had been afflilited since 1869 . Present Edwards. The total registration for 191213 was 196 ; graduates, 56 .

See special Announcement Adv. page 41

III. 7.-Edinburg University. Ineorporated 1862 as the Chicago Northwestern College, became Edinburg University 1870. Fraudulent. Extinct.

III. 8.-Bennett Medical College, Chicago. Organized 1868 as the Bennett College of dropped and present title assumed in 1909 dropped and present title assumed in 1909. Absorbed the Illinois Medical College in 1910 and became by affiliation the Medical
Department of Loyola Unlversity. First class graduated in 1870, and a class each subsequent year. The dean is Dr. Naxiwas 395 ; graduates, 43.

111. 9.-Northwestern Unlversity Woman's vedical School, Chicago. Organlzed 1870 as Woman's Hospital Medical College. The word "Hospital" was dropped from the title in 1879. First class 18i1, a class graduated each year except 1872 . Became W'oman's Medical School of Northwestern 1902 when the college became extinct.

III. 10.--Chicago Homeopathic Medical College. Organized 1876 , first class graduated $18 ; 7$, and a class graduated each subsequent year, including 1904 when it merged with Hahnemann Medical College. 
III. II.-University of IIIInois Coltege of Medicine. Chicago. Organlzed Isxa as the Collece of Phyalcians and Surgeons. First class sraduated 1853 , and a clas. graduated class graduated 1553, and a clasi graduated
each subseyuent year. Itecame yedical each subseyuent year. Itecame Hedica Department of the Cnlrersity of Illinoly by 1910. The relationshis was canceled in June. 1918. but restored in March. 1913. The Amerlean Medica! Mlssiouary College was absorbed in 1910 . Cnirersity assumed was assumed. The dean is Ds. William $\mathbf{E}$. quine. Total reglstration for 1912.13 was 533 : eraduates, 133.

see spertal Annownement tele. puge $s s$ III. 12.-Chaddock Schnol of Mediclne. Qulney. Organlzed 1882, as the Quincy Collese of Medlcine, reorkanized 183s, taklng the atove sitle. First class graduated In 1883, and a class graduated each subsequent year. Including 1890 , when it became extinct III. 13.-Harvey Medical College, Chlcaro. Organlzed 1891. Arst class graduated 1893 . and a class graduated each subsequent y ear. Including 1905 , whe

III. If.-Dational Medical Lnirersity, chlcago. Incorporated Aug. 22. 1891, as the Cago. Incorporated Aug. 22. 1891, as the Dropped the word "Homeopathlc" in 1895 and in 1900 tonk the present title. First class graduated 1892 and a class graduated each subsequent year. Deelared not In food standing by the llil

IIl. 15.-lferlng Medical Colleze, chicazo. Homeopathic. Organlzed 1892. first class graduated 1893. and a elass graduated each subsequent year. In 1902 absorbed Dunlam Medical College. Closed in 1913.

III. 16.- Jenner Medieal College. Chicazo. Organlzed 1892, flrst class craduated 1596 . and a class graduated each subsequent year. enrolnent tor 1912-13 was 191; graduates, 11.

III. 1:--lllnols Medleal College, Chleago. Organlzed 1894. first class graduated 1895 , and a class graduated each subsequent year, Includlnz 1910 , when it

III. 18.-Dunham Medical College, chlcazo. Orfanlzed 1895, first class graduated 1896. a class graduated each year, inclualed 1902, when it merged wlth the Herlng Medical College.

III. 19. - American Medical Missionary Collece. Chlcago. Orcanlzed 1895. first class carried on at Battle Creek. Mich clinleal studles In Clilcago. The last class graduated in 1910, when it was ahsorhed by the College of phralcians anil surgeons. IIl. 20.-Chlengo College of Medieine and Surgers, Physio-Medical. orrandzed 1897. no classes graduated. In 1890 if merged with the Chicazo Pbyslo-Medical College to Porm the Colleze of Medlcine and Surgery,
Physlo-Medical.

III. 21.-Independent Medical College, Chl. cago. "Wlploma mill." charter revuked $15: 4$.
fraudulent raudulent

III. 22. - Chicage College of Medicine and Surpary. (Chleago. Graanlzed in 1901 as the Chlcago biclertlc Medlcal Conlege. in 1402 became the Amerlcan tinlece of Nellicine and Surgers. In 1902 it pecame the VMdica] Department of Valparaion Iniversity. Dropped eclectlclsm in 1905. Assumed pres: ens title in 190\%. Alnortied the cullere of Medlelne and surgery, l'hylomedleal, in 1911. Flrat clam graduated 1903. and a dean is Jir. W. J. Hutler Tho total regis. tration for 1912-13 was b12: graduaten is. (Do not confise wlth I1! 5,

III. 23.-lleartmen Melleal Inllowe. Ahlcago. orzanlzed loni. Prst clars gradustol 1901. a class graduater each sutwosiluent III. 24.-College fif lihyslcians and sur. ceots of the Ipper Mlss]sslpot, Itock Is]aut Organlzed in Ixis. Firat clases graduaseit in 1849, when it was romoriol so tiecikuk

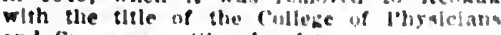
and surgeons. (see la. 1.)
III. 95.-Northwesturn College of Mid. wlers, chicagn, nreanlacel in is: Fraudulent. Itemelind to Inalianabulis in lois and lecatne ll, lneflana $t$ llege of vedlcine and llidwifery Kagines lave. (see Ind. 24

111. 26-Chlengro rollege of scuncee or

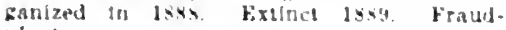
ulent.

11]. 27-Naflonal luivarsty of lll!nols, Chlcago. irganlzed 158?. Extuct 19y0. Fraudulent.

111. 2s.-Cerman college of Mevlteine and 1syl by Johann lialok. Chartered feb. 19. tlnet.

111. 29.-Cerman IIoneopathlc Vedical College, Chicagn. Chartered Dec. 3, 1s91. by Johann Nalok. Fraudulent. Fixtinct. Chartered pec. 28. 1891, by Jnhinn Malik. Fraudulent. Extinct.

111. 31.-German Academy of Ilisviatrlc Physlclans. Chicago. Chartered in is 92 by Johann Malok. Fraudulent. Extinct.

111. 32.-German - Imerican Ilomeopathic Medical College, Chleago. Chartered in tinet.

III. 33.-German College of Gynecology. Pedlatrics and obstetrics. Chicago. Char-
tered in 1592 by Johann lialok. Fraudtered in 1592
ulent. Exitnct.

II1. 31-International Medical Misslunary Institute. Chlcago. Organized about 1895 Extinet.

111. 35.-Illinols Health Lnirersly, Chlcago. Organized by “J. Armstrong, M.D. Presiden" et al. Charter resoked Al,ril 3 . $189 \%$ Fraudulent. Succerled by the Inde-
pentent Medical college and the Metropolitan Medieal College. (See 111. 21 and 11. $3 \%$

III. 36.-Illinois Standard College of MedIcine and surgery, Chleago. Fxisted about 598. Extinet.

111. 37.-Metrnpolitan Medleal College, Chlcago. Organized in 1899 by" "J. Armstrong, M.D. Prealdens." es al. Closed by
injunction 1900. F.xtlnct. (see Fraudulen College llst.)

111. 38.-Duton Medical Colleze, Chicaro Operated about 1903. Fraudulent. Frtinct.

III. 39.-Reliance Medleal College. Chi cago. A night school orzanized in $190^{\circ}$ First class graduated 1909. Last clas pravluated in 1911. When it became extinct. III. 40.-sicientific Medlcal Collece, Chi. the Metropolitan Medlcal (ollege contucted by "J. Armutrong. M.ll." et al. Fraudulent. Closed by nostal autherltite In 1900.

III. 11.-Lombarl College Medical pepartment, Cialesburg. Organized in 1903, held one sesslon when 20 students were enrolled. Gare only unc leas of the Nenleal colirse.
III. 42.-Chicago Hospital College of Med. leine. ilicago. "irginlzel in 1911 . char.

\section{INDIANA}

Ind 1.--Indiana Med:ral Vislleze, Jat porte. Organled lRAt as the Medical be partment of la lopte lolretaity taking

Ind. 2-Modieal cullege of Eranurille Granlzed 1st!. Arst clave gruluated 18.00 clarves haduated to lsit: suspembled lsit

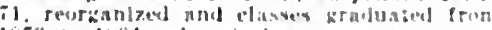
is is to 1381. When it lieesmo eximet.

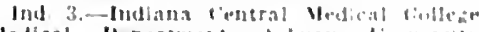
Medienl leparomest Arbury luversits lud 4.- Indiana Medical collowe loudian

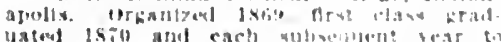

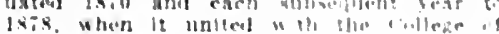

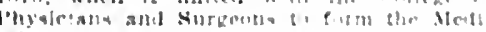
al tinlene of Intlatia

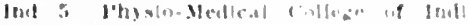

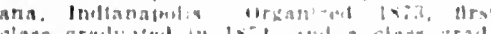

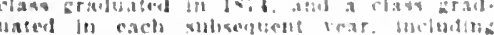
1:00\%, when 19 becatie entmet

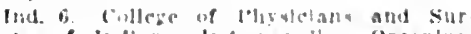

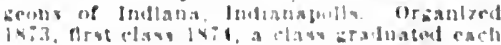

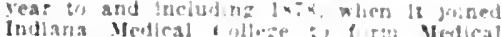
colleto of |ullana

Jus : Wedteal rellowe of Fine Wayne

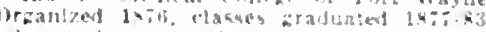
when th the ame extlont.

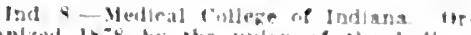

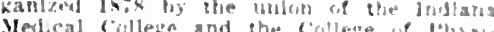
clans and supiceons of Induana bis: claws aradiated ixag class each submeruent yeas

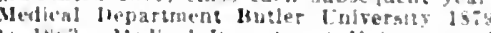

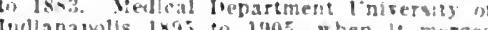
lutlanapolls $1 \times 45$ b 1905 , when it merged with celutral colleze of I'hyslcians and sur. Geons and Firt Wayne College of Mediclne Verlleine of linrdue L'nlsersity.

Ind a. Central rollege of Inyslelans and surfents, Indlanapolis. Organlzed lyis. flrst class graduated 1890 , and a class zrad. uated cach sufsequent year. In 1905 merzed with Fort Wayne tolleze of Medicine and Medical follege of Indiana in form Indlans lledlcal tollege. School of Medicine b'urdue nirersity.

Ind. 10-Fort Wayne Colleze of Medlclne. bort Wayne. Organlzed 1579, first class
graduated 1580 . class gradualed each subsequent year. except 1839 . In $190 \mathrm{~J}$ merzed with Medical College of Indiana and Centra College of Physlcians and Surgeons to form Indlana Medleal College. Sehool of Mediclne of Purdue l'nirersits.

Ind. 11.-Indlana Eclectic Medical Cullege, Intianapnlis. Organlzed 1980 ab-
sorbed Heach Medical Institute in 1956. sorbed liesch
c'losed 1890.

Ind. 12-Curbls J'hysto-Medlcal Institute. Marion. Granized 1581: extinct 1590.

Ind. 13.-1lospital Medical Colleze nf Eransrille. Ortanized las2. trs: class 1853 , extinet $18 x 6$

Ind. 15.- Meach Medical Institute. Indlanapolis. Organized In 1853 as the Beach Vtedlcal tollege. Took present name in 1854. Merged with lndiana Eclectlc Medi-

Ind 16.-Edelecte College of Physicians and surpeons. Indianapolis. Oranlzed 1591). Hrst class graduated 15.1 and a class grad: uated each subser.

Ind. 17.- Folectic Medical Iulleze of Indiand, Indlanapolis. Thls schoul was or. fanized In 19(1). Fisit class graduated 1903. A class araduated each subseluent
year, Including logs. when it suspended. owing it recoguitlin having been wlthdrawn by the Indlana state Roant of Medlcal Fixaminers.

Ind Is- Indiana liedical snlleze. Sch(m)

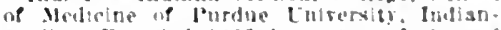
apolla. Foundel 190: by unlen of [entral follege of lingletans and surgoons. Fors

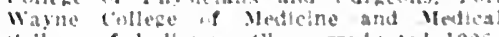
follebe of Indlana ilaxs grobuated 1906. lini, In lons it merged lnto the lndisnd loniserity sithol of Medlethe

Ind. 1:t - Inicrian Vibleal colloge. In

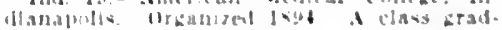

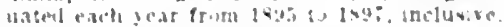

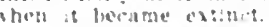

Ind 20.-Indiana University Schoot of Medicine. Mramazed in $14: 0.3$. but diel nut

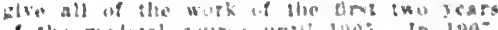

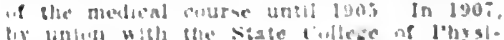

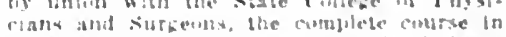

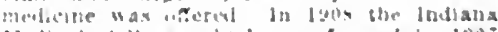
verlleal cullece. Which nat formel in 120 : liy the meter of the Ilnfieal college of

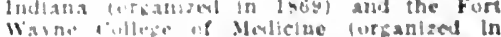
(aia) morbicl lnto de. Two years of colleglo

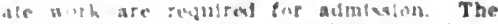
work ef the Hrat year la emphasted nuly at Hownlugton. The work of the obliet three "uns is all at lndlanapults. A nith op: has lieen aldeal. The sectetary at Hloom. Imathin is Iir Is. I) Myers: the dean is lir. "harles 1". Eomerson. Indianamolls The araduaies, ti.

ser apreal Ingownerment Idr. moe $\$ 2$ 
1ud. 21.-State College of Physleians and surgeons. Indianapolis, in aftilation with the Indlina Unlversity. Was organized in the spring of 1906 . Graduated one class in cersity School of Medleine.

Ind. 23.-University of Indiana, New Albany. Organized in 1833. Fraudulent. Extinct.

Ind. 24.-Indiana College of Medlelne and Midwifery, Indianapolis. (hartered in $18 \mathrm{~s}$ by one charles 1'. Hell. Fxtinct about 1888.

Ind. 25.-Undversity of lndianapolis. Indianapolls. Diplomas appeared in Euglatud dated 1891. Fraudulent. Nim-existent.

Iud a-Curtis l'hysto-lledical College, Indianapolis. Organized 1893 . Fxtinct 1895.

Inil. 27 --University of Medicine. Indlanapolis. Organlzed 1897. First class graduated fu 1598. No evidence of othic "dasses. Extinct.

\section{IOWA}

Iowa 1,-College of Ihysicans and sur reons, keokuk. Orsanized at llock Island in I848 as Medical Department of the Uniersity of the [vper Mississippi. In 1849 mored to Keokuk as College of Physiclans and Surgeons. First class at Rock Island 1849, next class at Keokuk 1850. A class graduated each subsequent year and untll and including 1899 . In 1854 became Medical Department Inlrersity of Iowa. In 1870 resumed name of College of Physicians and Surgeons. In 1899 merged with Keokuk Iedical Coljege to form Keokuk Medical college, College of 1'hysicians and Surgeons.

Iowa 2.-Iowa Medical College, Keokuk. Organized 1858. Extinct 1860 .

lowa 3.-State University of lowa College of Medicine Iow City Organized 1869 flrst class graduated $18 \% \mathrm{i}$, and a class gradwated each subsequent year. ln $1913 \mathrm{ab}$ sorbed Drake University, College of Medicine. The dean is Dr. James R. Guthrie, Dubuque. Total registration for 1912-13 vas 99 ; graduates, 16 .

lowa 4--State University of lowa College of Homeopathic Medicine, Iowa City. Organized 1877, first class gracluated 1878 and a class graduated each subsequent year. The dean is Dr. George Royal, Des Moines. Tolal registration for 1912-13 was 13 ; graduates, 6 .

Iowa 6.-Drake University College of Medicine, Des Moines. Organized in 188 as the Iow a Eclectic Medical College, Medical Department of Drake Unirersity. In 1883 the name was changed to the Iowa Medical College, Eclectic. In 1887 it re sumed its former name and merged into the sumed ts former name and merged suto the In 1903 it again became the Medical Department of Drake University with its present title. The first class graduated in $\mathbf{1 8 8 2}$ and a class graduated each subsequent year. Absorbed the Keokuk Medical College, College of Physicians and Surgeons in 1908 . In 1913 merged with the State University of Iowa, College of Medicine.

lowa $7 .-K i n g$ Eclectic Medical College, Des Moines. Organized 1883, flrst clas graduated 1884. Extinct about 1889

lowa 8.-Sioux City College of Medicine. Organized 1890, first class graduated 1893, a class graduated each subsequent year, including 1909 , when it became extinct.

Iowa 9.-Keokuk Nedical College. Organized 1890, first class 1891, classes graduated each year, including 1899 , when it merged with College of Physicians and Surgeons to form Keokuk Medical College, College of liysicians and Surgeons.

Iowa 10,-Keokuk Medical College, College of Physicians and Surgeons. Formed 189 by union of Keokuk Iledical College and the collece of Physicians and Surgeons, Keokuk. First class graduated 1900 , a class graduated it was absorbed by Drake Lniversity College Medicine at Des Moines.

Iowa 11.-Council Rluffs Medical College Council Blufts. Organized 1S93. Extinct 1895. No graduates.

\section{KANSAS}

Kin. 1.- Kinsas Medical College, Independence, Organized 1872, graduated two asses. Exunct 18\%.

Kan. 2.-University of Kansas School of Medicine, Lawrence and Kiansas City. OrGanzed 1880, preparatory course until 1905. when the Kansas City Medical College, the cofiege of Physiclans and surgeons and the velleo-fhirurgical college were absorbed. First class graduated 1906 . In 1913 absorbed the Kansas Nedical College The dean of the sclentlfic department at lawrence is Or. Mervin T. Sudler, The dean of the clinical department at liansas City is lor. Samuel J. Crumbine. The numtifi: graduates.

Kan. 3-Kansas Medical College, Topeka. Orumized 1890, first class graduated 1892, and class graduated each subsequent year, except 1!01, when a four years" course was
begun. In 1903 it became Medjcal Depart megun. In 1903 it became Iredical Depart with the Unirersity of Kansas, School of Iedicine.

Kan. 4.-College of Physlelans and Surgeons, vedical Department Kansas City University, Kansas City. Organlzed 1894, first class grarluated 18.95 , class graduated each class graduated 18.5 , class graduated each was absorbed by the University of liansas School of Medicine.

Kan. 5.-Wichita Medical College, Wichita. Organized in 1889. Suspended after one session. No graduates.

Kan. 6.- Kansas City College of Medicine and Surgery, Kansas City. Organized 1897. A class graduated 1898 when it mored to Kansas City, Mo., and became tho Medico-Chirurgical College. (See Mo. 32.) Kan. T-Eelectic Medical University, Kansas City. Organized in 1898 in Kansas City, No., first class graduated in 1900 . Removed to Kansas City, Kan., in 1907. In 1908 assumed the name Western Eclectlc to Kansas City, Mo., in 1909 and resumed its first title. (See iIo. 33.)

\section{KENTUCKY}

Ky. 1.- Kentucky School of Medicine, Louisville, Organized ISI 7 at Lexington as Medical Department Transylvania University, first class graduated 1817 , and classes graduated each subsequent year until after vedicine. Succeeded in 1850 by Kentucky School of Medicine of Louisville, first class graduated in 18.5 and a class graduated each subsequent year, including 1908 , when each subsequent year, including 1908, when the Unlversity of Louisville.

Ky. 2.-University of Louisville, Medical Department. Organized 1837 as Louisville Medical Institute, first class graduated 1838 and classes graduated each subsequent year except 1863, became Nedical Department
Iniversity of Louisville in 1846. In 1907 the Kentucky University Medical Departthe Kentucky University Medical Depart-
ment and in 1908 the Kentucky School of ment and in 1908 the Kentucky School of IIedicine and the Louisville and Hospital is Dr. W. Edward Grant. Total registration for 1912-13 was 255; graduates, 77 .

ser sperial thnonncement Alv. page 42

Ky. 3.-Eclectic Medical College, Loulsville. Chartered 1848. Extinct.

Ky. 4.-Louisville Medical College, Loulsville. Organized 1869, first class graduated 1870 and a elass gracluated each subsequent year, including $190 \pi$, when it merged with the IIospital ('ollege of Iedicine, forming the Louisville and Hospital Medical College. Ky. 5.-Hospital College of Medicine, Nedical Department Central University of Kentucky, Louisrille. Organized 18:4, first class graduated 1875, and a class graduated each subsequent year, including $190 \pi$, when it merged with the Louisville Iredical ColIfedical College.

Ky. 6.-Jefferson School of Medicine. Iouisville. Organized $188^{2}$, graduated one class and suspended.

Ky. 7.-Louisville National Medical College Medical Department State University, Louisville. Colored. Organized 1888 , flrst
class graduated 1889 . Iast class graduated in 1912. Extinct. liy. 8.-Southwestern IIomeopathlc Medical College and liospital, Louisville. organlzed 1892, first class gruduated 1894, and a class graduated cach subsequent year, including 1910 , when it became extlnct.

Ky. 9,-Kentucky Cnulversity Medical Department, Loulsvilie. Organized 1898, first class graduated $18 ! 9$, and a class graduated each subsequent year, flicluding 1906 . It merged into the Medical Departn

Eniversity of Louisville in 1907 .

liy. 10.-Medical Department, State Lniversity (Colored), toulsvile. Organized in 1899. In 1903 it merged with the Loulsville Cational Medical College.

Ky. 11.-Ioulsville and IIospital Medical college, Louisville. Organized In 1907 by the union of the I,ouisville Medical College and the IIospital College of Medicine. A class graduated in 1908, when this college inerged into the Medical Department of the Iniversity of Loulsville.

\section{LOUISIANA}

La. 1.-Tulane University of Louisiana, School of Medicine, New orleans. Organ ized in 1834 as Medical College of Louisiana, first class graduated 1835 , and a class graduated eacli subsequent year except 1863-65. Transferred to Medical Department University of Louisiana 1847, became Medical Pepartment of the Tulane University 1884 The dean is Dr. Isadore Dyer. The registr thon for $1912-13$ was 296 ; graduates, 69 .

La. 2.-New Orleans School of Medicine. Organized 1856. Extinct 1870.

La. 3.-Charlty IIospital Medical College New orleans. Organized 1873. Extinct

La. 4.-Flint Medical College of New Or leans University (Colored), New Orleans. Organized 1889 as the Medical College of New Orleans University. First class gradsubsequent year except 1896 and 1911 . Nanie changed to the above in 1901. Suspended in 1911 .

\section{MAINE}

Me. 1.-Medical School of Maine, Medical Department of Bowdoin College, Brunswick, Organized 1820, first class graduated 1821 and a class gradualed each subsequent year. The dean is Dr. Addlson S. Thayer, Portgraduates, 13.

Ie. 2.-Eclectic Medical College of Maine, Lewiston. Incorporated 1880 , charter re voked by State Legislature in $188 \%$.

Me. 3.-Druldic University of Maine, Lewiston. Incorporated 1880, char

Me 4.-Portland School for Medical Instruction, Portland. A preparatory schoo only. Organized 1856, chartered 1858. Ex tinct 1902. Did not grant degrees.

\section{MARYLAND}

Md. I.-University of Maryland, School of Medicine, Baltimore. Organized 1807 as the College of Medicine of Maryland, first class graduated 1810, and classes graduated each subsequent rear. In 1812 became Unlversity of Maryland School of Mediclne. The dean is Dr. R. Dorsey Coale, Baltimore. The total number of students registered in $1912-13$ was 293 ; graduates, 49.

Md. 2.-Washington University School of Medlcine, Baltimore. Organized 1827 as Medical Department Washington College, Washington, Pa. First class graduated 1828 , and a class graduated each subsequent year. In 1840 the above title was assumed. In 1851 hecame extinct. Reorganized in $186 \%$; in $18 ; 7$ merged with college of Physicians and surgeons of Baltimore.

Md. 3.-College of Physicians and Surgeons, Baltimore. Organized 1872, first clas. praduated 1873 , and a class graduated each subsequent year. In $187 \vec{i}$ absorbed Washington Lniversity School of Medicine. The dean is Dr. Chas. F. Beran. The total registra tion in 1912-13 was 234 ; graduates, 60 .

IId. 4.-Baltimore Iredical College. Or ganized 1881, first class graduated 1882, and 1913 it merged with the Lniversity of IIary1913 it merged with the
land, School of Nedicine. 
Md.5. - Woman's Medlcal college uf Italti. more. Organlzed 1882, drst class graduated 1883 , and a class graduafed each subsequent year, excepting is98, Including 1910, when the college became extinct.

IId. 6.- Baltimore InIrerslty sch(m) of Medlcine. trganlzed ISS4, flrst class gralu. ated 1885 , and a class graduated each subated 1885, and a class graduated each subsequent year

Md. 7.- Johns Hopkins University Medical Department. IBaltJnore. Oráanized ISs:. preliminary course only until 1s9.?, first class graduated 1897 , and a class graduated each subserguent year. The dean is lir. J. Whltridge Willams. Total reglstration In $1912-13$ was 351 : craduates, 76 .

see sipecial Announcement Adr. page \&z Md. 8.-Allantic Medical College. Halt. more. Organlzed is90, as the southern graduated IS92, and a class kraduated eacli subsequent year. Including 1910, when is tecame extunct.

Md. 9.-Maryland Medical College, Baltimore Organized 1898 , thrst class graduated 1899, and classes gradiated each subsequext year. Fixtlnet in 1913

Md. 10.-Medlco-Chirurkical and TheologIcal Cullege of Chrlst's Institution, Balt. more. (Colored.) Chartered in 1900 by six negroes, only one of whom had an II.I. degree, source of this being unknown. Ii graduates hare applled for license in any state since 1902.

Md. 11.-Eastern Univeroity School of Medicine, Baltimore. Wrganlzel In 191" as the Eclectlc School of Ilediclue of Milton Enlretsity, but later took the abore tlite. Its dean is reported as not licensed in Mary. land, having falled to pass the llcense examInation. This college is offelally reported as not recogulzed by the Maryland State Buard of Medical Fxaniners.

\section{MASSACHUSETTS}

Mass. 1.-Harvard University Medical . Orkanlzed 1782, first class graduated 178s, and a class graduated eacls kubsequent year. The dean is Mr. Edward H. Bradford. The total registration for $1912-13$ was 285; graduates, 60 .

Sire sproinl Announcement Alr. page 40

Mass. 2.-Berkshire Medlcal College, Pittsfeld. Orkantzed in 1823 as Medical lepartment Whllams College. Viraduated 1,138 students. Extinct 1867 .

Mass. 3.-New Englanil Female Medlcal cullege, Boston. Ifomeopathic. Organlzed 1848. In 1874 merged with Boston Unirer aity School of Medicine.

Mass. 4-Worcester Iredical (ollege, Hclectlc. Organized 1848 as New England Hotanlco-Medical College, reormanlzed 1852 as Worcester Medical Crillege, Fclectlc. Mored to Bnston 185i, to Worcester 1858 Fixtlnct 1859 .

Mass. 5.-Boston University School of Medicine. Joston. Homeopathic Stroulyed 18:3. In 18:4 New kingland Female Jedical College was merged Into lt. p'yst class craduated 1874, and a class graduated eaclı subsequent year. The dean is br. John ''. Sutherland. Total reklstration for 1412.13 was 48 : graduates, 11.

Mass. 6.-College of Physicians and Surgeons. IBoston. Organized 1880. Frovt class graduated J8R2, and a class graduated wabh subsequent year. The dean is Ir. Thoma 1). Crothers. Total students pecistered 191:

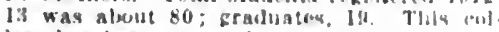
lege has deen reported not recngufsed by the "lassachurets Medleal Siclets

Mass. 7.-Tufts College Medical Sehool.

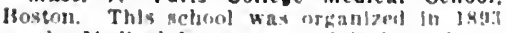
an the Melleal Jepartment of Tufty follege Iir. Fecleric M. Nrlgos la verretary. Total reglatration for lal: I.3 was it:; gradu. ates, 8.5 .

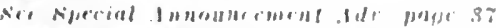

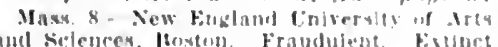

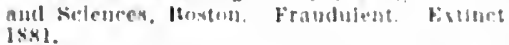

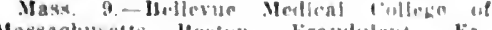
Mnssachus
Mass. 10--Medical lepartment of the American lenfuerslty of Itoston. Ifoston. Fix. inet iss:

Masq. 11-First Mediral collene of the Amer

Jass, 12.-Fiscelsjor Medical coliene, Hus

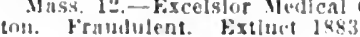

INas. 13. - lleserved (whllege of I'h) ricians and surgeons, springfleld. Frandulent. rix thet 1503

Mass. 14.- thark Lnirersity Medical lleDid not grant degrees. Fixtinct.

\section{MICHIGAN}

Mich. I.-University of Michigan Deoart ment of Medicine and Surgery. Dun Mrloor. trganized 1550, first class griduated is 51 and a class graduated each subseifuent year. The dean is Dr. Vletor C. Vaughan. Trot ates, 42 .

ser

Mich. 2.-Detroit Meclical iollege. or ganlzed 1ses. first class graduated 186! and a class graluated each jear to 188 ;
when it consolidated witl the Hicloigan (n). lege of Medicine to form the lietroit rollege of Medicine.

Mich. 3.-Detroit Homeopathle Medicul college. Organlzed 15\%. Extinct isig.

Mich, 4.-MIchigan IIomeopathic lledica college, Lansing. Organlzed 18::. Extinct

Mich. 5.-University of Michigan Homeopathic College, Ann Arhor. Organized 1875. tirst class graduated in $187 \%$ and a class raduated each subvequent year. The doil 1912.13 was 63 ; graduates, 13.

Mlch. 6.-Michigan College of Medicine. betrolt. Organlzed 1sso. First class graduated 1ss1, and a class graduated earli year to 1s8: When it consoliflated with the De-

Mich. 7.-Detroit College of Medicine and Surgery. Formed 18.7 by consolidation of letroit Medical College and the Mlichigan letroit College of Melleine. Iresent tille assumed in 1!n 3. First class graduated lsse and a class kraduated ench subsequent year. and a class kraduated ench subsequent year. enrolment for 1!12-13 was $19 \%$; graduates. 27.

Mlch. 8.-Mlchlgan Pollege of Medicine and Surfery, letrolt. Organlzed 1s8s, flrst class graduated in 1859 , a class graduated each subsequent year. In 1903 consolidated with Saginaw Valley Medlical Cullege

Mich. 9.-Saglnaw valley Nedical college, Saginaw. Organized $1896^{\circ}$ : tirst class gradu ated 18:5, and a class kraduaterl fach subseduent year Including 1903 , when it con-
solidated wlal, the Jichlgan iollege of Medicine and surgery.

Mich. I0.- Virand Raplds Mudial college Incormorated lsyz; flrst class graduated 18:18, and a class graduated each subseijuent yrar. Including 1907, when it became extiuct

Mich. Il-Detrolt Iomeopathic college (1rganized in 189:4: flrst clase groduated in 19u11: a class craduated enth sulsepurnt ear. Fixtinct in 1012

Mich. 12.-Michlgan Sichoul of Hofumeph athy aud surgery, betrolt. Ituorpurated 3. ISti.i. Extluct.

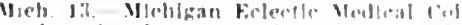

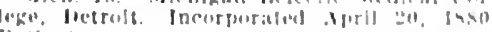
:xtinct.

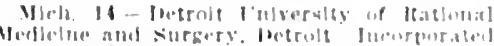

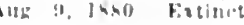

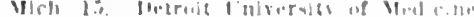
metrot

Wirh

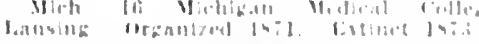

\section{MINNESOTA}

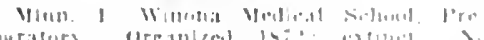

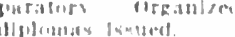

$$
\text { II:111 }
$$

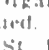

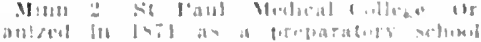

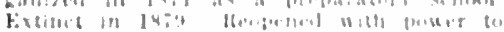

grant degrees In 1ans. Clasues grasluated In leab atul jean. In lows le meraed with the frnmewta lompltin! follege and was alisorturd by the l'mberstry of Minnesula II:

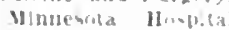

II...vinal tollege.

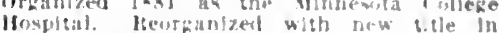

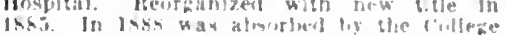
of Medicine and surgery of Mingesolat l"ne. rersity

Minn. 4-University of Minnesola College of Medicine and Surgery. Minues;ylls. I) kanbes laks. At that line lis only tunc Lind Was to examine for the dearees of B B and II.J In Is.s. by the consolsdation and alowrsition of the st. l'aul Medical Cinllege and the Minnesuta Howpltal College, lis bresert tatis has aswamed. First class araduated Ins and a class zraduated each partment of isamine Iniversity. I Ave-gear course is ohligatory for all students who matrliculated for the sessions of 1s10-11 and thereafter. The dean is lir. E. l', Has izti: tratuates, 45.

Minn. Si... Minneapolis College of l'hysi. rians and surgeons. urganized in 1853: flrst class graduated 181884 and a class traduated in each succeding year. From isst to 18.7 inclusire the degrees were cotsferrol by the Tnlversity of Vinnesuta. In farta becane Medical Department Handine inlrersity. In 1908 it merged with the college if Medicine and surgery of the Inirersisy of Mlnnesota. The last class Graduater in 1:11 according to the terma of the agreement that Mamline Iniversits would grant degrees to students enrolled at the time of the merfer whose guafifcations institution.

Minn. 6-Inirersity of Minnesota College of llomeopathic Vedicine and surgery. 13rhanized isst as Minnesota Ilomeopathic Medical College. In ls8g it became the Ifomeonathic Medical Deparment of the
l'nirersity if Minnesota. The tlrst clase fraduated in 3889 ancl a class braduated each suberuent year. Including 190: when the department was abolished by the Boand of Itegents.

\section{MISSISSIPPI}

Miss. I.-University of Mississippl Medical Department. Oxford. Tlifs schoel was criatized ln lons. Only two years of the mediral conrse are giren. In 1908 a clinical department $\mathrm{n}$ as estallished at vicksturg but was disconthued in 1910 after otse class had leen fraduafed. The dean is Mr. W. S. $101 \cdot-13$ in 34 ?

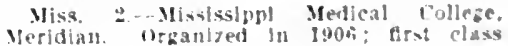

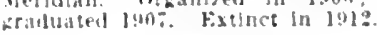

\section{MISSOUR!}

Mo. 1.-Mlswenti Medical Pollege, St

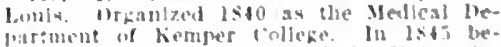

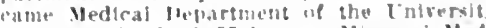

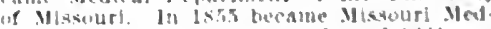

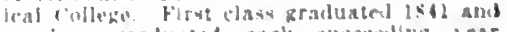
a elast craduated cach succoevling bea

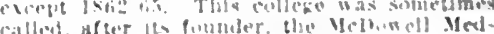

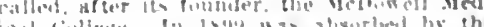

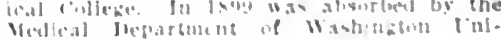

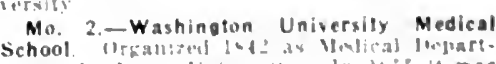

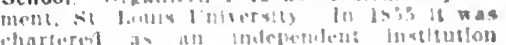

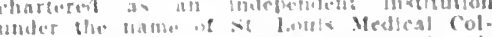

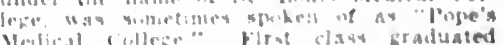

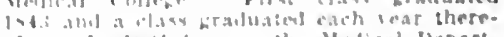

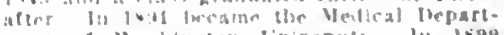

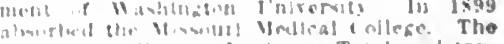

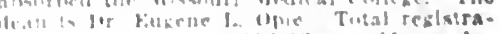
Mo 3.-University of Missourt Medical Department. Coblumbla buandimel isto. Mrat lass ormeluated Into. No clasues were grad-

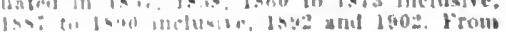


1845 to 1855 located in st. Louls. Itemgantzed lsiz. Last class uradinted in 1909 when the teaching of the clinical trars wis
suspended. Total registratlon for 191:was 1.5

No. 4.-Huntwht Medieal colleges, st louls. Incorporated 185.5 as St. Lonis ("ol 1959 became llumboldt lustloute In Istit

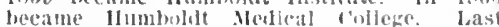
ciass graduated in 1869 , when it hecime extinct.

No. a.- Homeonathic Medical college of Mllssourl, st. Hollis. Orgathized isisy: firs class gruduated 1810 and a class graduated eacli year except 1862 to 1864 . Reorganized 1882 and absorbed Hering Vellical college and st. Louls follege of Itomeoplathic l'hysi

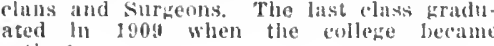
extinet.

Mo. 6.-St. Louls College of Homeopathic Physiclans and surgeons. Organized 1569 with the Ilomeopathic Iferlical College of Missourl in 1882

Mo. 7.-St. Louis College of Physicians and Surgeons, Saint Louls. Organtzed 1869 as the college of Physicians and Surgeons tirst class graduated $18 \pi 0$ und a class graduated each subsecullent year until 1873, lieorganized with the present title in 18\%. A class was gritduated each subsequent year. The secretary is Dr. E. T. Brand. Total registration for $1912-13$ was 38 ; graduates,

Mo. 8. Kansas City Medical College. Organlzed 18tig as college of lihysicians and surgeons of Kansus (ity". Above title asin all subsequent years including 1905. when it was absorbed by the school of Medleine of the Lniversity of liansas.

11\%. 9.-Homenpathic Medical College of St. Lonis. Organized 1873. Fraudulent. Extlnet

Mo. 10.-American Medical College, St. Louis. Organized 1873 as an eclectic college; first class graduated in 1874 and two classes graduated each subsequent year up to 1883 . since which time one class annually has been graduated. Dropped eclecticisin in 1910. In 1911, the Barnes Medical coller was merged Into it. Became the Medical Department of the Natlonal L'niversity of Arts and sciences in 1912. The dean is Dr. James INoores Ball. Total registration for 1912-13 was 211 ; graduates, 33 .

Mo. 11.-Medical College of Kansas City. Kansas City. Organized in 1869. Three sessions were held. Extinct in $18 \tilde{i}_{3}$

Mo. 12.-St. Louis Ilahnemann Medical College, St. Louis. Organtzed 1873. Graduated one class of four students. Extinct 1874.

Mo. 13.-St. Louls Eeleetic Medical College. Organized 1874. Extinct 1883. Closed by legal process.

Io. 14.-. St. Joseph Hospital Medical College. Organized 18i6. First class graduated 1878. In 1882 jolned with College of Pinyslclans and Surgeons of St. Joseph to form St. Joseph Medical College.

11o. 15.-College of Physicians and Surgeonns of St. Joseph. Organized $18 \% \mathrm{~s}$, graduated three classes. In 1882 merged with St. Joseph Hospital Medical College to form St. Joseph Medical College.

Mo. 16.-Wering Medical College, St. Louis, Organized 1580. No graduates. In 1882 united with the Homeopathic Medical Coliege of Missouri

Mo. 1i.-.Joplin College of Physicians and Surgeons, Joplin. Organized 18s0, first class Graduated 1881. Extinct 18s4.

In 18.-Xortlawestern Medical College, 5. Joseph. Organized 1879, flrst class 1881 . Extinet 1894

Mo. 19-Toplin Medical College, Joplin. Orfanized 1881. Extinct 188.

Mo. 20.- T"niversity Medical College, Kansas (its. Organized 1881 as University of Kansas City Medical Department. First class present name. In 1911 it discontinued the courses of the flrst two years. Extinct in cour 1913
Mo. 21.- Kansas rity IIspital College of Medicine. Organlzed IKS: first rlass gratdu-

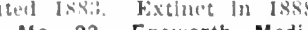

Mo. 22,-Ensworth Medical College, St.

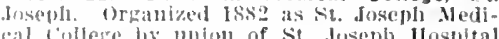
Medleal college alld college of physiclans and surgeons of St. Joseph. First class craduated 1883 , and a chiss graduited each worth Ifedical collere in 1888 . In 1905 merged with rentral Medical college to form Ensworth-l'entral Medical College. In 1907 resumed the name kinsworth Medical College. The secretary is 1). T. E. fotter.
'Total registration $1912-13$ was 20 ; gridu-

No. 23.-Woman's Medical Coflere, St. tollis, IItom

V1). L1.- Beaumont IIospital Medical ('olJere it louis. Orrauized 1886 , first class fraduated 188-. Latst cliss in 1901 when it joined with Marlon-Sims Nedical College to form Marion-sims-heaumont Medical College.

No. 25. St. Louis Hyglenic College of extinct about 18.3

Mo. 2fr.-Kansas (ity IIomeopathle Medical College. Orpanized 1\$88, flrst class graduated 1859 . Inited in 1902 with IIahnemann Medical College of the Kansas City University to form Kansas Clty II ahnemann vedical College.

Mo. 2\%.-IIarion-Slms College of JedIcine, St. Louis. Organized 1890 . First class graduated in 1891, a class graduated each subsequent sear until 1901, when it united with Beaumont Ilospital Medical College to form Mfarion-Sims-Beaumont College of Iouis University.

Mo. 28.-Barnes Medical College, Saint Louis. Organized 1892, first class graduated 1893 and a class graduated each subsequent year including 1911 when it merged with the American Medical College.

Mo. 29. - Central Mcdical College of St. Joseph. Organized 1894, first class gradusequent year. In 1905 merged into the Ensworth Medical College.

Mo. 30.-Woman's Medical College, Kansas City. Organized 1895, first class graduated 1896 and a class graduated each subsequent year until 1903, when it became extinct.

Mo. 31.- Hahnemann Medical College of the Kansas City University. Kansas City.
Organized 1896 as the College of IIomeoOrganized 1896 as the College of IIomeo-
pathic Medicine and Surgery of the Kansas nathic Nedicine and Surgery of the Kansas in 1900 . First class graduated 1897 . United in 1902 with Kansas City Homeopathic Medical College to form Kansas City IIahnemann Medical Collewe.

No. 32--Nedico-Chirurgical College of Rity City (Kan.) College of Medicine and Surgery. Reorganized with the above title in class graduated each subseouent year. In class gradinated each subsequent year. In 1901 it absorbed the Columbian Medical
College. In 1905 absorbed by the School of Medicine of the I'niversity of Kansas.

Mo. 33.-Eclectic Medical University, craduated 1900. Removed to Kansas City Kansas, in 190\%. Assumed name of Western Peturned college of Medicine and Surgers. resuned its former nam. Mo.. in 1909 and Dr. D. R. Alexander. The total registration Dr. 1. R. Alexander. The total registration for 1912-13 was 50 ; graduates, 13 . ReState Board of Health and by twenty other State Board of Health

Mo. 34.-St. Louis University School of Medicine, St. Lonis. Formed in 1901 by union of Marion-Sims Medical College and Beaumont Hospital Medical College, with the name Marion-Sims-Beaumont liedical College. First class graduated in 1902.

was the Mledical Department of the $\mathrm{St}$. Louis Was the Medical Department of the St. Louis The dean is Dr. Don Roscoe Jaseph. Total number of students registered for 1912-13 was 233 ; graduates, 69 .

see spccial funouncrment titr. pase is
Mo. 35. - Kansas City Hahnemann Medical College. Foundert in 1902 by the union of the liansas City Homeopathic Medical Col lege and the Ialmemann Wedical college of the Kansas lity liniversity First clas. graduated in 1!t03 and a class mrande Moses $T$. lummels, Total registration for 1912-13 was 55 ; gruduates, 8 .

.11). 3fi--Occidental Collere of Physicians and Surgeons, Jopliu. Incorporated 1880. IIal no classes. Extinct I8si.

Mo. 37. St. Lonls Woman's Medical Col lege. Organized 1894; classes graduated in 1895 ant 1896 , when it becano extlnct.

Mo. 38.-Mlssourl Eelectic Medical Col lefe, Kansas City. Extlnct about 1898. rersity of st. Louls. Fraudulent Extluct abrut 1885

110. 40.-IIippocratean College of Medicine, St. Louis. A night school organize III 1907. No graduates. Extlnct in 1910. Kansas city. Organlzed 1898. First class graduated 1899 and classes graduated each subsequent year. Merged with the MedicoChirurizical college In 1901.

No. 42.-Mllssouri Schonl of Midwifery and Diseases of Women and Children, St.
Louls. In operation about 1891. Extinct. Fraudulent. Operation about

Neb. 1.-University of Nebraska, College of Medicine, Regular lyepartment, Llncoln. Organized 1870. Extinct 1887.

Neb. 2.- University of Nebraska, College of Medicine, Eclectic Department. Organized 1883. Extinet 1885.

Neb. 3.- Lnlversity of Nebraska, College ganlzed 1883, flrst class 1884. Extinct 188.

Neb. 4.-Cotner University Medical College, Eclectic. Orcanized 1890 as Llncoln Iedical College, frost class graduated 1891 and a class graduated each subsequent year; assumed present title in 1911. The tration for $1912-13$ was 35 ; graduates, $i$.

Neb. 5.-University of Nebraska College Or Medicine, Omaha. Organlzed 1881 as Omaha Medical College, the outgrowth of a preparatory school established in 1880 under the name of the Nebraska School of Medicine. First class graduated in 1882. Became MIedical Department Omaha University in 1881. In 1902 afflliated with the Unirersity of Nebraska and became College of
Medicine of the University of Nebraska. The first two years are given at Lincoln. The last two years only are glven at omaha. The acting dean ls Dr. Robert H. Wolcott. Cniversity of Nebraska, Lincoln. The total registration in 1912-13 was 78 ; graduates, 9 . See special Announcement Adv. page 4

Neb. 6.-John A. Creighton Medical Col. lege, Medical Department of the Crelghton Unlversity, Oniaha, Organlzed 1892, first class graduated 1893 and a class graduated L. Mnirhead. Total registration for 1912-13 was 182 ; graduates, 39.

Neb. 7.-Nebraska College of Medicine, Lincoln. Organized 1005. Classes were graduated in 1907,1908 and 1909 , when the chool became extinct.

Neb. 8.-Nebraska Medical College. Eclectic, Linenln. Organized in 1910 . Held one cal College. No graduates.

\section{NEW HAMPSHIRE}

N. H. I.-Dartmouth Medical School, Hanover. Organized under the trustees of Dartmouth College in 1797, flrst class gradu-
ated 1798; a class gradnated each subseated 1798; a class graduated each subseDartmouth College. After the class of 1914 is graduated the school will discontinue clinical teaching. The dean is Dr. John 21 .
Gile. Total enrolment for 1912-13 was 27; graduates, 10.

see sperial Anuonnecment Adv, page is

N. H. 2.-New England University of Arts and Sciences, Mranchester. Incorporated in 1876. Charter repealed in $187 \%$. Fraudulent. N. H. 3.- - University of New Hampshlre,
Department of Iedicine, Nashua. Incorporated in October, 1888. Fraudulent. Extinct. 


\section{NEW JERSEY}

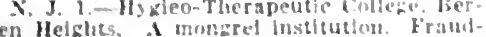
ulent Charter repealed lsib.

5. J. 2. Mealleal und surgical ridlegn of

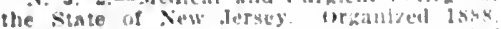

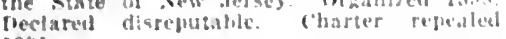
1891

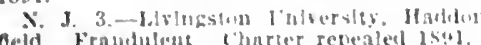

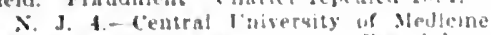
and siclence. Jersey firy. Fraudubent. and selence. Jersey

\section{NEW YORK}

N. Y. 1,-Columbia University, College of Physicians and Suroeons. New York. IIr ganizel in 180 : by the regents of the liti. versliy of the state of rew rork under the

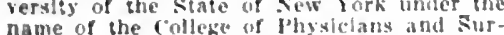
name of the college of Now york. The first ceons In the (1) of New lork. The frst ated each sulveguent year. The college was origlnaliy orkanized in 1760 as the lledical Faeulty of king's cullege. wlitch gruduated its first class In 1769 . It was suspended ganlied in 1ige as the Medical raculty of ganlzed in lige as the Medral raculty of 1693 to $179 \%$ Incluslve. 1803 to $1507 \mathrm{ln}$. eluaire and in 1,10 . Mennwhile the college eluaire and in liso. Meanwhile the collece of Physlelans and surgectis in the City of New york was orfanized and in Isli a retaluing the latter title. It lecame the Medical Iepartment of Coluu.bia Infrersity in 1860 and was definitely merged Into Columbin Ĺnirersity in isoi. Present title assumed in 1908. The dean is Vr. Samuel W. Lambert. Total reglstration for 1912-13 was 339: graduates, 99.

v. Y. 2-Colleke of Physicians and Surgeons of the Western Dlstrict of New Fork Falrfleld. Organlzed 1812. first class graduated 1816 and a class graduated each subsequent year untll 1840. When it beeame extinet. Giraduated 589 students.

N. Y. 3,- Albany Medical College, Albany. Orzanized 1835, first class kraduated 1839 , united with cinion Lniversity 18:3. The reglstrar is lir. Willis (i. Tucker. Total registration for 1912-13 was 239; graduates. 18.

x. I. 4-Genera Medical College, Genera Organlzed 1835 as the Nedical Instifution of Geneva. First class sracluated in 1835 and a elass graduated each subsequent yenr excep 1834. Isecame Cieneva Medlcal Culluge in 1861. Last class graduated In $187^{2}$, when it merged into the colleze of l'hyslcians and Surgeons

y. Y. 5-New York Lnireralty Medical Collece. Organized 1841 as Medical Jopart inent of the I'niversity of the City of New York. Assumerl above title 1896 . Flrst class gralluated in $18+2$ and a class graduated each subsequent year incluclling $16: 18$, when it unted with Mellerue Iospltal Hedical college in form iniversity and Bellerwe Hospital Medical itollege.

N. Y. 6.-University of Buffalo, Medical Department. Orignized 1 $\$ 40$. firt class gralluated 1847 and a class graduated exilh grabsequens year. Aborled Medleal beyst. subsequeut year. Absorled Medleal bejart ment Nlagara "nlverslty Isigs. The dean is Ior. Herbert U. W1912.13 was 22I: graduates, 4.

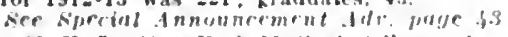
s. Y. Tow York Medical leulleke Mr ranized isso. First class graduatud ls:l and a class graluated eacls aulseiluent

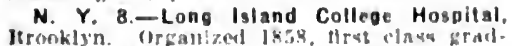
Itronklyn. Orgaltzed lo:s, flrst clase grat. uated in 1800 and a claws draduatod in wach

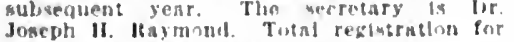

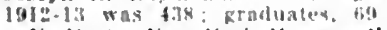

N. Y. 9.-New York Homeopathle Medical College and Hospltal. Hrannlzel Isis. In corpuratid in lstio as Ilomerigathe Mevilcal Colloge of blue state of New Yurk In lybls

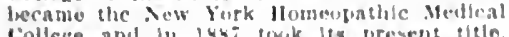
Flrmi class graluated in 1801 and a class

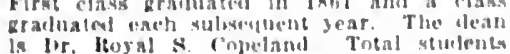

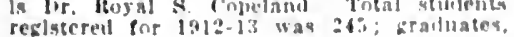
rest.

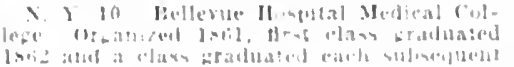

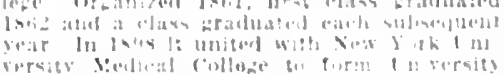

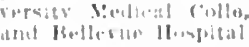

N. Y. 11,-New York Mediral College and Hospiral for Women. Honeopahic Mesint

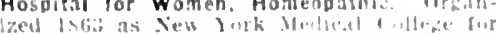

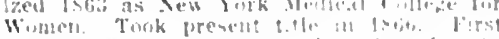

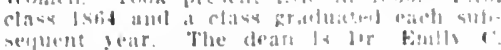

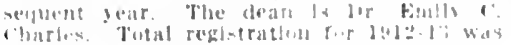
fi: gradmates.

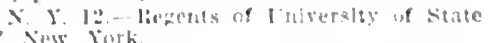

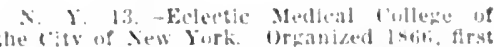
the ("is of lew York Organized latit. first

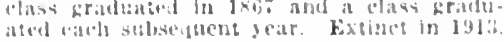
$\therefore Y$ If Womatas Meatical college of the Nen lowk Intlrmary for Woment and istis, first rlass 1800 and a clats fribluated ench subseluent year Including 1s99, whell ench subselfuent

N. Y. 15.- Syracuse University College of Medicine. Orfanlzed lRiz as college of

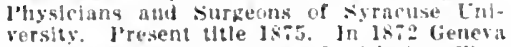
Medlcal college was mertall with it. First class graduated 1s:3. The dean is br. registered for 1912-13 was 87: gradiates. regist.

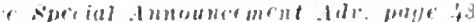
x. Y. 16.-Cunted states Medical College. Orkanized is 8 , closed ly surreme conrt of the state of New lork isst. The diplomas rurk Leglstature.

r. 1. 17.-College of Physicians and surgeons, ltomeopathic, Buffalo. organlzed Is 39 as the Ilomeorathic College of Ithrsiclans and surgeons. Changed title to college of Iliysletans and surpeons in 15 so.
First class isso. Flosed by order of the supreme court of the state of New York 1884 . The diplomas of the college were inate lezal S. Y. IS.-Nlagara In/versity Medleal
Jepartment. Wrganized 1853, first class craduatel issi and a class graduated each subsenent year Including lsas, when it consolitilted with the Medical
the Cniversliy of Butralo.

N. Y. 19.-University and Bellevue Hos. of the New Cork ine (Medical Jepartmen. formed in 1 sis by the union of New York Eulversily Mcdical colloge with liellevue Jtosplal Medical college. Flrst class krad. Ifospltal Mcdical college. Flrst class krat subsequent your. The denn is lor. Figbert subsenuent velur. The denn ts lor. Figbert
Le revre. Total registration for $1: 12=13$ was 3.32 : graluates.

N. Y. 20.-Cornell University Medical college, liw lurk lirganized 184h. llrst class gradunted 1s:u and a class groluated fourse to taken at Siew York or at Ithacas. the last three betirs at Now Yurk. Tlie dean is Inr. William M. Trilk. Tutal regls.

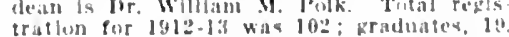

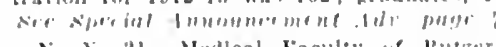
N. Y. 21-Modloal Faculty of Itutger's

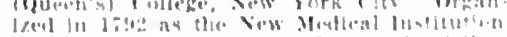

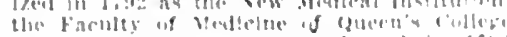

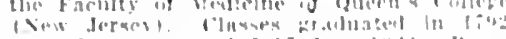

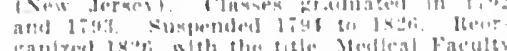

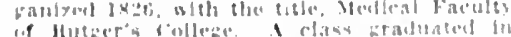

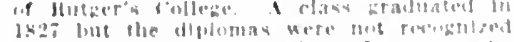
lof the Sew York lenard of Itogenty In efors was then natle to resive the collende

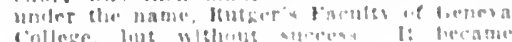

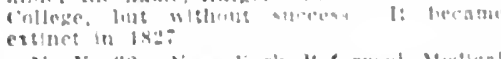

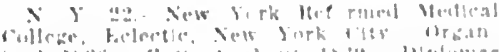

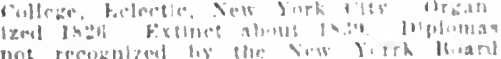
not recognt
ni lteconts

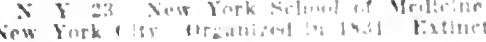
$183 .:$

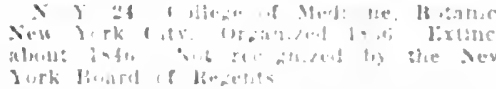

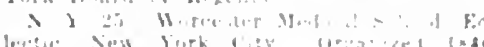

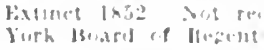

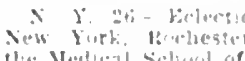

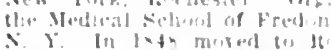

llie abrise title In lat

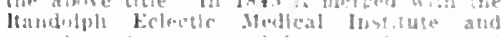

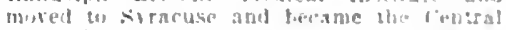

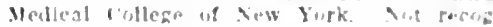
nized lis ble Xew York board of liegents

X I. 27. Mandoluh Firlertic Mediral In

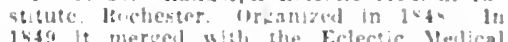
Insilute of Xely Y

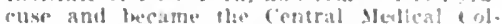
lege of New York. Nut rewandizet by the New lork Hoard is llezentw.

X. Y. 2s Itochester Felecte Med al fol. Ifoe, lochester. Organized at Syracuse li lork ly the unlon of the Fichoste Medical Institule if Yew liok wish the Bandolph Eclertir Mrdical Inatutute. In 1950 remored b) Itocliester and became the Pucheater Ec. lectic llodical lollece. kitunct in 1852 . It was not rebognized by the Xew lork Board of liegents.

s. Y. 29 - Syracuse Medical Colleze, Ke. lectic, Rncliester. Organized 18.50 . Fisincs Boaril of Regents.

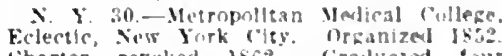
tharter revoked 16f2. Ciraluared tour
classey. Diplomas not recomnized by the classes. Ihplomas bot recost.

x. Y. 31.-Frcelvin Merleal College. New York city. Incorpornted Aprll 10. 16: In inct. Isnard of Regeuts.

‥ 2 . 32.-New York llygelo-Therapeuslc College, New York (1ty. Incornorated Anril 15. Is5i. In New Ynek Cing llirectory IS5 to 1 sift. Extinct in 1 sst an attempt was made to reorganize the inatituston in the leter.

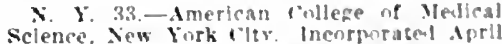
2. 185s. No erldence that any sestuns were helil.

X. Y 34 -New York Prejarawry schmol

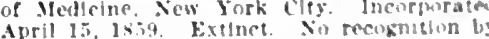
the Sew lork Burd uf lieants.

$x y$ r. 35 - Nuw lork Free Medloal (t) lecte for Women, Now lork city. rharparel

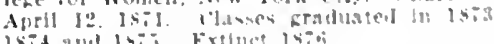

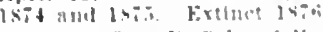

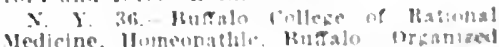
18:9 Fratldulent kxtincs liepored to

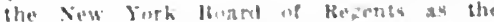

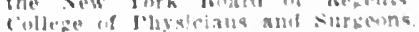

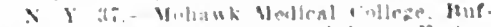

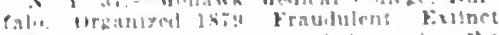

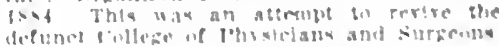

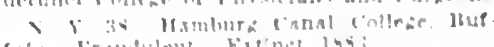

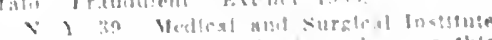

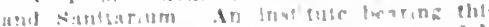
allit fult

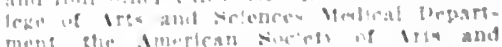

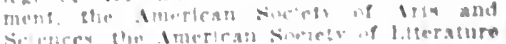

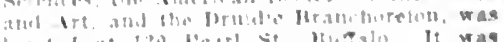

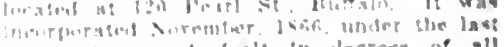

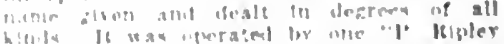

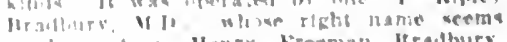
- lian leen Honry freman Israbtury.

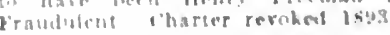

y II Jow Yirk inllege of Mag.

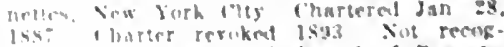

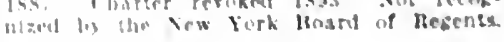


N. Y. 41.-New York Institute of Medical Science. New York Chy. Organized 18si.
Not chartered. Fraudulent. Fxtlnct nbout Not 1893 .

X. Y. 42.-Mreparatory Medical College, New York City and louglikeepsic. OrganNot recognized by the New rork lBoard of Regents.

N. Y. 43.-Fordham University Sehool of Medieine, New York City. Organized in 1905. First class graduated 1009. The dean is IIr. Wlllam 1". Healy. The total registration for 1912-13 was 136 ; graduates, $3 \mathrm{I}$.

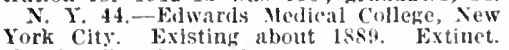
Not legaliy chartered.

\section{NORTH CAROLINA}

N. C. I.-University of North Carolina, ized 1879 as a preparatory school. In $1890 \mathrm{it}$ began teacling the work of the first two vears of the inedical course. In first two years of the medical course. In at Raleigh. Classes were graduated from at Raleigh. Classes were graduated from
1903 to 1910 inclusive when the clinical department was discontinued. The dean is Dr. I. II. Manning, Chapel Hill. The total registration for 1912-13 was 54 .

N. C. 2.-Edinborough Medical College,

N. C. 3.-Leonard Medieal Sehool (Colored). Hedleal Department Shaw Univerored). Hedleal Department Shaw Univer-
sity, Ralelgh. Established 1882. A class síty, Ralelgh. Established 1882 . A class
was graduated in 1886 and $1 \mathrm{n}$ each subsewas graduated in 1886 and In each subseiluent year. The president is Charles $F$. 97 : graduates, 22

N. C. 4.- North Carolina Medieal College, Charlotte. Organized in 1887 at Davidson as the Davidson School of Medicine. It was a preparatory sehool only, not granting any degrees until 1903, when it was chartered under its present name. The flrst class was graduated in 1893. Removed to charlotte in 1907 . The course covers four vears of eight months each. The dean is vears of eight months each. The dean is Dr. Walter 0 . Nisbet. The total registra
tion for 1912-13 was 85 ; graduates, 26 .

N. C. 5.-Wake Forest Sehool of Medieine, Wake Forest. This school was organized in 1902 . It glves only the flrst two years of
the medical course. In $1910-11$ it enrolled 38 students. The secretary is $\mathbf{E}$. B. Earn38 students. The secretary is $\mathbf{E}$. B. Earn-
slaw. Total registration for 1912-13 was 30 .

․ C. 6.-College of Physicians and Surgeons, Arlingtorl. Organized in $18 \pi 1$. Extinet. It is not known that it erer graduated a class.

\section{NORTH DAKOTA}

N. D. I-University of North Dakota Col1905. Gives the first two years of the medical course. The dean is Dr. Harley E French. The enrolment for $1912-13$ was 14

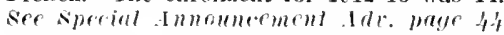

\section{OHIO}

๑. 1.-Medical College of Ohio. Organized 1819, first class graduated in 1821 . Cincinnati Iledical College was merged in 1846 . In 1857 Miami Medical College merged until 1896 became the Medical Department of the Iniversity of Cincinnati. In 1909 it again merged with Miami Medical College and merged with Miami Medical College and the University of Cincinnati.

o. 2.-Eclectic Medical College, Cincinnati. Organized in 1832 as Worthington Medical College. Suspended 18s9-1843. Pemored to Cincinnati, 1843. Becane the Eclectic Medical Institute in 1845. Absorbed the American Nedical Collere in 1857 and the Eclectic College of Medicine and Surgery in 1859. First class graduated in 1833 and in each year thereafter except 1839-45 inclusive. Changed name to Eclectic Medical College in 1910. The secretary is Dr. enrolment for $1912-13$ was 92 ; graduates, 26 . O. 3.-Staring Medical College, Columbus. Organized 184\%. During sime year it absorbed the Medical Department of Willoughby lniversity. A class graduated Medical College. In 1907 it united with the
Ohio Medienl University to form the staring-ohio Medieal College.

0. 1.-l'hyslo-Medical college, Cincinnat Organized 1836. Graduated classes unti 1880 when it hecame extlnet. Niso known as the Clnelnnall Literary and seientlfle Institute.

o. 5.-Botanteo-Medical College of Ohlo. Cluartered 18:3. Extinet 1850 .

0. 6.-Western Reserve University School of Medieine. Clevelant. Organized 1843 as c'leveland Iiedical College. Sometimes refer red to as the Inulson Medical College. First class traduated In 1844, and a class graduated each silbserquent rear. Assumed prescut title 1881 . When the majority of the faculty of the Nedical Department of Woos ter University mited with it. In 1882 the board of trustees of Western Reserve unl rersity eonferred the ald enundem degree of
I.D. on all graduates of the cleveland M.D. on all graduates of the cleveland the Universlty of Wooster Medical lepart ment. Absolbed the ('leveland College of Physledans and Nurgeons in 1910. The sec-
retary is Dr. F. C Waite. Total enrolment retary is $1 \mathrm{r}$. F. C. Waite. Total e
for $1912-13$ was 161 ; fraduates, 38. secesperial Innoumemsit idr. page 39

o. T.-Cleveland University of Medicine and Surgery. Organized 1849 as Wester College of IIomeopathic Medicine. First class graduated 1851 . In $185 \pi$ the name was
changed to Western Iomeopathie College. n 18 i0 became IIomeopathlc IIospital College and absorbed the Homeopathic Nedical Collexe for Women. In 1894 became Cleveland Unirersity of Medicine and Surgery. In 1898 joined with Cleveland Medical College (Homeopathic) to form

o. 8.-Cincinnatl College of Medicine and Surgery. Organized 1849 , first class graduated I852. The last elass graduated in 1902 when it became extinet. Its department for women was the Woman's Medical College of Cineinnati.

o. 9.-Miami Medical College, Cincinnati. Organized 1852, classes graduated 1853-7. In 1857 merged with Medical College of Ohio, but was re-established in 1865 and a class graduated eaeh subsequent year, in-
cluding 1909 , when it merged with the Medicluding 1903, when it merged with the Medieal College of Ohio to form the Ohio-Miaml
Medical College of the University of CinMedica

cinnali.

o. 10.-Physio-Medical Institute, Cincinti. Organized 1859. Extinct 1885 .

O. 1I.-University of Wooster Medical Department, Cleveland. Organized in 1864 as the Charity IIospital Medical College. First class graduated in 1865. Assumed above title in 1869 . In 1880 part of the faculty united with cleveland Medical College to form Western Reserve University Medical Department. The other part of the facult reopened the University of Wooster Medical Department in 1881. (See 0. 12.)

o. 12.-Cleveland College of Plyysicians and Surgeons, Medical Department ohio Wesleyan University, Organized in 1881 as the Medical Department of the University of wooster. The first class graduated in 1882 It became the Medical Department of ohio Wesleyan University and assumed presen title in 1890. In 1910 it merged into the Western Reserve Lniversity Medical Department but

o. 13.- Pulte Medical College, Cincinnati, Homenpathic. Organized 18\%2, first class graduated 1873 and $a$ class graduated each subsequent year including 1910 when the subsequent year including 1910 when the college was merged with the cleveland Cleveland-Pulte Medical College.

o. 14.-Columbus Medical College. Organized $18 \% 5$, frst class graduated in 1876 , 1892 .

o. 15.-Physio-Eelcetic Medical College, Cincinnati. Organized 1876. Fraudulent. Extinct 1879

o. 16.-Ainerican Eelectic Medical College, Cincinnati. Organized 1876 . Last
class graduated in 1896, when it became extinct

O. 17.-Mfedical Lniversity of Ohio, Cin1891. Fraudulent; diplomas not recognized.
O. 18.- Northwestern Ohlo Medical College. Organlzed 1883 as an outgrowth of
the Toledo School of Medicine: flrst class the Toledo School of Medlcine; flrst ciass graduated in 1884 and each year thereafter
until 1891 , when the school beeame extinct.

o. 19.-Toledo Medical College (Medical Inepartment Toledo ['nlversity'), Toledo. OrLanized 188:, first class graduated In 1883 aniI il class graduated in each subsequent vear. 'Tles dean is lir. Arthur W. Fisher. Total enrolment for $1912-13$ was 32 ; gradthates, 15.

0. 20.- Woman's Medical College of Cincinnati. Founted In 1887, first class graduated 1888. The last class graduated in 1895 when it joined wlth I'resbyterian IIospital alli Woman's College to form the
Menorlal Woman's Medical College.

o. 21.-Laura Memorial Woman's Nedieal College, Cinciuuli Oranized 1895 by the merier of the Woman's Medical College of cinclnnatl with the Presbyterian Iospital and Woman's Medical College. First class graduated 1896. Last class graduated 1903, when it became extinet.

o. 22. - Nationa! Nornal Untversity College of Medieine, Lebanon. Organized 1889 sequent year until 1896, when it becane extinct.

0. 23-Cleveland Medical College, Homeopatlic Organized 1890 flrst class 1891 Joined Cleveland Untrersity of Medicine and Surgery to form Cleveland Homeopathic Medical College in 1898 .

o. 24.-Presbyterian Hospltal and Woman's Medical College, Cincinnati. Estaband a class graduated each subsequent and a class graduated each subsequent year, including 1595 , when it united witl form Laura Memorlal Woman's Medical College

o. 25.-Ohio Medical Unirersity, Columbus. Organized 1890, first class gradusequent year, including 1907, when it merged with Starling Medical College to form the Starling-ohio Medical College.

0. 26.-Cleveland-Pulte Medical College. Formed in $189 \mathrm{~s}$ by union of Cleveland Unirersity of Medicine and Surgery and Cleveland Medical College with the title of Cleveland Homeopathic Medical College. In $19 \mathrm{I} 0$ it absorbed the Pulte Medical College, Cincinnati, and assumed the present title. The first class graduated in The dean is Dr. George H. Quay. The total registration for $1912-13$ was 85 ; graduates, 23 .

o. 27.-Cincinnati Medical College, Cincimmati. Organized in 1834. Merged
the Medical College of Ohio in 1846.

o. 28.-Willoughby University Medical Department, Willoughby. Organized 1835 In 1847 it merged into the Starling Nedical College.

O. 30.-American Medical College, Eclectic, Cincinnati. Organized in 1839 . In Institute.

o. 31.-Eclectic College of Medicine and Surgery, Cincinnati. Organized in 1855. Classes were graduated in 1857 , 1858 and
1859 . In 1859 it merged with the Eclectic 1859. In 1859 it
Medical Institute.

o. 32.-International Electropathic Institution, Mentor. Chartered under the laws of Pennsylvania in 1861 as the Electropathic Institute. Moved to ohio in 1876. Extinet in 1894. Not recognized by the ohio State ination.

o. 33.-Homeopathic Medical College for vomen, Cleveland. organized in 1868 Merged into the Homeopathic Hospital College in 1870 .

o. 34.-American Health College, Cincinnati. Organized in 1874 and reorganized in 1876. Conducted by a Dr. Campbell, who "vitopathic system." Fraudulent. Extinct about 1886 .

o. 35.-Zanesville Academy of Medicine, Zanesrilie. Organized in 187t. Under the to examine candidates who wished to prac- 
tice medcine, and if found qualified ksue certifleates to that effect. Thls right was exerclsed In aix of seren Instances after a written and oral examlnatlon. Owlng to by order of court in issi.

o. 36.-Toledo School of Medicine, Toledo. Organized in $18 \mathrm{is}^{3}$ as a school for Instruction only and did not confer degrees I held three sesslons and was then sus pended. (see 0.15 .)

o. 37,-Darton Medical rulrerslty, liaytnn. Oeganlzerl 18rot, classes graduated in

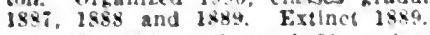

D. 35.-Ohio College of Obstetric4. Mediclne and Mldwifery, Incinnati. Charued in 18s9. Fixtinct. Fratudulent.

o. 39-1lygela Medical College, Cinclanatt. trganlzed 1893 , first class graduated 1895. Xo clasy fraduated in 159\%. Last class graduated 1598, when li became Board of Mledical Reglstration and roxam Inatlor.

o. 40.- Starling-Ohio Medical College. Columbus. Orkanized ln 190. by the unlon of the starling Metical follege with the Ohlo Medleal I'nirersity. First class grad
uated 1908 . The dean is Lir. W. J. Means. the sotal enrolment for $1913-13$ was 263 ; graduates, 33.

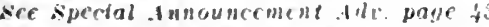

0. 4l.-The Ohio-Miami Medical College of the University of Cincinnati. Irranized in 1909 by the unlon of the "Sedical college of Ohlo (founded In 1819) with the Miaml
Medlcal College (founded in 18:32). The Medical College of (thlo became the Medical lepartment of the L'nirerslty of Cincinnati. April 26, 1896. Under a similar agreement. March 2. 1909, the Mlanil Medical college also merked Into the vinlverslity. when the present title was taken. Two years of cullege work are reutuired for admlssion. The course corers four years of eight months each. The dean is in. "hrlstian $\mathbf{K}$ Holmes. The total registration for $1910-13$ was 80 : graduates, 26 .

Se sprcial Annisurimeul Adr. page it

\section{OKLAHOMA}

Okla. I.-University of Oklahoma Medical School. Torman and Oklahuma City. Organlzed lisg. Gave only the tirst two years of the medical course untll 1910 , when clinlcal department was ormanized in oklaclinleal department was oreanized In Oklat
homa City. The dean is Ir. W. J. Jolly. homa City. The dean is Inr. W. J. Jolly 1912-13 was 32 ; graduates.

Okla. 2.-Epworth rollegt of Medleine Oklahoma clis. Orginlzed 1904. Classe were graduated from 1907 t/ 1910. inclusive, when the college lecame extinct.

Okla. 3.-Twentieth tentury physio. Pravulen: Chater revokel In 1804 . The dean of this colleze was II. Warner Newby. a "grastuate" of the Indevenden: Merlical college, achlcago diplorna mill. The see"

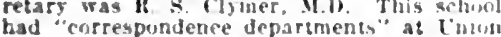
had "correspondence departments" at cumb
Clts. Mleh. and Ifatfeld. P'a. Circulars were sent out alvertlaluh diplomas at $\$ 10$ were sent out alvertialug diphlomas at slo each under the name of "nhares of th" Twentleth century lealth Assoclation. Trensleth century Medical cullege cal practire anywhere In the Inltoel state wlthout ans intrrferemen liy the state lsoard M. A. Oct. 1, 1904. prage ono ।

Wkla I Oklahoma Youdiral college

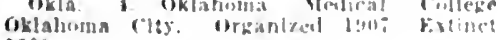
1900\%.

\section{OREGON}

Ore. 1 Whllamette l'muremes Viention Department. Nalem. orgatizizol latio, al Salen, flrst clave graduated forit. and

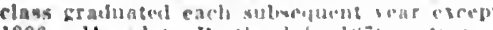
1896. Moved t. Portland in lach. resurned

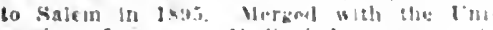

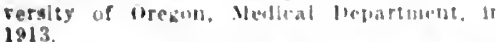

Ore. 2.-University af Oregon Medical

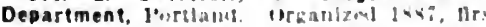

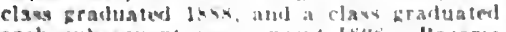

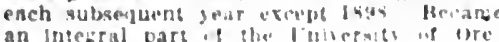

kon In litlo Absurled Whamethe labersisv Medteal liepartmens in 191 th The dear is ins. I. J. Mackenzle. The tital toumber of students for 1912-13 way is : vraduater.

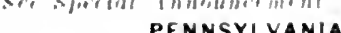

Pa. 1-University of Pennsylvania Department of Medicine. I"lilladelymtat Dräan

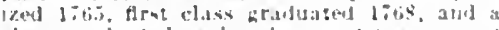
clast gratgated each sulmenturnt year eacept

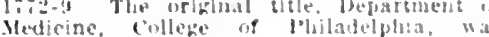

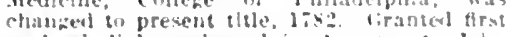

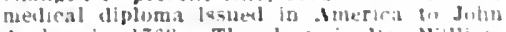
Archer la liss. The dean is lof. Willism 3epper. Traduates, 100

Pa. 2- - Jefferson Medical College, l'tula delphia. Grganlzed lazi as Mediral liepari ment Jeferion colleze, Canomsturg: tirst class graduated in lowti, and a clase graduafed each sulvequent bear. The sub-dean fur 1912-13 was 680: foraduate's, 1:ti.

la. 3-1'ennsylranla Medical college, Pluiblelphis. Organized 18:4. It was the Nedical lepartment Pennylrania "ollege. tiettysburg. In 1859 absorbed l'hiladelphia colleze of Medlcine and Nurkery. Alworhed in $1 \times 63$.

Pal. 4.- Philadelphia college uf Medleine and surgery. organized 1846; merged la. 5-Eranklin Medical College, phila Arlphia. Cranized 184i. Frelnet 185:

1'a. fi.-Homeopathle Mertical College of Petmsntrania Phidalelphia. Organized

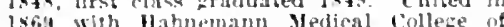
Philadelnhia to form the Halnemann Nedical College and Hispital.

Pa. 7-Woman's Medical College of Pennsylvania. I'hilatelphia. crganized 1850 ritst class arduated is.? and a class

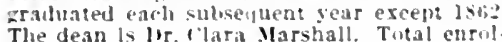
ment for 1912-13 was 43 : wraduates 21

I'a. 8-penn Medieal ['niversity, philadel-

phial. Organized 1s5.5. Surpented $1 \times 6 \%$ to 18it. Extinet last.

Pa. 9.- Hahnemann Medical College and Hospital. I'hlladelphia, Homentarhic. 11rganized in lith as the Home pattic Netlical college of lemnsylranita. In Ists it united with the Hahnemann Nedical College class Eraltuated 1800 and a class fraduatem each subsequent vear. The dean li lir.

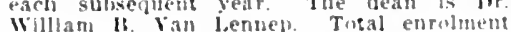
for 1412-13 was 92: :roduates. 31

10. 10,- biurulu inivervity Medical de partmests oxtord. Usganized lo:0. Extlnct isi:

Pa. 11.-Medico-Chirurgical College of craduated Ines. and a clane áraduateal edch

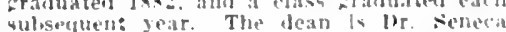
Fisture Total enrulment 191:-13 was 314. artadilitere it

Pa. 12. University of Pittsburgh. Medi. cal Department. 1'ltisburath. Organlzed lsst as the Western Pennorleania Mediral lept. lebe: Hrut plasy graduated lks. and a clow gradusted each sulueduent year Narlis

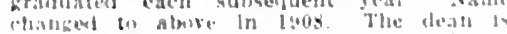

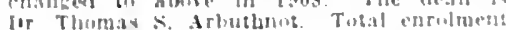

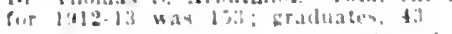

Pa. 13. - Temple University Medical De

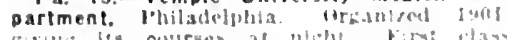

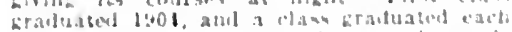

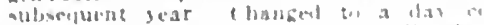

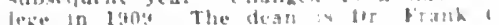

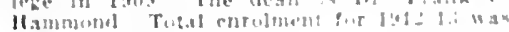

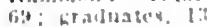

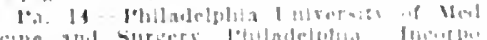

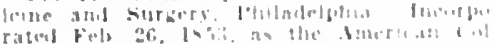

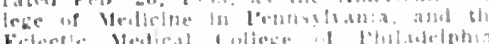

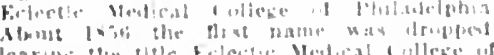

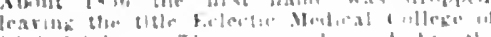

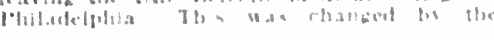

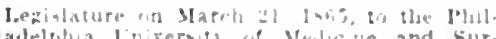

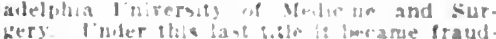

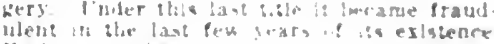
Extince [II 14.31

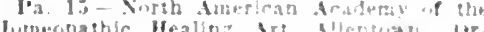

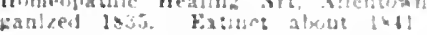

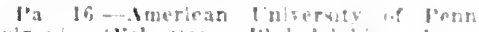

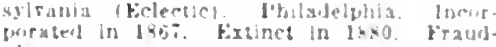
whent.

PA 1:- Eclerge Medical rolleze of lean.

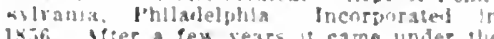
control of onle burhinan and became tratul wlent fixtistet 1wio.

P'a. 19 kilpegropathic Inatisuse. plalla

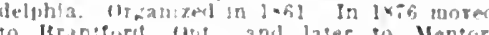

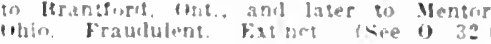

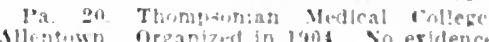
:" shoul that clasidu were wer held.

\section{PHILIPPINE ISLANDS}

P. 1. 1.-University of St. Thomas Medical Department. Namilat Pnuersity fuunded by

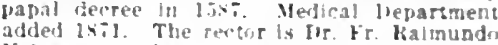
lelanfuez: the secretary of the medica department lo bolc. Blas is Alcuaz.

P. 1. 2.-University of the Philippines. College of Medicine and Surgery. Manila.

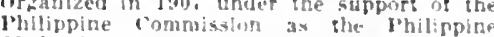
Phelucal colldere chanced the Philinpina Mellucal colleze changed ittle to the Muse in 1910 The dean is In. William Minstrase. The total en

\section{RHODE ISLAND}

ll I l llrusn I'nirersity Medical Me-

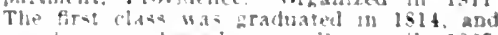

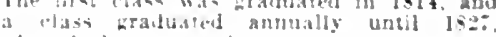
"Wheth it treame extinc:

\section{SOUTH CAROLINA}

S. C. 1.-Medical College of the state of South Carolina. charleston. Founded 10? as Vediral College of south larollna. First

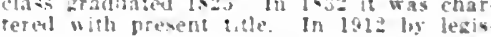
latire efiactment it betame a state inoliustimb clowes Eraduated all years excont

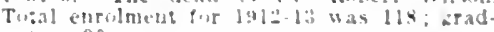

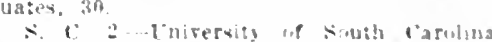

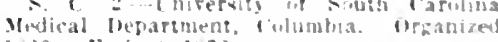
istif Fuxtuet 1ais

S. C. 3. Tharlesten Vedeal Schmol

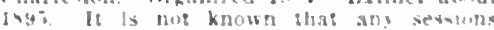
were lie?id

\section{SOUTH DAKOTA}

S D. University of South Dakota.

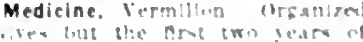

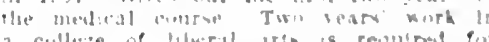

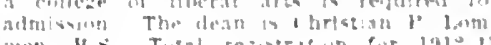

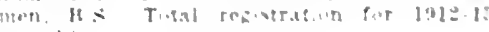

\section{TENNESSEE}

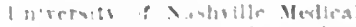

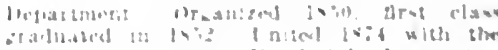

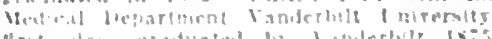

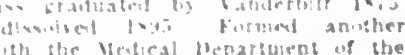
of Tentanese th l:00\%. esch tnat:

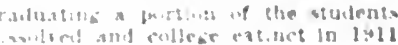

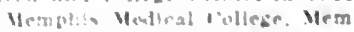

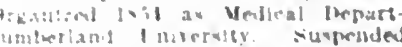

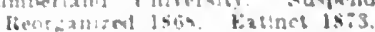

ficiectic Medlcal Invibuse, Mem

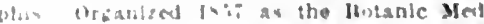

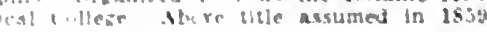

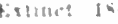

Tonul shelbs Medical rollege, Nish

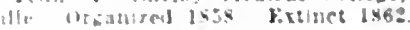


Tenu. 5.-Vanderbilt University Medical Department. Nashville. Granleed isit and Inited with the Melleal bepartment rnilsy. first class praduated 1875, and a class graduated eneh subinguent year. "The secretary is Dr. L. L. Burch. Total enrol secretary is Dr. L. F. Burch. Total enret-

Tenn. 6.-University of Tennessee, Cellege ef Medicine, Memphls. Organizoli is 76 at Nashville as Nashville Medical colleze. Became Medical Department luirersity if 'Temessee 1s:9. First class gratuated Isic, and a elass fraduated each sutwernch year ville Jedical pepartment, each institution granting datrees to a portion of the graduates eacll year. louion was dissolved in I!11. The trustees of the linirersity of Nishelle by formal action of that luarl Namede Unirersity of Temessee (allege named the University of Temesser medleal teaching, Iransferring all of its rollege and hospital ejuipment to the successor. This college then removed to Memphis, absorbing the College of Physicians and surgeons. merged in 1913. The dean is l)r. lluber Thomas Brooks. Total reglstration in the combined schools in $1912-13$ was 383 ; fraduntes T'ni\%. Temm,

II. C. 7.-Meharry Medical Cellege (Colored Naslivile. Organized 1876 as the ored), Naslisile. Organized 18 is as the Medical Department of Central Temessee class graduated each subsequent year. Central Tennessec. College became Walden Lnlrersity in lion. The dean is Dr. G. W.
Iubbard. Total reglstration for 1912-13 was $322 ;$ graduates 88

Tenn. 8.-Memphis Hospital Medical College, Memphis. Organized 1880 . First class graduated $188 \mathrm{I}$, and a elass graduated each subsequent year. Merged with Lniversity.

Tenn. 9.-Chattanooga Medical College. Orranlzed I889, flrst class graduated 1890 und a class graduated each subsequent year including 1910. when it became extinct. It was the Medieal Department of Grant to the University of Chattanooga.

Tenn. 10.-Lincoln Memorial University, Medical Department, Knoxville. Organized 1889 as the Temnessee Medical College, first class graduated 1890 , and a class graduated class graduated 1890 , and a class graduated each subsequent year. Affliated With the Medical Department of Lineoln Memorlal University in 1906 , assumed present title sity in 1909. The dean is Dr. Charles P. 9s: graduates, 19.

Tenn 11.- Lniversity of the South Medical Department (Sewanee Medical College), Sewanee. Organized 1892, first class gradunted 1893 , and a class graduated each uated 1893, and a class graduated each
subseonent year. College extinct in 1909.

Tenn. 12.- Knoxville College Medical Department (Colored), Knoxville. Organized is95, discontinued 1900 .

Tenn. 13.-Knoxville Medical College (Colored), Knoxville. Organized 1900, following the discontinuance of the Medical Department of Knoxville College. Classes graduated in 1900 and in all subsequent years except 1906 and 1907 . Last class graduated in 1910 , when the college became extinet.

Tenn. 14.-University of West Tennessee, Medical Department (Colored). Organized at Jackson in 1900 . Removed to Memphis and a class graduated each subsequent year. The dean is Dr. M. V. Lynk. Registration for $1912-13$ was 45 . gracluates, 13.

Tenn. 15.-College of Physicians and surgeons. Memphis. Organized 1906. Was sometimes referred to as the Lnirersity of Memphis, Medical Department. The first class graduated in $190 \%$, and a class graduated each subsequent year. Absorbed by the Unirersiby of Temmessee Medical Department in 1911 .

Teun. 16.-Tefferson Medical Association, diplomas. Extinet about $18 \% 5$. Said to have been an examining board only.
Tenn. 17. - IIamnlhad Medieal college, Momphis. oryan?ed 18s9. Fxtinct 1896. Fo graduates chring 1893 to 1896 Inclus

Tomn. Is. Clattanerga Natirnal Medical Exilnet in $1: 08$

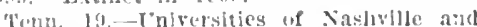

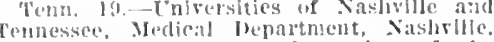
Organlacel in l:403 by the uninm of the "Yealical Deparlments of the infrersity of Sashrille and the Iniversity of Tennessee.
inton dissolved in lyll. (see Tenn. 6.)

\section{TEXAS}

Tex, 1. Texas Medical College and IIospital, Galveston, Organized in Iseit as the Galveston Medical College; reorganized unier the name of Texas Medieal college and llosintal in 1873 ; extlnet in

Tex. 2.-University of Texas, Medical Department, Galveston. Organized 1891 : tirst class graduated $18 \% 2$, and a class traluated each subsequent year. The dean is 1)r. William s. Carter. Total registration
for $1912-13$ was 153 ; graduates 43 .

Tex. 3.-Fort Worth School of Medicine, Department of Fort Worth Unirersity in 1894: flrst class graduated 1895, and a class graduated each subsequent year. In class graduated each subsequent year. In $191 \mathrm{I}$ it assumed the present title and ment of the Texas Christian Tniversity. Bccame Integral part of latter instltution in 1913. The dean is Dr. I. C. Chase. The total enrolin Tex. 4.-Bayler University College of
Medicine. Dallas. Orcanized 1900 as Universlty of Dallas Medical Department. The first class graduated in 1901. In 1903 became the Medical Department of Baylor Unirersity at Waco with Its present title. In 1904 it acquired the charter of the Dallas Cary. Total registration for 1912-13 was 91 ; graduates 21.

Tex. 5.-Physio-Medical College of Texas, Dallas. Organized 1902, first class graduated in 1902, and a class graduated each subsequent year, including 1908, when it combined with the College of Mediclne and Surgery, Plyysio-Medical, of Chicago.

Tex. 6.- Southern Methodist University, Medical College, Dallas. Organized 1903 as the Southwestern University Medical Colgraduated 1904, and a class graduated each subsequent year. The dean is Dr. John 0 . subsequent jear. The dean is Dr. John o. 65 ; graduates, 14.

Tex. 7.-Gate City Medical College, Texarkana. Organized 1902 . It was the outgrowth of the Medical Department of Sulpliur Rock (Ark.) College, organlzed in class graduated each subsequent year, inctuding 1908. when it became extinct. This college was exposed by the Arkansas Iedical Journal, Aug. 15, 1907. page 134. Mee Journal A. M. A., Oct. 19, 1907, page See Journal A. M. A., Oct. 19, 1907, page 1385. Recognition withdrawn by the Texas vember, 190\%. Reopened at Dallas in 1910 . caught selling diplomas in 19II. Its dean Dr. J. W. Decker, was convicted and sen-

Tex. 8.-College of Pbysicians and Surgeons, Dallas, Organized 1903 as Bell Medleal College. First class graduated in 1904 . and a class graduated in each subsequent year. In February. 1905, assumed present title. During 1909-10 was not recognized by the State Board. Extinet in 1910 .

Tex. 9.- Iniversity of San Antonlo, Medical Department, san Antonio. organized in $188 \mathrm{~s}$

Tex. I0.-Dallas Jedical College, Dallas. It was the Medical Department of Trinity lniversity. Organized in 1900, first class Fratuated 1901, last class graduated 1904 , when it was merged

Tex. 11-University of Hedicine and Surgery, Dallas. Organized 1906 . Held no sessions. Extinet.

\section{UTAH}

Utah 1.-University of Utah School of Medicine, salt Iake city. Organized in medleal course. The enrolment for 1912-13 in: Ib.

l:al 2.- Neclleal Instltution of Morgan l:tah 2.--liedleal Instltutlon of Morgan
("ity, Morgan clty. Extlnet about 1883.

\section{VERMONT}

Vt. 1 - Castleton Medical College, Castleton. Ormanized in IS18 as the Castleton Medical Academy. In 1821 name changed to Vormont Academy of Itedleine. Sus1811 name again changed to Castleton Medical College. Graduated 350 students during its existence. Extinct in $186 \mathrm{I}$.

Vt. 2.-University of Vormont College of Medicine. Chartered in 1822, flrst class IS23, and a class traduated each subsequent year to 1836 lnclusire, when the school
suspended. IReorganized in $\mathbf{1 8 5 3}$ and elass graciuated In 1854 and each subsequent year. The dean Is Dr. H. C. Thkham. graduates, 37 .

sec sipeciel Innouncement Id 2 . page 45

Vt. 3.-Vermont Medical College, Woodstock. Organized 1827 under name of Clinical School of Medicine. Incorporated with above title in 1835 , became extinct 1856 . A reputable college. (See Vt. 4.)

vt. 4.-Vermont Medlcal College, Rutland. Incorporated 1883 by Amerlcan Health Soclety. Extinct 1893. Fraudulent. Do not confuse with Yt. 3.

Vt. 5.-Trinlty University College of Medleine and Surgery of the State of Vermont, Bennlington. Incorporated in 1889 . Fraudulent. Extinct.

Vt. 6.-Union Medlcal Institute, Newbury orfanlzed In 1887. Fraudulent, Extinct.

\section{VIRGINIA}

Va. 1.-University of Virginia, Department of Medicine, Charlottesville, Organized 1827, first class graduated 1828, and a class graduated each subsequent year except 1865 . The dean is Dr. R. H. Whitehead. Total enrolment for 1912.13 was 91 . graduates 14.

See special Announcement Adr. page 4t Ya. 2.-Medical School of the Valley of Virglnia, Winchester. Organized 1826. ExtInct I86I.

Va. 3. - Winchester Medical College. burned 1861. Extinct.

Va. 4.-Medical College of Virginia, Richand 1838 as Medical Department Ilampden Sydney College. Present title Is54, frst class graduated 1840, a class graduated each subsequent year. In 1913 the University College of Medicine was absorbed. The dean is Dr. Stuart McGuire. Total registration for 1912-13 in the two colleges was 416 ; graduates, 83 .

Va. 5.-Randolph Macon College, Medical Department, Prince Edward Court House. organized I840. Extinct 1855 .

Va. 6.-University College of Mediclne Richinond. Orranized $\mathbf{1 8 9 3}$ as the College of Phrsicians and Surgeons: present title in 1894; first class graduated in 1894, and a class graduated each subsequent year. Absorbed by the Medical College of Virginia In 1913.

\section{WASHINGTON}

Wasli. I.- Lniversity of Washington Med ical Department, Seattle. Organized in 1885. No sessions held.

Wash. 2.- Northwestern College of Biocheming in 1889 as the Washington Biochemic Medlcal College at North Yakima. Removed to Spokane and took above title in 1892. Ten days after the charter for this institution was obtained, George M. Carey, a non-graduate in medicine, registered a diploma which he had Issued to himself. (Rauch.) Fraudulent Extinct about 1893.

Wash. 3.- University of Spokane Falls, College of Medicine, Spokane. Organlzed 1890. No session ever held. Extinct. 


\section{WEST VIRGINIA}

W. Va I. -West Virainia University Col. lege of Medicine. Morsantown. Organlzed In 190: and glves unly the tlrst two years of the medical sourse. The dean is $1 \mathrm{D}$. John $x$. Simpson. Toul regisiration for $1912-13$ was

\section{WISCONSIN}

Wis. 1.-Mllwaukee College of rhystcians and surgeons. Knowt alsu as the coney Mraudulent. Fitinct. charter annulled issi. Fraudulent. Fitinct. "harter annulled lis3. Wh. -Wlsconsin i"ollege of l'hyslclans and Surgeons, Mtlwaukee, organ!zed 1sa3, Arst class graduated 1394 and classes grad-
uated each subsequent year. In 1913 all its property was sransferred to the Mar. quette Cinlrersity School of Medicine and it became extinet.

Wls. 3.-Milwauke Medical College, Mi! waukee. Organlzed 1syt. tirst class grad. uated 1895, and a class graduated each sub-

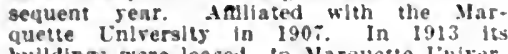
sity scbool of Medicine and it becane

exinct. 4-Wisconsin Felectic Medical School. Established 1894. Pedjled diplomas. but never graduated a class. Sup. pressed 1598

Wis. 5.-University of Wisconsin College Cives but two years of the melical course. The dean is Dr. Charles 12 . Bardeen. The enrolment for 1912-13 was 66

Wis. 6.- Marquette University School of Wedielae. Mlluraukee Oranized in Decem ber. 1912 . by lease and purchase respectively of the Milwaukee Medical college and the Wisconsin college of l'hyslclans and surgeons. Heglnning in 1913 the entrance requirements included, in addliton to a fur year high schonl educatlon, one year of chemistry, biology and a molern language. Beginalng with the session of 1914-15. two years of college work will be reluired The dean ls or. Louis F. Jernain. The untes. 8 .

\section{MEDICAL COLLEGES OF THE DOMINION}

\section{MANITOBA}

Man. 1.-Manitoba Medical College. Winnlpeg. It is the Medical Faculty of the liniverslty of Sianitntua. Orzanized 1883 unted each subseruent year The dean is Dr. H. H. Chown, Winnipeg. The total regls. tratlon for 1912-13 was 154; graduates, 29.

\section{NOVA SCOTIA}

N. S. 1.-Oalhousle University Medical Faculty, lialifar Incorporated so the llallex lledleal college in is.5. Ireorinalzed ax an examinlug fac. ulty separato from the llailfax Nedica tollege in 1885 , In 1411 . In accorlance wlth an agrement hetween the governors of Inallousle I'niversity nul the corporation of the Hallfax Metlical intlege. the work of the latter instltupion was discon. eatubltathed toy the Infrecilty faculty was rangement between Daliousle Infrersity and the prorincla! Nellcal Hoard of Nova seisia the final protessonal examinatlons are cinducted confolnoly by the eniverste and the loard, and candidates nay jualify at the same time for their acadenic degrees and the provineial license First class

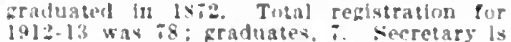

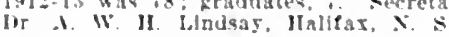

\section{ONTARIO}

Ont. 1.-Universlty of Toronto. Faculty of Medicine. Tornto. Organized 184: as bulished in is53. Repstablisher in 158 . The ciurse of study covers tire years of elate months each. In lang it absorhed Trinitia rnveralty and in 1903 it absorbed Trinity Nedical College. The secretary is 19. D. I'rimrose. The total regi

Ont :-Toronto school of Medicine, $T_{1}$ runto. Organized in 18t7; aftliated with Unirersity of Toronto. $195 \%$ : affliated also wh Victorla Lniversity. Exinet 18s\%.

Ont 3.-Trinity Medical College, Turonto. Organized In 1853 as the lpper Canada school of Medlcine, suspended in 1854 . reorzanized is:0 as Finculty of Mediche of Trinlty college: constluted a separate cor. poration culled Trinity Medical college. Is:-: andiated with Trinlty [niversity and Iniversity of Toronto, $18 \mathrm{~s}$ : zeconstituted as Iedical Faculty of Trinty r'niversity. of the Cinirersily of Toronto. 1003

Ont. 4.-Victorla Lnirersity Medical Department. Orzanized 1853. Fintuct 1869 Also known as Rolph's school. Vleboria liniversity conthued to grant medical degrees, howerer. until 1902. When It was absorbed by the Iniversity of Toronto.

Ont. 5.-Queen's University Medical Faculty, Klngston. Organized Is 4 , flrst clase graduaterl In 1855, and a class gratuated each subsequent year. The faculty was originally a department of the Iniverslty. tiut a separation took nlace in 1866, when the school was conducted under the charter of the Royal College of Physicians and

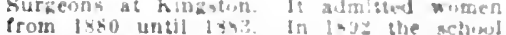

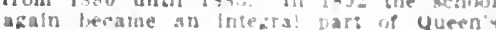
Ciniverally A tre-ber med!ral course The total reaglatiotion in $1: 1 \%-13$ as graluates, ti)

Ont. 6. - Western Universily Medical OC. partment. Lundon. Jrivanized la J $=1$. Arat class grafuated in las. and a clans hras. uated each gear sulweglentive The reg (i) $1912-13$ was 104 ; Eraduates.

uns : -Kingaton Woman's Meducal (inl. leze. (organtzed Is43. The dergems were granted by queen's Intverslty with which 8 was amliated. kixtincs los

unt. 8.-contario Mealcal rollese tor ared with the inivervits of Turonso Inil. empowered to grant degrees.

\section{QUEBEC}

Que. 1.-McGill University. Medical Fac. Institurion. ISef as Montreal Medical lichill iniversiss in lfog: frst clasa grad. uated under the unirersiby auspices in 1833 . No sesulons tretween 1836-34 nwing to polis ical troubtes in 1905 atonothed baculis of Velleine Inirersigy of kishop robleze. The registrar is Tr. John W. Sicane. Number uf suldents

aue. 2--Ecnle de Medecine et de Chirurale. organized 1s43. Incormirateed itst classes graduated 1843 to 1891. incluare when it united with Iaral Inirersiry. Nedica! Faculty. at Montreal.

Que. 3,-Laval University, Medical De partment, Quebec. The Quebec sichul of Medicine, nratnized in 1sts, liecathe in Medical Mepartment of Laval Inives. class first clas, craduated ln 1835. and a dean is br. If 3 thern quetec. The enrolment ior $1913-13$ was bif; graduates. 2.

Que. 4.- Montreal Sehool of Medicine and Surgery, Montreal. Organized in lsis a the Medical Department of Laral Lnlrer. sity. l'resent name nisumed in 1911. First class graduated in 14.9 in 1891 absorteed the Foole de Medeclne et Chirursle. The for 191:-13 was 150: graduates, 33

Que. 5-Iniversity uf Jishon Collepe. Faculty of Medicine. Montreal. Organized 18:0, flrst class tiraduated 15:1. and classe ralluated each subserfuent year: in 190 was ahsorbed by McGill Lalversity Mellica livartment.

Que. 6.-.: Ianrence Schml of Mell-

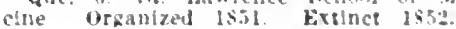

\title{
POST-GRADUATE MIDICAL COLLEGES
}

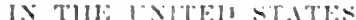

\section{ALABAMA}

Ala-G1.-Graduate School of Medicine of the University of Alabama, Are. $F$ and oin St.; ItIrmin

\section{CALIFORNIA}

Cal.Gi.-San Franclsco Polyclinic and Post-Graduate Medical School, 143 Fllimnre St. San Franciwco. The serretary is lor. Martin Rezensturger. 1218 Heal Mlig

\section{ILLINOIS}

III.GJ._Chicago Pollelinle. $\$ 19.221$ w Chlcagu Are. Thicago. The secrubary is Dr. Majenlm J.. Harrls, :3 I Silate sit.

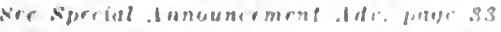
III.G2. - Illinois Post-Graduate Medieal

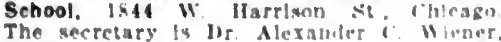
32 The serate st.

III.G3.-Post-Graduale Medical School.

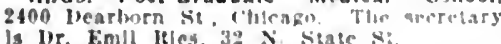

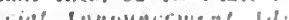

III.Gs.-Chicago Eye, Ear. Nost and Throat Colleve, 20h fo Wanhingt on st, ChI cinen, The secresury
inan, 31 $x$. State st.

III.G5.-IIlinois School of Electrotherapeu-

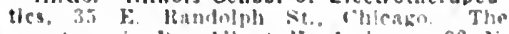
state st.
stary lit llwert II.

La.GI.-New Orleans Polycilale. Tulane dre and lifuerty Sit. New orleatis The dean Is Dr. Chus. I. Chasulenac, ol t tum!

Mass.fol.- Harvard University Gadunte School of Medlelne. The dean is pr. Horace I1. Arnold. Missoupi

Mo.Gl.-Kansas City Post.Graduate Med. ical School and Hospital. OIf Independence

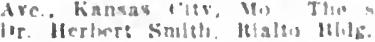

\section{NEW YORK}

M.Y.O1.-New York Posf.Graduate MedI.

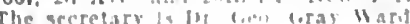
Ji

N.Y.G2 - Nex York Polyelinte Medical School.
The secretary is lir. Wm. Van Valzah Haves. 36 W 50th st

N Y.G3,-New York School of Clinical

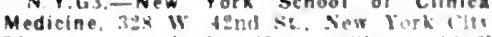
The secretary is Jo fromer lithey of N.Y.G4. - Manhattar Post - Graduate School of Ophthalmolosy. Otology and Larynoology. $=10$ t: bith ke. Yew lork Fines. 11 h. tuin st:

N.Y.GS-School of Ophthalmologr and ololugy, 13th si nud ed Are.. Dew lork City The secretary fa for. (ees. \& bionn.

\section{OKLAHOMA}

Okis GI.-Southwest Post-Graduate Medi.

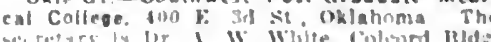
PENNSYLVANIA

Pa.Gi-Philadelohia Polyellnic and Col. tege for Graduates in Medicine. Latoban Atwin fisth st. I'tifludelohia. The dean is 


\section{FOREIGN MEDICAL COLLEGE KEY-TABLE}

cote.-This list includes the key number and addresses of foreigu colleges arranged alphabetically ly countries, also the llcensing lodies of England, Scotland and Ircland.

\section{ARGENTINE REPUBLIC}

Arg. 1.-Lntversidal Naclonat de Buenos Alres, Buenos Aires.

Arg. 2,-Universidad Nacional, cordova.

\section{AUSTRALIA}

Austl. 1.- InIr. of Adelalde, Adelaide. Anstl. 2.-Vinls, of Nellourne, Melbourne.

Austi. 3.- Cniversity of sydney, sydney.

\section{AUSTRIA}

Aus. 1.-Karl Franzens Lniverstät, Gratz. Stỵia.

Aus, 2.-Icopold Franzens I'nlversltat Innsbruck, Tyrol.

Aus. 3.- Cniwersytet Jagiellonski w Krakowle, hrakow, Galleis.

Aus. 4.-C. K. Uniwersytet Imlenia Cesarza, Franciska I., Iemberg, Galicia. Aus, 5.-K. K. Deutsche Karl-FerdinandAus, 6.-C. K. Ceská inversita KarloFerdinandora, l'rague, IBo hemia.

Aus, 7 -Kalserliche Königliche Lniversitit, Vienna, Nether Ausiria.

\section{BELGIUM}

Belg. 1.- I'nlversité Iblore de Bruxelles, Brussels.

Belg. 2.- Inniversite d l'Elat de Gand Ghent.

Belg. 3.- Inlverstte de Ilege, Liege.

Belg. 4.-Unlversite Catholique, Lowrain.

\section{BOLIVIA}

Bol. 1-Universldad de La Paz, La I'az.

Bol. 2.-Universldad de Sucre, Sucre.

\section{BRAZIL}

Braz. 1.-Faculdade le Medlcina, Cirurgia e Pharmacia, Brazil

Braz. 2.-.-Faculdade Livre de Medicina e Pharmacla, Port Allegre.

Braz. 3.-Faculdade de Mediclna, Cirurgia Pharmacia, Rio de Janeiro.

\section{CHILE}

Chi. 1.-Unirersidad de Chile, Santiago.

\section{CHINA} rhina 1.-Hcngkong Collegc of Medieine,

China 2.-East China Union Medical College, Nauking.

ChIna 3.-The Union Medical College, Jekin. China 4.-Woman's Medical Scliool, shangChina 4,- Womai.

China 5.-Canton University Medical College. China 6.-South China Medical College, Canton.

\section{COLOMBIA}

Colombia I.-Cniversidad de Bogota, Bogota. CUBA

Cuba I.-Cniversidad de la Habana, Havana. DENMARK

Den. 1.-Kjobenharns Unirersitel, Copenhagen.

\section{EGYPT}

Egy. 1.-Kasr il Aini (School of Medicine) Cairo.

\section{ENGLAND}

kng. I.-Lniversity of Birningham.

Eng. 2.-Cniversity of Bristol, Bristol.

Eng. 3.-Cniversity of Cambridge.

Eng. Durham Cniversity, Durham.

Eng. 5.- - - niversity of Leeds, Leeds.

Eng. 6.- - Iniversity of Liverpool.

Eng. T.-Zniversity of London.

Eng. S.- Victoria Lniversity, Manchester.

Eng. 1 - Cniversity of Oxford.

Eng. 10.-Lniversity of Sheffield.

Eng. II.-Licentiate of the Royal College of lhysicians, London.

Eng. 12.-Nember of the Royal College of Pliysicians, London.
Eng. I3.-Feitow of the Hoynl college of lhysiclats, London.

Eng. 14.- Ialentiate of the Royal College of surceons, Eurtand.

F.ng. I5.-Nenber of the Royal college of

Eng. 16.- Fellow of the Royal college of

surgeons. Eugland.
jug. 17.-Ideontlate of the Apothecaries' Society of Iondon.

Eng. 18.-Iicentiate in Nedicine and Surgery of the Apothecarles' Soclety of Iondon.

\section{FRANCE}

Fra. I-Universito de Bordeaux, Bordeaux. Fra. 2.-Universite de Illle, Lllle.

Fra. 3-Unirersite de Lyon, Lyons.

Fng. 4.-Inlverslte de Iontpellier, MontFra 5 - Inllier.

Fra. 5.-Inlversite de Nancy, Nancy.

Fra. 6.-Universite de Paris, Paris.
Fra. T--Universite de Toulouse, Toulouse.

\section{GERMANY}

Ger. I-Königliche Frledriche-Wilhelm Ger. 2-Rheinische Thiversitat, Berlin, Prussia. cer. 2.-Rheinische Friedrich-Wilhelms Ger. 3.-Königliche Universität, Breslau, Ger. 3.-Königliche

Ger. 4.-Königl. Friedrich-Alexanders LnlGer. 5.- Grossherzogliche Badische AlbertLudwigs Universität, Freiberg, Baden.

Ger, 6.-Grossherzogliche Hessische Iudwigs Universität, Giessen, Hesse.

Ger. †.-Königliche Georg-August Univer-

sität, Gottingen, Prussia.

Ger. 8.-Königliche Unlversität. Griefs-

wald, Prussla.

Ger, 9-Vereinigte Friedrichs Universltät Halle-Wittenberg, Halle,

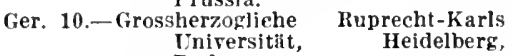
Baden.

Ger. 11.-Grossherzogliche und Herzogllche Sächsische Gesamt-Universitut, Jena, Thuringia.

Ger. 12.-Könlgllche Christian-Albrecht Universität, Kiel, Prussia.

Ger. 13.-Königliche Albertus Universtăt, Konigsberg, Prussia.

Ger. 14.-Universität, Leipzig, Saxony.

Ger. 15.-Universität, Marburg, Prussia.

Ger. 16.-Könlgliche Bayr, Ludw|g-MIaxlmilians Unirersität, IIunich, Bavaria.

Ger. 17.-Unlversität, Rostock, Mecklenberg. fer. 18.-Kalser-Wilhelms Universität, Ger. 19.-Konnigliche Eberhard-Karls Untversität, Tübingen, Wurtember $20 .-$ hönte berg. Julius-Maxlmilians Cniversitiat, Wïrzburg, Bararia.

\section{GREECE}

Greece I.-National University, Athens. GUATEMALA

Guat. 1.-Facultad de Medicina, Guatemala. HAITI

Haitl 1.-L'Ecole Nationale de Médecene, Port au Prince.

\section{HONDURAS}

Hond. 1.-Facultad de Medicina, Tegucigalpa.

\section{HUNGARY}

Hung. 1.-Budapesti Kiralyl Magyar Tudomany-Egyetem (Royal Hungarian University), Budapest.

Hung. 2.-Kolozsvári Magyar Királyi Ferencz-Josef Tudominy-Egyetem (Roversity) burg.

\section{ICELAND}

Ice. I.-School of Physlclans, Reykjavik.

\section{INDIA}

Indla 1.-Unlversity of Bombay.

India 2.-University of Calcutta.

Indla 3.- Panjab Unlverslty, Lahore.

Indla 4.- University of Madras.

\section{IRELAND}

Ire. 1.-Queen's Unlversity, Belfast.

Ire. 2.- National Unlversity of Ireland (formerly Royal University of Ireland), Dublln.

Ire. 3.- Inlversity of 'Dublin, Dublin.

Ire. 3.-Tnlrersity of Dublin, Dublin.

Ire. 4.- Royal college of Surgeons,

Ire. 5.-Ifeentlate of the Kings Queens College of Physicians, Ireland.

1re. 6.-Iicentiate of the Royal College of Ihysiclans of Ireland.

Ire. 7.-Member of the Royal College of Physicians of Ireland.

Ire. 8.-Fellow of the Royal College of Physicians of Ireland.

Ire. 9.-I Icentlate of the Royal College of Surgeons of Ireland.

Ire. 10.-Fellow of the Royal college of Suryeons of Ireland.

Ire. II.-Iicentiate of the Apothecarles Hall of Dublln.

\section{ITALY}

Ita. 1.-Regla Lnlrcrsita degli Studi, BoIta. 2.- Cniversita degli Studi, Cagliari, Ita. 3.-Iibera Universita degli Studi, Ita. 3.-Libera Universita degli Studi, Ita. 4.-Regia Cniversita degli Studi di Ita. 5.-Libera Universita degli Studi di Ferrara, Ferrara.

Ita. 6.-Regla Instituto di Studi Superiori Practicl e di Perfezlonamento, Florence.

Ita. 7.-Regla Unirersata degli Studi,

Ita. 8.-Regia Universita degll Stud!, Mes-

Ita. 9.-Regia Universita degli Studi, Mo-

Ita. 9.-Regia Universita degli Studi, Mo-
Ita. I0.-Regla Universita degli Studi,

Ita. II.-Regia Naples.

Ita. 12.- Regla Universila degli Studi, Pa-

Ita. I3.-Regla Lniversita degli Studi,

Jta. I4.-Regla Lniversita degli Studi, Pavia.

Ita. 15.-Università Libra degli Studi,

Perugia.
Ita - I - Regla Unirersita degli Studı, Pisa

Ita. 16.- Regla Unirersita degli Studi, Pisa.

Ita. IS.-Regla Lniversita degli Studi, Sas-

Ita. I9.-Regia Ĺnlversita degli Studi, Siena. Ita. 20.-Regia Universita degli Studi, Turin.

\section{JAPAN}

Jap. 1.--Imperial Unlversity, Kyoto

Jap. 2.-Medical School of Formosa, Tamsui

Formosa.
Jap. 3.-Iniperial University, Tokyo.

Jap. 4.-Medical School of Alchi, Aichi.

lap. 5.-Medical School of Chiba, Chlba.

Jap. 6.-Medical School of Kanazawa.

Jap. 7.-IIedical School of Kumamoto

Jap. 8.-Nedical School of Nagasaki.

Jap. 9.-Medical School of Okayama.

Jap. 10.-Medical School of Sendal.

\section{MEXICO}

Mex. 1.-Escuela Nacional de Medicina IIexico.

Mex. 2.-Monterey Escuela de Medlcina de Nuora Leon.

Mex. 3.-Escuela de Medicina y de Farmacia de Jalisco. 


\section{FOREIGS MEDICAL COLLEGES}

NETHERLANDS

Neth. 1.-Cintrersltelt ran Amsterdam, Am.

Neth. 2.-Rijks-L'nirersiteit to Groningen, Gronlngen.

Neth. 3.-Rijks-Enirersitelt, Leyden

Neth. 4-nijks-Linlversltelt, itrechi.

NEW ZEALAND

New z. 1.-Iniversity of New Zealand, Wellington.

\section{NORWAY}

Norw. I-Kongellge Frederlks Lnlrersltet, Chrlstianla,

$$
\text { PERU }
$$

Peru 1. - In]rersldad Mayor de San Marcos, Llma.

\section{PORTUGAL}

Port. 1,-linlversldade de Colmbra.

Port S-Escola Medico-Cirurgica, ILstoon.

Port. $9 .-$ Escola Medico-Cirurglca, IIston.
Port. 3.-Escola Medico-Clrurglea, Oporto.

\section{ROUMANIA}

Rou. 1.-Lindrersitatea din Bucurestl, Bukharest.

Rou. 2-Cniversltatea dIn Jasl, Jassy.

\section{RUSSIA}

Rus. 1.-Kejserllga Alexanders Cniversitet, IIelsingfors, Exgland.

Rus. 2.-Imperatorskij Jurjessilj iniversltet, Jurjey (formerly lorpat).

Rus. 3.-Imperatorsklj hasanskjj Lniversi. tet, Kazan.

Kus. 4. - Imperatorsklj Charkovskj Cinjrersltet, Kharkof.

Rus. 5.-Imperatorsklj Lniversitet Sr. Vladi-

Rus. 5.-Imperatorskij Lni
mlra, Kle?

mlra, Klef.
Rus. 6.-Imperatorskif Nuskorskis, Lnirer. sltet. Moscow.
Rus. :--Imperatorskif Nororosilskly ['n]versitet, Odessa.

Rus. 8.-Tonsklj [niversitte. Tomsk, S1. berla.

Itus. 9.-Imperatorskif Varavskif Lulver. sltet. Warsaw.

\section{SCOTLAND}

Sent. 1.- T'nirerslty uf Alherdeen, Alereen. sent. 2.-I'nlverslty' of st. Indrews, vundee.

sicut. 3.--1ntrersity of Fidnlurgh.

sicot, t.-Srhoul of Mediclue of the lioyal ('olleges, billnburgh.

scof. i. - Infrerslty of filascow, filasgow

sicot. E.-Inderson's College Mtedical sehuot. Cilasgow.

scot. :... st. Mungo's follege and Glasgow Koyal Influmary, filaskow.

sion. S. Western Medical school. flasgow.

scot y. Idcentlate of the koral college of I'hyslclans, kdinburgl.

scot. 10.-Menter of the Royal inflege of l'byslelans, Edinburkh.

Scot. 11.- Fellow of the Koyal cullege of Physlclans, Fdinburkh.

scot. 12.-Llcentiate of the Royal College of surgeons. Edinburgh.

Scot. 13,-Fellow of the Royal College" of surgeous. Edinburgh

scot. 14.-1.lcentlate of the Royal Faculiy of Ithysletans and surgeons of Glasgow.

scot. 1.7.-Fellow of the hoyal Faculty of Giasgow.

\section{SF'AIN}

Spa. 1.-Inirersidad de Barceloua, BarceJona.

sua. 2.-Facultad de Medicina, Cadiz.
Spa. 3.-Inlversidad de liranala, firangda.

Spa. - Lindrerstdad de 1 cntral de Espana. Madrid.

spa. 5-Cinlverwidad samzian.

Spa 6.- inirersidad, Sarazosas.

spa. :- Cntrersidad ie Serilla, seville

Spa. 8.- Indrersldad lilierar!a. Valenele

spa. 9-Inirersidal, Valladoid.

\section{SWEDEN}

swed. 1.-Kungl. Karollnska ["ulrepsiclet. lund.

Swed. 2-Karolinska Instlutet, stockhoim.

swed. 3.-hung! Cnirersitetet I L'gsala Losala.

\section{SWITZERLAND}

Swltz. 1.-liuiverslth?, Hasel.

switz. 2.- hantonale Cnirerslut, Berme switz. 3.-Cnirersita: Fribourz.

switz. 4-Intrenslte de Genere. Genera.

swisz. 5.-linfrersite. Lausana.

Switz. 6--inirersitit yew thatel

switz. F.-linirersits, Zurch.

\section{SYRIA}

Syr. 1.-Syrlan I'rotestant College. Beirut.

Syr. 2.-Linirersiza Salnt Joseph de Hey routh, Helruz TURKEY

Turk. 1.-- Iniversity of Constantinople. URUGUAY

Irug. 1.-Cnitersidad. Monterldeo. VENEZUELA

Venez. 1.-livirersldad, Caracas.

\section{WALES}

Wales 1.- Iniversity of Wales reandif School of Mtedlelne), Cardit.

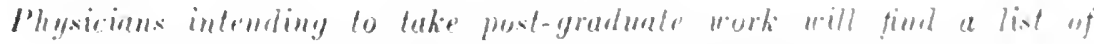

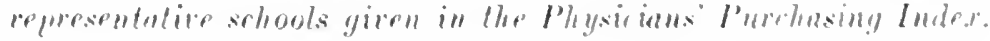
see palye 1 .

Physirans who may desire to refor youn!l romen to relinhle trainim!

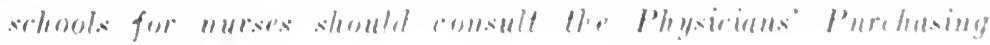
ludeat page 12. 


\section{MEDICAL LIBRARIES}

\section{OF THE UNITED STATES, CANADA AND PHILIPPINE, ISLA DDS}

Noth.-The followlug list Includes lihrarles belonglug to medleal socletles, liospitals, medical colleges, slate boards of health, ecc The llwures indicate the number of rolumes.

\section{ALPHABETICAL LIST}

Adrondack cottage sunltarium Medleal Llbrary $\ldots \ldots \ldots \ldots \ldots \ldots \ldots$. y.

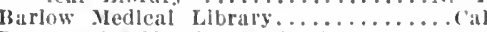
Boston City IIospltal Medical Library Mass.

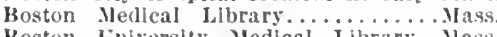
Boston Culversity Medical Library...Mass. Carnegle Llbrary of I'ttsburgh, hed-

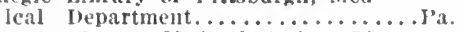
Chenango County Medlcal Soclety Li-

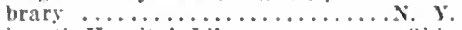
CInclmiti IIospltal Library........... ohio cleveland Medleal Library issociation.ohlo ('lereland-I'ulte Medical College Ji-

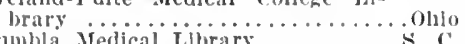
columbla Medical Llbrary............. s. Cooper Medical College Librnry............. Department of Pathology, Cornell Unlversity Medlcal College........ Y Eclectic Medlcal College Library....... ohlo El J'aso County Medleal Society il-

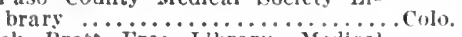
Enoch Prait Free Library, Medical Flanders Medlcal Jibrary of the Law rence General Hospital........... Mass Forbes Libraly, Medical Department...Mass. Hahnemann Medleal College Lubray.....Il.

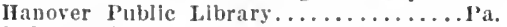
Indinuapolis Public Libriry, iredicai Depurtment ................... Ind. Jeffersun County Medical Library............. Jefferson Medicnl College Library........ I'il. Jersey City Public Library, Medical Department .................. Crerar IJbrary,

Jedical sciences..............lll.

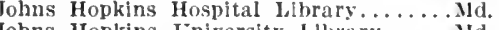
Kansas City Medical Library ("lib............... Lane Medical Llbrary of stauford

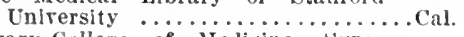
library-College of ifedicine, syracuse University ........................ George Washington Cniversity.... Department of Medicine, University of Maryland.......................

lbrary of College of Medicine of

Department of Medicine, Iniversity

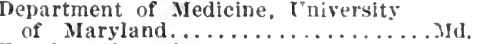

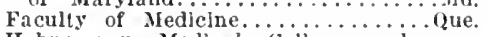

Hahnemann Medical College and

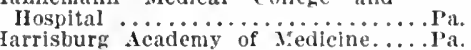
Harrisburg Academy of Medicine.................... Harrard Medical school............... Mass. Jefferson County Medical Society........ Lackawanna County Medical Society. Pa.

Tufts College Medical school............. Library of the Academy of Medicine of Cincinnati....................... Academy of Medicine............... College of Medicine, University of

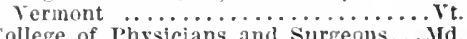
College of Jhysicians and Surgeons....Md. college of I'hysicians and surgeons ('ol umbia l"niversity.............. $\mathrm{Y}$. Collece of Pligsicians of Philadelphia.Pa. Deciltur Medical society..............

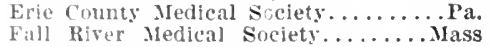
crentria vedical Sociery of Ghatham

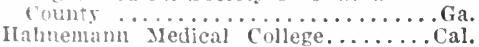
If mepin ("ounty Vedical soclety. vinn. Kalamazno Aerdemy Iedicine........ Mich. huzerne county Medieal society.........
Marifuette linlversity school of

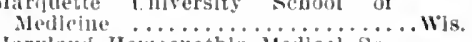
Maryland Homeopathic Medieal Societs
ledical and chiruraical Faculty of

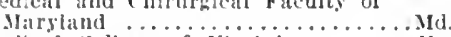
Medical college of virginin............ Medleal Department of Dirtmouth

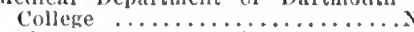

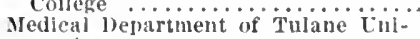

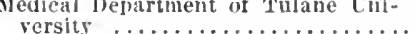
vedleal Department, Lutrersity of

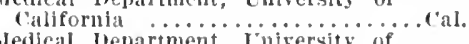
Vedical bepartment, iniversity of . Tex.

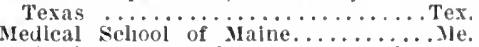
Medical soclety of the city and County of Denver............. Colo. Medical Society of the County of redical society of ihe County of 1 . Kings $\ldots \ldots \ldots \ldots \ldots \ldots \ldots \ldots \ldots \ldots \ldots$ Medico-Chirurgleal College ........... Pa. Iimicipal Ilyglenic Laboratory........ (ia. New Haven Medical Association.... Conn. New York Academy of Medicine...... Y. New York IIomeopathie Medical

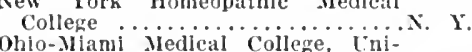
Ohio-Mlani Medical College, Ini-
versity of Cincinnati........... ohlo Philippine Bureau of Science........... Pittsburgh Acadeny of Medicine............ Pueblo County Medical Society..... Colo. Ramsey County .lledical Society.... Mimm. Rhode Island IIedical Soclety......... I. I. Rockefeller Institute for Medical

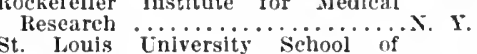
St. Louis Unjversity School of ...

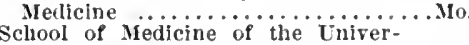

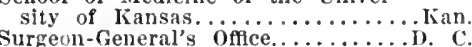
Surgeon-General's office............... c. Thurber Medical Assoclation.......... Mas. United States Naval Medical School.D. Vancouver Medical Association........... Washington University Ifedical School... Mo. Wayne County Medical Society........ich.

Woman's Hedical College of Penn-

sylvania $\ldots \ldots \ldots \ldots \ldots \ldots \ldots \ldots \ldots . . \ldots$. LIbrary, Morgai County Medieal Society. III. Library School of Medicine, University of Alabama.......................... Louisville Free Public Library, Medical Department ..................

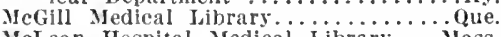
IeLean Hospital Medical Library.......... Medical Department Library of the University of Oklahoma......... Okla. Iedical Department of the Cniversity of Pennsylvania Library.............

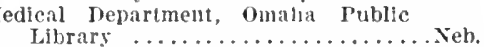

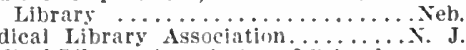
Medical Library Association. ........
Medical Library Association of Scliuyl-

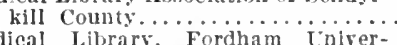
sity school of Medicine.............

Ledical Library of the College of iny-

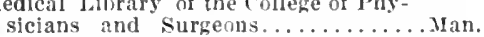
Medical Library of the Pennsylvania Hospital ..............................

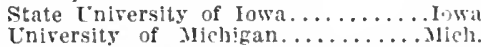
Medical Library, University of $\mathrm{Mis}$ -

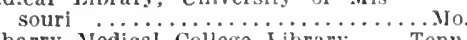
Meharry vedical College Library..... Tenn. Iriffin County Medical Society Li-

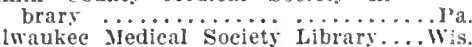

Mussey Medlcal and Sclentlfic Ifbrary ohjc New Hampshire State Library, MedIcal Department................ H New York Public Llbrary .................. I New York State Medieal Librnry....... I Northwestern iniverslty iedical

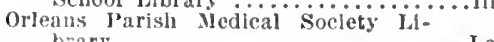

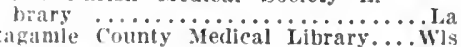

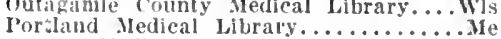

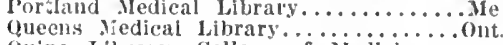

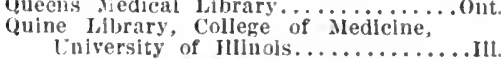

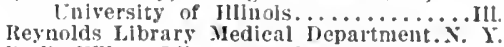
li. 13. Wilson Mibrary, Medical Dejartment of the Ciniversity of Ore.

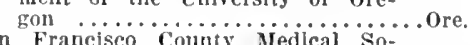

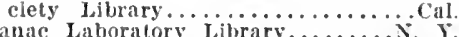
Saranac Laboratory I ibrary...........

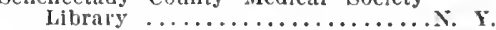

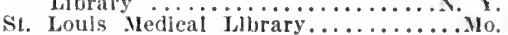
St. Louis I’ublic Library Ifedleal $0 . .$. Mo.

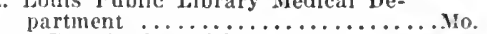

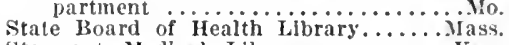

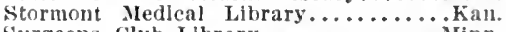
Surgeons club Library. .................. Minn.
Treadwell Library,

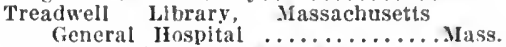
University of Buffalo Medical Library N.

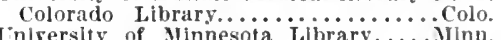

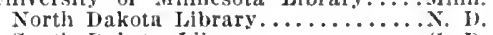
South Dakota Llbrary.................. D. Igo County . Medical Soclety Library... Ind. Washington Medical Library AssociaWashington Medical Library Associa- Wash. Western ieserve University Medical . Wash.

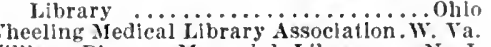
Willam Pierson Memorlal Library...... J. Worcester District Medical Library........ Jass. york County Medical Soclety LIbrary...P'a.

\section{NUIIBER OF LIBRARIES, 146} ALABAMA

Birmingham

Library of Jefferson County Medical Society, 4th Ave, and I9th St., Birmingham, Ala. Established I905 by elght physicians. Llla May Chapman, Librarlan.

\section{Mobile}

Library School of Medicine, University of Alabama, St. Anthony and Lawrence Sts., Moblle, Ala. Established 1859 by State of Alabama. W. L. Cahall, Librarian. 2,500 .

\section{Los Angeles}

\section{CALIFORNIA}

Barlow Medical Library, 742 N. Broadway, Los Angeles, Cal. Established 1906 by physicians of Los Angeles. MIss Jessie A. Wier, Librarlan. 4,550 .

Los Angeles County Hospital Library. 1100 Mission Rd., Los Angeles, Cal. Established 1914 by Los Angeles County. Dr. C. If. Whitman, Librarian.

\section{San Francisco}

Cooper Medical College Library. Sacramento and Webster Sts., San Francisco. Lane Medical Library of Stanford Lniversity, Sacramento and Webster Sts., San Francisco. Established IS95 by Levi Cooper Lane. Louise Ophuls, Acting Librarian. $3 \pi, 66 \pi$. 
Library of the Hahnemann Medleal Cot lege. Maple and Szeramento sis., San pranclsco. Established 1900 by' Irs. samuel and Janes Iflleuthal. Dr. Guy $r$. Vannlne. Librarian

Llbrary of the Medical lepartment. Iniversity of Callfurnia. Pamassus Ave. Tniversity of Callfurnla, Parnassus Ave. ulty. Milton B. Lennon, M.D., Llbrarian ulty.

San Franclsco Couney Medical Soclety Library, 135 Stockton St. San Frabclsco. Dr. Leo Kloesser, LItrarlan. \$870

\section{COLORADO}

Boulder

Unlversity of Colorado Library, Houlder Colo, Establlshed 1885 . C. Henry Smith. Librarian. 2,880 .

\section{Colorado Springs}

bl Paso County Medical Soclety I.I hrary. Cascado and Cache La louilre Sts. Colorado Sprjugs. Colo. Establislied 1900 by 21 Paso Couniy Medical Soclety. M. D. Ormes, LJurarlan. $2,900$.

\section{Denver}

Library of the Medical Soclety of the Clty and County of Denver. Metropolitan Blds. Denver. Establlshed 1893 by the Colorado Medlcal Library Assocla tlon. Merged Into the Denver Academy of Medicine 1905. Became property of the Medical Society, 1912. Dr. A. J. Markley, Librartan. 15,000.

\section{Pueble}

Library of the Pueblo County Medical Society. Central Block, Pueblo, Colo. Es tabllahed 1896. Dr. W. W. Bulette, LI brarlan. 4,538

\section{CONNECTICUT}

Hartford Library of the llartford Medical soclety, Tunt Memorial Mldg., 38 prospect St. Hartford, Conn. Established 1873, by Ilartford Medical Library Assoclation. Ior.

Walter I. Steluer, Librarian. $\$ .500$.

\section{New Haven}

Llbrary of the New Haren Medical As soclatlon, 152 Terople St. New IIaven, Conn. Fastablished 1807 by Jew Have Iedical Association. Dr. Gustarus kiliot, Librarlan. 6,000 .

\section{DISTRICT OF COLUMBIA}

\section{Washingto}

Llbrary, Department of Mtdlelne, lieorge Washlagton Unlterslty, 1325 II St $\mathrm{N}$-W Washington. Establlshed about is25 by the University. Emll Walter, Librarlan. ,537.

Llbrary of the Bureau of the Public Health Service, 3 B St., S.-E.. Wasluington. Asst. Surgeon Itichard A. hearny. Librarian. 6,000

Library of the Surgeon-General's oftice, ith and $B$ Sts. S. W. Washlngton Fstabliahed 1864 br Dr. John \&. Bllling

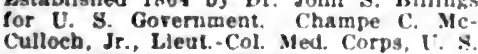
Army, Librarian. 175,000

Library of the United States Nara Medlcal School, 24th and E Sts. X. W Washington. Eatablished 1902. J. A Neu. Librarlan. 15,500 .

\section{GEORGIA}

Savanaat

Library of the Georsla Medical soclety of Chatham County, Medleal IHlyk.

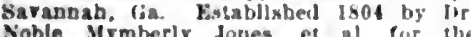
Georma Medical Hoclety. IIr. 1. II. Itas. sett. Lubrartan. 3,000 .

Library of the Munleipal Hyglente lab. Lhbrary of the Munleipal Hyglente Lah. oratory. Board of Sanilary Commlsuicunery.

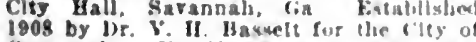
Sarannah. i. H. Isasueti. L.tbrartan 1,000 .

\section{ILLINOIS}

Chicago

Hahnemann Sedlcal fullege library 2811 Cottage Grove Avr. ('hlcagen Fistab) Usbed 1860 . W. Ilenry Witson, YII. Libratlan. 2,000.

John Crerar Idturary. Jepartinent of Medical sclences, 110 ;. Wabsah Ire Chlearo. Kistablished 1906. Ibepartment Librarian. Dr. Audrey linss. 61,000
Llbrary of Kush Medical College, Iits IIturrison st, Chleago. Establlshed 1809. Mlss $C^{\circ}$. A. Macciaulit, Librarlan. 19,522 Northwestern Unirersity Medleal School titorary tablislied 1598 by Alumil of the Medical School. Ir. Waiter II. Bubllg. Librarian.

Quine Library College of Mmllat I'nirersity of Illinols, Congress and Niss Meta il Loomls, Librarlan. 13.789. Decatur

Library of the flecatur Mellcal suclety, citizens Title and Trust H/dg., lecatur.

Jacksenville

L Abrary, Morgan County Medical Suclets". Public Llbrary Bldy. Jacksonville

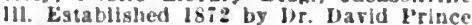
Filia B. lawrence, Librarian. 2,613 .

\section{INDIANA}

Indianapelis

Indianapolis l'ubllc Lubrary, Medica! lepartment, $\$$. Merldian st.. Indlanapolls. Established 1898. Fllza (i. Browning. 1.i brarlan. 11,075.

\section{Terre Haute}

Vigo County Medlcal Soclety Library Emeline Falrbanks Memorial Library, Terre llaute, Ind. Mrs. Sallfe C. Hughes, Librarian. $; j 0$

lowa City

\section{IOWA}

Medical Library of the State University of lowa, lowa Cliy, Jowa. Jennle k. Hoberts, Acting Llbrarlan. 6,500.

\section{KANSAS}

Rosedale

lilbrary of the School of Mediclne of the Intrersity of Kansas, Rosedale, Kan. Fs. tablisbed 1905. Sarah E. Stauton, Ll brarian. 2,310 .

Topeka

Stormont Medlcal Library, State llouse, Topeka, Kan. James L. King, Librarlan. 3,114 .

\section{Leuisville}

\section{KENTUCKY}

Jefferson County Medical Library Mitherton HIdg., Loustille, Ky. EstabIIshed 1906 by Jefferson County Medlcal Library Commisslou. Anna L. Gor, Li. brarlan. 7,000

Loulswile Free Public Litorary, Medical llepartment, th Are.. Library 11 , and $3 \mathrm{~d}$ si. loulsrille. Estahllshed 1905 by City of Joulsrille. (ieorge $T$. Settle, Ldbrarian. 900 .

\section{LOUISIANA}

\section{New Orteans}

Library of the Medlcal Devartment of Tulane intrersity, 1551 Canal st., New brleans. Fotablistied 1843. Misg Jane tirey lRogers, Librarlan. $\$, 500$.

Orleans I'arlsh Medjcal soclety Lubrary. $14 \mathrm{l}$ Elk ly. New Orleans. Fistabllshed 1sis by orleans Paris Medical soclety. ir. Unward 11. King, Librarian. 12,000

\section{MAINE}

Brunswick

library of the Medical Schuol of Maine Itrunswick. Ne. Establlshed 1820 by trus tees of kowdoin follece It fieorse Little, lolbrartan. \$000.

Portland

[Drtland Mefical Lihrary. 99 Bramhalt St. Jurtland, Me. Eutablished $1895 \mathrm{~b}$ f. Ifult: recstabllshed 1911 by the Matue Vedleal Arsuclation. Marcla a lithos l.llorman. 1.040.

Ballimore

\section{MARYLAND}

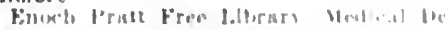
bartuene. 106 W. Mullerry 81 . Jall more bistablished 18s: ltoruard sitelner, I,fhrartan 1,300

Johns lloukins llowplen! Lhirary. Nirbh

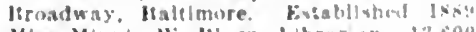

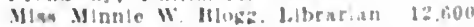

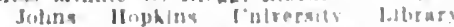
Menmanent and Washtngton she Halb.

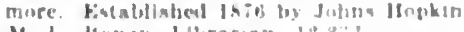

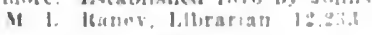

liturary of lyepartment of Medictoe cilverslty of Marsland IHaltumore tabllwhed I813. sumuel Want, leterarian. I 2.500 .

Llbrary of the College of Physletans and Surgeons, Calvert and Saratoga Sits. Haltimore. bistablished 1905. Lucy G. Mlake, Llbrarlad. 1,340.

Library of the Marjland Homeoparbic Medleal Snclety. 1130 $x$ Mount ke. Baltimore. M. M Dean, Librarian. 600

Llbrary of the Medical and Chirurgleal Faculty of Maryland. 1211 Cathedral 8 . Italtmore. Fistabllahed 1830. Miss Marcta

c. Noyes, Librarlan. 23,000 .

Beston

\section{MASSACHUSETTS}

Hoston Clty Hospltal Medical Library. 818 Harrison Are. Baston. Establlshed 1891. Dr. John II, MeCollom, Librarian. 3,040

Boston Medical Library, \& Fenway. Hovton. Bistabllsbed 1875, [1r. John W.

Farlow, Llbrarlan. $\$ \$ .000$.

Isoston Lntrerslty Medlcal Lolbrary, so E. Concord St. Boston. Fistablisbed is:3. Dr. Anna T. Loverlng Llbrartan 5000

Jibrary of Harrard Medical School, 210 Lon ntrood Ave., Boston. Sarah R. Bart lets. Librarian. 23,000.

Library of Tufts College Medical School 416 IIturington Ave., Boston. Fatub llshed 1893 by Faculty of Tufes College Medical school. Miss L. A. Maso, LIbrartan. 3,000

State Board of Ilealth Llbrary, Boston. Established 1869. Mark W. Richardson. I.D., Librarlan. 1,000

Treadwell Library, Massachusetts Gen eral IIospital. Blosiom St. Boston. Es tabllshed 18it by Massachusets General IIospltal. Mrs. Grace W. Myers, Librarian. $\$, 345$

\section{Fall River}

Lifbrary of the Fall Rirer Medical Soclety, 109 \&. Main st. Fall RJver. Fstablislied 1901. Georgo L. Bichards, M.1). l.tbrarian. 1,200.

\section{Lawrence}

Flanders Medical Library, of the Law rence fieveral llospital, Lawrence, Max. Eistablshed 1812. J. Forrest Kurnham. IIII. Liturartan. 480

\section{Milford}

Library of the Thurber Medical Assovlation. Main and Y'rospect Sts. Mulford, Mass. Establlshed 1558 by Thurber Medlcal Ásoclation. Wr. J. M. French, Li brarian. 200 .

Northampton

Forbes labrary, Stedical Departmen: Finthanpton. Mass. Established 1894 by Judge (harles Folward Forbes. Jos. IA Rivy llarrison, Librarlan. 5,000.

\section{Waverley}

Mel,ean Iospltal Medleal I.lbrary, W2 rerley. Mas. Eutublished 158:. Miss Kathlev Jones, Jabrarlan. 5,12.

Worcester

Worcester J1sirlct Medical Library, 18 Elm St. Wincester. Mass. Establiahed 182:- Dr. Merrlek Lincula, Labraman. $9.9: 1$

\section{Ann Arber}

\section{MICHIGAN}

Iculleal Lutery of the ["ulresalty of Mleblgun, inn Arbor, Mich. Estubliahed 
physhoians. Mrs. Carrie C. Jones, lobrat lint. 4,860

Lndversity of Minmesota Lilmary, Min

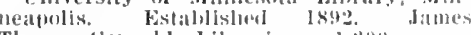
Thayer (ierould, Librarian, $1,200$.

\section{Rochester}

Surgeons (1ub liforary, 110 Went Zam bro st., laveliester, Mimm, Fistablished $1896 \mathrm{by}$ surgeou's ('lul). Nlice Elluthorfle. Librurian. 200.

\section{St Paul}

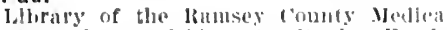
Soclety, Lowry blag., sit. l'aul. Extab

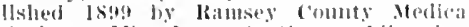

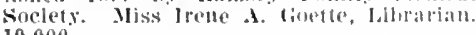
10.000 .

\section{Columbia}

\section{MISSOURI}

Medicul labrary, Iniversity of Missouri (olumbia, Mo. Eslablished ls.:3 loy l"ni rerslty of Missomrl. Henry a. Severames. Isbrarian. 5.5.5.

Kansas City

Kansas ("iby Medica! Lilnary ('luh, Rialto Jldg. Kansas rity, Mo. kstabIlshed 19I2 ly physicias and

kansus City.

st. Louis

Inibrary of the st. Lomis lniversity School of Medicine, $1402 \&$. Iirand Ave. st. Lonls. Established Iotit by st. Homl. Caviversity, s. F. Waldeek, loibrarian. 8,000

Library of the Waslington Iniversity Medicul School, 19tl and locust sts. st. Lonis. Reorganized 1910 . Helen II Tiester Librariantizon

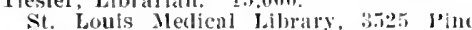
St. St. Louis, Established is.9. Frank J. Lutz, M.1)., Librarian. 14.450.

st. Louis ibublic Librily, Medical bepartment. Olive, I3th and 14th Sts.. St. louls. Established 1865 by ("ity of st Jouls. Arthur E. Bostwick, libralian 6,386

\section{NEBRASKA}

Omaha

Library of College of Medicine of lniversity of Tebraska, 42d and bewey Are. omaha. Neb. Fstablished 1904 by iniver sity of Neluraska. Ifrs. A. ('. Berry, Librarlan. 6,000 .

Medical llepartment, Omaha l'ublie Medical hepartment, Onina publie Library, 19th and llarney Sts., Omala,
Neb. Established 1905 by Omaha-louglas county Medica! Sociely. Editl Tobitt librarian. 3,000

\section{NEW HAMPSHIRE}

Concord

New Hampshlre State Library. Melical Department, Concord, $\mathrm{x}$. H. irthur $\mathrm{H}$ C'lase, Librarian. 12,000 .

Hanover

Library of the Medical Department of Dartmouth College, Hanover, X. H. Es tablisher 1769 by Eleazer Wheeluck C. C. Stewart, Librarian, 8,000 .

\section{NEW JERSEY}

Jersey City

Jersey City Public Library, Medical bemartment, $\$ 12-486$. Jersey Are., Jersey

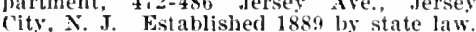
Esther E. Burdiek, Librarian. $2,700$.

\section{Newark}

Medical Library Association of Newark, 1-11 Washington st. Newark, N. 1. EsJohn Cotton Dana, Librarian. 2,500.

Orange

William Pierson Memorial Library. Free Lihrary Bldg., Main St. and Essex Ave, Orange, N. J. Established 1901 by liegular physieians of the Oranges and neighborliond. Dr. l'almer A. Potter, Li iritrian. 2,812 .

Albany

\section{NEW YORK}

New York State Medieal Library, State Education Bldt. Albany, N. Y. Estab-

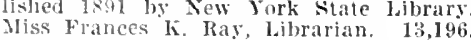
Brooklyn

Libraly of the Medieal soeiety of the County of kings. 1:13 Bedford Ave.
Broutilyn, Established 1845 by the Medi

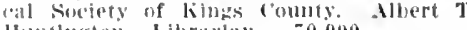
Iluntherton, Libraliu. $70,000$.

Buffalo

loiversity of Buffato Medical library -4 Ifigh ti.. Butralo. Established 1sis i) 'rrusters of the rulcersity of Buttilu.

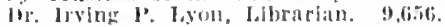

\section{New York}

leostment of patimlogs, cormell l'n: versity Medical dollege, 47, lat Are, New Vork Established 1894. Hr. F. S. T'Fsue rance, Jibrarlan. $\overrightarrow{0},(0) 0$.

Library of the College of l'hysiclans and surmens, columbla "niversity, 437 II. intl st. New Jork Alfred L Robert libirarlan. $2,500$.

libriry of the New York Aeademy of Mediebe, 17 W. tid st. New York. Fstublisled 1847. Mr. Joh $\mathrm{s}$. Browne. liburino. 10,000

libury of the New York Eye and Ear Jullrmary, zis, "d Are, New lork. Fstablished lmo0. lo. Hetrry C. Irrice, l.lbrarlan. 1,000.

Library of the New rork Homeopathlo vledical college dial st aud ive A New

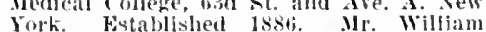
(ion, labrarian. 4,000.

Ciw, Libriman. 4,000 . Medical Researeh, $6 b_{\text {th }}$ st. and Ave. $A$, New York. Established 1904. Miss Lillia M. D. Trask, Librarian. 7,000

Vedical library Fordham Lniversity Sclnool of Jecioine, Pelham and :Bd Are.. New York. Established 1409. Mliss Jarion J James, Jibrarian. 3,000 .

New York I'ublic Library, vedieal thepatrment, tifi, 5th tre New lork. Bstablisbed 189.\%. F. H. Anderson, jirector. $\$, 000$.

Norwich

Clemango County Medieal society library, Norwich, $N$. F. Established 1910 ly Chenango County Medleal bociety.

Poughkeepsie

Library of the Iledical Socjety of the (imunty of Dutehess, 54 Nathet st., A. I. Peckliam, M.D. Chairman Library Commltee. 2,025

\section{Rochester}

Reynolds Library Medieal Department, 1.\%0 Spring St.. Rochester, X. Y. Established 1884 by lortimer $F$. Resnolds. Anne R. Collins, librarian. 3,451 .

\section{Saranac Lake}

Adirondack cottage Sanatorium Medieal Library, Saranac Lake, $\mathrm{N}$. Y. (Trudean 1'. O.). Established 1901 by Dr Lawrasom Brown. Fred 11. IJeise, Libratian. 360. Saranac Laboratory Library. Saranae Lake, $\mathcal{X}$. Y. Established 1893 by Elward L. Trudea. 1 ino.

\section{Schenectady}

schenectady county Jedicul Society Lilurary Tnion and seward sts., schenee tady $Y$ Established 1911 by scheneetady County Medical society. 11!.

Syracuse

library-college of Nedicine, syracuse Viversity, 309 Orange St., syracuse, N. Y. Established 1906. Dr. Frank W. Marlow, J.jbrarian. $" 100$.

\section{NORTH CAROLINA}

Chapel Hill

Library of the Iniversity of North Carolinal. ('hapel IItll, $N$. C. Established 179\%. Lonis K. Wilson, Librarian. 3,500 .

\section{NORTH DAKOTA}

University

Iniversity of North liakota Library, Vuiversity, $x$. D. Fstablisled 1883 by the state. Mr. Clarence Sumner, Librarian. 2,000 .

\section{Cincinnati}

\section{OHIO}

Cincinnati Hospital Library 12 th St. and Central tre Cineinnati Established 1870. E. W. Mitchell, M.D., Librarian. 18,460

Ecleetic Medical College Library, 630 w. 6 th St., Cincimnati. Established 1845 hy the Eclectic Jedical College. Dr. J. K. scudder, Librarian. 2,000 .

Librury of the Academy of Medlclne of 'inclunatl, $\because 5$ E. sth St. C'inclnuatl. Arch I. corson, Lubrartut. $3,500$.

Llliray of the ohio-Miami Medleal col lege, Iniversty of clucinnati, cilfton Ave. and blue st., fincinuati. Frances Currie librarlan. 2.730.

Mussey Jidinal aud Siclentific Llbrary 62:4 The N1. ('meimati. Establlshed 1800 by Jo. William H. Mussey, X. J). C. lindges, libruriun. 6.034 .

\section{Cleveland}

I'levelatul Medleal Lllorary Assoclation 2:318 I'rospect die., ('leveland, Ohlo. Es tallished jo!t by the medical profession iil fleveland. ilrs. S. M. Harding, LIliralliti. 19, 158

Cleveland-julte Medical College Library, ila Muron lid., cleveland. Established $18.51, A$. M. Jaris, Librurian. I,000.

Western Reserve l'nlversity Medleal LI-

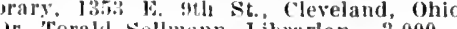

Norman

\section{OKI.AHOMA}

Medical bepartment, Llbrury of I'iiverslty of Gklaloma, Sornan, Okla. Es tablished 189\%. Jesse lee Rader, Librarian. 600 .

Portland

\section{OREGON}

K. B. Wilson Library, 761 Lovejoy St., l'ortland, Ore. Fstablished 1893 by feine. Jir. John D. Macharen, Lbbrarlan. 1,840 .

Erie

\section{PENNSYLVANIA}

liluray of the Erie County Medical Society, l'ublic library Bldg., Erie, I'a. Fstablished 1902 by Erie Connty Medieal society. Dr. Frei E. Ross, Librarlan. 66.5 .

Hanover

IIanover l'ublie Library, Carlisle st. llanorer, ['a. Established Oct. 4, 1911, by endowment. Jiss Mabel Champlin, Librarian. $2+1$

\section{Harrisburg}

library of Harrisburg Academy of MedIcine, $319 \mathrm{~N}$. 2d St., Harrislurg. I'a. Established 1896\%. C. R. Phlllips, Librarian. 3,300 .

\section{Lewiston}

Miftlin county Medical Society Library, l.ewiston, l'a. Establlshed 1908 by Miftin Connty ledical Soeiety. J. A. C. Clarkson, Librarian. 200

\section{Priladelphia}

lefferson Medieal College Library, 10th and Wa!nut Sts., Philadelphia. Established 1848 by Women's Auxillary of Itfrerson Medical College. Mr. Charles Frankenberger, Librarian. 5,300 .

Library of Hahmemann Medieal College and Hospital, $226 \mathrm{~N}$. Broad St., above lege and Hospital, 226 N. Broad St., above Race, l'hiladelphia. Fstablished 1850.
Mr. T. L. Bradford, Librarian. I5,000.

Mr. T. L. Bradford, Librarian. I5,000, of Philadelphia, 19 \$. 22d $\mathrm{St}$., Philadel. phia. Established 1788 by College of l'hysicians. Charles Perry Fisher, Librarian. 100,158 .

Jibuary of the Medico-Cblrurgical Collegre, 1609 Areh St., Philadelphla. Established 1907. Dr. A. C. Morgan, Librarian. $4,500 \%$.

Library of the Woman's Medical College of l'ennsrlvania, 2Ist st and $x$ College Are. I'hiladelphia. Establlshed 18\%0 by Womans, Medical College. Adelaide Ward Pecklam, Chalmau Library Committee. 1.522 
Library of the I'itsbursh Acaleny ut Medlelne, 3 fernando St. I'ltishurgh, I'a

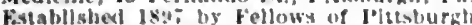
Acablems of Meilleine. Dr. Henry

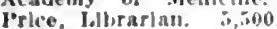

\section{Pottsville}

Metleal library Issochatlon of Schuml-

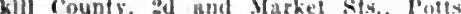

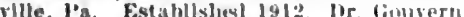
eur il inver, Lllirarian. joc.

Scranton

library of lackawanna cinunty Medl. eal Soclety, 130 Washingtun Ave. Sicran

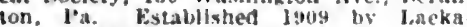
wanua Melleal setetety. J. M. Wain. wright, Lltirarlan. 2500 .

\section{Wilkes-Barre}

Llbrary of the luzerne county Medical Soclety, Anthracite Bldg. Wilkes-larre. Pa. Fistablished about is93. Lewts II Taylor, Idbrarlan. 5,425

York

York County Medical soelety L.tlorary. Court House, Fo Market st. York l'a Estabilshed 1900 by the York (i)turty Medlcal Soclety. Iir. Istuel H. Hets. J.lbrarlan. 2,000

\section{Providence}

\section{RHODE ISLAND}

l.ibrary of the Rhode Island Merlical Soclety, 106 Franeis st., l'rorldence, R. I. Hstablished 1879 by Klunle Island Hedical soclety. (ieorge I). Horsey, Iobrurian. 25,000 .

\section{Columbia}

\section{SOUTH CAROLINA}

Columbla Medleal I.llirary. Y. M. C. A Bldk. Columbla, S. (". Estabutisherl igt? by Columbla Medical soclety. Irr. II IV. Rice, Acting secretary for sinclety.

\section{SOUTH DAKOTA}

Vermilion

Eniversity of South Dakotal library. Clarix and Yale Sts., Vermilion, s. D. Es tablished 1882 by the slate. Miss Mallet k. Rlebardson, Llbrarian. I, 200 .

\section{TENNESSEE}

Nashville

Meharry Medleal lolluge librar!. Nasth ville. Tent.

\section{TEXAS}

Galveston

lubrary of the Melleal 1Mefurtment,

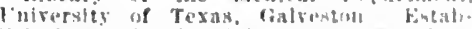
Ilsherl txis by the rniverstey. Mlas bethe l. Illihe, Jollifarlan. $\$, 4: 0$.

\section{VERMONT}

\section{Burlington}

liftrary of the College of Methclose lini versity of lismont, Pearl St. purtiugton, 1. Fstabllshed by The Iniversity. Molen k. Slatluck, L.hrarlan. 3,0in

\section{Richmond}

VIRGINIA

Dilirary of the Medical college of $\mathrm{V}$ ir ginla, iotlo and "lay" sts. Richmosul, Va. Established 1900 Irr. E. C. I. MIIler, librartan. 4,000

Sealtle

\section{WASHINGTON}

Wasbington Medleal Lilorary Assodatiou, Colul Mldg., Seattle, Wash. kistabltshed 1s9s. Hlice H. Johnson, Luhrarian. $4,000$.

\section{Wheeling}

\section{WEST VIRGINIA}

Wheeling Medical Library Assoclation. Wheeling, W. Va. Esbablished Is94; Frank Le Moyne Ifupd, in charge. I

Appleton

\section{WISCONSIN}

cutagamle counly Malical library melda st. Mpleton. W/s. Fstabllshot 1:40! hy outagamie county Mefleal sociely:

Milwaukee

library of the Marquetle liniversity silhorl of Medicine, fth St. and Heserroir

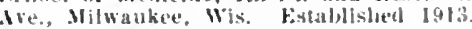
1)r. Manride Hendersum, Librarjast. 3,00$)$

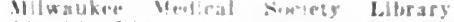

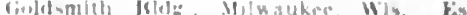

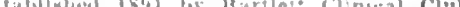

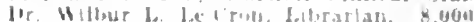

Manila

\section{PHILIPPINE ISLANDS}

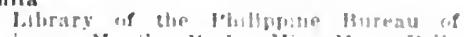
Molence, Manila, 1". I. Mian Mary leulk. l. Il, rarian

\section{CANADA}

Kingston

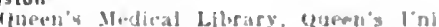

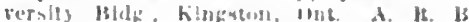

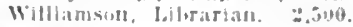

Montreal

Lifrary of Facults of Mediclne, Monu-

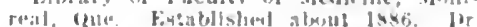

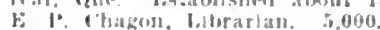

Metill Medical Library Montreal, Que. Fistabistied Ixa. Mtisy it. It. 'harlton. bolirariasi.

Toronto

llirary of the Icadeny of Medicine, 13 quecrl's lark, Turunto, Out Eistabllshed

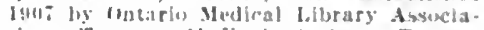
tion, Toroste liplical Suclets, Turonts rlinical soclety, and Toronto Pathologlcal foclety, Miss lontse k. Masoln, Idbrarian. (iv,(1i)!l.

Inlversiles of Toronte Library Gueen's

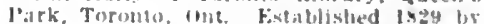
charter and grant of crown lands. Il. H latigton. Librarian. $\$ 5,100$.

Vancouver

l.Ibrary of the Vancourer Medteal Asso. riatfon, liols Ifastlngs $5 t$. W Vaneourer, Ii. 'C Kistallished dout oy vancures Medleal fisceiatlon. Mias Mary .1. 1". Maceagan, Librarlan. 3,000

\section{Winnipeg}

Medical ldtrary of the follege of phy. sicians and surgeons of Maniloba por-

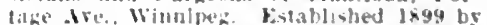
lote councll of The rollege of l'hostelans and surfeons of Mantuba. Miss s. II Iinclatyre, Libratian, $=000$

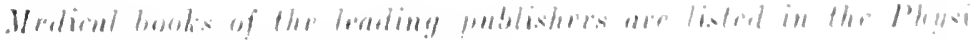

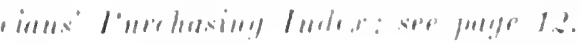




\section{MEDICAL JOURNALS}

\section{OF THE UNITED STATES, CANADA AND PHILIPPINE ISLANDS}

NoTF.-The following list includes official publications of state societies, journals devoted to one of the several specialties of medicine, boards of liealth, alumni, etc., the year estabished, publisher, editor, when issued, and subscription rate.

\section{ALPHABETICAL LIST}

Abnormal Psycliology, Journal of. ... Mass. Advanced Therapeutics, Journal of ....... $Y$.

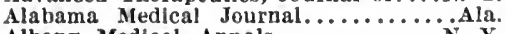

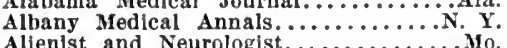

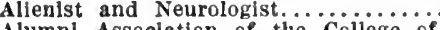
Alumnl Assoclation of the College of
Physiclans and Surgeons, Journal of...Md. Physiclans and Surgeons, Journal of.
lumnl Reglster, University of Pennsylvania

Amerlcan Academy of Medicine, Bületin of the........................ American Association for the ConserAmerican Institute of Homeopathy, The

Journal of............................

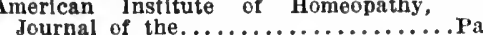

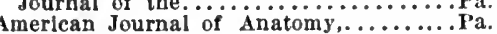
American Journal of Clinlcal Medicine.....III. American Journal of Diseases of Chil-

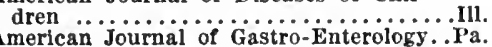
American Journal of Gastro-Enterology..Pa. American Journal of obstetrics and Diseases of Women and Children.... N. Y. American Journal of Ophthalmology......Mo. American Journal of Orthopedic Sur-

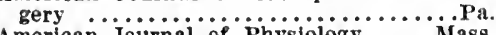

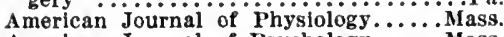
Amerlcan Journal of Psychology.........Mass. American Journal of Public Health.... N. Y. American Journal of Surgery.......... Y American Journal of Surgery ......... Sclences, .................................

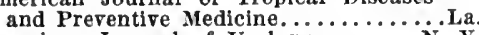
American Journal of Urology.............. American Medical Association, Journal of the ...........................

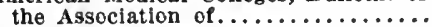

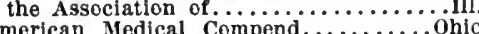

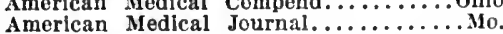

American Medical Journal...............

American Medicine $\ldots \ldots \ldots \ldots \ldots \ldots \ldots \ldots \ldots \ldots \ldots \ldots$. Y

American Practitioner. American Quarterly of Roentgenology... Mich.

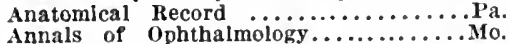

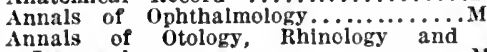

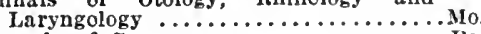

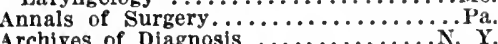
Archives of Diagnosis

Archives of Internal Medicine............. III

Archlves of Ophthalmology ........... Y

Archives of Pedlatrles................ Y

Archives of Roentgen Ray............. Y.

Arizona Medical Journal................

Arizona State Board of Health Quar-

teriy Bulletin ...................... Ariz. Arkansas Medical Society, Journal of...Ark Buffalo Medical Journal............... Y. California Eclectic Medical Journal..... Cal California Medical and Surgical Re-

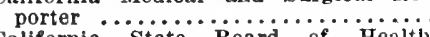
Californa State Board of Health

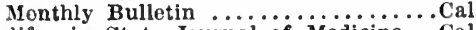
California State Journal of Medicine...Cal.

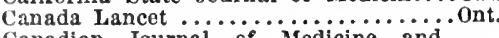
Canadian Journal of Medicine and Surgery ......................... Ont. Canadian Medical Association Journal. . Ont.

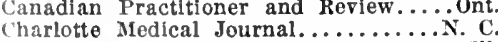

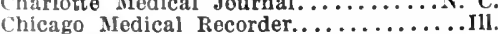
Chicago Medical Society, Bulletin of Chicago Medical Society, Bulletin of Chicago School of Sanitary Instruction,

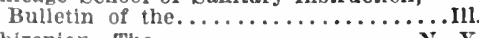
Chironian, The................... Y. Cleveland Medical Journal.............ohio
Cilnlque

Colorado iedicine

Co

letin of Health, Bul- Colo

Columbus iedical Journal..................... Comparative Neurology, The Journai of..Pa Comnecticut State Hoard of Health

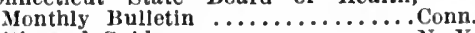
Critic and Guide.................. Y. Cutaneous Diseases Including Syphilis,

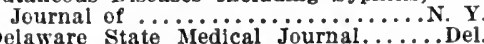
Denver Medical Times, Utah Medical Journal and Nevada Medicine........ Colo.

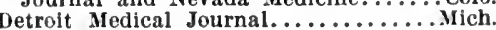
Dietetlc and Hyglenic Gazette............. Y

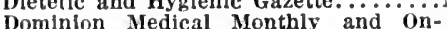
Dominion Medical Monthly and onEclectic Medical Assoclation Quarterly,

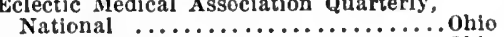

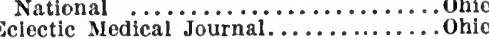
Electic Review $\ldots \ldots \ldots \ldots \ldots \ldots \ldots \ldots \ldots \ldots \ldots$. Y. Experimental Medicine, The Jour-

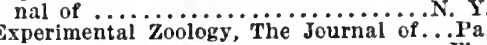

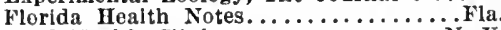
Good Health Clinic.................. Y Good Health Magazine................. Hahnemannian Monthly $\ldots \ldots \ldots \ldots \ldots \ldots$. . . . Harper Hospital Bulletin....................

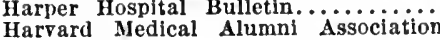

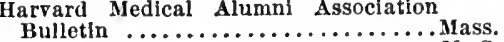
Bulletin $\ldots \ldots \ldots \ldots \ldots \ldots \ldots \ldots \ldots \ldots \ldots \ldots \ldots \ldots \ldots$. C. Homeopathic Envoy $\ldots \ldots \ldots \ldots \ldots \ldots \ldots \ldots$. . . . Homeopathic Recorder $\ldots \ldots \ldots \ldots \ldots \ldots \ldots$. $\ldots$ Pa. Hospltal Bulletin of the University of .Md.

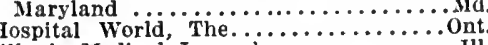

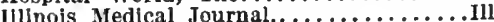
Illinois State Board of Heaith, Bulle-

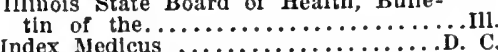
Index Medicus $\ldots \ldots \ldots \ldots \ldots \ldots \ldots \ldots$. $\ldots \ldots \ldots$..$\ldots \ldots$. Indianapolis Medical Journal.......

ly Bulletin of the .................

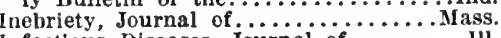
Infectious Diseases, Journal of ..............11. International Hospital Record............. Mich. International Journal of Surgery......... Y. Interstate Medical Journal...........Mo. Iowa Health Bulletin............... Iowa Iowa Homeopathic Journal............. Iowa Iowa State Medical Society Journal... . Iowa

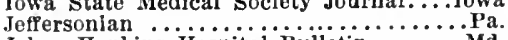

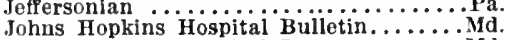
Johns Hopkins Hospital Reports................ Journal-Lancet of $\#$ Health Administration and Sociology ......................... ournal of the Indiana state Medical Ind

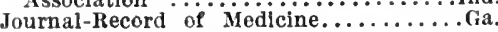
Kansas City Medical Record.............. Kansas Medical Society, Journal of .....Kan. Kansas State Board of Health Monthiy Kansas State Board of Health Monthly Kan.

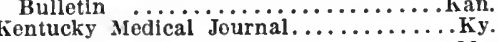

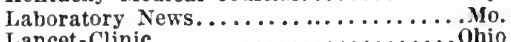

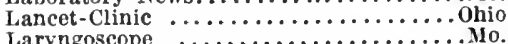

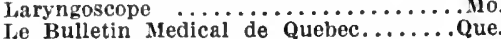

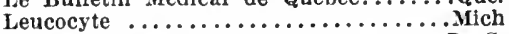

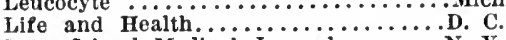

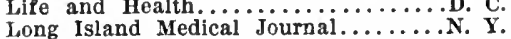
Louisiana State Board of Health Quar-

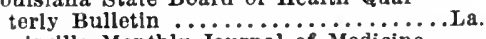
Louisville Monthly Journal of Medicine

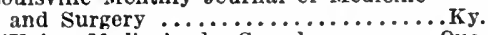
L'Union Medicale du Canada......... Que. Lylng-In Hospital of the City of New
York, Bulletin of the.............. Y.
Malne Medical Association, Journal

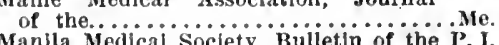
Maryland Medical Journal...............

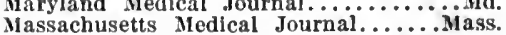
Massachusetts Medical Journal........ Mass.
Massachusetts State Board of Health, Massachusetts State Board of Health,

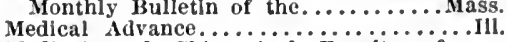
Medical and Chirurgical Faculty of Maryland, Bulletin of ................ Medical Association of Georgla, The

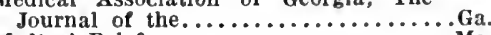

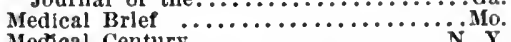
Medical Century $\ldots \ldots \ldots \ldots \ldots \ldots \ldots \ldots$ N. Y. Medical Council $\ldots \ldots \ldots \ldots \ldots \ldots \ldots \ldots$ Pa Medical Examiner-Practitioner ..............

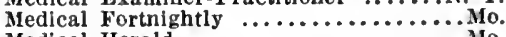

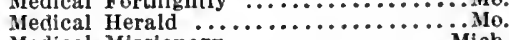

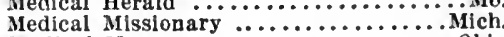

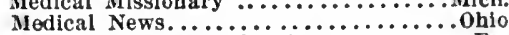

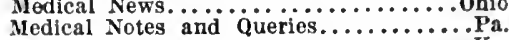
Medical Progress ....................

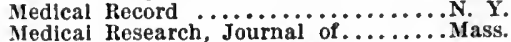
Medical Research, Journal of................... Medical Sentinel ................... Medical Society of New Jersey, Journal

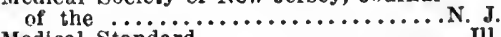
Medical standard .................

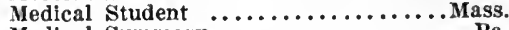
Medical Summary $\ldots \ldots \ldots \ldots \ldots \ldots \ldots \ldots \ldots$ Pa.

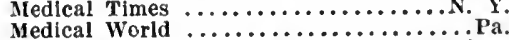

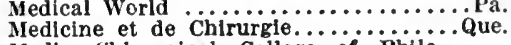
Medico-Chirurgical college of Phila-

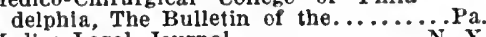

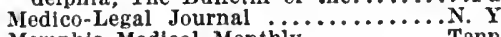
Memphis Medical Monthiy............. Tenn. Mental Pathology, Journal of ........... Y. Michigan Monthly Bületin of vital

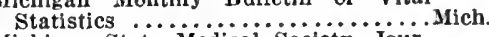
Michigan State Medical Soclety, Journal of $\ldots \ldots \ldots \ldots \ldots \ldots \ldots \ldots \ldots \ldots$. Mich.

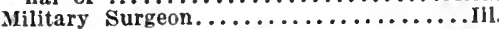

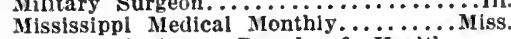
Mississipp! State Board of Health,

Health Bulletin of the .................. Missouri State Board of Health Quarterly Bulletln ..................... Missouri State Medical Association,

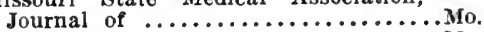

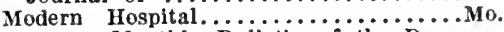
Montana Monthly Bulletin of the $\mathrm{De}$ partment of Public Health...........Mont Monthly Cyclopedia and Medical Bul-

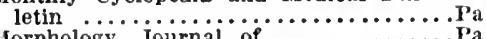

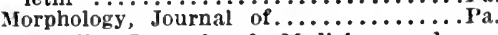
Nashville Journal of Medicine and

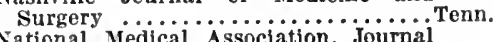
National Medical Association, Journal

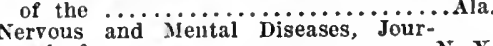
nal of $\ldots \ldots \ldots \ldots \ldots \ldots \ldots \ldots \ldots \ldots$. Y. New Albany Medical Herald............. Mass.

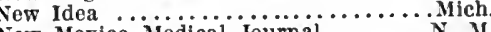
New Mexico Medical Journal........... M. New Orleans Medical and Surgical

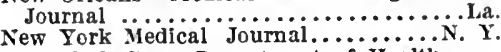
New York State Department of Health Monthly Bulletin ................... Y. New Yorker Medizinische Monatsschrift ..................... Y. North American Journal of Homeop-

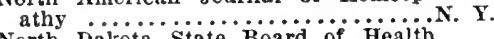

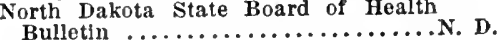
Bulletin .............................. Iedical Society, Bulletin of the.......Ill. 
Sorthwest Meallciue ............Wash. Northwesfern linlversity iledical

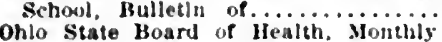
Ohlo State Board of Health. Monthly onlo

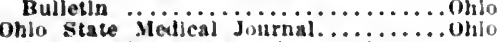
Oklo state Nedical Jomrnal.......... Journal of the......
Old Dominion Journal of Medicine and

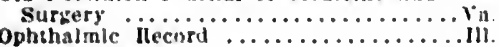

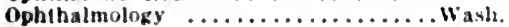

Ophthalmology and Oto-Larynsology.

Ophthalmologs and Oto-iaryngolozy;

Juurnal of $\ldots \ldots \ldots \ldots \ldots \ldots \ldots \ldots$ ra.

Oregon State Bonrd of Healeh Bulletla..Ore.

Oto-Laryngology, The Index of...........ll.

Oundoor Ilfe. The Antl-Tuberculosis

Magazlne, Journal of . $i$................ Y.

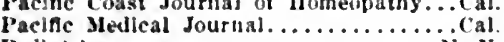

I'edlatrles ...................... Y.

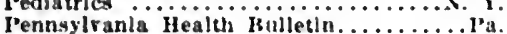

lenussiranla Medical Journal..............

I'harmacology and Experluental Tlier-

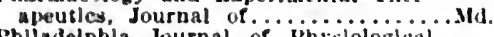

Phlindelphla Journal of Physiological

Therapeutlcs

Phllipplne Journal of sielence............

Physlcal Trainlug $\ldots \ldots \ldots \ldots \ldots \ldots \ldots \ldots$.

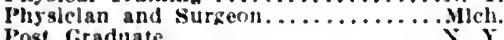

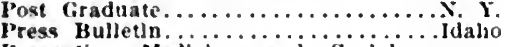

I'reventive Nedicine and Soclology.

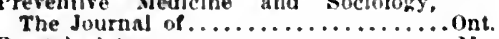

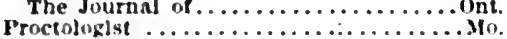

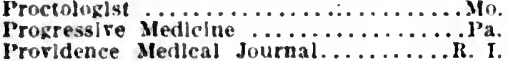

Irovldence Mledlcal Journal ................ I.

Psycho-Asthenles, Journal of ............

Psychological Clinle $\ldots \ldots \ldots \ldots \ldots \ldots \ldots \ldots \ldots \ldots \ldots \ldots \ldots$
Psychological Index

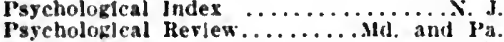

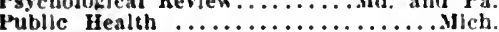

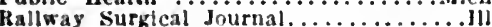

Rhode Island State Boari of Healti.

Rush Iledical College, Bulletin of the

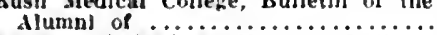

Soclety of Medical Hilstory. Bulletin

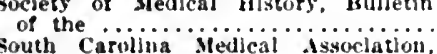

South Carolina Medical issoclation,

Journal of the .......... Carolinu state Board of ieaiin

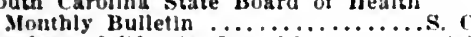

Southern Calltornda Practitioner ..............

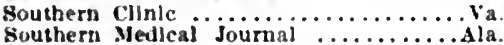

Southern Medlclne and surfery........ Tern.

Southern Practitloner ............. Tenn.

Southwest Journal of ilediejne and

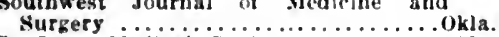

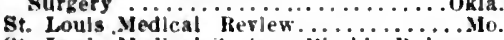

St. Louls Medical Revlew i Mouls Medical society, Weekly iüi-

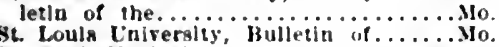

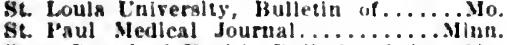

State Board of Health. Bulletin of the. . .lla.

state Board of Health, Hulleth of the... Me.

Stute Board of Health of Kentueks,

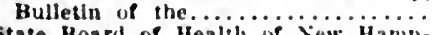

state Board of Health of Jew Hanu-.

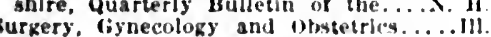

Surkery, (iynecology and Dtstetrics...
Surgery, (iynecology and Obstotrics

Surgery, Gynecology and bbstotrics
with Internatlonal Alstraet of Sur-

Teunesue ...............................

Journal of the ................ Tin

Texas inurier-Record of Meilicine.... Tr.

Texas Medical Jumrnal ........... T*

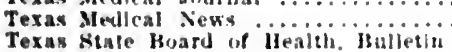

Texas state Hoard of Health. Halletin

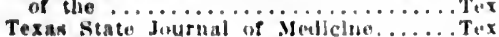

Therapeutle Jigest ................. (bhlo

Therapeutlc dianctle................

Theraveutic becort ......................

Therapenticn and Defeslen, Journal of, Mas.

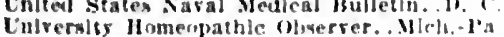

Univeraty of liulorado Merlonl inulle.

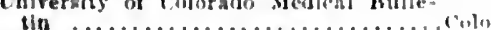

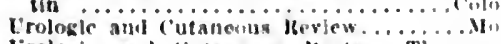

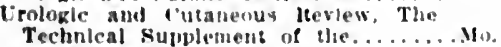

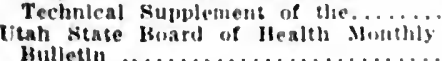

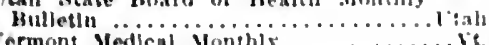

Vermont state Joard of Health Quar-

cerls isulletil

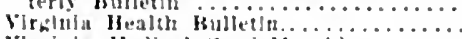

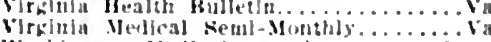

Washingent Nedleal Anmals..........

Waslimgton state lsoated of Health HI-

Jonthly Bulletin ..............Wash.

Western Canada Medleal Journal..... Man

IIestern Menleal Xewy

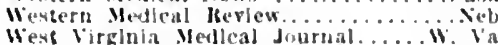

WIsionsle Modieul Jisurnal...........

Wiseonsin Inelical kecorder............

terly Bulletin

Coman's Vedleal Jourual..........

NLIIHFIK OF JOLRNALS, 27.

ALABAMA

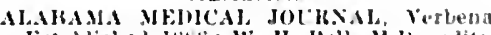
Established Isos; W. II. Hell, .1.l1., editos and publlsher; monthly; \$2.00.

SATIUNal Mrlucal associatiox, Joldsil, OF THE. Tuskegee Institute Eitablished 1909:- John A Kenues, if.

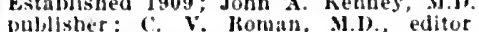
puljisber;

Sot'TIER. MEJICAL JoLlKNal (Journal of the Southern Medical Axsuciation), Val Antwerp Bldg., llobile, Ala. Fistablished 1!08; E. T. Lowe l'ubllshing Co.. Nashrille, Tenn., publlshers; seale llarri

I.D., editor-in-chlef; monthly ; \$2.00.

STATE HOAKH OF HE.ITH OF AIA BAYA BLILETIX OF THE lontgomers Established - ; state Board of llealis. inblishers; monthly; free.

\section{ARIZONA}

AKIZOX. STATE IBOALD OF HFALTI

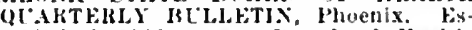
tablished 1:00; state Bourd of liealth. mublishers: It. $x$. Looney, II.L., editor quarterly: iree.

ARIZONA MFIMICA, JO[Rxil, Ihoentx Fstablished 1y13: Wurner Watkins, editor bl-nouthly; $\$ 2.00$.

\section{ARKANSAS}

MKKANSAS MEDICAJ SOCIETY, JOLIR NAL OF' TIF, Jittle llock. Establislied 1901: Irkunsas Mledleal soclety, publish ers; Wm. IR.

\section{CALIFORNIA}

CALIFORNIA ECIFCTIC MFIICA, JOCR NAl. los Angeles. Eivtablished 1908. Callorna Folectlc Nelleal College, pul.

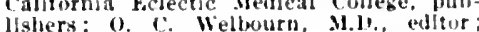
monthly ; \$1.06.

CALHOKNIA MEDICA AND SLRGICA] HEPOliTEIR, Grant Bldg., Los Ingeles. Eistabljshed 1900 ; A. S. Dodge, I.I... edi. tor: monthly: \$1.00.

CALIFUISNA :TATE; BOARI OF HFAITI

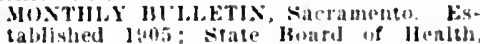

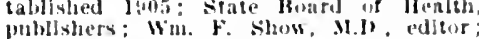
prinhe.

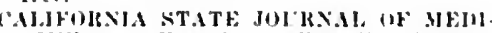

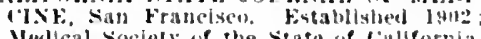
Medleal sociely of the state of Pallfornia. publlshers: Mhlip Mllls Junes. M.L., ell tor: menthly: $\$ 1.00$

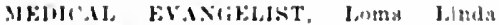

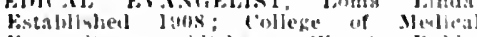
Frangelists, publishers: W. A Mulle

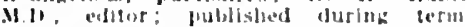
mumbilisy : 80 inentw

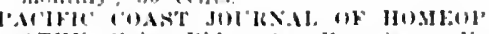

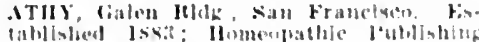

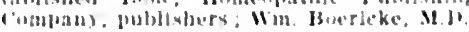
(mlitior; muthly ; 8: (10)

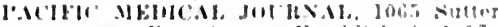

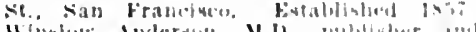

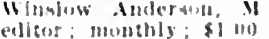

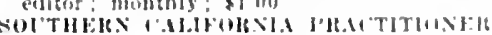

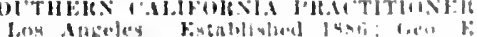

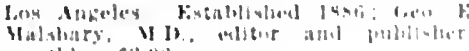
mototl1]?: $\$(2,00)$.

\section{COLORADO}

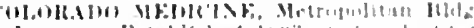

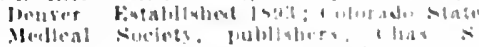

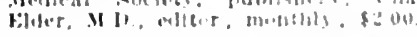

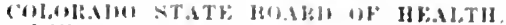

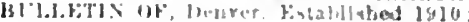

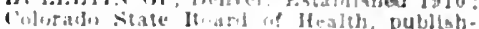

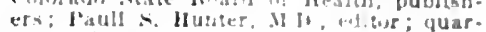
terly: free

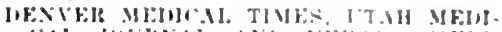

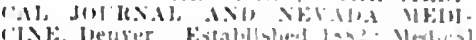

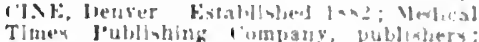

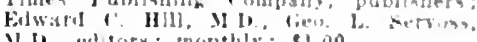
1] [D., colters: monthly: \$100.

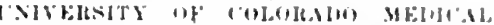

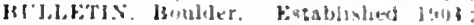
publiahed joy the inlversty: Arthur $J$

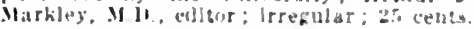

\section{CONNECTICUT}

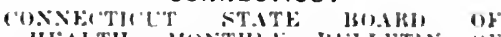

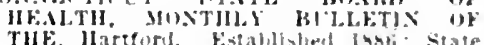

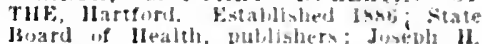
Towusend, II II., editrit; montlly; pree.

\section{DELAWARE}

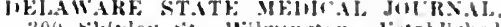

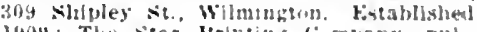
140!1: The star I'rinting company, pulilishets: liluert lobin. M.II., edtus: monthly: 81.00; pree.

\section{DISTRICT OF COLUMBIA}

IXI) Iste; Carnegle jestitution of Washersion, publinhers; Ficlding H. Ciarrisun, II I). editur: munthls : \$s.0010.

LIFE ANI HEALTII, Takoma l'ark, Wash-

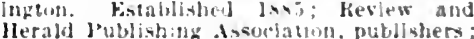
lieorge llenty Heald, M.ll, editer; motht. $1 y:$ : \$1.00

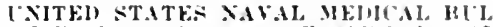
LETIX, Washington Established 190: Furean of Medicine and surnery, publish ers and editors: quarteriy: \$1.00.

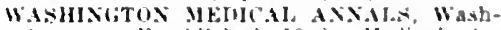
infoul. Established 190y: Medical soers; I). S. I.amb. M.I). chairinan editorJal committee, bi-monthy : \$1.00.

\section{FLORIDA}

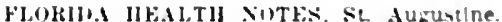
Established is9:; liecord compang publi-hers; Jas. Y. Purter, IIL. edlitor:
munthly; 50 cents.

\section{GEORGIA}

JOIRNAJ-RECOIW OF MEMICINE, 23 W. Alaliama st., Itlanta. Fistalolished 1556: E. W. Allen, publisher Edgar (i. Ballen. ger, ill. entlur: nosthly: $\$ 1.00$

IFILIL ASsOLIATIOS OF GEOLGIA, THE Jolkil, it THk. Harbou Hids. Augusta. lia Established Iyll: publlibed inder directlon of the council: $W$. Lyle, II.I., editur: monthly" \$1.0io.

\section{IDAHO}

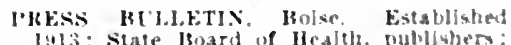
kalin ralk. M.l., wilur: weekly: free.

\section{ILLINOIS}

MFHe IN Jo[

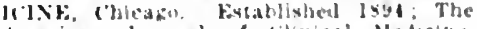
Imerican Jubrial of flameal Vedictie. (lace) publeslers; W. Ahbott, Ill

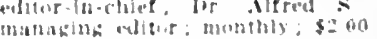

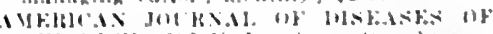

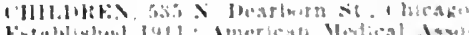

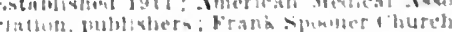

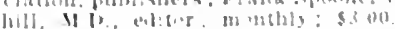

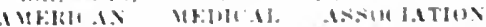

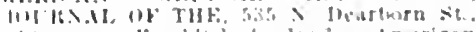

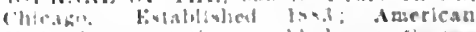

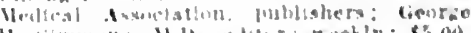

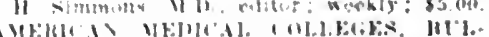

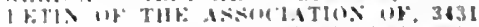

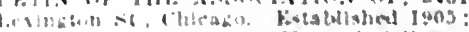

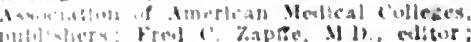

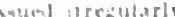

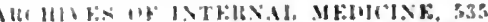

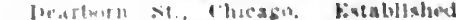

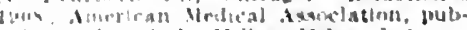

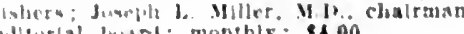
calfintal lwont: atonthly: \$1.00. 
rHICACA MENCAL RECOLDEIR, PHIIman IBldg., Chlcago. Extallilshed I892: Medical Recorder publishing compuny, publishers; A. 13. keynulds, M.1), E. I. Doter ing, M.D., II. T. Myford, M.1s, editors monthly; ; $\$ 1.00$

CIICAG MEDICA SOCIETY MULETIS

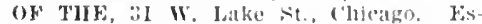

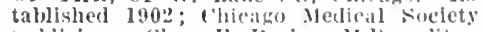
publishers; (has. I1. I'arkes, M.1\%., editor weekly ; munual duet.

CHICAGO SCHOOL OF SANITARY IN. STRICTION, B1LLETIN OF' THE, Clieago llealth lepartment, publishers: (ieo. 13. Young, M.I., manaring editor; s. St.

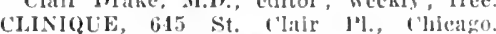
Established 1 1800 . Ilalsey Bros. Company. Established 1sso; Inalsey Bros. Company: moutlily ; $\$ 200$.

ElLANGWOOH'S THERAPELTS', $32 x$. State St. Chlcagro listablished 1907; lisher; monthly; $\$ 1.00$

ILLINOIS MEDICAI JOIITAL, 3338 Ogden Ave., (hicago, Estiblished 189!); Illinols State Medical Society. mublishers; Ilenry G. Ohls, II.D., managing editor.

ILLINOIS STATE BOALD OF HEALTH, BULLETIX OF TIIL, springfield. Established 1904; gratis.

INEECTIOUS DISEASES, JOUISNAL OF, Chicago. Established 1904; Memorial Institute for Infectious IVise ase, publishers; Iudvir IIektoen, M.I., and Fiwin 0. Jordan, Ph.Ib., editors; bi-monthly, $\$ 5.00$

MeIrCAl APVANCF, Bataria. Established 1872 ; The forrest l'ress, pullishers; J. 13 S. King, MI.D., editor; montlly; ; $\$ 2.00$

MEIDICAL STANDAIL, 536 S. Clark St., lard \& Company, publishers: montlyy $\$ 1.00$.

NILITAIS SURGEOX, $535 \mathrm{x}$. Dearborn st. chicalo Jstablisled 1896: Association of Military surgeons of the United states, publlsliers; samuel C. Stanton, 11.W., Brig
Gen. 111. N. G. (retired), editor; monthly; $\$ 3.50$.

NoltTll SHORE IBHANCHI OF THE CHICAGO MFIICA1 SOCIETY, BULIETIN OF TIIE, $32 \mathrm{~N}$. State St., Chicago. Established 1909; Chieago Mredical Society, publishers: W. $k$, von Zelinski, MI.D., publishers; wonlhly ; free to nembers.

NORTHWESTER UNIVEISITY NEDICAL SCIOOL, BULLETIN OF, Chicago. Established 1901 ; Chas. A. Elliott, M.D., and
Allan B. Kanavel, M.D., editors; quarterly.

OPHTIIALMIC RECORD, $7 \mathrm{~W}$. Madison St, Chicago. Established 1891; II. A. F'ox, publisher: Frank Brawley, II.D., editorial secretary; monthly; $\$ 4.00$.

OPHTHALMOLOGY AND OTO-LARYNGOLOGY, JOURNAL OF, Chicago. EstabAlbert Il. Andrews, Mi.D., editors and publishers; monthly; $\$ 2.00$.

OTO-LARYNGOLOGY, THE INDEX OF, 2551 N. Clark St., Chicaro. Established 1911 ; Jos. C. Beck, M.D., editor and publisher; monthly ; $\$ 3.00$

RAILWAY SURGICAL JOLRNAL, Chicago. Established 1894; H. W. Baumgartner, publisher; L. J. Mitchell, M.D., editor monthly; ; $\$ 1.50$.

RISH MIEDICAL COLLEGE, BULLETIN OF THE ALUMSI OF, Rush Medical College, Chicago. Established 1905; Alumni Association, Rush Medical College, publishers B. M. Linnell, M.D., compiler; six issues it year; $\$ 1.00$

OCIETY OF MIEDICAL HISTORY, BLLLETIN OF THE, 1i43 $\mathrm{W}$. Harrison st., Chicago. Established 1911; Geo. H. Wearer, M.D., secretary editing committee, $1743 \mathrm{~W}$. LRGERY GL.; irregularly; ; $\$ 3.00$ per IUC. Chicago. Established 1905; Surgicil publishing Company of chicago pubIishers; franklin H. Martin, II.D., editor; monthly ; $\$ 5.00$.

SLRGERY, GYNECOLOGY AND OBSTETRICS W'ITH INTERNATIONAL ABlished 1913, SLRERY, Chicago. EstabCompany of (chicago surgical Publishing H. Martin, M.D., editor ; monthly ; $\$ 10.00$.

\section{INDIANA}

INIVINAIOIJS MEIUICAL JOURNAL, $241 /$ Kentucky Are., Indlanapolls. Fstablished 1897: Melleal and surgical vonltor Com pauy" pullishers: Samuel E. Earp and Alemlert W. Brayton, ellitors; monthly $\$ 1.00$

INIIINA STATE BOAIT OF HEAITH Mt) TIII H HLLLETIN OF THE, Indian apolls. Fstablished 1900 ; Wm. H. Mur forl, state H'rlnter, publisher; $J$

JOURNAl OF 'TIE INUIANA STATE MED ICAL ASSOCITIOY, Furt Waye Establlshed 190x; Indiana State Medical Asso clation, mublishers; Albert F. Bulsun, Jr. II.D., editor; monthly ; $\$ 1.00$.

NEW AIBANY MEDICAL HEHALD, NeW Albany. Ystablished 1881; Chas. A. Edelen. AI.1)., editor; monthly; \$1.00.

\section{IOWA}

IOWA HEAl'II BULLITIN, Capitol Bldg. bes Moines. Establlshed 1887; State Boarl of IIealth, publishers; Guilford II. Sumner, M.D., editor; quarterly ; free. IOWA IONEOPATIIC JOUINAL. Des Moines. Established 1907; G. A. Juntoon M.D. editor and publisher; Issued nonthIy ; $\$ 1.00$.

IOWA MEDICAL JOURNA, Des Molnes. Established 1894 ; E. E. Dorr, II.D., edi tor and publisher; monthly; $\$ 2.00$.

IOWA STATE MEDICAL SOCIETY, JOURNAL OF TIIE, Washington. Established 1911: Jowa State Medical Soclety, publishers; D. S. Fairclill, editor; monthly ; $\$ 2.00$.

\section{KANSAS}

KANSAS CITY MEDICAI, RECOKD, Kansa City. Established 1883; B. H. Ralph, M.D. elitor and publisher; monthly ; 50 cents.

KANSAS MEUICAL SOCIETY, JOURNAL OF TIIE, Kansits City. Established 1901. Kansas Medical Society, publishers: James W. IIay, editor; monthly; $\$ 2.00$.

KANSAS STATE BOARD OF HEALTH, NONTHLY BULLETIN OF THE, Topeka. publishers; S. J. Crumbine, M.D., editor monthIy ; free.

\section{KENTUCKY}

KENTUCKY MEDICAL JOURNAL, Bowling Green. Established 1903; Kentucky State Medical Association, publishers; A. T. MeCormack, MI.D., editor; bi-montbly $\$ 2.60$.

LOUISVILLE MONTHLY JOURNAL OF HEDICINE AND SUItGERT, $705 \mathrm{~S}$. 3d St. Louisville. Established 1895; Jobsen Printing Company, publishers; H. H. Grant and H. E. Tuley, M.D., editors montbly; $\$ 1.00$.

MEDICAL PROGRESs, Louisville, Established Iss4; The Nedical Irogress Company, publishers: John \$. Moreman, M.D. editor ; monthly ; $\$ 1.00$.

STATE BOARD OF IIEALTII OF KENTUCKY, BULLETIN OF THE, Norma Heights, Bowling Green. Established 1911 ; State Board of Health of Kentucky, publishers; J. N. MeCormack, editor ; monthly ; free.

THERAIEUTIC RECORD, Louisville. Es tablished 1905; Robt. C. Kenner, MI.D.
publisher and editor; monthly; \$1.00.

\section{LOUISIANA}

AMERICAN JOURNAL OF TROPICAL DIS EASES AND PREVENTIVE MEDICINE, New Orleans. Established 1913; American Journal of Tropical Diseases Company, Ltd., publishers; Creighton Wellman, M.D., editor; monthly; $\$ 2.00$.

LOUISIANA STATE BOARD OF HEALTH MONTHLY BULLETIN, New orleans Established 1910; State Board of Health, publishers; Miss Agnes Morris, editor monthly; free.

YEW ORLEANS IEDICAL AND SURGICAI JOURNAL, New Orleans. Established 1844; New Orleans Medical and Surgical Journal, Ltd., publishers; Charles Chassaignac, M.D., and Isadore Dyer, M.D. editors; monthly ; $\$ 2.00$.

\section{MAINE}

STATE BOARI ON HEALTH, BULLFTIN ()F TllF, Augusta. Established 1905; State Boara of IIenlth, publishers; $\boldsymbol{\Lambda}$. G. Young, M.D., edltor; bi-monthly ; free.

MAINE MFUICAL ASSOCIA'TION, JOLI NAl OF" THE, 148 Park St., Portland. Fstablished 1910; Southworth 13ros., pub-
lishers; Frank $Y$. Gilbert, editor ; monthly; $\$ 2.00$.

MARYLAND

ALIMSI ASSOCIATION OF THE COHJEGF OF PlYSICIANS AN1) SURGEOXS 1897: Wn. S. Gardner, M.D. and John Ituhrílh, M.D., editors; quarterly, $\$ 1.00$.

AMEIRICAN JOURNAI OF INSANITY, Bal timore. Established 1844; Jolms Ilopklns I'ress, publishers: F. N. Brush, M.J. managing editor; quarterly ; $\$ 5.00$.

HOSI'ITAI BUILETIN OF TIIF UNIVEH SITY OF MAISYLAND, Baltimore. Established 1905; Hospital Bulletin Company, publishers; Nathan Winslow, M.D. monthly ; $\$ 1.00$.

JOHNS IIOPIIV HOSIITAL BULLETIY, Baltimore. Established 1890; Johns Ifopkins Press, publishers; Rupert Norton, M.D., editor; monthly; $\$ 2.00$.

JOHNS HOPKINS HOSPITAL REPORTS, Baltimore. Established 1890; Johns Ilopkins Press, publlshers; published at Irregular Intervals; $\$ 5.00$. per volume.

MARYLAND MEDICAI JOURNAL, Balt more. Established 1877; Medical Journal Company, publishers: Nathan Winslow I.D., editor; unonthly; $\$ 2.00$.

MEDICAL AND CHIHURGICAL FACULTY OF MARYLAND, BULLETIN OF, 1211 1908: Medical' and Chlrurgical Faculty publishers; Drs. A. P. Herring, John Ruhrïh and J. Stalge Davis, editors; monthly ; 25 cents.

PHARMACOLOGY AND EXPERIMENTAL THERAPEUTICS, JOURNAL OF, Baltimore. Established 1909; The Williams J. Abel, M.D., and Arthur K. Cushny, editors; every two months; $\$ 5.00$

PSYCHOLOGICAL REVIEW, Baltimore and Lancaster, Pa. Established 1895; P'sychological Review Company, publishers. J. B. Watson, editor; bi-monthly; with J. B. Watson, editor; bi-mont
Psychological Bulletin, $\$ 5.00$.

\section{MASSACHUSETTS}

ABNORMAL PSYCHOLOGY, JOURNAL OF Boston. Established 1906; Richard G'. Badger, publisher: Morton

AMEITCAN JOUIXÁ OF PHYSIOLOGY Back Bay (Boston P.O.). Established 1898; Plimpton Press, Norwood, publishers; W. T. Porter, managing editor ; monthly; $\$ 5.50$ per volume.

AIERICAN JOURNAL OF PSYCHOLOGY Worcester. Established 1887; Florence Chandler, publisher; G. Stanley HaIl, editor ; quarterly ; $\$ 5.00$.

BOSTON MEDICAL AND SURGICAL JOUR. NAL, 101 Tremont St., Boston. EstabE. W. Taylor, M.D., editor: R. M. Green, M.D., assistant editor; weekly; $\$ 5.00$.

HARVARD MEDICAL ALUMNI ASSOCIATION BULLETIN, Boston. Established
1895; privately published; Robert M.
Green, I.D., editor; irregular; 50 cents Green, MI

per issue.
INEBRIETY, JOURNAL OF, 703 Washington St., Boston. Established 1876; Therapeutie Publishing Company (Inc.), publishers; T. D. Crothers, M.D., editor; bi-monthly $\$ 2.00$.

MASSACHUSETTS MEDICAL JOURNAL, Boston. Established 1881; Bay State Pub-
lishing Company, publishers; R. A. Reid, lishing Company, publishers;

MASSACHUSETTS STATE BOARD OF HEALTH, MONTHLY BULLETIN OF THE, Boston. Established 1883; Wright and Potter Printing Company, publishers; IIark W. Richardson, M.D., editor; free.

MEDICAL RESEARCH, JOURNAL OF, BOSton. Established 1896; Harold C. Ernst, M.D., editor
vals; $\$ 4.00$. 


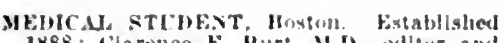
1X88: Clarence b. IIurt, M.I., edltur and publisher; monthly durling torm: $\$ 1.00$.

XEW EXGLANI MEHCAl, (:IZETT k, Hoscon. Bstabllshed 1stib: Medleal Gazetse Publishing ('ompany (Ine), publishers: Dewitt (i. Wherx, II 1.. nanaging ellitur Conrad Wessethott, M.J., A. II. King

ISYCHOLOCICA, IILLETIS, Sorthamp. ton. Kistabllshed 1s:4; D'sychologleal Rerlew Company, pullishers: Arthur II Herce, edltor; monthly : \$2.50.

THERAPFITICS AND DIETETICS, JOLRTherapeutic fublishing Company publlsh ers: 1. F. Howes, etltur; monthiy; $\$ 1.00$.

\section{MICHIGAN}

AMFRICAN QUAITEIIL UF ROENTGEX OLOGi, 32 Adams Are. W. Detrolt. Fstabllshed 1908; The imerican Koentgen hay Soclety, Columbus, 0 ., publistrers; Chlcago, asslstant editor; quarterly : $\$ 500$.

URTROIT MEDICAL JOULNAL 103 Broadway, Letrolt. Established 1901; Detrolt Medical Journal Company, publlshers; James H. Dempster, B.A., M.D., editor; monthly: $\$ 1.00$

GOOD HEA1TII MAGAZISE, Battlo Creek. Established 186i5: Good Ilealth l'ublishing Company, publ!shers: J. H. Kellogk, M.L. editor; monthly ; \$1.00.

IARPER HOSPITAL BUII.ETIX, Detrolt. Hatablished 1890; Hoard of Trustees of Harper Ilospltal, publlshers: John X. Bell, If.D., editor; quarterly; $\$ 1.00$.

INTERNATIONA, MOSUTTA UECORD, DEtroll. Establjshed 189:; llel T. Sutton. editor and publisher; weekly; 1.25.

LEUCOCTTE, Letrolt. Established 1895: Alumnl Assoclation of letroit Colleze of Jedlelne and surgery, nulilshers; U. C. Jamlson, I.

MEDical MISSIONARY, Batte Creek Es-

tablished 1892; Amerlean Jedical Jissionary Assoclation, publishers; fieo. C. Tenney, editor; monthly: 50 cents.

MCHIGAN MONTILY HLLLETIX OF VTTAL STATISTI's, Jansing. Established 189:; state Board of llealth, pul Ilshers: Fredk. C. Martindale, editor: monthly: irce.

MCHIGAN STATE MEUICAI SOCIETY. JOURNAL OF, Grand Raplds. Fistabllshed 1902 : Mlchigan state Medical Soclety publishers; F.C. Warnshuls, M.L., editor: monthly; $\$ 2.00$.

NEW IDEA, Detrolt. Establlshed 1s:9; Frederlck Stearns d Company, publlshers monthly : \$1.00

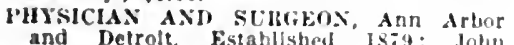
and Detrolt. Estahllshell is:9; Johi lisher: monthly: \$2.60.

PUBLIC HEALTH, Lanslng. Eutabllshel 1885: State Hoard of Health, Dublishers K. L. Dixon, M.D., editor: yuarterly and I. L. Dixon,

THERAPEUTIC GAZkTTE, Detrolt. Fistab Ilstred 1sib: r. (i, sinift, pul.: llobit A. Ilare, sill, edltor : monthy ; \$2.114

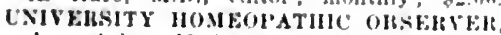
Ann Arbor .llch., arbl lancaster. Ia. publisted by the Cinterslty Ilomeopathic Observer Company, o $x$, Queen st., lan. caster, l'a. Essablished 1900: editur. I

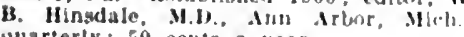
yuarterly; so cents a year.

\section{MINNESOTA}

JOL'NAI,-1.A.E.T, S39 Lumber Fxchange

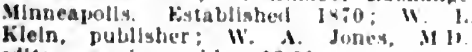

edltor: seml-monthly: $\$ 2.00$.

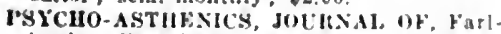
bault. Fistablished 1596 Amerlion inos clation for the study of the reeble Mladed. publishers; A. C. langers, II II and stan, edlurs: iquartorly: $\$ 1.00$

ST, P'AUL MFIICAl, Jor:livil, se. I'aul katablisherl 1s9s; Itammes Combity Medica Soclety, publlshers: Hurnshle Foster, M. II. edlor-In-chlef: Chas. F. Sulth, Jr. II matiaglue edltor: motstily ; $\$ 250$.
MISSISEII'L MEUI'Al. MONTII, Y Feks burg. Festablislied Is97; F. r. Ifoward.

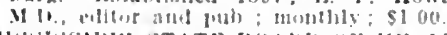

MISSISSIJ'I STATE BOAM OF HFALTI HE:ALTII II'Ll.t.TIN Uk' THE, Jackson.

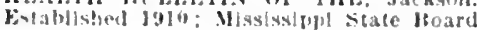
of healle, publighers; F. II. lialloway, of bealth, publlshers; f. II lialloway,

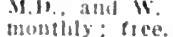

\section{MISSOURI}

AHENIST ANI NETHUI,OEIST, 3859 W charles llamilton IJughes, M.l?, editor and Charles lfamilon Hughes, 1

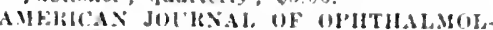

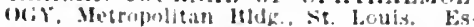
tahishel Isst; Adolf dit, M.ll, editor and publisher: monthly: s3.50.

A.HFHC.AN MEUCAL JOLIXNA, 5055 Page Blvo, st. 1.ouls. Establisted 1873 ; Mont. II. Ilam!ln, H.1., editor and vublisher inonthy ; $\$ 1.00$.

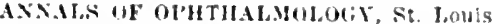
bistablished 18t:; Meyer Wlener, M.ll and Claresce l,obl. M.D., editors; quar terly; $\$ 4.00$

ANXALS (1F' OTOLOGY, HIINOLOGV ANL IAlk Niolog; st, Louls. Established 189:; Jones 11 . I'arker. publister; 11. W. Lob, M.D., editor; quarterly; \$4.00.

INTELSTATE HEDICA JOLHSAL louis. Fistablished 1543: Interstate ifedi cal Journa! Company (Inc.), publishers who $r$. Ball and Philip Skrainka, mat aging editors; monthly ; $\$ 2.00$.

LAHOIB.ATOKY NFWS, so3 $x$, diarrison Ave. l'ubllsbing company, publishers: Medical Gradwobl, M.I1., editor; montlily; $\$ 1.00$.

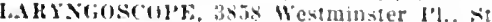

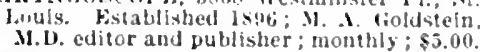
MFDLCAl, BHIE, st. Louis. Fstablished Is:3; Ilenry li. Strong, publisher; Thoma (\$. likinson, M.W., editor; monthly; $\$ 1.00$ MEINCAL FORTNICIITLY, st. Luvis, tistabllshed 16y2; Fortulghtly I'ress Company, publishers; Thos. A. Hopkins, II.I1. pany, publishers; Thos. A. II

MELHAL HERALI, St. Juseph. Extablshed I881; Charles Wood Fassell, M.11, pub lisher; Charles Wornd Fassett, M.1r., and s. Grover Burnett, M.D.. editors ; monthly;
\$.00.

MISSOLRI STATE HO.AHL OF HE.MLTH QLAITEIHY BLLLETIN, Jefferson rity. Establishod 1910; II cimpany, publishers; J. I. li. Adcoek M.11 dilur quarterly o 1 .

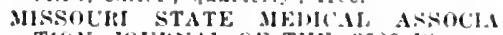

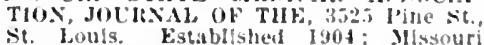
St. Louls, Established 1904 ; Mllsour J. Giodwln, M.D., edtur; nonthly: \$ol 00 MODEHA IIOSt'tTAh, St. louls. kstubllshed

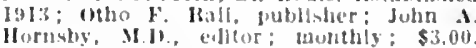

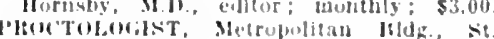

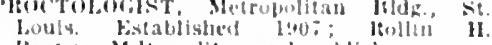
Barnes. II I., editor and publistier; "Har.

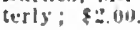

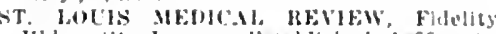

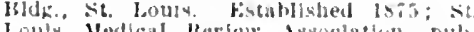
lonls Medical Rerlew Aswoclatlen, pubT Lol is line

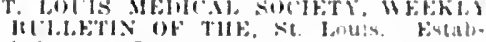

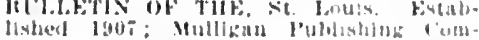

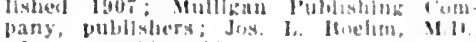
editur: werkly: \$1.00.

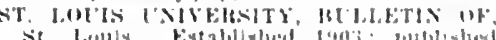

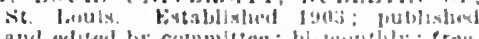

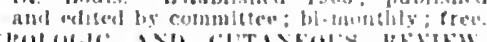

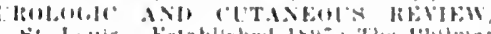

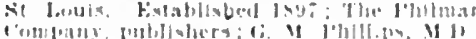

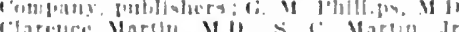

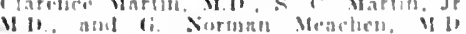
colburs: menthis: $\$ 2010$

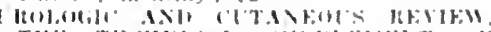

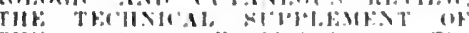

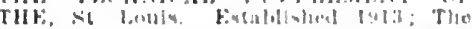

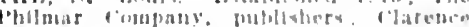
Martin, "I" li Jurmill leacleen, 4 l",

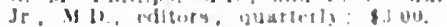

MONTANA

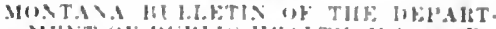

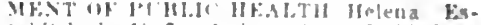

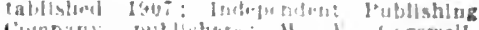

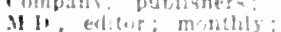

\section{NEBPASKA}

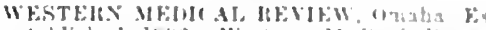

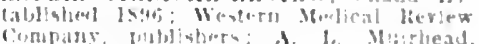
CII, whent: monthy; $\$ 200$.

\section{NEW HAMPSHIRE}

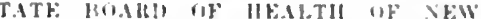

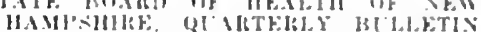
IF" THF: Cincurel Fixablished 1400 : siate lusird of llealch. publother: Irring d. Watgor, MID., eutitor; frea.

\section{NEW JERSEY}

MEIHCOL SUCIETY WF NEW JHISSEY

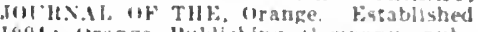
1604: Orange loblishlog ciumpary, publlshers: 1. C. Eingllsh, edltor: monthly:

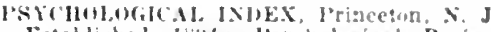
Fotablished 1kut; I'sychological Review Company, publishers: H 1 . Warten, edi. for; itatly; $\$ 1.00$.

\section{NEW MEXICO}

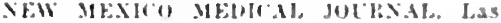
Crures. bistahished 1905; New Merlco State Mediral society, pullishera: h. E. Mckride, M.W., manazing editor; nonthy $\$ 2.00$, \$1 00 to members.

\section{NEW YORK}

AHANCEA, THEHAVET'TIS, JOTRNAL

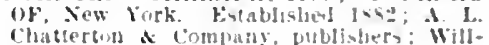

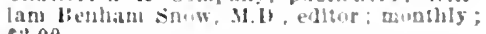
$\$: 00$.

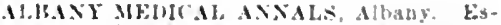
tablisted IFol: Mlumnl of Mbagy Medl. cal college, inblisters; J. Montgonery

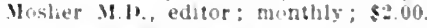

A WIEAX ISSOCIATHX FOR THE CON. SFIt ITION OH VISLN, IUTLETIS OF Tlik. Metronoltan Tumer. New lork. Fsthe converration if Vistoll, bubllshers: 1) C' Mesturtie editer

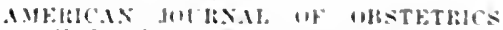

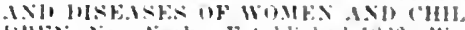

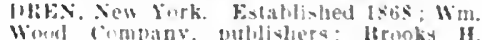

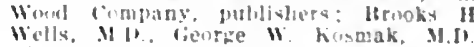
"diturs: numbly: \$50 01 .

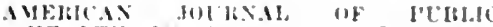

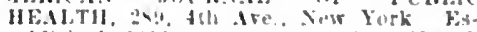
tablishel Iyil: American lublle Heald Asuciation, nublinters: Iofingston bar rand, If.1\%, edlitor; tunthy; \$2 00.

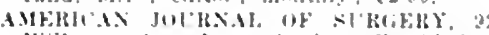

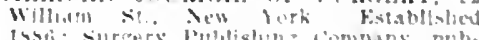

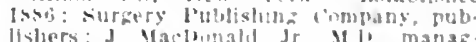
Int edefor: monthly: $\$ 1.00$

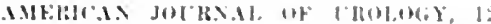

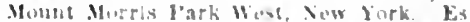

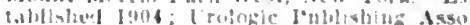

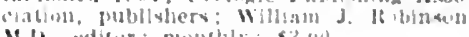

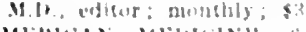

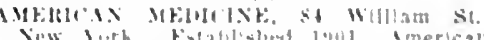

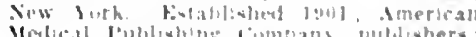

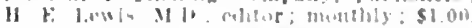

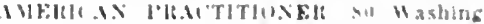

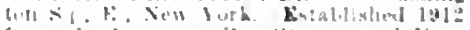

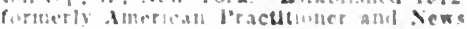

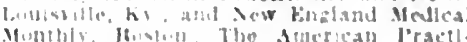

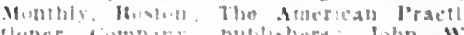
slance compans, puldubers gohs 11

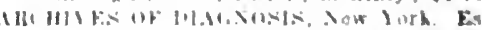

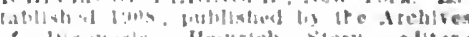
Whiltals Hemish stern, Nltor

IIf Is]

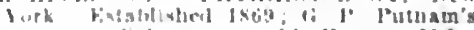

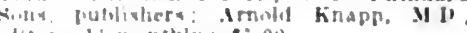
edlitis: in- nonthly: $3: 00$.

MUIIIES UF l'kULATHE. Now York riviallished Isst: k. It. Treat \& Company. molifly: $\$ 300$ 
Alt'HIV OF EOENTGEN HAY, 141-45 W 36 th st. New York. Itebman Company. monthly; $\$ 4.50$

BUFFALO MEDICAL JOIIKXI, 228 Summer St. Buffalo. Establsied I 845 . Benedict, A.M., M.II., editor and publisher: monthly; $\$ 2.00$.

ChlloNiAN, Avenue $A$ and 63d st. New York. Established 1882; Aschey and (Gor

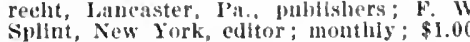

CriTIC AND GUIDE New York Estallished 1903: Critle-(iulde company, publishers; Wm. J. Robinson, II.1., editor monthly ; \$1.00.

CUTANEOYS DISEASES (INCLIDINE STIPILLS, JorkNAL oF, 14l W. 36th company, publishers: George $3 t$. Nackee, M.I. editor; monthly; $\$ 5.00$.

DIETETIC AND HYGIENIC GAZETE, 87 Nassaul St., New York. Established 1884 Gazette P'ublishing Company, publishers J. I3. Inuber, N.D., managing editor monthly ; $\$ 1.00$

ECLECTIC: KEVIEW, 242 W. $73 d$ st., New York. Established 1901; (ieo. W. Bos kowitz, is.1).,

EXPEHMENTAL MEDICINE, THE JOUR NAL $O F$, New York. Hstiblished 1896 kockefeller Institute for Medical lkesearch, publishers; Simon Flexuer, I.D., editor; monthly ; $\$ 5.00$

GOOD HEALTH CLINIC, 209 W: Borden Ave., Syracuse. Established 1898; $\mathbf{L}$. Elmer lieeler, M.ID., editor and publisher. monthly ; 75 cents.

INTERNATIONAL JOURNAL OF SURGERY, 100 Willam st.; New York. Established 1887 ; International Journal of Surgery Company, publishers; Frank C. Lewis,

LONG ISLAND MEDICAL JOUKXAL, Brooklyn. Established 1907; Associated Physiclans of Long Island, publishers; Henry (i. Webster, N.D., editor; monthly; $\$ 2.00$.

LYING-IN HOSPITAL OF THE CITY OF XEN YOKK, BLLLETIN OF THE, 307 $2 d$ Are., New York. Established 1903, Lying-In IIospital Press, publishers; Geo.

MEDICAL CENTUKY (A Journal of Homeopathic Medicine and Surgery); 1133 Broadway, New York. Establislied 1893; publlshers; W. A. Dewey, editor; monthly ; $\$ 2.00$.

MEDICAL RECORD, New York Established 1866; William Wood \& Company, publishers; Thomas L. Stedman, N.D., editor; weekly ; $\$ 5.00$

MEDICAL REVIEW OF REVIEWS, New York. Established 1895; Frederic H. Robinson, publisher; Ira S. Wile, MI.D., editor: monthly: $\$ 2.00$.

MEDICAL TIMES, 108 Fulton St., New York. Established 18i2; Romaine Plerson, publisher; H. S. Baketel, M.D. editor; monthly; $\$ 1.00$.

MEDICO-LEGAL JOURNAL, 39 Broadway, New York. Established 1883; Clark Bell, editor and publisher; quarterly; $\$ 3.00$.

MENTAL PATHOLOGY, JOURNAL OF, New Tork. Established 1900; State l'ress, publishers; Louise G. Robinovitch, MI.D., editor; bi-monthly ; $\$ 2.50$.

MERCK'S ARCHIVES, New York. Established 1899; NIerck \& Company, publishers; monthly; $\$ 1.00$.

NERYOUS AND MEXTAI DISEASE, JOURNAL OF, 64 W. 56th St., New York. Estahlislsed $18 \pi 4$; Smith Ely Jelliffe, M.D. publisher; Nilliam

NEW YORK AIEDICAL JOURNAL, 62-68 W. Isroadway, New York. Established 1843 A. R. Filiott Publishing Company, publishers: Charles E. de Medicis Sajous, M.D., LL.D., superrising editor; weekly;

NEW YORK STATE DEPARTMENT OF HFAITH MONTHIY BULLETIN, Albany. Established 1s84; New York State Department of IJealth, pubrishers; monthly.
NEW YORK STATE JOUINAL OF MEDICINE, 17 West $43 d$ st., New York. Established 1901; Medleal society of state of New York, publishers; Joln Cowell M

NEW YOLKEIR MEDIZINISCIE MONATS SCHILFT, 616 thadison Ave., New York. Established 1889: A. Itipnerger, M.D. editor and publisher; monthly ; $\$ 3.00$.

NOITTI AMERICAN JOLRNAL OF HOMEOPATHY, 1748 Broadway, New York. Es(Litul.) publishers: Eugene II, porter M.1.), and IIIIls ' Cole, M.I., editors; monthly: $\$ 3.00$.

OITDOOI LIFE, TIE ANTI-TUBERCULOSIS MLGAZINE, JOURNAL OF THE 289 th Ave., New York. Established 1903 ; Journal of the Outdoor Life Publishing Company, publishers; ['hillp 1"

PEIIATRICS, 355 W. 145th St., cor. St Nicholas Ave., New York. Establlshed 1896 : Pediatric Publishing Company, publishers: Wim. Edward Fitch, M.D., editor : Nonthly ; $\$ 2.00$.

PHYSICAL TIRINING, 124 East 28th St. New York. Established 1901; Physical Directors' society of Y. M. C. A.'s., pub-
lishers: Geo. J. Fisher, MI.1., edlltor; monthly (July and August excepted) $\$ 1.50$.

POST (BRADIATE, 303 E. 20th St., New York. Established 1884; New York Post (iraduate Medical School and Ilospital, publishers; 0 . S. Hlllman, M.D., editor monthly; $\$ 1.00$.

\section{NORTH CAROLINA}

CHARIOTTE MEDICAL JOUINAL, Charlotte. Fstablished 1878; Edward C.
Register, monthly; $\$ 1.50$.

HEALTH BLLLETIN, Ralelgh. Established 1884; North Carolina State Board of Health, publishers: Warren H. Booker, C.E., editor ; inonthly ; free.

\section{NORTH DAKOTA}

SORTH DAKOTA STATE BOARD OF IIEALTH BULLETIN, Devils Lake. Established 1908; C. J. MeGurren, N.
publisher and editor; quarterly; free.

\section{$\mathrm{OHIO}$}

AMERICAN INSTITUTE OF HONEOPATHY, JOURNAL OF THE, Rose BIdg., Cleveland and Lancaster, Pa. Established 1909 ; the American Institute of Homeopathy, publishers; $\$ 2.00$.

AMERICAN MIEDICAL COMPEND, Toledo Established 1874; Toledo Medical and Surgical Reporter Company, publishers; 0 . Hasencamp, 21.I., editor ; monthly ; $\$ 1.00$. CLEVELAND MEDICAL JOURNAL, 2318 I'rospect St., Cleveland. Established 1902 Iishers: Oscar T. Schultz, M.D., editor monthly ; $\$ 2.00$.

COLUMB's NEDICAL JOURNAL, Columbus. Established 1875 ; C. C. Hollenback, publisher; C. S. Carr, M.D., editor: monthly ; $\$ 1.00$

ECLECTIC MEDICAL ASSOCIATION QUARTERLY, NATIONAL, Cincinnati. Established 1906 ; Lancet-Clinlc Publishing Company, publishers; William N. Mundy,

ECLECTIC NEIICAI JOURAAL, 630 W: 6th St., Cinciunati. Established 1836; John V. Scudder, M.D., publisher ; Harvey
W. Felter, MI.D., editor; monthly; $\$ 2.00$.

LASCET-CLINIC, Cincinnati. Established 1841 ; Lancet-Clinic Publishing Company, publishers; Chas. H. Castle, M.D., editor weekly; $\$ 3.00$.

MEDICAL NEWS, 606 North St., Cincinnatl Established 1914. A G. Kreidler, II.D., editor; weekly; $\$ 2.00$.

OHIO STATE BOARD OF HEALTH, MONTHLY BULLETIN, Columbus. Established 1888; Ohlo State Board of I.D., editor ; free.

oHIO STATE MEDICAL JOURxaL, Columbus. Established 1905. Ohio State Medical Association, publishers; J. H. J. Upham, N.D., editor; monthly ; $\$ 2.00$.
THEKAYEUTIC DIGEST, 501 East 5th St. Cincinuati. Established 1902; Therapeutic Dlgest l'ublishing Company, publlshers; Albert H. Hussey, M.D., editor; b]-monthly: $\$ 1.00$.

WOMAN'S MEDICAL JOURNAL, Cinclnnat! Established 1893; Woman's Medical Jour nal I'ublishing Company, publishers: Margaret 11. lkockhill, managing editor; monthly" $\$ 2.00$.

\section{OKLAHOMA}

OKLAHOMA STATE MEDICAL ASSOCIATIOX, JOLIBNAL OF TIIF, Muskogee, Established 1908; Muskogee Printing Company, publishers; C. A. Thompson, editor;
monthly ; $\$ 2.00$.

SOUTIWEST JOURNAI, OF MEDICINE AND SURGERY, El Reno. Establlshed 1901 : Fred II. Clark, M.D., and J. M. Cooper, M.1.., publishers and editors; monthly ; $\$ 1.00$.

\section{OREGON}

Medical sextiNel, Selling Bldg, Portland. Established 1893; Medical Sentinel Publishing Company, publishers; IIenry OREGON STATE BOARD OF HEALTII BULLETIN, Selling Bldg., Portland. Established 1903; State Printer, publisher; Calvin S. White, editor; quarterly; free.

\section{PENNSYLVANIA}

ALUMNI REGISTER, UNIVERSITY OF PENXSYLANIA, Hale Bldg., Phlladelphia. Establisher 1895; General Alumnl lishers; Horace Mather Lippincott, editor; monthly ; $\$ 2.00$.

AMERICAN ACADEMY OF MEDICINE, BULLETIN OF THE, $52 \mathrm{~N}$. 4 th St., Easton. Established 1891; American Academy of Medlcine, publishers; Charles Miclntire, II.D., editor; bl-monthly ; $\$ 3.00$.

AMERICAN INSTITUTE OF HOMEOPATHY, THE JOLRXAL OF, Lancaster, Pa., and Rose Bldg., Cleveland, Ohio. Established 1907; American Institute of Homeopathy, publlshers; J. Richey Horner, editor; monthly; $\$ 2.00$.

AMERICAX JOURXAL OF ANATOMY, Philadelphia. Established 1900 ; The Wistar Institute of Anatomy and Biology, publishers; Henry MIcE. Know

AIERICAN JOURNAL OF GASTRO-ENTEROLOG Y, $802 \mathrm{~N}$. Broad St., Philadelphia. Established 1910; Philadelphla L. Brinton, 1i.D., editor; quarterly; $\$ 1.00$.

AMERICAN JOLRNAL OF ORTHOPEDIC SURGERY, 1012 Walnut St., Philadelphia. Established 1893; P. Blakiston's Sons \& Company, publishers; A. Mackenzie Forbes, I.D., Chas. F. Palnter, M.D., and Nathanlel Allison, M.D.

AMIERICAN JOLRNAL OF THE MIEDICAL SCIENCES, Philadelphia. Established 1820 ; Lea \& Febiger, publishers; G. Morris P'iersol, 1.D., editor; monthly; $\$ \mathbf{5 . 0 0}$

ANATOMICAL RECORD, Woodland Ave. and 36th St., Pliladelphia. Established 1906; The Wistar Institute of Anatomy, pubmanaging editor; monthly; $\$ 3.00$.

ANNAIS OF SURGERY, Philadelphia. Established 1884 ; J. B. Lippincott Company, publishers; Lewls Stephen Pllcher, M.D., editor; monthly ; $\$ 5.00$.

COMPARATIVE NEUROLOGY, THE JOURNAL OF, Philadelphia. Established 1891; The Wistar Institute of Anatomy, publishers; C. Judson Herrick, Unirersity of Chicago, managing editor; bl-monthly; $\$ 5.00$

EXPERIMENTAL ZOOLOGY, THE JOURNAL OF, 36th St. and Woodland Ave., Wistar Instltute of Anatomy and Blology, publishers; Ross G. Harrison, managing publishers; Ross G. Harrison, managing editor; lssued
volun?es ; $\$ 10.00$. 


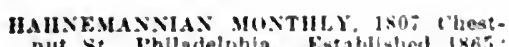
nut st. Ihlladelphia Establlshed $1 \times 65$ : lishers: (3. Marlan Weils, M.L., editor; monthiy: $\$ 3.00$

HOMEOPATHC ENVOT, 1011 Areh st. Phlladelphla Fiablished 1801; E. I'. Anshusz, editor and jublisher; inonthly : 25 cents.

HOSEOPATHC IECORUER, I'hlladelphla Establlshed 1886 ; Hoerlcke of Tafel, pub. Ilshers: E. 1'. Anshutz, edltor; monthly; $\$ 1.00$.

JEFFERSONIAX loth and Walnut sty Philadelphia. Establlatied 1899; J. S and A. D. Clarke Company, publishers; M. A. slocum, editor; monthly during term; $\$ 1.00$.

MElical cotxill, Phlladelphia. FstabIlshed 1896; Mrs. J. J. Taylor, mbllsher: T. S. Blalr, MII, elltor: monthly : $\$ 1.00$

MEDICAL NOTES ANI QLFRIES, $237 x$. Front St. Phlladelphla. Estibllished 1903: Medical Notes and Quertes Company, publlshers: H. W. Cattell, M I. editor: \$1.00.

MEDICAL SUMMAll 232i Park Are. Phlladelphla. Estatilished $18 ; 9 ;$ R. H. Andrews, M.D., editor and publisher: monthly: $\$ 1.00$.

MEDICAL WORLD, Phlladelphla Established 1883; C. F. Taylor, M.D., editor and publisher: monthly; $\$ 1.00$

MRDICO-CHIRLRGICA COLLEGE OF PHILADELPHIA, THE BCLLETIN OF THE, 17th and Cherry Sts., l'hliadelphia. College of Phlladelphla, publisher: Seneca Egbert, M.I., edltor; quarterly: iree.

MONTHLY CYCLOPAEDA AND MEICAL BULI.FTIN, Phlladelphla. Fistablished 1898: F.A. Davis Company, publishers: 1898: F. A. Daris Conipany, publishers ; C. E. de M. Sajous, M.W.. L.L.D.. J. Madtson Taylor, A.B. M.L., and Louls T
M. Sajous, B.S., M.D., edltors; $\$ 2.00$.

MORPHOLOGY, JOLRNAl, OF, Phlladelphla. Established 1887; The Wistar Inatitute of Anatomy and Blology pubIII.: quarterly : $\$ 9.00$.

OPITHALMOLOGY, OTOLOGY AND IARYNGOLOGY, JOLKNAL OF, i.ancaster, Pa. and 162 W. 5 th St., New York. M.D. publlsher: A. Worrall I Palmer. M.D. and J. L. Mortat, M.D., editors ; monthly; \$2.00.

PENNSYTVANIA HEAITH BVLLETIN, Harrisburg. Fistablished 1909 ; State Department of Health, publishers; s. G.
Dlxon, M.D., LL.I.., editor; monthly; Pree.

PENNEYLVANIA MENICAL JOLRNAL. Athens. Establlshed 1897; organ of the Medical Soclety of the state of Pennsyl. ranla; Cyrus l.e stevens. M.D., editor and publlsher; monthly; $\$ 2.00$.

PHILADELPIIA JOLRNAI OF IUYSIOLOGICAL THERAl'EITICS, lill fireen 8t. I'hlladelphia. Established 1904: Alumni Assoclation of I* (). I. \& S. M.T." publlahers: Louls ion Cotzhausen. M.l) I'h.G., editor: quarterly: $\$ 1.00$

PROGRrssty : Mbulcist, Phlladelphia. Establlahed 1898; Lea \& Feb/zer, pubIIshers: Uotart Amory IJare, M.L., editor: quarterly: $\$ 6.00$.

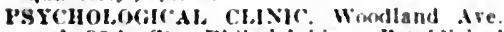
and 36th st. Philadelphla. Futabllshed

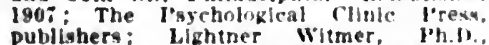
publishers: Lizhtner Witmer, Wh.l.' september: $\$ 1.50$.

\section{RHODE ISLAND}

PROVIIENCF, MEIHCAL, JOLRNAL, I'TUY dence. Establshed 1900; I'rovldence Med Ical Assoclasion, publishers; F. T. Jeciers, SI.D., edltor; bi-monthly ; 1.00 .

RHODF ISLANI" STATH: HUAKU (OF HEALTII, HLILETIN OF THF. l'rovi. dence Fatablished I888; Klinde Intand State Hoard of llealth, pulllshers: liarl.
ner $T$. Swarts, editor: Irregularly'; free.

\section{SOUTH CAROLINA}

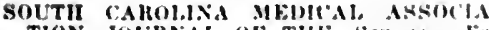

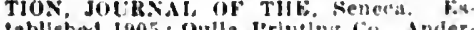

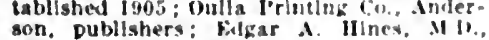
editor: monthly: $\$ 200$

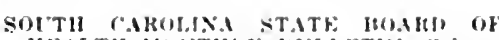

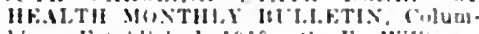
lula rivtablabed 1910: $\mathbf{r}$ r. Wlllams, MII. editur: Pree.

\section{TENNESSEE}

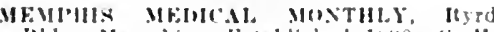

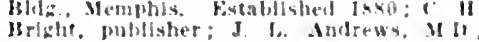
edltor: monthis: $\$ 1.00$.

NASHVILE JOIJNAL UF MFInINE

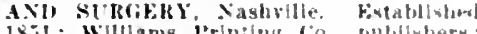
1. $\$ 1.00$

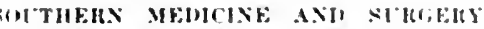
('hatunomga. Established 1904; Kaymone Wallace, M.J., editor and publisher monthly: $\$ 1.00$

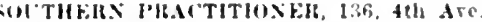
Nasholle. Established lsig: 1tecring J. Koberts. M.l., edifor and publisher monthly : $\$ 1.00$

THENKSEF STATE MEUICAL ASSOCIA TIIN, JotRNAl, OF THE, Nashrllle. EsPablished 1408; Nich I'rinting fompany, publlshers: Perry Bromberg. M.I.., editor. monthly ; $\$ 2.00$.

\section{TEXAS}

TEXAS COLRIER-RECORI OF MEIICINE Fort Worth. Extablished 18s0; Stiluel Prescoti, puhllsher; $\&$ 1. Hrewer, M.I. edltor; montlaly: \$1.00

TFXAS MEDICAL JOIRIII. "The Red Back," Alstin. Established 1885; F. E Danlel, M.D., editor and publisher; monthIy ; $\$ 1.00$.

TEXAS MEMCAL NFWS, Southwestern life Insurance Bldg., Dallas. Establlshed 1831: Matthew M. Smith. M.I., publisher and editor; monthly ; $\$ 1.00$.

TFXAS STATE HOARD OF HEAITH, HEL LETIN OF THE. Austin. Establlshed 1908; Texas state Board of Health, pubIisliers; R. 1'. Babcock, editor; nonthly Pree.

TEXIS ST ITE JOIRNAL OF MEUICINE. Fort Worth Evtabllshed 1905. State Medlcal Assoclation of Texas, publishers; IInl man Taylor, M.L., editor; monthly; \$1.50.

\section{UTAH}

I'TAII STATE BOARD OF IIEALTH MOXTHLi HILLETI, Salt lake City. Estatollshed - State Hoard of Health. publlshers

\section{VERMONT}

VFHMONT MFDICAl, MONTHL, Burling ton. Established 1895; Burlington Medi cal Publishing Company, publishers: II. C. Tinkham, M.It., and H. H. Stone, MII. edltors: montlily: $\$ 1.00$

VEHMONT STATE BOARH OF IIEAITII

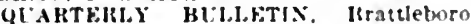
Established 1902; State lioard of Ifealth. publisters: Charles $r$. Walton, M.In. edltur: quarterly; free.

\section{VIRGINIA}

OLW MOMINION JOERNAL OF MEMICINE

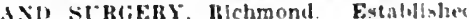

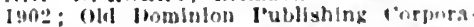
tion, publlshers: J. Mctaw Tomphis. II I. celltor; monthly: $\$ 2.00$.

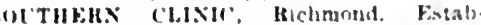
listed 18:s: C. A. Hryce, M.I)., emlltor and publstier: monthls: \$100.

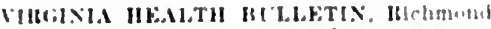

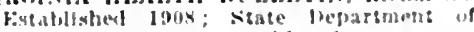
llealth. publisler: monthly; face

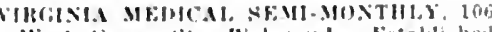

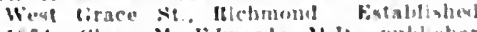

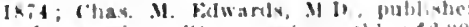

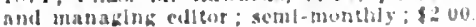

\section{WASHINGTON}

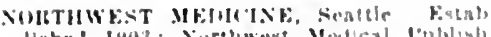
lishenl 1903: Corthwest Mlouleal louldinh

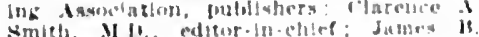

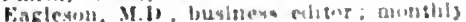
$\$ 2.00)$

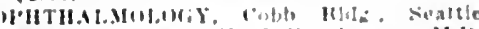

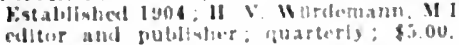

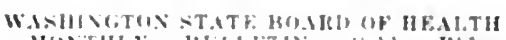

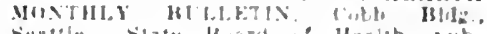
listers: bugrue li kelley, Illo, editor: juarteriy, free.

\section{WEST VIRGINIA}

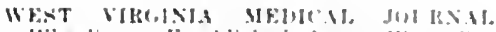

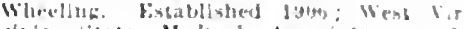

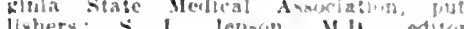
inunthli: : 1 . Bo

\section{WISCONSIN}

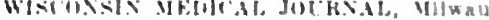
kere butalulatued 1903; Siate Medleal sinctety of Wiaconsin, publintiers: I W. Vyeri, MI, aditor: monthly : 00

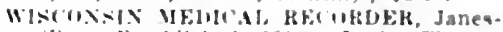
ville. Establlsted Is9s: J. I'. Thorne, II. Jullisler: F. Van kirk and

WISIONSIN STATF, IBG.MUI) UF HFALTI

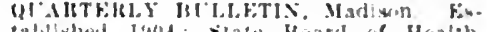

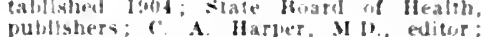
publishers: f.

\section{PHILIPPINE ISLANDS}

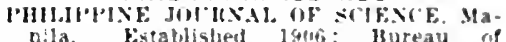

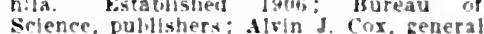
editor: Section 1 , themleal and rieriluglcal sclences and the Industries $2 . \mathrm{An}$ : secIina B. Trupleal Medicine, \$3.no: Section Biology, Ethnology and Anthropolingy, $\$ 2.00$; entlre journal. $\$ .00$; each section six numbers ver year.

\section{CANADA}

CANIII I.A.CET 200 ddelalde st. Toronto, Ont. Fiviabliahed 1s68: Ontario l'ublishing company publishers John II. B. editors; monthly; $\$ 2.00$.

CAXAlHAX JOTRXIL OF MEMITINE ANII STRGiERY. Toronto, Ont. Established 18.4; W. W. Youne.

CANAMAN MEHCAL ASBOCIATIOS JOLR. vil. wlih which is incorporated the Mintreal Medical Journal, founded 1871. and the Maritime Medleal Nen 3,63 bay Mlirang * ro., pullishers: Indrew Macphail. Mr. edstor: mouthly ; $\$ 500$.

CANAIIA I'LACTITIONH ANI IEVIEW, Turonto. Gut. Fintablished 16:5: Adam 11. Wrigh, M.D. W. II. B. Alkins, M.D. and Fonthly $: \$ 2.00$.

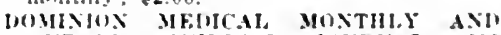

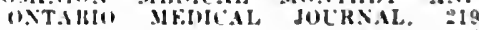
Sparlina Ri.. Toromu. Omt. Established 1.4:- Cieotze tillote M.W. managing editor and publisher; monthly: $\$ 2.00$.

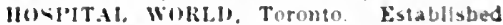
1:119: I .1. Young, II D. managlng editur: monlhly: $\$ 3.00$

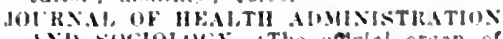

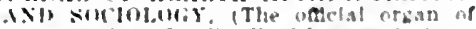

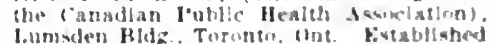
1:40) Vork pulllwing compant, 1.9d. publishers: Inucan $\$$ Anderwin. "I1" exllew and mandger: monthls: \$: $0 \mathrm{n}$.

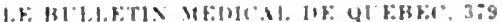

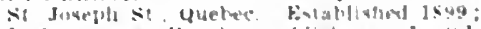
fonflanme a Proula, muldobers: $J$ od.

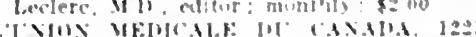
lest Vulier st. Monireal que Fistab. Jak Allert lersage. II ll.. mbles: monthls 3: 10

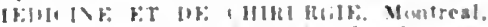

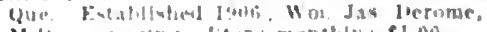
Ith minasmb afint; monthly: $\$ 100$

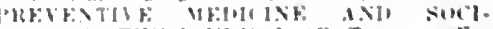

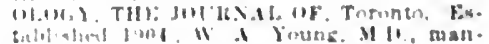

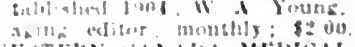

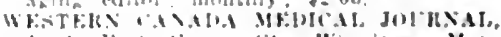
I A bust (iarr) ("t. Wimniper Wan. ellow: mosulh!s: so on

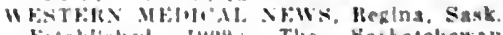

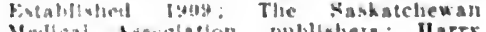
Murell, II., chalrian: menthly: \$1.00. 


\section{MEMBERS OF SPECIAL SOCIETIES}

NOTE.-Thls ilst includes names of members of these socicties arratuged alphaletically iny states. Numbers in parenthesis following the names indicate socleties in whicil membersinip is held.

\section{INDEX TO SOCIETIES}

\section{SURGERY, GYNECOLOGY, OBSTETRICS AND ANHSTHESIA}

\section{A-SOCIETIES}

NUMBER OF MEMBERS 1229

1. Amerioan Association of Obstetricians and Gynecologists.

2. American Gynecological Society.

American Orthopedio Association.

4. Amerioan Proctologic Society.

5. American Surgical Association.

6. Southern Surgical and Gynecological Association.

7. Western Surgical Association.

8. Boston-0bstetrical Society of Boston.

8. Boston-Obstetrical Orthopedio Club.

10. Brooklyn Gynecological Society.

II. Chicago Gynecological Society.

2. Chicago Orthopedic Society.

13. Chlcago Surgical Society.

14. Cincinnati Obstetrioal Sooiety.

15. Now York Obstetrical Society.

16. New York Surgical Society.

17. Philadelphia Academy of Surgery. 18. Philadelphia - Obstetrical Society of

19. St. Joseph Surgical Society.

20. St. Louis-Section on Obstetrics and Diseases of Women.

21. American Association of Anesthetists.

22. Surgeons' Club of St. Louis.

23. St. Louis Surgioal Society.

24. Washington (D.C.)-0bstetrical and Gynecological Society.

25. Washington (D.C.) - Surgical Society.

26. Interurban Orthopedio Club.

27. Milwaukee Surgieal Society.

\section{ALABAMA}

\section{Birmingham}

Cunningliam, Russeil M. (6) Woodward Bldg. Daris, John D. S. $(1,6) 2031$ Are. G.

Hefflin, Wyatt (6) Brown-Marx Bldg.

Heftlin, Wyatt (6) Brown-Marx
Hogan, E. P. (6) 800 S. 20 th St.

Hogan, E. P. (6) 800 S. 20 th St.
Jordan, Wilitiam Mudd (6) The Woodward. Lupton, Frank A. (6) The Woodward.

Mason, J. M. (6) 1915, 16th Are., S.

McAdory, Wellington P. (6) 2430 , IIth Ave., $\mathrm{N}$.

Morris, Lewis Coleman, (1, 6) Enpire Bldg.

Rogers, Mack (6) First Natl. Bank Bldg.

Talley, Dyer Findley $(1,6) 1808$, 7 th Ave.

Torrance, Gaston $(1,6)$ Woodward Bldg.

\section{State at Large}

Baker, James Norment (6) Montgomery, Ala. Baldridge, Felix E. (6) Huntsvilie, Ala.

Cole, Herbert Phalon (6) Mobile, Ala.

Gavin, G. E. (6) Mobile, Ala.

Goggans, James Adrian (6) Alexander City, Ala.

Hill, Robert Somerville (6) Montgomery, Ala.

istin, Wm. M. (5, 6) Mobile, Aia. A: $>$ Isaac Lafayette (6) Montgomery, Iishers,

\section{ARIZONA}

NE.V YOR en H. (26) Phoenix, Artz. IIFAITH ARKANSAS

Establisine ARKANSAS $(1,6)$ Littie Rock, Ark. ment of 1 .

\section{CALIFORNIA \\ Los Angeles}

Cooke, A. Bennett $(4,6)$ Story Bldg. Kiger, Wm. H. (4) Consolidated Realty BIdg.

Hoore Elward C (i) H W Heliman Bldg.

Roberts, Jean Margaret (21) 1229, W. 230 St.

\section{San Francisco}

Botsford, Mary Eilzabeti (21) 807 Francisco St.

Ely, Leonard WW. (3) Stanford University.

Gibbons, Henry Waiter (1) 350 Post St.

Hunkin, Samuel J. (3) 1153 Bush St.

Huntington, Thomas W. (5) 350 Post St.

Rixford, Emmet (5) 1795 California St.

Sherman, liarry M. $(3,5,7) 350$ Post St.

Stillman, Staniey (5) 2101 Webster St.

Wakefieid, W. Francis B. (2) 1525 Sutter St.

Watkins, James T. (3) Unton Square Bldg.

Williams, Edith Ifammond (21) 41, 5th Are.

Zobel, Alfred J. (4) Shreve Bldg.

\section{State at Large}

Buteau, Samuel H. (1) Oakiand, Cal.

Hagadorn, Mary E. (21) Pasadena, Cal.

Holister, John Chamberlain (13) Berkeley, Cal.

Lockwood, Charles D. (7) Pasadena, Cai

Newman, Henry Parker $(2,11)$ San Diego,

Cal.

Sherk, Henry H. (7) Pasadena, Cal.

\section{COLORADO \\ Denver}

Cinarles, Robert L. (21) Metropolitan Bldg. Freeman, Leonard $(5,7)$ Metropolitan Bldg. Grant, Wm. West (7) Mack Block.

Heath, Horace Samuel (4) Brockman Bldg. Jones, S. Fosdick (3) 1405 Gienarm St.

Packard, George B. (3) 732, 14th St.

Parsons, Carl G. (21) Metropolitan BIdg.

Powers, Charles A. $(5,7)$ Stedman Bidg.

Wetherili, Horace G. (7) Metropolitan Bldg. State at Large

Edwards, Ernest Gard (7) La Junta, Colo.

Kahn, Maurice ( $/$ ) Leadville, Colo.

Mayhew, David P. (7) Colorađo Springs, Colo.

\section{CONNECTICUT}

Carmalt, Wm. H. (5) New Haren, Conn.

Cook, Ansel G. (3) Hartford, Conn.

Ingails, Phineas H. (2) Hartford, Conn.

Lambert, H. Bertram (21) Bridgeport, Conn.

\section{DISTRICT OF COLUMBIA Washington}

Abbe, Truman $(24,25)$ Stoneleigh Court.

Balloch, Edward A. $(6,25) \quad 1511$ Rhode Island, Are., N.W.

Borden, William C. $(6,25)$ The Rochambeau.

Bovee, Join Wesley $(2,6,25) 815$ Connecti-

cut, Ave., N.W.

Chipman, Clíne N. (21) 606 , 6th St., S.W. Coriey, Karl (24) 1787 Columbia Rd., N.W. Corley, Karl (24) 1787 Columbia Rd., N.W. Crook, Harrison (25) 1101, 15th St., N.W.

Donnally, Harry H. ${ }_{\text {John }}(3,25,26) 1621$ Connecticut Ave., N.W.

Erving, Wm. G. $(3,25,26) 922,17$ th St.,
Fowler, H. A. (25) 1332 Massachusetts Ave., N.W.

Fremont-Smith, lirank (24) 1808 Massachusetts Are., N.W. N.W.

Fuller, llomer G. (25) The Farragut

Grasty, Thomas S. D. (24) 1273 New Hampshire Are.

Groover, Thomas A. (25) 1410 M St., N.W Hagner, Francis R. $(6,25) 17$ th and 1 Sts. Hooe, A. Barnes (25) 1220 , 16th St., $\mathrm{x.W}$. Johnson, Joseph Taber $(2,6) 926,17$ th St. N.W.

Kelley, John Thomas, Jr. $(24,25)$ 1312, 15th St., N.W

Kerr, Harry H. (25) $1742 \mathrm{~N}$ St., N.W.

King, Aibert F. A. (2) 1315 Massachusetts Ave., N.W.

Lawson, Huron W. (24) 1117 Vermont Ave. N.W.

Lehr, Louis C. (25) $173 \pi$ H St., N.W

Jewis, Duff G. (25) 13II, I4th St., N.W.

lowe, Thomas Francis (24) $205 \mathrm{H}$ St., N.W. Magee, M. D'Arcy (25) 1623 Connectleut Ave., N.w.

Magruder, Ernest P. (25) The Farragut.

Martin, Thomas C. $(4,25) 1725 \mathrm{~N}$ St., N.W Miller, Gideon Brown $(2,24,25) 1730 \mathrm{~K}$

St., N.W.
Mitcheil, James F. $(5,6,25) 1344,19$ th St., N.W.

Moran, John F. (6, 24, 25) 2426 PennsylNeill, Thos. E. (24) 1213 Connecticut Are., N.W.

Parker, Edward M. (25) 1726 M St. N.W Prentiss, Daniel W. $(24,25) 1213$ M St. N. W.

Reeres, William P. (25) 100 E. Capitol St Reichelderfer, Luther H. (25) 1721 Connecticut Ave., N.W.

Riggles, John Lewis (25) 1424 K St., N.W. Shands, Aurelius R. (3, 6, 25) 901, 16th St. N.W. Snyder, Arthur A. (25) 1126, 16th St.,
N.W.

Sowers, Willam F. M. (25) 1707 Massachusetts Are.

Sprigg, William Mercer (24, 25) 815 Connecticut Ave.

Stavely, Albert L. (25) 1744 M St., N.W. Stokes, Charles F. (5) Nary Department.

Stone, Isaac Scott $(2,6,24,25)$ Stonelelgh Ct.

Sulitivan, Robert Y. (24) The Burlington.

Thompson, Joseph F. (5) Cumberland Apts Van Rensselear, John (25) 815 Connecticut Ave., N.W.

Vaughan, George Tully $(5,6,24,25) 1718$ I St., N.W.

Wall, Joseph S. (24) 2017 Columbla Rd. Weilington, John R. (25) 1723 Connecticut Ave., N.W.

White, Charles S. $(24,25)$ 911, I6th St. N.W.

Willson, Prentiss (24) 2000 P St., N.W.

Young, William G. (25) 1523 L St., N.W.

\section{FLORIDA}

Jaeksonville

Holden, Gerry R. (6) 215 Laura St Rogers, Carey P. (6) 221 Laura St. Simpson, James $K$. (6) St. James Bldg. Turck, Raymond C. (7) Consolidated Bidg. 


\section{State at Large}

Iolmes, Joses Blllington sanders $(1,6)$

Tampa, pla.

Llncoln, Walter Rodman (1) Cocoa, kla.

\section{GEORGIA}

\section{Atlanta}

Earnest, Joln G, (6) (andler Hldk. bakin, Willam silmpson (6) lieorglan Ter-

(joldsmith, Willlam s. (t) $2 \pi$ Iackle st.

llodsson, Fred (i. (b) i: W. Peachtree st

Hoke, Mllohael $(3,6) ; 2$ W. Leachtre sit. Jones. Fdward G. (6) Fourth Natloual Bank BId

Mekat, Floyd Wilcox (6) I'eters Bldp.

Nleolson, Willam 1'errin (6) Forsyth Bldz

Noble, liconge Henry, (I, 2, 6) 180 S. I'ryo st.

Westmoreland, Wills Foreman $(1,6)$ Eifuit able Bidg.

\section{State at Larpe}

Doughty, William H. Jr. (6) Augusta, Ga.

Waring, Thonas $P$. (6) Sarannah, (ia

White, George R. (1) Sarannah, tiis.

\section{ILLINOIS}

Chioago

Adams, Charles (13) $32 \mathrm{~N}$. State St

Adolphus, l'bllp (II) 1639 Washlugton Blyd.

Allport, Waiter It. (13) 607 kush St

Andrews, kdw. Wyllys (i, $;, 13) 32 \mathrm{x}$

State St.

Andrews, Frank T. $(2,11) 32 \mathrm{~S}$. State $\mathrm{St}$ Bacon. Charles S. (11) 2156 sedjulck st.

Barrett, Channing W. (1, 11) 32 . State St.

Beek, Carl (13) $108 \mathrm{X}$. State St

Beck, Emll (i, 13) 2551 N. (l)ark St.

Behrendt, Arthur J. (12) 2026 Fowler st.

Resley, bredertek $A$. $(i, 12) 104 \mathrm{~S}$. Ilich Igan Are.

Bevan, Arthur U. (5, 6, 12, 13) 129 s Mlchigan Are.

Blanchard, Wallace $(3,12)$ 15 k. Washing

ton St.
Bouffleur, Albert I. (13) $24+9$ Washington Bird.

Buford, Coleman 1:. (13) 1:2 s. Mich!gan Ave.

Burry, James (13) 208 S. La Salle st.

Byford, Henry T. $(2, i, j, 11) 122$ s MlchIgan Are.

Cubblus. Willam R. (13) 29 F. Madison st.

Curtls. Arthur H. (11) iot S. Mlehigitn Are. Arthur 1. (11) 104 s. Mlichigat

Daris. Carl B. $(\%, 13) 122$ s. Mlehlgan

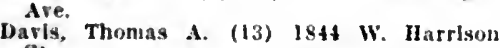
St.

Darison, Charles (13) 30 N. Mlchlgan Ave De Lee, Jas. R. (ii) $25 \mathrm{k}$. Washlngton St. de Tarnowsky. George (13) 45is Hroadway Doane, I'hlllp s. (11) I0t Michigan lie.

Dodils, Robert (11) 394ti fottage lirove ive

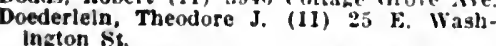

Doertng, Fdmund J. (II) 81 F. Madison st. Dorland, Whllam A. N. (11) i W. Madisot

Dutfley, Fmlllus Clark (2, 11, 13) 1:2 S. silchigan Ave.

Dyas, Frederlck (:. (13) $32 \mathrm{x}$. State st.

Farle, Frank $\boldsymbol{H}$. (1) 22 b. Washlugton st

Eisendrath, Danlel $x$. $i, 13)$ 31 $x$ state St.

Frank, Jacob $(12,13) 32 \mathrm{X}$. State se

Frankenthal, Jester t:. (ii) it $\$$ Wabasil Are.

Friend, Fmanuel (1:) $5 \mathrm{~S}$, Wahash

Fuller, William $(\tau, 12,13) 104$ s. Michigan Are.

Gillmore, Robert T. (11) 30 X. Mlehlgan Are. (ioldspolin, Albert (1, I1) 2130 (levelanel Ave.

Goldsine, Mark T. (11) $3: \times$ state $\mathrm{Nt}$

Grabam, David W. (13) 15 k. Wastultigton St.

Greensfelder, Jouls $A$. (1:1) $1114 \mathrm{~S}$. IIICh Igan $\lambda$ re.

Ialstead. Allert busard $(i, i, 13)$ is $x$ State St.

Hardon, Hobert W. (12) ih N. State Nt.

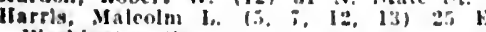
Wiashingtous

llarwha, Willam M. (13) $31 \times$ state st.

Heaney. Nuble s. (11) 123 Mlchican dre.

llerb. Isabella C. (21) 5 ido Marylani ire.

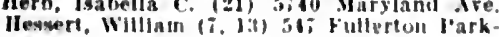
lesver
way.

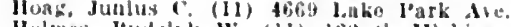

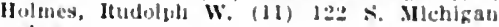
Ale.

Jarols, Charles M. (12) 31 N. Sitale st. Jotes, Walfer (c) (13) $15 \mathrm{k}$. Washlngton st. Kathlhe, Charles b. (13) 32 x. State st. Kanarel, Allen Jb. $(5,7,13)$ is $\times$ sitate st. kerr, Normin (12, 13) $32, \mathrm{~S}$. State st. hiscen.

livifiher, liustav (11) $10 \mathrm{~N} \mathrm{x}$. State st.

Kun\%, sylvan (13) :32 N state st

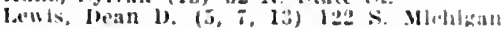

Ale.

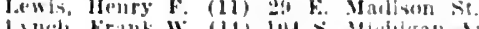

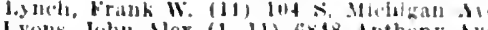

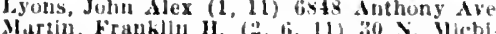
hau ire.

uc.urthur, Lewis

$\therefore$ Ilielilgau die.

(1) $1: 2$ Mejermld, Andrew (1) il $x$. Ninte st Slorf, l'aul F. (13) 1403 Larrabee st. Mortan, Wllliam h. (1:3) 3:25t; lutilana dre

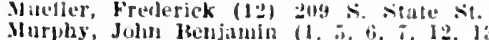
lot s. Jlihlgat Ne.

Nelson, haniet $T$. (11) 2tim) Imliana Ave

Uclisner, llbert J, (5, $6,1: 3)$ 2lut sedg whek sit.

(blisner, Fidward II. (6, I2, 13) 2038 Lant ('t)

wens, John F. $(5,13)$ 15 E. Washlingua

laddock, Clias. E. (II) 106 s. Mlohigan Are Parker, (harles A. (12) 7 W. Madison sit. st.

I'erey, Nelson II. (13) 2106 sedpwlek St.

I'hemlster, Dallas 13. (13) l:2 s. Michlgan Ave.

Plummer, Samuel C. $(7,13) 25$ E. Washlng ton St.

Porter, Jolan I. (3, 12) 7 W. Madlson st.

Iteed, Charles $B$. (II) $31 \quad \mathrm{X}$. Sitate $\mathrm{si}$

Isichter, Harry il. (13) 2jth and hearborn Sis.

Mdlon, John $(3,12) ; \mathrm{W}$. Madlson st.

Rlebel, Ernest C. (1:3) 302 W. 631 sit

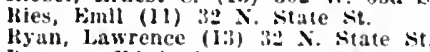

liyerson, Edwln W. $(3,1,1)$ 1:2 S. Mielngan

Are.

Schmauch, George (1I) $32 \mathrm{~N}$. State st.

schroeder, Wllliam fo. (13) 31 N. State

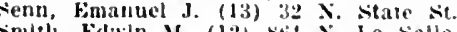

nnith, Edwin M. (12) sei X. La salle st

Ntalil, Frank A. (11) 31 N. State St

steele, Danlel $A$. K. (13) $3 i$ N. State st

Stowe, llerbert M. (11) 4355 Onkenwald

Swenson, Carl G. (13) \$t0 Fullerton r'ark way.

Test, Frederlek C. (12) 31 N. State st.

Thomas, Henry $\mathrm{k}$. $(1: 2) 31 \times$. State st.

Thompson, George $r$, (23) 600 Blue Island Ave.

Thompson, Willlam M. (II) $32 \mathrm{~N}$. State $\mathrm{St}$

Van llook, Weller (13) 31 N. Sitate sit.

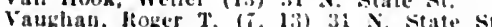

Watklus, Thomas J. (2, 11) jot stalt st tran ive.

Webster, John Clarence $(2,11)$ 104 S. Mleh

Wlener, Alexander C. (12) $32 \mathrm{X}$. State st State at Large

Jacon, Joseph Barnes (1) Macomb, III. Italley, tilluert ta. (12) Wak lark. It Hack, Ciarl H. (i) Jacksomvllle, Iil Chrlatle, Robert 3 . (i) Quilucy, II rollins. (1leford : (i) Veorla, III

Ilollowbush, Joseph It. (i) Itock 1sland. III Krelaler, dicorga $X$ (i) surlngtlda. III

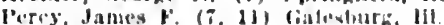

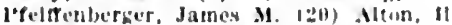
Sala, St. Filno M. (i) ltock Isinnd, Iil Tinemas, Vietor liarwin (:t) Eillott, 14

Will, vibo H. (11) Ieuría, Ill.

\section{INDIANA}

Indlanapolis

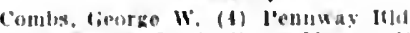
('onk, lieurge J. (f) Hume-Malsis lthle Fastenan, J. It. (i) 331 y lolan are st. Faxtman. Thumas Haker (1) lennway llide.

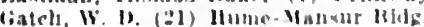

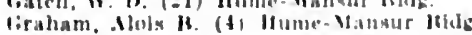

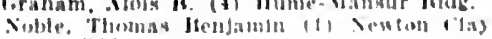
jumi [t]d:

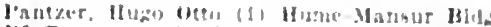

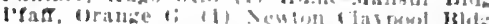

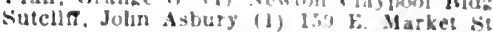
State at Larpe

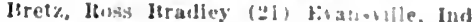
cumb. Charles $x$. (2) Thero fliute, Ind livller, K. Fo (2i) iviumbis, list

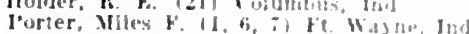
isosenthal. llaurlece i, il fil wayne, Ind Walker, Filwlin $(1$, ei) Evanbille, Itid

\section{IOWA}

Des Moine

Cokenower, Janes W. (i) I'tlea lslock le ford, Willam Ilarper $(a 1)$ Flyna Hido Fay, ollver J. (i) Eipultable Mldg.

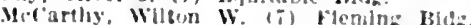

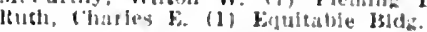
Dubuque

Hancock, John C. (i) Wank and Insurance Itlidis.

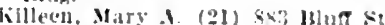

l'ond, Alansun M. (i) $120+$ lokeurt st.

\section{State at Large}

Broekman, Tasld ('. (i) Ostumua, la Iturge, sibertus J. (i) Juwa city, In

Fairchlld, Davlu Sturgess, Jr. (6) (Jinti)

alrihlla, Ihavid Sturglss, Sr. (i) Clinton, Ia James, tharies $s$. (i) (enterville, Ia depson. Willam $(z)$ sionx (ity b.

knott, Van Buren. (i) Sloux ilty, Ja littiz. Lawrence $W$. (i) l larenjort, I Macliae, Ilonald Ir. (i) councll firutfs, la kowan, Chas. J. (13) lowa Clty, Ja. Achroeder, Veter U. (:1) Varenport. Ja. Thompson, Jenjamin (i) Tama, la.

Warren, John $x$ (i) Sloux city b.

\section{KANSAS}

liasham, Darid W. (i) Wichlea, Kan Howers, (harles E. (i) Wichita, Kun. (iray, George Jorrls (i) Kansas (lty, Kan. sudler, Merrin T. (z) Lawrence, Kan.

\section{KENTUCKY}

\section{Loulsville}

Atell, Irvin (i) Ailuerton Itld

Frank, Lotsls $(1,6)$ Itherton $131 \mathrm{~d}$.

lirant. Henry II. (6) Atherton Iklg.

Iranes, (iranrllle S. (4,6) Masonle Blda

Helm. John W. (2i) Sthertun Hild

Hendon, George $i$ (b) Atherton Blide

Horine, Emmet $\vec{F}$ (21) $103 t^{\circ}$ Jardstuwn $\mathrm{Rd}$

Mathews. Josegh M. (t) Masonle Blez

MeMurtry, lewls $\$$. (1, 5, (i) Atherton Hid. Onderdonk. Willian A. (2b) Itherton lild: lioberts. Willlam 0. (b) Itherton IHlit? sehachner, August (b) $s+6$, th die Sherrlll J. (iarland (1, i) lehertinn lld: Vance, Ap. Morgan $(1,6) \quad s 35,5$ th Ale Wathen. John It. (6) idt, th Aie.

Windell. J. T. (6) 715 W. Jetterson sit.

$$
\text { State at Large }
$$

Itarrow. David (5, 6) Le'xington, Ky

\section{LOUISIANA}

New Orleans

vilen. Carroll W. (b) 1:11:- Loulslana Jie

Itatehelor, daniex Y. (6) de1 ranal st

llowm. Jeffersum $D$ (ii) (bel canal st

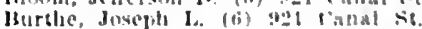

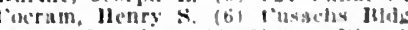

Dama, Joseph if (i) Malsom Manche Mhe Kohlmann. Witholm (t) Ma!son lilanche I3lig.

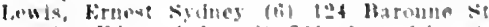
Martin, bitmund "1 (ti) itl carendeles se Matas, fludolph (5. b) 3.103 l'rythania se.

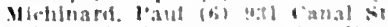

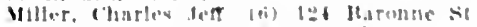

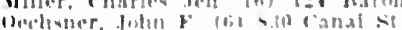

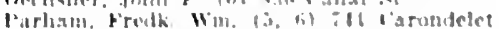

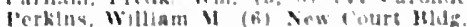

suluchul balnubl (3) Whitues lientral liank

IIII.

State at Large

Whllamm, rifoy 11 (bi) latterson, Ita

\section{MAINE}

Portland 


\section{MARYLAND}

Baltimore

Ashly, Thomas A. (2) 1125 Madison Are Baer, Willam S. $(3,26) 4$ E. Madison St Itoodrood, Joseph C. $(5,6) 904 \mathrm{~N}$. Charles st.

Branlaam, Joseph II. (I) 2200 Eutaw I' Cone syduey llilton (3) 2:32t Lutaw lit. Cullen Thomas s (a, (i) 3 w. Preston st Davis, John Staige (b) I200 ('atheriral st. Davls, Samuel (irlfith, Jr. (21) 1230 Light sit.

Farle, Samuel T. (4) I43I Jinden Ave. Fayerweather, Rondes (26) $529 \mathrm{~N}$. Charles St.

Finney, John M. T. (5, 6) 1300 Eutaw I'l. llalsted. Wm. S.. (5) 1201 Eutaw l'l.

Hebl, irthur (4) J'rofessional BIdg.

llundley, John Mason (6) 1009 Cathedral St.

IIunner, Guy Le Roy (6) 2305 St. Paul St. Johuson, Itobert W. (5) I0I IV. Frauklin St. Kelly, Howard A, (2, 6) 14 I8 jutaw 1'l.

Martin. Frank (6) 1000 Cathedral st.

latt, Walter Brewster (6) 802 Cathedral

St.

Riely, Compton (3) $2025 \mathrm{~N}$. Charles St.

Russell, Wn. Wood (fi) I 208 Eutaw Pl.

Sellman, Willam Alfred Belt (I) 5 E. Biddle st.

Smith, WHilam s. (1) 528 Hanover St.

Taylor, Itobt. Tunstall (3) $2000 \mathrm{~N}$. Charles

St.
TIffany, L. Melane (5) 831 Park Ave

Tiffany, L. Mclane (5) 831 Park Ave. thedral St.

Winslow, Randolph (6) 1900 Mt. Royal Ter-

race.
Young, Hugh H. (6) $330 \mathrm{~N}$. Charles St.

\section{MASSACHUSETTS}

\section{Boston}

Adams, John D, (9) 261 Beacon St.

Adams, Zabdiel B. $(3,9) 166$ Newbury st.

Blake, John Bapst $(5,8) 65 \bar{\gamma}$ Boylston St.

Blake, John G. (8) 212 Beacon st.

Boothby, Walter M. (21) 508 Commonwealth Ave.

Bottomley, John T. (5) 165 Beacon St.

Brackett, Elliott G. (3, 9) 166 Newbury St.

Bradford, Edw. H. (3, 5, 9) 133 Newbury St.

Brown, Francls Henry (8) Hotel Buckminster.

Bucholz, Carl Herman $(9,26)$ Massachusetts General Hospltal.

Burrage, Walter L. (2) 282 Newbury St.

Cheever, David (8) 20 Hereford $S t$

Cheever David Wm. (5) $55 \%$ Roylston $\mathrm{S}$

Cotton, Frederic Jay (21) 520 Cominonwealth Are.

Cushing, Ernest W. (2) 168 Newbury St.

Cushing, Harvey $(5,6)$ The Peter Bent Brigham Hospital.

Cusling, Hayward W. (5) i0 Commonwealth Ave.

Dane, John (3, 9) 29 Marlboro St.

Darenport, Francls H. $(2,8) 419$ Boylston De Normandie, Robt. I. (8) 355 Marlboro St.

Elliot, John W. (5) 124 Beacon St

Frledman, Leo $v$. (8) 425 Marlboro St.

Gay, Geo. W. (5) 665 Boylston St.

Gllman, Chas. S. (4) 419 Boylston St.

Goldthwalt, Joel E. $(3,26) \quad 372$ Marlboro St.

Graves, W. P. (8) 244 Marlboro St.

Green, Charles II. $(2,8) \quad 78$ Marlboro St. Greenough, Robert B. (5) 377 Beacon St. Hare, Chas. Henry (8) $\mathbf{4 8 3}$ Beacon St.

Harrington, Francls B. (5) 201 Beacon St. Hill, Thos. Chittenden (4) 384 Commonwealth Ave.

Hubbard Joshua Clapp (8) 86 Bay State Road.

Legg, Arthur Thornton $(3,9) 535$ Beacon $\mathrm{S}$

Lotlirop, Howard Augustus (5) 101 Beacon

Iovett, Robert W. $(3,9) 234$ Marlboro St.

lund. Fred B. (5) 527 Beacon St.

Mactusland, Wm. R. (9) 240 Newbury $\mathrm{St}$.

Marey, Henry Orlando (6) 180 Commonwealth Henry

Mixter, Saml. Jason $(5,6) 180$ Marlboro St.

Monks, George II. (5) 67 Marlboro St.

Morse, John Lovett (8) 70 Bay state Road. Newell, Franklin Spilman $(2,8) 443$ Beacon St.
Osgood, Robert B. (3, 9, 26) 372 Marlboro

Page, Calvin G. (9) 128 Marlboro St. P'iliter, Charles F. $(3,9,26) \quad 372$ Marl. boro st.

Porter, Cliarles A. (5) 254 Beacon St: lieynolds, Fdward $(2,8) 321$ Dartmouth $\mathrm{St}$ liogers, Mark H. (9) 485 Beacon St. Scudder, Charles F. (5) 209 Reacon St. Sever, James W. $(3,9) 234$ Marlboro St Soutter, Robert $(3,9,26) 133$ Newbury St Stone, James S. (9) 234 Marlboro St.
Storer, Ialcolm (8) 476 Joylston St. Swatn, Howard T. (8) 226 Commonwealth

Ave.
Thorndike, Aligustus $(3,9) 601$ Jeacon St. Torbert, James k. (8) 252 Marlboro St. Wadsworth. Richard (i. (8) 374 Beacon St. Varren, John Collins (5) 58 Beacon St. Warren, Iohn Colling (5) 58 Beacon St.

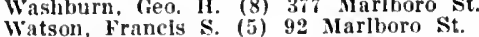
Whitney, Wm. Fiske (8) 228 Marlboro St. Young, Ernest B. (8) 434 Marlboro St.

\section{State at Large}

Coolidge, Frederick S. (3) Plttsfleld, Mass Emerson, Benj. Kendall, Jr. (26) Worcester, IIass.

Gage, llomer (5) Worcester, Mass.

HIldreth, John Lewis (8) Winchester, Mass. Houghton, Sllas A. (8) Brookline, Mass. Jackson, Ralph W. (4) Fall Kiver, Mass. Stevens, Edmund H. (8) Cambrldge, Mass. Worcester, Alfred (8) Waltham, Mass.

\section{MICHIGAN} Dotroit

BelI, John Norral (I) Washington Arcade. Blodgett, Wm. Ernest (3) 30 Adams Ave. Carstens, J. Henry (1) 620 Woodward Ave Hirschnan, Louis J. (4) Washington Arcade. lenks, Nathan (1) 22 witherell St. lenks, Nathan (1) 22 Werte, Danlel (3) 362 Jefferson Ave. Longyear, Howard Williams (1) 32 Adams Longye

MacMillan, James Alexander (4) Smith Bldg. Manton, Walter Porter $(1,2) 32$ Adams Ave. W.

McGraw, Theo. A. (5) 73 Cass St.

IcVeigh, James A. (4) Smith Bldg.

Morley, William Horace (2) Fine Arts Bldg. Schenck, Benjamin R. (2) 32 Adams Ave.

Yates, H. Wellington (1) Gas Office Bldg.

\section{State at Large}

Abrams Edward T. (1) Hancock, Mich.

Bolse, Eugene (2) Grand Rapids, Mlch.

Boys, Chas. E. (21) Kalamazoo, Mich.

De Nancrede, Chas. Beylard Guerard Ann Arbor, Mich.

Dickinson, Wm. I. (4) Saginaw, Mich

Peterson, Reuben (2, 6, 7, 11) Ann Arbor Mich.

Sample, Chester H. (T) Saginaw, Mich.

Smith, Richard Root $(2,11)$ Grand Raplds, Mlch.

\section{MINNESOTA}

Minneapolis

Abbott, Amos Wilson (7,11) 1717, 1st Ave., S.

Benjamin, A. E. (7) Donaldson Bldg.

Byrnes, Wm. J. (7) Masonlc Teniple.

Corbett, J. Frank (7) City Hall.

Dunsmoor, Fredk. Alanson (7) Andrus Bldg.

Eitel, Geo. G. (7) 1375 Willow St.

Geist, Emll S. (3) Syndicate Bldg.

KImball, Hannibal H. (7) 602 Nicollet Ave.

Law, Arthur A. (7) Syndicate Bldg.

Mann, Arthur T. (7) Donaldson Bidg.

Moore, James E. $(5,6,7)$ Syndicate BIdg.

Rochford, Wm. E. (7) Syndicate Bldg.

Schwyzer, Gustav (7) Donaldson Bldg.

Stewart, Jeremiah Clark (7) Syndleate Bldg.

Sweetser, Horatio B. (7) Masonic Temple.

$$
\text { St. Paul }
$$

Colvin, Alexander R. (3) Lowry Arcade.

Dennis, Warren A. (T) Lowry Bldg.

Gillette, Arthur J. (3) Moore Bldg.

Ilactaren, Archibald $(5,7)$ Lowry Bldg.

Ritehie, Harry P. (7) Lowry Bldg.

Rothrock, John L. (i) Lowry Bldg.

Schwyzer, Arnold (i) 123 W. Tth St.

\section{State at Large}

Andrews, John Wesley (i) Mankato, MInn. Collins, Arthur N. (7) Duluth, Minn.

Courtney, walter (i) Brainerd, Mlinn.

Judd, Edward Starr (7) Rochester, Minn.

Iagie, Wm. H. (7) Duluth, Minn.

Mayo, Chas. H. (5, 6, 7) Rochester, Minn.

Mayo, Wm. J. (5) Rochester, Minn.

Stewart, Chas. Adams (7) Duluth, Minn.

MISSISSIPPI

Crawforl, Walter W. (6) IIattlesburg, Miss,

\section{MISSOURI}

Kansas City

Binnle, John Falrbalrn $(5,7)$ Rlalto Bldg. Frankellburger, John Martln (4) Rlalto Bldg. Frick, W'm. I. (7) Rlalto Bldg.

Griftith, Jefferson Davls $(3,7)$ Rlalto Bldg.

Hertzler, Arthur E. (i) Itialto Bldg.

llill, Hown $(i)$ Iialto Bldg.

Jackson, Jabez Nortl $(5,7)$ Argyle Bldg.

Iux, Paul (21) Rialto Bldg.

Pearse, Herman E. (7) Kialto Pldg.

Reynolds, Wm. T. (7) Artyle Bldg.

Sutton, Walter S. (2I) 650 Everett Are.

\section{St. Joseph}

Jyrne, John 1. (19) Corby-Forsee Bidg.

Camplell O. Beverly (19) Hughes Bldg.

Hlam, Wm. T. (19) Corby-Forsee Bldg.

Forgrave, Harrison S. (7) KIng Hill Bidg.

Geiger, Jacob $(\overline{7}, 19) 614$ Francis St.

Heddens, James Weir, (I9) KIng Hill Bldg.

Mefilothlan, Arthur B. (19) King fill Bidg.

Pope, Arche Edwln (21) Logan Bldg.

Potter, Thompson E. (19) $120 \mathrm{~S}$. 7th St.

Told, Luther Anson (7, 19) Corby-Forsee

Bldig.

Wallace, Chas. H. $(7,19) 301$ N. 8 th St.

$$
\text { St. Louls }
$$

Allison, Nathaniel $(3,7,22,23) 537 \mathrm{~N}$. Grand Ave.

Amyx, Robert F. (22) 1943 N. 11th St

Ayars, Treston if. (20) Delmar Bldg.

Babler, Edmund Adam $(7,22) 4826$ Delmar

Blyd.
Bailey, Fredk. Warren (22) Metropolitan Bldg.

Barnes, Rollin H. (4) Metropolitan Bldg.

Bartlett, Aurelius Willard $(6,7,22)$ Metro politan BIdg.

Blair Vilary Papln $(6,7,22)$ Metropolitan Bldg.

Brown, John Young (1, 6, 7, 22) Metropoll$\tan$ Bldg.

Cale, George W., Jr., (22) 4960 Laclede Ave.

Carson, Norman B. $(5,22,23)$ Humbold Bldg.

Caulk, John Roberts (23) Humboldt Bldg.

Clopton, Malvern B. $(7,22,23)$ Humboldt

Bldg. Bldg.

Crossen, Harry Sturgeon $(1,2,7,20)$ Metropolitan Bldg.

Dean, John McH. (22) Metropolitan Bldg.

Deutsch, William S. (22) Llster Bldg.

Dorsett Edw. L. (20) Wall Bldg.

Dorsett, Waiter B. $(1,6,7,20,22,23)$ Wall Bldg.

Ehrenfest, Hugo (2, 20) Metropolitan Bldg. Elbrecht, Oscar H. (1, 6, 20, 22) Metropolltan Bldg.

sselbruegge, Frederick C. (20) 3736 N 11 th St.

Fuchs, Walter H. (20) 3202 Lafayette Ave.

Gehrung, Eugene Chas. (2) 3857 Westminster Pl.

Gellhorn, George (2, 20, 22) Metropolitan BIdg.

Glaser, Martin J. (20) 1825 S. Jefferson Ave. Glasgow, Frank A. $(6,23) 3894$ Washington Blrd.

Grant, John M. (22) 536 N. Taylor Ave.

Hall, Willis (20) Humboldt Bldg.

Hanser, Herman A. (20) 3651 Delmar Blvd. Hill, Roland $(7,22)$ Lister Bldg.

HInchey, F. (20) Humboldt Bldg.

Hoffmann, Phillp $(3,22) 3657$ Delmar Blvd.

Hypes, Benjamin M. (20) $1615 \mathrm{~S}$. Grand Ave.

Jonas, Ernst $(1,6,20,22) 465 \mathrm{~N}$. Taylor Ave.

Kerwin, William (20) 4900 Laclede Ave.

Kirchner, Walter C. G. $(1,6,22)$ Metropolitan Bldg.

Leighton, William E. (22) Humboldt Bldg. 
Mudd. Harrey G. (3, i, 22, 23) Humboldt

Inds.
Murphy, Fred T. $(5, i, 22)$ Washlnaton Indversity Medical schiol.

Myer, Max wavhington le2) Wall Mldg.

jewinan, Iouls folward (i) $53 \mathrm{si}$ Waterman Are.

Nicholson, Clarenee M. (i. 22) 4 ino Ollve st.

O'Relliy. James Archer (3) Humbolit Blab.

lassleur, Louls (22) Metropolitan Mlde.

beder. Francis Le $S . \quad(1,6,20,22) 634)^{\circ}$

Berlin A ve.

Ii)e. Pell F" (20) Delmar $\mathbf{b l d z}$

Kohertion, Villlam .1. (2-3) Humboldt BJig.

Rothsteln. Ilugo (20) 3309 :. I3th st.

Royston, Grandison Delaney (20) Delmar Bldg.

Sachs, Ernest (22) 1806 Locust st

Saunders Wdw. W. (20) I.lster Bld

Schlossstein. Adolph George (20) 3153 Longfellow Bind.

Schlueter, Rohert F. (2:2) 909 I'ark Are.

Schwartz. Ilenry (1, 20) 440 X. Newsteat Are

Seellg, Major C. (t, 22) Wall Hidg.

Smlth, Carroll (22) Humbold Itldg.

Spaln, Kate C. (20) 5706 Etzel Ave.

Swahlen, Percy II. $\{20\}$ Metropolltan Bld

Tausslg. Frederlck Joseph $(2,11,20,22)$ Metropolltan BIdg.

Tilles. Randall Solon (20) 521: Delnar Blrd

Tuholske. Herman $(6,22,23) \quad 463 \quad x$. Taylot Are.

Tupper, Paul Yoer (22, 23) Wall Hadg.

Valle, Jules F. (20) 4975 Maryland Ate.

Voot, Wllliam llans (20) Metropolltan Bldz.
Wobus, Relnhard E. (20) 1105 sallsbury st.

\section{MONTANA}

\section{Butte}

Schapps, John C. (3) Owsley Block.

Withersponn, Thomas (asty $(6$, i) Murray Hospltal.

\section{NEBRASKA}

Lincoln

Mackinnon, Artemas I. (i) First Xational Rank Bldg.

Orr, Iflram W. (3) Blchards Block.

\section{Omaha}

Darls, Byron Bennett (i) Bee Bid

Findley, Jaimer $(1,2$, i1) Brandels $\mid 11 d \mathrm{~d}$

Jonas, dugust F. $(G, ;)$ krandels Ildg.

Iord, John Prentlss $(3,3)$ Clty Sational Hank Bldz.

Stokes, Arthur $\boldsymbol{C}$. (i) Itrandels Bldk

Summers, John tidward $(\bar{i}, i)$ Brandels Bldg. State at Large

Beede, SImon C. (T) Iravid City, seh.

\section{NEVADA}

Roblson, Martln A. (21) Reno, Ner.

NEW JERSEY

\section{Nowark}

Guenther, Fmll Firnest (1) 159 W. Klnney st.

III, Charles I. (1) $1 \times 8$ cilnton Are

III, Edward Joseph $(1.6)$ loog Iroad st.

Pinneo. Frank W. (21) 199 (iarslue st.

Twinch, sldney Arthur (3) at Fulton st.

\section{State at Large}

Barton, James M. (.j) Nilantlic I'tty. X.J.

li]cklnson, (iordon $\mathbf{K}$. (1) Jerkey clis, X.J.

Faton. Alvin It., Jr. (21) Ellzabeth, X.J.

Ferguson. Itobt. Henry (21) kist Orange.

Harris. Inllander 1. (2) Jiatersun. N.d.

Hedges, Fllis $w$. (1) liatutleld, X.j.

Marvel, Emery (i) dilantle l'ily. J.

Marvel, Fmery (I) dilantle l'ty, S.d.

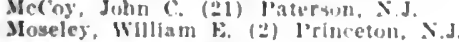

\section{NEW YORK}

Brooklyn

Inaldin Iemuel (i. (10, Iii) as siluermer horn st.

Beach. Halvh I $(10,15)$ (i). Flls lie.

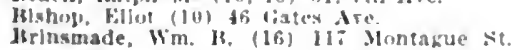

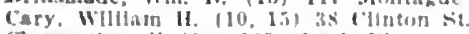

Chase, carroll (io) lowg l'ark l'

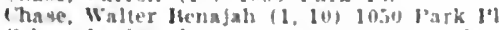

Cole, Charlos knox (D) Milante and vin derbilt Ares.

Comminkey, leo J (10) 149 , 6ith Aro

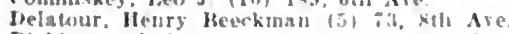

Dlekinmon, Holver! 1. (2, 10, 13) 16s (1/n ton st.

Glliwon, liordon (10) 176 state st.

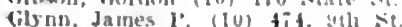

Gritteh Nibert Farnsworth (10) 1135 gcean

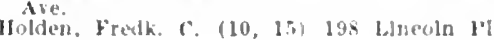
II unpstone, 11. 1'aul (10, 15) 327 Mashlng (1) 11 .

Hustey, AHzustus I. (10, 15) 167 Haneock st. Hyde, ilarence Reglnaid $(10,1,1): 4:$ lienry Juld. Alliert M. 110) 375 Grand die.

Kinght, Fronk H. (I0) 50,7 th Ibe

Krutkil, Isaac liavid (21i 8t: l'ark 11

Mackirlt, Juhn rubell (10) t117, flintun st

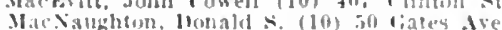

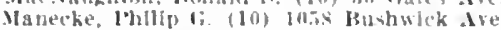

Matheson, A. llors (10) 37, Th Are.

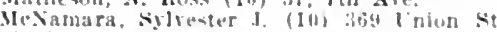

Napler, charles I. 13) 100 Lafayelte Ave.

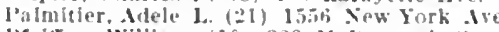

l'pelter, Willlam (10) 3os Mcllonough si

lobcher, Lewis s. (i) 145 gates Ave.

l'olak. John Oslorn (2, 10, 15) 287 Cllntson Are.

Pumeroy, Kalph H. $(10,15) 511$ Sostrand

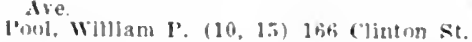

Hoberts. William I'. (18) 2189 (Tlarendon st

Rushmore, John ID. (5. 16) 126 Montague s.

Sammis, lieotge Frank 121) bi [Decatur st

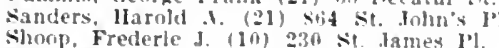

Shoop, Frederle J. (10) 230 st. lames 11.

Taylor, Jay it. (10) 1:35, lsedford Ave.

Tong, lieorge iw. (10) 429,34 st.

Truslow, Wilter (3) 239 Giates ive.

Wade, llenry Nhert 11,10$) 495$ (ireene lre.

Watt. James (15) it4 (cllnton st.

Woolses. Wm. Caran (21) 85 La Fasette Are.

Zimmerman, Victor L. (10) 271 stuyvesant Are.

\section{Buffalo}

Martow, Bernard (3) \$\$1 Lelaware Are

congdon, tharles Ellsworth (1) 859 IIumboldt l'arkway.

Hayd, Herman Emil (d) 493 Delaware Are

King, James E. (I) 1245 Main St.

Le Hreton. J'rescott (3) 125 Allen st.

lothrop. Harl $H^{2}$. (1) 153 Delaware ire.

Meisentarch, Roland 0 . (3) 1t0 sllen st.

l'lummer. William W. (3) 520 Franklin s.

\section{New York City}

Abue. Rohert (5) $13 \mathrm{~W}, 50$ th st.

Idans, 1 " T (15) 43 F. 5xth St

Ilbee, fred H $(3,20)+0 \mathrm{t}$, tlist

Halley, Harold 1 (15) 269 Jexington Are

Bambidge, William seaman (1, 21) 34 Giamercy Park.

bandler, samuel Wylls (I) $134 \mathrm{~W}$. sith st

Barrows, $C$ C. (15) $63 \mathrm{E}$, itith st

Blssell, J. 1) ougal (2, 1.5) 219 W. 7.81h st

Blake, Josegh A. $(5,16), 108$ F. 65th st

Koldt, Hermann J. (2, 6, 15) 34 t: bilst $\mathrm{s}$

Brettauer, Josien $(2,15) 1063$ Madison Are

Brewer, fieorge $\mathrm{k}$. (i, lif) $16 \mathrm{~F}$. tith st.

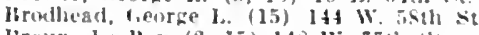

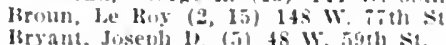

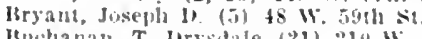

Isuchanas, $T$. Dryslale $(21) 21041$. 5ith st

l"aldwell. Willian F. (15) $149 \mathrm{~W}$. itth st.

'arrel. Nlexls (ii) Howkefeller Institute for

Medloal Lesearch.

rhambers, lorter $f,(6,15) 49 \mathrm{~W}, 5$ th $\mathrm{s}$

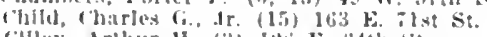

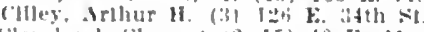

reveland, ('lentent $(2,15)$ to $\mathrm{k}+1 \mathrm{st}$ st "ehurn. liaymolyd i. (2I) Slith st. and Hruadway,

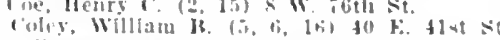

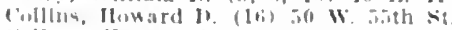

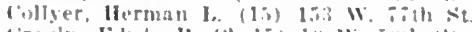

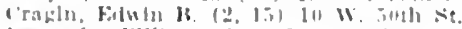

lartach, Whllam (li) ti ll. ind st.

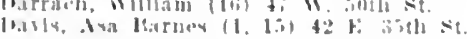

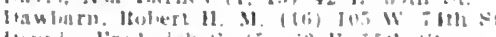

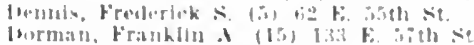

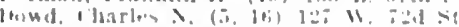

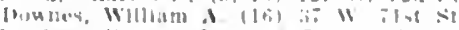

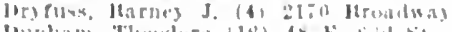

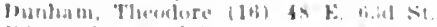

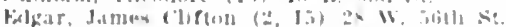

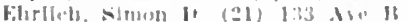

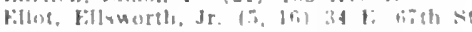

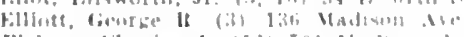

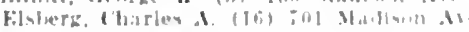

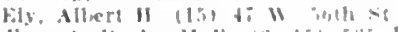

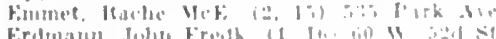

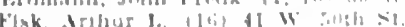

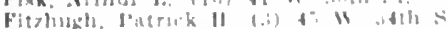

Flakg, l'aluel Jus, (2), lob lentral l'ark, s Fllnt, Justin, Jr. (17) tiv w oth st.

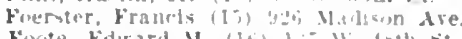

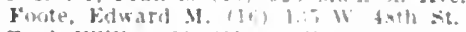
Ford. William M. (1) 5ir to to

Frank, leelert T. (2, 15) gn, l'ark tre

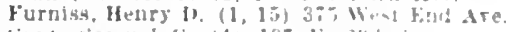
Gant, samuel fi, (4) 137 k. b) st

liliney virgll r. (3) 16 bark Ave.

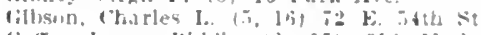
lioffe, lames Hidle $(2,151610$ Madison dre.

Grat, Hermann (15) fil F. I4lst St.

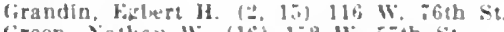
Green, Nathan 11 . (16) 11 . 50 th $\mathrm{St}$ fiwathmey, James T. (2l) fll b. flst st llarrar, Jimes . liken (1) 347 . 2d die. llartwell, Inhn 1 (I6) 27 F, fist st.

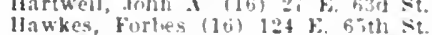
llawkes, forlues (16) 124 fo bith st. Heals, Willam l'. (1.i) 5is lark lve.

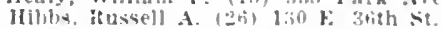
113ll. liadore Jeenn (1) blig Madlson Are Hirnns, Ciardner (1.i) $1: 3$ W. 13tith s: Hizror. James Morley (16) 1.5 E. 3ith St Ifolling Arthur F. (t) 103 Park Ave.

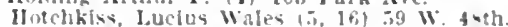
Hunt, Tharles Spalding (21) 352 w, 51 ist Jacolus, Artuur M. (1i) 131 W. 70th st. Iaeger, Charles H. (3) til lark Are. Jarman. fieorge W. $(2,15) 54 W .76 t h s_{t}$ Jellughus, Charles F, (1:) 1161 l'ark Are. Johnson, Alexander B. (5, 16) 116 k. 5ith st Kammerer, Frederick (i) il E. 6hith st. lillanl, ottis (i. T. $(i, 16)$ it w, ith $S$ Knapp. flinton B. (15) $30 \%$. A dre.

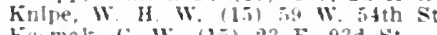
komak, f: W. (1.i) 23 E. 9.3 st Krug, Florian 12.15$) 616$ Madison Are. Lamlert, Adrlan $)^{\circ}:(16)$ lis E. ilat St Lee, Iturton I. (16i) $128 \mathrm{~F}_{8}$ i34 $\mathrm{SL}$

l.llenthat, Howard $(5,15)$ is $f_{\text {. }}$ itth St.

longt, sanuel (6) 1210 , inth 5 .

Lolenstine, Ralph Wildo $(1,15) 155 \mathrm{E}$

Lumbara, Jos. Fowarl (21) 1997, ith Are

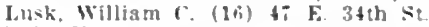

J.yle. Henry 1I. M. (16) 50 E. 53 d st uynch, Jernnte M. (t) 5\% F. 50d St Malbutt, Jolan 31 (15) 19 , ith Ave llallet, (C. II $(15) 2+4$ w. $30 \mathrm{~d}$ st Marumey Willian $\mathrm{I}$ (15) $12.5 \mathrm{~F} .55$ th st Wartin. Walton 116$), 5 \mathrm{~W}$, 50th si Marx. Sinon (15) $94 \%$ Madison Are. Wathews, Frank s. (1ti) ba W. 50 th St, Helean. Malcolm $(2,15)$ as F. lahth st.

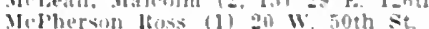

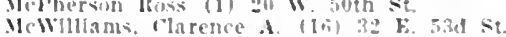
Wereness. Harry b... ir. (201) 200 w lotib

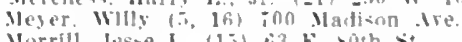
Worrill, lese I. $(12)$ di. F. soth s:

Morrls, Rubert Tutte $11,6,16)$ bilo Math soll itre.

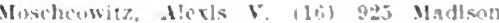
Ire

Murray, Francts w. (3) 32 W. 30 h st.

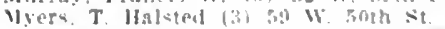

Nithen, llilly, w, (3) 110 b, isth si

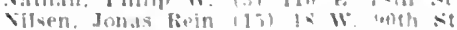

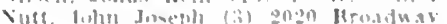

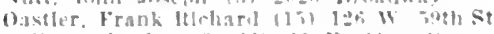

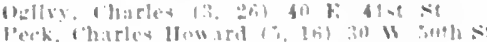

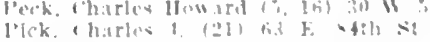

Duhlut? Fonat W

loult. Willian W.

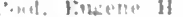

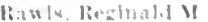

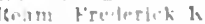

filce. From IV

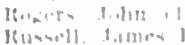

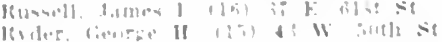

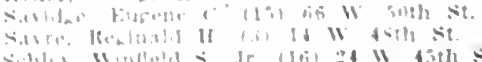

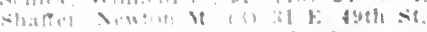

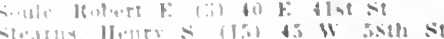

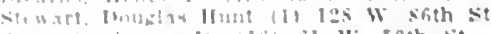

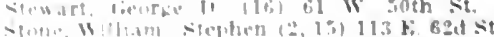

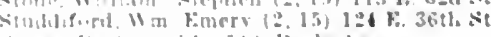

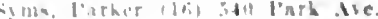

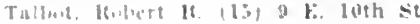


Taylor, Alfred s. (16) 115 IV. 5ith st.

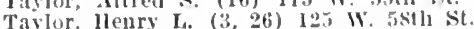
Taylor, lloward $\mathrm{C} .(2,15)$ 3. if. 50 th st.

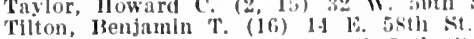
Townsend, Wlsner k. (3) 125 W. 5stl st Tull, Filw. E. (15) to E. 41 st st. Turnure, Percy it. (16) $55 \mathrm{~W}$. 4tuth sit. Vedín. Alma (21) 224 E. listh st. Vincberg, IIIram N. $(2,15)$ 351 Mraclison Aic.

Voorhees, Jas. Dltmars (15) 106 F. 6, 60th st. vosburgh, Arthur s. (1ti) 137 E. Byth sit. Waldo, lialph (1, 15) 54 W. T1st sit.

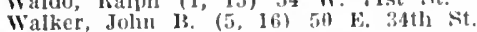
Wallace, Chilrlet on (3) $50 \%$ Madison dve.

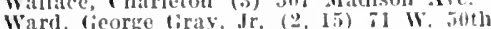
Ward, Wilbur (15) 24 w. 50th st.

Weir, Jlobert $F$. (5) 30 W. 50 th St.

Wells, Brooks if. (2, 15) 523 Mallson Are. West, Jimes Nephew (1, 15) il W. 491 h st Whltman, Itoyal $(3,16) 283$ lexlngton Are Wlener, Itlchard f., (15) 48 k. 65th st. Wlener, Solomon (15) 6i W. $\$ 9$ th st. Wylle, liohert II. (15) 72 W. 52 st. Wylie, W. (iill $(2,15)$ 28 W. 40 th . $i t$.

Yeoulans, Frauk C. (4) 2.20 w. $594 \mathrm{th}$ St.
Young, John V. D. (15) 138 W. 71 st St.

\section{State at Large}

Boyd, James Peter (1) Albany, N.y. N. Buettuer, Jolun (21) Syracuse XY.

Cooke, B (15) Cooperstown

Cooke, J. B. (15) Cooperstown, vernon, X.Y. curlting, Arthur" Wells (5) Albany, N.Y.

Fitch, Ralph R. $(3,26)$ Rochester, X.Y.

Ford, vills $\mathrm{E}$ (2) Utica $\mathrm{SY}$

Mlller, Aaron Benjamin (1) Syracuse, X.Y.

Horlarta, Douglas C. (1) Saritoga Springs,

N.Y.

Mumford, James G. (5) Cliftom Springs, X.Y.

II urray, Dwight II. (4) Syracuse,

Pearson, Wo. Libby (1) Schenectady. N.Y.

Poucher, John Wilson (I) P'oughkeepsie,

N.Y.

Sadlier, James Elgar (1) Pouglhkeepsie, N.Y

Sampson, John A. (2) Albany, X.Y.

Vander Veer, Albert $(1,5,6)$ Albany, $\mathrm{x} . \mathrm{y}$

Vander Veer, Edgar Albert (5) Albany:, N.Y.

\section{NORTH CAROLINA}

Abernethy, Clande Oliver (21) Raleigh, N.C.

Glbbon, It. I.. (6) Charlotte, N.C.

Long, Joln W. (6) (ireensboro, N.c.

Lott, Henry Stokes (1) Winston-Salem, N.

Norris, IIenry $(6,17)$ Rutherfordton, N.C.

Royster, Hubert A. (6) Raleigh, N.C.

\section{NORTH DAKOTA}

Aylen, James P. (i) Fargo, N.D.

Sorkness, Paul (i) Fargo, N.D.

\section{OHIO}

\section{Cincinnati}

Bonifield, Charles Lybrand (1, 6, I4) 409 Broadway.

Caldwell, Charles Edw. (6) 1110 Cross Lane. Caldwell, John A., Jr. (14) 350 Ludlow Ave. Carothers, Robert $(6,14) 409$ Broadway. Carpenter, Julla w, (14) 2636 Park Are. Cole, Alfred 1". (14) Ortiz Bldg.

Colter, Leroy $S$. (14) 3410 Clifton Are Cone, Stephen E. (14) 194 E. McMillan St Drury, Alexander (14) 836 Lineoln Ave. Fischer, Martin Henry (14) Unirersity of Cincinnatl.

Freiberg, Nibert H. $(3,6) 19 \mathrm{~W}$. 7 th $\mathrm{St}$. Gillespie, William (14) 670 June St.

Haines, William D. (7) 1606 Freeman Are Hall, Joseph Arda (1, 14) 628 Elm St. Hall, Rufus Bartlett $(1,6,14) 628$ Elm St. Hahnston. J. Ambrose (14) 19 W. 7th Ave. Johnston, J. Ambrose (14) 19 W. ith Ave.
liehoe, Edwin J. (14) 1322 Chise Are. Kehoe, Edwin J. (14) 1322 Chase Are. Lamb, Frank Heady (14) $940 \mathrm{E}$. McMillan St. I.andis, John H. (14) City Ilall.

Mckee, Ldw. Sydney (14) 19 W. ; th St. Mevechan, $F$. Hoeffer (21) 639 W. 7 th st Miller, John D. (1) Yorfolk Bldg. Mitchell, Edwin Waterman (14) Reading Rd. and Ridgeway Are.

Olirer, John C $(5,6) 628$ Elm St.

Palmer, Chauncey D. (14) 3539 lteading Rd Pirrung, Joseph Edw. (14) 1218 Walnut St. Porter, William D. (14) Melrose Mldg. Reed, Chas. Alfred Lee $(1,6,14)$ Gorton Bldg.
Hicketts, 13. Merrll $(4,7)$ 4th st, and Broadway.

1towe, James W. (14) 20 W. 9th Are.

shields, Jerey (1.1) G Gartleld l'l.

Souther, charles Thaddeus (14) 628 bim st, stanton, Byron (14) Savannah Ave.

Stark, Sigmar (I, 14) II 1/2 \%. 8th st.

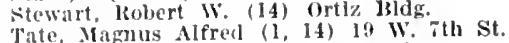
Trate, Wagnus Alfred (1, 14) 19 W.
Walker, Eilw. W. (5) 30 W. 8 th st. Wennlng, Wm. IIenry $(1,14) 114$ Cianfld l'l.

Whitacre, Marlon (14) 2206 Auburn Ave. Withrow, Joln M. (14) 22 W. ith st. Woodward, IIenry l. (14) Melrose Cleveland

Allen, wulley l'eter (5) 8811 luclld Are.,

N.F.
bunts, Frank li. (5) 1021 lrospect Are, S.F. Crile, Geo. Washlington $(1,5,6)$ Osbo

IIamann, Carl A. (5) Ostorn Bldg. IIumiston, William llenry (1) Itose Pldg.

Lo Ferre, Walter Irwin (4) Le

lobb, Hunter (2) Itose Bldg.

Scott, N. Stone (1) Citizens Bldg. Stern, Walter Gustave (3) Schofleld Blig. Teter, Charles K. (21) ltoss Bldg.

\section{Toledo}

bice, Wllliam Gordon (1) 240 Michigan St Duncan, James A. (4) 1107 Broadway. (iillette, William .J. (1) 1613 Jefterson st. Jacobson, Julius II. (1) 2050 Franklin St. Kirkley, Cyrus A. (2) 141, 11th St. MeKesson, Elmer lsaac (21) 2233 Ashland Are.

Moots, Charles W. (1) Nicholas Bldg.

Smead, Lewis Frederic (i) 242 Michigan St. Smith, Charles North $(1,7) 234$ Michigan St.

\section{State at Large}

Baldwin, James Fairchild (1) Columbus, 0 . Cadwallader, Jonah Clifford (14) Norwood, 0. Frans, Geo, B. (4) Dayton, 0 .

Hamllton, Charles Sumner (1) Columbus, 0 . II amilton, Edw. A. (4) Columbus, O. Heady, James F. (14) Glendale, 0.

Lickly, Ira M. (2l) Lima, 0 .

Icclennan, Benjamin Rush (1) Xenia, o. Stamm. Martin (1) Fremont, o.

\section{OKLAHOMA}

Coley, Andrew Jackson (6) Oklahoma ('ity, Okla.

\section{OREGON}

\section{Portiand}

Coffey, Robt C $(6,7)$ Sterens Bld Iacḱenzie, Kenneth Alexander J. (5) Cor-

Madlgan, Mary V. (21) MIorgan Bldg.

\section{PENNSYLVANIA}

Philadelphia

Adler, Lewis H. Jr. (4) 1610 Arch St. Allen, Francis Olcott, Jr. (17) 2216 Walnut St. Allen, Jesse Hall (18) 1325 Pine St.

Allis, Oscar H. $(5,1 \%) 1604$ Spruce St. Anspach, Brooke II. $(2,18) 119$ S. 20th St. Applegate, John Chew (18) $3540 \mathrm{~N}$. Broad. Arnold, Jesse 0 . (18) 2503 N. 18th St. Ashliurst, Astley P. C. (5, 7) 811 Spruce St. Ashton, Win.- Easterly $(2,18) 2011$ Walnut. Astley, G. Mason (18) 5211 Glrard Ave. Babcock, Wm. Wayne (18) 2033 Walnut $\mathrm{S}$ Baer, Benj. F. $(2,18) 2115$ Chestnut St. Bainbridge, Empson Haines (18) 1425 Bainbridge,

Baldy, John IIontgomery $(2,6,18) 2219$ De Lancey St.

Barnard, Everett Pusey (18) 119 S. 19 th St. Barnes, Chas. S. (18) 35 S. 19th St.
Bermardy, Henry L. (18) 321 S. 11th St. Beyea, Henry D. (18) 1734 Spruce St. Bland, Pascal Brooke (18) 1621 spruce St. Bloom, Homer C. (18) 1433 Walnut St. Boger, John A. (17) 2213 N. Broad Boyd, Geo. It. (18) 1909 Spruce St. Carmany, Harry s. (17) 336 Green Lane. Carnett, Joln B. (17) $123 \mathrm{~S}$, 2oth St. Carr, Chas. D. (18) $350 \mathrm{~S}$. 16th St. Chandler, Swithin (18) 225 S. 20th St. Clark, Elizabeth M. (18) 1411 N. 18th St.
Clark, John G. (2, 6, 18) 2017 Walnut St. Coles, Stricker (18) 2103 Walnut $s t$.

Crandall, Thomas 1. (18) 1824 Chestnut St.

Da Costa, John Chalmers $(5,17) 2045 \mathrm{Wal}$ nut st.
Daris, Elwarl 1'. $(2,18) 250$ South 21 st St. bivis, fwilymti. (3, 5, 17) 1814 spruce St. beaver, Harry (lay $(1,5,17,18) 1415 \mathrm{~N}$ Broad sti

caver, John 1slalr $(1,5,6,17,18) 1634$ Walnut st.

oespard, Duncan 1. (17) 1806 Pine St. Downes, Andrew J. (18) 2266 N. Woodstock. pulles, Charles W. (17) 4101 Walnut St. Imean, IIarry A. (18) 2721 W. Lehigh Ave. Elmer, Walter (G. (17) 1801 Pine St. Frck. Theodore A. (18) 251 S. 13th St. Everitt, Ella B. (18) 1807 Spruce St. Flsher, John M. (18) 222 S. 15th St. Foulkrod, Collin (18) 4022 Chestnut $S t$. Franklin, Melvin M. (18) 1633 Spruce St. Frazier, Charles 11. (5, 17) 1724 Spruce st. Gibbon, John II. (5, 17) 1608 Spruce St. Hammond, Frank C. (18) 1729 Arch St. IIammond, Levi Jay (18) 1222 Spruce St. Ilammond, Levi Jay (18) 1222 Spruce St. Il ammond, Wilbur C. (18) 655 N. 12th St. liarte, Richard H. (5, 17) 1503 Spruce St. IIarte, Richard H. (5, 17) 1503 Spruce St. Hearn, Wm. Joseph $(5,17) 2119$ Spruce St. Heineberg, Alfred (18) 1642 Pine St. Hewson, Addinell $(17,18) 2120$ Spruce St. Higbee. Wm. S. (18) 1703 S. Broad st. Hirst, Barton Cooke $(2,6,18) 1821$ Spruce. Hirst, John C. (18) 1823 Pine St.

Hodge, Edward B., Jr. (17) 346 S. 16th St. Hopkinson, Oliver (18) 1424 Spruce St. Hutclinson, James P. (5, 17) $133 \mathrm{~s}$. $221 \mathrm{st}$. Ingle, Henry B. (18) 1987 Falrmount Ave. Ingle, Henry B. $(18) 1987$ Falrmount
Jopson, John H. $(5,17) 1824$ Pine St. Jopson, John H. $(5,17) 1824$ Pine St.
Keen, Wm. W. $(5,17) \quad 1729$ Chestnut St. Keen, Wm. W. $(5,17) 1729$ Chestnut Keller, Albert P. (18) 136 Race St. Kelly, James A. (17) 1510 N. 17th St. Kennedy, James W. (1) 1409 Spruce St. Klemm, Adam (18) 1204 W. Lehigh Ave. Knipe, Norman L. (18) 701 S. $52 \mathrm{~d} S t$ Krusen, Wilmer (18) 127 N. 20th St. Leaman, Henry (18) 832 N. Broad St. Le Conte, Robert G. $(5,17) 1530$ Locust St.

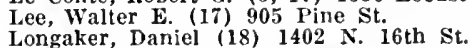
Loux, Hiram R. (17) 1819 Walnut St. MacCarroll, D. R. (18) 2505 S. Broad St. Macfarlane, Catherine (18) 1709 Pine St. Maier, Fredk. Hurst (18) 2035 Chestnut st. Marshall, Clara (18) $258 \mathrm{~S}$. 16th St. Martin, Collier F. (4) 1831 Chestnut St. Martin, Edward (5, 17) 1506 Locust St. Massey, G. Betton (18) 1831 Chestnut St. McGlinn, John A. (18) 113 S. 20th St. Mears, James Ewing (5) Land Title Bldg. Mears, James Ewing (5) Land Title Bldg. Merrill, Wm. Jackson (26) 1927 Chest
Miller, Morris B. (17) 2117 Pine St. Miller, Robert (18) $336 \mathrm{~S}$. 7th St. Mitchell, Charles F. (17) 342 S. 15th St Mlontgomery, Edward E. (2, 18) 1426 Spruce. Muller, George P. (17) 1729 Pine St. Mutschler, Louis H. (17) 2030 Tioga st. Nassau, Chas. F. (17, 18) 1831 Chestnut St. Neilson, Thos. R. $(5,17) 1937$ Chestn Noble, Charles P. $(2,6,18) 1510$ Walnut St. Norris, Chas. C. (18) 1503 Locust St. Norris, Rlchard C. $(2,18) 500$ N. 20th St. O'Connell, John A. (18) 2130 Pine St.
Ott, Lambert (18) 831 N. Broad St. Ott, Lambert (18) 831 N. Broad St.
Outerbridge, Gco. W. (18) 2040 Chestnut St. Parke, Wm. F. (18) 1739 N. 17th St. Pearson, John S. (18) 1507 Christlan St. Pfeiffer, Damon B. (17) 2028 Pine St. Purnell, Caroline M. (18) 132 S. 18th St.
Raudenbush, James Stricker (18) 3633 N. 15 th St.

Reckefus, Chas. H. (18) 506 N. 6th St. Reynolds, Chas. B. (18) 2003 Diamond St. Roberts Harvey M. (18) 1443 S. 2d St. Robinson, E. T. (18) 1906 Pine St. Robinson, James Weir (17) 326 S. 16th St. Rodman, John Stuart (17) 2106 Walnut St. Rodman, John Stuart (17) 2106 Walnut St.
Rodman, Wm. L. (5, 17) 1904 Walnut St. Rodman, Wm. L. $(5,17) 1904$ Walnut St. Ross, George G. $(17,18) 1721$ Spruce Santee, E. I. (18) 534 N. 6 th St. Schell, James Thompson (18) 1303 Locust St. Schumann, Edward A. (18) 15 Pelham Rd. Seabrook, Alice M. (18) 2137 N. College Ave. Chestnut St.

Siter, Elijah H. (17) 1818 S. Rittenhouse Sq.

Skillern, Penn Gaskill, Jr. (17) 241 S. 13ti 
Spreese, John (1i) 2206 Locust st.

Spellissy, Jos. M. (3, 1 i) 110 s. isth St.

splta, Loula (18) tliz girard ite.

stamm, Camlle Jos. (18) 1412 Dlamond st Stellwagon, Thomas $C$ (1i) $18: 11$ thestuut st.

Stewart, Francis T. $(3,17) 311 \mathrm{~S} .12 \mathrm{th}$ st. Stewart, Reul (18) 1840 (ireen st.

Strittmatter, isldor $\mathrm{I}^{\prime}$ (Is) $999 \mathrm{x}$. Coth st. stryker, Samuel s. (1S) $3 \$ 33$ Wainut st. Stuckert, Harry (is) $2116 \mathrm{~N}$. 2lst Ni. Stuckert, Harry (is) 2116 . Nolst. Nurks sweet,

Tallant, Alice W. (18) 180 i spruce st.

Taylor, Willtam J. $(3,5,17) 1925$ rine St.

Taylor, Wm. L. (18) $1340 \times 12$ th st

Thomas, Benjamin A. (1i) $116 \mathrm{~s}$. 19 th st

Thomas, Thomas T. (1i) 2005 chestnut $\mathrm{s}$

Tracy, Stephen E. (1S) 15:i Spruce St.

Tunnell, Stephen Wilmet (IS) $24_{2} \mathbf{N}$. 15 th St.

Uhle, Alexander A. (15) 1831 Chestnut St.

Virich, Feorge A. (IS) $309 \mathrm{~S}$. 12th St

Walker, Warren (17) 1632 snruce st.

Watson, Edward W. (18) 38 s. 19th st.

Wells, Wm. H. (IS) 1135 spruce st.

Wells, Wm. II. (1S) 1135 Spruce st.

Wharton, Henry R. (5. 1i) 1725 Spruce st.

Whlte, James Wllliam $(5,10)$ isto S. kittenhouse so.

Whiting. Albert D. (17) 1523 Spruce st.

Whllams. Phlllp F. (1S) 1911 line St.

Wilson, H. Auæustus $(3,1 i) 1611$ spruce $s t$.

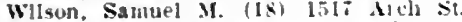

Wilson, Wm. Kevnolds (18) 1709 spruce s

Wood, Alfred C. (1i) 2035 Walnut St.

Wood, Alfred $F(1 ; 18) 1501$ Snruce $S t$

Woods. Blchard $F$. $(3, i, 1,292 \mathrm{~S}$. $16 \mathrm{th} \mathrm{St}$. Pittsburgh

Beach, Willam M. (4) Besserner Bldg.

Blume, Frederlck (1) Jenkins Rlds.

Buchanan, Johin J. (5) 1409 N. Mighland Are.

Elphinstone, James Wade (21) 3544 Californla Are.

Foster, Curtis smlley (1) Dlamond Bank Bldg.

Hazzard. Thos. L. (4) Bessemer Bldp.

Iugglns; Raleigh Russell (1) Westinghouse Bldz.

Langfiti, Willam Sterllng (1) Jenklns Bidg. Maxwell. Wm. Clark (21) Highland Bidg.

McCurdy, Stewart L. (3) Jenkins Arcade

Bldk. $K$. Isadore (1) Jenkins Bldg.

chlldecter, Chas. Bushtleld (1) Park Bldg.

Sllrer, Davjd $(3,26)$ Jenkins Bldg.

Sllver, Davld $(3,26)$ Jenkins Bldg. Jenkins Bimpson.

Stlllwagen, Charles A. (1) Mlghland Bldg.

Swope, Lorenzo W. (1) Park Blds.

Welss, Edward Aloysius (1) Jenkins Bldf.

Wercler, Xavier Oswald $(1,6)$ Jenkins Bidg

Ziegler, Chas. Edw. (1) Forbes and Halket

Sts. State at Large

Davisson, Alexander If. (18) Ardmore, Pa.

Duer, Edward L. (18) Bryn Mawr, Ma.

Estes, Wm. L. (5) South Bethlehens, 1'

Guthrle, George W: (5) Wilkes-ltarre, Pa.

Kennedy, Geo. W. (21) Sharon, Pa.

Kunkle, Wesley $F$. (21) Willtansport, Pa.

luhr, Augustine C. (1s) St. Marys, Pa.

Mecis, Itobert Burns (21) Sunbury, 1'a.

\section{RHODE ISLAND}

Providence

Pitzrerald, Vance Lee (4) 17 Battey st. Hammond, Roland $(3,9) 266$ Heneflt st. Jones, Arthur Thons (1) 214 beneft st.
Keefe. Jhin Whlliam (1) 259 Beneft st.

Pechlian, rrank E. (3, 9$)$ 260 Beneti st

\section{SOUTH CAROLINA}

Charleston

Bulst, I. I. (b) 279 Meeting st.

latheart, ltribt. S. (6) 55 Hassell st.

Multally, lane (b) 51 Meetlug st.

Whaley, Thos. P. (6) St. l'tillip and Went

worth Sts. State at Large

lineres. Le Grand (6) Columbia \& $C$.

$$
\text { SOUTH DAKOTA }
$$

lottam, (illbert 1i. (i) sluux Fulli, S.D.

\section{TENNESSEE}

Memohis

Crisler, Joseph Augustus (b) Exchange Bldg.

Jeik». John L. (4) Tennessee Trust Bldg.

Smythe, Frank Lavle (b) Porter Blds.

Taytor, William Woot (6) Randolph Bldg.

\section{Nashrille}

Barr, Mchard Alexander (6) First National Bank Bldf.

Bryan, Worcester A. (6) 180 , Sth Ave.

Burch. Luclus E. (6) Fve Bldg.

Caldwell, Roberi (6) Jackson Bidg.

Eve, Duncan (5) Ere bldg:

Fort. Lufus E. (6) 209 , ith Ave., $x$.

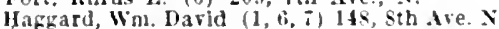

Mctiannon, Matthew (b) He sid

\section{Are., $\lambda$. State at Large}

Alexander Eben (1i) Knoxrlle, Teln

$$
\text { TEXAS }
$$

Moore, John Thomas (6) Houston, Tex.

Rosser, Charles M. (6) Dallas, Tex.

saunders, Bacon (b) Ft. Worth, Tex.

Schilling, Nicholas (b) Cedar Biyou. Tex.

scot, Arthur Carroli (6) Temple, Tex

Thornpson, James fidwin $(5,6)$ Galreston, Tex.

\section{UTAH}

Salt Lake City

Baldwin, S. C. (3) Templeton Bldg.

Kerr, Archibaid A. (i) Boston Bldg.

\section{VERMONT}

Burlington

Hawley, Donly C. (t) 204 pearl st.

\section{VIRGINIA}

Richmond

Baughman, fireas (6) $20 \times$. Laturel St.

Bosher, Lewls C. $(1,5,6)$ 422 E. Franklin. Mryan, Robert C. (6) Grace Hospital.

Horsley, John shelton (6) st. Ellzatieth's Hosplital.

Juhnston, George B. $(5,6) \mathbf{4 0 5}$ E. Grace St.

Lalioque, G. 1'. (6) 501 k. lirace st.

Maclean, Henry stuart (6) tol W. (irace St.

ilathews, Willam P. (6) $605 \mathrm{E}$. (irace St.

Mcfivire, Stuart (6) 513 E. Grace St.

Mefuire, Wm. Edward (6) $411 \mathrm{E}$. Cirace st.

Jobins, Charles kussell (6) \& W. tirace St.

Taylor. Hugh M. (6) 218 E. Franklin St.

Tompkins, Christupher (6) 116 E. Franklln.

Willis, Achille M. (6) 405 E. Grace st.

$$
\text { State at Large }
$$

(;ale, Joseph A. (b) Troanoke, Va.

(iwathney, Lomax (6) Norfolk, Va.

IIarrlson, (ieorge Tucher $(2,15)$ (harlotes rille, ia.

Hawley, Hens. F. (Is) Fortress Munroe, va. liazen, Charles if (i) Bun Air, Va.
Irvin, Janieg S. $(6)$ Hanwille, Va. f.elph. Southgate (bi) Norfolk, Va

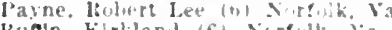

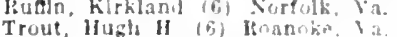
Watts, Stephen II. (T. 6) Charluttesrille, Va Wygur, John 19 (6) Clipron biag. V'a.

\section{WASHINGTON}

Cralz, Danlel Hram (1) ['t. Ingelos, Wash Fagleson. Jameq B. (i) Seattle. Wash. intes, kiserets of (i) Seattle, Wash Netf. James Mishell (13) swokane, Wath
iWhitacre, In race J. (b) Tacoma. Wash.

\section{WEST VIRGINIA}

Cannaday, John Eigerton (1, b) Charleston, w. Ta.

\section{WISCONSIN}

Milwaukee

Batchelor, Wm. A. (2i) 1109 Kinnelinnlc Ave.

Hrown, Horace M. (2i) 3 al Yrospect Are. Copeland. Frnst (2i) 141 Wiscons!n St.

Erans, Curtis A. (2i) 513 Astor St.

finenslen. Fredk. J. 12i) 141 Wliconsin st

Hliz, Henry B. (25) ll1ti sycamore st.

lemon, Chat $H$ (i) loblic servlee Bide.

Levlngs. Alfred H. (i) 308 Farwell Are.

Marks. Sulon (5) 6 1'rospect Are.

Puls, Arthur J. (2i) 548 , 6h St.

Rogers, Ihllip F. (2i) Matthews Bids.

sayle, Robert (f $(7,2)$ Caswell Block.

Seanan, filluert Fo (2-) Goldsmith Blds.

Sifton, Harry A. (2i) 519 Astor St.

rates, John Lawrence (i, 1., 2.) It W Wh. consla St.

\section{State at Large}

Connell, F. Gregory $(6, i)$ Oshkosh, Wis. Ground. Wn. E. (i) superior, Whs.

linahan, J. R. (i) Green Bay, Wis,

Prince, I. H. (21) Madison, Wls.

snith, Joseph F. $(6,13)$ Wausau, Wis.

CANAL ZONE

Estes, Weston Burgess (21) Canal Zone.

\section{PHILIPPINE ISLANDS}

Daris, George Gilbert (13) Manila, P. I.

CANADA

\section{Montreal, Quebec}

Armstrong, George E. (5) 320 Mountain St Burtue, Wesley (:1) to33 Western Ale. Chininan, Walter W. (2) 285 Mountaln St Forbes, A. Mackenzle $(3,26) \quad 455$ Guy st. (ioodali, James 18. (2) 2; Bishop st. Howell, WHIlam B. (21) 64a Dorehester st Hutchison. James A. (5) 354 IICKay st Shepherd Francls J. (5) 152 Mansfeld st.

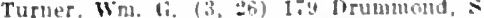

\section{Toronto. Ontario}

Bruce, Herbert Alexander (5) if E. Blont St.

Mekenzle, Bart E. (3) 16 Rloor St., E.

Primirose Alexander (5) 100 College st

starr, Clarence 1. (3) 2:04 bloor St.

\section{Winnipes, Manitoba}

Galloway. Herbert 1. Il. (3) Geil Broadway.

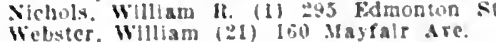
Canada at Large

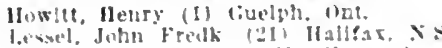

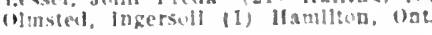

\section{OPHTHAI.MOLOGY,

\section{B-SOCIETIES}

NIMH:H OF MENHELS, 1,00

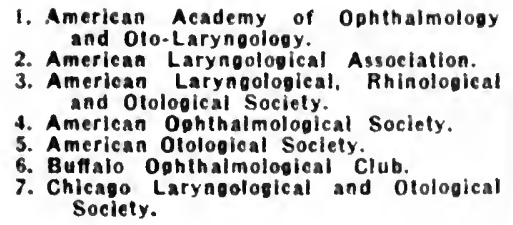

8. Chicago Ophthaimological Socicty.

9. Colorado Ophthalmological Society.

10. Detrolt Ophthalmological and Otological Club.

11. Detroit Oto-Laryngnlogical Society.

12. Los Angeles Co. Med. Assn.. Eye. Ear. Nose and Throat Section.

13. Milwaukec Oto.Ophthalmic Club.

14. New England ophthalmological Sociely.

15. New England Otological and Larynoo. logical Society.

16. New York Ouhthalmolngical Sociely.

17. New York Otological Society.
18. Omaha Ophthalmological Otologicai So-

19. Pacinc Coast oto-ophthalmological So. clety.

20. Philadelahia Laryngolonical Socicty.

21. Philadeiphia Putyclinic Ophtaalmic So. cirty.

22. Philadelphla-section on Ophthaimology of the Collece of Physicians.

23. Philadelphia-section on Otology and Larynology of the College of Physl. cians.

24. Philadelphia-Wills Hospital Ophthal mic Soclety. 
25. Puget Sound Academy of Ophthaimology and Oto-Laryngology.

26. Rhode Island Ophthalmological and otologloal Society.

27. St. Louis-Ophthaimic Section St. Louis Medical Soclety.

28. San Francisco-Section on Eye, Ear, Nose and Throat.

29. The Minnesota Academy of Ophthalmol. ogy and Oto-Laryngology.

30. Washington (D.C.)-Society of Ophthalmologists and Otologists.

31. Northwestern Oph-Lar-Rhin-Otic Soclety.

32. Southwestern Michigan Triological Soclety.

33. St. Louis-oto-Laryngological Section St. Louis Medical Society.

\section{ALABAMA}

Kïkpatrlck, Saml. S. (1) Selma, Ala. ledbetter, Samuel i. (1) Birmlngham, Ala Maumene, Alfred li. (l) Moblle, Ala. Thigpen, Chas. Alston $(1,3)$ ilongomery, Ala.

Thlgpen, Frank M. (3) Montgomery, Ala.

\section{ARIZONA}

IIarbridge, Delamere F. (24) Plioenlx, Ariz.

\section{ARKANSAS}

Buckiey, J. Homer (1) Ft. Sinith, Ark. Caldwell, loht. (1) Little Rock, Ark. Moulton, Ilerbert (1) Ft. Smith, Srk. Rowland, John F. (1) Ifot Springs, Ark. scales, J. William (1) Pine Blutt, Ark. Short, Zuber N. (1) 11ot Springs, Ark. Vinsonhaler, Frank (1) Little Rock, Ark.

\section{CALIFORNIA}

Los Angeles

Anderson, Helen (12) Bradbury Bldg Babeock, Wm. D. (12, 19) Hibernian Bldg. Brown, John Mackenzie (1, 12) Brockman B3ldg.

Bulfard, Frank D. (12) Marsh-Strong Bldg. Burrell, Henry Lesile (1) lfollywood.

Cloud, Marshall M. (I2, 19) Grosse Bldy.

Detling, Frank E. (12) Title Insurance Hidg.

Dudley, Wm. II. (1, 3, 12, 19) Exchange Bldg.

Ellis, II. Bert (1 3, 12) Bradbury Bldg.

Fleming, Ernest W. (1, 3, 12) Trust and sarings Bldg.

Graham, Richard Watson (12) Consolldated lealty Bldg.

Hammon, Glem II. (7) loth and Figueroa St.

Harris, loss A. (12) 1424 S. Broadway

Hastings, Hill $(3,12)$ Trust and Sarings bldg.

Hastings, Seman W: (12) ITellman Bldg.

Ide, Clarence E. (12) Brockman Bldg.

Kelsey. Arthur Jouis $(12,19)$ Wright and callender bidg.

Klefer, Thugo A. (I2) Fay Bldg.

Kress, George H. (12) Bradbury Bldg.

Kyle, dohn J. $(1,3,12,19)$ Title Insurance Bldg.

Lefler. Anna B. (12) Wright and Callendar

Llbby, Arthur A. (12) Bradbury Bldg.

Lund, Geo, J. (12) Audltorlum Bldg.

Mansur, Leon W. (12) Brockman Bletg.

Maclelsh, Archibald Isyle $(4,12,19)$ Brockman blig.

MeCoy, Geo. W. (12) Security Bldg.

IIcCoy, Thos. I. (12) Security Bldg

Miller, Frank W. (12) If. W. Hellman Bldg.

Miller, lRobert W. (12, 19) Laughlin Bldg.

Montgomery. Colonel H. (12) Trust and Savings Bldg.

Murphy, Wm. Warren (12) 307 S. Broad-

Olayam, Joln Y. (12, 19) Grant Bldg.

l'lillips, Frank $A$, (i, s) 1615 , 2d Are.

lhogers, Abert Cliark (12) Spring and 5th

Steplienson, Chas. C. (12) 6th and Hill Sts.

Stivers, (lias. G. (i) Auditorium Bldg.

Therpe, Lewis s. (12, 19) Marsh-Strong

Thorpe, Lewis S. $(12,29)$ Wilcor Bldg

True, Herbert F. (12) Consolidated Realty Bldge

Worthington, Major 1I. (8) Laughlin Bldg.

\section{Oakland}

Allams, John E. (19) Cnlon Savings Bank Bidg.

Brinkerhof, Himer Ellsworth (19) Flrst Nitional Bank 13lde.

('ard, Edgerton F. (19) Central Hank Bldg. Frlediman, Wm. Lioyd (19) 1225 Washington sit.

kolilmoos, Henry .T. (19) 1307 Broadway, Morse, Fred Wellington (19) Oakland Sav. lugs Bank lididg.

Musser, Francls 13 . (19) I327 Broadway.

finomas, II ay ward (1. (19) Daizlel Bidg.

Wythe, Stephen (19) 577, 14th St.

\section{Pasadena}

Dilworth, Wm. D. (12) Chamber of Commerce Bidg.

(iriflth, IT. M. (12) 461 F. Colorado st.

Mckellar James II. (12) Chamber of Commeree Bldg.

Reed, Tames Ross $(12,19)$ Chamber of Commerce.

leynolds, Ralph W. (12) Chamber of Commerce Bldg.

Roberts, Wm. Humes (1, 3, 12, 19) $461 \mathrm{E}$. colorado St

Warner, James IIenry (II) 973 Elizabeth Zuili, Wn. I. (12) St. Louls Block.

\section{San Francisco}

Alexander, Edgar W. $(19,28)$ Butler Bldg. Arnold, J. pennis (3, 28) I 46 Grant Ave. Bater. Adolf Bernhart (28) 177 Post St. Black, Iames A. (28) 2505 l'aclfle Are. Htake, Wm. Ford $(1,19,28) 240$ Stockton St.

Brady, Geo. T. (28) Phelan Bldg.

Bricea, C. R. (28) I66 Geary St.

Broderlek, Richard G. (28) 2741 Union St.

Brown, Vincent de $P$. (28) 145 Commonwealth Ave.

Buckland, Owen (28) 391 Sutter St.

Carl, Chas. W. (28) 86 Post St.

Colen, Albert (28) 146 Grant Ave.

Cohn, Robt. D. (28) 126 Stockt on St.

Conlan, Francis .T. S. (28) 135 Stockton St.

Connolly, Thos. Wm. (28) Hearst Bldg.

Cox, Rosamond Loulse (28) 2405 Washington St.

Crothers, Wm. H. (19, 28) 240 Stockton St.

Deane, Iouls C. $(19,28) 350$ Post St.

Dolman, Percival (28) In Europe.

Dow, Burritt Newell (28) 209 Post St.

Dressel. Gustav (1, 28) 209 Post St.

Flynn, Anna Marle (28) 391 Sutter St.
Franklin. Watter S. (1, 28) Butler Bldg.

Frederick Mareus W. (1, 28) 135 Stockton St.

Gallagher, John Jos. (28) 166 Geary St.

Glaser, Edw. Frederic $(19,28) 391$ Sutter St.

Graham,

Green, Aaron S. $(19,28)$ Shreve Bldg.

llall, Anson P. (28) 291 Geary St.

Hart, Henry H. (2s) 744 Howard St

IIart, MIorton Edwin $(19,28) 246$ Powell St.

Henderson, Jos. J. (28) 240 Stockton St.

IIopkins, Fdw. K. $(19,28)$ Butler Bldg.

Hopklns, Wm. E. $(1,3,19,28) 2335$ Pacific

Ave.

Horn, Henry $(19,28) 209$ Post St.

Houston, Albert J. (28) 350 Post St.

Hulen. Vard II oughton $(19,28) 135$ Stockton.

II nnsaker, Hiram W. (28) Paclfic Bldg.

Johnson, Abel W. (28) 350 Post St.

Kearney, Wm. Bernard (28) 3384, 23d St.

Kingwell. Jolin J. $(19,28) 135$ Stockton St.

bowitt, Frederick C. $(19,28) 291$ Geary St.

Lucchetti.

Martin, Wm. A. $(1,19,28) 126$ Stockton St.

ICCarthy, Chas. F. (2s) 111 Ellls St.

Mccarren, Horatio S. $(19,28) 291$ Geary St.

Itckee, Nlbert B. (28) 350 Post St.

McMurdo, J. R. (2S) 240 Stockton St.

Merritt. Geo. W. (28) 2323 Washlington St.

Molqaard, Jens (28) 833 Market St.

Nagel. Carl S. G. (19, 28) 209 Post St.

Obarrio, Peter De (19) 240 Stockton St.

Payne, Redmond W. (28) 146 Grant Are.

'hilip, John Harold (28) I33 Geary St.

Pischel, Kaspar (3. 28) 1817 California St.

Rosenthal, Adolph G. (28) 162 Post St.

Selfridge, Grant L. $(1,19,28) 240$ Stockton.

Serviss, Thos, W. (28) Flood Bldg.

Sewall, Edw. Cecil (1, 19.28) 166, 1st Ave

Shortlidge. Edmund D. (19, 28) 209 Post St.

Smith, James F. (1, 28) 86 rost St.

Simlth, Larz A. (28) 170l Larkin St.

Stepliens, John M. (28) Shreve Bldg.

Stcplens, Wm. 13. (28) Shreve Bldg. Sumner. Percy $(19,28) 126$ Stockton St. Swett, Wllbur M. (28) I 66 Geary St.

Trask, Sampson (28) I324 Octaria St.

Wagner, Henry Lewls $(1,2,3,28) 5$ is sutter st.

Welty, Cullen $(1,19,28)$ Shreve Bldg. Wiborn, J. Auburn (28) 39 I Sutter St. Wintermute, Geo. P. (I9) Shreve Bldg. Woolsey, (hester H. (28) 350 Post St. Woolsey, Mark H. (28) 350 Post St.

\section{State at Large}

Allerton, Henry $A .(3,5,17)$ Palo Alte, ('al. Andrews, Jos. A. $(4,5,16)$ Santa Barbara, Cal.

Briggs, Geo. A. (19) Sacramento, Cal.

Briggs, Wm. E. $(1,19)$ Sacramento, Cal.

Christlansen, llans B. (19) Sallnas, Cal.

('hurch, Benjamin F. (12, 19) IRedlands, Cal.

Fee, Geo. (19) San Dlego, Cal.

Hamlln, Francls A. (I9) Bakersfleld, Cal.

llosmer, Chas. M. (1,9) San Diego, Cal

Jordan, Peter A. (19) San Jose, Cal.

Lamkin, Burt B. (19) Fresno, Cal.

Moore, Wm. Ollver (16) St. Helena, Cal.

Outwater, Saml. (1) Rirerside, Cal.

l'helan, Henry Du Rest (28) Ft. Barry, Cal

Pounds, Thomas C. (19) San Dlego, Cal.

Powel, Barton J. (19) Stockton, Cal

Rogers, Frances L. $(12,19)$ Long Beach, Call.

lyan, Lawrence Reginald $(1,8)$ San Dlego, Cal.

Spencer, Geo. A. (19) Sacramento, Cal.

Sweet, Robert B. (12) Long Beach, Cal.

Swift, Eugene L. H. (12) Berkeley, Cal

Thomas, Jerome B. (19) Palo Alto, Cal.

Trowbridge, Dwight H. $(3,19)$ Fresno, Cal.

Wagner, Edw. R. (19) San Jose, Cal.

Wllliamson, Wm. P. (19) San Dlego, Cal.

\section{COLORADO}

Colorado Springs

Dennis, Frank L. (1) $501 \mathrm{~N}$. Tejon St. Frledmann, Arthur C. H. (9) 1611 Wood Are.

Magruder, Alex C. (9) Burns Bldg.

Marbourg, Edgar M. (9) Burns Theater Bldg.

Neeper, Edward R. (1,9) Exchange Bank Bld

Paterson, James A. $(1,3,9) 305 \mathrm{~N}$. Tejon St. Robinson, John R. (1,9) The Colchester. Solenberger, Amos R. (3) 825 N. Nevada Ave. Denver

Aufmwasser, Hugo w. (1, 9) Mack Bldg Bane, Wm. C. (1, 3,9) Metropolltan Bldg. Black, Melvlle (1, 9) Metropolitan Bldg. Boyd, F. (1) 909,17 th St.

Carmody, Thos. Edw. (1, 3) Metropolitan Bldg.

Chase, John (1) Majestic Block.

Collins, E. W. (1) Metropolltan Bldg.

Conant, Edgar F. (9) 722, 14th St.

Coover, Davld H. $(1,9)$ Metropolitan Bldg.

Crisp, William H. (9) Majestic Bldg.

Foster, John McEwen $(1,3)$ Stedman Bldg.

Gallaher, Thos. J. $(1,3)$ Californla Bldg.

Hess, Wm. L. ( 1,9$)$ Callfornia Bldg.

Hillard, Walter (1, 9) 14 I5 Welton St.

Jackson, Edward (1, 4, 9) Majestle Bldg.

Libby, George F. (1, 4, 9) Metropolitan Bidg.

Lockard, Lorenzo B. $(1,2,3)$ Metropolltan Bldg.

Matson, Wm. F. (9) Central Sarlngs Bank Bldg.

Mckeown, Elmer E. (9) Stedman Bldg. Monaghan, Danl. G. (9) 1673 York St. Rivers, Edmund C. $(4,5) 1632$ Welton St. Sedwlck, Wm. A. (9) Metropolltan Bldg. Stllwill, Hirain R. (9) Majestic Bldg. Strickler, Jarid A. (9) Empire Bldg. Strickler, Jarid A. (9) Empire Bldg.
Walker, Chas. E. (9) Jacobson Bldg.

\section{State at Large}

Daris, Arthur I. (9) Durango, Colo. Orendorft, Otis M. (9) Canon Clty, Colo. Pattee, James J. (9) Pueblo, Colo. Ringle, Chas. A. $(1,9)$ Greeley, Colo. Spencer, Frank R. (1, 3,9) Boulder, Colo. Wallace, Franklin E. (9) Pueblo, Cólo.

\section{CONNECTICUT}

\section{Hartford}

Crossfleld, Frederlc S. (15) 75 Pratt St. 


\section{New Haven}

Alling. Arthur $x .(t, 16) \quad 25 \%$ (horeh st. Carmalt. Wim. II. (t) abl st. Roman st. Iting, Henry W. (t, 5, 16) 28.5 (hurch st. Suerry, Frederlek $N$. (3) 33 Colleze st. Swaln Uenry l. (a) "yo York st.

\section{State at Large}

burroukhs, Geo. M. (I) lanlelson, Conn. MeLaury, Frank H. (3) llestjort, Coun. Miles, Henry 5 . (4, 16) Mrldgejurt, (onn. Miles. Henry s. $(4,16)$ Mrldgejurt, (con Munger, Carl b. (3) Wuterhury, (comn.

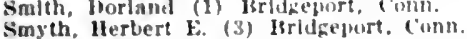

wilson, Frederlek II. (f, s, Ii) Bridgiport, Conn.

\section{DELAWARE
WiImington}

Fllegood, Joshua A $(1,3)$ Eonttable lild. Mekay, Read J. (5) Broomo and Chestut Sis.

Tybout, Richard IR. (2t) Equltable Bldy.

White, Charles I'. (20) Furd Blilg.

DISTRICT OF COLUMBIA Washington

Bennett, Adolphus B., Jr. (30) The Farracut.

Bryan, Joseph H. (2, 5, 30) $\$ 18$, Iith St.

Burke, John W. (30) 1610 i st.

Buter Wm, K $(4,30)[207$ il St, $\times$.

Chlsoln. Franels I. (1, 30) The Ruchambeau.

Datmey, Virglalus $(1,2,30) 1633$ Connectlcut Are.

bje, Hobart S. (3. 30) $132 \%$ L St., X.W. Fox. Wm. H. (4. 30) 1826 Jefferson ilace. Greene, Louls S. (t. 30) 1610 I St.. S.W. Henning, Samuel Carl $(1,30)$ The Bochambeau.

Hyatt, Frank (3) The kochambeau.

Kimball, Arthur H. (I, 30) The Farragut.

Lamb, Rovert s. (1, 4, 30) The cerll.

lamb, kobert s. (1, (, 5,30$) 1420 \mathrm{k}$ st..

Lorlng.

Matone, Witson I. (30) 1325, 13th st.

varmion, Wn. V. (4) Fill, 13th st., X.W

Maxon, Wm. 33. (3. 30$)$ li217 contectlcut ive., X.w.

Matherson, drthur (t) 2026 ll st. N.W.

Vekimmle, Oscar A. II. (2, 3, 5,30$) 1330$

Mass dre.. X.w.

Miller Maurlce F. (39) 1618 II St

Moore, Jead (I, 30) The Itocliambean.

Muncaster. Stewart B. (3(1) $90 \%$, Ititl st.

Muncaster, Stewart B. (30) 90\%, Itith
Newell, Wm. s. (30) 3309 , I6th st.

Yowell, Wm. S. (30) 3309 , 16th st.

Ikleharison, rlias. II $(1,2,3,5,31)$ 13ti ionectleut Are. Xw

Heharilson, James J. (30) I5ng, 16th St.

Rlchey, stephen (o. (4, 5) 732 . Ifth st

Selbert, Kdw. G, (30) Ist? I se viw

Shute, Danl. K. (1, 30) 1719 De sales st

Walker, tteglnald it. (30) Q18. Iith sit.

Walker, weglnala it. (30) Th, fith st.

Wells, Walter A. (I. 3, 30) The Bochambean,

\section{FLORIDA}

Heggle, Jorman M. (1) Jacksonville, Fla

\section{GEORGIA}

Atlanta

Calhoun, fohtnlzy (d) Candler lblut

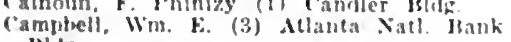
bidis.

lookey, Hugh M. (I) Candler Bhlg.

Hoy, loubar $(1,2,3$, t) Cirand Hpera Honse.

\section{State at Large}

liullard, Wm. I. (I) Culumbus, (ia

lisle, Wm. (". (i) Angusta, tia

Martla, Henry II, (1) Savannah, (in.

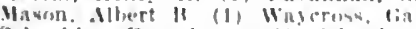

Sclinelder. Francls I (1) Columbur, (ia

Shorter, James II. (1, an Hacon, din

\section{IDAHO}

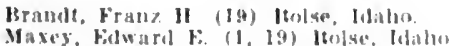

Nourse. Wobt. I. IIoj Isutue, Idaho.

\section{ILLINOIS \\ Chicago}

Stele, Lutwig II (s) gon s state st

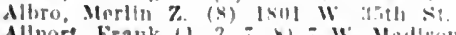

Allpore. Frank $(1,3,7,3)$ i W, Mallum si

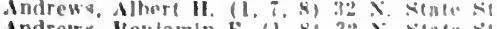

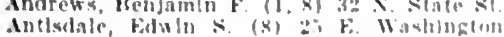

st.
lrery, fredk. T, (1) ga k. Mallson st
Ballenger, Wm. L. $(1,2,3, \%, s) 31 \times$ siate sit.

Barr. Wm. A. (8) $32 \mathrm{~N}$. State st.

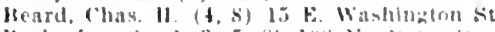
Heck. Jus. ( . (1, 3, 7, s) lus x. state st.

berperon, Jus. $z$. (1, i) lut s. Mhlohat live.

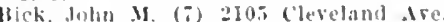

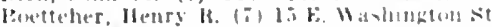

Hrawley, Frank (1, 7,8$)$ †. W. Madison st Mrode, Whand [D. (1) i W. Madisem si.

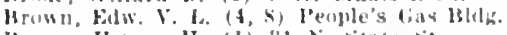

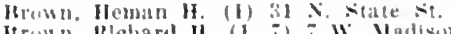
Itrown. Mlehard II. (1, i) $i$ W. Madison st. Burkholder, Jacub F. (k) lok N. State st. cimpledl, James T. (7) it k. Washingtom st. cuscellerry, Wm. E. (1, 2, 7) 15 E. WashIn:an st.

('aranaugh, John A. (1, i) i W Maltson st. Clement, ('hus. E. (s) 15 k. Washlugtom st. Collurn, Jes. E. (s) 1.5 k. Washington sit.

Curwin. Irthur M. (F) 15 k. Washington si. Cralg, Alexancler 16 (I) $333 \mathrm{x}$. Hearborm st.

Croker, Frulerlek $x$. (I) $31 \mathrm{X}$. Siate st. marlige, (harles (i. (s) 120 s. Michigan Ire

bould, Oscar (1, f, s) 31 s. State st.

lunean. Aclelabie (1) $25 \mathrm{E}$. Washington s. Fillis, John B. (8) 15 E. Washington st.

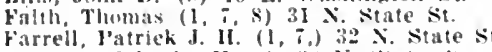

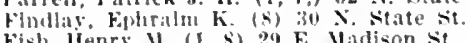
Fish, lienry .1. ( 1 , s) 29 Fo Mudison st.

Fisher. Wm. I. $(1, s) 31$ s. State st.

Flske. Wibld (i, s) 25 k. Wushingt on st.

riske, (ieo, $6,(1,4,7,7$, s) 25 E. Wish ingtom st.

Fletcher, John 1t. (1, 7) $32 \mathrm{X}$. State St. Francis, (Harles H, (s) 7 F. Washington

Frank, Ira (1, 3) 104 \&. Mehigan Ire. Frank, Mnrtimer (s) $31 \times$ state st. Freer, otto) T. (2, T) 25 F. Winshingten st, Friedierg, stumton A. (7) 104 S. Mlichigan Are.

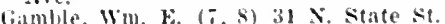

fatrliner, biwlin J. (s) 1.5 k. Washington st.

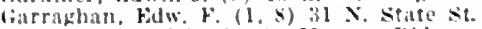
Ciuldenture, Jlchael (s) IIonroe Bldg. Cool. Jobert II. ( $1.7,8) 7$ W. Malison st. (iridle, llarry searles $(1,8) 32 \mathrm{~N}$. State st. lirim, llysses Jushua $(1,8)$ 31 $x$. State st. Cullford, l'aul (s) 7 W. Madlson st Hall. Ilfred M. (s) Marahall Field Innex.

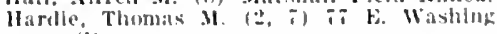
ton st.

Harper, dohn E. (I) lin N. State st.

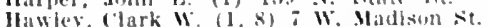

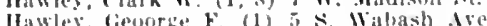

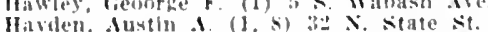
Howlen. Sustin it (

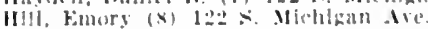

IIuffman, John 16. 11, 4) $31 \times$ state st

Ilofinger, Jaeques (i) is $x$ Waband lie.

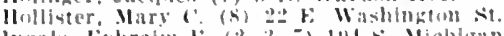

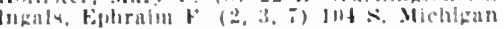
dite.

Jarelan, lipo. T. (s) $10 k \mathrm{x}$. State st.

lithn. Ilarry (i) 31 a state si.

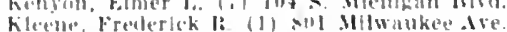

Kleent, Frederlek l: (1) All Milwankes

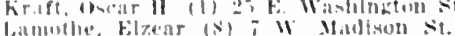

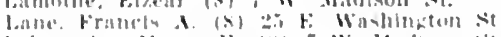

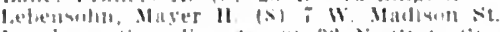

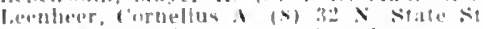

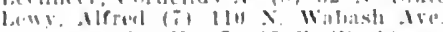

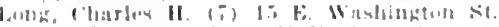

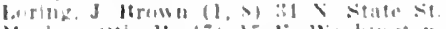

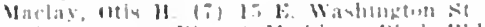

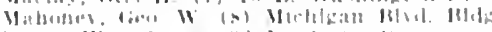

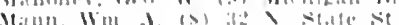

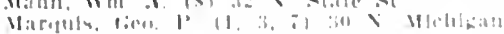
in

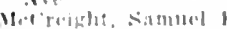

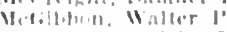

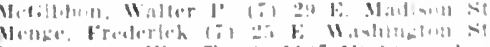

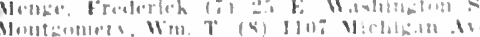

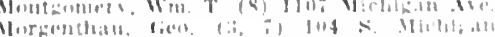
$110^{2}$

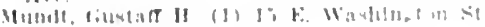

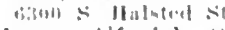

Nurray, dlfruel is

Nimec villy

Vinlue wim 1 .

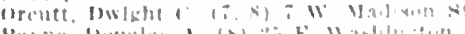

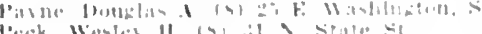

Peteran, W. A (s) susg Wharop Are

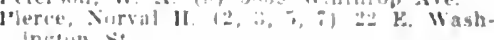
influm sit

Plnokarl, i hay. I

Mllikian

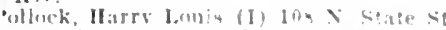

l'usey, Irown (4. k) 7 w. Val son st?

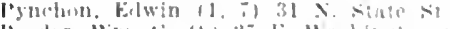

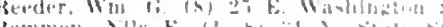

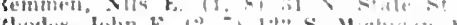

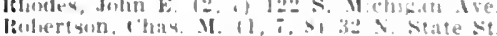

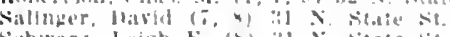

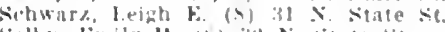
Sielly, kimlly II (a) $32 \mathrm{X}$ state st.

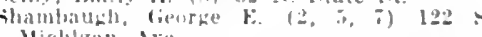
Mirligan Ave

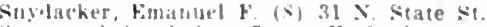

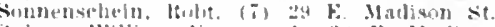
splece. Willan hoeniz 1) 2y k. Madison

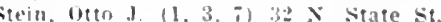

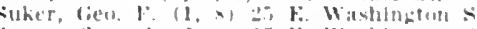

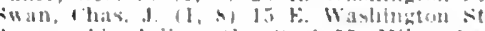

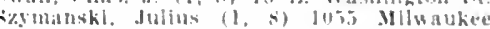

Thomas, Iomer M. (7) 110 $\mathbf{x}$ Wabash Are Thomsen-yon (olditz, (irambus $(1,8) 32.1$ sitate Sit.

Tlinen, Kichard J, (I, S) lot S. Ifichigan Ave.

Torrison, lieo, - 1. (i) 31 N. State st

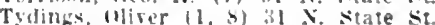

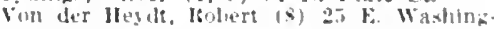
ton sit.

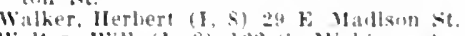

Walter, Whl (1, s) 1:2 \& Mlehlyan ire

Ware, J.jman (k) a2 F, Wabhington si

Wescutt. Cassius D. (1, t, : 1 E. Washingtou st.

Whalen, (has. J (i) 1 i $\mathbf{k}$. Washlngton st. Whitheld, dien W. (7) : E E. Waslington st Wilder, Win. II. (1, 4, 8) 12: \$. Mchigan Wilsun, John (i. (2, 5, i) loti s. Michigan ilsing.

Woud, Casey A. (I, s) ; W. Midlsun st

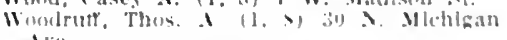

\section{State at Large}

Idams, Mlyn L. (1, s) Jachsonville, Ill.

dlen, (ienrge $b$. (x) dilrora. IH.

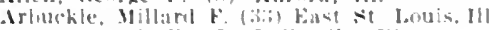

luten, Frank k. (I) Iselleville, III.

Bout (ieo 15 (I) Evanston III.

Mradley, bowin Ii. (I) Feorla. III.

Brobist, (has. It. (1) Peurla. III.

Mrmelerick. Frank W. (1) Sterling. III.

Burkhardi, Chas. $F^{*}$ (A) kflugham, Iit

Clark, Iolin s. (s) reeport, HI.

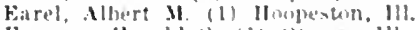

Evensed, llarold (1). (1) Mteawa, 111.

Fringer. Wim. It. (1. s) linehford. Ift.

failey, Wm. W. (s) Howningtan, IIt.

bavil, blw, r. (1, s) Wathegan, III.

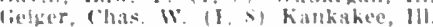

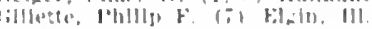

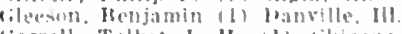

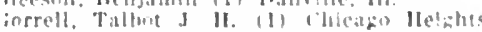
III.

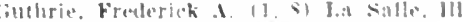

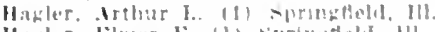

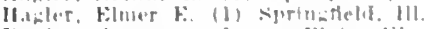

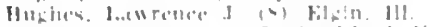

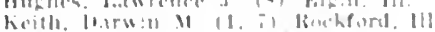

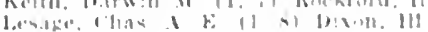

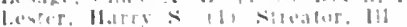

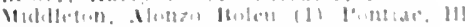

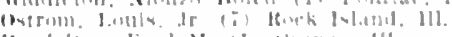

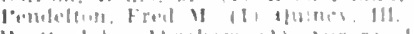

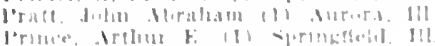

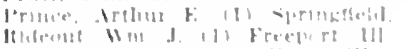

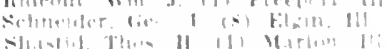

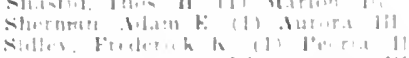

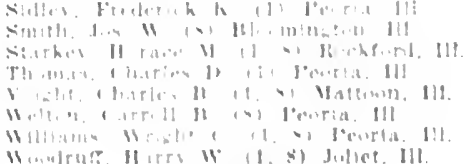

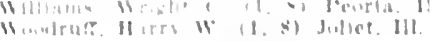

INDIANA

Indianapolis

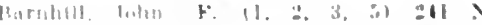

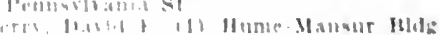

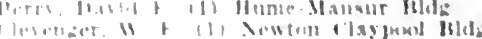


Cline, Lewis $(1,3)$ Willoughby BIdg.

leath, Frederick Carroll (1) Newton Clay pool Bldg.

Hood, Thomas C. (1) Newton Claypool Bidg. Layman, D. W. (1) Hume-Mallsur lildg.

Layman, D. W. (1) Hune-Mallsur l3ldg.
Masters, J. I.. (I) $320 \mathrm{~N}$. Mterldian St.

Masters, J. L. (I) 320 (i) Aterldian St. life Bldy.

Morrison, Frank $A$. (1) The W'illoughby.

Newcomb, Joln kay (1) Hume-Mansur IBldg.

overman, Frederiek V. (1) Irume-Mansur Bldg.

Page, Lafayette ( 1,3$)$ IImmo-Mansur Bidg.

Pfaffin, Clas. A. (i) Newton Claypool l3Idg.

Row George samuel (1) Indiana Pytlian

Bidg.

Sharp, Walter Nevins (1) II ume-Mansur

Bldg. william s. (1) 11umo-Mansur Bldg.

Tomlin, William S. (1) llume-Mansur Bldg.
Wales, E. Dew. (1, 3, 5) Hume-Mansur

bldg.
Wills, E. A. (1) II une-Mansur Bldg.

\section{State at Large}

Bartholomew, A. C. $(1,8)$ South Bend, Ind

Brose, L. D. (1) Evanswille, Ind.

Bulson, Albert E., Jr. $(1,8) \mathrm{Ft}$. Wayne, Ind.

Cochran, Robert w. (1) Madison, Ind.

Fwing, U. B. G. (1) Richmond, Ind

Ferrls, Edgar (i) New Castle, ind.

Freeman, E. D. (1) osgood, Ind.

Griffith, Benjamin B. (1) V'inceunes, Ind.

Hadley, James William (1) Frankfort, Ind

Hager, Walter A. (1, 8) South Bend, Ind.

Heitger, Joseph Daniel (I) Bedford, Ind.

Hay, Iilton T. (1) l'ortland, Ind.

Jay, Milton T. (1) l'ortland, I
Johnson, J. E. (1) Marlon, Ind.

Kelper, Geo. F. $(1,3,8)$ La Fayette, Ind

Knapp, A. J. (I) Evansville Ind.

Knapp, Bleeker (1) Eransville, Ind.

Knapp, Geo. (1) Vincennes, Ind.

Lent, E. J. (8) South Bend, Ind.

Miller, Charles E. (1) Muncle, Ind.

Norrls, Saml. C. (1) Anderson, Ind.

Ravdin, Marcus (1) Eransville, In

Read, Horace G. (1) Tipton, Ind.

Ruby, F. M. (1) Union City, Ind.

Smith, Milton (7) La Porte, Ind

Spohn, Geo. W. (1) Elkhart, Ind.

Worrell, J. P. $(4,8)$ Terre Haute, Ind.

\section{I0WA}

Amos, A. R. (I) Des Moines, Ia

Balley, Fred W. (1) Cedar Rapids, Ia.

Bates, Wm. (31) Ft. Dodge, Ia.

Boiler, Wm. Fred (1) Iowa City, Ia.

Bussey, W. J. (31) Sloux City, Ia.

Carroll, Frank (1, 8) Cedar Rapids, Ia

Carver, W. F. (31) Ft. Dodge, la.

Crary, A. W. (1) Boone, 1a.

Crawford, David A. (1) Guthrie Center, Ia Dean, F. W. (1, 18, 31) Council Bluffs, Ia. Dean, Lee W. $(1,7,8)$ Iowa City, 1 .

Enfield, Chas. (1) Jefferson, 1a

Engle, H. P. (1) Newton, Ia.

Franchere, F. E. (31) Sioux City, Ia.

French, Royal F. (1) Marshalltown, Ia

Harkness, Gordon F. (1) Davenport, Ia.

Heard, Mary Kathrina (1) Iowa City, Ia.

Henninger, L. L. (18) Council Blufrs, Ia.

Ivins, Harry M. (1) Cedar Rapids, Ia.

Johnston, William H. (1) Muscatine, Ia.

La Force, Bert D. (1) Ottumwa, Ia.

La Force, E. F. (1) Burlington, 1a.

Langworthy, Henry Glover $(1,8)$ Dubuque,

la.

Lapsley, R. M. (1) Keokuk, Ia

Lauder, Clark Hays (1) Grinnell, Ia.

Lewis, Eugene R. $(1,3,8)$ Dubuque, Ia.

Littig, J. V. (I) Davenport, Ia.

Murphy, Frank G. (1) Mason City, Ia.

Pearson, W. W. (1) Des Moines, Ia.

Roost, Fred (31) Sioux City, Ia.

Singleton, E. M. (1) Marshalltown, Ia

Sinall, W'm. B. (8) Waterloo, Ia.

Walker, IH. L. (S) Cedar Rapids, Ia.

Young, H. B. $(1,8)$ Burlington, Ia.

\section{KANSAS}

Alkire, H. L. (1) Topeka, Kan.

Caffey, llugh B. (1) Pittsburg, Kan.

Dorsey, J. G. (1) Wichita, kan.

Esteriy, 1). E. (1) Topeha, Kan.

Hamilton, E. E. (1) Wichita, Kan

Jamison, Thos. H, (1) Wellington, Kan.

Johnson, J. H. (1) Coffeyville, Kan.

Jones, W. Monroe (8) Hutchinson, Kan.

Nagee, Robert S. (1) Topeka, Kan.

Snith, Richard C. (19) Beloit, Kan.

\section{KENTUCKY}

Louisvilie

Cheatham, Wm. $(1,3,4) 305$ W. Chestnut St.

Irabney, Samuel G. (1) 216 W. Chestnut St. IIall, Gaylord C. (1) 526,4 th St. llays, Samuel B. (1) Atherton I3ldg. Lederman, Isaac (1) Atherton Hldg. lay, James M. (1, 3, 4, 5) Atherton Bldg. Reynolds, Dudley s. (1) Norton Bldg.

\section{State at Large}

Behrman, Michacl (1) Covington, Ky. Bledsoe, Robert W. (1) Covington, Ky. Givens, Lamme $\mathbf{s}$. (1) Cynthiana, ky. liser, Jefferson D. (1) Lexington, Ky. Offuit, Wm. N. (1) Lexington, Ky.

Reynolds, Henry G. (1) Paducah, ky.

leynolds, John 1s. (1) Mt. Sterling, Ky.

Stucky, Joseph A. (1, 3, 5) Lexington, Ky.

Thomasson, Wm. J. (1) Newport, Ky.

\section{LOUISIANA \\ New Orieans}

Bruns, Henry D. (4) 211 Camp St.

De Roaldes, Arthur W. $(2,5) 624$ Gravler St. Feingold, Marcus (1) 124 Baronne St. Joachim, Otto (3) Nacheca Bldg.

Lynch, Robt. Clyde (3) 614 Bravier St.

L'Kelley, James 1. (3) 830 Canal St.

Scheppegrell, Wm. (1) Audubon Bldg.

Sinith, Victor C. (1) Maison Blanche Bldg. State at Large

bowling, Oscar (1) Shreveport, La.

\section{MAINE}

Portland

Allen, Jolun II. $(3,15) 717$ Congress St.
Fisher, Stanwood E. (15) 190 State St.

Gilbert, Frank Y. (I) 148 Park St.

Holt, Erastus E., Jr. (I) 723 Congress St.

Holt, Erastus

Congress $\mathrm{St}$.

Moulton, Willis Bryant (5) 180 State St.

Smith, owen (15) 692 Congress St.

Spalding, James A. $(1,14) 627$ Congress St. State at Large

Austin, Lewls King (I) Waterville, Me.

Beach, Sylvester J. (15) Augusta, Me.

Clough, Herbert T. (I5) Bangor, Me.

Hill, J. Frederlck (15) Waterville, Mo.

Turner, oliver W. (1) Augusta, Me.

\section{MARYLAND}

\section{Baltimore}

Bordley, James, Jr. (4) 330 N. Charles St.

Carroll, James Joseph (4) Professional Bldg.

Crouch, J. Frank (5) $513 \mathrm{~N}$. Charles St.

Friedenwald, Harry (1, 3, 4, 5) $1029 \mathrm{Madl}$ son Ave.

Harlan, Herbert $(4,5) 516$ Cathedral St.

Hartman, Jacob 11. (2) 5 W. Franklin St.

Johnston, Richard Hall $(1,3) 807 \mathrm{~N}$. Charles St.

Johnston, Samuel (2) 204 W. Monument St.

Mackenzie, John Noland (2) $605 \mathrm{~N}$. Charles St.

Peterman, Harry Elmer (1) 114 W. Franklin st.

Randolph, Robert L. (4) 609 Park Ave

Reik, Andrew J. Neilson (3) 506 Cathedral Reik,

St.

Rosenheim, Sylvan (3) 1710 Linden Ave.

Tarun, William (1) 613 Park Are.

Theobald, Samuel $(4,5) 970$ Howard St.

Winslow, Jobn R. $(2,3)$ The Latrobe.

Woods, Hiram $(1,4,5) 842$ Park Ave.

Worthington, Thos. C. (3) 1022 Madison Ave.

\section{MASSACHUSETTS}

\section{Boston}

Amadon, Alfred M. (5, 15) 543 Boyleston St.

Barnes, Harry A. $(3,15) 205$ Beacon St.

Blake, Clarence J. $(1,3,5,15) 226$ Marlboro St.

Blodgett, John H. (15) 390 Commonwealth Ave

Boardman, William S. (15) 63 IIt. Vernon

St.
Bogan, Frederick L. (15) 374 Marlboro St.

Borden, Charles R. C. $(3,5,15) 520$ Com-

monwealth Are.

Bossidy, John C. (14) 419 Boylston St.

Brainerd, John B. (15) 419 Boylston St.

Bryant, Alice G. $(1,15) 502$ Beacon St.

Chandler, Henry B. $(4,14) 341 / 2$ Beacon St.

Chenery, Wnı. E. $(3,15) 222$ IIuntington Ave.

Clieney, Fredk. E. $(1,4,14) 126$ Common. wealth Ave.

Tap, Edinund W. (4, 14) Iotel Puritan.

C'lark, Jos. 1'ayson (2, 15) 71 Marlboro St.

Cobb, Carolus M. (15) 419 Boylston St.

Cobb, Frederic C. $(2,3,15)$ 11 Marlboro St.

Coftin, Rockwell A. $(2,15) 234$ Clarendon St.

Coolidge, Algernon, Jr. $(2,3,15) 613$ Beacon st.

Crockett, Eugene A. $(3,5,15) 298$ Marlboro st.

Cummings, John Francis (15) 96 Huntington Ave.

Daly, Wllliam J. (14) 31 Massachusetts Ave. De Blols, Thomas Amory (2) 523 Newbury St.

Derby, George S. (4, I4) T Hereford St.

Derby, Haskett $(4,14)$ Blue IIIll Ave.

Dixon, Lewis S. (4, 14) 232 Clarendon 5 .

oble, Ernest E. (5) 122 lluntington Ave.

Drury, Dana W. (15) 407 Marlboro St.

Easton, Elwood T. (14) 209 Newbury St.

Ellis, Edward K. (14) 232 Clarendon St. wealth Ave.

Farlow, John W. $(2,15) 234$ Clarendon St. Faunce, Calvin B., Jr. (15) 42 Spring Park Ave.

Garland, Frederlck F. (15) 485 Beacon St. Goodale, Joscph L. (2, 15) 258 Beacon St. Greene, Danl. Crosby, Jr. $(2,3,15) 483$ Beacon St.

Greenwood, Allen $(1,4,14) 101$ Newbury.

Hall, Wm. D. (4, 14) 416 Marlboro St.

Hanmond, Philip $(5,15) 483$ Beacon St.
Haskell, Henry H. $(4,14) 29$ Commonwealth Ave.

Hawkins, Henry (14) 397 Marlboro St.

Heffernan, David A. (15) 69 Newbury St.

Holmes, Edgar M. $(3,5,15) 531$ Beacon St.

Hurley, Edward D. (14) 419 Boylston St.

Hurley, Joln J. (15) 541 Commonwealth Are.

Ingles, Harry .J. (15) 483 Beacon St.

Jack, Edwin E. $(4,14) 215$ Beacon St. Jack, Fredk. I. $(3,5,15) 215$ Beacon St. Jeffries, Benj. Joy (14) 15 Chestnut St. Jones, Charles D. (14) 137 Newbury St.

Kerr, Isabelle D. (15) 821 Beacon St.

Kilburn, Henry W. (4, 14) 192 Marlboro St. Knowles, Wm. F. $(3,15) 220$ Clarendon St. Knowlton, Charles $\mathrm{L}$. (15) 574 Warren St. Knowlton, Charles $\mathrm{L}$. (15) 574 Warren St. Lancaster, Walter B. $(1,4,14) 101$ Newhury.
Leland, George A. $(2,3,5,15) 354$ Commonwealth Ave.

Lewis, James P. (I5) 543 Boylston St. Loring, Robt. G. $(4,14) 10$ Arlington St. Lothrop, Oliver A. (15) 101 Beacon $\mathrm{St}$. Lougee, John L. (I5) 535 Beacon St.

Lowell, Wm. Holbrook (14) 101 Newbury St. IcDonald, Samuel J. (14) 657 Boylston St. Morse, Henry Lee $(5,15) 112$ Marlboro St. Mosher, Harrls P. $(2,3,5,15) 828$ Beacon St.

Newton, Edward R. (15) 419 Boylston St Noyes, Margaret I. $(1,15) 103 \mathrm{St}$. James Ave.

O'Brlen, John F. (15) 401 Bunker Hill St. Plummer, Edw. II. $(5,15) 583$ Beacon St.

Powers, George H., Jr. (15) 298 Marlboro St.

Proctor, Francis I. (14) 397 Barlboro St.

Putnam, James J. (14) 106 Marlboro St.

Quackenboss, Alex. $(4,14) 143$ Newbury St.

Reardon, Timothy J. (15) 76 Commonwealth Are.

Robbins, Chandler (15) 386 Commonwealth Ave.

Ryder, George H. (I4) 427 Marlboro St.

Shanahan, Timothy J. (15) 419 Boylston St. Smyth, Dancan Campbell (15) 127 Newbury St.

Smyth, Patrick Somers (I4) 69 Newbury St. Spalding, Fredk. M. $(4,14) 390$ Commonwealth Ave.

Spear, Edmund D. (5) 100 Boylston St.

Standish, Myles (1, 4, 14) 72 St. James Ave.

Sterens, H. B. (14) 419 Boylston St.

Tenney, John A. (1) 419 Boylston St.

Thompson, Peter H. (14) 308 Commonwealth Ave.

Tobey, George L., Jr. $(1,15) 416$ Marlboro 
Wells, Da:il W. (1) The Wextuninter.

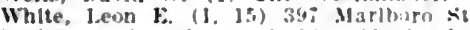
williams, Chas. H. $(4,8,14) 2069$ Busiston si.

St.

\section{Springneld}

Calkins, Cheney H. (14) 14 Maple St Carleton, Ralph (1t) 10 Temple St. Cralg. Wn. G. (t) $31 \%$ Main St. Dillon. John $\mathrm{A}$. (15) 310 Jaits st. Goodell. Win. (15) 6 Chestnut st. Hopklns, Frederlck k. $(2,3,15)$ 25 $11 \mathrm{arrl}$ son Ave.

Irwin, Vincent J. (1) 351 Jaln St.

\section{Worcester}

Rerry, Gordon (15) slater Bldg.

Berry, John C. (14) i Hlighland St

390 Maln St.

kstabrook, Charles T. (14, 15) 390 Main st.

Getchell, Altert $C^{\circ}(2,15) 6$ linden St.

Harrower, Darid, Jr. (f, 5, 14, 15) 9 Eim st.

Lorell, Darld B. (t, 5, 14, 15) 32 Pearl St.

\section{State at Largo}

Baker, Harry B. (1) Taunton, Hass.

Caswell, Bertram II. (15) Winterhill, Mass. Clark, Frederick T. (1) Westfleld, Mass.

Collins, Josesh D. (15) Northampton, Mass

Cook, Snow P. F. (14) Gioucester, Mass

Foster, Ellis Edwin $(1,14,15)$ New Bed-

ford. Mass.

French, Charles E. (15) Lowell, Mlass

Fuller, Ernest P. (14, 15) Lawrence, Mass.

Haddock, Charles W. $(4,14)$ Heverly, llass.

Hennessy, William W. (15) salem. Ilass.

Hussey, Edward J. (1t, 15) Molyoke, Mass. Jackson, Olirer H. $(3,15)$ Fall hiver, Mass. Jessaman, Leon W. (15) Framingham, Mast. Jones, Elgin W. (1t) Lynn, Mass.

Langmald, Samuel W. (2, 15) -Hrookline, Mass.

Mclntlre, Frederlck J. (15) Lynn, Mass.

Merrill, Wm. Howe (1, 14, i.j) Lawrence, Mass.

O'Helly, Willam F, (15) Lynn, Mass.

potter, Lester $\boldsymbol{k}$. (15) New hedford. Mass.

I'osts, Joseph H. (1t) Julyoke, Jass.

P'reble. Wallace (15) Cambridge. Mass.

Proctor, lercy C. (15) liloucester, ltass.

Richards, George 1. $(2,3,5,15)$ Fall River, Mass.

Ryder, Delano Richmond $(1,15)$ kall Rirer, Mass.

Thompson, George H. (1) North Adams, Mass.

Whitnes, Edward M. (I4) New Bedford, I39.

\section{MICHIGAN}

Detroit

Amberg, Emil (1. 5, 11) 200 Woodwart Are. Beattie, Hobt. (10, i1) fas nalce Bldg

Hegle, IIowell L. $(10,11)$ smlth Bldz.

Campell, Inon X. $(1,10,11)$ smith Bldy.

Camptell, Duncan $\lambda$. (11) smith blif

Chambers, Chas. I. $(10,11) 32$. Wam, Ave.

Connor, Ray $(1,10,11)$ Washington Areade Colltinan. Robers w. (1, 11) lot pore st. Gleason, John E. $(10,11)$ Washington Arcade.

Coux, louls J. $(1,11)$ sterens Bldp.

Grant, lee E. (10) Washington Arcade.

llart?, Jenry J. $(1,3,11)$ : lilckes, P'reston II. $(1,11) 32$ Adam Ave., W.

Livingsione, Peler J. $(1,10,11)$ Fine Arts B!dg.

Malre, Lewls F. (1) is Washington Ire.

Mcclelland, Carl (C. (11) Washingion Areate.

MeFall, Guy IIarrlson (II) Washlngten Areade.

Bercer, Klchard Edw. (11) lias Onlce bldt.

Miner, Stanley fi. (1, 11) iti cadlilac sic

Odell, Anna (1) Kresge llitg

Parker. Walter lkob. $(1,4,10,11) 32$ dit ams Are.. IV.

Potter, Wibls A. (11) Washinglon arcatle Renaud, lieo. 1. (1) bine Arts Btha.

Sanderson, Iermon $11,(1,10,11)$ Wasluing ton Arrade.

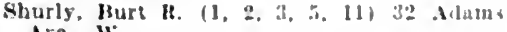
Are., W:

simpson. Harnld benn (11) g: k: Grand Kiver ire
Smlth, Fugene 110,11$)$ Ma Mans Are, W

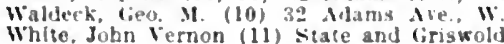
Sts.

Witson, llarold $(10,11) 32$ Adams Are., W State at Large

Baker, Chas 1I. (1, 11) Bay Cits, Mich. liard, William ili rolme vilch Brensieln, falw. J. (1, 3t) Kalamazon, llich Buyce. tieo. 1f. (i) Iron Mtountain, sich Buyce. W'm. 13. (1) Escanaba. Mch 'antleid, lay histop (3), 5. 11) Ann Arber itich.

Carllng. Wm. II. (32) Mattle ('reek. Mlled.

thuman, $\mathrm{A}$. Mas, Muskegu, Min.

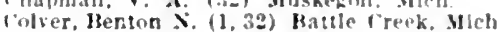
bunlap, Hartey it. (32) Battle treek, alleh. lianter, W. 132) Muakezon, Wh Cirant, freelk. k. (1, 32) Kalamazth), Mich llitughes, wilfred $(1,1), 32)$ Hattle Presk, vich.

Horulugen, Harry J. (s) Marquette. Mich.

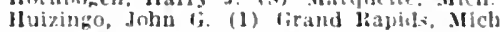
liwen, Arthur E. (II) bainsing. Nich

J'aterson, Everard W. F. (32) Grand Rapieds, Iilch.

Kiker. Eugene $v$. (11) Flint, Wheh.

lingers, Arthur \&. (1) Saginaw, Mich.

kugers, Jolu is i32) firind lapids, Wich. Boller, douls A. (1, 32) Grand Mapids. llich.

slaek, Watter 1.. (11) Saglnaw, Mich. sielght, laymond 1. (1,32) Battle rreek, Mieh.

siocum, George (1) Inn Arbor, Mich

Tolley, Edward Whitfeld (1) Grand kap ids, Mich.

Irquhart, Kny T. (32) firand Ravids, Nich Welsh, 11. Enmet $(1,11,32)$ (irand Hap ids, Mieh

Whbur, Edw. I. (1,32) Kalamazoo, Mlleh

\section{MINNESOTA \\ Minneapolis} Sidrich, Alanson fi. (29) Pillobury IB]dg. Campbell, Robt. A. (29) Tonaldson 13ldf E.riesun, Jolun G. (29) Syndieate IMdL. herrick, stanley E. (29) Donaldson Hidg. leavitt. Henry M. (29) Nicollet Are.

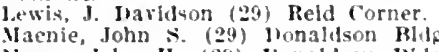
vorse, John if (29) junaldson bids Horton, Howard Mel. (29) Andrus Bidg. ilurras, Wm. R. (1, 29) syndleate hidr Tewhart, Horace (1, 29) Donaldson Bldig.

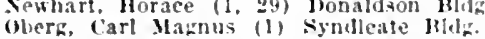

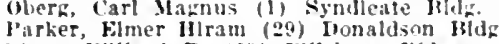
P'inen, Willard B. $(29)$ I'illshury lide. Porteons, Willam $\mathbf{x}$ (29) Plllsbury B!dg. pratt, fred J. (1, 29) 320 central cre.

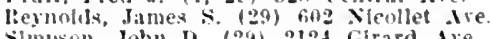
simpon, John D (29) $212 t$ firrard Ave. spratt, thas. $x$. $13,4,291900$ Nicollet Ave suratt, Tharles d. (29) 900 Ninollet Are

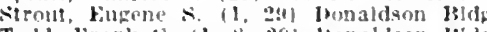
Tinkl, frank 1 , (1, <, agt bonaldson Mld Watson, dames Afred (29) Andrus Mhy.
Wileox, M. Hussel (291 Vorweglan Huther

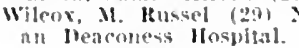

Wunl. Domplas $\mathrm{f}$. (1, 29) Domaldson blut

\section{St. Paul}

Beandonx, Henry Dlerander (1, 29) J.04 r) Bhli:

Mettlingen, Joseph W. (20) Lowry duner

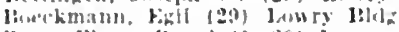

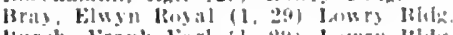

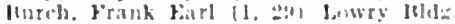

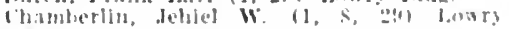
iresale.

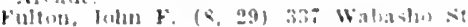

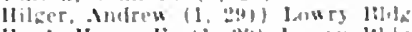

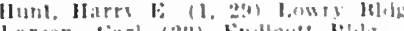
Latraen, tarl (201) Endlente billd

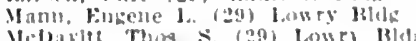

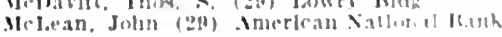
Hilli:.

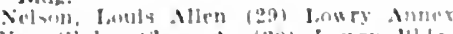

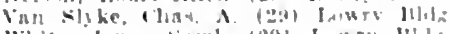

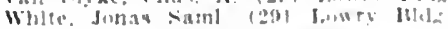
Whblame, Curneflut of 10,16 the si

\section{State at Large}

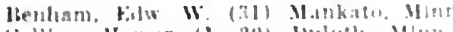

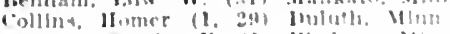

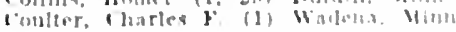

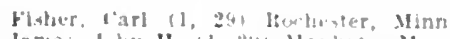

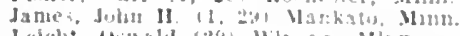

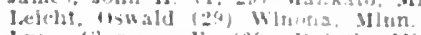

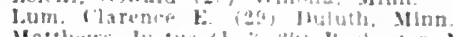

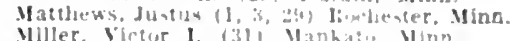

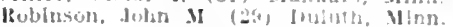

\section{MISSISSIPPI}

furry, Holert $s$. (1) Jachsutt, Miss.

\section{MISSOURI}

Kansas City

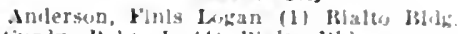
curds, Bulte. J. (t) Halto lilds

finster, llat (i) llth ant Wialnus sta. Huwart, Jesegh Wm. (1) Mtalio blitg. dochtenterg. Joseph $\mathrm{S}$. (1) Mlalto bidg Jogan, James Elmore 12, 3, 5) 12us Wyalsduste st.

Mott, Joth s. (1) Itialto Bld

sawtell, Jeseph Filuran (1) Walcheim

Thomison, Henry fo (1) Arazle Bitg. Weaver, Juhn s. (1) Malto Bldg

\section{St. Louis}

Alt, Adolf $(1,4,5,25) 505 \times$ Graud Are

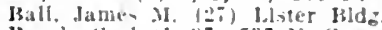
larck. Carl (1. 20) 537 N. Grand Are.

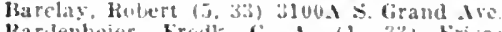
Bldy.

Barries, Nheron S., Jr. (1, 33) central Sittunat rank bijg.

Blilck, Wm. Daris (1,33) Metrutwlltan Bldz Jusse, filwin H. (2-i) log3 X lorand die. lisyan,

Calhoun, James (b. (2) Metropolitan Blag.

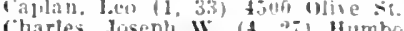

Chartes, Juseph $11 .(4,2)$ llumboldt Bldz s. Grand Aste

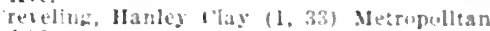
halme. Aiphonse F. (1, 3:3) Metropulitan Bldi:

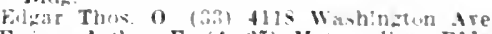
Fuing, Arthur $F_{0}(t, 2 \pi)$ Uetropolitan Blds.

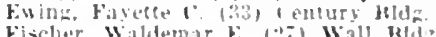

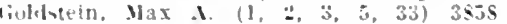
Westminster l'?.

tireen. John, Jr. (1, g-7) Metropolitan Bidz. liross. Iuliu - II. 120\% bith and Locust sto

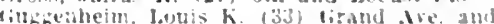
nlibe s:

cimdelach, 1 Armin (1, 3as tirno olve st

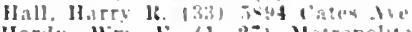

Iardy, Wm. F. (1, 2-i) Metropolitan Bhe Hendersin. Frank 1. (1, 25) Ilamkalds Blug.

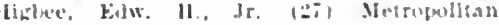
klilr.

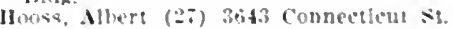

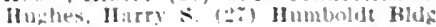

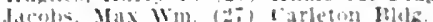

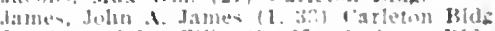
lenntug. John Ellis (1, 2i) Carleten Blde

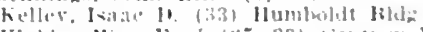

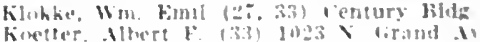

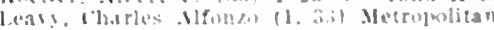
Mld

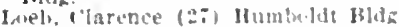

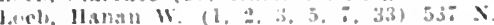
litand lies.

Luedle. Wm. 11. (20) Metropolitan Bldz

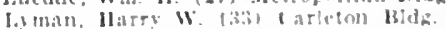

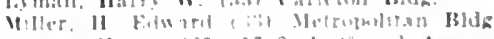

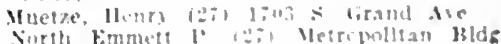

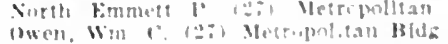

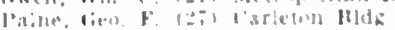

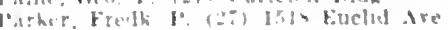

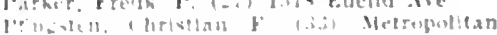

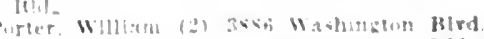

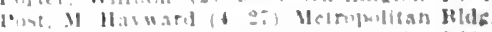

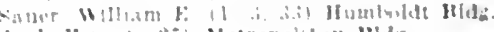

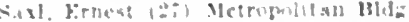

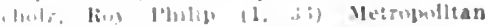

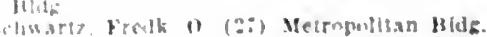

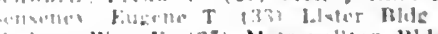

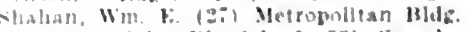

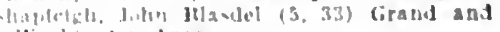
WIrlingeon trents

Shomaher Juhn $\mathbf{k}$ (1. ai) Carleton Blus. 
Shoemaker, Wm. A. $(1,4,2 \pi)$ Carieton Midg. Simom, Freitk. (33) Metropotitan Hidis. Simon, Fretk. (C) (3.3) Metropotitan Bhig. ington Are.

Spencer, lloratlo N. (5) 2723 Washington Ave.

Spencer, Sedden (5, 33) 2725 Washtngton Are. Wiener, Neyer $(1,8,27)$ tith and oifre st. Wifson, Alvah M. (33) Ifumbotut Bldg.

Wolfner. Henry L. (2i) bitil and Olive sts. Woodruff, Fredk. E. (27) Metropolltan Bidg. W'yche, ('has. (33) liumbolit likdr. Sfate at Large

Ralley, Itarold (1) sipringteici, Mo. Keliey, siml. G.. Jr. (I) Sedaili, Mo.

Noyes, Guy L. (1) Columbia, Io.

\section{MONTANA}

Donovan, John Alexancier (1) Butte, Mont. NEBRASKA

Lincoin

Dayton, Wm. Lindsay (1) Funke Tilig.

IIayman, Fdward Chapman $(1,18)$ First National liank nidg.

\section{Omaha}

Arnold, Harry L. (18) City National Bank

Bldg.
Baulster, John Mouro (18) Brandeis Theatre Bidg.

Bryant, DeWltt C. (18) City National lank isldg.

Bushman, Louis I. (18) City National Bank Bldg.

Cailfas, Wm. F. (18) Brandels Bldg.

Gifford, Harold (1, 18) Brandels Bldg.

Hammond. Jerry C. (18) City Nationai Bank jildg.

Isaaces, David (18) Brandeis Bldg.

Lemere, Henry Bassett (18) Brandeis Theatre Bldg.

Lindquest, Adoiph B. (18) Brandeis Bldg. McPherson, Jos. B. (18) City National Bank Bldg.

Ioriarty, Pierre colon (18) Brandels Bidg. Iulten, Thomas R. (18) Brown Block.

Owen, Frank Styles $(1,18)$ Brandeis Bidg. Owen, Frank Styles $(1,18)$ Brandeis Bldr. P'atton, James M. (1, 18) Brandeis Badd. Potts,

Rubendall, Clarence (18) Brandeis Bldg. Uren, Ciaude Thomas (18) State Bank Bldg.

Wherry, Wm. P. $(1,18)$ Brandeis Bldg.

\section{NEW HAMPSHIRE}

Bradford, Henry W. $(4,14)$ Wolfeboro, X.H.

Carleton, Elmer H. (15) Hanover, N.H.

Kittredge, Frank E. $(3,15)$ Nashua, N.11. Jaclitilan, Andrew L., Jr. (15) Concord,

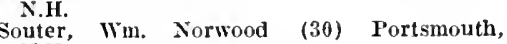
Souter, ' Wm. NEW JERSEY

Adams, Chas. F. $(1,20,24)$, Trenton, N.J.

Adams, Chas. F. $(1,20,24)$, Trenton,
Ard, Frank C. $(3,16)$ Plainfleld, N.J.

Atkinson, James Wm. (3) Paterson, N.J.

Chambers, Talbot $\mathrm{K}_{\text {. }}(1,3)$ Jersey City, N.J. Corwin, Theodore W. (3) Newark, N.J. Cramer, Alfred, Jr. (1, 24) Camden, N.J. N.J.

Emerson, Linn (1, 3) Orange, N.J.

Gould, George M. (4) Atlantic City, N.J.

Johnson, Walter B. $(3,4,5)$ Paterson, N.J.

Meliwaine, Chas. H. (4) Newark, N.J.

llevay, James C. (24) Atlantic City, N.J.

Scarlett, Kufus B. (3, 20) Trenton, N.J.

Simcox, Lawrence (20) Ocean City, N.J.

Sondern, Paul F. (3) IIontelair, X.J.

Sutphen, Theron Y. $(1,4,5)$ Newark, N.J.

Upham, Heten Frances (1) Asbury Park, N.J.

Wilson, Norton L. (3) Elizabeth, N.J.

\section{NEW YORK}

\section{Brooklyn}

Arrowsmith, Hubert $(1,3) 17 \theta$ Ciinton St. Bailey, Fred D. (4) 260 Hancock St.

Braisin, Wm. C. $(3,5,17) 556$ Washington Are.

Collins, Burnett C. (3) 645 St. Marks Ave. Cox, (has. X. $(3,5) 257$ Jefferson Are. French, Thomas $R$. (2) 150 Joralemon St. Ingalls, James $W$. (4) $8: 4$ Lafayette Are. Jameson, 1'atrick Chalmers (4) 139 IIon-

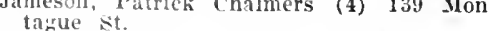
Lutz, Stephen H. $(3,5,17) 284$ Hancock
Price, Ilenry R. $(4,16) 435$ Clinton Ave. leynolds, WHiard $(\mathrm{i},(4,16) 1165$ Dean $S$ IRushmore, John D. $(4,5,16) 129$ Montague sit.

Shattuck, Warren S., Jr. $(3,5) 160$ Clinton sit.

Sheppard, John E. $(3,5,17) 130$ Montague

Witerman, James S. (3) 676 St. Marks Ave.

Wood, Joln scott (4) 172 , 6th Ave.

\section{Buffalo}

Andrews, Herman D. $(1,6) 486$ rranklin sit.

lemett, Artluur G. $(1,6) 26$ Allen st. Blataw, Edmond E. $(1,6) 327$ Frankitin St. Rrown, Ciayton M. (1) 510 Defaware Are. Burrows, Lorenzo, Jr. $(1,6) 482$ Fratuklin st.

Clemesha, Jolm C. (6) 329 Frankiln St. cott, Chester Chas. (1) 1195 Main st. cots, (ien. F. (1, 3) 1195 Main st. Cowper, Haroid Wm. (6) 543 Franklin St. Fairhairn, doln $F$. (1) 131 Allen st. Fell. Geo. E. (19) I. S. Morgan Bidg. Fherty, Iohn I. (1, 6) 429 Franklin st. Flagg, John 1). (1, 6) 384 Frankiin St. Forsyth, Edgar A. (1,3) 322 Franklin St. Francis, Lee Musten (1, 4, 6) 575 Delaware Ave.

Glosser, Herbert H. $(1,6) 448$ Franklin St. Grove, Benj. H. (6) 334 l'earl St.

Grove, Hobt. K. (1, 6) 239 Delaware Ave. Hinkel, Frank Whitehill $(2,3) 581$ Delaware Are.

Howe, Lucien $(1,4,6) 522$ Delaware Are. Hubbard, Aibert E. ' $(1,6) 372$ Franklin St. Lewis, Francis Park $(1,6) 454$ Franklin St. Lewis, Fred Daniel (6) 188 Franklin St. Mooney, James J. (3) 490 Delaware Are. Mulford, IIemry J. (1) 143 Allen St. P'liiifips, William $L_{\text {. }}$ (I) 449 Frankiln St. Renner, Wm. S. (1, 2, 3, 5) 341 Linwood Are.

Rogers, Benj. F. (1) 222 Franklln St. Satteriee, Kichard H. $(1,6) 187$ Delaware Are.

Starr, Eimer G. $(1,6) 523$ Delaware Ave. Weed, Harry M. $(1,6)$ 405 Franklin St.

\section{New York City}

Abraham, Joseph H. (3) 130 w. 58th St.

Adams, John l. (3, 4, 5, 17) 38 E. 51st St. Madison Are.

Bacon, Gorham (5, 17) 47 W. 54th St. l3allin, Nlilt on Julius (1) 53 E. 58th St. Beil, Geo. H. $(4,16) 40$ E. 41 st St.

Berens, T. Passmore $(2,3,5,17) 35$ Park Are.

Blackwell, Hugh B. $(3,5) 148$ W. 58th St. Blodgett, Frank J. (5, 17) 140 W. $72 d$ St. Bosworth, Francke H. (2) 41 Park Ave. Bowles, Fred. J. (1) 121 W. 93d St. Brown, H. Beattie (3) 40 E. 4lst St. liruder, Joseph (1) 78 W. 114th St. Bryant, Wm. Sohier $(1,3,5,17) 19$ W. 54 tir St.

Callan, Lewis White $(4,16) 461$ W. 14lst St.

Calian, Peter A. $(1,4,16) 452$, 5th Are. Carhart, Wm. Metle d'Aublgne (1) 616 Miadison Ave.

arter, Wm. W. (1) $69 \mathrm{~W}$. 50th st.

Chappell, Walter F. $(2,3)$; E. 55th St. Chishoim, Wim. Alexander (3) 62 11. 53d

Claiborne, John -H. $(1,4,16) 11$ E. 48th St. Clemens, James B. (5) 10 E. ilst St. Conkiey, Cornelius G. $(2,5) 53$ W. 56 th $\mathrm{St}$ Cocks, Gerhard H. (3) $13 \overline{-}$ E. 54 th St. Coffin, lewis A. $(2,3) 156$ W. 58 th St. Coggeshall, Hellry (3) 40 E. 58th St. Cohen, Martin (1) 1 W. 85th St.

colm, Felix (1) 31 E. 60th St.

Cowen, Wm. (5) 35 E. 60th St.

Culbert, Win. Ledlie (3) 16 E. 54th st.

curtis. H. Holbrook (3) 118 iladison Ave Cutler, Colman W. $(4,16)$
Davis, Achilles Edw. $(1,4,16)$
50 W. 37 th Davis,

Davis, Geo. Elwin (3) 50 W. 37 th St.

velaran, D. Bryson (2) 40 E. 41 st St.

Dench, Edward B. $(3,5,17) 15$ E. $53 d$ St. Dennett, Wm. Sawyer $(4,16) 8$ E. 49 th St. Dixon, Geo. Sloan (1) 40 E. 41st St. Duane, Aiexander $(1,4,16) 139 \mathrm{E}$. 37th $\mathrm{St}$ Duel, Arthur B. $(3,5,17) 27$ E. 57th St Enerson, Joseph B. (4, 5, 16, 17) 40 E 4Ist St.

Fowler, Edmuni l'rince $(1,3) 616$ Madison Ave.

Freudenthal, Wolf $(1,3) 1003$ Madlson $A$ ve ridenlerg, Percy 11., Sr. $(1,3,4,5,16)$ $60 \mathrm{k}$. $5 \sin$ st.

Friedman, Lavid (1) 808 West End Are. Frothingham, Hichard (2) 616 Madison Are. Gleismann, Josepin W. (2) 616 Madison Ave. Glogan, Otto (1) 1320 Madison Ave.

Ciraef, Cinarles (3) 1076 Boston IRd.

Griftn, F. Harrison (3) 55 W. 4ith st.

(iruening, Enif $(3,4,5,16,17) 36$ E $57 \mathrm{th}$ sit.

(iuntzer, John 11. (3) 40 F. 4lst St. Iarris, Thomas J. $(2,3,5,17) 104$ E. 40 tí St.

Iaskin, Wm. H. $(3,5,17) 40$ E. 4lst St. Ilays, Harold Mt. (I) 11 W. 81st St.

Ifeld, keuben Johnson $(1,3)$. 616 Madison Are.

llepburn, Nell J. $(4,5,16,17) 317 \mathrm{~W}$ 23d St.

IIolden, Ward A. (4, 16) 8 E. 54th St.

IIope, (jeorge R. (2) 159 W. $72 d$ St.

Hopkins, Frank T. $(5,17) 182$ W. 58th St. Horn, John (3) 72 E. $92 \mathrm{~d}$ St.

liubby, lester M. (1,3) 27 W. 68 th St.

IIunter, Iwlght $W .(1,4,16) 80$ W. 40 h St

IIurd, Lee H. $(1,3)$ 15 E. 48th St.

Imperatorl, Charles .J. (1) $245 \mathrm{~W}$. $102 \mathrm{~d}$ St. Ingerman, Sergins if. (1) 1843 Madison Ave.

Irwin, Frank Newton $(1,16) 4$ E. $43 d$ St. Jarecky, Herman (1) 138 w. 86th St.

Jordan, Richard (5) 165 W. 58th St.

lienefick, Jos. A. $(3,5,17)$ 78 E. 54th St. Kerrison, Phillp I). (1, 3, 5, 17) $58 \mathrm{~W}$. 56 th St.

Knapp, Arnold $(1,4,16) 10$ E. 54th St.

Koller, Carl (4) 681 Madison Are.

Kopetzky, Samuel J. $(1,3) 616$ Madison Ave.

Krug, Frnest Fredk. (1) 12 W. 44th St. rambert, Walter E. $(4,16) 112$ F. 35th St. Leterman, Moses D. (3) 58 E. 75 th St. Lewis, Robert $(3,5,17) 48$ w. 40 th St. Loughran, Robt. Livingston (3) 62 W. $52 \mathrm{~d}$ coughra

Lynch, John B. (4) 151 W. 74th St.

Mackenty, John Edmund (3) 43 w. 54 th St Macpherson, Duncan (3) 127 N. $851 \mathrm{~h}$ St. Malcolm, P'ercy E. D. (3) 55 W. 55 th St. Marpie, Wilbur B. $(1,4,16) 46$ E. $53 \mathrm{~d}$ St. May, Chas. Henry $(1,4) 698$ Madison Are. Mayer, Emil $(1,2) 40$ E. 41 st St.

IlcAulitfe, Geo. B. (5) 616 Madison Are. IcClelland, Lefferts A. (3) 2 Rector St. IIcCoy, John J. $(1,3) 157$ W. $73 d \mathrm{dt}$ IeCullagh, Samuel (3) 35 Park Are. Ickernon, James F. $(1,2,3,5,17) 62 \mathrm{~W}$. $52 d$ St.

Meierhof, Edward L. (1) 1140 Madison Ave. Miai, Leonidas L. $(1,3) 23$ W. $36 \mathrm{th}$ St. Ililler, Frank F. (3) 22 W. 31st St.

Mittendorf, Alfred Derby $(1,16) 140$ Madlson Ave.

Mittendorf, Wm. F. $(1,4,16) 140$ Madison Ave.

Mortimer, Wm. Golden (1) The Nevada, Broadway and 70 th St.

Myles, Robert C. $(2,3,5) 46$ W. 38 th St. Oppenheimer, Henry S. $(4,16)$ il E. $43 \mathrm{~d}$ sit.

Oppenheimer, Seymour $(1,3) 45$ E. 60th St. Page, John R. $(3,5,17) 127$ E. 62d St. Payne, Sanders M. $(1,4) 542$, 5th Ave. Perkins, Charles E. $(5,17) 127$ W. $82 \mathrm{~d}$ St. thillips, I

Pooley, Thomas R. $(4,16) 40$ E. 41 st St Quinlan, Francis J. (IT) 66 w. $52 \mathrm{~d}$ St.

Rae, John B. $(3,5,17) 247$ W. 70 th St.

Reese, Robt. G. (1, 4, 16) 50 w. 52d St Rice, Clarence C. (2) 123 E. 19th St. Richards, John D. $(3,5,17) 203$ W. 56 th

Robinson, John A. (3) 40 E. 41 st St. Saunders, Truman Lawrance (5) 43 W. 50 th St.

Schoonmaker, Perry (1) 2345 Broadway. Shannon, John R. (4, 16) 17 E. 38th St.

Sharp, J. Clarence (3) 62 W. 46th St.

Shine, Francis W. (16) 37 E. 30 th St. Skeel, Frank D. $(1,4,16) 147$ W. 57 th St. Smith, Harmon $(2,3) 44$ W. 49 th St Steel, Geo. E. (3) 256 W. 79 th St. Stephens, Franklin M. (5) 19 W. 54 th St. Sterens, George T. $(1,4,5) 40$ E. 41 st St. 
Strouse, Alfred $\mathrm{S}$. (1) 79 W. 50 th st.

Thomson, Juhn $j_{\text {. }}(3,3,5)$ io $W$, tith st.

Thomson, Edzar 5 (t, ito) 405 Prark tre.

Toeplitz, Max (IF)

Torok. Frrin (4) 210 F. Krmadway. 11. Tygon, IIt.

Valk, Franels (1) Itit E. fist st.

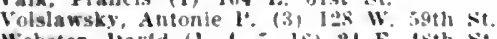

Webster, basid $(1,4,5,16), 2+$ Fo. Asth st

Weeks, John $\boldsymbol{k}_{\text {. }}$ (I, f lit) 16 k. Sith st.
Weinsteln, Joseph (i) 261 Central Park Are.

wheelcr, John M. (16) 80 W. toth st. Whithe, Fredk. (3, 3, 17) 19 W. Tith st.

Wlener, Alfred (J, 3) 616 Madlson Are.

Woodward, Jullus H. (1) 200 W. $38 \mathrm{sth}$ st.

Wootton, Herbert W. (16) 319 Lexington

Are.

Wrighi, Jonathan (2) $x$. Y. Post Graduate Hedleal School.

Yankauer, Sldner $(1,3) 616$ Madlson Are.

Yates, Darld Gilbert (3) 149 W. $81 \mathrm{st}$ St.

\section{State at Large}

Adams, Alpheus F. (t, 3) Newburg, N.Y. Bedell, Arthur J. (1, 4) Albany, X.i.

Blackham, Geo. F. $(1, b)$ bunkirk, Y.Y.

itritten, Geo. S. (1) Syracuse, X.Y.

Case, Geo. I. (1,6) Folmita, X.Y.

Conboy, Phillip (I) Rochester, XY.

Craton, Saml. Boyce (1) Syracuse, N.Y.

culver, Chas. M. (t) Albany, X.Y.

baly, Walter s. (3) Ogdensburg, X.Y.

Dryer, W'm. Mulvahlll (1) Amsterdam, X.Y.

Farrell, Thomas H. (3) Ctlca, I.Y

Foster, Mattllas L. (1, 4) New fochelle, $x$.

Fowler, Saml. Robertion (I) syracuse, XY.

Halsted, Thomas H. $(2,3,5)$ syracuse, Xy.

Klrkendall, John S. $(1,3,6)$ Ithaca, N.Y.

Lewls, Geo, Ii. (1) syracuse, X.Y.

Marlow. Frank W'm. (4) Syracuse, X.Y.

Marson, Sands C. (t) Ltlea, X.Y.

Mefaw, James F, $(3,5)$ Watertown, X.Y.

Merrill, Cyrus $s .(t, 5)$ Allany, N.Y.

price, Norman w. (1) Nlagara Falls, N.y.

Reger, Harry S. (1) Jamestown, N.Y.

Rincueberg. Fugene X. S, (1, 6) Lockport, $\therefore$...

Roe, John O. (2, 3) Rochester, N.y.

Kont, Arthur G. (3) Albany, X.Y.

Sackrlder, John K. (6) Jamestown, X.Y.

Smith, Angelo J. (3) Yonkers, X.Y.

smith, Honer E. (I) Norwicle i.

Ssuell, Albert $c$ (t) Mochester, $Y$.

snow, Sargent F. (i) Syracuve, X.Y

Thelsen, Clement F. (2. 3) Albany, N.Y.

Toms, Samuel W. S. (I) Yyack, XYY.

Voorbees, Sherman ( 1 (fi) Filmira, $\mathrm{X}$

Watson, Henry II (I) Bingliamton, N.Y.

Wheelock, Edward $(4,5)$ Rochester, XY.

wilson. if. (c. (1) Jhacd, X.Y.

\section{NORTH CAROLINA}

Battle, Kemp 1'. (2) Ralelgh, X.(.

Greene, Jos. Berry (3) Asbeville, $x c$

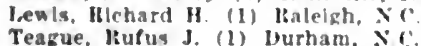

\section{OHIO}

\section{Clncinnati}

Allen, Samuel billsworth (I) 2 "2 W. ith st. Ayres, Stephen Corper 14, in 4 W ith st Ayres, Wylle Melcean (1) i W. ith st. Campleell. Wm. II. (1) 19 W ith st. Darls, Francls W. (I) 41 , Broadua

Fitzpatrlek. Thomas $v \cdot(I, 3) 19$ w. ith st.

Harrts, Win. 1․ 11) dirotum Jiddg

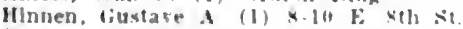

llolmes, Chrlstlan $\mathrm{f}$ (1, $2.3,4$, i) $10 \mathrm{E}$. stlis st.

Husses, Allert Ea (1) 16 k: ith sit

Iflaner, Samuel 11,3$)$ :2 W.

keller. Wm. Selnald $\{1\}$ ith and ltace sis

King. Clarence J. (I) ith and liace site

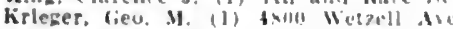

lamb. Prelk. Win. (1) it $\mathrm{k}$ sill st

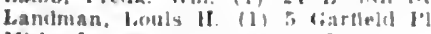

3lthefer. Wm (1) 1! W. itls st.

Murphs, John Weslet (1, 3) \& ith st

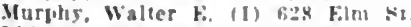

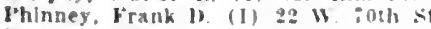

ltanly, John (1) 93ri Clark st.

Kay, Vletor (I) tirutun Mids:
Sanders. Adthon $F$ (1) viroton Fidd

Sattler, Molvert 11,1$)$ dirnton Mldg.

stanlery. Henrs (I) 8 ks th st.

stoll, harl Luelwig (1) lil W ith st.

Tongeman, Thas. W. (1) "en we sth st,

Thompson, Eds: If, (1) 1! W ith st

Thenpusm, dotun A. (3) figx Folm se

Thravler, vllen lientun (a. 3) ith and tace siti.

Thrasher, A. Wade (3) Provldent lsank I3lal

Viall. llerrlek $\mathrm{T}$. $(1,3,8)$ at k. we sit.

\section{Cleveland}

Allwitt, Nm. J. (3) Joennox HIdse

Hruner. Win. Esans $(1,4)$ New England Hag.

Hurke. Thos. Alorslus (1) Bose Hlda.

Chamberlln, Whllam bricker (3) Osborn

Bids.

Cogan. James folw. Francls (1) Rose Bldg.

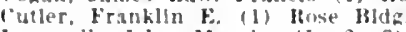

herersill, John Marin (1, 2, 3) Othorn Mind

Large, Seond Herbert $(1,3)$ Roze Rldg.

lauder. Esward (1) Oslorn Mldz.

Lenker, John Nicholas (I) Oshorn HIdf.

Lincoln, WHlliam $k$, (2, 3) Lemnox Rldg.

fowman, John Henry (2) 180t l'ruspect

Are., S.:

Metz. Koy B. (1) Ostrorn Bld

Metzentaum, Myron $T$. (1) Rose Blag.

Mlllikin, Benj. L. (t) 1110 Fuclld Are

Monson, sliandor Henry (1) Lennox Hidg

Rust, Fdwln (f. (1) Lemnox Blde.

Sliackelton, Wri. E. (1) Oshorn Bldg.

Shermaln, Harrls f. $(1, t)$ Rose Blalg.

stuart, Chas collins il Lennor Bldg.

Tuart, Chas Collins (1) Lenno Bla

Tuckerman, Werner Hopklns (1) Osborn

HIdz.

\section{Columbus}

Brown, John Edwln (1, 3) 239 F. Town St.

Clark, Chas, F. (t) 188 k. state se

Heckler, Frank I. (1) 106 k. Hroad St.

l.tnhart, chrlstopher P'. (1, 3) 350 E. State

st.

Means, Chas. S. $(1,3) 130$ Butles Are.

schaetfer, fieo. $C$. (1) 112 F. Broad St.

stillman, Frank i. (3) 118 F. Broal st.

sulzer (iustavus 1. (1) $23 \%$ E. State st

Timberman Andrew J $(1,4,5)$ II $\mathrm{E}$.

Broad st.

Wrlaht, Iohis Westley (1) Central Nallonal Bank Blatr.

\section{Toledo}

Alderdyce, Wm. W. (I) Nashr Bldg. Alter, Francis if. (1) Naumee Mlves hi. lue Vilhlss, Allen (1) 922. Norwond Are.

IIvluartl, Thomas $(2,3,5,11)$ vicholas Blde.

Jacolit. Frank (1) Folton Rlde.

keller. Tlows. $F$, (I) The spitzer Bldz.

I.a salle, Iames If (3) 220 Mlehlyan st.

Lukens, Chas. (I) eIs Nilchlgan st.

\section{State at Large}

Baron, frederlck stewart (1) Zaneswllle, O

Rattels, Mary M. (1) Aslualula, O"

kinner, llurace (I) bastoti.

Carnes. Allert rlayton (1) Hamllton, 0

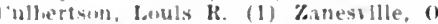

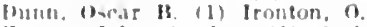

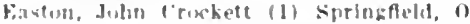

Ciarlée. Jerro 11 (1) Mansfleld 0

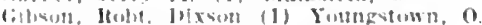

lirunt. James lieorte (1) Mkron, 0 .

cinthrle, duvtin lee (1) Lancaster.

IIarria. Harry 1s. (1) Maston 0

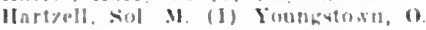

1l:atch. I'lark 1t. (I) Newark, (1)

16i11 irthine $J$ (1) Cambets of

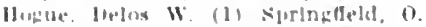

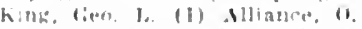

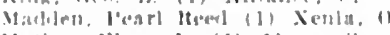

Mather, kilmer l. (I) Jhrom,

Wllette, Juhn W. (1, e) laston, o

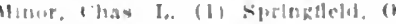

Vounsmit?, Blney $k$ (1) lotaln, $"$

burgan. Chalmery do 1 li Ciallon,

Porsor reduand 11 (1) TImm, "

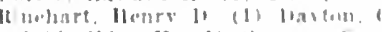

sulblul, fillw II 11 ) Cansun. (1)

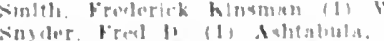

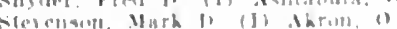

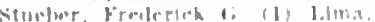

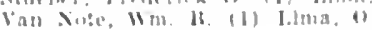

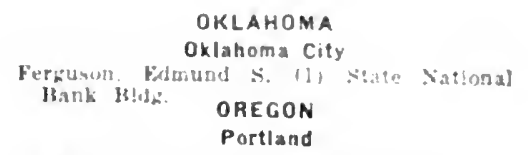

Ainslie, fieo. (19) rregonlan Ithog

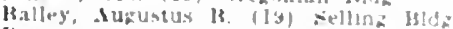

Healamont. John $r$, (lg) Medleal [Blce?

Bruere, liuntave $r$ (t. Ig) Journal I3tot

Cassetal Frank b. (19) leekum likd

Chamberlaln, rhas. T (Is) Journal Kide

(oghlan. Johin $x$ (1, ls) selllng Jldls.

lials. Italph Ferrlen (19) selling Hus.

livekson, Juhn fortest (19) selllisg lidg.

Faton, Frank bianey (19) kroadiuay bld.

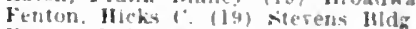

Fenton, Raluh A 11 is sterens Jilig.

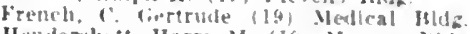

IItedershutt, Harry M. (IG) Morgan Blds.

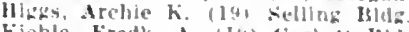

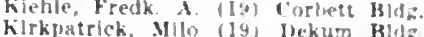

histner, rrank is (If) Journal Hids

Mccollom, John Wallace (19) Morkat Bldg Ilc(iml, Joseph I. (1, Ig) Hroalway HIdq Oxtradner, Ciarwoul II. (19) Oreconlan Bld: lioth John H. (19) Oregonian Wide.

stewart, Juhn I 190 Grefon

Welr, Fred Itamilton (14) Medleal Blde Wiond, Willam J. (4, 14) Drezonian Bldg. Wriglit. Shernan F. (19) Medleal Bldg.

\section{State at Larpe}

Findley, Marcus C. (19) firantw Pass, Ore.

Culldon, Omar 1R. (19) Eugene, Ore.

learce, ("latude M. (19) Baket, Ore.

Reamer, Flwlu F. (31) Salem, Ore

steeves, Burpee L. (19) šalem, ore

Taylor, James Branch ( $x$ ) Eucene Ore.

Waugh, Justln W. (19) Hood Rtver, Ore.

Wetherbee, Jos. Rolbins (19) Langlots, Ore.

\section{PENNSYLVANIA}

Philadelphia

Appleman, L. Francls (?1, ge) 305 s. Iöth St.

kabbltt, James Addeson (3, :3) 1901 Chestnut st

Baer, lienj. F., Jr. (2a) 2040 (hestnut st Baldwin, Kate W. (I) 1117 sliruce st. Balentine, Percy I. I I, 21 , If) $\$ 11$ \% (hestnut st

batrott. Warren (C. (20) atio $\times$. 1ith st

Bemls, Royal W. (20) 2512 X ith st

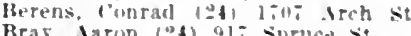

Bras, Aaron (2f) 917 sprued st

Broun, sanuel H. $(1,2 t) 1401$.IL Vernon

Tuchanan, Mary (I) 2104; Chestnut st Murns, Louls J. I. (20) 1906 (hestust st Butler, laljh $12,5,2: 3)$ la:t (hestnut st Hutt, Mriam M. (1, "t) 170I Chestrut st.

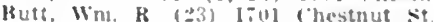

larpenter. Johu T. (t, as) allto ("hestaut it

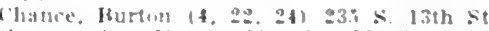

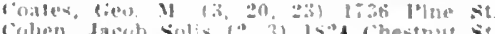
Cuhen, Jacub sols 12,3$) 1524$ ("hestmat se

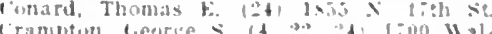

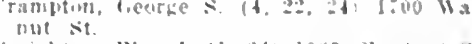
Frobton, Win. d (1. a) 1905 Thentrut se

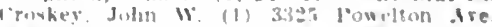

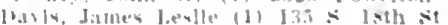

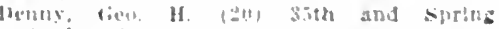
liarlen sit

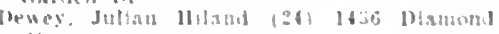
sit

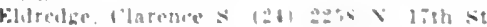

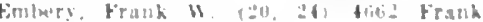
firrel Nie

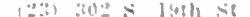

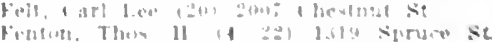
(1) liantha in

If Inth st

Fivlicer liraish

解

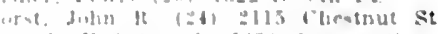

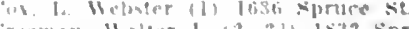

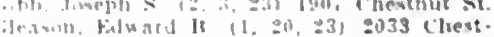

inut sit

(imldart, Hertert M. $1^{\circ}$ : 01 133s spruce St 
Goldberg, Harold G, $(4,22, \quad 24) 1925$ chestuut sit.

fordon, Benjamin I. (24) 1316 S. 5th St Grayson, Charles 1'. $(2,3,23) 262 \mathrm{~s}$. 15th st Griscom, John Mliton (24) 1925 Chestnut

Sit.
Hansell, Joward F. $(1,4,21,22) \quad 1528$ walnut St.

lleed, Chas. Rlttenlıuse (1, 4, 21, 22, 24) 1700 Walnut st.

Hitschler, Wm. $\mathrm{A}$. (20) 1212 siruce st

Ifolloway, Thomas 13. (4, 22) 1819 ihestnut St.

Jones, Charles J. (24) 1507 Locust St.

Jones, Horatio $(C$. (21) bito Woothand Are. Kuufuan. Alexander sipencer (1) 254 s. litll sit.

Keeler, Joseph C. (1) 124 S. 1sth St.

Keeler, Joseph C. (1) Sivice st.

Kinpe, Jay C. (1, 22) 2035 (hestuut St

Krauss, Frederlek (1, 2.2) 930 Franklln st.

Kyle, David Braden $(2,3,5,23) 151 \%$ Walnut St.

Langdon, II. Maxwell $(4,22) 2018$ Cliestnut st.

Lewls, Fielding O. (20) 261 s. 17th St.

Maccoy, Alexander W. (2, 23) $216 \mathrm{~s}$. 15th

St.
Mackenzle, Gcorge w. $(1,20) 1831$ Chestnut st.

Makuen, fieo, Iludson $(2,3,5,23) 1627$ Walnut sit

Marshall. Heo. M. (23) 1819 spruce st.

Marter, Llmiaeus F. (24) 1631 lace st.

Matlack, Ellwood (20) 1631 Girard Are

Menal, $11 \mathrm{~m}$. M. (20) 143 N. 20th st.

llongel, Fruest (1) 1429 Tioga St.

Ilyers, Tallyrand I). (22) 1521 spruce St.

Off, Henry . (3) $323 \mathrm{~S}$. 20 th St.

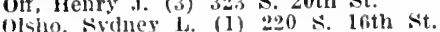

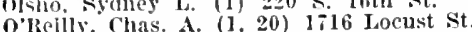

'alckare, Francis R. $(2,3,5,23) 302 \mathrm{~s}$ 19th St.

Parlsh, Benj. I). (23) 29 S. 19th st.

Parrish, Ilenry (20) 5343 Baltimore Are.

leter, buther C. $(1,21,24) 1527$ spruce St

Pllllips, Richard J.' (4) $123 \mathrm{~S}$. $39 \mathrm{th}$ St.

locard, Henry L. (24) 1922 Race st.

Pontius, 1'aul J. $(1,24) 1831$ Chestnut St

Posey, Wu. C. (1, 4, 21, 22, 24) 2049 Cliestmut st.

Pyle, Walter L. $(4,22) 193 \mathrm{~L}$ Chestnut St Ratclifle, Necluney $(4,22,24) 1906$ Chest nut st.

Randall, Burton Alexander $(2,4,5,22,23)$ $171 \%$ Locust St.

Reber, Wendell $(1,21) 1212$ Spruce St.

Ridpath, Robt. Ferguson (20) 1633 spruce st.

Ring. Gassaway Oram (4, 22) 2014 Chestnut st.

Risley, J. Norman $(1,4,22,24) 134 \mathrm{~S}$ 20 th St.

Risley, Samuel D. $(4,21,22,24) \quad 2018$ Chestnut St.

Roberts, Walter (3, 5, 23) 1732 spruce St.

Rowland, Alexander if. Carroll (20) 3704 Spring Garden St.

Sajous, Chas. Eucharist (2) 2043 Walnut st.

Sargent, Albert Alonzo (21) $130 \mathrm{~s}$ line $\mathrm{st}$ Sartain, Paul J. (22) 212 W. Logan Sq.

Sautter, Alvert C. (1, 4, 22) 14:1 Locust St. Saylor, Edwin S. (22) 2005 Chestuut St.

Schneidemann, Theodore B. $(1,4)$ Profes sional BIdg.

Schweinitz, George E. de $(1,4,21,22) 1705$ Walnut St.

Schwenk, Peter N. K. (1, 4, 24) 14 I Broad st.

Selss, Ralph w. $(5,23) 255$ So, 17 th St.

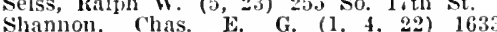
Spruce St.

Shoemaker, Wm. T. $(4,22) 109 \mathrm{~S}$. 20th St.

Shumway, Edw. A. $(4,22) 2007$ Chestnut St.

Skillern, Ross Hall (1, 3, 20) 2032 Chest nut st

smith, Seth Maccuen $(1,3,5,23) 1429$ Spruce St.

Solis-Cohen (See Cohen)

Somers, Lewis S. (20) 3554 North. Broad

stanffer, Nathan F. (23) 4833 Baltimore Stiles. Chis. Mildwood $(1,24) 1831$ Chestnut St.

Stout, Geo. C. (1, 2, 3. 23) 1611 Walnut St Stout, Philip saml. (20) 4701 Chester Ave.
StrawbrldLe, Geo. $(4,5) 202$ S. 15th St.

strouse, Fredk. II. (20) 1301 N. Broad st. Sweet, Wm. I. (1, 4, 21, 22, 24) 1205 spruce Sit.

Thomas, Chas. Itermon $(4,24) 36: 4$ Chestnut st.

Thomson, Archlbald G. (4, 22) Stock Exchange bldz.

'lhoringt on, James $(4,21,22) 2031$ Chestnut

St.
Tomlinson, Wm. Hubbs $(1,20) 1212$ Spruce st.

Tunis, Jos. 1'. $(3,23)$ st. Martlus.

Turnbull, Chas. Smlth (1) 1935 Chestnut St.

Turner, John H. (22) 1833 ('hestuut St.

Vall, Wn. Penn. (23) 1906 Chestnut St.

Villsant, Eugene 1. $(3,23) 1629$ (hestnut st.

Watson, Arthur W. (2, 23) 126 South 18th St

Watson, Waller W. (21) 1712 Walnut St. Witson, Wm. Newbold (20) 636 S. 48th St Willianis, Carl $(4,22) 67$ School Lane.

Wood, George Bacon (2, 3, 23) 129 South 1 sth St.

Zentmayer, Wm. $\quad(4,21,22,24) 1819$ Sipruce St.

Zlegler, $\mathrm{s}$. Lewis $(1,4,22,24) 1625$ Walnut St.

Zimmerman, Mason W. (22) 1522 Locust St.

\section{Pittsburgh}

Allyn Geo. W. (4) Emplre BIdg.

Beane, Geo. Walters (1) Jenkins Arcade Bldg.

Curry, filendon F. (1) Westinghouse Blds Jay, Ewing w. $(1,3,5)$ Westinghouse Bldg.

Dickinson. Breese M. (1) Keenan Bldr. louncan, Joseph L., Jr. (4) Jenkins Bldg.

Eastman, llenry (i) Park Bldg.

Ierkel, Elw. B. (1) Jenkins Bldg.

Jackson, Cheraller $(1,2,3$,$) Westing$ house Bldg.

Kineedler, Geo. Clyde (I) Jenkins Bldg.

Krebs, Adolph (1) Jenklns Bldg.

Lippincott, James A. (4) Jenkins Bldg.

Mabon, John S. (3) 721 Sandusky St.

IcCready, James Homer (1) Empire Bld

villigan, Robert (3) Westlnghouse Bldg.

owens, A. Charles Klngsley (1) Jenkins Bldg.

Robeson, Wm. F. (1) Westinghouse Bldg.

Sandels, Christopher C. (3) Westinghous Bldg.

Sterrett, John Kennedy (3) Ilighland Bldr. Stieren, Edward $(1,4,5)$ Westinghouse Bldg.

Turnbull, Thomas, Jr. (3) 835 Western Ave willetts, Joseph E. (1) Westinghouse Bldg. Wishart, Chas. A. (1) Bessemer Bldg.

$$
\text { State at Large }
$$

Ball Michael V. (1) Warren, Pa.

Barker, Olin G. A. (1) Johnstown, Pa

Becker, Harrey If. $(20,24)$ Sunbury, $p^{3}$.

Buckman, Ernest U. $(1,4,5)$ Vilkes Barre, Pa.

Carr, Geo. W. (1) Wilkes-Barre, Pa.

Cocklin, Chas. C. (24) Harrisburg, Pa.

Corser, John B. (1) Scranton, $\mathrm{Pa}$

Corson, Gco. R. S. (1) Pottsville, Pa.

Culp, John F. (3) Harrisburg, $\mathrm{Pa}$

Dennis, Darid N. (1) Erie, Pa.

Doane, I. Leo (1) Butler, $\mathrm{Pa}$.

Dunn, Ira I. (1) Erle, Pa.

Frey, Clarence L. (1) Scranton, Pa

Harrls, Clarence M. (1) Johnstown, Pa

Jobson, Geo. B., Jr. (1) Franklin, Pa.

Kistler, Clinton .1. (24) Lehighton, $\mathbf{P a}$

Klinedinst, John F. $(1,24)$ York, Pa.

Love, John King (1) Easton, $\mathbf{P a}$.

Lowman, John Bodlne (3) Johnstown, Pa

IcAllster. Iohn C. (1) Ridgeway, Pa

Murray, Gilbert D. (3) Seranton, Pa.

Park, John Walter $(1,3)$ Harrisburg, Pa

Parker, Frank C. (24) Norristown, Pa.

Pyfer, Howard $(1,21)$ Norrlstown, Pat

Roderlck, Edward R. (24) Wilkes-Barre,

Rohrer, George R. (24) Lancaster, Pa.
Shope, Samuel Z. (20, 24) Harrlsburg, Ia

Shreve, Owen Mr. (1) Erie, Pa.

Taylor, Lewis H. $(1,4,5)$ Wilkes-Barre. $\mathrm{Pa}$.

\section{RHODE ISLAND}

\section{Providence}

Abbott, Harlan P. $(15,26) 274$ Benefit St.

Adams, Frank M. (26) 97 Broad St.

Astle, Christopher J. (26) 278 Broad St.

Best, oliver F. (26) 90 Broad St.

Bigelow, Frederlck Norton $(15,26) 265$ Benefit St.

Blanchard, Howarl E. $(15,26) 236$ Broad st.

Capron, Franklin P. (4, 5, 14, 26) 118 Aingell St.

Fenruey, Frank A. (26) 940 Broad St

Fisler, Alvah A. (26) 231 Broad St.

llarvey, Fdwin B. (26) 183 Broad St.

IIarvey, Norman D. $(1,4,5,14,15,26)$ 114 ivaterman sit.

Hawklns, loseph F. (26) 141 Westminster St.

Hayes, Albert 1\%. (26) 128 Broad St.

Leech, James W. $(14,26) 111$ Broad St.

Iason, lieo. (26) 7 l Broad St.

Molaughlln, Wm, C. $(14,15,26) 574$ Broad St.

Messenger, Harry C. (26) 170 Broad St.

Porter, Lewls B. (15.26) 277 Benefit St.

Raia, Vlto L. (26) $2 \pi 2$ Broadway.

Rogers, Frederlck T. $(14,26) 111$ Broad St.

Van Benschoten, Geo. W. (26) 188 Broad St.

$$
\text { State at Large }
$$

Beck, Horace F. $(15,26)$ Newport, R.I.

IIess, Peter W. (15, 26) Pawtucket, 1R.I.

Jacoby, Douglas 1. A. $(1,26)$ Newport. R.I

Jenekes, Frank II. (26) Woonsocket, R.I.

\section{SOUTH CAROLINA}

Jervey J. Wilkinson $(1,3)$ Greenville, S.C. Kollock, Chas. Wlison $(1,4)$ Charleston, S.C.

Mauldin, Leland Osgood (1) Greenrllle, S.C. Parker, Edward F. (3) Charleston, S.C.

\section{SOUTH DAKOTA}

Alway, Robt. D. (31) Aberdeen, S.D.

Bower, Chas. A. (31) Mitchell, S.D.

Frudenfeld, IIenry II. (31) Madlson, S.D.

Grosvenor, Lorenzo N. $(1,7,8,31)$ Huron, S.D.

IIill, Leslie G. (31) Watertown, S.D.

Keller, Saml. A. (31) Sioux Falls, S.D.
Koobs, Herman J. G. (31) Scotland, S.D.

Parsons, Jos. G. (31) Sloux Falls, S.D.

Putnam, Edmund D. (31) Sloux Falls, S.l).

Putnam, Frank I. $(1,31)$ Sioux Falls, S.D.

Rudgers, Denton W. (31) Yanktown, S.D.

Thomas, Benj. J. (31) Huron, S.D.

\section{TENNESSEE}

\section{Memphis}

Ellett, Edward C. (1, 4) Exchange Bldg.

Farrlington, Pope M. (1) Memphis Trust Blilg.

McKinney, Richmond (1) Bank of Commerce and Trust Bldg.

Micule, Winston T. (1) Central Bank Bldr.

Minor, James Lancelot (4) Randolph Bldz.

Simpson, Wm. 1. (1) Exchange Bldg.

\section{State at Large}

Broyles, Charles J. (1) Johnson City, Tenn. Cullom, Marvln M. (1) Nashville, Tenn.

Deitrich, Wm. A. (1) Chattanooga, Tenn.

Hale, Geo. W. (4, 5) Nashrille, Tenn.

Hogshead, J. McChesney (1) Chattanooga, Tenn.

Kincaid, John H (1) Knoxille, Tenn.

Savage, Giles C. (1) Nashville, Tenn.

Smith, Frank T. (1) Chattanooga, Tenn.

Vaughan, Geo. E. (1) Clarksville, Tenn.

\section{TEXAS}

Arnesworth, Horace T. (1) Waco, Tex.

Bell, James H. (4) San Antonio, Tex.

Boyd, Frank D. (1) Ft. Worth, Tex.

Carpenter, Eugene R. (1) El Paso, Tex.

Cary, Edward H. (1) Dallas, Tex.

Duckworth Guilford M. (1) Cuero, Tex.

Hartsock, Frederick M. (1) Ft. Crockett, Tex.

IIcReynolds, John 0 . (1,3) Dallas, Tex.

Moss, Robert E. (3) San Antonio, Tex.

Warfield, Clarence (I) San Antonio, Tex.

UTAH

Hetzel, Clarence Charles (1) Ogden, Utah.
Stauffer, Frederick (1) Salt Lake Clty, Utah.

Gorham, George H. (15) Bellows Falls, Vt.

\section{VIRGINIA}

Richmond 


\section{state at Large}

Hedges, Halstead $\&$ (3) (harlothenlle, $V_{3}$ Jones, Clarence lurter (3) Newport News. Ya.

Kennon, Bererley K. (3, t, 5) Norfolk, Va Kent, James L. (3) lpulaskl, Va. Myers. Harry I. (3) Norfolk. Va Woodward, John 1\% (3) Norfolk. V'a

\section{WASHINGTON} Seattlo

Adams, Frederlck W. (19, 25) (ob) Mhth Bently, Freulerlik J. (19, 2.5) Coht Hids. Buens, Arthur k. (14, 25) (obt lilds. Burwell, Edmund B. (2.) Cobh Rldg. Coltlver, samuel $\mathbf{x},(25)$ Vorthern bank Bide.

Cooke, clinton T. (19, 2:i) Ilaska IHdke Cunningham, Wm. F. (2J) ('obb Ilulg. De lieck, Darld (25) l.eary Jthlg. lowllng. Jay Thomas (25) Cobb Bldg. Gray Conner E. (25) Lumber Excliange Bldg.

Greenstreet. Abner G. (19, 25) Cobb Bldg.

Hawley, Alanson W. (25) Leary lildg.

llenumeon, James A. (25) Cobb Bldg.

Hotrman, Walter $F$ (a) J.eary bidg.

Hotrman, Walter F. (25) I.eary lildg.

Klomptner, Louls II. (19, 25) Cobb lldg
Mackinnon, John A. (19, 25) Alaska Isldg.

Nadeau, Fonda (19) Cobb IIdg.

Perrs, Richard W. (25) Anerican liank Bldg.

Plummer, Reginald Copeland $(19,25)$ Cobb Bld 5 .

Pontlus, Nevin D. (25) Cobb Bldp.

Seelye, Walter $K$. (19, 25) american Bank

Blds.
Stlltson, Hamllton $(1,19,25)$ Xorthen

Bank Bldg.

Stubbs, Fdw. J, (25) Cobb Bltlg.

Swift, Geo. W. (25) Cobl) Rldp

Wanamaker, Allison T. $(19,25)$ Colsb Bldg.

Wood, Clarence Renson (tii) (ubb Bldg.

Wood, Nathan I'utnam (25) Cobb IBldp

Wurdemann, Ilarrs 5 . $(1,19)$ Cobb Bldg.

\section{Spokane}

Anderson, Fnoch M. (19) Paulsen Rldg. Brazeau. Stephen I. (19) Paulsen Bldp

Frost, Wim. \$. (19) IIy de Bldg.
Greene, Uonala A. (19) Ohd National ltank Hlils.

Jupkins, siott It. (10) Fernwell Wlock

Johuston, Wllson R. (In) I'aulsen Bldg.

Vasey, Clarence $A$. (I. 4, I:0) Paulsen

Bldy. State at Large

Cameron, Wm. C. (25) Taroma, Wauh

Chase, E. Frank $(19,25)$ I Yaklma, Naul.

Findley, Ilarry l'. (25) lierolt, Wash

livolenow, Jorman 11. (19, 2i) Eicrelt. Wash

Jones, Joslah (19, 25) Tacuma, Wan

l.a Motte, Henry (I9, 25) Manctir. Wash

Thompson, James If. (19) N. Yaklma, Wash. Torney, Samuel J. (25) Bellingham, Wash. Van Kirk, Frank 3. (19, 25) Bellingham, Wash.

Wheeler, Frnest (. (29) Tacoma, Wash.

Wing. P'ellg Benson (2.5) Tacoma, Wash.

Zener, Chas li. (19) Wenatchee, Wast

\section{WEST VIRGINIA}

Flsher, Mark 0. (1, 3) I'arkersburg, W Va Jouchery, Daniel C. (I) Clarkshurt, W.Va. Joors, Thomas W. (1, 3) Huntington, W.V. WyHe, Chas, B. (1) Morgantorn, W. Va.

\section{WISCONSIN}

Milwaukee

Bat.1. James 1. (13) Wells l31dg

Harndt, Midon A. (13) 30 Z Cirand Are.

Harnes. John S. (13) Colulimith Bldr.

Haur, Finil $p$, (13) 2el Grand Are.

Reebe, Claude S. (1, 13) 173 Wlsconsin St

13lack, Velson il. (1, 8, 13) Wells BIdg.

Cofrey, Chas. I. (13) 221 Cirand Are.

Higgins, samel fieorge 11,13$)$ Wells Hdg.

IItz, Jenry h. (1, 13) 1llt, sycamore st.

llogue, liustavus I. (1, 1:3) 410 .lelfersun st.

MclBeath, II arry Francls (13) 121 W'lseonsin st.

Jefister, Franz (1, 13) Majestic Rldg.

llegan, Fugene 1 . (13) Irun Block

Seaman, Gilbert F. (13) Roldsmith Hlig.

stanley, Wm. S. (1:) 1:0 Wisconsin St.

stohe, llerman (1, i) Furnpe.
Taugher, Nirloum I (1.) Majentle Blda.

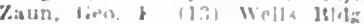

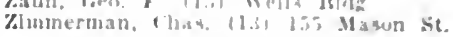
state at Larpe

Mraclfeid, Jihn A l. (l) I.a Croser. Wis. Conkey, (liarles I1 18.29 ) Superlor. Wis.

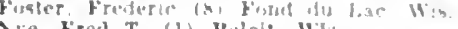

inane, Arthur la (1) bau Clalce. Wis.

\section{WYOMING}

Strader, Geu I. (1, 9) Chegrente, Wyo. HAWAII

Hor, Mllton (13) Hilo. TH

\section{CANADA}

Montreal, Que.

Hirkuth. Ilerbert $\$$. (1, 2. 3, 5) 252 Mountall sit

ligers. Giredon W. (4) 346 Mountaln St

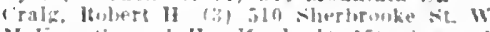

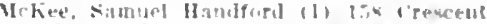
Huckleston, Hapold S. (1) Io: Sinnley St. Iiwgers, James T. 11) so rrescent St.

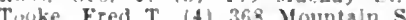

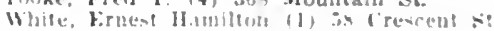
Toronto, Ont.

Istown, John l'plee (a, 3) a colleze Si.

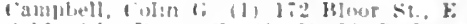
Cioldsmlth. Perry (f. $(1,3) 84$ Carlton st. Tones Siewbald $C$. (1) 67 Bloor SL W. Ickelves, llexander ll. (15) 193 libur Mchetrey

Reeve, Itichard t. (1, 4. i) 13 lilon st. F leyerson. Geo. A. Sirling (1) 66 (college St Whart, lodide i lifh] (3) 49 lirusienor. st Canada at Large

Hell, Benjamin C. (1) Brantord. Ont.

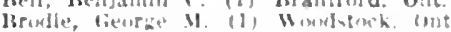

Irown. Wm. Harold (1) Filmonton. Alta.

Forster, Frederlok J. li. (1) Siratford, Out

lirant, Harty l. (t) Falls liew, Ont

WeJutioh. John H. (4) sit. Jahn, Xls.

Vortun, John l'. (I) Hamliton, Ine.

smlil, w Harrey (3) Winnlger. Man.

sutherland, Joseph fo (1) St. Catharines. Ont.

Watsun, Harry J. (1) Winnlpeg. Man.

\section{DERMATOLOGY AND UROLOGY}

\section{C-SOCIETIES}

NCMBRR OF MHMHELS, 4t,3

\section{American Association of Genito-Urinary} Surgeons.

2. American Dermatological Assnclation.

3. American Urological Association.

4. Boston Dermatological Club.

5. Boston-New England Branch of the American Urological Association.

6. Chicago Dermatological Society,

7. Chlcago Urological Society.

9. New York Dermatologioal Society.

10. New York-Manhattan Dermatological Society.

12. New York Society. American Urological Association.

13. Philadelohia Dermatological Society.

14. San Francisco-Section of Urology.

\section{ARKANSAS}

Hot Springs

Collinge, Howard $r$. (3) lugan-situart [B]!:

Collinga. S. 1'. (3) Dugan-Stuart Iblg. brennen, (: Travls (3) 30216 (entral Are. Laws. Wm. V. (3) Jugan-stuart Mlda.

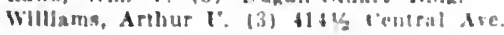

\section{CALIFORNIA}

Los Angeles

fanopell, Baloh R. (2) Hrockman Md:

bakln. Wirt H. (3) Los Ingerles Intevinent Bulg.

MacGowan. Granclle (3) liwner Mkly.

Newmark. Phllp (3) Marah sitroug Mdg
Roth yeon Jos. (i) Jrochman Bldz

Williams, Jalnh (3) Jos Angeles lnjestment IId

San Francisco

Mllerson. llarry kerelt (2) otn storktonst.

Inazet, Isouls (3. It) 760 Warket st.

culver, feorge Dewltt (2) 323 lieary st.

Falon, (ieo. Ho (3. It) 393 (ieary sit.

Fredlander Darld $(3,14)$ itt lirant swe.

ciross. Louls $(3,14)$ t5 kearny si

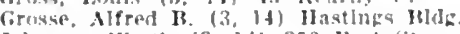

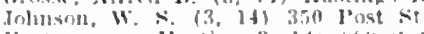

heoluszyner, Martin 13,14 , 149 sulter s

Meromnell, k. l: $(3,14)$ tot supter st.

Meyer. Henry $(3,14) 2+0$ Sitorktom st

Molony, Martin $(3,14) 209$ Post sit.

Uontgomery, bonglas Wm. (2) 323 Geary st

Horrow, Howard (2) 135 stockton Si

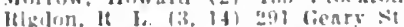

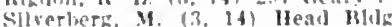

spencer. John iampledl (3) $13 \%$ stochton

sis.

Talt, f modles (14) Butler Mlale.

Vorkl, Vleter io, 13, 14) 38 lush st

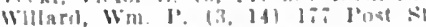

\section{State at Laroo}

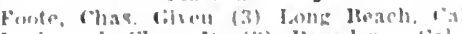

lowkwom!. "has Jo (:B) lensalenat, ial.

liplnle, liev. 1, (3) litklamd, ('al

\section{COLORADO}

Denver

Javis, Jolu It. (3) Merupullen Whe Bale, Wm II. (:) Metropullian Mils

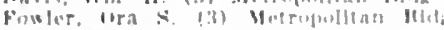

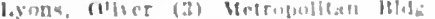

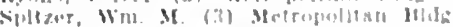

\section{CONNECTICUT}

Hartford

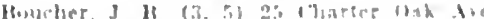

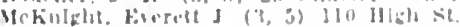

Smith, olser $\mathrm{C}$ (3. a) it Hlgh st.

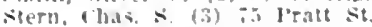
New Haven

learnes 16 \& (i) 103 York St

Lellls, krancis II. (3), 12) 296 columbus Are

\section{DISTRICT OF COLUMBIA}

\section{Washington}

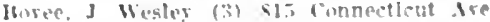

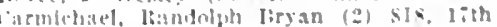
si

Finber, Harry $1(1,3)$ lans Masachuarts A10. 111

Fuller, Honer (f. (3) The Farragul

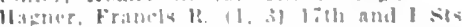

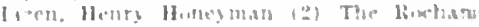

lienutu

king tormest $r$ (3) Hond nutio

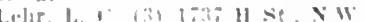

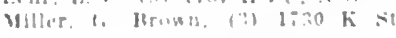

GEORGIA

A lianta

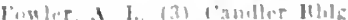

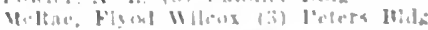

ILLINOIS

Chieago

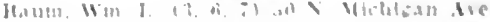

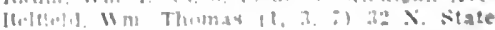

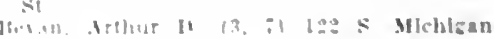

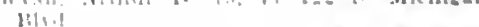

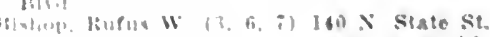
Heruerman J.culs W. (3, ;) 101 s. MIdht. hisn . Iin

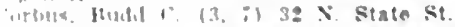

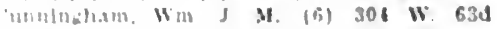

Fandpath. lianlet $>$ (3, :) 31 X. Stata st. 
Fisenstnedt, Jos. Spiro $(3$, 7) $32 \mathrm{x}$. State St.

Flschkln, Edw. A. $(3,6,7) 32$ x. State st. Friedrich, Louis 11. $(3, i) 318$ Center st. Frost, Horace Hird (3) $31 \mathrm{~N}$. State st. Cirasse, wanl. F. (3) $803 \mathrm{~W}$, Jiadison st. IIarris, Fred Gillette $(2,6) 104$ s. Michigan Are.

IIarris, Malcolm Ia S. $(3, \pi) 25$ E. Washington St.

llerbst, ltobt. Harry $(3$, i) $32 \mathrm{~N}$. State St. IIurlburt, Sherman Jtoger (6) $32 \mathrm{~N}$. State St Kollseher, Gustnve $(3,7) 108$ x. Sitate st Koli, Irvin s. (3, i) Marshall Field Tildg.

Kraus, Harry Adlams $(3, i)$ I08 $\mathbf{N}$. State st.

Kreissl, Fillep (3) $5 \mathrm{~N}$. Wahash Ave.

Kretschmer, Herman $\mathrm{H}$. $(3, \pi) 29 \mathrm{E}$. MadIson St.

Iespinasse, Victor D. $(3,6, \pi) 7 \mathrm{~W}$. Madison St.

Lieberthal, David $(3,6,7), 31 \mathrm{~N}$. State st. Lydston, Geo. Frank (3) $32 \mathrm{~N}$. State St.

Mackey, Artlur Norton (6) 3420 Sheffleld Are.

MacMartin, Duncan R. $(3$, i) 20 W. Jackson Blivi.

McClinton, Nelson F. $(3,7) 32$ x. State st. If Ewen, Krnest Lewis $(2,6) 25 \mathrm{E}$. Waslsington St.

Mckenna, Chas. M. $(3,7) 108 \mathrm{~N}$. State St. Mowrs, Albert E. $(3,7) 3505$ Indlana Ave. Ormsly, oliver S. $(2,3,6) 32 \mathrm{~N}$. State St. l'ardee, Lucius Crocker $(2,6) \quad 15 \mathrm{E}$. Washington st.

P'usey, William Allen $(2,6)$ T W. Madison St.

Quinn, Wm. A. (6) 122 S. Michigan Blyd.

logers, Danlel W. $(3, \tau) 2204$ S. Michigan Are.

Schmidt, Louls E. $(1,3,6,7) 5$ S. Wabash

Are.
Senn, Wm. N. $(3$, i) 25 E. Washington St.

Simpsen, F. E. (6) 59 E. Madison St.

Stlllians, Arthur Wm. (6) 7 W. Madison St

Welfeld, Joseph $(3,6) 209$ S. State St.

Zelsler, Joseph (2, 6) 32 N. Xichigan Ave.

Zurawsky, Kasimir A. $(3,7) 32 \mathrm{~N}$. State St. State at Large

Potthoff, Ernest W. (6) Oak Park, 11 .

\section{INDIANA}

Indianapolls

Brayton, Alembert Winthrop (2) Newton Claspool Bldg.

Chariton, Frederick (3) Hume-Mansur Bldg. Eastman, J. Rilus (3) 331 N. Delaware St. Er(man, Bernard (3) Newton Claypool Bldts. Hamer, Homer fr. (3) Hume-Nansur Bldg. IcCown. P. E. (3) Hume-Mansur Bldg.

Moore, H. A. (3) Hume-Mansur Bldg.

Wishard, W. N. $(1,3)$ Hume-Mansur Bldg. State at Large

Barnett, Chas. E. (3) Ft. Wayne, Ind. Walker, Edwin (3) Eranswille, Ind.

\section{KANSAS}

Trueheart, Marion (3) Sterling Kan.

\section{KENTUCKY}

Louisville

Abell, Irrin (3) Atherton Bldg.

Bloom, lsadore N. (3) Atherton Bldg.

Frank, Louis (3) Atherton Bldg.

Wathen. John R. (3) 526, 4th Are.

Weber, Harry C. (3) 501 St. Catherine St.

Windell, J. T. (3) 115 W. Jetferson st. State at Large

Wheeler, Carl L. (3) Lexington, Ky.

\section{LOUISIANA}

New Orleans

Chassaignac, Chas, L. (3) 211 Camp St.

nyer, Isadore (2) 124 Baronne St.

Nelken, Abe (3) 305 Baronne St.

\section{MAINE}

Portiand

Foster, B, B, $(3,5) 653 \mathrm{~A}$ Congress St.

Mitche11, Alfred, Jr. $(3,5) 65 i$ Congress St.

\section{MARYLAND}

Baltimere

Bevan. Chas. F. (1) 80 - Cathedral St.

Burnam, Curtis Field (3) 1418 Eutaw Pl.
Geraghty, Wohn T. (1) 330 N. Charles St. tilichrist, 'Thomas Casper (2) $330 \mathrm{~N}$. Charles Sit.

IItumer, Guy Leroy (3) 2305 st. Paul st. Keliy, IIoward Atwood (3) 1418 Eutaw 1 ' Llkes, sylvau II (3) 1134 linden Ave. Josenthal, Melvin S. (3) is N. lloward st Walker, lieo. (3) 1 E. Center St.

Wolf, W. 13. (3) 113 W. Franklin st. Young, 11. II. $(1,3)$ \$30 N. Charles St.

\section{MASSACHUSETTS} Boston

Allen, Gardner W. (3, 5) 419 Boylston St. Balch, Frunklin G. $(3,5) 279$ Clarendon st. Rurney, James D. $(1,3,5) 374$ Marlboro St. Binney, Horace $(1,3,5) 205$ Beacon St. Blake, John 13. $(3,5) 65 \%$ Bboylston St.

Bowen, John Templeton $(2,4) 14$ Marlboro St.

Brigts, Fred $(3,5) 31$ Massachusetts Are. Brown, Perey $\mathbf{E}$. $(3,5) 15 \%$ Newbury st. Burns, Fredk. Stanford $(2,4) \quad 237$ Marlborough $\mathrm{st}$.

Cabot, llugh (1, 3, 5) 87 Marlboro St. Chase, llenry II. $(3,5) 409$ Marlboro St. Cheever, David $(3,5) 20$ Hereford St.

Chute, Arthur L. (1, 3, 5) 350 Marlboro

Clark, Geo. O. $(3,5) 142$ Beacon St.

Codman, Ernest A. (3,5) 227 Beacon St.

Cotton, Frederie J. (3) 520 Commonwealth Are.

Crosbie, Arthur H. (5) 260 Clarendon St. Cunningham, John H., Jr. $(1,3,5) 46$ Goucester $\mathrm{St}$.

Davis, Lineoln $(3,5) 205$ Beacon St.

Harding, George Franklin $(2,4) 419$ Boylston St.

llowe, James Sullivan $(2,4) 437$ Marlboro St.

Jolunson, Frank M. $(3,5) 43$ Tremont St.

Lund, Fred B. $(3,5) 52 i$ Beacon St.

Mixter, ('has. G. (5) 180 Marlboro St.

oliver, Everard Lawrence (4) 362 Commonwealth Ave.

o'veil, lichard F. $(1,3,5) 379$ Beacon st. lerry, Henry J. $(3,5) 636$ Beacon St.

porter, (has. A. $(3,5) 254$ Beacon St.

Post, Abner (1, 2, 4) 16 Newbury St.
Quinby, W. C. $(3,45) 250$ ('omnonwealth Quinby
Ave.

Scudder, Chas. L. $(3,5) 209$ Beacon St.

Smith, Geo. G. (5) 309 Marlboro St.

Smith, Chas. Norton $(2,4) 437$ Marlboro St.

Tenney, Benj. (3, 5) 308 Marlboro St.

Thorndike, 'raul (1, 3, 5) 24 Marlboro St. Towle, Harrey P. (2, 4) 453 Marlboro St.

Watson, Francis S. $(1,3,5) 92$ Narlboro St. White, Charles James $(2,4) 259$ Marl-

White, James Clarke (2) 259 Marlboro St. Whitney, Chas. M. $(3,5) 591$ Tremont St. Young, E. B. $(3,5) 434$ Marlboro St.

\section{State at Large}

Peck, Roy H. (3, 5) Springfield, Mass.

Beal, IJoward W. $(3,5)$ Worcester, Mass.

\section{MICHIGAN}

Detroit

Biddle, Andrew Porter (2) J. IIenry Smith Bldg.

Manton, Walter Porter (3) 32 Adams Ave., W.

Potter, Geo. E. (3) 1491 Woodward Ave.

Robbins, Frederiek W. (3) 101 Fort St., W.

Varney, IIenry Rockwell (2) Washington

Arcade. State at Large

Wile, Udo Julius $(2,6)$ Ann Arbor, Mlch.

\section{MINNESOTA}

Minneapolis

Owre, Oscar (3) Masonic Temple.

Wright, Franklin R. (3) Donaldson Bldg. St. Paul

Foster, Burnside (2) Lowry Bldg.

Kelly, Wm. D. (3) Lowry Bldg.

State at Large

Braasch, W. F. (1,3) Pochester, Minn. MISSOURI

\section{Kansas City}

Block, Jacob (3) Argyle Bldg.

Hall, Frank J. (3) 1208 Wyandotte.
Mark, Eruest (a. (3) 3336 Coleman Rd. MeBride, Wm. L. (2) Rialto Bldg. Mecallum, Francls M. (3) Gloyd Bldg. l'orter, Allen L. (3) kialto Bldg.

\section{St. Joseph}

Elan, W. T. (3) Corby-Forsee Bldg.

1'aul, Thomas 11. (3) 9 th and Francis Sts.

$$
\text { St. Louis }
$$

Hochm, J. 1., (3) $717 \mathrm{~W}$, 8th St.

lloogher, 1. leland (3) Central National Bank lidg.

Burford, ('yrus E. (3) Century Bldg.

Carson, Norman B. (1) Ilumboldt Bldg.

Caulk, John R. (1) Humboldt Bldg.

Engman, Martin Feeney (2) IIumboldt Bldg.

Gradwohl, tutherford 3. H. (3) $803 \mathrm{x}$, Garrison Are.

Grindon, Joseph (2) 3894 Washington Blvd. Ilopkins, Thomas A. (3) Century Bldg. Jacobson, Henry (3) Central Natlonal Bank Bldg.

Johnson, H. McC. $(1,3) 5567$ Waterman Are.

Kane, R. Emmett (3) Ilumboldt Bldg.

kiurtzeborn, Edwin E. (3) 4900 MePherson Are.

Lewis, Bransforl $(1,3)$ Century Bldg.

Lyon, Hartwell N. (3) Humboldt Bldg.

Mook, Willam 11. (2) 537 N. Grand Are.

Mudd, Harvey G. (1) Humboldt Bldg.

Phillips, Geo. M. (3) Commercial Bldg.

liavold, Amand N. (3) Chenteal Bldg.

Seherck, Henry Joseph (3) Century Bldg.

Suggett, Orril LeGrand (3) Metropolitan Bldg.

Westerman, Clarence I. (3) Syndicate Bldg. Wolf, Alexander S. (3) Century Bldg.

\section{NEBRASKA}

Linooln

Angle, Edw. J. (3) Funke Bldg.

OMAHA

Schalek, Alfred $(2,6)$ Brandels Theatre Bldg. Stokes, Arthur Charles (3) Brandeis Bldg. Summers, John F. (3) Brandels Bldg.

Sumney, Herbert Clayton (3) W.0.W. Bldg.

\section{NEW JERSEY}

Newark

Corrigan, Geo. F. $(3,12) 344$ La Fayette St. O'Crowley, C. R. $(3,12) 12$ Lombardy St. F'atton, J. Allen (3) Med. Dept. Prudentlal Life Ins. Co.

Ward, William J. (12) 20 Falrmount Ave.

\section{NEW YORK}

Brooklyn

Beers, Nathan T., Jr. (3) 97 Gates Ave. Harris, Burton S. $(3,12) 475$ Greene Ave. Narsh, Edward H. (3, 12) 448 Ninth St. Morton, Henry H. $(1,3,12) 32$ Schermerhorn St.

Nucklow, A. E. $(3,12) 300$ Sumner Are.

Muren, Geo. Morgan $(3,12) 56$ Livlngston St.

Pentlarge, Victor H. (12) 380 Sterling Pl. Pileher, Paul M. $(3,12) 145$ Gates Ave.

Rathbun, Nathaniel P. (12) 442 Greene Ave. Read, sturdirant $(3,12) 135$ Clinton St. Sherwell, Samuel $(2,9) 33$ Schermerhorn St. Winfleld, James MacFarlane $(2,9) 47$ Halsey St.

\section{Buffalo}

Carpenter, Thos. B. (3) 533 Franklln St. Gardner, James A. (3) Electrlc Bldg. Wende, Grover William (2) 471 Delaware Ave.

Wheeler, Darid F. (3) 519 Franklin St. Wilson, Neison W. (3) 49 Niagara St.

\section{New York City}

Abrahams, Robert (10) 25i W. 88th St. Alexion, Alexander $(3,12) 157$ E. 27 th $\mathrm{St}$. Alvarez, Jos. R. $(3,12) 46$ E. 92 d St. Asch, Joseph J. (12) 780 Lexington Ave. Ayres, Winfield $(3,12) 616$.Jadison Are Bangs, L. Bolton $(3,12) 40$ E. 41st St. Barringer, Benj. S. (1, 3, 12) 109 E. 34th. St.

Pechet, P. E. (10) 40 E. 4lst St

Bedell, Chas. E. $(3,12) 634$ W. 135th St.

Begg, Colin L. $(3,12) 131$ E. 17th St.

Bierhoff, Frederick $(3,12) 10$ W. 61st St.

Bissell, Jos. B. (3, 12) 46 W. 55th St.

Blasuccl, Ernesto $(3,12) 679$ Lexington Are. 
Blelman, Asher (10) 121 E. 92d st-

Boldt. liermann J. (3) 39 E. 61 st St.

Brand, Adolph 13,12$)$ is 31 Madlson Are.

Brewer, Geo. E. (1) 16 F. 6th st.

Hronson, Bdward Hennet $(2.9) 10$ W. 49th St

Brouner, Walter $B,(3,12) 2 i \mathrm{~W}$, gth $\mathrm{st}$.

Buerser, Leo (3, 12) (1) E. Alst st.

Bugbee, llenry (i. $(3,12)$ i $\mathrm{E}$. flst st.

Bulkley, Luelus IDuncan $(2,9) 531$ Madison Are.

Carney. Thos. J. (3) $306 \mathrm{~W}, 103 \mathrm{~d}$ S

Chetwood, Charles H. (1, 3, 12) 25 l'ark Are.

Clark, J. Bayard (1, 3, 12) 616 Madlson

Are.

Creamer, Joseph M., Jr. (12) 234. Mroadway.

Dade, Chas. T. (9) $25 \mathrm{~W}$, 30 th st

Delacrolx. Arthur C. (3) statlon J, Rox 2 Dolphin, Benj. E. $(3,12) 430$ E. I1hith st Doyno, Gennaro $(3,12) 325 \mathrm{k}$. Jith St

Echeverria, Martin J. $(1,3,12) 60 \mathrm{~W}$, ilst St.

Edgerton, Francls Cruger $(1,12) 19 \mathrm{~W}$. 50th

Et. Et, Georze Thompson (2, 9) 128 F. 3ith St.

Erdmann, John F. $(3,12) 60 \mathrm{~W}$. 52d st.

Ewald, Louls A. $(3,12)$ 48 E. sith St.

Fleming, Henry C. (12) 2030 Broadway.

Fordyce, John Addlsotn $(2,9)$ \& W: Tith St.

Fox, feorge Henry (2, 9) 616 Madison Are.

Fox, Howard $(2,9,10) 616$ Madison Are.

Fuller, Eugene (1, 3, 12) 252 Lexington Are.

Furniss, Henry D. $(3,12) 373$ West rins Are.

Gallant, Alhert E. $(3,12) 70$ E. $66 \mathrm{th}$ st. Gardner, Faxton E. (1) 616 Madison Ave. Gelrlnzer, Darld (12) 1186 Madlson Are.

Geyser, A. C. (10) 231 W. $96 \mathrm{th}_{\mathrm{h}} \mathrm{st}$.

Goldenberg, Herman (2, 3, 12) Madison Ave and 6.3d St.

Gotthell, Willam S. $(2,10) 154$ W. Tith $S$

Gray, Herbert L. $(3,12) 238 \mathrm{~W}$. 22d St

Greene, Kobt H. $(1,3,12)$ is F. $56 \mathrm{th}$ St. Gulteras, Ramon $(1,3,12) 80$ Madison Are. Hall, Robt. W. $(3,12) 118$ E. 2ith st. Harrigan, Anthony llart $(3,12) 249 \mathrm{~W}, 102 \mathrm{~d}$ St.

Hatch, J. Jefingwell $(3,12) 30 \mathrm{~W}$. 51st st. Hawkes, Forbes $(3,12)$ 12t E. 6inth St. IIayden. James Raynor (1, 3, 12) I21 W. 55 th $\mathrm{St}$.

Heltzmann, Iouis $(3,12) 110 \mathrm{~W}$. isth st.

Holder, Oscar H. (9) 301 W. $120 \mathrm{th}$ st.

Huhner, Max $(3,12) 320$ central 1'ark W.

II sman, Abraham (12) 40 E. 41 st St.

Jackson, (jeorge Thomas (2, y) 11 k. 48th St.

Johnston, James C. $(2,9) 115$ E. 56th St. Kemp, lobt. Coleman $(3,12) 103$ E. 5ith

Keses, Edward L.. Jr. (1, 3, 12) 109 E. 34t। St.

Kllbane, Fdwand F, (12) $104 \mathrm{~W}$, ilst st.

Kinch. Chas. A. (10) if W. 69th st.

Kingalury, Jernme $(2, y, 10) 32 \mathrm{w}$, 8 th st.

Lee Edw. Wallace $(3,12) 616$ Madison dve. Leriseur, Frederlck Jacob (2) 40 E. 83311 si. Hackee, Georke Miller (2, 3, 9, 10, 12) 5k W. 58 th st.

Mackae, Thomas (12) $221 \mathrm{~W}$. 73 s st.

Mason, Frederick S. (3, 12) 12, tith Nve.

Meliowan. John $r$. (3) 40 F. 41 st st.

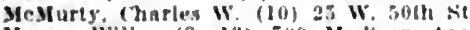

Meyer, Wills, (3, 12) i00 Madison ive

yonse-Lesaer, A, $(3,12)$ 16,4 W. i2d st.

Nordeman, Herman $r$, 13,12$) 6,5$, 45h st.

Ochs, Bens. F. (10) 310 Convent ive

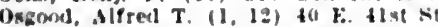
Ouimann, Ludwig (10) 1239 Marlison Are. Parounactan, Y. 18. (10) 133 F. 29els st.

Pedersen, James (i, 3, 12) 20 k tlst st

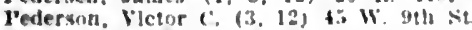

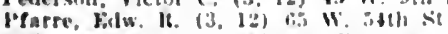

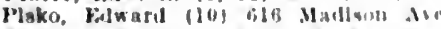

Pollizer, sikmund (2) 31 k. Goth si.

Jorter, W. II, $(3,12)$ (t) W. 834 sit.

Putnati, $(C, 1$. L. (12) 121 k. 3xith st

Reynolds, Walter $s .(3,12) 132 \mathrm{~W}$. G3d st.

Hoblnson, Andrew ituse $(2,9) 159 \mathrm{~W}$. tsth st.

Hobluson, Wm. J. 13, 12) I: Me Morris l'ark.
Sntwutein. I) L. (10) 324 W sith st Schaplra, Saml. Willan (3,12) I8ti Madl. $\sin$ Are.

Schwarte. IIans Jorgen $(2,9)$ 106 k. 30th st.

Seay. Cornellus J. $(3,12) 111 \mathrm{~W} .82 d \mathrm{st}$ sherman, Abram dincoln (12) 561 W, Isoth St.

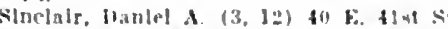

Sinlth, Brrest Filsworth (3, 12) 50 k. H1st St. : ties. 35 E.

sinith, Freslerlek W. (12) to $x$. tlat st sinth, staford $B,(12)$ zo: W. Elst st Siquler, J. Bentles, Jr. $(1,3,12)$ t9 k. tyth

stern, llelnrtch $(3,12) 250 \mathrm{~W}$, $73 \mathrm{~d}$ st

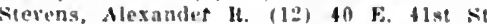
Stewart, Douglas 11. 13, 12) 128 W. stith st. swinburne, Gen, kunwles $(1,3,12$ ) 64 Stith st.

Tllton. Jenjamln T. (12) If F. 58 th St Townsend, Terry $\mathrm{M} .(3,12) 171 \mathrm{~W}$. ist st Trimble, Willlam B. $(2,9) 24$ F. Esth st Volentine Jullus J $(3,12) 171$ iv ilyt Van der Poel, John $(1,3,12) 56 \mathrm{~W}$. 52d st Ware, Martlu W. F. $(3,12)$ 2i E. 81 st St. Wels, Ludwig (3, 10, 12) t2 W. 91st st Whitehouse, llenry lloward (2.9) 38 E. t9th st.

Whithng, James R. Jr. (3) 1; F. 38th st. Whe, Fred $(3,10,12)$ 828, Lexlnuton Are. Wirren, fieo. W. $(3,12)$ 117 E. 62d St. Wolbarst. $A .(3,12) 113$ E. 19 th St. Wyeth, Geo. A. (3, 12) 30 K. 42d St.

\section{State at Large}

Blanchard, Geo, W. $(3,12)$ Highland Falls, N. Y.

Mount. L. B. (10) Mllany, X.Y

peck, Geo. A. (3, 12) New Rochelle, N. I

Held, Wm. B. (3) Rome, N.Y.

Rugkles, F. Wod $(1,2,3)$ Bochester, N.X. Snyder, Win. H. (12) Newburgh, X.Y.

\section{NORTH CAROLINA}

IcIntyre, Henry B. (1:) Fh Caswell, N.C. OHIO

\section{Cincinnati}

Heldingsfeld, M. I. (3) 19 W. ith St. Rarogli. Angustus $(2,3) 5$ Garfield 13 Micketts. Benjamin Merrill (3) th and Broadway.

Smlth, E. Otls (3) 19 W: ith St.

Tanter, Elmore B. (3) 19 W, ith st.

\section{Cleveland}

Corlett, Wullam Thomas (2) 3618 suclld Are.

wower, Wm. Ealgar (1,3) 6912 Euclid Ave. Sanford, Henry I. (3) Osborn Bldg.

\section{Toledo}

Farpster, ('has. M. (3) inj Madlson Aro Jacubson, Jullus if. (3) $23 !$ Michlgan st. Keller, John (i. (3) Wayne Bldse.

Mclionlgle, Murray B. (3) 2a7 Mirhlgan st Walker, Hobert s. (3) Nicholas Blds.

$$
\text { State at Laroe }
$$

Foumans, Thomas G. (3) Columbus, 0

\section{OREGON}

\section{Portland}

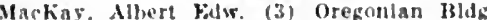
Itchay II. F (3) Eilers IBld

Hand, Uariul il. (3) Morgan Hud

Whitesulde, Geo. shattuek $(1,3)$ Journal inlih.

\section{PENNSYLVANIA}

Phlladelphia

Munney, 'has. W. (3) 111 . Suruce st Hrown. Maurlee (13) bes sprure st. (hrlvelan. Hilary 11 (1) 3321 sprure st. Barls, (has. S. (13) 1931 spruce se

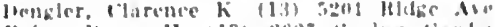

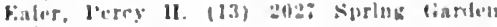

Fluck bolwarel 13 (13) 11:00 litrares

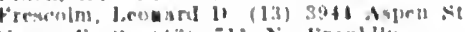

bans, fo (1) ill $x$ r rankllu

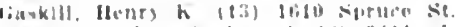

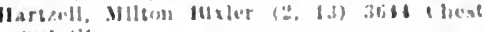
sist sit.

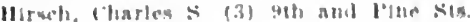

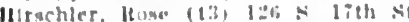

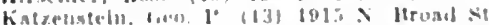

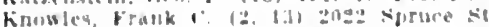
tarux. Iftram 16. (3) Isto Walnut st

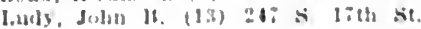

Martin, Fitw. (1) 1:0, loneust st

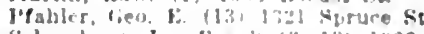
Schamliern. Jay Frank (:, 13) $19: 2$ Spruce St.

siter, billuh 11 (1) lin of hiltenhouse so.

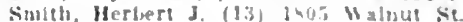
Stelwagon, llenry Welghtman (2, 13) 163. sipruice sit.

stout, bimanuel d (13) 1401 oxford st. sitrlckler, Nlbert (13) $03 \%$ tilrarl Are. Ihle, Nlexander A. (1) 1331 thestrout st Walker. Warren 16 . (13) le.32 spruce si. Wroul, Alfterl e. (1) 203: Wabuut si Zulick, llowell s. (13) 2115 W. Frie Are

\section{Pittsburoh}

Burt James (' (3) Weasinghouse bldte blsifue, Thomas I. (3) Jenklng Blup. IIartung, Frerlerlck A. (3) Keenan HIdz. Hawklny, Jnhu A. (3) Jenklns Arcade. Holliday, fien, $A$. (3) Jenkłns Bldg. Sitewart, Jibeson (3) Keenan Mlde.

\section{State at Large}

Corson, Edward F. (13) ('ynxyd, Pa.

\section{RHODE ISLAND}

Providence

Cooke Chas, O. (5) 251 Broad St. Fifrord. Nathanlel H. $(3,5) 13$ fireen St. IInye. Hendy J. (5) 194 Hroad St Jones, Arthur T. (5) 214 lhenefle st. Keefe. John W. (3. 5) 259 Beneat St. Kingtnan, Luclus C. (5) 212 Benefit st l'lts, Ilerman C. $(3,3) 210$ Benent SL Smlth, Fugar R. (3.5) 68 Rrown st. Terry, Herbert $(3,5)$; Broad si

\section{TENNESSEE}

Memphis

Haase, Marcus (a) Memphls Trust Blde lendergrast, Lawrence II. (3) Memphis Trust Bldg.

\section{Nashville}

Gleun, Wm. F. (1) Flrst Natl. Bank Bld: TEXAS

Tamieson. Wm. Ross (3) Fl Paso, Tex. Uctilasson, Iroy J. (3) Galreston, Tex Shelmire, J. R, (3) Hallas, Tex.

Walih, Ferdinand C. (3) San Antonlo. Tex.

\section{VERMONT}

Townsend, Wm. Warren $(3,5)$ Rutiand, $\mathrm{VL}$ VIRGINIA

Benton, Frederlck I. (12) Norfolk, Va lostier, 1. 1. (3) Ithehmond, Va Bryan. Bobert $(2$ (3) Hehmond. Va. Hirschler, Javid lee (3) Norfulk. Va.

\section{WASHINGTON}

Fotthrop, Fulward H. (3) Spokane, Wash. Peterkin, liuy s. (a) Neattle, Wash. Smith, Jacob s, (3) Rellingham, Wash.

WEST VIRGINIA Wheeling

Hupd, Frank J. (i) bl, Itth st

\section{WISCONSIN}

Milwaukee

Hact flarence $A$ (b) 198 Wimonsin SL Hlekford, lonuls i" 13) fanker Hids

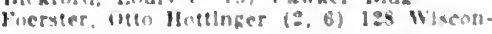
sin si.

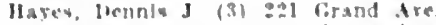
Jenner, Whers li (3) 614 lilusuker st. Thlenlaus, Clas. 1). (3) sisj ('ambridge Are.

State at Large

Veger, introal Mt. (3, la) Milladure, Wh.

\section{CANADA}

Montreal. Que.

l.anterman. Maxwell (3) 120 l'sel si.

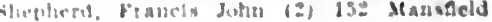

Toronto. Ont

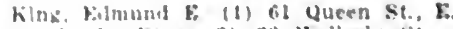

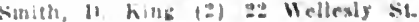

\section{Canada at Large}

Pletcluer if ll (3) Winneber, Yan. biculon, fien, S. (3) Vancourer, B.C. 


\section{PEDIATRICS AND INTERNAL, MEDICINE}

\section{D-SOCIETIES}

NUMBFils of MrinBlis, 591

1. American Pediatric Soclety.

2. Chieago Pediatrie Society.

3. New England Pediatrie Soeiety.

4. Philadelphia Pediatrie Society.

5. St. Louis Pediatrie Society.

6. Association of American Physicians.

\section{CALIFORNIA}

San Franciseo

Brown, Philip K. (6) 350 l'ust st.

lucas, Wm. Filner (I, 3) Medlcal Dept. Enly. of Cal.

Mofltt, Herbert C. (6) 240 stockton sit

l'orter, Langley (I) 240 sitockton sit. State at Large

Soper, Alexander (.., Ir. (2) Fresno, Cal. COLORADO

Sewatl, Henry (6) Denrer, Colo.

\section{CONNECTICUT}

New Haven

Biumer, Geo. (6) 64 Trumbull st.

Jinde, Jos. 1. (3) It3 lork sit.

Steele, IT. M. (3) 226 Church st.

Tilestom, Wilder $(1,6)+24$ Temple St. State at Large

Goodenough., Elw. W. (3) Waterbury, Conn. DELAWARE

Wales, Josejh I'. (4) Wilnington, Del. DISTRICT OF COLUMBIA Washington

Acker, George $y$ (I) 913 , I6th st

Adams, samuel S. $(1,6)$ Is0I Connecticut Are., N.W.

Anderson, John F. (6) 25 th and E Sts., N.W. Bolton, B. Nieade (6) $1523 \mathrm{~L}$ St., N.W. linyoun, J. J. (6) 1423 Clifton St., N.W
Kober, Gco. I. (6) 1819 Q St., N.W.

\section{ILLINOIS}

\section{Chicago}

Abt, Isaac Arthur (1,2) 104 S. Michigan Are.

Allen, Thos. (i. (2) 5721 Kellwood Are.

Allin, Frank W. (2) 3218 Jackson Blrd.

nuberg, Samuel (2) Children's Hemorial Hospital

Babcock, Robt. I1. (6) 30 x. Michigan Blrd. Beifield, Albert II. (2) 104 S. Michigan Are. Belknap, Frelk. W. (2) I203 N. State St. Billings, Frank (6) I22 S. Michigan Ave. Black, Kobt. Alfred (2) Del l'rado Hotel. Bowes, Leon M. (2) $603 \mathrm{I}$ Circle Are. Brennemann, Joseph (2) 31 N. State St. Britton, James A. (2) S1s Gilpin Pl.

Butler, W'm. Joseph (2) TW Madison St. Campbell, Grace H. (2) '330I W'ashington Campbell.

Capps, Jos. A. (6) 122 S. Michigan Ave

Chancellor, Phillp S. (2) 2732 Pine Grore

Are.

Cheney, Henry W. (2) 1230 E. 63d St.

Cliurchill, Frank Spooner $(1,2) 1259 \mathrm{~N}$.

State St.

Conner, Eispeth YI. (2) 742 W. Congress St.

Cotton, Alfred C. (I, 2) 3218 W. Jackson Blrd.

Curtis, W. Pingree (2) 3265 Cottage Grore Are.

Davis, Effa V. (2) 32 N. State St.

Dennis, Geo. J. (2) 108 N. State St.

Dodson, John iI. (2) 5s06 Blackstone Are.

Edwards, Arthur R. (6) 104 S. Michigan Are.

French, Wilbur If. (2) $395 \mathrm{~s}$ W. 16th St,

(iill, Jolin J. (2) 5708 Harper Are.

Gowen. (iuy A. (2) 501 w. 26th St.

Grulee, Clifford G. (2) 122 S. Michigan Ave IIelmholz, Henry F. (2) 104 S. Jlichigan

Are. Hess, Julius II. (2) 5501 Prairie Ave. Jampolis, Mark (2) $106 \mathrm{~S}$. Michigan Are. Johnstone, Mary M. S. (2) 1703 W. Jackson Blvi. lirost, Hoht. A. (2) 300 E. 6lst st. hackner, firnest (2) $31 \mathrm{x}$. Slate St. Lapham, Anna Ross (2) 755 Bowen Are. Malkin, Max (2) $2822,121 \mathrm{~h}$ St

Merril, Julia 11. (2) 3012 Nortl Ave. Mlchael, May (2) 32 N. State st.

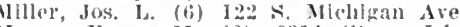
Moore, bimma M. (2) 6314 Stony Island Are.

Porter, John L. (2) 7 W. Madison St. f'reble, Roht. 13. (6) $30 \mathrm{~N}$, Michigan Are. Quinlan. Win. W. (2) 29 Madison St. liogers, Dant. W. (2) 2204 Mlthlgan Ave. Schram, David L (2) $31 \mathrm{x}$ state st.

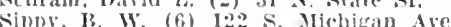

Wade Clias. (6) 122 . Wrikan Are. Walker, Saml. J, (2) 125 E. Chicago Are. Walls, Frank X. (2) 31 N. State St. Weaver, Geo. II. (6) 1745 W. Harrison St. Wells, H. G. (6) Cniversity of chicago. Young, Josephime $\mathbf{k}$. (2) $\mathbf{i}$ W. Madison St. State at Large

Balderston, S. V. (2) Kranston, 111. lioler, Albert iI. (2) Erinston, lil. Van Derslice. J. W. (2) Oak Park, Ill. West, John (C. (2) Batavla. III.

\section{INDIANA}

Boud, Chas, S. (6) Richmond, Ind.

\section{LOUISIANA}

New Orleans

Butterworth. Wm. W. (I) Maison Blanche Blder.

\section{MAINE}

\section{Portland}

Welster, Fred. I' (3) Y.M.C.A. Bldg. Welch, F. J. (3) 698 Congress St. State at Large

Stubbs, Richard II. (3) Augusta, Me.

MARYLAND

\section{Baltimore}

Abel, Jolnn J. (6) Roland Park Branch. Barker, L. F. (6) 1035 N. Calvert St. Borge, Thos. R. (6) 21 W. Chase st. Boges, Thos. R. (6) 21 W. Clase Friedienwald, Juhus (6) $1013 \mathrm{~N}$. Cliarles St. Futcher, Thos. B. (6) 23 W. Franklin St. IIowland, John (1, 6) Johns Hopkins Hospital.

Knox, J. I. M. (1) 804 Cathedral St. Meyer, Adolf (6) Johns Hopkins Hospital. Ruhräl, John (1) 1 I E. Chase St.

Thayer, W. S. (6) 406 Cathedral St.

Welch, Wni. II. (6) 807 St. Paul St.

\section{MASSACHUSETTS}

\section{Boston}

Adans, Zabdiel B. (3) I66 Newbury St. Arkin, Jouis (3) 366 Commonwealth Are. Arms, Burdett L. (3) Mass. Institute of Teclinolony.

Blakeley, David N. (3) 53 Monmouth St. Boutwell, Horace K. (3) 416 Marlboro St. Bowditeh, Henry 1. (1, 3) 416 Marlboro st. Broughton, Arthur (3) I0 Roanoke Are. Broughton, Arthur N. (3) T Roanoke A Brown, Percy Emerson (3) 155 Newbury St. Buckingham, F. M. (3) 342 Marlboro St. Bullard, Wm. N. (3) 89 Marlboro St. Cabot, R. C. (6) 1 Marlborough St.
Christian, Henry A. (6) Francis St. and Inuntington Ave

Coriat, Isadore H. (3) 416 Marlboro St.

Cones, Win. Pearce (3) 31 Massachusetts Are.

Craigill, George A. (3) 18 Hereford St. Cronin, Michael J. (3) 520 Beacon St. De Normandie, Robert L. (3) 355 Marlboro

Dunn, Charles Hunter (1, 3) 178 Marlboro St.

Earl, George H. (3) 160 Longwood Are. Edsall, David L. ( 1,6$) 80$ Marlboro St. Ely, Theodore W. (3) 374 Marlboro St. Emerson, Win. R. P. (3) 657 Boylston St. Emmons, Artate Rd. Ernst, Harold C. (6) 240 Longwood Are. Tairbanks, Arthur W. (3) 591 Beacon St. Fairbanks, Arthur W. (3) 591 Beacon St. Fitz, Reginald H. (6) 18 Arlington st.
Floyd, Cleaveland (3) 1398 Beacon St. Frothingliam, ('hanuimg, Jr. (3) 5 I Hereford St.

IIohart, Mary F. (3) 657 Moylston St. IIoward, Arthur A. (3) 416 Marlhoro st. Iowell, Wliliam W. (3) 279 ('larendon $\mathrm{St}$ Jackson, llenry (6) 380 Marlboro st. Jackson, James M. (3) 230 Bearon St. Joslin, E. I'. (6) S1 laty state Itol. Kelly, Wm. bugan (3) $5 i$ Hancock St. Kimpton, Arthur If. (3) 59 Ashford st. Ladld, Maynard (1) 270 clarcudon $S t$

Larrabee, Kalpl (C. (3) 520 Commonweallt Are.

Locke, Elwin A. (6) 311 Beacon St. l.ord, Fredk. T. (6) 305 Beacon St. Maltory, F. B. (6) Harvard Medlcal School. Jlason, Nathandet is. (3) 485 Beacon St. Merrick, ltobegt Michael (3) I8 Mt. Ida Rd. Mixter, (has. (i. (3) 180 Marlboro St. Morse, John Lovett (I, 3, G) T0 Bay State Rd.

Nurphy, Tlmothy J. (3) 372 Dudley St. I'alfrey, Francis W. (3) 80 Marlboro St. Parker, Willard s. (3) 355 Marlboro st. l'earl, Samuel M. (3) I27 Chambers St. I'erey, Karlton G. (3) 8 Gloucester St. Ifafr, Franz (6) Mlarvard Medical School. Powers, Geo. H., Jr. (3) 298 Marlboro St. I'ralno, Gaetano (3) 159 Harrlson Ave. I'ratt, Jos. II. (6) 317 Mariboro St. l'rescott, Wm. II. (3) 28 Court Square. Prince, Morton (6) 458 Beacon st.

Putuam, Charles 1 '. (I, 3) 63 Marlboro St. Putnam, James J. (6) 106 Marlboro St. Rhea, Lawrence J. (3) I'eter Bent Brigham Hospital.

Richardson, Mark W. (6) State House Risley, Edw. H. (3) 527 Beacon St. Robbins, IVm. B. (3) 356 Marlboro St. Rosenau, M. J. (6) Harrard Medical School. Rothblatt, Ifarry L. (3) 39 W. Cedar St. Sadler, Roy A. (3) 1750 Washington St. scudder, Charles 1. (3) 209 Beacon St. sears, Geo. G. (6) 426 Beacon St. Sisson, Warren R. (3) F'eter Bent Brigham Hospital.

Snith, Richard M. (3) 329 Beacon St. Smitl, Theobald (6) Harvard Medical School.

Strong, Richard P. (6) Harvard University. Swain, Howard T. (3) 226 Commonwealth Are.

Swift, Edith Hale (3) 110 Bay State Rd. Swift, Walter B. (3) 110 Bay State Rd. Sylvester, Charles P. (3) 879 Beacon St. Talbot, Fritz B. (1, 3) 311 Beacon St. Thomas, John Jenks (3) 88 Bay State Rd. Torbert, James R. (3) 252 Marlboro St. Townsend, Charles W. $(1,3)$ T6 Marlboro St. Vickery, Herman F. (6) 263 Beacon St. Vincent, Beth (3) 295 Beacon St.

Wentworth, A. H. (I, 3) 352 Marlboro St. Wentworth, Mark H. (3) 86 Bay State Rd. Williams, Francis H. (6) 505 Beacon St. Williams, Harold (I) 528 Beacon St.

Withington, Chas. F. (6) 35 Bay State Rd. Wylie, Eugene C. (3) 556 Washington St.

\section{State at Large}

Bancroft, Edw. E. (3) Wellesley, Mass. Bancroft, George A. (3) Natick, Mass. Barker, Frank J. (3) Concord, Mass Barron, E. W. (3) Malden, Mass. Bixby, oliver E. (3) Lynn, Mass. Braley, Henry H. (3) Concord, Mass. Butler, Wm. H. (3) Fall Rỉer, Mass. Cliampion, II errill E. (3) Arlington, Mass. Chandler, Norman F. (3) Medford, Mass. Crandell, Arthur R. (3) Taunton, Mass. Curry, E. F. (3) Fall River, Mass. Demuison, A. S. (3) Lynn, Mass. Denny, Francis P. (3) Brookline, Mass. Dervin, I. J. (3) Somerville, Mass. Donoran, S. E. (3) New Bedford, Mass. Eastman, Alexander C. (3) Springfleld, Mass. Eustîs, Richard S. (3) Cambridge, Mass. Field, Henry M. (3) Norwood, Mass. Fisher, Irving J. (3) West Nerrton, Mass. Gale, Harold A. (3) W'inchester, Mass. Gifford, John H. (3) Fall River, Mass. Gilbert, Louis iv. (3) Brookline, Mass. Handy, Harry T. (3) Scituate Center, Mass. Haskell, Nelson C. (3) Amherst, Mass. 
Hastings, Rotert W. (3) Mroubline, Mass. Holmes, May 5 (3) Worcester, Mass. Houghton. S. A. (3) Ifroukline, Mast. Junt. Rejal (b) Mrenkline, Mass.

IJunt, Wm. O. (3) Newtonville, Mass.

Johnson. ErIc St. J. (3) Niew hevforl. Mass.

Jouett, Fred R. (3) Cambridge, Mass.

Keerer. Ilenry Floyd (3) Iuburndale, Mass.

Kelly, Mlchael (3) rall hiver, Mass.

K'lng. Geo. C (3) Fall Rirer, Mass.

Kite. Walter $C_{\text {( }}$ (3) MHlinn, Jass.

Lane, Walter A. (3) Mttion, Mass

Longstreth, Morris (i) inmbridize, Mass.

Maugan, J. J. (3) J.ynn, Mass.

Marrell. Mary W. (3) Fali River. Mass.

May, Ceorte $\mathbf{E}$ (3) Newfon center. Mass.

Jickibben, Wm. Watsm (3) Worcester.

Mass.

Miller, Lester C. (3) Worcester, Mass.

Mmlet, Charles s. (3) Mrockton, Maxs.

Moore. J. Herbert (3) Hrookllne, Mass.

Percy, Darld T. (3) Arlington, Mass.

Percy, Fred B. (3) Brookline, lias

Pllsbury. W. W. (3) Newburs port, IJass.

Pratt, Chas A. (3) New Bedford. Mlass.

Spaulding, Edith K. (3) Suuth Framingtam,

Mass.

Stlokney, bawln P. (3) Mrlington, Mass.

Sylrester, 1'. 11. (3) Xewion 'enter, Mass.

Torres, John 1". (ii) Atudover. Man.

Webs, llarold It. (3) Irlington, Mass.

Wentwoth, Carollne Y. (3) Sewton Highlands. Mass.

Withlngton, Aifreda B. (3) IPlttifled, Mass.

Worthington, Arthur if. (3) Dethatm. Mass.

Young, James Herbert (3) Newton, Mass.

\section{MICHIGAN}

Cowle, Darid Murray (1) Inn Irbur, Mich.

Ifewlet, Albion (6) Ann Arturs, Mich

Jennlags, Charles Godwin (1) Detrult. Mich.

Nory, F. (f. (6) Aun Arthor, Mleh.

Vauzhan, Victor $C$. (6) Ann Arbor, Mich.

Warthin, Aldred S. (6) Ann Arbor, Mleh.

\section{MINNESOTA}

Minneapolis

Schultz, fred Wm.. (2) Monaldson Blds.

Sedgwlek, Julius $1 ;.(1,2)$ syndicate Bldg.

State at Large

Greene, Chas. L. (6) St. laul, Minn.

Wisson, Louls It. (6) Itochester, ininu.

\section{MISSOURI}

\section{St. Louis}

Altirecht, F. If. (5) Ilumboldt Mldg

Barker, Wm. S. (5) $3 \times 55$ Delmar lisid

Bassett, Sam T. (5) 5599 Etzet Ave.

Behrens, L. H. (5) Tlmes Bilda.

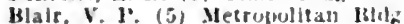

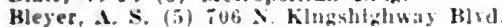

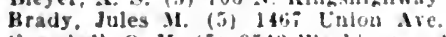

Campbell, O H. (5) $35 t 2$ Washangton Are.

Chapman, Henry $x$ (5) 3814 Washington Are.

Dock, lieo. (क) 1806 bacunt ist

Plschel. W. E. (6) llumboldt lide

Gordon, Prank ‥ (5) Lister Blag.

Hemjelmans, Theodure $\because$ (5) Grind Ave and ollve st.

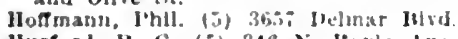

llurford, r. (5. (5) $345 \mathrm{x}$. liosle ive

kourl. M. F. (I) Navarre Midh.

loesy, daron (5) Hater 1Bld:

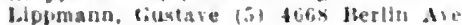

loeb. Ley (b) Barmard skin and laueer Ilospital

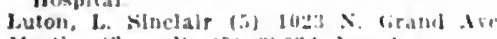
Martin, Chas. 1* (5) 3903.1 jece Ne.

Murphy, Fired T. (3) Washlugtan Pntrersity

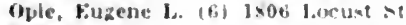

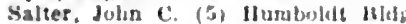

Saundera, E. W, $(1,5)$ Llater b/d"

Tooker, Charles W, Jr. (5) Merromblat islos:

Tuttle. Ceorge 31. (i) 401: Marsland Aro

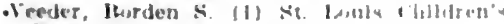
Is campitial.

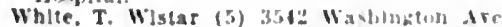

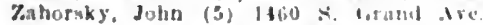
Stale at Large

clemens, Jancs It. (3) (Tayton, MW.

\section{NEBRASKA}

\section{Omaha}

McClanahan. Haery M. (1) Henndels Hug

\section{NEW HAMPSHIRE}

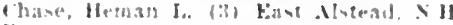

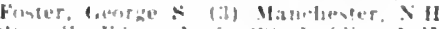

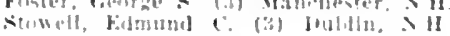

\section{NEW JERSEY}

Atlantic City

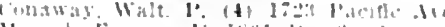

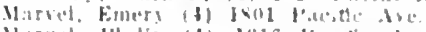

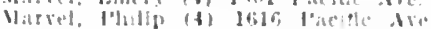

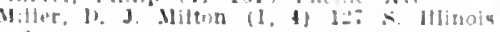
irio

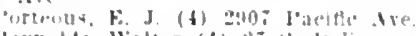

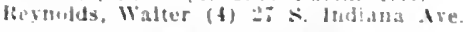

$$
\text { State at Large }
$$

Metiongl. (1) Newark. NJ

\section{NEW YORK}

New York Cit

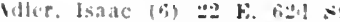

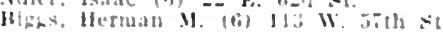

Hovaled, [lavit] (1) 130 E. 60th it.

Hrannan, Juhn W. (6) to W. IIst

Brooks, Harlow (bi) if W. toth set

Calle, Augustus (1) $: 53$ Madison Are

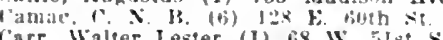

Carr, Walter Jester (1) 68 w. Ist st.

Chapin, Henry Dwiglit (1) ji W. 5ist st.

iole, kufus 1. (6) 960 rark Are.

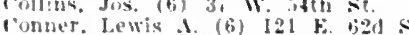

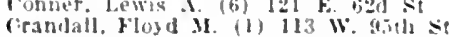

llana, chas. I. (b) 5.3 W. Mad st.

lloruing, Juhn (1) 12t W. sist st.

Folng, James (6) Cornel] Iathorators.

Flexner, simon (b) 150 L. 6Ist sit

Freeman. Kowland (i. (1. b) 211 W. 50 th st.

llaynes, Royal s. (1) 355 Went find Are.

Jeiman, lfenry (1) $30 \mathrm{~W}$. ssth se.

Herman, Charles, (1) $2.00 \mathrm{~W}$. sath si.

Holt, I. Emmett $(1,6) 14 \mathrm{~W}$. $55 \mathrm{th} \mathrm{st}$.

Huber. F. (1) 209 k. lit? sit

Jacubl, ibraham (1) $19 \mathrm{kt}$. tith st

Janes, Walter $B$ ( 15 ) 17 W ith

Ianeway. Thermote 1 ( $(6) 131$ k: 60 th $\mathrm{st}$

kerley rharles (; (1) $130 \mathrm{~W}$. Int

Koplik, Henty (1, 6) 30 E. 621 st

I.afetra, d. F. (1) 113 b. bist st

l.ambert, Sand. W. (ii) 130 F. 33th St.

Lifinan, Fo (ti) $1 \leq 0$ E. fith st.

longene, Warfleld T. (b) bSo Madison Are

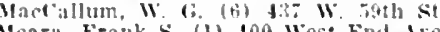

Meara, Frank s. II) ton West Fnd lre.

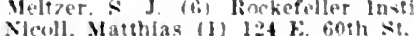

Northrup, Whlllan 1 . (1, 6) 57 F. Fath St.

Jark. Wm. II. (t) 3 is with si.

Plsek, ciodfrey K. (1) 36 k. 629 st

kussell, Fredk. Fuller (fi) Mit, I s.

sachs, Rarney (b) 116 W inth st

simith. I. 1. (6) Is 11.51 it $5 t$

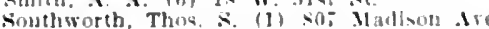

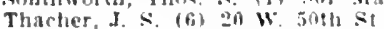

Thacter, I. S. (fi) 20 W. 50 th $S t$ toth st

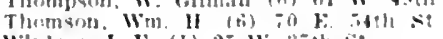

Winfers, J. k. (1) 25 w. 3ith s?

\section{State at Large}

Haldwin, F. It. (fi) Saranac lakie. N Y

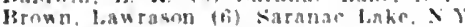

Carv. ('has (fi) Bumilo, y

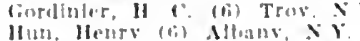

Jonke, II If (1) Naranac lakm N I

Putter, I, s. (3) Syracuse, $\mathrm{Y}$

Slaw. Henry I, $k$, II Nlpass I Y

nnow, Irving M (I) Mufralo, I '

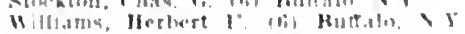

NORTH CAROLINA

Sorrts. Ifenry. It Itutherfortiom. I

\section{OH 10}

Cincinnati

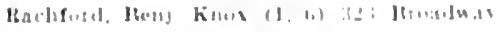

Cleveland

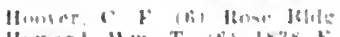

Henard. Wm $T$ (b) Is:le k:

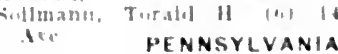

Philadelphla

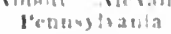

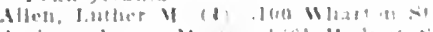

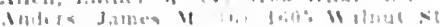

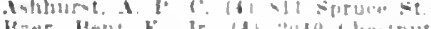

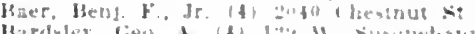

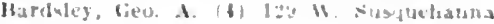

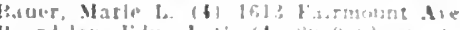

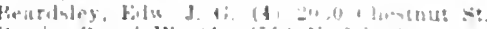

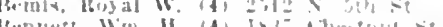

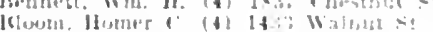

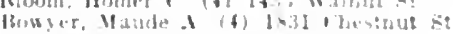

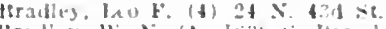

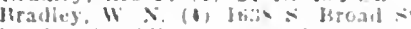
loraly, fratklin (t) lalj bankfurd tre

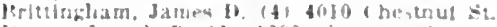

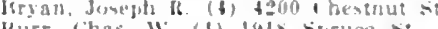
Burr. 'has. W. (f) lot suruce st. larmany, Harry 5 . (t) 3oni direen lage

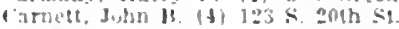

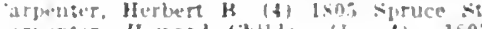
itruenter. IIowatd rhllds (I, f) 1905 siruse se.

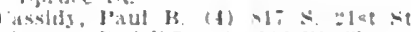

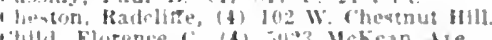
'thlld, Flurence 1 (4) 50,3 Mckean die.

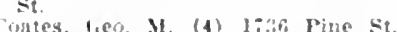

(ohen, Myer solls (t) tluz (i)ratd Ave. ('ohen, solonon solis (f;) 172.7 Walnut st coler. Thomas 1. (t) 27, s. I5th st.

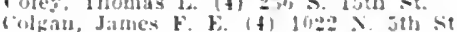

(omlin. W. M. J. (6) Jerterom Medileal i'oltege

Corwell, Walter s. (4) Caly Hall

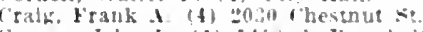

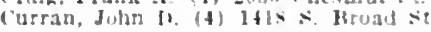

llavls, fiwlym f. (t) 1314 suruce st

Jeethan, sylventer 3 . (1) $443 x$.

lifekon, Frank lirake (t) INt suruce st

lillard. Henry K.. Jr. (t) al s. \#uth sh

loorwirth, thas. V. (f) 1500 birle Ale

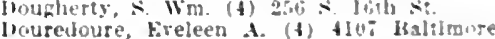
Aiv.

Drayton, Wm. Jr. (t) 1316 I.ncus: st

Einier, Waller 6 (1) 1901 Ilne st.

Fily, Thomas (. If) 201 s (hestnut st.

Firt, Clifforl 1s. (4) 117 s. 201 st.

lesguson, Allnert 31. (t) in k. Juhnson St

Fife, Charles $A,(1,4) 2033$ docuss st

Fuuthred, collan (t) tots chestrut st

Fox. Hertert (1) 3402 I.orust s

Fraley, frederich (t) $314 \leq \mathrm{i}$ ih s:

Fazier, Cbas. II. (4) ligt spruce s:

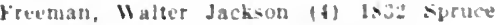
st.

Eussell, II II $(4,6) 2033$ IVulnut St,

ciertard, irthur 11. (t) 2110 Inine st

(ilboun, John H. (t) loos spruev st.

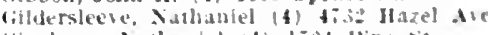
(inslure, Nithantel (4) lind line st.

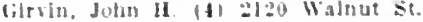

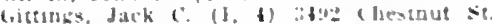

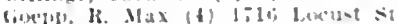

firahim, biluin k. (1, t) 1:13 spruce st

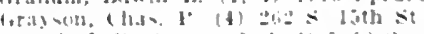

(irtati, J. I'. (rozet $(1,1,0) 1310$ spruce st

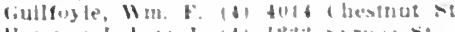

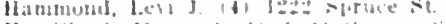

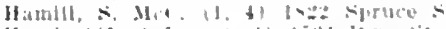

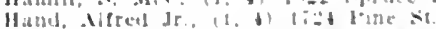
Hare, llubart a (b, (i) Isul suruce st.

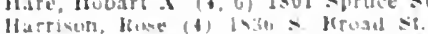

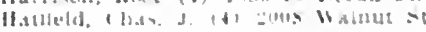

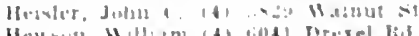
Hewsen. Whism (t) Goth Frexel lid

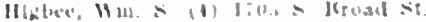
Hill, Hum ate h ill jols \& 1:th si

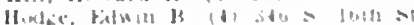

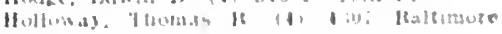

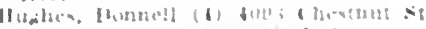

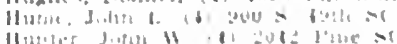

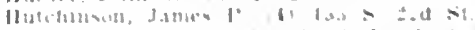

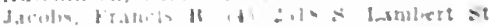

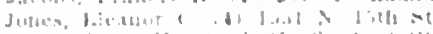

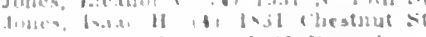

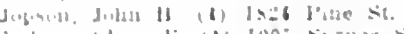
Justorla, thas

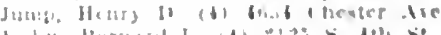

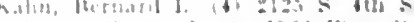

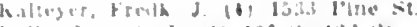

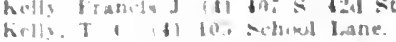

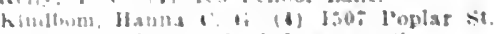

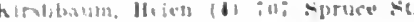


Kunwles. Frank Crozer (4) 2022 spruce $\mathrm{St}$ Eolme, John A (4) $92 \%$ s. st. Bermard st lirauss, Frederick (4) 930 x. Frankilu sit. Krumbhatar, Edward 13, (4) Iniversity of I'a kive, D. Braden, (4) 1517 Walnut Sit. Landis, II. It. I. (4) 11 s. 21 st st. Leach, Wimon w. (4) 2118 sipruce st. Le Bontiller, Theodore (4) $9 \mathrm{~s}$. $21 \mathrm{st}$ st le Conte, kobert. (i. (4) 1530 Iocoust st lee, Walter Estell (4) 90 ; 1ine st. lefcoe, ('has. II. (4) $1420 \mathrm{~N}$. 13 th st. Leicly, Joseph (\$) 1319 Locust St. Levi, Isaac Valenthe (4) 1736 N. 16th st. Icwis, Jorris J. (4, 6) 1316 Locust st. lowenburg. Ifarry (4) $1927 \mathrm{~N}$. Broad st. Lytle, Isaac $W$. (4) $1,527 \mathrm{x}$. 20 th St, Macfarland, Frank 11. (4) $1827 \mathrm{~s}$. 2d st. Mallon, Edw, A. (4) 1511 N, 1 Ith st. Marvel, Inenry V. (4) 4839 Baltimore Ave Mecombs, Robt. S. (4) $130 \mathrm{~s}$. 2201 St. Mecrae, Thos. (6) 1627 spruce st. Mekee, James H. (4) 1212 spruce St Metheny, Samuel A. S. (4) 617 s. 43 id st. Mlller, Mary T. (4) 313 N. 33d St. Miller, Walter M. (4) 5100 Sipruce St. Mills, II. Brooker (4) 1411 Sinruce st. Mitchell, John K. $(4,6) 1730$ Spruce St. Morrls, Filliston 1. (4) 128 s. Isth St. Iiiller, Geo. $P$ (4) 1729 Pine st.

Mulrenan, John l'. (4) 1228 s. Broad St. Newlin, Arthur (4) 1804 Pine St.

Newmayer, Solomon W. (4) 1834 Girard Are.

O'Connell. John A. (4) 2130 Plne St O'Hara, T. A. (4) 2204 Pine St. Osthelmer, Maurice (4) 2202 DeLancey Pl. Ott, Lambert (4) $831 \mathrm{~N}$. Broad St. Packard, F. R. (4) 304 S. 19th St. Parlsh, B. D. (4) 29 S. 19th St.

Pearce, R. M., Jr. (6) I'nlversity of Pennsylvania.

Pemberton, Ralph (4) 2224 Locust St. Pepper, Willlam (4) 1811 Spruce St Plersol, (Geo. M. (4) 1927 ('hestnut St. Potts, Chas. S. (4) 2018 Chestnut St. Reckefus, C. H., Jr. (4) 506 N. 6 th St. Reddie, Jacoblna S. (4) 880 N. 41st St Reed, Howard (4) 1829 Diamond St. Relfr, E. Panl (4) 5051 Chestnut St. Repplier, Sldney J. (t) 4521 Chester Ave. Rheln, John JI. W. (1) 1732 Pine St. Rheln, Itobert D. (4) 2016 Pine St. Riesman, Darid $(4,6) 1715$ Spruce St. Roberts, Walter (4) 1732 Spruce st. Robinson, Edwin T. (4) 1906 Pine St. Robinson, Wm. D. (4) 2012 IIt. Vernon St.
Rodman, doln stewart (4) 2106 Walnut St. loe, Wm. J. (4) 1322 locust St. Roussell Albert E. (4) 2108 I'lne St. lugh, Jamey T. (4) 1616 spruce St. Ryan, Maria I'. (4) 1246 s. Hroad St. Saller, Joseph $(4,6) 1830$ spruce St. Scbatfer, ('in rence W. (4) $2010 \mathrm{E}$. York St. Shamber, Jay F. (d) 1922 Spruce st. Seabrook, Alice (4) $2137 \mathrm{x}$. College Ave. Sellikovital, Solomon (4) $93 \% \mathrm{~s}$. 3d st. Shoemaker, Iarvey (4) 2011 ('hestnut St. Slegel, Alrin F. (4) IGIs Pine St.

sinclulr, d. Falconer (4) $4102 \mathrm{Wa}$ Wut St. siter, Eiljah II. (4) 1818 s. Rittenhouse S Spangler, kalph 11. (4) $221 \%$ s. Broad St. speese, John (4) 2206 Locust St.

Starr, 1outs $(1,4) 1818 \mathrm{~S}$. Rittenhouse $\mathbf{S}$. stensel, Alfred (6) 1811 sipruce st Stevens. Arthur A. (4) 314 S. 16 th st. Stout, lhillp S. (4) 4701 (hester Ave Stryker, siln s. (4) 3833 Walnut St. Sturterant, Charles S. (4) 4321 Frankford Ave.

Tallant, Allce Weld (4) 180 T Spruce St.

Tilley, J. E. (4) 218 S. 20 th St.

Target, John 1). (4) 1112 Jackson St.

Taylor, Alonzo E. (6) University of Pennsylvanla.

Taylor, Wm. J. (4) 1825 Plne St.

Teller, W. H. (4) 1713 Green St.

Thomas, Frank W. (4) 27 E. Mt. Airy Are. Twaddell, Thos. Poage Hunt (4) 4203 chester Ave.

Tyson, Thos. Melior (4) 15,06 spruce St. Walker, John K. (4) 1915 Rittenhouse Sq. Watt, Charles Channing, Jr. (4) 6605 Wayne Ave.

Weber, Chas. H. (4) 2148 Pine St.

Welch, Wm. M. (4) $141 \mathrm{I}$ Jefferson St.

West, Chas. W. (4) 1823 Plne St.

Westcott, Thompson S. $(1,4) 1720$ Pine St. Wharton, Henry R. (4) 1725 Spruce St. White, Courtland Y. (4) 1808 Diamond St. Wllkes, LeRoy A. (4) $735 \mathrm{~S}$. $22 \mathrm{~d}$ St.

Williams, George Lewis (4) 5545 Sprague

Wilson, James C. (4) 1509 Walnut St.

Wood, Alfred C. (4) 128 S. 17th St.

Woodward, Geo. (4) McCallum St., near Mermaid Ave.

Woody, Samuel Sidney (4) Phlladelplila Hospltal for Contaglous Diseases.

Worden, Charles B. (4) 13th and Market Sts.

Young, James K. (4) 222 S. 16th St.

Zimmerman, Mason W. (1) 2104 Chestnut St

\section{State at Large}

Boyle, Morrls 1'. (4) Glenside, I'a. Branson, Thomas F. (4) Itosemont. P'a Clouk, Jos. Howard (4) Ardmore, $\mathrm{Pa}$. ('orson, F. F. (4) Cynwyd, la. ('ross, Sumner II. (4) Jenkintown, Pa. havisson, Nlexander IJ. (4) Ardmore, Pa. Faton, Perelval J. (1) Plttsburah, Pa. French. Mary F. (4) Ardmore, l'a. Gillland, Sam iI, (4) Marietta, Pa llunt. ('has. J. (4) IIarrisburg, I'a. Junifer, fr. Vletor (4) Lausdowne, Pa. lewis, Bertha (4) Bryn Mawr, Pa. Nicholson, Percival (4) Ardmore, Pa. P'ieasants, Henry .Ir. (4) West Chester, Pa. Foyer, 13. Franklin (4) Harrlsburg, Pa. Service, charles A. (4) Bala, Pa. silarpe, John s. (4) Haverford, Pa. shlck, Mary 11. (4) Elwy, Ja. Stein, Walter J. (4) Arduore, Pa. Taylor, Mariana (4) St. Davids. Pa. Weidner, Frances (4) Chester, Pa.

\section{RHODE ISLAND}

Providence

Calder, Ilarold (:. (3) 232 Elmwood Ave. Chesebro, Fdmund D. (3) 2 Hawthorne St Jordan, Wm. H. (3) it6 Academy Ave.

\section{VERMONT}

Burlington

Johnson, Charles K. (3) 75 Grant St.

\section{WISCONSIN}

Milwaukee

Myers, Albert W. (2) 141 Wlsconsln St. PORTO RICO

Ashford, Bailey K. (6) San Juan, P.R.

\section{CANADA}

Montreal, Que.

Adami, J. Geo. (6) 34 Macgregor St. Blackader, Alexander D. $(1,6) 236$ Mountain St.

Finley, Fredk. G. (6) 273 Bishop St. Hamliton, W. F. (6) 287 Mountain St. Lafleur, Henri A. (6) 215 Peel St.

Martin, Chas. F. (6) 240 Drummond St Toronto, Ont.

Balnes, Allen Mr. (1) 228 Bloor St. Leathes, John B. (6) Universlty of Toronto. Iacallum, A. B. (6) University of Toronto. Machell, H. T. (1) 95 Bellerue Ave. Ifclhedran, $A$ (6) 151 Bloor St. Itudolph, Robt. D. (6) 302 Bloor St.

\section{Canada at Large}

Wesbrook, F. F. (6) Vancouver, B.C.

\section{NEUROLOGY AND PSYCHIATRY}

\section{E-SOCIETIES}

NUMBER OF MEMBERS, 846

1. American Neurological Association.

2. Boston Society of Psychiatry and Neu. rology.

3. Brookiyn Society of Neurology

4. Chicago Neurological Society.

5. Detroit Society of Neurology and Psy. chiatry.

6. Maryland Psychiatric Society.

7. New York Neurological Society.

8. New York Psychiatrical Society.

9. New York-Wards Island Psyohiatric Society.

10. Philadelphia Neurological Society.

il. Philadelphia Psychiatric Society.

12. Washington (D.C.)-Society of Nervous and Mental Diseases.

13. American Medico-Psychological Association.

\section{ALABAMA}

Bondurant, Eugene D. $(1,13)$ Mobile, Ala McCatferty, Enit L. (13) Mt. Vernon, Ala. lartlow, William D. (13) Tuscaloosa, Ala Searey, James T. (13) Tusealoosa, A1a.

\section{ARKANSAS}

Greene, James L. (13) Little Rock, Ark.

\section{CALIFORNIA}

Los Angeles

Allen, Charles L. $(10,13)$ Brockman Bldg. Kern, Wim. B. (13) Exchange Bldg. Orbison, Thomas J. (10) Brockman Bldg.

\section{San Francisco}

Lustig, Danl. D. (I3) 146 Grant Are. Stone, Elmer F. (I3) 291 Geary St.

Willhite, Osear C. (4) 240 Stockton St.

\section{State at Large}

Allen, Fredk E (13) Talmage, CaI

Clark, Fred P. (13) Stockton, Cal.

Hamilton, Gilbert V. (I3) Santa Barbara, Cal.

Hatch, Fred W. (13) Sacramento, Cal.

MeBride, James H. (1, I3) Pasadena, Cal.

Podstata, Vaclav H. (4) Llvermore, Cal.

Richards, Robt. L. (13) Talmage, Cal Stocking, Leonard E. (13) Agnew, Cal. Williamson, Alonzo P. (13) Santa Monica, Cal.

COLORADO

Busey, Alfred F. (13) Ridge, Colo. Ia Moure, Howard A. (13) Pueblo, Colo. Pershing, Howell T. (1) Denver, Colo.
Stevens, Frank T. (13) Colorado Springs, Colo.

Work, Hubert (13) Pueblo, Colo.

\section{CONNECTICUT}

Diefendorf, A. Ross (1, 7, 8, 13) New Haven, Conn.

Givens, Amos I. (13) Stamford, Conn

Hallock, Frank K. (1, 2, $\tau)$ Cromwell, Conn.

Haskell, Chas. N. (i) Bridgeport, Conn.

Ia Moure, Chas. T. (13) Lakerllle, Conn.

Lord, Sidney Archer (2) Middletown, Conn.

Mailhouse, $\operatorname{Max}(i)$ New Haren, Conn.

Noble, Henry Smith $(7,13)$ Middletown, Conn.

Pollock, Henry 11. (13) Norwich, Conn

Ross, Donald L. (13) Mansfield Depot, Conn.

Ruland, Fredk. D. (13) Westport, Conn. -

Smith, Edwin E. (13) Norwalk, Conn.

Thompson, Whitefield $\mathrm{N}$. (13) Hartford, Conn.

Waterman, Paul (i) Hartford, Conn.

Worcester, Saml. (13) South Norwalk, Conn.

\section{DELAWARE}

Carey, Harris May (13) Odessa, Del.

Hancker, Wm. H. (11, 13) Farnhurst, Del. 


\section{DISTRICT OF COLUMBIA Washington}

Barton, Wulfed 3. (13) 1730 Connectlcut De Weese, Comellus (6, 12, 13) The Farrazut.

Glascock. Altred (12) Government Hospltal for Insane.

Hlckling. Danlel Peres (12, 13) 1301 thoule

Island Are.
Hough, Wm. II. (12) Government Hospital por Insane.

Jemon, Hazson T. A. (12) 903 M St.

Logle, Renj. Iush (12, I3) 1836 Contivetlcut Are.

Macatee, Henry C. (12) 147s Harrard st. N.15.

Iactlgan, John Joseph (12) The Congresslonal.

Ifender, Chas. A. (12) $30 t$ rhode Island Are.

Randolph, Buckner M. (I2) $2010 \mathrm{R}$ st.

Rohins, Wm. L. (13) The Hochamleau.

schwinn, f. H. (12) Government Hospltal

for Insane.
shute, Danl. Kerfoot (12) 1719 De sales st.

slmpson. John C. (13) 1121 Massachusetts Are. $\mathbf{N}$. W

Taylor, Lewis Harrle (I2) The Cecll

White, Willan A. (12, 13) Government

williams, Tom A. $(10,12,13) 1705 \mathrm{~N}$ St.

\section{GEORGIA}

Allen, Henry D. (13) Mllledgerllle. Ga.

Green, Fdward M. (13) Mllledgerllle, Ga.

Jones. Lodriek if. (I3) Mllledserllle. Ga.

\section{IDAHO}

Grens, John W. (13) Oroflno, Ida.

\section{ILLINOIS}

Chicago

Bassoe, Peter $(1,4) 15$ E Washington St. Reard, Chas. II. (4) 15 E. Washington St. Blllings, Frank (4) J:2 S. Mllcblgan Are Brown. Sanger $(1,4,6,13) 5 \mathrm{~S}$. Wabash Are.

Church. Archlbald (1, 4) J'ullman Bldz.

Crotan, Alfred ' $C$. (4) Fleld Annex Bldg.

Darls, Haim 1. (t) 108 .. State St.

Davls, Nathan Smith (1) $;$ W. Madison st.

Dewes, Mehard $(1,4,13) 15 \mathrm{E}$. Washing-

Edwards, Arthur Robln (4) 104 S. Michlgan Are.

Favili, Henry Balrd (4) 122 S. Michlgan Are.

GIII. James Cornellus (4) 104 s. Michlnan Are.

Goodkind, Maurlce Louls (4) $31 \mathrm{~N}$. State St Grinker, Jullus (1) 32 v. State St.

IIall, Geo. Washington (i) $104 \mathrm{~s}$. Jilchlgan Are.

Hamlii, Ralph C. (4) 15 F. Washington St. Healy, Wm. (4) Jurenlle Court.

Hecht, D'Orsay $(1,4,13)$ I04 S. Michlgan Are.

Heym, Albrecht (4) i w. Madison St Ilolmes, Bayard (4) 108 $\mathrm{X}$. State St. Ilulten, Jacob $F$. (4) 3fil s. Ashland Are Klog. Oscar A. (4) i W. Madlson st. Krumbolz, Slgmund (t) 104 s. Mlchlgan Are.

Kuh. Sydney $(1,4) 31 x$ state st.

Lodor, Chas, II, (1) 3136 indiana st.

Mettler, L. Harrison (4) 31 X. State st Miller, Jos. 1. (4) $122 \mathrm{~s}$. Mlchlikan A ve. Mix, Chas. Louls (t) 104 s. Mlehlgan Are yoyer, Harold $\mathrm{X} .(1,1) 31 \mathrm{~N}$. State st Patrick, Hugh Tabot $(1,4) 25 \%$. Washing Ion st.

Pectral, Jos. J'. (13) 26th st. and Jawndale Are.

Pletrowlcz, stephen $U$. (J3) gog s. State st

Pogue, Mary E (13) 108 Y State Si

pollock. Luts j. (4) 15 k. Washington st.

pollock. Labuls J. (4) 15 H. Washing

quine, Wrown (f) i 11 . Madison St.

schmide, Otto 1. (4) $5 \mathrm{~s}$. Wabash Are.

Slppy, Bertram Vielton (i) $122 \mathrm{8}$. Mlehlgan Are.

Solomon, Mejer (4) 151: $\mathbf{s}$. Kerlzle Are. Stearns. Wm. Ii, (13) $104 \mathrm{~S}$. State sit.

wulder, Wm. II. (i) 122 \& Mlchlean dre

Wood, Casey Albert (t) $;$ W. Madison st

\section{State at Large}

Athon. Wm. I. (13) Marslinll, III.

Carrlel, lenry it. (13) Jacksomvilie, III
Clark, Samuel $x$. (1) Ilospltal, III.

Colth, Kugent (13) l'eorla. 111

(romks, Win. A (13) Hork Island. III, bollear, .lliert II. (f) Jacksonville, III.

IIlus!ns. Italph T. (13) klg!n, III

Norbury, frunk i', (4, 13) springfleld, 111 . singer, Harold [1. (4) Hosplial. Ili.

Wilnus, sidyey I). (1, 13) Hockfurd, ill. bellers, liers, A. (13) l'eorla, 11 .

\section{INDIANA}

Musce, Eliward I'. (13) Madison, Ind Fidenluarter, fieo. Fredk. (13) Indlanamlls. lind.

Franklin, Charles M. $(6,13)$ lafarete, Ind Laukhlln, Plias. F. (13) Evansille, Ind. snith, saml. Edwin (13) East Haren, Ind. Tertlinger, Fred W. (13) logarsport, Ind.

\section{IOWA}

Applegate, Chas. Franklin (13) Mt. I'leas ant. Ia.

Barstow, James M. (13) Councll Blurts, la. Beach, iena Allee (13) cherokee, Ia.

Chllgren, ti. Arthur (13) Burllngton, la.

Crumbacker, Wn. r. (13) Indevendence, Ia.

Donohoe, lieo. (13) Knoxrllle, Ia.

Hill, Gershom H. (13) Des Molnes, Ia

Long. Thos. Lee (13) Cherokee, Ia

Nef,. Mary lawson (13) Ies Iolnes, Ia.

Seybert, Frank T. (I3) Councll Bluffs, la.

Voldeng, Jathew Nelson (1:3) Cherokere. In.

Whllams, Fdtward M. (1, 10) slou

\section{KANSAS}

Bludle, Thos, C. (13) Topeka, Kan

Pery, Middleton Lee (13) Parsons, Kan.

Ihls, Lyman 1. (13) Orerland Park, Kan.

\section{KENTUCKY}

Gardner, Wm. Finmet (13) Laketand, Ky.

Nerlt, Chas. A. (13) Lexington, Ky.

Sights, Henry Preston (13) Hopkinsrille, Ky.

sirague, (ieo. lercy (13) Jexlngton, Ky.

leaman, Ilalcolm H. (13) Henderson, Ky.

\section{LOUISIANA}

New Orleans

Hummel, Edward If. (1) 921 Canal st Van Wart. Roy Melean (13) Malson Hlanche Bldg.

\section{State at Large}

Plerson, Clarence (13) Jackson, La.

\section{MAINE}

Hedin, Carl J. (13) West lownal, Me.

Hills, Fredk. I. (2, 13) lkangor, Me.

Mtller, Henry w. (2, 13) Iugusta, Me.

Swlf, Henry II. (2, 13) l'ortland, Me. Me.
Vaughan, I'hllip II. (13) Yarmouth. Me.

\section{MARYLAND}

\section{Baltimote}

Barker, L. F. (1, I0) Johns Hopkins Hosvital.

Kerkley, Henry J. $(6,10,13)$ 1305 l'ark Are liake, Joln i). (6) 1014 W. Lafayette Are. Hruns, J. Martln (b) 1401 l'ark Are.

Burrow, Trigant (b) j0; st. I'aul st.

liymes, tharles If (10) 207 F. l'reston st. iamplell, C. Mactle (s) Jolus Hopkins Hospleal.

onrnell, Win. Isurgess $(6,13)$ Inlon Trunt IBlak.

kinsur. (7)arles It. (6) Jark Helghes amb singer die.

Flannery, Prank J. (6) SIt. Hope Ave. and

port samuel J. (6) tielston lielghts.

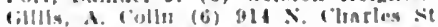

Gundry, l.ew Hs H. (6. 13) 114 W. Franklln Sit.

Hamburger, labula I. (B) 1:ni Eutaw 1"

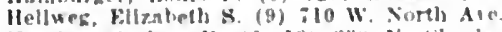
Ierring, Irthur 1'. (8, 13) $33011 \mathrm{~N}$. 'barles Sit

Hiil (barlos $(i$ (6, 13) k21 Hamllum Terrace.

Hurel. Henry M. (6, 13) Jolus Iforkin Ilispltal.

Knaps. Iluhart i: (6) 1216 F l'reston si Meyer, sdole (1, 6, 8,13$)$ 101: $x$ ('aliert

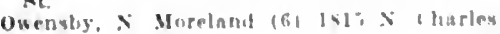
st.
Pleasants, J. Hall (6) mog Lnlrerslty I'arkway

I'rlee, Marshall I. (f, o F. Franklln kit. s.hwartz. William $b$ (b) $1299 \mathrm{X}$. Carollne

grear. Irvlng J (bi) IRI0 Vallwan Are. Stuare, It. I) V. (6) 935 s?. I'aul \&!

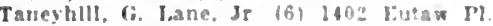
Thayer, Wm. S (19) 406 Catherlat is Thomas, IJenry Y. (1, 6, 10) 1225 Madtson itre.

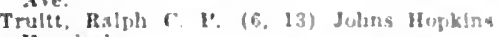
Il nupltal.

Whklus. lien. T. (b) a x. Rrondway.

WHllams. John W. (5) 1128 rathedral St. Young, Jlugh II (6) $330 \mathrm{~N}$. Tharles st.

\section{Siate at Large}

Asper, Kurt 3. (6) Towson, Md.

Black. It. M. (6) Cecllton, Md

Ifrayshaw. Thomas II (6) (ilenhumle, Md. Brush, bilust $x, 11,6,10,13$ ) Townson, IId.

Hullard. Eirnest (6, 13) Mnckrllle. Md.

carey, Charles J. (B) Cambridze, Md.

Clark. Jow. Clement (B. I3) sykestlle, Md.

Cogkina, Jesse Carroll (6, 13) Iaurel, Md.

bunton, $11 \mathrm{~m}$. Rish, Jr. (fi, 13) Towson, Yid.

Fahrney, Henry l'. (b) Frederlck. Md.

Garrett. R. E. (6) Catonstllle. Md.

Gorsuch, James $\mathrm{F}$. H. (6) rork. Md.

Gundry, Nlped T. (6. 13) Cainnsrllle, Md.

liundry, Rlehard $F$. $(6,13)$ (atonsrllle, Md.

Hocklng, fieo. H. (6) Gorans, IId.

Keatlng, Frank W*. (5) Owlngs Mllls, Md.

Morrls, J. X. (6) sykesrllle, Md.

Norrls, Mllion It (6) Eldersberg, Md

I'urdum. H. D. (6) sykestlle. IId.

Rlgzs, Ceorge II. $(6,13)$ Ijamarille. Md.

sargent, George F. (6) Towson. Md

Sloan, Martln F. (6) Towson, Id.

Smart, I. filbbons (6) lutherrllle, Yd.

Todd. Wm. J. (6) Mt. Washlngton, Md.

Wade, J. Percy $(6,13)$ Catonstille, Md

White, W. Rushmer (6, 13$)$ Elllcots cits. Id

Winterode, Holt. I. (6. 13 ) Crownstlle, Md. Wolr, Cieurge B. (6) Towson. Mld.

\section{MASSACHUSETTS}

\section{Boston}

Adler. Herman Morrls (2) it Fenwood Rd Ayer, James lourne (2) 518 Beacon st Haldwln, Henry Cutler 11, 2, 13) Is6 Commonwealth Ave

Kuland. E:llslta $\leq$ ( () sog k. Hroadway Brlfgs, Lloyd Vernon (13) 64 Reacon St. Bullard, Wm. Norton (1, 2) 59 Marlboro

Corlat, Isador H. (3) 416 Marlboro st. Courtney, Juseph W. $(1,2) 436$ Marlloro st.

Cowles, Bdward (1, 2, 13) 419 Boylston St. Cushlng. Harrey (1) The Peter kent Brigham Hospltal.

Dewey, rbis. fifnson $(2,13)$ it dlhan st. Jowning. Dana Fleteluer (13) 119 Foylaton st.

Palrianks, Arbur Whlard (2) 501 Beacon st.

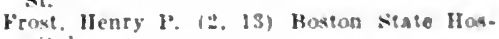
pital

Fuller banl IIunt $(2,13) 6$ Whlnut St

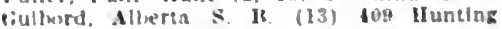
Are.

Howarl. Ileplont llure (2, 13) Veter Hent Brlgham ll ospltal.

Jelly, Irthur : (2, 131 10 Arilngton st

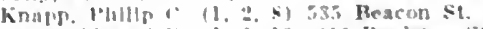
l.ane, blward H. 11. - 131 19 Hoglston st. Sobes. Wm (1, 2. 13) 119 Buslaton si Paine. I.Intun (11) 1 . \& Marino IImplial.

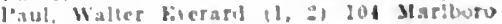
leit. Yobter (1. -) fis peacen st

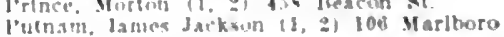
l'utnam. lames Jatkwun (1, 2) 108 Marltoro

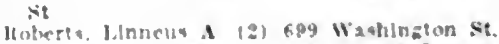

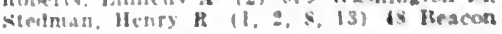
swifl. Walter H. 12) 110 Hay siate Rd. Tallor, Balward Willys (I, :) 4 S Marlboto fiomas John Jenka $(1,2)$ so hay siate III)

Wallisi, (iporge $10,(1,8) 199$ Marlboro St. Watrman, fien d (1, 2) 410 lleacon si. Wentworth, lewell b". (13) 36 state Houve. 


\section{State at Large}

Abbot, Filw. S. (2, 13) Wurerley, Mass. Albut, Florence Hale (I3) West Newton. Mis.s.

13eckley, Chestur C. (2) Lancaster, Mass. Burley, Benj. T. (2) Worcester, Mass. Channing, Walter (1, 2, 1i3) Brooklne, Mass. Cushing, Harrey (2) lirookline, Mass. Dearborn, (ieo. V. N. (1:3) Cambrldge, Mass Drew, Chas. A. (2. 18) Woreester, Mass Edgerly, Jonathan Frank (I3) lilucoln, Ifass Emerson, Ernest 13. (13) Bridgewater, Mass. Fernald, tiuy (i. ( 2,13$)$ ('oncord Junctlon Mass.

Feruald, Walter F. $(2,13)$ Waverley, Mass. Flood, Everelt (2, 13) Palmer. Mass. French, Edward H. (2, 13) Medfleld, Mass. Goss, irthur $1 .(2,13)$ Taunt in, .lass. IIoch, Theodore A. (2) Waverley, Mass. llodsklus, Morgan Brewster (2) P'bluer, Mass.

Houstoll, John A. (2, 13) Northampton, Mass. Eline, fieo, M. (2, 13) Hithorne, Mass.

Kunwiton, Wallace M. (13) Arlington Helghts, Mass.

Mellus, Edward (13) West Newton, Mass. Mellus, Edw. Linden (10) Brookline, Mass. Myerson. Abraham (2) Taunton, Mass.

Nett, Irwin II. (2, 13) Foxboro, Mass.

Nichols, John Holyoke (2, I3) Tewkesbury, Mass.

Nins, Edward J. (13) Sprugtleld, Mass. Norton, Eben C. $(2,13)$ Norwood, Mass. Packard, Fredk. II. (2) Waverley, Mass. Page, IIartsteln W. (13) Baldwinsville, Mass. Paine, Nathanlel Emmons (13) West Xew ton, Mass.

Quinby, Hosea M. (13) Worcester, Mass. Ripley, IIorace G. (I3) Taunton, Mass. Scrlhner, Ernest V. $(2,13)$ Worcester, Mass. Southard, Elmer Ernest (1, 2, 13) Cam brldge, Mass.

Spalding, Harry O. (13) Westboro, Mass. Stick, Henry I. (2, 13) Worcester, Mass. Thompson, Chas. E. $(2,13)$ Gardner, Mass. Torney, Geo. II., Jr. (13) Brookline, Mass. Tower, Freeman A. (2) Fitchburg, Mass. Tuttle, Geo. T. $(2,13)$ Warerley, Mass. Wallace, Geo. L. (2) Wrentham, Mass. Webber, Saml. G. (2) Brookline, Mass. Wllbur, IIubert G. (2) Fall River, Iass.

Wlswall, Edward H. (13) Wellesley, Mass.

Wood, Henry W. (2, 13) New Bedford, Mass.

\section{MICHIGAN}

Detroit

Amberg. Enil (5) 270 Woodward Ave. Babcock, Warren L. (5) Grace Hospital. Ballin, Max (5) 355 Woodward Are. Clark, Davld R. (5) 347 W'est Grand Blvd. Connor, Guy L. (5) Washington Arcade. Emerson, Justin E. (5, I3) I2s llenry st. Freund, Hugo A. (5) 355 Woodward Are. Haass, Ernest W. (5) Fine Arts Bldg. Hitchcock, Charles Wellman $(5,13) 270$ Woodward Are.

Inglis, David (5) 32 Adams Ave., W. Ives, Augustus W. (5) Gas Office Bldg. Jennings, Charles Godwin (5) 435 Jefferson Ave.

Levy, David J. (5) Washington Arcade.

Manton, Walter Porter $(5,13) 32$ Adams Ave., $w$.

Newberry, Fredk. H. (5) 1425 Grand River Ave.

Parker, Walter R. (5) 32 Adams Are., W. Taylor, Wesley (5) 2 - Grand Rirer Ave., E.

\section{State at Large}

Barrett, Albert Moore (1, 5, 13) Ann Arbor, Mich.

Burr, Colonel B. (1, 5, 13) Flint, Mich. Camp, Carl D. (I, 5) Ann Arbor, Mlch. Campbell, Earl H. (13) Newberry, Mich. Canfleld, Roy Bishop (5) Ann Arbor, Mlch. Christian, Edmund A. (5, 13) Pontiac, Mich. Huber, Gotthelf Carl (5) Ann Arbor, Mich. Kilingmann, Theophil (5) Ann Arbor, Mich. Long. Oscar R. (5, 13) Ionia, Mich. Marker, John J. (5) Eloise, Mich. McGregor, Robt. (5) Saginaw, Mich. Munson, James D. (13) Traverse City, Mich Noble, Alfred I. (5, I3); Kalamazoo, Mich. Ostrander, Herman (5, 13) Kalamazoo, Mlch. Riley, Wm. H. (5) Battle Creek, Mich. Stone, Wm. A. $(\overline{5}, 13)$ lialamazoo, Mich.

\section{MINNESOTA}

Minneapolis

Balduin, Jauls 13. (I:3) C'nlrerslty IIospital lanblton, Artiur S. $(4,13)$ Flllsbury lkldg. St. Paul

Rigrs, Chas. Eugene $(1,13) 350$ IRoberts St. State at Large

Freeman, Geo. II. (13) Willmar, Minn Kilhourne, Arihur F. (I\%) liochester, Minn. IPfelps, R. II. (13) St. leter, Minn. Welch, Geo. O. (I3) Fergus Falls, Mlun.

\section{MISSISSIPPI}

Buchanan, James M. (13) Merldian, Miss. Stewart, Nolan (13) Jackson, Miss.

\section{MISSOURI}

Kansas City

burnett, Stephen Grover (13) 3100 Euclid Ave.

Kuhn. Wm. Fredk. (J3) Rlalto Hilg.

P'untom. John (1, 13) Rialto Bleg.

Koblison, (i. Wilse (I3) Itialto Bldy.

skong, A. 1. (13) lilalio Hidg.

$$
\text { St. Louis }
$$

Atkins, Henry S. (13) Grant and Big Bend Sts.

Barnes, Francis M., Tr. (6) Ilumbolelt JHidg.

Bliss, Malcolm A. (1) Jiumboldt Bldg.

Campbell, Given, Jr. (1) 5165 Washlngton Are.

Charldock, Clias. Gilbert (13) 3705 Delmar blive.

Fry, Francis thodes (I, 13) Ilumboldt Bldg. Graves, William W. (1) Metropolitan Bldg. II ughes, Chas. H. (13) 3858 W. Pine Blid. Schwab, Sldney Isaac (1) Humboldt Bldg.

\section{State at Large}

Callaway, Larkin 1I. (13) Nevada, Mo. McAllaster, Benj. I. (13) King City, Mo. Overholser, M. I. (IS) Harrisonville, Mo. l'ettijohn, Abra C. (13) St. Joseph, Mo.

Woodson, C. R. (13) St. Joseph, Mo.

\section{MONTANA}

Knight, Arthur Clyde (13) Butte, Mont. Scanland, John ir. (13) Warm Springs, Mont.

\section{NEBRASKA}

Isurnet, Anne (13) Lincoln, Neb.

Williams, Benj. F. (13) Lincoln, Neb.

\section{NEVADA}

Edwards, John B. (13) Mason, Nev.

\section{NEW HAMPSHIRE}

Baker, Benj. W. (13) Laconia, N.H

Bancroft, Chas. P. (2, I3) Concord, N.H. Brownrigg, Albert E. (2, 13) Nashua, X.It. Coles, Wm. W. (13) Keene, N.H.

\section{NEW JERSEY}

Jersey City

IIasking, Arthur P. (13) 318 Montgomery St. king, Geo. W. (13) 239, 2d St.

Sevin, John (13) 43 Montgomery St.

\section{Newark}

Beling, Christopher C. $(7,13) 109$ Clinton Ave

Gale, Geo. Bancroft (13) 936 Broad St. Hinckley, Livingston S. (13) 182 Clinton Ave.

Mead, Sarah R. (i) 2 Lombardy St.

\section{Trenton}

Cort, Paul L. (11) 144 W. State

Cotton, Henry $A .(1,7,8,10,11,13)$ state Hospital.

Felty, John C. (11) State Hospital.

Funkhouser, Edgar B. (II) State Hospltal.

Taylor, Walter A. (13) 68 Prospect St.

$$
\text { State at Large }
$$

Bryant, Percy (13) Rahway, N.J.

Davis, Wm. Price (10) Atlantic City, N.J.

Evans, Britton D. (13) Greystone Park, N

Gesregen, Wm. E. (13) Bellemead, X.J.

Gorton, Eliot (13) Summit, N.J.

Hallowell, Madeleine A. (10, ii) Vlnleand, N.J.

Halsey, Luther M. (I3) Williamstown, N.J. Kindred, John J. (13) Bellemead, N.J. Millspaugh, Danl. T. (13) Paterson, N.J. Parsons, Richard H. (13) Mt. Holly, N.J. Paton, Stewart $(1,8)$ Princeton, N.J. Payne, Guy (I3) Cedar Grove, N.J. Ramsey. Wn. E. (13) Perth Amboy, N.J.

Simbth, IIarry V. A. (13) Secaucus, X.J. Smith. J. Anson (I3) Blackwood, N.J. Snavely, Earl II. (6) Cedar Grove, N.J. Stern, Samuel (11) Atlantic Clty, N.J. Warren, 1). Edw. (7) Passalc, N.J.

Wecks, lavld F. (11, 13) Skillman, N.d.

\section{NEW MEXICO}

smith, llarry M. (13) East Las Vegas, N.M.

\section{NEW YORK}

Brooklyn

Agnew, Anna M. (3) Clarkson and Albany Ares.

Blerwirth, Julius C. (3) 253 IIenry St.

lilock, slegfrled (3) 8.18 Greene Ave.

Brockway, Robt. O. (3) 67 Hansom Pl.

Brownlng, Wlllam $(1,3) 54$ lefferts Pl.

IBrush, Arthur Conklin $(3,7) 29 \mathrm{~S}$. Portland Are.

Cardwell, Jolun C. (3) 77 Downing St.

Clark, Itaymond (3) 310 Clinton Ave

Crawford, Frederlck D. (3) 184 Joralemon St.

Eastman, Frederic C. $(3,13) 1268$ 13ergen St. Fitzgerald, John F. (3, I3) Clarkson Ave. and is 39 th $S t$

Frlschbler, Chas. Paul (3) 1180 Hancock St.

Fuhs, Jacob (3) 871 Park Pl.

IIaneock, I. C. (3) 135 Cambridge I'l.

Ilicks, Edw. E. (3) 1168 Dean St.

Ifolley, Erving (3) Clarkson and Albany Ares.

liene, Joseph A. (3) 64 Greene Ave.

lierr, Le Grand (3) 42 Gates Ave.

Krause, Jacob Travers (3) 699 Greene Ave. Lloyd, Thos. Mortimer (3) 125 Pierrepont St. Lulirsen, Ernest Frederlek (3) 292 Greene Ave.

TacCoy, Ceril (3) 184 Joralemon St.

Iacumber, Jolun I. (3) 291 De Kalb Ave.

IncEntee, Edw. James $(3,7) 196$ Hancock St.

Meagher, John F. W. (3) 961 St. John's Pl. Morrison, James F. (3) 303 Albany Ave. Morton, Lawrence J. (3) 8801 Ft. Hamilton Parkway.

Moseley, W. B. (3) Clarkson Are. and 39th St.

Ohly, John H. (3) 22 Schermerhorn St. Rabinovitz, Meser A. (3) 183 Vernon Ave. Rome, Russell M. (3) 246 Clermont Ave. Rothenberg, Slmon (3) 1851, 86th St. Smith, Henry M. (3) 184 Joralemon St. Smlth, Jos. (3) Clarkson and Albany Ares. Somers, Fibert M. $(3,13)$ Iong Island State Hosnital.

Tilney, Frederick $(3,7) 161$ Henry St.

Tracy, Ira (i) Clarkson and Albany Aves. Vosseler, Theodore L. (3) 370A Monroe St.

\section{New York City}

Adler, Isaac ( $\tilde{\text { ) }} 22$ E. $62 \mathrm{~d}$ St.

Abrahanison, Isador (7) 20 E. 69 th St.

Altman, Emil (i) 746,5 th St.

Atwood, Chas. E. $(\tau, 13) 14$ E. 60 th st.

Auzal, Ernest Wm. (7) 127 W. 58th St.

Balley, Pearce $(1,7,8) 52$ W. 53d St.

Barnes, Edmund J. (9) Bellevue Hospltal.

Barton, Amos E. (9) Manhattan State Hosnital.

Booth, James Arthur $(1,7) 129$ W. 7 th St. Brill, Abraham A. $(\tau, 13) 55$ Central Park, W.

Brill, Nathan Edwin $(1,7) 48$ W. 76th St. Brown. Willet S. $(3,7,13) 56 \mathrm{~W} .56 \mathrm{th}$ St. Carpenter, Elon N. (7) 58 Central Park W. Casamajor, Louis (7, I3) 342 W. 56th St. Cheney, Clarence 0. (9) Wards Island. Clark, Leon I. ( $1,7,8,13) 84$ E. 56 th St. Climenko, Hyman (i) 252 E. Broadway. Collins, Joseph $(1,7) 37$ W. 54th St Corning, James Leonard (7) 53 W. 38 th St. Cunningham, Richard Hoope (7) $60 \mathrm{~W}$. 10th St.

Daley, Robert M. (i) 43 E. 27th St.

Dana, Charles L. $(1,7,8) 53 \mathrm{~W}$. $53 \mathrm{~d}$ St.

Daris. Thomas k. (9) New York Hospital.

Day, Homer L. (9) Wards Island.

Devendorf, Fredk. C. (9) Ward's Island.

Dixon, Geo. Arthur (7) 15 W. 49th St.

Dold, Wm. Elllott $(3,7,13) 616$ Madison Are.

Dunlap, Chas. B. $(i, 9) 527$ W. 121st St. 
Fisk, Jacob C. (3) 2030 Broaltuay

Pltch, Allen (:) 38 W. 56 th St.

Flut, Austin (13) IIs F. 19th st.

Folsom. Halph I. (9) Warda Jiand

Praenkel, Joseph $(I, i) 21$ f.. $8: d$ st.

Friak, Horace W. (i) I W. 83i st.

Garretson, Wm. Van Pelt (7) 112 W. sith St.

Garrin, Wm. C. (0) Wards Island.

Galchtel. A. Lawrence (i) $250^{\circ} 11.44$ th $\mathrm{si}$

Goodhart, Simon I. (6) 34 W. Sith st.

Grezory, Menas $\$$. $(1,7,8,13)$ Hellevue Hospltal.

Haberman, Jtiles Vlctor (i) 60 W. 85 th st. Hamllton, Allen McLane il) $3 t^{\mathrm{k}} \mathrm{t}$ toth st. Hanmond, Graeme M. $(1, \div, 8,13)$ io W 35 th St.

Harrison, Danl. A. (3, I3) is Central Park

Hariland, Frank R. (9) Ward's Island.

Herring, W. C. (7) 435 W. $119 \mathrm{th}$ St.

HinkJe, Reatrice Y. (i) 115 k. 31st st

Hirsch. Wilitan (1, \% s, 1:3) E. bith st

Hoch, Auzust $(1,7,8,9,13)$ Wards lsladn.

Hoyt. Randal Edw. (i) $2: 6$ W. 39 th St.

Humphries, Henry $\mathrm{H}$. (i) to F. HIst St.

llunt, Fdw. L. (i) 54 W. 5oth $\mathrm{st}$

Hunt, James Ramsay (I. i) 20 W. $501 \mathrm{~h}$ st.
Huteblnson, Anna E. (9) Manlsatian State Irospltal.

Jacoby, Georze W. (I, i) It w. $32 \mathrm{~d}$ St.

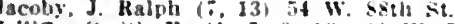

Jelline, smith E. (i, $7, \&, 131$, 1 W. 5eth

Karpas, Morrls Jacob (i) Hellerue Hospltal.

Kelleher, James 1'. (9) 1,5 Manhattin Are.

Kellog

Kenneds, R. F. (i) 20 W. 50th st.

Keschner, Moses (:) 264 ith $S t$.

Klrby, Feorge $11 .(7,8,4,13)$ Manhattan State Jospltal.

Knapp, John R. (9) Manhattan siate Hospital.

hinopf. S. Adolphus (13) 16 W. Bith St.

Knopf, S. Adolphus (13) 16 W. 9.th st.

Kruna, Rlchard B. (T) II E. Asth St.
Lawrence, George Alfred (i) It: W. Sith st

Leahy, Sylrester R. (9) Wards Islind.

Leale, Chas. A. (5) $60 t$ Mad!son Are.

Leszynsky, Willam M. (I, i) I45 W. ith St.

Lererty, Alexander S. (i) rot St. Nicholas Are.

Lundell, Nils. 0. (9) St. Ftanels Ilospltal.

Mabon. Wm. $(\%, 8,9, j 3)$ Manhattan state Ifospital

MacCurdy, John T. (9) Ward's Jsland.

MacDonald, Carlos F. (8. 13) is E. tith st,

Ma.Phee, John J. (i. 13) 853 , ith Are.

Macs. Wm. Sustin (i3) I Madlson Are.

Malones, Wm. J. (i) to F. God St.

McKelway, John Jrvine (13) 312 W. zoth st.

surras, (irace Peckam (o) $50 \mathrm{~W}$. $15 \mathrm{th} \mathrm{St}$.

Myers, Glenn E. (9) Wards Island.

Noyes, Wm. Ilradbury (7) $221 \mathrm{~W}$. 3 ith st.

Oberndorf. Clarence $\mathrm{F}$. (i) $249 \mathrm{~W}$. itth St.

Oppenhelmer, Henry s. (i) il f. 1 il st.

Packer, Flastus ( $\bar{b}, \mathrm{x}, 13$ ). (R/verdale)

Parker, (ieo. M. (13) il W. $52 \mathrm{~d}$ S!.

Peterson, Fredk. (1, $7,8,13$ ) $20 \mathrm{w}$, 50th st. Phllitps, Arthur $\mathfrak{X}$. (9) Manhattan State Hospltal.

Pitman. Mason W. I. (13) 17 Batters Pl.

Poate, Ernest M. (Y) Manhaltan State IIuspltaj.

Porter, Wm. Henry (i) 46 W. 834 st.
Pou, Robert F. (i) 20 w. $50 \mathrm{th}$ st.

Ititchard, Wm. Broadus (i, 13) $143 \mathrm{~W}$ i2d $\mathrm{st}$.

Proul, Thos. I. $(7,13)$ a W. stith st.

Hafel, Henry (i) 106 W. 8ith St.

Bohert.mo, Frank w. (13) 111 west Find Are.

Rosenbluth. Bens. (i) 13 Madison Are

Howe, John $T$. W. (9, 13) Manhattan state Noopllal.

Bacha, Harney (1, T. 13) 11; W, :ath it

Salmen, Thos. W. (i3) so tinlon sis

schlapp. Max l: (1, j, 13) to b. ilue st

Scrlpture, Fisward Whecter (1. ; 13) i:n Broadway.

Shaffer, Newton Yelman (i) 31 F. 4th St.

simlth. Whlllp (9) Warels Jsland

Soper, Srthur E. (9) State Houpltal. Wardt Islanit.

Spellman. Dwlehe $S$. (9) Wartis Island.

Starr, Moses Allen $(1, ;)$ o $w$ itth $s$

Stelnach, Wm. (7) 239 k. 501 st

sloerzer, Chas. II 191 Ward's Island.

sirausa, Iarael (1, i) $3: 33$ (entral lark W
Taylor. Nered s. (a) 113 W Bith st

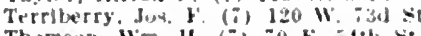
Thomson, Wm. 11. (7) 60 k. 5th se Thornton, Mehael $j$ (i) Hellevie IIompltal. Tlmme, Walter (i) 133 W: izd st Turner, Heve (13) $522 \mathrm{i}$. Itgth st.

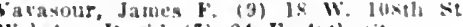

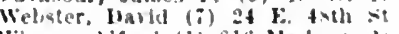
Vlener, Alfred (1) 616 Mallison lie.

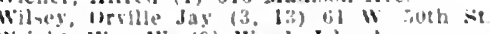
Wriblt, Wm. W, (9) Wards Inland.

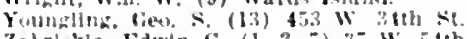
Zalirlakle, fdwin 6 , (1, 3, i) 37 W. 5th st

\section{State at Large}

Ingell. Folward B. (1) Hinchester, Ni: Irehanliautt, La Salle (1) Albany, N.Y Irmstrong, Saml. T. (13) Katonal. N.

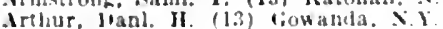

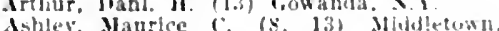
S.I

litker, smith (1) Cilea, X.Y.

lRamfurd, Thos. F. (13) syracuse. IY

Hasset?. M. Intoene (10) iooperstoun, X.)

Bennet, Allee (10) Juffalo, X.l.

Holten, James $h$. (13) Jeacon, X.Y.

Hond, Geo. F. M. (13) Yonkers, X.Y

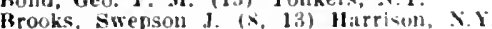

lamplelt. (ico. B, (1:i) Tllira, X.Y

capron, Arthur J. (13) oweg, N.y.

Chapln, John B. $(10,13)$ Canandalqua, N y

Chrlstian. Frank J.. (13) Elmira. Ni

Colller, G. Klrly (13) sonvea, Xil:

rook. Robt. $\mathrm{G}$ (13) Cananialgua, i $Y$

bougherty, Wm. J. (i) Youkers. Ny.

Elllott, Iliram (3. 13) sutfern, $X Y$

Elllott. Rout. M. 13,13$)$ Willa rd. X.Y.

Ferris, Albert.

Gordinler, llermon C. (1) Tros, N.y.

Granger. Wm. It. 17, I3) Bronstlle. N. Y

Hamllton, Saml. W' (13) "tiea. X.Y.

Hanes, Filward L. (13) lochester, N.Y

laviland, Clarence F. (13) K!nga Park, N.

lleyman, Marcus $\mathrm{F}$. $(\tau, 13)$ Central lslip. I.1. X.Y.

Howard, Eugene H. (13) Rochester, Ny.

Hun, Henry (1) Albany, S.Y.

liurd Arthur W. (13) Buffalo $\times$

Ifutehings. Hlehard II. (13) Otdensburg, N.y.

Lamb. Holit. Is. (S. 13) Troy. X.Y.

Jambert, Charles i. (9) white Plains, X.Y

Iewls, Darld R. (3) Whitestone, I.I. N.Y.

Lyon, Chas. F. (13) Jinghamton, X.Y.

Jon, (13) White Plains, $\mathbf{S}$

Yatzinger, Herman (;, (1:3) IBuffajo, X.

May. James V. (13) Allany, N.Y.

Meriafin. Chas. G. (13) Kings lark. XY

MeNerney, Wm. J. (9) Syracise. N.Y.

Mosher, Jesse M. (1. 13) . Mlbiny N.Y.

Junann, James F, (13) Sonyea, N.Y.

Vevln, Fthan A. (13) Xewark, X.Y.

Sorth, rhax. II. (13) Iannemora, XY.

Onue, Bronlstaw $(1, i)$ Amityrille. I

lalurer, Harold J. (1:i) Itló. N.Y.

fsarsons, llalph W. (i) Osinlning. X.Y

Jatterson, thrlstopher J. (13) Truy, X. Y.

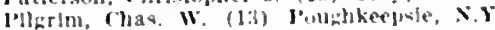

fotler, Fara B. (13) Hochester. SY.

l'utnam. Emina (13) l'awling. X.

Futnam, James W. (1) Butalo, X.r.

Russell. Win 1. (s, 13) White lelatis. $x)$

liosanoff. .1. J. (13) Kluk 1'ark. N)

liven Witter G. (13) Nliany. $>$

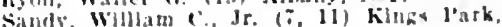

X.Y.

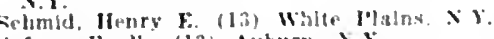

Sefton, Frosk (13) Auhurn, IY.

Shanalian, Wm, T. (13) sunyer, X.Y

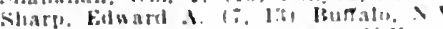

skinner. Wm, W. (13) Cieneva, N'

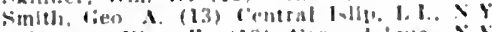

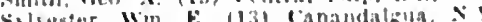

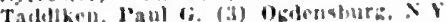

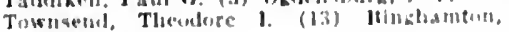
Ni:

Twohey. Juhn J. (13) Jutalo. $\mathrm{x}$

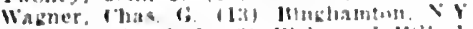

Wolgand, Frank J, (3) Hichnomel Hill, 1, x.y.

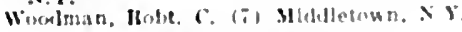

\section{NORTH CAROLINA}

carroll. kola \& (13) Awheulle. Y

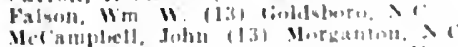

Taglor, I
NORTH DAKOTA

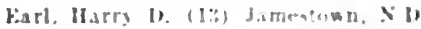

Hoqublos, II: M. (1B) Jasnestoun, NI.

OHIO

Cincinna:

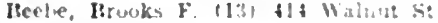

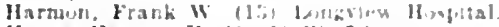

lfople, llorman II (1) 19 W : in $=t$

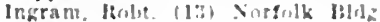

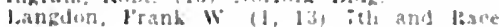

Sto.

Willams, Herohul of (13) rinclanat] Starl. iarlum.

Wolfstedn, basid 1. (1) $22 \mathrm{~W}$, th st

Zenner, Ihilly (1) t3a liare st.

Cleveland

rark, thas H. (13) siate Juspltal for Insine.

Howard. Alams B (13) lione Bldz

l.enls, Jas. If. (13) Hine Bldy.

Columbus

Euerick. Girn J. (13) Instluthen for

Fephle-vinded.

Dilliam, Thas. F. (13) State Hnstital

llarling. Gen. T. Jr. (13) 31 F F. State st. siminlatratlon.

stuckton, fieo. (13) 151 r. Jiroad st

Willams, Guy II. (1:3) Cofumbus siate Hos

$$
\text { plial. Siate at Large }
$$

inalier Firl Irultaze (1:i) Jayton, O

Bralley. Imalel 1. (13) Akron, O.

rink, li. Harrey (13) weford, 10.

Eyman. Ifenry ic (13) Massillon, n

Fordyce. IIra 0, 113) Athens."

Kimeon, ren, G. (1.3) rialliph

inller, Louis (5) Tolerto. (")

Iriteharl, Wm. H. (13, Gallimlls. 0

Ratie los y (13) lovion, 0

searl, IIm. A. (13) riyalonga Falla, 0.

\section{OKLAHOMA}

Grletn. Darla W. (13) Nirnan, Ok!a

OREGON

Portland

cree 1lenry W. (13) selling bld:

lillenple. liob. J. (13) selling Bldg.

\section{PENNSYLVANIA}

Philadelohia

Wlen. Nired th. (1, 10, 11 1) 2013 spruce st

Auderson, Fila M. (10) Ihiladelphla llos nital for Insane.

B] Momfleld. Maximblian Jarld (10) 2mis y lark Are.

linchrorh. Max I1. $(10,11) 1539$ Plne :

Bull. Farl llanford (2) ftol Marhet st. ile.

Irubaker, sibert I'. (10) stati loweltum

huchley, Nlwert 1 . (10, I1) Frlends Asturn for the Insane.

murr. inaslen it (1, 10, 11, 13) 1918

spruce st.

Cadwallader. Whllam B. (10) lilo Iaku<t st. (amcrosa, llorace 1. 110) 10:4 siruere si chase kolnert it 110, 11, 1:b) krend Inglum for the Inasne

coup bwen (11\%, 11, 13) ttod Varbet st.

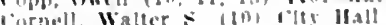

lo. Costa, John ihalmers (10) Qutj Walnut st.

lluand. Julson (I0) 317 s lath $x$

leercun. Frabcis Xavier 11. 10. 11) 1:19

Walnut st.

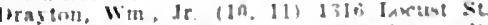

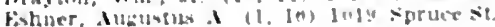

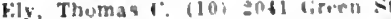

For

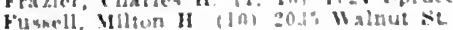

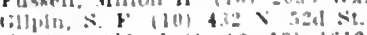

liorlow. Alered (1, 10, 13) 141: spruces st Hamll, Sumber II (10) ls: Esture st.

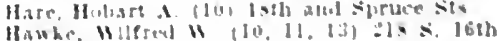

Hulluway, Thonias 11. (10) 1:19 Chestnut st

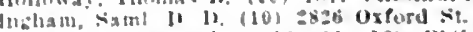

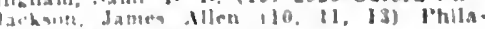
Irlobia Houplal for lowane.

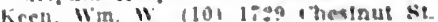

firmmiliat balward it (10) tindvenits of

1.ano, lenter Henry (10) lis Mellatehem lolke 
Heopold, samuel $(10,11) 1632$ Franklin st. lewis, Morris J. (10) 1316 Locust $\mathrm{St}$. I.Indawer, Fugene (10) 2018 ("hestmit St. Lloyd, James H. $(10,11) 116 \mathrm{~S}$. 21st St. Lillum, Seymour 1). $(1,10,11) 216 \mathrm{~S} .15 \mathrm{th}$ $\mathrm{St}$

Iccarihy, Danlel J. $(1,10,11,13) 2025$ Walnut st

Meconnell. James $1 \%$. (1, 10) $701 \mathrm{~N}, 40$ th Sit. Meyers, Miton K. (10) l.jag s. Broad st.

Mils, Charles $k$, $(1,10,11,13) 1909$ ChestMills, Char

nut St.
Mltehell, John K. $(1,11) \quad 1730$ Spruce St.

Morrlson, Wm. H. (10) sn21 Frankford St.

IIoulton. Albert li. $(10,11,13) 49$ th and Market sts.

Mulrenen, John I'. (10) $1228 \mathrm{~S}$. Broad St.

o'Brlen, loin P. (10) 2733 F. Clearfleld St.

o'llara, Thomas A. (10) 2204 Plne St.

Orton, Samuel T. $(2,13) 4401$ Market St.

Pepper, Whllam (10) 1811 Spruee St.

Petery, Arthur K. (11) 1536 Dlamond St.

Phelps, George F. (10) 6019 Fansdowne Are.

Phlllips, Horace (11) Land Title Bldg.

Potts, Charles S. $(1,10,11) 2018$ Chestnut St.

Price, George E. $(10,11) 1830$ So. Riltenhotise $\mathrm{Sq}$

Pritehard. Wn. C. (10) 5616 spruce St.

Rhein. Iohn IIenry W. (1, 10, 11, 13) 1732 Pine St.

Rhein, Robert D. (10) 2016 Pine St.

Rlesman, David (10) 1715 Spruce St.

Robinson, Benjamln (11) 643 S. 52nd St.

Roblnson, Wm. Duffeld $(10,11) 2012 \mathrm{II}$. Yernon st.

Saller, Joseph -(10) 1830 Spruce St.

Schweinltz, Geo. E. de (10) 1705 Walnut St.

Schlvely, Mary Allee (10) 318 Wlnona Are.

Sinkler, Franels W. (10) 1606 Walnut St.

Smith, Allen J. (10) 39th and Locust Sts.

Splller, Wllliain G. (I, 10, 11) 2046 Chestnut St.

Spltzka, Edw. A. (10) 5104 Larehwood Ave. Swallow, Frank W. (11) 2042 .11t. Vernon St. Taylor, John Madison (10) 1504 Plne St.

Van Gasken, Frances C. (10) 115 S. 22d St.

Welsenburg. Theo. H. (1, 10, 11, 13) 2030 Chestnut St.

W"elss, Benjamin P. (10) 630 spruce St.

White, Ellen P. Corson (10) $216 \mathrm{~S}$. 15th St.

Wlghtman, John G. (10) 2030 Wallace St.

Wilson, George (10) 5000 Walnut St.

Wilson, James C. (10) 1509 Walnut St.

Wood. Horatio C. (10) 4107 Chester Are.

Woodbury, Frank (11, 13) 218 S. 16th St.

Woods, Matthew (11) 1307 S. Broad St.

Yawger, Nathanlel S. (10) 2005 Chestnut St.

Pittsburgh

Diller, Theodore $(1,10)$ Westinghouse Bldg. Mayer, Edward E. (13) Keenan Bldg. Mekennan, Thos. M. T. (1) Jenkins Bldg.

Walker, Wm. K. (1) Westinghouse Bldg.

\section{State at Large}

Baker, Jane Rogers (13) West Chester, $\mathrm{Pa}$. Darllngton, Horace H. (10) Concordville, Pa.
Harvey, Eilis Marslull (11) Medla, Pa. 1111, Siamuel S. $(11,13)$ Weruersville, J'a llutefinson, llenry A. (13) Dixmont, Pa. lime, Bayard (10) West Chester, P'a. ketl, latlih (: (11) Columbia, l'a. kinuey, (C. Spencer (13) Faston, Pa. Klops, Henry 1. (13) Allentown, l'a. Mayberry, (has. B. (13) Retreat, 1'a McCafferty, Geo. W., Jr. (11) Waymart, Pa. ICCall, Flizabeth C. Spencer $(10,11,13)$ Bryn Mawr, Pa.

Mekinniss, ciyde k. $(10,11,13)$ Norristown, I'n.

Meredith, IIugh B. (13) Danvllle, 1'a.

Mitchell, Ilarry W. $(2,10,13)$ Warren, Pa.

Iurdock, James Moorehead (13) Folk, Pa.

Orth, IIenry $\mathbf{L}$. (13) IIarrisburg, Pa.

Ott. Isaac $(1,10)$ Faston, Pa.

Jeterson, Iessie M. (11) Norristown, Pa.

lisehardson, Wm. W. $(10,11,13)$ Mercer, l'a.

Swalm, Chas. Joseph (11) Norristown, Pa.

White, Grace E. (11) Ardmore, Pa.

Winter, S. Ellzabeth (10) W. Conshohocken,

Wale, Mary M. (11, 13) Jewisburr, Pa.

\section{RHODE ISLAND}

Providenoe

Blumer, Geo. A. (2, 13) Butler Hospital. Farnell, Fred James $(2, \tau)$ 335 Angell St.

Ilall, Henry (C. (2) Butler Hospltal.
IIcDonald, Wim., Jr. (12, 13) 188 Black stone Blid.

liuggles, Arthur H. (2) Butler Hospital.

\section{State at Large}

Barnes, Ilarry L. (13) Wallum Lake, R.I.

Ilarrington, Arthur H. (13) lloward, R.I

rage, Chas. W. (13) Watch HIll, R.I.

\section{SOUTH CAROLINA}

Babcock, James W. (13) Columbla, S.C. SOUTH DAKOTA

Adams, Geo. Sheldon (13) Yankton, S.D.

Hummer, llarry R. (13) Canton, S.D.

Mead, Leonard C. (13) Yankton, S.D.

\section{TENNESSEE}

Campbell, Mllehael (13) Bearden, Tenn.

Douglas, Albert E. (13) Nashville, Tenn.

Neely, James J. (13) Bolivar, Tenn.

Somerville, IVm. G. (13) Memphls, Tenn.

\section{TEXAS}

Allison, Wilmer F. (13) Ft. Worth, Tex. Bass, Thos, B. (13) Abilene, Tex.

lieverly, Albert Fitzhugh (13) Austin, Tex.

Iloody, Geo. H. (13) San Antonlo, Tex.

Preston, John (13) Austin, Tex.

Turner, John S. (13) Dallas, Tex.

White, Frank S. (13) San Antonio, Tex.

UTAH

Calder, Danl. H. (13) Provo City, Utah.

\section{VERMONT}

Lawton, Shaller E, (13) Brattleboro, Vt. sears, F. Willam (2) Burlington, Vt.

\section{VIRGINIA}

Brown, Geo, W. (13) Wlllamsburg, Va, Brunk, Oliver C (I3) Richmond, Ya. be Jurnette, Jos. S. (13) Staunton, Va. 1) rewry, Wm, F. (13) l'etersburg, Va. Illusdale, Guy $(1,10)$ IIot Springs, Va. king, John C. (13) Marion, Va.

l'rlddy, Allert S. (13) Madlson Ilelghts, Va.

\section{WASHINGTON}

Semple, John M. (I3) - Spokane, Wash. Simith, Robt. I'. (13) Seatle, Wash.

\section{WEST VIRGINIA}

Barlow, Chas, A. (13) Spencer, W.Va. Guthrle, Lewis V. (13) Iluntington, W.Va.

\section{WISCONSIN}

Recker, Wm. F. (13) Milwaukee, W's. Beutler, Wm. F. (13) Wauwatosa, Wls. Caples, Byron ir. (13) Waukesha, Wis. Gorst, Chas. (13) Mendota, Wis.

Mitchell, Roy E. (13) Fau Clalre, W's. l'owers, Ileriert Wm. (I3) Wauwatosa, Wls. Ricksher, Chas. (13) Lake Genera, Wis. logers, Arthur W. (13) Oconomowoc, Wis. Sherman, Adin (13) Winnebago, Wis. White, Moses J. (13) Wauwatosa, W's. Wilmarth, Alfred W. (10) Chlppewa Falls, inis.

\section{WYOMING}

Soller, Chas. H. (13) Evanston, Wyo.

\section{CANADA}

Montreal, Que.

Chagon, E. Philipne (13) 16 St. Famlle St. Macphail, Andrew (13) 216 Peel St. Kussel, Colln K. (1, 2, 7) 218 Bishop St. Shirres, David A. (1, 2, 13) 670 Sherbrooke st., IV.

Villeneure, Geo. (13) 322 St. Denls St.

\section{Teronto, Ont.}

Clarke, Chas. K. (13) Toronto General Hospital.

Forster, James M. (13) Hospltal for Insane. Meyers, Donald Campbell (13) 72 Heath St., W.

\section{Canada at Large}

Anglin, James V. (13) St. John, N.B. Beemer, Nelson H. (13) Mimico, Ont. Brochu, M. D. (I3) Quebec, Que.

Burgess, T. J. W. (13) Verdun, Que. Doherty, Chas. E. (13) New Westminster, B.C. English, Walter M. (13) Hamllton, Ont. Goodwill, V. L. (13) Charlottetown, P.E.I. Hattie, W. H. (13) Dartmouth, N.S. IIobbs, Alfred T. (13) Guelph, Ont. Vitchell, John C. (13) Broekville, ont. Moher, Thos. J. (13) Cobourg, Ont. Porteous, Carlyle A. (13) Verdun, Que. Robinson, Wm. J. (13) London, Ont. Ryan, Edward (13) Kingston, Ont. Wilson, Wm. T. (13) Penetangulshene, Ont. Young, David (13) Winnlpeg, Man.

\section{PATHOLOGY, BACTERIOLOGY AND ANATOMY}

\section{F-SOCIETIES \\ NUMBER OF MEMBERS, 1,423}

1. Amerioan Assooiation of Anatemists.

2. Amerioan Association of Pathology and Bacteriology.

3. Los Angeles-Cliaical and Patholegical Society.

4. Chicago Pathological Sooiety.

5. Des Moines Pathoiegioal Society.

6. Minaesota Pathological Society

7. New York-Academy of Pathological Science.

8. New York Pathological Sooiety

9. Omaha Pathological Asseciation.

I0. Philadelphia-Pathological Society of Philadelphia.

\section{ALABAMA}

Birmingham

Graham, George S. (2) 1641 Ave. II.

\section{CALIFORNIA}

\section{Los Angeles}

Alden, Eliot (3) Brockman Bldg.

Allen, Chas. L. (3) Broekman Bldg.

Anderson, Chas. W. (3) Brockman Bldg.

Beckett, Wesley W. (3) Pacific Nutual Bldg.

Black, Stanley P. (3) Auditorium Bldg.

Brainerd, Henry G. (3) Exchange Bldg.

Brem, Walter V. (3) Brockman Bldg.

Browning, Chas. C. (3) W. P. Story Bldg.

Bullard, Frank D. (3) Marsh-Strong Bldg.

Campbell, Ralph R. (3) Brockman Bldg.

Cochran, Guy, (3) 6th and Main Sts.

Coffey, Titan J. (3) Marsh-Strong Bldg.

Cole, George L. (3) Auditorium Bldg.
Duffleld, Wm. (3) Auditorfum Bldg.

Edwards, Wm. A. $(3,10)$ Security Bldg. Ellis, H. Bert (3) Bradbury Bldg. Flsher, James Tucker (3) 6th and Hill Sts. Fleming, Ernest W. (3) Trust and Sarings Bldg.

Fulton, Dudley (3) Merchants National Bank Bldg.

Gerson, T. Perciral (10) W. P. Story Bldg. Hastings, Hill (3) Trust and Savings Bldg. Howard, Henry W. (3) Auditorium Bldg.

King, Joseph II. (3) Brockman Bldg.

Kress, George H. (3) Bradbury Bldg.

Kurtz, Carl (3) Douglas Bldg.

Loblngler, Andrew S. (3) Marsh-Strong Bldg. McNeill, Harrey G. (3) 321 W. $3 \mathrm{~d}$ St.

Niller, Frank W. (3) H. W. Hellman Bldg. Moore, Edward C. (3) H. W. Hellman Bldg. Ioore, Melvin L. (3) H. W. Hellman Bldg. Ioore, Ross (3) Fay Bldg.

Morton, Lewls B. (3) Brockman Bldg. Nilehols, Chas. B. (3) Grant Bldg. 
Orbison, Thomas J. (3) Krockman Bldg. Pahl, leter $C$. H. (3) Consolidated Realty

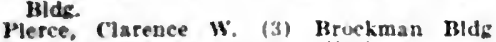
Pletce, Clarence W, (3) Bruck

Powers, luther H. (3) (Ity Hall.

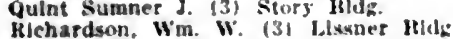

Hogers, Albert $f$. (3) siring and jth st.

smith, Rea k. (3) Hrockmin Bldg.

solland. Albers (3) Wright if callender Bids.

Veley. Jay II. (3) Kradlury IIdz.

Witherbee, Orritle O. (3) Audltoriun Bids.

\section{San Franelsco}

Blalsdell, Frank F. (I) ligo I a ke St. Cooke, Jean V. $(2,10)$ inliersity of $\mathrm{Cal}$.

Cummlogs, Wu. T. (2, 10) Southern Paclfc Co. Hospltal.

Dickson, Ernest C. (2) lane Hospltal.

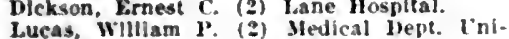
versity of Callfornla. ophuls. William (2) stanford inlierslty Medical School.

\section{State at Large}

Claypole. Edith J. (2) Berkeley, Cal. Gas. Frederick b. (2) Berkeles. (al. (ilenn, Robert A. (10) Oakland, Cal. king, Chas. Lee (3) Pasadena, Cal.

Lockwool, Chas. 1). (3) l'asadena, Cal. Manwaring. Mufred H. (2) stanford Inl rersity, Cal.

Sattison, Fitch C k. (3) Pasadena, Cal.

Meyer, Arthur W. (i) I'alo Nlto. ('al.

Yoody, Rovert Orten (1) Berkeley, Cal.

Newcomb. Arthur T. (3) Pasadena, Cal.

Pottenger, Francis M. (3) Monroria, Cal.

Roberts, Wm. H. (3) I'asadena, Cal.

Rush, Granville Y. $(2,8)$ Herkeley, Cal.

sherk, Uenry H. (3) Vasadena, tal

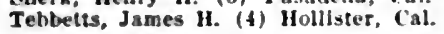

\section{COLORADO}

\section{Deaver}

Jones, Saml. Fosdlck (8) 1405 (ilenarm St. Willams, Wm. W. (2) Jietropolltan Bidg

\section{CONNECTICUT}

\section{New Haven}

Bartlett, Charles d. $(2,8) 150$ York St. Churchman. Joho w. (2) 308 Crown st. Ferts, Harry Burr (I) 395 St. Itonan St. Fllns, Joseph Marshall (1) 320 Temple st Harrison. Ross Gransille (1) is Hillhouse Ave.

Lang. Wm. P. (i) 1223 Chapel St. Schaeffer. Jacob Parson (1) 150 York se.

Smimow, Max R. (2) 850 lloward Are.

\section{State at Large}

Borle, Staces W. (i) (ireenwleh, Conn. Givens, Amos J. (i) stamford, Conu. landry, Arthur B. (10) Hartord, Conn. kuswell, Erans Dounton (10) Koxburs, Conn. Stlliman. Cras. K. (8) Mystlc, Conn. - Steiner, Walter $\boldsymbol{H}$. (2) llartford, Conn.

Wright, Frank M. (i) Stamford, Conn.

willams, Carl Alonzo (i) New bondon, Conn.

\section{DISTRICT OF COLUMBIA}

\section{Washington}

Anderson, John $f^{\prime}$ (:) $35 t h$ and $F_{*}$ sts. N.W.

Baker, Frank (1) 1901 Hiltmore Are.

Butterfeld Elmore $\mathrm{E}$. (8) $1321 \mathrm{~T}$ st. N W Cart william l'hlllips (i) 1418 L st. 1 . Irtilicka, Ales (I) 29th and Tilden sts. N.w.

Kinyuun, Joseph J. (2, 10) 14:3 Chiftus sit. Lamb. Danlel smith (1) elit isth sit N. 1 :

Morgan, James budles (1) 919 15th si., N.W.

Nichols, Henry J. (2) Army Medleal sirhomi. Selby, John H. (B) 1621 Connectlcut Ire. N. $\mathbf{w}$.

weat, Charies Ignatius (1) 924 M st. $x$ w FLORIDA

I. Engle, Edward M. (10) Jacksonrllle, Fia GEORGIA

\section{Atianta}

Collins. Katharlne K. (2. 8) lia. State

Hoard of llealih.
Harris, Henry $\mathrm{F}$.
(2, 10) state loard of Healus.
Savannah
Hassett. Victor II. (1) (ity Hall.

Bassett. Victor II. (4) ity Hall.
Corson, Eugene It. (I) 10 Jones sit. w. State at Large

Lamar, Kichant V. (2) Augugta, Cia.

\section{ILLINOIS}

Chicago

Nit, Jos. L. (4) $1832 \mathrm{~s}$. Halsted st. Imtrera. Sanuel (t) ihildreus Memorlat Ilespital

Arkin, Morris 1. (1) 2701 Frerzreen Ave. Hacon, (harleg s. (t) 2156 Sedgwhek st Ihasuce, l'eter (t) 15 F. Waghlngton st. Kartlett. Frank $k$. (t) 1532 tonkresq st Haum, Wm. L. (f) $30 \mathrm{~N}$. Michlgan Ire. Heck, ('arl (t) $108 \mathrm{~N}$. State Nit.

keck. Jox. r. (t) $108 \mathrm{x}$. State st

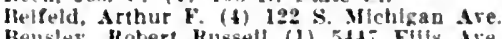
Rensley, Hobert Russell (1) 5iti Flifs die. Revan, Irthur Dean $(1,4) 122 \mathrm{~S}$. Mlligan Are.

ltillugs, Frank $(2,4) 122 \mathrm{~S}$. Mlchigan Are Rrown, kdw. Y. 1. (t) Peoples lias Hide. Brown, Sanger (t) is. Wabash Are Bryan, John $C$ (t) 553 is Sherluan $k d$. Buhlig, Walter H. (t) $31 \mathrm{X}$. State st. Capps, Jos. A. (t) 122 s. Mlchlgan Ive. Chanceltor, thitp s. (t) $2: 32$ Plne Grove Are.

Corbus, Budd Clarke (t) $32 \mathrm{x}$. State.

Corper, llarry J. (4) 2751 Windwor Ave.

cotinn. Alfred $(C$. (t) $3218 \mathrm{w}$. Jackson bird.

Croftan. Alfred C. (t) Field Annex Bldz.

Crovder, Thos, In (t) pullman $\mathrm{HId}$.

Cubbins, Wm. H. (t) 29 F. Maditon st

Culbertson. Carey (t) Ios $:$. State st.

rurtis, Arthur il. (t) 104 s. Michican ave

Dage. Thos. 1. (2. 4) 8 J. Stale st.

Dahl. Srenning (i) 2029 Plerce Are.

Darld. Vernon $($ (t) $:$ Wadison St.

Darls, lart

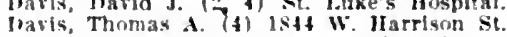

lavis, Nathan S. (t) $i$ W. Madison st.

lovis, Nathan s; (t) i W. Madison st.

he wits, 1,ydia M. (1, 2) Lulverstty of ("hicago.

Diek. Feo. F. (2. i) 122 s. Mlchican Are. bodson. John Milion $(1,4) 21$ F. Washing ton Sit.

bunn. Filizabeth Hopkins (1) 15 F. Wash. Ington sit.

Edwards, Arthur R. (1) 104 S. Michigan Are.

Elliote rhas, A. (4) 29 F. Madison.

Farlll Henry $B$, (t) $122 \mathrm{~S}$. Mlchlgan Are Futterer, Gustar (t) 15 k. Wasbington st. Gardner, Stella M. (t) $31 \times$. State st.

Gehrman. Adulph $(t)$ si $x$ siate st

Glllmore, Robt. T. (t) 30 ×. Michigan Are. fioldsmlth. Alexander A. (t) 29 k. Madiann st.

firadle, IIarsy S. (t) $32 \mathrm{X}$. State St

Grahan, bavtd Wilson (i) it k Washing. ton st.

(iraham. Fvarts A. $(2,4)$ 15 F. Washlngton sit

Grim. Tlymes J. (t) 31 x. State St.

Hamburger, Walter W $(2,4) 104 \leqslant$ Mlch. lgan Nie.

Uamlli, Filwin (d) 2901 Warren Ate.

IIanilli. Itaifh 1: (1) $15 \mathrm{k}$. Washington st.

II. nulleon. Ilice $(2,4)$ sino s. IIalstel st.

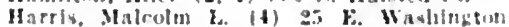

Ilarris, Sorman Mcl. (2, t) Iniversity of ithleago.

Ilartmann. Fredk. Stecle (t) 600 Biue Irland fire

II. ineck. Nine l'aut (4) $3: x$ siate St. II.ktoen, I. Lutvls (2, 4) $1: 43$ W. Har racon sit

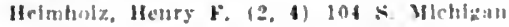

Here, labella $(4$ (4) 740 Maryland tre

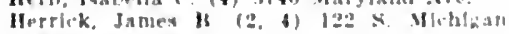

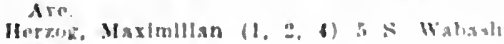
Ase.

Heqsert, Willtam (t) sit ki Puttersur. l'sirkusy

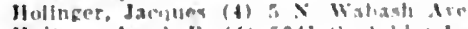

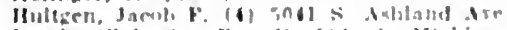

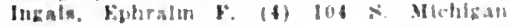
ine.

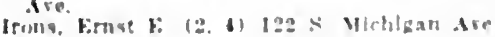
Jarkon. Harry (b) itio F. Stst st.

Jackoron, della II. (2, 4) Mlchael Heese Ifoxpital

Jaculue, John I. (1) is. Mabauh are

Johlling, James W. (2, i) Mlchael Reewe Humpiltal.

Johnson, Frank s. (t) 252 l'palrie Are.

Koetsoler, Kari kutual (:-4) 106 s. Slich. lasan die.

Kretwotumer. Herman L. (t) ag k. Madisun St.

Kuh. Sylney (4) $31 \times$ state st.

Kises, I'reston (1, 21 5221 Kernumbl Ave

lane, Erancly A (4) $725 \mathrm{~F}$. Washington sit

le count, bawin It. $(2,4)$ Gi)es Monge

Leuls. lrean 1). (1. H) 122 S. Michlgan Are lelererhat, liavid (t) $31 \mathrm{x}$. State st.

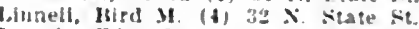
loomis, Filw. H. (4) lit Washington SL l.snch, Frank W. (1) 104 Hichigan Are. Macllartin, Duncan It. (t) $20 \mathrm{~W}$. Jackson Hivd.

Mi'Irthur, Iewis L. (4) 12: s. Michizan Are.

Mchenna, Chas. 11. (t) 104 s. Michigan Are. Mellng. Nels. (" (4) 3201 Armilaze ire Miller. Joxeph 1. (t) I Mondy, Nelbert M. (t) St. I.uke's Hoaptial. Montehead, Fredk. H. (4) li2: s. Michlgan die.

Moyer, Harold $\mathbf{x}$. (t) $31 \mathrm{x}$. State St.

Mueller. Geors, (t) 203 si siate st.

Murphy, John B. (4) 104 s. Michlgan Are.

bchsser, Alwert John (4) ilo Sedinwick St

Orusby, Ollver S. (t) $3: \pm$ state St.

Oshsner, Filw. H. (t) 2038 Lane Ch

Opradovec, Joseph (f) i235 l'nion ire.

1.arker, thasles Aubres $(1,4) ; W$. Madl. son $\mathrm{St}$.

I*atrick, Hugh T, (4) aj E. Washington s: Phemister, Jallas B. (4) 12. \&. Mirhigan Sie.

lietrowicz. Stephen $R$. (t) $209 \mathrm{~s}$ State St. I'Irnnt, Ferdinand II. (t) 2083 Eiergreen Ire.

lobliok, Iouls J. (t) 15 F. Wauhington st. lortis. Milton Moses (b) 129 \& Mfchlam Are.

Post. Wilbur E. (t) $122 \mathrm{~S}$ Mlichlgan Are. Preble, Roht. B. (4) 1518 N. Mearborn St l'senderasi, Joseph (t) 3201 Park Ave. lusey, Krown (4) $;$ it Madion st Purey. Wn. Allen (4) $:$ is Marlison St. yıune, Wm. F. (t) $31 \times$ state st.

Fituson. Steqben W. (1) 2431 s. Dearborn

Retzer, Robert (1) 343 : Womdlawn Are. Riley, Flosd A. (t) las s Mlablgan Are.

Hes. Emil (t) $32 \times$ siate $S t$ Iboherg, Oscar Theudore (4) $: 339$ Foster Are.

livienow, Fow. Carl $(2, t) 122$ S. Mlchlgat Are.

Rothxteln. Thor (2) 122 S. Michlgan Are kyan. Iawrence (4) $32 \mathrm{X}$. Sitate st.

santec, Harris $k_{\text {. }}$ (1) 2806 Warren Are

Selifert, Eolwarl 1 . (1) $11: 3$ Mllwatee Ire.

Shambatgh, Feorice F. (1) 122 s. Michl. gan ire.

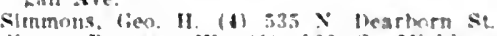

sipuy, liertran w, (t) las s. Mlchiean tre.

sfaymaker, Saml. Itoht (4) :5 F. Washlngton $s$

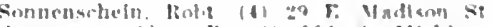

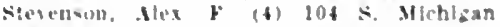

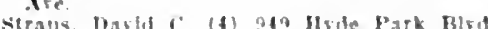

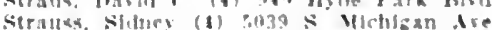
stromse, solonum (1) $10 \mathrm{~s}$ : Mirhtean Ire.

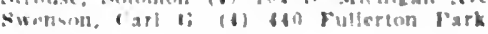
way

Thut, farmis, J (4) geth lemoune Si

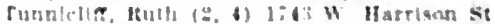

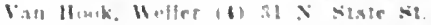

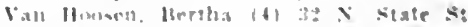

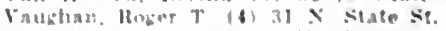

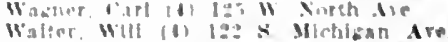

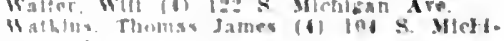
ball No

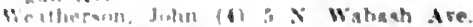

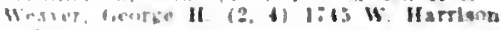
Wivier, John ("larmee $(2,4) 104$ S. Mlebl-

weluger, lialoh W. (2, t) as r. Washlngton

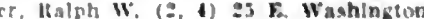


Welis, Edw. Franklin (4) $4: 44$ Woodlawn Wells, IIarry Gideon $(2,4)$ Universlty of ('lileago.

Wescott, Casslus D. (4) 22 E. Washlngtom st.

Wesener, John A. (t) "31 $\mathrm{X}$. Siate St.

Whise, Melohiur (4) $12 \%$ N. Western Are.

Willer, Wm. II, (4) Iozs. Nithlgan Ave.

whllams, John (c. (4) 5it Fullerton l'arkway.

Willainson, Chas. S. (4) 13.5 N. [letuborn

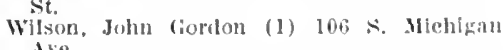
ire.

Woodyatt, ltullin T. $(2,4)$ 104 S. Mlchigan

Are. Aveit, Fredk. Robt. (2, 4) 401t; Vincennes Geit, Fredk. Robt. $(2,4) 4$
Ave.

Brennecke, Ilerman A. (4) Iurora, III. Gavin, Edw. Ford (4) Wallkeran, III. Blatchford, Frank W. (4) Winnetka, Ill. Kerr, Eilis lirk (4) Oak lark, Iil.

\section{INDIANA}

Alburger, Henry lk. (10) Indianapolis, Ind. Myers, Burton D. (1) Bloomington, Ind. l'otter, F. C. (10) Indiamapolis, Inci. Potter, F. C. (10) Indianapolis, Ind. Wlison, James Meredith (I) Indianapolis, Ind.

\section{IOWA}

\section{Des Moines}

Blerring, Walter L. (5) Equitable Bldr.

Condon, Jos. R. (5) Flynn Bldg.

Crowley, Daniel F. (5) Flynn Block

Cullen, George (5) IIippee Bldg.

Dorr, Edw. E. (5) Citizens Nat'l Bank Bldg.

Dublgg, Thos. F. (5) Fleming Bldg.

Fay, Oilver J. (5) Equitable 13ldy.

Glomset, Danl. J. $(2,5) 1235,3$ Ist st.

Grimes, Ell (5) Fleming Bldg.

Hill, Gershom H. (5) Equitable Bldg. Minassian, II rootune A. (5) Flynn Bldg Page, Addison Carey (5) Finuitable Bldg.

l'arker, Kalph H. (5) Equitable Bldg.

Parker, Itoht. L. (5) 3510 , 6th Ave.

learson, Wm. W. (5) Equitable Fidg. Peck, John H. (5) liquitable Bldg Posner, Edw. R. (5) Citizens Natl. Bank Bidg.

Priestley, James T. (5) Fleming Bldg. Ruth, Chas. E. (5) Equitable BIdg.

liyan, Granville N. (5) Capitol City Bank Bldr.

Sauders, Wm. E. (5) Equitable Bldg.

Steindler, Arthur (5) Flynn Bldg.

Stoner, Alva P. (5) Equitable Bldg.

Strawn, John T. (5) Equitable Bldg.

Throckmorton, Tom. B. (5) Equitable Bldg.

Welpton, Hugh G. (5) Citizens Nat'l Bank Bldg.

Bldg.
Werts, Chas. M. (5) Equitable BIdg.

\section{State at Large}

Albert, Ilenry (2) Iowa City, Ia.

Burt, C. W. (5) Valley Junction, Ia.

lloward, C. P. (2) Iowa City, Ia.

l'rentiss, H. J. (I) Iowa City, Ia.

Scheuer, M. II. (5) Valley Jumetion, la.

Sinith, Ferdinand J. E. (5) Little Rock, Ia.

\section{KANSAS}

Milne, Lindsay S. (2) Rosedale, Kan. Sudler, Jerrin I. (I) Lawrence, Kan.

\section{KENTUCKY}

Louisville

Baldauf, L. K. (2) 9 Eastorer Ct.

Hathaway, Joseph H. (1) 9 Maple Ct.

\section{State at Large}

Pryor, Joseph William (1) Lexington, $\mathbf{k y}$.

Evans, Newton Gordon (2) Murray, hy.

\section{LOUISIANA}

\section{New Orleans}

Bean, Robert Benmett (1) $\mathbf{2 3 3 5}$ Calhoun St. Couret, II. J. (2) 3803 Camp St.

Duval, Charles W. (2) 2024 Richmond Pl.
Mann, Gustave (1) Tulano University.

Matas. Rudoly (1) 3523 I'rytania st.

Van Wart, Itay Mel. (2) Malson Jtanche Bidg.

Weis, J. D. (2) I0S Baronne St.

\section{MAINE}

\section{Portiand}

(ierrish, Frederick IIenry (1) 675 Congress Sit

Milonough, Folward Josejh (1) 51 Deerlng sit.

sinth, Charles venulson (I) Matue deneral llosiplat.

Toble, Waiter E. (1) 3 Deering st.

\section{State at Large}

Elliot, Gilbert M. (1) Brunswick, Me.

Whitler, F. N. (2) Brunswick, Me.

\section{MARYLAND \\ Baltimore}

Austrlan, C. R. (2) Jolins IIopkins IIosjital. Bloodgood, Joseph C. $(1,2) 90 \pm \mathrm{N}$. Charles

St.
Cone, Claribel (2) The Marlborough.

Clark, Eliot R. (I) 1904 Eastern Ave.

Crowe, Samuel J. (2) 1206 Inden Ave.

('ullen, Thos. S. (1, 2) $3 \mathrm{~W}$. Preston St.

Essick, (harles Rhein (I) is 07 North Car olina St.

Evans, Herbert MeLean (I) 2036 L. 3 Lst St.

Ford, W. W. (2) 1024 Cathedral st.

IIalsted, William Stewart $(1,2)$ I201 Eutaw

l'l.
Ileuer, George Jullus (I) Johns Iopkins Iospital.

Kelly, Howard Atwood (I) 1418 Eutaw I'l. Kemp, George T. (I) 8 W. 25 th St.

King, J. H. (2) 1227 N. Calvert St.

Lewis, Warren Harmon, (I) 1931 E. 3Ist St., N.

Mall, Frankin P. (I) 1514 Bolton St.

Meyer, Adolf $(1,2) 1012$ N. Calvert St.

Moss, Wm. L. (2) Johns Hopkins Hospital. Sabln, Florence R. (I) 1431 Park Are.

Smith, J. Homes (1) 37 W. Preston St.

Sprunt, Thos 1'. (2) Jolins Ilopkins Hospital.

Thayer, william Sidney (2) 406 Cathedral st

(ieorge (I) I F Center St.

Welch, William H. $(2,10) 80 \pi$ St. Paul St.

Whipple, G. I1. (2) Johns Hopkins Hospital.

Winternitz, Milton C. (2) Jolns IIopkins liospital.

\section{State at Large}

Jamar, John II. (10) Elkton, Jd.

Lull, George F. (10) Takoma Park, Md.

\section{MASSACHUSETTS}

\section{Boston}

Adler, Herman M. (2) it Fenwood Itd.

Arms, Burdett L. (2) Mass. Institute of Teclinology.

Ash, James Earle (2) Harward Medical School.

Begg, Alexander S. (1) Harvard Medical School.

Bremer, John Lewis (1) 295 Marlboro St. Bowen, John T. (2) It Marlboro St.

Brooks, William Allen (1) 167 Reacon St.

Cheever, David (1) 20 Hereford St

Christian, Henry A. (2) Francis St. and Huntington Ave.

Conant, William Merritt (1) 486 Commonwealth Ave.

Councilman, Wm. T. (2) Harrard SFedical Sehool.

Cushing, Harvey (2) Peter Bent Brigham Hospital.

Dexter, Franklin (1) 247 Marlboro St.

Edsall, David Linn (10) 80 Jarlboro St.

Ernst, Harold C. (2) 240 Longwood Ave.

Fabyan, Marshal (2) 379 Commonwealth Are.

Floyd, Clereland (2) 1398 Beacon St.

Foot. Nathan C. (2) Ilarvard Medical School.

Frothingham, Channing Jr. (2) 51 Hereford St.

Goetsch, Emil (1,2) Peter Bent Brigham Hospital.
Homans, John (2) 164 Beacon St.

liopklus, Samuel A. (2) 235 Marlboro st.

Jacohson, Conrad (2) I'eter Bent Brlgham II ospital.

Karsner, IIoward T. $(2,10) 240$ Longwood Are.

Leary, Timothy (2) 44 Burroughs St.

Lewis, Fred. T. (I) Harvard Medleal school.

Mallory, Frank 3. (2) Harvard Medieal sichool.

Mefollom, John H. (2) Boston City Ilospltal

Mixter, Samuel Jason (I) 180 Marlboro St. Nichois, F. II. (2) 294 Nariboro St. Ordway, Thomas (2) 695 Huntington Are. lage, Calvin G. (2) 128 Mariboro St. Pratt, Jos. If. (2) 317 Marlboro St.

lthea, Jawrence J. (2) Peter Bent Brigham IIospital.

Richardson, Oscar (2) 485 Beacon St.

Robey, Wm. Henry Jr. (2) 202 Commonwealth Ave.

Rosenan, Milton J. (2) IIarvard Medical School.

Smith, Theobald (2) Harrard Medical school.

Strong, Richard P. (2) IIarvard Medical Sehool.

Taylor, Edward W. (1, 2) 457 Marlboro St. Tyzzer, Frnest w. (2) Irarvard Medlcal School.

Verhoeff, Fredk. Herman (2) I0I Newbury st.

Warren, John (1) 58 Beacon St.

Weysse, Arthur Wissland (I) 421 Jarlboro st.

White, Charles J. (2) 259 Marlboro St.

Wolbach, Simeon B. (2) Harvard Medleal sihool.

\section{State at Large}

Balch, Alfred W. (2) Brookline, Mass.

Conrow, Matthias W. (T) Springfield, Mass. Varling, Eugene A. (2) Cambridge, Mass.

Flournoy, Thomas (8) Pittsfleld, Mass.

Iloward, Fredk. II. (I0) Willlamston, Mass. Kinnlcutt, Roger (2) Woreester, Mass.

Jongstreth, Morris (I0) Cambridge, Mass.

Mellus, Edward Linden (1) Brookline, Mass.

Southard, Elmer E. (2) Cambridge, Mass.

Tickerman, Frederick (I) Amherst, Mass.

\section{MICHIGAN}

Ann Arbor

Barrett, Albert Moore (2) University Ilospital.

Camp, Carl D. (2) 924 Baldwin Ave.

Cowie, David Murray (2) 122 N. 4th Ave. De Nancrede, Chas. Beylard Guerard (10) 504 S. State St.

Edmunds, Charles Wallis (2) Lnirersity of Michigan.

Iewlet, Abian Walter (2) 1835 Cambridge Rrl.

Huber, fothliel Carl (1.2) 1330 Hill St.

Novy, Fredk. Geo. (2, i0) 721 Forrest Ave. Rowlind, Wm. D. (i) 317 s. State St.

Streeter, George Linius (I) 1025 Martin I'l. Vaughan, Victor C. (2) 221 S. State St.

Warthen, Alfred Scott (2) 1020 Ferdon Rd.

\section{Detroit}

Fremnd. Ilugo A. (2) 355 Woodward Are. Meloy, Carl R. (2) 636 Woodward Ave. Vaughan, Victor C. Jr. (2) 1939 Woodward Are.

\section{State at Large}

Dixon, Robert I. (2) Wahjamego, Mich.

Peet, Max. M. (10) Ypsllanti, Mich.

\section{MINNESOTA}

\section{Minneapolis}

Abbott, Amos W. (6) 1717, 1st Are., S

Adair, Fred L. (6) Donaldson Bldg.

Aurand, Wm. H. (6) 800 Washington Are. Avery, J. Fowler (6) Donaldson Bldg.

Baker, Earnest L. (6) Donaldson Bldg.

Baldwin, Louis B. (6) University Hospltal.

Baxter, Stephen H. (6) 2000 Hennepin Ave.

Beard, Riehard o. (6) Donaldson Bldg.

Bell, Elexious T. $(1,2,6) 215$ Walnut St.

Bissell, Frank S. (6) Donaldson Bldg.

Bradley, Chas. H. (6) Donaldson Bldg.

Chesley, Albert $(2,6) 904$ University Ave.

Chowning, Wm. M. (6) Donaldson Bldg.

Collins, Herbert 0 . (6) City Hospltal.

Condit, Wm. H. (6) Syndicate Bldg. 
Corbell. J. Jrank (2) Health lept. Plty IIall.

Drake. Chas. R. (6) swedlsh llospltal.

Drake, Chas. R. (6) Nwedlsh llospltal.
Erdman. Charles Anilrew (1) Colversity of Minnesota.

Farr. Robl. 1: (6) keid Corner.

(ielst, Emll s. (6) Syndlcate Bhis.

Green. Lugene $h$. $(6)$ lleld (orner.

liamliton, Arthur $s$ (6) Pillsbury Blalg.

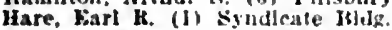

IIartzell. Thos. B. (6) Ponaldsin Bldg.

Head. Feo. D. (6) Donaldson Blde.

Alrschfelder. Arthur I). (1) Villersily of Minnesola.

fiynes, John B. (6) 3349 Lniversity Are. S. $\mathbf{E}$.

Irrine, Ilarry G. (i) Syndlcate Rld:

Jackson. Clarence II. (1) Inlverslty of Minnesota.

Johnson. Win. C. (6) Unlverslty of Minnesota.

Jones, Herbert W. (6) Pillsbury Bldg.

Jones. Wm. A. (6) Plllsbury Bldg.

Larson, Winford Porter (2) 614 9th Are. S. E.

Law, Arthur A. (6) Syndleate Bldr.

Lee, Thomas G. (1) Lniversity of IInnesota.

Llete. John W. (6) Reld Corner.

Litzenberg. Jennlngs C. (6) Donaldson Bldg.

Mann, Arthur T. ( 6 ) bonaldsol1 Bldg.

McDanlel, Orlanna $(2$, b) 914, 2d Are., S

McDanlel, Orlanna $(2,6) 914,2 d$ Are.
Moore, James F. (6) syndicate Bldg.

Moore, James F. (6) Syndicate I
Moren, Edw. (6) Donaldson Bldg.

Morrison Angus W. (6) l'illsbury Blig. Yullin, Robert II. (2) Cnlvers'ty of Minne-
sota.

Murray, Wm. R. (6) Syndlcate Bldg.

Sootnagel. Chas. F. (6) Andrus Ridg.

Poppe, Fredk. II. (ti) IPonaldson Bidg.

Rees. Soren P'. (6) 512 Nicollet Ave

Hingnell. Carl J. (b) 512 Nicollet Are.

tobertson, Harold E. (2) 50 : Essex St.. 8. $\mathbf{E}$.

Schuliz, Fred W. (6) Monaldson Mide.

Schwayzer, Gustar (6) bonaldson Bldg.

Seashore, Gllbert (6) Andrus Bld:.

Sedgwick, Jullus $P$. (6) Syndicate Blyg.

Strachauer. Arthur C. (b) syndicate Bidf.

Aweetser. Horallo B. (6) Masonle Teuple.

ilrich, Ilenry L. (6) Syndicate Bld.:

Weston, Chas. G. (6) Heid Corner.

White, Solon Marx (6) Bonaldson Blug

Wileox Archa F. (6) Donalilson BJdg

Wilcox. M. Hussell (6) Norweglan Lutheran

Deaconess Ilospital.

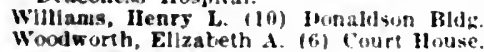

Wright, Franklin R. (6) Houaldsin Mldr.

\section{St. Paul}

Armstronz, John M. (6) Lokry Rldz.

Bacon, Lyle C. (6) Low ry Hlda.

Ball, Chas. K. (6) lowry Hldg.

Barton, Mroses (6) 763 Holly ire

Bendle. Wm. D. (6) low ry Blfs

Boerkmann, bilward (f) Lowry Hlde

Colvin, Alex $\mathrm{R}$. (i) Low ry lilly.

Coivin, Alex R. (b) Low ry Inly.

Parl, fieo. (6) Endicotl Bldit.

Ferzuson, James C. (6) Moore 13hlg.

Freeman. Chas. D. (6) lowry llidg

Gunllan, James S. (b) lowry klld

Greene, Chas. I.sman (i) l.oury itldg.

Hall, Alex K. (6) Jowry bldy.

Hammes, Ernest M. (6) rindlcott |Blig.

Hammond. James 5 . (6) lowry Jilde.

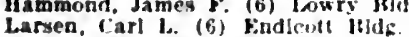

Larsen. Farl 1.. (6) Findlentl lidd

Lerche. Wilhelm (6) Lowry Blils.

Olson, Fredk. A. (6) l.owry Hil:

Ramsey. Walter $k$ (6) Low ry thd

Rigzs, Chas. E. (6) 350 lloleert st

Ritchle, liarry I. (6) Lowry Itldg.

Rothroek. John i. (6) (оокry Jls.

Schwyzer, A. (6) 123 W. th 5 .

Zimmerman. Harry 13. (6) Lowry Blin

\section{State at Larse}

Reebe. W. L. (6) st. Cloull. Minn

Braasch, Wm. F (i) Rochester, Ninn

Collins, Arthur $S$. (6) Juluth. Mirn

Busterman, (ico. is, (6) Hochester. Minn

Fisher. Cari (6) IBochenter. Minn.

Judd, Edwarl \&. (ti) llochister. Minn

Judd, Edwarl \&. (f) lechester. M

Linneman, Nicholas $I_{\text {to }}\left(f_{f}\right)$ julutls. M/1

Nacrarty. Willaim (2) (2) Rotiester, Minn
Martin. Thus. K. (6) Inuluth, Mins. Matthers, Justus (bi) Hichester. Minn Mayo. Fias. II (b) Iishester. Minn.

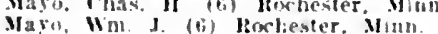
ICtirath. Bernard $F$ (a) liochester. Min

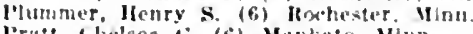

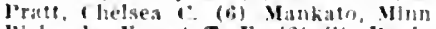
libbards. Firneat T. F. (2) St. Yaul, Mlm

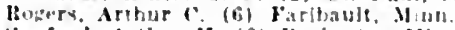
Sinford. Artlane H. (6) llowllester, Mtun. Shetelon. Walter 11 (b) dewhester, Minn. Envter, fiew. W, (ti) Belle l'labe. Mim Tuahv, Edward L. (ii) Duluth, Min

Wllan, Louls Blanehard (1. 2) Reoluever Ilinu.

valin. Honore D, (b) Mankato, Minn.

\section{MISSOURI}

Kansas City

IIall, Frank J. (4) I208 Wyandotte s'

Itertzles. Arthur E. (I) klalto Bldg.

IIII!, IIoward (1) Illaleo Bld:

schorer, Elwin II. (a) Kialto Rldg.

\section{St. Louls}

Barnes, Ngernon S. Jr. (10) Natlonal Bank Bld

Blalr, Vilray Papin (I) Metropolitan Bldg

Irock. George (10) ISOG I,neuxt sit.

Feisher, Moyer s. $(2,10)$ liarnard skin and Cancer Hospltal.

Uarrts, Downey. L. (2) Metropolitan Bldg.

(I) 5.35 . Grand dre.

skin and Cancer llosthe

Ople. Eugene 3. (2) Isob Locust St.

Pohlman. Nagust G. (l) St. Louis Inirer sity.

Rontinson. Geo. Canby (10) 4914 Forest Park IRlual

Sachi, Emest (1) 1s0ij Locust St.

Schoemaker, Daniel M. (1) 1602 S. (irand ire.

Seclig. Major G. (1) Wall Bldy.

Sluder, Creenfield (1) 3ife Washfu;ton Are.

smith, George Milton (I) ISOf I.must St.

Taussig. Frederick Joseph (I) Metropolitan BId!g.

Terry, Robert Innea (I) lsof Locust S:

Thempson, Ralyh L. (2) 1402 S. Cirand Ave

Tupper, l'al Yuer (I) Wall Blde.

Veuder, Burden $s$. (I0) St. Iouls Children's IIospital.

\section{State at Large}

Dolley, David II. (:2) Columbia. Mo

lliller, Walter McXab (1, :, Columbia. IIo.

Mlichell, Oliver W. II. (2) Columbia, Mo.

\section{MONTANA}

\section{Butte}

Potter, Peter (I) IIennesy IHIr Withersfoon. Thomas iasey (I) Murruy
Jlosplial.

\section{NEBRASKA}

Omaha

Akin, Ilenry I. (\$) City Nat'l Bank Mhds.

Andersun. Win. $x$ (g) Continental b!k.

Hliwe Belney W. (4) Mrandeis Theate

[3]dg.

Brldzes, bison l. (9) Jisandels Theatre lldis.

Thrlatle. Burton W. (9) hee Rlds.

comblon. Mbert 10. (2) Nicholas Sern Iluspital.

$15 l_{12}$

conlln, Frank M. (s) Braulels Theate

Itlds.

Jide. Drtitur o. (?) Mrantess

Findley. I'almes (9) Mrandele 13lile

Fltzsiminus Nexander W. (9) Hrandets Theatre hidg

Ford. Mirharl Joucpls (a) clity Natlonal Itank Hils

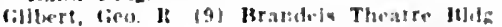

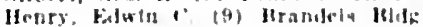

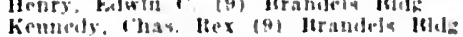

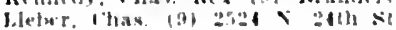

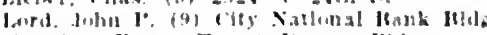

Mannfug, Hernes $T$ (9) loarcon llit:

Minire. Jedin clide (o) Mrandels ftlde

Newell, Ttaq. II (t) elty Natlonal Itank Ind:

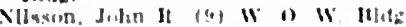

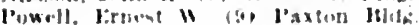

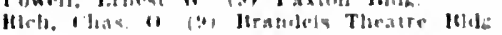

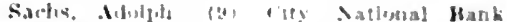

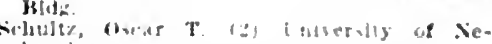
Silinitis,

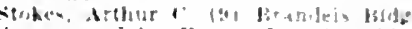

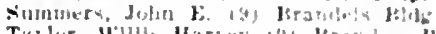

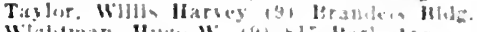

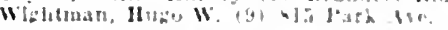
State at Large

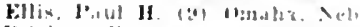

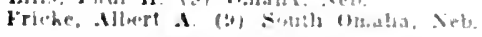

\section{NEW HAMPSHIRE}

Fromt. Cilman lublusic (I) Halloser, I

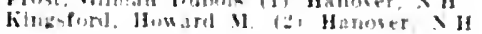

\section{NEW JERSEY}

Newark

Church Clus Ut (i) 110 loruat si

Hetrikh. Llewelly E. (i) Wiss Hud

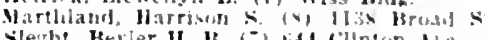
ilezht. Hevjer II 13. (I) eft tillnton the

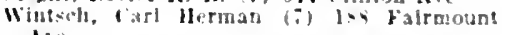
Is:

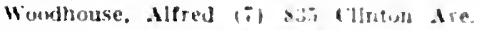

\section{State at Large}

Balley, Fredk, $\mathfrak{k}$ (s) kllkaleth, x.J.

Conaway, Walt londer (10) Mtlantle cley. I.J.

Chureh, Chas. I. (i) b'assaje. N.J.

llabls, Albert is (I) Comben $\mathbf{y}$

II ammond, Frederlck $s, 12 t$ Trenton, $N J$

lllckman, Walter A. (10) l'rinceton, ij.

Maps. Iloward I. (i) Vasale, N.J.

Mclaughlln. (Geo, E. (E) dersey flly, xJ.

Mersheimer, Chrlstian 1I. (i) Jersey (ity, X.I.

Paton. Stewart (I) princeton. $\mathrm{N}$.

keybolds, llarry (i) (i) Vassalc $\mathrm{N}$

keynolds. Walter in dilantle Clis. $x$ J.

liogers, llarry (i) Orange. X.J.

stern. Samuel (lit) Allantic (ity, XJ.

\section{NEW YORK}

Brooklyn

Aen. Wn. II. (i) il Gates Are

Berhuer. Irmo (i) ti Jierremat st

Hrowning, WJ]!Jam (I) if leteris l'].

Bursham, Clark (i) lve vlintun st.

(amplell, William trancls (I) 3.01 (jintou Ire.

be Nyse. Jercy I. (i) bis llaneock 51

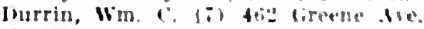

Becles. Rolert of (1) 6.1. J0th st

Freenan. Wm. H. (i) 263 Irlington Are.

llotke. Franz $\mathbf{k}$ w: (i) 30 irene Are

Hopkins, Joseph $f$, (s) sio Wa-hington ire.

Iszard. Walter IR. (i) It I St. Mark Are

Johnston. Keulues T. (T) मi: k. Parkuay

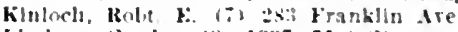

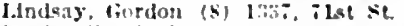

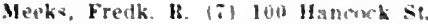

Mnak, llarris (a) atio l'ark l'l.

Nolle. llarrlet Janlet (b) abe lutnara Are.

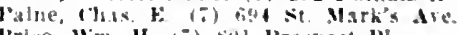

l'rice. Wm. II. (7) sil l'rovjest l'l.

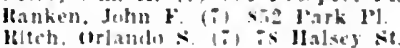

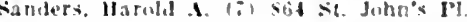

Topry, Henjanin $T$ (\&. s) 193 Iiedfond

Tilues, Frederlek (1) libl Irney st.

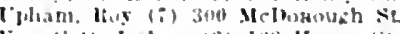

Van fout. Johna 1:1 los IIenry st.

Walmstry, lint: $\vec{b}$ (i) 191 l'utram Are.

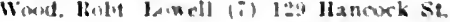

\section{Bufralo}

lents, (harles 1 . (2) st prante st. lhuman, Freal b (a) ffi Delawaro Are. Castord. Harver H 12. 101 113 Hich St. lithoun. Jamer I 11 1 10 Mariner SE lyon, irring I (2) sil Franklin st.

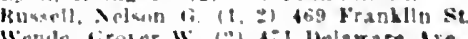

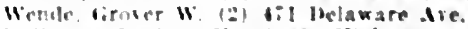
Williama, llertert $l^{\circ}$, (2) of lligh st.

\section{New Yort City}

Whine, Kulpert (s) 13 W soth st.

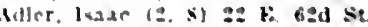

Atkinv, lolind th. (i) $106 \mathrm{~W}$. 96th st

Isers. Hurace b: $(:)$ s:o laxlagton Are

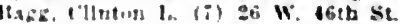

Itall. Jinfih II. (i) get Itirenide Inrire.

lian: Hollarl $T$. (x) libs W. llih se 
Bastedo, Wnlter A. (8) 57 W. 58th St, Jeach, Bennett shcidon (8) i44 W. 85 th St Beebe, silns 1'. (2) 17 F. 38 th st. Beer, biwin (8) $48 \mathrm{~W}$. 7 th St. lienson, leuel A. (i) 8 W. 49th St. Terkeley, Wm. N. (s) 133 E. tist St. Bickley, lobt. S. (7) 455 W. 34tis st.

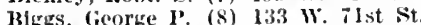
Bingham, Anson H. (7) Broadway and s5th. Bishop, Jouis Faugeres (8) 54 W. 55 th st. Bishop, Win. H. (i) 667 Madison Ave Blake, Joseph Augustus (1) $10 \mathrm{~s}$ W. bith st. Bochm, Emil (R) Bellerue Ifospital.

Bolduan, (harles F. (\&) Ft. Washington Are and 17 oth $\mathrm{st}$

Bovalrd, David (8) $13 i$ E. 60th St. Hoyle, Chas. (i) (i) 40 E 4lst st. Bradier, John C. (7) 837 Matison Ave. Brill, Nathan E. (8) 48 W. Foth St. Brocier, Nathan E. (7) 321 , 6ih st. Brooks, Harlow $(2,8) \quad 4.4$ W. 9th st. Brown, Aifred .J (1) 156 E. 64th St. Brow, Tinomas D. (i) 210 W. $5 \pi$ th St. Buerter, leo $(2,8) 40$ E 41 st st. Bull, Carroll G $(2,4)$ Rockefefler Institute. Burrow, Montrose $T$. $(1,8)$ Cornell Untversity.

Carleton, Bukk G. (i) i5 w. 50th St. Carleton, Sprague (7) $75 \mathrm{~W}$. 50 th $\mathrm{St}$. Carter, De Lancy (\$) 1030 Inrk Ave. Case, Wm. I. (7) 68 E. 86 th $\mathrm{St}$ Cecll, Russeli L. (8) 123 E. 62d St. Chase, J. Oscoe (i) 214 E. 53d St. Clark, Bert B. (i) 200 W. 86th St. Clark, Byrou (T) 251 V 75 th St. Clark, James Bayard (8) 616 Madisoll Ave. cour (7) 39 W. 67th st. Cohu ulfred F. $(1,2,8) 315$ Central Park w Cole, Rufus I. (2, 8) 960 Park Are. Cole, Jiarian lage (i) 1748 Broadway. Cole. Hills ( 7 ) 1748 Broadway. Coleman, Danl. E. S. (i) 101 W. 78 th St. Coleman, Warren (8) 58 w. 55 th $\mathrm{St}$. Coley, William B. (8) 40 F. 41 st St. Collins Vtm (7) 135 , 5th Are.

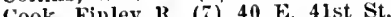
Cookeland loyal S. (i) 58 (central Park W. Copeland, Woyal 5 . (i) 837 Madison Ave. Crump, Water (6. (6) 49 W. $52 \mathrm{~d}$ St. Danforth, Loomis L. (7) 40 W. $52 \mathrm{~d}$ St.

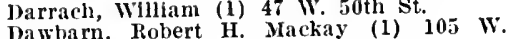
74 th $\mathrm{St}$

Dearborn, Fredk. M. (i) 855 ith Are. Denton, Myrol P. (8) 129 F. 30th St. Dieffenbach, Wm. H. (7) 256 W. 57 th $\mathrm{St}$ Dixon, George A. (8) 15 W. 49th St. Donfuick, Geo. C. (i) 70 W. 55th St. Dowling. John Wm. (7) 616 Madison Are. Dowling, John Wm. (7) 233 Lexington Ave Duncan, Chas. H. (7) 233 Lexington At Dunham, Edw. K. $(2,8)$ 35 E. 68th St. Eisenbrey,

Elsberg, Chas. A. (8) 701 Madison Are. Eiser, Wm. J. $(2,8) 28$ th St. and 1st Ave. Emmet, Thomas Addis (8) 89 Madison Ave. Ewald, Louis A. (8) 48 E. 87 th St.

Ewing, James $(2,8) 264$ W. 57 th St.

Fwing, James $(2,8)$ W. $(2,8) 717$ W. 17th. Ferguson. Jeremlah Sweetser $(1,8) 330 \mathrm{~W}$. 28 th $\mathrm{St}$.

Field, Cyrus W. $(2,8)$ Bellerue Hospltal. Fobes, Jos. H. (7) 1 W. 68th St. Fordyce, John A. (8) 8 w. 7 th St. Flexner, Simon $(2,8,10) 150$ E. 61st St. Foster, Harold A. (7) 859, 7th Ave. Fox, Fred J. (8) 124 E. 19th St.

Frank, Robert T. (8) 983 Park Ave. Freeman, Rowland G. (8) 211 w. 57th St. Faines, John S, (7) $200 \mathrm{~W}$. 7 1st St. Gaines, John S. Bern Budd (1) 110 F. 16th St. Garbat, Abram Leon (2) 71 E. 91st St. Garrison, John B. (7) 616 Madison Ave. Gibney, Virgil P. (8) 16 Tark Ave. Gillingham, Horace P. (i) 170 W. $82 \mathrm{~d}$ St. Ginnever, Arthur (i) 39 W. 58 th $\mathrm{St}$. Goodman, Abraham L. (8) 136 W. 87th St. Hall, Ilorton E. (8) Bellevue Hospital. IIallet, Geo. De W. (i) 274 W. 86 th St. Hallock, Frank if. (T) 150 W. 80 th St. Hanes, Fred W. (8) 170 W. 72d St. Harrington, Gove S. (7) 487 W. 145th St ITastings. Thos. W. (2) 172 E. 71st St. Jatch, John L. (10) 30 W. 51st St. Haynes, Irving Samuel (1) 107 W. 85 th St. Helfrich, (has. If. (7) 542, 5th Are. Heimuth. Wm. T. (i) 774 Madison Are. Hess, Alfred F. (2) 16 W. 86th St. Hill. Darid B. (i) $30 \mathrm{~W}$. 48tin St. Hiliman, Oliver S. (8) 303 E. 20th St.
Ilolilster, Fredk. K. (7) 521 Madlson Ave. Holt, luther Enmett (8) 14 W. 55th St. Ifonan, Wm. F. (7) 15 W. $73 \mathrm{~d}$ St. House, Waliace B. (7) 135 W. 78 th St. ltull, (ieo. A. (7) 123 W. 730 St. IImphreys, Fred 13. (8) 630 W. 141st St. llumt, James R. (10) 20 W. 50th St Ituntington, (ieorge S. (1) $437 \mathrm{~W}$. 59th St. Huntoon, Frank M. (8) $42 \%$ W. 160 th St. Jackson, Frank W. (8) 555 Madison Ave. Jacoht, Airaham (8) 19 E. 4ith St. James, Jobert C. (8) 58 W. 55th St. fames, Walter 13. (8) 17 W. 54th St. Janeway, Theodore (C. (S) 131 E. 60th St. Jeffries, Ferdinand If (8) 341 W. 50th St. Jessup, Iavid S. D. (8) 601 W. 113th St. Jones, Robt. M. (i) 136 Madlson Ave. fudson, Adoniram B. (8) 53 Washington Sifuare.

Kast, ludwig W. (8) 771 Madison Are. Kaufman, louls R. (T) 150 W. 80 th $\mathrm{St}$. keller, Fred C. (8) 255 W. 90th St. Kellorg, Edwin $W$. (7) 855 , 7th Are. Kessel, Leo (8) 146 Central Park W. Kimbali, I'aul w. (8) 121 k. 64th St. King, Wm. H. (7) 64 W. 51st St. Kneer, Ferdinand G. (8) $236 \mathrm{~W}$. 5lst St. Fohn, Albert (8) 122 E. $58 \mathrm{th} \mathrm{St}$. haidlaw, Geo. F. (7) 58 w. 53d St. Jamb, Albert R. (8) 146 E. 74th St. Lambert, Adrian V. S. (1) 168 E. 7 1st St. lanbert, Alexander (8) 43 E. $72 d$ St. Lambert, Robt. A. (8) 437 W. 59th St. Jangmann, Gustar A. $(2,8)$ i21 W. 57 th St. Lapowski, Boleslaw (8) 180 W. 58th St. Iarkin, John H. (8) City Hospital. Leale, Charles A. (8) 604 Madison Ave Leale, Medwin (8) 852 lexington Ave. reao, Francisco Garcla Pereira (i) 575

Levin, Isaac $(2,8) 119$ W. 7 lst St. L'Fsperance, Iilise (8) Cornell Medical Scilool.

Lewis, Danlel (8) 616 Madison Are. Libman, Richard (8) 565 Park Ave. Lockwood, Geo. Roe (8) 18 E. $52 \mathrm{~d} \mathrm{St}$. Loizeaux, Leon S. ( t) 155 F. $72 \mathrm{~d}$ St. Longcope, Warfield $(2,8) 680$ Madison Ave. longcope, Frederick Albert (7) 2 W. 86 th St. Lutton, Geo. W. (7) 59 F. 65th St. Lynde, George S. (8) 148 w. 85th St. MacAdam, Edw. Wallace ( 7 ) 17 E. 184 th St. Maccallum, Wm. Geo. (8) 437 w. 59 th St. Mac('urdy, John T. (2) Ward's isiand. Machale, Ferdinand (8) 317 E. 87th St Mar.Neal, W. J. $(1,2,8) 303$ E. 20th St. Maeder, John S. (7) 123 W. 121 st St. lahuken, Harry c. (7) 33 w. 6lst St. Mannken, Harry C. (8) 150 F. 40th St. Mandlebaum, Fredk. S. $(2,8) \quad 1300$ Madison Mandle

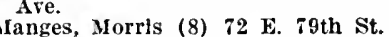

llanuheimer, feorge (8) 41 W. 5lst St. Mlarkoe, Janies W. (8) 20 W. 50th St Mayer, Abraham (8) 40 E. 60 th $\mathrm{St}$. Martin, Walton (1) $25 \mathrm{~W}$. 50 th $\mathrm{St}$. Nattison, Norman D. (7) 33 W. $42 \mathrm{~d}$ St. McAlpin, David Hunter (8) 68 Willlams St. IfCDonald, Ellice (8) 174 W. 58 th St. McDowell, Geo. IV (7) 40 E 41 st St. McDowell, Geo. Marshail W. (7) 571 Park Ave McDuffe, Marshall W. (7) 571 Park Ave. McLean, Wm. (7) 391 West End Ave. McMichael A. R. (7) 971 Madison Are. McNutt, Sarah J. (8) 265 Lexington Ave. McWhorter, J. E. (1) 435 W. 59 th St. Meltzer, Sami. J. $(2,8) 13$ W. 121 st St. Meyer, Willy (8) 700 Madtson Ave. Milier, James D. (7) $70 \mathrm{~W}$. $52 \mathrm{~d}$ St. Moeller, Henry $\mathrm{N}$. (8) 341 W. 57 th St. Hoore, Saml B. (i) $265 \mathrm{~W}$. 81st St. Moore, Saml B. (i) 265 W. 81st St.
Morgan, Thomas H. (1) 349 W. 5lst St. Mosehcowitz, Alexis V. (8) 925 Madison Ave. Moschcowitz, E. (8) 41 W. $83 \mathrm{~d}$ St. Iosser, Fredk I. (i) 784 Dawson $\mathrm{St}$ Munson, Edwin S. (T) 8 W. 40th St Murphy, James B. $(1,8)$ Rockefeller Institute.

Murray, Archibald (8) 36 Gramercy Park. Iyles, Robert C. (8) 46 W. 38th St.

Noguchi, Hideyo (2) 66th St. and Are. A.

Norrie, Van Horne (8) 21 W. 37th St.

Norris, Charles $(2,8) 2131$ Broadway.

Northrup, William P. (8) 57 E. 79 th St.
Noyes, Wulliam Bradbury (8) 221 W. 5it Oberbeck, August F. G. F. (7) 292 Manhat$\tan$ Are. Oleott, Geo. P., Jr. (7) 977 Lexington Ave.
Oppenheimer, Bernard S. (8) 125 W. 86th St.
Ost rom, Ifomer I. (7) 130 W. 57 th St. lackard, Charies W. (8) 445 l'ark Ave. Jappenhelmer, Alwin M. $(2,8) 309$ W. 99th Park, Wllliam Hallock $(2,8) 315$ W. 76th St. l'atterson, Henry $\$$. (8) 130 E. 62d St. l'ease, Iferivert 1). $(2,8,10) 39 \mathrm{~W}$. 38th St. Peterson, Frefierick (8) 20 W. 50th St. I'hthips, Carlín (8) 166 W. 72d St.

Jolk, William M. (8) 7 E. 36th St.

l'ollitzer, slgmund (2) 51 E. 60th $\mathrm{St}$.

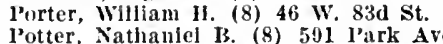
l'rudden, Theophlie M. $(2,8) 160$ Central Park S.

Rabe, Rudolph Fredk. (7) 616 Madison Ave. KankIn, Egbert G. (i) 226 W. 59th St. Ray, Edgar 'T. (8) 824 St. Nlcholas Are. Rice, Clarence C. (8) 123 E. 19th St. liordan, Patrick D. (7) 1273 Lexington Ave. litchie, Fred (i. (i) 247 W. $72 \mathrm{~d} \mathrm{St}$. Roberts, Geo. W. (i) 170 W. 59 th St. Rebinson, Andrew R. (8) 159 W. 49th St. Rous, Francis Jeyton (2) Rockefeller InRous, Francis Jeston (2) Rocket Rusself, Fredk. F. (2) M.C., U.S.A. Sachs, Barney (8) 116 W. 59th St. Satterlee, Francls Le Roy (8) 6 W. 56 th St. Satterlee, Geo. R. (8) 125 W. 58 th St. Satterthwate, Thomas E. (8) 7 E. 80th St. Sayre, Reginald Hall (8) 14 W. 48th St. Schlapp, Max G. (8) 40 E. 4 Ist St. Schley, Winfleld Scott, Jr. (8) 24 W. 45 th St. Schulte, Hermann Yon W. (1) 437 W. 59 th St.

Schultze, Otto II. $(2,8) 72$ Lafayette St. Sehwartz, Benj. (8) 1902, 7th Ave. Schwarz, Herman (8) 50 E. 91st St. Seaman, louis 1. (8) 247 , 5th Ave. Seward, Fredk W. (i) 200 W. 70 th St.
Seward, John Perry (7) 200 W. 70th St. Shelby, Edmund P. (8) 116 W. 74th St. Shepard, Geo. A. (7) 859, 7 th Ave. Simonson, Jeremiah T. (7) 46 W. 85th St. Sittenfield, Maurice J. (8) 73 E. 90 th St. Smith, Ernest E. (8) 50 E. 4 1st St. Emith, Frederick M. (7) 56 w. 50 th St Emith, Frederick M. (7) 56 W. 50 th St.
Sondern, Frederlc E. $(2,8) 200$ W. 56th St. Sondern, Frederlc E. (2, 8) 200 W. $56 t h$.
Stearns, Guy B. (7) 180 W. 59th St. Stein, Arthur (8) 11 E. 68 th St.

Stein, Richard (8) 79 E. 79 th St.

Stcinhardt, Edna $R_{\text {. }}(2,8)$ Research Laboratory, E. 16th St.

Stewart, Ralph A. (7) 616 Madison Ave Stimson, Danlel M. (8) 28 W. 37 th St.

Stow, Bond (8) 200 W. T0th St.

Stow, Bond (8) 200 W. 70 th St.
Strong, Lawrence W. (8) 90 Morningside Drive.

Strowger, Chas. W. (i) 163 W. 91st St. Swift, Edw. P. (7) 170 W. 88 th St Swift, Homer F. (8) Rockefeller Instltute Hospital.

Symmers, Douglas $(2,8) 338$ E. 26th St.

Taylor, Richard M. (8) 301 E. 20th St.

Teets, Chas. E. (7) 353 , 5th Ave.

Thacker, John S. (8) 20 W. 50th St.

Thalhimer, Wm. M. (8) 46 W. $83 \mathrm{~d}$ St.
Thomas, Philip C. (7) 44 W. 77 th St. Thomas, Philip C. (7) 44 W. 77 th St.
Thro, William C. $(1,2) 547$ w. 158th st. Townsend, Irving (T) 150 E. 59th St Turck, Fenton B. (4) 14 E. 53d St.
Turner, Reeve H. (7) 522 W. 149th St. Turner, Reeve H. (7) 522 W. 149th
Tuttle Edw. G. ( 7 ) 61 W. 51st St. Tytler, James E. (7) 113 W. 126th St. Van Beuren, Frederick T., Jr. (8) 812 Park Ave.

Vance, Benj. Morgan (8) Bellerue Hospital.

Vanden Burg, Wm. H. (i) 30 W. 48th St. Vogel, Karl M. $(2,8) 680$ Madison Ave. Von Bonnewitz, Orlando R. (7) 2030 Broadway.

Wakefield, Homer (8) 106 Morningslde Drive. Walker, Henry F. (8) 18 W. 55th St.

Wallace, Guy (8) Bellevue Hospital.

Wallin, Alfred C. (7) 468 W. 145th St.

Ward, Wilbur (8) 24 w. 50th St.

Warren, Mortimer (8) Roosevelt Hospital. Webster, Carlos Green (7) 371 Bedford Park Blvd.

Weil, Rlchard $(2,8)$ 970 Park Ave.

Weisse, Faneuil D. (1) 36 Gramercy Park.

Welch, John E. $(2,8) 138$ W. 70th St.

Welt-Kakels, Sara (8) 71 E. 66th St.

Whipple, Allen 0. (1) 981 Madison Are.

Whitney, Geo. W. (T) 213 w. 137th St.

Wiener, Richard George (8) 48 E. 65th St. Wiener, Solomon (8) 67 W. 89th St. 
Whicox, Herbert $\mathrm{H}$. (9) $159 \mathrm{E}$. Foth St. Wlicox, Sldney F. (i) 11 W. $52 d$ sil. Willams, Auna w. $(2,8) 549$ itiverwise Drive.

Wilson, John E. (i) 616 Madlson Are.

Wilson, hotr. $J$. (8) 549 Miserside Drive.

Withington, Irving platt (i) $55 \mathrm{th}$ st. and ith Are.

Wollsteln, Jartha $(2,8) 325$ Central Park W Wood, Yrancls Carter $(2,8) 200$ W. 56 th st. Graduate Medieal School.

Wylle, Walker (ill (8) 28 W. toth $S t$

Zinsser, Hans $(2,8)$ sit w. 103d st

\section{State at Large}

baldwin, biward R. (2) Sarause Lake, Y.Y Beattle, Joseph II. (i) Dubls Ferry N.Y. Peers, Merrlit I. (i) Middletown Jellby, (ieorge $\mathbf{H}$. (2) Albany, X.Y. Bernsteln, Harry s. $(2,8)$ Albany, $x . y$ blrch, Chas. E. (7) White Plalns, $\mathrm{N} . \mathrm{Y}$. Brewster, Geo. F. (i) Mlddletown, X.Y. Brickner, Samuel Max (1) Saranac lake,

Burt, James k. (i) Jake George, X.Y. Cheesman, Timothy M. (2. 8) Garrison, N.Y. Coca, arthur F. (2. 8, 10 ) Flushing, $X Y$ Couch, louls B. (i) Nyack, N.Y, Cralg, Joseph Darls (i) Albany, N.: luckworth, Willard D. (i) White plains, N.Y.

Ellis. IJubert (i) Elmhurst, N.Y. Eimmel, Alfred c: (i) Mlt. Vernon, XY. liardy, Arthur H. (i) Mi Vernon, NY. liarrey, Samuel Clark (s) Liberty, $\mathrm{Xi}$ Hawn, Clinton B. (2) Albany, N.Y. IIII, Eben Clayton (1) P'uughkeepsie, XY. Henderson, Alton S. (i) Huntington, X.Y. Fufrman, Otto (s) Albany, ... ires, Nathantel II. (i) ML Vernon. N.Y. ires, Nathanlel II. (i) Ml Vernon,
Kelth, Horace G. (i) Yonkers. N.Y. Kerr, Abram T. (1) Ithaca, N.Y. King, Herbert M. (2) Loomls, N.Y Kinghorn, Hugh M. (2) Sarande Lake, X.Y Kingshury, Benjamin $F$, (1) ithaca, $\hat{y}_{\text {K }}$ Krause, Allen $\mathrm{K}$. (2) Saranac Lake, N. Krumwlede, Charles, Jr. (2, 8) Bronx
X.Y. Jacobson, Frank A. (i) Sewhurg, N.l: Jempe, George Fiustare (1) Lilb lake, I.Y Miller, Carlos J. (6) White I'lalns, Ny. Moore, Veranus A. (2) thaca, $\mathbf{Y}$ : Powell, Wm, M. (10) (layton, xis. Rltchle, Ellsha R. (7) Brewster, N.Y. Hoberts, Darld J. (i) New Hochelle, Xy Sampson. John Albertson (i) Albany, if Sayre, Harry $C$ (i) Warwlek, N.Y. Simpson, Sutherland (1) Ithaca. N.y L.I., N.Y

stanton. Fdwln McD. (2) Schenectady, N.Y Steensland, Halbert Severin (1,2) syracuse N.Y.

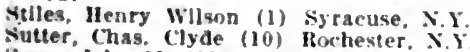

Swan, John M. (10) Hochester,

Trotter, James P. (7) Yonkers, N.:

Wadsworth, Augustus B. (2. $\mathrm{xl}$ Albany, I Y

White, fieo. S. (i) Yonkers, X. Y

Winne, Charles k., Jr. (2) Jlilany, X.

\section{NORTH CAROLINA}

Blggs, Montgomery H. (10) Hutherfordton.

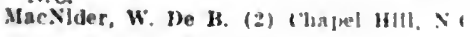

\section{OHIO}

\section{Cincinnat}

Malone, Kdward Fall (1) "The Naplewusl"

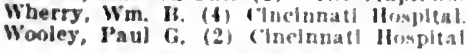

\section{Cleveland}

(rille, Georke W. (1, 2) $0+1$ w)rn Holg

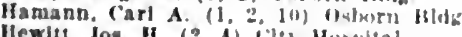
llewltt, Jos. H. $(2,4)$ rley Hompltal. Howard, Wm. T. (1. 2) $3 \times 3 \times$ Fo bisth st

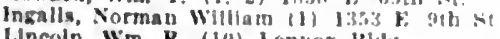
l.Ineoln, Wra. R. (10) bennox Blug:

Marine, Darld (2) Wiestern Itevervi Weduenl school.

Perkins, Itoger G. (a) Wevtern Hiverse Mid. Iral school.

\section{Stale al Large}

liayhurst, Fimery line (1) iolumbus, I) Mecamplell, Fugetie $F^{*}$. (2) Columbus, "

\section{PENNSYLVANIA}

Philadelphia

Ibbutt, Alexander $C .12,10)$ lnburalty of Veunsylvinta.

Adler, Lewls H.. Jr. (10) 1610 Arch si

ddison, Wn. lienry fitzerald (1, 10)

Inlwersity of Pennsstiania.

Nlen, Nifrod lleqhald (2) 2013 spruce St Hllen, lather M. (10) 3100 Wharton sit. Nliyn. Herman tt. (10) 501 s. 42d st. Huders. Nndrew 110$) \quad 2200$ N. $200 \mathrm{ll}$ Nit. Anders, Janies It (10) libi5 Walnut st. Inspan.h, Brooke 3. (10) 119 s. toth st irtelt. Henry (10) $1521 \mathrm{~N}$ sth st.

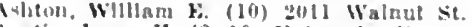
lioth, James 11. (2, 10/ [ulserslly Hosjital. Hatson. Wu. Wayne (10) 20:3 Walnut st linker, lieo. Fs (10) lsix sirnce st. llaner. Marle i. (10) 1013 Falrmount Ave lkatrdaley, Edw. John fillesple (10) 2030 ihevinut sit.

lestes, Henry, Jr, (10) 260 s. Jith St. Hehrend. Moses (10) 142\% $\mathrm{T}$. Broad St. Kennet?. Win. H. (10) 1837 Chestnut st. litereus. Mernard (10) 2061 Chestnut sit. hereus, Bernard (10) 2041 Chestntit st lernhelm. Allert (10) 1225 spruce st. Bethel, John I'. (10) 182.5 Falrmount Are. liackwool, James bouglas, Je. (10) 534 Wasne die.

lHand, laseal Itrooke (10) 3621 spruce st Bochrodi. Max H. (10) 1533 Plne st. Poger, John A. (10) $2213 \times$ s. Itroad St. Bolce, J. Morton (10) $\mathbf{4 0 2 0}$ spruce $\mathrm{St}$. Bonnes. Charles W. (10) 111 St. Buyer, Henry Perclval (10) 4602 Baltimore ise.

Brinton, Ward (10) $1+23$ Spruce st

krown, Claude P. (10) 33d and Diamond Sits.

Hrown, Harry MacV. (I0) \$608 Haltimore Are.

Brubaker, Alvert P. (10) 3426 Powelton Are. kryan. Jos. Koberts (10) $\$ 200$ ('hestnut st Buckley, Nbert (C. (10) Friends' Asylum for the Insane.

Hurr, Charles W. (II) 1918 spruce st Ruscb, John Willtam (10) $2500 \leqslant 1$ sth st Cadiralader. Wlllams B. (10) 1710 Locust. ('arncross, Horace L. (10) 103 spruce st.

Carnett, John lerton (10) 1:3 s. 20th St. Carpenter, Howard Chllds (10) 1805 spruce

Care, Eugene A. (10) 590; J.ansdowne Ave iattell. Henry W. (10) 3709 spruce st. chestnut, James C. (10) 1817 rrankford Are.

Vlark, John F. (10) 2017 Walnut st.

Cohen, Abrabam Joseph (10) 523 ine st

(v)luen. Jacob solis (10) 1824 (hestuut st.

Crilien, Meger sulls (1ii) dliz rirard Ave

Cohen, Solomon solls 110$) 1505$ Walnut st

culey. Thomas luther (10) 25tj \& 15th st. roje, Thomas A. (10) 6riot liermantown Coplin, Wm. M, Late $(: 2,10)$ folt s. Asth (ralg, Frank o. (10) 2030 Chestnut st. crulce. Johit il (10) is 15 soruce st. (ryer, Matthew H. (10) 1623 Walnut st currle, Thomas 11. (10) 512 Lehlih Ire.

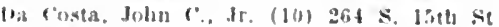

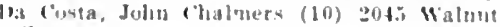

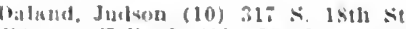

d'Aluery, Tellos J. (10) Fit X. foth st. liarrach. James (10) 50923 lirvelle st llavis, linllym Geo, (10) 1814 suruce sit. beaver, Harry Clay (10) 1415 \& Hruad st. beaser. John Mlalr (10) 1634 Walnut st. bercuts, Francls Xavler (10) 1719 Walnut

liespard, luncan l. (10) 1800 ine sit. liever. Francls $J$. (10) 319 \&. Isth st. libtentass, llenry (10) 115 bine st. Horrance, dieorge Murrls (io) 21025 Walnut Nis.

lurwurth, ('harles $V,(10)$ 1520 birte 160 inugherty, sherborne Win. (10) z'st s' loth

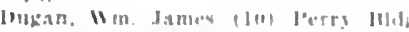

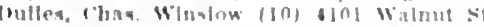

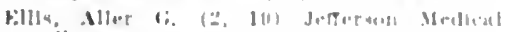
rollower

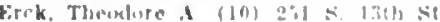

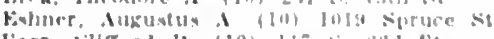

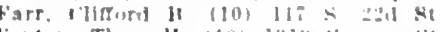

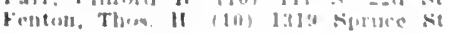

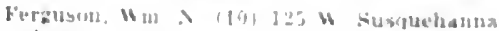
Are

Fetterolt. Vierrize (1, 10) 330 S. 16th St. Flfe Clias A 110$)$
Fischells. Fluber, Itenry M. (10) $102 \pi$ Inge st. Fllck, I.awrence $y$ (10) 33.5 I'lne st Fox, Ifertiert (2, 10) 3902 I.ocus? it for. 1. Wehster (10) 1636 suruce st Francine, Alters Phllip (10) 1932 Sprume st rizler, Thartes Harrison (10) 1721 Siruce

Feeman, Frank k. (10) 1231 X. Goth st Funk, Eruln II (10) Jeferson Hosultal.

Fusselt, Mllton lloward (10) 2035 Walnus sit.

litisler, Howard 11. (10) 35 High st.

fillbride. John J. (10) 193 Chestnut sit.

tillersleeve, Nathanlel $(2,10)$ Cniversity of l'ennsylvanta.

Ginsturg, Nathanlel (10) 1704 Pine St Girm, John H. (10) 2120 Walnut St Eligar Willes (10) $271+$ Colum. bla Ave.

Goldberg. Harold G. (10) 1925 Chestnut St Goldsmith, Sidney Byron (10) 2ti $\mathrm{S}$. $13 \mathrm{th}$ Goodman, Edw. II. (10) 248 S $21 \mathrm{st}$ Sh. Gordon, Alfred (10) 1812 Spruce St.
Graham, Edwin F. (10) 1;13 Spruce St. Gray, Clarence Hamliton (10) 1803 Chest. nut $\mathbf{S t}$

Grayson. Chas. Prevost (10) $262 \mathrm{~S}$. 13th St. freenman, Whiton J. (1) 351 is Woodland. lirifith. J. P. Crozer (10) 1810 Spruce St. inlloyle, Wm. Frank (10) tols thesizus. Gummes, Frank B. (10) 5 tis freene st. Gwyn. Jorman B. (10) $20 \mathrm{~s}$. 21 st St. IIamill. Saml. MeCHntock (10) I822 Spruce St.

Hammond. Ler! Jay (10) 1922 Spruce St. Hand. Alfred, Jr. (10) 1724 Plne St. liare, Hohart Amory (10) $181 \mathrm{~h}$ and spruce. Hartz, llarry J. (10) 1002 Jackson St. llartzell. Milton R. (10) 3644 Chestnut st. Hatfleld, Chas. J (10) 2005 Walnut St. Hawke, Wlifred W. (10) $21 \mathrm{~S} S$. 16th St Head. Joseph (10) 1500 I,neust St. Helsler. Jnhn C. (1) 3599 Wainut st. llenry, Frederlek 1. (10) 114 S. 18th St. Jenry, John X. (10) 1906 Spruce St.

Ilewson, Addinell (1, 10$) \quad 2120$ Spruce st. HIII, Howard Kennedy (10) 339 s. 1sth st. llolloway. Thos. IB. (10) IS19 Chestnut St Hopkns, Arthur lladdon (10) 1804 Pine st Howul. Archibald Alexander (10) 1413 s isth sit.

Burvili-Holmes, Eirnest (10) 217 S. Alst st IIoy', Dan!. II. (10) 3604 Chestnut st. Ifughes, Wm. F. (10) 3945 Chestnut st Hume, John E. (10) 900 \&. 49 th st. llunter. John W. (10) 2042 Jine Si. Iry, Rober H. (10) 1623 Wainut sit. Jonas, Leon (10) $2233 \times$ N. Jith st Jopson. John H $(10)$ IS2/ Pine St. Judinn, 'has b' (10) 1007 Spruce si kaltiger Hrealk. J. (10) 1533 l'ine st. keene, floyd F. (10) 116 s. 19th st

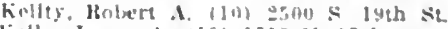
Kelly, James . 110$) 1310 \times 1$ ith st

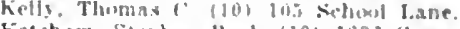
Ketcham. Stuphen lbuwh (10) 1630 fireen st kirby. bilumal 18 (10) 1202 suruce st

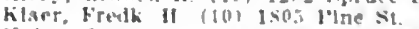
Kinipe, Jay ( IIII) 2033 Chestnut si

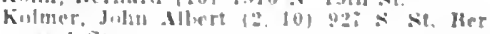
nard st.

Krumbhat, kolw a (10) linliegalty of l's Kyle. Warld litaden (Ji) lis? Wainut sL lalrel. John I. (101) 20: 5 lith st.

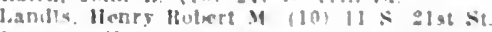

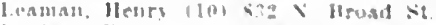

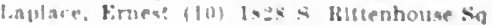

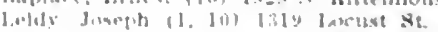

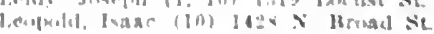

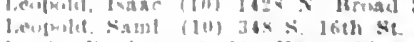

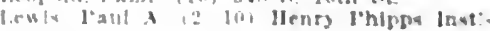
l.4"w Is. Murtis J (10) 1316 loncust se

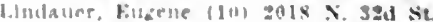

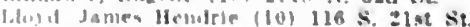
l,cultholx. balwart (10) $\$ 103$ Itlamond st. lech, louduls (10) 14:1 S 15th st. bustum. Seymont in Witt $(10) 216 \mathrm{~s} 13 \mathrm{th}$ 1.jon, it it vluent (10) j\$01 Jine st. 
Maler, firnest Geo. (10) 1:32:3 N. 1sth st Maler, Fredk. IInrst (10) 203: fhestmut sit

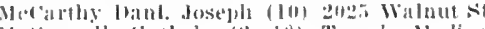

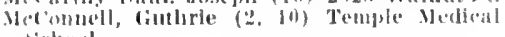
sichoul.

Mecrue. Thomas (10) ligz- sprute st.

Hevarlant, Joseph (2, 10) 442 W. Statlort st. (Gimatrown).

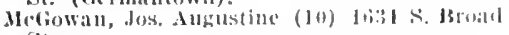
Sit.

Mrkee, James 11. (10) 1:319 Poplar sit.

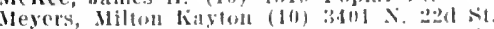

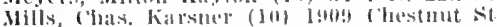
Mitcliell, Jolun lien rsley (10) 1730 spruce st. Mlonfgomery, ('lats. Ml. (111) 901, l'ine sit. Morrison, if. 11 (11i) sizel liankford Are Morton, Silml. W. (1i) 193:3 chestuut st Mlulter, Geo. 1) (10) 1729 l'ine sit. Mnsser, Jolin lierr, ar. (10) I!l11 line st. Soft, Joseph seal (10) c'ity llall.

Newllo Irtlum (10) 1s04 jine st.

Newton, Rolley J. (10) bl:3 Vhe st.

Nelole

Norris, Cluales (10) 150: 1, locust st.

Norris, Charles C: (10) 158." locust st.

Sorris, Geo. Mnt. (10) 1300 larist st.

o'keily, chas. A. (10) 1716 Locust st

Orton, sitmuel Torres (2) 4401 Market st Outerbridge, Cieorge w. (10) 2010 ('hestuut. lackard, Fraucls R. (10) 304 s. 19th st. patterson, Francls Denison (10) $210: 3$ locust

St.
Pearce, Rlchard M., ir. (2, 10) I'niversity of feunsylrania.

pemberton, kalph (10) 2.22t Loeust St.

lepper, Oliver llazard lerry (2. 10) 1811 sipruce st

Fejper, William (2, 10) 1811 spruce $S t$ Peter, Luther (C. (10) $15: 2$ S Sirure st. l'feitfer, lamon B. (10) 2028 line st. Ifahler, (ieorge $(\therefore$ (10) 1321 spruce st.

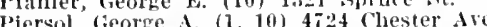

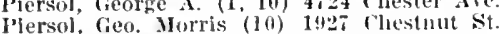
lots, (has. S. (10) 2018 rliestnut St. Randall, Alexander (10) 1934 Chestnut st Randakl, Burton Alexinder (10) 1717 10(ust st.

lieher, Wendell (10) 1212 spruce st.

lieckefus, (harles H., Jr. (10) $506 \mathrm{~N}$, 6 th St.

liees, Wm. T. (10) $3763 \times$. 18th St.

Repplier, sidney los. (10) 4521 ('hester Are. Rhelu, John Henry Wallace (Ii) 1732 l'ine. Rhein, Rolvert. D. (10) 2016 Pine st. Rhein, Robert. D. (10) 2016 Pine St.

Rlesman, David (10) 1615 Spruce St. Ringer. Arlolpli lrving (10) $451:$ leger sit. Rivas, Datulaso $(2,11) 6152$ Vime st. Roherts, John 16. (10) 313 S. 17th St. Roluertson, Wm. Egbert (10) 32- s. 17th st. Rolinson, Edwin Taylor (10) 1906 l'ine St. Robiuson, William Duffield (10) 2012 11t Vernon st.

Rodman, Jolin stewart (10) 2106 Walnut.

fodly, John A. (10) 1604 Pine st.

Roddy, John A. (10) 1604 Pine St.

Roe, Wm. John (10) 1322 locust
Rost.

Ross, George G. (10) 1721 spruce st.

Rucker, James B., Jr. (10) 2000 Areh St.

Saller, Joseph (10) 1830 spruce St.

Sappington, samuel W. (10) $124 \mathrm{~s}$. 16 th $\mathrm{St}$. saraent, dibert Alonzo (10) 130s l'ine st.

sartain, paul J. (10) :12 W. logan square.

saxon, Gordon Joel (10) 5314 sipuee st.

Sclaffle, Karl (10) 4719 Baltimore Ave.

schambers, Jay Frank (10) 1922 spruce st.

schumann, Edw. A. (10) lis l'ellatm Ro.

scloweinitz, George 1. de (10) 2040) (lhestnut St.

Schweinitz, cieorge Fdmund de (10) 1705 Vialnut st.

Shaw, John Joseph (10) $5104 \mathrm{x}$. Broad St.

Shields, Wm. (i., Ir. (10) 414 sichool lane.

shoemaker, Harrey (10) 2011 Chestnut $\mathrm{N}$. Sinclair, Joln F. (10) 4103 Walnut St.

Sinkler, Franeis W. (10) 1606 Walnut St.

siter, Elijah H. (10) 1818 s. Rittenhouse Square.

skillern, Penn-Gaskell (111) 241 S. 13th st. skillern, Penn-liaskell, .Jr. (10) 241 s. 13th. smail, John IIamilton (10) 170. Clerry St. smith, Jllen dohn ( 2, in) Yniversity of Pennsyliania.

Somers, lewis s. (10) 3554 x. Broad St.

spefse, Joln (10) 2206 Loenst. St.

Finler, IVilliam G. (10) 4409 Pine st.

spellisid, loseph il. (10) $110 \mathrm{~s}$. $18 \mathrm{sth}$ st.

spitzka, Edward Anthony (1) J1(14 Jarehwood Are.
Stollwagon, 'lhouas f', Ir, (10) 1831 ('hest nut st.

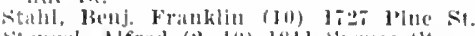
Slengel. Alfred (2. 16) 1 \$1 I spruce st. Sterens. Arthur .1. (111) 31.1 S. 16th st

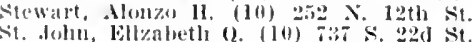
visut, (ieorge flymer (10) Ibll Walmut st Sitout, lhilly s. (10) 4 iol Chester Are. strittinatler, Isidur l'. (10) 1949 No. 6th St stryker, simutel s. (1ii) 3833 Wabuut St.

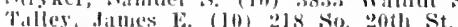

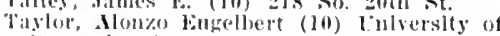
ilot, Alon\%o

Teller, Wlllian II. (11) $171: 3$ (ireen st thomas, Betij. . I. (10) 11 li so. I9th st.

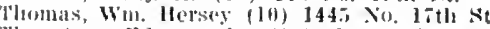
Thornton, Edw. Quin (10) $13: 31$ plite st

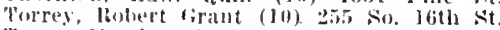
'Traes, Martlat (2) 5lis Wayme Are. l'racy, stephen F. (1ti) 152i Spruce St. 'Tureker, llenry (10) 2000 l'ine st. Tumis, loseph lpiec (1) St. Martins. rurner, Linton (10) 450 Ifycenm Are.

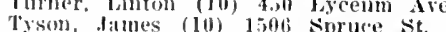
lyson, Thos. Mellor (10) 1506 sprice st. lile, Alexander A. (10) 1831 ('liestunt sit. fllom, Josephus Tucher (10) 24 ('arpenter Sit. (fiermantown)

Vandervoort. thas. A. (111) :3311 No. lbroad St.

Fan Viasken, Francis ( $(10) 115$ So. $22 d$ St. Van limej, finstave $A$. (i) 1825 rhestnut

Vaux, Sorris Wister (10) \$a(1 Germantown ive.

Walsh, foseph (10) 732 pine St.

Weichman, Fredk. beforest (10) $242 \mathrm{~N}$. 61 st Nisenburg. Theo H. (L0) 2030 Chestnut. Westeott, Thompson s. (10) 1720 line st. White, courtland $Y,(2,10) 1808$ liamond st.

White, Ellen l'. ('orson (10) $216 \mathrm{~s}$. 15th St White, dames Williau (10) 1810 S. Ritten-

house Sq.
Whitewas. Harold M. (10) 1924 Chesinnt. Whiting, slbert brajer (10) 1.223 Spruce. Wieder, Henry S. (10) 2137 No. 15th St.

Willar(l, DeForest 1'. (10) 1933 ('hestnut.

Williams, l'hllip Francis (10) 1911 l'ine St.

Willson Roht. Newton (2, 10) 1827 Spruce.
Wilmer, IIarry Bond, Jr. (10) 6019 (iermantown Ave.

Whlson, lames ('. (10) 1509 Walnut St

Wilson, samuel M. (10) 1.51\% Arch St.

Wise, Henry Moses (10) 1640 Erie dre.

Woll, Miehael f. (10) Temple Cniversity.

Wond, Alfred (. (10) 2035 Wilnut

Wood, George Bacon (10) 129 So. Isth sit.

Wood, Wilson r. (10) 1326 l'ine st.

Worden, Class. Beatty (10) 13th and Market Sis.

Fome, Charles IIouston (10) 4813 Baltimore Are.

Zimilick, Aithur .1. (10) Green and Harvey sts.

Zimmerman, Mason W. (10) 1522 Loeust St.

\section{State at Large}

Aiken, Thomas (i. (10) Berwyn, Pa Ball, Michael Valentine (10) Warren, la.

likle, Paul H. (10) Mifflibur, Pat.

liuchwalter, Josejh $\perp$. (i) lloyersford, Pa

Cohoe, Benson A. (1) I'ittsburgh, Pa. bavisson, Alex. It. (10) Aromore. Pa liewees, $\boldsymbol{X}$ aron Lovett (10) Inaverord, Pa buar, Edward L. (10) Bryn llawr, Pa. Gilliland, Saml. H. (2, 10) Marietta, P'a. Ereen, Elyar Moore (10) laston, pa., litehens, Arthur I'arker (10) (ilenolden, I’a.

Holman. Wm. 1. (2) Pittsburgh, Pa.

linnt, (has. J. (10) Harrisburg, Pa.

liane, Bayard (10) West Chestor. Pa.

lieating. leter IfCall (10) Wawa, 1'a.

lieunedy, louls T. (10) Pottsville, l'a.

Kilot $z$, Oskar (2) Pittslourgh, $\mathbf{P a}$

liotz, Adam L. (10) Easton, ]'

Juders, Chatles W. (10) Cynwy, Pa.

Lukens, George Thomas (ii) Conshohocken. $\mathrm{Pa}$

MacLachlan, W. W. (4. (2) I'ittsburgh, Pa Varl'lail, Margareta (10) Harrisbure, l'al. Vathan, Darid (10) Norristown, I'a.

pancoast, IIenry K. (10) Bala, Pa.

Radasch, lenry E. (i) Wynewood, Pa.

Richardson. Russell (10) Newtown. Pa.

Royer. Benj. Franklin (10) Harrisburs, I'a

Sliarjess, Wm. T. (10) West Chester, Pa
sififer, Henry F. (10) North Wales, Pa.

Suyth, Ienry Fleld (10) Wayne, l'a. Sommer, Henry .J. (10) Hollidysburg, Pa. Stotsenhurg, iames Mrl'hersou (I) Ridley l'ark, l'a.

Swalm, (harles d, (10) Norrbtown, I't. "Taylor, lowis 11. (10) Wilkes-lsarre, l'a Joilmin, Ilarry (10) Ilaverford, la.

Welts, Gen. II. (10) Wayne, l'a

Weston, laul (i. (10) Warren, I'a.

Wllson, foln 1). (10) S(ranton, l'a.

Wllson, Oscar 11. (10) cllifton Helghts, Pil.

\section{RHODE ISLAND}

Burgess, Alexamler M. (2) l'rovidence, It.I. Fultin, Frank '1". (2) l'rovidence, R.l.

Woul, llaroli Is. (10) Slocum, R.I.

\section{SOUTH CAROLINA}

lyncli, kenreth II. (10) (harlestown, S.C.

SOUTH DAKOTA

Grosiellor, Lorenzo $\mathrm{N}$ (4) Ifuron, S.lbak.

IIer\%berg, Mortimer (10) Vermllion, S.lonk.

TENNESSEE

Mecotter, Rollo E. (1) Nashville, Tem,

\section{TEXAS}

(arter, Wu. Spencer (1i) Galreston, Tex.

Kelller, Willian (1) Galveston, Tex.

schaefer, Iarle charlotte (1) rialreston, Tex.

VIRGINIA

Hazeu, Charles Morse (1) Bon Mir, Vat.

Howe, linbertus J. If. (1) Meherrin, Fil.

Whitehead, lichard IIenry (1) University, Va.

WEST VIRGINIA

Arkill, Aaron (4) Jorgantown, W.Va.

\section{WISCONSIN}

Boretti, Athert $F$ (t) 690 Farwell Are.

Le Cron, Wilbur L. (1) 141 Wisconsin $S$

Warfleld, louis M. (2) 141 Wiseonsin st.

Wenstrand, lavid E. W. (4) 104 New lnsurance Bldg.

Yates, John l. (2) 141 Wisconsin St.

\section{State at Large}

Bardeen, (Jarles la. (1) Madison, Wis.

Bututing, (laarles Henry $(1,2,4)$ Madison, Wis.

Evans, Joseph S., Jr. (10) Madison, Wis.

lliller, Willam Snow (1) Madison, Wls.

Rarenel, Mazyck $P$. (2, 4, 10) Madison,

ivis.

Wilmarth, Alfred W. (10) Chippewa Falli,

\section{PHILIPPINE ISLANDS}

lovis, Geo, (i, (4) Ilanlla, P.I.

Foster, lieo. B., Jr. (10) Manlla, P.I.

Gilman, lhilip Kingsworth (1) Manila, 1'.l. Sehmitter. Ferdinand (1) Manila, 1.I.

\section{CANADA}

\section{Montreal, Que.}

Abbott, llaud E. (2) 28 juroeher st. Adani, John (i. (2) 34 Macyregor St. Archibald, Edw. W. (2) 160 Metealt st. Bruere, Andrew A. (2) 214.5 Mance St. (amplell, Roland P. (2) 249 Mountain St. (iruner, Oskar (c. (2) Royal Vietoria liospital.

ciurd liavid Frazer (2) 124 Bisloon $\mathrm{St}$ hartin, Charles F, (2) 240 Drummond st. llce(arthy, Joln (i. (1) 11: St. Mlarks S Mckee, Sami. 11. (2) 158 ('rescent St. lleakins, John C. (2) 392 Nountain St sliepherl, Francis John (1) 152 Mansfleld. Todd, 1. 1. (2) MeGill University.

Fon Eberts, Edmond M. (2) 219 Peel St. Toronto, Ont.

('aulfeild, Alfred H. W. (2) 3 St. Thomas. Fitzgerald, John G. (2) University of Torouto.

Leathes, John B. (2) 61 Oriole Road.

Mabee, Oliver R. (2) 419 Bloor West.

Hackenzie, John .J. (2) Toronto University. l'rimrose, Nlexander (1) 100 College St.

\section{Canada at Large}

Bell, Goldon (2) Winnipeg, Man. ('onnell, Walter 1. (2) Kingston, Ont. Fidlar, Edward (2) London, Ont. Hill, Hibbert W. (2) London, ont.

Revell, banl. G. (1) Edmonton, Alta.

Robertson, Alexander R. (2) Vaneouver, B.C. Vineent, Swale (2) Winnipeg, Man. Wesbrook, Frank F. (2) Vancouver, B.C. 


\section{ROFNTGFNOIOOG}

\section{G-SOCIETIES}

NTMEIS OF MRMBE, IS, It:

1. American Roentgen Ray Society.

2. New York Roentgen Ray Society.

3. Phlladelphla Roentoen Ray Society.

4. Chlcago Roentgen Ray Society.

\section{ALABAMA}

Birmingham

Fdmonson, Jolın H. (1) First Siational Hauk IHIjg.

\section{CALIFORNIA}

Los Angeles

Sullund, dibert (1) Wright and callender Bldg. COLORADO

Rrown, Iouls Gordon (1) Colerado suriugs. Colo.

Stover, Georke II. (I) Benver, Colo.

CONNECTICUT

Bergman, A. I'. (1) New Haren, Comn. Bmone, w. Tyler il Nurwlch, fons. Heubleln, Arthur ( (1) Mastford. Conn

Nadlet, A. (i. (1) New Itaven, (onn.

skinner, Clarence $\mathrm{E}$. (I) New Haren, (oum.

Van strander. W. II. (1) Harufurd, Conn.

\section{DISTRICT OF COLUMBIA}

\section{Washington}

Groorer, Thomas A. (1) 1410 N $\mathbf{x} ., \mathbf{X}$. Selby, John H. (1.2) Itizl founectirut IVe.

\section{FLORIDA}

Cunnlnghatn, Lester W. (1) Jacksonville,

Yla.
perry, Paul C. (l) Jacksunville, Fla

kogers, Carey 1\%. (I) Jacksonville, bla.

\section{ILLINOIS}

\section{Chicago}

Beek, Emil $(1,1) 25.11$ N. Clark si.

Grege, Arthur W: (4) Jisbert Buras lles. pital.

IIartung, Adubh (1, \&) 2615 shefteld Aie,

liubeny. Maximlilan J. (1) $11 \mathrm{X}$. Siate st

hlorstad. Andrea (4) 27:5 W. Yorth Ave.

Ormaby: Ollter $\$$. (1) 3: $x$. State st

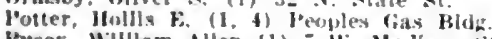

Pusey, Wullam Allen (1) i W. Madison st.

Turley, Frances 1: (4) Mchael itcese Hix plta!

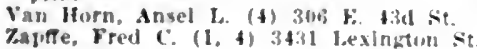

\section{INDIANA}

- Indianapolis

Cole. Altert M. (1) Hume-.Mansur 13!la.

Indenuth, f: O. (1) Hune-Mansut Blab

State at Lerge

Clark, stanley A. (1) Sioutl 1kend, Ind

\section{LOUISIANA}

New Orleans

firanker, Anedere (1) gas lanal it

Hateh. Fisward s. (1) Malsoll Hlanelu Mlile

\section{MARYLAND \\ Baltimore}

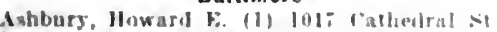
Baetjet, Frederlok II. (1, "2) \& F. Madivent sit

cotton. Allertua (1) 1:3113 Marbland Ar

Jeetjell, W. Mirintlan (1) 170? Fiutaw IV

\section{MASSACHUSETTS}

\section{Boston}

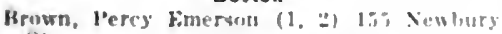
st.

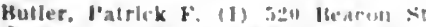

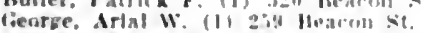
Gearge. Afral il. Holmes, fion Wluslow (1) go Rencom Porter, Tharles I (1) 2.14 Bescuis State at Large

Burgess, (Tharles J. (1) l.an rence, baus Dould. Walter d. (1) somerville, Maқ?

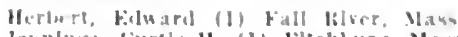

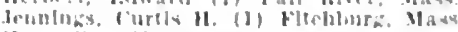

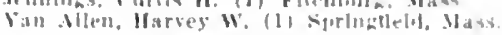

\section{MICHIGAN}

Detroit

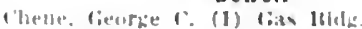

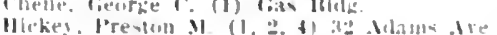

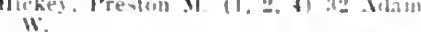
stevens, llolltn H. (1) stevens IIdg. State at Large

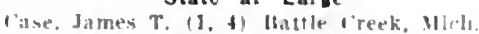

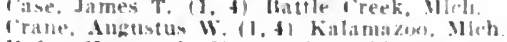
llulst. Henry (1, 2j lirand liaplds, Mlld.

\section{MINNESOTA}

Barsiless, Dellle $M$ (1) St. Paul, Minu.

farman. Russell $\because(1, t)$ Rechester, Minn Ionalison, llas. A. (1) Minneaplls. MInn

\section{MISSOURI}

Iboslus. Win. I, (l) fialation. Mo.

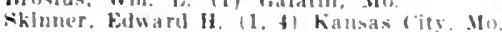
Titerimgon. M. B. (1) St. louls, Mo.

\section{NEBRASKA}

Whek, W. H, (1) Omalua, Jeb

NEW JERSEY

Westcett, Wm, (. (1, 3) Atlantic City, N.J.

\section{NEW YORK}

Brooklyn

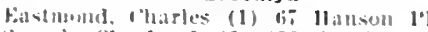

search, charles d. (1) tia franklln die

\section{Buffalo}

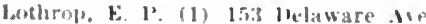

Meisenball, Roland if. (1) 140 . Nllen st

18eu, deonard (1) sitl smiti si."

$$
\text { New York City }
$$

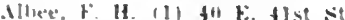

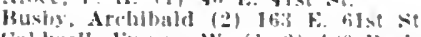

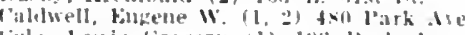
cule, lew is liregory (1) lus lourk lie.

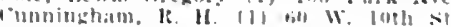

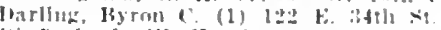

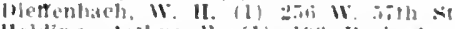
llolding. Irflur to, (1) la:i lark lie.

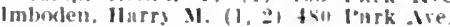

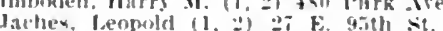

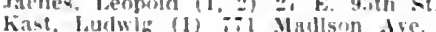

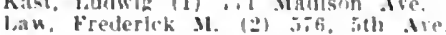
l. l.eamilug. Fidward (1. 2111 k. fith Mankee, lienrge 3. (1. 2) is W. ixtl st Mortoll. William d, (1) 19 k. gails.

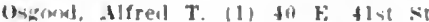
Quimby, .1. J. (1) to k. Hist st lemer, John (2) :- W. IEth st. Sienart. Whllam H (1. 2)

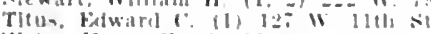

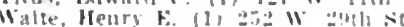

\section{State at Large}

Whell, Illeert J. (1) Sigrabuse, Xi

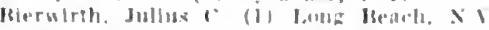

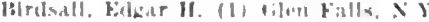
Hlanehard, lieorace II (I) llikltand Falls (i.

IBural, Jutin II (1) Sigraruza, Ni

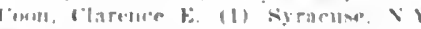

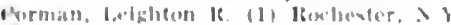

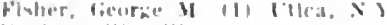

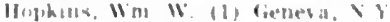
llull, quupuan il (1) Trus, yl

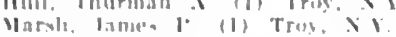

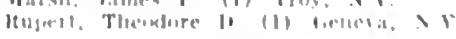

$0+10$ Cincinnati

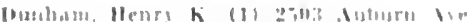

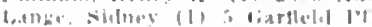

\section{Cleveland}

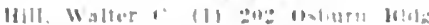

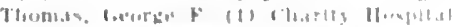

$$
\text { Seale at carge }
$$

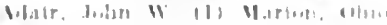

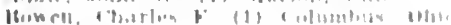

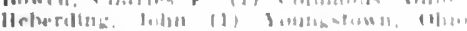

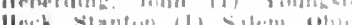

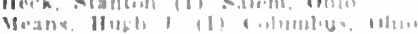

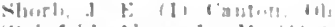

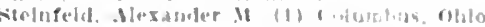

Tucher. Eluln 10 (1) Tolealin, (1)

\section{PENNSYLVANIA}

Philadelohia

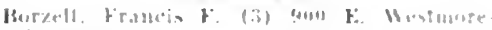
land ot

bowet, liavted 1: (1, 3) gages. st. Bermard

llaland, Judion 11,3$) 31:$ s. 18:h st [14-1itt, Willlam, Ir. (1) 130 lirren lane

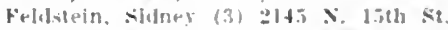

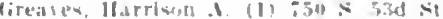

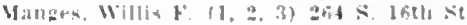
Mcfullin, saml M (1, 3) 1:25 Areh sit.

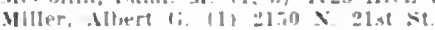

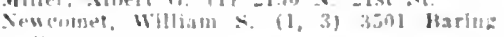
st.

l'fuller, lienrge t. (1.2. 3) 1321 sipuce st sillambers. Jas $F(3) 1922$ sprure st. sitelluagon, Jenry W. (3) 1634 spruce st. stewart. Thos \& $(1,3) 301$ s. Isth st. sueet. Willam M. (1, 3) 1205 suruce st

\section{Pittsburgh}

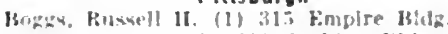
lirier, lieo. W 11 . 19 denklns Bldz dohurion, fierrge C. (1, 2) b\$1 rulton sit.

\section{State at Large}

Brady, William r. (1) sicranton. Pa lirententu, l'ark I'. (1) tomesoler, l'a. Mabrer, duneph M. 11/ Waslington, Pa. Meter buwarl di, (1, i) Reading, l'a. l'amenast, Jesiry K (1, 2. 3) Kald, l'a

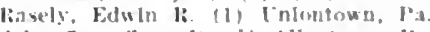
Acllaeffer, Ilias 11. (1) Allentoun, la Threlkeld-folwards, Herbert $(1,3)$ south Itrthlehem, I"n.

Warlhans, F lo. (1) Wilkes-lkarte, Ja. Weaber iunis s (1) Jork, lin.

Williams, Ton 1:. (1) New iasle, l'a.

\section{RHODE ISLAND}

llanimorid, koland (I) I'rorldence, it

\section{SOUTH CAROLINA}

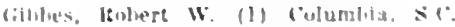

\section{TEXAS}

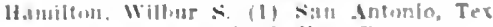
Martli, Jalmes M. (1) Mallias, Texas.

\section{VERMONT}

lathlon, slialler E. (1) Brattlelmuro, It VIRGINIA

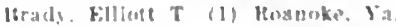

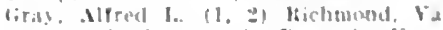
11.tzen. Ilarles

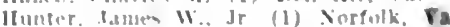

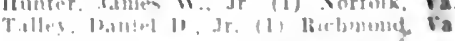

WEST VIRGINIA

Ifuimlu, Will I. (I) Wheullug. WI Ia

\section{WISCONSIN}

Milwakes

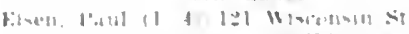

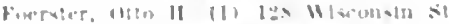
Stale at Large

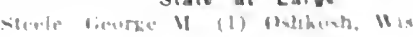

CANADA

Montreal, Que.

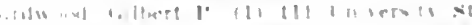

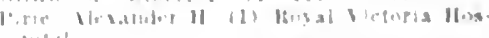

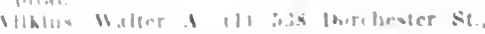
II

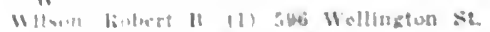
Toranto. Ont.

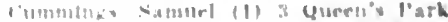

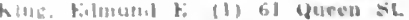
Canada at Laree

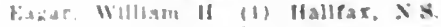

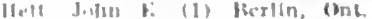

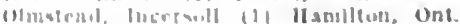




\section{NUMBER OF PHYSICIANS AND HOSPITALS IN THE VARIOUS STATES AND PROVINCES}

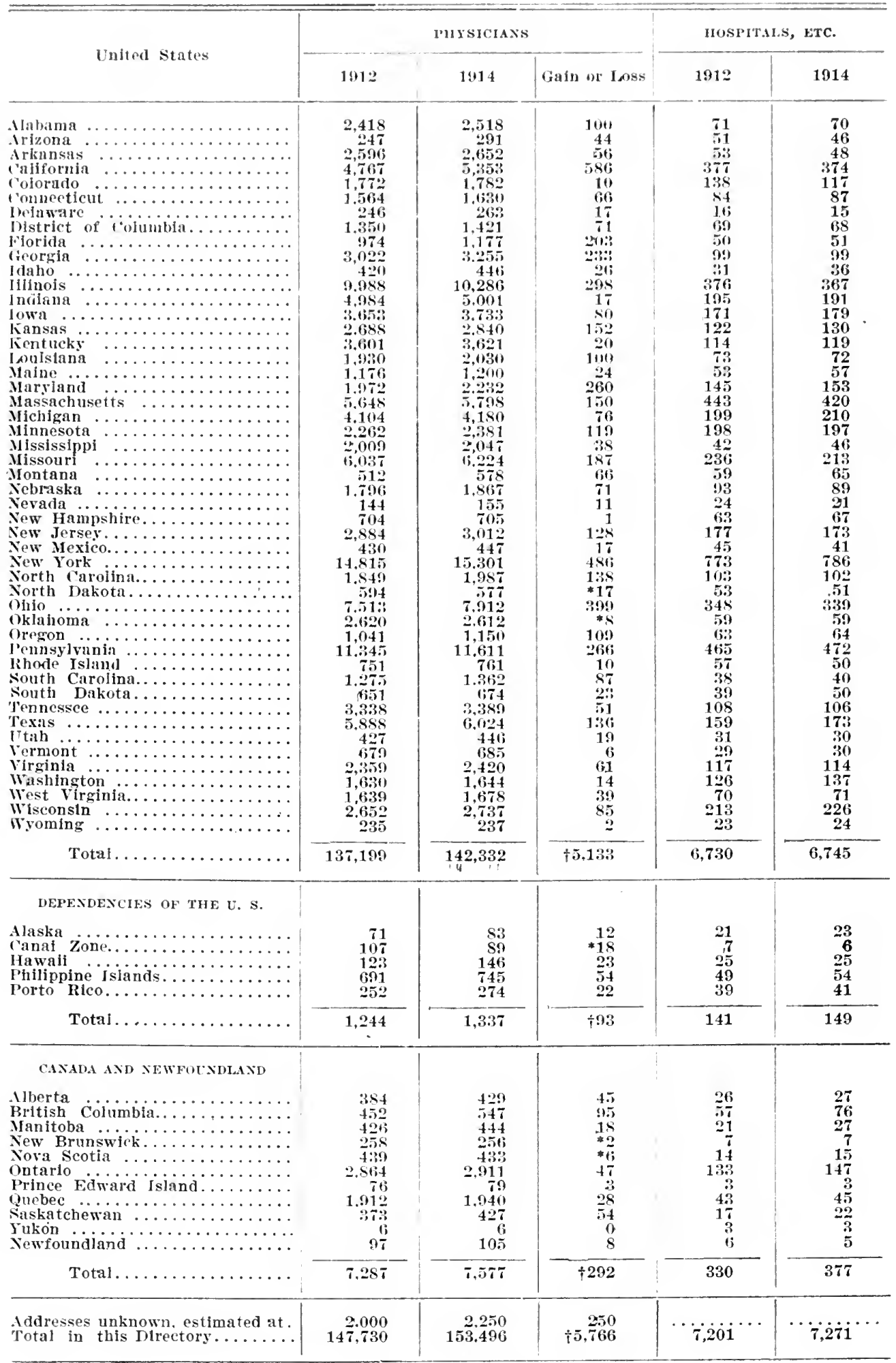

* Ioss. 


\section{ALABAMA}

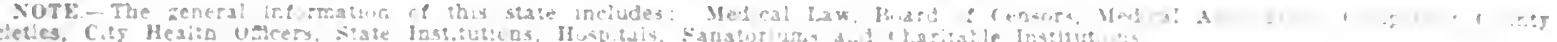

\section{ALABAMA}

Population (1910 sensus)

2.138 .093

Number of Countles.

67

Number of Physterans

Meers Stape Association. Dec. 31. 1913.

$1.5+3$

Area of State in Square Miles... 51,993

\section{MEDICAL PRACTICE LAW OF} ALABAMA

\section{An Ac:}

To Rerulate the Pracice of Medictie ia tae sisie o: Alabama

Sec:on 1. HUMRO OF EXAMINERS : The Board of Censurs of ihe Medical dosnciation of the siaie o: Alshuta. as cr.asisuled undez the laws now id sorce. of which mas
hereafter be in force. is hereby constituied a Sisie Board of Med:cal Exama.gers, and is hereby charzed with lise duiter and cluthed with ihe purets bereinafie: prescr. Wet

Sec 2. ExAMIISATIONS: That ar spoll. cant for a cert:Acate of Tual.2catlon bo usea: diseases co bumsin teinza bs arj systers of treatmeat whatsuerer shall, accoriling to rules prescrtbed and siandardj esidtisbed by the Medical Assiciabic a of the Siate of Alabams, be examined. In witinz, by the Siate Board if Mledical Eraminerg in ibe lo!lowinz named branches cl aredical learn. iog. 20-wIt: Chemistr. anatomy. Lhyslotosy. ing. 20-wlt: Chemis:ty. anatoms, Lhystoiong. diazaosis of d!seuses: obrtetics and ritisie deal aperablons: Ejnecritay; mayor and minor surzery: phssical diaños:a: diseases of the ese, ear. Dose and throj: : and braiene and aedical jurisprudence.

Sec 3. APPLICATIONS: Tha: an app!:cant sball. tefore being perm.tiel bi enier upon an examina:lon. Anl out an apdlica: . n blank. glriaz bis name aze, res.dence. C 1relereaces and such othes data as the sine Rourd of Medlcal Examirers mas reilu.re. The applicant shall make stalar.: that bu ts the person be represer:s th.msal? in le and that re will ia.tifin'ly chaste all rules apreming the examibsior. Ang toetrber of the siate kuagu co Hedcal Examlaes, of the supervis is of exarinatina apgnin:ed by and hard. Is berehr alith ized to adminlsies the oath prescr.ted Th bonad aha! have the r.zht ir reflise? as in rendee h!m unvurils5 ! acoulersh $D$ on the onedical re iest

sere (CERTIVICATE: Tha: when an

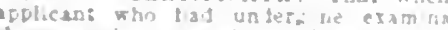

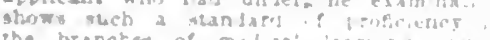

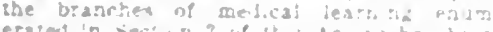

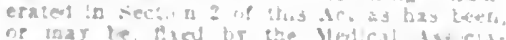

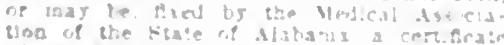

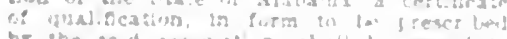
by the sad ate divin. slial! te issued: the apoliran:, whech cort.f ate shajl catule

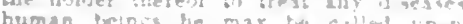
treas in acouplanre with the barbngy

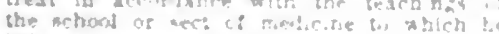
the wehoin

sec. s. STISJE(TA EXEMTEL. ThA wher an appicant sidies in whinz bla? ?

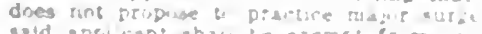

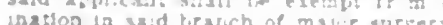

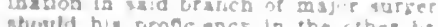
of rentical learninz nameil in sectip of ecmical tearting nameat in secto' h a this Act reacb the miandard entabliatier: by the Yed.cal dswelation of the viate

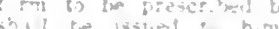

-ball castle hin th treat

muan beings te may tus

vest in accordance $w: 2 h$

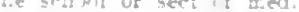

meil cas; prorlued. that the bulder ath the

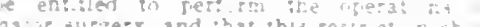
An if surgery, and :hat this resir $c$ t il shis. apale on the pace of the cezinoste.

sec. 6. RE.EXAMNATloxs: That rhen an applican: tails in 2 :ain the stardatid

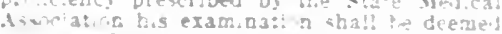
msuccesíul such applicati st.dil hww rer, tee en:.tled to an ther examuat a $\mathrm{st}$ from the date of the preced is examinatia

Sar. - MLST FJJE CERTIFIL ATE: That phyician th ho rece res a ceriecale? lualification shall, wi:han len dars alte? icsung in a couniy. Sle such cers.9caie is the otice of the julze of pritase of sarb

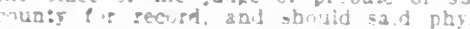

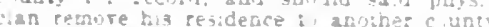
re stall wiah.n sald time hare h s cers. cale re-recurded. Anp lallure or the par cf the holder of a certicase of qual Acat in (1) compls iun stail reader such certecste guld ard

Sec 9. PERISTER UE PHYSUIANS

Tha: the yudze of pribate of a c, un: s shali Tha: the yudze of probate of a c un:s shali be called the "Reziser of Fhysicians." in Which brin shall be recorted all ce:-ifcaies of qualiacaion bied by phyac ans of the crumis. The pee 1 recrlat rach certilcate shall be fits cents it some lime esch sear the said julie 1 Irotsie sball irrmard in the state B srd if Meical Ex amiaers a full rep $x$ t the narm of a

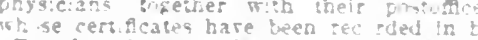
ance $p, r$ the precer no jear; aad if any physcian whise certecate was al reprried thail hare tored from the r.unt5 of shall

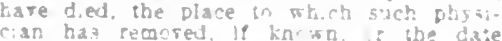
i lte deash. as the cave way be, sball be ter tient.

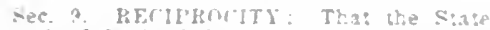

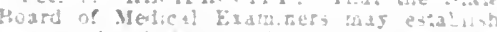

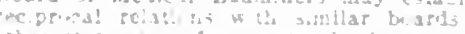

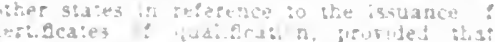

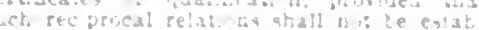

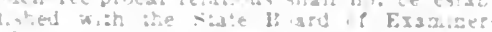

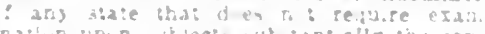

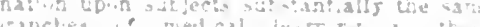

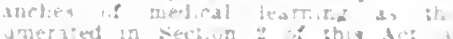

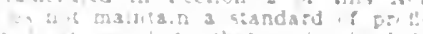

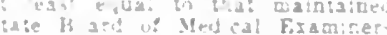

ano Whes such rec.! rural iela:

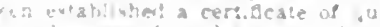

at be coued with li exam!nat porents er dence iba

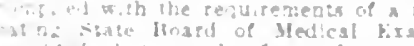

povidul tha: on the tace of a

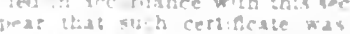

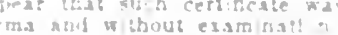

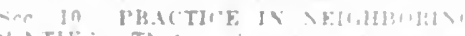

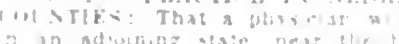

viaie tiall to at.

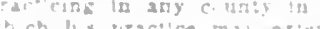

am rapion. provided llia: le

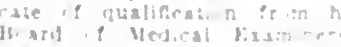

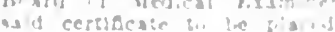

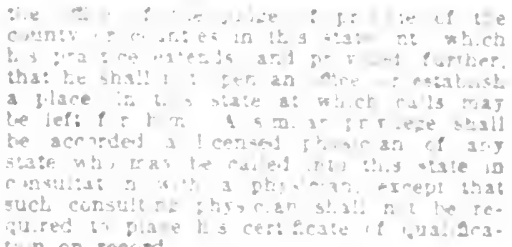

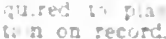

Sec 1: F.YYYT TIONS FROM EXAMISA TIOX. Tha: :?e sia:e llian! te Medeal

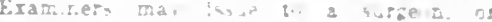
amsis:ant juine.n: : :te [n.sed siates Atary I Vary, of of the I a.ied states lubl.c

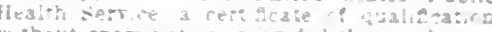

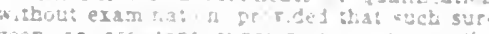

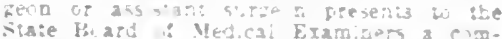

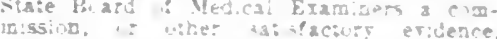
thring :hat l.e a a wed.cal hice: of the Linited Sisies Army. Nary, or Publ.c kiealth Serrire, as itae raie war to and por r.ded.

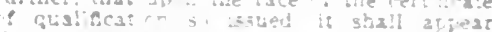
that the cet tede and pis li erserias: a

SeC. 22. BESOKINI CERTIFICATE OF QTALIFICATIUN TO PKACTIE MEDICINE: The s:ate B and hit Verical Eramther may ter he a passicien's ceristabe

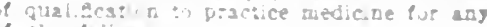

1. ['-az sp.r is us rinous is mait a puors

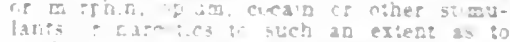
perder b.m unsale a unpeimable as a racAnver

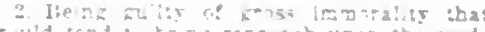
Fin'd ifnd? :- r.: eer? arb upon the coed.

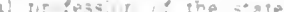

Berta zu:ar i! ur: : essinal enndue

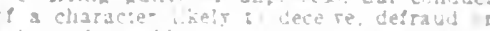

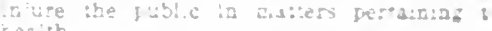
t.es : $:$.

4 Adreriss na birmet? his gractice

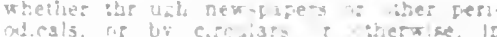

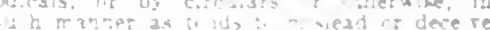

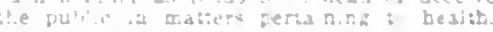

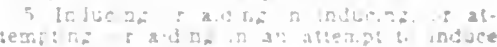

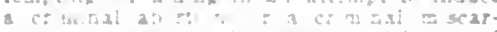
raze $r$ s r.moli ite aimite deiders. I

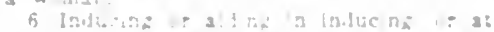

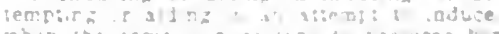

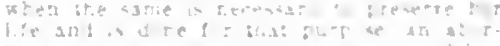
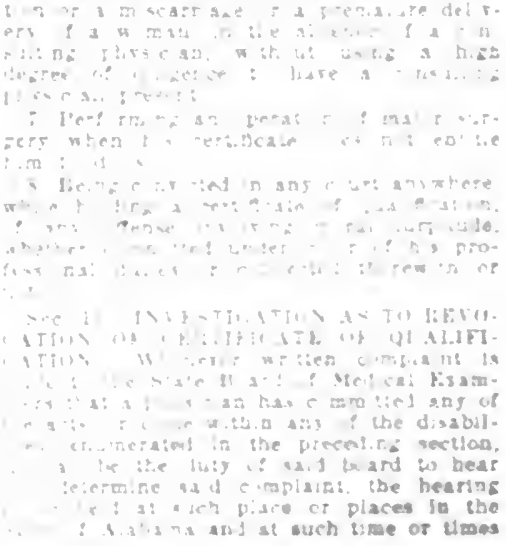
as the hoari may decide upon from time to thine; anl the board mily adjouln such hearing from piace to place and from time to time. The person whose qualitication under comsideration shall lave not less that wenty days' written notice of the time ant place of the Inltial hearing, which notlee plaint.

Such notice may be served by any sherlft of the State of Alibatmit. Ol liy any member of the Medical Assoriation of the state of Nlabaua, and if served by a member of said association, the return if service shall be sworn to by sali member before some offleer anthorized to administer uffilarits. But if said person is out of the state, ol evades service. or cinnot be served in person, then the service may be made by malling a copy of the complatint and of the notice of sald person at his last known postoffice adares n this state, and the returu shail show that ervice has been made ln this manner. The nvestigation shail he held with as little pullicity as practieable, conslstently with fair and impartial hearing, and the complainant and the person whose gualification is under consideration, and any other person who nay be permitted to do so by the board shall have the right to introduce all such oral testimony or written testimony, or both, as the board may deem relevant to the issues involved, and the right to be heard in person, or by counsel, or both. The board shall have fuil power to permlt the complaint to be amended at any time. The board shall aiso lave the right to determine all quesions as to the suftleiency of the complaint. as to procedure and as to the aduissibility and weight of evidence; and the law and mles of pleading and evidence in the court shall not be applicable to such hearing, but the board shall determine all questions of p!eading and evidence aceording to its own idea of justice and propriety. If the person whose qualification is under consideration absents himself, the hearing shall proceed absents himself, the hearing shach bearing witin his absence. To any such learing witnesses may be subpoenaed om its own motion or on the demand of either the Isoard of Bedical Examiners, or by the person at the time discharging the duties of said offlcer, and such subpoena may be served by any sheriff of the State of Alabama or by any mentber of the Medical if served by a member of said association, the return of service shall be sworn to by the return of service shall be sworn to by said member before some ofticer authorized sworn by said chairman or said person discharging the duties of said officer. Any vituess failing to attend shall be liable to a penalty of two humdred dollars, to be recovered by the Board of Medical Examiners if the witness was summoned on behalf of this complainant, or by the person whose (qualification is under consideration if the witness was summoned on his behalf, by suit In any court of competent jurisdiction. But in such suit the witness may offer in bar of said suit, and have the validity thereof passed upon, any excuse he may have for such non-attendance. In any sueh suit the return of the subpoenit and certifieate of the non-attendance of the witness by the chairman of the Board of Medieal Examiners, or the person at the time discharging the duties of sajd officer, shall respectirely be prima facie evidence of said service of subpoena and said nonattendance. Any witness attending any such hearing shall immediately upon his dishearing shall immediately upon his discharge as a witness be paid by the board two dollars per day for his attendance and from the place of the hearing not exceedin hree cents per mile for each mile traveled, to be paid out of the funds of the State Board of Health. If the board is of the opinion that the number of subpoenas desired by sald person whose qualification is under consideration is umeasonable it may, for the witnesses abore what it considers a reasonable number, require of said person reasonible nimber, require of the mileage aud wer diem of said witnesses. After the hearing the board may return to said person that portion of said deposit which was for
witnesses whose evidence shows that tley were not unreasonably summoned. Evhlence by cieposition may also be taken, the eomthe boird, and the law and practice as to the positions of courts may be followed in far as they alle deemed reasonably appliea far as they at'e deemed reasonably applicable by the board; and no such deposition
shall be suppressed for any cause whatever shall be suppressed for any cause whatever wis fairly taken and no injustice will result from its admission. Wlienever it has been established lyy the judgment of the court of competeut jurisuletion that a physician has committed any of the nets or come within any of the disabilities enumerated in the preceding section, the fling of a certlfied prece of such judgment with the board shall copy of such juthment with the board with be stiffelent to justify such revocation withthe opinion that fairuess to said physleian requires that regular hearing be held.

Sec. 14. ItEVOCATION ANI REPORT TO JUDGF OF PROBATE: Whenever the State Board of Medical Examiners decides to revoke a certiflcate of qualification. said board shall make an order of revocation, and shall give written notice thereof to the judge of probate of the counties in which such certifleate of qualification is recorded, and said judges of probate shall thereupon forthwith enter upon the margin of the the same has been revoked and the date of revocation.

No irtegularity or informality in the meet Ing of the board, or the conduct of the said neeting, and no irregularity of notice to members thereof of the meeting, if it be a the ralldity of the hearing and order of revocation; but no order of revocation shall be made if less than seven members of the board are present at the time said order
made, or if two or more of those present vole agalinst such order.

Sec. 15. EFFECT OF REFOCATION ; NEW CERTIFICATE: Whenever the certiffcate of qualification of a physician has to practice medicine lin this state, provided that the state Board of Medical Examiners may issue to such physician, either with or without re-examination, a new certificate or without re-examination, "it deems such course safe and just. Upon receipt of such course safe and just. Cpon receipt of such
new certiflcate of qualification it shall new certiflcate of qualification it shall
become lawful for such physician to re-enter upon the practice of medicine.

Sec. 16. PLACE OF EXAMINATION That all examinations under this Act shall be conducted at Montgomery, and that the State Board of Medical Examiners shall fix the times at which examinations shall be held, provided that not less than two examinations shall be held annually.

Sec. 17. FEE: That the fee for an examination shall be ten dollars, which amount mist be paid in advance of the examination and to such persoll as the
board may anthorlze to recelpt therefor. board may anthorize to receipt therefor. A fee shall not be returned to an unsuccessful applicant, but such applicant shall
be entitled to a second examination without be entitled to a second examination without second examination is obtained within on year after the date of the first examination. See. 18. DISPOSITION OF FEES: That after defkaying all expenses of holding an examination, such as furnishing blanks paper, postage, certificates, the services of supervisors, clerical help, ete, the remaining funds shall be equally divided amon the ten members of the state Board of Medical Examiners.

Sec. 19. PENALTY FOR PRACTICE WITHOUT CERTIFICATE OR REGISTRA TION: That any person who treats, or offers to treat, diseases of luuman beings in this state by any system of treatment whatsoever without having obtained a certificate of qualification from the State Board of Nedical Examiners sball be quilty of a misdemeanor, and on conriction shall be fined for each offense not less than flfty nor more than five loundred dollars, and may be imprisoned for not less than one nor more than three months. A physician whose certiflcate of qualification is not on recor in the county in which he resides sliall not be entitled to recover at law any compeneases of humall belurs.

Sec. 20. IKFCOMUS OF ExAMNATIONS That the State IBoard of Medleal Examiners shali keep complete records of all examtnations held by it, giving the name, age, resilence. college and date of graduation (if a graduate), of each applicant examined, tocether with the results of such examination, The said IBoard of vedleal Examimers shall also keep compiete mlnutes of all its proceelings, which minutes shall be so preceedings, which minutes shall be so preoccasion arise for referring to them.

Sec. 21. AlMMINISTERING HOWE RFMEIIES; F.MERGE.NCIES: That nothing in domestic remedies in a family by any mem. ber thereof or ber thereof, or prohibit any person from rendering service to a slek or injured person rendering such servlce does not pursue the occupation of a physician.

Sec. 22. REPEALING CLAUSE: That this $A$ ct shall be and are hereby repealed. Sec. 23. DATE EFFECTIVE: That this Act shall go into effect on and after the first day of July, 1907 .

Approved April 5, 1911.

\section{STATE BOARD OF CENSORS}

Aeting as a state Board of Medical Examners and as a state conmittee of Public Health.

W. H. Sanders, Chairman, Montgomery S. W. Welch, 'Talladega; I. L. Watkins, Talley, Birmingham; I. W. Johnstone, Tuskegee; R. M. Cunningham, Birmingham; gomery; S. G. Gay, Selma.

MEDICAL ASSOCIATION OF THE STATE OF ALABAMA

Offleers 1913-14

Robt. S. Hill, President.........Iontgonery

Martin L. Malloy, Vice-President.... Eutaw J. ‥ Baker, Secretary..............Gadsdent Henry G. Perry, Treasurer......... Iontgomery W. H. Sanders, State Health Offeer...

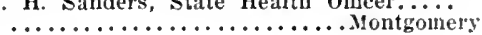

Component County Societies of the Medical Association of the State of Alabama ALTACGA COUNTY James Tankersly, Presldent.....Autaugaville
C. Rice, Secretary.............Prattville BALDWIN COUNTY C. L. Mershon, President. ............ Fairlope
Geo. L. Lambert, Secretary....Bay Minette BAIBBOUR COUNTY

W. R. Belcher, President........Baker Hill

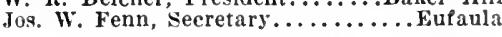
BIBB COUNTY

M. C. Thomas, President.......... Blocton
H. L. Cunninghan, Secretary... Centerville BLOUNT COUNTY

IV. T. Cantrell, President....Blount Springs J. T. Hancock, Seeretary........... Oneonta BULLOCK COLXTY J. R. Oswalt, President...... Union Springs
H. I. Dlsmukes, Secretary... Union Springs BUTIER COLNTY

J. I. Mitehell, President...........Montere CALHOLN COUNTY

( Moore, President............Annlston

J. W. Landham, Secretary............ Anniston CHAMBERS COUNTY

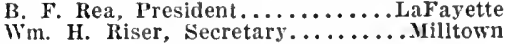
CHEROKEE COUNTY S. C. Tatum, President................. Icenter 
CHLTON COUNTY

J. Hayes, l'resldent............... Clanton T. Mareus, Secretary.............Clanton CHOCTAW COLNTI

1. D. James, President..........Pennington i. F. Lltllepage, Secretary........... Butler CLARKE COUNTY

Isham Klmbell, Presldent..........Jackson J. M. Cobb, Secretary...........tirove IIIII Clal COUNT

Wm. H. Prlce, I'resldent..........Ashland B. C. Scarbrough, Secretary.........Ashland CLEBLRNE COUNT:

S. I. B. Blacke, Presldent........ Frulthurst Lee Roy Wright, Secretary........... Iefin COFFE: COLXT:

C. P. Ilayes, Presldent. . . . . . . . . . EIba W. i. Lewls, Secretary ........... Enterprise COLBERT COUNTY

w. IL. Greer, Presldent.......... Tu*cumbla J. $\boldsymbol{T}$. Haney, Secretary.......... Tuscumbla CONECUH COUNT

W. G. Halrston, President......Burnt Corn W. F. Betts, Secretary............. Erergreen coosa count

W. H. Moon, President.........t;oodwater Saml. T. Cousins, Secretary......... Equallty cuvisgton colsty P. D. MrGhee, Presldent.......... Lockhart
D. J. Campbell, Secretary.......... Dozler CRENSHAW COUNTY W. P. Knlght, Presldent............. I.urerne CULLMAN COUNTY

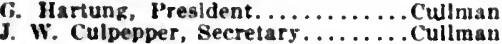
DALF COUNTY

1. Black, President.......... Mld land Clt

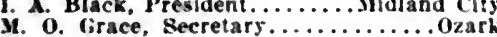
DALLAS COUNTY

* B. Ward President................ Selma

B. B. Ward, President........................ Kelma DEKALB COI:NTY Olln May, Presldent............F. Payne
W. F. Quin, Secretary..........Ft. Payne ELSHORE COLNTY

Jesse Gullidge, Presldent..........Tallassee

Jesse Gullidse, Austin. Secretary.......... Wetumpka ESCAMBIA COUNTY Jon. E. Rose, l'resldent............ Fullard ETOWAH COUNTY J. II. Wood. President..................ttala FAYTTE COENT

J. D. Young, Presldent............. Fayette

J. A. Branyon, Secretary............. Fayette FRANKLIN COLNTY

James Copeland, Jresldent.......... Red Bay

W. A. Gresham, secretary...... Hussellville GENEVA COUNT

G. W. Smith, I'residetit.......... Slocumb

ii D. Smlth, Secretary............Malverne GREENE COUNTY

G. A. Moote, I'resldent............. Kutaw HALE COUNT

J. Iluggins. Presldent .............. Newbern Charlea A. Poellnitz, secretary..lireensboro HEXIX COLNTY

T. J. Tloyd, President............. buterllle HOLATON COUNTY

Henry fireen, I'resident.......... Buthan M. S. Davle. Secretary............ Dohbar Jarkstin rolst:

A. X. Blakemore, l'resident....... senttsboro Jos. X. Blakemore, Secrutary........ Secotsuluru JEFFERSON COCXTY

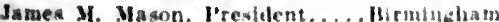
Hames M. Mason, Iresilent..... Mirminghats L.A.M In (WI:NT)

6. 8. Llarksdale, Iresident........ Fernlonnk T. II. loung, Secrefary........... Yerment
I.AI'IREIUAI.F COLNT

Lewls W. Hexprez. I'restdent........Florence H. M. Davis, secrutary.............Flurence 1.AWIENCE COUNT

W. U. Taylor. l'resldent....... Town l'reek s. It. sinders, secretary............. I.EF, COTNTY D. H. Uennett, Fresident.......... Opelikat J.MF:TUNE COLNTI

11. I. liarbs l'resldent.............then i. King Secretary..................... I.OWNHFS COLXTY

N. t. James, President.......... Hasneswllle Frank shackelford, Secretary.... Letohatchie MACON COUNTI

W. J. Magruder, P'restdent........Tuskegee C. Thiompson, Secretary........... Tuskege MADISON COLNTY

Edgar C. Blanton. President..... New Market Edgar kand. Secretary........... Huntsille MAHENG;O COLNTS

J. Whitfleld, I'resident........ Demopolis C. W. Brastleld, Secretary............ Winden MAIRION (COLNTY

II. W. Howell, President..........llamilton

I. s. White, Secretary...........llamilton MARSHAL, COUNTY

P. B. Lusk, Presldent......... . Guntersrille lim. Earl Noel, secretary...................... MOBIIE COLNTY

Kuftin A. Wright, l'resident..........Mbile w. W. Scales, Secretary................ Moblle MONKOE COLNTY F. S. Dalley, I'restdent...... Tunnel Springs
T. F. Dennis, Secretary......... Nonroeville MONTGOMEKY COLXTY Fred Wllkerson, I'resident........Montgomery
Yaul S. Jertins, Secretary.....Montgonery MORGAN COUNTY

1. 3. White. President..........thartsells Wim. illiford Balley, Secretary,...... Decatur I'ERRY COLNTY

C. K. Smith, Iresident........... Ilamburg

J. B. Hatchette, Secretary........... Jarion J'ICKESA COLSTY

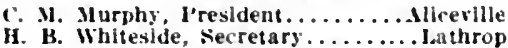
PIKE COLNTY

W. K. Sanders, I'resident........... Troy H. If. Weedon, secretary............ Troy HANDOLPH COLNT W. G. Floyd, Presldent........... Koanoke KLSSELL COUNT

IV. B. Hendrick, I'resident. ........Hurtsboro

I. C. Willams, Secretary.... il iatchechubbee SIIELBY COLITT

E. C. Payton, Presldent..............ton

J. 1. Held secretary.....................terallo ST. CLAIK (UI:NTY

W. It. Johnson, President.......... Ashrille

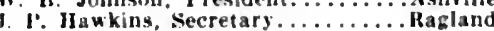
SIJTEK cot'NTS

k. H. Hale, Iresldent.............. York 1i. S. Hrockway, Secretary........ i.ivingston

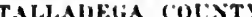

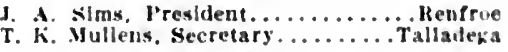
TALLAFOOSA IOITTY

II. Ii, Carieton. President....... butlegrilte A I. Iarlas, Secretary........ Viexander (It) TESCAloOSA IOINTY

(ieo. I Кли, Iresldent......... Tuscahresa

3. B. Ellote, secretary......... Tuscalows

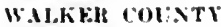

A. A. York, I'resident............. thughte

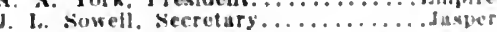

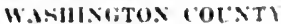

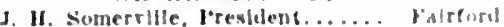

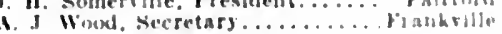
WH.tW: IM NT

Jentio Juned J'restilent.

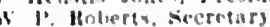

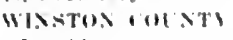

f. 1)ron, Frestuent.

c. A IIfret, scerelary
HEALTH OFFICERS IN CITIES OF 3.000 POPULATION AND OVER

Nabama Ciey.............W. It Acton Annlston................ W. Landham Bersemer............... W. Waller Ifirmingham............. Hubt. Nelson lecatur.

bottian................ stough

Eufaula................... F. Tlaluzer

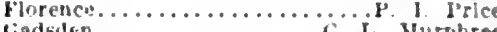

liadslen............. I Murphree

Greenville.................... L. Lerdue

IIuntsrille............... E. Eryer

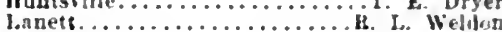

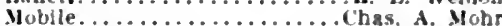

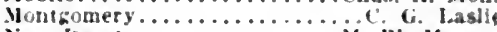

New Decaiur................. W. Murras

Oneunta................. I. Sitansberry

Opellka................. s. Bruce

Phoenix.

Selma.

shetheld.

.............. Maxuel

Trowe.................... P. Cason

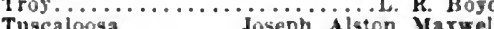

Tuscalona Alon Maxwell

Tusctumbla.............. M. Mlerce

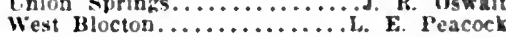

\section{STATE INSTITUTIONS}

East Lake

Alatama Hoys Industrial School. East Lake. Ala. (Birmingham P.o.). Established 1900 : reformatory: 30 beds: J. N. Klllough, (Birmingham), whysiclan; D. H. lieakley, superintendent.

Montevallo

Alrbama Girls' Technlcal Institute. Monterallo, Ala. Fatablished 1896; 30 beds: D. L. Wilkinson, physlclan in charge.

\section{Mountain Creek}

Alabarua Confederate Veterans' Home. Mountain Creek. Ala, Fistablished 1903. is heds: J. $P$. Fllswerrs obyslclan in charge; j. J. Simpson, superintendent.

\section{Mt. Vernon}

It. Vernon Hospltal, Mt. Vernon, Ala. Fistabllshed 1902: for the colored insane 900 beds; J. T. Searcy (Tuscaloosa), med. Ical superlntendent.

\section{Talladega}

dlabama School for Negro Deaf and llind. Talladera, Ala.: 6 heds in hosplta depariment: J. S. Grares, superlntendert Alabama School for the Bllad. Talla dera. Ala. Esstablished Isti: 90 beds: B. B. Simms, physician; J. II. Jahnson. principal.

Alabama School for the Deat. Talladega, dla.: It beds in hospltal depart ment.

Deat. Dumb and Hind Asylum. Tal ladega. Ala. For colored Datients: J. F Johnson. princlual.

\section{Tuscaloosa}

Bryce Hospltal, Tuscaliosa, Ala. Fstab. tshed 18.53: pulifle: for the white Insane 1.500 beds; J. T. Sesrey, medlcal superinterdent.

\section{Wetumpk}

Alabama State Tuberculosis IIonplal. Wetumpka. Na. Bostsbllshed 191:: publle: convlets only: tuberculosis: 140 beds: J. II Auntin and J. T. Fowler, phrs!. rintis in charge.

state lonaltenilary llowpltal, Wetumnka.

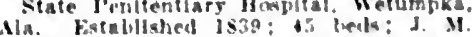
Austin, physlclan fr charbe: B. I. John. soll. superintendent.

\section{HOSPITALS, SANATORIUMS AND CHARI.} TABLE INSTITUTIONS

Alexander City

congars linfrmary. Alexuluer tyty. Ala

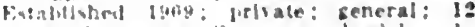

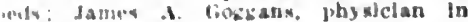
Jiarge.

Anniston

sulfera llomplial, 500 l.elghton Are., AnHatom. Na totablished 190\%: private: bi boids: 15. It and W. I. Sellers, physl.

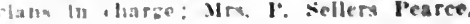
atureristedudent. 
St. Lulike's Hospital, 1405 Lelghton Ave., Anniston, Ala. Fstablislied 1912; public and private : 24 beds: no contaglous cases uccepted; Miss Dickert, superintendent.

Bessemer

Filizabeth Duncan Memoria] IIospita] $1710,3 d$ Ave., Bessemer, Ala. Established 1906; publle and private; general ; 50 beds; United Charitfes in charge; Margaret $A$. Kean, supcrintendent.

Fossll I Iospital, Bessemer, Ala. Fstablished 1902 ; private; 6 beds; malntnlned by the Tennessee Coal, Iron \& RaIroad Company; S. E. Cirout, clilef surgeol. Company; S. E. F. Irout, chlef stran, physician in charge. . F. IIogan, physician in charge. Iron \& Rallroad Company, Bessemer, Ala.; 22 beds; T. I. Conwell, physictan In charge.

Readers lIospltal, Bessemer, Ala. Establlshed 1902 ; maintained by Tennessee Coal, Iron \& Rallroad Company ; 24 beds; S. E. Grout, clifef surgeon; W. W. Compton, physlctan in charge.

Birmingham

Birmingham Inflrmary, Birmingham, Ala. Established 1913 ; prirate; 100 beds : Mirs. Golightly, superintendent

Davis lnfirmary, Birmingham, Ala. Established 1891 ; private; surgleal ; 20 beds: J. D. S. Davls, phystelan in charge.

sec spcrial Announeement Adv. page 69.

E. M. Robinson's Inflrmary, 1431, 11th Ave. South, Blrningham, Ala. Established 1911; prlvate; 25 beds; E. M RobInson, medical superintendent

IIillman Hospltal, 602 S. 20th St., BIrmIngham, Ala. Established 1888; public; general; charitable; 200 beds; E. P. Hogan, niedical superintendent.

Ishkooda Hospital, Birmingham, Ala. Established 1908; maintained by Tennessee Coal. Iron \& Rallroad Company; S. E. Grout (Bessemer), chlef surgeon; w. W. Compton (Bessemer), physlclan in charge. Compton (Bessemer), physician in charge. Lynnhurst Cottage Sanatorium, Birming-
ham, Ala. (R.F.D. $\tau$ ). Established 1911; tuberculosis; 20 beds; A. C. Watts, medical director.

MeAdory Private Infirmary, Birmingham, Ala. Established $1910 ; 12$ beds; W. P. McAdory, physician in charge.

Red Mountain Sanatorium, Birmingham Ala. (R.F.D. 4). Established 1910:32 beds; Mlss Kathryn I. Malone, superintendent.

Salration Arny Rescue Home, 3301 Ave. E, Birmingham, Ala. Established 1905 ; private; for women; 30 beds; II. R. Coston, physician in charge; Miss $M$. Graham, superintendent

South Highlands Infirmary, Inc., 1127 S. 12th St., Birmingham, Ala. Established 1910; general; 00 beds; Mrs. Mary B. Irwin, superintendent.

St. Vincent's IIospital, Birmingham,

St. Vincent's IIospital, Birmingham,

Ala. Established 1899 : public; general;

Talley Infirnary, Birmingham, Ala. Es-

tabltshed 1898; private; 10 beds; Dyer F. Talley, physician in charge.

Corona

Corona Hospital, Corona, Ala. Established 1903: private: ceneral: 6 beds:

w. M. Cunningham, physician in charge.

\section{Dothan}

Blacksher r Brothers' Infirmary, Dothan,

Ala. Established 1902; private; 21 beds

R. D. Blackshear, physician in charge.

Moody Infermary, Dothan, Ala. EstabItshed 1913; general ; $f$ beds; C. W. Hil-

liard, physician In charge.

East Tallasse

Edward R. Lett Infirmary, East Tallassee, Ala. Jistablished 1910; medical and surglcal.
Ensley

Cunningham Ilospltal, Fnsley, Ala. Established $1900 ; 12$ beds; maintained by the Tenmessee Coal, Iron and Rallroad Company; Lloyd Noland, (Birmingham). physician in charge.

\section{Enterprise}

CotPee County Sanitarlun,, Enterprise, Ala. Fstablished 1905; prlvate; general 20 beds; P. T. Flemlng, medical superIntendent.

Gadsden

Ralis' Sanitarlum, Gadsden, Ala. Established 1907; private; $\Lambda$. W. Ralls, surgeon in charge.

\section{Greensbore}

Carson Sanitarlum, Greensboro, Ala. Established 1902; private; for surgical and medical cnses; 10 beds; $S$. C. Carson, physlcian in chargo.

\section{Huntsville}

Humtsille City Infirmary, Iluntsville, Ala. Established 1904; public; 25 beds: maintained by Board of Ladies; Mrs. Maude Horner, superintendent.

Madison County Hospltal, Huntsville, Ala. Established 1900 ; small-pox only; 60 beds; 1 . E. Lryer, physlcian in charge. Mobile

Alabama Maternity and Infants Home, Moblle, Ala. Established 1911; public; 36 beds; L. L. Duggar, visiting physiclinn. Catholic Male Grphan Asylum and Industrial School for Boys, Moblle, Ala. Established 1847 ; private ; 125 beds ; C. N. Owen, attending physician; P. J. M. Acker, attending surgeon; Brother Fabian, superintendent.

Church Home, 206 s. Warren, Mobile, Ala. Established 1861 ; private; 42 beds; Episcopal churches or Alabama in con-

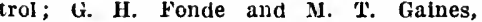
attending physiclans.

City Hospital, Broad and St. Anthony Sts., Mloblle, Ala. Established 1830 ; private and publlc; general; 195 beds; $D$. B. Faust and J. W. Terrill, physiclans.

Hannon Home for Áged, Mobile, Ala. Established 1903; private; for destitute men over 60 years or age; 75 beds; $W$. ' $T$ '. Henderson, physician; Little Sisters of the Poor, in charge.

Home for the Aged of the Little Slsters of the l'oor, Mobile, Ala. Established 1901; private; 50 beds; Wm. T. Henderson, physiclan in charge.

Inge-bondurant sanatorium, Moblle, Ala Fstablished 1899; private; general; 40 beds; H. T. Inge and $E$. D. Bondurant, physicians; Miss M. L. Phares, superintendent.

Mobile County Poor Asylum Hospital, Mobile, Ala. Public; 100 beds; F. Ml. Inge, physician in charge; $\mathbf{H}$. Murray, superintendent.

Mobile Female Benevolent Soclety, Mobile, Ala. Establlshed 1827; public; home for old ladies; 14 beds; Jennie L. Harkness, matron.

Ifobile Infirmary, 348 Springhill Ave., Molile, Ala. Establlshed 1910; public; general ; 52 beds; DeWitt C. Dillard, R.N. superintendent.

Protestant Orphan Asylum, 859 Dauphin Way, Mobile, Ala. Established 1833; private ; 56 beds; J. J. Peterson, attending physician; Mrs. Annie H. Malone, superintendent.

Providence Infirmary, Moblle, Ala. Es tablished 1853; prlvate: 125 beds: Thos. Gaines, resident physiclan.

Salvation Army Industrlal Home, Mo blle, Ala. Established 1908; public; for destitute men; 35 beds; $A$. N. T. Roach and $S$. F. Hále, physiclans; Captain S A. Iong, in command.
Southern Inflrmary, Springhill Ave., Mobllo, Ala. Established, 1907; privato: general 40 beds: T. H. Frazer and W. 1R. Jackson, physiclans in charge; Miss $\mathbf{E}$. R. Schlund, superlntendent.

St. Mary's Catholle Female Orphan Asy lum, 357 Conti St., Moblle, Ala. Established 1838; 100 beds; Slsters of Charlty In charie.

Unlted States Marine Iloaplal, Moblle, Ala. Fstablished 1835; government Instltution for treatment of merchant marine seaman; general; 50 beds; Surgeon $R$. H. voll Ezdorf in charge.

\section{Montgomery}

Ilale Infirmary, Montgomery, Ala. Established 1890; public; negroes only; 20 beds; Miss Petra I'lnn, G.N., guperintendent.

Highland Park Sanatorlum, Montgomery, Ala. Established 1893 ; private; 30 heds; Isaac L. Watkins, physlclan in charge.

Laura Hill Hospital, 729 S, Lawrence St., Montgomery, Ala. Established 1897 ; pripate; surglcal only; 40 beds; L. I.' and R.' S. IIIII, medical managers and proprletors; Miss C. MeCann, 8uperintend-

Montgomery Ant1-Tuberculosis Camp, Upper Wetumpka Rd., Montgomery Ala. Grell, phystclan in charce

St. Margaret's IIospltal, Montgomery, Ala. Established 1902 ; private; 100 beds: Sisters of Charity in charge.

Normal.

Virginla MfCormack Hospital, Normal Ala. Establtshed 1912 ; 15 beds; W. I. Buchanan, superintendent.

Opelika

Dr. Palmer's Sanltarium, Opelika, Ala. Established 1905 ; private ; 5 beds; J. G. Palmer, medlcal superintendent.

\section{Pratt City}

Carroway Infirmary, Pratt City, Ala. listablished 1910 ; private ; 12 beds ; C. $\mathrm{N}$. Carroway, physiclan in charge.

Selma

Burwell Inflrmary, Selma, Ala. Established 1907; private; for colored patients general; 15 beds; I. L. Burwell, physician chartre.

King's Sanatorium, Selma, Ala. Estab Ilshed 1896; private; 30 beds; Goldsby King, physlcian in charge.

Union Street Private Hospital, Selma Ala. Establlshed 1905 ; private ; 40 beds Samuel G. Gay, president of medical staff. Vaughan Memorial Hospital, Selma Ala. Established 1911 ; prlvate; general; 30 rooins; F. G. DuBose, phystelan in charge; Miss G. K. Gruver, R.N., superintendent.

Talladega

Talladega College Hospital, Talladega, Ala. Established 1906; public; for col ored patients; 12 beds; Mlss Ellza I. tage, R.N., superintendent.

Talladega Infirmary, Talladega, Ala Establlshed 1911; public; general; 20 beds; Miss F. 0 . Mason, guperintendent. Tusealoosa

Tuscaloosa Infirmary, Tuscaloosa, Ala. Established 1907 ; private; 16 beds; Geo. R. Rau, physlcian in charge.

Will amson-Faulk Inflrmary, Tuscaloosa

Ala. Established 1910; private; 12 beds

W. M. Faulk, manager.

Tuskegee

John A. Andrews Memorlal Hospital Tuskegee, Ala. Established 1893; prlvate; general; 65 beds; John A. Kenney medlcal superintendent. 


\section{PHYSICIANS OF ALABAMA}

KEY TO ABBREVIATIONS, SYMBOLS, ETC.

Names In capitals slgulfy nembership in the County Suclety and State IssociaUhon. (DOE, JOHN).

Indicates Fellowship in the American

Ied. Assn. (InOF, Jolis

(b75) Year of blrtb. [medls H, homeopath: $\mathbf{F}$, eclectlc; P-S, jhyslo Md. 09 , College and year of graduation.

O Information recelred does not show gradu. atton.

\section{8.-Surgeon.}

Ob-Obstetriclan.

ObG.-Obstetriclan, Gynecologlst.

G.-Gsnecologtst.

Or.-Orthopedist

Pr. Proctologist.

Opr-Ophthalmologist

A.-Aurist.

R.-Laryngologlst, Rhlnologlst. (1's9) Vear of llcense.

(5) In practice before passige of present law and lheetwent by Hilng diploma or ly years of practice

11) lictost bue

(b) Informatlon received does nivt show llicense.

I.A. I'nited States Army.

M.L. C...... Medical Keserve Coms.

SPECIALTIES ARE INDICATED AS FOLLOWS

ALR.-Aurist, Iaryngologlst, Hulnologlst. OALR.-Ophihalmologlst, Airlist, Jaryngologist, Khinologist.

U. - I'rologtst. -

D.-Dermatologlst.

Pd.- redialrist.

N.-Yeurologlst.

P. - l'sychiatrist.
1...... Inlled Siatey Nary.

I. vistice.

college prositlons held are Indlcated by aliberiated inte of josition. folloned by key number of collene. For key to culleges see inslde fromit cover bane.

$\{\mathrm{A}, 3$, IBi, (t) Niemberthly In minecla

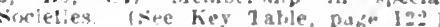

WHEN THE ABBREVIATION REPRESENTING A SPECIALTY IS FOLLOWED BY AN ASTERISK ( THE PHYSICIAN CLAIMS HIS PRACTICE IS LIMITED TO THAT PARTICULAR BRANCH OF MEDICINE: WITHOUT THE ASTERISK. THAT HE IS ESPECIALLY INTERESTED IN, BUT DOES NOT LIMIT HIS PRACTICE TO. THAT BRANCH. THIS INFORMATION CONCERNING SPECIALTY IS BASED ON PERSONAL DATA FURNISHED BY THE PHYSICIAN AND IS NOT VERIFIABLE.

\section{ALABAMA}

ABANDA, 125, CHAMBERS

CLARK, JAMES THOMAS $\left(b^{*} ; 6\right)-A l a$ 1.11: (I'II).

ABBEVILLE, 1,141, HENRY

Blacklldge, John Rlchard-Ala.2, 89 ; (I'9I)

FLoID, THOMAS J-La.1,0;: (1'0;)

LLE. 'LCIEN TEXSENT - Ala.2,04 LFE, LLCIEN TEXNENT - Ala.2,04 NICHOLS, LUC'US SIIFRMAN-Ala.2,'97; (l'97)

Steagall, Albert Sidney-Ala.2,'88: (I'88)

VAIN, JAMES IBOBT. (b'il)-Ala.2."99 (100): R.F.D.

VICKFRS, WM. CHAS. (1)'82)-I,a.I,08; (1.05).

ABERNANT, 300, TUSCALOOSA

Jones, $\boldsymbol{F}, \mathrm{H} . \rightarrow$ : $(1+)$.

Jones, Hufus C. $\rightarrow$ Ala.5,'98; (1'98)

Mcthee, Hobt H. (b+6t)-Tenn.j,'s7; (1).

ACKERVILLE, 50, WILCOX

WILILAIS, EUGENE EDWARD-Ala.2,04 (I'02)

ACTON. 1,200, SHELBY

CLAJTON, EIWALD I HFTON (b) \& Ala.t,09: (l'09).

strock, Chas. Stewart $\left(b^{\prime} ; 6\right)$-Teno.j,04 (1'04).

AOAMSVILLE, 649, JEFFERSON

GL.SGOW, KUIST, A.-Tenn.11;00; (1"1,1)

ADDISON, 100, WINSTON

OBTON, ALLEX FISYIN (b'S0)-Ga.12, US' (1'0s): $\mathbf{G}$.

AKRON. 100, HALE

GEISIN, WJi CHHISTUIIHI: - Ky.4, is $(1,-8)$.

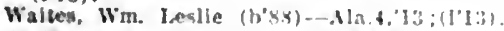

ALABAMA CITY, 4.313. ETOWAH

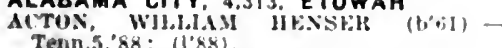

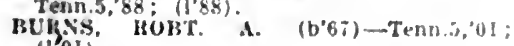

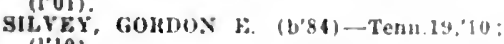
(l'10).

ALAMUCHEE (R.F.D., CUBA), I00, SUM -

JONES, JOS, F,-(;A.11,03: (1'01)

ALBERTVILLE, 1.544 , MARSHALL

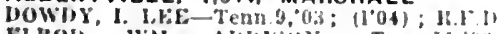

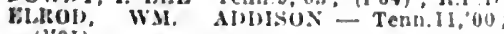
(1'01),

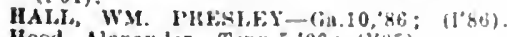

Hood, Alexander - Tenn.., 00 : (l'0,

IIATT, FHEET MASSFIFILI) (b'8s)Ala.e,11: (l'11): R.k.l). 4

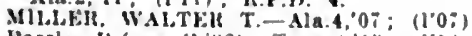

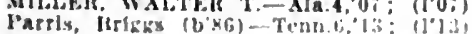

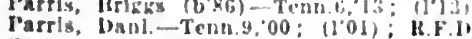

seot, . Nariba-0nt.3.11; ( )
SIFRMAY JAMES R-Ga.9,89: (1'85)

SIII', MONTCOMFRY GIIBERT $\left(\mathrm{b}^{\prime} 79\right)$ Tenn. $5,00:\left(l^{\prime} 01\right)$.

TIIO)AS, joHN R. (b'05) - Tenn.1,02; $\left(l^{\prime} 02\right)$.

ALDRICH, 450, SHELBY

Duncan, Arnott Kell (b'89) - La.l,'12: I'I:).

ALEXANDER CITY, I,7I0, TALLAPOOSA Allen, Larcus B, (b'8t)-La.1,12; (1'13). CHAIMAN, JAMES A.-Ala.2,05; (1'05) K. F.I. \&.

CHAPMAN, JOHN ARCIIE R. (b'84)Nla.:'I2: (1'12); R.F.D. 4 .

l"EAX, NEAL BAKEK-La.1,05; (l'05).

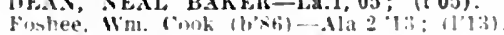

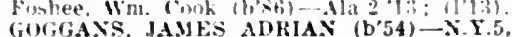
$\because 7(1+2) ;\left(A 6^{6}\right) ; S$.

BHFFIN, JAMES ÓliS-Ala.2,00; (I'00) K.F.D.

IIAIILA A ARON IAFAYETTE (b'bl)

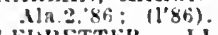
1. FIMBTTKR, LLEWEILYN HEISNDON

IIAIFORD, GiO. CLEMFNTS-O; (l'sï):

RF.IF.

STIEFT THOS. IEZFKIAII (b'at)-1'a.2 OOO: $\left.11^{\prime} 00\right) ; \mathbf{S}$.

ALEXANDRIA. 50, CALHOUN

MHHARG, ROSCOF, I.FE-N!a.2,06; $\left(1{ }^{\prime} 06\right)$. ALICEVILLE, 640, PICKENS

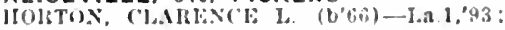

Jones, lee F. (bot3) (in.1,98, Tenn.11,9s: (1); : not in practle.

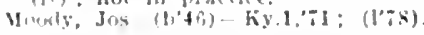

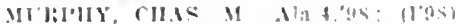

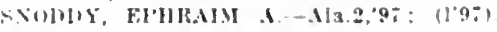

ALPINE, 100. TALLADEGA

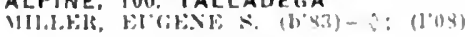

ALTON, 200. JEFFERSON

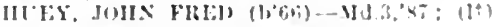

ALTOONA. 1.0\%1. ETOWAH

H.ज.l. I. W $\theta ;(1 \div)$

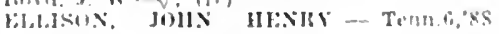
(1.4?

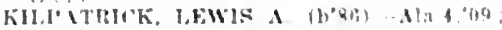
(1) 100$): O B$.

AMERICA. 100, WALKER

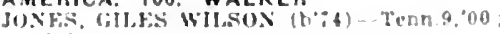
$110 ;$;

ANDALUSIA, 2.480, COVINGTON

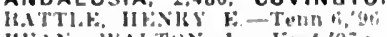

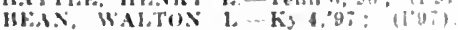

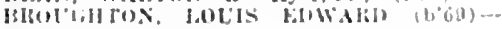

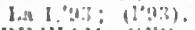

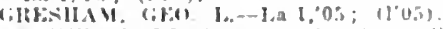

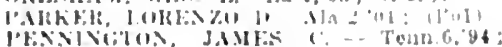

(i॰is).
NP.-Neuraloglat, I's yhlatelst.

I. - Internlst.

T.-Tuberculotberaplst.

Anes.-Anesthetlst

LD.-Iaboratory Dlasnostlelan. [alat. R.-Aceinologít, Hadlologlst, RoentrenoloPath.-Pathologist.

Bact-r. Bactericoloerts.
RAY THOS, QLIXCY-Ca.5.95: (1'94).

HIIIARDS, AlBFit M. (b'6)-Jd.9,04: (1) 0 e

ROLERS, wM. THOS_A!a.2,00; (l*0I)

SMITH, ELCFEE R.-IId.9,03; (1'04).

ANNISTON, 12,794, CALHOUN

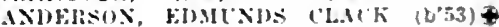
-Ky.1,7\%; (1'\$5); i109 Wilner Are.: ofice, $110 \div$ - Wliner Are.

Buwe OCK, ROBT. LEE-Va.1,8i, (1's8); $1: 00$ Quintard Are.

BHOTHELS, THOMAS JFFFERSOX (b79)

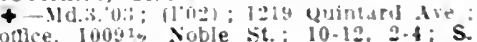
cllllixis, It HA B. T. (b69)-La.1,06; (10ij); 519 b. 6h St.: ondice, 1023 Noble [ILLk, FLIJAII L-Tenn.11,06; (1.06): 10.0

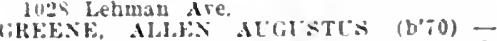

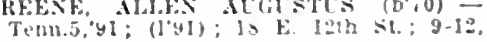

Harris, Ifardy Flening (cul.)-Tenn.:05: (1); 17w Mullerry si

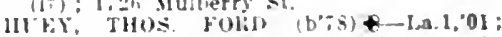

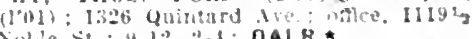
ville st. : -1:2-4: OALR.*

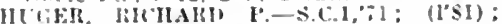
lanl Wilmer Are.

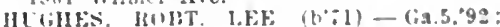

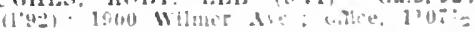
Xolile st.

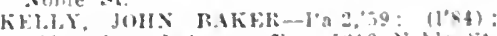

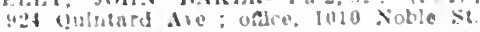

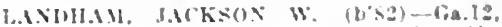
11: (1.11): I: 13:5 wilner Ave.: adted, t b

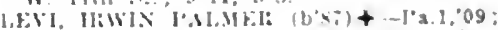

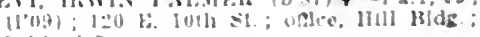

I.filli, "Holldet: AlMA (bsis)-Tenn.6.

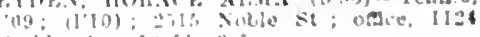

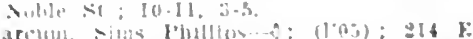

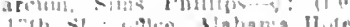

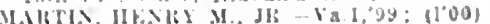

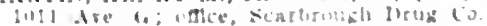

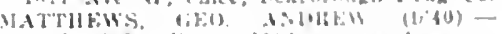

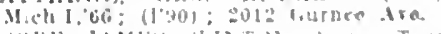

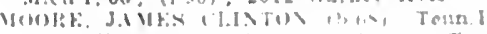

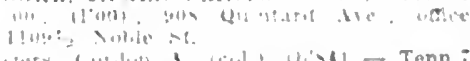

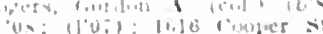

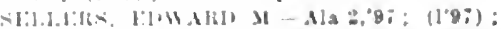

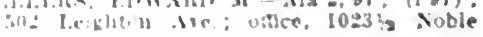

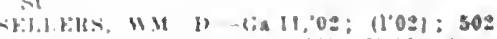

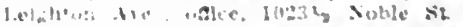

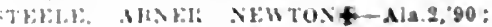

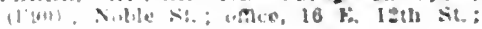


TAYIOK, JAMES RATCHFORD-Ga.5,'98; (1'9S); 100 E. 7th St.; aftlce, Sinith bldg.

Thomas, (has, Edw (col.).-N.Y.8, 90 ; (1'90) : 300 B St. : office, 124 W. loth st. $8-10,2-4,7-8$

VANN, PUU DE LACY (b' 72$)-A l a .2,96$ (l'96) ; 1603 Noble St. ; offlce, $11171 / 2$ Noble St. $9-12,3-6$

Walker, James Fleming $\left(h^{*} 47\right)-K y .2,92$; (l'92): 924 I,eighton Avo.; oftlee, 10IO Noble St.

Warren, Wm. Janes-Ga.5,'89; (I'89) ; not In practlce.

Weaver, Frank Crosby (b'87)-Ala.2,'12; (l'13): Sellers Hospltal.

Whiteslde John veIntyre (b'62)-Tenn 5, '84: (1'94); 700 Qulntard St.: ofllce, I10716 Noble st.

Wikle, Jesse Iane-Ga.1,79; (1'8I); not In practice: 1010 Noble St.

Vilhorn, Daniel W. (col.) (b'80)-N.C.3, 09: (1'10) ; 1701 Nulberry St.

ANSLEY, 50, PIKE

BROACIT, FRANCIS MARION (b'55) -

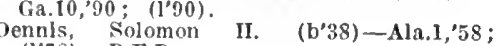
(l'78) ; R.F.D.

ARAB, 150, MARSHALL

Hinds, Montgomery I.-Tenn.5,'9I; (l'92).

Illnds, Wh. T.-Ala.2,'90; (l'90)

ARITON, 43I, DALE

Norris, Roy Hart-Ala.2,'97; (1'97)

Matthews, Augustus Douglas (b'86) Ala.2,11: (l'12)

PATTON, JOHN IAMPTON - Md.9,02. (1'02).

ARKADELPHIA, 207, CULLMAN

IEE, GENERAI, ROBT.-Ala.4,'06; (1'06).

PARKER, DOE J. (b'69) - Teun.8,'99; (l'99).

ARLEY, 10, WINSTON

DENNIS, DAVID R. (b'40)-0; (l'02).

ARNOLD, - WILCOX

HADDOX, WM. THOS. (b'33)-La.1,59; (1'79).

ASHFORD, 479, HOUSTON

CUMMINS, MANLEY LAFAYETTE-Ala.2, 06 ; (1'06).

FILLINGIM, WM. HENRY - Tenn.6,'96; (l'03).

GLOVER. CHESTER ARTIIUR (b'83)Ga.12,'10; (1'10).

Pate, Walter E.-Ga.5,'93; (l'94).

Stokes, James Eldridge-Ga.9,92; (l'97).

ASHLAND, 1,062, CLAY

JORDAN, JOS. WILEY (b'60)-Ga.5,'91 ; (1'87).

NORTHERN, THOS.-Ga.5,'78; (1'87)

OWENS, ARTHUR H.-Ala.2,05; (1'05)

OWENS, SEABORN WESLEY-O; (1'87)

PRICE, WM. HUGH (b'79)థ-Ala.4, 10 ; (1'11).

SCARBROUGI, BEMON CREIGHTON (b'85) -Tenn.19,'I1; (l'I1).

ASHVILLE, 278, ST. CLAIR

BEASON, WM, A-Md.3,93; (1'93)

Green, Bernard Law (b'7 i)-Tenn, 5,08: (1'08).

JOHNSON, WM. BUI.GER - Tenn.5,05; (I'05).

ASPEL, 26, JACKSON

Gattis, Henry Franklln-0; (l'82).

ATHENS, I,715, LIMESTONE

CRUTCHER, JOHN SIIS ( $\left.{ }^{\prime} 65\right) \oplus$-Tenn.5,

'89; (1'89).

DARBY, HENRY ALONZO (b'75)-Ala.4, 01; (l'01) ; R.F.D.

DUPREE, MARVIN WARD (b'80)-Ala.2, 03; (l'03).

Glaze, Andrew Lewis, Jr. (b'87)-Tenn.5,

HAGÁ, WII. JAMES (b'62)-Pa.2,84; (1'84)

HUGHES, JOHN FREDK. (b'84)-Ala.4,'10 (1'12) ; R.F.D.

Jones, Thos. Crittenden (b'43)-Ky.2,76; (l's8).

KIXG, CHLS. ORDWAY (b'86)-Tenn.5,09; (l'09)

Moore, Elisha B. $\rightarrow$ : (l'78)

PETTCS, BENTON SANDERS (b'69)Tenn. 5, 92 ; (l'92)

PETTTS, Jo'. ALBERT-Tenn.I,'68; (1'7).
Sowell, $W, 0.0 ;\left(I^{\prime} 78\right) ;$ IR. F.1).

Vaters, Archibald C. '(b'70)-Tenn.1,'00; (l'I0).

ATMORE, I,060, ESCAMBIA

BYIRNE, D.IVII) C., Jl?, (b'86)-Ala.2,09; $\left(l^{\prime} 09\right)$.

Christian, James C. $\rightarrow$ : (1†).

IAARER, GEO. H.-Gá.11,'02; (1'02)

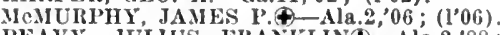

PEAVY, JULUS FRANILINt-Ala.2,'88; (1'88).

Peavy, Jullus Franklln Jr. (b'S6)-Ala.2. '12: (l'12)

WEBB, AIFRED PELIAR (b'73)-Ala.2, '96; (1'97).

ATTALLA, 2,513, ETOWAH

GILIILAND, IIENRY FORNEY-KY.4,90; (I'90); R.F.D.

IINBY, ELANUS K. (b'80)-Ala.4,02 ; (l'03).

McConnell, Robt. Franklln (b'54)-Ga.10,8I ; (l'8I) ; $\mathbf{P d}$.

STEWAITT, GUY E. (b'89)-Ala.2,04: (l'04) STEWART, JOIIN POPE (b'60)--Ala.2,'8\%: (l'85).

WOO1), JAMES IIARDIN, (b'57)†-Teun.5, '82; (l'82).

AUBURN, 1,408 , LEE

DHAKE, JOIIN HODGES, SR. $(1,45) \mp-$ Ga.5,67; (l'81)

STEADII I, OIIVER MARSHALI-TeHU.9, '94; (1'87).

YARBROCGH, CECIL S. (b'78)-Tenn.6, $\theta 1$ : (l'0I).

Yarbrough. Frank Reid (b'a 2 -Tenn,6,'98; (I'98); P.

AURORA (R.F.D., BOAZ), 62, ETOWAH

Slaughter, Chas.' Jefferson-D; (I'8I).

AUTAUGAVILLE, 313 , AUTAUGA

HERRMANN, JOHN WM. IIARVEY (b'86) -Ala.2,08; (l'08)

TANKERSLEY, JAMES-Ala.2,06; (I'06)

AVONDALE, 3,600 , BIRMINGHAM

CAFFEE, SAMI. RICHMOND (b'55)-310.1, '81: (1'81)

MARTIN, HEZEKIAH LOUIS.

(See Birmingham.)

IARTIN, WADE AUGUSTUS.

(See Birmingham.)

SCOTT, EDGAR MARVIN.

(See Birmingham.)

BAILEYTON, 63, CULLMAN

WINN, JOHN THOS.-Tenn.6,'93; (1'95).

BAKERHILL, 20, BARBOUR

BELCHER, WM. REE (b'68)-Ga.10,'89; (l'90).

BANKS, 307, PIKE

BEAN, JAMES M.-La.1,'83;(l'83) ;R.F.D. I. ICEACHERN, CONLEY PINKNEY $4-A l a .2$, $96 ;(1 ' 96)$.

WATSON, HUEY (b'78)-Ala.2,08; (1'08) ; G.

BANKSTON, I00, FAYETTE

SMITH, JOHX GARDNER-Ala.2,'89; (1'89).

WEATHERS, JOS. THLRMAN (b; 6$)-$ Tenn.I,'08; (1'09).

BARLOW BEND, 200, CLARIKE

COBB, WM. FLÓYD-Tenn.5,'95; (1'95).

BASHI, 32, CLARIKE

DAVIS, ILOUIS J.-Ala.2,'95; (1'96).

BATTLES WHARF, 50, BALDWIN Scott, Harvey Edw. (b'55) - Tenn.5,'80;
(I'8).

BAY MINETTE, 749, BALDWIN

HALL, JOS. - Ala.2,'OI: (l'0I)

IAAMBERT, GEO. LEE-Ala.2,'94; (l'95)

ICLEOD, JOHN C. $\left.\left(\mathrm{b}^{\prime} 80\right)-A\right] \mathrm{A} .4,00 ;\left(l^{\prime} 00\right)$

BAYOU LABATRE, 56, MOBILE

Persons, James Turner-Ala.2,'90; (l'90).

BEAR CREEK, 600. MARION

Plillips, Wendell Veto (b'76)-Ala.2,01 ;

SHERMIAN, JOHN RANDOLPII (b'71)Tenn.9,'97; (1'96).

BEATRICE, 345, MONROE

BRADFORD, B. R.-Ala.2,04; (1'04)

STALIWORTH, WM. ALLEN - Ala.2,'93; (l'93).

BEAVERTON, 150, LAMAR

SMITH, JAMES CLEMENT (b'86)-Mla.4, 'II; (1'II).

BEDFORD, 32, LAMAR

Box, Wm. I.yles (b'82)-Ala.2,'06; (1'05)
BELGREEN, 300, FRANKLIN

(IASGOW, THOMAS JEFFEIRSON (b'81)Ala.2,'10; (l'11).

UNDERWOOD, NIATROD EDGAIR (b'69)Tenn.9,00; (1'02).

BELK, 75, FAYETTE

HARTON, JOHN BARKLEY (b'49)-Tenn.8, 95 ; (1'96) ; Ob.

NEWTON, OLIN E. (b'81)-Ala.4,'II; (l'11).

BELLAMY, 500, SUMTER

HALE, ROBT. EUGENE (b'74)@-Tenn.9, $05:(1,05)$.

IAMKIN, THEODORE (b'79)@-Ala.4,'10; ('10).

BELLE ELLEN, 400, BIBB

Cryer, Geo. A. (b'77) - Tenn.5,'03; (l'04)

BELLE MINA, I00, LIMESTONE

PETTUS, JOS. JEWETT (b'80)-Ala.2,'08; (l'08).

BELLEVILLE, I69, CONECUH

BRAILEY, ELY (b'36)-Pa.1,'57; (l'84)

SKINNER, PERCY B. (b'80)-Ala.2, 05 ; (l'05).

BELLVIEW, 一, WILCOX

MeMlllan, Chas. H. (b'8I)-Ala.2,09; (I'09).

BELLWOOD, 20I, GENEVA

Bush, David A.-Ala.2,07; (1'07).

Lingo, Joln Henry (b'68) - $0 ;\left(l^{\prime} 97\right)$.

BELMONT, 76, SUMTER

IIESTEK, F. LEE (b'73)థ-Tenn.6,'06; (1'06).

BENTON, 600, LOWNDES

CLEMENTS, HENRY CLAY (b'76)--Ala.2, ; 1 (1’99).

(l'08).

BERLIN, 75, DALLAS

KENDALI, WM. QUINTON - Md.?,'80 ; (1'80).

BERMUDA, 100, MONROE

Ferguson, Angus Maybin-Ala.2,03; (1'03).

BERRY, 372, FAYETTE

BOBO, ARLINGTON HENRY (b'85)-Ala.4, '11 ; (1'11)

'hristlan, James Saml. (b'84)-Ala.4,'12 ; (l'12) ; R.F.D. 2.

Collins, J. WW. (b'51) $\rightarrow$; (l'84)

. IT (l'03).

BESSEMER, 10,864, JEFFERSON

Aldridge, Jonas W. (col.) (b'70)-Tenn. 7 , 99; (l’02).

Ansley, John Saml. (b'40)-Ga.5,77 ; R.F.D.

Bainter, D. A.-Ala.4,'05; (1'06).

BAXDY, EDWIN C. (b'60)๑-Ala.5,'98; (l'98): 1927 Arlington Ave.

Berry, James Crawford-S.C.1,'95; (l'95). Burchfield, Newbern Braum (b'82) -Tenn.9 $07 ;(1>07)$

Carter, John Watson-Tenn.I, 74 ; $(1, \tau 8)$.

Coleman, Win. Henry (col.) (b'70)-Tenn.7, 00; (l'0 I)

COMPTON, WHEELER WILKINSON (b'77) (4-Tenn.5,03; (1'03); 2200 Clarendon

CONWELL, THOS. ISAAC (b'8I) $९$-Tenn.1 03; (l'04) : Medical Department Tennessee Coal, Iron \& Railroad Company.

Denson, Fred Hammond (b'89)-Ala.4,'I2 ; (l'I3); R.F.D. 2

DONALD, THOS. C. (b'76)-Ala.2,'97; (l'97) ; 1822 Ave. D.

Downing, James Henry (b'60)-Tenn.8,'96; $\left(l^{\prime} 97\right) ; 2006$ Dartmouth $\Lambda$ ve.; offlee, 2051 19th St. ; II-12, 4-5.

Glllen, Bert Cecil (b'79)-Tenn.8,'12; (\$) ; 630,19 th St., $\mathbf{N}$.

Gregg, Eugene J. (col.) (b'74)-Tenn. 7,05 ; (1'05).

GROUT, SAML. EUGENE (b'77)@-Minn.4, 99 ; (l'01) ; Reader's Hospltal.

HAMIITON, WWATER FIEMING (b'82)Ala.4,07; (l'13); R.F.D. 4.

HARRIS, CARL A'TICUX' (b'87)-Ala.2,'10; (1'11); 3d Ave. and I7th St.; offlce, $213 \frac{1}{2}$ x. Igth St. ; 8-10, 2-4.

HOGAN, ROBT. ELIAS (b'75)@-Ala.4,01; ( $\left.1^{\prime} 01\right)$; 8-9, 4-5.

Howard, Wayne Cox (col.)-Tenn.7,'05: (1'05); 1st Ave and 19th St.

Johnson, Roy Earnest (b'i9)-Tenn.5,09;

(1'09); 1809 Dartmouth Ave, offlee, Trotter Bldg. ; 8-9, 2-4. 
LACEY EIMAIRD PARISII (h'56) PTenn.5.83: (1'83): 1802, sth At

2102\%. 19 th st. i 10-12. - S. S. (1) 1 ) : I.F.D. $5:$ Ob.

(I'st) I.F. D. A.F, 1

Folea. Klchand S (b'6i)-Ky.1,'39; (1'39) 430, ith St.: $6-7,12-1$.

Razsdale, villeon clay, Jr. $(1,80)$-Tenn.1 Of: $\left(1^{\circ} 06\right)$ : 1931 Arllugton Are: oflce 21 iz. $^{2} 19$ t. st. : $9-11,2-4$

ROBIXSOS. THOS. FIBANKI.IS (b-56)Tenn.1,80: (I'SO); 1616 Iserkley Are. cnce, 1831. 2d Are.: 10-12. 3-5.

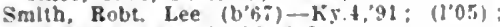
1912 , th Are.: $11-12,6-8$.

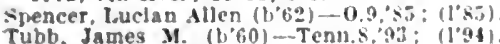

Tucker, Faster Wond (1, s(1)-Nla.,13: ( ) 1916 Clarendon Are. WALDRO , K. W. (b't) $\$-k y .96$ :

WALDROP. WY. II. (b':4)-Tenn.S.'99 (199): 2000 Arlingtion Are.; offlce, 221 \% 19 th st. $9-12,2-5 ;$ OALR.

WALLFR, GEO. NE LOACH $\left(b^{\circ}, 0\right)$ - Tenn.5 99: (1'99): 1615, 20 Are.: ortce, 2103 190 th $S 2: 3-4$

WISTERS, JOS. SCHOFIEI.D $\left(b^{\prime} 66\right) \$$ Ky.4, 90 (1'90); $210 \times 1$ s.th st.

wOOD, Wissto: CASS (1,52)-Ga.5, 81 (1'si)

BEULAH (R.F.D., BLANTON), 118. LEE
WHFELIS, WADE: KINAKI-Ky.2,'85

Jarbrouch Chas, SCGa.5:97: (1)9i).

BEXAR, 300, MARION

BROW. JAMES RIAS (b":9)-Tenn.8,'12; (1'13): R. 1 .

IOORMAS, ICHULES IUCIEX-0; (1'88)

NoRTIISGTON, JAME L. - Tenn.8,0\% (1):-): U.F.

8IG CREEK (R.F.D. GRACEVILLE, FLA.) 30. HOUSTON

AXIRESS, DAVID G.-Tenn.?,04; (1'04).

\section{BILLINGSLEY, 256, AUTAUGA}

DOWNS. BLBERT HOHTON (b'i) Teun.9,00; (1'00)

Marlar. Alonzo J. (b'60)-Tenn.8.32: (1'94).

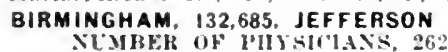

ARERXATIS, JUNEN CAIWALAHEKLa.1,60; (1'78); $4: 0$. 1st Ave.. Viest knd.

Ahney, John s. (b'a)-Tenn 8,05; (1'06); Z2, 1st Ave. uflce, Farley Hldg

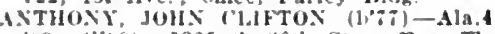

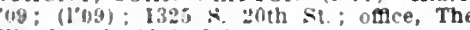
Woodward; $10-1,3-3$.

ASHWORTH, ItOHT. FHASEl: (1,'81) -

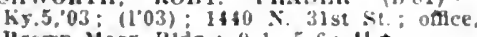
I rown-Marx Bldg. : 9-1, 5-6; U.

Ballard, Asa kl wy $\left(b^{\circ}:\right)^{\prime}-0.13,02 ;\left(10^{\prime} 02\right)$ 1330 , ith Are... 5. : ance, Farley kidg. Ballard, Asa Nathaniel II.-1).13,76: (l'st) $1105 \mathrm{~N}$. 25 th st.; omce, Farley Bidg.

RANCROFT, JOSEIH DOZIER-Tenn.5,'94 (1०94): 7922 Cnderwond Ite

BAXKSTOX, HCHAHI "UOH'BDEH-La.1,

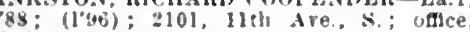
$20 \pm 9 \%$. 2d Ave

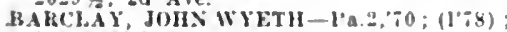
$\$ 16$ S. :oth St. offlce, Flrst Natlonal Hank HId

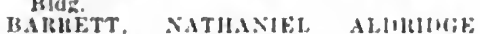

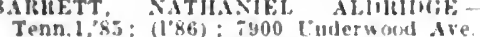
Tenn. $185 ;(186) ;$ iy

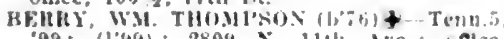

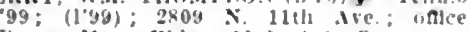
Brown-Marx IIIIg,: $11-1,46 ; \mathrm{S}$

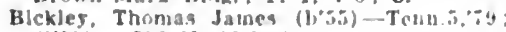
(1'81): 1:12 $x$. 13th ire.

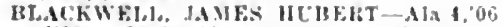

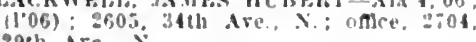

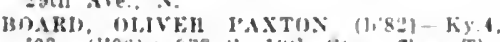

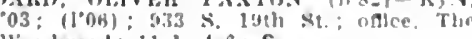
Womlwarl: $11-1,4-6 ; S$.

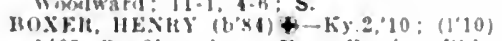

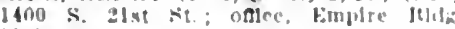
$11-1$.

Bralfurd, Ferillnami In (cel) (b'st)

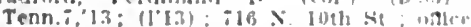

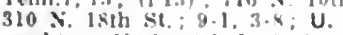

Ibroughton, Nathanlel J. (enl.) Tenn :.05 $(105)$ : :289 \$. 6ivt si

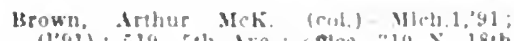

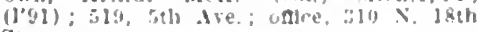

Hryant, Henry (1ay $(1,45)-111.6,16)$ (1'12) 616 ×. 1fith st. nalce, $171 \% 3,34$. We

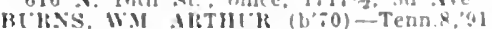

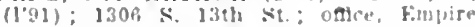
HId: $: 10-1: 3-5: R$.

Carfee. Wm il. (b92)-.tla.4:13; Introm. IIlliman Ilospleal.

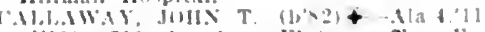
11'11): 19. 1st Are., Elyton; nalce. Hom plre rildg.: $\mathbf{U}$.

CALLES. WM. RLSEELL-LA.1,03; (1"0.3)

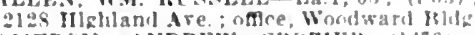
AVEROS AODREW ritozIE:I: 10".91-

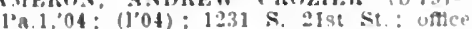
linodward Mld:

arpenter, Nathan H--1.a.1,45; (1'98) til Princeton Are.: nfice, Emplre Hly C.SEY. EIUEWORTI STEHIIENS (b'T) - Ala.4,00: (1.00): 2181 llighland tve

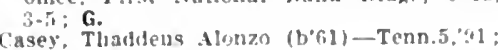
(1'91): 2401,26 th Are. $\mathrm{X}$. Then (I'06): 2401. 2bth Are., X.; once, 2600 (l'06) : 2401. Whth Are.,

CHAMBLEF, ZACHAliAII UITTON (b') -Ala.4.00; (1'00): 2601, 20th tre. offec, $2600,21 \mathrm{st}$ Are., $\mathrm{X} ; 11-1$

CHFATHA M, THOMAS AIFRED (1, 8 - $)$ Pa.2.09: (1'11): (J.ewisburg); oft

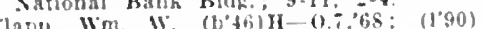
III Loulse Ire: affece, First Natlonal Bauk Bldg.

Cocelola, louls $\rightarrow:(1,00): 1500$, sth dre.

COCKE, NORBORSE LAGE $(b \div 8)+-V a .1$ 00 ; $(104)$; $2010 \mathrm{~s}$. 2sth St.; offlee, First Satlonal liank Blde.; $10-12$.

COCKF, P.ITL I.EE (b'T5) - Va.1.99 (L'03): 1820 s. lith Are ; offec, Brown Marx l3ldx.: 10-12, 2-4.

COILINS. JAIIF II.FXAXDER $(t, 69 ; 7$

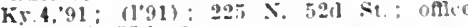

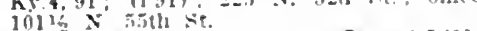

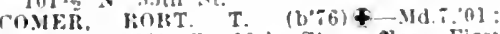
(1)01): 1231 s. 1 th St.; nflce, First Natirinal Bank I3lde : 11-12:30. 3-t

OMPTOX FFIIX IIF.NRY (b'se)fTeun. 50 : (1's5): 1722 . ith dre : oflee Flrst Satinnal rank Bldg. 9-11 3-5. (b'7s) f Md: :03: (1,05): 1022 syeamore st.; nalce, Emplre Blde.; $9-12,2-1$ lrof of Ophth. Alat

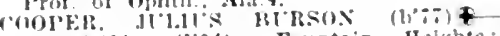
Tenn 904: $(104)$ : Fountain Helghts: oflce, First Satlonal Hank Hidz: 11-12 $2-5 ; \mathrm{S}$.

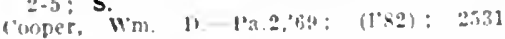

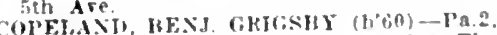
83: (1'S3): 1 Falrrlew Nircle: oflce. The woolward.

COPELASH, MILES AXF (b'GS)+-Ala 03. Tenu11,03; (1'03): :21 0.3. Tenulo Hide $10-1$ t.

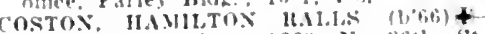

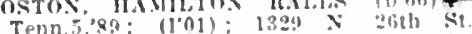

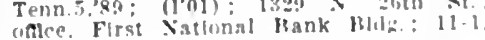
4.5: 0 b.

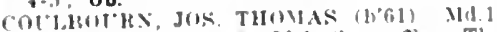
Q6: (1'si); I1] s. 3011 si.; "alce, The Vionelwaril.

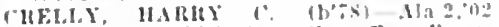
$(1.02): 2: 16$, Ineh dre., s.: once, kimpire Hdig: b-12, 2-5

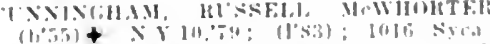

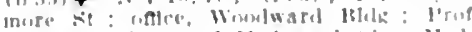

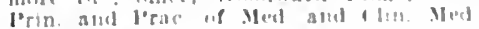
Nal $1:(.1+i): S$.

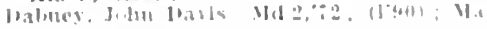

Milser

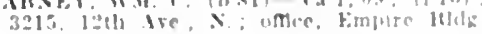

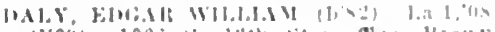

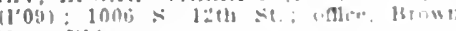
Marx Mlele

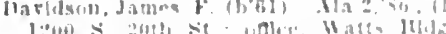

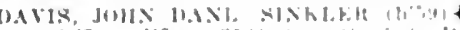

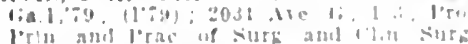

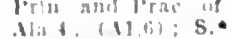

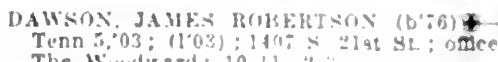

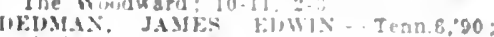

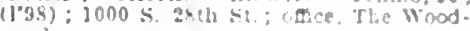

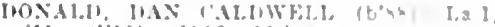
11: (1'11); 1912, 11th Ire. 5 , wee

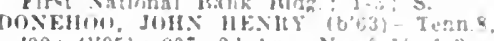

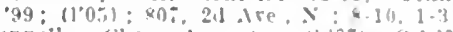

bonnelly, ('lias sugustus (2,8\%)-01,08: (1'10): 1125,12 ? $\mathrm{h}$

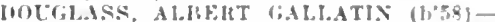
Tenn.5,81; (1's1); 2924 Are. r; uflee, Fistey" IBldo.

DOUGLASS. JOHX NJa.400; (1'01): 901 11th Ire.. S: office, $20: 2 \frac{1}{3}, 2 d$ Are.

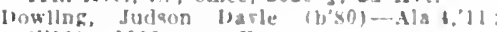
(l'11) : 1910 Are. 1:

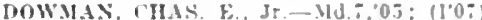
1516, 16th Arr.. S. : nflece. Emplre Hidz: $12-2$

Dozier. Byron T-M19.28,9:; (1000): 211? Hunblat Are : w

Dozter, Wrion Thuma-1;a, i4: (1'si) $2100 ;$ Humbold Are.; oftice, 2020, lst Ave : $8-6$

DRAKF, CII.IS. HIXTEK-Y.3.1,06; 11"06) $1104 \times 30$ th st: nflce, The Wondward. OREXIEN, WESLEY FARLE (b'S2) Y.Y.1.06; $(1,05): 3212$ Glenn

American Trust Bldi $10-12$
Jos

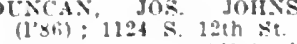

Edelman, Louls (bos) $\rightarrow$ : (199); 1914 10th Ive, s.; uflce, Firsi Natlond lbanh I3!dg.

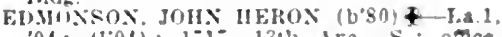
04: (104): 17i, 13th Ire. S ; omce (15i).

ELKOIRIE, HIICKEI, AIEXIXIIER (b'30)+-Tenn.1,01; (1'06):349 Cedar st. : once, The Wombitrl: 10-12, 3-5: G.

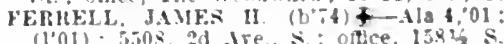
(1'01) ; 5.00\%. 2d Ire..s; oftice, 1582 S

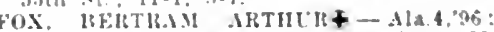

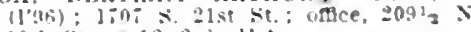

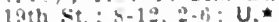

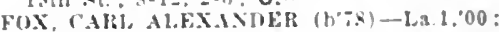
(lino): Kemor Apte, notce, Hrown-Marx Bldg: $:-1$.

pox. i.eon Nexander $(5,20)-0.11,12$; (l'13); Brwan-Marx Blas

Freeman. U. II. Jr. $\mid$ cost) (b's3)-Tenn: Ar: Allli): 119

(i)

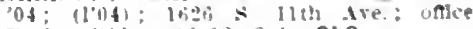
Firley llidz: 10.12. 2.1; ObG

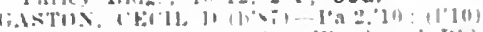

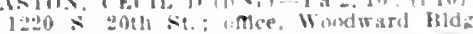

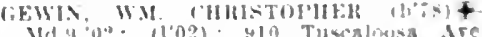

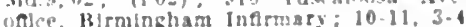
S.

Gibunl Edwarl I.ce (h'\$9)-Ala $4: 13$ (1)13; ; IIIlman IIospitat.

insherg, Iyman Max (b's6)-Md. 60 : (1'12): Einptre Hlas.

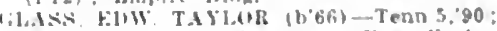
$(1+40): 1436$ X. 3lo st.: ance, Farley Blelt: : 1:-1.

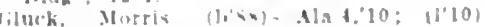
$1: 20,: 11$, i

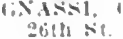

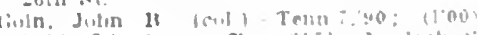

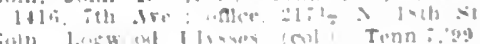

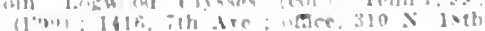
sit S. 1: H121:

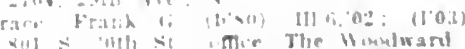

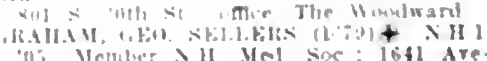

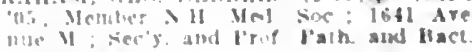

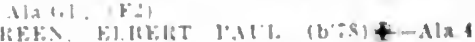

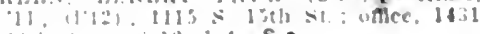


Freen, Plillmer Bruce (b'52)-Tenn.5,75; (l'85) ; 809 S. 12th St. ; oftce, Farley Bldg. IIagler, 1'rultt LaFayetle-N1a.2,'91;(l'91): $2026^{1 / 2}, 1$ st $\mathrm{St}$.

IIAMRICK, ROBT. HAMPTON (b'67) Ga.5,95; $\left(1^{\prime} 96\right) ; 1008$ S. 14th St.; oftlce. Enipire Blde.; 10-12:30,5-6.

Hanklns, John Mddleton - Tenn.1, 07 ; $(1,07) ; 6609$, 1st Are.; ofllce, 6510, 1st Ave. : $7-9,2-4$.

Hankins, Win. D. (b'72)-Tenn.8,96; (l'09) 7600 , 1st Ave.; $10-12,2-4$.

Hanna, Henry 'Plerce (l,86)-Ala.4,'12 (1'13) : 1600 Allen St.; office, Enipire

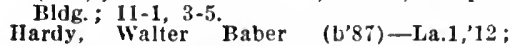
(1'12); Brown-Marx Bidg.

HARRIS, ARTHUR BUCKNER (b'76)(-

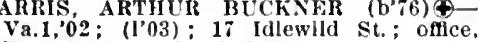
Flrst Natlonal Bank Bldg.

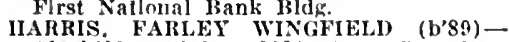
Ala.4,09; (1'10); 2031 Are. G; offec, Davls Infirmary; $12-2 ; \mathrm{S}$.

HARRISON, WM. GROCE (b'.1) - M-Md, '92; (1'92); 3818 Cllff Rd.; office, EmLaryn., Ala.4; OALR.

HEACOCK. JOS' DAVIS (b'69) 9 -La.1,92 (1'92); 3916 Summit Ave.; offce, First (1'92); 3916 Summit Ave; off

IIEFLIN, JowELI, T.-II. 1,$93 ;(1 ' 94)$; 712 N. 2lst St.: office, Fmpire Bldg.; $2-5$.

(I'85): 3216 ClIff (b'60) $\odot$ - Pa. 2,'84; (l'85); 3216 Cllff
Marx Blug. ; (A6).

HOGAN, EDFAR POE (b'72) $7-A l a .4,09$ (1'08); 800 S. 20th St. ; 12-2; Sec. and Assoc. Prof. Gyn. and Abd. Surg., AIa.4; (A6); $\mathrm{S}$.

HOGAN, GEO. ARCHIBAID (b'71)-Ala.4, $96 ;(1 ? 96) ; 800$ S. 20th St.; 2-4, 7-8; Asst. Prof. of Surg., Ala.4 ; S.'

HOSSAN, Prof of Surg., Ala.4; S. (1'03); 800 S. 20th St. ; 11-12.

Hogeboom, Chas. Barland $\left(b^{\prime} ; i\right)-T e n n .9$, $00 ;(100) ; 2213$, 7th Ave.

HOLIIDAY, WAITER HIOMER (b'6i)@Tenn.11.01; (I'0I) ; 2116 Oak Are.; offlce. Osceola Slation.

Hough, Hugh L. (b'78)-Ala.4,08; (1'09) ; $3201 / 2$ S. 20 th $\mathrm{St}$

Howard, J. E. (b'58)-Tenn.6,'87; (1'95); 717 N. 18th St.; office, Farley BIdg.

Howell, James M.-Tenn.8,04; (1'04); 2509 HEBBARD. WIIDER D. (b'71) $\odot-I 11.11,95$ ( ) Member Miss. State Med. Assn.; 2524 13th Are.. N.; office, First National Bank Bldg. : $10-12,3-5 ; G$.

Huckabee, B. E. (col.)-Tenn.7,02; (1'02) ; 920,8 th Are.; office, 2001 Ave. A.

Irey, Barna $P . \quad\left(b^{\prime} 61\right) \longrightarrow$; (1\%); 1820, 5tl Are., N.; office, Farley Bldg, : 9-8.
James, Milton $P$. (b'85)-Ala.4,11; (1'11) ames, Mllton P. (b'85)

JENKINS, LUCKEY ANDREN (b'65)Ala.2.'89; (1'89); 3536 N. 27th St. ; offlce, $30001 \%$ N. 27th St. : 10-11, 2-3.

JOHNSTON, HARDEE - Va.1,'95; (1'96) ; 1231 Whitaker St.; office, The Woodward; $11-1 ; 1 . \star$

JONES; CAPERS CAPEHART (b'46)Pa.14,70: (1'79); 7932 T'nderwood Are.

JONES, DEVOTIE' DENNIS (b'44)-MI.1. "72; (I'T2) ; 5602, 2 d Ave.

Jones, Robt. Arthur-Ky.2,'86 ; (1'86) ; 1922 14 th Ave., S.; offlce, Farley Bldg. Jones, Thomas Annerson (b'67)-Ala.4, 98 ;
(1'98); 7612, 1st Ave.; 8-10, 1-3.

Jordan, James L. (b'89)-Ala.4,'11; Intern, South Ilighlaud Infirmary; 10-12, 3-4.

JORDAN, IORTIMER HARVIE-La.1,07 $\left(l^{\prime} 07\right) ; 1220$ Avalon St.; offlce, The Wood-

JORDAN, WM. MUDD (b'73)๑-N.Y.1,95; (1'95); 1106 Crescent Ave.; office, The Woodward; $3-4 ;(\mathrm{A} 6) ; \mathrm{S} . \star$

KILLOUGH, JOHN NEWTON (b'65)-Ky.1 87 ; (1'S7) ; 5608, 2 d Are., S. ; offtce, 1011/2 N. 55 th St.

Kirsch, Maxwell Darld (b'82)-La.1,'12; (1'12); 1418, 8th Are.

KNOWLTON, JAMES WILEY (b'5i) (5Tenn.5;83; (1'83); 1318 Huntsville Avc. : KYSER PHILP 10: (1'09); 1005 S. 20tl St.; offlce, First National Bank BIdg. ; 10-11, 1-3.
HWDBETTER, SAML. I.EONIDAS $\left(b^{\prime} 55\right) \oplus$ liv.2,79; $(1,79) ; 1630,10$ th Are., S.; oflce, lirst Natl. Bank Bldg.; 9-1, 3-5; (B1) ; OALR.

I.ee, Frank John (b'80)-Ala.2,'08; (1'08) 1031, 3d Ave.

ILSTER, BELFORD S. $\left(b^{\prime} 84\right)$-Tenn.5,07 ; (1'08); 3426 Clite lid.; office, Einplre Bldg.

I.EVY, HARRY P. (b'80)-N.Y.1,05; (1'05); 802 S. 13th St.; oflce, The Woodward ; $10-12,4-5$

Lewis, Archibald Stuart (b'62)-Ky.2,'85; not in practlec; $719 \mathrm{~N}$. 21 st $\mathrm{St}$.

I.WWIS, FRANCIS PORCHER (b'44)-
S.C. $1 ; 7 ;\left(I^{\prime} 80\right) ; 832,41$ st St., N.; office S.C.1, 77 ; $(1+80) ; 832,41 \mathrm{st}$ St.

Lewls, James M. (b'64)-Tenn.5,'87 ; (1'88) ; 930 Woodland Are. : office, IIood IBldg.

Lewis, Thomas Knlght (b'84)-Tenn.5,'12; (1'13) ; 2021, 6th Ave., N. ; oftice, Woodward Bldg. : $11-12: 30,3-5$.

IONG, WM. IW (b'74)-Tenn.9,96; (l'03) 3024 Mountain Ave.; offce, Fmplre Bldg.; $12-1: 30,5-6$

IOTTERIIOS, GEO. (b'86)-Pa.1,'10; (l'13) ; 1121 Cullom St., N.; offce, Fmplre Bldg. ; $11-1,4.5$

OVE, WM. JONES-Ala.2,93; (1'93) ; 1318 N. 2 fith St.; offlce, $2029 \%$, 2nd Ave.

Lovelady, R. F.- 0 ; not in practice; $220 \mathrm{~S}$. 61 st St.

LOWREY, JOHN MCPHFRSON (b'74)๑Md. 3,97; (1'02); 1912A lfith Are., $S$. offce, First Natlonal Bank Bldg.

Juckle, Lorenzo Foster-Ala.4,'10; (1'10): 920 S. 13th St. ; $11-1,2-4: 30$.

LULI, CABOT (b'74) 9-MICh.1,99; (l'01) 1112 Elm St. ; offce, Flrst National Bank Bldg. : 12-1. 2-4; 1 .

LUPTON, FRANK ALLEMANG $\left(\mathrm{b}^{\prime} 73\right)$ Id.7,99; (1'v0); 2105, 16th Ave., $S$. offle, Woodward Bldg.: 10-11, 3-4; 'Prof'. Obst., Ala.4: $(\Lambda 6) ; 0$ b.

Maclin, Robt. B. (col.) - Tenn.7,05; (1'05)

2809,29 th Ave., North Birmingham.

Magruder, Thomas Vanuoy (b'86)-Ta.1 10; (1'11) ; 2120, 10th Are., S.; omce Amerlcan Trust Bjolf.

MARTIN, HEZEKIAH IOUIS\$-Tenn.5,'81 (1'81); (4415 Ave. E. Avondale); oftice 207 S. 41 st St. ; 10-12, 2-4. MARTIN, WWADE AUGUSTUS (b'84)-Ala. 41 st St. : $10-12,2-4$.

IASON, E. MARVIN (b'78)@-Md.7, 06 ; (1'07); 1820 Ave. I ; nffice, Empire Bldg.

MASON, JAMES IIONIROE (b'71)@-La.1, 99; (1'99); 1915, 16th Ave., S.; office Emplre Bldg. : 2-4:30; (A6) ; S.

Iason, Ulysses G. (col.) -Tenn. 7,'95; (l'95) 1525,7 th Ave.; oflce, 17171/2, 3d Are.

IAY, EUGENE E. $\$$-Tenn.1,00; (1'01) ; Bank Bldg.

May, Frank H.-Tenn.11,'98; (1'99) ; 1131 X. 31 st St. ; office. Brown-Marx Bldg.

ICADORY, WEIIINGTON PRUDE-Va.1, 97 ; (1'99) ; 2430, 11th Ave., N.; Assoc. Prof. of Surg., Ala.4; (A6).

McDaniel, Joe Crosby (b'86)-Ala.4,'12 (1'13); 114 N. 24th St. ; 8-11,3-6; Ob. ICGAHEY. MOBT. GOONLOE (b'87)-Ala.4 '12; (1'12); I12 S. Hawkins St.; offlce, 9. 2.4: Anes.

McGlathery, Fountain S. (b'60)-Teun.5;'82;

IIcHenry, Armand Goldsmith (b'88)-La.1, '13; Intern, St. Vincent's Hospltal.

MCKINNON, HECTOP A. (b'69)-Ala.4,'10; (1'10); 1412 Tusealoosa Are., West End nffice. First National Bank Bidg.: 10-4.

MCLAURINE, RERNARD (b'85)-A'la.4,'10 $\left(l^{\prime} 10\right) ; 1600 \frac{1}{2}$, 6th Ave.; offlce, Empire Bldg.

IICIEAN, CLAUDE COOPER (b'84)Tenn.5,08; (l'08); 175 E. 68th St.

MCLESTER, JAMES SOMERVILLE (b'77) -Va.1,99 ; (1'02) ; 3917 Cliff Road; offle Empire Bldy. ; 1-5; Prof. of Med. Ala 4; I

McQuiddy, Robt. C. (b'S4)-Ala.4,'12; (1'13) Whitefleld Flats; office, Emplre Bldg.

Jeadow, Albert Elí (b'60) H-0.13,'83, Ill.10, '99; (1'83); 1109 S. 30th St.; office, First National Bank Bldg.; 10-12, 2-4; S.

Meadows, James Allen (b'84)-Ala.2,'12; (1'12); St. Vincent's Hospital.
Mehaffey, Jonathan Wm. (b'87)-Ala.4,'13; (1'13); 301 $1 / 2$ Spring St. $10-12,5-8$.

ITCHELI. HENRY EUGENE (b'67)offce, Faricy Bldg. : 11-12, 3-5.

MOB1.EY, loIJT. V. -Ala.2,'89; (1'89) 1211 N. 251h St. ; ofllce, 20291/2, 2d Ave.

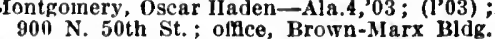
900
Moody, Vlncent's Hospltal.

MOON, WMME'T IIMBROUGII (b'67)-

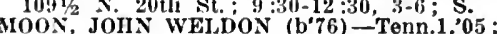

(1'05) ; 330 Fmma Ave.; office, First Natl. Bank 'Bldg. ; 11-12, 3-4; I.

Moore, Chaliners Haie-Mid.7,'13; Assistant physlclan, South Highlands Infirmary. MOORE, DAVID S., JR. $\left(b^{3} 86\right) \oplus$-Ala.4, 08 ; MOORE, DAVID S., JR. (b'86) \$-Ala.4,'08;
(l'08); 816 S. 20 ih St. ; offce, South HIghland Infirmary; $\mathbf{S . \star}$

MOORE, JOHN AUS'TIN申-Md.3,'85; (1'85) ; 731 S. 20 th $\mathrm{St}$.

MOORE, Jos. G. (b'88)-Ala.4,'11; (1'12) : 517 N. 21st St.; offec, Empire Bldg. ; $10-12,4-5 ; \mathrm{S}$.

ORLAND, MARVIN ERASTUS (b'75)offce, 2705,29 th Ave., N. ; $9-10,2-4$.

Offee, 2705, 29th Ave., N.; 9-10, 2-4. (l'05); 2428, 35th Ave., N.; offec, 2705 , 29 th Ave., N. ; 8-9, 4-6.

MORIIS, LEWIS COLEMAN (b'72) @-Va.1, '92; (l'93); Glen Iris Park; office, Emand Abd. Surg., Ala.4; $(\mathrm{A} 1,6) ; \mathrm{S}$.

Morton, Thos. Clark-Tenn.9,'91; (1'84) ; 1024, 1st Ave.

Moten, Pierce S. (col.)-Tenn.7,'06; (l'06); 613 S. 16th St. ; offlce, 20011/2 Ave.A. urphy, Grover E. (b'86)-Ala.4'11; (1'11) ABERS, FRANK EDMUNDSON $\left(b^{\prime} 70\right)(-$ Va.1,03; (1'03); 2519 Linden St. ; office, First Natlonal Bank BIdg. ; 10-12; 1.

NABERS, SAML. FAUST (b'74)-La.1,09; (l'08); 2023, 13th Ave., S.; offec, First Natlonal Bank Bldg.; Óp.‡

Nelll, Juther Clarence (b'77)-D.C.1,04 ; (1'04) ; 1610 Huntsville Are. ; offee, 1807 1/6

4th Are. : 10-12, 2-4.
NELSON, ROBERT-Ala.4,'05; (1'05) ; Cullom Flats; offee, Emplre Bldg.; Asst. l'rof. clln. Micros., Ala.4.

NICE, CHAS. IICKINNEY (b'82) @-Pa.1, '04; (1'05); 1232 Iroquols St.; offlce, The Woodward; $9-11,4-6$.

Nolan, Michael McCormack (b'87)-Pa.2,'12 : (1'13); 1241 Iroquols $\mathrm{St}$.

NOLAND, LIOYD (b'80) -9-Id.4,03; (]'13) ; 1109 S. 26th St.; oftice, Brown-

NoRMAN, GEo. ROBT. (b'S6)-Ala.4,'11; (1'11): 310 S. 23rd St.

O'CONNEII, EDWARD-N.Y.19,07; (l'09) ; 1005 S. 28 th St. ; office, The woodward. O'CONNELL, GEO ALBERT (b'82)-la.1, '06; (1'07); 2177, 11th Ave., S. ; offlce, The

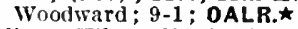

Oliver, IIilary F.-Pa.1,'58; (l'81) ; $215 \mathrm{~N}$. $53 d^{-3 t}$.

PARKE, THOMAS DUKE (b'57) (-Ky.4, offlice, First Natlonal Bank BIdg.; 11-12, $4-5 ;$ Pd.

Patton, James L. (b’ 79$)$-Tenn.8,00; (l'00); 4904, 1st Are.; offlce, 5003, 1st Ave.

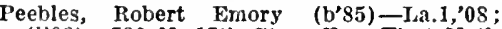
(108); 730 N. 17th St.; offee, First Natl. Bank Bldg. ; 10-12, 2-4; Ob.

PETERS, URBAN JOS. WHITEHEAD (b'69) $9-P a .1,98 ;$ ('00); 2800 Mountain Ave.; office, Empire Bidg.; $1 . \star$

Porter, Danlel Wm. (col.) (b' (b)-Tenn.7, 05; (1'06); 907 N. 51st St. ; 8-10, 3-4.

PRESCOTT, WM. ERNEST-Ala.4,00; PRINCE, EDMOND IORTIMER $\left(b^{\prime} ; 6\right) \oplus$ Ala.2,'01; (l'01); Idlewild Park; offee, South Highland Infirmary.

Puckett, Robt. H.-Ala.4,'07 ; (1'07) ; 1432 AlIen St., $N$.

RANSOM, WM. WALTER (b'68)-Tenn.5, '88: (1'88); 1920 Ave. D.

REEVES, PHIIIP ULMER (b'75)-Ga.1,01; (l'02); $2209,32 d$ Ave., N.; offlce, 2704 , 
REID, AI.BEIT MAKTIX (b'8s) 07: (l'0 $)$; Mrst National bank bldg.

RENDER, CAILL DAVIS $\left(b^{\circ} 80\right)$ Kv,l 07: (1'12); Memiler Ky. Stale Med. Assn.: 326 s. 20 ih st; onle, Howtward Blds. : ii-1,,$i-6$.

REYNoLDS, PREDK. KNoxt-Alat,01: (l'01): 125, lat Are., biyton.

RIGGS. EnW, POWF.LI-IId.3.81; (l'81) 1035 sycamore St.: once, The Woodward.

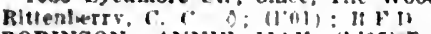

ROBINSON, ANxt: MAY (b'65) Pa.; cos: $(105)$; fos 1411 ire. st: oflce Brown-Marx Rldz. : 10-12, 2-1

ROBIYSOX, EIISIIA MH.HAR (b'63) Tenn.5, 85 ; $\left(1^{\prime} \times 6\right)$; (ilen Irls l'ark; once, 1431, 11th Are s

Robinson. Jas. B. (b'49)-Tenu.5, 82: (1'75) ; $5461,2 \mathrm{~d}$ Are. $\mathrm{s}$.

ROFERs, Gastoi w. (b'st)-Alat,il (1.11): s119 Highland Are.; oftce, Emplre Blds: : $10-11,3-4$; 5 .

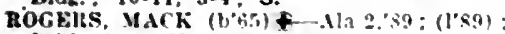
9118 Are. II: nalce, Firt Xati lank Blds. : 11-12. $3+5 ;(16) ; \mathbf{S}$.

Rosamond, Ethbert Cole-Ky.4,"93; (1'93); 2420 , 34th Are., $x$.

Rosamond. Wm. Luclus-Ky.1,'91: (1'91);

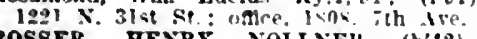

ROSSER. HENRY NOILNEI (b't2)Ga.5."69: $(1+79) ; 115,10$ th Are., s.: offlee. The Woodward

RUCKER, EDMTND W.. JR. (b'78) Colo.5,04; (1'08); Reemor Apls. : onfice, The Woodward; 10-1: ALR.

RUPEIPI, CHAS. MTRRAY (b'7a) Ala.2,00; (l'00); 3400 Alt-mont Rd. ofle, Emplre Rlds. ; $10-12$. 2-4: N.»

Russell. Kalph M.-YY.10,'ss: $\left(I^{\prime} 89\right): 1320$

Huntsrllle Are.; office. intis N. 18th st.

Sannders, Wm. Phllin (col,) (boni

Tenn.-13; $(1.13) ; 612$, th A se.. Tenn.:-13: (1'13); 612 , th Are..

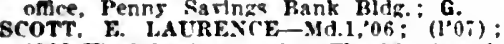
1108 Virglnia Are. omce. The Woodwaril. ScoTt. FDGAR MARVIN $\left(b^{\prime}, 6\right) 0$-Ala.2, "01: (1'01): 3819 Are. F': Cofilce, 41212 . 4lst St. Arondale); $9-11,1-5$.

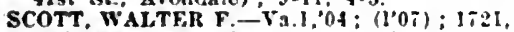
13th Are., S.: onice, Emplre Bldz.: 10-I. 2-5: U.*

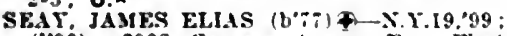
(1'99): 2908 Cyuress Ave.: oflce, First National Rank Bidg

EILERS, MENRY GKAHAM -Tenn.5, 00 ; (1'00); 1111 Tuscaloosa Are., West End. BELLERS, IRA JACKSON (b':2) (2-Tenn.5, '97: (1'97): 1500 Beech St. once, Flrst Natlonal Bank Bldg.; 11-1, 3-5; ObG.*

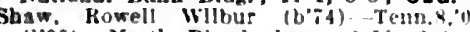
(1'00): North Blrminchan: s. If ,

Shelton, Jos. Rlehard (t'90)-Tenn.5,13; Intern, St. Vincent's IJosplial.

HOLL. HDw HENKY-1'a.3,56; (l'is) i09 N. I6th st.; 8-6.

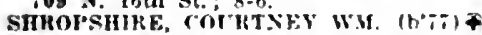
Tenn.6,00: (1'03): 2913 Junlper Are. office, First Natlonal Bank Pldz.; 8-1:30

SHUGFRMAN, HARRY lHILIP (b'si)Md.,08: (l'05); 1921 Are. If: offec. The Woodward: 1.t

SIBIEY BALNEY DINIBAR $\left(\mathrm{b}^{\prime}, 0\right) \uparrow$ Ala.4,98: (1.99): 2150 Hzhland Aret: OALR.

Slms, Jark II.-Fia.10, $82: 11 \dagger) ; 1230 \div 1211$ St. : omce $200 ; 1 / 2$.

SXIDER, JACOlt Roscor:4-Tenn :, $\left(1{ }^{\prime} 02\right) ; 1215 \mathrm{~g}$. 12th St.; oflce. The llind ward: I'rof. Ped. Ala A: Pd.

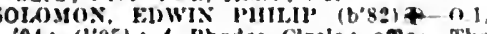
of: (1"05): 1 Khodes Pircle: omce. The Woodward: $9: 30-11: 30$. $2: 30-5$

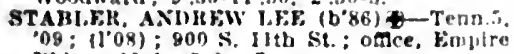
Bldg.; $11-1,5-6$ : 5 .

Stewart, Roscoe Conkling (b'85)-Ala.4,'13; Intern, Hlliman Hosplial.

strickiand. James J. ( $\left.b^{\circ} ; 9\right)-L a .1,04$ : (1'04): Mason Ifotel: omce. Farley Midz.

STIBHIS, SAML GAINES (b'80)Ma.7,07: (1.07): $1606 \mathrm{~B}$. I3th St.; once, The Woodward: II-1, 4.5 .

STIBHS, IEO. HANIITON (b'68) P-Ga 10 , 95: $\left(19 g_{i}\right)$ : 1800. 12th Ave. s.: odce. The Wontwarl: 9-1: OALR.
Sutton, Frealk. It. (b'391-Mich.1,81: (1'02) ; 1523, 31st Are. $X$; ance. 3104 'N. I6th

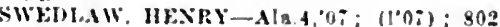
S. Isth SB: once, Chamber of rommerce ilitit.

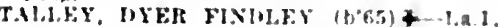

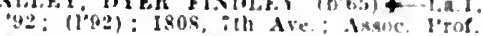
surg., Ala.4; (Al, 6$)$.

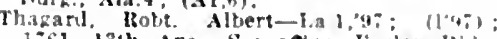

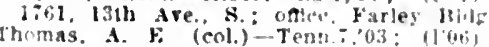
Themas. A f: (eol.)-Tenn $: 03:$ (loit) Thmas: Joseph Turner (c.l) (b's)Tenn.:05: (1'05): 604 be!! sie.: once 1730 s. 4:h . Ire

(6m. B. $\left(b^{\circ}\right)-k y 2 \div 8$ : not in practice: $60: 00$. 1st Are.; oase, Farle Blilg

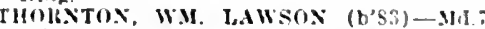
10: (1'10): 1000 Crescent lve.; onle Fmplre llde: $\mathbf{S . \star}$

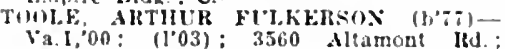

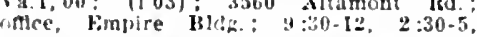
Assoc Prof. Ien.-Irli. Surt. Mlat.

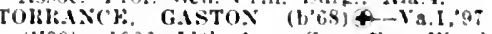
(1000); 1006. 11th ire., s.: aftlee, Word ward Bldg.: 11-1; (Ai,6): S.

WALKFR, ALFRED A. (b'81) †-N.Y.20,

NJKFR, ALFRFD A. (b'8L) 05; (l'05): 3837 Cresc

Walker, James Oley (b'8s)-Tenn. 5.'13: Intern, st. Vincent's Hospital.

WARI, HENRY SILASP - Tenn.1,2S (1'99) : 1108 N. 31s! St.; once. Empir Bldg; 11-1; I'rof. Neur. and Clin. Med. Ala.: NP.

WIRD, Wilter ROWLaND (b:6) Tenn.9,00; (1.00); $1+1 \mathrm{~s}$ \&. $15 \mathrm{~h}$ St. calce. Farley Bldg.: 10-12, $3-5$. WATKINS, Mil,Es ABERAATHY (h85)-

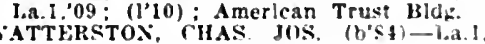

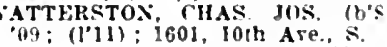

WATTs, ANTI COSTA $\left(b^{\prime}, 0\right)-k y,{ }^{\prime}, 2$ (100): R.F.D. $i ;$ once, Ly nhurst Fiot

tace Sanatorfun: T.
WEICH. STEWART H. (b'\$1) $\$$-N.Y.20 07; (1'10) ; 2805 Juniper Are.; oftlce,

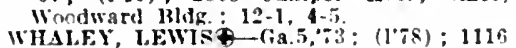
WHALFy, LEWISQ-Ca.s;3: $(178) ; 1115$ wiflix, cirAs.-Ala.2,96; (l'96); 60 : N. 2lct; oftce, First Sational Wank Blds WITER, WM. IIITON (b'63) \$-N Y.t. 91 ; (l'01); 1224 flen vlew Rd.; once. The Woodward: 11-1, 3-5.

WIIEL, CH.IRFX'CF CIG 08: (1'09): Wondirard BIdg.

WII.IAMS SIINEY L.-Tenn.9."94: (1.94) $909 \times 43$ S! : ofloce, $430 !$, I01h Are.. $\times$ williams, Thos. Ferfert (b,90)-Ala 4,13 (l'13): Illtmian IIorpital.

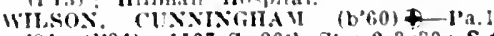
'st: (1'st); 1107 S. 20 th st.: $2 \cdot 3: 30 ;$ S. wlison, luther Firin (b'se)-l'allil (1'13); 913 s. 1sth si.; oflce, lirumnMarx Bldg: 204

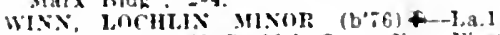
00: (1.00): 140 s. igth st. : once, blrst National liank Jidg.

Wowlall. Percy II (t';4)-Tenn.loti (Ostentath): 1011 Fula s: : ntice, First Yint?nal liank Blug: : 9-12 "-

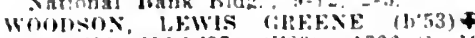
Ya.1, $96.9111,87 ; 11881 ; 1726$ \&. 1941

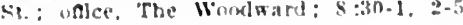
Op. (10ne): 172ti, Ith Are., s.: once, The Wimlenst

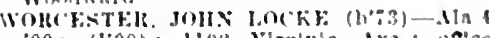

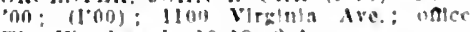
The womlward; 10.12.24

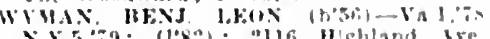
x 15,79: (1880): all6 H!ghland be

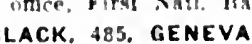

Mridive, liarnard Tllman (b'83)--.1la 2:04 $(100,6)$

lantord, W. IR. (b'84)-Ala.2.06: 1100i) BLOCTON, 2.500. BIBE

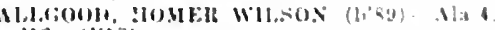
$12:(1,13)$

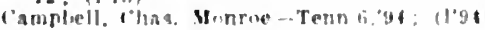

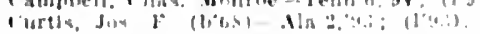

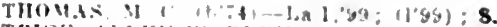

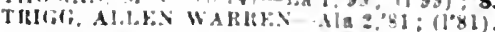
BLOSSBURG. 1,500. JEFFERSON JA'KSiN, I.EOSIbAS YHATON (b\%3)Mla 4,01: (101)

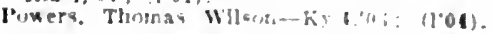

BLOUNT SPRINGS, 300, BLOUNT

'ANTRELL, WILSON TLRNE:K-KY.8,06:

\section{BLOUNTSVILLE, 287, BLOUNT}

Halmes, Wri. Tally-Tenn.E.'6s; (1.88).

Wald, Harrey l.eandeg-Tenn 1.03; 11'03),

BLOWHORN, 30, LAMAR

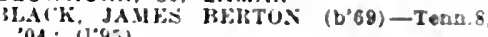
04: $(1.8 .3)$.

BLUE SPRINGS, 117 , BARBOUR

MELAECIILIS. JAMES IVANL (b'80)Ala.2."10: (l'10)

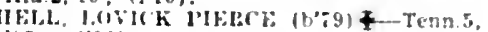
$05 ;(100)$.

BOAZ. 1.010. MARSHALL

OOLFY, HEAMON SHEPLEY (b'8\%) -

Gli,EsIlt: WIlliay T. (t.64)-Tenn.9. "48: (1'48

IIorsles, IIEnry Iee-Tean.1,04; (1'08)

IIF.D. 4. IAVID A. (b'60)-Tenn.8,'96;

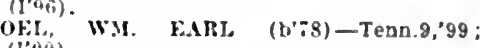
(1"vo)

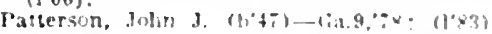

BOGUECHITTO. (ELEANOR P.O.) 50

DALLAS

Moseley, Flljah luckla-Ia.1,:5: : (1’:8)

BOLIGEE, 200, GREENE

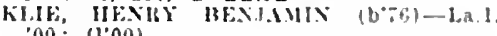
00: $(1,00)$

THETFORD, KE.XYON-Ya.1,99; (I'03)

TIICE. DANI. HAI.L-Ky.4, $03 ;\left(l^{\prime} 03\right)$.

BOLLING, 350. BUTLER

HENIVERON, IIILARY HERRERT(b'82) \& Ala.2,08: 11'08).

BOYLES, - JEFFERSON

LAVENIEK, WM. A.GFKXON (b;3).llat,09; (l'10).

PEARCE, HLL. EVERETT (b'-9)-Ala.

Wallace, Saml. II. (b's0)--Ala.4'II; (1'13) foo rark Kow : $8.10,4-6$

Vriche, Solon Westculs $(b, 95)$-Ala.t.11: (1'11).

BRADLEYTON, 150, CRENSHAW

Ford, Jullan C.-Mo.:.'96; (1'96).

BRAGGS, 20, LOWNDES

I.HATIFKWOOH', ELBERT FOCNTAIXAla.2,07: (1'0b).

F.E. WSi. F.K.XET (b'86)-Ga.l1,06: (I'06).

BRANCHVILLE, 89, ST. CLAIR

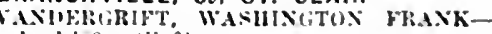

lai. $1,: 0: 19: 0)$.

BRANTLEY, 803. CRENSHAW

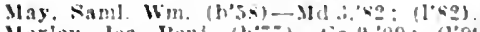

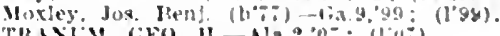

BREMEN. 65. CULLMAN

Jollstos, I'likstux T. a fi,-Tenn.6.

89: (1.96): K F.1)

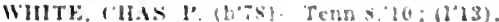

BRENT, 300, BIBB

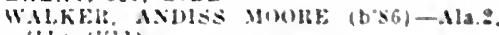
"II: (II]1)

BREWTON, 2,183, ESCAMBIA

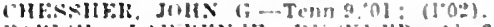

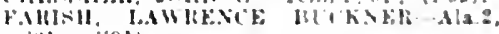
(1) : 11'0 11.

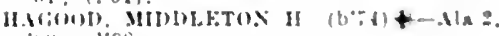

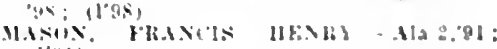

$(1, y)$

(l, 0,0$)$

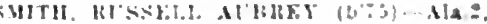

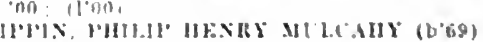

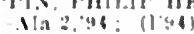

BRIDGEPOHT. 2.12S. JACKSON

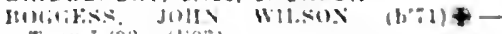

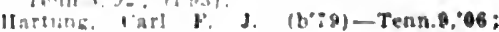


J.IMES, S.LML. IENIIY (b'BO) \&-Tenn.9, 06 ; $(106)$

damps Wu. (b'48)-Temn.T,'76: (1's2).

lee, Ellsha I.-Tenu. I, 72; (I'82).

P’ierce, franklin Duane (b'53)-N.Y.5, is.

BRIGHTON (BESSEMER P.0.), 1,502, JEF FERSON

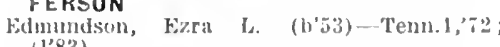
(1'83).

Kimnette, Jackson l'lavius-(ia.9.92: (['yz) BRILLIANT, 700, MARION

BELL, CIAIUE (1)'Ti)-Tenn.9,04; (1'04).

Wlllams, Larkin Wiley (b'4s)-0; (1'8s).

BROOKLYN, 350, CONECUH

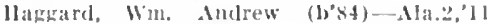
(I'II)

IIawthorn, Henry Mabury (b'83)-Ma.2,'10 (1'10).

Jones, irban L. (b"is)-Mo.3,"04: (l'04)

BROOKSIDE, 623, JEFFERSON

Sorrell, Howard H.-Ala.4,'08; (I'08)

BROOKWOOD, 1,500, TUSCALOOSA

EJ_GIN, RAYMOND T.-Tenu.I,07; (l'07)

BROWNS, 200, DALLAS

SMITH, JA.IES CEIIIAS (b'82)-Ala.2,'05; (1'05).

BRUNDIDGE, 815, PIKE

HEAN, JAMES FIANK (b'88)-La.I,'I0; (l'10).

IICKELSON, ROI'T. CIIAS.-Tenn.2,01; (l'0I)

Hendrick. Lowndes (b'64)-Ala.2,'90; (l'y0) JOHNSTON, JOHN DAVID (b'76)-Ga.11 00 ; (l'0I) ; K.F.D.

"00; (l’01); R.F.D. (1'89).

REYNOLDS, GROVER CLEVELANI) (b'S4) -La.1,'11; (1'11).

1REYNOLDS, JAMES WALTER-Ala.2,85; (1's6).

ROBERTSON, JAMES WILEY-Ala.2,'93; (1'93).

BUENA VISTA, 200, MONROE

HESTLE, WM. MONROE (b'55)-Ala.2,'85; (l'88).

BUHL, 200, TUSCALOOSA

Booth, Janies Lawrence (b'86)-Ala.4,'I1 ; (l'1i).

Deal. Seaborn Edgar (b'69)-Ala.2,'94; (1'94).

Deal. Wm. Wilbur-Ala.2,'04; (1'03).

BURNSVILLE, 200, DALLAS

WALKER, LEROY MeCORLISS (b'86)Ala.2,'11; (l'11)

BURNT CORN, 33, MONROE

FOUNTAIX, HUGH THOS.-Ala.2,72; (l'79)

HAIRSTON, WM. GEO. (b'84)-Ma.9,04; (1'04).

\section{BUTLER, 250, CHOCTAW}

LITTLEI'ARE, GEO. FRED. (b'85)-La.1, 09; (1'07); U.

MASON, HENRY HOWARD - Ala.2,03; (l'03).

BUYCK (R.F.D., TITUS), 20, ELMORE

POYYELL, OSCIL C. (b'-6)-Tenn.9, 02 ; (1'03).

CALERA, 754, SHELBY

ATKINS. JAIES MARION (b'7̈)-Tenn.11, 06; (l’07)

MOTLEY, SAIIL. D.\&-Ky.9,03; (1'04).

CALHOUN, 75, LOWNDES

AILIN, M.APY k. (h'46) $+-\mathrm{I} a .7,76 ;\left(1^{\prime} 12\right)$ Hember Med Soc of the State of Pa. (4050 Sanson St., Philadelphia ; l'81).

CALVERT, 150, WASHINGTON

WEBB, FRANCIS ASBURY $\oplus-A 1$. 2,'81; (l’91).

CAMDEN, 648, WILCOX

BENSON, JAMES COOK-Ala.2,'87; (1'86). BONNER, ERNEST-N.Y.10,98; (1'04).

JoNES, J. HEUS'rIS $\$$-La.I,'0I' (1'01).

JONES, THOS. WARBCRTON - N.Y.1,90; (1'90)

JONES, WINSTON B.-La.1,01; (1'01).

lilLPATRICK, RUFUS HALL - Mla. 2,88 ; (l'38).

MOORE, WM. W. (b'72)-Tenn.5,96; (1'96). CAMPBELL, 100, CLARIKE

Armistead, Lee $\rightarrow$; $\left(1^{\dagger}\right)$.
CAMP HILL, 896, TALLAPODSA

IIAMNER. IIARI'ER TALIAFERLO (b'66)-

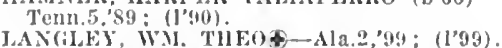

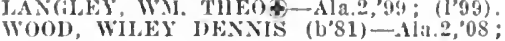
(1'09)

CANOE STATION, 50, ESCAMBIA

1111. Clark (b'85)-Ala.2,'11: (l'II).

STAIJWORTI, JAMES I'.-G.11, $\left(17\right.$; $\left(10^{\circ}\right)$

CARBONHILL, 1,627, WALKER BALISWGER, JOS. WM. - Tenn.5,84;
(1'87).

GILDEI, GEO. S.-Ala.2,'93; (1'94).

MADDOX, STERIIEN E,-Tenn.9,01; (1'01). IANASCO. TITUS (b'73) - Tenn 8,97 $(1,97) ; P d$.

PEIRY, SAML. MILIER (b' 73 -Tenn.5, 94; (1'94); OALR.

Whitney, Olly' 1I.-Ky.4,'90; (1'90).

CARDIFF, 426, JEFFERSON

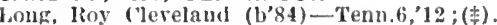

Shell, ('has. C. (b'82)-Ala.4,09; (1'09).

CARLOWVILLE (R.F.D., MINTER), I84, DALLAS

AIISON, SAMIL. BEEKMAN (b'67)-Ky, 1 , '89; (1'93).

CARROLLTON, 444, PICKENS

HIIL, HUGH WILSON (b'82)-Ala.2,'0.1 (1'04)

HIILL, SAML. HENRY-Ky.2,70; (1'78)

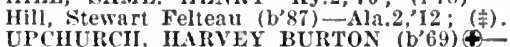
Ala.2,'92; (l'92).

CARSON, I0, WASHINGTON

PALMER, RANSOM D. (b'63)†-Ja.1,'86 ; (1'86)

CASTLEBERRY, 225, CONECUH

CARTER, JOEL HERBERT (b'81)-Ala.2, 'I 0 ; (I'10).

IJOILAND, RICHAR

JFNa.2,90; (1'90).

CATHERINE, 200, WILCOX IeINTOSH, EDW. LEROY (b'78)-Ga.11,

Van DeVoort, IJorace, Jr. (b'85)-Ala.2, 10 ; (1'13).

CECIL, I00, MONTGOMERY

ICDade, James C.-Ga.1,72; (1'78).

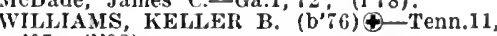
07 ; (1'08).

CEDAR BLUFF, 264, CHEROKEE

IEELIATH, WM. SPARKS - Tenn.8, 00 ; (1'00).

Sigrest, otho R. (b'78)-Ala.4,'08; (l'07).

CEDARVILLE, 250, HALE

JONES. ISAAC NEWTON (b'83)-Ala.4,'09; (l'10).

CENTER，256, CHEROKEE

CARDON, SAML. GARRETT (b'78)-Ala.2 02; (1'02).

SEWELI, WM. ASBERRY (b'77)-Ala.4, 12 ; (1'12)

TATUM, SAML. C. $\left(\mathrm{b}^{\prime}, 11\right)-$ Tenn.5,'93; (1'94).

WHITE, WM. Y.-Tenn.5,'87; (1'87).

CENTERVILLE, 730, BIBB

CUNNINGHAN, HORACE LEON - Tenn.5.

'I0; (l'I0). STEPHEN C. (b'68)-Ala.2,02 ;

$\left(l^{\prime} 02\right)$.
NICHOLSON, WM. JOHN (b'61)-Tenn.5, '84; (I'S6)'; G.

PETFRs, Wu. MARCUS (b'78)-Ala.4,06;

SCHOOLAR, THORNLEY EDWARD (b'68) Tenn.5, $92 ;\left(l^{\prime} 92\right)$.

WILLIAMS, MARTIN BARBOUR (b'78)Ala.4,07; (1'07).

CENTRAL, 100, ELMORE

JUSTICE, OSCAR S.-Ala.2,'S5; (1'85).

CENTRAL MILLS, 200, DALLAS

TAYLOR, WAI. IIEXRY' (b'61)@-Ala.2,'87 ; (1'87).

CHANCELLOR, 60, GENEVA

STANLEY, WH. AIFRED (b'90)-Ala.2, 'I2; (1'12).

CHANDLER SPRINGS, I00, TALLADEGA

SHADDIX, MARION LEONARD (b'85) $4-$ Ala.2,'10; (1'10); R.F.D. 1.

CHAPMAN, 10 , BUTLER

TIPIINS, HENRY KEENER (b'81)థIll.22,08; (l'08).
CHATOM, 200, WASHINGTON

CHASOS, JOLN (b'66)-Ky.4,05: (l'05) CHAVIES, 46, DEKALB

Balley, Alexander IIenry-o; (1'89).

IIall, John Decard-(;a.10,92; (1'97).

CHELSEA, 400, SHELBY

Boozer, Wm. Henry (b'86) - Ga.12,09; (1'09).

CHEPULTEPEC, 200, BLOUNT

AHIGOOD, WM. IBALNETT - Ma.10,78; (1'78).

CHEROKEE, 269, COLBERT

AIAMS, WHY SIMEON (b'84)-Ga.1,08; (I'I0).

O'IRelly; Jolın Edw.-Ala.2,74; (1'84)

WILILAMS, CIIAS. W.-Tenn.1,'73; (1'81).

CHICKASAW, 100, WALKER

ICCULIAR, J. A.-Tenn.5,'99; (l'99).

CHILDERSBURG, 449, TALLADEGA

HUTCIIISON, WM. II. (b'67)-Tenn.9,'93; $\left(1^{\prime} 97\right)$.

rane, II enry Bascum (b'54) - Ga.5,'95; (1'93).

Naff, John Mortlmer (b'61)--Tenn.1,'85;

POWEIL, TIOMAS JFFFERSON-Md.1,'66 ; (1'86); not in practlee.

SHEREK, MOSES FASON (b'83)-Tenn.9, '08; (1'10); R.F.D. CHINA GROVE (R.F.D., LINWOOD), I50,

SIMS, HORACE JAMES-Tenn.6,'06; (l'06).

CHISHOLM (MONTGOMERY P.O.), MONTGOMERY

Sanderson, Frank I. $-A$ la.2, 01; (I†).

CHOCCOLOCCO, 250, CALHOUN

Caffey, Benjamln Franklln (b'86)-La.1,

CITRONELLE, 935, MOBILE BLEWVETT, MLANS (b'67) - Tenu.6,'91;
(I'95).

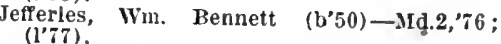

NEWBERN, VANDY W.-Ala.2,01; (l'01).

Shaeffer, C. A. (b'6t)-Md.4,'93; not in.

Wells, Chas. N. (b'69)-0.26,'04; not in practlce.

CLANTON, 1,123, CHILTON

EIIAND, JOHN DANL. (b'85)-Tenn.19,'11 ; (1'12); R.F.D.

GRAGG, VINCENT JONES $\left(b^{\prime} 78\right) \oplus-L a .1$, 08: (l'06); G. HAYES, JULIUS POE (b'70)-Tenn. 8,96 ;

99: (1'99): PERCY ISAIAH (b'79)-Tenn.5, JOHNSON, ÁTHUR (b'88) - Tenn.5,09; (l'09).

JOHNSON, NAPOLEON S. - Ala.2,'01; (l'01). JOHNSON, SAIL. EARIE (b'89)-Tenn.5,

Latham, Luther Mlddleton-Ala.2,'92 ; (1'92). MARCUS, TIIOS. J. (b'71) - Tenn.8,'10; (l'10).

MATTHEWS, EMMETT A. - Ala.2,87;

CLARENCE (R.F.D., ALTOONA), 53, BLOUNT

IOORE, DAVID SANDERS (b'52)-Ga.5,

CLAYHILL, 59, MARENGO

Jackson, E. F. $\rightarrow$; (\$).

CLAYTON, I,I30, BARBOUR JACKSON, BENJ. FRANKLIN (b'83)€ROBERTSON, WH. HENRY (b'61)@-Ala.2,

SIIART, WILSON ALPHEUS (b'61)-Ky.4, WINN, JAMES J. (b'42)€-Ga.5,'60; (1'81). CLEVELAND, I50, BLOUNT

Brice, James Arthur (b'81)-Ala.4,'13; (l'13): R.F.D. 1

DENTON, N. C.-Tenn.5,'05; (l'06)

MILES, WI. COWDEN (b'T4)-Ala.4,'99;

Tidwell, Ephraim Lonnle (b'81)-Ala.4,'13 ; (1'13).

Wittmeier, Jos. S.-Ky.5,'00; (l'01). 
CLINTON, 100, GREENE

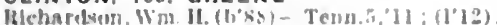

CLIO, 580, BARBOUR

(iluver, Maximllan $\rightarrow$; (1'98)

MeIXIIS, W. R.-Tenn.8,96: (1'99)

SH.THE, ERSRST F-Tenn.6.98: 11081

SHAW. WM. MILLEUE (b*9)-Tenn9. $03:(106)$.

TIJ.Lils, Jolx s. (b'8l)-Tenn.9,0 : (lino

WALIATK, GEO. OSCAR-Ala.2.'91; (1'91).

CLOPTON, 20, DALE

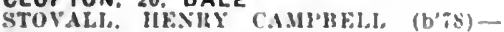
Ga.12,08: $(1.08)$

Weems, Wh. M.-Aln.e.92; (1t)

Whichim, Arthur Lee (b'88)-Ala.2:10: (1'I1).

CLOVERDALE, 150, LAUDERDALE

C'ORNELIUS, DANI. IRI'IIARD (b'8I) 1i. 12,"08: (1'08).

MORIIS, DREWAIY JACKSON (b'53)(It) : R.F.D

PAULK, SAML. OLTISON - Tenn.5.'85; (1'88).

COALBURG, 250, JEFFERSON

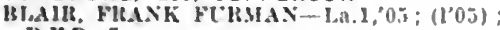
IR.F.D. $\%$.

COAL CITY, 685, ST. CLAIR

IIARILIS, FiIBIRY ("II.IS. (b'80)-Ala.2.04: (1'04)

IIAKMIS, FSAC ALLEN (b':3)-Tenn.II '98; (1.99)

COALING, 250, TUSCALOOSA

Cannon, I)anl. Pugh-Tenn.5,'95: (1'95).

COALMONT, 100, SHELBY

Iloore, Chas. Walton (arey (b'Bi)-Alat, 13: (1'13).

COAL VALLEY, 400, WALKER

WOODSON, JOIS I.ANDON (b'69) - Tenn.5, '92: (1'93)

Woulson, Iandon Aubry-Y.a.4,60; (1'91).

COATS BEND (GADSDEN P.0.), 85,

ETOWAH

BASKIN, IIRRSCIFT, VIRGIL-Ala.2,98; (1'98).

COATUPA, 100, SUMTER

l'ruett, liarld Phlllips (1)'92)-Ala.2.'06; (1'06).

COCHRANE, 200, PICKINS

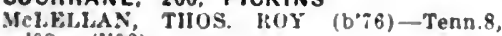
03: (1'02).

CODEN, - MOBILE

I'KTERS, KOHT. H. (b'-1)-Ala. 2.'94: (1"04)

COFFEE SPRINGS, 503, GENEVA

(arter, J. I). -0 : (1'85)

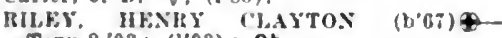

Tenn.8.03: (l'03); Ob.
SMITH. WM. W. (b't8)-Tenn.9,00; (1'03).

COFFEEVILLE, 104, CLARKE

RIDSON, JAMES TIIOS. $\left(b^{\circ} 64\right)-A l a .2,94$;

$\left.(1)^{2} 94\right)$.

ROIBISOX, AMOS NEAI, (b'59)-Ala.2, 93: (1'94).

COKER, 30, TUSCALOOSA

IBROWX, C'HAS. C'LIFTON (1,79) - Tenn.1I 05: (I'05).

COLEANOR, 800, BIBB

WIJIJAMSOX, JOHN SHULEIt - TEnu.5, 04: (1'03).

COLLBRAN, 100, DEKALB

KIlllan Henty Elllot- (l'89): KF.I

WIEELEK, JOS. AlkixiNUER (b'ib) Ala.4,07: (1"07).

COLLINSVILLE, 673, DEKALB

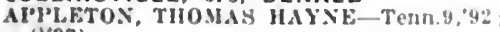
(1'92)

BOril, J. JOS, H-Tenn 3,$00 ;\left(10^{\prime} 00\right)$

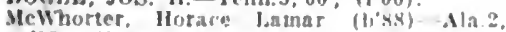

13: (1'13)

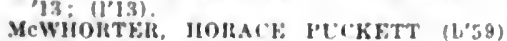
-Tenn.5;81; (1'85)

COLLIRENE, 130, LOWNDES

Jordan, Henry W', (b'83) - Tenn.8,12; (1'12).

COLUMBIA, 1.122, HOUSTON

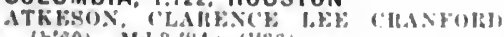

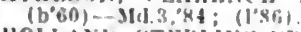

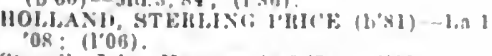

Stovall. John Jenry - (ia.5.'59: (1"89).

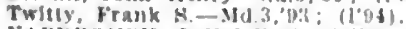

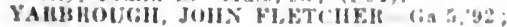
(l'92).
COLUMBIANA, 1.079 , SHELBY

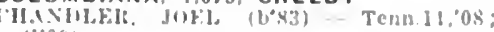
(1'09).

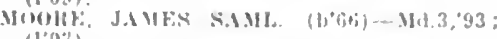

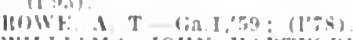

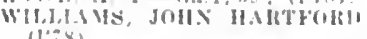

COLUMBUS CITY, 80, MARSHALL

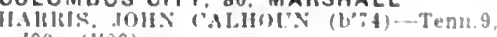
$0(1 ;)(100))$

COMER, 200, BARBOUR

HIIISTUY JAMFS IAAFAYETTE (1, I2)-

Thenn 9, 01 : $(1002)$

COOPER, 50, CHILTON

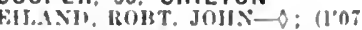

WISE, W.I. THI.T, (b'6i)-Cia.10,'89: (1'94).

CORDOVA, 1,747, WALKER

[DIS. HAN1. M.-Gn.10,89: (1'94)

MH.LKR. JuH, M.-Tenn.5, 85 : (1'85)

TIBIS, HLASTI'S HARDY (b'80)-Tenn.9. $03:\left(1^{\prime} 06^{\circ}\right)$.

WAJDROP, AJJEN MARION (b'78) T०MIII, 08: (1009).

COREY, 136, JEFFERSON

"AlRIIIIAL'L WM MONHOE (1,83)Tenn.1.,09; (1'07).

Donald, Jos. Glenn (b'8i)-La.1.'II; (f'll).

CORONA, I,500, WALKER

CINNINGHAM, WI. NOODY (b'58) \& Tenn 54 , (1'84).

Wricht, David IItidon (b'81)-Tenn.5.08 ('08): R.F.J. 1.

COTTONDALE, - TUSCALOOSA

JACKSON, CIIAS. BINFORJ) (b'62) Ga.5,86; (1'85); R.F.D.2

COTTONTON, 50, RUSSELL

EISROD, JOHT. FRANKIIN (b.82) Tenn.9, 05 ; $(1,05)$.

COTTONWOOD, 500, HOUSTON

Chalker, Benj. C.-ia.9,97; (l'9i).

Matthews, John Irartman-o: (1'88)

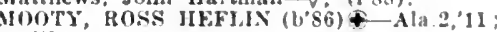
(1'11).

COURTLAND, 478. LAWRENCE

CLARKE. JOHX KJNG, JR. (b'6I)-Tenn.5 '82; (l'88).

MCMAHOX, WM. JACK-N.Y.8,60; (I"61)

RIGNEY, PALLA-La.1., 0 : (1.05).

COVIN, 60, FAYETTE

HOJLIS, JONATHAX SHELTON-Ala.2,84 (1's1).

COWARTS, 150, HOUSTON

IYALS, W.II II-Ga.5,'37: (l'95)

Cor. 50, WILCOX

GODHOLI, JOHN (ALHOUN-0; (1'T9)

CRANE HILL. 55. CULLMAN

I'HICE. WU. II ENRY-Tenn.6,'90; (l'98)

CRAWFORD (GIRARD P.0.), 200, RUSSELL

l'hl1jus, Jovlek W: (b'36)-1,a.1, bi: (1'83).

CREWS DEPOT, 150, LAMAR

Collins, Francls A.(1)'70)-Teun.8,'y2;(1'92)

CRICHTON, I00, MOBILE

ATKISS. JAMKS HAVII

(see Moblle.)

(ioff, McImnls Ianuat (b'8i)-Ma.2,12: (1'13)

CROPWELL, 105, ST, CLAIR

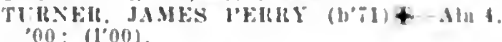

CROSS KEYS (R.F.D., SHORTER), 25.

CROSS K

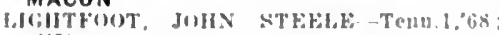
$(1 ; \%)$

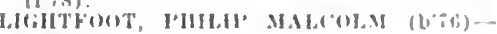
IIn 2,$00 ;(1,00)$.

CROSSVILLE, 250, DEKALB

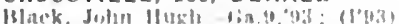

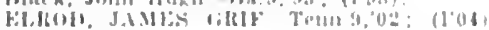
II H II

smlth, siaml l'arial fis I.'s : (1989),

Wyall, j. J ? (1'v!b)

CRUDUP, 50, ETOWAH

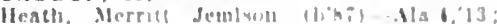
(1'1:3)

CUBA, 650, SUMTER

H.FHAOI, J.W WH

THenn. 11,$01 ;(1,02)$

stullanurtio. Fratik is

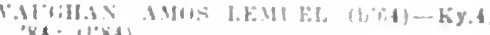

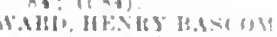
not in fractlec

CULLMAN, 2,130, CULLMAN

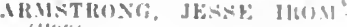

$(103)$

(3.1IIII)

$(1,82)$

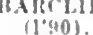

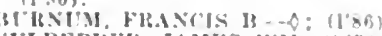

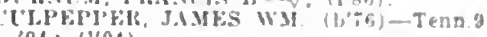
04: $(1,04)$

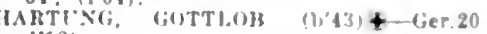
(1.92).

JAYS ILCTIER \& Tenn.9.'00: (1'0I)

MARTIN, ASA I'RI('F-Tenn.9,97; $\left.1 l^{\circ} 97\right)$ MAITTN, JAMFA ('ORDHE - Tenn.5,05; (l'05).

MES. (FERRIT (b'i4)-Xeth.1,0l: $\left\{l^{\prime} 10\right\}$

ODEN, JAMES HE.NII-0: (1'86): J.E.I.

VAN, THOS. PACK (1, 4$)-$ Teñ.9,06; (l.06)

CUNNINGHAM, 30, CLARKE

Cowan, ('larence E. (b'83)-Nla 2,11) (1'11).

CUSSETA. 150. CHAMBERS

IIARAI.SON, TIIUS. H.-Tenn.S.99; (1'99)

DADEVILLE, I,I93, TALLAPOOSA

IIART, Bl'GE:HE WAJKLH - Md.6.91; (l'91) : R.F.D.

MCCLESDON, JOS. WLLY (b.6i)-Pa., '88: $(1.88)$

NEW WAX, SAMJ. H.-Tenn \& 95 : (1'9\$)

SHEPARD, ORLANDO TYLEB - AJA.1,61; (1'82); U.F.D.

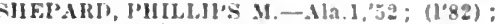
not in vracilce.

VINES. WFO. WASHIXGTUX - La.1,72: (l'82); not in practice.

DALEVILLE, 500, DALE

Townsend, Albert Lerl-Tenn.1,99; (1'99).

Townsend, Ausedn F-N1a:293; (1'93)

DANCY, 20, PICKENS

S.IOTHEIRS, IROJ!T, E, LEE (b*3)-Ala.2. 99 ; (1.04).

DANVILLE, 179, MORGAN

BLRCH, JOHS THOS.-Ala.4,06: (1'06):

DAPHNE, 549, BALOWIN

Monre, Walter X. (b'5)-Ky.4.03; (1'04).

DAVISTON, 127, TALLAPOOSA

HOIGE, EJORY h.-(ia.12,09; (1'09).

DAWES. - MOBILE

Hncy, Jobt, C.-Ma.2, s: : (I'si)

DAWSON, 125, DEKALB

IHRIIIIT, WM. IRA-TENI.5,"90; (1'91).

DAYTON, 382, MARENGO

LUCKHART. WH. C. (b'C0)-Ala.2,'89: $(1,89)$.

Malone, J. C.-Tenn 8.01: (1'01)

DE ARMANVILLE, 125, CALHOUN

Chltwom, Wm. O.-Tenu.11,03; (1'01)

DEATSVILLE, 194. ELMORE

HSTR: HOKUHCAI JAMES ELHOTTCia.5.95: $(1.93)$

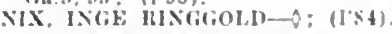

DECATUR, 4.228, MORGAN

BAILE. WM. CLIFFULD (D'S2)-Ala.?.

(106).

Cahlu, Newlyn k. (col.) (b's3)-D.C.3,'0s: $\left(10^{\circ} 08\right)$.

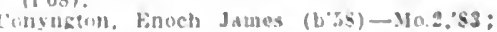

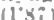

IINSUORF. WM. LFWIS (b'51)-Tenn.3. Gilt:k, (102) (1.10).

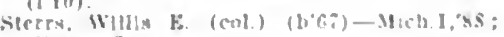
$(1 \times s): S$.

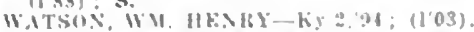

DELMAR, 100, WINSTON

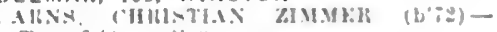

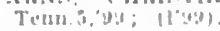

DELTA, 50, CLAY

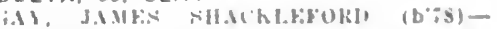

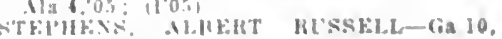

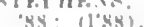

DEMOPOLIS, 2,417, MARENGO

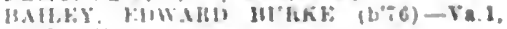

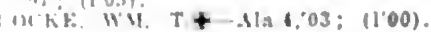


HAND, SAML. PATTON (b'59)Ð-La.1,'84; (1's? 3 ).

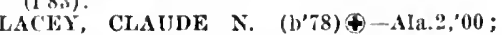
(l'03).

SAVAGE, THOS. CALDWELI (b'79) $€-$ Ala.2,'II ; (1'I2)

WHITFIELD, JAMES I:RYAN-I'a.1,67; (I'82).

Wilkerson, Gco. II iram (col.) (b'71)-Tenn. 7 , $, 97:(1,97)$.

WILSON, ISHAII G.-Ia.I.'68; (l’78)

DINGLER (R.F.D., LINEVILLE), 48, RANDOLPH

Lles, Madison nekalb -0 ; (l'7)

DIXON'S MILLS, 200, MARENGO

TUCKER, JOIIN SAML.—Ala.2,06; (I'06).

DIXONVILLE, 40, ESCAMBIA

Smith, Price Il. (b'61)-Ala.2,'94; (l'94).

DOGWOOD (R.F.D., MONTEVALLO), -

SHELBY

Harrlson, Henry W.- $O$; $(1 \dagger)$; not in practice.

DOLOMITE, I,000, JEFFERSON

Gwin, Paul Eugene-La.1,'06: (l'06)

Naff, Mortlner IIudson (b's7)-Ala.4,'12; (1'12).

DORA, 9I6, WALKER

CROWE, PINK P.-Tenn.5,'82, Tenn.1,'83; (I'78).

PHILLIPS, ALFRED B.-Tenn.5,'83; (I'85)

TAIT, PORTER KING@-Ala.4,03; (I'03).

Wilson, John Lcbron (b'83)-Ala.4, 11 ; (l'12).

\section{DOTHAN, 7,016, HOUSTON}

BARNET'T, THÓS. IIERIWETIIER-Tenn.5, 99: (I'99).

BLACKSHEAR, RANDALL DAVIS-Ky.I, '92; (1'94)

BLACKSIFAR, W.1. JOS.-Ky.1,'92 ; (I'92)

CARLISLE, SAML. OSCAR-Tenn.5,94 (I'94).

CHAUDRON, PERCY OCTAVE (b'86) (3-

Ala.2,11:'(I'11); $\mathbf{S}$

DAVIE, MERCER STHLLWLLLO-La.1,99 ; (l'99).

ELIIS, JAMES LEWIS (b'61)-Tenn.8,'86; (1'86).

GREEN, HENRY (b'67) (4-Ala.2,92; (1'92). Grimes, R. I. (col.) -N.C.3,05; (1'06).

HAMMOND, GEO. ABNER-Md.4,' $\$ 4$; (1'84).

HICKS, DORMAN MARVIN (b'79)-Ky.2, ,06; (I'06) : R.F.D

HILLIARD, CHAS. WESLEY (b'71)-Ala.2, 95; (1'95) ; OALR. *

HOWELL, WM. C. (b'S $) \oplus-G a .11,08$; $\left(I^{\prime} 0 T\right)$.

Middlebrooks, Wm. Edward (b’88)-Ga.19, '12; (1'13).

MDDLEBROOKS, WM. THOS. (b'63)Ala.2,'86; (I'86); G.
OOODY, EARLE FARLEY (b'80)(-La.1,

'03; (1'03).

STOUGH, MARVIN SIMEON (b'7T)-Ga.11, 99; (1'99).

IVILLIANS, WM. HENRY (b'65)-Tenn.S, '91; (I'91).

DOUBLE SPRINGS, 200, WINSTON

BLAKE, THOS. M. (b'72) - Tenn.1,07; (1'07).

BONDS, WM. RILEY (b'63)-Ala.2,92; ELBORN, THOS. POLK (b'45)- $)$; (1'02).

DOWNS, 100, MACON

Drakeford, John Ernest-Ky.1,'93; (1'92).

Sankey, Jos. Malloy-Ala.2,04; (I'04).

DOZIER, 288, CRENSHAW

CAMPBELL, DANL. J. (b'78)-Miss.2,09; (I'09).

MERRILL, Jos. P. $\left(b^{2} 74\right)$ - Tenn.8,03; (1'02).

DUDLEYVILLE (R.F.D., DADEVILLE), 95, TALLAPOOSA

CARLETON, WM. GEO. (b'58)-Tenn.5, '82; (I'82) ; R.F.D. 4.

FARGASON, CRAYTON C. $\left(b^{\prime} 74\right)-$ Ga.11, '04; (I'04).

DUNBAR, - WASHINGTON

WOON, JOHN WESLEY (b'36)-Va.4,60 ; (l'87).

EASONVILLE, 73, ST. CLAIR

MeCLELLAN, ROBT. LEE-Ala. 2,97 ; (I'97).
EAST LAKE (STA., BIRMINGHAM P.O.), - JEFFERSON

JONES, CAPEISS CAPEIIART.

(See Birmingham.)

EAST TALLASSEE, 2,000, TALLAPOOSA

Jett, Edmond R. (b'82)-Ky.4,05; (I'07) WARIEN, WH. ALLFN-Ala.2,'85; (1'85). ECLECTIC, 3I5, ELMORE

DARK, VIRGIL (b'87)-La.1,'11; (l'12),
IOWLE, JAMES AUGUSTS-11a.2,'90 ; (I'90).

EDEN, I65, ST. CLAIR

GKAY, JESSF AIANZO (b'61)-Ga.10,93; (I'93).

Laney, Marcus Warland (b'63)-Tenn.5,'93; (l'00).

EDNA, - CHOCTOW

ROBINSOX, HENRY W. (b'73)-Tenn.8,'01 ; (I'01).

ELAMVILLE, 200, BARBOUR

Faulk, 1. W: -0 ; (1ث).

ELBA, 1,079, COFFEE

BLUE, JASPEI DIXON- 0 ; (1'85)

BRADLEY, HENRY RANDÓLI'H-AIa.2,'96 ; (I'96).

COSTON, WM. HENRY-Ga.10,'89; (1'89). HAM, NELSON MATTHEW - Ala.2,'98: (1'98); R.F.D.

HAYES, CHAS. P.-Ǩy.4,06; (1'06)

IIXSON, CLARENCE WA. - Ala.2,08; (I'08); R.F.D.

ELDRIDGE, 120, WALKER

ASHMORE, BRYANT T. (b'62)-Tenn.9,'01 (I'01).

GALLAGHER, JOHN L.-Ala.2,'92; (I`92).

ELISKA, 5, MONROE

Bryars, Jesse Floyd (b'80)-Ala.2,'05;; (l'05). COLE DAVID DU BOSE (b'i1)-Ala.2,'97. (1'98); Ob.

ELKMONT, 188, LIMESTONE

MAPLES, JOS. IIEMANS (b'77)-Tenn.1 05 ; (1'05); R.F.D.

MAPLES, WH. ELLIS-Tenn.1,03; (l'03) Powers, Alvin Dow (b'83)-Ala.2,'11; (I'11) Williams, Geo. Allen-Tenn.6,'80; (I'81).

ELMORE, 300, ELMORE

ROSWELL, FRANKLIN A-Ala.2,00; (l'00).

HAKMION, J. S. (b'85)-Tenn.9, 07 ; (I'07) ; R.F.D.

ELROD, 35, TUSCALOOSA

Hughes, Robt. Lee ( $\left.b^{\prime} 71\right)-$ Tenn.1,05; (l'05). Mills, Joel- $\longrightarrow$; (lî).

EMELLE, 300, SUMTER

SWAIN, SIMEON SEBASTIAN $\left(b^{\prime} 78\right)-$ Ala.2,01; (I'01).

EMPIRE, 300, WALKER

SOWELL, WALTER S. (b'74)-Ala.2,'99; (I’99).

YORK, AARON ALBERT-Ala.4,'06; (l'06).

ENSLEY, 8,000, JEFFERSON

BLACK, JOHN WM. (b'i9)€-Ala.4, 09 ; (l'10).

CLARK, NATHANIEL GUIDO (b'72)-Ala.4, '9S; (I'98)

Clements, Merit DeWitt (b'87)-La.1,12; (l'12).

CLOUD, ROBERT EMMET'T (b'76)థ-La.1, 10 ; (I'09).

COWAN, ALVIN

CUNNINGHAM, HIODIE EZRA (b'7

Ala. 4,$00 ;\left(\mathrm{I}^{\prime} 00\right)$.

FIEIDS, ELBERT TILES $\left(\mathrm{b}^{\prime}, 7\right)-$ Y.Y.19, '99; (1'99); $\mathbf{S}$.

FONVILLE, WiI. DRAKEFORD (b'78)La.1,'05; (I'05).

GASTON, ANDREW MAFAYETTE (b'84)-

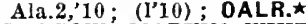

GLASGOW', MARVIN WHITEIELD (b'i8)@ -Tenn.5, 01; (I'01).

Gnasso, Enrico' R. (b'84)-Ala.4,'13 : (l'13) Gray, Edward Waters (b'81) - Ala.4,09

HENDON, WM. THOS.-Ala.2,'98; (I'97)

Johnson, Frank H. (b'82)-Tenn.9,03;

KENT, JOH'S THOS. (b'70)-Ala.2,'95; (I'95).

MANN, SIDNEY HENRY (b'74)@-AIa.4,

'01; (l'01). Webster Bullock (b'89)-Ia.1,

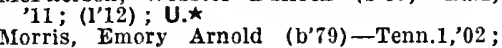
(1'02).
Noble, Robt. I'. (b'81)-N.C.I,'07; (1'07). ROBBINS, JESSE EI.BERT (b'62)-Ga.10 '86; (1'86).

Rollbins, Wm. Jesse (b'89)-('a.11,'12; (I'13)

Robertson, A. (i. (col.)-N.C. $3,05:\left(l^{\prime} 05\right)$.

Simpson, Frank S. (col.) -N.C.3, 02; (1'02)

SIRINGFIELD, THOS. JEFFERSON - 0 (l'76)

Sugg, Thos. Lealand (b'60)-Ky.1,'88; (l'89) TEDDER, CHAS. ERNEST (b'86)-Ala.4 12 ; (1'12).

Thompson, Curry Eugene (col.) (b'80)-

Walker, Chas. Robt. (b'70)-'Tenn.5,'98; not in practice.

Wheeler, Thos. Tyler (b'76)-Tenn.9,00;

WYNNE, WM. IIALIA-Ala.4,97; (1'97).

ENTERPRISE, 2,322, COFFEE

BYRD, BENJ. I.-Nla.2,'92; (l'92).

COLLEY, AARON THOS. $4-\mathrm{Ky.2}, 94$; $\left(1^{\prime} 94\right)$.

FLEMING, PORTER THOS. (b'69)@ Ky.4,'94; (I'94),

Harrlson, KIng W.-Ala.2,'96; (l'97)

LEWIS, WAITER AUGUSTUS (b'67)-IAa.1 $97 ;\left(1^{\prime} 97\right)$

Sellers, Joel C. (b'70)-Tenn.5,'94; (1'94).

THROWER, BENJ. FRANKLIN (b'83)Ala.2,'11; (1'12); R.F.D.

Treadwell, Luclus M. $\rightarrow$; (1'85)

WHITE, HENRY HERBERT - Ala.2, 05 (1'05); R.F.D.

Woodall, John Brooks (b'88)-Tenn.8,'11 ; (1'13) ; R.F.D.

EPES, 374, SUMTER

MILLER, JAMES KEARNEY - Tenn.1,'05; (I'05).

Mlnus, Jos. A. (b'82)-Ala.4,08; (l’08) ; Pd.

REED, JOHN H. G.-Ky.4,'90; $(1,90)$.

EQUALITY, 200, COOSA

COUSINS, JAMES COLUMBUS -Md.6,'9I ; (I'9I).

COUSINS, SAM TOWNSFND (b'86) Ala.4, 10 ; (I'12)

HUNTER, JOHN T. (b'64)-Ala.4,'01 ; (l'01)

NOLEN, JOHN A. M.-AIa.2,04; (I'04).

ESCATAWPA, 50, WASHINGTON

BLAKE, THEODORE MILLER (b'72)Ala.2,00; (1'00); (Fruitdale).

ETHELSVILLE, 50, PICKENS

PARKER, SHEPPIE R. (b'84)-Ala.2,'09 (l'09).

SPRUILL, G. E.-Tenn.8,'01; (l'01) ; R.F.D 1.

TOKES, WM. THOS. (b'80) - Ala.2,08; $\left(l^{\prime} 10\right)$.

Wyatt, Rufus R. (b’57)-Ky.5,'93; (t) ; R.F.D. 2.

EUFAULA, 4,259, BARBOUR

BRITT, WALTER STRATTON $\left(b^{\prime} 77\right) \oplus$ N.Y.10,98; (1'98).

COPELAND, WM. PRESTON (b'45) N.Y.10;70; $(1,78) ;$ OALR.

EEN, JOS. WALLACE (b'73)-Ala.2,'11; (1'11).

LEWIS, WM. GABRIEL-Ga.5,'84 ; (l'84).

IcCoo, Thos. Vivian (col.) (b'83)-N.C.3, 06 ; (I'07).

TISINGER, LOUIS FIELDING (b'84) $\rightarrow$; ( $\left.\mathrm{l}^{\prime} 0 \mathrm{~T}\right)$.

Weedon, Walter R. (b'74)-Ky.1,'94; (l'94). WOOLLEY, C. MORGAN (b'72)-Ala.2,93; (l'93).

EUTAW, I,00I, GREENE

CALDWELL, EDWIN VALDIVIA (b'82)Ala.2,07; (1'06).

CAMERON.' MATTHFW BUNYAN $\left(\mathrm{b}^{\prime} 60\right) \oplus$ -Ala.2, 86 ; (I'86).

GRIFFITH, HOWARD ASA (b'83)-Ala.4, uclus, Rlchard

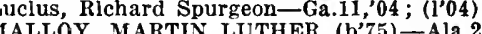
'99; (I'99).

MOORE, GEO. AMOS-AIa. 2,90; (I'90).

SMITH, ARMAND PFISTER - Ky.1,75;

SMITH, THOS. McG.-Ky.1,'07; (1'07).

EVA, 30, MORGAN

Dodson, Robt. Bruce (b'89)-Ala.2,'13 (I'13).

EVERGREEN, 1,582, CONECUH

BELO, FREDK. ARTHUR (b'38)-Pa.2,'70;

BETTS, not in practice. '92; (I'92). 
HAGOOL, JOHS W,-Ala.2.'98: (l'98),

NEWTON, GUY GUERDON (b'73)-Ala.2. '97; (1'93).

RUBACH CARL (b'66)-Tenn.2.96; (l'96) STALI,WORTI, EMMETT IEMCEL (b'T0) 1.-Na.2,'94; (1'94).

EXCEL, I5O. MONROE

MASON, WH. ALIAN-Ala.2,06; (I'06).

FACKLER. 175. JACKSON

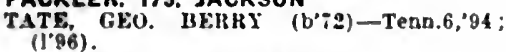

FAIRFIELD, - JEFFERSON

Carmlehael, Joslah Nall (b'85)-.Mla.4, I3; (1'13).

PEIfGLSOS, BURR (b't)-X.Y.1,96: (I'13).

FAIRFORD, 59, WASHINGTON

SOMERVILAF, JAMES HEVIT (b's2) Ala.2,06; (1'06).

FAIRHOPE, 390, BALDWIN

Sukinson, Clara E.-Ia.3,, 66 ; not in practlce.

Greeno. Harrls Soper-N.Y.10,82; not in practice.

MFKSHON, CLARENCE 1. (b'il) $\$-$ - Ia.f. '98; (1'99).

Mershon. Geo. Alonzo (b'52)-0.10,'82; not in practlce.

Pease, Hiram Lowell-IIl.6, $\because 7$; not in pracUce.

Sheldon, Geo. A. (b'6i)-Ala.2,92; (1992)

ob.

Slosson, Edw. C. $\rightarrow$ : $(1 \dagger)$ : not :n practice.

FALCO, COVINGTON

onxsox, JOHX H. (b'76) - Ga.9,06 (1'06).

Lindsay, Ralph Resnolds-Ga.I,'12:. ().

FALKVILLE, 335, MORGAN

HCXTER, FELIX B. (b'60)-Tenn.5,'81; (1'81).

STRINGER, WM. LOWE (b'80)-Tenn.9, :04: (1'08): Pd.

FARILL, 25. CHEROKEE

FARILL, JOHN PAUL (b'60) - Ga.5,'91; (I'8i).

FARLEY, 50, MADISON

Russell, Christopber Ilugo (b'84)-Ala.4, 12: (1'13).

FAUNSDALE, 352, MARENGO

YORLOW, KOBT. I'ROSSER (b'8I)-Ala.2, '11: (1'i1).

MOSELY, DANL. COLEMAN - Ala.2,'85; (1'88).

FAYETTE, 636. FAYETTE

BLACKBLRN, CARL BELTON (b'i5) Tenn.6.03: (1.03)

BRANYON, JANES A.-KY.4,'92; (1'92)

GRAHAM, WM. ALEXANUER (b'59)-Ky.4, '92: (1.92).

MILLER, ROBT. II. - Tenn.9,02; (1'06) R.Y.D.

PETERs, THOS. MaIHoN (b'64) - Ala.2. '90; (i'90)

Randolph, J. F.-Tenn.8,'98: (1'98).

ROBERTS, JOUN M. - Sia.2,07; (I'0i) R.F.1.

SAYAfie, FICTOB (b'66) - Tenn.5.89; (1'89): R.F.D.

YOUNG, JAMES DAI'SIE (b'68)-Tenn.8, '94; (1'94).

FAYETTEVILLE. 200, TALLADEGA

Hoore Clit (1) \&5)-Al34.13: (1'13).

FELIX, 47, PERRY

RAY, THOS. JACKSON (b'66) \&-TenU. 8, 96

FELKINS (R.F.D., ARKADELPHIA), 20. CULLMAN

Abtutt, James $\rightarrow$; (I"SB) ; R.F.1).

FERNBANK, 175, LAMAR

BARKSDALE, GEO. SIT.AS (b'Til)-Tenn.8, '99; (1'99) ; 8 .

Seas, Mark Hobulns -0 ; (1';

FINCHBURG, 200, MONROE

HOLMES, SIHLWY (b'A - Ala.2,"95: (1'96).

Smith, Rayford Agee (b'86) - Ala.2.12: (I'13).

FITZPATRICK. 398. BULLOCK

DARNEIJ, HENS, FRANKIIN-0; (1'83)

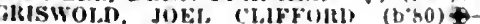
Tenn.5,05; (1'05) ; 16.F.D.
JOHSSOX, OSCAR (b'66)-Ala.2.96; (1'96)

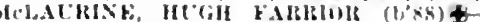
Tenn.5.11: (1'11).

FIVEPOINTS, 200. CHAMBERS

MIl.FORl, II. A.- C: (l+)

I.ITE, (iBo. A-Ala.2.04; (1'04!

FLAT TOP (LITTLETON P.O.), -, JEFFERSON

WITTS, JOHX WADE-La.1,04; (104).

FLINT, 229. MORGAN

Wiggins, James Ilarvey, Jr. (b'7)-Ala.2. $09:(1+)$

FLOMATON. 539, ESCAMBIA

IIERNETHY, WM. L. $\left(b^{\prime}, 0\right)-A l a .2,94$; (194).

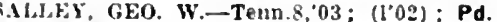

FLORALA, 2,439, COVINGTON

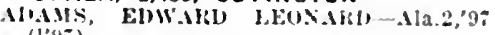
(1'Yi).

idus P.-(;a.10,84: ()

ClaYTON, ARCIIE LEONARD (b'i2)Tenn.9.05: (l'05).

GALAAWAY, HLETCUER W.-Tenn.8,03; (1'03)

PIILLLIPS J. P.-Tenn.8.95; (1'98)

SMITH, WM. H. (b'63)-Teun.8,86: (l'08) NYNS, ANDHEW LEE (b'62)-Md.1, 89 ; (1'03)

YOUNG, FERRIN (b'sĩ)-Tenn.5,'09; (I'09).

FLORENCE, 6,689, LAUDERDALE

Arnold, Moody Warren-Tenn.5.'l2: ( $($ )

CAlLOWAY, WH. JOHNSON-Ala.4;03; (1'03).

DAVIS, ROBT. NERRITT (b':4)-La.1,'95:

DESI'REZ, LEWIS W. (b'49)-Ala.2, ;1; (l's 8$)$

DUCKETT, LEE F.-Tenn.6,'94; (1'02)

HARDIS, E. BURKE (b'73) -Ky.4,96; $\left(1^{\prime} 96\right) ; O A L R . \star$

JACKSOY, AL A ALBLTUS (b'85)-111.6. II: (Pi2): G.

Jones, Archle (col.)-Tenn. T.97; ( $\left.{ }^{\prime} 97\right)$.

KERSA(HAX, WM. JONES (b'59) - Tenn.5, '80: (1'88).

Llndsey, Eugene C.-Tenn.5,95; (1'09).

PEEISON, JAMES M. (b'63)-Tenn.5,'91 $\left(1^{2} 91\right)$; not in practice.

Exx. RICHARD L. (b'6a)-Tenn.1,03 (I'03); G.

'BICE, PELICY ISAAC (b'61)-Tenn.5, 86 (1'8i).

BOBISSON, JOIN ABNER IRUIT (b'41)-

No.:2, 1 ; ; (1'7s)

STANLEY, WM. HILL (b'5t)-Tenn.5,'si; (l'ss).

uggs, James Thos (col.) (b'it)-D.C.3,03 (1'06i).

TCRNER, WM. HHOOKS, SR. (6'TS) Tenn. J, 04: (1.04); K.F.

MATSU, CHAS. Mcalifis (t'59)-La.l, S1: (1'sa)

FLORETTE (R.F.D., SOMERVILLE), 10 MORGAN

kennell, Isham Watkins (b'11)-Tenn.1,67; (ID) 6 ).

FOLEY, 200, BALDWIN

LUIIENIG, WM. II. (b'52) - 19.3.90

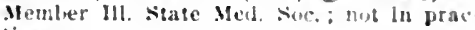
Hee.

Molit, ERNFST A. (b8I) - Ky.4,06 (l'0Bi).

FOREST HOME, 300. RUTLER

(iarrett, James Jefferson-tia.9.82; (1'82)

"Hall, contad-alia.e's": (l'yi)

WAH. IRICHAKD Al.1BERT (b'69)-La.1. "H: (I'94)

FORKLAND, 100, GREENE

logare, Jullen Kelth (b'bs) - N.Y.5.8G: II'si)

- itrus

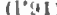

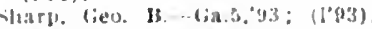

FRANKLIN, 150, MONROE

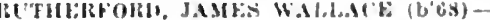

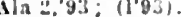

FRANKVILLE. 75, WASHINGTON

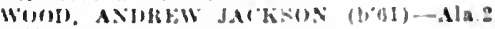
. $101:(1.01)$.

FREDONIA (R.F.D. WEST POINT, GA.) T2U CHAMBERS

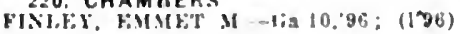

FRUITDALE, 250, WASHINGTON

HLAKE. TIIHUOORE MH,LER

(Sce Escatawua.)

Sau Alrsdale, II. C $\rightarrow$. (14)

FRUITHURST, 257, CLEBURNE

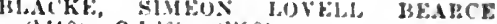
(b.40)-0.1.69: (1.98).

FT. DAVIS, 200, MACON

PRATHER, JOHIN $\left(\mathrm{b}^{\circ} 86\right)-A 1 \mathrm{~A}, 2,09$ : (1'09)

FT. DEPOSIT, 893. LOWNDES

BIA K, JAME. IIF.NII) - Ilt

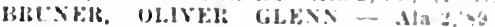
(1'xy)

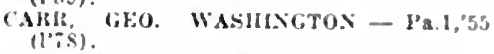

COLEMAN, HENRY NEAI $\rightarrow$ : (1"02)

(RIM. WM. B.ALTON-Ala.2,88; (1'88).

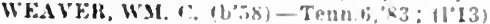

FT. MITCHELL, 50, RUSSELL

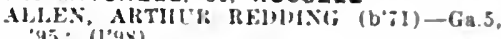
'95; ; $(1,98)$.

FI. MORGAN, - BALDWIN

HOGGESS, JOHN SAMLEL (b'73) -0.9 98; Surg., L.S.l.H.s.; Moblle Quaranthe station

FAMBOW, EMMAL JAMES $\left(b^{\prime}-1\right)$-Cal.2

"10 ; Ist Lleut., M.K.C., U.S.A.

CiARCIA, LEON C. (b'83) -M0.34,04: capt. M.C. Lis.

LAlGHLIN, JAMES IHTRNATT (b'36) Va.1,12; A.Surg., C'S.P.H.S

FT. PAYNE, 1,317, DEKALB

WIFF. WM. SAYERS (b'61) - Ala.9,'\$9: (1'90)

Cireen, Wm. Mastln-Tenn.5.7\%: (1'85)

llaralson, Jeff B.-Temn.8.85; (1'\$8); not in practice.

MAY, OLIN (b'60)-Tenn.9.'94: (1/99).

QIT. WM. EVERETT (b'51)-K5.1,'SI:

WARRIS, WM. FRNFoT-Ala.2,05; (1.05).

NHGIT, CHAS. WESLEY (b'65)-Ala.2 93: (1.93).

FULTON, 518, CLARKE

AlMAMS. BENJ. PIIANKLIN (b's3) Ala:-08: (1'00).

HWIS, JOSIAY EDWAILL-Ala.2,00; (l'y(i): $\mathbf{S}$.

FURMAN, 125, WILCOX

ItCls:OX, ELLAS GEO-Ala.2,06: (1'06).

PALALE, W. B. (b'as)-La.1,93; (1'00).

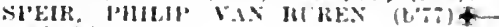

.11a.2.00: (1'00)

sletll, moss rislle (b.st) Ky.2,08 (108)

FYFFE, 15. DEKALB

Buzhee, John twarett -113200 s: $\left(10^{\prime} 10\right)$

WILSOS, 11. W. TenH.9, $\theta 0$ : (róL)

GADSDEN. 10,557. ETOWAH

MPI.FTON, IITCHI 1. (b*65)-Tenn.5.99

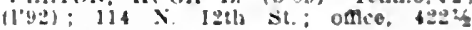
Broand St. 11-2

Baker. Dani. Ilarrls $\left(b^{\circ} 61\right)$ - Tena.5.'8z: (l's2) - fi2: Walnut st

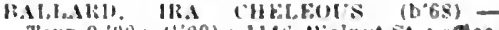

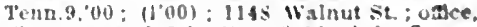
(hestnut and 5 th sta. : $\$-10,4 \cdot 6$ : G.

MAS, HEAS II L MINSTON - Md.6.06

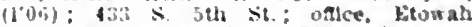
Trust and sintugs Hank Bldg. 1.

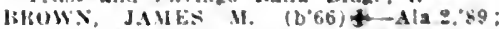
$\left(11^{\prime} \times 4\right): 615$ Turrerstine Are, osdce, Chest-

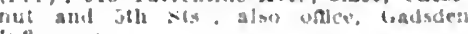
Inthrinary

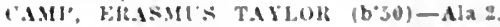

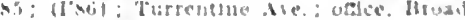
si : \$. $12,0-3$.

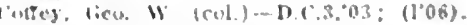

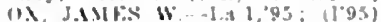

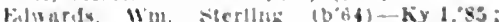

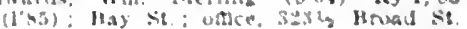
$10-12,0$

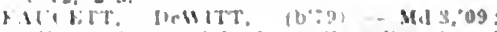

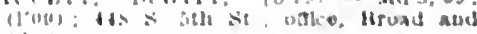
in sis

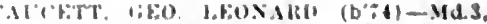
0.3: (1 0.5): 102 kruad st.; omce, Mroad

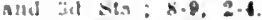

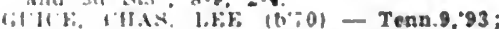

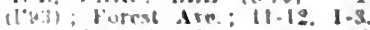

Utulsun, rranalln $\mathrm{S} .(6,45)$ - Tean.1, it: $(1+4 i)^{2}$ 
IITGHLS, MILES PRESTON (b'80)†Tenn.5,06; (1'05); 1016 Forest Ave.

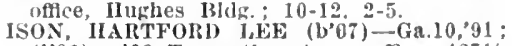
(1'91); 409 Turrentlne Ave.; offlee, $4271 / 2$ Broad St. : $8 \cdot 9,2-3$.

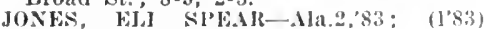
stocks Bldy. LEACII, JAIIES F. (b'74)-Tenn.I,'00

IcBroom, Fellx G. (col.)-Tenn.7,04 $\left(1^{\prime} 04\right)$.

MURIIIRES, ('LAUDE I. (b'i2)-Ala.4 02; (1'02); 239, 8tit st.; oflice, stock 13ldg. ; 9-11, 3-5.

Plaine, Chas, L. (col.) - Tenn. $7,{ }^{\prime} 00 ;\left(l^{\prime} 00\right)$

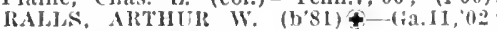
(l’02): Gth Ave.

SAVAGE, HENRY J.-La.1,01; (1'01)

GAINESVILLE, 532, SUMTER

Glbbs, Jesse Augustus-Ala.2,0 07 ; $\left(l^{\prime} 0 \pi\right)$

Goodloe, IIarry Kílng (b'86) - Tenn.5,'1I; (1'11).

HARWOOD, ROBT, ELLYSONーAla.2,'00; (I'00)

GALLION, 220, HALE

Turk, Wm. I.-T'enn.6,'82; (1'83)

GAMBLE MINES, 35, WALKEA

DEWIESE, THOS. PETERS (b'60)€Tenn.5,'85; (1'85).

GANTT, 300 , COVINGTON

BLAIR, WMI. MARTIN (b'88) - Ala.2,'10 $(1 ' 10)$

BOZEMAN. THOS. C.-Ala.2,92 ; (1'92).

MERIWETHER, FRANK V. (b'8i)-Ga.11, 08; (1'08).

GANTTS QUARRY, 300, TALLADEGA

BATSON, DAVID C. $\left(b^{\prime} i \tau\right)$ - Tenn.I, 05 $\left(1^{\prime} 07\right)$.

GARDEN GITY, 250, CULLMAN

Copeland, Chas. P. (b'i8)-Ala.4,'I1; (l'I1).

GARLAND, 250, BUTLER

NETTLES, WM. DAVISON (b'84)-Ala.2, '10; (1'10).

GARNSEY, 75, BIBB

SPARKS, WU. ANGELO (b'75)-Ala.2,05 (1.05)

GARRISON POINT (R.F.D., BREMEN), 70, CULLMAN

HARIIS, WM. R.-Ga.1,'8T; (l'92).

GASTONBURG, 145, WILCOX

GASTON, DAVID FINIS-La.I,'82; (1'82).

GATE CITY, 675, JEFFERSON

WILBAVKS, WMES GRIFEIN (b'84)Ala.4,'12; (1'13).

GAYLESVILLE, 204, CHEROKEE

MCWIIORTEL, ROBT. LEE - Ala.2,'87; (1'87).

GEIGER, 200, SUMTER

LAVENDER, CIAUD BELTON (b'82) Tenn.8, 08; (1'09); Pd.

Pinson, Chris H. (b'82)-Tenn.8,06; (\$),

GENEVA, 969, GENEVA

Ard, James Henry (b'50)- $\rightarrow$; (l'88). (1'96).

CHAPMAN, ABNER RICHARD (b'65)Tenn.5,'88; (1'88)

CHAPMAN, 'CHAS. HICK (b'85) - La.1, 09 ; (1,09).

DISMUKES, LEWIS LEON (b'T0)-Tenn.6, 99 ; (1'99).

FLEMIING, HILLARD FILMORE (b'57)Ky. 4,90 ; (l'88)

JUSTICE, ROBT. LEE (b'i1)-Ala.2,'94; (1)94).

VAUGHAN, ANGUS E. (b'75)-Ky.4,05; (l'05).

GEORGIANA, 999, BUTLER

MORRIS, WMI. ELI (b'68)£-Ala.2,'97; $(1 ' 97)$.

SHANKS, RUFUS GE0. (b'75)-Tenn.8,'0I :

Watson, James Crawford (b'75)-Ala.2,'98; (1'98).

WATSON, ROBT. HUNTER (b'r 4$)-$ Ala.2, '05; (1'06) ; R.F.D.

GILBERTOWN, - CHOCTAW

ALMAN, SAML. (b'73)-Ky.4,98; (1'98).

Granberry, J. L.-Ky.4,'9I; (1'91).

GIRARD, 4.214, RUSSELL

Norris, John P. (b'64)-Ga.5,'91; (1'01)

Prather, Robt. Clark (b' 75$)$-Ala.2, 98 . (l'98).
GLEN ALLEN, 100, FAYETTE
("ochran, W'm. Jefferson-; (1'88)

GLENWOOD, 336, CRENSHAW

llowden, Coley C. (b'86)-Tenn. 8,'13; (官),

IINCHENER, WM. HENRY (l’05).

GOETHITE, 50, TUSCALOOSA

MILNEIR, GEO. MAIRVIN (b'7t)-Ala.4, 00 ; $\left(l^{\prime} 00\right)$

GOODHOPE (R.F.D., ECLECTIC), ELMORE

LETT, HARRISON TEMPLETON-IAa.1, '75; (1'84).

GOOD WATER, 740, COOSA

ARGO, EUGENE-Tenn.5,'91; (1'81).

MATTIIEIS, JOIIN THOS. - Ga.I,'73 (1'84) ; R.F.D.

IOON, WM. IIENIR (b'4t)థ-Ala.2,'79; (1'83).

PENTON, JOHN ABNER MId.3,00; (1'01) I'ETERSON, ALBERT IEFFERSON (b'59) -Tenn.5, 89 ; (l'89) ; R.F.D.

Salter, l'aschal I'reston (i'48)-0; (1'84). GORDO, 707, PICKENS

BEELI, WYY. STILIMAN-Ala.2,06; (1'06) DAFIS, JOHN LONGMUE - Tenn.5,'88 (1'88).

Daris, John L. (b'6i)-Tenn.1,'91: (1'91). DUNCAN, WALLACE W.-Ala.4, 00 ; $\left(1^{\prime} 99\right)$;

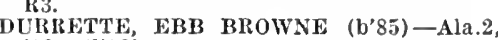
12 ; (1'12)

Kirk, Albert T.-Tenn.8,02; (l'02) ; R.F.D 'AT'TON, ROBT. O'CONNEL' (b'80) -Tenn.9 00 ; $\left(1^{\prime} 01\right)$.

PRICE, ALBERT BASCONB - Ala.2,'9S ; (1'99).

GORDON, 293, HOUSTON

BOX, CHESTER CLYDE (b'84)\&-La.1,'09; (l'I0)

MCDANIEL, FRED I.EONARD (b'91)€Md.1,13; (1'13).

VAULiHN, D. HORATIO (b'63)-Ga.5,'88; (1'89).

GOSHEN, 347, PIKE

ILAMII, 'IRHY WYNNE (b'53)-Ky.4,76;

Kyzar, James IIugh (b'89)-La.I,'13; (1'13).

GRAHAM. 200, RANDOLPH

Haynes, Robt. C.-Tenn.9,'06 ; (1'08).

GRAND BAY, 175, MOBILE

Fort, Mannie $A .\left(b^{\prime}-2\right)$-La.1,03; (1'04).

GRANT, I00, MARSHALL

Walls, Wm. Wiley (b'84)-Nla.4,'13; (l'13) GREEN HILL (R.F.D.. ST. JOSEPH, TENN.), 75, LAUDERDALE

Stutts, Ilenry Lee-Ala.2,'00; (1'OI).

GREENSBORO, 2,048, HALE

BORDEN, JAMES I'ENINGTON-Ala.3, '75; (I'78).

CARSON, SHELBY CHADIVICK $\left(b^{\prime} 46\right)$ \& La.1,'90; (1'79).

DOMINICK, JOHN ROBT. FRANKLIN (b'47)-Ga.1,'il; (1'85) ; R.F.D.

HONETTE, REUBEN FLETCHER (b'T0)y.y.

POELLNITZ, CHAS. AUGUSTUS (b'i6)La.1,01; (1'01).

SHIRLEY, JOS. EMIL

(See T'iscaloosa.)

Spencer, Geo. M. $\rightarrow$; (1'78) ; R.F.D.

Whey, James W. $\left(b^{\prime}-9\right)-I 11.17,05$; $\left(1^{\prime} 05\right)$. (1.99).

GREENVILLE, 3,377, BUTLER

BRYAN, JAMES JAFAYETTE (b'T2) Ala. 2,01; (1'01).

FOSTER, JAMES OSCAR (b’ 6 6)-Ga.11,06 (1'06).

HAWKINS, MACK CREECH, JR. (b'82)La. $1,{ }^{\prime} 07 ;\left(I^{\prime} 06\right)$.

KENDRICK, JOHN AARON (b'72)-La.I, .94; (I'94).

Nuttall, Harry Montgomery (b'a1)-Mich.1. $04 ;(1$; 04$)$

PERDUE, JAMES LEWIS-Ala.2, 75 ; $\left(1^{\prime} 75\right)$. STABLER, LORENZO V. (b'i5)\&-Tenn.5, '98; (l'00).

STALLINGS, THOS. DANL. - Ala.2,'89; (1's9).

GROVE HILL, 300, CLARKE

Armistead, Isaac Grent-Ala.2,'13; ( ). ARMISTEAD, JAMES WESTBROOK-Ala.2,
,83; (1'89).
Cammack, Kossuth Rothchlld (b'88)Ala.2,'13 ; ()

COBB, JESSE MONROE-La.1,93; (I'93). I'UGH, MlBEITT SIDNEY - KY.1,92; (1'93). PUGH, JOIN T.-Tenn.5, 97 ; (1'97)

SKINSER, JOHN S. (b'70)-Ala.2,'97; (I'98).

GROVEOAK, 50, DEKALB

C.LSEY, MARTIN IJUTHEIR - Tenn.9,'01; (i'01).

GUIN, 356, MARION

Shelton, Wm. H. (b'68)-Tenn.8,01; (l'01).

SIZEMORE, DANL. MIDDLETON $\left(b^{\prime} 79\right)$ Tenn.1, 07 ; $\left(10^{\prime} 0 \%\right.$ ).

GUNTERSVILLE. 1,145, MARSHALI

FIUNNELL, ROBT. FOSTER (b'82)-La.I,

Haden, Robt. II. (b'83)-Tenn.1,09 ; (l'09). Jackson, James M.-S.C.1,49; (1'86)

JORDAN, DAVID CARNES (b'73)-Tenn.8, $92 ;(1,92)$.

LUSK, PHOCION B. (b'66) - N.Y.10,91 ; (1'91).

Maples, John Henry (b'48)-C; (1'86)

TIIOMASON, JAMES HENRY (b'82) -

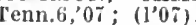

GURLEY, 750, MADISON

GRAIIAM, BENJ. EMMETT (b'73)-Tenn.1I, 94: (1'94).

WILLIAMSON, EDWIN OJIVER (b'73)Tenn.9,'98; (1'98).

GURNEE, 200, SHELEY

SUITH, THOS. O. $\left(b^{\prime} T 6\right) \rightarrow ;\left(I^{\prime} \cup 7\right)$.

HACKLEBURG, 286, MARION

Brooks, Thos. P. W. (b'47)-Ga.9,'97. (1'05) ; retired. GOGGANS, KIMBRO BUCK (b'68)-Tenn.8, $93 ;(1 \circ 93)$.

MIXON, GEO. WESLEY-Ala.2,'04; (1'04).

HACODA, 40, GENEVA

BEDSOLE, JAMES-Ga.9,'06; (1'06).

HAGLER, 47, TUSCALOOSA

Owens, John H.-Tenn.8,'99; (l'99).

HALEBURG, II0, HENRY

WOOD, GORDON LEE-Ala.2,'10; (l'I1).

HALEYVILLE, I,III, WINSTON

BLANTON, ATTICUS GWTNN (b'81)Tenn. 9,07; (l'07)

CAMAK, DAVID IIUBBARD $\rightarrow ;\left(l^{\prime} 84\right)$

HOWELL, WM. E. (b'68)-Ala.4,,$^{\prime} 00$; $\left(\mathrm{I}^{\prime} 00\right)$ LEE, JOHN DAVID (b'76) (8-Tenn. 8, 00 ; OLIVET.

(1,06).

ROI,EN,

CHAS. A. (b'76)-Tenn.1,06; (1'89).

BENJ. WALLACE $\left(b^{\prime} 54\right) \rightarrow$;

TEPHENS, MIt.LARD L. (b'82)-Ala.4, TAYLOR, JOS, CALHOUN (b'64)-Ala.2, AY 88 : (1'89)

Woods, I. W.-Ky.4,'81; (1'81).

HAMB BURG, 190, PERRY

Boyd, Austin Francis JefPerson (b'87)Ala.2,'13: (

-Ala.2,09: (1'09).

HAMILTON, 422, MARION

BURLESON, JOHN RUFUS (b'73)-Tenn.8, $97 ;(1,97)$.

CLARK, WII. FELIN (b'40)- 0 ; (1'88); HOWELL, HILL WRIGHT $(b, 86) \uparrow-T e n n .1$, 09; (1'09).

JOHNSON, JOHN CARROLL (b'61)-Ky.5, WHITE, MARVIN SPEARS (b'79) †-Ky.4, O3T; (1'03).

HAMMAC, 300, ESCAMBIA

RANKIN, HOWARD PAYNE (b'80)-La.1, 10 ; (1'I0).

HANCEVILLE, 464, CULLMAN

HAYES, CHAS. (b'79)-Tenn.9,03; (1'03); YEILDING, JOHN-Tenn.9,'94; (l'94).

HARGROVE, 350, BIBB

WILLIAMSON, GEO. WII. (b' 63$) \oplus-T e n n .5$, 00 ; (1'09).

HARTFORD, I,159, GENEVA

COX, WMI. C. $\left(b^{3} 45\right) \rightarrow$; (1'88); R.F.D.

FLEMING, JOHN A (b'53)-Ala.2,'86;

FLEMING, JOHN CLIFTON (b'71)-Ala.2, '91; (1'95). 
1.0WELL CHAS In. (b'13)-Ala 2,00 : $\left(10^{\circ} 00\right)$.

IVFXRAIKK, OSCAR LEE (b“3)-Cia.3 $93 ;(1,00)$

shute, Jos. $v \rightarrow$; $(1 \% 88)$

WIJJIAMSON, GEO. WASIINGTON (b'6t) -Ala.2:"93: (1.93).

Foung. Frank Walker (b'S9)-Nla.2,'12 (1'19)

\section{HARTSELLS. 1.374. MORGAN}

ROOTH, WY. M. (b'i4)-Tenn.5, 02: (1'03) Brindley, Thadueus B. (b'66)-lia.9,'91 $(1.00)$ : IR.F.n.

L.OVbIADY. WM. H.-Ala.2,97; (1'96)

MCIEL, HUGH CLAIRK (b'i5) - Tenn.1,98 (1'02).

RITTF.XBRRY, BAXTEK-Ala.4,'99; (l'99)

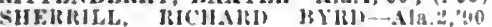
(1'94).

Turney, Jos. SImpson-Tenu.5,'S2; (1'82)

WHITE, ARTHL'R MARION (b'9)-Ala.t 09: $(1 * 10)$

Wilson, Abel Robert3 (b'3i) $\rightarrow$; (l'85).

HATCHECHUBBEE, 250, RUSSELL

D.A VIK, MEISS 0 ; (1'98)

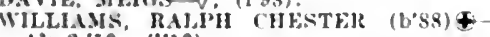
Ala.2.10; (1'10).

HATTON, (R.F.D., TOWN CREEK), 60 , LAWRENCE

HOWELI, \&. R.-Tenn.8,'s8; (1'88).

HAVANA, I37, HALE

ABERNATHY, TIOS. PIXXEY-Tenn.8,"99 (I'99).

HAYNEVILLE, 400, LUWNDES

BIFORD, WM. IFWIS $0:(1,78)$

JAME, NORMAX GILCIRIST (b'it) Ala.2,"98; (1'98).

MARLETTE, CYRLS FDMOND (b:5i) K5.4;88; (1'91).

HAZEL GREEN (R.F.D., NEW MARKET), 75. MADISON

ICCOWX, WALTER S. $\left(b^{\prime} ; 0\right)$-Tenn.6.'93 (1'03).

\section{HEAOLAND, 1,090, HENRY}

BIR1) WILLIS ALONZ0 (b'6)-Tenn.8, Ga5: (1'01)

BCIMESJAW, LEF ROY $\left(\mathrm{b}^{\prime}-5\right) \$-T e n n .9$ 99: (1'99)

BERIESHAW, SHELBI L. (b'80)\$ Tenn.1.08: (I008).

SCOTT, MAllCLS TILIILS CICERO-Ala., "9i; (1'97).

Scols, Marvln-Ala.4.05: (1'0-5)

sporman, Chas, N-ila.2, 86 ; (1'8i)

HEALING SPRINGS. 50, WASHINGTON

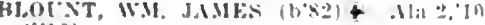
(l'10).

HEFLIN, 839, CLEBURNE

Heason, l.ewis (b'85)-Gia.11,12; (1'12) IR.F.1). 1.

DCKE, JBFFELSON D.VIS - tit.10,81 (I'88)

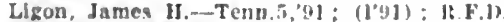
WRIFIIT, HEE ItOY-TenH.1,00; (100).

HELENA. 400, SHELBY

H.IY'. WM. I. (b'58)-MIA.2:8i: (1'8i)

TRLCKS, JAMES FHANK (b'82)-I.a.1,07 $\left(1^{*} 06\right)$.

Weed siaml Lafayelle-Nla 2,86; (1'8i)

WE.F, WAJTER AJVA (b'83) - M1.9,05 (1'05)

HENAGAR, 85, DEKALB

IHILLII'S, JUNES BENAIERIR (b'8l) KY, 2,10; $(1,10)$.

HENDERSON (R.F. TROY), 80, PIKE

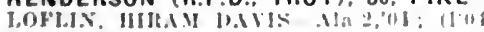

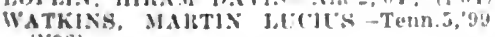
(1'98).

HERBERT, 300, CONECUH

HLAIR, WHSLFY MIFXAXIUISI (b'S3) J.a.1.'05: (1'04).

HERRINGTON (BREWTON P.O.), - ES. CAMBIA

MARTIX, JOII FI.JAII-O; (I'79).

HICKORYFLAT IR.F.D. STROUD), 100 CHAMBERS

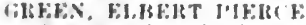

(See standing linek.

HIGH BLUFF (R.F.D., HARTFORD), 10, GENEVA

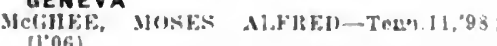

HIGHLANO HOME, I00. CRENSHAW

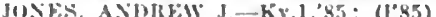

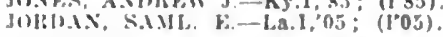

HIGH SHOALS (R.F.D., WEHADKEE), 76. RANDOLPH

llealliers, Wim. $\rightarrow$ : (1'8i).

HIGHTOWER, 30, CLEBURNE

LINISLY JFIG FMIAII M. (b'68)-Tenn 9, $\because \pi ;\left(1+y_{i}\right)$.

LAndey, Wim. Jenry-Tenn.9,"94; (194)

HILLSBORO, 202, LAWRENCE

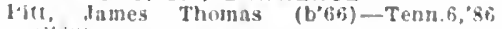
(I)

W.ILKEK, D. C.-MIa.4,05; ( / 0.5$)$.

HODGES, 43, FRANKLIN

Fl,IPU, I.A F.M!N IEWTON+A]a.2,04 (i) (i)

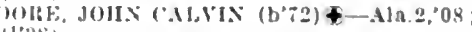

HOKES BLUFF, 300 , ETOWAH

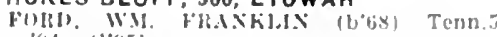
$(44 ;(1,95)$.

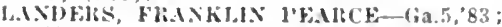
(1.83).

HOLLINS, 688, CLAY

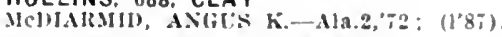

HOLLY PONO, 144. CULLMAN

Hinley, Wm. M.-Tenn.5."79: (l'84).

WATTS, IIENLEILSOY F,-(iD.11,"02: (1"02).

HOLLYWOOD, 234. JACKSON

MeCLFSWON, WM. LAFAYETTF-Ala.2. $94 ;\left(1^{\prime} 96\right)$.

STr;, G. b.-Tenn.9,06; (1'06).

HOLT, 500, TUSCALOOSA

IH.Al.I. J.MISS S.M.H.-Tenn.1, $00^{\circ}:\left(1^{\prime} 00^{\circ}\right)$

HONORAVILLE, 75, CRENSHAW

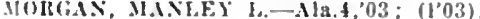

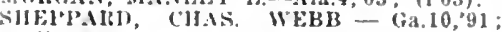
(l'91)

HOPE HULL, 50, MONTGOMERY

[iavls, Leroy W.-(ia.1,53; $\left(1{ }^{\prime}-8\right) ;$ IR.F.1)

ICl.E.A, JAMFS XE.A,-La.1.98, Ma.2,"99 (1'39).

Siluchelford, Clarence Wntts (6.8\%)-La.1

'I : not lil practlce: H.F.J.

T.AKELSIEL, WM.KY.9,06; (1'06)

HOPEWELL, 250, CLEBURNE

110LลT()., JoIIX I'. (b'\$6)...Tenn.9,04: (I'04).

HULL, 300, TUSCALOOSA

I1.MIS, J.MES FIEIK. (b'S3)-Na.2, 0 ; $(1 \circ 0 ;)$

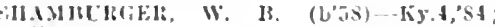
(1'91).

HUNTSVILLE, 7,611, MADISON

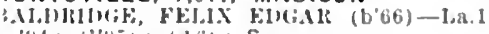
(94: (1't): $(.16): S$.

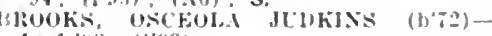

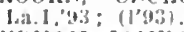

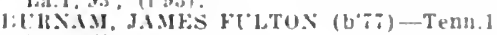
"al): $(1,99)$.

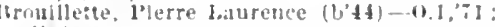
(1) 84

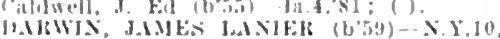

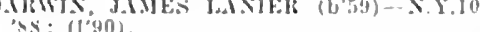

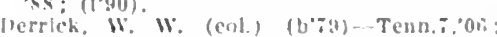
$\left(I^{\prime} u+j\right)$.

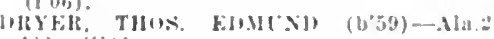
(xi): (I'xeis)

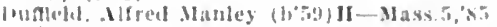
$(120)$.

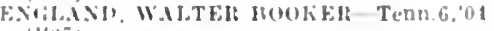
(10i)

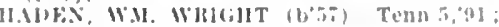

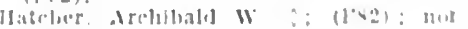

Mractlee. THF,

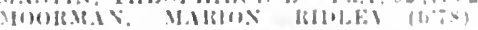

Temn.11, 00 : 1)01): OALR.

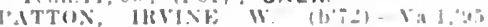
110.94

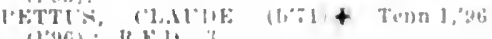

(1) in

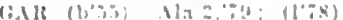

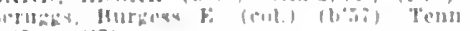

Shelly, anthong $\mathrm{I}$

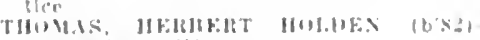
Temn 6., os: $11^{\circ} 00$ ?

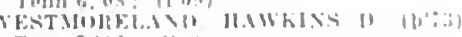

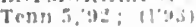

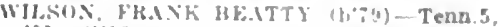
$01:(1 \cdot 10)$

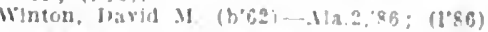
HURTSBORO, 764, RUSSELL

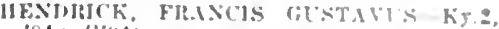
$294 ;(1244)$

HFNLRICK, W.U,TEL HRAXH.M - Ky. 90 : $\left.11^{\prime} 90\right)$.

I'ISCHAI, GEO [NEXNS (b't;)-X.' $71:(1,88)$

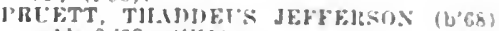
- lia. 2.93; (1'03)

IDER (R.F.D., HENAGAR), 48, DEKALB

Hansarl, Wm. Simlon (b'-8)-.Tenrs? (l'0i)

INVERNESS, 200, BULLOCK

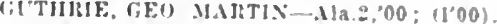

IFONATON, 982, TALLADEGA

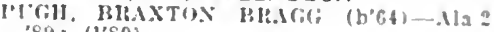
$\left.89:(]^{2} 89\right)$

ISNEY, 150, CHOCTAW

'IHISTOPIEIR. FHANK EVANS (bGGi-

K. 1, 0 , 4: (1"9)

JACHIN, 39, CHOCTAW

IIIRISTOPIIFR. WALTEI H $\left(b^{\circ}: 0\right)-$

Tenn.8,01 : (1'01).

JACKSON, 1,379, CLARKE

KOROTCHS, BKYAX (b'ti) - KY. , 69

'liAPMA. GROSS SCILCGS-dla.2,:9; (1'84).

IICKS, IAMAITINE OIIANDO $\left(\mathrm{U}^{\prime}+3\right) \downarrow$ I1a.2.71; (1'84)

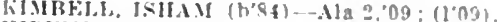

KIKVIN, THOS. C.-Ky.4,93: (1'93)

JACKSONS GAP, 350. TALLAPOOSA

13:Inks, Jos. Told! (b'89)-Fia.11,13: (1'13)

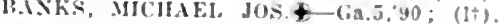

JACKSONVILLE, 2,23I, CALHOUN

MIBEHY, CIJFFOHI) GOODMAN (b'83)Ila.4.10: $(1,10)$.

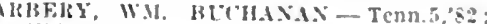
(1'82)

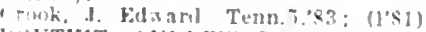

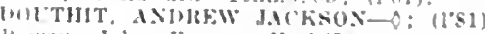

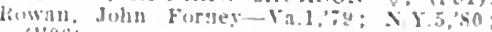
(1'06)

Sirgen?, (19car-Tenn.5.80; (1.88)

JAMES, 423, BULLOCK

11.MUHSOS, WM. HEXRY\& - Tenn.9.93:

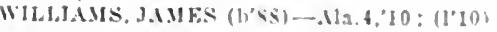

JASPER, 2,509, WALKER

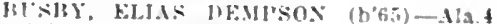
10: (1'11): H.F.J.

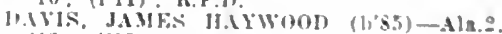
12: $\left.11^{\prime} 13\right):$ : 5 :

(口)miwis, Jos. A.- Ma.2,74: (1\%s).

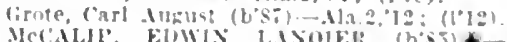

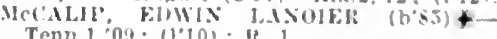
Tenn.1.09: 1110$) ; 13$.

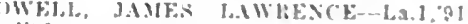
11931.

TON.ML. INDREM MCAJAMS (h०5) +

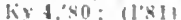

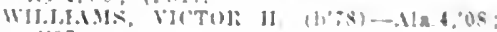
10,1

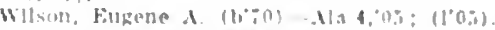

JEFFERSON, 20\%, MARENGO

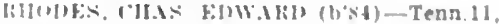
(1): (1, (1):3)

JEMISON, AI3, CHILTON

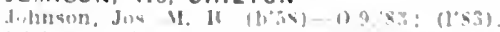

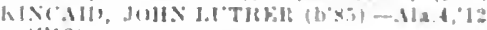
(I)1:)

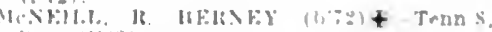

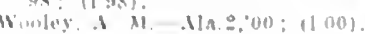

JENA, 20, TUSCALOOSA

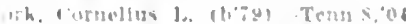

JERICHO (R.F.D. HEIBERGER), $\$$. PERRY

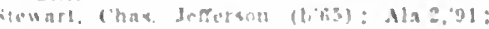

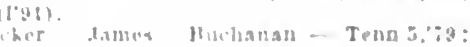

JOUNS, 500, JEFFERSON

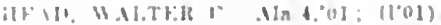

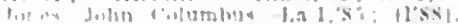

JONES, 100, AUTAUGA Vartin, Jean II. (b'SI)-MISA 2.09. Teun \&, 
JONES CHAPEL (R.F.D., CULLMAN), I50, CULLMAN

COSSEY, JAMES THOS.-Ga.10,'91; (l'96). JORDAN (R.F.D., ECLECTIC), 80, ELMORE Milner, Samt. R.-Ala.2,'y1; $\left(1^{\prime}, t^{\prime}\right)$.

KEENER, 100, ETOWAH

Dowdy, Edgar Lee-Tenn.1,77; (1'76).

NORGAN, GEO. WASHNGTON - Tenn.6, '89; (1'89) ; K.F.D. :.

KELLERMAN, 100, TUSCALOOSA

MERKIAM, GEO. C. (b'ti) - ('A.11, 0 , (1'02).

KELLYTON, 300, COOSA

MAXWEL, CECIL KELLY (b'6i)-Ala.2, '91; (1,92)

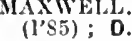

KENNEDY, 26I, LAMAR

Asheraft, James Henry-Ala.2,'05; (l'05).

Asheraft, virgil Lee (b'86)-Alit.2,'is (l'12) ; R.F.D. :

DAVIS, CIAS. A. (b'84)-Ala.4.'12; (l'12) Jones, Tarley Wm. (b'75)-Tenn.5, 00 ; (1'00) KEXNEDY, JOHN $0 .-$ Ala.2,'82; (1'82)

Shackleford, Walter Lee (b's)-Tenn.s, '13; (1'08) ; R.F.D. 3.

KENT (GRADY P.0.), 44, MONTGOMERY Garrett, Allen Jefferson-Ala.2,'93; (1'93).

KILLEN, 65, LAUDERDALE

MAPLES, JOIN MALCOLM - Ky.2,07 $\left(1^{\prime} 0 \tilde{)}\right)$.

WILLIAMS, GEO.- 0 ; (1'90)

KIMBERLY, 800, JEFFERSON

Messinger, F. R.-Md.3,'02; (\$).

KINSTON, 150, COFFEE

AKINS, JAMES LUTHER (b'S5) -Ala.2, 'II; (I'II).

Ballard, Benj. R.—Tenr.6,'94; (l'94) ; R.F.D

KIRKS GROVE (R.F.D., CAVESPRING, GA.), 36, CHEROKEE

Cook, Edward Augustus (b'53)-Tenn.5,'s! (1'8 4 ).

IKNOXVILLE, 100, GREENE

HAMILTON, SAIIL. GREEN - Ala. 2,02, $\left(1^{\prime} 02\right)$.

PATTON, THOS. JEFFERSON - Ala. 2,'06 (l'06)

Pearson, Edward C.-Ky.2,'T3; (1'S4); not in practlce.

LACON, 55, MORGAN

COOK, WILEY H. (b'40)-D; (1'86).

LAFAYETTE, 1,632, CHAMBERS

GAINES, Wil. D. $\left(\mathrm{b}^{\prime} 70\right)$ ( $)$-Ala.2,'92; (1'92)

GKADY, ZACHARY TAYLOR (b'49)-Ga.5, $80 ;(1781)$

REA, BENJ. F.(4-Ala.2,'85; (1'86); Op.

WHEELER, N. A.-Ga.II,'07; (1'07).

LAMAR, I50, RANDOLPH

Traylor, Geo. Washington-Ga.I,'9I ; (1'94)

LAMISON, 250, WILCOX

FUDGE, WALTER (b'7)-Ala. 2,09; (l'09). Kimbrough, Flavius Franklin, Jr. (b'66) La.I, $89 ;\left(1^{\prime} 90\right)$.

MOORE, ZADOK (b'71)†-Ala.2,95; (l'95).

LANDERSVILLE, 200, LAWRENCE

EENNELI, JANIES WATTIE $\left(b^{\prime} 7 t\right) £$ Ala.4,01; (l'0I) ; Ob.

LANETT, 3,820, CHAMBERS

MICLENDON, W. Il. (b'72)-Ala.2,'96 $\left(1{ }^{9} 6\right)$; Nember Med. Soc. of Ga

RUTLAND, JOHN BLAKE (b'51)-Ga.I0 '80; $\left(1^{\prime} 82\right)$.

WELDON, ROBT L.-E-Ga.9.'92; (1'00).

LANGDALE, 500, CHAMBERS

LAYFIELD, JOHN W.-Tenn.I I,99; (li) Member Med. Assn. of Ga.

MARSHALL, W. L.-Ga.II, 06 ; $\left(l^{\prime} 06\right)$; R.F.D

LAPINE, 250, CRENSHAW

Naitel, St. John (b'56)-Tenn.1.'s1; (l's0)

LARIINSVILLE, 246, JACKSON

Cahoon, J. X.-Teun.9,'05; (1'05).

LATHROP, - , PICKENS

WHITESIDE, HAMLIN B. $\left(b^{\prime} 82\right) \oplus-A l a .2$, 'I0; $(1,10)$.

LAWLEY, 100, BIBB

CLEVELAND, J. S.-Ala.4,0T; $\left(\mathrm{l}^{\prime} 0 \bar{T}\right)$.

LEEDS, 810 , JEFFERSON

CAFFEY, HUGH THOS. (b'59)-Tenn.6,'83 (l'83).

$\left(1^{\prime} 90\right) ; \mathrm{Pd}$
L.A WhExCE, WM. O. (b'85)-Ala.4,09; $\left(1^{\prime} 09\right)$.

Nurton, II. F. -O; (1†).

LEESBURG, 100, CHEROKEE

Vatthews, Jolm Patrick ( $\left.b^{5} 53\right)$-Tenn.6,'86 (l'87)

LEHIGH, 300, BLOUNT

SIIEY'HERI), SAML. TINSON (b'T̃5) -Ga.11 '02; $\left(1^{\prime} 03\right)$

LEIGHTON, 540, COLBERT

DOAN, JAMLS BAILEY (b'テs)-Teln.8, 01 (l'01).

Gramling, James W.-Ala.2,0l; (l’01)

GRAES, LEAXDER JOHNSON (b'82)Ala.4,'10 ; $\left(1^{\prime} 10\right)$

HASTYRSON, JOHN H.-Ky.2,89; (1'89).

LENTZVILLE (R.F.D., ATHENS), 25 , LIMESTONE

Kyle, Wm. IBalley-Ala.2,89; (1'89).

LETOHATCHIE, 300, LOWNDES

POWELL, CLIFTON WOODREFF - Ala.2, '91; (1'94).

POWELL, GEO. NORMAN-Ala.2,'96; ( $\left(1^{\prime} 9 \pi\right)$ SHACKEI,FORD, FHANK (b'68)-Nla.2, 98 $\left(l^{\prime} 98\right)$

LEWISBURG, 50, JEFFERSON

CHELTHAN, THOS. AIFRED.

(see Birningham.)

LEXINGTON, 150, LAUDERDALE

Cotton Spencer Franklin (b's1)-Ala.2, 09 (1'lit)

Harris, Leo. Clay (b'86)-Tenn.6,'13; ( ).

LIBERTY, I00, BLOUNT

MORKIS, JOS. WALKEL-Tenn.I, 04 ; (l'04)

LIM ROCK, 180, JACIKSON

Zimmerman, Albert S. (b'69)-Teun.II,'97; (1'99).

LINCOLN, 250, TALLADEGA

Brooks, Alpheus olin-Ga.10,'Si; (l'8i).

COLIIN, JAMIES PICKETT (b'63)-Ky.I, ,y1; (1'91).

HILL, JAMES HENRY (b'8I)क-Ala.4,09; (I'09).

Lane, Albert W.-Ga.I2,'06; (l'10)

Vandiver, Chas. Walden (b'70)-Ala.2,04; (l'05).

LINDEN, 600, MARENGO

BRASFIELD, CHAS. W.-Ala.4, 03; (l'03). DUNNING, GUY JENNINGS (b'85)-Ala.? 'I1; (1'11).

Jones, Green Ervin-Ga.10,'82; (1'83).

KIMIBROUGH, WM. LEONARD (b'59)-La.1, '8I; (l'81).

STUNE, AU $(1 ' 86)$.

LINEVILLE, 1,053, CLAY

BARFIELD, JESSIE MI.-Ga.11,'01; (l'0I).

GAY, COLEMAN P.-Ga.10,'97; (l'97).

GAY STONEWALL JACKSON (b'63) (ra.10,'88; (1'88).

Hilt, John L.-Ga.10,89; (l'89)

MANNING, JOHN THOS. (b'64)-Tenn.5,

'85; (1'87). 92 ; $\left(l^{\prime} 92\right)$

STUCKEY, THEODORE MALCOLM (b'86) Ala.4,'I1; (l'11).

LINWOOD, 100, PIKE

CROWDER, JOHN W.-Tenn.11, 04 ; (1'05).

Grant, Chas. Augustus (b'81)-Tenn.6,'08; (I'I2) ; R.F.D. I

Satter, E. S.-Ga.9,'92; (1'93).

LITTLE RIVER, 70, BALDWIN

Cloud, Wm. O. (b'65)-Ala.2,'yi ; ( )

LITTLETON, 300, JEFFERSON

DAVIE, JUDSON (b'51)-Ga.I,'72; (l'81).

SIITH, CHAS. IIENRY-Ala.4, 03 ; (1'03).

Smith, Elisha Baker (b'87)-Ala.4,'12 ; Assistant physlclan.

LIVINGSTON, 877, SUMTER

BROCKIWAY, DUDLEY SAML. (b'53)-

Ala.2,'78; Pa.2,'8I ; (l'81).

IcCAlN, WI. JASPER-Ala.2,91; (1'91) SCALES, JOHN PERKINS (b'72)-Ky.4,'97; (l'98).

LOACHAPOKA, 357, LEE

CURTIS, ROBT. CLANTON (b'70)-Tenn.8, 0I ; (1'01).

LOCAL, 12, ESCAMBIA

SELLERS, CLARENCE EUGENE-Ala.2,'04 ; (l'04)
LOCKHART, 600, COVINGTON

MCGEIIEE, PAITI, DUNCAN (b'86)-Ala.2, $10 ;(1,09)$.

LOUISVILLE, 483, BARBOUR

BENNI'I'T, BENJ. FRANKIIN $\left(\bar{b}^{\prime} 70\right) \oplus$ Ala.2,'93; (1'93).

NORTON, ROET. OLON (b'83)-Ala.2,'Il; (l'I1)

PATTERSON, ROHT. B.-Ga.11,'99; (l'99).

I'ATTERSON, THOS.-(3a.5,'69; (1'82).

Stephens, David Dudley-Ala.2,95; ( $\left.1^{\prime} 95\right)$.

LOWER PEACH TREE, 700, WILCOX

CLRTIS, ALONYO IB.-Ala.2,'82; (I'82).

GIBSON, ALIBElRT M.-Ala.2,'85; (l'88).

KIN(; EDWIN DOCK (b'51)-Ala.2,'81 ; (l'84).

MAYEK, KOSSUTH A.-Tenn.8, 00 ; $\left(1^{\prime} 00\right)$

LOWNDESBORO, 400, LOWNDES

HAGOOD, ROBT. BRAGG $\left(\mathrm{b}^{\prime} 79\right) \oplus-\mathrm{I} \Omega .1$, 05 ; $\left(1^{\prime} 05\right)$.

(ligROUGI, JOIN HENKI-Tenn.2,'94, $\left(l^{\prime} 94\right)$

Powell, Chas. Wm.-Ala.2,90; (1'90).

LOXLEY, 70, BALDWIN

VAN IDERSTINE, REGINALD - Ill.5,'06; $\left(l^{\prime} 06\right)$.

LUVERNE, I,384, CRENSHAW

Garrett, James D. (b'88)-La.I,'12; (l'12).

HOLN, Jos. IRICHARD-Ala.2,'87; (1'87).

Kendriek, Blshop Marvin-Nla.2,03; (1'04).

Kendrlek, James Evans-Ala.2,69; (1'82).

KNIGHT, WNI, PETER-Ga.10, 02 ; (1'92).

Tankersiey, F'lix M. T. (b'62) -Tenn.6,85, La.1,95; (1'85).

LYNN, 60, WINSTON

HHLL, ROBT. LEE (b'83) $\oplus$ - Ala.4,09; (l'09).

MABEN, 200, JEFFERSON

MIcQueen, Jos. P. (b'88)-La.1,'11; (1'12).

SMITH, EUGENE ROBHET, JR.' $\left(\mathrm{b}^{\prime} 72\right)-$ Tenn. 9,$00 ;\left(l^{\prime} 00\right) ; \mathrm{S}$.

MADISON, 426, MADISON

KYSER, JAMES ALLEN (b'80)@-La.I,'II (1'II).

PRIDE, WM. T. (b'65)@-La.1,95; (l'95).

WIKLE, LUTHER LAFAYETTE' (b'55)Tenn.6,'88; (1'88).

MADRID, IGO, HOUSTON

HERRON, DARRELL JEFFERSON-Ga.5 '84; (l'88).

MAGNOLIA, 500, MARENGO

SLADE, IIENRY (b'50)-Ala.2,'72; (1'si).

MAGNOLIA SPRINGS, 200, BALDWIN

GAIHIARD, THOS. HAMILTON-Ala.2,'06 ; $\left(l^{\prime} 06\right)$.

Howe, Chas. Lester (b'86)-Ky.1,'93; (1'93).

MALVERN, 100, GENEVA

SMITH, HENRY DAMON (b'90)-Ala.2,'I2; (1'I3).

WARD, THOS. J. (b'56) $\rightarrow$; $\left(1^{\prime} 88\right)$.

MANCHESTER, 500, WALKER

CANIP, H. ('. (b'79)-O; (l'08).

MAPLESVILLE, 500, CHILTON

Kay, Wm. Eli ( $\left.b^{\prime} 78\right)$-Md.9, 05; (1'05).

PARNELL, CHAS. N-Ala.2,'91; (l'91)

Potts, Van Buren-Aia.2,05; (1'0́4).

MARBURY, 一, AUTAUGA

Albriglit, Chas. W. (b'61)-0.3,'97; ().

MARGARET, 600, ST. CLAIR

BURWELL, HOWARD BEIRNE $\oplus-P a .2,04$; (l'05).

MARION, 1,834, PERRY

BARRON, WM. ROWAN-Va.4,63; ( $\left.\boldsymbol{l}^{\prime} 78\right)$.

DOWNEY, WM. THOS.-Ky.2,70; (1'70) : R F.D

GORDON, SAIIL. A.-Ala.2,95 ; (1'95)

HANNA, ROBT. CUNNINGHÁI $\oplus-\mathrm{Ky} .5$, '02; $\left(1^{\prime} 02\right)$.

HATCHETTE,

PERRY, SA.II.-S.C.I, 54 ; (1'78)

Robinson, Byron W.-Ky.4,'92; (1'92)

ROBINSON, CORNELIUS B. (b'íl)-Ky.4, '92; (1'92).

SWANN, EDWARDథ-KY.1,95; (1'95).

MARION JUNCTION, 200, DALLAS

DONALD, JAMIES MARION (b'62) -Ala.2, '84; $(1,84)$.

MAROS (LOCAL P.O.), 100, MONROE BAUMHAUER, THEODORE C. $\left(\mathrm{b}^{\prime} 80\right) \oplus-$ Pa.1,'03 ; (l'06). 
MARVEL, 400, BIBE

VASCE, JAMES GLEXX (b'sl)t-Na.t. $05:(1,05)$.

MASON, 75, ESCAMBIA

Douglas. Sllas W. $\rightarrow$ : (1'SB).

MAUD, 39. COLBERT

MINLEY W.I. A. $\left(b^{\prime}: 5\right) \rightarrow 0 ;\left(l^{\prime} 09\right)$

MAY, 150, TUSCALOOSA

WHEAT, JaMES M.-Tenn.1,07; (1'0i).

MAYLENE, 350, SHELBY

POW, JOHI ROBT. (b'79) Tenn.11, 03 (1'05).

MAYSVILLE, 218. MADISON

HOWARD, iSAAC W. $\left(b^{\prime}, 0\right)-T e n n .8,9 s$ (I'00).

MeCALLA. 45, JEFFERSON

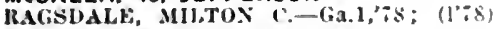

MeFALL. 820. CALHOUN

BARKEI, ERASTL'S THOMAS (b';0)

Tenn.8.'99: (1'99).

MCKENZIE, 75, BUTLER

MCCANE, JAMES JORDAN (b'60)-Ja.1, '82: (1'82)

MOORER, WALTER B.-Ala.4,03; (1'03)

McKINLEY, - MARENGO

Lee. Earl Foster (b'7)--1la.2,03: (1'04)

MeMlllan, T. N.-1la.2.'95; (1'91)

MESHAN, I5. PICKENS

Duncan, Jobn Francis-Nla.2,7t; (1'TS).

HILL EDWARD IICKFTT (1'0I).

MeWILLIAMS, 184, WILCOX

BOBERTS, W. I'-Teun , $^{\prime}$ 4; '(l'04).

MELBORNE, 30. LAMAR

SIZEMORE, W. CLAREXCE-Tenn.I, 04 (1"04).

\section{MELTONSVILLE, 50, MARSHALL}

JOHSSOY CERTIS (b'B4) - Tenn.19,11; (1'11).

MELVIN, 75, CHOCTAW

Rudder, John W. (b'8:)-Tenn 1, $07:\left(l^{\prime} 07\right)$

Smith, John Alexander (b'S6)-dJa.2,'11;

(1'ii).

MERIDIANVILLE, 185, MADISON

Fisslinger, Wade Hampton - Tenn.11,01: (1'01).

midland city, 539. Dale

BLACK, IRBY ANDREW' (b'Sz)-Ala.2,'10 ; (1'll).

COLEMAN, LEVY ATICU'S (b's8)-Ala.2, $12 ;(1,13)$

ESPY, CURTIS-Tenn.11,04; (1'04).

MILAN, 22, JACKSON

SENTELL, JAMES HOCSTON $(b, A R) P$

Tenn.6.'04: (l'06)

Mille RVille, 60, Clay

SLACGHTER. MYLES JASIER (b'il)Ala. 2,05: (1'05).

MILLPORT, 529. LAMAR

Black. W. A.-Tenn.8,95; (1'94)

Blakeney, lewis C. $-0 ;(1 ; i)$.

BLAKENEY, WALTEL W, - Tenn.8,01 (1'01)

CLANTON, Al.BERT W. (b'80)-M149.2,0\%: (1'07): R.F.I)

Coleman. Luther Shannon $\left(b^{\prime} ; z\right)-b:\left(l^{\prime} 00\right)$

COLIXS, AlONZO k-KY.40; (l'91)

Seay. Wm. A.-Tenn.8.04; (iv04); 0 b.

MILLTOWN, 100, CHAMBERS

RISER, WM. HE.VIV (1'81)-Ma.2.08 (100\%)

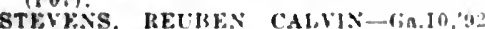
(1'82).

MINTER, 325, DALLAS

STKICKLANI, MACK MLTON (b'75) F

Ala.2.00: (1'01)

MOBILE, 31.521, MOBILE

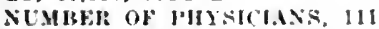

ACKER, FALL, JEHUME MURHA (b'70)

Ala.2,92: (t'92): 151 Covernment St

omce. 133 fiopernmens sis. :

Adams, John Thinav (h'so)-Ala.z,09: (109): 315 sirlnghll Are.: unce. 15 Daupliln st ; $y-i$.

ATKINS. JAYES DAVIL VI 2,06 ; (1'0i) springhll Are and ihlenter se.: onlow. 5.5 $x$. Conception St, latse onled, ("rech (on).

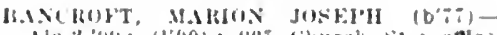
1la.2,"49: (1'00); y03 chureh st.; ontce 200 Si. Francis St : $: 30-11,3-4,7-5$; Asst. l'rof. (10ut., Ala.

BECK, JLLILS ÉlWAKU, (b'-8)-Ala: 12: (1'12); sos Augusta si.; oflce, 100 st. Jusepll st. ; $11-1,6-8$

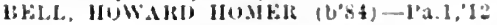
(1'12): Cnatersly of Alabama

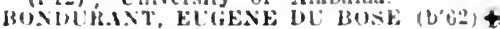

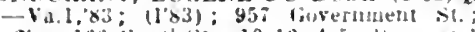
onlce, 166 Conel st. : 10-12, 4-5; bean ant l'rof Heni

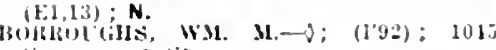
livernment st.

Brown. Quarles Jemison (b'-4)-.1la.2, 00 (I'00); $12 \mathrm{~s}$. fieorgia Ave.; ollice, 210 lixulbin sit.; 9-6; U.

Brown, Rolit. Inwight (b'it)-Ill.14, (1'06); 910 Savannal st.; onte, $10 \%$. (1)

Brown, Win. F. (cul.) (b'al)-X.c.3, 05 $(1,05)$; "erdar and llercules sits.; oflice. $5551 / 2$ Datuphin st.; $9-10: 30,12-5,5-7$

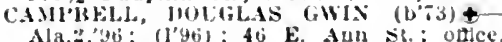

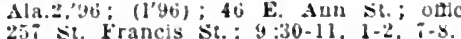
AHTrir, HEvirY rose, Jl:. (b'su) l'a.l,'vs; S.surg, C.S.l'II.S.; Jemuer Med. Assn. of Isthmian, C.Z.; C.S. Marine llospital.

Chapman. (has. Edward (b'- 8$)-A l a .2,00$

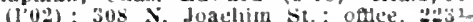
Dauphin st.; $11-1,5-7$

Chapman, J. I'. (b's5)-Na.2,12; (1'13) 150 Mchigan Are, ottice, 202 Cont st larke, Wm. Ilarrey (b'os) - Nla.2,yt (l't) : Old shell lid., near hilmanlock. COLE, HERBEITT HHALON $\left(b^{\prime}>0\right) \downarrow$ MU.

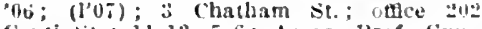
Conti st. 11-12, 5-6; Assoc, I'rol. Gylt., Na.": Edmonson swlet (b'sl)-Ala.2,13; southern intirmary.

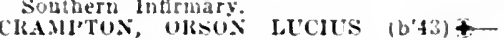
N.Y.10,65; (l'is); 105 $\mathrm{S}$. Conception St. $10-11,3-4, i-8$

lean, leon (b's6)-1lit.2,13; () ; Marine II ospital.

DEISIFALX, HOLT, CLAREXE (b's)Ho.2,11; Member Mo. State Mud. Assn. I's. Marlue Huspital.

vickson, Thos. A-l.a.1,42; (1'92); 251 turernment st. otice, Fan Antwerp kld.

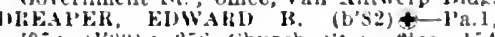
07; 1109): 256 Church st.; onlice, 15t Government st: $4-11,2-4,6-7 ; 0$ o

DLG(i.IS, LLEWELLYN LLWWIG $\left(\mathrm{b}^{\prime} ; 6\right)-$ Ala.2,95; 1194); 104 lapier Ire. fice, fidelia lldg. '9y; $(1049)$; 15 Montauk Are. ; wtlle, $4 \mathrm{~N}$ Clathurn st

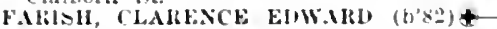

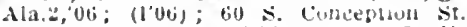

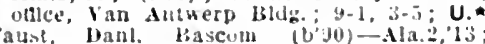
aust, banl, bascum
(l'fi): City llosptal.

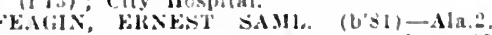

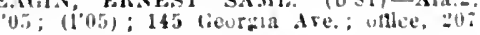
Cutit st.

Festorizzl, Ingelo (1,64)-1la.2,85; (15) 411: Cimername st. : unlee, tio

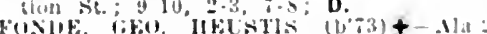

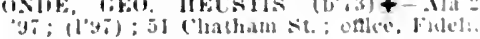
likle. $9: 30-10: 30,12-1,4-7: 30$.

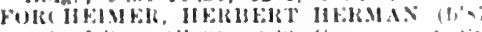

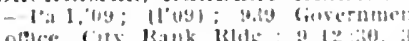
OALR,

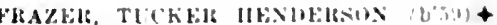

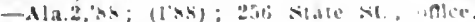
let sit. Micltat st. : y-11.

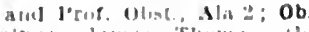

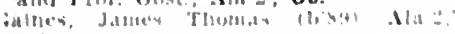

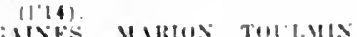

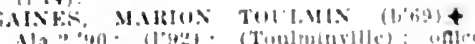

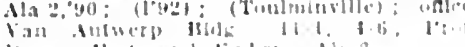
lerm, Ilime noml timlers . Nis

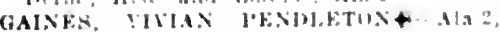

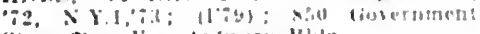

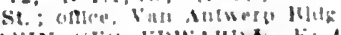

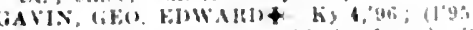

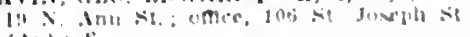
$(1,)^{\prime}: 8$.

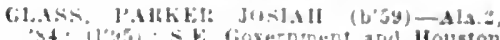
4: $\left.11^{\prime}, 5\right): 50$ fovernment and llouston Sts. ; once, 63 X. Concevters Si.; 9-11, -4. 1

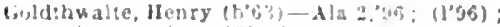
Itrol Itt bractice: 920 Guverntmert st

lla:s, Tuxey banel (b'y) - 1 la.2,12 (1'12); 113 Church st. ntice, Van AntHerv Blut: : $3-30,2-3$,

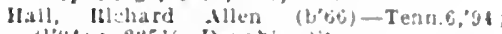

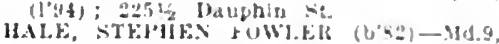

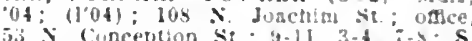

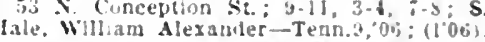
Harris, olver Hood-Mla.2, 35 ; (1.3t): 203 s. Conception st.

llakILS, SFill:; $\left(\mathrm{b}^{\circ}, 0\right) \&$ Va.1,94; (1'94) git forernment st.; unce, Van intwerp lildg. : $10-1 ; 1 . \star$

IIarris, Thomas Nathatel (col.) (b'6s)-

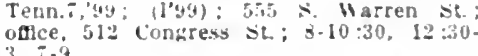

Harrisulu, Jantes Francls (b'5l)-Ya.l, :3 $\left(1^{\prime} 10\right) ; 10 \%$ St. Joseph sit. I'pot. Chem. Na.3.

HENUKRSON, WM. THOMAS (b'es) Mich. $996 ;(1996)$; 415 Spring Hull dre. office, 259 St. Francis st.; 8-10, z-4.6-7.

IIE.KK, JUIL's (i.-Tenn.1,04; (1'06)

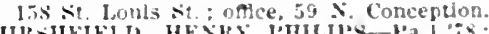

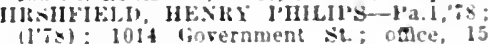
s. Cunceptlon si?

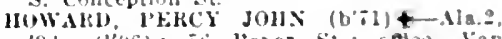

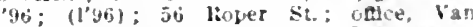
Antwery Bldi:; $9: 30-11,2-4,7-8 ;$ Asoce prof surg., Alis.

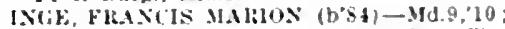
(1"10); 9.it corternment sl.; uttce. Cits liank Bldh.; $9-11,2-3,6-7$

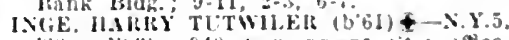

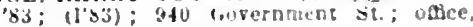
59 st. Joseph St. ; 1-10, after 1.

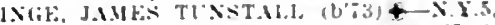

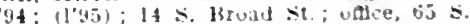
st. Finanuel st.: $10-11,5: 60-\%$

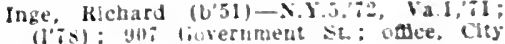
Bank Hdk, ; $y-10,1-2,7-8$

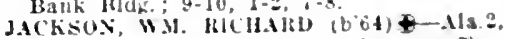
ss; (1'ss); 16: st. Nichael si: wace. 16t st. Hchael st.; 8-10, 3-5; I'rot surg, Ala.2.; $\mathrm{S}$.

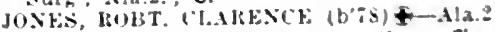

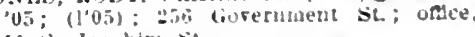
11 S. Jialchim St

JOXE., WM. CL.llik (b"s9) Ala.207; se; Gorernment

Francls sto Washogton (bs)-Ala: 1: Intern, Mobllo Iatlrmary.

kimbrutigh, Julin. Jr. (b'ss)-Tean 8,13 ;

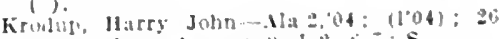

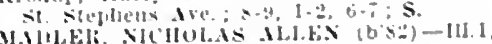

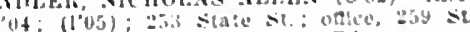
Francis st: $9-11,3-6,0-7$; Pd.

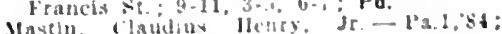

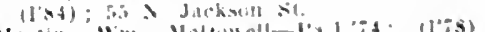

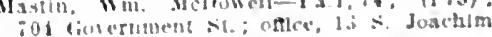

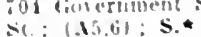

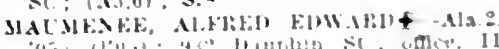

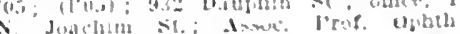
ils.: (16])

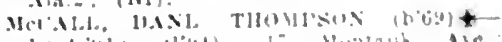

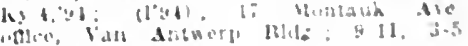
Pd."

IC 1)

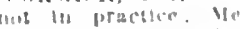

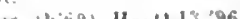

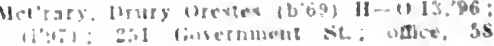
Emantuel si

MHTILF, MIIHIT WEST (b'st)

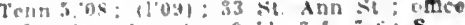

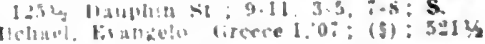
lostulition sit

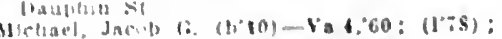
ilot in bractice: 1303 lauphin st. 
MOHI, CHAS. A.-N1a.2,'84; (1'92); 252 Si. Anthony St; ottle, Van Antwerp Ala.2.

MOODY, HENRY ALTAMONT $\left(\mathrm{b} \mathrm{f}^{2}\right)+$ Ky.2,66; (1'87) ; :304 State st.; Prop. Ther. Int. Med. and I'harmacognosy, Ala.2.

Myers, Augistus 1'. (b'58) 11-M0.5,'88: (1'88) ; 222 old sliell Rd.; offle, $10 \overline{\mathrm{T}} \mathrm{N}$. Conception st.; $9-12,3-6$.

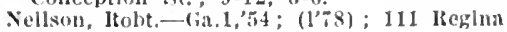
Ave.

practlee: 110 Georgia

(1'0I); not ln practlee: 110 Georgla Ave

Tenmeso (1)'-9)Tenn.6, $02 ;(102) ; 3015$.
offlce, Van Antwerp 13ldr.

OWEX, CALVIN NORRIS - Ala.2'ss : (1'88) ; 51 G Governnent St, ; oftice, $154 \mathrm{St}$. Francls st.

PADRETT, WM. AlEXANDER (b'î) Ala.2,'10; (l'11) ; Government st. Loop; ufflce, Van Antwerp Bldg.

Peterson, Edgar Ardis-'Tenin.5, '02 ; (l'02) 203 s. Gcorgia Ave, offlce, Bienville IIntel ; $9-10,12-1,5-6$; $S$.

P'TTERSON. JAMES JESSE - La.1,99; (1'01); 854 Government St.; office, Yan Antwerp Bldr.; $12-2,5-7 ; S$.

I'IIILLII'S, WA. FOWKE RAVENEL $(1,63) \uparrow-D . C, 1,90$; Member Mell. Soc. of 1.C.: Ínlversity of Nlabama ; l'rof. Anat. Ala.2.

PIGH, SIDNEY STEWART (b'63)-La.1, '89; (1'89); $255 \mathrm{~N}$. Conceptlon St.; offle, $66 \mathrm{~N}$. Conception st. ; $9-11,2-4,7-8$.

Reares, Jesse Ullman (b'85) - La.1,08 (1'08); 259 s. Georgia Are.; office, Van (l'08); 259 S. (ienrgia Are.; office, Van

Reares, Nell I,eConipte (b'82)-Ia.3,09; not in practice; $259 \mathrm{~s}$. Georgla Ave.

Roach, Alexander Nicholas Talley $\left(b^{\prime} ; 8\right)$ Tenn.11,01; (1'02); 53 Rapler Ave. office, $58 \times$. Conception St.

Roe. C. K.-Ky.4, T1; (1'06); Spring IIill.

ROE, LEE WRIGITT-N1a.2,'01; (1'01) ; 1004 Texas St.; office, Van Antwerp Bldg.; I.

Roper, Florence Turner-Mass.5,03; (1'04) ... Michael St.

RISHI, JOIIN OSGOOD-Nla.2,04; (1'05) : 255 St. Anthony St.; office, Van Antwerp Bldg.; 2-4, 7-8; Assoc. Prof. Gen.-Urin. Dis., AIa.2

RYAN, ANDREW HOWARD (b'85)-Mo.2, 10; Member Mlssouri State Med. Assn. Iniversity of Alabana; l'rof. Plysiol. Ala.2.

SCALES, WILLIS WEST (b'i6)-Nla.2,96 $\left(1^{\prime} 96\right) ; 54$ Old Shell Rd.; office, 119

SCHWARTZ, JOS.LLa.1,01: (l'01)； 505 Church St. ; offlee, 65 St. Emanuel st.

SELLERS, NEAL EDWARD (b'81)-Ala 2, '05; (1'05); 51 S. Bayou St.; offee, 58 St. Emanuel St. ; $11-12,6-7$.

sherard, Frank Ross (b'r2) - Pa.1,94; (1994); 5 r N. Jackson st.; $9-11,2-3,7-8$. simington, Alfred Dennis (col.) (b'68)Tenn. 800 ; (1'01); 650 st. Michael St.

SILDGE, EDWARD SINMOAS $\left(b^{\prime} 86\right) \oplus-$ Pa.1, 09 ; (l'10); 54 s. Jackso

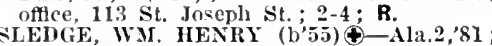
(1'80); 54 S. Jackson St.; office, $113 \mathrm{St}$. Joseph St. ; $9-10,2-3$

Spottswood, Irillon J.-Ala.2,90; (1'92) ; 258 St. Francis St. : $9-10,1-3, \bar{i}-8$.

TONE, JOHN IIAMILTON (b'i2) †-D.C.1, '95; Maj., L.S.A., retired; 1057 Govern ment st.

Taylor, Ilerbie Andrews (b'90)-_la.2,'12 (1.13); U.S. Marine Hospital.

TERRILL, EDWARD CHAPIX (b'86)-AIa.2, '09; (1'10); 415 Spring Hill Are.; offee, 15 spring Hill Are.; 8-10, 3-5, $7-9$.

Terrill, James Walton (b'8s)-Ala.2,13: (1'13); ('ity Hospital.

TERRILI, JOSHUA D.- $0.1,85$; (1'92) ; 980 Dauphin St.; office, 154 Spring Hill'Ave THAMES, EUGENE (b'83) - AIn.2,'10 (I'10) ; 261 X. Joachim St. ; office. Cont
and Jackson Sts.: 8-10, 12:30-1:30, after $5: 30$

THAYER, ALFRED ENWARD (b't33)-N.Y.1 '84; Member Texas State Med. Assn. not in practice; Spring IIill Are.; P'rof. l'ith. and Bact., Ala?
Thomas, dames Grey (b'70)-Ala.2,98; (1'y9:) oflee, $53 \mathrm{~N}$. Conceptlon $\mathrm{St}$.

rol EZLORF, ItWDOL,PII 11.\$-D.C.1,94; Surb., U.S.I.II.S.; Marlne Hospltal: Assoc, IProf. of Trop. Med., Ala.2

Wird, Alfred G., Jr.-Aln.2,94; (1'94); x. liroad St.; office, l'ollock Bleg.

Waters, IIInton Wright (b'90)-Ala.2,'13 (1'13); Cnlted States Marine Hospltul. Wllllams, Ilenry Roger (col.) (b'69)Tentu. 7 ?00; (1'00) ; 606 Dauphn St.; whises, IOHN MALER (1,84)-Ala.2,07; $\left(1^{\prime} 0\right)^{-} ;$s s. Bayou st. ; offee, Van Ant werp Bldlg.; $11-1,6-7 ; \mathrm{S}$.

"INTHROI', GILMAN JOS. (1,80)£-MI.7, $06 ;\left(1^{\prime} 09\right) ; 170$ Contl St, ; $11-1,5-6 ; S . \star$

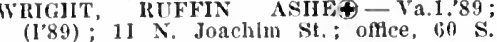
ronceptlon St. ; Assoc. Prof. Laryn., Otol. and Rhln., Ala.2.

MONROEVILLE, 616, MONROE

I3.1YLFS, WIILARD T.-Gia.11,02; (l'02). COXWELL, AIVIN B. (b'84)-Ky.4.0i (1'07).

DENXIS, THOS. EDMIUND (b'80)-Tenn.11, 'OS: (1'09).

MONTEREY, 300, BUTLER

(1'13).

MONTEVALLO, 923, SHELBY

ACKER, CILAS. THOMAS-Ala.4,00; $\left(1^{\prime} 00\right)$; OALR.

ACKER, JAMES WILSON (b'3i) $\rightarrow 0$; (I'78). GIVHAX, EDGAR GILAIORE (b' 60$)$-Ala.2, 94; $(1,94)$.

REID, JOHN INZER (b'31)-Tenn.1,06; WILKINSON, DAVID LEONIDAS (b'72) \&La.1,'94; (1'94).

MONTGOMERY, 38.136. MONTGOMERY

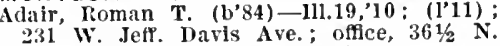
Iawrence St. ; $9-11,4-5.7-8$.

ANDERSON, BENJ. FIRANKLIN (b'80)Ala.2,05; (l'09); R.F.D. 4.

ANDERSON, IOHN MOHDECAI-N.Y.5,'91: (1'91); May Ants.; office, $19 \frac{1}{2}$ S. Perry

ND. (1'86) ; $529 \mathrm{~s}$. Court St.; offlee, $4 \frac{1}{2}$ Court Sq. : $11: 30-1: 30,3-4$.

BAKER, JAMIES NORNENT (b'76) \$-Va.1, '98: (1'00): Sec. Med. Assm, of the State of Ala.; 602 S. Perry St.; office, Bell Bldg.; $8: 30-10,3-5 ;(\mathbf{A} 6): \mathbf{S}$.

BALDWIS, BENJ. JAMES-N.Y.10, ‘; (1'83).

BARNETT, CLIFFORD NATHAN THOMASAla.2, 05 ; (1'05).

Barton. J. F. $\rightarrow$; (1'03) ; 413 MHIdred St.

BILIING, SAML. AYDELLOTTE-N.Y.10, 97: (1'97); 14 Capitol Are.: office, 100

Dexter Ave.

BLUE, JOHN IIOWARD (b'ĩ) X.Y.I, '01 ; (1'01); Extension S. Hull St. ; office, I3eli Bldg. ; 12-2.

Boswell. Fredk. Felix P. (b's8)-Nla.2,'13; Intern, st. Margaret's Hospltal.

BOYD, I. II.-NIA.2,0I ; (1'01): Htghland and Forrest Ares.: office, 12 Court Sq.

Buchanan, Jolnn P. (b'69)-Ala.2,'92; (l'90); 1 Jeft. Dasls Ave.; offlce. 221/2 N. Court

St. 08; (1'10); 20 Sayre St.; office, Bell

Caffey, Frank C. (col.) (b'T0)-Tenn. i,'99; (I'99) ; 2 Houston St. ; $7-10,3-8$.

CENTERFIT, SAMIL. E, - N.Y.5, 98; (1'99) 416 IIigh St.; offlee, $191 / 2$ S. Perry St.

CHAPMAX, BENJ SIDNEX-XY.5,92 ; $\left(I^{\prime} 92\right): 804$ Washingt on $\mathrm{St}$.

DAWSOE, HARRIS PICKENS (b'84) \&La.1,10; (109); 526 S. Lawrence

DENNIS, ANDREW' J. L.-Ga.10,'90; (1'94) Bell BIdy.

DENIS, GEO. A. (b'72) $4-G a .10,93$; (1'93); 410 S. Hull St.; office, Bell Bldg.; Q-1, 3-5; OALR. *

DeRamus, James A. (col.) (b's2) - Tenn. i, '11; (I'12); 9 Westeott St. , 07 : (l'07) : 414 Adams St.; office, State 07 ; $(1,07) ; \quad 414$ Adams
Board of Health, $9-1,3-5$.
Dungee, Alfred Coleman (col.)-D.c.3,90: (191); 226 .Jelt. Darls Ave.; office, $27^{-1 / 2}$ court st

ItOBT.-N.Y.10,'93; (1'94) $514 \mathrm{~S}$. IIull St.; office, $131 / 2 \mathrm{~S}$. P'erry' St. GItEIL, GASTON J. (b'78) $4-N . Y^{\prime} .1,01$ $\left(1^{\prime} 02\right) ; 506$ Montgomery St.; offlee, Bell 13ldik. I1-1, 4-5: Pd.

HAItiLEIt, JAMES WO13T,-Ala. 2,97; (1'97)

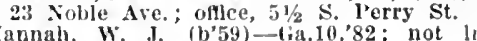
practice : 622 s. Court St.

Harris, (has, (s)ar, Jr. (b)'88)-D.C.3,'13: ( ) : 81:3 Adams si

IILL, LUTIIER IJEOSIDAS (b'02)↔-N.Y.5. '81; 1'a.2,'82; $\left(11^{\prime} 81\right) ; 422$ S. P'erry St. omce, 21 s. P'erry st. ; $9: 30-10: 30$ $4: 30-6: 30$.

IILL, ROBERT SOMMHRVILIE $\left(b^{\prime} 70\right) \biguplus-$ N.Y.5,91; (l'91); l'res. Med. Assn. of the
State of Ala. : 105 Gilliner Arc.; offce, 21 State of $\mathbf{A l a}: 105$ Gilmer Arc.; offce,
S. Perry ; $9: 30-10: 30,5-6 ;(\mathbf{A} 6) ; \mathbf{S} . \star$

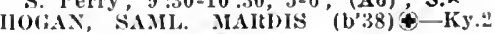

73; (I'80); 115 Sayre St.; offlce, $11 \mathrm{Dex}$ ter Ave.; 11-I.

IIUBBAIH, THOMAS BRANYON (b'8i)N.Y.1,'10; (l'12); 1043 S. l'erry St. office, Bell I3ldg.; $12-1,5-6 ;$, s.

OWEIts, SOLOMAN 428 Columbus St.

Kendrick, Wm. Toulmln $\left(b^{\circ} 55\right)-\mathrm{Ga} .5,76$; $(1 \% 8) ; 48$ Halcomb St.; office, 12 Court sq. ; $11-1,4-5$.

Kîrk, 'Eben Bell-Ala.2,'85; (1'85).

KIRKPATRICK, MILTON BARNES (b'i1)laa.1,'96; (1'96); 214 Sayre St.; offlce, Bell IBldg. ; 11-12: 30 .

IAASLIE, CARNEY G. (b'78)-Md.3,03; $\left(1^{\prime} 03\right)$; Bambridge and Monroe Sts. office, Bell Bldg.

LAW, WM. LAYAR (b'70)థ-La.1,'94; Blds.; $9-5 ; 1 . \star$

LAY, HARRY TOULAIN (b'79)-Va.1,04; (l'04) ; $533 \mathrm{~S}$. Ilull St.; offlce, $14 \frac{1 / 2}{2}$ Dexter Ave.; $11-1$.

VARKS, ('HAS. L.-Va.1,04; (1'06); 2: W'llson St.; office, $5 \frac{1}{2}$ s. Perry st. ; 10-1 $4-6 ;$ D. $\star$

MARTIX;, WM. GRAVLEE (b'59)-Tenn.8, 93: (1,95).

ICCONNICO, FRANK H.-Ia.1,99; (1'99); 23 South St, ; offlce, Bell Bldg. ; 1 I :30-1. MCCRUMUIN, NORMAN HENRY-Tenn.5, ,84; (1'85).

MeGEIHE, WILLIAM WALLACE $\$-A l a .2$, 07 ; (1'08); 1201 S. llull $\mathrm{St}$; oftice, 25 Dexter Are.

MERTINS, I'AUL STEARNS (b'T6)〔 Mass. 1 , 00 ; (l'01) ; 410 S. P'erry St. ; office, Bell Bldg. ; $9-1,3-5$; OALR.

MLLIGAN, RUFU LEE (b'80) - Tenn.1, '03; (1'03); 24 Mobile St.; office, Bell Bld

Mohr, Herman B. (b'58)-Nla.2,'9I; (1'92); State Board of Health

MONTGOMERY ARTHLR HLGH-Ga.j,
98: (1'98); 518 Clayton St.; office, Beli Bldg.

MOSS, PHILIP BALL (b's3)థMId.7,09; (1'10) ; 607 Forrest Ave.

yOUNT, BERNARD-La.1,00; (1'06); 319 Clayton, St.; office, Bell Bldg.

vorthcross, David Caneen (col.) (b'76)1ll.11,'06; (I'05); 6 Sheppard Ave.; office, $111.11,06$; ( ( 05$) ; 0$ Sheppard Ave. ; office,

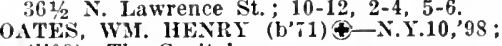
(1'00); The Capitol.

ORR, JOHN FRASER (l,T8)-Scot.3,01: (I'10); 821 Washington St.; offlce, State Board of Health.

I'earson, Coleman Ferrell-Ala.2.'00; (l'00) 619 Jadison Ave.; office, $51 \frac{1}{2}$ Dexter Ave. : $12-2 ; \mathrm{Pr}$.

I'ERRY, HENRY GAITHER ( $\left.b^{\prime} 60\right)-G a .9$, '87; (1'88); 221 Sayre St. 'ERSONS, HENRY STANFORD (b'68)

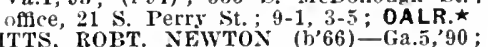
$(1990) ; 116$ Grove St.; offlce, 100 Dexter

IOLLARD, CHAS. TEED-La.1,97; (1'97); 406 S. Perry St.; offlce, Bell Bldg.

Rankin, Wm. R.-Ga.11,01; (1'01).

REYYOLDS, GIBSON (b'ĩ) $€$-N.Y.1,01:

(101); 109 S. Perry st.; $12-1,3-4,7-8$. 


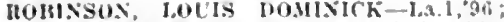
(1'90) : 203 Moulton St.; ontee, |lell |l|dx. Rushln, James Thomas-Tenn.6, 83 ; (1'84) Rushln, James Thomas-Tenn.6, 33 (

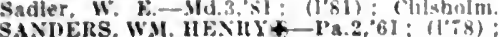
Chalman state IBoari of Jipdical kixam. Iners: tis 8. tawrence st. oflce. simt Board of Itealth: Eimer. l'rof. Ophils and state Med.: Mla.z.

saurll, Brnest Max $(1,63)-111.6,02$; (l'(0.i) St. Mess Kal: : ".

Scott, Andrew lakayctle $\left(b^{\prime} 73\right)-M o .28,96$. (196); Y.M.C.A. HIds. : oflce, $26^{2} / 2$ Com merce st. : $9-12,2-3$.

mete Darld H. C. (col.)-Tenn.7.95: (195)

Seott, Darld H. C. (col.)-Tenn., $95:$ (I'95): scolt, Jephtha tewton (b'53) Mola.2, si: $\left(18^{\prime}\right): 2 i 1 / 5$ Comnerce st.

SELLEIS, WIIBLIR ALIEX-Ala, , 04 $\left(1{ }^{\prime} 04\right) ; 601$ Folder st. : ontce, bell Hidg. 9-1. $5:-7:$ : U.

SMITIT, JAMES I.EL (b'8\$)-Ga.ll, 10 (I'II): Selma Ri.: oflce, 15!. Dexter Are.

STEISER, SAML, JACKSON (b5\%)Tenn.J.;9: $(1,69)$; s. Court st.; unlee. 12 Court Sa.

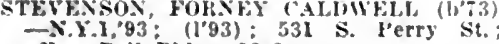
-X.l.1."93: $(1 ' 93): 531$ s. lerry st.
onde, Bell Bldg. 12-2.

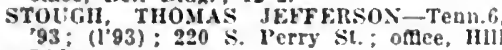
'93; (1'93): $220 \mathrm{~s}$. l'erry st.; oflee, IIll STOCGH, WILIIAM VESTA-Ala.2,07; (l'0i); 22 Whitman st, of ce, llell Bldg (1'05); 211 Church st.; ofte, 151/2 Dexter ire.; $11-3$.

THIGIEN, CHAS. ALSTON (b'65) L-I,

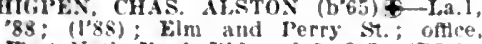
Flrst Natl. Wank Blde : 9-1, 3-5; (BI,3) TIIGIEX FRANK M. (b'6i) Ia.1,91 (1’91): $619 \mathrm{\&}$. Court St, ; oftce, First Xiatl Bank Bldg: 9-1, 3-5: (B3); Op.

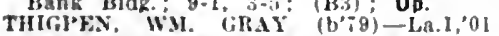
(l'01): Flrst Natl. Bank Hldh. : 9-1, 3-5.

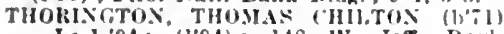
-I 1. 1.94; (1.94): It8 W. Jeft. Davls Ave, offlee, 5/s liextre Ave.; 12-1.4-5; Ave:

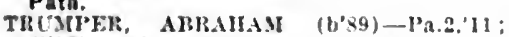
(1'12): Lab., State Board of Health; Lo. ian Felt, Geo. Welby $\left(b^{\prime} 44\right)-K y .2,70$; not In practlce; 28 Pine St.

WALLER, GEO. PIATT-N.Y.5,92; (1.92) : It. F. D. 5 .

Washlngton. Wim. II. (eol.) (b'83)-Tenn. (06: $\left(f^{\prime} 06\right): 27:$ S. Jackion st., oftec, 12I1/2 Monroe St. : 9-10, 1-2,6-7

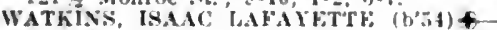
X.10;8: (1’86); Porest Ave: oftle. First Nallonal lank Hldk: $3-5 ;\left(\begin{array}{l}\text { (A6) } \\ \text { Fant }\end{array}\right.$ First

WESTCOTT. WM. B.-N.Y.I.02: (l'02) ;

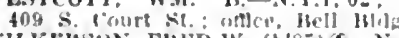

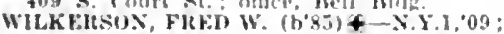
(1'09); 302 Church sit.; once. Bell hidg. II :30-1.

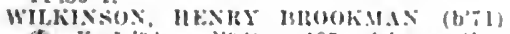

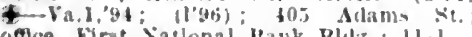
offle, Kirst National Hank Blyz.: 11-1

Wllson, Cato H. (col.)-Tenn. .,99: (1'94)

(I'Bt): 301 (nureh st.; oflee, i iourt sq.

MOORES BRIDGE, 300, TUSCALOOSA

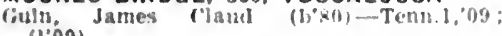

mothers, Wm. Jonas (b's9)-Ala.2, Smothers.
$(1 \cdot 85)$.

MOORESVILLE, I37, LIMESTONE

Caln. John J,-Tinn.5.86; : (l'06)

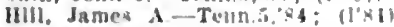

MORRIS, 299. JEFFERSON

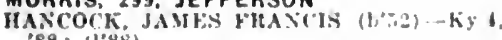
88: (1'8\%).

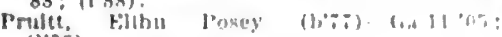
(1'0).

Whisenant, Lew I I) -8 : (1'78)

MORVIN. 48. CLARKE

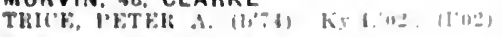

MOTLEY. (R.F.D., WADLEY), 100, CLAY

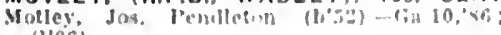
136

MOULTON. 354. LAWRENCE

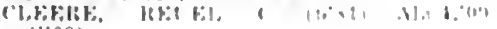
(l'09)

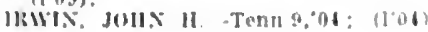

IIWIS, HOHERT PUICF (hoi)-dla $\$, 10$ :

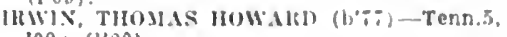
$00:(1200)$

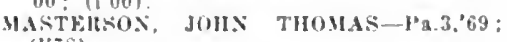
$(1 ; 5)$.

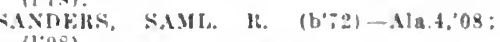
(I*ก).

MOUNDVILLE, 253. HALE

klllot,. IBenj, Frauklln, Jr. (b'S6)-Ala.2. $12:(1,12)$.

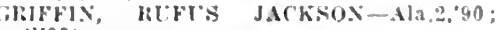
(1"90).

MOUNTAIN CREEK, 300, CHILTON

FLASHELILI, JUHA ['. $\rightarrow$; (I'St)

MADIOX, JOS. W.-Tenn.6,00; 1101$)$.

MT, ANDREW, 300. BARBOUR

WHITE, ROHT. LEF-.lla.2,'98; (I'98).

MT. CARMEL (R.F.D., SELLERS), 90 MONTGOMERY

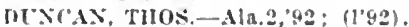

MT. HOPE, 300. LAWRENCE

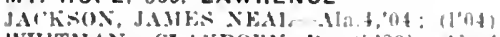

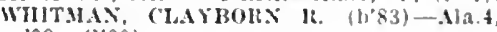

09; (l'09).

MT. MEIGS, 150, MONTGOMERY

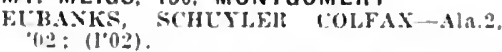

MT, STERLING, I00, CHOCTAW

LTTLELA(iF, THOMAS MI-Na.2,01 (1'01).

MT. VERNON, 800, MOBILE

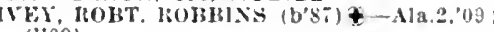
(I.09)

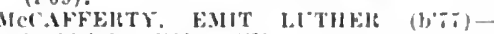
Ga.11,02; (1'02); (E13).

Perdine, Thos. Derote (b's9)-11a.2,'13 (l'13); Mt. Vernon Insane Hospital.

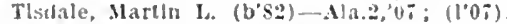

MT. WILLING, 23I, LOWNDES

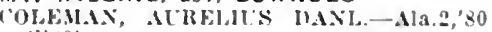
(l'so).

MULBERRY, 60, AUTAUGA

EIWAHIS, (FEO. TRAYLOH (b'sb)-Nla. 12; (1'12).

\section{MULGA-JEFFERSON}

D.IIKINS, JAIHS TOLIYFR (b'8H)-Ala.2 099: (I'09).

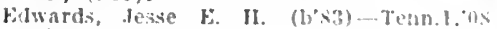
(l'1:2)

MUNFORD, 400, TALLADEGA

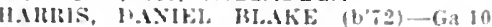
97 ; (1'09)

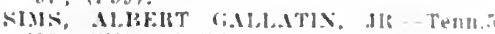

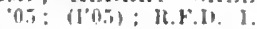

MYRTLEWOOD, I50, MARENGO

HIler, lesse (c. (1)'

NADAWAH, I0, MONROE

calne. Vanghn Holme; (bisc) - Ma.2,9a (1'Div).

NANAFALIA, 600 MARENGO

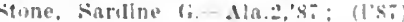

NATURAL BRIDGE, 150, WINSTON

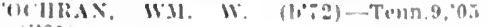
$(1,0,9)$

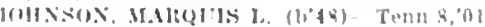
(l'sii)

NAUVO0, 392, WALKER

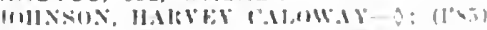

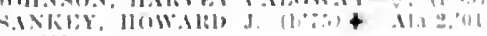
(1001).

NEALS MILL (R.F.D.. MILIPORT). PICKENS

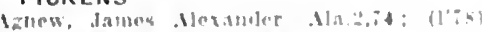

NEEDHAM, 10, CHOCTAW

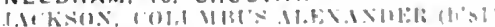

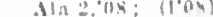

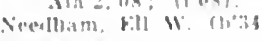

NEWOERN, 3I3. HALE

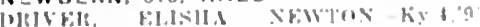

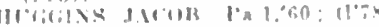

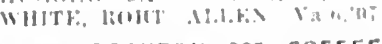

NEW BROCKTON. 32\%, COFFEE

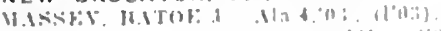

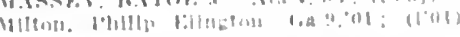

NEW CASTLE, - IEFFERSON

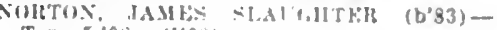
Ten 5, $08:(1 \circ 0)$

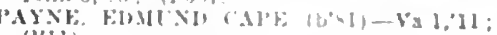
(1) II)

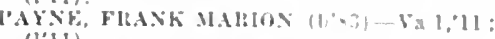
(1'il).

NEW DECATUR, 6,118, MORGAN

Hlack. Wm. f'real-Tenn.5.90; (l'g)

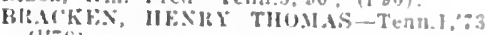
$11 \div \times 8)$.

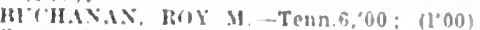

Carswell, Fontaine lee $(4 ; 2)$ - i, 1,00 $(1,0 ;)$.

(HFAll'T, CAlVIN SIINEY (b6i)-

Mlat.9i; $(197) ;$ S.

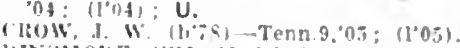

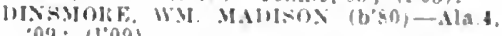
003 : $\left.11^{\circ} 03\right)$.

Caston, l'aul theres (b'a) - Tenn.5.'is: II'is).

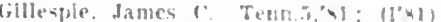

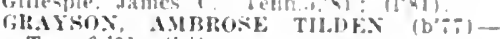
Tenn $n, 01 ;(1 \div)$

GT"NTEl, JOS. LEON (b'a)-Tewn 3,"94: (l" +4$)$ : OALR.

MRRIS, MICH.АЕ, WM. Q-QUe.1,90:

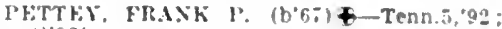

sHFI.TAx, JOHS BEXJ. $\left(b^{\prime} 60\right)-110.2 .96$ : (['ati)

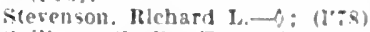

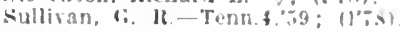

NEWELL. 80, RANDOLPH

corvorn, liobt. ('leseland (b'3:)-Ga.12,19. (1'13).

NEW HOPE, 30I. MADISON

ILISN. RUSCOL; IBILINT (b's?)-Tenn,6,

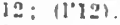

CIRIFXTEl:, J.MYES AI.I.F-N-11a.9.96: (1.90i)

Hinds, IIarry - Hn 2.04: (l'04)

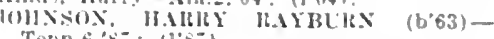

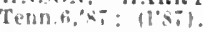

NEW LEXINGTON, 38, TUSCALOOSA

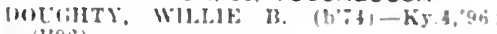
(1.916).

STEWART, 0.EAl: F-Tenn?,06 : (1.06),

NEW MARKET, 300, MADISON

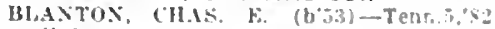
$(1+2)$

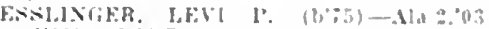
(l'03): OALR.

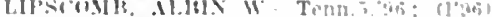

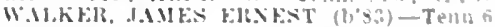
OS: 1losi

NEW SITE (R.F.D. ALEXANDER CITY) I50. TALLAPOOSA

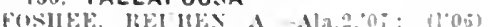
II. F.H

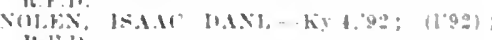
Ii: 11

NEWTON, 524, DALE

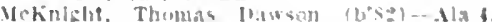
12: (1) (1) (1) (1)

NEWTONVILLE, 50, FAYETTE

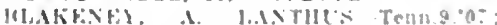
$110^{\circ} 0: 3$

NEWVILLE, 522, HENRY

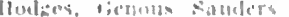

(3).

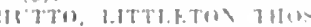

(1). $110: 310$

NICHOLSVILLE, 30. MARENGO

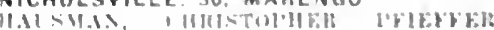
(b) ila:"10: 1101 .

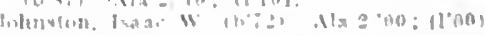

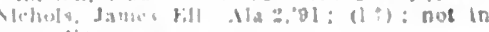
praceler

NOIMAL. 98, MADISON

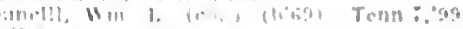

NORTH MOBILE, IO, MOBILE

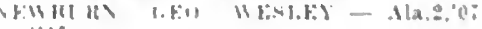


NORTHPORT, 500, TUSCALOOSA

BLLL, CHAS. PATTON-Tenn.I,'03; (1'03). HAGLER, EDW. CLEVELAND-Na.2,04; Kllk, ARTHUR AIBURTUS-Ala.2,'9i ; (1'97).

NOTASULGA, 512, MACON

SANDERS, ANDREW JORDAN (b'66)Teun.6,'94; (l'94) ; R.F.D. 1.

WARD, WM. SOLOMON (b'67)-Ga.10,90 ; (1'95).

WELDON, JESSE LEE (b'84)-Ala.4,'I1; (1'12).

WILLIAMS, CIIAS. ELIAS (b'7s)-Ala.2, 04: (l'01)

OAK GROVE. - MOBILE

Gray, Henry W. (b'73)-Ky.1,'02; (1'13)

OAKHILL, 300 , WILCOX

JONES, JOS. HARVEY-IAa.1,'80 : (1'82).

MCWILLIAMS, FOWARI ("OPTON N.Y.10,98; (1'98)

OAKMAN, 1,065, WALKER

GRAVLEE, WAT. LOUIS-TeUn.I,'82; (1'82). JOHN'TON, NO.II A.-Temn.I, 07 ; (1'07). ODOM, JEREMIAII NEWTON (b'67)-(aa.5, '95; (1'95).

STEPHENSON, IIUGH WATSON (b'54)Ala.2,'s0; (1'88).

ODENVIILE, 75, ST. CLAIR

CHANDLER, JAMES ROBT. (b'81) $8-$ Ala.4,09; (l'I1).

COOKE, WA. PRAYTOR (b'it)๑-Tenn.1I, $00 ;(1,07)$.

OFELIA (R.F:D., LINEVILLE), I8, RANDOLPH

Gauntt, Elbert Tillman-Ga.5,'78; (1'84).

OHATCHEE, 40, CALHOUN

IIcLeod, Alexander (b'90)-Md.4,'13: (1'13). MIEHARG, WM. GRAY-Tenn. 8,'99; (l'99).

OLD SPRING HILL, 100, MARENGO

ABERNETHY, WMI. HENRY (b'87)-Ala.2, 09; (1'09).

OMEGA, 50, BULLOCK

AYRES, CH.AS. J. (b'69)-Va.4,'86 ; (1'86). ONEONTO, 609, BLOUNT

Davidson, Alvin S.-O; $\left(\mathrm{I}^{\prime} \mathrm{T} 6\right)$.

DENTON, MARVIN $\left(\mathrm{b}^{\prime} 80\right)$ - Tenn.1,05 ; $\left(1^{\prime} 07\right)$.

HANCOCK, JESSE THOS.-NIa.2,77; (1'78)

STANSBERRY, CIIAS. LEE (b'68) $4-$

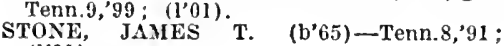
(1,91).

OPELIKA, 4,734, LEE

BAILARD, IRA W. (b'84) $\rightarrow$; (I'05)

BENNETT, $\triangle$ BIJAH BENJ. (b'56)-iId.3, '8I, (l'81).

BRUCE, HOMER S.-Ga.5,'9I ; (l'9I).

Bullard, Clarence C.-Ga.9,91 ; $(1 \dagger)$.

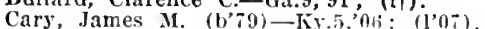

COOPER, GEO. HAYES-Tenn $9,{ }^{\prime} 0 \mathrm{I}$; $\left(\mathrm{l}^{\prime} 00\right)$.

Darden, John W. (col.)-N.C.3.'0I: (1'02).

LANGLEY, O. VELPEAU $\left(b^{\prime}\right.$ ' 1$) \notin$-NI.4, '93; (1'93).

Lindsey, Eugene A. (col.) (b'82)-Tenn.7, '08; (l'09).

LOVE, WM. JOS. (b'60)-Ga.5,'82; (1'85). MOORE, GILMER H. (b'79)屯-MI.9,04; (1'04); Pd.

PALMER, JESSE GARY-MId.3,'84; (l'94), PERSONS, RENLS C. $(b, 00)+$-NY Y.5, Med. Dir., Commodore, U.S.X., retired.

THONAS, MERRICK DOWDELL $\left(b^{\prime} 77\right) \oplus$ N.Y.I,04; (1'04); Nember Hed Soc. of the State of New York.

OPP, 863, COVINGTON

DALTON, TOBEY E.-Ga.9,'94; (l'95).

MeLEOD, JOHN C. (b'78)ङ-Ala.2,'04; (1'04).

STEWART, BEN.J. C. $\oplus-A l a .2,00$; (1'00)

WATERS, HARVEY AU(iLSTUS (b'88)-

Ala.2,'12; (1'12); R.F.D. 2.

ORRVILLE, 255, DALLAS

MOORE, LAWRENCE HENRY $\left(b^{\prime}, 7\right) \oplus-$ Ala.2,0I; (1'0I).

SUT'ON, ROBT. LEF (b'64)-D.C.1,'89 ; (l'89).

WILsox, JoHN Wม. (b'78)-Tenn.5, Q3; (1'04).

OWASSA, 100, CONECUH

HEATI, HENRY OLIYA-Tenn.I,'06 ; $\left(I^{\prime} 06\right)$.
OXFORD, I,090, CALHOUN

lulgon, Arthur W.-Tenn.5,'84; (l'04).

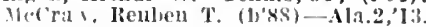

RELVES, THOS. BDWIN (b'76)-Tenn.1, 06 ; $\left(1^{\prime} 06\right)$

WILIIAMS, MARK JOHNSON€-Ala.4,02 ; (1'02).

OXMOOR, 556, JEFFERSON

lield. Janies (b'83)-Aln.2,'I2; (1'12).

OZARK, 2,229, DALE

AlB), Dillastu' BYRON (b'61)—Tenn.5,'8t;

BELL). SEABORN BENTLY - Ga.9,92 ; (1'05) ; R.F.b.

Coleman, IBenj. Franklin-N.Y.5.69; (1'75). CO'TER, WM. AlRNICE (b's2) \&-Ky.2,09; (1'I0).

CCLLEXS, FRED. BACON (b'63)- -0 ; (1'97); G

GObWIN, WM. F. (b'84)-Ala.2,09; (l'09). GRAlE, M.LCOY OZRO (b'84)-Temn.5, , 09 ; ( 1 ' I 0$)$

HOLMAN, IIENDERSON LOONEY (b'74)Tenn.s, $98 ;\left(l^{\prime} 98\right)$

MISON, DANI. PORTER (b'80)-Ga.11, 02; (1'02); R.F.D.

REYNOLDS, JOIIN LEONARD-Ala.2,07 ; (1'07).

Reynolds, Robt. Davis-Ali.2,80; (l'87).

REYNOLIS, ROH'. DAVIS, JR.-Ala.2,05 ; $(105)$.

PAINTER, 25, DEKALB

ISBELL, Al'THUR L. (b'83)-Ala.4,'12; (1'13).

PAINT ROCK, 534, JACKSON

CLARK, JOHN FRANKLIN (b'80)Ð-Ala.2,

Sherrill, J. Homer (b'r'4)-Tenn.9,'04; (1'03)

PANOLA, 190, SUMTER

Young, Robt. Lee (b'62)-Ala.2,89; (1'87).

PANSEY, 106, HOUSTON

SANDLIN, E. G.-Tenn.5,07; (1'06).

PARRISH, I0, WALKER

BUSBY, STEPHEN SAMIPSON (b'79)Ala.4, 08 ; (l'08)

ODOM, JAMES IVAN (b'72)-Tenn.8,'98 : (1'95).

PATSBURG, 150, CRENSHAW

DONOVAN, HARRY ARTIIURÐ-KY.2,07 ; $\left(I^{\prime} 0 T\right)$.

PATTON, 300. WALKER

CIILTON, DAVID H. (b,76)థ-Ga.11,02 ; $\left(1^{\prime} 02\right)$.

PEADRO, 25, BALDWIN

VAN IDERSTINE, REGINALD.

(See Loxley.)

PELL CITY, 530, ST, CLAIR

MARTIN, ROBT. A.- -Tenn.5, $01 ;\left(1^{\prime} 01\right)$.

PENNINGTON, 165, CHOCTAW

CHRISTOPHER, JOHN CHILDS (b'65)-

KY.4,'94; (1'94).

JAMES, A'SILEY DARIING (b'76)-Ala.2, 01; (1'01).

PERA (R.F.D., KINGSTON), I20, GENEVA JAY, JOHN I). (b'42) $-\triangle$; (1'96).

PERDIDO STATION, 75, BALDWIN

McKinley, Chas. F. (b'82)-Ala.2,'07; (1'07).

PERDUE HILL, 282, MONROE

Broughton, Wm. Edward (b'89)-Ky.2,'10 ;

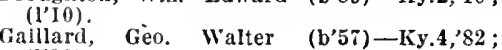
(1'S2).

PEROTE, 195, BULLOCK

THOMASON, JAMES IVILEY (b'80)-Ala.2, 'I0; (1'I1).

PERRYVILLE, 100, PERRY

FULLER, EMMET LEE-Ala.2, 00 ; (1'01).

PETERMAN, 50, MONROE

NETTLES, DANL. R. $4-A l a .2,01$; (l'01). NETTLES, ROBBINS (b'88) - Ala.2,'i1; (1'I2).

PETREY, 200, CRENSHAW

ABERCROMBIE, HENRY S. $\diamond$; (1'98).

PHIL. CAMPBELL, 60, FRANKLIN

UNDERWOOD, NAOMA PRICE (b'82)Tenn.9,06; (l'06).

UNDERWOOD, OSCAR 0. (b'80)-Tenn.9, 04; $\left(1^{\prime} 04\right)$.

PHIPPS, 25, HALE

TIDAORE, DODSON WRIGHT-Tenn.II, '99; (1'99).
PHOENIX, 4,555, LEE

Fioyd. Asliby (b'66)-La.1,92; (1'95).

Tillery, Bert (b'88)-La.1.'11; (1'11).

WATKiNS, RICHARD S., JR. (b'59)-Tenn.5, '81; (1†).

PICKENSVILLE, 214, PICKENS

GASS, WM. DAVID-Ala.4,99; (l'99).

PIEDMONT, 2,226, CALHOUN

KINABREW, WM. HENRY - N.Y.5, 73; (l'83).

(1'96).

Sparks, Horace 0.-Ga.11, 02 ; $\left(1^{\prime} 02\right)$.

Teaque, Frank 13. (b'52) - Telin.6,'80; $\left(l^{\prime} 80\right)$.

VAN SANT, J. W. $\rightarrow$; (l'06).

PIGEON CREEK, - , BUTLER

Jernigan, Robt. Lewis (b'89)-Tenn.8,'13 ; (1'13).

JORnAN, JAMES S. (b'8I)-Teun.8,'12 ; (1'I2).

PIKE ROAD, 100, MONTGOMERY

llerlwether, Thomas, Jr. (b'84)--Ala.2,09 ; (l'I0).

RUSMING, THOMAS ELBERT-Ala.2,'90;

PINCKARD, 54I, DALE

CARY, REIUS G. (b'71)-Ky.1,97; (1'09).

PINE APPLE, 627, WILCOX

DONALD, ERSKINE GRIER - Ala.2,93 ;

DONALD, JAMES GLENN (b'79)-Ala.2, $01 ;\left(l^{\prime} 01\right) ; \mathrm{G}$

RAMSEY, DÁYID W.-La.1,70; (1'78).

IOBERTS, JAMES W. (b'74) $₫$-'Tenn.8, 07 ; (1'0i).

Watkins, Clarence Cleveland (b'85)-Ala.2, II ; (1'11).

WATŚN, B. WALNE (b'66)-La.1,'86 ; $\left(l^{\prime} 86\right)$.

PINE HILL, 470, WILCOX

GODBOLD, PERCY ELLIS (b'79)-Ga.11, ,02; (1'02).

LEE, JOHN ANDREW (b'53)-Tenn.5,'87; ( (l'9i).

MAYO, L. H.-Ala.2,06: (l'06).

PINE LEVEL, 250, MONTGOMERY

BROACH, NORMAN LESLIE (b'81) (3) Ga.12,'09; (1'03).

PITTS, ÁthaNasius MARCELLUS Tenn.6,98; (1'0I) ; R.F.D.

PINSON, 45, JEFFERSON

BRANYON, ARTIIUR C. (b'82)-Tenn.8, 03; (1,03)

LOVE, JOHN-Ala.2, 00 ; (l'06).

PIPER, 2,000, BIBB

JENKINS, JOHN FELIX (b'75)(4-Ala.2,'01 ;

(1'02).

PISGAH, 65, JACKSON

Hlays, Geo. 'T.-Ga.5,'88; (l'87).

PITTSVIEW, 150, RUSSELL

JOINER, WM. THOS.-Ga.5,91; (1'91).

PLANTERSVILLE, 150, DALLAS

MARTIN, THOS. M. (b'73)-Tenn.5,'99; (l'99).

McArthur, Andrew Patterson (b'62)-Ala.2, $85 ;(1,85)$.

WALLACE, ARCHIE D. (b'77)-Tenn.8,07; (1'0i).

PLATEAU, 200, MOBILE

CANTHON, EDLY WILKERSON (b'74)Ala.2,08; (1'08).

PLEASANT HILL, 500, DALLAS

HARRELL, WM. SOMERVILLE (b'81)La.I,'04; (l'04).

RIG(iS, WATT SAML.-MId.3,'93; (1'93).

PLEASANT SITE (BELGREEN P.0.), 65, FRAN KLIN

THORN, JAMES AARON-Ala.2,03; (1'02).

Underwood Floyd Richard $\left(b^{\prime} 90\right)$ - Ala.4

'12; (1'I2).

POINT CLEAR, 43I, BALDWIN

SCHOWALTER, VOLNEY MeR. (b'68)(Ala.2,'90; $\left(l^{\prime} 90\right)$; $S$.

POLLARD, 599, ESCAMBIA

FINLAY, DAVID HUME (b'75)Ð-Ala.2, ROSE, JOS,

PONDVILLE (R.F.D., CENTERVILLE), 20 , BIBB

KROUT, CHAS. F.-Ala.2,'95; (1'95). 
PORTER, 125, JEFFERSON

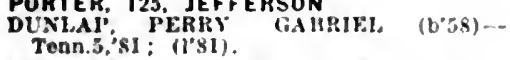

PORTERSVILLE. 150, DEKALB

Bush, Geo. Volney-6ia.10;(10; $(1 \cdot 99)$; R.F.1).

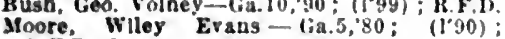

R.F.D. 1.

PORTLAND, 80, DALLAS

BOYKIX. SAMI. SWIYT (b'68)-Ala,2,96; (1'9s).

POWDERLY (R.F.D., BIRMINGHAM), 300. JEFFERSON

Hayes, Wm. Isaac-Rin.10,95; (1).

Wilks, Antrun EvWand- dia.t.04; $\left(1^{\circ} 09\right) ; \mathbf{s}$.

PRAIRIEVILLE, 100, haLe

BHOWDH: WM. M. - ''a.2.8S; (1'85)

Dugzar, Heubea IIenry (b'3i)-l'a.l,'ss (1'78).

STAPLES, JAMES G.-KY.2,01: (1'01).

PRATT CITY, 3.600, JEFFERSON

Baldwin, L. W. (col.) - Tenn. î, 0t: (l'0t)

BONDS, JOHX NERLITIL-Tenn. ,"60; (1'06)

BROW: Gro. WASHINGTON (b'48)

Ga.5; ; : $(1 \cdot \pi)$.

Cale, Charney (b;5)-Tenn.8,04; (1'05).

CARROWAT, CHAS. IEWTON-Ala.4, 02 (1'02).

Edwards, A. Jos (b'si)-Ala.t,12; (1'13).

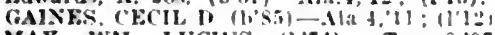

MAY WM. LCCLS (bit)-Tenn.si

MeGHHEE, HENAY THOS. $(1 ; 5)-$ Na.2. 04: (1.04)

SEAY, SAML. CLEVELAND (b'S4)-Pa.2 08: $\left(10^{\circ} 08\right)$

Stakg, John Bell (b'60)-Tenn. 5.85; (1'85)

Weltorn, M. D. (col.)-Tenn. , of; (1'01)

Whorton, Win. Waller-Tenn.s;99; (100).

PRATtVILLE, 2.222. AUTAUga

GOLSOS. ROET. NARION (b'65)-Tenn.G. $91:(1994)$

RICE. CLARENCE (b'68)-Nla.2,'95; (1'95) MITY, MALCOLM DANL. - X.Y.5,91 (I'BI).

TAYLOR, GEO. MALCOLY-Ga.11,05: (1'05).

Thomas, E. M-Nd.3.07; (1'0I).

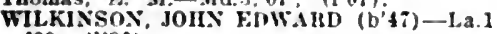
$69:(1+80)$.

WLKIXSON, JOHN F.DWARD, JH. $(6 ; 8) \uparrow$

-Tenn.1i,00; (1'00).

PRINCETON, 70, JACKSON

ROBERTSON, WY. HAHEY-O; (1'08)

PUSHMATAHA, 100 , CHOCTAW

Ilom, Edward G.-Ky.1.01: (1'01)

PUTNAM, 49, MARENGO

Gillespie, Hubi. Clanton-Ky.4.83; $\left(1^{\prime} 90\right)$.

PYRITON. 200, CLAY

CAMPREIL. WI. A.D: (1t).

QUINTON. 100. WALKER

AUXYORD, FilANK 0 . (b'i])-Ga.5, 93 ; (1'95).

Hancoek, Meda Waller (1,'s3)-Tenn. 11,08:

(l'09): not in practice; $R$ k.l. 1 .

Ilerson, ('yude Thos. (h'8s) - Nla.2,'11 (1'11).

Sparks, Darjd Hoyt (b'\$9)-La.1, 12: (1'13)

RAGLAND, 483. ST. CLAIR

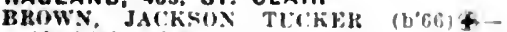
Ala. $4: 97$ : (1"9\$)

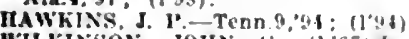

MIJkIssox, Jolls li. (b6i) - Tenn 6 02: $\left(1^{\circ} 02\right)$.

RALPH. 50, TUSCALOOSA

HAMINEB, SAML. COLTMHT'S (bis)

Ala. 2,09: (I')

TAYLOR, WM. TH(1.,-NIa 2.93; (193).

RAMER, 300, MONTCOMERY

ATIEY, CIANTUN BAY $(1,80)$. Na.2:10

COWIITS,

A. [1. (b'80)-1la.2.11; 11211)

RANDOLPH, 350, BIBB

Plekerlng, Alfrel Iturl (b'e6)--sh 2.11 (1'11).

Woolles. Chas. Iewls-s: $(109)$

RED BAY, 472, FRANKLIN

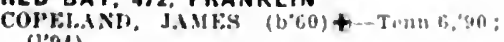
(l'gs).

COPki,ANn, oscall-Tern g.R2: (1'ss) (1'93).
RED LEVEL, 317, COVINGTON

FAL,YI, JAHES It--1la.2.91: (1'91),

SMTH. WM. It-\$1a.2.8B: (1'se)

TERRY, JAMES EOWAH) (U'T)-AIA.". os:; (102).

REELTOWN (R.F.D., NOTASULGA), MACON

JOIINSOX, WM. SAML. (b'8:)-Tenm. Iy,']1 (1'i1).

REFORM. 550. PICKENS

WOHOS. WAITYIl LEF-Ala 2.06: (l'06)

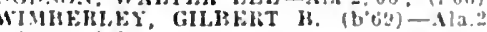
998: (1.92).

RENFROE. 85. TALLADEGA

SIMS JAMES ANTUNY - TER.1.0: : (l'0i).

REPTON, 33I, CONECUH

KLILLY, KIINALD LAMAT - Ita.2,00 (1'05):

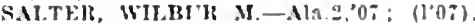

REPUBLIC, 350, JEFFERSON

Bacles, James Alfred $\left(b^{\prime}-s\right)-A l a .4,03$; (1?03).

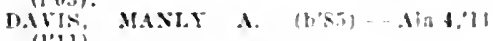
(1'11).

RICKEY, 60. TUSCALOOSA

IIARRIS, ELIBERT N. (b'S0) - Ala.4,0T; (1'07).

RIDERVILLE, 500. CHILTON

RIDERVILLE 500, CHILYON

SENTEFF, LOUIS IIENRY (b'\%9) Ala.2,

04: (1.04).

RIPLEY, 150, LIMESTONE

Hindman, wasld S.-Tenn.s.(13; (l'0i): R.F.D.

RIVER FALLS, 760, COVINGTON

kirklln, Marlon dugustus (bns)-Na" 13; (1'13)

I'EARSON, W. WHATLEY-Ala.2.99; (101).

RIVERSIDE, 277, ST. CLAIR

Roherson, lohn T.-Nla.4:03; (l'03).

RIVERTON. 63, COLBERT

HCWIORTER, CEO. TH,CHMIIS (H+9)$0:(1, Q 1)$

RIVER VIEW, 200, CHAMBERS

IIodzes, Wyati T.-Ala.2,'92: (1'9i).

ROANOKE, 2,034. RANDOLPH

MISHAROOX, HESIL BEAIREAARDIJ 3,$85 ;(1 \cdot 85)$. Floyl, wit. Girsos (b.52)-Mll.1.78; (1192).

InOPER, JnIIx wH-1'x.2:84: (l'st)

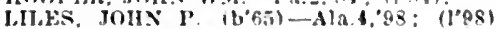

STEYHSON, WM. WORTII - Ala.2,03 (1) 031 .

STRIILI, JoIN THos, (b't1)-Ga.l,99: (1)99)

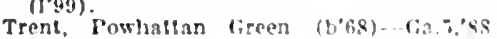

wooth FRANk RICH.IRD-Tenn 9,01 (100); R.F.D.

ROBA. 100, MACON

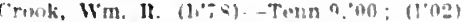

POBERTSDALE, 300, BALDWIN

ABMSTHAN. SYINEY D.IVIISON (bos) -110.2.10; 11111 .

ROBINSON SPRINGS (R.F.D.. ELMORE), 70. ELMORE

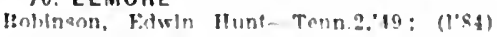

ROCKFORD, 600, COOSA

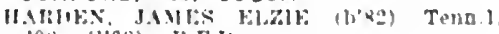
on: $(1,00):$ It F I1

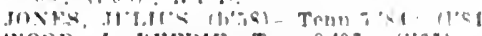

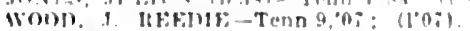

ROCK MILLS. 319, RAN DOLPH

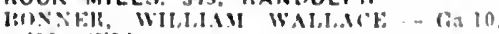

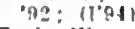

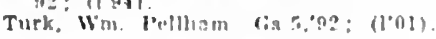

ROCK RUN, 3GO, CHEROKCE

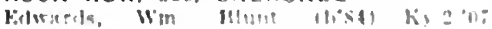
(10i).

ROCK SPRINGS. 20. ETOWAH

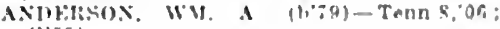
(l) 051

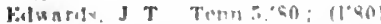

ROGERSVILLE, 150, LAUDERDALE

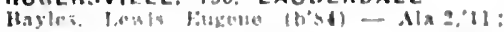
$(1.11)$

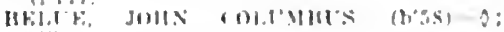

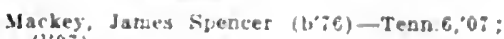
$1120 ; 1$

Pate, Jesse Amerlcus - Ky a.'os: (1'8i).

Wearer, I. A. $\rightarrow$ : (l'm): ILo! in uractsce. ROUND MOUNTAIN, 2I0, CHEROKEE Jirow?. Nexanter It

ROY. 4\$2, MONROE

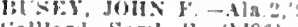

lialliarl saml s. (b.96)

bu Uency

MCMILIAN, SAML. H-tia.11,0:: (1'02)

ROYAL, (R.F.D., BLOUNTSVILLE), 24.

BLOUNT

Hellenger, J. $\mathrm{F}-\mathrm{A}$ : (1'\%:)

RUSSELLVILLE, 2,046, FRANKLIN

CI.ARK, WM. JOSIAII (h'e9)-Ala.4,"95: (1'\$6).

Ct.XkKE, JollX k., st.-Tenn 1,"36; (1'88)

('LERE, WM. W. $\left(\mathrm{b}^{\circ}, 2\right)$-Tenn.5.82: (1'88)

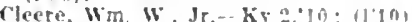

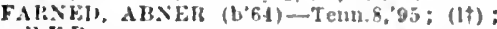
IR.F.n.

GRYSIIM, WAITER ASA (L"-7)-Tenn.5. $00 ; 1100$

II.JRKIS, FilJAII MeCII.LOGH (b'62)+ Tenn.., si: (1's:) : R.F.I. s

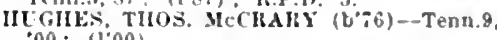
$00:(1,00)$

HUGHES, IFY, PORTFR-Ky.1."96: (1'05). CXDFRIOAI, NISIROD T. (b'61) \&-Ala?. S8; (1'88).

RUTLEDGE, 230. CRENSHAW

IORN RICIIARD KERSEY - Ga.9, 81 : (1'Bi).

SAFFORD, 150, DALLAS

leques, Chas. Ires-I.a.1,93; (1'96).

SAGINAW, 200, SHELBY

PAYNF, TIIOS. II.-Nla.2,'96: (1'96).

SALCO. - MOBILE

LITTIF, OTIS W. (1)*a)-Ky.2,'1l: (1'11).

SALEM. 350, LEE

MCLAIX, ANDRFW D.-Ala.2,0I: (l'01).

SALITPA, 31, CLARKE

AMMISTLAD, JOIIN I. (b'83)-Md.9.09: (l'0s).

FLEMINi, נОН: w. (b'+9) - Ala.2,79; (1'84).

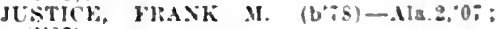
(1.0\%).

SAMANTHA, 2\%, TUSCALOOSA

NOILIS, JGIIS NATHAX (b't)-Tenn.I. 09: (109).

SAMSON, 1,350, GENEVA

BHIAND, W.I, IXDREW (10"5s)-Ga.10,'s: : (l'st)

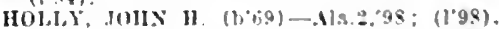

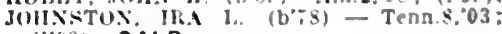
(10(13) : OALR.

LFWIS. BNEJ. JEFYERSON (b'it)-Ala. $99:(1 \% 90)$.

Malone, Fugene r. (h'it)-Ala.2.92: 11'91)

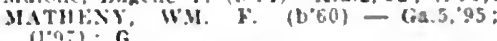

RIVFHAIK, JUKSON J. - (;.9:9\%:

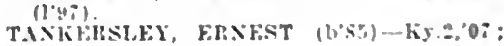
$\left(I^{\circ} 0^{-}\right)$.

SANFORD, I 2 , COVINGTON

NIX. (iF, r.-Te"x.2,"01: (1"S4)

SARAGOSSA. 100, WALKER

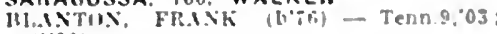
(i०06).

SARDIS, 25, DALLAS

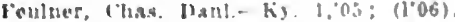

SAWYERVILLE. 200, HALE

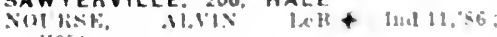

AYRE, 300, JEFFERSON

I.ITYI, SOO JEFFERSON (1) 0.51 .

SCOTISBORO. 1,019, JACKSON

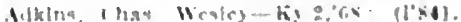

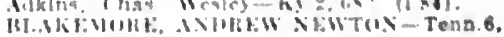

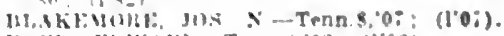

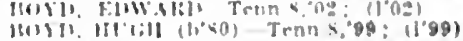

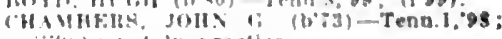
il:un! lint ln braclice.

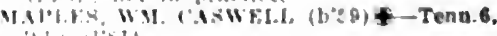


SEALE, 312, RUSSELL

H.('INY, HCHAlW HENNETT (b'S6) (:11.12,11; (1'11)

I'HATIFE, WM. BITISER (b'4i) \& (ia.5, - i. (loss).

SEARIGHT, I20, CRENSHAW

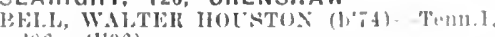
W6: (1'06).

SEARLES, 700, TUSCALOOSA

lighn, Clarence Eugene (b\%) Tenul, 05 ; $(1,0 \%)$.

\section{SECTION, 250, JACKSON}

Nerord, John Hirrey- (I's?)

SIITH, EITHEE WOBISETT $(1,43)$ Tinn,1, 'ti:; (l'00)

SELFVILLE, 13, BLOUNT

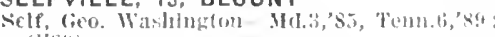
(I's!).

SELLERS, - MONTGOMERY

Garreft, Hichard II. J. (b'80)-YH(1.9, '02; $\left(1^{3} 0: 2\right)$.

SELMA, 13,649, DALLAS

Archer, IIlam lihan (col.) (b'ĩo)-Tenn.ï, 08; layue tniversity.

Powen, Wm. (col.) (b'76) - N.C.3,10; (I'II) : I9 Franklin st.

Burwell, Incoln Latconia (col.) - N.C.3, 89 ; (l's9).

CALLOWAY, ELGEXE (b'83)-N.Y.19, 05 ; (l'10); 706 bathas Are.; ofllce, Alabama Are. and (')urch st. ; 9 - 1 .

('HAI'MAN, JOHN THOS. (b'63)-Ala.2.

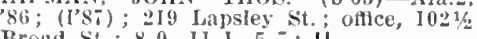
Broand St.; $8-9,11-1,5-7 ; U$

('HINOLA, JAMEs NATTERFIFLI) (b'so) -Lal. l, 05 ; (l'06i); tist IIabry St. ; offlce,

Cowart, Win. II,-Ky.2,05; (1'05); not in

W IBOSE, FRAXCIS GOONWIN (1);3) Ia.1,"93; (1'43); 400 Laiuderdale st. oflle, 902 Alabama Ave. ; 1:230-1; S.

ELEBASH, CUARENCE COLCII (b'88)La.1.'09; (I'11); 515 Selma Are.; olftce, 902 Alabama Are.; $9-10$, I2-2; I.

CRISS, JOIN NEHLSON $\left(b^{\prime}, 9\right) \notin-V a .1$, St.; ofture, I06 jiluderdale sit. ; I1-2; $\mathrm{S}$.

GAY, SAHL. GILBERT (b'64)૯-Ala.2,'87 (I'si); 1217 Alabama St.; offlee, 1006 Broad St. ; $12-2$.

GROYES, JÓs, ASBLRY (b'30)-S.C.1,'54 (1'78); not in practice; 402 Enlon St.

HARIER, WI. WADE (b'68) \&-La.1,91 (l'91); $131 \mathrm{~S}$ Parkman St.; offlce, 120 Iroad St.: 12-2:30.

HOWARD, THOS. GREENWOOD-Md.2,'68; (1'78); 642 Mlabry St.; offlce, 928 Broad St. ; $12: 30-2$

JONES, JEE (b'8I)-Va.1,09; (1'10); 525 Lamar St.; 12-2; D.

KFNAN, JASIES (b'76)-Ya.1,97; (l'04) 209 Washington St.; offlce, 120 Broad St. ; $12-2 ; \mathrm{S}$

K1SG, GOLDSBY \& - S.C.I,'80; (l's0): King's Sanatorium.

KIRKPATRICK, SAML. (b'65) †-Tenn.5 '88; (I'88); 610 Broad St.; office, 902 Ilabamal Are.: 4-1; (BI): ÓALR.

LOCKHART, THOS. ERNEST - LA.1,90 (l'90). Th. T,'90 Moorer, John Wesley (col.) - Tenn.7,'99; PHIJJIPS, WHLLAM CRAWFORD - LA.1,

'ULLEX, CLARENCE JOS. (b'74) $\rightarrow$ (l'05); 813 (ireen st.; office, 91 I $1 \frac{1}{2}$ Broad St. ; $1-3$.

ROGAX, B.IRXEY BURXS (b'75) $\$-$ Tenn.9 '96: (1'96); 406 Church st.; office, 1010 Alabama dre. SKINNER, IIA CLIFTOA (b'78)-Ala.4,
'0I; (l'01); 612 Alabama Ave; oflice, 01; (l'01); 612 Alabama Are.; offlee, 231 Broad St.; 12-2.

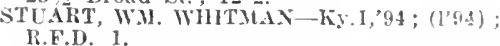
WAIR, EDWARI) BIRTON (be0)-N.Y. 's?; (1'82); 610 selma st.; offlee, Broad and Selma Sts.; 12-2.

SHEFFIELD, 4,865, COLBERT

BLAIR, HLCH WALTER (b'62)-Tenu.5, BHAK, WYAT'T HEFLIN†-Tenn.5,'S?; EYAX', IBOLAND CURTIS (b'75)-Tenn.II 0.5: (['11:5); OALR.
MAYWRL, WALTER JOIIX-Tenn.11,01; $\left(1^{+} 0_{2}^{\prime 2}\right) ; \mathbf{O b}$.

SHELBY, 1,000, SHELBY

IBAIINON, JAMES LUCIAN-KYY.1,00; (l'00)

SHORT CREEK, 150, JEFFERSON

Vhus, J. B. $\rightarrow$; (1†).

SHORTER, 500, MACON

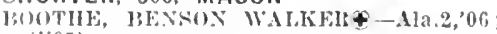
(1'05)

LET'HFH, FHAXCIS MARIOX-Ta.1, '6t;

SIKESVILLE (R.F.D., ALMOND), 50, CLAY

KILAGORE, IAMEA J.-Tenn.8,01; (1'01).

SILAS, 50. CHOCTAW

TANI.FY IOS. MONROE (b'8i)-Tenn.6, Thtor. $\mathrm{F}$

SILURIA, 100, SHELBY

Morris. llarry Rembert (b'84)-Temm.1,06; (I00)

SILVERRUN, (JENIFER P.0.), 48, TALLA. DEGA

Railey, Robt. M.-Cia.5,'66; (l'86)

('T)THRIF, NAMETTE II. (b'83)-Tenn.5, $05 ;\left(l^{\prime} 05\right)$.

SIMCOE (R.F.D., CULLMAN), 20, CULL. MAN

BHINDIEY, BETHEA P.-Ga.9,'92; (l'92).

SIX MILE (R.F.D., ASHBY), 50, BIBB

BINTIN, WM. PATTLE (b'-3) $₫$-Tenn.8, $00 ;(1,0 \mathrm{~s})$.

SKINNERTON, 12, CONECUH

JAILEY, JOHN J.-Ala.2,'06; (l'06).

SKIPPERVILLE, 92, DALE

MIXSON, WM. HANL. (b'70)-Tenn.9,'98; (l'98); R.F.D.

SLOCOMB, 896, GENEVA

CIIALKER, WM. YOUNCE (b'T0) $\Longrightarrow$; (l'97).

balton, Christopler Columbus-Cia.9,'90; (l'90)

DOTCHTY, MORDECAI LDWAHD (b'5)Teun.9,'03; (1'03).

HEHHING, (iEO. H. (b'77)-Ga.9,98; (1'00).

SMITH, GORDON W. (b'69)-Ky.4, 92 ; (1'92).

SNEAD (R.F.D., ALTOONA), 75, BLOUNT ('opeland, Robert Ellis-Ala.2,"07; (l'07).

SNOWDOUN, 200, MONTGOMERY

(allowin, James Wesley-Tenn.5,'82; (1'82).

MASON, JOS. CJUUIP-N.Y.10,'81; (I'81).

SOCIETY HILL, 100, MACON

Mullin, Wm. IaaFayette-Ala.2,00 ; (1'04).

SOMERVILLE, 265, MORGAN

l'eck, Cleero Fain-Tenn.8,'90; $\left(1^{\prime} 90\right)$

RLSEEIL, THLS. JACKSOX (b'71)-Ala.2, 04; (l'04); (Woodland Jills); G.

SPEIGNER, 100, ELMORE

IIU1)DLESTOX, ROBT. J.EE - Ga.1,'80; (I'8?2).

SPFING GARDEN, 100, CHEROKEE

Fmerson, J. Forrest-Tenn.9.94; (1'98)

WIITE, THOS. NOEI-Ga.I, 60 ; (1'87).

SPRINGVALLEY (TUSCUMBIA P.O.), 100 , COLBERT

WALEL, PAYID HARRIS - Tenn.5,82 ; (1'81)

SPRINGVILLE, 350, ST. CLAIR

('ayton, Isonntar Marcus-Tenn.9,'0s; (l'08).

Martin, John How'urd - Nla.2,'93; (1'99).

SPROTT, 50, PERRY

I'IRYOK. ROBT. B. (b'79)-La.I,'05; (I'06) ; R.F.I). 2.

SPRUCE PINE, 65, FRANKLIN

PAR NES, THOMAS B. (1)'55)-Tenn.2,'73; (l'se)

TXNERWOON, ANUREW JACKSON-O (1"02).

SOUAW SHOALS, - TUSCALOOSA

loumans, William Forrest (b'-8) -S.C.1,06; (1'11).

ST. STEPHENS, 100, WASHINGTON

KIMBILOEGH, WM. E.-Ala.2,'83; (1'87).

STANDING ROCK, 300 , CHAMBERS

GREEN, EI,BEIT PIERCE - Ga.12,"99; (1'99); (Hickory Flat).

STANTON, 400, CHILTON

DuBose, J. J.-Ga.5,'95; (I'95).
STEELE, 100, ST. CLAIR

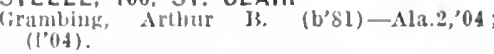

STE.RLING (R.F.D., BERRY), -, TUSCA-

LOOSA
Stubbs, Ji, II. $\rightarrow$; ( (†).

STEVENSON, 574, JACKSON

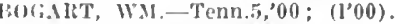

FosTEl, (iTo, WINTHEL (b'56) Tenn.5, $82 ;(1,82)$

GEXTIS, WAMLS A. (b'80)-Ala.2,05;

(1) (0).

PINCE, IHSSE I,EE (b*5)-Ala.2, 99 ;

RUSSFR, WAITER (b'T6)€-Tenn.5,'98; (l'02); (Anderson, Tenn.).

smurlers. Wilter ('- Tenn.8,90; (1'91).

STOCKTON, 943, BALDWIN

AlKIN, WM. (:. (b'64)-Ala.2,01; (t'01).

HASTIE, JOHN IIAMILTON (b'77) -Tenn.6, :98; (1'99)

IODGSON, PHILII MOJITON (b'65)-Ga.5, 89; (1'89).

STOUTS MOUNTAIN, 500, CULLMAN

¿OVETT, WM. JEFFEISÓN (b'87)-Ala.4, 09 ; (l'09).

STROUD, 100, CHAMBERS

Coleman, Jiram F.-Ga.10,'82; $(1 \dagger)$.

SUGGSVILLE, 336, CLARKE

AILIBERG, CHAS. ISAAC - Ala.2,'87; (I'S8).

SULLIGENT, 619, LAMAR

3T'CKELEW, JUDGE CRAYTON-Tenn.9, '98; (l'98).

Ilollis, Danl. Dlxle-0; (1'84).

JACKSON, JOHN A. (b'72) - Tenn.8,'99;

MOLJOY, JANL. Jíl'RRAH (b'82)-Tenn.1, RDDEN, RAYMOND HOLIIS (b'79)£Tenn.8,01: (1'01)

REDDEN, ROBT. JAMES $\left(b^{4} 48\right)-M d .2,72$; (l'7 7 ).

SUMMERFIELD, 383, DALLAS

CHISOLM, ROB'T. I'ATIICK $\left(b^{\prime} 70\right)-A l a .2$, '93; (1'93).

SUMMIT, 150 , BLOUNT

Haden, Andrew Wade-Tenn.5,'82; (1'82).

SUMTERVILLE, 300, SUMTER

IVRENN, W.I. JOS. (b'81) $4-A l a .2,08$; (l'08).

SUNFLOWER, 7, WASHINGTON

MCCRARY, GAINES C. (b'83)€-Aln.2,'07; (l'0i).

SUNNY SOUTH, 125, WILCOX "08; (1'09).

SWANN (R.F.D., ALMOND), 20, RAN-

Jordan, Chas. Alexander-Ga.10,'84; (1'87)

SWEET WATER, 75, MARENGO

JONES, JAMES D. (b'66)-Ky.1,'93; (1'94).

SYCAMORE, 500, TALLADEGA

HANULET, JOHN 0.-Tenn. 8,04; (l'04)

SYLACAUGA, 1,456, TALLADEGA

BIANNON, WADE HAMPTON, JR. (b'87) -Ala.4,10; (1'10).

CASTIEIAN, HOWELL L. (b'71)屯-

Temm.II,0l: (l'01).

CONAWAY, IIAGNG ElJ (b'68)-Tenn.1, 88 ; (1'88)

CRADDOCK, FELIX HOOD $\left(\mathrm{b}^{\prime} 66\right) \oplus-$

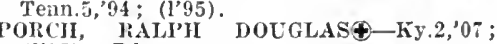
(l'0i); Pd.

PRUET, MADISON JASPER (b'69) Tenn.8,96; (l'96).

SORREL, WM. HENRY $\rightarrow$; (1'86).

stewman, William T. (b'53)-0; R.F.D. 3.

TAIRANT, JAMES RHCHARD (b'6L)Nla.2.87; (1'87)

SYLVANIA, 19, DEKALB

CIAYTON, OLNEY WAJKER (b'75)甲Tenn.9, 07 ; $\left(\mathrm{I}^{\prime} 0 \mathrm{~T}\right)$.

Weathington, L.ee (b'88)-Ala.2,'13; (l'13).

TAFF, 25, CHEROKEE

STONE, LEONARD RICE - Tenn.9,05; (1'05)

TALLADEGA, 5,854, TALLADEGA

BOYD, FREVK. WM1-Ala.2,'06; (1'06).

Brothers, W. H. (b'82)-Tenn.7,08; (l'08).

Brunmit, W. H. (col.)-Tenn. 7,$04 ;\left(\mathrm{l}^{\prime} 04\right)$. 
BIRT, WM ELLERT La 1.00 ; (1.05): U Casod, latis Elayolb: - Tents, (1):-isi.

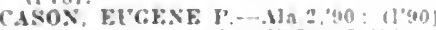

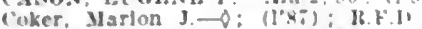

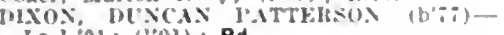
[.a. 1,01: (1'01): Pd.

HARIRISO JOHIX TISSIRL - GA.5,81; (1's6); not in practlce.

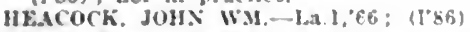

Jonea, Filisha llenry (b'83)-Tenn.14,09: (1'09)

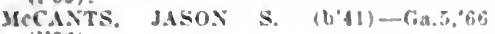
(l's6).

MCLLIN THOS KYOX $\rightarrow$; $(198)$

YORTHE: CHAS. STEPHEX (1)6i)-(ia.5 91: (1'91)

SALTER CLARESCE LAXGLE (U'S5)Ala. 2,"11 : (1']1).

SIMMS, BE.N. BRITT (b.59)--1'a.2.85 (1'\$6).

WARWICK, BISHOP B. (b'79)+LA.1,02 (1'02).

WEI,CH, SAML WALLACE (b'61)\$Wren. Edward Balley (b'bl)-Ala.2,'90 (1'90)

TALLADEGA SPRINGS, 50, TALLAOEGA GRIMES, JOHX WALTER (b'68)-Tenn.11,

woon, "1sade D. (b'i4)-Tenn.11,01 (1002).

TALLASSEE, 1,347, ELMORE

Dorough. John W'm.-Ga.5,94: (1'94).

GLLLIDGE, JESSE $\left.\left(b^{\prime}, 3\right)-\mathrm{Ala} .2,00 ;(1)^{\prime} 00\right)$.

Warren, Timothy DeWlut (b'8,)-Ga.11,09; (1"10): Pd.

Weldon, Jos. H. (b'89)-N1a.2.'13; (1'13).

TAYLOR, 175, HOUSTON

BATES, IKBY ClYDE (b'Ss)-Mla.2,11; (1011).

TENSAW. 200, BALDWIN

Coghlan, Malachl (b'60)-Ala.2,"92: (1'92)

THARIN, 100. MONTGOMERY

Sankey. GeO. L. KY.4,'T6: $(1 ; 8)$.

THEODORE, 277, MOBILE

Havard, Hardy barld (b'sy) - Ala.2.'1l: (1'11)

Macer, Irobr. C.-Ala.2,8i; (l'8i).

THOMAS, 1.500. JEFFERSON

Cross, Thes, - : (1)

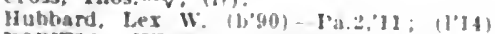
FOWELL, HENRI BLIOS (b'St)-.Ma.2 '10: $(1+10)$.

THOMASTON, 200, MARENGO

Frazler, AIfred S.-Tenn.5,'06: (l'06).

HANI, LESIE: MTHUY' (b's0)-Ky.9,04

HARKYLL. WM. B. K K.4,05: (1,05)

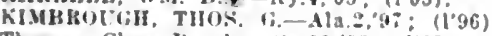

Thomas, Chas. Brooks-dia.10.83; (i.83).

THOMASVILLE, 1.181, CLARKE

DAVIDSON. JA. ESS S.-Ala.2.91; (1'93)

GILHOLE, JOHN AIRCALE-Ky.4's6:(1'86)

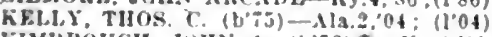

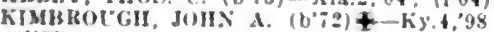

(1'98)

s.ow, Jomx Louts (b'68) - Ala.2.91

WHTE. ATKXANDER I. (b'66)-TenH.S . $98:(1.9 i)$

\section{THORSBY, 500, CHILTON}

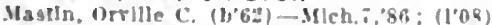

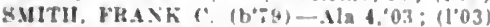

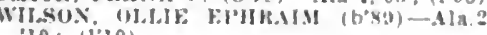
"10: (1'10).

TILL (R.F.D. GEORGIANA), 19, BUTLER

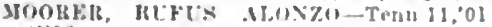
(1'0\%).

TINELA, 25, MONROE

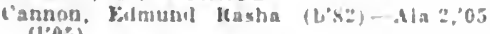
(1,0is).

TITUS, 25, ELMORE

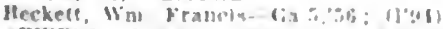

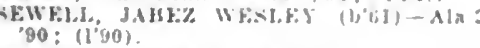

TOINETTE, 23, WASHINGTON

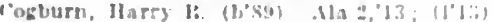

TONEY, 60. MADISON

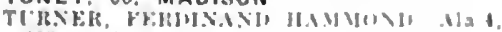
03 ; 18031 .
TOWN CREEK, 34\%. LAWRENCE

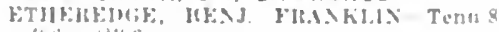

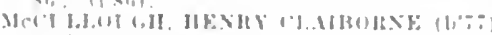
N1: $2005 ;(1,03)$

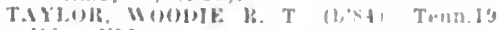
in: 17.101

TOWNLY, 235, WALKER

Henden, I l. $\dot{y}:$ (l)

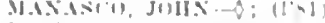

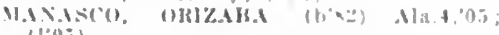

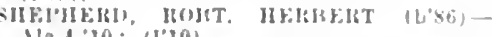
Ma.t, 10: (I'10).

TRIANA \{R.F.D., MADISON\}, 200, MADI. SON

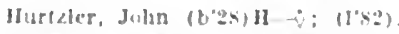

TRIMBLE (R.F.D., CULLMAN), 40, CULL. MAN

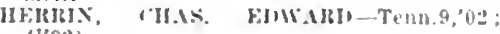
(l'0)

TRINITY, 198, MORGAN

BUEAS, FHATK-KY.5,98: (1'98).

EMF.AS, IS. A. (b'-9) - Ky.5,05; (1'05).

TROY, 4,96I, PIKE

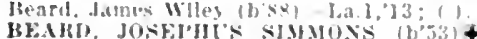

X.Y.5, $76:(1 \% 9) ; 0$ A A

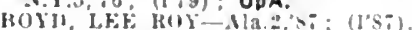

lirewer, Jarnes drals (col.) (bso)-X.C.3. $09:(109)$

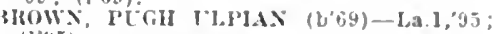

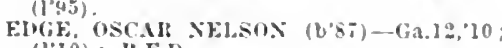
(1'Ii) : H.F.D.

FOKD, ELCHANA G.JUNER- ; (178).

Iunds, samb. Karford leot.) (boti Tenn.i, 0 r.

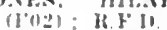

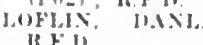

(b;:6) - .11a 2.01

SANIFRs. WM. B. (b'60)—-Ga.10,85:

SANIIERS, WM. SHELPY $\left(\mathrm{b}^{6} 68\right) £-$ Tenn.5. (4): (1)

STILLINGS, IOOMER SYLVANLS (b'it) 11. (l) Pd

Tenn.19.'11: (1)

This Tenn

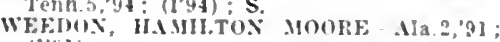
(1'91).

\section{TRUSSVILLE, 742, JEFFERSON}

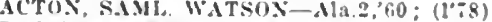
BURNCM, HESIY ('LIY-Md.3,92: (1"42).

TUNNEL SPRINGS, 150, MONROE

I.MISEY, FIEIDF. STHALFHA (b'6) Ala. 2,il: (I'Ti).

TURKEYTOWN (R.F.D., GAOSDEN), 33, ETOWAH

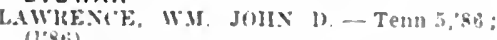
(1'Bti)

TUSCALOOSA, 8.407. TUSCALOOSA

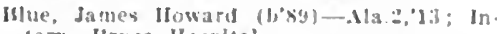
tem. Iiryce Jlaspltal.

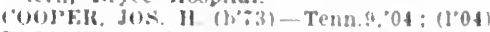

EILLUTT, JOS. BE.NJ. (b'80)-N/A.2,05:

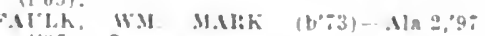

$(1,9): S$.

FITTS, U.STUN+-N 1 1.95: (I'00)

(H) $12:(112): s$.

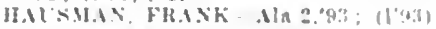

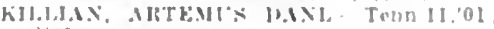
(lol)

it

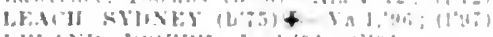

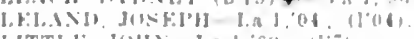

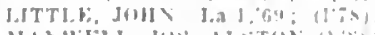

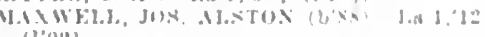
(1) $0: 11$

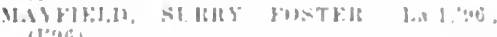
(1)

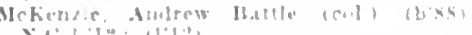

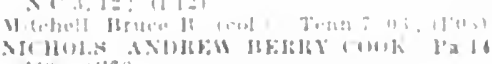

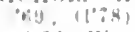

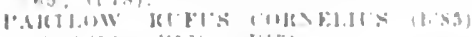
Nat 1:1:, (1.13); (1.13)

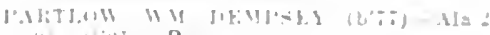

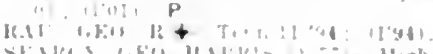

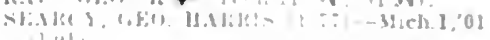

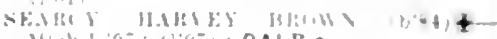

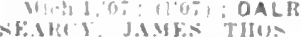

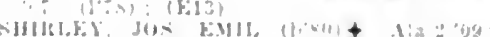

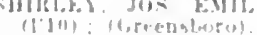

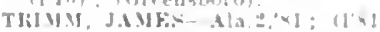

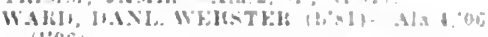
(1'ment)

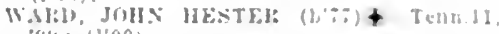

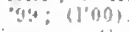

Neare, fied Aurustua (col) (b'o $10.1,30 ;(109 \times)$

WMLLAMSWS, JAMES L.EWIS - Ala Z,'G!: (1'yl).

TUSCUMBIA, 3,324, COLBERT

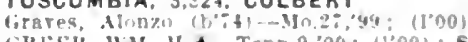

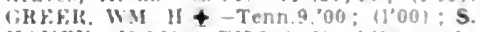

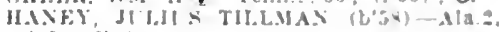
$31:(1, y=3)$

PALMEK. 'HAS. RI'HAHI (b"Ha)-Tenn 5.

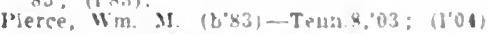
TUSKEGEE, 2,803, MACON

Howard, Hobr. Heary (b'86)-Ala :.11: (I)

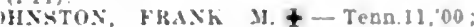
(1001).

JOHXSTUNE, holls War (b'6) Ala. $8: 1181)$

Kenney" John A. (ent.) (b'it)-X.c.3.01; MAlikt) $(1,90)$.

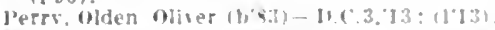

SMITI, MILTON MeliRATH - K) 4 : TAYlob, THOS, FRANRIS (L82)

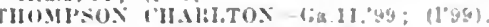

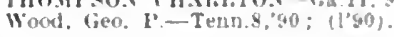

TYLER. 50, DALLAS

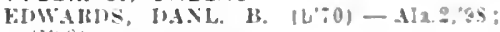
(1:48).

UNION, 100, GREENE

SMTI, THOS. II KY 1,94: (1':4)

UNION GROVE, I00, MARSHALL

BARNARL, WM. F. (b'A1) - Ala:205:

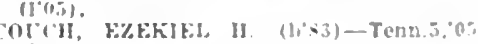
(1.05).

UNION SPRINGS, 4.055, BULLOCK

Mllen, Mex. lieo, Wm. (col), -Tenn i,gr: $(1,99)$

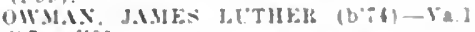

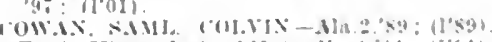

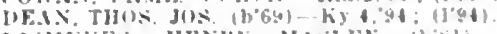

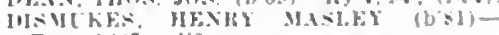
Tenn $6.00^{\circ}$ : 1109$)$.

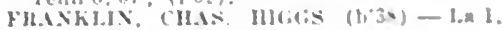

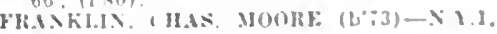
:48: (195)

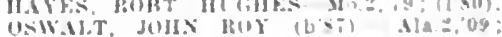

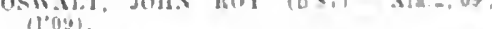
$(1002)$

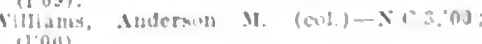

UNIONTOWN, 1.836, PERRY

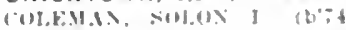

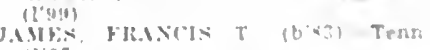

Fou. James kutus

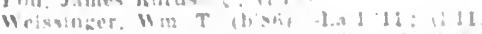

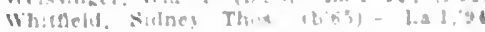

SALLEY HEAD, 233, DEKALB

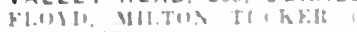

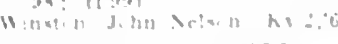

VANCE, 96, TLISCALOOSA

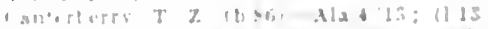

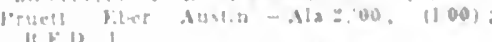
If le l l

VANGALE。-, MARENGO

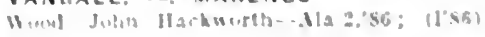


VERBENA, 400, CHILTON

BEIL, WAITER HOWARD (b'64)-Ga.5. $88:$ (I'89).

DOW

Tenn.1,'08; (1'10).

VERNON, 423, LAMAR

BOX, DANL. WILLIAMS (b'59)-Ala.2,'85: (I'85).

IORTON. DICK CAMERON (b'T0)-Tenn.8 $97 ;(1,97)$.

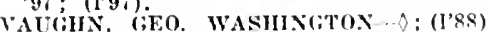
YOUNG, TILINEN H.(1)76)-La.1,03; (I'03). VETO. 75. LIMESTONE

WHITFIEID, THOS. ALFRED (b'86)Tenn.1,08; (llcensed Teuu.'07) ; Member Tenn State Med. Assn.

VICTORIA, I00, COFFEE

lsraswell. Wm. C. (b's0)-La.1,10: (I'09) Crock. Wm. Ilenry-Ala.2,'84; (l'85)

FoLSOM, IARION A.-Ala.2,'07; (I'07).

VIDA, 148, AUTAUGA

Campbell, Virgll 0.-Ala.4,97; (l'97).

VILLAGE SPRINGS, 20, BLOUNT

CLAYTON, BENJ. LAWRENCE-Tenn.5,'83 ; (l'82).

VINA, 400, FRANKLIN

ATWOOD, ABNER LOWE - Tenn.1,0 ' ; (l'07).

\section{VINCENT, 995, SHELBY}

Chandler, Edward Pendleton- - ; (l'79).

EMBRY, JAMES CARL-Ga.5, 89 ; (1'89).

VINEGAR BEND, 540, WASHINGTON

THOMPSON, W.I. A. (b'83)-Tenn.6,'04; (1'04).

VINEMONT, 100, CULLMAN

CORNELITS, IUTHER BARNETT (b'79) -Ala.4,12; (1'13); R.F.D. 1

HUMPHRJES, ROBT. D. (b'59)-Ca.9,'92 ;

(1'96): R.F.

WALIING, IOHN HENRY (b'40) $\rightarrow$; $\left(l^{\prime} 89\right)$.

WIIHITE, SIMEON M.-Tenn.8,'91; (l'91)

VREDENBURGH, - MONROE

Chapman, Ieiland Woodard (b'84)-Ala.2, '11; (1'11).

WADLEY, 426, RANDOLPH

CIARDY, ANDREW JACKSON (b'76)Tenn.9,00; (1'01).

Hodges, Wm. Arthur (b'84)-Ga.11,'13 (1'I3).

WELCH, CARL BELMONT (b'85)-Ga.11, ,06: (l'06).

WELĆI, JA IES M. (b'54)-Ga.10,'92; (l'92)

WALNUTGROVE, 204. ETOWAH

Iurst, James A.-Ala.2,'?0; (l'91)

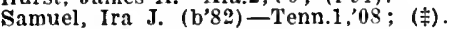

WALTER (R.F.D., CULLMAN), 50, CULL. MAN

Graf, Chas. C. (b'82)-Ala.4,'13; (l'13)

WARD, 30 , SUMTER

HALL, THOS. OWEN-Tenn.8,'06; (l'06)

WARRIOR, 660, JEFFERSON

COLLINS, EDGA R (b'84)-Ala.4,06; (l'06) FENNELL, IAWRENCE SHEFFIELD (b'74) -Ala.4; 10 ; (1'10).

MARTIN, WII. GRAVLEE (b'59)-Tenn.8, '93: (1'95).

McCARN, O. C.-Ala.4,07; (1'07).

IITCHELL ROBT LEE-Tenn 9,94: (l'95).

Young, Walter Baker-Ala.4,'01; (l'01).

WATERLOO, 435, LAUDERDALE

Desprez, Louis Willoughby, Jr. (b'91)Ifl.22,'13: (l'13).

LEE, JOHN WM. (b'52)-Ky.1,'90; (1'95).

POWERS, ALEXANDER HAMILTÓN-Ky.2, $71 ;(1 ' 95)$.

WATSON, JAMES ALEX. (b'74)-Ala.4,03; (l'03).

WATEROAK, 10, HALE

DAVIS, ANDREW RUFUS (b'5i)-Ga.10 '90:' (l'90).
WATSON, 1,000, JEFFERSON

GRESIAM, ANDREW BEITON-Ala.4,01 ; (I'01).

WAVERLY, 170 , LEE

COGiIN, FOUNT RANDELI, BOYD (b'7 $)$ Ala.2, 11 : (l'11).

HANSUN, WM. C.-Ga.5,'89; (1'89) ; R.F.D Meclendon, Jlenry L. (b'75)-Tenn.11,99; (l'00).

WEAVER, 350, CALHOUN

MEHARE; SIIELTOA THEODORE-Tenn.8, 00 ; $\left(10^{\prime} 00\right)$.

WEBB, 256, HOUSTON

Granger, Frank G. (b'90)-Ga.11,'12; (l'12). IIILSON, LEWIS T. (b'78) - Ga.11, 09 ; (l'09).

WEDOWEE, 435, RANDOLPH

likOSS, CIIAS. MONROE-Ala.2,08; (l'0s) IIOOD, JOS. ROBENTSON (b'33)-Ga.6,'57 (l'85).

MASIIBURN, FRED ROSS (b'83)-Ga.12, $10 ;(1212)$.

SWAN J, C.-Ga.5,90; (l'95).

Wligh', ColunBus B. (b'72)-Ga.5,'98; (I'98).

WEOGUFIKA, 200, COOSA

I'RUETT, JAMIES WW (b'67) - Ala.2,92 (1'92).

WEST BLOCTON, 892, BIBB

ALEXANDER, JAMES FRED. (b'71)'Tenn.5,'93; (1'93).

BLOOMER, WMI. (b'83)-Ala.4,03; (l'03) DAVIE, NUCKOLS THORNTON (b'87) La.1,09; (l'09).

IONES, CIYDE WHITE (b'87)-Ala.2,'12 (1'12)

PEACOCK, IOVICK EDWARD (b'70)Ala.2,'92; (l'92).

\section{WEST BUTLER, - CHOCTAW}

Rudder, Bryant Carr $\left(b^{\prime} 86\right)-T e n n .19, ' 11$; (l'll).

WEST END (STA. BIRMINGHAM P.O.) 一, JEFFERSON

SCHOOLAR, MILTON CARSON (b'62)N1a.2,87; (l'87)

Tann, Sidney J. (b'75)-Ga.1,00; (1'00).

WEST GREENE, 75, GREENE

STARKEY, LAKE LOUIS (b'76)-Ala.4,'02 ; (l'02).

WESTMORELAND (R.F.D., BETHEL, TENN.), 50, LIMESTONE

ESTES, DAVID G. (b'78)-Tenn.6,'01; $\left(l^{\prime} 01\right)$ Wilkinson, Thos, J. $\rightarrow$; (\$).

WETUMPKA, 1,103, ELMORE

AUSTIN, JAMES MAXWELI (b'79)-Ala.2, 04; (1'04).

Cook, Conrad E. (b'47)-La.1,73; (1†); R.F.D. 2.

FOWIER, JAMES THOS. (b'63)-S.C.1,'83; (1'83).

GAIBLE, WM, MEIVIN-Ky.4,'87; (l'87). MOON, ED. P. (b'76)-Tenn.5,98; (1'98).

RAY, JAMES WARE (b'79) $9-$ La.1, Ti; (I'n9).

SEWELL, NEIL BAKER-Tenn.5,'86; (1'86).

WHATLEY, 187, CLARKE

GODBOLD, JOHN COOPER, JR. (b'88)Ala.2,11; (I'11).

Shaw, Bobt. Eugene-Ala.2,'98; (1'99).

WHISTLER, 2,000, MOBILE

GAY, NATHANIEL SCALES $\left(b^{\prime} 77\right) \oplus$ Ala.2,00; (1'01).

Jones, Paul R-Tenn.5,'98; (l’98).

WHITEPLAINS (R.F.D., CHOCCOLOCCO), 202, CALHOUN

Williams, Cieo. Coke $\longrightarrow:\left(l^{\prime} 81\right)$.
WICKSBURG (R.F.D., NEWTON), 25, HOUSTON

FLOWERS, JAMES II.-Tex.4,'05; (1'06).

WILMER, 500. MOBILE

Jrewton, Wm. B.-Ala.2,00; (l'02).

WILSONVILLE, 933, SHELBY

BLACI, ORLANDO E. $\left(b^{3} 75\right)(-T e n n .1 I$, 00; (l'01).

Boyer, Jos. Buford-Ky.4,'92; (1'92).

SHOTHERS, BLANNELHASSETT H. (b'64) -Ala. 2,'85 ; (l'85).

WINFIELD, 419, MARION

Farnest, James Franklin (b'50) - ; (l'88).
Earnest, Warren Ilnwood - Tenn.8,04; (l'04).

IILl, HOBT. LEROY (b'80) Q-Tenn.8,05; (1'05).

IIOLLIS, MURRAY C. (b'84)-Tenn.8,08; ICCRA ITY, WM. JEFFERSON (b'62)-
Tenn.8,'93; (l'93).

WISE (R.F.D., LAFAYETTE), 10, CHAM-

ISON, JOSIAH ALLEN-Ga.10,87; (1'87).

WOMACK HILL, 50, CHOCTAW

I.ENOIR, THOS. R.-Ala.2,'91; (l'92).

WOODLAND MILLS (R.F.D., LACEY'S SPRINGS), 46, MORGAN

RUSSELL, THOS. JACKSON.

(See Somerville.)

WOODLAWN (STA., BIRMINGHAM P.O.), 一, JEFFERSON

BELL, ALSE WILSON (b'73)-Ala.2,'97 ;

COILLNS, THOS. (b'88)-Ala.4,'12 ; (l'13)

FARRAR, WM. CAAS. (b'79)-Ala.4,08: (l'08).

Heddleston, James Lawrence (b'31)-S.C.1 55 ; (1'88).

WOODSTOCK, 500, BIBB

MARTIN, CHAS PATRICK - Tenn.5,00; YY, JACOB USRY, JR. (b'64)-Tenn.6,'93 ; (1'93).

WOODVILLE, 800, JACKSON

McGahey, Jos. Jefferson- $\rightarrow$; $\left(1^{\prime} 86\right)$.

WOODWARD, 795, JEFFERSON

Brooks, Louis Porcher (b'84)-Tenn.11,07 ; (䒠).

Hays, Robt. Bartholomew (b'86)-Ala.4,'13 (l'13)

MeDonald, Chas. Wesley (b'67)-Tenn.1,04 (i'04)

WYLAM, 3,000, JEFFERSON

very, Wyatt H. (b'80)-Tenn.8,'12; (青)

Caldwell, Wm. Drayton-Tenn.5,'88: (1'88)

DAVIDSON, MARION TABB (b'87)థ-0.41, '11; (1'12)

IlcDiarmid, Thos. S. (b'84)-Ala.4,09; (l'10).

McDONALD, FREDK. WM.(-Ala.4,'05 (l'06).

MIller, Ira Lee (b'90)-Ill.22,'12; (l'13).

Miller, James Alfred (b'84)-Ill.22,'i3; ROUNTREE, WAITER $S$. (b'73)@-Ala.4 '00; (l'00).

YANTLEY, 25, CHOCTAW

Miller, Saml. T. (b'7T)-Ala.2,'01: (I'04) Phlllips, Jacob P.-Ala.2,'85; (1'86).

YOLANDE, 1,000 , TUSCALOOSA

CARPENTER, BURNEIL S. (b'82)-Ala.2, 05 ; (I'05).

YORK, 7IO, SUMTER

HALE, ROBT. HADDEN-Ky.4,'79; (1'80).

Knighton, Thos. A.-Ky.4,89; (l'90)

MeDANIEL, JOS. COLUMBUS (3-Ala.2,04 (l'04).

FOR KEY TO SPECIALTIES, ABBREVIATIONS, SYMBOLS, ETC., SEE PAGE 157 


\section{A RIZONA}

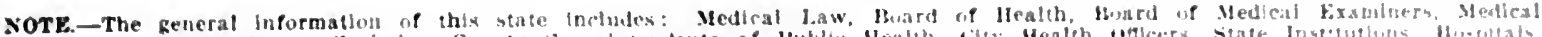

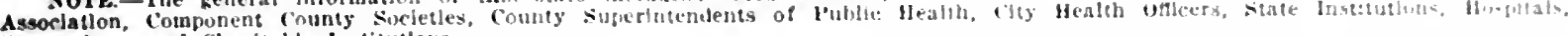
Sanatorlums and Charltable Institutlons.

\section{ARIZONA}

Population (1910 census)........204,354

Number of Countles. 14

Number of Physicians.

291

Mombers of Stale Association, Dec.

Area of State in Square Miles......113.956

MEOICAL PRACTICE LAW OF ARIZONA

\section{An Aet}

To Regulate the Practlce of Medlclne and Surgery, Osteopathy, and other Systems or Modes of Treating the Slck or Afflicted; and to Yrovide for the Appolntment of a and to Provide for the Appolint and to Prescribe Its Powers, Dutles and Com. Prescribe

Be It Enacled by the I.eglslature of the State of Arizona

Sec 1. APPOINTMENT AND MEMBERSHip. The governor shall appolat a board SHIP: The governor shall appoita a bonra of Medical Examiners to be known as the of Arizona, consistling of fire members, each of whora shall have resided in Arlzona for a periud of three sears next before his appolntment. such appointments shall be made every sscond year, as follows: Two members from the allopathic school of mediclne of the State of Arizona, one nember from the homeopathle school of medicine of tise the homeopathle school of medicine of the State of Arlzona, one member from the
eclectle schoul of medicine of the State of eclectle schinl of medicine of the State of
Artzona, and one meinber from the osteopathic school of medlcine of the state of Arizona. Vacancles occurring in the repreahall be nlled by appointment by the for: emor from sald profesitons. The sppulintment of each member shall he for a serm of two years, aud untll his successor is appolnted and qualined: provided, however, appolnted and quallied provided, that no professor, Instructor or other per. con in any manner counected with in inan mediclne or surgery or osteopathy shall be appolnted a member of said board. It shail require the affrmative rote of three menliers of sald board to carry any motlon or resoluton, to adont any rule, to pass any measure of to authorize the lssuance of any merobers of sald board ahill cunstitute a mernbers

Sec. 2. QCAIIFINf; : Fach member of asld board shall. Jefore entering upnn that dutles of h!s once, take the constitutionat oath of once, and shall, in adfision, tuake oath that he is a gradunte in merllecise und surrery of usteopathy, and a licenserl prac. surkery of usteopathy, and a licenser prac: osteopathy, of thls state.

sec. 8. HXAMINITIUN: Sa!d mar! ahall crandze on or before the frat Tuerday of August, 1913, liy electinz from it number a wresident, vica-president. secomil vec-president, necretary, and treautires. Whin the pleasure of sald brand. Sald lowisl whall the pleasure of sald briard, hald hiant mlatl hold Its rekular mectinga In the catnat uf the state on the IIrst Tuesday di distuary. Dower of alfournment from time ti t:liw untll buslness is ronclueled. Epecial nirut Ings of the boril may te held at such bino as the barti may dewignato

ser. 4. For AtION: The oflice of the sald boand shall be lis the Sirte capitat and in all lekal procectinge againut the

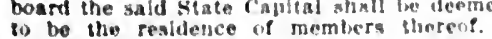

Sec. 3. RULK.s: Sald hoard may, from llue to 1hne, adont such rules as may be necessary to enable it to carry inte effect the procision of this act. Any member ters pertaining to the duties of sald board, and the froard shall have authority to take evidence in any matter cognizable by it.

Sec. 6. WHFINITION OF PRACTIC!. Iny persun shall be reganded as practicing medicine wlilin the meaning of this act who shall, within this State, (a) by adrertiscment, or by any notice. sign or other
indication, or by any statement, printed, written or oral, in public or in private, made, done or procured by himself or her self, or any other, at his or her request. for him or her, claim, announce, make known or pretend his or her abllity or willngness to diagnosicate or prognosticate, any human diseases, llls, deformities, defects, wounds or injurles: (b) or who shall so adrertise or make known or claim hls or her ability or willingness to prescribe or administer any Irug. medicine. treatment, method or prac tice. or to perform any operation or manipulation, or to apply any appartus, or application, for cure, amelloration, correction, reduction or mediflcation of any human dis. ease, ill, deformity, defect. wound or injury. for hire pee, compensation or reward, promised offered, expected, received or accepted. directly or indirectly; (c) or who shall. vithin this staie, diacnosticate or prognos iscate any human disease, lil, defornity. defect. wound or infury. for hire. fee. reward or compensation, promised, nffererl. expected. received or accepted, directiy or indirectly: (d) or who shall within the state prescribe or administer any drug, medicine. treatment. niethod or practice. or verfurm ans operation or manipulation. ir apply any apparitus cir appllance for the cure alfertation amelioration correcilot. recuction or modification of ans human dis ease. III. deformity, defect. wound or injury. enr hire. fee. compensation or reward, prom ised. offered. expecied, received or accepted. arent of any person. flem or cor uncation, in the practice of medtcine as herinbefore set forth: (f) except it be in the adrertlsement or practice of fentistry. nidtwifery or pharmary, or in the usual minsimess of optlcians. or of rentors of iental or surieal instruments. almatus alul aspliances. Fractione mediche withth the meantng of this act is construed to inelwe the practle of oxtenpathy. FUISM UF (CETHFICATL:

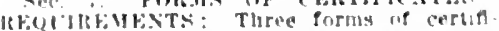
ItF. the seat fherouf and signed by the prost wen ind tio secretary: tirst, a certifled

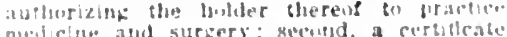

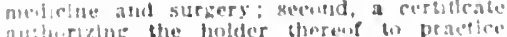
nuthorizhe the holeler therest lo practice

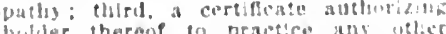
"holler thereof to prastece uns utlice

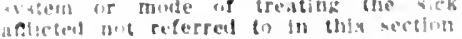

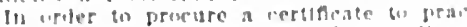

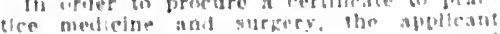
(fur vuch rertiticatel must thlo with ated

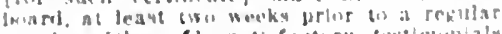

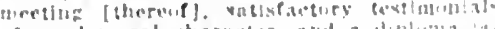

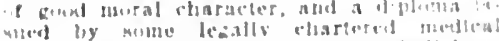

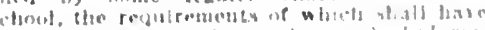

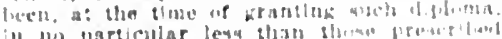

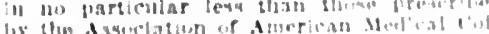

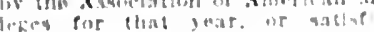

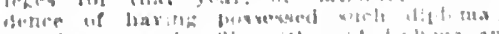

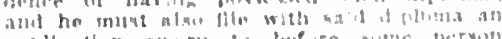

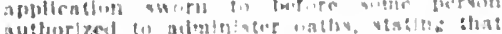

he is the person named in said diplina. that he is the lawful holder therest and that the same way procured in the regwithout fraul or miqrepresentation. The said appllcation whall the made ugm a blank purnished by sath board, and is sliall conturnistied by salit boarl. and in she medl. tain such intmrisan concerning the meds. tion of the afplicant as sald board may by rule provide. Auplicanis who have falled to met the abnre requirements nust be
rejected. Applicants for a certincate to fractice osteopathy shall be subject to the atrove rexulations, except that in place of the diploma hereinlefore referret to, they shall be required to flle a diplota from legally chartered college of osteopathy, har. itig a course of instruction of at least twenty months, requiring actual attendance. and after 1908, of three years of nine months each, and including the studies examined upon under this act. Applicants for a certiflcate to practice any other system or node of treatment not in this act referred to, shall be subject to the abore regulations. except that in place of the diglomas bere Inbetore referred to, they shail the required to fle a dipluma from a lecally chartered ment whlch the applicant claims of intends to tollow.

In addition to the requlrements abore set forth all applicanty for a certiflease mus be personally examined by sald buard a io thelr qualifcations. The examination shall be practical in character and des!rner in discorer the applicani's finess to practice his prufesston. and shall be, in whole ot in parp, in irrititis, on the followill, histology, gynecolory, pathology, bacieri ulogy, chemistry, and torcology, Dhystol-

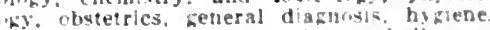

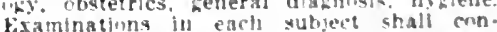
ist of pot less than sen oues:ons, snswer in which shall be matred up.11 a seale of zero to ten. All anplicaute must cibtain min less than a keneral arerage of is mer rens. and nut less than 60 per cent in an one subject. Applicants who can who al the Eranted a credlt of fre pres cent. Ch the general arerage, and 3 per cont. didationat for each rubsenuent ten years of such prac Qhe He must rovetre ning less than retit. on arts chlec subject, howerer.

The examinatun pabets shail form at part of the recuris of the boand and hist

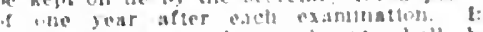
sald examinatlon the arbilednt slatl te finorn and Jestabtod by tumber only and

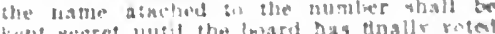

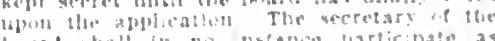

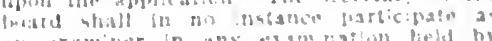
int raming

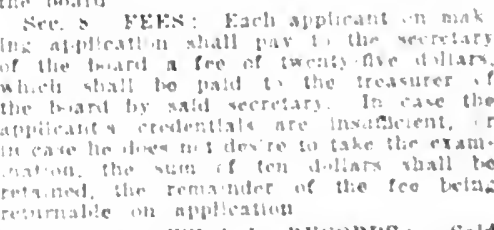

11F"1 1.1, HECURES: sald a.p the emoin recont of all Its

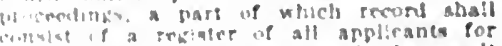

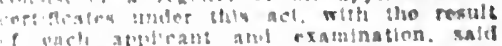
o wacl, anguram and examination. Mald

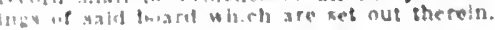


Sec. I0, RECORD]NG CFItTHIC ATES Fvery person holding a certifleate athoriz Ing him to practlce medicine and surfery or osteopathy, or any other system or mode of treating the slck or aftlieted, in thi State. must have it recorled in the ontio of the county recorder of the connty in whleh the bolder of sald certiflcate is irace ticing his profession, and the fisct of such cate by the county recorder recording the same. Fvery such person, on each rhange of his reslinee, must have his certifleate recorder in the county to whlch te shall recorded in the county to whleh te shall
have ehanged his residence. The absence have changed his residence. The absence
of such record shall be prima facie evidence of the want of possession of such certifleate Any person holding a certifleate who shal practice medicine or surgery or ostenpatiny ir any other system or mode of trentling the sick or afflicted, in this state, or who shall atsempt to practlee medicine or surgery or osteopathy, or any other system or this state, without forst having fled hls certificate" with the county recorder as hereln provided, shall he deemed guilty of herein provided, shall be deemed guilty of fine of not less than twenty-five dollars nor fine of not less than twenty-five dollars nor
more than one hundred dollars or by imprisonment for not less than thirty days nor nore than slxty days, or by both such fine and himpisonment.

Sec. I1. COLNTY RECORD: The county recorder shail keep. in a book provided for the purpose. a complete list of the certiflcates recorded by him, with the date of the publle inspection during his office lours.

Sec. 12. REVOCATHON; ENIROFES SIONAL CONDUCT: said hoard must re fuse a certificate to any applicant gullty
of unprofessional conduct: but before such refusal the applicant must he cited by cltation, sigmed by the secretary of the board, and sealed with its seal. No such citation sliall be lssued except upon a of the board, charging the applicant with having been guilty of unprofessional conduct, and setting forth the particular acts duct, and setting forth the particular acts On the filing of such complaint the secretary must forthwith issue a citation and inake the same returnable at the next session of sald board occurring at least thirty days next after flling the complaint. Such cltation shall notify the applicant of the time and piace, when and where the matter of said unprofessional conduct shall be heard, the particular unprofessional conduct with which the applicant is charged and that the applicant shall fle his written and that the applicant shall file his written answer. under oath, within twenty days
next after the service on him of said citanext after the service on him of said cita-
tion, or default will be taken against him, and his application for a certlficate be refused. The attendance of witnesses at such hearing shall be compelled by subpoena issued by the secretary of the board, under its seal; and said secretary shall in no case refuse to issue any such subpoena, upon a fee of twenty cents being paid him for such subpoena. Said eitation and sald subpoenas shall be served in accordance with the statutes of the state then in force as to service of citations and subpoenas generally, State then statutes of this are hereby nade applicable to the subpoenas provided for herein. If any person refuses to obey a suhpoena served upon him in accordance with the statutes of this state then in force providing for the manner of serving subpoenas, the fact of such refusal shall be certified by the secretary of said board, under the seal thereof, to the sunerior court of the county in which the service was had, and said court shall thereupon proceed to hear said matter in accorlance with the statutes of this state then in force as to contempts for disohedience of process of this court; and should said court find that the subpoena has been legally serred, and that the party so serred has wilfully disobeyerl the same, it shall proceed to impose such penalty as provided in cases of contempt of court. In all cases of alleged unprofessional conduct arising under this act, depositions of witnesses may he taken, the salle als In civil cases, and all the provisions of the stututes of this state then in force as to the taking of depositions are hereby made applleable to the taking of depositions under this act. If the uppleant board his answer, muder oath, to the charges macte agalnst him, wlthin twenty duys after service on hlm of said citation or within such further time as the board maty give deenied sufficient by the board, defautt sliall be entered agralnst him, and hls application refused. If the charges on their face be refused. If the charges on their face be jolned thereon by answer, the board shall jolned thereon by answer, the board shall that end shall hear such erldence as may be adduced before it; and if It appear to the salisfaction of the board that the applicant is gullty as charged, no certifleate shall be Issued to him. No certificate shall be refused on the ground of unprofessional tully of such conduct within two years gullty of such conduct within two years
next precesling his application. Whenever next preceding his application. Whenever any lolder of a certiflcate herein provided
for is guilty of unprofessional conduct, as the same is defined in this act, and the said unprofessional conduct has been brought to the attention of the board granting sald certificate, In the manner hereinafter pointed

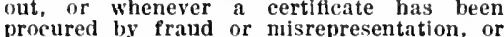
issuerl by mistake, it shall be their duty to, and they must, revoke the same at once, and the holder of sald certificate shall not be permitted to practice medicine, surgery or be permitted to practice medicine, surgery or osteopathy, or any other system or mode of treating the sick or afflicted in this State. such holder is elted to appear and the same proceedings are had as is hereimafter provlled in this section in case of refusal to issue certificates. Said secretary, in all ister the fact of such revocation and shall certify the fact of such revocation, under of the county in which the certificate of of the county in which the certificate of the person whose certiflcate has been
revoked, has been recorled; and said recoked, has been recorded; and said margin or across the face of his register
of the certificate of such person, the following: "This certificate was revoked on the $\ldots \ldots \ldots$ day of $\ldots \ldots \ldots$," giving the accordance with said certification to him by said secretary. The recorl of such revocation so made by said county recorder shall be prima facie evidence of the fact therenf, and of the regularity of all the proceedings of said board in the matter of said revocation. From the time of the
revocation of a certificate the holder thereof shall be disqualified from practicing medicine or surgery, osteopathy, or any other
system or mode of treating the s!ck or afficted in this state.

The words "unprofessional conduct," as used in this act, are declared to mean:
First: The procuring, or aiding or abetting in procuring, a criminal abortion.

Second: The wilful betrayal of a professional secret.

Thirl : All advertising of medical business which is intended, or has a tendency, to deceive the pulblic or impose upon credulous or lgnorant persons, and so be harmful

injurious to the public morals or safety.

Fourth: All advertising of any medlcine or of any means whereby the monthly periods of women can be regulated
menses re-established if suppressed.

Fifth: Conviction of any offense involving moral turpitude, in which case the record of such conviction shall be conclusire eridence.

Sixth: Habitual intemperance use of alcohol or narcotic drugs.

Serenth: The personification of another name.

Sec 13 POVERS OF BOARD : Said board shall have the power to employ legal counsel and clerical assistance and to $\mathrm{flx}$ the salaries of the same and to incur such other expenses as may be deemed necessary to earry Into effect the provisions of thls act. It shall also tix the salary of the secretary, not to exced the sum of twelve lundred doliars yer annum, and the sun to be paid to the other members of said each, for each and cvery day of actual service in the discharge of official dutles: and said board may, in its discretlon, add to sald sum necessary traveling expenses. The expense of said boird, lncluding the salary of secretary, shall not exceed the amount provided. All money in excess of the actual expenses of the board shall be patd annually into the state treasury.

Sec. 14. PENALTIES: Any person who shall practice or attempt to practice, or medicine or surgery, osteopatliy, or any medicine or surgery, osteopatly, or aly other system or mode of treating the sick state, without having, at the time of so doing, a ralid, unrevoked certificate, as provided in thls act, shati be guilty of a shall be puntshed by a fne of not less that one hundred dollars, nor more than flve hundred dollars, or by Imprisonment for a term of not less than slxty days, nor more than six months, or by both such fine and inprisonment. In each such conviction the fine shall be paid, when collected, to the fine shall be paid, when collected, to the State treasurer, and shall constitute a practitloners as defined in thls act, the said practitloners as defined in this act, the said
fund to be paid to the sald boards upon warrants drawn therefor by its secretary, and the said board is authorlzed to proseeute all persons guilty of a

Sec. 15. FRAUDULENT R E C O R D : Every person fillng for record, or attempt ing to fle for record, the certiflcate issued to another, falsely claiming himself to be the person entitled to the same, shall be guilty of a felony, and upon convictlon as are provided by the laws of this State for the crime of forgery.

Sec. 16. Any person assuming to act as a member of the State Board of Medlcal Examiners without so being a member, or who to be issued, or seal, or cause to bo sealed, a certificate authorizing any person to practlce medicine or surgery, or osteopathy, or any other system or mode of treating the sick or afflicted, in this State, shall be guilty of a felony, and shall be punished
by imprisonment in the State penitentiary by imprisonment in the State penitentiary
for a term of not more than fire years.

Sec. 17. WHO MAY PRACTICE: Any person who holds an unrevoked certificate from the Board of Medlcal Examiners created "by an Act to Amend an Act to Reg; which was approved March 18, 1897, or from the board of examiners created under the provisions of Chapter 1 , of Title 53, of the Revised Statutes of Arlzona, 1901, or from the board of medical examiners created by an Act of the Legislative Assembly of the Territory of Arizona, entitled "An Act to Regulate the Practice of Nedicine," approved Jarch 19,1903 , shall be entitled to practice medicine and surgery in this State the same as if such certiflcate has path who has qualifications as set forth in Sec. 7 , and who shall establish to the satisfaction of the board that he or she was actlvely engaged in practice in the bill shall be entitled to receive a certiflcate bill shall be entitled to

Sec. 18. EXENIPTION: Nothing in this act shall be so construed as to inhibit service in the case ar emergency, or to edies; nor shall this act apply to any commissioned medical officer in the United States Army, Navy, or Public Health ServStates Army, Navy, or Public Health Service, in the discharge of his official duties; nor to any licensed dentist when engaged Nor shall this act apply to any practitioner from another State or Territory, when in 
actual corsultation with a liecrived practl tloner of this stute, if such practitluter lo at the sime of such comsulsaton. a lleensed uractitloner of the state or Territury in whlch he resldeg: prorlded, that wucly jeas titloner shall not open an oflec or appilnt a place to meet patients or recelve calls

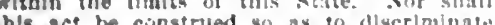

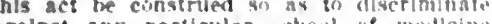
agalnst any particular setiond of umstleine or surgery or osteopathy or any wher system or mode of treatlug the sick or anilepd. or to Interfere in any was with slie practice of rellglon: provided, that nothlng hereln shall be heli to anply to or to regulate any kind of treatment by prayer: and provichel Purther, that all sanltary laws and regulat tlons regarding contaglous or infectlons $111 \mathrm{~s}$ easea applicable to practitloners of medleine. easea, applicable to practitloners of nedtethe. of any systen or mote of ireating the sick of any systent.

Sec. 19. All acts or parts of acts in conflict with the proristons of this apt are hereby" repealed.

Approved March 22, 1913

\section{ARIZONA BOARD OF HEALTH}

Gor, Gen. W. I'. IInnt, l'restclent, I'hounis: Atsy,-Ge1, G. l'. Bullard, Vlce-Presldent, Phoenlx; Robt. i lonnes, Secretary and Superintendent of Fublie Health, Jrescutt.

BOARD OF MEDICAL EXAMINERS

J. E. IIutrman, Jresldent. Tucson: W. H Sargent, First Vice-l'resident, l'hnentx; 1 . T. sturceon, Second Fice.l'resident, filobe: John Wix Thomas, Serretary and Treasurer. Ithoendx: Geo. W: Martin, W.O., Tucson.

\section{ARIZONA MEDICAL ASSOCIATION} Oficers 1913-14

Ira F. Ilufman, l'resident......... Tucson John W. Flinn, Ist Vlce-l'resldent. . Presontt E. B. Ketcherside, al Vice-presldent. Inma Kay Ferguson, 3d Vlce-Presldent.... Vuma C. F. Yount, Secretary............ I'rescott K. 1. Kenneds, Treasurer................ (ilobe

\section{Counellor Distriets and officers}

Surthern Inatrlet.-3. H. Whitesities, touncllor, Kingman

Southern 1)latrlet. - It. J) Kennedy, coun. clior, Gilobe.

Component County Societies of the Arizona Medical Association Coculsk COLNT

F. Herendeen p'resdatif.

IIarry A. Iteese, viecretary.

Hisliee coconixo CH:xts

F. M. Miller, P'resilent............tiagstan Chas. W. Sult, secretary......... Flagstatt Gila colvt

IR. I). Kennedy, President... Gilube Chas. T. Sturzeon. Secretary.

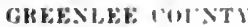

A. M. Tuthlll, Iresident.

Edw. I. Ifeed, Secretary" Maticon'A IOIST)

whllard snith, l'reslileut...

Chav. 18. Palmer, Neretary. MOHAYE: PUIDT

Wim. It Incher l'resident.

A. M. Cowle, secretars. IIISA (11)

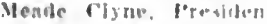

$\because$ A. Thoman, secteliat SANT. CKI\% IOI ITS

A. II. Nonn, I'resident.

W. $b$. Chenoweth, secrotary

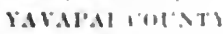

c Carlson. l'revilene

Wurtuel iliferin

jhom $\ln x$ Jinesitx

Kingman kingiun

Tur sus Tu[.4.

Ningales

visulea YLMA

J. Kinteheratule, I'publent

i. Jacols. secretary.

COUNTY SUPERINTENDENTS OF PUBLIC HEALTH

Pistulls

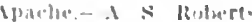

inclitise. L. I. Viner.

(*)

cilla- II. li, for

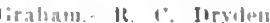

circenles.- 1. i. w. Hurtel

Maricupa--11. A. Mughes

Inhare. Jotin R. Whitevides.

Vavain-1. W. Huzell.

Fina-- lieo. J Troutman

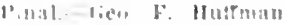

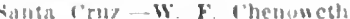

Varapil....June W. Holnu

lima b la kethersille.

HEALTH OFFICERS IN CITIES OF 2,000 POPULATION AND OVER

Bisbee............... Italnh F. Hereudeen tulfton........................ W. Burteh bouglas.................. W. Mandel tilobe. . . . G. For

Ierome.................. J Murrieta

Morenel.................. II. M. Cansler l'hoenir.................. keauchamb

Prescote...............I. T. Southworth

Tueson.................... E. Erepin

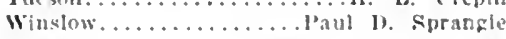

Vuma..............Itenry Vance Clymer

\section{Florence}

\section{STATE INSTITUTIONS}

Arizona siate l'rison IIospital, Florence,

Arlz. General: W. (i handell, physleian In charge.

Leupo

Enlted States Indlan Serrice Hospital.

Leupl, Ariz. For exclusive use of In.

llans: 10 beds; Ilownrd T. Chlld, physl. clan in charge.

\section{Phoenix}

Arizona State IJospital, Ihmenix, Arlz. Establlshell 188f: public nervous and

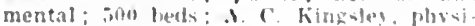
clan In charae.

\section{HOSPITALS, SANATORIUMS AND CHAR ITABLE INSTITUTIONS}

Bisbee

Calumet and Arlzona IInspital. Hivbee.

Arlo. Eistablished 1,402: 30 beds: $X$ Bledsoe, plisslelan in charge

Copper Qucen Ilospital, Bishee, Ariz. Establlstied 1903; prirate: 100 herls:

Francls F. Shine, medleal superiusetulent Cilfton

Arlzona lomper fompany llospltal. (lif

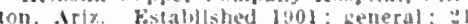
beds: $T$. I smith, medlcal superintendent Sthannon lloupleal. flifton. Ariz. Fotal. llshed 1904: prisate; nasintalned liy the Shannon copper loo.: teneral: 12 heals. F. It Melphecters, physlcian In charke.

\section{Dougla}

Inlunet Hespleal, Jouglas, Ariz. Fis tablelual 1a03: Ecreral: is belle: $r^{*}$ Wrighe, playslelan in elaarge.

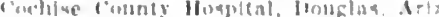

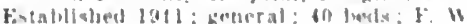
Ramlat, phyalctin In charge.

\section{Flaostaft}

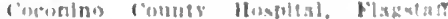

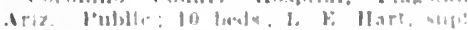
Florence

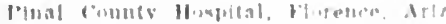

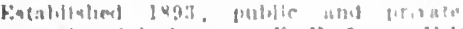

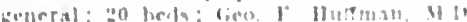
sumerintiondant

\section{$F t$. Deflance}

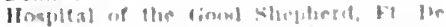

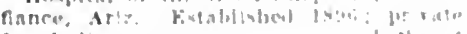

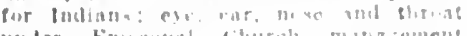

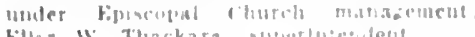

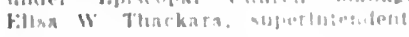

Globe

A.lla county Hospla! 1, Are Arlz Vos.

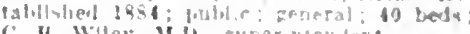
It Whev M.lW, supermentert.

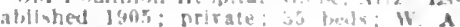
II olt. phoweian In charse.

Goldroad

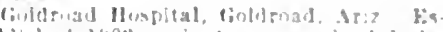
tablshed lyot: prirate: chelleral: I beds: T. II White, M.J., superinterdets.

\section{Hot Springs}

('astle llat Springs, IInt Sprlnza, Apiz

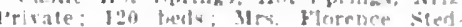
man. manaier

Humboldt

llumbolit: Hoapital, Itumboldt, Arlz

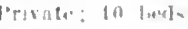

Jerome

Inisel verde copper Company"s llosp:ial, Jerume. Irlz. Fintabllshed 1900 ; pri. vate: kentinl; 26 beds: A. J. Mursleta chief surger:

Metcalf

Arlzona fomper f'ompany llospltal. Mei

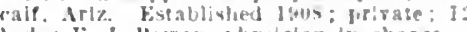
beels: F. J. Kowan, physleian lis charge.

Miami

Mlaml Inablrallon Hospleal, Mlami, Ariz Eatalllahed 1y10: penetal: 0 beds; Joln r. llacon, surgen in charge.

\section{Morenci}

loetrolt copper Mining Compans's IL plial, Morencl, Ariz. Establithed $159 \%$ prirate; general: it beds: A. M. Tuthll Dhuslclan in cliarge.

Iongellow Junital, Morenct, Arlz. Es tablishel 1:nl: zeneral: 20 beds; (. b: Coondrich. libyolctan in charge.

Nogales

Ifra Vonte Sanatorium. Mountaln Vlew. Nogales. Ariz. Fovablished 1911: prirate:

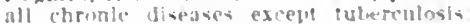
If cheds: I I litistetter and II. W. I'urds. phrsicians in charge

St. Inseph's llosuital, Nozales. Arlz

Oatman

Tom Keed Hoaptal, Oatman. Artz. Es tablished 1009: jrivate: zeneral: s heds: 1. R. Whitesliles (Kingman), phrsiclan in charge: I. M. Francls, superintendent.

\section{Phoenix}

lieger: Inu. Phoenlx, Iriz. Fatabllsbel 1408: prlvste: 30 leeds; $\boldsymbol{F}$. A. Statgord. nhysictan in charge.

Harwind flame, thoents Arly Esablished 1910; privite: 25 heds: tent houses On lulurcular cases: il A. llughes, nbysi.

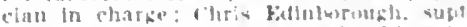

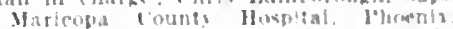
Artz. Estoblished 1ses: 75 beds: 1. I liameron. pligselan and superintendent Marleopa ciunty Tuberculosis linapial.

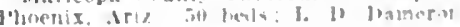
chief physiclan: I rose 11 :11. supt

Whoenir Indun selumel Hospital. Tho

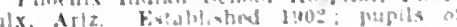

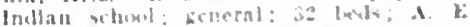
Marden, uhwilan in charce

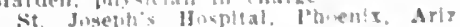
Extablished la00: nrivale: : 3 beels.

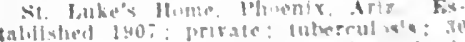

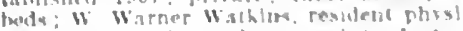
cian: lier it $K$ it whe sumeriutendent

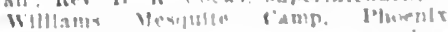

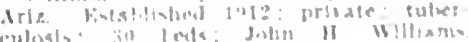

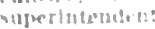

Prescott

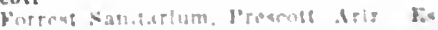

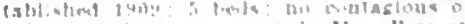

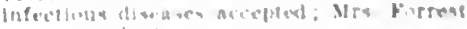
superinterateis

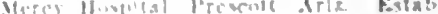

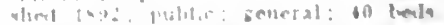

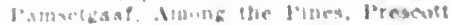

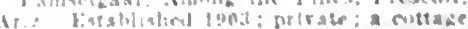

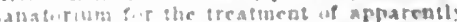

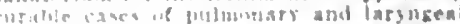

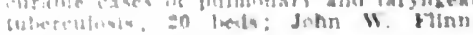
thivitun in rlates

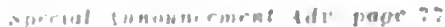

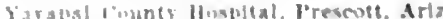
lublic: 00 linds. (C. Vount, physleian in itharse. 
Sacaten

Ilma and Marlcopa Indlan Reservation Hospltal, Sacaton, Ariz. Establlshed 1881 ; 26 beds; $H$. Austin Delcher, physlclan in charbe.

Safford

Graham County Hospital, Safford, Ariz. Establislied 1881; 8 beds; W. E. Platt, physlciall in charge.

Tucson

Rodgers Hospltal, Inc., $123 \mathrm{~S}$. Stone Are., Tueson, Ariz. Established 1907 ; prlvate; general; 20 beds; J. I. Butler, M.D., superlntendent.
St. Mary's Hospital, Tucson, Arlz. Established 1880 ; private; speclal department for tuberculosls; 80 beds; Sisters of St. Joseph, In charge.

Tueson Arizona Sanatorlum, Tucson, Ariz. Establislied 1907 ; private; tuberculosis ; 50 beds: Jeremiah Metzger and Saml. H. Watson, medical directors.

Whiteriver

Ft. Apache Tuberculosls Camp IIospital, Whiteriver, Ariz. Established 1911; publie and private; for Apache Indlans only; 20 beds.
WIIIIams

WIllams Ilospltal, Wlllams, Arlz. Establlshed 1808 ; prlvate; reneral; 14 beds :

P. A. Melick, physlclan in charge.

\section{Winslow}

Santa Fe Coast Lines IIospltal, Winslow,

Ariz. Established 1901, private; for em-

ployees only; Oscar $\mathbf{S}$. IBrown, physiclan in charge.

Yuma

Yuma County Hospital, Yuma, Ariz Public and private; 15 beds; E. B. Ketcherslde, physiclan In charge.

\section{PHYSICIANS OF ARIZONA}

FXPLANATORY NOTE.-Date of license glven after each name is not to be recognlzed as indicating the year In whleh the indivldual began practice in the state, but as the date of license under the present law, whlch became effective IIarch 19 , 1903 . Physlcians in the United States Indian Service and officers of the government medical services are not subject to the state practice act.

KEY TO ABBREVIATIONS, SYMBOLS, ETC.

Names in capltals signlfy membership in the County Society and State Associathon. (DOE, JOHN).

- Indicates Fellowship in the Amerlcan Med. Assn. (DOE, JOHN@).

(b'75) Year of blrth.

$\mathbf{H}$ homeopath; E, eclectlc; P-M, physloMd. 7,09 , College and year of graduation. 0 Information received does not show graduatlon.

S.--Surgeon.

Ob.-Obstetrlclan.

ObG.-Obstetriclan, Gynecologist.

G.-Gynecologist.

Or.-Orthopedlst.

Pr.-Proctologist.

Op.-Ophthalmologist.

A.-Aurist.

LR.-Laryngologist, Rhinologlst. (l's9) Year of llcense.

(5) In practlce before passage of present law and licensed by filing diplonia or by years of practice.

(1†) Licensed but year not known

(f) Infornation received does not show llcense.

U.S.A., United States Army.

M.R.C., U.S.A., Medical Heserve Corps.

SPECIALTIES ARE INDICATED AS FOLLOWS:

ALR.-Aurlst, Laryngologlst, Rhlnologist.

OALR.-Ophthalmologist, Aurist, Laryngologist, Rhinologist.

U.-Urologist.

D.-Dermatologist.

Pd.-Pediatrist.

N.-Neurologlst.

P.-Psychiatrist.
U.S.N., United States Navy.

M.R.C. U.S.N. Medical Reserre Corps.

U.S.P.H.S., Unlted States Publlc Health Service.

College positions held are Indicated by abbreviated title of position, followed by key number of college. For key to colleges see inside front cover page.

(A1,3, B6, C4) Membership in speclal Societies. (Sce Key Table, page 122.)

NP.-Neurologist, Psychlatrlst.

I.-Internist.

T.-Tuberculotherapist.

Anes.-Anestbetist.

LD.-Laboratory Diagnosticlan. R.-Actinologist, Radlologist, RoentgenoloPath.-Pathologist.

Bact.-Bacteriologist. THE PHYSICIAN CLAIMS HIS PRACTICE IS LIMITED TO THAT PARTICULAR BRANCH OF MEDICINE; WITHOUT THE ASTERISK, THAT HE IS ESPECIALLY INTERESTED IN, BUT DOES NOT LIMIT HIS PRACTICE TO, THAT BRANCH. THIS INFORMATION CONCERNING SPECIALTY IS BASED ON PERSONAL DATA FURNISHED BY THE PHYSICIAN AND IS NOT VERIFIABLE.

ARIZONA
ARIVACA, I00, PIMA
Ball, Jos. H'IIY (b'60)-N.Y.5,'91 ; (l'06).
BENSON, I,039, COCHISE
JONES. JOHN FliNALLIN (b'63)-Mo.24,
'S9; not In practice.
Morrison, James N.-Ill.4,'85; (l'05).
POWELL, CHAS. S. (b'54) (-T-Tenn.5,'S5;
(l'04).

BISBEE, 9,019, COCHISE

BLEDSOL, NELSON CHAS. (b'T6) $\$-$ Cal.6,03: (l'04).

BRIDGE, GEO. A. (b'73) $4-N . Y .1,02$; (1'04)

COHEN, MORRIS D. 4 - Md.3, 04; $\left(l^{\prime} 05\right) ; G$.

FEIRGUSON, ROBT. (b'75) $9-C o n n .1,03$ (1'05); Ob.

HAWLEY, CHAS. FRANCIS $\left(\mathrm{b}^{*}, 0\right) \oplus$ Ill.10,97; (1'03).

HERENDEEN, RAIPH EUGENE (b'87)Cal.9,09; (l'09).

HUNT, CHAS. HANNIBAL (b'76)-Cal.1, 03 ; (1'03).

Ingels, Anson B. (b'75)-Mo.8,9ti ; (); Pd.

LEONARD, JERONE ICKAIG (b'84) III. 4,06; (1'10); $\mathrm{S}$.

PATTON, OLIVER BEIRNE (b'75)-Va.1 05; (l'12).

REESE, HARRY A. (b'68) - Mo.2 7,96 ; (1'08).

SIIINE, FRANCIS EPPES (b'71) †-Va.1, $95 ;\left(l^{\prime} 03\right)$.

WA'TKINS, THOS. (b'82)-Va.4,04; (l'08).

BUCKEYE, 400, MARICOPA

Franklin, Wayland R. (b'87)-IIl.22,'12; (l'12)

Leister, F. L. (b'69)-Mo.10,'97; (1'0-).
CAMP VERDE, 300, YAVAPAI

Hughes, Colt Inge (1'82)-Ky.2,09; (1'09) (Indian Service); Camp Verde Śchool.

CASA GRANDE, 357, PINAL

Gungle, Edward Jos. (b'86)-Mo.34,'13; (1'13).

CASHION, - MARICOPA

LITTIA, STILLMAN D.-Ue.l,'03; (l'03) ; Member Me. Med. Assin.

CHANDLER, 一, MARICOPA

Gilhert, Kramer Martin (b'82)-Ia.6,'08; (1'12).

Jordan, Fred Covington (b'83)-Ia.6,'08; (l'13).

CHIRICAHUA, 200, COCHISE

Phillips, James Iiley (b'63)-Tenn.6,'89;(\$).

CHRISTMAS, 200, GILA

Harman, Fellx C. (b'82)-0.3,'05; (1'11).

CLIFTON, 4,874, GREENLEE

BOGUE, HENRY VIRGIL (b'84)థ-Mid, 09; (1'11); OALR.

BUIT(H, LEWIS A. W. (b'75)-111.1,97 (l'0\%) ; Ob.

ELLIOTT, ADDISON EUGENE (b'76) III.1, 08 ; (1'12).

IICPHEFTERS, T.ARL R. (b'82)-Ky.1,'05; (l'05).

REED, EDWARD YORTH (b'i)\&-Ill.1, 04; (1'11).

SMITH, TURNER BURTON (b'78)-IM.1, 04; (1'07).

COCHISE, 175, COCHISE

Ellis, Jay Bartlett (b'52)-Ill.4,'92; (1'11).

COURTLAND, 914, COCHISE

BAIl ${ }_{4}$, HENRY T. (b'73)థ-Кy.5,'03; (l'09).
CROWN KING, 200, YAVAPAI

NORTON, HARVEY G. (b'76)-MInn.4,00

(l'12); Mlember Minn. State Med. Assn.

DOUGLAS, 6,437, COCHISE

ADAMSON, EDWARD WM. (b'79)๑Mich.1,'04; (l'05); S.

ARMSTRONG, JAMES J. P. (b'71) -0nt.3, 93; (l'03).

CRABTREE, GEO. H. (b'70) (-Pa.11,'93 ; Maj., M.C., U.S.A.

DAYID, VERNON C. (b'82) (-III.1;07; ( ) ; OWNS, MYRoN LAFAYETTE (b'71)Pa.2.'99; (I'05); OpA. *

GREENE, WM. ARNOLD (b'69)-N.Y.5,'95; (l'06).

INGOLD, JOHN GEO. (b'78)๑-III.11,09; 1st Lieut., M.C., U.S.A.

IUND, CARL HAYES (b'76)-Mich.1, 00 ; (l'06).

MCGEE, HARRY STOWE (b'77) -Mich.1 02; (l'05); Member Wash. State Med. Assn.

RANDALL, FRANK WILBCR (b'74)-MI0.8, 99; (1'03).

RANDOLPH, WM. MANN (b'70)-Va.1,90; (l'13); Member Med. Soc. of Va.

TUTTLE, LYNN J. (b'69)-Mich.1,02 ; (l'04).

VANNEMAN, ALBERT WALTER (b'62) †Pa.2,'97; (l'09).

WRIGHT, FREDK. T. (b'65) $\oplus$-Mlch.1,'99 ; (l'03).

DUNCAN, 1,200, GREENLEE

BRILEY, JAMES HERBERT (b'75)-Mich.1, '03; (l'11).

MOORE, THOMAS A.-Ont.5,'83; (1'03).

FLAGSTAFF, I,633, COCONINO

Henney, Wm. Henry (b'78)-Neb.5,0?; (\$).

Manning, Geo. F. (b'37)-Ala.2,'74; (l’03). 


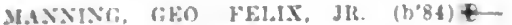
Ala.".'10: (1'10) Peyton (h'ss)-Ala.2,'I1;

MILLEI, ELWIS SEYMOLU $\left(\mathrm{b}^{\circ} 00\right)+-$ N. $1.6,79:(1+03)$

Nichols, (beo. (larence $(b ; 22)-111.1,94 ;$ not In practlee.

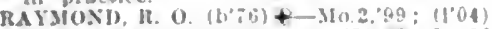
SCHEMMAXX, ALRKIRT H (b's)+ Ha.l2,

SULT, CILAS. W: (1"79) +- D. C g,06; (1'10) FLORENCE, 807, PINAL

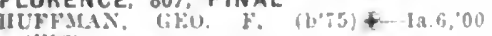
$\left(1^{\prime} 12\right)$

RANDELL, WALIACE G. $\left(b^{\circ} \bar{T}\right)+-I 11,14$ :

\section{FT, APACHE, 360, NAVAJO}

HARIBL, HAIBHIT YOHTER (b'S2)+Va.6,09; (I'09); Ist l.leut. M.C., U.S.A.

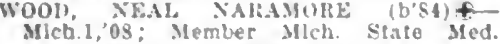
Soc.; Ist Lleut., II R.C., I.S.A.

FT. DEFIANCE, I50, APACHE

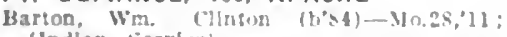
(Indian Serrloe)

WIGLESWOHTH, ALERT MATTHEW

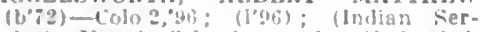
Hce): Narajo Subool; Nember N.II. Med. SOC.: OALR.

FT. GRANT (BONITA P.O.), - GRAHAM

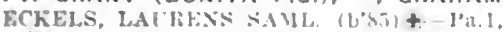

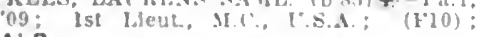
AL. R

WAJIACE, AGNES MCKEE (bJI)-Kan.3, $193:$ (l,0

FT, HUACHUCA, 400, COCHISE

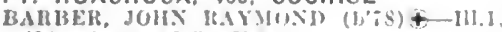
02; Capt, M.C., U.S.A

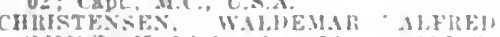

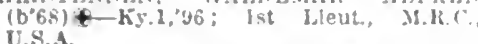

MCMUIBDO, HFW BERNARD \& Va l,07: Ist Illeut., SI.C... I.S.

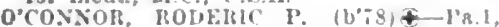
00: Maj. M.C.. T.S.A.; Op.

FT. MOHAVE (MOHAVE CITY P.O.), MOHAVE

Rellly, Francls St. Clalr (b'\&6) - Pa.2,09; (Indlan Serrice): kt. Mohare School.

GANADO, 100, APACHE

Kennedy, James D. (b'til).-111.1\%,02; Mcl, Misslonary, Navajo lminns: OALA.

GILA BEND, 200, MARICOPA

RICIAKDS, LIOYI HII)RIQUE (b'75) †-N0.:01; (I'03); (Indian service).

GILBERT. - MARICOPA

Rowell, Frank D. (b'70)-Mo.20,9\%; not in practlce.

GLEESON, 600, COCHISE

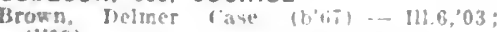
(1'09)

GLENDALE, 250, MARICOPA

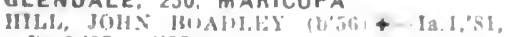

IILl, J011: IU1)

PEAKSU:; JOHA MAXWELA (b'85)to J.C. 2,$0 ;:$ (1'05).

GLOBE, 7.083, GILA

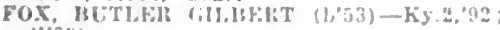

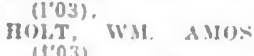

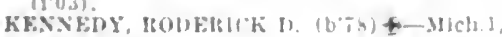
103: $\left(1{ }^{\circ} 04\right)$.

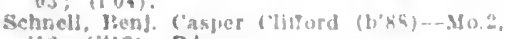
12: $\left(1^{2}(3) ;\right.$ Pd.

Sotel, Constautine I livi) Milil l,11

(I'13).

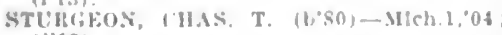
$110.0)$.

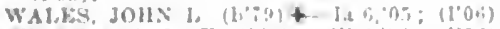

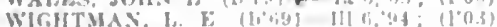

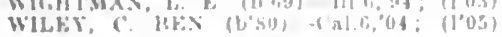

GOLCONDA, IS8, MOHAVE

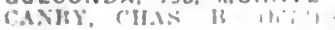
(I"0;)

HAYOEN, 382, GILA

NORMA., HISANIIIS $\left(l^{\circ} 09\right)$

HOLBROOK, 400, NAVAJO

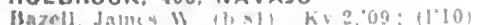

HOT SPRINGS, 50, YAVAPAI

Utquhart, Joh! (" (b"3) - Srol 3.63.
JEROME, 2.393. YAVAPAI

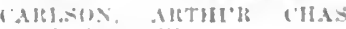

('ally'lu: (1'lu)

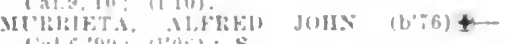

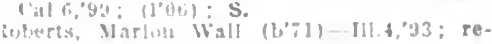

tirel.

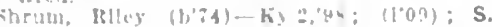

KEAMS CANON, 25, NAVAJO

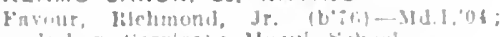

Indian serv!ce): Mogul sidimi os; In-

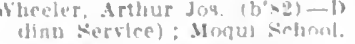

KINGMAN, 2.000, MOHAVE

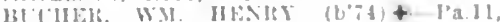

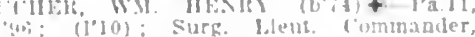

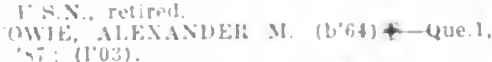

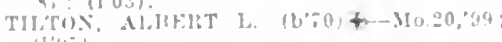

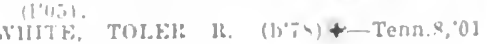
(I) 14 (1)

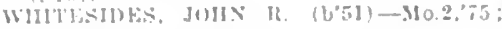
(I) 03 .

LEUPP, - COCONINO

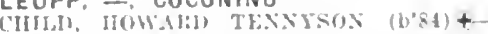

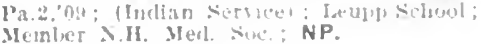

LIGHT. - COCHISE

Marvhall. Wm. Ridule (b'5)-III.22,09; not in practice.

MAMMOTH, 65I, PINAL

Butler, I'jerce Mason (b'6e)-X.Y.10,"93: (1'03)

MCALISTER, IO, COCHISE

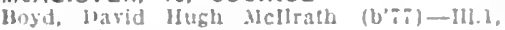
'01: (市)

MESA. 1,692. MARICOPA

Mrack, Murlun W. (b92)-Ky,4, it: (1'03)

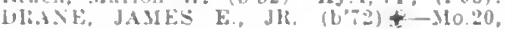

Selson, Julibus IBeruard $\left(b^{\prime}, 0\right)-M 0.34,04$

(jenshaw, ElI C. (b'a)-Ark.2,11: (1'll)

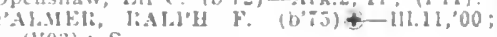
$(103) ; \mathrm{s}$.

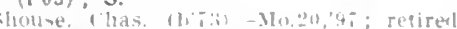

METCALF。2,500, GREENLEE

IfUWI. EDW. J. (b'As) + III.1.03: (1"00)

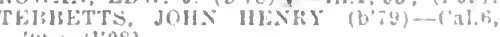
'Us: (1'08).

MIAMI, 700, GILA

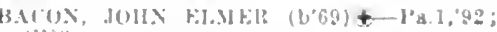

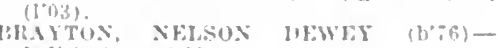
(1) 1.14.4: : 11 11).

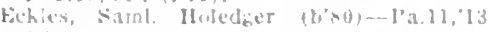

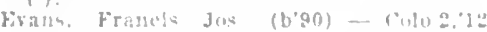

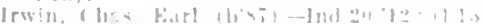

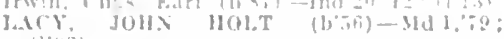

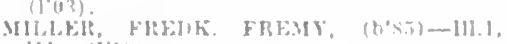

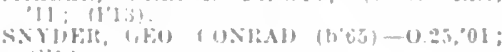
(1) I:-1.

MORENCI. 5.010, GREENLEE

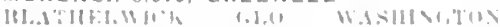

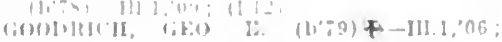
$11 \cdot \pi \div 1$,

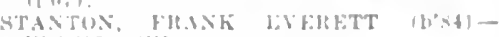
[1] $1,10:(1,10)$

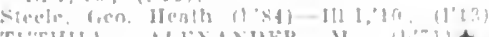

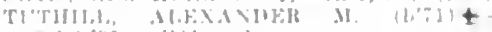

"11+1:

Jenandin, llorit

NOGALES, 3.311. SANTA CRUZ

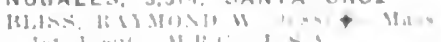

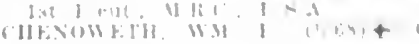

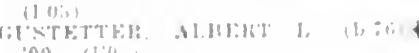

no, 11 (1)

(1.03)

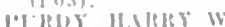

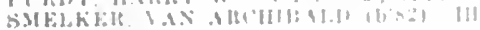

-os: (1.00)
PALO VERDE, 250 MARICOPA

Kiay. III , II

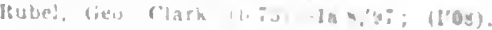

PARKER, 426, YUMA

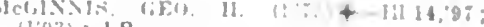

(I'03); LR.

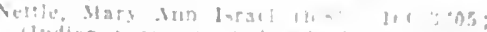

PAYSON, 300, GILA

Bisser, Cluristlan II

PEARCE, 700, COCHISE

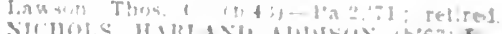
B: (l"0ti); Member siate. Med. Asso. of

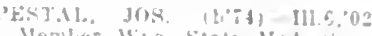

(I'II):

Memine? Wyo. Siate Mrat. Six

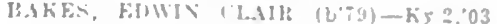

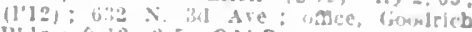

Hhle; ; $12,2-5 ;$ OALR.

B.II:I, EIREST WM. (b\%:)-111.1,95;

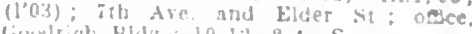

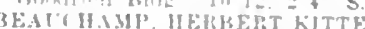

Ind , (1): (1'04)

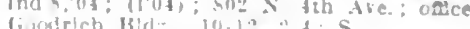

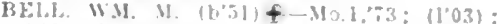
loos $\mathrm{N}$ inenter si. oflce, $11 \mathrm{~W}$. Adam

Foldo, I.orenzo (b':1)-Cal. 1.93; (1'12): 30 \%. Is:

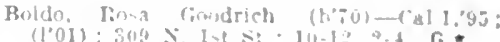

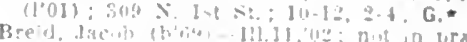

lire Indian sillomil. (1'03): 50 , F. Jortand št.

Brownflel. Walph K. (b'so)-yo.32,03: (1'Io); $16 \mathrm{~F}$. IIonoue St.

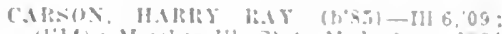

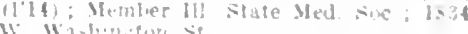
Conner, Larid Lewla (b:3)-A; (1003): (Oitengath): 1304 iv. Van burey s:

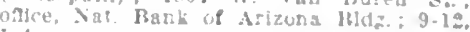
i-t.

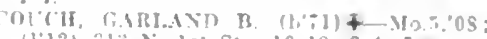

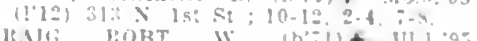

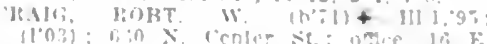

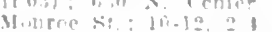

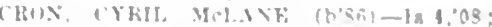

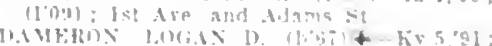
(I'0:3): sos $x$ ith Are; wace, :1 $\mathrm{k}$ Wa ih.ngeton: $9: 30-12.8-4$

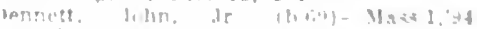
horan, lonul is thes

ill W lirgnd are

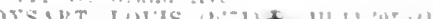

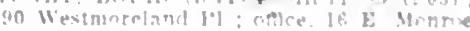
s: $: 10.1 \cdot 21: 5$.

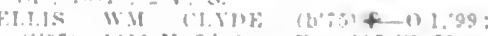

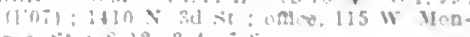

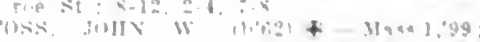

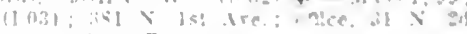

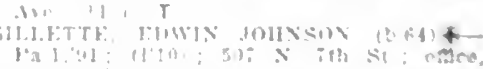

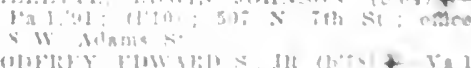

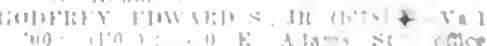

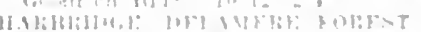

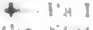

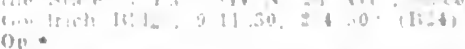

11,1

111 1il

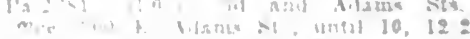

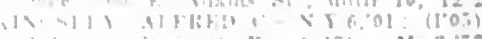

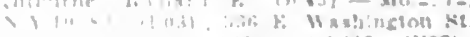

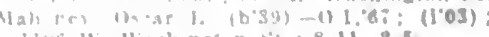
II II II Wh:nEturn si: $8 \cdot 11,2 \cdot 3$,

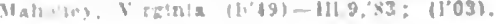




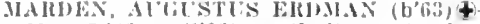
Ilass.5,89; (l’03); (Indian servloe) l'hoenix selooul

MAITIN, ANCH (b'61)—-HI.1,'s5: (I'03) xos X. ad A Ae.; oftce, loodrlch Bbldg. ! $11: 30,2-4: 30 ; 0$ pA. *

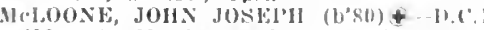
10 ; ( ) Member Ned. Assu, of Isthmlin

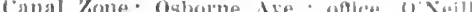
lBldy.; 10-12, $2=4 ;$ OALR, *

MHLS, HAHIAY PA(iE $(1,63)+-110.34$

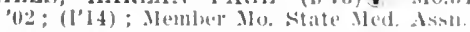
I'athologist. Nitte Ilespital.

Monleal, Grant S.-0.1,'s3; $\left(\mathrm{l}^{\prime} 0 \mathrm{~T}\right) ; 33 \mathrm{~N}$ 2d If e.

Joore, Joln F. (b'58)-Md.3, $! 30$; (l'13) $333 \times$. 20 st

Nichols, vllertus B. $(1,79)-M 13.3,04$; (1'12); Domofrio Bldi:

P.HAMER, CHAS. H. (1, '79)-Md.7,07; (1'12) 1308 W. Washington sit.; ofllce 21 r Washlngton sit.: 10-I2, 2-5; T.

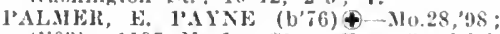
(1'03) ; $1105 \mathrm{~N}$. 1st St.; offlee, Coodrleh Bldg. ; $10-11,2-4$.

l'ERKISS, FRHD 1'AYYE (b'81)-Ky.4, 06 (1'12); 401 F. 1'ierce st. ; ottlee, Goodrleh B](g. ; $10: 30-11: 30,3-5$

1"IATII, OT'TO KRNST (b'64) \& $0.9,96$; (1'03); (Los ollros); oflice, Guodrich $131 \mathrm{dg},: 10-12,2-4$.

IEDFWHL, FIANCIS HAMLTON (b'79) -Md.7.06: $\left(l^{2} 07\right)$; 200 E. Van Buren St.; offlce, $34 \mathrm{~N}$. Center St. : $10-12,2-4$.

Reed, Gilbert S. (b'50)-ill.4, 78 ; (1'03)

S.IRGENT, WM. 11. (b'82)-III.8, 05; (1'08) 516 E. Willetta St.; offled, (ioodrich Bldg. ; $10-12 ; 2-4$

sims, chaude Wdison $(1,79)-1$ nd.18,06: (l'06); (Indlan servlce); Yimil School, (illa C'rossing.

SMITH, WILLARD (b'76)†-0.26,98, Pa.2, '00; (I'08); 805 x. 4th Ave.; office, Natt. Bank of Arizona Bldg.; 1-5; S.

Stafford, Fredk. Allen (b'69)-111.4,95; (1'08); Desert Inn Sanltarium.

Stroud, Reginald James Henry (b'86) Colo. 2,12; () ; 810 N. 6th AFe.

SWETNAM, JAMES M. (b'41)-Mich.1, ;0 ; (l'03); 1748 W. Adams St.; offlee, 8 N. $2 d$ Are. ; $10-12,2-4,7-8$.

Tafel, Robt. M. (b'58)-11.8,'95; (1'0.) $623 \mathrm{~W}$. Adams SI.; offee, $309 \mathrm{~W}$. Adiums. Taylor, John Thos. (b'7 7 )-Mo.28, 02 .

THAYER, LAWHENCE H. (b'72) '00; (l'03) ; $520 \mathrm{~N}$. 4 th St. ; offlee, $315 \mathrm{~N}$. 1 st St. ; 10-12, 2-4.

THOMAS, JOHX WIX (b'57)-I11.10,91; (1'03); Sec. Board Med. Examlners; $121 \%$ N. 2d'St.; office, Natl. Bank of Árizona Bidg.; 10-12, 2-4; T.

THOMAS, ROY ECCLES (b'81) -IH,1,07; (l'07); 220 E. Noreland St.; offlce, Natl. Bank of Arlzona Bldg. ; 10-12, 2-4; T.

WATKINS, WM. WARNER (b'83)థ-Va.4 06: (l'06) ; (ioodrich Bldg.; T. *

Wright, Eli-E-111.8,85; ( ); H.F.11.6.

WILKINSON, WM. W11LING (b'69)@-Ill.6. '01; (l'11); Menber Colo. State Ned. Soe.; 144 N. 2d Are.; $9-11,2-4$.

WILLIAMS, ALLEN HAMILTON (b'68) Soc. 37 , Holley st. offee,

Bldg.; 10-12, 2-4; (A26); Or.
Wlllams, Marian Walker (b'73)-11d.7,0l ; not in practice; 37 Holly St.

Wortman, Melvin L. (b'61)-Mlo.24,'88; not Nortman, Melvin L. (b'61)-Mfo.
in practice; 538 E. Culver St.

in practice; 538 E. Culver St.
WYLIE, WIXFRED (b'55) $\oplus$ IHI.1, 7 , N.Y.8,78; (1'05); 04 N. Centre St.; office, 120 N. Ist Ave.;10-12; S.

PIMA, 500, GRAHAM

DRYDEN, ROBT. CRAIG (b.5\%)-Mo.1, '80; (l'09).

PIRTLEVILLE, I,500, COCHISE

ZIMNERMAN, ISAAK WOSIIKOVICH (b'63) ๑-Rus.10,'85; (1'03).

PRESCOTT, 5,092, YAVAPAI Iha, Warren E. (b'40)-N.Y.3,63; (l'03). (1'03); T.夫

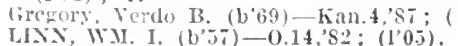

1.0ONEY, BOBT. NELSON (b'70) +-Tenn.5, 9s: (l'03); Sec. Arlz. 13d. of llealth.

ICNAL1, JOIIN MItYAN (b'65) +-Cal.5, 'vij, ('al. 7,$02 ;(1,04) ; \mathbf{S}$.

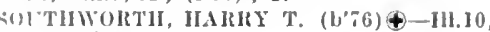
(1) I (1"04); S.

WH, (1'12); T.*

SUT'NT, ('IARENUE EDGAR (b'74) b.C.2,96; (l'03); Sec. Ariz. Med. Assn; s.

RAY, 25, PINAL

'RAWFORI), JUHX E. (b'80)-I'a.12,05; (l'07); $\mathrm{S}$.

llart, F. J.- N.Y.13, 83 ; $\left(1^{\prime} 03\right)$

James, Ilarry J.-Ont.I,07; (1'12); 1602 S. Cnlon dve.

RICE, 300, GILA

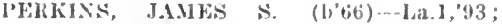
(Indian Servlce).

SACATON, 250, PINAL

Jelcher, Ifatetl Austh (b'8t)-Md.1,0 ; (Inelian Servlce); I'lma School; $\mathbf{T}$.

\section{SAFFORD, 929, GRAHAM}

llartin, Geo. Seoll (b'86)-Ky.2,09; (l'13) McI'HIl'T, WHLISS ELTON (b'84)—-Ky.4, 07 ; (l'09)

Platt, Wm. E. (b'59)-ky.2,'94; (1'03).

HEWEL, HENRY Y. (b'75) $\uparrow-0.6,02$

(1'11) : Member 0. State Med. Assn.

STRATTON, J. NLWTON (b'79)-Tex.6,07 $\left(l^{\prime} 07\right)$.

Warmer, llenry J. (b'60)-Tex.2,99; (1'03).

SAN CARLOS, 50, SAN MATEO

Herman, Marquerlte Bailey (b'88)-1'a, 11: (Indian Service); San Carlos Sehool. HFR.MAN, MAXWELA (b'88) †-Pa.2,09 (1ndian Serrice); Member Med. Soc. of the state of $P$ il.

Taylor, Jos. J. (b'66)-IIo.10,'93, Io.7,08; (Indian Service).

SAN SIMON, 8I, COCHISE

Alexander, Monroe L. $\longrightarrow$; (ま).

SCOTTSDALE, 75, MARICOPA

Lat Kue, Franklin (b'5t)-Pa.2,85; not in pratlee.

SELIGMAN, 300, YAVAPA

('artmell, Francis H. (b'82)-Ky.9, 04; (1'06). KOEBIG, WALTER CHRISTIAN S. (b'84)Cal.9,'10; (1'11); Member Med. Soc. of the

State of Cid.

ST. JOHNS, I,200, APACHE

Bouldin, Thos. J. (b'78)-(ia.11,01; (l’09)

Roberts, Alonzo S.--Ind.8,00; (l'08).

ST. MICHAELS, -, APACHE

Gottbrath, Norbert J. (b'79)-D.C.2,'12; ().

SUPERIOR, 200, PINAL

Ilolm, Edgar (b'7 7 )-Ill.6,03; (l'03).

TEMPE, 1,473, MARICOPA

AlEXANDER, RALP1I L. (b'76)థ-Jo.20

03 ; (1'03); (Indlan Service).

Brechan, Ferd. C. (b'78)-Ia.8,03; (I'00).

Ioeur, Benj. B. (b'71)-Ark.1,'96; (I'03).

TOMBSTONE, I,582, COCHISE

Hughart, Harry H. (b'76)-Ya.6, $00 ;\left(1^{\prime} 03\right)$

Welch, Grace W. T. (b's8)-Cal.2,'11; (\$)

TUBA, 25, COCONINO

Wilson, IIenry Kirke (b'7t)-Ill.6,'00; (In

dian Service)

TUCSON, I3,193, PIMA

EITLER, JOEL IVES (b'75) $+-11.7,0 \mathrm{I}$

(1'12) ; 123 S. Stone Ave. ; S.

'IYNE, MEADE (b'82) ๑-Ill.6, 07 ; (l'10) 701 N. Park Are.; offlce, 123 S. Stone Ave. : $11-12,3-5$

CREI'1X, HENRY E. (b'62)-IH.11,'86 ; (I'03): $38 \mathrm{~S}$. Stone Ave: $10-12,1-4,7-8$ DODGE, GEO, EUt'ENE $\left(b^{\prime} 73\right) \oplus-V a .1,96$ (l'12); $106 \mathrm{~N}$. Stone Ave.

FENXER, HIRAM W. (b'59) \-0.1,'s1 (l'03); Paseo Redondo; offlee, 9 E. P'en nington St.; $9-11,2-4 ; \mathrm{T}$.

HUFFMAN, IRA E. $\left(\mathrm{b}^{\prime}, 0\right) \oplus-\mathrm{Ia} .6,01$ : $\left(1^{\prime} 0 \pi\right)$; Pres. Board of Med. Examiners and Ariz. Med. Assn. ; 825 E. 3d St.
KIXISLFY, WM. A. (b'76)-Que.3,08; (I'I1)

MET\%(iLA, JEREMLA17 (b'76) - I11.1,01 (l'11): 'Tueson-Arizona Sianatorlum ; 9-1. OLCOT'R, ARTHUK WV. (b'65) $4-M 0.2,87$ $\left(l^{\prime} 03\right) ; 234 \mathrm{~N}$. Main st.; 54 N. Stone Are. ; $10-11,2-4,7-8$.

l'llling, Henry II. (1,45)-111.4,70; (1'03): $643 \mathrm{~N}$. Stone Ave.; offlee, $116 \mathrm{~N}$. Stone ive. ; $8-11,1-4$

QUINTON, CHAS. HYHON (b'78)-Mo.I0 12; (Indlan Servlce); San Xafler School. Rodgers, Mark A. (b'68) $\boldsymbol{\oplus} \longrightarrow$ Y'a.1,9I; (1'04) $123 \mathrm{~s}$. Stolle Ave, ; $11-12,3-5,7-8$

lrowley, Wim. Theodore (b'69)-Mll.5,01; $\left(1^{*} 03\right)$; 928 E. 9 th St. ; offlce, 56 N. Stone Ave.; OALR.

SCINIIBEL, A. GARFIELD (b'80)-0.26, $06 ;\left(l^{\prime} 06\right) ; 401$ Speedway ; offlce, $21 \mathrm{E}$ Pennington St. ; 10-12, 2-4, 7-8; Pd.

Schraller, Chas. Adolph (b'70)II-Cal.5,'93; (l'03) ; Sauta Irlta Ilotel; 11-12, 2-4.

SERVIN, GUILLEIHO R. (b'6I)-Nex.3, '85; (1'04); (Indlan Servlce); 505 S. 6th Ave. ; $8: 30-10,2: 30-4$.

Simpson, James (b'71)-Mo.2,03; (l'11): E. Speedway ; offlce, $108 \mathrm{~N}$. Stone Ave.

THOMAS, CHAS. ANSLEM (b'7 $)$-La.1, '05;(1'12) : 30 E. I'ennington St. ; 1-3, 7-8. TROLTMAN, GEO. D. (b'67) $+-0.13,91$; $\left(\mathrm{H}^{\prime} 08\right) ; 637 \mathrm{~N} .6 \mathrm{~h}$ Are.; offlee, $40 \mathrm{~s}$. Stone Ave.; LR.

Walls, John Rogers (b'67)-Ont.3,'91: (l'03) 530 E. Ist St.; office, $118 \mathrm{~N}$. Stone Are.

WATSON, SAIL. HUMES (b'77)๑-Ill.1, 99; (l'12); Tueson-Arizona Sanatorlum; $10-1 ; \mathbf{T}$.

WHITYORE, WH. VIXCENT $\left(\mathrm{b}^{\prime} 62\right) \oplus-$ Cal.6,'90; (1'03) ; 314 S. 6th Ave.; oftlice, $123 \mathrm{~S}$. Stone Are. : 11-12, 2-4, i-8.

VALENTINE, - MOHAVE

1tiggs, Lester Davld (b'80)-Mo.20,04; (Indian Serrice); Truxton Canon School; U.

WHITERIVER, 32, NAVAJO

Fralic, Harry B. (b'8I)-Pa.11,05; (Indian Service); Ft. Apache School.

\section{WICKENBURG, 570, MARICOPA}

lielth, Duke (b'86)-Cal.6,'04; (1'06).

CUINBY, STEPHEN CRAMER (b'68)Ky.4,'99; (l'13); Member Ky. State Med. Assn, ; G.

Rudd, Wm. Mann (b'27) $\rightarrow$; (1'03).

\section{WILLCOX, 1,411, COCHISE}

Wllson, John Crofford (b'79)-Ind.9, 03 : (l'04).

WILLIAMS, I,267, COCONINO

Jeffrles, Clymer D. (b'81)-Ga.11,02; (1'06). MELICK, PRINCE ALBERT (b'69) No.24,'92; (1'03).

Rounsevelle, Arthur G. (b'68) - Mo.8,'89; (l'03).

\section{WINKELMAN, 400, GILA}

Ilalsey, Bee Bartow (b'62)-Md.1,85; (1'10)

Marden, M. G. (b'76)-Ky.2,'02; (l'03).

\section{WINSLOW, 2,38I, NAVAJO}

Bazell, Roscoe Gould (b'79)-0.1,'01; (l'06) Brown, Oscar S. (b'58)-0.3,86; (I'03) (1263 W. 10th St., Riverside, Cal. ; l'96) Hathaway, Chas. L. (b'72)-Ia.10,02; (1'03). Sampson, Geo. P. (b'54)-0.9,'80; (1'03). Sprankle, Paul Darling (b'79)-Pa.2,04; (I'08).

YUMA, 2,914, YUMA

AP, JOHY HENRI (b'66)థ-Ore.1,'92; (l'03).

CLYMER, HENRY VANCE (b'63)-Ore.1, 90 ; (1'03).

FERGUSON, RAY (b'69)-.Mo.8,'99; (l'03). JACOBS, LEON (b'78) -Ill.1,'03; (Indian Service).

Fetcherside, Enoch Blackburn (b'46) Tenn. 6,'84; (1'03).

KETCHERSIDE, JAMES ANDREW $\left(b^{\prime} 74\right) \Phi$ -T'enn.6,'93; (1'03); OALR.

KNOTTS, ROY R. (b'83) $\oplus$-Ore.1,08; (I'08); OALR.

WHLS, EUCLID C. (b'85)Ð-Va.4, 06 : ('08); R.F.D. 1. 


\section{ARKANSAS}

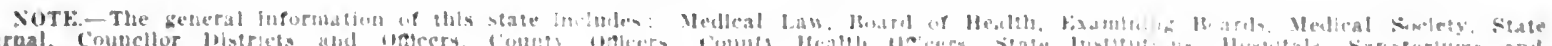

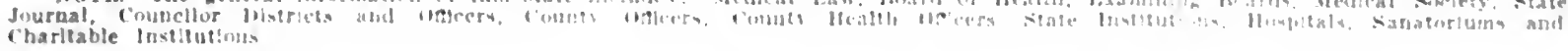

\section{ARKANSAS}

Population (1910 census)

Number of Counties.

Number of Physlelans.

Members state Socioty. Dec. 31 1913.

Area of State in Square Miles

1.574 .449 73

2.652

1.117

53.335

MEOICAL PRACTICE LAW OF ARKANSAS

\section{An Act}

Te Hegrulate the Pructice of Medicinte and surgers, and lorwliding for the Appolntmentical tree boards of state

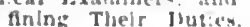

Be II enacted by the fieneral Assembly of the state of Arkansas:

Section 1. MFMBEIS OF MOARI, H HW APPOINTED: That the medica: examtuers hereln provided for shall consist of three boards: One of physiclans and surgeness boards: One of thisiclans and surgens: Soclety of Arkansas": One of physjcians Soclety of Arkatuas": one of physjeians
anil surgeons. recommenderl by "The Irkansas sitate belectic M!ellical soejety." and one of physiclans and surgeous, revomnended by "The Arkansas "Iectical Suciety."

There shall be seren (i) nembers of each prard. appolnted so as to have une member from each Congresslonal Jistrict upon each bonrd. The appuintment shall be ande by the fiorernor from a list of names presented the fiorernor from a list of names pre
by the respectlre medica! strictles.

see 2. VAlAsclks: That the members first appolnted oll the hroards shall he dirlded into two (2) classes, the flrs: class to conslst of four (i) suembers appolutevl for (xo 12) years, the second clasy of three (3) niembers shall te appointel for four (1) years, and thereafter all appointmets shall be for four (1) years.

Vacancles In the sald lmards shall be flled as they occur by appoininents from listy
furnished as provided. Io meruber shall furnished as provided. No merulier shall succession; and no niember, or professur. or teacher In a miedical college or schon! or unlverslly, baving a medleal departnient, shall be appolnted ujon the boril.

sec 3. OkGaNizATIOI: Withln thirty dass after their appointments the respective boands whall meet and orzanlze by elocetlug a president. aecretary and treasurer of thelr resjective inarts.

The treasurer of each of the vald twards shall give toond In auch amount av ma! he dewignated by the bonad, conditloned for the falthtul disbursement of all musels ceming into hls bands as such treavurer.

Each of the sald brords sluall have a common seal. The prewldent and serposary ahall have power to arlinlulater ontlis for the purposes of tists Aft. The menthers of the boarda shall, befure cuterint upros the dlacharge of thelr luties, take the ath prescrlbed by the conatitution of thls state
for state oficers.

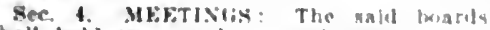
hall bold two regular stated mecting fuer year, to-wls: The necond Turulaye las vias and Novemine, at wuch plates as $a$ majurtis

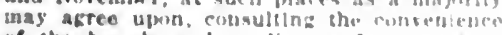
of the boards and applleaise fut cammilla tlon and certincater.

special meetinges ma le helu upus tho

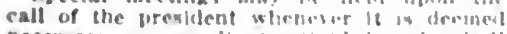

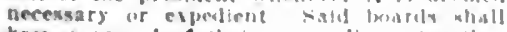

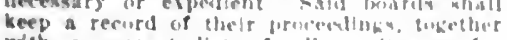
with a correct lint of all apulicanta for With a correct llat ut all alpulicante fur

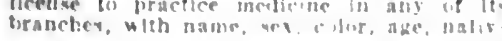

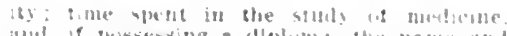

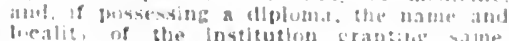

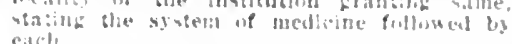
cacili

This record shall also state whether the

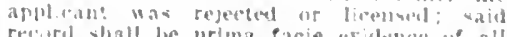

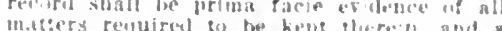
certifleate isouled under the weal of sald tuard, and algned by the brentelent astil

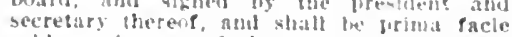

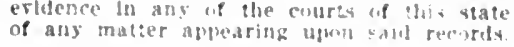
Sice 5. TITLE (IF BOARH: The mards

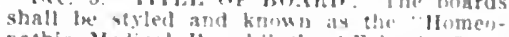
pathic Medica! It arcl." the "Ecterbic State Vedical Itoard." and the "None Metical Boarl of the Arkansis Medicall soclety"

The "llomenathic state Medical Hoard" shall examlne all apblients sho bure

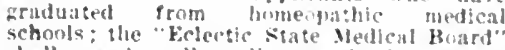
shall examine a!l andlicants who hare gradmated troun the relectic medieal schooly: and the "state Medical Huril of Arkansas Menlleal Socicty" sliall examine all other apmlicants.

The loards shall act separately and inderendently of each other, and wherever this let refers an and defmes the duties of the inard, it shall he construed as referring to their acting separately, as well as independently of each uther.

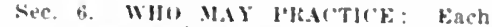
person nuw fracticing medicine in this state shall. whin ninety days after the passage of this Act, nregare it uritten statement

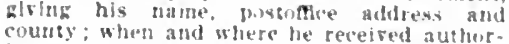
ity to practice medicine by this state

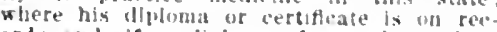
ord: and, if a liplonils. froms what schocl or medical college lisuded: such statement shall be sworn to before sine ottlcer autlorIzed to administer oaths, and shall be forsarded to the secretary of the board represcritug his schonl of medicine

rescritis hlis school of medicine. If If shall appeat from such statement
that such berson was regularly authorlzed t" practice mediclne under the then evlsting laws. the sald board shall reiblster the name of vich person in thetr list uf accerdlted Jihyslelans. and lssue to wuch perwill a cer. tifiease that hls name has leen placed upon such list. If it sllall alsuear from the statement that wich persun has not been that his difloma is llut from a reputable niedieal aclimel ur colleces. or, if prom any

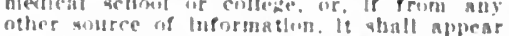
other aource of luformathon, If alutl appear refuse bu lavbe to which jerion a certifleate.

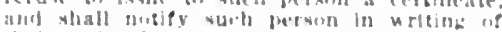
their refusal and the reavin therefur if

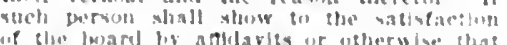

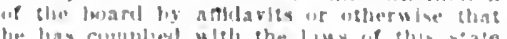
he hav complial wlell the liny uf blus sate

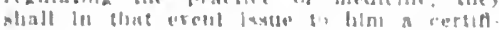

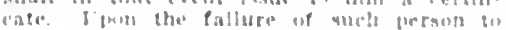

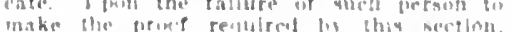

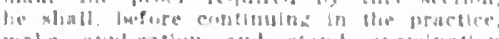

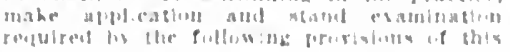
A.t

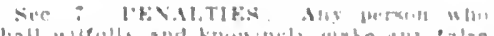

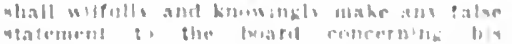

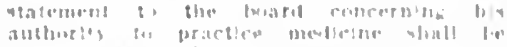

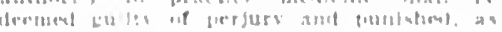

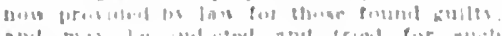

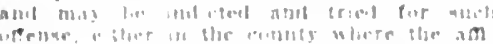

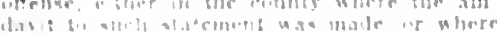

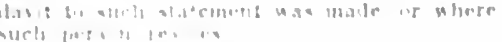

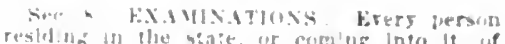

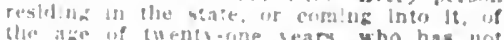
llac ace of tuenty-rine sears, who has not clne urder the ex!stine lawe. makinz absll. ciblen th reolute: under the provlslous of hiv Aut fur the wurb of practlelng mediton to the secrestall firs: make applica-

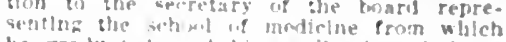

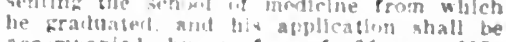
Accompanim by a pee of ficen (\$15) todlars. this fce leoing P.r plamination and cant shall fresent the the bast ablufactrory crlence of traduation prom a repulable

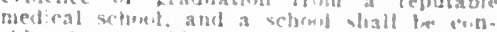

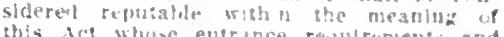
this Ac! whur entrance regulrentents and

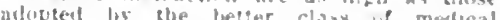

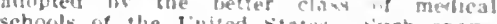
Intatons mav pe writipn or oral snet shall be of a practical chatacier atd comducied

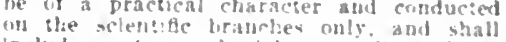
incluife anatomy, physingy, medtcal chemistry, materia mellea, therapeutics, theors atsl practice ne medicine. pashology, bacteri. ology, surgery, olmetrios, byneviluas atud hyging All ques:tmss and answers, with grades attached, whald the preverrevd by the sacretary por wht gear. If. In the "gining necessary qualtflcations. the board shall issue o him in cersitica:

The loardi may, at their discretten. arrange fur ractpricity in licelse with the authurities of states and territuries having requlrements eyual in those of those cytal:lished ly the boards. and erers person deslring fleense under reciproclty must make

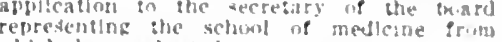
which he fraduated

liconse may lex grasted applicants for Ilcense under such reclprocity un pasment if twenty-fise dollars

The poards may refuse w or mar rerohe a Hense for the following eauses, b-wis:

(a) thrunic and persistent inehriesy

(i) The practice of criminal abortion.

either as priseval or atethe

(c) comrletion of the crtme Inruiring moral turvitude

(d) lublicly altertlsing spedal apulity in reat or cure chron!c and incurable disesces

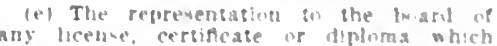

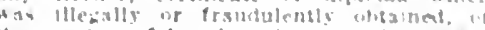

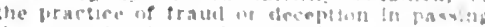
slee examination in complands for vore lating the prostslons of thls eretions the copy uf the esmulaint, and bitiris heasing

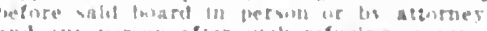

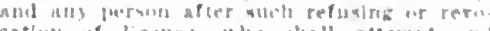

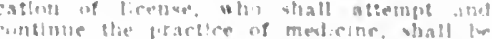

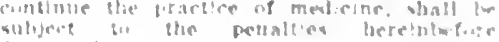
demeritiant

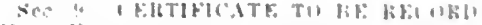

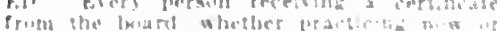
heraper licrused t:o practuce shatl hase

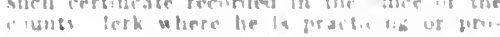

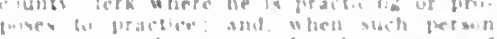

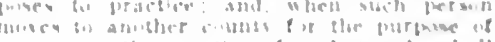

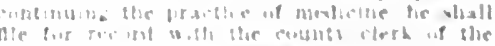

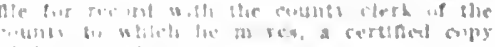

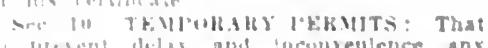

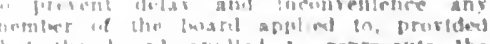

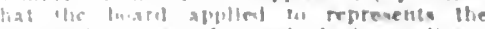

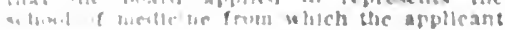


graduated, may grant a temporary permilt to pructice, upon the payment of the fee required for applicants, and after a satisfactory examination, such permit shall not continue in force longer than until the next regular meeting of the board, and shall not be granted for a longer period than two months in advance of the nex regular and stated meeting of the board.

Sec. 11. PENAITIES: Every person who shall practice, or shall attempt to practice medicine in any of its branches, or who shall perform or attempt to perform my surgical operaticy for nuy person, or lipon any person within this state without tlrst having complied with the provisions of this Act shall be deemed puilty of " inisdeAct, shall be decmed guilty of a misdemeanor, and upon conviction thereof shat be punshed twenty-fire $(\$ 25)$ dollars nor more than
five hundred $(\$ 500)$ dollars, or by luprisonment in the county jail for a period of not less than ten days nor more than ninety days, or by both fine and imprisonment, and each day of such practlce shall constltute a separate offense.

Provided, howerer, That this sliall not apply to persons now engaged in the practice of medlcine until ninety days after the of medicine until ninety days after the passage of thls net, the time

Sec. 12. ITINERANTS: Any Itlnerant rendor of any drug, nostrum, ointinent or application of any kind, intended for the treatment of disease or lnjury, or who may, by writing, print or other methods, profess to cure or treat diseases or deformity by to cure or treat diseases or deformity by any drug, nostrum, manipulation or other be In violation of this law and punished as be In violation of this law and punished as provided. This does not apply to person
who obtaln certificates as hereln provlded.

Sec. 13. DEFINITION OF PRACTICE Any person shall be regarded as practicing medicine, in any of Its departments, within M.D. or M.B. to his name, or, repeatedly prescribe or direct for the use of any person or persons any drug or medicine or other agency for the treatinent, cure, relief of any bodily injury, deformity or disease.

Provided, That nothing in this act shall be construed as to prevent any person from adminlstering domestic remedies without recelving any compensation therefor, and celving any compensation therefor, and
nothing herein shall apply to the so-called midwlves.

Sec. 14. COMPENSATION OF MEMBERS : The secretary of the board shall provide the board with blank books, certificates and such stationery as is necessary for the transaction of the business pertaining to their duties. All money received by the board shall be disbursed by the treasurer upon the warrant of the secretary counterslgned by the president of the board.

The nembers of the board shall receive as a compensation for their services the sum of ten $(\$ 10)$ dollars per day for every day actually engaged in the discharge of their duties under this act and the secretaries shatl receive such additional salary as may shall receive such additional salary as

be flxed and agreed upon by the boards.
The members of the boards shall pay their own traveling expenses and hotel bills. The members of the boards shall look to and be dependent entrely upon the fees provided herein for their compensation, and all other

expenses in connection with their duties.

It shall not be lawful for said boards, or any inembers thereof, in any manner whatever, or for any purpose, to charge or obligate the state for the payment of any money irhaterer. If, after paying all legitimate obligations of the board for stamps, printing, salary of secretary, etc., there should not be sufficient sums on hand to pay each nember his per diem in full, the amount shall be prorated; but if at the end of the year there should be a greater revenue than sufficient to meet all obligations, such surplus shall remain in the treasury to be used in expenditures of the boards during the succeeding year.

Sec. 15. ANNUAL REPORTS: The boards shall annually fle with the governor a report of their transactions during the year, giving the names of all to whom they have the system of medicine practiced by each, atid shall in sucli report show the amount of money receivel and from what source, the amount expended and for what purpose, and shall embody in their report any other inatters or facts decmed expedient, and make such recommendations for the limprovement of the practice of medicine in thls state as may be deemed advisable.

If the boards shall hare sufficient funds on hand to pay for same, they shall have said reports printed in pamphlet form and furnish each physlclan in this state with a copy thereof.

Sec. 16. ACT IN FORCE: All laws or parts of laws in conflict with this Act are hereby repealed, and this Act shall take effect and be in force 90 (lays after its passage.

Approved Feb. 17, 1903.

\section{The Gant Law}

Section 1. ADVERTISING OR SOLICITING: PROFESSIONAI, SFCRECY ; PENAlties : That any physiclau, surgeon or person eligaged in the practice of medicine in the state, for the purpose of procuring patients, employ any solicitor, capper or drummer, or shall subsidize or employ any hotel or boarding-house, or advertise hls business or remedles by untruthful or improbable statements made in his advertlsments, circulars or cards, or who shall obtain any fee or compensation from any one festly incurable disease is curable, or who festly incurable disease is curable, or who shall wilfully betray or expose any profes-
sional secret learned by him from his patient sional secret learned by him from his patient or patron, or who shall become an habitual cine or surgery whlle such habitual drunkard, or administer any niedicine or perform any operation while drunk, shall be deemed guilty of a mlsdemeanor, and on conviction be punished by a fane not less than twentyfive dollars $(\$ 25)$ and not more than two hundred dollars $(\$ 200)$, and by a revocation of his license to practlce medicine and surory, whlch such revocation shall be adjery, which such revocation shall be adin whlch he is tried and convicted, and at the same time.

Sec. 2. CONVICTION OF CRIME; PENALTIES: That whenever any physiclan and surgeon, or person engaged in the practice of medicine or surgery in this state, shall be convicted of any crime and misdemeanor, convicted of any crlme and misdemeanor, other penalty or penalties inıosed upon him other penalty or penalties iniposed upon him, to practice medicine and surgery.

Sec. 3. ABORTION: That If any physician or surgeon or other person engaged in the practice of medicine shall commit the crime of abortion, or aid or abet in the commission thereof ; provided, this section shall not apply to any abortion produced by any regular practicing physician for the purpose of saving the mother's life, he shall be adjudged guilty of a felony and punished by imprisonment in the state penitentiary for a period of not less than one year nor more than five years and his license to practice shall be reroked.

Sec. 4. That any physician or surgeon or person whose license to practice shall, on conviction under the provisions of this Act, have his license revoked, may appeal from the judgment of conviction, but shall not, pending the appeal, be permitted to practice either medicine or surgery, and if he does so practice, or attempts or offers to so practice pending the appeal, he shall be punished in the same manner and to the same extent as if he had never had any license to practice.

Sec. 5. That after the expiration of one vear from the date of the revocation of the license of any physician and surgeon, under this act, he may appeal to the proper medical board for a new license, and may be relicensed, if he shall satisfy the board that
is qualified, has reformed and is worthy.

Sec. 6. That all laws and parts of laws in conflict herewith are hereby repealed, and this Act shall take effect and be in force from and after its passage.

Approved Feb. 17, 1903
STATE BOARD DF HEALTH

F. B. Young, Springdale; B. A. Fletcher, Augusta; S. A. Southali, Lonoke; W. P: Lark, Mend; G. A. Wuckner. Dermott; Morgan Smith, L. A. Buckner, Dermott ; Morgan Smith, rison, Assistant Health Offcer, Litle Rock.

\section{STATE MEDICAL BOARD OF THE
ARIKANSAS MEDICAL SOCIETY}

One Member Appolnted from Each Congresslonal DIstrict

J. C. Wallis, Presldent, Arkadelphla ; F. T. Isbell, IIoratio; W. F. Ellis, Fayetteville; I. J. Stout, Brinkley; M. Fink, Treasurer, Stewart, Secretary, Pine Bluft.

HOMEOPATHIC STATE MEDICAL BOARD One Member Appointed from Each Congressional District

Victor H. Hallman, President, Hot Springs; Geo. M. Love, Rogers; W. B. Ilughes, Ilttle Rock; C. S. Bungart, Ft. Smith; Perry C. Williams, Texarkana; Ida
J. Brooks, Little Rock; Scott C. Runnels, Secretary, Little Rock.

\section{ECLECTIC STATE MEDICAL BOARD}

One Member Appolnted Prom Each Congressional District

R. M. Jernlgan, Presldent, Rector ; Pearl H. Tatman, Eureka Springs; J. I. Vall, Lycurgus Gardner, Atkins; W. C. Dalhenbaugh, Plne Bluff; Claude E. IJaws, Secretary, Ft. Smith.

\section{ARKANSAS MEDICAL SOCIETY} Officers, 1913-14

Frank B. Young, President....... Springdale I. E. Moore, 1st V.-Pres............... Searcy S. L. Steer, 2d V.-Pres......... Hot Springs F. G. Richardson, 3d V.-Pres. Heber Springs Clinton P. Meriwether, Secretary, Little Rock

\section{State Journal}

Journal of Arkansas Medical Society, Little Rock, Wm. R. Bathurst, editor.

\section{Councilor Districts and Officers}

First District.-Crittenden, Clay, Craighead, Greene, Lawrence, Mlssissippl, Polnsett and Randolph

Second District.-Cleburne, Fulton, Independence, Izard, Jackson, Sharp and White counties. L. E. Willis, Councilor, Newport.

Thlrd Distrlet.-Arkansas, Cross, Lee, Lonoke, Nonroe, Phillips, Pralrie, St. Francls ford, Councilor, Cotton Plant.

Fourth District.-Ashley, Bradley, Chicot, Cleveland, Desha, Drew, Jefferson and Lin-
coln counties. E. E. Barlow, Councilor. coln cou

Fifth District.-Calhoun, Columbia, Dallas, Lafayette, Ouachita and Union counties. J. S. Rinehart, Councilor, Camden.

Sixth District.-Hempstead, Howard, Little River, Miller, Nevada, Pike, Polk and Sevler counties. C. A. Árcher, Councilor, De Queen.

Seventh Distrlct-Clark, Garland, Hot Springs, Montgomery, Saline, Scott and Hot Springs.

Eighth District.-Conway, Johnson, Faulkner, Perry, Pulaski, Yell and Pope countie

W. A. Snodgrass, Councilor, Llttle Rock.

larion, Newton, Searcy, Stone and Van Buren counties. A. M. Hathcock, Councilor, Harrison.

Tenth District.-Benton, Crawford, Franklin, Logan, Sebastlan, Washington and Madison counties. J. T. Clegg, Councllor, Slloam Springs. 

County omcers of the Arkansas Medical

ARKANSAS COUNTY W. 11. Boswell, Presldent............ Wimy Wa ASHIEY COLNTY

A. D. Knott, Presldent..............W Whot BAxter COUNTI W. C. Tipton, Tresldent.....Mountaln IIome
J. J. Morrow, Secretary.............. Cotter BENTON COUNTT

J. T. Powell. President............. Maysulle
R. T. Henry. Secretary........ Bentonville ROONF COLNTY

J. J. Johnson, Presldent......... Harrlson

BRADLEY COUNTI

C. $\times$ Martin, I'resldent........... Warren

B. H. Green, Secretary............... Warren CALHOUN COUNTY E. T. Jones, Presldent............. Hampton
Chas. T. Black, Secretarj....... Thornton CARROLL COUNTY

W. D. Ezell, Presldent...... Fureka Sprlngs R. II. Huntington. Secretary. Eureka Springs CHICOT COUNTY

M. M. Norton, President....... Lake Vlllage CLARK COUNTY

S. X. Doane, Presldent..........Arkadelphla W. T. Row!and, Secretary........Arkadelphla CLAY COUNTY

M. V. B. Waddle, President......... Success
J. J. Isatumer, Secretary.......... Cornlng CLEBURNF COUNTY

F. G. Richardson, Presldent... Heber Springs Horace E. Rut, Secretary.... Heber Springs CLEYELAND COCNTY

W. L. Hartsell, l'resldent..........Rison

II. 0. WIlson, Secretary............. Randall COLUMRIA COUNTY

w. A. Stevenson, Presldent........Magnolia

C. D. Sterens, Secretary........... Magnolla CONWAT COUNTY

C. D. Clark, President............sorsilltin W. i. I'resley, Secretarg............ Morrillton CRAIGHEAD COUNTY

I. W. Iutterloh, Presldent........Jonesboro CRITTENIEN COUNTY

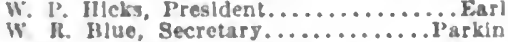
cross coustr

R. Longest, Fresident............ Wryne

IALLAS COUNTY

11. II. Aikinaon, President........ Fordyce

C. J. March, Secretary................. Fordyce DESHA COUNTY

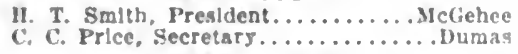
DHFW COUNTY

F. IR. Cothan, President..........Montlcello

W. A. Brown, Secretar............. Monticello PACLKNER COUNTY

C. W. Hlakely, lreslolent.......... Conway

J. s. Westerfield, Secretary.......... (tonway YRANKI.IN COUNTY

T. H. Blakely. I'resldent........... Coal IIII Thomas Douglass, Secretary........... Ozart FULTOX col'st

C. W: Culp, lrealdent.....Mamsioth Surlng

d. 1. Weathers, secretary.............saletu (iARI.ANI COUNT:

(Included In Hot springa-fiarland Couniles.) Gillavt count:

d. B. Shaw l'realdent............ Shoridan Inren Wallin, Secretary................. Sherldan GIIEFNF COIXNTY

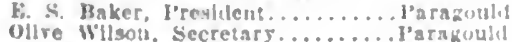
HFMITSKAL CORNT

s. J. Wearer, I'residen:.

M. V. Fussell, Secretary. hot shixfs cotity

k. T. Iramllit, l'reslilent.
k. Y. Phllllps, Secrotary.
HOT SPRISGS-GARLAND COUNTY

9. L. Steer, Presldent..........Hot Sirlnks M. F. Jount, Secretary.......... Ilot Sprinzs HOWARD COENTY

1. A. Mutchlnson, l'resldent........ Nashrille

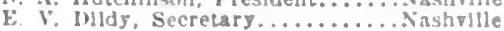
INAFPENDENCE COUNTY

1. Hayden, I'reshlent............ Iethescla

I. s. Crals, Secretary.......... batesrlllo 12.ARD COLXTY

F. A. Baxter, l'resldent.......... Melbourne $1 \mathrm{~m}$. Imllari, Secretary..................... JACKSON COUNTY Ira H. Frwln. Iresldent........... Newport
II. O. Walker, Secretary......... New port JEFFERSON COUNTY

T. Woodul, l'resldent.........I'lne Bluft T. I'alner. Secretary............Plne Blur JOHNSON COUNTY

John F. Bradley, Presldent...........Lamar mnle Hays, secretary............ Lisusilla LAFAYETTE COUNTY

D. W. Bright, I'resldent.......... Lewlsville IA AWENCE COLNTY

G. M. Watklns, Prestdent....Walnut MIdge II. H. McCarroll, Secretary...W Walnut Rldíe LEE COUSTY

C. W. Chaffln, Pres!dent.............Moro Thos. II. Ingram, Seeretary......... Marianna LINCOLX COUNTY

I. D. Watts, Presldent............. Trro

T. W. Ralnes, Secretarr................ Tiar cit I.ITTIE RIYER COUNTY

T. T. Shackelford, Presldent......Foreman

WV. E. Vaughan, Secretary,.......RIchmond LOGAN COUNTY

N. E. Armstrong. Preaident......Boonerllle A. 1. Hederick, Secretary.......... Boonerllle LONOKE COUNTY J. D. Ward, Jresldent............ England
John F. England, Secretary....... England MADISON COLNTY

13. A. Moore, Presldent...........Mindsrljle

5. 0 . Berrs, Secretary............Hindsille MARION COLNTI

G. F. Elam, Presldent............... Erns
L. V. Weast, Secretary......... Yellrille MLleER COUNTY

16. 1. Grant, I'resldent......... Texarkana

1. II Lanler, Secretary........ Texarkana MISSISSIIPI COUNTY

II. F. Crawford, I'resldene..........Wllson Thomas (. Brewer, Secretary......... Usceola MONROE COLNTI

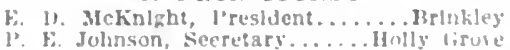
MONTGOMFIE COTNTY IV. D. Freenan, l'reshed.......... Id SEVADA COLNTY

IV IV. Rlee lresldent............ Prescott

1. Huchinan sectetary......... l'rescoth OUACIITA COUNTi

1. W. Meck, l'resident............. Camuln

.. Early, Secretary............ lokith cotitit

I I somerlef, I'reshlent.

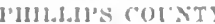

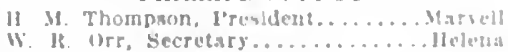
J'IKk: col'st

$\therefore$ J. Silaghlater. I'resldent.

I: 4 . Minture Secromary.

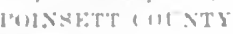

loiris, l'reandens.

camplent

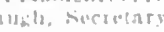

Jul,k (1) $\backslash T$ y

1. If Watklos, l'rosideft

linet: (1) $>$ Tr

I) 11 aye I'rewlome

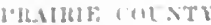

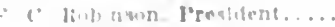

James l'siber, secrotary

iilen wist

Ilarrisbura llarrisiug inisclor

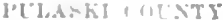

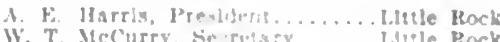
W. T. McCurry, Se rutagy..... . . Illile Rock lia.inon

Jhy W: Brown, l'restuent.

W. F. Ilamll, Secre?ary.

SAliNE COI:NTy

Warren Kolley, l'res!dent...

SFAIR'Y COCNTI

Ira Smlih, Tresldent. h haugh, secrelary. SRIBASTIAN CULNTY

S. Ilolt, l'resldent............ Smlth SEVirir cotati

IV. K. WIstom, l'res!dent......... Le Queen

¿. F. Kltchens, Secretary........... De Queen ST. Fliavis cotsty

. C. Itegnolds, l'restelent.............. ('ut

D. 1. I'clion, Secretary......... Fortest City UNION COLNT

i. J Meciraw, P'resldent......... El porado WASHINGTON COLNTS

F. F. Ellls, Jres!deat..........Fayeterllle II. II. Towler, Secretary.......... Fayetierillo WHITE COCXTY

E. II. Barker, President......... Center Hill I. R. Majors, Secretary................. Searcy WOODRLFF COLATY

It. X. Smlth, Presldent..........Ausus?

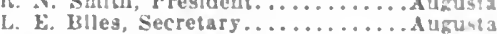
YELL COUNTY

iv. R. Rrewer, l'resldent.

J. 11. Linzs, secrelary................. Daringl!

\section{COUNTY HEALTH OFFICERS}

vunt

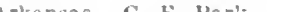

Ishley.

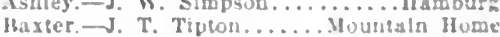
Penton. -J. A. Feryus........... Hofer Bcone.-I). E. Frans..............llarrisoa Bradley -G. L. Wllson.........llermltaze Calhoun.-D. F. Witson...........llampton Carroll. $\rightarrow$ C. A. Georie........... berryville hicot-W. W. Easterlizg............. (hjou hirot. W. W. Easterins.......... Chicor Cleveland._. A. Iughes. . . . . . . . Rison columbia.-II. A. Loncino......... Masmolis conway. C. D. Clark.............. Storritlica caighead.-C. M. Lutterloh......Junesboro 'ramford.-M. s. Dllire!l........ Vin liuren I'rittenden.-I. C. Mcbay...........Marion Crusis -W. II. Mckle... liallas $i$ J March.

mees - II. I. Jupe.

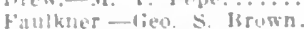

ramhlin-F. W. Mlachburn.

Fulenu... J. I. Weathers.

Garland-J \& Woml.

II it sirige - It. I jhilitis

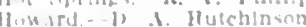

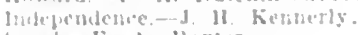

Jat - - i. Haxber...

Jacksul. - V. l. Watwon.........

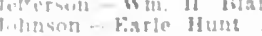

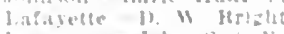

l.awrtuce - J hn swinlic.

l.e's. 10. L W Whtaments.

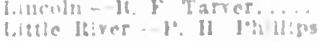

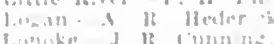

Maliw II Yri Yumbil

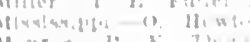

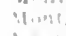

inisita

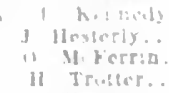

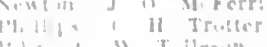

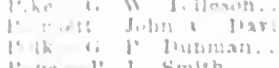

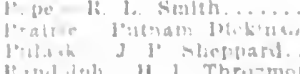

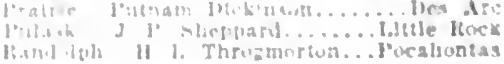

Furjuce

ioneticello

Conumy

Sialeru

low spriag:

Marnguula

Mashrillo

llatearllle

Mellourae

Nongurs

dine li!u? Clariasrllle alewisrtlle Marianna sier clis An?de we Isimule icliville Terazkana climerela yis lita j'rescols Jaster Ilelena Kirtiy Harriabur tuaclirilito 
Saline--J. M. Plililips.............Benton Scott.-L. D. Duncan..............Waidron Searcy.-s. G. Danlei...............tarshull Sebastian.-E. C. Myers.............. Smith Sevier.-Chas. A. Archer...........De Queen Sharp.-T. J. Woods......... Evening slaade Stone.-R. L. Brewer.......... Miountain View Union. - R. E. Rowinnd.............. Eldorado Van Buren. - John McMahan........... Clinton Washington.-1I. D. Wood............... Chetteville Washington.-11. D. Wood........... Yhite.-J. R. Linzy............... Jardanelle

\section{HEALTH OFFICERS IN CITIES OF 3,000} POPULATION AND OVER

Argenta.................... J. Barlow

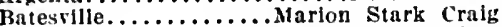
Blythevllle................J. F. Sanders Canden.................... S. Rinehart Eldorado .................... B. Wharton Eureka springs................ F. John Fayettevilie.................. H. Towler

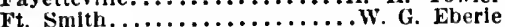
Ft. Smith................ E. King Heiena................

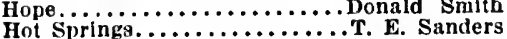
Jonesboro .................. W. Jackson Little Rock. .................. K. Judd Marianna.$\ldots \ldots \ldots \ldots \ldots \ldots \ldots$ Whitfleld $\mathbf{B}$. Bean

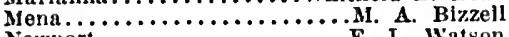

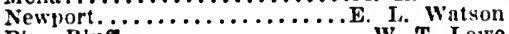

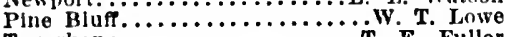
Texarkana.................. F Van Buren................. L. Parchman

\section{STATE INSTITUTIONS}

Booneville

Arkansas Tuberculosis Sanatortum, Booneville. Ark. Established 1910; public : tuberculosis; 110 beds; John Stewart, medical superintendent.

Cummins

Arkansas State Hospital, Cummins, Ark. Established 1905; Por prisoners held at the State Farm; 20 beds.

Little Rock

Arkansas Deaf-Mute Institute, Little Rock, Ark. Established 1868; 299 beds; S. P. Vaughter, physician in charge; I. B. Gardner, superintendent.

Arkansas School for the Blind, Little Rock, Ark. Established 1868; capacity $\mathbf{1 7 5}$ pupils; $A$. Watkins and S. P. Bond, physicians in charge; John H. Hinemon, physicians in

State Hospital for Nerrous Diseases (Arkansas Hospital for the Insane), Little Rock, Ark. Established 1882; public; nerrous and mental; 1,625 beds; J. L. Greene, physician in charge.

State Penitentiary Hospital, Little Rock, Ark. Established 1876;100 beds.

Sweet Home

Arkansas Confederate Home, Sweet Home, Ark. Estabilshed 1891; 75 beds; G. K. Mason, medical superintendent.

HOSPITALS, SANATORIUMS AND CHARArgenta ITABLE INSTITUTIONS

Iron Mountain Railroad Emergency Hospital, Argenta, Ark. Estabilished 1909; private; general: Theodore Freedman, physlcián in charge.

Batesvilie

Kennerly-Dorr Sanitarium, Batesville, Ark. Estabiished 1905 ; private; surgical: 14 beds; $R$. C. Dorr, physician in charge.

\section{Crossett}

Crossett Hospital, Crossett, Ark. Established 1909; private; general; 25 beds; J. E. Sparks, niedical superintondent.

\section{Eureka Springs}

llotel Dieu, Eureka Springs, Ark. Established 1901 ; public : 45 beds; Slsters of Nercy, in charge.

Nagnetic Spring Sanitarium, Eureka Springs, Ark. Established 1904 ; private 55 bcds; C. A. Reed, pliysician in charge.

Fayetteville

City llospital, Fayettevilie, Ark. Estabished 1913; general: 30 beds; Miss Ruth iniley, R.N., superinténdent.

Ft. Smith

Ft. Smith Hospltal, Ft. Smith, Ark Est ablished $1908 ; 16$ beds; J. E. Ludean medical superintendent.

Sebastian County Hospital, Ft. Smith, Ark. Established 1908; public; 70 beds: Jamcs $\mathrm{Hal}$ Neal, physician in charge; El Ilester, superintendent.

Sparks' Jemorlal Hospital, 916 S. 12th St., Ft. Smith, Ark. Established 1901 public; 100 beds; Miss Elizabeth Hatch, superintendent.

St. Fdward's Inflrmary, Ft. Smith, Ark. Established 1906; 40 beds; Sisters of Mercs, in charge.

Heber Springs

Heber Sanitarium, Heber Springs, Ark. Established 1911 ; public ; 20 beds ; Horace E. Ruff, medical auperintendent.

\section{Helena}

Helena Hospital, Helena, Ark. Established 1909 ; general; 30 beds; Jiss E. C. Balls, superintendent

Phillips County Hospital for Sick and Insane Poor, 530 Market St., Helena, Ark. Established 1902 ; public; general; nervous and mental; 8 leds; C. H. Trotter surgeon in charge; L. D. Frizzell, supt. Hope

Dr. J. L. Kelly's Sanitarium, Hope, Ark. Established 1898. private. narcotic and alcoholic addictions; 12 beds; John L. Kelly, physician in charge.

\section{Hot Springs}

Army and Navy General Hospital, Hot Springs Ark Established 1883: general: 130 beds: Lieut. Col. Francis a. Winter, Medical Corps, U. S. Army, commanding. Barry Hospital, 4 Water St., Hot Springs, Ark. Established 1890 ; private; 40 beds; Wm. H. Barry, physician in charge.

Crystal Street Hospital, 1 Crystal St., Hot Springs, Ark. Established 1905; general; 20 beds; G. K. Martin, supt.

Dianond Joe Sanitarium, Hot springs,

Ark. Established 1901 ; private ; 20 beds;

J. W. MicClendon, medical superintendent. Edwards Hospital, 252 Cedar St. Hot Springs, Ark. Establlshed 1911; surgery ; 25 beds; $A$. J. Edwards, physician in charge.

Garland County Hospital, Hot Springs, Ark. Established 1886; general; 30 beds; John S. Wood, county physician, in charge; J. R. Seaton, superintendent.

Ozark Sanatorium, Olive and EIm Sts., Hot Springs, Ark. Established 1899; private; generai; 40 beds; Wm. V. Laws, vate; general;

Dr. Pace's Sanitarium, 432 Spring St., Hot Springs, Ark. Estabilshed 1908; private; 15 beds; Chas. W. Pace, physician in charge.

Pythian Sanatorium, Church and College Sts., Hot Springs, Ark. Established 1908 ; admits colored cases; 12 beds; $C$. M. Wade, medical superintendent.
St. Joseph's Infirmary, Cedar Terrace, Hot Springs, Ark. Established 1888 private; 250 beds; Slsters of Morcy, In charge.

\section{Jonesboro}

St. Bernard's Hospital, Jonesboro, Ark. Fstabiished 1900: public : general ; 65 beds; Benedictine Sisters, in charge.

\section{Little Rock}

Little Rock Colored Inflrmsry, 1701 High St., Little Rock, Ark. Established 1913 . 8 beds; G. W. Hayman, physician in charre.

Littie Rock Sanitarium, 1223 Wolfo St. Little Rock, Ark. Established 1900; private; 35 beds; $W$. C. Green, physician in charge; Mrs. Etta Green, matron.

Logan H. Roots Memorial Clis Hospital, 119 Sherman St., Little Rock, Ark. EsDooley, medical superintendent.

Nlosouri Pacifle Raliway Emergency Station, 2121/2 Joulsiana St., Little Roek, Ark. Established 1897 ; private ; for use of employees: 150 beds: (Annex St Vincent's Infrmary): W. F Smith, division surgeon; H. W. Browning, house surgeon

Physicians and Surgeons Hospital, 1300 Lincoin Ave., Little Rock, Ark. Estabiished 1906 ; 100 beds; W. A. Snodgrass, physician in charge.

Pulaski County Hospital, 30th and Jones Sts Little Rock Ark Established 1881 public ; 300 beds; J. P. Sheppard, physician in charge.

St. Luke's Hosnital, 20th St. and Schiller Ave., Little Rock, Ark. Established 1911; private: surgical cases only; 30 beds; J. P. llunyan, surgeon in charge.

See Spccial Announcement Adv. page 78

St. Vincent's Informary, 10th and High

Sts., Little Rock, Ark. Established 1888; public; general; 250 beds; H. W. Browning, senior physician.

Osceola

West Side Inflrmary, Osceola, Ark. Established 1901. pripate: 10 beds; Thos

G. Brewer, physiclan in charge.

\section{Paragould}

Paragould Sanitarium, Paragould, Ark. Established 1905 ; general ; 30 beds; H. N. Dickson, physician in charge.

\section{Pine Bluft}

Davis Hospital, Pine Bluff, Ark. Established 1910 ; public; genersl; 85 beds : Miss Belle Mlcknight, superintendent.

Florence Sanitarium, Plne Bluff, Ark. Established 1908; private; general; 30 beds; Arthur C.' Jordan, physician in charge.

Jefferson County Almshouse Hospital, Pine Biuff, Ark. Establiahed 1900: public; 25 beds; W. H. Blankenship, physician in charge.

\section{Quinton}

St. Paul's Hospital, Qulnton, Ark. Established 1909; maintained by Brothers of St. Yaul ; 80 beds.

\section{Rogers}

Dr. Love's Sanitarium 506 E. Spruce St., Rogers, Ark. Established 1909 ; private; general; 10 beds; Geo. M. Love, physician in charge.

\section{Texarkana}

Dale Sanitarium, Texarkana, Ark. Established 1902; general; 30 beds; J. B. Dale, physician in charge.

St. Louis Southwestern Railway Hospital, College Hill, Texarkana, Ark. Established $1887 ; 164$ beds; C. A. Smith, chief surgeon; H. H. Smiley, assistant surgeon. 


\section{PHYSICIANS OF ARKANSAS}

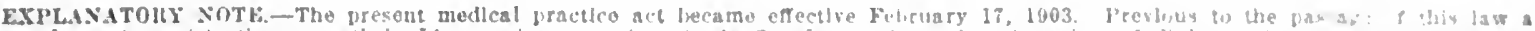

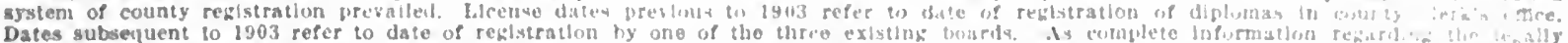

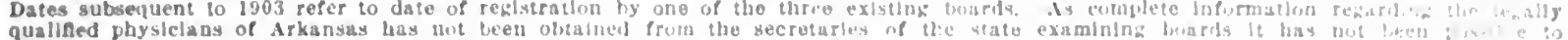

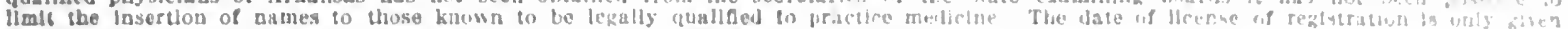

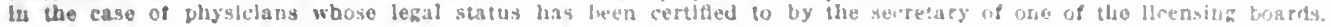

\section{KEY TO ABBREVIATIONS, SYMBOLS, ETC.}

Names In caplials slcnlfy membershly in the County Soclety and state Assoclathon. (DOK, JOHN).

Indlcates fellowing in the Amerlcan Med. Assn. (DOE, JOHXt)

(bois) year of birth.

y1 bomedic.

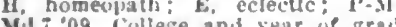

0 Iafornaclon receired does nut show graduallon.

S.-Surgeon

Ob.-Obistetrlelan.

ObG-OHsterticlan, Gynecologlst.

G.- Finnecologlst.

Or.-Orthopedist.

Pr. - I'roctulosist.

OD.-Ophthalmologlst.

A.-Aurlst.

LR.-Laryngologlst, Rhinologlst.

$\left(I^{\prime} \times 9\right)$ Year of llcense.

(3) In practlco before passinge of present faw and licenson by Hilng dipluma or by verts of practlce.

(1t) licensed hut year not known.

(\$) Infurmation recelved does not show lleense.

[. S... fulted States Army.

M. Ib., U.s.A., Medical lieservo Corps.

SPECIALTIES ARE INDICATED AS FOLLOWS

ALR.-Aurist, Laryugnloglst, Rhlnologlst

OALR.-Ophthainologlst, Aurlst, Laryngol. oflist. Ithluologlst.

U.- Crologlst.

D. - bermatologlst.

Pd.-Tedlatrlat.

N.- Neurologlst.
I.N.X. Cultoul Sitatey Nary.

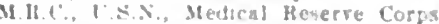

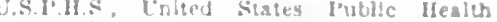
viervilce.

Collece insittons held are Indicated by abbrevlated title of [msttion. fillowed by key number of collexe. For las to collezes fet Inslue frnnt enver page.

(A1.3, Bb. C4) Hemberahid in ovedal fincletes. ised hey Table, page laz.)

WHEN THE ABBREVIATICN REPRESENTING A SPECIALTY IS FOLLOWED BY AN ASTERISK ( THE PHYSICIAN CLAIMS HIS PRACTICE IS LIMITED TO THAT WARTICULAR BRANCH OF MEDICINE; WITHOUT THE ASTERISK. THAT HE IS ESPECIALLY INTERESTED IN. BUT DOES NOT LIMIT HIS PRACTICE TO. THAT BRANCH. THIS INFORMATION CONCERNING SPECIALTY IS BASED ON PERSONAL DATA FURNISHED BY THE PHYSICIAN AND IS NOT VERIFIABLE.

\section{ARKANSAS}

ABBOTT, 300, SCOTT

Edney, W. F. A. (b'50)-D: (l'03).

AOA (R.F.D.. ADONA), 100, CONWAY

Irardlson. Thos. W: $\left(b^{\prime} s 4\right)-0 ;\left(I^{\circ} 05\right)$.

Lankford, John II. (b'50)-O; (l'03).

ADONA, 180. PERRY

Marlln, (ieo, A. E. (b'53) $\rightarrow$; (l'03).

Nix, James $M\left(b^{\circ}, 55\right) \rightarrow 0$ : $\left(l^{\prime} 03\right)$.

AGNOS, 30. FULTON

Rhosus, John W.-O: (l'03).

AIN. 100, GRANT

Whltehead, Sllas H. (b'72) - Tenn.8,'92; (l'03)

ALABAM, 25, MADISON

Morrlson. W. d. C. $\left(b^{\prime \prime} 34\right) \mathrm{f}-0$; $\left(l^{\prime} 03\right)$.

ALEXANDER, 14t, PULASKI

Cruss, D. G. (b'B5) $\rightarrow$; (1'03).

Dunnahuo, IsenJ. S.' (b'60) - Ark.1.88 (1'0:3).

Parell, James D. M. (b'58)-0: (1'03)

Powell, M(J)

STEEI). CHAS. J. (b"76)-Ark.1,03; (1.03) : Ii.F.D.

WAHI, WM. WESIY (U'70)-Ark.I,02: (I'03)

ALICIA, 168. LAWRENCE

FI,BEHS, \& W-MO :05: $(1006)$

Montell syduey (i. $\left(b^{\prime} 6 y\right)-8$ (j'03).

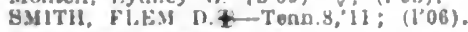

ALIX, 500. FRANKLIN

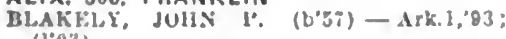
(1.03).

ALLEENE, 125, LITTLE RIVER

Alcriary, It. 1) $\rightarrow$ : (I'05)

ALMA, 565, CRAWFORD

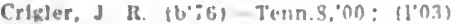

Gallowny, Qulnce Itudoly $\left(b^{\prime} i z\right)-T e n n .1$. OOf: (1'03).

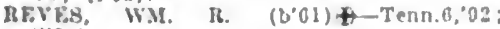
(1'03)

Shary, James C. (b'68) -Tenn.6,82; (1'03).

ALMYRA, 252, ARKANSAS

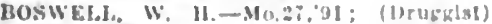

Flelds, J. iv $\left.\left(b^{\prime}\right)^{\prime} i\right) \rightarrow$; $\left(l^{\prime} 0.3\right) ;$ it $k^{*}$ I).

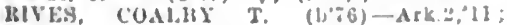

(1) II).

ALPENA PASS, 300, BOONE

MeCURIY, DA.VI, KIHTLAXI) (b'79)Ark. 1,01: (1.03).
ALPINE, 100, CLARK

Doughiy, IHUI. A. $\left(b^{\prime} \times 0\right) \rightarrow$; $\left(1^{\prime} 0\right) ; S$.

ALSTON, 75, FRANKLIN

RAMHO, WM. W. (b'5:3)-Ky.2.84: (1'03)

ALTHEIMER, 350, JEFFERSON

MISS, ALEXANDEK DOWSING (b'S1) -

l,a, l, 08: (l'0s).

Spann, ('ecll Eldon (b'84)-0.2"12: (l'12)

ALTUS, 659, FRANKLIN

Buts, Elva (b'81)-M0.29,03; (1.03); not In practle.

HOLSTON, HUGH (b'73)-Ala 4,10: (1'03)

I.OST JAIES LOLIS $\left(b^{\circ} 83\right)-110.34,0 \vec{i}$; (I'08).

ALUM, 25, SALINE

MLLTOX, JOHS IV (b'5)-Arkl, O4: (1.03).

AMITY, 8I3, CLARK

Blggs, Wr. E. (b.62) F-Mo.10,'s5: (1.03).

I1) a $\%$ a. $(1,4 i)-0 ;(190 ;)$

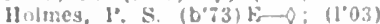

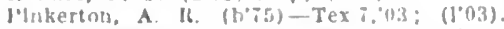

Watson, Willas S. (b'5il-Mo.1,'s: : (1'03).

ANDERSON, 72, IZARD

Illukle, Breckenrluke (b's') $\rightarrow$; $\left(l^{\prime} 03\right)$.

lliukle. J, 13. $\left(b^{2} 81\right)-0 ;\left(1^{\circ} 05\right)$

ANNOVER, - CLEVELAND

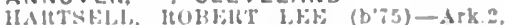
'10: $(1+)$.

ANTIOCH, 20, WHITE

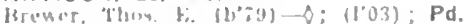

ANTOINE, 300. PIKE

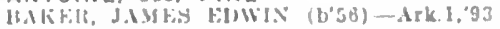
(1'u:i)

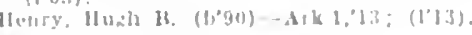

APLIN ISO, PEHRY

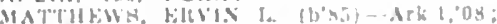
(1'i) 1 is

MATTHEIH, JAMES M. $(6: \%)$-Tenn.

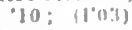

APPLETON, 300. POPE

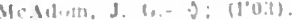

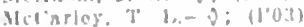

ARDEN, TOD. LITTIE RIVER

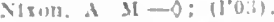

ARGENTA, I1,138, PULASKI

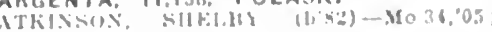

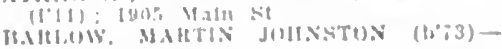
Tems s, 04: $(1005)$.
Mlackwell, Mitchell II. (col.) (b'61)-Tenn.i, hown. Alevander Hamliton (col) (b'if) -

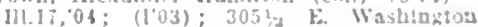
Ale.

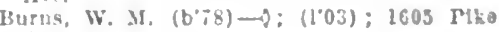
Are.

Burrus, Herbert $\mathrm{D}$.

(see Elttle Hock.)

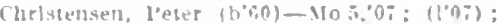
209 locust st. : ordere. 501 L E. Washluztull St. : 10 12, 2.4. $3.5 ; U$.

Foster, John K. (b's.9) E-Mrk.1.96: (1'03).

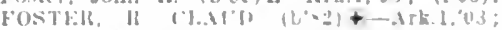
$\left(l^{2} 03\right): 410$ Maple st.

Freaduan, Theodore (h'st) - Mo.34.0i: $(10: 0): 11: E_{1}$ 14h $S_{t}:$ valce, 110 k. 1th ㄴ. ; [1-1:, 1-3, 7-8; S.

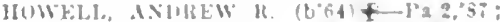
(1'03): 300 w $1: h$ st.; otec, 100 k. th

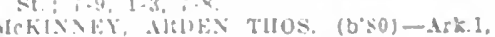
09 : (1'0y).

Mrlaln, Wm. K. (67\%)-Tenn 8.03: (1003).

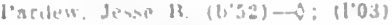

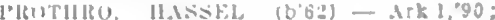
11.031

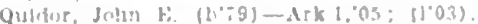

SHAlt, fllwIX (1052)-Tenn.s, s1: $\left(1^{\circ} 03\right)$.

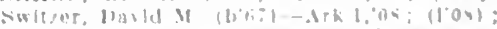

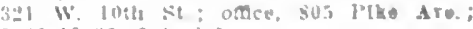
$8: 30-10: 10,2 \cdot 1, \quad 3.9$.

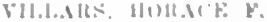

isice Ifttle Iluck )

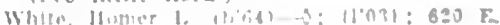

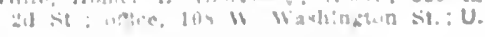
ARKADELPHIA, 2.745, CLARK

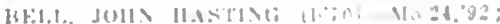
(1) 031

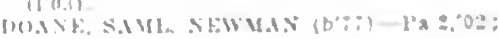
(1) $0: 1$ )

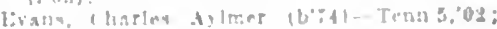

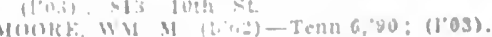

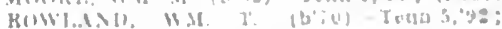
(1'0.i)

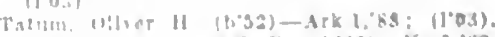

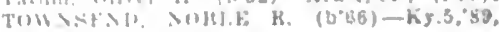

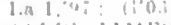

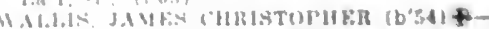

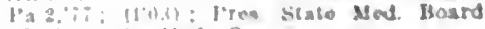
of the tor slod $90 x$.

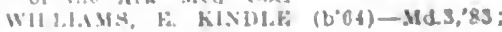
$(10, i)$ 
ARIKANSAS CITY, 1,485, DESHA

MAC CAMMON, V. (b'70)-Ky.l,98; (l'03) Roblnson. Thos. I. (b'74) - Ky,2,69: (!'03) SMITH, COTESWORTH PINCKNEY (b'46) (4-Ky.2,73: (l'03)

ARKANSAS POST, 50, ARKANSAS

Hudson, John A. (b'61) $\longrightarrow$; (1'03).

ARKINDA, 160, LITTLE RIVER

Johnson, Chas. F. (b'41) $\rightarrow$; (l'03)

ARMADA, - CRAWFORD

Whillams, Jolin M. (b'58)-T'cnn.5,'84 (1'03).

ARMOREL, 300, MISSISSIPPI

Nall, lRobt. 1'.-Tenn.8,'92; (1'04).

ASHDOWN, 1,247, LITTLE RIVER

Beller, Allen $T$. $\left(b^{\prime} 55\right)-0 ;\left(l^{\prime} 03\right)$; not in practice.

BISIIOI', ALBERT BYRON (b'51)-Mo.1,'87 ; (l'03).

Hale, H. A. (b'56) $\rightarrow$ : (l'03).

KIRKHAM, ZILLIBA L. $\left(\mathrm{b}^{\prime} 68\right) \oplus-\mathrm{Ky} .2,95$; (l'03).

MARR, S. C.-M0.7,93; (l'03)

PIIILLIPS, PAUL HAMILTON (b'81)-La.I 04; (l'03).

RINGGOLD, JOHN W.-Ark.1,'90; (l'03).

Wood, A. Neal (b'65)-Ark.1,'90; (l'03).

YORK, WM. W. (b'76)-Tenn.8,'01; (1'03).

ASH FLAT, I50, SHARP

Bullingsley, Charles L. (b'84) $\rightarrow$; (l'08)

Garner, J.' Ronald (b'62)-ML.1,'79; (l'03)

ATHENS, 115 , HOWARD

Chlldress, Arthur J. (b'82) - Mo.33,'13; (l'03).

ATKINS, 1,258, POPE

DARR, ROY W. (b'78)-Tenn.1,01; (l'03). Gardner, Lycurgus (b'82)-Ill.8,08; (l'09). Grimin, Ernest P.-Ark.1,07 ; (l'06); R.F.D.

Gullett, Geo. T. (b'36) $\longrightarrow$; (l'03)

Kolb, IWm. Burge (b'86)-Tenn.8,'I0; (l'08).

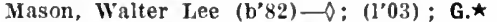

MONTGOMERY, WIIIAM ANDREiv' (b; 56$)$

(4-Tenn.8,'89; (l'03).

Warren, D. J.-E-O; (l'03).

ATLANTA, 150, COLUMBIA

COOKSEY, WM. PATE (b'72)-Tenn.1,'99 : (l'03).

AUGUSTA, 1,520, WOODRUFF

BILES, LEF E. (b'73)-Ky.1,'05: (l'03)

BREWER, EDWARD F. (b'67)-Tenn.8, 03

DUNGAN, CALVIN EDWARD (b'81)-Ark.1,

'10; (l'10). BLETCHER, BURRELL A. (b'62)-N.Y.10,

PATTERSON, ROBT. QUINCY (b'71)Tenn.5,'00; (l'03) ; S. (b'75)-Tenn.8, 04 ;
PUCKETT, OWEN 'E. (b

SMITH, ROLAND NOAH (b'66)-Ky.1,'93 (I'03).

AURORA, 40, MADISON

Ilars, chas. P. (b'46) $\rightarrow$; not in practice.

Scott, James M. (b'54) -0; (I'03).

SPURGEON, JOHN H. (b'65)- (1'03).

AUSTIN, II7, LONOKE

Curry, James B.-E- (l'03)

Hodge, Saml. D. (b'67) $\longrightarrow ;\left(l^{\prime} 03\right)$

Parker, Samuel (b'49)-Ark.1,'92; (l'03).

AUVERGNE, I50, JACKSON

Clements, Geo. M. D. (b'45) E-O.2,'69; (l'03)

Neal, Wm. P. (b'75)-; (

NORRIS, RUTIAL ORBRA (b'85)-0.2,'12 (1'12).

AVA, 72, PERRY

Green, B. E. $\left(b^{\prime} 58\right) \rightarrow$; (l'03)

AVERY, 6, LINCOLN

Richards, L. B.-Tenn.8,'9s; (l'05)

AVOCA. 100, BENTON

RICE, THOS. II. (b'55)-Mo.1,'82; (l'03).

AZOR, 50, NEVADA

Owens, Frank M. $\left(b^{*} 75\right) \rightarrow$; (l'03).

BALCH, 50, JACKSON

Smith, Saml. W. (b'72) $\rightarrow$; (1'03)

BALD KNOB, 617, WHITE

CLARK, WM. A. (b'68)-Mo.7,'92; (I'03).

(I.FVELAND, JOS. C. (b'52) 4 Mo.I,'88; (1'03).

BANKS, 200, BRADLEY

Smith, Samuel Ernest (b'85)-Tenn.19,'11; YNIPERVOOOD, TOHN ALIEN (b'75)-Tenn.8,08: (1903).
BANNER, 25, CLEBOURNE

Ward, Otto T. (b'T5)-Tenn. I,07; (l'03).

BARBER, 25, LOGAN

IIornsby, Wm. W. (b'78) $\rightarrow$; (l'03).

BARDSTOWN, 200, MISSISSIPPI

CAMPBELL, JAMES H. (b'67)-Ky.2,'91 ;

NOACK, P'AUL G. (b'67)-Tenn.8,'96; (l'03).

BARFIELD, 110 , MISSISSIPPI

ILodges, (iuy (b'89)-Ark.2,'10; (l'12).

Mason, Clnelnnatus Hine Mllier (b'84)Tenn.6,'12; (1'09)

IrcCall, Whecler S. (b'87)-M0.28,'10; (1'12).

BARING CROSS (LITTLE ROCK P.O.), PULASKI

I'urdam, A. L. (b'52) $\rightarrow$; (l'03).

BARLING, 100, SEBASTIAN

Benefield, James H. (b'67) $\rightarrow$; (l'03).

Harrod, Keuben Taylor (b'67)-'Tenn.6,'91; (1'07).

BARREN FORK, 350, IZARD

EVANS, LORENZO TIPTON $\left(b^{\prime} 80\right) \Theta-$

Tenn.8,'07; (l'05).

BARTON, 250, PHILLIPS

Brown, Edwln Thos. (b'81) - La.1, 04; (l'03).

BASS, -, NEWTON

Yates, G. 'W. (b'69) $\rightarrow$; (l'05)

BASSETT, 20, MISSISSIPPI

Nowlin, Robt. T. (b'79)-Tenn.8,'13; (l'03).

BATES, 272, SCOTT

Atkins, W. T. (b'67)-Mo.7,07; (l'03).

Cline, R. C. $\left(b^{\prime} 55\right) \mathrm{E}-0$; (l'03)

Tollison, Lorenzo D. (b'70) $\longrightarrow ;\left(l^{\prime} 03\right)$

BATESVILLE, 3,399, INDEPENDENCE

Ball, Wm. F. (b'74)-Mo.2,97; (1'03).

CRAIG, MARION STARK (b'84)-Tenn.5,

'11; (l'11).

DORR, ROBINSON C. (b'58) (4-Mo.1,'83; (1'03).

Dorsey, L. J. $\left(b^{\prime} 41\right) \mathrm{H} \rightarrow$; $\left(l^{\prime} 03\right)$

GRAX, FRANKLIN A. (b'77)-Tenn.8,'05; (l'03); R.

HINKLE, CHAS. G. (b'75) 9-Mo.2,'03; (l'03); OALR

JOHNSTON, OSCAR JOE TANNER (b'83) -Tenn.1,07; (1'05).

KENNERLY, JAMES H. (b'48)-Ky.2,76 ; (l'03).

LAWRENCE, WM. B. (b'54)-Pa.2,7 7 ; (l'03).

Weaver, Mosby C. (b'55)—Ky.4,77; (1'03).

BAUXITE, 300, SALINE

BRUNNER, ELISWORTH CROCKETT (b'87) 4 -Tenn.5,'10; (1'11).

BAY, 500, CRAIGHEAD

Crawford, John E. (b'70)-Tenn.1,'03; (l'03) Ralnes, Hugh L. (b'80)-Tenn.8,'03; (l'03).

BAYOU METO, 100, ARICANSAS

Wlnters, H. B. (b'73)-ML0.7,06; (l'0i).

BAY VILLAGE (R.F.D., HARRISBURG),

100 , CROSS

Berry, Alonzo A. (b'65)-Ky.1,'86; (l'03).

BEAR, I50, MONTGOMERY

Jennings, Orville (b'72)-Ark.1,97; (l'03).

BEARDEN, 439, OUACHITA

(lemens, James P. (b'88)- (l'09) ; ObG.

Henry, Cad A. (b'86)-Tenn.1,08; (1'07).

MAHAN, JOHN MI.(-Pa.2,'77; (l'03).

Thompson,. Henry Fay (b'80)-Ark.1,'09; ('08).

BEAUDRY, - GARLAND

Pogers, James H. (b'05) $\longrightarrow$; (l'03).

BEEBE, 873, WHITE

ABINGTON, W. H.-Tenn.s,'96; (l'03).

Bobbitt, T. B. $\left(b^{\prime} 50\right) \longrightarrow$; (1'03).

Hall, Ezra T. (b'38)-Mo.1,69: retired.

Jungkind, Bernle F. (b'82) -Ark.2,09; (l'0s).

Smith, Wim. C. $\left(b^{\prime} 60\right) \rightarrow ;\left(l^{\prime} 03\right) ; 0 b$

Tabor, Geo. Ewing (b'77)-Ark.1,12; (l'12)

Worthington, Saml. M. (b'68) $\longrightarrow$; (l'03).

BEE BRANCH, 142, VAN BUREN

Brittaln, Andrew J. (b'69)-Tenn.8,'99; (1'03).

Cole, Stanford Marchal (b'63) $\rightarrow$; (l'03).

BEECH GROVE, 20, GREENE

LAIB, JONES HOLSTON $\left(\mathrm{b}^{\prime} 79\right)$ - Ky.5. '05; (1'03).

BEEDEVILLE, - JACKSON

Flanary, Geo.'M.' (b'74)- $\bigcirc ;$ (l'03).
BEIRNE, 450, CLARK

Kerstan, Aug. F. (b'38)-Ga.9,'82; (\$).

BELCHER, 100, WHITE

Grlftin, J. T. (b'51) -0; (1'03).

BELFAST, 25, GRANT

Sheppard, Irvin (b'67) $\rightarrow$; $\left(l^{\prime} 03\right)$.

BELLEFONTE, 296, BOONE

ALLIBRIGIFT, SAMIL. JEFFERSON (b'85)Ark.1,13; (I'13).

CALIWN, LUTHER II. (b'78)-Ark.2,'11 ;

Arkansas State Board of Irealth.

Finch, Alpheus D. (b'49)-Tenn.5,'85; (立).

Finch, Carl (b'79)-Tenn.5,01; (\$).

Keele, Wm. B. $\left(b^{\prime} 60\right) \rightarrow$; $\left(1^{\prime} 03\right)$.

BELLEVILLE, 335, YELL

Grace, John (b'68)-Tenn.5,'93; (l'03).

IIARKNESS, JOHN H. (b'48)-Ark.i,'81 ; (l'03).

Parker, Geo. C. (b'58) $\longrightarrow$; (l'03).

BEN LOMOND, 431, SEVIER

ARMSTRONG, BLLA M. (b'68)-Ky.2,'92; (1'I1).

CLINGAN, ANDREW J. (b'68) @-Ark.1,'02 ;

MUS'03). '12; (1'12).

BENTON, 1,708, SALINE

CRAWFORD, JAMIES B. (b'85)-Ark.2,'10 ; (l'08).

Fisher, Danl. N. (b'46)-Ark.1,'96 ; (l'03).

GANN, DEWELL (b'63) $\odot-G a .10,86$; (l'03)

S.
Gann, Dewell, Jr. (b'90)-Ind.20,'13; (l†)
KELLEY, WARREN

(l'03). JOHN MORGAN-Ark.1,'91 : (1'03); $\mathbf{G}$

Rowland, Edgar J. (b'48)-Ga.1'T6; (l'03).

WALTON, JAMES W.(4-Ark.1,'92; (1'03).

BENTONVILLE, 1,956, BENTON

CARGILE, CHAS. H. (b'53)(-Pa.2,77 ; (l'03); 5 .

HENRY, JAMES T. (b'47)-Tenn.1,73 ; (l'03).

HENRY, RICHARD T. (b'83)-Ark.1,'11; (1'11)

1 UFFMAN, KENNETH BOWLES $\left(b^{\prime} 83\right) \emptyset-$ Mo.34,10; (l'09); Member Mo. State Med. Assn. : Pd. (l'03).

Hurley, Thos. W. (b'34)-Tenn. 2,55; (l'03). LINDSEY, JAMES H. (b'62) \&-Ark.1,'84;

MOODY, WM. C.-La.1,70; ( ); Member State Med. Assn. of Tex.

PICKENS, WM. ALEXANDER (b'84)-

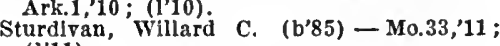
(I'11).

BERGMAN, 150, BOONE

BAINES, SIVARTZ (b'67) $\oplus$ - Ark.1,'06 ; (I'05).

BERRYVILLE, 785, CARROLL

GEORGE, CHAS. AIBERT (b'81)-Mo.2,'03 (l'03)

GEORGE, WM. P. (b'47)-M0.2,75; (l'03).

HARVEY, WMI. A. (b'83)-Mlo.34,09; (l'08).

MATHIS, .T. B-Ill.17,'96; (l'03)

Molloy, J. H. (b'46) $\rightarrow$; (l'03); not in practice.

POYNER, ISAAC M. (b'63)-Ark.1, 90 (l'03).

BERYL (R.F.D. CONWAY), I50, FAULKNER

Harrod, James (b'4I)-Tenn.6,'78; (l'07).

BETHESDA, I50, INDEPENDENCE

HAYDEN, JEFFERY (b'84) - Ark.1,'10 : (1'10).

JEFFERY, PAUL H. (b'83)-Ark.1,'10; (1'09).

BIGELOW, 350, PERRY

BLACKWELL, WM. I. (b'69)-Ark.1,03; (1'03).

Holiman, J. H. (b'66) $\rightarrow$; (l'03)

KUBALE, EDWIN (b'74)-Ark.2,11; (1'06). 1ONCRIEF, JOS. J. (b'58)-Ark.1,97; (1'03).

VERMILLION, WM. H. $\left(b^{\prime} 43\right)-0.2,77$; (l'03).

BIGFLAT, 107, BAXTER

Adams, Erasmus Edw.-Mich.5,'77; (1'03).

Pate, John C. $\left(b^{\prime} 70\right) \longrightarrow$; $\left(l^{\prime} 03\right)$.

Smith, Robt. David $\left(\mathrm{b}^{\prime} 59\right)-$ Tex. $7,{ }^{\prime} 0 \mathrm{~T}$ : (1'03). 
BIG FORK, 433, POLK

simpson, Lora A. (b'al)-0; (t'03).

BIGGERS, 435, RANDOLPH

Brumley, Geo. W. (b' $\$ 3)-8:\left(l^{\circ} 03\right)$

Johnson, John J. (b'68)-Tenn.8.94: (1'03)

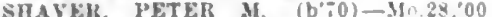

(1)03).

shores, Wm. B. (b'6s) $-0 ;\left(l^{\prime} 03\right)$

BILLS, 65, PIKE

THOMASSON, JOSEPII B. (b'62)-Ark.l,

$$
\text { '94: (l'03). }
$$

BINGEN, 130, HEMPSTEAD

Gosaell. Chas. F. $\left(b^{\circ} \% 0\right)-0:(1 \% 03)$

BIRTA, 30, YELL

Georse, John X. (b'70)-Tean.8.'99: (1'03).

Stralt, Claudo W. (b'84)-Tenn.8,'10; (1'08).

BISCOE, 250, PRAIRIE

Fowler, Ieary C. (col.) (b'80)-Tenn.7,09; (1'09): $\mathbf{S}$.

Odom, Élljah B.-Tenn.:98; (l'03).

BISMARCK, 90, HOT SPRING

Balley. Wm. II. $\left(b^{\prime} 71\right)-0:\left(I^{\prime} 03\right)$.

Custer, Joslah B. (b"62) $\rightarrow$ : $\left(1^{\prime} 03\right)$.

BLACK OAK, 100, CRAIGHEAD

Barrett, Reuben Honroe (b'82) - Tenn.8,11; (l'11).

Ylsber, Robe Jeterson (b'i4)-Tenn.1,01: (1'ii).

Earord, John $\left(b^{\prime}: 1\right) \rightarrow$ : (l'03).

BLACK ROCK, 1,078, LAWRENCE

COFFMAX, JAMES W. (b"1i)-KY.2,":L; (l'03).

Darldson, C. A. (b'63) $\rightarrow$ : (l'03).

STEEN, THOMAS ENOCH $\left(\mathrm{b}^{\prime} / 8\right)$-Tenn.19. 11: (1'13); Member Miss. State Med. Assin.

FARREN, GUS. A (b'66) -.10.1,94; (l'03)

\section{BLACKTON, I50, MONROE}

Terry, Pleasant E. (b'it) - Tenn.t "99; (l'03).

BLACKWELL, 30, CONWAY

Eddy, J. J. (b'64) -Ark.1,02: (1'03).

BLAINE, 75, LOGAN

Boblnson, G. W. -0 ; (1'03).

BLAKEMORE, 45, LONOKE

Harris, W. D, -0 ; (1'03).

Tumer, Wr. S. (b'34)-Tenn.5.82: (1'03) not in practice.

BLALOCK (R.F.D., TINSMAN), 150, CAL. HOUN

IJardy. Marlon (b'58) $\rightarrow$; $\left(1^{\prime} 03\right)$.

BLAND, 22, SALINE

Guber, J. M. (b'IT):-O: (l'03)

Roberts, Wasland D. (b'5i)-D; (1.03)

BLEVINS, 200, HEMPSTEAO

BELL, MINTO (1,70)-Ark.1,10; 11'11)

BLISSVILLE, 296. DREW

BAKER, J. JELL (b'05) Tenn. 8,01 (I'03),

Barnes, Lewls Chesley (b'85)-Tenn.6,"12: (1'Is).

BLOOMER, 100, SEBASTIAN

Hartlck. Wm. If. (D'5\&) $\rightarrow$; not in uractleo.

BLUE BALL, 19. SCOTT

Pool. Thos. Jefferson (b:s(0)-Ark l, 13 (li13).

BLUE MOUNTAIN, 200, LOGAN

Head, Whllam $M .\left(b^{\circ}-6\right)-O$ : (l'03)

Mobler. Wm C. $(2.55)-M 0.1,5:$

BLUE SPRINGS, - BRADLEY

Yowler, T. A. - $;$; $\left(1^{*} 03\right)$.

BLUFF CITY, 50, NEVADA

Whaley, Edgar $\$$. (b's3) - Tenn.\$:10: $11^{\prime} 10$

BLYTHEVILLE, 3,849, MISSISSIPPI

Caldwell, C. A. $\rightarrow$ : (1'03).

FKANKIIN, MIUAIIM I, - Mo.25, 43 (l'0t).

Marln, Sierling d'rlce (b'73)-Mo.20,03 (1.03)

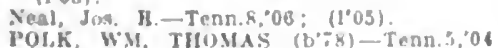

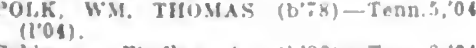

Robinsun, Findley A $\{8.80\}$ Tenn.8,0 (1.03).

SANDEHS, JOHX FRANKLIX (b'B) IIs.

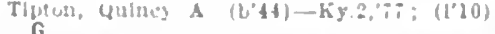
TUHRFNTINE, MUCIELAI:S FENEST (b':1+-Tenn 1:03: (1'13); Member

BOARD CAMP, 35, POLK

Santurl, Chas. (b'59)-i; (1'03).

BODCAW, 200, NEVADA

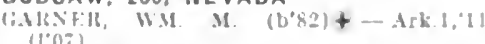
$(100)$.

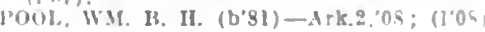

BOLES, 90, SCOTT

lirutron, C. C. -0 : (1"03).

BONANZA, BII, SEBASTIAN

PAlKS. ILPU'S FHANCIS (b'76)-ATK 2 11]; $\{1,11\}$.

Smith, J.ewls C. (b'59)-Ark.1,84: (1'03)

BONO. 200, CRAIGHEAO

Armour, (has. Ilarry (b'i2)-Tenn 8,95 ; (I'03).

Barnes, Porter K. F-0: (1'03)

Ilobblu, J. E-Tenn 8'04: (1'03).

SIMPSOX, WM. SIIELL (b'82)-Ark1,09: (I'0s).

BOOKER, 20, PULASKI

Matthews, Jos. II. (b'69)-Ark.1:93; (1'03).

BOONEVILLE, 1.631, LOGAN

AHISTRON(; NEWELL E. (b'58)-Ark?

02: (1'03).

Baker, Forrest Pltt (b'89) - Ark.1,12: (1'12) : T.

BASKERVILLE, WILLAM F. (b'65)-La.l. 89 ; (1'03).

Blacknall, (ius. T. (b'49)-0; (1'03)

HENERICK, AUSTIX R. (b'bi) $\mathbf{R}$-Teno.S, 02 ; (1'03).

Lewls. J. W. (b'51) F-0; (1'03)

ICCONNELL, SAML PAUL (b'83) +

Mo.31,06; (106); T

Ros3, Wm. F. (b'61) $-0 ;\left(l^{\circ} 03\right)$; not in practice.

STEWART, JOHN (b'69)-Mo.28,04: (J'13) :

Member Mo. State Med. Assn.: T.

Strange, R. F. $\left(b^{*}: 2\right)-\overrightarrow{0} ;\left(l^{\prime} 03\right)$.

BOOTHE, 35. SCOTT

logan, James E. (b"il) - O; (l'03).

BOOTY, 15, ARKANSAS

Roberision, Ira B. (b'53)-Ky.1, 90): (l'03).

BOUGHTON, 100, NEVADA

MeDaniel. F. W. (b'81) -0: (l'03).

BOYDSYILLE, 200, CLAY

Custer, W. I'. (b'6s) 0 ; (l'03).

McAuley, k. M. (b'ts) $\rightarrow$ : $\left(l^{\prime} 03\right)$.

BOYNTON, 350, MISSISSIPPI

Hubbard, W. H. - : (l'03)

BRADFORD, 382, WHITE

Alten. Irobe. C. (b'36)-Aek.1,09: (1'0s)

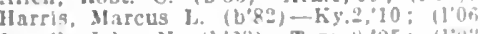

lorell, John N. (b'6s)-Tenn.s,95; (1'v:

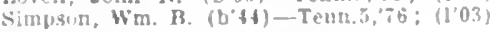

BRADLEY, 123, LAFAYETTE

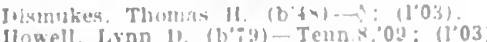

BRANCH, 271 , FRANKLIN

Akin. W. r. (b'it)-Tenn.s, 04 ; (d'03)

(iamm.ll, stirllng I'rlce (b"tis) - $\theta$ : (1"03)

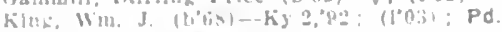

BRAZILS, 3I, SALINE

licuberta, iv. i) (b.ji)-0; (1'03)

BRIGGSVILLE, 50, YELL

Ierall. W. II $(1,+3)-i ;(1,03)$

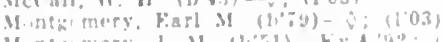

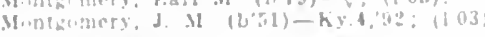

BRICHTSTAR (R.F.O.,BLOOMBURG, TEX.)

50, MILLER

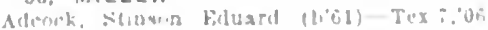

(1'0.1).

III.

II I KIIIS

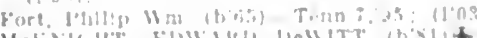

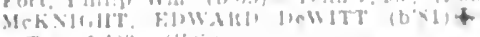

Term.5.03: (190) , 8 B : $1 \mathrm{I}^{\circ} 03$ )

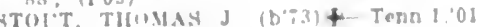
(1.09).

BROCKETT, I \$0, RANDOLPH

Jishurn, Jame W (t?:3) Tra $10.03 ;(1.03)$
BROOKLAND, 500, CRAIGHEAD

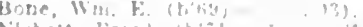

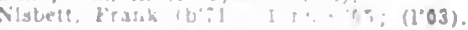

BROOM, 30, LAWRENCE

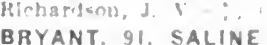

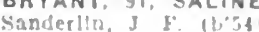

BUCKNER, 210, LAFAYETTE

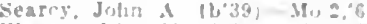

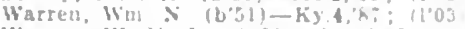

Warren, W $\times$ Jr (\$) - (

BUCKRANGE, 175, HOWARD

WHU!,IT, ('AlWALI.AIIER

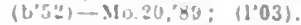

BUCKVILLE, 85, MONTGOMERY

Bruwulng, Firtegt lay (b'3l)-Ark.l,'13

Pool. Marcus $V\left(b^{\prime} 57\right)-6$ - $5,79:(1003)$

Shaw, Jos. W.. Jr. $\left(b^{\circ}, b_{i}\right)-i ;\left(l^{\circ} 03\right)$

BUENA VISTA, 175, OUACHITA

H.SLTOSI, X. ト $\longrightarrow ;(1.03)$

BUFORD, 30, BAXTER

IIIFl', JOE ACETIS (b'68)-MO:,06:

(1'03): $\mathbf{0 b}$.

BURDETTE, 700, MISSISSIPPI

Webr, Charles F. (b'5i)-Tenn.5,08: (1"08).

BURNVILLE (R.F.O., GREENWOOO), 32.

SEBASTIAN

Seamans, John-0: (1'03).

BUTLER, 250, MISSISSIPPI

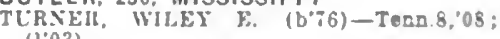
(l'03).

BUTTERFIELO, 70, HOT SPRING Green, Theodore $11 . \quad\left(b^{\prime} 59\right)-$ Tena.8,"98:
(1'03).

BYLER, 60, IZARO

Byjer, J. I. (b'56) $\rightarrow$ : (1'03)

BYRON, 28, FULTON

Woods, nwen $\mathrm{B}$ ( $(2 \div 0) \rightarrow 0$ : $(1203)$.

CABOT, 4\$1, LONOKE

Blair, F. I'. $\rightarrow$; $\left(l^{\prime} 03\right)$; (Dentlst).

Cranberry. George W.. Jr. $\left(\mathrm{b}^{\prime} 80\right) \rightarrow$; $\left(1^{\prime} 03\right)$

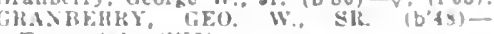

Tenu, : : : (1'05).

Herring, Jihn IInsell (b'59)-Tenn. S.'13:

$\left(l^{*} 13\right) ; S$.

Herrod, James Lee $\left(b^{\prime} 35\right)-0$ : $\left(l^{\prime} 03\right)$ : nos in inacllce.

Herrod Will's Iee (bo3)-Ark. $2.91:(1.03)$.

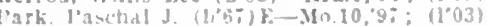
$\left(l^{\prime} 03\right)$

boss, sulun 11 (1:-3) $11-$ II1.10,79. (1"11): OALR *

White. Ll. II, (b'b0)—: (1003).

CADDO GAP, 30, MONTGOMERY

Alford. Juhn $E^{\circ}\left(b^{\prime: 11)-T e x .706: ~(l ’ 03) ~}\right.$

Mel. ki.i.

CAIRO, 20, UNION

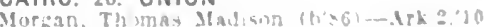

CALDWELL, 5n, S?. FRANCIS

chiluell Nism Ii, (b'i!) Teans.ll:

CALEDONIA, 23, UNION

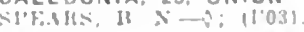

CALICO ROCK, J01, IZARD

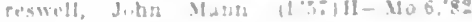

11.03

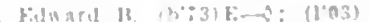

SIIT13
11.031

CALION, 40, UNION

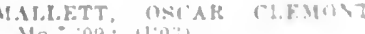

CAMDEN. 3,993. DUACHITA

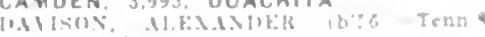

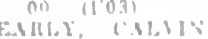

(I) nom

Il uilwon, lien W It it - Vd 1,:3 11031

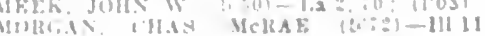

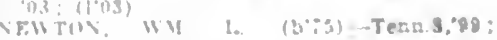

स.W T1

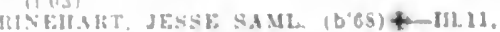
$00 .(1,0) 31$.

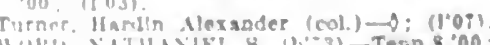

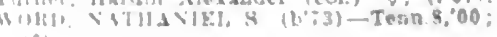


CAMP, II5, FULTON

Randall, O. T. $\rightarrow$; (l'03).

CANEHILL, 400, WASHINGTON

Bean, Joln I. (b'74)-Mo.7,'09; (l'03).

CANFIELD, 100, LAFAYETTE Wallace, Thomas M. (b'6 6 )-Tenn.8, 04 ;
(I'03).

CARDEN BOTTOM, 50, YELL

JACKSON, NORBORN H. (b'43)-Ark.1,'8I ; (l'03).

CARDIFF, 2, SCOTT

Cox, James B. (b'r 0$)-0$; (l'03).

CARLISLE, 516, LONOKE

Alexander, W. J. D. (b'36) $\rightarrow$; (1'03).

CRAWFORD, CHAS. LEE (b'63)-Mo.7, 93 ; (1'12).

Dudley, J. B. (b'5l) $\rightarrow$; (l'03).

Nuzzy, Fred (b'6I)-Mo.5, 07; (l'06).

CARTHAGE, 386, OALLAS

COX, C. C. (b'82)-Tenn.8,'06; (1'03)

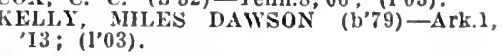

CASA, 310, PERRY

Cleveland, James W. (b'79) $\rightarrow$; (l'09).

Sweet, Frank IR. $\left(b^{\prime} 77\right)-0 ;\left(I^{\prime} 03\right)$.

CASH, 60, CRAIGHEAD

IIorn, Lorenzo D. (b'53)-E-O; (l'03).

Llle, II. J. $\rightarrow$; (l'03).

CASS, 70, FRANIKLIN

BOEN, ALBER'T L. (b'68)-Ark.1,'07; (l'03).

CATO, II8, FAULKNER

Hardcastle, J. I. (b'39) E-O; (l'03).

l'alret, J. Frank $\rightarrow$; (l'03).

CAULKSVILLE (R.F.D., RATCLIFF), 145 , LOGAN

Nell, J. R. $\rightarrow$; (l'03).

CAUTHRON, 300, SCOTT

Atklns, C. A. $\longrightarrow$; (l'03).

Jones, W. A. (b'5 7$) \rightarrow$; (l'03).

CAVE CITY, 278, SHARP

Burge, T. Geo. (b'72) $\rightarrow$; (1'03).

GRAY, CHRISTOPHER C. (b'60)-Tenn.5, '88; (1'03).

CAVECREEK, 30, NEWTON

Fralley, Denton M. G. (b'68) $\rightarrow$; $\left(l^{\prime} 03\right)$; not in practlce.

CAVE SPRINGS, -, BENTON

HIGIFILL, ELISHA J. (b'73)-M0.28,'99; (l'03).

Hubbard, Ella Sturdivan (b'79)-Tex.4,05; (l'03).

CECIL, 25, FRANKLIN

Downey, Robt. Lee $\left(b^{\prime} 73\right) \rightarrow$ : $\left(1^{\prime} 06\right)$.

CEDAR GLADES, I00, MONTGOMERY

Lewallyn, W. Nelson (b'80) - Ark.2,'11; (1'08).

CENTER HILL, 75, WHITE

BARKER, EPHRAIM R. (b'77)-Mo.33,'06; (1'07).

Pendergraft, Jessee $\left(b^{\prime} 6 \tau\right) \longrightarrow$; $\left(l^{\prime} 03\right)$.

CENTER POINT, 328, HOWARD

Duncan, Wm. (b'69) $\rightarrow$; (l'03).

Knox, I'eter-Tenn.5,77; (1'03).

CENTER RIDGE, 150, CONWAY

Cross, v'lrgil D. (b'50) $\rightarrow$; (l'03).

Halbrook, John F. (b'74)-'Tenn.8,02; (l'03).

JACkSON, JAMES HENRX-Ark.1,'91; (l'03).

CENTERTON, 50, BENTON

Chambers, Robt. O. (D'53)-Mo.5,'77, M10.28, 94; (I'03) ; S.

Duncan, Marion W. (b'69)-Tenn.8,'99; (1'03).

CENTERVILLE, 250, YELL

Fleming, John F. (b'66)- $\longrightarrow$; (I'03).

McCarty, I. R. (b'66)-Tenn.5,88; (l'03).

WORSHAM, MORDICAI A. (b'5i)-Tenn.8, '83; (I'03).

CENTRAL, 50, SEBASTIAN

Bachelor, J. H. $\longrightarrow$; (l'03).

CERROGORDO, 250, LITTLE RIVER

HARVEY, H. (b'5S) $\longrightarrow$; (l'03).

CHAMPAGNOLLE, 100, UNION

JOHNSTON, CHAS. B. (b'i1)-Tenn.8, 01 ; $\left(1^{3} 03\right)$.
CHAPELHILL (R.F.D., DE QUEEN), 185 , SEVIER

Hammonds, John W. (b'39)-Tenn.1,67 ; (l'05): not in practlice.

CHARLESTON, 576, FRANKLIN

Ballinger, Isaac W. (b'90) - Ark.1,'12 (1'12).

BENEFIELD, C. E. (b'r1) Tenn.8,'02; (l'0:3)

Bollinger, Wallace H.-Ark.1,07; (1'05).

Crandall, John M. (b'53) E-0; (l'03).

Iudson, EImer M. (b'69)-Ky.2,90; (1'03).

Northum, Alex. C. (b'62) $\rightarrow$; ('03).

CHERRYGROVE, 100, GRANT

Canip, Jullus II. (b'42) $\rightarrow$; (l'03).

CHERRY VALLEY, 300 , CROSS

Grifin. Walter L. (b'T7) - Tenn.15,'07 : (1'06).

Jones, Charles P. $\left(b^{\prime} 51\right)-$ Tenn.8,'83;

HIIGORE, J. J. (b'68)-0; (l'03).

CHICKALAH, 200, YELL

Brown, C. C.-T'enn.1.75; (l'03).

Rollans, II. G. $-\infty$; (1+).

Rollins, D. I. $\rightarrow$; (1'03); R.F.D. 1.

Rose, F. W. (b'7 7 )-Man.1,00; (1'03).

CHICKASAWBA, 250, MISSISSIPPI

Lunsford, C. B. ( $\left.\mathrm{b}^{\prime} 72\right)$-Tenn.8,'96; (1'03).

CHICOT, I00, СHICOT

EASTERLING, WM. W. (b'68)-N.T.5,'89; (l'03).

CHIDESTER, 300, OUACHITA

PURIFOY, W. A. (b'70)-Tenn.8,'99; (1'03).

RUSHING, JETER L. (b'79)థ-Tenn.8,'03; (l'03).

CHISMVILLE, 50, LOGAN

Arbough, R. C. $\rightarrow$; $\left(1^{\prime} 03\right)$.

CHOCTAW, 75, VAN BUREN

Holloway, Wylle R. (b'68)-Ark.1,07 ; (1'03).

Hule, Jesse Henry- $\rightarrow$; (1'03)

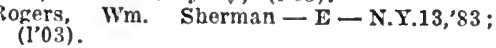

CINCINNATI (R.F.D., SUMMERS), 100 , WASHINGTON

PITTMAN, JAMES (b'7l)-Mo.7,'98; (l'03).

CLARENDON, 2,037, MONROE

Boals, N. 0. (b'52)- (l, 03$)$.

Frazer, J. W. (b'25)-La.1,'60; (l'03)

GILBRECH, AIBERT H. (b'76)-IIl.17,01; (l'04) ; OALR.

Jockhardt, Natbanlel H. $\left(b^{\prime} 73\right)-$; (\$)
Meadors, Robt. Connell $\left(b^{\prime} 86\right)-$ Tenn.5, 13 ; (1*13).

MILLER, J. C. (b'79)-Tenn.8,'02; (1'03)

MURPHY, NATHAN E. (b'70) $9-K y, 2,97$; (1'03); $\mathrm{S}$.

Thomas, Philip Emerson, Jr. (b'90)-Tenn.8, 'I3; (1'13)

THOMAS, PHILIP E. (b'56)(-MI0.1,78; (1'03).

CLARIKDALE. 250, CRITTENDEN

PARKER, ARTHUR CLARENCE (b'85)(6I.a.I,'I0 ; (1'09).

CLARKSVILLE, I,456, JOHNSON

Gray, Lawrence C. (b'85) - Tenn.15,09; $\left(l^{\prime} 06\right)$.

HAYS, ANNIE (b'63)-Ml.11,'03; (l'03).

HUNT, FARLE HOUSTON (b'86) -La.1, 09; (l'08); U.

HUNT, WM. R. (b'64)-Ark.1.89; (l'03)

KOLB, JAMIES S. (b'64)-Ark.1,'92; (1'03)

IcKennon, Archibald M. (b'52)-Pa.2,'74; $\left(I^{\prime} 03\right)$; not in practice.

ROBINSON, CHAS. E. (b'53) $\odot-P a .2,{ }^{\prime} 80$; (l'03).

CLAUNCH, 90, CRAIGHEAD

Bates, Chas. Albert (b'87)-Ark.1,'12 ; (l'12) ; Op.

CLAY, 75, WHITE

Buice, J. C. $\left(b^{\prime} 60\right) E-0$; $\left(l^{\prime} 03\right)$.

McAdams, John Chas. (b'75)-Tenn.9,05; (1'03).

CLEARWATER (LEACHVILLE P.0.), 26, Henderson, Thomas W. $\rightarrow$; (l'07).

CLEVELAND, I64, CONWAY

Colay, John H. (b'80)-Ark.1,11; (l'07);

CLINTON, 297, VAN BUREN

Hunter, Robt. Marrin (b'79)-Ark.1,'11; (l'11).

Medahan, John S. (b'85)-Ark.2,'11; (l'11).
CLI0, 163, CLEVELAND

Raker, S. F. - ; (l'03).

CLOVER BEND, 60, LAWRENCE

Andrus, F. ; (1'03).

CLOW, 80, HEMPSTEAD

Walker, Wm. Morgan-Tenn.1,94; not in practice.

COALDALE, 350, SCOTT

Ferguson, Fd. $\left(b^{\prime} 72\right)-0 ;\left(l^{\prime} 03\right)$

COAL HILL, I,229, JOHNSON

BLAKELY, TIIOMAS B. (b'59)-Ark.1,'83; (l'03).

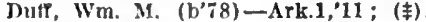

PORTER, WM. C. (b'68)-Ark.1,'08; (l'03).

COLEMAN, 20, DREW

Avery, II astlngs D. (b'59) $\rightarrow$ : (l'03).

COLLINS, 197, DREW

IISENBEE, ALEXANDER MARCEIJUS

(b'86)-I,a.I,'10; (1'10).

SMITH, ROBERT N.-Tenn.8,'97; (l'03).

COLT, 50, SAINT FRANCIS

Casbeer, Jos. L. (b'78) - Tenn.15,'10 ; $\left(\mathrm{l}^{\prime} 07\right) ; \mathrm{G}$.

REYNOLDS, JAMES C. (b'81)-Tenn.8,04: (l'04).

COLUMBUS, 200, HEMPSTEAD

AUTREY, JAMLS R. (b'59) - Ky.4,'89; (l'03).

Darnall, Henry Herbert $\left(b^{\prime} 79\right) \longrightarrow ;\left(1^{\prime} 03\right)$.

COMBS, 200, MADISON

Davis, Edward Gates (b'65) - Kan.4,'98; (1'12).

COMINTO, 20, DPEW

Cooper, Jefferson L. (b'55) $\leadsto$; $\left(1^{\prime} 03\right)$.

Moody, IVm. Henry (b'66)-Tenn.8,'99; (l'03).

CONWAY, 2,794, FAULKNER

Baugh, Wm. F. (b'54)-Ark.1,'85; (1'03).

Bell, James F. $\left(b^{\prime} 55\right) \rightarrow$; $\left(1^{\prime} 03\right)$; not in practlce.

BLAKELY, GEO. W. (b'80)-Ark.1,07 ; (1'03).

Brannon, Edgar o. (b'50)-Tenn.6,'79; (l'03); not in practlce.

BROWN, GEO. SNIDER (b'50)థ-N.Y.10, 77, N.Y.5, 77 ; (1†); S.

Coker, James Mi. (b'53)- (l'03).

Cureton, Hugh E. (b'67)-Árk.1,'95; (l'03).

DICKERSON, CECIL IIARROD (b'83)-Mo.2, 10; (l'10)

GREESON, WM. R. (b'50)๑-Tenn.5, 82 ; (1'03)

Harrod, Geo. (b'69) $\rightarrow$; (l'03); R.F.D.

Haydon, Owen Kahr' (b'89)-Kan.3,'13; (l'13).

Niattison, Chas. A. (col.) (b'63) $\rightarrow ;\left(l^{\prime} 03\right)$. ICCOLLUM, ISAAC N. (b'67)-Ky.2,'94; (l'03).

ICMAHAN, JOHN E. (b'60)-Ky.2,00; (l'03)

Muse, James M. (b'67) $\rightarrow$; (1'03).

Prlchard, Allen Courtland (b'82)-0.2,'13; (1'07); S.

SNODDY, THOMAS B. (b'76)-Ark.2,'11: (l'03).

WESTERFIELD, JOS. S. (b'52) $\$-\mathrm{Ky} .2,80$; l'03).

CORD, 65, INDEPENDENCE

ICADAMS, Yan D. (b'80)↔-Tenn.9,'05; (l'04).

\section{CORINTH}

HOWARD

Roundtree, J. M. $\longrightarrow$; (l'03).

CORNERSTONE, 250, JEFFERSON

Harrison, W. W.

(See Pine Bluff.)

CORNERVILLE, 125, LINCOLN

Vick, Thaddeus W. (b'38) $\diamond ;\left(l^{\prime} 03\right)$.

CORNING, I,439, CLAY

BLACK, J. CURTISS (b'88)-Ark.1,'11; (l'11).

Bowers, John W. ( $\left.\mathrm{b}^{\prime} 61\right)-0$; (l'03).

Gray, Geo. D.-Md.2,'68; (1'08). LATIMER, NEWTON J. (b'69) $\mathbb{B}-\mathrm{Ky} .1,{ }^{\prime} 95$;

MCKINNEY, ASBURY B. (b'61)-Ky.4,'92; (l'03).

NELSON, FLETCHER L. (b'80)-Ark.1,06; (1'06). 
Scott, Wm. C. $\left(b^{\circ} 65\right)-0.140^{\prime 90}$; not in practlce.

sismpsor, A. ROSS $\left(b^{\prime} 60\right)-\mathrm{Ky}^{\prime}, 2,82$; (I'03).

\section{COTTER, 894, BAXTER}

CANNADY. CRFED T. (''52) - Tenn.8,98: (103).

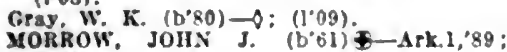
(I'03).

wilson, R. S. $\left(b^{\circ} 36\right) \longrightarrow$; (1'03).

COTTON PLANT, 1,081. WOODRUFF

BRADFORD, TILLMAN BROOKS (b'65) -

Tenn.5,'92; (1.03).

BROWX, E. BURKE-Ky.4,03; (1'03)

GEPHART, ROSCOE T. (b'73)-III.17,99: (1'05).

Yathls, Wm. J. (b'51) - Tenn.5:79: (1'03).

MCKNICHT, CHESTER HOWARD (b.84) Tenn. $5,07:\left(10^{2} 07\right)$.

Morris, G. U. Frank (col.) (b':6)-Tena.7, 04: (1.04).

COUNCIL, 25, LEE

Pearson, Win. H. M. (b'79)-Tenn.8,09; (I'06).

COVE, 400, POLK

Gray, M. F. $\rightarrow$; (1'03)

James, Andrew C. $\left(b^{\circ} 45\right) \rightarrow:\left(1^{\prime} 03\right)$.

Mullins, Frank C. (b'i2)- 0 ; (1'03).

COY, LONOKE

White, Luther W. (b'83)-Ark.1,09; (1'06).

CRAWFORDVILLE, 400, CRITTENDEN

Crockett, Robt. Newton (b'82)--Tenn.8,'11; (गII).

HANEN, JOHN T. (b'52)-Tenn.5,'76: (1'03)

HARE. THOYAS $S$, (b.84) -Tenn.8.04: (103).

CROCKETT (R.F.D.. PIGGOTT), 30, CLAY Crockett. Wallace Henderson (b'89)-Ark.1. '13: (1)]3).

CROSSETT, 2.038. ASHLEY

Arrington, Wm. II amton (b'5s) $\rightarrow:\left(J^{\prime} 03\right)$

Brantley, Edwin T. $\left(b^{\prime} 45\right) \rightarrow 0:\left(l^{\prime} 03\right)$.

Gray, Geo. T. (col.) (b'82)-Tenn.7.10; (1)

Setzler. Geo. HIlbalrd (b'6t)-Tenn.8,'06 (I'03)

SPARKS. JOS. EVERETT (b'76) -Tenn.8. 03; (1.03).

Vlnes, Crawford lee (b's3) - Tenn. 9,20 (iili)

WILKES, ELBERT HATS (b'7) - Irk.2 09: (108).

CUMMINS, 250, LINCOLN

Getitry, James Ely (b'81)-Ark.2,'11; (1'11).

CURTIS. - CLARK

Boorland, Siml. R. (b.'-44)-0; (1'03).

CUSHMAN, 244, INDEPENDENCE

BONE, OSCAR LASLEY (b'83)-Tenn.8. :08; (108).

DAHOMA (R.F.D., CHARLESTON), 15. FRANKLIN

IIudson, Kelth E.-Tenn.5.85; (1'03).

DAISY, 136. PIKE

Yecks, Chas. Scott (b'84)-Tenn.8.09: (l'09).

DALARK, 23!, DALLAS

Matlock. Thos. T. (b'53)-M0.24:00:(I'03). Wilson, John Fellx (b'il)-Ark.1,97: (1'03).

DALTON, 12, RANDOLPH

Brown, fieotge Willlam (b's3)-Ark.l,10 (I'10)

Dalzon, John W. (b'36) 1:-Mo.10,80: (103)

DAMASCUS, 300 FAULKNER

Harris. Thos. (b'e4) $\rightarrow$ : (1.03)

Ifutto, Anderson 1. (b'6) E- D; (l'03).

DANVILLE, 803, YELL

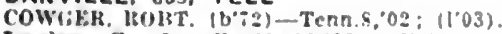

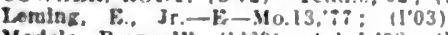

Madole, Berry Wr. (b'69)-Ark.i.98; (1'03).

DARDANELLE, I,757, YELL

Cunnlnghem, isenj. Lee-laa.1.0\%: (1'00).

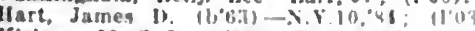

Kirkaey, 31. C. L. $\left(6^{\circ} 69\right)$-Tenn.8.96: (1'03)

LINZY JAMES $\mathrm{H}$ (b.68)-Tenn.8.97 (l'03).

LOVE. I. E. (6'32)-3) $1.7 \%: 11 \cdot 03)$

Meclure iv $x$ (b.69)-(ia 10.85 (1103)

MILLER, SAVIL E. (b'bi)-ATKlol (I'03).
DATTO, 244, CLAY

NEWKII!K, CIIAS. If. (b'tl)-Ind.12,92; Ark 1,06.

RICHAHISOX, MELVIX C. (b'85) AFk.2. 11: (1"11).

DE ANN (R.F.D.. EMMET), 100, HEMP. STEAD

Whinple. II. W. (b'42)-D: (1.03)

DEAN SPRING (R.F.D., ALMA), 65, CRAW. FORD

Witchell. Thos-0: (1'03).

DECATUR, 2\$6, BENTON

BIFFINITON, GEO. HI-13.10:00: 11.031.

EtBANKS, FELIX G. (b'65)-Airk.1."sĩ;

DELANEY, 150 , MADISON

Inabney, This. C. (b'0) E-O: (1.03).

DELAPLAINE, 50, GREENE

H'TPHFASOS. ROBT. L. (b'68) - Tenn.8. 03: (1'0?)

DELAWARE, 20, LOGAN

JEWE1.1, VICTOK I. (b'90)-Ark.1,'12: (11.12).

Monse, J. HI- Y $\rightarrow$ : (1'03).

DELIGHT. 339, PIKE

IIemby, Win. P. (b'- 8$) \rightarrow$ : (1'03)

LAI'CIITER, NCTEN J. (b'70)-Mo.28,09 (1'03).

STOKES, B.IILIS S. (b'69)-Ark.1,02: (1'03).

Wall, Sami. B. (b'29) $\rightarrow$; (1'03)

DELL, 162, MISSISSIPPI

Bundren, Geo. A. (b'4i) $\rightarrow$; $\left(1^{\prime} 03\right)$

DENMARK, 34, WHITE

Fraser, W. It. (b'ii)-Tenn. S,04: (l'03).

DENNING, 757, FRANKLIN

IIAPROD, J.MIES C. S. (b'66)-Tenn.8,91; (1003)

DENTON, 12, LAWRENCE

MORRIS, JAMES W. $\left(L^{\prime} 66\right)$ - T-Tenn. 8,94 $(1,03)$.

DE QUEEN, 2.018, SEVIER

ARCHET, CHAS. A. (b'6)-Ill.11,04 (1)0 0 i)

BEACCIAMP, JETHRO II, (b'5I)-Tex.6, .05: (I'05). OLJYER O. (b'30)-Mo.20 HAMMON[S,

'00: (1'03). OL S.-KYt.04: (1'03): OALR

HOl'KINS, IR $L \rightarrow-\left(1 \frac{1}{1}\right)$

KITCHENS, CHAS. E. (b'81) - Tenn.8,09 (1'03)

WISDOM, WM. EVA.YS (b'86)-K5.5.04 (l’03).

DERMOTT, 1,662, CHICOT

BAKER, EIWOOD (b':3) †-Tenn.8,01 $\left(I^{\prime} 03\right)$.

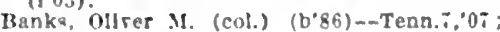
(Inos).

BARLOW, EDWARD E. (b':3) Tenn.8, 02: (1'09).

BL..NKs, JoHs T. (b'61)-Ta.1.'8s: (1'03).

Boal. Wm. 1'-0.3.01: $11^{\prime} 231$

coleman. samuel C. (col.) (b'79)-Teun. $\%$ 03: (1003).

Duke. Gllbert D. (col.) (b'65)-La.4.98; $\{10.3\}$.

STISSUi HARRY CLAY (b'53) \&-KY.2,

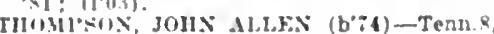
01: $\left(10^{\circ} 03\right)$.

DES ARC. I.051. PRAIRIE

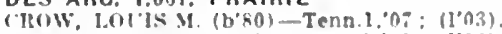

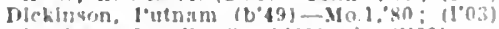

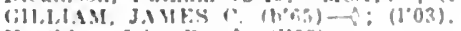

Kinthley, Johu R. - : $\left\{1{ }^{\prime} 03\right\}$

DESHA, 50, INDEPENDENCE

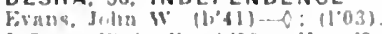

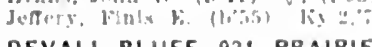

DEVALL BLUFF, 924. PRAIRE

DEVALI, III?טI,I] (l'03)

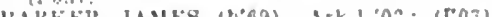

loaker, Luke (b'as)-0: (1'03)

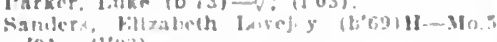
(9): $(10,0,1)$

DE VIEW, 100. WOODRUFF

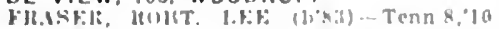
$10^{\circ} 104$

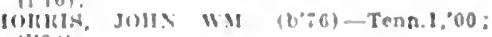

DE WITT, 831, ARKANSAS

IHEIHICK, IIENIRY C. (b"59)-Ky.,"90: (1.03)

HOJ.('OMB, THOMAS J. $\left(b^{6}, 7\right)-M n .1,87$; ( 103$)$

Kelley, Robt. J.-Tenn \&.00: $11^{\circ} 031$

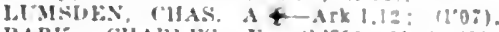

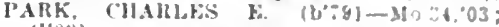
(I'03).

IBAs(o) C. W:-Tenn \&.06: (1003)

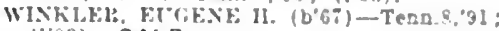
(1"03) ; OALR.

DIERKS, 272, HOWARD

Joneq. Walter De Wol?. (b'tt)-Pa.14,6i: $(T 0.3)$

IRoterts, w. w, $\left(b^{*} 4 f\right) \rightarrow$ ( $\left.f^{*} 03\right)$

DODDRIDGE, I50, MILLER

Cabanisa, J. A.- $:$ : 1]'n?

DONALOSON, 100, HOT SPRING

COX, JOIIX A-Tenn.8.93: (l'03).

DOTA, 50, INDEPENDENCE

Dorr. Janies I". (4"56)-31,1,81; (1"03).

DOUGLAS, 298. LINCOLN

IIXON, CHARTKS W3. (b*\%9)-KY.:,04; (1'03).

DOVER, 385, POPE

Hrown, lin. J. (b'ii) $\rightarrow$ : (l'03).

Camplell. (C. K. $\rightarrow(1,03)$

Ianley, R. is $\left(b^{\circ} G 4\right) \rightarrow:(100)$

Ruft, Sami. Wert (b'31)-Ark 2,08: (1'08)

Trult, Edward I) (h'6i)-Ark.l,93; (1'03).

DOYLE. 50. HEMPSTEAD

Ball, H. F. $\rightarrow$; $(1,0: 3)$

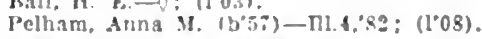

DRAKES CREEK, 200, MADISON

HII.I. X. J. (b;:0)-O: (1'03).

DRIGGS, 75, LOGAN

Dorrough, Joe (b'ss)-Ga.9.10: (l'11).

DUBLIN, 60, LOGAN

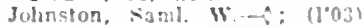

DUFFIE 10, HOT SPRING

Bray, Thomas L. (b'8t)-Ark.1,10: (\$).

DUMAS, 500, DESHA

BOWl.FS, THOS. H. $\left(5^{\prime} 55\right)-M 0.1$ ' $\$ 8:$ (!'03).

ISOM. ALPHONSO (b'83) + Mo.7.06: (1.05) : $\mathrm{S}$.

o'veal. Wr. f. (col.) (b'.5)-Tonn.i,03; (1"0:3).

PRICF, CHAS. C. (1,"2)-Va 6."36; (l'03)

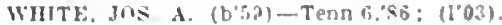

DUNNINGTON, - INDEPENDENCE

Baynham. Chas. W. (b*io) H-Mo.5:92: (103).

DURHAM, 40, WASHINGTON

Carter, lieo. W. (b', 2$) \rightarrow(1,03)$

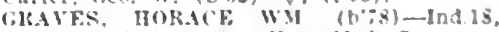

"0⿱宀: (1"12): Member Kan. Med. Soc

DUTCH MILLS, 70. WASHINGTON

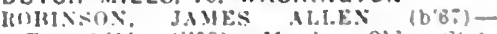
Tunn.6.9: (J03): Member Okla. State

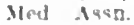

DYER, 433, CRAWFORD

tyres, Jns. II. (h'b6)-Ky 2.91: ("03)

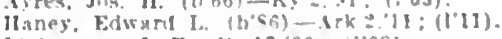

livingsion, J. F.-l'a 17,"69: (I'03).

EAGLE MILLS, 1,200, DUACHITA

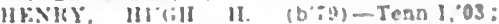
$(1 / 03)$

EARL. 1,542, CRITTENDEN

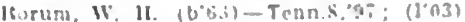

Filwarl. Jatues llenty lobl.) (b'sliTern : $: 10 ; 1010)$

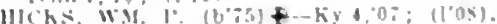

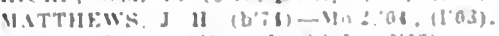

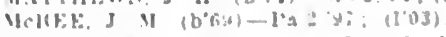

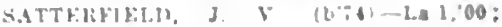

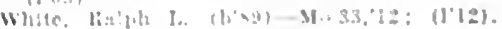

EDGEMDNT, 342, CLEBURNE

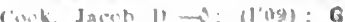

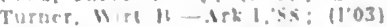

EOMONOSON, I30, CRITTENDEN

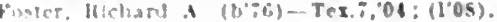

Tachep 3. T foul l A. (1)03].

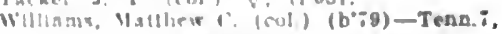
Io: nut In irsatice. 
EDNA, 一, JOHNSON

HAII)GRAVE, GEO. L. (b'81)-Ark.1,11; (1'I1) ; 0b.

EGBERT, 75, WHITE

Ellis, W'lley A. (b'40)-Tenn.1,69; (l'03).

EGGER, 50, POLK

I'llllpot, Will W. $\rightarrow$; $\left(l^{\prime} \theta 3\right)$

EGLANTINE (SETTLEMIENT P.0.), 75

VAN BUREN

Daniels, X.. II. (l' 50$)-0$; (l'03)

IJutto, J. W- $\rightarrow$ : (1'03).

EGYPT, 100, CRAIGHEAD

Mcllrath, J.'T.-1nd.2,'81; (1'03)

EIGHT MILE, 10, JACKSON

Owens, M. B.-Tex.7,'03; (1'03).

ELAINE, 10, PHILLIPS

Chandler, Thomas Collins (b'81) $\rightarrow$; $\left(1^{\prime} 06\right)$

PARKER, ORLIE (b'82) $\oplus$ - Tenn.8,'12; (1'I2).

ELDORADO, 4,202, UNION

GEORGE, ISAAC MI.-Ark.I,'s1; (1'08) ;

OpLR.

McCall, Danl. (b'73) $\rightarrow$; (1'03).

MCGRAW, s. J. $\rightarrow$; ( $\left.\mathrm{P}^{\prime} 03\right)$.

MITCHELL, JOSEPH GROVER (b'85)La.1.10; (1'11) ; Pd.

MOORE, Jón A.' (b'73)-Tenn. 8 ,98; (1'03) NIEHUSS, H. H. (b'76)€-Tenn.8, 02 ; (l'03); Prof. Med. Ark.1.

PINSON, THOS. M.-Ark.1,'80; (l'03).

Plnson, Wm. J. (b'60)-Ark.1,'82; (1'03)

not in practlce.
PURIFOY, LAWRENCE L. (b'82)-Tenn.8, '03, La.1,13: (1’03)

ROWLAND, ROBT. ELMORE (b'80)-La.1, 03; $\left(1^{\prime} 03\right)$.

Sheppard, J. M. (b'63)-Ark.1,'97; (l'03)

Washington, Isaac J. (col.) (b'65)-La.4,

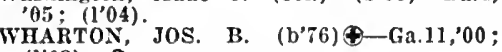
(l’03); S.

ELERSON, 3, JEFFERSON

Hogg, G. A. (b'40)-Tenn. 1,'61; (1'03) ; not in practlce.

ELIZABETH, 200, FULTON

Niblett, Saml. W. (b'58) E-Tex.7,03; (1'03).

Sutton, Owen 0 . $\left(b^{\prime} 72\right) \rightarrow$; (1'03).

ELKINS, 100, WASHINGTON

Swift, Chas. E. (b'i4)-O; (l'03).

ELLIOTT, 138. OUACHITA

Plunkett, C. M. $\longrightarrow$; (1'03).

ELLIS, - CLARI

Smith, E. S. (b'53) $\rightarrow$; (l'03).

ELMO, 75, INDEPENDENCE

WILSON, WI. F. (b'79) - Tenn.11,03 ; (1'03).

ELM SPRINGS, 25, WASHINGTON

FERGUS, JAMIES W. (b'52) - Tenn.8,'9I:

SLMMERS, DAVID C. (b'56)-M10.28,97 ; (I'03); OALR.

EL PASO, 200, WHITE

Bruce, Walter H. (b'79)-Ark.2,07; (l'07).

Edwards, D. H.-Ark.1, 02 ; $\left(l^{\prime} 09\right)$.

EMERSON, 600, COLUMBIA

Clayton, Augustus Saml. (b'33) $\rightarrow$; (l'03).

IIcIIahon, W. S. $\left(b^{\prime} 57\right) \rightarrow$; $\left(l^{\prime} 03\right)$; R.F.D. 1 .

IIullins, Geo. Eihert (b'73) $\rightarrow$; (1'03)

TWITTY, G. WALTER (b'i7)-Tenn. 8,04 ;

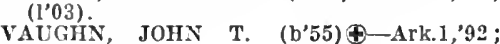
(1'03); R.F.D.

WALKER, JOHN C. (b'ôT)-Tenn.8,04; (1'03); R.F.D.

EMMET, 270, NEVADA

SANDLIN, JOS. TOLBERT $\left(b^{\prime} 80\right) \oplus-A r k .1$, '11; (1'i1).

ENDERS, 50, FAULKNER

Clark, Wm. I. (b'57)-Ark.1,97; (1'03).

ENGLAND, 1,407, LONOKE

Alter, Wm. M. (b'50) $\rightarrow$; (l'03) ; G

Beakley, N. B. (b'63)-Árk.1,93; (1'03).

BEATY', SAMIL. S. (b'76) - Mo. T'03; (1'03) Carroll, Isaac L. (b'i $i)$-Tenn. $\tilde{i}, 10$; $\left(l^{\prime} 10\right)$;

CHENAULT, JOHN C. (b'67)-Ark.1,95; (1'03).

EXGLAND, JOHN FRANKLIN (b'87)Ark.1,'12; (1'12); G.

Harris, Ernest H. '(b'81)-Ark.2.'11; (1'11) ; R.F.P.

Leake, D. J. (b'53) $\rightarrow$; (l'03).
Murchison, A. J. (b'61)-Ky',2,93; (l'03). Tunkersley, J. ( WAR1), ORAN I). (b'74)-Tenn.1,'02; (1'03). ENOLA, 104, FAULKNER

Wilson, W'm. II. (b'i5) -

ERIN, 15, GRAIIT

JONES, JAMES EDWARD (b'83)థ-Ky.2, 10 ; (1'08)

EROS, 50, MARION

ELAM, GEO. F. (b'47)-Ark. 1,89; (1'03).

ESSEX, 15, WHITE

Welr, $Y$. W. (b'5T)- - ; (1'03).

ETNA (R.F.D., OZARK), 50, FRANILLIN

WEAR, WM. II. (b'67)-Ark.1,'11; (1'04).

EUDORA, 606, CHICOT

ANDERSON, ALEXANDER GORDON (b'ĩ) - Ky.1,90; $\left(1^{\prime} 03\right)$.

DOUGIAS. SMITH WALKER $\left(\mathrm{b}^{\prime} \mathrm{t} 0\right) \oplus$ Ark.2,'11; ( (1'08)

MILLER, R. DESMOND (b' 70$)-0$; (l'03) PARR, IIOLLY II. (b'78)-Ga.11,06; (l'05) Thompson, J. Lee (b'78)-O; (1'08).

EUREKA SPRINGS, 3,228, CARPOLL

BOLTON, JOHN F. (b'80) $\oplus-\mathbf{M} 0.2,04$; $\left(1^{\prime} 03\right)$

Davls, Chas. E. (b'44)-Mlich.1,74; (1'03) Ellis, C. Fremont $\left(b^{\prime} 56\right)$ H-N.Y.9,79; $\left(l^{\prime} 03\right)$ EZELL, WM. D. (b'59)-Ia.1,85; (1'13).

FLOYD, RUSSELL GREENE (b'51) NIo.2, 6 ; ; (1'03) ; U.

HUNTINGTON, ROBT. HOWARD (b'T9)-

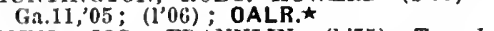
JOHN, JOS. FRANLILIN (b'75)-Tenn.1, $05 ;\left(1^{\prime} 04\right)$

JORDAN, JOIIN D. (b'46-Ky.2,'72; (l'03). Milligan, Arthur A. (b'59) P-AI-0.10,'83; $\left(l^{\prime} 04\right) ; r$.

PACE, HENRY (b'73)↔-Mo.2,'03; (l'05). Porch, Jos. Smith (b'47)-Ky 2,74; (l'03).

Reed, Chas. A. (b'41) - Mlch.1,'62; (l'03). Regan, Milton R. (b'60) H-Ill.10,'89, Ill.4 05: (1'03).

Tatman, Albert E. (b'70) E-Ga.9,'04; (l'04). Tatman, Pearl H. (b'67) E-No.10,'99; (l'03). EVADALE, I50, MISSISSIPPI

Currie, Saml. Addison (col.)

(b'83) -

Tenni,'12; (1'12)

EVENING SHADE, 239, SHARP

Cralg, Geo. E. (b'42) $\rightarrow$; (l'03)

WOODS, THOS. J. (b'50)

EVERT (R.F.D., ROMANCE), 25, WHITE

Goldlng, C. M. C. (b'66)-Tex.7,06 ; (1'03).

West, James H. ( $\left.b^{\prime}+9\right)-\triangle$; $\left(1^{\prime} 03\right)$.

EVERTON, 300, BOONE

COOPER, BURPEE (b'82)-Ark.1,'12; (l'12).

Johnston, T. P. (b'58) $\rightarrow$; (1'03).

Lay, Shelby (b'57)-Ark.1,98; (I'03).

EXCELSIOR (GREENWOOD P.0.), 65,

Stephens, J. R. (b'51) $\rightarrow$; : (1'03).

FAIRBANKS, 50, VAN BUREN

Brittain, James E. $\rightarrow$; (I03).

FAIRVIEW, 50, DALLAS

Rutherford, Thos. F.(b'61)-Ark.1,83; (l'03).

FARMINGTON, 175, WASHINGTON

Feathers, Charles W. (b'81) $->$; $\left(l^{\prime} 03\right)$; 0 b.

FAYETTEVILLE, 4,471, WASHINGTON

Batchelder, Franklin Pitman (b'56) - Ill.1, 81 ; (1'13) ; R.F.D.

DINWIDDIE, ROBT. R. (b'57)-MIo.7,96 ; (1'03).

ELLIS, EDWARD F. (b'63)(-Mo.1,'85; (1'03); $\mathrm{S}$.

GABBERT, WM. THADDEUS (b'67)-Mo.7, '89; (1'09); Pd.

GREGG, ANDREW S. (b'5i)-Mo.2,81; (l's1).

Griffiths, Thos. E. (b'66)-0.6,97; (1'11).

Harr, Harry Thos. (b'69)-Md.1,'92; (1'03).

HARDIN, NINA VASHTI (b; 78$)$ (1)-Ark.1, ,05; (1'03).

Jennings, Morgan Biddle (b'63)-Mll.1, 86 () ; R.F.D. 1.

Jennlngs, Theresa Kline $\left(b^{\prime} 67\right)-M 1.18,01$ () ; R.F.D. 1.

MLLER, OTEX (b'68)@-Mo.2,93; (1'03) ;

NOORE, ALBERT IRVIN (b'62)-Mlch.1, '84; $(1,03)$.

PADDOCK, CHAS. B. (b'63)-Ky.4,'98;

Read, James S. (b'40)-Mo.5,'69; not in practice; R.F.D. 2.
SOUTHWORTII, JAMES RICHMOND Tenn.5,78: (\$) (b'79)-Tex7,02: (1'04)

TOIILR, HALRY HUNT (b'85)-Pa.2,'07; (l'11); U.

WELCH, WM. BLACKWELL (b'28) 4 Tenn. 1,59; (1'03); not in practlce.

WOOD, HARYYY DOAK (b'47) (-Mo.2,72: (1'03).

YATES, WM. N. (b'51) Mo.1,78; (1'03).

FELSENTHAL, 273, UNION

PERIRINE, J. M. (b'44) - ; (l'03)

FINCH (R.F.D., PARAGOULD), 45, GREENE

IIyde, Walter $\mathrm{E}$. $\left(\mathrm{b}^{\prime}(\mathfrak{y}) \longrightarrow\right.$; $\left(\mathrm{l}^{\prime} 09\right)$.

FISHER, 165, POINSETT

Dodel, $\Lambda$. I. $\rightarrow$; (

FAKES, JOHN DAVID (b'69)-Mo.28,09 Ky.5,00; (1'09); Member Mo. State Med. Assn.

FITZHUGH, 25, WOODRUFF

RAGSDALE, VELPEAU HIILI-Tenn.1'06

(1'13); Member Med. Assn. of the State of Ala.

FLAG, 25, STONE

Smlth, J. W. (col.) (b'65)-Tenn.7,'99; (l'03). FLIPPIN, I50, MARION

Huddleston, Fellx Grundy $\left(b^{\prime} 60\right)-M 0.28,95$; (1'03).

MATTHEWS, JASPER THOMAS (b'85)Ark.1,'12; (1'12).

FLORAL, 100, INDEPENDENCE

Newton, Chas. (b'45) $\rightarrow$; (l'03)

Ward, Robt. H. $\left(b^{\prime} ; 6\right)-A r k .1,12$; not in practice.

FLORENCE, 50, DREW

Holland, E. E. $\rightarrow$; (l'03).

Lord, R. R. $\rightarrow$; (1'03).

FORDYCE, 2,794, DALLAS

ATKINSON, HENRY H. (b'80)-Tenn.8,

HARRISON, FREDK. E. (b'71)-Ky.1,94 (I'03)

HOPE, OLIVER WILBERN $\left(\mathrm{b}^{\prime} 83\right) \oplus-\mathrm{K} y .2$ 10 ; (l'08).

MARCH, CLAIBORNE J. (b'53)๑-Mo.1,'80 : $\left(l^{\prime} 03\right)$.

McLaughlin, Charles ( $\left.b^{\prime} 63\right) \rightarrow$; $\left(l^{\prime} 03\right)$.

SIMMONS, WALTER H. (b'79) 8 -Tenn.5, 03; (l'03); S.

Thomas, Chas. F. (b'70)-Tex.7,04; (1'03). Waters, J. A. (b'58)-Mo.1,'85; (1'03).

Worthington, Wm. Lewls (b'62) $\rightarrow$; (i'03).

FOREMAN, 1,000, LITTLE RIVER

Massie, Frank I'. (b'73) $\rightarrow$; (1'03).

MItchell, J. B.-Tex.7,05; (l'03).

SHACKELFORD, LABON C. (b't1) - Ky.1 ,07; (1'03)

SHAĆKELFORD, THEODORE T., JR. (b'\&2) -Ky. 2,'10; (I'09).

SHIREY, WESLEY' L. (b'67)-Tenn.8,'95; (l'03).

STEVENS, DOLPHUS L. (b'83) -Ark.2 '10: (1'09).

Treadway, Paca H. (b'58)-Ark.1,'94; (1'03). FORMOSA, 40, VAN BUREN

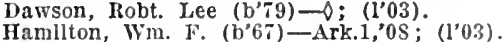

Holbrook, Danl. J. ( (b'r2) $\rightarrow$; (1'03).

FORREST CITY, 2,484, ST. FRANCIS

ALLEY, WM. H. (b'61)-Tenn.5,'81; (1'03)

Allman, T. A. (col.) (b'70) $\rightarrow$; $\left(l^{\prime} 03\right)$.

BOGART, JULIUS A. (b'69) (-A-Ark. 1,02 ; (103).

BOGGAN, P. P. (b'52)-Ky.4,74; (l'06); S. LONGEST, JAIIES T. (b'72)-Tenn.6, 03 ; (1'03).

MCDOUGAL, JAMIES F. $\left(b^{\prime} 60\right)-\rightarrow$; $\left(1^{\prime} 03\right)$;

not in practice.

PELTON, (l'03). DANIEL A. (b'65)-Mro.28,97; (1'03).

P'P0OL; EMIIETT J. (b'46)-Tenn.1,'75;

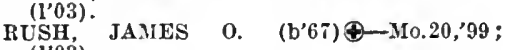
Williams, Donald J. (col.) (b'i4)-Tenn.7. .05; (1'04).

FOSTER, 10, RANDOLPH

SPIKES, JESSE M. (b'85)-Ark.1,'11; (I'11).

FOUKE, 300, MILLER

Rice, Joseph T. (b'52)-Ala.2, '72; (1'03).

Smith, wlley J. S. (b'57) $\rightarrow$; (1'03). 
FOUNTAIN HILL, 100 ASHLEY

Smlth yllen L (b'81) -..? (1"0

Nowds, Jess $T$. (b'a) - Irk.l.1.:

FOWLER (R.F.O.. CARDEN BOTTOM)

30. YELL.

WILSON, ELTON L. (b.79) + Lat 1 93 (1"03).

FRANKLIN. I50, IZARD

Ashles. 11. $W \rightarrow 0$ : (1'03)

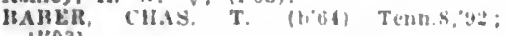

FREEMAN (LAUREL P.O.). 5, POPE

Dare, John W. (L'54)-O; (1.03).

FRIENDSHIP, 75, HOT SPRING

Wozencraft, Llewellyn C. (b'69)-Ark.1,08 (1'03): Pd.

FT. DOUGLAS, 30, JOHNSON

Michelsen, John C. $\left(b^{*} 35\right) \multimap$ : (l.03)

Mitholland, J. L. $\rightarrow$; (l'03) FT. LOGAN H. ROOTS (ARGENTA P.O.).

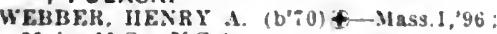
Maj., M.C. U.S.A.

FT. SMITH, 23.975, SEBASTIAN

AMENT, WILHLR PHANK (b'3)-Mo.2Q, us i18 $\mathrm{x}$. ith St; otlce, i13 Garrison Are. $10-11,3-4$

Braun, Geo. II (b'62)-xi13,8i: (光)

$621 \times$. 15 in St: once, 311 Garrison Are

Brooksher. Samuol L. (b'68)-Ky.2,'94 (1'03); G0s s. 20in si. : offce, i1314 (iarrison ive: 11-12,3-5; LD.

Brooksн (1'03): $1015 \times 12 \mathrm{kh}$ St.: uffce, :13 Gar rison Are: il-1:, 3-4.

BUCKIES, JAMES HUMER (b'i5)-LA.1, 96 : (1.03) : 415 > 13 th St. : oftlce, Fyrst Nail. Bask Bldg. ; $4-12.2-5$; (B1): OALR. Bungardt, Carl \&, (b'i)-Mo.31,02. Mo.20 05; (1'11): 700 \$. 12+h St.; oftce. Virs Xationa! Hank Bidg. $10-12,3-5$

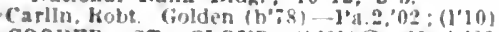

COOPLR, ST. CLOCD (b'61) \&-Mo.1.82 (1"03) ; 104 \%. 15th St. : offlce, Flrst Nat? Bank Bidg: : $10-12,2.4$ : $\mathrm{S}$.

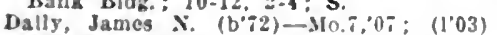
610 S. 19th St.; oflce, $91 \%$ (Garrlsol 610 S. 19 th $S t$.

DORFXTE, DRF, H. (b'-s)-Tex.s, 0 III.22,13; 2323 Tulls Are.: oflec, Met chants Naslonal llank blalg: : 10-12, OALR. $\star$

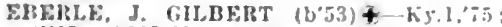
(1'03): 1203 N. Ith st. ; oftce, dolly liar rison ive: in. 4 -

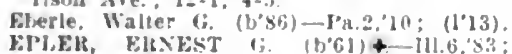
(1.02): 5:11/5 Garrison Are: 10-12, $2-4$ ALR,

FOLT\%, JAMLS A $\left(b^{\circ} 7 s\right)+$ La.1,01: $10-12,3-30: S$

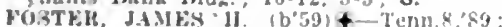
(1'03); 521 Garrlson A ve.

FOSTER, MLE.S FV E.ltETT (b'Si)-Ha.2 $09:(1,10): 501 \mathrm{~N}$. $1 \mathrm{xth}$ st. : unlce. 521 Garrison Are. : $10-i:=2-4: S$.

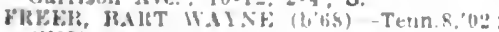

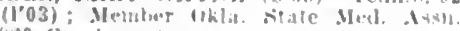
s:0 Ciarrimen die.

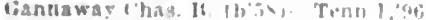

Ciant. James H-Mo.2." 91 : (1.03).

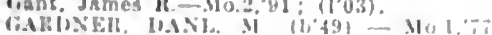

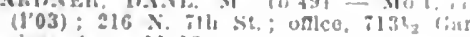
rlson A10: 11.12

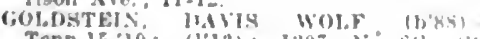

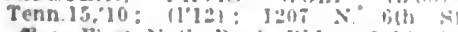

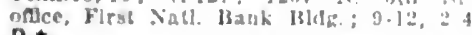
D.*

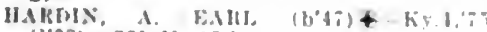

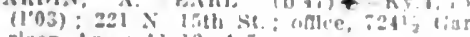
rlson A re. : $11 \cdot 12.15$.

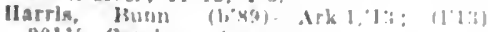
goly fiartwon Nio

Harrison, steven if (oul) - Tonn :an

(1'04): 6ol oth st (rol) Tomm... an

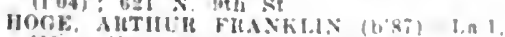
09: (10.05); Coldman IIned; unie. Flrst Nisil. Bank Hlls: : 3-5: 8.

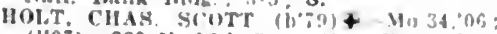

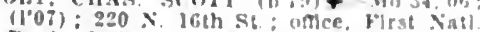

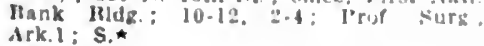

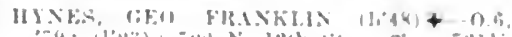

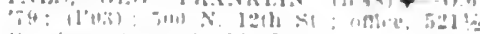
Giarrlan An $11-1+3 \cdot 1$

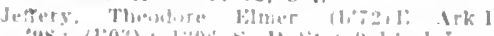
"as; $(100): 120)+11$

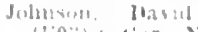

(160): (a)

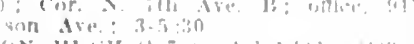

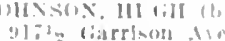

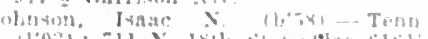

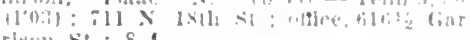

riven $\$$ : : : S- 4

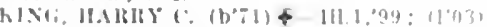
6:- liarrison ire.

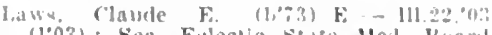

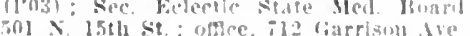
in-1:2, $2=1$

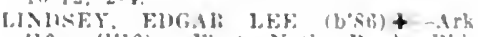

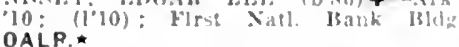

OONEY, MOUN IOS. MUIMAMS (b'84)

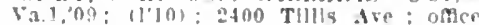
lerchants Nall, Bank Bldg; $9-12,2-4$ OALR.

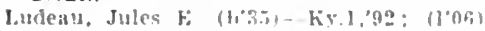
Hecorkle, dames \& $(1,35)$ - Tunn. 160 $(103): \ln 2$ \. 17th sit.

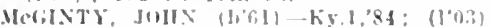

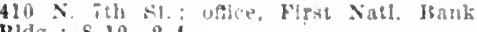
Blde. ; $8-10,2-1$

Monte. Jolun 11. (col.) (h'63)-Tenn.:.98

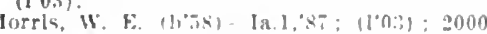
l.ltile liork Are

Morrissey, Indrew Jackson- $\theta:$ (1'06): 1101 fiarrison Are.

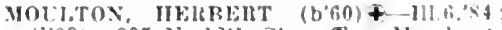

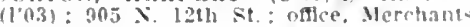
logk live $9-4$ (RI):OALR

YFLS, F.RHETT CAMPBEI.T (b.S)

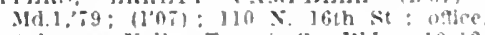
Irkansas Valley Transit (o. lidg : $10-12$ $2-4 ; 0 b$.

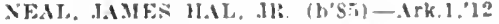
(1'12): $1117 \leqslant$ sish st.: offlce, liank of Commerce I3ld: $9-12,2-5$

real. Wh. J. (b'72)-Tenn.1.05: (l'03) $11^{i} x^{x}$ sth st. once. $91 \% 16$ Ciarrison Are. : $U$.

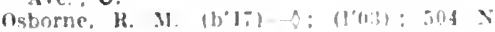
fith sit.

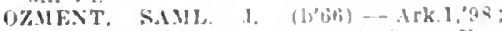
Mo.2;,01: (1'03); ;0l s loth st: onder,

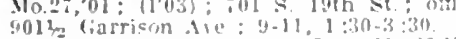

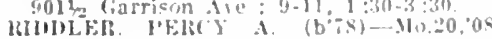

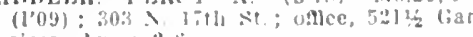

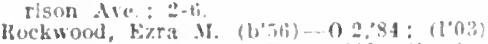
418 \&. dith st.: anlce, tolito iatrisum lie.; $10-12,2-4: G$.

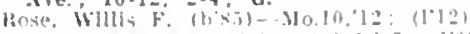

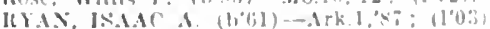

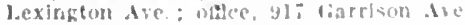
$10-12,2-5$

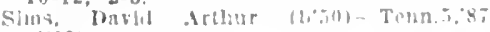
$(1,03)$

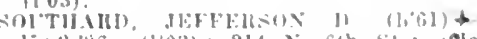
ky:36: (1+03): 214 $x$ fith si.: once,

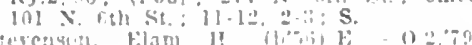

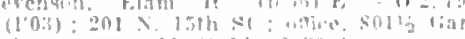

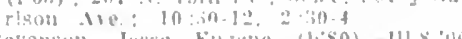

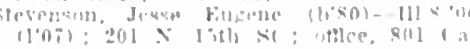

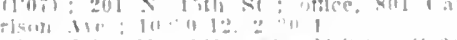

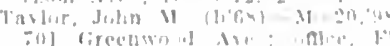
liank lole

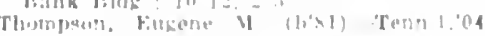

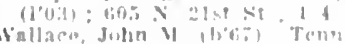

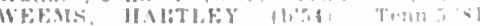
1100?

Wlill:1:, Al 1.1

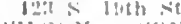

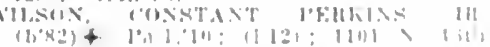

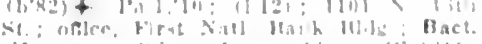

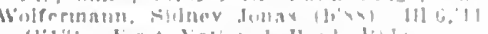

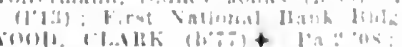

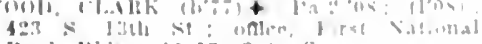
linnk Mhla $10-1 \%=1: 5$

Wiatt. Jotht. It|ri
FULTON, 647, HEMPSTEAD

II:SllFils, HE.TIS

(l'03)

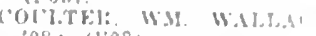

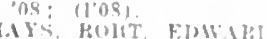

11003 ?

WHOER, SYTAFY J

\section{(llo 03 .}

GAINESVILLE, 100, GREENE

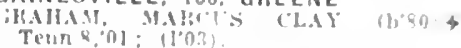

lutchins, Whes jo

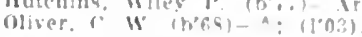

GAITHER (HILL TOP P.O.), 85. BOONE

Fowler. Tllden 1". 11,"til—; (1003).

GALLOWAY (LITTLE ROCK P.O.). 50. PULASKI

lweed, It. h. \&. (col.) (b'ef)-Tenn :?03:

GAMALIEL: 75, BAXTER

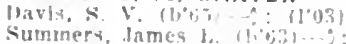

GARLAND, 277, MILLER

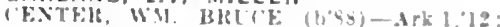

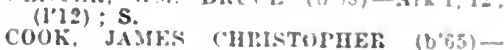
COOK. JAMkS (

Ilough. Charles I. (b'61)-Pa.2,83; (1'03).

GARNER, 150, WHITE

sloan. John B. (b:1)-U!ch. :993: (1:03)

GARNETT, 35, LINCOLN

Weatherali, W. M. (b'69)-Ter.5,06: (1"03),

GASSVILLE, 200. BAXTER

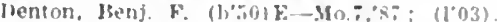

liackler, Chrisley A. (b*9)-0; (l'03).

GENTRY, 668, BENTON

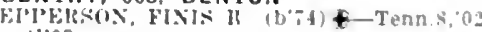
(1'03).

IIARDY, BFRT. WITI.M (b'83)-MO.,02

( ) : Member Arlz. Mell Aisn.

ramsey. Thompson $(\therefore \quad(\mathrm{b}) i 1)-k y 1.91$ :

WILSOS CIIAS STFWIRT (b"F)+

I10.34.05: (1'13) : Member Mo. Med. Ass?.

GEORGETOWN. - WHITE

Alexander. Frank stanler-a : (1'03)

GHENT, - MONTGOMERY

II hnisn, J $\rightarrow$; (1'03)

GIFFORD, 20, HOT SPRING

Decker, Arthur J. li. $\left(h^{\circ} b i\right)-.10 .29,20$

III.00: not in practlor.

GILIKEY (ROVER P.O.). I00, YELL

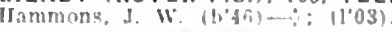

GILLETT, 256. ARKANSAS

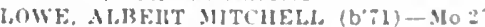

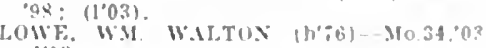
1]'031.

GILLHAM, 29I, SEVIER

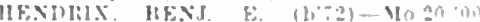

(1) (0:⿱艹:)

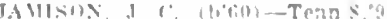

GLEASON, 60, CONWAY

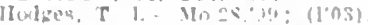

GLENVILLE, 35. NESADA

Hlostrely. I liz i : I

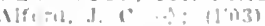

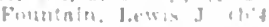

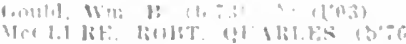

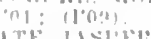

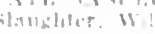

GOSHEN. 125. WASHINGTON

ROSNELL, 25, MISSISSIPP!

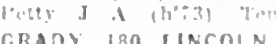

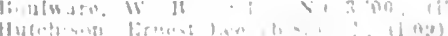

GRANGGLAIZE, 30, JACKSON

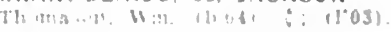

GHAND LAKE, 330 . CHICOT

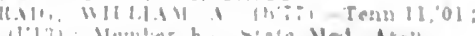

GHANNIS, 500, POLK

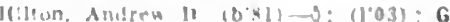

I'hllput. James lasac (b',5)-1: (1003) 
GRAPEVINE, 200, GRANT

Capel, Caldwell B. (b'84)-Ark.1,'13; (1'13).

GRAVELLY, 130, YELL

Blackwell, J. W. C. - 0 ; (1'03)

MONTGOMERE; HENRY L. (b'68)-Ark.1, $94 ;(1,03)$.

GRAVELRIDGE, 30 , BRADLEY

Roark, Wyley N.-T'enn.1,07; (1'06)

GRAVETTE, 569, BENTON

Foster, w. 1). (b'53) $-0 ;\left(l^{\prime} 03\right)$.

IHUGIrks, GKO. A. (b'70)-Tenn.5,'94; (l'03).

IRlch, Andrew J. (b'69) E-O; (l'03).

Ross, (icorke D. (b'is)- $\rightarrow$; (

GRAYS, 135, WOODRUFF

BREWSTER, 13. (b'T9) $\rightarrow$; (1'03).

GRAYSONIA, 77I, GLARK

BOYD, FRANCIS MAliON (b'85)-Ark.1 '13; (1'13).

GREENBRIER, 250, FAULKNER

Ilardy, Ifenry Baxton (b'73)-Ark.2,'11; (l'03) : IR F.D. I : G.

HENDERSON, GEO. L. (b'71)-Ark.1,07 ; (l'03).

Kelso, Samuel Taylor (b'78)-0; (1'03)

Lleblong, John S. (b's0)-Ark.1,'11; (1'11)

WILlJAMS, EARL T. (b'81)-Ark.1,'10; (1'03).

GREEN FOREST, 635, CARROLL

Donaldson, Chas. IV. (b'73)-Ark. 1,'03

MORROW, FRED R. (b'72)-Tenn.8,00; IORRON

POYNOR, ERTON E. (b'8L)-Ark.1,'04;

PRICE, CHAS. THOS. (b'72) $\oplus$-Tex.7, 06 , Mo.7'12; (1'03).

GREENLAND, - WASHINGTON

Thompson, John S. -0 ; (l'03).

GREENWAY, 390, CLAY

Lyell, Charley R. (b'67)-0; (l'03).

Myers, liobt. W. (b'74)- ${ }^{\prime}$ : (l'03)

Wallace, James W. (b'59)-Mo.7,93; (1'03)

GREENWOOD, 1.124, SEBASTIAN

Gillesple, Wm. J. (b'80)-Tenn.1,01 ; (l'03)

Hesterly, E. L. (b'43)-Ga.5,'91; (1'03).

McKelvey, A. A. (b'66)-Ark.1,'94; (l'03)

PERRY, JOHN T. (b'75) 4 -Ark.1,06

(l'03). Marcus L. (b'70)-Tex.8,06; (l'03).

WARE. BERT L. (b'83) 8-Ark.1,'09; (l'07).

GRIFFITHVILLE, 202, WHITE

MILLER, WILBUR J. (b'69)-Ark. 2,08 (1'03).

\section{GRUBBS, 178, JACKSON}

GEOHGE, CHAS. ELMIORE (b'68)-Ark.1, 09; (1'07); S.

Loftin, Wm. R. (b'65) $\rightarrow$; (l'03).

Mecurry, John H. (b'75) $\rightarrow$; (l'03).

GUION, 296, IZARD

BALDWIN, WARREN S. (b'71)(-Tenn.5, $92 ;$ ().

Estes, Waiter H. $\rightarrow$; (1'03).

GUMLOG, 75, POPE

BRITT, J. B.\$-Ark. 1,06; (1'03).

GURDON, 1,284, CLARK

CUFFMAN, JOHN H. (b'63) ๑-Tenn.5,'89; (l'03).

Kirby. D. W. (b'80)-Tenn.8,04; (1'03)

MeAlpin, Wm. J. (b'36)- ; (l'03)

Mclain, Chas. W. (b'82)-Tenn.8, 09 ;

McLaln, John T.-Tenn.8,'12; (l'03).

Mitchell, James J. (b'45)-IIo.7,83, Ky.2,

(99; not in practice.

GUY, 350, FAULKNER

Banister, Benj. F. (b'90)-Ark.1,'11; (1'11).

DEIARNATT, JAMES W. (b'71)-Ark.1,05; ('’03).

Glover, Andrew J. (b'70) $\rightarrow$; (l'03).

HACKETT, 363 , SEBASTIAN

Rudell, John C. (b'56)-Tex.7,07; (l'03)

Rudell, Wm. P. (b'ST)-A rk.2,11; (l'11)

Scott, Lester L. (b'83)-Ky.2,'07; (1'06).

HALCOMB (R.F.D., LOCKESBURG), 20 SEVIE

McCroskie, M. R. (b'84)-Mo.33,'11; (1'11).

HALLEY, 257, DESHA

MctiEHEE, EDW. CHAS. (b'86) †-La.1,'10; ( ) ; Member Miss. State Med. Assn.
HALLIDAY, 100, GREENE

HITDGINS, JAMES J. (b'88)-Ark.1,'12; (1'12).

HAMBURG, 1,787, ASHLEY

Clavis, Waiter M. (b'7')-Tex.7,03; (l'03) Eastor, Wm. E. (b'31)-0.6,'53; (1'03); not in practice.

I.Indsey, W'm. H. (b'43)-Ala.2,'77; (l'03) not in practlec.

NORMAN, WM. S. (b'51) $\oplus$ - La.1,75; (l'03).

SCOTT, EDWARD M. (b'76)\$-Tenn.5, , 00 : (l'03)

SIMPSON, JOIIN WM. (b'57) $€$-Tenn.5, HAMILTON (R.F.D., CARLISLE), I4, LONOKE

Brletz, Sam1. J. (b'46)-Pa.1,'68; (1'03).

Ilardy, Frank 1. (b'86)-Ark.1,'i3; (l'09).

HAMPTON, 353, CALHOUN

JONES, ENOCII T. (b'67) †-Tenn.8,01 ; (I'03).

Tobin, Chas. Petite (b'54)-La.1,'T9; (1'03). W1LSON, DAYID F. (b'61)-Ark.1,'9I (l'03)

Wooldredge, W. B. (b'76) $\rightarrow$; (l'05).

HANCOCK (R.F.D., MONETTE), 70, CRAIG-

HEAD
Marcum, Henry Oscar $\left(b^{\prime} 69\right) \longrightarrow$; (1'03).

HAPPY, 50, LEE

Lyels, Jullus C. (b'78) - ; (1'08).

HARDY, 329, SHARP

JOHNSTON, WMI. (b'76)-Ky.9,03; (1'03) Moore, John C. (b'66)-Mo.10,98; (l'03).
Parks, Calvin Hess (b'78)-0.2,'10; (l'13).

Parks, Calvin Hess (b'78)-0.2,'10; (l'

HARMONY, 50, JOHNSON

OGII.VIE, JAMES W. (b'5I)-Ark.1,92; (1'03).

HARRELL, 300, CALHOUN

JONES, ERNER (b'77)-Tenn.8,02; (l'04)

HARRIS, 65, WASHINGTON

Carter, N. Dllford (b'83)-Mo.20,'11; (1'11).

HARRISBURG, 942, POINSETT

DAVIS, JOHN C. (b'67)-Tenn.8,'03; (l'03) Ileidmann, A. C. (b'61) -Mo.7,83; ( ) HLNN, JOHN THOMAS (b'77) $€-\mathrm{Ky.4}, 04$;
(1'07).

Jacobs, E. L. (b'32)- 0 ; (1'03).

Jacobs, H. L. (b'52)-8; (1'03).

Miller, Andrew D.-Mo.I,'91; not In practice

Redden, James E. (b'84)-Ark. 2,08; (l'08).

Steele, James M. (b'61)-0; (1'03).

VERSER, WM. W. (b'75)-Tenn.8,09; (l'03)

YARBRACGH, ROBT. ELBERT (b'83)Ky.2,'10; (l'09).

HARRISON, 1,602, BOONE

Bishop, Richard B, (b'85)-Mo.33,'13; (l'13).

Brand, W. M. (b'81)-0; (1'03).
EVANS, DAVID E. $\left(\mathrm{b}^{\prime} 55\right)-$ Ark.1,'96 ; (1'03).

FOWLER, JAMES H. (b'75)-Tenn.8,'07; (1'03). HATHCOCK, ALFRED M. (b'54)-Mo.1,78;

JOHNSON, JOHN J. (b'61)థ-Mo.27,'96 : (1'03).

KIRBY, FRANKLIN BEVERLY (b'77)Mo. 2,04: (1'03).

KIRBY, LEONIDAS (b'50)Ð-Mo.2,76 ; (l'03).

ROU'TH, CHAS. M. (b'72)-Ark. I,'05; (1'03)

ROUTH, HUGH L. (b'44)-Tenn.5,'85;

(l'03). JOHN LESTER (b'47)-Mo.2,'80; (l'03) ; Anes.

Tapscott, C. V. (b'67) $\longrightarrow$; (1'03).

HARTFORD, 1,780 , SEBASTIAN

Chambers, IV. C. $\rightarrow$; (l'09).

Davenport, Charles Pierce (b'53)-Tenn.5, '89; (1'03).

Hunt, Walter J. (b'87)-Ark. 1,11; (l'11).
Johnson, Frank w. (b'53)-Mo.1,'86; (米).

JONES, E. B. (b'63)-Tenn.8,93; (1'03).

Routh, H. P. (b'79)-Ark.1,'04; (1'03).

HARTMAN, 500, JOHNSON

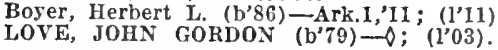

HASKELL, I00, SALINE Gwaltney, Boulanger (b'87)-Ark.1,'13;
(1'13).

HATFIELD, 300, POLK

Campbell, Cyrus A. (b'75) $\rightarrow$; (1'03)

Johnson, Callie (b', 0$) \rightarrow$; (1'03).
HATTIEVILLE, 50, CONWAY

Tate, Alvle B.-Ark. 1,07; (\$).

HAVANA, 621, YELL

BRITT, HENRY A. (b'78)-Ark.2,'11; (l'03)

IIefflugton, Calvin F. (b'52)-0.2,'91; (1'03).

liltehell, John E. (b'61) $-0 ;\left(l^{\prime} 03\right)$.

HAWES, 50, GARLAND

l'hlllips, J. A. (b'il)-Ark.1,03; (1'03).

HAYNES, 350 , LEE

Irradford, Win. S. (b'60)-Tenn.5, 84; (1'03).

Haynle, Wm. Robt. (b'63)-Tenn.8,05; (1'03).

HAZEN, 687, PRAIRIE

CAILAAIAN, EUGENE A. (b'77)@-Ark.I,

Everett, Wm. C. (b'66)- 0 : (1'03).

LEE, WILLIE ALLEN, $\left(\mathrm{b}^{\prime} 60\right)-\mathrm{Ia} .1,93$; (1'11).

LYNN, JOHN ROLAND (b'67) †-Tenn.8, PORTER,

Ky.11,'08; (1'03).

ROBINSON, FRANK C. $\left(b^{*} 62\right) \oplus-A r k .1,96$; (l'03).

HEBER SPRINGS, 2,000, CLEBURNE

Crosby, Cyrus F. ( (b'67) E-O; (1'03).

Crosby, Geo. W. (b'46) F- ; (l'03).

HORNBARGER, WM. J. (b'60)-Ark.I,'84 ; (1'03).

RCIIARDSON, FOSTER G. (b'71)-Ky.2,

RUFF, HORACE E. (b'73)क-Mo.1,'94;

$\left(l^{\prime} 04\right) ;$
STARK, CALVIN

TURNER, SHELBY A. (b'77)-Tenn.8,04;

Underwood, A. J. $\rightarrow$; (l'03).

HECTOR, II5, POPE STANFORD, JOHN MITCHELL (b'79)-
Tenn.8,08; (1'03).

HELENA, 8.772, PHILLIPS

ALTMAN, GUSTAVE GRAUMAN (b'82)థKy.4,'07; (1'08).

Beasley, Andrew Dumas (col.) (b'84)Tenn.7,'11; (1'11).

Clark, Peter W. (col.) (b'64)-Tenn.7,'93 : (1'03).

COX, ALLEN ENNIS (b'72)థ-Tenn.5,'94; COX, ARIS WELLINGTON (b'82)-Tenn.I, '06; (l'08). ELLIS, JAMES BAXTER (b'78)@-Pa.2,

FINK, MONTAGUE (b'66) $\rightarrow-M 0.1,87$; (l'03).

Hargrove, Sebastlan Henry (col.)-Tenn.14, '04; (\$). MORRISS (b'77) - Tenn.8,01: (l'13); Member Med. Assn. of State of Ala.

Houser, Napoleon B. (col.) (b'69)-N.C.3, '91; (l'03).

KING, WM. C. (b'77) $\$$-Tenn.8,'01; (1'03). Moore, Friarson (b'55)-N.Y.10,79; (1'03) NICHOLS, JAMES W. (b'78)-Tenn.9,02; (1'03).

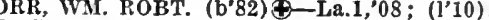
RUSSWURM. WM. C. (b'61)థ-Ky.4,'84 La.1,'90; (1'03).

Sanford, John H. (b'90)-Tenn.6,'13; ( ).

TROTTER, CLIFFORD H. (b'68) $\Theta$-La.1, $92 ;(1 ' 03)$.

Williams, Richard $\Delta$. (col.) (b'77)-Tenn.7, 02 ; (1'03).

HENSLEY, 500, SALINE

REED, C. C.-Ark. 1,'06; (1'03)

HERMITAGE, 247, BRADLEY

REASONS, W. BUNION (b'76)-Ga.9,'09 (l'03).

WILSON, GEO. L. (b'69)-Tenn.8,'00; (l'03). WOMACK, WALTER E. (b'70)-Té.8,'05; (l'03).

HICKORY PLAINS, 250, PRAIRIE

Warbritton, J. E. $\rightarrow$; (l'03).

Young, J. H.- $\longrightarrow$; (1'03) ; R.F.D. 1.

HICKORY RIDGE, 300, CROSS

Allen, Marsball (b'75)-Mo.28,'07; (1'06).

HIGDEN, 336, CLEBURNE

HALL, HARVEY JETHON (b'8I)Ð-Ark.1, $10 ;(1,10)$.

HIGGINSON, 192, WHITE UTLEY, FRANCIS EDWIN (b'81)-Ark.1, 


\section{HIGHFILL, - BENTON}

WILKS. FILAXCIS MARION (b:?2)-0kla.t, 10; (1'03).

\section{HIGHLAND, 50, PIKE}

BELI, JAMES L. (b'6S)-S.C.1,97; (1'03) HIGHROCK (CUSHMAN P.0.), 50, INDE. PENDENCE

Twlly, Marcus L. (b'46) $\rightarrow$ : (l'si).

HINDSVILLE, 200, MADISON

BERRY, F. O. (b'il)-Ark.1,05; (l'03).

MOORE, WM. ALEX. $\left(b^{\prime} 66\right)-C o l o .2,95$; (1'03).

ROBERTS, DAVID CARSOY (b'So)-Ark.2, 11: (\$).

\section{HIWASSE, 125, BENTON}

GORTON, CHAS. W. (b*2)-Mo.29,00; (l'0s).

HOGAN (GLADYS P.O.), 40, VAN BUREN

Burns, Chas. H. (b'43)-O: (1'03).

HOLLAND. 200. FAULKNER

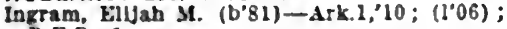

R.F.D. 1

MABRY, THOMAS (b'79)-Ark.1,06; (l'03).

MeDonald. Wm. T. $\left(b^{\prime} 65\right) \rightarrow$; $\left(1^{\prime} 03\right)$.

HOLLY GROVE, 536, MONROE

Johnson. Jullus M. (b'24) $\rightarrow$ : ( (1'03).

JOHNSOX, PAUL EDWARD (b'82) †-Ky.2,

09: (l'0s).

SYLAR, THOS. B. (b'- 4$)-$ Tenn. 8,01 : (1'03)

Taylor, Jobn T. (D'33)-Vt,3,'53; (l'03)

Willams, R. M. (b;i)-Tenn.t, $05 ;$ (10i).

HOLLY SPRINGS. I13. DALLAS

Wozencratt, ollver o. (b'49)-Mo.1,'76 :

(1'03)

TOZENCRAFT, WM. L. (b'80)-Ky.1,0\% : (l'05).

HOLLYWOOD, I50, CLARK

Carter, Edward E. (b'-6)-Tex.7.05: (l'03),

Darldson, L. P. (b'8l)-A; (l'08).

HOLMES, 20, RANDOLPH

JOHNSON, R. R. $\left(b^{\prime} 80\right) \rightarrow$; $\left(l^{\prime} 03\right)$.

HON, 75, SCOTT

Campbell, Edward S. T. $\rightarrow$ : (l'03); Ob.

HOPE, 3.639. HEMPSTEAD

CANXON, GEO. EMSETT, (b':0)\$-Ky.1,

'98: $\left(l^{\prime} 06\right): S$.

CARRICAN, P. B. (b'72)-Mo.1,99: (l'03)

GARRETT, HOSEA J. F. (b'61)-MIo.1,' 86 ; GILES, HY. ROBT. (b':6) Tenn., $0^{\prime} 02$;

GILLESPIE, LEROX J. (b'48)-\$(0.1,"86; (1'03).

HEXRY, JOKN A. (D'62)-Ky.4,90; (l'03)

KELLY, JOII LUTHER (b'68) - Ark.1. '98; (1'03).

Lewis, Chas, 31. (col.) (b\%6)-Tenn.7,05; (1'06)

Martindale, Geo. K. (b'63)-Tenn.9,'99; (1'03).

RUSSFiL, M. V. B-Tenn 9,04: (l'03)

Banderfur, John B. (b'34) $\rightarrow$ : (1.03).

SANER. WM. F. (b'65)-Ky.4,88: (1'03).

SMITII. DONALD (b'il)-Tenn.8.04: (l'03).

stewart, Wm. N. (b"56)-Tenn.8,98; (1"03)

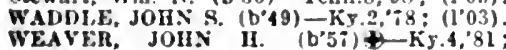
(I'03).

Wearer. Robt. Fllls (b'91)-Ark.1,'13; (l'13)

Wilson, Robt. M. (b'56)-Mo.1, ;9: (1'03).

HOPEWELL. 24, BAXTER

Lackey. Wm. II If $\left(\mathrm{b}^{\circ} \mid \mathrm{K}\right) \mathrm{E}-\Omega$ : (l'03)

HORATIO, 605, SEVIER

Dleklnson, Geo, l. (

Uenry, Geo. A. (b'66)-0; (1'03); not in practlce.

I8BELL. F. T. (b*5)-Tenn.8, 01: (1'03).

HOT SPRINGS, 14,434, GARLAND

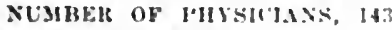
Balley, W. T. $\left(\mathrm{b}^{\prime} 36\right)-K y .4,94 ;\left(I^{\prime} 03\right) ; 33 ;$
Benton St.

BAIRY. LINDA HENRY (b'65)-MA4,91 (I'0i): 113 llazel St.: oalce, 10s Itath St. : $9-12,2-5$

Barry. Wm. II. (b'36)-Tenn. 2,"38: (1'03): 321 Grand Are.; ualce, los Hall st. : $9.1:$

Battles 203 Curl St: omce. 420 Malrern St. : 9.12 2-4.

Beebe, Joseyh A. $\left(b^{\prime} 80\right)-K a n .4:^{\prime} 01:\left(10^{\circ} 03\right)$ : Are. ; 9-12, 2-5
BIGGS, ONVIS ERTLE (b'76) - MI0.28,08 ; (1'04): 314 l'ark sve.; onlee, 364 Central Ave. : $8.12,3-5$

Blajues, Julin A- $\rightarrow(103): 36+$ Central Are.

Blaydes, Rezlo Owings (b'62)-N.Y.1,89; BONNIWELL, HAKR MELVIN (b:0)III.19.05; (1'13); Member Xeb. Suce Med Assn, : "il Celar St.; odtce, Arkansas Sallonal Hank Bldz.

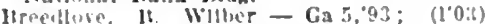
Ark. Jall Bank Bld

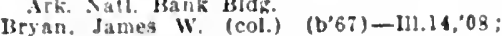
(1'0x) i10 Gulphor St.

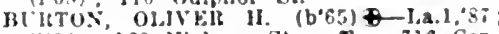
$1031 ; 128$ lllckory St.; once, 716 Ceniral Are.: $9-12.2-5$

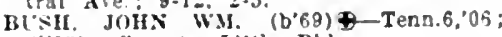
(1'03) : Sumpier-Little Bluz.

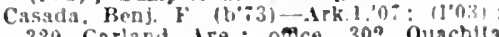
Gre Garland Aro.

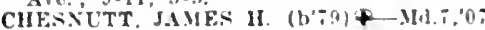
(1'06): $\mathbf{g} 000$ lower Central Ire. : offec logan-stuart Blde: : 9-12, $2: 30$

Choate, Wn. G. (b'83)-0.2,04; (l03): 4:02 Central Are, $9-12,2-5$

COLLINGS, MOWARD, P. (b'65) T-N.Y.10, 91: (l.03); 602 Quapaw Are.; ofice. Dugan-Stuart Bldg.: 9-12, 2-5: (C3)

COLLINGS, SAML. P. (b'45)-l'a. 2, 70 ; (l'03): 805 lark Are.: office, DuganStuart Bldg.; 9-12, $2-5 ;$ (C3).

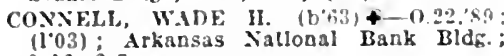
$9-12,2-5$

COOK. ABNER HLGH (b'S6) Q-La.I, 10 ; (l'09); 135 Cedar St.: ofice, Dugan-

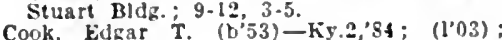
51 s. Central Are.; oftce, 364 Central Are. Comle, Fannle Wooten (b'tis)-Tenn.1,'
(1'05): 356 central Are.; 9-12, 2-5.

COX, WAITER EDWARD (b'7) \&-Ark.1, '1:; (l'l2): 1:0 llenderson si.; odlce, Citizens Natlonal Bank.

Curtis, James Webh (b'56)-D.C.3,'ss ('03) : 3:2 E. Grand Are.; office, 41 : Church St: : 9-11, 2-5.

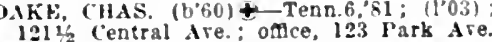

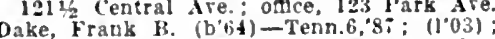
101 Park Are.; office, Dugan-Stuart Kldg. $9-12,3-5$.

DAKE; WALTER MARSHALL, (b'55) Pa.y,7:; (1.12); 833 l'ark Are.; vallce. Dugan-sífuart Bldg.; 9-12.2-4.

DAVIs, ROBT. (i. (b'i1) -1'a.2,0l (1'03) : 42016 Central Ave.: 9-12, $2-$

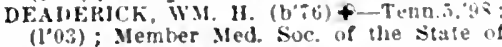
(l'03); Member Med. Soc of the
IY.; 552 lark Ave.; 9-12, 2-5.

Dennis, James $w$. (b'is)-Tenn.11.01 (1'03) : fizt Central Are.

DE WOODY, LOCIS C. (b'6s)-Tenn.8, 20: (l'03): l00 ('entral Mle: ottle

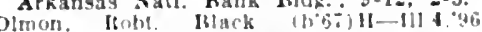
(l'03) : Dugan-stuart Bldg.; 9-12, 3-5. DRESNEN (11.A. TRAVIS (b'64) †-111.1. '.5: (103) : Irennen Courl: otlce, 302!: Central Ave; 9.12; (C3)

Duron. virgli k. (bit) k-Molo.ne $(1003)$ : 200 brexel st: orlee, 700 11,4 rith Whe $9 \cdot 12,2-5$

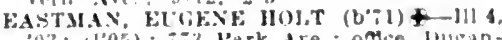
$\left.03 ; 1 l^{3} 05\right) ; 733$ l'ark Are ; ome, louganStuart Lidg, ; $9-12,3-5 ; 1 . *$

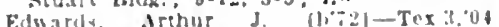
(1004): $25 \%$ centar st.; nace, sumbler

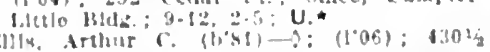

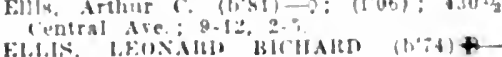

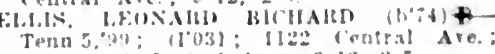

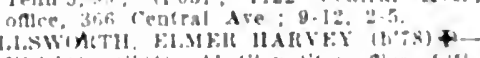

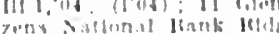

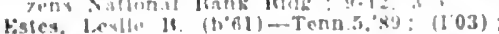
309 botirh st. ; omee, $503^{1 / 2}$ (entral ive. 12

Frwhis, soll $(1068)+-k 9.5 .95:(109)$ sumperer-1.110 11!d

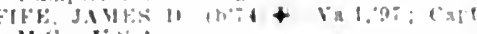

Flanders, J. A. - $\because ;(0, j):$ :0 Malvern

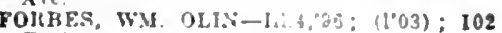

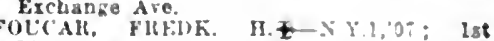

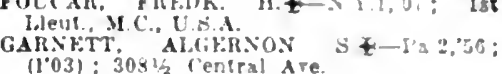
Graves, Hchard B. (b'42)-G: (2.03)

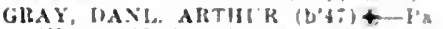

(1’03): 319 (irand Ave.; uce, Arkansas Niatl. Hank lildk. $9-12,2-5$

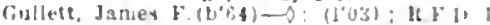

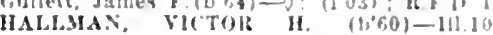
86 ; 111.4,03: (1.03) : P'res. Homeo. State

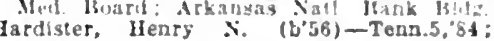
$\left(I^{\circ} 00^{\circ}\right)$.

HARBEILL, MARTIX I, $\left(b^{\prime} 60\right)-T e n n l, 88$ : (1'03) : Arkansas Vatlonal lank Hdg

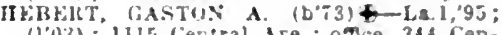
(103) : 1115 Central Ire.; oflce, 344 Central Are. : 9-12.

Hendersoll. Wm. B. (to'79)-Cia.12,"11: (l'13). Ickion. Wm. II. $(1, ;, i) \rightarrow 11031: 1122$ Central Are. oflce, Iugan-Stuart Bldg: (I'03); 410 Garden St. : oatce, 366 Cenital Are. $9-12,2-5$

HOLLANI, ESTILL DOXANA-Mo.2, ; IIOLLAND, THOS. ESTILL $\left(\mathrm{b}^{\circ} 19\right) \mp-\mathrm{M} O \mathrm{~T}$ it: (1'03): Ozark Sanatorium, oflce. Itolt, A. II. (b'61) $\rightarrow:\left(1^{\prime} 03\right):$ ilo s. Are. Holt, A. II. (b'61) $\rightarrow\left(10^{\prime} 03\right): i 10$ S. Are. 151 Cedar st.; once, 370 Ceniral Are: $9-12,2-3$.

Horn. E. E.-Russla 8,68 ; $\left(l^{\prime} 03\right)$; Godulard Hotel.

HOKNFR, JOS. SMITH (b'5s) — Md.1.53:

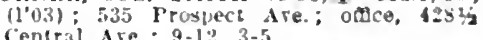

HURER, EDWARD G. (b'82) -MIch.1,05;

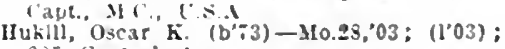

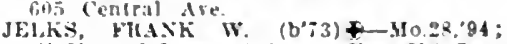
(i"u3); 450 Prospect Are.; otice, 213 Central Are.; $9-12,2-5$

JWLKS, JAMES TIIOS. (b'80)\&-Tenn.8,"03, La.1,'04; (1'03): 439 Prospect Are.; of:

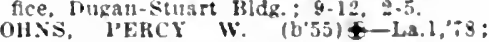
(livij): 3624 central A re

Keller, James M. (b'32)-Ky.2,'52: (1'04): 233 (edar St.

king. Jacol) 1I. (". (h'60) - . Irk 1.59: (100\%) $303^{2}$ 3d st, oftice, Cltizens National Bank Blig:; 10-12, 3-6.

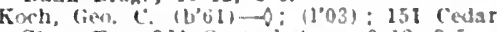
St.; once, 364 Central Ire.: $9.12 .3-5$

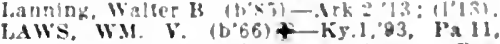
00 : 11031): Ozark sanaturlum: odjce, lougan-stuart lBhdg. $9-12,3-30(13)$

LIVINCSTON, JOSkfll JEROME $\left(\mathrm{b}^{\circ}: 5\right)+$ to: 2 central die.: 0 b.

Mackoy, Frank Win. (b'79)-11111.9.: (l'bl): Mumbath balley sancartun 9.11 $3-5: 1 . *$

MART1S, EDW. II (b'65)+-0.1.8i : (1906)

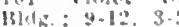

Mchlam, liob: - 111 1,5: (101): 119

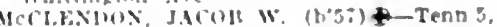

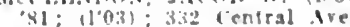

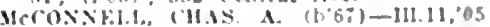
(1)05i

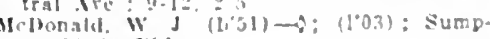
per-lilllo Bldk.

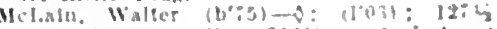
lentral Ale; odes, ilsti lestral Are:

Jamey Fusice (b69)-Tex 10.01:

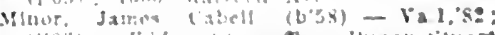

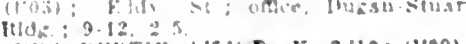

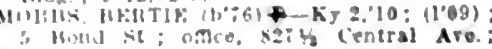

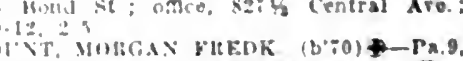

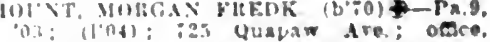
lubststuart libs: 9:30-12, $2: 30-5$ : LD. $\bullet$ 
orr, 1. M. (b'70)-0; (I'03); Arkansas National jank Bldg.

I'arc, Chas. Wm. (b'sl) E-I11.8,'10; (1'08) 432 Spring St.; ofllce, $6291 / 2$ Contral Ave. $8-12,2-5 ;$ NP.

Parker, Wm. Li. (1)'5\%)-Ia. I,'9I ; (1'03) Dugan-Stuart Bldg.

Payne, Jos. 13. (b'34)-Tenn.2,55; (1*03) Iloward Arcade.

Pearson, Jocl W. (b'40)-Md.2, 72 ; (J'06)

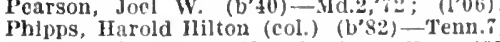
08: (1'08): 409 Church st.; offle, 407 Malvern Ave. $9-12,2-5 ; U$.

PROCTOR, JOIIN MARVIN (b'7t) Tenn.6, 06 ; (1'03); 422 l'rospect Ave. : office, 364 Central Are.; 9-12, 2-5; U

Pullen, J. J. $\rightarrow:\left(1^{\prime} 07\right) ; 224,2 d$ St.

TUITDUM, EINEST AIFXANDER (b'86) 4-Va.1,'10; (1'I2); iII I'rospect Are.
office, l)ugan-Stuart BIdg. : 9-I2, 3-5.

office, Dugan-Stuart Bldg.; $9-12,3-5$; 06 (l'06); 602 r'ospect Are.; offle, 6261/ Central Are.

Reamy, Sandford (b'28)-Ky.2.'51; (l'03) 2292 Central Are.; 9-12, 2-5.

Rlder, Ernest Bascombe (b'88)-Ky.2,'12 (1'12) ; 8271/2 Central Ave.

Roberts, Chas. M. (b'66) - Tenn.5,'92 ; (l'03); 366 Central Are.

ROBERTSON, JOS. ALFRED (b'63) Tenn.8,97; (1'03); 233 IIobson Ave. office, Citlzens Natlonal Bank Bldg.

ROWLAND, JOHN FRANKLIN (b'75)(Tenn.6,01; (1'05); 122 Garland Ave. offlee, Arkansas Natlonal Bank Bldg. 9-12, 2-5; (BI) ; OALR.

Rowland, liosa B. '(b'83)-Ark.1,'12; (l'13) 400 Quapaw St. : offlce, 600 Central Ave. ; 8-12. 2-5; OALR.*

SANDEIS, T. E.-La.I, 05 ; (I'05) ; $4301 / 2$ Central Are.

SHAW, ARGUS D. (b'69)-Mo.27,93; (l'03); 604 'Hobson Ave.; offlce, $626 \frac{1 / 2}{2}$ Centra Ave. ; $9-12,2-5$.

SHAW, J0S. B. (b'79)-Ar.k.I, 05; (l'03) ; 626 Central Are.

SHELTON. THOS. II. (b'71) $\odot-M o .7,05$ (l'03); 111 Cedar St. ; offle, 366 Cen(l'03) ; 111 Cedar St. ;
tral Ave. : 9-12, 2-5: U.

Shlppey, Elíjah A. (b'33)-Ky.2,'54; (l'03) ; 745 Pleasant St.

Shockley, S. F.- 0; (l'03) ; 224 Jackson Ave.

SHORT, ZUBER N. (b'73)థ-Pa.9,'95 ; (1'03); Majestic Hotel; offlce, Dugan-

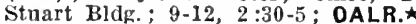

SIMPSON, ROB'T. A. (b'73)-Tenn.8,'99: (l'03); 14 Oak rawn; office, Arkansas National Bank Bldg.; \&:30-12, 2-5; U.

Simpson, Wyatt Farmer (b'82)-Ark.1,'i3 $\left(l^{\prime} 09\right) ; 430 \frac{1}{2}$ Central Ave.

Slaight, John I. (b'5i)-Ark.1,'89; (l'03) I043 Garland Ave. ; offlce, 2121, 3d St. $9-12,2-5 ; \mathrm{G}$.

Snale, Wm. W. $\left(\mathrm{b}^{\prime} 31\right) \rightarrow$;

(l'03) ; 512

Whittington Ave.

SMITH, JAMES WAITER $\left(\mathrm{b}^{\prime} 60\right) \oplus-M 0 . I$ 90 ; (l'07); Arlington Hotel, offlce, DuganStuart Bldg. ; $9-4$

Smith, Wlliam Kate (b'88)-La.1,'13; (1'13) 121 Park Ave.

Sneed, Arthur L. (b'73)-Mo.7,'00; (1'03) Arkansas National Bank Bldg.

SNIDER, WAlRREN L. (b'78)-Pa.11.02 (I'II); 403 Prospect St.; offlce, DuganStuart Bldg. ; $9-12,3-5 ; \dot{U}$.

STEELE, S. B.4-K5.4,94; (1'03) ; 3621/2 Central Ave.

STEER, SAML. L. (b'T6)-Pa.1,'98; (l'03) Majestic Hotel; office, $514 \frac{1}{2}$ Central Ive. $9-12,2-4$.

STRACHAN, JAMLS BOYD (b'82)-Ky.2 05; (1'07); 851 Park Ave. ; office, DuganStuart Bldg.; $9-12,3-5 ; \mathrm{S}$.

Taylor, J. E. Marvin-Ark.1,12; (\%).

Taylor, Richard H. (b'37)-Tenn.2,55 Pa.1,57; (1'03) : Sunpter-I,ittle Bldy.

THOIPSON, EARNEST L. (b'T)-Tenn.I, '02; (1'03); Gaines Block.

THOMPSON, MALCUE GILL (b'49)థIy.2,7s; (l'03); 500 Holly St. ; offlce. Thompson Block; $9-12,2-5$.

THOMPSON, MURRAY GILL, JR. (b'89)Ark.1,'10; (l'10); 500 Holly St. ; office, Thompson Block; 9-12, 2-5: U.

Tixumon,
R.F.D.

(I'03) : 'iorrence, Allon c. (col.) (b'89)-Tenn.7, '12; (1'12) : 136 Wahoo St. IIBB]A, ALBLIRT II. $\left(b^{2} 76\right)+$ Mo.32 " $05:$ ( I'05); 628 Quapaw Ave; offce, 424 Central Ave.; $\mathrm{S}$.

ian Leer, sáml. c. (b'61) $\mathbf{E}-0 ;\left(l^{\prime} 03\right)$ 8 Cedar I'errace; office Caines Block; $9-12,2-5 ; 0$;

I'AUL T. (bº)-IId.4,'93: (1’03) ; Dugra-stuart Blde.

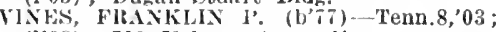
(l'03); 7ll Ilobson Ave.; $U$.

Wacie, Clando M. (col.) '(b'63)-Ky.7,'91; (1'03); 312 Gilphil St.; offlee, 315 Malverı Áve. ; $9-12,2-4$; U.'

Walker, Da Costa (b'81)-0; (1'03) ; 129 IIlekory st.; $4-12,2-5$.

Walker, Samuel (i. (col.) (b'84)-Tenn. 7 , 08; (1'08); 125 Center St.; ofllce, 515

allace, Henry C. (b'45)-0; (l'03); 356 ('entral Ave.

WEIL, SANL. D. (b'71)@-Md.3,95; (l'03) ; 344 Central Ave.

Vestmoreland, J. W. (b'38)-Tenn.1,59; (I'03); 868 Quapaw Are.

Whitacre, John Chas. ( $\left.b^{\prime} 70\right)-I a .3,,^{\prime} 7$ $\left(l^{\prime} 09\right) ; 702$ Park Are.; N. $\star$

WILLIAMS, ARTHUR U. (b'55) †-Mo.1 78 ; (l'03); 420 Quapaw Are.; offlce, $414 \frac{1}{2}$ Central Ave. ; 9-12,2-5; ('C3).

WILLIAMS, FELIX M. (b'6I) क-Tenn.5 91; (l'03); 408 Prospect Ave; offlee, 3421 Central Are. ; 9-12, 2-5.

Central Are. ; 9-12, 2-5.
WINEGAR, EDWIN F. (b'66) \&-11.5,'98; (l'03) ; 1 Cpper Park Ave.; office, 346 Central Are.; 9-12, 2-5.

WINTEI, FRAXCIS ANDERSON (b'67) Mo.2,'89 ; Lieut. Col., M.C., U.S.A.

woOD, JOHN S. (b'83)-La.I,06; (I'05) ; 1622 Central Ave.; offlee, 364 'Central Ave. ; 9-12, 2-5.

POTTON, WM. TURNOR (b'i8) \&-Md.1, 39; $(103)$; 155 Cedar St. ; offlce, DuganStuart Bldg. ; 9-12, $2-5$

right, Lycurgus B. (b'48)-Pa.14,'68 (1'03) ; 256 Cedar St. ; offlee, $7361 / 2$ Central Ave. ; $9-4$

Young, Linus Clarence $\left(b^{\prime} 83\right) \rightarrow$; not in practice; 2 Whippoorwill St.

HOUSTON, 250, PERRY

Burge, John W. (b'70)-0; $\left(l^{\prime} 07\right) ;$ G.
JONES, ROBT. A. (b'73)-Tenn.8,03;(l'03) Paschal, John I. (b'40)- $\rightarrow$; (1'03).

HOWELL, 150, WOODRUFF

SBORNE, JOHN M. (b'74) †-Pa.2,'96 (1'03).

HOXIE, 9I5, LAWRENCE

Pringle, John Eberle (b'53) - Mo. 1,74: (['03). STIDHAN, JOHN HENRY (b'78)థ-Ark.2 '10; (l'06)

THOMIAS, EARL (b, 58$)-M 0.2,05$; (索).

HUMPHREY, 380 , ARKANSAS

BUNN, ARTHUR DUDLEX (b'79)-Tenn,I 1 '0I; (1'03).

FOWLER, ARTHUR (b'80) - Ark.1,'07 (l'06).

HUNT, 100 , JOHNSON

Mrden, Louis N. ( $\left.\mathrm{b}^{\prime} 54\right) \mathrm{E}-0$; (I'03)

JACOBS, LUSTER IRVIN (b'85)-Ark. I '11; (1'09).

HUNTER, 508, WOODRUFF

Porter, Melville A. (b'82)-Mo.28,'07 (I'06).

HUNTINGTON, I,700, SEBASTIAN

Brown, Elmer J. (b'S3)-Ark.1,'10; (1'06)

Morsely, S. M.-O; (l'03).
wOODS, GEO. G. (b'78) (4-Ark.I,'04 (I'03).

HUNTSVILLE, 540, MADISON

BOHANNAN, JOHN H. (b'80) (-Ark,2,'10 (1'10).

KNIGHT, M. $\left(b^{\prime} 41\right) \rightarrow$; $\left(l^{\prime} 03\right)$

YOUNGBLOOD, FREDK. (b'67)-Mo.24,'97 (l'03)

HURRICANE (R.F.D., MABELVALE), 46 , SALINE

Wright J. D. (b'66) $\rightarrow$; (l'03).

HUTTIG, 1,240, UNION

BURNS, ROBT. PAUL (b'72)-Tenn.11,0I (1'03).

Cashin, John E. (b'72)-Ky.5,'93; (l'13).

Magee, Luke F. $\left(b^{\prime} 73\right) \rightarrow 0 ;\left(l^{\prime} 03\right)$.

MAHONY, FEPGUS OLAMII (b'79)-La.I, 08; (1'06).

\section{IMBODEN, 600, LAWRENCE}

HATCHER, WIIGIT WOODARD $\left(b^{\prime} 84\right) \oplus-$ Tenn.8,'09: (1'08)

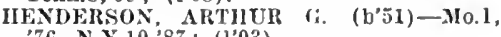
76, N.Y.10,'87; (1'03).

POINDEXTER, JOEL C. (b'65)-Ky.5,'96; (l'03).

INGALLS, 25, BRADLEY

CIOW, MARVIN THACKER (b'ii) Tex.7,03, Ala.4,12; (l'03).

IONE, 50. LOGAN

Ewart, James B. (b'43)-Tena.8,91 ; (l'03). Smlth, W. U. $\left(b^{\prime} 71\right)-T e x .7,03 ;\left(I^{\prime} 03\right)$.

Turner, Wm. II. (b'62)-Tex.7,08; (I'03).

ISLAND (BEVERLY P.0.), 25, SEBASTIAN I)arls, E. W. (b'70)-Tenn.8,0I ; (l'03).

IUKA, 200, IZARD

IIall, W. J. (b'58) $\rightarrow$; (1'03)

Ilason, Jaines J. (b'72)-Ark.2,'II; (1'07).

JACKSONVILLE, 250, PULASKI

IIudson, C. II. (b'80) $\rightarrow$; (l'06).

I'ardew, Aithur A. (b'76)-0: (i'03).

JAMESTOWN, II4, INOEPENDENCE

King, K. W. (b'79) $\rightarrow$; (1'03).

JASPER, 242, NEWTON

Bradley, Wm. A. (b'7I)-Ga.5,95; (l'03).

ICFERRIN, JOHN O. (b'72)-Ark.1,05; (1'03).

JEFFERSON, 50, JEFFERSON

Covington, Robt. Lee (b'68) $\rightarrow$; (l'03).

JENNY LINO, 500, SEBASTIAN

MEANS, CHAS. S. (b'81)-Ark.I,'09; (l'08).

JERSEY, 25, BRADLEY

Glnn, Wm. Taylor (b'81) -0 : (l'04).

Shaw, John W. (b'63) E-0.2,'84; (l'03).

JESUP, 20, LAWRENCE

GUTHRIE, THOMAS C. (b'80)-Ark.2,08; (l'06)

JOINER, 200, MISSISSIPPI

OWENS, WMI HARRIS (b'80)-Ga.II,'09: (1'1I); U.

JONESBORO, 7,123, CRAIGHEAD

ALTMAN, JOHN THOMPSON, JR. (b'83)Tenn.5,08; (l'08); Pd.

Blirns, Joseph L. (b'5I)-Tenn.5, 79; (I'03). Claunch, James R. (b'33) $\longrightarrow$; (l'03).

ELLIS, IRA WALL (b'88)-Tenn.8,'12; (l'I2)

Ells, Wm. S. (b'59)-Mo.24,'93; (l'08).

Ezell, Edward L. (col.) (b'60)-Tenn. 7,'99 ; (l'03).

Gracey, Lafayette F. (b'6I)-Tenn.8,'91;

HALTOA, WM. c. (b'69)-Tenn.8,00 ; (l'03)

HARRISON, BENJ. L. (b'67)-Mo.28,'99; (l'03).

JACKSON, WM. W. (b'63)-Tenn.8,'96 ; $\left(\mathrm{l}^{\prime} 03\right)$

LUTTERLOH, CHAS. M. (b'62)-Tenn.5, 90 : (l'03).

LUTTERLOH, PEARLIE WATSON (b'85) Mo.2,'10; (1'10)

McAdams, Herbert H. (b'84) $\rightarrow$; (l'05)

Moreland, Saml. W. (b'51) E-Mo.10,'\$6 ; (1'03).

Moreland, Wm. Hubert (b'86) - 0.2,'13; (1'13).

PIERCE, ALBERT G. (b'48)-La.1,'85; (I’03)

RAMSEY, JAMES WILSON (b'77)థ-IIl.1, '02; $\left(l^{\prime} 10\right)$; OALR. *

RATLIFF, RUFUS W. (b'65)-Tenn. 8,00 ; (1'03).

Smlth, Wm. Howard (b'80)-Tenn.8,07; (l'05); R.F.D. 2.

STROUD, HOMER A. (b'75)-Tenn.8,03; (l'04).

WILLET', ROBT. HERMAN (b'81)-Ky.2, 'IO; (l'12)

\section{JUDSONIA, 746, WHITE}

Eastland, J. S. (b'45) E-Pa.14.'70; (l'03).

Huntley, James C. (b'71) E-0.2,'97; (1'03).

LITTLE, ROBT. LEE (b'65)-Tex.8, 06 ; (1'03).

WOODYARD, WM. HENRY LEE-Tenn.8, 94 ; (l'03). 


\section{JUNCTION CITY, 1.063, UNION}

Kuah Albert Richard-1IL.3.'B

ELKINS, WM. NOAH (D'R3)-Tenn. b, OS: (1006).

Hale. G. T. (b'34)-M10.10::6; (1'03)

HARPER, WM. L. (b'it)-Ky.4.94; ( ( 03$)$ MeDonald. M. $\left(b^{\prime} 64\right) \rightarrow:\left(l^{\prime} 03\right)$.

MILES, WALTEK 1.EE' (D'S4)-I.a I,09 (1) 08 )

SELLERS, WTLLIAN-La.1, $70:\left(10^{\prime} 03\right)$

Sykes, Arthur II. (b'61)-Ark. 1,95; (1'03)

KENSETT, 200, WHITE

HABRISOS, ARTHUB G.-Tenn. 8,'01; (1'03)

KEO, 230, LONOKE

Bowers, Austln I (boit)-Tenn 8.03; (1'03)

Zuber, Lee (b'65)-Ark.1,01; (1'03).

KERRS, 300, LONOKE

Brewer, John F. (b't4)-Tenn.8;01: (1'03)

KINGSLAND. 443, CLEVELAND

JonkisoN. S. C. $\left(b^{*}: 9\right)-A[k .1,06$; (1'05)

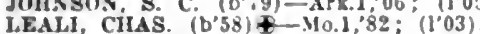

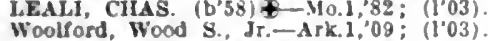

KINGSTON, 150, MADISON

Allen, Chas. Smlth (b'54)-Ark.1, 13: (1'13).

Boomer, Forrest Allen $\left(b^{\prime}, 0\right) \rightarrow$; (1'03).

Mooney, Wm. II. (b'64)-Ark.d,0i; (1'03).

KIRBY, 100, PIKE

Sutton, Sldney lekalb (b'3i)-X.1.5, 37

not in practice.

TOLLESON, GEO. W. (b'70)-Aik.1,98 (1'03).

KNOBEL, 362, CLAY
Blackwood, Jefrerson Dar!s (b'S8)-Tenn.8, 13: (1'13).

Blackwond, S. P. (b's6) $\rightarrow 0$; $\left(1^{\prime} 00^{2}\right)$

CUNNISG, I. H. $\rightarrow$; $\left(1^{\prime} 03\right)$.

KNOXVILLE, 300, JOHNSON

Kllburn, Jessle F. (b'63) - ; (l'03).

LACEY, 100, DREW

Baker, Sherwood Astuton (b'a2)-Tex.8,0s (1'03).

Morrlson, Henry Alex. (b'î3) $\rightarrow$; (I’03).

LACONIA, 130, DESHA

Cllatt, John (b'68)-Ky.4.'91; (1'03)

liardle, Wm. B. If. (b'28)-s; (1'03) LADD (R.F.D., PINE BLUFF), 200, JEF.

Patton, Alfred B. (b'60)-D; (1'03).

LAFE, 37, GREENE

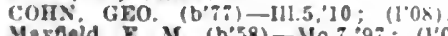

Maydeld, E. M. (b'38)-Mo.7;97; (1'03).

LA GRANGE, 310, LEE

YOSTER, GOLDEN F. (b'4\%)-0.2, 84 ; (l'03).

RUESWURM, SAML. CLARK (b'69) Tenn. 8.'99: (1'03).

LAKE CITY, 448, CRAIGHEAD

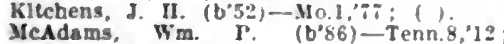
IcAdams, $1 \mathrm{Wm}$. r. $\left(b^{\circ} 86\right)$-Tenn.8,'12; (1'12): $\mathrm{Pd}$.

Roberts, Fred (b'a 2)-Tenn.6,07: (1'03).

Tillotson, Chas. Fben (b'5) $\boldsymbol{E}$-Ind.5,9:; (1'03).

\section{LAKEPORT, 25, CHICOT}

Johnson, Vlclor M. (b'63) - Jrk.1.'96, X.Y.10,88: (1'03).

LAKE VILLAGE, 1.074, CHICOT

UENRY, ROBT, N. $\left(\mathrm{b}^{\prime}(0)-K\right)$. 4 , 93 : (j'03):

MCGEHEE, EDWAHก $b^{\circ}$. (1'60)+-Ala.

"94: (1'03): S. 93: (1'03); 5 .

\section{LAMAR, 520, JOHNSON}

Barger. Marlus I. ('s'84)-Ark I,'12; (l'J')

BRADIEY, JOHS F. (b'3) -

BURGESS, MAIISHAL, E. (b'-9)-Tex, 03: (1'03)

Burzess, Thos. E. (b'0)-Tex.7.03: ( $\left.{ }^{\prime} 03\right)$ HIJDDLESTON, (iko. MAYS $\left.1 \mathrm{~b}^{\prime} 62\right)+$ Tenn.3, 9 !: : (1.03)

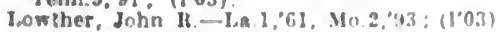

MANIEY, HOHT. $\therefore$ (b'S5) ArK I.1? $\left(10^{\circ}\right)$.

LANEBURG, 75, NEVADA

Nelms. ('has. $r$ : (10,72) $\rightarrow$ : (1'03)

LANTY, IA, CONWAY

Stover, Genter $l^{\circ}\left(b^{\prime} B{ }^{\circ}\right)=9 ; 11^{\circ}(1)$

LAPILE, 150, UNION

BUCKLEY, EMBISY AILLS (b') - Tonn 6 '08: (l'08).

Fodvards, Farly $\left(b^{\circ} \div 0\right)-0$ : (l'03)

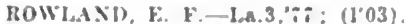

Smlth, Jolth L. (h'52)-Tex.8.05; (1'03).

LAUGHLIN (R.F.D., STEPHENS), 50, CO. LUMBIA

Firans, J. I: (b'63)-:? (l'03)

LAURATOWN, 30, LAWRENCE

STEPIILAS, JPHMY M. (b'ii)-Ala t:04: (I03)

LAVACA, 350, SEBASTIAN

"HFYMAX, JOS S. (b":) - Ath 2.0 (105).

J'erklns; W. M. (8'31) -Mo.1:83; (1'03).

LEAD HILL, 700. BOONE

IWHINCER, JOLIX (b'39)-MOL,'82; (I'03)

coker, U. I. (b'79)-0; (1'03)

Jackson, Greene B. (b'64) $-0 ;\left(1^{\prime} 03\right)$.

LEOWIDGE, 46, PERRY

TIPDIIt, l.ee (D'38) $\rightarrow$ : (1*03).

LEOLA, 398, GRANT

llutler, James T. (1,'59) -0 : $\left(1^{\prime} 03\right)$.

Joyce, M. J. H. ( (b'53)-Ark. 1,04: (1'03)

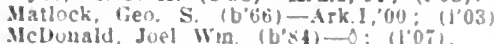

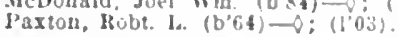

LEONARO, 100, CLAY

LUNT, JAMES JIIILLIP (b'î) - Mo.28, $00 ;(111)$.

LEPANTO, 154, POINSETT

Darls, James A. (L'68)-K5.5,95; (1'03).

LESLIE, 1,898, SEARCY

Butler, I. S. (b'76)-Ark.1,10; (1'09).

COTTOX, J. OLIYEK (b'a)-\$10.28,99 (1'03)

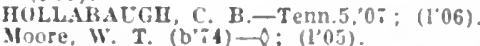

RORERTSON, LOCIS D. (b'64)-Ark.1,'12; (1.03).

SMITH, IRA (b'T0)-AIK. 1,07: (1'03)

LETONA, 100, WHITE

HOI.T, CALVIX ZEXO (b"89) -Ark.1,12; (12)

A. (b'3) $\rightarrow$; (1'03)

LEWISVILLE, 1.500, LAFAYETTE

Andrews, John Sedgrick (b'0)-Ya.1,96; $\left(1^{\prime} 06\right)$.

Barham, Oscas T. (t,it)-Ark.2,11: atsigtant physletan.

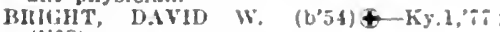

Chisholm, (ieo. 11. (b'66)-ه: (1'03) fUUMANS, FIEDK. WM. (b'66)-H11.1,91:
(103).

LEXINGTON, 75, STONE

Clark, Francls M. (b'T0)-0; (1'03).

LIBERTY, - BLOUNT

cole. J. H. (b'b4) $\rightarrow$; (1'03)

LIMESTONE, 84, NEWTON

liennelt, Alfred $\left(b^{\prime} 50\right)$-Aik.l,'si; $\left(l^{\prime} 03\right)$.

LINCOLN, 292, WASHINGTON

Blackburn, Thos, W. (b'59)-AIk.1,92; $\left(1^{\prime} 03\right)$

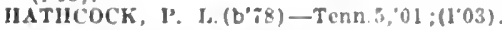

LINDSEY, 25, CRAWFORD

Austln, Ilonosla (b'68)-Mo.10,98: (1008).

LINE, 20, DREW

Hurnory, Fill T. (b'T4) $\rightarrow$; (l03)

LISBON, 50, UNION

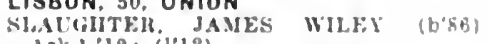

Atk.1,12: (1'12)

Thurman, Ii. J. (h'34) -O; (1'03)

LITTLE ROCK, 45.941, PULASK!

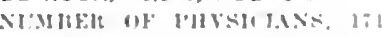

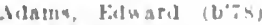

Itattery sit.

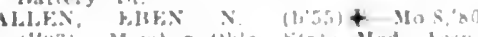

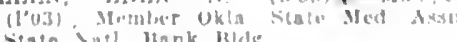

State Natl. llank lids

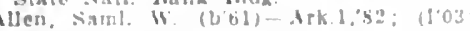

10010 bictury

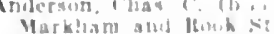

Apk 1.000:(1000 :

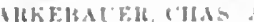

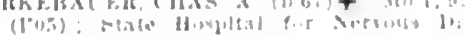

(1)

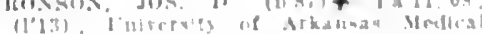

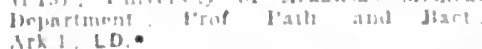

Austin. Chas. Fral (b'uk, Il1 :20.12: (1'12):

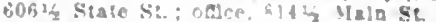

BAILEY, WALTEA E. (1'03) 2102 Htock St: $18,2,20$ - Malo

Baln, Burleg Carl $\rightarrow$ :

BATHU'LST, WM. It (W'

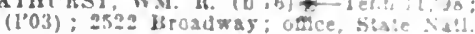
Bank Bldz: 9-12: sec. and loru? lerru and Syjh, Ark I: D.*

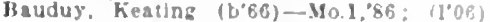
1401 Cumberland St; omce, 110 W: $9: 2$

MENTLRY, CALLE FDWIS (b'3) - ArR 1,

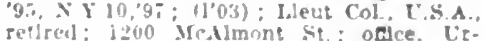
guhar: Lildz: 11-12, 3-6; Assoce Prot Surz. Arts. 1 S.

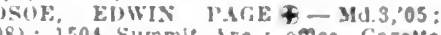
(1)08): 1504 summle Ave; ance, Ginzette

lond. John B. (b'3i)-M0.2,65; (1'03);

800 W. Warkhans so

HOSI, STFKLIN1; HRICE (b'88)-Ark. '12: (1'12): 82z loutslana st: catce.

losce, Saml. Geo. (b'si)-Kan.6,09: (1'0s): 6th Are. and Palm St.; Ottice, State Nau. Bank; 9-11, 1.2; S

Bradley, Idus L.-Ark.1,09; (1'08); 1413 W. ith st.

lsrlckey, Wm. X. (b'54) $\rightarrow$; (1'03) : 10243

Brooks, Ida 3nsepblae-Mass.5, 91 ; (1'92): 219 F. 10 th st. : $2-6 ;$ NP.

BROWNING, HIARY W. (b'85)-A:k. l, 1! (1'11): St. Vincent's Intrmary; S.

Bruce, Warten J. E. (col.) (b'b:)-Tern. '86: (1'03); 1102 rulask1 St.; oflce, gos cianes 5

Rurrus llerbert D) (2'59)--.190,25,03; $\{1+\}$ 12:23 W. 4tb St.; (Argeata; 9-12, 1-4)

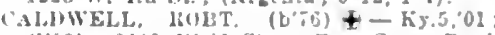
(1'09): 2100 Wole St.: (uftce, Stare Bank rise. Lar, Nose and Throab, Ark.1; (H1): OALR.*

Campbell, Eugle Ara (b's 8 -Tenn.8,11; Sitate Hoard of Health.

CAMMCRAEL AARON LEE (b'/3) Ark.1,04; (1'03): 3422 W. 11th SL: uodec, Southern Trust Bldig: $9+12,2-5 ;$ Bact.

litio Broadwas; odlce, 900 scott St: 4. $12,2-5 ;$ OALR,

CHESNITT, CUAS, RAPHALL (b.82)KY. $2,05:(1,06)$

Coon, Arthur Hafrour (b'83)-Tens.19,11; (1'13) ; Y.M.C.A. Blds.

Corney, Robt. H. (b;6)-Ark.2.11; (1'03): 720 I doulslana St; once, Relgler Blug. $10-13,3-5$

CLNNINGHAM, JAMES C.(b'81)-Md.9.03: (1'03); 2509 Galnes St.; once, Pythlan Castle IIall; l'rof. Obst. Ark.1.

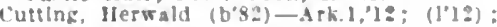

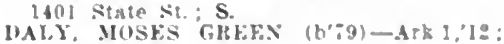

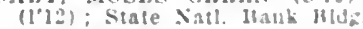

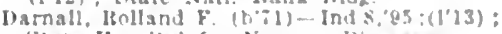

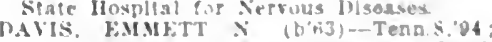
(1'03i: 61.5 F. th st. ontec, Sisic liank

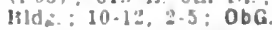

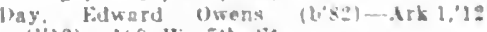
(1'12) : 119 WI, ith st

MHBELI. JAMES $1+$ Apk 1:04: $\{100\}$

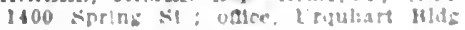
l'rot Anai ith

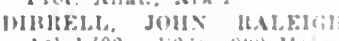

Ark 1,00: 110S1: g0y Ma

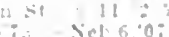

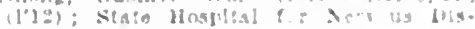

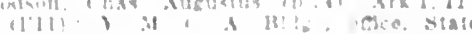
that But"

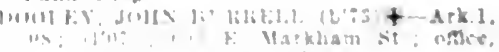

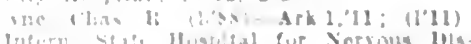
cases

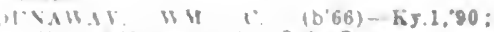

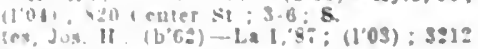

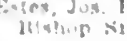


FALISI, JAMIES VINCENT (b'85) - Ky.11, '0S: (I'09) ; 419 Arch St.; oflece, state Bank Bldg.; $9-10,1-3,7-8$.

FLETCHER, (iEO. BEALD (b'88)థ-Ark.I '12; (1'12); State Hospltal for Nervous FIINN, BEAUREGARD W. (b'62)-Tenn, 8 '81; (1'03); 1620 Spring St.; ottce, Stato Bank Bldg.

FLY, T. M. (b'80)-Ark.1,03; (1'03) ; Caultol Bldg.

Forster, Fimma Screeton (b'83) $\rightarrow$; (l'03); 1118 Loulsiana st.

Freemyer, Wayne Neal (b'83)-Ark.1,12 (I'12) ; 1113 W. 3d St. ; oflice. 613 E. $2 d$ St. ; $8-12,2-5,7-9$.

FRENCH, FRANK LUCAS $\left(b^{\prime} 60\right) \oplus-A$ '82; (1'03) ; 1700 Broadway; oftece, 2141/2 Louislana St. ; 10-11, 3-5.

Gaines, Darld B. (col.) - Tenn.7,'94; $\left(1^{\prime} 03\right)$ : 1720 Izard St.; offce, 1111 W. 14th St.

GARIRTT, ALVA A. (b'73) - Ky.1, 06 (1'13); Member Ky. State Med. Assn. Southérn 'Trust Bldg.

GARRISON, ClIAS. W. (b'84)(-)-Tenn.8,05; (l'08): 901 W. 10th St.; office, State Board of IIealti.

Gates, Stanley M. (b'90) $-\Delta$ rk.1,'12 ; (1'12) ; 2011 Broadway.

IBSON, LORENZO P. (b'55)↔-Pa.2,77 (1'03); 223 E. Tth St.; oflee, Urquliart Bldg. : $2-5$

Gill, Jos. F. (b'73) - Tenn.8,'02 ; (l'03) ; Hollenberg Bldg.

Goodwin, Wm. (b'80) - Ark.1,06; (l'06) ; 1203 Scott St. ; office, 909 Maln St.

GRAHAM, , ANDREW J. (b'61)-Ark.1,'81; (l'03) ; not in practlee.

Gray, Álfred Fredrlc (b8)-Tenn.8,'08; (1'03).

GRAY, OSCAR (b'74)థ-Ark.1,04; (1'04); 2401 Battery St.; office, State Bank Bldg. 8-11, 2-5, 8-9; Ássoc. Prof. Gyn., Ark.1.

Green, W'm. C. (b'68)-Ark. 1, 05'; (1'03); 1223 Wolfe St. ; $9-12,2-5$; $\mathrm{S}$.

GREENE, JAMES LEON (b'61)థ-Vt.2,'84; (1'11) ; P'rof. Nerv. and Mlent. Dis., Ark.1; (E13); NP.

HANKISON, ORLANDO CONRAD (b'66) (4)Tenn.5,92; (1'03); 1620 W. 20th St.

HARDEMAN DAN Bldg. ; 9-11, 2-4:30;

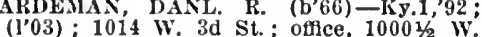
(l03); 1014 W. 3d St.; office, 1000 1/2 W. Ped., Ark.1.

HARRIS, ALEX. EVERETT (b'78)-Pa.2, '01: (1'03) ; Freldrlca Hotel ; office, Urquliart Bldg.; 9-10, 2-5; P'rof. Clin. Med., Ark.1.

Harrls, Robt. L. (b'75)-Ark.2,07; (1'06); 1120 Welch St.; offlce, 112 W. 9 th St.; $11-12,2-5$.

Harris, R. J.-Ill.4,71; (1'06) ; 1815 W. 11th St. ; offlce, 911 E. $2 \mathrm{~d}$ St.

Harrod, J. R. (b'62) $\rightarrow$; (1'03); 15th St. and Park Lane.

Hayman, Geo. W. (col.) (b'65)-Tenn. T,93; (1'03); 1701 High St.; offlee, 614 W.' 9 th St.

Hickman, Jason Otis (col.) (b'80) -Tenn.7, 04; (1'04); 1923 Cross St.; offece, 7011/2 Main St. ; $10-12,4-6$

Hlckman, Sherman B. (col.) (b'86)-Tenn.7, '11; (1'11) ; 1919 Cross St. ; office, 7011/2 Main St. ; 8-10, 2-4.

Htggins, Homer Allen (b'85)-Ark.1,'12; (1'12); Freiderica Hotel; offlce, Urquhart Bldg. ; 11-12, 3-6.

HODGES, E. E. (b'79)-Ark.1,06; (l'04): 2304 Wright Ave.; office, Donaghey Bldg.; $10-12,3-5$.

HODGES, THOS. E. (b'59)-Ark.1,88; (1'03); 5011/2 Main St.; offce, $921 \frac{1}{2} \mathrm{~W}$

HOLIMAN, JAMES E. T. (b'67)-Ark.2,07 ; (1'03); 1100 Schiller Are.; office, 1201/2 Mlain St. ; 9-12, 2-5.

Holmes, Glen McK. (b'85)-Ark. , $^{\prime} 11$; (1'11) ; Capital Hotel; offee, $1081 / 2$ W. $2 \mathrm{~d}$ St.; $9-1,2-5,7-9$

IIOOKE, SAI WISHARD (b'85) - Ind.20, 09; ( ) ; Member Ind. State Med. Assn.; State Bank Bldg.

Hughes, Thos. B. (b'49)-Ky.2,'83; (1'03) ; 375 iw. 16 th $\mathrm{St}$

HUGIITS, WM. B.-Ill.10,'89, Ark.1,'89; (I'03); 1122 Cumberland St.; offee, 900

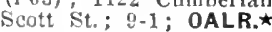

IIURIRLE, FRANK E. (b'81)-Ark.1,11; (1'11); 221 1. 6th St.; office, 109 W. Tth Ish, Geo. Wm. Stanley (b'84)-Mass.1,09; (1'10); Mosale Temple.

Iry, John B. $\left(b^{3} 78\right)-0 ;\left(l^{\prime} 03\right) ; 2 d$ and Sherman sts.

Jackson, Coo. Franklin (b'i8)-Mo.33,'11; (I'I1); 109 Vlctory St.; $3-5$.

Jennings, Chester (b'58)--La.1,83; (l'03); 1221 Scott St.; oftre, $2011 / 2$ W. $2 d$ St.

Johnson, IIorace Wre. (b'52)-Mo.18, 86 ; 25 th sits.

JOHNSTON, ELIJAH EDWARD (b'79)Ark. 1,10 ; $\left(1{ }^{\prime} 10\right)$; 817 E. $2 d$ St. ; 8-12, 2-4. ones, Danl. W., Jr. (b'7c)-Tenn.5,01; (1'03); 1100 Lonisiana St.; office, 309 W. 5th St.

Jones, Marvin H. (col.) (b'81)-Tenn. 7,'12; (\$) ; 515 E. Washington Are, ; office, 506 E. Washington $\mathrm{Ar}$.

JUDD, ORANGE IING (b'73)↔-Ark.1,05; (1'04): Frelderlea Hotel; office, Banker's Trust ; Bldg. ; 10-12, 2-5; Prof. Mled., Trust $\mathrm{S}$.

Junkln, Sanil. 1. (b'78)-Ark.1,08; (1'03): R.F.D. 4.

King, Robt. Rogers (b'85)-Ark.1,06; (l'06) ; 115 E. $22 \mathrm{~d}$ St. ; office, Donaghey Bldg.; $10-12,2: 30-5$.

Klng, Strodder U. (b'53)-Ky.2,'86; (1'03) ; 1 i 22 Gaines st. ; Urquhart Bldg.

Klnsworthy, John H. (b'66)-MI0.24,92; $\left(1^{0} 03\right)$; 2024 w. 16 th St.; offce, State Natl. Bank Bldg.; $9-11,3-5,8-9$.

KIRBY, HENRY HODGEN (b'83) $\$-M 0.2$, $06 ;\left(l^{\prime} 05\right) ; 502$ Oak St. ; offce, Southern Trust Bldg. ; 10-12, 2-4; $\mathrm{S}$.

KORY, ROSCOE CONKLIN (b'84) $\oplus-$ La.1, '10; (1'10); 1008 Cumberland St.; office, State Bank Bldg.; 10-12, 3-5; G.

Lamb, Wm. A. (b'82)-Ark.1,09; (1'09); 4000 W. 11 th St.; office, 19 th and Pine Sts.; $9-12,2-4$.

LENOW, JAMES HORACE (b'50)๑-Pa.2, ' 2 ; (1'03) ; 904 W. 2 d St.; office, Gazette Bldg. ; 9-11, 2-4; Emer. Pro?. Gen.-Urin. Dis., $\Delta$ rk.1.

Lewls, Arthur (col.) (b'70) - Tenn.7,'99; (1'03).

Lewls, Francls M. (b'59) - Tenn.8,'99; (1'03); $611^{1 / 2}$ E. $2 \mathrm{~d}$ S

Lewis, Henry C. (b'74)-Ark.2,'10; $\left(l^{\prime} 10\right)$; R.F.D. 4.

LEWIS, JACOB F. (b'53) E-0.2,72, Ill.8, 80 ; (l'03); 514 W. 3d St.; offee, State Bank Bldg. ; 11-12, 2-5; 0b.

MANGLESDORF, WM. F. (b'79)థ-Ark.2, '10; (l'09); 2115 Chester St.; office, 2051/2 Main St. ; LD.*

Marberry, Flavius J. (b'59) $\rightarrow$; (1'03); $13231 / 2$ W. 7th St.; offlee, $15231 / 2$ W. 7 th St.

MAXWELL, RALPH L. (b'79)-Ark.1,07; (1'07); 1616 Dennison St.; offce, 112 W. 9th St.; $9-10,3-5$.

MAY, WÍLEY S. (b'70)Ð-Ga.9,'93, Ark.2, Masonlc Temple; $9-1,2-5 ;$ OALR.

MCCASKILL, MELVIN E. (b'82)-Mo.34,05; (1'03); 129 N. May St.; offce, $210 \%$ Louisiana $\mathrm{St}$.

NcCormack, G. A. (b'73) $\longrightarrow$; (1'03) ; Univ. of Arkansas.

cCURRY, WM. T. (b'70)-Tenn.8,97; (1'03); Kempner Apts.; offee, State Bank (1) ; 9-12,2-4; OAL' $\star$.

IcFarláne, Duncan B. (b'41) $\rightarrow$; (1'03); 717 W. $3 \mathrm{~d}$ St.

McGILL, ALBERT G. (b'81)-La.I,'06; (1'04); 1722 W. 9 th St.; offlee, State

Bank Bldg.; 10-12, 2-5. (1'08); 1116 North St. ; offee, State Bank Bldg.

McRAE, WASHINGTON M. - Ark.1,07; (1'06); 2 I24 Spring St.; office, $1201 / 2$ Main St. ; $10-12,3-5$.

MEEK, EDWARD (b'53) $\uparrow-M 0.8,77$; (l'03) ; 1110 Capltal Ave.; offce, 1110 W. 5th

MERIVETHER, CLINTON P. (b'73) $\oplus-$ Mo.1,93; (1'03); Sec. Ark. Med. Soc.; 1805 Arch St.; offlce, Southern Trust

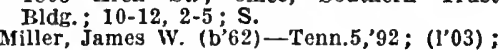
12 th and Volmer Sts.
MILILE, WM. HAMILTON (b'67)-Ark.1, '88, N.Y.10,89; (1'03); 1206 Cumberland St.; offtee, 109 W. Ftb St. ; 2-5.

Minter, Wm. 1. (b'50) $\rightarrow$ : (',03); R.F.D 4. Moore, Grover Cleveland (b86)-Ark.1,'13; (l'13); St. Vincent's Infrmary.

Murplyy, Patrlek (b'87)-Ark.1,13: (1'13); State IIospital for Nervous Diseases.

Norcott, John C. ( $\left.b^{\prime} 58\right)-T e n n .8,91$; (1'03); not in practlee; $2500 \mathrm{~W}$. 13th $\mathrm{St}$.

OGDEN, MAIILON D. (b'81) $\$$-Ark. 1,04; (l'03) ; 20I Gaines; office, Banker's Trust

PATE, CORLY NORFORD (b'78)-Tenn.8, '03: (1'03); 1201/2 Main St.

PEMBERTON, EDW MRD M. (b'81)-Md.9, 202, Md. 3,03 ; (1'03); 2100 Ringo St.; office, 223 w. 3d St.; 9-12, 2-4; Prof. Physiol., Ark.i.

PETTUS, COWLEY S. (b'77) $\oplus-K y .9,04$; (1'03): 1300 W. 3d St.; office, State Bank $12,3-5$.

(1) Proctor, Feaster LeGrand (b'i5)-Tenn.1

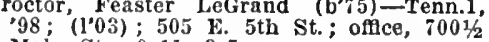
Main St. ; 9-11, 3-5.

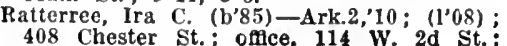
$9-12,2-5$.

REAGAN, IUTHER D. (b'79) $\uparrow-A r k .2,08$; (1'08); Marion Hotcl; offce, State Bank

ROBERTS, DELPARDE W. (b'84)థ-Ark.1, '11; (1'11); State Hospital ; N

Root, Dwight C. $\rightarrow$; ( $($ ) ; German Natl. Bank. Runnels, Scott Clark (b'82)H-Ind.18, 07 ;
( ); Sec. Homeo. State Med. Board; 900 scott St.

RUNYAN, JOS. P. (b'69)థ-La.1,'90;(1'03); 1902 Schlller Are.; offlce, State Bank Bldg. : 9-10, 2-4; 'Prof.' Surg., Ark.1; $(A 1,6)$.

Sadler, Win. Iroyd (b'84)-Ark.1,'13; (1'13) ; St. Vincent's Infirmary.

SAXON, ROBT. LEE (b'74)-Tenn.1,04; (1'03): State Natl. Bank Bldg.; 9-11,

Schoppach, Annle A. (b'62) - Ark.1,01; (l'03) ; 1401 State St.; 2-5.

SCOTT, CHAS. V. (b'67)-Ark.1'04; (1'03); 210 Wolfe St.; offlee, 2091/2 W. $2 \mathrm{~d}$ St.; $8-9,1-5,7-9: 30 ; S$.

Scott, Homer (b'81)-Ark.1,13; (1'13) : Urquhart Bldg.

Scott, Saml. Augustus (b’53) - Ky.2,'77,
La.1,94; (1'03); 2023 w. 23d St. ; offee, Wright Are. and Wolf St. ; 3-5.

Scroggin, James Henry (b'84) - Va.1,'11; (l'09); 2309 Gains st.; office, $108 \frac{1}{2} \mathrm{~W}$. (2TPPAPD JOS $1-4,7-8$,

( 00 ; (l'03) ; offce, Pulaski County Hospital; 8-9, 2-5.

SHERRILL, KORAH ELLIS (b'73) $\oplus$ Mo.28'11; (l'12) ; Mlneyer Llbrary Co. SHINAULT, CHAS. R. (b'67) $\oplus-$ La.1, 90 ; Smith, John Henry (b;i5)

(1.04). 19th St. and Plke SMITH, MORGAN (b'68)@-Ark.1,'89; La.1 04; $\left(l^{\prime} 03\right)$; State Health Offlcer; 2222 Loulslana St.; offlce, State Natl. Bank Bldg. ; $3-5: 30$; Dean and Prof. Dis. of Chil., Ark. 1 : Pd.

MITH, WELLS FERRIN (b'71)-Mo.24,'98; (l'03); $2101 / 2$ Louisiana St.

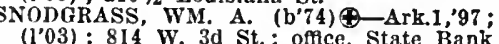
Bldg. ; 10-11, 2-5; Ássoc. Prof. Surg., Ark. 1 ; S. $\star$

STEWART, SAML. S. (b'72)-Mo.2,'98; (1'03); 900 Scott St.; office, Urquhart Bldg. ; $9-10,4-6$.

STOVER, ARTHUR REECE (b'69)๑-Mo.1, '93; (1'03); ; 23 Wright Ave.; offce, 111 Chem., Ark.1.

STREET, HARRY NORWOOD $\left(\mathrm{b}^{\prime} 68\right) \oplus$ La.1,90; (l'09); 2103 Naple St.; offce, Suggs, H. W. (col.) (b'65)-Tenn.7,99. (l'03) ; $524 \mathrm{E} .21$ st St.; offlee, 612 W. 9 th St: Taylor, 'Wm. Houston, (b'47)-Tenn.5, '75: (1'03) ; 115 Arch St.

THOMPSON, LOYD OSCAR (b'82) '10; (1'10); Menton Apts.; oftee, 2d and Sherman Sts; $8-10,1-6$. 
Thornton, J. G. (col.) (b'73)-Tenn.7,02: (1'03): 701 , 9 ih $\mathrm{SL}$

Vall. James L. (b'69) F_-0.2,"99; (1'03); 91 ; Center St: $9-11,2: 30-3$

VAUGHAN MILTON $\left(U^{\prime} 6 \%\right)-\Delta$ rk.1,92 (1'03); 2201 Broadway; offce, leigler Bide

TALGHTER, SAML. PAUL, (b'il)-Ark.l

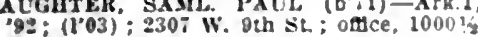
'

VILARS, HORACE F. (b'70)-Ark.2,11 (1'11): $1521 \mathrm{~W}$. ith St: (oflce, 403 II ain St. A rrenta).

TINSONHALER. FRATK (b'64) - Y.Y.1 85: (1'03); 500 E. 9 th St: oftice, it $\mathrm{F}$. Capltol Are. : 9-12, 2-3; I'rot. Dis. of Ese. Far, Nose and Throat, Ark. : (B1) OALR.*

WADLEY, BENJ. JAMES LEF (b'83) † Ark. 2,09: (l'0 ) : II Broadway; ofice, 120 Main' St: 10-1,2-5.

WALT, DAVID' C. (b'6t) - Tenn.8, 84 (1'03): 802 Scott SL; oftice, State Nat! Bank Bldg.

WATKINS, ANDERSON (b'76) क-Ark. 1,97 (1'03): 1838 Arch St. : office, Stato Ban Bldz. : Prof. (Gen.-Lírín, Ils. and Assoc Prot. Surb. Ark.1: S

WATkiss, JoHs cilssox $\left(b^{\circ} 79\right)$-Ark.1. 03: (1'03): 406 Broadway; oftce, 7001/2 Main St: g-12, 2-5: Assoc. Prot. Dls. of Ese, Ear, Nose and Throat, Ark.1; OALR. Wasman, Armour K. (b'80) - Árk.1,0J; (1'03): 1100 Wolfe St: oflce, Urqubsrt (1'03): 1100 Wolfe St.; offce, Urqubs Bidf.

WAYNE, JAMES RORT. JR. (b'83) 110 s. Cross St. : 9-12, 2-4.

Wheat, Sheoberd D. (b'6i)-Tenn.8,'91; (1'03); 506 State St.

Whitnes, Clifion $5-\mathrm{H}-\mathrm{Q}:\left(\mathrm{I}^{\prime} 03\right) ; 202 \mathrm{k}$. lith St. ofice, $501 \frac{1 / 2}{3}$ Maln St.; 9-12. $1: 30-5: 30$

WILLS, LEON CLIFTORD (b'S2)-Pa.2.0 (1'13): Member Med. Soc of the State of Pa.; Urquhart Bldz.

WTT, CALFB E. (b'B3) - K5.5.'96; (1'03) : 1868 Gaines St.; oflce, 109 W. ith St: Prof. Mat. Med., Phar. and Ther., Ark.1. Wolfe, Rasmond Clyde (b'ss)-Ind.20,'1: (1'13); 8141/2 Maln St; 9-12, 2-5, 7-8; Anes.

Youne, John M. (b'66)-Ark.1,95; (1'03; Y 15 ,

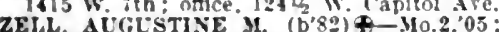
(l'06): 1315 IcAlmont St: oflee, Mana Bldg.: $9-10,2-4, \div-8$.

LOCKESBURG, 748, SEVIER

Boyce, Wm. Thos. (b'tl)-Mo.1,'81; (1'03).

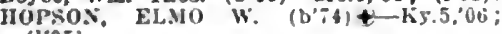
(1) 0.51 .

Marwell, D. A. (b'57)-Tenn.8,'89; (1'03). NoRwón, MERRILSAA L, (b'75) 18 Mo.24,96; (1'03)

Tatum, Jos. L. $\left(6^{\prime}: 1\right)-0$ : $\left(1^{\prime} 03\right)$.

LOCUST BAYOU. I50, CALHOUN

Iatheock, Fdmond I.-Tenn.8,00: (1'03).

LONDON. 303. POPE

COOK. LOCIS A. (b'58)-Ark.1,95: (1'03) BYL. AI.HEITT W. (b'75)-TeロI.8.00; (1.03). LONE INN, 64, FRANKLIN

CIOCKEIt, JAKE TIIOS. (b'33)-Tenu.A 83: (1'03).

LONEPINE, 20. JOHNSON

King, lleubeb E. $\left(b^{*} ; 9\right) \rightarrow$ : $\left(1^{\prime} 03\right)$

LONOKE, 1,547. LONOKE

BEXTON, TUOS. E. (b'\%(6)-Tenn.8, 01 : (1"03).

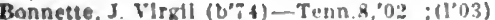

COKX. FUIKEST A. (U'65)-Tenn.J.91: (1'03).

CUNNISG, JollN R. (b'61) \$-Ky.I,'94: (I'03)

Hlne, (has $W$ ( $\left.\mathrm{b}^{\prime}+4\right)-0$; (t)

Rons, Jas Follett $\left(\mathrm{b}^{\circ} 84\right)-\mathrm{M}_{0.35}, 09 ;\left(\mathrm{f}^{\circ} 10\right)$

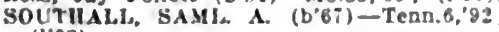
(1'03).

Whers, Entl guarlew. Jr. $\left(0^{\circ} 90\right)$-Tenn.15, "11: (1"13)

\section{LONSDALE, 200, GARLAND}

Bumngtun, Turner E. $\left(b^{\prime} \cdot 9\right)-0 ;\left(1^{\prime} 03\right)$.

IIIII. L. A $\rightarrow:$ : (1.03).

LORADO (R.F.D., JONESBORO), 25. GREENE

Estes, Saul J. (b.74)-Tenn.8.02: (1.03) Lamb, Albert L. $\left(b^{*} 35\right)-0$; $\left(1^{\circ} 03\right)$.
LOFINE. 75. RANDOLPH BLRK, JAMKS M. (U's0) $\%$ :
Member state Med. Assn. of Tex.

(1'03)

LOWELL. 193, BENTON

HARHISON, ANDHEW J. (b'T0)-A.K.I,01; (1'03).

LOWRY, 75, BOONE

Wereberry. R. D. $\left(b^{\circ} 50\right) \rightarrow$; $\left(1^{\prime} 03\right)$.

LUNSFORD, 125, CRAIGHEAD

Wiaddell, Gracey (6.58)_.110.28,98; (1'03).

LUXORA, 677. MISSISSIPPI

IULISON, TILO FRANKLIN (b'82) $\mp$

Tenn.8, $07:(1,07)$

L.0WIIY, S. A. (b'6t)-Tenn.8,00; (1'03)

Ifcreight, J. S. (b'il)-0: (['03).

LYNN, 10, LAWRENCE

lilrmlugham, W. B. $-0:\left(H^{\prime} 03\right)$.

"Faro(k, AltiluR L. (b':0)-Tenu.6,01 (1.03).

MABELVALE, 65, PULASKI

ELLIOTT, JAMES EDWIN - Ark.1,03; (l'03): Pd.

MADISON, 400, ST. FRANCIS

Fingland, ik. D. (b'60)-0; (1'03)

Wells, J. R. $\left(b^{\prime} 35\right) \rightarrow 0 ;(1.03)$.

Vlles, Leonard D. (col.) (b'T6)-Tenn.;,'11; (1'11).

\section{MAGAZINE, 968, LOGAN}

Guise, Jos. Andrew $\left(b^{\prime} ; 2\right) \rightarrow 0 ;\left(1^{\prime} 03\right)$.

IIartis, J. D. $\left(U^{\prime} 5 b^{2}\right)-\left(l^{\prime} 03\right)$;

Hooper, wm. F. (b'66)-H11.11,90; (1'03).

SCUTT, EARLI' F. (U'SI)-Ky.2,"0'; (1'05)

MAGNOLIA, 2.045, COLUMBIA

BAKER, JOHN J. (b'73)-Tenn.8:02; (1'03) ; R.F.I.

Dlckens, Jefr H. $\left(b^{\prime} ; 6\right) \longrightarrow$; (l'03).

Fields, wm. 31. $\left(b^{\prime}-1\right)-0$ : (1'03); R.t.D.

HLNT, WM. J. (b'76)-Tenn.S,02; (l'03); IK.F.D.

Jack, John J. $\left(b^{\circ} \div 0\right) \rightarrow 0 ;\left(I^{\prime} 03\right) ;$ R.F.D

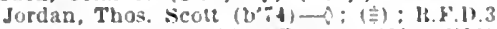

LONGINO. H. A. (b'59) Ho.1, 50 : (l'03).

SMITI, IAKKS M. (b'78)-Tenn,15,0s: (1'03) ; Pd.

STEFFX', CORBIX D. (b'70)-Ky.1,91: (l'03).

STEVEXSON, WM, ANDREW (b'78)-Ky.2, 07 ; $\left(1{ }^{\prime} 10\right)$.

Wilbourn, Champ E. (b'63) E-Ga.9,?9; (I'03).

MALVERN, 2,778, HOT SPRING

llooker, 1. L. $\rightarrow$; $\left(I^{\prime} 03\right)$.

BRAMLITT, EDWARD TURNER (b'54) Ky.4,76; (1'03)

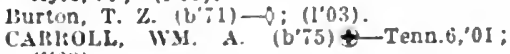
(1'03).

Cummins, Wm. Albert (col.) $\left(b^{\prime} / \vec{t}\right) \rightarrow$ : (1'03).

Forde, fico. I'. A. (col.) (b's2)-Tenn.T.'13; (1'13):

IIIII) III"CII (b'-3)-110.28,98: (1'03).

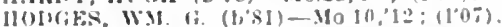

McCIAY, ElWOOD II. (b', 6 ) \$-Mo.24,01: $11003)$

PIIILLIPS, REUBEN Y. (b'65)-Ark.1,'91 ; (1'03)

WILLIAMS, JAMFS M. (b'56)\$-Tenn.8, : (l.03).

MAMMOTH SPRING, 817, FULTON

(IIA'MA., AII'II SYLVESTER (b'86) FTetn.1.0 0 ; $\left(l^{\prime} 13\right)$.

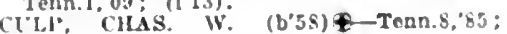
(1.03)

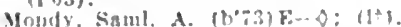

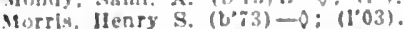

SIGI.EH, JUS. A $\left(0^{\prime} 63\right)$-Tenn.8, $87 ;\left(10^{\circ} 03\right)$ Op.

MANDEVILLE, 200, MILLER

Burorel, James llacon (6'69)-M0.24,'96; (1'0ei).

V. A. -Tex.i:06: $(100)$

MANILA, 562, MISSISSIPPI

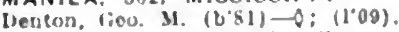

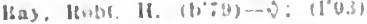

MANSFIELO, 8I6, SEBASTIAN

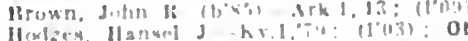

Nichelvon. Wm. R. D. (b'ss)-Tena.5.8I: (1'03).

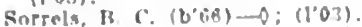

s(urse, James II, $\left(0^{\circ} 56\right)-8$; $\left.11^{\circ} 03\right)$.
MARIANNA, 4.810. LEE

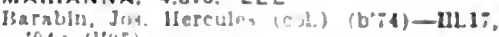
04: (1?0:5)

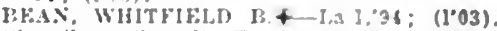
Chandler, (arroll T.-Tera 5, 54 ; (103): INGRAM, THOS. HARKINS (b'82) \& Tenn.5,10: (l'12); OALR.

J.ONiLEY, WM. W. (b"55)-: 11.031.

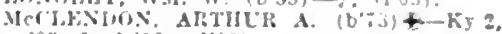

Money, Fdward James $\left(b^{\prime} ; 6\right)-$ III.1:;05; (l'11).

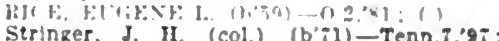
(1) $\left(\frac{4}{4}\right)$. (1.03)

I.XOCII $5.11111+-$ Tenn 1.05:

WLIAMSON, OCTAVILS LAMAR (b" 7 ) - I,0.1.01: (1003)

MARIE, 25. MISSISSIPPI

HAMSER, JAMES HLKBERT (b\%2)

Ky.9.06; (l'13); Member Ky. Srate Med. A 850

MARION, 250. CRITTENDEN

Barton, Robi. White ( $\left.{ }^{\prime} 60\right)-M d .3,84$;

Iann!ng, Wm. Edward (b'34)-Tenn.8,09:

(1.09), kim. Edward (b'85) -Teno,8,09:

MCVAY, LOGAX C. $\left(b^{\prime}, 5\right)$ \&-Tena.3,04: (1'03)

MARKED TREE, 2.025, POINSETT

Balrd, Jos. IA, (1)'s3)-Tenn.15,10; (1'09)

Black, James Robt, (b'59)-Tén.8.'93

rarlington, Menry Spright (b'3s)-Mlaz.

Hinton, Jullus Acton-Tenn.5,' 96 ; (1'03).

PAlliLL, GEO. EARL (b'82)-Mo.29.03; $(1 \cdot 08)$.

Smythe, Albert E. (b'ss)-Ind.9, $\$ 3$ : (1'03). Taylor, Beng. F. (b'72)-Jlo.28,93; (1'03).

MARMADUKE, 780, GREENE

BRADSHER, RORT. EDWARD (b; $; 6)$ ? Tenn. S.04: (1.03).

Carlı, ltobt. Caldwell (b"50)-Tenn.".,":; $(1003)$

Iarkins, James F. (b*81)-O; (1.09)

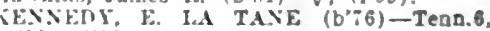
'00: (1'03).

MARSHALL, 558, SEARCY

Cypert J. I (b'50) $\rightarrow$ : (1'03)

DANIEL, SAML. G. (b'6i) -Ky.2,"95; $(1,0.3)$

Flndley Furene $\left(b^{\prime} 82\right) \rightarrow:\left(l^{\prime} 03\right)$.

Heard. W. W. (b'66)-A: (1'03)

WOOD, ED. W. $(0 \% 0)-K 5.5 .04$; (103).

MARTINVILLE, 25, FAULKNER

MartIn, WM. W. $\left(D^{-73)} \longrightarrow\right.$; (1'03).

MARVELL. 356, PHILLIPS

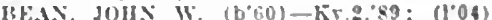

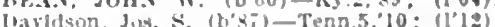

Kendall, Eulls A. (col.)-Tenn. , $^{\circ} 02$; (I'03)

G. G.tsh, Juha Bastlet: (b'63)-Tenn.s, 01 (1'03)

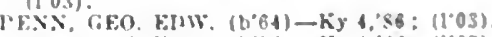

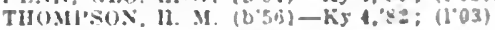
MAYFLOWER, 50, FAULKNER

Holloway, Liza klris (b'id) - Ark.1, 13 (1.09).

Summcrs, James Arthur (b'81) $\rightarrow$; (1'03)

MAYNARD. 295, RANDOLPH

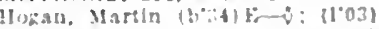

lofts, John 16. (b'is)-Tenn.I,00: (1'03)

MAYSVILLE, 300, BENTON

I'OWFLI, JIMKS THUS. (B'G!) MOS: 03 : (1"03).

MAZARN, 7. MONTGOMERY

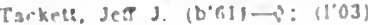

MCCRORY, 637. WOODRUFF

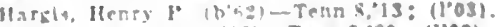

Jelks, Lemuel A. (0.66)-Tenn.5,58; (1'03): 0 o.

(c)

sielf. Sicull 3 (b':3)-Traa.8,99; (1003).

MEGEHEE. 15\%, OESHA

I3rown. RJ Newran (b'il) - IIL6.0i;

(1'0i): S. $(1010)$ 
STUART, JASPER M. (b'tii) - Ky.4,00; WIITr;, ROBT. FRANK (b'74)-Tenn.1,ol; (1'03)'

MCKAMIE, 75, LAFAYETTE

COLQUIT', SAML. W. (b'S0)Ð-Ark.I,'12 ; (l'03).

blckens, walton clyde (b'79)-0: (l'03); R.F.D.

MCNEIL, 482, COLUMBIA

Reagan, W. T. (b'82)-0; (l'05)

SANDERS, GEO. I'. (b'73)-Tenn.8,04 (1'05).

SAUTER, THOS. E. (b'76)-Ga.9,05;

WHALFY, WM. T. (b'65) - Tenn.8,98; (1'03).

MELBOURNE, 282, IZARD

BAXTER, EDWARD A. (b'53)-Ky.2,79;

(l'03).

Harris, Chas, 1. (b'82)-Ky.5,04; (1'03).

Morton, lkufus H. (b'3i)-Mo.10,78; (1'03).

Rector, Claudlus Ezra (b'96)-Mo.10,'12; (ま).

MENA, 3,953, POLK

BIZZELL, MATHEW A. (b'7s)-Ky.4,03 ; (l'03).

Bogard, John T. (b'71)-Tenn.8,'99; (l'03). Cochran, Chas.-11l.1,'84; (1'06); not in practice.

Darts, John R. (b'67)-Mo.7,'89: (1'03)

Dunbarn, Bernard E. (b'7)-5; (1'03) ; not in practlco.

DUNMAN, GONZALES P. (b'\%0)-Ark.l, 00; (l'03).

ELIIOTT, FRANK B. (b'7 (1'03).

Fletclier, Thos, M. (b'6i) -Ark.1'89: (l'03). GTNNELS, COLUMBUS C. (b'73)-Mo.7 02: (1'03).

Gunnels, Levi R. (b'66)-Mo.7,02; (1'03).

HAMM, JOSEPH S. (b'58)-Tenn.8,'95; (1'03).

Hilton. Jesse G. (b'74) E-Mo.10,'05; (l'03). Lee, Francis A. (b'6 7$)-0$; (l'03).

PARKS, WM. P. (b'73) †-Ky.5, 96 :

Yandlver, Wn. C. (b'57) $\rightarrow$; (l'03)'

WATKINS, PHILIP R. (b'66)-Tenn.5,'93; (1'03).

MIDDLEBROOK, 25, RANDOLPH

Swindle, Wm. T. (b’54) E-Wis.4,'96; (l'03).

Wlison, Moses (b'40) E-O; (l'03).

MIDLAND, 639, SEBASTIAN

Davenport, E. M.-Ky.4,75; (1'03).

Howard, Bennett W. (b'66) - Ark.2,'11; (1'03)

MILFORD, 25, SEVIER

Muldrow, W. S. (b'49) $\longrightarrow$; (l'03).

MILLVILLE, I,000, OUACHITA

BYRD, E. J. (b'75)-Tenn.8,02; (l'03).

MILLWOOD, 30, LITTLE RIVER

Combs, J. B. $\rightarrow$; (l'03).

MILTON, - GARLAND

Plttman, Henry Thos. (b'55) -0 ; (1'03).

MIMOSA. - MONTGOMERY

IIURPHEY, JOHN HAMPTON (b'78)-0; (l'04).

MINERAL SPRINGS, 432, HOWARD

Ilolcombe, Jeff T. $\longrightarrow$; (l'03); R.F.D.

Lee, W'm. Rldley (b'81)-Tex.7,07; (ま).

Luck, J. Luther $\left(b^{\prime}, 5\right)-0$; (l'03)

Hivers, James Mathew $\left(b^{\prime} ; 2\right)-T e n n .8,02$; (1'03).

MINTURN, 25I, LAWRENCE

Barnett, B. J. W. (b'5i) $\longrightarrow$; (l'04).

Seel, Val F. - ; (1'03).

MIST, 25, ASHLEY

HANSON, CHAS. P. (b'\&1) - Tenn.9,'05; (l'03); R.F.D. 2.

Higgins, James H. (b'72)-Tex. 7,03 ; (1’03) ; R.F.D. 2.

Locke, Edw. L. $\left(b^{\prime} 76\right) \rightarrow$; (l'04).

MONETTE, 559, CRAIGHEAD

Fisher, Geo. Clary (b'69) - Tenn.1,0I ;

GRADY, NEEDHAM HARVEY (b'52)-Mo.T, ,01; (1'03).

Turner, T. J. (b; 1 (l'03)-Io.28, 00; (1'03).

Whlliams, Joseph M. (b;56) - Tenn.8,'s3;
MONROE, 100, MONROE

Bogard, li. C. $\left(b^{\prime} 70\right) \longrightarrow$; (1'03).

BRAILEY, WM. T. (b't5) 9 -Tenn.9,03: (l'03).

MONTICELLO, 2,274, DREW

BEST, JAMES MILTON (b'75) क-111.22,

State Med Soe.

BROWN, WM. A. (b'43)-Tenn.1,69; (1'05).

COILINS, A. S. J. (b'70) - Tenn.8,94: (1'03).

COlkLIGAN, MICHALL B. (b'52) - -Scot.3, 71 ; (1'03).

COTHAM, EDWARD RALPH (b'80)

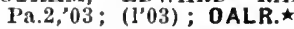

DUCKWolt'Tl, FRED I. $\left(b^{\prime} \tau 8\right)-T e n n .9,05$; (1'03).

Klmbro, B. P. (b'64)-Tex.7,07; (l'03)

Kimbio, Silas o. (b'80) - Tenn.1,06: (l'03).

KIMI31ko, WM. C. (b'35)-Mo.7,84; (1'03). 'OPF, MARDELLE YATES $\left(b^{\prime} 69\right) \oplus-P a .2$, $93 ;$ (1'05).

MONTREAL (MIDLAND P.0.), 45, SE. BASTIAN

IIesterly, Nlijah H. (b'73) $\rightarrow$; (l'03).

MONTROSE, 250, ASHLEY

SIIIIMAN, W. IIENRY (b'72)-Ky.4,04; (1'03).

WAIKD, B. II. $\left(b^{\prime} 71\right)-0 ;\left(l^{\prime} 03\right)$.

MORELAND, - POPE

Snlder, Saml. Monroe-Tenn.8,'ll

MORGANTON, 150 , VAN BUREN

Graddy, Saml. J. (b'68) $\longrightarrow$; (l'03).

MORO, 100, LEE

CHAFEIN, CUlt'TIS W. (b'80)-l'enn.8,'03;

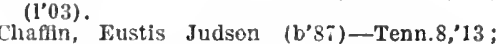
(l'13).

WILSFORD, ALBEKT LOUIS (b'68)-

Tenn.6,'88; (l'03).

MOROBAY, 107, BRADLEY

Brazzel, Russell D. $\rightarrow$; $\left(1^{\prime} 03\right)$.

MORRELL, 500, ASHLEY

Iarrington, Charles B. (b'81)-La.1,05; (l'08).

Taylor, Ira S. (b'79)-Tenn.9,05; (1'03).

MORRILLTON, 2,424, CONWAY

Adams, Robt. J. (b'50)-Ky.2,73; (l'03). BEAIKDEN, FRED (b'84)-Ark.2,07; (1'06). BRADLEY, ADAM ROBT. (b'64)-Tenn.8, '89; (1'03).

CLARK, CHAS. D.๑-Ark.1,98; (1'06).

GORDON, FRANK (b'53)-Ky.4,74; (i'03).

LOGAN, BENJ. C. (b'75)€-Ky.4, 02 ; (l'03).

MARTIN, JAMES S. (b'71)-Va.1,96;

ARTIN.

Mattison, Ellle (col.) (b'T6)-Tenn.,$^{\prime} 08$; (1'09).

Patton, John W. (b'67)-Ark.1,'89; (1'03). PRESLEY, WM. L. (b'55)-Tenn.5,'82; (1'03).

RINGGOLLD, GEO. W. (b'65)-Ark.1,'86 ; (1'03).

YATES, GEO. (b'73)-Ark.1,04; (1'03).

MOSCOW, 30, JEFFERSON

Hilbourne, J. F. (b'82) $\longrightarrow$; (1'03).

MOTZ, 50, MILLER

Smitlı, G. D. (b'78)-Tenn.8,02; (1'03).

MOUNTAINBURG, 100, CRAWFORD

IItchell, Thos. Morgan (b'57)-Tenn.6,'92 ; (l'03).

MOUNTAIN HOME, 446, BAXTER

MOONEY, LEON M.-Ark.2,'07 ; (ま).

Simpson, Jos. H. (b'62)-Mo.1,87.

TIP'TON, JAMES T. (b'65) - Tenn.8,'91 ; $(103)$.

TIPTON, WM. CLARENCE (b'82)-Ark.2, 08; (l'06).

MOUNTAIN VIEW, 272, STONE

BREIVER, JOS. M. (b'60)-Tenn.5,'82; (l'06).

Luther, Joel E.-Ark.1,'97; (l'03).

MT. IDA, 225, MONTGOMERY

FREEMAN, WM. D. (b'63)-Ark.1,'99 (1'03).

KENNEDY, LEROY STAHL $\left(b^{\prime} / 4\right)-K y .4$, 05; (1'03).

Wingfield, Jos. D. (b'62) -O; (l'03).

MT, JUDEA, 69, NEWTON

Blackwood, James C. (b’59) - Tenn.8,'92; $\left(1^{\prime}(03)\right.$.
MT. LEVI, 37, JOHNSON

GIIAVE, STEPHEN M. (b'70)-0; (1'03).

MT. PISGAH, 100, WHITE

Jackson, Littlle B. (b'68) $\rightarrow$; (l'03).

MT. VERNON, 250, FAULKNER

Watson, 'Thos. C. (b'78)-Ark.1,09; (1'03). MULBERRY, 722, CRAWFORD

Campbcll, C. J. (b'76) -0 ; (1'03).

11ill, Lorenzo G. (b'61)-Tenn.0,'92; (l'03).

IIUNT, ELBER'T C. (b'62)-0; (1'03).

Stewart, Thos.-Mlch.7,96; (1'03).

Wigley, James A. (b'72)-Ark.1,'12; (l'03).

MUNDELL, 24, CARROLL

Webb, J. H. $\rightarrow$; (l'03).

MURFREESBORO, 516, PIKE

AIFORD, THOS. F. $\left(b^{\prime 74}\right)-$ Ark.1, 05 ;

Alford, Wm. D. (b'36)-Mo.10,78; (1'03) ; not in practlce.

Allson, Walter Gladwin (b'69) E-Ky.11, 08; (l'08).

BIACK, EVAN M. (b'60)-Ark.1,01; (1'03). ROBERTS, JORDAN LUCAS (b'70)-Ark.2, 10 ; (1'03); Pr.

Thomasson, Saml. J. $\rightarrow$; (l'03); not in practice.

MURILLO, 10, SEARCY

IReves, Marshall C. (b'55)-0; (l†).

MYRTLE (BERGMAN P.O.), 20, BOONE

Balnes, IV. T. (b'44) $\rightarrow$; (1'03).

NADY (SUMMER P.0.), 25, ARKANSAS

liobertson, Ira B. (b'53)-Ky.1,'90; (l'03) ;

NASHVILLE, 2,374, HOWARD

DALY, JAMES M. ('(b'68)-Ark.1,97; (l'03)

DILDY, E. V.-Tenn.6, 06; (l'03).

GIBSON, WI. M. (b'69) $₫$-Tenn.8,04; (l'03).

HALE, A. WILSON (b'i8) \$-Tenn.19,'11; HOPKINS, JESSE S.-Tenn.l,06 ; (1'04)

HUTCHINSON, DAVID A. (b'48)-Md.3,'80; (l'03).

Nelson, C. H.-Tex.7,06; (l'03)

Simpson, W. B. (b'75)-La.1,00; (l'03).

TOLANI, WM. HENRY (b'6') - Tenn.I 90; (l'03).

NATHAN, 50, PIKE

Strasner, Thos. (b'69) $\rightarrow$; (l'03).

NATURAL STEPS, 100, PULASKI

Moreland, Little B. (b'62) - Ark.1,98; (l'03).

Nawlin, Walter A. (b'79)-Ark.1,08; (1'06); not in practlee.

NAYLOR (R.F.D., VILONIA), 80, FAULKNER

Dunn, Osear Orlando (b'85) - Ark.1,'11; (l'II) ; R.F.D.

Reynolds, Jessee M. (b'43) $\longrightarrow ;\left(l^{\prime} 03\right) ; 0 b$.

NEELLY (R.F.D., DARDANELLE), 25

YELL

Jackson, Norborn
Ark.1,01 ; (1'03).

NETTLETON, 1,080, CRAIGHEAD

Howell, John C. (b'67)-Tenn.8,'09; (1'03). WALKER, BENJ. F. (b'69)-Tenn.8, 03 (l'03).

Wester, Wm. E.-Tenn.8,'05; (l'03).

NEWARK, 595, INDEPENDENCE

EVANS, ADD A. (b'77)-Tenn.8,'01; (l'03)

Lawton, Wm. P. (b'32) $-0 ;\left(l^{\prime} 03\right)$.

Mccloud, Augustus L. (b'67)-0; (1'03)

IOORE, WM. PINK (b'88) - Ark.1, 12 (l'12).

ASCOE, VIRGIL LYNN (b'îl)-Tenn.5, 93; (1'03).

Poe, Llndsey G. (b'69)-Tenn.1,93; (l'03)

RODMAN, THOS. N. (b'68) - Tenn.8,02 (1.03)

ROE, JAMIES B. $\left(b^{\prime} 70\right)-A r k . I, 04 ;\left(l^{\prime} 03\right)$

NEWBURG, 75, IZARD

Billingsley, Arthur W. (b'82) $\rightarrow$; (l'08).

Kent, John F. (b'71) E- 0 ; (l'03).

NEWCASTLE (R.F.D., FOREST CITY'), 10, ST. FRANCIS

OIIVER, ROBT. E. (b'83) - Tenn.1,0T: (1'05).

NEW EDINBURG, 435, CLEVELAND

HAMILTON, ANDREW J. (b'64)-Ark.1,'93; (1'03).

JUNIUS (b'85)-Tenn.19,'10; (1'10):

ANCE, JOHN O. (b'6i)-Ky.I,'91 ; (l'03) 
NEWHOPE, 125. PIKE

Alford, Abner A. $\left(b^{\prime} 34\right)-T e x .3 .04:\left(10^{\circ} 03\right)$. NEW LONDON. 100. UNION

Bdwards, Ldward E. (b\%8) $\mathrm{E} \rightarrow 0$ : (1*03).

FAIRISIS, JAMES II EXRY (b'iz)-TEXs, "08, Ark. $]_{0}$ '10: (\$).

NEWPORT, 3.557, JACKSON

Alen. Andrew J. (b'68)-Tex.7.'0? ; (l'03) BEST, ALONZÖ IEE (b'75)-Terin.s,01 (I'03). ERWIX. IRA II. (b'80)-Ark.2.10: (1'03) :

Ford, Zach. Io $\left(b^{\circ} 63\right) \rightarrow$ : $\left(1^{\circ} 03\right)$; R.F.D.

GRAi. Crists roBt. (b's3)-Tenn.s.0s (1'08).

JoNEs, oscar EVE $\left(b^{\circ}: 8\right) \ngtr-T e n n .5,02$; (l'03).

MARTIS, CHAS. W. (b::3)-Ky.5,05: (106)

Mart ren (b'56)-Tenn I, 7,05 (j.03)

Owen, Henry (b'56)-Tenn.I.'T: (1'03).

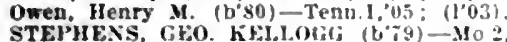

STEI'HENS,

Taslor, Danl. B. (col.) (t':5)-Tenn. :03 (l'03).

WALKKR, IIEXRY O. (b'78)-Mo.2,02 (1.03).

WATSOX. ELBERT 1. (b*5) 8-N.Y.1,00 ; (1)01).

WTI.IS, LEMLEI, EDWIN (b'62)\&-Mo.1.

86: (1.03): $\mathbf{S}$

NIMMONS, 25, CLAY

betchon, Saml. Fidgar $(1,49)-0$ f, is (l'03).

NIMROD, 60, PERRY

MeRee, Robt. IL. (b;'; $\rightarrow$; (I'03)

Wallace, Charles T.-ATk.1,97; (1003).

NORFOLK, 200, BAXTER

Rector, James M. (b'i!l of: (l'n3).

NORTH LITTLE ROCK (LITTLE ROCK P.O.). - PULASKI

Smith. Clement A. (col.) (b':it)-Tenn.:,02 (I'03): OALR.

NoRVElle (HIghland P.D.), 一, PIKE Purtle, Christopher Columbus (b'-9)ATK. I, 07: (I'03).

OAKFOREST (R.F.D., MARIANNA), 30 , LEE

J.FWTS, J. F. (b'6l) $\rightarrow:\left(l^{\circ} 03\right)$.

OAK HILL. - CARROLL

REYXOLDS, JAMES K. (b'7 6$)$-Irk 2,'1 (I'I1).

OAKLANO, 100. MARION

Adams, Arthur Tletor (b'82)- $\rightarrow$ : (l'0i)

enklns, Wm. l'atrlck (b'50) - Ark.1,12: (l'12)

OARK. 30, JOHNSON

PATTKRSON, CILAS. H-Ark. 1.96: (1'03)

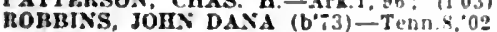
(l'03).

OGDEN, 397, LITTLE RIVER

Hutt, I. $\mathrm{X} \rightarrow \mathrm{O}$ : (1'03).

OIL TROUGH, 64, INDEPENDENCE

Burke, II. Gldeon $\left(b^{\prime} \div 1\right)-0 ;(1,03)$

West. J.- : (1'03).

OKEAN, 100. RANDOLPH

Cooper, James W. $\left(b^{\circ} 65\right) \rightarrow 0$ : not In pracIlce.

CUDp. Hobs, W. (b's3)-D; (l'0R)

OKOLONA, 399. CLARK

Ilughes, Fellx A. (b'-5)-Ark 1,05; (1'03)

Huctres. Fred T. $\left(b^{\prime}+8\right)-0:\left(1^{\circ} 03\right)$

Ros, Ilendrlc Arnold (b.84) - I"a 2.12 (1'13).

Roms, James S. $\left(b^{\circ}, 4\right)$ - La 1, $78:\left(1^{\circ} 03\right)$

OLA, 516, YELL

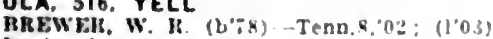

Darts, Geo. C (b'84)-O: (1'09)

Ilarkey, Him. I $\left(b^{\circ} 50\right)-A r k 1,9.2:\left(l^{*} 03\right)$

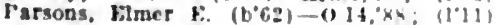

OLMSTEAD (R.F.D.. IACKSONVILLE), IS. PULASKI

stanley, M. b. $\left(b^{\prime}(0) \ldots \theta:\left(1^{\prime} 03\right)\right.$.

OLVEY, 50, BOONE

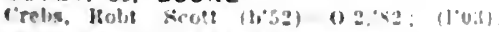

OMA, 100. HOT SPRING

Hendernou, A. M. $\left(b^{\circ} 5,5\right) \rightarrow:(1003)$,

OMAHA. 300. BOONE

HLTT, WIIIIIII Al.1N (b': - Irk 2.10 (1'031.

Cox. Timothy rien. (1,69)--i: (1'03)
ONEIDA, 73, PHILLIPS

b'erguson, Johu A. (b"si)-A; $(10 \%)$

OPAL, - POLK

Morrls, kichard I". (b"\&6)-Irk1,12: (1"12)

OPHIR (WOMBLE P.O.), 50, MONTGOM.

ERY

Collier. Alfred AI. (b'ati) $\rightarrow$ : (I'03).

OPPELO, 61, CONWAY

Grimn. Itchard M.-Tex.7,0: ; $\left(1^{\circ} 03\right)$.

OPTIMUS, 40, STONE

Benbrook, Chas. F. $\left(b^{\circ} 44\right)-8$ : $\left(1^{\circ} 03\right)$.

OSAGE, I35. CARROLL

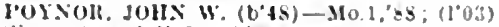

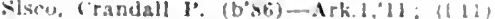

OSCEOLA. 1.767. MISSISSIPPI

HKEWH. THOS. H. (b.51) - ky.4.74 $\left(l^{\prime} 0: 3\right) ;$ Pd.

Clark, Wm. Henry (i. (col.) (boit)-Tenn. "1:-: (1.12)

IINAYNT, HENKY ILAY (L4t)

Tenn.1, :3; (l'03). MALLOHX (1,50) $\$$

Tenn.s.09: (l'0s). MALLOHX (1.50)

HOWTUS, ULFANDEl: $\left(b^{\circ} 80\right)-k y .503$; 1005

PIEWIT, KOBELT $\%$ ( hy.t. St: (1'03).

TAllol: THOS HANKLAS $(1,09)+$ Tent?:0\%: (1'10); OALR.

OVERCUP (R.F.D., MORRILLTON). 47. CONWAY

Kiridred, Z. T. $\left(b^{\prime} 50\right)-0 ;\left(l^{\prime} 03\right)$.

OWENSVILLE. 110. SALINE

Burgess, Fred J. (b.83)-Ark.2.10; (1'07)

l)arls, W. S. (b'5)- (l'03).

OXFORD, IIO, IZARD

simith, J. If. (b't9)-Tenn.8,'99: (l'03)

OZAN, 129. HEMPSTEAD

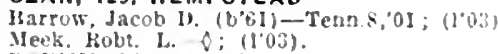

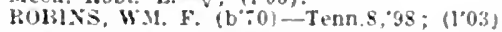

OZARK, I,146, FRANKLIN

BIACKBLILN, EDWARD W. (D':5)\& Tenn. 5, 00: (l'03)

Bridges, Joshua C-Mo 5,81 ; (1'63).

Carter. Wallace A. (b'3I)- (1'03); not in practice.

(l'03): $\mathbf{S}$.

Turner. Heury If $\left(\mathrm{b}^{*} 43\right)-\mathrm{k} y .2,70 ;\left(10^{\circ}\right)$

WAKREN, GEO. DAVIS (b'st) Ark.1, li: (1.09).

WILLAMS, IISON F. (b'6i) Ark.l.'? $(1.03)$

OZONE, 60, JOHNSON

liradley, (ieo. (b'3s) $\rightarrow$ : not in practice.

PALATKA, 87, CLAY

STEWAHT, OLLIE IIEEW ( $\left.{ }^{\circ} 82\right)$ - III.29.0\%:

PALESTINE, 173, ST. FRANCIS

Inplehy. Scoll-La.1,01; (l'08).

Auter, Clarence Monroe (b'5i)-111.13.05; (l'06).

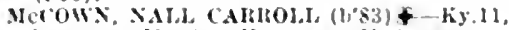

'(1): 1): Member ky. Siate Mled. Ams?.

PALMYRA, 30, LINCOLN

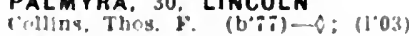

PANGBURN, 130, WHITE

Fraser, Noah E. (b'so)-Tenn.8.'0s: (l'0s)

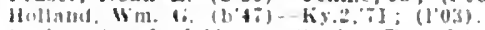

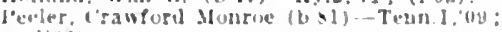
(1'U1;)

PARAGOULD, 7,500, GREENE

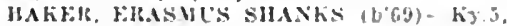

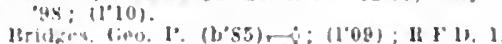

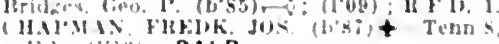
12: $11121:$ OALR

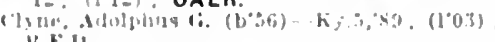
if 11

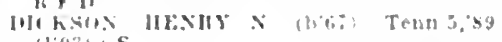

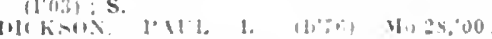

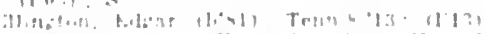
budngtoll, Waltor Filward (b.63)-Tenns. $13:(1013)$

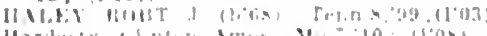

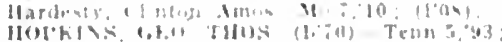

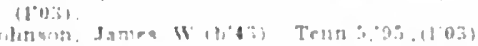

KEXTUS, FUKET MEKE $(6 \% 8) 6-$

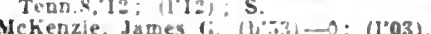

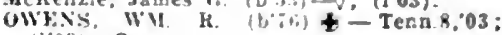
$(1.03): \mathbf{s}$.

scotT. H.LIX M. (10.51)-Tenn.5.81:(1.03).

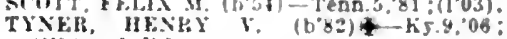
(1"03): $11.11 \%$.

paraloma, 194, SEVIER

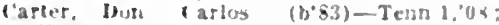
(1) $0 .$, )

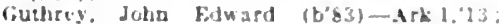
(1'13): $\mathrm{S}$.

PARIS, 1,497, LOGAN

BE.XNET, WM. IIOKACE (b'6) 1 -Ark.I.

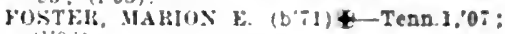

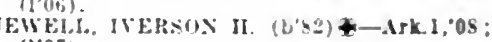
$(1.0 \%)$

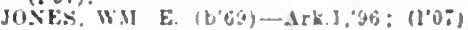

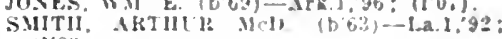

SMIII, JoHx d. $(1,54)+-$ Tenn.3.78:

(1.03) : $\mathbf{S}$.

PARKDALE, 383, ASHLEY

GEURGE, H. FHANK (b"5)-Tenns,04: $(1.03$, (2)

H.WhISS, MAHTIS CASEITY (b'6s)Ky: : $93:\left(1^{\circ} 03\right)$

Ilolliday, Benj. Vranklin (boo)-Tex.ios:

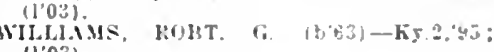
(1'03).

PARKIN, 150, CROSS

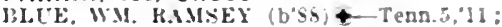

(1'11)

snuth. J. Brown (bol)-Tenn.6.93: (1903)

sm:th. Isichard $S$. (b\%5)-D: (1'0.3).

PARK PLACE, 75 , LEE

liray, fisha Nonrce (b'so)-Tenns,os:

Iyard, John s.- hy.5."s1; (l'03).

PARKS, 28, SCOTT

lincan, B. W. (b*a) $\rightarrow$ : (I"03).

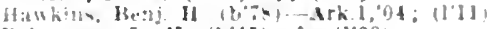

lioberson, I. K. $\left(b^{\prime} 45\right) \rightarrow 0$; $\left(1^{\prime} 03\right)$.

PATMOS, 200. HEMPSTEAD

Camp. Cicers $\left(b^{\prime} ; 2\right) \longrightarrow 0 ;\left(1^{\circ} 03\right)$.

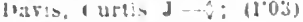

PEACH ORCHARD, 300, CLAY

Sancomb John L. (b.55)- (1.03).

ihares, Chas, Lee (b's3)-S; $(105)$

PEARCY. 172. GARLAND

Tablor, lieo. T. $\left(b^{\prime 3}:\right) \rightarrow$; $(1 ' 031$.

PEA RIDGE, 200, BENTON

tiaines. Idelbert II. (b'3t)-Mc.:s, as:

(IREFNE, LEE O. (b'79) $9-\mathrm{Mo.7.02:}$ (l,03): Pd.

PEARSON, 10, CLEBURNE

BEASI.KE, HAMER S. (b'69)-ATK 1,0S: (1.03).

PEEL. 65, MARION

Hoberts, J. G $\left(\mathrm{b}^{\circ} 3 \mathrm{~S}^{\circ}\right)-0 ;\left(1^{\prime} 03\right)$.

PENDLETON, 25. DESHA

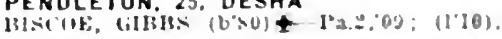

PERRY, 300. PERRY

Farish, Amos 1I. $\left(\mathrm{b}^{\circ} 68\right) \rightarrow$ : $\left(1^{*} 03\right)$.

(1)tes, Louls T. (16\%) irk 1.03: (1003): 1t. 1. 1. 1.

Sirencer, Marlon $\mathrm{x}\left(10^{\circ} 53\right) \rightarrow 0:\left(1^{\circ} 03\right)$.

PERRYVILLE, 353, PERRY

IIOWNAL, M.INIIIF \%. (b'61)-0:, so: (1.03).

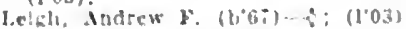

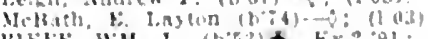

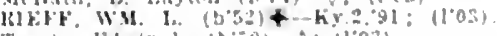

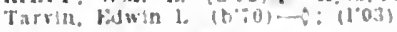

PETTUS, 600, LONOKE

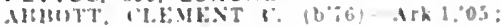

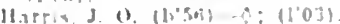

PIGgotT, 1.150. Clay

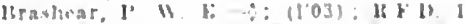

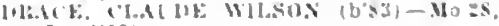

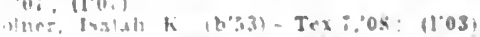

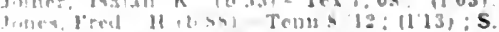

Vonfe. I,enta I" (h'66)-g (1.0:).

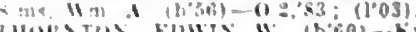

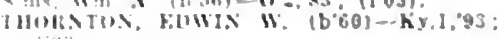




\section{PINE BLUFF, 15,102, JEFFERSON}

Boll, (ieo. W. (col.) (b'64)-Mo.10,92; (1'03) Blackwell, Owen G. (b'73)-La.I,01; (l'03) 1900 Olive St. : office, Bank of Plne Bluff Bldg. : 11-12, 3-5: $\mathbf{S}$.

Blackwell, R. 1'. (b'53)-D; (1'03) ; Bank of

Plne Bluff.
BLANIENSHIP, WM. IIUNT (b'66) Id.3,'93; (l'03) ; 1700 Chestnut St. ; offlee 115 Pine'St. ; $9: 30-12,2: 30-5 ;$ Pd.

BREATIVIT, W. (b'i1) (8)- Ky.5,94 (l'03) ; $618^{\prime}$ Ash St. ; oflce, Clitizens Bldg. : 9-12, $2-5$; OALR. *

BRUNSON, ASA (1,72)-Teun. 8,99; (l'03) 700 l'ine st. offlce, Cltizens Bank l3ldg. $10-12,3-5$.

Carter, Lucretia Annye (col.) (b'75)-111.16 '12; (1'12); 1006 W. P'ullen st. ; offlce, Masonlc Temple.

CARUTHERS, CAMILLUS K. (b';4) $204 \%$ Máln St. ; 10-12, 2-4; Ob.

(branklin 1.' (b'53)- $\bigcirc ; \quad\left(l^{\prime} 03\right)$ 1061/2 Pine St.; 8-12, 1-5.

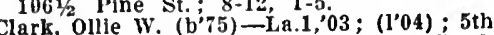
Clark, Ollie W. (b'75)-La.1, 03; Ave. and Laurel St.

Bldg. ; 8-10, $1-3,{ }^{7}-8$. $-0 ;\left(1^{\prime} 03\right) ;$ R.F.1).4

CRUMP, JAMES F. (b'73)-Ark.1, $05 ;\left(l^{\prime} 03\right)$ 210 Mrain St.

CRUTCHER, WM. (b'66) P-Pa.2,'96;(1'03) 805 Pine St.; offlee, 201 W. $2 \mathrm{~d} \Lambda \mathrm{ve} ; 3-5$.

Dallaugl w' C. (1'50) $\mathrm{F}-0.2,81$; (1'03)

DOSS, NOBLE CAMP (b'84)-Ga.11,'12 (1'13).

GALLEGHER, BARNARD H. (b'63) Tenn.8,'91:; (1'03); 918 W. 5th Ave.; offce, Citizens Fank Bldg. ; 9-12, 2-5.

Gamble, Charles O. (col.) (b'75)-D.C.3,06 (l'09) ; 915 Missouri St.; ofllce, 215 E. $3 d$ St. $8-11,4-7$.

GLOVER, CHAS. A. (b'73) - Ark.1,'04 (1'03); 819 Ohio St.; offlce, 201 W. 2d. St. ; 9-12, 2-5.

Harrison, W. W. (b'64)-Tenn.8,91; (l'11) : 420 W. 4 th

Hunt, T. J. (b'54) $\rightarrow$; (l'03); R.F.D

James, Danl. E. (b'67) E-Tex.8,'08, Ga.9, '10; (1'10); R.F.D. 1 .

JENKINS, JOHN $\mathrm{S}$. (b'74)-Tenn.1,'99 (l'03); 1103 W. Barraque St. ; offlee, Citizens Bldg. ; 9-i2, 3-5; S.

JOHN JAMES WM. (b'68)-Tenn.8,'96 (I'03); 422 W. 11th Are.; offlce, $202 \% 2$ Main St. ; $10-12,3-5$.

JORDAN, ARTHUR CLIFFORD (b'60)@Tenn.5,86; (l'03); 1519 S. Cherry St. $3-5 ;$ s.

Jordon, H. L.-Tenn.7,'03 ; (l'03) ; Masonic Temple.

KITE, NOAH S. (b'40)-Tenn.8,'86; (I'03) 2424,13 th Are.; oftice, Brasher Drug Co. $10-12,3-5$.

LEMUN'S, JAMES M. (b'62)-Tenn.8,'93; (1'05): 1018 W. 6th Ave.

LOWE, WM. THOS. (b'81)๑-Tenn.1,05 (1'03) ; 122 E. 16th St.; office, Barraque and Pine Sts.

LUCK, BENJ. D. (b'79) $\rightarrow-P a .2^{\prime} 03 ;\left(l^{\prime} 03\right)$ 903 w. 5th Ave.; oflle, 105 Chestnut St. $10-12,2-5 ; S$.

Magee, J. L. - ; (l'09); $211 \frac{1 / 2}{\longrightarrow}$ Main St.

MCNULLEN, EDWIN CLARE (b'79)-IIl.1 07; (1'12); I6th and State Sts.; offee Merchants and Planters Bldg.

Orto, Zaphney (b'42)-0.9,72; (1'03).

PALMER, JOHN T. (b'i8)-La.1,05; (l'03) ; 1819 Poplar St.; offec, Barraque and PIne Sts. : $10-12,3-5$.

ROWELL, FRED. CLEVELAND (b'83)Ark.2,'08; (l'08); 1116 W. $23 \mathrm{~d}$ St.; offle Citizens Bank Bl'dg; 8-12, 2-5.

Sacconi, Ambrose (b'46)-Aus.3,70; (1'03). Savin, Jessie Ella Sweet (b'80)-Md.5,'01 (l'03); 520 W. 2d Are; oflice, Barraque and Pine Sts. : $9-12,2-5$.

SCALES, J. WM. (b'64) - -Tenn.5,88; (l'03); 1104 W. 6th St.; office, 2041/2 Main

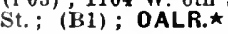

SMITH, JOHN S. (b'70)-Tenn.8,01; (1'03). SPILLYARDS, JESSE SOLOMAN (b'82) Tenn.8,'11; (l'11); 1406 State St.; offec $1201 / 2$ S. Main St. ; $8: 30-11,2: 30-5 ; \mathrm{G}$.
STEWAIT, WM. S. (b'69) Ky.5,05 (1'03); Sec. State Med. Board of Ark lled. Soc. ; 1502 Cherry St.; offlce, Citlzens Bank Bldg.; 10-12, 2-5.

Stratlss, Alvin Weil (b'90)-Ia.1,12; (l'13) 715 W. 4th Are.; offlce, Citizens Bank Bldg. 2-4; $\mathrm{s}$.

Taylor. Wm. Oliver (col.) (b'76)-Ill.16,'08 (1'10); 2514 W. 14th Ave.; office, 220 State St.: $9-11,12-3: 30,6-8$

THOMISON. ARTHUI GEO. (b'51) Đ-Ia.1 80 ; (1'03); 907 W. 6th St.; oflce, 105 Chestnut St.; 2-4.

Thompson, Rlchard Clough (b'61)-N.Y.10 '84: (1'03) : not in practice; 519 W. Barraque $\mathrm{St}$.

TROUPE, A.IOS W. (b'56)†-Ill.1,84 (1'03); 917 W. 5th Are.; offle, $2041 / 2$ Main St. : $10-12,2-4$

WALLIN, LOR EN (b'87)-Tenn.6,09; (l'09) West Find Statlou.

Watson, Wm. E.-Tenn.13,02; (1'03) ; 1019 Missourl St.; offle, Masonlc Témple $8-10,1-3,5-6$

WILLIAMS, HARRY EUGENE, JR. (b'85)La.1,08; (l'06); 418 E. 12th St.; offlec, $1141 / 2$ Majn St.

WILLIAMS, IIENRY E. (b'55)-Tenn.8, '84, La.1,'86 ; (1'10)

WITHERS, JOHN WRIGHT (b'55) $\oplus-N . Y .5$ 79 ; (1'03); 1223 W. 6th Are. ; offlce, Citlzens Bank Bldg. ; $10: 30-12,4-5$.

WOODUL, THOS. W. (b'78) -Ark.2,07 (1'06); 140 E. 17th Are.; offle, Barraque and Pine Sts.; 9-12, 2-5.

PINNACLE, -, PULASKI

Ault, Harrey J. (b'57)-Ga.11,05; (l'03).

PLAINVIEW, 853, YELL

ALBRIGHT, JAMES L. (b'66)-Tenn.8,'91;

BALLENGER, WM. E. (b'74)-Tenn.5,'99 (l'03).

Green, Joln Wesley $\left(b^{\prime} \pi 1\right)-0 ;\left(l^{\prime} 04\right)$.

LINZY, C. B. (b'77)-Ark.1,06; (1'03).

PLEASANT PLAINS, 151 , INDEPENDENCE Hook, J. A. (b'82)-Tenn.8,'04; (1'03).

Ray, Dalton II. (b'83)-Ky.2,07; ()

PLUM BAYOU, 15, JEFFERSON

Burton. Wm. M. (b'44)-Ill.1,69; (1'03) not in practice.

McBeth, Madison Manie (col.) (b'72)Tenn.7,00; (l'03).

\section{PLUMERVILLE, 495, CONWAY}

GOATCHER, ARTHUR L. (b'/2)-Tenn.1 02; (1'03).

HORTON, NEAL (b'81)-Ark.1,06: (1'03) Jones, W'm. A. (b'59) E-0.2,80; (1'03)

Lane, Edward C. (b'64)-Ark.1,'96; (1'03).

Noore, John H. (b'67)-N.C.3,'99; (l'03).

POCAHONTAS, 1,547, RANDOLPH

BLACK, GUY MARION (b'75)-T'enn.15,'10 (1'03)'

BROWN, JOHN W. (b'78)-Mo.28, 03 ; (1'03)

Hall, L. H. (b'67)-\$Io.7,99; (l'03).

HAMIL, WM. E. (b'79)-Mo.34,02; (l'03)

Hughes, Wm. Ed. (b'69)-Tenn.8,'00; (l'03).

Pringle, Cyrus E. (b'61)-Mo.1,'83; (1'03).

SCIIEID, CARL J. (b'61)-Tenn.8,'95;(l'03).

Seheidt, Chas.-Tenn.8,'95; (l'03).

THROGMORTON, HIRAM L. $\left(b^{\prime}, 70\right) \oplus-$ Mo.27,'98; (l'03).

POINT CEDAR, 25, HOT SPRING

Emory, F. L. $\rightarrow$; (l'03).

POINT PETER, I5, SEARCY

Groggins, R. E. B. $\left(b^{\prime} \mathbf{6} 0\right) \longrightarrow ;\left(l^{\prime} 03\right)$

Hamm, Silas G. ( $\left.b^{\prime} 7 \tau\right)-T e n n .8,12$; (1'12).

POLLARD, 50, CLAY

HILLER, JOHN P. (b'77)-Mo.7,03; (1'03)

POPLAR GROVE, 150, PHILLIPS

Holtzclaw, Jeddie Foster (b'86)-Tenn.8,'10; (l'09).

PORTIA, 367, LAWRENCE

Buercklin, F. W. $\rightarrow$; (l'03)

ROBINSON, WM. J. (b'64) $\odot$-Tenn.8,'97 ; (l'03).

PORTLAND, 823, ASHLEY

COCKERHAM, HENRY E. (b'73)-La.1,'95;

CONE, $\triangle N D R E W$ E. $\left(b^{\prime} 76\right)(-\mathrm{Ky} .4,98$; (l'03)

Sherrer, Fred M. $\left(b^{\prime} 73\right) \rightarrow$; (l'05)
POTTSVILLE, 205, POPE

Gardner, R. H. (b'46) E-0.2,'83; ( (1'03).

Jean, Itobt. Marion (b'78) E-0.2,12; (l'03).

POUGHKEEPSIE, 200, SHARP

Sullivan, Everett L. ( $\left.b^{\prime} 80\right)$ - Ga.18,00;(l'12).

Tibbels, Wm. O. (b'75) E-Mo.10,'06 ; (1'03).

POYEN, 30, GRANT

Byrd, John L. (b'59) $\rightarrow$ : (1'03).

Quinn, Lot L. (b'4T)-A rk.1,95; (1'03).

PRAIRIE GROVE, 774, WASHINGTON

BREWSTEIt, JAMES HENIY (b'61) Mlo.1,86; (l'03).

McCOKMICK, ElIHRAIM G. (b'55) $\odot$-Mo.1, $81 ;\left(\mathrm{l}^{\prime} 03\right)$.

W. H. (b'74)-Tenn.5,94; (1'03).

SMITII, THOS. CLARKE (b'74) 8 -Ill. 8,, 05 ;

(): Member Ill. Stite Med. Soc.

PRAIRIE VIEW, 200, LOGAN

IIlgdon, Wm. H. (b'78)-Tex.7,05; (1'05).

PRATTSVILLE, 100, GRANT

Cole, Chas. F. (b'68) $\rightarrow$; (l'03).

Harrey, T. A. (b'39)-Ky.4;'76; (l'03).

PRESCOTT, 2,705, NEVADA

$\Lambda$ ntoine, Geo. W. (eol.)-Tenn.7,'06; (1'07).

Arnold, W. E. (b'38)-Ga.5,'61; (l'03).

BUCHANAN, ALBERT S. (b'81)థ-Ark.1, '05; (1'03); $S$.

BUCHANAN, GILBERT A. (b'84)-Ark.1, '11; (l'11) Joslah S. (b'69)-Tenn.1,'03 ; Chastain,

Cox, J. E. (b'79) E-O; (l'03)

UESTERLY, SIMEON'J. (b'63)థ-Tenn.8, 96 ; (1'03)

REEDER, ARTHUR AUGUSTUS (b'74)Tenn.5,01; (l'03)

RICE, WM. W. (b'68)@-Mo.24,'98; (1'03).

PRINCETON, 132, DALLAS

CHEATHAN, HUGH $A$. (b'80)-Tenn.8,03; (1'05).

Lea, Weldon W. $\left(b^{\prime} 50\right) \rightarrow$; (1'03).

PROCTOR, 140, CRITTENDEN

Keller, Lawrence Larry (b'86)-Tenn.6,'13 ; WINTER, WOODYE ALBERT $\left(b^{\prime} 80\right)(1)$ Tenn.8,'10; (l'06).

PROVO, 200, SEVIER

Kolb, Harmon J. (b'68)-Tenn.1,04; (1'03) ; R.F.D.

PYATT, 75, MARION

Lair, J. Frank $\left(b^{\prime} 62\right)-$; (l'03).

QUITMAN, 471, CLEBURNE

Al!lson, Wm. MI. (b'41) E-Mo.10,'76 ; (1'09).

Fleming, J. T. ( $\left.b^{\prime} 66\right) \longrightarrow$; ( (1'03)

Kiessinger, J. S. (b'71)-Árk.1,06 ; (1'03).

Wood, A. B. (b'69) $\rightarrow$; $\left(\mathrm{l}^{\prime} 03\right)$.

RAIFORD (HAMPTON P.0.), 300, CALHOUN

Dunn, Cornelius B. (b'47)-Ky.1,76; (l'03).

RAMSEY, 25, DALLAS

Frizzell, D. H. $\rightarrow$; (1'03)

MeDonald, James Henry $\left(b^{\prime} 32\right) \rightarrow$; $\left(l^{\prime} 03\right)$.

Reiser, Geo. F. (b'66)-No.2,98; (1'03).

RANDALL, 15, CLEVELAND

Glover, Brooks B. (b'57) -0 ; (1'03).

WILSON, HORACE OLIVER (b'83)@Ark. 1,$10 ;\left(1^{\prime} 10\right)$.

RATCLIFF, 175, LOGAN

HARKINS, RICHARD A. (b'82)@-Tenn.I, 07 ; $\left(1^{\prime} 05\right)$

RAVANA, 150, MILLER

Boyd, James M. (b'71)-Tenn.8,'12; (1'03).

RAVENDEN, 350, LAWRENCE

BALL, CLEO CLEVELAND-Mo.2,04;(l'03)

Ball, Ernest ( $\left.b^{\prime} 85\right)$ - Tenn.5, 08 ; $\left(l^{\prime} 08\right)$; not In practice.

RAVENDEN SPRINGS, 189, RANDOLPH

IIarnden, Geo. S. ( $\left.b^{\prime} 67\right) \rightarrow 0$; (l'03).

HULL, H. B.-Tenn. 5 , $07^{\prime}$ ' (1'03).

Nixon, John H. (b'74) E- ; (1'03).

RAWLS, 10, ASHLEY

Jones, Wm. Ernest (b'63)-Tenn.8,'94;(l'03).

RECTOR, 1,859, CLAY

Donaldson, M. ( $\left.b^{\prime} 46\right) \rightarrow$; (l'05).

Earle, Chas. G.-Ky.2,91; (l'03).

HUGHEY, MOSES C. (b'7 7 ) - Tenn.8,'03; $\left(1^{\prime} 03\right)$.

Jernigan, Roscoe Martin (b'81) - Mo.10,'10 (1'08); Pres. Eclectic State Med. Board. 
Iynch, H. A-E-Mo.10,00: (l'03)

Oullaw, Morgan (b"\%i) -Mo.28,97: (1003)

Parrlsb, Walter 0. (b'75)-Tena.1,9s :

(1.03), Wailer 0. (b75) - Tena.1.93

Slmmons, W. Henty S.-E-M0.10,96: (1'03).

REDBIRD, 25. MONTGOMERY

Bates, Stephens C. (b'26)-O: (l'03).

REOFIELD, 278, JEFFERSON

Cunningham, Thos. J. (b'80)-Ark.2,'10 (1'03).

Reynolds, Joseph M. (b'47)-Ky.1,82; (1'03).

Sbope, Andrew D. (b'73)-Tenn.9,'98; (\$).

RED FORK, 127, DESHA

Hydrick, Edw. C. $\left(b^{\prime} 63\right)-d ;\left(1^{\prime} 03\right)$.

REOROCK, 10. NEWTON

Sutton, Simon Solomon $\left(b^{\prime} 53\right)-0:\left(l^{\prime} 03\right)$,

REYNO, 290, RANDOLPH

Cox. F. W. (b'78)-0; (1'03)

Hill. Fred. $\left(b^{\prime} 43\right) \rightarrow 0:\left(l^{\prime} 03\right)$.

Xicks, A. M. (b'62) - Tenn R, $88 ;\left(l^{\prime} 03\right)$

Salth, Robt. Oscar (b'8t) - Tenn.8,'10: (1'07).

\section{RICHMOND, 300, LITTLE RIVER}

Dunn, John M. (b'33)-Mo.2,'61: (l'03)

Rhodes, James F. (b'61)-Ark.1.86; (l'05)

VAUGIIAN, WM. E. (b'0)-Ky.2, $; 3$; $\left(l^{\prime} 03\right)$.

RICHWOODS, 20. LAWRENCE

Bayan, Chas. E. (b'82)-0; (l'03).

White. Wm. Henrs (b'8l)-0: (l'04).

RIODLE, 15, SEVIER

Whitaker, Emmel E. $\left(b^{\prime} ; 1\right)-0$ : $\left(1^{\prime} 03\right)$.

RING, 26, RANDOLPH

Darts, Allen (b'46) E-O: (l'03).

Rodzers, Nathanlel A. (b'60) E-i; (l'03).

RISON, 725, CLEVELAND

HARTSELL, WM. L. (b'\%2) †-Tex.10,03: (1'03).

HUGHES, ARRANDA A. (b'86)-Tenn.15, 10 : $\left(1^{\prime} 10\right)$.

MeMuntes, John S. $\left(b^{\prime} 34\right)-0$ : (1'03).

RORERTSON, ALBERT B. - Ga.9,0s: (I'06).

SADLER, HENRY D. (b'62)-Ark,1,'91; (1'03).

ROBINSON, 49. BENTON

Crockett, Chas. S. (b'73)-Tenn.5;84; (1'03).

ROCKY (POTTER P.0.), 62, POLK

Connally, David W. (b'71)-Tex.7,05:

Connally, Robe T. (b'41)-0: (1'03) ; R.F.D.

Stark, Allce M (b'43)-Michl,79; (\$); R.F.D. 2.

ROGERS, 2.820, BENTON

Curty. Wm. Y. (b'11)-0.2.74: (1.03)

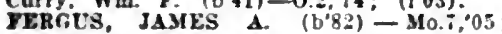
( $\left.l^{\prime} 04\right)$.

Lenor, Wm. IIarrison $\rightarrow$; (1'03).

Love. Geo. Y (b'73) II-3in 35,09: (1'09).

Muller. Ww. Menty-Ont.3,'91; (1'03)

PICKEXS, EDGAB E. (b'78) -Tenn.1,01 (1'03).

RICE. CI.INT A. (b'65)-Ark. , 01 : (l'03)

RICE, RUTUS S. (b'63)-M0.7, 01 ; (1'03).

ROLAND, 25. PULASKI

BnONKs, CADMt's M. (b'83)\&-Ark.2,10 (1'00).

RONDO. 150, LEE

Copeland, Thos Alerander $\left(b^{\prime} 6 \theta\right)-0$; WHITE, HARRY I, $-K y^{\prime}, 11,08$; (1'09).

ROSBORO, 320, PIKE

BAKER, WY. JITT (b'03)-Ark.1,91 ; (1'00).

ROSE BUD. 100, WHITE

HASSELL, A. It. (b'.3)-Tenn.8, 02: (1'03) : Pd. Wm. Sldney (b'66)E-Tex.i,03: (1'03).

ROSIE, 75, INDEPENDENCE

WYATT, WM. A. (b'66)-Mo.28.99: (1'99).

ROSSTON, 200. NEVADA

Mendentall, Thoq. Jonea $\left(b^{\circ} 65\right) \rightarrow:\left(1^{\prime} 03\right)$.

ROVER, 200. YELL

GILI,UM, ARTHIII D. $\rightarrow$ : (l'06)

ROWELL. 23. CLEVELAND

Adama, Thoman l. $\left(\mathrm{b}^{\prime}: 3\right) \rightarrow 0$ : (1'05).

RUDY, 93. CRAWFORO

Venulng, John Howe (b'82) E-0.2,'10: (1'11)
RUSH, 75, MARION

Ware, John C. (b'49)-Ark.1,86: (1.03).

RUSSELL, 147, WHITE

Iluraker, G. H, (b;0)-Tenn.10,29; (l'03).

RUSSELLVILLE, 2.936. POPE

BEILYMAN, IAWKEXCE I). (b'78)-Ark.l, '05: 11.03).

CAMJIELL, JoHN Si. (b'59) Tenn.8,'90; (1.03).

DlRMMOND, ROBT, M. (b'36) -Tenn.3, 81: (1.03): Pr.

Fimlson. Isaac II." (b'55)-Tenn.5:'s8; (1'03). IIIS', JAMES F. (b'7t)-Ark.2,07: (1,03) James, Jos, I.ee (col.) (b'36)-Tenn.7,12: (1'12).

MILLER, SAMI. AIBERT (b'6\%)-Tenn.6. 94: (1.03): OALR.

POWEI.L, JAMES WM. (b'78) Ark.1,05 ; (1'03).

Rafsdale, Albert S. J. (b'63)-Ky.2,"90:

Ragsdale, Louls T. (b'38)-Ark.1,88, (1'03), lloss, Chas. J. (b'66)-Tenn.8,'92; (1'03).

Wifis, IRERT B. (b'73)-Tenn.8,96: (1'03)'.

RYE, - CLEVELAND

Wilson, Johr Samuel (b'\%9) - Ark.1,13 (1'09).

SAGE, 60, IZARD

Black, Jas. K. P. (b'\$1)-Tenn.1,'77; (1'06); ot in practice.

SALADO, 100, INDEPENDENCE

Reres, L. E. - 0 : (1'03).

SALEM, 800, FULTON

CANTRELL, F. W. (b'56) - 0 ; (1'03).

WEATIERS, JAMES I. (b'80)-Tenn.8, $0{ }^{\circ}$; (1'0T).

SARATOGA, 400. HOWARD

Cannon, Wm. H. (b'5t)-Tenn.6.'90; (l'03).

SARDIS (R.F.O., PATMOS), 40. HEMP. STEAD

Rarbam, W. C.-II-O; (1'03).

SAYRE, 150, OUACHITA

POWEIL, RRAXTON $\checkmark$. (b'is) $\$$-Tenn.s, .99: (1'03).

SCOTLANO, 100, VAN BUREN

Burns, Calrin H. (b'40)-0: (1'03).

Fmmons, Aaron M. (b': -0 : (l'03).

Fmmons, John $C\left(b^{*}+1\right)-0 ;\left(l^{*} 03\right)$.

Hatchel, James King-0; (1'03).

SCOTT, 83. PULASKI

Henderson, Thaddeus

(b'79)-Ark.1,'11: (!'06).

n!ck, Arthur (col.) -0 : (!'04).

KIRKLAND, SAML. DAVIS $\left(b^{\prime} 80\right)-A$ rk ? $11 ;(1,11)$.

Pennington, J. A. $\rightarrow$ : $\left(l^{\prime} 0 \pi\right)$.

Taylor, Anderson J. (col.) (b; ; ) - Tenn.t, 08: $\left(\frac{1}{2}\right)$

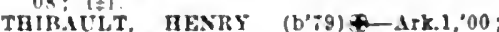
(1)03): KF II.; As:on. I'rof. Med., Irk.1. SCOTTSVILLE, II3. POPE

MIMcan E A $\left(b^{\circ} 66\right) \rightarrow:\left(l^{\circ} 03\right)$.

splllers. Henrs F. (b'80) $\rightarrow:\left(l^{\circ} 03\right):$ not in DTacile.

SCRANTON, -, LOGAN

IIFE, FWERETT NEWTON (b'TB)-TEn.3. 02: (l'03).

SEARCY, 2.331, WHITE

Faust. Jolun W' (b'at)-Ky.5.93: (1"03).

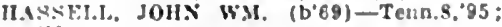
$(1,03)$

JFi.K., JARRFTT M. (b'4i) Tenn.6.78: $(1.03)$

Jonen, IIngh $C . \quad\left(b^{\circ} 49\right)-0 ;(1.03)$

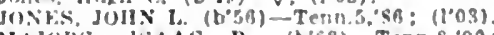
MAJuis (Alli $R$. (b's)-Tenns, 90 : (1,03).

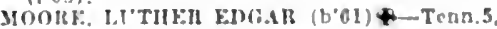
R.5: (1, 03$)$

TAl'sint SAYI. THOSAS, J18. (b'S4)Tarscotb. 4, T, (b'33) - Tenn.2."38; (1'03)

SELMA. 125, DREW

Kimhro, Chas. II (D;is)-Tex.:;0i: (103).

SETTLEMENT, 200, VAN BUAEN

Cinrke, James $16(10+4)-\Delta:(103)$

sturderant. W J. (b'i)-8: (1003)
SEYPPEL, 250, CRITTENDEN

"ullen. Thomas J. (U"is) - ren 8.02: (1'03)

Ifley, Erle Alex. (L'o!-Teñ.8, 13

SHARK, 40, YELL

Lusby, J. C. (b'49)-Tear h."20; (1.03).

SHAVER, 25, BOONE

Seal, Anderson $\left(b^{\circ} 50\right) \rightarrow$; $\left.(1)^{\prime} 03\right)$.

SHAW, 90, SALINE

Scot:, James lierry (b':5) $\rightarrow$; 1103)

SHAWMUT, 60, PIKE

Burleson. Jos. J. (b':5) $\rightarrow$ : (1\%03)

SHELBYVILLE, 50, SHARP

Ellls, conley S. (6"'3)-Ky.4,05: (1'03).

SHERIDAN, 481, GRANT HT"TLEI, JOHN L. (b'G5)-Ark.1,94; 30.28 ,

Goodman, Jamea M. (b'C 8$) \rightarrow:$ (1'03).

KEI.IY, OIHE R (t'85)-K5.2.09; (1.08)

SIIAW, JAMES H. (b'4)-Tena.1.82:

WAILIS, JAREX (b'5)-Tenn.5,09: (1"03)

IOT"NG, JOHX KEFX $\left(b^{\circ} 80\right)+$ Tenn.l,09 (1'09).

SHERRILL, 350, JEFFERSON

(irege. Jack \& (b'8.5)-0.2,"12: (1'12)

House, J. s. (col.) (b'65)-Tenn. "94; (l'03)

Pratt, Edward C. $\left(b^{\prime} ; 0\right)-A r k 1,11 ;\left(l^{\prime} 11\right)$

SHILOH, 25I, CLEBURNE

Blrdsng. Thos. Calvin (b'it)-Ma.28,05 (1'03).

SHIRLEY, - VAN BUREN

Dlckens, Geo. W- -0 . (1'03).

Ilutto, Henry (b'69)'- (1'03).

SHULER. 30, UNION

MAYFIEI.D, ANUREW MEEK (b'81)Ark l,06 : (l'04).

SIDNEY, 100, SHARP

(iray, D. Wesley (b':s)-Tenn 8,'03: (\$). Woodyard. Benf. B. (b'69)-Tenn.8,94; (1'03).

SIDON, 1.100, WHITE

Gibson, E. B. (b'56) -0 ; (1'03).

SILEX, 35, POPE

FLslier, Wo. 11. J. (b'6t) $\rightarrow$; (1'03) ; R.F.D. $1: 0 b$.

MIRPHY, JAMES M. (b.49) $\rightarrow$ : (1.03)

Nichols, James Y. (b'3t)-M0.22,31: (1.03).

SILOAM SPRINGS, 2,405, BENTON

BEARD, JAMES HARVEY (b'il)-TEnDS.

ing: (1'03).

ClEGi, JOS. T. (b'50)\$-Tenal,:3;

DCCKWORTH, FR.AKLIN M. (b't)-Mo.2. 97 ; (1.08) ; OALR.

Greene, Edward 13.-IL.6,'S5; not In pracslce.

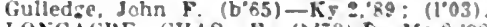
LONGACHE, CHAS. E. (b\%3)+Mo.5,98: (1'10).

Sexton. Josbua z. (b'i1)-Tena. 5:

SMILF: JOHX L. (b"it)-Tenn.1,90

MIII.

Webster. J. W. (b'4i)-3(0.1,94: (1"03).

SILVER, 50, MONTGOMERY

Suth. San-fis.5.85: not In uractice

SMACKOVER, 150, UNION

HIASTU., IIENISY (1. (b'\$4)-ATK 2,10:

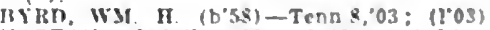
NoRTON. JAMES M. (b"83)-Aik.2, II (1'11).

STFIMMAN,
SMEAD, SO, CALHOUN

ilichle. Chas burard (bie).

SMITHVILLE, 300, LAWRENCE

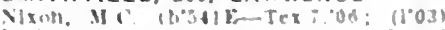

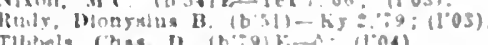

THbels. Chas " (b'ig)
SNOWBALL. 35, SEARCY

Haker. Ansalom $\&$ (,$: 0) \rightarrow 0:(103)$.

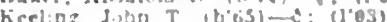

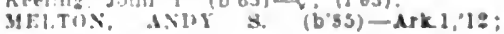

(1) $1 \div 1$.

liuT. I. I'. (b.30)-

SNYDER. 60, ASHLEY

I'ackes, Juln loo (b:"3)-Ky.1,91: (1'03).

SOCIAL HILL. 63, HOT SPRINE

III.IKLLY, MITTHEW 31. (b'S6)-Ask. $(1,0)$. 
SOLGOHACHIA, 75, CONWAY

Morrow, Wm. Frank (b'54)-0; (1'03)

SONORA, I0, WASHINGTON

Benrden, Jolin Martin-Mo.28,'00; (1'03).

SPADRA, 600, JOHNSON

Horner, John R. $\rightarrow$; (l'03).

Stewart, Jos. I. (h'56)-0; (1'03).

SPARKMAN, 35, DALLAS

Smith, James Yates (b'7I) - Tem, 8, 08 ; (1'03).

SPIELERVILLE, I00, LOGAN

THOMPSON, HUH'T. C. (b'62) -Ark.1.91: (1,03).

SPRINGCREEK (AUBREY P.0.), 75, LEE

Snipes, W'in. B.-Tenn.5,'88; (l'03).

SPRINGDALE, 1.755, WASHINGTON

('IIRISTIAN, DODSON (b'51) $\bigoplus$-Mo.2,80; $(1,03)$.

May, Sandusky A. (b'54)-Mo.8,80; not in

LININGER, PILBE-Mo.30,03: (l'03)

MARTIY, JAMES ELSWORTII $\left(b^{\prime 7} 7\right) £$ Mo.2,02; (1'03). 'ERKINS, CIIA

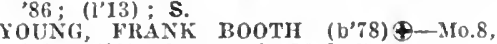
00 ; (1'03); 1'res. Ark. Mred. Soc.

YOUNG, JOLIN (b'57)-Mo.1, '76; $\left(1^{\prime} 03\right)$

Young, Wm. IT. (b'46)-Mo.8,'s3; (1'03).

SPRINGFIELD, 300, CONWAY

Cole, James II. (b'7i) $\longrightarrow$; (1'03).

Stephens, A. H. $\left(b^{\circ} \div 0\right)-0 ;\left(1^{0} 03\right)$.

SPRING HILL (R.F.D., HOPE), I50, HEMP. STEAD

IIIll, Geo. M. $\longrightarrow$; (1'03).

Stokes, Win. I. (b'i1)- ; (I'03).

Wood, Frank O. (b'63)-O; (1'03); R.F.D. 1.

SPRINGTOWN, 140, BENTON

CLEMIER, JOSEPII L. (b'67)-MI0.8, 01 ;

SCOTT, CHARLES (b'56)- $\rightarrow$; (l'03).

SPRING VALLEY, 30, WASHINGTON

POTTS, JAMES R. (b'55)-ATk.I,'97; (1'03).

ST. CHARLES, I50, ARKANSAS

Parker, Danl. S. (b'36) $\rightarrow$; (l'03).

Word, James $F$. $\left(b^{\prime} i 9\right) \rightarrow$; $\left(1^{\prime} 03\right)$.

ST. FRANCIS, 459, CLAY

Crow, Chas. Lewis (b'67)-N10.7,08; ( ).

McGúre, John E. (b’8I)- 0 ; (1'06).

ST. JOE, 159 , SEARCY

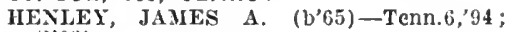
(l'03).

RoGERS, WM. F. (b'64)-Ark.I,'88; (1'03).

Stephenson, J. S. ( $\left.b^{3} 35\right)-0$; (l'03).

Turuer, E. M. - 0 ; ( $(\neq)$.

ST. PAUL, 430, MADISON

Acree, Walter Enls $\left(b^{\prime} 78\right) \longrightarrow$; $\left(1^{\prime} 0 \pi\right)$.

Dabney, W. P' $\rightarrow$; (l'03)

Kidwell, Geo. (b'44) $\mathrm{E} \longrightarrow$; $\left(l^{\prime} 03\right)$

Southerland, Henry R.' (b'6I)-Tex.t, 0 r (1'03).

ST. THOMAS, 50, MISSISSIPPI

Joyner, Dewitt C. (b'48)-Ky.4,61 ; (\$)

STAFFORD, 32, YELL

Dooly, J. A. $\left(b^{\prime} 75\right)-0$; (1'03).

STAMPS, 2,3i6, LAFAYETTE

BAKER, FELIX E. (b'65)థ-Tenn.8,96 . (1'03).

Ellis, Garland Augustus (b'87)-Tenn.7,'12 ; (1'12)

Garner, J. A. $\rightarrow$; (1'03).

Harvey, Sparks Christopher Algernon (b'83) -Tenn.7,'10; (1'10).

HOOVER, ALVEY S. (b'59)-Tenn.8,'89

(1'03). Walter Lee (b'81)-Tenn.8, 02 ;
Kitchens, (1'03).

Norwood, Chas. Mr. (b'40)-0; (l'03).

ROBERTS, JOHN C. (b'70)€-MO.28,99 () ; Member Mo. State Med. Assn.

STANFORD (R.F.D., WALCOTT), 9 GREENE

Self, Geo. S. (b'it) $\rightarrow$; (l'03).

STAR CITY, 396, LINCOLN

MCCLAT, ,T. K. (h'כ0)-Ky.4,'is; (l'03)

B.INES, "THOS. W. (bi3) - Ark.1,07

liussell, Manley Holland $\left(b^{\prime}, 3\right)-0$; $\left(l^{\prime} 03\right)$

TARYER, BFNJ. F. (b'64)థ-KY.2,'91; (I'03)
STAVES, 150, CLEVELAND

CARTEL, JOHN D.-T'P. 8,06; (l'03).

STELLA, 35, IZARD

Stroud, W. Jeff $\left(b^{\prime} 56\right)-0 ;\left(1^{\prime} 03\right)$.

STEPHENS, 572, OUACHITA

I'artee, Ernest C. (b'7I) - : ( (1'03).

Partee, Norf G. (b'88)-A rk.2,'10; (寺)

Thompson, Chas. E. $\left(\mathrm{b}^{\prime} 80\right)-\mathrm{ky} \cdot 8,06 ;\left(\mathrm{l}^{\prime} 03\right)$.

THOMPSON, JACOB S. (b'5i)-Ky.2,82; $\left(l^{\prime} 03\right) ; 0$ b.

STEP ROCK, 15, WHITE

Buckmaster, Robt. Nelson (b'69)-Tex. i, ; $\left(1^{\prime} 03\right)$.

STONE (KINGDON SPRINGS, P.O.), i9, MARION

Yatthews, M. D. I. (b'55) -0 ; (1'03).

STORY, 25, MONTGOMERY

Crook, W. C. $\left(b^{\prime} \div 2\right) \rightarrow$; (l'03).

STRAWBERRY, 100, LAWRENCE

Croom, Hiram-Tenn.8,'89; (l'03).

lluskey, J. M. (b'81)-D; (1'03).

STRICILLER, 30, WASHINGTON

Stewart, C. II. (b'68) $\rightarrow$; (1'03).

STRONG, 465, UNION

COLVIN, AINSLEY R. (b'71)-Tenn.8,'95: (1'95).

Mayfleld, IIugh F-Tex.7,06; (1'04).

MCMATII, JOHN T. (b’69)-Ark. 1,$05 ;\left(l^{\prime} 03\right)$ MLRPIIY, (:E 0 . W. (b'72)£-La.I,94 (1'03).

STEVENSON, FRANKIIN PIERCE ( $\left.b^{\prime} T 0\right)$ -Tenn.5,92; (1'03); not in practice.

STUTTGART, 2,740, ARIKANSAS

Bryant, John B. (col.) (b'S5)-Tenn.7,'13; (1'13).

Connor, Davld Jos. (col.) (b'83) -Tenn. 6 , '12; (1'12).

Froehlich, W. Rudolph (b'77)-Ger.20,03; (l'08).

Hayward, Chas. Evershed-IIl.I,'86; (1'06). HILL, BENJ. LEVIN (b'68)-Ark. I,91; OHN, MILTON CARR ( $\left.b^{\prime} 77\right)$-Tenn.1,03; OHN, MILLTON CARR $\left(b^{\prime} 77\right)$-Tenn.1, 03 ;
$\left(1^{\prime} 03\right):$ LR. MOOREHEAD, WM. H. (b'64)-Md.4,'86 ; (1'03).

MORPHEW, LEANDER H. (b'58)-Ja.9,91 ; (l'03).

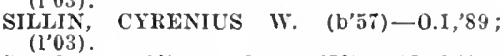

Struthers, oliver C. $\left(b^{\prime} ; 0\right)-K y .2,01$; $\left(1^{\prime} 03\right)$; not in practice.

Swindler, Edwin Booth (b'83) - Tenn.8,'12 ; (1'12).

\section{SUCCESS, 379 , CLAY}

LYNCH, RICHARD CALVIN (b'86)-Mo.28, '10: (1'10).

WADDLE, MARTIN VAN B. (b'72)-Mo.24,

Walker, John F. $\rightarrow$; (1'05).

SUGAR GROVE, 200, LOGAN

Dorrough, Jonathan (b'79) - Mo.I0,09; (1'08).

SULPHUR ROCK, 252, INDEPENDENCE

Bevens, Thomas A. (b'47) - ; $\left(1^{\prime} 03\right)$

Hodges, Robt. H. (b'56)-Ky.2,'82; (1'03).

LONG, WMI. J. (b'65)-Ark.,$^{\prime} 97$; (1'03).

ROBERTSON, SAML. N. (b'79)-Mo.28,07; (1'05).

Wright, Luther R. (b'73)- 0 ; (l'03).

SULPHUR SPRINGS, 500, BENTON

BARNETT, JAMES Z. (b'42)-Mo.I, 68 ; (l'10); Nlember OkIa. State Med. Assn.

Belknap, Jules $\left(b^{\prime} 55\right) \longrightarrow$; $\left(l^{\prime} 03\right)$.

McCracken, James W.--11lch.I,'66; (1'03).

SUMMERVILLE (R.F.D., TINSMAN), 25, CALHOUN

Jones, Wm. B. $\longrightarrow$; (1'03).

SUPPLY, I50, RANDOLPH

FOWLER, CIIARLIE ANDY (b'83)-Ark.I, ino; (lí).

SUTTON (R.F.D., EMMETT), 75, NEVADA Sutton. John II. (b'6 $) \rightarrow$; (l'03).

Tompkins, Jos. C. $\left(b^{\prime} / 2\right) \rightarrow$; $\left(1^{\prime} 03\right)$.

SWAN LAKE, 250, JEFFERSON

Brunson, W. E. $\rightarrow$; (l'03).

SWEDEN, 10, JEFFERSON

FERGUSSON, JOHN POITERENT (b'87) $)$ -Ark.2,09; (1'08).
SWEET HOME, 100, PULASKI

Mason, Geo, K.-Ark.1,'90; (1'03).

SWIFTON, 290, JACKSON

CAUSEY, GEO. A. (b'73)-Tenn.8,'00 ; $\left(l^{\prime} 03\right)$.

Morton, Robt. F. (b'74) E-Mo.10,'11; (1'03).

TARRY, 18, LINCOLN

IIARDIN, ROBT.-Ky.2,'10 ; (l'08)

Wllliamson, Jeland (b'GI)- 0 ; (1'03).

TAYLOR, 100, COLUMBIA

Hudnall, \&. T. (b'79)-; (l'03).

Yeates, Wm. B. (b'57)-O; (1'03).

TEXARISANA, 5,655, MILLER

(Sce Terarkana, Tex.)

BARTI.ETT, CARRIE K. (b'65)-IIl.9,'98 ; not in practice; Member 111. State Med. Soc.; Ir.F.D.6.

BECK, EDWIN I. (b'67) - Tenn.8, 97 ; (l’03) ; (Texarkana, Tex.; t).

COLLOM, SPENCER ALLEN.

(See Texarkana, Tex.)

DALF, JOHN IRICHARD (b'49) $4-P a .2,72$; $\left(1^{\prime} 03\right)$.

Dale, Jobt, Rodney (b'85)-Va.I,'13: (1'13). Draper, Thomas Jefferson $\left(b^{\prime} 52\right)-K y .2,78$; (1'03).

FULLER, THERON EARLE (b’85) Tenn.5,08: (1'08): Member State Med. Assn. of Texas; (also Texarkana, Tex. : t) ; OALR. $\star$

GRANT, ROBT. LEE (b'C4) - 0.1,'86; (1'0:3); Member state Med. Assn. of Tex. HCNT, IPRESTON.

(See Texarkana, Tex.)

Jackson, Andrew Weldon (b'84-Tenn.7,'II;

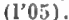

Johns, James M. (b'49) $\rightarrow$; (l'03) ; R.F.D.4.

KELLY, K. M. (b'60)-Tenr.8, 99 ; (1'03).

KITTREILL, THOHAS F.

(See Texarkana, Tex.)

KOSMINSKY, LEONCE J. (b'7 7$)(-M d .1$, '06; (1'06).

LANIER, LUCIAN HERBERT.

(See Texarkana, Tex.)

LEE, AUGUSTLS G.

(See Texarkana, Tex.)

Lennard, F. II. (b'50)-Ky.I,84: (1'03).

LIGHTFOOT, JEAN A. (b'62)-L-La.1,92 ; (1†): (Texarkana, Tex.; t).

MANN, ROBT. HOWELL TAYLOR (b'68) ITed Assn of Tex.; (f) : OALR.

McMahon James (b'44)-Ont.5,73; (1'03). MIDDLETON, BENJ. CRABB (b'82)-Ark.1, 'I2; (1'08); Member State Med. Assn. of Tex.

Mitcham, Scott L. (col.) (b'67)-Tenn.7, $00 ;(1,03)$.

Montgomery, SamI. I. (b'56)-Tex.3,01; (1'13).

Read, W'm. $\mathbf{K}$.

(See Texarkana, Tex.)

Smlley, Harry Herr

(See Texarkana, Tex.)

SMITH, CHAS. ADNA

(See Texarkana, Tex.)

Walker, S. F.-Tenn.8,'01; (

WEBSTER, HERCULES R. $\left(b^{\prime} 56\right) \oplus-M o . T$, '81; (1'03).

Williams, Perry C. (b'68) H-0.23,'91; (l'03).

THORNTON, 611, CALHOUN

BLACK. CHAS. T. (b'82) - Tenn.8,06;

(l'03). THOMAS E. (b'76)థ-Tenn.8,'99; (1'03).

Smythe, Chas. H. (b'65)-Mo.20,95; (l'03).

THREE CREEIS, I50, UNION

STEWART, CHAS. A. (b'66)-O; (1'03).

TILLAR, 180, DREW

FLETCHER, GEO. W. (b'69)థ-Tenn.8,'96 ; (1'03).

PIPKIN, JOHN W. (b'69) $\oplus-A r k . I, 90$; $\left(1^{\prime} 03\right)$.

STANLEY, ADLIA C. $\left(\mathrm{b}^{\prime} 52\right) \oplus-M 0.7,98$; $\left(1^{\prime} 03\right)$.

TIMBO, 100, STONE

Maxey, Nathaniel Coleman (b'74)-Ark.1, II; $\left(1^{\prime} 0 \mathrm{~T}\right)$.

Stephenson, Andrew J. (b'63)-Ark.1,'98; (1'03). 
TOKIO. 30. HEMPSTEAD

Holt, J. M.-Tentr.6,08: 1103

TOLEDO (RISON P.O.), 43. CLEVELAND Standeid, 3. F. (b'Gy)-AFk.1.90; (1'03). TOMBERLINS, 100, LONOKE Gibson, J. II- $-8 ;(103)$. Whitehead, Paul Darld $(6 ; 0)-M 0.7,98$ (1'03).

TRASKWOOD, 228, SALINE

PEICKETT, CIIAS. (6.6 - Irk.1.04 (1103).

WrJle. J. E. D: (l'03).

TRENTON, 130, PHILLIPS

BRUCE, WALTR: BARWICK (b"3)Tean.11,01: (1'03).

TRUMANN, 300, POINSETT

ALEXANDER, MEVEL S.H: (b\%0) Tenn.s, 12; (l'03).

Buxton. Fva Joanna (b'63)-111.2.9:; (

Camplell. 6. O. (b'75)-Tenn.5.02: (1'03)

Garrett, John J. (b'68)-Tenu.6.00 : (2'03)

TUBAL, 25, UNION

Taylor, J. C. $\rightarrow$ : $\left(l^{\prime} 07\right)$

WALLER, WH' LANNIE (b'85)-Tenn.19. 10: $\left.(1)^{\prime} 10\right)$.

\section{TUCKER, 200, JEFFERSON}

NIVEN, JOS. D. (b'6i)-Tenn. 5.94; (1003)

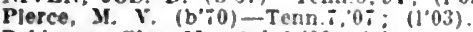

Robinson, Glen Y.-Ark.1.09; i

TUCKERMAN, 583, JACKSON

GMAIAM, JOSEY'HCS S. (b'65)-X.Y.10, 89 ; $\left(\mathrm{P}^{\prime} 03\right)$

JAMSON, OSCAR A. (b'T) -Mo.28, 01

Jernigan, Adolphus Wann (b's0) E-Mo.10 11; (1.03) KIMBERLIN, KENNETI $K$. (b's3) - Ind. 8

SLAYDES, LETI T. (b'i4)-Mo.1.95 $(1,03)$.

TUPELO, 205, JACKSON

MeDoweli, Vardiman M. (b'57) $\rightarrow$ : (1'03)

Plerce, w. $x \rightarrow$; $(103)$.

TURNER, 100, PHILLIPS

Case, Wm. B. (b'il)-Tenn.5,94: (1'03).

HALL, LABURN (b'56)-Ky.4,"82; (l'03).

TURRELL. 200, CRITTENDEN

Reed, Francls M. $\left(b^{\prime}, 0\right) \rightarrow 0$; (l'03).

TYRO, I5O, LINCOLN

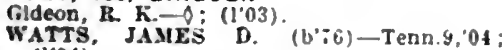
(1'04)

TYRONZA, 250, POINSETT

Cobb, John Mcllenry-Tex.:,04; (J'03); G MCDANIEL, EDWARD C (b'T)-MO : (l'03).

UMPIRE. 136. HOWARO

Yearcan, Wm. Melvla (b:i)-Irk.1:10;

UNIONTOWN, 200, CRAWFORO

Mlicbell, J. It. (6'81)-Ark.2.09; (1'06).

Walker, w. k. (b'43) - 0 : (1'03)

UPLAND, 52, UNION

Morgan, Y. E.-l.a.l.'T4: (1'03)

VALLEY SPRINGS, 200, BOONE

Jackson, G. I. $\left(b^{\prime} 66\right)-3$ : (1'03).

VAN BUREN, 3,878, CRAWFORD

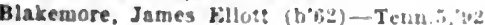
(1'03).

Bourtand, Othello M. (b) 59 -Tenn 5,81 N.Y.10,83; (1'03)

Burlingame, Ralelgt Walser (6'83)-35, 33. '12: $\left(11^{\prime} 12\right)$

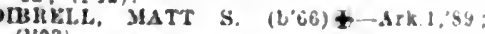
(1'03).

Rell. Alesander porter 111 forit

leVerre, Wells il. (bogili lli.14, sa (l'03).

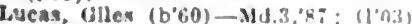

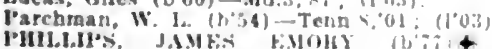

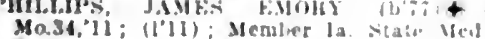

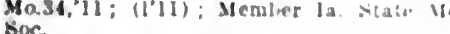
soc

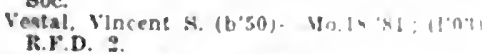

VANDERVOORT, 500, POLK

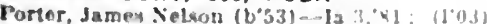

sanders. Win A. (b'81)-M1).33, 11: (113)

VANNDALE, 500, CROSS

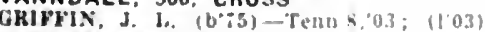

VARNER, 920, LINCOLN

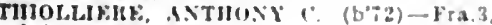

94: $(1.03)$
VAUGHN (R.F.D., BENTONVILLE), 17 BENTON

VESTA, 50, FRANKLIN

Vienvers, tinoch IR. (b'b)

VICK, 250. ERADLEY

Jarksite, loivis .I. (b'J1)

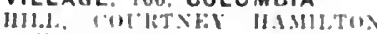

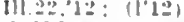

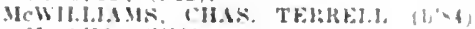

KY...'10: (1'1\})

VILONIA, 34, FAULKNER

IIOWN. JOS. II. (b'SI)- . Irk.1.07 (!'03)

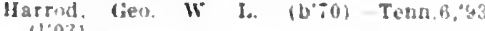

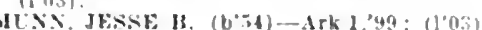

VINCENT, 200, CRITTENDEN

HEILICK, (IIAS, FERHSAND (b"us)KY.4: $91:(1 ' 03)$.

VINEYARD, 250, LEE

HE.ITY. WM. SCAIHF (b.63)-Ky.2.92 (I'03).

VIOLA, 275. FULTON

Suttons, d. B. (b'by) $\rightarrow$; (I'03)

VIOLET HILL. 75, IZARO

Smlth. Jett D. (b'ii)-Tenn.8,95; (1'03).

WABASH, 100, PHILLIPS

RFIIRERT, JOHN C. (b'S6) $\rightarrow$; $\left(l^{\prime} 06\right)$

WABBASEKA, 450, JEFFERSON

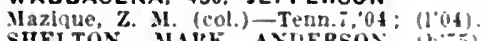
SHELTON MAIK ANIERSON (b) Tenn.8, 08 ; (1'03).

WAKE, 18, BAXTER

Henderson, R. M. (1'38) $\rightarrow$; (I'03)

WALCOTT, 149, GREENE

COTHERS, TH.U. (b79) - TenH \&, 0: (1'04).

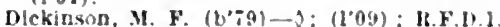
MAJORS, WM. NACK (b's1)-Tenm.8.12 (I'0S).

\section{WALDO, 597, COLUMBIA}

BEASLEY. JOSHCA $\mathrm{l}^{\prime}$, (b'62)-Tenn 8, $\mathrm{b}^{\prime}$; (!'03).

Reasons S. A. (b'68)-Tenn.8.94: (l'03)

SOLTEK, AUTHLK J. (b'SI) - (ja.9.05 (1'03).

WALDRON, 900, SCOTT

Berlll, Cheres (b'49)-1 (I'03).

Hlakney, simon $\left(b^{\prime} 53\right)-8 ;\left(1^{\prime} 05\right)$

vuncan, Fredk. B. (b'T6)-Teun.8, 03 (l'03).

DLXCAN, LORENZO D. (6.6i)-Ark.1,97; $\left(1^{\circ} 03\right)$

Lemlng, Isaac K. (b'32)--Mo.13,7\%; (l'03)

Sulliran, James 11. I (b) 10)-0: (1.03).

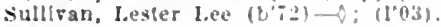

WALLACEBURG (R.F.D., BLEVINS), 91. HEMPSTEAD

lowersons, R. A- : $:(103)$

WALNUT HILL (BRADLEY P.0.), 300, LAFAYETTE

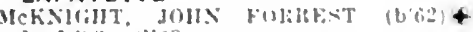
La.1, "U?:? (1'03).

WALNUT LAKE, 8\%, DESHA

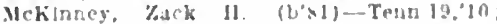

WALNUT RIDGE, 1.798, LAWRENCE

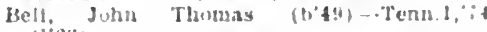

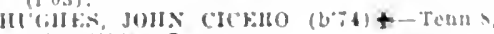
$03: 11.031: 00$.

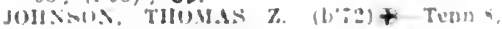

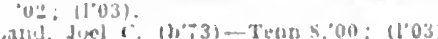

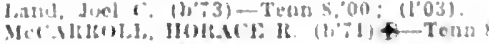

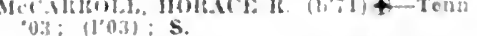

che

(1) (1)3)

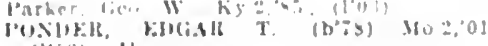

sMITH, WIb.l.M A. (b.el)-ky.1,9.s (I) 03 3

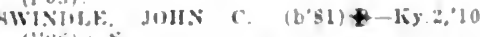

Tolvisti. (c. (c. (4.76)-Ky.3.00; (1.03)

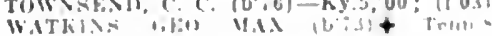
(0)! 11

WALNUT TREE。 200, YELL

Cowger, Thutran $\left(b^{2}+6\right)-D$ : $11^{\circ} 006$
WARO, 210. LONOKE

Yonce dacne W. W

WAREAGLE, 195. BENTUR

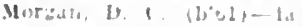

WARM SPRINGS, 100, RANDOLPH

WARREN. 2.057, BRADLEY

Browne, Garretl li. (Lidu). I

Terat $=10 ;(1010)$

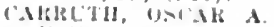

(l'u3).

Davls, s. JI. (L4:3)- $; 1103)$; nut in prac-

Follis, Walier sloney (D.83)-Tenu.s, 1 '?

(1'09).

FlkE. WM. T. (bli5)-Ark.1.96; (1'03).

likkex, H. Il " (1'03).

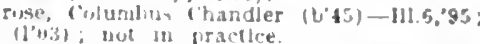

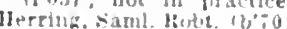

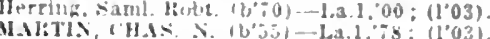

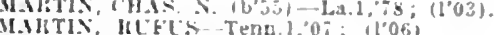

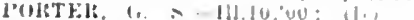

WASHINGTON, 399. HEMPSTEAD

G.JliNEL. T. J. (6'60)-Ga.3.'81; (1'03\}.

WASHITA, 40, MONTGOMERY

YHEFIMAN, ISAAC N-Tex.7:03: (1'03)

stullvan. Wim. Alustin $\left(b^{\circ} 64\right)-y^{\circ}\left(l^{\prime} 03\right)$.

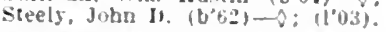

WATALULA, 28, FRANKLIN

Hansberry, Shrabara Jay (b'64) $\rightarrow$ : (1'03)

WATSON. 50, DESHA

Cook, John W: $\rightarrow$ : (1'0i)

Furbish, Louls l'. (b'e8)-Tenn.8.98; (1'03).

WATTENSAW, 25, LONOKE

Childers, Jonathan II. (b'il)-Arik1,01:

WAVELAND, 90, YELL

Liuderwood, Firlc Ollo (b'si)-Ark.l,li: (l'12)

WEBB CITY, 200, FRANKLIN

(ilHBONS, WM. II. (b'it)-Ark.1.07; (1'03).

WEDINGTON (R.F.D., RHEA), 30 ( WASH. INGTON

Whon. E. \&. (1069)-Tenn.R.'s9; (L"03).

WEINER, 232, POINSETT

MLCOTT, GEO. H16OWN (b'90)-M0.10.'1: : (1.12)

Wherif, Jobn $\mathrm{P}^{\prime}$ (b'6h): $\therefore ; 11^{\prime 04}$

WELCOME (TAYLOR P.O.), 32. COLUMBIA Mlen. 11. H. (b'39) $\rightarrow$; (1'08).

(meal. James is (bobi)-O: (1003).

WELDON, 250, JACKSON

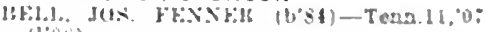
cuson, Willis (cols) (bio)-Tenn 14:04

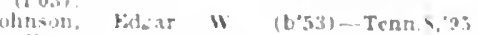

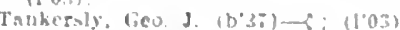

WESLEY, 100, MAOISON

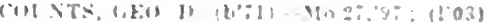
WESSON. 694. UNION

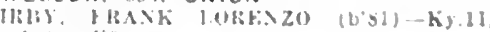

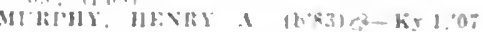

WESTERN GROVE, 100, NEWTON

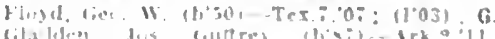

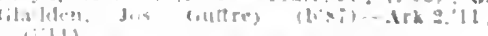

WEST FORK, 200, WASHINGTON

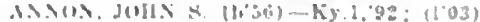

WEST HELENA (HELENA P.O.), PHILLIPS

Maller. (h.l

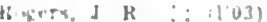

WEST POINT, I16, WHITE

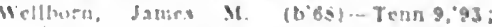

WHEETLEY, 3JO, ST, TRANCIS

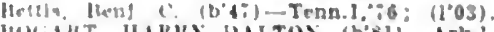
HUCIIT, H.SBAY DALTON (b'81)-Ark),

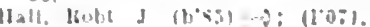


WHELEN SPRINGS, 250, CLARK

Epperson, Lee B. $\rightarrow$; (I'03).

llarner, Mark A. (b'64) $\rightarrow$; (l'03) : R.F.D.

WHITE, 200, ASHLEY

Erwln, Ernest D. (b'80)—Tenn. 15, 08 ; (1'08). Spencer, Samuel J. (b'53)-Ky.2,79; (1'03).

WHITEROCK, 100, FRANKLIN

Jeffers, I. F. $\rightarrow$; (l'03).

WHITTON, 25, MISSISSIPPI

Conner, I'hlllip A. $\left(\mathrm{b}^{\prime} 79\right) \rightarrow$; $\left(\mathrm{l}^{\prime} 07\right)$

WIDEMAN, 200, IZARD

Jones, Stephan $\left(b^{\prime} i 1\right) \rightarrow$; (l'03).

WIDENERS, 245, ST, FRANCIS

DARNALL, ERNEST (b'83)-Tenn.8,08 : (l'06).

Ferrell, Alex. B. (b'49)-La, 1,73; (1'03).

Ferrell, Stanley A. (b's1)-Tenn.8,'12; (末).

WILLCOCKSON, 100, NEWTON

Stacy, S. S. (b'40) $\rightarrow$; (l'03).

WILLIFORD, 100, SHARP

Barr, AustIn Flint (b'85)-Pa.2,'12; (1'12).

Garner, H. Boyd (b'6S) $\rightarrow$; (1'03).

WILLISVILLE (R.F.D., ROSSTON), 50 NEVADA

Brandon, Chas. W. (b'76)-Tenn.8,'04;

McDonajd, Wm. Alvin (b'8i)-Tenn.19,'11; (1'i1).

Tyson, John (b'63) $\rightarrow$ : (1'03)

Warmack, Emlly E.-O; (1'03).

WILLOW, 7I, DALLAS

Burks, James A. (b'75)-Ark.2,'10; (1'07); S.

WILMAR, 929, DREW

Harrls, SIdney (b'69)-Ky.1,'92; (l'03).

Riley, Harvey C. $\left(b^{\prime} 7{ }^{7}\right)-A r k .2,08 ; ~\left(1^{\prime} 08\right)$.

WILMOT, 622, ASHLEY

Barnhardt, Luther C. (b'55)-M0.1,'81 ; (l'03).

Cobb, I. Thad. (b'77) $\rightarrow$; (l'03).

CRANDALL, MATTHEW CLAY (b'87)Tenn.19,'11; (1'09).

McDermott, Edward O. (b'65)-Ky.2,'87 : (1'03).
Princehouse, Henry F. (b'68) $\mathrm{F}-0$; (l’03).

Watklns, Charles H. (col.) (b'71)-Tenn.7, 09: (1'09) ; G.

WILSON, 500, MISSISSIPPI

CRAIG, EARL E. (b'78) -Tenn.6,07; CRAWFORD, HUGH F., JR. $\quad\left(b^{\prime} 82\right) \oplus-$ 'Tenn.8,'03; (1'03).

WILTON, 294, LITTLE RIVER

CATIIEY, ARLEY D. (b'89) - Ky.2,'12; (1'12).

Gorham, I. G. (b'56) $\rightarrow$; (l'03).

WINCHESTER, 300, DREW

CASTILE, HERMAN (b'88)†-Ky.2,'11; (1'11)

CHEAIRS, JOHN T. $\left(\mathrm{b}^{\prime} 49\right) \oplus-\mathrm{Ky.5}, 91$; (1'06).

WINFIELD, 25, SCOTT

Patterson, Lyndsey ollver (b'69) $\rightarrow$; (1'03).

Plummer, W. H. $\longrightarrow$ : (l'03).

WINSLOW, 289, WASHINGTON

Baehr, John Luther (b'36)-Pa.3,61; (1'03).

Gray, Thomas Ellsberry (b'74)-Mo.8,01; (I'03).

Jones, Chas. E. (b'58)-Tex. 1,'88; (1'03).

Mahan, w. W.-Ky.2,70; (t).

Miller, Geo. E.-H-0.13,'85; (l'03).

WINTHROP, 600, LITTLE RIVER

Kennedy, J. R. (b'73) $\rightarrow$; (1'03)

Mathews, Paul M. (b'7I)- - ; (1'03).

VAN ALSTYNE, FRANK L. (b'77)-Ky.4 04; (1'03).

WITHERSPOON, 84, HOT SPRING

Howard, Geo. W. (b'48)-D; (立).

WITTS SPRINGS, 45, SEARCY.

Dixon, Ephralm M. (b'66) $\rightarrow$; (1'06).

Drewry, James H. $\left(\mathrm{b}^{\prime} 49\right)-$; $\left(\mathrm{l}^{\prime} 03\right)$.

WOLF BAYOU, 20. CLEBURNE

Spinks, Jobn (b'52) $\rightarrow$ : (l'03).

WOMBLE, 552, MONTGOMERY

BA(idiETT, ELI ALBER'T (b' 7 ) -Tex.7,06, Mo.7,'11; (1'03); G.

Leferers, Robt, R.; (b'81) $\rightarrow$; (l'03).

STCEART, JOHN B. (b'r8)-Ark.1, 03 ; (l'03).
WOODBERRY, 100, CALHOUN

Jones, Willis C. (b'70) $\rightarrow$; (1'03).

WOOSTER, 95, FAULKNER

Burnett, Martin C. (b'74) $\rightarrow$; (1'03).

Evatt, John W. $\rightarrow$; (l'03)

Ilutto, Jos. A. (b'78) $\rightarrow$; (1'03).

WYE, -, PERRY

ALLEN, ELZORA BUTJER (b'73) @-Pa.7, '04; (1'II) : Member Med. Soc. of D.C.

ALLEN, JOHN (b'66)€-D.C.2,08: (1'i1).

Inllmore, Kollin Slossen, Jr. (b'89)-Mo.2, '12; (1'13).

WYNNE, 2.353, CROSS

Barner, wlley B. (b'56)-N.Y.1,'84; (1'03)

Clowers, John T. (col.) (b'70)-Tenn.7,02;

(1'03); ; G.

HARE, JACOB L. (b'60) -Ky.1.'89; (1'03). Llpsey, Len. H. (b'67)-Ky.2, 91 ; $\left(l^{\prime} 03\right)$.

LONGEST, RUFFIN (b'69)-Tenn.1,'99; (l'03)

Mackle, James D. (b'52)-Ky.2,76; (l'03)

McKIE, WM. H. (b'80)-Tenn.8,04; (l'03);

STEWART, THOS. JOE (b'77)-Tenn.8, 02 : (1'03).

YARBRO, 25, MISSISSIPPI

HILL, ELIJAH VINCENT (b'77)(-Tenn.8, '

YARDELLE, 22, NEWTON

ShInn, Thomas J. $\rightarrow$; (l'04).

YELLVILLE, 463, MARION

ELTON, ALBERT M. (b'81) Ark.1,'06 ;

THONPŚON, JAMES 1. (b'58)-Ark.1,'92 ; (l'03); Ob.

WEAST, LUCIAN M. (b'77)-Mo.28,'00 : (l'03).

ZAMA (THEO P.0.), 35, NEVADA

Shell, E. Everett (b'71)-Tenn.6,'94; (1'03).

ZINC, 173, BOONE

Taylor, Geo. W. (b'71)-Ark.2,'10; (2'03).

ZION, 25, IZARD

Dlllard, James A. (b'83)-Ark.1'10 : (声)

DILLARD, WM. HILL (b'75)-Ark.1, 05: (1'03).

FOR KEY TO SPECIALTIES, ABBREVIATIONS, SYMBOLS, ETC., SEE PAGE 187

Read the introductory, pages 53-54, that you may know what the book contains.

Consult the contents, page 51. Refer to the index, page 52.

The information is here, but much of it is available only through the use of the key.

Key to the abbreviations and symbols, pages 55-56. 


\section{CALIFORNIA}

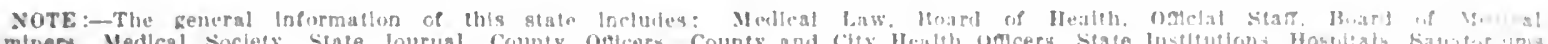

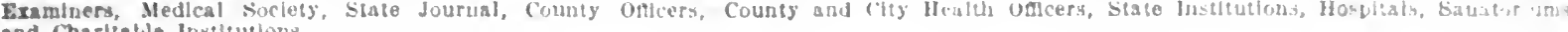
and Charitable Institutions,

\section{CALIFORNIA}

Population (1910 census) .......2,377,349

Number of Countles............ 59

Number of Physiclans......... 5,353

Members State Society, Dec. 31. 1913

Area of State in Square Miles..... 158,297

\section{MEDICAL PRACTICE LAW OF} CALIFORNIA

\section{An Act}

To Regulate the Examlnallon of Applicants for Llcense, and the Iractice of Those Llcensed, to Treal Diseases, Injuries, Doforcuttles, or other I'hysical or Mental Condistons of Human lielngs: "o Establish - Bosard of Mledical bisamincrs, to l'rorido for their Appointment and l'rescribe het Powers and [utles, ant to liepeal an act entlied An Act ror the Kegrulation of the Practlce of Jedlcine and sursery, osteov. athy, and othet Systems of Modes of of Callfornia, and for the Appointment ot of Callfornia, and for the Appointment ut B Hoard of Medical kixaminers in the Marct 14, Iy0\%, and acts amendafory thereof, and also to repeal all nther acts and parts of acts to confllet with this act.

The people of the State of California do enaci as follows:

Section 1. BOARD OF MEILICAL EXAMINEKS: A buard of Medical Kisumuners to conalst of ten members, and to be knuwa as the "Bosert of Medical Fixaminers of the Stato of Californla," is hereby created and established. The governor shall appoint the mecubers of the triard, each of whom shall baro been a citizen of this atate for at least Bre years next preceding his appointment. from among perwos who hold licenses from mong perwas who hold licenses under suy of the merlical pract.ce acts of polntment all racisfletey on the buard. The term of once of each menber shall be pour years: provided, that of the Hest buard apolnted, three menibers shall to appointed for one year. twr for fwo years, two fir that thereatier all aprolntmenly shall he for four sears, except that apjolntments to fllt
vacancies shall if por the unexpred term Vacancies shall th for the unespled term
only. Yo person in any manner own my only. Vo person in any manner own mp any Interest in any college, seluw or Invit-

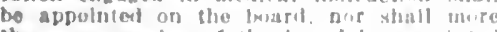

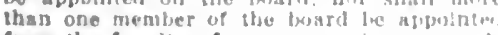
from the faculty of any one university. coul. lege. or other elucational irustlution The governor shail have punce on romalno Prom

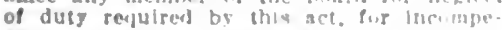
tency, or for ungrofesalannl enruluet buch

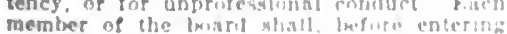

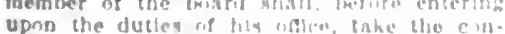
stitutlonal oath of onlen

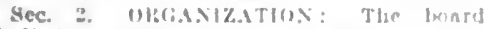

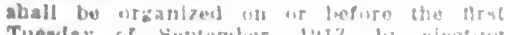

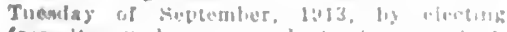

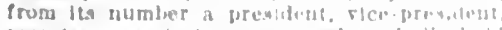

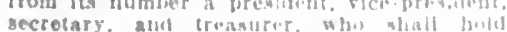

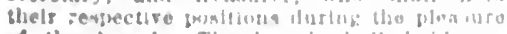
uf the buard. The imaril shall bull whe meetiog armually logelmuna:

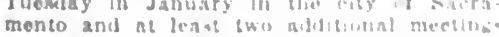

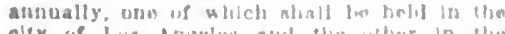

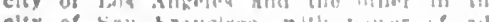

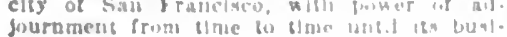

ness is concluded: provided, however, that

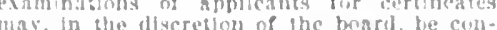
dincterl lil any nort of the state devinnated hy the bunrd. Special necturs of the buard mity be held at such tine and folace as the maty be held at such tlate and place as the
boart may deximate. Sotlce of each reguliosar may deximate. Sotlce of each requar or steclat meetinz shall tre gelren twices meceing in one daily paper pullished in the cliy of sitn Francisco, one publintsed in the elty of Sacramen(o), and one jublished in the city of los Angeles, which notice whall also ypeclfy the tme and place of board shall receive through ity secretary mard shall recelve through ity secretary

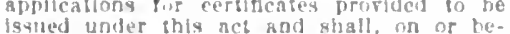
isalled under this act and shall, on or he-
fore the flryt day of January of each year. pore the flrst day of January of each year, transmit to the govermer a full repurt of all
Its proceedlngs together with a rebrert of 11.4 recelpts and disbursements. The board shall, on of hefure the first day of January of each sear. coninile a complete direciory giving the addresses of all persons within the state of californta who holil unrevoked llcensey to practice under any medical practice act of the state of cilifornta. which license shall in any manner auturize the lreatment if human beings por diseases, injurics. defornities, or gny othes physical jurict. deformities, or stiy other physical authertzed to reoguire sald persons to furnish such information as it may deem necessary (i) enawle it to cumplle the direcury. The directory shall contain in addition to the utames and addresses of satul persnns, the nianes and symberls indicating the bitte, nane or names, schonl or sctionols, which such jurson has allended and prom which grachusted the date of issuance of the kraduated, the date of issuance of the and a statenent of the form nf certifcaie helu. The directory shall be jurma facte tridence of the right of the person or persous named therein to practice It ihall be the duty of erery perwin himldnt a llcense to practlce uniter any mealical act up thly state, or why may here:tster be sis each and erery chanto of restldence, givang latth the ofd and the new aldiress.

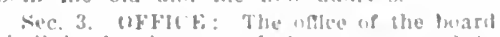
shath the la the chly of sacranche and in all lexul procedimes nomilive the Intard sabi of the members therent.

Siec f. Jollells: The luard may from time be time aldint siscth rules as may lie

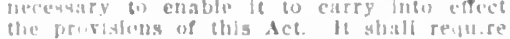
the antrmalise vite of sesen mambers if

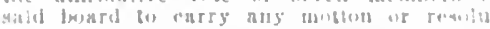

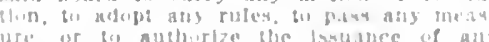
cereislatis" as in thy net problitial Any

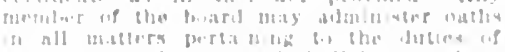

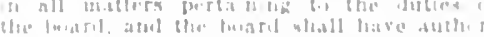

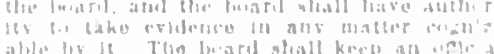

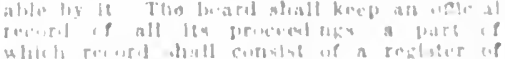

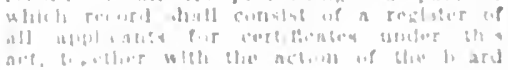

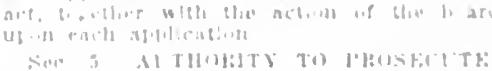

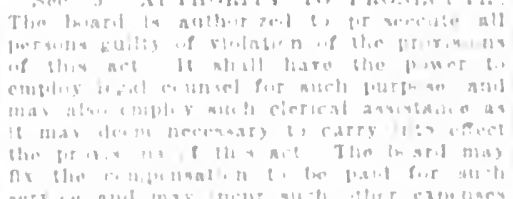

a. It may deem necensary. It shall als. the sum of elinteren bundred dollary $(\$ 1, a 06)$ per annurn. and the sum to be Dald to nther memtiers if the mart not to exceed ten dollars (\$10) jor dlem each, for each and evory dar of netual service in the disharie

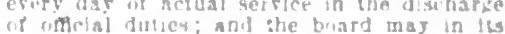
discreton, alde bo sald sura necessary irarelIng expenses.

Sec, bi FIN : All rees collecterl on of ille lsward ni lled cal Eramuers. and all recives of every kisul and bature stiall he reprirted at the beginn.ng of each menth. Por the munth prectutinz, (b) the state amount of sucl collecilons shall be paid inte the state treasury, and shall le crediud to a fund in lie known as the buard of yedical Examiners' contingent fund, which fund is hereby created. Siuch cuntingent fond shall be for the uses of the kward of Medl1:al Examiners and out if $\| 1$ whall be risid all salaries and all cther expenses necessarily Incurres In carrying luto effech the prorlsions of this act. In amouge nus to

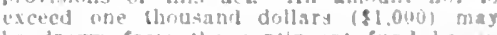
be dramp from the contingent fund herein reated, th be uned as a revolring pund where cant adrances are necrequary; but expenditures Prom such revilr.11: furd must be sulsantiated by rnuchers and ilemized statementy at the cnd of each Hical year, ls made by the board of cuntrol.

Sirc. i. FEFs: Frery afplicant for a certifleate stiall ons bit the secrelary of the
imiard a fee ut twents-fre dollary (\$25). which shall he pald to the ireavuper of the bural by sald secretary in case the ampli:cant's crestentals are insumplent or in case he dres not levire to take the examinaticn. ianel, the remalnder of the pee treng re surnatic on abnication.

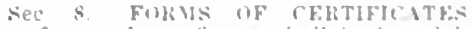
Twe forms of certiflcales shall lie tistled by sald tromb under the seat thereup ant tisnol hy the previlent and secretary a frot.

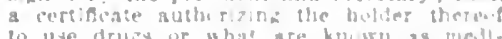

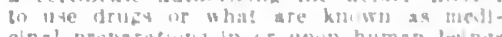

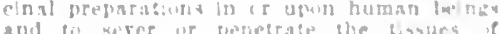

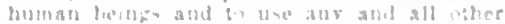

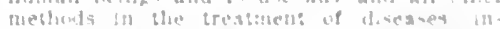

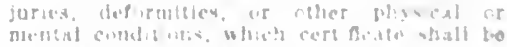

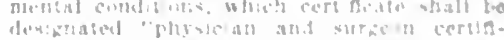

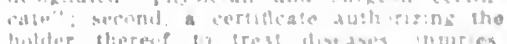

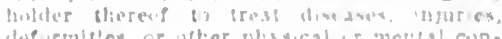

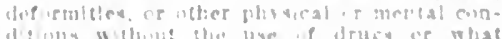

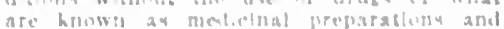
wlihout in agv manther seret ng or pene-

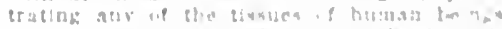

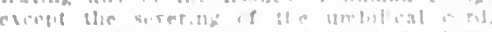

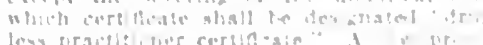

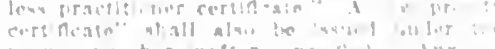

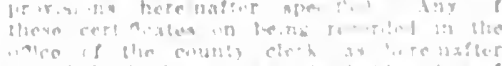

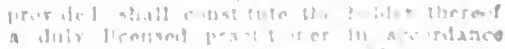

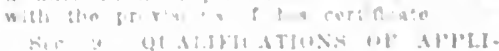

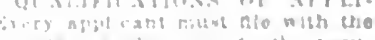
nertas or if bis the resu.

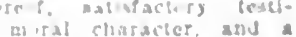

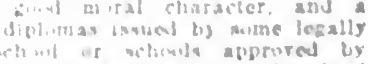

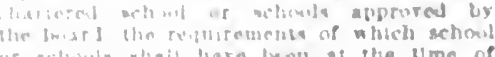
or wrtionts shail have then at the llme of 
degres less than those required under this det. or salisfactory evidence of haring pos. sessed sued) (lipioma or diplomas, and must fle an afflarit stating that he is the person llamed in said ilploma or diplomas, and that he is the lawful holder thereof, and that the samo was procured in the regular course of instruction and examination without fraud or nisrepresentation ; provided, that in addition thereto, e:teh apilfiant for a "physiclan and surceon certificite" must study each such course to hare been of not less than thirty-two weeks' duration, but not necessarily pursued continuously or but not necessarily pursued continuonsly or shall hare futerrened between the heginning shall hare fiterrened hetween the hegrining of any colrse and the beginning of the preceding eourse; provided, further, that an applicallt for a "dirugless practitioner certificate" must show that he has attended two courses of stuly, each such course to have been of not less than thirty-two weeks' ruration, but not necessarily pursued continuously or consecutively, and that at least ten months sliall lave intervened between the beginning of any course and the beginning of the preceding course; provided, also, ning of the preceding course; provided, also, that before July 1, 1918, in lleu of the diploma or diplomas and preliminary re-
quirements herein referred to, where the quirements herein referred to, where the
applicant can show to the satisfaction of the Board of Medical Examiners that he has taken courses hereinafter required in a school or schools approved by the board totaling for applicants for "drugless practitloner certificates" not less than sixty-four weeks consisilng of not less than twentyfour hundred hours, and for "physiclan and surgeon certificates" totaling not less than surgeon certificates totailing not less than one hundred twenty-eight weeks consisting of not less than forty-elght hundred hours,
it being required that all applicants shall have recelred passing grades in all such courses, that the applicant or applicants shall be admitted to examinat

respective form of certificates.

biank furnished by said board and it shall contaln such information concerning the inedical instruction and the prellininary education of the applicant as the board may by cation of the applicant as the board may by rule prescribe. In addition to the requirements hereinabove provided for, applicants for elther form of certificate hereunder shall
present to said board at the time of making such application a diploma from a Callfornla high school or other schnol in the state of California requiring and giving a full four years' course of same grade, or other schools elsewhere, requiring and giving or its equivalent, approved by the board, or its equivalent, approved by the board, together with satisfactory proof that he is the same was procured in the regular course the same was procured in the regular course the applicant may present: (1) a certiflcate from the college entrance examination board, or the college cxamining board of any state or territory showing that such applicant has board; or (2) if such applicant be thirty years or more of age he may show to the satisfaction of the Pnard of Iledical Fxaminers proof of preliminary education equivalent in trainine power to the foregoing requirements. After Jan. 1. 1919, every applicant for a "physician and surfeon certificate" shall in addition to the foregoing requirements present to the board satisfactory eridence that before berinning the study of medicine he has completed a course which includes at least one year of work, of college grade, in each of the subjects of physics, chemistry and biology.

Sec. 10. EDUCATIONAL REQUIREMENTS: Applicants for either form of certificate shall file satisfactory evidence of having pursued in any legally chartered chool or schools, approved by the board, a

rse of instruction covering and includ-

following minimum requirements:

"physician and surgeon certificate." $\$ 25$ hours.

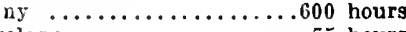
$\log \ldots \ldots \ldots \ldots \ldots \ldots \ldots$. 5 hours

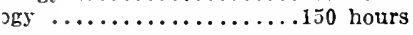

Group 2. 620 hours.

Elementary chemistry and toxl-

colngy ...............140 hours

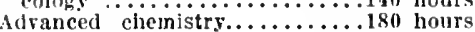

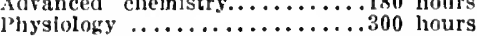

\section{Group 3. 700 hours.}

Flementary bacteriology ......60 hours

Adranced bacteriology ........10n hours

Hyqlene ............... 90 hours

Pathology .............450 hours

Group 4. 240 hours.

Materla medica ........... so hours

Pharmacology ................

Froup 5. 1.120 hours.

Dermatology and syphllls......45 hours

General medicine and general

diagnosis ................700 hours Genito-urinary diseases ....... 45 hours Nervous and mental diseases...180 hours
Pediatrics ................150 hours Group 6. 965 hours.

Yaryngology, otology, rhinology. 60 hours Ophthalmology ...........60 hours Surgery and surgical diagnosis. 500 hours
Orthopedic surgery .........45 hours Orthopedic surgery $\ldots \ldots \ldots \ldots . . . .$.

trotherapy, $\mathrm{x}$-ray, radiother-

apy, hydrotherapy .........300 hours

Group 7. 300 hours.

Gynecology ..............105 hours

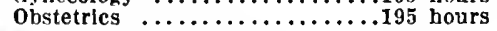

Miscellaneous. 30 hours.

Ethlcs, jurlsprudence, etc..... 30 hours

........4,800 hours

For a "drugless practitioner certlflcate."

Group 1. 645 hours.

Anatomy ..............510 hours Histology $\ldots \ldots \ldots$

Eiementary ehemistry and toxl-

Giementary chemistry and toxl-
cology $\ldots \ldots \ldots \ldots \ldots \ldots \ldots \ldots \ldots 120$ hours

cology $\ldots \ldots \ldots \ldots \ldots \ldots \ldots \ldots \ldots \ldots \ldots \ldots$
Physiology $\ldots \ldots \ldots \ldots \ldots \ldots$

Group 3. 375 hours.

Elementary bacteriology .....66 hours

Hyglene $\ldots \ldots \ldots \ldots \ldots \ldots \ldots \ldots \ldots 45$ hours

Pathology .............270 hours

Group 4. 420 hours.

Diagnosis ...........

Manipulative and mechanical

therapy $\ldots \ldots \ldots \ldots \ldots \ldots \ldots \ldots 260$ hours

Group 6. 300 hours.

Gynecology $\ldots \ldots \ldots \ldots \ldots \ldots \ldots .105$ hours

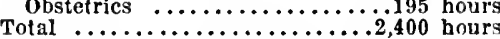

In the course of study herein outlined the hours required shall be actual work in the class-ronm, laboratory, clinic or hospital. and at least ejghty (80) per cent. of actual attendance shall be required; provided, that the hours herein required in any one subject neer not exceed serenty-five (75) per cent. of the number specified, but that the total number of hours in all the subjects of each group shall not be less than

Sec. I1. In addition to above requirements, all applicants for "physician and surgeon certificates" must pass an examinalowing subjects :

1. Anatomy and histology.

2. Physiology

3. Bacteriology and pathology.

4. Chemistry and toxicology.

5. Obstetries and gynecology.

6. Materia medica and therapeutics, pharmacology, including prescription writing.

7. General medicine, including clinical oscopy.

8. Surgery.

9. Hygiene and sanitation.

All applicants for "drugless practitioner certificates" must pass

1. Anatomy and histology.

2. Physlology.

3. General diagnosis.

4. Pathology and elementary bacteriology.

5. Obstetrics and gynecology.
6. Toxicology and elementary chemistry. llykiene and sanitation.

Provided, That a person who holds a "drugless practltinner certlficate", and who presents evidence of having successfully completed the additional courses required as liercinbefore provided, shall be permitted to take his examination in subjects required for a "physician and surgeon certiflcate" without being reex

All examinations shall be practical in character and designed to ascertain the applleant's fitness to practice his profession, and shall be conducted in the English language, and at least a portion of the examination in each of the subjects shall be in writing. There shall be at least ten questions on each subject, the answers to which shall be marked on a scale of zero to one hundred. Each applicant must obtain no less than a general average of 75 per cent., and not less than 60 per cent. In any two subjects; provided, that anv applicant shall be granted a credit of 1 per cent. upon the granted a credit of 1 per cent. upon the general average for each year of actual practice since graduation; provided, further, that any applicant for "physician and surper cent. each in seven subjects. and any applicant for "drugless practitioner certiflcate" obtaining seventy-five (75) per cent. each in fre subjects shall be subsequently reexamined in those subjects only in
he failed, and without additional fee.

The examination papers shall form a part of the records of the board, and shall be kept on fle by the secretary for a period of one year after each examination. In said one year after each examination. In said and designated by number only, and the name attached to the number shall be kept secret until after the board has finally voted upon the application. The secretary of the board shall in no instance particlpate as an examiner in any examination held ject in which examination is required under this Act shall be provided by the Board of Medical Examiners upon the morning of the day upon which examination is given in such subject, and when it shall be shown that the secretary or any member of the
board has in any manner given information in advance of or during examination to any applicant it shall be the duty of the governor to remove such person from the Board
of Medical Examiners, or from the offlce of secretary.

All certiflcates lssued hereunder must state the extent and character of practice which is permitted thereunder and shall be
in such form as shall be prescribed by the board.

Sec. 12. MEDICAL OFFICERS OF U. S. ARIIY AND NAVY: Any medical director. inedical inspector, passed assistant surgeon, or assistant surgeon of the United States Navy, honorably discharged, or temporarily detached, or placed upon the retired list without being discharged from the medical department of the United States Nary, or who by resignation has honorably severed surgeon of the United States Army, honorably discharged, or temporarily detached or placed upon the retired list without being placed upon the retired list without being cischarged from the medical department of the United States Army, or who by resigna-
tion has honorably severed all connection with the service, is hereby authorized to practice medicine and surgery within the state of California, by flling a sworn copy
of his discharge, if he be discharged, or of the order temporarily detaching him or the order placing him upon the retired list, with the State Board of Medical Examiners board that by resignation he has honorably left the services of either the Army or Navy. and paying said board a fee of fifty dollars $(\$ 50)$; provided, however, that this provi$(\$ 50)$; provided, however, that this provision shall not apply to any contract sur-
geon in the United States Army or Navy geon in the United States Army or Navy, Rescrve Corps of either said Army or Navy.

Sec. 13. Sald board must also lssue a "physician and surgeon certificate" to any 
Intos the holder thereol to practlce medicine and aurzery in the atate of Callfornia, upon parment of - regtstration fee of afts dollars (850), upon the following terms and condiHons and upon satisfactory proof thereof. Vix: The apolleant shall produce certla: cato entiuing him to practice medicine and surcers, as provided for in sald "physiclan and surizeon certincate." lasued elther by the Ward of omcer athorized by the law to lawe a certlacate entitilng such applicant so pradice mediclne and surgery, elther in to District of Cotumbla, or in any state or Ditory of the United States, or if such writory of the United States, or If such cartlecate thall have been lost, then copy of Yedical Isaminers of the state of Californil that the copy is a correct copy. Sald carlibeate must not hare been issued to such afflcant prior to the first day of August enl collece from which such appllcant may hiv rraduated, and the requirements of the hand which was lecally suthorized to issue ach certificate permitting such applicant to prectlco medletne and aurgery shall not have prectlce medletne and aurgery shall not have bean, it the time such certificato was Inowed. In any derree or particular less than of certifeate so practice medicine and gareery in the rtate of California at the which may bereafter be required by law and which may be in force at the time of the imance of anj such certincate: and provided, farther, that said applicant shall ilo furmish from the board which issued Bald certifeate evidence satisf actory to the Board of Medical Bxaminers of the state of Callerali, showing what the requirements certibeate, at the date of such issuance. If arrer an exnmination of such certlacato. and the production on the part of the applicant of guch rurther ressonable eridence of the culd requirements as may be deemed necesans by the Bound of Medical Examiners of 2. state of Callfornla, and any other of rurther exemination or Investigation which sald board mas see at to make, on its own of the board issuing anch certibcate were, of the board issuing ouch certincate were, when suld certificato was issued, in any ments provided by the laws of the state of Califoriala, the date of the Issuance of such certificato, he will not be entitled to practice wlthin the state of Callfornia with. out appllextion with the sajd board to practee medicline and surgery within the state of callfornle, in the erent that such applicant has been duly licensed prior to Aur. 1.1901 and has practiced mediclne and surkery in anotber atste or territory, or the District of Columbla, for a perlod of time commencing prior to the frst day of August, 1901. Such taln a tho full name of the apolicani: (i) all institutions at wheh he hes studied and the perlod of such medy, and all Instltutions from wh!ch he has graduated: (c) atatement of whaterer cortiecate or certincales to practice medihim, and surgery may hare been issued to cate and a deseription of the same, and if requitred by the boand. She certifleate themalres. or antlafactory prone of thelr Ispance: (d) a statement of all piaces in and surgery: (c) such other ceneral information as to bis past practlce as may be required by the sald loard. Tho said board shall mile such independent Inrestjication of the character. ability and atanding of the applleant as if may deem proper and noces. ary, and if it shall nnd after nuch Inrest! ration that anid applicant has been a prac-
detns pbysiclan and surgein in any other state or tersitory or the District of Columbia. prior to Auguat 1, 1901 , and prlor to sald last named dale has been duly licenses so so practer, and that hia reputation an wuch menlty in ad sursenn is burd ln tho commenity in which be has wo practired modi. examiation on day sulting the convenl. exce of the board not more than $\mathrm{s}(\mathrm{x}$ (6) ence of the boand not more than six (6)
months subsequent to the presentation of aald application. Sald examination shall be
oral. practical. and clinical in nature, and full consideration shall be giren to the duration and character of tho applicanta duration and character of tho applicanta ination it is determined by a majority rote of the sald medical cxaminers conducting safd examination. that such applicant is so qualifted to practice medicine and surgery within the state of Callfornia, and that hls reputation and standing in the communits in which he has prevlously practiced is gowd, the sald applicant shall be entliled th re: ceire a "physician and surgenn certincate. Each applicant on maring such application shall pay to the secretary of the borard a fee of nfty dollars ( $\$ 50)$, which shall be paid to the treasurer of the board, of wh!ch
gum forty dollars (\$40) shall be returned to him should he not recelve a certiflate hereunder. All certincates lssued pursuant to this section shall be marked across the face thereof "reclproclity certiacate."

Sec. 14. RECIPROCITY-SUSPENSION
OR REVOCATION OF LICENSE: Sald OR REVOCATION OF LICENSE: Sald board must refuse a certincate to any applithe filing with the secretary of aworn complaint. charglng the anplicant $w !$ th harthe secretary must forthwith - issue a citation, under the seal of the board, and make the same returnable at the next regular sesthe same returasble at the next regular sesslon of said board, occurring at least thirty citation shall notify the applicant when and where the charges of said unprofesslonal cant shall fle his written answer, undor oath, within twenty days nert after the service on him of sald citation, or that default will be taken against him and his application for a certífcale refused. The attendance of witnesses at auch bearing may be compelled by subpnenas jasued by the secretary of the board under Its seal. Sald cltation and said subpoenas shall be served In accordance with the statutes of this state then in force ss to the serrice of citations and suhpoenas generally, and all the provialons of the statutes of this state then in are hereby made applicable to the subpoenas and elistions provided for hereln. UDon the secretary's certifsing to the fact of refusal of any person to obey a subpmena or citation to the superior court of the county in which the service was had sald court shall thereupon proceed the statutes of this state then in porce as to contempls for disobedience of process of the cnurt, and ahould said court find that the subprena or citation has heen legally wllully disobered the ssme. Ii sluall proceet to impoce such penalty as provided in cases to impoce such penalty as provided th cases unprefessional conduct arising under this art. depms!lons of witnessey may he taken. the same as in eiril cases. and sil the prort-
sfrins of the sfatutes of this state then in force as in the taking of depostlions are herebr made anplicable to the takinz of depos!llons umler this act. If the appiteant loart his anxwer, under oath, with!n twen: lays after serviee on him of sald cliation. or within such further time as the buart
may allow, and the charges on thetr fare may allow, and the charges on thet fare
shall to dermed sumcient by the prard, de shall he decmeds sumcient by the tward. de canlt whall be entered agalust hing, and his pace be deomel sundelent by il.e inart. aml losue be folned thereon by answer, tle ter, anel to that end whall heas kuch proper eridence as may be alliuens before il: and that the nunteant is culley as charged. B' certincisto shill be townel lo hlin. No cor incate shall be timatiol in the aritund of unprofeatenal crnllet unlex tion apolicant has leren bullty of auch ponduct within lwo erre any hidider of a certincate hereln broricled fur is aulliy of unpropreslonal couduct. as the aame in dennoul in this $A C t$, and the

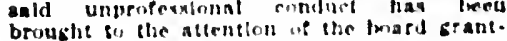

Ing sald certifcate, in the manner hereinarcer pruvided, or whener'? a certineate has ton, or Issued by mistake, i the person holding such certiflcate is firuti 1 t.) the ysacucing contrary to the provisinst lieerre t and of this act, It shall be the duat if atis hard elther to suspend the right if the bother of sald certificate to practice pis a per exceeding one year. or in lis discret. revoke his certincale. In the ereas inch shall not be en:itled to practice thereunde durloz the term of suspension: but. upir. the explration of the term of sald sumper. slon, be shall be relnstated by the board and shail be entitled to resume his practice. unicss it shall be eatablished to the satls faction of the bosid that said person so suspended from pracsice, has, during the term of such suspensinn, practiced in the state of California, in which erent the boand shall revoke the certiflcate of such verson. No such suspension or revocation shall be made same proceedings are had as is herelnbelore provided in this section in case of refusal to issue certiflcates. Sald secretary in all cases of suspension or revocation shall enter cases of suspension or revocation shall enter on rerocation, as the case may be, and shall certify the fact of such suspension or rerocation under the seal of the board. to the county clerk of the countles in which the certificates of the person whose certincate has been reroked is recorded; and sald clerk must thereupon orite upon the margin or tificate of such person, the following: "The holder of this certiflate was on the - The day of this suspended for day of certiflcate was retoked on the the day, month and year of such rerocation. or length of suspension, as the case may be. in accordance with sald certiflation to hlm by sald secretary. The record of such sus: pension or retocation so made by said county clerk shall be prima facle eridence
of the fact thereof. and of the recularity of all the proceedings of said bourd in the all the proceedings of sajd bord in the matter of sald suspension or rerication. used in this act, are hereby declared to mean :

Firsl: The procuring or alding or apet ting in propuring of a criminal aborion. fessional secret.

Third: All adrertising of medical busimess which is intended or bas a tendency to
deceire the nublic or impose upon credudeceire the nublic or imprese upon credulous or ignorant persintis. and so be harm-
ful or injurtous to pulilic tnorals or safebs

Fourth: All adrertising of any medic:ne or of any means whereby the monihly menses re-estahlished if suppressed.

Fleth : Conviction of an cfense tnridr:ta moral surntude, in whtch case the
of such convecton stiall be ernetus.

dence.
sixth: Ilatituai intemperance.

sereuth: The personation of anuthes

neced prarstionier

Elihth: The use, by toe holder of any

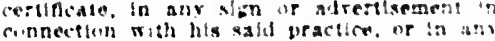
afrurtisement of announcement if hls tras.

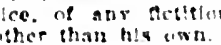

Ninbli: The use, by lie bolites of a "drthe less hactillomir certiniste." of drue

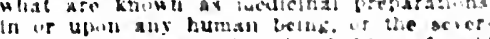

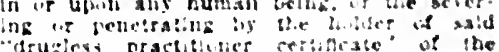

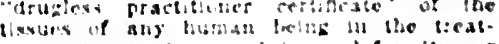
mest of any dicesec lajurs, deformally, or human inoms. esicut the serortas of the umblitien! cont

Tonth: Alvertsing. announclas or alsting. direntiy. Initirertly, it in substance. by any stil, carl, newspajer aurertivement, of ot ber

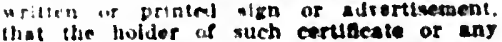
uther perann. company. or sacociatios by which he in eruployed or la whow service 
he is, will cure or attempt to cure, or will treat, uny veneresl disease, or will cure or attempt to cure or treat any person or persons for any sexual disease, for lost manhood, sexual weakness, or sexual disorder: or being employed by, or being in the service of, any person, firm, association, or stating.

Eleventh: The use by the holder of a "drugless practitioner certificate" of the letters "M.D." or the words "doctor of mediclne," or the term "physician and surgeon," or the term "physician," or the term "surgeon." In connection with lits name or in connection with his practice, or otherwise, upon any sign, card, advert

Sec. 15. Every person holding a certlflcate under the laws of thls state authorizing him to practlce any system or mode of treating the sick or afficted in this state must have it recorded in the office of the county clerk of the county or counties in which the holder of said certlficate is practicing his professlon, and the fact of such recordation shall be endorsed on the certiflcate by the county clerk recording the same. Any person holding a certifleate as aforesaid, who ahall practice or attempt to practice any other system or mode of treating the sick or afflicted in this state, without baving flrst fled his certificate with the county clerk, as herein provided, shall be deemed guilty of a misderneanor and shall be punished by a fine of not less than twenty-fire dollars (\$25) nor more than one hundred dollars $(\$ 100)$, or by imprisonment for a period of sixty days, or by both such fine and imprisonment.

Sec. 16. COUNTY REGISTRATION : The county clerk shall keep in a book provided for the purpose a complete list of the certificates recorded by him, with the date of the record; and said book shall be open to public Inspection during his offlce hours.

Sec. 17. PENALTIES: Any person who shall practice or attempt to practice, or who advertises or holds himself out as practicing, any system or mode of treating the slck or afticted in this state, or who shall diagnose, treat, operate for, or prescribe for any disease, Injury, deformity, or other mental or physical condition of any person without having at the time of so doing a valid unrevoked certificate as provided in this act, or who shall in any sign or in any advertisement use the word "doctor," the
letters or preflx "Dr.," the letters "M. or any other term or letters Indicating or implying that he is a doctor under the terms of this or any other act, or that he is entitled to practice hereunder, or under any other law, without having at the time of so doing a valld unrevoked certiflcate as provided in this Act, shall be guilty of a misdemeanor and upon conviction thereof shall be punished by a fine of not less than one hundred dollars $(\$ 100)$ nor more than six hundred dollars $(\$ 600)$, or by imprisonmen for a term of not less than sixty $(60)$ days nor more than one hundred and eighty (180) days, or by both such fine and imprisonment. Upon each such conviction the fine shall be paid. when collected, to the state treasurer, and a report thereof shall be made to the state controller.

Sec. 18. BARTER OF DIPLOMAS OR CERTIFICATES: Any person, or any member of any firm, or official of any company, association, organizatlon or corporatlon shall be gullty of a misdemeanor and upon conviction thereof shall be punishabie by imprisonment in the county jail for not less than ten (10) days nor more than on (1) year, or by a flne of not less than one hundred dollars $(\$ 100)$ nor more than one thousand dollars $(\$ 1,000)$, or by both such fine and Imprisonment, who, individually or in his offlial capacity, shall himself sel or barter, or offer to sell or barter any certiflcate authorized to be granted hereunder, or any diploma, affidavit, transcript, certificate or any other evidence required in this act for use in connection with the granting of certificates or diplomas, or who shall purchase or procure the same either directly or indirectly with
Intent that the same shall bo fraudulently used. or who shall with fraudulent intent used. or who shall with fraudulent intent alter any diploma, certificste, transcript, in obtaining a diploma or certlficate required herennder. or who shall use or attempt to use frauduiently any certificate, transcript, afflavit, or diploms, whether the same be genuine or false, or who shall practice or attempt to practice any aystem of treatment of the sick or afflicted, under a false or assumed name, or any name tedical Examiners of the state of Callfornia on its certificate issued to auch perfornia on its certificate issued to auch pertreatment, or who shall assume any degree treatment, or who shall assume any degree or title not conferred upon hlm in the
manner and by the authority recognized manner and by the authority recognized that tie has received such degree or title, or who shall wilfully make any false statement on any application for examination, license or registration under this act, or who shall engage in the treatment of the sick or afficted without causing to be a conspicuous place in his office the name of a conspicuous place in his office the name of each and every person who is associated
with or eaployed by him in the practice of with or eaployed by him in the practice of the sick or afflicted, or who shall, within ten days after demand made by the secretary of the board, fail to furnish to said board the name and address of all such persons nssociated with or employed by with which he is or has been connected at any time within sixty (60) days prior to any time within sixty (60) days prior to said notice, together with a sworn statement showing lnder and by what license employee or employees, is or are, or has or have been, practicing medicine or surgery, or any other system of treatment of the sick or afflicted (nrovided that such affldavit shail not be used as evidence against under this section)

Sec. 19. FRAUDULENT USE OF CERTIFICATE : Every person fling for record, or attempting to flle for record, the certificate Issued to another, falsely claiming entitied to such certiflcate, shall be guilty of a felony, and, upon conviction thereof, shall be subject to such penalties as are provided by the
crime of forgery.

Sec. 20. FRAUD: Any person not a member of the State Board of Medical Examiners who shall aign, or issue, or cause to be signed or issued, any certiflcate authorized by this act, shall be guilty by a flne of not less than one hundred dollars $(\$ 100)$ nor more than six bundred (\$600) or by imprisonment for a term not $(\$ 600)$ or by imprisonment for a term not less than sixty (60) nor more than one
hundred and eighty (180) days, or by both such flne and imprisonment.

Sec. 21. PRIOR CERTIFICATES: Nothing in this act shall be construed to prohibit the practice by any person holding an unrevoked certiflcate heretofore issued under or validated by any medical practice act of this state, but all such certificates may be revoked for unprofessional conduct in the same manner and upon the same
grounds as if they had been Issued under tbis act.

Sec. 22. EXEMPTION: Nothing in this Act shall be construed to prohibit service in the case of emergency, or the domestic administration of family remedies; nor shall this act apply to any commissioned medical offler in the United States Army, Navy or Public Health Service, in the discharge of dentist when engaged exclusively in the practice of dentistry. Nor shall this Act apply to any practitioner from another state or territory, when in actual consultation with a licensed practitioner of thls state, If such practitioner is, at the tlme of such consultation, a licensed practitioner in the state or territory in which be resides; provided, that such practitioner shall not open an office or appoint a place to meet patients or recelve calls within the limits of this state. Nor shall this Act be construed 80 as to discriminate against any partleular school of medicine or surgery, or any other trestment, nor to regulate, prohibit or to apply to, any kind of treatment by prayer, nor to interefere in any way with the practice of religion.

Sec. 23. OTHER ACTS REPEALED : An act entitled "An act por the regulation of the practice of nediclne and surgery, ostenpathy, and other systems or modes of treating the sick or afflicted, in the state of California, and for the appolntment of a Board of Medical Examiners in the matter of said reculation," approved March 14, 1907 , as amended by a certaln act approved March 19,1909 , as amended by a certain act approved May 1, 1911, is hereby repealed, in confilct with thls act are bereby repealed.

\section{CALIFORNIA STATE BOARD OF HEALTH}

Martin Regensburger, President, San Francisco; Wm. Le Moyne Wills, ViceSacramento; F. K. Ainswortb. San Francisco; James H. Parkinson. Sacramento; cisco; James H. Parkinson, Sacramento; Secretary, Sacramento.

\section{Official Stafi}

Wm. F. Snow, Executive Officer and State Registrar, Saeramento; John F. LeInen, Assistant to Secretary, Sacramento ; Louls Angeles; Geo. D. Leslie, Statisticlan, Bureau of Vital Statistlcs, Sacramento: M. E. Jaffa, Director Food and Drug Labo-
ratory, University of California, Berkeley; ratory, University of California, Berkeley; W. A. Sawyer, Director Hyglenic Labora-
tory, University of California, Berkeley: tory, University of California, Berkeley:
Chas. G. Hyde, Consulting Engineer, Berkeley.

BOARD OF MEDICAL EXAMINERS

W. W. Vanderburgh, D.o., President, San Francisco; Fred. F. Gundrum, Vice-President, Sacramento ; Chas. B. Pinkham, Secretary, State Capitol, Sacramento; Harry F. Alderson, San Francisco; H. V. Brown, A. Campbell, Los Angeles: H. Clifford Loos, San Diego: iVm. T. Molony, Los Angeles; D. L. Tasker, D.0., Los Angeles, Cal.

\section{MEDICAL SOCIETY OF THE STATE OF} CALIFORNIA

Offlcers 1913-14

Fitch C. F. Mattison, President, Pasadena

Barton J. Powell, 1st Vice-Pres... Stockton George Tucker, 2d Vice-Pres.......Riverside Pbilip Mills Jones, Secretary.....................

\section{State Journal} Callfornia State Journal of Medicine,
San Francisco, Philip Mills Jones, M.D., editor.

\section{Councilor Districts and Officers}

G. C. Kenyon, Chalrman, San Francisco. Councilors at Large.-John C. Spencer, Francisco; O. D. Hamiln, Oakland.

First District. - San Diego, Riverside, Orange and San Bernardino counties. C. Yan Zwalumenburg, Counclior, Rlverside. Second District.-Los Angeles, Ventura, Santa Barbara and Kern counties. Geo.
H. Kress, Councilor, Los Angeles.

Third District.-San Luis Oblspo and cilor, Salinas.

Fourth District.-Fresno, Kings, Tuolumne, Merced, Marlposa, Madera and Stanisiaus counties. Geo. H. Alken, Councilor, Fresno.

Fifth Distrlet.-Santa Clara, San Mateo, San Benito and Santa Cruz counties. Antrim

Sixth District.-San Franclseo county. C. G. Kenyon, Councllor, San Francisco. 
Seventb Distrlet-Alameda, Contra Costa. San Jnaquin and Calaveras

Elghth Dlatrict-Alpine. Amador, Butte, Colusa, El Dorado. Glenn. Invo, IAssen. Minde. Mono, levada, Placer, I'lumas, Sacramento. Shasta. Slerra. Sisklyou, Sut ter. Tehema. Yolo and Yuba countles. Jas. ter. Parkinson. Councllor, Sacramento.

Ninth Distrlct-Del Norte, Humboldt. Lake, Marla. Mendodno, Xapa, Sonoma. Solano and Trinity couniles. John II. Kuser. Councllor. San Rafael.

Component County Socletles of the Modical Society of the State of California ALAMEDA COLNTI

Dudley Smith. Presldent.......... Oakland Elmer E. Brlnckerhor. Secretary... Oakland BUTTE COENTY

Vdward E. Baumelster, I'restdent.....Chlco Eu. F. Gaschell. Secretars........... Chico CONTRA COSTA COLNTY

W. S. Georre, Prealdent...........Antloch

1. B. Flizpatrtck, Secretary.......... Martlnez FRESNO COUNTY

C. O. Mitchell. l'resident...........Fowler

R. Willson, Secretars.............. Fresno GLENX COUNTY

John A. Randolph, Iresident......Wlllow

Frank M. Lawson. Secrets-5........ Willow IUMBOLDT COLNTY

C. T. Wallace, President........... Eurek

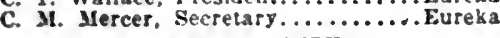
KERX COLNTY

Francls A. IIamlin, Presldent.... Makersfleth A. I. Fraser, Secretary........... Bakersfield LOS ANGELES COUNTY

Wm. M. Lewis, President.......Los Angeles Geo. H. Kress, Secretary........Los Angeles MARIY COUNTY

o. W. Jones. Iresident.......San Anselmo

Arthur B. Mars, Secretary......... Sausalito MENDOCINO COUNTY

F. E. Alleb. Prealdent............ Talmage MERCED COLNTY

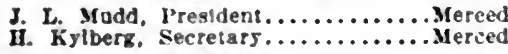
MONTEREY COLNTY

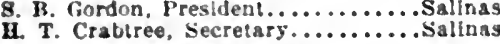
NAPA COUNTY

D. F. Osborne, l'resident. .......St. Ilelena

0. T. Schulze, Secretary.............. ORANGE CUUTTY

I. A. Johnaton. Presldent........ Anahelm

John Wehrly, secretary............. Santa dna ILACEK COUNTY

G. II. Fay. Preslitent.............. Auburn J. Cordon Jackas, Secretair........... Auburn RIVESIDE, COUNT

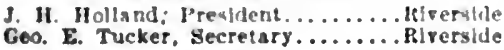
sacrauesto ColNTy

G. I. Sterengon, P'reaident.......sacramen:o

†. Y. Shaw, Secrelars.............. Saccamento SAN HENITO COLNTY

L. C. Hull, Prestdent............. Holliater

Y. 0. Niash. Secretary............ Ilollister SAN BFHNALDINO COUNTY

Benj. F. ('hurch. J'realdent....... liedlande

C. G. Mllllard. Secretary........... Redlands SAX DIE(;O) COLNTY

Harold A. Thonipoun, l'resldent. San blege

B. J. O'Viell. Secretary........... San Dlego SAX fitancisco cotsty

Arthur A 0 velll l'reyldent San praneleco Rene Bine. Secretary..........san Franclaco SAN JUAQUIN COUNTY

J. D. Dameron. l'restilent...........truckton haymond T. Mcfiurk, Secretary.... Stockton SAN LUIS OHISI') COLNT

C. J. McGovera. I'resldeat. .San Luls Oblspo II. $W$. Jones, Secretary.....San Luls Oblapo SAN MATEO COUNTY

w. C. Chldeater, Hrewldent........ Man Maten w. C. Baker, secretary.............. Man Mateo
SATT BABUARA COUST

T. A. Stodidard. President.... Santa Jarbara William T. Barry, Secretary...santa Harbara SANTA CLAIIA COUNTY

X. H. Bullork, Presldent..........san Jnse Charles 11 . Ilare. Secretary............. Jan Jose SANTA CRI'Z COUSTY

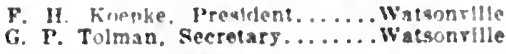
SHASTA COUNTY

E. J. Comlsh. Pres!dent......... Dunsmulr B. F. Saylor, Secretary.............Reduing SOLANo count

w. S. S. Young, Pres!dent.......... Vallejo SONOMA COLXTY

J. W. Scamell. Preslelent.........Santa Rna I. Howarl. Secretary......... Santa Rosa TEHAMA COLNTY

F. J Balley, Presldent......... Red Bluf F. II. Bly, Secretars,.......... Red Blut TULARE COUNTY

C. II White. Prestdent........... Visalla A. W. Prextinn. Secretary........... Visalla TLOLLMNE, COTNTY

Wim. Iyman Hond. President.........Sonnra Weorge C. Wrtaley, Secretary............. Sonora VENTLRA COUXTY

B E Mfrill, Presiclent........Santa Taula

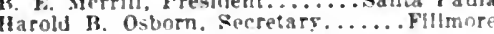
YOIO COTXT

H. D. Lamhead. Presldent........ Koodland Frances L Newton, Secre:ary.....Woodland YTRA-STTTER COLNTY

A. L. M!l!er. Tresldent...........Marysrllle

\section{COUNTY HEALTH OFFICERS}

County. Address. Alameda. - C. L. Mckown.............Nlles Alplne.-Fred S. Dunlap........Markleerllie Amador. F. F Findlcoti..........Jackson Butte. - L. Q. Thompson............Gridles Calnveras. -ien. F Pache...... Angels Camp Colusa - C. A Pnage ............. Colusa Contra Cnsta.-W. S. Georze........ Antinct

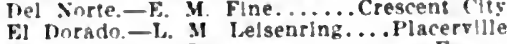
Fresno.-G. L. I.one............... Fresno Fresno._G. L. Lone............... Fresno Humboldt. Carl T. Wallace.......... Eureka

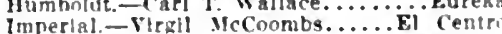
Inporal. J. Woodia........... Independence Inso.-1. J. Wondla............ Independente Kintr. C. I. Scott............... Hanford

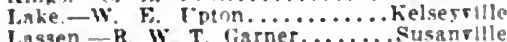
Lasaen. - R. W T. Garner........ Susanville Los Angeles. $-\mathrm{F}$ o sawser..... Los Anzeles In Pln-J. H. Kuser............... Mn Matael

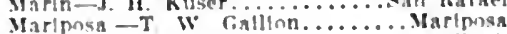

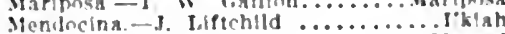

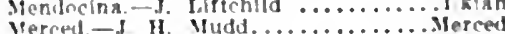

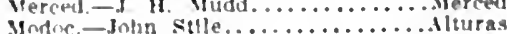

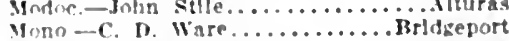

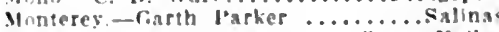
Vorala - rarl $p$. Jines....... Grass Valley Drange.Jubn Wehrle.......... Santa dna

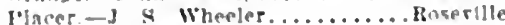
Jiuma - Wm. F. Siran............. Quines

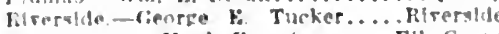
Sncramento,-Ilugh lientile....... Elk Grove San Jenitn-J If W'bonnell.......Holllater San bernatllun.--Phllp M. Sarage.....

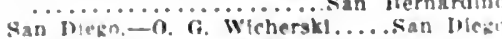
San l'rancisco.- II. (i. Lrodrlek.

.......................... Pan Fanctero San l,uls ublepn.-II. M. tox

........................ Luk ()blem Santa Harhara-j. C. Halnirilice.

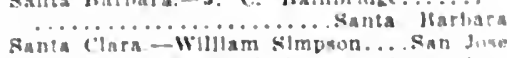
santa (ruz - W II. keck....... Sivta tru

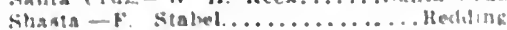

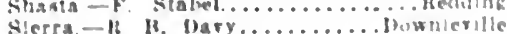
Slakiyou. - J. Meriliy............... Jieka

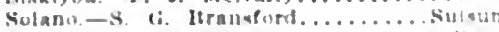

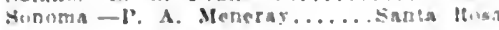

Sianislaus.-J. Is. Henneranuth..... Modests Siutter. $\mathbf{E}$. Jacnbs............. Mertdian Tehama - W. F. Macgard.......... Corminz Trinlty.-D. H. Flelds........ Wearerrllio Tulare-W. A. I'reston........... Visalla Ventura.-A. A. Mauthardt........ (n) Yolo. - K. J. Blerlns...........Wordland Juba. -J. H. Uart.............Marysrille

HEALTH OFFICERS IN CITIES OF 5.000 POPULATION AND OVER

Alameda.................. Nlerongmus dihambra................ E. Corey

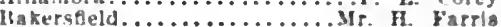
Kerkeley.................... J. Benton kureka................. presno.................. R Wilson Imtip Beach................ H. Newman ms Angeles................. Mt. Pourers Marysrille................ Wt. Mt. Meek Napa................. J. D Treaumay Oakinnd...................... Ewer

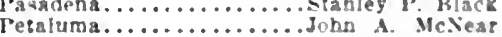

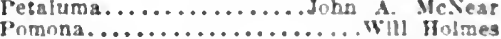

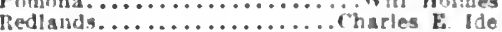

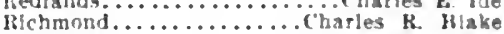
Rirerside.................. Thos. R. Grim:b Sacramento.............Wre. $k$ Llndsaj san Bernardino............... Y. Ham San Dlegu.................. K1. Stead

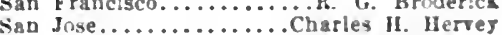
San Rafael...................Wade stone Santa Ana.................. I. Clark Santa Barbara............. D. A. Conrad Santa Cruz................... E. Psper Santa Uonica.............. H Parker Santa Rosa...............Jackion Temple stockton................... Hudson smythe Vallejo................. \& Peterson

\section{STATE INSTITUTIONS}

Agnew ablisted lsss; public; tor the lnsane: 1.\$00 beds: Leonard stocking. MD., superimtendent.

Berkeley

Callornta School for the Deat and Blind. Warring Si- Berteley. CaL. Estabitshed 1560 ; public: 250 beds; L. K Mlltigan, superlatendent.

\section{Eldridge}

Sinnoma Siate llome, Eldridfe, Cal. Established 1583: for the care and tralning of peeble-minded and cpllentles: $\mathbf{2 0 0 0}$ beds: Wri. J. li. Dawson. medical suderInsendert.

lone

rrestun Schml if Induatry. Waterasn Cal. (lone 1'0). Fistablished Is94; public: reformatory for boys: 000 beds: G. G. llawkins. Dhsolcian; Calrta Destick. super!ntendent

Napa

Ilume for the recble-Minded, Napa. Cal. Napa stale llospitai. Napa. Cal. Esablistied is 5 ; for mental diseases: 2,000 lutchisens.

Oakland

Indusirlal IInme for the Adult Blind of the state of Califor:1ts. 360! Telegraph Are. lakland. ('al Estubllshed Isss: charte; Jos. Sanders. superlasendent.

Patton

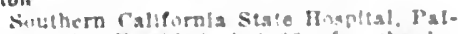
ton. I'al. Fistolishml 1:43: Por tho Insuperintendent.

Represa

llimpltal Department of Folsom state lotion. lirtress. Ial Eatablished isso:

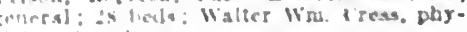
liotan in inaree.

. Sincoñ chis. (al. (tan Rafael Po.). Eutabllahed 1058: cenesal: ses beds: J. II. Kuscr, alferillne physiclan: Ker. Brotber l'aul, sugertintendent. 
Stackton

Stockton State Hospital, Stockton, Cal. Established 1854 for the lusane: I 900 beds; Fred P. Clark, physiclan in charge. Talmage

Mendocino State Iospital, Talmagc, Cal. Established i893; public: nerfous and mental: I,050 beds; Rohert L. Rlehards, medial; 1,050 beds;

Whittier

Whittler State School, Whittier, Cal. Establislied 1891; Industrial and edueationai: 20 beds; J. P. (irceley, superintendent.

Yountville

Veterans' IIome IIospital, Yountrille, Cal. Established 1883 ; general ; for old soldiers; 250 beds; Col. D. M. Merae, phystelan in charge.

\section{HOSPITALS, SANATORIUMS AND CHAR- Alameda. ITABLE INSTITUTIONS}

Alameda Sanitarium, 2054 Clinton St., Alameda, Cal. Míss Kate Creedon, supcrintendent.

Broadway Sanitarium, 1542 Broadway, Alameda, Cal. Established 1906; nervous and mental; 16 beds; Grace Míninger, physician in charge.

Albion

Albion Hospital, Alblon, Cal. Establlshed 1908; general; for Albion Lumber Company employees; 12 beds; H. H. Wolfe, physlcian in charge.

\section{Alhambra}

Alhambra Sanatorium, El Sueno, Alhambra, Cal. Established 1902; private; for nerrous and digestive cases; 12 beds Francis E. Corey, physiclan in charge. Alta

Alta Sanatorlum, Alta, Cal. Establlshed 1909; prlvate; tuberculosls; 40 beds; W. J. Broome, M.D., superintendent.

\section{Alturas}

Modoc County Hospltal, Alturas, Cal.
Established 1884; general; 14 beds; W. E. Coppedge, medical superintendent.

\section{Anaheim}

Anaheim Sanltartum, Anaheim, Cal. Established 1910 ; private; 25 beds; general; narcotic and alcoholic; Marshall E. Beebe, business manager.

Antioch

Valley Hospital, Antioch, Cal. Estab-

lished 1912; public and private; 15 beds;

E. A. Diggins, physician in charge.

Arcata

Trinity Hospital, Arcata, Cal. Established 1907 ; private; 25 beds; G. W. McKinnon, physician in charge.

\section{Arrowhead Springs}

Arrowhead Hot Springs Company, Arromhead Springs, Cal. Established 1906; public health resort; Seth Marsball, superintendent.

See Special Announcement Adv, page 62 Aubura

Placer County Hospital, Auburn, Cal. Established 1866; public; 100 beds; R. F. Roorey and G. H. Fay, physlcians in charge.

Slerra Hospital, Auburn, Cal. 20 beds: Mrs. L. D. Le Sach, matron.

\section{Bakersfield}

Kern County Hospital, 19th and Oak Sts., Bakersfield, Cal. Established 1884; public; 80 beds; T. M. McNamara, county physician and surgeon, in charge; Franz physician and surgeon, in

Mercy Hospital, Truxton Ave. and C St., Bakersfleld, Cal. Established 1910 ; public; 60 beds ; Sisters of Mercy, in charge. San Joaquin Hospital, 27th and I Sts., Bakersfield, Cal. Established 1910; pubIic ; 30 beds; Misses Quinn and O'Donnell, in charge.

Scuthern Paciflc Company Division Hospital, Bakersfield, Cal. Established 1903; private; 6 beds; C. W. Kellogg, A. F. Fraser and $\mathrm{H}$. iv. Owen, physicians in charge.
Banuing

1)r. King's Sanatorlum, Banning, Cal. Established 1900; private; tuberculosis: 25 beds; John C. Klng, physician in charge.

Southern Slerras Sanitarium, Banning Cal. Fstablished 1913 ; tuberculosis; private ; 20 beds; L. M. Ryan, M.D., superintendent.

Beimont

Callfornla Sanatorlum for the Treatment of Tuberculosis, Belmont, Cal. Es tablished 1910;50 beds; Max Rothschild (Burlingame), physletan in charge.

Gardner Sanitarlum, Belinont, Cal. Es tablished 1902; prlvate; for nervous and tablished 1902 ; prlvate; for nervous and
mental diseases, alcohol and drug addiction; 50 beds; $\Lambda$. M. Gardner, president and medical superintendent.

Nerve Rest Sanltarium, Belmont, Cal. Estallished 1911; private; nervous and mental; 18 beds; R. J. McAdory (San Francisco), physlelan in charge.

\section{Berkeley}

Alta Bates Sanatorlum, 2460 Webster St., Berkeley, Cal. Established 1905 general; for women and chlldren; 35 beds; Miss Alta Bates, superintendent.

El Reposo Sanitarlum, 2222 Chapel St. Berkeley, Cal. Established 1907; general; 35 beds; A. J. Sanderson, physiclan in charge.

Rooserelt Hospital, 2001 Dwight Way, Berkeley, Cal. Fstablished 1905; private; general; 40 beds; L. C. Shingle, superintendent.

Unlversity of Callfornla Infirmary, Berkeley, Cal. Established 1906; for students only; 40 beds; G. F. Reinhardt, physician in charge; Míss Ethel Sherman, superintendent.

\section{Bonita}

Dunbar's Sanitarium, Bonita, Ca1. Established 1900; private; country home for invalids; 8 beds; Frank A. Dunbar, physlclan in charge.

Bridgepert

IIono County Farm and Hospltal Bridgeport, Cal. Established 1906; publle; general; 14 beds; C. D. Ware, county physlclan (Bodie); Mrs. Edith Olds, superintendent.

Burbank

Burbank Hospital, Burbank, Cal. Established 1908; general; 12 beds; E. H. Thompson, medical superintendent.

Burnett

Porter Sanitarium, Burnett, Cal. Established 1905; health resort; 30 beds; Charles Sanford Porter, physician in charge.

\section{Byron Hot Springs}

Byron Hot Sprlngs Sanitarium, Byron Hot Springs, Cal. Established 1880, pri

vate; 20 beds; $L$. Mead, superintendent.

Calistoga

Hot Springs Sanitarium, Calistoga, Cal.

Caspar

Dr. Franklin Sanitarium, Caspar, Cal.

Cedarvilie

W. D. Coates Hospital, Cedarville, Cal.

w. D. Coates, In charge.

Cemeat

Cement Hospital, Cement, Cal. IV. G. Chico

Chico Sanitarium, Chico, Cal. Established 1905; private; general; 12 beds; C. C. Landis, M.D., superintendent.

Enloe Hospital, Chico, Cal. Establisbed 19I3; public ; 18 beds; N. T. Enloe, superintendent.

Sacramento Valley Hospital, Chico, Cal Established 1912; public; 20 beds.

Sisters' Hospital, 843, 2d St., Chico, Cal.

Established 1904; general; 40 beds; Miss Ellen Wharton, superintendent.

\section{Chula Vista}

McNabb Hospital, Chula Vista, Cal. Establlshed 1913; 40 beds; conducted by Frederika Homé for Aged.

\section{Coalinga}

San Joaquin Hospital, 252 E. C St., Coalinga, Cal. Established 1910; private; general; 15 beds; Mrs. Harriet J. Heatwole, R.N., superintendent.

Colfax

Colfax School for the Tuberculous, Col-

fax, Cal. Established 1908 ; tuberculoais ;

60 beds; Robt. A. l'eers, medical director.

Sce sperial Announcement Adv. page 8 Colma.

IIome Sanatorium, Colma, Cal. F. M. Thompson, in charge.

Coreaco

Swedish Health Sanitarium, Coronado, Cal. Established 1910; 10 beds; Tell J. kerggren, physlctan in charge.

Decete

Masonic IHome Hospital, Decoto, Cal. Established 1910; general; 16 beds ; Frank IB. Hartman, superintendent.

\section{Dinuba}

Dinuba Sanatorium, Dinuba, Cal. Established 1912; private; 10 beds; Miss Elizabeth Holcom, in charge.

\section{Dunsmuir}

Dunsmuir Hospital and Sanitarium, Dunsmuir, Cal. Established 1910; general ; 15 beds; Edwln J. Cornish, medical superintendent.

\section{El Centre}

St. Thomas Hospital, El Centro, Cal. Eatablished 1907; public; 60 beds; Slsters of Mercy, In charge.

\section{Elsinore}

Elsinore Sanitarium and Rest Cure, Elsinore (Hot Springs), Cal. Established 1913 ; medical and health resort; 20 beds; M. A. Schutz, physician in charge.

\section{Escondido}

Rock Ledge Sanitarlum, Escondido, Cal. Jessle B. Dodds, physician in charge.

\section{Eureka}

City and County Contagious Hospital, Eureka, Cal. Established 1907; 10 bers: clty and county health offlcers, in charge. Eureka Recefving Hospltal, Eureka, Cal. Established 1897; for insane : 4 beds county physician, In charge.

Humboldt County Hospltal, Eureka, Cal. Established 1894; charitable; 120 beds James H. Boyce, superintendent

Northern California Hospltal, Eureka, Cal. Establlshed 1907; general; 65 beds Chas. E. Falk, M.D., general manager.

Sequola Hospital, 6th and H Sts., Eureka, Cal. Established 1903; private 72 beds; R. Felt, physiclan; Miss Ida Iason, superintendent.

Union Labor Hospital, Harrls and $\mathbf{H}$ Sts., Eureka, Cal. Established 1906; general $; 60$ beds; B. M. Marshall, surgeon in chief; R. O. McKeon, superintendent.

\section{Fairfax}

Arequipa Sanatorium, Fairfax, Cal. Es tablished 1911; for tuberculosls; private; 40 beds; Phillp King Brown (San Franeisco), medical director; Miss L. Nora Harnden, superlntendent.

\section{Fellows}

Jolunson Hospital, Fellows, Cal. Established 1911; general; 14 beds; J. Thomas Johnson, physician in charge.

Ferndale

Ferndale General Hospital, Ferndale, Cal. Established 1910 ; private; 12 beds

Francis M. Bruner, physlcian in charge.

French Camp

San Joaquin County Hospital, French Camp, Cal. Establisbed 1899; general; 300 beds; $\mathrm{Wm}$. Friedberger, MI.D., superintendent.

Fresno

Burnett Sanitarlum Company, Fresno and $\mathrm{S}$ Sts., Fresno, Cal. Establlshed 1897 ; private; 50 beds; Mlss M. E. Smith, superintendent.

Craren Sanitarium, Fresno, Cal. Es tablished 1907; private: I2 beds; Miss Jeanie Craven, superintendent and matron. Cross Sanitarium, Fresno, Cal. Mlsses Fraser and Woodside, in charge.

Eastgate Sanltarium, $1437 \mathrm{~J}$ St., Fresno, 
Fresno County Hospltal, Ventura Are. Fresno, Cal. Establlshed 1903: zeneral: 145 heds: liuy Itanson. M.D. supt. Sample Sanatorlum. Fresno, Cal. Established 1913: 23 beds: T. N. Sample, chlef physlcian: Mlss O. F. Thompson, supt.

\section{Ft. Braee}

Ft. Bragg Kospltal, Ft. Bragz. Cal. Fstabllshed 1887: prlsate: 20 beds: Geo. P. Purlenky, physlclan in charge.

\section{Fullerton}

Fullerton Hospltal, Fullerton, Cal, H.s.

tablished 1903; prirate; 16 beds: Mlss R. C. Alberts, superintendent.

Gllroy

Glimy Private Hospital, Gilroy, Cal. Establlshed 1900 ; private; 12 beds; J. A. Clark, physlclan: Geo. A. Wentz. supt.

Glendale

Glendalo Sanltarlum, Glendale, Cal. Establlshed 1904: general; 80 beds: II. F. tablshed 1904; general; 80 beds; H. F. Rand, gurgeon
superintendent.

\section{Grass Valley}

Grass Valles Surgical Hospital, Grass

Valley, Cal. Established 1909; surgical;

s beds: II. Grace Franklin. supi.

W. C. Jones Memorlal Hospltal, Grass

Faller. Cal. Established 1907; private;

seneral, nervous and mental; " 20 beds:

Miss R. Palmer, superintendent.

\section{Hanford}

Clty and County Hospltal, Hanford, Cal. Establlshed 1893; 35 beds; B. W. Moore. superintendent.

County Hospltal, Hanford, Cal. Charl-

table and old people; general; 30 beds; $R$.

Motberal, physiclan in charge.

Hanford Sanitarium, Inc. Hanford, Cal.

Established 1908; publlc; general; 25

beds; Mlss M. M. Austin, matron.

\section{Hayward}

Hayward Sanatorlum, Hayward, Cal. Established 1911; private.

Rest Awbile, II ayward, Cal. Establlshed

1910: prirate: for convalescents.

\section{Healdsbure}

Healdsburg Medical and Surgleal Home, Healdsburz, Cal. Establlshed 1890; gen: superintendent.

Seawell's Sanatorlum, 117 North St. Ilealdsburg. Cal. Establlshed 1908: surgleal; 6 beds; J. Walter Searell, phrs!clan In charge.

\section{Hobart Mills}

Slerra Nerada Hospltal, Lobart Mllls.

Cal. Established 1904; general; 15 beds;

I. I. Swauger, physlclan in charge.

Hollister

Hazel Hawking Memorlal Hospltal, IIolIlster, Cal. Fotablished 1907: general: 15 beds: Dorothy C. Irew, superintendent. San Benlta County Ilospltal. Hollster.

Cel. Establlshed 189-: publtc: 32 beds:

John Buts, superlntendent.

\section{Kenaett}

Mammoth Copper Company's IIospltal. Kennetf, Cal. Kstabllshed 1907: general: if beds; J. I'. Sandholdt, physlelan in charge.

\section{La Mesa}

Parka Sanliarium, La Mesa, ('al 16 beds: J. A. Parks, physletan In charge.

\section{Lindsay}

Alta Vlew Sanltorlum Lindsay, Cal Established 1312: surgleal, inedical and maternity cases; 6 beds; Miss Stella [1]llon. II. 0 ., In charce.

\section{Livermore}

Llermose Sanltarlum, Llvermore, (al. Established 1502; ceneral; spectal devars. ment for nerrous and mental caves; 100 beds: John W. Itotertson. physlclan in charge.

See spectal inneurrornont lil: foup

Loma Linda

Loma Lolnda Sanliarium, lona Lifnda. Cal. Establislied 1805: 100 heots: Wilthur H. Smitb. surigeon: W. $\boldsymbol{A}$. Ruble, medleal sunerintendent.

\section{Long Beach}

Irong Jeach Santiarlum, 10:h St. and Ilnden Are.: lenng leach lat kistab-
Smith and Abble Wilnegar Simpson house physiclan and surgeon: W. Itay Simpson. manager.

Seaslde Hospltal, 14th and Mamolla, long Beach, Cal. Estalillshed 190\% prisate: seneral: 30 beals: V. Itoy Townrend. physlclan; Annes E. Smith, sunt.

\section{Los Angeles}

Angelus Hospltal, Washington and Trin. Ity Sts.. Los Angeles, Cal. Established 1904; Ceneral; 100 beds: II arriec W. Pohl, superintendent.

Banksea Place, 522i Santa Monica Itral, 1.os Angeles, Cal. Establlshed 1909 ; nervous cases; 25 beds; K. I. KImbal1, superintendent.

Irarlos sanatorlum, Charez Rarine Bd. neas Elystan I'ark Ave.. Los Anzeles, Cal. Kistabllshed 1902; charitable: for tuberculosis cases: 43 beds: Waiter C. Klorz. physiclan in charge: Cároline W. Bentley. superintenilent.

Bimint IIot Springs and Sanltarlum, 3d St. and Vermont Are., Los Angeles, Cal. Fstabllshed 1906 ; 50 beds; C. II. C. Wal. ters, medical director.

Callfornla Hospltal, $1414 \mathrm{~S}$. Hope St. Los Angeles, Cal. Establlshed 1897; pri. vate; general; 200 beds; Walter Lindley. medical director.

Chlldren's Hospital, Sunset Blrd. and Vermont Are., Los Angeles, Cal. Establlshed 1901; general; 100 beds; Mlss Marion L. Fannler, superintendent

Clara Barton Hospltal, $447 \mathrm{~S}$. Ollve St., Los Angeles, Cal. Established 1904; general; 80 beds; Herbert $F$. Barton, phys!clan in charge.

Crocker Street Hospltal, 418 Crocker St. Los Angeles, Cal. Fstabilshed 1901 ; prlvate; general; 75 beds; R. L. Byron, sur geon In charge.

Detention Hospital, Charez Rarine Rd., Los Angeles, Cal. Fistabllshed 1906 ; public; small-pox only; L. M. Powers, medlcal superintendent.

Fleld Ilospltal No. 1, Natlonal Guard of Callfornla Station, Frpostion Park, Ios Angeles, Cal. Establlshed 1913; mll!tary; los beds; Chas. W. Decker. Maj. M.C., N.G. Cal., commanding.

Florence Critteruton Home, 1626 Sante. St., Los Angeles, Cal. Established 1892: prirate unfortunate firls and babies; 30 lieds: Mrs. F. M. Freenan. superintendent.

French Beneroleat Soclety Hospital. 5.31 College St. Los Angeles, Cal. Established 1869 ; publle and prirate; 30 beds: Mrs B. Boyd, superlntendent.

German Hospltal, 4.33 S. Soto St. Los Angeles, Cal. Established 1903; prirate: 25 beds; Joseph Kurtz, physlclan in charge.

Harrlet f. Cunnlngham's Hosplial, 135: Valencla St. Los Angeles. Cal. Estal Ilshed 1901: private: 8 leds: Mrs. Marrlet (i. Cunnlngham, superintendent.

VIighland rark Sanatorium, 5605 Hub Se. I os inceles, Cal. Private; is heds: Maude Summers, superintendent.

Hillstde llospltal, $1035 \mathrm{~W}$, ith St. los Angelry, Cal. Fostablished ions: private in beits: Fita C. Jeancon, medlcal super inendent.

Ilollentreck llome for the Aged, 573 S

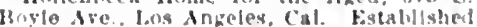
Isifi: prisate: 9 bem: Rev. Wus Votmg, kuperinendent.

Hume sanltarlum, 3525 Central st, Jos Angeles. ral.

Vispltat of the food simaritan, Orange and IVtunce sis los Aurcles cal E:

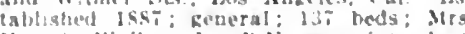
II ratle Walker, Jr, H.X., supermenten Institupe of llecliasical irthopmlics.

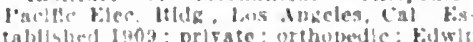
iablislacl 1903 : prisate: orthopedlc: kilwlo llerluert lisasell. physician In rharge.

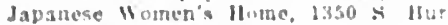

linglum dre low Allibeles.

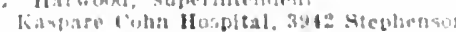
Ar., 1,09 Inzeles, l'al. Fintabilished 1:b00

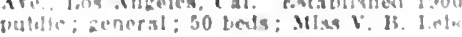

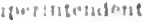

La reenta Sanainrlum 3011 W. Tomble

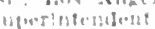

Los Angeles Cly and rounty Detention IIospltal, Charez Karine HA. Los angeles,

Los Angeles County H. 3p:al, 1100 Yla slon Rd. Los Angeles. "al. Kivesbliatied $18: 0$; general; 1.000 beds: Chas. H. Wult man, medical superintendea:

Los Angeles Hospita!, F. Ith atd Mic Garry Sts., Los Angeles, Cal. Kistall!glim ly00: general: 31 beds: John leland Jones, medical superlotendent.

bos Angeles Inflrmary, Sunset Plrd. and Beaudry Are., I,os Angeles. Csl. bistab IIntred lfor: Leneral: Slsters of 'har. charge

Ios Anreles Oryhans' Home, El Centro and Waring sts., los Angeles, Cal. Es tabllshed 1880; 100 beds: Mrs. MIar Matthews, superintendent

Los Angeles Itecelving Hosplual, $108 \mathrm{~S}$ IIIII St. Los Angeles, Cal. Fastablished 1889 : seneral; 16 beds; C. E. 7ertong. chlet surreon.

Methodist Hosplial of Southern Call cornla. 2825 S. Hope St., Ios Angeles Cal Established 1909; Reneral: 120 beds; C. Armstring. R.S., superintendent

Misgion Hospltal, 1148 S. Figueroa s: Los Angeles, Cal. Mrs. Lutura Jamison,

Paclic Hospital. $1929 \mathrm{~S}$, frand Are. Los Angeles, Cat. Establlshed 1899; gen eral; 60 beds; W. M. Lew!s, M.D. pres! dent and manager.

Pasadena sanltarium. (located at South Passdena): oflce. 933 Tlile Insurance Bldz: Los Angeles. Cal. rstablished 1907 ; prlsate; zenersl inralldism: for nervous and mental diseases: 60 beds T. W. Bishop and E. J. Blttian, physi lans In charge.

Radium Sulphur Springs, Melrose and Gower Sis., Los Angeles, Cal. Establlshed 1908 ; prlvate: $\mathbf{4 0}$ beds; G. P. Gehring. physiclan In charge.

Salration Army Industral Home, $12-$

Wilmington S?.. Los Angeles, Cal

Salration Army Rescue and Maternlty Fome, $26 \pi 0$ X. Grimin St.. Los Anzeles, beds: M. Lee Martin, M D superlntendent.

Santa Fe Cosst Ltnes Hosplat Assocla t!on. St Louls and 6th Sis. Los Anceles. Cal. Fistablished 1899: prirate ployees only: 80 beds; $x$. H. Morrlson. chlef surgenn.

Santa Rita Hospltal. Ios Anzeles, Cal. Fstablished 1902 : public and prirate: speclal department for tuberiulosl cases: 3 beds: MIldred Irene Frost, G.N., superIntendent.

Southern Callenta Ssnatorium, Seml. Troplc l'ark, Los Angeles, Cal. Estab. lished 1911: private; tuberculosis: :0 beds: C. A sbeprard, medical directorst. Anues Maternity Hosplial, 1503. Figueroa st. Los inzoles. Cal. Fstab. *. Menonalit superintenden:

Victorla l'rivate llexpltal, 1001 F. :9th St. Iris Auceles Cal b'stabllsbed 1918. ceneral: In beds; Maude Y. liroddy, R. sumerintendent.

Westlake Itospltal, 6te s. Alrarado si. los Angeles. (a) Establlshed 190\%: gen eral: 25 leels: P. Mt. Helbourn, residen: nlyoiclan: Anna Shaw, superlatendeut Woman's llospilal, lats s. Flower : cos Anteles, Lal Mrs I D liste. matron.

Women's Alliance Maternlis

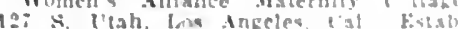
liwhed 100:: matemite

Nir li McNelle phyviosn la chare

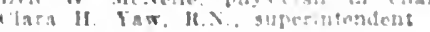
los ciatos

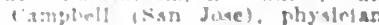
ar.turb. Iov cintus, Cal Fos

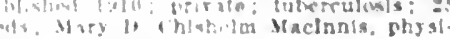
an in rliasec 
Maricopa Maricopa Hospltal, Marlcopa, Cal. Es-
tablished 1911; private: 14 beds; H. N. 'Taylor, physician in charge.

Martinez

Contra Costa County Hospital, Martinez, Cal. Established 1880; mblic; T0 beds; w. A. Hough, suncrintendent.

Marysville

Rideout Memorial Hospital, 5th and $\mathrm{F}$ Sts., Marysrille, Cal. Establlshed 1908 private: general: 35 beds; Funnie $\mathbf{E}$ Southern, superintendent.

St Francis IIospltal, Marysville, Cal. 25 beds; Mrs. Duran. superintendent.

Yuha County Hospital Marysville, Cal.

Established 1864 ; general; 99 beds; Chas. H. Bell, superinfendent.

Mccloud

McCloud Mospital, MeCloud, Cal. Established 1900: public and private: general: 24 beds; Robert T. Legge, surgeon In chief

Mentone

St. Thomas Aquinas Sanatorium, Mentone, Cal. Established 1901: tuberculosis only ; 30 beds; G. G. Moseley, physiclan in cliarge.

Merced

Nerced Sanatorium, 356, 21st St.,

Merred. Cal. Established 1909; general

12 beds: Edna Boling, superintendent.

\section{Mill Valley}

Mill Valley and Mt. Tamalpals Sanltarium. Mill Vallev. Cal. Private: 35 beds: Frank T. Lamb, physician in charge.

\section{Modesto}

Evans' Hospital, Modesto, Cal. Estab-

lished 1910; private; general; 25 beds

C. W. Evans, physiclan in charge.

Modesto Sanitarium. Modesto, Cal. Established 1903: general: 30 beds: B. F Surryhne, physician in charge.

Monrovia

Pottenger Sanatorium for Diseases of the Lungs and Throat, Monrovia, Cal. Established 1903; office, Title Insurance Bldg., Los Angeles; tuberculosis; 100 beds; Francis Marlon Pottenger, medlcal director.

Sce Special Announcement Adv, page 52

Napa

Benj. Shurtleff Hospital, Callsioga Ave. and $G$ St.. Napa, Cal. Established 1911; general; 10 beds; S. M. Doherty, L. Welti,

E. Z. Hennessey, physlcians in charge.

\section{National City}

Elwyn Sanltarlum, Natlonal Clty, Cal. Established 1913; public: 16 beds; E. S. Coburn, physician in charge.

Paradise Valley Sanitarium, National Clty. Cal. Estabijshed 1904; general: 70 beds; Wm. J. Johnson, physician in charge.

\section{Needles}

Coast Lines Hospltal, Needles, Cal. Established 1888; for rallway employees principally ; 7 beds; A. S. Parker, physlcian in charge.

Needles Cottage Sanatorium, Needles, Cal. Established 190\%; tuberculosis; 30 beds; Chas. A. Shepard, physician in charge.

\section{Nevada City}

Nevada County Hospital, Nevada City Cal. Established 1855; general; 100 beds

Alfred $H$. Tickell, physician in charge; $G$.

A. Stewart, superintendent.

Watson-Peterson Sanitarium, Nerada

City, Cal. Private; 6 beds; Miss E. McD.

Watson, superintendent.

Oakdale

Oakdale Hospital, Oakdale, Cal. Established 1911; general; 8 beds; Myrle Lewis, superintendent.

Thompson Sanitarium, Oakdale, Cal. Private; J. G. and 1. B. Thompson, physicians in charge.

Oakland

Acropolls Sanatorium, 24th Ave. and E. 26th St., Oakland, Cal. Established 1908; general; 25 beds; Ida M. Sanderson, superintendent.

Dr. Case's Sanitarium, 3423 Webster St. Orkland, Cal. Establisbed 1905 ; for alco- hol and drug addiction cases only; 18 beds; C. L. Case, phystelan in charge.

Sce special Announcement dur. paye 80 Claremont Ilospital, Oakland, Cal. Established 1895; public and private; 50 beds; operated by Claremont Hospltal Association; Loulse Adams Krone, superIntendent.

County Recelving Hospltal, 5th and Franklln Sts., Oakland, Cal. Public, 20 beds; emergency cases; 0 . D. Hamlin, medical superintendent.

East Bay Sanatorium and Maternity Hospltal, 3113 Telegraph Ave., Oakland, Cill. Fistablished 1895 ; private; 37 beds; Mllsses Mary Hall and Ellzabeth Wilson, superintendents.

Fabiola llospltal Assoclation, Moss Ave. and Broadway, Oakland, Cal. Established 1876 ; general; 125 beds; Board of Managers, in charge.

Fred linch Orphanage, Oakland, Cal. Established 1891; general; 150 beds; R. L. Jump and W. M. Beckwith, visiting physicians: Mrs. Pauline E. Towne, superintendent.

Juvenile Detention Home of Alameda Co., 419, 19th St., Oakland, Cal. Established $1906 ; 20$ beds; A. S. Kelly, physiclan In charge.

King's Daugliters of Californla Home for Incurables, 3900 Broadway, Oakland, Cal. Established 1897 ; public ; special department for tuberculosis cases; 100 beds; $A$. S. Kielly, physician; Mrs. K. J. Simmonds. superintendent.

Nauheim Sanltarium, 470, 28th St., Oakland, Cal. Established $190 i$; private; 50 beds; H. S. Maxson, physician; W. H. Maxson. surgeon in charge.

Oakland Central Hospital, 524 Wlllam St., Oakfand, Cal. Estahllshed 1905 ; pubIlc; 25 beds; Miss Carty, superintendent. Oakland Maternity Hospital, Inc., 157 Grand Ave., Oakland, Cal. Establlshed 1910 ; 12 beds; Mrs. Maude Barnes, supt. Pfund-Dietz Orthopedic Sanitarium, 12.25 Washu St., Oakland, Cal. Established 1908; private; H. L. Dietz, physlcian in charge.

Pruvidence Hospital, Broadway and 26th Sts., Oakland, Cal. Established 1905. public; 80 beds; Sisters in charge.

Samuel Merritt Hospital, Hawthorn and Webster Sts., Oakland, Cal. Established 1909; public; 80 beds; Theo. Olmsted, physician in charge; Miss Lillian White, superintendent.

St. Anthony's Hospital, 827 Brush St., Oakland, Cal. Established 1905; public; 70 beds; M. M. Enos, surgeon-in-chief ; Miss D. Climm, superintendent.

St. Joseph's Home for the Deaf Mutes, 4002 Teleyraph Ave., Oakland, Cal. Oceane

Halcyon Sanatorium, Oceano, Cal. (Halcyon P.O.). Established 1906; nervous, narcotlc and alcohollc; private; 25 beds; Wm. H. Dower, medical supt.

\section{Orange}

Orange County Hospltal, Orange R.F.D.,

Cal. Established 1902; general; 60 beds;

John Wehrly (Santa Ana), county physlcian, In charge.

Oreville

Butte County Infirmary, Oroville, Cal.

Estublished $18 \div 9$; public ; 100 beds; W. F.

Gates, physician in charge; M. L. Copeland, superintendent.

Oroville Hospital, Oroville, Cal. Established 1906; 20 beds; Miss Agnes Currln, superintendent.

Park Sanatorium, 422 Bridge St., Oroville, Cal. Established 1911; general; 10 beds; Miss Charlotte Reagan, supt.

Oxnard

St. John's Hospital, Oxnard, Cal. Established 1908; general; 40 beds; $W m$. R. Livingston, A. A. Maulhardt and Allen Peek, physicians.

\section{Palm Springs}

Desert Inn, Palm Springs, Cal. EstabIIshed 1909; nervous and tuberculosis; 30 beds; H. L. Cofiman, medical superintendent.

\section{Palo Alto}

Peninsula Hespltal, Churchill Ave, and Cowper St., Palo Alto, Cal. Established 1910 ; general; 40 beds; Mrs. M. E. Barry, superintendent.

\section{Pasaden a}

Ballard Pulmonary Sanitarium, Mary and Delacy Sts., Pasadena, Cal.

Las Encinas Sanitarium, Pasadena, Cal. Established 1904; general and nervous disense; 55 beds; Stephen II. Smith (Los Angeles), physician in charge.

La Vina Sanatorium, R.F.D. No. 2, Pasadena, Cal. Established 1910 ; private; tuberculosis; 60 beds; Henry B. Stehman, medical superintendent ; Caroline McQuiston, resident physician.

Martyn Sanatorium. Pasadena, Cal. Established 1910; private; 20 cottages; tubercular cases; Geo. Martyn, physiclan in charge.

l'asadena Hospltal Assoclation, Pasadena, Cal. Established 1892; Beml-prlvate: general, except contaglous dlseases; 100 beds; Mlss Llla Pickhardt, R.N., superintendent.

Petaluma

Dr. Hufiman's Sanltarlum, Petaluma,

Petaluma General Hospital, 6th and I Sts., Petaluma, Cal. Established 1906; private; 26 beds; Mrs. Elsa Little, superintendent.

\section{Placerville}

El Dorado County Hospital, Placervllle, Cal. Established 1860: public; general; county almshouse and hospltal; 70 beds; L. M. Lelsenring, physlclan in charge. Placerville Sanatorium, Placerville, Cal. Established 1904; general; 20 beds; W. A. Reckers, physician in charge.

Wrenn Sanatorlum, Placerville, Cal. Established 1912; general; 12 beds; Jos. Wrenn, physican in charge.

\section{Pomona}

Pomona Valley Hospltal, Pomona, Cal. Established 1904; general: 45 beds; Miss Mabel Wickersheim, superintendent.

\section{Portersvilio}

It. Whitney Hospital, Portersvllle, Cal. Established 1908; maternity and surgical: 6 beds; Lyda Buck, superintendent.

\section{Red Blufi}

St. Elizabeth's Hospital, Red Bluff, Cal.

Established 1908; public; 14 beds; Sisters of Mercy, in charge.

Tehama County Hospital, Red Bluff, Cal. Established 1886; general; 50 beds; Ernest E. Thompson, physician in charge; E. J. Conard, superintendent.

\section{Redding}

Shasta County Hospital, Redding, Cal.

St. Caroline Sanitarium, Pine and Sacramento Sts., Redding, Cal. Established 1907; general; 15 beds; F. Stabel. M.D., superintendent; Mrs. M. F. Crawford, matron.

Redlands

Redlands Hospital Assoclation, Clark and Nordina, Rediands, Cal. Established 1904; general; 36 beds; T. M. Blythe, physician in charge; Josephine Archer, superintendent.

\section{Redonde Beach}

Redondo Beach Hospital, Redondo Beach, Cal. Established 1913; general; 18 beds; Mrs. Bessle Ashley, superintendent.

\section{Richmond.}

Abbott Hospital, Richmond, Cal. Establlshed 1908; private; 30 beds; C. L. Abbott (Pt. Rlchmond), surgeon; L. A. Martin, physician in charge.

\section{Riverside}

Riverside County Hospital, Rlverside, Cal. Established 1893; public; 70 beds; S. D. Pettes, superintendent; W. W. Roblee, medical director. 
23 beds: H. J. Hund, medical superin. tendens.

\section{Round Mountain}

Shasta Land and TImber Company II $\mathrm{s}$ plial. Terry's Mtlls, Round Mountaln. Cal.
Fstablished 1904: ceneral; 5 beds : T. S. Long. M.D., superintendent.

\section{Sacramento}

Home of Merclful Savlor for Inralld Chlldren, Sacramento, Cal. l'ublle; 25 Cels. 31 rs J C Ifiudson superiutundent Igo Sanitarium, $15 \div 5 \mathrm{~L}$ st.. Sacramento Cal. Establlshed 1910; private: 10 beds: Loulse Igo, physician in charge.

Marquerite Home for Iged Women, 161\% ith St. Sacramento, Cal. Fistabilished 1884; Reneral: 20 beds: S. E. Slmmons. attending physiclan; Mliss s. If. Clarke, superintendent

Mater Misericordiae Hospltal, 23d and R St. Sacramento, Cal. Established 1895 . maintalned by Sisters of Merey; general maintalned by Sisters of Merey ; general:
163 beds: J. A. Slgwart, medlcal super163 beds

Mlaternity llome, $1818 \mathrm{~N}$ St., Sacramento, ('al. 15 beds; Mrs. J. E. Ruggles, superlintendent.

Sacramento City Receiving Hospital. Sacramento. Cal. Established 1SSj; putlic: emergency: 5 lieds: $W . k$. Lindsay. physlctan lis charge. Sacramento County IIospital, Epper
Stockton Rd. Sacranento, Cal. ExtabIlshed 1859; feneral: $32 \%$ beds; J. H. Harris, medical superintendent.

is, medhem lactfle Company Emergeney nospital. Sacramento. Cal. Established 1850 : for comuany employees: 25 belds F. K. Ainsworth (San Franclsco), visiting physlclan.

Toklo Sanatorium. Sacramento, Cal.

Wentworth Jospital, 2516 l St., Sacramento. Cal. Established 1900; private; 30 beds; E. M. Wilder, physieian in charge Mlss Dorothy Burns, superlatendent.

White Hospital, 2yth and J sts., Sacra. mento, Cal. Established 1910; gereral 60 lieds: J. L. White, madical superintendent.

\section{Sallnas}

Jitu Bardin Ilospltal, Salinas, Cal. Establlshed 1yot; ferieral: 20 berls; Miss $U$.

L. Cresson, l. N., superintendent.

1. Cresson, h..., superintendent.

Established 1856: publie; 69 beds; S. B. Gordun, attending whysician.

Salinas Valley Santariun, Salloas, Cal.

Sami. B. Gordon and Garth Yarker, physlclans in charge.

\section{San Bernardino}

Bennette sanitarlum, 5 th and D Sts.

San Bermardino. Cal. Fistablished 1911

general: 14 beds: 3. A. Bennette, phys! caan in charke.

Kamona Huspltal, San Bernardino, Cal. Establistied 1910: Drisate: cencal: beds: H. W. MiUs, M.L., superintendent. San Bernardiso Cuunty Hospulal, San Bernardmo, Cal. Established 15 it: publie: general; 150 teds; I'blllp 34 . Savage, physiclan in charce.

\section{San Diego}

Azuew Sanltarium and IJospltal. 5th and Beech Sts., San biego, Cal. Extabliwherl 189y: keneral: takes U. S. Marme llospital patients: 100 veds: ir. Guchenauer.

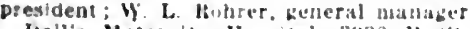
Inall Maternity Hovpital, 3920 is si.

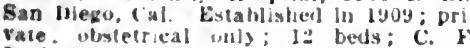
Vale. obstetrical chly;

Isolation Huspital, San Dlego, Cal. Fossablished 190\%; small-bux only: 20 beds: C. C. Valle. whisictan in charge.

San Vieko county leneral flospleal, san Dleso, ('al. Establlwhed Ixsz; general: 250 becla: 1. 1O. Webster, whyslclau charge.

St. Joseph's Sanltarfun, 6th st. ant Cnirersity Ave., San lolego, Cal. Estat. Iished 1890; maintulned by sisters of Merey : publle: I:0 beds; I'. C. Memutudino, Ban Franclisco

Adler sanainrlum, 1590 Kroadway, San

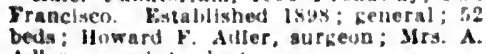

Bering Sanltarium, 300 Page St., San Francisco. Fistablished 1902; private; for aleohol and drug addiction cases: 20 bedy: K. F. Hering, physlclan in charbo; Miss
M. B. Hrazelton, supertntendent.

Buena Vista sunatorlum. 21 Buena Yista Are. San Francisco. Kistabllshed is93; private; 55 beds; $\$$. F. Long, manager and chief surpeon.

iafifurna Conflnement Home, 2012 Folson si. San Franciseo.

Callfornia Sanatorlum. San Franelseo. Estallished 1910; private; tubereulosis: 60 leels; Max Rothsehild, uhysiclan in charge.

('ity and County Hospltal, Rellef Home Tract, San Francisco. Established 1850 public: 350 beds in general bospital, liji) beds in special department for tulerculosis cases: Departnent of l'ublle Health, chirge: C. II Wollenberk, warden.

Emergency Hospltal Service, San Fran. clseo. I central and \& branch knergency Hospltals wlth ambulanee sersice: 1 insane lletentlon Hospltal; publle; general 60 beds; Board of llealth in eharge Florence f'rikenton liume, 3i6, 20ih Are., San Frilucisco. Established sy. public: firls and womon: materity; 25 beds; Mrs. M. S. Loton, inanager.

Floreace $x$. Ward Sanatorium, 119. Ilyde St., San Francisco, Establlshed 1911 ; surglcal and maternlty; 30 beds Florence $x$. Ward, plasteian in charge: Chrlstlue $C$. Mlnugh, superlntendent.

French llospltal. San Francisco. Established is;2; general; 250 beds; J. Jacobs, resident phystian; Joln Arees, superin. tendent.

litruan IIospltal, Ith and Noe Sis. San Franclsco. Evtahlished 1854; General: 250 beds: Frank \$. Fimal, resluent Dluysichan; W. Roeht, superlutendent.

Ilahemann Hospital, Callornia and Manle Sis., San Francisco. Established 1945; genera!; 140 beds; W. Maguire. superintendent.

Hebrew llome for Aged Dlsabled, 2504 How ard st., san Franciseo. Established 1584: general: 35 beds; E. M. Weiss. risiting ploysictan; F. M. Gladstone, pliysiclall in charte.

llospital for Chlliten and Training Sehoul for Nurses and Alexander Mater nlty Cortage, 3700 Califorma st., San beds; Jean M. Jartin, resideut phrsieias In cliarge: Win. 1). Scurlock, suyerintendeut In charge.

Hospital of Veterans' Ilome, 333 Kearny St. San Franciseo. Established lsst: public; general; 20 heds; Col. W. M. Mc

Irsing Sanatorium, 906 Ealdy St., San Framelico. kistablished lulls: private genteral: 14 beds; " M. Mtelean. chie? surfeon: Filla c. Irving. superintendent. lsolation IIospital, Ita Harn and Army Sty sall Eranceseo Estiblished lavopublie: for leprosy, small-pox and bubinle matue cases: 100 beds: Hepartment of Jublic llealeh, In charge: Aribur
O'tell, physician-In-chitel and superin Jubly's Sanatorium, IJoward and zlst

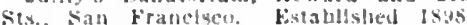
private: 35 preds; lieo. If. Jullly, myst ciall III cliario.

Lane llnoplat, stanford lnisersity Meelienl beyartment, Clay and Weloster sts. San fratuensey, Estathislied ts:ot fublic and provate; semeral: li5 beds:

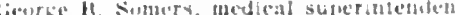

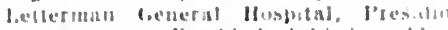

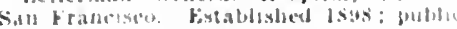

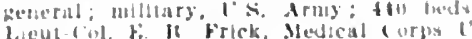
s. Amy in cummatul

hifery Ilosplal corporation. I'blon

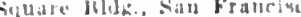

MeNutt !lospital, loss lilte st, san

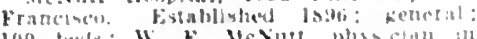
100 be
cliarase

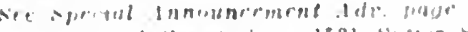

Mernorial sanatorluru, 1321 Sutter st.

San trancinen.
Misston Branch Eusergener Hospltal, 23d St. and l'otrero Are., Sin Francisco. Established 1400

Mrancisco. Hospital. ij Ce's st. San beds: A. W. Morlon, whystolan ln charge Mi. Zlon Hospltal, 2341 surtet st. San

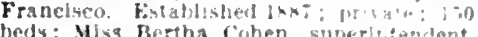
lacifle llebrew irman disymara and

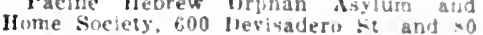
sllver Are. San Fraricisco. Established 18.3 ; privite: for orbhans and the aed 18.3 ; profate: for orbhans and the acel:
240 beds: Sanuel l.anger and Gustar Schnee, superintendents.

Park Emergency Hosplal, Stanjan st. near Waller. San Franeiseo. Establlshed
189 .

Post llospltal. Ft. Mlley. San Franelseo. Established 1902; ceneral; 14 heds; W. H.

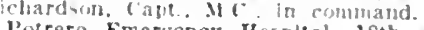
Potrero Emerzency Ifosplial, 18th and lished ig03: public; 12 beds; Mlasson Teets, physiclan in charge.

liellef Honse of Azed and Infirm, san Francisco. Eutahlished 1854 ; public: 1350 beds: 250 chronle beds; $17 \mathrm{~m}$. liennes and M. I Judell, surgeous; C. M. Wollenterb. superintendent.

San Francisco Hone for Incurables. 1412 Fulion Si., Sin Francisco Establlshed 1908 ; pritate: 30 beds: W. E. San prapenting phssteran.

San Frapciseo IIospital, Potrero Are. and :2d St. san Francisco.

San Franeisco Lying-in Home, 1191 Oak maternlty; 25 beds: Franklin k. Lord, physician in charze; Mrs. Mary Fon Allmen. superłntendent.

San Franelsch lylng-In Hospital, $\$ \$ 33$ Clement Si., san Franciseo. Enstablished 1 stis; public; 12 teds; Einily G. Llarrison, passician in charge.

San Frauclsto Yaternl1s. 1135 Valenels St. San Francisco. Exiablished 1904: private: charitalue: maternits: Aired Baket spalding. medical director.

San Franeisen pulyclianc Huspleal and Post fitaduate schoul. lijtj Jackson st. Sati Franciseo, Fostablished lsis. private general: 10 bets; chas. (i. Levison. plisslcan in ehatpe.

Sua Franclsco Sabatorlum, 1911 Van
Ness Are., san Franchero. Establlshed 1911: nersuis and ateobolic: 15 beds: I1. I. Batchelder, sujerintendent.

Segrewation Hosmial for women, $6 \& 4$ Commercial st. san Francisco. Wm. F.

Sulthern Paciflc Company li spltal. Fell and Haker sis. sian Franeisco kstabplovees only; 270 beds: $r$. K. Mansworth cluaf surfein and maniser.

St. Catherine's Home and Tralming

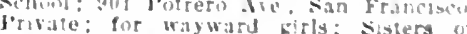
Mercy, in charge

sit. Franeis llosplal, Mush and Hyde generall 120 heds: John liallwey, brest dent: Mlss Elizabeth It Jaru,csin, suver Intelident.

Sil. Juseph"s II ospatal and Hoine, l'ark

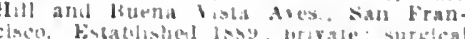

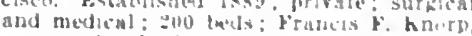
sureenn-tn-chief; Wu. Itamiarten, vigit-

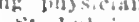

Sit. luhe's Hespital, Vinteme: and ormy

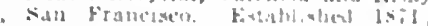

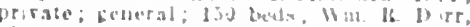

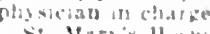

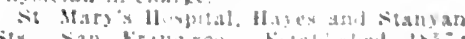

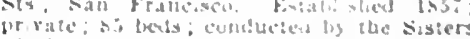
$\because$ Mere

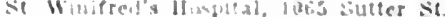

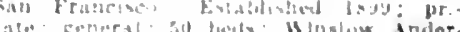

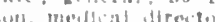

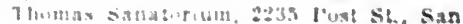

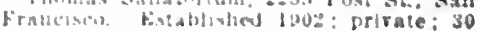
Leviv; Mrs. Dupa Theouss. sumeriatendent.

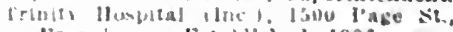
san Prancisco Esbatulined 1906: Een-

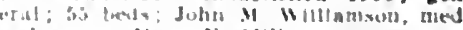
teal supe; Mary V. Mlllas, matron. 
Union 1ron Works Company Employecs Llospitul, Pennsyivania Ave. near 18th Hospital, Pennsyivania Ave near 1907; st., San Francisco, Estabilshed 1907 beds; William Eugene Buoli, physlcian in charge.

United States Mariue Mospital, 13th Are. and Lake Sts., San Franclsco. Fs tablished 1875; pubilc; general; 150 beds : R. N. Woodward, surgeon in conimand.

University of California Hospital, 2

and Parnassus Are., San Francisco. Es and 1907 ; public ; reneral ; 100 beds John $A$. Kluge, acting superintendent.

\section{Sanitarium}

St. IIclena Sanitarium and IIospital Santarium. Cal. Established 1878; nublle : teneral : 125 beds; George Thomason, physician in charge.

Nee special Announcement $A d r$. page $7 \mathrm{r}$ San Jose

Belvedere Hospital, 115 N. 5th St., San Jose, Cal. Established 1906 ; private; 40 beds; Misses Roseberg and $\Lambda$. Phelps superintendents.

Bird IIaven Hospital, Pomona and McClellan Ares. San Jose, Cal. Establislied 1907 . private. for nervous and backward children: 16 beds; Mrs. Sarah Wood, superintendent.

Blaney Isolation Hospital of O'Connor Sanitarium, Race and San Carlos Sts. San Jose, Cal. Established 1910; pubilc infectious diseases; 14 beds; Sisters of Charlty, in charge.

City Recciving Hospital, San Jose, Cal. Established 1888; public; admits police cases and city indigents; K. C. Park, medical superintendent.

Columbia Hospital, S. Market St. and Auzerais Are. San Jose, Cal. Established 1912 ; private; 30 beds; Mrs. F. H. Paterson, superintendent.

Garden City Sanitarium, San Jose, Cal. Established 1898; general; 50 beds; Lewis J. Belknap, physician in charge.

Japanese Hospital, 565 N. 5th St., San

Jose, Cal. T, Kuwahara, superintendent.

Nippon Sanitarium, San Jose, Cal. Establlslied 1908; private; 24 beds; Japanese Hospital Association, in charge.

O'Connor Sanitarium, Race and Sa Carlos Sts., San Jose, Cal. Established 1889; public: general; 110 beds; J. Un derwood Hall, president of medical board; conducted by Sisters of Charity.

San Jose Sanitarium San Jose, Cal. Sisters of Charity, in charge.

Santa Clara County Hospital, Santa Clara Valley, San Jose, Cal. Established 1885; public and private; general; 17 beds; D. R. Wilson; physician in charge.

Woman's Hospital, San Jose, Cal. Es tablished 1907 ; private: 12 rooms.

Women and Children's Hospital, 5th and Reed Sts San Jose Cal Established 1911 ; public ; 20 beds; Mrs. Mabel B. McTernan and Miss Olive P. Waiton, stuper intendents.

\section{San Leandro}

Alameda County Hospital and Infirm ary. San Leandro, Cal. Established 1868 public: general; 600 beds; C. A. Wills medical superintendent.

San Luis Obispo

County Hospital, San Luls Obispo, Cal. 60 beds; .J. F. Lewis, superintendent

Pacific Hospital, San Luis Obispo, Cal Established $1910 ; 25$ beds.

San Luis Sanitarium, San Luls Obispo, Cal. Established 1902; general; 25 beds: W. M. Storer, physician in charge.

\section{San Mateo}

Church of St. Matthew Red Cross Hos pital, San Mateo, Cal. Established 1908 general; 50 beds; W. C. Chidester, physi cian in charge.

San Mateo County Hospital, San Mateo, Cal. Established 1876; public, general, 50 beds; Wood C. Baker, county physician in charge; J. R. Eubanks, superintendent.

San Rafael

El Sereno Sanitarium, San Rafael, Cal. Established 1898; prirate; for the aged and infirm; 15 beds; Kate Lydon, R.N., in charge.
San Rafael Cottage Ilospital, San Rafacl, Cal. Estabilshed 1905; private: 16 beds: no contagious cases accented IIrs. L. M. Adams and Mrs. E. Schaer, Ars. L. M. Adam

San Rafael Sanitarium, San Rafael Cal. Estabłished 1906 ; private ; 16 beds; Wade J. Stone, physician in charge.

\section{Santa Ana}

Santa Ana Hospital Assoclation, Santa Ana, Cal. Established 1902; private ; 50 beds. II 13all, physiclan in charge Katherine Rutherford, matron.

\section{Santa Barbara}

County Ilospital, Santa Barbara, Cal Established 1890: public: 30 beds: Thos. Hicks, superintendent.

Miradero Sanitarium, Santa Barbara Cal. Established 1898; private; 25 beds Miss Bradford, superintendent.

Santa Barbara Cottage Hospital, Third Ave., Oak Park, Santa Barbara, Cal. Established 1892 ; public; general; 50 beds Mrs. Laura I. Mitchell, R.N., superintendent.

Santa Barbara Sanitarium, Santa Bar bara, Cal. Established 1908; private; 8 beds.

St. Francis Hospital, Santa Barbara, Cal. Established 1904; general; 30 beds Sisters of the Order of St. Francis in charge.

\section{Santa Clara}

Osborne Hall, Santa Clara, Cal. Established 1901; private; for feeble-minded and old and mental diseases; Antrim F. Osborne physician in charge.

\section{Santa Cruz}

Hanly Sanitarium, Cliff Drive and Beach Hill, Santa Cruz, Cal. Established 1904; general; 35 beds; Bessie McHugh. superintenden

Mission Hill Sanitarium, Santa Cruz, Cal. Established 1908; private; 14 beds M. J. Gates, superintendent

Santa Cruz County Hospital, Emeline. St., Santa Cruz, Cal. Established 1880; public ; general; 80 beds; W. H. Keck, physician; B. F. Crews, superintendent.

physician; B. F. Crews, superintendent.

Santa Cruz Sanitarium, Santa Cruz, Cal.
Established 1903; private; 20 beds; Miss Daisy Fauglit, superintendent.

\section{Santa Monica}

Ideal Sanitarium, 4th and Oregon Sts Santa Monica, Cal. Established 1909: private; 20 beds; Mrs. L. B. Mullen, superintendent.

St. Catherines Hospital, Santa Monica Cal. Established 1907; general; 25 beds Catherine T. Lowery, superintendent.

\section{Santa Rosa}

Katharine Sanitarium, Santa Rosa, Cal. Private; 15 beds; Míss Silvia Hatch, superintendent and matron.

Mary C. Jesse Hospital, 815, 5th St., Santa Rosa, Cal. Established 1908; prirate; 17 beds; J. W. Jesse, surgeon in charge.

Santa Rosa Hospital, 741 Humboldt St., Santa Rosa Hospital, ple and J. IV. Scamell, surgeons in ple and J. W. Scamell, surgeons charge; Miss Marion Hill, superintendent.
Sonoma County Hospital, Santa Rosa, Cal. Established 1877; public; 50 beds: P. A. Meneray, physician in charge.

\section{Saratoga}

Odd Fellows Home of California, Saratoga, Cal. Established 1895; private; for indigent odd Fellows, their widows and Rebekas; 28 beds in hospital ; Geo. IV. Burgess, medical superintendent.

Scotia

Scotia Hospital Association, Scotia, Cal. Established 1910; public and private; general; 30 beds; E. L. Cottrell, medical superintendent.

Shaver

Fresno Flume and Lumber Company Hospital, Shaver, Cal. Established 1895; private; general; 12 beds; Louis A. Frary, physician in charge.

Sierra Madre

E1 Reposo Sanatorium, Sierra Madre, Cal. Established 1892; 40 beds; tubercuiosis; Geo. F. Washburne, physician in charge.

Soldiers Home

National Home for Disabled Volunteer Soldiers, Paciflc Branch, Soldiers Home,

Cal. Estabilished 1888; 302 beds.

\section{Sonoma}

Broadway Sanitarium, Broadway St., Sonoma, Cal. Established 1906; private: 10 beds; medical and surgical; Mrs. T. H. Green, matron.

\section{Sonor}

Bromley Sanltarlum, Sonora, Cal. Fstablished 1903; prlvate; general; 40 beds;

R. Innis Bromley, physician in charge.

Sierra Ilospital, Sonora, Cal Established 1907; private; 10 beds; E. T. Gould, physician; Misa R. Costa, superintendent.

Tuolumne County Iospital, Sonora, Cal. Established 1896 ; public; 100 beds; $\mathbf{E}$. T. Gould, physician in charge; Andrew Shine, superintendent.

Soquel

Beechler's Sanitarium, Soquel, Cal. Established 1902; private; for asthma and chronic diseases; 25 beds; James Beechier physician in charge.

\section{South Pasadena}

Pasadena Sanitarlum.

(See Los Angeles.)

\section{Stirling City}

Stiring City Hospital, Stlrling City, Cal. Established 1911; private; general 20 beds; Joseph R. Cornell, M.D., superintendent.

\section{Stockton}

Clark's Sanatorlum, Centre and South Sts., Stockton, Cal. Established 1871. private: nervous, mental narcotic : 75 beds; R. B. Knight, attending physician Mr. James M. Anderson, superintendent.

Dameron Hospital, $1045 \mathrm{~N}$. Lincoln St. Stockton, Cal. Established 1912; private; 60 beds; J. D. Dameron, medical superinendent.

Ricker's Sanitarium, 1629 E. Washing ton St., Stockton, Cal. Mrs. K. A. Ricker superintendent.

St. Joseph's Home and Hospital, Stockton, Cal. Established 1899 ; private; 170 beds; Dominican Sisters, in charge; Miss A. McDonald, superintendent of nurses.

Stockton City Emergency Hospital,

Stockton, Cal. Established 1905; 12 beds:

L. R. Johnson, surgeon in charge.

\section{Sugar Pine}

Sugar Pine Hospital, Sugar Plne, Cal. Established 1902; general; 18 beds; Frnest Winton Cleary, physician in charre. See Special Announcement Adr. page 81

\section{Sutter Creek}

Sutter Creek Sanitarium, Sutter Creek, Cal. Established 1907; general; 22 beds: Taft

Taft General Hospital, Taft, Cal 20 beds; M. W. Pascoe, physician in charge.

Truekee

Truckee Hospital, Truckee, Cal. Established 1907 ; private ; 20 beds; Leta $A$ Hudspohl, manager.

Tulare

Tulare Hospital, 134 N. 6th St., Tulare, Cal. Fstablished 1907 ; general ; 8 beds Miss Katherine Stacy, superintendent.

Tuolumne

West Side Sanitarium, Tuolumne, Cal Establish 1900; private; 12 beds; E. H Reid, superintendent.

Turlock

Turlock Sanatorlum, 601 Marshall St.

Established 1911; general; 12 beds; Pearl Battey, superintendent.

\section{Upland}


Vallejo General IIospital, Vallejo, Cal. Establlshed 1911; general; 25 beds; Mary II. Bradles, superintendent.

\section{Ventura}

Ellzabeth Bard Memorlal IIospital, 609 Flr St. Ventura, Cal. Established 1901: private; general: 22 beds; Margaret E: Waller, superlutendent.

Visalla

Fenwick Sanltarlum, Vlsalla, Cal. Establtshed 1908; general; 10 beds; sliss D. V. Fenwick, superintendent.

Tulare County llospltal, Vlsalla, Cal. Establisbed 1861; public; 25 beds; Frank Osburn, superlntendent.

Visalia General Hospital, Vlsalla, Cal. Established 1910; prirate: : beds; Mlss E. A. Holland, sujerintendent.

\section{Watsonville}

Watsonville Hospital. Watsonrille, Cal. Establlshed 1895; prlvate; 14 beds; Bessie Sullivan, yuperintendent.

\section{Weaverville}

Trinlty County Hoxpital, Weaverville, Cal. Fistablisted 1550; public: keneral: 30 berk: E. E. llarrican, auperintendent

\section{Weed}

Weel Inspital. Weed, Cal. Established 1:04: 30 beds: contaglous diseases not ac. cepted: Wm. L. Tebbe, superlntendent

Whittier

Whitter Hospltal, Whittler, Cal. Gen. eral: 9 leds: Mrs. S. fi. Ford, superin. tendent.

\section{Willow}

Glen tounty IIospital, Willow, Cal. Established 1895 ; publlc; general; 30 beds: C. W. Lund, physiclan; Wr. Leake, superintendent.

1). Purktt's Sanatorlum, Whllow. Cal. Fstablished 1907; privato; maternity; i prels: Theodora T. I'urklt, medical superin:endent.
Wilmingten

l'elronuet Hospital, Wilmingtna, Cal Fstablished 1909; prirale; y beds: $\mathbf{F}$. M relronnet (Los ingeles), medical superIntendent.

Woodland

Woolland sanitarin. Wividand. Cal. Kostablished 1903: prirate; genceral: 25 beds; Fred It. balrchild, Mill, president Yolo County Hospital, Wordiand, I Established 1860; general; :0 beds; 1'. I' Lawson, superintenden:

Yreka

Mt. Shasta llospltal, Yreka, Cal. H:3tabilsted 1911: prirate; 10 beds: Chas. IIadley ('arlson, medical superintendent. Slskiynu County llospttal. Yreka. Cal. Established 1856: zeneral: i5 veds; E. F. Brickley. superintendent.

Yuba City

Susser County Ilospital, luba Clty, Cal. General: 26 beds: Allen F. Gray (Miarysville). physlcian in charge.

\section{PHYSICIANS OF CALIFORNIA}

ExplaNatory NoTE. Physicians In the Enlted States Indian serrlce and oftcers of the gorernment tredleal serrlces are not subject to the state practice act.

\section{KEY TO ABBREVIATIONS, SYMBOLS, ETC.}

Names in capltals signify membersbip in the County Soclety and State Assoclathon. (DOE, JOHX).

Indleates Fellowship in the Amerlcan

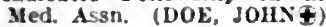
(b) Med. Assn. (DOE.

(b'i5) year of blrth. [medlc I, homeopath: E, eclectic; P-M, physlo Yid.7,09. College and year of gratuation. $\checkmark$ Information recelved does not show graduation.

S.-Surgeon.

ObG.-Obstetrlclan, Gruecologis:

G. Gynecologist.

Or.-Gynecologist.

Or.-Orthopedist.

Op.-Ophthaimologist.

A.-Aurist.

LR_Laryngologist, Rhlnologist. (l'\$9) Vear of llcense.

(¿) In practlce before passage of present law and licensed by thling diploma or by years of practlce.

(1); Licensed but year not known.

(市) Information received does not show llcense.

I.S.A. Cnlted States Army.

M.R.C., U.S.A., Medleal Reserve Corps.

SPECIALTIES ARE INDICATED AS FOLLOWS:

ALR.-Aurlst, Iaryngologist, Rhinologist.

OALR.-Ophthalmologist, Aurtst, Laryngolugist, Ihinologlst.

U.- Lrologist.

D.-Dermatologist.

Pd.-I'edlatrlst.

N.-Neurologlst.

P.-I'sychlatrlst.
U.S.N., Inlted States Nary.

M.R.C.. U.S.N., Medical Keserre Corps.

L.S.P.II.S., Cnited States I'ublic Ilealth

collece positions held are indicated by abbreviated title of postlion, followed by key number of college. For key to colleges see Inside front corer page.

(A1,3, 136. C4) Membership in special siocieties. (ste hey Table, page laz.)

\section{NP.-Neurologist, Psychlatrist.}

1.- Internist.

T.-Tukerculotheraplst.

Anes.- Inesthetist.

Lo.-Laboratory Dlagnosticlan.

R.- [Etst. Path.-Pathologist.

Bact.-Bacteriologist.

WHEN THE ABBREVIATION REPRESENTING A SPECIALTY IS FOLLOWED BY AN ASTERISK ( $\star$ ) IT INDICATES THAT THE PHYSICIAN CLAIMS HIS PRACTICE IS LIMITED TO THAT PARTICULAR BRANCH OF MEDICINE; WITHOUT THE ASTERISK. THAT HE IS ESPECIALLY INTERESTED IN, BUT DOES NOT LIMIT HIS PRACTICE TO. THAT BRANCH. THIS INFORMATION CONCERNING SPECIALTY IS BASED ON PERSONAL DATA FURNISHED BY THE PHYSICIAN AND IS NOT VERIFIABLE.

\section{CALIFORNIA}

\section{ADIN, 500, MODOC}

TIXSMAN, CHAS. M. (b'66) B-la.1.'98;

(1'00); (Indian Service).

AGNEW, 100, SANTA CLARA

(See Oakland.)

Cuttlag, James Arthur (b'83)-Cal.1, 11 : (1'11).

MACK, CLIFFORD WILMOT (b'84) Mleh.1,08; (l'13): Member Mlch. State Yled. Boc.: $\mathbf{P}$.

Mullen, Eugene Wendell (b'7t)-Mlch.1,05: (1'11): P.

stocking, l.eohard E. (b'49)-Mo.2.'76; (1'01): (E13): P.* White, Margarei (6':8)-Cal.2,09; (1'09)

ALAMEDA, 23,383, ALAMEDA

Ballard, Dorcas Laura Lowoll-Cal.I,'89: (1'90); 323i Brlgks Are.

Benjamin, F. W.-Mass.2,60; (1'81) : 2129 Buena Vlsta Are.

Bronson, C. W,-H-Cal.5,'84; (I'8i) : 1235 l'ark Ave.

Brow:, MAUItCE: W. (b'67) P-Pa.1,94: (1.04): 3223 Central Aro.: ođlce, 13464 Park st.: 2-t, 7-8.

BULLARD, CHAlliES TRFAT (b'i6) Cal. I, 10: $\left(11^{\circ} 10\right): 2037$ Clinton Are.

Burns, Rlchard Eari (b'84)-1a43.08; (l'12) : 1445 Fernalde Hlyd.
Card, Wm. S.

(See San Franclsco.)

(1.INESS, WM. ROBT. (b'35)-Ont.5,59: $(1 \circ-6)$ : retired; ano inion st.

Cluness, wm. Koss (bot)-Cal.2.'s?; (1'90): 900 Union St.

Crittenden, ('has. F.-II-Cal.5, 02 ; (1'02) ; 2300 Central Are.

b'Enelyn. Fredk. W.

(See San Eranclsco.)

1) ( ) : 1513 Finclnal Ave.

EIl.IS, JAll Es A. (b'Ts) \&-Cal.2,03; (l"(t) ; 1515 Benton St.; oflec, 2t05 silnta rlara die.

Fletcher Mary Delano (b'62)-Cal.1. $8 t^{\circ}$;

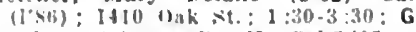

Fouchy, Alphonse 1).-II-Cal.5,87: (l'si): "31:il Santa Clara Are.: I-t.

IIAMI.TON, JAMES KIAll (b's0) —-('al.2. 0.t: (1'04): 1275 Wiber St.: onlce, 1217 Lincoln Are.; $1-3,7-8$.

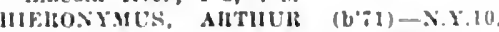
yi: (1002): s3i Laurel st.: oflece, libil lark sit. : i-3, $:-8$

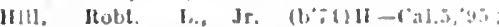
$(1905): 15 t$ kicrett st: NP.*

llosford, fidwh T. (hos)-In.9.93: (1.98)

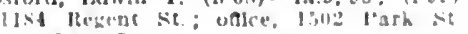
- $6,6-8 ; C$.

Hosford, Win. J. (b'66)-Cals.2.90) (1'98)

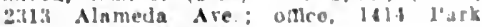
Ave.; 10-12, 2-4, 6-8.
KEYS, ERSEST M. (b'55)-la.1."7s; (l's9): 1725 San Jose Ave.: offce, 1361 l'ark St: $1-3,-8 ; \mathrm{Pr}$.

H.M. WM. TAPPAN (h'6s) T-N.15,95: (1"02): 1200 San Antonlo Are.: oflee, 1361 Park st. : $1-3, \vec{i}-8$

McQuesten, Chas. Aurustin (h't1)-N.L.L, tit: $\left(11^{\prime}, 6\right): 1529$ Cnton st. 1 -

MILER, HAHOID Al'STIX (b\%3)F (al. $, 03:$ (l'03): it0 Sauta Clara Are: nftice, 15 wis Welvier st: I:30.t. i-s; G. Mulnger, lirace (all, 04 : (1'04); 1542 Brendway; $10-12 ; N$.

()barrio, l'eter de.

(Sio San Franclsen.)

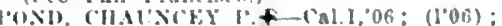
lollo Ceneral are. $3 \cdot 30-5$

lovil IIE⿰氵 (1.0); Mlaneda and central Aies. $1 \cdot 3$.

licevl. IBoardman (b't2)-I'a 1,"7s: (1999) $3 t 0$ S. Tiranada Ave

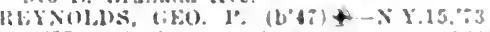

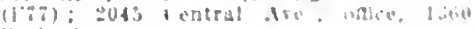
l'ark st

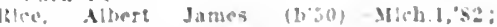
(101): 1019 Morton st

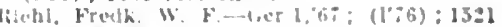

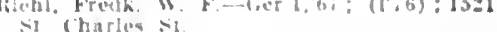

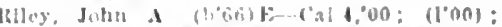

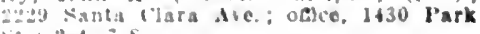

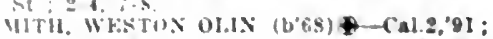

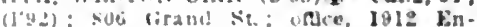
clual Ave.: 1-3, :-s. 
STAFFORD, AUREN ALFRED $\left(\mathrm{b}^{\prime} 60\right) \oplus$ Cal.1,96; (1'96); 1915 Santa Clara Ave. $\mathrm{I}-3,7-8$.

STEPIIEXS, JOHN MHLER.

(see San Franelseo.)

STEPIIENS, WM. BARCLAY.

(See San Franelsco.)

stlolbam, Lewis Whbur (b'6.3) - IH.1.', (1'91); 1729 Santa Clara Ave.; oftlee, istil Park Are. : 1 -4. $7-8$,

Sutcllffe, llenry I1, (b’70)-Ore.2,97; (l’99) 1400 J'ark st.; offlce, Alameda National Bank.

Tarter, Albert Preston (b'60)-Cal.2,'82 (l's.i) : 3101 Central Ave, office, 1.104 (1) St. ST)

'l'erry, Saml. I'erciral (b'61) - Ind.9,'96: $(199)$; 1834 San Jose Are.; offlec, 2405 Sinta clara Are.; 2-4, 7-8.

TISDAIE, CIHAS. LEWIS.

(See San Francisco.)
Tisdale, Thomas Price (b'30) H-0.7,58; (1'77) : 2300 Central Ave. ; I-3.

VAN ORDEN, KATE I'. (b'58)-Cal.1,'79; (l's0) : 1125 1'aru St.: 1-3.

van Orden, Leander (b'5i)-Cal.1,80 (l'84) not ln practice: 1125 Paru St.

ALBION, 500, MENDOCINO

Wolfe, Honer Holslnger (b'84)-Cal.1,'09; (1'09).

\section{ALCATRAZ, I7I, SAN FRANCISCO}

GREENLEAF, IIENIT S. $\left(b^{\prime}, 0\right)+$ - Pa.I '95: Maj., M.C., U.S.A.

MILLER, ALVIN CIIAS. (b'86) †-0.1,09; 1st. Iileut., I.C., U.S.A.

ALDERPOINT, - HUMBOLDT

LAY, FRE1)K. H. $\left(b^{\prime} 51\right) \pm-N . Y .10,78$ (I'95); Member 1 tah state Med. Assn.

ALHAMBRA (BRANCH P.O., LOS AN. GELES), 5,021, LOS ANGELES

(See IAOS Angeles.)
ALEXANDER, CHAS. BEE (b'i5) †-Mo.28, 07 ; ( ) ; Member Wash. Sitate Med. Assn. ; 5 S. Garfield st.

ARMSTRONG, JOHN MONROE $\left(b^{*} 56\right)-$ MIich.1,85; (1'95); 122 N. Granada St. offlce, 31 W. Main St.; $2-4$.

Bishop, Herbert Fiske (b'72) I-1'a.9, 00 ; (l'06).

Case, Martha shattuck-Cal.1,'95; (l'96)

('ORBETT, J. FREMONT (b'56)-0.6,'80 not in practice; Nember Wis. State lled. soc.; 234 \&. Curtis Aie.

COREY, FRAXCIS E. (b'46) \pm -Mich.1, 68 ; (l'03).

Crowell, Isabel-Cal.6, 06 ; $\left(1^{\prime} 06\right)$; not in practice.

Elwood, Frank B.-Mo.8,'82; (l'87).

Keown, James Archibald (b'71)-Miass. 1,'94 (l'11).

KIEFER, HITGOA

(See Los Angeles.)

Lane, Daniel E.-H-Ill.4, 78 ; (I'88).

IInney, Ernest Wilson-Kan.3,'95; not in practice.

Purcell, Ruth (b'80)-Cal.2,'Il; (l'11)

Shatfer, Chas, Porter (b'63) - Mo.7, 92 Pa.2,95; (1'09).

simons, Frankilin D. (b'58) - Ky.2.93; $\left(Y^{\prime} 10\right)$

SIITH, VIRGINIA T.

(See Los Angeles.)

Worster. Wm. W. (b'78) ...Ill.19,'01; (1'01) OALR.

ALLEGHANY, 500, SIERRA

Clayton, Wm. Amos-Ia.1, 76 ; (I’99)

ALPAUGH, 250, TULARE

HORNOR, DAYTON H. (b'b8)૯-IHIIT,'99; (l'06)

ALTA, 25, PLACER

Broome, Wm. J. (h's 3 )-Ont.1,07; (1'10):

ALTADENA, 100, LOS ANGELES

Newkirk, Garrett.

(See Pasadena.)

WRIGHT, THOMPSON B.

(See Pasadena.)

ALTON, 200, HUMBOLDT

IIOWARD, BLRT FOSTER (b'71)థ-Hl.6, "9s: (1'09)

Foung. James A. (b'0)-IIass.7,97; (l’99).
ALTURAS, 916 , MODOC

COLPEDGE, WALTER EINWIN $\left(\mathrm{b}^{\prime}\right.$ ' II $0.28,98$; (1'04) ; D.

(Bibson, Alexander (b'6 ) -Mo.1,'89; (l'89).

Stlle, John (b'76)-Cal.1,'00; (1'00).

AMADOR CITY, 854, AMADOR

Jynch, (jeo. L.CCal.7,06; (l'06).

ANAHEIM, 2,628, ORANGE

BFERF, JAY 1.EE (b'74) 4 -Ill.6,"03; (1'03) Davis, Walter Watklns (b'79)-Pa.12,'03; (1'12).

Freeman, Wrm.

(siee Fullertom.)

llarvey, ('hester W. (1)'52) - X.Y.1,75: (1'i9)

JANSS, JOHN J. (b'56) \&-I'a.2,'84; (l'10) JOIINTON, HERBERT AIJAN $(\mathrm{b}, 73) \notin-$ Cal.6,98; (l’98); S

OSBORKE, ALBERT E. (b'i4)-I'a.1,97; (1'97).

Parker, Don I-Ill.4,04: ( ).

Cal. 2,'11: (1,12).

TTER, IOHN WILIIAM (b'72)†-Cal.2, $10 ;(1)^{\prime 10) ; 0 b . ~}$

ANDERSON, 837, SHASTA

13EII, CHAS, APTIITR (b'-6) -Cal.1, 00 $\left(l^{\prime} 00\right)$.

Dozier, 1. F.Ga.6,59; (1'78) ; not In practice.

Tabler, Levl J.-Tenn.9,'91; (1'91).

ANGEL ISLAND, 285, MARIN

BILINGS, WM. CHESTER $\oplus$-Mass., ,94 Surg, U.S.P.H.S.; Immigration Service. I.S.P.H.S. ; Quarantine Station.

IFNKINS, LUTIER WALKLIR (h'81)III.1.11; (l'13); A. Surg., U.S.1'Ils. Immigration Station.

ANGELS CAMP, 3,000, CALAVERAS

COOPER, GEO. P. (b'80)\$-Cal.1, 06 ;

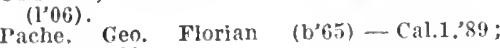
(1'90); 0 b.

Weirich, Fimer W. (b'66) H-Cal.5,'89 ; $\left(l^{\prime} 90\right)$.

ANTIOCH, 1,076, CONTRA COSTA

DF WITT, JOIN W.A-Cal.1,'92; (l'93).

Diggins, Fdward A.-Cal.1,'97; (I’98).

GFOlRGE, WORTII SCOTT-Ky.1,87; $\left(1^{\prime} 87\right)$; R.

ARBUCKLE, 743, COLUSA

IIammer, Arthur Wesley (b'82)-H1.6,'11;

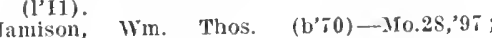
$(1,9 i)$.

'etersen, Dagmar (b'88)-Cal.2,'11; (l'11); ob.

Ward, Edgar K. (b'テ1) - Cal.7.02. Ill.6, '08; (1'08)

ARCATA, 1,121, HUMBOLDT

Hadley, James Augustus (b'83)-Cal.1,'11;

(l'11). ENIVARD J.-Cal.2,'94; (1'94).

Ilill, walter Howard (b'88)-Neb.6.'13: ( )

HOLEL, FRANCIS R.4-IIl.1,85; (1'91)

MCKINNON, (:EO. WASHINGTON (b'64) -Que. 1,88 ; (1'89); S.

Menefee, Joseph Senury-Cal.2,'98; (1'99). Menefee, P. MI-No.2,71; (I'77); not In practice.

AROMAS, 300, SAN BENITO

Buehler, John WWm. (b'69) - Ill.10,'95; (l'09).

ARROWHEAD SPRINGS, -, SAN BERNARDINO

Socgaard, Erick-Ill.11,01; (l'01).

ARROYO GRANDE, 900, SAN LUIS OBISPO

CAVANAGII, PETER (b'J6)£-Mich.1,'s3; (l'99).

CLARK, CIIAS. S.-Cal.4,'85; (1'85) ; Ob.

Paulding, Edwin L. (b'49)-0.1,'82; (I'83).

ARTESIA, 500, LOS ANGELES

Haskell, Pliny Fisk (b'-7)-Ill.19,'02; (1'12).

ATHERTON (REDWOOD CITY P.O.), SAN MATEO

SH.IRP, JAMES G.

(See Sau Francisco.)

ATWATER, 150, MERCED

KINNE, ELAIER F.-Cal.6,06; (l'06)

LAXGDON SAMUEL WALTER R., JR. (b'33)-Cal.2,98; (1'00).
AUBURN, 2,376, PLACER

Couture, Alfred N. (b'68) H-Cal.5,'94, Cal.4. '96; (1'95).

Couture, Fila R.-E-Cal.4,'95; (1'95),

FAY, GEO. HOWARD (b'64) $4-\mathrm{Cal} .1,02$; (I'02) ; 0 b.

MACKAY, J. GORDON (b'78)Ð-Ont.3,01; IROONEY, ROBT. FLEMING (b'42) †-QUe.I, $70 ;(1,77)$.

AZUSA, 1,477, LOS ANGELES

Atklnson, Leonard Woods (b'59)-Mass.5. '84; (1'01); 0 b.

ILLIS, SAML. AUGUSTA (b'61)๑-Ill.I , ' $86 ;\left(l^{\prime} 95\right) ; 0$ b.

H11, John Emmett (b'71)-Pa.2,97; (l'01) ;

BAIRDSTOWN, 50, LOS ANGELES

Foye, Frank Alonzo (b'81)-Cal.9,'12; (1'12); ObG.

Kutch, John.

(see Los Angeles.)

BAKERSFIELD, 12,727, KERN (See Kern.)

RROWN, NEWBERN N. (b'82) $\oplus$-Cal.9, 05 ; (l'06); 401, 18th St.; offee, I'roducers Bank Bldg. : 10-12, 2-4, $7-8$.

BIROWN, NEWELL J. SR. (b'54)€-N.H.1, 78; (l'97); Producers Bank IBldg.

BUCIINER, GEO. O. H.-Cal.1,07; (l'08) ; $1316,191 \mathrm{~h}$ St.; office, Hopklns Bldg.

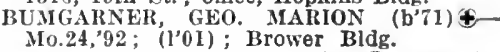

CREASE, FREDK. JOHN (b'68) ४-Tenn.1I, 98 ; (l'01); 2109, 19th St. ; offlce, Chester Ave. and 19th St.

CREASE, HENRY GEO.๑-Pa.2,91; (1'01) ; Hopkins Bldg.

CUNEO, PETER JOS. (b'84)↔-Cal.1,'11; (1'11); 1704 Baker St. ; offlce, Hotel Metropole; $10-12,2-4,7-8$.

Davls, Chas. Alra (b'56)-Tenn.5,'81; (l'85) $18: 9$ 'T'ruxton Ale.; office, Old Fish Bldg. $11-12,2-4,7-8$.

ELLIS, KATILARYN W. (b'67)-0.8,90; (I'00) ; 620 Lake St.

FOWLER, WII. STOWE (b'57) †-II1.11, 88 ; (198); 1995 Truxton Ave; offee, 19th and II'Sts. ; $10-12,2-4 ;$ OAĹR.

FRASER, ALEXANDER I. (b'66) $\oplus$-Cal.6, 97 ; (1"98); 721 Oregon St.; office, Froducers Bank Bldg.; 2-4; also, Southeru Pacille Emergency Hospital; 10-12, 7-8.

GUNDRY, FRANK JOS. (b'77) $\oplus$-Cal.1, 06 (I'06) ; 2301 B St.; offle, Redlick Bldg. $1-4,7-8$.

HAMLIN, FRANCIS ALLAN (b'71)@-Cal.I, '08; (l'08); 2120 B St., offee, Hopkins Bldg. ; $10-12,2-4: 30$; (B19) ; OALR .

HULL, JAMES PORTERFIELD (b*72)థCal.2,'95; (1'95); Scofield Apts.; oftice, Brower Bldg. ; 2-5; S.

KELLOGG, CLARENCE W. (b'66)-Cal.1

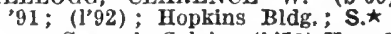

Long, Samuel Calvin (b'71) H - Cal.5, 01 ; (I'01); 1715, I7th St.; offlce, W.O.W. Bldg. ; $10-12,2-4,7-8$

LONG, SEELEY FREDERICK, JR. (b'83) -Cal.2,'10; (l'10); 2123 C St.; offlee, 1626,19 th 'St. ; $10-12,2-4,7-8$.

McKenzie, Malcolm K. (b'55)-Mlch.2,'81 ; (1'94) ; 624 Monterey St.; 10-12, 1-4.

MCNAMARA, THADDEUS M., JR. $\left(b^{3} 80\right) \oplus$ -Cal.1,05; (l'05); Hopkins Bldg.

Mitchell, Frank W. - N.Y.1,'80; $(1 ' 84)$ Producers Bank Bldg.

Morrls, Chas. Alfred (b' $\left.{ }^{\prime} 2\right)-$ Cal. $\tau,{ }^{\prime}, 2$, N.Y.19,09; (l'02); Old Fish Bldg.

Owen, Henry wuson (b'68)-Kan.4,01. (l'01): 2119, 17th St.; office, Hopkins (l’0I) ; 2119,17

Pawlickl, Casimir Francls (b'72)-Cal.2, 94; (I'95) ; Producers Bank Bldg.; 10$12,2-4, i-8 ; U$.

REES, REES BYNON (b'68) - IId.1,00, Mlass.1,01; $\left(l^{\prime} 06\right)$; 2012 Cedar St.; office, old Fish Bidg.

ROGERS, CHAS. ALEXANDER (b'51)€Ia.1,78, Ill.1,79; (l'79); 1831 Cheste Ave.; office, old Fish Bldg.; $2-4$.

ROGERS, HOMER-Cal.6,'97; (l'97); old Fish Bidg.

SABICHI, GEO. CARLOS, $\left(b^{\prime} 78\right) \oplus$-Cal.6, 04: (l'04): 1620, 17th St.'; offce, Producers Bank Bl(g.; 10-12, 2-4. 


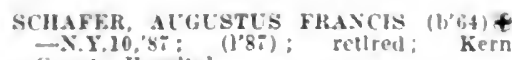
County Hosultal.

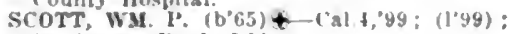

Producers liank Bldz.
S.MTH, SAMI. F.t Cal.6,95; (1'95); S.IITI, SAMI.

Hopklns Bldg:
Wells, Allen W

wractlce. (); Member IIl. stabe Med. Soc.: Mlid Msh BIdg.

WORTHISTON, I,OIS (b'75)‡-(9al,1,9: (l'98); $1503 \mathrm{G}$ st.; oftlce, I'roducers Bank Bldg.

BALLARAT, 56, INYO

Burney. Thos. M (b)'mo) l'a.l

BANNING, 1,000, RIVERSIDE

KING, JOHX C. (bos3) \&-Tenn.1," t: (1's5) (Indian Servlce): Ualk Sched: T. (1'07): T.

SMIIEY, WALTEL C. $\left(b^{\prime} 80\right)+$-ral.g, 06 ; (1'0i).

BARD. - IMPERIAL

Rooney, Chas, k. (b'SH-Nel).6.'11:

BARSTOW, 500, SAN BERNARDINO

Anderson, B. C. Mo.1, $81 ;(1.01)$.
Whate. John Ogden $\left(b^{\prime} 46\right)$-Tenn.1, 69 ; 11'gs): not in prantlee.

BEAUMONT, H07, RIVERSIDE

Lashlee, Horace B. (b'tb)ll-310.7, 75: (l'si) : not in practlce.

TAyioR, THOMAS FHANCIN (b'of) X.1.10:80: (1'98).

West, Fred bonnell (b'6 6$)-0.250^{\prime} 03 ;(1 ' 10)$.

BECKWITH, 100, PLUMAS

Decker, John Caldwell-('al.J,04; (I'04).

BELL, 120, LOS ANGELES

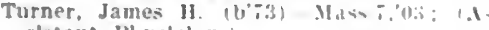

slstant Plyslolan.

BELMONT, 900, SAN MATEO

Helpum, IIendrlck Nelson (b'st)--111.1,'11: (1'12).

BELVEDERE, 481, MARIN

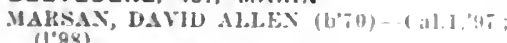
(1.98),

MCKEXNK, ALTHR C

(see san franclsco.

SCOTT, FLORENCE+-Cal.2, $93 ;(1,4 ;)$.

BENICIA, 2,360, SOLANO

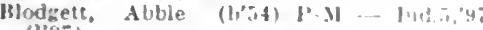
(l'g-i).

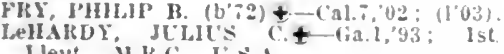
Lleut., M.K.C., C.S.A.

cFarland, Wm. Lee (b'6s)-110.s,'90; (I'g1)

BERKELEY, 40.434, ALAMEDA

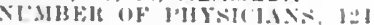

Adams, Abner L.-Mo.2,78: $(178)$ : 2301

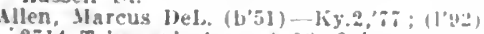

27 it Telegraph ive. : $9-12,2-4$

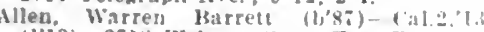

(l'13): 2ily Webster st. ; offce, First. Uonal Bank Bldg.

Allen, Woodson (b'5t) E-O.2.st; (1'xi)

2is Webster st.: offec, First Salthit

Bank Bld : 2-4:30

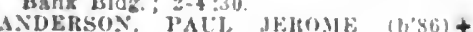

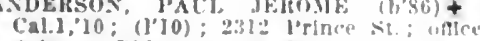
Acheson IBldg: il-12; S.

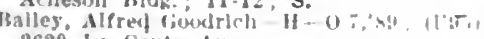
2620 lo conte die

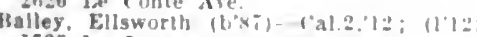

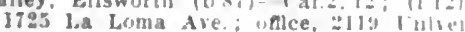
mity Are.; 11-1, 3-5, - 8 ; 0b.

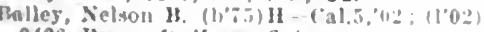

2120 Itancroft II as; 2 - 1 .

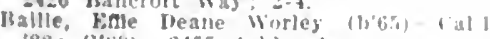

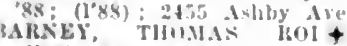

|103): 2 II I Infa sit. ; $3 \cdot 5$.

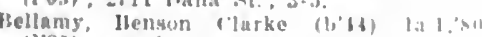

(1'81): not In Jiractice: 1931 firore si

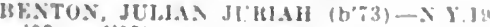

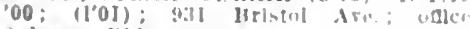

Acheson Hlls: :-4.

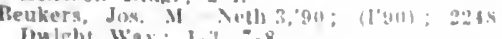

Inulght Way: $1-i, ;-8$.

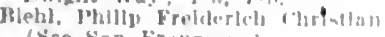
(sice san Frincimen,
Boerlcke, Wm.

(See San Franclsco, )

Boone, Wm. Hoserie $\left(b^{\prime} \$ 4\right)-\left(y_{1}\right), 12$ (I'12): 2014 Hlake st. once, Thaser BHIIUMAN, OLGA LOCISE $(0,86)+$ Mleh.1.10; not in practlee; Murler HII siate Nent soc : 2627 Hearst Ave.

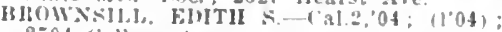
2704 college Are.

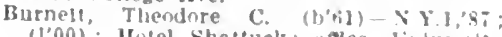
$\left(I^{\prime} 00\right)$ : IIofel Shattuck; oflce. Tiulverslig of callermia.

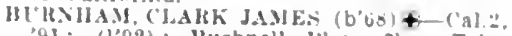
91: (1'92): Hushnell 11.: nalce. Telegragh Are. and Bancroft Way: $2: 30-4: 30$

CINHFLl, WM. HOWAH, (bs)-Cal.2 11: (l'11): 2il6 stuart st. : oftee Berkeley Natlonal Bank Mddr.

Carpenter, Allen M.-Cal.1.45; (145); 2525 llearst Ire; oflce, Icheson iblug.
$10: 30-12,3-4 ;-8$

ARPENTER, FRI

N.Y.6,91; (1'93); 2830 College (b'68)(hristiansen, Rushmer (hristlan (b) la.3, 13: inlrersity of callfornla; LD.

CLAYOLF, EDITH JANE (b''04; ( l'05): 2826 (iarber s?.; ( Fu)

Cohn, Isadore E-Cal.1,'si; (1'81); log spruee sit.

OR.WWALL. FIKANK.

D.ilis Nan Franelsco.

(I'7i) : 1127 shatuck tre

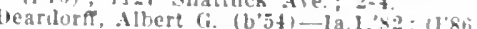

2153 Vine st.; offlce, First Xational Banb bldl. ; 11-12. 2-4:30.

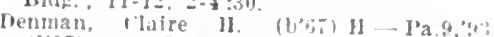

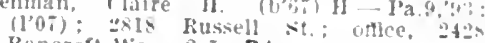
Bancroft 11 ay $2-3 ; \mathbf{P d}$

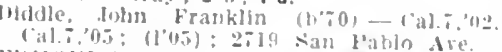

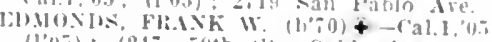
(1'0.i): (2) $45,59 t h$ st.. Oakland); offlee.

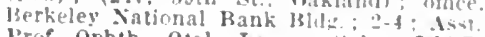
l'rof. Ophth., Otol., Laryn. Al. OALR, Eldridge, John R. (b'64)-('al.l, lit: llo ZnI: Garber St. : NP.

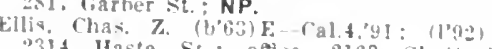
2314 Haste St, oftce 2l69 shattuck Ave. ; $1-4$

Farrar, Jos. Teel (b'50) E-(a1.4.91:11',1) 2192 slaturk Ire.:- $2-4$

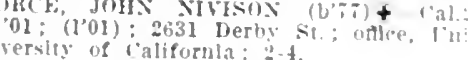

Furster, Wm. Martln.

(See San Francisci.)

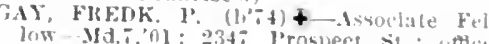

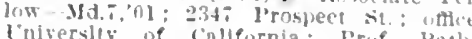

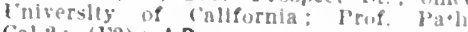
(al.: : (F2): LD.

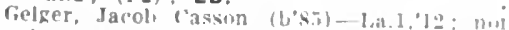

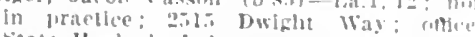
state Hyglende laburatrizy.

Gille Hyglende laboratrog. ("al.2,'49; (l'99);

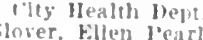

inver, Fllen leart

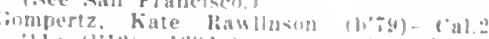

11 11?

RAIIII. M.IRIHNITU. II.

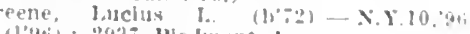

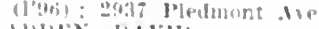

(Sion i) aklant)

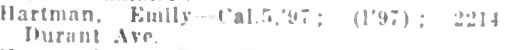

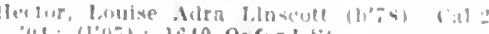

"us: (1'0) : bito Ovford sit.

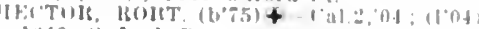

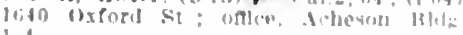

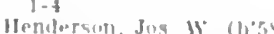

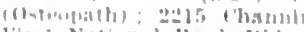

l'iral National Itank lthe

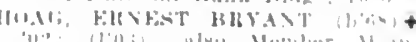

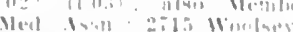

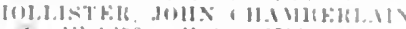

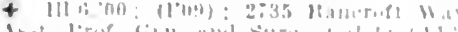

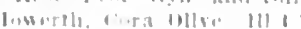

lice: zefol promperet it

lutelinge infuluet
Jones, John Ww-Ten:1,90; (1'90): 2131 Unirerslty sit.

Kelly, Frank liewls (L's - Cal z, 12: (I'12): 2241 l'arker Sit.

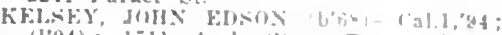
(1994): 1511 Arch 51 fice. Acheson KIKK, AlHERT W.

(kee san Francisro)

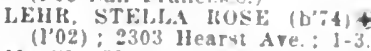

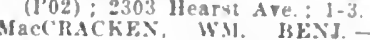
(1'11): Meniner lifd. Soce of the Yitase N.Y. 1702 Euclid Ase

MARSHALL JOHA SAYRE (b't6) S.Y.l5iti; not in practlce; Jlember 111

State Mled Sce 2913 plne Are.

Cal.1,96; (1'36); 244 (iarber St: oce Berkeley Xallonal rank HIdg; 2-1; Pd. Jccormac, James T. (b'5\%)-Ore.1,'s?: (I037): 1:40 Yiolo Are.

Ifciee, Inlta New(i)mil (b'et)-D.C.l.y.

not in sractlce; " lanoramic 11 ay.

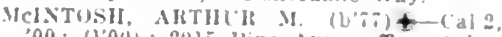

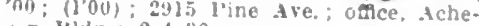
sun Hlikg.; $2-t: 30$

MCLFAN, HOH'T. ARMISTEAD

(See san Francisco.)

McXulty, IIarry James (b'-3)-Cal.1, 95

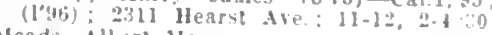

Meads, Alluert Manson.

Isee (bakland.)

lilly. Herbert c'largo-Cal.z,'01;

MITCHEI, LLSIE KEED (b;1)-Colo.2,

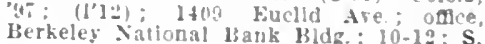

Mitchell, Wm. Larl (b'sy)-1'olo.2,13:

(l'13); 311\% shatuck Are.

Moffett, Edward Daris (b'62)-Ind.9,86:

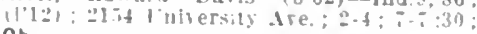
Ot.

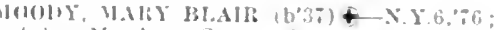
(): Memler Comn. State Med. Suc.;

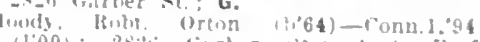
1100): 2s-b fitrber sto; Asst. Prot Inate ('al:z: (Fl).

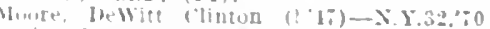

(当): Lancaster bidg.

thean (b't5)-Cal.1, $\$ 9$; $(1,90)$

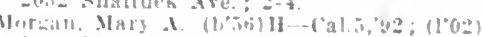

avu benvenue st. $2-4$

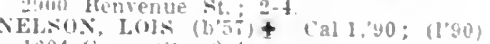

leint ripule :il: : :-4

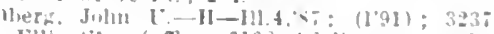
bllis st. (ofice, 6105 bleline st. Oaklandl.

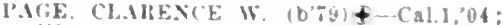
(l'04) : 274 Lerby st.; nffice, Berkeley

IINTER, (ifokrik L.

Fee Fan Francisco.

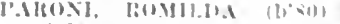

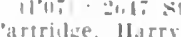

(soe san Fraucisou)

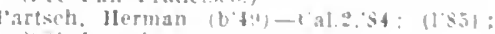

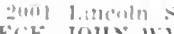

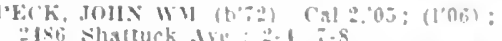

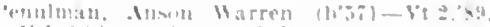

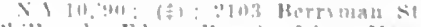

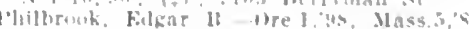

11'(00) ; 1530 Hawelumbe Terrace.

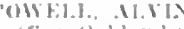

a)

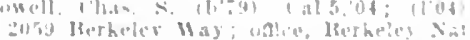

lienk lik! : 2.4

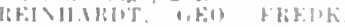

(l)

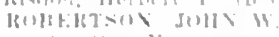

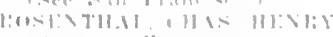

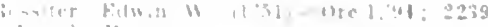

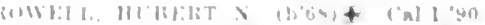

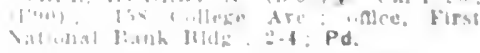

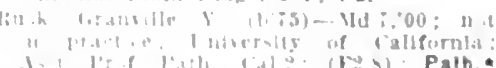


SAMPSON, MAY H. (b*i) $\oplus$-Cal.1, 06 ; (1'06) : 2714 Alcatraz Ave.; offce, Berkeley National Bank Bldg.

SANDEKSON, ARTHUR JAMES (b'65) Cal.1,91, Mlcb.1,95; (l'93); 2222 Chapel

St.; 2-4; N.
SANDOW, B. FRAN(IS (b57) †-I11.6,91; ( ); Clareinout Park.

Savage, Clarles Wilbur (1)54)-Mo.5,76 $\left(1^{7} ; 6\right)$; not in pructice; 2339 Ward St.

SAWYER, WILBUR AU(1UST US (b'79)\$offce, University of Califorula; 3-4.

Schloss, Auron.

(See San Francisco.)

Schnelder, Albert (b'63)-Ill.11,'8⿰ ; not In practlce; 1325 Arch St.

Shafer, James E. (b'63) H-Cal.5, 97 ; $\left(l^{\prime} 97\right)$;

o815, Wooleer St. 2-4

SHEF'FIELD, HONER HIENRY (b'69)‡Cal.7,01:' (1'01); 2014 Lincoln St.

Shepard, Gilbert (b'38) II-Ill.4,'70; (1'96) 2218 Russell $\mathrm{St}$

SIMPSON, FRANK WM. (b'TI)-Cal.2,'00 (1'00) ; 2446 Channing way; $2-4$.

Snilth, Clark (b'43)-Tex.1,'81; (1'84) ; 3110 Ellis St. ; $9-4$.

SNOOK, JOIN (1,61)†-Cal.4,'86, Ill.11, 94; (1'86); 2125 Prospect St.; office, Berkeley National Bank Bldg.: 1:30-4.

Southard, Carroll 0'13. (b'74)-Cal.7,01 (1'01): (Phefan Bldg.; 11-1, 2-1; San Franciscol; Prof. Chem. and Metallurgy, CaI. T; OALR.

SOUTIAHD, WM. FREEMAN

(See San Francisco.)

SWIFT, EUGENE L. H. (b'63)-N.Y.I,'84 (l'04); Maj., U.S.A., retlred; 601 Canon Drlve. Beverly Hills; (B12); 0 p.

THOMPSON, JOIIN EMMETT. (See San Francisco.)

Thomson, Herbert Sedgefleld (b'82) - MId.7 '09; (I'13) ; 2510 College Are.; $2: 30-4: 30$; $\mathrm{S}$.

TONER, MARK F.

(See Oakland.)

Van Tassell, Fred Hugh (b'78)-Cal.2,04 (l’04) ; 3027 Grove St. ; offlce, 2982 Ade-

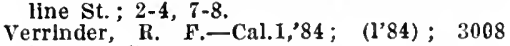

Duncan St.

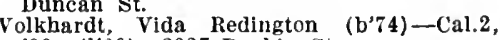
'99; (1'00); 2927 Deakin St.

Vall, Benj. P.-H-Pa.9,'80; (l'81) ; 2251 Pledmont Are.

Walworth, Chas. IIarper (b'65) E-Cal.4,97 Cal.7,01; (1'01); (852, 54th St., Oakland); offee, 2168 Shattuck Ave.; 1-4.

WATERMAN, HFLEN J. (b’56)థ-Pa.7,97 ; (l'97) ; 2741 Woolsey St.

WILLIAIS, CLARA LOUISE (b'70)థMd.7,02; (l'03) ; 1409 Euclid Ave.; office, Berkeley' National Bank BIdg.; 2-4.

Berkeley National Bank BIdg.
WINTERMIUE, GEO. PRESTON.

WINTERMUTE, GEO. PRE
(See San Francisco.)

WoOD, WM. ALMON (b'76)థ-Cal.6,'06 (1'69) ; 2440 Prince St.; offlce, 2251 Telegraph Ave.

WOOLSEY, FRANK R.-Cal.1,'94; (1'94) 2244 Dwight Way; office, First National Bank Bldg.; 2-4.

BIG CREEK, -, FRESNO

ROSENBERGER, JOHN ASHBY (b'72) Pa.2,'94; (l'94).

BIGGS, 403, BUTTE

Caldwell, Buchanan-Tenn.6,87; (l'87).

HAWKINS, ORWIN C.-Mo.2,71; (1'77).

BIGPINE, 147, INYO

Harrey, Geo. W. (b'62) E-Cal.4,'94; (I'94).

BISHOP, I,190, INYO

Dorrance, Chas. E.-Mich.1,'92; (l'92).

DOYLE, GUY P.-IIl.1,'94; (1'97); (Indian Service) ; Bishop School.

Doyle, Helen MIcK.-Cal.2,94; (l'95).

Shute, John W.-H-Cal.5, $00 ;$; (1'00).

T'urner, Chas. Edward-Cal.1, ${ }^{\prime} 94$; (1'95).

BLOOMFIELD, 206, SONOMA

Cockrill, Bruce T.-Cal.4,'92; (1'92).

BLUE LAKE, 800, HUMBOLDT

HOONEY, CHAS. NEIL (b'83)-Cal.I,'06: (l'06).

Wood, Grantille N. (b'44)-Ill.6,'78; (1'01).

BODEGA, 220, SONOMA

Cheney, Florence V.-E-Cal.4,'91; (1'92).

BODIE, 750, MONO

Ware, Chas. D.-0.1,'88; (1'95).
BOLINAS, IIO, MARIN

Gibson, Richard E.-Cal.1,91; (l'92).

BONITA, 15, SAN DIEGO

DUNBAR, FRANK A. (b'56)-Mass.1,'83: (l'00).

BONSALL, 3I, SAN DIEGO

(ilrd, Nina L. Nlen (1's5)-0.12,10; (1'12).

BOSTONIA, 400, SAN DIEGO

Mathewson, Eugene $\left(b^{\prime} 60\right)$-Colo. $3,^{\prime} 94 ;\left(l^{\prime} y b^{3}\right)$.

BOULDER CREEK, 544, SANTA CRUZ

CAESAR, WM. J.-Cal.7,'97; (1'97).

BOYES SPRINGS, - SONOMA

Parramore, Ldward Lyttleton - Ky.I,'89. Pa.2,'91; (1'89).

BRAWLEY, 88I, IMPERIAL

Bossert, Clarence Sanborn (b'73)-D.C.1,

De Biois, E. Myrtle Wellcome (b'78)-Cal.6, 05: $(1,06)$ : not in practice.

Lindsey, Laurence Lo (b'79) - Cal.9,'09; (I'10)

Mller, Jos. Abraham (b'29)-Pa.3,64; (I'T4) ; not ln practice.

BREA, - ORANGE

Charleston,Vernon C. (b'85)-Cal.9,'12; (I'12).

BRENTWOOD, 325, CONTRA COSTA

COOK, FRANCIS STEVEN (b'65)-Cal.2, '87; (1'88).

BRENTWOOD PARIK (SOLDIERS HOME P.0.), - LOS ANGELES

Janss, IIerman.

(See Los Angeles.)

BRIDGEPORT, 224, MONO

Childs, F. A.-Cal.4,95; (1'95).

White, Mary Parker (b'74)-0re.2,'03; not in practice.

BROOKDALE, 50, SANTA CRUZ

PHILIIPS, WM. ALFRED (b'60)-0.6,'88 ; $\left(l^{\circ} 9 i\right)$.

BUENA PARK, 200, ORANGE

HASSON, DAVID WM. (b'4i)-Ia.3, $7 i$; (1'93).

BURBANK, 400, LOS ANGELES

Black, Stephen S.-H--0.13,'75; (1'84).

CLINE, HARRY X. (b'78) $4-\mathbf{M o . 2 ,}, 05$; (l'13); Member Ill. State Ned. Soc. THOMPSON, ELMER HARMON (b'78)థIll. 1, 03 ; ( $\left(1{ }^{\prime} 05\right)$.

Ward, Benj. Briggs (b'80)-0.6,07; (l'10). BURLINGAME, 1,565, SAN MATEO

Haskell, Carrie A. Goss (b'67)H-Ill.10, $78 ;\left(l^{\prime} 79\right)$

Kiersted, Henry Stevens-Pa.1,93; not in

practice. $05 ;\left(1^{\prime} 05\right)$.

Power, Florence B.-Ore.1,93; (l'94).

POWER, HENRY D'ARCY.

(See San Francisco.)

ROTHSCHILD, MAX.

(See San Francisco.)

(See San Francisco.)

BURNETT, 500, LOS ANGELES

ATWOOD, J. BURROWS (b'64)-111.1,91; not in practice; Member State Med. Soc. of Wis.

Porter, Chas. Sanford $\left(b^{\prime} 62\right)-$ N.Y.5,'93; (1'96).

BURSON, 25, CALAVERAS

MARCH, WM. B. (b'59)-0.2,'84; (1'84).

BUTTE CITY, 279, GLENN

GATLIFF, WH. WALKER (b'57)@-Mo.7, '84; (1'85).

BYRON, 350, CONTRA COSTA

HAMMOND, JAMES WM. (b'56)-Cal.4,'97 ; (l'98).

CABAZON, - RIVERSIDE

CRAWFORD, JAMES C.-Tenn.11,'04; not in practice; Member Med. Soc. of the State of $\mathrm{Pa}$.

CALEXICO, 797, IMPERIAL

Flinn, Homer John (b'89)-Cal.9,'12; (1'12). PETERSON, FRED W. (- Ill.6,05; (I'05); (office, Ei Centro).

Richter, Henry Carl (b'81)-Pa.2,'06 ; (l'08).

Smith, Wm. Fawcett (b'41)-Ire.3,'63; (I'09).

CALISTOGA, 75I, NAPA

Abrons, Harry (b'82) - N.Y.1,09 ; (l'10).

Banta, Wm. -E-0.2,78; (1'78)

Bernard, Lydia H. Plummer (b'78)-Pa.12, 08 ; not in practlce.
BLODGETT, WALTER LeR. - Cal.1,95; (1'95).

Porter, Wm. II.-Mleh.I,'73; (1'86).

CALPELLA, 140, MENDOCINO

ApLynne, Guy Elmont (b'87) II-Mo.26,'99 ; (I'00).

CAMBRIA, 500, SAN LUIS OBISPO

Fossum, 0tto Bergerson (b'72)-Cal.7,09; (l'11).

CAMINO, 100, ELDORADO

CIIAMBERLAIN, GEO. LAFAYETTE (b'69) †-111.1,91; not in practlce; Member Milch. State Med. Soc.

CAMPBELL, 700, SANTA CLARA

Blanchard, Thos. Loftln (b'86)-Cal.1, 09 : $(1,10)$

Cooper, Chas. Noah (b'44)-111.6,69; (l'90).

Terrlll, Waiter Irvlng (b'84)-Ne.1,09; (1'11); ObG.

CAMPO, 200, SAN DIEGO

Boyd, Carl B. (b'73)-D.C.2,'98; (Indlan Service) : Campo School.

CAMPTONVILLE, 387, YUBA

LOLD, FRED K.-Ky.4,94; (1'95).

CAPAY, 304, YOLO

CRAIG, THORNTON-Que.1,'76; (1'76).

CARMEL, 500, MONTEREY

Beck, Jos. E.-Ia.4,87; (1'01)

HIMIELSBACH, WM

(See Watsonville.)

Lane, Lucia Marie-Pa.7,88: (1'88).

Smlley, Virginla Wlckliffe-Pa.7;'8i; (l'88).

CARPINTERIA, 300, SANTA BARBARA

Cauch, Robt. (b'32)H-Ill.4,77; (l'77).

Downle, Cullen L.-Mlch.1,71; (1'93).

Henderson, Harltn Clvde (b’74)-Ill.1,96 ; (\$).

CARRVILLE, 20, TRINITY

Farnsworth, David Carl-Cal.6,'06; (1'13).

CASTROVILLE, 800, MONTEREY

WATSON, VAN BUREN (b'46)-Ky.1,'80 ; (l'89).

CEDARVILLE, 500, MODOC

Coates, Winston Decatur (b'58)-Cal.4,96; (1'96).

Meredith, Jesse Thos. (b'51)-Ky.1,79; (l'95).

Whittler, J. Yorke-Mo.10,'87; (1'99).

CENTERVILLE, 750, ALAMEDA

ADAMS, JOHN M.-IIl. 1,'82; (l'00).

EAIERSON, HARRY W.-N.Ý.1,'92; (1'92).

ORMSBY, E. A. (b'70) @-Cal.4,96; (1'96).

CERES, 200, STANISLAUS

Cartwright, Sanford Warren (b'73)-Cal.2, '08; (1'09).

Kennedy, Wm. N. (b'58) E-Cal.4,'98; (I'98) ; Ob.

CHICO, 3,750, BUTTE

BAUEMISTER, EDWARD EMERY (b'78)

BROWNING, CHAS. LOT (b'61)-Cal.1,994; (1'95).

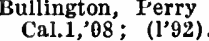

Crabb, James N.-Ia.1,78; (1'79).

ENLOE, NEWTON T.(8-Mo.1,'95; (1'01):

GATCHELL, ELLA FRANCES $\quad\left(b^{\prime} 53\right) \oplus$ Mass.6,89; (l'95)

GATCHELL, WILLIS IAE FOREST (b'54)Me. 1,'82; $(1,00) ; 0 p A L$.

GOUGUET, LOUIS JEAN ERNEST (b'81)@ -Cal.1,08; (l'08).

(1'97).

Harvey, John W-E-Cal.4,'87; (1'87)

Johnson, Wohn Willard-F-Cal.4,'87; (l'87); (1'04).

Landis, Amos J. (b'49)-Ind.8,'80; (1'89). LANDIS, CHAS. CALDWELL (b'82)-D.C.1, '12; (1'12).

Meyers, Emery L. (b'79)-Neb.6,06; (l'10)

MOULTON, DAN HAZEN (b'78)@-Cal.2 02 ; (1'02).

Ollver, Cassius A. (b'56) $\mathrm{H}-0.13,{ }^{\prime} 80$; ( $\left.l^{\prime} 80\right)$.

Rodley, Herbert Ellls (b'84) - Cal.7,'10;

(I'10); Ob.

Rodley, John Ells-Mo.I,'81; (1'88)

STANSBURY, OSCAR (b'52)@-Md.1,73 ;

(l'76).
Stebbing, Preston G.-IIl.1,71; ( ) ; R.F.D. 1.

CHINESE CAMP, 200, TOULUMNE

STRATTON, DANL. EDGAR (b'63)-Ia.4, '86; (1'87). 
CHINO, 1,444, SAN BERNARDINO CALLSTON, JOITN WLYTREE (b'85)-Cal.1, Cas: (1'08)

coxr: Dokikax B. (b'45) - N.11.1.'85;

(i): Member R.I. Med. Soc.

(): Mrember R.I. Med. Soc. 93 ; (1.93).

REED, ELGAR $\left(b^{\circ} 65\right)+-0.9^{\circ} 93 ;\left(10^{\circ} 93\right)$

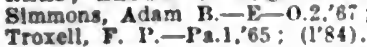

CHITTENDEN. 3!, SANTA CRUZ

WORTIINGTOX, GEO H (b'ii) Q-Cal. ot: $\left(\mathrm{l}^{\prime} 04\right)$; $\mathrm{S}$.

CHULA VISTA, 100. SAN DIEGO

Bryan, Lugene Ilenry (('67) - Ky.5,'94; (1'01).

Latta, Lella (b'57) - Ill.9,'ss ; (1'90) ; Grant 13lock, 5 th St. $10-19,0-5$

Morrell, J. Frank-E-0.2,73; (1.83); not In practlce.

Rosburg. Aurust Henry.

(See San Dlego.)

CIENEGA (LOS ANGELES P.0.), -, LOS ANGELES

Otrwall, Harold Aumustus (b'(4)-Cal.1,"9s: (l'99).

CLAREMONT, I,114, LOS ANGELES

Bradles, James (b'36)-111.6,'6s: retired.

Edrar, Xelson (b'77) -IIl.1,02; ('08).

Geer, Francls H. -0.1, \%; (争)

Hawles, Edwin P. (b'56)二0.6,84: ()

Myers, Robt. Pooler (b'39)-Ga.4,60; re

tlired.

STOUGHTON, ARTIUR FOLNEY (b'72)0.25,'98; (1'11): Member Conn. State MHOM. SOC. 80; (1'99)

CLOVERDALE, 823, SONOMA

Carlco John W. (b'61) - IAa.1,'8s: (1'98) LEDTARD, CORY C. (b'83) - Cal.6,"06: (1.06). CORX C. (b83) - Cal.6,06:

(l'00).

\section{CLOVIS, 1.200, FRESNO}

Clark, Nellle L.-Neb.5,'98; (1'99)

CLARK, TRACY R. (b'55)-Mo.1,'80; (l'99)

MCMURTRY, MILTON SCOTT, JR. (b'81)Mo.3,04; (l'04); Ob.

MeMurtry, Muton' Scolt, Sr. (b'56)-Mo.l, MeMurtry, Muton Scott, Sr. $\left(\mathrm{b}^{\prime} 56\right)$ - Mo.1

Pendérgrass, Wm. Claston - Tenn.5,'99; (l'99).

COALINGA, 4,199, FRESNO

COX, J. EMIT (b'65) -110.29,'95; (1'98) :

HUTCHISON, CHAS. WESLEY (b'83) \& MOU.11,08: (1'10): Ob.

Titany, (l'10). Elmer N-Ia.3,'s8; (1'92)

YATES, WM. CHAS. (b'65)-0.2,'si ; (1'87).

COLFAX. 615, PLACER

Brovn. Robt Saml (b'56)-0.14'83 : (l'91)

BCSH, HENIY CHESLEX (b'86) -Cal.2,

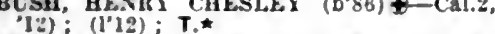

PEERS, ROBT. AIWAY (b'75)\$-Ont.3,'99; (l'99); T.

Rollins, Jarrot Laban (b'59) - Mo.3,'83;

BOONEY IIENRY THOS. (b'6) - Cal.1, 02: (1'03).

COLLEGE CITY, 300, COLUSA GIbbons, Clitord Holcomb (b'52)-N.Y.5,

COLMA, 293, SAN MATEO

Benttle, W'm. (G.-Cal.i, 00; $\left(l^{\prime} 00\right)$

COLTON, 3.980, SAN BERNARDINO

CllAMIPION, JOS. A. (b'63) \-0.1,'85; (l'95).

Crane, Walter Raymond (b'84)-N.Y.1, I:

IA (') MOTTE, JATIMEIt A. J. $\left(b^{\circ} 84\right)$ Colo.5,08; (1'08)

PRITCHAItD, FKANK H. (b'c7)-Mass.5 89 ; (1'03)

Whitwer, Chas. F. (b'70)-111.11,98; (1'06).

COLUSA, 1,582, COLUSA

Cason, Georce 1.-Mn.3,7\%: (1.77).

POAGE, CHAS. AlLEN" (b'/3) -Cal.1, 01: (1'01).

Rathbin, Wm. T. Cal.2,'92; (1'03).

COMPTON, 922. LOS ANGELES

HOLCOMHF, ARTILIG L. (b'05) \&-N.Y.5 '85: (1'89).

JFNNINGS, CIAS. R. (b'64)+Md. 6,90 : (1'95).
CONCORD, 703, CONTRA COSTA

Bancroft, Eileanor S.-Cal.2,"96:

R.F.D. 81 .

Flnney, Win. N. (b'59)-Mo.1,78;

(1.97);

Mekenzle, Geo.-ont.1,91: (1'91)

NFFF, FIRANCIS FELIX (b'62) -'Pa.2, 87 (1's9).

CORCORAN, 500, KINGS

PFE:LY, JOHI THOS. (b'iB) + Cal.6,"06: (I'06).

CORNING, 972, TEHAMA

case, Fillas P. (b'50)-Ia.3," 55 ; (l"00)

Dawson, Thyron F. (b'5i)-Mllch.1,'86, Pa.2,

10: (1'93) : mot in practlee.

Dotson, Ell K. (b'73)-Ia.3,01; (1'12)

Magcard. wm. F (b'55)-Ia.1:79: (1's0)

liudolph. Oswald F. (b'52) $-0.8,85$; (l'94)

NYIEl:, AIONZO D. (b'76)-Ky.1,97;

Member Wash. State Med. Assn.

CORONA, 3.540, RIVERSIDE

Capns, W'm, (b'40)II-0.13,'83; (l'87).

Chapman. Finrence I. Slinms $\left(b^{\prime} i i\right)-0.25$, 03: (1'08)

CHAlMAN, wM. П. (b'7) (1'10).

COLLIXS, WM. FRANCIS $\left(b^{\prime} 86\right) \Phi-\mathbf{Y} .19$, II: (1'12).

חAIS. WY. SEYMOUT (b'61)-0.9, 85 : (1'si).

McNary. Ollver C. (b'49)-Pa.2.82: not in Dractice.

ROOT, ROMEO RICHMOND (b'70) Ill.11, $02:\left(l^{\circ} 06\right)$

SHTH. ERSEST H.-Ill.10,'91; (1'01)

Staftord. Alburn Ifatthlas (b'65)-X.Y.5, 89 ; (l'89).

CORONADO (BRANCH P.O., SAN DIEGO), 1.477. SAN DIEGO (See San Diecn.)

Bergaren. Tell Jobn-I11.19,06; Swedish Morements: not in practlce

RROw:, DóvGLAS (b'69) $4-$ Y.Y.1,94: (1'10).

Resenll, Henry $x$. (b'-9)-Mn.2.ns: ()

KNFEDLFR, WM. ITTWT (b'56) 4-P'2.2.

19: (1'05) : Maf. I'S.A. retlred.

LORINI RAFAFLE (b'59) $9-$ Pa.1,' 81 ; (1'02)

YATFS, JOHS CALNWFLT

(See San Dlezo.)

COTATI, 100. SONOMA

llelman, Erelrn-11].19,99: (1'01)

COTTONWOOD, 450. SHASTA

Gllllind, Adelbert Blackford $\left(b^{*} 49\right)$ - Tenn.9. $94 ;$ (1'97).

COUNTY FARM, - LOS ANGELES

Shank, Clyde F. ('十'83)-Cal.2,'12; (1'12).

COURTLAND. 135. SACRAMENTO

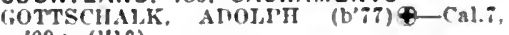
'09: (1'10).

COUTOLENC, 25, BUTTE

Sielfer, Ilomer M.-II.6.95; (l'01)

COVELO, 300, MENDOCINO

Hogshead, John S.-IO.:,99; $(1,00)$

dlan Serrlce

osborne, G. K.-Cal.4,95; (1'95)

COVINA, 1,652. LOS ANGELES

(Sce alon Los inceles.

CIARKE, ROY MASNISG (b'83)\&-D.C.I

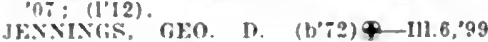
(1) 00 )

Mnrrls, Frank (1) (is) - $0.3,292$; not lu prac-

Ilce: R.P.D. 2. (b's) \&-N.Y.10,s3 (l'on)

THORPE, LEWIS SINBORN.

(Sice Loq Angeles.)

COWELL (CLAYTON P.O.), - CONTRA

\section{COSTA}

Cone. Frank B. (b'34)-0.1,8t; not In pracilce.

CRESCENT CITY, I.11\%, DEL NORTE

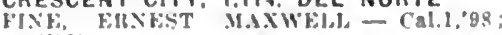

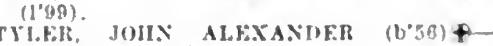

Tenn.5,'82; (1,00).

CROCKETT, I.800, CONTRA COSTA

CROCKE TT,

(1.12)

CROWS LANDING, 250, STANISLAUS

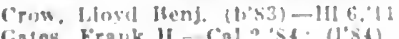

CUCAMONGO, 300, SAN BERNARDINO

WFHER, AlRTIIUL LEO (b'83) —-M1.6,10 : (l.10); (fiplad)

CUPERTINO, 140. SANTA CLARA

DURGIX, FIOWIX IIARVEY - Jass.5."89: (l'98).

McDougall, Wrn. Duncan-X.Y.G.' $\{2 ;(1 \cdot 8 i)$ : R F D.

DALE。 CO, SAN BERNARDIND

BISOOKS, FZRA It.-1a.3,'s6; $\left(\mathbb{R}^{\prime} 36\right)$.

DALY CITY (SAN FRANCISCO P.O.), -

SAN MATEO

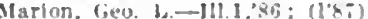

DANVILLE, 200, CONTRA COSTA

HFAMHR, HOWAHD C.-Md.1,'S5; (l'01)

DAVENPORT, 500, SANTA CRUZ

NITTIER. ADOL'H NICHOLAS (b'86) Cal.s,09; (1"09).

DAVIS, 832, YOLO

BATES, WAITER FARNEST $\left(b^{\prime} 60\right) \mp-$

Cal.2.'81; (1'84).

SCHOFE, \&. F. (t'8t) †-Cal.1,08; (1'08).

DAVIS CREEK, 45, MODOC

Chappelle, C. Carleton (b'i2)-Cal.5,03; (1'05).

DECOTO, 250, ALAMEDA

Chamblin, Marquls Rlchardson (b'28) - Pa.2, '50, Cal.1,60; (1'86).

Hanley, James Chapman $\left(b^{\prime} i i\right)-C a l .7,07:$ (1'09).

DELANO, 437, KERN

Copeland, John Albert (b'i5) - Ia.3,00;

(1'12), (1'88).

DEL REY, 100, FRESNO

Graham, Lyle-Colo.3,"98; (1"00)

DIAMOND SPRING, 267, ELDORADO

Nusbaum, Adolph Arthur (b's6) $-0.12,11$; (1'11).

DINUBA, 970, TULARE

LOPER, ASBLRY NELSON (b'59) Mleh. 1,'90: (l'01).

MOOHE, JAMES A. (b'52)-Ky.2,'81; (1'82): Pr.

Mortion, Robt. Fdward Lee (b'69)-Mo.2i, $9 \pi ;(1,9 \pi)$.

Tlit TSOA. CLARENCE A. (b'66)-X.Y.5. Waltérs, I'ain

(l'0s)'

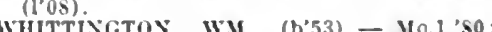
(1'91).

DIXON. 827. SOLANO

II all, Lester I'arker (b'76)-Cal.1,'9; ; (1'98).

Morrison, H. F.-Cal, 1,'97; (1'95).

Rlersor, Robt. L. (b'6t)-X.'.'.'s; ; (1'90). DOS PALOS, 550. MERCED

HARTWFLL, RORT. WM, (b\%5)-Cal.I. '11; (1'11).

Mcclelland, James Hugh (b'ss)-Call.'12:

PARISH, FREDK. WATSON (b\%0) Cal.8,10; (1'10).

DOWNEY, 1,500, LOS ANGELES

Barnebee, James Hosea (b'i5) - Ill.1,02: (I'Ii).

HAVGOON, ATTICLS GREEXE (b'i0) Tenn.5, 91 : (1'91); Pd.

DOWNIEVILLE, 500. SIERRA

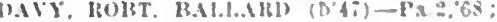

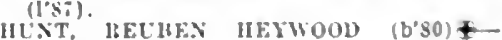
Cal.i, 05: (1'05)

DUCOR, 100, TULARE

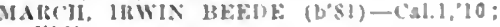
(I'10)

DUNCANS MILLS, 300, SONOMA

HA) (1'00).

DUNSMUIR, 1.719, SISKIYOU

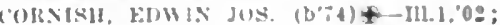
(1'01)

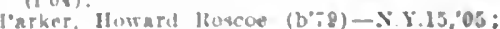
(1"12); DALR.

DURHAM, 180, DUTTE

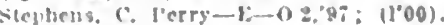

DUTCHFLAT, \$00, PLACER

liarues. L.uzerne Hruce (b'St)-Cal.5, Os: (1'0y). 
EAGLE ROCK (LOS ANGELES P.O.), LOS ANGELES

$$
\text { (see Los Angeles.) }
$$

l) unning, Frank W. (b'55)-N.Y.5,'86; (1'04).

Kioeberle, Theodore-fia.I,'85; (l'86) ; not in practlce.

Mcliurney, Matthew Reed.

(See Los Augeles.)

Thomson, Isaura Inez Śceley (b'80)-Ill.4, 04: not in practice.

EAGLEVILLE, 400, MODOC

Kennedy, N1llo R. (b'75)-Cal.7, 03; (l'03). Stokes, Robt. I. (b'76)-Md.3.,0?; not in practlce.

EAST AUBURN, 600, PLACER

Snypp, Theodore (b'60) E-0.2,'83; (1'01)

EAST OAKLAND (OAKLAND P.O.), ALAMEDA

DIETZ, HENRY LOUIS.

(See Oakland.)

Stlrling, Chas. (b'55)-Ill.11,'88: (l'89)

STIRLING, MARION F. (b'55)-Jll.9,'85;

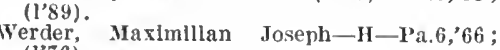
$\left(1^{2} 76\right)$

EDGEMONT, - LASSEN

Bolton, Becker B. (b'70) E-CaI.4,'91; (1’95) ; Ob.

EL CAJON, 500, SAN DIEGO

KNOX, CHAS. RANDALL $\left(b^{\prime}, 7\right) \oplus-I 11.19$, 03; (1'10).

EL CENTRO, 1610 IMPERIAL

Apple, Wm. Waiter (b'61) - Ky.5,'92; (l'02). Carter, Frauklin IIarvick (b'87)-Ill.11,'11 (1'12).

JESSEE, GEO. M. (b'59)-0.1,'87; (申); Member Ky. State Med. Assn.

Luckett, Thos. O. (b'79)-Pa.1,05; (1'11).

IcCombs, Virgil J. (b'7 - Cal.6, on : $\left(l^{\prime} 00\right)$.

Peterson, Fred w

(See Calexico.)

Robblns, Ona Mae-Cal.5,01; (1'03).

ROBINS, MORRIS C. (1,70) (1'13); Member Wash. State Med. Assn.

ELDRIDGE, I.050, SONOMA

Beynon. J. H.-Ill.22,'13: ()

DAWSON, WM. JOS. GREMIEY $\left(\mathrm{b}^{\prime} 46\right) \oplus$ N.Y.5, $67 ;(1 ' 77)$

GENUNG, MABEI, A. (b'79)-('al.9.'11 ( $\left.I^{\prime} 11\right)$.

GRAY, EDWARD (b'49) - N.Y.1,75; $\left(1^{\prime} 77\right) ; N$.

ELK, 430, MENDOCINO

SAWYER, EDMUND HOUGHTON (b'81) IIass. 1,08; (1'09).

ELK GROVE, 467, SACRAMENTO

BEATTIE, HUGH-Cal.1,'96; (l'96)

Kerby, Clinton, Jr.-Cal.1,04; (l'04)

Wildanger, Fredk. Johu (b'61) - Ill.6,'95: (1'99).

EL MONTE, 350, LOS ANGELES

Charlesworth, Geo. J.- Ont.3,'85; (I'88)

Corpe, Seymour L. (b'66) H-Ill.4,94; (1'11).

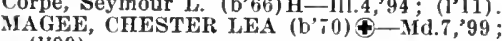
(I'99).

Mordoff, Chas. Espy (b'83)-Cal.9,'10; (l'12).

Saylin, Isaac-N.Y.6,'99; (1'04).

EL RIO (MONTALVO P.O.), 250, VENTURA

Togt, Edward Albert-Mo.1,'74; (1'94) ; not in practice.

EL SEGUNDO, - LOS ANGELES

(IALLUP, HOWARD AUGUSTUS (b'84) \&Cal.1,'11; (1'11).

ELSINORE, 488, RIVERSIDE

Arenschield, Edwin M.-Ia.3,'83; (l'94).

Keeler, Geo. Denison-0.19,'s9; (l'92).

Schultz, Michael A. (b'64)-Cal.6,'99; (1'00).

EMERALD BAY, - ELDORADO

Seward Lee S. (b'89)-Cal.5.'1:; (l'13); OALR.

ESCALON, 60, SAN JOAQUIN

Avery, Norman M. (b'54) E-K5.4,'94 (1'94).

ESCONDIDO, 1,334, SAN DIEGO

CRISE, BRƯCE I. (b'79)-Cal.6,03; (1'03)

CRISE, DAVID (b'46)-Pa.2,'72; (1'88).

Dodds, Jessie Benton Brown (b'57)-Ill.9,

'S7; (1'12); $\mathbf{N}$.

Ealy, Albert E. (b'46)-Pa.1,'70; (l'99) ; not in practice.
I.AlZALERE, JOHN V', (b'59)-X.Y.6,'84 ( I'95).

Muray, F. W-Mo.10,87; (I'87) ; not In practice.

ESPARTO, J00, YOLO

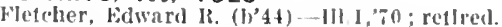

ETIWANDA, 175, SAN BERNARDINO

Myers, W'm. I'ark (b'7 6$)-0.1,06 ;\left(1^{\prime} 06\right)$

shepherd, Aaron Jeon (b'5) - 0.13, '78; (1'87).

ETNA MILLS, 5I8, SISIKIYOU

liathurst, Eolwh Wm. (b54) - ('al.1,77; $\left(l^{\prime}, T\right): 0 p L$.

llaines, Wm. H.-Ia.1,98; (1'98)

NUTTING, CIIAS. W. (b'52)屯-(ia.5, 76 ; $(1,78)$.

Nuttlng, Chas. W., tl. (b'84)-Cal.l,'12; (I*12).

EUREKA, II,845, HUMBOLDT

BRYAN, LIOY'l) (b'84) +-Cal.2,'] I ; (l'11) 707 , bth St.; office, $210 \mathrm{~F}$ St. ; $1-3,7-8$ IIAI, JOIN N.t-CaI.2,04; (1'04); 1633 D St. ; offlce, 428, 5th Ave.; 11-12, 1-?, 7-8; ÓbG.

DORAIS, LOUIS P. (b'65)-Cal. 7,01 ; (l'01) 207, 5th St. ; $2-5$; OALR. $\star$

FALK, CHAS. C.\&-Cal.1,'97; (I'98); 4th and $\mathbf{F}$ Sts. : 10-12, 1-3:30.

FALK, CURTIS 0.†-Cal.1,'97; (1'98) : Cormick and Sinclair Bldg. ; $10-12,1-3: 30$; FELT, RAE (b'69) \&-Call.2,90; (1'91); 1415 Broadway; office, $210 \mathrm{~F}$ St. $1-3 ; \mathrm{S}$.

Foster, Seth Burnham-Y.Y.i, $69 ;(1 ; 6)$; $828 \mathrm{G}$ St. : $8-10,2-4$.

Gibson, Lewis D.-CaI.7, 05 ; $\left(1^{\prime} 06\right)$; 5th and

Goyer, E. II-Cal.4,'93; (I'93); Weck Block. GROSS, HAROLD G.-Mass.1,93; (l'93); not in practice; 5 th and $F$ Sts.

Gross, Reuben-Scot.5,'62; (1'76); Gross Block; 1-3.

Loofbourrow, Thaddeus L. (b'67)-Ill.1,90; (1'95); 1202 C St.; oftice, 319 E St. ;

MARSHALL, BENJ. M.-Cal.7,'02; (l'03) ; Carson Block; 1-3, 7-8

MERCER, CIARENCE MAVEL (b'82)Pa.2,07; (1'07); 2607 H St.; offce, Gross OTTMER F,

offle, 4th and FNCE H.-Cal.1,'87; (1'88); Perrott, Walter I St.; $1-3,7-8$

E St. Walter L.-Cal.1,'98; (1'99); 309

Pet. ; 9-12, 1-4, $;-8$

Pierce (l'02)

634, Geo. W. (b'68)-N.X.10,'92; (1'93) ; 634 H St. ; offlce, Carson Block; 9-10, $1-3,7-8$.

UNN, WM. JAMES $\left(b^{\prime} 67\right)-$ Cal.1,05: (1'05); offlce, $3 d$ and F Sts. ; 10-12, 1-3,

INCLAIR OIVER W (b'09) Que.1,'91; (1'92); offlce, 805, 3d St. ; mith, Arthur M.-H-Ill.4,'83 ; (l'83) ; 723 , 3d St. ; 2-4, 7-8.

WALLACE, CARL T. (b'81) - Que.1,08; (l'09); 631 E St. ; offce, Georgeson Bldg. ;
$1-3,7-8$.

Wallace, Wm. H.-N.Y.5,'78; (1'83) ; GeorWalsh, Jos. Francis (b'84) - Cal.1,09;

Wells, E. W.- $0 ;\left(1^{\prime} ; 6\right)$; not in practice. WING, LAWREYCE (b'81) - Cal.1,07; (l'07).

EXETER, 500, TULARE DUNGAN, JAMES FORNEY (b'66)-Tenn.5,

McLEAN, ALEX, DAVID (b'67)-Ky.5,'95; (l'96).

MIX, PERNIER ALBERT (b'\%)क-Cal.2, 04 ; $\left(l^{\prime} 04\right)$.

FAIROAKS, 500, SACRAMENTO

Beauchamp, Harry H. (b'72)-0.9,04; (1'06).

BRANIIALI, ROBERT NICHOLAS (b'78) (-11l.6,02; (1'02)

Buffum, Eugene Howard (b'69) H-Ill.10,'93 : (l'98) ; OpA.ネ

HANVEY, CHAS. BRACE HEWITT (b'56) -Que.1,'83; (I'94).

FALL BROOK, 310 , SAN DIEGO

Doak, Thos. Coffing (b'7T)-Cal.6,08; (l'08).

Ross, Albert-Ind.8,'92; (1'95)
FALL RIVER MILLS, 350, SHASTA

'RATT, MATIEW D. (b'69) - Cal.2,'(10 (['0I).

Wheeler, Chas. If.-E-0.2,'89; (I'89).

FELLOWS, 200, KERN

Curl, Chas. A. (b'02)-IIl.6,'85; (l'92).

Johnsin, Joln T. (b'82)-l'a.2,'09; (1'11).

FERNDALE, 905, HUMBOLDT

BIRTNLR, FRANCIS HARION (b'65)\$-

N.Y.10,90; (l’99); S.

ANE, JOHN ALEXANDER (b'73) †-Cal.1, '98: (1'99)

RING, II. J.-III.8,7\%; (l'88); Ob.

FILLMORE, 125, VENTURA

Blzzell, Frands A.-Ala.2,79; ().

IINCKLEY, JOIIN I'.-Vt.2,'75; (l'90).

ANNING, WIlL R. (b'75) $\odot$-Cal.6,02; (l'08)

SBORN, HAROLI' BLACKMAN (b'84)S.C.1,09, N.Y.1,'II; (I'12).

FLORENCE, 750, LOS ANGELES

Cate: Fredk. Symon (b'61)-IId.1,'98; (l'01).

FOLSOM CITY, I,500, SACRAMENTO

Cress, Walter Wm. (b'85)-III.11,12; (l'13). (l'93).

iIADDING, CHAS. F. (b'56)↔-Cal.4,97; (1'97)

SLALGHTER, KENTUCKY JOHN (b'43)Mo.7,'84; (1'88).

Smlth, II. Watson-Ill.1,70: (I'80).

FORESTHILL, 658, PLACER

IcCullough, F. E. (b’99)-Pa.1, 06; (l'11).

FORTUNA, 883, HUMBOLDT

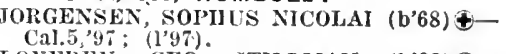

LOVEREN, GEO. STILLMAN (b'83)థ-

Rockwell, Orville (b'79)-Mllch.1,'06; (l'12).

FOSTER, 63, SAN DIEGO

(rregg, Rolt. J. (b'43)-Pa.2,66; (l'78) ; not in practice.

FOWLER, 675, FRESNO

Crawford, Wm. T. (b'63)-Pa.12,'89; (l'04). Golden, John-Mich.1,'69; (l'91).

IITCHELL, CHAS. OTIŚ (b'79) @-Colo.2,

MOR'íl'07), MOSES A.-Tenn.1,'97; (l'99). Wilson, Adam Donaldson-Scot.3,'86; (1'92).

FRENCH CAMP, 233, SAN JOAQUIN

Stagner, Chas. Elmer (b'83) - Cal.1,'12 ; (I'13); San Joaquln Hospital.

FRESNO, 24,892, FRESNO

Adams, Wm. Lanier-Cal.1,06; (1'06) ; Forsyth Bldg.

AIKEN, GEO. HENRY (b'45)థ-N.Y.1,69; (1'89) ; 315 Van Ness Are.; offlee, Patter-

son Bidg.; $10-12,1-4$

BARR, WARDEN T. (b'71)€-Cal.1,'96; (l'96) ; 1725 J St.; office, Rowell Bldg. ; $11-12,2-4$.

Benedict, Chas. Winchester (b'61)-Pa.9, '87; not in practlce; R.F.D. 3.

BENEDICT, WM. LEMUEI, (b'85)-Mlch.1, '12; ( ); Member Mich. State Med. Soc.

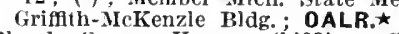

Bland, George Harper (b'69) — Cal.7,'01; (1'01) ; Rowell Bldg.

Brown, Chas. Everett (b'79) - Cal.5,'13 ;

BURKS, FJoYD L. R. (b'83)@-Pa.2,'08; (1'08); Forsyth Bldg.; 11-12, 3-5; S.

Burks, Wm. Tillman (b'58) - Cal:7,'00; $\left(l^{\prime} 00\right) ; 1633$ J St.; offlce, Fresno County Land Company Bldg.; 11-12, $1 ; 30-5: 30$. COLIINS, CLINTON DARWIN (b'85) $4-$ Cal.1,'11 ; (l'11); Patterson Bldg.

Couey, Elmer J. (b'76)-Cal.7,00; $\left(1^{\prime} 00\right)$; 2706 Thomas Ave.; offlce, Rowell BIdy.

COWAN, ANGUS B. (b'71)屯-Cal.1,'93; (l'94); Forssth Bldg.; 2-5.

CRAYCROFT, HARRY' JUDGE $\left(b^{\prime} 7 \%\right) £$ Cal.1,04; (1'04); 1549 l. St.; offlce, Forsyth Bldg. ; 10-12, 2-5.

CROSS, WAI. WALTER, JR. (b'73)థ-Mo.2, '97; (l'97) ; 937 U St.; office, Patterson Block；1-4; S.

DICKENSON, CLARENCE FITZHCGH (b' (-Cal.2,'94; (1'95); Rowell Bldg. DOYLE, OLIINE BURTON (b'75)థ-Ky.l. '98; (1'98) ; 3020 Tulare St. ; office, Rowell Bldg. ; 10-12, 2-5; G.

DUUNN, EUGENE CLARENCE (b'54)N.Y.5,81; (1'89); 1707 J St.; offlce, Patterson Block; 11-12, 2-4. 
Gebhart, Lrastus Manfred (b'5j)-0.9.' is (1.84): 1362 I" St.

HARE, GEO. ANIIIEW $\left(\mathrm{b}^{\circ} 5 \pi\right)+$ Mlch.1

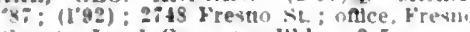
county land Cotnpany Bldg.: $2-5$.

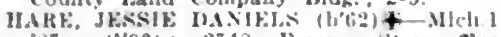
8: (192): 2715 kresno st. omce. Fresio County Land lompang IHdo.

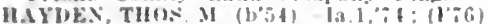
2155 Intador st : omce, l'attersin Blnck 10.12 . $2-5$

Ilines. Isaac Wright (b'56)ll Mass.i,?0 $(1 ' 95): 333$ Illackstone Ale.: unlee, 1010 St: $10-12,2-1$

HOLLIXGWOKTH, RORT, M.ACKSHF.IR - Pa.2,02; (1'04); Forsyth $31 \mathrm{l}$; ; 10.12 HÖPKINS, GRACE I. TIURNE-C'all, $01 ;$ (1'04)

llopklns. Itenry st. Cieo. Lyons (h'35)Pa.l.'55: (1\%7): 132: K St.; aftce, 3029 Mariposa St. : il-t.

MOPKINS, HowARb H. (b';6)-('al.1,0t (1'04); 1525 Maln St: offec. Flrst

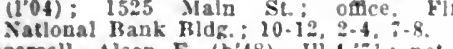

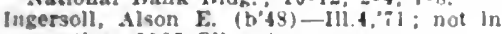
Dractlce: 1105 0llre Are.

INGRAM, CHAS. H. (6'it)-Cal.1:03; (1'03): 927 V St. omce, Rowell Blut.; ; 3.5

Johnston, Chas. E. (b'69) - Ind.5,"96; (1999) Edgerly Blug.: 10-4.

Joues, Ilobt. Meirln. 3r. (b's')-Tenn.5,'13. (l'13): Rowell Rldg.

JORGEXSF. N. NEIL (b'31)-111.59,09: (l'09) County Hospiltal: $11-12,2-5,7-8$

KJAERBYE, CLARIS PFTER H. (b'6i) Den.1,92; (1'9i); 232 Van Jess Are. offce, Rowell Bidg.; 10-12, 2-1:30.

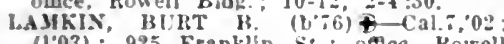
(03): 925 Franklin st. offece Rowel Bldg. : 9-12, $1: 30-5: 30$; (B19) ; OALR

l.ong. Geo. Lee $\left(b^{\prime} 58\right)$ H ('al.5, 36 ; (1'86): $134 \mathrm{~K}$ St: oflce, Rowell 13ldg.

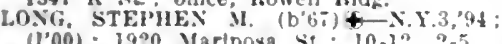

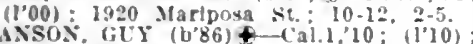
MANSOS GLY (b'8

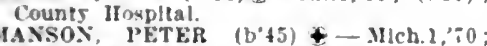
(I'91); Marlposa and $K$. its.

Martln, Jackson L. (1,6i)-Mleh.I,"99 (l'0l): J and Fresno Sts. : 2-4, ;-8,

MATHEWSON, CARLETON (b'j)-Cal.I, 100: (1.00): Republlcan Iildy

Mathewson. Has Arlogasi - Call, 00; (1'01); 18t8, 1st St

MALPIS, JAMES LAWRFXCE (b'6 Mo.7,90; $(1990)$; 1561 l. st.; offec, l'at terson Block; 11-12, 2-4

Melcbonlan. 1. 3.-1'a.2, s'; (1'89)

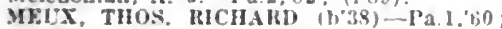
(1'89): 1007 R St.; once, 2030 Marlposa St. : $9-12,3-5$

MULER WALTER PALMFIR (b'59)-I' I 83; (1'01); 102h I St.; oflce, 2042 Iariprina St. $9.12,1-5$.

Murayama, Mitogoro (b'k1) - 0.11,1: : (l'13) : $935 \mathrm{E} \mathrm{St}$

Newbury, Denwood Nuwal Ldringston (b'vio) -N.Y.1.96; (1.01): 923 Hremer Ire. ofice, Land Company Bldg. : $9-12,2.4 ; G$

sicholson, James Whilard (b'si)-Tenn '13: (l'13): Fresno County IItuspltal.

OKONOGI, B. -0 ; $(1: 01) ; 736$ v st.

PETTIS, JOHN HURBARD (b"i) + MIch.1,06: ( ) : Grimth IIckenzle Blde $: 30-3: 30: \mathrm{S} . *$

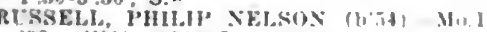
8.8; (1'91) : $1505 \mathrm{~J}$ St: oflec, $1010 \mathrm{~J}$ St $10-12,1-5$

SA.YPLE, THOS. X ... ( $31,1,0):$ (1'0) Forsyth Rlag. 10.12, 2-5. is

SAFAGE, WM. WIXTÓN" (b'8t-rall, 09 (l'09): Kepulllcau Illa.

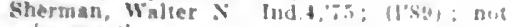
In vractlce.

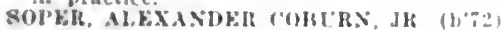
- III. 1,01: Member Jll siate Moel sine mod in practlo

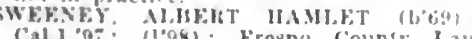
(al.1.97: $\left.11^{\circ} 98\right)$ : Fresno County Land (omians" lide: $11.2-4,7-8$.

Thortse, Walter M. (hosi)-ral. 1, $43:(194)$

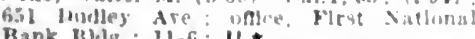
Rank lHklk.; 11-6: U.

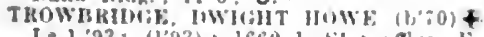

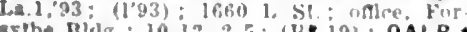
sythe Huc.: 10-12, 2-5: (13.19); OALR.

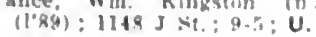

Van Valkenburk, Chas. C.-Mllch.1, is: (1's1); not in practice: $1125 \mathrm{~T}$ St.

WALKE, JOHX IOHT. (b'it) $9-30.98$ 98: (l'01): 2II Van Ness Ave; onle, Tulare and $\mathrm{K}$ sts.: $10-12,1: 30-t$ OALR. *

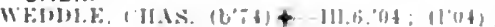

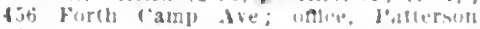
Block: $10-12,2-4$.

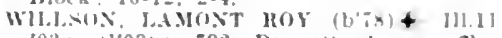
03: (1'03): 732 Dennet dre.; ufice lepubllean IBldg. 10-12, 2-4.

WHIGIT, FHEUK. LENEX $(1,0,4)$ K) (1'9:3)

FRUITVALE (BRANCH P.O. OAKLAND), - ALAMEDA

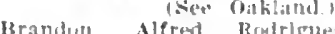

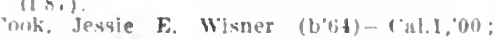
lo(t) ; 14.i3 High st.

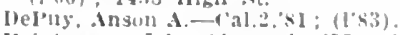

lleinimann, John M. Cal 2,$7 ;(i * 03)$; not in practlce.

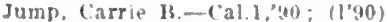

NORTH(OTT, ElIR.IM (b'il) - Mich.s,

FT. BAKER (SAUSALITO P.O.), MARIN

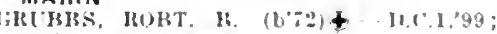
Maj. M. C., I.A.

FT. BARRY, - MARIN

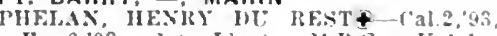

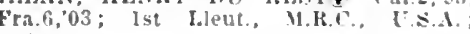
(I) 23 ).

FT. BIDWELL, 362, MODOC

Lelthead, Clas. E. (b'75)-Ia.3,95: (1'0I).

slatery, peter A. (b'i5)-Veb. $0^{\circ} 08$ (Indian servlec): Ft. Bidwell Schnol.

FT. BRAGG, 2.408. MENDOCINO

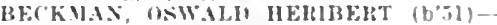
I"a.28st: (1'95)

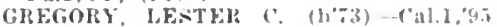
(1.95).

Lendru!n, Bimey Nexamder - Cal.2,02: (1'0:2)

Purlenky, dieo, 1'-C(*al.2,01; (1'01)

FT, JONES, 3I6, SISKIYOU

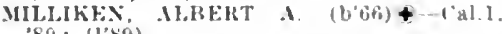

FT. MASON (SAN FRANCISCO P.O.). SAN FRANCISCO

DESHON. GFil. IULHFE: (h'bq) \$ N.Y.10,

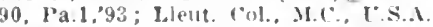

FT. MCDOWELL (ANGEL ISLAND P.O.). - MARIN

MCLELIAX, GEO. HIJISON (h'st)

M]ch.2.07: ('atut. MC.. I'.s...

MIRRAX ALEXIXDEll (b\% + I.C. os: Member Me. Med. Insn. ; Mpe. M.C. I.S.A.

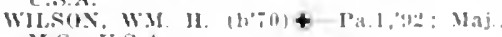
MC.. T.S.A

FT. MILEY (SAN FRANCISCO P.O.), SAN FRANCISCO

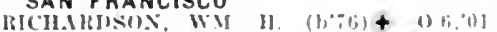
Capt., M.C. I.S.

FT. ROSECRANS (SAN DIEGO P.O.).SAN DIEGO

HIRNHTT, TIIOS WIIII $(1, \times 2)+\times Y 1$ os; INt I.lent. M. I. I I I

FT. WINFIELD SCOTT ISAN FRANCISCO P. 0.) - SAN FRANCISCO

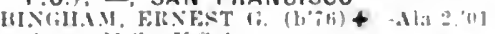
cant. Mi is 1

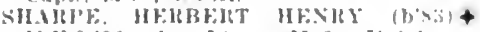

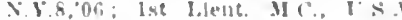

FULLERTON, 1.725, ORANGE

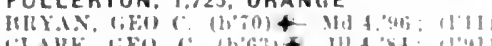

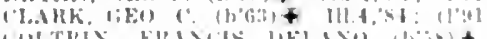

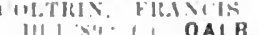

marllyon, Thomas sent.s.80: (1's!n)

troul. It है |)

Freoman, Wm, $\left(b^{\prime}+1\right)-\operatorname{lnd} \downarrow$

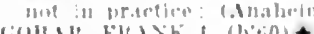

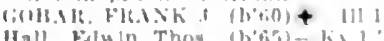

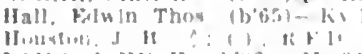

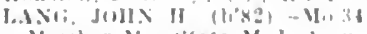

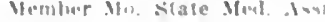

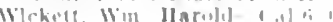

$n$ ititil:
GALT, Y85, SACRAMENTO

Christlan, J. 'T l'ill.1, 1): (1'02)

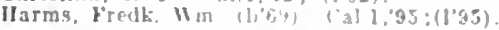

GARBERVILLE, 284, HUMBOLDT

Rossler, lewls l'aul (b'5a) - Vi:2, is; (1"89).

GARDENA, 425, LOS ANGELES

Ball. 3,hn J.

(sipe Iax ingedesis

WIRF, FRA.VIS IBFIMUNT (b\%: + ('ग10)

STI: (I"OS)

GARDEN GROVE, 400, ORANGE

Guinan, Filward Pobe (b's)-Cal.1, 11 (1'11).

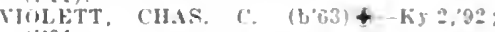
$(1,04)$

GASTON (P.O. WASHINGTON), - NEVADA

Sprague, Fred Felloms-Call.1.2: (1'9.3)

GEORGETOWN, 724, ELDORADO

III'KMAX, WM. S.-Tenn.5, Th. Tenn. 1, : : l'S6).

GEYSERVILLE, 400, SONOMA

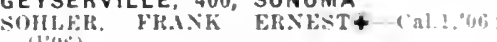
( $\mathrm{l}^{\prime}\left(10^{\circ}\right)$.

GILROY, 2,437, SANTA CLARA

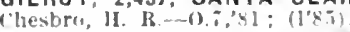

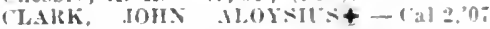
(l'07); S.

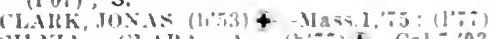

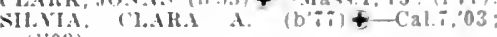
(1.03)

THAYK, J.ME.S WM, (b"5t)+-1a.1,":9: (I'SB').

GLENDALE (BRANCH P.O., LOS AN. GELES), 2,746, LOS ANGELES sov los threles

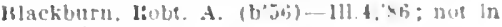

practice HORACE RISSELL (b') + Md. $1.03 ;\left(10^{\prime} 09\right) ; 0$ bG

BRY.YT, AILEX L.t-Ia.6.3:; (I'0]).

Jurrows. (linton $\mathbf{A}$.

(set Ios ingeles.)

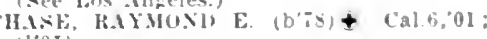
(1.0I)

Comstuck, Belle d. Wuud (b:40)-(al.6."09; (1'lo)

COMST(PCK, IANI. IMEI.OS $(6,90)+-111 . T 3$. (0): : (1'10).

(onrail Indrew (1)

(see I.ns Angeles.)

Curtis, ("luas. ('-11-J11.4: it: (l’yi)

FLIRST. OLIVER 3. (6'5i) +-1a.3,83: nut In Iractice; Member Kan. Med. sinc:

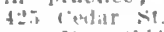

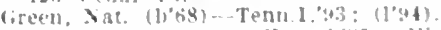

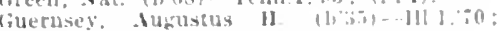
(1'12)

Hawkins-Ambler, dien. I

Hedter Thos. II (b'3s) - lit l, 65: llot in

practlce.

(l'Ai); OALR.

Leadsworth. John It

isce los Angeles.

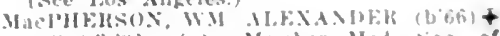
(lnt.b, : ( ) : Membe

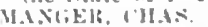

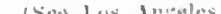

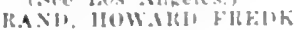

(sine los incestes

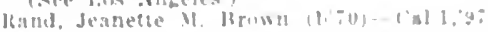

(1.01)

sulih. Harry clyclo

(Size Ias Anzoles

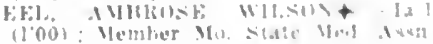

anderbines, Henry

111 t, $4: 3:(1): 001$

GILNDOHA. 1.500, LOS ANGELES

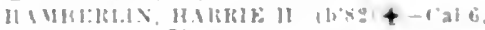

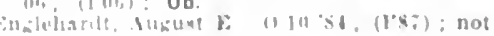

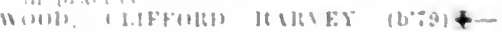


GLEN ELLEN, 1,000, SONOMA

FRANCIS, LOFTUS IIAItLEY (b'58) Cal.4,97; (1'07).

GLENN, - GLENN

FLIAS, WALTER L. (b'75)-Mo.ĩ.'97 ; (1'12)

Fellows, Adalbert 12. (b'49)-Ill.6, 69 ; re tlred.

GOLD RUN, 98, PLACER

Ilood, Fred Chas, (b'55)II $\rightarrow$ Cal.5,'S4; (l'S4).

GONZALES, 600, MONTEREY

BINGAMAN, ELMER WILEY Cal.2,07 (1'07).

GRAFTON. - YOLO

bixon, Thos. Harry-Yt.2,'99; (1'99).

Freeman, Eugene Nesblt (b'60)-Tenn.5,'85; (1'92).

GRASS VALLEY, 4,520, NEVADA

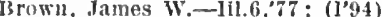

Cliappoll fico, E-Cal.7,05: (1’05)

Graftin, Jolin C. (b'69)-N.Y.9,95; (l'01)

JONES, CARL POWER (b'78) $\$$-Cal.1,07;

$\left(l^{\prime} 08\right) ; S$.

JONES, JOHN TAYLOR (b'75)-Cal.1,'98; (l'9S)

GREENFIELD, 25, MONTEREY

Clark, James Harrison $\left(b^{\prime} 41\right)-N . Y .10,72$; (1'6).

GREENVILLE, 300, PLUMAS

Morel, Henrl Auguste (b'77) - Pa.2,07 ; (1'07).

Wlison, Ernest Frerett (b'83) - Cal.7,06 (l'06); (Indlan Service); Grcenville School.

GRIDLEY, 987, BUTTE

Beck, Ida Annetta (b'7 7 )-Colo.4,'06; (l'12) ; ObG.

Beck, Peter S. (b'52)-Ia.4,'87; (I'01).

Lavy, Wm. S. (b'72)-Cal.5'04': (l'04)

Martín, Elmer E. (b'65)-N.Y.3,'92; (1'05).

Thompson, Lewls I. (b, 6$)-$ C'al.2,02; (l'02).

Thompson, Lewls Q. (b'50)-Ark.1,'84 ; (1'84).

Turner, Danl. J. (b'53)-Ill.8,79; (I'01).

GUADALUPE, 500, SANTA BARBARA

FRANKLIN, JOHN HENRY (b'80)-Cal.2, 06: (1'06).

GUERNEVILLE, 780, SONOMA Scheuer, Gerard A. J. (b'68) E-Cal.4,'96 ;
(l'96).

GUSTINE, 300, MERCED

Barnes, Jesse Walter (b'85)-Cal.1,'12 ; (l'12).

Johnson, Dwight David-N.Y.5,'83; (l'93).

HALCYON, - SAN LUIS OBISPO

DOWER, WM. H. (b'66) $4-N . Y .15,91$; (l'11); $N$.

HALFMOON BAY, 1,500 , SAN MATEO

BROOKE, WM. ANSYL (b'64)-Cal.1,97; (1'98).

Ferrln, Jos. A. (b'86)-Cal.7,07; (l'10).

Morgan, Chas. Lewis-Cal.2,'96; ' $\left(l^{\prime} 96\right)$; not in practice.

Pltcher, Josephine-Cal.1,'03; (1'03).

HAMILTON GITY, 200, GLENN

STANSBURY, MIDDLETON PEMBERTON (b'78) $4-C a l .2,07 ;\left(1^{\prime} 07\right)$.

HAMMONTON, - YUBA

GRAY, FRANK PIERCE (b'52) ๑-Cal.1,'95; (1'95).

HANFORD, 4,829, KINGS

CRAWSHAW, JOHN ALLEN (b'79)-Ill.11, 05; (l'07); OALR.

CUTTLE, FREDK. (b'75)-IIl.11,04; (l'05).

Dixon, R. Edmond (b'61)-Va.1,'91; (l'94).

Felton, L. E.-N.X.10,'71; (1'91).

Foster, Ernest C.-Cal.2, $02 ;\left(l^{\prime} 02\right)$.

Motheral, Raphael-Tenn.5,'03; ( ( '04).

Robbins, Budd (b's6)-1l1.11,'i2; (1'12). ROSSON, CHAS. TILDEN (b' 6 ' 9 -Cal.7,
'03; (I'03).

HARRIS, 27, HUMBOLDT

Pollard, Frank (b'66)-Mo.27,91; (1'91).

HAWTHORNE, 120, LOS ANGELES

Worthen, Lewis J.

(See Los Angeles.)

HAYWARD, 2,746, ALAMEDA

Alexander, Geo. E. (b'47)-Pa.2, 73 ; $\left(1^{\prime} 76\right)$. BILLINGSLEY, URBAN CLARK $\left(b^{\prime}, 75\right)(0-$ Cal.1,04; (1'04)

BROWNIYG, FREDK. WM. (b'65)†Scot.9,12,14,'s8; (l'94).

Galbraith, Archibald M.-Cal.1,'89 (l’89).
Long, Thomas Sherman (b'84)-Cal.1,'12; (l'13) ; $\mathbf{S}$.

MEDROS, Jos. J. (b'69)-Cal.1,94; (1'95). NIFLSEN, SOREN $\left(1 \prime^{\prime} 78\right)$ - hen. 1,06 ; $\left(1^{\prime} 08\right)$. Wliliams, Annle W.-Cal.4,'86, Mich1,'92; (1'86) : R.F.D. 1.

HEALDSBURG, 2,0I1. SONOMA

Bond, Elmer C. (b'74)-Cal.4,'99; (1'99). Carmichael, Asi Bartholow (b'y7)-Pa.2, '11; ().

CoNirT, JOHN CHRISTY (b'72)థ-Cal.1, 04; (l'04).

SEAWFLI, JAMES WALTER (b'79) $\bullet-$ Cal.2,01; (l'01); S.

STONE, MACK V.' (h'75)-Cal.2,96; (1'96) ; A.Surg., Ileut. U.S.N., retlred.

SWISHER, JADIES R. (b'49)-Cal.2,77; (1'7i).

Wearer, Chas, Warren (b'55) - 0.1,79; (I'84)

WIIEELER, IRA ABBEY (b'61)\$-Cal.4, '94; (l'94).

HEMET, 992, RIVERSIDE

Eadle, Andrew Beattle (b'59)-0nt.3,'86, N.Y.10, 86 ; (1'10).

Miller, Henry 0.-Cal.1,'93; (l'94).

Morse, Douglass Howell (b'85)-Md.7,'10; (l'13) ; $\mathbf{S}$.

SIMONDS, PAUL EDWARD (b'\%6) -Cal.6, 08; (I'09); LD.

Smith, Louisa (b'68)-N.Y.15,98; ( ).

WESTON, JOIIN B. (b'53) - Pa.1,78; (1'89); not in practice.

HERMOSA BEACH, 679, LOS ANGELES

JAYNES, MANNING $\left(b^{\prime} 66\right)+0-\mathrm{Ia} 3,07$; (I'10).

HIGHLAND, 1,600, SAN BERNARDINO

BURKE, EDWARD WILBUR $\left(b^{\prime} 74\right) \oplus-$

Il1.11,'01; (l'05).
EVANS, JOHN HEDLEY (b'66) $\oplus-\mathrm{M}-8$. , $^{\prime} 00$; (1'00).

Howson, Carl Robt. (b'85)-Cal.9,'13; (l'13).

Wilmot, Wm. H. (b'34)-Ia.1,'58; (1'92).

HILTS, 60, SISKIYOU

DOZIER, EARNEST (b'77)@-Cal.1,08; (l'08).

HOBART MILLS, -, NEVADA

Swauger, Harry Lesel (b'75)-Cal.1,05; (l'05).

HOLLISTER, 2,308, SAN BENITO

Curtls, Ralph Gardner (b'78)-Pa.2,01; (l'01).

HULL, LEONARD C.4-Cal.1,93; (l'94).

NASH, FRANCIS ORLANDO (b'42)-Me.1, $68 ;\left(l^{\prime} 76\right)$.

o'Bannon, Richard Wm. (b'69)-Mo.7,90 ; (l'91); $\mathrm{s}$.

O'Donnell, Jos. M. (b’78)-Cal.2,02; (l'02). ROOKLEDGE, PERCIVAL L. (b'78)-Cal.6, 04 ; (1'05).

TERBETTS, JAMES HENRY (b'ธ7)-N.H.1,

'81; (1'85); (F4).

HOLTVILLE, 729, IMPERIAL

Wells, Geo. F. (b'44)-Mo.18,'89; (l'89).

Wimp, Wm. H. (b'82)-Ky.4,'05; (l'10).

HONCUT, 418, BUTTE

Horton, Theron W.-Ia.1,'63; (l'88).

Van Male, John James (b'58)-Cal.4,'87; (l'87).

HOOPA, 20, HUMBOLDT

Anderson, Carl A. (b'79) - Minn.4,'05; (1'10); (Indlan Service); Hoopa Valley School.

HORNBROOK, 250, SISKIYOU

Plimell, John T. (b'35) E--0.2,78; (l'99).

HUENEME, 800, VENTURA

Lamb, Horace G. (b'60) E-Cal.4,'01; (1'01).

HUGHSON, 25, STANISLAUS

Lorimor, John H. D. (b'61)-Ind.8,'89; ().

Parrish, Wm. Henry-Ore.1,'89 ; (l'97).

Skinner, Haven Day-Ia.6,'04; (I'06).

HUNTINGTON BEACH, 815, ORANGE

Clark, Delbert A.-Ia.3,84; (l'97).

SHANK, GEO. AUSTIN (b'62)-Ky.1,'98; (l'98).

HUNTINGTON PARK, 1,299, LOS ANGELES

Bames, Otto (b'85)-Cal.9,'13; (l'13)

Hubbard, Clinton De Witt - Mich.1,'91; (l'08).

Lacy, Jasper N. (b'58)-Mo.20,'00; (l'00)
THOMPSON, IVESLEY $\left(\mathrm{b}^{\prime} 44\right) \oplus-0.9,69$; (1'88) ; D.

IDRIA, 300, SAN BENITO

Dowling, Stanley Waldo (b'87)-Cal.1,'12; (1'13); S.

IGO, 148, SHASTA

FLORA, GEO. E.-Md.4,'95 ; $\left(\mathrm{I}^{\prime} 00\right)$.

IMPERIAL, I,257, IMPERIAL

Moore, Luther lleml (b'88)-Ill.11,'I2; (1'12).

Standlec, Claud E.-Cal.6,'07; (1'08).

INDEPENDENCE, 407, INYO

Woodln, Irvlng J.-N.Y.8,'74; (l'83).

INGLEWO00, 1,536, LOS ANGELES

liartlett, Howard Geo. (b'69)-N.Y.8,'91; ( )

IINDMAN, SAML. JAMES $\left(\mathrm{b}^{\prime} 56\right)(-\mathrm{Md} .3$,

'81; (1'97).

PITNAM, ILARRISON A. $\left(\mathrm{b}^{*} 77\right) \oplus-\mathrm{Cal} .0$, 04; (1'04).

RAINIE, FRANK (b'64) $\oplus-$ Mlch.1,89; (l'10); Member Mlch. State Med. Soc. : First Natl. Bank Bidg.

REREIt, WM. WORRALI (b'56)@-Pa.1, $79 ;(1 ' 12)$.

IONE, 876, AMADOR

Frizell, John P. (b'62)-Ire.5,'88: (l'94)

IAWKINS, GEO. GILES (b'80) $\oplus-M 0.2,05$; (l'06).

IRVINGTON, I,000, ALAMEDA

Anderson, Longworth Shuttleworth - Cal.1, '98; (1'99).

GRIMMER, E. M. (b'81)-Cal.5,08; (l'09).

Lutz, Chas: V. A.-Pa.1, 77 ; (1'84).

ISLETON, 84, SACRAMENTO

LEIMBACH, JOHN HERBERTథ-CaI.2,'02 ; (l'02).

JACKSON, 2,035, AMADOR

ENDICOTT, EDWIN E. (b'74) $९-K y .1,{ }^{\prime} 94$; (l'94).

Franklin, Blake (b'76)-Cal.7,'04; (l'04).

Gall, Alexander M.-Cal.2,93; (1'94).

JAMESTOWN, 600, TUOLUMNE

CONGDON, CHAS. E. (b'65)-Ky.2,'94; (1'94).

JAMUL, 45, SAN DIEGO

Wade, Wm. N. (b'63)-Pa.1,'92; (1'92).

JOHNSVILLE, 3II, PLUMAS

Bolton, Manzanito B. (b'74)-Cal.4,99; (1'99).

KELSEYVILLE, 400, LAKE

UPTON, WM. E.-Ind.10,89; (1'99).

KENNETT, 2,500, SHASTA

SANDHOLDT, JOHN P. (b'80) ๑-Cal.2,'04; (1'05).

KENNY, 62, MENDOCINO

Purdon, John Edward (b'39) - Ire.3,'85; (l'98).

KENTFIELD, - MARIN

Rankin, John Edward (b'41) - N.Y.6,'91;

(l'93); not in practlce.

KERMAN, 400, FRESNO

ARNOLD, D. ELMER (b'68)-Ill.11,'93; (l'12).

IKERN (BRANCH P.O., BAKERSFIELD), 1,500 , KERN

Lee, Belle AI.-Cal.7,'98; (l'99).

KERNVILLE, 210, KERN

Gibson, Richmond E.-N.Y.6,'90; (1'92).

KESWICK, 1,800, SHASTA

SEVENMAN, GEO. IVM. (b'73)-Cal.1,'94; (I'95); (Redding).

KING CITY, 900, MONTEREY

BRUMWELL, DORUS (b'59) - Ky.1,'89; (l'89).

Fuchs, Hugo W.-Cal.4,'97; (l'97).

KINGRIVER, 40, FRESNO

Powers, Chas. H.-H-Mass.5,'83; (l'83).

KINGSBURG, 634, FRESNO

Glllespie, J. A. (b'61)-IIl.11,'95; (l'06).

Nuckolls, Wm. L. (b'66)-Ill.11,'04; (1'04).

Phillips, R. O. P.-Ill.6,72 ; (l'85).

SMITH, FLORA W.-0.2,93; (1'93).

SMITH, THOS. D.-0.2,'92;'(1'93).

KNOB, I50, SHASTA

Hoskins, Greg (b'86)-Cal.1,'10; (l'11). 
LA JOLLA, 500, SAN DIEGO

COREY, MARTHA M. DUNX (b'32) 9 Pa.7;79: (1'93)

HoWAIR," EDWARD (b'52) \&-Mass.1, 87 ; (1'06).

RItler, Mary E. B. $\left(b^{\prime} 60\right)-C a l .1,{ }^{\prime} 86$ : (l's6) Sapero, Kalmen C. $\left(b^{\circ} 66\right)-K y .4,91 ;\left(l^{\prime} 95\right)$

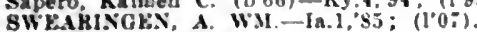

LAKE CITY, 100. MODOC

Hildebrand, Marcus C.-Tenn.9,97; (1'00)

LAKEPORT, 870, LAKE

Crals. Mundoch A (b'60)-Que.1's6: (I'86) Pearn. Walter II. (b'60) F-('a).4.32; (1'92)

Stipp. Henry I: (b'52)H-Mo.5:-66; (1's5)

LAKESIDE, I00, SAN DIEGO

IREYS, JUNIUS TAYLOR (b'75) -Pa.1, 00: (1.03).

LA MANDA PARK. 250, LOS ANGELES

Collle, Jos A.-IIl.6,'98; (l'09)

Harpster, John W.-III.1,'91; (1'97).

LA MESA, 500, SAN DIEGO

I'ARKS, JOS. ANDKEW.

(See San Dlego.)

MALLERY, JOHX H.IKKY (b'is) \& Cal.2, 02: (l'03); Ob.

Rawlins, Saml. T. (b'41)-0.8'75: ().

Samson, Chas. $(\mathrm{b} ; 3)-111.1,99$; LŔ.

Samson, Chas. (b'-3)-lll.1,'99; LR. -95: (1"95)

Zochert, L. W. (b'75)-Wls.3,9:; (1'12).

LA MOINE. $\rightarrow$ SHASTA

Petch, Phlllp Henry (b'si)-Cal.1,09; (1'09).

LANCASTER, 125. LOS ANGELES

A rwlne. James Tevis (b'72)-Tenn.11.'94: (\$)

Burt, Leander W. (b'33)-Cal.6,05; (j'09)

LANKERSHIM, 200, LOS ANGELES

Fuster, Martin L. $\left(\mathrm{b}^{\prime} 45\right) \rightarrow 0$ : ( )

LA PORTE, 214, PLUMAS

Mussey, John M.-H-Vt.1,'54; (1'76)

LARKSPUR, 594, MARIN

MCCUE, JAMES EDW.

(See San Francisco.)

LATON, 400, FRESNO

Hardman, Chas. W.-Ill. '78; (l'Ot)

LEMONCOVE, 100. TULARE

Montgomery, Robt. Bruce (b'80)-Tenn.5,

01: (1'01); not in practice.

LEMONGROVE, I50, SAN DIEGO

White, Fredk. Paul (b'ti)-Ky.2,' $\leq 8$; (

LEMOORE, 1,000, KINGS

Brown, Albert A. (b'73)-Cal.7,'08; (1’08); (Deat'st).

Byron, Edwin H.-Cal.4, 00 ; (l'00).

Byron. Wm. I'. (b'73) E-Cal.4,04; (1'05)

YATES, JOS. ERXEST-CAI. 6 ;04; (104); S.

LINCOLN, 1,402, PLACER

Hyde, Orra Crosby-Cal.l,"98; (l'98).

Manson, John (b'49)-Ont.t, 66: (l'85)

LINDEN. I50. SAN JOAQUIN

BUCKI,EY. WM. LANGDON (b'i0) -

Ore.2,94: (1'94).

LINDSAY, 1.814, TULARE

Gorton, Mary L. $\left(b^{\prime} 50\right)-111.3$, , $^{\prime}$ : (\$).

HUGHES, ANNIE LAUKIE BOND $\left(b^{\prime} 62\right)-$ Cal.4,97: (1"9i).

LOCKE, cluAT'́N W. (b'62)-Ky.4,88; (1'12).

PIERCE, RORT. E. (b'56) Mass.5,'79; $\left(l^{\prime} 80\right)$; not in practlce.

8TALIAXG, FIANK LKSLIE (b'71)

Kं 1.01 ; (1'01).

TOLKTILLOTT, WALTER WALLACE; -

Cal.I.'04; (l'03).

LIVE OAK, 278, SUTTER

Higgins, Irving W. (b'78) - Mlnn.4,04: $(1 \% 04) ; 0 b$.

Rlce, Jeise A.CCAl.5.09: (1'11).

LIVERMORE, 2,030, ALAMEDA

Bybee, Addison (b'T6) - III.11.'0t; (I'13).

Mefili. Henry Gordon- Y.5.

Meyers, Wallace Jongfeliow (b'81)-Cal.2 (1):

Mylott, Mary A. (h'70)-Cal.1,12: ().

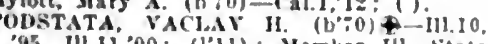
95. III.11,00: (1'11); Iember III. Sinte Med. Soc.: (rit): NP.

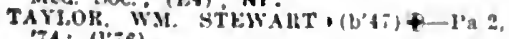
$74:(1 ; 6)$.

Warner, James Kyle-Cal.2,"91; (1'92).
LIVINGSTON, IIO, MERCED

IIICKS, JAMES M.-Cal.4,96; (1'97)

KIrchhofter, Fredk.-Cal.2,87; (1'87).

LOCKEFORD, 612. SAN JOAQUIN

3ARROER, NATHAN R. (b'53)-Pa.9.'81: $(1 \cdot 82)$.

I'riestley, Jos. G. (b'5i)-Mo.1,80; (1'84).

LODI, 2,697, SAN JOAQUIN

ALTHCK. SAMl. R.

(See Woodbrldse.)

BL'CIIANAS, HOHT. AMBROSE (b'66) Cal.4.96, Cal.5,"98, Cal., $03 ;\left(1^{\circ} 96\right)$.

HURCHALD, E. ADELBEKT (b'4)-0.11,

i?: (1'81) : LD.

Wm-Cal.1.73: (1'-6).

Gardner, John Melrin (b'it)-Tenn.1,09;

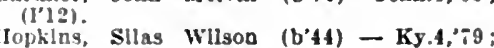

(1'99). wh.ToN M. (b'65) -Cal.4,91

(1'91).

Moyer, Frank E. (b'63)-Mlch.1,'94; not in

practlce.

Myers, John Jos. (b'65)-Cal.7.39; (I'99).

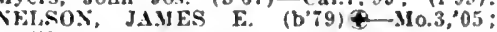

(I'05)

SAKGFNT, J. P.-N.Y.10,'86; (1'8i); not in

practlce.

stannard, Walter D. (b'39) - Mllch.1, 65

(1'93).

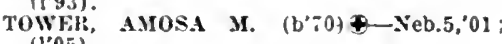
(1'05).

LOMA LINDA, -, SAN BERNARDINO

ABBOTT, GFORGE KNAPP (D'80) -II!.19, 03; (l'04): Dean and Prof. Phys.-Ther. and Prace of Med., Cal. 12; 1.

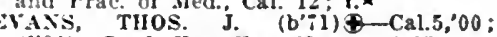
(I'00); I'rof. Eye, Ear, Nose and Throat, Cal.12.

Georre, Wm. Aaron (b'66)-Mlch.1,'94; (1'i1); Prof. Anat. and Pelric Surg., Cal.12: S. DOROTHY T. (b'64)-Pa.j. IARBALGH, DOROTHY T. (b'64)-Pa.j,

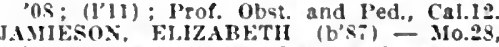
10 ; (); Member Mo. State Med. Assn.

Kell. Geo. Wm. (b'87)-N.Y.1,12; (Patho) og(st); College of Iledical Erangellsts.

VISI.EY, EDWARD HENITY (b'\$1) F-IIl.19, 04, Cal.2,11; (l'11) : Memuer Mlch. State Yhed Soc: Prof Chem. and Mat. Med. Cal.12.

RAI.12. WELLS AILEN (b'68) \&-III.19.

06: (1'J0): Prof. Path. and Ract., CaI.12 Shryock, Alfred Q. (b'71)-Ill.19,'99: (1'11) not in practice; Sec. and Prof. Hist. and Fmbry., Cal.12.

Truman, Archle wm. (b's4) - Colo.2.0s (1.09); I'rof Ihyslol and Nenr. (a) 10

White, Julla A. (b'69)-II1.19,00: (1'06)

\section{LOMPOC, 1.482, SANTA BARBARA}

Rrown Fredk a (b'-9)-Cal1,06: (l'06)

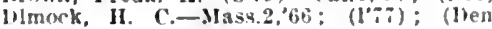

GHAIIIM, JAMES WM. $\left(b^{\circ} 50\right)$ - Ore.1.'83 (l'84).

Ilelges, Laurence F. $\left(b^{\circ}\right.$ it) - IIl.6,04 (1'10)

Kelliher. Mayrllle S. (b'6t) - Pa.9,91 (l'me).

LONE PINE, 250, INYO

WHIJamson, Mark Angle-Cal.1,02: (1'02)

LONG BEACH, 17,809. LOS ANGELES

Hardill, John Warren (b'82) - Cal.2,'11 (10) ;

Bell Invla Iteece (b'36) II-Neb.3.85

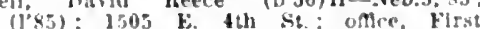
Natlonal Hank Hlik.: 10.12, 2.4

Bjolion, Frank D.-11-0.7?: (1'01) : First National liank Bldz. : $10-12,2-4$, after : (1) wman, Arthur beerlng-1).8, \$9, Mat3.5 -42: (l'03); Masonle Temple.

BITW:, Josiaf SCOTT $\left(b^{\circ}-5\right)+-11111$, 02: (1'12); Member state Med

Wh: kilrot Natlonal Hank lHap.

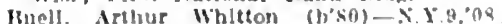

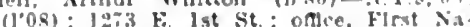
tiona! liank Bitg.

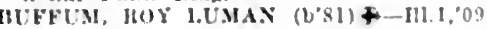

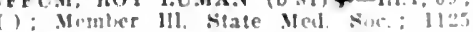
Vilin Ave.

Chittenden, Itorace W. $(1,76)-$ Yo 20,99 (I"01): 3HOL Annhletn st.
Chiltenden, R. II (b'35)-X'Y,8,66, II.II. Q4; (1'01): 321 I'lise Ale,; once, 132 E. ist st $9-12,1-5$

CHALY, HERBVET HIRRISON (b'i2)111.1,"32: Petired; R.r.

Conlln, Berthold M. J. $\left(\mathrm{b}^{\prime} 50\right)-\mathrm{C}^{\prime} \mathrm{l} .3 .75$ (101): Ine St. and Ocean Ave; 11-12, $1-2, i-9$.

Cook, Alonzo fi. (b'39)-I11.," 1; (I'\$1) not In practlce: 632 Orange Are.

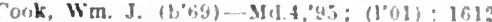
E. Ist St ; ofrce, 11 Pine dre.; 9-11, 1-4.

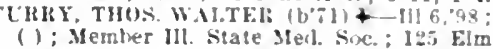

Cuthbert, Wm. I. (b'31)-I11.1.'62; (1'88) not in practice.

Irewlt, Italph $3 .\left(b^{\prime} 6\right)-[11.1,71$; not in tractlce: F'lrat Natlonal liank Blils.

DICKERSON, WILIER LAMBERT (1)56)111.1,93; (1'11)

DODSWORTII, HOHT. M. (b'6i) Cal.i, oOSEEL, THEOHIHIS CLOSBY (b'53) 4-Ind. $, 79:(1 ' 99) ; 335$ w. Ocean Are.

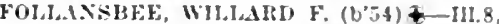
S1, III.11, 26 : not in practice: Memler Colo. State red. Snc; 03 Veliraska Are (1'12): Kennebec Hotel; oflce, 138 w: Ocean Are.; 10-12, 1-3, $;-5 ;(C 3) ; S$.

Freeman, Ernest M. (b'64)-Cal.2,93: (I'94): 1330 E. ith St. nffce, First Vatlonal Bank Bldg.; $10-12,2-4$.

Galbralth, Fieo. H. (b'75) - Mo.34,04: (1'06): 1810 F. Tth st. once, Farners. Ilecchants liank Bldp: $10-12,3-7,7-5$. Groff, Sution Itenry (b'ss)-1a.6,'10; (1'10): l.oma and state Sts.

GU1NN, JAMES H. (b'56) \&-Mo.8,'S6; ( ) : 1056 E. 1st St.

Hall, Geo. K-F-Cal.4,'98; (l'98)

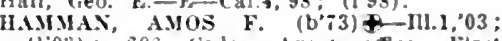
(1.03): 606 cedar Are.: offle, First Viational Kank Bldz. : 11-12, 2-4.

HANSFE, CALL ANTHON $\left(b^{\prime}+t\right) \notin-111.8$, llarvey, Edwin R. (b'if) E-0.2,01: (1'02) 522 Cedar St.; onlce, Sational Hank Bldg.; 11-12, 3-5; Frof. Geueral Diag. Cal.t.

Haynes, Robt. W: (b'61)-Pa.1, 81 : (1'si): 1420 F. Ocean Are.

HFISZ, EMII, J. (b'62) \&-III.9,95; (1'10): осенл Aте.: G.

Hlatt, l.erl J.-0.1,'s4; (Naturopath).

IIIL, WALTER B. (b'75) \$-Cal.6.09; (1'09); 420 Cedar ire.: 11-12, 2-1.

Holmes, Albert 0 ( (b's6)-Cal.2,12; (l'12); HOYT, HENKI F. (b'54) \&-0.3,'s: : (I'II): 332 W. Broadwas.

llufr, Molvin 13,

(See Ios Angeles.)

ONES, WIIIAAI HARRIMAN $\left(\mathrm{b}^{\circ} \div 6\right)-$ Cal.1.99; (1'99); Hotel Virginla; odice, 131 Dlne Are: $24: \mathbf{S}$.

KINSLEY, MFPIIAS MANI. (b'5S)-Pa.8. 95: (1) 23 F. Iroadway.

Lougheed, Geo. D.-(int.4, 69 : (1'ns)

Kirkland, Reyj. F, (6'-0)-lli.11, "ss: (1'8s) Iarsh, Ella Whinple-Ore.l,s3; (l'ss): 1149

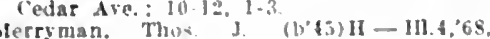
X.9.69: (1) $313 \mathrm{~W}$. Hruaduay

Moore, Tilghman K. (fite)-Mo.g.'es; not in practice.

Morrison, lidhart L.-Man.1.23; not in joratice: 13 cedar st.

Niwll, Wy II-111.1.93: (1.03): 33" (1)alyy sit.

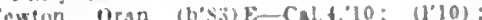

llishy llariwell Bho: g-1: to: l'rus IIy: IMl

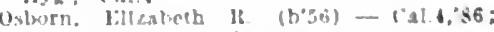
(I's9): arg kenncliec Are. ( $\left(b^{\circ} 34\right)(1)=82:(1 \cdot 98):$ Jiatirell

Randall. Thiow. Jaterson.

(Sw las ingeles

HANUM! RAS. WALLACE (b'69) if WIs: 1 tot k. the st. 
Ritchey, Joln B. (b'40)-0.9, 69 ; not in practice; $520 \mathrm{~W}$. 7 th st.

IoGERS, FRANCES L. $\left(b^{\prime} 64\right)-\mathrm{Ia} .3,91$; (1'06); 362 Junlpero Are. : oflee, fong Peach); 362 Junlpero Are. : oflee, 1.0ng loach Natlonal Bank

KOGERS, TJUNAS LOWRY $\left(b^{\prime} 78\right)$ \&-Ia.3, '09; (I'10); 355 Junifuero Ave. ; nflce, Long IBeach linnk lildg.; 10-12, 3-5; S. Pacific Ave, olfice, First National Bank Pacif

SELLERY, ALIBERT CLIFTON (b'i5) $\leftrightarrow$ Que.1,04; (I'06); 2101 I'ark Btvd. ; offlce, Long Jeach Bank IJIdg.; $10-12,3-5 ; \mathrm{S}$ shlipey, lioderlek Hotfman (b'79) - Mo.34, ,06; (1'12); II35 Chestnut St.; offlce, First Natlonal Bank Bldg. ; $10-12,3-5$; Pd.

Shlrk, Frank M. (b'71)-Mo.29, 96

3123 Thiresa $\mathrm{St}$

SIMPSON, ABBIE IVINEGAR (b'65) 111.9,94; (1'02); 10th and Linden Sts. : $10-12,2-4$.

SINGLETON, WM. T., JR. $\left(\mathrm{b}^{\prime} 83\right) \oplus-\mathrm{Mi} 0.20$ '0s: ( ): Mtember Mo. State Mel. Assu. The Cynthia: OALR.

Smith, Fellx G,-Mo.22,8s; 251 E. 2 l St.

Smith, Wilburn 11. (b'80)-111.19,05, Pa.2 '07, Eng.11,15,'I1; (l'13) ; Long Beach Sauitarium; Prof. Surg., Cal.12

Stalford, Geo. A. (b'67)-1a.6,93;

1202 Linden Ave.

SWEET, ROBT. BALLANTINE (元 6 ( $)$ IIl.1,02; (1'06)；325 W. 10th St.; offlce, Natlonal Bank Bldg.; 9-12, 2-5; (BI2); OALR. *

Taylor, RaIph L. (b'71)-Colo.1,'93; (1'13) ;

I 20 w. 5th St. : $2-4, \tau-8 ; S$.

Terry, Roy Albert '(b'86)-Ind.20,'10 ; (1'11) ; 525 W. 10th St.; offce, Flrst National liank Bldg. ; I1-12:30, 3-5; S.

TOWNSEND, VINTON ROY $\left(\mathrm{b}^{\prime} 8 \mathrm{I}\right) \oplus-\mathrm{Cal} .6$, 09; (1'09); 1004 Plne St.; office, First National Bank; 11-12, 2-5; $\mathbf{s}$.

Upjohn, Wm. C.-Mlch.I,'75; ( ) ; 1735 E. Broadway.

Upjohn, Mary H. (b'53)-Mich.1,7\%; (ま);

1735 E. Broadway.

Wallace, Elias J. (b'5

421 Atlantic Ave.

WATERMAN, CLARENCE o. (b'74)(Cal.6,04; (I'04); 517 E. 21 st St.; office, 38 Pine Ave.; 2-4; Anes.

Waters, Orthello - Jll.5,'86: (क) ; First National lank Bldg.

WELSH, PRUDENCE M. (b'70)€-III.9,99; $\left(l^{\prime} 06\right) ; 345 \mathrm{~F}$. Ocean Ave. office, II Pine Ave. ; $10: 30-12: 30,2-4 ; 0$ bG.

Wherry, James W. (b'60)-Ill.11, 99 ;

115 W. $2 d$ St.; op. $\star$

IVIGHTMAN, WM. C. (h'61) $₫$ Mo.1,'84 Member Neb. State Med. Soc.; 534 E. 16 th St.

WOOD, JAMES WALTON (b'56)థ-Ill.I1, '83; (1'88); 125 Cedar Ave.; offlce, 38 Pine Are.; 10-11, 2-4.

Woods, Clárence H. (b'7I)-I'a.2,96; (l'98) ; 34 Magnolia St. ; office, 1st and Pine Sts. ; 10-12, 2-4.

WOODS, ELIZABETH (b'56)†-Md.5,91; retired: Nember 0 . State Ied. Assn. 11730 Golden St.

LOOMIS, 307, PLACER

Barton, Orren L. (b'59)-0.1,'79; (1'89).

LORDSBURG, 954, LOS ANGELES HUBBLE, JOHN EDGAR (b'64)థ-Va.1,'9I ;
(I'06); Pd.

LOS ALTOS, 60, SANTA CLARA

IIE NIEDMAN, WLADIMIS FEDORA (b'54) -D.C.3,84; (1'12).

Mclermott, Wm. Patrick (b’43)-Cal.2,'74; ( 1 ' 6 ).

YEATES, EDW.-Ire.5,9,'86, Ire.6,'93; (1'98).

LOS ANGELES, 319,198 , LOS ANGELES NUMBER OF PHYSICIANS, 1,142.

Abbott, Geo. Bartlett (b'79) - Cal.4,'06; (Naturopath) ; $19281 / 2$ Bonsallo Ave.; of fice, Union Oil Bldg.; $9-5$.

Abramson, Max Jacobs (b'81) - Cal.9,'II (1'11); 1165 E. 21st St.; offce, Lissner Bldg.; $10-12,2: 30-5$

ADAMS, CHAS. BLACKSTONE (b'72)థIa.3,'97 : (I'08) ; 1028 W. 36 th St. ; office,
ADAMS, WILSON WESLEX (b'53)\$--111.I 83; (1'92); Member IIl. State Med. Soc. 1407,4 th Áve.

AINIEX, IRANK C. (b'79)(-IId.7,06 (l'11): 1355 Orange St. ; oflice, John l'11); 1355 Orange St. ; Oflice,

Alsbitt, Atathew S. -N.Y.13,71; (l'94); 1235 W. 50th St.; oflice. 122 W. 3d; $10-12,2-5$ Albert, Walter (b'83) II-Cal.5, 07 ; (l'07) 734 E. I 4 th St. ; 2-4, 7-8.

AJDEN, ELIOT (b'74) $\rightarrow$ Mass. 1,01 ; (1'06) ti20 Norton Sit.; oftlce, Brockman BIdg.; $3-5 ;(\mathrm{F} 3)$; $\mathrm{S} \star \star$

AIIAN, JAMES T. M. $\oplus$ Cal.6,03; (1'03) 2707 S. Ilarvard 13lvd.; offlce, Auditorlum

ALLEN, ADDIE 13ROWN (b'ĩ) $4-C a l .9$, '10; (1'10); I712 Maple Are.; offlce, Bradluary I3ldy. ; 10-4.

Nlen, Albert (h'86)-IIl.1 1,12; (1'12); Los Angeles County IIospital.

Allen, Carlton Stewart (b'84)-Cal.6,09

(I'09); Paciflc Electrlc Blde.

ALLEN, CHAS. LFWIST-Md.1,87; (I'07) 214 Andrews BIvd.; office, Brockman Bldg. : 2-4; Asst. l'rof. Clin. Neur., Cal.2 (F10, 13, F3); NP.

$(110,13$, F3) : NP.
Allen, Chas, Wellington (b'55)-Vt.2,82 ; (l'0I); I619 W. 22d St.; offlee, Black Bldg. ; $10-12$.

Alter, Saml. Mltchell (b'88)-Mass. I,'12 (1'12) ; 1759 Allesandro St. ; office, Grosse Bldg. $2-4 ; N$.

ALVAREZ, LUIS F. (b'53)థ-Cal.1,'8T (l'87); $2180 \mathrm{~W}$. 25 th St.; offlee, $211 \mathrm{~W}$ 1st. St. : $9-11,2-4$

Ammann, Francls Xavler (b'90)-Cal.9,'12 (l'12); 1702 S. Magnolia Ave.

Anderson, Alice G. Huntington-111.4,'86 (I'09) ; 1621 S. Grand Ave.; offlce, 607 HiIl St. ; $11-4$. Anderson, Anton-Colo.1,'95 ; (1'01) ; $38201 / 2$
E. 1st St.

ANDERSON, CHAS. WILLOUGHBY (b'79)థ -Que.1,03; (1'06); 2181 W. 25th St.; office, Brockman Bldg.; 2-4; (F3).

Anderson, Gustare E. F. (b'63)-1ll.1,93 . (1'95); 676 Westlake Are.; office, 933 s Hill St. ; 10-12, 1-4; $\mathrm{N}$.

ANDERSON, IIELEN ORASTELLA $\oplus$ Cal.2,96; (1'96); Hotel Clark; office, Bradbury Bldg:; (BI2); Op.

Anderson, Jennie H. (b'86)-Colo.2,'11; (l'12) ; 1288 W. $23 \mathrm{~d}$ St.

Anderson, John B.-Mo.28,'99; ( ) ; 1435 E. Wright St.

ANDREWS, HENRY JAMES $\left(b^{\prime} ; 8\right) \oplus-I 11.6$. '07; (l'09) ; 1328 wilcox Ave.; offlce, 6404 Hollywood Blvd. : 10-12, 2-4.

Hollywood Blvd:; 10-12, 2-4.
ANDREWS, HOWARD (b'77)†-Ill.11,06 ; (l'I0) ; 1631 Hudson Ave.; office, $67791 \frac{1}{2}$ Hollywood Blrd.; 1-4; S.

Andrus, Nancy Loulsa-0.19,'87; (1'99) ; 6424 Dix St.

ANTON, FRANCIS L. $\left(b^{\prime} 76\right) \oplus$ Cal.6,'99; (1'99); 3012 S. Figueroa St. ; office, Exchange Bldg.: 2-5: S.

ARMSTRONG, MAURICE MORAY (b'/3)థ -Cal.6,'02; (l'02) ; 1432 Malvern Ave.; offlce, 8 th St. and Broadway; $2-4$.

ARMSTRONG, VETURIA CIARK (b'66)Ind.8,'98; (1'00); (1721 South St., Pasadena); offec, Ván Nuys Bldg.; 1 -4.

Aronchik, Bernard (b'80)-Pa.11,'12 ; Assistant Physician; 832 Sunset Blvd.

Arvin, Hugh T. (b'69)-N.Y.10,'92; (1'11) ; rvin, Hugh T. (b

ATHON, LEWIS HARLAN (b'87) -111.11, '10; (l'11); 1039 W. 61st St.; offlee, $71211 / 2 \mathrm{~S}$. Vermont St.; $2-5$.

Auerbach, Louise (b'85)-N.Y.20,'II; (l'13) 3325 s. Main St.; 1I-12, 2-4, $7-8$.

Austin, Silas Addison (b'43)-Ill.1,77 ; (1'89); 427 Temple St. ; office, $534 \mathrm{~S}$. Broadivay ; $10-12,1-3$.

BABCOCK, WM. D.థ-Ind.2,78; (1'87) 1225,4 th Ave.; office, Hibernián Bldg. 9-4; (BI2,I9); OALR. *

BACON, CHAS. EVAN (b'65)@-Mo.8,'90; lingsworth Bldg.: $10-12$ Drive; office

BAGG, CHAS. P. (b'66) \&-Cal.6,'88; Surg.

Lieut. Commander, U.S. N. retired; 1024 Arapahoe St.; office, Bradbury Bldg.; Arapahoe St.; offtce, Bradbury Bldg.

Bahrenburg, John E. (b'5 $)$-Mo.I, $; \tau$; (1'01); (Tropico); office, $2 d$ St. and
Balley, Chas. A.-I't.2,78; (l'98); 223 S. IIobart Blrd, ; offlce, Auditorlum Bldg. $9-12: 30$.

Halley, Wn. Carey-E-Cal.4,03; not in practlce; 1465 Regina Lane; offce, Henue IHIdg. ; Irof. Chem. and Tox., Cal.4.

Baird, Alex. Pollock (b'60) - Cal.4, 01 ; (1'01); 1407 . Ialiantonga Way; oftlce, so! Eagle Rock Ave.; 2-5; Prof. I’rin. and Prac. of Med., Cal.4.

B.IKER, CHAS. (b'72)†-0.1,99;

Baker, Clark Dyer (b'7I)-Ill.1,'03 ; (l'08) 4541 l'rospect Ave.; offlce, 1702 N. Yer mont Ave. ; $10-12,2-4$ Ball, John J. (b'54)-Ia.3,83; (l'01); (Gar-
dena); office, $3161 / 2$ S. Sprlng St. ; $9-4$, $7-8 ; \mathbf{U}$.

Ball, Seymour E.-M10.34, 03 ; (1'07) ; $34041 / 2$ S. Vermont Ave. Minnesota St. ; office, Bacterlological Laboratory, City IJall.

BANCROFT, IRVING REED (b'72)థoffice, Brockman Bldg.; U.ネ

Banta, Margaret-Ill.19,'03; (I'II) ; 4230 . Brighton Ave.

BARBER, DAVID CASSAT (b'62)థ-0.9, '86; (l'86) ; 683 S. Harvard Blvd.; office, '86; (1'86) ; 683 S. Harvard Blvd. ;

Barber, Edward Thos. (b'39) - Cal.2,'66 : (I'76) ; $96 \%$ Arapahoe St.; 10-12.

Barbrick, John Fraser (b'68)-0.16,'93, Ga.I 1,00, Cal.4,'10; (l'10); 718 s. Alvarado St.; office, Consolidated Realty Bldg. ; 10-12, 2-5 ; Prof. Ophth., Otol., Rhin. and Laryn., Cal.4.

BARLOW, WALTER JARVIS (b'68) 4N.Y.1,92; (1'95); 2329 S. Flgueroa St.; office, Security

Barnard, Frank S. (b'59) H-Pa.9,'94; (l'96) ; 837 S. Union Ave.; offlce, Auditorium Bldg. ; 2-5. S.

Barnum, O. Shepard (b'67)1I-N.Y.9,'93; (l'93); not in practice; Byrne Bldg.

Barnet, Fred I. (b'85)-N.Y.3,'08; (l'12) 1755 W. Adams St.

BARNHART, WM. (b'76) $\oplus$ - Cal.6,'06; (l'06) ; 2025 E. 3d St.; offlce, Wright and Callender Bldg.; 10-12; Ob.

Barr, James-Ill.4;80; (1'95); 1400 W. 86 th St.

Barrow, John Vincent (b'77)-Ill.1,'11; (l'11); 2935 Roxbury St.; office, Consolidated Realty BIdg.

13artlett, David J.-Neb.5,'92; (1'00); 84 ,

Barton, Arthur Louls (b'73) - Colo.2,'97 ; (l'03) ; 1628 W. 25 th St. ; office, Grant Bldg.; 2-5.

('98): I5 TERT P. (b'66) †-Pa.2,'90; S. Olive St.; $10-12,2-5$.

Bartow, Winfield Lincoln (b'i6)-N.Y.8,01; (1'07); Mason Bldg.; 12-4; Op.

Bassett, Foster W. (b'61)-Ml.6,'89; (1'97) ; 1312 W. 5 th St.; offle, 205 S. Broadway; $1-4$.

BATTELLE, ERNEST L. $\left(b^{*} 53\right) \oplus-111.10,86$; (1'86) ; 1404 Magnolia Ave.; office, $322 \mathrm{E}$ 7th St.; $2-4,7-8$.

Bay, Othar Sylranus (b'83) - 0.25,'06 : (1'12); 615 Bixel St

BAY, SAML. G. (b'76)๑-0.25,'98; (l'11) ; Member Ohio State Med. Assn; 7607 Whitsett Ave.; offlce, 4328 Central Are.; 1-5; G.

Bayless, Herman Gordon - 0.1,'78; (1'97); 1221 W. 7 th St. ; office, Grant Bldg. ; il-1, 3-5.

Bayley, Alvin J. (b'87)-Cal.2,'12; (1'13) ; Los Angeles County Hospital.

Bayley, Walter A. (b'80)-Cal.6,05; (l'05) ; 1218 W. 48 th St. ; office, $4703 \mathrm{~S}$. Vermont Ave. : 2-4.

Basliss, Edward B. (b'63) - 0.1,'85; (Optometrist) ; 1129 S. Figueroa St.

BEACH, EVERETT C. (b'80)-Md.4, 07 ; (l'09) ; 918 W. 48th St.; offlee, Laughlin Bldg. ; $3-6$; Pd.

Beach, Geo. H.-N.Y.9,'63; (I'\%6) ; 1336 W. 30 th St.

Beard, Jaines (b'58) E-Cal.4,'99; (I'99); 602 Euclid St.; office, Fay Brig. ; $9-4$. 
Beatty, James Davld (b'r9) - Io.2, 01 : (1'09) : 2224 Crenshaw HIvd. (itlce, 424 (1'08): 2224 Crenshaw HIVd.
8. Broadway: 1-4; 0ALR.

S. Broadway: 1-t; OALR.
BFCKHTT, WESLEY WILBUR (1)37) + Cal.6,88: (1'89): 2218 Harrard livid. onlce, Paclnc Mutual 13lig. : $-4 ;(13) ; S$. Beebe, Curtls it. (b'62)-Iil.10,'s3: (1'96): Investment Islde: $9-3,1-4$

Hemls, Orton Irving (b'69)-Me.1.96; (\$); 4265 Arlington St.

BENNETT, CIIAS. I. (b'68) - IIl.10,90, ENNETT; Cl1AS: I. (b'68) 8-Ill.10,90,

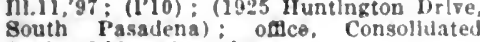
South Pasadena):

IENNETT LALRA B.\$-Ore.1,01 ; (1'01) : (San Pedro); oftce, $608 \mathrm{~S}$. Maln St.

BERRY. A NDREW J. (b'65) $₫-\mathrm{Ky} .2,90$, Mo.29.97; (l'01); 3012 Brighton Ave. oftce, llolllngsworth lildz; ; 10-12, 2-4, ;-s. ETTIX, MONA EI.FANOL $\left(\mathrm{b}^{\prime} \mathrm{S} y\right)+$ Cal." '12; (l'l2); 1025 N. Figueroa St. ; ulllce Auditorium Bldg. : 4-5; LD.

BEWLEY, MAUITTA H.-Cal.6,00; (1'01) $222 \mathrm{~N}$. Vendome St.; once, Hollingsworth Bldg.: 12.4 .

BICKNELL, FREDK. T. (b'\$2)£-I11.1,70 (1'6) ; 419 v. Broadway: oftlce, 304 s. Broadway; 1-4.

IIGGS, LLMER LeROY (b'i4) †-III.18, 01 (1.01): 111 N. Marlposa Are.; unlee Title insurance Bldg.; $10-12,2-4$.

Minford, Nellle (b*2)-111.9,01: ( ) : Gen. Del.

Blshop. Herbert II. (b'44) II - Conn.1,65 (l'92); 262 i Hoover St.; $9-10$ 2-4.

BISHOP, THOS. W. (b'T0) $\$$ N.Y.10,95; (l'05): (Pasadena Sanitarlum, Soutl Pasadena); offlce, Tltle Insurance IBldg. 3-5.

BLACK, STANLEY P. (b'59) (1'98): (470 Maylln St., Pasadena): of flee, Auditorlum 13ldg. : 10-1; Consulting Pro?. Path., Cal.2; (F3); Path.

ulackwell, John (iarretson (b'a3)II-1'ia 00: (l'02): Fremont llotel.

Blake, Alfred Fdward (b'61)-310.1.'94 (1'94); 1724 Elmwood Are.; offce, Inter natlonal Bank Bidz: 11-4.

Blake. Wendell 1'hlllipps (b'S s)-Cal.9, 13 (1'13); $1409 \mathrm{~W}$. J4th st.

Blakeslee, L. K.-III.4, 83 ; (I'88); 108 W 2d St.

Hlanchar, Wm. Otts (b'74)-Ill.10,03, Cal.9, 13 ; (1): $606 \%$ F. $21 \mathrm{st} \mathrm{St}$.

Blass, Leo (b'82)-Mo.7, 08; (1'09); 527

BLATHERWICK, ALEXANDER AHTHUI (b'81) क $111.1,09 ;\left(l^{\prime} 11\right) ; 366$ W. 59 th
Pl.; office, 6100 Moneta Are.; 10-12.

Bleazby, Lewla F.-Mlch. 7,$99 ;\left(l^{\prime} 02\right) ; 119$ S. Itampart St.; omce, $316 \frac{1 / 2}{\mathrm{~S}}$. Spring St. ; $1-3$.

Boatman, Harry F-1Il.1,02; (l'08); 1531 widd st.; onlce, $42 i$ w. 5 th st

Bock, (has. (b'70)-Inl.10.97; $\left(l^{\prime} 03\right) ; 1194$ W. 30th St. offce, ;03\% S. C'entral Are.: 1. 1 .

Bogue, Ilomer A. (b'61)-Vt.2, 86; (年) ; 1009 Gramercy Drlve

BOHN, A. GELTUUDE WOLFEIMAN (b'T0) -Ind.9:94: (乎); Member Ind. State Med. Assn. : 812 w. loth se

Bollnger, Hugh J. (b'88)-Ill.1,'13; Intern Los Angeles County llospltal.

BONYNGE, CHAS. W. $\&$-Cal.6,03; (l'04) 535 8. Virgll $\Lambda$ ve, ofjce, suditorium Bldg. Boody, Fred Jos. (b's5)-Cal.9,'13; Jukris. Los Angeles County IIospltal.

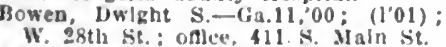

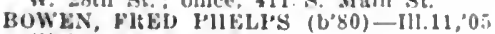
(1'10): 2911 S. IIupe St: onjee, I. W. Hellman lilds.; 2-5.

BOWEIt WM. Gro. (b'04) - Eug.17, 86 , Eng.11,15,87; (l'gs) ; 163y \$. I.a lirea Ave.: once, Germaln bldh. : $10: 30-12: 30$,

Bowers, Chester Herbert (U'87)-Cal.9,'13 Intern, Los Angeles 'onuty llospltal. BOWMAN WM. BUKLEY (b'85) - Mo.34 $10 ; \quad\left(l^{\prime} 10\right)$ : Nershey Armis:

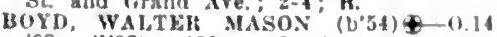
'83: (1.87); 432 S. Boyle Ave.; onlee, 118 \&. S. Spring st. : $1-5 .-7 \cdot 8$. Boser, Jobn Jra (b'86)-Cal.8,'12: (1'12)
Boynton. Sumner Hamllton (b'45) II-1'a.6

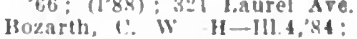

A llargard llat way: 10-12, 1-4.

Brackeit, Aurlick s. (b'46)-N.Y.13,82 (1'97): 1336 W. 11ih st.; 11-4.

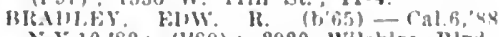
F.Y.10,89; (1'89); 2920 wilshire Bird. office, Black Bldy: 11-12, 2-4.

Bragg, Benj. Franklin (b'ig)-

Main St.; offce, Natlonal llotel.

BRIINERD, MENRY GRFFN (b'52)申 III.1;78; (1'87): 1661 Orange St. : offee Exchange Bidg: : $3-$

Brandel, Harry McPlierson (b'\$9)-Ill.1.'12 (1'13): 135 s. Ilobart Hivt.

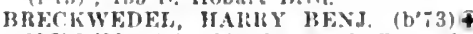
X.1.00; ( ; : Memher Med. Sroce of the State of X.Y.; Ilotel I,elphton.

Breltllag, Carl Adolph (b'86)-111.6,'13 Intern, bos Ingeles County Hospital.

BREM, WALTER V. (b'75) -II.6.04 (l'11); 932 Maltman Ave.; offlce, Brock man man Bldg. : 1 - is:

Bresee, Melvin A.-Cal.6,"96; (1'98); not In practlee; 941 s. Bonnle Brae st.

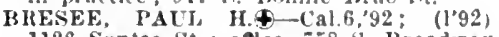
1126 Suntee st.; onlee, 758 S. Broadway 10-12.

BHIDGE, NORMAN (b'4t)-111,6,68, Ill.1 78; (1'91): also Member Ill. State Med Soc.; 10 Chester 11.: office, The Audi torlum; Emer. Prof. of Med., III.I; I.ネ

Brlll, Wm. (b'64)-N.Y.1,87; (1'89); 446 $10: 30-12: 30,2: 30-4: 30$.

BRIMIIALI. SILAS IOHN - MInn.4.'02 (1'05); 417 W. Are. 52 ; oflce, Wright and Cállender Bidg.

Brooks, John II.-Ky.1, 't1; (l'11); 475s Yoneta Ave.

BROOKS, STEPHEN HIIVEIK (b'53) \ Mass.1, $82 ; 602$ Carondelet St.; Senlo Surg., U.S.I.H.S.; Wlleox Bldg. ; 9-12:30,

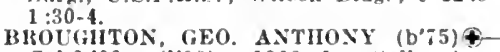
Cal.2,98; (1'96); 1966 la salle Are. offle, Wright and Callender Bldg, ; 11-12, 1-4.; $\mathrm{S}$.

Brown; Blanche Chrlstine (b'78)-Mich.1 03: ( ); 1064 W. 7 th St.

BHOWN, CHARLOTTE MARIE (b'79) Cal.2,10; $\left(1^{*} 10\right)$; Consoltdated Bldg.

BROWN, EARLE MASON (b'66) Mich. '01: (l'10): P.A.S., Lleut. U.S.N. retired

Brown. Francls Earl $\left(b^{*} ; 8\right)-$ N.Y. ${ }^{\prime}$ os (l'08) ; Burllngton Apts. ; oftce, Filfor

Brown. Harry $Y .\left(b^{\prime} i 5\right)-111.8,02$; (1'07) (it3 Euclld Ave; oltice, 204 li stephenson st. F'rof. Ped." ('nl.4; Pd.

BHow. IRA E. (h'T5) Cal.6,04; (I'04) 22: 2 W. 2 th st.; Nember Ariz. Mal Assil.

HROWN, J. COLYILI.E-Cal.ti, 05: (1'07) 1215 E. Adams St.; offle, 1034 F. Adanis

HIOWN, JOHN MACKFAZIF $\left(\mathrm{b}^{\prime} / 8\right)+$ (Int.6,09: (I'09); 520 st. Andrew's l'l mice, lirockman Bldg.; 10-12, 2-4 (131,19); ALR.

Brown, l'age-la.2,70; (1'84): 2313 Ken word Ave.; 10-12,3-4

Irown, T. Floyd (bo7)-Cal.6:01; (l’01) It33 Nlbany st.; onlce, 610 s. Hriadudy

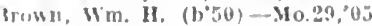
1. i2d $^{2} \mathrm{sit}$

Brownflold, Wm. Henry (b'90)-\$0.34,13: Intern, sistora Humital.

HHWWINC, CHAS. (IIFTON (b'til) +

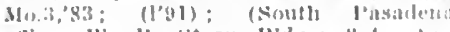

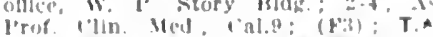

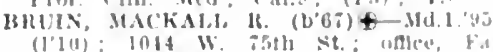

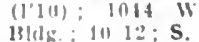

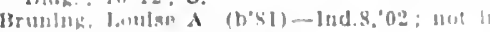

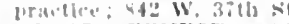

BWYNT, ERNFST ALHELT (U US) + l'a l, 10 : (l)

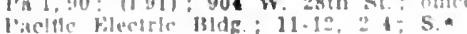

IIYSON, CHAS. WM (W'C3)+Ial, 82 (I'86) : llotel Darby ; oflce, 4to S. Spring

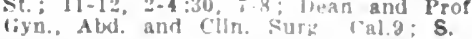

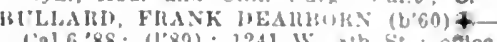

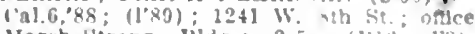
Marsh-stro

linllard, James Horey (b*t, (1'85): $10 i t$ W. Kens!ngton Kil. : atice Bultard Bith. : 10-12, 2-4.

Bullard. Margaret Mead ib'7t) - ('al d, $0^{\circ}$ $\left(l^{\prime} 10\right) ; 2118$ Cambrllge st.

BTHLARI, ROSE TALHOTT $\left(b^{\prime} 64\right)+$

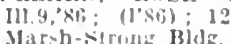

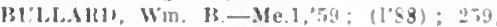
23d Ire.; $8-10,5-7$

bullock, innle soplia (b'73) - 1'a.:12

( ) : 1.341 F. Vermon Ar.

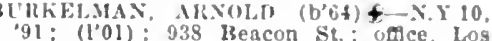
Angeles Investment Bldp ; 10-12, 2-5.

Burleish. Geo. W.-E-Ind.11,'8\% (l'si) Broadway.

BUKNS, FHANK WALKER (b:50)-III.11 98 ; (1'13); 607 Hobart Blvd.: D.

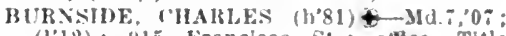
(1'12): 415 Franclsco st. : once. Tutle Insurance $B$ ld

BI 13IRLLL, IIENRY JESLIE (b'59)-IH.11, 's8; (I'12); Hollywood; (BI); OALR.

Burrows, clinton A. (b*9) Cal.t, 04 (1'04): (Cilendale): offee, $\$ 1$ w. Sth St.

Burton, Kobt. Ifenry (b'bi)-1il.11, 92 (l'03); 1948 Estrella st.; offlce. Cirosse Bldg. : 11-12, 2-5

Butler. Edwin H.-E-Mo.10,83; (1'95) 5300 S. Figheroa Si.

Butler, oliver W. (b'8i)-Cal.2,12; (1'12): Los Angeles County Ilospltal.

Butterfield, Rupert 0 . (b'6i) II-Colo.4,01. $\left(1^{\prime} 10\right) ; 1782$ W 25 th $\mathrm{St}$

Butterfleld, Wm. Webster (b'45)-XY.10 68 ; (1'96); 137 S. Hoover St. ; $12: 30-2$

BYINGTON, FRANK S. (b'69)-Ky.4,96; (1'97); $2063 \mathrm{~W}$. Washlngton St. once Wrlght and Callender Bldg.; 11-12 $1: 30-4$.

BYION, RALPH LOCIS (b'82) Cal.9,'08 (1.08): $920 \mathrm{~S}$. Alrarado St. oftice, 524 : Spring.

Caben, Ceasar Geo. (b'85) - Cal 6.'09 $\left(1^{\prime} 09\right)$ : 1220 Westlake Are, oflle, Brock man Bldg.

CAHEX, EDMOND M. (b'85) †-Cal.6.08 (1.08): 1408 Magnolla Ave.: oflce. San Fernando Bldg. : $10-12$, 2-4

CAHOON, GIIACF WMSON-Minn.t,"9: (1'12); 1604 W. 39th st

Caln, Luther M.-Ca1.9.05: (1'06): 795 W. 49th l'

CAIN, MACDE Fl.OHF.NCF (b०5)-MIass. "98; (1'12); Hollingsworth Blig.; 10-12. $1-3: 30$.

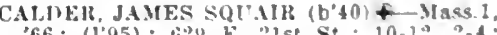
Pd.

Campoll, Eurene (b'36) H-X.Y.9:78: (1'83); Lelghton Hutel: unlee. ith St. and (irand Are.; 11-1.

Canphell, Matthew N. (b'it)-Ire.1,0 : (l'07) : 148 W. 3stl st. oftice, 496 . Sprlug st: $10-12,2-4$

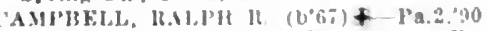

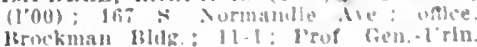

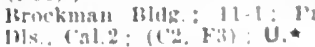

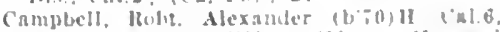

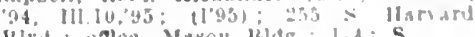

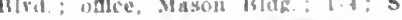

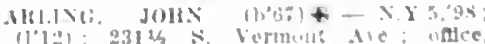

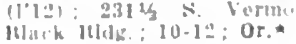

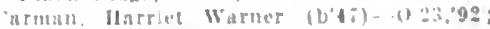
sey 1.mintl st.

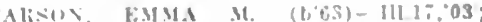

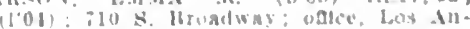

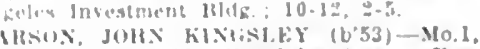

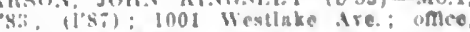

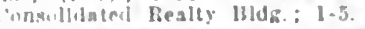

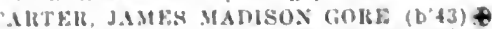
III. 6,$180 ;(119)$ : $1300 \mathrm{~N}$. llobarl Hird. 
CARTER, RAY AIDEN (b'86)-Cal.9,'13 (1'13); 2711 rentral Ave.

CAITER, WM. ELMER (b'82)థ-Cal.9,'08; (1008); IIowell Terrace; offlce, Lissner Bldg. 10-3; Asst. I'rof. Med., Cal. 9 .

Cass, branga Murlel (b'87)-1'a.iz, 10 (1't1) ; not in practice; 1642 lield st. Casselman, Delmer Louis - N.Y.10,73; Castle, Claude Ifenry-110.20,03; (\$); 2943 Walton $\Delta$ ve.

CHAFFIN, RAFE†-Cal.6,07; (l'07) ; 453 S. Soto st. ; oflece, Security' Bldg.

Chamberlin. Myron II. (b'45) H- $0.13,78$ : (1'94) 130 iv Ave, 55 ; office, $130 \mathrm{~N}$ Ave, $55 ; 10-12,2-4,7-8$.

Chambers, Wm. James (b'64)-Pa.2,90; (1'01) ; 2122 s. Western Are.; offlce, Fay ildg. ; $1-3$.

Chupln, Anna Dewey (b'71)ח-III.4,02 (l'03); 5336 Monta Vlsta ; 8-10, 2-4; ObG. Chapmnn, Richard Beck (b'î4)-Cal.1,'96 (1'96) : $510 \mathrm{~s}$. Spring $\mathrm{St}$.

CHARLTON, ALBEIT' TUTTON (b'82)III.1,09; (I'10); County Hospital ; office, Stimson IBldg. : 11-1

Choate, James J'-Mo. 2,79; (1'86); 223 W. $2 \mathrm{~d}$; office, 215 w. $6 \mathrm{th}$ St.

CHOATE, JOSEPII LYNN (b'83)(-)-Md.7 '10; (1'10); 1652 Hobart Blvd.; office,

CLAIR, FRANK F. $4-C a 1.6,05 ;\left(1{ }^{\prime} 05\right)$ 1700 E. $22 \mathrm{~d}$ St.; offlce, Los Angeles Investment Bldg.; $2-4$.

Clapp, Chas. Ioss (b'55)-111.10,'87; (l'07) 827 San Antonio Ave.; office, 3838 Stephenson Ave.; $2-4,7-8$.

Clark, Edga W W-H-Ill.4,'68; (1'89); not In practice; 1848 Morgan Pl.

Clark, Nannie C.-II-Ill.4,'89; (1'89); 727 Brent St.; oftice. Auditorium Bldg. ; $1-5$. CL.ARK, WM. SUMMER (b'56)\&-Ind.9 '81; (1'89); 2210

Clarke, Elmer A. (b'48) H-0.7,'78; (l'82); 2011, 8th Ave.: Office, O. 'T. Johnson Bldg.; 11-12, 2-4; T.

Clarke, Olive L. (b'69)-Pa.7,'95; (l'01) ; $805 \mathrm{~W}$. Pico $\mathrm{St}$

CLARKE, WM. 'T. $\left(b^{\prime} 76\right) \oplus-$ Ont.1,99, Scot.9, 12,14,'04; (I'01) ; $1777 \mathrm{~W}$. Jefferson; ; $1-3$.

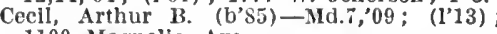
1100 Nagnolia Are.

CLEMONS, E. JAY (b'77)-IIl.11, 02 ; (1'13) 246 N. Union Ave.; offlce, Black Bldg. $10-12,2-4: \mathrm{Pr}$ *

CLINE, JOHN W. (b'71) \&-Col0.2,'96; () Nember Wash. State Med. Assn.; 4354 Melrose Ave.

Clinton, Edwin Morenhout (b'82)—Cal.9,'10 (l'10) ; 44081/2 Noneta Ave.; office. Wrigh and Callender Bldg.; 10-1, 7-8; OALR.

Closson, Leon Monroe (b $\left.{ }^{7} 73\right)$ - Mass. 1,02; (l'03); Mercantille Trust Bldg.

CLOUD, MARSHALL MORGAN (b'68)థN10.8,'92; (1'06); Capt., U.S.A., retired 679 Ardmore Ave.; office, Grosse Bldg. 10-12, 1-4; (B12,19) ; OALR.*

COCHRAN, GUY (b'73) $\oplus$-N.Y.1, 00 ; $\left(\mathrm{l}^{\prime} 03\right)$ 234 Loma Drive; offlee, $6 \mathrm{th}$ and Main Sts. ; $10-12,2-4$; (F3) ; S.*

Cochran, Wm. G.-H1.1,'69; (1'81); 1550 W. 2d St.; offlce, Byrne Block; 10-12, 2-4.

COCKE, JOIIN VINTON (b'83) †-Cal.9, '11; (1'11); 1316 W. 41st Pl. ; office, 6th and Main Sts.; 11-12, 2-4.

COFFEY, TITIAN JANIES (b'74) (4)Cal.6, '98, Pa.1.'99; (l'98); 694 S. Ardmore Are.; offlce, Marsh Strong
Asst. Prof. Obst., Cal.2; (F3).

Colburn, Edgar L.-H-Ill.4,'87; (1'96) 1401 Douglas St.; offlce, 321 W. 3d St.

Colburn, Iola M.-Cal.6,95; not in practice; 5604 de Longpre Ave.

COLBURN, JOHN R. (b'54)థ-M0.2,78 (1'88); 984 Westmoreland Ave.; office, Story Bldg. ; 2-5.

COLE, GEO. LLEIVLLYN (b'61) $\oplus-$ N.Y.10, '86; (1'87); California Club; office,

Auditorium ; 2-4; (F3). (
COLLER, GRANVILLE J. (b'54) - Mlch.1,'80 (1'07): 714 w. $32 \mathrm{~d}$ St. ; office, $610 \mathrm{~S}$ Broadway; $1-4$

Collier, Francis Marion (b'58)-Colo.1,95 (1.07); Wright and Callender Bldg.; 10-5 OALR.*

Collins, Thos. Shields (b'66)-Ky.5,86 (1'00); not in practice; $2425 \mathrm{~W} .23 \mathrm{~d}$ St.
COLLIVER, JOHN ADANS (b'72)థ-Cal.2, 99; (1'99) ; 1207 W. 3d St. ; office,

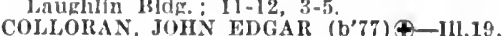
,02, Iil.6,'07; (1'09); 1547, 6th Ave.; oftce, 610 S. Broadway; 2-4.

Colloran, Maud Atherton (b'73) - Ill.19,02 (1'10); 1547, 6th Ave.; oftice, Story Bidg. G.

Compton, Clarence Sumuer (b'82)-Cal.2, '12; (1'12); Los Anzeles County Hospltal. Conerty, Jaines Matthew (b'83)-Ill.11,'12; Intern, Cailifornla llospital.

Congdon, Amandas Maria (1)'5i) - N Y 6,92 $\left(1^{\prime} 97\right) ; 1212$ S. Grand Ave.; $1-4 ; T$.

Conrad, Andrew 0. (b'68)-Cál. 4,'92 (1'93) ; (Glendale); office, 517 S. Broadway; Prof. Gyn., Cal.4.

Conway, Jessle B.-Colo.4,'97; (1'97); 1101 W. 48th St.; offlce, Mason Bldg, ; 9-5. (l'08) ; 849 S. Bonnile Brae St.; office, Story Bldg.; 11-12, 2-4.

COOK, EDWARD J. (b'72) $\oplus$-Cal.6, 97 (1'99); 1155 Elden Ave.; office, $356 \mathrm{~s}$. spring St.; $11-12,2-4$.

Cook, Flmina Farquhar-1a.6,88; (1'01): 5419 Pasadena $A$ ve.

COOKE, A. BENNETT $\left(b^{\prime} 67\right) థ-T e n n .5$. 91; (1'12); Member Tenn. State Med. Assn.; Story Bldg.; $(\mathbf{A 4}, 6)$.

Coneland, John Chas. (b'72) - Md.6,96 (1'01); 343 S. Oxford Ave.; office, 2021, S. Broadway; $9-4$.

Corey, Jasper W.-Mo.7,'89; (1'00) ; 538 E. 16 th St.; offlce, 523 W. 8 th St.

Corwin, Guy Philander (b'55)-Minn.4,'89; (1'99); 2665 Sulphur st.

Costlgan, Geo. D.-Cal.1,'92; (1'94)；624 W. 43d Pl. ; office, 4II S. Maln St.

COTTER, PETER GREGORY (b'57)(N.Y.3,'87; (l'04) 729 S. Burlington Ave.
offlee, H. iv. Heliman Bldg. : 11-12, 2-4. office, H. IV. Hellman Bidg. ; 11-12, 2-4.
CoTTLE, CASSIUS CLAY (b'65) 89; not in practice; Member Iowa State Med. Soc. ; 1408 Algoma Ave.

COWAN, JAMES REA (b'80)(3-Cal.6,09; (1'09); 162 Ardmore Ave.; offlce, Grosse Bldg. : $2-4: 1 . \star$

COWGHL, EUGENE PARK (b'78)-Mo.3 104; not in practice; Member Mo. State Med. Assn.; 1721 E. $43 d$ St.

COWLES, JOSTAH EVANS (b'55) $\oplus-M d .1$ "80; (1'89) ; 1101 w. Adams St.; offlce, American Bank Bldg.; 10-12, 2-4.

Cowperthwaite, Allen Corson (b'48) H-Pa.9 69; ( ) ; Black Bldg.; Emer. I'rof. Mat. Med. and Ther., Ill.4.

Cox, Herbert Thos.-Cal.4,'13; (1'13); 5600 York Blrd.; Prof. Hist. and Embry., Cal.4. Cralk, Chas. W. (b'73)-Mo.20,00; $\left(\mathbf{l}^{\prime} 00\right)$ 2686 W. Pico St.

Crawford, ollve (b'79)-Cal.9,'13; (1'13) : 6th and Hill Sts.

Creaghe, John O'D.-Ire.6,69 ; (1'12)； 225 Sunset Blvd.

CREAMER, MICHAEL S. $\left(b^{\prime} 77\right) \oplus-K y .1$, '06; (1'06); 1720 Hobart Blvd.; office,
Homer Laughlin Bldg.; 2-5; Pd.

CRILEY, CLARENCE HOLMES (b'81)థPa.1, 07; (l'09) ; 1621 Ingraham St. ; of Anat., Cal.9; S.*

Crist, General' G. (b'64)-Ky.1,'90; (立) 411 S. Main St.; $U$.

Crocker, Harry B. (b'77)-Cal.4,00; (1'00); 227 W. 7 th St. ; $1-4$

Cross, Henson H.-Ia.1,'83; (1'88); not in practice; 661 Lucas Ave.

Crossan, John Wesley (b'83)-Mo.34,'11; (1'11); 666 Carondelet St.; office, 424 S. Broadway: 1-4.

CRUM, ROBT. LESTER (b'81)-Mo.34,'11 (l'11) ; 217 W. Santa Barbara Ave.; of flce, Douglas Bldg.

Crutcher, Ernest (b'58)-Tenn.5,79; (l'01); (Redondo) ; offlce, Exchange Bldg.; 10-12, $2-4$.

Cummings, Chas. J.-Ia.1,'82; (1'01) ; 250 W. 57th Are.

CUMMINGS, ROLLAND STANLEY (b'79) dalle Ave.; office, 7th'St. and Grand Are. dale.

CUNNINGHAM, ROBT. LAW (b'80)丹Md. 7 ;07; (1'09); Hotel Alexandria ; office
Security Bldg.; $10-12 ; 1 . \star$
Curtis, Chas. Fred (b'63)-Me.1,'89, N.Y.10 '90, Ill.15, 00 : (1']0) : 1543 Martel Ave. office, 6404 Hollywood Blvd.; 2-5.

Curtlss, F. IIomer (b'75)-Pa.1,'09; (l'11) Sherwood Apts. : oflice, Black Bldg. Dabney, Franklin K.-Mo.5,79; $\left(l^{\prime} 00\right) ; 822$ W. 6th St, ; offlce, 736 w. $7 \mathrm{th}$ St.

Dabney, Smith-0.7'30; ( ) ; 1021 Denver Ave.; offlce, 320 W. 8 th St. ; 10-1, 2-3;

DAKIN, WIRT BRADLEY (b'84) $\$$-Cal.6, 08; (1'09); also Member Ill. State Med. Soc. : Slerra Madre Club; office, los Angeles Investment Bldg.; 10-12:30, 2-30$4: 30$; (C3) ; U. $\star$

DALE, HARIY M. (b'67)-Ia.3,94; (l'01) 3701 S. Main St. ; ofllee, Hollingsworth B]dg.

Danlelson, Samuel-E-0.10,'80; (l'99) ; 2341 Sheridan St.; offlce, $101 \frac{1 / 2}{}$ S. Broadway: $9-4,7-8$.

( ) Member Neb. State Med. Assn. ; 605 E. Washington St.

DAVIDSON, ANSTRUTHER (b'60)

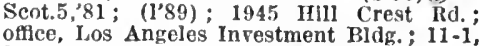
3-4; Assoc. Prof. Derm., Cal.9; $\mathrm{D}$.

DAVIES, BERTRAII CHAŚ. (b'78) - Il.11, 05: (1'05); (Monrovia); office, Title Insurance Company Bldg.; 11-12, 2-4;

aris, Andrew P. (b'35) H-O; (t); $154 \mathrm{~W}$. 23d St. ; $2-5$.

avls, Magnet Jervais (b'65)-0.8,'96 Davis $424 \mathrm{~S}$. Broadway. (l'78); 1726 Cherokee Ave.; ofllce, $424 \mathrm{~S}$. Broadway ; $8: 30-5: 30$.

DAVIS, TILODORE GARRISON (b'55) $\$$ man Bldg.

DAWLEY, CHAS. G. (b'79) 4 -Cal.6,03 (l'03); 517 N. Boylston St. ; office, 424 S. Broadway; $11-12,3-5 ;$ S.

, Robt. Y. (b'76)-Cal.6,'97; (1'97); 238 IV. 42d Pl. ; office, $206 \mathrm{~s}$. Sprlng St. ; Dean, Chas. James (b'83)-Ill.22,'09; (l'12) ; $3271 / 6$ S. Spring St.

DECKER, CHAS. W. (b'77)థ-Cal.6,'06; W. 16th St.; 1-4; S $07 \cdot(7)$ Member Jed. SOC of the State $\mathrm{N}, \mathrm{Y} \cdot \mathrm{B} 0 \mathrm{X} 123 \cdot \mathrm{S} \star$

DEERING, WALTER EVERETT (b'77) $\oplus-$
Cal.6,'02; (1'02); 7124 Hollywood Blvd.; offlce, 6404 Hollywood Blvd. ; 8-9, 2-4; Pd. de Escobar, Fred Wm.-N.Y.5,'91; (I'05); 1055 N. St. Andrews Pl.

Degnan, Saml. Bryan-Mo.28,'97; (击); 553 S. Hope St.

DeIANE, VIOLA FRENCH (b'64)-IIl.9,'91. retired; Member State Med. Soc. of Wils. 2265 Inez St.

De Monco, Almo (b'57)-Colo.3,'90; (l'92) 740 S. Broadway; Prof. Elec. Ther. and X-Rays, Cal.4.

DENNIS, MARY E. D. (b'70)๑-Cal.6,'97; (I'97) : 1217 Trenton St.; 1-4. ERRICK, JOS. STEPHEN (b'82) $\rightarrow$ DETLING, FRANK E. (b'77) 9 -I11.6, 01 (l'01): 153 N. Robinson St.; offlce. Title Insurance Bldg.; 10-12, 3-4; (B12); OALR. *

DEVITT, THOMAS GEO. (b'67) $\oplus$-Ont.3, 94; (1'01); 248 S. Olive St. ; offlee, Secur1ty Bldg. : 2-4.

Dial, Eugene A. (b'60)-Ky.4,'86; (l'87) : $1837 \mathrm{~N}$. Wilt on Pl.

Dlee, Seth Delmer (b'71)-N.Y.5,'97, N.Y.20 99 ; (1'01); 1736 Orange Drive; Holly -

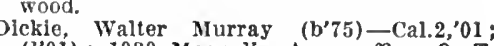
(l’0i) ; 1030 Magnolia Ave.; offlce, O. T. Johnson Bldg.; 11-12, 2-4.

Dlckinson, Danl. K. (b'49)-Mo.1,77; (1'01): 1003 Beacon St.

Dlckson, Clarence B. (b'58) H-0.7,'83 (l'88); 2212 W. 24th St. ; office, Auditorium Bldg. ; 11-4.

Dietrich, Henry (b'76)-Ill.1,'98; (l'13) ; 2926 Brighton Ave.; Assoc. Prof. Ped." Cal.9.

Dietsch, Curt Oscar (b'67) $\rightarrow$; (l’02); 1453 Bellevue Ave.; office, Delta Bldg.; 11-1, 2-4. 
DILLINGIIAM, FRANK $s .\left(b^{\prime} i s\right) \Phi$ (al.6, 00 ; (l'00); 667 Irolo St. ; office, Llssner

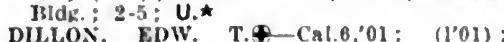
664 S. Westlake Are.; offico. Itrockman IBldE. : 1-5, :-8: S.

Diren, Geo. Baphleld (b; $; 6)-I 11.11,01$; $\left(I^{\prime} 10\right): 6135$ IIollywnod Ilvd.; $2-4$ : S DoDGe, WM. (b'5\%)女-Ia.1, 78 ; (1'8s) Ilotel Chlckasaw : ottlce, Frost Bidg.: 1-4. Dorsey, Mebecea Leo-Mass.5,'s3, N Y.14, 93: (1 93): Pacinc Flectric 1his

ty, Lambert L.-Mlch.1,"73; (1'9:); 1420 Fodgemont Blrd.

ougall, John Park (b'it) E-Cal.4,04 $\left(t^{\circ} 04\right)$; 3815 Ingraham st.; otthe, Wouglas Bldg. : 2-4.

DOUGHERTY, PATRICK $\mathrm{S}$. $\left(\mathrm{b}^{4} 46\right) \uparrow-11.6$ '84; (1'87); 2014 Flyueroa St.; ontee, 405 S. IIll st.: 2.4 .

Douglas, Charles Henry (b'31)-X.Y.10,';6: (l'8s): $137 \mathrm{~S}$. Marlnosa IVe.; $9-12,2.4$

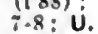

Dowis, ALFRED J. (b'a) (1'02): 2374 W. Washlugton St.; oftlce o. T. Johnson Bidg. : $11: 30-12: 30,2-4 ; G$. DOZIER, BARTON (b'51)-I'a.1; ; $;\left(1^{\prime} 6\right)$ 952 S. Bonnle Brae St.; offlce, $405 \mathrm{~S}$. IIIII St. : $2: 30-5$.

Drake, Fmma F, A. (b'49)-Mass.5,'82; not In practlce: $1703 \mathrm{~W}$. 24th st.

Drollinger, Śchuyler C. (b'56)-0.2,'S1 ; (\$): 3016 Is Salle Ave.; offlee, $843 \mathrm{~S}$. Spring st. : $2-4$.

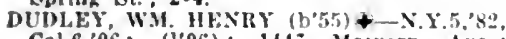
Cal.6,06; (1'06); 144: Malrern Are; oftice, Exchange I

DUFFIELD, WM. (b'66) $8-\mathrm{b}^{\prime} \mathrm{P}, 1,93 ;\left(1^{\prime} 00\right)$; $1259 \mathrm{st}$. Andrews 1'l.; oftlce, Audjtorlum Bldg. : 1-4: (F3).

Dukeman, Wm. H. (b'55) - N Y Y 50 . (1'87); 1116 Lake St. : oftce, Grant Bldg. 2-3:S. REX D. (b'86) 4 -Cal.6, 09 : (1'09); 162! S. Grand Ave.; offlce, Van
Nuys Bldk.; 11-12, 2-4; S.

DUNDAS, ROBT. C. (b'68) -111.1,'90; (1'97): 2709 X. Broadway : 1-3, $7-8$

DUNSMOOR, JOIN MARCUS (b'55) Cal.6,00: (1'00): $2331 / 2$ N. Frand Are.

DUNSMOOH, NANifie C. $\left(b^{\prime} 60\right) \&$ Cal.6 00 : (1'00); $233 \frac{1}{2}$ N. Grand Are.; office, Laughlln Bidg.; 2-4.

Dunsmoor, ltobt. Morrls (b'83)-Cal.4, 13 (1'13); 5526 Homalne; offlce, Stors IBldr. Dunton, Wallace A.-Cal.6,'92; (l'92); 2310 Ocean Vlew Are.; offle, Iligglns

Bidg.; 1.4. U0; (l'04): Ilotel Woodward; ofllce. Fay Bldg. : 12-1.

EAUS. ERASTUS FINTN - Mo.10.' (I'00) : 1829 W. 25 th St. ; oflce, Call fornla Bldg. : $y=11,2-5$

EAltiNG, EDWis w. (b'81) - Cal.1,05; (l'05); 206 W. Santa Marbara Are.; offce, I14 F. Santa Barbara Ave.

EARLE; CIIAS. IIEXIIY-N.Y.10,89; (1'06) : 940 Grattan St.; ođce, Anditorlum Bldg. : $10-12,2-4$.

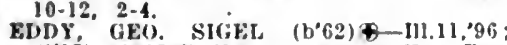
(1'97): 2823 s. Vermont Avo.; offce, Fer nando Bldg. : 1-4.

EI) BI.MAN, DAVIi) W. (b'68)-N.Y.5,'91 (I'02); 1018 klden Ave.; once, Irradbury

Hock: 1-4; S.
EIWWALDS, SAJL. G.-0.1,'83; $\left(1{ }^{\prime} 00\right) ; 103$ s. Inwan s?: $9.10,2-4,7-$

EDWARDS, WM. A. (b'60)+-1'a.1,81 : (1'89): 3406 W. Adams St.; once, secur: liy Blde.: (E3,io).

Ehrllck, Isenj. 1'-1'a.1,00; (1.00): 411 s. Main st.

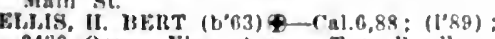
2430 Ocean Vlew Ave: omce, liralliury Block: 10-12, 2-4:30; 1'rof. Oplitl.. Cal.2: (131,3,12, F3); OALR.

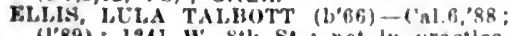
(l'89): 124 W. Stl St.; not In practlce

ELLIS, MELVIN (b'82) +-(al.6, 09 ; (l'09): 1710 W. 6th st.: onice. Sulf furlum Bldse. : 11-4.

Ells, Richard W. $\left(b^{\prime} 44\right)-M ! c h .1,71 ;\left(l^{\prime}, 6\right)$; $338 \mathrm{~W}$. Jefferson st.

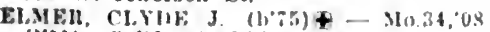
(l'11); Callernla Bidg.
FMbitSON, HENRY K.-0.12,'97; (1'00): 1056 F. 2till St.; oflco, 405 s. IIIIt St. : $10-12 ; 0 b$.

Ertl, Mary S.-II-111.4,87; (I"90) ; 3927 Naoml Are. Errin. 'has. Hekle-Cal.4,12; () ; tirmut Bldiv.

Estes, Florella-Mass.5,'90; (l'98); 839 N. Normmalle st.; offlce, Andltorlum Ibldg. $11-12,2-4: 30$.

EVANS, CIIAS. W. (b'62) $9-0.3,{ }^{\prime} 87 ;\left(10^{\prime} 04\right)$ lis $\mathrm{N}$. Soto st.; onle, $104 \% \mathrm{~s}$. Cumnilngs $\mathrm{st}$; $1-4, ;-8$

Frans, (hesley 1. (b'88)-Cal.2,'12; (1'12) ; los Infeles County IIospltal.

Erans, Darld Jullus (b'69)-I11.4,98; (1'00); jo 0 s. IIII st

EVERSOIE, HENRY OWEN (b'ii) othice, Audltorlum Blik.; $9-1:$; I.

Fahy, John Eugene (b'76)-I'a.1,01; (1'06) 1151 F. 20tl Sit.; 9-1.

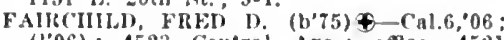
(l'06) : 4523 Central Are.; once, 4521 Central Ave ; 2-4.7-S: $\mathrm{S}$.

Farles, Francls $\mathrm{x}$. (b'5i)-Mlch.6,81; 130 F. Ave.

FASU, IIARY BUCKI.EY (b'59) \$-Cal. '9i; $(1 \cdot 97) ; 2121 \mathrm{~N}$. Broadway; $2-4,7-8$. earon. Wm. Max

1315 Thalla St.
Fellows, Alfred (b'72)-ni.6,96; (1'90) 2624 'S. Figueroa St.; oflice, 406 'S. Sprlin ist.

FERBFRT, JOHN C. (b'72) $€$-Cal.6.'97; (1'97): Callfornta Club; otfice, Bradbury Bldg.; $1-4$.

FEItIY, Flidxcls C. (b'80)-Cal.6,03; (1'09): 163: $>$ llobart Blvel.; offlce Kerckliof IBldg.; 10-12, 2-4. Kerckliof Bldg. $10-12,2-4$.
Finch, Geo. W.-E-Cal.4, 90 ; V. 5th Si.; 10-12, 2-4.

Flnch, Will $(\therefore$ (b'73)-Ky.2.98: (1'4S) 1306 W. $41 \mathrm{st}$ 11.; offee, San Fernando Blde: $9-12,1-5$

FINLEY, THFODORE FAW (b'75) oflce, lirockman Bldg.: i]-1, 2-4; $\mathbf{5}$.

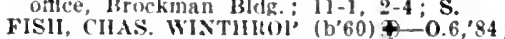
(I'95) ; $2120 \mathrm{~S}$. Unlon Are.; oflice, LaughIIn Bllk. ; 11-12, 2-5.

Fisher, Mhis. Nibert (b'6) - Cal.9,'13 (1'13) : 1103 F. 221 st. Flsher, Ira C. - Ind.8, $84 ;(l ' 84)$; 6415 Ruby
St.; 9-12, 4-6.

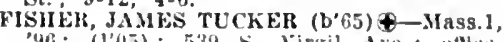
"40: (1'05); 539 s. Virgil Are.; uthe" Hollingsworth Blalg.; 2-4; I'rof. Neur. and Psych.. ('al.9; (F3); NP.*

iske, Wm. Clarenco-N.Y.8,93; not in practlce; Huntlngton l'ark.

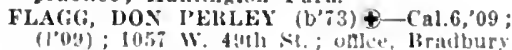
Isldg, I-4; Pd.

FLANIAliNX, I. E. -Va.1, 84 ; ( ) Member Med. Soc. of Ya.; $6 \pm 0 \mathrm{~s}$. Figueroa st Fla.MIXi, EITEST W. (b'il) - Mleh.1 ' 55 ; (1'\$9) : 966 Hoover St.: untce, Trust and silrings Hidg.; 10-12, 2-t; ( $161,3.12$ (Fi) : ALR.*

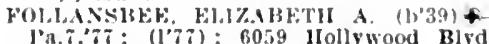

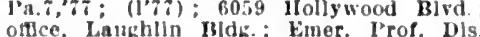
of thill., cal.2.

Folsom, Edward C. (b'45)-Mass.1, (is $\left(1^{\circ}-9\right) ; 333$ w. 2d St.

Fortet, Alplutisus J.- Itelg.4,94; (1'?5) 1047 s. Honnle Brae St.

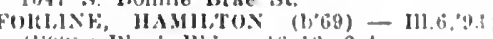

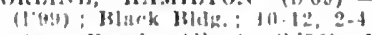

Foster, Frank Abert (b'5s)-Mlleh.1, 85 ; ( ) : fold Wall St.

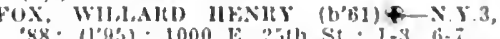

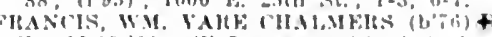

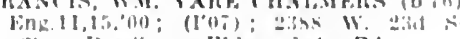

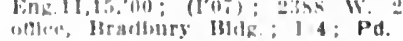

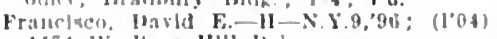

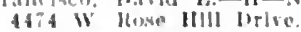

Frank, Morrls A. \&. (b'8t)-1'nl,b, ps

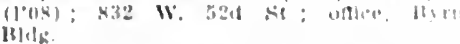

Frary. Burdett Serage $\left(b^{\circ} ; 0\right)-M 1 \cdot 1+1,02$

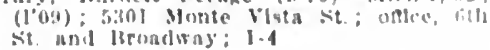
Frelerleks, layld I'. (li,:a) $(100 \%):$ it W. Ilellman It]i:
Freelman, (has.-f'a) f, $03 ;$ (l'03); 334 W. $411, \leq 1$.

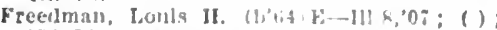

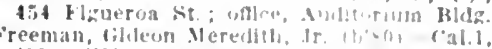
'03: (1'03): 4.3131,

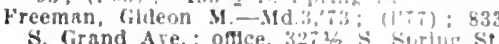

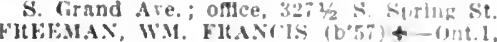

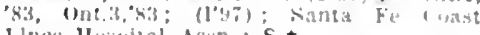
linos llovillat $\Delta$ sin.

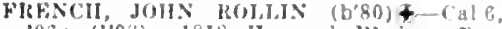
66 ; (1"08); 1818 Harrard Blvd.; once Really Iblig.: 2-4.

French, I'lcknes (b'5) -0.9;73; (I'12); 321 W. Bd st.

FIBICK, lOSALI) JACKSON (b' it) \&-Cal.2, Hrockman Whig.; Asst. Yrot. Clin. Med., Cal. 2; 1.

Frlesen, Jacob Frank (b'80) - Ill.11,0\%: (l'l3); 4523 Central Ave; once, 4521 ('entral .lle.; $2-4, \bar{i}-8 ; 0 \mathrm{~b}$.

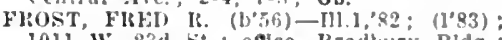
1011 w. 23d st.; once. Bradbury Blds. $11-1,3-4: 30$.

Fllost, LOWKI,L CHESTEI (u'82) \&-Cal.2, 11: (1'11); Vista st.; oftice, G404 lIoltswood Hilsd.; $9-10,12-1,7-8 ; \mathbf{N}$

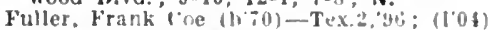
5935 S. Flzueroa St.

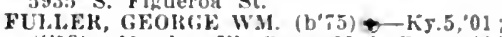
(1'13) : Member Ill. State Med. Soc, ; 124 Park Vlew; onlee, Black Hldz: : $2-5 ;$ S.

Fuller, Levi IJulbert-N.H.1,'ss; (1'ss); Title Insurance Bldg.

Fullmes, Burt Fmerson (h;0) ll-Ia.4,02, III.19.'04; $\left(l^{\prime} 06\right)$; 1222 Gordon St.; offlce, Fergison Bldg.

FULTON, DUDLEY (b'i4) $\mp-\mathrm{Pa} .2,99$; (I'01): 2700 lisand Ave.: Oflde, Merchants Satl. Jank Bldg.; 2-4; Asst. jrof. P'rin. and Prace of Med.. ral.2 (F3).

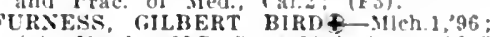
( ) Member N.D. State Mled. Assu.; 5015

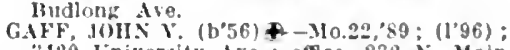
"\$20 Iniversity Are; offlce, 232 X. Main Si. 10-12, 1-4: S. (1'10): 2102 Hooper Aie.; 2-4, i-8.

(albralth, Wm. J. (b't0)-0,8, 80 ; ( ); 2020 liearlawood Drive: $\mathbf{S}$.

Gardner, Placlda (b'83)-Mlch.1, 11: (1'11): lealty Blds, 9-11, 4-5.

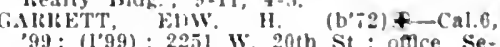
curity Bldg.; $10-12,2-4$.

Fates, Amella levinson (b'66)-Call, 94 .

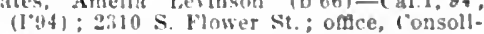
tated liealty Mldg; $2-4$.

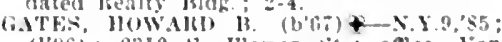
(1'06) ; 2310 s. Flower st.; omle, Van Ning lilete: 2-4.

Gaynur, Jolu J.-N.Y.1:, s1; (192): 309

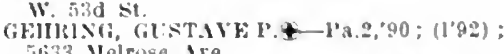
cinis. Ilelrose itre.

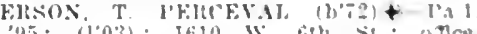
w. I. Stors lulle: i-t: (rio): Pd.

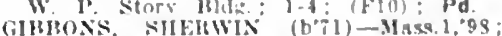
(l.05): 1639 st. Andrews li,; onles, Ilibernian Bdg: : $10.11,2-4$

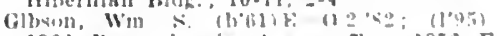
1002 Pennsyiranta Ave, onter, 1956 F. Int st: : 2.4, $7-8$

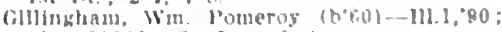

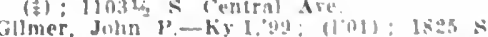

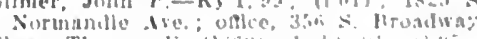
Blass. Themas $r$ lliber

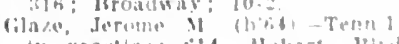

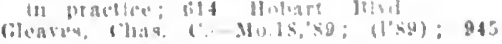
$\therefore$ mirm si

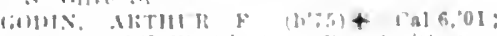

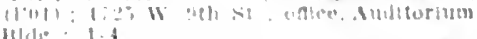

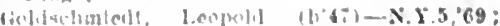

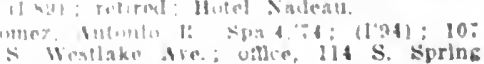
Sit Interi, lus Angelos Infrmary. 
Goodrlch, Edwln G.-Cal.6,03; (1'03) ; 3759 Miple Ave.; offlee, 406 S. Maln st. $12-2: 30$.

(IORHON, FlRANK II. (b'66) - IIL.1,91 (198); 812 S. Bonnle Brre st. ; ollice. Iribernlan Bldg.; $11-12$, 2-4.

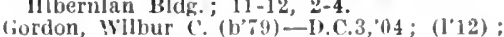
Fordon, Yllbur ('. (b'79)-I).C.3,04; (1'12)

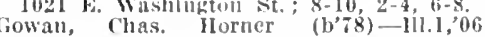
(1'09); 1751 w. 2ad st.; offlee, I'reifle vilectric 13ldr.; $10-12,2-4$

Gradle, Fanny Searls (b'51)-Mlch.1,75: not in pratice: 3553 lad (resta ('

Graf. Nhert F-1'a.11,93; (l'01);

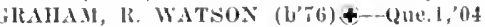
(I'10): 6th and Itampart Blvd.; oflec, fonsolidated Realty Bldg.; 12-3; (BI2); 0p. *

GRANGER, Al'THI STANIEY (b's1 III.1,09; (1'11); 1207 WV. 3rl St.; otllee, lsockman Jldg.; 11-1, 2-4.

(irant, Wm. L. (b' $(67)-l 11.1,93$; (l'0s) ; 634 W. 4 th St.; oflice, 4525 Moneta Ave. $10-12,2-4$.

(iRAY, ETTA G. (b'80) \&-Cal.1,06; (l'06) 1188 S. Bronson Ave.; offlee, Hollings worth Bldg.; $2-4$

Gorth Bldg.; 2-4.

679 s. Rampart Blid.; offle, Aulitorum Hldg. : $3-5$.

(ireen, Wm. 1).-Ont.4,'86; (l'86); 1191/2 S. Sprlug sit.

Gregory, Lyman-II-1ll.10,'87 ; (1'88) ; 528 W. Vernon Are.; oftice, 434 ' S. Hill 'st. Cireth, August-Cal.2,94; $(1,94) ; 748$ w. 7th GRIFFITH, ROBT. BIAKE (b'76) $₫$-Cal.6, 04; (I'04); 1500 Elevado St. ; offlee Black J3ldy.; 2-4.

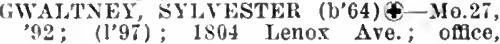
$92 ;\left(l^{\prime} 97\right) ; 1804$ Lenox Ave.; offlce,
Grosse Bl(lg, ; 11-12, $2-5 ;$ Prof. Clin. Grosse Bldl:
Med., Cal.9.

I Iadden, John vavis $\left(b^{\prime}-1\right)-111.4,96 ;\left(l^{\prime} 12\right)$; 6016 llays Are.: oftlee, 4 th st. and BroadWay: 12-5; ObG.

IIACADOKS, JESSE LEE (b'72) \&-Cal.6, '93; (L'93); 333 W. ad st. ; office, Bumiller Bldg

Hagan, Ralph (b'72)-Cal.6,'95 ; (l'95) ; 758 Lake St.; offlce, 424 S. Broadway $11-12: 30,3-5 ;$ S.

Haigh, Frederic-Ill.4,'9s; (1’97) ; 340 Byrue Bidg.

HAIGIT, HARRY WM. (b'84)-MIAss.1,'12; (I'12); 1916 s. Union St.; office, Wrlght and callender Bldg.; 2-4.

Hailstone, Chester E. (b'66) E-Cal.4,91; (1’91): 1045 Ingraham St.

HALE, GEO. V. (b'58)-Y'a.2,'83; (l'96); not in practice; 800 Temple St.

Hall, Ardelle 'T. ('b'56) H-111.10,'83; (l'01): 1409 s. Flower St.; $10-4$.

HALL, tilLES S. (b'69) \&-111.1,97; (1'9s) $2 I 1 \mathrm{~N}$. liampart st. ; oftlce, 1 'acifte slectric Bldg. ; 10-12, 1-3.

Hall, Harry Clay (b'53)-0.1,'83: (l'04). $107 \mathrm{~N}$. Fremont St.; office, 1 st and Hope sts. ; $10-12,2-5,8-9$.

Hall, Jannes S. (b'- 2 -Cal.6, 00 ; (l'00) ; 1954 s. Grand Are.; offlee, $22: 3$ W. $2 d \mathrm{St}$. 9-11, $1-3: 30,7-8$

IIall, Wu. E. (b'87)-Cal.9,'12; (l'12) ; 4115 Normandie Are.; offce, Grant Bldg.; also 3563 Normandie Ave. : 10-12, 2-4.

Jamblin. Roald $\mathbf{F}\left(b^{\prime} 55\right)-0.6,80$. $236 \mathrm{~S}$ iv. $31 \mathrm{st}$ st.

IIamer, Thaddeus F.- 0 ; luot in miactice 1001 W. 21 st St.

Hamlin, Ira Peters-Mo.30,01; (1'01); not in practice: 3447 s. Flower st. : $2-5$.

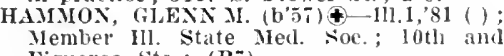
Figueron Sts.; (Bi).

Hammond, Nettie E. (b'67)-Cal.6,'96; (l'9i) : Block Bldg.

Hamrick, Martin P. (b'85)-Pa.1,'11 ; (1'11) $456 \mathrm{~s}$. Spring st.

IANKIN, CHELIA MARY $\left(b^{\prime}-4\right)$-Eng 4,'03; (1'10); Hollywood.

HANLON, EDWARD RUSSELL $\left(b^{\prime} 76\right)+-$
Cal.1,99; $(1,00) ; 1443$ W. 49 th st.; oftice, 1156 Central Ave.: 2-4, $7-8 ; \mathbf{S}$.

Hanna, Edward A. (b'64)-Ill.6,'86; (l'00) 646 St. Paul Are.; office, Unlon Oil Bldg. $4-12,2-5$.

Hansen, Homer A. (b’-2)-0.19,'95; retired; Wilshire St. and Rampart Blvd.; offee, Consolidated Realty Bldg. llansen, John Eibert (b'80)-Net.5,02; ( ) ; 6001 Yucea St.

Hauson, Estelle C. Merrill (b'6L)-X.Y.14, 91; wot In practlee; 2210 Highland Ave Hauson, Wayne Person (b'88)-1'a.z,'12 (teachlng) ; 2405 W. Jelferson st.

lauson, Wlibor Flsk (b'45) - Ill.1, 85 ; (l'99)

$1126^{\circ}$ Angellna St. : offlce, $105 \mathrm{~F}$. 1st St.

IIARIRS, ROSA ALLEN\&-tll.1,99; (I'96) 6:3 s. Bommie Brat st.; vllice, 4:4
Broadway; 10-12, $2: 30-4: 30 ; \quad$ (J12) Broadway
OALR.

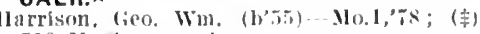
$518 \mathrm{~N}$. Serrano tre.

Harrisoll, Wm. Cole (b'41)-lat.1,82 (1'88); 837 Jake st.; 8-10,3-f;; S.

IIART, LASHEl ' (b'79)@-N.Y.15,03 (1'10) ; 1317 W. 51st J'l. ; oftloe, 'Title II

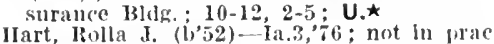
tlce; 1549 W. 4 ith St.

liart, Trusiell Mitchell (b's0)-('al.2,'11 (I'12); 1619 W. Tth St.; offlee, $608 \mathrm{~s}$ Main sit

IIIRTIHLL, ELEANOR A. (b'61) \&-Wis.2, '02; ( ); Member Ky. Med. Assu. ; 2500 W. Pico si

HASTINGS, HIILL (b'74)†-Va.1,'95; (1'01) 5402 Russell Are.; offlee, Trust and sav ings Blde.; l'rof. Otol., Ithin., Laryn. Cal.2; (B3,12, F3) ; ALR. *

HASTINGS, SEMAN WOOI (b'7)-Cal. 08; (l'08); 2401 W. 9th St.; offlce, H W. Hellman Bldg.; 11-5; (B12); OALR HASTREITER, ROIIAND FREDK. $\left(\mathrm{b}^{\circ} 75\right)$ \& -.Id.7,01; (1’04); 2211,20

Iatchor am ' (I'95) ; 2068 W. 29 th St.; office, Bradbury Bldg. ; $11-3$.

IIAIRY, SAMJ. S. $\left(\mathrm{b}^{\prime} 47\right) \notin-M 0.2,89$; (l'01).

Iawkes, Wm. James (b'48)H-Pa.6,67 (l'98): 515 Norton Ave.; offlce, $357 \mathrm{~s}$. Jill St. ; $11-12: 30,2-4$.

Hawkins-Ambler, Geo. A. $\left(b^{\prime} 62\right)-\operatorname{Ir}^{2}, b$, Eng. 15.'89, ścot.3,'!1 :

Blolg. ; 10-12, 2-4.

IIAY, ENIJ, o. $\left(\mathrm{b}^{\prime} 64\right) 屯$

1553 E. 1 st st.; $1-3$, - C.

igen Lemoyne St.; office, 40 ; $\mathrm{S}$. IIill st.

IIAYLS, NELLIE \&. $\left(\mathrm{b}^{\prime} ; 6\right) \odot-C a l .6,04$; (l'04); 717 E. 27 th St.; office, Ferguson BIdg. ; $2-4$.

HAYNES, JOIN RANDOLPH (b'53) 4-1'a.1, Consolidated Realty Bldg.; 11-3.

Iayward, Henderson (b'45)-D.C.2,'69 (1'95); 2501 Wilshire blvd.

HEATH, HORACE SAML. $\mathbf{4}$ Ind.9,'98;
Brockman Bldg. ; $11-1,2-3 ;(\mathbf{A 4})$.

Brockman Bldg. ; $11-1,2-3 ;(\mathbf{A 4 )}$
ledderly, Alfred H.-Ind.6,'75; (1'01) ; 1313 S. Main St. ; office, 355 S. Broadway ; $10-12,2-5$.

Heerdink, John W, - Cal.1.'84,

HEFFERTAN, WM], T. $\oplus-0.1,89 ;(1,00)$ Jonathan Club; office, Title Insurance

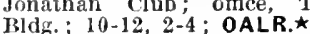

Hendrys, Truman C. (b'45)-Mich.1,69; not in practice; 5127 Sscot Ave.

HENRY, WALTER O. (b'58) (-N.X.10, ' 9 ; ( ) : The Darby; G.

IIERBER'T, IIENRY (b'66)థ-Aus.7,91 ; (l'04); 1421 Courtland St.; offlce, Grosse 13ldg.; 11-12, 2-4; Assoc. Prof. Med., Cal.9.

HEIRIIANN, ARTJUR J. (b'65)£-Ill.L,

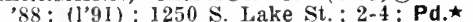

Hickman, Allen R. (b'68)-Ill.1,94; (l'01) 1001 W. $22 \mathrm{~d}$ St

HILL, ALBERT LYON (b'82) \&-Colo.5,08; (i) ; 340 W. 4lst Pl.; Pd.

lWilshirelph W.-Ky.4,76; (l'88); 4031 $1-3,7-8$.

HILL, ROBERT B. (b'86)థ-Mo.3,09; ( ) Nember Mo. State Med. Assn Brockman Bldg.

HILLER, ALBERT WILLIAM (b'79) $\$-$
Cal.6,09; (1'09); 1706 Santa Barbara Ave.; $2-5,7-8 ; \dot{S}$.

Hilton, Harriet J. T.-Mich.1,'T3; (1'94); 837 W. 51 st $\mathrm{Pl}$

HINMAN, CLAYTON JAY (b'73)\$-Ill.6, '04; (1'08) ; 3416 Eagle St. ; office, 3949 Stephenson Are.; I-4.
HITCHCUYK, WM. WESLEY IKELD (b'J4) Ill.1,70, N.Y.10,81; (l'87): $2700 \mathrm{~S}$.
(irand Ave. ; offlce, Merchants Natl. Bank lidg. ; 2-4.

lltt, Adrlison Winter (b'64)-Ky.4,88; (1’01); 38634 S. Normandie Are.; olflee, 6th St. and Broadway; 2-4.

IIoag, Sanford (b'37)II-0.7;71; ( ) ; 723 W. 3d st.

Hofmann, Mary Ellen-Cal.5,96; (1'96). $928 \mathrm{~S}$. Iope St. ; office, $210 \mathrm{~W}$. $7 \mathrm{th}$ St. Iogan, Garrett l. (b'63)-N.Y.3,'87; (1'93) $840 \mathrm{~W}$. Adams St. ; oftlce, 106 W. $3 \mathrm{~d}$ St.

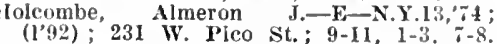
Ioleran, Janes F.Cal.6, 08 ; (I'08); 245 S. Beaudry Are.; oflce, Broadway ('entral Bldg.

IIOLGATE, CHAS. ERNES'T $\left(b^{\prime} ; 6\right) \oplus$ Cal. 9 , 08; (1'08); 1323 Alessandro St.; office, Ileliman lilg.; $9-12,2-5,7-9$.

Hollingsworth, Loren D. (b'8z)-cal.6,'05 (I’12); 130 I W. $501 \mathrm{~h}$ St. ; offlee, Broadway Central I3ldg.; $10: 30-12,1: 30-3: 30$.

Holman, Wm. Frank (b'7)-Ky.4,06 Cal.4,12; (l'11) ; 723 W. 43d Pl; ; offlce

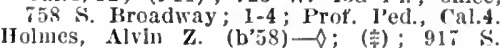
IIill st. : $9-\overrightarrow{0}$

Jlolsman, ('has. K.-Cal.4,96; (1'97) ; $116 \mathrm{~s}$ Ilain st.

I"lrlch II. (b'51)-Ky.2,'75; (l'03) 1039 E. Vernon Ave, office, 610 S. Broadway; 10-12, 2-4.

IIoppins, Annie NI (b'39) H-Ill.10,'80 fopjuins, Henry I. (b'4I)-Ill.10,83; (l'88) 628 W. I'ico St.

HOHN, WALLACE L. (b'60) \&-Pa.2,'95; ( ); Nember Colo. State Med. Soc. ; 1959 Estrella st.

HOLSTMANN, ELSA H. (b'86)-Cal.6, '08; (1'08);670 E. 49th St. ; offlce, 524 s Spring St. : $9-11,2-4$.

Horton, Enma L.-Mass.6,0I ; (1'0I) ; 1609 Van Ness Are.; offlee, Black Bldg. ; $10-4$. Houghton, Arthur D. 0 ; (l'03);

House, Augustus Farlin (b'47) - $0.6,71$. retired; 1861 Whitney Are. : 2-4.

HOWARD, HENRY W. (b'65) - Ill.1,'90 ; (1'06) ; 2627 Severance St.; offlce, Auditorium Blfg.: :-4; (F3); S.`

Iloy, Franklin P.-II-Pa.9,79; (l'86) ; 1433 F. $48 \mathrm{tl}$ St.

Hubbard, Arthur Wm.-N.Y.6,'87; not in practice; $120 \mathrm{~N}$. Spring St.

Iubbard, B. Roswell (b'53) E-0.2,79 (l'01); 616 Bixel St. ; offlce, Ferguson Bldg.; $11-5$; $\mathbf{S}$.

IIIFF, LUCIIS J. (b'72)థ-Cal.6,05; $\left(l^{\prime} 05\right)$; 7364 Hollywood Blyd.; $8-5 ;$ LR.
Huff, Melrln B. (b'56)--N.Y.6,85; (l'90) (902 Melvin B. ( $\left.b^{\prime} 56\right)--N . Y .6,85 ;\left(l^{\prime} 90\right) ;$
Linden Ave., Long Beach); office, Black Bldg.; 11-2.

HUGGINS, WALTER LESLIE (b'72)థN.Y.3,99, Cal.6,08; (l'08); 860 S. Ard
more Ave.; office, Consolldated Realt Bldg. : $2-4$.

IIUGHES, IIENRY WEST (b'58)-N.Y.1,'85; (I'88); 500 W. $23 d$ St.; office, Hibernian Bldg. ; $10-12$.

Hull, Foster Miller (b'89) - Cal.9,'12;
(1'12); 3311 w. Temple St. ; offee, 58 s' Broadway

HUIFREYILLE, DANL. LOUIS (b'i4)III.1,96; not in practlce; Member Mo. State IIed. Assn.; (Pasadena); offlee, Hellman Bldg.

Humfreville, Danl. W. (b'43)-0.1.64; ( ); 2544 Elsinore Ave.

Humphrey, Vivian A. $\left(b^{\prime} 59\right)-0$; not in practice; 625 W. 47 th St.

IIunt, Iohn Wesley (b'34) - X.Y.5,'59 (1'89); 158 W. Jefierson St.

Hunt, Verne Carlton (b'88) - Ill.1,'13 ; Intern, Los Angeles County Hospital.

HUNTER, GEO. GRAHAM (b'76) $\$$ CaI.2, 06; (l'06); 256 S. Occidental Blvd.; of flce, Exchange Bldg. : $2: 30-5$; NP.

HUNTOON, HARRY A. (b'80)థ-Cal.6,'08 ; $(1,10) ; 1029$ W. 56 th St. ; office, $5426 \mathrm{~s}$ Vermont Ave.; 2-4, 7-9.

HURST, STITH T. (b'44) \-Ill.1, T1; not in practice; Member III. State Ned. Soc. 1623 Winona Blyd.

Husted, Singleton-N.Y.1,79; (1'92); 122 II. $3 \mathrm{~d}$ st. 


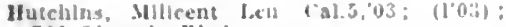
732 Olympla Bird.

Hutchlngon, C. Stuart (b'it)-Ill.Il, 9s (1'0s): 501 S. Gramercy Pl.: oflce, ;58 S. Hrondway: 10.12, \&-4: 1rof. Obst. Cal. 4.

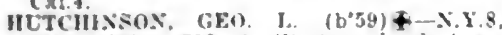
Q4: $\left.11^{\prime} 83\right): 310$ s. Westmoreland Ave: once, Paciflc Flectrlc Hlds. : $11-12,2-4$; (1999): $281 \%$ Menlo tre. ontce, 3 st and Ibroadway : $11-12,2-4: 30$

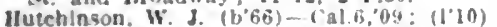
ined's Camn No.

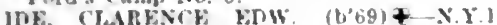
"94: (1"11): 1225 W. 5th st. : othe", Brock91: (111):

nan IBlds: (11!2\}.

Ikouchl, Klyomltsu $\quad\left(b^{\circ}, b^{\circ}\right)-(\cdot a l .:, 01$ (1.01): $1243 \mathrm{~W}$. Jefrerson $\mathrm{St}$; uffice, 125 San l'edro St. : 9-11, 2-t.

mingworth. Geo. M.-Jll.6;:74; (1's); 919 Orme A Te.

Iserl W. Kawar (b'80)-Cal.1,12; (1'12): 1133 Trenton St.; 1-5.

how T.-Salsel Med. 'oll. lapan,97: (1'99); $326 \mathrm{X}$. San Pedro st.

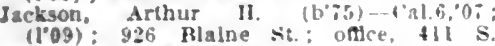
(l'09): 926 Rlalne
Jlaln st: $10-12,2-5$.

Jackson. Edward It. (b'48)-0.8, it, Pa.9 '\$1; not in practlce; $1466 \mathrm{~W}$. 46 th $\mathrm{st}$

J.ATKOS, JOS ADDISUS $\left(\mathrm{b}^{\prime} 7 \mathrm{i}\right)+-V t .2$. 99: (l'00); lieverly Illls IIotel: oftce, 6 - 63 llollywood Blvid. $3-8$

Incoble, Judson Douglas $\left(b^{\circ} 56\right)$ F- - 0.2,'s5: (I's7): not in practice: $1100 \mathrm{~W}$, 45th st. omce: Los Angeles Inrestment BIdg. : 9-4

Jacobs, Edw. H. (h'-s)-III, 0 : ; (II) $4 \times 03$ \&. Normandle Ive

Jacobs, Jos. $($ h'-8)-0.12, 0 ; ; $(1,11) ; 1: 22$ Mlessaudro St. : 2-4, 6-7

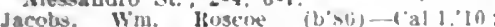
(I'II) ; 45t S. Flgueroa st, oflice, Fersuson Blde; 10-12, 2-4; S.

JACOBSON, MOSKS-("al.1,01 : 1 l'01) : 1224 Ionla St: : otace, $93 \%$ E. Ist St. Windsor Janss, Ed,

Janss, Herman $\left(b^{\prime}: 6\right)-111.11^{\prime} 99:$ ( $\left.b^{\prime} 99\right)$ (Brentwood Park); onte, Paclic Electric Bldg.

Janss, Peter-X.Y.10,'85; 11'25) ; 811 Hea con St. $9-12,2-4$

Jard In! Alessandé \& (b-i) Ita.20, (l10): $342 \mathrm{X}$. Main sl.: onter, Baker Block: 2-4.

Jauch, Joseph Wllhelm (b'63) —switz. i,:86, Ger.20,83; $(1.901 ; 400 \div$ (;rand Are. ofmee, Germaln Mlds.; 10-12, 2-4.

Jeancon, Etta C. (b's:)-(1.2,05; (1012) 1035 $11.5 \mathrm{th}$ St. onlce. Auditorim Blde I1. $1,3.5: G$.

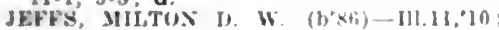
(I'11); 213 \$. Framercy Fl.; oflce, 3519

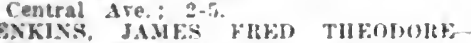

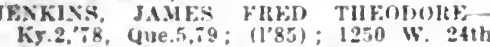

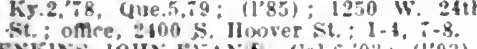

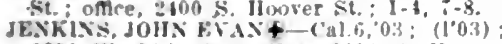
$10: 0 \mathrm{~W}$. 2tth st.; oflice, $2400 \leq$ Hoover si.

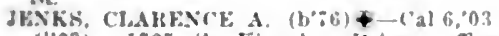
(l"03): 1725 s. Kingsley lirlse: omlee. Brockman IBlelg: 2-5.

Jesherg. Slmon IIenry (b'86) - Cal.9.'13; 80: $0_{\text {. }} 21 \mathrm{st}$ St ; Intern, los inzeles County liospital.

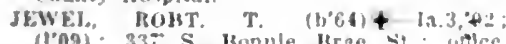
Consolldated Realty HIdg; 11.4; ObG.

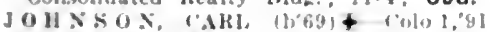
11'12): 3434 bublum Are. onve, Mer chanes Trust IHdh.; $2-1$

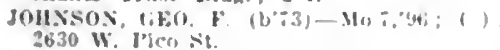

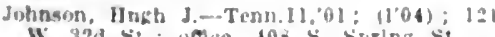

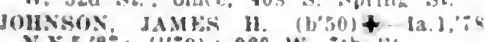
X.Y.5.'8: $(1.99): 920$ w. th s.

Jolunson, Julla If. Y.-1'a :,03: $(100) ; 1 ;$ fi W. Adanis st.

J11.

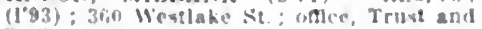
Siavings Hus: 10-12, 24

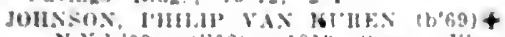

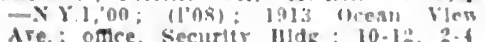

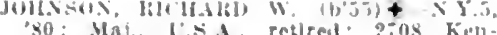
: MnJ. P.d. retled: 2:08 Ken-

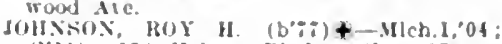
(l'1); ist IIohart Blvd.; once, $350 \$$ Biprlag si.

JUIXNAX, WII.TER SIINE) (b'il) Mass. 1, is (1"02): 1, bi: W. Adams st nttice, story Bdy; $2-4$; sec. and l'rue Dhes: Inl.9: ObG

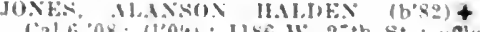

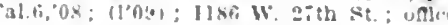
Bradtury Ibldg: 10-12, 4-ti

Jolles. ('ummlns L'. (b'49)-10.9:73; (1'89) nut in prartice: 2101 s. Ciramerey lly. JoNk: EDW Dol $0: 3$, 'al.9, 07 : (1'07); 2721 Portland Pl.

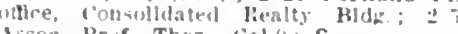
Asso". Prof. Ther., raly: S

Jones, Frank C. (b'ti) N. Nich.1, so :

vathl : :-15 Darwh Ale.

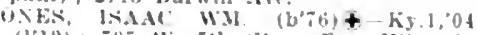

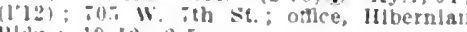
Helt. : $10-1: 2,2-5$

Jones, John Leland (b'50)-Ky.4, "2, Ky.1, ustlce (l'ut): Van Nuys Iotel; unce, H. IV Ilellman Bldg. :-5: $\mathbf{S}$

Kalllwoda, Hector (b'59)-0.1, si; (l'yn): $410 \mathrm{X}$. Beaudry Are.; oflice, 1069 Temple sit

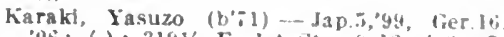
06; ( ): $319 \mathrm{y}$ E. Int st.; 9-12, t-ti G

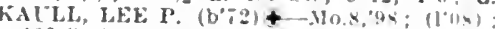
666 S. Carondelet; onlce, irant Bldg. : 2-4 Kean, Jos. Walter (b'8t)-1'a.2, (06; $11^{\prime} 121$ Ferguson Bldz.: $s: 30-10,4-6$.

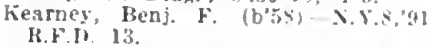

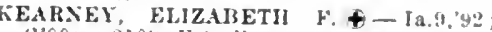

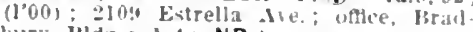
hury Bldg.: 1-4; NP.*

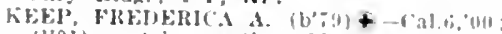
(1’01): not In practloe; 20,5, W. stl st

Feller, Irvi B-\$Id, $113 ;$ ( ): 6317 Frath lin Circle.

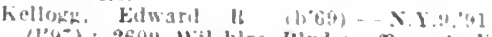
(1'si): 2600 Wilhlre Hod; otace, Iud forium Hldg.; OALP.*

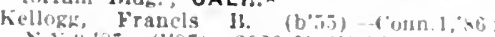

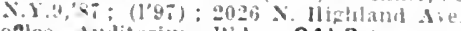
oflce, Aulitorim BHA.; OALR.*

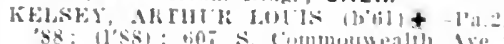

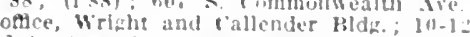

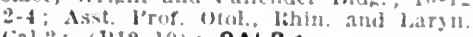
(al.2; (112,13); OALR. *

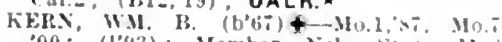
00: (1.93); Member Neb. State Med. Assn. : Fxclange lkldg

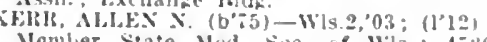
Member sitate Med. Sioc. of W's. 4500 ment Blitin.

Kerr, Harlan T. (1562) II 0.7, $86:(1003)$ $1123 W^{*}$. 3ith sit; otlece, blu s Bruald way; $9-12,2-5 ;$ OALR.

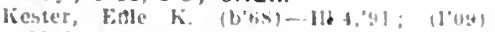
$11: 3$ 11. 2⿺辶 st.

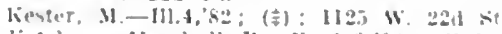
ketchum, Marslall H.-F-0.2, 82 ; (1'si) (Nanta Monlea): nftice, Audtorlum Mldi.

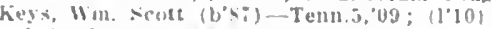
106: 1.36ma Are: $11-12,2-4: 50$

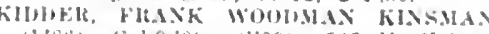
(b'st) ral.9, 195 : (l'09) : 5ti $x$. Ilobar

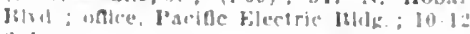

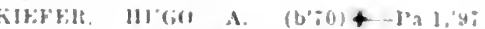
(1'yi); (Alhambra): once, fay Hid?. 10-1\%. 24; Asme I'rof Ushth. Cal: H1:1

K!ber. Thos 's II

hitikil. WH. H. $\left.(1)^{\circ}: 6\right)+11,19,00 ;(101)$

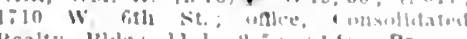
Itealty liles: 11 1, $2-5: 1,11$ Pr.

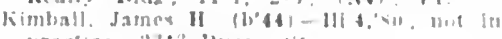

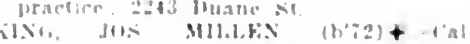

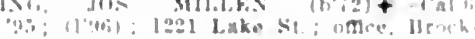

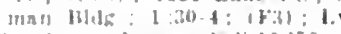

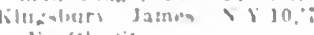

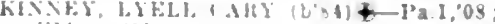

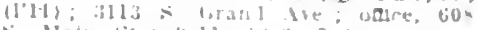

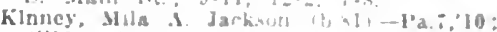

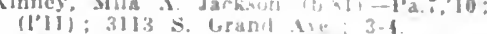
KIIR⿴囗十

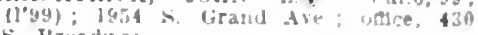
S. Hrisatuas.

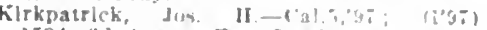
$1534,2 d$ Are. iflce, Bradiurs Blas

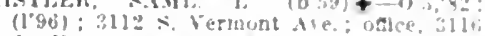
s. Vermont ive: $\$-11$.

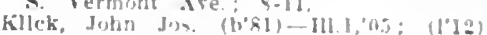
-050 Jolmes ive : omce, I6ris? F. Flot ence Are. $2.4 ; D$.

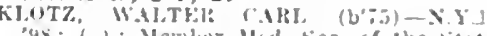
"yx: ( ): Memluer M(t). Sine of the state of X. Y. Barlow Eanatorlum.

lextington tre

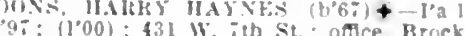
man Ibldz: $10-12$

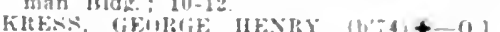
$99:(1,03)$; Hotel Alrarado; inde. bradlury Bldz: 10-12. 2-4:30: See and I"ro: Ilyg., 1"alla; (B)2, N3): OALR*

Krudor. D. Tonjes (bosil)-Ill.4.3: (I00) i2t; Illl St. offlce, Wratht and Callender Blize ; 1-4

KRTHLL, FPENK. JOHS $\left(b^{*} 33\right)+-111.1$, sI: (l'sa); $1857 x$. Normandle Ave.

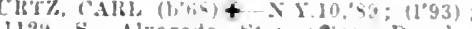
Il2! S. Alvarado st. oflen, Douglas (bidg.

KIRT\%. 10s. (6.42)-1'al.2."72; (l'b(i): lisnl Tolerman s? once, Dunglas Rldz. 11-12,4-5; Emer. I'rof Ortho. Surg., Cal.2

Kuich, John (bo,3)-Ind $74 ; \quad(190)$ : (Baledstown): oflee, Mradhury Blds.

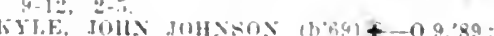
(l'ii); also memher Ind State Med. Soc afian serfance s' : ince. Title Insurame Islale: Prof opol. laryn. and Rhtn., ral.: (B].3.12.19); OALR.

Ia lloree, De Wiet-X Y.3, i0; (100); I32] IV. $52 \mathrm{~d} \mathrm{St}$.

Jangitun, $f$

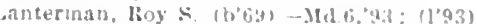

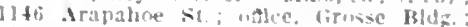
$10-12,2-4$

AdSIIIR, lifo II $\left(b^{\prime}+3\right)+111.1 . ; 2$

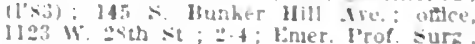
1'al.z.

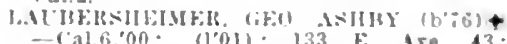
-('al.6.00; (1'01); 133 L. Are 43 Laws, ovld 5 . 11,$04 ;(199): 3102$

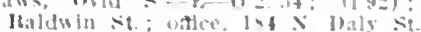

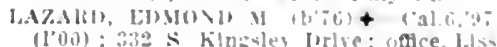

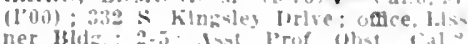
ner It

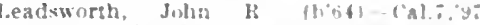

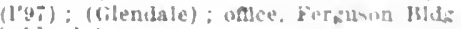
$4-12.2-4$

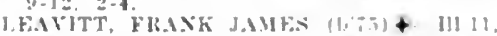

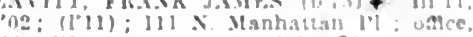
139 Western Are., : : $5 ; 0$ o.

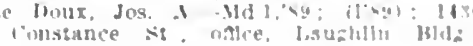
10. $12,2-4$

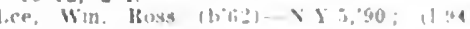
4iil) W lith $\leqslant$ :

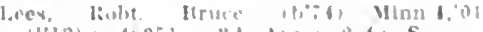

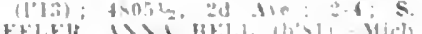

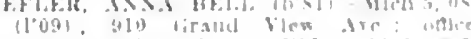
Writai and ("allenuer Hld

III:1; OALR.*

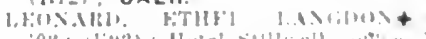

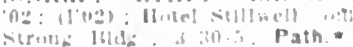

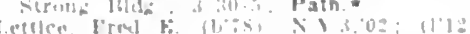

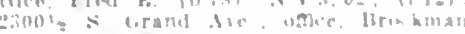
lilutis: $: 4$

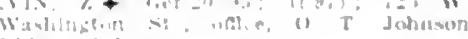
III.

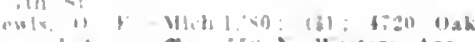


LEWIS, W.Y, MONKOE (b'5i) †-N.Y.10, '79; $(192)$; $3016 \mathrm{~S}$. Higueroa $\mathrm{St}$; ; offlce, Story Bldg. ; $2-5 ;$ s

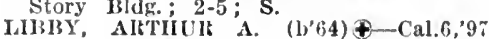
(1'97); $(665$ Orange Grove Ave., Pasa$\left(1^{\prime} 97\right) ; \quad(665$ Orange Grove Ave., Pasa-
dena)

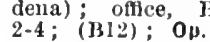

Libby, Walter Emery (b'86)-Cal.2,'12; (1'12); Los Angeles county llospltal.

Light, Ted Carey (b'7) l-1ll.8,'01; (1'06) ; (San Pedro)

LINDLEY, WALTER (b'52)\$-N.Y.8,75; (1'i6); 2007 s. Flgueroa St. ; office, 1414 S. Hope st. S Flo

Lindsay, Johnson C-0.9,72; (1'89) ; 1035 I.incoln St. : offlee, Bryson Bldg.

Linliart. Lawrence Ritclile (b’si) - Cal.9, '13; (); 731 E. 33d St.

LISSNER, II ENITY 11. (b'75) †-Cal.2, 03; (l'04) ; $942 \mathrm{~S}$. Burllngton St. ; offlee, I.issner Bldg.; 2-5; Asst. Prof. Clln. Med.,

Littlefleld, Edmund Win. (b'86)-Ill.11,'12; Intern, Jos Angeles County IIospital.

LOBINGILR, ANIIRE STEWART $\left(b^{\prime} 62\right) \oplus$ -MIlchl,'89: (l'01); 511 S. Westmoreland Ave.; offt

Lochman, W'm. II.-Ia.1,74; (1'89) ; 502 W. 6 th $\mathrm{St}$

Logan. Chas. C. (b'64)-Mo.29,97; (1+); 1253 Crenshaw Blrd.; offlce, 442 s. Spring St. ; $9-5$.

Loomis, B. Joadman-N.Y.6,'84; (l'97) ; 924 E. 56 th St.

LOOMIS, MELVILLE LE R. (b'76) क-Cal.6, 00 ; $(1,00)$ : Californla club; offlce, W. I. Hollingsworth BIdg.; 11-12, 2-5.

LOVE.IOY, EDWARD DELAND (1'13); (Pasadena); offlce, Brockman Bldy. ; 10-12; D.*

Low, Triumph C. (b`72) H - Ill.10,97 ; $\left(1^{\prime} 00\right)$; 1417 S. Hoover St.; office, Anditorlum Bldg.; $11-12: 30,2-4$.

LOWELL, CHAS. H. (b'75)థ-Cal.1,'96; (1'96) ; A.A.Surg., U.S.N.; 140 I N. Hobart Blvd.: offee, San Fernando Bldg.; $9-4 ; U$.

L 0 W I A N, CIIAS. LEROY 4 -Cal.6, 07: (l’0i); 132 N. Hobart Blvd.; offlce, Audltorium Bldg.

L U N D, GEO. JESSE (b'59)-Ill.1,82; (1'96); 1227 Maryland St.; office, Auditorium Bldg. : 10-4; Assoc. Prof. Otol., Laryn. and Rhin., Cal.9; (B12); OALR. $\star$ LYON, GEO. E. (b'63)†-N.Y.I,'87; not in practice; Member Mo. State Med. Assn. : 718 S. Alrarado St.

MacCLOSKEY, RICHARD CLYDE (b'77) -Ill.6,'11; (1'13); NIember Ill. State Med. Soc.; $22101 \frac{1}{2}$ W. Jetferson St.

MacDonald, Harley Edgar (b'78)-0.25, 06 ; not in practice; 2324 London St.; offlee, Pacific Mutual Bldg.; $8: 30-4: 30$.

MacFarlane, Nowland (b'76)-MIo.24, 00 $\left(1^{\prime} 00\right): 5217 \mathrm{~S}$. Main St.; I2:30-2:30.

MacGOWAN, GRANVILLE (b'57) $\oplus-$ Pa.1, 79 ; (1'86); 3726 W. Adams St. ; offce, Llssner Bldg. ; 2-5; Prof. Gen.-Urin Surg., Cal.2; (C3) ; U.

ACKENZIE, WILBUR W. $\left(b^{\prime} 69\right) \oplus$-III.1I, 96; (1'13); Member Wash. State Med. Assn.; 2739 Budlong St.; office, Los

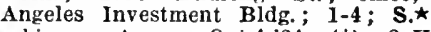

Mackinnon, Angus-Ont.4,'64; (\$); 8 Huntington Drive.

MACLEISH, ARCHIBALD C. (b'83)-Cal.6 '08; (1'08) ; 616 Kingsley Drive; office,

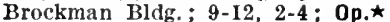

MACLEISH. ARCIIBALD LYLE (b'54)థ -Scot.3,'81; (1'94); 616 Kingsley Drive; offle, Brockman Bldg.; 10-12, 2-4; $(B 4,12,19) ; 0 p$.

Maharg, Win. S. (b'64)-Ill.14, 01 ; not in practice; 3500 E. $3 \mathrm{~d}$ St.

MAISCH, ARTHUR F. (b'73) $(-M O .1,96$; $\left(1^{\prime} 11\right) ; 392$ S. Conmonwealth Áre. office, Auditorium Bldg.; 2-4.

Major, Elverton E. (b'54)-Ill.1,'78; $\left(1^{\prime} 00\right)$; 230i. 6th Ave.

MALSBARY, GEO. E. (b’73)థ-0.I,'96; (l'11); also Nember Ohio State Med. Soc.; Anditorium Bldg.; 12-2.

MANGER, CHAS. C. (b'i1)Ð-Pa.11,'06 (l'11) ; (Glendale) ; offee, California Mann, Harry Herbert (b'84)-Ia.3,'08; Intern, Los Angeles County Hospital.
Manning, Edward Carnes (b'50) II-Ill.4, '83: (1'85) ; 1504 S. St. Andrew Il.: offee, 357 's. Hill St.

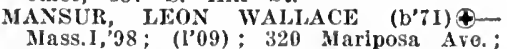

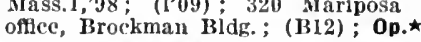

MARTIN, MARSIIALL LEE (b'78)@-Cal.6, '07; (1'07); $24171 / 2$ N. Broadway; 2-4,

Martlndale. John IIoward (b'59)-N.X.5,'85; (l'00); Rampart and 6th Sts.

MARTYN, (iEO. (b'68)థ-Eng.1 $t, 92$, Eng.11,15,93; (l’07) ; (Pasadena); offlce, Securlty Bldg. ; 1-3; T.

MARXMILLISI, IIAIERY G. (b'7T) $\nrightarrow-0.1$, 97; (l'06); 3800 W. I6th St.; offlce, (irant Bldg.; $1-4 ; \mathrm{S}$.

Mathis, Elbert Nelson (b'56)-Ill.1,'84; (1'88) ; Securlty Bldg.; 10-12, 2-4.

May, If. Cameron (b'83)-Cal.5,08; (l'08) ; 3970 Brighton Are.; office, $210 \mathrm{~W}$. Tth St.

MAYNE, WM. HAWTHORN $\left(b^{\prime} 72\right) \oplus-$ Cal.6,00; (l'01); 1674 Roosevelt Aro.; offlee, Brockman Bldg.; 12-1, 2-4.

MCARTHU1, DUNCAN' D. (b'75)-Cal.6, '05; (1'07); 801 s. Hope St.; office, Security Bldg.

MCAltTHUR, PETER R. (b'69)థ-Ont.I, '99; (l'00); $924 \mathrm{~W}$. Washington St. ; offle, $959 \mathrm{~S}$. Figueroa St. ; $2-4,7-8$.

MCARTHUR, WM. TAYLOR (b'66)థOnt.1,95; (1'95); 2025 S. IVestern Ave. oflece, Security Bldg.; 2-4; S.

McBurney, Matthew Reed-Pa.9,99; (1'07); (227 Paloma Ave., Kagle Rock); office, 424 S. Broadway.

MCCANN, DANL, BRADFORD (b'59)๑Ill.I,' 90 ; $(1 ' 96) ; 1507$ A S. Main St. ; 8-10, $12-3 ; \mathrm{G}$.

McCARTY, ISAAC A. (b'59) (-Mo.7,'83; (l'99) ; 1264 W. Adams St.; 1-2.

McClish, Clark Is.-Cal.2,04; (l'04) ; 2927 Brighton Ave.; offee, I760 W. Adams St.

McClure, Leonard Dclmore (b'76)-Ia.10, 00; ( ); 555 s. Grand Ave.

AcCOY, GEO. W. (b'7I)@-0.9, 04 ; (l'04); 314 S. Nlanhattan Pl.; office, Security Bldg. ; 9-12, 2-4 ; Assoc. Prof. Ophth., Cal.9; (B12).

MeCOY, THOS. J.థ-Ky.1,'80; (l'87) ; 1459 Norton Ave; office, security Bldg. ; 9-12, $2-4$; Prof. Ophth., Cal.9; (B12); OALR. McDANIEL, JUHN L. (b'58) @-Ga.1, 83
(I'09); 6923 Converse Ave.; 10-12, 7-8. McDonald, Henry Mlchael (b'87)-Cal.2,18 (1'12); 2982 Dorchester Ave.; office, San (l'l2) ; 2982 Dorchester Ave.
Fernando Bldg. ; $10-12,2-4$.

McGARRY, JOHN ALEXANDER (b'75) $\odot-$ Cal.6,98; (l'99); $660 \mathrm{~W}$. Washington st. ofllee, Douglas Hldg. ; $10-11: 30,2-4$.

McGrath, Peter James (b'73)-N.Y.3,'95; (1'01); 115 N. Coronado St. ; offlice, 430 S. Broadway; 10-12, 2-4.

Mckee, Wm. Clifford (b'85)-Mid.7,'13 ; Intern, Calif ornia Hospltal.

MICKENNA, WILLIAM JAMES (b'80) (Ia.3,'10; ( ) ; Member Kan. Med. Soc. ; 5619 Normandie Ave.

McKibbon, Rupert Edw. (b'74)-Ont.1,'97 ; $\left(l^{\prime} 00\right) ; 433$ W. 46 th St.

Mclinney, Samuel P. (b'61)H-Iil.10,'86 ; (l'0I); 943 W. $32 \mathrm{~d}$ St.; offlce, Grant Bldg. ; 2-4.

McLAREN, JAY L. (b'61) Q-N.Y.8,'88 (l'99); 620 S. Flower St. ; office, Title Insurance Bldg.; 11-12, 2-4; $\mathrm{S}$.

McLAUGHLIN, WM. E. (b'70)-Minn.4, 96; (l'09); 1833 Crenshaw Blvd.; office, Van Nuys Bldg.; 10-12, 2-4.

McNAB, THOS. REID (b'77) $\rightarrow$-Cal.2, 03 (1'05); 519 Westmoreland Ave.; offlce w. I. Story Bldg. 10-12, 2-4.

McNair, Wm. R. (b'74)-Pa.2,99; (1'99); 315 S. Broadway.

MeNaughton, James A. (b'69)-Ont.I,'93; (l'00); 4200 Pasadena Ave.; offlce, Luckenbach Bldg.; $2-5$; S.

MCNELL, HARVEY GORDON (b'80)૯Cal.6,'01; (1'01); 219 N. Union

MCNEILE, LYLE GILLETT, (b'85) @-Cal.2, '10; (1'10); 912 S. Normandie Ave. office, Auditorium Bldg. ; II-I; Ob. $\star$
MENEILE, OLGA MUItRAY (b'83)థ-Cal.2, I0; $(1,10) ; 912 \mathrm{~S}$. Normandio Ave. oftlee, Auditorium Bldg. ; $2-5 ; \mathrm{G}$

McI'lerson, Geo. Ml. (b'41)-Mich.1,66; ( ) ; 2017 W. I2th St

MCREYNOLDS, ROB'T. PHILISPS (b'7I) $\rightarrow$ -I'a.1,95; (1'06); 18 Berkeley Sq. ; offlce, Coulter IBldg.; I-4; S.

(l'07) Blyd.

MLLLFNTHIN, MICIALL ARTHUR (b'83) -Mlinn.5.06: (1'12); Nember Minn. State Med. Assn.; 1066 Eagle Rock Drive: office, Black Bldg.; 10-12, 2-4; R. *

Meramble, Clarence 'E. (b'68)-N.Y.5,'94; not in practice; 188 W. 4Ist St.

Morrill, Carlton Śmith-N.Y.5,'82; (1'91) ; 1820 W. IIth St.

(b'58)-Mass.I,'8I ; Ilope St. S. S. Flower St.; offlee, 4 II S. Main St.
MILLER, CHAS. F. (b'48)-Cal.2,74; $\left(l^{\prime}, 6\right) ; 1230$ E. 46th St.; offlce, 4501 S. Central Ave.; $10-12,1-5,7-8$.

MILLLR, FRANK W. (b'71)ஷ-111.1,'94; (1'99); 2076 Ilarvard Blvd.; offce, II. W. Hellman Bldg.; II-5; (B12, F3); Op.ћ Mlller, James Theodore - Ill.1,'84; (1'03); 2189 Cambridge St.; offlc

Miller, John S. ( (b'58) E-Mo.3,'79, Mo.10, ' 80 ; not in practlce; 743 Carondelet St. MIILER, ROBT. WARREN (b'50) 9 -Ia.I, 76 ; N.Y, 10,'87; (1'88); I141 W. Adams St.; office, Laughlin Bldg.; 10-12, 2-5;

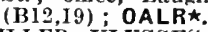

MILLER, ULYSSES G. (b'67)๑-Mo.27,'91 ; (l'04); 152I Harvard Blvd.; offle, Hibernlan Bldg.; 11-12, 2-4; G.

Millsap, Koy R.-Cal.6,03; (Naturopath); 153 W. $23 \mathrm{~d}$ St.

MILLSPALGH, WILLARD P. (b'72) \$N.Y.I,'00; (1'03); 123 S. Alexandria Ave. office, Laughlin Bldg.

Minney, Geo. M. (b'72)-Kan.3,03; (ま) 2273 w. 20th St.; offlce, Trust and Savings Bldg.; OALR.

Minney, John E. (b'46)-Mo.8,'80; not in practice; 2273 W. 20th St.; offlce, 215 IOIONY

IOLONY, WM. RICHARD (b'79)-Cal.6,'0I;
(I'01); 2417 Juliet St. ; offlee, Exchange Bldg. ; I1-12, 2-4.

MONTGOMERY. COLONEL HARRY (b'78) ? -Ont.1,02; Eng.II,15,'07; (l'07); $392 \mathrm{~S}$. Reno St. ; offlee, Trust and Savings Bldg.; 10-12, 2-4; (B12) ; ALR.ネ

Montgomery, C. Fredric-Ill.10,'95; (1'01): 1034 Grattan St. ; 2-4.

MOORE, ALBER'T 'WM. (b'76)థ-Cal.6,'04, Pa.I,'05; $\left(l^{\prime} 04\right) ; 320$ Conmonwealth Ave.; office, Consolidated Realty Bldg.; $2-4$.

MOORE, DWIGHT S. (b'66) $9-$ Neb. 1,87 ; (1'12); 722 S. Bonnie Brae St. ; offlee, MOORE, EDWARD CLARENCED-Cal.6, 04; $\left(l^{\prime} 04\right) ; 554$ S. Serrano Ave.; office,

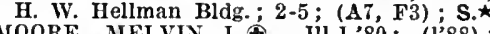
340 Kingsley Drive; office, H. W. Hellman Bldg. : Prof. Obst., Cal.2; (F3).

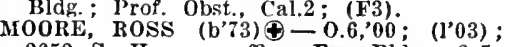
2652 S. Hoover; office, Fay Bldg. $3-5$; Asst. Prof. Psych., Cal.2; (F3); NP.`

Moradian, John K. '(b'70)-Ill.I4,'97, Ill.11, 01; (l'01); 84I S. Flower St.; offlee $6561 / 2$ S. Main St. ; $9-11,2-4,7-8$.

IORRIS, MARGARET M. $\left(b^{\prime} 70\right) \oplus-C a l .6$ '07; (1'07) ; 502I Gramercy Pl.; office, Hollingsworth Bldg. ; $2-5$; (F3); Ob.
MORRISON, NORMAN H. (b'53) (6-Mo.8, ' 0 ; (1'87) ; 1263 W. Adams St.; offce, Kerckhoff Bldg.; $10: 30-12,2: 30-4 ; S$.

Morton, Geo. (b'62)-Mo.20,'97; (1'01); $443 \mathrm{~S}$. Main St.

MORTON, LEWIS B. (b'78) $($-Ia.3,01 ; (l'09); 720 Irolo St. ; offlce, Brockman Bldg. ; 2-4; (F3) ; S.`

Morton, Wm. A. (b'44)-Ky.4,75; ( ) ; 3875 MOSELEY, EDWARD B. (b'46) (-Pa.I 68 ; Brig. Gen., U.S.A., retired; 315 W. Franklin $\mathrm{St}$.

Mosher, Frank Orson-N.H.1,'96; (l'06) ; 264 E. 29 th St. ; offlee, 610 S. Broadway ; 
Mummert, Austln James $\left(b^{\prime}, 72\right) \rightarrow 1$ a.9,'98 (1'01): 1506 llobart IHrd. : oflce, Audt (1'01): 1506 Il obart IIrd. : (Iflce,
torlum Blds.: $1: 30.5: 30:$ OALR.

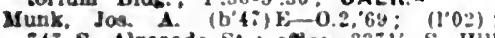
it? $\mathrm{S}$. Alvarado $\mathrm{St}$; oftce, $337 \mathrm{\zeta}_{2} \mathrm{~S}$. IJ!l St: 11-12, 3-1; Dean and Prof. Cllmatology, Cal.4.

MURPHY, CIAIRE: W. Cal.6,'91; (1*92) 114 W. $20 \mathrm{th}$ St. oflce, Los Angeles Inrestment Bldg.: 2-4: S

Murphy, Lou J. (b'Douglas Bldr.

TURPIIY, WH. WARRFY (b'46) \$-Mo.1 76. N.Y.10,'s4: (1's6) : 9 it $\mathrm{S}$. Vermont Are : offee, $30 \%$ S. Broadwas: 9-12, 1-t (B12); OALR. *

Murray. James Thomas (b'79)-M!nn.5.0; (1'10); $450 \%$ S. Figueroa St.; offlee. 4507 I's Moneta Are.: $2-4$.

MYERS, TILS. CHALUERSP - Cal.6,00 ; (1'00); $21 \%$ W. Santa Harbara Are. ; oftec, Trust and Sarings Bldg.: 10-12, 1-3:30.

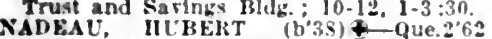
$\left(l^{\prime} ; 6\right) ; 223$ w. 2d st: 10-11, 2-4, $;-8$. Sance. Hlram I.-I1]. 1, : $(1,99) ; 1234$ W 29 th St. ofice, $256 \mathrm{~S}$. Spring $\mathrm{St}$.

Neal, Benj. E. $\left(b^{\prime} 6 i\right)-0.9,89$; not in practlce: 909 Gramercy $P$

NRGIEY, jaMES Cisper (b's3)PMlch.1,10: (l'11): Crocker Street Hoa. pltal: offlce, Paclfic Flectrle Blds.; 1 -2. 4-6, $7-8 ; U$.

Nelwon, Chas, Fredk. (b'84)-1ll.1,'ll: (1'11): 4615 wilton Pl.: oflle, Los

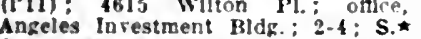

Angeles Inrestment Bldg; 2-4; S.
Nelson, Fred Howell (b'88;-Cal.9.12 (1'12) : 415 E. Adams St: otlce, Hibernian Bildg.

Nelson. Thomas J. (b'7s)-Cal.1,03; (l'03) 969 W. 32d St. ; offec, 609 E. 6!th St. $11-12,1-4$.

Nerlus John wllson (b" (1'11): 925 S. Alrarado St.; otfce, Fay B1ds. : $12: 30-4$.

Nowberry, Frank J. (b'58)II-Ill.10,'s III.17,'99: (1'03): 938 s. Bonnle Brae St. vatice, Wright and Callender Bldg. : 9-12, 3-5.

Newklrk Idamson B. (b'58)-Ill.1.'80 ; (1'89): $313 \mathrm{x}$. Soto st.; office, $218 \mathrm{~s}$, Broadway; $10-12,2-4$. Newlln, Wm. L $=0.2,: 2 ; \quad(1 \% 85): 2615$

NEWMARK. PHILIP $\left(b^{\prime}, 9 s\right)$ क - Ger.1, 91 (1'97): 4362 Falrmont Lrive; oflce, Marsh Sirong Bldg. (C3) : U.

NEWTOS, EIW irkr (b'il) $\notin-$ State of Pa Marsh Strong Bidg.

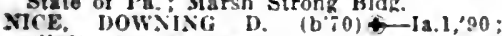
(l'0i) : itl E. Adams st; offce, Doriglas Blds.: $12-4$.

NICHOLs, CHAS. BYROX $\left(b^{\prime} 4 i\right) \uparrow-\mathbf{H}, \mathrm{L}$ 71; (1'88); 1006 Park Vlew Are; aflce,

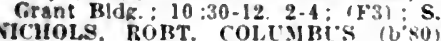

NICHOLS, ROBT, COLCMBI'S $\left(b^{\circ} \times 0\right)$
IU.6.11; (1'12): 3002 Stephenson Are.: $2: 80-5$.

Nikhlkata, Asazo (b'75)-Jap.3,'39; Cal.i. 06: (1'01): 462 Incommua Sit.

Noble, Mary J.-Cal.2,"46; (1.97) ; 1320 W. 46th St: : omce, Auditorlim Hlde.

Soon. Nicholas $K$. (b'6t)-Mo.8,93; (I'93) 21108 . Grand Ave; offce. Thorpe Hldp. $3-4,6-8$

NORTON CHARLES WOITH (h's5) Consolldated Kealty Bldg.: 1.4: U.

NoutoN, FKA.NK I.-('al.6.01: (1'01) $1464 \mathrm{~W}$. $25 \mathrm{th} \mathrm{Si}$ : oftce, $O$. T. Johnson Bldx.

NUTTING, FloYD J. (b'68) \&-Colo.'9z: (1'9i): (Venlce): once. Consolldated Really Bldg.; 9-11, 2-4; OALR.

'Rrien, John llenry $\left(b^{\prime} ; 0\right)-(' a l .2,96$ : $\left(I^{*} 96\right): 940$ Everell $S t$; omce, 221 w. ith St: $1-4,7-8$.

(b'81)-Cal.6.08: (1'08) St. : $2-4$.

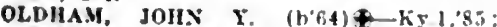
(105): $2110 \mathrm{~s}$. Wevtern Ale. nfmec Grant Bldz.: 10.5: (I112.19): OALR.

Opp, l'aul Alered $\left(b^{\circ}: 9\right)-C a l .9,08 ;\left(Y^{\circ} 08\right)$ : Si01 S. San Pedro St: oace, 3623 Maple Ave.

Orbison, James Archibald (h'si)-111 11,13 los Angeles County Ilospltal.
ORHSON, THOMAS JAMES (b'66) Fa.1. denat) office, Brockman bldg loe. I'asadenal : offlce, Brockman lbidg: l'rof Al

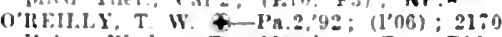
Hholart Blvd; nomee. Merchants Truat Bldg. OLTLAW JOII: SUTTON (b'63)-D.C.3. 91: $\left(l^{\prime} 00\right): 230$ W. $30 \mathrm{th}$ Si.; ofice, 102 S. Surlng st. : 1-5.

OWb., JAlOIl 1.-Kan.3,92: (1'08); 640 L. 2 ith St. : office, $7929 \mathrm{~S}$. Vermont Are

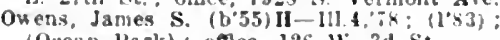
(Ocean l'ark); omce, 126 W. $3 \mathrm{~d}$ St.

PAIIL, I'ETFE' C. H. (b'69) \& III.s, 93 . Consolldated Itealty Bldg. : $2-4 ;($ F3); S.* PAll.ETTE. FolW M. (b'-4) Cal.6.9s; (1.99): $\$ 50$ S. Hoorer St; offle, Trust and sarlngs Bidg. : 10-12, 2-4.

Pll.MEIt, CHAS. T. $\$-$ Pa.11,04; (108): 312.2 Normandie st.

PAlMEN, EIWIX ORADIAH (b';) H-istot ifoligweod islid.: 1-4; 5 .

ralmer, Ifelen Cooles-N.Y.11,95; (1'13) (South l'asadena): oftce, L. A. Inrestuent Bldg.; 9-12; OpA.*

I'almer. Whiton 11.-H-O.: 79 ; (1'94); 920

W. 35th Pl. ; 12-2.

I'ark, Lottle C.-Ill.9,'S1; (l's9); $1041 \mathrm{~W}$

Parker, John Livingston $\left(b^{\prime} 76\right)-P a .2,00$ : - El Centro st.: 2-t: $S$.

Parker, Wm. C. (b'4) $\rightarrow 0.3$, , $^{\prime}$;

(1'8:) ;

PASCOE, ELMER R. (b's2) Cal.6,0s: (l'0s); 300 s. llarvard Blrd.; oflece, 405 S. Hill st. : $9-11,3: 30-5$.

Patrlc, G. E. (b'S5)-Cal.9,12; (1'12); 1119 W. Goth St.; offlce, Hollngsworth Bldg. Payne, Jos. Riches (b'61)-Cal.2,'82; (l's3) lutland Apts; oflce, $505 \frac{1}{2} \mathrm{~s}$. Main st. $9-12,1-5,7-8 ; \mathbf{S}$.

Peelbles, James Martin (b'22)-Pa.14,76; (l'14): 5719 Fayetle St.

EIHONNET F. M. (b'58)-No.7,87

(195) 1069 E. 5th St.

(1'94); i23 stewart St; $10-11,3-4$

I'epper Chas, Tehbs (b'ti)-I'a.2,69.

(l'ss); 601 s. Ilampart Blrd.; oflce, I 1916 S. Spring St. : 10-4.

Jeppers, Chas. II. (b'T)-\$eb.6,'12: (1'12) 625 Bixel St.; once, Auditarlum Temple

Percival, Francls bolln $\left(b^{\prime} 60\right)-\mathrm{N} . \mathrm{Y} .1$, '89; (1'02): Abbotsford Inn: offec, Los Angeles Investment Bldg.: $9: 30-5$.

PERKEX, AlIRIAN BENTON $\left(b^{\circ}: 4\right)+$

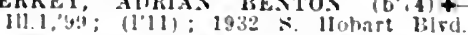
onice. Tiqe Insurance Blig.: $2-4$.

PEIRY. WM, F, (b'5s)-ky.1, $\$ 5$; (1'ss) 1123 W. 2 sith St.; ontice, Hollenbeck livtel: $10-12,1-3$.

PETELSOX, AXDFRs (b'81) \&-Cal.9,09: (l'og) : lion Misslon Jd.: otlee, Wright and callender IHIdg.: 4-8.

PETTKR, IIE(iNAI.l S. (bis)-Cal.6:0: (1.0:): 2223 icotl ire.: oflce. 85114 s. Central Aie. $8-10$ Are. oflce

I'helps, farl kilton (b', 8$)=\left(\right.$ al.6,06: $\left.11^{\prime} 10\right)$ 1593 W. 4 kth st. : onlce. 411 S. Main St. IIII,1l's fllis FolTux (b) + mallil 03: $(1,12)$ : Menber Issn of Isthmlan $\%$ ith anil IIIII sis. $2-4$ : $\mathrm{S}$

IIIS,4t: (1'la); 1615, 2d Are. : (111,s): OALR.

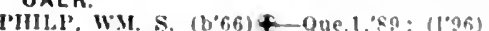
1413 Van Ness Are: ontee, ("onsulliaterl liealty lildz.: $11=12,2-4$

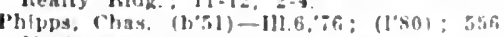

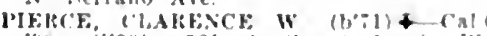

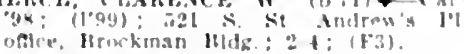

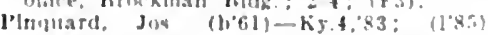
211:0 W 39 th 11 .

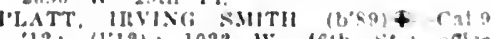

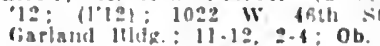

rollarid, Jnhn Wesley ibolo (1)01): Ilutel bankerwhlm: untce tisan lide: $10-12,2-1$

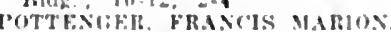

Pousette, Wm. Courhose-Ont.3.97: (1'00): 5:-29 II arold Was.

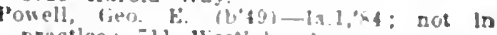
practlee : 11 Weetlake Al
Powell. Thomad (b'37)-

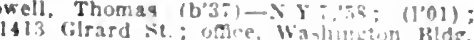

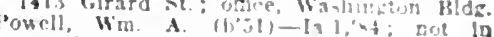
firactlce: 11 Westlake Are

POWF.R., I.ITIIR MII.TON $(1,0,3) \mp$ Md.2, 7 ; $(185) ; 1022$ Alrarado st.

othee, Clty Ilall: 8-9: (F3).

raft, Girafton H. $(\mathrm{h} / \mathrm{l})-111.4$ to

5323 Santa Monlea Iird, oflce, 235 s.

Prendergast. John w. (b'58)-0.1.82: 'reston. dames $\mathrm{L}$. (bet) $31 \mathrm{st}$ st.

260 Wilchire Bird.

Price, Marshall F. (host)-Ill 6,0 , (l's not in practlce; 1704 s Bonnle Brae St I'rlage, IIenry (b'00)-Cal.6.07: (l'09);

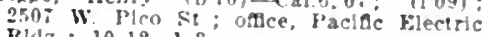

l'ritchard. Win. Firin (b.59) H-lll.10,86 (l'shi); 939 Fiden Ave.; oflce. Grosse

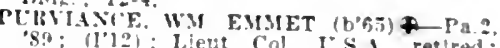

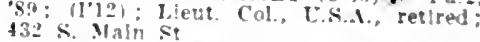

Putnam, Mary Parks (b'4l)-Mass.6.94;

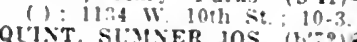

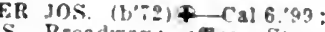
Bydg ifle, Story Blde: $1: 30-4:$ (F3) : S

Wy. Mann-I'a.2's9; ( ); 626

RAFFRTY OGDEN $\left(b^{\prime}, 00\right) \mp-\mathbf{Y}$ Y.1, 8 (1'10): Lleut. Col., L.S.A., retired; inl: rersity Ciut.

IACIAND, DALJAS $C$ (b's4) F-M0.2.07: (1'09); 1526 Winfleld St: office, Delta Bld: 2-5: Irop. Iath. and Hyz., Cal.9.

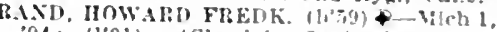
94: (1'01): (Glendale Sanitarium: :9. 1]-1. $6-7 ; \mathbf{G l}$

Randall, Thomas Jefrerson (b'6n)-Mo.20. "99: (1'01): 945 \&. Bonnle Brae St. (once, 13 imcrican Ire., Iong Reach).

Rankln, John Thompion (b'ia)-Calci,03 (l’03): 2637 Pasadéna Are

athone, Chas, ( ${ }^{\circ}\left(b^{\prime}(65)-\right.$ Y.Y. 1.93 (l'00) : 1552 W. 49th St.

130. Millard st.

RAY, FIELEIICK SYIVANLS (b'sa) + M(1.:0s: (1'11): 121 Xi inlon die: once, Brochman Bldg. 2:30-4:30: S. RAl, III.I.1. k. (b) 33$)+-$ Md 7.09

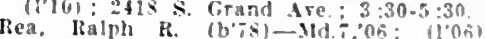
Rea, Imalph R. $\left(b^{\circ}-8\right)-M d-06:(100):$ $51 i_{2}$ F. St Andrers I'l.

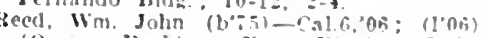
(Ocean lask): once, Iflgolns Rlde 10.12.

Recd, W. F.-Mo.15.'s1; (I's4): $15: 1$ Vects!

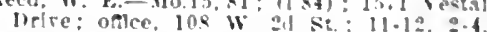
RFES, HALRY CLAYTON (bis)-Tenn" 9s: (1'12): 2050 W. Enth PI: once Ilthernlan ildg: :-5; ob.

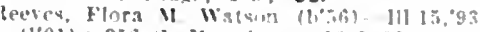

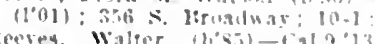

ponti Ilallhato liee unce larb (1'13)

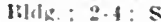

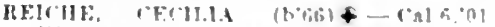
$\left.11^{\circ} 01\right): 4803$ Monres are omce. ans Broadivas: 1:-0.? ?-5

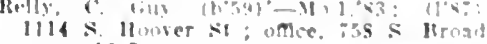
was $: 10-5$

Iocinsmilt?

nelis, (1) (1)

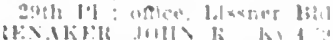

$\therefore$ lormation

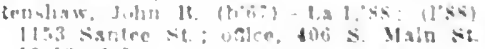

lowm, rati $c$ (b)

lifer. Angeles counte llimpleal. not in praction: Merniber Med Soe

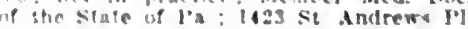
Reynulitu, Anma Markley (b'46)-I'a.7' 55 uin in practice: 239 i. Kowan Aro. 


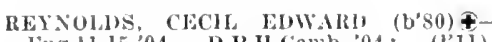
Fing.11,15,04, D.P.H.('amb.,04; (l'11) II otel Clark; oflec, Excliange Bldg REY N.

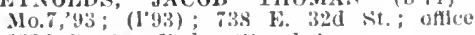
2825 S. San l'edro st. ; $1-4$.

lice, Henry $x$. (b'43)-111. I, 86 ; (1.47) 1514 s. Vermont Are.

lichardson, (ieo, llenry (b,70) $11-111.10,91$ (l'91); 26iti s. Hobirt Blvd.; olllece. I06 ed St.: I- I-

IRHARDS(I), WIILIAM w. (both) \& Ill.6:90; (105): 375 S. Accidental Blvd. oftice, Ijissnel IBldg.; $z-5 ;$ l'rof. Surg. ('al.2: $(1,3)$ : S. *

HICHTEli, Lol'ISF MAY (b'64)t 111.3

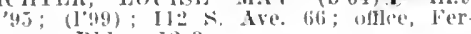
guson Blder ; 12-3.

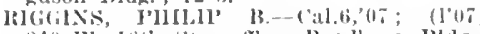
$840 \mathrm{~W}$. Itith st.; olflee, Bradbury l3ldy.

MOBER'SS, JEAN MARGALET (b'S1)+ Cal.2,10; (1'10); [2.29 W, 231 st. (A21); T.

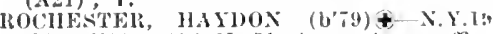
02; (1'11); $156 \mathrm{~N}$. Marilosa Ive.; offlce

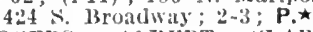

ROGERS, ALBERT ('LALK (b'50) N. $5.5,73 ;(1 \times 7) ; 1527$ Shatto st. oftle Spring and 5th Sts.; 10-I2, 2-4; (1312, F3): OALR.

llogers, Jincoln (b'67)-Cal.6,96; (J'96) 1450 Oak frove Ave, office, 759 Broadway.

Rohrdanz, liobt. Wm.-111.1,91, I'a.I, ta3 not In practice; R.F.1). 4

Romaine, IIannah M.-II-Ill.4,87; (1'87) 1615 Normandic tre

Rome, John S. (b'40) -Mich.1,66; (1'86) not In practice; 4915 Normandie Are.

IROOME, IDOTI'I NIWARI, JR. (1,89) ('al.2,12; (1'12); 1515, 6th

Grant Bldg. ; 10-12, 1-4; S. not in liractice; 1041 Beacon st.

3OONEY, IIENRY M. (b'78) A-Micll. 1,03 (1'04); 1025 Gramercy Drive; offlce, Brockman Bldg. ; $2-4$.

cosE, FRAXCIS M. (b'41) \-0.3, 60 ; not ju practice; Nember Minu. State ned Assn.; 606 S. Bomie Brae St.

Ross, Almond Bartlett-Cal.1, 07 ; (l'07): Grosse IBldg.

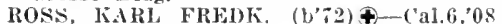
(1'08): 1639 v 24 th St, office, Bradbury B̈ldg. ; 10-1

ROSS, MOSES HODGE (b'\%9) - IJI.1, 0I (1'05); 4015 W. Adams St.; offlee, Anditorium Bldg. : 11-1: ObG.

Rossiter, Luey' M.-111.13,01; ( ); 1624 N Normandie Ave.

Roth, Geo. Henry (b'77)-Cal.7,09; (1'11): 326 West Are. 53; office, 5203 Monte Vista St.: $10-12,2-4$.

Roth, Jules F.-IId.6,92; (1'96) ; $1406 \mathrm{~S}$ Bonnie Brae st.; offlce, Crant 'Bldg.

ROTH, LEON JOS. (b,73) 4-Cal.6,01 (1'01) ; 512 S. Oxford Blvd. ; office. Brockman Bldg. ; 10-12, 2-4; (C3); U.

Rothschild, Śaml. (b'76) - No.2,02; 2.13 W. 18th St.; $9: 30-1 ;$ G.

ROTHWELL, WM. T. (b'85) \-111.11,'10 (1'II) ; 2053 WF. Jetrerson St. ; $2-5 ;$ Pd.

Rowley, Quinton J. (b'57)-T'a.2, 84 : (1'84) 2071 La Salle Ave.; office, Story Bldg. $9-12,2-4$.

Royer, Henry clay (b'46)-0.7,'56; (1'88) ; (111, 7th St., Terminal Island); office, Wilson Block; 1-4.

Rubin, Barney (b'58)-Ky.1,93; (1'01) 227 Mercantile $\mathrm{Pl}$.

Russell, Edwin Herbert (1,'57) H-Mass 5, 80; (1'83); 2702 Halldale Are.; office, Paciftc Electric Bldg.; 10-4; N.*

Russell, Robt. Gordou (b; $; 6)-111.1,99$ (1'01); 1030 S. Union Ave. ; office, Grosse Bldg.; 10-12, 2-4.

Grosse Bldg: $10-12,2-4$.
RYDER, BAIARD EDW. (b'74) $\oplus-111.11$, 00 ; (1'13); Member $N$. D. State Med. Assn.: Union Oil Bldg.

RYERSOA, HELEN IOCISE (b; 79$)-I I 1.11$ 03: (京); Member III. State Med. Assn. 19.4 Tamarind Ave., Hollywood.

Salisbury Saml. S.-H I'P.9,73; (l'87) ; 2600 Wilshire Blid: office, Bradbury Bldg. : $10-12,2-4$.

Pa.l'01: (1'72); AXNONIO (b'68)-

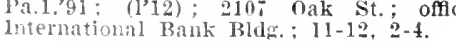

Sample, James A. (6.-0.1, $80 ;() ; 1827 \mathrm{~s}$. Inlon Are

Sanborn, Fletcher (ireene (b'68)-('al.2,'01 (I'01); I727 Burlington Ave.; olfce, $533^{\circ}$ S. Grand Ave.; $10: 30-1$

simborn, Francis' A.-Vt.2, 59 ; (1'S(i) ; 4002 sunset Blid.; $2-5$.

Saphro, Elisabeth Mueveen Collier (b's5)-(olo.2.'04; (1'13) ; 115 Alyine st.

sphro, Victor Osear (b'55)-Colo.2,10 (1'13); 415 Alpline st.

Saunier, Andre; Jackson Crosby (b'5,) Mlch. 1,81; ( ) ; 144\$. VIrgil Ive.; office, Bradbuly Bldg.; 10-4

sawyer, Hdmund o.-0.3,'so: (1's9); 1126 Gordon Ave.: offlce, 2672 W. l'ico st

salujer, Sarah 1Iall (b'51)-0.3,'80; (1'89) 1126 Gorclon Ave, othlee, 1. O O. F. Bldg. CIIERFEE, JAMES F. (b'63)-1nd.8,98; (1.05); 1505 Arlinzton St.; oftiee, 2650 w. H'ice st.; 11-I2, 4-5.

sehlosser, Altred (i. IR.-Ill.1, $71 ;(1,00)$ not In practice; Hollywood.

seduluilt, Alugust (b"6t). - Mo.27,92; ( ) 5111 s. Vermont Ave.

cichuldt, Chas. J. (b'53)-0.2,93; (1'93) 743 F. $33 \mathrm{~d}$ St. ; office, 844 S. Hill st. ; $9-4$ SCIIMIT" $\%$, JOHN $\left(b^{\prime} 54\right)+-111.1,82 ;\left(\mathrm{r}^{\prime} 88\right)$ 3000 s. Main St. ; $11-3$.

SCHNEIUER, EIWIN HENRT (b'86) $\$$ Minn.4,10; (1'12); 233 Ridgewood Are. offlee, Los Angeles Investment Bldr. $11-1,2: 30-5 ; \mathrm{S}$.

SCHOLL, ILBER' I. +-III.1, 80 , ('al.2, ,90 $\left(I^{\prime}, 0\right) ; 1336$ S. Main St. ; 2-4.

SCHLOEDEK, LEO. ADEKMO (b'80) Cal.6.07; $\left(10^{\prime} 07\right) ; 933$ Irolo St.; office, Exchangé Bldg.; 1-4.

Schroeter, Oscar 'Victor (b'80)-I11.11,05 (I'12); 4307 Dalton Are.; offlce, $607 \mathrm{~s}$ IHill St. : $10-12,2-4$.

Schultz, Walter Wm. (b'87)-Cal.2,'13 (l'13): 933 W. 36 th 1'1

Schurmeicr, IIarry Leach (b'83)-111.6,'11 (1'13); Marsh Strong Bldg.

Sehwartz, David Z. (b'8i)-Cal.9,'13; (1'13) Wright and cullender Bldg.

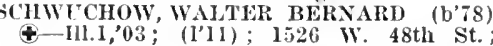
office, 4712 ‥ Normandie Ate. ; $1-3,7-8$. SCOTT, ALFRED IAIIES, JR, (b'81) Cal.6,09; (1'09); 911 W. 2d St.; offlce, W. P. Story Bldg. ; $2-4 ;$ Pd.

ACOTT, ALFlEl J. (b'58) \-Mich.1,'82 (l'04); 721 W. Washington St.; office Auditorium Bldg. ; 2-5.

Scott, Geo. H. (b'29)-J'a.2,'57 ; (1'98); not in practice; 621 Norton Ave

scott, Wn. (:. (b'38)-0.8, 62 ; (1'92) ; 1026 W. 3sth st.

SCROGGS, (ITSTAVES A. (b'55)\&-Pa.2 79 ; $(1,01) ; 1039$ W. 21 st St.; office Auditorium 13ldg.; 10-12, 2-4.

scudder, H. Ford- 0.2,93; (1'01): Cal. Eclectic Nedical College; Prof. Anat. Cal.4.

EABOLT, GEIRTILDE CLOWES (b'81)థ-
Cal.6,07; (1'0\%): $1036 \quad$ N. Bonnie Brae Cal.6,07; $\left(1{ }^{\prime} 07\right): 1036$ N. Bonn
St.; office. 307 s. Hill st. 11-1.

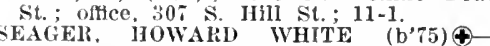
Ill.1,'96; (I'08); 413 S. Alexandria Are. ; oftice ; $424 \mathrm{~S}$. Broadmay; $2-5 ; \mathrm{S}$.

SEAMAN, EDGAR D. (b'55)屯-N.Y.1,84; Bullard Block; $10-12,2-4$.

Seeber, Cornelius W. (b'54)-Mo.1,'72; $\left(l^{\prime} 00\right) ; 1437$ W. 25 th st.; offlce, Wright and Callender Bldg.; 10-12, 3-5; $\mathbf{s}$

sessions, Oscar V. (b'52)-Ill.6,82; (1'8:3) ; 1091 W. 35th St. Severson, Wm. R. (b'i2)--Ill.11,01; (l'05)
507 W. 5th St.; office, 124 W. 4 th st. $11-1,2-5$.

SEWALl, CHAS. ALBERT (b'49)-Pa.1, 72; (1'99); 1039 Florida St. ; office, Douglas Bldg.

Sexton. Chas. Loyal (b'68)-Cal.1,95 (1'95); 1900 Ocean view Ave. ; offce, 430 $(195) ; 1900$ Ocean Vlew Ave. ; off
S. Broadway ; $10-12,2-4,7-8 ; U$.

S. Broadway ; $10-12,2-4,7-8 ;$ U.
SEYMOLR, ELEANOR (b'77) $\oplus-$ Cal.6,03 ; (1'04); Pacific Hospital; oftice, Consolidated Realty Bldg.; 2-4; Anes. Seymour, Francis A. (b'43)-Ky.1,'64, S. Broadway; $10-2$.

SEYNOLR, JAMES HARVEY (b'60) \& N.Y.1,83; (l'89); 1691 W. Adams St. Surg. and Clin. Surg., Cal.9.
Shaffner, 'Thomas Luclus-Cal.6,'89; (1'89) 1320 Illnols $\mathrm{St}$. ; offlce, $145 \mathrm{~s}$. Spring $\mathrm{st}$. $12-4$

Shattuck, Alrin (b'80)-Cal.9,'13; (l'13); 1515 Maple Are.; office, Laughlin Bldg.

SHATTUCK, GWO' s. (b'43)-Mleh.6,'81; $\left(l^{\prime} 90\right) ; 1103 \mathrm{~W}, 418 \mathrm{st}$.

SHAT'T'CK, IIOUART I'ARKER (b'78)థN.Y.20,03; (1'11); 5350 La Cresta Ct. office, Laughlin 13ldg. ; 11-12, 2-4; S.

sherlu, Emily F.-Ill.4; 01 ; (\$); 643 W. 57 th St.

Shelton, Bernard (b'74)-N10.27,97; (l’01); 524 s. Spring st.

Shepherd, llovey Learned (b'70)11-Mass.5, 95; (l'09): 2241 Cambrldge St. ; office, $35 t^{i}$ S. Broadway.

sherer, W'n. Walter $(1,78)$ - Cal.6,06; (1'06) ; 528 S. Westmoreland Ave.; office,

456 S. Sprlng St. ; $2-5$.
SHLRIRARL, LDW. EVFRTT (b'73)\$liclu., 00 ; (1'04); 133 S. Normandie Ave,; olfice, Title Insurance Bldg. ; 11-12.

Shlbley, John I. (b'55)-Que.1,'85; (1'85) ; 1656 W. 24 th st.

Shickle, Chas.-Mich.1,90; $\left(\mathrm{I}^{\prime} 0 \mathrm{7}\right) ; 016$ Wilton Pl. ; offlce, Story Bldg.

Shirey, JIarlan 1I.' (b'83)-Pa.2,04; ( ) ;

I3I F. AVe. 40. HARLAN (b'75)\$-Pa.1, '02; (1'12); Member Med. Soc. of the State of N.C. ; 2005 Congress Ave. ; office, Iarsh Strong Bldg.; S. $\star$

shores, Andrew J.

(See Salt Lake City, Ltah.)

hores, Geo: W.

(See salt Lake City, Utah.)

SIILLMAN, LEON (b'85)-Cal.2,'11; (1'11) :

845 s. Hill St.

(b'51)-N.Y.15,'88; $\left(1^{\prime} 89\right)$

2100 lai Salle Ave.; office, Temple Audi -

torium Bldg. ; $10: 30-12: 30,2-4$.

SH ITRLEFF, FIED. CAZEAUX (b'67) $)-$
N.Y.8,91; (1'96); 1414 MIllard Ave. : N.Y.8,'91 ; (1'96); 1414 Mllla
office, Auditorium 'Bldg.; 2 5.

ickler, L. N. (b'84)-Árk.1,08; (1'10) 1701 Pleasant Ave.

silverman, Herman (b'67)-Md.6,'96; () ; Lissner Bldg.

Simmons, Horace $\mathrm{M}$.

(See Baltimore. Mid.)

Simpson, Wm. C.-N.Y.10,73; () ; 6127

Piedmont Ave.

Simpson, Wm. Irvin (b'74) - Ill.1,99; (l'13); O. T. Johnson Bldg.

SKEEL, DONALD WALLACE (b'73)థ-
Cal.6,'99; (I'00), 2232 Juliet st. ; office Crosse Bidg. ; 11-12, 2-4; ObG.

SKINNER, CYNTHIA A. (b'61) $4-I 11.9$, '90; (1'10); 2628 Pasadena Ave.

Slater, John H. (b'65)-I11.11,98; (l'09) ; 1448 Oak St.; offce, Black Bldg.; $11-12$,

slaughter, Charles Vernon (b'71)-No.8,97; (宊) ; 757 S. Hope St.

SIEEPER, KARL R. $\left(b^{\prime} 75\right) \oplus-$ N.H.1,00, Cal.6,'06; (1'06); 622 S. Rampart Blrd.; office, Union OH Bldg. 10-12, I-5; ALR. Mich., $98 ;(1,06) ; 310$ N. Proadway $10-11,2-5,7-8 ; \mathrm{G}$.

SMALLEY, CILFFORD ALLISON (b'77) \&Ind. 8,04; (I'04); 1000 W. $23 \mathrm{~d}$ St.; office

Wrlght and Callender Bldg.; $1: 30-4$.

1020 W. Pico St. : Wright and Callender 1020 W. Pico St.;
Bldg. ; 10-12, 2-4

Bldg. ; 10-12, 2-4.
Smith, Benj. Mosby (b'60)-Md.1,'88; (1'99) ; 315 W. $62 \mathrm{~d}$ St. ; 10-12, 2-4.

SMITII, BERTNARD (b'76)\$-Ill.1,04 (1'06); 2321 S. Figueroa St.; office, Smith, Caroline R.-1ll.4,'03; (l'03) ; Hayward IIotel.

Smith, Chas. Edgar-II-0.7,74; (1'84) ;

mith, Everett R. (b'46)-Ill.1;73; (1'84);

(South Pasadena); offlce, Bradbury Bldg. : 1-4.

Smith, Geo. B.-Ill.1,03; (1’06); 1822 Arapahoe St.

SMITI, HAROLD HEBER (b'82) क-Mass. 1 '10; (1'11); 2523, 4th Ave.; office, Brockman Bldg. ; $2: 30-4: 30 ; 1 \star$.

Snith, Harry clyde (b'-5)-0.2,99, Neb.6. '01, Cal.4,'12; (1'12); (Glendale); office, Consolidated Realty
IIat. IIed., Cal.4 Pd. 


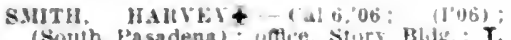

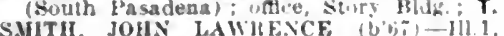

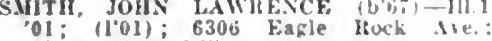
ofeco, 30 ; 8 . HIII st.; 3.4

Smlth, Haiph Nicliol-lllt,03: (I'05, Hotel Hayward; oftce. Jolinson Bldg.

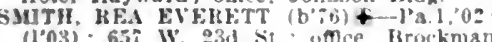
Blde; $2-4$; (F) : S.*

SMITH, VIRGINIA T (l'b0) -.Masta (Iro1): (Alhambral: otllee, 344I

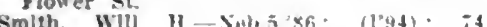

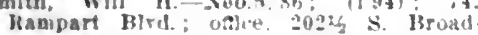
was: $8-4,7-3$. solLANI" Al,BEMT (b):3) + Cal.6.00 (I'01): "irlght and (A)

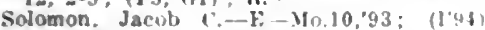
1044 s. Ponnle lirat st. oftice. Tith Insurance Bldg.: $4-12,-4.84)$. $110 t$ Ression: once,

Southw orth, A-H-O.:69; (1'86); 1504 Jagnolla Are

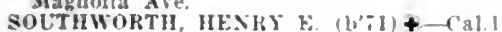
00: (1'00): zelda duts, oftee, Wrigh and Callender Mdg.; Assor. I'rof. lign. cal.4; 5

Spates, Fdiwla d1. (b'71)-IH. 35.10: 104ten patb) : th and lill sts.

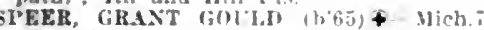
92: (103): 122 \& Walton ly. Noftive Frost Bldz.: 2-4; $S$.

SPEICHER, ASA F. (h'55)- N.YI, SI (1'99) : 3005 Vernuni Ire. onlee, 405

Hiln St.: $10-12,2-3,6-3: 30$

SPEIK, FREDK, ATOL.PH (b'82) \& 111.] "Oi: (l'12) (South Pasadena); oftce

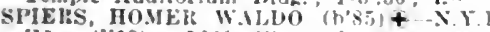

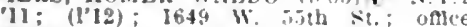
Wright and Callender Bldk.; 3-5; Pd.

SQUIRE, IIERBERT A. $\left(b^{\prime} 60\right)+$ N 86: (1001): 814 Francheo st. : rotice SQUTRE Angeles Member Dir Ned soe. खi. Hil STADFIELD, CLAYTON (;RI'BE (b'SE) CaI?:"10: $\left(11^{\prime} 10\right): 515$ F. 1 . $1 \mathrm{~h}$ St.

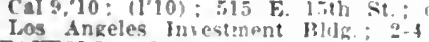
STAFTOKI, OWTA ROGERS (b'-6) I Cal.6,01: (1'01); 3:60 s. Vermont Ace. atice, 3754 s. Vermont Ave : $2-4$ stahl, w. Fred-cal.9.15: (1'05):

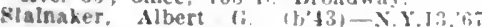

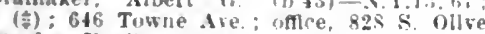
staplés. Yredk Nathe ince,

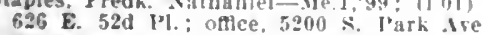
STENLOM, PRANis WHTE (b'it)

$0.9,85$; (1'85): $3111 \mathrm{x}$. Broadway; nffice. Trust Bldg. : $11-12,2-4$.

STERTERG, J.MNS $(6,95)$ Siate Bldg.: 10-12.2-4; S

ETEIIENS, IMUIN" H (b): 99 : (1'11): 3610 's Van vens the : oftce Pacific Electrle Bligh: 10-1?, $2-4$

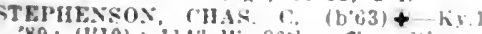
$89:$ (l'10) il13 II: 3nith office, bith an Hill sta. 9-12.

IISA Uagnollia dre.

STEVFNS, CIAS. EVFRLTT (b'GO) WIS 05: not In practlce; Nember state Hev

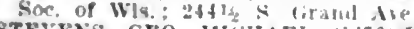

STEVENS, GEO. MICIAE.L, (b'0) Pantazes theater nide. 24th s.

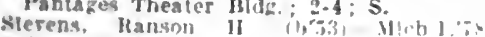

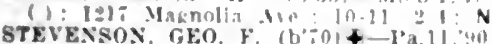
STEV ( ) Y.M.C.A. BJdg.

Stawart, Dudley W-111.6."6r; (1'8i)

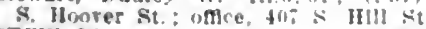

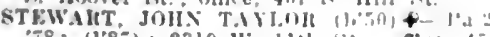
"78: (1'8\%) 2319 W

sti. . JOHE JiY

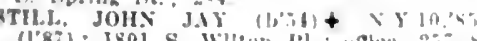
$1187): 1801$ s. Whllem [D

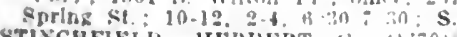

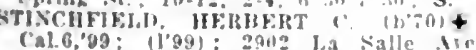
once, th and vialn sts $10-12=$ a

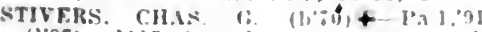

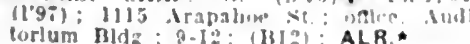

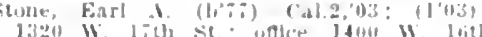
st.

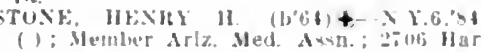
iaril Eilrd.

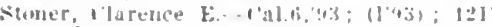

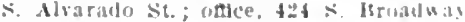
$11-12: 30,+-5$

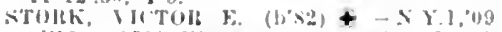
(1'11): 1000 Western Ale.: intsce, Brurkman Hildg.: 2-4; Pd.*

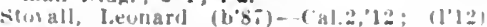

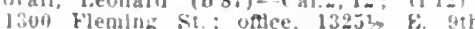
St: $11-122-4, i-8 ; P d$

strong. Fillith Josephine- Mo 29,07 ; (1) 41: Helnom Are.; offree, H. W. Ilellman B!dg.

strous, Ilarrison kdw. (b'abl-Coln.2. (1) St.; offlee, 2l tuder Ernest B.-

kiney belce. suckow, Juh $k$. (b'i2)-Cal.6,05: (l'io 6it8 E. Vernon Are,; omce, Bryson Blug 648 k. Ver

Suyarman, Herman (b'88) - Neb.6.'li (I'12):" 953 s. Hope St.; oflice, Audi torlum Blds.

YNDE, PETER HAROLD (b'Ti) \&-[11.]A 01, III.11.02; (1.05); 2209 E. th St. ofice. Tille Insurance Bldg:

SIXIIX, PETER OLAF $(b, 7)+$ - Cal $0 \%$; $(100)$ : 1526 Girard st. nftice I. IV Hellinan Bldg.; 1-4.

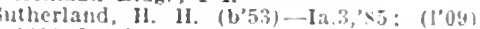
t3ot Isripheon Are.

swackliamer, (hester Ray $\left(b^{\prime} \times b^{\prime}\right)-111.1,13$; Intern, lounty IIospital.

WEET, FARL BELTRANI (b'i5)-Pa.1 '98: (1'95); 1615 s. St. Andrews pl.

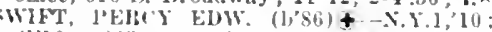

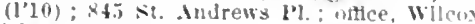
Bldg. : $12-1,2-4 ; \mathbf{S}$

syer, Wm. Henry (b'sos-ral.tint: (l'04)

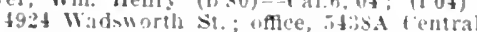
Are, ; $2-4,7-8$

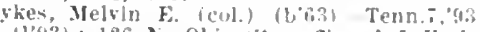

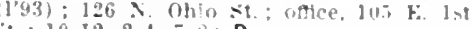
sit.; $10-12,2-4,7-8 ; 0$.

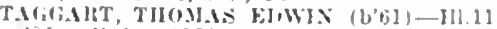

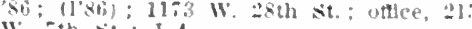

Tanaka, Juhei-Jap.3,94: (I'06): 607

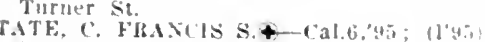

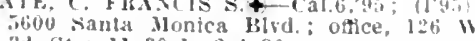
ad St, ; $11: 30-1,2-4: 30$

Taslor. (has. S. (b'52)-111.6, 75 ; 1101); 154 ; . Andrews $1 \%$; ottlce, $405 \div$. Hill

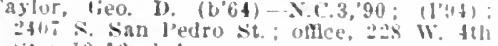
it: io-ian ledr

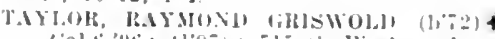

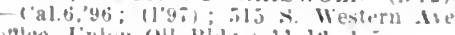

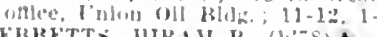

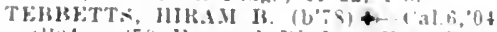

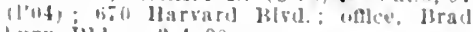
loury lutg.: :-4:30.

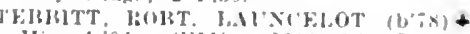
Winntint: (l'11): 26:2 W. :2h offlce, firant Blate. ; l-3.

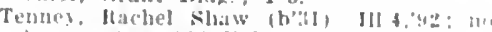
in bractice: 926 Valencia

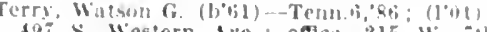
st. : 2.4

Thathe Jo

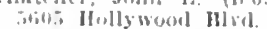

Thlele, Wm. A. A (b'togs calb.

1it x. Iteatury Are

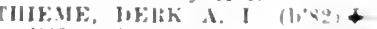

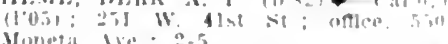

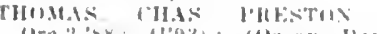

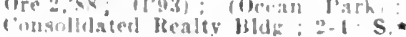

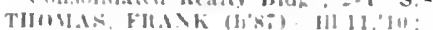

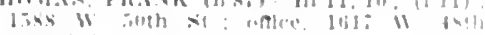
si: $: 2 \cdot 4$

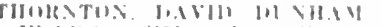

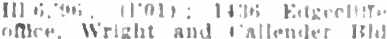

Tlonrmton, James $\{1$, ill $\}$ Cal " 110 19:-: E:tyentan I'arti
THIII'E, ALTIIL Ninn 4.97; 11.94):

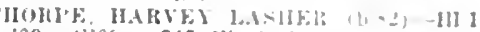

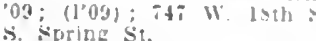

THOKPY, LEWIS

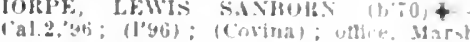

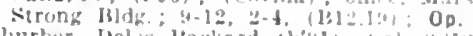
Thurber. Delins 1 nekard $\left(b^{\prime}+1\right)-13 t^{2}, 12$ (1'1:2); $508:$ w. 30th St

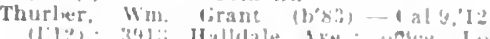

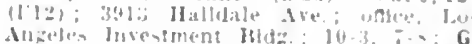

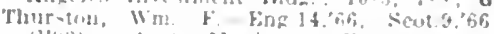

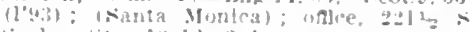
Firln: st.: 111-1:2. $0-4$

Tillotson. Thas. Honter (b's)-Ill.11, met

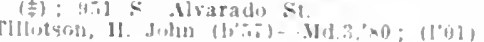

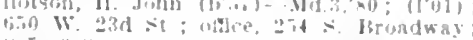

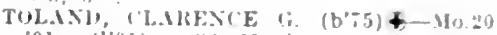

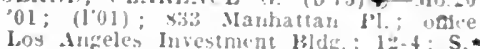

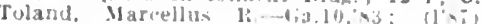
iig s. Broudwas.

Tower, Ora Isalab

$44^{-}$s. Hope St.

Towler, Wm. l'radley-0:12.,6?

120 W. Aith st.

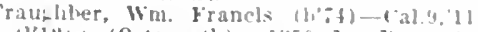
(1'12); (Osteopath); 1359 la Brea office. IIolliugsworth Bldz: : 10.

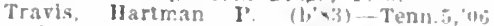
(1'10): 2915 I'asadena ive.: offlce, $240 t$ X. Hruadway; 1:30-4:30: OALR

TREW, NIEL CILAS, (b'O2)+Cal a,

TRIMMFR, EPAIRNTTE 1,TTIER (h'B3) +

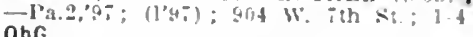
ObG.

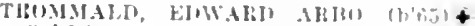

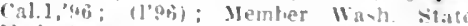
Jed. Asin.: (san Pedrol); riflee, ith and Spring Sts. : 11-12, 2-4: OALR.

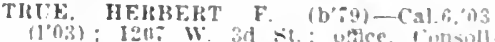

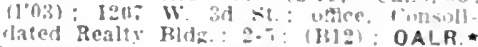

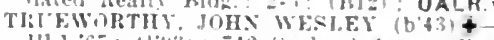

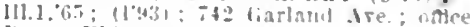
Byrne Hill : 10-12.

Tryen treel if al,

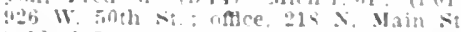

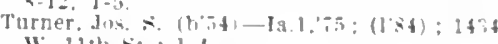
W. $112 \mathrm{~h}$ st. 1 : $1-4$

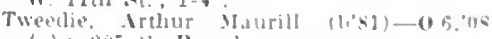
Tyler, 17 . Brondws

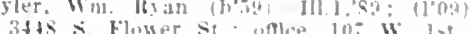

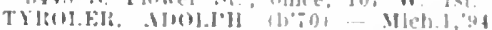

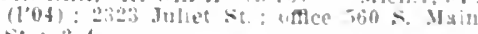

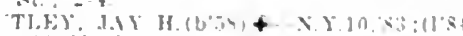

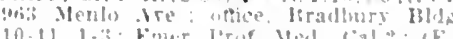

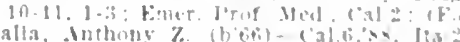

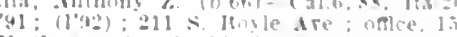

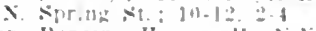

ath Bepgen. II

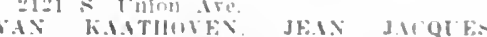

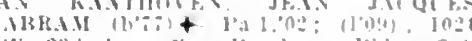

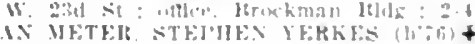

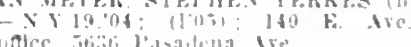

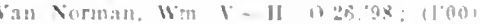

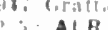

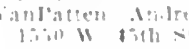

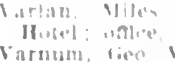

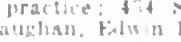

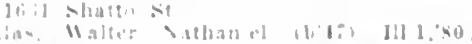

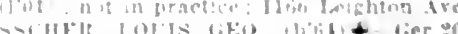

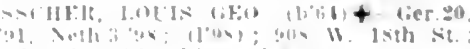

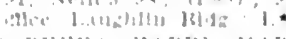

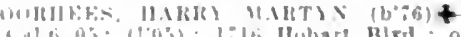
por. Mrorkman kid: : 10 
Vreelaand, Henry E.-IIl.1,91 ; (1'95) ; 2100 W. 3Ist St. ; II-4; U.

Waddeli, Wm. F. (b'64) II-0.13,'s7; (i'95) : I133, 5th Ave.; ofllce. O. T. Johnson Block; 10-1, 3-5; OALR. ^

Wade, Win. L. (b'41)-ind.8,'79; (1'87); 243 E. Adams $S$

WAGGONER, EUGENE I. (b'58) †-IIl.I0 '89; (1'06); 222:3 Juliet St.; oflce, Wright and Callender litdg.; II-I2, I :30-4.

WAGNER, ANIREW FREMONT (b'67)£Pa.I, 99 ; $\left.(1)^{\prime} 05\right):(1074 \mathrm{~N}$, Los Robles Ave., Pasadena); offlce, $5 \mathrm{I} 6$ F. Washington St.; Prof. 'Chem., Bact. and Clin. Mlleros., Cai.9.

Wagner, Rolit. - No.I,79; (1'99); 1635 Ingraham st

Wagstaff, Martha P. T.-111.9, '75; (1'84); 2113 N. Broadway; II-3.

Wakeman, Natian I. (b'66) -0.23,93; (1'00); 231 W. 28 th St.; oflce, 254 S. Broadway ; $9-5 ; U$.

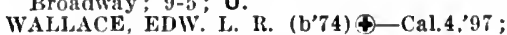
(I'97) ; 945 Orange; office, Garland Bldg. WALLER, (iEO, PIILLLIPS, JR. (b'84)IId.3,'Il ; (I'II) ; 644 Hellotrope Drive; offee, Byrne IBldg.; $1-4: 30$

WALRATH. GEO. B. (b'66) -Cal.6,95; (L'95); 1401 Santee St.; office, Security Bldg. ; 1 -4.

Walters, Cassius M. Clay (b'69)-I11.1,'92 : (): Bimini Hot Springs Sanitarium.

WARD, EDWIN DAVIS (b'76)-Ca1.9,0 ; ; $\left(1^{\prime} \theta 8\right) ; 747 \mathrm{E}$. Washington St.; offce, Ferguson Bldg.; D.

WAROEN, CARL CLEGHORN (b'68)థ$2-4$

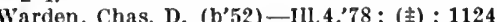
E 27 th St: offece, Jason Operg House Waring, Guernsey P. (b'52)-111.18,'97; not in practice; H. W. IIellman Bídg.

Warner, IIorace Emory (b'88)-Cal.5, 13 ; (i'13); 2237 Harvard Blyd.; offlee, Consolidated Realty Bldg.

Wass, Anne T.-111.9,'82;

Griffin Are.; $10-11,2-4$

Wass, Lizzie R.-Ill.9,'82; (1'88); $2661 \mathrm{~N}$. Griffin Ave.; 10-11, 2-4

Watson, Chas. V. P.-E-D; $\left(1^{\prime} 76\right) ; 1239$ Fedora St.

WATSON, HARRY G. (b'69) $\oplus$-Conn.I,'98; ( ); Nember Med. Soc. of the State of N.Y.: Brockman Bldg.

Webb, Benj. 0. (b'54)-IIl.1,78; (1'94); 837 E. 2Ist St.

WEBER, LOUIS $\uparrow-N . Y .5, ' 80$; (I'04) ; 4000 $\mathrm{S}$. Figueroa $\mathrm{St}$

Weber, Wm.-E-Cal.4,'84; (I'84); 2241/2 E. 37 th $\mathrm{St}$.

Weber, Wm. Louis (b'85)-Cal.6,'08; (l’08) : 400 S. Figueroa St.; office, Paciflc Electric Bldg.; $2-4: 30 ; s$.

Weddle, Waiter Ethelbert (b'77)-Cal.2,'11;

(I'II) ; 666 E. 46th St.
Weed, Francis Tudor (b'59)-Mlch.1,95; Veed, Francis Tudor (b

Welbourn, Ociasco Carlo (b'71) E-0.2,91 ;

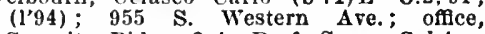
Security Bidg. ; 2-4; Prof. Sury., Cal.4. Weibourn, Pina M. (b'82)-0.2, $07^{\prime}$; (I'07) 644 S. Alrarado St.; offce, Security Bidg.: 1-3 ; Prof. Bact., Cal.4; G.

Wells, H. I. (b'39) E-0.2,78; (1'87) ; 1193 F. 5 fith St.; office, $406 \mathrm{~S}$. Main $\mathrm{St}$

wEXZLICK, 'wM. (b'54) - Mass.1, 88 ; (I'99) ; $625 \mathrm{~S}$. Figueroa St.; offlce, Auditorium Bldg.; $10-12$.

Werner, Ewald Aifred s. (b'86)-Cal.9,'I0 ; (1'10); 833 S. Grand Ave.; offce, Exchange Bldg.; $10-12,2-5$.

WERNIGK, REINHARD (b'6I) $\oplus-\mathrm{b}^{\prime} .1,82$; (1's7): 1933 Ocean View Ave.; offce, Marsh Strong Bidg.; 10-I2, 2-4 :30.

WESSELS, WALTER FREDK. (b'80)(III.II.'03; (l'II); Los Angeles Athletic Club; office, Titie Insurance Bldg.; 1I-12, $2-4 ; 1 . \star$

WWST, FREDK. B. (b'69)థ-Mo.28,99; (I'BI) ; I553 W. I1th St.; office, Exchange Bldg.; II-12, 4-5; G.

WHARTON, CHAS. GREEN (b'83)-Me.1, '11; (1'II); 5502 Towne Ave.; offlce, Tissner Bldg.

Wheeler, Amsden E. (b'54) H-0.7,'80; $\left(1^{\prime} 85\right)$; 723 Hartford Ave.; office, Brad: bury Bldg. ; $12: 30-4$.
Wheeler, Geo. W. (b'61)-0.9,'90; not in practice; Hollywood.

White, Clárence H.-Ind.10,91; (l'01) ; 107 N. Union Ave.; offlce, 4231/2 S. Spring St. WHITE, IlARRY OSCAI (b'64) -III.I3 '96, Iil.1I,'04; not In practice; Member IIl. State Med. Soc. ; 516 E. Washington St.; Prof. Anat., Hist. and Embry., Cai.9.

WIITE, PLRCIVAL GEO (b'8I) Q-Que.I, 05; (1'09) ; 23I\% ScartP St.; offlce, H. W. IIellman Bldg. : $2-6$.

White, Wendell (b's0)-Ind.20,09; (l'12): 2103 Central Ave, offlce, 307 S. HIll St.;

I0-12, 2-4.
Whitfled, Amelia Martha Atkins (b'57)Mlch.5,78, Ili.4,83; retired; I520 W. Ifith. Mllch.5, 78, Ili.4.83; retires; I520 W. Ifth.
WHITLOCK. ROBT. (i. (b'79) \$-Cali, 07; (i'07); 72I S. Hope St.; office, Paclfic Electríc Bidg.; $10-12,2-4,7-8$.

WHITMAN, CIIAS, H. (b'56) $\oplus-$ Ill.8, 86 ; lil.II, 90 ; (1'94); 1100 Mission Rd.; of flce, Wright and Callender Bldg.; $1: 30-4$; Prof. Clln. Surg., Cal.9; $\mathrm{S}$.

Whitney, Augustus A. (b'50)-N.Y.10,73; (ま) ; 932 Georgla St

WICKLAND, CARL A. (b'61)థ-Ill.18,00 ; ( ) ; 6027 Hays Ave.; 2-4.

Widnéy, J. P.-Cal.2,66; (I'76); not in practice; 3900 Marmion Way; Emer. Dean and Prof. Med. : Cal.2.

Wilcox, Lewis K.-Mo.3,52; (1'84); 1414 W. 30 th $\mathrm{St}$.

WIIDE, KATE - Cal.6,98; (1'99); 747 Crocker St.; 2-4:30

VILEY, EDWIN H. (b'77)-IIl.6,0I ; (1'05) : 3576 Arlington Ave. ; office, Lissner Bldg. : $4-5: 30$; $\mathrm{S}$.

Williams, Llewellyn J. (b'78)-Ky.4,06 ; (C); $911 \frac{1 / 2}{}$ S. Berendo St.

Villiams, Percival Miiton (b'86)-IIl.6,'11; (l'II) ; 625 S. Hope St. ; offlce, Brockinan Bldg. : $2-4$

WIIIIAMS, RALPH (b'71) $\oplus$ - Cal.6,'93; (I'93); 533 Manhattan Pl. ; office, Los Angeles Inrestment Bldg.; 10-12, 2-5; Prof. Derm., Cal.2; (C3) ; U.

WIIIS, WM. LE NOYNE' (b'53) $\oplus$-Pa.1, '82; (1'83); (1150 Garfleld Ave., South Pasadena); office, Marsh-Strong'.Bldg.; $2-4$.

Wilmar, Alvin Hillis (b'88)-Cal.2,'13; In tern, Los Angeles County Hospital; S.

WILSON, ANDREW P. (b'76) -Cal.6, 02 ; (I'02); 448 S. Catalina St.; offlce, Los Angeles Investment Bldg. ; 2-4; $\mathbf{S}$.

wllson, De witt C. $\left(b^{\prime} 47\right)-N . Y .10,70$; (‡); $1302 \mathrm{~S}$. Gramercy $\mathrm{Pl}$.

Wilson, John C. (b'88)-Cal.2,'12; (1'12) ; 6404 'Hollywood Bivd.

Wilson, John E.-Pa.2,'95; (l'00); (Den$(t, s t) ; 2219$ W. 9th St. ; offlce, Frost Bldg. Vilson, Loren Everett ' (b'84) - Cal.9,'I2; (1'12); Consolidated Realty Bldg.

Wilson, Saml. G.-Pa.2, 73 ; (1'88); 937 E. $21 \mathrm{st}$ St.

VING, ELBERT (b'52) †-Ill.6,'82; (1'02); also Member III State Ired. Soc: 2 I56 iV. Adams St. ; offlce, $560 \mathrm{~S}$. Main St. ; $2-3$; $\mathbf{N}$. Winter, Frank E.-D.C.2,06; 444 S. Hope St.

Wise, Kenneth D.-Pa.2,65; $(1 ' 76) ; 957 \mathrm{~S}$. Burlington Are.; office, $1251 / 2$ S. Spring. WISER, FRANK CLAYTON(b'70)-Ill.1,'91; (l'12); not in practice; 70I Beacon St. offlce, Garland Bldg. ; 10-12, 2-4.

WITHERBEE, ORVIILE $0 . \oplus-$ IIl. 6,93 ; (1'93) : I020 S. Burlington Ave. ; office',
Auditorium Bldg.; 2-4; Prof. Surg. and Auditorium Bldg.; 2-4; Pro

Woodroffe, Helen L. Hill (b;71)H-Colo.4, 00 ; (I'00) ; 607 S. Hill ; $10: 30-2 ;$ G.

WOODWARD, ASA GEO.' (b'87)-Ill.6,'11 (I'I $)$; I727 W. 53d St.; II-12, 1-3. WOODWARD, FRANK ALBERT (b'84) Ill.6,'12; (1'12); 1723 W. 53d St.

Worthen, Lewis J. (b'49) H-I11.10,'88; ( ): (Hawthorne); office, Consolidated Realty B]dg. ; 9-12, 1-5.

WORTHINGTON, MAJOR H. (b'79) \&-nl.6, OI ; not in practice; Nember IIl. State Med. Soc.; Laughlin Bldg.; (B8); OpA.

Wright, clifford A. (b'82)-Cal.6,07 ; $\left(1^{\prime} 07\right) ; 23 I 0$ E. Ist St.

YERXA, CHAS. W. $\$-C a l .6,03$; (1'03) ; 639 S. Westlake Ave.; office, Paciflc Electric Bldg.; 11-12, 2-4; S.

Yoakum, Finis E.-Ky.5,'85; (1'95) ; $140 \mathrm{E}$ Avenue 59 ; offlce, 406 S. Main St.; I0-1.
YOST, FRANCIS OIIVER (b'71) -Mass.1, $93 ;(193) ; 2831$ N. Broadway; $2-4,7-8$; Prof. Ped., Cal.0; Pd.

Young, Frank P.'( (b'70)-Ky.1,'93; (1'09); $338 \frac{1}{2}$ S. Hill St.; oflce, Wright and Callender B1dg. ; 1-4.

Young, Nestor A. (b'43)- 0 ; (\$); (Glen(dale); offlec, Douglas Block; $9-5$.

YOUNG, OSCAR O. (b'68)-Mo.8,96; (年) : Member Kan. Med. Soc.; 228 W. $52 d$ Pl. ahn, Lorenzo Paul (b'75)-Ill.10,'04; (l'04). 5254 Monticelio Ave.

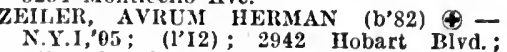
N.Y.I, 95 ; (1'I2) ; 294

ZELINŚKY, FRANK (b'69) $\oplus-$ Cal.1,01; (l'01) ; 948 S. Figueroa St. ; office, Auditorium Bidg.; 10-12, 2-4.

ZERFING, CHAS. E. (b'73)-Pa.I'95; (1'05) ; Hotel Lelghton; office, Story Bldg. ; $2-4$;

Albert F. (b'71)-Cal.6,05: (l'05) ; 112 S. Townsend St. ; offleo, Black I3lclg.; 1 -3.

UBER, AUGUSTA (b'81) - Cal.2,'II ; (1'II); 2500 W. 8th St.; 2-5; Anes.

LOS BANOS, 745, MERCED

(lifn, Alonzo P. (b'66) - Tenn.6,'91; (l'96); S.

Jadarola, Raymond (b'74)-Cal.I,'03; (l'03). CCLELLAND, JAMES L. (b'52) Q-Cal.5, '84, Cal.1,'97; (l'98).

Mcclelland, Sophla J.-Cal.7,00; (1'00).

Morettl, Raffaele (b'76)-Ita.6,'03; (1'12).

Wade, Chas. F.-Cai.1,'89; (1'90).

LOS GATOS, 2,232, SANTA CLARA

Anderson, Annle Mary Slate (b'66)-Eng.7, '92; (i'02); G.

Anthony, Richard Selden (b'65)-Cal.1,'94, Mich.I,'95; (l'94); S.

Chamberiln, Chestér U. - H -N.Y.3,'70 : (l'94).

Gober, Robt. P. (b'58)-N.Y.10,'84; (l'84).

Hansen, Agnes Emille (b'82)-Cal.7,'07; (i'10).

Hubbell, Geo. M. (b'74)-Conn.1,'96; (1'96). Knowies, Frank w. (b'58)-111.1,'83: (1'83). MacInnis, Mary C.-Cal.5,'96; (1'96).

Patterson, Anne Jennings - E - Cal.4, 87 ; (1'87).

Small, Chas. K.-H-Cal.5,'96; (1'96)

MITH, HERBERT EUGENE (b'57)-Pa.1,

'82; not in practlce; Member Conn. State Med. Soc. ; Emer. Prof. Chem., Conn.1.

Urquhart, Richard Alex. (b'50)-Va.1,'74; (1'88).

LOS MOLINOS, - TEHAMA

BURNHAM, MELVIN P. (b'79) (3-Mass.1, 00; (I'II); also, Member Med. Soc. of

LOS OLIVOS, 220, SANTA BARBARA

LUTON, GEO. R. 9 -Ont.3,'04; (l'05).

LOWER LAKE, 395. LAKE

Weiper, Henry B. (b'48)-Il1.1,'84; (1'88).

LOYALTON, 983, SIERRA

Coates, G. L.-E-Cal.4,'96; (1'97).

LUDLOW (STAGG P.0.), 25, SAN BERNARDINO

Ronan, Richard Robt. (b'85) - Cal.3,'12; (l'12).

MACDOEL, 40, SISIKIYOU

Campbell, Wm. Scott $\left(b^{\prime} 57\right)-I l l .1,85$; not In practice.

MADELINE, -, LASSEN

Smith, Carl Lynn (b'72)H-Cal.5,'06; $\left(I^{\prime} 06\right)$.

MADERA, 2,404, MADERA

BURCH, ELMER LEE (b'69)@-Cal.7,05 ; (l'09).

Butin, John L.-Mo.18,'82; (l'91)

HEI, V, LEVI ST. JOHN (b'69)-Mich.1,'99; (1'01).

McMulin, Smith (b'64)-Kan.3,'00; (l'0I). Milton, Richard L. (b'64)-Ky.1,'93; not in practice.

RANSOM, DOW H. (b'80)(-Cal.1,07; (I'0T); $\mathbf{S}$.

Reid, Wm. C. (b'54)-Ky.2,77; (l'77).

Rinker, Casper L. A. (b'77) - Cal.6,'08; (l'09).

MAMMOTH, -, SHASTA

GRUBBS, THOS. ELMER (b'88)-Cal.2, '10; (1'12). 
MANHATTAN, 75, LOS ANGELES

Robblns Walter S. (U,59) - N.Y.8,'89; (1'98); R.F.D. 1

MANTECA, - SAN JOAQUIN

Cross. SAML. X.-0.13, $77 ;(1,78)$.

GOONALE, ROBT. H. (b'í) -Cal.6, '0 : $1.09)$

MANTON, 140, TEHAMA

Host, Waiter Chas,-Cal.i,06; ( )

MANZANAR, - INYO

JoNis, CHAS. D.-Ill.6,"7; not in prac. tice; Member III. State Med. Soc.

MARE ISLAND (VALLEJO P.O.), - SOLANO

CAMERER, CITTE BRADLFY (b'84) $\$$ Mo.34,09: P.A.S., Heut., U.S.X.

COIE, Howsox WHITE, JR (b'7 $\$$ Va.1,02; P.A.S., Lleut, U.S.S.

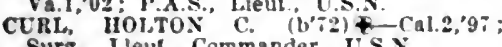
Surg., Lleut. Commander. U.S.S

CATES, MANiLF F. (b'63) \& 'a.11,'s8 Med. Insp., Commander, L.S.

HoEX. WALTER s. (b'i) + -va.1,02

Surz. Lleut Commander. U.S.X.; Yary Yard.

Massey, Wm. IInkle (b'86)-Cal.1,'12: Nary Yand.

MORAN, CHAS, LEO (b'a) P.A.S., Lleut. U.S.N., Member Mass. Med. Soc.

ODELL, HENRY E. (b'71) -Mlch.1,95:

Surz. Ilent Commander U S.X.

SMITH, CHANDLER WHITE (b'83) Pa.9,07; P.A.S., Lleut. U.S.X.

THOMAS, GEO. C. (b'SI) \$-Pa.2,06 P.A.S. Heut. U.S.X.

MARICOPA, 750, KERN

Page, Perryman F.. Jr. (b'79) - Tenn.5, 09 (1'10).

TAYTOR, HARRY NEAFIE (b;3) N.Y.10, 98 ; (1'07).

MARIPOSA, 400. MARIPOSA

Gallion, Thos. Wm. (b'J5) - Tenn.6,'85; (l'01): D.

MARTINEZ, 2,115. CONTRA COSTA

FITZPATUICK, FARI. BERTON (b'si) \$. Cal.8, 10 : (l'10).

MERRITHEW EDWTS w-Cal.1,05: (lo05)

RATTAN, Hisk (b'57) 8-Cal.1,85: (1.86).

SWRETSER, GEO. W. (b'79)-Cal.2,01 ; (1'01).

MARYSVILLE, 5,430 , YUBA

BARR, JAMES IIOLMES (b'58)-II1.6,'90 (1'93); (Yubs City).

GRAY, ALLEN EARL (b'si) F-Call,'ll (I'ii).

GRAY, FVERETT EDWIN (b'8i)-Cal.1, 11: (1'11).

Kaufman, Bernard (b'34)-Cal.1.09; (l'09)

Kaufman, Bernard (b'S4)-Cal.1.09: (1'09)
MILLER, ALBEHT L. (b'61) †-II.1,'96: (I'04),

PowELi, NAVID (b'48) -Cal.1.71, Cal.1, 82: (1'76).

Russell, Wlimer W. (b'32) H-0.13,'66: (I'90).

STRATTON, GFO. W. (b'65) 7-Mo.1,'83

(l'88). Fredk. Hoyd (b'83) II-Cal.5,06 ; (1'06).

Tapley, Jos. F. (b'62) II-III.15,95: (1'95).

MAXWELL, 350, COLUSA

Desrosicr, (ieo. W. (6"73)-Cal.1,'94: (1'95).

MAYFIELD, 1.041, SANTA CLARA

Selbert, Franklln Monroe (b'65)-0.12.'D1 (1'92).

MECLOUD, 200, SISKIYOU

HEGGE, HOHT. THOS. (b',2)—Cal.2.'09 $(1 \% 99)$; $\mathrm{S}$.

RUNCKB., GEO. IIFITY (U⿳5口) Cal.1. 08 ; (1'08).

MEKITTRICK, 200, KERN

Benner, Stillman Marlon (b.54)-1]1.1,79: (1'95).

COOK, WM. HARRIS (b'55) - 111.1,"76: (l'8i)

Prouty, H. V.-E-Cal.4,04; (1'05)

MENDOCINO. 1,000. MENDOCINO

Monre, Leland 0. W. (b'xy) - cal.z.'12 (l'12): 930 santa clara Are.

Pelrsol, Frank C,-Cal 4,95. cal.i., 00 ; $\left(1^{\prime} 00\right)$

Preston, Russell Walton (b*78)-Cal.1,03;
MENTONE, 225, SAN BERNARDINO

HAYS, LEWIS MOKMISON (b'72) III.I6, 06 : not in practlce; Meruber 11l. Siate Med. Soc.

MERCED, 3.102, MERCED

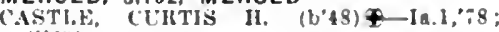
$(1,5,3)$

D.VIS, RRETT (b'84)-Kan.2,09; (l'09) DeIOSS. HERISFRT \&-IH.I,'8S: (l'92).

KYIIL:HG, HJALMAR ('́65)-Cal.4,93;

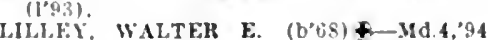

(I'98). JA I.EROY (b'RI) $+-\mathrm{M}_{0.20,08}$ (1)08)

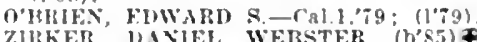

ZIIKFR, NANIEL WEBSTER (b'85)कf'al.1,"0s: ll'08)

MERCED FALLS, 50, MERCED

C.MIISON, VRANK E. (b'61)-I11.11:S6 : (1'86).

MERIDIAN, 199, SUTTER

Jacobs, E. V.-Mo.1,'81; (I'84).

MESA GRANDE, 80. SAN DIEGO

Sindall, laurel $\mathrm{R}$. (b'ti)-111.10,95, Mch.7, 03: (Indlan Servlce)

MIDDLETOWN. 7IO. LAKE

Deckelman. Carlotta R. Spellman-Cal.2,00 : (1'00).

MILL VALLEY, 2,551, MARIN

Buckland, Owen.

(See San Franclsco.)

Spottlsmood, John J.-Cal.1.,94: $\left(1^{r} 95\right)$

STOWF, OSCAR PARK (b'S2)-Cal.t, 09 ; (I'I0).

MILLVILLE, 361. SHASTA

Heryford, henty W.-Ta.1,'S5; (l'91)

MILPITAS, 400, SANTA CLARA

Ehle, IIram Barber-Ill.4,'82, IIl.1.'88:

(1's8). Rensselaer J.-N.I.5,'s4; (l'00).

MODESTO, 4.034. STANISLAUS

ANKFR, IBLSISA C. (b'55) - III.11,91; (1*92): Yember IIl. Sitate Mfed. Soc.

Bundy, wm. C. (b, 45$)-71.11,85 ;$ not in bractlce.

CLARK, IRA JOS. (b'70) $\$$ Colo.5,08 : (l'12).

Dearlorn, Ray Russell (b'8s) - Vt.2,'11: (1'13)

DeLAl'PE, FRED RCSSEIL (b'at) \&-Cal.ı, $97 ;(1.98)$.

FANS. CIAIBORNE W. (b'59)\$-Cal.2,

FIIK, FI'GESE YFRNOX (b's3) \$-Cal.1. O8: (l,08); G.

Feenster, Thos. (b'50)-Mo.10,'S2, Mo.:,'95: (1'96) : R.F.D. 1

Fuller, James P.-Mlch 4, 72 : (l'78).

Grlswoli, Chas. 11.-lli.io.'87: (1'87)

HEXXEYUTH, JOHX i. $\$$ - Mnn.t, 90 : (1'91).

IIOSMFR, JAMES EIDRED (b'63)-Mich.1. '9: : (l'12) ; Member Ore. State Med. Soc. : OALR.

Johnson. Lllla King-111.9:97: (1'02)

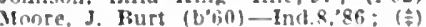

Nasts. Horace W. (b'61)-N.Y.9, St; not In practlce.

Frather, Lemetrlus Jones (b'49)-Ky.4, :6: $(1 \cdot 98)$.

Robertson. Jack Comer-Tenn.5.98 ; (l'os)

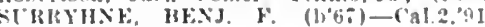
(1)?0)

Willhlte. Wm, J. (b'3 6$)-1 a \cdot 1,6 i ;\left(1^{\prime} 76\right)$.

MOHAWK. $\rightarrow$, PLUMAS

Mllner. Hents Nelson (b'5\$)-Ill.6,"86: (I'SB)

MOJAVE, 231. KERN

Hall, Edwin Ilines (b'S4)-Cal.9,0S: (I'04).

MOKELUMNE HILL, 1,000 , CALAVERAS Brownlee, Geo. benholn (b'5:)-B.a.1, S?

strikk, SIMON FIL,MOIE: (b.36)('al.1.98: (1'99).

MONROVIA, 3.576, LOS ANGELES

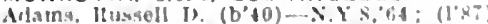

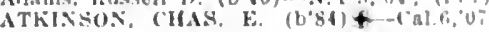
( $\left.10^{\circ} 0\right)^{\circ}$.

IAVIES, IHERTRAM CHAS,

isce bos ingeles.

FEHR, Hr:ill (br73)-111 1, 89; not In

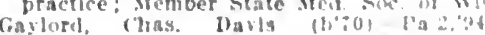
(I'10)
Kirschner, Harry E. (\$'SO)-Pa.2,'02; (娄):

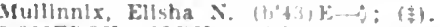

I'OMEROY, JOHX LAlRAIBEE (b's3) 8

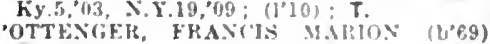
+ $0.8,{ }^{\prime 2}$ : $\left(1^{\circ} 95\right)$; (Tlie Insurance POTTKNGER, JOS. EHBERT (b'Ts) ('al. $6.05:$ (l.06)

BHMISCTON, 1.EWIS D. (bo9) -Cal.6, 109: (1.09).

RICHARIS. JAMES WM (b'8I) $+-0.9,05$; (l'I) ; T.

MORINSON, FRAXK NFALL (b'it) + I'a.1. $95:(1,08): \mathrm{T}$.

ROWE. MFLVIN JOHN (b'80) F-Mich.I,

03: not in practlee: Nember licb. Suate Ied soc.

Sanger, S. E. (b'65)-Cal.5,08; (l'09)

Templeton, (has. A. $(2,69)$ - Ill 1.95 ; resled.

WIEELFI, LAWHENCE X. $\left(b^{\prime}, 0\right)+$ Cal.6, $93 ;(1.9,3)$.

WHllson, Foster F. (1),53)-0.5,7i; (1792); not in practlce.

Winslow, Chas. F. (b'55)-I11.1,'82; (1'95): not in practlce.

MONTAGUE, 274, SISKIYOU

Dwinnell, Geo. W. (b'61)-I1].1.'s5: (1'92).

HI's, CHIS. (b'SI) -('al.1.,06; (1'06).

MONTEBELLO, - LOS ANGELES

TREWIIEILA J.MES S. $(b, 0) \mp-111.6$. .05: (1.06).

MONTECITO, 800, SANTA BARBARA

HAMITTOY, GII,RERT VAN TASSEL. (See Santa Rarbara.)

Hurst, Julus Harold.

(See Santa Rarbara.)

PARK, CIAS. C.-N.Y.10,'SS: (1'94).

MONTEREY, 4.923, MONTEREY

IBROTT, EDWIX K. $\left(\mathrm{b}^{\circ}+0\right)+$ Illch.1, il:

Darles. Wm. Menry (b'34)-Scot.3.,5i;

(l'ib): not in practice.

MFAX. F.I.MER A (b'îl-Pa.1,98; Mal.

HATH.WAY. I.FYY II (b, I) —-Va.1.01;

Cant. M.C. [C.s.A. : Presidlo.

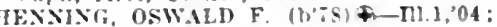

Ist. I.leut. M.R.C., I'S I. : Presidlo.

LITHE. WM. A. (b'68) \&-Y.Y.10,95: (1'95).

MacChesney, Douglass Archlbald Coudrey (h०:2)-Cal.1.97; (1"95)

McAlulay, Martln-Cal.5.04; (I'04); S.

Ictulas, Sarah Hatton - II - Cal.5.04: (l'05).

TFAlYY, WALTFR I. (U"i1)-Cal.z.03:

(1'04).

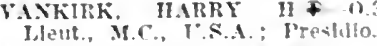

MONTICELLO, 233. NAPA

l'rose, Thos. W. (b'55)-0.14,"84; (1'92).

MOORE PARK. - VENTURA

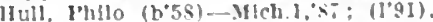

MORGAN HILL. 607, SANTA CLARA

IHglins. John Turner (b'tí)-MInnd,"P4: (1.84).

Seumelsier, Anton Firnest $\left(\mathrm{b}^{\prime} \$ 2\right) \mathrm{H}-\mathbf{I l 1} .10$. $28 \%:(1.10)$.

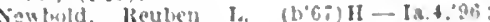
(ling)

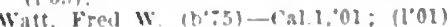

MOSS BEACH, 50, SAN MATEO

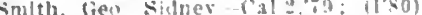

MOUNTAIN VIEW, 1.161, SANTA CLARA

Sdams, (chas. Fill (hif)-X 11 1.94: (1'Dt).

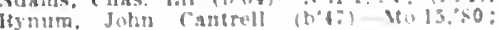
$(1.90)$.

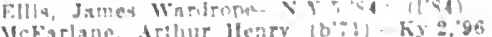

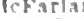

MURRIETTA, I50, RIVERSIDE

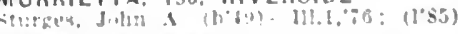

NAPA, 3.791, NAPA

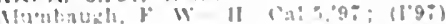

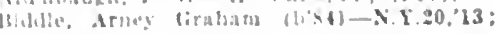

Hroun, fiev. Jermiah (b' 19$)-C a L=96$ :

I31 $11^{\circ}+60$. (I"i)! 
('alduet, Chas. Blanchard (b'si)-('ill.1,'ll; (1'11); D.

CHAFFEE, FRANK-Mich.l,'ss; (1'00).

CREES, IOORT (b"59) + ('al.2'94 (194)

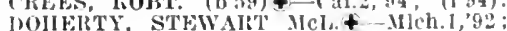
$(1,00)$.

bomnelly, bdward l'ramels-cal.1, 4 ; (l’ol);

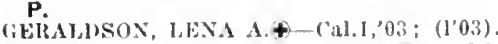
HENNESSEL, EIIIX $\%\left(b^{\prime}\left(t^{2}\right)+\right.$ Ind.s, '84; (I'86i)

HOISIOLT, ANDIRW W. (b'58)£-Cal.1, , 82 (ier.10,'84; (1'80); CIIn Prof Med., 82, fier.

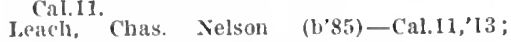
(l'13).

Lowery, James Edward (b'6I) -N.Y.10,'st;

Hot In practice.
MATTHEWS, ADELBERT $\left(.,\left(b^{\prime} 75\right) \$-M d .4\right.$,

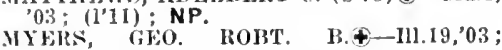

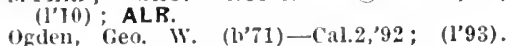

Palmer, Wm. IIenry Harrison (b'40)-Ore.1.

Pond, Milo Buslinell (b'35)-Cal.2,65;

PI'TSIFER, LEONARD M. (b'68)-N.Y.5, 88: (1'93).

Kansom, Jack Kelunedy (b'81)-Cal.1,'10; (l'10).

Johertson, Jolu-('al.t,99; (l'00); (Dentist)

Jo(iklis, JOIIN B. (b'66)-Cal.1,'96; (1'96). SCJILIZE, OTTO TIIEODOR (b'81) 4 ('al.2, $207:=\left(l^{\prime} 07\right)$.

Stetson, 13cij.-E-Ill.s,90; (1’90).

Stetson, Bcnj.-E-Ill.S,'90; (1'90)
Taylor, Robt. F.-H-O.13,'77; (1'83)

Taylor, Robt. F-H-O.13,78; (1'83). (V'ELTI,

Wightman, Annie B. (b'60)11-Cal.5,'85; (I'86).

NATIONAL CITY, I,733, SAN DIEGO

ALILEN, WILL L. $\left(\mathrm{b}^{\prime} 59\right) \oplus$-Ia.7,'89; (l'01) Member Ia. State Med. Soc.

COBURN, ELWYN STEVENS $\left(b^{\prime} 64\right) \notin-$ I'a.11,95; (1'12)

FLY, EDWARD MONROE $\left(\mathrm{b}^{\prime} 66\right) €-\mathrm{Pa} .2$ '94; (1’98); S.

GILCHRIST', COJIN (b'61)థ-Mich. 7,88 not in practice; Member Wash. State

Johnsoll, Theodore F. (b'51)-Ill.6,'; ; ; (l'8i).

JoHNsox, WM. JOHN (b'75)€-Ia.3,'10 ; not in practice.

McFarland, Rensalier (b'47)- 0 ; ( ).

Moore, Aunie Norton (b'46) H-Mich.3,'72; $\left(l^{\prime} s 0\right)$; not in practice.

Orcutt, olive J. Eddy-Mich.5,'82; (l's9)

OWEN, CARL S. (b'is) $4-111.6,04 ;$; (I'06)

Parker, Alice C. $\rightarrow$; $\left(1^{\dagger}\right)$.

Parker, Horace P. (b'i4)-Colo.2,'06; ( )

NATIONAL SOLDIERS HOME, - NAPA

Crane, Harold Jeroy (b'89)-Mich.1,'12; Assistant Physician.

NEEDLES, I,500, SAN BERNARDINO

BOLAND, ARTHUR EDWARD (b'86) Ill.11,00; (l,10)

PARKER, ASHLEY STEPHENS $\left(b^{\prime} 71\right) \oplus-$ I.a. 1,'93; ('’93).

SHEPARD, CHAS. ANGELL $\left(b^{\prime}\right.$ il 1 N.Y.6,'96; (l'00).

NEVADA CITY, 2,689, NEVADA

IIULLER, CARL LOUIS (b'61)૯-Pa.2,'s8;

S.IWYER, WMI. P. (b'64)†-Pa.1,'91; (1'94); OALR.

TICKELL, ALFRED II. (b'64) $\uparrow-G a .10,91$; (I'92).

NEWCASTLE, 503, PLACER

Allen, Ralph Edgar (b'89)-Cal.1,'12;

Horne, Frank Lisle (b'79)-Cal.1,'10; (1'10).

NEWMAN, 892, STANISLAUS

Armistead, Howell Venable (b'59)-Cal.2, '85; (1'85).

GREGORY, CALVIN L. (b'52)థ-0.8,'74; (I'S5).

Mays, irm. H.-Cal.2.73; (l'01)

NICOLAUS, 125, SUTTER

BAIRD, HARRY RICHARD $\left(b^{\prime} 75\right) \oplus-C a l i$,

'06; (l'09). (1'94).
NILES, 1,837, ALAMEDA

IIARCOURT, LUKE AIRTIIUR (b'38)N.Y.6,'68; (1'89); Member III. State Med. Soc.

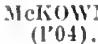

NORDHOFF, 218, VENTURA

SAEGER, IBENJ. LEVAN (b'53) - Mich.I, '78; (1'89).

Taylor, Artliur Wilson (b'5\%)-N.Y.1, 80 : (1'03) ; Capt., U.s.A., retired.

VAN IATTEN, PIILIP S. $\left(b^{\prime} r_{2}\right) \oplus-$ N.Y.I, 98 ; (1'08).

NORTH FORK, 125, MADERA

Gates, Mark Gorman (b'86)-Cal.2,'10 : (l'i1).

NORWALK, 500, LOS ANGELES

(iroorer, Jolun F, (h'37) E-Ga.7,61; (1'76) OTIS, LEROY JEWTIL (b'74) †-IIl.19,99; (l'01); Or.

NOVATO, 400, MARIN

ANDERSON, CIIAS. HOWE (b'67)-Cal.1, 92 ; (1'92).

Thompson, Chas, II. (b'42) - Pa.6,67 $\left(l^{\prime} 76\right)$.

OAKDALE, 1,035, STANISLAUS

Burbank, Herman E.-Ill.6,'83; (1'89)

Endlcott, Rlchard Henry (b'45)-ra.1, 75 ; (1'6).

McKIBBON, FRED W. (b'75) - Vt.2,99; (1'09)

THOMPSON, IRVING BOYD - Cal.1,07; ( 1 ’0\%).

FOUNG, J. AUDLEY (b'76)\$-Mlch.9,'01, Cal.1,04; (1'04); ALR.

\section{OAKLAND, 150,174 , ALAMEDA}

(See Berkeley, Frultvale, and San Francisco.) NUMIBER OF PIIYSICIANS, 317

ABBOTT, PHILIP FANNING - Cal.1,01 (1'01); 25 Crocker Ave.; offec, Union Sarings Bank Bldg.

ADAMS, JOHN ELMER (b'76)థ-0.12,'98 (l'10); Key Roule Inn; office, Union SavIngs Bank Bldg. ; 9-12, 3-4; (B19).

ADAMS, LEMUEL PAYSON ( $\left.\mathrm{b}^{\prime} 75\right)(-\mathrm{B} t .2$, 99; (1'00) ; 265 Lee St. ; offlce, Centra Bank Bldg. ; $2-4$; Prof. Surg., Cal.8; S.

AlKEN, ILO ROBT. (b'66)-Cal.5,98 (1'98); 327 IIanover Ave.; offlce, 1225 Washington St.; 1-3

AKERLY, JAMES' CIARK SMITH (b'60)Cal.1,'S5; (l'85) ; Hotel Athens; offce Delger 13ldg. ; $1: 30-3: 30,7-8$.

Aldrich, Carra Schofield-H-Cal.5,'95 (1'95); 336 Wayne Ave. ; 1-3, $6: 30-7: 30$.

ALEXANDER, ARCHIE A. (b'80)-Cal.2, '07; (1'07); 1017 Chestnut St. ; offlce, 1207 Broadway.

Anthony, Jiabel E.-Cal.7,'06; ( ); 1610, 8th St.

ARDENYI, JOS. (b'6z)థ-Tenn.6, 01 ; (l'01) ; 3753 Pledmont Ave. ; office, Bacon Bldg. ARNOLD, CHAS. SAXON (b'68)-Cal.8,06 (l'06) 909 Castro St. offles, 1206 Broad(1'06); 909 Castro St.

Baldwin, Robt. Oliver (b'65) - Cal.2;'85 (l'85); 342 Hawthorne Ave.; offee, 1225 Broadway; 11-12, 2-4, 7-8.

BALL, JAU DON (b'80)థ-Va.1,'02; (l'02) ; Thornhill Rd.; office, Daziel Bldg.; 10-11; Prof. Nerv. and Ment. Dis., Cal.8.

Bartlett, Thos. P.CCal.7,99; (1'99); 917 Grote St.

Bateman, Frank I.--H-Cal.5,'96 ; (1'96) ; 1435 Filbert $\mathrm{St}$.

BECKWITH, WARD M.-N.Y.1,'89; (1'91); $1529,23 d$ Ave.

BELL, HARRY DUDLEY (b'78) $\oplus$-Cal.1, 04; (1'04); 26 Randwick Ave.; offlee, 1328 Washington St. ; 10-11, 2-4, 7-8.

Berges, Edmond Raoul (b'76)-Cal.7,97 ; (1'97) ; 2049,41 st Ave. ; $1-3,7-8$.

Bixby, Wilfred Everett (b'83) - Cal.2,07 ; (l'0i) ; Pliysicians Bldg.

Boolsen, S. L. H. -H-Cal.5,'06 ; (1'06) 1711,24 th Ave.; office, 2284 E. 14th St. Asst. Prof. Path., Cal.5.

Boone, Reunetle E. Hughes (b'45)-N.Y.15, '81; (1'95); 698, 17th St.

Boone, Wm. Roscoe.

(See Berkeley:)

BOWLES, FRANK HERBERT (b'80)థ Cal.1,09: (I'09); $2101 \mathrm{EIm}$ St. ; offlee, 427 Adams St.
BOYES, EDWIN JOS. (b'64)థ-Ont.3,'90, Ont.4,'00; (1'91); 553 Oakland Ave.; of -" flce, Central laank Bldg,

liradley, Lawrence IInll (b'58) H-Ill.4,'80 ; $\left(1^{\prime} 80\right) ; 1731,11$ th Ave.; offlce, 1254, 23d Are: $2-4,7-8$

IBAZELTON, CIARA II. HOLMES-Cal.1. 95: (1'96); I965 Telegraph Ave.

BIRNCLERIOFF, ELMEIR ELISWORTH (b's3) †-I11.11,08; (1'09); 202 E. 12th st. ; ofllee, First Nảı. Bank Bldg. ; (B!9); OALR.`

BIRIXCKERHOFF, G. ERIVIN $\left(b^{\prime} 62\right) \oplus$ Ill.11,'85; (1'90); (326 El Cerrlto Ave. Pledmont); offlce, Delger Bldg, ; $9-12,3-4$.

Brown, vila Pringle (b'56)-0re.2,96; $\left(1^{\prime} 97\right) ; 420,37$ th $\mathrm{St}$; $1-3$. Brown, Wm. W.-Ky.2,72; (1'77) ; 2928,1 Ith
Ave., F. ; $9-10,2-4,7-8$.

BROWNE, GEO. 'ECIL $\left(\mathrm{b}^{\prime}, 6\right) \oplus-\mathrm{Md}, 3,99$ : (1'99); 5019 Foothll Blrd.; offle, 1822 Fruitrale Are, ; 1-3, $7-8$.

Burns, J. B.-('al.4,94; (1'94) ; (Dentist) ;

245 Acton PI. ; offce, 1429 Broadway ; $9-4$.

Burton, Henry Guild (b'46)-N.Y.5, 69 ; (1'94) ; Capt., U.S.A., retired; $271,23 d$ St. Bush, Alice (b'62) H-Cal.5,'91; (1'91); 431 Lagunitas Ave.; $2-4$.

Butcher, Lelia Belle $\left(b^{\prime}, 4\right)-C a l .5,08$; (l'10); 2936 Telegraph Ave.; offle, Thayer Bldg.

BUTEAU, SAML. H. (b'64)-Cal.1,89; (l'90); 2702 Telegraph Ave.; offce, 1307 Broadway; 2-4; (A1); $\mathrm{S}$.

Byron, Albert F.' (b'72)-Cal.4,'95; (1'95) ; 5690 San Pablo Are.; offce, 525, 13th St. : $10-12,2-4,7-8$.

CALDWELL, EDSON KNOX - 0.1,'83; (1'84); 1911 Fruitvale Ave.; offce, 1353 Fruitvale Ave.

Caldwell, Euler Jones-Pa.2,91: (l'01) ; 3915 Randolph Ave.; offce, 1206 Broadway.

CAIIEN, JOHN HERBERT $\oplus-\mathrm{M} 0.5,90$; $\left(1^{\prime} 90\right) ; 1521$ Fruitvale Ave.

CAMPBELL, FRANK MCLEAN (b'86)-Ill.6. 11; (1'12) ; 1097 Stanford Ave.

CARD, EGERTON F. (b'53) \-Cal.1,85; (l'86) ; 424 Perkins St. ; offlee, Central

Bank Bldg.; 10-12:30, $1: 30-3: 30$; (B19)

Carter, Richard Henry (b'71) - Cal.1,95: (1'95); 5685 San Pablo Ave

CASE, CALVIN LUTHER (b'65) $\oplus-0.3, ' 96$; (1'97); 3423 Webster St.

Chamberlain, Harriet L. - H-Cal.5, 00 ; (1'00); 938 Adeline St.; 10-11, 7-8.

CHAMBERLAIN, NELSON HOYT (b'68)థMich.5,92; (1'93); 350, 29th St.; offec, Union Savings Bank Bldg.

CHAMBERS, WILFRED ERNEST $\left(b^{\prime} 74\right)(-$ Cal.7,06; (1'07); 519, 27th St.; offlce. 1206 Broadway; $2-4, \boldsymbol{i}-8$.

CHANNELL, DUDLEY B. (b'53) - Ore.1,'94 (1'98); 2835 Webster St.; offlce, 1028 Washington St.; 2-4.

CHANNELL, WMI. LEON (b'82) -Cal.1, $05 ;\left(1{ }^{\prime} 06\right) ; 1731,4$ th Are.; oftice, 1028 Washington St. ; 2-4, 7-8.

Chapman, Sainl. Ezra-0.7,74; $(1 ' 77) ; 1430$ Filbert St.

Cheeney, Walter Sylvester (b'75)-Cal.4, 05 ; (l'10); 385 Hanover Ave.; offle, Thayer Bidg.

CLARK, ERNEST M. (b'84) -Vt.2,'08; (1'10) 556, 23d St.; offle, 1206 Broadway.

CLARK, J. EIMET' (b'70)-Cal. $\tilde{7}, 01$; (l'01); 2340 'Telegraph Are.

CLARK, THOS. JAMES (b'74) $\oplus$-Cal.2,'99; (1'99); Ross and Harwood Sts.; offlce, Oakland Bank of Savings Bldg.; 10-12; Sec. and Prof. Gen.-Urin. Dis. and Derm. Cal.8; D.

CLARK, WM. AMIE (b'71) $\oplus$-Cal.1,92; (l'93); Claremont Manor; offlce, 1206 Broadway ; S.

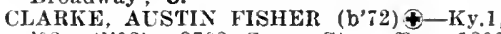
92 ; (1'92) ; 3702 Grove St. ; office, 1206 Broaciway; 2-4.

CLOW, GEO. B. NEWELL (b'56)థ-Ia.1,'80, III.1,'83; (1'81); 75 Vernon St.; offlce 172, Telegraph Áre. ; 11-12, 2-4.

Cobb, Chas. Duane (b'71)-Mo.34,04; (1'11) ; 4103 Telegraph Are.; offlce, 1225 Wash-

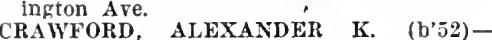
Ill.4,'80; (1'99); 226 Lake Shore Blvd. office, Union Savings Bank Bldg. ; $1: 30-4$. 


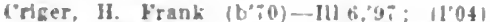
2431, 10 h Are.; "mire, 2930 Sacrament

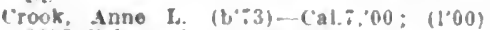
603: Telegraph Are.: 10-4

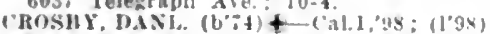
liol Frultrale Are, onle, Ioza Fruit rale Are. ; 1 -3.

CROWI.EY DF.NIS DAVID (b'58) \& 1418 Broalwas" athenian Club; surg. and clln. Surk., Cal.s: S.

Crump, John Moore" (b'54)-X.1.5, is (I'03): ass 3 Bronkdale ire.

CUNDIXIIAM, ARTIILR I., (b'66)-l'a $90:$ (J'40): IIotel (Iakland; onter, Enlon Sarings Kank lldg.; $2: 30-5$.

('LRDTs. ('ARI, ELWARI) $\left(b^{*}, 6\right)+$ Cal.j 00 ; $(1,00) ; 748,53 \mathrm{~d}$ st.; office, 1322 Broadway; $11 \cdot 12,3$.

Curtls, Elllo:t D. (6'45)1]-III.4,'83; (1'91) $3: 51$ Shafter atre; oflce, Hiake Block 11.12, 1.4.

MAGGETT, EARL HAMPTON (b'T3) f Cal.8,09; (1'09); 1631 San Pablo 2-4. i-8; Assoc. I'ros. Phrslol. Cals.

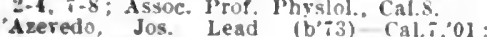
(101); 790 , sth St.; 11-12, 2-4, $7-3$.

DeFarla, John Haptist (b', 1)-Port.2,'96 $\left(l^{\prime} 05\right): 1304,8 t h$ st.

De La Rue, Kilwin-Tenn. 6,'86; (I'85); 1249 E. 14th st.; $10-12,2-4,6-5$,

DE PUY, CLARKX'E ALGISTLS (b'82) + Cal.:05; (1'06) ; 460, 12th St: offlce

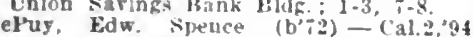
(1'94); 3316 F. 12th St; oflee. $3212 \mathrm{~F}$. 14th $5: 1-3,7-8$

Derrlck, Geo. II. (b'66) F-Ual.4,95; (I'95); 425 Vernon st.; unlee, Paclfle Bldg. $11-12,3.4,7-8$

lerrick. Vlctory A.-('al.;.98; (1'98); 16tl and Jefrerson sts. : 1-3.

Devine, Cornellus Thos. (b'so)_Cal.2.07 (l'08) : St. Mark's Hotel; onjee. Fulon Bank of Sarlngs Blug.; 1-3, i-s

WIETZ, HENRI LOLIN (b'T3) + 'al.4 36 (1'96); (East Oakland); Ofice, 12.5 WashInzton St: $2-4$.

Dlmmlek, Jos. (b'42) $\rightarrow$; (\$); 1710 Webster Are.

DODDS. THOS. GARFELI, $\left(h^{\prime}-S\right)+$ Cal.2,

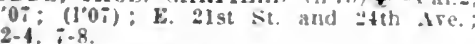

Ith St.: 2-4.

Downing. Augusta Paxton-Cal. :,02; (l'02) : 2530 Sistle Si. : $9-5$

DOWNIXE, EDGA DAIE (b'si)-Cal.1,11 (1'11): 2530 Myrtle St. : $9-5$

Drennan, Pauline Glaser-ial.1,04; (1'04): 4130 San Pablo Are.

rew, A. Jamer.

(See San Franclsen.)

WLKES, CIIARLES ALFREI) (b'72) Cal.1.95: (196); 6000 Claremont tre. omce, Central Bank lidg: 2.4

Dukes, II. C.-Ia 6,'s'; (1'92): 450, 65th

3026 form. Lit.

(1'00):

[IDU1,

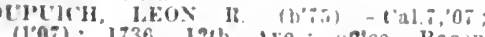
(107): 1736, 13h we.; unice, Jaron Hlock.

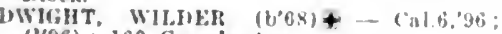
$(196): 160$ frande Ave.

HIMONIS, FRASK W'.

(seo Merkeley.)

Limundann, James

5006 F. ith st.

(See san franclwon

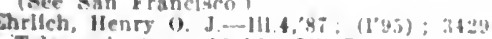

Telegraph Ave in-12;OALR

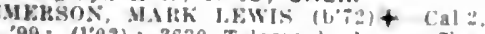
'99: (1"02): 3630 Tulegraple Ave : inso" 1307 Kroalway; $2-4$

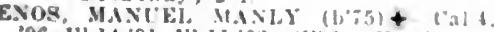

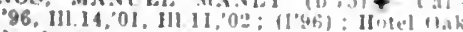
land: St Antbony's Hospltal: is.

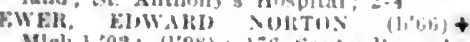

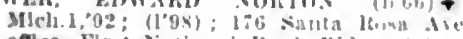
offce, Flrst Xational Ibank Bldp:

Prof. (iyn and lobet ral.s: $\mathrm{ObC}$

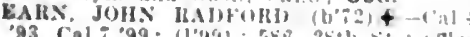

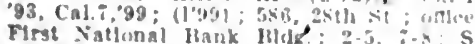

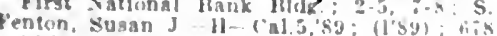
lith sit.

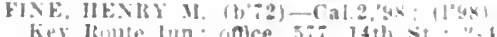
FIx KItI, MAHTIN HENkY.

(sive l'melnnatl.)

Fisher, llars k- ral.2,00; (1.03); th stitll st

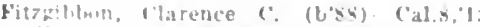
$11 \% 12,260$ insedale die.; NP

Func, F $1-111.10,35:$ (a) : 1732 Frankli

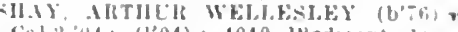

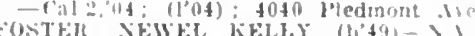

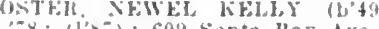

Foster, Winfred N.-Mass.5, 6is, 1 th $x$ : : $2-4$

Freeman, thas Henry-Cal.2,94; (1"4ti) ire.

Fricke, lichard--Mh.6,91; (1'98); 507, Illt: st. I I0-12.2-1

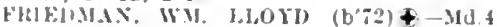

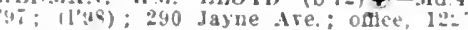
Wishington st. 2-4; (1;14)

C.I.KRAITH, ALEXANIEH (b'il) +-1ll.

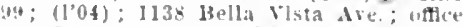

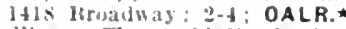

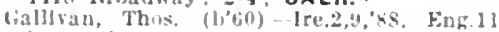
xu; (l"y1); not in practlce; ito lenos

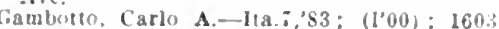
Teleqraph Are. ; $7: 30-9$, I-3. $;-s$.

Gamble, Aaron Walter (b'3i) - ivi, $5 s$ (1) a Aaron Walter

Garmon, John Oscar-Mich.j, :-; (l's:) 144,81 st ire

Clenn, Kobt. Alexander (b'8s)-Pa.1,'11 Ilawthorne and Webster Sts.: (Fio) Path.

(inldson. Malinda-ore.1,84; (I'st); 648 F. lth s

GREEN. JACOH S.ML. (b'7z)-Cal.1,9s (1'98): S11 Girore st.; oflce, 1106 Hrond-

GIEGORY, A. MARTIS (b'6s) †-Cal.6,01: (101): 16.39. 4ith Are.

iraham, Gubert Fuller.

GRISSIM, JOHX DE LAFAIETTE (b'by) + - N.Y.1,93; (1'95); 585 Walsworth Are. offce, First Nat1. Bank Hldg.; 11-1:2,2-4. Gugllerl, A. A.

(See San Francisco.)

HAIIDEX, INAVID (b'5) \&-('al.1,94 (1'99); (2716 Telegraph Ave., 13erkeley)

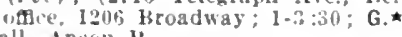

Hall, insou $y^{\circ}$

(See San Franclsco)

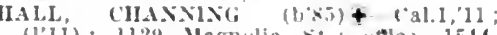
l'11): 1129 Yagnolia

Hall, T. 11.-E-Cal.4.'s; (l'st): $2-75$

Telegram Ave.; ndice. 70 Troadway

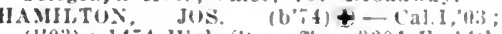
(l'03): itit High st.; offlee, $3204 \mathrm{k}$. Ith St. : $1-3$.

HAMLIS, OLIVEIR DEVETA (b'0)

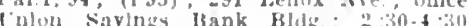
Prot, cliu. Sure. Cals; $\mathrm{S}$.

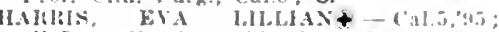
(l'yis); Hotel (laklant:

Nathoral Itank Hldg.; $3-5$

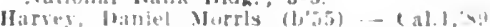

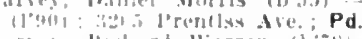

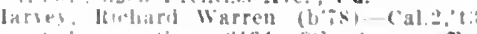
mot in Jralthe: 2134 , wh Are. ofluce ('al 2.

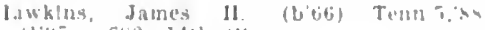
$11 \div ; 0 ; 6 \times 0,14$ th $5 t$.

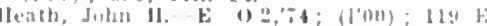

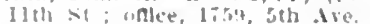

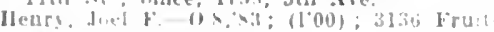
vale Are

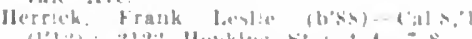

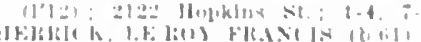

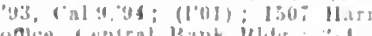

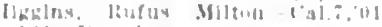

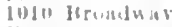

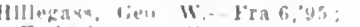

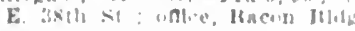

H]1.IJAIL!, IRI TII (b'64)-1114:0

aid:at Telograph Are.

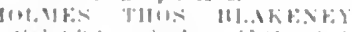

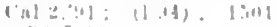

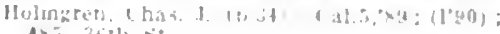
1ulm, 36th si

$5 \div-1+\mathrm{h}$ : $: 2.4$

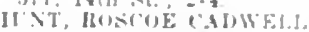

(1.9:) (114; (1.12); Momber

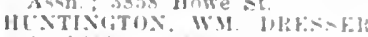

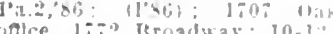

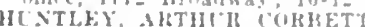

(a1.;, (13; (804); 406 Huilson

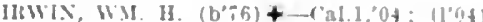
1433 West st. nflice, First Fational bank lidda : $2-4,7-8$

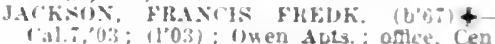
ral Bank lldk: 11-3.

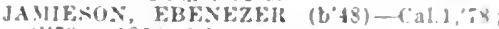
(1'-8): 126\%, xth Are

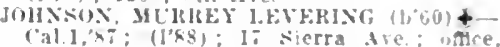
rirst Nallonal liank Bldz; :-4.

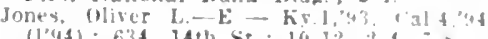

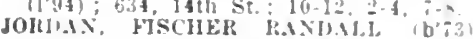
Call, 95 ; (1.95); 311 Walownrth Are oftlee, 1106 lroadway; $4-4$

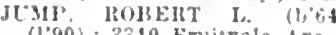

(190); 3340 Fruitrale are

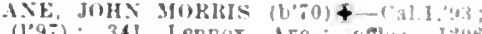

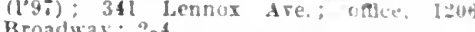

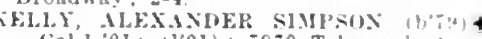
-Cal.1,01: 11'01); 5970 Telezraph ive oftce. First National liank BIdg. ; $:-4$, $7-7: 15$; Prot. Uper. Surg. Cal.s.

Kelly, Lewis bdw. (b'44)H-I'a.9, ;6; (l'is): loiti, loth are.

Kerzan, Hetry sidney (b'71)-Mich, 8, ot; (1)afi: 469 ban Huren si. oflce, 132.3 IBroadway; $:-4$.

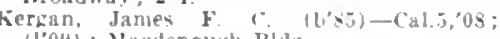
(ln!t) : Vatodonoush Bldy

kergan. Juhn Thendore (hs5)-Cal.5.'10 : (110); 210 Iake shore b\|rd; odce, 1302 liroadway.

hergan, William W", (6,5l)-Mich $8,89:$ $\left(l^{\prime} 47\right)$; 21 t Lake Shure Blod. ; office, 1295 Washington st: : $3-5$

Kessilf. John J. (6.62)-1a.3, 95 ; (1'01) il Jeffersu st

hibhe. IInora Elles (b'b3) - Callogs (1'99); 306t Flurida st ; 1-3.

Kilgore, Lucy li. (b's2)-Cal,5, $09 ;(1,10)$ ast E. 14 th $5 i$; $3-$.

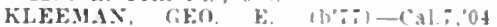
(l'06); 5-3. 31 st st.: onlce, Blake Bidt $11-12,2-5,7-8: 30$

Klonk, F. W. Max-Mu.4:4; (1"48); 3336 KXiox, Mli.s

14th si. ; 11 -

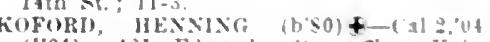
(1004); 461 Edwards st: onlee, Enjog Saringe lsank Hldg: :-4, :-8

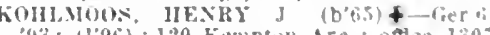
93; 1196$) ; 120$ Kempton Are: mince, 130 Brodulay: 10-1:3-5: (B19); OALR.

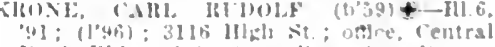

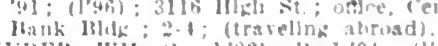

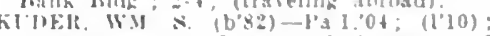
alse Memluer Wtyl. sece of the state of

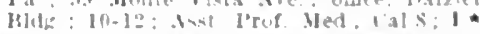

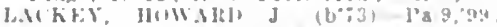

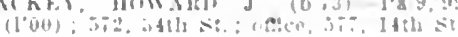
(100) 10.11 .

1.amb. susatl 3. 113heraun

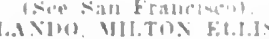

lihiner lihi,

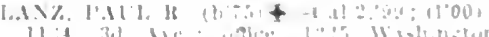

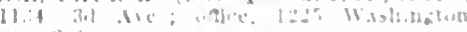

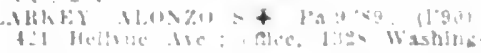

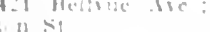

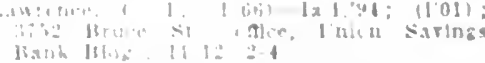

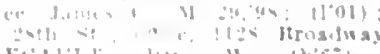
$1130 \mathrm{~F}:$

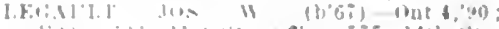


Leonard, Ralph-Ill.1,82; retired; 121 Pearl LILIFNCRANTZ, AUGUST (b'47)థ-III, 70: (1'82) : 465 Fuirmont Ave.: ollice, 1965 Telegraph Are.

LOHSE, JOIHN LOUIS (b'76)థ-Cal.8,06 ; (I'06); 80 Monte Vista Ave.; office Dalzlel Bidg.: 2-4: Prof. Anat., Cál.8.

Lundegaard, Eilward M. (b'89)-Cal.8,'12; (1'12); 621 Merrimac St.; offlce, 1121 Washingtou st.

Lyons, Adium (b'59)-MInn.5,'98; (l'01); 1843, 8tl Ave.; oflace, Delger Bldg. ; 10-12, $2-5$.

MAHFR, JERFMIAII (b'4S)†-Hl.l, 82 ; (I'89); 3409 Grove St.; 2-3:30, 7-8 Emer.'Prof. Prin. and Prac. Med., Cal.8. MAINE, ALVA F. (b'76) -Ky,2,0l; (1'01); 6434 Colby St.; offce, Nalzlel Bldg. $2-4$.

MAJORS, ERGO ALEXANDEI (b'77) Cal.2,'92; (1'02); 5749 Grove St.; offlce,

Iakinson, Frank Roscoe (b'86)-Cal.8,'13 (l'13); 26th St. and Broadway; offlee, 13 th St. and Broadway.

MAKINSOS, HERBERT A. (b'73)ФUnion Pank of Savings Bldg.; $10-12,2-4$. Marvin, Geo. I). (b'62)-Mlch. 7,86 ; (1'88); 1176 Jones $\mathrm{St}$.

MASTEN BENJ, B.(-111.8,95; (1'96) ; 957,8 th St.; offlee, Union Savings Bank Bldg.

Mauzy, Wm. Peter (b'54)-N.Y.10,75: (1'76); not in practice; 997 vermont St. Maxson. Harrlet S.-Mich.1,'85; (1'88); 410 28 th St. ; $10-12,2-4$.

MAXSON, 'WILI.IS HENRY (b'55)-MIlch.1, 83; (1'88); 410, 28th St. ; 9-12.

May, Eugené S. (b'81)-Pa.1,02: (1'13) 1461 Allce St.; office, Dalziel Bldg.; 2-4

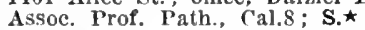

Mayon, James L. (b'58)-Cal.1,79; (1'79); 1533 Market St. ; $10-12,2-4$.

McAllister, Oscar Orville T. (b'85)-Cal.8, '13; (l'13); Macdonough Bldg.

MCCLURG, KÁTHERINE $\uparrow-C a l .1,03$; (1'03) ; 17 Prospect Ave.; offlce, 350, 29th St.

10-12.
McCornack, Wm. A.-Cal.1,73; (l'76); not In practice; 2103, 24th Áve.

McVEY, CHARLES LELAND $\left(b^{\prime} 83\right) \oplus-$ Cal.2,09; (l'09); 3912 Telegraph St.

Meacham, S. F.-Ia.1,'82; (l'99); 211 Santa Clara Áve.; offlce, 577,14 th St

MEADS, ALBERT MANSON (b'82)-Cal.2, 08 ( office, 1307 Broadway; 2-4; U.

offce, 1307 Broadway; $2-4 ; U$. '85; (1'85); 3211 Grove St.; offle, Macdonough Bldg. ; 11-12, 2-4:30.

Metcalf, Olive B.-E-Cal.4,'83; $\left(l^{\prime} 83\right) ; 825$ 22d St.

Miller, Chas. N.-E-Cal.4,'88; (l'88) ; 2152 High St. ; 3-5.

Miller, W.' Hinton-Ill.II,'86; (1'88); 463,

$41 \mathrm{st}$ St. $\mathrm{Wm}$ F.-E-Cal.4,95; (1'95);

Mlllhone, Wm. F.-E-Cal.4,'95; (1'95);

8320 E. 14th St. $2-4$; Up.
MIILIKEN, WILLIAM PATTON (b'64)Cal.8,10; (1'10); 3858 Howe St.; offece, 496, 20th St.; $2: 30-4: 30$

MILTON, JOS.' LEO (b'70) $\oplus-$ Cal.2,'91 ; (l'93); 3020 Telegraph Ave.; offce, Dalziel Bldg.; Prof. Ortho. Surg., Cal.8; Or.

Miner, Mark L. (b'74)-Cal.2,03; (1'03):

M303 E. 14 th St. ; 1-3, 7-8.

MZNER, WM. G.

(See San Francisco).

Monroe, Chas. A.-H-0.23,'95; (l'96) 9333 E. 14 th St. $2-4$.

MOORE, GERTRUDE (b'83) 9 -Cal.8,07: (l'07) ; Bauer Apts.; office, Thayer Bldg. 1-5; Assoc. Prof. Path., Cal.8.

Morrill, Frank Browne.

(See San Franclsco.)

MORSE, FRED WELLINGTON (b'55)(4Cal.2,'91; (l'92); 1565 Madison St.; of flce, Oakland Savings Bank Bldg.; 9-12, $1: 30-3: 30 ;(\mathrm{B} 19)$

MOYER, JONAS J. (b'67) $\uparrow$-Tenn.11, 00 ; (1'01); 1222 E. 28 th St.; offce, Thayer Bldg. ; $11-12,2-5$.

MUGLER, FREDERICK ROLLA $\left(b^{3} 84\right)$ Cal.1,'10; (1'10); 506 E. 16th St.; offlece, 577,14 th St.; 2-4, 7-8.

Muller, Otto J.' (b'58)-N.Y.8,'87; (1'95) 1330 Market st.
MUSSEK, FIANCIS IRBFR (b'60) -Pa.1 85; (l'94) ; 262 Vernon St. ; oftlce, 1327 Broadway: 10-12, $1: 30-4$; (1319).

Iutchınor, John F.-Man.1,96; (1'00) ; 3215 Brookdale Ave; offlce, 577,14 th St.

NELSON, CHAS, ROBT (b'71)థ-1'a.12, '95; (1'95) ; 5500 College Ave.; onllee, 1327 Broadway: $2-4,7-8$

NUSBAIMEK, i'AULINE S. $\left(b^{\prime} 58\right) \oplus-$ l'a. 7,$00 ;\left(l^{\prime} \theta 0\right) ; 2346$ Valdez St.

Oberg, John U.

$$
\text { (see Berkeley.) }
$$

Okabe, Takujl (b'73)-Cal.7,'08; (\$); 602 Vebster St.

Olmsted, Theodore (b'57)-Cal.1,87; (l'87); Supt. Merritt 1lospltal.

ORR. JANE (b'72)- Mass.7,01; (1'04): 1400,8 th St.: $10-2$

OVEREND, EDIUUND J. (b'54)-S.C.1,83, Pa.2,'84: ( $\left.l^{\prime} 84\right) ; 1222,4$ th Ave.; offlee, 1322 Rroadway; $12-3$.

PARDEE, GEO. COOPER (b'57)-Ger.14, 85: $\left(1^{\prime} 85\right) ; 072,11$ th $\mathrm{St}$

PARISH, HENRY I,INOLN (b'65) क-Cal.1, 90 : (1'90); 1138, 8th St.; office, 1418 Broadway.

Paterson, Edw. Mortlmer (b'44)-Mass.1, '71; (1'86); 1947, 8th Ave.; 2-4, 7-8.

Paterson, Effe Walte (b'71) - Cal. 7,01 ; (I’01); 1947, 8th Ave.; 2-4.

Peterson, Alfred C.

(See San Francisco.)

PIERCY, ARTHUR T. (b'57) - Ia.3,'86; (1'91): 136 Bollta Ave, ; office, Bacon

Bldg. ; $11-12,2-4$.
Plumb, Jary C.-N.Y.13,'86; $\left(1^{\prime} 86\right) ; 3510$ Telegraph Are.

Telegraph Are.
POMEROY, (BEO. T. $\left(b^{\prime} 7 \overline{7}\right) \oplus-\mathrm{Cal} .8,06$; (I'06); 594,27 th St.; offlce, Delger Bldg. : 2-4.

POND, JAMFS IIAVEN (b'62)\&-Cal.8,'10 (1'10); 1032 Bella Vlsta Ave.; offlce, First National Bank Bldg.; 11-12, 2-4.

PORTER, WM. SURBER (b'67)-Pa.1,'96; (l'95); 348 Edwards St.; offlce, 1206 Broadway; 3-5.

POSEY, ADDISON CORNELIUS (b'49)Ky.1, $75 ;\left(l^{\prime} 77\right) ; 465$ Vernon St. POWFLL, ALVIN (b'83) $\oplus$ - Cal.2,'08

PRATT, ALBERT HARLOW (b'44)-Cal.1 72 , N.Y.10,78; (1'76); 418 Vernon St. offce, 1307 Broadway; $10-11,1: 30-3$.

Prindle, Edw. C. - Ilch.1,76, N.Y.1,77; $\left(l^{\prime} 86\right) ; 5601$ Grove St.

PRUETT, WM. CLIFFORD (b'79)-Cal.7. RUTT, WM. CLF, 10th Ave.: office, 582, 15 th St.; $2-4,7-8$.

Purcell, Edward (b'83)-Ore.2,'11; (l'12): 3404 Andover St.; offlce, First Natlonal Bank Bldg. : 10-12, $7-8$.

PURNEIL, WII. WHIPPER (b'69) $\oplus$-D.C.3, 93; (1'01); (South Berkeley); oftlce, 1225 Washington St.; $10-11,2-4,7-8$.

PURVES, JOHN (b'67) 4 -Cal.7,'99; (l'99):

729,17 th ; offlee, 577,14 th ; $1: 30-4,7-8$.

QUEIROLO, CAESAR A. (b'67) $\$$ Switz.4. '97; (l'98); 892 Isabella St. ; 1-3, 7-8. Rea, Thos. (b'80)

Telegraph Ave. (b'72) $\$$-Cal.4,00, Cal:7,
REINLE, GEO. G. 01; (I'01); 334 Park View Terrace; office,

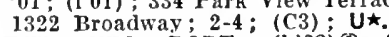

RFID, WM. ROBT. (b'68) $\$$-Cal.7,08; (1'09) ; 3726 Ilnden St.; office, 3820 San Pablo Ave.

RICKEY, ADDISON W.-Ill.1,74; (1'77) 779 , 5th St.; (offlce, South Berkeley).

ROBERTSON, JOIN W.

(See San Francisco.)
Robinson, Edward B. - ont.5,'91; (l'94) 4330,13 th Are.

ROWE, CHAS. H.†-Cal.1,'98; (1'98) ; 119 , 13th St.; 2-4, 7-8.

Rutherford, Gemel B. H.-D.C.3,'80; (l'85); 725,39 th $\mathrm{St}$.

Rutherford, Walter S.-Cal.2,03; (l'04); 577,14 th St.; offlee, 550, 27th St.; 11-12, $2-4,7-8$.

SAMPSON, JACOB HENRY (b'66) \$-Tex.2, 94 ; (l'08); 520 Chetwood St.; office, 577. 14 th St.

SANBORN, WM. KELLY (b'65)-Cal.2,'93 (1'94) ; 1379, 8th St.; office, 1307 Broadway; $11-12,3-4: 30$.

Schumann, H.-Mo.10,76; (1'89); 31 Randwlck Ave. : offlce, 1307 Broadway.

Schutz, Milton Henry (b'83) - Ill.6,'08; (l'13); 506 Thayer Bldg.
Selfrldge, Clarence M. (b'60)-Pa.9,'87; (1'87); 2631, 11th Ave.

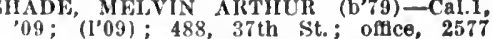
San Pablo Ave.; 2-4, 7-8.

SIIANNON, JAMES M. (b'55) -K-Ky.4,'81; (1'93) : 1729 Telekraph Ave.: 2-4.

SHIELDS, LILLIAN (b'74) $\oplus$-Cal.1, 02 ; (l'02); 4120 Gillbert St.; offlee, Unilon Savlngs Bank 13Idg.; 2-4.

SIIUEY, SARAII ISABEL (b'50)-Cal.2,78 (1'79); 1829 Adellne st.; office, 1307 Broadway.

SILL, EDIV. RICHARD (b'62) -N.Y.1 89 ; (1'90); 1451, 11th Are.; oflce, 1203 E, 14 th St.: 1-3, 7-7:30.

SIMON, ERNEST G. (b'73) $9-M 0.20,04$; (l'05); 607,34 th St.; offlce, Unlon Savings Bank Bldg. : 10-12, 2-4.

SLA VICH, JOIÍN F. (b'81)-Cal.2,04; (1'04); 181 Santa liosa Ave.; offlee, Coml. Bldg. SMITII, ARTIIUR CLARKSON (b'82)Cal.8, 07 ; (l'07); 486, 27th St.; offlce, Cal.8,07 ; $\left(l^{\prime} 07\right) ; 486,27$ th St. ;
Oakland Bank of Savlngs Bldg. ; $1-3$.

SMITH, ARTHUR M. (b'72) 4-Cal.1,'99; (l'99); 748 Adeline St. ; 2-4, 7-8.

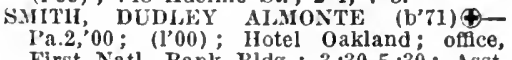
First Natl. Bank Bldg.; $3: 30-5: 30$; Asst. 'rof. Chil. Dis., Cal.8; 0 b.

SIITH, KIRBY B. (b'69) $\oplus-$ Cal.1,96; (l'96); 2012, 47th Ave.; office, $4704 \mathrm{E}$. 14 th St. : $2-4,7-8$.

Smith, Lawrence Benton (b'61)-0.6,86; (I’00) ; 3252 E. 14th St. ; $1: 30-3: 30,7-8$. Smith, Leon J. - Mo.20,86; ( ); 1018 Broadway.

Smith, Thos. Orde (b'46)-Ire.3,78; (l'04) ; 2335 E. 17 th St. ; $9-10,2-4,7-8$.

Smith, WIIber Gray (b'59) - Md.1,'80; (I'88) ; 5231 Locksley Are.

Stansby, Chas. John (b'51) - Eng.17,79, Eng.11,15,'80, Belg.1,'82; (l'10); 713 Telegraph Ave.

Stark, James (b'46) E-Cal.4,'89; (l'90); 1410,8 th St. ; 1-4, 6-7:30.

Stark, John Henderson (b'86)-Cal.8,'12 ; (1'12) ; 1410 W. 8 th St.

Steele, Fredk. A. (b'63)-Vt.2,'84; (1'99) ; 524, 13th St.

Stine, Reuben Linden (b'63)H-Ill.4,'91; (1'12); 1607 Telegraph Are.

Stout, John C. (b'46) E-Mo.10,78; (l'82) ; 1152 E. 14th Are. : 1-4, $6: 30-7: 30$

STRATTON, ROBT. THONPSON (b'62) 496,20 th St. ; 2-4.

Stratton, Wallace C.-H-Mass.5,78; (1'93) ; 142 Kempton Ave.; oflec, 473, 14th St. STRIE'TMANN, WM. H. (b'80) 8 -0.1,05; (1'12); 344 Warwick St.; offlee, Central Bank Bldg.; Assoc. Prof, Physlol., Cal.૪; 1.

Sundstrom, Edw. Sigfrld (b'80)-Rus.1, '10; (l'12) ; 492, 37th St. ; 2-4, 7-8.

SUTHERLAND, HESTER M. ${ }^{-}$-Cal.1,'02 ; (l'02); Fablola Hospltal.

SUTHERLAND, ROBERT THOMAS (b'83) Cal.2,08; (1'08); 1215 E. 14th St.; 1-3, $7-7: 30$.

AN, BENJ. RALPH.

(See San Francisco.)

SWALGER, LUELLA STONE (b'71) office, Union Savlngs Bank 2-4.

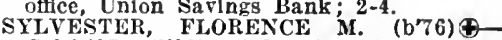
Cal.2,'07; (1'08); 716 Arimo Ave.; offlce, HOMS HAYWARD

Pa.2,'87 ; (l'87) ; 2949 Summlt St. ; offlee, Dalziel Bldg.; 11-12, 2-4; Prof. Ophth. Otol., Laryn., Cal.8; (B19); OALR.

THOMPSON, J. GOODWIN (b'65)@-Cal.2, '94: (l'94) ; 1204 Telegraph Ave.

TIFFÁNY, EDW. V. (b'65) - Cal.2,'94 (1'95); 2360 E. 22 d St.; offece, Bacon Bldg. 2-4, 7-8.

odd, Francis J.-Mich.1,'83; (l'94); 342 Grand Ave.; office, Security Bank Bldg. $11-12,1-3,6-7: 30$. ODD, JAMES HAMILTON (b'46) - Cal.1. 577,14 th St. : $2-4$.

Tomkins, Jos.' Geo.-E-Cal.4,'91; (l'91) ; 2258 E. 15 th St.

TONER, MARK FERDINAND́ (b'67)-Pa.2 '93; (1'99); (Berkeley); offlce, First Natl. Bank Bldg. 
Toogood, James Farle (b'80)-CaJ.6,08; (l'09): 3301 Telegraph Ave.; otlce, Thayer Blde: $2.4, i-8$.

Uth. Eranzelline Brlgham-E-111.8,'86: $(1 ' 86): 1307$ Marnolla St

TCKERSON, JOHX IRVIXCS-Cal.2,05: $\left(l^{\prime} 05\right)$ : 1559, 8th St.

YON ADELEXG, LiNW. (b'67) \$-Cal.2, 92: (I'92); 40\%, 29th st.; oflce, 1206

Broadway: 2-4; 1'rol. Med.. Cal.8; 1.

Wakefleld, Wm. IIow ard $(b, 76)$-Cal.8, 12 ;

(I'0 $0^{\circ}$ : 1842 . 19th Are: ofice, Unlon Savings Bank: $2-6$

Wallser, John Carl-Swltz.1, it: (l'st); not in practlec: $300 ;$ Bona sit.

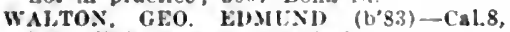
12; (l'12): Merrlt Hospltal.

Walworth, Chas. Harper.

(See Berkeley.)

Watson. Mary J. (b'40)-Cal.5,02; not in practice: 2829 , 11th Are.

Weatherbee, Lewls B. (b'80) F-Cal.t,09: (1'10): 6203 Colleze Are. : 1-4, $7: 30-8: 30$. WhAVER, DON DICKIXSOS (b'89)-Mich.1 I1: (1'il): St. Yrancis Apts.

WEBER PHLLIP HENRY (b'SI) - Cal.1,

Webster. Herbert T. (b'36) E-0.2,'69; (1'82) ; 2826 Myrte St. 10-11:30, 2-4.

Weltman, Chas. L.-Cal.t'9s: (l'9s) : 630 E. 11 th St.: oflce. 655 F. 12th St.

wrixik, ADOLPH FREDK (b'63) Cal.7,'98; (1'98); 2319 Webster St. ; ottce 1225 Broadway; $2-4,7-8$.

Wescheke, Emil ( 152, $91 \mathrm{~h} \mathrm{St.:} \mathrm{ottlce,} 515$, ith St. : 10-12, $t-8$

West, Jacub Hlal (b'6i)-Cal.l,'94; (''94); 778,14 th St. : offee, 1027 Broadway; $9-8$. WILCOX, WILBUR J. (b'50)-Cal.2,'85 (1'86) : $1043 \mathrm{E}$. $18 \mathrm{th}$ St.; $2-4$.

Wilder, Chauncey H.-III.II, $95 ;\left(l^{\prime} 04\right) ; 953$ F. itth St.

wilkes, Farrington-Cal.2,94; (1'94) : 4238 Howe st. : oftice. Commerce" Bidg.

WINSLOW. THOMAS HARTLEY (b';0)111.15,"96; (1'07): (321 Ramona Are., Pled mont) : offlce, Unlon Sarings Rank Bldg. -I; OALR. *

WOOD, JAIES BITRIS (b'68) "92: (1'96): 6002 San Jablo Are. 1 -3.

WORLEY, HARRY FRANCIS (b;i) $\phi$ 13.9,96: (1'01): 1075, 53d St.: oftice. Bacon Bldg. : I:30-4.

WYTHE, STEPHEN+Cal.1,95; (1'96) 4247 Terrace St.; omce, $57 \%, 14 \mathrm{th} \mathrm{St}$ (B19) ; OALR.

OAK PARK IBRANCH P.O., SACRA. MENTO), 600. SACRAMENTO

HAWORTH, MORIRIS WELLS.

(See siacramento.

Ort, Alexander-Ky.I."81; (l'96).

OAKVILLE, 264, NAPA

Leonhardt, Saml. C. (b'66)-I'a.2.8:? (考)

OCCIDENTAL, 200. SONOMO

YORIEEST, RICHARD A. $\left(b^{\prime} 60\right) \&-\mathbf{Y} Y^{*} 10$ 83: (1'92).

OCEAN BEACH, 100, SAN DIEGO

CRAWFORD, WIJ.LAM W. (See San Dlego.)

OCEANO, 250. SAN LUIS OBISPO

Beyer, llerman (1'36)-X.X.10,'69; (1'03):

OCEANPARK, 3.119. LOS ANGELES

ANDEISON, OSCAR D. (b*11)-111.18.02 (I"08).

CRISPIX, EGERTON LAFAYETTE - Md. . 06 ; $\left(\mathrm{l}^{\prime} 13\right)$.

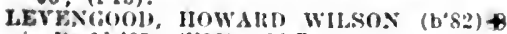
$-r^{\circ} a .110^{\circ} 05:\left(1^{\circ} 06\right) ; A L R$.

Magee, Irvin I (b'59)-0.1.83: (I'11).

Nuttall, John I'rlce, Jr. (b':8)-Ky,.5,02 (l'10).

Owens, James $\mathbf{S}$

(8ee Los Angeles.)

Reed, Wm. John.

(See Los Angeles.)

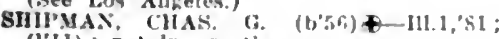
(I'I): not in practice.

Smlth, Alonzo I), (b'41)-X. Y.1, 6i; not in

practlee.
THOMAS, CHAS. I'RESTON.

(Liee 1.0s Angeles.)

ron Wedelstaedt, Geo. S. $\left(b^{\prime}-4\right)$ II-Minn.B. 97 : (l'97).
DCEANSIDE, 673, SAN DIEGO

Amick, D. H.-Ore.I'S8: (I'S8).

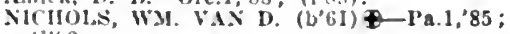
$(1.42)$

KFID, KOHT. S.-O.3,98; (1"04).

OILCENTER, 35, KERN

liahrenhure, ('eo. k: (b'>0)-C'a1.6,03; (1'03). OLEANDER, 116 . FRESNO

ICIIOISON, ALBRHT R.-Mleh.1,"79; (1'95).

ONTARIO, 4.274, SAN BERNARDINO

B.ICON, DAYID N.A-Tenn.9,92: (1'00)

hall, fredk. Spencer-X.1.5,95, MU.3,04 $(1,9 i)$

Davls, Edward J.-N.Y.3, 6 :

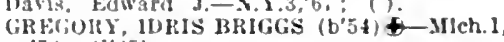

Henke, Geo. Bens. (b's4)-Cal.5,'13: (1'13).

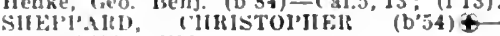
Ont. $4.90 ;(1999)$

Slmpson, Win. s. (b'4i) H-Jll.4, 6 ; $\left(\mathrm{l}^{\prime} 02\right)$ OALR.

Smart, Eillott l'lummer (b'85)-Cal.9,'12 (1'12): $\mathrm{Ob}$

Tremper, Rolt. H.-Mich.1,75; (1*98); not In practice.

WARMER, CHAS. ANDREWF-MICh.I,03; (l'OS).

ORANGE, 2,920, ORANGE

CHAPLISE, FRANK LEITOY (b'i9)-III.6 06 : $\left(1^{\circ} 06^{\circ}\right)$.

DOMAN, ARTILR HENIRY (v'-9)-Cal.9 '11; (1'I1).

Tumman, Jos. E. (b'53)-111.18,'97 : (1'9i). (b.67)-Mo.20,'99 13) : Nember Kans. Med. Soc.; OALR PARKER, IDA 13. (b'69)-('al.6,95; (1'95) ROYER, DANIFL FRANKI.IN\$-Pa.2,75 (1'y-).

\section{ORLAND, 836, GLENN}

IGIICK, S.MLEL $\left(b^{\prime} 54\right) \mp-0.14$, , S\$: (1'9I)

Martin, Dale L. (b's6)-111.6, (04: (I'II).

OROSI. 500. TULARE

Denninger, I'aul (B.-H-II.4,'39; (I'90).

Furtuey, Ilenry-Ia.1,'85; (l'ss): not in iractice.

HAMILTON, ISAAC BEESON (b'58)-l'a.1 $83:(1,88)$

THLFBLOO1), W.M. F.\$-Ind.5,97; (1'97).

OFOVILLE, 3,859, BUTTE

Giates, W. F.-E-Mo.10,'s3; (1'si).

KAIRSEL, JAIFS IIENRY M. (b'tt)'3.2.68; (]$\left.^{\prime} 76\right)$.

KUSEL, FII A (b'74)\&-Cal.1,95: (1'95)

Legzet, Cordella I3urt-Cal.1, $89 ;(1 \times 90)$.

Newbold, Edwin Henry (b'il) II-la.4,93. 111.11,00; (1'93)

REAHD.I. THOS, B. 7 -Cal. 2.82; (1'85)

Tucker, klljah J. (2'50) E-Mo.10,'s2; (l'91). Whlelng, Frank 11. (b'6)-Cal.1,06; (l'06)

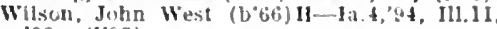
00; (1'95)

OTAY, 140. SAN DIEGO

Warner, ("has. (C. (b'-4)-Cal.5, 03,1 'a 2,05 ( ).

\section{OXNARD, 2.555, VENTURA}

AVERT, RALHH W. (b',6) -III.6, 02 (l'05): S

Korts, Jenj. Frelk.-Cal.1.'95; (1'95).

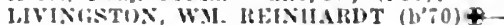
$111.11,43:(1.99) ; \mathbf{S}$.

MAULHARIT, ADOH'H ANTONE: (b"i4) - Ias3.1,98: (1'99). PFFK, ALLEX II. (b'78)+Cal.1,04:

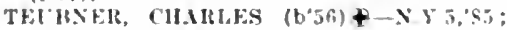
(I'8.8)

PACIFIC BEACH, 75. SAN DIEGO

Adam. Ilerman (i. (b"ai)-0.3.94: (1"0A).

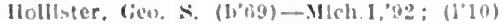

PACIFIC GROVE, 2,384, MONTEREY

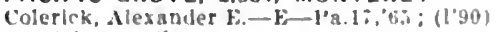

not in juractio.

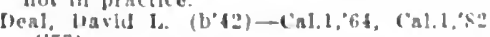
$(1 \% ;)$.

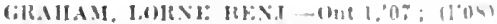

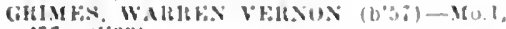

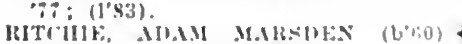

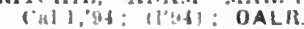

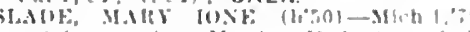

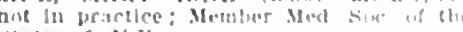
siate of $\mathrm{x} y$
Swayze, Ormlston W--II-0.7,89: (1'89).

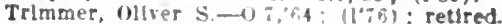

YATHS, HENAY NEWTON (bof) -0.2 $91 ;(1.92)$

PALA, 100, SAN DIEGO

Jckinley, Frank J. (b'\%)

PALMS, 150, LOS ANGELES

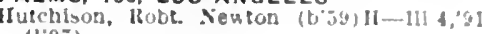
(1' 97 )

MOLTEXSEN, WM. S.

(See Santa Monlca.)

PALM SPRINGS, 150. RIVERSIDE

COF'MAN, HAHRY L. (b'66)-1'a.11.01 (1'01): (Indisn servlce)

PALO ALTO, 4.486, SANTA CLARA

Adams, Wm. Louls-La.l,'90; (1'9I); not In practlce.

Alderton, llenry Arnold (b'63)-X.1.1,85; ( ) ( 13.3517$) ; A L R$.

RIACK, IIOWARl) (b':2)\&-0.3.96: (I'00). Burke, Marlon (b't:) - Y.14,95; (1'01): not in practice.

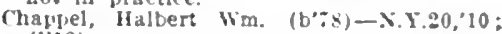

Coyle, John (b'39)-N. Y.5,69; (1',6)

EI.Y, LEOXIII, W

(See san Franelseo.)

JOII.HOX, EHITH ECGFNIE (b"72) X.Y.20,0z; $\left(1^{\prime} 0-1\right)$.

KIRK, Joslih H. +Cal.1,06: (1"06).

Sleser, Arthur Wm. (b'3)-Mid.7,05; not

In practice; r'rof. Anat., Cal.11; (FI).

MORluW, HowaItD.

(See San Francisco.)

MOSIER, CLELIA IICEL \& Md.,00; (1'00); G

NAGEL, CARL S. GLNTIER.

(See San Francisco.)

I'hilllps, La Forest E.-Cal.1,'99: (l'99).

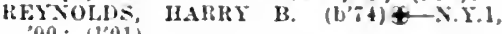
; (101)

EXNOLIS, ROBT. GALIAHER, JR. (b'il) t-Cal.2,03; (1'04).

ongers, Lee Omar (b'5I)-X.Y.10," 4 ; (l'iti); not in practlee.

PENCER, JOIIN YAIY'BELI.

(see san Franclsco.)

wetl, Wllbur Maurice.

(Siee San Francisco.)

Thomas. Benj. (b'0)-Cal.2.01; (1'01): OALR. *

THUMAS, JEROME IBEERS $\left(b^{\prime} 6{ }^{*}\right)+$ X.Y.S "9:2; (1'10) ; (B19); OALR.*

WHBEL, RAI LIMA:

(see san franclsco.)

WILIAAMS, THOS. II. (b"il) \& $\$ .1,01$ (1'01): $\mathrm{s}$. WILSOY CARL GHOVES $\left(\mathrm{b}^{\circ}: 9\right)+$-Cal.:

PARADISE (R.F.D., ORLOFF), 93, BUTTE Compton. Andrew J.-E_O.:-

Lorett. Win. I3. (b'ti)-(1)

MACK, WM. H.-O., St; (1'Sio)

PARLIER, 350. FRESNO

Mallarian, Krekore II. (b'70)-Mich., ,00: ( ) : R.F.I1. :

PASADENA, 30,291, LOS ANGELES (Nee suuth l'asadena

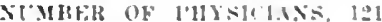

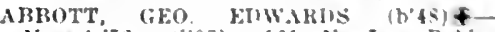

IIsss.1,72: (1"95): 161 N. Los Robles Ave; unice, chamber of connieres B!dg.: $9: 30-1$ :

Aterbury, Boudinot $r .\left(b^{\prime 3}\right)-\mathrm{N}$ y $10,7 s$

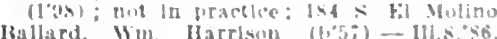
lil.11 (1) (1) staven lik: : 11:12, 2.4

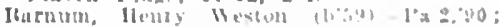

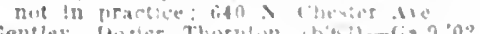

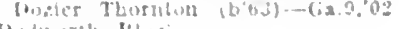

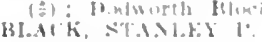

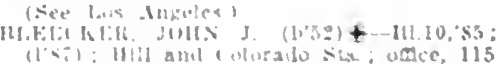

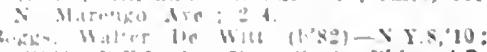

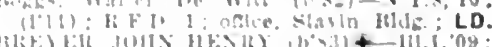

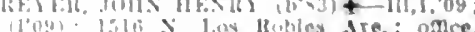

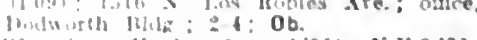

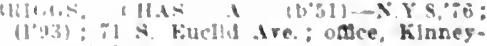

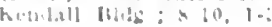


BRIGGS, SOLON (b'45) $\oplus-$ N.Y.3, 69 , Illch.1,75; (I'95) ; 139 s. Euclid Are. $8-10,1-2$.

IBurr, Wm. Alton (b'40)1l-Ill.4, 69 ; not in practlco; $440 \mathrm{~S}$. Lake Are.

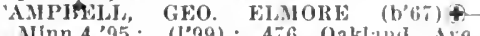
oftce slavin 13ide: $: 246.5$

Case, Gldeon S.-MIlch.I,'00; (1'92); not in

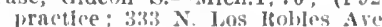

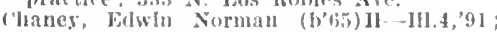
(1'97) ; 914 E. Colorado st.; ottice, Dodwortis Bldg.; $i-11$.

('haphn, Alonze Itussell (b'59) - Ill.1,83

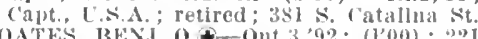
N. leuclid Are: $1-3 ; \mathrm{s}$.

coNUT, JOS. DAYTON (b'T) +-X.M (i) (I04): 284 l'almetto Drlve: onno S. Louis Islock; $10: 30-11: 30,2-4$.

commor, Frank M. (b'69)-I'a.11,97; ( 150 Arroyo Drive; $0 p$.

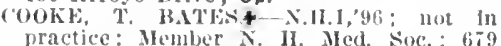
I'rospect $\mathbf{S}(1$.

oolidre, John W. (b*53) - Mich.5,79. (l'08); Dodworth Bldg.

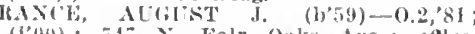

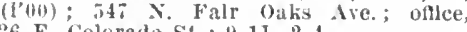
crosly, d. lloward Ky.4,7s; 696 santa Barlara st.

Cundy, W'm. A. (b'60)-Colo.3,'96; (1'01) $395 \mathrm{~s}$. Nentor St.; offtec, 1)odworth Bldg. [Dalton, John $C\left(b^{\prime} 49\right)-0,3,{ }^{\prime} i t ;\left(I^{\prime} 01\right)$; not in practlee; 264 Marengo Pl.

1)avies, David Chas. - (b'33) - III.6,'81; (1'99) : 1413 . Marengo Avo

IDACON, GEO. (b'55) +-H11.1,'85; (1'87) Commerce Bldg.; 10-11:30, 2-4; 0b.

DeFord, Paul F. (b'67) II-MId. 1,89; (I'00) 155 x. Marengo Ave. ; $10-12,2-4$.

1)LIYORTH, WM. DENNISON (b'T1) \& office, Chamber of commerce Bldg.; 9-I2, 2-4; (BI2) ; OALR

Engelinann, Rosa (b'60)-III.9,'s9; ( ) ; 1235 San l'asqual $\mathrm{St}$

ENYES, ADALBERT (b'63)థ-Aus.7,89; $\left(1^{2} 97\right) ; 170 \mathrm{~N}$. Orange Grove Ave.;

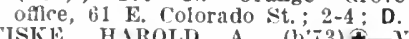

FISKl, H.AROLD A. (b'73)‡-it.2,95; (l'01) ; 389 N. Las Robles Arc., office, chamber of Commerce B]dg; $10-12,2-4$

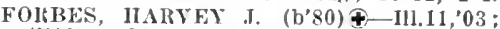
(l'10); 1365 N. Lake Ave.; offlee, $65 \mathrm{E}$. Colorado St

Force, Jacob 1. (b’43)-N.Y.3,' 71 ; (\$) ; 651 S. Pasadena Are.

Fox, John Jos.-Mass. 5,76 ; not in practice: 786 sunset Ave.

Fraser, Alexander $C .\left(b^{\prime} 5 \pi\right)-Q u e .1,7 \tau$; not in practice; 567 Jackson St.

Fundenberg, Geo. Baer (b'63)-Pa.I, '87; (1'12) ; 727 E. Colorado St. ; 9-10, I-3; Ob.

Gilmore, Mlarcia-Nlich.1,'84; (1'S5) ; 535 Ladera St.

Goodno, Win. C.-II-Pa.9,'70; not In prac-
tice; 397 S. El Molino, St.; Emer. Prof. lled., Pa.9.

GRIFFITH, HARRY MELVIN (b'3)€ 461 E. Colorado. St. ; 9-12, 2-5; (BI2) OALR. *

CRINNELI ${ }^{2}$ FORDYCE $\left(\mathrm{b}^{\prime} 44\right)-0.9,{ }^{\prime} 73$; $\left(1^{\prime} 85\right)$ : $690 \mathrm{E}$. Orange Grove Ave.; office, il2 E. Orange Grove Are.; 10-12, 1-3.

HAGADORN, MIARY L. (b'57) \& CaI.6, 92 (1'92) : 376 E. Colorado St.; 2-4; (A2).

HAMAAX, IACIUS H. (b'45)€-III.I, 78 ; () Nlember State Yred. Soc. of Wis. $1045 \mathrm{~N}$. Lake Are.

IIOIT, HENRY AMRHOSE (b, T5) —-Mass 1 , 05 ; (); Member Mlass. Med. Soc.; I8IS Walworth Are.

Hopkins, Cary N.-Ill.11,92; (1'94) ; R.F.D. I

HIJIFEVILA, BANL. LOUIS.

(See Los ingeles.)

ACKSON, JOSEPHINE A. (b'65) - - 111.9

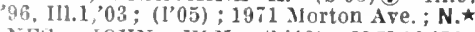

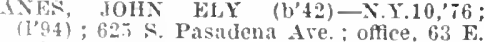
(19.9); 62.5 . Pasil
Colorado st.; $2-4$.

Jones. Tabbot-N.Y.10, 78 ; not in practice;
Kessier, Howard Dysart (b'76)-I'a.9,'01; (I'09); 503 S. Los Itobles Are.

KING, CHAS LEF (b'53)†- H18.6, 80 (1'94); $70 \mathrm{~s}$. buclial dve.: office, Centril

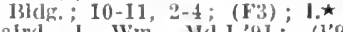

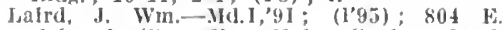
Colorado St.; oflice, lnion Sarings lhank I3ldg.: 10-12, $2=4, \tau-8$.

Jank. James (b'31)-N.Y.10,79; (I'S8) ; not In practice; $25 \mathrm{~W}$. Nountain st.

LIBBY, ARTIIU1' A.
(Sce Los Angeles.)

IOClWOOD, CHAS D. (1)6S) —-IH.6,'96; $\left(l^{\prime}(00): 295\right.$ Markhan $1^{\prime}$. ; offee, Dodworth Ilddg. ; 11-12, 2-4; $(A 7,(3, \mathrm{~F} 3) ; \mathrm{S} . \star$

LOVEJOY, EDWARD $D$.

(Aee Los Angeles.) (1'07); Ilotcl Maryland; Offke, Chamber of commerce Bldg.; $11-12,2-4$; $S$.

MACKLIX, HOBT, KIFKPATIICK (b'85) If1.6,'1 I; (1'11); $1147 \mathrm{~N}$. Nentor Are.

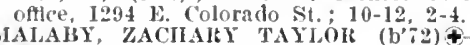
Mo.24,93; (1'9i); 666 N. Raymond Ave. oflice, Chamber of Commerce Rldg. $2-4 ; \mathrm{s}$.

MARKOLF, HARRY FOSTER (b'81)† Ilass.I, 08 ; (1'10) ; 320 Center st. ; oftice, Sl.2vin Bldg.: 10-11, 4-5.

MARTYN, GEÓ.

(See los Angeles.)

MATTER, LAOYII E.MLESON (b'T9)-III.I, 04; (1) Mlember Wls. State Med. Soc. $321 \mathrm{~N}$. Marengo Ave.

MATTISON, EUGENE (HIAIINI (b'81)↔ office, Chamber of Commerce Bldg.; 10-12, $2: 30-5 ; \mathrm{S}$.

MATTISON, FITCH $\therefore$. b. (b'61) 4 -III.11 88: (l'98) l'res. lled. soc of the State of Cal.; 295 W. Californta St.; office, Chamber of Commeree Bldg. : $2: 30-5$, (F3) ; S.

MATTISON, SAIIUEL, J. (b'75)\&-IIl,6, 04; (1'04); 125 Bellefontaine St. ; office, Chamber of Commeree bldg.; $2-4: 30$.

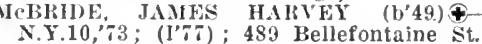
offee Dodworth Bidg: 10-12: (E1,13) : $\mathbf{N}$

office, Dodworth Bidg.; $10-12 ;(\mathrm{E} 1,13) ; \mathrm{N}$. (1'99); 417 s. Mentor Are.; office, Slavin Bldt. ; 10-12, 2-4.

MeGarren, Chas. Win. (b'58)-Ill.1, 79 ; not In practice; 466 Fillmore $\mathrm{St}$.

Ickellar, lames Henry (b'83)-Cal.6,'05: (l'05) ; 481 Eldorado; offlee, Chamber of Commerce Bldg. 9-11, 2-4; (BI2); Op. (1'04): 747 Center St. ; office, Chamber of Commerce Bldg.; $10-12,2-4$.

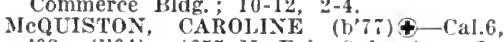
'03; (1'04); (655 พ. Fair Oaks Ave., La Vina); office, Slarn Block.

Mitchell, Lllian S. (b'73)-111.9,'99; (l'13);
336 W. Bellevue Drive: 10-12, 2-4; OALR. MIXSELL, RAYMIOND BOILFAU (b'82)N.X.1, 07 ; (l'12) ; 491 Arbor St.

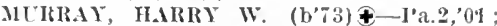
$\left(1^{2} 01\right) ; 760 \times$. El Molino Ave, ; offlce, $B$ O. Kéndall Bldg.; $10: 30-11: 30,2-4 ;$ G.

NEWCOMR, ARTIIUR T. (b'T1)廿-Md.4, 40 s. Maréngo Ave. 10-12: (F3) : I* NEWCONB, AlTIUR T. (b'71) \&-Md.4, CaI.6,'08; (1'08); 69 S. Wilson Av.

oftce, 44. Marengo Ave, 10-12, 2-4. (Altadena); offlce, Colorado and Fair Oaks Sts.; $9-12,1-4$

Nichols, Walter E. (b'75) H-N.Y.9,03; (1'03); I15 N. Marengo Are; 10-12.

NIXON, ANNE WILSON (b'4I) \&-Cal.I, '92 not in practice; 461 E. Colorado St. 06 ; (1'06); 1290 Summit Are.; office, 309 E. Colorado St.

ORBISON, THONLS JAMES.

(See Los Angeles.)

Osburn, P. P. (b'83)-Cal.6, 09 ; (1'10); not in practice; $735 \mathrm{~N}$. Los liobles Are.

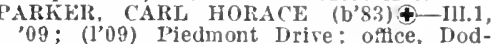
worth Bldg. ; 11-12, 2-4.

Parker, Kezia' A. (b'76)-Colo.2,'06 () :

198 E. Orange Grove Are.

Patton, Edward A. (b'58)-0.9,'80; (l'89): 194 N. El Molino Are.; ALR.
Pyle, llenry G.-O.7,94; (1'09); 520 0akland Are.; oflice, central Blds.

freed, James Itoss (b'80) - .Ilch.I, 05; (l'0.5) ; $645 \mathrm{~N}$. Haymond Ave.; offlce, (1312,19) : OALR*

Iteynolds, Harrlet Chapman (b'69) II-0.23, .96: (1, 10): $564 \mathrm{E}$ E. Colorado St.

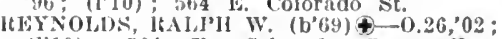
(l'10): 564 E. Colorado St.; office, $1: 30-4 ;($ B12) ; OALR. $\star$

Ithyan, Walter Wesley (b'72)-0.3,03; Itichardson, Aubrey J. (b'59)-Pa.9,'82 ; retired; $27 \%$ E. Bellevue Drive.

HoIBEHTS, WM. HVMES (b'72) \&-Cal.J, 94: (1'94); 461 E. Colorado St. ; 9-1; (IB $1,3.12, \mathrm{t} 9, \mathrm{~F} 3)$; OALR. $\star$

Hose, lichard T. - Mo.2, 70
Merldian Are.; $9-11,2-4$.

Itosenberger, Edmund 'S.-Pa.2,78; (1'93) ; 48 S. Falr Oaks Ave.; $8-10,4-6$.

loSS, JOILN WAITON (b'43) †-La.1, '68; Medlcal Director; Cant., U.S.N., retlred; It.F.U. 1.

Rowland, Francls F. (b'47) - Pa.2,73; (I's8); 225 State St. ; 11-12, 2-4.

loyal, Álbert 13. (b'53)-1Il.1,'77; (1'94);

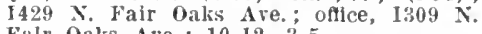
Falr Oaks Are, : 10-12, 3-5.

HEILK, IIENIRY IIOWARD (b'65) \&-Pa.2, '87; (1'88); 268 S. Orange Grove Ave.: SIIERIY, HENRY-Ill.10,80; (1'95); $46 \mathrm{I}$ F. Colorado St.

Smlih, Asbury G. (b'59)—Mass. 1,'83; (1'89) ; 152.5. Lake Ave.
SNITH, STEPHEN

Mlch.1, 05 ; (1'07); N.

(b'5e) STEHMAN, HENIY' B. (b'52)€-1'a.2,'76;

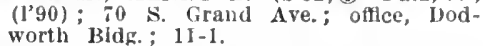
SWEARINGEN, SAMLEL P. (b'52)-0.14, '83; (1'86); 133 . W. Green st.; office, 10 TOWER, FRANKLYN J. (b'68)-Ill.11, 90 ; (1'03); 99 E. Colorado St.; 2-4.

Tracy, Coyle J. (b'67)-Md.4,'97; (1'98); 778 N. Los Robles st.; office,
Commerce Bldg. : $10-12,2-4$.

COmmerce Bldg. ; $10-12,2-4$.
UP DE GRAFF, TIIAD S. (b'37)-Pa.2,'s3 ; (I'93); 233 Columbia St.; oftice, Chamber of Commerce Bldg.; 9-I2,3-4; OALR. $\star$

Van Riper, Cornellus S. (b'37)-N.Y.1, 59 ; (!'99); not in practice; 718 N. Raymond Ave.

Van Slyck, Darld Bernard (b'29)-N.Y.6, 52 ; (l'8i); 116 S. El Nollno St.; offlce, 307 E. Colorado St. : $9-11,2-4$

(See Los Angeles.)

Wakefleld, James I.-IIl.1,'68; (1'87) ; not in Dractice; 287 LIncoln Ave.

ARNER, JAMIES HENRY (b'60)๑-N.Y.8, '99; retired; Member Mich. State Med. Soc.; 973 Elizabeth St.; (B1I).

Waterman, Wm. Whltney (b'74)-N.Y.1,04; not in practice; $840 \mathrm{~N}$. Mlchigan Ave. EIR, FILANCIS ALVIN (b'38)

Wickens, Louls Edward (b'36) E-0.2,73 ; $\left(1^{\prime} 97\right)^{\prime}$; not in practice ; 715 N. Mentor Ave, WIIAAMS, CHAS. C. (b'55) \&-Mass. 1,'86; (I'99) ; 767 , Ist St.

WILLIAMS, THOMAS ARTHUR (b'65)థ-
Cal.1, 01 ; (1'01); 906 E. Orange G10re Are.; office, SIarin Block; $2-4,7-8$. WILSON, JOHN MILLER ( $\left.\mathrm{b}^{\prime} 69\right) \uparrow-$ Ill.11, "02; (1'05); 26 N. Chester Ave.; ottice, Woodhouse, Henry J. (b'50)-Pa.2, 89 ; $\left(1^{\prime} 96\right)$; not in practlce; R.F.D. 1

WligHT, THONIPSON B. (b'64)-0.14, 86 ; (1'07) (Altadena) ; office, St. Louls Block; 2-4: I'rof. Nled., Cal.9.

Yacoubi, Hazarabed Boghos (b'64)-Mo.1,
'91, Pa.2,'93; (1'09); 469 Jackson Ave. office, Chamber of Commerce Bldg. ; 2-5.

ZUILL, WM. LEANDER (b'54)--Pa.1,'84; $\left(1{ }^{\prime} 04\right) ; 427$ s. Mfaclison St.; office, St. Louis Block ; $9-4$; Prof. Otol., Laryn. and Rhin., Cal.9; (B12).

PASO ROBLES, 1,441, LUIS OBISPO

CLARKE, BENJ. FRANKLIN (b’54)€Cal.1, $7 ; ;\left(P^{2} 77\right) ; \mathbf{G}$

Paso Rolites Hot Springs. 


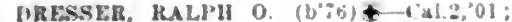
(101)

Glass, James H. (b.57)-3/d.3,'84: (1"86).

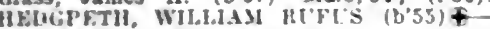
Y10.1,"91; (1'91).

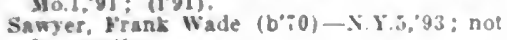
in practice.

STRATTOX, 1.EON B.-M11Ch.9:99; (1'01).

PATTERSON, 73, STANISLAUS

Yeld, Augustus Marton (b'60) - Call.,96: Cal. 6,"03; (l'96): S.

Perdue, Labon C.-Mo.1, 80 : $\left(1^{\prime 00}\right)$.

PATTON, 25. SAN BERNARDINO

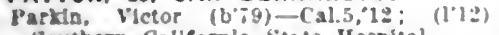
Southern Callfornla State Ilospltal.

REIL:, JOHX A. (b'\%5)-Mo.5.98; (I'09)

Stmpson. Jessle Harrlet (b"73)-Cal.5,05 (1'05)

Warte, Edwla (b\%5) H-Pa.9.99; (l'01)

webster, Geo. Max (b'; 3 ) H-Cal.5,"02 ; wlleox, Franklin s. (b, 4$) \mathrm{H}-\mathrm{Pa}_{2}, 9,94$;

(1'12)

PENNGROVE, 100, SONOMA

MULLkR. A. C.

PERRIS, 500, RIVERSIDE

Coppel, Frank II. (b'64)-I'a.2,'91; (1'91) not in practlce.

Reese, J. W. -la.3, "70: (l'Rt

SHELDON, D. W. (b'72) \pm Colo.2. ${ }^{2}$ \% (1'10).

PESCADERO, 984, SAN MATEO

THOMPSON CLARENCE V' (b'SI) + Cal.1,03: (1"04)

PETALUMA. 3,880, SONOMA

Anderson, Mlexander $\left(b^{\prime} 4:-3\right)-M a s s .4,64$ (1?:6).

Anderson, James Ciarfield (b'8J)-Cal.i,o9 (1'lo).

Beckurltb, Fdmund ( $\left.b^{\prime} 36\right)$ H-0.7;6.5; (l'ks) oot in practice.

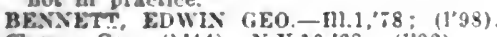

Cleary, Geo (b't4)-X.Y.10,"6s; (1'99).

Dunean, Robt. B.-Mo.1, $3 ;(1 ' 30)$

Gossaze. Ilarry S. (b'68)-Cal.1,"93; (l'94)

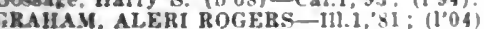

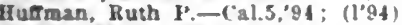

IVASCOVICH, GEO-Cal.1; 8 ; $(1 ; 8)$

Lorentzen Harold L (b'65) H-Cal.5, 00 Cal.i,02: $\left(1^{\circ} 00\right)$

Lamsden, Arthur Gomez (b'8:)-Cal.7,06 (l'09)

MeALLAY, MARION B. (b'7s)-Cal.5, 05 (1'0s)

MeXear, John A., Jr. (b'69)--( all.1, 93; (I'y4); not in practice.

O'Brien, John T. C Cal.2,'9n; (1'96)

PEOILES, STCART Z. (b'-3)+-Ca1.2.04 (1'04).

URBA., KURT (b'62)-r'al.2.'83; (I's3)

PIEDMONT (OAKLAND P.O.), 1.719 ALAMEDA

BRTCKEKHOFF, G. ERWIS

(See Oakland.)

HLNTINGTON, WM. IKESSEIS

(See Oakland)

Mouser, Bend. Truer (b'33)-\$.X.10,75: $(178)$ : retlred; l'rof. Hyz. and Sanltation. Cal.8.

Murphy, John Y. C. (b'5l) -Mass 6,"9!; (

Hiskiow, THOH. H.InTL,

(Shee Oakland.)

PINOLE, 798. CONTRA COSTA

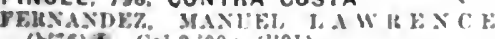

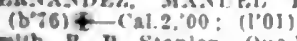

swich, R. II. Sianley-que.I,96: (1'99).

PITTSBURG, 2.372, CONTRA COSTA

BAUTKR, LLCCIAN A.CAl.4,99: (l'99).

GRFGORY, FRAVK STARR $(b, 55)+$ rail 100: $(100)$.

PLACERVILLE, 1.914, ELDORAOO

telsenrlng. luther AT. (b'iA)-Nels.",01 (1'01).

Mullkeli, A. $\rightarrow\left(11^{\prime} ; 6\right)$

RAXTZ, STHIHE IIRTEL ( 23 : (1'90)

RECKRKS, WM. N'GT'STt's (h'ipi)

Cal, 1,01: 11.01)

Wrenn, John Q. (b'+1)-0.1, :B; (1'Q1).

Wrenn, Jos. T.- "al.:.0B: II"A0)

PLANO. - KERN

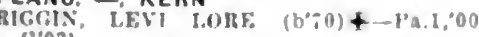
(10) 031
PLEASANT GROVE, |39, SUTTEH

Gearbar. Sylvester ('arpenter (b'6s)-l'a ?

95: (1'10).

Pleasanton, 1.234, ALAMEDA

Case, falm A.-MIch.1,70; (I'86)

Cope. James H1. (b"i3)-Cal.8,09; $\left.1 l^{\prime 09}\right)$

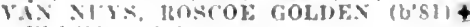

$111,11: 11,1: 2)$

PLYMOUTH. 500, AMADOR

IBusan. Thrs, (b'45) - Pen. I, bx: (1'\%6)

not in practlce.

Norman, Wm. A.-Cal.1,8: : 1 $\left.1^{*} 48\right)$

POINT ARENA, 497, MENDOCINO

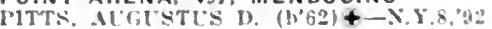
(1PY:3)

POINT LOMA, I00. SAN DIEGO

Coryn. Herlert A. W. (1, 63$)$ - Eng 1.,'s? (l'oii); not in practlee.

FOSTE. It it do It

(see san llego.)

IATISHR. HYMA.

(see san lliego.)

Ross, I,ydla (b'59)-111.s,88; not in practice.

Van Pelt, Gertrude Wrokofr $\left(b^{\circ} 56\right)$ - Ja.i, 's6; (1'00): not in practice.

Wllcox, Emma Dudles (b'0) II-Mo.5.'91, X.Y.11,9:2: $\left(1^{*} 10\right)$

Winkler, Itose-11-111.19,'98: (1'00).

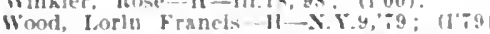

POINT REYES STATION, 100, MARIN

Caranagh. Stephen I'atrlck (b'b3)-1'al.1. 33; (1.94).

POINT RICHMOND (RICHMIOND P.O.) 2.100, CONTRA COSTA

ABBOTT, CLARK LOIREZO (b'i)-111.1.

CAMPBELL, PALMERSTON CORNICK

(b'68) + Wo. I8,90; (1'90);
Scroggs, Walter R. Cal.1,95; (1'96).

POMONA, 10.207, LOS ANGELES

Armstrong, Eudolyhla ("oncklín (b'39)-

P'a,, $69 ;$ (1'88); not in practlce.

Balrd. James clinton (b'53)-Tenn.5," 82

Ja.1,"s3: not in practlce: 904 Wllllams st.

BIXRY, FDWARD MARCEII.CS (b'59) \& $2 \mathrm{~d}$ Si. and Garey Are.; 10-12, $8-4$; OALR. *

BIEED, IOREYI Y $\left(b^{\circ} 63\right)+-111,203$ (l'95); $2+2$ W. Holt Ire : offlce, Pomona Falley Hospleal; $9-5$; LD.

Cashon, P.A-Ky,, $64 ;\left(I^{\circ} 96\right)$; not in practice: it2 Ni. Park St.

Crank. F. Derritt-H-I 13,"43: (1'si)

D.IIS, SHFLDOX FITCH $\left(b^{\prime}, 54\right)+-I a 4$ 99: (1's8) 612 N. Park ire once. Inrestment Bllg: $10.12 .2-5 ; A L R$.

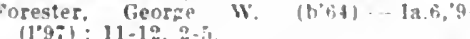

Garcelon, Frank $(1,+8)$-Me.1, i0; (l'se)

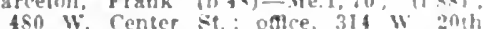
St. ; $10-30-12,2: 30-3$

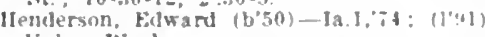
Inlon Hlick

HU1.MFs, WIL, HAMMOND (b.s.)-III.6. 11: (1'12): 412 : Towne Ave.: omce I'omoria Investment R!dg.; $10-1: 3-5$ II"NTINGTON, FH.I.A F. (b'62) J(1): nut ln practlce: Member III Siate Med Som : RF $\mathrm{F}$

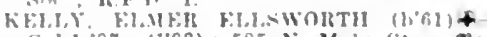
Cal 1, $9 \%:(1 ' \$ 8): 5.55 \times$ X. Maln St: nflee Hanvler Hlnck: $2-3$; $\mathbf{S}$.

KF.YYO FRANK P1ERCE (b.53)

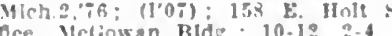

nupe lawrence E, 11.12): Inrestment Hlale; S.

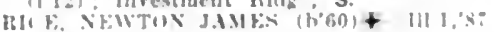

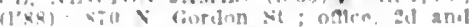
"Thumiss sia. z-?: Ob.

smlth, Rulut lice (bial-Tenn. 1, 0a: $\left.(1)^{\prime} 13\right)$ :

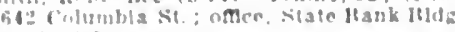

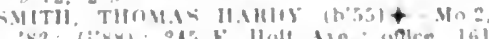

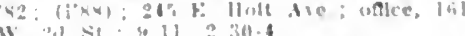
swlvilt jus $K(1, i)+$ tolo 3,02

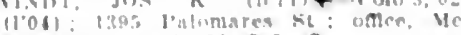

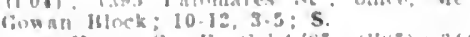

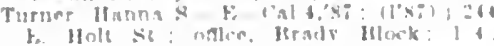

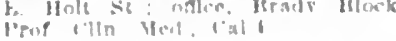

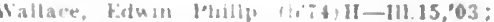
(1'06): Gilbos and Gartell sits : cmce, Mc. liowan llork: 10-12,

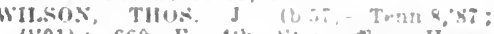

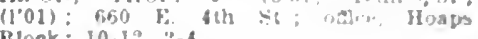
Block: I0-12, 2-4.

POPE VALLEY. 266. NAPA

Hesersdor?

PORTERSVILLE, 2.696, TULARE

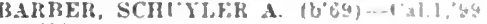
(1.99).

Vales, Oral I-Cal.:,01; (1'0I)

Daly. James F.-Cal.t.9́s: (1'05).

kmers, Edgar ian Vurmail (b'89)-ont 1 , 11: (1'1:)

Fimory, 16. J. Ilunter-11 $0: \because 82 ; 1$

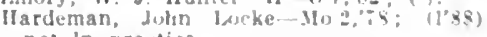
not in vractire.

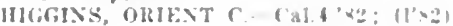

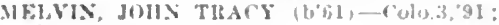

(I'08).

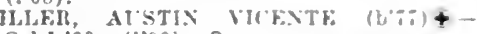

Cal.J.99: (1'99): S.
AKLFY, HEWT.ETT W. (b'S0) + -N. Y.1: 04; (l'0í).

shepard, Leonaru A. (b'52)-0.9,73; re tired

PORTOLA, 100. PLUMAS

Bennet, Irvln Edmuad-Colo -. $\$ 9.1$ I'a.2,'91 (1'12); $\mathrm{S}$.

Ilensel. Lawrence M ....In. Is \&.5: (1.93) l.asswell, Bert James-(al.4.01; (1'01)

POTRERO, 80, SAN DIEGO

Mertumann, Bernard $5 .-11-I^{3} 9.25$ (1'sis).

POTTER VALLEY, 576, MENDOCINO

IIopkins. Thomas I'-Cal.2.'S0; (l'80)

PRINCETON. 309; COLUSA

imlther, John .1. (b':2)-Culo.3,93; (1'01).

PUENTA, 220, LOS ANGELES

Bedford, Alfred I.-Pa.?:?; (1'93); 393 F. St.

QUINCY, 519, PLUMAS

Goray, James l'billp (b'6i)-Mass.1.91: (1) 0 (1)

STIN, WY EARNSHA (b'iq) \&-Cal.: "06: (1'09).

RAMONA, 2IO, SAN DIEGO

IIanford, Wm. James $(1,35)-X .1 .9,233 ;(1)$

Scolt, Gavin S, -Scot.5,'S4; (1'97).

RANDSBURG, 1,000 . KERN

Garvin, thas. Luts $\left(b^{\prime \prime} 0\right)-(2 a) 1,95$, ( 1296$): S$.

RAYMOND, 500, MAOERA

TOMp, Thomas M. (b'T0) H-IIl. 10,'?: (1'98)

REO BLUFF, 3.530. TEHAMA

IMAII.FY, FRANK JAMES $\left(b^{\prime}, j\right)+$ ('aI.I.

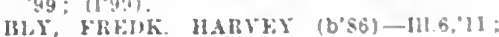
(I'11).

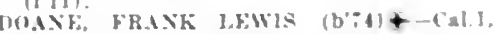
$03:(1,0: 3)$

(INFI, WIITER (b'9)-Cal 1.04: 1104

l.ewls, buma A.-Ca! i, as: (1+99).

OWEX, JOS. ALIEX (b'59) + Ky., SS (1)

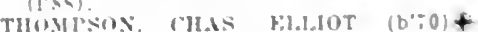

('all, 96 : (1994): G.

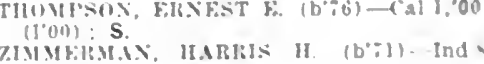

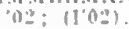

REDDING, 3,572, SHASTA

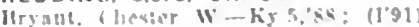

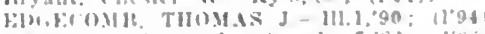

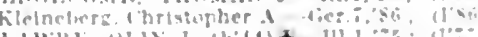

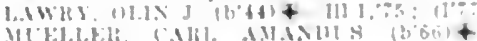

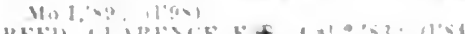

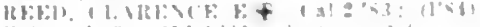

IB.ilini.

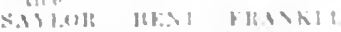

3. $37.31 .03: 11051$

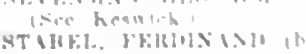

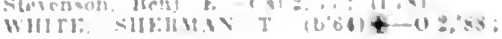


REDLANDS, 10,449, SAN BERNARDINO Allan, Robt. T. (b'60)-Scot.3,'86; (1'88) : 707 W. Highland Ave.; 9-12, 2-4.

AVEY, JOHN L. (b'65) †-Ky.2,91; ( ( 101$)$ 215 Cajon St.; othice, 213 ('ajon St. ; 10-12. BLYTIL, THOS. MOORE - N.Y.10,'80 (1'88); 229 Cajou St.; $9-12,2-4$.

BURKE, WM. P.t-Ill,11,94; (1'94); Bow Ct.; offleo, Masonle Templo.

CIULCH, BEXIAIIN FIRAKIIN (b'58) + -Ma.3,88; (1'ys); 118 Cajon st.; $9-1$;

Davls, Carroll Church (b'86)-La.1,'10 ; ( ) ; 118 Cajon $\mathrm{st}$

Denlson, Mary-1I-Mlleh.5,90; (1'98); 411 Cajon St.; 11-3.

DIhl, WALLACL W. (b'T)†-Pa.1,00; (1'12); 125 Cajon st.

FOLIRNS, FRANK HOWARD (b'84)-1a.4, 10; (1'11); 314 W. Colton St.; offlce, Y. M. C. A. Bldy.; 10-12, 1 :30-4.

Haskell, Jenry M. (b'52) - N.Y.10,78; (l'01); not in practice; 122 The Terrace. Hill, lloward Gilman (1)'76)-Cal.2,03; (l'03); 14 Clifton Are. ; oflee, 105 Cajon St. ; $8: 30-10,3-5$.

Hill, Merrill Washington (b'49) H-Pa.9,'71 ; (l'ss); 14 Clifton Are.; ofllee, 105 Cajon St. ; $8: 30-10,1: 30-3$.

HJLLIARD, CARLOS G. (b'z)థ-Conn.1, '04; (l'10); 122 Cajon St. ; 10-2; S.

IDE. CHAS.' EDWARD (b'74)-Hll. , 00 ; (l'01); Snnnyside near Cypress; offle, Iasonic Temple: $2-4$.

Jolinson, Wm. M.- E-0.10,'s5; (l'93) ; 27 W. Ollve st. ; $9-11: 30,2-5,6: 30-7: 30$

Lingle, Geo. E. ( $\left.b^{\prime} 70\right)-0.2,92$; not in practice; 9 E. Cypress Are.

MaCDÓNALD, EVERETT A. (b'TI)థ-0.1 95 ; (l'00); 204 W. Highland Are.; oftice, 107 Cajon St. ; $9-11,2-4$; OALR.

MOSELEY, GAYIL GRAHAM-Ky.1,'94; (1'99); 449 Chestnut Are.; oflice, 126 Cajon'St. ; 10-12.

POWER, WALTisR B. (b'74)-N.Y.1,95. (1'02); 233 Cajon St.; $10-12,5-6$.

SANBOŔ, CHRISTOPIIEH ALLEN $\left(b^{\prime} 55\right) \oplus$ -N.Y.10,'82; (I'88); 127 Clifton Are. offlce, Masonic Temple; 10-11, 2-4

SHRECK, JOHN ADDISON (b'64)థ-Ill.1, '91; (l'02) ; 328 Alvarado St.; office, 5 th

Spoor, Wm. L. (b'62)-N.Y.8,'86; (l'87) ; orange and State sts.

STILILIAS, DANL. C. (b'42) $\odot-111.6,69$. not in practice; Hember Ill. State Med not in practice; Hember

Soc., 414 W. Colton Ave.
Stolz, Mary Adelaide (b'53) H-N.Y.11,97; (l'97); 351 Cajon St. ; $10-12,5-7$.

SWEENEY, MARTIN' J. (b'67)-N.Y.10 93; not in practlce; Mrember Med. Soc of the State of $\mathrm{Pa}$.

TALTAVALL, WM. A. (b'59)థ-N.Y.1,'85 (l'03) ; 428 Walnut Are. ; offlce, 126 Cajon St. : $10-12,2-4$.

TYLER, HOELL (b'55) (-N.H.1,'81; $\left(1^{\prime} 94\right)$; Wynne, SIdney 112 Y. (b'70)-Mass.1,'94; (1'95): 242 Cajon St. ; 10-12.

REDONDO (REDONDO BEACH P.O.), LOS ANGELES

Crutcher, Ernest.

DA VIS, THEODORE GARRISON.

(See Los Angeles.)

REDONDO BEACH, 2,935, LOS ANGELES BUTT, ERNEST GEO. (b'86) \&-Mo.20,'09; (l'09); Pd.

Hancock, David Robt. (b'70)-0.3,92; (l'94)

Hembree, Atlas T. (b'70)-Cal.1, 05 ; (l'05)

REDWINE; 25, MENDOCINO

Callinan, Daniel F., Jr (b'67)-0.14,'91 (1'01).

REDWOOD CITY, 2,442, SAN MATEO

Bowerman, Albert C. (b'50)-Ont.1, 76 ; (1'87).

CHAPIN JOHN ENDICOTT (b'il) $\uparrow-M 0.2$ 09; (1'12); Member Mo. State Med. Assn. ; ObG.

ROSS, JOS. LOUIS-III.1, 79 ; (1'79).

REEDLEY, 1,800 , FRESNO

HARE, JOHN DANL. (b'57)-Mlich.1,'90 HAWKINS, GEORGE AUGUSTUS $\left(\mathrm{b}^{\prime} / 1\right) \oplus$ Whitney, Lucy (1'95). (1'97).
RIALTO, 300, SAN BERNARDINO

CREDIFORI, DAVH) B. (b'64) †-Me.1, McIICGH (1'03) TIIOS. RICHARD (b'70)థMich.5, 01; (l'i1): Member 11l. State Ated. Soc.

RICHMOND, 6.802, CONTRA COSTA

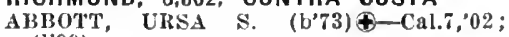
(l'09).

BAREEX, HAWIAS NATHAN (b'77)कN.Y.19,00; (1'02).

IBIAKE, CHAS. R. (b'68)†-Cal.2,'91; (1'92); OALR.

Brown, 'Warren Bateman-0.3,88; (1'89). CAlPENTER, HAkRY $I_{0}\left(b^{\prime}, 5\right)$ f-Cal. 7 . 04; (l'09); La Belle Bldg.

CUNNINGHAM, W. EVGAK (b'78)-Cal.1 04: (l'04)

Delninger, Marguerite $\left(b^{\prime} 76\right)-\mathrm{Ca} .2,02$; (1'02); 0 b.

Fraser, Wm. W. (1'48)-Ill.8,'72; (1'97); 607 Macdonald Ave.

LIJCAS, WM. STHLLWELL (b'76)\&-Cal.1. 01: (1'01).

MAPTIN, LOUIS A. (b'76)-Cal.7,'02; (1'04).

Riley, Louis K. (b'42)-Cal.1,'82; (l'82). VESTAL, HALL $\left(b^{\prime} 74\right) \oplus-C a l .1,00$; (l'00) S.

RIONIDO, -, SONOMA

SCHMELZ, CHAS. JOSEPH $\odot-C a l .2,{ }^{\prime} 94$; $\left(1^{\prime} 95\right)$.

RIO VISTA, 884, SOLANO

DOWNING, WM. EVERTS (b'80)@-Cal.1, 03; (1'03).

Makemson, Winfleld S.-0.1,'84; (1'87)

McKINNON, ALOYSIUS J. (b'70)-Cal.2 '03; (1'04).

Powers, Allan Raymond (b'81)-Cal.1,'12; (1'12); OALR.

RIPON, 200, SAN JOAQUIN

BISSELL, NELSON CLIFTON (b'69) Cal.1,04; (I'05); $\mathrm{s}$.

CHIAPELLA, JOS. O. (b'80)-Cal.6,'05: (1'06).

GOULD, NED BURKE (b'80)-Cal.1,08; (I'08).

REVERBANK, -, STANISLAUS

Pressley, John B. (b'59)-Cal.2,'82; (1'83).

RIVERDALE, -, FRESNO

BOYD, WILBUR TRAVIS (b'75) $\odot-C a l .9$, '11; (1'11).

RIVERSIDE, 15,2i2, RIVERSIDE

ATWOOD, HARRY ALLEN (b'62)
Ill.4, 90 ; office, Ópera House Block; 10-12, 2-4.

BAIRD, JAMES GORDON (b'46) (-)-Qne.1 70 ; (1'90) 1213 Main St.; 10-12, 2-4.

Bailard, J. Stow (b'62) H-Pa.9,'89; (l'89)

BROWN, ARTHUR LEON (b'72)(-0.1 '96; (1'11); 107 Whittier Pl.; office, 833 Main St. : 10-12, 2-5.

Main St. ; $10-12,2-5$.
Brown, James F. (b'49) H-0.13,75; (1'89): 1134 Main St.; OpA.

Brown, Oscar S.

(See Winslow, Ariz.)

CIJARKE, LOUISE HARVEY (b'59)(4Pa. 7,92 ; (1'93) ; 1046 Orange St.; 10-12, 2.4.

COLBURN, JEFFERSON MARTAIN (b'58) $-M 0.26,95$; (1'97) ; 809 W. 3d St. ; offlee, 7th and Main Sts.; 10-11, 2-5.

Currie, Albert Harlan (b'85)-Hl.8,'11 (l'11) ; 1132 W. 8th St.; offlce, 946 Main St.; $9-11: 30,2-5,7-8$.

Darling, Orange C. (b'56) E-0.2,'82 ; (l'96) ; 698 , 14th St.; offlce, 883 Main St.; 10-12, $2-4$.

DICKSON, CHAS. S. (b'49)-I11.6,77; (l'88); 370 Main St.; offlce, 859 Main St. ; $10-12,2-4,7-8$.

GIRDLESTONE, CHAS. WM. (b'68) Que.1,'92; (1'93); 1305 Main St.; 8-10 $2-4$.

GRIFFTTH, THOS. R. (b'65)థ-Mass.5,'98 (l'01); 10 Aurora Drire; offce, 764 Main St. ; 8-10, 2-4.

HOLLAND, JOS. H. (b'55)-Ill.4,'88 : (l'97); 681 Magnolia Are.; office, 10th (1'97) 681 Magnolia Ate.;
and Main Sts.; $2: 30-4: 30$.

Jarris, Jos.-N.Y.10,'66, Ont.4,'67 ; (1'79) ; 1090 Pine St.
Johnson, Robt. B. (b'39) $\mathrm{H}-0.7,69 ;\left(\mathrm{l}^{\prime} 00\right)$; Kansas Ave.; offlee, 10 th and Main Sts.; $2: 30-4: 30$

Ialoy, Sarah E. (b'50) H-Ill.4,'90 ; (1'95) : 527 , 7th St.; offee, 560, 7th St.; $9: 30-$ $10: 30,1: 30-3: 30$

MARTIN, HUGII RALI'II (b'75) -III.11, '01; (l'01); 1023 Maln St. ; 11-12, 2-4; S. MeSHANE, BERNARD E. ' (b'70)-III.11, '95; not ln practlce: Member Kan. Med. Soc.; 1252 Almond St.

MOSS, ROBT. E. (b'73) $\oplus-$ Mo.27,'97 ; (l'09) ; 160 E. 8th ; offee, Loring Bldg.

outwater, Sanil. (b'57)-N.Y.5,79; (l'y9) ; 166 IIidalgo Pl.; offlce, 8th and Maln Sts. ; $9-12$, after 2 ; (B1); OALR.

PAYTON, WM. B. (b'56) Mich.1,81; (1'92); 450 Orange St.; ofllce, 859 Main St. ; 8-10, 2-4, 7-8.

Pone, Geo. Chester (b'61)-N.Y.5,'89; (ま). ROBLEF, WM. WAILACE (b;2)\$-Cal.1. '95; (1,96); Main St.; S.

Sawyer, Wm.'B. (b'54) -Mass.1,79; (1'82) ; 202 E. 7 th St.; office, Dickson Block; 9$11,2-4$.

Scott, Henry H.-Ont.4,60; (1'80); Chlcago Ave.

Strong, Arthur Ernest (b'75)-N.Y.15,98; (1'11); 52 Aurora Drive; office, Loring Bldg.; $9-12,2$ :30-5; OALR.

Sulcer, Abrahan A.-Ill.1,'66; (1'87) ; 1062 9 th St.

Tilden, Adelbert D. $-0.2 ; 76 ;(1 ' 90) ; 466$ W. 8 th $\mathrm{St}$.

Trevelyan, Geo. Hamilton (b'79)-Cal.6. '07; (l'07) ; 10-12, 2-4.

TUCKER, GÉO. EUGENE' (b'79) 03; (1'06); Linden St.; offlce, 764 Main St, : $10-12,2-4$.

VAN ZWAIUWENBURG, CORNELIUS (b'62) $9-M l c h .1,85 ; \quad$ (',00); 1111 Main St.; offlce, Glenwood Bíock; 11-12, $3-5 ; \mathbf{s}$.

walker, Archlbald Dunn (b'65)-Ont.5,'88; (l'96); Magnolia Ave. (Arlington).

WALKER, ARTHUR W. (b'74)-Neb.6,04; (l'04); 1397 Maln St.; offlce, 826 Main St. ; $9-11: 30,2-4$; OAĹR.

WILLS, WM. BURDICK (b'75) -IIl.11 '01; (1'01); 461, ith St.; offce, 946 Main St.; 10-12, 2-5.

Whiting, John A. (b'62)-Mlich.7,'87; not in practice; 432 Magnolia Ave.

WOOD, EDWARD HENRY (b'68) - -Md.3 94; (1'08) ; 633 Magnolla Ave.; offlce, 745 Magnolla Áve. ; 8-10, 1-3, $6: 30-8$.

ROCKLIN, 1,026, PLACER

Fletcher, Henry D. (b'74)-Cal.1,'97; (1'98). Rugg, Sumner Perclval (b'53)-N.Y.10,'79; (1'79).

ROHNERVILLE, 600, HUMBOLDT

Callihan, Robt.-Pa.2,74; (1'84).

ROSECRANS (VENICE P.O.), -, LOS ANGELES

PALMER, FRED. W. (b'72)@-Mich.1,'94; Capt., M.C., U.S.A.

ROSEVILLE, 2.608, PLACER

ASHBY, RICHARD HARRINGTON $\Theta-C a 1.1$, '86; (1'86).

Koesberg, Josephine C.-Ore.1,'90; (1'90); not in practice.

Wheeler, Jos. Suley (b'55)-Scot.9,12,'9I; (l'94).

VOODBRIDGE, BRADFORD (b'63)థ-

Cal.1,'83; (1'84).

ROSS, 556, MARIN

HUND, FREDK. JOHN (b'58)థ-N.Y.5,'79 ; (1'82); S.

Hund, Harry Otto.

(See San Rafael.)

ake, Edward Hills.

(See San Franclsco.)

UGGLES, HOWAPD EDWIN (b'86)-

SACRAMENTO, 44,696, SACRAMENTO

Affleck, James Thomas-Cal.1,'89; (1'89) : 7th and $\mathrm{J}$ Sts.

Arbogast, Jacob Lewis (b'67)-Cal.1,99; (1'99); 1524, 17th St.; offlce, $7-9 \frac{1}{2} \mathrm{~K}$ St. ; $10-12,2-4,7-8$.

ATKINSON, FOSTER LINCOLN (b'60)థIIl.1,85: (1'86); 1317, 23d St.; offec, Baldwin, Wm. Hedges (b'50)-Pa.2,75 ; $\left(1^{\prime}, 6\right) ; 1130 \mathrm{~N}$ St.; offlce, $1029,2 \mathrm{~d}$ ' St. $10-12,2-4$. 
BARSARD, HAROLD DEWEY (b's ) Cal.1.12; (1'12); Sacramento Counts

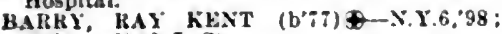
(1.01): 2512 L $\mathrm{St}$.

BEATTIE, WM ALFRED (b*s)-Cal.1. '12; (1'12): 2411 1' St.; otice, 801 i st: $11.12,2-4$.

Boyer. Jephtha Sllas-111.1,'93.

(1'01) :

$\mathrm{K}$ st.

Brlggs, Asahel F. (b'51)-111.11,96: (1'08)

Z211 G St: omce, $1005 \mathrm{~K}$ St. : 11-12, 2-4. Brigrs, Evelyn-3Id $7^{\circ} 00 ;(1,00) ; 1300$ I St. BRIGGS, GEO. ABIEL $\left(b^{\prime} 80\right)+C a 1.2,05$ (106) 2015 E st : offce, $1003 \mathrm{~K}$

BRIGGS, WALLACE ALVIN $\left(b^{\prime} 48\right)$ + Michini: $(1 ; i): 1300$ I St: oftece $1005 \mathrm{~K}$ St. : $:-4$.

BRIGGS WILIAII EILERY (b'53) -

0.12,7: "(l'79): 2209 II st.: offlce,

$1005 \mathrm{~K}$ St. ; 10-12, $\$$-4; (B1,19); OALK.

Buckmann, Hensy H. (b's2) Cal.1.0s: (1'10) 3734 Magnolla Ave $2-5,7-8$.

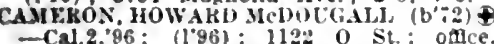
Fiks' Bldg.; OALR,

CARTWRIGHT, CIIAS. OGLFN-MIch.1,'89: (l'94); Odd Fellows Tetuple; 10-11, 2-4,

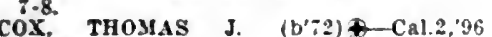

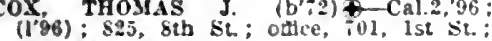
1-3, $7-8$.

Cranemiller, Mary M. (b'60)H-Ill.4.'90; (to90); \$15, 10 th St.; $10-11,2-4$, after : CULYER, JOUX THAXER (b, 0 ) 00: (l'00); 3500 Marnolia Ave.; 1-3; 6-8

Darts, Artbur Iee $\left(b^{\prime} 97\right)-$ I11.8.'13: ( ):

Soulhern Paclfc Company Emergency Ilospltal.

Dillon G. Parker (b'72)-Mllch $\approx 96$ (1'05); 910, 14th St.; oflce, $710 \mathrm{k} / 2 \mathrm{St}$ $11-12,2-4, i-8$.

DRYSDALE, GEO, NELSON (b'66)-N.S.1. 91 (1'93): 2225, 28th St, oftce, 9th and $K$ Sts. : $2-4$

DEFFICX. GEORGE WOODWARD (b':1)CaL2,'98; (l'98); 1014 H St.; office. Parmers and Mechanles Bldg.; 10-12 -4.

Fdouard Chas. (b'75)Que.1,'99: (l'03) ; Suller Club; oflce. Peoples Bank Bldg: : 10-12, 2-4; OALR.

Mdi,05; (l'05); 1123 il st; oflce, Parmers and Mlechanles Bldg.: 2-4; S.

PAY, PRANKLIX GOBLE (b'65) '86; $(1.86)$ : 1729 G' St.; oflee, ith and J Sts.; 2-4, 7.8 .

Flsher, John Hajes (b'80)II-Cal.5, 05 ; (l'05); 910, 14th St. ; oflce, $7191 / 2 \mathrm{~K}$ st. $10-12,2-4,7-8$

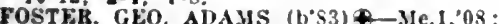
(1'11); 2518 Q St.; oftce, $1005 \mathrm{~K}$ st 11-12,2-4; $\mathrm{S}$

GUNDRUM, FREDK. F. (b'80) ₹-Ma. os: (l'10); 2300, ist ire.; oftice, 1021 , 10th St. $3.5:$ Lo

Haake, Chas. Henty firutue (b'88)_-.Y.I.1 13: (): Southern Paciflc Company' Emergency Hospltal.

Ialkht, $X$. llerhert-II-111.4.'90:

Hagelsteln Bldr. : 2:5, $j-8$

ANNA. WM. JANES (b'64)-Cal.1.'\$9 (189): $9104 \mathrm{~d} \mathrm{St}$

MARIS, JUNIES RIKAINARI (b'82) Cal.1;08: (J'08); 528 บ J st. : 3.4.

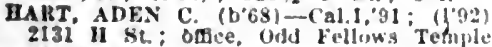
$10-12,2-4$.

Natch. Pred W.-1'a.2,73; (1'65): State Capltol: (E.13)

HAWOHTU. MUIRIS WELIS $\left(b^{\prime} 75\right)+$ Mo.28,01; (l.01); (2:18, 2d lie.. 0lak Park): once, \$21 J Si, 10.12, 1:30.5

MENDERSON, ANDRFW MITCIELL (b'69) (9-Cal.1.93; (I'y4): 1600 il St.: offce. $1005 \mathrm{~K}$ St. 2.4

lenderson, Wlillam Howard $\left(1,1^{\prime}, 8\right) \mathbf{E}-\mathbf{C a l} 4$ 94: (1'95): 2024 H St. : aftce, 1204/ SL: $10.12,2.4,7.8$.

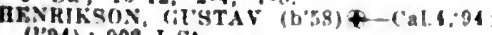
(1'94): $902 \mathrm{~J} \mathrm{SL}$.

IHgeins, Aubrey rrancls (b'84)-I'a 1.05 OWABD. BLRT Foster (b-1) $10-12$.

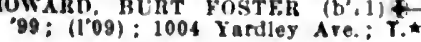

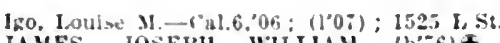
AMES, JOSEIII WILLIAI $\left(\mathrm{b}^{\prime}, 6\right)+$ Cal.1:00: $\left(l^{010)}: 1315\right.$, azd St: oflice. Jamison, Win. Riley

(1'95); $15 \mathrm{~h}$ st.; $9.5,7.5: U$.

ohnson, kdwat finoch $\left(b^{\circ} 80\right)-111.6,11$ :

(1'11); Sacramento Couniy IIospital.

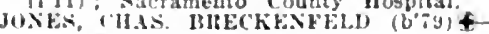

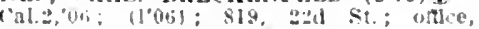
j021, 10 h st. $3-7 ; \mathbf{S}$.

KHLLOC(; DONALD A. (b'36)-XY 10 s9; (1'95); i15. 17th $\mathrm{St}$ : oAce, Hagel stein IHldg.: $11.5, i-8$

K If U 1. L. P'lRAXK (b'73) \&-Cal.I, 00 (100): 4 th and $k$ ses. 10-12, 2-4. $7-8$ La Brie, Fdmond-Q

IINUSA? WM, KINKADE (b"i) $¥$ ral.2, 01; (1.01): 1716 N St.; oflce, $1005 \mathrm{~h}$ St: $3.5 \%: 8: \mathbf{S}$.

LOIZEATX, kiOLARD S. (bo)-X.X. 02: (10s): 816, 14th St. : oftice, Board of Health; $8-5 ;$ LD.

LOOK, HALLKCK 11. (b'62)-N.Y.1,'s: (1'90) : 780 1" St.; once, 1027, th sh $9-12,2-4,7-3$

LYNCII, JERKE GEO. (b'78)-Cal.1,06; (I'06); 1320. 18th St.; oftice, 1021, 10th Martin, James Thurston (b'50) H-OMich 5 '83; (1'85); $1200^{\circ}$ o St.; Q Qtice, l'eoples Bank Hldg. ; $10-11$, 2-4, $;-8$. McDONXELi, CLAREXCE il. (b'79) $\$$ 110.28,09; (1'09); 1519 , 13th St.; oflce, yth and $k$ sts. : $-4,7-8$.

ICKEE. CHAS. KRADFOKD (b'85)-D.C.1 $07 ;\left(1^{\prime} 07\right) ; 2405$ M St.; oftce, Elks lildg. $3-5, \div-8$

MCKEE, JAMES ANDERSON (b'54) Calt,'s0; 111.1.'S6; (1'86); 2727 I' st. offce, Eilks B!dg. : 2-4, 7-8.

MCLEAX, DUXCANA-Ont.1,91; (1'95) $1223 \mathrm{~K}$ st. : oftlce, $904 \mathrm{~J}$ st.; $10-12,2-4$

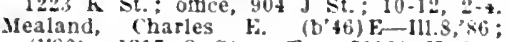
$(1 ' S 6) ; 1217$ o St.; offec, $\pi 191 / 2 \mathrm{~K}$ St.; $10-12,2-4,7-8$

Merritt, Elsie H. (b;6)-111.19,01; not in practice: 1316,10 .h St.

Miller, Allan P. (b's0)-Que.1,05; (1'09) not in practlce: Forum Bidg.

Iottu. John A.- - Cial.t,'95; (I'95) ; 5221/, $\mathrm{K}$ St.

Morse, sllas Elvert-Mo.20,'52; (l'87) ; 2817. $35 t h$ st.

Murray, Carl L.-E-Cal.4,90; $(190) ; 1007$ 8 th $\mathrm{St}$

CAIIL, CONSTANTE A. (b'75) 9 -Cal.1, 02 (1'02); $603 \mathrm{~K}$ St.; $11-12,2-4,7-8$

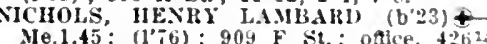
J St.;2-4.

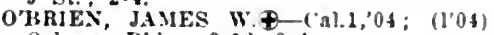
Ochsner Bldg.; $8-12,2-4$.

I'AlKINSOX, JÁMES H. (b'59) \&-Ire.9.79 Ire.5, 80 : (1's2); 1601 I St; odtce, 1000 K it.: 2-4.

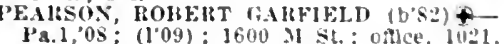
10 th se: $2.4,-$

PITTS. FiCGEN H. (b'70) T-Tenn 9,00 (1'01); 1331 1. St.; oftce, 1021, 10tl St. $11-1 \ldots 2-4,7-8$

1'OORE, JAMES F. $\left(\mathrm{b}^{\circ} 54\right)+-111.16 \mathrm{~g}^{\prime} 9 \mathrm{~s}$ (101); 1901 I St.; offlee, $1005 \mathrm{~h}$ St.

P'yburn, tivo. (b'31) 11-0.7,59; (1'78); 1011 il st. : $9-10,1-3, i-8$

HAJOTTE, EWOLAUI) CHAS. FAHIL: (b'75) que.1, $4: 0$; (1.03): Sutcer (lut:

leynolds, louls tieo $\left(b^{\prime}, 0\right)-111, b 0^{\circ} 0 x^{\circ}$ (1'0s) ; 1312, 3d st.; offe, 719 ts $\mathrm{k}$ st.

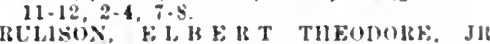

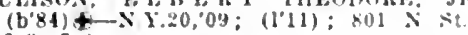

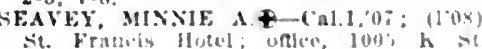
Sit. Framis Hote

10-11, 2-4, i-8. 08: (1"0s): 2630 l' St.: onder, g(h and K sits.: : :-1.

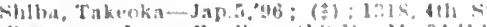

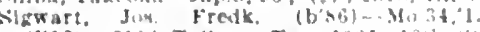
(1'12): 2114 T St.; once. 1021, 10th sit

Ilra innuel \&. da-Cal.i, $01 ;\left(10^{\circ} 01\right)$

ani it bus.

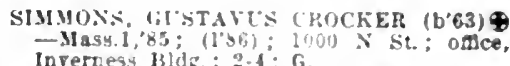

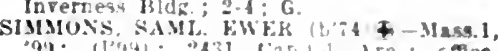
930 ( I'93): 2431 t'a

S.TOW, WM, FEEMAN

$(1) \% 4, f-f a\} .1$ llealth: (stanford ritrer

J si.; clln. I'for. Hyo and bubloc llealth Cal.11.

snyder, James Roe $\left(b^{\prime} 89\right)-\mathrm{N} 1.15,12$ (1'13); Sacramento County Hospltal; LD

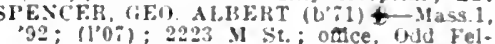
lows Temple; $10-12,2-1$; (1319); OALR. Sproat. Saml. MeCos (b'\$9)-Mich.1.13; ( ) : Southern Pacloc Company Emergency llosiltal.

Stern, Arthur Alonzo (b'66)-Cal.2,'95 (196) : 2505 31 St. ofice, $7194 \mathrm{~K}$ 'St. STEVESOX, GEOHGE I.-Cal.2,99: (1'00); 6.18 $\mathrm{K}$ st.; ortce, Peoples Hank H1dg: $2-4,7 \cdot 8$.
TRADER, HAIVEY w. (t'59) -Md.3 35; (192): S. Sacramento St; OAlce, 1021 N. 10 th st. ; 10.2

SLNBIRNT, WALTEIR ISRAEL $\left(b^{\prime} 65\right)$ I Cal. $99 ;(1 ' 49) ; 1618$, ith st. : $1-3,7-8$ (1'84); 801 is st : $10-12,2.4$ i.8

Takeoka, Minokichl $\rightarrow$ : (l'ul): 314 is st $10-12,3-5$

Thompson, Ashles-Ala.2,"S0; (1'00); 1225,

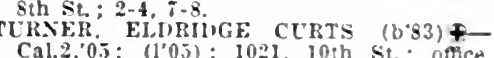
$8 * 9$ J St; (1 05$) ; 1021,10$ th St; offce, TVITCHELL, EDWIRI W(M)DLASO (b'a) +CCal.1.92; $(1.93)$; Peoples sarngs katk $131 \mathrm{dm}: 2-4 ; 1$.

TOLARD, FRANCIS XAYIER F-ont.t, 91

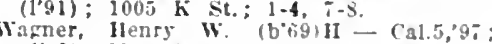
$\left(1 y^{\prime} y^{2}\right): 2011,215 t \mathrm{St}: 2-4$.

Waller, William John-Vt.2;97; (1.98); 900 J St: : $10-12,2-4,7-8$

ward, John Millon (b'75)-111.6.0 0 ; (1'0s)

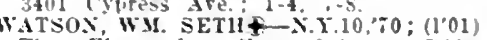

The Eimwood; nflice, Ochsner Bldg. $10-12,:-4 ; N$.

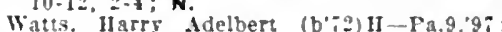
(l'01): 1126, 16th st.; oftlce, Odd Fellows Temple: $2-4, i-s$.

VELLS, SAMLEL J. (b'68)-Cal.1.'99: (1799); 34:6 Orange Are.; ollce, 3200 Orange Are.; $\$-9,2-4,7-8$

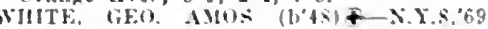
Pa.2:70; (li6); th and J sts.: offece. WHITE, JOHI IISANDER (b'7t) -Cal.2 01 ; (1.01): 2514 il St; offce, $5231 . \mathrm{J}$

wiLDFu, ENWIX MITTON $\left(h^{\circ}-1\right)+t$ tal. 00; (1'00): 21i25 i St; uflce, $1005 \mathrm{~h}$ St. : 2-4, $7: 30-8$.

wilson, (ivistarus-IIleh.5,03: (1"04): Forum Bddg: : $:-4 . ; 8$

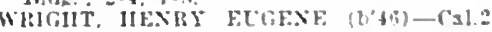

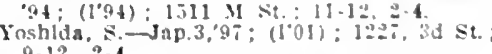
$9.12,2.4$

SALADA BEACH, 25, SAN MATEO

MCllonald, R. C.-Mass. 1.:3; (1'0!)

SALIDA, I20, STANISLAUS

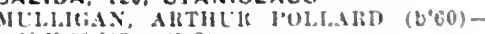
X. 1. 10,93: (1,93).

Muscare, Hobt. (i. (b'bi)-Ma.s.s9: not in Bractice.

SALINAS, 3.736, MONTEREY

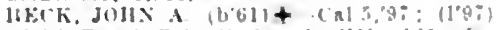

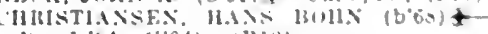
ben.1.9t; $1100,131: 4$

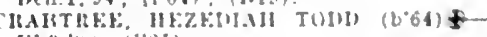

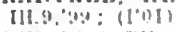

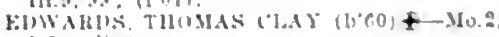

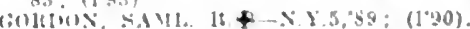

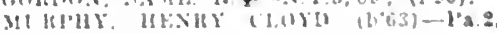

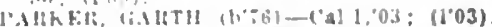

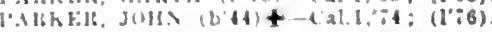
SAN ANDREAS. 1,531, CALAVERAS

I1)I,1NII, JIISUS AKTIIIK (b'58)('al. 1:91: (1.96). 


\section{SAN ANSELMO, I, 53I, MARIN}

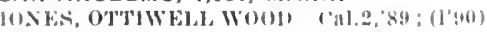

SAN BERNARDINO, 12.779, SAN BER NARDINO

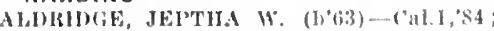
(1'84) : $224 \mathrm{~F}$ st.

Andrews, liubert Franklin (1,69) - 111.11, 99 (1'04); 425, 4th sit.

Baylls, Jobn N. (bo5)- l'at, st: (l'si);

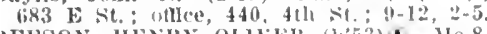
BEESON, HEXIT OLIVEH (b3) \& Mo.8 '80; (1'11); 965,5 th st.: 1-:?, i-8.

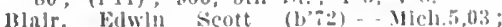

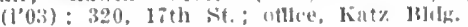
$8: 30-12,1: 30-4: 30$

Derenlug, flenry C.X.Y.6,71; (175) ; 837 (1) St.

llellolf, Frank 1. (b'tie) Mo.26, (4); not in practlee:-15iti N. Fist

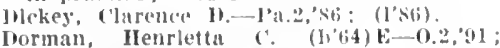
(1'06); Waterman Canyon.

(iardner, Frank It. (b'66)-X. Y.9,04; (1'12)

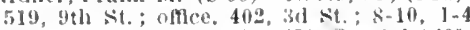

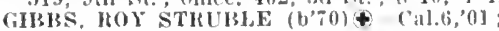
(I'01); $626,6 \mathrm{th}$ st.; oflyce, 425, Ith st. $10-12,2-4 ; 0 b$

Ham, James' (i. (1) $\$ 4)$ - ('al.6, 07 ; (1'08) 391 oth st.; offlee, 429 in st.

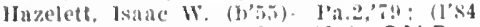
440 , th St.; $9: 30-12,3: 30-6 ;$ OALR.

Hurley, James Morgan (h'43)- $0.8,65$ (1'87); 602 F st.; ottlece, 433 S. Bd st. $8-12,1: 30-4$.

Johnson, A. Keyes (b'52) II - J11.4, ‘s (l'83); 5.9 . Ih st.: ofllce, rourt st.

8-40, -4, 7. s. (1'04). 54l A rrowhead he, otllee, (hamher of ('ommero Bly.: $10-12,1-3:$ Anes.

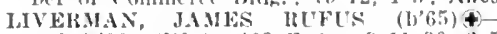
Ark.1,00; (1’01); 468 E st. ; 9-11:30, :-5 7-8; OALR. *

Manclia, Jicob swartley-X.Y.'s, (I'01)

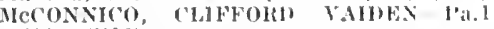
02 ; $\left(1^{\prime} 06\right)$

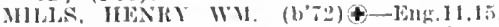
95; (l'03); 4 th and $\mathrm{F}$ sits.: oftlee, ('llam ber of Commerce Blily.; 11-12, 2-5: S. *

Murply, Wm. J-N.Y.3, 1 ; (13); E and th $\mathrm{th}$ Sis.

Nash. Marle Antolnette Bemette (b'57)Cal.1.'85; (l'sti); Bennette l'rivate Hos pital; oflice. $4 ! 9$ D) st. ; $2-4,7-8$

OWEN, GIIJERT ROY (1) T)-Mich.5.'01 (l03); stis Is St.; oflce, New Garner Bloch; 10-12, 2-5.

Rowell, George 13all-que.1,'s4. Ont.5,'86 Fur.15.'S4; (l'SR); 3d and L sts.; 10-12, $2-5$.

SAVACAE, l'HIJI M. $\left(b^{\prime} 8 B\right)+-$ Cal.1, 07 (l'0-) San Hernardino County Jfospital. Soott, James Eowin (b'53)-111.1.78; (1'92) 350 , th st. oftce 4 (is Court

stiles, Wm. H. (b'53) H-11l.4, is; (1'86) 705,5 l st: office, 471 4il st, $y-11$ $2: 30-50$.

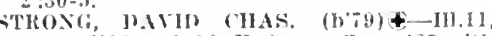
02; (1'03); 1!10 E St, ; otlle, 425, 4ti St. $10-12,2-4 ; S . \star$

Trevino, lonaciano $\left(b^{2} 66\right) \ldots$ Mass.6,96 (l'01); 122 Allen St.; offee, 404.31 St. $10-12,3-5 ; \mathrm{S}$.

SAN BRUNO, 480. SAN MATEO

Bohm. Firnest Anselm (b,54) II - .10.5,90 $(1,112)$

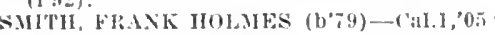
(l'0.) .

Welss, Saml. (b'85)-N.Y.20,09; (1'09).

SAN DIEGO, 39,578 . SAN DIEGO

$$
\text { (sice Coromado.) }
$$

NUMBEI OF PHYSIIANS, 150

AJIEN, FIANCES MORTON (b'6s) $\oplus-$ Mlich. 1,96; (1’08); $4014 \mathrm{~K}$
Timken Bldg. ; 10-1; Pd.

ALATIN, ROBT, EMMETT (b;2) \&-Mo.1 $\because 7 ;\left(10^{\prime}\right) ; 944$ Spruce st.; oftlee, Ameri can' Jational 1rank Bldg.: '10-12, 2-4.

werill, Maria Brown (b'35) $\mathrm{H}-$

(l’0) ; 3230 G St.; 10-12, 2-4.

IXTEL, SALION BHAE (b'55)-0.11

so: (12); 2067 Front Nt. ; 11-12, 2-4; N

H.TK, AlFRED FDWARD (b'so)

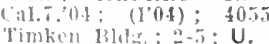

Beleher, Janes Le $\left(\mathrm{b}^{\prime} 47\right)-M 0.2,{ }^{2} 71$; not in

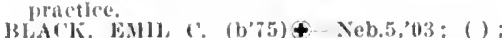
Yember Texas state Med. Assm, ; th st. and finlversity Are

BOIANI, MICAJII (b'7i) $4-\mathrm{Va}, 1,05$; I'A.S., Jeut., U.S.N. ; Menber Med. Sine. of $\mathrm{Va}$; $384 \mathrm{~s}, 4$ thi $\mathrm{St} . ; \mathrm{S} . \star$

Hostlek, John Benton (b,75) - Cal.6,'13

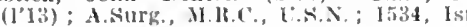
sit.

Briner, Ellen Martin (b'69)-Colo.3,97 not in practlee: 4til and Madison Sts. BUHKE, DWWITT ('LINTON (b'si)-Ky.2

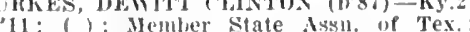
3629 linsas st.

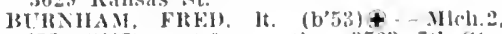
$77 ;(198)$; not in practice; 3563,7 th St. $1-4$.

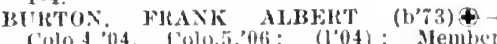
Colo.4, to4, Polo.5.06; (1'04

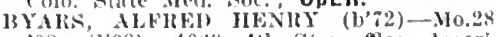
98; (1'98): 40t:9, 4th St. ; ottce, Ameri can Notional Bank 13ldg.; 12-3.

Campbell, Frank .I. (h'62)-11l.6,"00; not lu practice: 1aturell and Albatross sts.

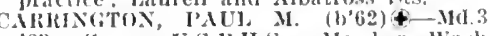
83: Surg., U.S.l'II.S.; Member Wish. stilte Mel. Assn.

Carter, lloss s. (b'83)-Md.7.; $10 ;\left(l^{\prime} 10\right) ; 1843$

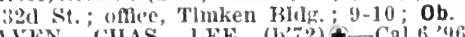

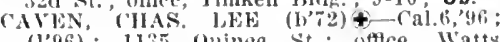
(1'96); 1135 quinee St.; offlee, Watts 13ldg.; : $1: 30-4$

Caren. Frangeline 16. (b'76)-Cat6, ('os: (1'99); not in practice.

chamberlah, lawrence s. (b'73) - Kan.3. 02 ; not in practice: sth and relar sts. onlee, spreckler lidig.

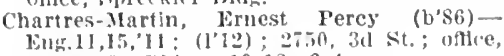
Sivreckels Blug.: 10-12, 2-4.

CHARE, MONTROSE W. (b\%2) $\uparrow-.110 .1,96$; llemtier Ark. Med. Sor.

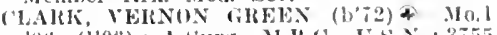
96: (I’06) ; A.turg, M.K.C. U.S.N ; 3755 ith sit.: ofluce, American National Bath Bldy.; ; $2-4$.

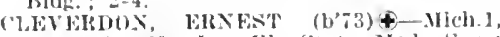
o:3; (); ifember III. State Med. Soc. 4470 Georgia St.

(oad, Nicholas fiay o, (b'52) - vt.2.8T ( ) :, 3563 Kansas St.

Cocliran, Jos. S. (b'73)-111.11,97; (I'11) 5th and If Sts.; offlee, Granger 13lock.

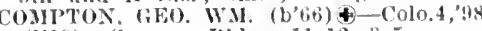
(1'98): (rranger I3ldg. : 11-12, 3-5.

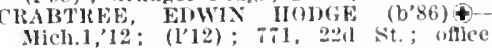
Mcxeese HIdg. ; 10-12, 2-5.

Crandall, Allce II If-Neb.5,8 ; 111.9,'87 $\left(1^{\prime},(i) ; 5\right.$ th and $C$ Sts.; $10-12,2-4$.

CRAWFOIRD, WILLIAI W $\left(b^{\prime} 73\right)+-$ Colo.2,11; (1'12);

(1) (I'11) 4074 Falmount tve.; offce, Witts (111); 4074 Farmount Ave. , offce, Wiats

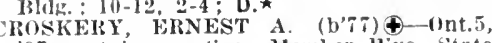
97 ; not in practice; Member Wyo. State ved. Sioc. : 1054, 24th St.

cummings, Wm. M. (b'38)-Ia.t,'s] ; (l'9s); lbis St. and Broadway.

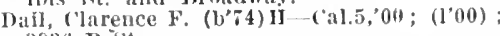
$3936 \mathrm{~B}$ St.

1) EHIB VSIIILF, ALBEKT 1。 (b'5I) - Ind.R 's6: (1's8); 734,21 st St.; oftlce, Grantrer Bidg. : $10-12,2-4$

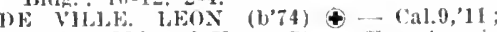
(l'11) ; 32d and Cpass Sts, ; oflee, Anterican Nall. 13ink Bldg. : 10-12, 2-4, 7-8: T DINGEMAX, FKANK jORDAN (b'81) \& Mo.34,06; (l'11); 32d and Cedar Sits. offlee, spreckles 13ldg.; 11-1, 4-5; OALR. *

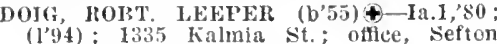
(l’94) ; 1335 Kalm

DONNELL, IOBT. H. (b'78) $\uparrow-M e .1,01$; (1'13); Member Me. Med. Assn.; Hotel (irant.

Drake, Francls $N . \quad\left(b^{\prime} 52\right)-P a .2,7 \pi ;\left(1^{\prime} 7 \pi\right)$ University Ave. and 30th St. ; 8-10, 6-8. (1'12): ABRAHAM HE

DWIGIIT, HEXRY L. (b'60) $4-\mathrm{N} . \mathrm{Y} .5,94$ ( ); Member IIass. Hed. Soc.: 1234 Westerby st.
EDWAIKIS, CARHF, HITCHCOCK (b'70)IItch.8,98; (1'91); 1\$20, Ist St.; 2-5; OALR, *

Escher, John F, (1)"43)-Ǩy.1,"78; (1'85) ; $1042,8 t_{1}$ St.; olllee, 1023, 5th st.

FEF, GFO.-Mich.7, 02 ; (1'97) : 1219, 25th At. ; oftlce, Timken Bldg.; 10-3:30; (B19); OALR. *

(intherine-Cal.1,'93; not in practlee: 1219,25 th st.

Ferds, Edmond (b'42)-Tenn.1,69; not In practlce; $3611 \mathrm{~B} \mathrm{St}$.

Fletcher, 0. I- $-0.10,80 ;\left(1^{\prime} 98\right) ; 516$, $1,5,2-12,2-6$.

(l’06) 1013T, JUDSON (b'08) †-Pa.I, 09 ; Block; $10-12,2-4$; OALR.

FostEk, It. de H.4-Cal.5,'99; (1'99): (I'olnt Ioma); offlee, Watts 13!dg. ; 10-12, -4: OALR. *

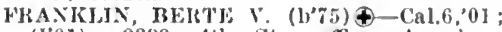
I'0I); 2333,4 th st. ; offtee, Anerlean Nutional Bank 13lihs. : 11-12, 2-4.

FrARY, LOUIS ALLSTON (b'65) $\$$-Ill.1, $87 ;(1,94) ; 4088,2 d$ St.

GOC'HENALEI, DAVIDA-Pa.1,"68; (1'86) 3534 , 5th St.; offlee. Sefton 13lock; 10-12, $2-4$.

GOFF, HARHY NEVHLLE (b'59)\&-Que.1 93; (1'06); 3580, 5th St.; office, Watts Bldğ. ; 11-1, $2: 30-5 ;$ Pd.

GOONMAN, CELIA W, TAYLOR $\left(b^{\prime} 59\right) \mp$ 1448 University Ale.: $9-10,1-3 ; G$.

Grandlean, Arthur (b'46)-0.8,'95; not. in practlce; 4086 Albatross St.

Ilarding, Maynerd $(\therefore \quad$ (b'is)-Colo.5,'96 (1'I3); 2812 El Cajon Are,; office, Tlinken

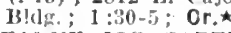

FEAKNF, JOS. CARTER $\left(b^{\prime} 51\right)+-P a .2,72$; $\left(1^{\prime} 92\right) ; 4$ th and ish sts.; $8-10,2-4 ; \mathrm{S}$.

IIENSEL, FUGENF A. (b'67) \&-III.1, 95 (l'01); $3735,2 \mathrm{~d}$ St. ; offlee, Granger Bldg.;

$10-12,2-4$.
Jrerluhy, John Stephen (b'83)-N.Y.6, 09 (l'1\%); 4622 Geoligla St

IIERRICK, AIBRR'T B. (b'51)-N1/ch.1, '79 (1'98); 826 w. Washlngton St. offle: W. WR

Herrick, Albert B., Jr. (b'89)-Cal.s,'1:' $826 \mathrm{~W}$. Washington St.

HI1.JIAN, J. E. (b'60)-Ill.11,'86; (l'99) ; New Southeru llotel; office, American Natlonal Bank 13ldg. ; 10-12, 2-4; Op.*

Hofiman, K. Ora (b'68)-0.2,'91; (l'08) 4288 Cleveland st.; offce, franger Hlock. HOSMER, CHAS. MORTON $\left(b^{\prime}, 4\right) \oplus-P a .1$, '00; ( ) : Member Colo. Stafe Med. Soc. ;

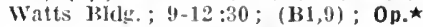

IIULBEIT, IROB'T. G. 4 -la.1,'80; (l'88); Grant llock; 10-12, 2-4, 7-8.

IHONES, ITTIIERFORD HUC'IIARD (b' —-Cal.2, 00 ; (1'00); 3921, 2d St.; offlce, Timken Bldgr.; I1-12, 2-4.

JA('KSON, JAMES A.Cal.6,03; (l'03) ; Spreckles 13lilg.; 2-5.

IENNISON, JOIF EGBERT $\left(\mathrm{b}^{\prime} 68\right)+$ Hinn.4,94; (I'09); 3768 , 5th St. ; offlce Watts 13ldg.; 11-12, 2-4.

Keegan, Iawrence Thomas (b'-8)-Cal.4, 01; (l'01); 965, 5th St. ; 10-12, 2-5.

Keith. Jumes H.-X.Y.5,94; (1'96); Spreckles 1ildy.

kelley, Wm. Preston-Ky.1,'91:

(1'98):

1127,6 th st. ; $10-12,2-8$.

EN1)A1.L, OSCAR J. (b'59) \&-La.1,'84; $\left(1^{\prime} 99\right) ; 1 \mathrm{st}$ and Spruce Sts.; offlce, Granger Block; 10-12, 2-4; S.

Kennedy, Clarence E. (b'76)-Ind.8,98; not in practice; 1371, 5th St.

Kinyon, llenry E. (b"58) H-1ll.4,90; (屯) 1211, 2sth St.; office, $3702 \mathrm{~B} \mathrm{St}$.

KL]ETSCH, OTTO (b'61)-Ger.6,'86; (l'01) ; $16.54,1 \mathrm{st}$ St.

LEISEXIRIG, HENRY G. (b'60)Ð-Neb.1, 83; (1'01) ; 3020, 2 d St. ; offce, American National Bank Bldg.; 10-12, 2-4; R.

Leisenring, I'eter S. (b'29)-Pa.3,'52; (1'93) 71i, 22d St.

LEWIS, J. PERRY (b'65) - - Hl.4,95; (l'96) ; 1548 Ash St.; offlce, Sefton Block; $1: 30-4$. J.ISTINER, IIYMAN $\left(b^{\prime} 80\right)-$ N.Y.9,'04; (l'09) ; (Point Loma) ; offlce, Jrls Theater Hidg. ; 10-11, 2-1; Pd. 
LITTLF, THOMAS COE (b'it) \&-Xeb.A, 96 (12): llotel San Dlego; oflec. Amerlcal Natlonal Bank lthd": 10.18: NP.

LCXG. ALYRED nOW (b"6) -Mas. 1,0 $\left(1^{\circ} 10\right) ; 3 \% 90,3 d$ si.; onter. Waits bht: LOOS, HABRY CLIFYOBD (b'83) †-CaI.1, - 5 : (1'05): 2915,30 h st. : ofce. Timken Mle. $11.12,9.5$

Luscomb, Chas, F-Mlch. 1,76 : (1'90) 3624. ith st.

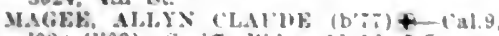
05: (1009): Serlits Hids: : 11-12, $\$-5$

MAGEE, THOS I. (D) 36 -Tenn. 1,63 (1'\&1): Scrits H/dn: $10.12,3-5$.

MALONEY, ROHT. LEK (b'5)-Ga.11,03 (III): Amerlean Nallonal Bank bidg. $10-18,3-5$

MANX, EWWARD $10 X\left(b^{\prime}, 5\right)+X Y .6,00$ (1'10):3005, th st: ufles. Timken Block: 1-1: 0bG.

Mapes, diesnolids J. (1)\%2)-111.11,9: : $(1,10)$. MaRSU, OTTO liko. (b'sti) + la.t. 09 $(109)$ : st1, 16th st.: wace, firminger

McCormick, pranklln 1. (b'55)-1a 9,98 ; (t): 210 Glemwan Irtie

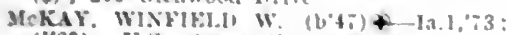
(I's9); U.S. Uuarantine station; U.S.I. I.s.

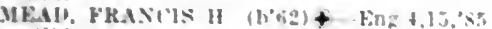

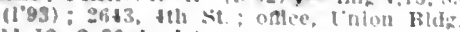
11-18, : $: 30-4: 1 . *$

Millari, Fondyce liust $\left(0^{\circ} 31\right)-111,1,62$ $\left(1^{\circ}: 6\right)$ : not in practlce: $1916,3 d \mathrm{si}$

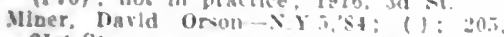
Ine st.

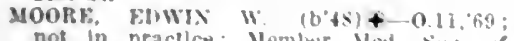
the Siate of I"a. Member led sin.

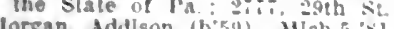

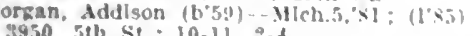
3950,5 th St.: $10-11,2-4$.

Joresen. Johu lianl., Jr (b'<9) - Teun i, l

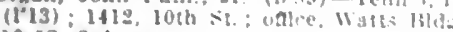
$10-12,3-1$.

Morris, John knox (b'bl)- hi i,?l, la 91: (1'96).

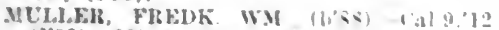
$\left(I^{\circ} 12\right): 901$ E Sircel: offle. sefun hlock $10-12.9+3$

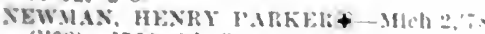
(lo 0 s) : 1560. sth si ; oplce, Timken lidg \$-1: (A2,11).

NIELSR: JOHX CHAS FNGFLBHAT

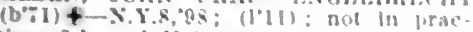
flce: $\sin$ and foner-ity sis. $10-12.3-5$

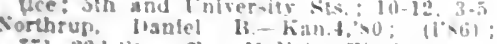

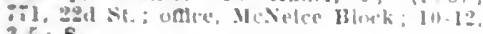
$3-7: 5$.

OATMAN, HUMkIR ( $\left\{b^{\prime}-10\right)+-1114.95$

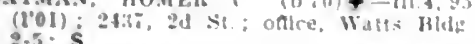

2-5: $\dot{S}$.

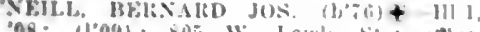

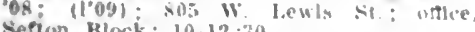

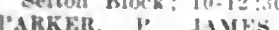

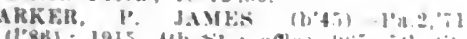

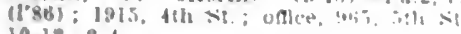
$10.1 \div, 2-1$

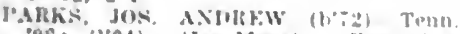
98: (104): (Ja Mesa): odre, liranger

(Wesley (bos) 2\$28, sth st.; 1.2.

Pearson, Urlendo (b'0) -Mo.1 s. San Illeco st.

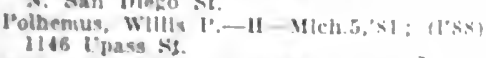

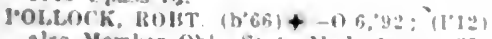

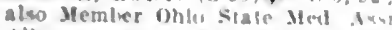
Albatrosw sil: onlce, Walts nillg

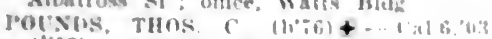

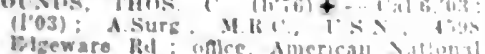

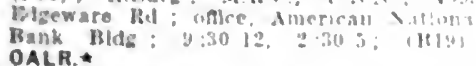

\section{OALR.*}

39*6 cleveland IN

Remondino, "' II. (1'09); 1s04, ith s?

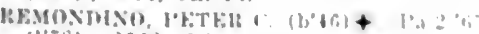

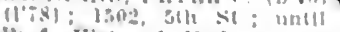

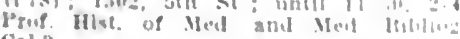
Cal 9.

Reyhor, firnest 1. $110^{\circ} 511$ - Tumb"

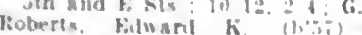
net in liracller: lais. Sil sis
Busburg. Nugusi Henry (b'*3)-1111,12:

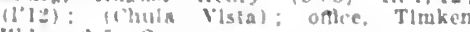
Hha: : $: 5: 5$.

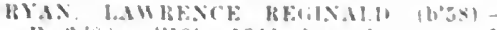

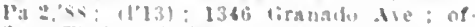

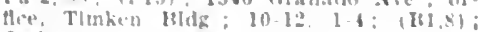
OpA. *

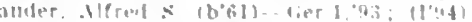

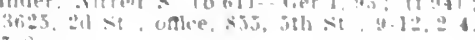
aifrert. Jish II (6.6.5)-111 1.95: (1'10)

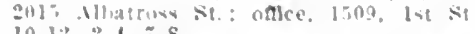

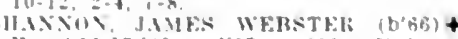

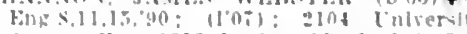

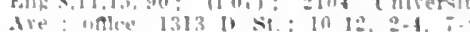

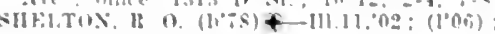
sorifle Blds: : $1-5$.

skewes. $T$ \& ir. $\|-0.13,85 ;(189) ; 602$ tirant .lle

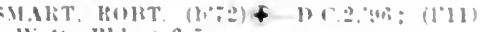
Watle Blele: : 2.5.

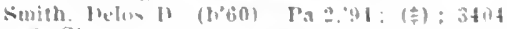

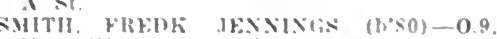

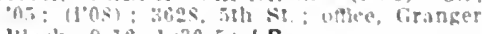
lllowe: $0.7: 1: 30-5:$ LR.

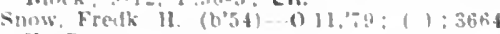
II. $S t$.

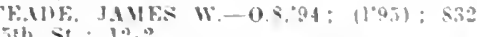
STHWIT, IMMROSE ( $(1,03)+5 y$

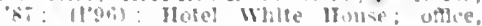
firaner lifinek: 11-3; $\mathbf{N}$.

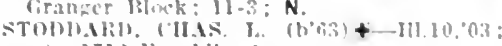
1 1: 1:1: Franklin Are.

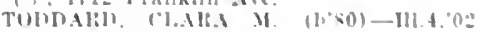
( ) : 1:1:3ranklln we

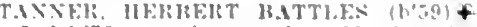

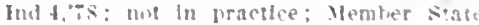
Med. Sur. of wis.

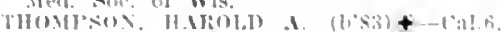

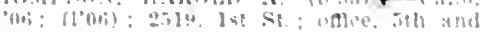
repoll sis; Path.

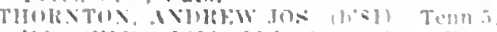

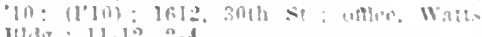
Hile: $11-12,2-4$

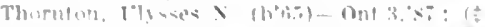

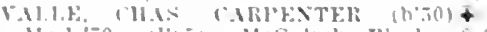

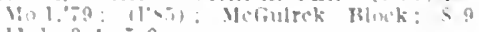

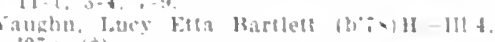

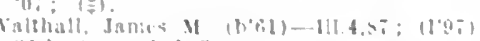

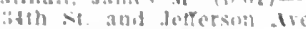

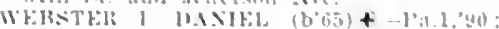

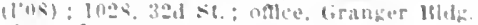
$\because+1:$ G.

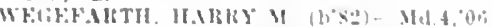
(1\%10): Biph and lig sis. onthe, spreokles

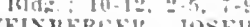

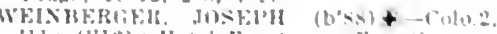
"11: (l'1:): irotel Barstow; oflow, Granger

Mlijo: $110,1,4: 30-5: 30$

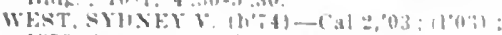
1309 lirwo st : otlee. Walk bidg: $10-13$. $25 ; \mathbf{O A L R}$.

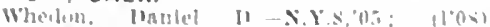

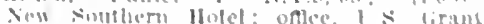
HII: : $1:$ NP

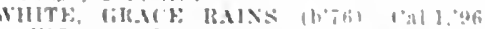

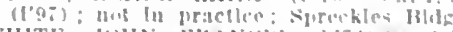

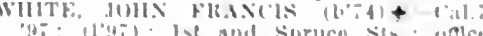

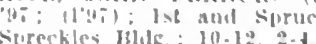

WHITELUK THOMAs sllN

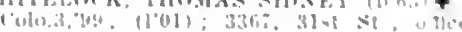
1026 . ish si : 10-1:-2;

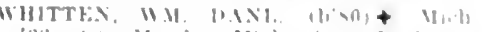
II sis liste

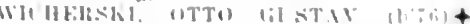

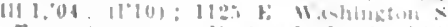

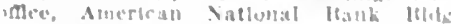

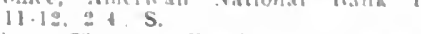

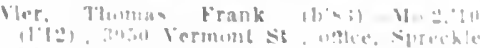

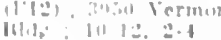

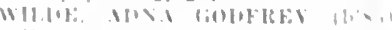

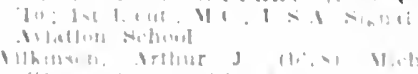
IIIt)

inn

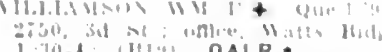

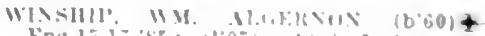

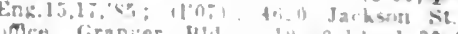

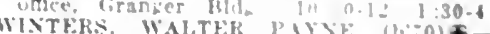
N.406: $11100 ; 020$ Datne; Waits Mld:

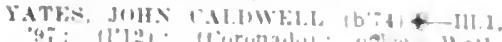
J3112: $11+121 ;$

SAN DUMAS, 1,200 , LOS ANGELES

Amos, Wm. MCll, (b't?)-la.1.71: (1.91) 1)es in wratice

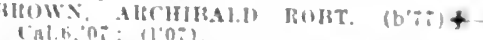

SAN FERNANDO, I.100, LOS ANGELES

Allen, llenty Connell (b"63) -X Y.5,"ss;

Allen, Kennesh Watson (bos)-Que.1, 10:

M.HEl, JOHN liAlMBATH $\left(b^{\prime} / 1\right)+$

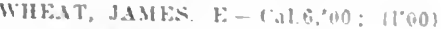

SAN FRANCISCO. \$16,912. SAN FRAN

face berkatey and Makand

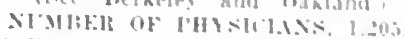

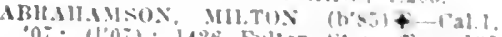

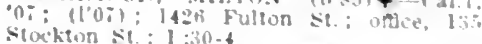
Akl? IIIII IIf

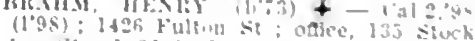
(101) : : : $1: 30-4: 1 . *$

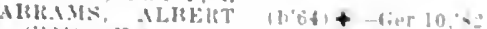

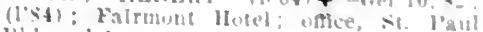
Klik. : 1.

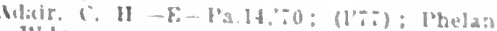
I3Idón.

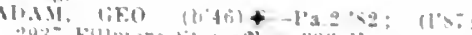
2937 Filmore is: othe, 333 kearrey s:

H.10 Tllo).

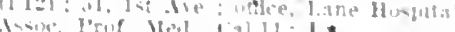

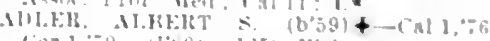

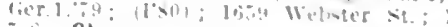
i- : ob

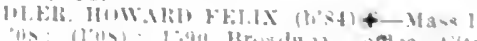

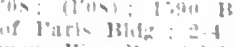

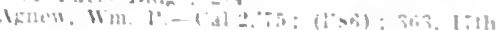

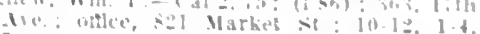

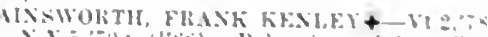

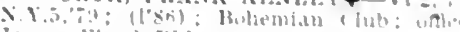
James flimel pids

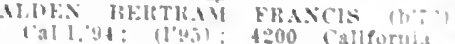

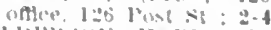

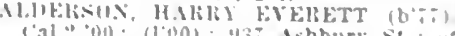

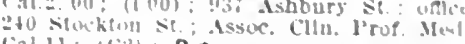
(a1.11: 1( 2 ) : 0 *

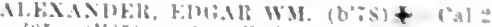

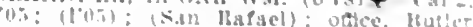
Hhis: 1. : (1319.25); ALR *

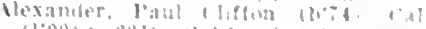

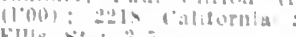

fills si:

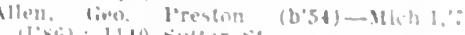
(1)(i) : 11+1) suller sit

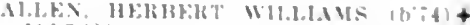

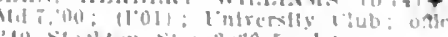

I.

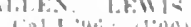

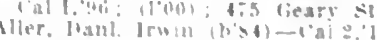

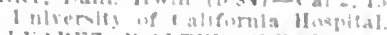

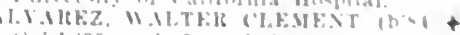
ลง 1,05

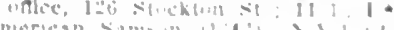

$=0,0$,

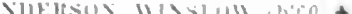

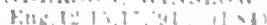

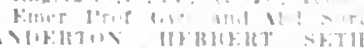

11,

(ind 
Apple, Benj.-Cal.1,93; (l'94) ; 648 Waller St.; oflce, 406 Sutter St. : 12-3, 7-8; U.* Armstrong, Bessle C.-II-Cal.5,'96; (1'96); 1790,46 th Ave; ofllec, 126 Stoekton St. ARNOLD, JACOB DENNIS (b'56)+-Md.2 76; (1'84); 146 Grant Ave.; (R3,28).

ARTIGUES, JOS. E.ML (b'63) \&-Cal.1,87; (l'88) ; 2232 Gruen St.; oflce, $205 \mathrm{Co}$ lumbus Are. ; $11.3 ; 1 . \star$

ASH, RACIEL IEONA $†-C a l .2,99 ;\left(1{ }^{\prime} 00\right)$; Post and Jones Sts.; offlce, 391 Sutter St. ; $2-4 ; 1 . \star$

Atkins, Albert James-E-Cal.4,'99; (1'99) ;

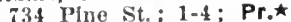

ATKINS, MILTON HAItRIS (b'69)-Ill.11, 94; (1'94); Hurlingamo Apts.; oftice, 291 Geary St. ; 11-1; OALR.

Atkinson, Archibald Amand - Cal.1,05; (l'05); 1174 Ellis Ave.

AUSTIN, MALCOLM OSGOOD (b'63)థCal1,95: (l'95); 1220 Insonle Ave. office, Anglo Bldg. ; 11-12, 3-4, 7-8.

BACIGALUPI, DAVID EUGENE†-Cal.2, '00; (l'00); 870 Union St.; office, 205 Columbus Ave. ; 1-3

BACICALUPI, JOUIS 1)OMINIC (b'75) Cal.2,96; $(1,96) ; 212$

BAER ADOLF BERNHAIT - Ca1.2,'03; (1'03) ; 3757 Clay St.; oftlce, 177 Post St. ; 10-12, 1-4; (B28); S.

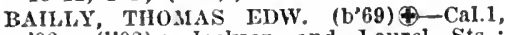
92; (1'92); Jackson and Laurel Sts.;

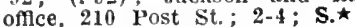

Baker, Chas. Reinhold-Cal.1,00; (I'00); 822 Devisadero St. ; $3-5,7-8$.

Baker, Clarence C.-Ky.1,'95; (l'95); Hotel Robbins; offlce, 995 Market St.; 1-5.

Baker, James Bartlett-E-Mo.10,83, 0.2, '93; (1'93)
Market St.

Baldwin, Walter Isaac (b'85) - Cal.2,'11; (l'11); 135 Stockton St.; 2-4; Or. $\star$

Ball, John (b'47) E-Cal.4,'94; (1'94) ; 1297 Market St.; 2-4, 7-8.

Ballance, Harriet Nevins (b'77)-Ill.9,01; ( ) : St. Luke's Hospital.

BANKS, WA. HENRY (b'74) - Cal.1,04; (l'04); 4402 California St..; offlce, 135 Stockton St. ; $2: 30-4: 30,7-8$.

BARBAT, JOHN HENRY (b'62)@-Cal.2, '88; (1'88); 1458 Sutter St.; office, 275

AARKAN, ADOLF (b'45) $\$$-Aus.7,'66; ARKAN,
$(1, \tau 6) ; 2209$ Laguna $(1,76) ; 2209$ Laguna St.; Emer. Prof. Structure and Dis. of the Eye, Ear

Barkan, Hans (b'82)-Mass.1,10; Lane IIospital.

Barker, Zachariah A. (b'83)-Ore.1,'08; A.Surg., M.R.C., U.S.N., Marine Recruiting Station.

BARMORE, WM. ALFRED (b'70)థ-0.1, 91; (1'92); 125, 17th Ave.; offlee, 196 6th'Are.; 2-4, T-8.

Barnard, Raiph P. (b' $; 9)-$ Cal.1,'05; (1'09) ; 903 Pine St.; offlce, 209 Post St.

Barnes, Anna Harris-H-Cal.5,'87; (1'87) ; 1804 Turk St.

Barnes, Paul Dewitt (b'88)-Cal.5,'13; (l'13); City and County Hospital.

Barnett, Geo. DeForest (b'84)-Cal.11,'13; (I'13); Lane Hospital.

BARKETT, GILBER'T M. $\left(b^{\prime} 69\right) \oplus-N . Y .10$, 95; (1’98); 1051 Cole St.; offlce, 275 Post St. ; $1: 30-4$.

BARRY, ERNEST \$-CaI.1,'95; (1'95) ; 3561

Clay St. ; office, 240 Stockton St.; 2-4; G.

Barsotti, Camille - Ita.6,'77; (1'92); 604 Montgomery St. ; 8-9, 2-4.

Bartholomew, John Young (b'82)-Cal.7,09; (1'11); 2421, 18th St.; 2-4, 7-8.

Bass, Fredk.-Ore.1,'85; (l'86); 2057 Green. Baumeister, Bernhardt H. (b'52)-Cal.2,'82; (l'84) ; 263, 29th St.; 1-3.

Baumgarteu, Wm.-Cal.2,02; (1'02); St. Joseph's Hospital.

BAZET, LOUIS $\left(b^{\prime} 48\right) \oplus-\mathrm{Pa} .2,76 ; \quad\left(\mathrm{l}^{\prime} 84\right)$; 2490 Fitbert St.; office, 760 Market St.; $(\mathrm{C} 3,14) ; \mathrm{U}$.

BEARDSLEE, ARTHUR (b'78) †-Cal.6,'07 : (1'09); 1166 Guerrero St.; offlee, 323 Geary'st.
BEASLEY, SILADWOITH OLDHAM (b'76) -Cal.1,97; (1'98); 650 Bu

BF̈:K, IIFNItY MÁITIN-Cal.2,96; (1'06) 729 , 5th Ave.; offlee, 760 Market St. $1-3,6-8$.

Beckingsale, Daniel Loftus - Scot.3,'72 (l'94); S.S. "City of Panama."

Beobe, Gertrude Esmond-N.Y.6,'91; ( 2007 Buchanan St.; offlee, 1095 Market St.

BEFRMAN, WILFRLD FENTON (b'78) Cal.2,01: (l'01) ; 3217 Jackson St.; office, Butler Bldg.; 1-4.

Bell, IIenry R. (b'54)-Md.1,79; (1'79); 3608 , 16th St.; 1-2,7-8.

Bennett, D. Gates-1]-H1.4,'90; (l'90) ; 2090 Devísadero St. ; 1-3; Prof. Obst., Cal.5.

BERG, ADOLI'H (b'73)@-Cal.1, 05 ; (l'05) 1462 Devisadero St.; offee, 86 Post St. $3: 30-5$

BFRGENER, GUSTAV J. (b'67) \$-Ind.8, '96; (1'10) ; 1275 California St.; offce,

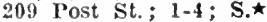

Berger, Albert J.-Cal.7,'04; (1'05); 3446 , 3446, 22d St. office, $1001 \mathrm{~A}$ Guerrero St. I'rof. IIIst., Cal.7.

BFRIXG, ROBT. EUGENE (b'71)థ-La.1, 95; (1'01) ; 300 Page St.; 10-12, 2-4.

BERNDT. RICHARD M. H. (b'56) †-Cal.2, 93: (1'94) ; 159 Carl St.; offlee, Butler Bldg. $2-4,7-8$.

BEI?TOLA, MAKIANA (b'68) - CaI.1,99; (1'99) ; 1059 Jackson St.; 1-3.

BEST, EIBRID(FE TOHN (b'87) †-Cal.2, '11; (1'11); 717 Clayton St.; ofllec, 240 Stockton St. ; 2-4.

Bettencourt, Jose de Sousa (b'51)-Cal.1, 77 ; (l'78); 251 Kearney St.; 9-10, 1-4. Biber, Paul E.Cal.2,03: (l'04); 1640 Washington St.; offec, 135 stockton St.

Biehl, Philip Freiderich Christian (b'50)Ky.1,'83; $\left(1^{\prime} 90\right) ; \quad(2149$ Stuart St., Rerkeley); offlce, 830 Market St.; 10-12,
$2-5$. Bigelow, Coniah Leigh-Cal.2,05; (l'06) 3746,21 st

BILL PHIIP AUGUST (b'80)क-Cal.2, 02; (1'02); 1125 Greenwleh St.; offlee, 602 California St. ; 2-4.

BINE, RENE (b'82) Cal.2,03; (l'04) 174, sth Ave.; offlee, 350 Post St. ; 2-4. Birdsall, George Wm.-Pa.2,95; (1'99)

1204 Sutter St. : 2-4.
BIRTCH, EAYETTE WATT $\oplus-$ Cal.1,07 ; (1'07) : St Iuke's

Bishop, Simeon-0.10,70; (1'91); 447 Eddy st.

BIACK, JAMES ALEXANDER (b'69)(- Ky.1,'92, N.Y.8,'93; (1'93) ; 2505 Paclfic Ave.: (B2S): Op.

Blalsdell, Frank Ellsworth (b'62)-Cal.1, '89; (L'89) ; 1520 Lake St. ; 1-3; Asst. Prof. Surg., Cal.11; (F1)

BLAKE, WM. FORD (b'74) $\oplus-C a l .1,03$; (1'03) ; 1001 Pine St. ; office, 240 Stockton St. ; $9-12,2-4 ;(\mathrm{B} 1,19,28) ; 0 \mathrm{p}$.

BLOCH, HERBERT I. (b'73) †-Cal.1;'94; (l'94) ; 2299 Sacramento St. ; offec, Ekan Gunst Bldg.; 1 :30-4.

BLUHM, GEO. I. (b'66)థ-I1.11,94; (l'01); 1924 Bush St. ; $1-3,7-8$

BLUM, SANFóRD (b'73)థ-Cal.2,96; (1'96) ; St. Franels Hotel; offlce, 126 Stockton St. ; 11-12; Pd.

Blumenberg, SamI. Purdy - E-Cal.4, 00 ; (1'00) ; 1895 Sutter St. ; 12-1, 4-7.

Bluxome, Jos.-N.Y.5, 57 ; (1'76); 625 San Jose Ave.

BOALT, GRACE S. IINFORTH $\odot-C a 1.2,98$; (1'00); 3018 Clay St.; offlee, Whitney Bldg.

BOARDMAN, WALTER WHITNEY (b'83) -Cal.1,09; (1'09); 2186 Californla St. ; offece, Lane Hosvital; 9-4; Asst. Prof. IIed. Cal.11: 1. $\star$

Bodkin, 'l'homas P.-Cal.1,'93; (l'94) ; 425 Fillmore St.; offlce, 425 Halght St. ; 2-4, i-8.

Boericke, Wm. (b'49) H-Pa.9,'80 ; (l'81); 391 Sutter St. ; 1-3.

BOHM, JOHN ERNEST (b'87)-Cal.1,'12 ; (1'12) ; 475 Guerrero

Boldemann, Llllie-H -Ca1.5,'96; (I'96)

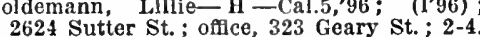

Booth, Sarah Anne-F-0.2,79; (1'84); 1545, 45th Ave.; oflce, 1097 Jake St.; $2-4$ Tellevue Itotel. Office, 391 Sutter St. $1-3$ BO'PIIF, AUGUST CAILL (b'66)-Cal.7,'99; (l'y9); 562 Clayton St.; $2-4,6-7$.

BOTSFÓL, MAITY EIIZABETH $\left(b^{\prime} 65\right) \oplus$ Cal.2, $96 ;(1 ' 06) ; 807$ Franclsco St. ; 1-3 ; (A21) Anes. *

Bowers, Mury 13.-Cal.7,98; (1'98); 1673 Sutter st.

Bowle, T. II. C.-Ger.16,79; (1'79); 294 Church St.; office, 2102 Market St.; 11-4. Bowman, Frank Austin-Cal.1,92; (1'93); 1235 Hydo St. ; offlce, 7 th and Market Sts. BOYD, SAMULI, GEO. $\$-$ Mass.1, 85 ; (1'85) ; also Nember Mass. Med. Soc. 2108 Scott St.; offlee, 133 Geary St. ; 2-5. Boyes, Mrnest B. (b'73)-Ont.3,'y6; (l'01): 2402 Larkin St.

Boyes, Wm. James Robert (b'62)-Cal.2,'95; (1'96) ; 382 Geary St. ; $10-12,3-5$.

BIRACKETT, GEORGE 'FRANCISD-Cal.1. 92; (l'92); 140 Noe St.; offee, Phelall Blag. : $1-4,7-8$.

BRADFIELD, GEO. M.-1'a.2,90 ; (l'07) 3309 Mission St. ; office, 414 Hayes St.
Bradshaw, Arthur F. (b'63) - Pa.2,93; (l'93); Phelan Bldg.

Brady, Geo. Thomas (b'73)-Cal.1,97 (l’99); 1994 Grove St.; offlce, Phelan Bldg.; 10-12, 1-4; (B28); OALR.ネ

Brady, Jos. Geo.-Cal.1,'02; (1'02) ; 1534 9th Ave.; offlee, 291 Geary St.; 1-3, 7-8. Breen, Mary A. (b'69)-la.3,'90; (l'10); 364 Eddy St. : $10-12,2-4$.

BREIT'STEIN, LOUIS ISIDOR (b'79) Cal.2,'03; (l'03); 1592 Washington St. ; office, 240 Stockton St.; 2-4; ObG.

BRICCA, C. R. (b'79)-Cal.2,05; (1'05) : 1330 , 4th Ave.; office, 166 Geary St. : $1: 30-4$; (B28) ; OALR. *

BRIGGS, LEROY HEWITT, JR. (b'83) Cal.2,'08: (l'08) ; 2768 Green St.; office 240 Stockton St. ; 2-4 *

Brinkerhoft. Enililie (b'79)-Cal.7,04; (1'05) ; 275,25 th Ave.; offlce, 395 Eddy

BROÁDNAX, MARY ETHEL-N.Y.11,05; ( ) ; 860 Hyde St.

BROD́RICK. RICHARD G. (b'70)-Cal.1, tired; 2741 Union St.; 1-3; Asst., clin. Prof. Hyg. and Public Health, Cal.11; (B28).

Bronson, Edith (b'86) - Md.7'13; (1'13) Hospital for Children and Tralning School for Nurses and Alexander Maternity Cottage.

BROOKE, ROGER, JR., (b'78) $\odot$-Md.4, 00 ; Maj., M.C., U.S.A.; Presidio.

Brooks, Jos.' Scholfleld (b'72) H-Ca1.5,'94; (1'95) ; 3773 Clay St. ; offlce, 135 Stockton St.; Prof. Anat., Cal.5.

BROOKS, WM. H. (b'68) 1 -Md.4,'89; Maj., U.S.A., retired; 660 Market St.

BROWN, ADELAIDE' (b'68) §-CaI.1,'92 : (1'92); 45, 16th Ave.; office, 240 Stockton St. ; $2-4 ; O b G$.

BROWN, PHILIP KING (b'69)(-Mass.1, '93; (l'93); 1, 25th Ave.; offlce, 350 Brown, Robt. (b'78)-Cal.7,11; (1'11); 275 London St. ; office, 3296 Mission St. 2-4, 7-8; Anes.

BRoW' PINCENT DE P.-Cal.1,03 (l'03); 145 Commonwealth Ave.; offce 111 Ellis St.; 10-12, 4-5; (B28)'.

Brownell, Edw. E.-Md.7,'99; (1'99); not in practice; 1700 Broadway.

Bruguiere, Peder Sather (b'74)-Cal.2,'98 (1'98); 133 Geary St. ; offle, 633 San Francísco St.; 3-5.

BRUMLAN, ARTHUR KARR (b'79) Cal.1, 08; (l'08); 2333 Pacific Ave. office, 209 Post St.; $3: 30-5: 30 ;$ G.
BRUNE, ALGUST E. (b'50)-Cal.1,75,

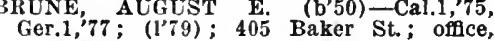
785 Market St.; 11-12, 2-5.

BRUNN, HARÓLD (b'74)(-Pa.1,'95; (l'97)'; 121, 5th Ave.; offce, Butler Bidg.;

BRUSCO. HENRY DOMENIC $\left(\mathrm{b}^{\prime} 86\right) \oplus$ Cal.1,08; (l'09) ; 1071 Union St.; offce, 583 Green St. ; 10-12, 2-4, 7-8.

Bryant, Edgar. Reeve' (b'66) H-Pa.9'89. (I’91); 3869 Jackson St.; offce, 350 Post St. ; 2-4; Prof. Surg., Cál.5. 

Bryant, Wm. Aurust-Cal.1,8t; (1'y4):2113

Buckland, Owen (b'g6) k-Cal.1,'87: (l's:) (MIII Valloy); oflce, 39 ! Sutter St. : 1-4 (IR28) ; OD.*

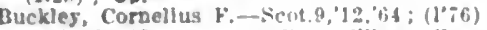
2614 Pactlc dye; atloe, Elkan Gunst Hids: II-19.

BICKLFY, F.MMA + - ("a1.2.002: (1'02) o235 lost Sis; odjce, 240 stockton St. 2:35 I'0st St:

BICKLEY VINCENT 1,. (b.50) +-CA1.2 '\$1: (1'\$5): 9 West Clay lark: $8-9$ offce, 333 Kearny st. : II-1.

Bushnell, (ieo. Edwari-Cal.1,'st; (1'92) not In practice; 202 Edgewood Aro.

BUFILL, WM. H. (b'75)+-('al.7.00 (1'00): Keystone Ifts. : oflce, 240 l'owell St: $: 2-4$

Rullock. Russ R-Cal.:'0I; (I'0I) ; 502 Dullock. Russ R.-Cal-a

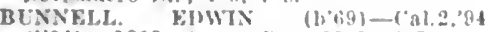
(1'94) is9s lieary St.; II-I, ti-7.

BUXNELL, STERLXY" th's2) T-Cat. 0 : (1’0s): Olympic Club; oflce, 240 Stockton St: 2-4: S. (1"97): 83 Jevluadern St.: oftce, 1194 VIcAllister St: $2-4=$

Burns, Matluda Watson (b'53)-Cal.1, 87 ; (1'88): 430n Jutah st.

Burquo, Jos. Geo. (b'49)-Ont.4.76: (l'01) ; $62 \%$ IIst Are.; offee, 70s Vallejo st. 9-12. 2-4, $i-8: 30$

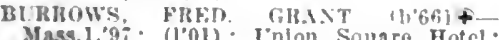
(Unlon Square Hotel. St.; 1-3, i.s.

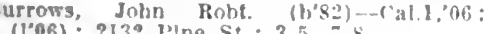

(106) : 2132 PIne St. : 3-5, $\overline{0}-8$.

Burt, Chauncey Ira (b-65)-Ia.I, ss:-1)

201 Powell St.

Burton, Benj. T. (b'59) -Ore 1,'sn: (1'sa) 64: Dth Are.; oflee, 1379 lieary st.

Buller, Fdmund Wm. (b'sf)-('al.1,"11: (I'Ii): Clay and webster sita.

BUTLER. JOS. (b',3)-Cal.7,.$^{\prime} 05$ 4392 IItssion $\mathrm{St}$

Byme, Winifred II.-F-Cal.4,96; (I'99) :

(1'06)

1325, th Are, ; $1-3,7-8$.

CADF, WM. T., JR. (b.83) - 0.9 .08 sidio.

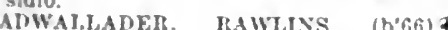
Cal.2.'93; (1'94): 1035 Gerry St : oflce. 240 Stockton St. ; 1.4: l'rof Obst. and Assoc. Prot. Alyd. Surgo ('al.7; S.

CACLERI GTDO F (b) $f-1$ S. Fong.11,15, $95 ;(1,93)$ : 2533 Larkln oflce, 20\% Mnntuomery Are.; $8: 30-8: 30$

Calderon, Eustorjlo (b'61) - Swisz.i,'si (1\%91); 561 Hydo St.; $1=4$.

Calhoun, James V-Cal.1,03; (J'03) ; 1293 riolden Gato Are.

Cameron, Ida B.-II-Cals.07: (1007) 101 W. Clay st.; ofldce, 133 tirstry st. $10: 30.3$

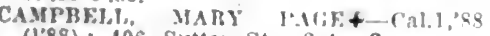
(1'88): 106 Sutter St: : $24 ; G$.

CAMPICKL, J'AI, +-NwIt\%,, 99, Fng 11 15,03; (l'08) : 2401 Larkin si.; once, 381 Bumb Si. 1-i: S.

CANAC-MABUIIS, FEHIXNND P. (h"TS

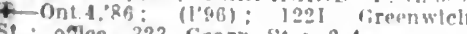
St; oflce, 323 ricary st. $2-4$

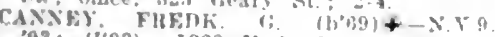

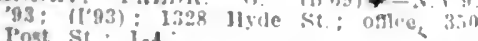

CARL, (UIS

3थl (R28).

Cand. Wim. S $(1,6,0)-c o l n .5,03: 110 \%$ (Alameda): infce, Winthask iblag: 10-4

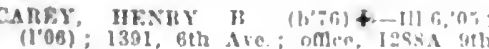
ire. : $7-8$.

Carmicbael, Mary Francen (1,69)- III 19. 02: $(1+10)$; 391 sutter St.; omre, (1,ll. ctren "n Howplini.

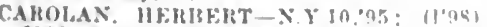

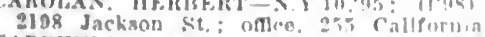
CARPENTEIt, FHAN MFXTIN (h'sh)

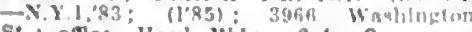
St. omre, lleal lirig.; :-4, G

Carpenter, Frank Wesley (ral gi: $11^{2} y 4$
CARsox, AiFo, R.-Cal.1,0I; $(1.01) ; 323$

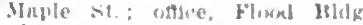

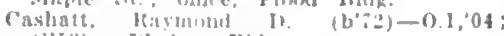
11'13); I'llelan JBldg.

Casper, Firvln J. (1,'ss)-Cal.1:12; (I'12): [201, z011 . We. : $2-4,7-8$

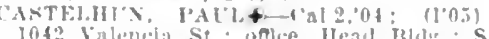
CASTLF, HAlBY EDWAII) (b'4)+ IHI,

Calton, Jos. Henry (b'90)-Cal.2, 'la; (l'13); (ity and rumes Hosyltal and Itelle? II inse Tract.

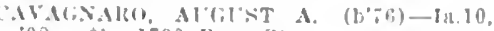
ne: 1 क) : 1:00 page st.

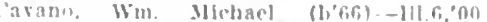

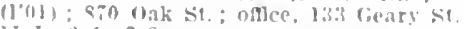
$11-1,2-4$; -8,

CERF, AIVIN F,DGAR (b'81) F-ral.7,04 $(1005)$ : $: 2942$ Washlngton St.; ofllce, 111 EIlls st. : $2-4$

IIIWITK, FREDK. CHFSTER $\left(b^{\prime}-2\right) \mp-$ lotio bevisiklero st. ; 1-4.7

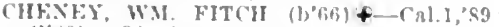
(l's9): 33 spruce st. oflce, 210 lost

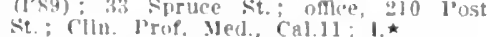
Chenoweth. Montend Scott (b'bi)-Mo.1. 90 ; (1'00); 1203 Cole; once, i]s Mar ket $S t$

Cherry, Edward Martin-Cal.1, 99; (1'99) cIII) Sacramento St.; $1-4, i-8$; 0. Conn.l., 240 stockton St?

Chlsmore, llarry J.-Cal.7,03; (乡); 19.2

Christal, John (b'4i)-Ire.9,75, Ire., 94 $(190)$; 1271 Plne st.; onlee, $15: 30$ Web-

Clark, Chas,-F-111.8,93: (1'95): 115 Scott st.; oflee, 1'acitic I Ildg.; $10-12$ 4-6:30.

rhilk, JoHX ROGERs + N.Y.1,95 (1"01); IsQ2 Gougl St.; oflce, st l'ost Sit. ; $1:\{1\}-4$.

Clark, Milton Francis (b's:s) - Cal.1,10:

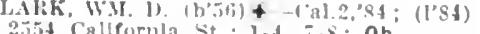

2ut Calfornla st. : 1-4, i-s: 0 b.

(199); 2710 Flluert st.; oflce, 240 siock ton si.: H-1.

Clayes, Wellingtion Irvlng (h,i $)$ - Cal.1, n3: (I'03): 1:97 Dolores st. : once, 2yth and
Lolores Sts.: 3-4.7-8: G.

leary, Sterhen-fal.2,94; $(1994) ; 26 \pi, 4 t h$ Are. : $1-3,7-7$.

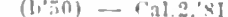
(l'st); 2let and lluwall sits, oflce, 3315

Mlission sit. ; $8-9,3-5,7-4$

"OFFEY, WALTER JFIRAMR (h'tis) +

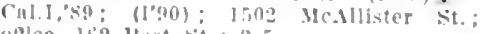
Colln, r. rook (all, $92 ;(192) ; 1362$

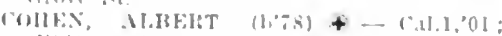
(I'i1): (sian Mateol) ance Itic lirant

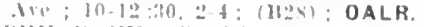

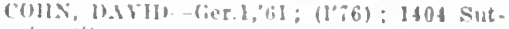

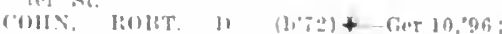

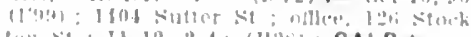

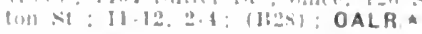

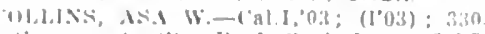
$\mathrm{s}$

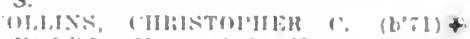

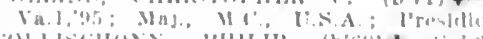

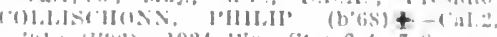

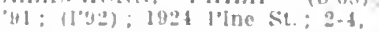

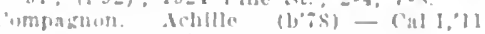

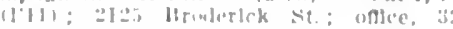

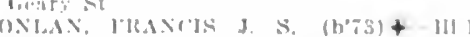

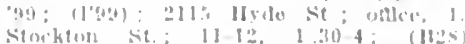
OALR.

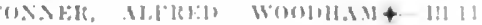

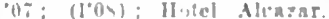

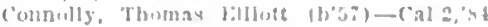

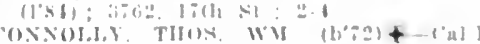

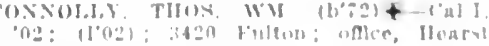

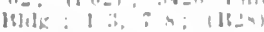

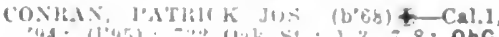

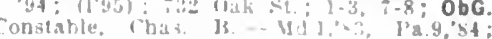

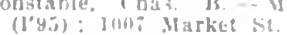

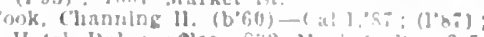

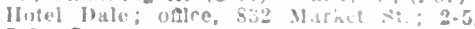

$7-8 ; 0 *$

cook, Cliristlana A-E-; $(1 \% 6) ; 136$ ?

firove it: 10.12, 1 :

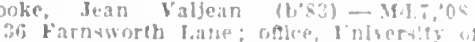

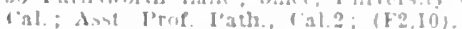

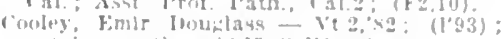

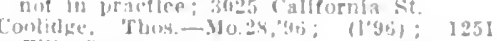
Fillis st

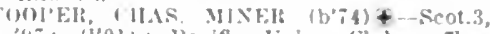
"47: (lnol): Parifle Unton Club; once, Hutier likga ; 1 .

myer, Sharshel Del'er (b'it)-ral.7,10; (\$); 140\%, ith . 11e : onlee, 13:3 (ieary St.

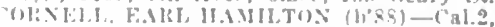

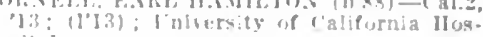
pitai

TIRNDIIL, FRANK (b'46) $\neq-0.2,69$ (1's2); (281] Stuart St. berkeley) nalre, ati lowell st. 9.3; 1319.25

OALR.

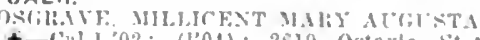

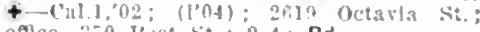
offle, 3.io I'est st. : 2-4; Pd.

Cottingham, lioht. (') (b'til) - Mo.3.'83: (1'8.5); 3:3l! lackson st.; oftlce, Pitclfle Blig.; 10-12, I-4; ALR.

"omper, Edzar Ward-ral.i, Mission st. ; $1-4,6: 30-7: 30$.

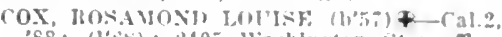

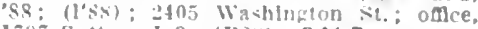

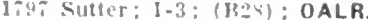

CRANK CIIL (TSTFIK $(1,66)+$ Mass. 1 . '99; (1'09): $237 \mathrm{~s}$ I'nlon st.; ottlce, 1155 Bnoh st. $1:: 00-4: 30: 0 r \star \star$

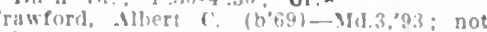
In priactive : vianent Medical School:

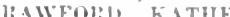

mit in nractice: Member yich. State yed. soc i.oga 11 yde sit

Crawford, W: F-Mdt,97; (1'00): 1300 JicAllister Sit. Fermon (b'63)-Cal.1,95;

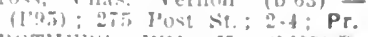

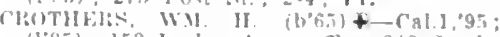

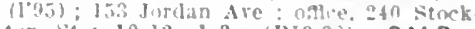
ton si.; 10-12, 1-3; (B)19,23); OALR.

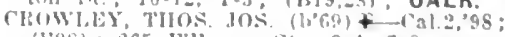

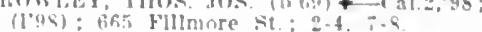

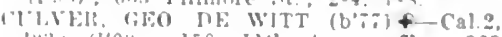
"tis; (lo03); 150, Ilth Are: oflce. 323 Cieary St: $10-12,2-4 ;(12): D$.

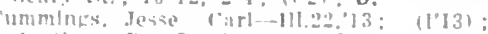
śnuplern Parife fompany llospital

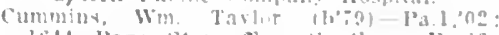
litt Jage st.: onle. Sumthern pacifle

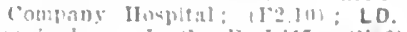

Cumningham, J. \&.-1'3.1, 17; (1'จ6): 135,

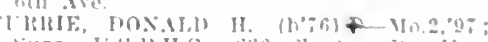

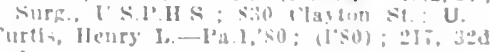
Cutpha, chas. Thendora (b'äill l'a a ys:

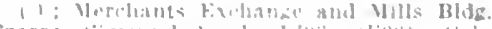

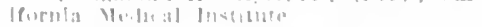

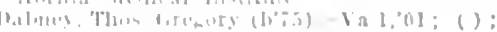
crueker JBlas

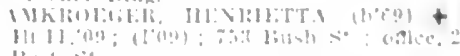

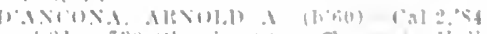

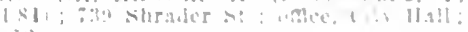

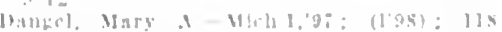

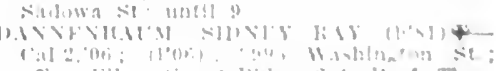

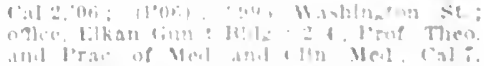

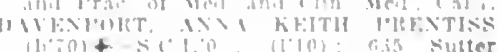

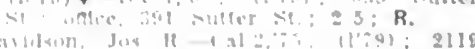

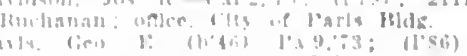

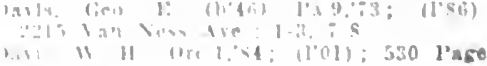


DAWSON, WM. C. $\left(b^{\prime} 79\right)-C a 1,2,07 ;\left(l^{\prime} 07\right)$ 1358 Clement St.; oftlce, 133 Geary St. $1-4,7-8$

Deakln, Stanley McClure (b'87)-Cal.9,'12; (1'12); St. Mary's Ilospltal.

DEAL, LOUISE BACON-Cal.1,'94 ; (1'94) ; 69 Falr Oaks St. :

DEANE, I,OUIs CIIALLES $\left(b^{*}, 0\right)+$ Cal.1, 91; (1'95); 3840 Sacramento St. ; office, $350^{\circ}$ Post St.: 11-12, 2-4; (B19,28); OALR. *

Deane. Tenlson - Cal.1,'88; (1'88); 1114 Green St.; offlee, 350 Post St.; 12:30 $2: 30,7-8$.

DE CHANTREAU, JACQUES DANI. (b'65) (-Fra 6,91: (1'92): 335 Stockton St. offce, 323 Geary St.; 10-11, 1-3:30.

De Ia Hautlere, Rosalle S. R.-H-11l.15, '99: (1'99) ; 1621 Golden (iate Ave.

DELMONT, FRANCIS (b'40) - Cal.2,74; $\left(l^{\prime} 76\right)$; 1813 Golden Gate Ave.; offlce, 618 Green $\mathrm{St}$.

DE LUCIS, CAV. ANDREA - Ita.20,'81 (1'95); 1703 Powell St.; oftice, 444 Montgomery Ave. ; $10-11,2-3,7-8$.

D'ERCOLE, VICTOR (b'69) $\oplus$ - Ita.20,'92 (l'01); 305A Columbus Are. ; $1: 30=3$.

Derham, Vincent Cliarles (b'86)-Cal.1,09: (1'09); 209 Post St.

deStone, Frank Geo. (b'63) 1:-Cal.4,02 (1'02); 409 O'Farrell St.; office, 12 Geary St. : $1-4$.

D'Erelyn. Fredk. W.-Scot.3,86; (l's 7 ) (904 Willow St., Alameda;

DICKINSON, CHESTEI CHAS. (b'89)111.11,12:' (1'12): Sonthern Pacific Com111.11,12; (12): Sonthern Pacific Company IIospital : offlce. Fell and Baker Sts
DICKSoN, ERNEST CIIAS. (b'81) $₫$ - Ont.1 DICKSON, ERNEST CHAS. (b'81) 4 Ont.1, Lane Hospltal; Asst. Frof. Med., Cal.11 (F2) ; 1,

Dllion, James Root (b'84)-Cal.1,12 ; (1'12) 2597 Sutter St. ; office, 209 Post St. ; $11-12$ $7-8$.

DILLON, JOHN FRANCIS $\oplus$ - Ia.3,'81 (1'81); 2597 Sutter St. ; offlce, llead Bldg. ;

Dixon, lloward Bucknam (b'89)-Cal.5,'13: (1'13): St. Mary's Mospital.

DODEL, TAVIFR (b'55) $\uparrow-$ Ger.16,'82 (1'84) : 1512 Ellls St.; 1-3, $5: 30-7-30$

Dodge, Washlngton-Cal.2,'84; (1'84); not in practice; 2129 Laguna.

DOLMAN, PERCIVAL4-Cal.1,05; (1'05) (In Europe); (B2S).

DoRR LFVI' LEVIIS $\left.\left(\mathrm{b}^{\prime} 40\right)-\mathrm{N} . \mathrm{Y} .10\right)^{\prime} 66$ $\left(1^{\prime} ; 6\right) ; 2678$ Fllbert St. ; office, 612 Market $\left(1^{\prime} 76\right) ; 2678$ Fllber
St. ; $11-12,1-4$.

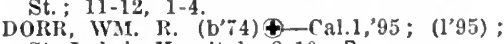
St. Luke's IIospital; 8-10; $\mathbf{S}$.

Dougherty, James C. - Md.6,98; U.S.A Transport Service.

Dougherty, WW. A.-Cal.1,'99; (1'00); 398 Guerrero st. ; $2-4,7-8$

Dow, Burritt Newell (b'64) - Cal.5,'95 Cal.7,02 ; (1'95); 2201 Larkin St. ; offlce, 209 Post St. ; $12: 30-4$; Prof. Ophth., Otol. 209 Post St.; $12: 30-4 ;$ Prof. Ophth., Otol.,
Rhin. and I.aryn., Cal.7; (B28); OALR.

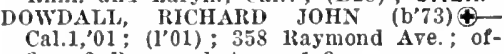
flee, 6 kaymond Are.: 1-3.

DOWNES, CHAS. SHERIDAN (b'64)థCal.7,00; (1'00); 930 IIayes St.; offlce, 133 feary st.; $1-3,7-8$

DOZIER, CHAS. ATKINSON (b'63) Cal.1,'87; (1'87) ; 827 Duboce Are. : offlce 209 Post St . 1:30-4; $\mathbf{S}$.

DRAPER, ALFRED LAWRENCE $\left(b^{\prime} 74\right) \subseteq-$ Cal.1,00; (1'01); 115 Presidio Ave.; of

DRAY, FliNK RAYMOND $\$$-Mass. 1,98; (1'98) ; 2525 Fillmore st. ; $3-5$

DRESEL, GUSTAV (b'56) $\uparrow$-Ger.18,'82 。 (1'84): 2879 Vallejo St.: offlce, 209 Post St.; 10-12, 2-4; (B1,28).

Drew, A. Damer' (b'59)-Va.1,'91; (1454 10th Are., Oakland); offlce, U.S. Quarantine Station.

ORISCOLL, EDWARD P. - Cal.2,'91; (1'92); 2027 Polk St. ; 1-3, 6-8.

Drossel, August Adolph (b'68)-Cal.1,'89; (1'89) ; 280 Noe St.; 1-4.

Duncan, Franklin Thos. (b'75)-Cal.7,'97; $\left(1^{\prime} 9\right)^{-}$; 725 Turk St.; offce, 291 Geary t. ; $2-4$.

Duncan, Hiram Burton (b'85) -Mo.34,'12 ; (1'12); 1638 Haight St.
Dunn, Mlchard H.-Cal.7,06; $\left(1^{\prime} 07\right) ; 870$ IIalght St.; offlce, 3 Clty Hall Ave.; $3-4$, 1UNN, ROBT.-Tex.6,"04; ( ) ; 209 Post St. WASTLAND, ORIN-Mo.1,'82; (1'01); 2804 24 th $S t$.

FASTON, DANIEL ELISIIA FOOTE (b'73) Cal.2,'95; (1'95); 900 llalght St. ; 1-3. 6-7

TTOV, GEO. I.EE (b'72) -Tenn.5,'94 (1'94); 140 Commonwealth Ave, office 323 Geary St. : 1-4; $(\mathrm{C} 3,14)$; U.

EAVES, JAMES (b'83)—-Scot.3,'10 (1'12); 2511 Octavla St. ; oftec, City of Paris Bldg.; S.

ERERT, HAR

ERERT, RUDOLPH GUSTAV $\left(b^{\prime} 54\right) \oplus$ N.Y.10,78; Col., M.C., U.S.A.

EIBRICHT, GEO. EILIOTT (b'73) -Cal.2, 99: (1'99) ; 2446 Washington St. ; office. 209 1'ost St. ; $11: 30-3$.

Edwards, IIomer C. (b'68)-Mlch.1,'92 ; $\left(1^{\prime} 00\right) ;(1130$ E. 28 th St. ; Oakland); of fice, $51,3 \mathrm{~d}$ St. : $1-4$.

EDWARDS, WMI-Cal.7,'97; (1'97); 240 , 9 th Ave, ; office, 133 Geary st.; 1-4

Egeberg, Júllus C.-Cal.1,05; (l'05); $910 \mathrm{~A}$ Devisadero $\mathrm{St}$.

EICHIER, AIARED (b'65) $\oplus-$ Cal.1,94; (1'94); 4400, 19th St.; offlce, 203 Church St. $; 2-4, \pi-8$

Eldenmuller, Wm. Cooper (b'56)-N.Y.5, 84 ; (1'84); 708, 2d Are.; offlce, 333 Kearney St. : $1-4$.

EIDENMUI,LR, WM. C., JR. $\oplus-\mathrm{Cal} .2,06$; (l'06); Wlitshire Hotel; office, 948 Mar ket St.; 1-3, 7-8.

EKLUND, OSCAR E.†-Cal.7,'02; (1'04); 717 Hyde; offlce, 391 Sutter St. ; 2-4.

ELLINWOOD, CIIAS. NORMAN (b'36) 11l.'58; (1'76): 2739 Paclflc Are. offlce, 2440 Devisadero St. ; $2-3$.

Ellinwood, Lathrop M'CD. (b'83)-Cal.8,'09; (1'13); 200 Cherry St.; offlce, $2440 \mathrm{De}$ vlsadero St. ; $2-4$

Ellls, Landon' R.-Cal.1,'94; (1'94); 1477 California; office, 162 Post St. ; 3-5.

ELOESSER. LEO (b'81) $\oplus-$ Ger.10,07 (l'09) : 94 Carl St.; offlee, 135 Stockton St. ; 2-4; Asst. Prof. Surg., Cal.11; S.

ELY, LEONARD W. (b'68)(-N.Y.1,95 Menber Colo. State Med. Soc.; (Palo Alto); offlee, Webster and Sacramento Sts.; Assoc. Prof. Ortho. Surg., Cal.11 (A3) ; Or. $\star$

EMMAL, FRANK S.†-Cal.1,01; (1'01) German Hospital.

Engle, Howard M.-H-Pa.9,'96; (1'97) ; 1140 Filbert St.

Ernst, Edw. Cranch (b'86)-N.Y.1,'11; Intern, Soutbern Paclfic Company Hospital.

ETCHEVERRY, MCHAEL, H. - Cal.7, 02 ; (1'03) ; 1810 Devisadero St. ; offlce, 391

Sutter St.
EVANS, GEO. II. (b'69)థ-Mich.,$' 91$; (1'91); 2601 Union St.; offlce, 133 Geary St. ; 1. $\star$

EVANS, MORRIS (b'73) $+-C a l .1,03$; $\left(1^{\prime} 03\right)$; 3224 Mission St. ; $1-3,7-8$.

Ewing, Edgar Edison (b'81)-Cal.5,'12 ; (l'12) ; Hahnemann Hospital.

FARENHOLT, AMMEN (b'71) - -Mass.1, 93: Surg., Lleut. Commander, U.S.S. Training Station.

Farmer, Jesse C.-E-Cal.4,'88; (1'88); 327 Church St

FARNUM, CHAS. E. 4 -Cal.5,'78; (1'78);

513 Devisadero St. ; 2-4,

Fassett, Edwin L.-H-Cal.5, 03; (1'03) ; 502 Clement St.; 2-4, 7-8; Prof. Clln. Med., Cal.5.

Faull, Carleton W. (b';2) - Ore.2,96; (1'96) ; 212 Leavenworth St.; 2-5.

FEELEY, MATILDA ANNE $\left(\mathrm{b}^{\prime}, 7\right) \oplus-\mathrm{Cal} .1$ 07 ; (l'08); 1700 Sutter St.

FEIILEISEN, FREDK. (b'54)థ-Ger.20, 77 ; $(1995) ; 400$ Claston St. ; office, 1211 Polk St. ; $1-3$.

FEHLEN, AUGUST (b'60) - Cal.1,'94; (1'95); office, 331 Church St.; 1-3, 7-8.

FENTON, LOLITA DAY BEW (b'71)-
Cal.7'99; (1'99); 863 Bush St.; offle, Cal.7,'99; (1'99); 863 Bush St. ; 0
Galen Bldg. ; 2-4; Prof. Ped., Cal.7.
FFOULKES, BRUCE (b'73)-Cal.1,'04; (1'94); 346 W. Clay St.; office, 146 Grant Ave. : 2-4; $\mathrm{S}$.

Flchtner, Gustav C-I-Cal.5,87; (1'87): 954 IICAllister St. : 1-3, 7-8.

FIELD, EDNA ItICKER (b'48) $\oplus$-Cal.1,'83; (l'83); 1230 Geary St

Flfe, Jos.-Cal.1,96; (1'9i) ; 3870 Jacksoul St. : offlce, 2802 Callfornlá St.

FISCIIEI, ELIZABETH FRANCIS JOYCE - Cal.2, 00 ; $\left(l^{\prime} 00\right) ; 544$ Irving $S t$

1329 Jackson St. : 1-3; N.

FISHER, ARTIIUR LAWRENCE $\left(b^{*} 75\right)+$ Md.T,'00; (l'00); 3333 Jackson St. ; offlee, 126 Stockton St. $2-4 ; \mathrm{S} . \star$.

FITZGIBBON, FRANK T-Cal.2,'94; $(1 " 94)$;
1831 Hyde; offce, 291 Geary St. $_{2}-4,7-8$. 1831 Hyde; offlce, 291 Geary St.; $2-4,7-8$. '77; (1'78); 2603 Stelner St.; office, 1114 Sutter St. ; $2-5$.

Flanagan, Leo Jos. (b'85)-D.C.2,'11 ; (1'11) 449 Dolores; offee, 16th and Noo Sts. 2-5.

FLEISCHNER, EMANUEL CHAS. (b'82)

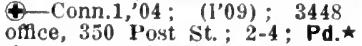

Flelssner Cuthbert M. (b'87)- Cal.5,'13 Intern, Clty and County Hospital and Rellef Home Tract.

Flemlng, Bartholomew F. (b'64)-Cal.2,'93; (l'94); 1783 Unjon $\mathrm{St}$

Flemlng, Stephen (b'78)-Cal.7,12; (1'13) ; Clty and County Hospital of San Franclsco.

Flood, P. 'II.-D.C.2,74; (1'76); 1223 Page St.

Floreth, Otto Pklly (b'81)-Mo.34,'13; Intern, German Hospital.

FLYNN, ANNA MARIA-Mllch.1,'92; (1'94) 745 Bilsh St.; offlce, 391 Sutter St.; $1-2$ 4-5; (B28).

FORD, CAMPBELI (b'64)-Cal.2,'91; (l'92) ; 742 Green St.; offlce, 246 Powell St.; $2-4 ; \mathrm{S}$.

Forster, Wm. Martln (b'58) E-Cal.4,'98; (1'98); (Berkeley); office, 709 Yan Ness Are.; 10-1.

Cal.2,'08; (1'09) : 136 Hugo St.; offlce. Cutter Laboratory ; Path. $\star$

FOTTRELL, MICHAEL J. (b'58) †-Cal.2, 87 ; (1'87); 2101 Devisadero St.; office, Phelan Bldg.; 11-12, 2-4, 7-8.

Fouch, Albert $N .0 ;(1,76)$; Paciflc Bldg. Fowler, Benj. L.-H-Mo.5,98; (1'01); (Sausalito); office, 787 Market; $9-5$.

Fox, Warren Franklln (b'90) - Cal.9,'13; (1'13); U.S. Marlne Hospital.

France, Gerald D. (b'89)-Cal.9,'13; (1'13) ; St. Mary's Hospital.

FRANIENHEIMER, JULE B. (b'73) Cal.1,98; (1'98); Granada Hotel; offlce, 240 Stockton St. ; 1.

Franklin, Goo. C. II. (b'87)-Cal.1,'12; (l'12); 234l Sutter $S$

FRANKLIN, WALTER SCOTT (b';6) $\$-$ Cal.1,'98; (1'98) ; Fairmount Hotel; oftce. Butler Bldg.; $1: 30-4 ;(B 1,28) ; O A L R$.

Fraser, Donald Andrew (b'86)-Cal.1,09; (1'09) ; St. Francis' Hospital.

FRATES, FRANK EDWARD (b'84) Cal. 2, 08; (1"10); 610, 7 th Are.; office, FEDRICK, MÁRCU'S WHITE (b'61) Ger.14,'88; '(1'95); 1426 Washington st. ; offlee, 135 Stockton St.; $1-4 ;(\mathbf{B 1}, 28)$; OALR. $\star$

FREEMAN, CHARLES E. (b'73)@-Mo.28, 99 ; Capt., M.C., U.S.A.; Letterman General Irospital, Ṕresldio.

Freeman, Clara M.-E-Cal.4,'85 ;

802 Filbert St.; 9-12, 1-5, 7-9.

FRENCH, CHAS. E. (b'79) $₫$-Cal.6,02 ; (1'02) ; 144 Arguello Blrd.; offlce, Plielan Bldg. : $3-5$; ObG.

Freyermuth, otto Geo. (b'76) H-Ill.4,03; (1'03); 1133 Guerrero; office, Phelan Bldg. ; 1-4; Prof. Ment. and Nerv, Dis.,

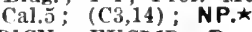

FRICK, EUCLID B. (b'67)థ-Cal,2,'88; Lleut. Col., M.C., U.S.A.

FRIEDLANDER, DAVID (b'77)థ-Cal.1, 98; (1'98); 139, 8th 'Are.; offlce, 146 Grant Ave. ; $11: 30-12: 30,2-4 ;(C 3,14) ; D$. Frink, Geo. K. (b'60)-Cal.1,'87; (1'87); 2626 vallejo St. 
Iritschl, Alfred R. (bo:i)-Cal.1,04; (I'04); 2134 Broadway: otce, Geary and Stocklon Sts: 1.3.

Fritu, Rose Sash (b'69)-Ill.5;11; ( ); 1201 Devlasdero sis.

FUSON, AMANDUS U, (b'69) \&-111.11:98; (1'99): 80 Hartlett St.: otce, 2580 Mlasion St.: 2-4, i-s. Galo, Herbert A.-Cal.2,79; (1'8:) : 2150 Yarkes Se.

Gallazber, John Jos.-Cal.1:95; (1'96) : 918 Brodertek St; odtce, 166 Geary: 12-4: $(\mathrm{B}, 23)$.

CALLWEY, JOHX (b'63)-Cal.2,85: (1'85); 1200 IIyde St.: ondce, $1: 7$ Post St: 1 - $4: 5$.

amble Wm. W.-II-M0.3, 81

(1'32)

1437 Fllimore St.

ARDNLE, SAML. J. (b'72) \& Cal.2,99: (1'99): 1001 Pine St.; oflec, 162 Post St.

Garllek, P. G.-H $\rightarrow$ Cal.5, $03 ;(1 \cdot 03) ; 225$ Sth Are: oflce, 202 Clement Are.; Assoc. Prof. Derm., Cal.5.

CEDGE, DONAIJ) MC('. (b'bl) +-('al.1.92 (1'93); 2924 Stelner st: oftice, plne and Stockton Sts.: $9: 30-12,1: 30-4: 30$.

Gedney, Fredk. M. (b'78)-Cal.1,03; $\left(1{ }^{\prime 03}\right)$; 3013 Filmore st. : 1-4

Creorse, Chas. G.-Cal.4;93; (1.94); 1902 Geary; omce, 51 Kearny St. Cere, Geo. G. (b'43) E-0.2, $1:\left(1^{\prime}, 7\right): 176:$ Waller st: ofce, 891 Market st. : 11-2. Gerlchten, Geo. P. ron-F-Cal.4,01; (1"01) Hannety Bldg.

GHIDELLA, EllWARD J. (b'\$1)-Ita. $\$ 0,0 b^{\circ}$ (1'11) also Member Vi. State Med. Soc. 164 Columbus Are.; oftice, $\$ 60$ Columbus Are: $2-4, i=8 ; S$.

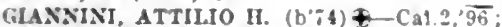
(1*96); 2745 Van Ness $\Delta$ ro.

Gibbon, John F.-E-I11.8,7\%; (1'7i); 1944 Calíforala st.; $11-12,5-6, ;-8$

GIBBONS, HENRY WALTER (b',i) Lee, 350 Pos? St: $3-5 ;($ (I) ; ObG.

GIBBONS, MORTON RAYMOXD $\rightarrow-$ Cal.1. '97: (1'98): 39:9 Washington st. : oflce. $330^{\circ}$ Post st. : $1: 30-3: 30$

Giberson, Nelson S.-Pa.2,76; (1'80); 2513 Unlon, St: otice, 1902; (l'80); 2815
Enlon St. 2-4, 7.8 .

GIOVANNETTI, RINALDO FAUL (b'82)Cal,1;11; (l'12); 564 San Jose Are.; orLee, 209 Post St

GIRABD, FRANK ROIT. (U"SI) +CAL? 03: (): Member Med Soc ol the Siate of Pa. Shrete Bldg. : S.

GLASER, EDWARI) FREU, (b'65) + (ald 95: (1.95): 980 Itush St. : ottce. 391 Sut ter St. : 1-1; (B19, 28); Op.

GLFASON, CHAS. D.-('al.2,02; (l'02) ; 781 Cole SL; offco, $17 \%$ Post St, ; 1:30-4; Pd. Glorer, Cosmos A.-Cal. 2, 43 ; (1"91): 169t

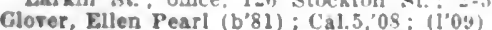
(2145 Webster 8t, Berkeley); once, 1195 Bush: 12-4.

Glover, Mary Ellzabeth (b'81) H-Cal.5, 0J (l'06); 1664 Larkln 8 t ; otlce, 135 Stock. ton St. : $11-2$

GOLDMAN; SAML AIVRUEM (b'81)

Goodale, Geo. Wm,-Cal.7,00; $(1,01) ; 1708$ IIrde'st: once, 06 II yulo st. Asst. Irof Clln. Surg., ('al.;

Goodale, Salem Wales (b'il)-Cal.i, 01 (l'01): 2587 -Mieslon st. $10-11,2 \times 4, i-8$ coopMas, EMANTLI. (b"5\%)-0.1, 92 (1'05): 3163 Mlsslon: once, zth and Alabaina Sts: $2-1,:-9 ; 0$.

Gos, Allce Morgan (b'j,i) $11-1114, "$, (I'90); I664 LarkIn st.; udre, 135 siowk ton St: $2-4$.

GOTTLIB, АВRАНАМ J. (\$) 81 + 10: (l'10): 1201 O'parrell St: once Schroth Bldg. : 2.4 ; Or.

Craham, Gllbert Fuller, (b"73)-Cal.1.85 (1'03): (Dentst): (2832 Summlt St, Oak land): omce. Shreve Islug.: 9.4 .

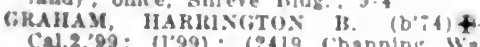
Herkeler): oflce 09 lost Channing Way Clin. Prof. Surt, Caldi; '(II.19,28) ALR.

GMAVES, JOHS IIENRY ¥ - CaIL"gB;

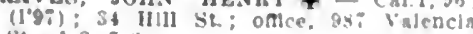

GREEN, AARON SAML. (b'78) COIO.5, 08: (1'09): 531. 9th Ave, amce, Shreve B!dg: : 10-1; (H19,28); OALR.*

GREEN, JONATIAN - CaI.1,"96,

$\left(1^{\prime} 96\right)$ :

143\% IIydo: ottce. 133 Geary.

GRFEN, LOÚIS DAVII) (b'80) $\$$ - Colo.s

09: (1'09): 531, 9th Are.: otece, 210

GREENWOOI\%, EARL SY. (b'

(l'0) llater sit.

GRIHFIX, CHAS. FRAXCIS $\left(b^{\prime} 69\right) \neq$-Cal 1 "91: (192): 1005 Judab St, oflce, 2804 Folsom St. : $2-4,7-8$.

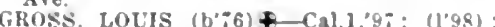
815 Dolores St. odice, 45 Kearny St. $11-12,2-4:(C 3,14): U, \star$

GROSSL, AI.FRED H. (b"73) \&-Cal.1,'94: (l'94): Falrmont Hotel; ofice, Hastings Hidg: 1.4: (C3.14); U.

Grossman, Fodw. Jorenzo (b־0)-Cal.1,94; (1'95); 721 Market St: 11-12, 2-4.

Grunlg, Louls II. -Ky.5;95; $(1 ; 95) ; 8 \%, 31$

St.; oflce, 122, 3d St.; $1-3, ;-8$.

Gugllérl, A. A-t-Cal.4,01; (1'01): (1091 ith Are. Oakland) : oflce, 20 Columbus. Gunn, Geo. (b'64) E-Cal.4,'93; (1'y3); 2835 Washlngton St. 10-4.

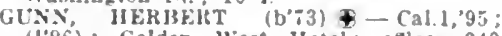
(l'96); Golden West Hotel; oflce, 240 Stockton St. 2-4.

UNN, J0IIN WM., JR. (b'-8) - Cal.1.03: (J'03) : 2385 Bryant Are; office, 2396 Bryant Are.: :-4, :-8.

Guntz. Adolph rictor (b'82)-Cal.i, 06 : (1'08); $\$ 26$ Oak St; ottce, $396^{\circ}$ Castro

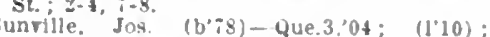
Stanford Hotel; oflce, Phelan Bldg. : 2-4, 1AS. SVLVAN L. $\left(b^{\prime} 83\right)+-M d .708$ : (I'10): 2299 Sacramento St.; oflce, $210^{\circ}$ Post st. : $1: 30-3: 30 ; \mathbf{S}$.

A BER, WM. J. (b'7z)+..N.Y.1,03; $\left(1^{\circ} 06\right)$; $\ddot{0-4} ; \mathrm{S}$.

IHDEILL, JOHY ALOFSITS $\left(\mathrm{b}^{\circ}-\mathrm{s}\right)+$ Call,04; (1'04); 297 Ilevisadero si: 4 ,

Uadles, lred 11.-Cal.1,96; (l"97); 214 Ash-

bury" St. ; oftce, 942 Market st.

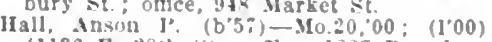
(1136 E. 28th st. oftce, 1205 Broadway. Uakland); also 291 Geary st.; $2-5 ;$ (B28) Ilall, Geo. Joyce (b०a)-Cal.1,12: (1'12)
500 , th Are.

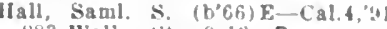

Shaller st.; 9-12; D.

MLI. WI. F. Mo.28,00; lst. Jleut Presidio.

HAMMONI, JOINSUN Flb NOIS (b's)

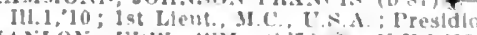

HANLOX, FUW WW $\left(b^{\prime}-1\right)+-1.1,93$ (1'94); 151, 22d Are, of
Grand Ares: $3: 30-4 ; 1 . \star$

HANLUS, JUHN STANLEI - Ca11,05 (l'05); 596 Ilaleht st

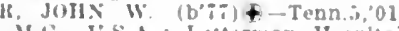
(apt., MI?., U.S.A.; Ietterman Huspltal,

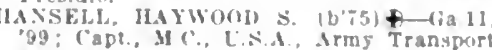
Serilce.

Hapuerstierger, Albert Karl (b'bi)-ral? 'Ax: (1'8y): 1300 liolden Gate Ave: 1 . Ilarbaugh, louss Wallace, (b'st)-Callif, lib (1'13): Cliby and ciounty llmpltal and aremer

lizes Halkbt St.

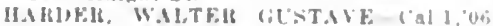
(l'06); 318 l'lerce st.; ufflec, 133 leesy

llardiug-Mason, Juhn-1'al t,00 : (1.0J) : l:2 IDolmar sit. : once, 135 sinckton st.

Il arringlum. juhn lies. (bxis)

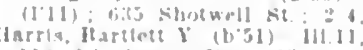

119. bll ofre; nalce, 13:1 lieary st 130.4

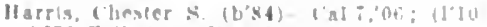

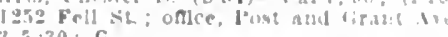

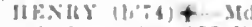

$242: 1,1,1$,
HARHISOY, E.MILY G T - ral.1,95; (l'95) : 2835 Clemens Ave : $133-3: 20$

II.ARRISON, SAMI. IXGELBY (U"3)-III.1.

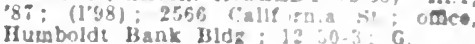
IAIBHSON, WM. H, JR (b'a) t fal. ob: $\left(10^{\circ}\right)$; 549. ith Are ; ntce, 12 Mar. ket St. : $2-7, ;-8$.

HAITT, HENRY IIERSCH - ral.1:" 1630 Hyde St: once, it How $11-8 ;(B 28)$

H.AIT, MOETON EUW1: (b'82)-Cal.2,04 (1'04); 2335 1"acllc Are; oflce; 215
l'owell st.; 10-12, 1-5; (IB19,28); OALR. HARTMAX. GEO. W. $\left(b^{\prime} ; 9\right)+M d . ; 08$. (1"09); 1204 Sutter st. : $1: 30-3: 30, i=8: U$.

Hartles; Koland E.-Cal.1.'\$9; (1'90); 126. 15th Are.: oftee, 391 Sutter SL

Harrey, Wm. A. (b'bi)-Cal.4,8k, Mo.7,95 (l'01): $4: 1$ (entral Are: omce, Paclac HARFY WM

114 Frederlck St $130-4$. HASHIMOTO, SHICGO (b'6i) \&-Cal.7,00; $\left(1^{\prime} 00\right) ; 1615$ Pougb St: : 2-3, 7-9

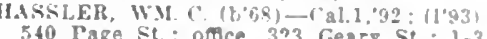
540 Pare St. ; otlce, 323 Geary St. 1-3:
Asst. Pro?. IIyg. and Sanlt Sclence. Cal.5.

Hatteroth, Wim. Henry Carl (b's0)-Cal.1. 0.3; not In practlce: 128\%, ad Are.: once. 232 Jowell St. ; 1.5

aren, Maude Noble $\left(b^{\prime 72}\right)-\mathrm{Cal} 1,00$ $\left(1^{\circ} 00\right) ; 611$ Baker St

HAWKINS, WM. JAMES (b'69) —-Cal.2, 90 ; Gealy, John Hopkinson (b'51)-Cal.1, $\mathrm{S} 1$

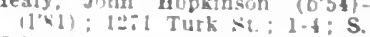

Helnzmann, whllmelm II. (b":6)-Cal.:;09 (1"03) : 146 Grant Are.

HZIZMANN, CIIAS. L. $\left(b^{\prime} 66\right)+$ Pa.1,6i: Col. I A...., refired; 37 Fresidlo Are

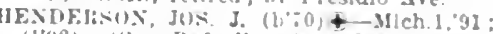

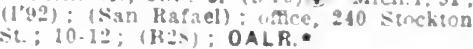
Hen

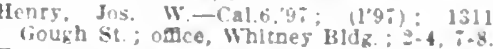

Hergert, Clara Alms (bo)-111 11, 23

Hospltal fur Chlldren and Tralnlng School for Nurses and Alexader Maternity Cottape.

HEIRING, HORT A \& LA 1,05: I.A SURB U.S. P.H.S. : Epldemic dut

IIERRIXITON EDWARN I. (b's1)+ Cal. $i, 06$
i-s: Pd.

HERRINGTON HOWARD † - Mch. 1,94 (1'94): 1529 sutter st. unel it:30, -8

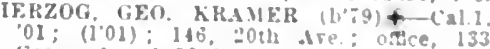
Geary $(1.01): 110^{\circ}$.

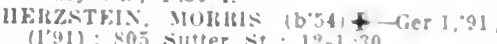
$(191) ; 805$ suster st: $12-1: 30$.

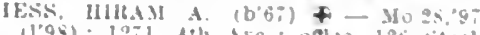

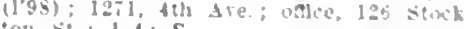

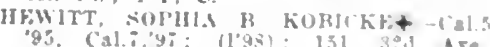

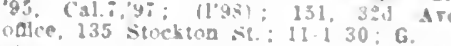

Hekey. John l'hill:n (b'is)-Mo::01 (1.0l); 2790 Harrimen si (1001): 41s, 3oth tre: nfelce. 330 pes?

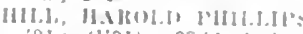

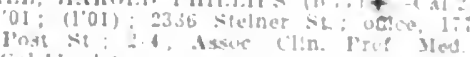

(al.11, 1.

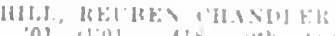

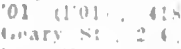

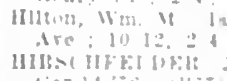

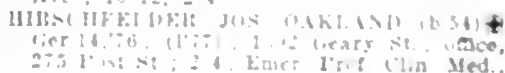

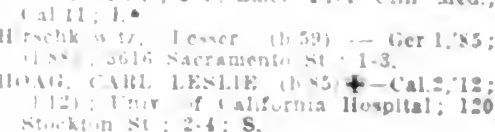

II.A: Jos hemulun Vo:;10; lntem. Culy (1ii) Tounty Hisurtal. 


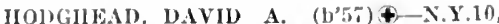
'84: (1'84) ; 3435 Sacramento st. ; ofllce, 3 Cíty Ilall Ave. ; 11-12.

HOFFMAN, HEIRIAN VERPLANK (b'82) f -Cal.2,05; (1’05); 126 Stockton St. ; $3-5$ $7-8$.

IIOFFMAN, LAWRENCF II. (b; $; 6) \mp-C a l . I$ 97 ; (1'98); 2335 I'taci

IOGAN. IAMES JOS. (b'72)థ-Cal.1,92.

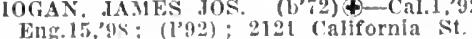

llolbronk, (ieo. Siory (b'73)-cal.1.'94 (l'y6) ; 545 O'Farrell St. ; offlce, 323 Geary St. ; $2-4,7-8$.

HOLSCLAW, FLORENCE MT (b'72)\&Cal.1,07; (1"07); 2217 I'acifle Ave, of 240 stockton St. ; $12: 30-2: 30 ;$ Pd.

IlOLT, JOHN M. (b'73) \$-N.Y.8,95; I'.A surg. I.S I.II.S.; 14th Ave. and lake St. $: 9-12 ; \mathrm{S}$.

IIOOKER, MARIAN OSGOOD (b,75)屯Cal.2,10; (1'10) ; 3277 Paclfte Are.

HOPIIXs, FDW. KIMBAJL $\$$ - Cal.2,'95 (1'95); Hotel Granada; offee, Butler Blds, ; 11-12, 2-5; (B19,28); OALR. *

IIOPliNS, WM. F. (b'58)†-Va.1,79, N.Y.5 30; (1’2); 2335 Pacitlc Are. ; oflce. 291 Geary St.; $9: 30-1: 30 ;(B 1,3,19,28) ; 0 A L R$. (1'99); I Ashbury Terrace; offle, ISth and Castro Sts. : $1-3,7-8 ; \mathrm{S}$

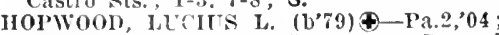
Capt., M.C., U.S.A.; Letterman General Hospital. Presidio.

HORN, HENRY (b’71)థ-Cal.1.'97; (l’98) Colonial IIotel ; offce, 209 I'ost St. ; 11-12, $2-4 ;($ B $19 ; 28) ;$ ALR.

HOUS'TON, ALBERT J. (b’74)థ-Cal.1,'98 (1'03); University Club; offce, 350 P'os St. ; $1-4$; (B28) ; OALR. *

IIoward, Edw. Stephen-I'u.2,96; (1'96) 2161 Sutter St.; Prof. Anat., Cal.

HOWARD, JOS. LOUIS $\oplus$ - Cal.1, 00 : Scot.12,02, Eng.11, 02 ; $\left(l^{\prime} 0(0)\right.$ : Ntewart Hotel ; olfice. I35 Stockton St.; $2: 30-5$.

IIoward, Katherine Irls-Cal.2,'85; (1'86); $290 \pi$ Filmore St.

Howard, Wm. Berry-Cal.2,87 ; (l'88) ; 405 Van Ness Are: $3-5$

HOWE, LOUIS PHILIPPE (b'80)థ-Cal.2 08: (l’09): Unirersity Club; office, 350 Post St. ; 2-4

Howe, Robt. Craven (b'75) - Cal.7,'03; (1'03); 1116 Eilis St.

Irowell. Edgar Henry (b'83) H-Cal.5,'07 (1'07); 2934 Jackson St.; office, 209 Post St.; Asst. Prof. Physiol., Cal.5.

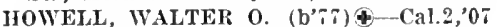
(l’0T); 133 Richland Ave,; 2-4, $7-8$; OALR.

Ilowitt, lichard I.-Cal.1,'91 ; (l'92) ; 2120 California St.

IUBBELL, GEO. R. (b'67) ४-Cal.1,90; (1'90) ; 480 Ellis St.; ofllce, Union Square Bldg. ; 1-4.

Hubbell, Harriet Horton Hanna-Cal.1,'90 (l'90); 1544 California st.; 10-12.

Huebner, Gustav Adolph (b'74)-Cal.1,99; (1'99): 156, 12th Are.; 1-3, $7-8$.

HUFFAKER, ANTHONY '(b'63) థ-Cal.1,'90 ; (1'90): Member Nev. State Med, Assn.; 1739 Pine St.; $2-4$; Pd.

Hughes, James 'Vincent-Cal.1,'95; (1'95) ; 2144 Hayes St.; offlee, 1138 Valencia St.; $8: 30-9: 30,2-4,7-8$.

Huglies, John Valentine-Cal.1,'96; (1'96) ; 2993,24 th St. ; $2-5,7-8$

HULEX, YARD HOLGHTON $\left(b^{\prime} 65\right) \uparrow-111.11$, '87, N.Y.I,'88; (1'99); 2335 Pacifle Are.; offlce, 135 Stockton St.; 10-1; (B19,2S); Op. $\star$.

Hund, Otto H.-N.Y.5,'80; (1'8I) ; 180 Sutter St.

HUNKIN, SAML. J. (b'64)థ-Cal.2,90 ; (l'9I); 1153 Bush St. ; 1-3; (A3).

Hunsaker, Hiram Walker' (b'63) E-Cal.4,'90; (I'90); 70 Cerritos Ave.; offlee, Pacific Bldg. ; 1-4; (B28); OALR.

Hunt, Helena A.-Cal.6,07; (1'08); 1070 Vashington St.

IIunt, Warren Cal. (b'90)-0.40,'11; Intern, City and County Iospital.

HUNTINGTON, THOS. W. (b'49) $\oplus$-Mass.1, '76; (l’S2) ; 2629 Pacific Ave. ; offlce, 350 Post St. ; 2-4; Emer. Prof. Clin. Surg., Cal.2; $(\mathbf{A} 5)$; S. $\star$
IIurd, Laura B.-II-Cal.5,97; (1'97); 1737 larkin St. ; omice, 209 Post Śt. ; $2-4 ;$ Asst. l'rof. Gyn. Cal.5; G

IUUliLY, JAMES RAYMOND (b'80)† Cal.2, 03 ; J'A.Surg., U.S.I'.H.S

Intchings, Robt. K. (b'69)-0.1,'91; (1'12) French IIospltal; OALR.

II OE, CIARENCE E. (b'82) - N.Y.1,09 (I'II) ; 845 Sutter St.; offce, 240 Stockton st. ; $1 ; 30-4$.

IYMAN, SOL.OMON (b'75) - Md.7,02 ; (l'02) ; 3421 Jackson St.; oftlce, Butler Bldg; $2-4 \cdot S \star$

INMAN, TIIOS. GEO. (b'72)-Cal, '94 (1’94); 4517 Callfornia st.; oftlce, 240 Stockton St.: i-3.

SNARDI, MARIOA-Ita.3,05; (I'06) ; 1436 Union St.; offlee, 166 Geary St.; $1: 30$ :30; ObG.

Jackson, W'in. J. (b'66) -Cal.7,98 ; (l'98) 2028 Leavenwortl St. ; office, 760 Market Jacobs, Jay (b'89)-Cal.1,'11; (1'11); 250 Van Ness Ave; office, French Hospltal.

Jacobs, Louls-Cal.7,01 ; (1'01) ; 1624 Sut-

JACOBS, LOUIS CLIVE (b'79) $\oplus$-Cal.2,'04; (l'04): Hotel IRichelieu; office, 1615 I'olk St. : $11-12,1-3$

JACOBS, SAML: NICHOLAS (b'82)Cal.2,08; (l'08); Hotel Richelieu; oflce, 209 Tost St. ; $2-5$; S.

Janes, Thos. Ingles-II-Cal.5,'88, $111.10,{ }^{\prime} 95$ (1'88) ; 1531 Sutter St. ; 2-4.

Jaues, Tryphinnle B.-Cal.5;'88, Cal.7,'98; (I'88); 1531 Sutter St.; i1-1.

JELLINEK, EML OTTO (b'65)థ-Aus.7, '92: (l'96) ; 2226 Washington St. ; office, Butler Bldg. : $2-4 ; 1 . \star$

IOHANSEN, ERNESTE A. (b'66)๑-Pa.2 '92; (1'92); 1809 Oak St. ; office, Whitney Bldg. ; 1-3; 1.»

Johns, Madeline E.-Cal.2,'03: (1'04); 650 Bush St.; office, 209 Post St.

JOINSON, ABEL W. (b,79) $\oplus$-Ill.1,01 (l'04); 160, 8th Ave.; office, 350 P'ost St. I2-4; '(B28) ; OALR. *

IOHNSON COFORD (b'84) - Cal.2,08 (l'08); 1751 Market St. ; office, 133 Geary Jolnson, Francis F. (b'69) - Cal.1,'94 (I’95); 2225 Howard St.; offlce, 350 Post OIINSON, IIENRIETTE AMANDA (b'73)థ -Ill.11,05; Member Minn. Sta

JOHNSON, WALTER SOULARD (b'69)ФN.Y.8,99; (1'04); 833 Cabrillo St.; offee, 350 Post St. : (Ć3,14) ; G,

JOHNSTON, JAMES HARVEY $€-C a l .2,07$; (l’08); 1271, 20th Ave.

Jones, Chas. L.-Cal.i,?97; (l'98) ; 1136 Guerrero St. ; $1-3,7-8$; Prof. Chem. Cal.7.

Jones, Lemuel Francis-Pa.1, 71 ; (1'92) 2996 Mlssion St.; office, $340 \mathrm{D} 26 \mathrm{th}$ St.

JONES, PHILIP MILLS $(b, 70)$-N.Y.8,'9I : (1'93): Sec. Med. Soc. of the State of Cal.; 135 Stockton St.

JONES, WALTER MATTHEW (b'83)థIo.2,07; Marlne Hospltal.

JUDELL, MALVINE I. (b'i6) - Cal.2,'98; $(1 ' 98) ; 209$ Post St.; $2: 30-4: 30$

JUILLY, GEO. HIPPOLYTE $(b, 7) \oplus$ Cal.2, 02: (1'02); 435 Bartlett St.; office, 133 Geary St. ; $4-6,7-8 ; 0$ bG.

JULIEN, EDW. HOOD (b'71)థ-Mich.7,95; (1'95); 480 Ellis St.; offee, 240 Stockton St. ; 1 -3.

KAELBER, ARTHUR $\oplus-$ Cal.1, 03 ; (1'03) ; 1099 Chesnut St.; office, 518 Sutter St. Douglas St.; $1-4,7-8$.

IAHN, ADOLPH JAIES (b'56)@-N.Y.10, ' 86 ; (l's6) ; 1284 California St. ; offlce, $\$ 6$ Post St. ; 10-12 ; Pr.

Kastendieck, John-H-N.Y.9,'78; (l'95); 644 Fillmore St.; 1-3, 6-8; Prof. Phys. Diag., Cal.5.

KAVANAGH, JOS. JAIIES (b'81)-Cal.2 '03; (l'04); 13I H Hyde St.; offlce, 560 Kearny St. ; $3-5,7-8$.

Karanagh, IIary Frances (b'79)-Cal.2,'0I (l'01) ; 1222 Jackson St.; $1-3$.

KEARNEY, PETER ALFRED-Cal.1,'84; (1'84); 2564 Sutter St.; 1-3, 7-8.

KFIRNEY, WM. BERNARDQ-Cal.7,03; (l'05) ; 3384, 23d St.; (B28)

KECK, FREDK. C. $₫$-Cal.1,94; (1'95) Olympic Club; office, 948 IIarket St.; 2-4 Prof. Elec.-Ther., Cal.7.
IEEFNAN, ALEXANDEIR S. (b' 22$) \oplus-C a l .2$, 98 ; (l'98); 2721 Folsoin St.; oftice, 16th

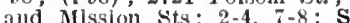

Keeney, James W - Y Y 10,74; $\left(l^{\prime} 79\right): 2618$ Buchanan St. oflec, 240 Stockton St.; I-3.

lelley, Gilbert A. (b'89)-Cal.9,'13; (1'13) ; st. I.uke's IIospltal.

KELLOGG, WILFKED II. (b'71)-Cal.2,'96; (l'96); 2820 Vallejo St. ; offlce, Board of Health ; Bact. $\star$

KELLY, JOHN P.-Ala.2,'98; ( ); Army Transport Servlce.

KENDALL, WM. P. (b'58)๑-N.Y.1,82;

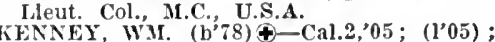
1379,6 th Ave.; oflce, 135 Stocktoll St. ; $1: 30-3: 30$

KENYON, CURTIS G. (b'46)థ-Cal.1,73 ; (I'76); Bellevue IIotel; offlce, 391 Sutter St.; $\mathrm{S}$

Kergán, John A. (b'6i)-Mich.8,'92; (1'9i) ; 145,26 th Are

ERR, WML. WATT (b'57)థ-Scot.3,'81; ('82) ; 2605 Callfornla St.; office, 391

líts, ELIZAB FTI E-Cal.1,99; (1'99) I331 Greenwich St. ; office, 391 Sutter St.

1331 Greenwich St. ; office, 391 Sutter St. ;
$2-4$.
KIERULFF, IIARRY NEIVTON (b'63)-Ia.3,

'92; (l'93); 68 Post St.
Kilbourn, Harvey B. (b'46) - Pa.2,79; (1'36): 476 Noe St.; untll 9, 4-6.

KILGORE, EUGENE STERLING (b'78)థMass.1,09; (l'11) ; 321 Parnassus Ave.

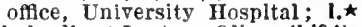

Kimberlin, - Lester Olin (b'84)-Cal.1,'11;

(l'11) ; Lane Hospital,
KING, CHAS. J.-Cal.1,06; (l'06) ; 429 Flll-

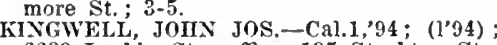
2233 Larkln St. ; offlee, 135 Stockton St. ; 2-4; (B19.28); OALR.

KINSLOW, FRANK A.@-Cal.1,06; (1'06) ; 1142 Railroad Ave.

KIKK. ALBERT W. (b'70)థ-Cal.7,00 : (1'00); (1927 Franclsco St., Berkeley) ; offle, 681 Market St.; 10-3.

KNAPP, EDW. V.9-Cal.1, 07 ; (1'08); St. KNAPP, EDW. V. 9 -Ca

Knight, Cameron-E-Cal.4,'92; $\left(1^{\prime 93}\right)$; 1824 Eddy St.

KNORP, FRANCIS FREDK. (b*72)థ-Cal.1 '92; (1'93); 3102 Clay St.; office, St. Joseph's Hospital; 1-3, 7-8; Prof. Prin.

and Prac. of Surg., Cal.7; S.
Knowles, Calvin Wm. (b'78)-Cal.7, 00 ; (l'00); 2296 Green St.; office, 177 Post St. : $10-4$.

Knowles, Saml. E. (b'48)-Cal.1,71; (1'76); Knowles, W'm. A. L. (b'55) - Cal.1,78 Cal.1,94; (1'94); (Dentist); 1967 Pine St.; offlec, 135 Śtockton St. ; 9-4:30.

Koerber, Lllie L. (b'79)-Cal.i, 06 ; (l'06); 200 Duboce Ave.

Krebs, Otto F. (h'76)-Cal.7,'08; (1'09); 22d and Folsom Sts.

Kremer, Roy (b'82) —Cal.1, 07 ; (l'10) ; 4052 , 18th St.; offlce, 948 Market St.

KREUTZYANN. HENRY JOSEF (b'55)Ger 4,'80: $\left(1{ }^{\prime} 86\right): 1054$ Sutter St : $1: 30-4$ Kroetz, Mary M.-H-Cal.5,'94; $\left(1^{\prime} 94\right) ; 3396$

16th St.: 1-3, 7-8. Wraiter (b'85)-Cal.1,'12; (l'12) ; 2418 Washington St.; offlce, 240 Stockton St.; $3: 30-5: 30$.

KRONFNBERG' HERMAN - Cal.2,06 (106) ; 3720 , 20 th St. ; office, Butler Bidg. $2-4$

KROTOSZYNER, MARTIN (b'61) 9 -Ger.14, '87; (l'88) ; 999 Sutter St.; 1:30-4

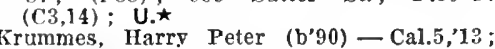
Krummes, Harry Peter
U.S. Marlne Hospital.

KUGELER, HENRY B. A. (b'70) @-Cal.2, 90 ; (1'90); 3636 Washington St.; offlce, 240 ' Stockton St.; $2-4 ; \mathrm{S}$.

KUFLMAN, CHASS. G.-Ill.1,'89; (l'92); 1252 Bush St.; I-4, 7-8.

Kuykendall, Jos.' A.-E-Cal.4,'96; (l'96);

LAFONTAINE, EMIMA C. $\oplus-$ Cal.1,'87; (l'88); 1211 Polk St.; 1-3; Ob. (l'92); 813 Oak St. ; 1-3.'

Lagan, Hugh (b'71) - Cal.2,93; (l'94) Folsom and 22d Sts. 

Lagan, John-Ire.5.'96: (1'35): 140 Halght
St.: 1.4. :-8.

LAIST, OTTO-Cal.6,00; $(1,00)$; 152; IIcAllister St.

Lake, Fdw. Jllls-No.7,95: (1'95); not in practlce; (IRoss); onter, Flond ridge

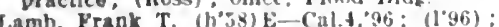

I,amb: Yrank T. (h'58) k-Cal.t,

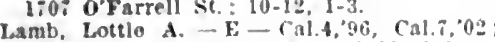
(1'96) : 1\%07 0'kaprell st.: 10-12, 1-3.

Iamb, Susan 1. Jalverson (bo6)-Ia.3.85: (1'10): (341I lialey st., Oakland); once. 240 Prospect St. : 1:-4.

Lamb. Wm. N. (b'61)-Ca1.5,94:

1802 Fllimore St.; 2-t, i-8; ObG

Lamoree. Edilh Anderson-Cal.1,94; (1'96): 810 MeAlllster St.; 1-3.

LANDER. CHARLES JOII: (b'5) क-Cal.;, '10; (1'11): 2964 Elllmore St. : aflec, Clty of Parls Bildg. : $2+4$.

Lane. Paul II. (b's2)-Ca1.1,07; (1'0i): 201 Hallowa Are.: I-5, 7-8.

Langstroth, Lorell (b'S0)-Cal.1,12; (l'12) Iane Hospltal.

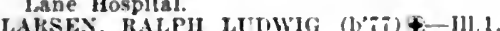

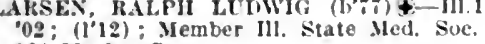
964 Market St.

Larson, Julla Pauline - Cal.2,'9S: (1'01) 1116 Valencla St. : 2.4

LARTIGAU, AUGUST JEROMF $\left(b^{*} ; 5\right)+$ Cal.2,"96: (1'96) : I5021'́ fiolden

Are.: oftice, 391 Sutter st.; $1-3$

Lasance, Christopher J. (b'64)-0.1,95;

( ): 692 San Jose Are.

Laughiln. Cly de B.-Cal.2,00; (1'00): 268 SIarket St.

Low, Hartland-Cal.5,93; (1"94); 5 I'resldio Terrace; Prof. H!st. of Med., Cal.5.

Law. Hubert Fdmund (b'88)-Cal.5,'12 ; (1'12); Monadnock Bldg.

cearltt, Edgar Irving (b'SI) - Cal.1,'10 : (1'10); 4501 Misslon st.; 2-4. $;-8$.

Lederman, Emanuel Darid (b'5)-N.Y.1, '98: not in practlee: 38 I'residio Terrace.

Lee, Adelebert Watts (b'79)-Cal.2,02; not in practlee; $110 \%$ Stanyan st.

Leffler, John (b'42)-Cal.,74: (1'76) : 1911 Sutier St, office, Paclfle Blilg.; $1-3,7-8$.

LEFRIS, JOHN HENRY (b's3) +-Cal. '10 ; $\left(l^{*} i 0\right)$; 4090 Farrell st.; onfe, 111 Ellis $\mathrm{St}$.

LELAND, THOS. B. W-Cal.2,9I: (1'95); LEGFELD, ABIIIIAM LEWIS $\left(b^{5} 50\right) \mp$ Cal. 1,7!: (1'84): not In practice: 1\$2 Sacramento St. oflee, 1804 Flllmore St. ; 2-5.

LENNON, MLTON HYIRE (b'it) ol: (1.01): 3806 Clay St.; olllce, 135 Stocktun St. : $1-5$.

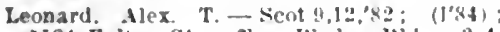
1124 Fulton St, ottce, Whelan Irlitg.; 2-4. $i=8: 30$.

LEONARD, JOHI VA GGHANP-Cal.2.0I : (101) ; 1220 Vallejo St; ofle, 126 Stock$(101) ; 1220$ 'allef
ton si: $2-4 ; U$

Lephakls, John (1; 78)-Cireece 1,99; (I'l2) 67. 9th Ave. onlce. 133 Geary st. : 1-?

LEVISON, CHAS, GAIIIEL (b'65)+-in!l '85: (I'90); 2249 Hroderick St. : oftlce, 350 I'nst St.

LVWTS, CYRIL FTTIUCK ( "04: (105); 380 Eddy st. : offlce, 135 Siockton st.

Lewls, Jos. (reøwell-II--I'a.9:75; (1:20) 3.5. I Frederlck St.

LEWIS, WM." H. (b'66) + Md.1.92: Ma M.C.. U.S.A.

LFWITT, FHEDK. CIINTON (1,83)

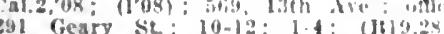
OALR.

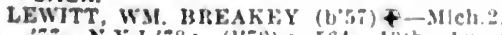
$7 \%$ X.1. 78 ; $(1 \% 8) ; 564$, 13th Sre ofice, 210 Poyt

Led. Cal.2: Pd.

Ichau, Frnest-Ger.2n,"86: (I'Si)

Sitockton St.

Linn, llugh Janies $\left(6^{\circ} 50\right)-\left[\begin{array}{l}0.1 \\ 78\end{array}\right.$ 1095 Slarket st.: $10-1$, fi-i

Lipneman. Caro Wuleram (h's)-Mass. 1,'10 (1'12) ; 0.32 sutter st.

LOGAX, HOSCOE: LKEt Cal.4,01: (I'01) 1328 Creen st. : oftee, 13:3 lieary St $1-3, ;-8$.

bong, Claude reveland (b's3) - ('al 1."11. (1'12): 3272 M/anlon sit.
ION1, HFIREIT F.VEILTT (b's6)-Ca!.2. 12: $(1 \% 2) ; 21$ Ibuena Vista Are.: 2-4 $6: 30-7: 30$

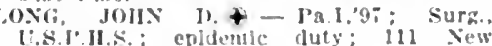
Montgomery st

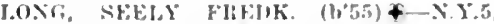

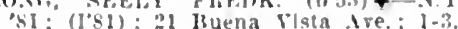

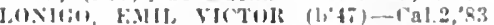
(1.4i): Fzb lkeach St.; oftes, 1362 Girant 11u: : $1-4,7-8$.

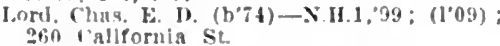

L.ord. Franklln F. (b'58)-Cal.2.80: (l'80) 1191 Oak sit.

oHr.)TZ, IоHT. JH. (b'88)-Cal.1,12 (1'12); German jinspltal.

I.I'CAS, WII. PALMER (b'80) $\mp 0.6,05$ Mepnlier Mass. Met. Soe. : 2513 Pleree st. nttice, Inlversity of Californla Hospital I'roe' Perl., Cal:2: (D).3, F2)

I.ICCIIFTTI, VICTOR F. - -Cal.2.'9s (l'nf): 10;4 Washington St.: oflce, 916 Kearncy St.: (B) 10.28$)$; OAL.

Lucey. I ianl. D. (b'3)-Cal.9,'13; (l'13); 145 (inerrero

Lueschen, Ivin F. (b'80)-Neb.6,04; (1'09): 959 Powell St.; offlce, Schroth Bldg. : 2-4; ODA.ネ

ILSTIG, MAXL INAVID (b'62) \$-Cal.2. 95: (1'85); Bellerve Holel; oftice, I\$6 frint lve.: 2-4: (E13)

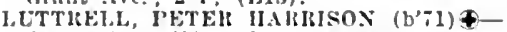
Cal.1,08: (l’08): 2615 Sacramento St: offlce, 210 Post st. : 1-4.

IUX, FPEntRICK WM. (b'61) F-Mass. 1 85; (1'85); I 655 Washington st.; oftice, 135 Stocktón St. : 1 -4

LYLE, ANNIE GALLOWAY (b'69) \$-Md. 7 , 02; (10.2); 1150 Frauklln St.: 11-12 $5-6 ;: G, \star$

I.YMAX. GEO. D. (b'\$3) $\oplus-\mathbf{N} Y .1,09$; (111); Eniversity Club; oftice, 240 Stockton $\mathrm{st}$

Lynch, Ellzatheth S.-II-Cal.5.'89; (I'90); 669 Castro St. ; 10-12, $7-7: 30$.

Lynn, Eithel Frace (b's1)-Cal.5,03; (1'0y) son Guerrero st.

MON, SAWEEI, B. (b'59) †-III.11,94 (1'39) ; 2018 Sutter $S_{t}$; 3-5, $;-8$.

MAIIEE, IAMES I. $\left(b^{\prime}-0\right) \mp-0.3,94$; Cant. M.C.U.S.A., Letterman General Hospltal. MacIONALI), GFO. (IILIS (b'60)-rent. \$3. Eng.15,'s4, Belg.1.'s6, Seet.1\%,'si (191) ; 2759 Broderick sit.: Aftlee.

IacnoYHID IOIIS yOYROE (b"69) (al.2.9!: (1.92): 1530 stelner st. oflce, 200 jost st, : 2-4, $7-8 ; \mathbf{G}$.

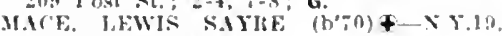
"19: (1'99) : 2840 Juchanas St. ; oflce. 240 stroktorn St.

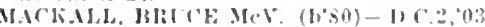
Intern, (ierman Josplan?

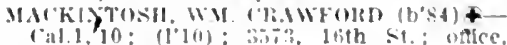

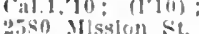

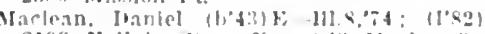
2137 Vallejo sit.; ontice, iss Market sit 11.2: ObG. *

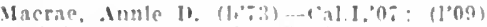

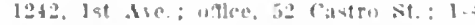

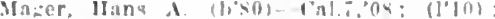
431 Elllmore St.; 1.:; l'rop. ligh and mite (al.t

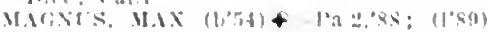

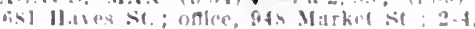
T. $P$ Pd

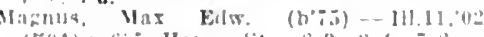

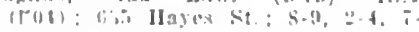

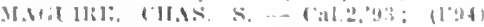

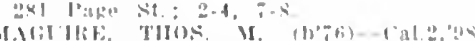

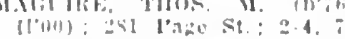

Mahan javle Jos cal potio

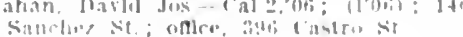

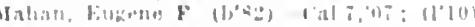

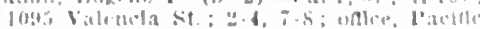
1110 : 10 311. 12.3n

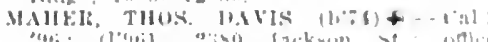

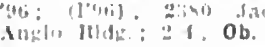

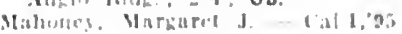

Jini lonithe are.

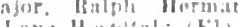

Maldonado, Albert-X.Y !9:37: (1987): 1173 MAlosiz, WM. M[TI:AY

12: $(1,12) ; 1101$ Buetro

MA.N, rila

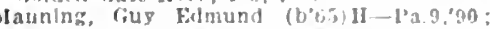

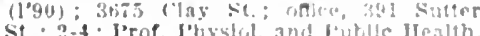
(Yais

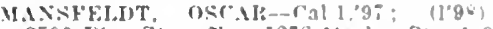

2590 I'lue St. : oflco. 127s Uniket St : 1-3

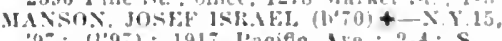

Mardis, Renj. Mllen (b'T0)-(9al, 192 ;

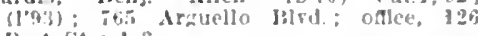
P'ost Sit. ; $1-3$.

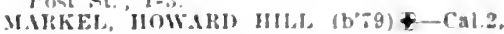
11: $(1 ' 11)$ : 127n, th Ave

Narks. Selby IJarold (b'\$9)-Cal.2,'13;

(1'2:b) : Inlrersity of falleornta lloapleal.

Varquls, Ferdinand J. Canac.

Canac-Marquls

Marshall, Jen! fillis-S.Y.1,61; $(1 \cdot 98)$ : not In practice: Hohemlan rluj).

Marahall, Malcolm Yeaman (t, 89$)$ - Mich.1. 13: Intern. Southern l'adflc County II os. pital.

Martin, Gen. II. (b'59)1I-Mass.5.'81; (1'\&!) Falrmont Ilotel: oflee, 135 stockton St. $1-3$.

Iarlln, Howard Gray - Cal.1.02; $\left(l^{\prime} 02\right)$;

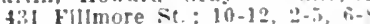

Martin, Jean M-Cal.9.05; (I'05); 2150 Larkin st.; 1-4, i-8.

Martln, Robt. S. (b'ti2)-Ill.1.95; (1'95) 2S3t Devisadero st.; 10-12.2-4

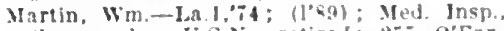
Conmander, U.S.X. retireff; 255 O'Farrell st: onfe, 133 fieary it.

MARTIN, WM. ARTIIR - lier10:32: (1'91); 850 Fell St.; offlce. I 26 Stockton St. : $1: 30-4:(B 1.19: 28)$; OALR.

Marfineaut, kuzent ID. CI. $=3$

3119 liuchanan st: : $12-3,-4$.

Wartine\%, Inlita Relle (b') $\left(l^{0} 08\right): 10-0$ Washington st.; 2-4.

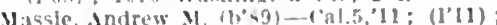
525 Turk St : ome Darid Fewes Blde.

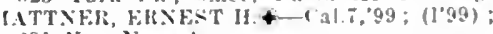
ti31 Van Jess Ire.

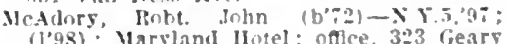
(1’98) Maryland llotel; office, $3: 3$ Geary

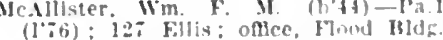

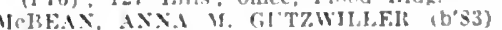
+ Cal $20 \%: 110 \%): 58 \%$ ith Are

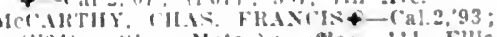
(1'?4) (xan Miten): wfice, 111 Ells St. : I-t; (BOS): OALR.

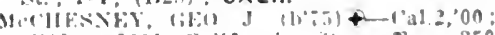
(1"1)0) : 2.201 (2all

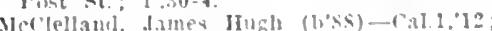

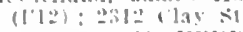

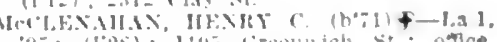

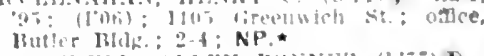

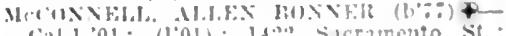
(all, 01 : 11011 : $1420250 \mathrm{sm}$

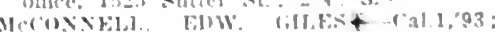
(1)94): 14:2 someramethe st: othes, $400^{\circ}$ Sulter se: $1-4:(1,3,11): U$.

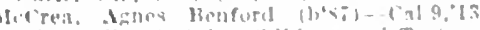

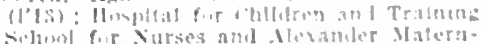

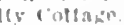

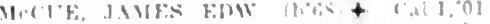

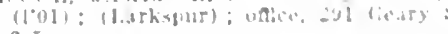

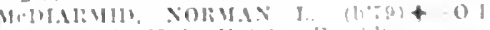

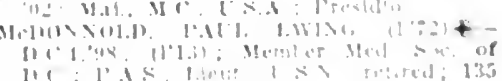
sionhiom st MALR.

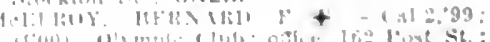

AHIt: IIOIC.1TIO \& $(1,64)+$ Xeb.5.

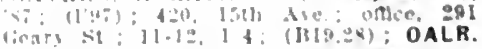

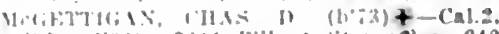

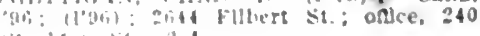


MCGILL, AVERT B. (b'65) - N.Y.5,'92 (1'92); 15, 6th Ave.; oflce, 291 Geary St. ; $2-4,7-8$.

McGorern, Francls P.-Ia.3,'8i ; (l'87 ) ; 2903 Mission St.

MCKEE, ALBERT RROWN $\left(b^{\prime} 62\right) \uparrow$-Cal.1, '86; (1'86); (Woodslde); 350 l'ost st. 10-1; Clin. Trop. Surg, Cal.11; (B28) OALR. *

ICKLNNEY, ARTHUR C. $\left(b^{\prime} 69\right) \oplus$ Cal. 08; (1'08)'; (1Bclvedere); oflce, 126 Stockton St. ; $2-4 ; 1 . \star$

MCKEON, FRANCIS II.๑-D.C.2,'02; P.A Surg., U.S.I.II.S.

McKevitt, Fugene Michnel (b'83) - Cal.7,'09; (l'09) ; 2645, 24th St. ; $1-4,7-8$

MIcharen, Wm. Melville (b'T3)-Cal.I,'99 (1'99): 1269. Sth Arc.; offlce, 111 Enilis St.; $2-4,7-8$.

MCIJFAN, RORT. ARMISTEAD $\left(b^{\prime} 51\right) \oplus-$ Cal.2,'44; (1'76); (Merkeley); offlce, 111 and Oper. Surg., Cal.2

McGllycuddy, V. T. (b'49)-Mich.2,69; not in practice; 222 Sansome $\mathrm{St}$.

MCIURDo, J. R. -Cal.2,'91; (l'91); 115 Beulah St.; offlce, 240 Stockton St.; 12-1, 2-5; (B28).

ICNAUGHT, HOWARD YOUNG + - Ont.3, 97 ; (t'99) ; 2211 Callfornla St.; office, 135 Stockton St. ; 9 -1 ; ALR. $\star$

IcNell, Warren Truett (b'83)-Cal.1.'12 (1'12) ; 2341 Sutter St. ; 2-4.

MCNULTY, ALBERT HENRY (b'79) $\oplus-$ Cal.1,05; (1'05); French Hospital; offce, Phelan Bldg.; 2-5, $7-8$.

ICNUTT, WM. FIETCHER, JR. $\left(b^{\prime} 76\right) \oplus$ Mass. 1,00 , Eng 15, 02 ; $\left(1^{\prime} 00\right): 1055$ Pine St.; office, 406 Sutter St. ; 2-4

MCNUTT, WM. F. (b'39) $\oplus-$ vt.2,'62; Scot. $9,12,65 ;(1+\tilde{5}) ; 1055$ Pine St. ; $1-4$; G.

MEAD, LOUIS D. (b'i5) $\oplus$ - N.Y.1, 02 ; (1'05); 1111 Jones St.; offlce, 135 Stockton St. ; $2-4$.

Neagher, Jos. F.-Cal.2, 02 ; (l'06) ; 126 Beaver St.; offlce, 4096, 18tis St.

Means, Saml 'Wm. (b'80)-Pa.11,'02; (l'03) ; Hotel Manx; offlce, 146 Grant Ave.; 2-4. Mehrtens, IIenry Geo. (b'86)-Cal.11,'I3; (l'13) ; Lane Hospltal.

MEIERDIERKS, WM. AUGUSTUS (b'70) $\oplus$ -Cal.1,95; (1'95); 318 Halght St.; 2-4. MEININGER, LEO L. (b'70)ษ-Cal.1,98: $\left(l^{\prime} 98\right)$; 3765 Clay ; offlce, 240 Stockton St. Mendei, 'Louls C. (b'70)-Cal.7, 01 ; (1'01); Iendel, Louls C. $\left(b^{\prime} 70\right)-$ Cal.7,
2000 Broderlck St.; 1-3, 7-8.

Mentzer, Mary E. Jones (b'78)-Pa.7,05; (1'12); 929 PIne St.; offce, 639 Bush'St.; $8: 30-10,4-5$.

Mercer, Ernest H.-E-Cal.4,'96; (l'96); 748 Baker St.; offce, 111 Ellls St.; 1-4,

Merrell, Chas, Goodwin-Cal.5,'86; (l'86); 917 Valencia St.

Merrlck, John Nervton (b'68) - 0.25,97; U.S.A. Transport Service.

MERRITT, EMMA SUTRO $\left(b^{\prime} 56\right) \oplus-$ Cal.2, '81, Fra.6.'87; (1'87); 48th Ave. and Pt. Lobos St.

MERRITT, GEO. WASHINGTON (b'55)Cal.2,'82; (1'87); 2323 Washington St. : $1: 30-3: 30 ;(\mathrm{B} 2 \mathrm{~s})$

Mervy, Alphonso J.-Cal.1,76; (1'76)； 14 and Church Sts.

MERVY, EMILE C.-Cal.2,'S3; (l'85) ; i28, $14 \mathrm{th}$ St. ; 8-9, $1-3$.

MEYER, ALBERT G. - Cal.2,'90; (I'91) ; 2599 Howard St.; 1-3, $7-8$.

MEYER, HENRY (b',0)€-Cal.1,93; (l'94) 995 Pine St.; office, 240 Stockton St. $1: 30-4 ;(\mathrm{C} 3,14) ; U \star \mathrm{U}$

MICHELSON, LEWIS (b'85) \&-Cal.1, 07 ; $\left(l^{\prime} 08\right)$; 580 Mcallister St. ; office, 209 Post St. ; 1 - 3 .

Mlllar, Percy A. (b'83)-Cal.1,09; (1'09); cillard Caroline $3-5, \quad$-8.

$\left(1^{\prime} 96\right)$; 541 Elizabeth St.

Miller, John Alexander (b’50)-Cal.2,'75 $\left(1^{\prime} 7 \tau\right) ; 560$ Post St.; 2-4.

viller, Thurlow S. (b'72)-Mich.7,'92 (1'97) ; 950 Pine St.; office, 960 Market St. ; $1-3$.

MINAKER, ANDREW J. (b'76)€-Cal.5, 99 , Cal.7, 02 ; (I'99); 600 Geary St. ; of fice, 6th and Market Sts.
Minaker, R. May - II - Cal.5,00; (l'01) ; 995 Market St.

Mish, Solomon C. (b'68)-Ky.1,'92; (l'93) : 873 Sutter St. ; $1: 30-4: 30,7-8$.

Mitchell, John Barnett (b'61) F-Cal.4,95 (1'95); 1469 Sacramento St.; offce, Shrevo Bldg. ; 1 -4.

MIZE, GUY ILAYNE (b'82)†-Cal.1, 06 ; (l'06) ; 1028 Ashbu

MIZNER, WM. G. $\oplus$-Cal. 1,$89 ;\left(I^{\prime} 90\right)$; (946, 26ith St., Oakland); offce, 391 Sutter St. MOFFITT, IIFRRERT CIIAS. (b'68) Mass.1,94; (l'97) ; I 818 Broadway; offce, 240 Stockton St.; Dean and Prof. Med. Cal.2; (D6); 1. ऋ

MOHUN, ClIAS, C. $4-C a l .2,90$; (l'91) 1817 Eddy St. ; offlce, 126 Stockton St.

MOLGAARD, JENS (b'68) $\oplus$ - Ia.3,'95 (l'97) ; 733 Castro St.; offce, 833 Market St. ; 1-4; (B28) ; OALR.*

MOLONY, JAMES J. (b'69) -Cal.2,91 (1'92); 907 Valencla st. ; $2-4,7-8$.

MOLONY, MARTIN $\rightarrow$ Ire.2,'88; (l'08); 1655 Washington St. ; offec, 209 Post St. $(\mathrm{C} 3,14) ; \mathrm{U}$.

Iontgomery, C. R.- $0.14,80$; Clty and County Ilospital.

MONTGOMERY, DOUGLASS WM. (b'59) $\oplus$ -N.Y.1,82; (1'86); 2350 Vallejo St. offce, 323 Geary St.; $10-12,2-4 ;$ (C2); D. $\left(1^{\prime} 85\right) ; 369$, ist St. ; $9-11,2-6$.

Montgomery, Wm. 0. - Cal.1,07; (I'07): 1496 Vallejo St.; 2-4, 7-8; Anes.

MOORE, CHESTER BIVEN $\left(b^{\prime} 81\right) \oplus-C a l .2$, 10; (1'10); 2101A Webster St.; office, 291 Geary St.

IOORE, IARRY S. (b'72) $\oplus$ - Ind.8,'98; (I'09); 2758 Unlon St.; offlce, 209 Post St. ; $1-4$; ALR.

MOORE, WM. G. $\oplus-$ Cal.2,'00; (l'00) ; 2336 Steiner St. ; offlce, 177 Post St. ; $10-12: 30$. Yoore William Leander (b'65)-Cal.1,89: (l'89) ; 2778 Plne St.; office, 344, 14th St. ; $2-4,7-8$

Mooslín, Maurice B. (b'i6)-Pa.11,01; (1’02); 1811 Flllmore st.; offlce, Paclfic Bldg.; I-3.

Morgan, Geo. F.-MIo.2,'84; (1'84); 3440 ORGAN, NORMAN DANIEL (b'85)థCal.1,'10; (l'11); 47921/2 Mission St. offlce, Phelan Bld́g.; $1-3: 30,7-8 ; \mathrm{S}$.

Morrlil, Frank Browne-N.H.1,81; (1'91) (1130 E. 28th St., Oakland); office, 51 3d St. : $10-4$; $U \star$.

Morrls, Chas. Lynn (b'8i)-Cal.5,'13 ; Intern, St. Luke's Hospital.

MORRIS, ROY HENRY (b'82)థ-CaI.1, 05 ; (l'05); 2816 Sacramento St.; offlce, 133 Geary St. ; 2-4, 7-8.

MORRIS, SAML. J. (b'7i) -D.C.1,01 Capt., M.C., U.S.A. ; Presidlo.

ORRISSEY, JOS. G.-Cal.2,'94; (1'94); 1210 Masonlc Ave.; 2-4, 7-8.

MORROW, HOWARD (b'74)థ-Cal.2,'96; (I'96); (Palo Alto); office, 135 Stockton St. ; 1-4; Clin. Prof. Derm., Cal.2 ; (C2). Morse, Arthur Henry (b'80) - Md.7, 06 ( ); University of California Hospital. MIORSE, CHAS. F. (b'74)€-Vt.2,'96; Maj. M.C., U.S.A.; Letterman General Hospital, Presidio.

MORTON, ADA SCOTT CONNER (b'79) Stockton St.: S.

MORTON, ANDREW WADE (b'67) Tenn.6,'92; (1'98); 771 Cole st.; office, Butler Bldg.; 1-4.

MOSS, JOS. MORA (b'66)థ-Cal.1,'94 ; (1'95); 930 Green St.; office, 146 Grant Are. ; 11-12.

Muench, Albert-Ky.2,'90; (1'00) ; 2432 Folsom St.; offlce, 91 , 3d St. : $9-1,5-7$

Muller, Fredk. Chas. (b'65)-Cal.2,'98; (I'98); 2486 Fulton St. ; 1-3.

Junger, Arthur Lee, Jr. '(b'83)-Cal.11'13; (l'13); Clty and County Hospital and Relief Home Tract.

MUNTER, LEO (b'75)€-Cal.1,04; $\left(1^{\prime} 04\right)$; 117 Beulah St.; office, Hewes Bldg.; 1-3, $7-8 ;$ G.

MURPHY, JAMES D. (b'73) - Cal.2,'96 ; $\left(1^{\prime} 96\right)$; 1393 Golden Gate Are. ; offlce, 162 Post St. ; 11.1
MURPIIY, JOSEI'H A. (b'76) Pa.1I,93; Surg., Lleut. Conmmander, U.S.N. Tralning Station.

MURPIIY, MARY TURNBULI, - Cal.1,'03 ; (l'03); 3732 Sacramento $\mathrm{St}$

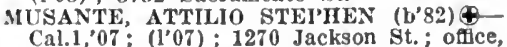
325 Columbus A re. ; $9-10,2-4,7-8$.

Myers, Bernard-E-Cal.4,'93; (1'93); 1212, 9th Ave.; 8-9, 1-3, 7-8

MYERS, MARK C. (b'61)—-Mo.20,'97; (l'08) ; Ilotel Washington: Pr.

NAFFZIGER, HOWARD CHRISTIAN (b'84) (4)-Cal.2, 09; (I'09); $2101 \mathrm{~A}$ Webster St. ;

NAGEL, CARL S. GUNTHER (b'58)థGer.1,'81; (1'01); (356 Addison Ave., Palo Aito); offlce, 209 Post St.; 11-1, 2-4; (B19,28)); Op. *

NAHMAN, ADOLPII IIERMAN $\left(b^{\prime} 77\right) \oplus$ III.6,09; (l'09); 9001/2 Derlsadero $S t$. $1-3,7-8$.

NAKABAYASH, M.๑-Jap.3,'97; (l'01); 1865 Plne St.; offlee, 1811 Pine St.

NAST, JOHN ERNFST (b'62)-Cal.2,'95 ; $\left(1^{9} 96\right) ; 3783,20$ th St.; office, 7 th and (l'96); 3783, 20th St.; of

Nathanson, Nilllcent E. Falck $\left(b^{3} 72\right)-$ Cal.2,'93; (1'94); 1624, 48th Ave.; office, 1112 Market St. ; $1-3$.

Naylor, Wm. Alfred Anderson (b'78)-Cal.7, '11; (1'13) ; 13I0A Page St.

Nelson, Arthur Barrls (b'71)-Ky.4,'96 ; (1'97) ; $2230,22 \mathrm{~d}$ St.; offce, 111 Ellis St. ; $10-1,6-7 ; \mathrm{S}$

Nelson, John Arch-Cal.2,'92; (l'93); 924 Irring St. ; $1=3,7-8$.

Neumann, Mark-N.Y.5,'80; (l'84); 1548 Steiner St.; office, 649 Kearney St.; U. Pine St.

NEWMAX, ALFRED (b'72)-Cal.2,96 $\left(1^{\prime} 96\right) ; 3447$ Clay St. ; office, 126 Stockton St.; 2-4; Prof. Clin. and Dldactlc Proct.

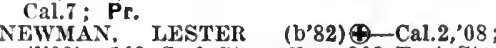
(1'08); 102 Carl St.; offlce, 209 Post' St. $3-5$.

NEWMARK, L E O (b'61)↔-Ger.18,'87; (1'90); Hotel St. Francls; offlce, 135 Stockton St. : $N$ *

NEWTON, JOHN CROCKETT (b'75)\&Cal.2,02 ; (l'02); 1832 Page St.; office, 291 Geary St. ; 2-4, $7-8 ; 0$ ObG.

NICHOLLS, ROBT. J. (b'80)-Cal.2, '04 (1'04); 1187 Church St.; offce, 240 Stockton st.; $12-2$.

Niemeyer, Harry Alhert (b'72)-Cal.1,'98; (l'98) ; 656 Clement St. ; 2-4, 7-8.

Noble, John Albert ( $\left.b^{\prime} 64\right)$-Cal.2, 88 ; (l'89); 191 Frederlck St.; office, 323 Geary St. Noble, Paul B. (b'77)-Cal.1,00; (1'00) 2298 Sutter St. ; 1-3; Ob.

Nourse, Beverly stephen-Cal.1,'96; (1'96); 379, 24th Ave.; office, 804 Clement St. $1-4,7-8$.

NULI, JOHN G.-Cal.7,96; (l'06) ; 846 Rall road Ave.; $1-3,7-8$;
Null, Nelle B.-Cal.7,06; (l'06); 846 Rallroad Are.

Nusbaum, Adolph (b'66)-0.6,91; (1'93) German Hospital.

Nussbaum, Adolph (b'85)-Ger.2,09; (1'09): 351 Jones St.

Obarrio, Peter de (b'74)-N.Y.1,'96; (l'11); (1211 Sherman St., Alameda); offce, 240 Stockton St.; 2-5; (B19) ; OALR.*

O'BRIEN, ALOYSIUS PAUL $\$-C a l .2,85$; (1'90); 2424 Gough St.; office, 126 Post St. ; $1: 30-4,7-8$.

OCHSNER, RICHARD I. (b'82)-Cal.2, 06 ; (l'07) ; 3593, 18th St.; office, 3004, 16th St. ; $2-5$.

O'CONNELL, MAURICE W. (b'78)-Cal.1, (1'99); 814 Grove St.; 1-4, 7-8.

O'CONNOR, JAMES HUNT (b'69) †-Cal.1,
'95; (1'95); 175, 21st Ave.; office, 162 Post St. ; $3-5$; S

O'CONNOR, THOMAS HUNT (b'80) $\oplus$-Cal.1, 08 ; (1'08); 355, 14th St.; office, 453 O'Donnell, Geo. W.-Ky.1,93; (1'93) : 1720 Geary St.; office, 1025, Market St.; $10-10: 30$, after $4,6: 30-8$.

$10-10: 30$, after $4,6: 30-8$.
OLESEN, U.S.P.H.S. 
OLIVER, ILARRY RFiVES (b'22) -Cal.1, 98: (1'98); :75l Unlon st.: ontre, Isutler Blitin.: $3-5$

OIIVHiR, JOS. A $\left(\mathrm{b}^{\circ} 62\right)+-\mathrm{Cal} 2,53 ;\left(1^{\prime} 90\right)$ 1825 Turk st.

ONEIL MHLVILLE F. (b'63) \&-Ia.6, 95 (198): 84 Halght st; odlce, 3925,1901 st. : $2.4,7-8$.

O'VEHL ARTILR NLOYSIL's (b'69) Cal.1,91; (1.92); Isolation Hosplal; $9-12$ OSESTI, SILVIO J. (b*75)+-Cal.2,"99 (1'01); 1 ils Jarkln St. : once, 281 Colum bus Are. 2-4.

opIUIs, wM. (b'71)+-Ger...95; (1.99) 114 Walnut SL; oflce, Stanford ["nlserslty Medical School; 9-12, 2-5; Sec. anil Prof. Path. Cal.11; (F2).

ORELLA FERMIX RALPII (b'67)-CaI.1. -92: (l'93): 2925 Plerce St.; oflice, 323 Geary St. : 2.4 .

orr. Robt. Harris-('al.2,"94; (l'96); ; 80 Iarket St.: 1.3 .

Osborve, James-Scot.5,72; (1'92); 2531 Sutter St: $8-10,1-3 ; 0 b$.

Osmun, Wm. F. H. (b'66)-Pa.2,'s9; (1*96) i15 Lake St. : offce, 133 Geary St: 2-4.

Ostrom, Earl E. (b's3)-Cal.2,'0: ; (l'13) 13:- Plne St.: $S$.

PATSTER, GEÓRGE I, O UIS-Cal.2,96 (1'96): (Berkeles); oflce, 135 stockton

I'AINTON, HARRY R. (b'-3)-cal.; 08 ; (I'08) ; 4798A Mlission St.; 11-12, 2-4, ;-s l'alache, Kate 0.-Cal.1,4l; (1'92); 263i Iaritin $S$.

PALMER, CAROLIS: B. (b'72)-('al.1, $06^{\circ}$

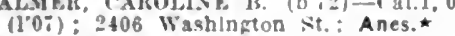

Palmer. Geo. II. (b'4t)H-X.'.9;65; (1'i6) retlred: 2446 Jackson St.; $2-4$; . Einer Irot. Surk. Cal.5; S

PARCE, ALEXAIIER DWICHT - N.Y.19 03: Capt. M.C. U.S.A.: Letterman General llospltal, Presidio.

Parklnson, Roy II. (b'90)-("al.1,"12; (1'12) So3 Douglass st.; 1-3, i-8: ÁLR.

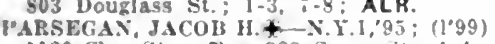
1120 Clay St, : oftice, 323 Geary st. : $1-4$.

I'Als. (l'06): 2497 Mission St.

Partridse, Ilarry-Cal. l,95; (1'95); (280t Hillegass Are, Berkeley); once, 3004. I6th St. : 1-3.

l'astor, Henry Holw, (b'56)-Cal.t, 24 . (l'84): 94 Lerant St. : 2-4, 6-8.

FATEK, HOI3T, (b'81)-MI.7,06" (1'06) 3363 Washlngton st.; oftice, $17 \%$ Pust St. : $1: 30-3: 30$.

Paton, (has. J.-Ca1.2,83; $(1.84): 45$, 6th Are. : 1-4, i-8.

Patrick, Marcla A. - I11.1,13; Children's Hospital.

Patterson. Alex. - Cal.1,93; (1'92); 1251. 5th Are,

"AC'SOX. CHAS. ARTHUR (b'82)+-Cal.2, $07^{\circ}:\left(10^{\circ}\right)$ : 2510 Jackson St.; offlce, 350 l'ast St. : 2.t.

Pawlick! Ladislaus (b'3l) - Ru4.5, 55 ; $\left(l^{\prime} ; s\right) ; 11000^{\prime} b^{\prime}$ arrell $s t$

PAYNL, RHDMONI) W. (b"65)-Cal.1,89; (1.91): 2300 Van Ness Are.; ottec, 140 Grant Are.; 11-10:30, 2-1:30; (B2:) OALR. *

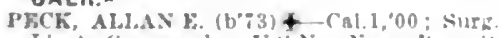
Ileut. Commanler, INA.; Nasy liecrult lng station.

Peel, Jonathan M-('al.1,"83; $(1.8 x) ; 1151$ Filbert sit.:-oulce, 323 lieary st. -

I'RRRY, ALFkEI W. (b'12)-La 2,62 $\left(l^{\circ}: 6\right) ; 1650$ callfurnla st.; entce, 1204 Sutter St: 1.3 .

I'eters, Francla j (b'ig)- Neb, i, 04, Nus. 09: 1): E14: Iont vit

Peters, Wm.-(cal.:,00; $\left(1^{\prime} 00\right) ; 1402,1$ th St. : 2.4, \%.8.

l'eterion, Alfred $r$ (b'54)Il-l'a.9: $\left(1^{\circ} i 8\right):$ (626 Fil lloraclo Ave., Oakland) once, 135 Stucktor st $10: 30 \cdot 12,2=5$ l'rof, Ophth., Otol. Ithin. and Iaryn Cal.s; OALR.

PETRIS, FIAXK I,-Cal.2,'91; 211 Comirall st. : $3 \cdot 5,7: 30-8: 30$.

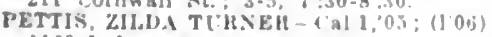
1168 bollores St.

Ithelan, slbert Fidward (b'3 3)-Que.5, 8 \% savlng Itank Midg: 10-4: OALR."

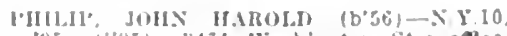
"95; (1195); $34 ; 1$ Washington St ofle

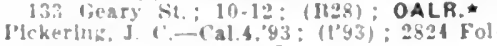
som si, ; $10-12,1-3,-8$.

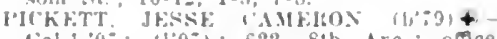
'al.1,07: 11"07): 622. sth

Plere, Horace f'. (b'89)-rolo.2,13: (1'13) Southern Paclfic liallroal llosgltal.

pletrafosa. Roxcu (b"-9) - Ita 10, " 33

rifis ('ulumbus tre.

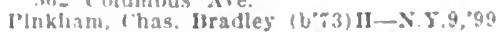
(1'00); Sec. Hoard of Ifed. Fixaminer. 2703 ibush st; once, 135 Stockton st. $11-1$

Hinney, Henry Beers (b'j]) -0 9, it: (I"Ss) not in practlee; 2830 "Buchanau s

I"INCHFL, KASIAR (b'i2) (1'90): 1817 (alleornla st. oflce, 135
Stockton st.: 1-3: (R3,28): OALR.*

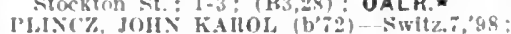
(1'01); 1896 Leavenworth st.; offlce, 916 Kearny St. ; $1-3, ;-8$.

PISMIRE, DAVII, IBRAVIILEY (b'69) ₹

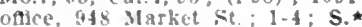

POEISEER, IIOLPH IDAM (b'66) —-Pa.I, (34: (l'96): 151\% liolden Gate Are. $8+12,1-6, i=9$

Pohelm, Jos. F-Cal.1,98; (I'98); Palace Hotel; offlce, 1700 Sielner St.; 2.4.

Pomeroy, Farl Spencer (b'ss)-Cal.t.'13 Intern, City and County Hospital and felle? Home Tract.

Poole, Wm. Edw. - Ore.1,84; (1'95); 10 Trenton St. : I-3

Pope Emma Whghtman (b'il)-Cal.2,99; (100); 45.3 Frederlek St.

OPE, SAXTON TEMPLF, (b'75)\&-Cal.2 99: (l’00) : 453 Frederlck St.; ođlce, Butlet Pldg. : 2-4

ORTER, LANGLEY $\left(b^{\prime}, 0\right)-c a l .1,9 t^{\circ}$ Fing.11.00; (1'03); 44 fommonwealth Are, oflce, 240 stockton St.; Clln. Irof Med., (alli; (Di); Pd.*

Potter, Clarence II.-II-Cal.5,'96: (l'96) 2034 Baker St.; offlee, 135 Stochton St. - $-4, \quad ;-8: 30$.

1'otter, Samuel 0. $\mathrm{l}_{\alpha}\left(\mathrm{b}^{\prime} \neq 6\right)-\mathrm{M} 0.5,-\mathrm{s}, \mathrm{Pa} 2$ Q8., Eng.12,21; (l'st); 1304 Franklin Sit.: $1-4$.

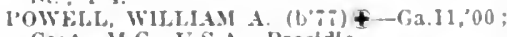
Capt., M.C. T.S.A.. Presidfo.

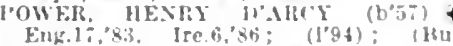
game); offec. 135 sinckins St. : 2-4; 1.*

l'uwers, ('arl lemonde (b'74)-Cal.1,04: (1'04): 1120 Masonic A

Market St. : 1-5: OALR. zith st.

l'ratt. Jean I'aul (b'8z)-Mdz:10: teach

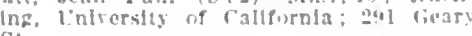
St

Irentlce, Irthur Dudicy-Cal.1,95; (1'96) $214,32 d$ dre

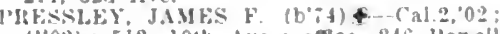
(l'02): 512, 10th Are; offlce, 240 l'omell

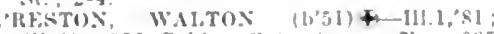

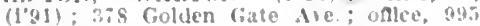
Market st.

l'rice, Thomas Linton (b'66)-l'a.11, 9 ;

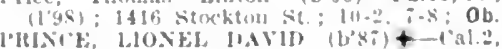
12; (1'12); Cintueraliy of laliforma llins

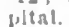

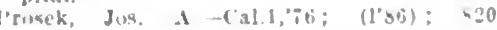
steluer st.

l'rusch. Nichulas Ilenry (b'st)-cal.l,09:

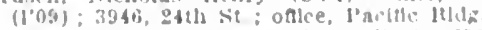

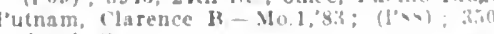
Gough st.

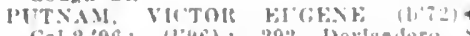
Cal. 2,$90 ; \quad(1,96) ; 28:-$ Pevtsadero

antc

se. once, 110 Z Valencla st

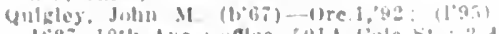
Ligi, loth Ale ; onke, suld fole : : : 4 $i=8$.

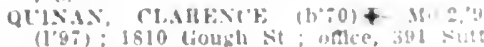
St. : $2-1$

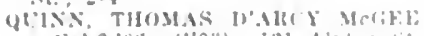

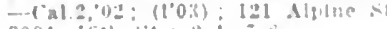

Qulnu, Wu I al

1605 New

rabe, b. A lit?

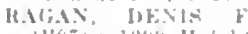

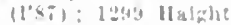

Pay, James Taylor (bofit)

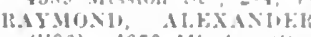

(1'06) : 4350 Mlaston sit.

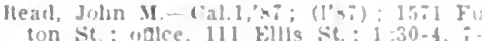

ICEAL, WM. PARSONS (b'it)

$(198)$ : 1685 sutter st. $2-4$.

HEEI), THIRLOW WEFD (b०

03 ; I'.S.S., Lleut., C'.S.S. ; Xary Depart. nent.

liceng, Jns. Domenlc (b'86)-Cal.1,09; (l'os): San Jise die. and Orepan lid Reeqe, R. Fduin (b'6.5)-ral.1.95: 1 1'95) (San Jose); oflice, 4.30 Market sit.; $9 \cdot 5$.

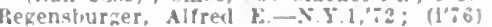

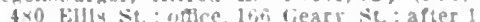
IHFGENABTRIEL, MARTIS (b's4)-Ger.l6. 75 ; $(1 \% 6)$ : I'res. Cal. State Board of Health; 3376 Clay St.; oflce, 209 Post KEIXSTEIX, ARTHCI HENRY (b'\&1) (al.1,0\%; (1\%0:) 3002 Clay st. ; oftce, 146 Grant Ale.; 11-12, 2-5; I'rof. I'byslol. Cal.i : U.

ISEIS, HALRY WILLAAM (b'si) + Cal.i. 09 ; $\left(\mathbb{I}^{\prime 09}\right) ; 5.3 \times$ shrader st.; odlce, Hewes 13ldg. : :-4, $7-8$.

IS EMMFL, AIVA JACOH $\left(\mathrm{b}^{*}, 6\right)+$-Cal.1,05: (I'05); 1405, ; th Are.; ofilce, 948 Market st. : 2-4; S.

REN\%, (ARL, (b'bl)+Cier.13,\$9; (1'-3); Member Med. Soc of the state of $X 1$. 126 sinckton sit

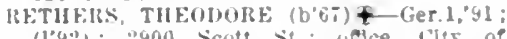
(1.92): 2900 seott Rice, Edward J.CCal.2,99: (l'9s); $8: 0$ lice, Ihlllp - H-III.15,"94; (I"01) : 995 PIne St. ; wfice, 209 I'ost st. : 1-5; OALR.*

RICHARDS, DEXTER XEWFLI. (b's?)

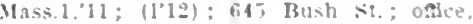

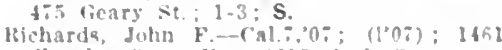
shrader st : offec 1009 . Isth st:

RITHALSON, GEO IIFNRY (bo + 1'a.1,"91; (1'01); 2917 "lay st.; 1-3.

RIchsteln, John J. (b'0) - Mo:2,96; $(198) ;$ s so fieary si.; otlce, 830 Marke? sit. : 30-4. i-R; U.

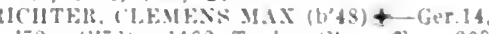
$\because 2:(1 ; i) ; 1102$ Taylor st.; otce, 209 1 ose Sit. : 1 .

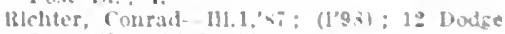
St. : onle, 1ti Larkin st.

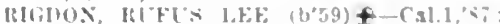

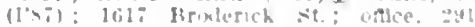
feary si : 1-3, i- ilin. "rot. Suz (al.11: $(13.14) ; U$.

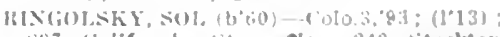

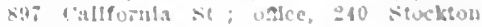
se. : 11-1.

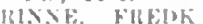

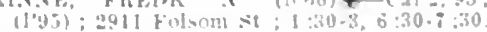

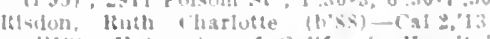
(1'13): ['nletrois of callomia linsplest

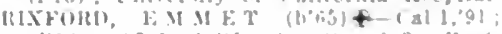
1192) : 1745 ('allforn!a

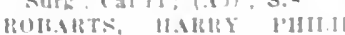

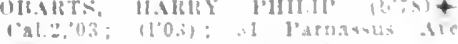

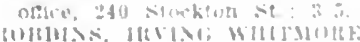

(11)

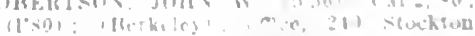

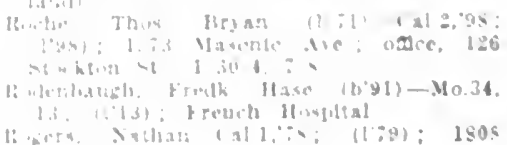

(hat: al $1, \because$; $(1 ; 9) ; 1806$ 
Roncovleri, Alfred, Jr. (b'87)-1'a.1,'11; (I'11) ; 86 P'ost St.

ROSE, JOHN MON'TAfile (b'68)-Cal. 12; (I'12); 853 De Haro St.

Rosenberg, Cárollue-Cal.2, 03 ; (1'03) ; 2900 Jackson St.

Rosencrantz, Nathan (b'6ĩ) - ('al.1,'ss. Ger.20,'90; (l’89) ; :34 Stockton St.; offlce, 25, $3 \mathrm{~d}$ St. : 1-4.

ROSENSTIR, JILIIS $\left(\mathrm{b}^{5} 50\right)+$ - - ier.20 72; (I'84); Bohemian Club; oftlee, 126 Stockton St.; 1-4; S.

ROSENTHAL, MDOLPH G. (b'i1) $€$ - Cal.1. 9.7: (1'94); 21 Scott St. ; office, 162 1'ost St. : 1-4; (B2S).

ROSENTHAL, CHAS, HENRY (b'56) Cal.1,'81, Ger.14,'84; (1'85); (2307 llearst Ave., Berkeley); oftlce, 209 Post St. : $11: 30-1: 30$.

Rosln, Clliton Nears (b'84)-Ill.8,'07

(l'12); City and County IIospltal.

(l'12): City and County IIospltal.
ROSS, FREDK. WM. (b'73) $\$$-Cal.1,'96; (l'97) ; 1462 Devisadero St.; offlee, 81 Post Śt. ; 1-3.

RO'TIIGANGLR, GEo. (b'65)屯-Cal.1,'88; (1'89) ; Surf., lleut. Commander, U.S.N. retired; IIotel Fairmont; offlce, 126 Stockton St.: 2-4; S. $\star$

ROTISCHIID, MAX广 $\longrightarrow$; (I'97); (Burllngame) ; office, 350 Post St. ; 10-12; T. RUDE, ANYA E. (1)'T6)-Cal.I,06; (l'06); 1501 Larkin St. ; ollice, 240 Stockton St. ; $2-4$.

Rumwell, Melvllle L-Cal.1,95; (1'95); 719 Ashbury St.; office, 240 Stockton' St. $2-4 ; \mathrm{S}$.

RUSS, RAYMOND (b'73) $\oplus-\mathrm{Cal} .2,00$; (l'01); 952 Bush St.; office, 126 Stockton St. ; $2-4 ;$ S. *

RUSSELL, TRACY GEORGE (b'73) $\uparrow$ N.Y.1,99; (1'00); 650 Busb St. ; offce, 146 Grant Ave. ; 2-4: $\mathrm{S}$.

RYAN, LOUIS X.థ-Cal.2,05; (I'05) ; 849 Devisadero St.; offlce, 177 Post St.

Ryan, Russell Colquhoun (b'S9)-Cal.5,'11 (1'11); 766 Sutter St.; offlce, 350 Post St. ; $2-4 ; \mathrm{G}$.

RYEI', MARSIIALI, B. $\oplus-$ Cal.2,'96 ; (l'96) ; 400 Steiner St. : $2-4, \tau-\tau: 30 ; O$ bG.

RYFKOGEL, HENRY ANTHON LEWIS (b'73)థ-Cal.2,'94; (l'94); 3962 Clay

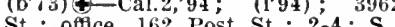

Sadicoff, D. Vera (b'90)-CaI.2,'11; (I'12); German Hospital.

SAIOMION, MAX (b'63)甲-Cal.1,'86; (1'36); 1634 Fell St.; office, 209 Post St. $1: 30-4$.

SAMPSON, ARTIIUR F. (b'55)-Va.1,78; (1'01); 3580 Washington St.; office, 133 (1'01); 3580 Washington
Geary St.; $11-12,3-4: 30$.

Sampson. Wm. Ashford (b'83) H-Cal.5, 09; (1'09); 1590 Sacramento St. ; $3: 30-$ $5: 30$.

Sanborn, Blanch Leonora Heiss-Cal.5,'99; (1'99) : 1261 Broderick St.

Sands, Raymond Arthur (b'S9)-Cal.9,'13; (l'13); st. Luke's IIospital.

Sankey, Mary J.-Cal.2,'94; (1'95) ; 731 San Jose A re. : 1-3.

SARTORI, HEXRY J. (b'71) -Cal.1,'93; (l'94): 2131 Broadway; offce, 460 Montgomery St. ; 8-9, 3-5.

SAWYER, HERBERT CARLETON (b'5̃) $\oplus$ Cal.2,'81; (1'82); 2428 Fulton; office. 291 Geary St, $11-1,2-4$

Scaparone, Carlo Gio Giaconi--Ita.20,'90 $\left(I^{\prime} 00\right) ; 1835$ Jones St. ; oflice, 4 Columbus Ave.

SCHALLER, WALTER FRANK (b'79)Cal.1,02: (1'02); 150 West Clay Park; office, 610 City of Paris Bldg.; $2-5$ Asst. Clin. Prof. Med., Cal.11.

Schaltenbrandt, Maria F. Spiess-F-Cal.4, '95; (1'95); 4051, 20th St.; 8-10, 2-5.

SCHEIER, RALPH BARTHOIONEW (l)' 80 ) (4-Cal. $z, 08$ : (l'08); 2373 Paciflc Ave.; offce, 126 Stockton St. : 2-4.

Schirman, Ralph J. (b,70)-Md.4,'93 (1'9s); not in practice; \$25 Van Ness Are.

SCHIRO, SALVATORE (b' 66$) \oplus-$ Ita.12, 00 ; (l'11); 905 Union St. ; offlce, 361 Columbia Are.

SCIILAGETER. HERMAN J. (b'/2)कCal.1,95; (1'95); 2021 California St. office, 240 stockton St.; $2-4$
Schloss, Aaron (b'62)-Pa.1,'83; (l'83) ; (2925 Ilillegass Are, Berkeley); offlec, 135 Sitockton sit.

Schmlelt, Adlolph Eruest (b'90)-Cal.1,'12; (1'12); 1803 Devisadero St. ; 2-4; $\mathbf{S}$.

Schmiedé, Rudolph Jos. (b'71) E-Cal.4, '99; (1'99); 1141 Golden Gate Ave.; 1-3, $6: 30-7: 30$.

SCIIITT, LIONEL SAMI. (b'77) \&-CaI.2, 01: (1'01) ; $2 \pi 27$ l'lllmore St. ; offlce Butler 13ldg. : 1:30-4; Sec. CaI.2; LD.

Schruitz, J.WF-Cal.4,03; (\$) ; 98 Cumberland st.

SCIIIOLL F.MILE (b'72) $\uparrow-$ Switz.1,96 (1'04); 1369 IIyde St.; offlce, 126 Stockton sit

Scholl. Albert Louls-Cal.2,'84; (1'85); 400 lubloce Ave.

CIIUMANN, CARL $\left(b^{\prime} 74\right) \$-N . Y .8,09$; () : Member Med. Snc. of the State of N. 11015 Van Ness Are.

SCHWARz, JACOB $\$$-Cal.2,04; (l'04); 3053 Californía St. office, Union Square birlg. : $1: 30-3: 30$.

SCIIWARTZ, CHAS, EDIVARD (b'78)Cal.9,'08; (1'12); 2128 Van Ness Ave. ofllce, 948 Market $S t$.

Scosseria, Frnesto (b'79)-Ita.7,05; (1'12) ; 616 Filbert St.

Scott, Allen Fimer-E-Cal.4,'83; (1'83) ; 1208 Market St.; offlce, 948 Market St.; $2-5,7-8 ;$ Pd.

Scott, Catherine Victoria Cochran $\left(b^{\prime} 10\right) \mathrm{H}$ N.Y 11, 78 : (1'89): 727 Rivera St.; offlce, 760 Mlarket St. ; $12: 30-3 ; \mathrm{G}$.

Scott, Charles M.-Ill.1,'83; (1'84); 371 0 ak St. ; $9-12,1-4$

Seibel, Philip H. (b’70)-Cal.1,92; (1’97) ; 205 ldgewood Ave.; office, Union Square Bidg. ; $9-5$.

SEID, MARTIN JOACIIM (b'88)@-Cal.1, '11; (l'11); 308 Ellzabeth St. ; offlce, 24th and Church Sts. ; 2-4, 7-8;

SELFRIDGE, GLANT' L. (b'63) 1 -Pa.9, '89; (1'90); 1914 Clay St.; offlce, 240 SHILING, NATHALIE; A. (b'67) - Cal. 94; (I'94) ; 2852 Sacramento St.; offlce, $3 \% 0$ Post St. $10-4$.

SERVISS, THÓS WILSON (b'56)-Que. 1, '81; (1'81); Flood Bldg.; 11-5; (B28); OALR. *

SEWALL, EDWARD CECIL (b'75) థ-Cal.1, '02 (1'02); 166, 1st Are.; Clin. I'rof Surg., Cal.11; (B1,19,28); OALR.` 4093,24 th $\mathrm{St}$.

SHARP, JAMES G. (b'68) $\oplus-$ Cal.2,'94; (1'94); (Atherton) : office, 135 Stockton St. SIIEEP', WM. LLOYD (b'81) \&-D.C.1, 06 ; Capt., M.C., U.S.A.; Letterham General Hospital, Presidio.

Sherman, Bessle-Ill.22,'13; Hospltal for Children and Training School for Nurses and Alexander Maternity Cottage.

SHERMAN, HARRY MITCHELL (b'54) $\begin{array}{ll}\text { N.Y.1,'80; } & \left(l^{\prime} 85\right) ; 2125 \text { Jackson St.; } \\ \text { office, } 350 & \text { I'ost St.; } 1: 30-4 ; \quad(\mathrm{A} 3,5,7) \text {; }\end{array}$ $\mathrm{S} *$

Sherwood, David HaIl (b'59)-Mo.22,'85; (1'98); i934 Post St

SHIELS, JOHN WIISON-Scot.9,12,14,'95; (l’98) ; 2559 Union St.; offlce, 323 Geary St. ; $2-4$

SHORTLIDGE, EDNIUND D. (b'71)£-Pa.1,

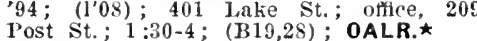
Post St.; $1: 30-4 ;($ B 19,28$) ; 0 A L R . \star$
SHUMATF, THOS. EDW.-Cal.1,'94; $\left(1^{\prime} 94\right)$; 2707 California St.; offlce, 86 Post St.; $1-3$.

SIEBE. FLIZABETH B.థ-Cal. $\tau$,04; (l'04); 1434 Taylor St.; 2-4.

Sll,VERBERG, MELVILLE' (b'6) 6 -Md. 7 , '02 ; (l'02) ; 3817 Jackson St.; offlce, Head Bldg.; 2-5; Prof. Gen.-Urin. Dis., Head Bldg. ; 2-5; Pror. Gen.-Urin. Dis.,

Simmons, Haydn il. (b'74)-Cal.2,'01; (I'01); 1721 Golden Gate Ave.; offlce, Phelan Bldg. ; 1-3, 7-8; U.ネ

Simon, Grace-Cal.2,'93; (1'94) ; 829 Fell St.; offlce, 754 Sacramento 'St. SIMION, MARTIN E. (b'78) - -Cal.1,99; Grant'Ave. ; 2-4; ObG.

SIMIPSON, JOSIAH A. (b'62) 9 -Cal.1,'91 ; (1'92) ; 363 Missouri St.; offee, 638, 20th St. ; 1-3.
Sinclalr, Rosa Munda-E-Cal.4,'02; (1'08); 3018 Webster St.

SKOONBER(; ARTHUl E. (b'84)-Cal.7, 07; (1'09) ; 232, 4th Avo.; offlce, Phelan bldg.; $3-5,7-8$

Slaughteer, Kate C.-Cal.5,09; (†); 701 Post St.; offlee, 133 Geary S't.

SLEMONS, JOSIAII MORIIS (b'76)\$Md.7,01; also, Member Med. and Chir. Fac. of Md. ; 3404 Clay St.; Prof. Obst. and Gyn., cal.2.

SMITI, WTHAN IIENRY $\left(b^{\prime} 64\right) \$-N . Y .10$, '89; (1'91); 26171/2 Octavla St.; office, Fac. of Md.; 3404 Clay St.; I'rof. Obst. and Gyn., Cal.2.

Smith, Lugene K. (b'80)-Cal.2,'04; Retired; 1725 Hayes St.

SMITH, HERBERT R. (b'70) - Cal.2,97, Cal.7,98; (1'98); 3760 Sacramento St.;

MITH, JAMES FRANKLIN (b'73) $\begin{array}{ll}\text { Cal.1,'94; } & \text { (1'95); 2366 Broadway St. : } \\ \text { oftice, 86 Post } & \text { St.; } 10: 30-4 ; \quad \text { (B1,28) ; }\end{array}$ OALR. ^

SMIITI, LARZ A.-Cal.1,'94; (1'95): 1701 Larkln St. ; office, Butler'Bldg.; 11-12, $1: 30-4 ;$ (B28).

SMITH, REGINAID KNIGHT-Md.3,'92; (l'00); 2600 Jackson St.; office, 391 Sut-

Smith, Robt. Bremner-Mo.24,'92; (1'92); 1933 Ocean Ave.

Smith, Stephen Harrison (b'83)-D.C.1,'06; ( ) : Presidio.

mith, Wm. 'T. F. (b'44)-Ill.1, 79; (1'92); SNOIV, CORYDON GOODRICHA-IIl.11, '04; Capt., M.C., U.S.A. ; Presidio.

NYDER, GEO. SA.M'L. '(b'75) \&-Cal.2, 05; (l'05); 932 Stanyan St.; office, 901 Stanyan St. ; $2-4,7-8 ; \mathrm{S}$.

SOBEY, ARTHUR LYNE (b'51) (-E-Eng.15, 72, Eng.11,73; (1'76); 851 Guerrero St.; office, 3116,16 th St.; $1-4$.

SOBEY, GIFFORD LYRE (b'80)-Cal.2,06: (l'07) ; 221, 30th St.; office, 3116, 16th St. ; $11-12,7-8 ; 0$ bG.

Soboslay, Jullus-Cal.2,'86; (1'86); 670 Fulton St. office, 995 Narket St.

soMERS, GEO. BURBANK (b'62) Stanford Universlty Stanford Universlty Medical School; 2-4;

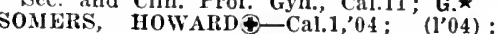
615 Post St.; offlee, 135 Stockton St. ; $3: 30-6,7-8$; U.

Soper, Richard Watts (b'69)-Ia.8,'98; retired; 1767 Hyde $\mathrm{St}$.

Southard, Carroll O'B.

(See Berkeley.)

SOLTHARD, WMI. FREEMAN (b'45) \&Mass.1,72; (I’81); $(2610$ Grant St. Berkeley); office, Phelan Bldg.; 10-12, 2-4; Prof. Ophth., Otol,, Rhin. and Laryn., Cal. 7 ; OALR.

SPALDING, ALFRED BAKER (b'74) (4office, Lane Hospital; Prof. Obst. and

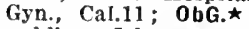

Spaulding, John M. (b'81)-Ky.2,'07 ; ( ) ; 81, 9 th St.; office, 156 , 2d St.

PALDING, OTIS BURGESS $\left(b^{\prime}, 5\right)+-$ Cal.1,'98; (1'98); 450 Jones St.; offlee, 625 Market St.; 10-12.

Spalding, Robt. B. (b'76)-Mo.27,'98; (l'09); 101 Post St. ; 2-4.

Spencer, Elizabeth A. (b'68)-Cal.7,'08; (Osteopath); 701 Post SI.; office, 133 Geary St.

SPENCER, JOHN CAMPBELI (b'61) N.Y.1,'85; (1'89); (Palo Alto); office, 135 Stockton St. ; $10-12,2$ :ś $0-4: 30$; (C3) ; U夫.

SPIRO, HARRY (b'75) $\oplus-\mathrm{Cal} .1,{ }^{\prime} 04 ;\left(\mathrm{l}^{\prime} 04\right)$; 742 Hyde St. ; 1 :30-3 :30, $7-8$.

Sponogie, Francls Marlon-0.11,79, N.Y.8, '85, N.Y.10,'86; (l'88); Merchants Natl. Bank BIdg.

Spriggs, Gertrude A.-Cal.7,00, 11l.11,03 ; (1'00); 1170 Fell St. ; 1-3, 7-8.

Spriggs, Lem Walter-Cal.7,99, Pa.2,04; (1’99); 1170 Fell St.; 1-3, 7-8; Prof. Path. Hist. and Bact., Cal. 7 .

Stadtherr, Anthony Louis' (b'90)-Mo.34,

'13; Intern, St. Joseph's Hospital and Home. 
Stadtherr, Fuward Fredlk. (b'88)-Mo.34. '13: Intern, St. Josepb's Ilusgltal and Home.

STADTMULLER. FI.J. SMTII $(1,93)-$ Cal.2,12: (1'12): \$19 kidds st. oflce, s81 Ashbury "st: 11.1 .

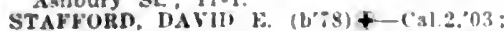
(1'03); 2178 l'lne st? oflce, 209 l'ost SL: :-4.

STANIFOLD, KExNFTI JAMISOX (b.89) -Cal.1,11: (l'11); 660 Busli; oftlce,

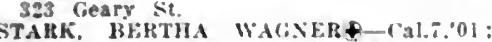

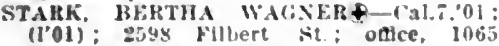
Sutter St.; 2-1: Assoc. Prof. Gyn. and Abd. Surz. Cal. $\%$.

starr, Fredk, R.-IIas.1,98; (1'94); 1202 Uaion St. : $1-3,-8$; Pd.

Stearns, Victor 'Jos._'al.1, 89 : (1's9): 1825 Sutter st. : (In turolie).

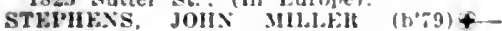
X.Y.19.03: (1'03): (1250 Bay Are. Alameda); once, shreve Bldg.; 10.1: Alameda)

(B28).

TEPIINS, WM. M.IRCHA (b'69) X.Y.1,93; (1'93): (1250 Hay st. Ala meda); otice, shreve Bllig.: 10-1 (B28) : OALR.

STEVEXS, IHURT SMITII (b'\% 0S: (1'11): Taylor and leary ste. : of flce, Butler $11 \mathrm{dg}$ : : 1-4; S. *

STEVHA, WM. EMERAOX $\left(\mathrm{b}^{\prime}, i\right)+$-Cal.2, "99; (t'00); 1007 lioush st.: office, $210^{\circ}$ Post St. 2-4; U.

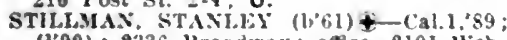
(1'90): 2336 Mroadway; office. 2101 Webster St. : 2-4; Prof. Surg. C.A.11; (A5); S.

STIREWALT, MENIYY WALTER F-CaL.2, 91: (1'91); 702 Oak st.; ottce, 391 Sutter st. : 9-10, 1-4. $7-8 . \quad$ (l.ss) Pare St.

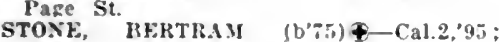
(1'96): 1112, 2tth St.; 1-3, 7-8; Hrot. Pbss. Diag." Cal.í.

Stone, Elmer F. (b'66)-Cal.1,90; (1'90): Ialace Hotel; offce. 291 Geary St.; (EL3).

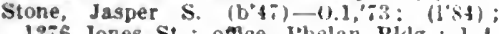
STONE, WAID JAMES (b'80)-Cal.2, 06 ; (l'06); 2007 Sutter St.

Storell, John M. (b'62)-- (at.7,01; (1'01): 632 Halght St. ; $2-4,7-8$.

STHANGi, SHFLIB' l'HII'I'S (b'76)Cal.1.'12: (1'12); 1658 sacramento St. : $6-7$; offce, 323 Ciears St.; 10:30-12:

Sturge, Firuest A.-Pa.1,'80; (1'89); 101 Scott St.

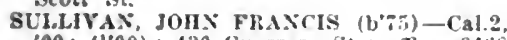
$00 ;(100) ; 430$ Guerreru St.; oflce, $34+58$ 1 ith $81 . ; 2-4$. i-s

SUMNER, PERCY (b'71) 4 (al.1.04; (1"04): 957 Jones St. : oflce. 126 stockton

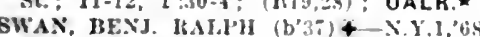
(1.84): (784, J01h St., Gakland); oflee, 222 Sansome St.

SWEF.NE), GEO. J.-Ca!.2,'00: (l'00) : 1946 Edily Si.: ofice, 1139 Masonle Are.; $1-6$.

Sweet, Anwa E.-(al.7.01; (1'01): 90.5 Market St.

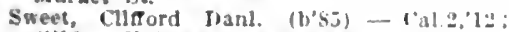
(1'12) : Universlty llospltal.

Swet, Wllbur Manrlco-1'al.1, $32 ; \quad(1,92)$; (I'alo Alto); odice, 166 Geary st.; $1-3: 30$; (B28) : OALR.

TAIT, FIRIKK. DLUIFY (1,62) - - Y Y 10, 6. Fra.6, 89; (189); 1595 (7lly

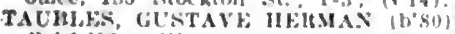
Cal.jos: l]0s): 2103 l'acllle Die face, 323 (ieary st. : 1 :30.4:30

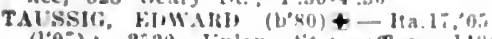
$\left.\left(1^{\circ}\right)^{\circ}\right)$; 2020 inlon sit. once, ifus stockion st. : $3-\overline{3}$.

Tavlogoolos, John Nilcola $\left(b^{\circ} 80\right)$ - firece 1. 02: (l'il): 200 lutuce st.: oflce, igs Mission st. $2 \cdot 5$

Taylor, albert Henry (b's, - Cal.1."xy; (1'89): 225, 261h Ave.; unleo, 350 l'ust

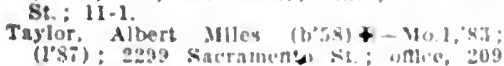
lont sit.: 2.1 : $S$.
Taylor, (has. Fdw. Ca $1,7,01 ;\left(t^{\prime} 01\right): 25 t h$ and Falr Oak Sits. urteo, thelan isldir.

THA.11, 2-1, $7-8$. 4:; $(198)$; 11:1 rirectiwloh st. : oflce. 13:5' Stochton st. : 1:30-4; G.

THXNEY, ELMKIS SETH $(1, T 0)+X I 1$ nest surg. Western Jepartment.

Terrlil, (bev, M.-1"a.1,83; (1'xis); 51:1 reary sit. : oflce. Nol Market $x$.

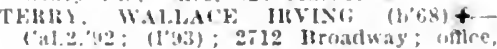
24l stockton sit.; 2.4; Irof. Surs., Cal.2 S."

Thiturlesu, Alex. (b'75)-Que.3.'03: (1'l11) lon! (ireenwleh st.; once, 323 feary st

Thoma: Frank (b'53) - Cal.4,96; (1'y+j) sle Turk sit, :-4, $;-8$.

Thomas, Mhilip Matson (b'72)-Cal.1, 96 : (1'96); 1005 Chesinut St.; otlce, 240 Stocktou st. : 2-4.

Thomas, Yerln C. $\left(b^{\prime} 75\right)-111.29 .04:\left(l^{\prime} 06\right)$; liotel Argonaut; ottlce, \$30 Market \$t.

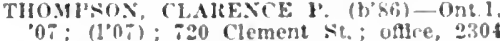
$07:\left(10^{7}\right) ; 720$ Clement

Thombson, Geo. Joward (1, bi, - Cal.l, "at; (1’91); 1822 sacramento sit; ottee, it99 Callenrnla st. ; 11-1, $\approx: 30-8$

THoMPsos, foln FMMETT-196.' (1"01); (86,07 Aleatraz st., Berkeley); oflec, 3 no l'ost St; 11-4

THORNE. ISAIC WALTON (b'72) + 'al.1,'96: (1'bo); 2634 Brnderick St.

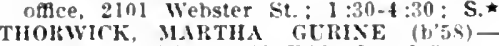
I1].11,01; (1"01): 340 Eddy $S t: 3-5$.

Thrasher, Marlon-Cal.2.90; (1'90); 636. f5th Are; offce, 1278 Market St.; I-4.

Tlliman. Frank Jos.-Cal.2,95; (1'49); 126 Stockton st.

TILLMAX, TILTON $\mathrm{k}+-(\mathrm{a}] .1,02:\left(\mathrm{l}^{\prime} 02\right)$; 2150 Jitekion st.; unde, 126 Stockton St. : $1-3, \div-5$

TISDALK, (HAS. JEWIS (1)'58)-111.4,78: (l'St); (160t Alameda Are, Mlameda) ; oftre, Butler BldIn.

TITClWOKTH, JAMES CIIS.-CaI.1,98: (1'9s): issl perkidero st.

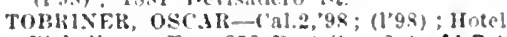
Iilchelieu; offle, 350 Post st.; 2-t; ALR.* Tomlinson, Richard Frank (b'73) $11-$ Cal. $^{2}$, $00 ;(100) ; 2220$ lerisadero st. : oftlee, Surz Cal.5.

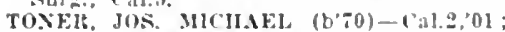
(1'01); 2iti Fair nak st.; ntlee, 405 Val encla st. : $2-4$. $7-8$.

TOPHA Y. EDW-("a1.2,02; (1'02); 1500 Clas sit; onlee, 126 stockton st.; s.

TOPPIS, FleANK JIXI.EY $(1,73)+$ Cal.1. 99; (l'39); 1ksf vallejo st.; onllee. 24n Sinckenn st. : 1-3:30:G.

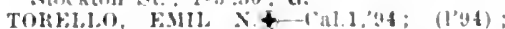
(Burllniame): ntlce, $4=63$ Missinn sit.

Townsend, Juln-11-(al.5, $81 ;(1,5) ; 1003$ Valencta sit.; $8-10,3-4, \quad i=8$.

Tranter, chas. Lee |b'ss)-1'al a.'13; (1'13) inlverslts of callforma liospital.

Trask, Sampsol-Mo.2,79; (13s); 13:4 Vctavla si.: 9-12.3-6; (1628).

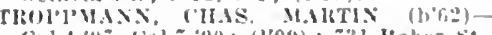

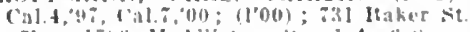

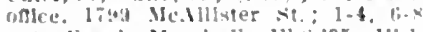

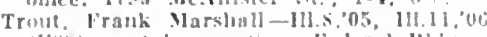
(los); not in practice: Folderil lith

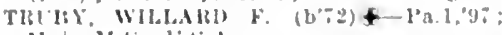
Mad. M. M. I I. A

Tuchlor, herander S.-E ( -11:- bian Jess are.

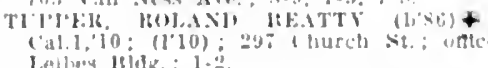

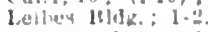

Turnbull, Mary i. Thempsra-1als,os (100): 20 Franklin st.

Turntiul, Iary HIthelmina

Turnbull. Walter 11--4al.5,04; $(104): 330$ sactratin

Tyler, lesatha buth-(1re:,0s: $(1,10) ; 10 \%$

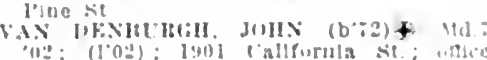
(1): (100) ; 1901 Pallfurula st
Van Wyke, Folwin ('o, fer (b'G9) -Cal.1,95: ran Velur, Ioanl. \&. Min.

Wormland Ave.

Veale. Nhuer liepler

11'001; :02 llalibe

(1'92): 3*1 liunh Sit.

TICTH, EITEST A.

1:30 Ficary sit: Path.

ILLII UIHET 133 licary st

Visall1, Joseph-Cal.5,11; (1'11); 2945. 22d St. ; 2-1

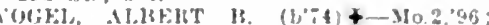
not in practire; Member Mo. State Med. Issn. : atis Fulton st.

Foje, julius C-Cail, 1,91; (1'99); 329 thurch St.; 1-4, ;-8.

IOX IER LIFTH. HALOLD OTTO (b\%5) -Cal.1."9: : $(1998)$; 2900 steiner st; offlee, Cierman liosplital; $2-1$.

ron Coldern, 'has, Erneve (b'85)-Cal.11.

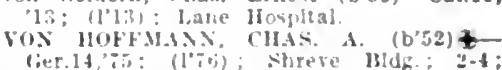
Finer. i'rof. lign, Ial.2: ObG.

von Werthern, llenry L ( (1'11) : $2(99$, Folstom st.

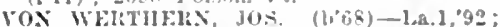
(192) : 2698 folsom st. : untee, 2696 Fol-

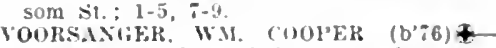
Cal.1,99: (1'99); 2305 lerisadero $\mathrm{St}$; oftre, 1t2 l'ost st.; $11: 30-12: 30,2: 30-$ $4: 30: T$.

VOWICKEL, FERDIXAND WIL H EL II (b'61) +-(ier.1,35; (1'92); 1200 Octarla St. : $2-4:$ S.

Frooman, Luey C. $-1+31.1,06 ;\left(1^{\prime} 07\right)$; 2009 Disisadern st.

W.ADEWORTH. ('HAS T1UTISS (b'\$9)-

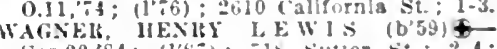
Ger.20,'s4; (1's:'):

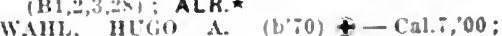

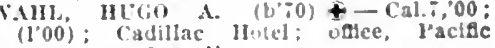
Mdg.; $2-1,7-8 ; U$.

11.MAs, Ml.X.

Turk st. : uflce, 947 li ave.

WAKHIFLI, W. FRANis b. $\left(b^{\prime} 66\right)+$

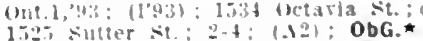

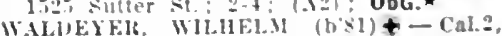

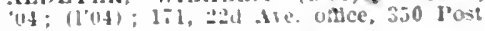

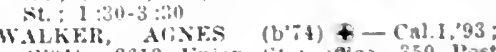
(1'44); 2613 Linion st.; vetce, 350 l'ost St. : $2-4 ;$; L.*

WAKEK, CALYT A. (1,75) \-Cal.1,05; (1'05): 292, il St.; nftlce, l62 l'ust St:

Wallace, Nur

Ilush si.

Waller, Chas, 15-F-ral.t.00; $\left(1^{\prime} 00\right)$ :

6s lost si: $9-12,2-1$.

Waller, Jullan L.-('al.:,04: (1'06): 161 Iuchanan st. ; utlie. 53 New Montgomery st. : :-

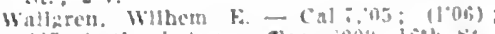

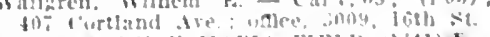

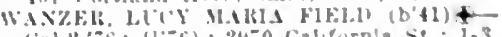
('al.2.76; (1"6); 2960 Cahmrma $52: 1.3$. Ward, Florence Nighingale (bo0)li-Cal.5, lisde st. : 1-3.

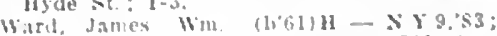
(1'si), ratrmunt llotel: Mle, 391 sut:

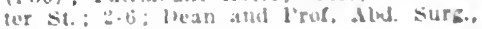
lisn. and bos?. Pals.

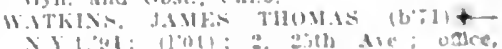

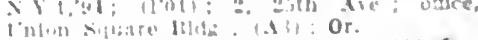

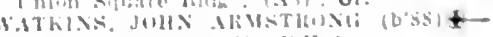

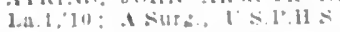

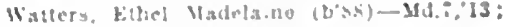

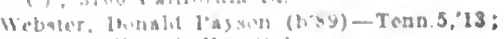

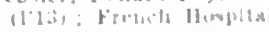

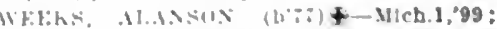

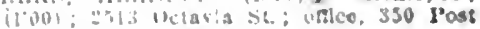

Erlivili,

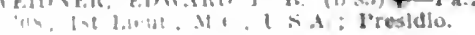


WEIL, CONRAD (b'67) $\oplus$ - Switz, 2,90 ; (l'94); 1912 Clay St.; ofllce, 203 l'ost St. ; $1: 30-3: 30$; S.

Welss, Edward Máxlmtlinn-Ca1.2,77; (1'79); 1907 Lineoln Way; offlce, 995 Market St. 2-4, $7-8$.

Welcl, Harrlet Jane Appy-F-Cal.4, $8:$ (l'S2) ; 2325 Sutler St. ; 2-3.

Welch Heury Seely (b'48)-NY 10, 20 $(1,76) ; 1627$ Jackisu st. imtil 10 .

VELTX, CUJLEN FIAACIS (b'6(i) + FELT', ClJLEA is Presidio Terrace

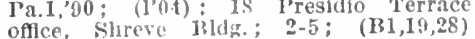
ALR. *

Wemple, Frmulet Le Roy, Jr.-Cal.2,'96; (l'00); 334 Sfockton St.; ofllce, 209 I'ost St. ; $10-12,1$ -

Westerhorg, Fredk, - vt.2,83; (1's6); it Delinar st.: office, 268 Market St.

WESTERFELD, OTTO FERDINAND $\left(b^{\prime} 75\right) \oplus$

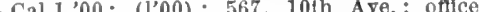
240 Stockton St.; 2-4; ObG.

Wetzel, Jolin Franklln (b'53)-Ore.1,'89; (1'93) ; 1003 Buchanan St.; offlce, Paciftc Bldg. : 2-4.

WFYER, GUSTAYUS ADOLPHUS\$-Cal.2, 99: (1'39); 308 Eddy St.; office, 126 Stockton St. ; 1-3:30, 7-8.

Wheeler, James Ilbert - II - N.Y.9.'84; (1’90): 13:9 Geary St, until $9,1-3,7-8$.

Wheoler, l'eter L. - N.Y.I, 66 ; $\left(1^{\prime} 76\right)$; not in practlce; 2012 IBroadway.

Whlte, Arthur H. (b'79)-Cal.7, 05; (1'05) 760 victorla Ave.; offlce, 2580 Milssion St. $12-3,6-8$

WHITNEX, JAMES L. (b'81) \-Mass.1,05 ; $\left(l^{\prime} 07\right) ; 2847$ Fillmore St.; oftice, 240

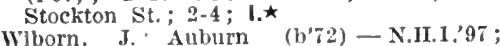
(1'00): 391 Sutter St.; 1-4; (B28) OALR.

WIEL, HARRY ISAAC (b'81) -Md.7, 05 (1'05); 3224 Washington St.; offlce, 135 Stockton St. ; $1: 30-4$

IWILBUR, RAY LYMAN (b'75)@-Cal.1, 99 ; (1'99); (1201 Bryant St., Palo Alto); office, Jane Hospital; Dean and Prof Med., Cal.1I ; I. $\star$

wiLcö. GLóver BRowN (b'78) Cal.9,'08; (1'11); 20 Franklin St. ; 2-4.

WTLLARD, WM. P. (b'77) $\oplus$ - Cal.2,'99 (l'00) ; 304 Maplo St. ; office, 177 Post St. $1-3,7-8 ;(\mathrm{C} 3,14) ; \mathrm{U}$.

WILLCUTT, GEO. H. (b'88)థ-Cal.I,'12

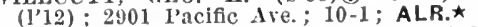

IVILLHTTE OSCAR C. (b'71)-Ill.1,'96 (l'II): Member Ill. State Med. Soc.; 240 Stockton St.; (E4).

WILLAMS, EDITH HAMMOND (b'76)

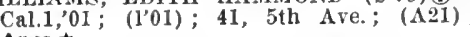
Anes. $\star$

WILIIAMS, FRANCIS (b'i1) $\oplus$-Cal. 7,00 (1'00); 1200 Masonic Ave.; 1-3, 7-8; $\mathrm{S}$

Willlams, Geo. Walter - N.Y.8,'86; (1'91) ist Market St.

Willams, Harry de Nell (b'79)-Cal.7,'06 (1'09); 2436 San Bruno Ave.; office, $320 \%$ Irissión St. ; $1-3, i-8$.

WILILAMS, ROBT. BARKER (b'63)-Cal.2, '87; (1'87) ; 135 Stockton St.

Williams, Walter J. M. (b'79)-Cal.2,02 ; (l’02) ; 763 Unlon St.; offlce, 310 Columbus Ave.; 1 -3.

WILLIAISON, JOHN MARSHALL-Cal.2, '35; (1'85) ; 1631 Oak St.; office, 209 Post St. : $2-4,7-8$.

WILLTTS, EMIMA K. (b'69) $\uparrow-$ I11.9,'96; (l'97) ; 3836 Sacramento St.; office, 240 Stockton St. ; $2-4 ; \mathbf{G}$.

WHLSON, FRANK P.-N.Y.1,88; (1'93); 2321 Jackson St.

Wilson, Geo. B. (b'61)-Cal.1,'92; (1'95) ; 504 Iraight St. ; $1-3, i-8$.

WILSON, HERMÓN FOWLER-Cal.7,'9s $\left(l^{\prime} 98\right) ; 1223,12$ th Are. ; offec, Monadnock Bldg. ; $12-3$.

Wilson, Matthew T.-H-Pa.6,'69; (1'86); 1666 'Fell St. ; 1-4, 7-8.

Winslow, Josephine E. Barbat-Cal.2,03 $\left(l^{\prime} 03\right)$; 1128 Sutter St. ; office, 1057 Sutter St.

WITERBERG, WALTER HOEPFNEP

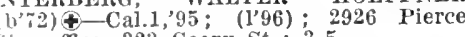
St.; offlce, 323 Geary St.; $3-5$.

WINTERMUTE, GEO. PRESTON ( $\left.b^{\prime} / 1\right) \oplus-$

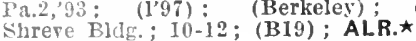

W'ise, Sarah E.-II-Cal.5,'93, Mass.6,'94; (1'94); IIotel Stewart; office, 291 Geary St. $; 1-3 ; \mathbf{G}$.

WOLFSOIIN, JULIAN MAST (b'83)-Md.7, 11; (1'11); 2502 Fllimore St. ; $1: 20-4$ HOON, GEO. A. (b'80)-Ill.6,05; (l'05) 434 IIyde St. ; offlce, Butler Bldg. ; $1: 30-4$ G.

VOOIS, ALICF MAIBEL $\oplus-$ N.Y.14,'85; (l'86)' Hotel Beresford; offlce, 391 Sutter St.; : $1-3$.

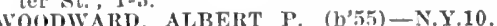
86. (1'89) 690 Oak St. $1-3,7-7: 30$ l'rof. Derm., Cal.7; D

WOOIWARD, RELI, M. (b'62)థ-0.9,'87; Surg., U.S.P.II.S. (l'89) : 1053 Oak St.

Woolsey, chester Howitrd (b'i1)-Cal.2,0I : (1'0I): 2730 lirolerick sit.; offlce, 350 Post St.; 1-4: (1328); U.

WOOLSEY, MARK HOPKINS $\left(\mathrm{b}^{\prime} 66\right) \uparrow-$ ('al.1,90; (1'90); 929 Asbury St. : offlce, 350 Post St. ; 10-12, 1-4; (B28); OALR. * vorley, Minnte Greenstreet. (See Sausalito.)

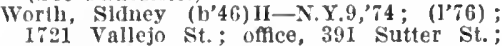
2.4; Prof. Ped., Cal.5.

WORTIINGTON, JOSEPH A. (b'79) $\emptyset-$ Mo.34,02; Capt., M.C., U.S.A. : Western Department.

Wright, Alvln Henrl (b'6̈) - Vt.2,'90; (1'04) 1010 Post St. ; office, 690 Market St.

Wrlght, IIenry Bllss-Ill.4,'67; (1'8I) ; 2820 Pine St. ; 10-11, 3-5.

Wright, H. J., Jr, (b'84)-Cal.5,'08; (1'08); 3689 Sacramento St. ; Asst. Prof. Htst. and Bact., Cal.5.

WRINKLE, GEO. SCOTT (b'82)-Cal.1,'09 (1'09); 110,29 th St. ; 2-4, 7-8.

WYMORE, WM. W. (b'66) $\oplus-$ Cal.1,'95; (1'95); 48 Castro St.; office, 3004, 16th St. ; $2-4,7-8 ; \mathrm{S}$.

Yeargain, Orville Wesley-Ore.1,'9I; (l'94); 1632 La Playa St.

YERING'TON, HENRY HERBERT (b'80) $\rightarrow$ N.Y.1,08; (l'10) ; 1510 Lake St. ; offlce, 240 Stockton St. ; 2-4; Pd.

Yetter, Carrle-E-Cal.4,'90; (1'90); 296 Chureh St. ; $1-3,7-8$

Young, Chester I.-Cal.1,07; (1'07); 706 Chenery St.; office, 1196 Guerrero Śt.

Young, Lester Harmon-Cal.7,03; (1'04); 2598 San Bruno St.

Younger, Edward A. - Cal.2,79; (1'89) Fairmont Hotel; offlce, 135 Stockton St

ZAICHECK, OTTO R. (b'85) ๑-Aus.7,'10 (1'12); Monroe Hotel; office, 135 Stockton St. ; $2-4$.

ZFEG, JOHN (b'73)-MIch.1,'96; not in practlce; Member Med. Soc. of the State of Pa. ; 402 Pierce St.

Zillmer, Adolph L. W. (b'78)-Cal.1,99. (l'00) : 3605, 23d St. ; offlce, 3601, $23 \mathrm{~d}$ St. : $3-5,7-8$.

ZOBEL, ÁLFRED JACOB (b'73) \-Cal.1 '98; (1'98) ; 352 Lake St. : offlce, Shreve

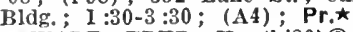

ZUMVÁLT, FRED. H. (b'80) $\oplus-\mathrm{Cal} .2,{ }^{\prime} 02$; (1'02) ; 1010 Lake St. ; offce, I35 Stockton St. ; $1: 30-4$

Zumwalt, Reuben S. (b'76)-Cal.2,'06 (l'06); 3468 Mission St.; 2-4, 7- 8 .

ZUSSMAN, SAMUEL $\oplus-G e r .18,88$; (1'91) ; 1411 Scott. St. ; 1-3, 7-8.

SAN GABRIEL, 737, LOS ANGELES

Iatthews, Thos. H.-H-Hll.4,'82; (l'97) R.F.D. I. (b'44)-N.Y.I0,79; retired; R.F.D. 1.

SANGER, 2,000, FRESNO Allen, Árthur Norman (b'68)-Pa.9,92;
retired.

FLENING, LUTHER P. (b'i6)థ-Cal.1,04;

MADDEN, THOMAS F. (b'80)-Cal. I,'04; (l’04).

SANITARIUM, 25, NAPA

Brown, Eftle Aubrey-Cal.1,97; (1'98)

Nelson, Ida May Shively Herr (b'68)III.9,'97; (1'13),

SAN JACINTO, 898, RIVERSIDE

Arnold, Chadwick Evans (b'75)-Cal.1,'0I (1'01); (Indian Service) ; Soboba School. Arnold, Harry J.-Md.3,'90; ( ).
Strasser, Fred K.-II-Mo.5,'89; (1'94) Strasser, Nellio If,-H-Mo.5,'88; (l'94).

SAN JOSE, 28,946, SANTA CLARA

Asay, Jacob Lambert (b'36) - I'a.1, 59 $(1 ; 6) ; 358$ S. 6 th St. ; $2-5 ; \mathbf{N}$

AVliky, CAROLINE LOUISE (b'65)-Cal.1, 97 ; (1'98); 96 S. Prjest St. ; offlce, ltyland Bldg.; 10-12, 2-4.

IBACHER, JOHANN ADOLA'H (b'75)థlass.1,11; (1'11) ; 46 williow st. ; oflice.

Garden City Bank 13idg.; 9-12, 2-5.

Balley, Willard Chapln $\left(\mathrm{b}^{\prime} 75\right)$-Cal.I,'99; (1'99) ; 312 S. 3d St.; office, 400 N 4 th St. ; $2-4$

BAKER, MOLGAN DILI,ON (b'80)-Cal.2, 04; (1'04); 85 S. 12 th St. ; offlce, Theatre Bldg.: 2-4.

BANGS, FRLD II. (b'58) †-0.7, 80 ; (l'84) : $300 \mathrm{~S}$ 14th St: offlce, $86 \mathrm{~N}$. 3d St. ; $1-3$

BEATTIF, DAVID A. (b'69)(-Ont. I,'92 (l'95); 399 S. 2d St. ; offlce, Rjland Bldg. ; $11-12,2-4$.

Belknap, Florence Adele-Mlch.1,'86; (1'92) ; 108 N. 3d St.

BELKNAP, IEWIS JEROME (b'55) \& Mich.1,88; (1'93) ; Garden Clty Sanltarlum: $8-10,2-4,7-8$.

BENEPF, JOHN L. (b'65) (-IIo.1,'87; (l'03); Garden Clty Bldg.

BIAIR, JAMIES C. (b'80)↔-Cal.2,05; (1'05); 7 Martin Ave.; office, First Viathonal Bank Bldg.; I1-12, 2-4.

Bloch, Leon (b'92)-Colo.2,'13; Intern, Santa Clara County Hospital.

Bowen, Jane N.-H-Cal.5,'91; (1'91) ; Berryessa Rd.

BROVIN, HENRY CALVIN (b'62)€-Ill.1, 87; (1'92); 595 S. 2d St.; offlice, Rea 131 lock; $2-4$

Bullitt, James Bell (b'63)-Ky.2,'89; not in practlce.

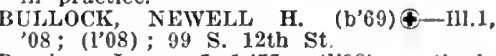

Bussing, James-12.1,77; (1'98); retired ; 550 N. 17th St.

Byl, John James (b'59)-Ill.6,'91; not in practice; $430 \mathrm{~S}$. 13 th St

Campbell, Matllda-Cal.4,'92; (1'92); 419 S. 6th St.

COTHRAN, ABRAHAM LINCOLN (b'65)థ -Cal.2,'93; (1'94); 196 N. 13th St.; $2=4: 30$.

Crockett, Crete Arnette (b'69) - Ill.4,'96, Cal.7,'99; (l'98); 441 S. 2d St.

DAVIS, WM. KING $\left(b^{\prime} 47\right) \oplus-\mathrm{Ky} .2,84$; (1'88) ; 59 Coe Ave.; offlce, Garden C1ty Bank Bldg.; 11-12, 2-5.

Dickinson, Almer Edwln (b'72) H-Ill.4,'97; (195) ; 92 S. 5th St.; offlce, First $\mathrm{Xa}$ tional Bank Bldg.; 10-12, $1: 30-4$.

Dow, Phineas K.-Mo.2,'80; (1'86); 1ะ9 S. 9 th st.

FILIPELLO, EUGENE AVVENTINO (b'68) (-Ita.20,'94; (1'95); 375 0rchard St. offlce, 54 S. Ist St.; $10-12,2-4$.

Freeman, Roscoe E.-H-Pa.9,'86; (1'89); Rea Bldg.

Fretwell, Wm. Joseph (b'68)-Mo.1,'88; (l'96): 145 Auzerais Ave. offce, IIs $\mathrm{S}$. ist St. ; $2-5 ; \mathbf{G}$.

Gates, Chas. O. (b'65)-Mo.8,'93; (1'95); 234 Lincoln Ave.

Gerlach, Frederlck C.-Pa.1,'94; (l'94) ; 223 S. $3 d$ St.; offlce, 68 S. 1st St.; $10-12,2-4,7-8$.

GOODRIDGE, HANNAH (b'64)-0.13,'03; (l'03) ; 135 S. Crtttenden St.; office, Gar den Clty Bank Bldg.

Grazer, Fredk. A. (b'5T)-Cal.1,'89; (l'90) ; 395 S. Market St. ; 2-4, 7-8.

GREENWOOD, EDNA M.-Cal.5,'97; (1'97) 140 N. $3 d$ St.

HABLUTZEL, CHAS. EDWARD (b'65)ゆCal.1,95; (1'95); 105 S. 11 th St.; offlce, Ryland Bldg.; 11-12, 2-4.

HALL, IOS. UNDERWOOD (b'68)థ-Pa.2, '89; (1'89); 216 Autumn St.; offlce, 45

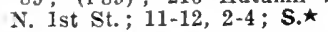

HARE, CHAS. BENJ. (b'73)థ-Ill.1, 08 ; (l'0S); 48 N. Morrison St. ; oflle, 8 N. Ist $\mathrm{St}$.

HEPPNER, ALBERT HENRY DANL. $\$-$ V.Y.8,97; (l'11); 942 , 10th St.; offlce, Ryland Bldg. ; 2-4, $7-8 ; \mathbf{G}$. 
HERVF, CHAS, HFRMON (b55)-0.2, 'S4; (1'85); 33 N. 3d st.; 10-12, $20-4$. IIlues, A. Don-II-Mass.5,92; (I'98); 541 L. Sansa Clara St. : odlce, i'orter Iblds. : $10-12,2.4$.

HITTELL, AMY G. BOWEN - -Cal.5,'86, Irass.6,'94: (1'86); R.F.11.21.

Holbrook, Fdward Ferrls (b;1)-Cnl.1,93 (1'94); 398 s. 15 th st.; oflce, 81 s. Ist (1'94): $:-5$

IIOIKI.NS, MARK r. $(1,78)+$ Cal.7,03 (1'03); 111 N. 12 th st.; once, Ryland Bldg,; $11-12,2-5,7-8$.

Ilowell, IIarrlett - ('al.5,'96; (1'9:); Flrst Nallonal lkank B!dz.

Hughes, John II arrlson (h'39)-('al.4, 87 (1'8i); not in practlce; 246 s. 9 th st.

JAY HT, A. C. A.-Vi.2,S9: (l'91); 520 S. 6th St. offlce, 58 s. lst St. ORDAN, PETER A. (b', ' + - I'a.2,01 $\left(l^{\circ} 03\right) ; 513$ S. 6 th St : ofllce, St S. 1st St: $10-12,2-4 ;$ (J119): OALR.

КАРP. МСНАF, พY. (b'66)-0.23,'95 (l'05); 197 S. 13 th St.; ofllce, Porter IU]dg. : $2-5: 30$

Kelth, Wm. Ell (b'52)-0.7,'75; (1'85); 693 S. 2d St.; oflce, Flrst Natlonal jank Bidr. : 11-i2, 3-5.

KOCHER, JACOR JOHN (b'76)\&-Pa9 06. Pa.2, 07 ; (1'07): 199 S, $16 \mathrm{th}$ St. of. Pa.2,07: (l'0i) : 199 S. 16th St.

Lampert, Louls (b'63) E- ; (l'97); 388 Ww. Fernando $\mathrm{St}$.

IANTz, VIOLA (b'74) Cal.1,08; (l'09) 378 's. 2d St.; oftce, Ryjead Bldg. $11-12,2-4 ; G$.

Spada, Francesco (b'64)-I11.11,'94: LEE UELEN\$-UICh.5,05; $(1,06) ; 140 \mathrm{~N}$. 3d $\mathrm{St}$.

LOEHR. BFRT F. (b'81)-Pa.8'09; (l'10); 345 S. 3d St.; oflce, Porter Bldg.; 10-11, 2-4, 7-8.

MeGinty, Arthur Thos. (b'74)-Cal.2,02; (l'02);675 S. 6th St.; offlce, 82 S. Fork St. McMIllau, Dugald-Mich. 1,$68 ;(1 ; 6)$; Itea Bldg.

Merrow, Islewella Marla_Mlch.5,05: ( )

MLrTow, Jewella Marla-Mleb. 80: (1'8i) ; 91 F. St. James St.; $11-12$

MILLER, SAML. B. (b'55)-111.1,78; (1'88) Member Wyo. State Med. Soc.; $201 \mathrm{~S}$ 13th St.

Mulcahy, Mlchael V'lncent (b'68) - Ont.1,89; (I'00) : 556 E. St. John St.; offlce. First Niatlonal Bank Bldg.; $10-12,2-4, ;-8: U$

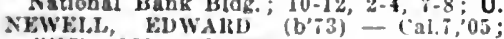
YEWEILI, LDWAlR

ollver, Andrew Sprague - $11-1$ - $a .9,81$; (1'01) ; 31 N. 2d st.; $11-12,2-4$.

Orlechla, Alfred P. (b'84)-N.1.8,11: $\left(I^{\prime} 13\right) ; 67$ W. Santa Clara St.

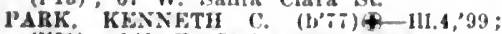
(I'01) ; 140 K. Carlos St. oflce, $84 \mathrm{~S}$ ist st. : 2-5.

Parkman, Wallace Ernest $\left(b^{\prime} ; 4\right)-C a l .2$ 96: (l'gr): it s. 15 th st. oflce, First National liank I3ldg.; $11-12,1-4, i=8$.

PATERSON, FliNK II. (b'75) 98: (1'98); St. James llotel; onlce, Columbla Hospltal.

Reese, It. Edwin.

(See San Francisco.)

Regll, Jnseph A. \$.-U.C.2,02; (I'03); 215 W. San Fermando St.

RICHARDS CHARI,ES M. $\left(b^{*} 81\right)+$

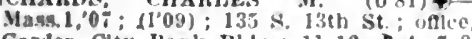
Garden Clís Ilank' Hldg.: 11-12, 2-4, T-8 Johinson, Johm M. (b'35)-1'i. i, 100 ; re-
tIred: 38,19 th st.

Ross, Thos. D.-Mlch. ".88; (1'88) ; Myland Bldz.

loossini, Taclio-11a.7,92; (1'93); First

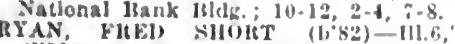

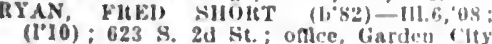
(1'10): 623 \&. 2d Ft. ; oflce,

SANForD, l'ÁU1, (h'50)-Ky.1,01: (1'91) 297, 0th St; once, 1kjland isldg.: $10-12$,
2.5, 7-8.

\$AI'H, 1.0119 VI(T) (b'85)-('al.2,00 $\left(1^{\circ} 00\right)$; 64 \&. 19 th st.; oflce, Garten Clty Bank Hidg. : 11-12, 2-4.
City

Saunders, Isurence A. $(1 ; 53)-K y, 4,76$; ( ): 745 Unlrersity Ave.

SEIFERT, Gro. W.-I'a.2, 83 ; $\left(\mathrm{I}^{\circ} \$ 4\right)$; J.e slifa islide. : 2-4.

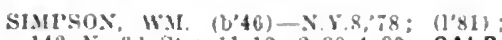
142 N. 31 St. ; 11-12, 2:30-1:30; OALR. SMITH, A.IBER'1' ST. J.\&-Mo.2,93; $\left(1^{\prime} 00\right)$; $106 \%$, 5th St. : oftce, Hyland Hdg. STICE, TYLE HAItMLON (b'69) + ('al.1, "91: (1'94): Stice Sanatorlum; once kank of Sian Jose Isldg.; $2-4$.

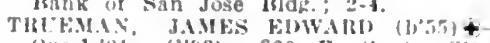
पue.1,81; (1"43); 360 F. Salla clara St. onlce, liarden cIty" Bank Mlldg. $10-12,2-4$

lirlel, biwarl John (1.33) - 0.7, 1 (1'si) : 63 N. 2d st. : $1-4$.

YAN HALSEM, SAMUES R.-1'a.02 (102):45B \& 14th st. offce, lorer Isldg. : $11-12,3-5$.

VA. DALSEM, WM. S. $\left(b^{\prime}-2\right)+-111.10$

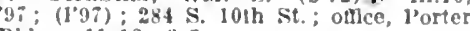
Bldg.; 11-12, 3-5.

Vetterling, Ierman C. (b'49) - II.t,'s3: (l's8): 527,24 th $S t$

WIFNER, EDWAM1) d, (b'62) +-MIch 1 '87; (1'00): 355 Reed St. offlce. 84 s. 1.st 'st.; 10-12, 2-1; (1319); OALR.»

Waller. Chas. Henry (b'6\%) - Pa.n,94 (1’94) : 615 E. Santa Clara St.; offlee, Porter Jidgr.; 11-12, 2-4. WAYlAS1, CHAS. A. Pn.9:91; (1'91);
140 N. 3d St. 2-5.

Welsster, IIannah E.-Cal.2,04; (1'04); 1195 Alameda Iro.

Whitien, Roscoe Albert (b'72) - Ill.11,97; $\left(l^{\prime} 01\right)$; 155 S. 8th St.; offlce, Garden Clty Bank Bidg.; 11-12, 2-5; Pr.

Whltnes, James P-Cal. I, 63; (1'76); Ven-

WILSOX, DOXEY ROBT. (b'84) -Cal.1 '08: (1'08) : Santa Clara County Hospltal. WISE, PIIIII I, \&-Cal.6,05; (l'05); 199 S. 16th St. : offce, Ryland Block; 10-12, 2-t; OALR. *

WISLOCKI, HCGENE JOHN $(1,61)+$ Aus.3,'si'; (1'91); $16 \mathrm{~S}$. 14th St.; oftlce, $26 \mathrm{~S}$. 1 st St. : $10-12,2-4$.

WRIGITT, II HXIRY J.' Is. (b'51) -0.8, 75 , l'a.2, $81 ;\left(1^{\prime} 89\right): 312 \mathrm{~s} .3 \mathrm{~d}$ St. ; office, Ryland BIdg. ; 11-12, 2-5.

SAN JUAN BAUTISTA, 326, SAN BENITO Thorpe, Thomas Franklln (b'68)-Cal.i,'04; (1'05).

\section{SAN LEANDRO, 3,471, ALAMEDA}

Beard. John Lyman (b'87) - Cal.5,'13; (l'13).

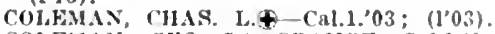

COLEMAN, GEO, LA GRANGE-Cal.1,03: (l'03).

II ouston, Elizabeth IIenderson (b'63) Mlch, $8,95:(1,96)$

IIouston, Elmer C. (b'66)-Ky.4,'s8; (1'96). Mason, Benj. F-Cal.2,75; (1's5).

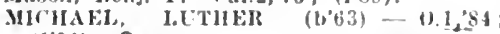
(1'94); S.

MLLER, ('HAS. IOWARD (b'il)†-Cal.1, 96 ; (1'9s).

WIIAS. CLARENCE A. (b,71) -Cal.1,03: $\left(l^{\prime} 03\right)$.

SAN LORENZO, 320, ALAMEDA

l'owell, Allert 13.-Cal.6,"01: (l'91).

SAN LUIS OBISPO, 5.157, SAN LUIS OBISPO

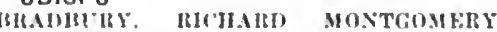
$\left(b^{\prime}, 8\right)+$ N. Y. 8,$89 ;(1,01)$

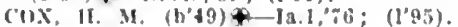

(iullfoll, Iames Anthony (b'87) - Mlch.1,'11 (1'12): S.

Jackson, Jos. Sirales $\left(b^{\prime} 40\right)-$ X.Y.10,74; $(1 ; 6)$.

Jíksov, ralle K. (b'78)-Cal.1,01: (l'0l).

Jolnstone, Falward 16-1a.1,92; (1'96)

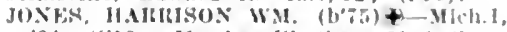
01: (1012); Nember 111. Shate Med. Noe. S.

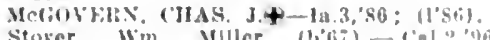

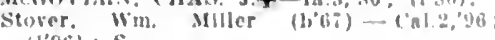
(1'm(i); $\mathbf{S}$

Wade, 1.3mats Trerltt (b'bi) - 111.8."

(1"1)

Vallers, Harry Seth $\left(b^{\prime}-1\right)-(a) 190$ (1'9.5)

SAN MARCOS, 50, SAN DIEGO

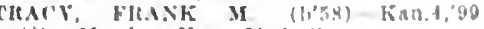
(A) Menuer kan. Med soc
SAN MATEO, 4.384. SAN MATEO

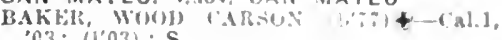
03: (1'03); $\mathrm{s}$

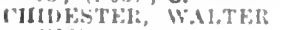

(1'Ofi).

Colien, Albert.

(See Sian Francls( (o).)

Goodspeed, lsace lowseue- If 1 , za

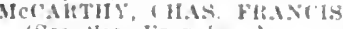

(Ree san Francoluron.)

Mokmisne,

WARHES, IIMIRY C.-Cal.2,04; (J'04): T.

SAN MIGUEL, 600, SAN LUIS OBISPO

IIC.Rul, Wllliam-0.12,84; (1'8R).

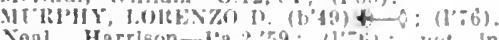

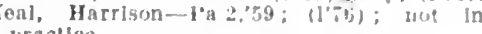
jracllce.

SAN PEORO, 3.500, LOS ANGELES

IENNEFT, HALWA 13

(Sce Jos Angeles.)

Bolton, M. Jlanche--r-Cal.4,9i; (1'yi).

lowlre, bumont $\rightarrow$; $(1,6 i) ; S$.

Gwaltiey, J. Sanferd" (b'59)-la.9.91; (1'98)

light, Tied carey.

(See Los Ingeles.)

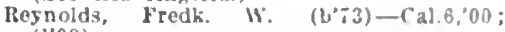
$(1,00)$.

Thibodo, F. H1-Ont.5.95: (1'96).

TROMMALD, FDIFARD ARBO

(See Los Angeles.)

PAN VOOHIEES, GEO. T. $\left(b^{\prime}, 0\right)+-0.2$ '93; $\left(\mathrm{I}^{3} 93\right) ; \mathbf{0 b}$

SAN QUENTIN, 300, MARIN

STANLEY, LEO LEONIDAS (b's6)-Cal.1, 12: $\left(I^{\prime} 12\right) ; S$.

Stolle, Francis (b's\%)-Cal.11,'13; (1'13).

SAN RAFAEL. 5.934. MARIN

Alexander, Filgar $1 \mathrm{Hm}$.

(See San Franclsco.)

Augustlnc, Saml. II. (b'52) -0.8,74; (1'75);

not In practlce.

DIDI.EY, IUIBERT W. (b'66)-Ta.2, 85 ,

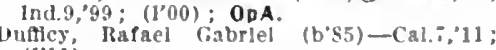
(I'1I).

HENIIFIRSON, JOS. J.

(See San Franelsco.)

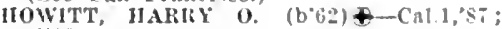
(l'86)

HUND, H.MRY OTTO (b's5) -1'a.11.'11; ONFs, WM. FAlR RINTON (b'c0) Cal.1, \$ 85 : (1'85)

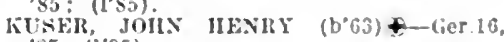
$85 ;(1,95)$.

Iarston, Chas. Benj. (b'\%3)-Cal.5:0s; (1'0s).

SANTA ANA 8.429 , ORANGE

BAI, CIIAS. DEXTER (b'50) \$-Que.5,'st;

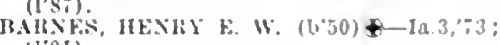
11.01).

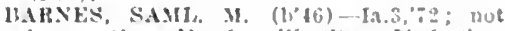
In practice; Nemter III. Siato Minl sac. $\left(1^{\prime}(3)\right.$; It.F.n. 1.

linkloy, F. II-A; not ln practlce.

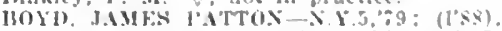

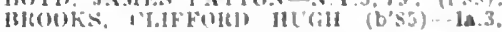

10 ; (1.11)

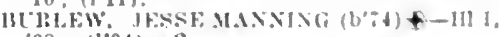
$03:(1004) ; s$.

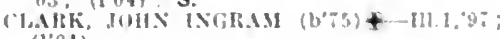
(link).

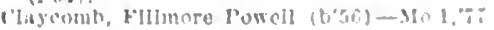
(1) 01$\}$.

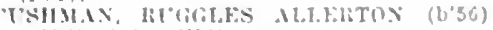
․11 $1,-3:(1,01)$.

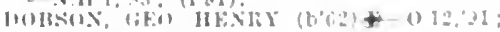
(1.01): OALIR.

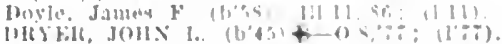

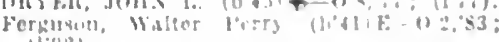
$(1,(1) 3)$

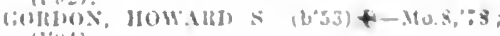
$(1+y)$

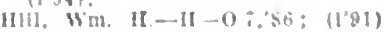

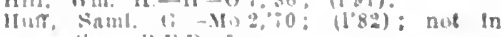
Langur. Where II (inl.3.94: (1.94): not In bractlice

in practico. 
Mills, Ira 1).-Ind.4,' 78 ; (1'87) ; not in prac-

Iteynolds, I'almer R.-Cal.6,'92; (1'92); not in practice.

Itobertson, Herbert Mlller (F'73)-Md.8,97

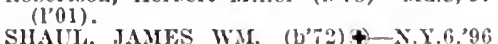
(1'09).

Stephenson, John L. (b'58)-Mlnn.4,'95; not in practice.

Wattle, Willella Ilowe (b'54)-I11.4,'86; (1'86); G.

Waters, Eli 1I.-.Ia.s, 86 ; (\$)

WEIIRLX, JOIN (b'tis)—II 1,90 ; (l'01)

SANTA BARBARA, II,659, SANTA BAR BARA

ANDREWS, JOS. ALFIRE (b'59) $4-N . Y . I$ 76 ; (1'9s): Mcmher Mfed. Soc. of the State of N.Y.; 12291\% State St.; 10-12 $([34,5,16)$

Bainbridge, James C.-F-Cal.4,94; (l'94) 1306 Garden St.; ofllee, Ilopkins Block I1 $12,2: 30-4: 5$.

BAlEWELI, BEX.J. (b'7) $\oplus$-Cal.2,02 (1'02); 1416 Bath St.; office, 1205 state (102); 1416 Bath st.; office, 1205 Stat SAltiry, W.M. TAYTOR (h'58)\$-N.Y.10, 84; (1'91); 132s Bath St.: offlce, Howard-Canfleld Rldg. ; $10-12,3-5$.

Bocseke, Elmer Julu's-111.6,'89; (1'92) ; 112 W. Ortega St.; offlee, 71 I Chapala St. ; 11 12, $2-3: 30 ; \mathbf{S}$.

BROWN, REXWALD (b'78) 4 -IIl.6, 03 ; (1'06); A.Surg., M.R.C., U.S.N. ; 233 E. Islay St.: offlee, Bothin Block; $2-5 ; \mathbf{S}$.

Cllfford, John Bruce-E-Cal.4,'94; (1'94)

Clow, Burtón Roderick (1,54) E- $0.2,89$ $\left(1{ }^{\prime} 90\right) ; 515$ W. De La Guerra St.; offlee, 905 State St.; 10-12, 2-4.

CONRAD, DAVID ANDILEW - Cal.2,93 (l'94); Porter Hotel; offlce, 1109 State

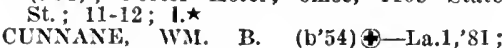
(I'84); 1327 De la Vina St.; offec, Clock Bldg. ; $10-11$.

Flint, Wm. H. (b'52)-N.Y.10,77; (l'96) ; The Herter Resldence.

GOULD, FREDERIC SALTONSTALL (b'53) R.F.Y. 78 ; (l'93); not in practice;

HAMLTON, GILBERT VAN TASSEL (b' 7 ) †-Pa.2,01; (l'09); (Montecito); office, Alken, Bldg.; (EI3); NP.ネ

II urst, Jullus Harold (b'73)-D.C.1,'03, Conn.1,04; (l'08); (Monteclto); oflece, Conn.1,04; (l'08); (IIontecito); ofllce, 1225 State St. ; 11-12.

KNOX, SAML. BUDD PAGE (b'39) $4-$
Pa.1,66; (l'76) ; retird; 914 Anacapa St Low, SAML. P.-Pa.9,'s9; (l'89); $9 \mathrm{~W}$ Victoria St. ; $2-4$.

Mansfield, Lois Fiteh-Ill.9,'76; (1'87); 1328 Anacapa St.; 2-4.

Merrill, Edw. Roscoe-Mass.1,'85: (1'86)

MORREY, HERBERT P.-Ia.9,'93; (l'01); 8081/2 State St.

Moseley, Henry Perkins (b'72)-N.Y.I,'9s; not in practice; R.F.D. 1 .

Poore, John Robinson (b'64)-Mass.I,'95 not in practice.

Reynolds, B. L.-H-Ill.4,'80 ; (1'94) ; not in practice.

SIDEBOTHA.I, D. HAIROLD (b'62)థEng.11,15,'87'; (l'91); 1936 Laguna St. ; offlce, I009 State St. ; 11-12.

Stambach, Henry L. (b'79) II - Pa.9,'79; (l'85) ; $15 \mathrm{~W}$. Victoria St.; 2-4; Pd.

Stambach, Ida $\mathbf{Y}$. (b'53) H-Cál.5,'88; (l'88) 1509 State St.; 2-4.

STODDAILD, CHAS. SIDNEY (b'46)-IIl.8, '74, N.X.10,'83; (1'86); 1215 Anacapa St.; offce, Fithian Bldg. ; $11-1,3-5$.

STODDARD, THOS. A. (b's) 4 -Cal.2,0 0 ; $\left(l^{\prime} 07\right)$; 1215 Anacapa St.; office. Fithian Bldg. ; 11-1, 3-5.

WELIS, GEO. S. (b'63) \&-O.13,92; (1'10) ; 1201 State St.; until 12; ALR.ネ

Winchester, Robt. Fulton (b'45)-MIe.I,'6: $\left(l^{x}+6\right) ; 412$ Hontecito St. ; office, Fithial Bldg. ; $10-11,2-4$.

Wright, Harold Walgrove (b'83)-X.Y.1,05;

SANTA CLARA, 4,348, SANTA CLARA

BEATTIE, JOHN IRVING (b'83)@-Cal.1,

$05 ;(1,06)$

Carpenter, H. F. $-\mathbf{H} \rightarrow$; $\left(\mathbf{l}^{\prime} ; 6\right)$.

FOWliR. GEO. WASHINGTON JOS. (b'6 + -1'a.1, 42 ; $\left(1^{\prime} 92\right)$.
ONBOLNG, ANTILIM ED(iAl (b'57)-l'a.1, 7\%: (1'86).

I'AÜl, MIDSON WALDO (b'61)†-N.X.10, $91 ;(1 ' 94)$.

SANTA CRUZ, 11,146, SANTA CRUZ

BHILI, WILIIAM ISIS $\left(b^{\prime} 75\right) \rightarrow$ Cal.2,'9R P.A.S., Ileut., U.S.N.; retlred; People's Bank Blilg.

Bennett, Juth Parker (b'56) H-Ill.4,'93 ; (l'94) ; 36, 2d St. ; 11-12, 2-4; G.

BLSII, BWXJ. HOWARD (b'84)'-Cal.1,'I1: (l'I I) ; 28 Darls St.; offee, I'eoples IBank 13ldg. ; $2-4,7-8$

BTSII, HIA CHAS.-Ill.1,'\$9; (l'91); 361/2 Pacifle Are. : 1-4, $6: 0$ : 0 -8.

Calkins, Chas. D. (b'57)-Ia.3,'s3 ; (\$) ; 369 Brondway.

Chamberllu, Mareus P. (b'49)II-Mo.5,75; (1'79); 82 Cayura St.; $2-5$.

Mary Ann - H - Mo.5,75. (1'79); 80 Cayviga St.; $10-12,2-4$.

CLAlRK, IULAUULT II. (b'35)-0.1,71; (I'S8) : Mission and King Sts.: 2-4.

CONGDON, WILIIS ROLLIN-Ill.1, 89 . (i'gf); Blackburn Terrace; offce, $361 \%$ Piciflc Ave.: $2-4$.

Cook, Wm. Wilder (b's6)-Mass.7,'10; ( ) 14 Washington St.

Cothan, Wm. Franklin-Cal.2,05; (l'05).

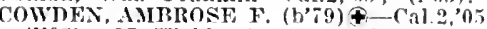
(1'05): 37 Highland Are.; oflice, Paclfic and Iincoln Sts.: 2-4, 7-8.

Ford, James C. (1)38)-Mo.1,59; (l'88).

Fulton, Phillp Randall (b'85)-Minn.4,'11; (1'13); 103 Clinton $\mathrm{St}$.

GATES, MORRIS J. $\left(b^{\prime} 70\right) \uparrow-K y . I, 94$; (l'94); 220 Misslon St.: office, 1161 Paciflc Ave.; 10-11, 2-4, $7-7: 30$.

Greenwell, Geo. Hunter (b'62)-Cal.4,05; (1'06): 117 Soquel Are.; $1-5$.

IIART, FItANK R.-Cal.5, '03; (l'03) ; Trust Blolit.

KFCK, wM. HUGUS (b'50)क-Pa.12,'s9; (l'01); 200 Soquel Ave.; ofllce, $44 \frac{1}{2}$ Paelfic Are.: $1: 30-4$.

IIIIENCRANTZ, GUY H. (b'76)-Hl.1,01; (1'01); Peoples Bank Bldg. ; 1-3.

Monnett, Hamlin V. (b'44)-Mro.27,'92 ; (l'01); I61 Seaside Ave.

Morgan, Francls E.-Cal.2,'81; (l'81); 9-12, $2-4$.

Morgan, Jenny M.-H-Ill.4,'84; (l'86) ; Fast Cliff Drive.

PARKER, CHAS. HADDEN (b'71) \&-III.16, T97; (Dentist); Member Ill. State IIed. Soc.; 59 ocean View Ave.; offce, 88 Preific Are.: R.

PIIILIIPS, PERCY T. (b'68) $4-0.6$,'89; (l'99); 122 Locust St.; office, IHihn Bildg. 2-4:S.

PIPLR, HARRY EIWIX (b'77)థ-Cal.2'0?; (l’02) ; 401 Ocean Are.; offlee, 96 Pacific

SoOTHILL, JOHN H. (b'61)థ-Ill.6,'83; (1'99) ; 114 Seabright Ave.

Stimson, James (b'33)-N.Y.5,'54, Ont.4,'55; (l'91); 11 Caledonia St.

Valker, Alice May C.-Mo.21,'86; (1'91); 98 Broadway.

York, James MicC.-Ia.1,'S5; (1'9I).

SANTA MARGARITA, 200, SAN LUIS OBISPO

IIastlngs, Jos. W. (b'65)-Ky.5,'01; (l'13).

SANTA MARIA, 2,260, SANTA BARBARA

Bagby, Henry Clay (b'60)-1Io.1,'81; (l'83).

l3rown, Bobt. W. (b'62) -Man.1,93; (l'98).
Childs, Benj. Nelly (b'69) E Cal.4,95; Childs,

COBIENTZ, LAMBERT B. (b'80)†-Cal.1,

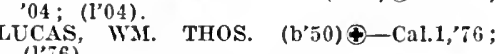
(1'76).

PARKER, ALBERT MUNRO (b'70) Paulding. Ormond Pinkerton (b'45) - II Soch. T5; (1'85)

SANTA MONICA, 7,847, LOS ANGELES

BALSLEY, JOHN ALLEN (b'73)Ð-Ill.6, '00; (1'06).

Case, Lynn H. $\left(b^{\prime} 77\right)$ H-Cal.5, 00 ; $\left(l^{\prime} 00\right)$.

HAMILTON, NEWELL HIRAM (b'52) IIl.1, '7; (1'93).

Hasse, Hermann E.-Ger.20,'61; (1'87) ; retíred.

Hunt, John S. (b'65) H-0.13,'91; (1'95).

Ketchum, Marshall B. (See Los Angeles.)
Lindsey, I'hlllp S. (b'62)-Me.1,'88; (l'94); not in practlce.

MOITENSEN, WM. S. (b'79) ↔-I1l.1,03; (l'06); (I'alms)

l'Alkklik, WM. H. (b'54)Ð-N.Y.6,'81; (1'00).

Reynolds, Marion Belle Stuckey (b'70)Mleh.I,91; (1'09) ; ObG.

WAGNElt, FliANK' J. (b'72) ๑-Pa.11,'01; (l'09)

Williamson, Alonzo Potter (b'54)-Pa.9,'76; (l'01); (E13).

SANTA PAULA, 2,216, VENTURA

('rawford, John (b'60)-0.14,'87; (l'00).

MERILILI, BEN.l. E. (b'71) $4-\mathrm{Pa} .9,01$, I'a.11,04; (I'I1); Member Sled. Soc. of the state of Pal.

MOTr, DAVID WALIACE - Mich.1,'81;

Strong, Jacob C. (b'68)-0.8,'90; (1'90).

SANTA ROSA, 7,817, SONOMA

BOGLE, SA.IUEI, SAFFELL (b'67) Tenn.6,'9l; (l'93)

BONAl, REUBEN M. (b'69)థ-0.25,'93 ; (l'03)

BURNETT, WM. F. (b'64)†-Ky.4,02; not in practlce: Member Ky. State Med. Assn. (1'94)'

CIINE, JOHN W. $\oplus-I a .1,81$, N.Y.10,'94; (l'84).

Hainlin, Roscoe Earl (b'79) - Cal.7,'07; (1'11); S.

CWARD, ALLEN RICHMOND (b'86) Cal.1,'Ii ; (l’I l).

JESSE, JA'MES WM. (b'57)๑-N.Y.5,'86 ; (!'86).

Juell, Nils R. H. (b'50)-Hll.1,84; not in

AIN, LIZZIE-Cal.5,'97; (1'97).

Maddux, Chas. P.-Cal.1,98; (1'99); not in practlce.

Maddux, James Everett-Cal.1,'94; (1'95) ; not in practlce; R.F.D. 4.

MALLORY, GEO. W. (b'60) - Cal.7,'00 ; $\left(l^{\prime} 00\right)$.

MeLEOD, JAMES H. (b'69)థ-Mo.27,'96 ; (1'98); OALR.

MENERAY, PRINCE ALBERT (b'58) Ky.1,'91; (1'93).

Nesbit, Jennie E.-Cal.5,'05; (l'05).

PRYOR, FREDD o. (b'í) $4-C a l .1,98$; (l'98)'

Rea, Chas. T. 1.-Pa.2,'59; (l'96)

Rohr, Silas M.-Md.4,'89; (1'92).

Ruddock, Edw. J. (b'45)-Mass.1,79; (1'85) ;

not in practice.

SCAMELL, JOS. WM. (b'74)థ-Cal.1,'98; (l'01); $\mathrm{S}$.

STUART, ANABEL MeG. $\left(b^{\prime} 40\right) \oplus-C a l .1$, $78 ;(1,78) ; P d$.

TEMPLE, JACKSON@-Cal.2,06; (l'06); ALR. *

Trachman, Henry J.-Md.6,'00; (1'01).

Vought, Joshua B. (b'49)-Mo.5,'84; not in practice.

YATES, FIIZABETH M. (b'59)-Cal.1,87; (1'88) ; Pd.

SAN YSIDRO, - SAN DIEGO

Arinstrong, Robt. (b'44) -Pa.2,'68; (l'85).

Blackshaw, Jos. E.-0.13,'91; (l'95).

SARATOGA, 1,500, SANTA CLARA

Burgess, Geo. W. (b'69)-Cal.1,95; (l'95).
HOGG, ROBT. LETCHER (b'73) $4-\mathrm{Ky.2}$, '93; (1'94).

SATICOY, 400, VENTURA

Sharp, Grace Honora-Cal.1,'99; (1'99).

SAUSALITO, 2,383, MARIN

Fowler, Benj. L.

(See San Francisco.)

Grimm, Chas. H.-Mass.1,'83; (1'85).

MAYS, ARTHUR HUGH (b'67) (-Cal.2,'87; (l'89).

SULLIYAN, WALTER HARVEY (b'62)Cal.1,'83; (I'84); S.

Vance, Allen Haines (b'54)-0.6,79; (1'11). Worley, IIinnie Greenstreet $\left(b^{\prime} 67\right)-C a l .1$, ' 88 ; $(1 ' 88)$; not in practice.

SAWTELLE, 2,143, LOS ANGELES

Crawford, Jos. G. (b'40) H-Cal.5,'92; (1'92).

FIELDING, GEO. A. (b'81)@-Cal.6,'02; (1'02). 
HAXXHEHG, JUHILS J. (b'39)-Den.1,64 not in practlce. IROMAUKA, NL'GUST H. (b'SO)†-I1!.6, $00^{\circ}:(1.0 \%)$

PAGL, JERFMIAH J. (b'4i) - Me.1,":2:

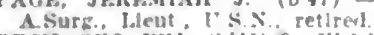
PECK, GEO. WM. (b'+1) + -111.1.90; (1.00) Rogers, Hobt. W. - Tenn.s.'s1: (l'9l) voldiers: Home.

SCOTIA, 1,500. HUMBOLDT

COTTRBLL, CILAS. C. (b'S3) \&-1'al.1, 07 (1.0\%)

COTTRFIL, F.MII,E IAESTER (bot)+Pa.2.,03; (1'04)

SEASIDE, 80, MONTEREY

D. (b.63) - Y.5.5.

(1'si): not in practlec.

SEBASTOPOL, 1,233, SONOMA

Hlackshaw, Jos. B. (b"79) H - Cal.5,'11 (1'11).

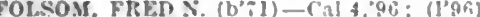

Ilurlbut, Fdwin T. M. (b'28)-X.Y, 6,67

KEATIS: D. JoHX Jos. (b'65)-Mo.28:01: (I.01)

KFRR, WM. J. $\mp-M 0.20,00:\left(1^{\prime} 00\right)$

Mlller, J. P.-K5.1,92; (1'97).

SELMA, 1.750, FRESNO

Barton, Ira (b'41)-SIlch.I,69; not in practice.

Booker, Thos. A.-Tenn.5,"9s; (l'9S).

Mower, Carrle F. Hastlngs $-0:$ (l's9)

Meracle, Geo. A (b, 75$)$-Calf, $06 ;\left(10^{\prime}\right)$

Roblnson, James H. (b'i4)-0.3.'02: (l'09)

STEINWAND, OSCAR WM. (b'69)‡-Call,

'97: (1'98): ALR.

WACXER, JAMES D.-Tenn.1,\%3: (1'82).

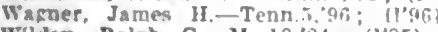

Wridey, ralph G-Mo.18'xi: (1"s5)

WIILIMMS, FRED H $\left(b^{3}, 5\right)+-M 0.20,00$ : (1'03): $\mathrm{G}$.

SHEEPRANCH, 249, CALAVERAS

Maddock. Louls-Pa.2,'93; (I'93).

SHERMAH, 375, LOS ANGELES

Mohn. Fredk. Yoss (b':6)-MInn.4,92: (1'98).

SIERRA CITY, 500, SIERRA

Levery, Wm. Andrew (b'72) F-C'al.4.9?; (1'99)

SIERRA MADRE, 1,303, LOS ANGELES

Krebs, Lloyd Lerny (b'4)-Pa.1.99; II'll

lee. John willard-..Y 1,74: (1'01).

MCKERRAS, RORT. HAMHTTON $(0,78)$ \% Ont.5.'03; (1'05).

Radehaugh, John M. $\left(b^{\prime}\right.$ is) - Pa.1, ':3; (1'891.

Washburne, Geo. F. (1,55) H-I11 10.83: reilred.

SIERRAVILLE, 370, SIERRA

Lnehaukh, John Indrew (b'b4)-0.3.99: (190)

SISSON, 636, SISKIYOU

Burk, Fien, Washlnzton-Cal.1,93; (l'34).

SMARTVILLE, 389, YUBA

GUIXAX, WM. JAMFE-Vt.2,00: (1'01).

SOLDIERS KOME, 2,300. LOS ANGELES

EAwards. Frank Aranld (b's1)--1).40,'10

A.Surs., Natlonal soldiers' Homs"

Mayden, Benj. Franklln (1,82) - Ifn.1,05.

keller, Websice Fels (b'sa)-n $11,13$.

Mlllman. Sianley A-Tenu 10.0.

Monre, John Jay $\left(10^{\circ} 88\right)$ - $10.12 ; U$

SOLEDAD, 508, MONTEREY

Bryant, Frouk. " James (b'ab)-Cart. 09

(1'11): $\mathrm{S}$.

Cralg, Thomas I.., Sr. (b'40)-Ial, 80 . (1'95).

\section{SONOMA, 957, SONOMA}

Arthur, Chas. II. (b'tii)-l'a a'bro: (I'gR).

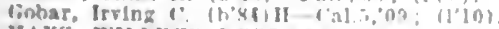

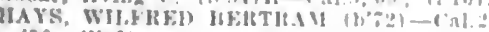
OB: (I'Ufi)

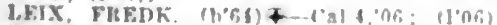

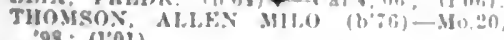
'98: (1'01).

SONORA, 2.029, TUOLUMNE

BHUMLEY, ROHT. INNIS (b'si) + -Cal. '82: $(1 \cdot 83)$.

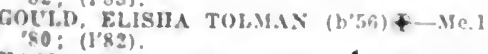

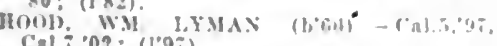
Cal. :02: (1'97).

Ca].,00: (1'11).
SOQUEL, 426, SANTA CRUZ

Beechler. James (b'39)-Pn 1::09: (1'45)

Cassel, Fillabeth I1.-111.9,83; (1'45).

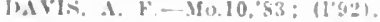

SOUTH BERKELEY (IND. STA., BERKE. LEY), - ALAMEDA

(wee Herkeley.)

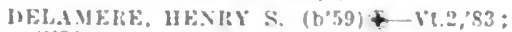
(l's:

Purnell, Wm. Whipper.

(see Oakland.)

liCKEY. ADUISOS W

(kee (lakland.)

Rowell. Ilenrletนa KIngdon (b'65)-Cal.1.'90

(1,:1): not in practlre.

Stockton, Clairo-Il-Cal.5.04: (J'04).

SOUTH PASADENA (BRANCH P.0., LOS ANGELES), 4.649, LOS ANGELES

(Son los Angeles nud l'asadena-)

ARMSTRONG, YETIMIA CLARK

(see Los inzeles.)

BENETT, CHAS. l.
(see LOS Intgeles,

MSHUP. THUS, W

(See Los ingeles.)

MITTMAN, ELGESE; J. (b'73) Ғ-MO. MO (I'II)

BHOWNIX, CHAS. CLITON.

(sice los Angeles.) COLLTER, HERRERT MCKAT (b'7)-
Minn.4,03: (1'04).

(WWLF, RORT. H. (1,';1)-0,6,01; () Nember Ky. Siate Med. Assn.; HAl Monterey Ild.; OpLR.

Heise, Ellen llartis (b'4s)-111.9,8:; not In practlce.

JOHNSTON, EHWMRD JAMES (b'\$1) + yinn.4,0s; (1'04).

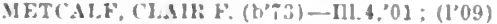

Meteale, Vetıa Ward-III.4,03; not in practlee.

Nichols, Theron $(b+41)-111.6,63 ;(1+86)$.

o'llonnell, Edward Jos. (b'35)-X.H.1,65 iot In practlce.

1'HIE, JOHX COLWFLI, (b'S3) £-H1.1, (0); : 1'l(1) ; Ob.

Palmer, Helen Cooley.

(See Los Angeles.)

Slocum. Saml. Mantor-N.Y.5,'79: (J'89).

SMITI, EVERETT $R$

(See Los Angeles.)

SITH, HAHVE.

(Seo Los Angeles.)

SIEIK, FREIR. AIOOILII.

(see Los Angeles.)

THOMHSON, THOS. 1. (b'55)-X.Y.S. 69 reqled; Nentier Inul. state Med. Sioc.

Walker. Chas. H. (b'bl)-X.Y.1,93; (1'93); not in practlee.

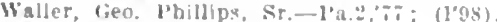

WILLE, WI LE MUTY

(sice loos angeles.)

SOUTH SAN FRANCISCO, 1.989, SAN MATEO

heith, Iran Whlqfel1--('al.5.11; (1'11).

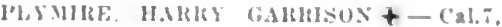
(10): 11 (10) : $\mathrm{S}$

SPADRA, 38, LOS ANGELES

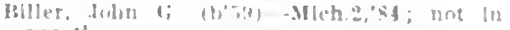

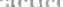

SPRECKELS, 150, MONTEREY

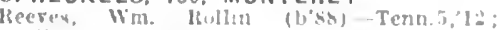
(1'l:)

ST. HELENA, 1,603, NAPA

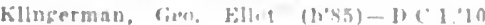
(1'11).

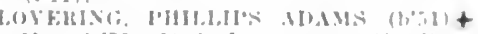

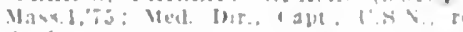
theds.

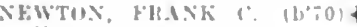
$(1,3,2)$.

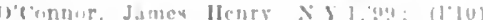

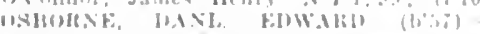
Mich $1,81:(1,92)$

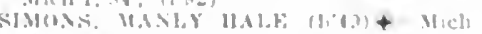

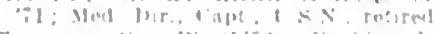

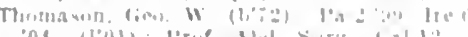

STANDISH, I00, LASSEN

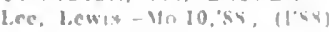

STANFORD UNIVERSITY, 700, SANTA CLARA

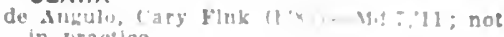
in practice.

practice.

GHAY, WM. WIXBOI"RS (b'5i), + X.1 10 5: Col., L.S.A., retirerl.

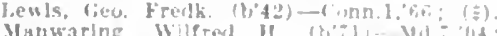

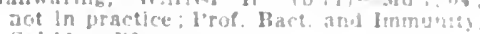

al. $11 ;\left(\mathrm{r}^{2}\right)$

Now, WM. FRFEMAN

tsee sacramento.

STEGE, 500, CONTRA COSTA

Breneman, Jos. T. (L's9)-la.3,:9: (1'92).

STIRLING CITY. 350 , BUTTE

inmell, Jos. IR. (b"a) - Cal.7,01; (1'01).

STOCKTON, 23.253, SAN JOAQUIN

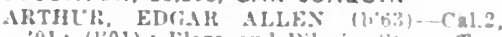
01: (1'01): Flora and lilgrim sts. : coflece. Stockton Sarings and Loan Mldg.: 11-12.

ACKL'S, WM. JAIES (b'si)-One3,0s: (106): $1520 \times$ Eldorado St. ; rafce, San Blackmun, kirnes? Llowood (b'i3)-Minnt 01: (J’05): 435 k. Hose st. ; onle, Rubli BJdg. : 10-12, $2-1,7-8$

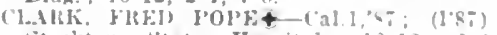
siockion siate Hospital; $10-12,2-1$ (F13)

LARKE, FISHER K.-Ky.1; 41: (1'91) : 32I W. Florat St.; oftce, Pliysicians Bidg.; - 1 - 4 , alter $i=1$.

CHAVHOTTO, JOHA VINCFIT - Cal.1.06 $\left(l^{\prime} 04\right)$; $1434 \mathrm{x}$. Monrue st. ; ostee, Gateway Blug.

MOSS, HARRY DELSPX (b'Gi) +-Cal.1, s9; (1'90); 300 W. Maznolla sir. once, Filks Bldg.; $1: 30-5$.

CIUSA, LESTEK F-Mo.5,73; $(1,76) ; 207$ II. Acacia si.; nflce, Filks Blik.

dal b'iaz, Antomlo Menot? $\left(b^{2}+5\right)-C a l .2,06$;

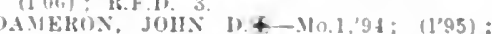

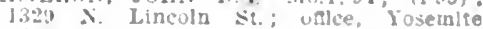
liluk.; $2-5 ; \mathbf{S}$.

Davison, Jnh Thorne (b'59) - coln, 1,ss: (1'13); $1036 \mathrm{~N}$. Sulter si. once, o $\mathrm{N}$.

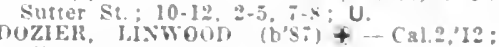
(1'12): liamerun Hosulal: LD.

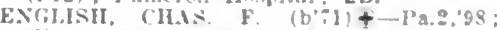
(1'se): 545 W. Flora st; uAlco, Elks Bldg.; 11-12, 2-1, i-8; S.

FITZVIERALD, WM. WHSAF (b'68) $t$

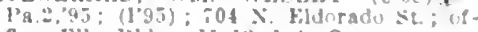

fice, Elks Bldig.; 11.1: 1-4: S

Foley, Koht. Fmmefl-III. s, so: (Is]): 150 W. Walnut St.; omce, $39 \mathrm{~S}$ sutter St: $9-12.1-4$

FHIFDBEKLER. WM. (b'86) \&-CMI.1,0s: (1"0S); San Joaquin county Homplas; of lice, Yomite Thealles klitg.: :-t; $\mathrm{S}$.

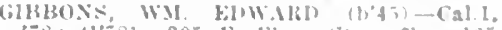
F: $(1 \% s) ; 205$ k. klur.1

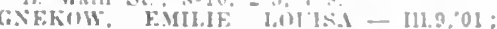

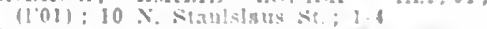

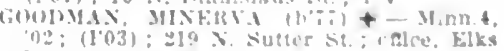
"02: $(103): 2190$

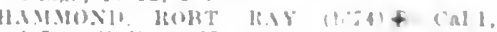

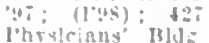

IIIItil:

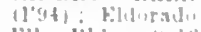

Bikn Mldi"

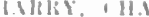
(linger

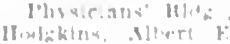

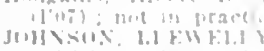

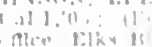

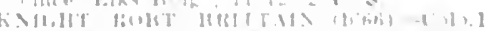
$1130.111 . \mathrm{K}+\ldots,(120) ; 30 \%$ Lil $110-$

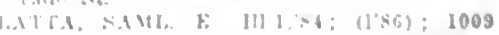

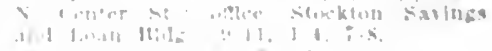

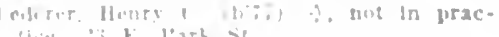


MCGURK, RAYMOND T. (b's3) †-Cal.1,09; $\left(l^{\prime} 09\right)$; 1045 N. Sutter $\$$ st. ; oflec, Physhcians' Bldg. : 11-12, 2-5

Meigs, John J.-MILs, 1,60; (l'82); 74I E Nieber Ave: 11-1\%

0'CONNOR, BYRON li, (h'38)-Pa.14,67 retired; Member' Kin. Ned. Soc. ; 1248 Opher st.

ollver, John Elward (b'63)-Pa.2,'s5 (1'96); $1107 \mathrm{~N}$. Commerce St.; offlce, 34 s. Suttcr st

OLIVIERT, LEONIDA-Ita.7,'84; (1'89); I34 Bridge St.; $10-12,2-5$.

PETERSEN, HENRY C. (b'76)(-IIL.11, 05 $(106)$; $825 \mathrm{~N}$. Commerce St.; office, Mail (3late: 11-12, 2-5, $6-8 ; P_{\mathbf{d}}$

NOWEIL, BARTON JEROME (b'73)థI'a.2,94; (I'95); 44 W. Acacla St. ; office 'hysicians' Bílg.; $9-12, \quad 2: 30-4: 30$

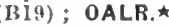

POWELL, DEWEY ROBT. (b'88)-Cal.2,'12 (l'12); 1617 N. llemter St.; offee, Physl-

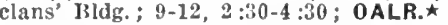

PRIESTLEY, SPURGEON FLOYD (b'68) -Mo.28,98; (l'85) ; 202 W. Poplar St. office, Elks Blde 2 2-5,7-8.

Prlestley, Wm. Fletcher (b'86)-Cal.1,'12 ; (1'12) ; $202 \mathrm{WW}$. Poplar St.; office, $423 \mathrm{E}$ Maln St. ; $10-12,2-5,7-8$.

RAY, DANL. YRANCIS $\oplus$ - Tenn.5,'88 (1'98); 446 E. Flora St.; offlce, Mail Bldg. SANDERSON, HENRY ELLIS (b'58) 4 Cal.1'85: (1'85) : Stockton State Mospital.

SIX CLARENCE 'LOGAN-0.3'01; (1'01) $1036 \mathrm{~N}$. Center St.; office, Wallace Bldg. ; $2-4: 30,7-8$.

SAYYTH, MIARGARET HAMILTON (b'75) -Cal.1,98; (1'98); Stockton State Hospital.

SMYTTIE, IIUDSON $\left(b^{\prime} 76\right) \oplus-$ Cal.2,01; (l'01); Stockton Hotel; office, Stockton Sarings and Loan Bank Bldg.; 10-12, 2-4, $7-8$.

Stockwell, Walter W. (b'60)-0re.2,'94 (l'94); 122 E. Main St. ; 9-11, 1-4, 7-8.

SWIFT, SIDNEY B.--Tex.1,'80; (1'87); 230 S. San Joaquin St.; office, 122 E. Maln St.

TAYLOR, MARY CAROLINE (b'66) Cal.1,05; (1'05) ; 230 W. Park; 2-4.

TUGGLE, SAML. P. (b'56) - Cal.2,'89; (1'89); Stockton State Hospital.

TULLY, JOHN J. (b'62)థ-Cal.1,'86; (l'86); 305 W. A cacia St.; office, Elks Bldg.; 11-12, 1-5, 7-8.

WALKER BENJ F, (b'7 $) \oplus-110.28,01$. $\left(l^{\prime} 01\right) ; 409$ W. Vine St.; offlce, Elks Bldg. $9-12$, I :30-5; OALR.*

WALKER, GEO. W. (b'75) $\oplus-$ Mo.28,97; (1'01); 409 W. Vine St.; office, Elks BIdg.; $9-12,1: 30-5 ;$ OALB. $\star$

Wheeler, C. M.-E-Ill.8,81; (1’98); 2120 S. San Joaquin St. : 9-11, 2-4, 7-8.

YOUNG, JUNIUS D.-Cal.2,81; (1'83); Stockton State Asylum.

YoUNG, WM. J.\$-Cal.1,97; (1'98); $144 \mathrm{~N}$. Eldorado St.; offce, Physíclans' Bldg.

ZEIMER, IRVING S. (b'80) -Cal.1,05 : (1'06); $1344 \mathrm{~N}$. II Iunter St.; office, $111 \mathrm{~S}$. San Joaquln St.; 10-12, 2-4, 7-8.

SUGAR PINE, 60, MADERA

CLEARY, ERNEST WINTON $\left(\right.$ b' $\left.^{\prime} 80\right) \oplus-$ Cal.2,'12 ; (1'12).

SUISUN CITY, 641, SOLANO

Bransford, Saml. Gant (b'69)-Mo.27,'01, Cal.4,97; (l'01).

Downing, Wm. Green-Mo.1,74; $\left(1^{3} 7 \pi\right)$.

Mason, Danl. Newton (h'43) E-Mo.10,'79; (1'85).

Starblrd, Geo. Arlo (b'7 7 ) H-Cal.5, 05 : (1'04).

SULTANA, - TULARE

GRAHAM, CHAS. MARTIN $\left(\mathrm{b}^{\prime} ; 4\right) \oplus-$ Cal.6, '08; (1'09).

SUNLAND, - LOS ANGELES

Hallack, H. Tuthlll (b'60)-N.Y.8,'83; ().

SUNNYVALE, 850, SANTA CLARA

Boetzkes, Peter Anthony Edward (b'48)N.Y.1,i2; not in practice.

Coleman, Earl Hampton (b'84)-Cal.5,'11;

HALI, GEO. PETER (b'88)-Cal.1,09; (I'09).
SUSANVILLE, 688, LASSEN

DOZIER, WM. ERWIN (b'64)-Va.1,'83; $\left(l^{\prime} 84\right)$.

Drucks, Edward S. (b'83)-Cal.7,'07 ; (1'09)

Garner, Robt. W. T. (b'82)-Ill.6, 07 ; (1'07).

Sbanks, Fredk. Hastlngs-Pa.2,'91; (1'91).

Walsh, Frank Denton (b' 64$)$-Cal.7, 98 ; ( $\left.\mathrm{I}^{\prime} 98\right)$.

SUTTER, 400, SUTTER

Addlngton, Davld Morgan-Cal.2,'79; (1'85).

SUTTER CREEK, 2,000, AMADOR

Goolman, P. S.-NIO.1,'90; (1'90).

ICLAUGHLIN, JAMES H. (b'62)-Ǩy.1,91; (1'91).

TAFT, 1,000, KERN

Galchouse, Frank $C_{\text {. }}\left(b^{3} 72\right)$-Cal.7, $02 ;\left(l^{\prime} 03\right)$. KEY, JOHN WALTER (b'80)థ-C'al.7, 01 (l'01).

Lawton, Chas. W. (b'80)-Cal.6,'05; (l'05).

l'ascoe, Marcus Wlllet (b'71)-ont.3,98: (l'11).

TALMAGE, 27, MENDOCINO

ALLEN, FREDK, EMERSON (b'65) $₫-$ Cal.7, 01 ; (1'01); (E13) ; NP.

REID, EVA CHARLOTTE - N.Y.20,07

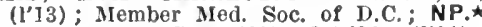
Richards, Robt. L. (b'69)-0.1,'94; (1'01) (E13) ; NP.`

Smlth, Donald Raymund (b'74)-Cal.1,'99;

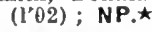

TEHACHAPI, 385 , KERN

BROWN, NEWELL J., JR. $\left(b^{\prime} 82\right) \oplus-$ Cal.9, 05; (1'06).

TEHAMA, 221, TEHAMA

Poket, Mary Elizabeth Beasley (b'70)Cal.7.03; (1'04).

TEMPLETON, 350, SAN LUIS OBISPO

HELGESEN, SEGRID-MInn.5,'94; (l'96).

MAGNUSSON, HERMAN V. (b'76)-Minn.4, 03; (1'11).

TERMINAL ISLAND (WILMINGTON P.0.), -, LOS ANGELES

Royer, Henry Clay.

(See Los Angeles.)

THALHEIM, - , STANISLAUS

Schueller, D. E.-Mo.10,'89; (l'94).

TIPTON, 366, TULARE

Iull, Frank Edgar (b'82)-Cal.6,'08; (l'08).

TOLUCA (LANKERSHIM P.0.), 50, LOS ANGELES

Blakeslee, Edwin-Mlass.2,'54; (1'92).

TORRANCE, - LOS ANGELES

Leake, Norman Augustus $\left(b^{\prime} 77\right)-$ Cal.2,'12 : (1'12).

TRACY, 362, SAN JOARUIN

LUCE, DOUGLAS (b'30)-0.3,'54; (1'78); not in practice.

Murrell, James Grant (b'43)E-Cal.4,'81; (l'81).

PINNIGER, SIDNEY ERNEST DAVIS (b'69) (t-Cal.1,96; (1'01); $\mathrm{u}$.

West, Jos. SImeon (b'44)E-0.2,74; (1'78).

TRINITY CENTER, 95, TRINITY

Rowell, W'm. Arthur (b'68) - Cal.1,9 1 ; (l'92).

TROPICO (TROPICO BRANCH P.O.), 100, LOS ANGELES

Bahrenburg, John E.

(See Los Angeles.)

DUNCAN, ARTHUR M. (b'50)-N.Y.10,78 ; (1'04); Prof. Dis. of the Eye and Ear, Cal.4.

Mabry, Wm. C. (b'71)-Mo.28,00; (l'11) MORSE, JASON (b'57) €-Mich.2; 85 ; not In practice; Member Mich. State Med. Soc. Tholen, Emil Francis (b'80)థ-Ill.1, 03 : (1'07)

TRUCKEE, 1,239, NEVADA

BERNARD, JOS. HENRY $\left(b^{\prime} 74\right) \oplus-$ Cal.1, $99 ;\left(I^{\prime} 00\right)$.

Bryant, Geo. Waldo (b'74)E-Cal.4,'97; (l'97).

TULARE, 2,758, TULARE

BECK, JOHN EDWIN (b'84)↔-Cal.7,'05; (l'06)

BLODGETT, THOS. DE HAVEN $\left(b^{\prime} 67\right) \oplus-$ Cal.1,94; (1'95); s.

CHILSON, WII. C.-Cal.2,02; (l'02).

FULLER, ROY NEWTON (b'85)థ-Cal.1, '08; (l'08)

ROSSON, ЈOHN B. (b'50)-0.1,72; (1'94).
TUOLUMNE, 1,200, TUOLUMNE

Frazler, J. E.-Ky.4,'85: (1'92).

REID, EUGENE HAMEIB $\$-K y .1,97$; (1'97).

TURLOCK, 1,573, STANISLAUS

Elllott, Lolward White (b'67) - Ia.1,97; (I'11).

JACOBSEN, PETER NATHANIEL $\left(b^{\prime} 80\right) \oplus$ -Cal.1,05: (l'05).

ULIEN, 'ERIC ALFIRED (b'84) $4-111.6,11$; (l'II).

REAIDAN, FRANK BIRCKHEAD (b'89)†Cal.1,11: (1'11).

WILSON, WI. IESTER (b'60)๑-Ind.8,87 ; (l'88)

UKIAH, 2,136, MENDOCINO

Cleland, llersche, O. (b'90)-Cal.1,12; Bowles, Geo. Richard (b'40) - Mo.2,66; $\left(l^{\prime} 88\right) ; P$.

I.tftchild. Judson (b'66) E-Cal.4,'93; (1'93). MALPAS, IDA M. LATHROP-Cal.1,97; $\left(1^{\prime} 98\right)$

McClelland, Hugh Kennedy-0.11,71; (1'77).

IREA, SAMI L. I. (4-Cal.1,'96; (l'96)

Stout, G. W.-F-Mo.10,83: (l'83).

Van Allen, Lew Knapp (b'80)-Cal.5,'09; (l'09)

UNO, 25, ELDORADO

Saunders, Zene W. (b'43)-la.1,'T5; (1'82). UPLAND, 2,384, SAN BERNARDINO

ABBOTT, FRANK FARNUM (b'83) Pa.2, 07 ; (1'07).

CRAIG. WM. H. (b'59)ゆ-Md.3,'86; (l'95). Dawson, James IIenry.

(See Narquette, Mlch.)

IKANKEL, OTTO WM.-MInn.4,, 00 ; (1'04). Keene, Walter Prince (b'70)-D.C.2,00; (l'08).

Marth, Geo. E. $\left(b^{\prime} 63\right)-0.9,{ }^{\prime} 95$; not in wERER, ARTHUR LEO.

(See Cucamougo.)

UPPERLAKE, 205, LAKE

Reynolds, Robt. Gallahor (b'41)-Mo.2,'71; (1'76).

Upton, Hugh (b'39)-Ind.10,'89; (1'01).

VACAVILLE, I,I77, SOLANO

Finan, Andrew Phillp (b'76)-Cal.1,02 ; Jenny, Warren C. (b'75)-111.10,01; (1'02). Mitchell, Franklin Plerce (b'53) E-Cal.4, '85; (1'85) ; R.F.D. 1

Palmer, Humphrey P.-N.Y.6,'91; $\left(1^{\prime} 00\right)$.

VALLEJO, 11,340 , SOLANO

BOND FREDK. TAYLOR (b'64)-Cal.2,'90 (l’90) ; 614 Obio St.; office, 416 Georgia St.: 1 -4.

BROWNLIE, JAMES WM. (b'84)-Cal.1,08; $\left(l^{\prime} \theta 9\right) ; 343$ Georgla St. ; $3-4,7-8$

Ch:lds, James Edw.--Mlch. 1,89 ; (1'01) ; 816 Alabama St.

DEMPSEY, ROBT. BOWNE (b'76) †-Cal.7, '03; (1'03); 944 Capltol St.; office, $2181 / 2$ Georgia St. ; 2-4, 7-8.

DORAN, ALEX. 'VINCENT $\oplus-\mathrm{Cal} .2,06$; $\left(1^{\prime} \theta 6\right) ; 520$ Sacramento St.

KLOTZ, BERNARD J. (b'79) $\oplus$ Cal.2,00 : $\left(1^{\prime} 00\right)$; 623 Georgla St. ; office, 341 Georgla St. ; $1-3,7-8$

Lain, Rachel B.-Ill.4,'90; (1'91).

LEACHMAN, REAII S. (b'77) $\oplus-C a l .1,12$; (1'12): 700 Sutter St.; offtce, 511 Marin

St. ; 11-12, 2-4, 7-8; LR.
PETERSON, EDWARD A. (b'81)-Cal.2,'07 ; (1'07); 321 Georgia St. ; $11-12,2-4,7-8$. REILLY, PAUL HERON ( $\left.b^{2} 64\right)$-Cal.1, 01 ; (1'01); 801 Marin St. : 2-4, 7-8.

Vallejo, Platon M. G.-N.Y.1, 64 ; $\left(1{ }^{\prime} 86\right)$

YOUNG, WM. S. S.-Pa.9,'88; (1'01); 623 Louisiana St.

VAN NUYS, 100, LOS ANGELES

PATTEN, ELMER E. $\left(b^{\prime} 70\right) \oplus-$ Cal.6, 06 ; $\left(1^{\prime} \theta 6\right)$.

VENICE, 700, LOS ANGELES

Conroy, Clare Pattee (b'67)-Que.1,'88; not in practice.

Kendall, Wm. Marcus $\left(\mathrm{b}^{\prime} 69\right) \mathrm{H}-0.13,92$; (1'01).

LE FEVRE, JOS. P. $\left(b^{\prime} 55\right) \oplus-$ Cal.2,'81; (l'83); U.

(See LOS IOYD J.

PALNIER, BYRON $\left(b^{\prime} 74\right) \oplus-0.3,00 ;\left(l^{\prime} 10\right)$. 
Sands, John B. $\left(b^{\prime} 53\right)$ E-0.2,93; $\left(l^{\prime} 01\right)$ Warren, llarold Sfanlford (b's3)-Cal.1, 03 (1'06)'.

VENTURA, 2,945, VENTURA

CUNXANE, TIIOS. EUWARD (b'66) Cal.1.93; (1'94).

IOMER, RALPII WM. (b'\$3)-Cal.2,11: (1'11); 0 b.

Huning. Fred. Henry (b'71)-X.Y.10,'96: (1'06).

JENSOX, CIIAS, ALFRED (b'i5)-MInn.4, 02: (1.12)

LEWIS, W1LL J. (b'82) \&-Cal.9,07; (1'08) :

ObG.
STOCKWELL, GEO, NOMMAX (b'6s) X.X.5, 1 ; (1.01); G.

VETERANS HOME, 20, NAPA

Crane, Homer Winfeld (b'\$1)-Cal.1,09:

Mellae, Donald M. (b'i3)-Cal.1,00; (1'00).

VICTORVILLE, 200, SAN BERNARDINO

Garcelon, Ilarris-Cal.6,04: (1'04).

Richards, Saml. Burgess (0'81)-Cal.9, 06 ; $\left(1^{\prime} 06\right)$.

VIDAL, 75, SAN BARNARDINO

IIerrjek, Stephen Solon (b'33)-La.1,'61 ; $(1.87)$.

VINA, 232, TEHAMA

Lappeus, Andrew J.-Mo.18,'Si; (1'92).

VISALIA, 4,550, TULARE

Farrow, EDWIN D.-I'a. I, T4; $\left(I^{\prime} \cdot 6\right)$.

Flich, Chas. Clereland (b'J4)-Mo.24, 90 ; (1'98).

Grore, Mlllard Flllmore (b'53) II-Cal.4,'s6, Cal.5, 86 ; (l'86).

MeSWAIs, THOS. OMAR (b'62)-Cal.7,99;

rege, Solomon C.-Mo.15,'s0, Kj.2,'s;; (1'95)

PATTLRSON, THOS. JEFFERSON (b'55)Cal.2:82; (1'84) : OALR.

PRESTON, ADDISON W. (b'S3) \&-Vt.2,"0i: (1'09).

Squlre, Wm. W.-II-III.4;76; $\left(\mathrm{l}^{\prime} 00\right) ;$ not In practlce.

WEAVER, BENJ. FRANKLIN $\left(b^{\prime} ; 0\right)+$ กI.1,93; (1'98).

WHITE, CARLOS 3. (b';2) \&-Ill.1,01; (1'01).

\section{VOLCANO, 433, AMADOR}

Smlth, Moses Edwln-H-Mass.5.75; (1'93).

WALNUT CREEK, 447, CONTRA COSTA

Cole, Carolyn C. (b'73)-Cal.1,01; (1'01).

Fraser, Wm. E.-MIch.1,61; not In practlce.

LEFCH, CLAUDE R. (b'6s) $¥-$ Cal.1,'94: (1'93).

WALNUT GROVE, 60, SACRAMENTO

Martln, Abel II.-Cal.1,89; (1'90).

WASCO, 120, KERN

Forg, Edward. Saml. (b67) - Mlch.1,97: JORUAX, ALFRED BERNARD (b'63) Mllch.5,'90, III.11,02; $\left(1^{\circ} 90\right)$.

WASHINGTON, 359, NEVADA

bu Mlleu, Emlle Arthur (b'52)-Fra.1,84, Cal.1.86; (1'86).

WATERFORD, 137, "STANISLAUS

Kaowlion, Jos. John (b'71) -Mo.2i,92 (1'92).

WATSONVILLE, 4,446, SANTA CRUZ

AVFRY, SAML. IIEMHTICUS (b'88)-III.1, BIXIY (l'12): AARON WM. (b'40)-Mo.10,ii;

(1'82). JAM, JAMS BIRD (b'B7) \&-Ore 2,03 ; (1'98); not in practlce; K.F.1) 1.

EASTERDAY, GFO. 8.-0.2,78; (1.00)

IIMMELSBACH, Wu, (b'62) - Cal.1,98 (l'Ds): (Carmel).
KOEIKE, FKEIJK. IERMAN (b'80) Cal. 1,03 ; $(1003) ; \mathrm{s}$.

PORThil, FinwiN 'F.-Cal.7,'04: (1'06). KOD(iES, SPEACER ClAY (b+8)-Ky. T2: $(1,90)$.

I'EIRKISS $\left(b^{\prime}, 0\right)-C a l .1$ WATTFIS, HFNRY GUSTAV (b'SA)-111.6 '11: (1'11)

WATTEISS, I'FTER KEMl' (b.5t)-1a.3,'ig: (1'93)

W.AWIND, CIYDE (b'83)-Pa.9,09, Pa.2, "10; (1'10)

WATTS, 1.922, LOS ANGELES

J.MIB, J['DSOX I. (b'48)-0.11,'50; (1'04)

RICHE, EDWIX JELES (b'81)-La.1,0j (1'10)

WEAVERVILLE, 1,100, TRINITY

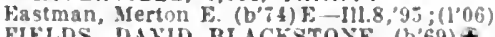
IF.LNS, DAYID BI.ACKSTONE (b'69) tLa.1,'93; (l'93).

Petch, Llewellyn Geo,-Cal.d,04: (1'0f).

WEED, 400 , SISKIYOU

TEBBL; FIIEDK. HENRT (b'70)‡-Ca1.2, '02: (1,02).

TEBIBE, WIY. E. (b'68)-Cal.1,99; (l'9i).

WESTPOINT, 266, CALAVERAS

Schacht, Bruno H. (b'52) E-Cal.4,'S6 ; (1'86).

WESTPORT, 393, MENDOCINO

SHERWOOD, OSCAR W. (b'62)-I11.11, 85 (1's9).

Smlth, Tracs H.-Cal.2;76; (l';6); not In practice.

WESTWOOD. - LASSEN

DAVIS, FTED J. (b'83) $₫$-Cal.1,07; (1'07)

WHEATLAND, 481, YUBA

ELISWORTH, AMOS D. (b'75)-I'a.9,00: (1'10).

I.owell, Frank S. (b'65)-Cal.1,"92; (1'92).

WHITTIER, 4,550, LOS ANGELES

Bogue, Herbert Edward (b'55) - Ill.1,'86 ; (1'95).

Bold, Francls James (b':0)-111.6,02; (1'0t)

Brabrook, Carollne Mlexander - 11l.9,93. (1'01)

Buchler, Emil Albert (b'i8) 11-I1l.10,04 III. 1, 05, Ill.11, 09; (l'09).

Coffin, Wm. V. (b'57) $-0.9,{ }^{\prime} 80$; (1'92).

blxon, Crrus k. (b'52)-ind.8, 81 ; (1'88).

ireene, Indley M. (b'53)-0.9,82; not in practlce.

Ilolton, Qulncy A. R. $-0.2 ; 71 ;(1 ' 86)$; l'rof Jlet., Cal.4.

HCNT, FERDINAXI) $x$. ( (65\%) $\$-M 0,1,84$ (192) : Member Minn. Stale Med. Assn

JOIINSON, LEVI DANL. (b'35) -111.8,81, Cia.5,9\%; (1'97); S

Marshburn, Wm. V. (b'35)-Ky.2,'S6; (1'96) Mller, Benj. F. (b';4)-IIl.1,97; (1'11).

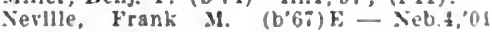
(I'11)

ROSENHERGER, HOMER G. (b's0) - - III, 07 ; $(1 \circ 08)$

Stokes, Wm. II. $\left(b^{\prime} 52\right)-0.14, ' s 2:(100)$

Stokes, Wm. II. (b'52)-0.1\&'s: $(1,00)+$ HLAS, HORA

WILSON, YAUL WHITE (b's5) -Minn.4,'12 (1'12).

WILLIAMS, 600, COLUSA

Klmball. Adolphus Wellington (b'58)-Ky.1. 82 , X.Y.5,"83; (1'83)

Salter, Ney Mllion (b'84)-Ill.6,'11; (1'11)

WILLITS, 1,133 , MENDOCINO

labcock, Haymond A. (b*89)-Cal.5,"l: (l'13).

Gunn, Francis Geo, (b'il) $\rightarrow$ Cal.1.00 : (1'00

Woelfiel, (6eo. A. (bos)-1a.1:9\%; (197).

WILLOW, I,139, GLENN

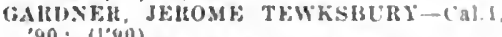

AWSON, FHANK MAY (b'78) +-Call, 09: $\left(l^{\circ} 00\right)$
LUND, CIIAS. W-Cal, : 03: (1*03).

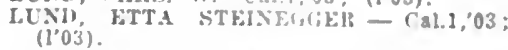

I'IIIKITT, THEODORA T. $(3,56)$ - CAl.1,'94: (1.45).

RANDUIPI, JOHA ANDKEW $\left(b^{\circ} 30\right) \mp$ (0.1,84: (1)88).

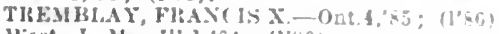
West, J. M.-Ill.1;6t; (1's0)

WILMINGTON, 200, LOS ANGELES

Slabaugh, Warren IIenry (b'st) -X.Y.10,"s3 (l'10).

WINDSOR, 483, SONOMA

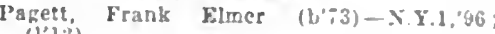
(l'l2).

WINTERS, 910, YOLO

Collings, Ifenry Andrews $\left(b^{\prime} 80\right)-C a l .7,11$ (I'11)

Halle, Jarnes H.-X.Y.10,23 ; (l'94)

l'eck, Ralyl Finory (b'il)-Call, 94; (1.98).

WODDBRIDGE, 203, SAN JOAQUIN AITILLR, SAML. H.-CaI.2,"49;
(Lodl).

(1'99):

chins, fred. (b'35) - C11 1,il: (1'83).

WOODLAKE, 40, TULARE

BLACKLEDGE, LINDLEY NINDE (b'60)Pa.8,'s0; (l'00).

PINKLEY, VHGIL MLO (b'84) T-Tean.5

08; (1'12); Pd.

WOOOLAND, 3,187, YOLO

IBEFBE, CHAS. E. (b'51) -0.e.1, 83 ,

BEEBE, LFI.A JUSE (b'81)-Cal.8, 0s;

BLEVIXS, WM. JOS.Mo.28,98: (1'98).

Clark, Chas. F-III.4, 81 ; (1'88).

FAIRCHILD, CIIESTER H. (b'il) -CaLl,

FAIRCHILD, FRED. R. (b'75) $\$-\mathrm{Cal} .1,02$; $\left(l^{\prime} 02\right)$.

Josce, Wr. Anthons-Md.6,00; (1'01): 6 . KIEI, IIFXIK MCBRIDE $\$$ - Mich., 69. Mo.2, 4 ; $(1 \% 6)$. LAWHLAD, HIRAM DAVIS (b'53) \&-Cal.I.

NEWTON, FRANCES LOCISE-Pa.:95; $\left(1^{\prime} 95\right) ; G$.

I3.ISUR, CLALE (b'83)—-111.6,08; (1.10) $\mathrm{S}$.

Royles, James T.Tenn.5:'86: (1'95).

W.IRD, MOSES WYLIE (b'56) t-Ca1.1,'93 (1.94); OALR.

WELGES, LOHENZ (b'3S) $\ \rightarrow ;(1,6)$.

WOODSIDE, 250. SAN MATEO

ICKEE, ALBERT BROWX.

(See San Franclsco.)

YERMO, -, SAN BERNARDINO

I'rosser, James D. (b'5\$)-Ind.22,'36:

YREKA, 1.134, SISKIYOU

Carlson, Chas. Hadleg (b'65)-Call, 94 $(198)$.

Collar, A. Judson-MIch.1,'si; $(120)$.

Goetsch, Allce J.-Ill.9,'9f; (1'01).

J0XK: JOS. $160 Y$ (b'SR)-Cal.1,12; (1'12)

McNulT, FllEk, J. (b'6)-Cal.1.96 (1'96).

Ort, Chas. S.-Cal.5, $00:\left(1^{\prime} 01\right)$.

ward, Irvin: Llnden (b'it)-Ore.2,9: (1'01).

YUBA CITY, 1,160. SUTTER

JAKR, JAMES IIOLMYS.

(seo Marysille.)

Kosby, Augustus Fo (b'te)-Cal $8,73:\left(l^{\prime} \mathrm{s}^{\circ}\right)$

McFayden, John $\left(b^{\circ} 50\right)-1$ a. 1, $76:\left(1^{\prime} ; 6\right)$.

I'EREL. THLSTE.X IULK (b'Si) + -No.1. '4: (1's8).

BICHARLSUX, NEWTUN FNO (b'7s)-

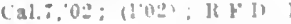




\section{COLORADO}

NoTE:-Tie general Information of thls state includes: Medical Law, Board of Health, Board of Medical Examiners, Medical Soclety, Stato Journil, County Otflecs, county and City Healih Offlcers, State Institutions, Hospitals, Sanatoriuns and Charitable Institutions.

\section{COLORADO}

Population (1910 eensus)

799,024

Number of Physicians.

782

Menbers State Sooiety. Dec. 3i. 19i3 813

Area of State in Square Miles......103,948

\section{MEDICAL PRACTICE LAW OF \\ COLORADO}

An Aet

To Protect the Public Ilealth and Regulate the Practice of Medicine in the State of Colorado.

Section 1. CREATION OF BOARD: A board is hereby established, to be known by the name and style of the State Board of composed of nine practicing physicians of integrily and ability, who shall be residents of and have been duly licensed to practice medlclne in this state, and who shall have been graduated from medical schools of high educational requirements and standing, and have been engaged in the active pracand hice the profossion within this state tice of thelr profession within this state for a period of at least five years. Said board shall perform such duties and possess and exerclse such powers relative to the protectlon of the public health and the concine In thls state as shall be in this Act prescribed and conferred upon it.

Sec. 2. APPOINTMENT OF MEMBERS : The governor sball appoint nine physicians, who shall possess the qualifications specified In Section $I$ of this Act, to constitute the members of said board. Said members shall be so classifled by the governor that the term of office of three shall expire in two, three in four and three in six years from the date of appointment. Biennially thereafter the governor shall appoint three thereafter the governor shall appoint three members, who section 1 of this Act tions as specifed in section 1 of this Act, each to serve for the term of six years, and he shall fill vacancies in the menber

Sec. 3. ORGANIZATION : Said board shall biennially elect a president, a vicepresident and a secretary-treasurer from president and a secretary-treasurer which their membersed to all licenses issued by them they shall, from time to time, adopt them. They shall, from time to time, adopt
such rules and regulations as they may deem necessary for the performance of their duties, and a schedule of minimum educational requirements, which shall be without prejudice, partiality and discrimination as to schools or systems of practice of medicine. When an applicant for a license offers to the board satisfactory proof that he has complied with such eduproof that he has complied with such edusaid schedule, the board shall accept such paid schedule, the board shall accept such proof as sufficient evidence of the educa-
tional qualiflcations of the applicant, to entitle him to a license without examination; provided however, that at no time shal said schedule for graduates after Jan. 1 1900 , specify the attendance on less than four full courses of instruction in four separate years in a reputable medical school. They shall keep on flle with the secretary of

Bo for public inspection a copy of their . for public inspection a copy of their Coleman, egulations.

(I'11). IPPLICATIONS: Any person

HALI, Gitain the right to practice med$(109)$ state, who has not heretofore so to do shatl, before it shall be lawful for lim to practice medicine in tilis state, make appication to said State Board of Medical Lxaminers, through the secretary-treasurer thereof, upon such form and in such manuer as shall be adopted and preseribed by the board, and ohtain from the board a license so to do. Unless such person shall have obtained a license as aforesald, it shall be unlawful for him to practice medicine in this state without flrst having obtained such a license he shall be deemed to have violated the provisions of this Act. All applicants for a license to practice medicine or for a renewal of any such license which has been revoked shall furnish the board with satisfactory evidence of good moral character.

Sec. 5. LICENSING AND PENALTIES : Said board shall have authority to administer naths, to summon witnesses and to take testimony in all matters relating to their duties. Said board shall issue licenses to nractice medicine to all persons who shall furnish satisfactory evidence of attain ments and qualifications under the provi sions of this Act and the rules and regulations of the board. Such licenses shall be signed by the president and attested by be signed by the president and attested by the secretary-treasurer of the board under
its adopted seal, and they shall be absolute authority to the persons to whom they are issued to practice medicine in this state. It shall be the duty of the secretarytreasurer, under the direction of the board, personally or by deputy, to aid the sereral clistrict attorneys of the state in the en. forcement of this act and in the prosecution of all persons charged with vlolating any of its provisions.

Sec. 6. FEES: There shall be paid to the secretary-treasurer of the State Board of Medical Examiners by each applicant for a license a fee of $\$ 25$, which shall accompany the application. Two-fifths of the fee shall be returned to the applicant in case the board shall refuse to grant him a license.

Sec. 7. EXAIINATIONS: Examinations of applicants for license to practice medicine shall be made by said state Board of Medical Examiners according to the methods deemed by it to be the most practicable and expeditious to test the applicant's qualifications. Such applicant will be designated by a number instead of his name, so that bis identity wlll not be disclosed to the nembers of the board until after the examination papers are graded. The subjects of written, oral or clinical examinations shall be as follows: Anatomy, physiology, chemistry, symptomatology, toxicology, pathology, surgery and obstetries (exclusire of materia medica and therapeuties). The credentials of applicants relating to their general reputation, their preliminary education and the courses of study they hare pursued, the degrees they have received, the number of years they hare been engaged in the lawful practice of medicine, their experience in general hospitals, medical departments of the Army, Navy and Public Health Service, licenses granted to them by other states and countries, and their experience as teachers of medicine, shall be given due consideration by the board in conducting its examinations. On in restigation of an applicant's credentials the board shall, when convinced that an applicant is qualifled to practice medicine, grant cant is qualifled to practice medicine, grant him a license thereon without further exsystem of practice and no person shall use the name of any system unless be holds a certificate from the state association of such system.
Sec. 8. RECOLUING; IICENSE : Every persoll who shall receive a license from the State Board of Medical Lxaminers shall of deeds of the county in which he resides, and sliall llkewlse have it recorded in the counties to which he shall subsequently remove for the purpose of practicing medicine. The failure on the part of the holder of a license to have it recorded before he shall beg: $n$ the nractice of medicine in this state shall render it null and void.

Sec. 9. REGISTRY OF LICENSES: The recorder of deeds of each county in this state shall keep for public inspection, in a book provided for that purpose, a complete list and description of the licenses recorded by him. When any such lifeense shall be presented to him for record he shall stamp presented to him for record he shall stamp menorandum of the date when such license was presented for record.

Sec. 10. REVOCATION OF LICENSE : The State Board of IIedical Examiners may refuse to grant or may revoke a license to practice medicine in this state, or may cause licentiate's name to be removed from the record in the office of any recorder of deeds in the state on any of the following grounds to-wit: The employment of fraud or deception in applying for a license or in passing the examination provided for in this Act; the practice of medicine under a false or assumed name, or the personation of another practitioner of a like or different name; the conviction of a crime involving moral tur pitude: habitual intemperance in the use of ardent spirits, narcotics or stimulants to such an extent as to incapacitate for per formance of professional duties; the procuring or aiding or abetting in procuring a criminal abortion; the obtalning of a fee on the representation that a manifestly incurable disease can be permanently cured; causing the publication and circulation of an advertisement of any medlcine or means whereby the monthly periods of women can be regulated or the menses, if suppressed, can be reestablished; causing the publication can be reestablished, causing the publication to any disease of the sexual organs, Any person who is a licentiate, or who is an applicant for a license to practice medicine, against whom any of the foregoing grounds for revoking or refusing to grant a license is presented to said board with a view of having the board revoke or refuse to grant license, shall be furnlshed with a copy before said board, in person or by attorney, before said board, in person or by attorney, board respecting the guilt or innocence of sald accused. Said board may at any time within two years from the refusal or revocation of a license or cancellation of registration under this section, by a majority vote, issue a new license or grant a license to the nerson affected, restoring or conferring all the rights and privileges of and pertaining to the practice of medicine as defined and regulated by this Act. Any person to whom such rights and privileges have been so restored shall pay to the secretary-treasurer a fee of \$I0 on the issuance of a new license.

Sec. 11. DEFINITION: The terms "practice of medicine," "to practice medicine," practicing medicine" and "practice medidefined to mean holding oneself out to the public as being engaged within this state in public as being engaged within this state in the diagnosis and treatment, of diseases or injuries of human beings, or the suggestion, recommendation or prescribing of any form lief or cure of any physical or mental ailment of any person, with the intention of 
recelving therefore, elther directly or Indi. rectly, any leo, sift or compelisution what. soever: or the malnienance of an offlice for the recentlon, examinatlon and treatment of ans person suffering from disease or injury of body or miad; or altachlng the title il.11. of body or miad: or attactina the tite abre. surgeon, doctor of any other word or athreriatlon to hls namo lndicsitre that such person ts engaged in the ireatment or diagnosis of the diseases or Infuries of liuman lielnes. publle as belng engaged within this whate in the diasnosls and treutment of diseases or injuries of human beingu, or shall surgect. recommend or prescribe any form of trea:ment for the palliation. relles or cure of any physleal or mental allment of any person with the Intertion of receiring therefor. elther directly or Indirectly, any see, glft or elther directis or Indirectly, shy fee, slfe or compensation thatserer, if shatl malntain an ofuce for the recemtion, examinatinn and treatment of diseased or Injurest himan belags, or shall attach the Utle of M.D.. surgeon, doctor or ans nther word or abbrerlation to his name Indicatlve that ab the engaged In thls state in the treatugnt chall not, In any of these cases, theretnforo have recelved, or shall not. In any of these cases then possess, in full force and virtue, a valld llcense to practice medicine under ine Inws of thls state, he shall be lcemed to be practeing mediclie wishout complying with practiclng medicline wishout complying with the provislons of this Act and in rlolation
hereof. Sothlng in this Act shall te construed to prohibit gratuitous servlre In case of emergency, nor the practicc of the reIIgious senets or general bellefs of any church whatsoever not prexcribing medicine or adminlsterlng drugs, nor shall it apply to commissloned surreons nf the [nlted fitatles Arms. Nary or Publlc Heald, Service, while so en iaged, nor to regularly licensed physiso engaged, nor to recularly licensed physicians called frum other states or territortes to attead specine cases In this state, not the practlce of dentistry, nor the practice of adminlstering drugs.

Sec 12. PENALTIES: Any person prac llcing medicine in this state without complylng with the provisions of thls Act, or alylng with the prorisions af thls Act, or vislons of thls Act, shall be decmed guilty of a misdemeanor. and on conrlction there. of shall be punished by a flne of not less than \$50 nor more than $\$ 300$, or by lmprisonment in the cousuty jall for not lesa baan ten days nor more than thirty days, or both. Any person presenting or attempting on fie, as his own, the diploma or certitlcata or credenilals of another or who shall pire elther false or forged eridence of any kind w the state Inord of Medleal kixaminers or whe state Itoard of Mledcal kixaminers or any member theren? In connection wlth an
appllcation for a lifense to fuctlce mediclne, or who shall practlce medicine unile a Palse or assumed name, of who shall Palsely persnuate auother praciltloner of a Ilke or different name. sliall be deemed rultis of a felony, and in convictsen thereof wall be punisheil by imprisunment in the seste penlentlary for a term of not lesa than one year nor onore than ten years as hard labor.

Sec. 13. DISHOSITHOS OF LICENSH. EEEs: All pees recelvel by the stati" Hosrd of sicdical Examiners and all num collected by any omcer of the law under this collected by any oflacer of the law under this Act shall be pald to the secretary-measurer and every monsh, depisit the sanie with ilap state treasurer, and the sald state treas. ure shall place antd money so recelred in il special tund. to be known as the pund if the Siate lioard of Medical Fixaminern. and sliall pay the samo out on warranta drawn by the auditor of the state therefir on rouchers lasued aud signel by the presulcus rouchers insued atud signed by the prostiflut moneys so receiverl and placel in sinil fumis moneys so recelverl ame placel in sinfl fumi may be used by the state Hoard if Ifedicial carrying nut the provisions of this Act. It tho ond of every blenuial perind, if there ahall remain in asld fund noy lalince, ard balance shall the iransferred to tho kurieral revenue fund of the state. The vecretary. treasurer of sald toard shall kefp a trun and all rouchers lasued by the poard. and on the flot day of lleecminer ue cach year he shall tlle with the gorernur of the gtate a repors of al] receipts and disbursements for sald boarl for the precenting fiscal year. Member op sald tonard shall recelre a per dlem for the tlme during which they whall be nctually engaged in the dlscharge of their duties, and the sertetary-treasurer shall rccelve a salary, sald per diem and salary

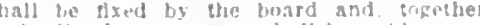
with all neher expenses, shall be paid wut of the pund of the siate Hoard of Merlical Fxamines.

Sec. 1t MFETINGS OF POARD: The Stice lyoard of Medical Fixamincry shall meet as a Poard of Medleal Framlners in meet as a Thoard of Medleal rxaminers in January, Aprll. Juls and lictoher of each year. and $n$ such other times and places aq may" the found necessary for performance rif their duties.

Isproved Inril 2n, 1905.

\section{STATE BOARD OF HEALTH}

Sherman Wlllams, I'resldent, Denrer Jacub Camphell, Vice-I'resident, Bnulder laull S. Hunter, Secretary and Freculire Oflicer, Denrer: Crum Epler, Pucblo; H. F. Merywenther, Denrer; Dr. I. G. Crosbr, Merywenther. Denver; Dr. L. (i. Crosbs, Inchelvey, Denver.

\section{STATE BOARD OF MEDICAL EXAMINERS}

C. S. Elder, Iresident. Ienrer; Luke Mac Lean, Vlce-President, Puento Bartz, WindSor: W. Wenver: Leonard F. Bartz, Wuray, Frank Rogers, Denver: C. B. Dyde, ireeley; A. C. Magruder, (nlorado sprlnss; Kelly and Iaines, Attorneys, Denrer; Darid A. Strickler, Secresary-Treasurer, penrer.

\section{COLORADO STATE MEDICAL SOCIETY} (iflcers I\$13-14

Oscar M. Gilbert, I'resident........ Boulder

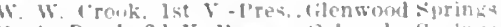
1i. A. Boyd, $2 d$ V.-P'res... lolorado springs A. If. Scont, 3 Vice-Prexident.......strong A. I. Scott, 3d hice-Prevident.......... Strnenter Ielrille Black, Secretary............ Wenrer

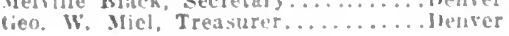

\section{State Journal}

Colnrado Medicine.

\section{Councilor Districts and Officers}

First Jistrict-- Boulder. I.arlmer, Mrand. Weld. Jongan, Sedgwick, I'hillpa. Morzan, Waslungton and Fuma couners. Jacol Chinman sterling and lien, Il Cattermole. koulder, councilurs.

Second District- - diiplu. "Thar dreek, Jef feran, llenver (city), Irapalus doms

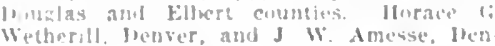
cer cumpolots.

Thirel Jostriot-Jark, Teller, Fremunt. Fil

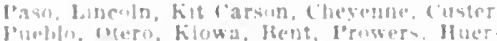

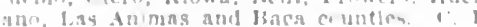

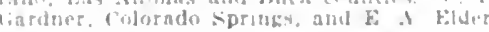
[Pethlo, ("i)uncllugs.

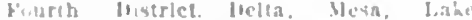
burny. Montrose, Chaffes. Cirsute, summ

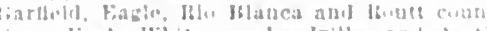

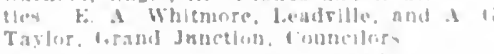

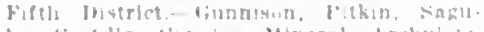

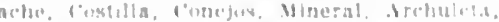

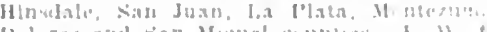

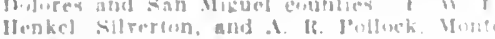
vista, fivinellirs.

Component Socteties of the Colorado siate Medical Sociel

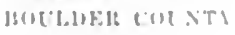

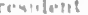

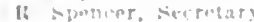

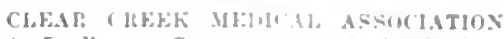
A. It Fraser, Seeresary .... ldabo sprlngs ('o.vi.Jus

1.

(Includal in san 1,1, i r Melical Society.

costill, ent :

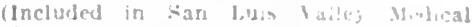
Soclety.)

I ROWLE PUITS

J. Workman. I'resident.....

J. E. Jefferey, fccretary............ IIEL.T.I COLNTY

W. II. I.nwls, I'resident...........Hitchklss

W. Scott iloland, secretary........ Jelia WFSVEL CITY ANI COLSTY

W. Il. Sharpley. l'restent.......... Denrer

W. .I. Wilh nsnil sceretary........ Jienrer F.ASTEIBS COLOHALO MEDICAL ASSI)(J.1T[1,N

Elwin a rlarke d'rewident..........krng fiarl 1). Mclill, Secreary.

F.l. F.ISO cul XT

O. Fiejue I'zesident ........ Wivelmen

Fimont ColNity

II: A. Hutwn, Jesidont........... FInrence (i.lkFIkI.1) (1) XT!

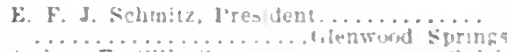

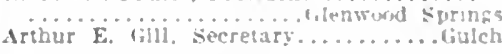
HLERFANI COLXTY A. R. Scott, President............. Strung
P. (j. Malhews, Sccretary..... Walsenturg LAKE COLNTY

k. J. Menonald, I'residert......... Leadrille

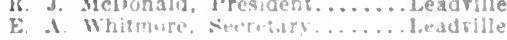
LAIIMEI: COLNTI

\&. C. Halley. I'resident........Ft collins

E. siver, secrebary........... cullins LAS ANMMA CULNT

E. J sonucll, Jresident......... Trunkad l.uliax cot:Ty

(Included in Nurtheast Colorado Medical sivery.) MEsA rot?TY

i. Deptham, l'rewdent . Airand Inneton

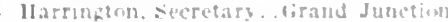
MIEHAL COTNTY

(Included in san luis Valley Medical sinciets.)

\section{MUTHOSE COLXT:}

Isalah Kuote loresident...........Montrose

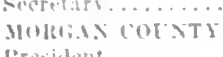

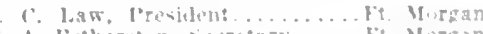
E. A. Fetherstun, vecretary......t Mor man

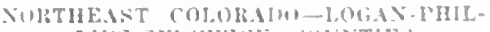

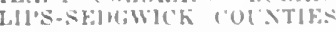

1. II Cork. I'resident........... Jutesburd

צ. Eugenta liarneb secretary........erting OTEIBO COEDTY

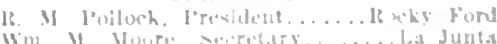
Othat IOITY

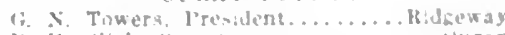
Ii. is slick, secresury...............huras

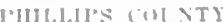

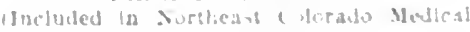

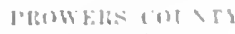

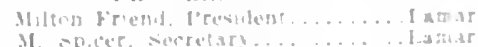

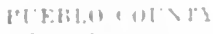

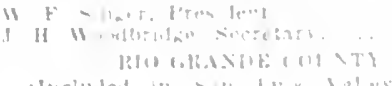

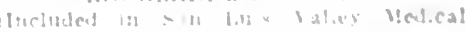
J11) IT $1114 \times$ II

Havien

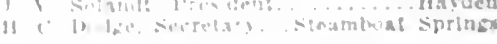
11.1 औ $11 \mathrm{k}$ ( 11$) \times \mathrm{T}\}$

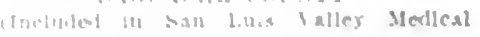

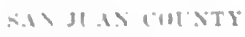

Find, frum ieme........... silverton 
SAN LUIS YALLEY-CONEJOS-COSTILLOMINERAL-RIO GRANDE-SAGUACHF COUNTIES

A. R. Pollock, President........Monte Vista I. L. Herriman, Secretary...........Alamosa SEDGWICK COUNTY

(Included in Northeast Colorado Medical Soclety.)

\section{TELLER COUNTY}

W. W. King, President....... Cripple Creek Thos. A. McIntyre, Secretary. . Cripple Creek TRI-COUNTY-KIT CARSON-CHEYENNELINCOIN COUNTIES

John 1. Beachly, President.........stratton C. W. Merrill, Secretary............ Burlington WASHINGTON COUNTY

(Inciuded in Eastern Colorado Medical Association.)

WELD COUNTY

Gieo. R. Pogue, President........... Greeley Charles B. Dyde, Secretary........... Greeley YUMA COUNTI

(Included in Eastern Colorado Medical Association.)

\section{COUNTY HEALTH OFFICERS}

County

Adams.-J. C. McCann........... Brighton Arapahoe.-John Simon ............ Fnglewood Archuleta.-Mary Winter Fisher.........

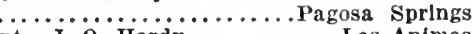
Bent.-J. 0. Hardy.............. Las Animas Boulder-Jacob Campbell..........Boulder Chaffee.-Finia Mcclure.............. Sailda Clear Creek.-

II. WV. Kírby. Georgetown

A. D. Fraser............ Idaho Springs Conejos.-D. Scott Schenck..........La Jara Costilla.-A. Aberg................ San Luls Delta._L. M. Burgess.............. Delta Denver.-Oscar Hayes............. Denver Dolores.-U. I. Albers...............Rico

Eagle -J. G. Gilpin............ Red Cliff Elbert. -J. S. Rogers................Klowa El Paso.-J. H. Brown.... Colorado Springs Fremont.-Hart Goodloe..........Canon City Garfleld.-W. W. Crook...Glenwood Springs Gilpin.-C. M. Frold...........Black Hawk Grand-_P. S. Rawls...Hot sulphur Springs Gunnison.-N. Mackintosh..........Gunnison Hinsdale. -H. L. Heath................... City Huerfano. - Ira B. Lahmer....... Walsenburg Jackson.-Mr. A. G. Malne.........Walden Jefferson.-J. P. Kelley.............Golden Kiorsa_-Geo. Sands...............Haswell Kit Carson.-C. A. Gillette.......Burlington Lake.-J. A. Jeannotte............ Leadville La Plata. - H. C. Turrell ............ Durango Larimer.-Curtis Atkinson................ Collins Las Anlmas.-E. J. Scannell........ Trinidad Lincoln. - W. J. Rothwell.............Hugo Logan.-J. C. Chipman........... Sterlin Mesa.-R. B. Harrlngton..... Grand Junction Mineral.-J. A. Biles................. Creed

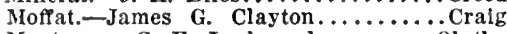
Montrose. - C. E. Lockwood........... Olathe Morgan.-A. F. Williams.........Ft. Morgan otero. -

Chas. H. Farthing.............. Ja Junta

L. P. Barbour.............. Rocky Ford Ouray.-W. W. Rowan............. Ouras Park.-V. B. Ayers.................... Falrplay Phillips.-F. M. Smith............. Holyoke

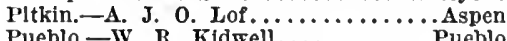
Rio Blanco.-Samuel French............ Rio Grande.-

J. McFadzean.

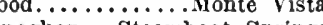

ghan.... Steamboat Springs Saguache.-0. P. Shlppey........ Saguache San Juan.-John S. Fox.............. Silverton San Miguel.-Edgar Hadley....... Tellurlde Sedgwick.-M. L. Babcock........Julesburg Surnmit.-J. F. Condon.........Breckenridge Teller.-J. H. Hereford. ....... Cripple Creek Washington.-James W. Kaylor.......Akron Weld.-W. W. Harmer.............................

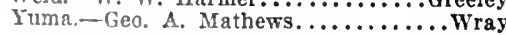

\section{HEALTH OFFICERS IN CITIES OF 3,000} POPULATION AND OVER

Alamosa................ Robt. Yan Sands

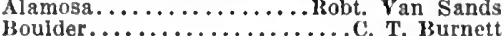

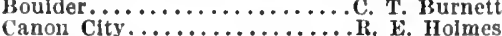
Colorado City................... L. Dantels Colorado springs............ omer $\dot{\mathrm{h}}$. Glliett Crlpple Creek............... A. McIntyre

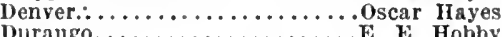
Durango................... E. Hobby Grand Junction............. Bert Gooding Greeley ................ H. Shleids

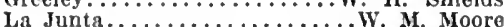
La Junta............... M. Moore

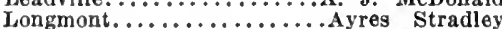

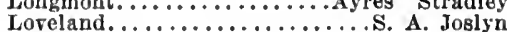

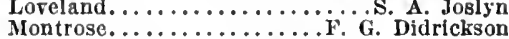
Montrose.................... Victor I. Prevost Rocky Ford.................. P. Barbour Sallda.................... Finla Mcclure Sterling. ............... H. Bush Victor............. Thomas

\section{STATE INSTITUTIONS}

\section{Buena Vista} Colorado State Reformatory, Buena Vlsta, Colo. Establlshed I892; A. J. o'Leary, physiclan.

Canon City

Colorado State Penitentlary Hospital, Canon City, Colo. Estabilshed 1876; general; 40 beds; T. D. Palmer, physlcian in charge.

\section{Colorado Springs}

Colorado School for Deaf and Blind, Colorado Springs, Colo. Established 1874; private; 11 beds; B. P. Anderson and E. M. Marbourg, physicians in charge; W. K. Argo, superintendent.

\section{Denver}

State Home for Dependent and Neglected Clildren, $2305 \mathrm{~S}$. Washington St. Denver. Established I902; public; 24 beds; W. E. Anderson, resident physician; C. A. Donnelly, superintendent.

\section{Golden}

State Industrial School for Boys, Golden, Colo. Established 1886; 12 beds In hospital : Robt. T. Venemann, pbysician in charge of hospital ; F. I. Paddleford, general superintendent of school.

Monte Vista

Soldiers' and Sailors' Home, Monte Vista, Colo. : 60 beds; J. H. Monlnger, physiclan in charge.

\section{Morrison}

State Industrial School for Girls, Morrison, Colo. Fstablished 1899; public general; 12 beds; M. Ethel V. Fraser, superintendent.

Puebio

Colorado Insane Asylum, Pueblo, Colo. Established 1879; publlc; insane; 1,190 beds; H. A. LaMoure, physlcian in charge.

Ridge

State Home and Training School for Viental Defectives, Ridge, Colo. Estabiished 1912; public; feeble-minded; 100 beds; A P. Busey, medlcal director.

\section{HOSPITALS, SANATORIUMS AND CHARi. TABLE INSTITUTIONS} Alamosa

Alamosa Hospital, Alamosa, Colo.; I5 beds; C. A. Davlin, physiclan in charge. beds; Robt. Van Sands, Chas. E. Morse and $\mathbf{C}$. $\mathbf{K}$. Smith, physicians in charge. Aspen

Citizens' Hospital Assoclation, Aspen Colo. Established 1890; public; medical and surgical; 14 beds; W. H. Twinlng, physiclan in charge; Mary MacDonald, matron.

\section{Boulder}

Boulder-Colorado Sanitarium, Boulder colo. Established 1896; general; I25 beds; H. A. Green, medical superintendent.

Boulder Tubercular Sanatorium, Boulder, Colo. Established 1909; private tuberculosis; 40 beds; I. I. Twaddell, superintendent.

University of Colorado Hospital, Boulder, Colo. Fistabllshed 1898; public: general; 30 beds; W. W. Reed, M.D., superintendent.

\section{Breckenridge}

Summit County liospital, Breckenridge, Colo. Public; 8 beds; J. F. Condon, physiclan in charge.

Brush

Hrush Hospital, Brush, Colo. EstabItshed 1911; private; for medical, surgical and obstetrical cases: 7 beds: Dymenberg, medical superintendent.

Eben-Ezer Mercy Institute, Brush, Colo.

Established 1904: private; tubercuiosis:

40 beds; Rev. J. Madsen, superintendent.

\section{Canon City}

Fremont County IIospital, Canon City, Colo. Established 1885; public; general ; 52 beds; , Hart Goodloe, physleian in charge; Dorothy $I$. Stevens, supt.

Goodloe Hospital, Canon City, Colo. Establlshed 1908; private; general; 20 beds; Hart Goodloc, physician in charge.

Dr. Graves' Prlvate Hospltal, Canon City, Colo. Established 1901; prlvate; general; 30 beds; C. Herman Graves, physician in charge.

Phoenix Lodge, Canon City, Colo. Established 1911; private; for tubercular cases; 5 beds; Mirs. Nettle G. Sheldon, supcrintendent

\section{Colorado Springs}

Beth-El Hospltal, 1400 E. Boulder St. Colorado Springs, Colo. Established 1904; public; general; 64 beds; John Z. Moore, medical superintendent.

Cragmor Sanatorlum, Colorado Springs, Colo. Established 1905; private; tuberculosls; 22 beds; Alexlus M. Forster, phys1cian-In-chief; M. L. Whitney, R.N., supt. Il Paso County Hospltal and Poor Colo. Established 1898; general ; 45 beds; J. H. Brown, physiclan in charge

Ei Paso County Isolation Hospltal, Bear Creek Rd., Colorado Springs, Colo. Established 1905; small-pox; 25 beds; 0 . R. Gillette, physieian in charge.

Glockner Sanatorium, Colorado Springs,

Glockner Sanatorium, Colorado Springs,
Colo. Established 1891; tuberculosis; 221 beds; conducted by the Sisters of Charity of Cincinnati, Ohio.

Idlewold Sanltarium, $3 I 1$ N. Logan Ave., Colorado Springs, Colo. Estab-
lished 1912; 10 beds; tuberculosis; Lois L. Shardlow, R.N., superintendent.

Myron Stratton Bome, Colorado Sprlngs, Colo. Established 1913; 60 beds; D. H. Rice, superintendent.

St. Francis Hospltal, Colorado Springs,

Colo. Fstablished I887 ; public ; general; 150 beds; Sisters in charge.

Star Ranch in the Pines Sanatorlum, Colorado Springs, Colo. Established 1903; private ; tuberculosls; 60 beds ; Edward Moore, medical superintendent.

See Special Announcement Adv, page 79 . Sunnyrest Sanatorium, Colorado Springs. Colo. Est. 1911 ; tuberculosis; 24 beds. Union Printers' Home and Tuberculosis Sanatorium, Colorado Springs, Colo. Establlshed 1898; private; generaI; special provisions for tuberculosis; I80 beds; J. B. Crouch, physician

Daley,

Crawford Pinons, Crawford, Colo. Established 1913; tuberculosis; R. W. E. Southworth, superintendent.

Cripple Creek

St. Nicholas Hospital, Cripple Creek, Colo. Established 1895; private; 20 beds; conducted by Sisters of Mercy.

Teller County Hospital, Cripple Creek Colo. Establlshed 1901; public; 29 beds

J. H. Hereford, county physician; Mrs. Sault, superintendent.

Del Norte

St. Joseph's Sanltarium, Del Norte,

Colo. Establlshed 1907 ; private; 30 beds; Sisters of St. Joseph in charge.

Denver

Adams Memorial Home, 2875 W. $33 d$ Are., Denver. 
dgnes Memorial Sanatorium, Montclals Sta., benrer. Established 1904 : privato: for tuberculasis only: I5l beds: G. W IIolder

Chlldren's Hospltal, 222I Downlng st. Deaver. Establlshed 1910; publle ane private: 35 beds; contactoins cases not accepted; Mrs. Oca Cushman. superintendent.

Colorado Chrlstan Home, $4325 \mathrm{~W}$ seth Are. Denter. Fstablisbed 1905 : Gederal; 38 beds; Mlss Ellizabeth Mlller, matron.

Colored Orphans and Old Folks' Ifonie Assoclation of Colorado, 873 Zunl St.

Denver. Mrs. Calle Camphell, matron.

Coltage IIome, 42: Falrfax St., Denver. Fstablished 1856; maternity ; for unfortunate girls: 12 beds; T. E. Taylor, chlef of medical staft.

Denver Clty and County Mospltal, W. 6th Are, and Cherokee St., Nenver. Establushed 18:9; general; 550 beds: Clarence W*. Hall, resldent physiclan

Denver Orpluans' Home, Colfax and $A 1$ blon Sts. Denver. Established 1890; publie; 160 beds: Mrs. Carrle S. Hubbell superintendent.

Denver Sheltering Home for Jewlsh Chlldren, 324: W. 19th Are., Denver. Esthbllshed 1908; private; 15 heds: Emanvel Fredman phrsiclan in charce: Yetta Baron, superintandent.

E. M. Byers Ilome for Boys, if W Alaueda Are., Denver. Fstabllshed 1992 reneral; 25 beds; Fred Iastleld, superinteudent.

Forence Crittenton Home, $4901 \mathrm{~W}$. Colfar Are. Denver. Fstabllshed 1\$96; pri rate for fallen girls: 53 beds: Ida Val eria Heers, nbyslclan in charce: Mrs. Helen Cotton, superfatendent.

Home League Orphanage, 5050 Yewton St., Denver. Mrs. Cora E. Ifind, superIntendent.

Dr. MeKay's Sanltarlum, 2839 Colfar Are. Denver. For narcollc druz addlc tlons, alcohollsm and nerrous diseases John H. McKay, physiclan In charge.

Mercy Hospltal, I6th Are. and Mllwau kee St. Denver. Esiablished 1902: pr! rate; 135 beds: silsters of Mercy In charge

Mt. Alry Sanatorlum, E. 12th Are. and Clermont St., Denver. Establlshed 1903 for nerrous and nental, alcohol and drug addletion cases; 20 beds; Geo. H. Neuhaus, phrsiclan in charge.

IIt. St. Vincent's Vome, Itowell Blrd. between W. IIst and W. 4th Ares., Denrer. For boys; Slsters of Charity in chirge.

3. W. Lare's, Mrs. Tent Sanatorlum. 4633 Vallelo St. Denver. Fistabllahed 1901 ; prlrate: for tuberculosls; 33 beds Mrs. W. W. Lane, superlntendent.

Sallonal Jewish IIospltal for Consump tires, Colfax and Jackson Sts., Denrer. Fatabltshed 1899; prlrate: iuberculosls: 135 beds: Moses Cullins, medical superin. tendent.

Oskes Home, 2325 W. 32d Ave., Den rer. Establlshed 1894; \{uberculosia; 10;0 beds: Hev..F. W. Oakes, suverjniendent

Park Arenue Ilospltal. l'ark Are. an Ilumbolds St Denrer, jistabllshed $1 \times 9$. publle; general; 95 beds: 11 . Lanborn superintendent.

Regla Coell Orphans' Home, 4325 Boulevard $\mathbf{F}$, Ienter.

St. Anthony' Hospltal, W. Jith Are and Qultman st., Henrer. Fistabllshed 1892 ; publlc; seneral; 250 beds.

st. Clara Orohanage, W. $29 t h$ Are., be tween Meacle and Osceola Nits. Jenver. Ststers of St. Francls lu charge.

St. Joseph's llospltal, Isth and Humboldt sts. benrer. Fistallished $1873 ;$ pr rate; goneral: 230 beds: silsters of ihar Ity in charge.

Sh Luko's Ilospltal, foth and l'carl Sts., Denver. Establlshed 1890: general: 140 beds: malntained by the fiplscopst Church: Wm. Clark, superintendeut.
Steelo Memorlal Hospltal, th Ave and Cherokee st. I Denver. Esiabllshed 182: for contaglous dlseases; publfc: $: \therefore$ veds ; Oscar Hayes, medical guperintendent.

Sunlicht Nanatorlum, 2727 W. $33 d$

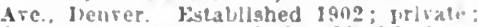
for tuberculosls: 4 beds: $M$. W. Yas (Golden), nlusician in charge.

Siwedlin Vistonal Sanatorlum for Tulkerculosis, 3451 s. Clartison St., Faglewood, Denver. Fotalillshed 1905; putille: 37 heds: "harles A. Bundsen, medleal director: livial Nywall, superlntemlent.

Durango

Mercy IIospltal. Durango. Colo. Estah. llshed 1854; Reneral; 54 beds; Sisters uf Mercy of Colorado in charge.

Ochsner Hospltal, Durango, Colo. Prl

rate; B. J. Ochsner, physlclan in charte

\section{Edgewater}

Sanatorlum of the Jewlsl Consumptires Relief Soclery, Edyewater, Colo. Estab IIshed 1901; tuberculosls; 140 beds; Ilermann Schwatt, physlclan in charge.

Englewood

Molkery Sanltarlum, 3700 S. Huron St. Englewood, Colo. Establlsbed 1901; prlvate; 18 beds; nerrous and mental diseases; Mrs. A. J. Thomas, superhtendent.

Falrplay

Park county House and llospltal. Falr play, Colo. Hstablished 1 Sso; public; io beds; $P$. X. O'Brien, superlntendent.

Florence

Sherldan Ilospltal, Santa Fe Are., Flor ence, Colo. I'rlvate: F. A. Sutorlus, medIcal superintendent.

\section{Ft. Collins}

Ft. Collins Hospltal Association, Ft Collins, Colo. Establlshed 1903; private general: 25 beds: Harriet A, Damson. R. sunerlntenden

Larlmer County Hospital, Ft. Collins, Colo. Fstabllshed 1895; publlc; 15 beds T. C. Taylor, medical superinténdent.

\section{Georgetown}

St. Juseph's Hospltal, Georgetown, Colo. Established 1850 ; public; 15 beds; $\boldsymbol{H}$. $\mathbf{W}$ Kirby, physlclan in charge.

\section{Glenwood Springs}

Gartleld County Hospital, Glenwood Springs, Colo. Establlshed 2597 ; public; Stewart, physlclan; J. H. Campbell, superintendent.

Gleuwood Śprings Sanltarlum, Glenwoon Sprlngs, Colo. Established 1905; general 56 beds; Sadie Allison, K.N., superintendent.

\section{Grand Junction}

St. Mary's Ilosyltal, Grand Junctlon Sisters of charlty 1895 ; general

\section{Greeley}

Greeley Ifospltal, 16th St. and 11t? Are., Greeley, Colo. ristablisbed 1904 publle; general; 35 teds; Mary 1. Scher merhorn, superintendent.

Wield County Hospltal, Creeley, Colo kistabllshed 1904; publlc; 26 beds; W. W llarmer, Justclan in charke.

\section{La Junta}

Atchlson, Topela \& Santa Fe llompital. La Junta, Culo Fistabllshed 18s0: prlrate: peneral: 45 beds: Frank Finney. surberin in charze.

'lity Ilospltal of La Junta, I,a Junta. crolu. rimtablished 1906 ; publlic; 30 beds Miss Ibella baris, matron.

Lat Junta Sanltarlum, 1.3 Junta, 1ulo. Entabllwhed 1905: 6i bedls: A. \$ Brunk, metical dlrector; J. M. Ilersliey, suberlo tenctent.

\section{Lamar}

Dr. Frlend's Sanaforluni, lamar, Colo.

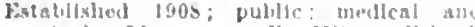
surbical; 0 roorus: $k$ Mlltura frlond phystclan la charge.

\section{Las AnImas}

Inlted States Naral Hompltal, Jay

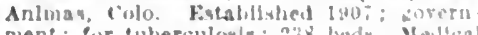
mene: for tuberculowis: $2: 2$ leorls Meolleal Inspeisur fico. II. lartiner, [" bily, in commanil
Leadville

New St. Luke's If. al tal Assoclatlon. lished 14a5: prirated lice. Colo. EstabDonald If i, superintenten, It. J. Mc. St. VIncent's Hosbial, Inon Hemlock pliceadnlle, folo bis : note, Maurlce Kahn, B. F Gridith and II. A. Calkins, medical staf.

\section{Littleton}

l.luteton IIosultal, Liticton, Colo. listabllshed 1912: vubilc; general; 15 bell Arthur McGugan, superintendent and owner.

Longmont

Lonfmont frospltal, Iongmont, Colo listablished 1907 ; pirate; general; 25

beds: $V$. I:. Pennock, physlclan In charge. Loveland

Sutherland's Hosnital, 545 Grant Are. Loreland. Colo. Established I598; gen. eral; to heds: W. IB. Sutherlasd, physl. cian in charge.

Manitou

Itontcalm sanatorium. Manltou, Colo.

led Crags Pritate llosultal, Manltou,

Colc. Fistablished 1909: 2. beds: Laurle

P. Sawin, superlntendent.

\section{Monte Vista}

Monte Vista Ilospltal, Monte Vista,

Colo. Fistabllshed $1913 ; 15$ beds: A. R

Pollock and Chas. Trueblood, nhjslclans

In charge.

Dr. Brethouwer's Private Hospltal, 534 S. Ist St., Montrose, Colo Established 1911; 10 beds; general; Mlss Berths Horman, superintendent.

ouray

St. Joseph's Fospltal, Ouray. Colo, Establlshed 18S4: prtrate; 24 beds; Sisters of Merey in charge.

\section{Pueblo}

Colored Orphansge and Old Folls" Ifome: Pueblo, Colo. Established 1906 publlc; 30 beds; Mrs. J. I. Watson, surerintendent.

Hydropathic sanlerlum, 301 s Vilc torla Are., I'ueblo. Colo. Established l\$os; prlvate; J. E. Marshall, medical

Marshall's Prirate Sanitarlum. Pueblo "olo. J. E. Marslaall, Jhyslclan in charge Fstablished 1905 : putlle: 65 beds; Mise Anna Burgess, superintendent.

Minnequa Hospltal, MInnequa and Iake Ares. I'ueblo, Colo. Fstablished isso. firlvate; seneral: malntalned by the Colorado Fuel and iron company: 210 beds: R. W: Corwin. chlet surfeon; Walter orrjtt. suberintendent.

I'ueblo county Honplial. Pueblo, Colo. Futalilished fopt: 2: lreds: W. R. Kidwell, physiclan in charge. Quarantine Hospltal, äll and Carthsge
sts., Pueblo. Colo. Fotshllshed 2303 ; small-mx; 16 heds; w. R Kidwell, counts plosician, in charze.

Rocky Mounialn Reseue and Protectle Leacue. 100 Hock I. Punblo. Colo. Ka ablished $190 \%$ : prlvate: rescue home; 1 : leds; Fugene Hrown, physlcian in charge sarred lleart crohatuane. I'uchlo, cinle

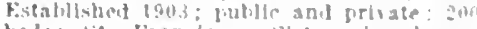

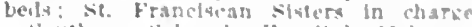
southern culoralo jhonltal lista and

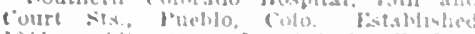
19!1: public" coneral: so leets: $b^{3}$ Jean IIolf, medfal superintendeme

sit. Mary lluipleal, Gulat and Pilkgu Ares I'ueblo, folo kistallshed liss:

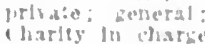

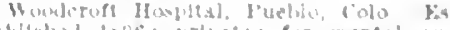
tathloled bas:; prlisto: for mental and

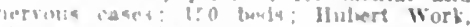
thys siclan in ibarke

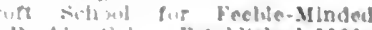

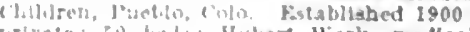
subertuenulene.

Rine

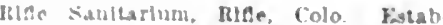
llshed lgo: grtrate: general: 10 beals: 


\section{Rocky Ford}

Pollock Ilospltal, Rocky Ford, Colo. Es tablished 1906; pulllc; surgleal; 12 beds; Robert M. Iollock, M.I., superintendént.

Rye

Idylwlld Sanatorhm, Rye, Colo. Estallished 1904; private; :0 beds; Atrs. W. (A Moody, superintendent.

Salida

Denver \& Rio Grande Iallroad IIospital 1st and $A$ sts., Salida, Colo. Establisher 1883; private; 50 beds; Llzabeth $\mathrm{A}$. Wells, superintendent.

Red Cross IIospital, $3 d$ and $G$ Sts. Salicia, Colo. Established 1901; private: general; 65 beds; Frank N. Coellems, physician in charge; Mrs. Thirza cole, smperintendent.
Silverton

Silverton Miners' Union IIospital, Sll verton, Colo. Establlshed 1909; publle general; 26 beds; A. Burnett, I. D., su perlntendent.

Telluride

Telluride Ilospital, Telluride, Colo. Established 189:3; privato; general; 32 beds ; Filyar IIadley, physician in charge.

Trinidad

St. Raphael IIospital, Trinidad, Colo. kstabllshed 1888; private; 100 beds; Sis. ters of Charity in charge.

Victor

Old Red Cross IIospital, Vlctor, Colo. Established 1902; prívate; general; "2"1 beds; C. L. Elliott, physlelan in charge. Wheatridge

Evangelical lutheran Sanltarium, Whentridge, Colo. Established 1905; tu- berculosls: 36 beds: Lorenz W. Frank, (Denver), medical director; John Schlerf' superintendent.

\section{Windsor}

Windsor Hospital, WIndsor, Colo. Establlshed 1909; general; 10 beds; T. B. Gormly and E. I. Raymond, physiclans in charge.

Woodmen Modern Woodmen of America Sana-
torium, Woodmen, Colo. Established 1908: private; tubereulosis, only members of private; tubereulosis, only members of
the order treated; I81 beds; J. A. Rutthe order treated; 181 beds; J. A. Ruttendent.

Yampa

Yampa Ilospital, Yampa, Colo. Establlshed 1907 ; 12 beds; L. A. Hubbard, physician in charge.

\section{PHYSICIANS OF COLORADO}

EXPLANATOkX NOTE.-The present medical practice act became effective Aprll 20, I905. License dates for preceding years indicate licenses issued under previous laws.

\section{KEY TO ABBREVIATIONS, SYMBOLS, ETC.}

Names in capitals signify nembership in the County Soclety and state Association. (DOE, JOIIN).

$\rightarrow$ Indicates Fellowslip in the American lled. Assn. (DOH, JOHNE)

(b'75) Year of birth.

[medic.

H, homeopath; E, eclectic; $\mathbf{P} \cdot \mathbf{M}$, physioH, lomeopath; E, eclectic; $\mathbf{P}-\mathbf{M}$, physi

$\checkmark$ Information received does not show graduation.

\section{S.-Surgeon.}

ObG.-Obstetrician, Gynecologist.

G.-Gynecologist.

Or.-Orthopedist.

Pr.-Proctologist.

Op.-Ophthalmologlst.

A.-Aurist.

LR.-Lidryngologist, Rhinologist. (l'89) Year of license.

(t) In practice before passage of present law and licensed by filing diploma or by years of practice.

(1) Licensed but year not known.

(ま) Information receired does not show license.

U.S.A., United States Army.

M.K.C., U.S.A., Medical Reserve Corps.

\section{SPECIALTIES ARE INDICATED AS FOLLOWS:}

ALR.-Aurist, Laryngologist, Rbinologist.

OALR.-Ophthalmologist, Aurist, Laryngologist, Rlinologist.

U.-Urologist.

D.-Dermatologist.

Pd.-Pediatrist.

N.-Neurologist.

P.- Psychiatrist.
U.S.N., United States Navy.

M.R.C., U.S.N., Medical Reserre Corps.

U.S.P.H.S., United States Public Health Serrice.

College positions held are indicated by abbreviated tltle of position, followed by key number of college. For key to colleges see inside front cover page.

$(\mathrm{AI}, 3, \mathrm{~B} 6$, C4) Menbership in special Societies. (See Key Table, page 122.)

NP.-Neurologist, Psychiatríst.

1.-Internist.

T.-Tuberculotherapist.

Anes.-Anesthetist.

LD.-Laboratory Diagnostician. [gist.

R.-Actinologist, Radiologist, Roeutgenolo-

Path.-Pathologist.

Bact.-Bacteriologist.

WHEN THE ABBREVIATION REPRESENTING A SPECIALTY IS FOLLOWED BY AN ASTERISK ( ) IT INDICATES THAT THE PHYSICIAN CLAIMS HIS PRACTICE IS LIMITED TO THAT PARTICULAR BRANCH OF M!EDICINE; WITHOUT THE ASTERISK, THAT HE IS ESPECIALLY INTERESTED IN, BUT DOES NOT LIMIT HIS PRACTICE TO, THAT BRANCH. THIS INFORMATION CONCERNING SPECIALTY IS BASED ON PERSONAL DATA FURNISHED BY THE PHYSICIAN AND IS NOT VERIFIABLE.

\section{COLORADO}

AGUILAR, 858, LAS ANIMAS

Bates, Carl Y.' (b'85) - Mo.20,'08; (l'10).

Davis, Jos Wm. (b'76)-Kan.2, 06 ; (l'10).

Gregg, Allen C. (b'73)-Mo.20,96; (l'08).

IIarbison, A. B. (b'58)-Pa.2,'78; (l'88).

HARVEY, ASA (b'53)๑-0.2,75, Mo.10,78,

Colo.2,'94; (I'93).

AKRON, 647, WASHINGTON

Clarke, Edith Leavitt-Mass.5,'85; (l'08).

CLARKE, EDWIN AUGUSTUS (b'63) \&-

Mass.5,'85; (1'07); OALR.

Hoyt, Arthur L. (b'67)-la.3,'96; not in

practice.
KAYLLOR, JAMES W. (b'7)-Ga.I0,97; (l'03).

SMITH, ROMANUS M. (b'54) (-Ky.2,'85; (l'08).

ALAMOSA, 3,013, CONEJOS

DAVLIN, CHAS. ALFRED (b'78) \&-Pa.11, 05; (1'06); S.

HERRIMAN, LEWIS L. (b'78) - Ill.4, 03 ; (l'11) ; OALR.*

MORSE, CHAS. EMORY (b'80)†-Colo.5, '09; (1'10); $S$.

Orr. Chas. L. (b'70)-Mo.2,'95; (l'96).

Rupert, James K. (b'71)-N.Y.6,'96; (l'98)

SHITH, CLINTON K. (b'83)-Colo.2,07; $\left(I^{\prime} 0 T\right) ; U$.

Van Sands, Robt. (b'72)-Ill.1,97; (l'99) ; Op.

ANTONITO, 68I, CONEJOS

BACA, JOSE F. (b'T0)థ-I11.10,'90; (1'91).

('allireath, Jos. H. (b'63)-N.Y.s,'89; (1'02).
SHELTON, EBERLE KOST, JR. (b'88)Colo.2,'II; (1'13); S.

ARAPAHOE, 25, CHEYENNE

DICKSON, LOGAN MI. (b' 79$) \oplus-I a .10,{ }^{\prime} 03$; (l’07).

HOMER, HEPMIAN CORWIN $\left(b^{\prime} 69\right) \oplus-$ IIl.11,98; (l'07); OALR.

AFRIBA, 200, LINCOLN

COLE, FREDK. EARL (b'84)-Colo.5,'08; (I'0S).

ARVADA, 840, JEFFERSON

Cochran, Clarence F. (b'50)-Mich.1,73;

Foster, Edwin L. (b'65)-Ky.5,'90; (1'99); Pd.

Greene, Edw. P. (b’59)H-Ia.4,'88; (l'93).

ASPEN, 1,834, PITKIN

JUDKINS, CHAS. W. (b'56) $4-P a .9, ' 81$; (l'88).

Lof, Anders J. O.-Colo.1,'96; (l'96).

Rucker, Pemberton T.-Colo.1,94; (l'94).

Twining, Warren H. (b'75)-Colo.3,00; (l’01).

AULT, 569, WELD

ANDERSON, ANDREAS $\left(\mathrm{b}^{\prime} 65\right) \Phi-C o l o .3$, '00; (l'00).

Craig, James W. (b'80)-Colo.4,'06; (l'06).

IIcCain, Addison C. (b'76)-Colo.2.'04; (l'04); Ob.

AURORA, 679, ADAMS

WEST, THOS. JOHN (b' 76$) \oplus-$ Colo.2,'04; (l’04); Member H.T. Med. Soc.
AUSTIN, 140, DELTA

CLAYBAUGH, JOS. P. (b'53) - IIl.I;'83; (l'88).

Loops, WaIter Albert (b'־8)-Wis.3,00 ; (\$) ; Pd.

Mfconnell, James E. (b'69)-Ill.1,'96 ; (1'09).

AVONDALE, 250, PUEBLO

WHITE, HENRY THEOPHILUS $\left(\mathrm{b}^{\prime} 71\right) \oplus$

La.I,'06; (l'08).

BASALT, 235, EAGLE

Kennedy, Erlo Elsten (b'80) - Mdd.4,'05; (I'08).

BAYFIELD, 227, LA PLATA

Downing, Robt. Lester (b'85)-Colo.5,'10; (l'II); $\mathrm{s}$.

Newland, Ellis W. (b'69)-0.3,'98; (l'00).

BENNETT, - ADAMS

Emery, Homer G. (b'54)-Mich.1,'87; (1'05).

BERTHOUD, 758, LARIMER

Cole, Wm. Wallace (b'50)-Ill.1,'79; (1'81).

Ilowell, James Dorn (b'65) - Ky.4,89;

(l'10).

MeCarty, David Wilson-Pa.2,'92; (1'93).

Smith, Frank Burton (b'82)-Colo.2,'11; (l'11); S.

BEULAH, 300, PUEBLO

Crawford, Harry B. (b'64)-Ia.6,'96; (\$).

BLACKHAWK, 668, GILPIN

Frold, Clarence Mauritz (b'81)-Colo.5,'05; (l'06).

BLANCA, 350, COSTILLA

Covell, Walter W.-Mo.28,'06; (1'13).

Soland, Louis Wesley (b'85)-Colo.5,'10; (1'10). 
BONANZA, 96, SAGUACHE

CANTWELL, BEXJ. T. (b', (1'00)

Kortrleht. Scott f: (b'69)-Ill.4.91; (1'00). BOULDER, 9,539, BOULDER

AlLEN, IIENLY W. (b'38)-Ja. 2,6̃; (1'81). Ambrook, Mary L. (b'50)-Ilich.I,'91; (1'91).

IBAIIt), WM. J. (b'61) \&-Ma.1,'8I: (1'9i). BEXNETT, ELIJAII C. (b'53)-Ky.2, '82; (1'08).

BIXGILM, WM. JOIS†-Col0.2,04; (1'04). Brown, Curtls (b'53)-Mo.l, it: (I'11).

Burdlck, Frank 0. (b'4s) H-[1].4.92: (l'03). BUIENETT, CLOLGH TUKHHL (b'83) + Mleh.I, 0s; (l'08): I'rof. Bact., Colo.2; I.

Buraham, Wm. A. $\left(\mathrm{b}^{4} 48\right)-111.1,7 \% ;$ not in practlce.

CAMIBELL, JACOB+-Colo.2,'8z; (I'88); Asst. I'rof. Surg., Colo.2.

CATTEISTOE GWO II. (b'68)+-Mlch. '91: (l'99); Prof. Mred. and Ped., Colo.2;

DODGE, IIORACE O. (b'40)-111,6,68; (I'81): not in practlce.

DURRIE, ANNA BELLE (b'75) †-111.19, 09: (1'13); Member Mlch. State Mell. Soc.

Farrand, Llvingston (b'6i)-X'.Y.1, 91

FARISINGTON, FITZ H. (b'62) —-M.3, 93 ; (1'93).

FISCHER, VALENTINE BENJ. (b'85)Colo.2,"09: (1'09).
CALE BENJ.

GIYFIN, CLAY EMERY (b'82)-Colo.2,08; (l'0s).

GIFFIN, LUMAN MOOLY $(2,50) \&-n 1.1$, i5 (1'81) : Proe. Surg., Colo. 2.

GIRBERT, OSCAR MONItOE (b"i) Mo.28,'98; (l’99); I'res. Colo. State Med. Soc.: Prof. Clin. Med., Colo.2; 1 .

GILLASPIE, CARBON (b'79) + Colo.2,05;

(1'05): Proe. Anat. Colo.2.
Golloos, DAvin (b'64) - Minn.5,9\%: (1'12); Menber MInn. State Med. Assn.

GRFFN, HIRAM A. (b' 70$)-M 0.29,98$; (1'02).

IIARI.OW, WM. P. (b'67) \&-31/ch.1,99: (l'04); Dean, Colo.2.

JOLLFY, WM. ALBERT (b'\%2)-1'1.2,96; (I'02).

Jones, John A. (b'T5)-Colu.2,"9:; (1'9i): U.

Klng, Femlng H. (b'61)-1a.6, '91, Mo.7,'93; (1'06).

Lake, Allce Mary-Colo.2.'96; (l'96)

LA ITUF, CLAUDE LOIRAINE (b'81) Mo.34,10: (l'12); Memler Okla state Med. Assm. : 941 l'ear! st.

LINDSAY, КАTE (b'42) $\oplus-$ Mlch.1, 66 ; (I'02)

ItcClory, Thos. A. (b'48)-Ind.8,'84: (l'93).

Mumna, Elmor L. (b'69)-Mo.28, 03 ; (l'03).

Nordlander, Anders G. E. $\left(b^{\prime}(6)-k y^{\prime} .2,02\right.$; (l'02).

Patterson, John Smallwood $\left(b^{\prime}, 9\right)-$ Colo.2, '02: (li02): not in jractlee.

PEEHLES, ALVIX HOY (b'8q) \$-MICh.I, 00: (1'08): I'rof. of I'rev, and ExIter. Med., Colo.2.

Poley, Cyrus W. (b'86)-('olo.2,11; (1'12)

Ihysglelans Hlde.

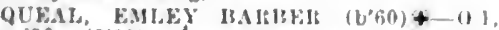
"90: (I'90): Prot. I'lisslut., ('olo.y.

REED, WAITFK W. (1)'66) +-(olo.2,9:3 (1'93) ; Isst. I'rof. Obst., Colo.2; ObG.

RORFITSON, EUGE.NE II. (U'6i)-Mlrh.l, $95:(1208)$.

SI'FNCER, FIRAXK IS. (b'\% :0ะ; (1,05): (11,3,3); OALR. *

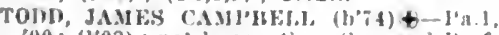
00 ; $(103)$; not in practlce; sce. and l'rop. l'ath., Colo.2; Path.*

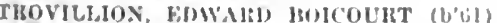
+- $111.1,{ }^{\prime 280 ;}\left(1^{\prime} 00\right)$.

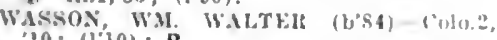
10: (1'10): $R$.

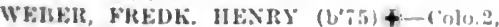
'12: (1'12).

WHHER, MAIRY A, STIOUA JAKKON $($ (b'84)-Colo.'2,11): (1'10)

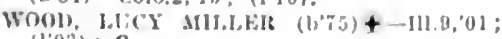
(1'03); 6
BOWEN, 15, LAS ANIMAS

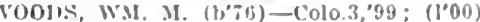
BRANDON, 80, KIOWA

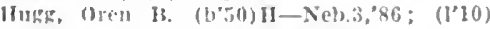
BRECKENRIDGE, 834, SUMMIT

(ondon, (Jas. K: (1,8:3)-Mich.1,12: (1'12)

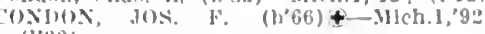
(l')?

GRAHAM, HUUPT VIXCE $\left(\mathrm{U}^{\prime} 0\right) \mp-K y .1$, 02: (l, $0: 3)$

Smltu, Win. (7. (1)'79)-Ky.4, $02 ;\left(1^{\prime} 02\right)$.

BRIGGSDALE, - WELD

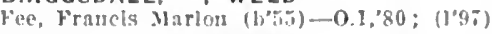

BRIGHTON, 850, ADAMS

Hexanuler, James F. (b'62)-Mo.I,'88; (1000).

Kinyon. Ellas L. - O.2,94: (1'03)

Iefann. John Charles (b'80)-Colo.5,'0s; (1'09).

IOORE, AlFRED H.

(See Denver.)

BRISTOL, 200, PROWERS

Jonaldson, Chas. Clarence (b'58)-0.6,'s7; (l'04): G.

OALR.

BROOMFIELD, 50, BOULDER

bimore, Ra!pl IVe Witt (b'76)-Kan.3,99; (1'10).

BRUSH, 997, MORGAN

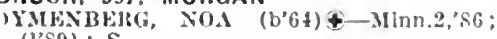
(l'89); $\mathrm{S}$.

Francls, Kichard M. (b'65)-Mo.1."39: (1'97)

Lusby, Allert C. (b'75)-Ky.5,'9s; (l'06) TURNER, WM. E. (L'62)-1a.6,?3; (1'98) BUENA VISTA, 1,041 , CHAFFEE

Ayers, Vletor B. (b'71)-IIlch. 1,92: (1'06). Macheman, Angus A. (b'-2)-Que.1,97; (l'98).

O'lears, Aust!n J. (b'82)-111.1,05; (1'09).

Weddle, John X. (b'j\&)-l'a.12,'st; (1'09)

BURLINGTON, 368, KIT CARSON

BEIGGLE, IRANK LESLIF (b'7i)-Colo.5, '0s; (l’08).

(illette, C. A. (b'is) $\rightarrow$; (1'89)

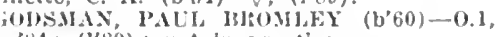
$84 ;$ (1'89); not in practlee.

IFIULII, CIIESTER WIJIAIMS (b'bs)III.1,90; (1'04).

BYERS, 125, ARAPAHOE

('utts, Kilmer H. (b'66) II-III.4,"99; (1005)

CALHAN, 125, EL PASO

'handler, Gllberr II. (b'S1) - Mo.25,05; (l'06).

Gardlner, llary Luulse (b'5i)-Colo.2,'95; (1'95).

iltovis, HALE O. (b'81)-110.29,03; (1'05).

CAMEO, - MESA

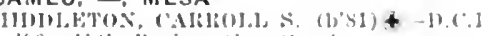
.06; I'S. Iteclamallon sirvice.

CANON CITY, 5,162, FREMONT

I(1)(1)TI, WM. (b'\$2)-M(l.1,65; (1'89).

Brablury, Janes 11 (b)"39)-110.2,69; (I'xI): not in practlec.

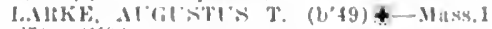
(1): $\left.11^{\prime \prime}(0) 2\right)$.

(6) (1'10): S.

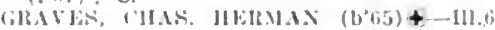

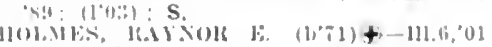
(1.11); $\mathrm{S}$.

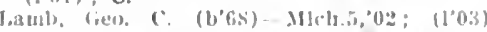

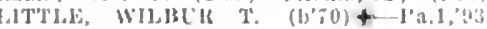
Iletil; T.

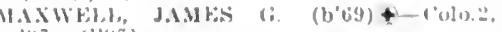

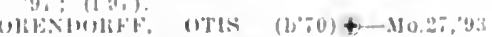
(1.04); (J3:); OALR,*

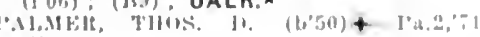
(l'x)].

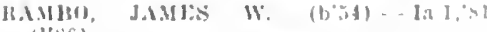
$\left(l^{\prime} \times f_{j}\right)$.

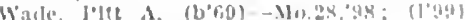
WIILIXE(I), (IIAS, II. (b'bi)

(I'y): OALK.

CARBONDALE, 28\%, GARFIELD

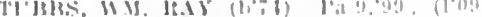

CARR, I00, WELD

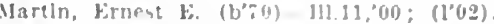
CASTLE ROCK, 365. DOUGLAS

llexander, lieo. E. (L's) - S.r.f.'s) $\left(l^{\prime}, 00\right)$

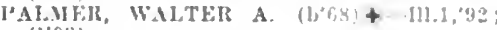
(l'03).

CEDAREDGE，295, DELTA

lust, Thos, Herbert (b'Tb)-la.8, $03:$ ( l' 11 ) HITOS, IOLIS CLINTOS (b'T) + Ky. $04:\left(1^{\prime} 06\right)$.

Hadsell, Chas. A. (b'54)-Mo.1,85; (1"07)

CENTER, 385, SAGUACHE

IRT'IIMUNI), GEO. EISEEST (b'80)-Ky.

Shatter, larl (i. (b'- 8$)-$ Colo.5,04; (l'04)

CENTRAL CITY, 1,728, GILPIN

Istjultl, Arthur C. (b"69)-_Il.1,'94: (l'94).

sambers, rilbert $(\therefore,(b 60)-c a 1.5,94$ : (l'01)

CHANDLER, 50, FREMONT

cattermole, chas. A. (b'il) - Mlch.1."9S: (1'0'3).

CHERAW, 150. OTERO

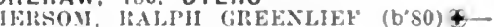
KY,2,10; (1,10).

CHEYENNE WELLS, 270, CHEYENNE

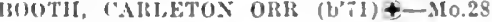
01 ; (1'11).

CLIFTON, 20, MESA

ilendeming, 1Kobt. W. (b'63)-Ore.2,'91 (l'0)

Oyler, Renj. C. (h'50)-Mo.10,99; (1999).

COALCREEK, 676, FREMONT

liddy, A. A. (b'43)-II!.6,'80; (I'S4).

COALMONT, - JACKSON

Eiclielberger, Thos. Wilbur (b'\$1)-Colo.5,

DS: (l'0S).

COKEDALE, 500. LAS ANIMAS

"I'NKEI, ROBT. C. (b'80) \pm Colo.5, 04 (I'04)

COLLBRAN, 156, MESA

lialer, Wm. II. (b'46)-Va.1,'71; (1's5).

Zinke, WIlliam (b'66)-Ill.s,'90; (1'90).

COLONA, 40, OURAY

Ibarclay, Henry Aretas (b'69)-Colo.5,06; (l'06)

COLORADO CITY, 4.333, EL PASO

umerman, coleman li. (b'sh)-Mo.2,'SL' (1'87)

INAIFLS, IIERMAN P. (b'ti) $+-111.6,92$ (l'03): G.

(IINMOIE, GEO. 1BENJ. (b'81)+-n1.6,"03. (1'04)

Inefer Fow A. (bob)-Mo I,9s: (1). "9s; (l’07): (1922 ('olorado dve., colorado Surings

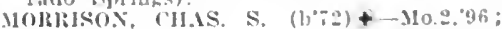
(l'02)

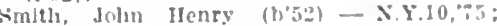
(1'4)

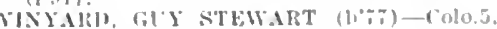
0:3: (l'os)

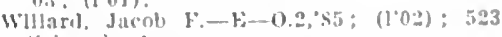
(ialorimb ats

Wole, Wu. (C. (1)63)-111.6, 99 : (1'91)

COLORADO SPRINGS, 29,078, EL PASO NLMHER OF IHYAICIANS, II:.

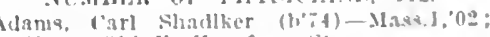
(105); :116 F. Iluertano se

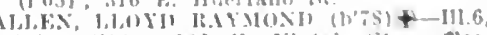
03: (t'os): 20.2 L. ['Intal st.; umee

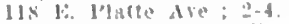

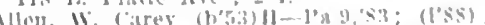

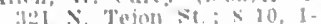

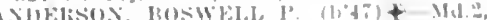

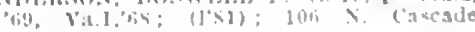

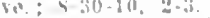

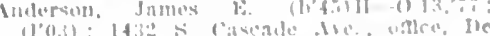
11, (1.3) $14: 32^{2}=$

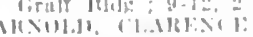

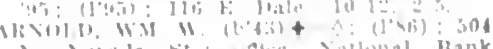

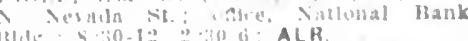

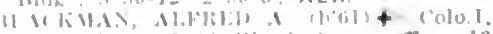

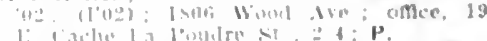

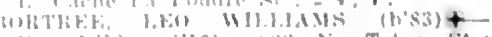
11:4x 1, 10: (1'10): \$12 $x$. Tefon st.

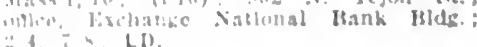


I3OYD, GEO. ARNOLD (b'64)†-N.Y.10,

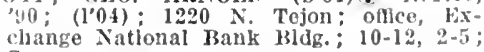
$\mathrm{S}$.

BROWN, JAMES IIORACE (b's4)-MO.:4 "07; (1'07); $802 \mathrm{~N}$. Tejon St.; ofllce, lilrst National Bank Blds.

BROWN, LOUIS GORDON (b'69) \&-(olo.1, 02: (1'02); 118 E. Donumeut St, ; $9-3: 30$ : R. $\star$

Caldwell, saml. 1. (1,53) pa.1,82; (1'91); not $\mathrm{ln}$ practice; 1129 Wood Are.; oflec, City Irealth Department.

('ampbell, W'm. A. (b'56)-0.1,'s0; (1'90) 424 . Nerada Avo. $1-4,7-8$.

CASELEY, WALTER N. (b'73)-Mo.29,95; (I'01) pendence Bldg. ; 10-12, 2-4:30; S.

CHAMBERIAIN. FRANK C. (b'fo)-Colo.3. '92; (1'92); 2016 N. Cascade Ale.; offre Flrst Natlonal Bank Bldg.; $9-12,2-4$.

CHESMORF, IIARRY P. (b'77) $€$-Mo.29, '00; (1'13); Member Mo. State Med. Assn.; 1119 N. Cedar St.

CHRISTOPHER, DAVID IRVINE $\left(b^{\prime} 46\right) \oplus$ N.Y.10.'74; (1'86); 1119 N. Weber st. : offle, IIagerman Bldg. ; 8-10, 2-4.

COOKE, JOIIN M. (b'53)-IIl,1, $87 ;\left(1^{\prime} 00\right)$; $1920 \mathrm{~N}$. Royer St.

CROUCII, JOHN BAKER (b'80)-111.6, '05; (1'12); also Member Ia. State Med. Soc. ; Unlon I'rinters' IIome.

DENNIS, FRANK L. (b'71)क-Ga.10,'93 : (1’99); 130 . E. San Mlguel St. ; offce, 501 N. Tejon St.; 9-12:30; (B1); ALR. $\star$

DEPEYRE, LOUIS N. (b'66) 4 -Colo.2,'97; (l'00); 1604 Colorado Ave.;

Duncan, Homer G. (b'71)-Pa.2,'95; (1'05) ; $22 \mathrm{~S}$. Tejon St.; $10-12,2-4$.

Ewing, Geo. Hamllton (b'69)-Colo.4, 05 ; (1'05) ; 321 F. Bljou St.; $1-4$.

Faust, Fredk. A. (b'65)-N.Y.9,' 86 ; $\left(\mathrm{l}^{\prime} 00\right)$; 819 N. Nevada Ave. ; $1: 30-3: 30$.

FERGUSON, JOHN H. (b'53) - Ia.1,80 ; $\left(l^{\prime} 00\right) ; 220 \mathrm{E}$. Huerfano St.; $2-4$.

FIELD. GEO. WM. (b'49)-III.6, 75 ; (l'08) Member State Med. Soc. of Wis.; 10-4 OALR.

FORSTER, ALEXIUS MADOR (b'80) Ky.2, 04 ; (1'11); Cragmor Sanitarium.

FRIEDMANN, ARTHUR C. H. (b'66) 4 Ger.4,'90; (1'04); 1611 Wood Are.; 10-1; (B9).

GARDINER, CHAS. FOX (b'57) $\oplus$-N.Y.10, '82; $(1 ' 84)$; 1112 Cascade Ave.; $2-4$.

GILBERT, GEO. BURTON (b'81) $\oplus-$ Id. 7 '07; (I'09); 817 N. Cascade Are.; T.

GILLETT, OMER R. (b'74)థ-Pa.2,02 (1'02); 320 N. Cascade Are.; offce, Bank Bldg. : $9-10: 30,2-3: 30$.

Grant, Richard S. (col.) (b'78)-Tenn. $\tilde{6},{ }^{\prime} 04$ (l'04) ; 325 E. Caramlllo St.; offlce, 117 E. Klowa St.; $10-12,4-5$.

Gray, Wm. A. (b'58)-N.T.6,'83; (l'02) (Dentlst); 1130 N. Cascade Ave.

GRIMIELL, G. H., SR. (b'35)-Ia.1,77 (1'06) ; 1319 Nevada Are. ; 10-12, 1-3.

GROVER, BURTON BAKER ' (b'58)థ-N.Y.8 79 ; (1'93); $1618 \mathrm{~N}$. Nerada Are.; offlce, Colorado Bldg. ; 9-11, 2-4.

GULL10N, WILBUR T. (b'75)-Mo.34,'06 $\left(1^{\prime} 06\right)$; 806 Colorado Ave.; office, Colorado Bldg. ; 9-11, 1-5.

HANFORD. PETER OLIVER (b'i1)థColo.1,'98; (1'98); 720 N. Nerada Ave.; $2-4 ; \mathrm{S}$.

HOAGLAND, HENRY W. (b'74)€-Pa.1,'99; $\left(1^{\prime} 00\right) ; 808$ N. Nerada Are.; $2-4$

Hombach, Wm. H. (b'89)-Neb.6,'13; Intern, St. Francis Hospital.

Hopkins, June S. D. (b'49) $\longrightarrow ; \quad\left(l^{\prime} 98\right) ; 20$ S. Tejon St

IITDSON, JOHN WM. (b'82) - Mo.22,'06 (1'11); Menber Mo. State Med. Assn. 124 S. Tejon St. ; $10-12,2-5$.

Huestis, Elbert L. (b'62)-0.1,'88; (l'97) 607 N. Tejon St.; offlce, 5 N. Tejon St.; $9-12,2-4$.

Igo, Cbas. W. (b'70)-Ill.6,'96; (l'04); 831 E. Boulder St. ; 9-12, 2-4, 7-8.

JAMES, THOS. LLEONARD (b'83) -Tenn.6, , 07 ; $\left(1^{\prime} 12\right)$; 1215 N. Nerada St.

(1) 03 ) Verada Are.
1.FNNOX, MALY MARTIN (b'79)Ð-N.Y.1, '03: (1'06); Giadstone Apts.; oflce Fxchange Natlonal Bank Bldy.; 2-4. lemox, Win. Gordon (b'84)-Mass. I, 13 (1'I3) : $1001 \mathrm{~N}$. Nerada Ave.

Lewls, John L. (b'73)-nl.5,04; (1'05) Bank Bldg.; 10-12, 7-8.

LOONIS, I'IIIJI' ALBERT (b'75)†-Ill.1, '00; (1'03) ; 1414 Culebra St.; offce, Burns I3ldg. ; $10-1$

Loub, Martin F. (b'76)-Colo.2,06; (l'06) 310 S. Nevada Ave,; offlce, Bennett Bldg. MADDEN, JAMES II. (b'60)\$-M0.1,'85; (1'93) ; 1401 Colorado Ave.; 9-11, 2-4.

MAGRUDER, ALEXANDER COVINGTON (b'6i) + La.1, 80 ; (l'00); 1331 N. Nerada Are; ; office,

MAIIONEY, JOS. JOIIN $\left(\mathrm{b}^{\prime} 84\right) \oplus-$ Colo.2, $07 ;\left(1^{\prime} 07\right) ; 18$ E. Monument St.

MARBOURG, EDGaR MARCELLA (b'64)థ -Pa.2,88; (1'90) ; 1019 N. Nevada Are. office, Burns Theater Bldg.; 9-12, 2-4; (B9) : OpA.*

Marlow, Win. D. (b'40) $\rightarrow$; (l'85); 111 Tejon St.

MARTIN, WIIBUR FISKE (b'63)-N.Y.1, '87; (1'95); 1303 N. Tejon St.; 9-11.

Mayer, Edgar (b'89)-N.Y.1,13; (); The Cragmor.

MAYIEW, DAVID P. (b'70)థ-Mich.1,96 ; (1'00) ; 725 N. Cascade Ave, ; 2-4; (A7). ICCIANAIIAN, ZENAS II. (b'71) \&-Colo.2, '94; (1'94); 1327 N. Tejon St.; office, Burns Bldg.; 11-12, 2-4.

MCCONNELI, JOHN FRANCIS (b'r3)†Ont.1,'95; (1'04) ; 818 N. Cascade Ave. $8: 30-11$.

McCorkle, Harry Beecher (b' $\tilde{\imath} 0)-\mathbf{M} 0.27$, 98 ; (1'11) ; Bank Bldg. McKay, Augustus F. (b'50) II-D.C.2,72 :

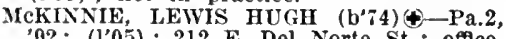
$02 ;\left(l^{\prime} 05\right) ; 212$ E. Del Norte St.; offlce, Exchange Natlonal Bank Bldg.; 2-4; S MILLER, LUCAS ALLAN (See Colorado Clty.)

IOORE, EDW. (b'76)థ-Mo.34,05; (1'12) : not In practice; also Member Mo. State Med. Assn.; Star Ranch Sanatorlum; T. MOSES, HOMER C. $\left(b^{\prime} 75\right) \oplus-N . Y .10,97$; $\left(l^{\prime} 06\right) ; 428 \mathrm{~N}$. Nevada Ave.; office, $\mathrm{Ex}$ change Natl. Bank Bldg.; 10-11, 2-4:30;

Iuir, Hannah T. (b'59)-Colo.2,'93; (l'93) $611 \mathrm{~N}$. Tejon St.

Muir, James T. (b'56)-Colo.2,'94; (l'94) 611 N. Tejon St.; office, Colorado Bldg. $9-12,2-5,7-8$.

MULLIN, IVM. V. (b'84) $\oplus-$ Colo.5,'08: $\left(l^{\prime} 08\right) ; 705 \mathrm{~N}$. Nevada Ave.; office, Burns Bldg.; $10-1$; ALR. *

Murray, D. L. (b'75)-Mo.20,'99; (l'02) 411 W. Bijou St.; $10-3: 30$

Myers, Helen 'T. (b'39)-I11.4,'83; (l'91): $221 \mathrm{~N}$. Weber St.

NEEPER, EDIVARD R. (b'67) $\oplus-$ - Ia.9, 91 ; (l'99) ; $2104 \mathrm{~N}$. Nerada Are.: offlce, Exchange National Bank Bldg.; 9-12:30

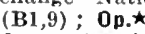

Nifong, Jefferson D. (b'62) - Mo.24,'93: $\left(1^{\prime} 04\right)$; $716 \mathrm{~N}$. Cascade Are. : office, Hagerman Bldg.; 10-12, $1: 30-3,7-8$.

Osincup, Chas. Hiram (b'62) - Md.4, 91 . $\left(l^{\prime} 05\right) ; 1430 \mathrm{~S}$. Tejon St.; office, Colorado Bldg. ; 9-12, 1-5.

PATTERSON, JAMES ALLENE-Pa.2,'82; (l'97) ; $805 \mathrm{~N}$. Tejon St. ; offlce, The Burns; $9: 30-12: 30$; (B1,3,9); OALR.*

PETERS, ALBERT H. (b'73)€-Ia.10,00 ; $\left(1^{\prime} 06\right)$; $318 \mathrm{~N}$. Cascade Are.; offlce, Colorado Bldg. ; 2-5.

Pickard, James A. (b'69)-Tenn.6,'94; (1'13); (Osteopath); 1819 N. 'Tejon St. offlce, Colorado Blag.; 9-12, 2-5.

RICE, DAYID H. (b'55) €-NO.1,'85; $\left(l^{\prime} 89\right)$. $11 i$ E. Pikes Peak Ave.

Richmond, Claude Ererett (b'87) -Mo.28,'09 ; (1'13) ; First National Bank Bldg.

Robinson, Goldsmith P. (b'52) H-N.Y.9, Ti $\left(1^{\prime} 88\right) ; 320$ F. Kiowa St.; office, First National Bank Bldg.; 10-12, 3-5; T.

ROBINSON, JOHN R. (b'55) - Pa.2,'82 (1'88); 124 E. Dale St.; offce, The Colchester; 9-12, 2-4; (B1,9); OALR.ネ
Rohlfing, Rudolf F. (b'80)-111.6,06 ; (l'06) 124 Cheyenne 13ird.; offlce, First Natlonal IBank 13iddg.; 9-11, $1: 30-3: 30$; Pd.

loss, James C. (1'64)-111.6,"91; (1'03)

ROTIIROCK, FRANCIS 13. (b'75) †-Mo.1, 999; (l'00); 1719 N. Tejon St.; offee, El Paso Nall. Bank Bldg.; 10:30-12

Ryder, Charles Tripp (b'85)-Mass.1,10 ; not In practlce; 1327 . Nerada Are. SCHAEFER, SOLOMON W. (b'85) ¿-Md.T 09: (1'13); also $\mathbf{M c m b e r}$ ore. State Med. Assn.; Glockiner Sanatorlum; T.

CIIOFIELD, JOHN VAN DOLAII (b'56)$0.9,78 ; \quad$ (l'06); 2 Colchester Apts. shellenberger, Chas. N. (b'56) II-0.13, i 8 ; (1'04); Tejon and St. Vraln Sts.; $9: 30$ $10: 30,2-30-3: 30$.

Shepard, Wm. A. (b'37) H-Ill.4,777; (1'98) 105 Cheyenne Rd. until $1: 30$; office, Colorado Bldg. : $2-5$.

SHIVERS, MARCUS ORELIUS $\left(b^{\prime} 7 i\right) \oplus$ Tenn.11,99; (1'09); I431 N. Tejon St. : office, First Natlonal Bank Bldg.; 10-12, $2-4$; $S$.

SOLENBERGER, AMOS RUFUS $\left(b^{\prime} 53\right)(-$ I11.6,'85; (1'00); 825 N.
$9: 30-12,2-4 ;$ (B3); ALR.

Spencer, Caroline E. (b'62)-Pa.7,'92; (1'93); 815 N. Tejon St.

SPICER, OLIVER W. (b'48)-III.6'73 : (1'81); 423 N. Weber; offce, De Graff Bldg. ; $9-10: 30,2.4$.

STEVENS, FRANK T. (b'67)థ-I11.6,93 ; (1'13); $317 \mathrm{E}$. San Rafael St.; offce, Exchange Natl. Bank Bldg.; 10-12, 3-4:30; (E13); N.

STEWART, JAMES RUSSELL $\left(b^{\prime} 82\right) \oplus-$ Mld.7,09; (1'12); $119 \mathrm{E}$. Wlllamette St. STOUGH, CIAS. FRANCIS (b'73) $₫$-III.10, '95; (1'00); $2030 \mathrm{~N}$. Cascade Ave. ; offlee, Hagerman Bldg.; $2-4$; $\mathrm{S}$.

SWAN, WILL HOWARD $\left(b^{\prime} 67\right) \oplus$-Mass.1, '91; $(1,00) ; 1440$ N. Nevada Ave.; $2-4$.

Thomas, John Byron (b'87) -Ind.20,09. (1'13) : Beth-El Hospltal.

TIMMONS, ELMER L. $\left(b^{\prime} 77\right) \oplus-K y .5,05$; $\left(l^{\prime} 05\right)$; $518 \mathrm{~N}$. Nevada Ave.: office, Exchange Natl. Bank Bldg.; 11-12, 2-4; ob.

TROSSBACH, HERMAN, JR. $\left(b^{\prime} 81\right) \oplus-$ Y.Y.8,0 ; $(1,09) ;$

UCKER, BEVERLEY (b'67) $\oplus-\mathrm{V}_{3.1},{ }^{\prime} 89$; (1'92); 1130 N. Nevada Ave. : 2-4.

VANDERHOOF, DON ALLISON (b'78)11..1, 03 ; (1'13) ; $1226 \mathrm{~N}$. Tejon St.; offece,

WALLACE, JOSEPH' $\mathrm{F}$, (b'74) -D.C, 99 ; (l'11); Modern Woodmen Sanatorlum;

WATT, HENRY C. (b'72)-Eng.17,'95; (l'05); 1801 Culcbra Are.; office, Burns Bldg. ; $10: 30-11: 30$.

WEBB, GERALD BERTRAM (b31)€ Colo.1,'96; (1'97)； 1222 N. Cascade Ave.;

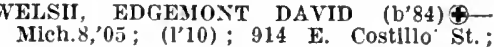
office, Colorado Bldg.; 9-11, 2-4.

WILSON, JOHN EDWARD (b'79) $\uparrow$-Mass.1, '05; (1'11) ; $2216 \mathrm{~N}$. Cascade Are.; office, $724 \mathrm{~N}$. Tejon St.; $2-4$.

WINSTON, ARTHUR L. $\left(\mathrm{b}^{\prime} 64\right)$ (-T-Tenn.8, '87; (l'12); Member Tenn. State Med. Assn.; 108 E. Boulder St.; office, Flrst Natl. Bank Bldg.; 9-11, 1-3; T.

Yale, Abby Albertine Bardeen (b'68)Wis.3, 03 ; $\left(l^{\prime} 03\right)$; not in practlce.

Zalesky, Rose Emma-Ill.11,'07; (专); 501 N. Tejon St.

Zillman, Otto Ernst (b'64)-Colo.2,'04; $\left(1^{\prime} 04\right) ; 416 \mathrm{~N}$. Prospect St.; offlce, $30 \mathrm{~s}$ Tejon St. ; $9-11,2-4,7-8$.

COLUMBINE, 40, ROUTT

Wilson, Thos. W. (b'55)-Ill.21,'99; not in practlce.

\section{COMO, 4II, PARK}

OSBORNE, CHAS. K. (b'73)-Colo.1,'99; (l'99).

CORTEZ, 565, MONTEZUMA

Johnson, Emil E. (b’82)-Ill.22,'12; (1'12). 
CRAIG, 392, MOFFAT Clayton, James A. Garfield (b'31)-I11.15,

DOWXS, JAMES K. $\left(b^{\circ} 54\right)+-1 \mathrm{a} .1, \because \mathrm{a}, 111.1$, '89: (1's2)

\section{CRAWF ORD, 200, DELTA}

Alleo, Archibald R. (b'51)-Ia.1,'ss: (l'07)

DAX. WILTON ANDREWS $\left(b^{\circ} \circ\right)+-111.6$ 08 : (1'10).

Grove, Axel F. (b'66)-Ia.10,03; (1.04).

CREEDE, 1,7\$1, MINERAL

HILES, JOHS A. (b'5?) \& Ia.1:?:; (I'92).

HOWELL, THOS. FREKUAX (b'72)-Kan.? 06: (1'07).

МсKIBBIx, sАML. (b'53) \$-Ont.,'sS (109).

CRESTED BUTTE, 904, GUNNISON

ORAM, ORLANDO AKCHIE (U'83) \&-

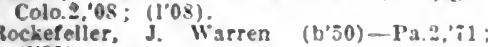
Rockefelter,
(1'81).

Taylor, Angus (b'6L)-Colo.3,'s9; (1'39).

CRESTONE. 231, SAGUACHE

DAVIS, MARK C. (b'65)-Ky.1,92; (l'03)

CRIPPLE CREEK, 6,206, TELLER

Brinton, Wm, T, (b's: - I'a.2,11; (l'13).

Dexwóy, JoHx A. $\left.\left(\mathrm{b}^{\circ} 64\right) \pm-6 \mathrm{a}\right), 85$; (l'95).

Hassenplug. Frank Atwood $\left(b^{\prime} 66^{6}\right)-P^{\prime} a .2,20$; (1'90).

HASSENPLIG, WTLL F, (b'66)\&-Pa.2,'92: (1'93)

HEREFORD, JOHN H. (b'61) \&-Mo.14,'8: ;

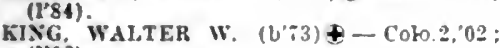
(l'02).

MeINTYRE. TIIOS. A. $\left(\mathrm{b}^{\prime}, 6\right)-\mathrm{Col} 0.3,02$; (l'02): D.

PARKER, LESLJE JAMES (b'80)-Colo.5 '10: (1'10); $\mathbf{S}$.

CROOK, 50, LOGAN

BARRETT, GEO. W. (b'il) -Mass.,$^{\prime} 03$; (l'04).

DE BEQUE, 149. MESA

UE BEQUE, WALLACE A. E. (b'11)

Colo.1,82: (1'81).
Cothard, Jos. Wm. (b'61) - Tenn.10,'91; Gothard,

Roe, Frank (b'6 $)$ - N.Y.5,93; (1'97).

DEERTRAIL, 75, ARAPAHOE

Woodward, Stlllman (b'76)-Fll.10,02:(1'04)

DELAGUA, 958. LAS ANIMAS

BLRKHARD, EDWIX I) $\left(b^{\prime} ; 0\right) \mp-$ Pa.I

95; (I'00); ObG.

DEL NORTE, 840, RIO GRANDE

DOANE. BKHT LEK\$-III.6,05; (1'06).

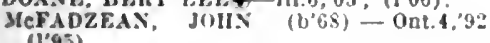

(1'95).

OELTA, 2,388, DELTA

Bralsted, Ilorace K. $\left(b^{\prime} 56\right)-M l c h .5, ' 80$ (1'89).

BURGESS, LLOYD MCDONSLD (b'70)t Mo.27,'93: $\left(1^{\prime} 05\right) ; \mathrm{S}$

BURGIN, CIIS II. ( $\left(\mathrm{b}^{\prime} 61\right)-\mathrm{M} 0.10,298 ;\left(l^{\prime} 04\right)$ CLELAND, WINEIELD SCOTT (b'82) Colo.5,'09: (1'09).

CondIt, II. Celestla (b'66) -Cal.7,02 ; (1'03)

Dorwer, (ieo. M. (b'2s) II-0.7.02; (1'b3).

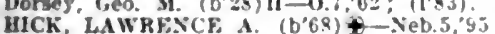
IICK, 1

Kinsley, Yrauk 1). (b'57)-Ma.3,82; (1'01) Mccartnes, ollver lerry (b'69t-rolu.3,0l (I'OI)

Meclanaban, Albert c. (b'c5)-111.1, 89 (l'05).

MeCHFW, PIEDK. A $\left(1,{ }^{\prime}(\mathrm{B})+-1 \mathrm{H}\right), 93$ (1'12): $s$.

MLLER, AUSTIN : (h'65)-III.11.95

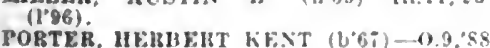
ORTER, HEIHIEIT:
N.Y.1,89:(1'04)

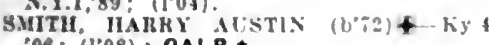
06: (I'08): OALR.*

stockbars. Albert UI. (b'32) $-0.8,79:(1.95)$

bot in practice.

DENVER, 213,381, DENVER

NUMHKK OH JIIYSICIAS., i26.

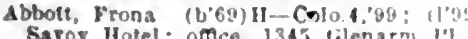

Saroy Hotel: omce, 1345 lilenarm l'l

ALBI, HLDOLIII (b'i4) $\rightarrow$ Ita 20,00

Allen Henry Jullan (b'39)-0; (1'si); 24 -

S. Bantock it.

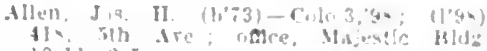

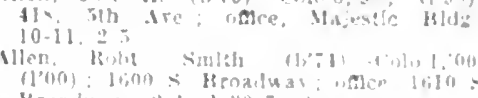

Msisker. linsmis 1. (b-83) J11 s,10:11\%0

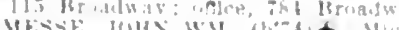

(1)

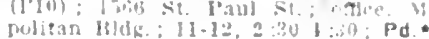

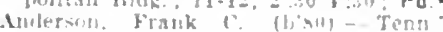

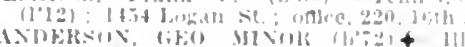

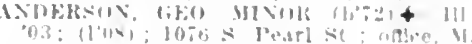

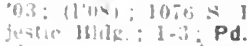

Anderstr, John ifylie (L5s)h ll a

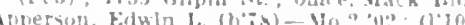

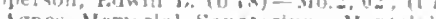

Arall, witert Jos. (1, 86$)-(0,0,2,10$ illio

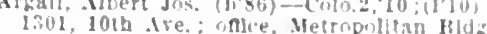

Armbruster, Clas. F. HI. (b'ti)-tolo.4.01

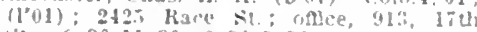
st. $;: 30-11: 30.2: 30 \div 30$.

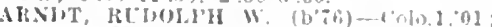
(l'01): 6.5 Logan sh: unlee, 1349 i allfornis St. : $10-11$,

ARNEILI, JAMES RAE $\left(b^{\prime} f 9\right\}+-M i c h$. $94 ;(1 ' 03) ; 1055$ L'ennsylrania st.; nnce,

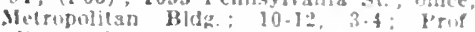
ilin Jed. (olog: i*

Atcheson, Geo. (b'66)-(nlo.1,33: (1'34) 1300 Lafayette St.; once. Ofera Hutuse Plde: 10-12, $2-4,-$

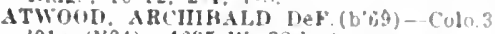
01 ; (1'04): 1635 W. 3sith sre.

ACFMWASSER, IIFGO W. (b'-0) - I'a 2 35; $(107): 4200 \mathrm{~W}$. 22d Are.; once, Hach Bldg. ; $10-12,2-4$; $($ H1,9); OALR. *

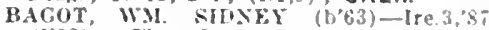
(1'92): The I'errenoud; oftce, Opers llouse Jlock; $3-5=\mathrm{s}$

Bailey, Walter II. (b'b9)-[11.4, 1431) Tremont ll.; onlee, If50 Tremont I'l. : : $9-5$.

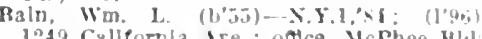
1:49 Callornia ire : oflce, Mc Phee Hlat Baker, Gen. Girlswold (b'49)-Mlch.1,'05 (1'bs): The standlsh; $10-11,2-4$

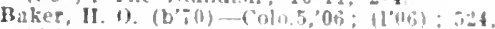
14 th st.

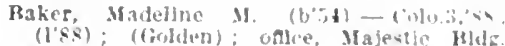

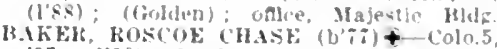

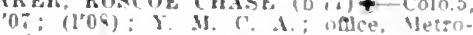
politan l31d\% : $10-12: 30,2-4: 30:$ LD.*

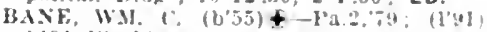

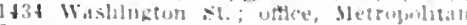
Hldir.: $9-1 ;$ I'rot

(H1,3.9): OALR.

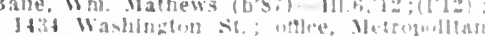
lili: ; 1 - $4,-8$

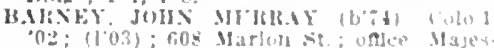

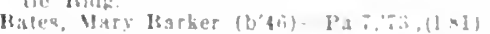

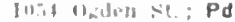

IRTES. MARY EIMAMFII (bol) + 11 ?

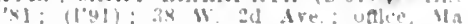

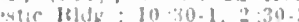

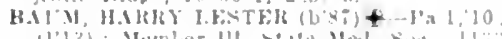

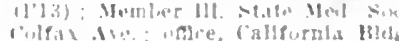
ALR.

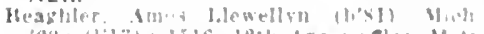

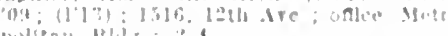

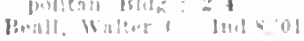

Nerally. Jubn T (bied)

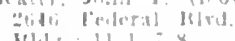

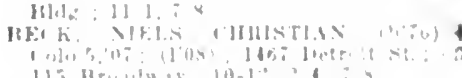

$11511+1102 y+10-1 \%=1$

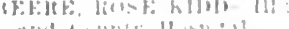

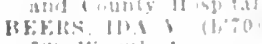

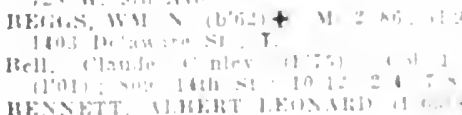

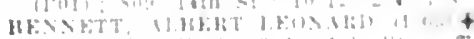

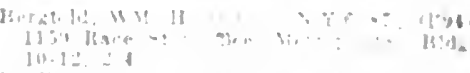

aFis

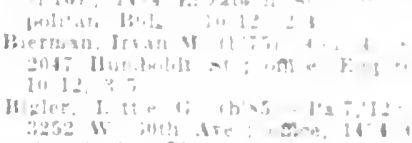

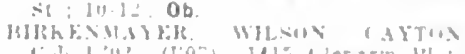

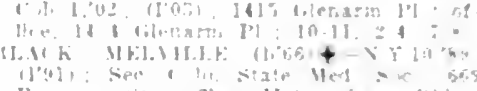

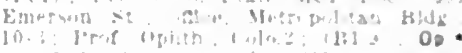

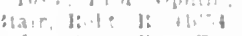

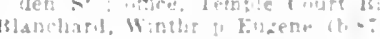

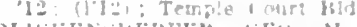

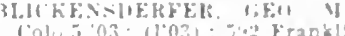

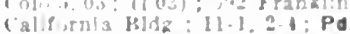

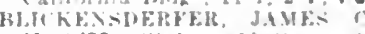

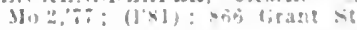

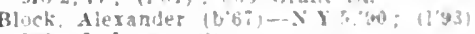

1, ly Lafasplie st

Blosier. Juhn Kulolnh

Bogan wallor

415 $\mathrm{k}$ inth ire alce, Gas and Elect: Hitg

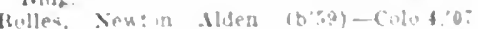

(l'ai); ill, 17t st: 10.12

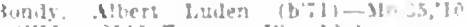

(l'11,: 2115 Tremon: $\left.b^{\prime}\right) ; 1:-1$

(1)

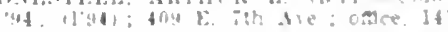

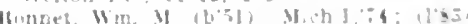

Harth Howk: 10-1:, $21, i$

HOXSHY SHKMUAY VIHAT (D'st)

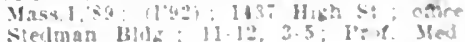
102: T.

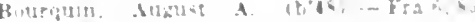

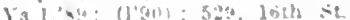

Kowen. Nexander \& $(050)-x>10,:$ Kalama!! $\div$.

howers. Jin.

Pr.*

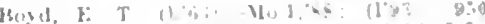

(i) ilen $\$ 1$ ir.

13.

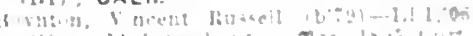
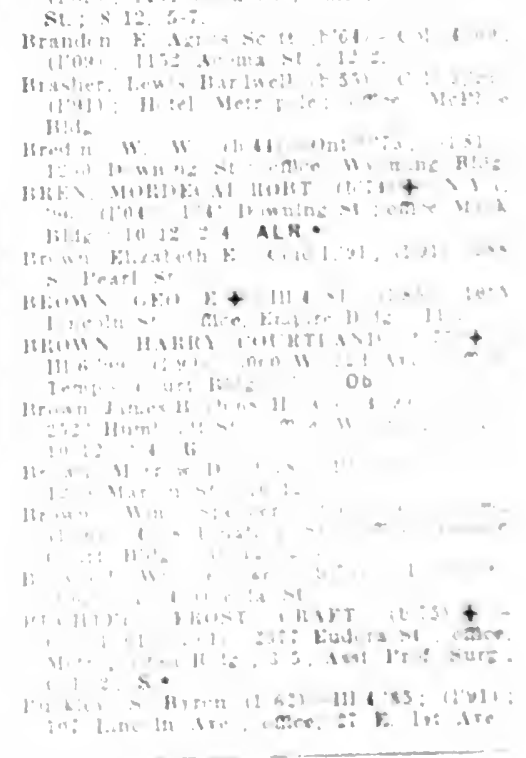
BUNDSEN, CILAS. A. (b'72)-Colo.3,02 ; $\left(1^{\prime} 03\right)$; 371 s. Emerson st. ; office, Metropolltan Bldg. : 11-12, 2-4; T.

Burdick, Jèsse R. (b'73) II-III.4,00; (1'04); 1566 Broadway.

BURDICK, WAID TIIOS. $\left(b^{\prime} 78\right) \uparrow-110.10$, 08 ; (l'11); 701 F. 14th Ave.; oftlee, Metropolitan Bldg. ; $2-5$; LD.

Burket, Robt. Śmitli (b's9) - Colo.2,'13; (l'13) ; St. Joseph's Ilospital

BURNIAM, NORMAN G. (b'29)-0.2,51 $0.7,55 ;(1 ' 81)$; 70s, 14th st.; until 10

BURNS, CIIAS. 1. (b'47)-Vt.2,'75; (I'81) ; $245 \mathrm{~W}, 4$ th Are, ; untll $10,2-4,6-7$

Burns, Horace lobt. (b'69)-Colo, 3,96: $\left(I^{\prime} 96\right) ; 2226$ IIIgh st. ; offlce, Mack $13 \mathrm{ldg}$. $9-12,2-5 ;$ OALR.

BUINS, THOS. HITCHELI, (b'68) $\oplus-$ Colo.3,'93; (1'92) ; 1252 Corona st. ; oflice, Metropolitan Bldg.; 2-4; Prof. Obst., Colo. 2 ; ObG. $\star$

Burruss, Edw. W. (b'65)-Mo.7,'86; (l'86) ; 3320 W, 29th Ave.

BURVENICH, CHAS. $11 . \oplus-M 0.29,97$; (I'02); $1026 \mathrm{~S}$. Washington St. ; offlee, 315 Temple $\mathrm{Ct}$.

Bushell, C. Edw. (b'76)-1a.10,00; (l'04) 2656 Eudora St. ; $9: 30-12,1: 30-4: 30$.

Busman, Herman (b'69)-III.13,03, 111.11, 05; not In practlce; 2571 Downing $\mathrm{St}$

Butman, Wm. Chas. (b'80) H-liy.s, 05 ; l'0s) ; 2075 S. Willams st.

Butman, WInthrop Warren (b'71)-Mo.3,97 ; (l'04); 1720 logan St. ; offlce, Wyoming BIdg. ; 11-12, 1-4.

Byles, Fredk. Gillett (b'53)-Pa.2,82 ; (I'01) ; 2249 Marion St.; office, Mack Block: 10-12, 1-3; Prof Hín Colo.2; Ob.

Cable, Geo. Louls (b'72)-0.3,'97; (1'04); 27 w. Ellsworth St.; office, Wyoming BIdg. ; 11-12, 3-5, 7-8.

Cain, Raymond W. (b'81)-Colo.2,11; (l'11) 115 Broadway; offlce, First Arenué Hotel; $10-12,2-4$.

Calhoun, Alex. W. (b'63)-0.12,90; (l'91) 258 Fox St.; offlce, 281 Fox st.; 9-10, $1-2,7-8$

Calkins, Richard T. (b'75)-Colo.5,'03 ; arm I'l. : $1-3,7-8$.

Calkins, Seba Boyd (b's0)-I11.1,204; (1'11); 349 s. Penn st.

Calvert, Sarah E. (b'53)-Colo.3,'95; (1'95) ; 2741 Gilpin St. ; office, 529, 16th St.

CAMPBELL, ALPHA JOHN (b'71)-Ill.1, '03; (I'03); 1848 Broadway; offlee, Metropolitan Bidg.; $10-12,1: 30-4$

CAMPBELL, LUCIEN DANIEI (b'58)థ-

Vt.2,86; (1'87); 1425 Cleveland $\mathrm{Pl}$

Campbell, Robt. M. (b'67)-Colo.1,93; $\left(l^{\prime} 00\right) ; 77$ S. Bannock St. ; 2-5.

CANBY, HARRY SUMNER (b'i6)-N.Y.19, '01 ; (1'02) ; 1440 Marion St.; offlee, Metropolitan Bldg.

CARLIN, PATRICK V. (b'54)థ-Colo.1,82 ; (l'82); 1400 Race St.; offlce, Knights of Columbus Bldg.

Carlin, Thos. J. (b'69)-N.Y.5,'92; (l'93) 1458 Corona St.; office, (ilenarm Pl. and 14th St.

Carlson, Benj. W. (b'74)-Mo.20,'03; (l'03) 3866 Cook St.; office, Wyoming Hidg.

CAKMODY, THO 11 A'S EDW. (b'75) Colo.5,'03; (l'04); 1901 Hudson St.; of-
flce, Metropolitan Bldg.; 2-4; (B1,3); flce,

Carpenter, Fred Howard (b’84)-Colo.5,'09; (1'10); 1027 Fillmore St.; office, Empire Bldg. ; 10-12, 2-4.

Carrer, Wm. B. (b'6 I)-Pa.11,'96; (1'96) ; 1328 Curtis $\mathrm{St}$.

CASE, AUSTIN G. (b'47)థ-N.Y.s, 73 ; (1's9); 945 Logan St. ; offlee, 1434 Glenarm ; $10: 30-12,3-5$; Pd.

Cassidy, Elizabeth (b'71)-Ill.9,97; (1'0S) 1400 Detroit St.; offlce, Wyoming Bldg.

Cassidy, Geo. divin (b'56) - Que.1,85; (1'12); 2131 S. Columbine St.

Cates, Alonzo Enoch-Colo.5,03; (1'03) ; Agnes Memorial Sanatorium.

Caughlan, Gerald V. (b'86)-Neb.6,'13; Intern, St. Anthony's Hospital.

Cecchini, Augustine Santina (b'88)-Colo.2, '13; (1'13); City and County Hospital.
Chamberla!n, Ralph S. (b'79)-Pa.12,03; (I'04); 190 s. Emerson st.; ofllce, Centra Savings Bank 13ldg.; $9: 30-11,1: 30-3$.

CIIAMI'LIN, HALRY HOWAIED (b'84) Colo.2,'12; (1'13) ; 1435 Washington St. ollew. Stedman IBldg.; $9-11,4-6 ; 1 . \star$

CHARLES, ROBT, L. $\left(b^{\prime} 79\right) \oplus-$ Colo. 5,04 (1'04); 1658 steele St.; offlee, Metropolltan Bldg.; 11-12, 2-4; (A21); Anes.

CIIASE, JOIIN (b'56) -Meh. 1,$81 ;\left(l^{\prime} 96\right)$ 923 Cornna St.; nffice, Majestle 13Iock 9-12, 2-4; 1'rof. Ophth. and Otol., Colo.2 (BI) ; OpA.ネ

CHASE, I'HILIIPS MAURICE (b's5)N.H.1,03; (['12); 1136 Logan St.; offlec Stedinan Blde.; 11-12, 3-5:30; S.

CIILIS, SAMI. BERESFORD (b'61) 9 N.Y.5, 87 ; (I'98); 1463 Iace st.; ottice, Metropolltan 13ldg.; 9-12, 2-5; Prof. Anat., Colo.2; R. $\star$

Clark. James L. (b'65)-Mo.1,'86; (I’88) 579 Falapago St. ; 11-3.

COFFMAN, FRANK R. (b'68)@-Colo.3, 90 : (1'90) ; 1634 Race St.; office, Metropolitan Bldg.: 10-12, 2-4.

COHEN, HASKELL MIER (b'75) †--N.Y.19, '99; (1'99); 1172 York St.; offee, Yietropnlítan Bldg.; $2: 30-4 ; S . \star$

Cohen. Saml. B. (b'86)-Colo.2,11; (l'11) ; 2221 Emerson $\mathrm{St}$.

Coller, Wm. Burton (b'71) - Pa.11,00 ; (l'01); $500 \mathrm{~s}$. Broadway until $9 ; 12-2$,

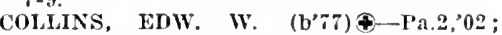
(l'03); 17 th Ave. and Emerson St.; offlce, Metropolitan Bldg.; 2-4; (B1)

COLIINS, MOSES (b'64) $\oplus-\mathrm{Ky} .4,85$ (l'01); 1401 Colorado Blvd.; offlee, Jew ish Hospital ; 8-5; I.

CONANT, EDGAR F. (b'67)क-D.C.1,'94 ; (1'06); 1560 Vine St. ; offlce, $722,14 \mathrm{th}$ St.; $9-12: 30,2-4: 30$; (B9); OALR.

COOPER, CLAUDE E. (b'78)-Colo.3,00; (I'00); 1516 Cook St. ; offlce, Metropolitan Bídg. ; 10-12, 2-4; ALR.

Cooper, Horace S. (b'71)-Colo.1,00; (l'00) 770 Jason St.; office, 604 Clarkson St. $10-12,2-4,7-8$.

COOVER, DAVID H. (b'52)థ-Pa.2,'74 (I’90); 1345 Logan St.; office, Metropolitan Bldw.; 9-1; 1rof. Ophth., Colo.2 $(\mathrm{B} 1,9) ;$ Op. *

Corry, John James $\left(b^{\prime} 74\right)-$ Colo.5,06 (l'06) ; 3054 W. 38 th Ave.

Cowell, Chas. I3. (b'66)-Colo.4,'98; (1'98) ; 1866 S. Pearl St.

CRAGIIEAD. WM. SPENCER (b'63)-Mo.28, '95; (1'01) ; 2257 California St. ; 9-11, 2-4. CRAIG, ALEXANDER CRAWFORD (b'82)Ill.6,07 ; (I'09) ; 1655 Sherman St.; offlce, 122,16 th Ave.; $2-4 ; \mathrm{S}$.

Craig, Helen Frances (b'83)-Ill.1,13; Intern, Denver City and County Hospital. CRAIG, WM. B. (b'55)-Mo.2,75; (I'82); 1573 Sherman Ave.; office, 122 E.

Craine, Louis El-Ia.6,91; (I'95); 94 Sherman St.; offlce, 1132,15 th St.

CREWS, GEO. B. (b'56) क-Ill.6,'83; (1'90) 2419 W. $32 \mathrm{~d}$ Ave.; office. Central Savings Bank Bldg. ; 9-10, 2-4, $7-8$

CRISP, JOHN DOUGLAS (b'58)థ-Colo.5, '05;' (1'03); 1347 Lafayette St. ; ofllce, Wyoming Bldg.; 10-12, 2-4;G.

CRISP, WM. HENRY (b'-5) $4-\mathrm{Col} 0.5$, 07 ; (l'09) ; 5.5 Washington St. ; offee, Majestic

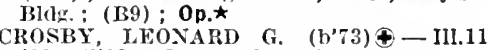
'99: (l'03); Metropolitan Bldg.

CUNEO, JOS. (b'56)-Ita.10,87; (1'90); 1149 Josephine St.; office, 1434 Glenarm Pl. ; 11-12, 2-4.

CUNNINGHAM, ALEXANDER A. (b'57) 0.9

Curfman, Geo. W. (b'44)-Mo.1,72; (l'92); 2711 Gaylord St.; office, 1900, 16th St.

Currigan, Martin Dominic (b'87)-Colo.2, 12 ; (l'13) ; 2256 Williams St. ; office, Knights of Columbus Bldg.

Curtan, Jobn Edw. (b's:) - Colo.5,'08; of Columbus Bid

CURTIS, HENRY B. (b'65)-Colo.3,'93;

(1'93) ; 123 Grant St.; office, Cooper Bldg. $9-11,2-4,7-8$.
DANAIIEY, THOMAS JOS. (b'80)-Colo.5, 09; (l'09); offce, 3231 Tejon St.

, Colo.2,'13; (P11) : Steele Memorlal Hospltal.

avls, lredk. Augustus (b'67)-Mass.1,'91 (I'04); Mafestle BIdg. ; 9-I 1, 2-4; Op.

avis, Jefferson Chapman W. (b'81)-Colo.2,
'12; (1'13); 3846 Lowell Bivd. ; office, 3492 W. 32 I Áve.: 10-12, 3-5.

DAVIS, IOIN 13. (b'74) - Colo.3,'02; (l'03) 1267 'Josephine St. ; offec, Metropolitan Bldg. ; (C3) ; U. *

havis, Wrlibur I. (b'73)-Colo.3,01 ; (1'01) ; 1005 W. 14th Ave.; 10-12, 1-3.

DAVIS, WM. HENRY (b'48) $\oplus$-Ind.4,71 N.Y.10,76; (I'81); 1136 Gaylord St. ; of flec, Metropolitan Bldg.: 10-12, 2-4, 7-8;
Prof. Derm. and Gen.-Urin. Dis., Colo.2; (C3); U.

Deacion, Ciara M. SIusher (b'73)-Mo.28,03; (l'04) ; 1807 S. Pearl St. ; 10-12, 2-4.

DFAN, EDW. F. ( $\left.\mathrm{b}^{\prime} 74\right)-C o l o .1,97 ;\left(\mathrm{I}^{\prime} 97\right)$; 180 Marion St. ; office, Knights of Columbus 13ldg. ; Asst. Prof. Clin. Surg., Colo.2. Dean, Marshall Henry (b'57)-0.9,78: (1'87) ; 516 Pearl St.; offlce, $529,16 \mathrm{~h}$ St DeFrantz, Charles D. (col.) -Tenn.7,05; (I'06);2734 Welton $S$ t. ; $2-4$.

DELEIIÁNTY, EDW. (b'67)థ-Colo.2,95 ; (l'95) ; 1565 Clarkson St.; oftlce, Knights of Columbus Rldg.

DeSOBE, JOSEPH ORRIN - N.Y.3,'99; (l'08); 2149 Welton St.

De Weese, J. M. (b'56)-Md.4,00; (I'01): 1245 York St. ; offlee, Emplre Bldg.

Dilliard, Edmund (b'59) H-Ill.4,'87; (1'02) ; 1326 W. Alameda Ave.

Dillon, James WIlliam (b'70)-Colo.5,'03; (1'04); 1064 Emerson St.; offlce, Centrai Savings Bank Bldg.

DIMOND, EDGAR BASCOM $\left(\mathrm{b}^{*} ; 6\right) \oplus-\mathrm{Ky} .1$ '97; (1'09); 3354 Federal Blvd.; offec, Majestic Bldg. ; 9-12, 2-4.

Dlsbrow, Albert A. - ; (1'05); 44 Lincoln St. ; office, Empire Bldg.

ITSON, AGNES MAY (b'84) $\$$-Colo.5 08 ; (l'09); 3141 Tejon St.; office, Metropolitan Bldg. ; 1-3.

DIXON, FRED. LOREN (b'57) $9-$ N.H.1, '81; (]'05); 1415 Race St.; office, 736 , 14 th St. ; $10-12,2-4$.

Dodge, Horace T. (b'56)-Cal.5,'87 ; (1'90); 2713 Stout St.; office, Jacobson Bldg. Dorr, Pearl Wheeler (b'75) H-Colo.4,'97; (197); 1366 Pearl St.

DORSET, BERNARD CHAS. (b'7 )-Pa.1, 04; (1'09); 1137 Sherman St. ; offece, 1434 Glenarm Pl. ; 11-12, 3-5.

Douglass, Atwater Lincoln (b'69)-Pa.9'95: $\left(l^{\prime} 08\right) ; 2951$ Blvd. F ; offlce, Empire Bldg. ;

DRECHSLER, WM. (b'75) $\oplus-$ Colo.3,'00 (1'01) ; 1488 Columbine St.; office, Mack BIdg. ; $10-12,3-5$

Dreyer, 'John Heino (b'68)-Mo.27,'98; (1'10) : 2371 Vallejo St.; offlce, 1206, 15th St. Orinkwater, Ray Lawrence (b'84)-Colo.2, '13; (1'13) ; Commonwealth Bldg.

DROWN. LINNAEUS MARSFALL (b'74)$0.19,00 ;(1,04) ; 2000,47$ th Ave.; office, 4688 Race St.

Dunklee, Harley K. (b'61)H-IH.4,'87 : (1'89); 1723 S. Logan St.; office; 1129, 17 th St.; $10-12,2-4$.

Durbin, Lévi T. (b'58)-Colo.1,'84; (l'84); 1921 Colfax Ave.; office, Tramway BIdg.

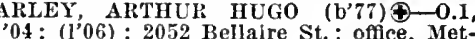

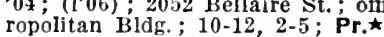

East, John H. (b'57)-Ia.3,'83; ( $\left.l^{\prime} 02\right)$; 1137 Vine St.; offlce, 1510 Glenarm Pl.

Ebell, Karl (b'71)-Colo.1,'01; (1'01) ; 333 Kalamath St.; offlce, 768 Santa Fe D́rive. ECKERSON, E D W. (b'53) - N.Y.6,'77; $\left(I^{\prime} 90\right) ; 2139$ Race St. ; offee, Metropolitan Bidg.

Edmundson, Wm. (b'41)-Ia.1,65; (1'81) ; 1451 Corona $S$

EDMUNDSON, WM. LACEY (b'85) $9-$
Colo.5,07; (1'07); 1451 Corona St.; office, Mack Block; 11-12, 3-4:30. EDSON, CARROLL EVERETT (b'66)
Mass.1,92; (1'96); Hotel Metropole; office, McPhee Bldg.; $9-10,2-4$.

EDWARDS, GEO. MÚRRAY (b'67)థ-Pa.2, '94; (1'99); 2405 Boulevard F; office. Symes Bldg.; $11-12,2-4$. 
EICNRERG, STAXLEY H. $\left(\mathrm{b}^{\prime} 81\right)+0.9$ Metropollian Bldg.: :-4: $\mathrm{S}$.

Elgler, Chas. O. (b'6s)-Ia.6., $s 8$; (1'04); $1300 \mathrm{~S}$. Viaylord Si. onte. Meiropulitan Bluk.; 10-12, 1-1; OALR.

ELDEH, CHAS, \&. (b'ss) + -Colo. 1, 9 : (1"96); Ires state Board of Med FramIners its clarkion st. tan BIdg.: $1-3$; l'rot. liyn. sure. Colo.: tan.

8.

LLIOT, HOW.ARD R. (h'5s) + Ont.l.'SI (l'00): 12 w. Ellsworth Ave; orlce, Itetropolltan B!ds.

Enlott. James Thas, (b'69)-0.25.99: (l'08) : 2024 Colorado Rivd.; onlce, Central Sar.

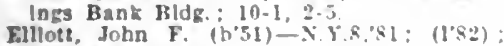

lor I York St.; oflce, s09, $1+\mathrm{h}$ st.; $11-2$. Ellis, A. Augustus $\left(\mathrm{b}^{\prime} 6\right.$ ) - Tenn.9, 93 ; (1'99); 15 w. IIth Are.

ELLIS, CHAITLF, AHTHTR (1)'Gs) +Albany Hotel: 2-4; $S$

Ells, Chas. A. (b'62)-Ky.1.'98: (1'04): 1037 Colfax Are; ofle, Commonwealth Bldg. $10-12,4-6$.

EISNFR, JOHN H. (b's5) F-X.T.10,66: (1'81); 1361 Curtis st.; office, 1014, 14th St.: $-6 ; 1$.

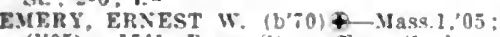
(1'05): 1541 Hace St, odlce, Stedman Bldg.

Emery. Lydla F. (h'bis)-Mo.28,05; (l'05); Commonwealth Ridg.: $10-3$

Enos, Chas, W. (b't?) H-Mn5, 4 : (l'89):

841 Washington; oftlec. Mack Hidg.; 9-12, $2-4$.

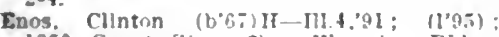

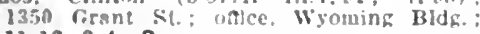
11-12. $2-4 ; S$.

Falrfeld, Wm. J. (b'Ti) - Y Y.10,'78; (l's9) Z39 LInenln Si.; nflce, 11.5 Rroadway;

FANT\%, THEISHAA S. (b'I) + Colo.3,00: (1)00): Oxford llotel: $9-10,3-\bar{T}$.

Fambam. Mary C. (b't2)-Illi,8I; $(190)$ : 1300 Adams St.

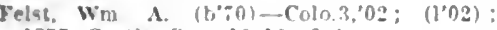

1355 Curtla si: $10-12,2-4$

Fenton. Thomas J.-111.11.06; $\left(1^{\prime} 10\right): 1511$

logan St. once, Majestle Mlif.

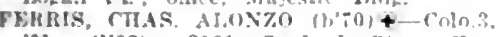
01: (102): 3121 Cavlorl st.; once. Metropolitan IIdJ.: 12.2: ODG.

Fezer. Florence $(1,83)-C$ (3). 2.13; (1'13)

County IImspital.

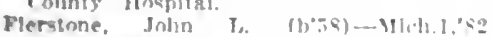

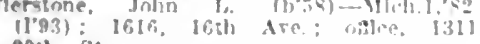
eoth st.

FIH,MFR PIHNFTT A (bis) KI 'AB: llnes: Jeniher la state Med. Sibc. anse \& Vennsylranla sis

Finn. Benj. Franklin (b'r)-

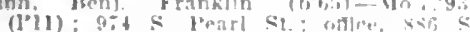
Pearl si. 4.12.

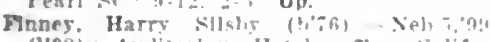

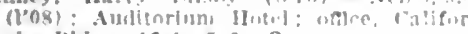
nla bilig: : it $]$, i.fi: $\mathrm{S}$.

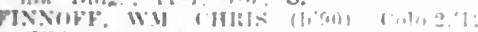

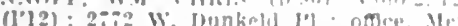
ropollian HJd: : 10-1: ALR.

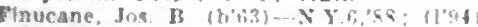

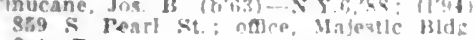

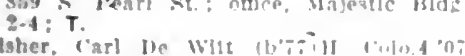

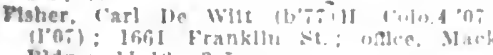
Hidg: $11.1 \%, 2-1$

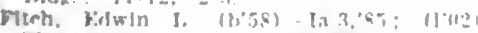
West Court IIntel; nflle, Fimplre Blit: 10-12. $2-4$.

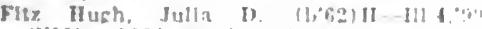
(1'99): 12:4 Varlon \&l

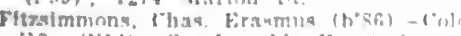
13: (1014): St. Josephla Huspital.

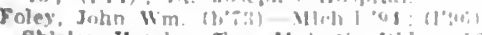

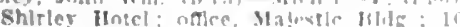
12. $2.4:$ OAL.

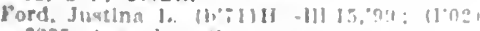
2335 Arapalioe st.

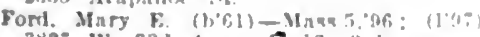
$3 \times 27$ W. 321 Ave: n-12, $2-1$

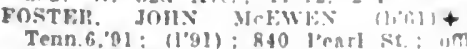

Tenn.6.81: (1'91): 840 l'rarl St, um.

Colo.2: (IB],3): OOAR.

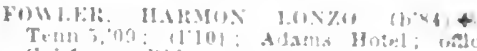

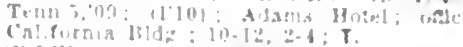

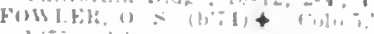

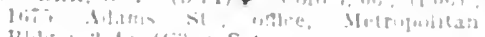

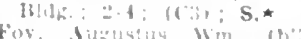

(1)(0)

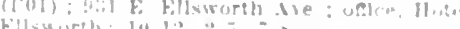

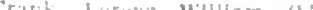

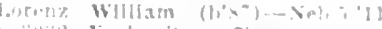

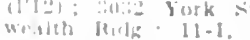

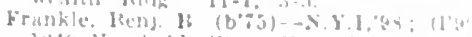

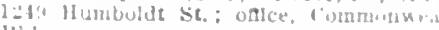
H?

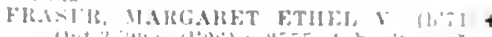

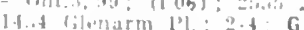

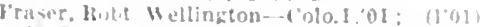
asu Marim st; uffice. (ipera $11,4$.

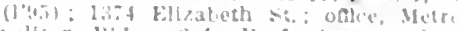

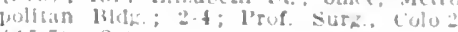
$(1,-7) ; \mathrm{S}$.

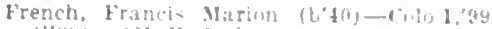

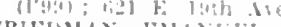

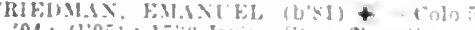
Sarings lank kmig. : "2-4

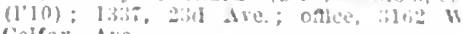
rnlfax Are.

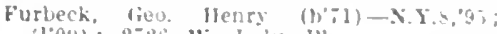
(1004): 272t w. loike I'l.

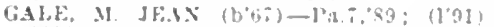

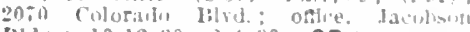
IHId.: 10-12:30, 2-4:30: 0p.

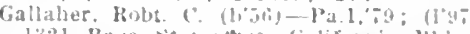
1:321 Bave st.: onthe Califurnia likdi=

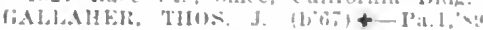

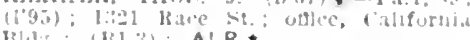
Mllik: ( 13,3$)$ : ALR。*

Gancre (lias V- III $1 \mathrm{~L}$,

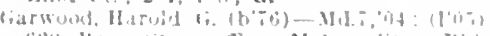

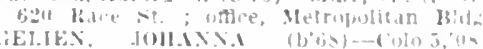
(I't) : 13:0 Franklin St.

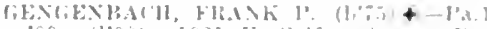

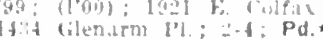

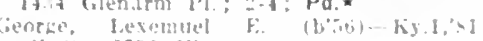
$(1, y-2)$ : $27-2=$ Vine $-t$

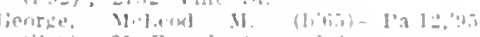

$\left.11^{*}: 40\right) ; 21$ E. Nh . I

$(1 \div ! 1):$

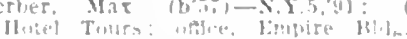

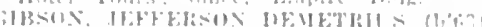

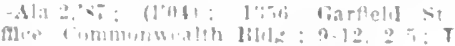

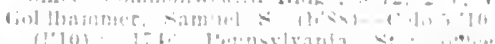

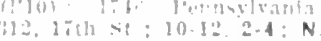

\section{(2)}

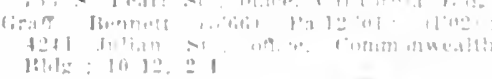

$181,1: 10$ : 12.
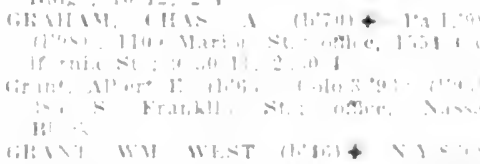

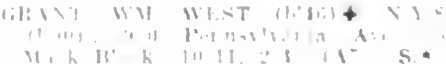

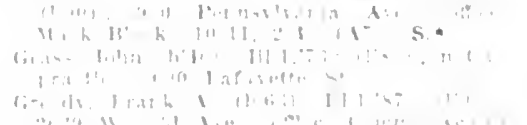

III hil.

III

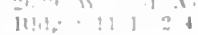

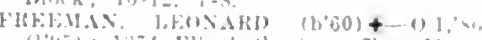
04: 1105$)$ : licill Irring sis; ottice. (enerd

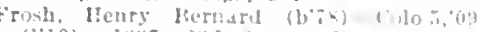

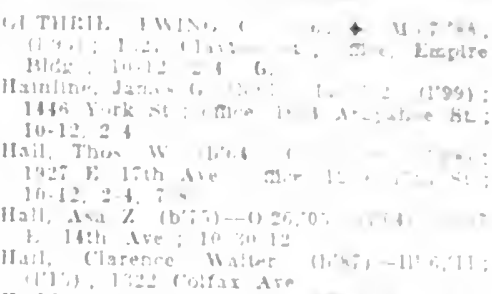

13.13.1 J1101.11 y $10591+1125 \times 1.0$

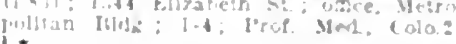

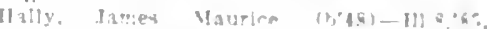

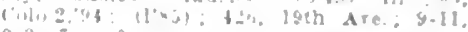

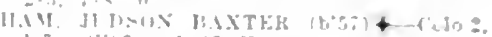

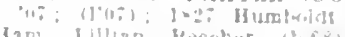

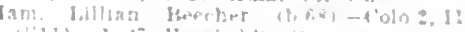

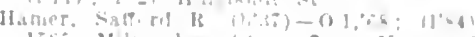

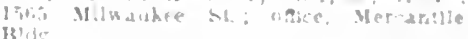

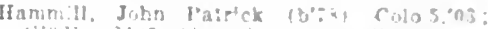

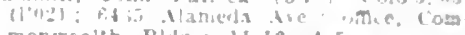

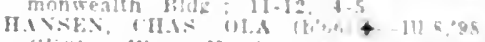
(l'pens): Weat Huel: nfter, lias ad

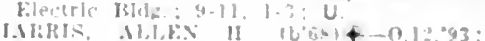

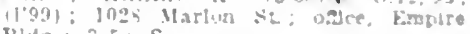
blilz: :-5: S.

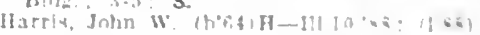

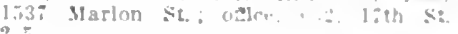

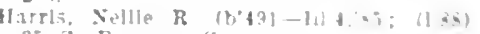

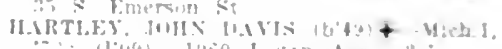

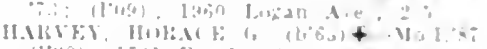

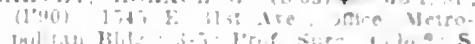

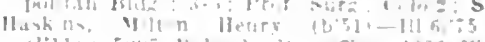

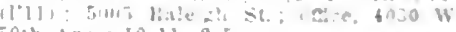

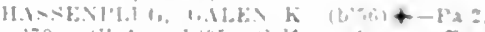

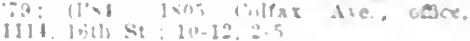

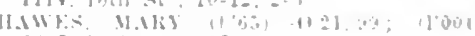
Iis: Wint - : : G

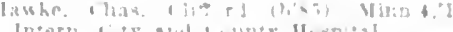

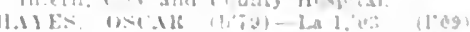

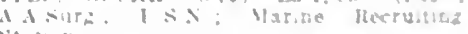

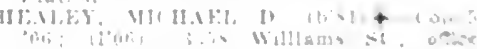

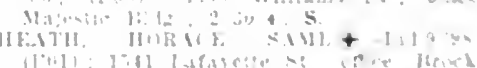

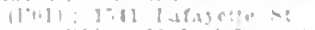

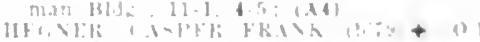
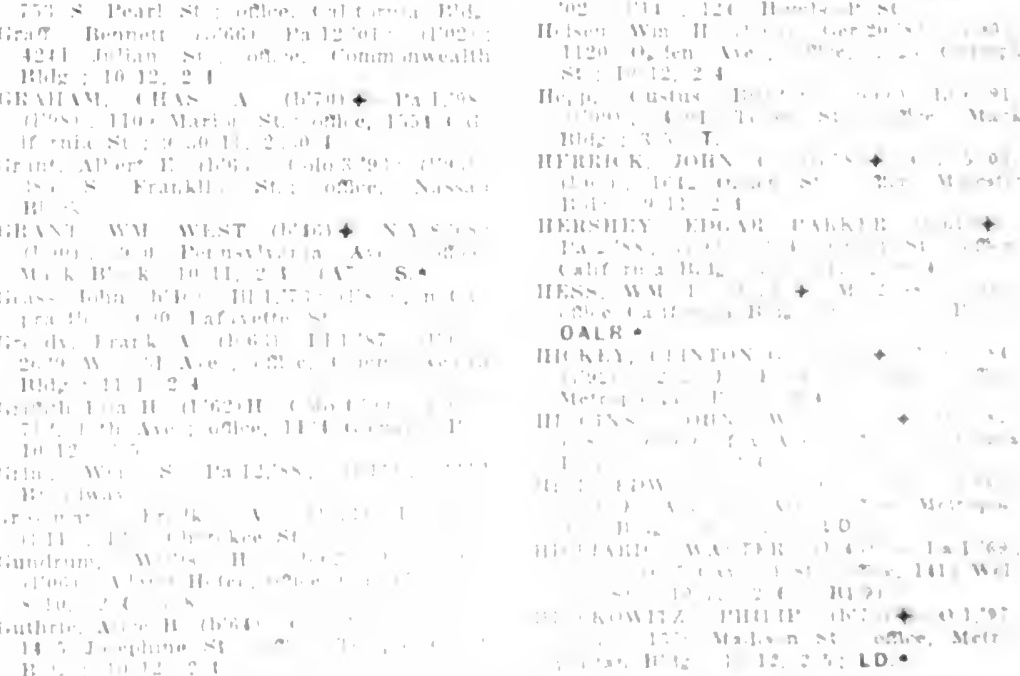
IIomart, Whlson lielth (b'87)-111.6,'13: Intern, Clty and County llospital.

Hodnett, Win. Perkhs (b'83)-Colo.2,'12 (1'12); Natlonal Safety Vault Bldg.

lIofmun, Goo. H. (h'73)-Ky.2,01; (l'01)

not in practlce; $2308,3 \mathrm{~d}$ Are.

Iloffman, Osee W. (b'75)-0.21,97; (1'98) Majestle Mldg.

IIOLDES, GEO. WALTER $\left(b^{\prime} 66\right) \uparrow-V t .2$. '95; (I'98) ; Qucbec St. and 6th Ave. ; T. St. Francls 11 otel; oftce, 105 E. 46 th Are. $10-12,2-4, i-8$

IOPKINS, JOIIN ROLPII (b'Ti)\&-Ont.1. 93; (L.R.C.I'.Edln.,93); (1'00); 1055 Corona St. ; oftle, Wyoming Bldg.; $2-4$; S. lopklus, Thomas Mayes $\left(b^{\prime}, 1\right)-$ Colo.1, 01 (I'01); 314 Detrolt St.; $2-4$

IORN, ANDREW \% (b'56) —-Mo.1, 80 , (1'40) ; 1451 Ellzabeth St.; offce, Counmonwealth Bldg.; 10-12, 2-5.

IIotchklss, Walter Kendrick (b'89)-Colo.2, '13; (l'13) : St. Joseph's Hospltal.

Hough, Louls (b'67)-Mo.1,91; (1'07); 1575 Race St. ; offlee, Iry. Exchánge Rldg. loward, Jolun 'Fredk,-Ill.11,02; (1'07); 12th Ave. and Onelda St.; offee, Majestic I3ldg. : 9-10, 4-5.

HOWARD, THOS. LEON (b'80) - N.Y.19, '05; (1'10); 1260 Mllwaukee St. ; offlce, Metropolitan Bldg.

Hoyt, Ralph w. (b'80)-Yt.2,05; (1'05) 1415 Glenarm Pl.; offlce, 634 ith St: 1415 Glenarin
$10-12,2-4 ; 0 b$.

Hudston, Ranulph (b'84)-Colo.2,10; (1'10) : 1540 Grant St.; offle, IIetropolltan Bldg. ; $2-4 ; 0$ b.

Hutf, Saml. A. (b'79)-Tenn.7,'02; (1'05)

254 i Welton St.; offlce, Kittredge Bldg. IIuffaker, John W. (b'52)-0.13,'78; (1'82) 1460 Columblne st.; offle, Opera House Bldg. ; $9-10,11-12,2-4,7-8$.

H'FFMAN, OSCAI? C. (b'60)-Colo.1,'94 (1'04) ; 1687 Mllwaukee St.; offlce, Em plre Bldg. 10-12, 2-4, Pd. HUGHES, TANDY ALLEN (b'60) -Mo.2, 728,16 th St. ; $10-12,2-4$.

II ultz, Eugene B. (b'78)-Mo.24,'00; (l'02); $1348 \mathrm{~W}$. Alameda Are.

Hungerford, Edwln (b'49)-N.T.13,74; (1'86); 333, 14th St

IINTER, PAULL STUART $\left(b^{\prime} \pi /\right)-C o l o .2$, 3101 (l'04); Sec. State Board of Health:

Hunter, Lw B (b,53) 8-9, 12-2, i-8.

323 s. Penn st.

IIurdman, Allan Graham (b'77)-0nt.5,01 Scot.9,12,03; (1'04); 1062 Pearl St offlee, California Bldg.; 10-12, $2-4$

Huxhold, August F. 10-12, 2-4. (l'9i) ; 2615 W. 25 th Ave; offlce, 1129, 17 th St.

Hyde, Henry Warren-Mllch.2, $78 ; \quad\left(l^{\prime} 92\right)$

323 W. 14th Are.; office, Quincy Bldg.

INGLIS, JOHN (b'69) ๑-0.25,'95; Ill.1, '96: (l'01); 860 Lafayette St. ; office,

Majestic Bldg.; $\mathbf{0 b}$.

GRAHAM, CLARFNCE BANCROFT, JR. (b'79) §-Id. 7,06 ; (l'09); 401 Franklin; office, 1405 Glenarm Pl, ;11-12, 2-3; ObG. $\star$ Irvine, Jos. C. (b'59) H-0.7,'84; (l's9) 2206 Tremont $\mathrm{Pl}$

Ilwin, Robt. Sloan (b'70)-MId.9,'04; (l'08) 1250 Cook St.; office, Wyoming Bldg.

AC'TSOF, HDW

¿-1'a.1,'78; (1'95) Bldg. ; Prof. Ophth., Colo.2,; (B1,4,9);

JAEGER, CHAS.\&-Mo.1,'88; (1'89); 148 Adams St.; oftlce, Metronolitan Bldg. James, Chas. B. (b'66)-Ky 1,$91 ;\left(1^{\prime} 97\right) ; 914$ E. $13 \mathrm{th}$ Ave.; offlce, Empire Bldg.; Ob. James, Wni. Danl. (b'82)-Colo.2,'13; (1'13)

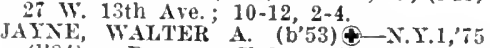
(1'84); Denver Club; offlce, NePhe Bldg. ; $9-10,2-4$ : Prof. Gyn. and Abd. Surg., Colo. 2 ; $\mathbf{O b G}$.

JOHN, GRANT HARULD (b'68)-Colo.5,'04 (l'04) ; 2815 S. Broadway; office, Majestic Bldg.; 11-2:30.

JOHNSON, BENJ. IRWIX (b'75)-Colo.1 99; (1'99) ; 1763 Gaylord St.; ALR.

Junson, James E. (b'71)-Colo.1,'95; (l'95) 5.7 Emerson St. ; offee, 1349 California St.
Johnson, Win. Elijah (b'88)-Colo.2,'13; Intern, St. I,uke's IIospltal.

Johnston, James C. (b'53) 1I-Pa.1,74, Pa.9, 75: (1'82) : 3125 Meade St.; onlce, 154 (thanua sit.

JONES, liO13T. L. (b'68)-Ky.2,98; (1'01) 964 Ogden; oftlce, 1210 , 17 th St.

JONES, SAMI. FOSDICK $\left(b^{\prime} 74\right) \emptyset-N . Y .1$, 02; $(107) ; 2001,11$ th Are. ; offlee, 1405

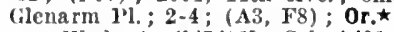

Jones, Wade A. (b'74) IJ-Colo.4,01; (l'01): 220. Marlon St. ; offlce, 911, $21 \mathrm{st}$ St

JONES, WM. WILEY (b'83) -Colo.2,09; (l'09) ; 1433 St. 1'aul st. ; offee, Metro politan 13ldg.

Judge, Walter E. (b'70)-C'olo.2,02; (1'02);

752 Kalamath st.

Keeler, Claude C. (b'80)-Mo.29,03; (1'05) 910,10 th Are.; offlce, 1434 Glenarm $\mathrm{Pl}$.

Keen, Emma J. (b'72)-Colo.3,'97; (l'97)

418 , 13th $S i$

Kelsey, Otls H. (b'66)-Vt.2,'92 (l'04); 59 Jincoln St.; offlce, Wyomlng Bldg.

Kentble, Warl Wallace (b'90)-Colo.2,'13;

(1'14); St. Anthony's Hospltal.

Kemble, Jewls H. (b'67)-Mlch.1,'89 (l'89); IIcPhee Bldg.; 10-11, $1: 30-3$.

KENNEDY, ARTHUR LEMUEL $\left(b^{\prime} 66\right) \oplus-$
IIass $1,01:$ (l’03); 835 Gaylord St. ; 8-10 Mas.

KENNEY, FRANK W. (b'60)๑-N.Y.5,'93; (1'98): 1500 Mtlwaukee St.; offlce, Stedman Bldg. ; 12-4; Anes.

lienney, Wm. Warren (b'i1)-Mo.34,01. (1'01); 1229, 21st St.; 9-11, 2-4.

INEXT. WALLACE C. (b'i2)-Colo.1, 00 (l’00); 1069 Cook St. : offee, Majestic Bldg: $10: 30-12,2-4$; Pd.

Kessler, Sherman M. (b'45) E-O; (I'93) ; not in practice; 1640 Tremont Pl.; office, Commonwealth BIdg.

Kestenbaum, Saml. H. (b'87) -Colo.5,'10 ; (l'11) ; 2716 W. Colfax Ave. ; 9-11, 2-4.

Keys, Chas. W. (b'44)-Ia.1, '78; (1'95) 2329 Ellot St.

rieyes, Henry S. (b'66)-Telm.11,'99; 4216 Umatilla St.

Kindig, Flora May Taylor (b'65)-Colo.3, '96; (1'99); McPhee Bldg. ; 2-4; G.

Kindig, Zoe Zita Mignonette (b'91)-Colo.2, '13; (1'13); McPhee Bldg. ; G.

KINNFY, JULIUS E. (b'56) $\oplus-N . Y .5,85$; $\left(1^{\prime} 93\right) ; 737$ Corona St. ; offlce, Metropolitan Bldg.; 9-1. Klrk, Robt. H. K. (b'65)-D; (†) ; Adams
Hotel ; offee, Wyomlng Bldg.

KLEINER, MOSES (b'66) $\$$-Conn.1,'88; (1'90); 1301 Franklln St.; offlce, Metropolitan Bldg.; 10-11, 2-4; Prof. Ther. Colo.2; i. $\star$

Kllukowstroem, Emll V. (b'54)-111.1,'96 (1'99) ; 209 Exposition Are. ; 8-10, 2-4.

KNOCH, NORBERT HENRY (b'88)-Colo.5 10; (l'11); 609 Colfax Are. ; offce, Ma jestic Bldg.; 2-4, $7-8$.

Kracaw, Austin Rodgers (b'86)-Colo.2,'11; (1'12); 1531 Washington St. ; oflice, Commonwealth Bldg.

KROHN, HARRY N. (b'80)๑-Mo.20,'04; (1'04); 1484 Garfield St.; offlee, Metropolitan Bldg.; 11-12, 2-3; U.

KROIIN, MORRis J. (b'78)@-Mo.20,03 (l'03); offlee, 2780 W. Colfax Are.; 2-4;

KRUSE, MAT B. TEELE (b'67) $9-$ Colo.2 '97; (1'97) ; 923 Lipan St.; offce, Central Savings Bank Bldg. ; 9-10, 2-4.

KUNITOMO, NOBUYA (b'79) ๑-Pa.11,'11 (1'12); 2705 Gilpln St. ; offlce, 1232, 21 st St. ; $9-12,3-6$.

LaCroix, Ray R. (b'90)-Colo.2,13; (1'13) 923 Lipan St.; offlce, Central Savings Bank Bldg.

Lake, Edw. F. (b'60)-N.Y.15,'82; (l'89); 1574 S. Clarkson; offlce, 1705 Lawrence St. ; $9-11,2-4,6: 30-8$.

LAMBERTON, ROBT. FLOYD $\left(b^{\prime} 78\right)+$ $0.26,03 ; \quad\left(l^{\prime} 04\right) ; 1270$ S. Lincoln St. office, Mack Bldg.; 10-12, 2-4.

Lamont, Walter A. (b'47)-Tenn.6,'83 (1'89); 448 Downing St.; 10-12, 2-5.

Lanigan, Thos. Leigh (b'82) - Ind.8, 05 (l'13) ; 1637 Lincoln St.

Law, Lorenzo Channing-Ind.5,'80; (1'83) Mcclintock Bldg.
LAWNEY, ELEANOR (b'51)屯-Colo.1,87; $(1 ' 88)$; 1654 Grant Are.; office, Majestic 13ldg. ; $10-12,2-4$.

IAZELL, EDV. WM. (b'78) - Colo.5,02 (I'02); 1018 Marton St.; offlce, Metropolltan Bldg.; 10-12, 2-4.

Ice, Danl. Schenk (b'85)-Mo.20,'12; Intern, Clty and County IIospltal.

Lee, Geo. Francls (b'87)-Colo.5, 09; (1'09) 3447 iryant St.; offlce, Wyoming Bldg

LEF, CFO. IIEI?13E1\}T ( $\left.b^{\prime} 7 \tau\right) \oplus-C o l 0.5,05$; (l'05) ; 2760 Vine St.; offlce, Commonwealth lldde; $10-12,2-4 ; S$.

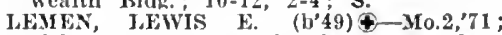
(1'81); 1605 Fennsylvanla Ave.; offlce, Majestic Bldg. ; $8: 30-10,2-4 ; S$.

JEVY, ROBT. (b'f4) †-N.Y.10,'84; (l'84) 1528 Ogden St. ; offlce, Metropolltan Bldg.; (B1,3); ALR.

Lewls, Mary J. Kaveny (b'09)-Colo.2,'96; (1'96) ; 3 S. Newton.

lewis, Robt. (b'84) - Ky.11,08;

Natlonal Jewlsh Hospltal; T.

LIBBY, GEO. FIANKLIN申 - Me.1,91 : $\left(l^{\prime} 00\right)$; 1755 Grant St.; offlce, Metropolltan Bldg.; 10-12, 2-4; (B1,4,9); Op. * Llebhardt, Laura L.-Mlch.1,'84; $\left(1^{\prime} 90\right)$;
1856 Washlngton St.; 10-12, $2: 30-4$. Lincoln, Clcero Lee, Jr. (b'86)-Mo.2,'09; (l'11); 3605 W. $32 \mathrm{~d}$ Are.; offlee, 3492 W. $32 \mathrm{~d}$ Ave. ; $10-11,3-5,7-8$.

LINDAHL, JOHN (b'65)-Ia.6,'88; (l'99) ; 11-12, 3-5 : ObG.

IJNGENFELTER, GEO. P. (b'73)-Mo.20 97 ; (1'02); 300 Marlon St. ; oflee, Metropolitan Bldg. ; 10-12, 2-4; D*.

LOCKARD, LORENZO B. (b'72) $\oplus-\mathrm{Pa} .1$ '94; (1'01); 665 Lapayette St.; offlce, ALR. *

Locke, Chas. F. (b'45) $\rightarrow$ N.Y.10,'81; (1'92); 1345 Glenarm Pl.; 9-10, 1-3, 7-8.

Locke, John Galen (b'72)H-Colo.4,04; (1'04); 1345 Glenarm P

(1'06) ; 2070 Colorado Blvd.; ofllce, 1434 Glenarm Pl. ; 2-4.

I.ongeay, Wm. H. (b'63) -Mo.2,'82; (l'94); Bank Bldg. ; 9-12, 3-5.

LOVE, MINNIE C. T. (b'55) @-D.C. 3,87 ; (l'93) ; 175 S. Lafayette St.

LOVE, TRACY R.-N.Y. 1,'06; (1'07) ; 175 S. Lafayette St.; office, Metropolltan Bldg. ; 1 -4. Lowe, Wilbur (b'78)-Colo.2,'11; (1'12) ; 863
Emerson St.

LOWEN, CHAS. JULES (b'86)-N.Y.8,'09; (1'11); 4136 Tennyson St.

lucy, Daniel R. (b'60)-Colo.3,96; (l'96) 3505 Navajo $\mathrm{St}$.

Lum, Sherman B. (b'52)-II1.14,'95; (1'99); offlice, Claston Block.

Lusk, Wm. Albert (b'70)-Neb.5,92; (1'08) 2901 W. $38 \mathrm{th}$ Are.; ofllce, 2705 iv. $38 \mathrm{th}$ Ave.; $9-12,3-5$.

(1'87), CHAS. B. (b'63) $9-M a s s .1,86$ polltan Bldg.; 2-4; Prof.' Surg., Colo.2;

Lyon, Roy Mulr (b'72)-Ill.4,'93; (1'93) ; 2849 Quitman St.

LYONS, OLIVER (b'74)థ-Ky.1,'98; (l'03); 428 F. 16th Are.; offlce, Metro-

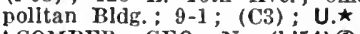

MÄCOMIBER, GEO. N. (b'54) $\odot-0.13,78$. $\left(l^{\prime} 90\right) ; 745$ whlllams St. ; offlce, 1415 ivelton St. ; $10-12,2-4$

Maddox, WW. B. (b'64)-Ia.9,'92; (1'00) ; 1498 S. Pearl St. ; 12-2.

Mahon, James R. (b'54) -Colo.3,97, Colo.4, '98; $\left(1^{\prime} 97\right)$; 510,18 th St.

MANN, A LF RE D (b'64)థ-N.Y.1,'92; (l'95) ; Hotel Crest; offlce, Majestic Bldg. ; $10-11,2-4$

MANNS, RUDOLPH R. (b'76) $\oplus-$ Colo. 3,00 $\left(\mathrm{I}^{\prime} 00\right) ; 2525 \mathrm{~W}$. $32 \mathrm{~d}$ Ave.; offlce, Mercantile Blidg. ; 10-12, 2-4.

MARKLEY, ARTHUR JACKSON (b'74)థ$0.9,03$; (1'10); 1410 Grant St.; offlce, Metropolitan Bldg.; 10-12, 2-5; Prof. Derm., Colo.2; $\mathbf{D}$.

Marshall, Linn B. (b'82)-Colo.2,'13; (1'14) ; St. Anthony's Hospltal.

MARSHALI, ROBT. MORRIS (b'72)థColo.2,03; (l'03); Metropolitan Bldg. 
Martin Herbert E. $\left(b^{\prime} 80\right)$ - Que.d,"02; (l'03) : 2324 Iranhoe $s t$

(1) J (I'8): 1756 Race; once, Majestle Blile. 1.4

Mastin, James Wm. (b'5i) II-Colo.t,'s8 : (1'00): $630,16 \mathrm{lh}$ Ave. ; offlce, Mack Bldg. $11-1,+-5$.

MATSON, WM. F. (b'64)-1a.3,'96; (['08) 1617 Cook St.: ortece Ceniral Savings Bank Blde: 9-18, 2.5: (B9).

MATTHEWS, RENJ. II A II T-Colo.2,06; (l'06); $2342 \mathrm{Etm}$ St: ontce, Metropolltan Blds.

Maul, Herman 6. (b'8s)-Colo.5.'10; (l'10) 1303 Vraln St.; ottlce, Mercantlle Bldg.

Max. Alfred Fiphralm-Colo.5,06: (1'06): $1016 \mathrm{E}$ loth Are: ofice, 2205 Lariner St. $10-11,2-4,7-8: U$

MAXWELL, JOHX WTLSON (b; $\% 2)-$ N.Y.19. "00: (1'00): Member Ohlo state Med. Assn.: 1516 Mllwaukee St.; ottice, Call. fornla Bidg.

McCarroll, Jas, (b'72)-Mlch.7,04; (l'05): 306 S. Broadway.

MCCARTNEY, FRANK M. (b'i5) \&-Colo.3, 02: (1'02) ; 2122 Gaylord St, o oflce, Mack Blde; $2-4 ; 5$.

MCCAW, JOHN AIFXANIER (b'66) III.1,01: (1'0i) : 874 Clarkson St.; ofice, Majestlc Blds.; 9-12, 3-5: ODA.

Mecullough, Frank A. (b'6l)-Md.6,97; (l'9i): 1649 Jadison St.

Mccurtain, Frank k. (b'i 1)-Colo, '97;

(l'97); 1936 Washlngton St.; ottce, Com: (197); 1936 Washlngton St.; otice, Commonwealth HIIdg.

MeDanlel, John w. $\left(\mathrm{b}^{\prime}, 0\right)-$ Colo.3,'95; (1'95): 2535 Curtls St.; oftec, 2057 Larlmer St: $10-12,2-4,7-8$.

MeDermith, Samuel T. (b'48)-Ky,2,76: (1'91): 1476 l'ennsylvanla St. : oftce, Wyoming Rldg.; 10-12, 2-5; OALR.

MeDermott, Geo lawrenco-III.1,97: (1'08)

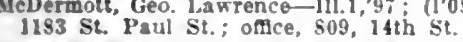

MeFАCHЕR., CHAS. G. (b'76)-Tenn.1, 00 ; (1'13): Member Mlss. State Med. Assn. Metropolltas Bldg.; Pd.

MeGee, Rea P'roctor (b'ai)-Colo 4 ,03. (l'03) ; 3349 Ellloft St.; oflice, Mack Bidg. 9-12, 2-5.

McGinn, Matthew Newton (b'70)-1'a.12,02 ; (l'03): 1554 Gaylord St.; oftce, 1434 Glenarm PI. MCGILLIVRAI, JOIIN C. $\rightarrow$ : (l'89); 1233 ,
I5th St.

MeGRAW, HFNRY R. (b'-3)+-Md.3,0I (l'01): 165 Franklln st: offce, Metropoll: in Bidz: $10-11,2-4 ; \dot{s}$

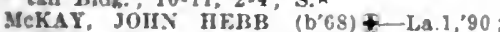
(1'04): 2939 colfax Are.: oftce, Metro: polltan Bldg.

Mckeen, Harold R. (b'78)-Mo.20,0 fi (l'08): Si. Lukes Hospltal.

MeKELVFI, SAMJ. IROITT. (b'61) 84: $(1.03)$ : 4403 W. 321 Are. : 1-4

Mekelrer Yan Drek (b'87)-Colo5,10. (I11): 3032 York sit.; offee, Common-

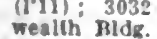

MeKelvey. Win. (b":2)-l'a.1,75: $543 \mathrm{~s}$. Lineoln Ave.

MCKFNNEY, GEO I". (b'5J)-111.1, 90 (1*09) ; 3025 Grore St.; 9-10, 2-3, i-s; Ob.

Mekenzle, (7has. Duncan (b'75)-Coln 2,12 (1'13) : 300 Velaware 8t. : offec, Majevtlic Bldg. : 2 - 4

Mckeown, klmer F. (b's0)-Colo.5,0J: $\left(l^{0} 05\right)$; 2406 W. 37tli Are. omce. Stedrunt B)da. $9-12,2-1 ;$ (IB9): OALR.

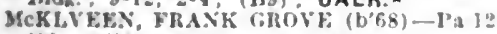
92: (1"98) : 83 \&. Hrualway: $2-1$

MCKNICHT, IIOWARD AI,IISOA (b'81)Pa.1,10: (1'13) : 1133 colfax St: offec Pa.1,10; (1'13): 1133 Colf

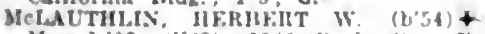

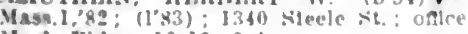
Mack IId : : 10-12, 2-4.

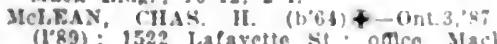
$\left(I^{\circ} 89\right) ; 1522$ Lafayctte Sif. Blde.

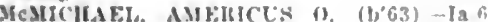
91: (1009): Nember-Mu. siate yel Ast1.: 20:0 firape st.: onlce. fentra Aart.: $20 \%$ Tirape St.: onlec.

MeXamara, John Wm. (b.77) - $0.1,01$ (1.06): 3150 rederal Bird.; odte. IInch Ii) le. ; $1-3$.
McNACGilT, FHANOIS If (bo

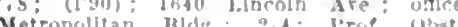
Colo.2. S

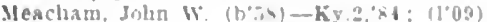
1119 si loul it once. (unumosealth Iblets.

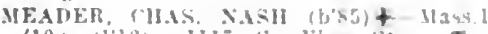

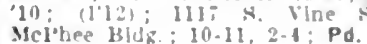

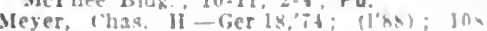
s. Clarkion

Meyer, Jukn li. Warren (b'S3)-ll! L,0 (105): A.A.Surg.,

MIFl, (iE:). W. (b'59)+-1.a $2: 83 ;\left(l^{\prime} 85\right)$ 20 F. Colfax Are.; offce, Metropolitat Hldg.: $10-11,3-5$; $\mathbf{S}$

MH:HLEY. IRA CIIESTER (b'S4)-Colos 05: (105): 1362 Josephine St. ; offle. Wyoning Blds.

Miller, Claude (b'so)-Colo.3, $02 ; \quad\left(l^{\prime} 04\right)$ 9 II S. I'ennsylranla Are.; otlce, Wyomlng 13]dg: : $11-1,3-5$

MILLER, SAML. W. (b'5i)-Pa.2, 81 $\left(18^{6}\right)$; 1273 Vine St.; nfice, Metropolitan

MIIIs, Hobert N. (b'40)-Vat,ffi; (l'00): 274 W. 26011 Are.

Mitchell, Geo. W,-13.2,60; ( ); 2203 Race sit.

(I"96) : It00 "ulumbine oftce Metropol tan Ridg: 2-5; Pruf Bact. Colo.2 : L. MOLEES, GEO. A. (b'-6) + Colu.3, "No: (l'00); 1258 Marion st.: ottee, Mack Bldg. : $10-11,2-4$; NP.*

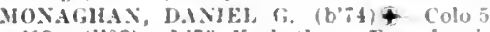
03; (I'03); 16:3 rork st.; oflice, Jacub son Blds.: (119); Op.

MONSOX, GEO LONH (b'\$2) + Colo.5,05 (l'04): 2115 F. 2tth Aie. oftice,

monwealth Hids : 10-12, $-1: 0 \mathrm{bG}$.

IOOKE SLFRE!l M. (b'65)-1'a.9.02 (l'02): (Hrlghton); onlee, Emplre Ibidg. $2-5 ; \mathbf{T}$.

Moore, Nilce T. (b'63)-Colo.3,'9; ; (109:) 1325 Cherokee st.; ottice, central savings llank Blig.

Moore, Clara II. (b'il)-Colo.2,97; (1'97) 2455 Clermont st.

Morgan, Juhn II. (t'ft)-Ky.1,90; (l'04) $85 \mathrm{~s}$. J'ennsylranla si. ; 10-12, 2-4. Morgan, shlnar - $0 ;(100) ;$ is 10 C'diforsta

Molt:ING, JAMkS F. (b'6s)+-111.1,91 (1'01); 228 I) laware st. ; otce, Mack lildg; $; 0-12,2-1 ;$ OALR.

Mortli, Martelle flint $(20 \% 9)$ - Ma 9, 04

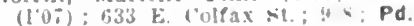

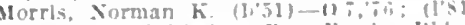

3539 lowell blid : ottle, kmplre Hat

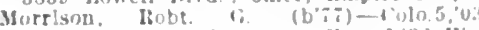

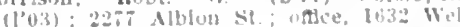

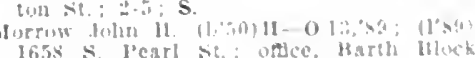

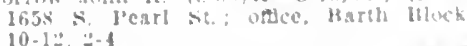

-

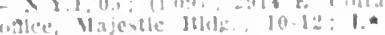

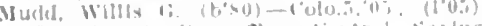
10 10ij l,rant oit.

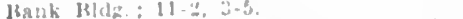

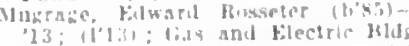

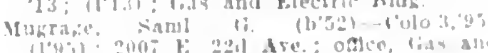
(1040); 2007 r: 231 Are.

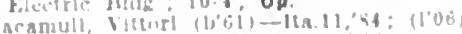

311: fiernan Amerluan Janh [blü

Saluka, Iutony ir

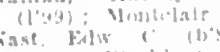

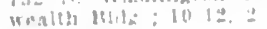

ceres, Frelk. Fonil

(1'0), lon: I'tearl

is,

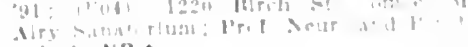

Pinlio: NP.

G.
Sext sit.

Siorde

(1')

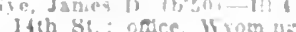

$a-1$

(1) 11 (1)

(1'xl): 10,0 I"ennsy

'ongor. Thim Walies

(101); 329 , Ilth Ave.

'Donnor, Willielmlna k"

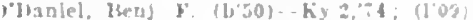

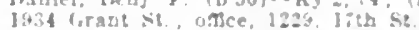

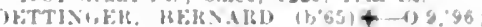

$(1.49)$; 134; lirant it, omee, Metropolitad \|\|$_{R}: 3-5 ; N P . *$

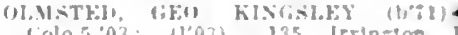

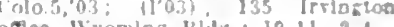

13taz: $10.11,2$.

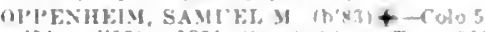

04: (1005): 1350 cirant st: ifuce, jeg l'sllfornla llida.

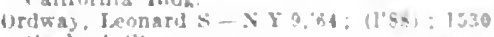
riaylord si.

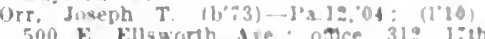
St: $9.11,3.5 ; 0.0 \mathrm{~s}$

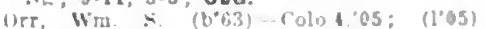
bis KIng st

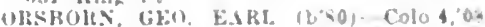
Coln ily. Gro Earta to tice, Wyoming Hiuz; 10-1:, 2-4; $\mathrm{s}$.

orvborn, Jeanette $R$ (b'as)-Colot. 0 :

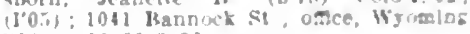
Bldg.: $12: 30-3: 30$

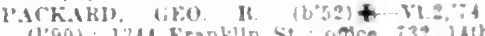

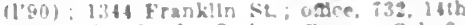
Si: "-1: I'rof. Ortho Surs. Culu? (A3) : Or.*

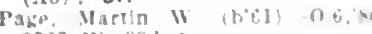

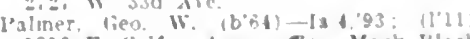

1310 F. Colfax Are.; oftoce. Mack Wlack:

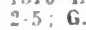

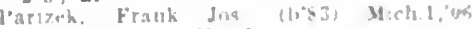
: Shirley Hintel

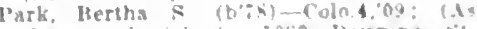
lapang plysiclan):

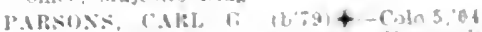

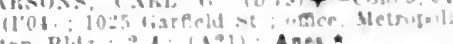
isn Blate :-1: (12) : Anes*

(1+1), 131\% Mnedela st

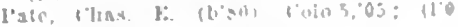

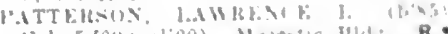
(ulo.5,0y: 11.09): Mansuc IIIs: R.

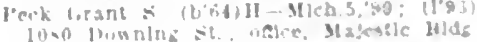
$10-12.21$

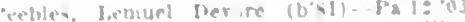

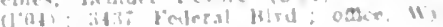

(17) $13 !$

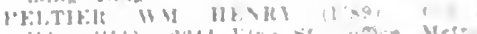

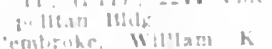

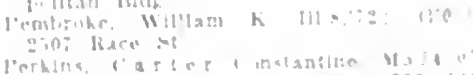

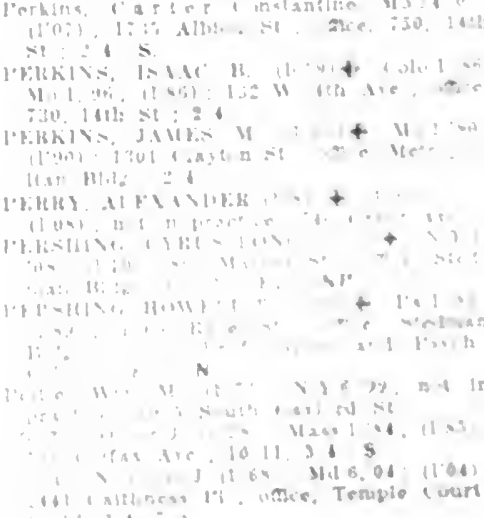


Phillins, Samuel Grover (b'63) - Mo.35,'10 ; (1'11); 808, 14th St.; 11-12,3-5, 7-8.

Pitney, Orville (b'75)-Mo.1,99; (1'07): 133 S. Logan Are.; office, 400 Bayari

PLACE, OLNEY GALEN (b'60)-Mich,1,85 $\left(1^{\prime} 02\right) ; 1716,17$ th dre

Pollard Alpheus L (b,5)-1at,93. (l'03) not in practice: 1045 Lincoln St, office, Foster Bldg.; ob.

Pollnek, Lillian Irvine $\left(b^{\prime}, 56\right)$ II-Colo.4,,$^{\prime}$; (l'97'; 3434,17 th Ave.; $10-2 ;$ G.*

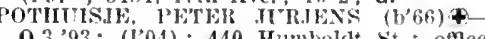
$0.3,93$; (1'04) ; 440 Humbollt st.; ofmce Central Sarings llank 13ly.; I0-12, 2-4. (l'02), 2261 Albion st.; office, Metropolitan Bidg.; $1-4$; ObG.

Powles, ĆTAS. A. (b'58) +-N.Y.1,83. (l'94); Unirersity Club; oftlce, Stedman Bldg. : $2: 30-4$; Prof. Clin. Surg., Colo.2; $(A, 5, i) ; S$.

PRATT, ELSIE SEELYE (b'73)क-Mich.1, 04; (1'04) ; 2555 Ash st.; office, 1434 Glenarm St.: $2-4$; ALR.

Pratt, Yerry K. (1,65) E-Mo.10,93; (1'94); 1334 Humboldt St.; offec, $711,1 \%$ th St. ; 10-12,3-5.

Preston, Miller Edwin (b'79)-Colo.5,03; (1'03); 1707 Franklin St.; office, Metropolitan Bldg. ; 2-4: $\mathrm{S}$.

PREWTT, FRANCIS ELGIN (b'6s)థColo.3,98; (1'95) : Brown Palace Ilotel; office, 632, 1 7 th sit. : $10-11,2-5$.

Price, Evelyn B. (b's2)-Colo.4,'08; (1'13)

438 Colfax Ave.; offce, Kittredge Bidr.

Pronger, Emma Daries (b'62) Neb.3, 85 , Ill.4,'86; (1'03); 736 Vlne St.; G.

Pruett, Frank A. (b'i2)-IIo.18,'?

\$21 F. 22d Are, ; 10-12, 3-4. (1,90) Rae, Anna Marshall (b

(197): 4826 Tennyson St.

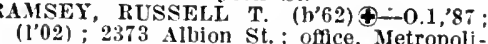
tan Bldg. ; 10-12, 3-5; Pd. Randall, Saml. J. (b'52)-0.13,'80; (1'96) ;

Ransom, Allen R. (b'57)-O; (1'92) ; Com-

monwealth Bldg.
Retd, Chas. C. (b'73)-Colo.4,'05: (l'04) 141 Einerson St.; office, Majestic Bldg. 10-12, 2-4; OALR.

Reinhardt, Eugenia J. (b'66)-Colo.4,97 ; (1'37); 1520 Mlarion st.; offce, Central Sarings Bank Bldg. ; 3-5.

Reiss, Theodore H. ( $\left.b^{\prime} ; 1\right)-$ Colo. 2,$12 ;\left(l^{\prime} 13\right)$; 917 Acoma St.; office, 1040 W. Colfax St

Rice, Chas. 0. (b'58)-Ild.4,90 (1,90) 1448 Elizabeth St.; offce, 15th and Stout Sts. ; 8-10, 2-4.

Richards, B. Franklin (b'51)-Cal.4,03; (1'04); Masonic Temple; 1-5.

RICHARDS, DANL. FRED. (b'82)-Colo.5 05; (l'05) ; 1400 S. Pearl st.; office, 1590 S. Pearl St

Richardson, Daniel A. (b'64)-N.Y.5,'89, Colo.4,'04; (1'94); 2200 Williams st

Richardson, John F. (b'56)-IIl.1,'88; (1'08); 1859 Lincoln St.; offlce, Ssmes Bldg. $10-12,2-4 ; S$.

Richison, Rush R. (h's1) -0.25,04; (1'13) ; 766 Marion St.; office, Mletropolitan BIdg. Rlehmond, James A. (b'63)-Colo.1,'92 (1'92) ; 611, 17th St.; 11-1, 3-5.

Rllance, Chas. Delmer (b'80)-Que.1, 06 (I'09); Hotel Plaza; office, Central Sar(P'09); Hotel Plaza; office, RINK, J. ALDO (b'74)Ð-Colo.5.'04; (l'04);
624, 14th St.; 10-11, 2-4.

Rivers, Edmund C. (b'58)-1Id.1,79; (1'83) 1632 Welton St.; $9: 30-3 ;(\mathrm{B4}, 5) ; 0$.

ROBB, FRANK C.-1a.9,94; (1'13); Nember III. State Med. Soc.; 1402 S. Broadway. Robb, Wm. John (b'83)-Colo.2,'13; (1'13); St. Joseph's IIospital.

ROBERTS, JUDSON o. (b'63)-Yo.20 392 (1'00); 1425 Wasbington St. ; office, Metropolitan Bldg.

Roberts, Una G. (b'61)-Colo.3,'93; (l'96) 53 Clarkson st. Roberts, Wm. (b'68)-Colo.5,'06; (1'06):

Robertson, Wm. M. (b'44)-Ia.1,'70, Ill.11, 83; (1'83); 946, 11th St (1'81); 2521 Franklin St.
Ioblnson, Chas, otts (b'86)-Neb.6,'12; () ; 515 1\%, 2d St.

ROBINSON, MCCAIN (b'83) - La.1,'11 (l'13); Member Ala. State Med. Assn. Phipes Sanitarium.

ROE, JOHN F. (b'72) $\oplus-111.1,99$; (l'01) Denver Athletic Club; oftice, Commonwealth Bldg. ; 2-4, 7-8,

ROEHR1G, GEO. F. (b'61)థ-I'a.2, 30 : (1'91); 1257 Fillmore St.; office, Metropolitan Bldg.; 11-12, 2-4.

ROEIIRIG, KARL FRANKIIN (b'85)-IIl.6, 07: (l'0 $)$; 1324 Fillmore St.; offlce, Iretronolitan Bidg.; 3-5; Anes.

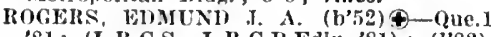
'81; (I.I.C.S., I.R.C.P.EdIn.,'81); (I'82) 222 IW. Colfnx Ave.; 1-3; Prof. Surg., Colo. $2 ; \mathrm{S}$

ROGERS, FRANK E. (b'72)-Que.1,'97; (1'38); 85.3 Lincoln Ave, offlce, Majestle Bldis. ; 2-3; $\mathbf{S}$.

ROOT, MATT li. $\left(b^{\prime} 64\right)-C o l 0.2,97 ;\left(l^{\prime} 97\right)$ 1441 Gilpin St. ; office, Coronado Bldg.

Rose. Henry f. (h'61)-Colo.3.'96; (1'96) 2411,15 th St.; $10-12,2-4,7-8$.

Rothwell, Augusta Moore (b'58)-Colo. 3,00 (1'00); 921 Clarkson St.; offlce, 1132, 15th St. ; $12: 30-3$.

ROTHWELL, EDWIN J. (b'42)†-Mich.1, 75; (l'82) ; 921 Clarkson St.; office, 1132, 15 th $S \mathrm{St}$.

ROTHWELL, PETER D. (b'49) $\uparrow-$ Mich.l, '81; (1'82); 58 W. Eilsworth St.; office, Wyoming Bldg. ; 9-10, 1-3, 7-8.

ROTHWELL, WM. JOHN (b'39)థ-Pa.2,'73; (l'88) ; 2073 Ogden St.; offce, Wyoming Bldt. ; 10-12, 3-5; Prof.' Med., Colo.2.

Roundlez, Pierre V.- $-\left(1^{\prime} 91\right)$; 521, 21st st.

ROVER, IIENRY W. $\left(b^{\prime} 62\right) \oplus-0.9,84$; (1'94); 2704 W. $32 \mathrm{~d}$ Ave, offlce, Clay St. and w. 32d Ave.; 1-3.

Rowe. Paul Grosvenor (b'78)-111.15,'03; (1'05) ; 620, 14th St.; 2-5; Ob.G $\star_{\text {. }}$

RUEGNITZ, LOUIS H. (b'69) - Ill.1, 05 ; (1'08); 2232 Albion st.; office, 1434 Glenarm Pl. ; $11-12: 30,2-3: 30$.

Russell, Lida B. (b'62)-Colo.4, 07 ; (l'07); 2681 Clermont st.

Sarkisian, Toros (b'65)-III.1,97; (l'03) 1135 Pearl St.; office, 1608 Broadway; $10-11: 30,2-5 ; s$.

Sattler, John II. (b'57)-0.12,'87; (1'07): 686 S. Pearl St.; 10-12, 1-4.

Scantleton, John Martin (b'89)-Ill.6,13 ; Intern, City and County Hospital.

SCHERRER, ELIIER A. ( $\left.\mathrm{b}^{\prime} 74\right)$ †-Mo.2,'97; (1'98) ; 1811 Grant St.; office, 722,14 th St. ; $2-4$.

Schram, Maud E. B. Martin (b'72)-Mich.1, 99 ; (1'09); not in practice; 1120 rearl St. SCHULTZ LOUIS HUBER (b'84) $\oplus-0.1$. '06; (1'08) : 871 S. Gilpin St, ; offce, Metropolitan Bldg.; $10-1 ; \mathrm{T}$.

SCOTT, WALTER S. (b'73)థ-D.C.1,96; (l'12) : Nember Ohio State Med. Assn.; 1434 Glenarro $P 1$.

Sears, Mark H. (b'58)-Ill.6,'83; (1'90); 351 S. Sherman Are.; office, German-American Trust Bldg.; $10-4 ; \mathbf{U}$.

SEDWICK, WM. A. (b'69)-MI.1,93; (1'9S); 950 P'earl St. ; office, Metropolitan Bldg.; $10-12$ :30, 2-4; (B9); OALR.*

SEEBAŚ, ALFRED R. (b'68) \&-Colo.1,93; (1'93) ; 2201 Raleigh St.; office, 1349 California St.

SEWALL, HENRY (b'55)థ-Colo.1,89: (1'90); 1360 Vine St.; offce, Yrajestic Bldg. ; $2-4$; Prof. Med., Colo.2; (D6) ; I.ћ Shafer, Harry Summers $\left(b^{\prime} 69\right)$-Colo.1,'01; (l'01) ; 315 S. Downing St. ; office, Metropolitan Bldg.; 10-12, 2-4.

Shaller, John 11-0.8, i4; (1'03); 1933 Downing St.; office, Commonwealth Blòg. ; 9 -5.

SHARPLEY, WM. H. (b'54) - Colo.3,'98; (1'98) ; 1333 E. 3d Ave.; office, Wyoming Bldg.; 3-5; Prof. Mled., Colo.2.

Shea, Robt. Macfeely (b'84) - Colo.2,'13; (1'13) ; Mercy Hospital.

Shepard, Arthur E. (b'76)-111.13,99;(1'01); Kaiserhof Hotel; office, Commonwealth Bldg. ; $1-3,7-8$,

SHERE, OSCAR M. $\left(\mathrm{b}^{\prime} 78\right) \oplus-$ Colo. 3,02 ; (1'02); 1443 Adams St.; office, Commonwealth Bldg.; $11-12,2-4 ; \mathrm{s}$
SHOLLENBERGER, CHAS, F. (b'57) Pa.2,85; (1'88); 2836 Federal Blvd.; offlce, 2309 Larlmer St.; $9-10: 30,1-4,7-8$;

Prof. Med., Colo.2; Ob.
SIlOTWELI, WM. F. (b'58) $\rightarrow$-N.Y.5,85 ; (1'89) ; 3359 Marion St.; until $9,1-2,6-7$. Sibbald, Geo. W. (b'65)-N.Y.10,'92; (1'08); 1404 Tremont Pl. ; $1-4$, after 6 .

Sibbald, Lillian Estelle Clarke (b'78)('olo.4,09; (l'09); 1404 Tremont St. $10-12,6-8 ; G$

SIMON, SALING $\left(b^{\circ} 70\right) \oplus$ Colo.3,95; (l'n5) ; 1316 Gilpin St. ; office, Metropolltan Bldg. ; $10-11,2-4$.

SIMISON, ADAM J. (b'78) $\oplus$-Colo.3,01 (1'02) ; 1258 Marlon St.; office, Commonwealth Bldg. ; 10-12, 2-4.

Singletary, Mario A. (b'55)-Colo.1,98,

Colo.4, 03 ; (l'99); 1506 W. 16th Avo.
Skillman, Claredon (b'61) - Mo.28, 03 ; (1'03); 2001 w. 41 st Are.

Smiley, lienry Chandler, Jr. (b'82)-Colo.5. 05; (l'05); 3032 Vallejo $\mathrm{st}$.

SMITH, FRANK SIMISON (b'69)-Mass.1, 95; (1'11); Member Mass. Med. Soc. 1112 Broadway; $1: 30-3,6-\tau: 30 ; s$.

mith, Jacob $\left(b^{\prime} 70\right)-N . Y .10,31 ;\left(l^{\prime} 91\right)$ 468 Ogden St.; offlce, 632, 17th St. ; 10-12, $2-4,7-8$.

Smith, Mary G. Gillette (b'56) - N.Y,13,'90 ; (1'91) : 4614 Bryant St. ; 11-3; G.

Smith, Richard Gilchrist (b'81) - Colo.2,'12: (1'12) ; 2900 Vine St.; office, Charles Block; $10-12,2-4,7-8$.

Smythe, Saml.'s. (b'39) H-Ill.4,67; (1'81) 1765 Sherman St.; offlee, Mack Mldg.; $9-10: 30,2-3: 30$

Somers, Frank M. (b'58)H-Ia.4,'81; (l'91) ; Sommer, Cluristain N. $\rightarrow$; $\left(l^{\prime} 03\right) ; 1435$ Stout

Spangelberger, Mathew A. (b'80)-Colo.5 04 ; (l'04) ; 459 bowning st.; office, 632 17 th St. ; 1i-1, 7-9.

SPERRY, MARY A.-Pa.7,90; (1'07); 2534 Ash St. ; office. Kittredge Bldg.

SPITZER, WMI. MLAXWELL (b'75)థ-N.Y.5, politan Bldg. : 10-12:30,3-5:30; (C3) ;U.* SPIVAK, CHAS. D. (b'61) $\oplus-\mathrm{Ca} 2,^{\prime} 90$; (1'96); 1421 Court Pl.; 2-4;

Spratlin, Paul E. (b'58)-Colo.1,92 ; (1'92) ; 2230 Clarkson St.; office, Good Block ; $9-11,2-4,7-8$.

Stahl, Arthur Wm. (b'85) - Colo.2,'12; (1'12) ; 1323 E. 34th Ave.; office, Metropolitan Bldg. ; 10-12, 3-4.

Stahl. Frank Winthrop-Colo.3,'01; (1'01) : 1272 Columbine $\mathrm{St}$.

STAUNTON, ARCHIBALD G. (b'69)-Pa.1. 93; (1'03) ; 1445 Downing St.; office, Central Savings Bank Bldg.; 11-12, 3-5.

Staunton, Rachael Bullard-Pa.7,'94; $\left(1^{\prime} 03\right)$; 1445 Downing St. ; 11-12, 2-3.

STEEVES, CHAS. P. (b'65)-Que.1,'96 ; (1'96); 437 E. 1st Are.; office, Majestic Bldg. ; 3-5.

Steinberg, Benj. M. (b'86)-Colo.5,'09; (l'09) ; 1240 Ogden St. ; office, Metropoli$\tan$ Bldg. ; 10-12, 2-4.

STEINER, JOS. MANNING (b'80)-La.1,04 ; (1'08); 776 Quehec St.; offlce, Agnes Nemorial Sanatorium.

Steinhardt, Ernest H. (b'76) - Ill.4,'13 ; (1'13) : Park Avenue Hospital.

STEMEN, GEO. C. (b'65) - Ind.10,'86 ; $\left(10^{\prime} 00\right) ; 1527$ St. Paul St.; office, Nretro-

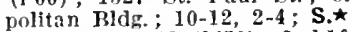

STEMLN, WM. E. (h'T0)-Ind.10,94; ( $\left.1^{\prime} 02\right)$; 1540 Washington $S t$. ; office, Metropolitan Bldg. ; 10-12, 2-4.

Stenlouse, Henry Merritt (b'S9)-Colo.2,'13 ; (1'13) ; Mercy Hospital.

Stenhouse, James (b'59)-Colo.1,'86; (1'86) : 2960 W. Denver Pl. ; office, Empire Bldg. ; $9-11$.

Stevens, Harry Lester (b'64)-Ml.11,'94; (l'11); 2801 Vine St.

Sterens, John LeRoy-Colo.5,'08; (1'08); 1326 Lipon St.; ; office, 620, 14th St. Stiffler, Geo. Wm. (b'58) - MQ.1,'87; Stiffer, Martin Luther-Colo.2,'13; (1'13) ; Mt. Alry Sanatorium.

STILWILL, HIRAM READ (b'72)థ-Ill.11, 01, Mo.2,'98; (1'03); 2044 Albion St.; of-

fice, Majestlc Bldg. ; 9-11, 2-4; (B9);0pA. 
Stockett, Benj. F. $\left(b^{\prime} 61\right)-$ Mo.1,'s6 ; (1'si) 3699 Franklln: ottice 2700 Lartmer $\mathrm{St}$. $11-12,4-5,7-8$

STOVER GEO. II. (b'\%1) Colo.1, 93 ; (1.93): 2001 E isth Are: ofice, itetroDolitan Bldz, 10-4; 'rof. Boent., Colo.: Dollian Bld

STRATTON, MAR REEl (b'69) \&-111.? 92: (l'92): 2160 S. l'nirerslty Are. ottice, 104 Broadway; 10:30-11:30, 2-4 Ob.

STRICKLER. DAVID A. (b'59)-1'a.9.81; (l'95): Sec Siate lloard of Med. ExanlIDers: 1520 York st: othce.

10-12, 2-4: (B9): OALR

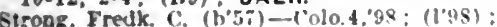
599 S. Lincoln St.; onlee, Commonwealti Bldg.

Strong, Italph W. (b'58)-Ill.4, $90 ;(1 ' 90)$ : 3925 Wolt St.

Stuver. Henry bim. (b'79)-Colo.2,13; (1'13): Merey Hospital.

SUNDERLAND. WM. EBF. $(6 ; 5)+11111$, '06: (l'11); 2509 Benton St.; oftlee, Metropolitan Blde. $11-9$.

SWFRDFEGER, FI.BF.lbT R. (b'81)-Colo.4 o4: (1'01): 3159 W. Asth Are; othce Masonle Temple: 12-3; OALR.

symon, Wm. Gardiner $\left(h^{\prime} \times 6\right)-C o l o .2,13$; $(1,13): 3025 \mathrm{~W}$. 25th Are

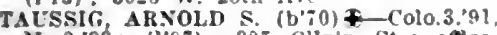
Mo.2,93; (1'95): 305 Gillpln st.; oftlee, Metropolltan Blifg.; :-4.

TAYLOR, 11 CGII L. $\left(\mathrm{b}^{\prime}, 0\right)+C$ Colo.1:3! : (1'91); 641 Vine St.: oflce, Majestic Bldg: $10-11,2-4, i-s ; s$

Bldg: $10-11,2-4,{ }^{7-5}$ S.

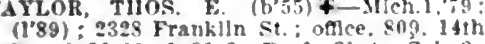
St: $9: 30-11,1: 30-3$; Prof. Obst., Colo.2; Ob.

TEMPLFTON, ABDI'L M. (b'59) \&-0.3.'S9 (1'06): Member Oblo State Med. Assn.: wyoming Bldg, 9-11, 2-4, T

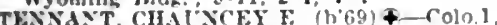
94: (1094): 1122 Race St. : oflce, Empire Bldz.: 2.4 : S. *

Thompson, Clinton E. (h'62)-rolot.9? (1'93): 349 S. l'earl St.; offce, st s. Broadway.

THOMPSOX. DAVIT (b'56) \&-Colo.1,'01 $\left(1^{\circ} 90\right)$; $; 66$ Kalamath St.

THOMPSOX. NATHANIEI. A. (h'79)-Ill, "os: (l'09): 1460 Jennsylranla st. : offce Ietropoltan $31 \mathrm{dg}: 11-30=2-8 ; \mathbf{S}$.

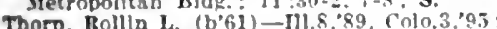
horp, Bollin L. (b61)-Ill.8.89, Coflo, $3,9,3$ and Flectric Bldg. : $10-12,3-5 ;$ Pr.

Thudlehum, Carl L. (b'6i)-MA.8,04:(1'12) looe vine St. once. Mack Bliz.

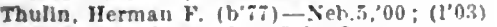
57 S. Broadway; 2-4, $;-8:$ S.

Tedt, Arthur O. (b'69)-III.10,92: (I'12): First Natlonal Bank I3ld

Tilen. John H. (b'si) -0.2,72: (1*00): $833^{*}$ Sherman Are.: once. ¿84 Rroadway; 1] $-4: 30$.

Tobln, P'eler Arthur (b'sï)-0.41,12: (\$) 1264 Corona St.

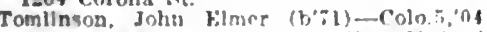
(1'04): 1921 ("hampa si.; oflre, Majestic Blde. : $10-11,1-2, \hat{0}-9$.

Trachsel. Fiw (b.61)-Kan 3.96: (1"0)1) 251 S. Washington St.; once, Wyoming B]de.

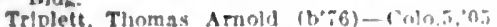
(les): 144l Josephlne st.; once, 140. Glenarm Pl. : $10-11,3-5$.

Tygart, Chester A.-Mo.28,98: $(1 \cdot 98)$ : Acnes Memorlal Sanatorlum

Van Gllder. [yell $\left.W(1)^{\prime}-7\right)-111.1,00:(1,00)$ 3953 Tejon St; ofnce, 611, 1:th Sit.; 10 12. 2.4 .

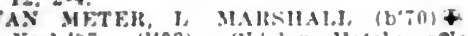
F.1."9i: (1'03): Sh!riey llotel; onter Enultable Hids: $10-11$. $5: \mathrm{S}$.

FAN MHER, SFYM(it) n. (heti) Pa.1.89: (l०a1): 1326 rolumblne ofdec. Callformin Lhdzz: $2 \cdot 4$

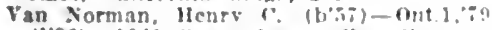
(1'\$6): 1949 rimat Ale.: oflce. C'onmun weallh Bldg. : $11-1,3.5$

VAN ZANT (HAS 11, (boll) +-0.9.4 (1'95): 13it Whilams st; oflce, Metro. polltan Rldg. : I1-12, 28; ;'rof. Pligwlol. Colo.2.

Vinland. otto S. (b'co)-colo t.08: (1.98) 3037 stout st.; omce, 1705 leawrence st. $9.11,2-4, \div-8$

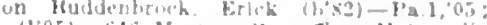

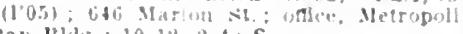

tan IBldin: $10-12,2-4: S$.

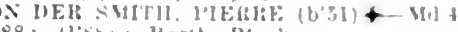
क

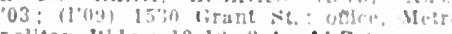

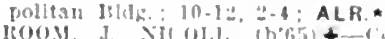

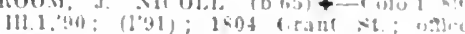
Mack blilt.

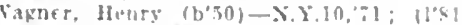
2133 Coivlurit st.

Wagner, Yapoleun (b'58)-Mn.7.84: 11:4

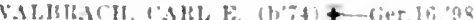
(1'00): 1954 sherman st : undere, Common wealth ind serman st

Widron, Martin John, Jr. (b's1)-ro!n?

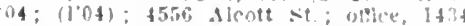
lienarin P.l.: 10-12, $2-4$

WALKER, CHAS E (b's1) + -111.1 א : (l'sy); 1732 lligh st.; oltre, Jacobson Rlel: : 10-1:, :2:30-4:20; 1 139);0p.

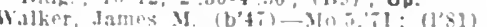

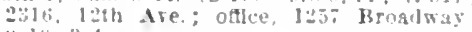

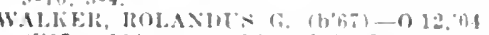

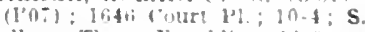

Walker, Thos, kranklin (b'a(1)-('oln.2.'1"

(1'13) : 1503 s. Washington si.; Path.

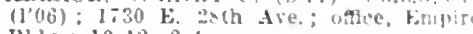
I3luge: in-1:2, $2-4$

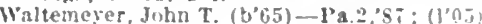

l:19 lieiroit st.

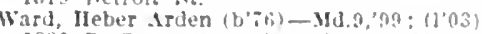
$1330 \mathrm{~S}$. Grant st.: once, Ilenver Medical Institute ; $9-12,2-6$

Waring. James Johnston $\left(\mathrm{b}^{\prime} 83\right)$-Colo 2,'I? (l'13) : Sgnes Memorial Sanatorjum,

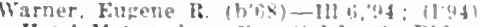
Hotel Metropule; oftre, Caltfornta Bldz.

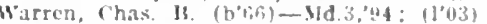

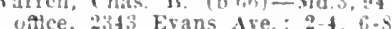

Watson. Arthur I' (b'sa)-Colo. 1, '0: ; (1'03) 1231 Ifuntwold st.; onlce, Mrtrotrolitan Plug.

Watson, Charles W: (b'52)-K5.2,74: (1'0!) oltlce. 1 In (cook st

Weht, John W. (b+3t) II- : (l's); $31+9$ larimer st.

Weiss. Frank Henry (b'y) - Xl'.1,"01

(1'11); 103\% 201 ire

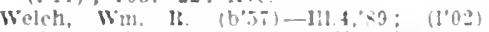

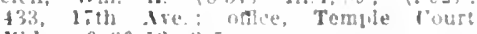
lillin. ; $9: 30-1:$,

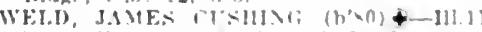

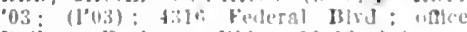

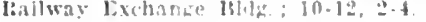

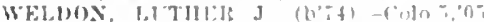

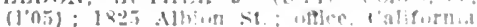

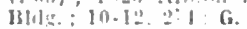

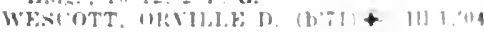

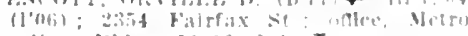

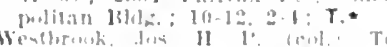

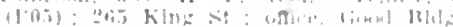
[1 1 -11.2-1

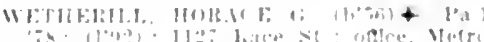

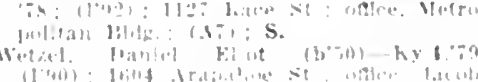

5n! $131+1,: 10.4 ; 0 *$

11-111 4 6i": (1'4)

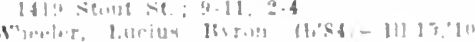

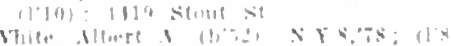
$2+28$ 1irtisn

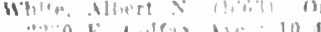

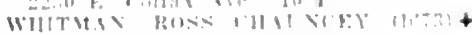

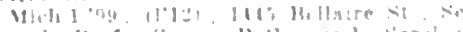

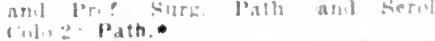

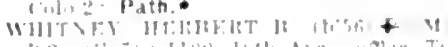

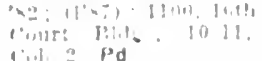

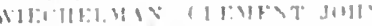

() 11,1

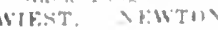

(1), 1,1,

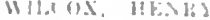

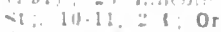

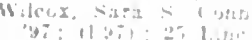

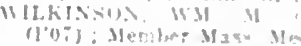

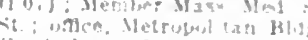

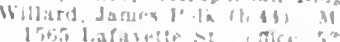

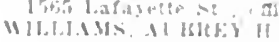

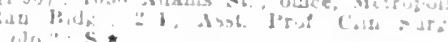

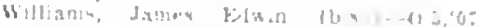

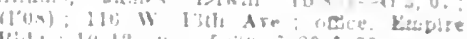

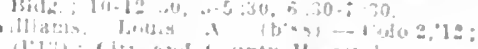

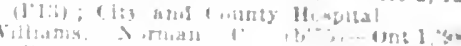

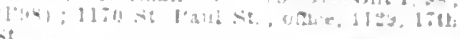

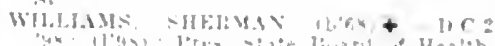

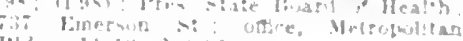

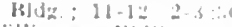

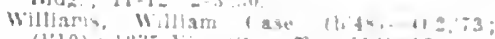

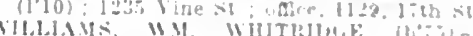

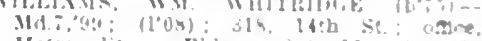

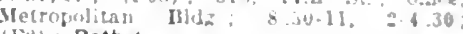
(Fi) : Path.*

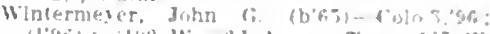

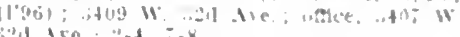

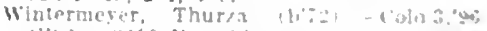

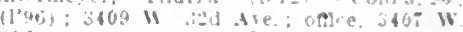

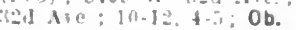

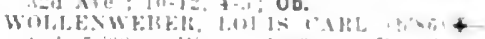

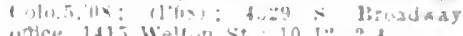

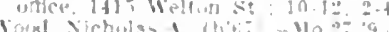

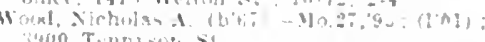

Wunding, Benj. Franhin (be:3)-I13 1.9n

(1900): :-11 sherstan st: uAce, l'entral Sabluge lsank br

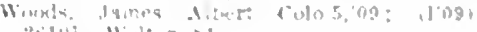

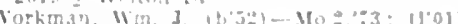
WORTHINTON. IXT⿰R丨 K $1699+$

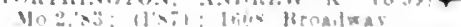

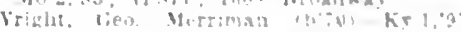

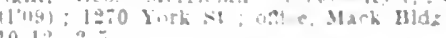

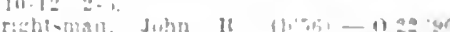

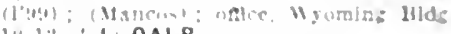
111-?:- - I: OALR.

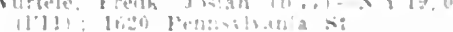

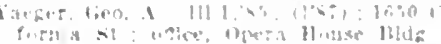

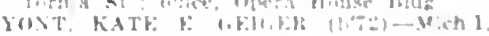

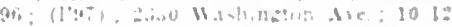
if: Obg.

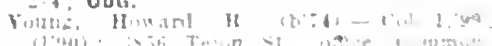

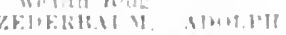

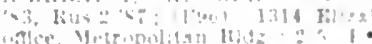

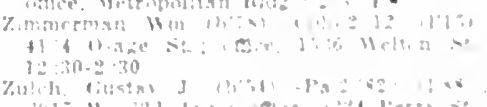

OILLON. 134. SUMMIT

STIUVi, Jill

DOLORES. 120. MONTEZUMA

DUNKLEY. HOUT

DURANGIO I GitB. LA PLATA 
IIurd, Lewis C. (b'57)-0.6,'85; (1'93). IIutchinson, A. Franklin $\left(b^{\prime} 70\right)-M i c h .1,93$; (1'04).

Lingenfelter, Howard Andrew (b'71) Y. Y. 19,99 ; $(1,09)$

McEwen, Wm. W. (b'53)-Mo.7;83; (1'99) Ochsner, Benj. J. (b'69)- $\rightarrow$; (l'02).

Richardson, Harry I. (b'72)-0.1,'95; (1'95) Tobblns, Allen IV. (b'74)-Colo.I, 01 : (1'02) Turrell, Hcrbert C. $\left(h^{3} 77\right)-C o l o .2,02 ;\left(l^{\prime} 02\right)$.

EAGLE, 186, EAGLE

DAHL, WMI. Z. (b'80)@Cal.7,04; (1'0,5); U.

GREFNE, TAY II

EASTONVILLE, 75, EL PASO

Anderson, Geo, Wm. (b'7I) II - Ia.4, 01 . (l'01).

\section{EATON, 1,157, WELD}

BEILROSE, NORMAN W, (b'64) $\oplus-\mathrm{V}^{\prime} \mathrm{t} .2$ '89; (1'90).

Carlson, John C. (b'74)-Colo.2,02; (1'02) Peck, Blrdsey P. (b'75)-Colo.4,'94; (1'04).

ECKERT, 175, DELTA

Houts, Saml. B. (b'36)-Mo.1,'60; (l'96).

EDGEWATER, 712 , JEFFERSON

Craichead, Jos. Whley $\left(b^{\prime} 90\right)$-Colo.2,'13;

(1'14) ; Edgewater Sanitarium.

Lewark, Sara D. Hosford (b'73)-Colo.2,'97 (1'97); 2512 Ames St. ; 2-4

MENKEL, IERMAN CARL-Colo.4, 06 ; (1'06).

SCHWATT, HERMAN (b'78)-Pa.1,06: (1'11)

Snyder, Edgar (b'49)-Ill.1, '76; (1'04).

EDITH, 293, ARCHULETA

SPECK, RICHARD THEODORE ( $\left.b^{\prime} 86\right) \uparrow$ Mo.35,'10; (1'13); Member Kan. Med.

ELBERT, 150, ELBERT

DENNEY, ROBT. H. (b'72) $\oplus$-Colo.3,'96; (1'96).

ENGLEWOOD (IND. STA., DENVER) 2,983, ARAPAHOE

CATRON, HOMER B. $\left(b^{\prime} 86\right)(-M 0.28,08$; (l'13); Member Ill. State Med. Soc.

GRIEGER, HUBERT $\left(b^{\prime} 70\right) \oplus-$ I $11.6,{ }^{\circ} 93$. (1'97).

Lutz, Mary A. (b'68) H-Neb.3,'86; (1'97)

Slmon, John (b'76)-Colo.5,07; (1'68); 0b.

Tuttle, Erastus A. (b'48) E-S; $\left(l^{\prime} 00\right)$.

ERIE，596, WELD

BIXLER, CLARENCE W. $\left(b^{\prime} 78\right) \oplus-$ Colo.2, 07; (1'07).

ESTES PARK, 300, LARIMER

BLANCHARD, IRVING DeLOSS $\left(b^{\prime}, 4\right)+-$ Conn.1,97; (1'12); Member Conn. State Med. Soc. ; T.

Wlest, Roy (b'77)-Mich.1,01; (1'02); Ob.

EVANS, 600, WELD

Averll, Henry Wilson (b'í6)-Colo.4, 07 Ill.11,'13; (1'07).

FAIR PLAY, 265, PARK

Dunkle, Frank (b'81)-Colo.5,'04; (1'04).

FLAGLER, 200, KIT CARSON

NEFF, O. S. (b'66)-Ill.4,95: (l'98)

WILLIAMS, HARRY L. (b' 70$)-C o l o .5,96$; (1'06).

FLEMING, 55, LOGAN

Jeffryes, Reuben S. ( $\left.b^{\prime} 57\right)-M 10.18, ' 88$; (1'04).

FLORENCE，2,712, FREMONT

ADKINSON, ROYAL C. (b'71) (4-111.1,95: $\left(1^{\prime} \theta 0\right)$

CUMMINGS, GEO. DAVID (b'59)థ-N.Y.10, '88. Colo.2,'96; (1'89).

HUTTON, YARDRY AMION (b'66)థ-III.15 03; (1'03); 0 b.

Moore, Frank R. (b'64)-0.14,'85; (1’96).

RUPERT, LEONIDAS ERSLINE (b'ii)Ky. 2,93; (1'03); S.

Stephenson, W. C. (b'43)-Mo.1,75; (1'81).

SU'TORIUS, FRANCIS A. (b'75)-N.Y.5,'96; (1'04).

FLORRISSANT, 268, TELLER

Vivian, Chas. S. (b'90)-Colo.2,'13; (1'13).

FORBES, 400, LAS ANIMAS

Wonds, Wilfrld P. (b'82)-Mo.22,'06; (1'06).
FOUNTAIN, 431, EL PASO

BROADWAY, ROBT. O. (b'67) $\oplus-\mathrm{K} y . \mathrm{I}, 93$; (1'13); Member Ill. State Med. Soc.

Gardiner, Wm. B. ( $\left.b^{\prime} 5 \theta\right)-K y .5, i 7 ;\left(1^{\prime} 95\right)$.

IIllgendore, Paul J, (b'66) II-Ill.10,'89; Io. 10,90 . (1,98).

WTTTER, ROY V. (b'74)-Neb.5,00; (1'04).

FOWLER, 925, OTERO

Hlgbee, Obadlah F. (b'61)-Ia.3,90 ; (1'09).

Meador, Arch. (b'68)-Mo.20,97; (1'05).

YAN DER SCHOUW, GFO. E. '(b'78) Colo.5, 04 ; (1'03).

\section{FRASER, 260, GRAND}

Anderson, Susan (b'7 $\theta)$-Mich.I,'97; (l'97).

Harrison, Fleet H. (b'75)-Mo.1,97; $\left(1^{\prime} 06\right)$

II urst, Wm. Neel (b'73)-Ia.9,'97; (I'10).

FRUITA, 881, MESA

Lockett, Wm. A.-Ky.2,'65; (1'88).

Masser, Chas. 13. (b'38)-O; (1'90)

PORTER, ROB'. B. (b'80) $\oplus$-Colo.5, 06 ; $(1 ' 06) ; S$.

Roys, Féruando-Ill.6,'81; (1'82).

White, II arry W. (b'76)-Ill. I0,01; (l'10).

FT. COLLINS, 8,210, LARIMER

ATKINSON, CURTIS A. $\left(b^{\prime} 74\right) \oplus-P a .2,00$; $\left(l^{\prime} 06\right)$

DALE, JOS. E. (b'69) $\oplus-0.8,94 ;(1,00) ; \mathbf{R}$. DE ARMOND, WII. N. (b'64)-Ia.10, 02 ; $\left(1^{\prime} 07\right)$.

Eakins, Clemens F. (b'74)-Colo.2,'13; (l'13). Gooding, Bert A. (b'65)-Ia.1,'87; (1'06). HALLEY, SAMUEL C. (b'69)-Mo.28,03 (1'04).

Havlland, Clarence M. (b'64)-Cal.6,'94; (1'03)

HOLL, GEO. L. (b'62) $\oplus-M o .28,98 ;\left(l^{\prime} 00\right)$. KICKLAND, WM. A. (b'68) \-Mich.1,'95; (l'95); $\mathbf{S}$

McHUGH, PETER J. (b'63) $\uparrow-M$ ich.7,'89; (1'91).

Miller, Nora Rice (b'68)-Colo.2,'08; (l'08).

NOR'TON, DANA 0. (b'74) - N.Y.9, 02 ; (1'03).

Qulck, Saml. T. $\left(b^{3} 43\right) \mathrm{E}-0.2,79 ;\left(l^{\prime} 92\right)$.

Reckly, Mary Daisy (b'r0) - Colo.2,02; $\left(1^{\prime} 02\right)$.

REPLOGLE, BENJ. FRANK (b'59)-IIl.10, '95; (I'04); G.

REW, ALBERT WHIPPLE $\left(b^{\prime} 76\right) \oplus-$ Pa.I '03'; (1'06).

SADLER, ELDEN LEONARD (b'75)-Ill.4, 00; (1'02); Pd.

Schofleld, Jos. Robt. (b'68)-Ill.6,'04; (1'07). STUVER, EMANUEL (b'56) $\oplus-0.1,80$; (1'95)

TAYLOR, THOMAS CIARKSON (b'66)Pa.1,95; (1'05).

Winslow, 'Wm. H. (b'55)Ф- Mich.1,'87 ; (1'07); OALR.

FT. GARLAND, 147, COSTILLA

CAMPBELI, JOHN P. - Mo.10,78

Member Ill. State Med. Assn.

FT. LOGAN, - ARAPAHOE

JUENEMANN, GEORGE F. $\left(b^{\prime} 75\right) \oplus-D . C .1$, '97; Capt., M.C., U.S.A.

SHOOK, JAY RÁLPH (b'78)(-Md.I,' $99^{\circ}$; Member Ohio State Med. Assn.; Maj., M.C., U.S.A.

WARINGG, JOHN B. HARVIE (b'84)థD.C.1,O? ; Capt., M.C., U.S.A.

FT. LUPTON, 614, WELD

Clock, K!re L. (b'63)-Mo.28,'99; (1'00)

Hubbell, S. J. (b'34)-Pa.2,'56; (1'81).

LEWIS, EDWIN (b'63)-Mo.29, 03 ; (1'03). IONISMITH, ARTHUR 'T, $\left(b^{\prime} 80\right)-C$-Colo.5, 04; $\left(1^{\prime} 04\right)$.

Wells, James w. (b'84)-Colo.2,13; (1'13).

FT. MORGAN, 2,800, MORGAN

Bowie, Robt. C. (b'78)-Colo.4,'02, Mleh.5, 'I1; (1'02) ; OALR.

EVAN's, EMERSON E. (b'64)-Kan.3,'94

FETHERSTON, ERNEST A. (b'74) (1)-Ill.6, 99; (1'09); OALR. $\star$

LAW,' JOHN CALVIN (b'70)-Kan.3,98, Ill.11,10; (1'11).

LOCKWOOD, FREDERICK W. (b'76)థColo.3,98; (l'98).

otis, Wm. D. (b'41)-0.11;74; (1'88); not in practice.

PACKARD, WM. A. (b'52)-Ia.I,'81; (1'88). WILLIAMS, ARTHUR FREDK. (b'8I) Colo.5, $\theta 3$; (1'03)

WILLSON, MARION ORR (b'74)-Ia.3,07; (I'I0).
GARDNER, - , HUERFANO

Clay, Chester W. (b'71)-Kan.3,02: (l'03): $\left(1^{\prime} \theta 6\right)$.

GENOA, 350, LINCOLN

Shaw, Saml. L. (b'71)-Ky.I,'98; (丰).

GEORGETOWN, 950, CLEAR CREEK.

Collins, Wm. R. (b'58)-Mo.2,84; (l'91).

Dubols, willard Cecll $\left(b^{\prime} 83\right)$-Colo.5, io; (1'11).

KIRBY, HARRY WALTON (b'70) $\oplus$-Pa.I, '96; $\left(1{ }^{\prime} 96\right) ; 0$ b.

GLENWOOD SPRINGS, 2,019, GARFIELO

CLARK, LEMAN GIBBS (b'58)-Ill.1,'84; $\left(1^{\prime} 87\right)$

CROOK, WM. W. (b'64) -1a.I,85; (1'84).

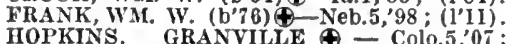
HOPKINS

HORAN, E. J.-Vt.2,95; (1'07).

Phelps, Edward Marshall (b't0)-0.1,96 ; (1'08).

SCHMITZ, EMILY F. J.(-Fra.6,'04; (['06).

Stewart, Chas. Mortimer $\left(b^{\prime} 70\right)$-Cal.7, 04 ; (1'05).

GOLDEN, 2,477, JEFFERSON

Baker, Madellne Marquette (See Denver.)

Baker, Mlchael (b'54) - Colo.3,'89; (1'89).

GARVIN, DANIEL EDSON (b'70) $\oplus$-IIl.19, 00 ; (1'02); 0 b.

Hood, Jos: 'Roblnson (b'74)H-Pa.9,98;

KELLY, JOHN PERRY (b'58)థ-Mlch.I, '81; (1'8I); $\mathbf{N}$.

Meyer, Paul ' $\left(b^{\prime} 54\right) \longrightarrow$; (1'82).

MINNIG, ARNOLD (b'82)-0.6,'08; (1'12) ; T.

enemann, Robt. T. (b'60) - Ind,2,'81; (1'13).

GOLDFIELD, 1,112, TELLER

Evans, L. Prlce (b'70)-Colo.3,01; (1'01). JONES, BENJ. F. (b'54)-Ia.I,'78; (1'96).

GORHAM, 350, BOULDER

WALKER, ALBERT GOULD (b'83) ÐColo.2,08; (1'08).

GRANADA, 359, PROWERS

Sperry, Edw, Lafayette $\left(b^{\prime} 56\right)-0.3,21$,

GRAND JUNCTION, 7,754, MESA

ADAMS, WM. THORNTON (b'64)-Ky.2, '89; (1'11); Member Mo. State Med.

BULL, HEMAN R. (b'62)๑-Pa.2,'87;

(1'87

Collins, P. Phelps (b'72) H-Ill.10'95; (1'98).

DAY, IIUNLEY S. (b'65) $९-\mathrm{Ky} .2,94$; (1'04).

Eldridge, Edw. F. (b'55)-N.H.1,'82; (1'92).

IIANSON, KNUD K. H. $\left(\mathrm{b}^{\prime} 74\right) \oplus-$ Colo.1, '98; (l'98).

HARRINGTON, ROBT. BRINE (b'79)ÐMass.7,'05; (1'07)

HENDERSON, HAMPTON S. $\left(b^{\prime} \% 7\right) \theta$

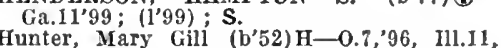
'99; (1'99).

Jaquétte, Mary C. (b'86)-Cal.6,'09; (1'11); R.F.D. I.

NEEDHAM, CHAS. NELSON $\left(b^{\prime} 74\right) \oplus$ Colo.2,'07; (1'07).

PALMER, HIRAM R. (b'56) -Ind.I0,'82 ; (1'08); OALR.

Parker, Thaddeus (b'69)-Mich.8,'91; (1'02). PLUMB, CARL W. (b'80)丹-Colo.5,06; $\left(l^{\prime} 06\right)$.
RED, CHAS. W. (b'75) $4-M 0.10,05$;

SICKENBERGER, JESSE URBAN (b',8)Va.4," 05 ; $\left(\mathrm{l}^{\prime} 06\right)$

STILES, FRANK N (b'66)-Ia.3,'93; (1'03) ; OALR. $\star$

TAYLOR, ARTHUR GEO. (b'70)థ-Mo.1, WARNER, GEO. R. (b'72)-Colo.3,'98;

WOOLWINE, CHARLES ROLLIN $\left(\mathrm{b}^{\prime} 81\right) \oplus-$ Va.4,'08; (1'13).

GRAND VALLEY, 300, GARFIELD

Hayward Corydon L. (b'68)-Pa.17,79; $(1 ' 00)$.

Miller, Fred Henry (b'83)-Ia.10,05; (l'05).

Mtaley, Franklln Henry (b'60)-Iil.1,'86; (1'i1). 


\section{GRAYCREEK, 576, LAS ANIMAS}

RISDALE, "WM, F. (b'6i) + III.I,"93: (1'99): S.

Thompson.

'11: (1'is).

GREELEY, 8,179, WELD

Allen, Wm. P. (b'70)-Ill.10,94; (l'95)

Archer, Davld Fo-II-3lo.5,"90; (l'13). BROMAN, OSCAR FRANCIS (b'Ti) Ylech 10,03: (1'04).

Burnard, Ilorace Wm. (b'63)-Ill.6,'89; not In practice.

CALL, CHAS. HESRY (b'58)-Mass.1,'s1 : (1'94). Chapman, Geo. Lincoln $\left(b^{\prime} 69\right)$-Ill.1,94:
$\left(I^{\prime} 10\right)$.

CHCRCII, WALTEI FREMONT (b'65) Md.3,93, Ml.1,'99; (l'01); S.

Dungan, James Arthur-Neb.4,97; (l'08).

DYDE. CHAS. B. (b'72) 4 -Ont5; $;$

(1'04): $S$.

TuQua, John W'lson (b'62)-I1l.1,95; (1'03).

GRATLY, ROBT. F. (b'53) -0.9,'80:

HARMER, WHLLAM WEBSTER (U*t)-

$0.25,00$ : $\left(11^{\prime} 03\right)$.

ICGHES, JAMES GH.BERT (b'61)\&-II.6, '92: (1,04): S.

KNOพ์LES, EDWT WIXSLOW (b's0) \&

11L11,"06; (1'11): R.

Kussart, Jácob (b'68)-Mo.9, 00, Mo.28,'01 ; $\left(1^{\prime} 00\right) ; T_{0} \star$

LAW, GULIELMCS (b'38) $\longrightarrow$; : $\left.l^{\prime} 81\right)$; not In practlce.

LEHAN, JAMES WM. (b'it)-Ill.1,9: ; (l'11) : OALR.

MEAD, ELLA AVERY (b'74)-Colo.5,'03; (l'03).

Mlller, John Knox (b'54)-Ill.1,"83; (1'91).

Mlller, Wm. L. (b'5\%) H-0.7,81; (1'94): S.

MUIYORD, CLAREXCE II. '(b'57) \&-Pa.I, ‘9. Pa.9,83: (1'83).

POFUE, GEORGE R. (b'61) \&-Yllch.7'92: (1०99); 1.*

REED, DAVID W: (b'55)-Colo.3,96; (l'96).

Reed, Fra A. (b'65)-Colo.3,96; (1'96); G.

RINGLE, CIIAS. A. (b'66) \&-I11.6,'92:

(1'02): (BI,9); ALR.

Sblelds. Wm. Henry (b'69)-Pa.11,'93;

(1'0s).

Thompson, Wm. Earl $\left(b^{\prime}, 6\right)$-Colo.2,03; (l'03): S.

Weaver, John A. (b'70)-Colo.2,'97; (1'97).

WOOD, WALTER H. (b'it) - Y.3,98:

(1'02).

WOODCOCK, BURCETT (b':5)-Ala.2,96; (1'05).

Wright, Wm. Otas (b'41)-Ia.1;73; (1'00)

GROVER, 45, WELD

MTCHEL, DAVID M. (b'7i) ‡-Kan.3,'10 (1'13) : Member Kan. Med. Soc.

STEWART, JAMES GOLIEN (b'31)€-111,6, '0t: $(1,0 \%)$.

GULCH, 400, PITKIN

GILL, Alt'Tiur F. $\left(b^{\prime}, \overline{6}\right) \oplus$-Colo.2, 01 (1'01).

GUNNISON, 1,026, GUNNISON

Haanon, Fitch l'belps (b'90)-Colo.2,"I:

I1 jate, Selson J. $\left(b^{\prime} 56\right)-18.3,81 ;\left(1^{\prime} 88\right)$.

Mackintosh, Jorman (b'58)-Y.Y.10,79: (I'81).

Mlller. Itarry C. (b'i ) - Ill.11,"08; (1'03)

Sanford Frank D. (b'51)-910.1.'2: (1'81)

Walker, Jefferson D. (b'61) - Mo.8,88; nut In Dractice.

GYPSUM, 300, EAGLE

Contay, Wm. I. (b'64)-Md.3,93; (l'01)

HARDIN, 50, WELD

MacManus, Mars W. (b'62) - ('olof,09: not in practice.

HARTMAN, 450, PROWERS

Fitzzerald, Dennle I. (b'il) -Mo.8,"00, Neb. 6,"05; $(1 ' 04)$.

HASTINGS. 693. LAS ANIMAS

CLRRT, KUWARD II. (b'66) †-Mo.27:99;

HASTY, 25, BENT

Asbbs. Wm. F. (b'50)-1a.1."83: (1'95)

HASWELL, 50, KIOWA

Serads, Goo. M. (b'08)-Md., 96; (1'10)

HAXTUM, 3\$I, PHILLIPS

Keesee, Walter II. $\left(b^{\circ}: 1\right)-M o .8 .91 ;\left(l^{\prime} 03\right)$

Ob. Clarence Johnstone (b'79)-Colo.3,"10: (1'10).
HAYDEN. 314, ROUTT

Enochs, Bott. Jones (b'83) - La.1,"09; (1'11)

G. (1.93).

HENDERSON, 200, ADAMS

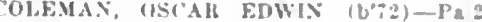

02: (l'0):; Member Utah State Med

Assin.

RISER, FREDERICK L. (b'5s)—MO.5, 84

(1'10); Member I"tah Slate Med. Asst.

HILLROSE, I00, MORGAN

Esilng, liuy $F^{\prime},\left(b^{\prime} 79\right)$-Neb.4,04; (1'04)

Classcork, Thomas Jefterson $\left(b^{5}-8\right)-K, 9$

04: (1'13): OALR.

HOEHNE, 300, LAS ANIMAS

McXeal, Wm. 1". (b'60)-Ky.6,82; (I'b5).

HOLLY, 724. PROWERS

PRATZ. FHEI) D. (b'\%0)-I11.11,98; (1'I0)

SIIEMMAN, EDY. MERRITT (b'66) +

III.,95, Colo.1,99: (1.99)

WIIsON, RICHARI) D. (b'60) -Q-Que.1, 94 $(1 " 96)$.

HOLYOKE, 659. PHILLIPS

Means, Frank M. (b*6) F-Nebt,03: (1'04) Smlth, 'rancls M. (b'59)-Md.3,'97; (l'88)

HOOPER, I3I, COSTILLA

HOHTOX, THOMAS C. (b's0)-Colo 2,12 (TI2).

HOTCHKISS, 600, DELTA

Bast, Lee (b'66)- I0, 03 : (1'07)

Coneland, W. Claude (b'bi)-Ill.13,03 (1104).

LEWIS, WALTER H. (b'62) - III.1,

(1'06).

MYERS, JAMES T. (b'68) - Mo.20,94 (1'y9).

Robertson, Jolun W6 (b'53) - Ia I, s2: (1's? Wllllams, Jos, Jones (b'5i)-Ga.1'90: (1'05) HOT SULPHUR SPRINGS, 182, GRAND Itawls. I'ercy Scott (b'so)-Colo.5,'0s; (l'0s)

HOWARD, 175, FREMONT

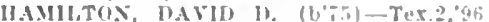
(1.03).

HUDSON, 210, WELD

CRAIVPURI, FilRLE-MO.3t,04

$\left(I^{\prime} 04\right)$

llatiber llyo Siate Yed sac.

HUGO, 343, LINCOLN

Bacon, Harry Edward (b'S1)-Colo.5, 0 s (1,0s)

Lloyd, Francla Wade (b'63)-Ky. I,

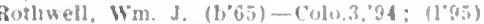

IDAHO SPRINGS, 2,I54, CLEAR CREEK Ashbaugh, Abraham (b'52)-III.1, 'A $\left(1{ }^{\prime}: 2\right)$ Ashballugh.

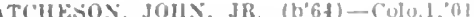
(1'(1)

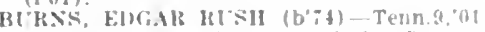
(1): Memler Med. Ascn. of the stape if Ala.

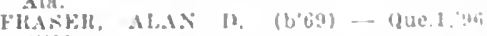
(1'01).

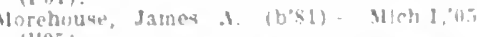
$(100)$

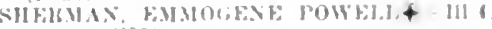

IOALIA, 100, YUMA

larcla, James $(1, \div 3)-$ Colo.2, $0: ; 11071$

IGNACIO, 60, LA PLATA

Malver, liob?. Matarfay (b'GS) - III 1,93 (1"I1)

ILIFF, 150, LOGAN

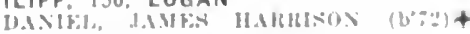

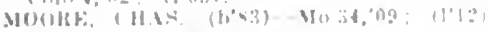

JAROSA, -, COSTILLA

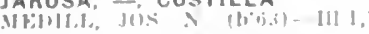

JOHNSTOWN. 198, WELD

ת

(1) 0 s

Whilliaker.

JULESBURG, 962. SEDFWICK

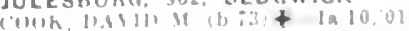

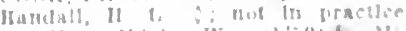

(14) 110 \%

KEENESBURG，35, WELD
KENDRICK, 15. LIACOLY

Kendrtck, Wm. Iletry-Ky: 9: : (101).

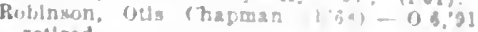

rellred.

KEOTA, I30, WELD

OISON, IDAYID di (b'S

KERSEY, 304, WELO

SI'Al:IDISI, WMI.

$\left.11^{\prime} 02\right) 1$.

KIOWA, 100, ELBERT

Carder, Jubn IS. (bos?)-X Y $8,:$

retired.

ilogers,

KIRK, 30, YUM

buncansin, James

(1'02)

KREMMLING, IAI, GRAND

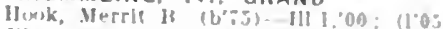

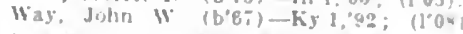

LAFAYETTE, 1.892. BOULDER

Braden, J. Marbball $\left.\left(b^{\prime} f i\right)-K j^{\circ}\right)$

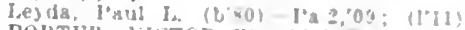

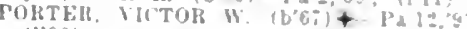

(llon)

LAIRD, 240, YUMA

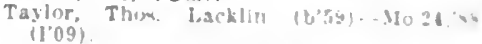

LA JARA, 448. CONEJOS

Hecker, Jos Norman-Kan.3,07: (1'0N

Blissard J. Morton-( ) l'0i: (100)

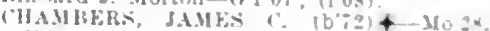

02: (l'03)

Schenck, I1. scols (b.al)-Ha 2,03; $1100 \%$

LA JUNTA, \$.15\$. OTERO

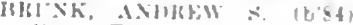

Clive

$\left.(102):()_{1}\right) ; s$

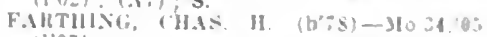

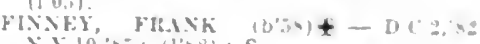

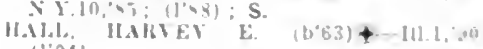
11 '04

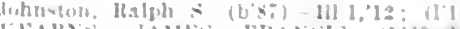

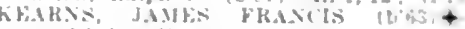

पue 1,yt: l'y ll.

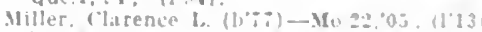

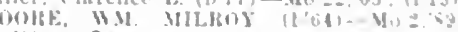
(1'(0;) : OD.

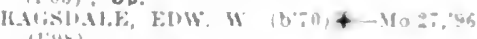
$(1, y)$.

STIHHS. MLBEIET LIKE 12651+-12 No., No; $(1,03)$ : $s$

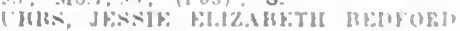

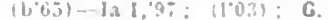

White Franct, y $1431 \mathrm{E}-4,10=$

LAKE CITY, H05. HINSDALE

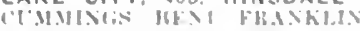

LAMAR, $29: \%$ PROWERS

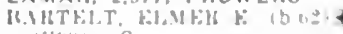

$(1,1 s+1), S$.

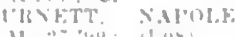

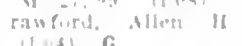

FkIIVI, F MIITUS

(1)

It.itis

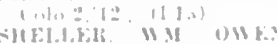

APORTE, IOO LARIMEH

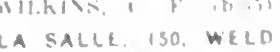

AS AVIMAS. OQS HENT uf the sisale ul

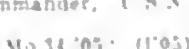
10.5) $\mathrm{va}: 4.9:$ 
Galnes, Jos. Ir. (b'65)-Mo.7,9I; (1'10) ; OALR.

GRIEVE, CHAS. C. $\left(b^{3} 73\right) \oplus-$ Ilch. 1,01 Surg., Lleut. Commander, U.S.N.

Hagemall, Silus Van (b'so) - Ill.11, $0 \pi$; (1'12); OALR.

Hardy, James o. (b'69)—I0.27,'97; ( $\mathrm{l}^{\prime}(01)$ IOLEILAN, CHAS. J. (b'80) - Pa.1, 0 \% P.A.S., Mleut., U.S.N. : Naval Ilospital.

I,afferty, Alfred I. (b'81)-la.10,'05; (l'12)

Jeedham, Perry A. (b'64)-N.X.I0,90; (I'93)

Leedham, Perry A. (b'64)-N. X.I, 90 ; Kas) ,00: Ilospital Steward, U.S. Naval IIospltal.

oRltal. RAIPH T. (b'72) f-cal.1,93: Surg., Lieut. Commander, Y.S.X.; Naval Hosplital.

RFED, FIWARD 1\% (b'84) †-Pa.1,05 P.A.S., Lleut., U.S.N. Naral llospital. Taylor, Amanda I. (b'58) II-Ill.4,96; (类). LA VETA, 691, HUERFANO

I,anme. James MeGrew (b'90)-Colo.2,'11; (I'11).

Lamme, S. Jullen (b'83)-Colo.2,04; (1'04) Roberts, Leonidas B. (b'56)-Colo.2,96 ; (1'96)

Springer, Sarall r. (b'70)-Ia.6,'86; (1'98).

Wrlght, James J. (b'69)-Ky.4,'92; (1'92)

LAY, - ROUTT

AlBOGAST, IBARZILLAI A. (b'4i)-Colo.I '83; (1'83).

LEADVILLE, 7,508, LAKE

CAIKINS, HINNRY A. (b'69)-Colo.1, 01;

GRIFFITH, BENJ. F. (b'65)థ-Colo.3,'89; (l'89).

JEANNOTTE, JOS. ADKEMAR (b'54)థ(que.3,75; (1396)

FAIIN, MAURICE (b'i3)૯-Mass.1,'98; (1'99); (A7); S.ネ

MACIFÁN, ARCIIBALn M. $\left(b^{\prime} 52\right) \oplus$ Ilch. 1,74; (l'8I)

MCDONALD, ALLAN J. (b'5i)-Mich.1,'90; (1'91).

MCDONAIA, RODERICL J. (b'62) $\uparrow$ Mlch.1,'95; (l'05). G. (b'76)-Ill.4, 00 ;
SCHALL, JAIES G. (I'II) ; OALR. * WHITMÓRL, EDW. A. (b'53)థ-Colo.3,'96;
(l'96).

LIMON STATION, 534, LINCOLN

KENNEDY, GEO. A. (b'79)૯-Colo.5, 06 ; (l'06) ; S.

KFSSENGER, J. D.†-Mo.1,'s9; (1'98).

LITTLETON, 1,373, ARAPAHOE

Crysler, Walter C. (b'T0)-Ill.13,01; (1'02)

Fowler, Chas. C. (b'70)-Ia.1,94; (I'06)

MeGUGAN, ARTIII (b'68)-Mich.1,92 (l'01); not in practice.

Moore, Geo. Cooper-1'a.2,99; (1'07).

LONGMONT, 4,256, BOULDER

ANDREW, CHAS. FISIIER $\left(\mathrm{b}^{\prime} / 1\right) \oplus-M O . I$, 35 ; (I'95).

ANDREW, JOHN (b'79)Ф-Colo.2,06 ; (l'06); $\mathrm{s}$.

Kennelley, Frank Clair (b'83)-Ill.11,06; (l'09)

MATLACK, JAIES A. $\left(b^{\prime} 74\right) \oplus-M 0.2,01$; (l'0T) ; S.

MCFARLAND, SAML. B. $\left(b^{\prime} 75\right)-M 0.26,01$; (l'01).

MORRIS, RALPII EDWIX (b'79) $\$$-Colo.2,

PENFOCK, VIVIAN RUSSELL $\left(b^{\prime} 70\right) \uparrow-$ Colo.2,94; (1'94).

Stradley, Ayers-0; (l's6).

Threlkeld, Richard I. (b',6)-Ky.4,'02 ; (l'09).

White, willard J. (b'72)-Mo.28,'96; (l'00).

LOUISVILLE, I,706, BOULDER

Lewis, Wm. Benj. (b'86)-Colo.2,'I2 ; (1'I3)

SNAIR, WALTER L. (b'i2)-Colo.2,0I (1'0I).

Van Landeghem, Frans P. N. (b'63)Colo.4,'0T; $\left(\mathrm{l}^{\prime} 0 \mathrm{~T}\right)$.
WOLFER, CARL (b'58) $\uparrow-C o l 0.2,90$; WOLFER,
$\left(\mathrm{l}^{\prime} 90\right)$.

LOUVIERS, -, DOUGLAS

Dumke, Clias. Ezekiel (b'81)-Colo.5,'06; $\left(l^{3} 06\right)$.

LOVELAND, 3,65I, LARIMER

BAILEY, MANDREN M. (b'55)†-Colo.1, '84; (l'84); Op.

Nember W. Va. State Med. Assn.
Cramer, Norman A. (b'68) II-Colo,4,02;

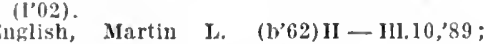
English, Martin I. (b'62)II - Ill.10,89; I'ord, John E. (b'65)-Mo.35,06; (l'06);

JOSLYN, SAML. ARCHIE (b'80)†-Colo.5, $04 ;(1,03)$.

MeFADDEN, JOIIN G. (b'70) -0.6,94; (l’94).

Spence, Wm. 1'. (b'76)-C'olo.5,'05; (1'05).

stewart, M. J" (b'61)-Ga.9,'95; (1'03).

Stewart, Win. S. (1)'64)-Pa.II, 87 ; (l'i3)

sutherland, Wm. J3. (b'51)-Ia.I, '6 (1'81).

Wrlglat, Ross E. (b'66)-Neb.5,98; (1'0I).

Wright, saml. A. (b'42)-No.18,83; (l'03).

LUDLOW, 210 , LAS ANIMAS

Durnell, Aubert (b'81)-Mo.34,'09; (1'10).

LYONS, 632, BOULDER Yates, Absalom Nelson $\left(b^{\prime} 6 \pi\right)-$ Colo.2, 00 ;
(l'0I).

\section{MANASSA, 788, CONEJOS}

Judson, Andrew Ir. (b'62)-Pa.2,'85; (1'95) traveling.

Tall Fradenburg, Geo. A. (b'7I) -Colo.1,'98; (l'99)

WORLTON, FREDK. DANL. (b'82)థ-Ill.1, 12; (l'I3).

\section{MANCOS, 567, MONTEZUMA}

Clark, Leonard H. (b'62)-Colo.2,'94; (I'9I) Egeness, Steplen E. (b’ 4)-Colo.4, 08 ; (1'08); T.

Trotter, Jay R. (b'74)-Ill.1,99; (1'03).

Wrightsman, Jolin $\mathbf{B}$.

(See Denver.)

MANITOU, 1,357, EL PASO

Acker, Frank W' (b'S6) - Colo.5,'10 (l'I0) ; $\mathrm{S}$.

BECK, LEYI II. (b'67) \&-Colo.3,'98; (1'99). Cooper, Fannie Coleman-CoIo.4,97; (1'97). Cooper, Francis M. $\left(b^{\prime} 54\right)-M o .10,77$; Ia.1, ' $80 ;$ (1'91).

CREIGHTON, BASIT B. (b'64)థ-0.1,92 ;

OCILBEE. HENRY M. (b'56)థ-0.6,'82 ; (l'S8) ; T.

MANZANOLA, 428, OTERO

Austin, Griffin H. (b'69)-Ont.5,93; (l'11).

Martin, Henry W. (b'75)-0.1,'9s; ( ).

leden, Bruce Armenius (b'63)-Tenn.5,'93; (1'95).

MARBLE, 782, GUNNISON

IIaxby, Henry Granger (b'61)-Colo.1,'92 ; (1'92); OpA.

STEPHENSON, FRANK B. $\left(b^{\prime} 75\right) \oplus-$ Colo.5, , 07 ; (l'0S)

SWIFT, HENRY HAVEN (b'55) †-Vt.2,'80 ; (I'II); Member Vt. State Med. Soc.

MATTISON, 30, ELBERT

WHITE, LEWIS CASS-Ia.1,92 ; (l'07).

MEAD, 114 , WELD

Dillingham, W. E. (b'79)-Colo.5, 03 ; (1'02).

MEEKER, 807, RIO BLANCO

FRFNCH, SAMUEL (b'69) $\oplus-$ Pa.1,'93 ; (1'96).

HUBBARD, ALLEN P. (b'67)థ-111.4,93; (1'02).

MONTGONERY, ROBERT C. (b'75)-Mo.34, 05; (l'06).

Sobernheimer, Ilarry B. (b'72)-Md.6,'03; (1'10).

MERINO, 200, LOGAN

LUTES, WM. BENTON\&-Colo.5,0: ; (1'09).

MESA, 210, MESA

ClAIG. $\triangle$ IiCHIE R. (b'62) - M0.21,'85; (l'91).

MILLIKEN, 100, WELD

Fuson, Carl Campbell (b'78)-Colo.5,'10 ; (1'10).

MINERAL HOT SPRINGS, -, SAGUACHE

Van Brunt, Edwin Wright (b'50)-Mo.1,'81; (1'09).

MINTURN, 24I, EAGLE

Holmes, Iírk W. (b'69)-X.Y.8,'95; (I'11).

MOFFAT, 100, SAGUACHE

Evans, Elias (b'43) Ind.9,'89, (l'11).

LONG, THONAS FRANCIS (b'73)-La.I, 08 ; (I'I2).

MONTE VISTA, 2,544, RIO GRANDE ABBOTT, HUBBARD H. (b'49)-NIo.I0,' 78 ;
$\left(l^{\prime} 00\right)$.

CHAPMAN, NORMLAN H. (b'54)-Pa.2,79; 1'S1).
KE(ILEY, EUGENE ALONZO (b'56) Ill.6,81; (l'I3); Menber Ia. State Med. SOC. OALR *

MONINGGL, JAMES H. (b'63) - 0.3,'88; (I'10). POLLOCK, ARTHUR I. (b'71) \$-Mo.2,"98;
(l'02); S.

TRUEIBLOOD, CHARLES (b'73)4-InU.8,

MONTROSE, 3,254, MONTROSE

ALIEN, JOHN Q. (b'51)屯-Ind.8,'83; (l'92); R.

BELL, 'SAMUEI H. (b'74) - Colo.1,'96; (i'36)

BRETHOUWER, CHRISTOPHER GARELD $\left(b^{\prime} 76\right) \oplus-$ Neb.4,01; 111.11,05; (l'09).

Coleman, Jos. N. (b'56)-Ky.1,'84; (I'89). II0.29, 03 ; (1,03).

Fisher, Hugh Francis (b'63) - Ill.4,'84; Mo.20,05; (l’06).

KNOTT, ALBERT WM. (b'76)-Mo.2,06;

KNOTT, ISAIAH, JR. (b'73)-Mo.1,98; (1'10); Member Mo. State Med. Assn.

Lingham, Harriette M. Collins $\left(\mathrm{b}^{\prime} 73\right)-$ Mass.5,'97; (1'98). ICNeill, Francis A. (b'49) E-0.2,74; $\left(l^{\prime} 88\right)$.
IIERTITII-PECK, ILAROLD H. $\left(b^{\prime} 78\right)$ Colo.3,"99; (1'99).

Monell, Caroline D. John (b'74)-Colo.5,'04; (1'04).

SCHERMERHORN, FRED. (b'56)థ-Mich.1, '80; (1'9́I).

Spring, John A. (b'78)-MOo.29,03; (l'04).

Wentch, Ge0. F. (b'58) H-Ia.4,'96; (1'10).

MONUMENT, 149, EL PASO

McConnell, W'm. (b'67)-Colo.1,93; (l'93). Rupp, Wm. H. (b'49) -Ia.1,'85; (1'94).

MORLEY, 20, LAS ANIMAS

FORD, DAVID EIIERSON (b'80)†-Mich.1, 08; (1'09).

MT. MORRISON, 350, JEFFERSON

Luce, Frank L. (b'54)-0.12,'83; (l'88).

NAVAHO SPRINGS, -, MONTEZUMA

Calkins, Royal W. (b'70)-la.4,93; (l'09) ; (Indian Service); Navajo Springs School.

Townsend, Benj. Ira (b'84) - Kan.2,08; (Indian Service).

NEDERLAND, 446, BOULDER

Phillips, John M. (b'52)-Mo.8,81; (l'07); Pd.

Rapp, Iohn IIenry (b'90)-Colo.2,'13; (1'14).

NEW CASTLE, 493, GARFIELD

LOCKARD, WILMER G. (b'67) ()-Md.4,'96;

Paxton, Rutherford H. (b'58) -MId.3,'85; (I'86).

NIWOT, I50, BOULDER

Sin!th. Geo. E. (b'58)-N.Y.13,'82; (l'00)

NORWOOD, 212 , SAN MIGUEL

BLAIR, MILTON M. (b'73) $\longrightarrow$; $\left(1^{\prime} 02\right)$.

Bollinger, Howard E. (b'71) - Mo.8,'94; (l'08).

NUCLA, IIO. MONTROSE

Keating, Win. D. (b'76)-In.6,'05; (I'08).

OAK CREEK, 222, ROUTT

Driscoll, WWm. E. (b'58)-0.1,'86 ; (1'96) ;

(Dunkley); S.
IORROW, ERNEST L. (b'81) 4 -Colo.5,'10; (I'10).

OHIO, I53, GUNNISON

Dudley, Wm. S. (b'60)-Mo.8,'84; (l'04).

OLATHE, 458, MONTROSE

Dennis, Elmer Grant (b'65)-Ia.3,'90; (l'10). GROVES, DANI. CHESTER (b'78)-Pa.1, ,03; (l'08).

LOCKWOOD, CHAS. EDW. $\left(b^{\prime} 71\right) \oplus-$ Mass. 7, 98 ; (1'07).

OLNEY SPRINGS, 130, CROWLEY

Johnson, Ross W. (b'88)-Colo.2,'11; (l'12). McKEEBY, FRED. E. (b'69) - Neb.5,'94;

$\left(l^{\prime} 02\right) ;$ G.
SNYDER, OWEN HOMER (b's 1$) \oplus-0.3,06$; (1'10); Nember Ohio State Ned. Assn.

OPHIR, 124, SAN MIGUEL

Farrar, Wyatt F. (b'53)-MIo.14,'82; (1'89). ORCHARD, 75, MORGAN

Braden, Wm. C. (b'66)-Colo.1,'92; (1'92). ORDWAY, 705, CROWLEY

Brooks, Wm. F. (b'60) H-Mich.5,'88; (l'14). JEFFERET, JAMES E. (b'69)-Mo.22,'99; (l'02). 
NeCLFAlS, FoAREST OTIS (1,85i)-IaA $09:(104)$

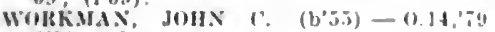
(1'09\}: 0 .

OURAY, 1.644, OURAY

HOWA., WM. W. (b' 49$)+-M d .3,78 ;(181)$

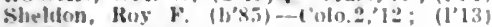

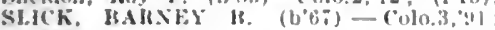
(1)99),

Stadler, Lesler C. (b'is\}-Ill.1.80: (I'0\%)

OXFORD, 500, LA PLATA

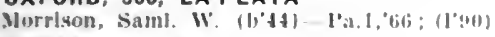

PAGODA, - ROUTT

Delwlller, Wns. K. (b'il)-N.Y.an: (1'03)

PAGOSA SPRINGS, 669, ARCHULETA

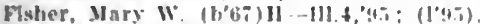

GREEXE. HGE Fl,OYD (b'\&)-1.a.1,0b (III).

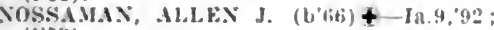
(1.03).

PALISADES, 900, MESA

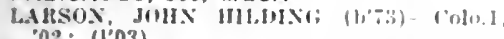
02: (1'03).

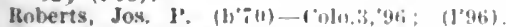

Tadlock, J. L.-Mo.1, 84 ; (1'07).

PALMER LAKE, - EL PASO

Baker, Fredk, leucl-XY.1,0:; ()

PAONIA, 1.007, DELTA

Allen, Austin R. (b'si) Mu, , is; (l'1l).

(ranford, hawrence d. $(1,48)=0.8,-i b$ $(1 / 9 i)$.

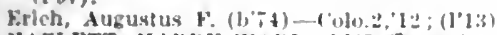

HAZLETT, HAKKY W.UD (b'65) - 'OOlo.3. 02: (1'02).

SEWCOMER, FLZABETI HORSEMA (b'80) - Colo.5, ${ }^{\prime} 07$ : (1'04).

NEWCOMER, NATHAX 1;. (b'9)-Culo, $06 ;\left(1^{\circ} 06\right)$.

PARKER, 100, DOUGLAS

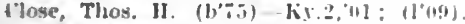

Luckle, James B. (b'88) - (rolu.2.'13: (1'1:2)

PARSHALL, 75, GRAND

Falth, Abrahan 11. (b'60) Ind.s, 81 ; , Mo.i. 'y2; (1'05).

PENROSE, 55, FREMONT

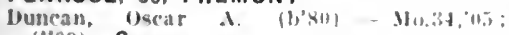
(I'09): G.

PIERCE, 350, WELD

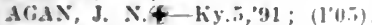

PITKIN, 250, GUNNISON

Good, Albert Huber (1''8:2)-I11.1.'11: (I'13).

PLATEAU CITY, 70, MESA

WATSON, WM, V. (b'63)-0.14.91; (]'01).

PLATTEVILLE, 430, WELD

DAWSOS, JAMES $k$. (b"55) - 14.1,"9: \{l'98\}.

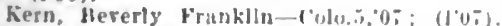

PORTLAND, 600, FREMONT

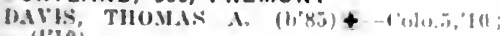

(1'10).

POWDERHORN, - GUNNISON

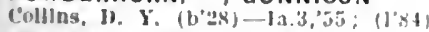

PRIMERO, 2,000, LAS ANIMAS

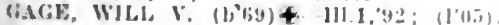

PRYOR, 20, HUERFANO

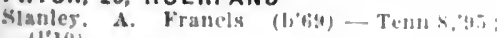
(1'10).

PUEBLO, 44,395, PUEBLO

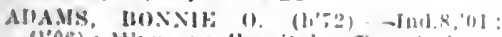

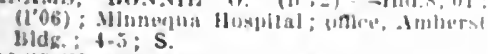

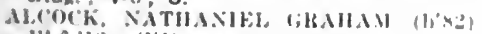

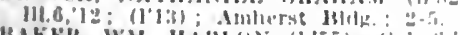

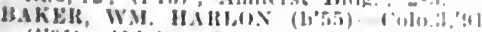

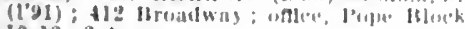
$10-12,2-4$

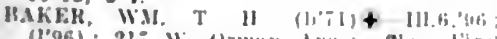
(l'96): 21: W Watlonal Hank llitk: : $11 \cdot 1: 2$

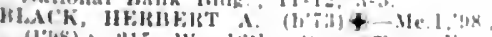

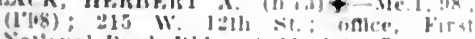

Nallonal Hank inllg.; $4-11,1-1,5$

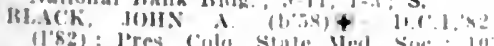

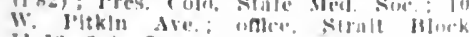
II. In!k!n $A$

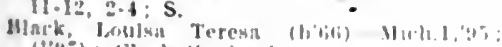
(8'yi): ('lurk Saultarlum

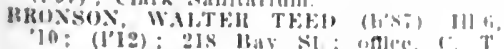

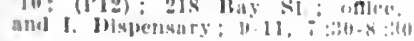

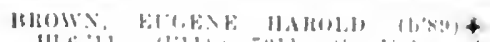
111.ti, 11 1111:

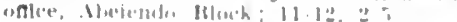

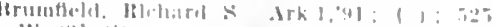

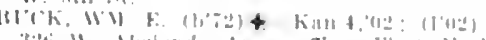

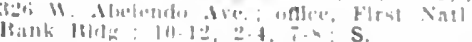

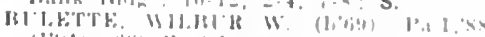

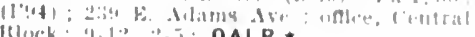
HFAlB (litix) 111 1

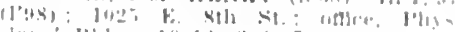

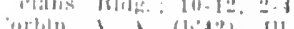

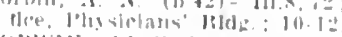

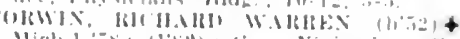

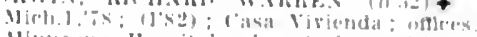

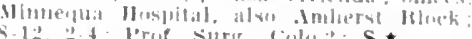

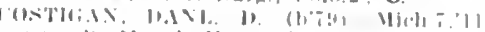

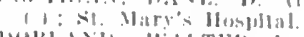

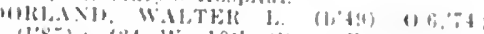

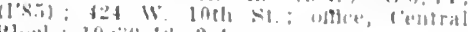

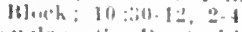

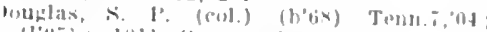

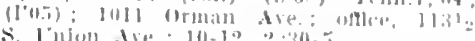
$\therefore$ (1)

II. M

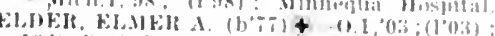

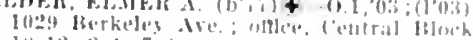
$116-12,2-4,-7-8$

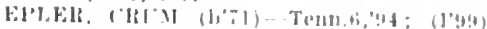

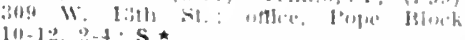

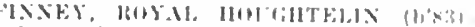

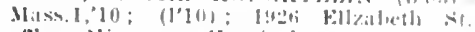

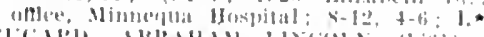

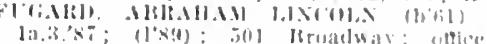

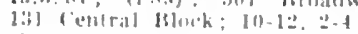

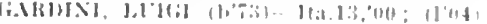

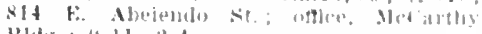

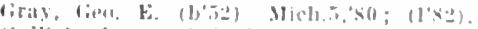

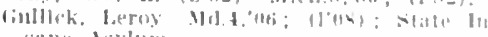
sime dsylum

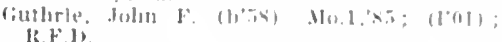

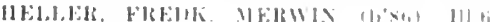
inger

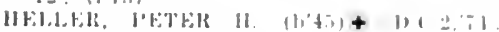

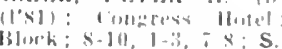

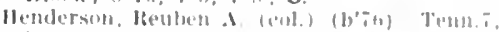

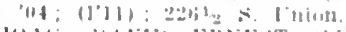

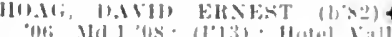

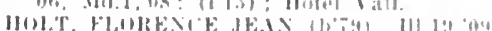

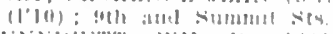

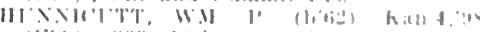

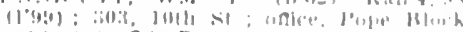
11. OOLR*

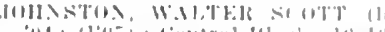

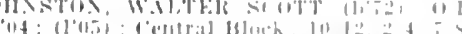

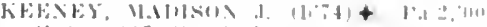

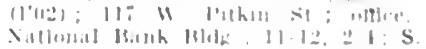

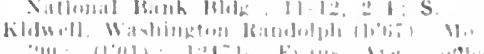

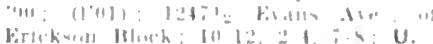

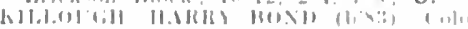

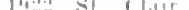

listion

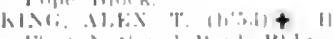

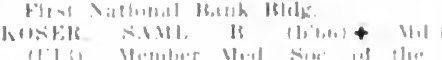

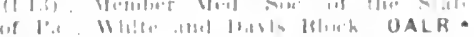

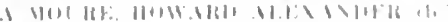

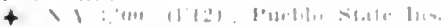

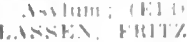

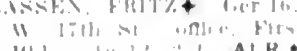

MOAL

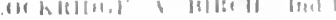

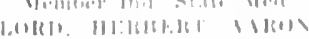

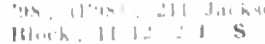

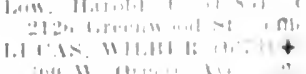

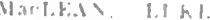

litur.

liing

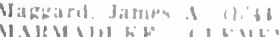

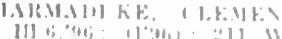

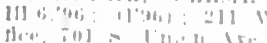

Harilall, Jifuem th

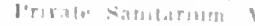

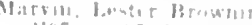

tili:

(1)

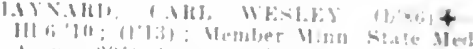
Pons

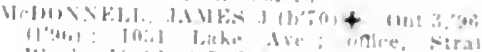

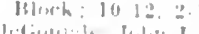

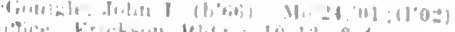

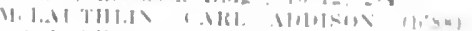

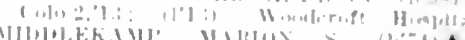

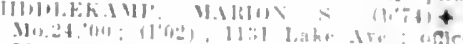

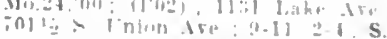

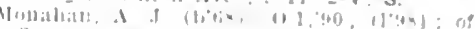

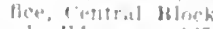

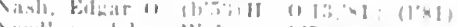

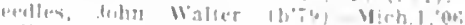

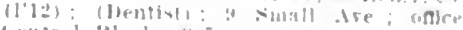

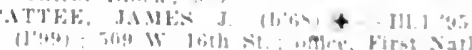

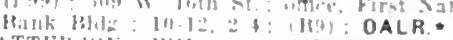

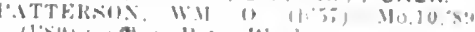

(1)

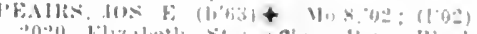

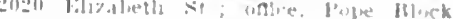
$111.12-19-4$

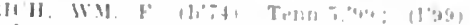

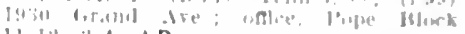

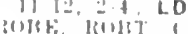

11:

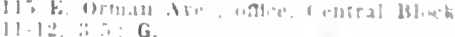

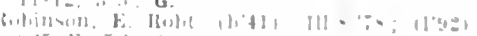

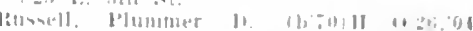

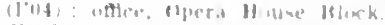

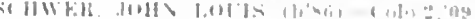

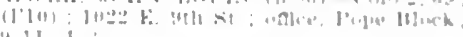

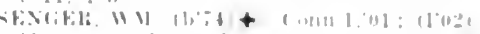

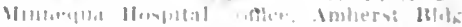

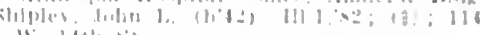
II. itth st.

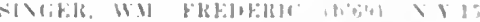
"untul| Th1

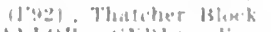

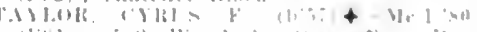
$11 \mathrm{~s}$

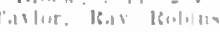

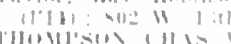

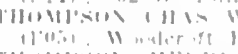

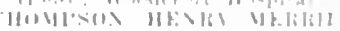

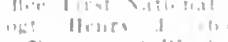
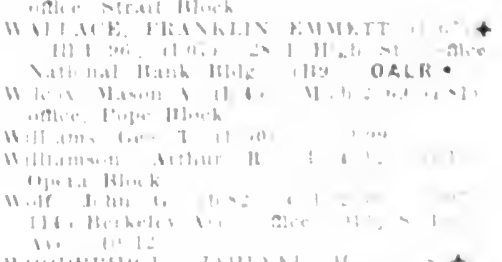

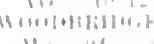

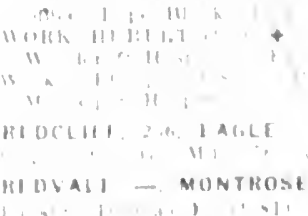

BESOLIS - ELIHET 
RICO, 368, DOLORES

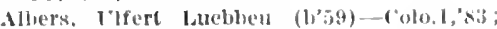
(I'si)

RIDGE, - JEFFERSON

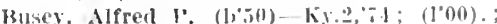

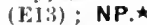

RIDGWAY, 376, DURAY

llalsteat, I. II. (b'8.i) - Ky.t.'(4); (['07)

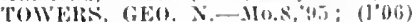

RIFLE, 698, GARFIELD

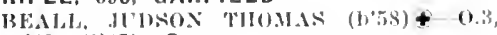
सI ; $(10 \%) ; \mathrm{S}$.

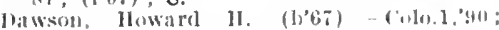
(l'91)

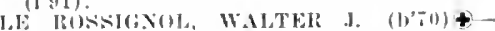

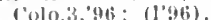

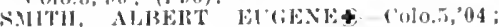
(l'04) ; Pr.

ROCKVALE, I,413, FREMONT

WH,LIAMSON, WM. ALAN (b'f2) -0nt.3, $86 ;$ ( 1293$)$

ROCKY FORD, 3,230 , OTERO

liarbour, llewellyn l'. (b'60),-0.6,'82, (1'99)

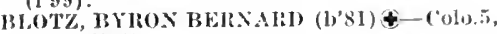
06: $\left(10^{\prime} 07\right)$.

Fenton, Ward E. (b'b1)-0.8,'s6; $\left(\mathrm{J}^{\prime} 90\right)$

IARTEY, IIENRY HARRISON (1, 60$)$

Colo. 1,97: (1,9i)

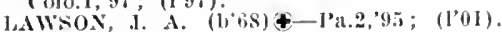

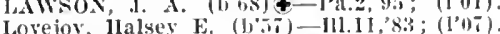

MAle WRAK W111HLM (b'65)-Mo.24

$92 ;(1,10)$

l'OLLOCK, ROBT. M. (b'58) \&-111.1,95: (1'00) ; S.

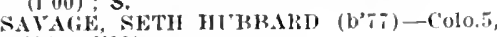
$08 ;(1,09)$.

Wolfe, lloy F. (b'is)I-III.10,0I; (1'01).

ROUSE, 550, HUERFANO

IIAl.LEY, WM. HFXIRY (b'82) $\$-.10 .20,0 \%$; (1'09)

RYE, 250, PUEBLO

CROZIER, RI'HL' B. (b'79)†-Mo.20, 0 ; (I'13); Member Mo. State Med. Assn.

SAGUACHE, 704, SAGUACHE

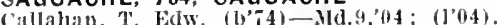

("allahan, T. Edw. (b'74)-Ild.9,'04; (1'04).

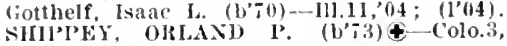
95 ; (1'95).

SALIDA, 4,425, CHAFFEE

COCIIFIS, FRANK N. (b'68)\&-111.6,'9l ; (l'?4);S. GEO. H. (b'7) $4-111.6,05$; $\left(1^{\prime} 07\right) ;$ S. (lini, law

IIartwell, Jessine Melicent (b'53)-Mass.5, is; (1'85)

JACliSON, FREDK. A. (b'65)-rolo.1,'88; (1'93); OALR.

Jones, Thos. $\left(b^{\prime} 60\right) \mathrm{H}-110.5 .92 ;\left(l^{\prime} 93\right)$

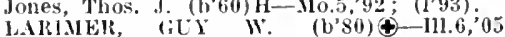
(1'0s); S.

Meclure, Finla (b'49)-IIl.,'76; (1'84)

Moxon, Thos. X. (b'64)-Mo.29,'96; (1'96).

P'arker, oliver T. (b',6)-Mo.20,97; (l'98) ALR.

J'lialen, Chas. Stephen (b'85)-Ill.6,'13 Intern, Denver \& Rio Grande R.R. Hospital.

Shatrer, Thos. I. A.-Colo.1,00; (1'01); S.

Swart\%. Fred Geo. (b'8i)-Colo.2,'13; (1'13).

SAN ACACIO, 25, COSTILLA

Blazer, Harold Elmer (b'64)-0.12.'90;

SAN LUIS, 900, COSTILLA

Aberg, Axel (b'63)-Colo.5,'(1).; (1'0.5).

smith, smithpeter $x . \quad$ (b66)-Ky.2,'94 (l'9s).

Bruce, Thos. Edw. (b'62)-Tenn.5, ${ }^{\prime} 93 ;\left(1{ }^{\prime} 06\right)$

SEDGWICK, 200, SEDGWICK

bavidson, Warren (C. (b'73)-111.4,'99: (1.03).

SEGUNDO, 600 , LAS ANIMAS

Adims, Ortus F. (b'T)-111.6,'01; (1'05).

SEIBERT, I 25, KIT CARSON

Bensinger, chas. Henry (b'70)-Colo.5,'06; (l'06).

BITMISER, ABRAIIAM M. (b'73)-Md.6. $02 ;(102)$

SEVERANCE, 150, WELD

Hullen. Eurgene (;. (b'74)-Ia.10,03; (1'03).
SILT, 250, GARFIELD

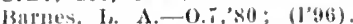

Hepler, Abraham Hudson (b'7)-.110.20,97 (1'(1)

SILVER PLUME, 460, CLEAR CREEK

Benners, James Wamyss (h'131)-Ky.2,93; (i). 4,$199 ;$; (1'I3)

SILVERTON, 2,I53, SAN JUAN

BI'RXWT'T, AITA L.IWREX('F (b'84)\& 111.22,08; $\left(1^{\prime} 049\right)$

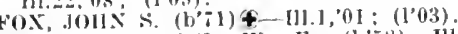

IIWNEE, FIEDK. W. E. (b's)-II.11, (9): (1'08)

SMUGGLER, I50, SAN MIGUEL

HBONSOX, HeFORFAT 1 . (I, TS)-111.22, 10 ; (1'11).

SOPRIS, 300 , LAS ANIMAS

FORHAX, "IHOS. I. $\left(\mathrm{b}^{\prime} 47\right)+-111,1,78$; $(1,78)$.

ST. ELMO, 46, CHAFFEE

Martin, Ell W. (b'52)-I'a.2,'78; (l'si).

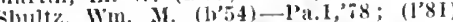

STARKVILLE, 1,000, LAS ANIMAS

HCCLICLE, (HAS. O. (b'67) \& 'olo.3,93 (1'93).

STEAMBOAT SPRINGS, 1,227, ROUTT

Blackmer, Frank J. (b'81) -I11.11,04: (1'07).

crannell, Alvin E. (b'71)-Mo.27,'97; (1'04)

Cruikshank, Geo. Iloum (b'71)-X.Y.s,99 (1'11).

DONGE, IIOLACE C. (b'T)\$-111.6,02; (l'03).

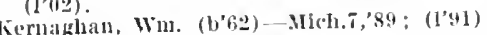
not lu pluetice.

Thompson, Iames Chas. $(6,-5)$-Mo.I, 97 ; (1'04)

Willett, Fredk. E. (b'83)-Colo.2,11; (1'12)

STERLING, 3,044, LOGAN

babcock, Myron d. (b'72) - la.10,01; (1'01).

BARNEY, CSH, JOIIS (II) I0) : 0

(1'92).

Fisher, Chas. Edmund (b',3)-Mich.3,72;

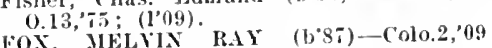
(l'09).

Greig, Wm. (b'52)-K.Y.10,81; (1'01)

Kellogg, Jlrah H. (b'72)-Colo.2, $06 ;\left(l^{\prime} 06\right)$

Perdue, l'erry F. -0 ; (l'08).

Stanton, Lewis Eurene (b'59)-1a.7,86 ; (l's 8 ).

STRATTON, 75, KIT CARSON

BEACHLY, JOHY VAWTFR (b'72)-Yo.28, $00 ;(1,08)$.

STRONG, 65, HUERFANO

SCOTT, AlTIX RUFL' $\left(b^{\prime}, 6\right)$ - $-111.16,06$; Ill.11,'07; (1'08).

SUGAR CITY, 808, CROWLEY

Sanger, Fannje A.-Mich.1,'82; (1'97).

Sanger, Marcus L. (b'57)--Mo.14,'81; (1'00)

Wan $\left(b^{\prime} 62\right)-111.11,93 ;\left(1^{\prime} 01\right)$.

wORKVAX, (roYD w. (b'84) $4-$ Colo.2, '11; (1'11).

SWINK, 310 , OTERO

Yewkirk, Henry Milo (b'70)-Mo.27,'9:; (l'11).

TABASCO. 30, LAS ANIMAS

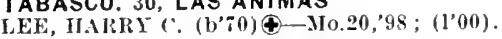

TELLURIDE, 1,756, SAN MIGUEL

('ROSS, JAIIES WILABOARX $S .\left(1 b^{\prime} \overline{\bar{i}}\right) \oplus$

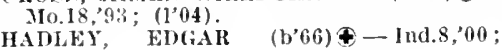
(1'03).

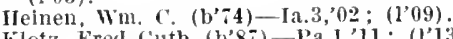

Klot 7, Fred (iuth (b'8i)-Pa.1,'11; (1'13).

Nordlund, Masie (b'54)-Colo.4,'9i; (1'97).

Rothwell, Matthew T. (b'78)-Colo.5,'03; (1'06).

THURMAN, - WASHINGTON

1]all, Fred C., .tr. (b'56)-Ǩan.3,'00; not in practice.

TIMNATH, I50, LARIMER

Carey, James D. (b'82)-Colo.2,'06; (1'06).

TINCUP, 64, GUNNISON

Incliowan, John Francis (b'58)-Ky.4,'80; (I' 82 ).
TRINIDAD, 10,204, LAS ANIMAS

IBMALA.IS, HORATIO b. $\left(\mathrm{b}^{2} 79\right) \&-\left[1.6^{\circ}\right.$ 03: (1'05): 439 Colorado Are: offle, [Bunk 13Idk.; $11-12,2-4 ; S$

Bernlnzsin, Fdward (b'6.5) - ita.6,'8! ; (1'03) "301 W. Maln si.

MBIIOAR, BEN.I. B. (b'82)-MIo.8, 03 (1'03); 615 F. Maln st, offlce, $318 \frac{1}{2} \mathrm{~W}$ commerclal sit.; $9-I 1,2-4,7-8 ; \mathrm{T}$.

cawley, Bernard M. (b'70)-Mo.28,4y9. (l'03) ; Arlmona and ("olorado Aves.

'hislolm, Arelilbald J. (h'i8)-N10.20,"0t; (1'06); Maln Si.; S.

('lausl, Vincenzo (b't6)-Ita.12,94; (1'13) 213 W. IIain st.

ESI'LY, JA.IIS Cr. $\left(b^{*} / 4\right) థ-K y .5,00$ (l'00); Malil and Anlmas Sts.; $3-10: 30$; $2-4$.

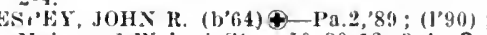
Main and Walnut Sis.; $10: 30-12,3-4 ; S$. rd, (ieo. R. (b'66) $\rightarrow$ No

Fox. Benedicla Beshaar (b'81)-Colo tof : $\left(1^{\prime} 06\right) ; 611$ k. Main st.; office, Elk Block; 9-12, 2-5

FREIDENTIIAL, ALFREI) (b'80) \&-Colo.3 ,02; $(1,02) ; 216 \mathrm{~W}, 3 \mathrm{~d}$ st.; offlce, $110 \frac{1}{2}$ F. Irain st. ; 10-12, 2-4, i :30-8.

Ilershey, John B. (b'56) H-0.7,79; (1'82) 222 W, Walnut St.; offlee, Elks Bldg.; $10-12,2-5$

Howard, Wm. S. (b'22)-Mld.6, 00 ; (1'04).

JAFFA, PEIRR Y (b'70)@-Colo. 3,$00 ;\left(I^{\prime} 00\right)$; 231 S. ('hestnut St. ; office, McCormick [3]dg. ; $10-12,2-4$.

O(;1.E, WM. II. (b'61)£-1'a.2,'82; (1'02) 522 Colorado Are.; offlce, Exchange Block; 9-10, I-3.

Presnall, Caleb W. (b'55)-Ky.2,'05; (1'13) 1202 Arizona St.; offce, Elks Bldg. ; $9-12$ 1-4; OALR. $\star$

Raizon, James (b'44)-Ill.1,91; (l'96); 300 W. Main St.

RICHIE, LEE T. (b'51)-Ia.10,00; (1'06); 301 E. $2 d$ St.; offle, 106 E. Mialn St. 9-12, 2-5; OALR.

ROBINSON, GEO. W. (b'50)థ-I11.6,79: (1'83); ;13 Willow St. ; offee, $106 \mathrm{E}$. Jialn St. $10-12,2-5$.

SCANNELL, EIIW. I. (b'-6)-N.H.1, 01 (l'01); Mecormick Block.

TIIOMPSON, DAVID GHLIORE (b'58)-Ia.3, '84; (1'83) : 616 Maple St. ; offlce, Colorado Bldg. ; $10: 30-12,2-4$.

VERNON, 90, YUMA

WORTII, (H.LS. M. (b'69) - Colo.4, 07 (1'11).

VICTOR, 3,162, TELLER

Brown, Annil F. S. (b'68) H-Ill.4,'93; (1'95).

Dinsmore, Wm. S. (b'69)-Colo.2,'11; (1'11) Elllott, ('has. E. (b'66)-Vt. 2,'88; Que.5, $89 ;\left(l^{\prime} 03\right)$.

HAYTS, ALFRED IRWIN (b'68)-Colo.2, '96; $(1,96)$.

HOWARD, CHAS. J. (b'73)థ-X.Y.1,97; (1'06).

POLLY, IOHN B. (b'64)-Ia.1,'96; (1'96).

POLLY, KATHERINE C. (b'70)-Ia.1,"96; (1'96)' Schoen, Watter Albert (b'87)-Colo.2,'11
(1'12).

THONAS, HARRY GEO. (b'69)-Neb.5. WALKER, ROBT. RITCHIE (b'86)-Ont.1,

Wood, Mina B. Gault (b'io)-Mich.5,00; ( )

WALDEN, I62, JACKSON

Flscher, ('has. H e n ry (b'66)-D.C.4,'98; (l'00).

Fischer, Peter Weimar (b'59)-Colo.2,91;

(l'91). Auqust Ilarold (b'78)-111.19,'06

111.1,08; (1'13).

WALL STREET, 62, BOULDER

Sutherland, C. M. (b'כ5) E-Hl.8,'7;; (1'98)

WALSENBURG, 2,423, HUERFANO

ABDUN-N1\%, ASSAD SIMON (b'85)-

Ill.6,'10; (1'11); S

ANDREWS, GEO. DORSON (b'60)-MIO.I, '93: (1'02).

BAIRD, THOS. DAVIS (b'53)-I11.1,7\%; (l'82).

(HAPYAN, WALTER S. $\left(b^{\prime} / 3\right) \notin-C o l o .2$. '96; (1'96). 
L.AIMEK, IKA 18. $\left.\left(b^{\prime} 64\right)+-M 1\right), 20,98:$

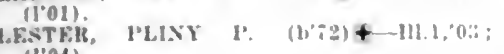
(1'04).

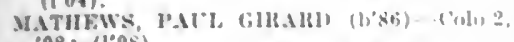
Oos: (1.08)

TROVIT, AlBFRT J. (b'(i) +-Mo.1, S9: (1)(99)

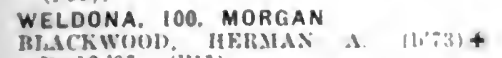
I'n.19,0:; (1'11).

WELLINGTON, 459, LARIMER

GPITH, CHIS. IS. (b'S1) + Nubli,"0:3;

(180i).

WESTCLIFFE。 232, CUSTER

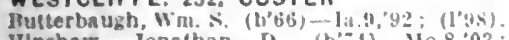
Illnshaw, Jonatban I0. (b\%4)-Mo.8,03: (1'03): Pd.

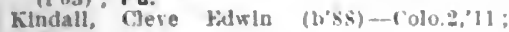
(1'11): $\mathrm{S}$.

WESTMINSTER, 127, ADAMS

Cialkins, Rlchard $\mathrm{T}$.

(see Ilenrer).

Russell, Rtchard (b'6.5)-Colo.3,"00; $(1900)$; WHITEWATER, 80, MESA

WBBLE, HOBT. B, (b'ti) - IUd.18, "116: (l'OS): OALR.
WIGGINS, 220, MORGAN

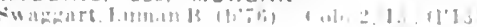

WILEY, 197. PROWERS

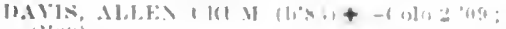
(l'o(n)

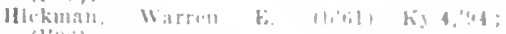
(1)(titi).

WINDSOR, 935. WELD

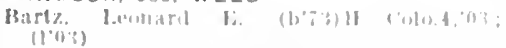

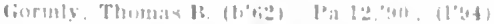

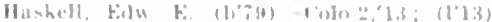

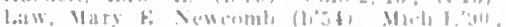

not in pracllew.

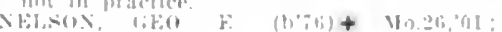
(1'(1)i).

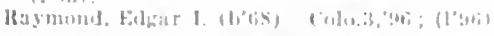

WOODMEN. - EL PASO

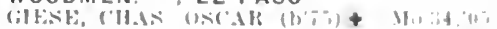
(1'10).

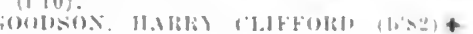

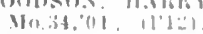

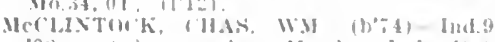
$9 x^{2}$ not In practipe: Inember lnd state Med. Asish.

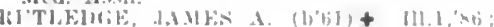
(1'12); T.
WRAY I OOON YUMA

B.ale. 1.: 1.

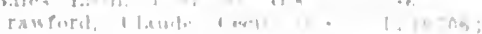
(1) lil,

Kitemiller Harrs

(1) $(1,4)$ OALR

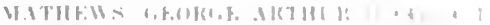

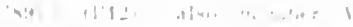
$\sum_{0 \rightarrow 1} \quad \sin$

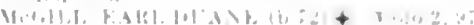

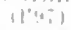

YAMPA, 332, ROUTT

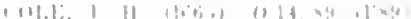

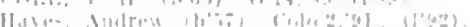

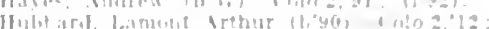
(i)

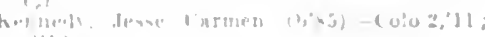
$1 \because 1 \geq 1$

YUMA, 333, YUMA

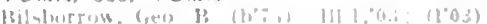

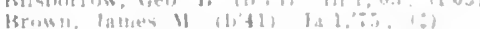

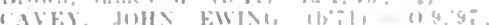
(I) $11 ;$ )

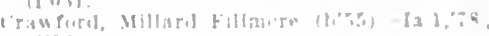
(1'J0)

Miller, Jimes L., or (trai) Ma.22.00 (1'11)

FOR KEY TO SPECIALTIES. ABBREVIATIONS. SYMBOLS. ETC.. SEE PAGE 268

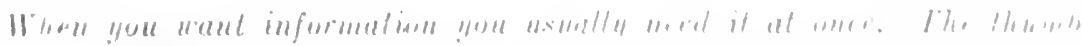

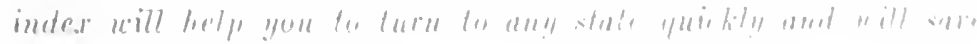
ther cormetis of the imeges.

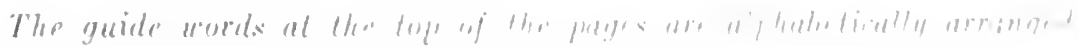

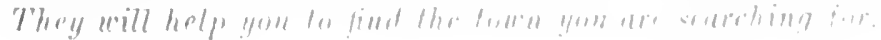




\section{CONNECTICU'T}

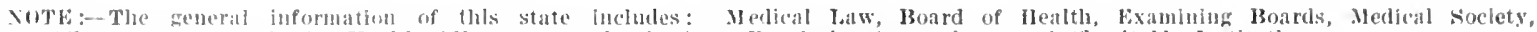
County Othlers, county and City Health oflcers, state lustlutions, flosjobtals, Sanatoriums and charitable Instltutions.

\section{CONNECTICUT}

Population ( 1910 census)

$1,114,756$

Number of Counties.

Number of Physicians.

Members State Society, Dec. 3i. 1913

Area of State in Square Miles.

885

\section{MEDICAL PRACTICE LAW OF} CONNECTICUT

Sectlon 47I4. WHO SHIAL IRACTICE: No person shall, for compensation, gain or reward, receiced or expected, treat, operate or prescrlbe for any injury, deformity, allment or disease, actual or lmaginary, of another person, nor practice surgery or midwifery, untif he has obtained sueh a certifieate of registrutiou as is in sectlou 4ij provided, and theil only in the kind or branch of practice stated łn sald certificate: but this chapter shall not apply to dentists while practicing dentistry only, nor to any jerson in the employ of the rnited states government whlle acting in the scope of his employment, nor to any person who sliall turnish medical or surgical assistance in cases of sudden emergency, nor to any person residing out of this state who shall be employed to come into the state to render temporary assistanee to or consult with any temporary assistanee to or consult with any
physician or surgeon who bas been vegistered physician or surgeon who lias been registered chapter, nor to any plysician or surgeon then actually residtig out of this state who shall be enployed to come into this state to treat, operate or preseribe for any injury, deformity, allment or disease from which any person is suffering at the time when such non-resident physician or surgeon is clairrosant who docs not use in his practice any drugs, medicine or poison, nor to any any drugs, medicine or poison, nor to any swedisb movement cure, sun cure, mind cure, magnetic healing or christian sicience, nor to any other person who does not use or prescribe in his treatment of mankind drugs, poisons, medicines, chemicals or nostrims.

Sec. 4715. APPLICATIUNS ; EXAMINATIONS; LICENSES FROM OTHER STATES : No person shall obtain a certificate of regis tration as in Section $4 i 14$ required until he has passed a satisfactory examination before for of the examining committees appointed for the purpose by the State Board of until he has filed with said board duplicate until he has filed with said board duplicate
certificates signed by a majority of said excertificates signed by a majority of said examining conmittee, stating that they have eine, surgery or midwifery, nor until he has filed with said board duplicate statements subseribed and sworn to by him on blanks furnished by said board, giving his name. age, place of birth and present residence. stating of what medical college he is a graduate and the date of such graduation. shall be required by sald banks. No person sliall be required by sald hanks. No person presents to the committee by whom lye is to be examined satisfactory evidence that he be examined satisfactory evidence that he incorporated and reputable medical college as determined by the provisions of Section 4718 of the general statutes, nor until he lias presented to said committee a certificate reputable citizens of this state, and also sitisfictory evidence that, before beginning he study of medicine, he was graduated from a college, high school, or preparatory school whose stamling shall be approved by saicl committee, or that his preliminary educatlon is equivalent thereto. From and after january I, 1914, no person shall be eligible to examination imder thls Act until he sliall, in addition to the foregrolng requirements, present to sald eommittee satisfactory evimedllches. lie fras completed a course of medliches, he thas completed a course of whleh included chemistry, physles atd general biology.

Any one of the examining committees appointed under the provistons of section $4: 16$ may accent the Jicense of any state Board of Medical Examiners of any state lin the in lieu of said examination, provided the applieant slatl present sueh license to the eximining committee before whom he apnears together with sere whom he ap bears, together with satisfactory evidence state examination of as ligh a grade and state examination of as ligh a grade and
of the same kind as that rectuired by said xamining committee, that he is a residen of this state or that he lutends in good faith to permanently reside hercin, that he has been in actual pratice for a period of at Jeast six months in the year immediately preceding the date of his application, and that he is of good moral character ind professional standing, and on the payment to said committee of the sum of $\$ 15$ he may receive a certitleate of the approval of

Any person passing such examination or ohtaining such certificate of approral and filing said certificates and statements shall receire from sajd state Board of Health, on pasment of $\$ 2$, a certificate of registration, wlich shall state that the person named has leen found (jualified so to practice. Each of sald examining committees shall file with of sald examining committees shath fle with the State Board of Health, within thirty days after the close of each examination, a tist of all applicants examined by it since shall also indicate whether each applicant passed or failed to pass such examination. Sec. 4716. CONSTITLTION OF EXAMI ING COMMITTEE: The Connecticut Medical societs the connecticut Homeopathic Medical Society and the connecticut Eclectic Medical Society shall each annually in December fle with the state Board of Heajth the name of one plipsician, practicing in this state, who shall have been recommended hy such medical society as a person competent to serve on one of the examining commitices appointed by the state Board of public acts of $18: 93$, and in case any vacancy oceurs on any of said examining conmittees the president of the society of whose memthe president of the society of whose nem-
bers said conmittee is composed shall nominate such a person to fill said racancy. Annually in Jamnary the State Board of Health shall appoint one member of each
of said committees, who shall have been nominated for such office as aforesaid, to serve five years, and said board shall in the same manner fill any vacancy occurring in any of said committees. Said committees shall be known as the Connecticut Medical Examining Board, the Connecticut Homeopathe Uedical Examining Board, and the Board.

Sec. 471\%. INTERPRETERS: Every examining committee provided for in section 4716 shall, when requested by an applicant for a certificate permitting said applicant to practice midwifery if said apphcant does not understand the English language, conof the language which the applicant understands. Said interpreter shall be furnished and paid by the applicant and shall gre the commitee conducting the examination satls-
fistory proof of bls abllity correctly to translate the language of the applicant into Finglisl. Whenerer such applicant shatl hare satisfactorily passed an examination, sliall be lssued as provided in section 4715. Sec. 4718. DATES OF EXAMINATIONS: The sald examining committees shall hold examinations on the second Tuesdays of Narcli, July and Norember of each year, at sucl places as they may deslgmate and at such other times and places as they shall vractice medicine or surgery shall be ex amined in anatomy, pliysiology, medical 'hemistry, obstetries, hygiene, surgery, pathology, dlagnosing, therapeutics, practice and materia medica. Each committee shall and materia medica. Each committee shat examinations in writhg, and both questions and answers shall be flled wlth and preserved for at least six years by the state
Buard of Health. Each of said committees shall make such rules and regulations for conducting said examlnatlons and the furtherance of the spirit of this Act, as from time to the it shall deem necessary. Erery visions of this Act shall be examined by visions of this Act shall be examincd by the committee representing the sime school uated; but before taking such examination he shall pay to the commlttee the sum of \$i, provided that the fee for examination
in millwifery alone shall be $\$ 10$. An applicant rejected by an examinlng committe may be re-examined by the committee before whom he appeared at any subsequent meeting of said committee. On the receipt of 4iis provided, the State Board of Health shall transmit one of said duplicate stateShall transmit one of said duplicate statements, together with a duplicate of the celtificate of registration in each case, to the
town elerk of the town wherein the person so fling said statement resides; and in case such person does not reside in the state of connecticut, the State Board of Health shall transmil said statement and certificate to the town clerk of the town in this state person, and said town clerk shall record the same in a book to be prorided for that purpose by the State Hoard of Health, and shall bose by the State Board of Health, and shah then return the same to the person who fled town clérk shall receive for such recording a fee of 25 cents, to he paid by the State Board of Health out of the amount so paid to it as aforesaid. The secretary of each of with the secretary of the state Board of Health a list of medical colleges or institutions recognized as Jegal and reputable by his societr, or all of such secretaries ma agree on a single list, and such llst or lists may be corrected as may be necessary.

Sec. 4719. REPEAL; PHARMACISTS IRESCRIPTIONS; PENALTIES : Nothing in this chapter shall be construed to repeal or affect any of the provlsions of any private charter. The provisions of this chapter shall not apply to ficensed pharmacists. All blysicians or surgeons practicing under the provisions of this chapter shall, when re tions in the English language. Every person who violates the requirements of thi section regarding prescriptions shall be fined $\$ 10$ for each offense. Every person riolating any provision of Section 4 il4 shall be fined not less than $\$ 100$ nor more than sequer fhe first oflense, and for each subthan $\sin 0$, or imprisoned in the county jail 
for not less than thlrty nor more than for not less than thirty nor more than nlnety dass, or both: the fine. When coltected, shall be gald one-half so the merson or corporation making the combialnt and Every person whe shall swear to any falke. hood in any statenent revulred by sectlin tijs to be nled wlth the sitale lisard is lealth shall be mullty of perjury. The stiate Koard of Healsh may appulus a clerk and fix his salary. to be pald only out of the fees and penaltes receired unler the pro reslons of this chapter.

Sec. 420. REVIOCATIOS HF CEITIFI. cits: The secretary of the situte lionrl if Health, upon the written request of all the members of any one of the examlang com. altrees mentioned in section filt, may re. rote and cancel the certiflcate of registratlon of ans person conrlctel of any crlme in the practlce of his professlonal business, in conrlcted of a felony but no one of the conrled of a telony, but no one or the examining columltee shall have the rlytat th request the revocation and cancellation of any one of the other examining commlttecs.

\section{STATE BOARD OF HEALTH}

E. K. Root, President, Hartford; J. H. Townsend, Secretary. New Haren, untce state Capliol, Hartford: A. W. Jhillips. Derby; Lewls Sperry, South Windsis: A. J.

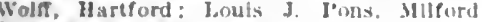
J. Fredk. Jackson. Hamden.

\section{CONNECTICUT MEDICAL EXAMINING BOARO}

J. Francls Calef, I'resldent, Miduletuwn iam. M. Garlick, Brligeport; W. L. Bar ber, Waterbury; John B. McCook, Hartford Chas. A. Tutle, Secretarv. Yow Haren.

\section{CONNECTICUT HOMEOPATHIC MEDICAL EXAMINING BOARD}

Wm. Plit Baldwin, New Haren; H. Roberts, Derby: F. b. Wlleox, wlllimantic E. H. Linnell, forwlch; E. C. M. Iall. Sec retary, New Haren.

\section{CONNECTICUT ECLECTIC MEDICAL}

John W. Fyfe, Chairman, Saugatuck; I. Marsh. Mansfleld ('enter: James $F$. IIalr, Brldgeport; Ernest A. Marklıabl, Dur ham: Thomas $\$$. Ilodge, Secretars, Tor rington.

\section{CONNECTICUT STATE MEDICAL SOCIETY}

Jncers 1913-14

11. Chester Brown, J"resddent....... Inanbur wim. S. Itulbert, Ist V.-I'res.........Winsted

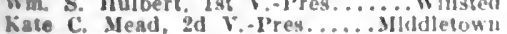
Kate C. Mead, 2 d . Pres........3lddletown J. H. Townsend, Treasurer........... Jew laven

\section{Component County Societies of the connec-} tleut State Medical Soelety

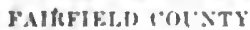

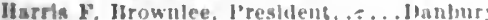

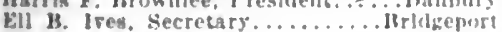

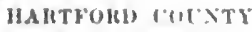

John 5. Dowllng, l'resident.........IIrtford Albert is. kellh, Secretary...........llartord

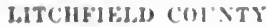

F. 8. Skia, J'resident.......... Falls villace" liobe. Hazen, Secrelary......... Thomastoh MIDLESRX ('II'ST

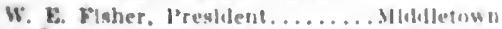

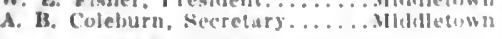
SEW HAVFS (OH'T)

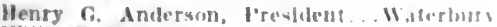

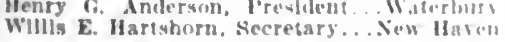
NEW INAMON COENT

1. 1. Rrewer. I'resldent............ Nurnich

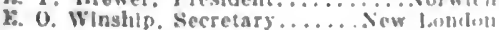

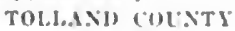

Wrabt I3. Hean, Hresident........ Wurkville

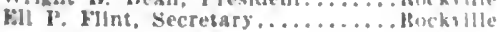

W19114111 101.95

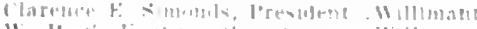

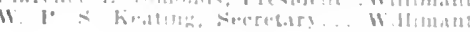

\section{COUNTY HEALTH OFFICERS}

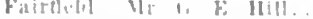

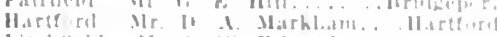

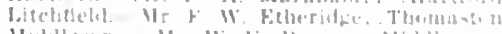

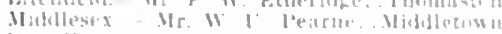

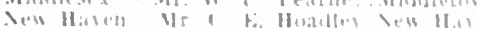

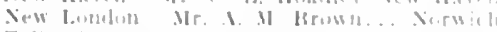

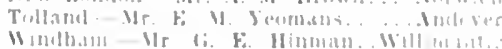

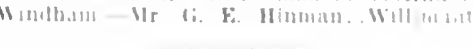

HEALTH OFFICERS IN CITIES OF 3,000 POPULATION AND OVER

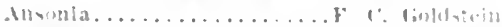
Ke.thes.

Rridhegimit

lisistel.

liatubury.

loerby

ireenwich.

llartoril.

Manchester.

Meriden.

Mlablequn

Xaugilute.

Yew Britaln.

New lovilon.

Nurwalk.

Norwleh...

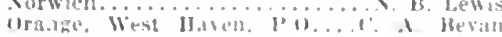

lusmam.................... 1.tlue

Ruckville. .

Shelinn.

soublington.

citamford.

Torringtont.

Wallingturd

Waterhury.

Willimantle.

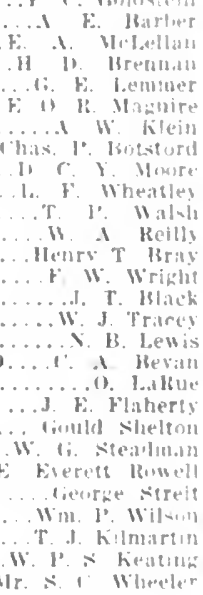

Hartford

\section{STATE INSTITUTIONS}

Imerican sichool fur the luaf, Harperel. (onn

colnecticut Institute for the Mind 3isi Wetherstleld st. Harteord, fonm. Eilura. lional: It E. (colloy, falleral subrem terulent

Ilartford Sanatoriam, Harterral, Cimn

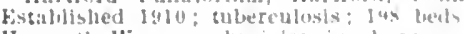

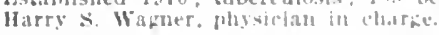

Lakeville

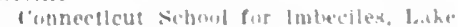

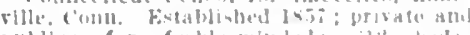

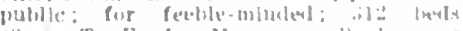

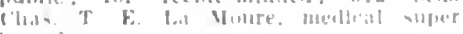
inicintent

\section{Mansfield Depot}

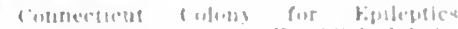

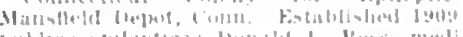

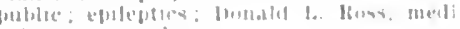
call superthteluberic

Meriden

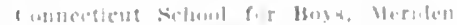

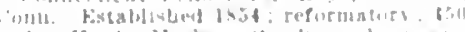

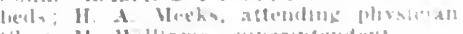

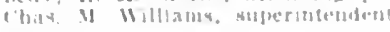

Middletawn

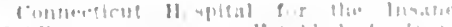

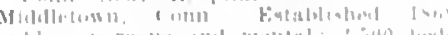
moflac morvous mul mollat

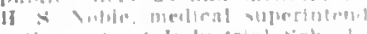

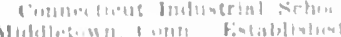

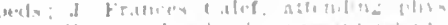

Myslic

$$
\text { (I) }
$$

(.).11:

Noroton Heoght

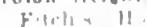

$$
\begin{aligned}
& 11,10.11 \\
& \text { lowis }
\end{aligned}
$$

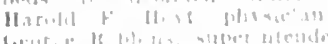

Norwich

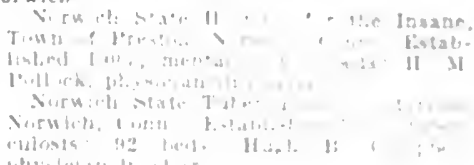

ilisicin:

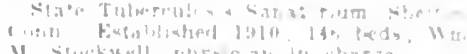

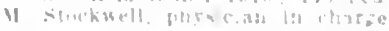

Wethersfield

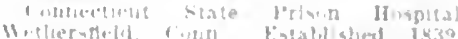

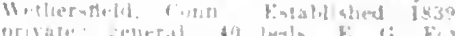

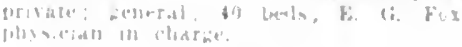

HOSPITALS, SANATORIUMS AND CHAR. ITABLE INSTITUTIONS

Bridgeport

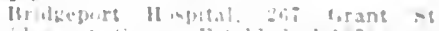

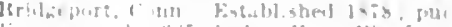

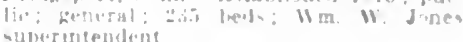

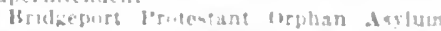
filrtleld Are. isnd fillaworti it. Bridge

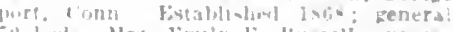
ill loels, Mrs, Fanly k. liusell, superin

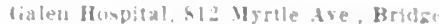
purs. Conn folatilialied 1000 pr:rate

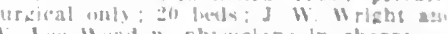
lece Wendun, phisiclano In charge kector lfospital. 11:5 lark Are. Hribe

inirt. Cunn. Folablislied ligig; prirate betl. Mary Coumlinan in charce.

st. Viment's Howrital. Isrideen

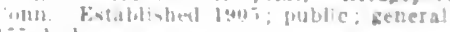
liti leeds.

Cromwell

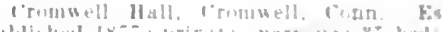

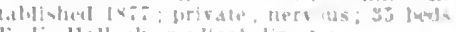
$f k$ Hallinek, mediloal direcitr.

Danbury

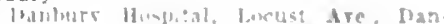

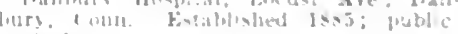
(i) ineth

Darien

Cedar Wild sanitariun, Haren. Cunn

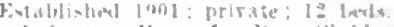

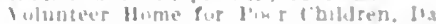

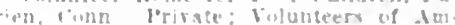
crkest, in chariet.

Derby

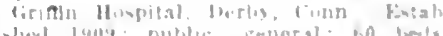

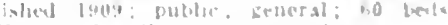

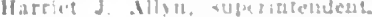

Falls Village

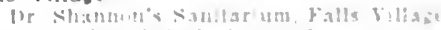

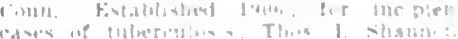

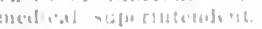

Greens Farms

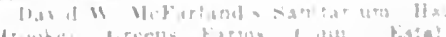

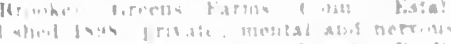

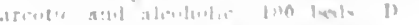

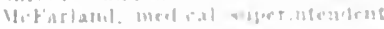

Greenwith

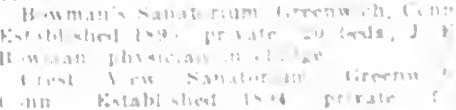


Hartford

Chater Oak p'rivate llospitai, :31 Weth. ersilede Are., Hartford, Corm. Fistatlished 1907; 16 beds; IIss M. C. Mat:Carry, superintendent.

Clity Hospital, 2 Holcomb st., Hartford, Com. Fistablished 1904; public; 11. beds; Hary C. Clifton. eity physichan ani surgeon, in charge; Wm. W' stillman, superinteugent.

liartfortl Hospital, Hartford, Comn. Katablished T85\%: private: gencral: 400 beds: ippletou is smith, medlcal superintendent; branch for tuberculosis, willintendent; branci

Hartford Retreat, 30 Washington sit. liartford, (ounn. Established ixt; private: berrous ind niental: 17.5 ledes ; N. Thompson, medical superintendent. Niles street l'rivate bospital, fill Niles st., llartford, comn. Established 1912; getuelal: Hisses Casstly and stimpson, In ehirige.

St. Francls' Ilospital, 370 Coilns St. Hartford, Conn. Established 1897; public general; 280 beds; (. C. Baliey, president of medical staff.

Walnut Lodge Hospital, Inc., 142 Falrfield Ave., Hartford, Comn. Established 1878; private; narcotlc and alcohollc; 25 leds; T. D. Crothers, physician in charge.

Watkinson Jurenlle Asyium and Farm School, 1100 Albany Ave., Hartford, ('omu. Establislued 1s74; private; for homeless hoys; 40 beds; E. B. simead, superintendent.

Willwood Sanatorium New Britain Ave. Hartford, Comm. Established 1902; private; branch of Hartford Inspital; incipient tubereulosis; 50 beds; W. B. Bartlett, resident physician.

Wilson Sanitarium, i4 Buckingham St., Itirtford, Conn. Established 1898; private; general; 30 beds; Miss Alice Marie Vilson, superintendent.

\section{Litchfleld}

Spring Hill Home. Litchfleid, (onm. Established 1858; mental and nervous diseases; 20 beds; John L. Buel, physician in charge.

\section{Meriden}

Meriden Hospltal, 181 Cook Ave., Meriden, Conn. Established 1893; general emergency; 5 t beds; Rose $\mathrm{G}$. Reed, superintendent.

New Haven County Tuberculosis Sanatorium, Meriden, Conn. Established 1910 ; 122 beds; James B. Dinnan, medical superintendent.

Middletown

Mlddlesex Hospital, 28 crescent St. Mlddletown, Conn. Established 1904; public; general; 70 beds; Agnes M. Wood, 1t. X., superiutendent.

\section{New Britain}

New Britain General Hospital, 92 Grand St. New Britain, Conn. Established 1893. public; general; 60 beds; lirs. Jenuie L. Basseti, superintendent.

Dr. Style's Sanatorium, 19 Court St. New Britain, Conn. Established 1896 ; private; 25 beds; W. Lyon, physician in charge; Miss Margaret Hart, matron.

New Canaan

1)r. Erooks' Sanatorium, New Canaan, Com. Established 1896; private ; tuberculosis; 28 beds; M. J. Brooks, phystcian in charge.

\section{New Haven}

Elm City Private Hospital, 62 Park St. New Haven, Conn. Established 1908; private; general; 37 beds; Wn. L. Soule, M.D., superintendent.

Grace Hospital, 1418 Chapel st., New Haven, Conn. Established 1889; public; feneral; 116 beds; Marian bittle, superintendent.

Ilospital of St. Haphael, 1442 chavel

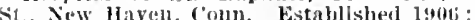
pullile; general ; 200 beds.

New Haven IIospital, Cedar and Broad Sts., New llaven, conu. Fstubllshed 1836; pubilc; general; 260 beds; Albert $C$. Thomas, superintendent.

siprlngside Home and Hospltal, New Havel, coun. Estublished 1889; publle; 80 beds in hospltal; Willis H. Crowe, medical superintendent.

Voie lnllmmrs, 376 l'rospect St. New Havel conn. Establlshed 1892; reneral: for rale students only: $3 \theta$ beds; Grace il. Nerritt, It.X.. superintendent.

\section{New London}

Joseph hawrence Free Public Hospital, New London, Comn. Establisbed 1912; 40 beds: J. G. Stanton, MI.D., chief of stitf: Miss Il. K. Prindervile, snpt

Memurlal Hospital Assoclation, 163 Garfield Ave., New London, Conn. Fstablislied 1893 ; public ; general; 60 beds; Nelle k. Burby, superintendent.

\section{Norwalk}

liensett Sanltarium, Norwalk, Conn. Established 1886; private; Edwln E. Sinith, plysician in charge.

forwalk Hospital, Norwalk, Conn. Established 1893; public; 35 beds; Alice 13 King, superintendent.

\section{Norwich}

(irand Vlew sanitarium, Norwich, Comm. Establlshed 1895; private; for mental and nerrous diseases, alcohol and drug addiction 35 beds; John D. Donohue, Jr., resident physiclan; John J. Donohue, medical superintendent.

Hillside Sanitarium, 125 School St., Norwlch. Conn. Established 1908; private; 7 beds; Clinton E. Stark, physician in charge.

William W. Backus Hospital, 326 Washington St., Norwich, Conn. Establlshed 1884; private; general; 84 beds; $F$. L. Hutchins, superintendent.

\section{Putnam}

Day-Kimball Hospital. Pntnam, Conn. Established 1845; public; general: 35 heds; Miss R. P. Webster, superintendent.

\section{Saybrook}

Dr. Luther's Private Sanitarium, Saybrook, Conn. Nervous and niental; 8 beds: ('. V. Luther (Brookiyn), physician in charge.

Sharon

Sharon Hospital, Sharon, Conn. Established 1910; general; i2 beds; Miss Frances Shank, superintendent.

\section{South Norwalk}

Wadsworth Sanitarium, Woodscourt, South Norwalk, Conn. Established 1903; private; 30 beds; Alrin D. Wadsworth, medical superintendent.

\section{Stafford}

(yril and iulia C. Johnson; Memorlal Hospital, Stafford, Conn. Established 1912; public; 20 beds; C. B. Newtor, chiet' of medical stali, Emma Margaret smith, R.N., superintendent.

\section{Stamford}

Dr. Barnes' Sanitarium, Stamford, Conn. Established 1894 ; private; nervous and mental diseases, narcotic and alcoholle addiction; 75 beds; F. H. Barnes, physician in charge.

see survith Announeement frlv. page 69. Dr. Givens' Sanitarium, Summer St., Stamford, Conn. Established 1891; prirate; nerrous and mental diseases, alcohol and drug addiction; 250 beds; Amos J. (ivens, physician in charge.
Peckham Institute, 25 Suburban Are. Stamford, Conn. Establlshed 1897; pri rate; devoted to. physlcal therapeutics; 1 beds: F. G. l'eckham, superintendent.

Stamford Itail Sunitarlum stamford, Collt. l'rlyate; for the insane; 140 beds. Sthuf ord 1Jospital, East Main St., Stam ford, Conn. Establlshed 1896; prlvate; 40 berls; Evelyn M. Wllson, superintendent. Stamford Tubercuiosis l'uvllion, Stamford, Conn. Jistabllshed 1910; 'T. Nitler, superintendent.

Thompsonvilie

lir. Vails" Snnatorium, Thompsonville, Conn. Jistablished 1890 ; private; 50 beds Edwin S. and Thorntoll $\mathrm{k}$. Vall, physiclans in charge.

\section{Waljing ford}

Gaylord Farm Sanatorium, Cook Hill, Wallingford, Conn. Fstablished 1904; public; tuberculosis; 100 heds; Darld $\mathrm{l}$. Lyman, medical superintendent.

\section{Waterbury}

Hrookside Home, Waterbury, Conn. Wm. fiood, physician in charge; Patrick Monahan, superinteudent.

Jennie $B$. Jang Hospltal, Waterbury Comn. Established 1905; private; 12 1)eds; Jennie B. Lang, superintendent.

Southmayd Home, 73 Wilson St., Water bury, Conn. Established 1898; pubile; 7 rooms; Mrs. Cornelia K. Shepard, superintendent.

st. Jary's Hospital, Waterbury, Conn. Established 1908: public : 120 beds: Ray mond J. Quinn, physiclan; J. F. Mumford surgeon; B. A. O'llara, medical superintendent.

Waterbury Hospital, Waterbury, Conn Established 1889; pubilic and private; general: 92 beds: E. Frederick Callender, Mary 1. Bustard, R.N., superlutendent.

\section{Watertown}

On-the-Hiil Health Resort, Watertown, conn. Established 1903; general; 20 beds; Chas. W. Jackson, physleian in charge.

See siperial Innouncement Adr. page $6 \mathrm{~s}$ Westport

Westport Sanltarium, Westport, Conn. Established 1891; private; nervous and melltal diseases; 100 beds; Fredk. D. Kuland, physician in charge.

\section{Willimantic}

Dr. Mason's Hospital, W'llimantic, Conn. Established 1907; private; 20 beds; Louis Irving Mason, pliysician in charge.

St. Joueph's Hospital, Wirlmantic, Conn. Established 1908; public; 54 beds.

\section{Wiiton}

St. Elizabeth's House, Wilton, Conn Established 1895; private; summer house of the Sisters of the Annunciation, 3740 Broadway, New York; for crippled and incurable girls; 30 beds; Samuel Huntington (Norwalk), physlcian; T. Halsted Jyers (New York), surgeon; Mother Superior, in eharge.

\section{Winsted}

Litchfield County Hospital, Winsted, Contablished 1901; public; general intendent.

Reidy Sanatorium, Winsted, Conn. Established 1912; private; surgical, 12 beds D. D. Reidy, surgeon in charge.

\section{Woodmont}

Pack Sanatorium, Woodmont, Conn. Established 1908; private; nerrous and narcotic; 14 beds; Robert E. Peck, (New Haven), physician in charge; Vernon 11 Boothby, R.A., superintendent. 


\section{PHYSICIANSOF CONNEC"ICLT}

KEY TO ABBREVIATIONS, SYMBOLS, ETC.

vames In aptals slgnify menaership in Jie County soelety and sitate Assoclat plon. (110k, Jollx).

Indeates Fejlowhin in plus Amerlewn Med. Assn. (1005:, 3011 1 +

(b)

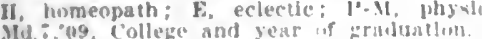

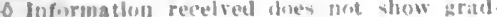
uatlon.

\section{S.-Sirgeon.}

ObG.-Obstetrheian, Cignecologlsi

G. (iy)

G.--ijneculogkst.

Or.-Urthoyedist

Pr.- Proctolosist.

Op.-Ophth

LR.-Laryngologtst, liblnologist.

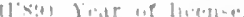

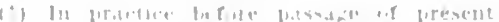

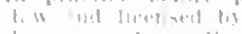

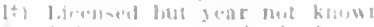

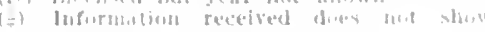
linenestine

I.S.1. linforl sitates Army

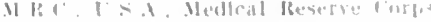

SPECIALTIES ARE INDICATED AS FOLLOWS

ALR. Auriot, largngologlse, Khimoleglat.

OALR. Moldtalmulogint, Jurlat, Laryngi,

(sglat, binthulogtse.

U. Vrulegint.

D. Hernatulugive

Pd. Peellatrist.

N. Penrolorivi

P. Injelitatriat.

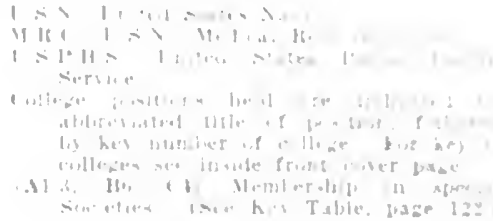

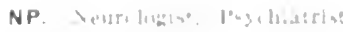

1. Internist.

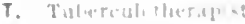

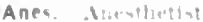

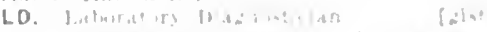

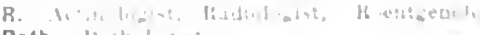

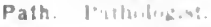

Bact. I8.u.tertstusint.

WHEN THE ABBREVIATION REPRESENTING A SPECIALTY IS FOLLOWED BY AN ASTERISK (*) IT INDICATES THAT THE PHYSICIAN CLAIMS HIS PRACTICE IS LIMITED TO THAT PARTICULAR BRANCH OF MEDICINE: WITHOUT THE ASTERISK. THAT HE IS ESPECIALLY INTERESTED IN, BUT DOES NOT LIMIT HIS PRACTICE TO, THAT BRANCH. THIS INFORMATION CONCERNING SPECIALTY IS PASED ON PERSONAL DATA FURMISHED BY THE PHYSICIAN AND IS NOT VERIFIABLE.

\section{CONNECTICUT}

ANSONIA, 15,152. NEW HAVEN

Aaronson, Mlchael $S$ (b'st)-N.Y.19,13: (I'13); 110 Jain St

Baker Scott K. (b'55)-Conn.1,79; (1'93): 23 Johnson $\mathrm{Si}$.

Conklln. Wm. H. (b"h0)--N. 1.5,"82; (J"93) ; 17s Maln st. ; $9+10, \because-4, i-9$.

COOPER, LOLIS EDWARD $\left(b^{\prime \prime} 62\right) 4$ Conn.1.'\$6: (l'98): 20 lester Si.; offlce. 58 Maln it, $8-9,2-3, i-8$.

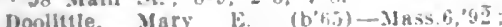
$\left(I^{\prime} 93\right)$; not in practice.

(['93): not in practice.

Fogart, lim.

Goldsteln, predk. r. (1;i9) - conn.1,93: (I'94): 8 ; Mal?

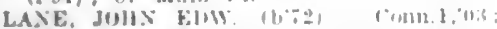
(103): Menber Wash. State Merl. Xswh.

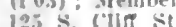

Mahuney, Jow. (i. (b\%9) -(0)11. 1,0:8; (1'1) \&)

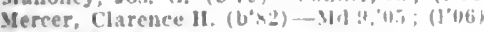
io Maln sit.

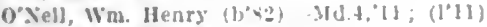
194 Valn St. : 4-10, 2-4, ;-x::30.

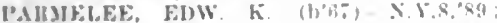

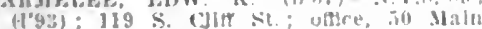

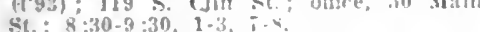

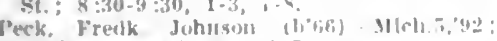
(1'93); 44 Maln sit.; $1=-\pi$

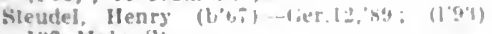
Iy2 Jaln St.

TOLBES, IICITON ISAA" (b'is)

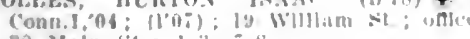
So Maln St.

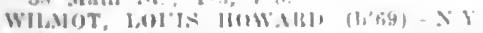

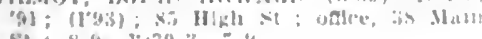
S1.: $8=6, \quad 1: 30-3, \div-4$.

BERLIN, 3.728. HARTFORO

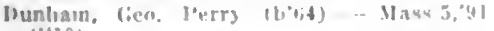
(1'10)

BETHEL, 3.792. FAIRFIELD

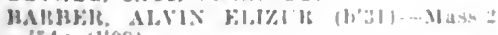
\$1: (1,93),

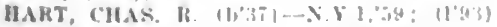

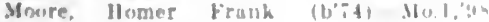
(I'98): 0 p.

Walte. Henry bolw.

(see New lork ing )

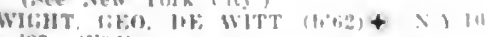
Ri: (l'y $\left.\left.{ }^{3}\right\}\right)$.

BLOOMFIELD, I.82I, HARTFORD

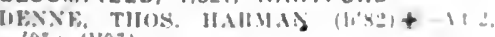
03: (1.0i).

BOLTON, 433. TOLLAND

Mann. Thos. Henty $\left(b^{*}+s\right), X, 1,210$ $(1)^{2}(103)$
BRANFORD, 2,560. NEW HAVEN

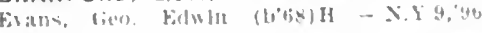
(1)ibi).

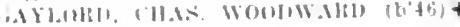
romen., $\because 2$; (1'03)

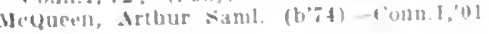
(1'11:3).

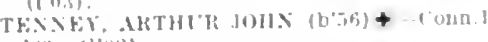
$\times 3:(1+43)$

BRIDGEPORT, 102,054, FAIRFIELO

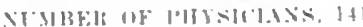

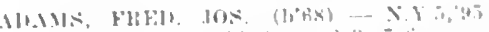

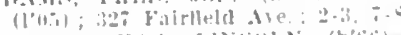

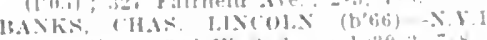

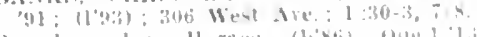

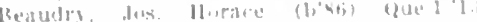
11.13

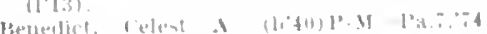

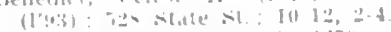

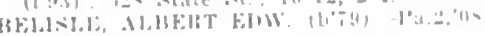
(Ino)

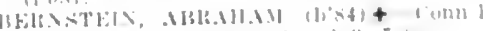

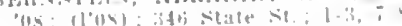

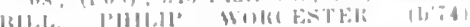

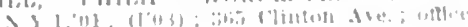

ill state si $\mathrm{S}$.

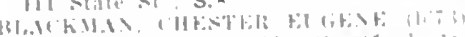

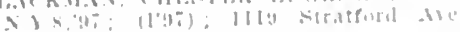

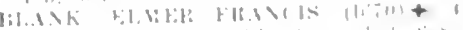

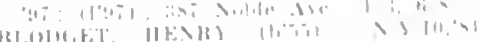

BI.1111, H.T, II E)M

(1)

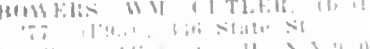

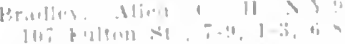

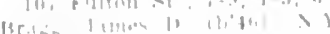

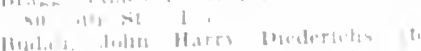

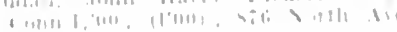

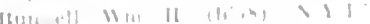

lewe stratfuri in

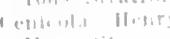

II.
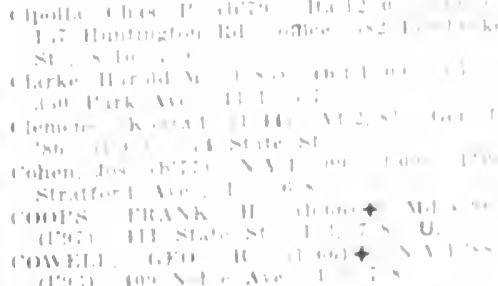

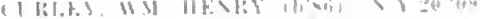

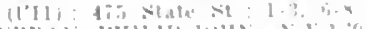

न titistate st.

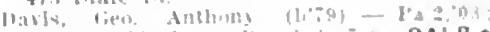

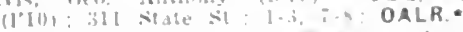

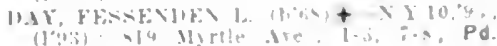

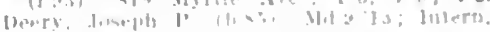
St. Vimerat' Ifrobltal

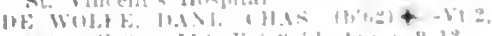

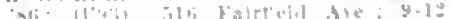

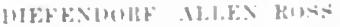

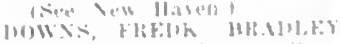

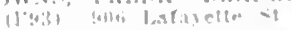

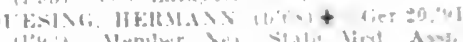

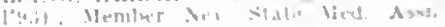

Hets \&: llath it

lupene kilw

siatus

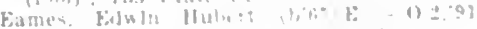

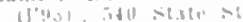

fillis. Tulls lovi.

(1'ati) Bit went lus

mokisterse Hri

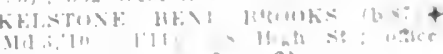

:It sith st

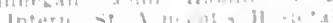

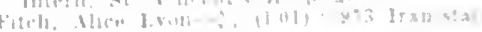

ine

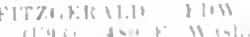

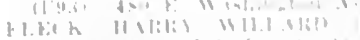

R

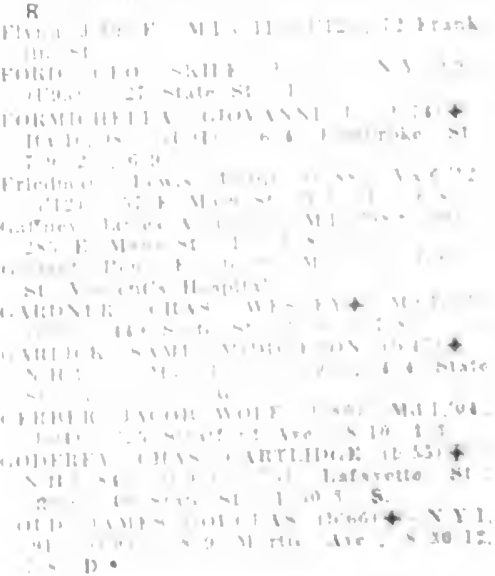




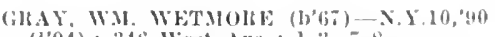
(1'94); 346 West Ace, ; $1-;: 7-8$.

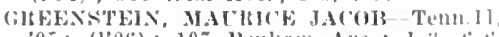

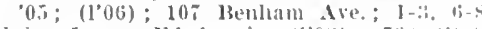

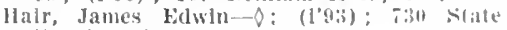
St. ; $1-3,0,8$.

Hal, Fitalis, , IR. (1,82) (1'09); 477 State st

Iall, Itufus Warren (b'T) - comm. 1,0z: $\left(1^{\prime} 0 z\right): 46$ l'ark st.

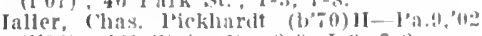
$\left(1^{*} 03\right) ; 461$ state st.; s-4) I-3,

llart, lienj. Ide (h'si)-NY.I, 04 ; (1'0s)

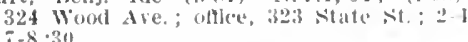

HASKFLL, ("HAS. NAHTM $(1,62)+-v 12$

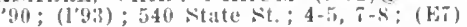

N. $\left(1^{\prime} 09\right)$ : 8 i I Park Are. : $9-10$ : Or. $\star$ lealy. Thos. F. (b'6s) N.Y.Is, $93 ;\left(1^{\prime} 93\right)$ 25 Yale st.; $1-3,6-8$

lerman, Harrls W: (1)'56) $-0 ;(193) ; 355$ Noble Are.

Hippolltus, l'aul Difrancesea (b's9)-C'om.1 12: (l’13): Bridgeport Hospital.

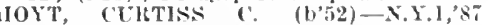
$\left(1^{\prime} 93\right): 1289$ state st. ; $1-3,6-7: 30$

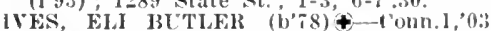
(l’04): 563 State st.; offlce, 56l state St.; $2-3,7-8$.

OHNSON, JOLN MIRRAY (b'it)-N.Y.8 $95 ;(1 ' 95) ; 385$ State St

KEANE, ROBT. BARXABAS (h०̈(6)-N.Y.19 03 ; $(1.04) ; 90 \mathrm{~N}$. Washington Ave.; 1.3 $6-8$

LRASNYE, TOHX FIRAXCIS (b'88)-111.2. '11: (寺); 720 Aretle st.

Krause, Fdw. (C.-Conn.1,02; (1'04) ; Madison Rd.

l.A FIEliD, WM. ARTIIUli (b'8I)-N.Y.9. 05; (1'05) ; 433 Ciolden HIill st.; offec, 233 Fairtield Ave, ; $1: 30-3,7-8 ; R$

IAMBERT, HENRY BERTRAM (b'84) l’a.2,'09; (l'l1); 411 State st. ; $1-3,7-8$; (A21); Anes.

LEVERTY, CliAs. JOS. (b'i) - N.Y.19 01 ; (1'02) ; 62 James st. ; offlce, 469 state St. ; $2-3, ;-8$

IOCKHAIT, REUBEN A. (b'70) 4 -Conn.I 91; (1'93); 760 Washington Ave.; 1-3, LYNCH, JOHN CHAS. (b'64)†-N.Y.5,'86; (1.93); 826 unrtle ire $3-4, i-8.5,86$

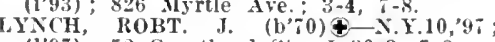
$\left(1^{\prime} 97\right): 52$ Courtland st.; $1: 30-3,7-8$ MacDonald, John Ios. (b'8.3)-Comn.1, 0 \% (1'1I) ; 915 North Ave.

Martin, 'Thos. F. (b'31)-N.Y.5.'T4; (1'93) not in practice; $2 S 9$ Golden Hill st.

Massinger, Omray' I.-Md.8,'97 ; (1'96) ; 400

State St.
MY, JACOB (b'50)థ-111.1,76; $\quad\left(1^{\prime} 93\right)$ 1816 North Ave.

MeCarthy, Danl. Jos. (b'82) - Ma.3,06 (1'06); its Washington Ave, $1-3,7+8$

MecoVER, HDW. FRANCIS-N.Y.19, 01 (l'02) ; 383 I'embroke Ave. ; offlce. 390 State $\mathrm{St}$.

McLellan, Edward Augustus (b'42)-Mlass.6, 94; (1'94); 105 Park St.

McQUEENEY. M. ANDREW (b'82)-('onu.1 05: (1'08) : 700 Noble Are.: I-3, $7-8$

MIIES, HENRY SIILIINGFORD $(b, 66)+$ N.Y.1,'91; (1'93); 417 State St.; 9-1; $(\mathrm{B} 4, \mathrm{I} 6) ; 0 \mathrm{p.} \star \mathrm{T}$ Monahan, lavid H. (b'62)-Y.H.1, 00 $(1 ' 00)$; 764 Myrtle Are

NETTlETON, IRTING LA FIELI (b'75) \& N. $8,98,(199), 885$ Noble Are.; 1-3, OBER, GEO. EUGENE (b'63) $\$$-Vt.2,90 (1'93) ; 632 Kossuth st. $1-3,6-8 ; \mathrm{D}$ O'HARA, WII. J. A. (b'64) 4-Ifd.3,93 (1'93) ; 361 Barnum Are.; 1-3, 6-8. SBORN, GEO. WAKEMAN (b'60)屯 N.Y.1,8\% ; (1’93) ; 888 Broad St. : $1-3,6-8$ PATTERSON, DANI. CLEVELAND (b's2) (-Md.3,06; (1'06); 653 Warren Are. office, 819 . Iyrtle Are. : 1-3, $7-8 ; \mathrm{s}$

Pasne, Clarence Niles (b'62) H-N.Y.9, 85 (1'93); 510 Fairfield Are.; 1-3, i-8 PETERS, HENRY LEBARON' (b'82)-Que.1, '07; (1'12); 467 State St. $4-5,7-8$; Path. TORTER, GEO LORING $\left(\mathrm{b}^{3} 38\right) \oplus-\mathrm{Pa}$

IRAT', NATHAN TOLLES (b';1)屯 Conn.I,04; (1'04); 1221 Stratford Ave.

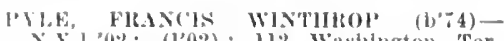
X.Y.1, (02; $\left(10^{\prime}\right)$; 112 Washington Ter race; oflce, 528 state st.; $2-4,7-8 ; \mathbf{P d}$

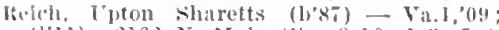
(1'11); 2162 x. Maln St.; 8-10, 1-3, i-8. tichardison, thas. II.- 0 ; (1'93); 33 l'ark 'Eerrace.

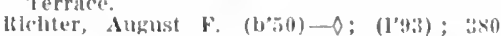
bisnmm Ave. : $-9,1-2,7-9$

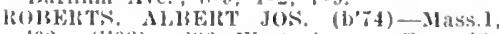
(02; (1'03) ; 2\$6 West Ale.; ontee, $4: 30$ state st.; $2-i k, 7-8$.

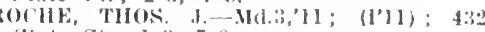
Slate St.: $1-3,7-8$

Rosen, Maurice S. (b'66)-O; (1’98); 493 Fairfield Ave.; $1-1, \tilde{4}=8$; OALR. *

ROWE, MICILAL TAMES' (b'66)-.II, 3,96 ; (193) ; 2169 Maln St.; $8-10,2-4,7-8$

siltier, Jacob (b'83)-X.1.13,"I0; (1'12)

(ifi? $\mathrm{E}$. Maln st.

Sanford, Chas. Kiwin (b'30)-Conn.1,'53; (1'33); 302 Falrflela Are. : $9-10: 30,7-8$

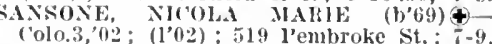
$1-3,>-9$

schevclk, Frank J. (1)53)-N.Y.13.'89 (1'93); 224 Shelton st.; offlce, $1190 \mathrm{I} \mathrm{em}$. broke st.; $8-9,6-8$.

CIICLLE, GEO. T. (b'78)-COMn.1,'ll (t'08); 473 Noble Are. : until 10, 1-3.6-8. THUIZ, IIERMAX s.-1'a.9, 01 ; ; (1'05) 390 State St.; 2-4, $7-8$

('rimgeour, Arthur (1)'83) - Y.Y.8, 09: (l'11); 701 Warren st, : 1-3, $7-8$.

HERMAN, FLORENCE A. (b'6i)థ-N.Y.I4 $91 ;(1,96) ; 528$ State St.

smlrnow, Louis (b’5)-( "onn.1,9.5; (1'95) 374 State $S t$.

SMITH, ANDREW JACKSON (b'39)-X.Y.I. '63; (1'93) ; 193 Barnum Ave.; 8-9, 1-3 TTll, DORIAND (b'75) \&-Conn. 1,99 (1'01) ; 653 Warren St. ; offlce, 836 Myrtle Ave, : 9-12, $7-8 ;(B 1) ; 0 p A . \star$

ITH, EDWARDS M. (b'60)(-N.Y.1,'82 (l'03) ; 867 Park Ave.; offlee, 340 State St. ; $1: 30-3,7-8 ; \mathbf{S}$.

mith, Ldw. Sylvester (b'万i)H-N.Y.9,'88 (1'93) : 951 Park Are. ; $1-3,7-8$.

smith, Ellzabeth Farlick (b'4i) E-N.Y.16, '82; (1'93); 450 Fairfield Ave.; $10-12,2-4$. SMITH, FRANK LLEWELLYN (b'55) N.Y.3,'83; (1'93); 2180 Main St.; offlce St. $1-3, \overline{3}-7$

smith, Jonathan D. S. (1),30) E-N.Y.16,'82 $\left(1^{3} 93\right): 459$ Fairfield Ave.; until 9, 2-4 $6: 30-8$

SMYKOWSKI, JBRONISILAW L. (b'83) Md.4.'11; (l'1I) ; 405 Barnum Ave.; 8-9 $1-3,6-8$

S.MTTII HEILBERT EDMTND (b'61) Que.1,'84; (1’97) ; 374 Tohn St.; offlee, $3 \pi$ John St. ; $8: 30-12,6: 30-8$; (B3) ; ALR.* SIRAGLE, CHAS. HARRT (b'80)-N.Y.J,
'04; $\left(1^{\prime} 04\right) ; 168$ w. Liberty St. ; 10-1, 4-6,
$0-8$.

Steinberger, Maurice (b'65)-Hung.1,89, N.Y.I3,09; (l'09); 617 Hancock Ave.; TEVENS, FRANK WM. (b'T3)థ-Conn.1

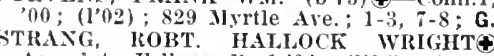
Assoclate Fellow-1'a.1,04; (1'05); (Dentist); I258 Park Are, offlee, 16 'Cannon Sit. : $9-12,2-4$

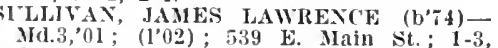
$6-8$.

Thomson, lames (b'89)-Ont.1.'13; Intern, Bridgeport Hospital.

TOPPING, JACOI REEN (b'53)-N.Y.5,'82 (1'93); 349 Noble Ave.; $1-3,6-8 ; \mathbf{S}$.

TOWNSENT, CHAS. RODMAN (b;2)

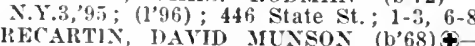
X.H.I,'94; (1'96):860 I'ark Ave. : $1-3,7-8$ TUKEY, FRANK MARTIN (b'70)૯-Mass.1 94; (1'94) ; 429 State St.; 1-3, $7-8$.

WARNER, GEO. HOWELL (b'T0)-Conn.1, $97 ;(179)$ : 849 Myrtle Ave.; 1-3, $7-8$ Warriner, 11 yron A. (b'56) - Mass.1, 84 VASON, DAVII BOTGHTON (b'-8)-N.I.1 '00; (1'02) ; 329 West Ave. ; $1: 30-3,6: 30-$
$8 ;$ ob.

WATERHOLSE, HENRY EDWIX (b'T) WATSOX, WA. CLARK (b'73) \& ; $2-3,6-8$ $(1,97) ; 446$ Stratford Ave. ; $1-3,6-8$.
WHAlNON, WM. LEk (1,82) †-Va.6,0, : (l'li); Member W. Va. Sitate Med. Assu. slo Myrtle Ire.; $\mathbf{S}$.

Wehb, Frank Frwin - Tenn.5,82; (i”o0): 1576 lranlstan Ave.

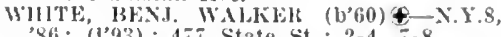
16. , 16) ALR.

Wood, Fugene 11.-N.1.8,'86; (1'93); $54 \mathrm{~L}$ Palrfleld die. : $1-3, \overline{7}-9$.

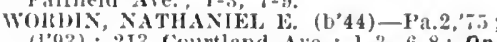
(1'93); 213 Courtland Ave ; 1-3, 6-8; 0 p.

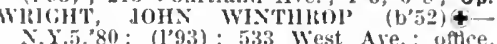
Sil Iigrtie Ave.; $2-4,7-9 ; S$.

BRIDGEWATER, 600, LITCHFIELD

Hay, liupert S. (b'8I)-N.Y.9,06; (1'09).

BRISTOL, 9,527, HARTFORD

13ISCKETY, AITTIUR STONE $\left(\mathrm{b}^{\prime} 69\right)+$ 1'9.2, $95 ;(1$; 96$)$

Breunan, Hubert Danlel (b'64)-Vt.2,'92;

(I'93). wiss, w. M. S. (b'70)-Md.6,93; (1'93).

Desmarais, Jos. Jlenry (b'64)-Ont.4,'89; $\left(1^{\prime} y 6\right) ; G . \star$

Dewey, Alburton Alonzo-0.2,'06; (1’08).

Griswold, Arthur W. (b'54)- ; $\left(1^{\prime} 93\right) ; \mathrm{G}$.

Hamblin, Frank Milton (b'73)-X.Y.9, $\left(l^{\prime} 09\right)$.

IIanralian, Wm. R.-Md.3,05; (1'05)

IIORTOX, WM. WICKHAM (b'5)-X.Y.5 $79 ;\left(1^{3} 93\right)$

'CONXEL, TIMOTIY GRATTAN (b'i) C'onn.I,'99; (1'99)

Robbins, Benj.'B. (b'-0)-X.Y.5,'94; (1'93) ; $\mathbf{O b}$.

Samborn, Edwin Parker-Mass.5,05; (1'06). Spring, Henry t: (b'74)-N.Y.5,97; (1'95). Tanner, John C. (b'73)-Md.6,97; (1'00).

Thorpe, Walter E. (b'58) H-N.Y.9,'86. (1'93); OpA.ネ

Iuson, Charles R. (b’46)-N.Y.8, ‘0; (1'93)

WHI'1, $\left(1^{\prime} 0 \pi\right)$.

Wllliams, Fredk. H. (b'45) $\rightarrow$; (l'93).

Woisard, Jos. 1. (b'85)-D.C.2,'09; (l'09).

BROAD BROOK, 1,382, HARTFORD

AILEN, HOWARD OLIVER (b'54)-N.Y.5,

BACKES, HAROLD SIMEON (b'79)-N゙.Y.8 03; (1'03)

BROOKFIELD CENTER, 400, FAIRFIELD

IYDER, CIIAS. AMBLER (b'75)-Conn.1,

BROOKLYN, 1.858, WINDHAM

TANNEll, AlFRED H. (b"52)-N.Y.I0,'T4; (1'93).

BURNSIDE, 1,856, HARTFORD

DEANE, HENRY ACGUSTUS (b'42)£N.H.1,'69; (1'97) ; not in practlce; R.F.D. Nungasser, IIenry w. (b'53)-0; (l'93).

CANAAN, 702, LITCHFIELD

ADAM, JOHN GEIKIE (b'78)థ-Ont.3,'00 : $(1,00)$.

('AMI, CHAS. W. (b'48)-N.Y.5,75; (1'93)

LEE, FRANK H. (b'62)-N.Y.3,'88; (1'93)

CENTRAL VILLAGE, I,521, WINDHAM

GARDNER, JAMES L. (b'54) - Vt.2,'81;

CHATHAM, 6I5, MIDDLESEX

Parmelee, Elmer S. (b'T1)-Pa.2,'89; (1'93).

Stiles, Henry R.-Conn.1,88; MaJ., L.S.A. retired.

CHESHIRE, I,988, NEW HAVEN

Denison, Chas. Neilson $\left(\mathbf{b}^{\prime} \mathrm{i} 0\right)-\mathrm{N} . \mathbf{Y} .8,93$; $\left(1^{*} 93\right)$.

KARRIIAN, EDW. WM. (b'52)-N.Y.5,'s4; (1'95).

Myers, Geo. E. (b'67)-Vt.2,'96; (l'96).

CHESTER, 1,419, MIDDLESEX

MIITH, FRED SUMNER (b'55)€-Conn.1, $82 ;(1 ' 93)$

CLINTON, 1,274, MIDDLESEX

FOX, DAVID AUSTIN, JR. (b'7i)-N.Y.I9,

Reynolds, Herbert S. (b'60) - N.Y.5,'SI; (1'93).

COLCHESTER, 978, NEW LONDON

Foote, Nathaniel (b'3I)-Mass.2,'52; (1'93). (1'12). 
Leal, SIalcolm (b'36) II -X.X.9.'9y; (but in practlee: Fomer. l'rof. Thew. and l'rav. if Med., N.Y.II.

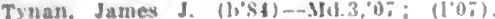

COLLINSVILLE, 2,140, HARTFORD

CAMPBELL, SHFLWOS SAMH STIRATUS

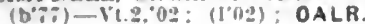

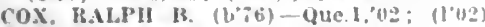

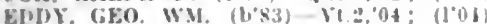

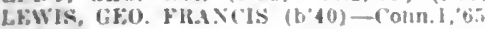
(1)

COVENTRY (R.F.D., ROCKVILLE), 1,606, TOLLAND

FISKF, ISAAC IPARSUSS (6'3\%)-N.Y.5, 95 (1'93).

CROMWELL. 2.188. MIDDLESEX

13L'SH, CHAS. F. (b'69)-Conn.I,"94; (1'94)

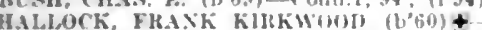

X. Y.1,8.5: $(1.93):\left(\right.$ E.1.2.7): $N^{*}$

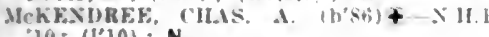
10 : $\left(\mathbb{l}^{\prime} 10\right): \mathrm{N}$

DANBURY, 23.502, FAIRFIELD

Barnum, Wm. A. (b'62)-IIl.s. $22:(193)$ :

ot Ner st. ; 1-3, $7-9$.

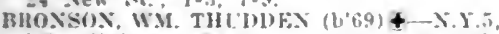

$48:(1,98): 41$ llest $51, ; 8-9,1-3,7-8 ; 5$

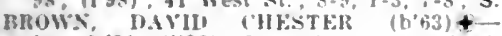
Conn.1.'81; (1'93) : I'res. Conn. State Med. Soc. ; 330 Mlaln st.; $\$-3,1: 30-3,6: 30-8$ : S.

HROWXLEE, HARRIS FENTOX (b'Gi) +

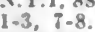

EVGLISH, RI'HARD M. $\{1, \div 2)+$ - Comn.\}, 95; (1.00); is? Maln St.; $9-10,0-4,7-6$ Culubert. Geo. A. (b"59)-X.1.1, s3; (1-93):

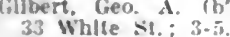

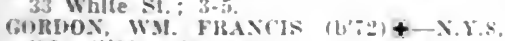
96: (1"96); 26 Wess st.: untll $10,2+4$.

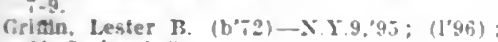
if Orchard sit.

Grinin, Saml. Y. $(1,43)-1.9,64 ;(1+93)$; 24 Orchard st. $10-12,3-5$.

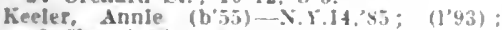

12 Chapel P.: $10-12,2-4$.

Knox, iouls (6. (t):50)-X.1.;2; (1'93)

32 White st.: 12-2, 6-8.

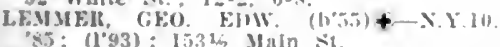
"85; (1'93): $15.3 \psi_{2}$ Main sit.

Machonald. Allan I'. (b' 11$)-111.4, '$ t (1"93); 268 Maln si. ; untll $4,2-4,6: 30-4$

HOOKE, HOWARI Ib. (b'68)-I'a.9, 93 ; (1.93); 6 Tuwer 1'l.; offlce, 203 Main st. 9-11, 3-5, $i \cdot x$

MLLLISS, SAML, FHEI)K. (b'83)+- N I. (4) $(106): 1 \%$ West $51: 2-4,50-4 \cdot 30$

Murray, Wm. H. (b'b5)-N.1.10,90; $(193)$; uot in practlce.

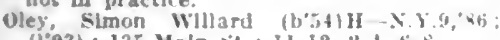

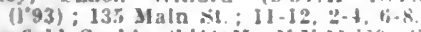

l'enfleld, Sophla $\left(b^{\prime}+1\right)$ iI-X.Y.11, 69 : $(1,63)$ 3ab Maln st. : 10.12, 5. 6 .

SCOFIELD, HVEHFT J. STEW.IRT (1, A.C.1.08: (1'10): 246 Maln Sis: 9-10. $1-3,-8$.

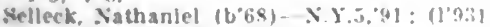

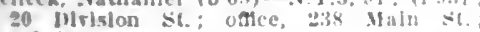
30 IIIrision
$-3: 30,:-9$

STKАTто: В.) 83: (1.93) : 173 Main si.

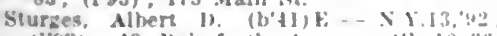
(I'93): 43 Walmforth Are; Hntll 10:30. $1=30-3, i-9$

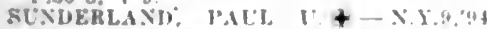
(1'94): 160 bear IIIII Ire : $-1-3,7-x$

Thlelcke, Geo, rimanuel $\left(b^{\prime}, 4\right)-$ Cunn 1, , In

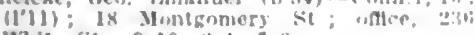
whlle st: $9.10,2-4.8$

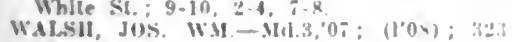
Maln Si.

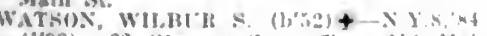
(1'93): 22 stevens st, offlec, "zto Maln St. ; $9.10,2-4$.

DANIELSON, 2,934, WINDHAM

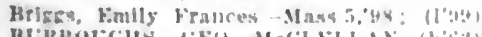

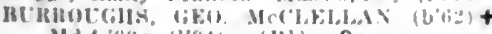
Md.f.01: (los): (H) ; Op.

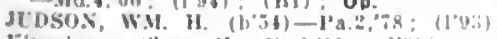

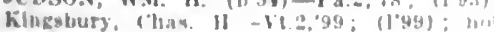
In praclice.

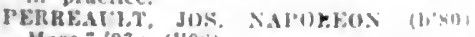

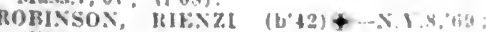
(I' 93$)$

Tudd, Frank 1",-Mas.s, : 99 ; (10:i).
DARIEN, 3,946, FAIRFIELD

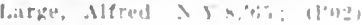

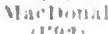

$(1,30)$

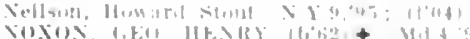

aXis. 1,E, IIt.)

DAYVILLE (KILLINGLY P.D.). - WIND.$$
\text { HAM }
$$

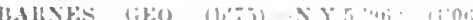

DEEP RIVER, 1.807. MIDDLESEX

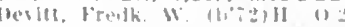

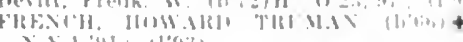

X.Y 1.:4: 11,931

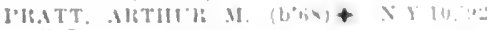

DERBY, $8.99 \%$, NEW HAVEN

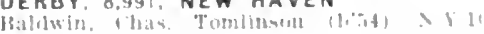

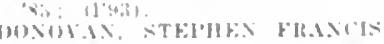

Md

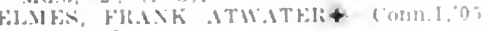
(100ij: S

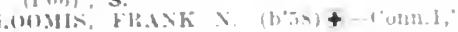

ing,

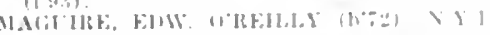

?ox; (1'nos)

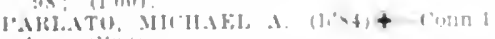

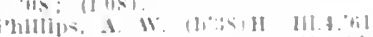

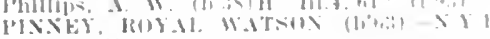
\&S: (1? 93$)$.

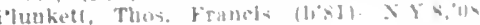
(10) 10 )

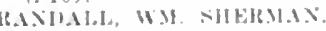

(N)e vlyelth

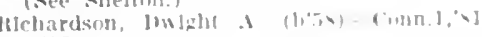
(1"93).

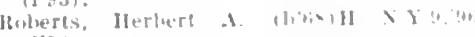

(1) 991 )

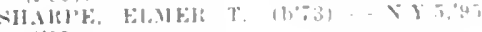

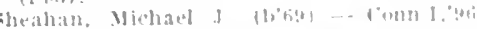

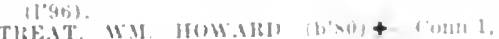

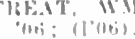

DURHAM, 600, MIDDLESEX

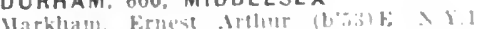

$\because \% ;(104)$

RINK. III.I

EAST BERLIN, 800. HARTFORD

II)IM, III. TIIOS. I III

in: $(1,03)$.

EASTFORD, 513, WINDHAM

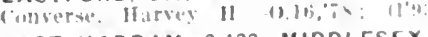

EAST HADDAM. 2.422, MIDDLESEX

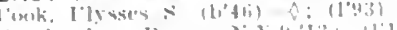

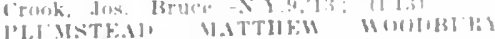

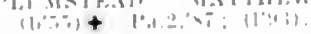

EAST HAMPTON. 1.4Z1, MIDDLESEX

likil $11 . \mathrm{G}$

li E.II $\ddot{*}$ : G. $11 \% 111$

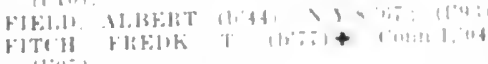

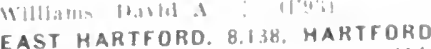

EAST HARTFORD. 8.138, MARTFORD

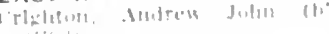

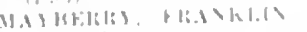

(i)

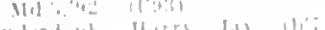

manlaratum

TH1 H. H. H11 11.1111 .111 $1 .-1+$

EAST HAVEN I, I05, NEW HAVIN

II!1].111:1101

EAST KILLINRILY, I GSO. WINDHAM

IIII.]. IIIIS

EAST NORWALK ISOUTH NORWALK P. O.), 3,500, FAIRFIELI)

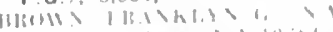

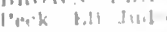

EAST PT CHESTER IPI. CHESTEH. N

PO 1. 2.000. FAIRFIELII
EAST WOODSTOCK I4 WINOMAM

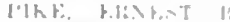

$+11.2128$

ELLINGTON 1.999, TOLLANO

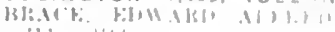

,j1 il i11,

ESSEX, 2,745. MIODLESEX

Hisluki: Firi, 13.1RTH

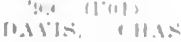

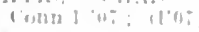

FAIRFIELD, 6,I34. FAIRFIELD

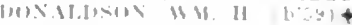

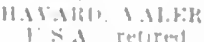

FALLS VILLAGE, G00. LITCHFIELD

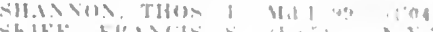

ARMINGTON B97 HARTFORD

FARMINGTON B97, HARTFORD (1) 111

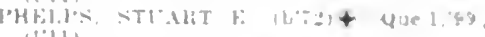

FITCHVILLE, 150, NEW LONDON

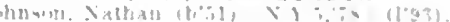

FORESTVILLE, 4.334. HARTFORD

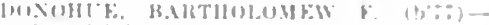

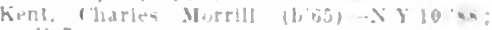
(1)

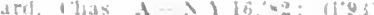

GAYLORDSVILLE, 316, LITCHFIELD

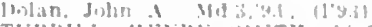

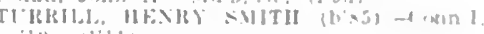

GEORGETOWN.900, FAIRFIELD

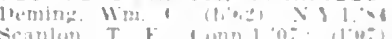

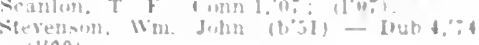
(limi)

GLASTONBURY. 4.796. HARTFDRD

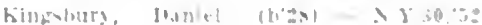

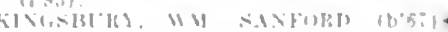

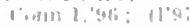

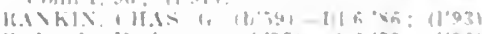

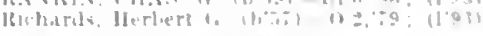
GLENBRO0K, 300, FAIRFIELD

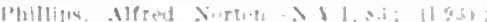

mot in pravince

GOSHEN, 673. LITCHFIELD

GRANBY, 1,383, HARTFDRD

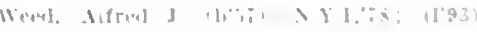

GREENFIELD HILL (R.F.D. FAIRFIELD).

400. FAIRFIELD

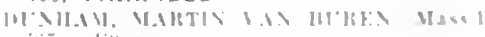

GREENS FARMS, 200. FAIRFIELD

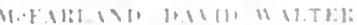

GRE JWW luTh 14 ,

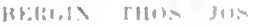

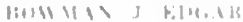

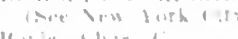

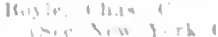

B., lo ota

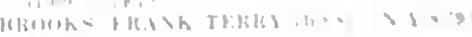

Bi lins 1141114

(1) 1106

1 11:ht 11011

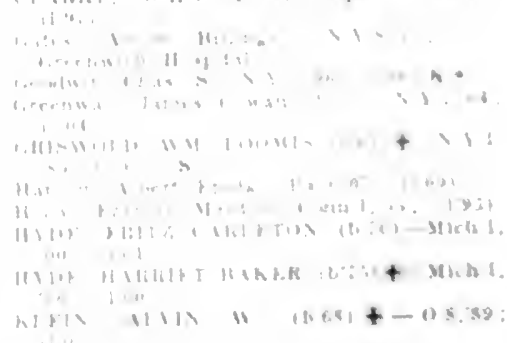


Kunwltm, fon Jerome (b'85)-Mass I, I2 ; (l'1:3)

W'IHXXELL, TIOS. J. (b*4) -X.Y.I5, 08 (In)

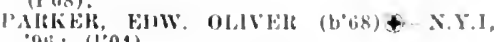
(OH): (l'04).

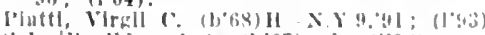

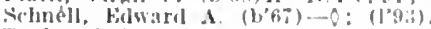

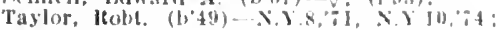
( I'95).

Thom[son, I. O (b)"

Tommasello, stanley (lo' (I"i): $)$.

GROTON. 1,895. NEW LONDON

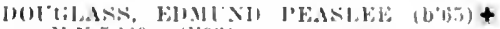
-

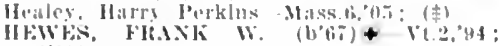
(1.95).

GUILFORD, 3,001. NEW HAVEN

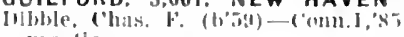

practlca.

IVickle, l'erry-X.Y.9,so: not in practlet.

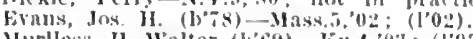

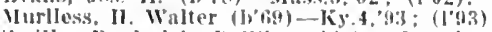

smilh, Frederlek bewitt (h's5)-Fa.9, 10 ; (l'I0).

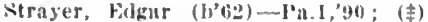

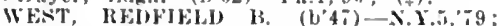
(1.93).

White, iaryl S. (1',66)-('oun.I, 'sI; (1'93).

HADDAM, 1,958, MIDDLESEX

Darllng, J. Homer (1,38) 11 V $1.1,59$; (1'93).

HAZEX, MINEIt $C$ (b'Q9)-Mleh.J, (1,?:3).

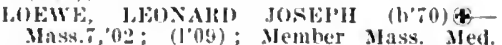
$\operatorname{Mns}$

HAMBURG, 250, NEW LONDON

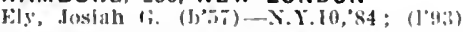

HAMDEN, 4,662, NEW HAVEN

l.AY, WALTER SIHDERS $\left(b^{\prime} 70\right) \oplus$-Conn.I,

HARTFORD, 98,915, HARTFORO

NIMIBEIT UF IHYAICIANS, 2.2.

ABKAMS, ALVA E. (b'56) \$-Y.3.3 81 (1'9.3); 903 Asylum Are.; oftce, 36 Pearl St. ; I0-I I $3-5$; LR.

ckerly, Theodore B. (b, 74$)$ - S.Y.s, 97 (l'97); 703 Maln Si.; $9-10,2-4,7-8: 30$.

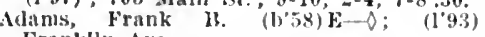
Franklln Are

ADAMS, HFitr k. (b'79) + Comn.1,02 (1.03); 194 High si.; 8-9, I-3:30. T-8. Albu, Max F. (b'sk)-(1'93); 40 Buck-

Allen, Wilfred cornell (b'tib) H-X.Y.t.'ss (l'04) : 200 sigourney st.; once, 6s Pratt St. : $1-4 ; \mathrm{G}$.

I.TOX, CHAS INE IASNEN (b'45) Hee, 7 I'ratt st.; $2-5$

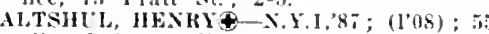
lifrard sre.: office, 902 Main st.; : $: 30-$ $5: 30 ; 1 . \star$

Andre, (iustare A. (b'70)-N.Y.5,9.5; (I'45) 298 l'ark sit.

Angell, Augustus A. (b'54)1I-X.Y.4,8I (I'03); 78 Vernon st.; offle, 904 Main

Arms, latrick Il. C. (b'55)-0; (l'95); 26 libery st.

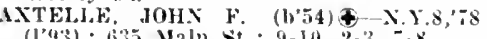
(1'43); 635 Maln st.; 9-J0, 2-3, $;-8$

Babbitt, IIenry Kradford-Mass. 5,58 ; (I'47). Bagnall, Elmer stanley (b'ss)-Mass.z,'I3; Intern, Hartford Ilospital.

BAIAEY, GEO. C. (b'66)-X.Y.5, $86 ;\left(l^{\prime} 94\right)$ 65 Chureh St.; $9-10,2-4,7-8$

BAIl.El, IIICHAEL A. (b'58)\&-Md.3, 93 (1'93); 434 Main st, $4-10,2-4,7-9$

BAILEY NEIL HERBERT Md.', 11 St. : $9-10,2-4,7-8$

BARROWS, BEXj. SAFFORD (boo) \&X.Y.5,87; $\left(\mathrm{l}^{\prime} 93\right)$; $164 \mathrm{High}$ st: $1-3, \mathrm{i}-\mathrm{s}$

B.ATLETT, WM. HRADFORD (b.80) Jass. 1,06; (I'08); 650 New Britain Are.; oflice, 42 High st. ; $3-5 ;$ T.

Beach, Carroll C. (b'it)-Mass.5,'99; (I'99); 206 Wetherstleld ive; office, T2l Man St. $; 9-10,2-4,7-8 ; \mathbf{P d}$

BEACH, CHAS. COFFING (b'56) †-X.Y.I, S2; (I't 3$) ;$ it Woodiand St.; offlee, 125

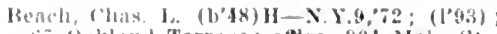
ii Oakland Terrace; offle, 904 Maln St. 10. $1: 3$

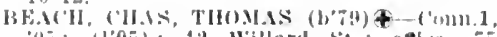

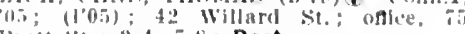
J'rilt si.: $2-4,7-5$ : Bact.

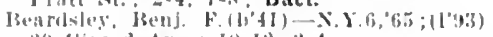
29 (iirard Ave: $] 1)-[2,2-4$.

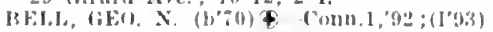
IfI sigulurmey st.; offlee, 44 Iligh st. $2-4 ; 5 . *$

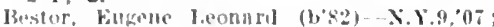

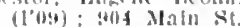

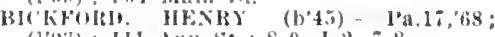

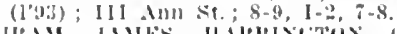

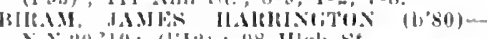
I )

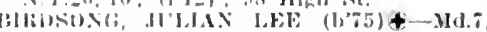

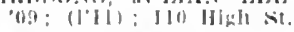

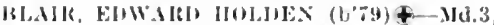

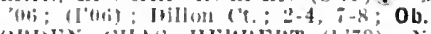

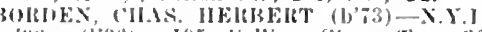
"Hti: (1901i); 195 f'ollins st.; ottice, 36 7)earl sit.

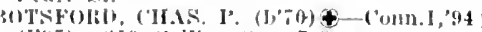
(I.95); 2 ig rollins st.: $7-8$

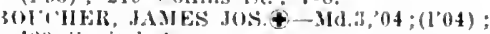
420) (ilultul Ave.

BOI'HEIt, JOHIN 13. (b'64) +-Ma.3,14 (1)44); $((13,5) ; \mathrm{s}$

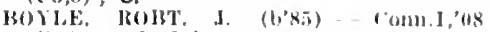

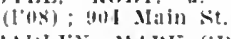

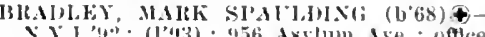

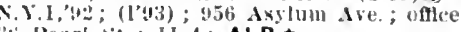
3t Pears st. : II-4: ALR, $\star$

HRANAl?D, C BIEWSTrit (b'it) $4-$ Comn. I,9s: $(1,02) ;: 37$

BRAYTOX. HOWARI WHFATOX (b'84) $\oplus$ Inss.1,10: (l'11); 150 capiol Ave, of Hee, 44 IIIgh St. ; $2-4$.

Bromley, lonl. Tyler-C'onn. 1,67; (守) ; 103 Ann st.

Brown, Harold Morris (b' 89$)-\mathbf{H}^{\prime}$ it.2,'13; (1'13) : Hartford Hospital.

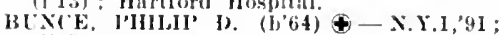

(195); (61 Edwards st. offlee, 98 HIgl si.; $2-4,7-8 ; 0 r$

byrmes, Joln l.eomara (b'90)-X.Y.3,'13; Imeru, st. Franels' Hospltal.

Cahill, Jos. H. (b'67)-XI16,92; (1'43); 14 . Sargeant St.; offlee, 1279 Main St.

Cantarow, Manl. (b'74)-Mass.7.'11; (1'11) 73 Windsor Ave; 1-4, 7-8; G.

'arter, Earle Buel (b'85)-Ild.','ll ; (l'13) ; t'3] 1ubany

Case, Frastus E.-N.Y.74; (1903) ; 902 Jain St. ; $10: 30-12,2-4$.

CHESTER, TIIOS. WESTOX (b'66)-XY.1 15; (1'96); 143 x. Tremont st. ; offec, 110 High st. : $2-4 ; 0$; Obg.

('LFTON, HARKY ('OJTMAX (b'69) I'a.1,01; (l'04); 242 Sigourney st. ; oftice. 98 High' St. ; $3-5,7-8: 30$

(OBB, ALBEITT ElW: (1, ?6: (1996); Asyium die. and suring st.

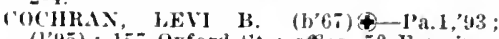
$\left(l^{\prime} 95\right) ; 157$ Oxford st. ; oftice, 50 Farming-
ton Ave. : $2-4,7-8 ; 1 . \star$

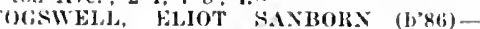
Ilass.I,12: (l'12); 122 High st. ; $2-4,7-8$ CONIIIX, JAIES H. (b'62)- vt.2,99; $\left(1^{5} 02\right) ;$ I New Irritain Ave; oflee, 89 Pratt si.; $1: 30-4$.

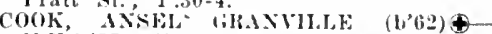
X.Y.1,87; (1'13); T2. Asylum are. ; uflee, 169 Allyn st.; $11-3 ;$ (A3)

(OSTELI, IIENK NICIOOJAS (b,8:3)IId.',10: (I'II); dil Belden si.; attce, lillon Court BIfly.

Couch, Arthur liokwell-H - X.5.9,05. (1'06) : $7 \% 2$ Asylum st.; $2-4,7-8$

cox, (ieo. Washington (b'84)-Md., "12; Intern, Ilartford Hospital.

CRALY, I.IVII), IIR. (b'42) †-('onn.1,69; (1.93); 926 Jain st.; $8-10,2-4,7-4$

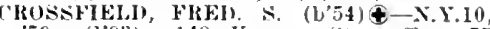
79 ; (193); 148 Kenvon st.; office, 75 Pratt St. ; 4-4; (B15); ALR.*

IROTHERS, TIIOS. DAYISOX (b'42)\&×.Y.3,65; (1'93): 14: Fairfleld Ave. ROWLEV, W. H.-X.Y.t, S9; (l'93); 15 Clarter Oak ire.

Daly, Chas. W. (b'83)-Md.3,'10; (1'10) 381 Capitol Ave.; 1-3, $7-9$.

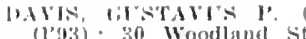

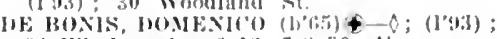
94 Windsor st.; $9-12,7-s: 30 ; U$.

bernlna, flinion bemas (b'8l)-Mll., I0; (1'10); 27 Wetherstlell ive.

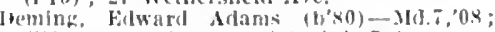
(1'08) ; I Niprlng si.; $8-3,2-4,7-8$

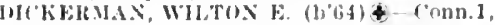

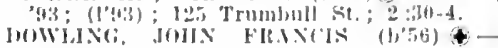

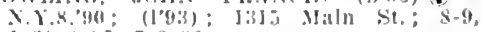
$1: 30-3: 30,7-8: 30$

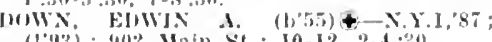
(1'43) ; 4102 Main st. ; 10-12, 2-4:30.

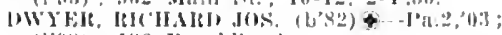
(l'0s); J\&6 Frankl]n Ave.

Inver, Wm. (lis(i) -... Md.7.'13: lutern, Ilartford Inosulat.

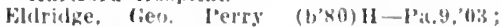
(I'05); 153 s'smour st, ofthe, 125 'Trumbull Sit.; $2-4, i-x$.

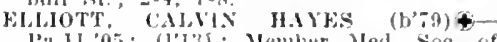
l'a.11.05; (1'13); Member Med. Soe. of the stalle of I'at, ; IIIgl st.; ObG.

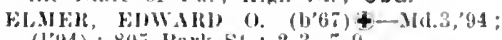
(1'94); 80.; l'ark st.; 2-3, 7-8

Enmett, Francis Arthur- Conn.I, 02 ; $\left(l^{\prime} 02\right)$; 19!5 Jilin st: $7-4,1-3,7-6$

English, Thester ferrin (b'85)-Mo.34,12; (I'] 2 ) ; :0 Washlngton st. ; P.

Farley, Edw. IJrendon (b'84)-Conn. 1,'11; Intern, Hartford Hospital.

Faulkner, lames francls (1)'84)-Mass.1,13; Intern, Hartord Josnital.

FELTY JOHA . WELIJNGTON (b'6(i) l'a.2,84; (1.97); 734 I'rospect Ave.; office, 1(1) Wain St.; $2-4: 30 ; \mathrm{S}$.

ISTllEL, ABRALAII (b'85) 4-X.X.19,09; (l'og); It Parllion st.; offle, 149 Wlnalwer Ave.; $8-4, \quad z-4,7-8$.

FTZGEILID, WM, H. (b'72) 8-Vt.2,95; (1'97); !04 Maln Si.; $10-1,3-5$.

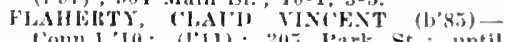

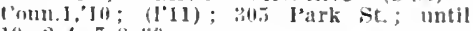
11., $2-4,7-8: 34$.

Flaberty, Jugh Franets-Comu.1,07; (l'07) ; Biter Park st.

iuller, Lafayette I’. (6'45)-T'a.17,67; (l’04); 721 Jain it.

aboury: Cieo. Napoleon (b'8t)-Mass.1,10 ; (l'10); I07 Jutnam St.; 2-4, i-9; Pd.

Garland, Robt. B. (b'82) - Md.3,13; Intern, st. Francis' Hosjutal.

GILL, MH(HAFl, I1. (b'73)\&-Coun.1,96: (I'47) ; 735 I'rospect Ire, offlee, 36 pearl st. ; [0-5; OALR. *

(iills, Wm. Lee (b's5)-M(1.7,'12; Intern, Hartford IJospital.

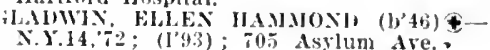

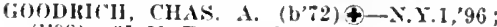
$(1998)$; 61 x. Beacon st.; offlee, 5 Haynes Nt. ; $2-4$ : $\hat{\mathbf{P}}_{\mathrm{d}} \star \star$

(irasso. Antonio (b'co)-Mass.6.08; (l'08); 1105 Main St.; offlce, 1026 Main St.

(ireenbert, Iohn 'Davis (b'88)-Comn.I,'10; (1'10); \& Wooster st.; (offlee, $82 \mathrm{~W}$. Main S... Few Britain : $7-9,1-3,7-9)$.

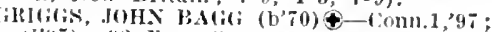
$\left(J^{3}(1) ; 42\right.$ Fern st. ; offce, 44 High St. ;

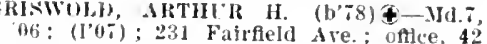
IIigh St.; $2-4,7-8$.

Gruss, Abraham Benj. (b'88)-Comu.1,12; (J'12) : 19:3 Main st.

firosrenor, Frank L. (b'75) - X.Y.6,00. (l'o0); loms boulerard st.; office, ino

InackJey, Chas. Elihu-Ja.1, 60 : (1"yf ) not in practice.

HAIL, lOS. B. (b'69)-Conn.1,92; (1'93); 10 Ciarden st. : $2: 30-4: 30$.

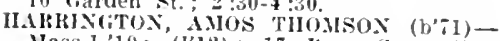
Ilass.1,10; (I'12); $1 \pi$ liuss St.; offece, 110 High St.; $2-4,7-8$

HATHEWAY, CLARENTE MORRIS-X.Y.10, '03; (I'06) I I0 High st.; $2-4,7-8$.
HAYLETT, HoWAKD B. Yt.2, 07 ; $\left(l^{\prime} 09\right)$;
150 High st.; $2-4,7-8$.

HEPBLIR, THOS. NORVAL (b'79) \&Ma.7, $05 ;\left(10^{\prime} 06\right) ; 133$ Hawthorn st. ; offlee, 42 High St. ; $9-10,2-4,7-8$

HELBIEIX, ARTHLR C. (b'-9) \&-N.Y.1. 02; (l'04); 181 Fern St.; office, $4:$ High st. : $2-4$; (Ci1); R. 


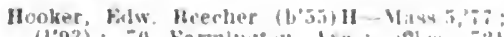

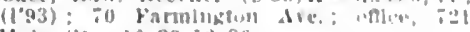
Matn st. : $10: 30-1: 30$

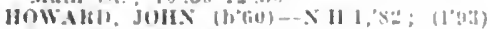
$133:$ Main st. 9.10, 1-8, :-4,

Jumn. Faul Kerere $(1,+t i)-4 ;(123) ; 3 !$ dafagette fre.

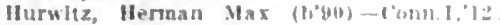
(I'1:2): 36 l'leasant sh.

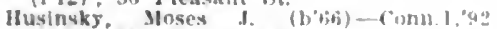
(1"93):" 251 Windsor Ave

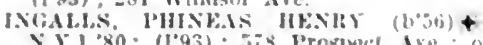
X.Y.1:80; (1'93); , is Proppeed lve:

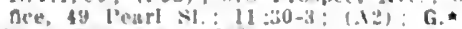
Isham, OHrer K. (h) Il Ulgh S! : 1-4, after s.

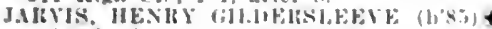
Mal.: 10; (1'10) : ys $111 \mathrm{gh}$ st.

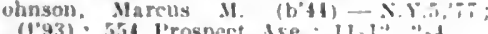
(193): 55 l'rospect Are : I1-12, -2.t

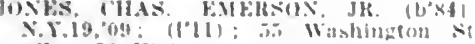

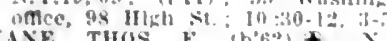

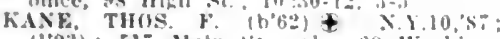
(1'93); 317 Maln st.; also 69 Wishing. ton st.

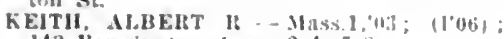
143 Farulugton dre : $2-4,-8$.

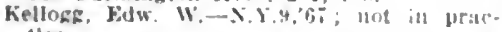

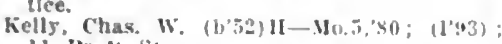
11 Pralt St.

KFENEDY PHIII THOS. (b'83)-Mass. 1 . 09: (l'10) : 43 Follwards st. ; office, fit Ann st. $2-4,-8 ; \mathrm{Pd}$

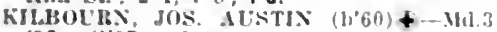
97: (1'96); ill ('illns st. uflce, Park st. : untl y, 2-4, $i-9$.

Kllbourn. Jos. Hirney (b'si) - Md.3, 11: (III): 111 Collins st.

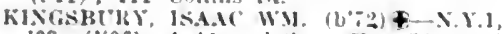
03: (1'06); I Alrood st.; iflee, 36 l'earl St.: $3-5$

Kinsella, Metrael Nlen $\left(b^{\circ} 8\right)-$ Masti, 12 ; Intern, Martford Hosplla!.

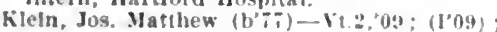
114 Wethersfeld Nie.

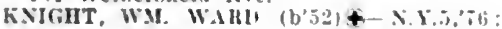
(1"93) : 254 Trambull St. ; uttice, (is learl si. : 9-12:30, 2-1:30.

Laden. Mlehacl H. (b"it)-X Y

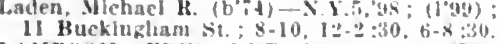

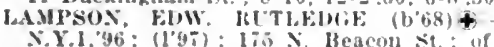

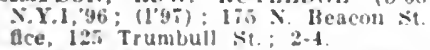

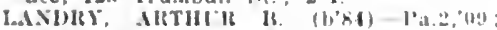

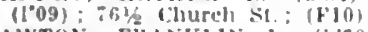

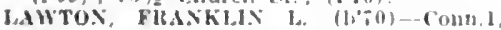

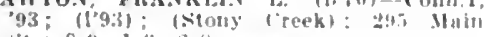

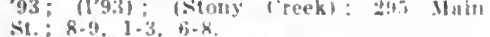
St. $8-9,1-3, b-x$

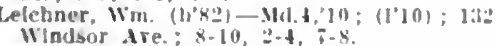
Lerlue, sinelair simeha $\left(b^{\circ} 8.3\right)-M 1.3,12$ : (I'12) ; 6y Windsor Are : oflee. : Villine Si. ; $6-10,0.4,7-5$

LFWIS, Jo1I 312 Farmliftun ive.

Le W'll, Abram (bii)-X. Y.20,00; $\left(1^{\circ} 0(0)\right.$ 63 Vindsar st.

Locke, Harts lestle pranklin (b'si)

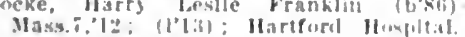

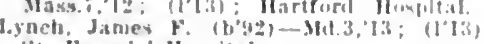
sit. Franels" lloxpltal.

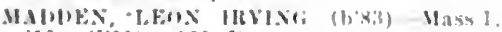

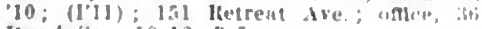
jeart se. ; jo-12,3-5.

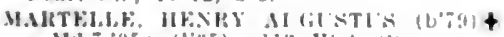

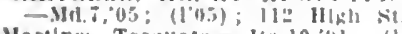

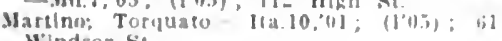
Windsor St.

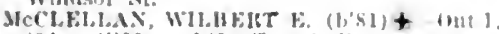
04: (l09); las Trunilull si.; loOALR. *

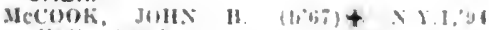

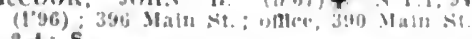

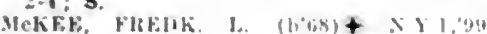
(1.99): 201 Sigonruey fre

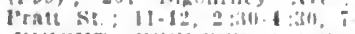

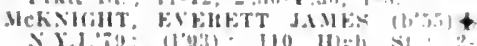
(C) $1.1, \because 9:$

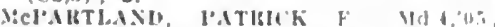

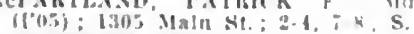

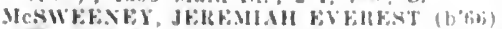

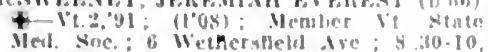
.
$2-1,6-8$.

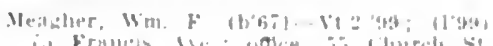

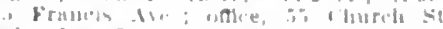
"III, I.

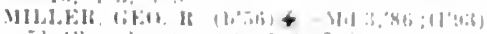

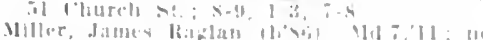

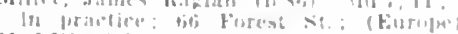

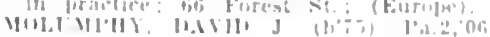
(1006): iा: 11:3110

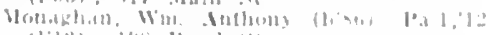

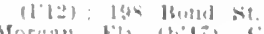

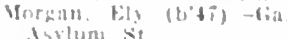

Ablum it

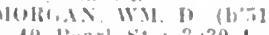

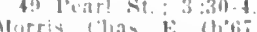

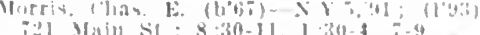

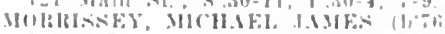

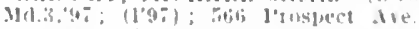

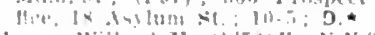

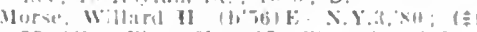

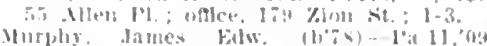

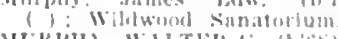

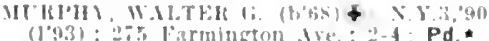

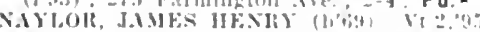

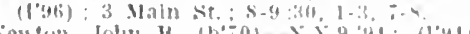

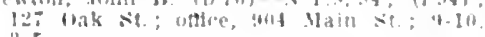

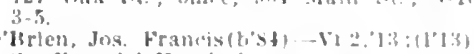

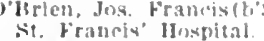

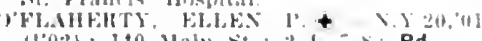

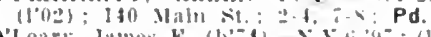

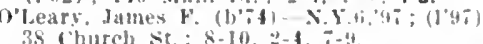

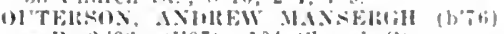

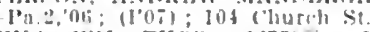

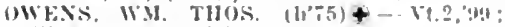
(l'9!): I firecnfleld Ave, othe, il); Maln

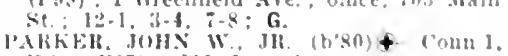
oti; $(1007) ;: 2+1$ iaurel st

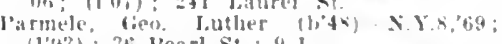

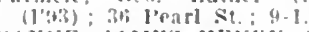

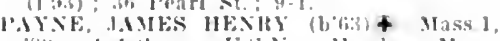

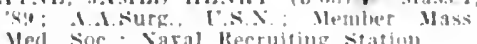

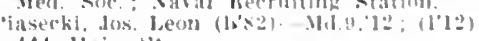

114 Main sit.

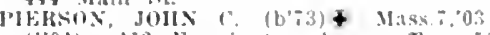
(1'0t); fle Farmington Ire: oflee, id w!ndsit Ave.: 2-1,

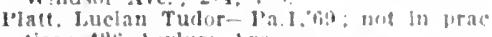

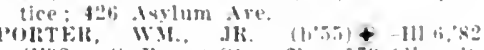
(1) $2-4$.

remingisa.

Maln st. Wh ti.

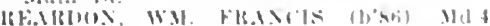

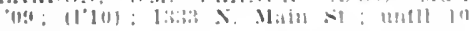

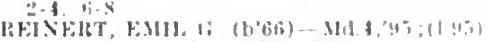

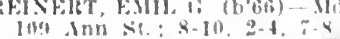

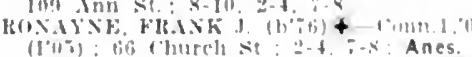

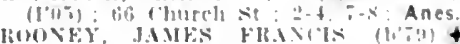

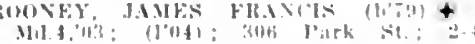

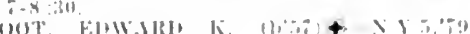

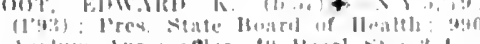

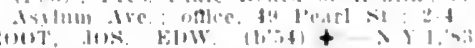

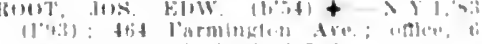

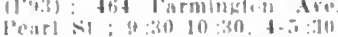

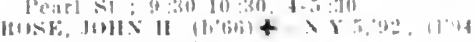

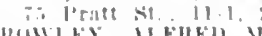

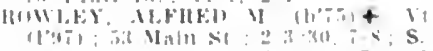

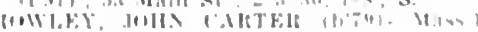

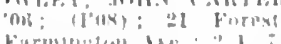

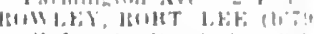

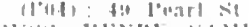

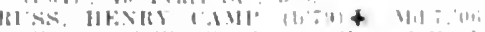

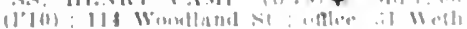
ureflelil ine: LD.

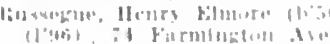

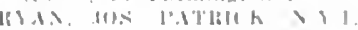

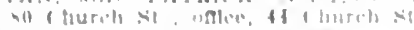

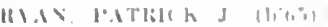

11 :ant. Blli l'urk si

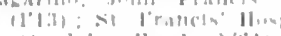

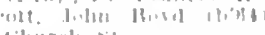

(liureh $>1$

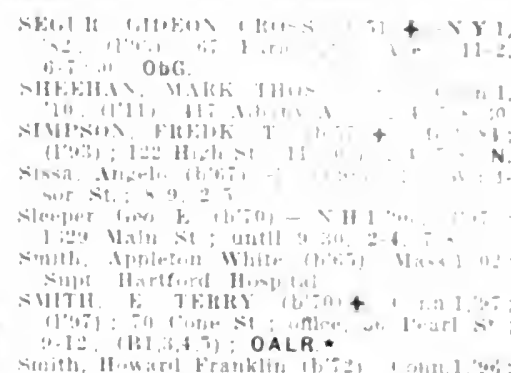

cimish, II - B

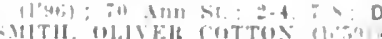

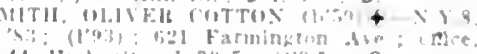

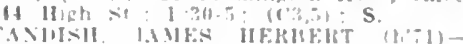

STANIISII I.AMKS IIEKHFIT (1, I)-

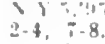

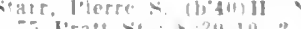

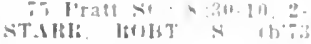

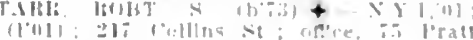

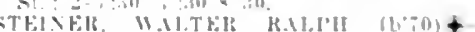

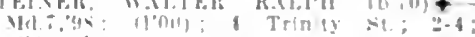
$(F+2): 1 *$

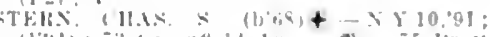

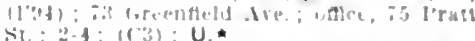

Sit:2-4; 113$) ; U$.

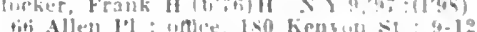

$1:: 60-4: 30$.

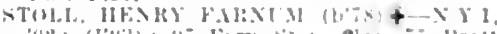

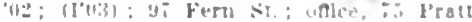
$\therefore:-1 ;: 1$.

atome. low

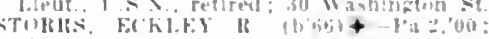

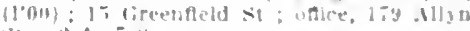
$\therefore$ : 2 - 1. :

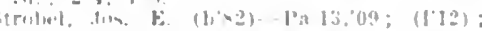

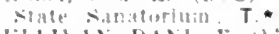

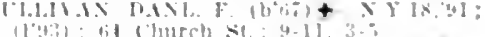

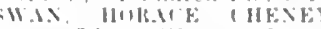

Ilase

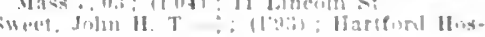
ittill.

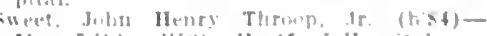

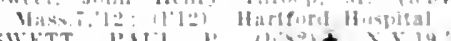

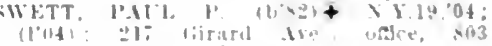

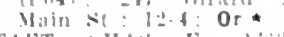

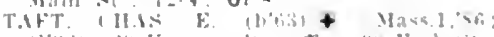

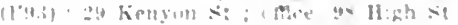

inmer, lames the

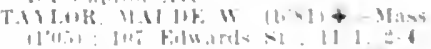

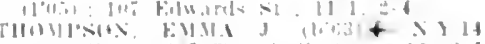

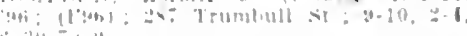

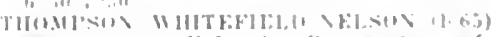

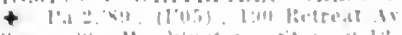

(1:1..) P.*

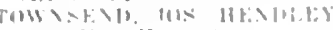

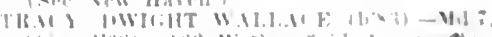

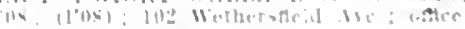

- Wetherafialal we

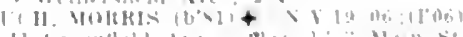

A

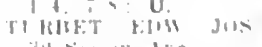

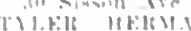

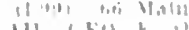

lairl st m, OALR.

an Vesee Mitam lace

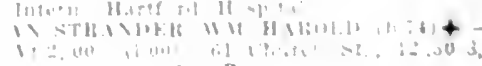

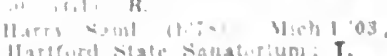

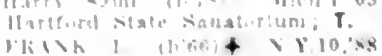

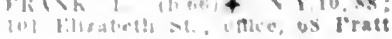

sil lo 1. llet 
Walker, Win. Hastlngs (b'78)-Mass 1, 11: (assistant phystclath); 30 Wusluinefon: P WIIt), JAMES W. ( 437 Capltol Ave. : $8-10,1+3,6-8$

WITElMLN J"Al

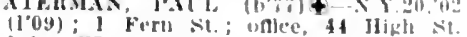

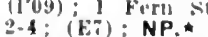

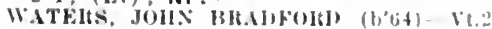

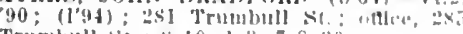
Trunbull st. ; $x-10,1-3,7-8: 30$

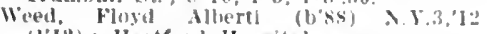
(l'12) Martorl Iluspital.

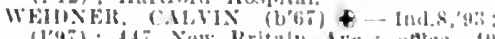

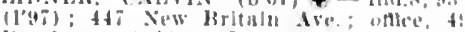
Pearl st: : :30-5: OALR *

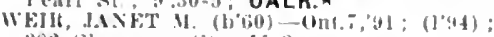
282 sigourney st. If.2

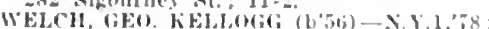
(I'931: Itt riarle's it.

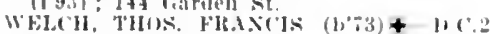

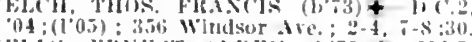

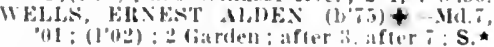
Wentworth. dolu Nlex. (h'88)-Mass.1,13; Intern, Hartford Hospital.

Whalen, Etiw. J. (b'\$6)-Comn.1, 08 ; (1'08) 004 Main St.

WEMMAN, OTTO (i. $(1,81)+$ I'A.1,0.5 (I'n5) : 377 Albany dre : 2-4, $7-$

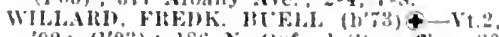
98: (1.03); $186 x$ (Ixford st. ; wftlce, so Willireh st.; $2-4 ; s$.

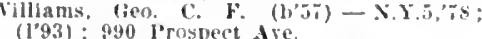

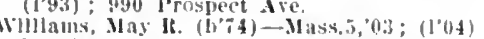
Illzhland ( $\mathrm{t}$.

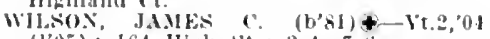
(l'0.5): 164 lligl st.: $2-4,7=8$

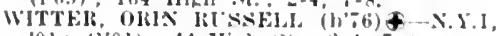

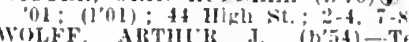

TrFo is isylumi st. : $2-4,7-8$.

Wrlght, Arthur Brownell (b6s) - N.Y.1,95; (1'13); 124 X. Beacon st. : office, 700 Main. YERAASON, ROBT. MOSELEY (b'85) $t$ FRGASON, RoBT, WOSELEY (b'85) $\$$
X.Y.1,09 (1'09); 11 Asylum Ave.; oflce, 002 Maln St. $2-4,7-8 ; 0 r$.

Young. ('has. IJenry (b'85)-I'a.2,13; I1tern, St. Francls' IIospital.

Zeman, Hurnhardt-Ky 1,0s; (1'08); 18 Florence st.; oftlce, 140 Wlulsor ire. $8-10,2-4, \div 9$.

HARWINTON (R.F.D., TORRINGTON), 1,440, LITCHFIELD

Blake, ("has. Iambert-Comn. I, 65; (1'93),

HAZARDVILLE, 1.750 , HARTFORD

HOLGHTON, SIMOS W. (b'49)-X.Y.10,'-9 (I'93).

HEBRON, 894, TOLLAND

I'ENDLETON, CYRCS JENRY (b:30)$0.6,60 ;(1,93)$.

HIGGANUM, 1,000, MIDDLESEX

Kellogg, Clitford Waleott (b'50)-Conn. I, '9t; (1'96).

Smlth, Lerny A. (b'43)-X.Y.I3,70: (1'33)

HIGH RIDGE (R.F.D., STAMFORD), 300 FAIRFIELD

WILIAMSOX, EDWARD ALGLSTLS (b'64) -X.Y.10,'86; (1'05).

IVORYTON, 645 MIDDLESEX IVORYTON, 645 MIDDLESEX
shannon, EHmer Ellsworth (b'76) H-1'al.9.
'00; (1'02).

JEWETT CITY, 3.023, NEW LONDON

(iorman, Joln 1'. (b'5.5) $\rightarrow$; (l'93).

Holmes, Sanford II. (b'41) $\rightarrow 0.2,84 ;\left(1^{\prime} 93\right)$ (1'93).

MeLaughlin, Joln Henry (b'85)-Md.8, 09 (1'10).

Rainville, Fred. F. (b'61)-Yt.2,9I; (l'92)

Sweet, John Byron (b'34) $\longrightarrow$; (1'93).

KENSINGTON, 1,878, HARTFORD

(iriswold, II atthew IJammond (b'87)-Vit.2, '13; (l'13).

(]'93).

KENT, 1,122, LITCHFIELD

13:1 rnum, Walter M. (b'60)-N.Y.1.'\$3:(1'03)

LAKEVILLE, I,200, LITCHFIELD

MISSELL, WU. (b'30) \$-Conn.1,56; (1'93). BLNEIA, WM. BASCOM (b'65)-N.Y.1, 91 ;

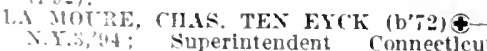
$X .1 .3,4$ s superintendent Conneet
Nillool for mbeciles; (EI3) ; NP.
LEBANON, 1,528, NEW LONDON

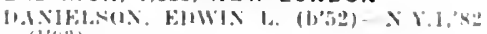
$\left(I^{\prime} \leqslant 3\right)$

LITCHFIELD, 903, LITCHFIELD

131'Kil., JOHIY L. (litil) - N.Y.1,88; (1'93) NP

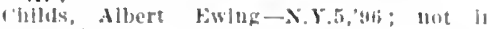
pritentere.

1. Fistisicis.

(1,yis).

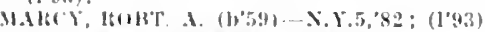

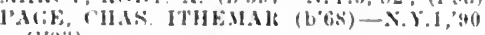
$\left(l^{2}(3,3)\right.$.

SEDGWICK, IAMES T. (U'(i.3)-X.1.5,85; $\left(l^{\prime} 9 ; 3\right)$

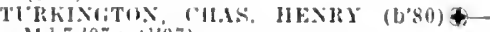
Md.7,0\%; (10\%)

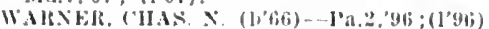

Westervell, Marvil \%.-II-X.Y.4,"39; (I'II).

LONGHILL, 400, FAIRFIELD

(;allup, (Hals, M, - Y.Y.J3,81; (1'93).

LYME, 746. NEW LONDON

livitr, kIJIS KIXG (b'80) - Md.a, 07 (l'0:)

MADISON. 1,536, NEW HAVEN

Aver. Alvello 11. (b'51)-Int.11,81; (1'!1)

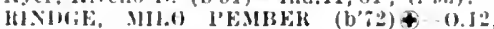

'05; (l'0 0 \%)

MANCHESTER, I3.641, HARTFORD

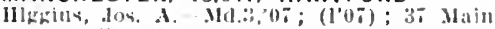
si. : offter, llegwot sit.

Holmes, le lerne (b'79) - Mass.5,04: (1'111; :15 Mitin st.; oftle, Depot Sil.

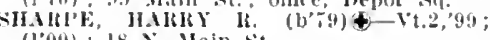

Whiton, prancis II. (b'ti) 一N.II.1, $62 ;\left(1^{\prime} 43\right)$

MANSFIELD. 1.977 , TOLLAND

CRAMM, WM. EHW: (b'T0)-YT.2,'95; (1'96)

MANSFIELD CENTER, 410 , TOLLAND

Marsh, Elliot H.-0.2, 11 : (1,93).

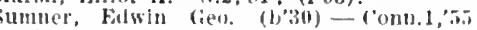

(1'03)

MANSFIELD DEPOT, 275, TOLLAND

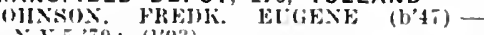
X.5.5,79; (193)

IUSA, JUOSALI LALIRECE (b'bI) + (Que'.l,'st:; (1'12); (Kis).

MARBLE DALE, I30, LITCHFIELD

Jensluw, Marmaduke if. (b'68) N.Y.9,'02: (1'45)

\section{MERIDEN, 32,066, NEW HAVEN}

Aritabile, Mfonso Louis (b'86)-Conn.1, (08 (l’08): 16, W: Main st. ; $7-9,1-3,7-8$

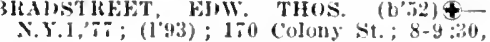
$1-3,7-8$.

conkE, Jos. A. (b'66) - Conn.1.43 ; (1'95); 27 dusley Ave; offce, $50 \mathrm{E}$. Mlaill St. $8: 30-4 ; 1-3 ; 7-8: 30 ; \mathrm{S}$.

Inals, (his. H. S. (b'f0)-X.1.5,66; (l'93) 60 l'leasant st. ; offlee, 13\% E. Main st. belesterniers, llorice Wm. (b'.11)-Vt.2, 85

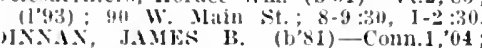
(100): W. Mutum B.

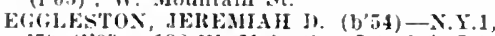
7! (1'93); 132 W. Małn st. ; $7-9,1-2,7-4$ YEXX. AVA H. (1,45)-IId, 3,$86 ;(1,93)$ 30 ('apitol Are.; office, 15 Colony st. ; 2-3, i-s; D.

Ferris. Anna Jackson (1)47) - Pa.í,'74; (1'43) ; 2.44 E. Main st. ; 9-11, 2-4. (iraelere, ('has dugustus (1)'41)-0; (1'93);

Greenstelt, Chas. Jacob (b's8)-Md.4, '12.

('1:); is k. Main St. ; $8-10,1-3,7-4$

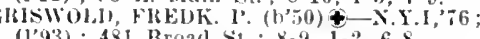

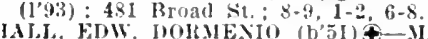

JAIJ, FDW. IOHMENIO (b'5I) $\mathbf{f}$-IIass.1, E. Main st.

Hewitt, Chas, E. (b'55) H-J'a.9.'93; (l'93) 70 Crown st.; offlee, 30 Colony sit.; $8-9$ $1-3,7=4$

Inll, A. irthur (b'70)H-l'a.9,04; (1'04); 33 Main st: 8-10, $1-3,7-8$.

kean, Jouisa J. Darnstaed - P'a.i, ${ }^{\prime} s i$ (1'93) ; retired.

LA POIXTE. J(1HX H. (b'66)-Que.3, (1.93); $381 / 2$ W. Main st.; $5-9,1-3,6-8$. LoCkWOOD, Howater D. F, (b'7) Conn.1,01; (l'02); 489 Broad st.; S-y,
$1-3,7-8$. JeCollough, Edw. Aloysius (b'68)-Mass.
M.Ëluan, Jarry Whllur (1,87)-Mass.5,10

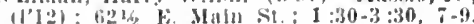

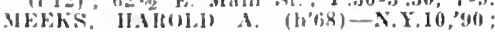

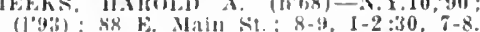

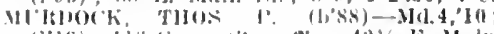
(1'10): I16 cirove st.: onthe, 421/2 E. Maln st. intl] [11, 2-4

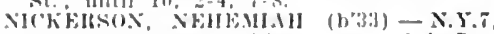

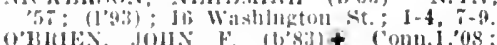

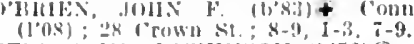

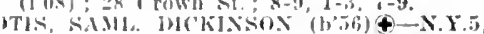

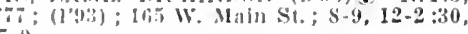

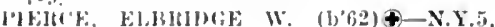
S.: (1) 43$)$; Waslilugtun st. ; oflice, 531,

II. Ifain St, : 4-12. vo (b'86)-Md.4,'10; (1ii); lis bilk st.

MITH, l'Alll I'AlikEIt (b'89)-Conn.I. l:2; (1"12): 67 Iinsley Ave.; offlce, 34 11. Maln st. $2-1,7-8 ; \mathrm{S}$.

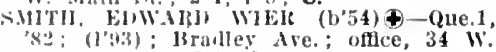
Mats st. ; $1-3,7-8 ; s$.

Stodlard. Jolin E.-II-Mass.5,04; (1'06); 34 II: Maln st.

IIIIIALI JOS $\left(b^{\prime}, 6\right) \oplus-$ i. 20,00 ; $\left(1^{\prime} 02\right)$; $7 \%$ W. Jain St. ; 8-10, "Ihic' ANs, (1"43) : 5.2 Jiberty st.

West. IJelen (b'68) H-Mass.5,96; (1'97); 1]6 F. Main st.

WIEATLEY, JOEIS FUEDK. (b'-6) $\$-$ Mass. 6,03 : (1'05); 174 Curtis st.; offlee, Whllams. Harry st Jolin (b'88)-Coun. 110: (I'II); State Sanatorlum.

Wilson, Elgar Adans (b',3) H-1'a.1,'81;

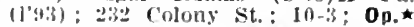

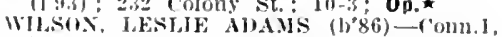

I11: (1'11) : 232 Colony st.; offee, W'llews

Block; $11-2$

MIDDLEBURY, 836, NEW HAVEN

Iristol, (ien. 13. (b'36) k-D; (l'93).

MIDDLE HADDAM, 550, MIDDLESEX

1..IIINON, (;EO. N.(b'65)-Conn.1,92;(1'93).

MIDDLETOWN, 11,851 , MIDDLESEX

BAILEY, ,1011 N EI,YOIE (b'62)-N.Y.1,'85;

BRAGDox, (iEt). ALBEIT-3]e.1,70; not in practice; Member Mass. Med. Soe.

BRowx, Locis R. (b'78)-Mass.

(1'11); 1lospital for Iusane.

CALEF, JEItEMAII FliNCIS (b'55) Conn.1,80; (1'93); I'res. Conn. Med. Examining loard; Iit Broad St.; 1-3, 6-8; Mlddlesex Hospital; 9-10.

CAMPBELL, AHTIIU J. (b'56)-Md3,'85:

(I'93) ; 148 Washington St.; $8-9,2-4,7-9$

COLBLIN, AITHLR B. (h'63)-N.Y.1,'90;

(l'93) : Hospital for Insane.

(D.T, EDGAR (b'75)-N.Y.1,03; not In pratice; 55 it. Vernon St.

ISHEL, IESSIE W. (b'78)థ-Pa.7,93: (l'94); llospital for Insane; Path.
"sHER, WM. E. (b'54) $\oplus-$ Pa.1,76; (1'93) Iospital for Insane.

Ires, Susanna Mary (b'67)H-Pa.7,'94; (l'01) ; 198 College St. ; 8-9, 1-3, 7-8.'

KENISTON, JAMES MORTIMER (b'48)-

Mass.1, 'if; (1'93); Hospital for Insane;

KENNA, WH. MATTHEW (b'68)-Conn.1, '92; (1'93).

KINGMAN, JAMES HENRY (b'60) $\oplus$ N.Y.1,85; (1'03); 159 Broad St.; 1-3,

Koplitz, John (b'22)-Ger.16,47; (l'93) ; II ain and Elm Sts. : $8-10,2-4,7-9$. LORI), SIDNEY ARCHER (b'69) 9 -Mass. 1 , ' $94 ;\left\{l^{\prime} 06\right) ; 151 \mathrm{Mt}$. Vernon St. (E2); N.' OVELAND, JOHN E. (b'64) \$-Mass.1,'93 $(1+34) ; 107$ Broad st. ; $2 \div 3,6-8 ; \mathrm{S}$.

Maitland, David Lewis-Pa.1,'95; (1'95) ; 56 Bruad 'st. ; 8-9, 2-4, 6-8.

IIcDougall, Jos. H. (b'55)-X.Y.9,'75;(1'93) ; 194 Court st.

IEAD, KATE CAMPBELL HLRD (b'67) -l'a. 7,$88 ;(1 ' 93)$; 165 Broad St. ; 2-3; G. IITC'HEI, JAMES THOS. (b'68)@-N.Y.5, $91 ;(1,94) ; 208$.Jain St.; 1-3, $7-8$.

IOENTAJ, JOHN H. (b'70)-Pa.2, 96 ; (1'96); 200 washington St.; $7-8: 30$.

ILPPIIY, JAMES (b'73)-Pa.1,95; (1’95); 


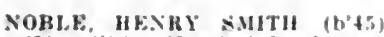

1193): Hospltal por lnusue + X.Y. P.

OLAN, DAN

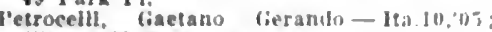
(J'06) ; 60 Ferry st.

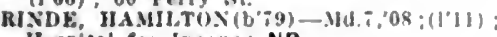
Hospital for Insane: NP.

Sage. Fredk. H. (b'01)-Y Y,9,84; (1'93) 64 Main St: : $8-9,1-2, \% .8$.

SIMONSOX, Jolis (b'si) - Mass." "ls $(1 \circ 0 s) ; 12+3$ MaIn $51,9-10,2-4,7-8$

STANLFi, CHAS, FVEIRT (b'5l) + Pan, 6 : (193) ; State Honplat

WALSH, THOS. YATHIK (b',6)

ALSH, THOS, PATHIK $\left(b^{\circ}, 6\right)+V t=$

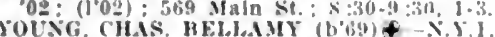

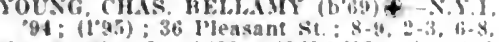

Joung. Wn. H. (b;0)-X.Y.1,9:; 1 1 : 100 III.th $\mathrm{St}$.

MILFORD, 4.366, NEW HAVEN

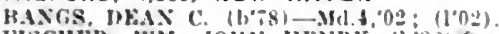

HISCHER, WM. JOHN HENIT $\left(\mathrm{b}^{\circ} \mathrm{R} 2\right)$ Conn.1.11: (1'1])

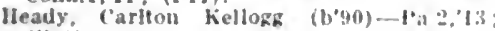
(l'13)

WES, JOH. W (b"i6) $\rightarrow$ Conn. I, $00 ;(1 ' 00)$

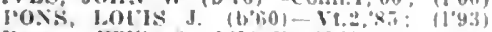
Futney. WHIlls s. (1) Pd.

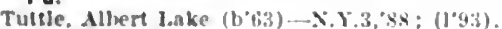

MONROE (R.F.D. STEPNEY OEPOT), 1.002, FAIRFIELO

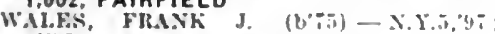
$(\mathrm{lg})$

MONTOWESE, 500, NEW HAVEN

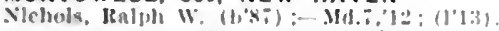

MONTVILLE, 2.395. NEW LONDON

11: (f'11).

MOODUS, I,200, MIDDLESEX

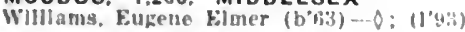

MOGSUP, 2,950, WINDHAM

ADA.MS. WTLL WALDO (b'159)-X.Y.10, (1. 13 ).

A.LES. CHAS. \$OAHI (b.5\%) - Vt.2,81;

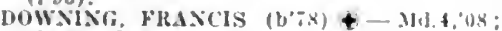
(l'08): 0 p.

MT. CARMEL, 421, NEW HAVEN

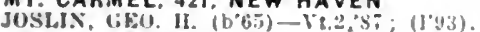

MYSTIC. 3.571. NEW LONDON

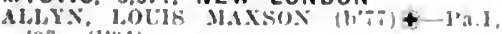

Bucklya, John K., Jr. (boi) - X Y.9.8\%; ( ] 93 ).

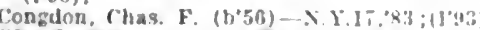

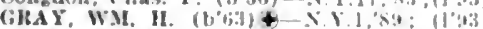

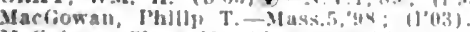

MeGulgan, Clara M. (b'bis) lo

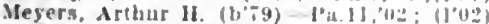

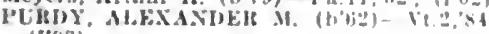
(I'93).

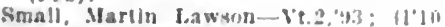

sthllman. (Thas. Ki)rtland-y ind: not in practlce: (F\&).

NAUGATUCK, 12,722, NEW HAVEN

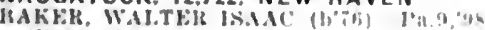

(1'99): $8-9,1-3,--8$.

(1'93).

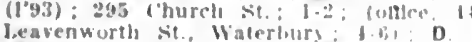

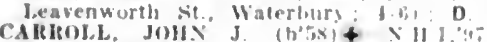

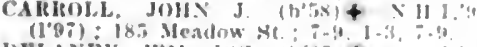

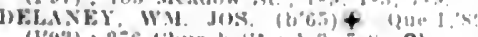

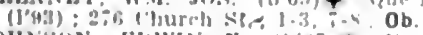

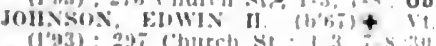

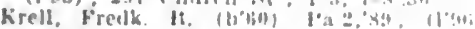

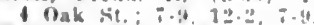

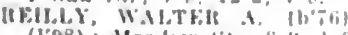

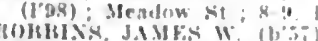

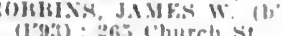

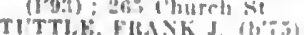
I. $=i$. $i-9$.

Wionfford, Theostor Niorlh

NEW BRITAIN, 43.9I6, MARTFORD

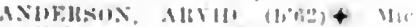

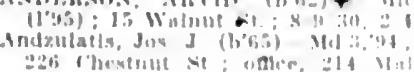

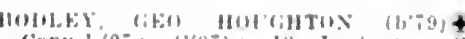
('onn.l,0i; (100\%): is lexjuklull sit.

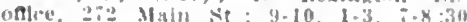

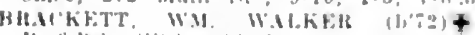

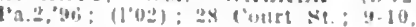

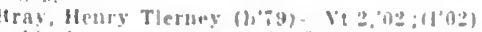
I4 inuri st : $8-1+1-3,7-1$

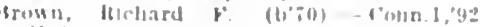
$(1: 1: 3): x 1$ C'lesenut $\leqslant t: x-110,2-4$

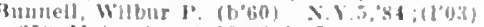
"z!t Itain xt. ; $10,2-4,7-9$

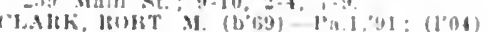

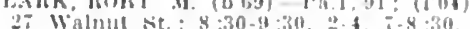

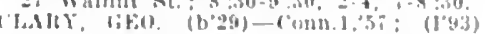

not li practlee: ata lalucoln st

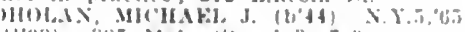

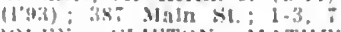

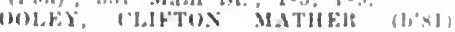

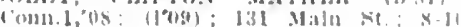
2-4. $i-4$

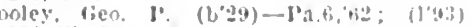
113 แ. Main sit.

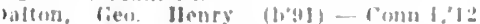
(1'13) ; ti $0_{\text {isk }}$ st

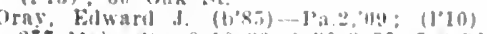
2:- Main st.: $9-10: 30,1: 30-3: 30,7-4: 30$

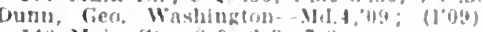
140 Main Si. : $8-9,=-3,7-5$

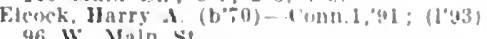

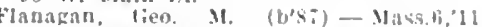
(1'11): 489 Yain sit.

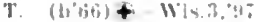

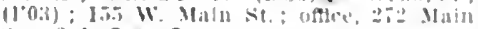
Nit. : $2-4,7-8 ; 5$

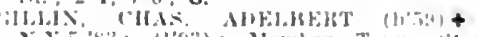

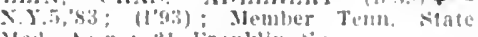
Med. Ixnn. : I franklin sis.

creanliurg. dohn liavis.

lsee Hartenril.)

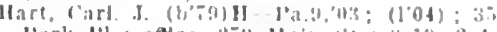

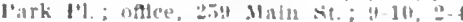
i-s: S.

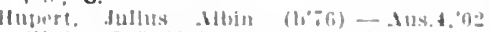

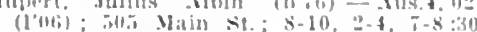

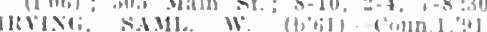

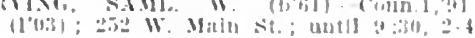
(1)

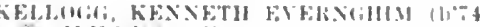

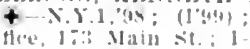

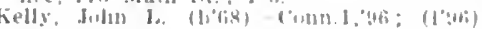
3 tis Mant

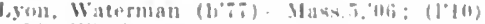

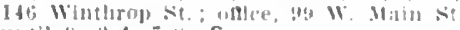

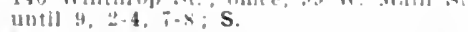

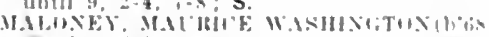

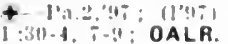

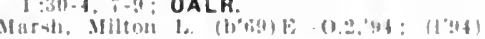

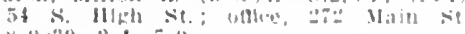
(2-!) $: 30,2-4, \quad ;-9$

Martin, John k. (boliz) X r to, an: (lati)

Mullgan, Thos (b+1)

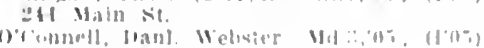

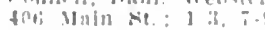

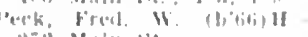

272 Maln 5

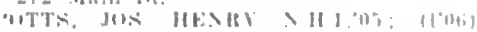

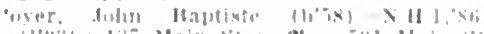

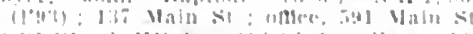

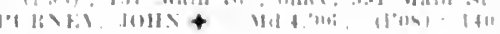

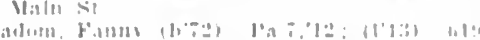

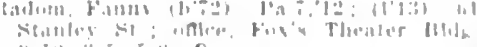

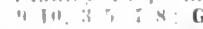

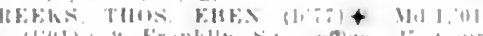

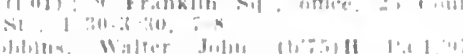

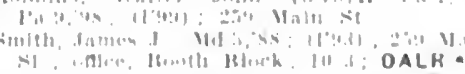

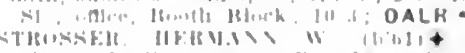

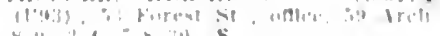

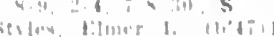

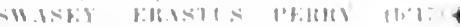

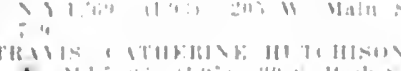

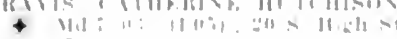

Volkenher)m. Vemelel

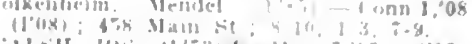

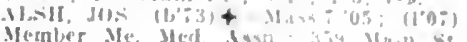

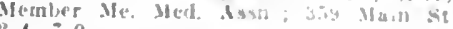

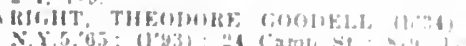

N.i.

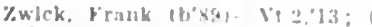

Mritala dieneral llospital.

NEW CANAAN, 1,672, FAIRFIELD

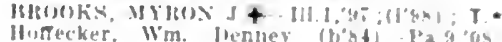
(I'1 1 (t)

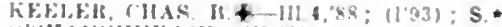

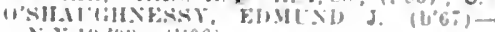

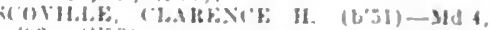
Whriblus

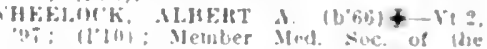
Nitate 118 S

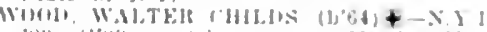

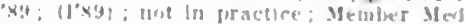
sing of the state of X.1.; l'rul. Sur:

NEW HARTFORO, 3.424, LITCHFIELD

(aya, 1. () H. (1mt.4:3; 1 993 )

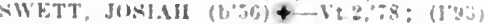

NEW HAVEN, 133.605, NEW HAVEN

NTMHEIt OF I'HISICIASS, 20:

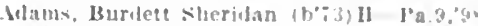

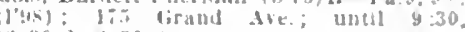
-

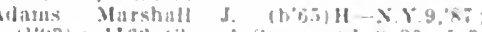
(1)(4.3) ; 1162 thapel s: : untul $3: 30,1-3$.

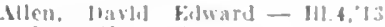

(1"13):

cirace Huspital.

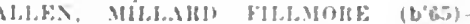
l'al.11,95; (1'4i); his lirwell dre.

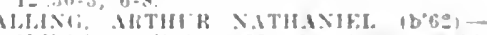

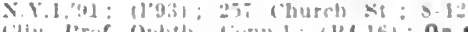

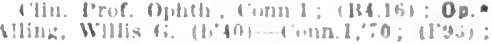
311 brunge of

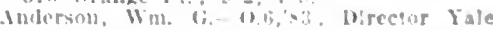

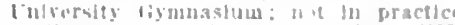

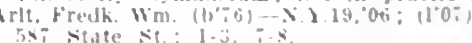

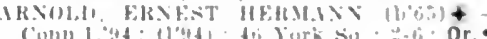

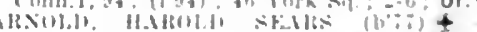

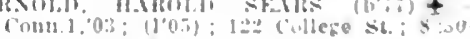

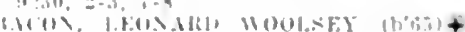
If. Malduln, Win. lose (1)

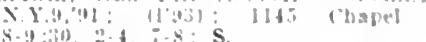

Barbour, llenry lirag (l, lork st : Isst. l'rof Jhar comn.1.

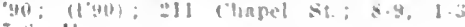

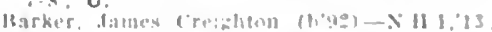

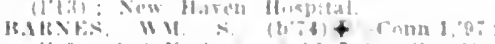

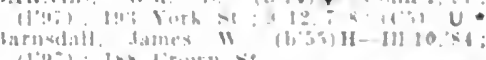

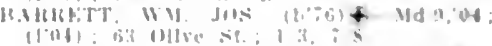

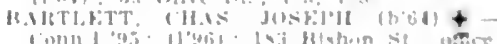

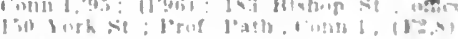
Path. *

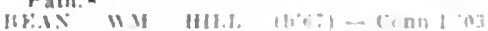
(1) 11,3$)$ : th llexane si

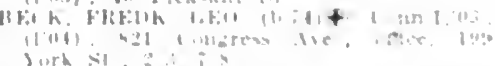

Bublowa

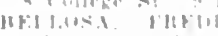

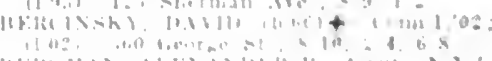

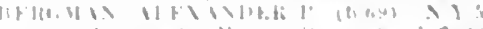

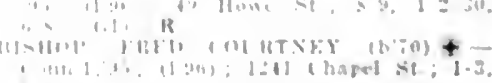

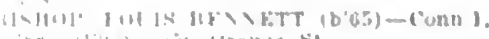




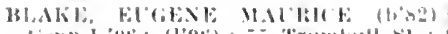

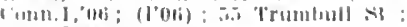
i.s. OpA.

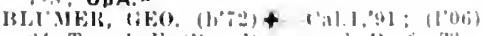

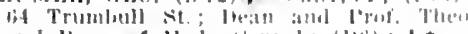

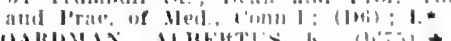

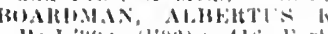

lat I,

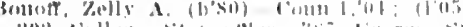

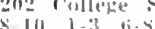

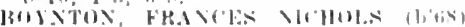

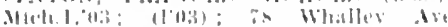

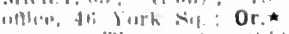

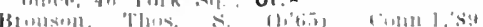

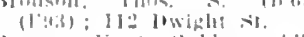

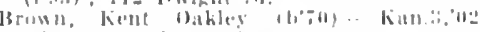

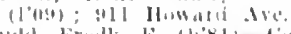

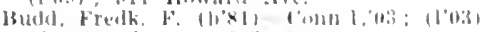

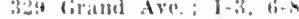

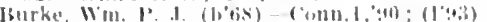
1.T

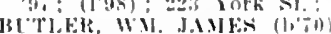

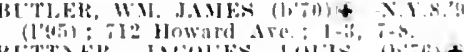
(1)

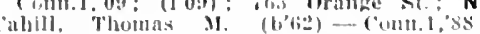

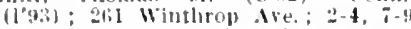

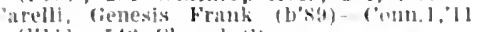
(1)11); 542 (hapel st

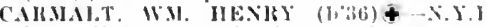

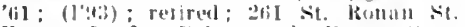
Emer louf lerin and l'ras siurn.

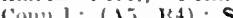

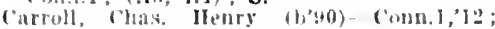

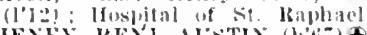

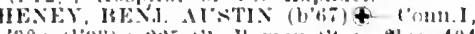

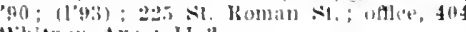

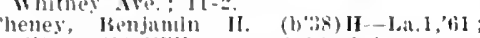

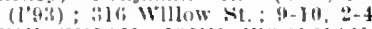

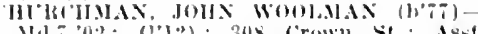

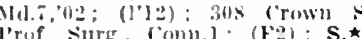

(t) $\left(l^{\prime} 06\right): 216$ Grind Are.:- $:-3,-8$.

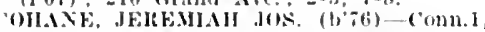

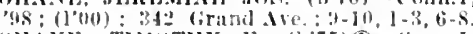

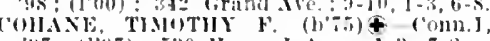

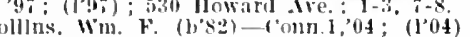
ollins. Wim. $k$. (1) 82$)-$

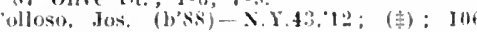
Winster st.

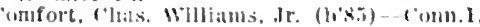
"11; $\left(1^{\circ} 130\right)$; Xew Haren Wispensiary : oftice,

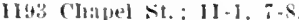

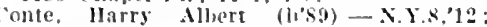
(1'i3) 158 st duln

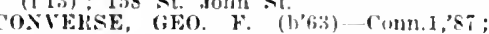
(1'03); l whalley dre.; $1-2,7-9$

comey, Wm. Joseph (b's)-Com.1,02; (1.02); 244 Main si.

CROWE, WHAS HAxporl (b'T4) $\mathrm{i}-3,6-8$.

D'Agostina, Franceseo (b.80) - Ita.10,05 (1'0!6): 621 Chanel st. : $7-4,1-3,7-8$

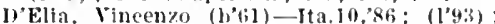

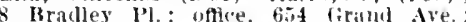
8-10. $1-2: 30,6: 30-7: 30$.

DeFOHEST, LUTIS St--ier.11,85; (1'93): 3235 Orange $81, ; 6-10,2-3: 30,7-8$

Degman, Fiward Jos. (b's5) - l'a,2,'13. (1'r3): IInspital of Si. Itaplacel.

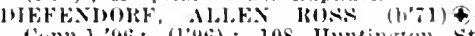
cimll. otthere $12: 4$

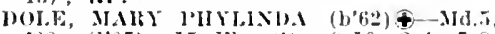
ss; (1.05) ; 15 flm st.; 1-10, 2-4, i-s Dow, Virgll it. (b'43)-Conn.1,'64; (1'43) 336 George $s t$.

Pryfus, Mlilton Leopold (b'90)-t'oun.l,'12; (1'13) ; 85 Ward st.

ELIOT, (IISTAYUS (b'at) - N.Y.I,80 $\left(1^{\prime} 93\right)$ : 200 Chureh st. : $2-3,7-8:$ NP.

Fsposito, los. Vincent (b'89) - Pa.2, 12 (1'13) ; fiti cirecene st.

Exins. Alex. Wm. (b'68) - Conn.1,92 (19i): not in prietice 142 cold spring.

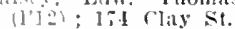

PEIRG $0-1$

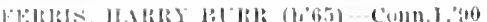

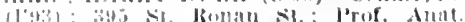
(am) I: (r)

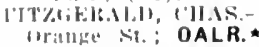

(1) OALR* (1,

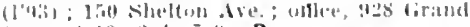

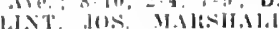

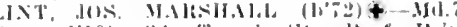

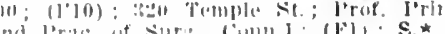

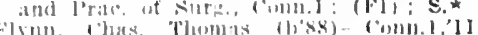

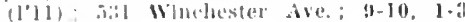
1.: : L D

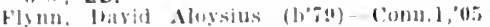
(1'th) :

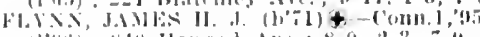

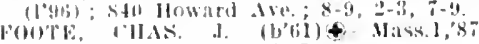

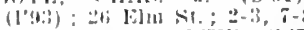

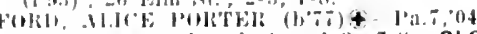

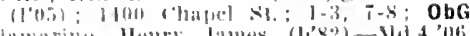

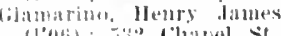

(17)

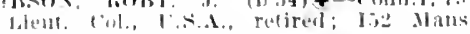
Hiche st

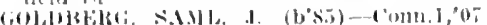

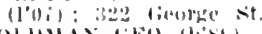

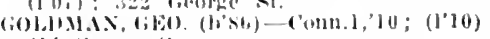
:\$14 liecorge st.

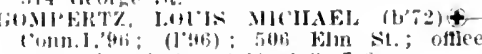

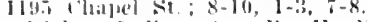

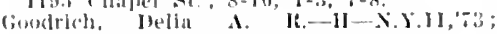

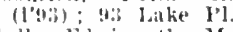

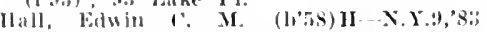

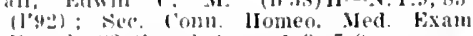

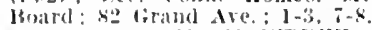

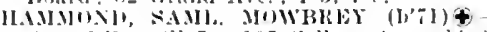

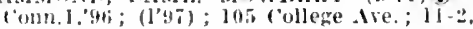
i-R; ALR.

Harris, lus. kdwards $\left(b^{3} 90\right)$-Conn.1,12 ; (1'12): 24 York si

Harrlson, Russ tiranville (b'70)-Ger.2,99; not in practice; 142 Huntington st. oflce, Vale liniversity; (F1).

Itarten, dames dloyslus (b'si)-mIdl.4,10;

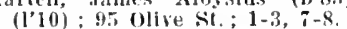

MAITSHOKN, MULAS ELAL (b'-2) $4-$ Minn.4,9s; (l'02): 1138 (hapel st.; $11-1: 30,7-8 ; \mathbf{S}$.

HaWkes, "WM. WHITAE (b'5i) \& 33 II 3 igh $; 9-10,2-3$

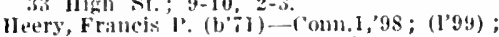
IIs Edwards st.; $8-10,1-3$, i-9.

Hendricks, Allert l. (b's0)-Conn. $1,0 \pi$ : (108); 24; Trumbull st.; $9-11, i-8$.

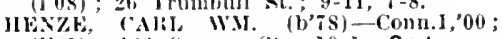

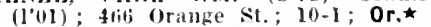

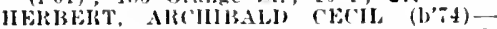
Va.4,04; (1'05); Hotel Taft; $9-10,12-3$, $6-8$

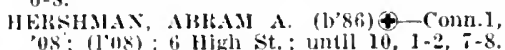
11 ESELEI, IIETMAX PIIILIP (b'79)Comn.1, $03 ;\left(1{ }^{\prime} 03\right) ; 323$ George St. mlldebrand, w. 1 r $\rightarrow$; $\left(1^{\prime} 93\right)$; i02 Howard Ive.

IIIrata, Isao (b'8z) - Conn.1,'12; (1'13); New Iaven Hospital

Howland, C'has. II. (b'51) H-Conn.I, 80 ; (195); 254 Ldgewood Are.; $8-9,1-3,7-8$. Hugo, John tieo. ( $\left.b^{\prime} 80\right)$-Md.3,03; (1'04) 5ist Perry st.

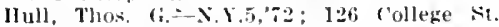
HYXES, THOS. NACENT (b'73)-COnn.1, 00; (1'01); 144] (hajel st.; 1-2; ObG.

Irwin, Vincent los., Jr. (h'si)-Conn.1,09; (lii).

Jekowit\%, diabriel .1. (b'83)_-Mass.5,07;

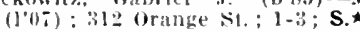

ames, lieo. Kielhard (b'85) - Conn.1,'10 (1'10) : 686 state st.

Jones, Bitnl. Alltion- - comn.1,92; (1'9:3) : (Dentist); 629 (hapel st.

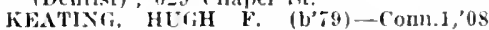
(1.08): 619 Howard Ave.; untl] 10, $1-3$ (i) 0 (0)-

Kelly, John Derin (b'46)-...Y...,80; (1'93) 139 Canal st.

SIEKNAX, EDW.ARD CHAS. (b's3)-Conn.1, "09: (1'09); 3 is whalley Ave.; 8-10, 1-2,

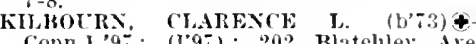
Conn.1.9-; (195); 202 Blatehley Are.

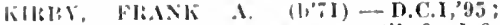
(1'an);

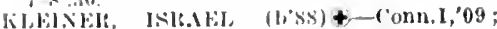
(I'I): la: laswrence si.; oftee, 19 ?

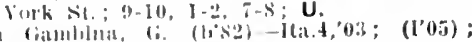
fiks IJwand Ave, ; $i=4,1-3, i-4$

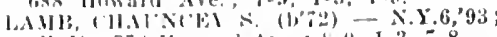

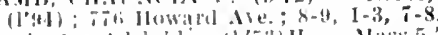

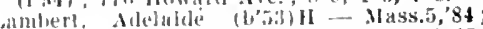
(1':6), sti liroadway ; 9-10, $1: 30-3,6: 45-$ (1.).

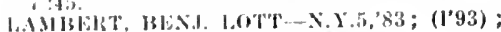
ins lluward Are. 11 :330-2, 6j-8,

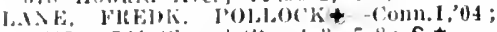

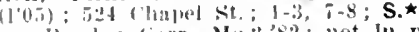

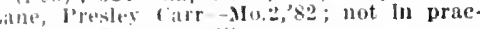
tice; 36 ir irange st.

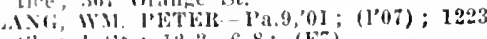
ionel st.; 12-2, 6-8; (Fi)

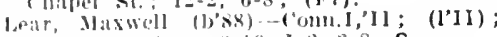
-slran Ave; 8-10, 1-3, b-8; S.

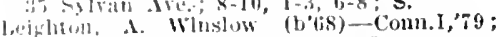
(1446) ; 21.5 Youth st. ; $19-2$, fi-8.

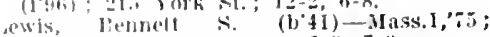
(10.3); 7 : lloward Ave.: 1 -3, $7-8$.

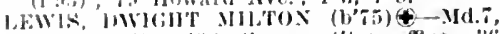
(1)1: (1'04); 438 reorge st.; offlee, 36

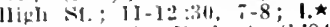

Limatre. Lonis Ilerlert $(1,84)$-Nd 1,06 .

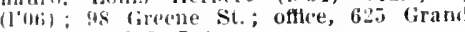
Ire. : $-1,1-3,-7-8$.

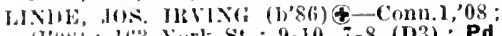
(1) lourk St. ; 9-10, i-8 (D3) ; Pd.

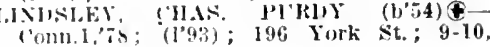
Cont.1, is ; (1393); 196 York st.; 9-10, Lines, jairus r. jo: Newlatl st.

Linguist, Maurice $F_{\text {. }}\left(\mathrm{b}^{\prime 69)}-\mathrm{N} . Y .9,91\right.$; $( \pm) ;$ i:g Whalley die., $2-4,7-8$.

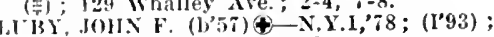
Ioll (hapel st.; $1-3$, in

LTIIXITOS, NHLSON A. (b79)-Conn.1, ,11; (11)3); 1252 ("hapel st.; $1-3,7-8$; $\mathrm{s} \star$

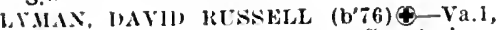
9!) : (1'04): (6;iylord Farm Sanatorium, Willing fordi): oftice, 42 Hlgh St.; 2-4.

WON, TIEA $W$ W (b'81) \&-Conn.1,03 (1'04) ; 193 York st. ; 8-10, I-3, $7-8$.

Wagill, Aulrey lawrence (b'i5)-ont.5, 08 ; (l'10); 68 Dixwell Are.

vahin, John looddy (1r'71)-N.Y.3,'94; (1'95); $11 \mathrm{t}$ Brownell st.

HAIIK, lAYES $\mathrm{s}$ (b'-2) - Conn.1,'96: (1'96): 26il orange st.; $2-5,7-8$.

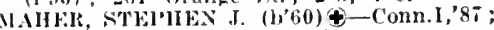
(1'43); 212 Orange $s$ t. ; $2-4$

Maher, Thos. Franeis (b'T 8 )-Conn.1, 01 (1'03) ; 705 bixwell Are.; untll 10, 2-4, $7-9)$

MAIHOCSE, MAX (bot) $₫$ Conn.1,78; (1'93) ; 45 Elm st.; 9-11, $7-8$, Clin. Prof

Neur.. Conn.1; (mi)

IIAKIANI, NICOLA (b'68)€-Ita.10,93: (107) 119 (ireen St.

IARSH, ARTHI:I WM. (b'5i)-Vt.2,82 $\left(1^{\prime}: 3\right) ; 1015$ Wharley Ave.; 8-9, 12-2 6-8; $\mathbf{0 b}$.

MeCABE, EDWARD MICHAEL (b'63) (Conn.1, 87 ; (1'93); 278 Orange St. ; 9-12

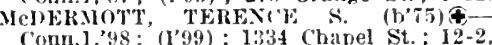
6.8; $\mathbf{P r}$

MeDONNELL, KALPH AYGLSTINE (b'68) †-Conn.1,92; (I'93) ; 1142 Chapel St.
$10-2,7-8 ;$ Clin. Prof. Derm., Conn.1; D.

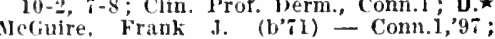
$\left(1^{\prime} 9\right) ; 18$ Elm St. ; $1-3,7-9$.

ICritiRE, WM. C. (b'8 i)-Conn.I,09; (1'04); 106 Park st.; 9-10, I-3, T-8; Pd. $\star$

MeINTOSH, EDWARD FRANCIS (b'60) -('onn.l, 15 ; (l'9i) ; 192 York St.; 8-9. CMaster, Gibert Totten (b'i3)-Pa.2,'98; (l':8); 42 Trumbull st. ; $7-9$; S.*

INXEIL, ROLLIN (b'3i) $4-$ Conn.1, 62 ; (1'43); 149 1radley St. ; 8-9, $i-8$.

Hellorne, Joln W. (b'56)-Pa.9,86; (1'93); 67 IIouston St.

Iendillo. Anthony Jos. (1,86)-Conn.1, 07 (1'07); 86 Canal St.; office, 18 Eim St. ;

Verrill, IIarry Palmer (b'8i) - Ill.1,'13 Intern, Xew Haven IIospital. 
Jllburn, Jolun |blekinsen (b'sl)-Il| 4, 10

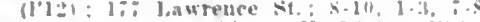

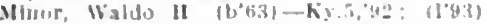
(bentist): 2il tirange st.

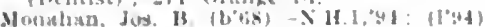

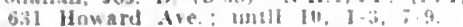

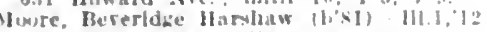
Inters, New Ilarem Ihospltal.

MOLLTOS, EDW. (1'9i) 237 lork $51.2-2$,

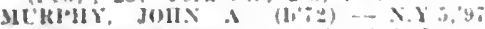

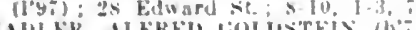

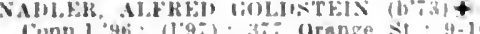
$1-3,6: 30-5 \div 60 ;($ ( 11$) ; 0$.

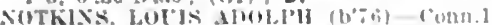

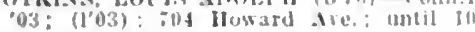
$1-3:-8: N$

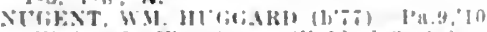

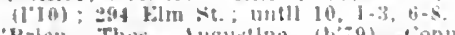

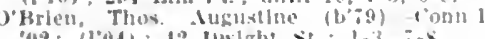

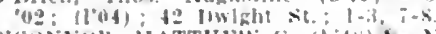

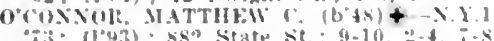

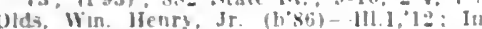
tern. New Haven 11 uspltilt

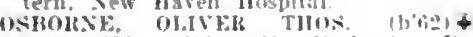
fonn.1,8t: 11.93$)$ : at: lork st, : l'sof fonn.1,84: 11 '93)

Ther., Cumn. Kirk (1'š) - (onn.1,1"

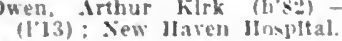

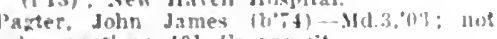
in practlce: 401 lieurze st.

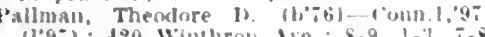

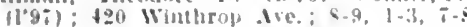

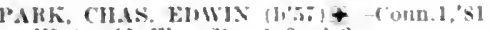

(1'9:4) : 42 kilm st. : 1-3, 6.

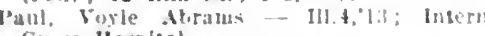
Grave liospltal.

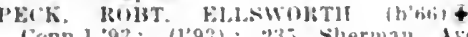
offce, 62 Hark st, $9-11 ; \mathbf{N}$

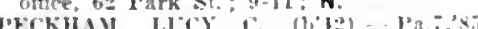

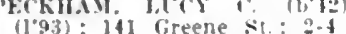

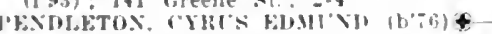
Conn 1,03; (104); 244 firam Ale.: $\overline{7}-9$ $1 \cdot 3,6.5$

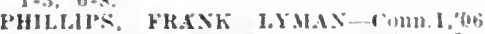
$\left(1 \circ n_{6}\right): 113$ Temple st: $1-3: 20,7-6: G$

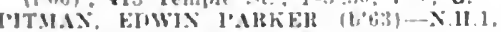
(9]: $(1 \cdot 93) ; 52$ sylinn Ire, : 8.9:30, 1-3, 6. $8:$ G.

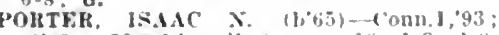

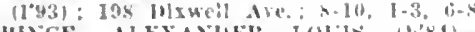

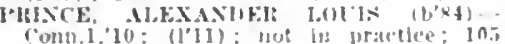
kikewind ive.

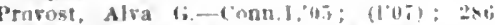

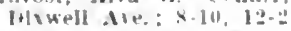

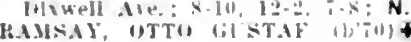

(1) 90; (1'00): 251 (hurch s1, ; 11-1: lrof obut. and (a) th., roms.l:

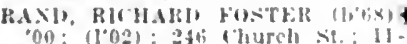

Rawling, (has (bost) $11-0 ;(104) ; 3+1$ How ard ive. 9-10, $1-4,6-k$

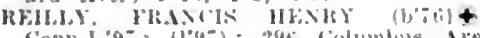

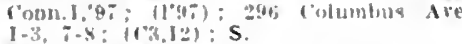

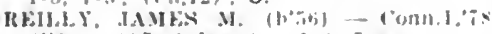

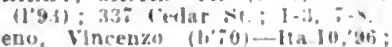

Heno, Vincenzo

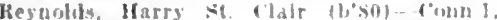

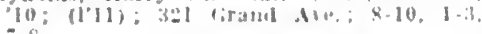

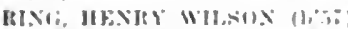

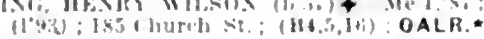

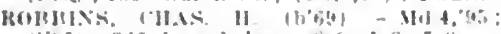

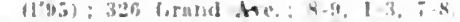

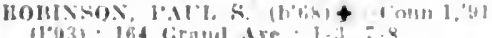

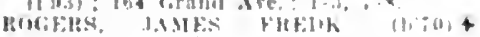

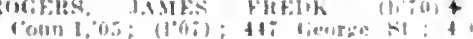
i-Q

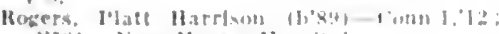

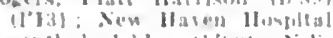

leosenthal, Inlulor $11,4 x)$ y lis,

Intern, Xien Hawn IInsulen!

Rulekrolut rharles irturar

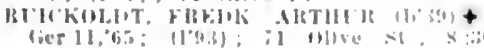
$9: 30,2.3,-3$

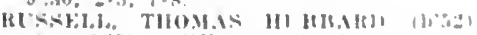
Iunn.1.

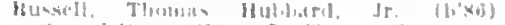

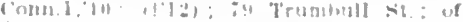

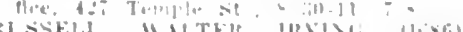

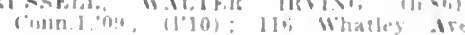

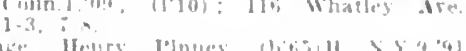

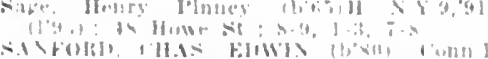

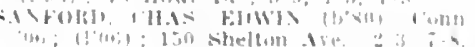

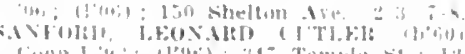

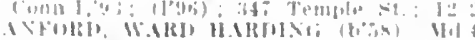

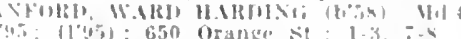

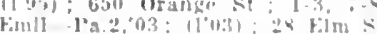

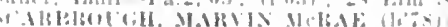

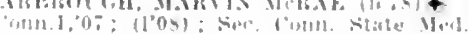
- IV llall si: 12."

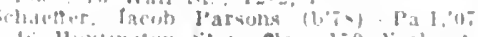

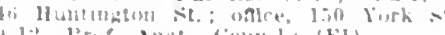

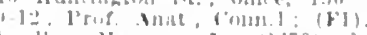

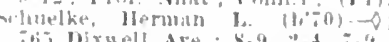

iti Dixwell Aro : 8 -9:

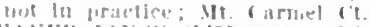

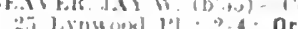

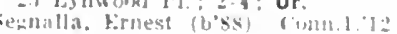

int iliajul is.

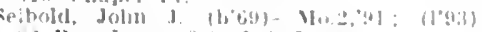

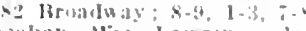

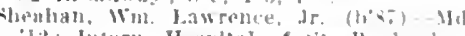

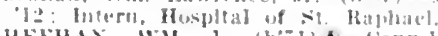

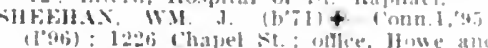

1 hapel sia. : 2-4. :-s: $S$.

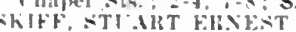

$40: 3: 4903\}$

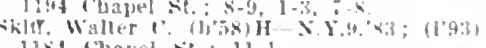

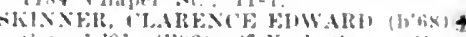

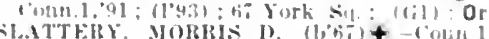

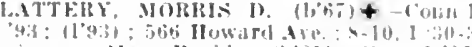

mirnow: Max laiskln (b'81)-('onn.1, on

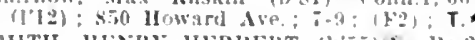

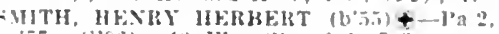

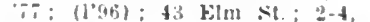

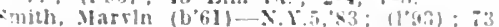

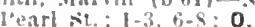

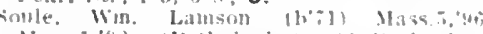

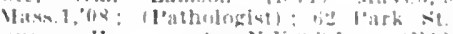

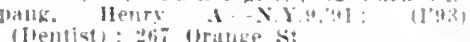

(1)

(u) (allere si: 10.

(Bi:) : ALR *

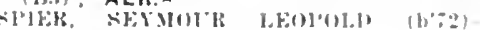

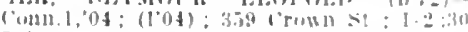

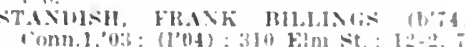

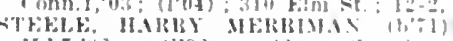

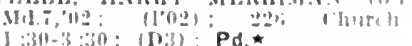

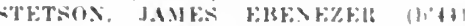

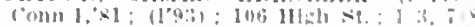

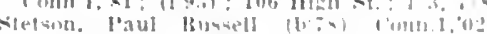

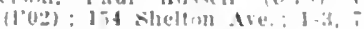

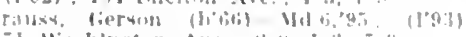

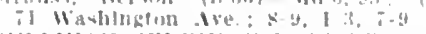

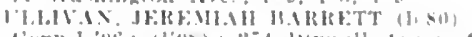

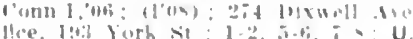

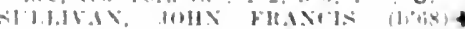

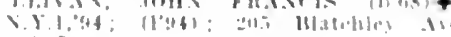

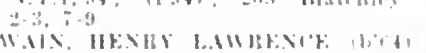

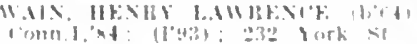

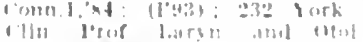

1 $11: 1$; OALR.

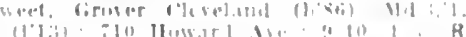

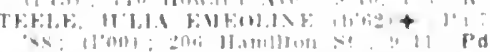

Thombs Mle

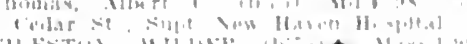

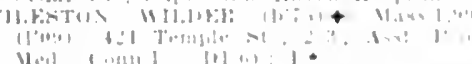

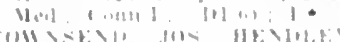

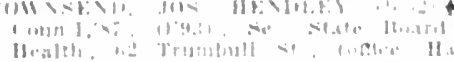

furt

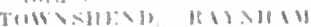

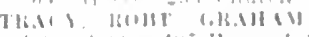

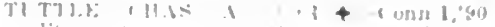
11: 1. 1.1\%,

thlon, crats

$11^{*} y$

II alker, Hitisit

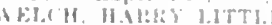

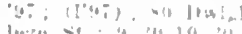

is rildil it vi

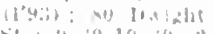

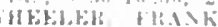

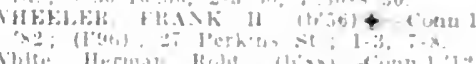

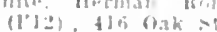

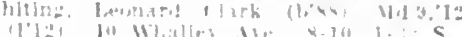

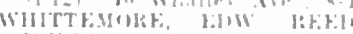

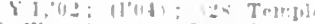

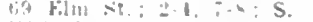

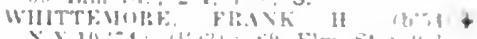

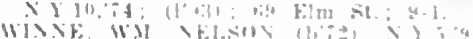

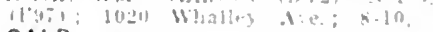
OALR.

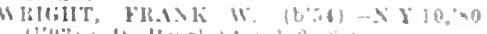

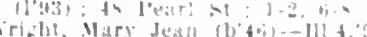
HRTENHKR, WM GHAKLE (ung. low

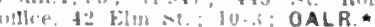

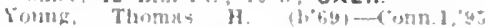

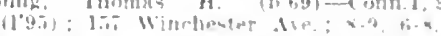

NEW LONDON, 19.659, NEW LONDON

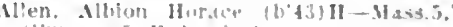

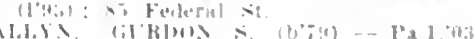

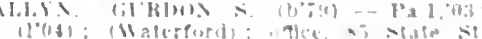

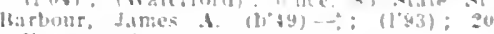
He misieall it

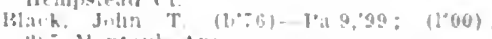

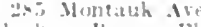

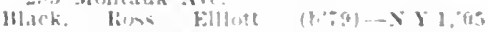

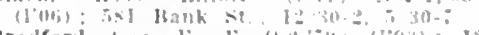

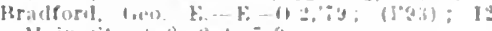

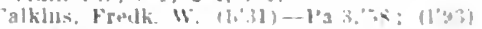
in inger Iי

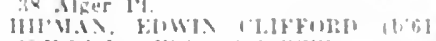

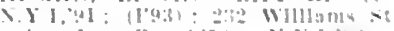

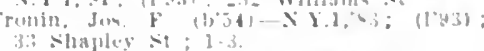

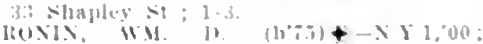

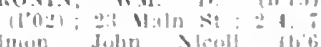

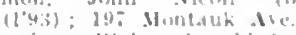

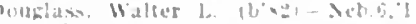

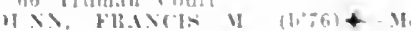

$+210.110 .0$

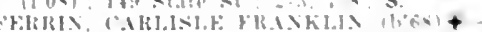

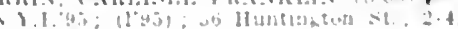
$7 \mathrm{Pd}$.

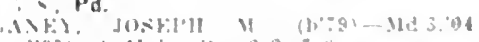

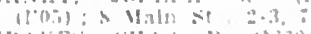

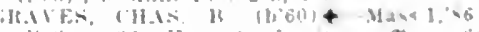

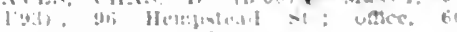

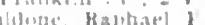

$(4+10,79,(194) ;=1$ St: it 1 i

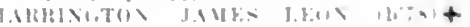
$1,: 1,20,3 ; 1 ! 0,3)$

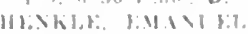

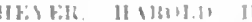

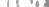

1.ang in

111 311

$1+1.11$ 11:It?

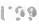

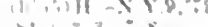

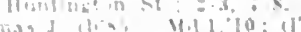

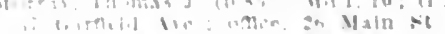

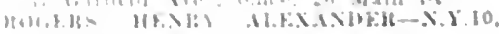




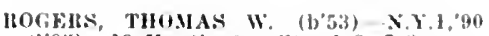
(1.93); 19 Ilumtlugton st: $1-3, i-8$. shlpman, loander K. (b'53) H-N.4.,83, (l'93) : 160 Ilempstead st: $\times-9,2-1$.

soltz, Thomas (b'84)-1'a.2,'I1;

8, state st.

sixTON JoHN (iHMAN (b' 18$)+$ Juntington st: a-4. -8

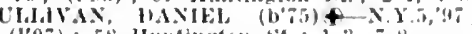
(1'97): 5 s Huntiugton st.;

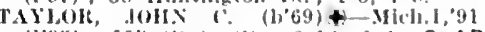

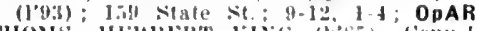

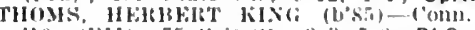
10; (11) ; 7? ("ole st.; $2-3,7-8 ; 0$ bG Willans, (art Nlonzo (1)'-2)- - 9.95 (199): 77 Vauxhall sit. ontce. State and Main sts. : $2-4-8 ;(F) ; 1$.

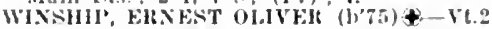
ous: $(1,00)$ : State st. : oftlee, Mnuwitring Hldg: : 9-4: OALR.

\section{NEW MILFORD, 5,0I0, LITCHFIELD}

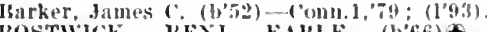

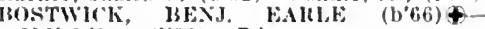
X. $.8 .90 ;\left(1^{\prime} 93\right) ; P d$.

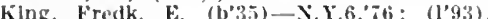

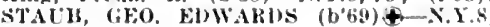
$93:\left(1{ }^{\prime} 93\right)$

WhtGHT, GEO. If. (b'6s)\$-N.Y.I, 94 (I'Y4); OpA.

NEW PRESTON, 300, LITCHFIELD

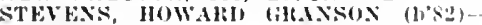

Mal. 4,04; (1'04).

NEWTOWN, 434, FAIRFIELD

iale. Frank J. (b'70) II -..Y. Y.9, 96 ; (1'03) kennedy, Wm. Clement (b's)-b.'.2.11, (l'tz).

NIANTIC, I,100, NEW LONDON

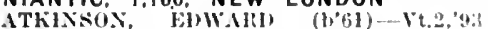
Thiss

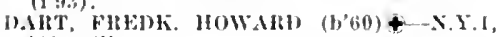
int; $\left(1,0: 0^{*}\right)$

Warner, Everett S. -N.Y.1, Ts; not in jrat tlce.

NOANK, 1,200, NEW LONDON

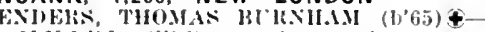
N.Y.1,6]; (1'a6); not in practle

IHLL, W.M. M. (b'6s)-Va.I, 97 (1'97)

Sherman, Ihenry 1.-La.2.88; (193).

NORFOLK, 1.541 , LITCHFIELD

H.M.INT, IHVING J,OL'IS (b'tit)-N.Y.8 ?10: (1":13).

Iohnson, lieo. Inwight (1)8Z)-Md.9.'13; (c)

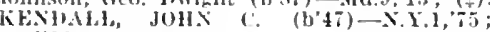
(1'93).

l'INEY, ALMON W. (b'79)-l'a.9,00 (l'01).

NOROTON HEIGHTS, 300, FAIRFIELD

IfOT'SE, ALHEIT LEWIS (b'6S)-('onn.1. $95 ;(1,95)$

HOYT, HAIOOLD FIIIIAMET (b'78)X.Y.3,04: (1'06); Surg. Soldlers' llome. Stilphen, liarry' I. '(b'83)-Vt.2,'13; (1'II). NORTH GROSVENOR DALE, 2,300, WIND. HAM

Chaguon, Jos. Simml. (b'58)-Out.4,'s: ; (l'93).

Roch, Emilien (b'64)-Ont.4, 40 ; (1'4:3).

Willians, Geo. W. H.-O; (l'y)

NORTH GUILFORD (R.F.D.. GUILFORD), 500, NEW HAVEN

uot in practlce.

NORTH HAVEN, 2,254, NEW HAVEN

GOOLYEAT, IIOB'T. BE.LITSLEY (b.'3.) Conn.1,68; (1'93).

IIfitiss, Gollid SHELTON (h'75)Comn.1,01 ; (l'01).

NORTH STONINGTON, I,I00, NEW LON-

HARRANGTON, ROB'T. E.ARL.4-Md.4, $\theta 6$; $\left(l^{\prime} 06\right)$.

Maine, Thurman Park (b'ss)-Pa.11,12; (1'12)

NORTH WOODBURY, 400, LITCHFIELD

Karmann, H. S. (b'56)-X.Y,5, ;6; (l'94)

NORWALK, 6,954, FAIRFIELD

Baldwin. I. H, (b'54) H-lll.4,8I : (l'93).

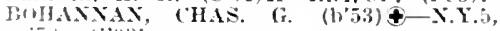

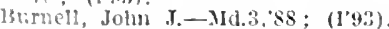

Rumel, Wm. Jarry (b'sI)-D.C.1, 06 ;

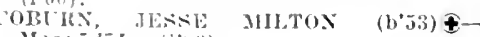
Masti, , I; $(10,0)$ lobson, Jus-X.Y.16,'80; (1'93)

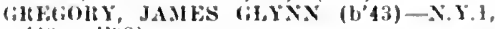

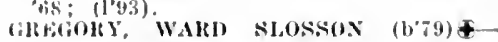
X. 1.0. : (J'05)

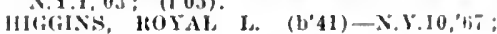
(1'93)

Hitcheock, Dexter (b'4.7)H - X.Y.9,7:3; (1"93)

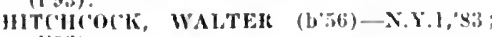
$\left(l^{\prime} 93\right)$

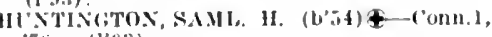
onti: (1'43).

smlth, Folwin fiverett (1,41)-N.Y.8,7l:

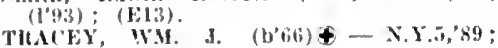

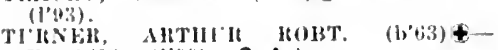
Fratio,94; (l'0(0); OnA.

West, iliram Is. (b', NORWICH, 20,367. NEW LONDON

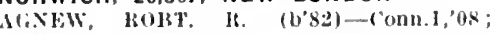
(l'os).

Alten. Jomahan H. $(4058)-$ X.Y.9.'s8; $(1,9 ;)$; iti ('hurel st. : $8-10,2-4,7-8$

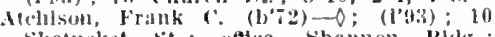
Shetucket st.; oftce, shannon Blily.; $2-4, \quad 7-4)$

Herry, derome prancls (b'46)-V1.2, I3; William W. Backus Jospltal.

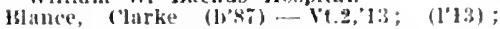
William W. Jsackus Ilospltal.

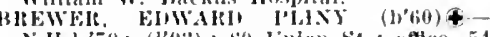
N. H.1,79; (193): S9 lnion st.: offlce, Broaldway ; $10: 30-12,2: 30-4 ;$ OALR.

Hrlugman, Mark s.. (b's6)-1'al, '11; (1'12) Forwlch state lfospltal.

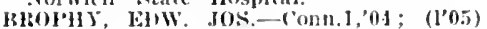
88 Central Ave, ; $2-3,7-8$.

HHOWXE, WH. TYLFle (1).5(i)-Mass.1, 's2: (1'93); 255 Broadway; $10-4,6-8$ (ii); $\mathbf{R}$.

('allalian, John W. (b'8s) - IId.3,'11; (1'11); 314 Main St.

'amphell, Hugh Ifaird (b'8.i)-I'a.1, 09 ; (l'l2); State Sanitarium

case Edwin W. -0 ; (1'43) ; K.F.D. 6.

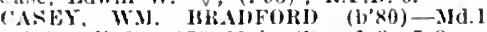
06; $\left(10^{\prime} 06\right) ; 279$ Main st. $1-3,7-8$.

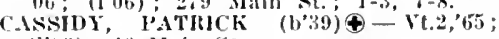
(1'43) : 46 Min st

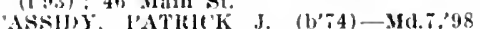
(l'ts): 4 (hurch st.; ofthe, 161 if ain St. $2-4,7-8 ; 5$.

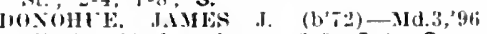
$\left(1 \cdot 96^{i}\right) ; 43$ Broadway; $2-3,7-3 ; \mathbf{S}$

mohue, John Daniel (1,xis)-ifd.4,0y: Intern, Grand Vlew Sinitarium.

Iboluce, John fames (b'58)-Md.4,0s superintendent, frand View sanitarimm.

miscoll, Wm. T.-Md.3,12; (1'12); $: 327$ Main st. ; offce, Alice Ibidg.; 9-10, 2-4, $i-8$

Erdinin, Thomas F. (b's3)-Pa.9,'07 (los); Norwidh Hospital for Insane.

Frans, John Harry (b'T) - N.Y.1, (0) (1'0:).

Faunce, (hristiani 1. (b'42)-N.Y.14,'so (1'43); 11 Williams st.; 10-12.

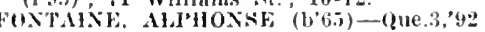
(1'9:3).

Freman, Albert Clarke $\left(b^{\prime}, 84\right)-V+2, ' l 3$; Intern, William W. Backus Ilospital.

(IIDDERSLEEVE, CHAS. ('IILI) (b'66) -1'0nn.1,'96; (1'97); 287 Lain st. $1-3: 30, \bar{i}-8$

Harper, Frances' .J. (1).59)-Cia.1,99; (1'00) 29 Boswell Are.; office, lol Maln St. $1-3, \overline{7}-9$

IIGGINs, IAHRY EIGENE (b'-2)$10,2-4$.

lones, banl. 1-X.Y.9, 'st: (1'93) : W. Iftin

KIMBALI. RUSII W. (b h2) —-X.Y.8, 90 (1'93); 167 Broadway; office, 21 Irroad way ; $2-4, \quad i-8 ; \mathrm{S}$.

LaPlerre, Arnaud Julian (b'85)-Vt.2,'10 (1'11) ; 287 Main si

LA I'IERRE, IEONE F. (b'76)-comn, 01; (1'01) ; 287 Main st.; $2-4,6-s$.

Lewis, Napoleon B. (b'69)-0.2,'94; (1'94);

341 Main St.; $1-3,6-8$

Linnell. Edward Ji. (b'53)II-N.5.9, Th (193); 171 Broadivay office, 43 Broald way; 10-12, 4-5: OALR.

Lovell, Fredk. Henry (b'61)-H1.4,'09; (l'10); Norwich State Hospital; NP.

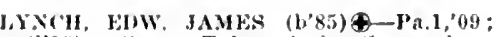
(1'09): State Tuberculosls sanatorlum. Manwarlug, fer Jay (b'72)-I'a.7,95; (1’95); 58 Ifroadway; $2-4$.

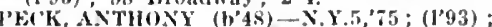
4 Silcliem 'Perrace: offlee, 13 Broadway $9: 30-4: 30:$ OALR *

ledrlck, Franklfu Jurche (b'86) - \$.Y.9. $133:(1,13)$; Sorwich IIospital for the Insine

l'klkis, (HAк. H. (1)'64)-N.Y.1,92 (1'4:3); ;o broad st.; offlce, 10 she(waket st. : 10)-12, 2-4; Op.

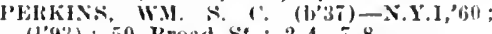
(1'93) ; 50 Broad St. ; $2-4,7-8$

Pollock, Jlenry M. (b'75)-Minn.6,97; (1'04) ; Norwich Hospltal for Insane; (filis). Purmort, Jennie (i. (b'76)-Nass.5, 01 (l'0s); Slate Hospltal.

luinn, James It. (b'90)-Md.9,'13; Jorwicl Hosiltal for the Insane.

HAHAN, HENNis J. (b'60)-Vt.2,85; (1'93): 317 IIa!n st. : $2-3: 30,7-8$.

SIITH, NEWTON PHIXEAS (b'52)-X.Y. '82; (1'93); 25 I'ark St.; 12-2.

couler, chas. Fletwer (b'6;) H-Pa.9,"4: (1'13) : State Hospltal for Insane.

stark, illnton E. (b's4)II-N.Y.9,'-8 $\left(l^{\prime}+3\right)$; 37 Slater Ave. : offlce, 49 Broadway : $8: 30-9): 30,2-4,7-8$

Tarbox, Luclte A. James-Mass.5, T5; (l':T) 33 Grove st. : $2-4$.

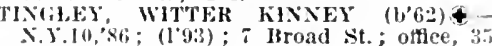
Iain $s t . ; 2-4: 30 ; \mathrm{s}$

Walker, lester F. (b'72)H-N.Y.9, 98

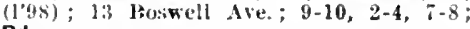
Pd.

Woodward, Esther sulia Harnard (b'-4) Mass.5,00; (l'13); Xorwlch State Hosriltal; NP.*

OAKVILLE, 900, LITCHFIELD

aade, Carl Johannes (b'8.5)-Comn.],'lo: ( 1 '10).

OLD MYSTIC, 800, NEW LONDON

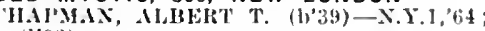
(1'93).

PLAINFIELD, 6.719 , WINDHAM

JIASE, AlTTIC'K ALVERDO (b'79) $\$-$

Mass.1,01; (l'02).

PLAINVILLE, 2,882, HARTFORD

STL1, JOHN NolkHS (b'5i)-N.Y.1,78; (1'9.3).

Frost, Lawrence Hubbard (b'89)-Vt.2,'13; (l'13)

Moody, ('has. W. (1,5i)H-N.Y.9,84 (l'93).

PLANTSVILLE, I,985, HARTFORD

Kelley, ('has. (b'59) E-N.Y.13,'83; (1'33)

POMFRET, 1,857, WINDHAM

Llcht, Wm. Henry (b'82)-Mld. ',11; (1) SERLOCK, SELDOH

POMFRET CENTER, 621, WINDHAM

Hanchet, Henry G. (b'53)-N.Y.9,'S4; hot in practice; R.F.D.

POQUONOCK, 1,060, HARTFORD

Callender, 'has, II.-X.Y.3,'89; (l'93).

PORTLAND, 3,425, MIDDLESEX

(JEIDEL, CHAS. BRIGHAII (b'80)

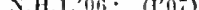

J'TTER, FRAXK FWWARD (b'54)-XY.L, s. $(1,93)$

F.NRS, 'L'SIMHAN A. (b'40)-X.Y.5,'62: (1'93)

SEARS, WALTER C. (1,68)-Vt.2,99; not il practlce.

PUTNAM, 7,280, WINDHAM

BLLLARI, MARGLERITE JANE (b'-8) -N.Y.20,04; $\left(10^{\circ} 04\right)$

$69:$ : $10 \% 3)$

LA RUE, OMER (b'49)-Ont.4,72; (l'93)

LOWE, IIFARY KLSSELL (b'49)-N.H.Y. $83 ;(1$ ' 93$)$.

Morasse, Louis Oride (b'60)-Ont.4,'84;

MORREL, FREDK. A. (b'5\%) $\mathbf{E - N . Y . 8 , ~}$

'85; (l'93). Iurphy, liernard

r'eckham, Katherine F.-Fa.t,'s9; not in

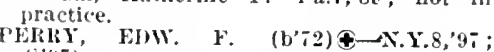
$\left(i^{\prime}(i)\right.$

Russell, John J. (b'65)-X.Y.9,'87; (l'93). 
REDOING, 1.617. FAIRFIELD

SMITI, ERNEST IIKMMN (b'63)-X Y I $89:(1293)$

REDDING RIDGE, 240, FAIRFIELD

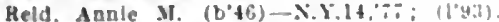

RIDGEFIELD, 1,114, FAIRFIELD

AJLKE. WM, HANF(JH), JR. (b"T2)X.1.1,99: (1'03).

Allen, Henry Willard (b'7i)-ba.11,0s (1)09).

BRION, HEXY AIILLMFR-O: (I'43).

(7urchlil, John Lenty-Mass 1,$60 ;$ (

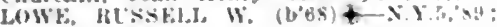
$(193)$

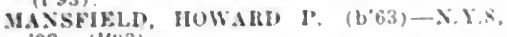
"93: (l'43).

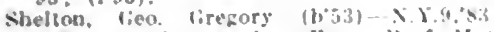
(l'yi); not in practlee; Homer. Heof. Mat Med. XY. $\mathrm{Y}, \mathrm{y}$.

RIVERSIDE, 310, FAIRFIELD

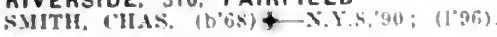

ROCKVILLE, 7,977, TOLLAND

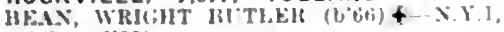
"95: (1'9.5)

braude, saml. Henty (bose)-..mul, lis

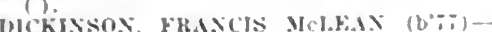
V.X.1.,05; (1003)

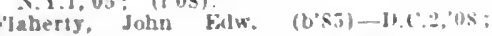
(J'09).

FIST, ELI PELCIVA, (b49) \&-COMnI, $\because 9:(103)$

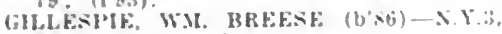
09 : 111.15, 13: (1'11)

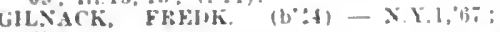
$(1 \cdot 9.3)$.

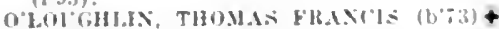

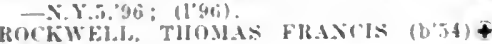
- XY. Y. S1: 11931 .

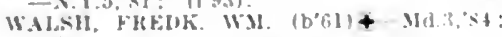
$(1,03)$

ROCKYHILL. I,187, HARTFORD

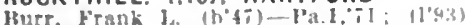

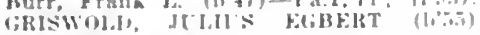

‥ Y.T,

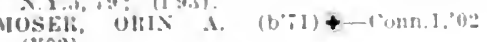
(l' $(2)$ ).

ROXBURY, 200, LITCHFIELD

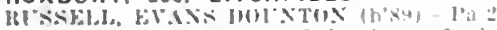
11: $(103)$ : Member Merl. She of the sitate of l'a.; $(F)$ (F); OD.

SALISBURY, 1,000, LITCHFIELD

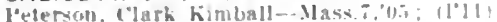

SAUGATUCK. 875, FAIRFIELD

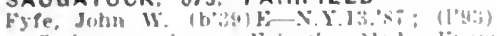

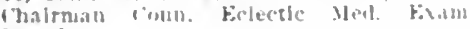
lhiard.

SAYBROOK, 1,907, MIDDLESEX

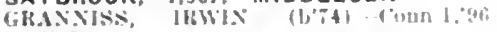
(1.9:).

SEYMOUR, 4,786, NEW HAVEN

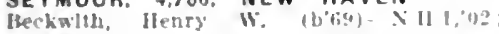

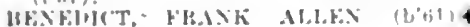

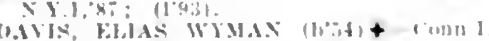

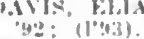

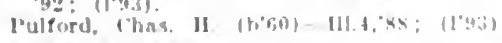

SHARON, 1,880. LITCHFIELD

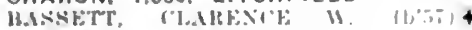

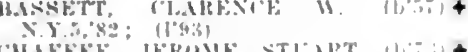

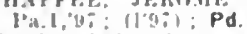

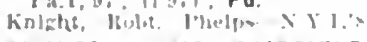

SHELTON, \$.807, FAIRFIELD

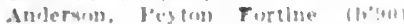

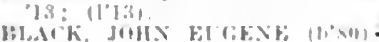

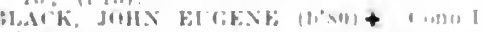
ink: 110,0

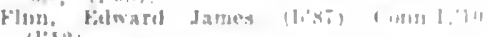
(I"I:

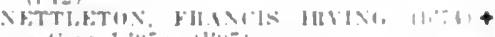

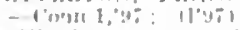

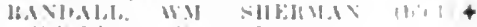

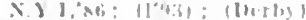

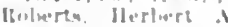

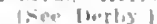

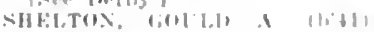

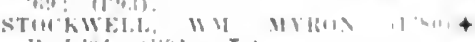

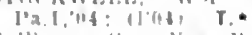

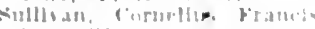

$1:: 11,1: 3)$
SIMSBURY, 2,537, HARTFORD

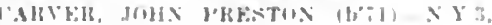

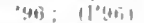

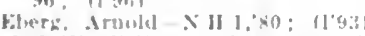

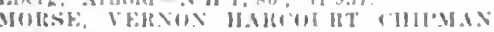

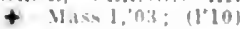

SOMERS, 1,633, TOLLAND

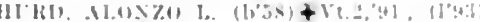

SOUND BEACH. 800 , FAIRFIELD

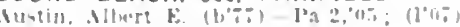

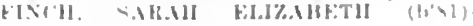

(1):21).'11: (1'04)

SOUTH CANTERBURY. 88. WINOHAM

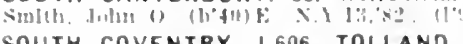

SOUTH COVENTRY. 1,606, TOLLAND

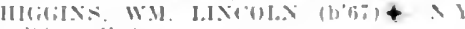

SOUTH GLASTONBURY, 1.205. HART

FORD

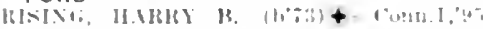

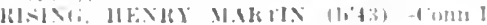

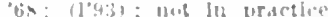

SOUTHINGTON, 3,714, HARTFORD

("uslung. Wm. H. (b")

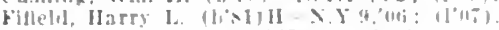

(ilwire, fhas, Henry (b"ais) Mals,ot; nut

pracicice

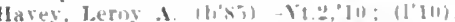

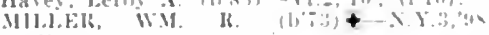
(l'(ini)

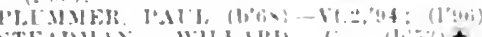
STEADMAN WIJHALII

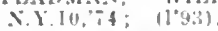

SOUTH MANCHESTER, 8.000, HARTFORD

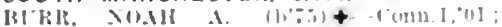
(I'il)

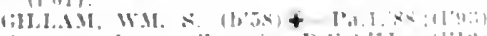

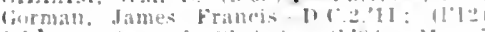

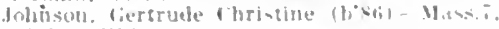
II: (I')

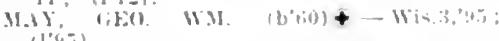

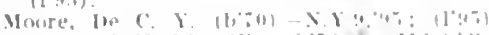

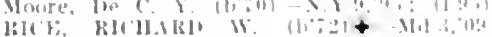

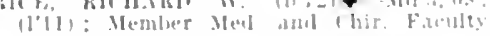
if $M$.

sion.

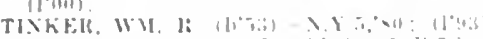

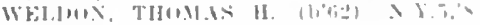

SOUTH MERIDEN, F00, NEW HAVEN

Murlarty Tharlute Varie TY.1\%,

$\left.11^{\circ}, 1\right)$

SOUTH NORWALK. 8,968, FAIRFIELD

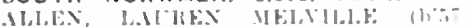

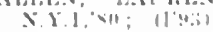

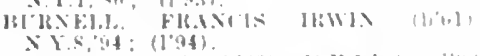

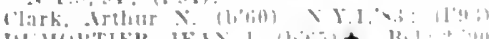

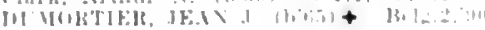

(1) 104$):$ S.

Week, lames Mllert

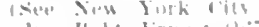

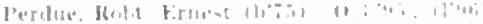

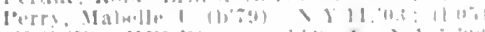

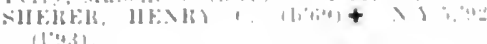

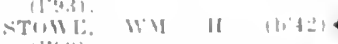

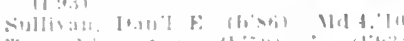

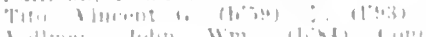

1.

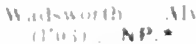

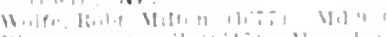

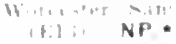

SOUTHPORT, I 499 FAIRIIELO

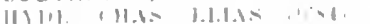

SOUTH WINDSOH. 2.251. HARTIOKI

SPRA GUE

SPRARUUE
LONDON

IIT 1:\% I III-

STAFFOHD SPRINGS 3.039. TOLLANI

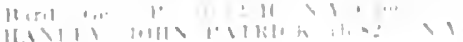

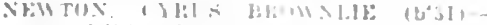

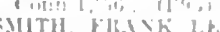

$1{ }^{2+4,3)}$

TIRETI

11'i1)

STAMFORD, 28,836, FAIRFIELD

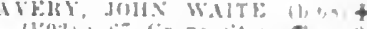

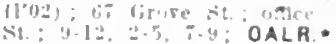

Whes. WIxtris.

isea siw liork tity

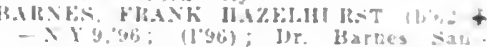
lartum: NP.

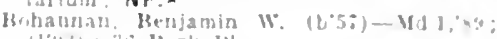

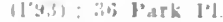

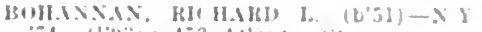
ti. Allamic st

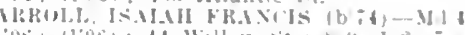

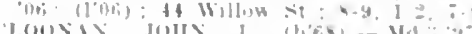

II,

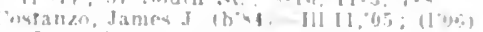

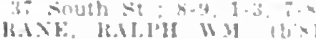

(100\% lo

(19.4) 10: suluth st

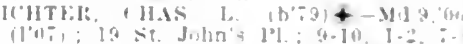

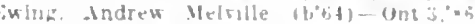

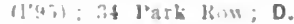

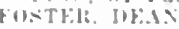

15ee vew link ( in )

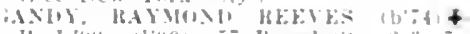

ob.

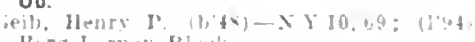

Hetp-bentury Bineth

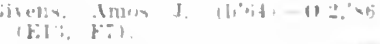

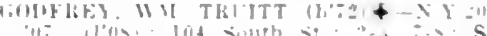

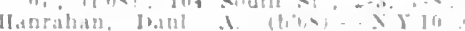

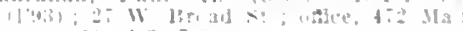

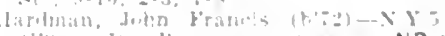

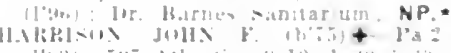

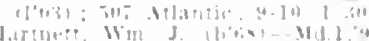

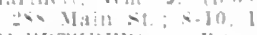

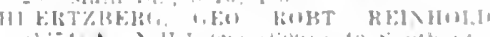

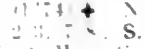

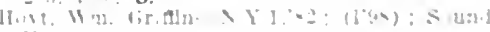

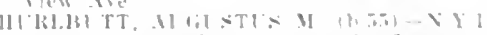

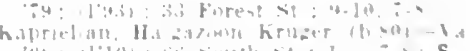

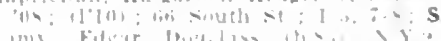

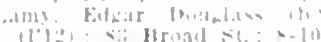

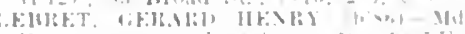

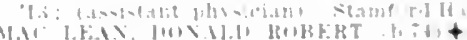

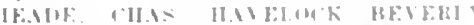

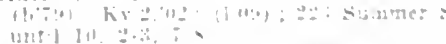

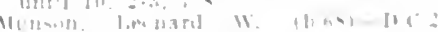

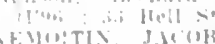

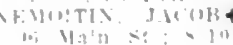

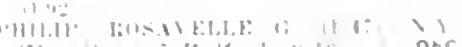

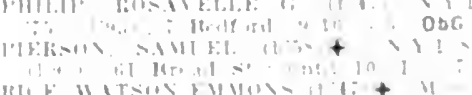

HeF

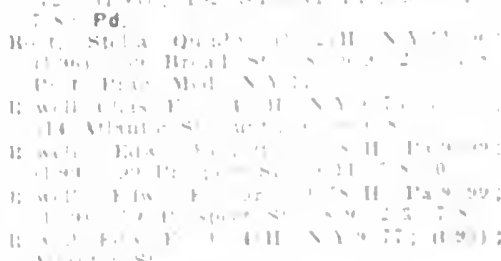

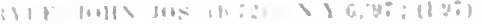




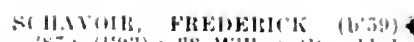

scor

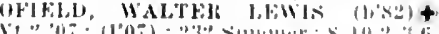
SHERBili. rito. $\left(b^{\prime}\left(b_{1}\right)+\right.$ N11,01

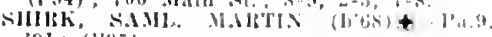
91: (1'05).

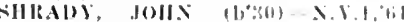

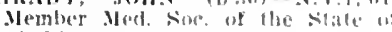

38 l'leilant st

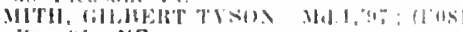
1111 :1: NP.

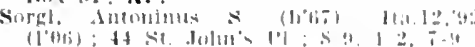

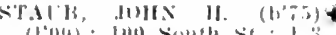

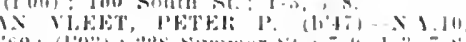

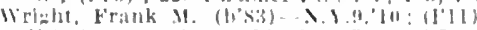
STEPNEY (R.F.D. STEPNEY DEPOT 163, FAIRFIELD

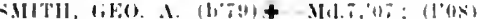
STONINGTON, 9.154, NEW LONOON

\section{(Illlard, $11 \mathrm{~m}, \mathrm{i}$}

(Nee Westerli: R. I)

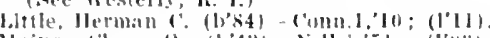

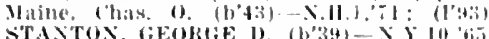
$\therefore$ TAST

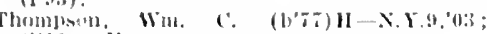
$(1 \cdot 10): \mathbf{N}$

Thurber, Herbert Tallman $\rightarrow$ : (l'nol.

STONY CREEK, 1,200, NEW HAYEN

LAIITTOS, FRANKLIN I.

(sce ilariford.)

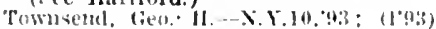

STRATFORD, 5.712, FAIRFIELD

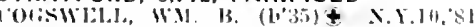
(193)

HOWIAND. De RTYTER +-N.Y. 06 (1'06): Pd.

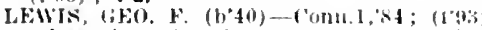
starkweather, rrank C. (b'ab)-1'all, si (I'):3).

SUFFIELD, 3,84I, HARTFORD

(ALWWELl, WM. E. (b'bi) $€$ Ill.4,94;

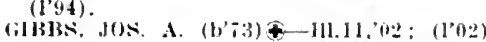

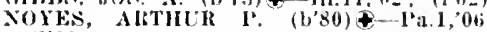
(1'10).

TAFTVILLE, 3,900, NEW LONDON

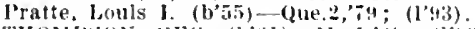

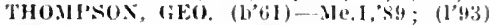

TARIFFVILLE, 690, HARTFORD

IIunson, Wm. H.-M(1.6,'92; (I'93)

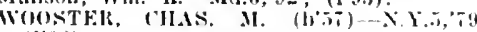
(193).

TERRYVILLE, 3,000, LITCHFIELD

IIIGCiNS, JOS. JOHN (1,70)\$-X.Y.1,92; () Nember Med. Sore of the stitte of

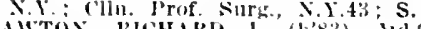

AWTON, RICHARD I." (b'83)-Md.4,08; (1.04)

WELLINGTOX, WM. W. (b'59)-Vt2,89; (1'03).

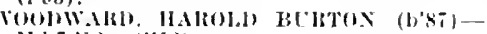
No.i, i2: (1.12).

THOMASTON, 3.533, LITCHFIELD

Ferguson, (ieo. II. (b'56)-N.Y.5, $79 ;(1293)$

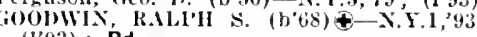
(1'93); Pd.

HAZEX, ROBT, (b'2 \$ N1,2,98; (1'02).

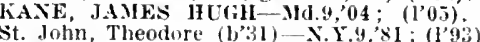

THOMPSON, 4,804, WINDHAM

TAINE, ROBEHT CHILD $\left(\mathrm{b}^{\prime} \mathrm{i} 3\right)+-\mathrm{N} . \mathrm{H} .1$, $00 ;(1.01)$.

THOMPSONVILLE, 5.900, HARTFORD

ALCORN, THOS. G. (b'69) - Mlass.6, 98 ;

(10.5)

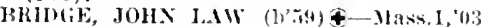

boW'D, MICHAEL J. (b'6t)†-IId.4,01;

FINCHI, GEO. T. (J'T4)-N.10, T7; (I'93) Mr'Hugh, Johm F. (b'Ts)-Mass. L,01; (1'05) simonton, Frank F, $\left(b^{2}+6\right)$-Mle.1, 03 ; (1'10). rail, Fdwin smith (b'tit)-N.Y.9's: (1.93).

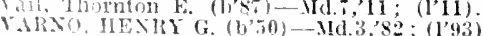
TOLLAND, 1,126 , TOLLAND

SIMMONS, WILLALI) IELSOX (b60)€
TORRINGTON, 16,840, LITCHFIELD

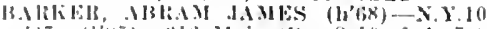

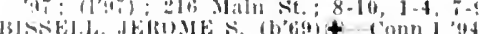

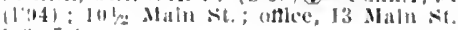

MIIIS IHAs. HI (b'33) +-Mlich lete

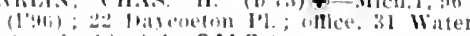
St. : Ii)-12, -4 ; OALR.

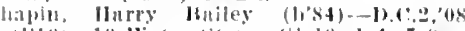

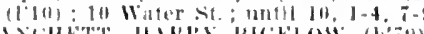

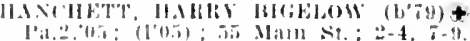

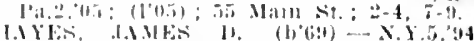

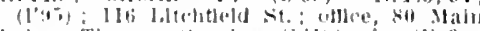

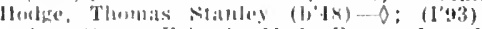

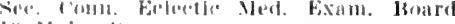
$198,1: 11$ is

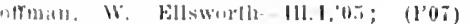

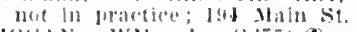

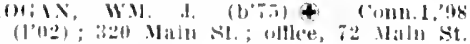
s-11, 1-3, $7-9: \mathrm{U}$.

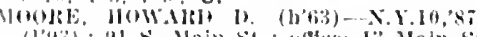
(1'013): 91 s. Main st, wher 13 Main st

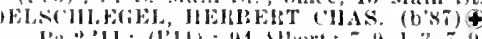

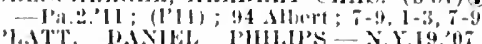
(1'09): 311 atken atre.

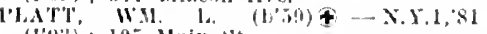
(I'4:3) ; 10.5 yHo st.

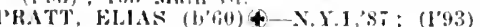
2:- bascoeton I't

Pulver, Frank $\$$ (1) (66) N.Y.9,99; (1'01)

l'uler, Cirate Coe (b'tis)- Fll.15,94; (1'94) RY.X, "IMOTII M. (b'73) - Mod.4,02 (l'03); 227 E. Main st.; office, 31 Wate

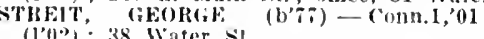
$\left(l^{\prime}(12) ; 38\right.$ Water st

Thomsen, Thomas leonard (b'T2) H-Tats $01 ;$ (l'02) : 319 I'rospect st. ; office, it . $8-10,1-4, i-9$

UNCASVILLE, 667. NEW LONDON

OX, MORTON EARL $(\mathrm{b}, \mathrm{T} 0) \uparrow-N . Y, 8,93$ (1'(3).

Taylor, Franris A.-Mass,6, 05 ; (1'06)

UNION CITY, 4,874, NEW HAVEN

May, Austin E. (b'50)-Vt.2,'79; (l'93).

UNIONVILLE, 2,078, HARTFORD

MORMISSEY, WM. THOS. (b) 82$)$-MId."3, 304: (1'09)

Ripley, Edwin Morgan (b'47) E-N.Y.13,'il (193)

White, Sarah J. (b'4I)-N.Y.11'73; (I'00) VOLUNTOWN. 779, NEW LONDON

Hoover, John HI. (b'61)-0.3,'94; (1'95)

WALLINGFORD, 11,155 , NEW HAVEN Atwater, Caleb flunlington (b'43)-N.Y.1 i not in practice.

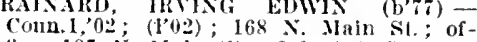
Hee, 127 ' Main st.; $8-9,1-3,7-8$;

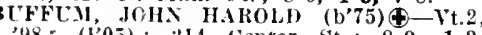
98 ; $\left(\mathrm{Y}^{\prime} 05\right)$; :214 Cenrer St.; 8-9, 1-3, $6: 30-8: 30$

Dawson, J. W, (b'7)-0.19,94; (1'94)

MMAN, DAYII HISSELL.

(See New Haren.)

Mac(iAlGHEY, JAMES D. (b'82)థ-Pa.2, 10; (1'10); 261 Center St. ; 8-9, 12-2, 6-8. NeCaln, l'aul 1'. (b'84)-Mldi.1,'11; Resident Physician. Gaylord Farm sinatorium.

l'owers, Ozro E.-Conn.1; 7 ; not in practice.

Kiordan, Wm. Jos., (b'85)-Md.4,09; (I'09); 52 Chitreh st.

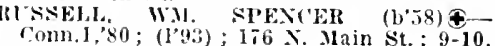
$1-3, i-9$.

Smith, ('has. F. (b'56)H-N.Y.9,'84; (1'93);

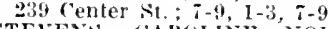

TEVENS, OAROLIN NOHTI (b'7)$6-8$

Webb, Chas. Valores-Pa.9,98; (I'98); 50 S. Main St. : $8-10,1-3,6-8$

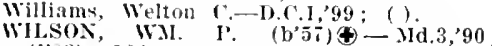

(I'y3); 124 center st. : $7-9,1-3,7-9$.

WAREHOUSE POINT, 1,382, HARTFORD

Kelly, Michiel J. (b'75)-IId.4,97; (1'97)

WASHINGTON, 1,747, LITCHFIELD

STEWART. HARKY E.ATON (b'8T)-COM.1, Wesiction

$98 ;\left(10^{\prime} 02\right)$
WATERBURY, 73,141, NEW HAVEN

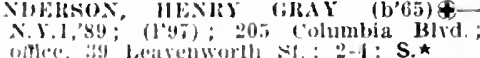

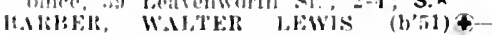
X.1.10,73; (1'9:2); 87 x. Maln st.; oftice, 4. Main st.; $9-10,2-4, i-8$

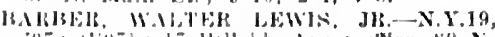

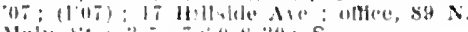

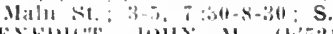

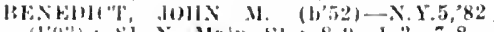
$(193) ; 81$ x. Malu St.; $8-4,1-3,7-8$.

HWANS, THEOHOHE $F$ (1)

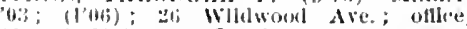

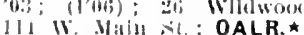

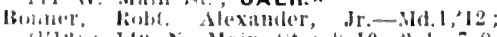
(1'L2); It11, Main st, $8-10,2-4,7-8$

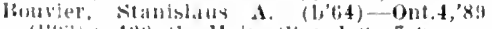

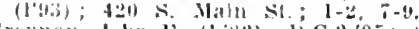

Breman, fuhn E. (b'22)-1).C.2,05; (1'07) 1 in $b$ yith st ; $8-4,1-3,7-8$.

BEENAAN, I'AlRe los. (b's:3) - conn.1

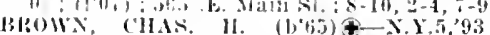
(1'93); 18.5 columbla Blvd, Offiee, 5 i $\therefore$ Main si. ; $2-4, i-8$; s.

11.1. THos. M.

(See Nambatuck.)

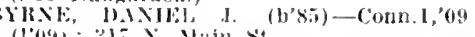
'allathall, l'at rick J. (b'60)-Ala.2,'92 (l'tis); liz cirove st.; ofthe, 4, $2 d$ Are. $10-1: 2,2-3: 30,7-4$.

('allender, Eurene Fredk. (b'89)-Conn.1, 'l2: (1'12); llaterbury Hospital.

(ameron, liugh A. (L'69) H-Pa.9,'96; (1't2); Melbourn Terrace; offlee, $314 \mathrm{~W}$. llain st. ; 8-11:30, 4-5:30.

CAsill, i.orls THOMAs (b'83)-D.C.2, (1) : (1'08); 32 wllow st. : $8-9,1-3,7-8$

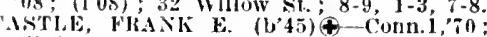

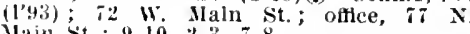

conkey, Caroline loot (b'44)-N.Y.14,81 $\left(1^{\prime}+3\right) ; 23$ Hillsdale $A$ ve, ; $9-10,2-3,7-8$ counors, Thonits Jos.-ild.1,12; (1'13) st. Mary's Hospital.

(OOLEY, MIUON 1. (b'59) क-N.Y.6,86: (1'3); 354 N. Wain st.; $2-4,7-8$.

(lo6) (36) fort Iflghtand Ave.; office, $79 \mathrm{~N}$

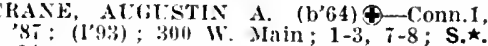

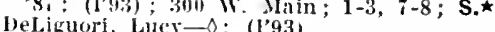
De Luise, Isacco (b'i8)-Ita.10,'03; (1'05); 260 Bank st. : $7-9,1-3,7-9$.

BENINA, ALLETTA BEDFORD (b'80) $\uparrow$ N.Y.20,05; (1'06); 5 Johnson St.; offlce, DEt IV. Main St.; $1-3,7-8$

4) $\&-N, Y, 1,0 I$ (1) $\left(1^{\circ} 04\right) ; 337$ E. Mlain St.; 8-10, 1-3:30,

Donahoe, Michael J. $\left(b^{3} 5 \bar{t}\right)-$ Pa.1,'96: (l'93); 325 E. Main st, ; $7-9,3-5,7-10$

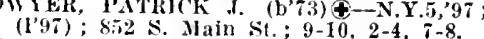

Egan, John Jos. (b'84)-Md.1, 07 ; (1'08) ; 18 Bergin st.; $8-9,1-3,6-8$.

ENGELKE, CH.AS, (b'69)థ-N.Y.1, 02 (1'02); 50 Buckingham st.; offlee, 50 Learenworth St.: $2-4,7-9 ;$ Pd.

Faber, Geo. A. (b'66) E-111.8, 88 ; (1'93) 182 Grand Are., $8-9,1-3,6: 30-8: 30$.

TARREL, JoH. ; E. (b'77) $6: 30-8: 30$,

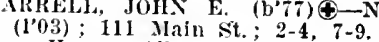

Fox, Harvey Albert-N.Y.13,78; (1'93) ; 50 Wood st.

Frank, 1'lilip (b'83)_Conn.1,07; (1'07); $255 x$. Main St.; $1-3,7-8 ; 1, \star$

RENEY, JOHN DANL. (b'70)-N.Y.8,'93; (l'g3) ; 28 Mitchell Are.; office, 111 W. Main st.; $9-11,2-3,7-8$.

FROS'T, CHAS. WARREN SELAH (b'57)N.1.1,80; ( $\left.\mathrm{I}^{\prime} 93\right)$; 54 Central Ave.; offec 52 Central Are.; 8-9, 1-3, 7-8; D.

ruin, John Wm. (b'83)-N.Y.8,08; (1'09);

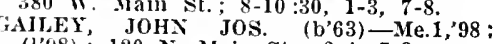
(1'98); 120 N. Main St.; $2-4,7-8$. ANCHER, JACOB (b'84) - N.Y.8,06; (1'06); 45 Center St. ; 8-10, 1-3, 7-8. cood, Wm. J, Alurray (b'85)-Conn.1,09; (1'10) : 82 ' Bank St.

GOODEXOLGH, EDWARD WIXCHESTER (b'65) \&-Conn.1,'93; (1'94); 44 Leavenworth St.; $2-3,7-8 ;$ (D3); Pd. 
(iv)

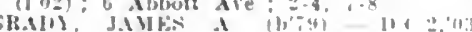
(1"ut):

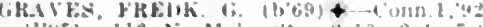

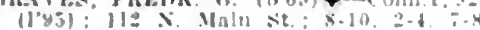

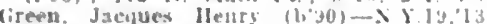

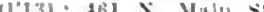

lirussman, Franz-111.21, g; ; 1195,

Albuth Ire.: 2-8.

lackell. John Francle (b'su)-Que.1.0ri (106): 461 $x$ Main st: 9-10, $2-4 . ;-?$

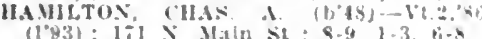

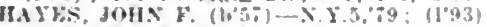
15 s. Elm st. $5-3: 30,1-2: 30 \div-8$

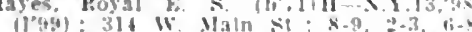

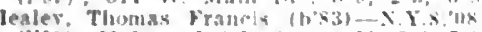
(l'05): Maln and cule sts. $4-11,2-3,7-8$

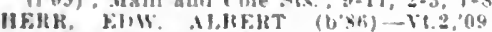

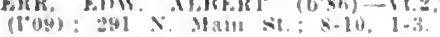

Hinckley, Walter (1.93) 12 rlenilng $\leq 1$

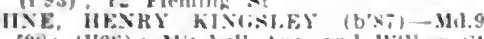
os: (los): Mirchell tre and Whlow si

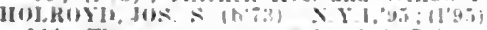

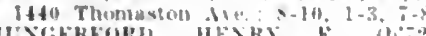

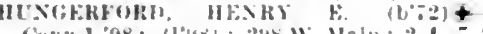

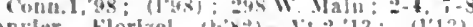
Janver. florlzel (tond Vi.2,13: (1'13)

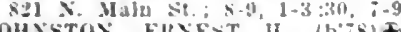

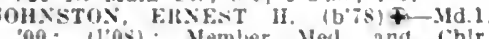

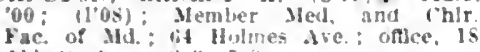
Ablot: Ire.: :-3, $;-3$

Kennedy, l'aul 13. (1, i:)-_.1.10,96 (1'96)

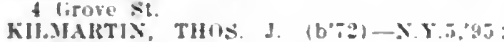
$\left(1^{*} 96\right) ;$ ts State st. ; $1-10,1-3,7-9$

Kirschloum, Haward Harry (b's) - (onn.l.

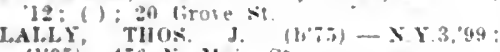
(1005) $476 \times$ Main st.

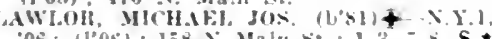

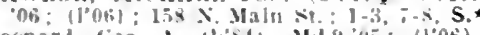

Iernard, (ieo. A. 11, $4 t)-1149,05 ;\left(10^{\circ} 06\right)$ 100 Cherry st. : $8-10,1-3, b-3$.

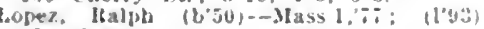
$3 i 4$. Main st.

1.uregub, Arthur (1962)11- 5.4 .983 (1.93) 148 lirand si

MAJONEY, MANIKL J. $160 \% 7 \%$

"96"; (I'98) : 11" ("owke st; oftice, it N

ranglal, fierand Chas. $\left(b^{\prime} 81\right)-I t a .100^{\circ} 0-$ (los) Maln st.

ICDOXILI, ARTHIR FHANIS (b\%) X.Y.1,05; (107) : 2xt, Main : 11-10, 1-3, 7-4

MeGrath, John H. (b's3)-Conn.1, 0 K (1.08): 309 F. Wain St.

MCLAREEY. TH(IS, J. (1)"in) + Md.3,97 (1.97): 695 F. IIalu Si. : ottice. 27 ('herry st. $9-10,2-4,7-4$.

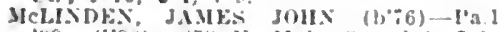
ys: (199); 855 x. Malu st, :-4, $7-9$

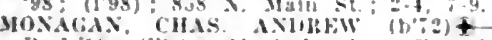

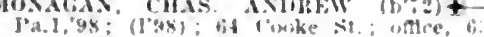
lenler st: 1-3, :-9.

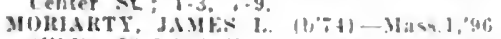
$(1 \cdot 96): 29$ Mitchell Are: oflice, it Cente SL. : $8.0,2-3,7-8$.

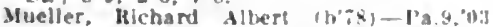
(1.03): $\$ 87$ X. Main sit. : s-9, 1-3, fi-

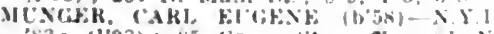

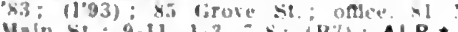
Maln Si: 9-11, 1-3, i-s; (B3); ALR.

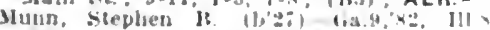
"xs: (1,y3): 35 lecarenuorth si. : $1-3,6: 30-5$

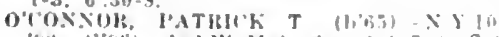

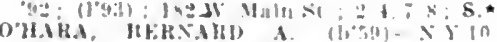

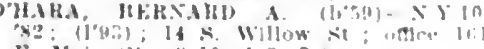
b. Maln si : x.10, 1-3, ; - is

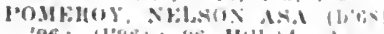

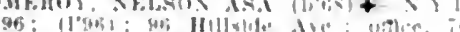
Center si: $1: 30-3: 30,-x$

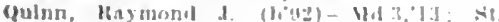
Yari's llomplial: 11 (1:

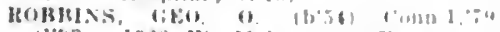

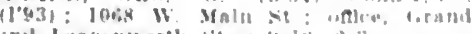

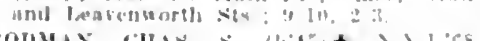
HOIM.4. (IIAX \& $(1,1 \%+1) 1.05$ (1'v3): 101 X Wain

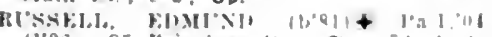

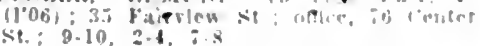

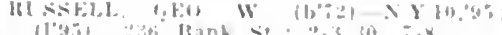

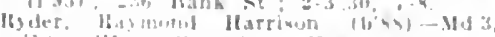

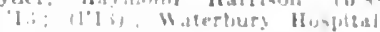

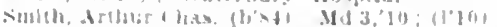

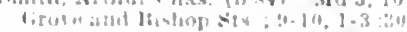

SMITI, FEIB!:16T l.. 19,:1:

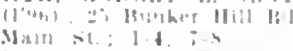

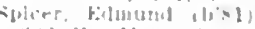

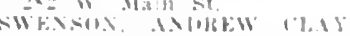

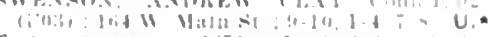

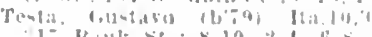

THधाз

(1'net):

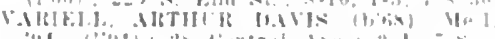

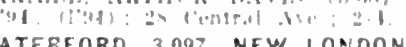

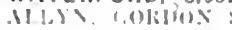

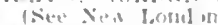

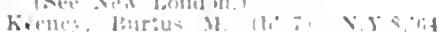

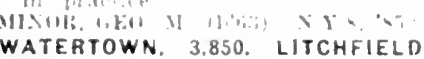

WATERTOWN 3.850 . LITCHFIELD

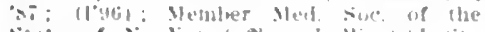

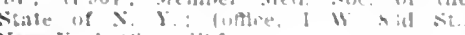

Ven lork

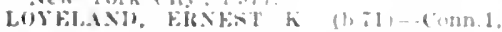

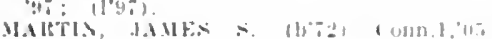
(1) 10.1

Munger, Willer

$\left(1^{\circ}+3\right)$

WATERVILLE, 3.000. NEW HAVEN

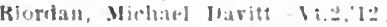

WESTBROOK. 950, MIDOLESEX

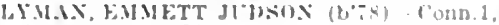

(100) : 0 b.

WEST CORNWALL, 200, LITCHFIELD

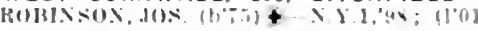

WEST HARTFORD, 4.808, HARTFORD

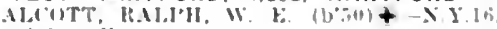

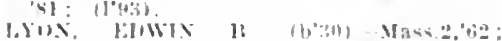

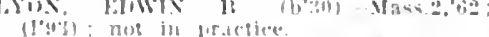

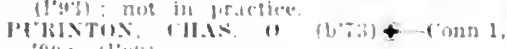

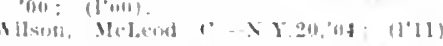

WEST HAVEN, 8,5\$3. NEW HAVEN

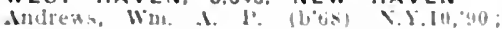
$(1,4-1)$

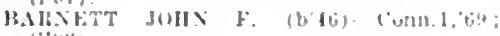
(1) $13 ;\}^{2}$

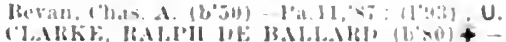

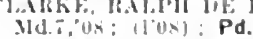

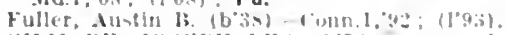

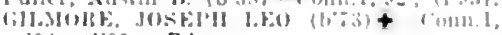

ofi: $(100$ i) : Pd.

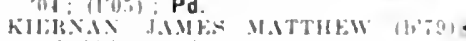

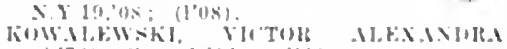
$16 \div 31-\left(\right.$ min $\left.1.02: 10^{\circ} 02\right)$.

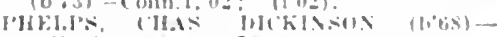

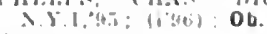

lis piratcilles

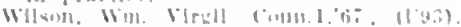

WESTPORT. 1.259。 FAIRFIELD

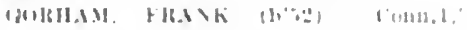

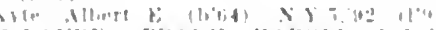

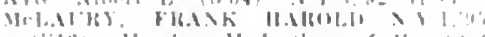

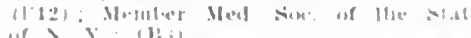

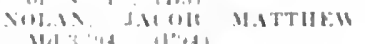

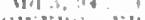

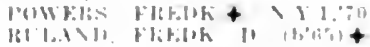

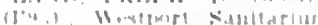

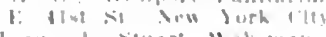

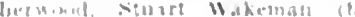

WEST SUFFIELD, 9IO, HARTFORD

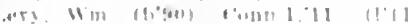

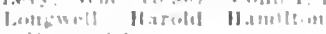

MIIn?

WEST WILLINGTON, Z3H, TOLLAND
WETHERSFIELD, 3,: 4 , HARTFORD

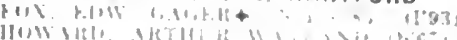

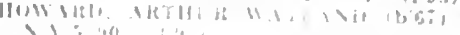

WILLIMANTIC 16.230 . NIOOHAM

$(13)$

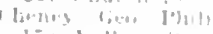

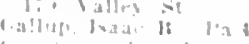

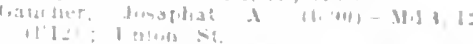

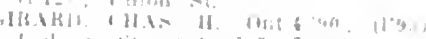

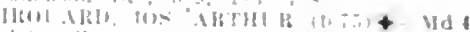

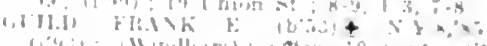

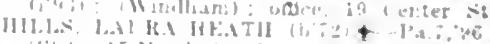

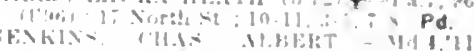

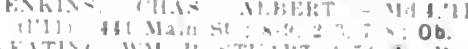

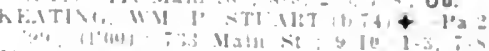

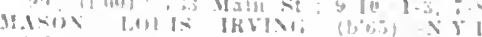

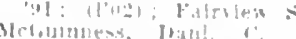

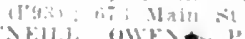

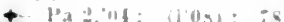

WHKEI, THF,

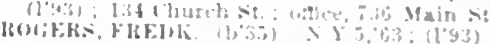

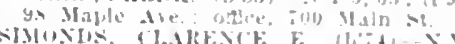

:IM1)

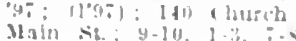

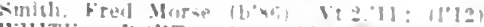

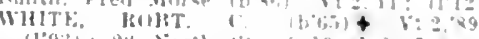

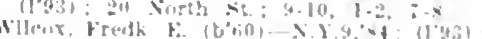

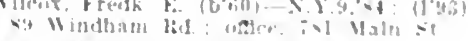

WINDHAM, 1.374, WINDHAM

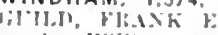

cere Willimantle.

WINDSOR, 4.I;8, HARTFORO

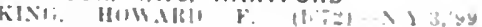
il' y.4.

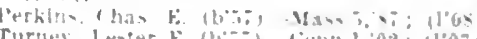

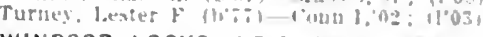

WINDSOR LOCKS. 3.715. HARTFORD

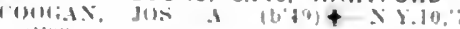

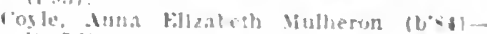

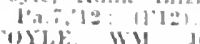

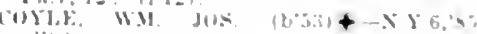
(1) 11331

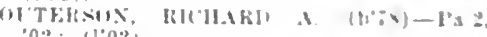

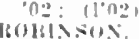

WINSTED. 7.754. LITCHFIELD

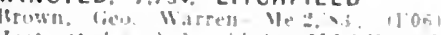

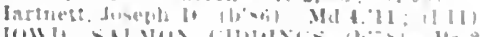

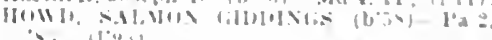

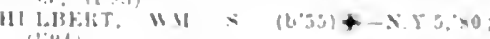

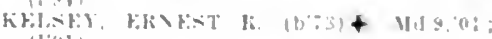
(l, (b)

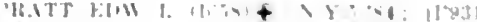

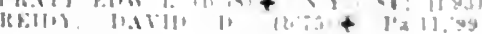

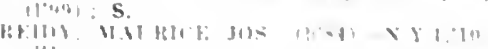

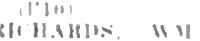

WOODBURY KBR. LITCHFIELO

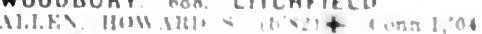

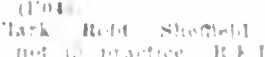

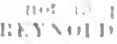

1V.? $1,1, x$

WOOOSTOCK 1.849, WINDHAM

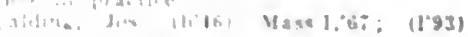

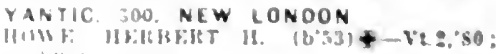




\section{DEL AWARE}

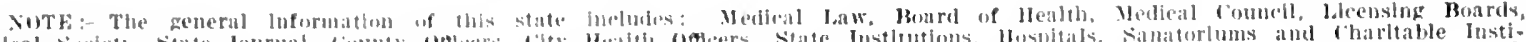

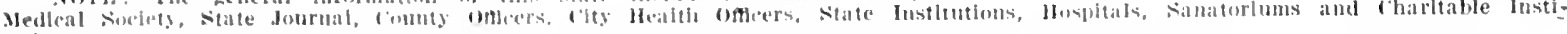
tutions.

\section{DELAWARE}

Population ( 1910 census) ....

202,322

Number of Counties. .

Number of Physicians.

Members State Society. Dec. 31, 1913

Area of State in Square Miles.

\section{MEDICAL PRACTICE LAW OF \\ DELAWARE}

\section{An Act}

llegulating the linctice of Mediclne and surgery in thls state.

PltFAMBLE: Whereas, The safety of the oublic may be endangered hy incompetent physiclans and surgeons, and due regard for public health and the preservation of human life demands that none but competent and properiy quallfeil physiclans and surgeon. shill be allowed

lie it enacted lys the senate and Inouse of hepresentatises of the state of lielaware Representatises of the Sitat
in ieneral Assembly met:

Section 1. ESTABISIIMFAT OF MFD (Al cor'sil That there shall be estallished a Medical Comeil of ltejaware, consistlng of the Chief Iustice of the state and of the lresicjent of the two state iboris of Medical Examiners provided for in this act. sec. 2. WFildXATION; RCLES: The sald council shall he known by the name and style of the "Mledical founcil of lyelaware" and may make wnd aldopt all neces sary rules, regulations and by-laws for their own goverument. not inconsistent with the laws of this state or of the linited states. and shall have power to locate and malntain an offee within this state for the tain an offec withil this state for the said council shall eonstitute a ijurum for the iransacton of business.

sec. 3. ORGANIZATION OF COIXCII. The sald coundil shall organize within ten dass from the date of the orranization of the two Boards of Medicil Examiners, and shall efeet from its own number a president and a secretary, who shall also aet a treasurer, hoth of whom shill hold their offlees for one year, or until their successor are chosen.

sec. 4. CoNlexsatiox: The members of sajd council shall receive, in addition to their necessary expenses. five dollars pter day each for each meeting of the council. hut sald per diem shall not expeel in any one year more than fifteen dollars. the same to he paid out of the fees heretnafter prorided for.

Sec. 5. MEETIXE: 'ERTIHIATES The said Medical council shall holl two stated meetings in each year, and may holi special meetings at such times as it may deem proper. It shall issue rertifieates for license to practice medicine and surgery to such applicants as have presented such liplomas as hereinafter rewuired and successully passed the examination hereinafter movided, and the said Medieal 'ouncil shal have no powers, duties or functions except is provicled for in this $A c t$

TWO EX.AIINING BOARDS PRO

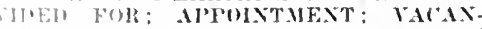
lES: That from and after the pasage of whis the the shall he, and continue to be two cerarats Bualla of Medical Fxaminers

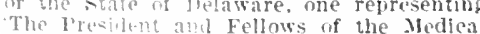
sonety of pelaware." and the other "The

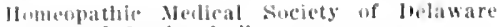
state and ['enlnsula."

Fach board sluall consist of flve members. and each of said number shall serve for a term of two years from the first dlay of Marih next after appointment. With the excolfion of those first appolnted, who shatl spre as follows, mumely: two of each hoard two years from the flrst day of Jareh. A. 1. 189.1

The fovernor shall appoint the nembers of sajd Board of Fxanmers, respeetively. from the lists of members submitted by sail meilfal socleties residing in thls state. metlcal srocteties residing in this state, Which llsts shail within ten days from the passage of this act, and on or before the
llrst fiag of every Jannary thereafter, he

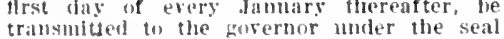
and signel by the secretary of the society so nominating.

From these lists of nominces. respectively, the governor shall. within ten days afler the receipt thereof. alyoint two separate Boards of Nedical Fixaminers, "ach board to be composed exriusirely of memters of the same medeal soclety. In case of the faihre uf either of the sald socletles to submit lists as aforesald, the governor shall appoint members in good standing of the eorreout other restrictions.

Fach one of the said appointees must be a registered physician in good standing. and shall have firicticed medlicine or surgery under the laws of this state for a periogl of not lesis than

The governor shall fill vacancies hy ateath or otherwise for unexpired terms of said examiners from the lists submited as aforesilil and mily remove any nember of either of ald boards for concinud neglect of the of said boards far comtimited negleet of the duties required by this $\lambda$ et. or on reenmsald menther may bo in aftllation, for unprofessional or dishonorable eonduct.

The gavernor shall in his flrst appointments designate the number of years for which each appointee shall serve.

The appointments of suecessors to those members whose terms of offle will expire on the first dity of Marcl of each year shall be made by the gerernor during the first ten iays of January of such rear, on the same conditions and refuirements as hereinlofore specified with reference to the apyointment of two separate examining boards, each to be composed excluslrely of mem-
hers of the same medical society, ats hereinlefore provided.

see. 7. IIESICXITIONS: said boards shall be known by the name and stvle of "Boards of Yedieal Examiners of the state of belaware." Every frerson who shall be slatl receive a rertificate of appointment from the secretary of state under his hand. Each of said boards of examiners shall make and aclopt all necessary rules, regulations and by-laws, not ineonsistent with the wherely to perform the duties and transes the business recuired under the provisions of this Act.

see. 8. DISPOSITIOX OF FEES: From the fees provided log this Act the Medical founcil shall pay. not to exceed said income, all proper expenses incurred by its provisions: and if any surplus above said expenses shall remain at the end of any year. it shall be apportioned among said medical societies pro rata according to the number of candidates examined by each.

sec. 1. ORGidxIZATION: The first meeting of each of the examining hoards. raspectivejy, shall be hell on the flrst Tues. laty of Juty, 1s!\%. At such meeting of each uf the buards, respectively, an organlzation shall be elferted by the election from their own memberslip of a president and secretary, for the purpose of examining anplicavits for certificate for license. Fach of ail hor of medical examiners shall hold all beclal meetings in fwo "Ir more stated or special neetings in mblip at such tines and places as they may mublic at such tinies and places as thes may ings a majority of the members of elthe board sliall eonstlute a fluorum thereof, but the examination may be conducted by a com mitte duly authorized by sald boards.

siec 10. (2IFsTIONS TO"BE SUBMIT'TE To rulvell: Fach Board of Verlicil Fiaminers, not less than one week prior to each examination, shall submit to the Volical council of belaware questions for thorough "xamination in anatomy, physiology, hygene; ehemistry, surgery, obsteturactice medicine and matcria medica.

The Medicil council shail select the questions for such examinations from the lists of culestions submited by the Poard of lledi(al fiaminers of the candidate's election. (a) Fxaminels of the candidates election: and shomb there lo eandidates for examination of any other school than the two ined by the comeil and some reputable practitioner in this state of such school. by ald (r)meil to be selected, upon questlon. selected from standard text-bonks on the abre subjects as taught by the school selected by the eandidate.

sec. I1. FXAMINATIONS: Sald examInations sholl be conducted in writing in iceordanre with the rules and regulation prescribed by the respective Boards of Medi call Fxaminers, and shall embrace the subjects named in section 10 of this Act. After each examination the Board of Medical witlut un act on the same. withitat unnecessary delay, act on the sayje. the presilent, secretary and each acting the president, secretary and each acting member of satio Bosult of examination, shall ers, stating the result of examination,
le iransmitted to the lledical council.

sec. 12. CERTIFICATE TO ISSEE: Om reveiving from either of said Boards of Ifedizal kxaminers such official report of the examination of any applicant for cer tificate for lirense, the Verlical Council shall issue forthwith to each applicant who shall have heen returned as having successfully passed the examination a certifleate to that iffect

The Hedieal Couneil shall keen a record of all certificates, when and to whom issued.

See. 13. APPLICATIONS: FEES; EXE.MlTIONs: From and after the passage of this det any person not heretofor a uthorized to practice medicine and surgery ill this srate, and desiring to enter upon such practice, shall deliver to the secretary of the lledical Council upon the payment of a fee of ton (\$10) doliars a rritten application for examination, together with satisfactory proof that the applicant is more than twenty-one years of age, is of good moral character, has obtained a diploma from some reputable literary or sclentific collece. or a certificate from the faculty of Delaware college simned by the president and at sested by the secretiry thereof that he or she is qualified to enter the freshman class (ff the Latin scientific course of the said college: and has received a diploma confer ring the degree of loctor of Jedicine, from some lesally incorporated merlical college, which. in the opinion of the vedical coun- 
ell, was til good standing at the lime of the

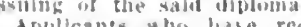

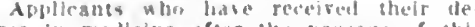
wree th thencine after the passage of this Ach. musst have purvued the stadly of medi. colne for ab lenst fun bears. Incluiling four seren arouths each. In ditforens years. porlor th the gransing of sald legree, in some legally Incorporalled melleal mollege or colleges approver by bie sedical formant ljon the making of sald payment and prof? the lledlcal finuledl shall fsive to suld ap. the Medleal foutued shall isiue to suld alp.

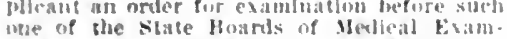
me of the siate Hoands of Mertical Esimselect. In case of fallure at any such exinination the enndidate. nfier the expirit tsen of slx monthis and ivithill two yeats shall hare the privllege of a seonnd easmination by the same Exarl to which apullof an additlonal fee. but if after six mouths oful afure aml befere two bears fron stich examinat

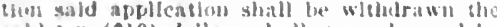
sada sen (\$10) dollars shall upon demand he rebrued. Provided, hast applicants for II1901 . and hare been in continuous and reputable practice for at leasl fire ycars since graduatlon: inay be abmitted to the examinations of one uf sald bodrds. upon certifled and satisfactory evidence of gorm! moral character, of thrce courses of inedical lectures In different calendar years. and of a che requirements of that tame: and provideul the requirements of that time: and provident uraduated prlor to July 1. A. It. 1896. and hare been in condnuous and reputalile practhe for al least ten years, may be aldinitteal to the examination of rilte of said board. บpon certifled atud satlsfactory evidence in moral character. of (wo) cuurses of moilical lecturen, In diferent calendar years, and of a rempetent academb educatlon accurding th

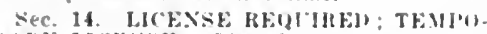
MAl LICFNS: : That from and after she lrassage of this ict. Is shall not tre lawful for any perwn to priactice medleine or surgery in thls state whlout having oblalned a license therefor as hereinafier provided. But a remporary license, of not less than two neeks nor more han forur months, may be

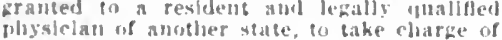
the iractlee of a resident and legally ijualifled phssleian of this state. during the Jit ter's temporary Illness or almence from the stale. ubron the wriften reguest of 11 physt. clau resldjng in this state, and the jay. mens to llee secretary of the lledical coun. cll lif a foe of iwo dollars (s:-) for the use liceuse rouncll, and when such temporrary such ficense slatl have the rlifh ta prac. such license slabll have the rloht to prate the time specitled la sald temporary lieense.

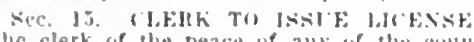
The clerk of the peacie nf any of the coull. thes of this state shall lestle it license wigned

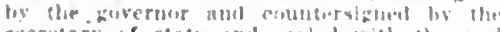
sectetary of state and saled with dise ked

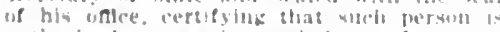

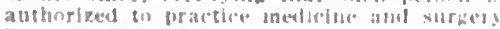
lin thls slate. couformathl lo the lak,

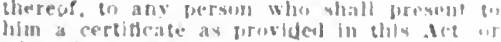

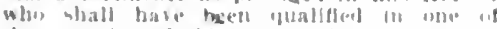

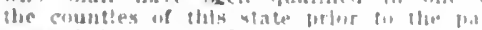

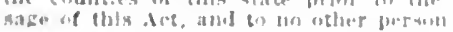

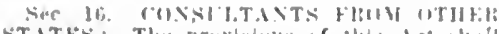

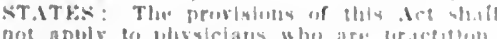
not apply to moviciars "he are braceltem

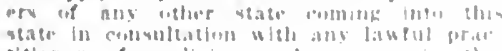

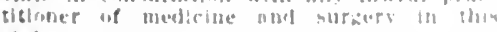
state.

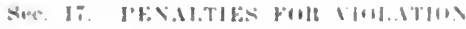

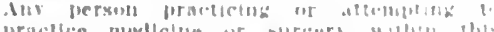

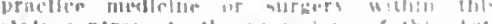

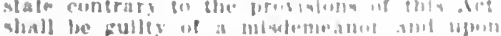

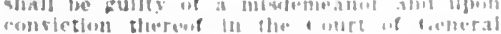

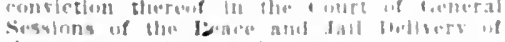

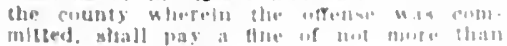

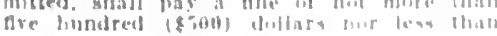

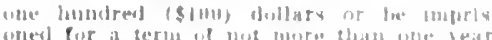

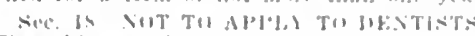

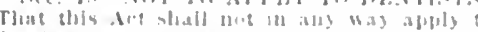

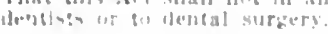

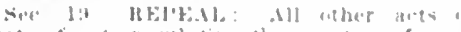

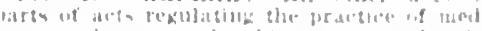

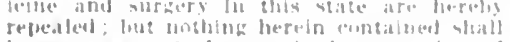

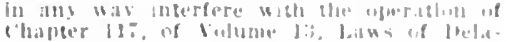

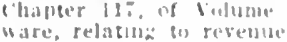

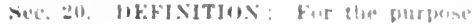
of this lot and the lo

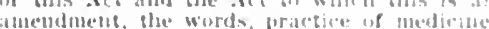

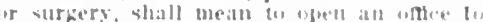

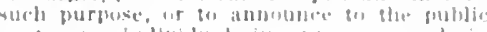
or to any indlviduat, in any was. a denire or willngness or reiddinfes bo trats the stek belaware. or bo luvestleabe or difighuationte

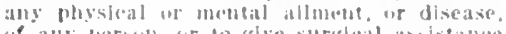
uf any persols, or to gelve surghteald andistance

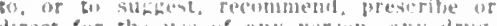

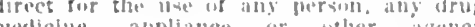
uediche. aspliance or usher agency. weter retiof or valliation uf any allment or

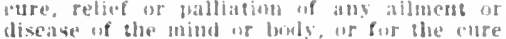

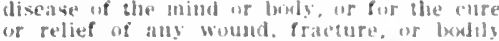
injury. "os deformity, after latring recerved or witl the intent of receiving therefor.

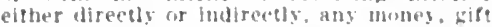
ot any otlue form of enmiensation.

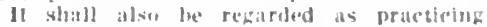
medicine within the neaning of this let if int one shall use in eronuection with jus or her name. the wortis or letters lir Jucker. I'rofessur. MIn. VIII. or Healer. ot any wether litle. word, letter ar other designation whled snaly imply or designate him or her as a practitsonor of melicine. or surzery. In tany of tos hatuches: provided that mothing in this . Let mor the det to which this is atl

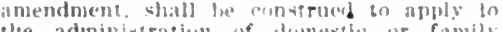
the administration of domestic ot fitmil remmies in cares of emergeney. ar in dew tists of dental surferens in the pristice of dentlsery, or to strzeolls of the lonited States Army or vity in the dischatge of

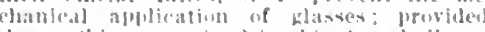
that uothing eomatined in this . Ire shall pre vent opticland from preparing e'ves fur test

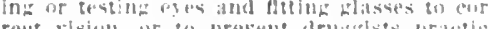

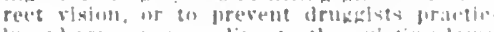
lug pharmacy accorling to the plsting laws. or to brerent the troitment of corms bunlons or the lusiness of manteurimg the the princtice of massilfe. The refurements uf sertion 1 of this ametument at in gateral

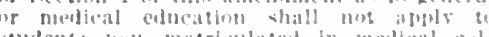
students mow matrieulatew in medical coll

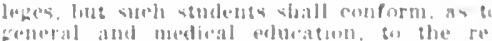

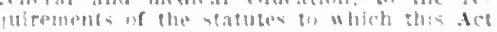
(1)

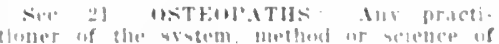

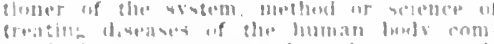

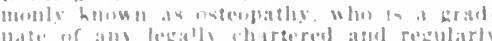

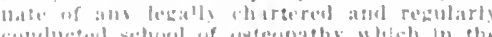

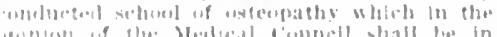

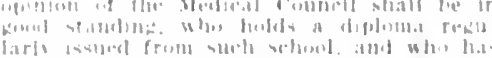

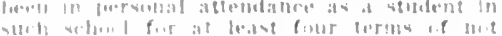

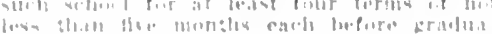

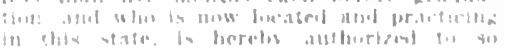

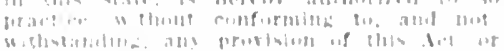

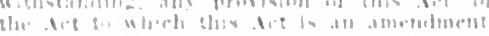

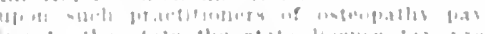

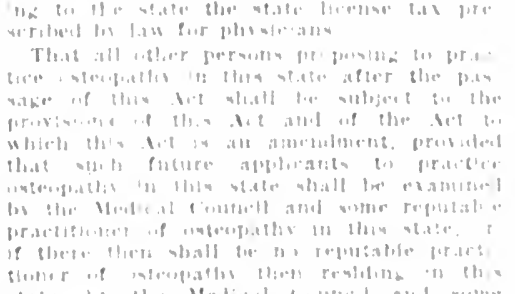

$\sin x \sin ^{-10}$ nae colver

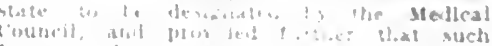

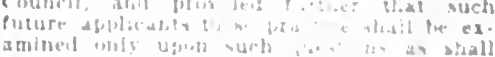

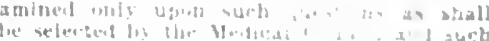

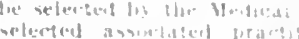

athis in allitt ,

intry, whotertis

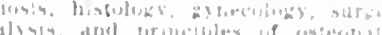

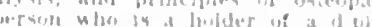

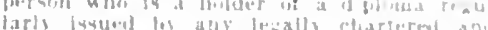

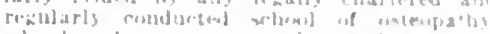

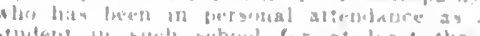

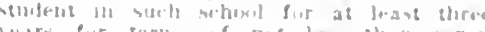

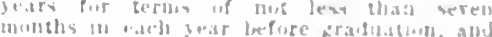
whe slatb confurm $b$ the prosisions rolative

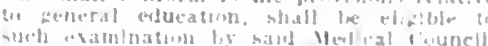

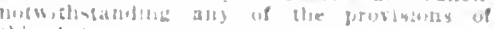
this .lot.

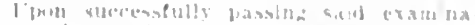

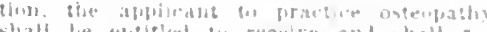

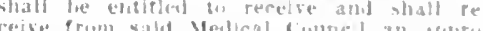
priate certhlleate entaling hats an pratere osteobatil in this siste. The clerk of the reace of ans of the countges of thls atate

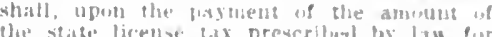

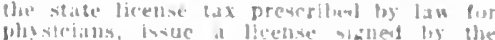
Fuveruor and condateralanted by the werepary alco certifylus the with the seal of hi

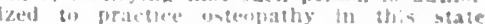
conformaldy to the law therent, po ald tre (u) who shall bresem to b!m sucll certif

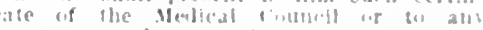

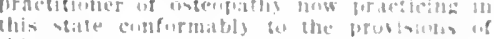
thls tre?

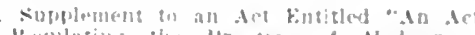

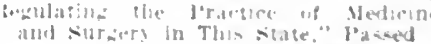
di forer. Inril 14, 16y

Be it interetel log the senate and House of

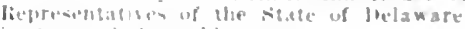

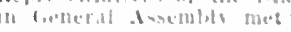

Neteton 1. ItklundIIS: That the

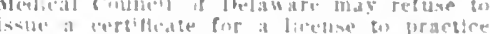

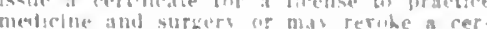

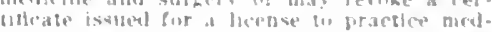

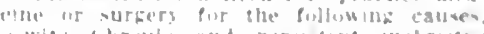

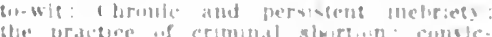

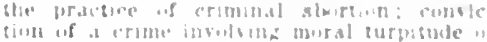

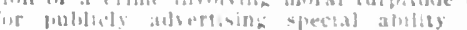

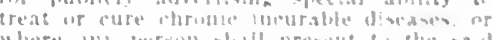

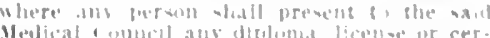

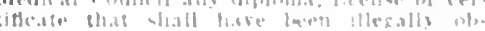

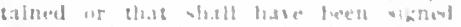

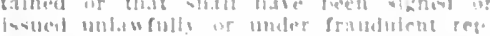

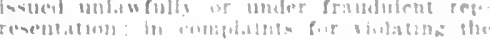

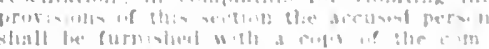

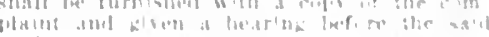

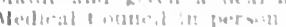

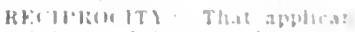

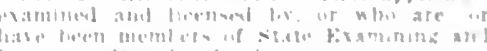

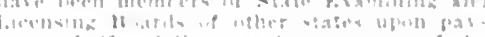

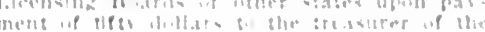

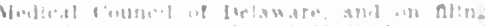

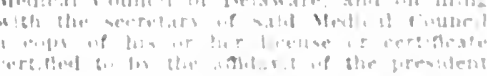

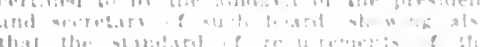
that

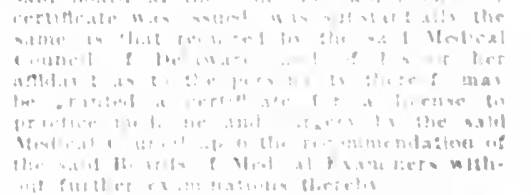

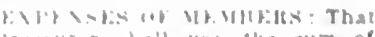

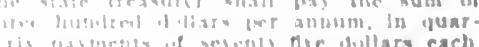

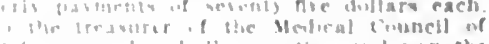

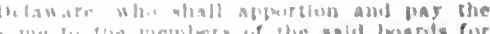


their necessary expenses, und in additions the dollars per day pach for ench member for every meeting attended, but said per dlem shall not exceed In any one yoir uore than twenty-five dollars.

Approved Murch 16, A. [I., Is9?.

\section{STATE BOARD OF HEALTH}

Wm. r. Orr. I'resident, Lewes; I, Wr, Ilif toll. Smyrun; W. F. Haines. Seaford; I. I

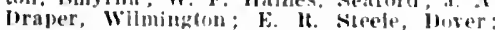

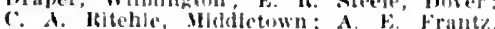
secretary and Executle onleer, Wiminetom.

\section{MEDICAL COUNCIL OF DELAWARE}

Chlef Justice Jame's Jennewlll, I'resident Wimington; Henry W. Briggs, SecretaryTreasurer, Wimlugton; F. S. Inderson lover.

\section{MEOICAL SOCIETY OF DELAWARE} EXAMINING BOARD

Henry W. Briggs, President, Wilmington I. S. Downs, bover; G. Frank Jones, lieorgetown; Wm. Wertenbaker, Witnington; I. II. wilson, Secretary, Dorer.

\section{HOMEOPATHIC MEDICAL SOCIETY} EXAMINING BOARD

E. S. Anderson, President, Wover; A. F. Frantz, Whmington: T. O. Cooper, Wilming ton; J. Paul Iukens, Wilmington; H. W Howell, Secretary, Wilmington.

DELAWARE STATE MEDICAL SOCIETY Officers 1913-14

Wn. P. Orr, Jr., I'resident........... Lewes Tullison H. Davies, Ist V.-Pres.......... Farnhtirst Wm. Marshali, 2d Y.-l'res............Mllford i. W. K. Forrest, Secretary.... Wulmington Samuel Rumford, Treasurer......Wilmben

\section{Councilors}

Peter W. Tomlinson, Wilmington; James H. Wilson, Dover; James Beebe, Lewes.
Stale Journal

Heluware state lledleal Journal, Whmlug(1). Nllurt Itobli, M.b., editor.

Component County Societies of the Delaware State Medical Society liENT ('0) NTY

Howard \&. lwhbl, Iresident....... smyrna lito. 1. M.kelwiy, sesretary.......... bover NFWCANTLE rOENT

i. W. K. Furest, preshlont..... Whinington

T. lovies secrelary........ Faruburst siosex coloty

Wim. I. Orr, Iresident............. Lewes

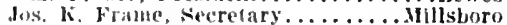

\section{HEALTH OFFICERS IN CITIES OF 1,000} POPULATION AND OVER

Delaware ('ity.............. H. C. Clark Dorer................. Fr. Ferman $c$ Taylor

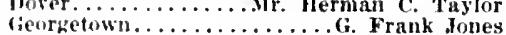

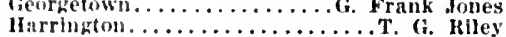
Lauref................... w. Fooks lewes.............. Hilram R. Burton Middletown.......... kdward M. Faughan Mhlford................ (G. Jawson IIilton...j. 3 . Hopkins and iv. E. bouglas Newark................ Jr. Jouis L. Curtis Newcastle................. Roth seaford............... Collins illmington................ J. Austin Eulison

\section{STATE INSTITUTIONS}

Farnhurst

Delaware state Hospital at Farnhurst, Firnhurst, bel. Wstablished 1889 ; for the insane: IVm. H. Hancker, medlcal superintendent.

\section{Marshaltion}

Ferris industrlal School for boys, Marshaliton, Del.

Hope Farm sanatorium, Marsballton, bel. (R.F.D.). Fstablished 1907: tuber: (ulosis; 4:) beds : Delaware Anti- Tuhereulosls soclety in chirre.

\section{wilmington}

Delnware Industrial Sehool for (iirls, Wilmington, Del. Ilrs. Jackson, superintencent.

\section{HOSPITALS, SANATORIUMS AND CHARI. TABLE INSTITUTIONS}

\section{Delaware Breakwater}

Inited states Marine Hospital, Del.lware Itreakwater, Jel. (Jewes P.o.). Fistablfshed 1854; general: ä2 beds: Aot. lng Isst.-surg. li. li. llart in eommand.

\section{Farnhurst}

Newristle County Jospllal, Farmhurst, wel. Fistablisted is Jinnes W. Foster, superintendent.

\section{Georgetown}

(ieorgetown Santarium, Georgetown, lef. Pnblic: tuberculosis.

\section{Green Bank}

New (astle county Workhouse, Green Bumb, Del. (Wilmington P.O.). Fstal,fished 1902; Jublic; is beds; Samuel $1^{\circ}$ liumpori, medica! superintendent.

Milford

Mliford Fmergenes Hospital, illford, vel. Kistabllshed 1908; jubllc; emergency cases not contaglous; 7 beds; S. II. D. Marshall, ntedical superintendent: Annite P. Reswloh, K.X., and Mina Hall, R.X. in charge.

\section{Wilmington}

Delaware Ilospital, 14 th and Washingtoit sts., Wilmington, Del. Established 1889 ; generul; 80 heds; Miss Jennette $F$. bumean, superintendent.

IIome of Merciful Rest, Wilmington, Del. Fstablished 1901 ; for incurables ; 10 beds :

I. Whitcroft, pretor.

Ifomeopathic Hospital, Wllmlngton. Del. Establislied 1888 ; publie; 66 beds; A. H Turner, superintendent

IDr. J. J. Jones' Private Hospltal, 1019 Delaware Are., Wilmington, Del. Established 1896; private; general; 30 beds; J. J. Jones, physician in charge.

Physicians and Surgeons' Hospital, 802 Adams St., Wilmington, Del. Fstablished 1910; publlc: 22 beds; A. B. Storey superiutendent.

St. Michael's Day Nursery and Hospltal for Babies, 20\% Washington St., Wilnington. Del. Established $1890 ; 27$ beds; Mrs. Mary E. Wright, superintendent.

Phamacentical preparntions advertised in the American Medical Direstory have been passed on and accepted by the Council on Pharmacy med chemistry of the American Medical Assoriation - refer to Physirians' Purchasing Judes. puge 1s. 


\section{PHYSICIANS OF DH.A.AWARH}

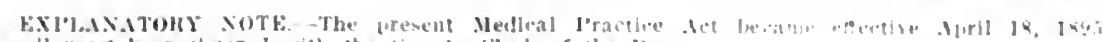

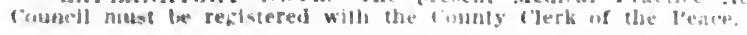

\section{KEY TO ABBREVIATDNS. SYMBOLS. ETC.}

Names ln capltals slanlfy menthershlp ln the county sivelety nid state Axvocla.

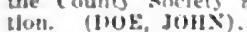

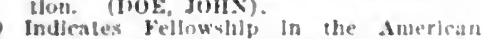

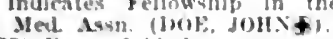

(b.3) tear of blrth. dmedic.

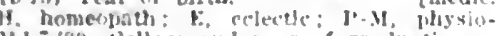
Mil.:.019, College and year of zraduation. informallow recelved does mot show grad. uation.

S.--Surgeon.

Ot.-Obstetriclan.

OtG.-Obstetriclan. fis neruluglse.

G.-Gyneculogist.

Or.-Orthopedist.

Pr.-I'roctologlst.

Op.-Ophthalmulogist.

A.-Aurist.

LR. - Jarymgologlst, IRh!nologlol. (1'sin) Jear of Hoenve.

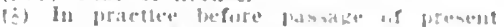
lan aldi] I cusced ]

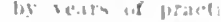

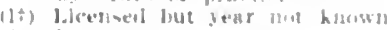

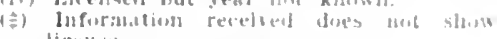
licentise

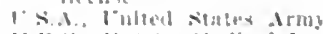

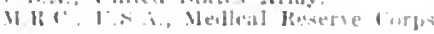

SPECIALTIES ARF. INDICATEJ AS FOLLOWS ALR, - Aurist, Laryngoluglat, Rhluologhat.

OALR. Mplithalmuloglat, Aurlat, Laryngalogist, lihluoboglist.

U. I rologlst.

D. Lrernatologlut.

Pd. -..-1'edlatrist.

N.- veuroboglist.

P. insychlallint

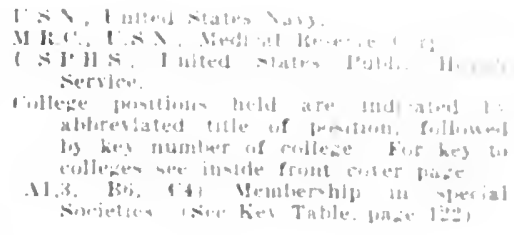

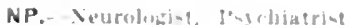

1. Intervilot.

T. Tuberiulculatraplse.

Anes. Niturbetul.

LD. Loileciratury lonamosticisy.

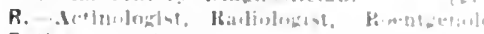
Path. -jothologlst.

Bact. [boterlulwitst.

WHEN THE ABBREVIATION REPRESENTING A SPECIALTY IS FOLLOWED BY AN ASTERISK ( IT INDICATES THAT THE PHYSICIAN CLAIMS HIS PRACTICE IS LIMITED TO THAT PARTICULAR BRANCH OF MEDICINE: WITHOUT THE ASTERISK. THAT HE IS ESPECIALLY INTERESTED IN, BUT DOES NOT LIMIT HIS PRACTICE TO. THAT BRANCH. THIS INFORMATION CONCERNINC SPECIALTY IS BASED ON PERSONAL DATA FURNISHED BY THE PHYSICIAN AND IS NOT VERIFIABLE.

\section{DELAWARE}

BRIDGEVILLE, 939, SUSSEX

CAHALL, IALRENCE U. (L'6l)-I'a.2, $96^{\circ}$ : $\left(10^{\circ} 08\right)$.

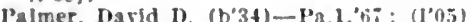

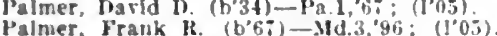

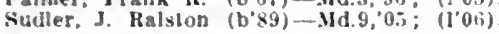

CAMDEN, 553, KENT

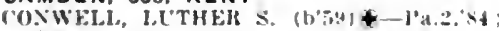

$\left.11^{\circ} 84\right)$.

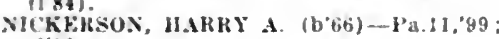
11'90).

CENTERVILLE (R.F.D., MONTCHANIN) 200. NEW CASTLE

CHOSSAN, JOHN WIIAARL (b'-1)-l'a.I, "94: (I'95).

CHESWOLD, 20I, KENT

inde, IIenry II. (b"i0)-MUl.6,9:; (1"05).

CHRISTIANA. 325, NEW CASTLE

l'eters, BenJ. B. (b'G2)-l'a.2.'B4; (I'S4).

CLAYMONT, 250, NEW CASTLE

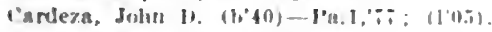

CLAYTON, 764, KENT

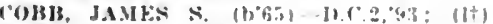

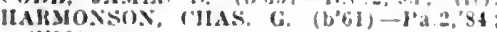

(1.00)

DAGSBORO, '176. SUSSEX

West, barl ("llfton (b'K5)-Jd.9,'l: (1'l')

DELAWARE BREAKWATER (LEWES P.O.) -. SUSSEX

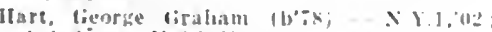

I.A.Sirr., I'N.J'H

DELAWARE CITY, I,132, NEW CASTLE

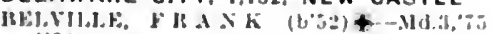
$(1 \div 6)$.

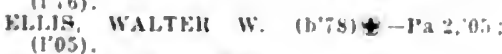

DELMAR, 530, SUSSEX

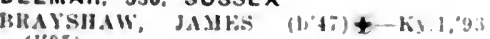
(1'0.3).

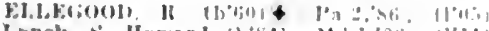

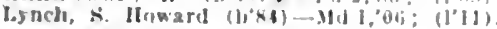
DOVER, 3,720, KENT

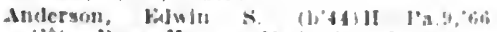
(11): I'res. Itomeo. Wod. Soc, Exambindu

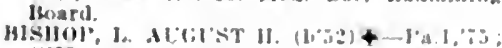

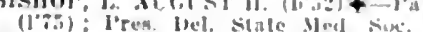

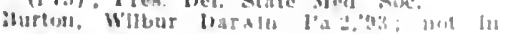

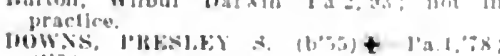
$(1 \% s)$.

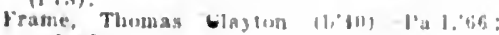
retires].

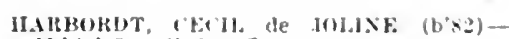

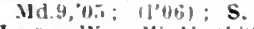

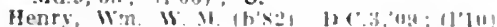

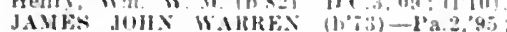
(I'0S) : OALR.

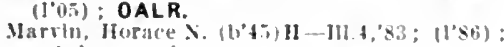
not in practice.

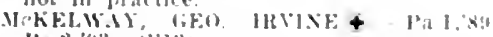

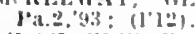

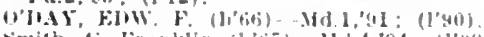

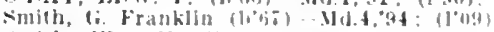

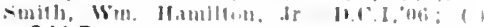
OALR.

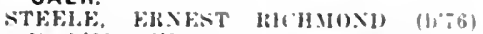
l'a.? 01 ; (1001)

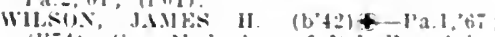

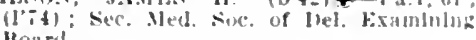
HOH 2 :!.

ELLENDALE, 216, SUSSEX

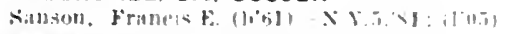

FARMINGTON, 300, KENT

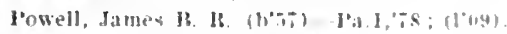

FARNHURST, 2I0, NEW CASTLE

HAVIK, T.IISUN H. (1)"6 (1'0x).

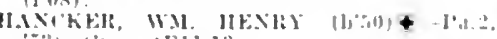
$\because 3)$ (1:i: (E.11.13)

FELTON, 451, KENT

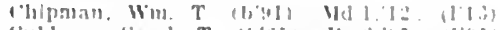

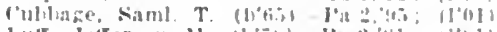

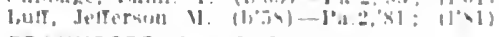

FRANKFORD, 395, SUSSEX

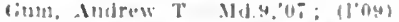

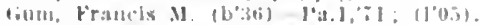

FREDERICA, 659, KENT

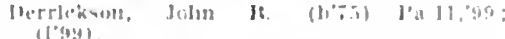

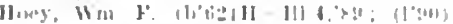

FT. DUPONT (DELAWARE CITY P.O). - NEW CASTLE

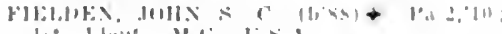

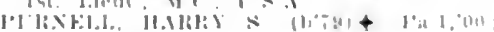
l'all. :1 1 , 1

GEORGETOWN, 1.109. SUSSEX

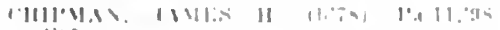
(1) (10)

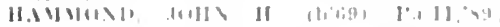

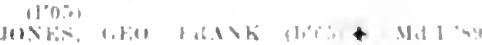

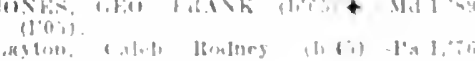

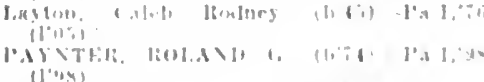

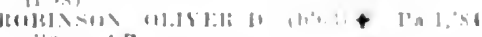
(1'0.) LA.

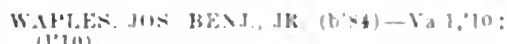

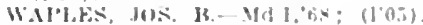

GREENWOOD, 362, SUSSEX

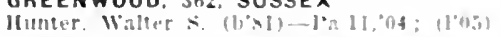

GUMBORO (R.F.D., MILLSBORO), 88, SUS.

SEX

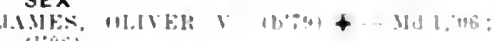
(]'oiti).

HARRINGTON, 1.500, KENT

liurke. Merrlt $\rightarrow ;\left(l^{\prime} 0 ;\right)$.

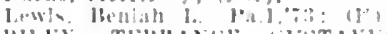

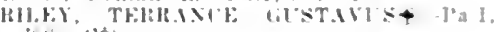

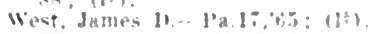

HOCKESSIN, 400. NEW CASTLE

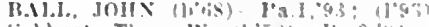

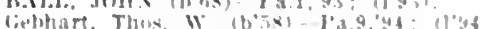

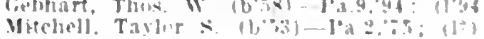

KENTON, 209, KENT

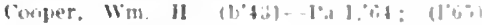

not in prontlet

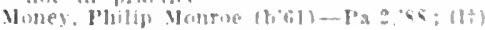

LAUREL, 2,166, SUSSEX

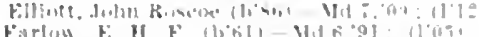

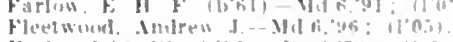

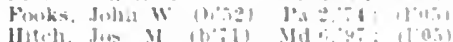

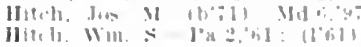

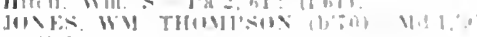

(1) $0 \div 1$

LEIPSIC (R.F.D., DOVET), 2JI, KENT

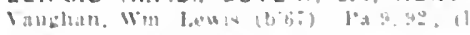

LEWES. 2,158, SUSSEX

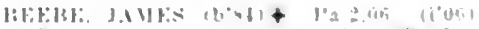

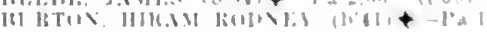

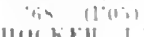

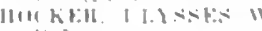

11

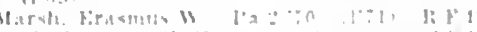

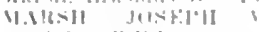

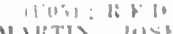

J11:illill

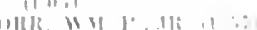

LINCOLN 367. SUSSEX

Hitrh th in 3 , t

LITTLE CRELK, 283, KENT

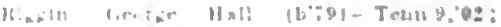

MAGNOLIA, 210, KENT

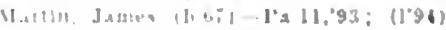


MARSHALLTON 450, NEW CASTLE

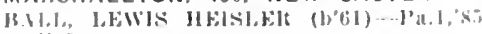
(1's.i)

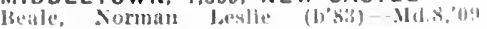

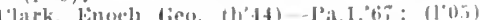

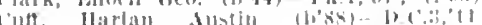
(1'11). W (1) a

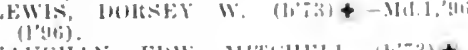

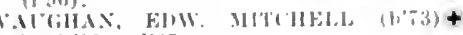

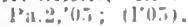

MILFORD, 2,603, SUSSEX

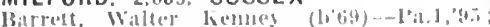

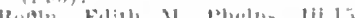

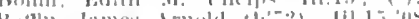

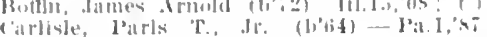
(1'si).

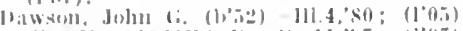

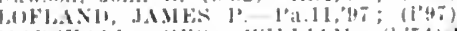

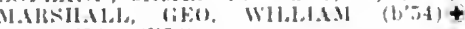
l'a.:" 26 ; $(176)$.

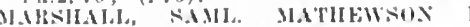

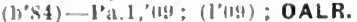

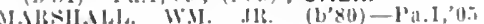
$(1,1,1)$. (1)

Iratt, John J,ynn--1'a.:2,44; (1)

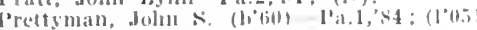

MILLSBORO, 451, SUSSEX

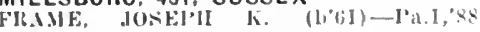
$(1005)$.

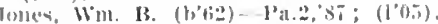

MILLVILLE, 193, SUSSEX

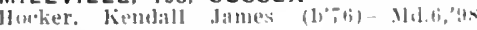
(1) 13$)$.

MILTON, 1,038, SUSSEX

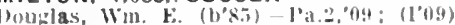

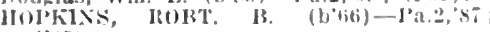

(l'11,i).

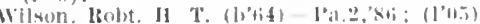

MONTCHANIN, 128, NEW CASTLE

Winds, Wm. Wilson (b'SI)-1'a.11,'9; (1'11): 1R.1.D. 1.

NEWARK, 1,913, NEW CASTLE

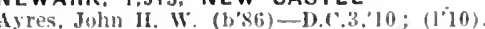

Ayres, John II. W. (b'86)-D.('3.'l0; (1'10).

BIAKE, (IIAS. HEXRY (b'iti) \&-IId.b.

liLLOCK, i

i:-; (1,7it).

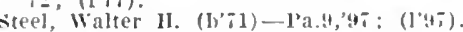

NEW CASTLE, 3,35I, NEW CASTLE

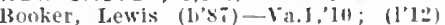

Hoth. Robt. Ray" (b'75) l'a.9,"n!); (1'09) OALR.

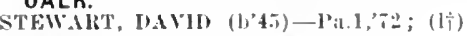

NEWPORT, 722, NEW CASTLE

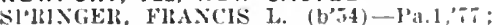

ODESSA, 585, NEW CASTLE

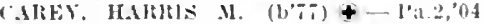

(1'114): (Fi13)

(')

Woods, walter $1 .\left(b^{\prime} 54\right)-1$ a.2, 6 ; not in practlee.

PORTERS, 40, NEW CASTLE

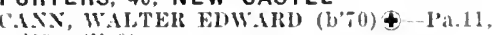
og; $\left(1^{\prime} 49\right)$.

REHOBOTH BEACH, 327, SUSSEX

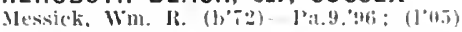

ROXANA, 155, SUSSEX

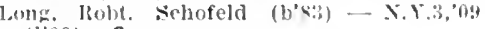
(l'0i) : G.

SEAFORD, 2,108, SUSSEX

Carter, Chas. H.-Md.6,'y5; (l'05)

Collins, stacy B.-Pil.2, íb; (帝)

HAINES, WM. FISHEI $\left(\right.$ b' $^{\prime}(62)+$-Ja.2, 88 ; (l'0.i).

Kuowles, Jacob C.-Md.3,'97'; (I'9s).
Janning, Ilarrison Martin (b'89)-1.2.,12 ;

(1'12).
Shipley, Anna C. (b'6o)-Ild.5, 02 ; (1'03).

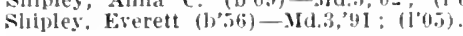

SELBYVILLE, 1,3\$2. SUSSEX

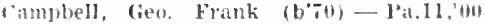

EYAXS. HORACE ELNER (b'82)-Pa.2,05;

SMYRNA, 1,843, KENT

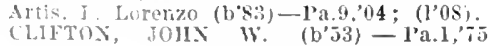

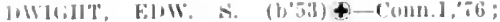

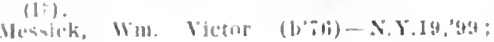

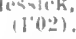

TOWNSEND, 494, NEW CASTLE

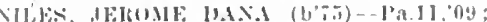
(1'11); $\mathbf{O b}$

VIOLA, 187, KENT

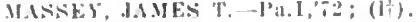

\section{WILMINGTON, 87,411, NEW CASTLE}

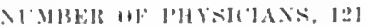

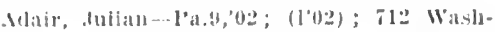
I11t toll sit.

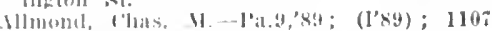
listimme sit.

Batllon, ('onwell H. (1001.) (1,75)-1'a.1,00) ;

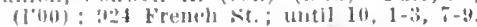

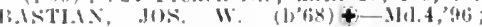

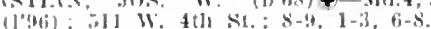

Inok, 1․ Inthony-.11d.1,00; (1'01); 1836 II. 4 th st.

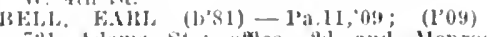
i:l Alams st.; thlee, 2⿺ and dlonroe Sis. : $8-4: 30,1-3,7-4$,

Be'mum, ('has, H. (J'tii) -1'a1.11,92; (1'11) 7:2 Villtever ive

Bircl. Wm. Eelwin. ir. (1,'sti) Mll.7,11: (): !ati West sil.; S.*

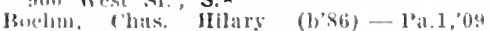

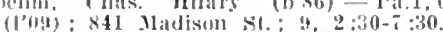

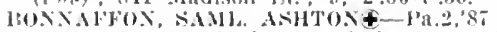

(1.12); Menber Met. Soc. of the State of

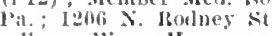

Bratley, Win. IIorace (b,4I) - Pa.2, this: (li) : not in joratiot"; 4 th and Rodney sts.

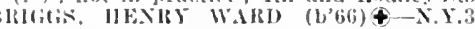
"94: (1)!h): l'res. Hed. Sor of bel. Examining Joard and see. Med. Council of leel. ; 1020 datekson st.; $i-4,1-3,7-8$.

B[CKMASTER, HARIEY (: (1)69)-Pa.1, "34; (1'94); 400 E. 4 th st.; $7-4,1-3,0-8$ ullock, Eita

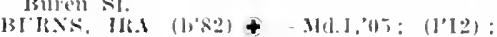

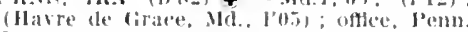
I.13. Station: $4-11,3-4$.

(armichat, (ieo. R.- l'a.9,'94; (1'94); 80 ; West sit. ; 8-4t, $2-3,7-8$

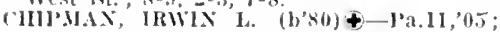

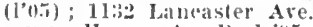

('leaver, llenry A.-l'a.1,95; (1'03); 1007 liest st.

(OOK, Tilus. D. (b'64) \& Pa.2, $94 ;(194)$;

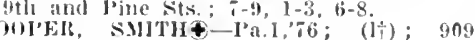

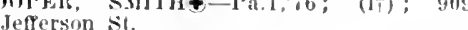

Jefferson st. West St.

'orkran, Mllard F--Md.1,84; (1†); 826 West st.

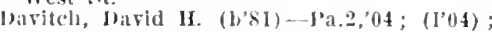
710 West st. : 8-4, 6-8

I'aly, F. IIarrey' (b'62)-1'a. I,'s5; (1十) ; 1221 Wasuington st.

The Lateour. Josephine White - 1'a,i, is $(1 \% 8) ; 706$ West st.

lougherty fierald i. $\left(b^{*} 80\right)$; Md.1.'0s. (l’09): isot Delaware Are.

IRAPEIR, J.MES A. (b, T4) $\$$-PA.I.'b8 (l'00): 1015 Washington St.; $2-3: 30$ $7-8 ; S$.

lburlum. (cecil B. (h's:)-Nel).ti,'19: not in practice: I0lo belaware Ave.

Edsall, Frank H. (I, 6:2)-1'1.1,85; not in pratice; $1307 \mathrm{~W}$. 13th st.

Follert. Saml. 1:-(col.)-H.C.3,91; (1†) 10th aud French Sits.

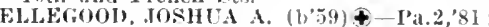
(l'81); $1 \% 03$ Franklin St, ; office, Elutut able Blig.; 9-1 : (B1,3)

Fil.EGOOL, ROBT. EIIIIS - Pa.2, (l'0) ; 408 belaware Ave.

EWING; SAMLEL RILEY (b'SI) - Md.9, 0 (1'07); 703 Washington st.

Fisher. John Lee (b'88)-I'a.9.'12; (l'12) : $102 \mathrm{~W}$ 18th St.; offlce, 830 West St. $8-4,1-3,7-8$.

Flinn, Irsine Monre (b'54)-Pa.2,'83, Pa.9 '8:; (1'83); 503 belaware dve.

Flin, Lewis $\mathbf{W}$, (b'58)-Pa.2,'83, Pa.9, 87 (1'83); 909 Washington st.; $7-9,1-3,6-8$ Flynn, Theobald Mathew Marie $\left(b^{\prime} ; 5\right)-$ Pa.1,11; (I'1:3); Sth and West sts.

FolREst, GEORGE W. K. (b'5)\&-Pa.1. (101 Jaekson st. ; 8-9, 1-3, 6-8.

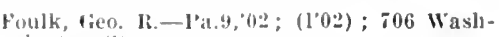
Ington st.

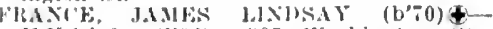
X.Y.1.42; (1'02); 80.5 Waslalngton St.

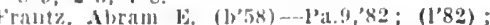

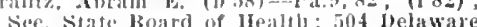

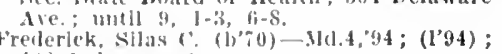
402 Inelaware die.

Prist, llarry dorrison (b'60) - Ja.2,'89; (l'in); sth and spruce sts.; unilil 9 , $1-2$. 6 ; -8.

(I'ty) in I Witehell (b'65) - l'a.9,'98;

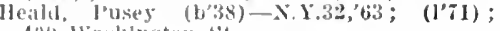
4041 Waslington st.

Holzman, Nark 13. (1)'82)-1'a.11,04; (1'12); $803 \leqslant$ J Jroome st.

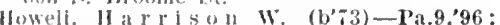
(1'4, s) : Sec. Honeo). Med, Soc. Examining Brara; $8 \geq 4$ Washlington st

lluglnes ("hatles W. (b'6i1) H-0.13,'93; (1'i1); 417 W. 81h st. ; untll 9, 2-3, 6-8.

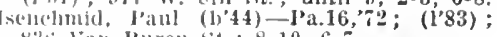
s.3ti Van Buren sit.; 8-10,6-7.

Jonkins, Bernard A. (b'85) - Md.3,09; (1'101; 2028 Market st.; $7-8,2-3,7-8$.

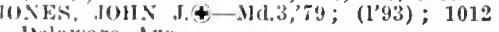
llelaware Are.

killey, slfreal 1.-Tenu.11,05; (1'05); 1307 linpont st.

kilrkwoul, 'Thomas (b'88)-Pa.2,'12; (1'13).

kileinvlulier, Wm. (;. (b'70)-1'a.2,'93; (1'33); 703 Yan luren st.; 8-9. 2-3, 6-8.

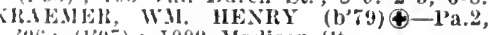
'ofi; $\left(10^{\prime}\right)$; 1009 Madison St.

Lentermath. forin Harvey (b'86)-1'a.1,08; (l'os) ; $81 \%$ Washington St.

linu, Willis (b'87)-MlI.1,'11; (l'13); 624 Franklin st. ; $5-8,1-3,6-8$.

L, inkens, J. P'aul (b'56)-1'a.9,78; (1) : \$11 Washington st

Ictolley, bant. I. (b'68)—.Id.3,'89; (l'89);

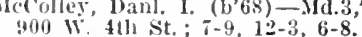

MCELF.TTHIK, iEO, C. (b'82)-Md.4, 10 ; (i'II) ; 81: W. 4th st.

MeEntee, Jiernard Jos. (b'86)-Pa.1,'11; (1'1"); 811 West St.

MKKIS, RHAl JENNINGS (b'43)-N.Y.10, 'tiT: (l'ti5); Broome and Chestnut Sts.; $4-1,3-7 ;(B 5)$.

Merrell, Alicert $(1,43)$-.Jo.10,75; retired; 917 dillun Ave.

Miller, Herman ș. (b'89)-Nd.3,'11; (l'11);

10 th and King Sts.; $10: 30,2: 30-7: 30$.

Miller, William 1'. (b'67)-Nid.3,87; (lit) : Millikin Poplar Sts.

lillikin, Thomas N. (b'62) - Pa.1,93; (I'93); 8th and bupont Sts.; oftice, 1701 W. Sth Nt.; until $9,1-3,6-8$; D.

limpan, James H.-l'Pa.2,'89; (1'95); 806 Washington St.

Jorrison, Napoleon B.-Pa.2,57; (I†) ; 126 King st.

Moslage, Emily L. (b'88) - Neb.6,'12 ; not in practice; 1012 Delaware Are.

Iullin. John W.-H-Pa.9,'86; (1t); 918 West st.; 8-10, 2-3, 6-8.

Negendank, Egmont T.-1'a.9,87; (1'87); 1112 Washlugton St.

9stro, Joln (b'84)-IId.1,11; (l'11); 6th and l'ine sits.

Ostro, Nichael-Md.6,'99; (l'99) ; 529 E. 6 th st.; offlce, 6 th and Pine Sts.; 8-10, OSTRO, SOPHIE (b'84)-Pa.7,'11; (1'11) ; 4 (i) Washington St.; $8-10,2-4, \pi-8$.

Palmer, IIarry W. (b'75)-IId.9,00; (l'01): 8 th and West Sts.; $10-12,2-4,6-9$.

'ALIER, JOHN, JR. $\odot$-Pa.1,'82; (1*) ; 1900 Delaware Aye.

Patton. Harvey B. (b'81) H-Fa.11, 03 : (1'03); 601 Van Buren St.; until 10, I-3,

l'enrson, freo. Burton (b'69) - X.Y.3,97; (I')1); 405 West St.; until $9,1-3,6-8$; ALR.

Pennoek, Henry R. (b'80)-Pa.9,02: (1'02) 万08 W. $91 \mathrm{~h}$ St.; 8-9, 2-3, ;-8; 0.

l'ierce, Wm. C-Pa.1,88; (I'88); 914 Jefferson st.

I'ierson, Frank F. (b'69)-Pa.9,'91; (1'91); 601 Washington St.: $8-9: 30,1-3,7-8$.

Postles, Wilbur E.-Pa.9,04; $\left(1^{\prime} 04\right) ; 222 \pi$ Market St.

I'YLE, JOS. P. (1'60)\&-Pa.1,'83'; (I'84) ; 809 West St. ; 8-9, 2-3, 7-8. 


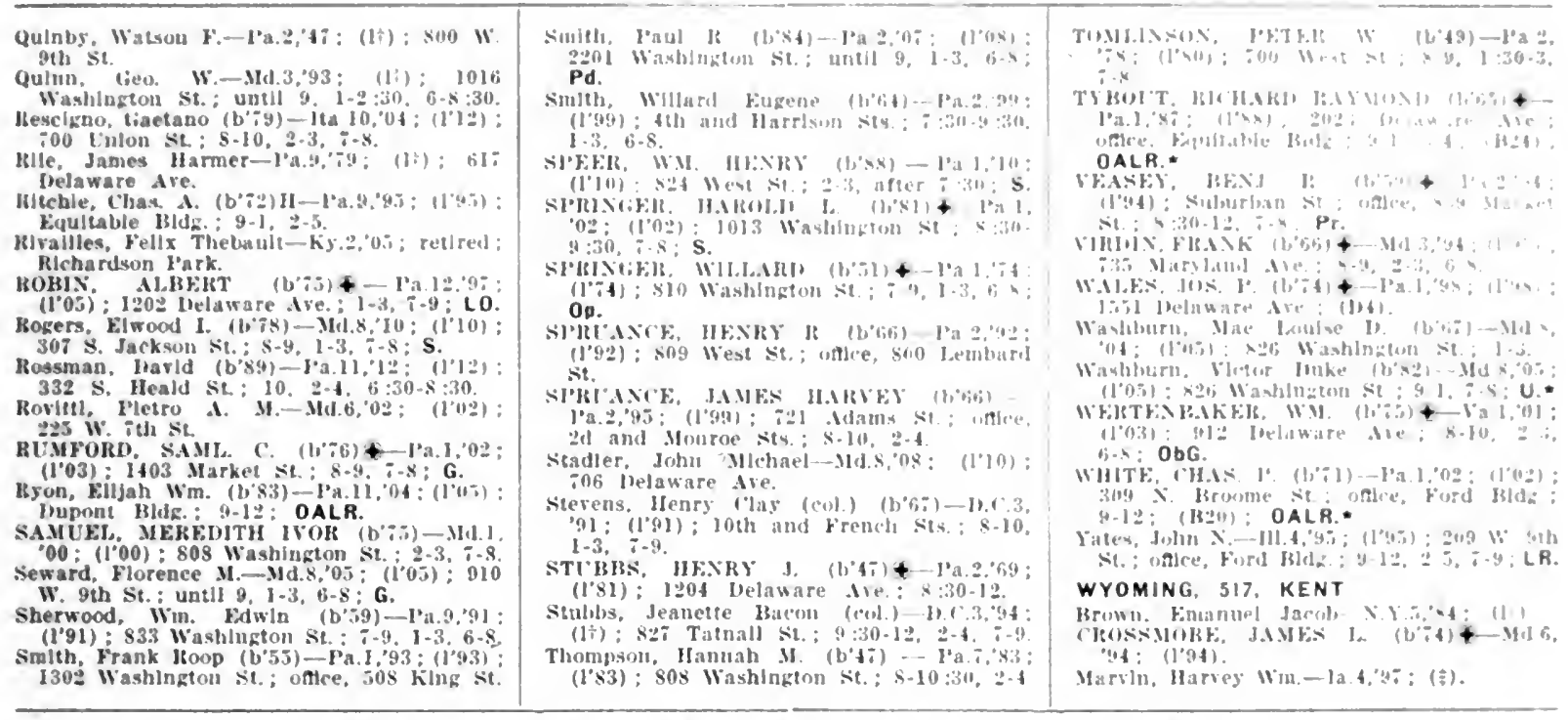

FOR KEY TO SPECIALTIES, ABBREVIATIONS, SYMBOLS, ETC., SEE PAGE 303

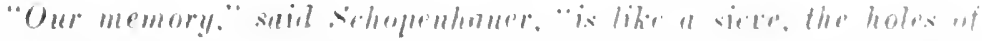
which in time get larger and larger." Is "le grow ohler we formet more easily. Constant refereme to the dibeter!n will fresten your mind and keep alive those mames and ablowses which aro an paxily forgoten. 


\section{DISTRICT OF COLUMBIA}

NoTE:--The teneral informatiun of this state includes: Medical law, Monrd of Medical Supervisors, Medieal sioclety, Official

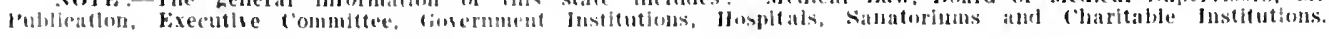

\section{DISTRICT OF COLUMBIA}

Population (1910 census) $\ldots \ldots \ldots . \ldots 331,069$

Number of Physicians.

1.421

Members District Association. Dec. 31. 1913 Area of Distriet in Square Miles...

\section{MEDICAL PRACTICE LAW OF THE
DISTRICT OF COLUMBIA}

\section{An Act}

To Iferulate the J'ractle of Melleine and surgery, to license Pligsleians and sur latling the Jrovlsions Thereof in

the Distrlet of t'olumbia.

J3e it ellartef by the Serate and Honse of

liepresentatires of the linited states of

America in compress assembled:

Section 1, (REATJOX OF BOAJu: That there shall be, and is herehy, created a Boit rd of Medical Supervisors of the listriet of Columbia, which shall consist of the presidents of the three boards of medical persons, not physieias one of whom stiall persons. not physielans, one of whom shall be learned in the linw, to be appointed by bla, each for a period of three yeurs, or until his suceessor is appointed: Prorifled. That not more than two members of the board of superrisors shall be adherents of any one system of medical practice: mol provided, further, that said commissioners muy remove, after due notice and hearing. any member of sald board for negleet of duty or other just callse, and that in catie of the death, resignation or renoval of any member the vaenney for the unexpired tern of said member shall be flled in the same manner as other appointments are made.

sec. 2. OlinaNIZATION: That the said Boird of Medieal Supervisors shatl elect it president, a vice-president, and a secretary sald boari shall make, subject to the ap. proval of the commissioners of the llistrict of columbia, such requations as may he necessirs to carrs into effect the provisions of this Act. Said board shall hold such meething as shall be necessary for the trans action of business. Said board shall superrise all examinations provided for in this Act. and shall lssue all licenses to practice medicine and surgery or midwifery in the District of Culumbia. Said hourd shall keep an officlal record of its meetings, also an ination for licenses to practice medicine and surrery in the District of Columbia said register shall show the name, age, place and duration of residence of each candidate, the time he or she has spent in medical study in or out of medical schools. and the names and locitions of all medical sehools which have granted said applicant any derree or certificate of attendance upon lectures in whether said applicant was rejected or licensed under this Act. Said register shall be prima facie eridence of all matters contained therein. The secretary aforesaid may be elected by said board from others than its own nembers; said seeretary shall also aet own members; said seeretary shall also aet inty the reunired by the Commissioners of the listrict of Columbia; sald seeretary shall have the power to administer oaths upon such haters as pertain to the business of said toral: said seeretary shall mail to the address of encl applicant a notice of the seven days tefore the examination, and at
Ionger perind if resuested by the applicatht ut the time of makitiz applicatlon.

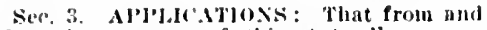
after the pastage of this Act all persons desiring to practice medicine and surgery il desiring to practice medicine ind surgery in coimulua shall apply to sald Board of Medical supervisors for a license to to so. Applicants shall submit to examluation upon the following named branches, to-wit Anatomy, physiology, chemistry, pathology, materia medica and therapentics, hyclene. histology, practice of medicine, surgery, obstetries and gynecolowy, disenses of the eyc and the ear, medical jurisprudence, and such other branches as said board shall deen atvisable. Falch applieant shall be deem atvisable. Fath applieant shall be rertifled by said board for examination as speedily as posslble to the board of medicat examiners whose members are adherents to
the system of mediclne whieh said applicant desires to practice; but sall board shall not eertify for examination any applicant until satisfictory proof is furnished that he or she is of Lood moral character and orer twenty-one years of age. nor until he or she has bresented a diploma conferring upou liim or her the degree of doctor of medicine. issued by some medient college authorized hy law to confer such degree: I'rovided. hy law to confer such degree: Provided, Thas said diploma, if lssued prior to July 1 , 1898 , shall be aecompanied by satisfactory
evidence that sald applicant has studied mediclne and surgery for not less than three years prior to the issue thereof, and if issued sulsequent to June 30,1898 , shall be accompanied by satlsfactory evidence that the applicant has studied medicine and stirfery for not less than four years prior to the issue of said diploma. Ali examinatlons shall be both theoretical and practical, and of sufficient sererity to test a candidat
fitness to practlce medicine and surgery.

Sec. 4. FEEs: That said application for a license to practice medieine and surgery in the listrict of columbia shall be made to the secretary of the sait Board of Medieal Superrisors upon a form preseribed by said board, and shail be accompanied by a fee hands of said secletary not less than two weeks before the day set for examination. weeks before the day set for examination. refusil to furnish any of the information ralled for or for other irregularity. All alled for or for other irregularlty. All secresary.

sec: 5. THLEE BOARDS PROVIUEI Folk: That immediately after the passatye of this Act the commissioners of the listrict of columbia shall appoint three boards of medical examinel's, one to be known as the
Buard of Medical Examiners of the District of tolumbia and to be composed of fire physictans in good standing, adberents to the regular systeni of medical practice; one to be known as the Board of Homeopathic Vedical Eximluers of the District of $\mathrm{Co}$ lumbia and to be composed of flve physieians in food standing, adberents to the homeopathic system of medical practice, to be sefected from a list of not less than ten names, submitted by a majority rote at some regalar meeting of the Washington Homeopathic Medical soriety, and one to be known as the Board of Eclectic Medieal Examiners of the District of Columbia, to be composed of five physicians in kood standing, adherents of the ecleetic system of medical practice, to be selected from a list of not less
than ten names, submitted by a majority than ten names, submitted by a majority Medical Society of the Distriet of Columbia. of the niembers of each board first appointed one shall be appointed to serve one year, two years, and thereafter each nember of each hoard slatl he afuointed to serve three vears, or until his sucressor is appointed: jrovided, That no member of either of suld bractice of medicine and surgery ln the bistrict of Columbia for less than flve years at the the of his appolntment: And provided further, That in event of the fallure of the of the Filectic. Medical Society of the Dlsof the Filectic Medical Society of the District of Colunibia, after fifteen days notice by the Commissloners of the listrict of sald, said Commissioners may appoint the members of the Board of Homeopathle Medical Examiners or of the Board of Eclectic Medleal Examiners without restriction as to nomination by the society in default; And provided further, That sald Commissloners Inay at any time remove any member of neglect of duty or other just cause, and that in case of the death, resignation or removal in case of the death, resignation or removal of any member the racancy for the unexthe same manner as other appointments are made.

Sec. 6. ORGANIZATION: That each member of said Boards of Medical Examlners of the District of Columbla shall, before
entering on the dlscharge of his duties, take entering on the dlscharge of his duties, take an oath to administer fairly and impartially the provisions of this Act. Each board shall
elect from its own members a president and secretary. Eael board shall hold a meeting for examination in the city of Washington oil the second Tuesday in January, April, July and oetober of each year, and continue so long as may be necessary to examine all applicants, and other meetings shall be held at such times as the Board of Medical hupervisors shitl direct. Each of said hoards shall cxamine, at the meetling Immediately following the receipt of the proper pervisurs, all applicants for lieenses to prac-
tiee medicine and surgery in the Distrlct of columbia so certified.

see. 7. Examinatons: That the several Boards of Medical Examiners shall, not less than one week prior to each examination, submit to the Board of Medical sujerrisors of the District of Columbia questions for thorough examinations in anatomy, physiologs, chemistry, pathology, materia medica and therapeutics, hygiene, bistology, practice of medicine, surgery, obstetries and gyneenlogy, diseases of the eye and the ear. medical jurisprudence and such other branches as said Board of Nedical Supertisors so submitted said Board of Medical tions so submitted said Board of Medical each examination, and such questions shall be the same for all candidates. except that be the same for all candidates, except that in the departments of therapeutics, practice tions shall be in harmony with the system of medicine selected by the candidate. Said examinations shall be conducted orally and in writing, In accordance with the rules and regulations preseribed by the Board of Medical supervisors, and shall embrace the subjects as stated in Section 3 of this Act. An official report of the result of each examination, signed by the president and the secretary and each acting member of the Board of Medical Examiners conducting such examination, slating the average attained bv each candidate in eaeh branch, the genera arerage, and the result of the examination, whether successful or unsuccessful, shall be transmitted to the Board of Medical Superrisors within fifteen days from the date of such examination. Said reports shall embrace all the examination papers, questions
and answers thereto. All such examination 
payers whall be kept for reference and in spec:lell for a periual of nut less than tlve JeAls.

sec 8 Jacesst: That if in the opit lon of a majorty of the buard of Bedical sitpervisors, after a careful examination uf the report of the Loard of Medical Fxam Iners by whleh any appllesut was exsulued. sajd applicant has falrly and stlo censfully passed such exambatlon ds hers limbetore provlded for, the lloard of Med. lcat supervlsors of tho fistrlet of umbla shall, as sim thereafter as pissthic. lasue to him a license slanem by the presi dent and the secretary of sald Mard anI attested by the seal of the listrles if Columbla. wlileh llewse shall entitle sate appllcant, after it is resistered as hereincery in the Wlstrlet of Columbia. NI lcenses Issued by sald boand shall lie num iered consecutirely, and a rexister shnll be kept by the secretary whowlng the number if each issue. date of Isxthe and to whom issued.

sec. 8a. IJCFisf: WITIIULT FXIM NATION: That the lloarl of Metleal supervisors of the Iistrlct of Columbia be and is hereby, authorlzed and directel to icense to practice medicine and surgery in sald bistrfet, wlthout examinatlon, any ap pllcant for such flcense who has beten ellcaged in the practlce of medleine and surgery in any other jurisdiction, whether a state, territory or Insular possesslon of the linited states, or a forelon couniry, subject to the following conditlons:

(a) No appllcant shall be llcensed who is not of good moral character and iree frou mental defects and drup hablts llable ti Interfere with the proper practlce of medlcine and surgers.

(b) Nor who, at the tlme of maklug appllcation. and for not less than tro years prior to the date thereof, has not been law fully authrlzed to practice mediene and

surgers, and actualls engaged in such prac
lce. in the jurlsdlction wherein be resldes

(c) Nor unless the applleant acculirel the right to practlce medlclue and surpery in such jurlsdictlon under coirditions equiva. to comply in order then tis hare practlced to comply in order then th hare practices Columbla

(d) Sor unless the jurisliction, by rirtue of whose license the applleant sceks exemption from examination in the lyistrict of Columbla, grants to licentiates of the Buard of Medical Sulvervisors of salil blstrict priflleges ediulralent to these whlch the applcants seek:

"(e) Xor untll the applleant has pald to the Hoard of Medleal supervisors afuresald such tee as may te fixed and reyuired by the requlations of said hoard, but not suore than the fee charced under simllar circum. atances by the jurisdletlon lig rirtue of whose license the appllestit seehs exemptlom frome llcerse the

"And satd linari of Medleal supervinots I* further authorlyed and directed to losue In faror of lis IJeentlates surb certifledies. If any, as may be recesisary to cuable such llcentlate, without cxamination, to obtinin licenses to practice medlcine and surgety in other jurtudletlonx, and 11 collen't for the lssue of such certiftrites surh fers as nus ive necessary to thefras the post of lomuling the anase and to towe such poes for that purpone.

"And sala Hoard of Medical siupervisury Is further authorlyed to dentermine all mat

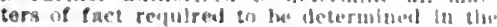

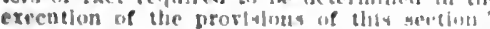

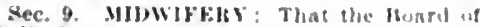
Meslleal supervisurs of the lolustet of l'a. Iumbla whall make, subject to the aporoval

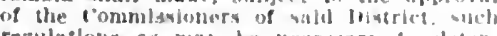

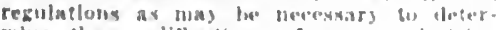

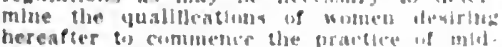
whery in the limetriot of ('olumbis. and whall Issue lieptases to sueth ay are. after exam charged for the examinutfug of mos abuli. cant eur muelo lleene a

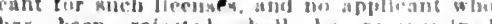

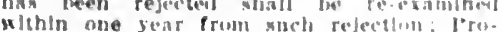

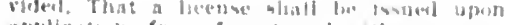

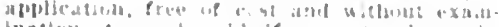

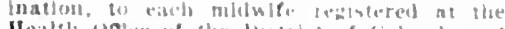

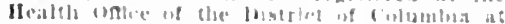
the time of the grassatge if thes Als

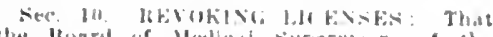
the Ibosed of Medlent surervastgy if the

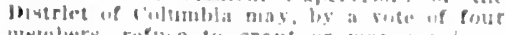
metubers. refuse to arant or mas revoke

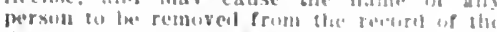
supreme cinet of the listringt if columblas and froun the resister of the llealid befto for any of the following cathe to- hit? enployment of fratod or dereption in basming employment of fratud or deroption in passing chronic inebrlety, the prover of torimint

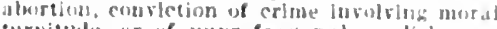
turpitule, or of morufessional ar dishonot nble conduce. lu romplatuts under this wh

thon the aceuset shall le furntshed with

ropy of the complatne rul gisen a hearing hefore sald board in person or by atborney. and wifuesses may the heard fur and cis trehalf of the soceused, and for and (it)

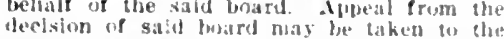
decision of sadid tward naty le taken to the and the de'dsion of sald court shall he Hal. sill board may at any time withen two years from the refusal or reveraton of a ilcense or the cancellation of regivtration under this section. by" a sote of four nemhers, Issue, whom exambation, a new license to the person so affocted, resturlus to latm or her all the rights and privileges of which lie or shi latil been deprived by sald bonat.

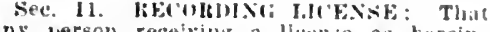
any lerson receiving a lidense as hereinbefore provided shall hare it retorded in the the Distrlet of (o)lunbia wlilutil three nonths from the dath of sild liconse, and the place from the date of sibl lichnse, and the place and date of record sha!l lue certitled therton
by sald clerk: and the buller of the license shall pay at ahe clerk of said court a fee of in cents for making llse recortl. I'lse hulder of sald license shinll. after the sime his leen recorded, exhlbit the same at the prostued fur blat purjose. his or her name and aldiress. Whenever al lleense is revoked by sald lioard of Medidil supervisirs the secretary therenf ahall repors that fact in writhe to the clerk of sald (court and to the

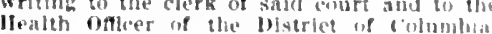

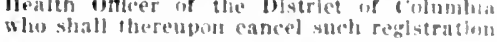

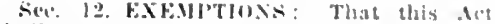

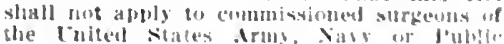
llealth sirvice, anr to regularly libensed pllysicians and surperans In atctual comsublat chen from other states or terriburles, hor to regularly livenual physholins and suraten actuslly called from wher siates or terr:

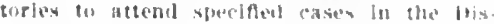
triet of colunblial. nor tes the treaturent if

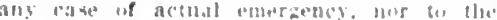

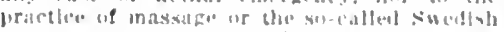

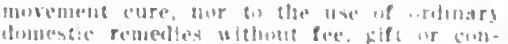

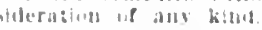

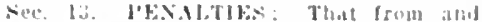

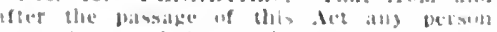

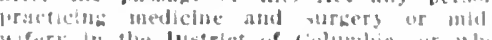
wifery in the lostriet of colutalia, or wh

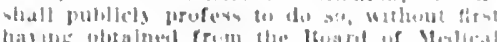

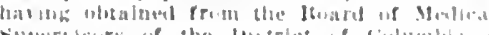

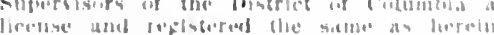

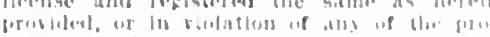

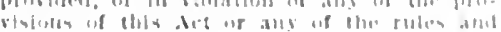

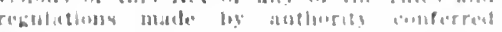

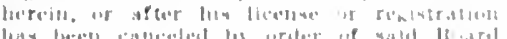

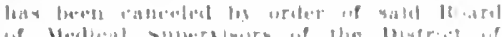

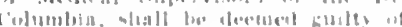

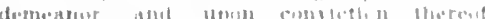

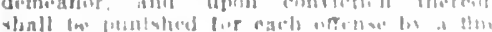

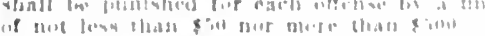

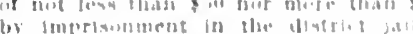
perioml of nut last ilasi ton

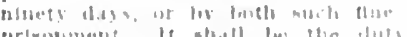

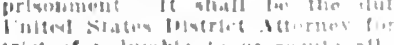

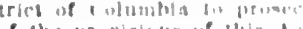

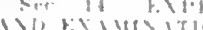

TESTISIIS

if the it warelat thell lie

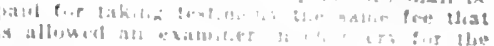

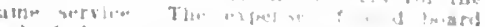

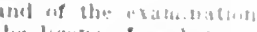

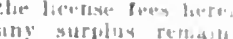

inine of taid

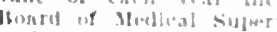

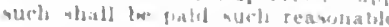

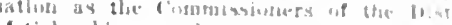

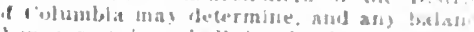
then remaining shall twe dir.tens among $11:$

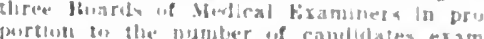

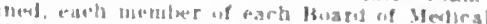

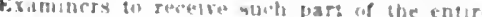

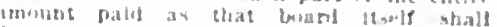
determine.

Ne' 15 WENTISTRY: That nuthe in this are slatll be entutrued to confsict with revulation of the pramtice it

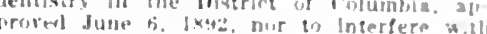
graduates of nidndard lental collesed resto tered under the provlalcons of sald art. In the extrotse of their prifexslon to the exten and within the linit of the curpiculurn of strch siandard dental collectes.

ser. 16. HEl'killa: That all acts of parte of acts. Reneral or epectal, not in

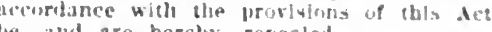
re, ind are hereby, repealed

Nipreved Jane 3,1 sion.

\section{BOARD OF MEDICAL SUPERVISORS OF} THE DISTRICT OF COLUMBIA

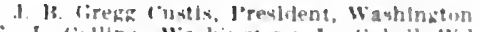
F. J. Collens, Washington: I. Calell Willlamston, Esid, Washington: Benjamin F. cerretar, Wanhingtom.

\section{MEDICAL SOCIETY OF THE DISTRICT} OF COLUMBIA

malers 1014

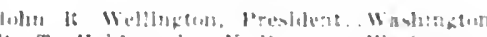

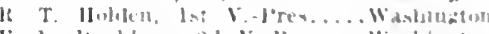

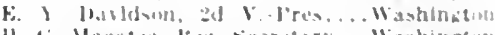

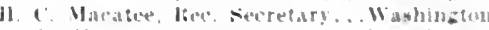

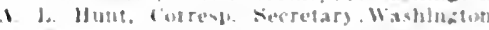

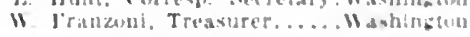

Official Publication

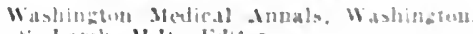
1 Lamb. Mts Holitur

Executive Committee

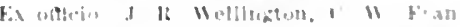

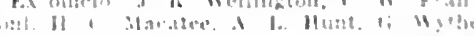
firod, II II Wiluter, f: A Hallen is li l..t!ul

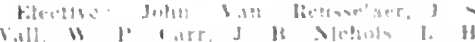

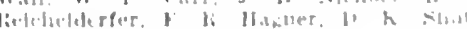

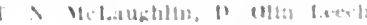

GOVERNMENT INSTITUTIONS

Washington
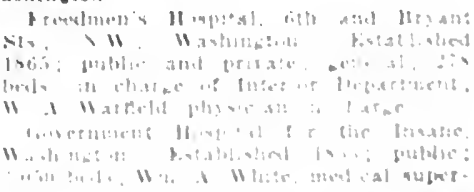

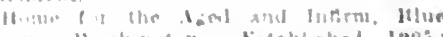
ristaluivin! boos

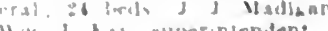

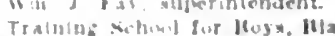

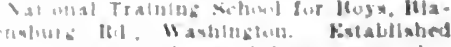

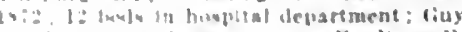

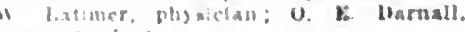
aineritutemitent 
siddlers' Home, Hock-reck-church lit. aud Poshur st. X.W., Wushingtou Es rabilshed Ix.s.; Brig. Gien. Gieo. H. Torney. surgen seneral.

Soldiers' Home Hospltai, Washingun. Estabilished 187t: prlrute: Holleral.

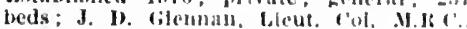
I'.s.A., medieal superintmulent.

Tinited states Marine Jospital. Washl ington. Isst. Surg. lich. W. 1. I'ettis, in cliarge

Inted States Navul Ilospltal foot ofth

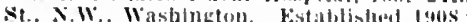

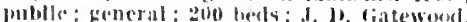
Y.s... medical director.

Waiter Ifeed Army liencral Jlospilat. (see 'Takoma lark, Mit.)

\section{HOSPITALS, SANATORIUMS AND CHAR ITABLE INSTITUTIONS}

\section{Washington}

Aged Women's Jome. I22. Wisconsin Are., N.W., Washington. Mrs. J. I, owens, manager.

Amerlean Reseue Workers Home for Women and chlfdren, 2.32, 3d st., N.w. Washingt on Establlsted 1904: nitrotic and alcholic; 11 beds; Horace Pnrtun. superintendent.

Assoclation for Works of Mercy, Wash. ington. Estabitshed 1ss,; private: maternity; 24 beds; L. M. Yeo, deaconess.

Baptíst Home, 324 $x$ st. X.W., Washington. Mrs. Sarah B. l'hllip, superintendent.

IBruen Home, 3300 o st., X.W.. Washington. Fstabilshed 1sit: $1 \mathrm{~W}$. I'. Reeres, physician in charge; Mrs. Eilzabeth $k$. physician in charge;
Fleck. superintendent.

Celitral Dispensary and Emergency Hospital, 15th and D St... X.W.. Washington. Estabtished $18 \% 1$; public and private ; renerat; 40 beds; Harry $s$. Lewis, medlcai superintendent.

Children's Country Home. Girall Rd. Washington. Established 1sss; prirate; for convalescent from non-contagious diseases; Reba J. Taytor, k.X., in charte.

Children's Hospital, If st. near $13 \mathrm{th}$. X.W. Washington. Established 15:0: public: I3: beds: Miss Margarel Woodworth, superintendent.

Columbia Hospltal for Women. 25th $\mathrm{st}$. and Pennsytrania Are., X.W., Washington. Established 1866 ; private and public; gynecological; 100 beds; J. O. Skinner, medieal superintendent.

Coiumbia Institution for the Deaf and numb, ith st. and Florida Are., X.E. Washington. is. Kerfoot Shute, attending, physician; Marj E. Schenck, matron.

Columbia Poixtechnic Institute for the Bind, 1808 H St., N.W., Washington.

Confederate Memorial IIome, 1322 Vermont Are., Washington.

District of Columbia Red Cross Day Camp, Washington. Established 190:" public; tuherculosis; 50 beds; Miss I. L. Strong, superintendent.

Eastern Dispensary and Casualty Hospital, 708 Massachusetts Are, N.E. Washington. Established 1888; public: 30 beds; Clapham P. King, resident physician; Wynona Brown, superintendent.

Edes Home, 30th and $N$ Sts., X.w. Washington. W. E. Worsiey, matron.

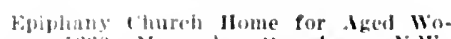

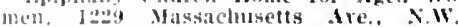
Wastingetul . It Shands, physician in rhariate.

$$
\text { Listopul bye. Ear and Throat Hospl- }
$$

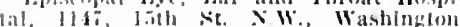
Fistablished is!a private: 82 beds: Mlise Filzal $\&$ Taylor. U.N., superintendent.

Eplscolal Home for chibren, Inacostia Washlngten. Establlshed 1845; puble ; lie heds; Mrs. Mary 1'. Wavenport, superintenrient.

Fiorence frittinton lope and Hetp Mission, 218, Bi st.. X.W., Washington. P'rlvate: maternity : 4t beds; Mrs. Flora II

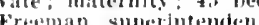

Friendiship fouse, $3 \pm 4$ Virginia Ave. S. F.. Wasingetol.

liallaudet cotlege, Washington. For the blinel.

Garfled Itemorial llospital, Fiorid: Are. opqosite loth St., N.W., Washing(on. Eistablished 18s4; private and free 1.0 bods; II. (C. Varrow, president of medical state. Jancler W Lindsia, chief resident physician; Miss (: M. Nevins, superintendent.

Cieorte Mauisby Memorial IIome, 230 C St. X.W., Washingtom. Itrs. Joanna I) Tyson, superintendent.

lieorgetown l'niversity lfospital, $x$ and sith sts. N.W.. Washtngton. P'vblic ane intrate: ino beds.

lieorge Washington Iniversity Hospital, 1333 if st., $\mathbf{N}$.., Wastington. Establlished 1898; privafe: general; 110 beds; I. Adolph kollings, resident physician? i. 1 . copping, superintendent.

fierman Orphan Asylum, liood Hoje Ra. Washington. Geo. K. Baier, attending physlotin; Carl Bergholz, superintendent. liome for Friendiess folored (irls, 1titi Euctid st., N.W., Washington, Alice $A$ Withis, matron.

Home for the Aged of the Little sisters of the Poor, 31 and $I$ Sts. S.E. Wash ington. Established 18i1; prtrate; 220 beds; John I. Repetti, phrsician in charge. Home for the Blind, $115 \mathrm{E}$ St., X.W. Washington. IRussell Main, physleian; Mrs. F. C. Fittings, matron.

Ifouse of the food Shepherd, Reservoir and 36 th Sts., X.W., Washington.

Industrial II ome School, 2525 Wisconsin

Are., N.W., Washington. Fstablished 1875; public; school; 140 beds; C. IV' Skinner, superintendent.

I)r. J. R. Francis Sanatorium, Washngton.

Lenthall llome for Widows, : $9 t i$ and ( st.s., X.W., Washington. ils. il. $A$ Hodges, superintendent.

louise IIome, Massachusetts Are. and lith st., N.W., Washington. Miss Mary 1I. llodge, superintendent.

Lutheran Eye, Ear and Throat Infirmary, $14 t h$ and $x$ Sts. $N . W$. Washington. Extablisired I884, ere ear mose and throat; out-patients oniy; $W$. surgeon in charge.

Jasonic and Fastern Star Home, Blair kd., Washington. Charlotte E. Waite, inatron.

Methodist Ifome of the District of $\mathrm{Co}$ lumbia, 601 iI St., X.W., Washington. Established 1890; private; 54 beds; II Aima Jones, matron.

Misston Home, 326 John Marshall PI., $\mathrm{N}$ w., Waslington.
Nationai Iome for Destitute Colored Women and ('hildren, $34.88,8$ th si. N.W. Washington. Fstahlished 1863;90 beds: Mrs. Era Iood smilh. superintendent.

Natlonal Iomeopathic llospital, 2d and $\mathrm{s}$ sts. N.W. Washington. Estabished ISSI: pubilc and private; generat: io beds: T. I.. Machonald, surgeon; Laura I. Slee, R.X., suqerintendent.

Sitional lutiseran Ilome for the Aged, Sitition K, Washington. Established I895: for ated; 36 beds; Flora Uhler, superintendint.

Nortileru Dispensary and Fmergency fospital, 3121, 14th st., N.W., Washing toll. Established 1911; 4 beds; Lewis B. "liwmson, phystcian in charge.

l'reshyterian Home for the Aged, 14:0 If st. N.W., Wasinington.

p'rovitence Inspital, $2 d$ and $D$ Sts., S.E., Washington. Establisbed 1861 ; private; 335 beds; M. F. Cuthbert, chief of tafi.

Reform School for Girls, Little Falls and Conduit Rds., Washington. Mrs. Elizabeth Whitney, superiutendent.

Sibley llemortal Hospital, N. Capitol and rierce Sts., X.W., Washington Estabilished 1894: generai; 150 beds; Hev. Wm. H. Wilder, superintendent; Miss Fannie L. Hinmán, R.N., superintendent of nurses.

Springer Sanitarium, 50I G St., N.W., and 438 , th St., N.W., Washington. $\mathrm{N}$. springer, nedical manager.

St. Ann's Infant Asylum, 2300 K St. N.W., Washington. Established 1860; lying-ln hospital attached.

St. John's Orphanage, 1922 F St., N.W.,

Washington. St., X.W., Washington. Established 185. st. Vincent's Female Orphan Asylum, 4th St. and Central Are., N.E., Washington. Stoddard Baptist Oid Folks' Home, Hamiiton Rd., Washington. Established 1901; public; for colored people; 14 beds; Irs. Laura F. Queen, manager.

Tuberculosis Hospital of the Dlstrict of Columbia, Cishur st., near 14th St., N.W., washington. Estabilished 1908; public; tuberculosis; 120 beds; Board of 'Charities, in charge; Wm. D. Tewksbury, nedieaj superintendent.

Washington Asylum and Jail, 19th and C Sts., S.E., Washington. Public; general; 200 beds; D. Percy Hickling, visiting physician; L. F. Zinkhan, superintendent. Washington City Orphan Asylum, 14th and S Sts., N.W., Washington. Established 1812 ; children; 150 beds; $L$. W. Glazebrooke and E. L. Mason, physicians; IIrs II. L. Squires, superintendent.

Washington Eve, Ear and Throat Hospital, No. 4 lowa Circle, Washington. Established 1913; public; charitable; 12 beds; M. IIoynihan, superlntendent.

Washington Home for Foundlings, is 15 , 15th St., X.W., Washington. 50 beds: Z. T. Sowers, physician, president of board of directors.

Washington Home for Incurables, $32 \mathrm{~d}$ and $S$ Sts., N.W. Washington. Established 1889 ; private; 60 beds; Clarence .1 . Dollman, physician in charge; Katherine F. Campbell, superintendent

Washington (D. C.) Sanitarium, No. 2, lowa Circle, City Branch. Estabilished 1905 ; prirate; medical ; 12 beds; Ilargaret R. Stewart, physician in charge. (See Takoma Park, IId.) 


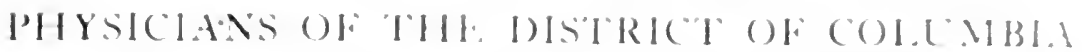

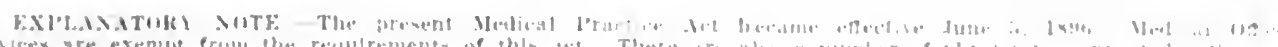

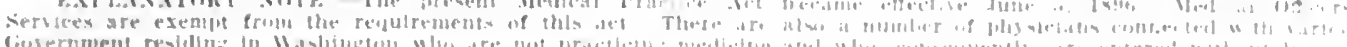

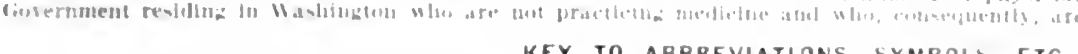

Xames In capltals sigubl mamberahip is the county simetis

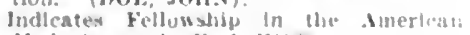
Med. Asen. I Hor. Jull. (bis) Vear of blrtls. II. homeopath; k. eclectle; I' M, fhyst.

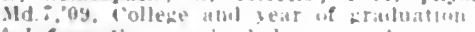
O Information recelvel deres nof sluow prial uatton.

S.-Surgeon.

Ob. Otastetrician.

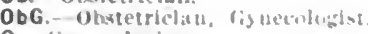

G.--iynecologis?.

Or. - Wrthopedist.

Pr.--I'roetuloglst.

Op.-Ophthalmologlst.

A.- - Aurtst

LR.-1anrygologlst, Ihluculoglst.

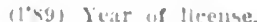

(2) In britchec leepere

lall

low bear of liractice

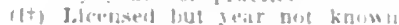

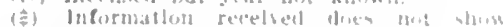
Hicense.

1 s... Inized states orms

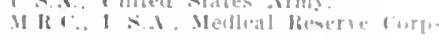

SPECIALTIES ARE INDICATED AS FOLLOWS

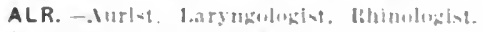

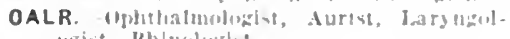
egiat, Ithlnoluglat.

U. I"rolengist.

D. Dermatuluintot.

Pd. Jendiatrise.

N. centuldemlet.

P. - Intoldiatrive

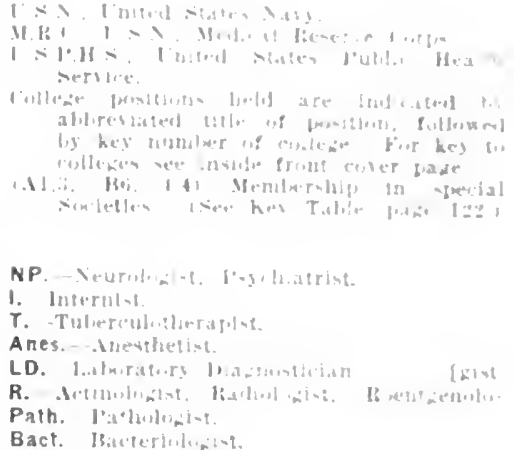

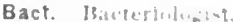

WHEN THE ABBREVIATION REPRESENTING A SPECIALTY IS FOLLOWED BY AN ASTERISK ( IT INDICATES THAT THE PHYSICIAN CLAIMS HIS PRACTICE IS LIMITED TO THAT PARTICULAR BRANCH OF MEDICINE: WITHOUT THE ASTERISK. THAT HE IS ESPECIALLY INTERESTED IN. BUT DOES NOT LIMIT HIS PRACTICE TO, THAT BRANCH. THIS INFORMATION CONCERNING SPECIALTY IS BASED ON PERSONAL OATA FURNISHED BY THE PHYSICIAN AND IS NOT VERIFIABLE.

\section{DISTRICT OF COLUMBIA}

WASHINGTON, 218,196, 0. C.

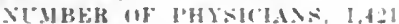

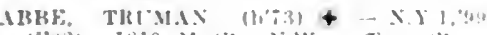

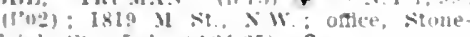

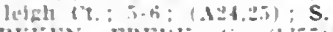

ABEKEX, FRblik 1; (b") + Mn:200

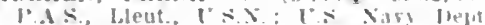

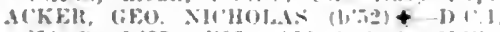

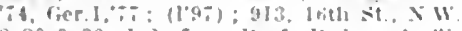

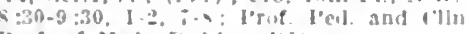
prof of Med., ri, i. : 1111;

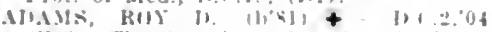

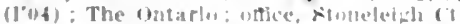

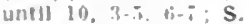

MIMS, SIMTEl, silliblt (b)

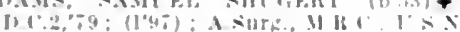

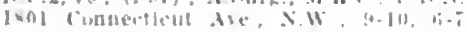

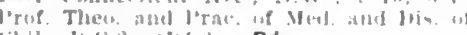

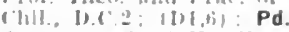

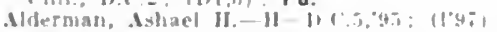

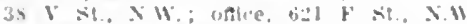

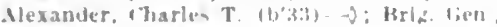

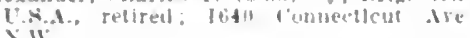

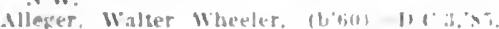

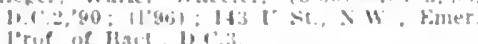
l'rut of Hail.. I) '.3.3.

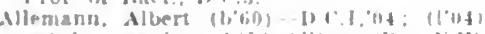

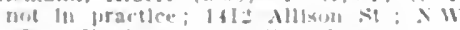
unte, V's Srmy Monlleal Mureism

Allen, Chas A $(1,4,1)-1,1,3,10 ; 11,11 i$ 1516 Virw Jerwey die I II

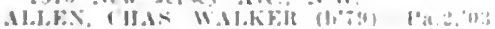

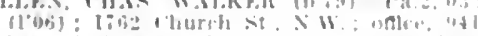

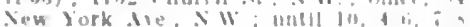

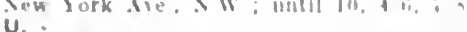
U.

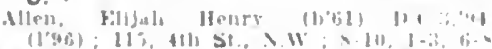

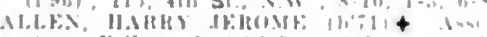

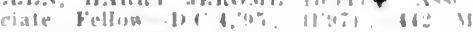

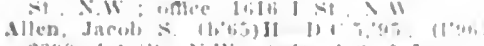

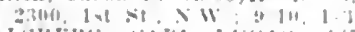

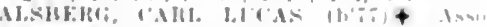

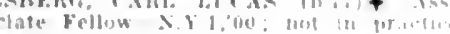
inate fellow $x$, ith 1 is

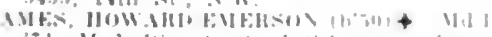

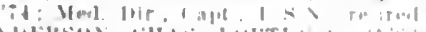

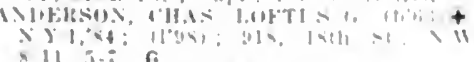
a $11,5,6$.

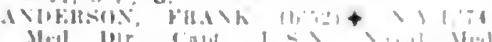

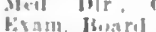

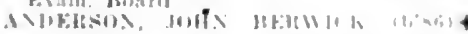

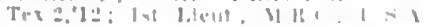

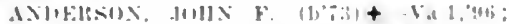

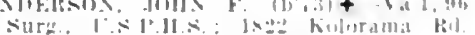

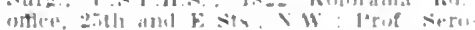

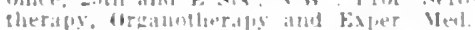
$1,1,5\left(1+i+k^{\prime 2}\right)$

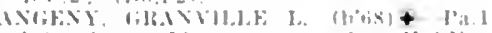
"4: Surg, Lieut. rommander, 1 "s.)

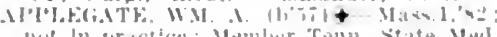

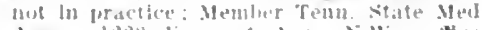

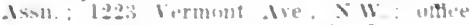

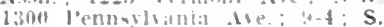

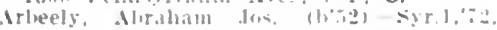

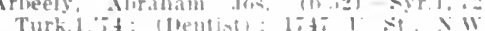

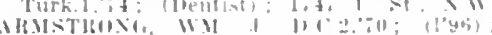

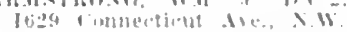

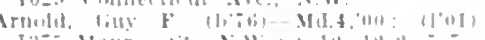

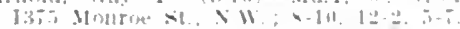

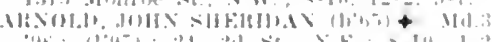

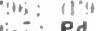

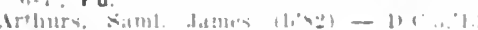
thition

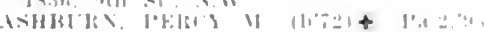

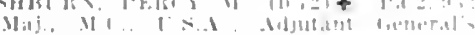

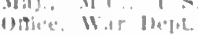

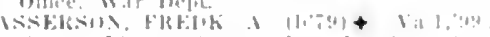

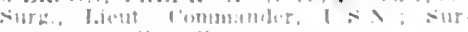

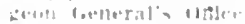

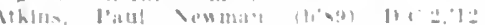
$110: 1: 1: 1: 1=$

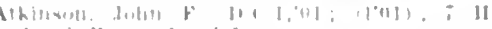

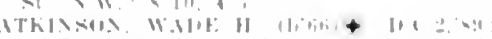

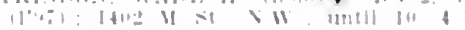

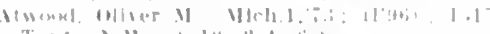
$7=1,11,11,24,1 ;=$

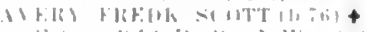

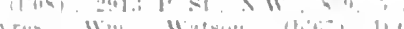

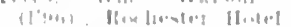

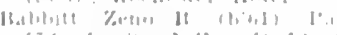

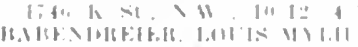

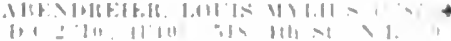

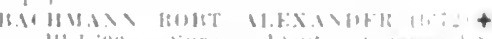

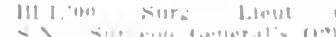

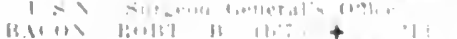

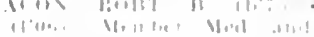

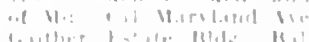

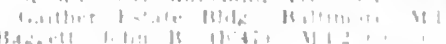

B.

3ile

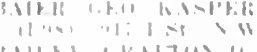

(111.1 1.16.11711 11 1

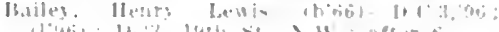

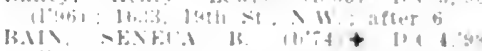

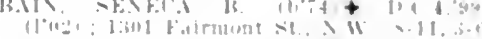

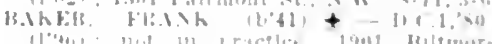

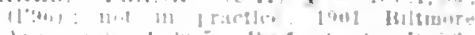

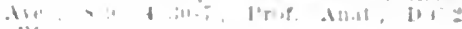
(1)

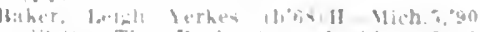

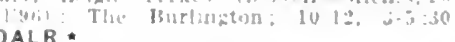

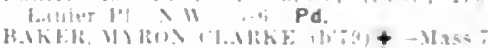

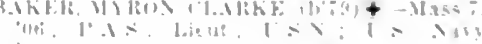

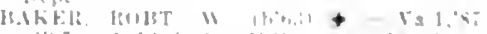
$1147,10101=1,111,11-10, \overrightarrow{0}$

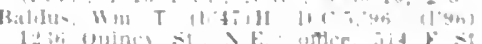

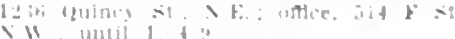

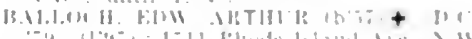

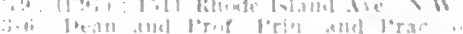

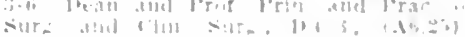

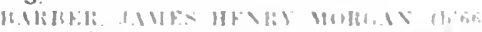

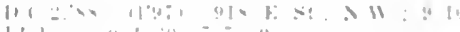

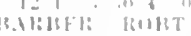

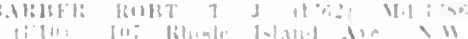

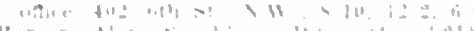

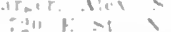

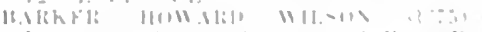

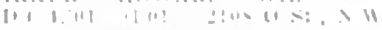

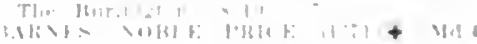

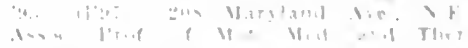

i,

i,

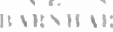

It $11,1:$

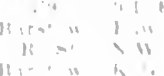

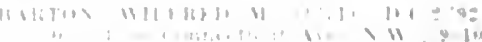

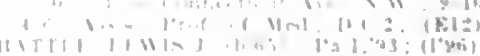

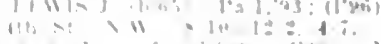

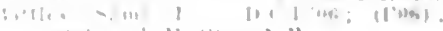




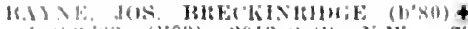

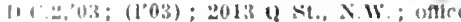
1141 cmnecticut Nre., X.W.; 8 I0, 2."

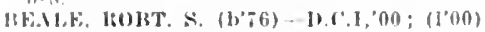

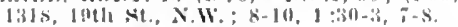

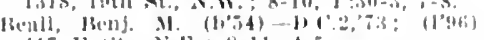
41 i 11 St. N.E.; $8-11,4-5$

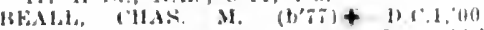
(103): The lienera; ofllee, $2635,14 t$ St., X.W.: $:-10,4: 30-7$.

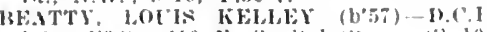

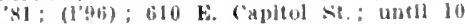

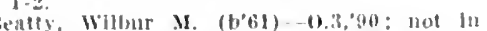

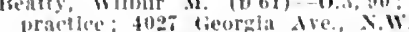

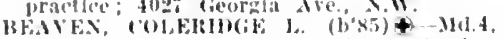

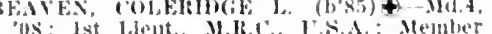

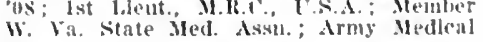
Sichool.

Beckley, Fugar It.-1).(c.3,97; (1'96); 527 I" sit., N.W.

leekloe, Arthir Eynon (b'85) - 1'a.l,'10 (1'10); A.surg, H.k... U....; $91 \%$ Isth st.. N.W

BEECHIN (WAS, HEE (b'81)\&-Mo.20 08: A.surg., lieut., I'A. S. F. Navy

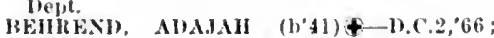
$(197) ; 1214 \mathrm{~K}$ St., N.W.; $8-10,1-2,5-7$

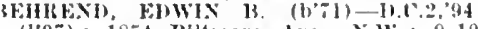

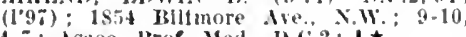

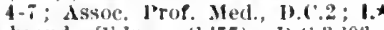

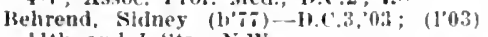
IIth and is sts., N.W

BFNETT, DBOHPHits $1 .$, .IR. (b'a) 2322, 19 th st. N.W. offlec, 1 th and i sts.; 9-12, 4-0; (1330); ALR.ћ

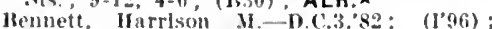
not In practice: 360 Eastern Are., rakoma Park.

Bennett, Ialtland Chas. (b'63)-D.c.3,93; (l'96); $2623,13 t h$ st., N.W.; $5-6$.

Bennit, Wm. W. (b'39)-11, (a, 31 ; (1'96): 1213,1 st St., S.F.; $8-10,2-4$.

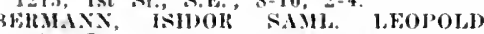
(b'4) 4 - lier 20,90 ; (1'9t); 2341 , I 8 th st., $N$. $;=1,4=t$, OALR. $*$

vard, Wm. A. (b'59)-1).C.4,94; (1'96); $17 \log ^{2}$,

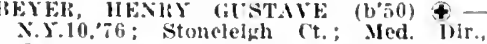
rapt., I.s.:. ; retired; surgeon General's

Biart, Vletor-Mo.1,76; Cajt., U.S.A. ; re= tired: Surgeon Gieneral's Offlce.

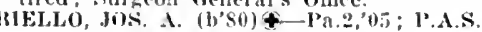
lleut., I.S.S.; Naval lospital.

Hoits, IOS. ROSIERS-D.C.1,07; (l'07) : 213, 11th St sit. $8=10,5-7$

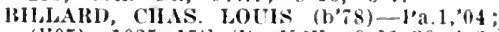
(1'05) ; 1025, 15th St., X. $15 . ; 9-11: 30,4-6 ;$ OAL

Mirdsail, Gregg Custis (b'8:) II-X.Y.9,04 (l'04); 1832 Kalorama lid. ; 8-9, $4: 36-6: 30$ LD.

HATWELL, DANL. T. (b'-4) $\$-D,(.1,00$; (105); 1325 Colunbia Rol., N.W.; 8-10,

ISIOCE, FKAXK I.EE (b'76)-D.C.2,01; (10I): 17th and I Sts., N.W.; 4-6; Op

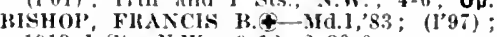
1913 i st., N.W.; 9-12, $2: 30-6$

IRISHOP, HARRY ALOSEILS (b.88) \&M.l.1,12; (1'12); 1913 I st.; N.‡

1BTTINo; ARVIL, W. - Ind.8.;00; () ; sit. S.

BIAIKWELL, FHWARD M. (i)'65) $\$$-Md.1, "90; Surg., Lient. Commander, U.S.S.: Burean of Mediclne and Surgery.

BlaAkWoon, NoRMA. J. (b'66) \&-Pa.2. 'S8; Med. Insp., Commander, U.S

Blaine, Robt. (f. (b'T)-D.C.2, 07 ; (1.07); $133 \mathrm{C}$ st.. s.E. : $8-10,5-7$

Blair, Jos. D.-D.C.3,95; (l’96) ; 309, lst St., s... ; until 10, after 6

Blike, levi C.D.C. 3,$98 ;(198) ; 40$ Rhode Island Ave., N.W

IBL.IKE, LOE'ISI II. (b'53) - D.C.1,93; (I'9(i); 40 Rhode island Are., N.W.;9-11,

BhAKITOXE, ILIAX CHEW (b's1)I.C.2.01: (l'06); 17 th and 1 Sts.; 9-11, Rliss. Chat Prof. Derm., D.C.2; U.^ 136 rolumbia lid., X.W.; $8-10,4: 30-6$.

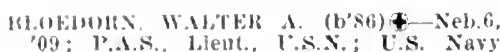

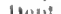

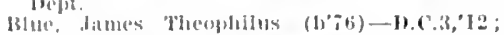
(1):3); 400 o' $\mathrm{Nt}$. N.W

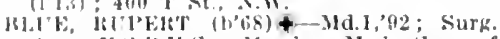
:ou. V.s.l'.11.s, ; Member Med. Soc. of the siate of rat, ; $180 \mathrm{~s}$ i sit., $\mathrm{N}$.

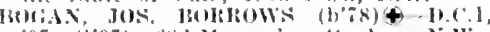
07 ; (lo0); thlt Massachusetts Ave. N.w. $8-10,4: 30-6: 200 ;$ Anes.

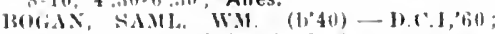
(1'90): The lackede: $8-10,6-8$.

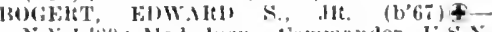

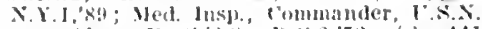

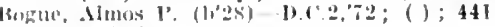
1) cus

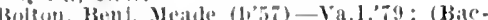
torlologlat); (Mcldan, Va) ; ontoe, 1523 1. St. N.W: (1)(i).

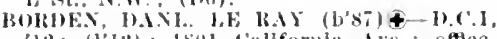

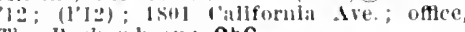
The lechambera: ObG

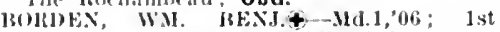

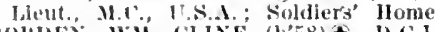

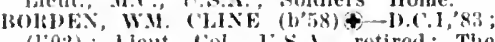
$(02)$; lifent. Fol., ...., retired: The

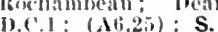

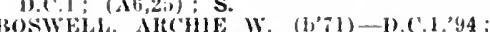
(1'(t): 0.2 Maryland Ave, X.F.; until

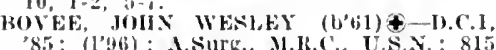

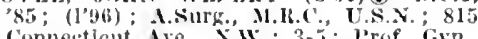
Connectleut Are. N.w; 3-5; Prof. Ciyn. $11.1 .1 ;(12,6,25,(3) ; \mathrm{S}$.

130WEx, WM. SIN(L.tIl $\left(\mathrm{b}^{\prime} 67\right)$ \$ Md.1, $88 ;(1346) ; 1339$ Commerticut dre, ; $8-9$ 5-6; (1il. prof. Olost., lo.t.1.

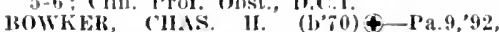
1). C. $^{\prime} 00$; (1) 02$) ; 1300$ Massachusetts Me., X.W. : : :

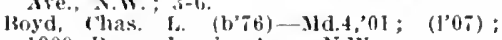
1909 Pennsylvania Are., N.w.

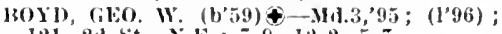
121,21 st., X.E. $;=9,12-2,5-7$

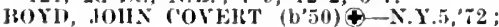
Met. Mir., ('apt., L.s.X., retired; 1621 , 22 (1 st., N.w.

BOYLE. "CORNELIL'S B. (b'64) -D-D.C.L, OYL; (IMT); Nlember Ifont. State Med. Assn.; 4113 Fessenden 1'l., \$.W.; $y-10$.

Boyle, Edw. Mayfleld (b'28)-D.(..3,02; (109); 704, lith St., N.E.; untli $10: 30$, $4-8: 30$

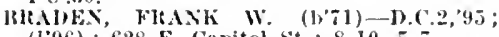
(196); 628 E. Capitol St. ; 8-10, 5-7

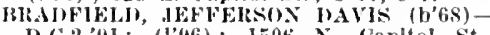
D.(.2,91; (1'96); 1506 X. (apltol St. $8: 30-9: 30,12: 20-1: 30,4: 30-6: 30$.

MAUY, ZAHOC MAVRIC (b'80)-D.C.1, 0.: (1'05) ; Kenilworth.

RRAISTED, WM. ('LALENTE (b'64) $4-$ N.. 1,86; Med. Insp., Commander i.s.:. : Surzeon tieneral's oftice.

BRANDEXBLIR, WIIBIR HENRY RIETZ (b'75)-I1.C.1,03; (1'03); 1416 ls St., N.W. ; $8-10,4-6$.

randt, Wm. Eugene-Ky.2,71, X.Y.10,7 (1000); 151 I l'ark lid., X.w.; after

Bratusun, los. H. (b'66) H-Nd.8,94; (I'96):

14:8 Massachmetts Ave., N.W.; 8-10, 4-6. recht, Nelson huval (b'85)-D.C.1,06; $\left(l^{\prime} 06\right) ; 422,14 t h$ st. : offlee, $609,22 d$ st. X.W: $8-10,12-1,4-7 ; U . \star$

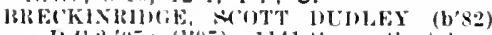
11.(2, $117 ;(107) ; 1141$ tonnecticut Are. x.w.; offlce, 1726 is si., X.11.;9-10,4-6; ObG. $\star$

Brenizer, (i. lilmer (b'64)-D.C.1,03 (103) ; 1332 I st., N.W ; 4-6.

Brent, ('larence Everett (b'85)-D.C.3,'10 (1'11) ; 1804 L. St., X.11; ; 8-10, 1-3, 6-8 BRICKEL, SA(Ks (b'86) U.C.1,12; (1'12); Washington Asyhm llospitul.

BRIGGA, JOHX BRAIOF(ORI, JR. (b'79) Id.t, 02; (1.04); $1628 \mathrm{~K}$ St., X.11.; 4-6; l'rof. of F'ath. and lsact., D.C.1.

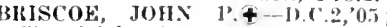

Stoneleigh it.

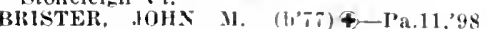
surg., Lieut. Commander, U.S.S.; Surgeon General's oftice.

Bronson, Chas. E.-D.c.2,'s3; (1'96); not in practice; 1354 Monroe st., N.W.

Brooks. Carroll A.-D.C.3,02; (1'02); 1321 T st., N.W.
lHLooki, FLETCHEK H. (b'75)\&-MId.4, 'He: l'A.S., licut., U.S.X.; U.S. Navy

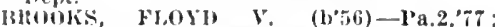
(1'96): 34 Bryant st., $\times$.w.; oftce, bond $1311 \mathrm{~J},: 11: 30-1,3: 30-5$

Jrontis, J. Henry-ID.C.2,65; (1'97) ; 3737 Mlohigan Ave, N.E.

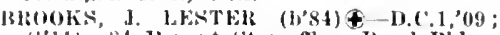
(1'11); 34 13ryant St. ; oflee, Bond Hidg. ;

lirouks, Ihilly liroome (b'64)-D.C.3,'s9; $(1+7) ; 3(16,3 d$ St., S.W.; $8: 30-10,2-3$,

t) Mary Nee-ll-D.C.1,94, Md.8. 95: (1"06); 1332 Massachusetts Are,

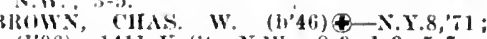
(I: 96$) ; 1411 \mathrm{~K}$ st., N.W.; 8-9, 1-3, 5- 6 .

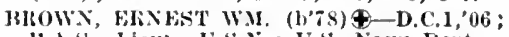

1.A.S., Leut., I.S.S.; U.S. Nary Dept.

HIOWX, HARKL LAL (b'75) 4-D.C.1,0I ; (1'02); I'A.S., tileut., U.S.N.; L.S. Navy Dent.

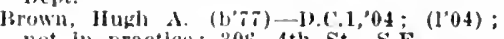
not in practipe; 306,4 th St., S.E.

Blowx, Johx w.ll $\left(b^{\prime}, 0\right)-1 ' a .11,96$; () ) Nember Met. Sioc, of the State of l'a.: 1450 o si., N.W

Irown, Jary Louise (b'68)-D.C.3,9s; (1.06); 181? vermont Ave., N.W.

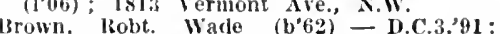

(l'96); 173i, 11th st., N.w.; 8-10,2-4, ; -8

Hrowil, sara Winifred (b'68)-D.C.3,04; $\left(l^{\prime} 06\right) ; 1450$ Q St., S.W.; until $9,6-8$. Brown, Wm. A.-Pa.2,'64; not In practlce; 1901,16 th St., N.W.

BHOWNELL, CARL DEWOLF (b'66)థY.Y., 88 ; Surg., Lleut. Commander, i.S.N.; surfeom (ieneral's office.

Bruce, Dorival D. $\rightarrow$; $(1 ' 82)$; R.F.D. 3.

Bruce, Whittington (b'8, - D.C.3,11; ( ) ; 523 Florida Ave., N.W

BIRUIBAL(il, MAIts MARCUS (b'62) $4-$

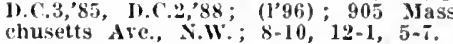

BlYAN, JOS, HANMioNo, (b'56)\$-Ya.1,

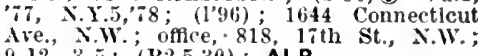
$9-12,3-5 ;(B 2,5,30)$; ALR.

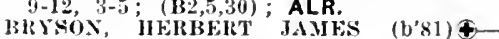

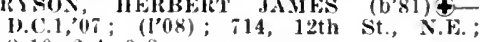
$8-10,2-4,6-8$.

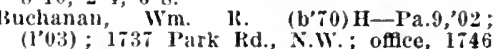
K St., X.W.

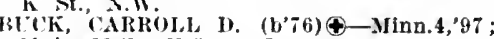
Maj., M.(., S.A.; Barracks.

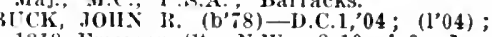
1318 Emerson st., N.W.; 8-10, 4-6.

Bulloch, Jos. Gaston Ballitie (b'52)-S.C.1, ;i; ( ) ; 2122 F st., N.W.

B'NKER, CHAS. WAITE ORVILIE (b'82) NKER, CHAS. WAITE ORVILIS (b'82)
I.Y.Y.20,05; I.A.S., Lieut., U.S.S.; 1.K. Nary beyt

ILBANK, (ARYL (b'80)-D.C.2,03: (1'04):2147 F st. N.W.; Asst. Prof. Prin. and Prace. Med., D.C.3.

II RCII, EDW. W. (b'T2) 4-1) C.,$^{\prime} 05$ (1,05); 336 Haryland Ave., N.E.: 8-10, BIRCH, WM. THOMPSON - D.C.1,94: $(1,96) ; 1627$ Connectlcut Ave., N.W. ; 9-10, BUKKE, JOHN WOOLFOLK (b'84)@-Ya.1, ,06; (I'10); 2219 California St.; offle 16101 St., N.W.; Asst. Prof. Ophth., b.C.2; $(\mathrm{B} 30)$

Burke, Thos. Wilkinson-D.C.2,84; (1'96); not in practice; $i 19$, 6th St., N.W.

Burritt, Alice (b'54) H-X.Y.14,79; (1'96); 1129,14 th St., N.W. $; 8-10,3-5$.

Burrit, Martha C.-H-Nd.8,98; (1'98); 1855 Callert st., X.W.

'12; (1'12) ; 2440 Nichols Ave., S.E. ; 8-10,

1 $\mathrm{SH}$, DAN1EL P. (b'68) - D.C.1,05;

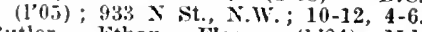

Butler, Ethan Flagg '(b'84)-Md.7,'10; (1'11) : $1535 \mathrm{I}$ st.

lontler, Sathaniel Purinton-Me.1,97; ( ) ; 2.218, 1st St., N.W.

(I'96); 1207 м St., (b'57)@-D.C.1,'82; $3: 30-5: 30$; Prof. Ophth., D.C.1; $(\mathbf{B 4}, 30)$; OALR. 


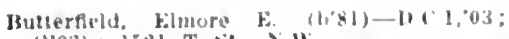
(1003): $17201 \mathrm{~T}$ st. $\times 11$

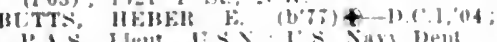

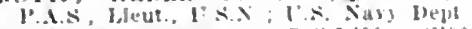

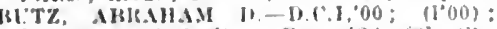

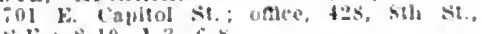
s....: $8-10,1-3,(;-8$.

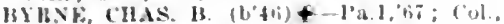

U.

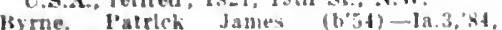

X.Y.10,"86: (190): 2it X sit. X.W.: OpAR.

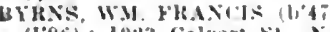
(I996): 1923 ralvert st, XW

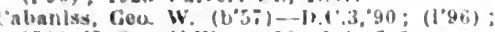

1 it4 $\mathrm{k}$ st. N.W: $8-10,2-4$ -

I"ahanlss. Wm. H. (lixis)-Va.1:11; kplsco

pal bye. Far and Thronas IIospleivi.

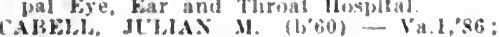

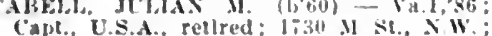
Capt., U.S.A. retlred: 1730 .

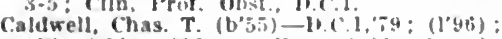
(Woodslde, Mil.): unle, 3921 (ieorsli Ave. N.W:

Caldwell, IJarry ("lark (b'os)-In.(.4,"00). D.C.1.03: (1'01): 3921 (ierrria ive. N.W.: untl 9. after 5.

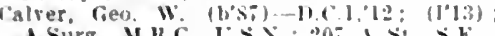

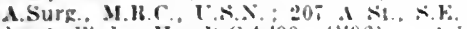
alvert, Finley H.-II. $4: 90 ;(1.96)$; not In practice: $1619,17 \mathrm{th}$ St. x.w.

CAMUES, ROLIA $(1, \because 2)+-1$ - 2,95 : ( ) Member W. Va. state Med. Instr.; 9I. 16th St., N.11:

Cameron, Malcolm (b't5) II-I'a.9.81

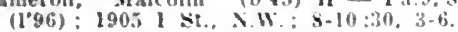

Campbell, Chas. B. (6'70)-11, 494 (1'96); 1731 I.amon! st. >.w.; offee. I66s lark Itd. X.W.: $8-10,4-5$

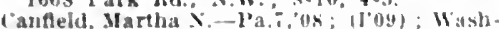
Inpton Sanllarium, lakona l'urk.

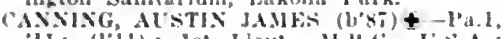
II: (I'11) Ist Lleut., M.M.'. L.S.A. Aruy Merlical School.

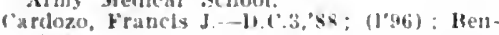

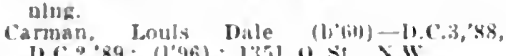
0.C.2.89; $(196)$ * 2310 \%

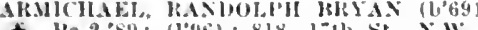

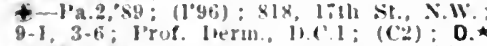

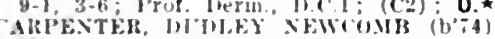
* Mass.1.9ti: surh. Heleut. Commander C.s...; surgeon fieneral's ontlce.

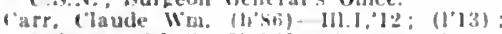

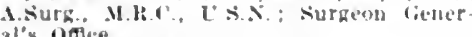

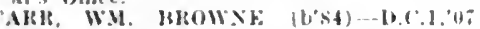
(1)i): Fentares lourts

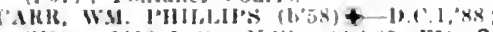

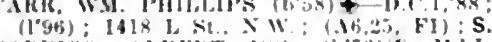

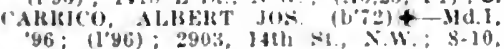

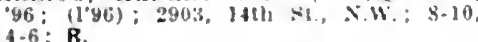

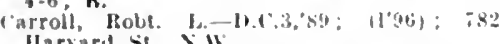
Ilarvard st. S.W. (1.09); 1913. औ St. N. W.

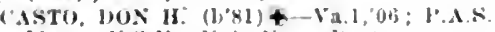
bleut L.s. I. I. Sasy lieve.

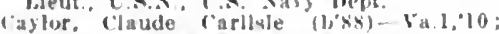
(1'li); 1033, fill St. X.t. onlre. II Vermont ire. : 10.12, 4.ti: R.

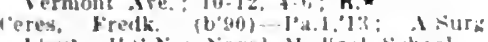

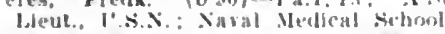

IHAWWICK, HeWITT, ${ }^{\prime}\left(b^{\prime} 58\right)$ t-J)(1 "9.5; $(1+46) ; 202011$ st, N.W ; unlce, $11: 0$ Vermut die., $\times 11:$ i.

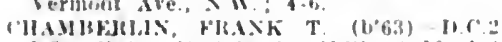

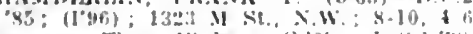

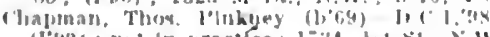

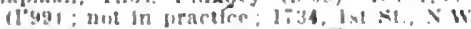

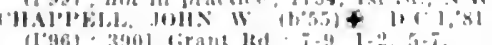

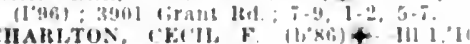

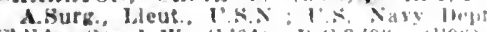

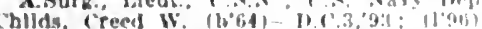

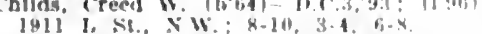

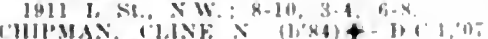

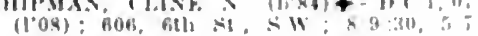
(A:3): Anew.

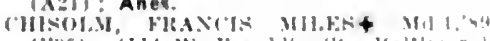

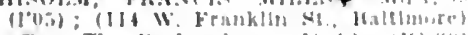

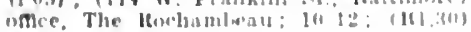
Op.

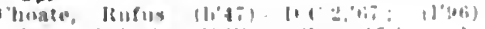

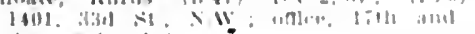

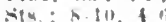

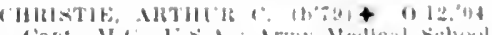

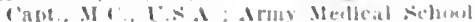

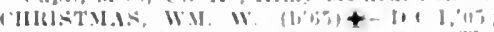

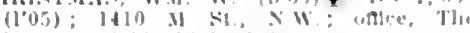

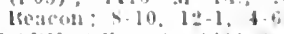

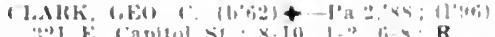

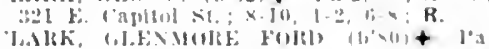
11, in: $10.1 \mathrm{~s}, 1$. inilionil

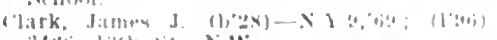

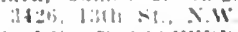

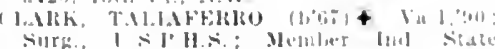

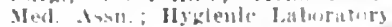

(1.,llk. WII Kalli. Jl: $(1,70)+11,1$

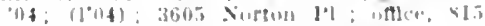

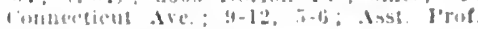

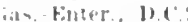

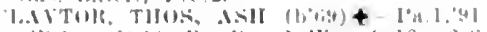

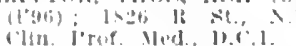

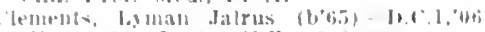

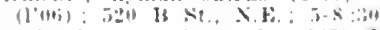

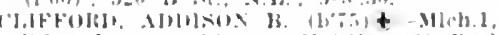

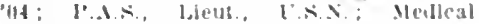

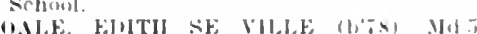

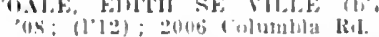

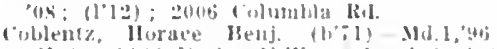

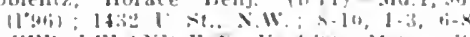

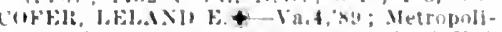

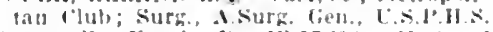
cogeswell, rrauk 13.-III.IT,0s; Natjonal Ilomeopathle II (sipltal.

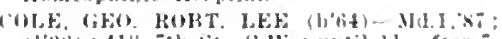
$\left(1^{*}, b\right) ; 11 \times$, ith st. \&.W : until 11 , after $;$.

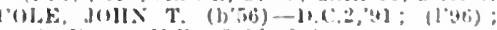

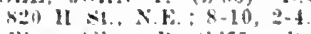

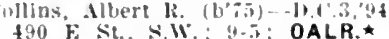

OJdAs, (HAS. KE.

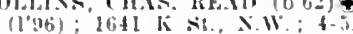

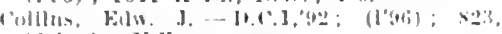
llih si., X.t.

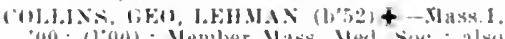
"(b): $110(10)$; Member Mass. Med. Foce a ave

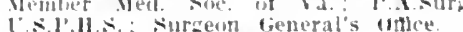

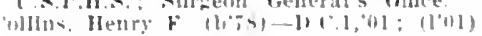

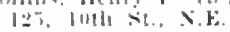

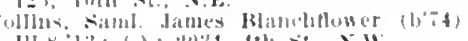

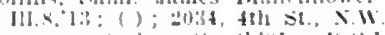

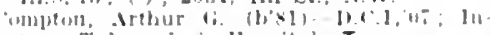
tern. Tuberouluxis Hespital: T.

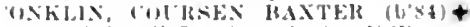

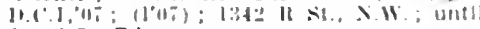
$10,3-P d$.

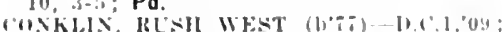

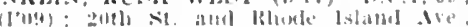

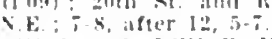

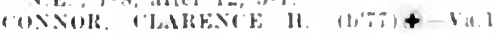

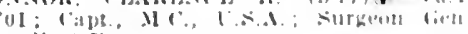
eral'y cintce

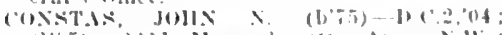

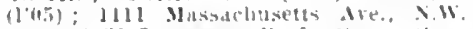

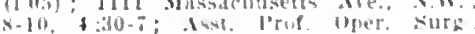

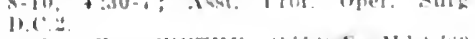

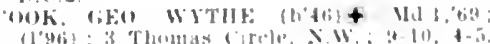

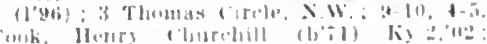

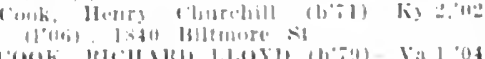

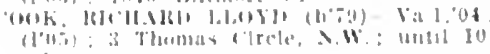

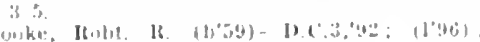

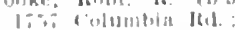

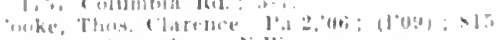
inumertrat Are., Nill

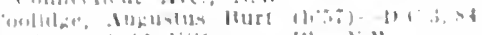

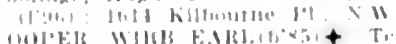

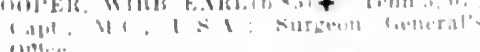

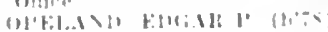

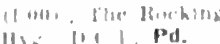

11) 1111 . Pd.

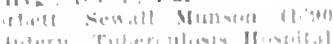

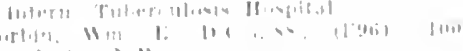

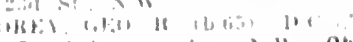

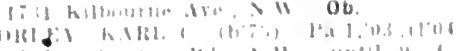

lis?
1,1 Mkt: 11-1 1:

obG.

$\mathrm{ObG}$

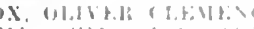

i.ti.

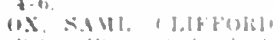

$4:-2: 11: 34$

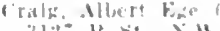

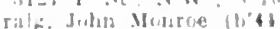

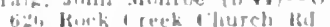

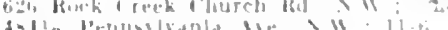

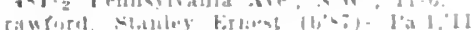

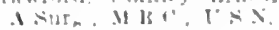

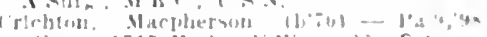

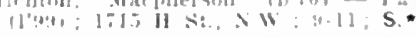

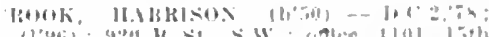

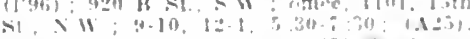

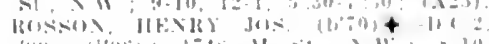

"HII: (10,

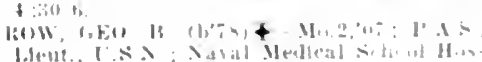
blial

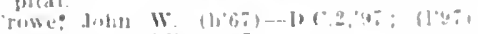

iof $\mathrm{T}$ - 1 . 11

itli lliarvaris se

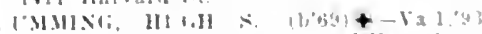

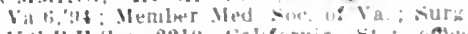

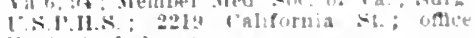

Iytriente labnrabury

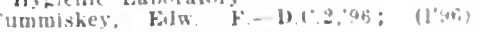

lit: 1 s?,$\times 11$

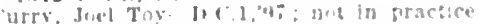

lei landoloh li., X w.

(urtis, Irthur lees the

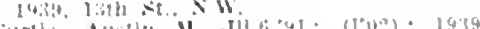

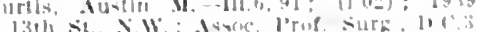

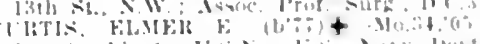

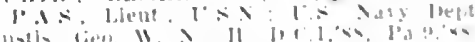

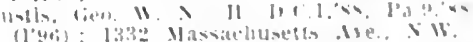

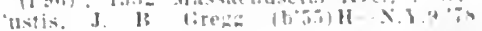

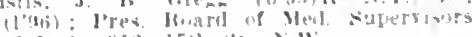

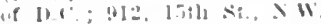

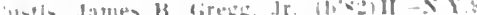

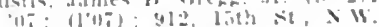

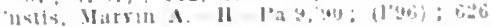
5. inpltul si: ODA

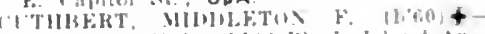

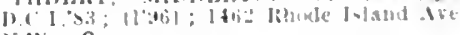
I W : G.

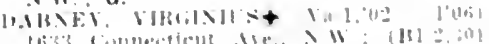
ALR.

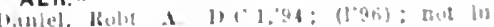

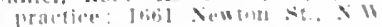

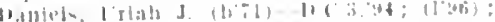

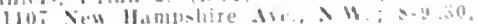
l:-1, $+\therefore=: 30$.

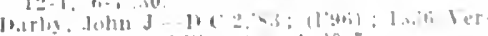
moni lie. $\mathrm{N}$ w

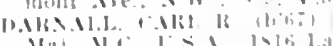

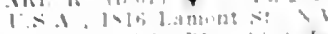

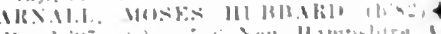

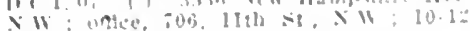

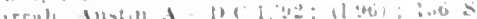

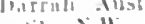

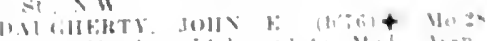

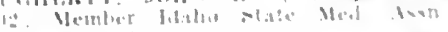
Indlan $x$ inger

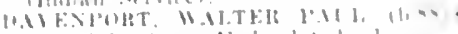

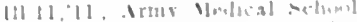

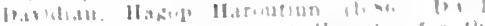
il litery.

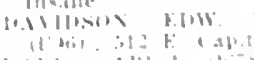

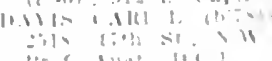

aw limat

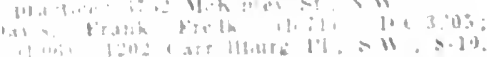

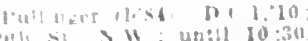

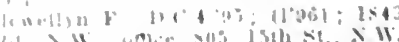




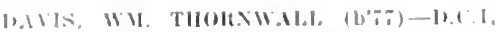
l'01); 9:2 fiurragut sil

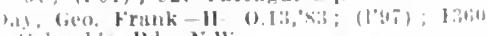
Colmmina kd., NiW.

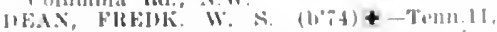

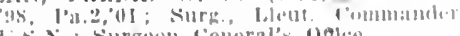

L.s.: surgeon lemerals onte.

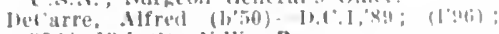

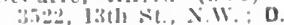

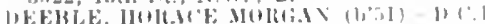

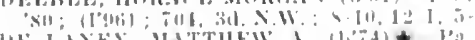

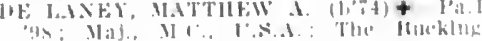

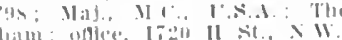

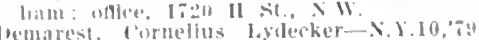

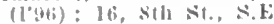

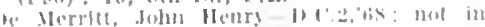

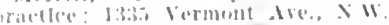

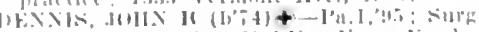

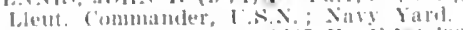

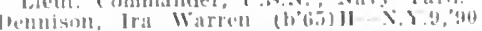
$(1+p+i)$ : The 1 yoming ; $8-10,4-1 ;$

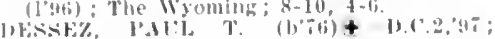

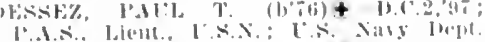

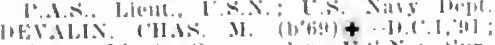
surp., bleut. Commander, 1.s.s.; surceon General's onllece.

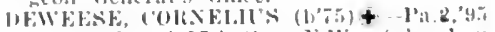

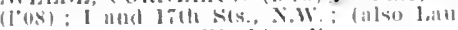

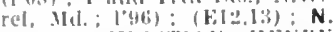

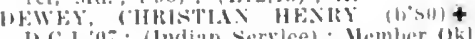
stale Ned. Issal.; Inelian imle.

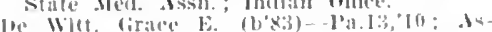

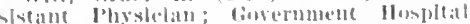
for the Insiane

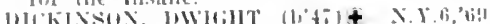

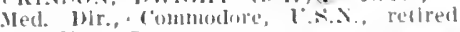

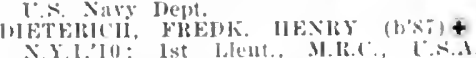
Armir Nedical sichoml.

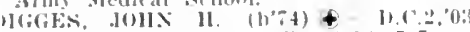
(103) 805 , 1st st. X.1.

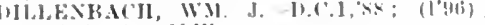
$1344 \mathrm{k}$ st., $\mathrm{x} . \mathrm{W}$.

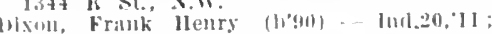

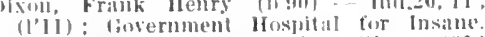

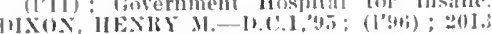
isit., x.11; $9-10,1-2,10-8 ; 0 b$.

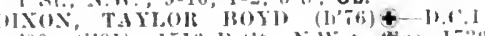

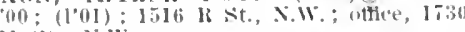

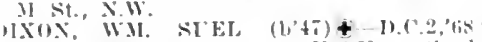
(1'96i); Med. Dir., Clapt., L.s.s., retired I.s. saty bept.

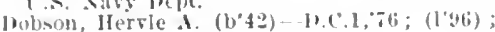
11s, ilth st., N.E.

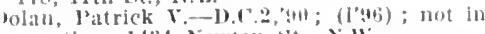
pratice: 1434 yewton st. X.W

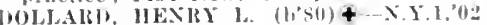

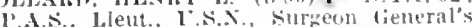
office.

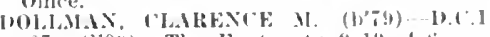
wi: (1'09); The Fontanet s-11), t-6.

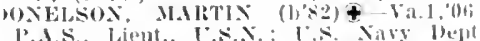

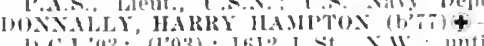
11.6.1, (103; (1,03); 16 I10, 4-(i: $:(\mathrm{A} \geq 4)$ : $\mathrm{Pd}$

Inuglas, dlanson s.-13.1.1, s, ; (196) ; not

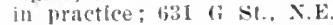

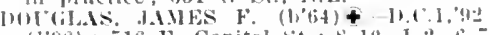
(1'96); 516 E. Capitol st.; $8-10,1=0.6-10$ bowling dimes (c)

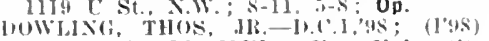
$17 \pi 1$ Lanier I'l., x.11; uffice, T'nion sia

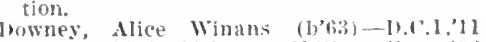
(1'12); $2473,181 \mathrm{~h}$ st., X.W.; oftce, 21124

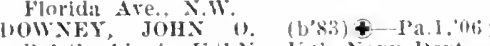

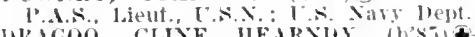

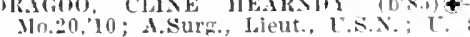
Mary I I

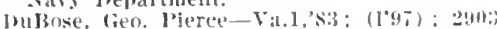
Q s.t. N.W. ; ntice, It. S. Pension Bureatu. ITBOSE, Wil. R. (brat) \&-Ya, I, Hed

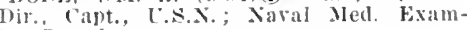
ing Board.

ther. Orlando (1,5s)-Pa.2.77; (); 613 thth st.. X.w.

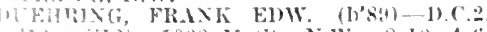

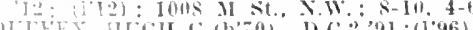

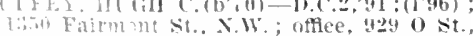

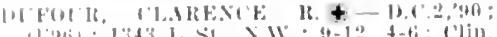

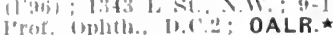

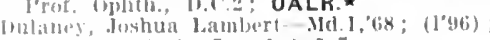

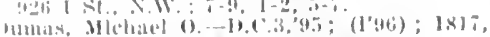

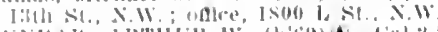

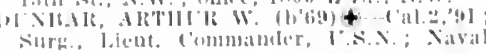
Ilis:ivitil.

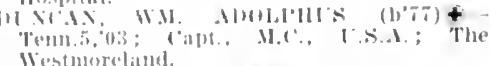

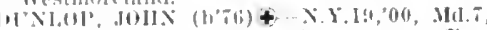
(1):

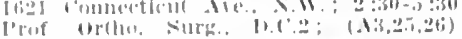
or

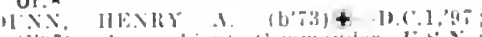

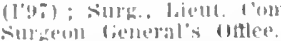

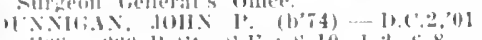

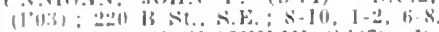

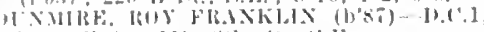

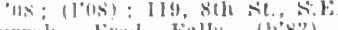

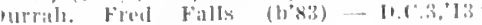
Freedmasn's llosplital.

muall. Wm. T. s, 0 ; (

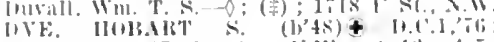

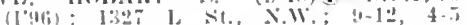
(133.301).

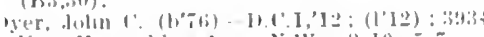

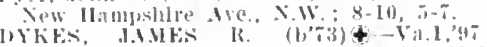

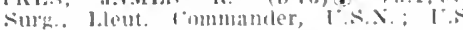
Nive lopet

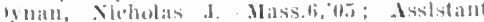

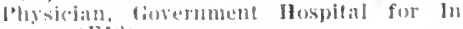
Salle: ( E I 12 )

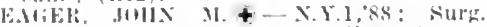
I.s.ll.s.: surgeon reneral's ome.

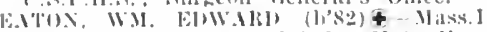

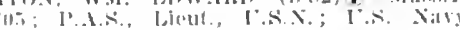

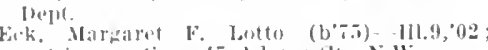
not in prateftice ; 17 Adams st., N.II.

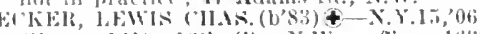

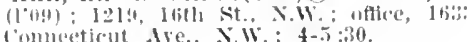
Commeticut dre.. N.W.; $4-5: 30$.

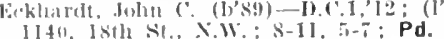

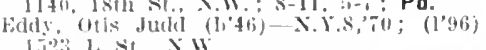

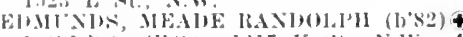

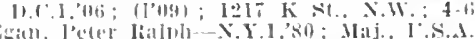

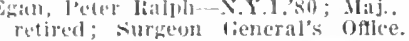

BHBRE, EHN. H. (1,81) - IId.4,

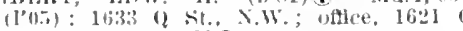
St. X.1W: A-ti; ObG.

Eisenherg, Grthur Alexinder $(108,5)-14.1 \%$ 11: 1.201; $\times$ st., N.W.

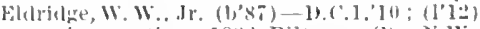
not in prattice; 1832 Biltme stor,

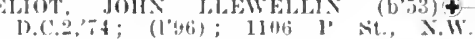
S-4::30, 6-7:30; Pr

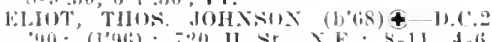

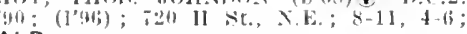
ALR.

ELLLOTT, HFXRY R.-Ya.1.4.5; (1'96) $241.5,20 t h$ st., X.W. oftce, The rarragut Ellioft, lesslie Elmo (1, Ts)--111.19,04: ( )

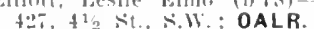

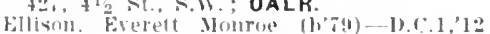

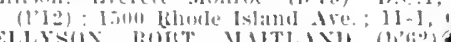

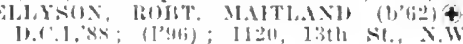

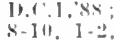

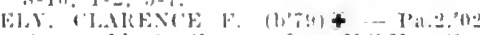
surg, litut. commander, l.s.s.; Sur frem lieneral'y offles.

Enery, oliver I. A. (b'b! not in pratetice; s09, 1.th si., N.W

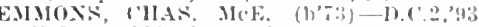

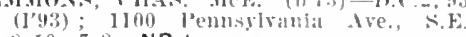

Fjpard, (ien. Irving (1) -3$)-11,1,1,11 ;(1 ' 11)$

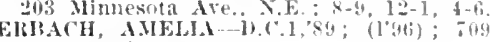
F. ('apitel st.

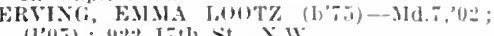

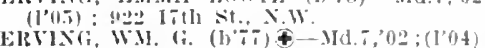

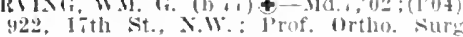
D.C. 3 ; $($ A $3,25,26)$; Or.*

Eseh, Victor H.-11, ( $\left.2,0.5 ;\left(10^{\prime}\right): 711,14 t 1\right\}$ St., N.E.; $8: 30-10: 30,6: 30-\div: 30$.

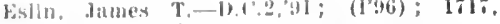
HA1, st., X.W

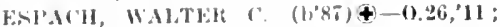

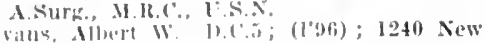

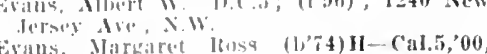

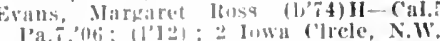

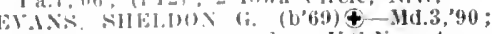
Hedl. [u-d, 'tmmander, L.s.s.; Army and Xavy (lub; NP.

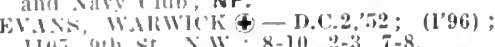

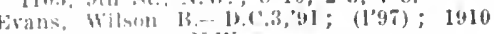

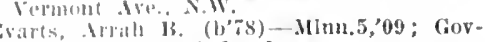
ermucut Hesplias for insane.

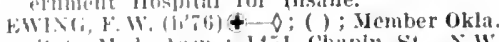
Shate Med Json, $14=1$ chapin St. N.W. FITINGL. ERXEST O. J. (b'80) \&-N.Y.I int:

Fre]th. Warren hexter-1).(2.1,95; $(1996)$; is T it. . X.11\%

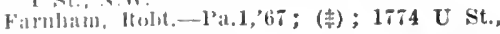
xill

FIIIELL. WIEY (HLNER (b'82) ๑-Pa.1 '14: I'...... Llent., U.S.N. Navy Yard.

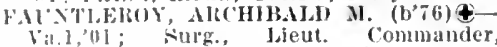
l.s.x : surgeon General's offece.

Featherstonlatugh, Thos.-X.Y.3,'T:; (1'96) nos In practice; 114 Maryland Ave., N.E.

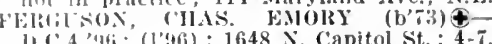

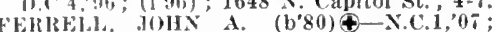
(): sere. Nerl soc. of the state of $\mathrm{x}$. () Dinthern Mledg. : : $9-4: 30$.

lerris, Sithan sherwood (b'85)-D.C.2,10 (1'1i); : 4 is Ontarlo Rd., N.W

Felzer, lewis W'm. (b'78)-D.C.1,10; (Biolopifal ('hemist); 1227 Irving St., N.W.; (tile,

FHLEBLOIN, IOHX P. (1,58)\&-X.Y.10, '17; (1'0:3); 2121 the Roy l'l., N.W.; office

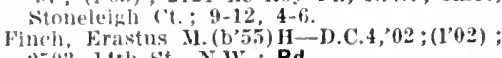

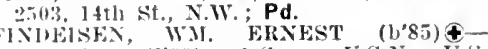
Y.Y.1,119; (l'(19): A.Surg., C.S.X.; U.S

FISLEY, CLARA BISAS-O; (1969); 1807 phelps plis.

Fischer, Melville Bendheim (b'89)-D.C.2, 'li: (): liet tanier l'l., x.W.

Fisher. Allert Kenrick (b'56)—X.Y.1,79: (1): The Plymouth.

FIsH 当th st. and Kalorama Ave., N.W.; 8-10, $4-1 i$.

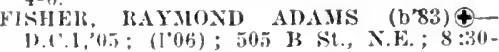
ii. $i_{-i}-\mathrm{G}$.

FlSKE, (HAS. NORMAX (b'i6)(-Mass.1, (100) ; Surg., Lieut. ("ommander, U.S.X. sturgeon cieneral's offiee.

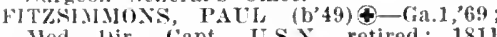
lled. 1rir. Capt., U.S.X., retired; 1811

Flcteher, chas. Cloyes (b'83)-D; (I'04); not in practice: ('ongress Heights.

lint, lames Jilton (b'38)-1lass.1,60: IlerI. lir., Rear Admiral, U.S.N., retired stoneleigh ct.

Flokla, SALVATORE (b'84)-Ita.10,09; (1'10); 732 Longfellow st. N.W.; offlee,

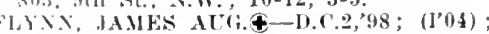
I:3:3 it st., N.W.; offlce, 13 th and Kenyon

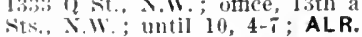

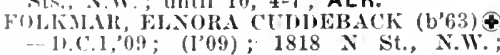
$10-11,3-5 ; G$.

FOOTE, JOIIX A. $\left(b^{\prime}-4\right) \oplus-D . C .2,06 ;\left(l^{*} 00\right)$

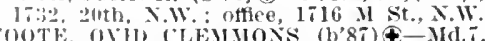

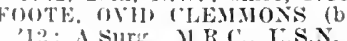

FORD, (1YDE S. (b'6i) $₫-N . Y .1,94$; yaj., II.C...... ; Idjutant Generul's Office. Folswools, W11. II. (b*:38) $€-$ Pa.1, 61 ; Brir. (ien., U.S.A., retired; 1425 Euclid St., N.W. Foster, banl. S. (b'42)-D.C.2,68; ( ) ; 19
lowa fircle, X.w.

FUSTEL, ROMILL'S AD.MBS (b'52) $\mathrm{E}$ Ib. (.1, '74;(196); 2207 Massachusetts Are. X.W. 
FOSTER, WARREX WODEX (b'J\&)Mesl sim. Itis lrving sit. \$ II

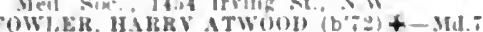
$01 ;(103)$; 2501 , 1 Hth st. : ince, 1332 Mas a

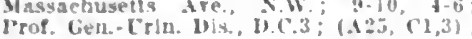

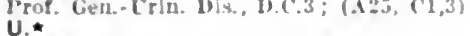

\section{U.}

OWLER, WM. C. (b'b4)

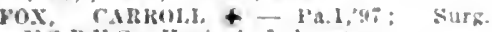
C'S.I. 11.S.: Ityglemle Laboratory.

Fox, lieo. l. (b'*1)-D.C.1,85: (1'96) (HAduden, M(1.): oflce, V...t. Jenslon lbu-

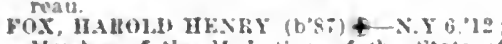
yember of the liel sioc ue the state of X.: Jst lient. M.R., i.A.A.; Army Medical Schonl

FOX, WM HE.XEY (h.5i) \$-D.C.I.'St $(196) ; 1896$ Jefterson Pl. X.w.; 4-5: (Bt.30).

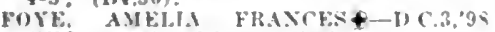
$(198): 1118,13$ h St.. $\mathrm{x}$.

RANCIS, EDW. (h'2)+-0.9.97; Surg. U.S.P.H.S.: Hyplenle laboratory

sancls, Milion Almota (b'81)-i), C.3,06 (l"0;i: 2112 lentusylranla Me., N.W. omce, 1102,9 th st.. N.W

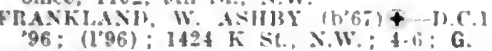

FRAXLIS, EIMENT T. M.- 11.C.1,05 (I06) $1315,19 t h$ se. I $3: 5$.

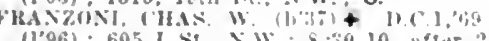

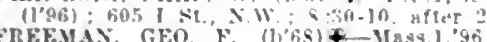
Surn. Lleut. Commander, Y.s. X.; Yaval Dlanensary.

Freeman, Henry W., Jr.-D.C.3,98: (1'99): 1900 , 13th st. N.

reeze, Harrls H. - D.C.1,90; (1'06): 2138 Callenta Ave.. x. W

FREMONT-SMITH, FRANK (b'5i) +-Pa.1 '\$3: (I00.5): (Bar llarbor. Me: 1t): ofnoe, 1805 Massachuselts Me. X.W.; $2-4$

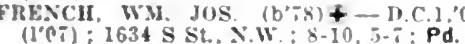

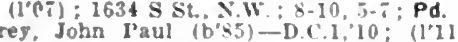

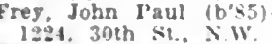

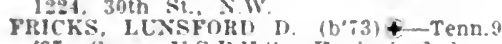

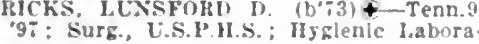
tory.

FRIEDRICR, LEON I. + D.C.1, SI: (1'96) Frlsble. Wm. H. (b.36)-1a.1,80: not in

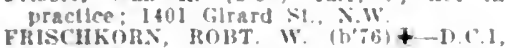
"04: (104): 124: Vewton st., X.k; s-10, rost, Ellis F.-I'a 2.37; $(1+96) ; 1939$, 1:th Prost, Ellis

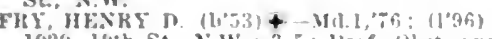
$1929,14 \mathrm{~h}$ St. X.W. 3-5; J'rof (Hitst. and

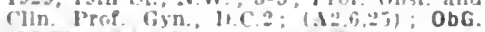
FULLER, HOMEK Columbla lin. XW: unlee, The Firragus; $9-10,4.6:(425, C 3)$.

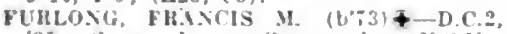
93: Surg. Loleut. fommander, L.S.X. Surgeon Geveral's once.

Galnes, James II. (b'ty) l'a.2:\%0: sur:

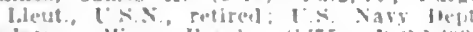
Cialaro, Wm. bank (1,751-1). 1,03: $\left(1^{\prime} 03\right)$ : $: 231 \mathrm{I}$ M! Vlew $1 \%$ \& $\mathrm{F}^{2}$.

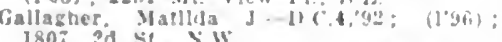
I80i, 2d St. ir

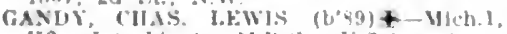
"I2: 15: I.leut, M.Jl". Y'S.A. Army Medical kehor

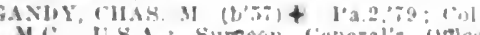

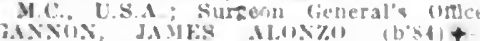

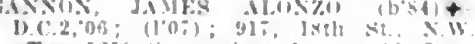
oace, 1219 Conmecticut Are. : $4-10,3-5$.

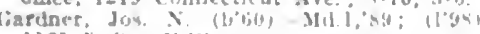
11:1 it sit. i w

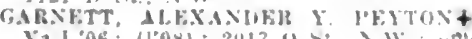

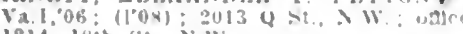
1214. Lis 4 ? N w

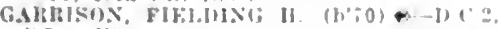

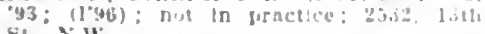

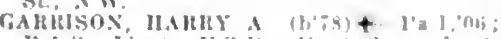

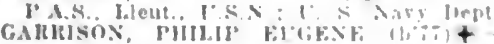

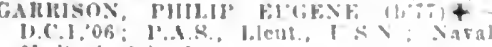
Jiedical schiml.

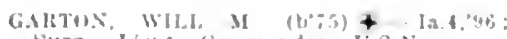
surg. Ifout. ('ommander, L.S.s.

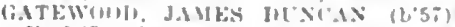

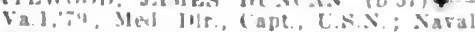
Medical sichoul.

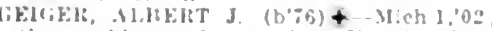

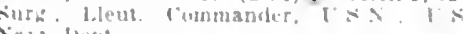
Xits liejt

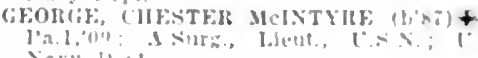

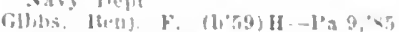

$312 \%$, l4h si. NW, $\$-9: 36,1-2,5-30$ fIJSAX, Fll $12-i$ : $; 0,4-6$.

Cillusum, Juhn Shakelford, Jr. (b-i)-Va.fo, 13; () ; sebley Ifospltal.

Giluson, Wm. $\therefore$ (1;3y)-I).C.I, (lork, Hureau of Medrege and surgery. Nily bept.

Gllhert. 1" Erelsu-A: (1'97) : 55 Qulucy I'l.

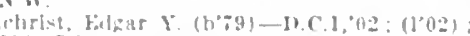

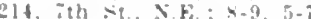

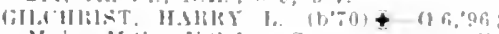
IIaj. M... I'L...: Surbenn lieneral"s inlee.

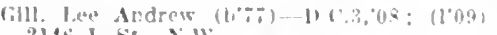
$2146^{\circ}$ I. Sit. N.W.

GIJ.L. W.I. T. $(1065)+$ I $6.1,25:(1094\}$

GLILESIE, J'IIIN MASUN (b'ख) +

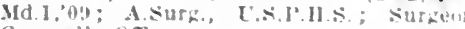
General's onter

GH.LETTE, IICBIB.ARD L-Md., $s+$ : (l'afi

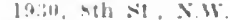

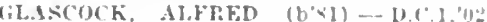
(l'oy): Corernment Hospltal for Imsane: (FI,

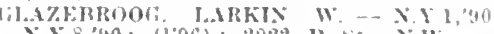

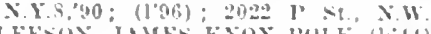

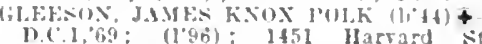

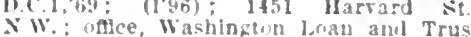
lide.: 10-1:, 1-5; Or.*

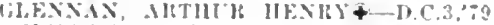

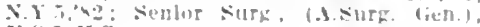
C s.I'is

Gennan, Chas. I.-D.C.2.83; (1997); 1:34

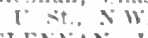

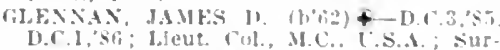
genn General's once.

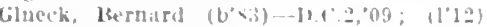
finvermment llowjltal for Insane.

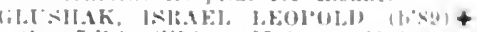

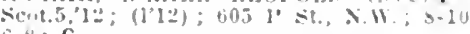
in- $8:$ G.

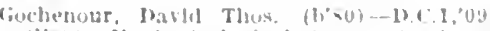

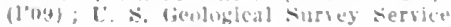

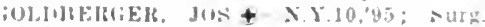

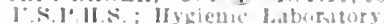

Goldsmieh. ifn. Thus (b"30)-dia.1,53

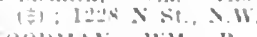

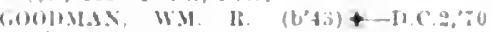

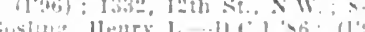

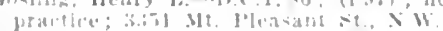

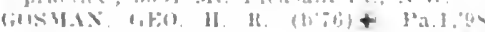

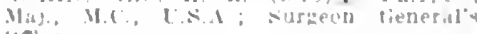
(I)

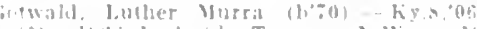

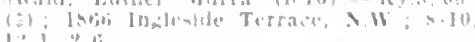

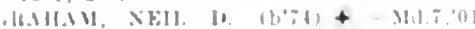

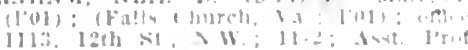

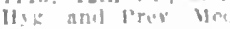

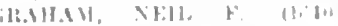

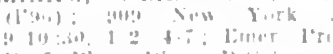

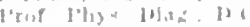

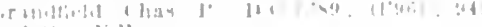

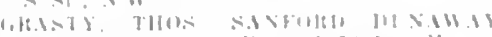

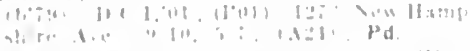

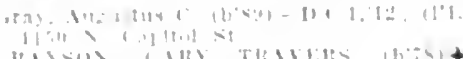

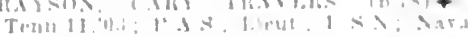

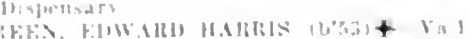

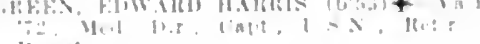
ii in 1

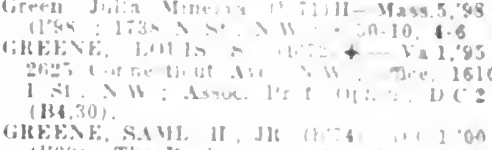

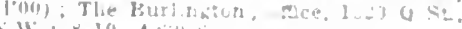

iréng. Wru. liesis

pjes in $11 \mathrm{th}$

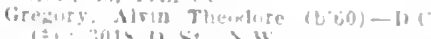

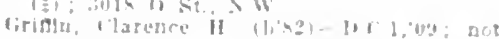

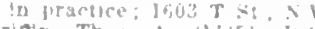

(iritn. Thes. A (bej5)-[1,1,94; (1)90);

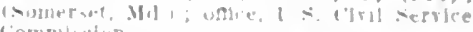

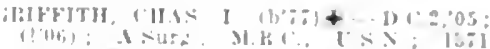

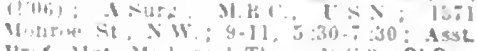

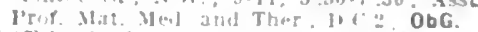

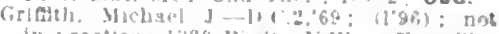
fn practice; 1300 W st., N W; odce, flly GIISTINGER, JII

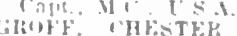

M.STH. $\left.r(1)^{2}+1\right)-M d+05$

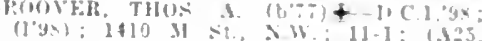
(il); $R$.

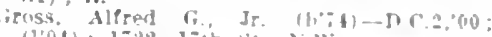

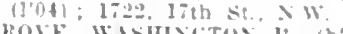

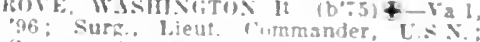
surieon lienceral's onlce.

GROW, ECGENE JIIILS $(1 ;-3)+$ SII 97 : Surg, Lleus, (inmaraer, $1: x$. surgenn lieneral's loflew

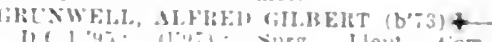

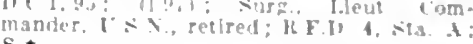
S.

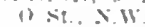

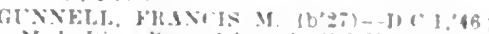
Med loir. liear Idm.ra], [K. X, retred:

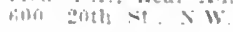

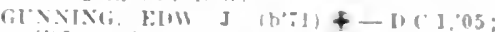
(10) 1010 Massachuseth Are., NW.

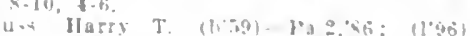

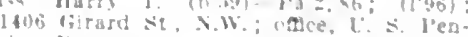
sion limerat.

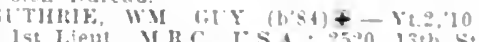

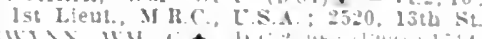

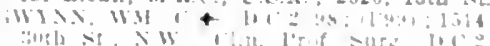

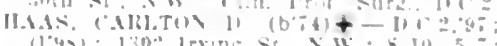
Pd.
Pd.

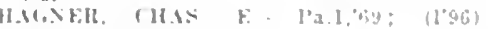
15:4. 19 th $5 t$

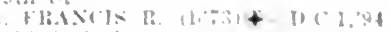

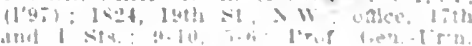
and

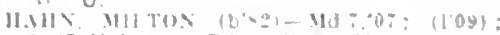

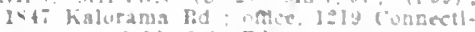
chi ire: $y-10, a$ : Pd.*

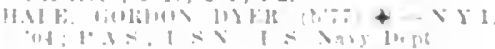

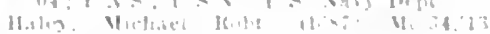

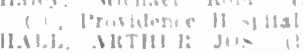

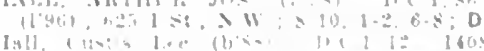

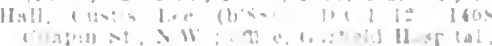
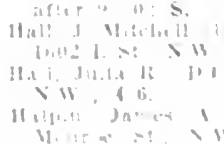

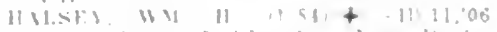

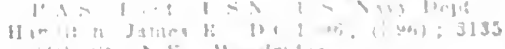

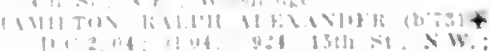

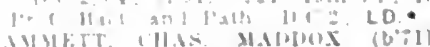

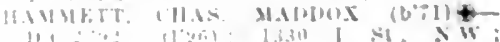

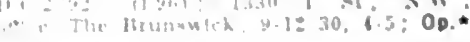




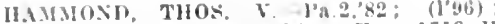
033 Florida Are. N.w, ; offlec, 1713 II : 5 .

llaminond, Thos. V., ir. (b'sc)-ra.", (112); 1 i13 11 S1., N.W.

Jannon, Saml. L. $(1,58)-$ I) ( . I, $88 ;() ;$ 354., 10 th st., N.W; oftlee, 27 John llardes?y, Jos. K. L.-I'a.2, 56 ; (1?60); The kenesaix.

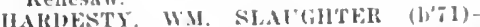
1) 1 (16: (l) : The Wellington; 4-6:30. HAIDIN, MERNARD JACIGSTON (b't0) t -10.1.1.95; (1'07); 1311 connecticut Are. N.W.: $: 3: 30-5$.

HAIDIE, HAIRKS THFOHOKE (b\%0)

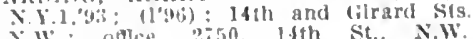
X.w. olloce

Wan. Walter $\left(11^{2} 86\right)-\mathrm{Va} 4{ }^{\prime 12}$ $\left(l^{\prime} 12\right) ;$ A.Surg., M.R.C., U.S.N.

IIMLIS, HEIBIBLT I. (b'74)\&-N. Y.6,9s Ist Ileut., M.It.C., U.S.A.; Mljutant General's once.

HARRISON, HERNAID H. (b'69)-1).C.3 03: (1'03): 641 Massachuselts Are. office, Home Bank 13idg. ; $8-10,3-5 ; U$.

Harrlson, John Stewart (b'55)-1'a.e.7: (l'17); 8 , sih St., S.F.

llarrison, Julla C.-0.23,93; (1.96); 17th and I Sts., N.w.

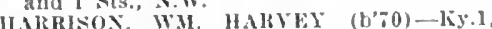
98 ; (Indian Servlce); Member Ind. State Med. Assn. i Indlan oflce.

HALT, JAMES W-I).C.4,97; (1'97); 2156 F St. N.W

HAKT, STANHEY DOTGLAS (b'81) \&N.Y.19,06; I'.A.S., Ileut., U.S.N

Harrey, Albion K. 'I'. (b'55) 1I-H11.10,88

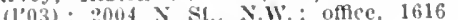
St. $\mathrm{N} . \mathrm{W}$.

HAKVFY, IHFBER MCK.-N.Y.10,67; $\left(1^{\prime} 96\right)$ not in practice; 2548,14 th st., N.W

UASRROÜCK, ENWIN M. (b'66)-D.C.2,95 $\left(1^{\prime} 96\right) ; 4909,14$ th St., N.W.; $3-5$.

IIassall, James Chas. (b's) - N.Y.3,10 ( ) Government Hospltal for the Insane. IISSELTINE, HERMAÑ E. (b'81)†-MI.4 04 ; A.Surg.. U.S.P.H.S. ; Jyglenic Laboratory.

Havenner, Geo. C.-D.C.3, 88 ; $\left(l^{\prime} 97\right)$; not in practlce; 1725 Minuesota Are., S.E

Haworth, Walter 1. (b'84)-Ind.20,10 A.surg., MI.R.C. I S Y

Hawxhurst, Howard If. (b'66) H-X.Y.9,'91 (196): i634 Connecticut Ave., N.W.; until 3-5: ALR.

9, 3-5; ALR. P.A.S., I.leut., U.S.A.; U. S. Navy Dept. Hayes, Joshua Robt.-Pa.1,55; (1’96); 1433 New Jersey Are., N.w.

Haynes, Henry Malcolm-D.C.1,'93; (l'96) not in practlce; $1347 \mathrm{Q}$ St., $\mathrm{X} . \mathrm{W}$

HAYNES, JANKS P. (b'80) Tem.5,0I P.A.S., Lleut. U.S.N.; I. S. Nary Dept. Hays. Melville A. (b'i5)-D.C.2,00; (l'00) 1344,416 St.

1344, 4 $1 / 2$ St.
Haysmer, Elam Dolphus (b'91)-Tenn.5,'12 Washington Sanltarium.

HAZEN, HENRY HONEYMAN (b; 79$)$ Id.7,06; (l'09); 1709 s St., N.W.; offlce The Rochambean; 3-6; Prop. Derm., D.C. and Clin. Prof. Derm., D.C.3; (C2); D. * HAZN, WM. P. C. $\$$-D.C.2

Iealy, Chas. Benedict-D.C.2,08

1726 y St., N.W.

HEIBERGER, IDA T.P-Pr.j's5; (l'96) Florida and Connecticut Ares., N.W:

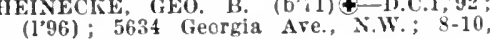
$2-3,6-7: 30$

IIHISER, ROBT. G. (b'7)£-Ya.1,00 P.A.S., Lleut., ['S.X.; U.S. Nary Dent HEITMULLER, GEO. NI. (b'69) ₹-Pa.1,'94

Helfgott, Na1han J. (b’\$5)-Md.9,'12; ( ) 1531,6 th St., N.W

Heller, Irma I. (h'70)_Itch.1,9y; (1'00): not in practice; 310 E. Capitol si. ; offlee, Gureau Engraving and Printing.

IHI.I.FR, JOS. MILTON $\left(b^{\prime} 72\right) £-$ D.C.2,'96

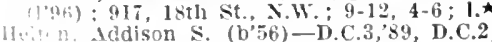
tddison s. $\left(b^{\prime} 56\right)-$ D.C.

1I E.MLET, WII. F, (b'-s)-J.C.2,04; (1'04)

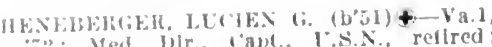

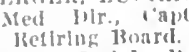

Nabil lieftrlug lionrd. 13. liarfleld Hospital.

HHNDING, SAMI CARI (b'80) \&-D.C.I 03: (1'07); 173:3 Oregon Are, ; offec, Ri (omectic

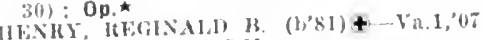

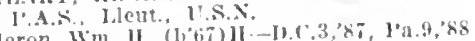

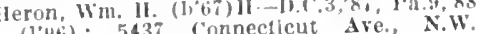
$(196) ; \quad 5437$ conneclicut Ave., ${ }^{N}$.

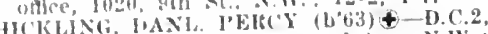

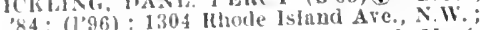
84: (lin. J'rof, Nerv, and Ment.

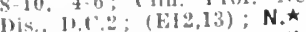

Holse, Martin Barbour $\left(b^{\circ} 86\right)-$ Va.1,11;

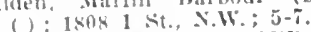

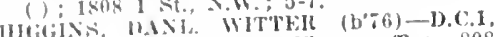
'ox; ( 108$)$ : Nariatogat Flafs; offee, 808 4i-8. JONTGOMERY - E. $\quad\left(\mathrm{b}^{\prime}, 9\right) \oplus-$ U.C.1,04: I'A.S., LIeut., U.S.S.; U.S. Navy bejt

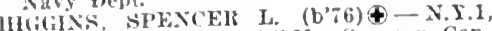
03 .'.S.S. Lictl., U.S.N. ; Surgeon Gen-

lilton, J. Franklin (b'79)- D.C.2,04:

(1'04) ; 1218 GIrard St., N.W

Itodge, Edwin Ihichard $\left(b^{\prime} 60\right)$ - D.C.2,92 (196); 1921, I9th st., N.W: : oflece, Irmy

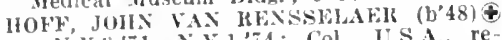
X.Y.3.'T1, N.Y.1,74; Col.

tired; 2112 Massach M. (b'68)-D.C.3,93; Hollorok, ("has. II. (b'6. - 9-10, 4-6. (I'02); 2542 Nehols A C., $(1,74)+$ N. I.8

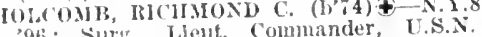
96 ; Surh. Ileut. Commander HOLUE RAYMOND T. (b'60) \$-D.C.2 , (1) (96); s02, 6th St., S.W.; \&:30-10

Uolland, Alexander W. (b'55)-Ky.2,'80; (1) Member Okla. State Med. Assn.; 31 E. Capltol st.

Iullifict, IIoratio 13udd (b'61)-Md.1,82; (1.96); 30 th and $Q$ st.s., X.W.; offlee, U.S. I'enslon Bureau; ; 9-4:30.

Holmes, John A. (b'74)-D.C.1, 04; (1'04) 80: Taylor St. N.W.; offle, P.o. Dept. HoL.MEs, MARY (b'i4) \&-D.C.4,00, Pa.t

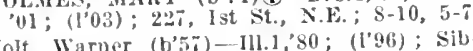

HoIt, Warner (h'5)-Ill.
ley Memorlal Hospital.

HOOE, A. BARNESE-D.C.1,96; (1'96) 1220 , 16th St., N.W.; (A25); ObG.

HOOE, KOBT. AKTIIUR (b'80)-D.C.1,06

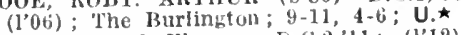

Hooper, Lionel Elcan - D. ('.2,11; (1'12) The Westorer.

Hoover, (ieo. Wm. (b’6)-D.C.1,10; (1'11);

1322 Vermont Ave.. N.W.

Iopkins, Alfred F.-D.C.2,03; not in practice; 1409 Hopkins St., N.W.

IIorlgan, Win. D.-W.C.1, 89 ; (l'y6); not In practice; 3028 Wlsconsin Ave., N.W.; office, U.s. Naral Obserratory.

Hornaday, Frank A. (b'79) - D.C.1,10; (l'11) $3509,14 \mathrm{th}$ St $\mathrm{Xill}$; Assoc. Prof. of Chem., D.C.1

HORX'BROOK, FBANK WIEELER (b'75)\& -Miss.1,05; (1'12); Member Mass. Med. Soc.; The lighlands; office, 1217 Connectlicut Ave, N.W.

Hoskins, James T, (b`53) H-D.C.5,'94; (1'96); not In practice; 1414 New Jersey Are., S.E.

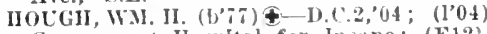
Government Hospital for Insane; (K12).

Honsel, Firman-1).C.3,95

II aryland Are. X.E.

Houston, Clysses Lincoln-Ill.8,'12; (l'13) 1444 l'ierce I'l., N.W.

Howard, Arcfurus lee (b'70)-D.C.2,'93 (l'96); 5516,14 th St., X.W; ; $8-10,5-7 ;$ Pd. HOWAKI, DEANE C. (b'- 0$)$ - D.C.l, 93 Maj., M.C., U.S.A.; Surgeon General's office.

Howard, James H.-D.C.3,'s3; (1'96); 1724 , sth St., N.W

HOWARD, JASIER VICTOR (b'82) \&-Pa.I

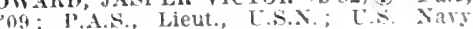
Dept.
Howard, Jos. T. (b'66)-D.C.2,89; (1'96) ; not in practice; penslons.

IOWAKI), STANTON WIEN (b'80)€-

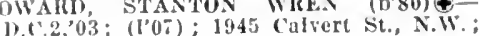

$8-10,5-7$.
Howard, Wm. James, Jr. (b'81)-I11.11, 08 ; (I'09); 600, 3al St., S.W.; office, 100 Massichusetts Ave., N.W.

Ilowe, Orwln F. (b'53)-Ind.8,'82; (1'96): 4:if l'ark ltil., X.W.; oftce, 800, 6th st. N.W. ; $8: 30-5$.

OTT, lROB'T, E. (b'79) 4 - Mass.I,0I geol General's offee.

Hrillteka, Ales (b'69)-N.Y.9,'94; not in practice; 29 th and Tilden sis., N.W: (FI)

IIudison, Wm. Burrows (b'78)-D.C.1,05; (1'05); 924,19 th St., N.W. ; 3-6: N.

HFF', EAlRLE IHANEAS (b'79) N.Y.1. "03; (1'07); I.A.S., Lieut., U.S.N. :

IILL, HOWARI) WANE (b'85)@-Pa.2,08; lst Lieut., M.C., U.S.A.; Member Med. eral's office.

eral's offec. 1:35 Massachusetts $\Delta$ ve. ; oftlce, 1217 Connectlcut Are, : $3-5$.

HUNT, ARTHUR I. (b'79) - D.C.1,05: (1'05); Cur. Sec. Med. Soc. of D.C.; 1120 Anes.

Huit, Danl. (b'89) - Pa.2,'12; A.Surg., M.R.C., U.S.N.

IIunt, IIenry J. (b'48)-N.Y.5,78; (l'96) : 1204 Girard St., $x .1 \%$

IIunt, Isaac Burton (b'79) - D.C.1,12: (1'i2) : $1408 \mathrm{~L}$ St., N.W.; OALR.

Hunter, Edwin C. (b'81)-D.C.2,03; $\left(\mathrm{l}^{\prime} 04\right)$; 107,4 th St., N.E.

HUNTER, MONTGOMERY - I.C.1,96; (1'96); 1728 P St., N.W.

Hunter, Oscar Benwood (b'88))-D.C.1,12 ; (l'12) ; 2021 H St., N.W. ; Prof. of Hist., Embry., and Assoc. Prof. of Anat., D.C. 1 HUNTINGTON, WM. HENRY (b'83) 4 D.C.1,10; (1'12); 2330 Massachusetts Ave., N.W.; office, 1217 Connecticut Are.; $9: 30-1^{2} 2,4: 30-6 ;$ OpAL. *

HURTT, HARRY†-Md.1,'95; (1'97) ; 1524

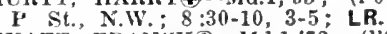

HYATT, FRANTK†-Md.1,72; (1'96); The Wyomlng; offlce, 815 Connectlcut Are.

$9-12,3-5 ;(B 3)$.
HYDE, CHAS. W. (b'7T) $4-D . C . J, 04 ;$ (I'05) : The Alabama; 9-10,4-6; Anes.

HYNSON, LAWRENCE MAXWELL (b'79)
†-D.C.1,04; (1'04); $1335 \mathrm{~N}$ St., N.W. $8-10,4-6$.

Ingrain, Thos. D. (b'43)-Pa.2,75: (l'96); 1332 I St., N.W.; offce, Penslon office. Israeli, Baruch-D.C.2, 97 ; (l'97); 1623 Q St., N.W.

(1’96) WH. A., JR. (b'73) $9-D . C .3,96$

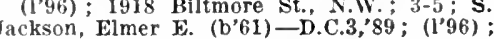
1202 Euclld St., N.W.

JACKSON, VIRGIL B. (b'68) ๑-D.C.1,94 $\left(I^{9} 96\right)$; 1330 I St., N.W. : 9-10, 4-6; G.

Jaeger, Henry Wm. (b'88)-D.C.1,'I1 ; (l'11); 424 E. Capltol St.; 8-10, 1-2, Jagers, Sallle Jones (b'49)-N.Y.13, in practice ; 2111 , isth St., N.W 1,96$)$; not

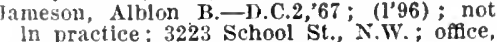
In practice ; 3223 School

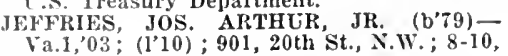

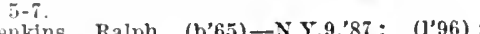
1732 Massachusetts Are., N.W.; offlce, 808, 17th St., N.W.

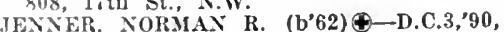
I.C.2,'91; (1'96); 1110 Rhode Island Are., X.W. ; 8-10, 1-2, 4:30-6; ob.

JENXESS, BURT F, (b'76)\$-N.H.1,99, P.A.s., Lleut., U.S.N. ; Receiring Ship.

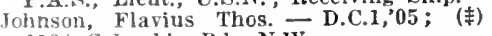
1124 Columbia Rd., N.W.

Johnson, Henry A.-D.C.1,89; $\left(l^{\prime} 96\right)$; not in practice; 1213 Lamont St., N.W.; office, War Department.

JOHNSON, HENRY L. E. $\left(b^{\prime} 58\right) \oplus-D . C .1$, $82 ;(1 ' 96) ; 1821$ Jefierśon Pl., N.W.; $10-12,5-7$. 
Johnson, Jarnes Francls-D.C.3.05: (1'06): $1450 \leq t . \times 1$.

Juhnson, Jolun llayden (b':3)-D.C. 3,00 (I'00): 1842 Vermont Are., N.W.: 8.10 , $1-3,6.5 ;$ Pd.

JUHNSON, JUS. TABFK \&-D.('2,65 X.Y.10,67: (1'06); (Cherrydale, Va.) offee, 926, $17 \mathrm{th}$ St., X.W. 9.12'; kmer. Prot. Gya. and Abd. "Surg., i).C.2; $\left(\mathbf{A}_{2,0}\right)$ :

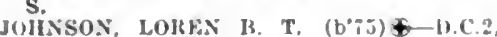

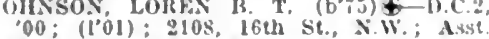
Prof. Hyg. and Dlet., D.C.2.

JHINSON, LOUIS A. (b'70) + - D.C.2, 92 $\left(I^{96)} ;\right.$ i11 C st. S.W, $\quad y-10,1: 30-2$

JUHSON, LUCIUS WAHILN (b's2) + Hed Soc of the state of IA.: islo, $19 t$ St: omce, Mllls BIdg.

JHISSON, I'AU1, IHOWEY ALDEX (b'i8) t-D.c.2.05: (l'05): 3205, lith st. N.W.; $8-10,4-6$.

JUHS:ÓN, STVART CIARKF (b'74)Johnston, Gabrlel F.-D.C.1,75; (199) 1650

3ONES, EDW, BAHTOX - D.C.1,02 (1.03): 1340, 21st St., N.W.; odice, 121 \% Connecticut Are, N.W.; $9-12, \quad 4-5: 30$

\section{ALR. *}

JUNES, LOUISE TAYLOR $\left(\mathrm{b}^{\prime}, 6\right) \$-M d .7$

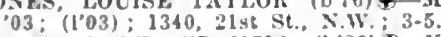

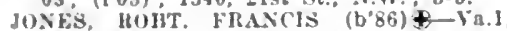
"0y; A.Surg., hent., U.S.S.; L.S. Navy Dept.

Jones, Thos. kdward $\left(b^{\circ} 80\right)-D . C .3,12$ :

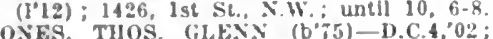

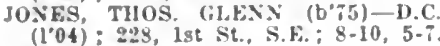

Jones, Wm. C. (b\%0)-D.C.3,03;" (l'04) 1215 W St. N.W.

Jones, whlls w. (b'7s)-D.c.3,04; $\left(\mathrm{l}^{\prime} 05\right)$; Deanwood lleights, N.k.; 8-10, 3-5.

Jordan, Llewellyn-1).(C.1,94; $\left(1^{\prime} 96\right) ;$ not in pracilce: $607,41 \mathrm{~h}$ st., N.W. ; oftec, U.S Treasury Department.

JUNC, FHAN\% A. R. (b'6s) \&-lier.14,94 (l'96); 1229 Connecllout Ave. N.W.; $9-12$ 4.6.

JUNG, SOFIE A. NOIMHOFF (b'bi).D.r.1,93; (l'96); 1229 Connecticut Are. V.w.: 9.12 .

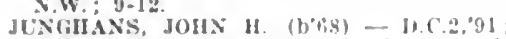
(1'96); 41 ; D St., N.E.; $8-10,12-1,4-5: 30$

Kalusowskl, Henry Fo-1).C.1,91; (1'96) Vatlonal College of l'harmacy; $9-4$

KARPHIKS. SIMON R. (b's0)t-i).C.4,02 (1'02): 1102, 5th se., N.W.; urtil 10, , $7: 30^{\circ}: \mathrm{G}$.

KAUFMÁ, HARIY MARX (b,

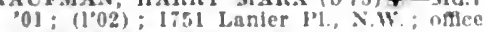
1120 Vermont Are. N.W.: in-11, $3-4$.

1120 Vermont Are., N.W.; $10-11,3-4$,
KAVENEY, JOS. J. (b'80)+-1),( 2,04

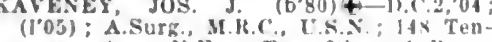
nessee Are., N.t. office, $6 t_{1}$ and J'(nn sylramla Are. S... $8.10,12.2,6.4$.

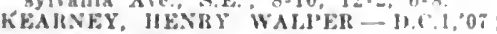
(I'0i); 12290 St. N.W.

Kearns, Harry Veal ( $\left(\mathrm{H}^{8} 86\right)$-Mich.1,12; 1 st Heut. M.It.C., U.S.A.

KRAKXY, H(HARI) A. (b'83) - La.1,05: A.Surg., U.S.P.II.8.

KEBLFI, LYMAX p. (b'63)+-1).(1, 06 (l'06): not in practlce: Jiswe Jark lid. N.W.: offle, U.S. Defartment of Agrlcul. ture: Asmoc. Irof. Mat. Med. and l'har. I). $P . \dot{2}$.

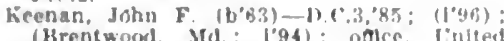
Jentes lension

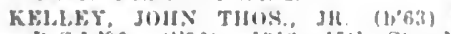

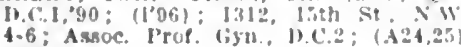
4.6:

Kelly, Dant. J...1) ( 2,$75 ;$ (1996); 1218

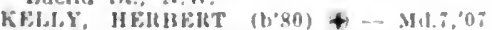

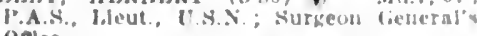
onice.

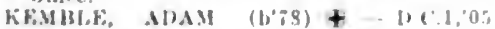

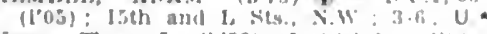
Kemp, Thas J. $(1,+5)-1,1,1$, un $(1,00)$ : l1127, 16th st.,

Kendrlek, Jtlcharil foon $(1,45)-V n$ I, 13 Intern. P'rorlifence fousplial.

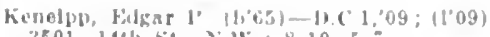

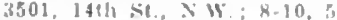

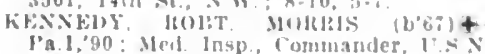
Ya. 1,90: Meil. Insp.

Naval Irispensar

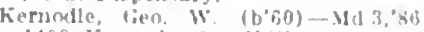
1409 kiennedy si. X.W.

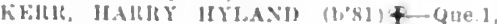
04: (1.04): 1:42 N St., N.W: (A25):

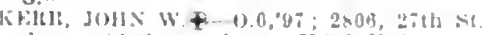
surb. (Asurg, (ien.), U.s l'.H. KFY SOTIIOHUN +- I.C.1,90; $(100)$

Ifriskil, (All \&. (b) 72$)+-b)(1,98$

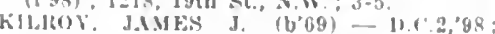
$\left(1^{2} 49\right) ; 1031$ st., N.W.: $\$-10,1-2,0-8$ Ob.

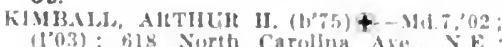

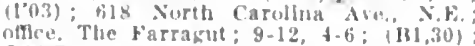
OAfle. T

Klanjall, Folward S. $\left.\left.(1)^{2} t 4\right)-1\right)(2,26 b ;()$ Lith and U Sts., N.W; onte, 1010 F St.

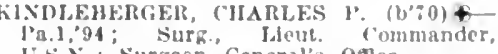

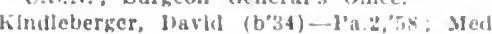
lilr., Rear Adulral, I's.x., retired; I".s Nary Dept.

KING, ALIBERT FREEMAX AFIRICALS (b't1) +-1).C.1, "il, 1'a.1, (i5; (1'96): 1313 (bassachusetts Are. F.th: $8-10,4-5$; l'rof. Obst., D.C.1; (A2).

King, Clapham Prlce (b'89)-Y'a.1,12; Is tern, casualty Hospltsl.

king, Cora Eiliza silth Eaton (b'tio)Mass.5,"92; (1'13) : The Olynupla; S.

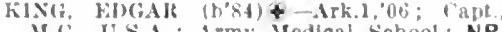

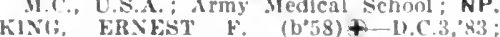
(l.96); The Plaza; oftce, Bond Hidg. $10-1,2-5 ;(\mathrm{C} 3) ; \mathrm{U}$

king. Harry cliftors (b) 85 ) $11-1^{3} 3.5 \%$ (l'0 ) : $1422 \mathrm{k}$ st.. X.W. 9.1; OALR. king, Wm. Kufus (l, $1422 \mathrm{~K}$ st., N.W.: $: 1 ;$ OALR.

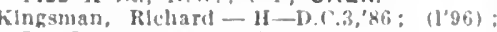
711 E. ('apitol St, ; $8-9: 30,4-t: 30$

Kimnan, Wu. A.-L.C.1,95; $(1960) ; 1110$ Falrmont it., S.W

KINYOCN,JOS. J.MES $(6,60)+$ N Y.10,"s? (I'03); 1423 clifton St., X.W. ; (jut, Fel K.ITK, ISAAC W. $\left(b^{\circ} 61\right)+$ Va. 4.85 : Nurg.
Iflent. Commander, U.S.N., retred; The Cordora

klttredge, Herman 1:
$14.39 \mathrm{R}$ St., X.W.

KIEMM, JOIN WM. (b)5s)-D.C.1,90 : $\left(l^{\circ} 96\right) ; 2008$ s st., N.w.

Knott, (has. o. (b'81)-D.1,1,12; (1'12) 1006 I St. S.E

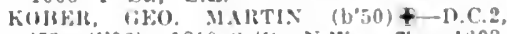
73: (1'90): 1819 y sit. X. w : onlee, 1603 , 19 th st. xiw. Dean and l'rof. 11 gr. and Hlet., 11. 2 ; (b)

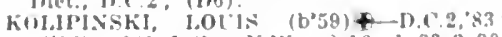
(1'96): 631 1 st. X W: $8-10,1: 30-2: 30$ ti 8.8

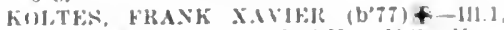

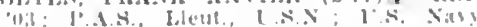
Dept

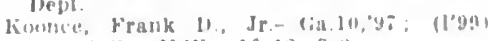
1000 M SL, X.W; $10.12,3-8$

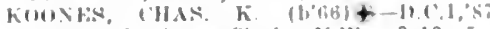

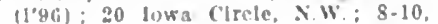

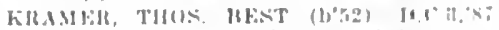

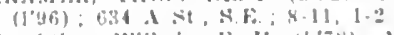

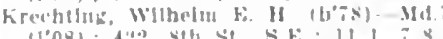

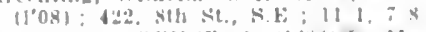

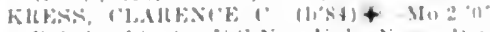

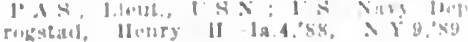

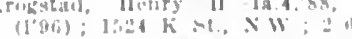

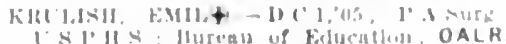

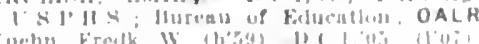

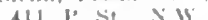
A

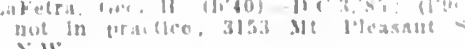
Niv.

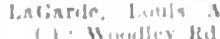

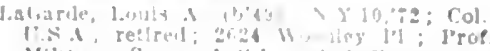

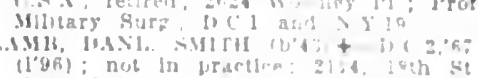

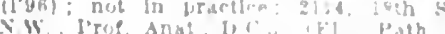

I..MI, INAHE, IIASI,I I"

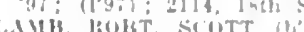

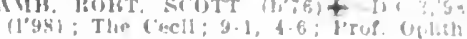

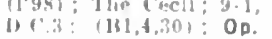

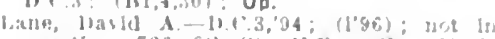
practice: iaf, kth st., N.F.; onfe, I: s Persition Burear.

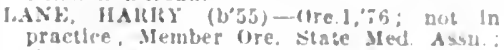
I:A. Senate.

laney, Frank I'.-D.(:3,"94; (I'96); 312,3d At. S II

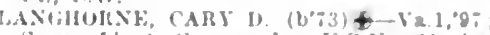
Surg, lewt. Comnander, U.S.X. ; Marine Harrack

laviNi, H(HAMI) HFARY (b'83)—Nary liept.

lickln, 1. Filward (b.2)-1) (.2.08 (1'10): 1726 M Sit. N.W: $y-10,3-6$

lassazue, Fetor Francls (b'05)-IIl 16.98; 1495 Siuton St., X.W.: U. S. Patent Oblec.

Latimer, (has. 11-.Md.3,'81; (1'96): 92 ; New York ire. N.W.

I.IWILN('), A,BERT L. (1,64)-1) (91,96; (I'9i) 1330 Massachusetts Are. W. W

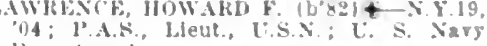
l)epartment.

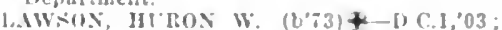

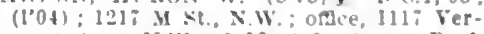
mont Are, XW: 8-10,4-6; Astoc. Prot. Ohst., 1). 1 ; (A24); ObG.

Leadley, (ieo. W. (b'6\%)-1). C.1,93; (1'96): not in Jisecice; The Van Cortanit.

LFAKE, JAMES PAYTOS (b'81)+-La1. 01: Jasa 1,0 ; A.sure, Y.S II Hyplenic Laborntory.

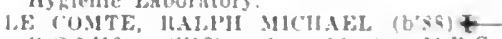
1) $9.2,10 ;(1,10) ; 1$ ist laleut., MH.C. I"A.A. Army Medleal Sillinol.

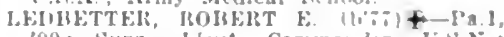
99 : surg, Lleut. Commamer, $\mathbf{s}$ : ravinl lfospltal.

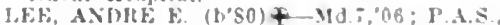

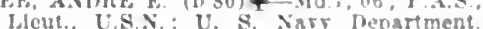
Lee, Mallo virginla Seams $\left(b^{\prime} i 4\right)-D$ C. 3 , '11; (l'12); 1020,3 औ st., S E.

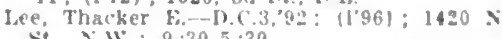
st., XW: $?: 30-5: 30$

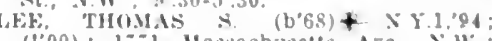
(I"00): 17\%1 Massachusetis Are. N.W: unice, 1603, 19th st, Xitw; y.10; Clin. l'rof. Med., D.C.2.

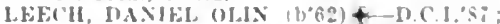
$(196)$; 1230 Massachinctls Are. Niw antll in, 4-1

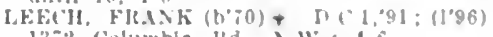
1372 columbla $\mathrm{Kd}$, i $\mathrm{W}:$ : 4.6

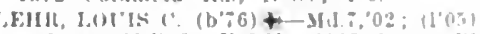

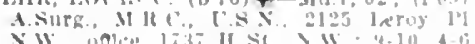

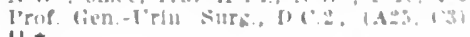
U.

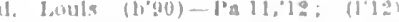

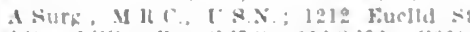

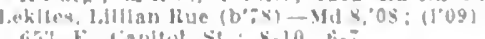

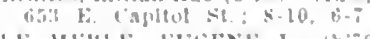

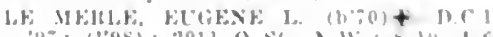

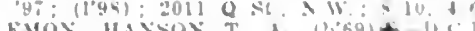

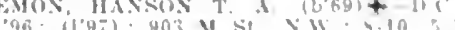
(kis).

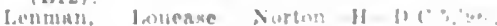
(1"H+1): 1:11, 1 1th st

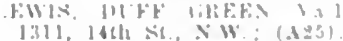

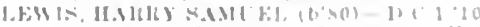

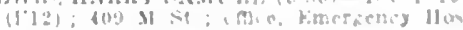
mitat

1411.

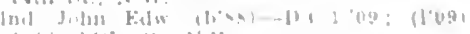

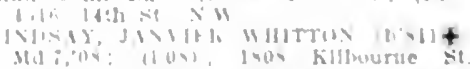

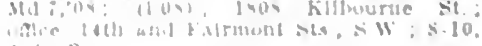

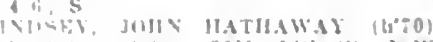




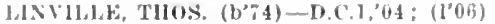
905, $10(12$ st., N.W ; 8-10, 4-6.

Ittle, Arthur Hikle (b'87)-1) (c.2,'1: (1'12); 1449 W st., N.W

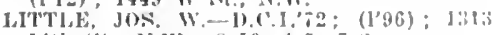
I4th st. N. W : 8-10, 4-5, $7-8$.

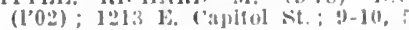

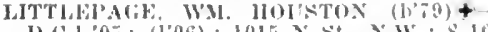
I. $(1,1,05 ;(106) ; 1015 \times$ st., X.W. $; 8-10$

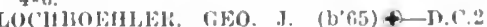
$89:(1340)=55 k$ si., N.W.; $8-9,1-3,5-7$

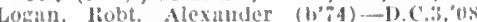
(I'04): 164 Now Jersey Ave. Niw. $8-10,6-4,8-8$

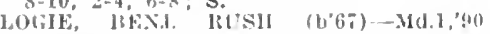
(1'04) ; Isist comecticut Ave., X.w. (

I ONGABALGH, RODOLIH I. (I)'S1)+ ('ul.z.'03; P.A.S., laleut., U.S.X.; IN

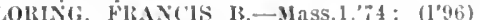

1420 K st., N.W.; 10-1, 4-5; (134,5,30)

OpA *

rosektim, Geo.-Ml1.4,97 ; (1'02) ; 1321 M

Lothrop, Lidwln S.-H-I).C.3,93; (1'96) ; 705 E. Capltol Si.

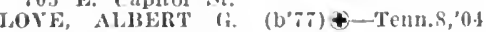
Capt, M.C., I.S.A.: Surgeon General's onice.

Lowe, II orare M.-Mlch.1,'s6; (1'96); 927 F St., X.F. : oftece, I.S. l'ension Burenu.

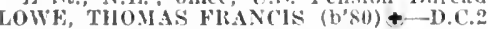

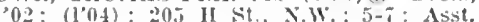

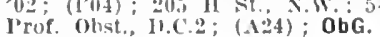

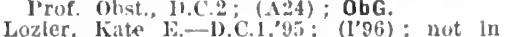
pritetlec; The olympla; ottlce, U.S. I'atent otlice.

Lucas, Malchiah M. (b'75)-D.C.3,05 (1'05) ; $456 \mathrm{~K}$ St., S.W.

IUCE, CHAS. ROSCOE (b'62) †-D.C.2,'85

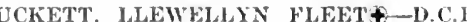
95: (l'96); 1419 lihode Island Ave., N.w IUMSDEN, LESLIE IEON (b'75)-Va.I 94; Surg., U.S.I'.H.S.; Hyglenle Laboratory.

Lynch, ("has. Parker (b'S5)-La.1,09: (l'09) : A.Sirg. M.R.C. U.S.N.

HNCH, ROBT. L.-D.C.1,'96; (1’96) ; 3931 ,

Lyon, Marcus W. Jr. (b'75)-D.C.1,02 (1'02); 48 V St., N.W.; Prof. Bact. I.C.3: Bact.

IYON, MAR'TIA MARIA BREWER (b'7l) -1).C.3,07; (1,0i); 48 V st., N.W.; 0-1:; Op. *

HSTER, WM. J. L. (b'69) †-Mich.7,94; Maj., M.C., U.S.A. ; Surgeon General's Ottice.

MACATEE, HENRY C. (b' $\% S)+$ D.C.1;00

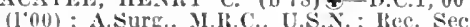
yled soc. of lo.C.; 1478 IIarvard St. Med. Soc. of $4-6$; $(\mathrm{HI})$

MacDonald, Geo. (b'44)-Mo.21,85; (1’96) $1204 \mathrm{G}$ St., N.W.; $9-10,1-2: 30,5-7$

Mactonald, Thos. L.-H-J'a.9,88; (1'96) 1501 Massachusetts Ave., N.W. ; $3-5 ;$ S. MACUEN, FRANCIS S. (b'73)-D.C.2, 01 ; (102); 3206 , 17th St., N.W.; until 10 1-2, $4: 30-7: 30 ; 0 b$.

MACKAI, LOUIS (b'67) \$-D.C.1,90 (1'yb) ; 30440 St., N.W.; $9-10,2-3,5-6$; clin. Frof. Med.. D.c.i.

MACNAMFE, ARTHUR M. (b'74)-D.C.2 $98 ;\left(1^{\prime} 00\right) ; 806$ o st., N.W. ; s-10, 4-6.

MADJCAx, JOHA hOs. (b'79) \&-D.C.2, 09 (1'10); The Congressional; $1-6$; (E12); S. ladigan, Patrick s. (b'ST) -

Madison, Benj. F. (b'52)-D.C. 2, $84 ;\left(l^{\prime} 96\right)$

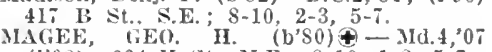
(I'0S): 604 H St. N.E.; 8-10, 1-2, $5-7$

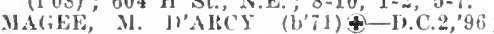
(1'96); 1633 Connecticut Are.; $9-11,6-7$ (A25); S. *

Magruder. Alexander F. (b'49)-D.C.1,71 Surn., Lieut. Commander, U.S.X., retired 1820 Jefferson 1'., N.W.

ATUDER, ERNEST PENDLETON (b'ĩ) +-D.C.I,02; (l'03) ; The Farragut; $4-6$; 'Tin. Frof. Surg., D.C.2; $(\mathbf{1 2 5}) ;$ S.* ALLAN, THOS. F. (b'5i)-D.C.2, 80 ; (196); s.20 Connecticut Are., N.W.; 8-10,

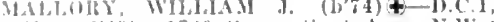
0.3: (fo3) ; 1720 connecticut Are., N. II. $4-1 ;: 1 . *$

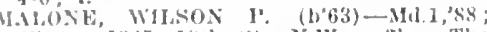

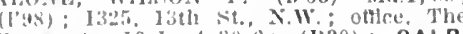
farragut: I0-1, 4:30-6; (1330); OALR MANCILSTEL, JOIIS D. (b'T5) $\$-11.1$ 49; 1'.S.S., liket., L.S.N.; U.S. Navy ficit.

Matil, Henry I. (1,4) - $0.3,75 ; \quad(1,98)$ 1840 Bilmare st., N.W.; offled U. S. lension lourcau.

MANXING, WILLAMM J. (b'i1) \&-1).C.4, 03 : (10.1): Ifin and N sts., N.W.; ontce, (iorroruntent Jrimting oftice.

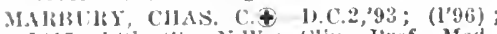
1015, lith st., N.W.; Clin. I'rof. Med. 1). 1.2

Marloury, Wm. Berry (b'85)-Va.1,09; ( ) ; 134, 19 th Nt., X.W; ; 3-5; S. *

Marnion Wim. V-l'a.1,46; (1'97); 1211 I36h si., N.W.; 9-12, 1-5; (134).

Harr, saml. S.-1).(.2,76; (1'97); 1318 Greoran st. N.W.

Marshall, Chas. H.-D.C. 3,$90 ;(1 \dagger) ; 2710$ 1'. St., N.W.

MARSHALI, COLLINS (b'56)€-D.C.3,'83 (1'4i); 2507 l'ennsylvania Ave., N.

MARTEL, LEON ALHIONSE (b'83) 1.1.2, 08; (1'12) ; 1339 Connecticut Ave., I. II:

Martin, Hamilton S. (b'78) - 1.C. 3,05; $\left(l^{\prime} 05\right) ; 1232,4$ th St., X.W.

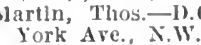

MALTIN, THOS. CHAs. (b'64)-0.7,'86, 0.12 , 47; $(106) ; 1725 \mathrm{~N}$ St., N.W.; $(A 4,25)$.

Martin, Thos. H.-0; $(1,06) ; 1725 \mathrm{~N}$ st. N.H.

Irarlin, Ulysses Grant Baldwin (b'86)D.C.3,'08; (1'09); $1310,28 \mathrm{th}$ st., N.W.

MARTYN, HERBERT E. (b'\%S) -D.C.1 04; (1'04); 614 L. Cajitol st. ; $8-10$, $5-7: 30$.

MASON, ELIJAH L. (b'îl) - D.C.1, 01 ; (I'01): The Portner; S-10, 4-6.

MASON, ROBERT FRENCH (b'69) †-Md.1 'y4; $(1,96) ; 1431,21$ st St., N.W.; 3-4.

MASON, WM. BEVERLEY (b'74) \&-Va.1 "99; (1'06); 1816 l? St., N.W. ; offlce, 1217 Connecticut Ave., N.W.; 9-12:30; (B3,30) ALR.

MASTERSON, WM. L.\&-D.C.1,95; (1'96) Stoneleith $\mathrm{Ct} . ; 9-10,4-6 ; 0 \mathrm{~b}$

Jathewson, Arthur-N. Y,5,61; not in practlce; 2026 R St., N.W.: Emer. Clin. Prof. Dis. of Ear, N.Y.S; (B4)

Maulding, James E.-U.C. 3,97 ; $(1>97) ; 626$ 9 th St., N.E.

MLY, IIENRY A. (b'74) - D.C.1, 99 I'A.S., Ijeut., U.S.N.; U.S. Navy Dept. ILZZE1, FRANT A. (b"63) - D.C.1,95 (1'96);2 T st. N.E. : office, 12s ilassa(1'36); 2 T St. N.E. ; offlee, 12S 1 a
chusetts Ave., N.W.; $9-10,12-1,4-6$.

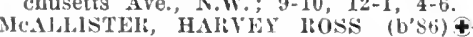
Md.T'I2; A.surg., M.R.C., U.S.N.; 19æ2 I St., N.W.

MCARDLE, THOMAS EUGENE (b'52)1..C.2, 79 ; (1'96); 1730 II St. ; until. 10, $12-1,4-6$

MCCARTHY, JOS. JUSTIN (b'87)-D.C.2,'11 (1'12) ; 1819 Adams MHIl Rd., N.W.; 8n10

MCCAW, WALTER DREW (b'63) †-Va.4 '82, N.Y.1;84; Col., M.C., U.S.A.; 2326, 19 th st., N.W.

McCLUHi, WALTER A. (b'52) \&-Pa.2,72; Med. Dir., Capt., U.S.N., retired; Stoneleigh $\mathrm{Ct}$.

MeConville, Wm. E. (b'6s)-Va.1,93; $148 \mathrm{U}$ st $\mathrm{x}$ iv.

Mecorkle, Thos. Owen (b'71) - D ; (十) ; 4700 Georgia Ave., X.W.; offlce, 935, 9th 'St. X.W.; $8-10,3-6$.

MeCormack, Danl. P.-D.C.1,90; (1'96) not in practice; 1325, 13th st., X.W. office, Treasury bevartment.

IIcCue, Jos. D. (b'SI) -Mass.6,'10; 310 Indiana tre. $>$ iv.

MCCULLOCH, CHAMPE CARTER (b'69) † -Va.1,'91, N.Y.1,'92; Lleut. Col., M.C. U.S.A.; Adjutant General's offlce.

MicCULLOUGH, FRANK E. $\left(b^{\prime} 70\right) \Phi-C a l .2$ 91 ; Surg., Lieut. Commander, Bureau of Hedicine and Surgery.
McDufle, Jos, Allen (b'60)- D.C.3,'97; $\left(1{ }^{\prime} 97\right) ; 1838,13$ th st., N.W.; 7-9, 4-8; Pd.

MeENERY, DOUGLAS W. (b'

Ye (it IIt) (I"96) ; Cosmos club; ofllee, 1339 L' St.,

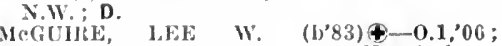
Y.A.S., hicul., U.S.N.; Naval Hospltal. McIntyre, Andrew J. (b'77) - D.C.2,02; (1'03); 2118 1'St., N.W.

MCKAIG; JOS, F.-D.C.2,'93; (1'96); 3122 , 18 ih St., N.W. oftlce, 511,13 th St., N.W. McliAY, JAMES tiEO. (b'72)-I'a.1,95;

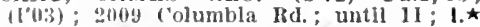
McKEE, WM. PINKNEY (b', 6$)$-D.C.1, 03 ; (I'06); 1634 s St., N.W.; Op. *

MeKeehan, Geo. Ilenry-1).C.5,'96; (l’98); 811 I Si., N.W.

McKlm, Wm. Duncan (b'55)-N.Y.1,78; 1rot In iractlce; 1701, 181h St.

MCKIMMIE, OSCAR A. M.๑-D.C.1,91; (l'96); 1330 Massachusetts $A$ ve., N.W.; Clin. Prof. Laryn. and Otol., D.C.i' $(B 2,3,5,30)$; OALR.

MCLAUGHLIN, ALLAN J. $\oplus$ - Mich.7,96;

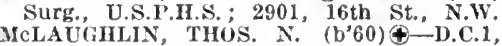
82; (1'96); 1226 N St., N.W.; $8: 30-11$, $3-6 ; 0$.

MeLAUGHLIN, WM. FRANK (b'81)-D.C.1, 09; 103 Ithode Island Ave., N.W.; office, 17 th and I Sts.

MCLEAN, ALLEN D. (b'73)๑-Mich.7'95' P.A.S., Lleut., U.S.N.; U.S. Navy Dept. MCLEAN,NORMAN T. (b'75)థ-Mass. 7,00 ; P.A.S., Lleut., U.S.N.; Naval Hospltal.

McIIULLIN, JOS. J. A. (b'85) †-Pa.2,08; 1'A.S., Lieut., U.S.X.; U.S. Navy Dept. MCNALLY,VALENTINE(-D.C.2,67; (1'96) ; Lieut. Col., U.S.A.; 1417 N St., N.W. 1506 St N.W.: Sec and Prof Gym. D.C. $3 ; \mathrm{G}$.

MCPHERSON, DORSEY MAHON (b'57) $\oplus$ D.C.3,75, D.C.1,94; (1'96); 1810, 15 th St., N.W.

McQuillan, Francls (b'77) - D.C.2,03; (1'03); 204 Pennsylvania Ave., S.E.

MEAD, THEO.-D.C.2,'69; (l'96); not in practlce; 928, 23d St., N.W.; offlce, U.S. Pension Bureau.

MEARNS, EDGAR AI,EXANDER (b'56) N.Y.1,'S1; Nember Med. Soc. of Va. Lieut. Col., U.S.A., retired; The North-

umberland.
MEARS, JOHN BOwDOIN (b'79)
O1; P.A.S., Lieut., U.S.N.; U.S. Navy EARS
Dept
Dept.

MELIIORN, KENT C. $\left(\mathrm{b}^{\prime} 83\right) \oplus-\mathrm{Pa} .1,06$; P.A.S., Lieut., U.S.N.; U.S. Navy Dept. Mellott, Samuel W. (b'61) - D.C.3,'97; (1'97); (Chery Chase, Md.); offlce, U.S. Patent office.

Meloy, Arthur Nourse-D.C.1,05; (1'05); 2409 Nichols Are., S.E.

MERRILL, THEODORE CLARKSON (b'72) -Mass.5,'99; U.S. Dept. of Agriculture. 01: (1'01): 2139 New Hampshire Ave. N.W. ; until 12, $4: 30-6: 30$.

MESS, WM. A. (b'83)-D.C.1,'07; (l'07); 453 G St., N.W.

METCALFE, RAYMOND F. $\left(b^{\prime} 77\right) \oplus$ N.Y.6,00; Maj., M.C., U.S.A. ; 1720 H St.
METZEROTT, JOHN H.( -D.C.1,'91; $\left(1{ }^{\prime} 96\right)$; The Alabama; offlce, 1110 F'St., N.W. $8-12,1-5: 30 ; 1 . \star$

Miller, Allen Erskine (b'58) - Pa.2,'87; (196) ; 4523, 8:h St., N.W.

Miller, Álonzo C. (b'7i)-D.C.3,94; (l'96); 1601 N. Capitol St.; 8-10, 1-2, 5-7:30; ALR.

MLLER, GIDEON BROWN (b'61)థ-Va.1, 90 ; (1'01); 1730 K St., N.W. ; $3: 30-5: 30$ ? Clin. Prof. Gyn., D.C.1; (A2,24,25, C3). ObG. $\star$

Miller, Harry Willis (b'79) - Ill.19,'02; ( ) Washington Sanitarium.

HILLER, MAURICE E. (b'68)థ-Pa.2,'95; (1'96); 1618 II St., N.W. ; 9-12, 5-6; Asst. Prof. Otol., Laryn. and Rhin., D.C.2 ; (B30): OALR.

HLLER, REUBEY BOYD (b'71)(-Mlch.7 93; Maj., M.C., U.S.A.; Army Medical School. 


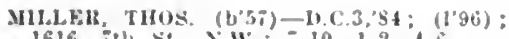
1616, ith st. N.W.; $510,1-2,1-6$. Mllier, Thus it.

Mllliard, Feter McD. (b's2) - D.C.3,'11: (111); 1324 U St. XN.w.; 8-10, 6-8.

Mullgan, Ice I'alrick (b'84)-D.C.a,'11; () $1 \div 37$ il st. N.W.

300 E. Capliol st. : $:-3,7.8 ;$ S.

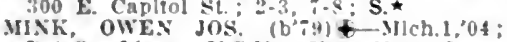

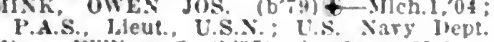

Inor, Wlulam C. (b'35) $\rightarrow$; Capt., L.S.A.,

retled; Adfutant General's onlec.

Mischenux, Yaul J.-1). C.,3,93; (1'96) : 701, ist Se, N.W.

Mitchell, Addle w. (b'69)-D.C.3,03; $\left(1^{\prime} 05\right)$; 817 T st. N.W

Mitchell, Andrew B.-Md.1,'66;

(1'96) :

Horve for Incurables.

Mtchell, Evelyn Groeshecek (b'79)-U.C.3, 13 ; ( ) : 604 Harvard St

ITCHELI. JMMES F. (b, 71$)+. M d .7,97$ (1'03): 1344, 19th St., X.W,; $3-5$; (A5, 6.25); S

Mitchell, John W: (b'-2)-D.C.3,91; (1'96) 51: T St. N.W.: 8-10, 5-7; l'rof. Mat. Med. and Ther., i.C.3.

MTCHELL, JOS. EHXYST $\left(b^{\prime}-1\right)+-I, C .1$, '03; (1'i) ; ; 1428 K st.; ontice. 510, 13th' Motiti, H. Watson (b'84)-Md.4, $07 ;$ (1'09);

1200 E. Capltol St. B St., S. E. ; unti $9, \mathbf{I}-3,5=-$

Montgomery, Charles W-H-D.C.5,94; $(1 \cdot 96) ; 623,61 \mathrm{~h}$ St., S.W.

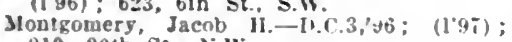
910 , 20th' St. X.W.

Montgonery, Winfleid S.-I (..3,"90; $(196)$; not In practlce; 1912. Hth se. $\mathrm{X}$. Mooney. Chas. J. (b'it)-Md.3,04; (1'04) 1211 X. Capltol st., $\$$. $; 8-10,12.2, t-6$ Moore. Jos. H. (b'45)-Mn.1, 33 ; (1'96); 1916 G St. $\mathrm{X} . \mathrm{W}$

Moore, J. B. (b'?9)-D.C.2,71; (1'ar); not In practlce 2713 s st. N.w.

MONR. MFin (b'66) क-D.C.1,06; (l'06): The Rochambeau; 9-12, 3.6; (131,30) ?

\section{ALR.}

Moore, Seth Eumitman (to.t. - 1'a.1.98 (106); 1825, I6th Nt. N.W.; s-10, 5-6

MOORE, WM. CAIBLL (b;9)-Va.1,02 (1"06): The Wyomlng; 4-6; Asst. Prot. l'hys. Dlag. D.C.2.

MORAN, JOHN F. (b'G4) \&-D.C.2,'s7 1'96); 9426 Pennsylrania Are. N.W. $9-10 ; 6-7:($ A 6.24 .25$) ; 0$ b.

MOIIGAN, FDWIX I.FE (b'55) \&-1a.4, $\left(l^{\prime} 96\right)$; The I'laza: 8:30-10, $1-5,-8$

Morzan, Ernest Lutlier (b'sj)-Md.7.'12 GII, 16 th St., N.W.: Asst. Prof. Inat,

MOHGAX, FRANCIS P. (b'65)-->1.1, 93 (1'U6):3915 Huntington st... $\$$.

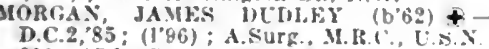
$919,15 \mathrm{th}$ St., X.W.; 12-1, 4-5; Assoc I'rof. Med. and Clin l'rof.' Med., I.C.1 (F1); 1.

MOKG.iN, WM. GERRY (b'68) —-I'a.1,93 (197): A.Surg, M.R.C I'S.Y. I I $1(6)$

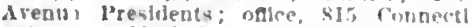

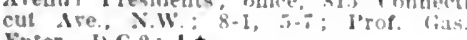

Hinter., Ii.c. 1 ;

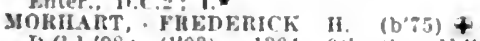
I.C.1,28; (1'93); 1321, 9ih sit. X.w 9-11, 1-6.

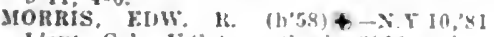

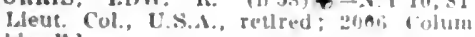
bla Hd.

goRkIs, (iko. f. $\left(h^{\prime} 60\right)-M d .184$; (J'96)

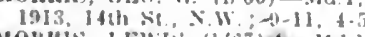

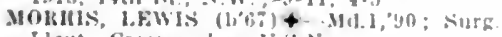
ldeut. Fommander, Iis.t.

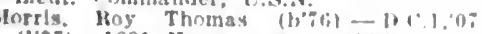
$(107) ; 1331$ Vermont Ave. X $11 .: 10-11$

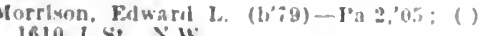

1610 i $\$ t, \ldots . w$

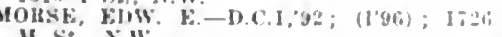
M Ni. N.W.

Morsell, Wm. r. W.C.1:88: $(199):$ not in

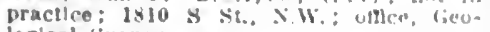
logleal survey.

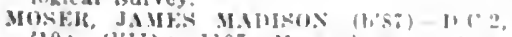

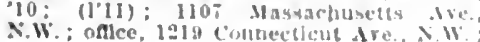
N.W.; oflec, 1
g-t:30; Anes.

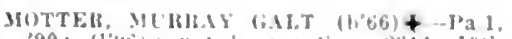
90 ; (1) Si. $\times$ II

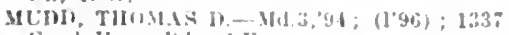
Froul Hope the s. E.

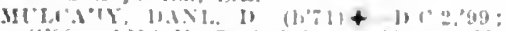
(I'9g) l2I N. Capilol se; $8-10,5=-30$

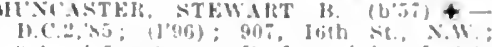

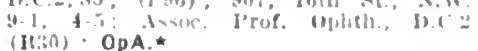

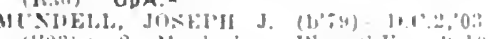

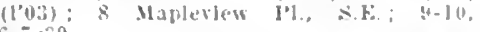

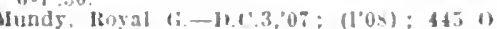

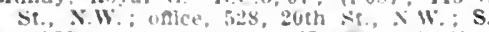

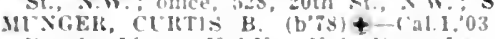

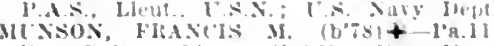

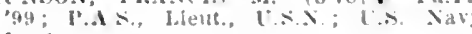
$1 \mathrm{lin}$ it.

Munson, Recinald-H-U, (.., $83 ;$ (1,96) 1:02 Wisconsin tre., X.W. : 8-10, 5- -

Murply, liennis John (b's6)-Mass. ;,10 Government Uospital for the insane.

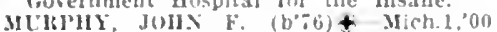
surg., lleut. Cominander, [......; sur geon General's ottice.

MCHPHY, JUHA HATRCK HEXIR (b'-9) -Mass.7, 10: Nember Mass. Med. Soc.

IIRIII JOS ULEAXIER (1.7) 1). C.1,05: (Indiall serrice).

Jurphy, saml. W- Va.4,63; () ; 3029 St., N.w

MIIIIY, WAITEK ('-D.C.1,:3; (1"36) $.50 \%$, th $\mathrm{st.} \times \mathrm{X} .1 \%$

lurray, liarrey illen (b'ti)-1).c.3,13; intert, Freedman's Hospiral

Napper, Waller Purcell-J).(․,91; (1'96) not in practlce; 1916, l3th st., S.ll.

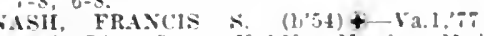

Ned Dir Capt is. Memler Med. soc of Va.: Lis. Naval Examinigg and ketirlng Boards.

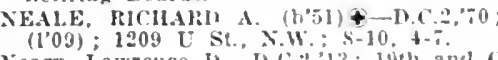

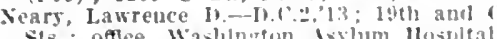
EFF, WALIACE (b, 20$)-0.1,79 ;(198)$ 15.li and I Sts.

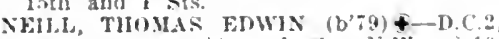
ov; (100s); 1344, 14th sit. X. W.: s-10 $\bar{i}-7 ;(124)$

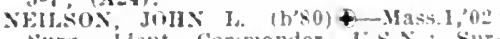

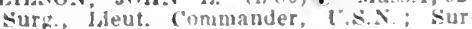
geon General's onlee.

Velson, Nesmilh perty (b'7i)-D.C.1,1il (1'12); not in practice; 23 linude Island ire., $\mathbf{Y}$.11.

Nenman, Lester (b'MS)-1).C.2,13; 160 , Lanier Pl. X.W.; unce, Georsetown Lniverity llospital.

NFITT, J.MES H.MSAY- M.C.1, $(1.96) ; 1820$ calrert si., X.W.; $8-10,1-3$

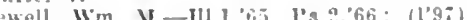

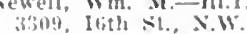

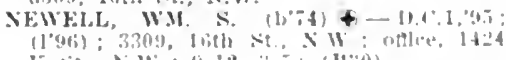

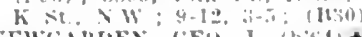

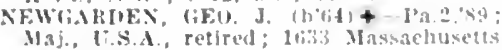
ive., N.U.

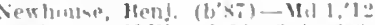

tith st.

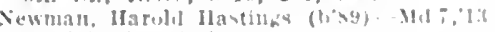
(iarblelul IJuspltal.

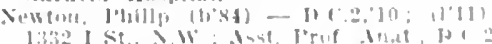

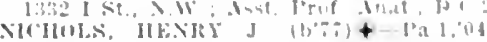

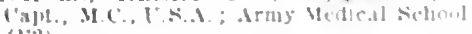
$(\mathbf{r} \div)$

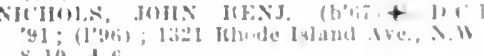

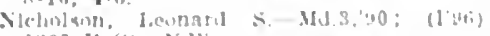
$130 \%$ II $S t, \mathrm{~N}$ W

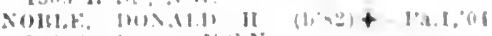

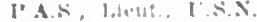

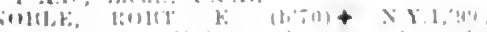

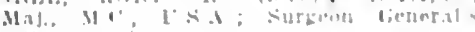
i) $(1 \mathrm{ich}$

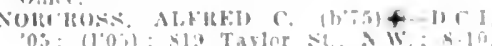
ob.

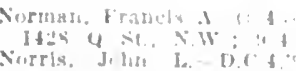

l'yis, ;

Hhole I tanis ire $\mathrm{N}$ i

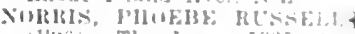

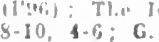

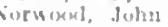

hisliriama lid.

Noyes, Hal Ho

in practice

Sumlu, Huh (b'ist

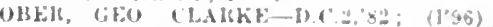

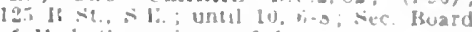

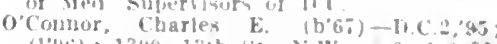

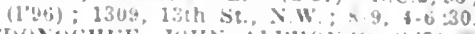

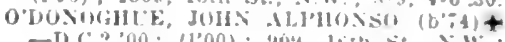

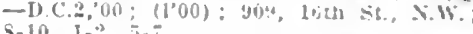
OLD, EDWAlil II, II $(t, 7 t i)+-V a .1,49$ :

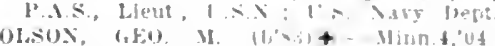

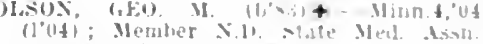
A.surg, Latent, I* fieneral's ortace: D.

O'MALLEY, JUHX J. (b'I) + Md.3,08

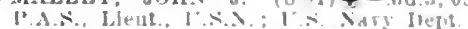

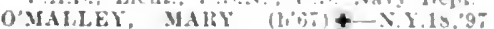

(1'0s): (invermment llospital ior lnsane.

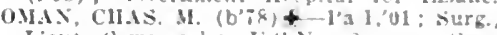

Lieut. Commander, L.S.X. ; surgeon Cieneral's oftire.

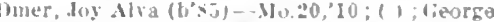

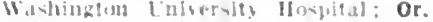

0'Sell, Dlllon farrett (b')--1) C.2,13 Gorernmeut Hosipial for the Insure.

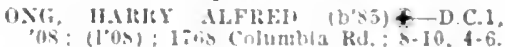

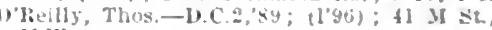
X.11

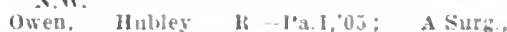

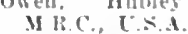

OWE., "W. OTW. (h"

Maj., L's..., refired; 2019 ontario Kd.

X.W. : odce, soutlern Bldin: I'rof. Prac

tical Inat. D.C.

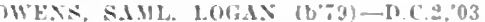

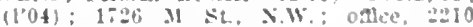

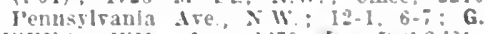

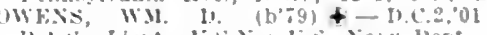

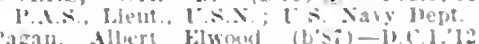

(1'13); 14tist Riltmore st

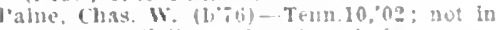
practice: ('Ir) Service Commleshom.

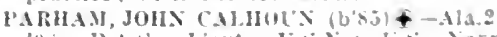

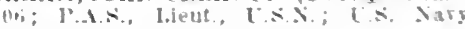
liept

lark, francis r...-1).C.3.8h; (190); :35 Fairmunt Are. X.W

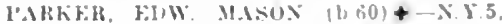

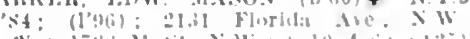

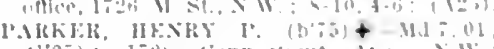

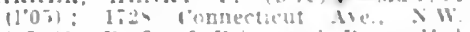

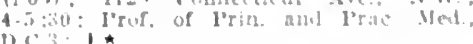

Parker, Holiun

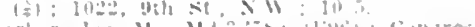
llevichts

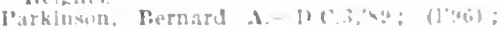
$1 \mathrm{k}=\mathrm{N} \mathrm{H}$

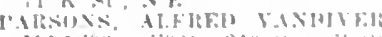

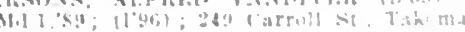
lit

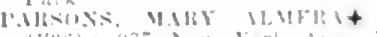

?h

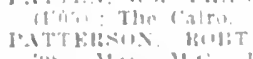

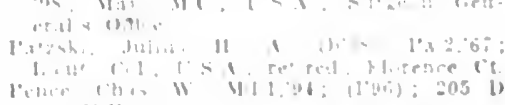

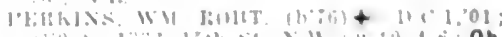

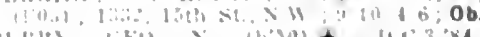

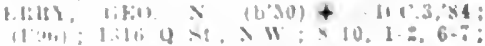


PEISONS, FLIBEHT E. $\left(\mathrm{U}^{\circ} 69\right)+-111.6,97$ Maj., M.C., U.S.A. A Adjutant lieneral':

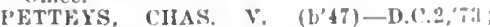
(1'96); 1211 Clifion st., N.YY.

PETTUS, WM, J. (b'63) \& Va. 'R A.Surg. Gen., T.S.1.11.s.; L20. Cont necticut Are. N.W

PETTYJOIN, JoSEPII-Tenn. 11,$07 ; \mathbb{P}^{\prime} . A$ Surg., U.S.I'II.S.; surgenn (ieneral's oftice.

l'k'FinEll, ('HAS. A. (b'78) D-D.C.1, 05 (1'06); 304 Rhode Istand $\Delta$ ve., N.IV $(5-10,5-i ;(1,12) ; \mathbf{R}$

PFEIFFER; J(1IX' AleTHIIR F. $(b, 85)+$ Md.4,08; Corerument llospltal for lusane.

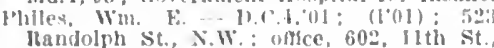
N.W, $10-12,3-6 ; 0$

Phllips. Walter F. (1),79)-D.r.3,07; $(108)$ 401 Florlda Ave., N.W.; 8-10,5-7.

l'lburn, John I, gegu (b'i2)-Mo.7, 10; (1'11) $1322,15 t h$ st. N.lV: Ob.

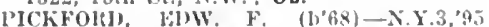
(1'96): 1010 E. Capltol St.; offlec, 422 8th St. S.F $9-10,5-7$

Plerre, Saml. II.-D.C.3,'93; (1'96) ; 2124 L st.. N.W. : $9-10,12-2,6-8$.

PIGiOTT, JOIIN BCHR (b'79)-Md.1, (l'09) ; 1400 if st., N.tW.

PILE, MAVME A.-MII.5,'34; (1'96); The Portner.

Inchback, Blsmarck 16. (b'68)-D.('.3,'91 527 Fiorida

Pitt, Jichard 5 . (b'so)-D.C.I,12; not in practice: 4224,8 th St., N.W.

PLEALWFIA, FRANK LFSTEH $\left(b^{\prime} ; 2\right)+$ Mass. 1,96: (1'09): Surg., Lleut. Con mander, U.S.N : N'aral Médical School.

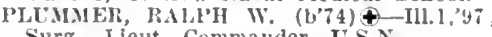
Surg., Lifeut. Commander, U.S.N.

l'OLE, SAMI. BOY'L (b'si) †-D.C. 1,09 (1'09); 216 , sth st., X.E.; office, Bureau Encraring and Printing.

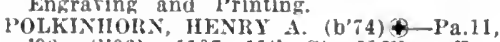
96; (1'96); 1107, 11th St., N.W:; offlce, 1201 I St., N.W.; 9-12,4-5:30; (B30) OpAL. *

'OOL, BFNJ. F. (b'54)\$-D.C.1,70; (l'96) 945 Rhode Island Are., N.W.: 8-10, 5-6. POOLE, THOMAS AUSTIN (b'73) \$-Md.6, 98: (1'09); 5611 Connecticut Ave., N.W. $8-12,4-6$,

PORTER, FREDK. EUGENE $(b,-5) \uparrow-$ Tenn.5,01; P.A.S., Lleut., U.S.X.; Sur geon General's Office.

Porter, James Andrew (b'72)-D.C.3,08 (l'09) ; Burrillie; untli 9, 6-8.

Posey, Orlando J. (b's8)-D.C.2,'12; 516 'Seward Sq., S. E.; P.

POST, DANA CECIl, (b'86)-Mlich.1,11 A.Surg., Lleut., U.S.N.; U.S. Nary Dept. OTTEI, JAMES ALBERT (b'87)-D.C.3, 06 ; (1'10): 300 , 2d St., S.E.; office, 606 Pennsylrania Are., S.E. ; 8-10, 1-3, 6-8 POULTOA, WM. E.-N.C.2,64; (1'96); 205 C. St., N.W.; oflce, $227,41 / 2$ St., S.W. 'OWEII, JUNIC'S L. (b'45) - Md.1, 67 Lieut. Col., U.S.A., retired; The Dresden.
ratt, Alexls I.-D.C.1,'89; (1'96); not in Fratt, Alexls I. - D.C.1,'89; (l'96)
practice; 626 Gresham Pl., N.W.

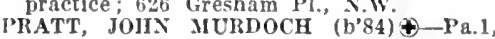
'08: 1st Ileut., M.R.C., U.S.A.; Army Medical School.

PRATT, LESTER LESLIE (b'85) $\$-0.3,07$; P.A.S., Licut., U.S.N.; U.S. Navy Dept. PREBLE, PALL (b'8l) \$-Nd. Surg., U.S.1.II.S. ; Hygienle Laboratory.

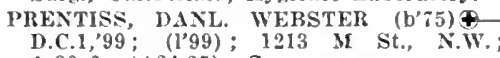
$4: 30-6 ;(A 24,25) ; S$.

PRICE, H.ARRY IT. (b'74)-D.C.1,02; (1'04); 819, 11th St., N.W.

PRICE, MALVERX IILLS $\left(b^{\prime} 66\right) \multimap-D . C .1$ 03; (1'04) ; 421 H St., N.E. ; 8-10, $12-2$

Price, Peter W. (col.)-Tenn. 7,96 ; (1'96) $1128 \mathrm{G}$ St., N.E.

Prlce, Wm. K. (b'50)-D.C.3,'88; (1'96) \$32, 22d St., N.W.; 8-10, 5-7,

l'riest, Howard (b'84)-Ky.9,06; (1'06) A.Sirg, M.R.C., U.S.A.; $91 \bar{\tau}$, 1 sth St.

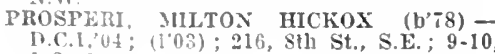

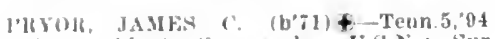
Surg., lalent. (ommander, L.S.X.; Sur Lein fiemeral's omlece.

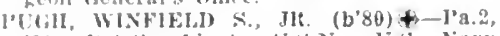

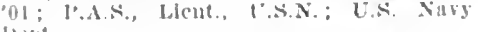
lolster Woodhury (1) In practice: 16i27 pobart st. Nili

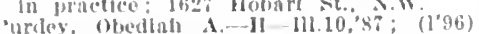
uraley, Obedinf

l'urman. James Jackson-1).1.3,'90; (1'1)6) not in practice: 313 F. Capltol st., N.Y. curman, 1.0uls ('--1).(.3,'84; (1'96); 1324 F. ('a])ltol st.

l'yles, Jolin (thester (1)'81)-1),(.1,04; (1'04); 910, 8th sit., sis. : $8-9,1-2,6-8$.

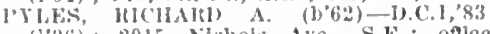
(1'96i) : $201 \%$ Nlchols Ave., S. W.: Quay, John Barton D.C.386, D.C.2,93

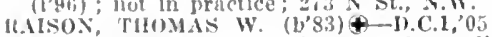
l'.A.S., Llent., I.s.s.; Surgeon General'

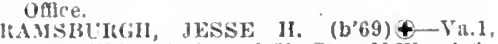
$95:(196) ; 15$ th and U. Sts., N.W.:4-6 ALR.

Itand, Wm. H.-Conn.l, 7 ; $\left(1^{\prime} 96^{*}\right) ; 1440$

liandall, Irthur T.-Ill.6,95; Hureau of l'enslons.

MANDOIJH, HCCKXER MAGILL $\left(b^{\prime} / 1\right)+$ Va.4,'9s; (1'04) : $2010 \mathrm{R}$ st., N.W.: oftice, 2002 I' St., N.W.; 3-4; Prof. Mat. Med. and Ther., D. C. 1 ; (HI

RANSHELL, ROBT. (ATHCALT $\left(\mathrm{b}^{\prime} 80\right)+$ I. C.1,'02; (1'03); '.A.S., Lleut., U.S.X. U.S. Nary Dent

lianterlerg, Lewis E. (b'42)H-D.C.2, (1'96); 3446 Oakwood Terrace, N.W. oftlce, 1 th and 1 sis. ; $9-1,6-7$.

RAY, ANTIlONY H.-Va.1,'95;

Raymond, John Underwood (b'50)-Jllch.1, 75 ; $\left(1^{\prime} 96\right)$; 1224 Euclld St. N.W.

'65; (l'96); 1224 Euclld st.. N.W. Comnecticut and Florlda Aves.; 6-8.

liealy, Francis Jos. (b'85)-D.C.2,'1: ; Emergency Hospital.

lleady, Mlchael J. (b'78)-D.C.2,05; $\left(\mathrm{H}^{\prime} 06\right)$ 3325 s St., N.W. ; $8-10,1-3,5-7$.

Reed, Jos. O. (b'53)-D.C.1,94; (1'96); 804 , lith St., N.W. ; 10-1,3-6; U.

RELDE, EIW, HIRAM (b'75)-Md.7, 02 ; (1'03); 300 M St., N.W.

HEEVE, JESSE NFWMAN (b'66) —-D.C.2 '93; (l'96); 926 Farragut Sq.

FEVES, ISAAC STOCKTON KEITH (b'81) †-D.C.2,'03; P.A.S., Lleut., U.S.N. U.S. Nary Dept.

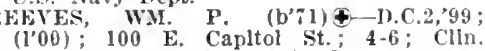
'rof. Surg., D.C.2; (A25); S

REICHELDERFER, LUTHER il. $\left(\mathrm{b}^{\prime} / 4\right) \uparrow$ D.C. 1,98; (l'99) ; 1721 Connecticut Ave., N.W.; 9-I0, 5-6; Clin. Pro?. Surg., D.C.1 (A25); $\mathrm{S}$.

EISINGEI, EMORY WM. (b'il)\&-D.C.2, '93; $\left(1 ' 9 b^{\circ}\right) ; 1228,16$ th St., N.W.; 8-10,

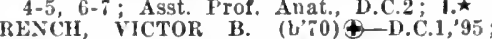
(1'96); 1300 Rhode Island Are., N.W. $9-1,4-6 ;$ OpAL. $\star$

RENNIE, WESLEY H. (b'76) $\$-P a .9,97$ surg., Lleut. Commander, U.S.N.; Sur geon General's Offlce.

Repetti, Fred (b'75)-D.C.1,06

$\left.\left(1^{\prime} \theta\right)^{\circ}\right)$

527,6 th St., S.E.; until $9,5-7$.

REPETT1, FREDK. F.\&-I,C.2,'95; (l'96) $52 \%$, 6th st., S.E. , 8-10, 5-

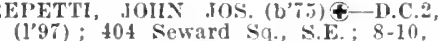

Rerllle, Laura Marie (b'4)-12a.t, (I'96); 101\%, 14th sit., X.w.; 10-12, 4-6, Reynolds, Dexter Pringle (b'78)-Teun. 7 , '02; (l'09) ; 2219 F St., N.W.

Rhecs, BenJ. Push (b'76)-D.C.1,09; (1'10) 1364 Oak St., N.W.

RHOADES, GEORGE C. $\left(b^{\prime} 81\right) \uparrow-P a .1,06$ P.A.S., Lieut., L.S.N.; L.S. Nary lept. Rlce, Chas. Saml--Pa.2,'91; 1915 N. Capitol St. ; office, Bureau of Penslons.

RICHARD, CHARLES $\left(b^{\prime} 54\right) €-N, Y .5,76$ Col., M.C., I.S.A. : 1860 Mintwood PL

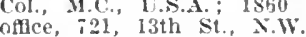

RICHARDS, ALFRED (b' 12$) \oplus-D . C .2,97$ $\left(1^{\prime} 97\right) ; 400$ Pennsylranla Ave., S.E. $8-10,4-6$.

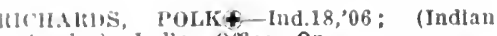
Sirvlce); Indlan offlce; $0 p$.

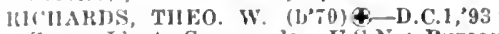
Surp., Ileut, Commander, U.S.N.; Bureau of Mediclne and Surgery.

lil'HAltLSON, cHAS. WIILIAMSON (b'61) + L's.1.81: (1'96): 131\% Connecticut ive. N. W. ; $12,3-5$; prof. taryn., khin.

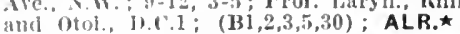

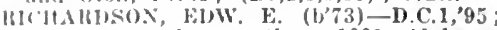
$\left(1^{*}(4,)^{3}\right)$ not in practice; 1001 Alabamá Ave. S.l.

illohardson, (ito. II.-D.C.3,90; $\left(l^{\prime} 96\right) ; 309$ 11 th st.. N.t.

IRIHAIRWNON, JAMES JCLIUS (b'68) कMd1.,89: (1'97); A.Surgo, M.R.C., U.S.N. otol., I.aryn. and Rhín., D.C.3; (B30); ALR. *

IICHAIINON, ROYALL ROLLER (b'75) Ya.1,'93; Surg., Lleut. Commander. I'.....; ; Surfeon ficneral's Offlee.

III HEY, STFI'11EN O. $\$$-III.6,76; (1'36); 1719 I St., N.W.; office, 732, itth St.

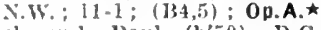

Rlchmond, l'aul (b'50)-D.C.2,92; (1'96) ; 1914 T'ennsylvanla Are,, N.W.; U. S Postoffice Dept.

Ricker, (ieo. E.-Pa.9,78; (1\%); 717, 12th

Mdgeley, Albert-D.C.3,00; (l'00); 950 S St., N.W. : Assoc. Prof. Anat., D.C.3.

RIGGLFs, JOIIN LEWIS (b'77) D D.C.1, (A25); ObG. ${ }^{\prime}$

RuGis, CllAs. E. (b'69)థ-Ia.3,92; Surg. lileut. Conmander, U.S.N.; Surgeon Genera!'s office.

Riggs, paniel 11.-II-N.Y.9,'82; (l'96); 1410 , 11th St., N.W.

RIKER, GEORGE ALBERT (b'79)Ф-Pa.2, Vediclne and Surgery.

lilordan, John Francis (b'89)-Mo.34,'12; A.Surg, M.R.C., U.S.N.

RIVES, WM. CABELLڤ-N.Y.5,77; (1'99) 1702 Thode Island Ave., N.W.

RIXEY, PRESLEY MARION (b'ฐ2) $\oplus$-Va.1, '73: Surg. Gen., Rear Admlral, U.S.X.', retíred; $1518 \mathrm{~K}$ 'St., N.W.

Roblins, Chas. S. (b'76)-I1l.1,01; (l'04); 435 Luray Pl., N.W.

Roberts, Edwin E.-D.C.2,94; $\left(l^{\prime} 96\right) ; 8$ Prospect St., Frlendshlp Helghts.

Roberts, Robt. Richford - $\Delta ;\left(I^{*} 96\right) ; 525$ Tennessee Ave., N E.

ROBINS, WM. IITTLETON (b'69)\&-Md.1, 90; (1'96); 1700, 13th St., N.W.: offlce, The Rochambeau; 3-5; (E13); N.`

Roblnson, Burton G. M." (b'79)--B.C.3,11; (l'I3); 84 iI St., S.W.

ROBINSON, DANA E.\$-0.1,96; Surg. U.S.P.H.S.

ROBNETT, AUSEY Hamilton (b'79) D.C.1, 05 ; P.A.S., Ileut., U.S.N.; Surgeon General's office.

ROGEHS, JOS DECATUR $\left(b^{\prime} 80\right) \oplus-D . C .1$, 02; (1'03) ; 1400 M St., N.W. ; $4-6: 30$; S. Rollings, John Adolph (b'89)-D.C.1,'12; (1'12): Intern, The George Washington University Hospltal.

ROMAN, FREDK. O. (b'66)-D.C.4,94; (1'96); 1337 R St., N.W.; 8-10, 2-3,6-8. Ross, Louise (b'73)-Mass.5,'07; (l'07) 1801 Calrert st., N.W.; $9-10: 30,4: 30-6$. ROSSITER, PERCEVAL SHERER (b'74)థU.S.N. ; Surgeon General's office.

ROSSITER, THOS. J. (b'72)-D.C. 4,02 ; (l'02) ; 820 D St., S.E. ; 8-10, 1-2, 5-7; $\mathrm{Pd}$.

Roth, Geo. Byron-Mich.1,09; not in prac-

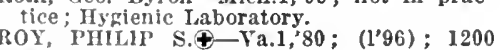
Mas, PHILIP S. $\oplus-$ Va.1, 80
Massachusetts Ave., N.W.

RiCKER, WILLIAM C.(-)-III.1,97; P.A. surg., (A.Surg. Gen.), U.S.P.H.S.; The Iresden; Bureau of Public Health' Serrice.

RUEDY, ROBT. CONRAD (b'76)↔-D.C.1, 04; (1'04); 621 Maryland Are., N.E. RUFFI, GEO Il. (b'76) $₫-D . C . I, 02$; $(1,03) ; 1101,14$ th St., N.W.; offle, 1746 K St., N.W.; $9-10,4-6$.

RUFFIN, STERLING (b'66́)థ-D.C.1,'90 ; (196); 1335 Connecticut Are., N.W. ; 
Russell, Arerley, 1. H. (1,33)-Va.1; ; Med. InsD., Commander, U.S.X., retired C.s. Nary lepe

kussell, Murray A. (b'Rl)- LI. ( 2.08 (l'08): 1732 Connectlcut Ave., X.W.: 3-j, $-3 ; 5$

If utherford, J. Baldwin-D.C.4'Bg: (1'96) 1115 lthode lsland Are., X.16:

RYDER. CHAS. F. (b'\%) Mass.1,

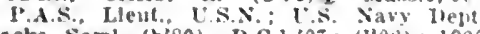
Sacks, Saml. (b'80)-D.C.1,07: (I'0s): 1000 x st., N.w.: $8-10,5-\%$

Sadler, Loren A. $\left(b^{\prime} 65\right)-0.60^{\prime} 90$; not in practlce: 1204 Decatur St., N.W.

Saffold. Guy Stark (b'80)-[1,1'1,05 (1'06); $1760 \mathrm{~T}$ st., $\mathrm{x} . \mathrm{w}$.

sarfold, James I'. (b'54)-D.C.I,'s5; (l'96) 1760 T St. X.W.: 8-9, 3-5.

SALANT, WHLLIAM $\left(b^{\prime}, 0\right) \nsubseteq-$ Assoclate Fellow-X,Y,1,99: 3429, 3tih IPl.: offce, Bureau of Chemistry; I'rof. Exper. I'har. I).C. 8 .

SAMSON, GKO. CLEMENT (b'48)-I'a.1,69; $\left(1^{\prime} 96\right) ; 2423$ jennsylianla Are. $\mathbf{S}, \mathbf{W}$.

anders, Chas. H. (b'83)-D.C.2,12: Intern, Garfleld Memorlal Hospltal.

Garfleld Memorlal Hospltal.
Sapplugton, Eirnest F. (b'80) HI-I'a.9, 06 ; $\left(1^{\circ} 06\right)$ : The Argyle; omce, 818, $15 \mathrm{th}$ st. X. W.: $3-5: R$.

SAVAGR, LIXNAEUS S. (b'i1) \&-Md.t. 93: (1'96); 623 Marsland Ave. N.E.

SAWTELLE, HFNRY F, (6\%8)\&-I11.11,02: (1.06): 3001 . 11th St., X.W.: $3-5$

SAWTELLE, HENRY W'f-D.C.2, 68 ; surg.

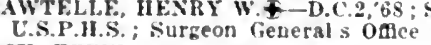

SCHAEFFEK, EDW. M.-D.C.1,68; (1"96); 1508 i St. X.W.: Lo.

SCHERESCIEWSKY, JOSEPH W. (b'73) -X.I.1,99: Surg., U.S.P.H.S.; ; 16 lkock Creek Church Rd., X.W.; ottce, Ilgglenlc laborators.

Schildrolch, Henry T. - D.( 2,$93 ;(104)$ : $1 \% 0$. 1st st.. x.w.

SCHMIDT, LAWIUECE, MALMICE (1) $\$ 3)$ I -11!.11,06; 1'A.S., Lleut., L.S.X.

SCHNEIDER, ELWIX CARL (b'80)

D.C.2.05; (l.06) : 1 it2 C St., N.W. 07: (1'07); 502 II St. X't.; $8-10,4-7$ Asst l'rof" Pluystol di

Schwinn. Geo, Iletry-b ( i, 'ys; Govern-

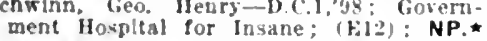

Scott, Egbert T. (col.) (b'8t) N.C.3.13; Intern. Freedman's Hospilal.

Scott, James It (b'86)-Cal, 1, l: : 1:71 Lanler P. N.W. Anatomlst of the PathoSchool.

SCOTT KAYMOND FWELL (b'89)-Mo.10, 10: (): Meniluer Mo. State Med. Iskn. ; 1749 ist. N.W

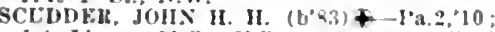
lst Llewt, M.C. L.S.A. Army Helleal School.

Scurlock, Herbert C. (b'75)-D.C.3,00 ; (1'01): not in practice: 428 rollege st. Yw: $8-10,4.5,7-8$ : Prof chem. D. 3

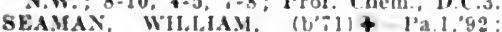

Surg., Lleut, Commander, L.S.S. Sur zeon General's Office.

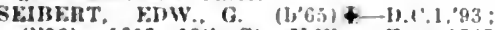

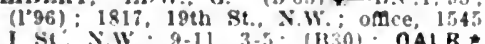

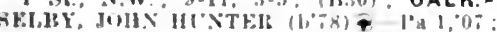

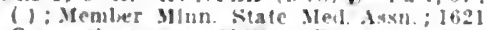
Connectlcut Ave., N.W: (F6, G1.2): R.

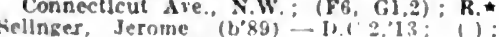
sellnger, Jerome (b
1120 Columbla Rd.

GELHAI.SE, VBNEST $1+1161$, it $(1.96)$; 640 i :
6.8.

SELLHALSER, IIAIII A - [1.1 1.99 (1.98): 1210 Massachusetes Me, 111

ofee, $640 \mathrm{fi}$ St., N. W: $9 \cdot 10,3-3$

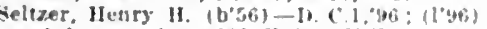
not in prectlce: $640 \mathrm{~F}$ st. N. F

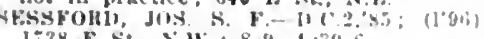
1738 F St, N.W.; 8.9, t:30.0.

Sewell, chas. $A$ il $11.3,93$; (1096): 112 ; $184 \mathrm{~s}$ st. $\mathrm{x} . \mathrm{W}$.

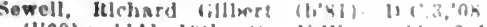

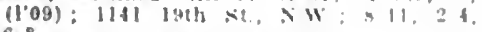

Shade, Nerin If - I'a 2,78: (1.90): 152

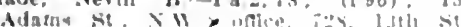
I $\mathrm{W}$

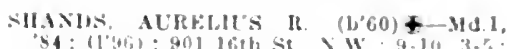

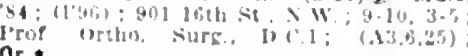
Or.

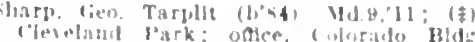

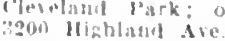

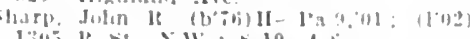

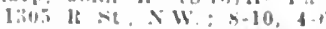

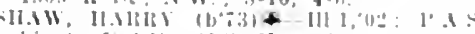

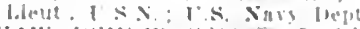

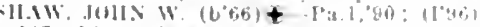

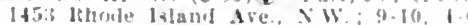

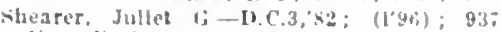
ven lork wre, $x \mathbf{w}$ : entre. Treasury lheprariment

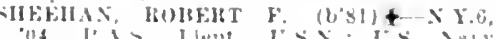

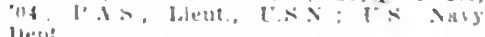

shekell, Mlorahan H.--1).12,63; (1'96)

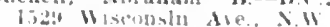

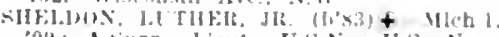
09; A.surg, I.leut, C.S.X; IXS. Navy

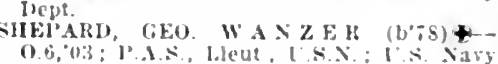
lievit

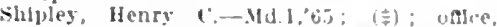
$141 \%$ Q St. X. X

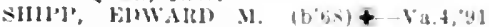
surg., lieut Commander, I.s. Sur geon fieneral's ufice.

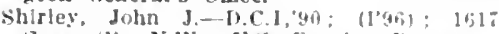
Swan st. X.W. ['.s. Penslon lubreata.

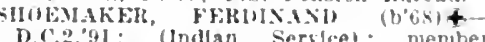
D. (2,291: (lndian Servlee): nember

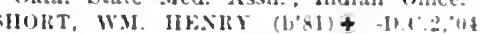
['.l. Blent IS.

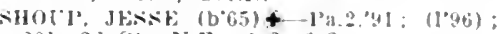
$201,2 \mathrm{~d}$ Sit. X.F. ; 1-2, 6-8

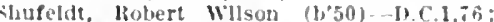

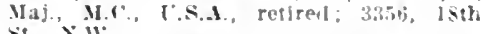

SHTTE, IHAXI. KEKFOOT (b'58) \&-D.C.I. 83: (1"96) : 1i19 lle sales st ril. 3:30-5:30; I'roe. Neuro. Anat and clln. I'rof "phel, D.C.I: |B1,30, E[2]; Op.*

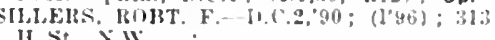
II st. $\mathrm{s}$.

simmons, Sherod S.-D.C.3,'95; (1'96); 2358 . bith si. N W' ; oftee, I's l'enslon kurean. Slmons, Jarry Emmerich (b'85)-D.C.J, 08 (ま) : 2415,20th St, X.w

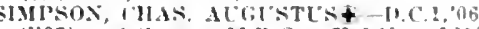
$\left(l^{\circ} 07\right)$ A.surg. M.R.C. U.S.X. I610,

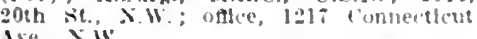
ive. X.W

SIMPOS, JOHS IllAKE (bos) + Mal,

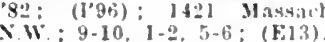

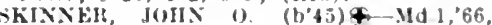
I'a.1.67: (l'04); Maj. l's.s reilred The Portner: odice, Columbla Hospltal.

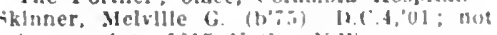
in prietlce; $1015 \times$ sit. N W.

Slattery, John J.- I) (1.3.42: (1006); 31 ;

Masyalchusett dre. 511

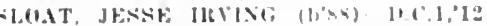

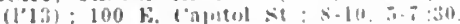

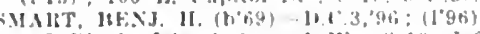

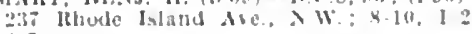

Mitil (IIS)

1i. $(1,5 x)+1 \times 21,40$

surs. loleut

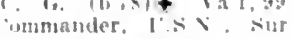

Leron liemeral's ontre

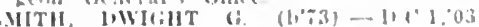

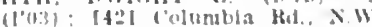

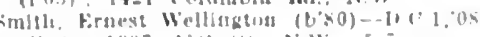

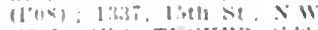

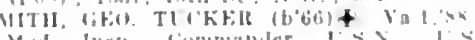
Vted Invi!

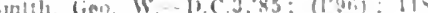

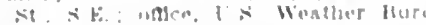

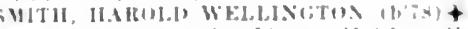

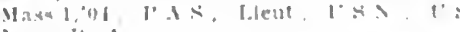

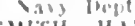

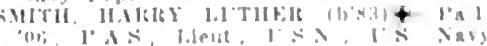
Inelis

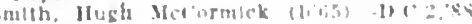

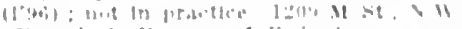

untere, 1 s leurcau uf risherles

ulth. Julia pirlunla (1)'b(i).

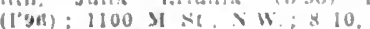

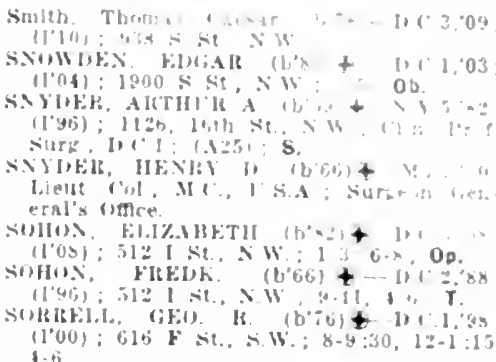

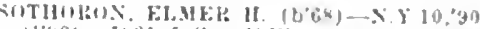
$(1.461 ; 1421$ I St., XW: $3.10,1.2,0 . b$ $(124) ; 0$ b.

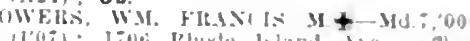

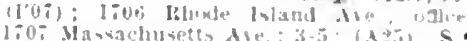

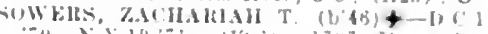

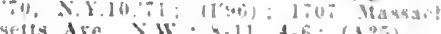

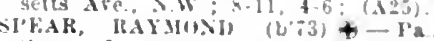

surs., bent. Commander, Ls.s; sur zerin General's nate

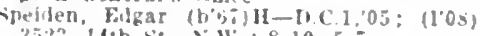
3523 , Ith st., X.16: $8-10,5-i$

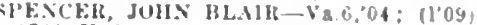
$176 \mathrm{~K}$ St. N.W. ontce, I:14, Isth st

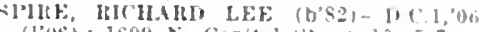
PHIiG, WM. MERCER (bo4t+D.C.

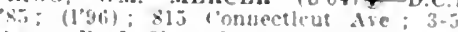
Avioc, Prof Obst. I.C. $2(124,25): O B G$. STANIEY, ARTHLW CAMH (bs)

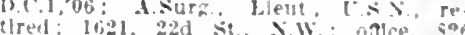

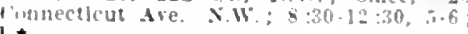

itanton. Lemuel J.-D.C.1,"94; 629 Isamont t., XW: ; utlce, l'enslon Hureal.

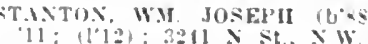

STALLE. MUREY H. (b'74)-Md4,'96 (1'46): 18 \& St.: X.W.: unt!! 11. $2: 30-8 ; 0 b \mathbf{G}$.

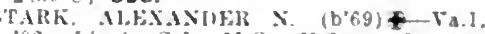
9.2: Lleut Col. MC.. I'A.A.; Surzent fieneral's once.

STAVELY, ALBERT LIVINGSTON (b'B3) -

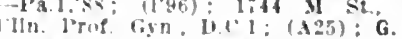

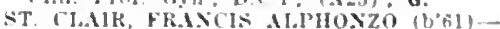

J) (. $1:-1,4-6: 0$

Ntearns, John sarzent (b"70) H-D.C 2.94

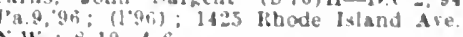
N.W.; $8-10,4-f)$

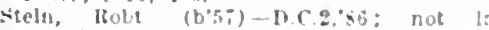
practlee: $y n$, th st st

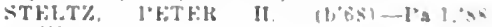
lons bil North Carolina tre.

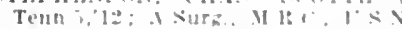

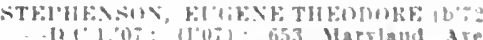

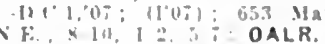

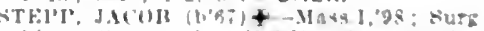

l. leut commander, I" $\mathbf{X}$ : surgeon tienL'* 1) nle

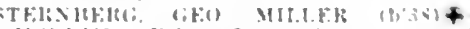

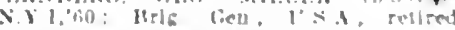
200: Mavsachuseles Iie y 11

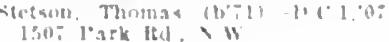

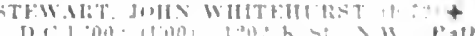
semart lialeh It. ih

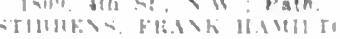

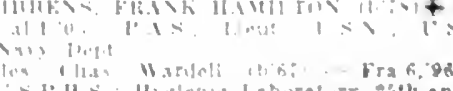

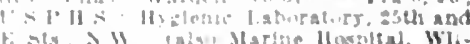

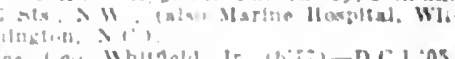

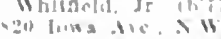

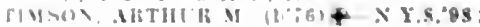

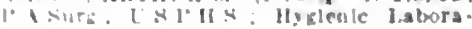


STIT'T, FDWAIL RIIODES $\left(\mathrm{b}^{\prime} 67\right)+$-l'a.l 's4: Ved Insp. conmiunder U.S.N.

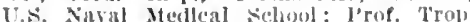

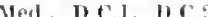

STOliks, CHAS. FliNCIS $\left(b^{\prime}(13)+-\mathrm{N}\right.$ Y. 'S4; Surg. Gen. liear Admlral, U.S.S. surgeon feneral's othler: (A'b)

STOXF, (1IAS. GIANVILAE (b'46)Md.1,72; (l'96); The kenesaw: $9: 4-30$.

STONE, ELtiFiN 1 . (b'til) +-Mass.1, 84;

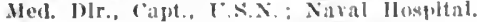

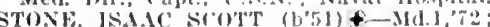
(1.96): 1618 Rhote lsland Ate. N.W. (I96) : l618 Rhote lishnd Ate, N.W.;

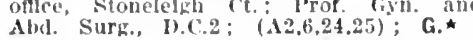

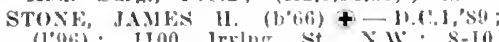
$\left(l^{\circ}(96) ; 1100\right.$ Jring st., N.W1: $8-10$ $5-7: 30$

Stout, Jos. Wuerson (b'sti)- I) C.1,'13: 2918 deorgla Are.; Assoe. Prof. l'lyssloi. and llar., D.C.i.

Stout, ilay Turner (b'si)-1).C.1,18; ( ) ; 453 Irving St.. N.W.

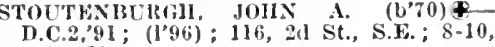
6i-8; $0 \mathrm{~b}$.

STRAWTOX, RENIFIt J. (b'\$4)€-Neb.6, '0.; I.A.S., Lleut., L.S.X.; U.S. Navy Depit.

Strawn, Fstll young (b's5) - D.C.3,'13 Freeimen's Hospital.

Street. Harlow R. $\rightarrow ;\left(10^{\prime}\right) ; 641$ E. Capltol St.

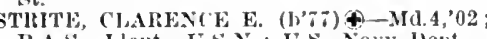
P.A.S., Heut., U.S.N.; U.S. Navy lent

STROBEL, MARY L O U IS E (b'54) \$ $2-4,0$

STROMBERGER, IFNRY IT. (b'66) H.C. I, $99 ;\left(l^{\prime} 00\right) ; 135$ Florida Are., N.W.

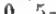

STUAIT, ALBFRT RHYT'T - Va.1,92 (1'96); 7 Dupont Circle, N.W.; 2-4, $7-8$

STUART, AllaN (b'64) \& - S.C.1,'89 Surg., LJeut. Commander, U.S.N. ; Surgeon General's Offlee.

STUART, .IMES D. (b'65)F-D.C.1, 92 : (1’96) ; 1315, l2th St., N.W. ; 9-10:30, 5-7.

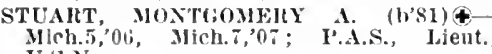
I. $\mathrm{M} . \mathrm{X}$ Stutz, John A. (b'60)H-N.Y.9,86; (l'06)
I645, I3th st., N.W.; 8-10,4-6.

SUIDDARTH, JAMLS L.CU.C.1,'68; (l'96); 609 II St, $\mathrm{X} . \mathrm{Y}$.

SULLIVAN, RORT. YOUNG (b'SI)-D.C.2 05; (1'06); The Burlington ; 3-5; (A24): $\mathrm{S}$.

Sullivan, Timothy J. (1,'74)-I).('2,'04 $\left(1^{\prime} 05\right) ; 512,6 \mathrm{th}$ St., S. W.

Summey, Benn W. $\left.\left(b^{3} 48\right)-D . C .2,86 ;(1)^{\prime} 96\right)$; SUTER, HEXDElisos - Pa.1,77; (I'96) : $3026 \times$ st., N.w.

Suter, W. Giren-D.C.4,'96; (I'96); 27 II SUTHERIN, JOHx w. (b'69) - D.C.3,02 ; (l'04); 1331 Vermont Ave., N.W.; $\$-10$,

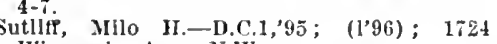
W'isconsin Are., N.W.

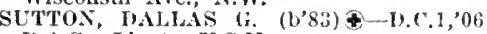
P.A.S., Lleut., U.S.N.

Swaln, IBenj. H. (b'59)-D.C.1,06; (l'07) 1334 Falrmont St., N.W.; $3-\bar{t}$.

SWAIN, OLIVEK ALDEN TINKILAM (b'68) -D. (.1,92; (1'96); 321 E St., X.F

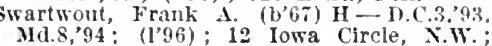
$8: 30-9: 30,3-5: S$.

Swett, Fred K.-D.C.1,'89; (l'96); not In practlce; 1478 Monroe st., N.W.; offce, U.S. Pension Bureau.

Swormstedt, Lyman Beecher (b'53) I-Pa.9. '7\%; (1'96); 2 Thomas circle, N.W.; 8-10,

SYIIE, WII, H. (b'/1)-D.C.1,04; (l'05); 2311,18 th st., N.W.; oftlce, 2445, 1sth st., Tait, John-N.X.30,54; not in practlce; 2536 , 14th St., N.W.

TALBO'TT, LDWARD I. (b'77) 9-D.C.2, '01; Capt., M.C., U.S.A., 162\%, 16th St.,

TALBOTT, TOHN ALLAN (b'82)\$-D.C.1, $05 ;(1,0)$; 2038,18 th St., N.W.; 8-10,

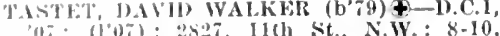

Tullor Adelbert A.-D.C.1,00; 3021 Ma(')mb st., N.W.; ofll'e, Bureau of l'en-

chlos. Nfred II. (b'5S) II-MIl.8, $95 ;\left(1^{*} 96\right)$ aylor, Alfred II. (b's.) II-M-

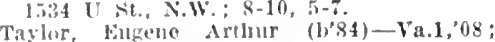
(1'I3); 1720 M St., N.W.

Taylor. James Hill llayes (b’at)-D.C.3,’09 (l'14): 1530 , 15th st., N.W.; 8-10, 6-8.

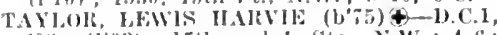
0.1; (1'03); 15th and I. Sts.. X.W.; 4-6: (Fis) : S.t

'aylor, Walter s'cott (b'si)-1'a.11,'13; Intern, Freduman's llospltat.

Tebls, Algernom s. (10'44)-Ky.2,'69; (击) ; 1215 l'otomac St., N.W

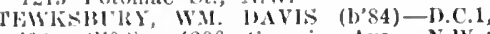
0\&: (108); 4200 licorgia Ave., N.W. onte. Tuleremlosis llospital; T. $\star$

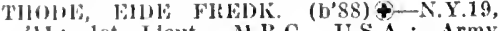
11; 1st Lleut., M.R.C., U.S.A. ; Army Merlicat school.

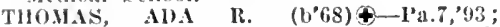
(1'96); $1400 \mathrm{M}$ st., N.w.; $8: 30-10: 30,4-6$ Thomas, Carrlo II.-1).C.3,'90; (1'96); not in practlce; 1629 New Jersey Ave., N.W. TIIONAS, JOHN D. (b'68) $4-$ Va.1,92 (1'96); 1720 if st., N.W.; 9-10, 5-6 l'rof. I'hys. Diag., D.C.2.

THONAS, WH. JOSHI GROOT $\left(b^{\prime}-5\right)-$ 1).C.1,08; (l’10); 2905, 14th St., N.W.; $8-10,+6$.

THOMHSON, HDGAR D, (b'71)-N.Y.8,'96 (1'9(i) : $1247 \mathrm{~N}$, Capitol st. ; $8-10,1-2,4-7$ TIIOMI'SON, HDGAL sAML. (b'72) $\$-$ No.21,93; Surg., Lieut. Commander I.A.N. ; Surgeon General's oflice.

THOMl'sos, Jos. C. $\left(\mathrm{b}^{\prime}, \mathbf{4}\right) \uparrow-$ N.Y.1,'96; Surg., Lleut. Commander, U.S.N.; Surgeon dieneral's offlce.

THOMl'SOX, JOS. FORD (b'37) $4-M d .1$, 57 ; (l'96); Cumberland Ajts.; Emer. l'rof. surg., Joc.1: (A5).

THOML'SON, JOS. LAWN (b'73)-D.C.1,04 (I.05) ; 1332 Massachusetts Are., N.W.; S

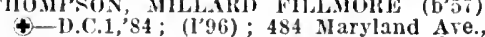
S.W.; $9-10,6-8$

Thompson, Silas S. (b'76)-D.C.3,'04; (l'05); \$5: R St., N.W. ; 8-10, 2-4, 6-8.

THOMSON, LEWIS BEE('HER $(1,49)-$ Il1.9,05; (1'10); 3423 , lith st., X.W. TIONSSEN, WM.' J. R. (b'51)-D.C.3,'s8; (l'y6) ; 315 C sit.

TIBHETS, AIBERT PEMKINS (b'84) कI). C.1,10 ; (1'10); 1223 Vermont Are.

N.W.; 10-12, 2-5. (101) ; 47.3 Florida Are., X.1F, ; 8-10,2-3 $5-\overline{7}: 30 ;$ Pd.

Tignor, Wm. L.-D.C.3,'96; (1'96); 921 S. TITLS, ELLIJII WIITE (b'85) †-D.C.1, 10; (1'10); 911, 16th St., N.W.; 9-10,4-6. TOBIAS, IIENRY W. (b'76)\$-D.C.1,01;

TOBIN, RICILARD F. (b'72) -D.C.2,05 l'05) ; 123, 11tl St., S.E. ; 5-

TOLFLLF, IIEIBBELT M. (b'73)థ-N.Y.10 97 ; Surg., Lient. Comnander, U.S.N. surgeon General's office.

Tolson. Wm. Alonzo (b'83) - D.C.3,06 ; (l'oi); 728, th St., N.W.; offle, 78 Defrees St., $N . W ; 8-10,1-2,5-7$.

Tomlin, Timothy iI. (b's3) - D.C.1,07 ; (l'07); 1011 13 St., X.E.

TOULON, AIFRED J. (b'82) †-Pa.11,'06 P.A.S., Lieut., U.S.X. ; U.S. Navy Dept Towner, Frank H.-Pa.9,'06; (1'06): 1204 Fewton st., X.E.; office, 1020 , 9th St. N.W.

Townshend, Grafton Jent (b'7s)-MI.1,'11. lutern, l'roridence Hospital.

Townsend, James Gayley (b'88)-D.C.2,'12 (l'12); Gcorgetown Hospital.

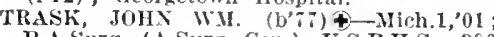
P.A.Surg. (A.Surg. Gen.), U.S.P.H.S.; 300 R St., N.E.

TRAYYOR, JOS. P. (b'-8)\&-Me.1,01 Surg., Lieut. Commander, U.S.N.; Surgeon General's office.

Trelbley, Chas. E. (b'82)-Pa.11,07; A

Surg., M.R.C., U.S.X.

TRIBLE, GEO.' BARXET (b's?) \$-Mo.2 06; P.A.S., Lieut., C.S.N. ; Naral Hospital.
'I'ribou, Howard Arthur (b'84)-Mass.1,'12; A.Nurg, M.It.C., U.S.N.

TlimbL, bols'r. \&. (b'65) - D.C.4,03; (1'0:3): $22: 2$. Isth st., N.W: : 8-10,3-5.

TIHMAN, JAMIS KI(IHARD (b'67)-D.C.1, "45; (1'96) ; 1750 I'ark kd., N.W.; after 9.

Turmer, Molyneaux Lawrence $\left(b^{\prime}, 0\right)-N . Y .8$, 93: (1'96); 1319 Massachusetts Are.,

Turton, Wm. Elmo (b'83)-D.C.2,08; (1'08) ; ath and Longfellow Sts., N.W.

TUT'TLE, ARNOLA DWIGHT\$-Md.1,06; Cajt., M.C., U.S.A. ; Soldler's Home.

Twogood, Merton Elwin-1I-Pa.9,06 ; ( ); $3 \cdot 131$, 14th St., N.W.

Tyler, Jobt. Bunyon - D.C.3,'96; (1'96): 1329 T' St., N.W.

Tyson, Edwin French (b'85) - D.C.3,'11; (I'12); 2124 is St., N.W. Maryland Ave., S.W.

VAIL, FRANK P. (b'71)-J).C.2,92, I'a.1, 94; (1'96); 169 Columbla Fid., N.W.; $9-10: 30,4: 30-6$.

VAIENTINE, AIOYSILS W. (b74) (4Md.1,04; (l'04); 606 Nortli Carollna Ave., S.E. ; $8: 30-9: 30,1-2,6-8$.

VALZ, EDW. VICTOIt (b'78)థ-Va.1,03; Member Med. Soc. of Va.; P.A.S., Lieut., U.S.N. ; U.S. Navy bept.

Van Cleave, w. Edgar (b'7 7$)-K y .9,05$; (Indlan Service); Indian office.

VAN RENSSELAER, JOIIN (b'62) †-D.C.1, '89: $(1 ' 97) ; 815$ Connecticut Ave., N.W.' until $9: 30,4-6 ;($ A25) ; S.

Van Reypen; $\quad \mathrm{W}$. K. (b'40)-N.Y.5,62; Surg. Gen., Rear Admiral, U.S.N., retIred; Surgeon General's Office.

Van sweringen, Walter (b'80)-Md.1,04 : (l'12); 1722 S St., N.W.; R.

VAUGIIAN, FEO. TULLY (b'59)@-Va.1, 79 N.Y.10,80; (l'04); A.Surg., M.R.C.', Prof. l'rin. and Prac. Surg., D.C.2; (A5, $6,24,25) ; \mathbf{S} . \star$

VAUGHAN, WM. WASHINGTON (b'86) \&D.C.2,12; (1'12); 1st Lleut., M.R.C., U.S.A. ; Army Medlcal School.

VEDIEK, EDWARD HRIGHT (b'78) 9 Pa.1, 02 ; Capt., M.C., U.S.A. ; Army VERBRYCKE, J. RUSSELI, JR. (b'85)कD.C.2,06; (1'06); 2307, 1st St., N.W.; office. The Rochambeau; until 10,5-6; I.

FINCENT, TIIOS. N. - Pa.2,'89; (1'96) 1730 M'St., N.W. ; $8-10,1-2,5-7$.

VON KESSLER, WILSON C. (b'85) ()
Pa.11,'11; lst Lieut., M.R.C., U.S.A.; The Pa.11,'11;
Purlington.

CONWEDEKIND, YUTHER T. (b'64) $\rightarrow$ Surgeon General's Office.

Wagner, Jlenry G.-D.C.2,'85; (l'96); 1015 K St., N.E.

WAGNER, WH. FINLEY (b'65) †-Pa.1,'90; (l'96) ; 501 L St., N.W. ; 8-10, 4-6.

WALKER, NLILEN (b'52) - Md.1, 86 ; (1'96); 739 Quebec St., N.W. ; 7-9:30, $5-7$.

Walker, James T. (b'69)-D.C.3,'03; (l'03) ; $600 \mathrm{I}^{\circ}$ 'st., X.W.; until 10, 1-2, 6-8.

Walker, Lewis A.-I.C.2,98; (1'98); 1401 Fairmont St. ; 8-10, 4-6.

WALKER, REGINALD R. (b'77) $\odot-D . C .2$ 00; (l'01); Florence Ct. ; office, 818 , 17th St., N.W. ; 9-12, 3-5; Asst. Prof. Laryn. and otol., D.C.2.; (B30); ALR.ћ

WALL, JOS. S. $\oplus-D . C .2,97 ;\left(l^{\prime} 97\right) ; 2017$ Columbia Rd.; Assoc. Prof. Ped., D.C.2; (A24).

WALLACE, CLIFTON ROBT. (b'84)-D.C.1, 07; (1,09); Nember Med. Soc. of N.J.; I2Ii) II st.; N.E.

WALSH, JOHN EDGAR (b'65) $\oplus-D . C .1,90$ (l'96); 202 E. Capitol St.; 8-10, 12:30$1: 30,6-8$.

Walter, Leroy D.-D.C.5,'95; (l'96) ; 1334 (; St., N.E.; 8-10, i-2, 5-8.

WALTER, WY. F\&DDC. 2,$92 ;\left(1^{\prime} 96\right) ; 487$ II St., S.W.; 8-10, 1-2, 5-7.

Warfleld, Wm. A. (b'66)-D.C.3,94; (1'96) ; 1901 , 11 th St., N.W.; until 10, after 5 ; 1'rof. Abd. Surg., D.C.3; G.

WARING, CLARENCE H. (b'S2) (3-Miss.2, oi: ( ) ; Member Miss. State Med. Assn. Army Medical School. 
Warlng, James Ilenry N. (cul.) (b'61)D.C.3,88, (196), A14 N. St., X.W., 8.10,

Warman, Wm. H. H. $\left(\mathrm{b}^{\prime} 40\right)-\mathrm{H}, \mathrm{C}, 80$ $\left(l^{\prime} 9 i\right): 1601$ Park Hd., N.W.; onlev, Penston bureau.

Warner, Carden Fredk. (b'S2) H-1'a.9,04: (1'06): 1825 U St. S.W.: once, s16, $15 t h$ SL. N.W.: 9-1; OALP.

WARXEl, JOHN WHLIAM (6'83)-X.Y.19, 09: (l'11): The Kochambeau.

WARXER, RICHAlBI A. (b'is) \&-D.C.2,01: (lol): PA.S., Lleut, U.S.N. Naval Ilos: pltal.

WARREN, BENJ. S. (b"i1) -La.L,91: Nember Mo. biate Med. Assn.; Surg. U.S.Y.II.S.

WARREN, GEO. WALTEK (b'63)-MId.6,92 ; (1'96); 1212 II St., X.E.; 8-10, 12-2,

Washburn, Wm. S-D.C.1.94; (1'96); not In practlce; $33 \mathrm{~d}$ and itittenhouse Sts. N.W.: once, U. S. C'tvil Service Commisalon.

Waters, Chas. II. (b'49)-Md.1,71; (I'05) : 1414 Q St.. N.W. ; until 10 , 4-6.

WATERS, CIIAS. L.FWIS (b'79)†-D.C. 1 05: (l'05); 1414 Q St., X.W. ; untkl 10,4-6. WATKISS, FIGAll W.-D.C.4.96; (I'96) 1373 Columbla ldd. N.W.:9-10,4-6:30

1373 Columbla ldd. N.W.; $9-10,4-6: 30$,
WATKINS, SAML. E. (b'il) - D.C.2,"92;

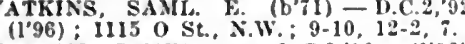

WATSON, JAMES A. D.C.2,90; (1'96) ; 2101 Nichols Are., S.K.

WRAVER, CLAIRACE A. (b'71)-Pa.2,92; (1'96); 1614 Q St., N.W. ; 8-10, 1-2,5-7.

WFBR, IANPHEAR WEShEv, JH. (b'86) Pa.1,11: 1st Lleut., II.K.C. ; Army MedIcal School.

WERB, NEWTON E.-D.C.4,01; (I'02): 1314 F. Capltol St.

WEHB, WALTER DUVAL (b'72) -N.Y.1, '95; Maj., U.S.A., retIred; 1803 ConneetIcut Aro., N.W.; Ássoc. Prof. Surg., D.C.2; $9-10,5-6 ;$ S.

Weber, Fredk. Clarence (b'78)-D.C.1,08: not In praclice; Bureau of Chemlstry. U. S. Department of Agriculture.

Webster, Jenore Perky--111.4,90; (1'07) 1366 IMarrard St., N.W.

WEFL, MARK D. (b'81)-Pa.2.'05: Capt. M.C. U.S.A.: Washington Barracks.

WELLINGTON, JOHS R. (b'65) \&-D.C.1 91; $\left(l^{\prime} 96\right)$ : Pres. Med. Sne. of $11 . \mathrm{C}$; 172 Connectleut Ave: : 9-10, 5-f; Cllu. L'rof. Surg.. I1.C.1: (125): S.

WELLS, WALTER A ÚGSTINE (b'70) I.C. 2,$91 ;(1,96): 815$ Connectlent Ave. N.W. 9-12, 4-5: Irof. Laryn. Ithin. and

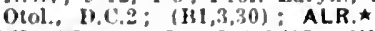

Wells, Wm. A., Jr.-D.C.3,07; (jo7) : 1161 Ist Ss. N.W.: Asst. Prof. Path., D.C.3.

Wenger, Wm. II. (b'69)-Md.3,96; (l'01) : 305 H St. N.W. OALR.

W FRBER, GUSTAVUS b. (b'64)-b.C.1, 94: (l'96): 1353 ( $\mathrm{St}, \mathrm{N} . \mathrm{W}$ : : untsi II, $1.2,4-6$.

West, Chas. 1gnatlus (b'68) - D.C.3,'95 $(1 \cdot 96) ; 024$ al st., N.W.; 9-11, 4-7; Assoc. (1'06); 024 al st.. N.W: ${ }^{9-11}$,

WBst, RICHAD T.-D.C. 1,$05 ;(105) ; 3: 17$ Georgla Ave. N.W.

WHARTUX, JGHN J., JlR. (b'33)-D.c:1,05. (1'06): Tho Northumberland.

Wharton, Ulysues Saml. (b'85)-J), C.3,'13 : Intern. Freedmau's IIospital.

WHEATLFY, CILAS $\left(b^{\circ} 82\right)$ - I.C.1,08;

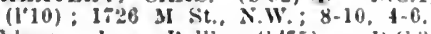

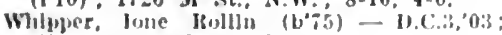

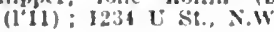

WHTE. CHAS. STANIFY (b'T) \&-II 1 .

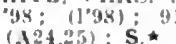

WHTE, livt:NoltT \& - N.Y. 1.05; (1) Member Mal. Sise, of the sinte of $\mathrm{X}$. Y.

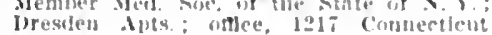

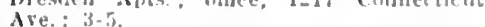
Are. ; 3- 30

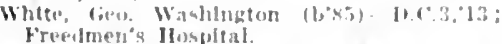
Hiltr wo losplial.

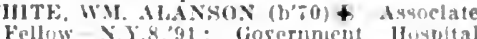

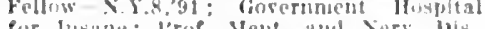

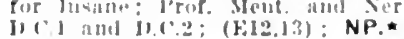

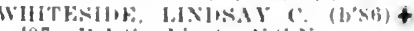

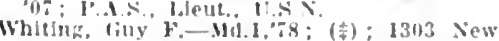
Il

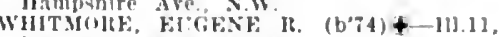
"\{!: Ma\}., M.1., U.S.A

Whitney, ('has. $\left.F^{\prime \prime},\left(b^{\prime} 5 i\right)-J\right), C .3,89$, [D.C.2 "10: $(1.46)$; not In vract/co; Ned. Ileferee, V. S. l'enshn Hureau.

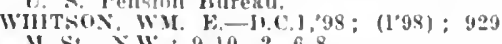
II st., $\mathrm{X} . \mathrm{W}: 9-10,2,6-8$

Whittington, Thos. A." (b'60) - D.C.1,96; (1’96); not in practlee; 1410 Delafleld $P l$.

WH.13LR. CRFSSY L. (b'6J) \$-N.Y.10,90 not in prnetlee; Member Micli. State If Soe. ; 1374 IIarvard St. ; Chlef Statistlelan. liurean of the Census.

Wilcox, Timothy F. (b'40)-N.Y.3,'6t:Brig Gell., I.S.A., retlred; 1841 Callformila st. N.W:

WIIder, James R. (b'65)-I1.C.3,'88; (l'96) : 2109 Pennsylvanla Are., N.W.; offlce, 412 B. St., S.E. : $9-10,3-4,6-8$.

WllDS, KOBT, HENRY (b's4) \&-SY.1 10; 1st loleut., M.M.C., U.S.A.; Army Meilical Schonl.

WILEY. HAISYEY WASIIIGTON $\left(b^{\prime}+4\right)+$ Associate Fellow-Ind.4, ;1; not in practire: 2345 Ashmead 1'].; ofice, Woolward Hldg.

Whgus, Allert $\left(b^{\prime} 46\right)-$ Ill.1,70; ( ) ; 1211 Columbla Hd.

Wliklnson, Alfred D.-1).C.2,93; (l"96) ; 455 Iassachusettsss ire, X.W.; office, I.S. Pens!on Bureau.

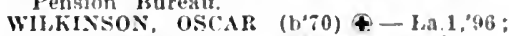
(1’01); 1408 I, St.. N.W. : $9-12,4-6$.

WILKINSON, WAITEK W. (h'T6) D.C.I 05: (1'05); The Hochambeau: 9-111, 5-6 1.

WILLIAMS, ALEXANUEK WATSOS (1,84) \& Md. ${ }^{\prime} 12$; (1'12); Ist Lleut. M.J.C. 3026 Q St. N.W

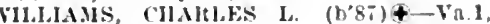
'11; A.surg., I's.l'.11.S.; U.S. ltevente cutter pahoma.

WHllaus, Greene D-1).C.3.83; (1'97) ; 1821 15th st. N.W

Willams, Harry J. (b'73)-D.C.3,03; (1'03) $310 \mathrm{~K}$ st., X.w: $9-2,7$.

Wlliams, lieglnali Osterley (b's3)-1).C.3, 12; (); 2020 , 5tu st., S.W

WILIJIMS, TOM A. $\left(\mathrm{b}^{\prime}, 0\right)+-\mathrm{Scot} 30^{\circ} 90^{\circ}$ :

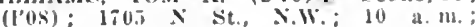
(bos); 170 : NP.

WHiston, Kdw. 1)-D.C.3,94; $\left(J^{9}, 96\right) ; 1512$ s st.. X.W.: l'rof. Meil. Juris, Iy C'3.

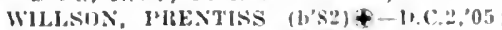
(1'0ti); "2000 1' st., X.W.: Asst. Prof (1) wet 1). (2: (.124).

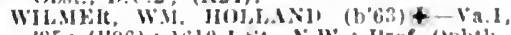
'85; (1'96) : 1610 I st.. X.W.: I'rof. Opht1. J). $(2 ;)(13+30)$

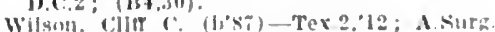

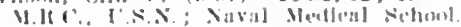

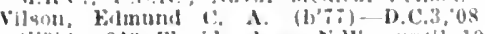

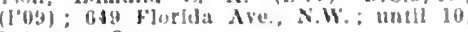
1.3. (i.); 0 p.
Wilsun Filw ("upn'

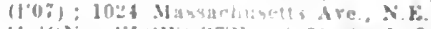

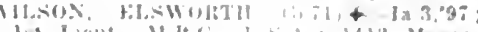

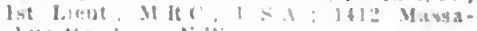

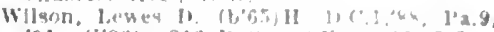

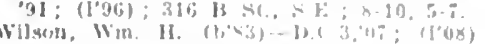
1515, 10th si. N 11

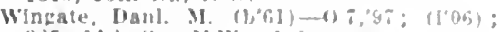
8:5, 14th st. X.W: 1-t?

WINS, 190101F K. $(1: 79)+-1,01,04:$

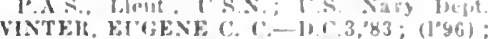

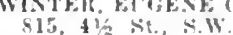

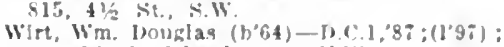
y2:3 lihoue Islanil Aie., X.

WOH.F. JAMFE TII!STOS (b'81)

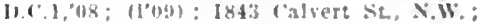
9-10, $5-6,7 \cdot 8 ; \mathrm{S}$.

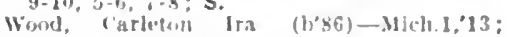
iroblence limspital.

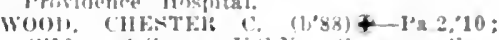
(1'10); A.surm. U.S.A.; Surgeon General's office.

WOOL, GFU. W. (h.63) \&-D.C.2."94:(1"96): $2900 \mathrm{P}$ Si. N.W. $9-10,1-2,5-6$.

WO(1), WM, HLF.ISANT (b'si)-1).C.1.03: (1'12): 227 B St. $\times$.

HOOILAND, KDW. FLAS $($ t'84) — Pa.I.

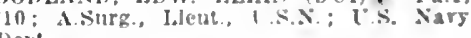
nept.

WOOHMAN, FRANC1S JUS. (b'51)-D.C.1. '85; (1'96) ; 634 a st. I F.

wools, EvGalt lo (b'82) -Va.1,04: sary belt. WOOLS. JOS. THATCIIEl:-IIICh.1,55; nos In practlec: Member Ohio State Med. Assn. : 459 i St. X.W. ; S

Woodward, llarry Wells (D'6s) H-I'a.9,91 : (1'96): 1318 Massacbusctis Are., N.W: 2-5:30; OpLR.

WOODWAI1), WM. CRFIGHTON (b'6i) 1.C. 2,$89 ;(1.96)$ : 17s: lainier J'l., X.W.: oflee, Itealth Offle: : l'rof. Med. Jurls. D.C.1: I'rof. State Med., I) C.:

Wooster, Mary I. 11-l).C.3,33; (1.96); 2021 l'ortner I']., X.W.

wright, Clarence Alexander (col.) $\left(b^{\prime} ; \%\right)-$

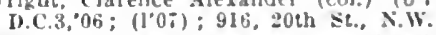

WITGH, HAMLTON (b'b) - Que.1,95; (I'07): not in practice; 1215, 19th SL. N.16.

Wright, Wilbur L. (b'59)-D.C. 2,94; (1'96) : 1628 park lid. 511

WYFTH. MARIBOHELGH CIILRCHILL

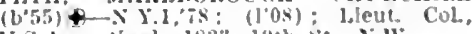
U.S.A., retired; $1829,19 t h$ st. X.W.

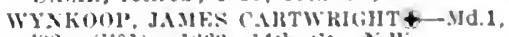
(92): (1.01); 160.? 1th st., N W

SAITALI. JUIN IHEPLLKX (b'56) -D.C.1,

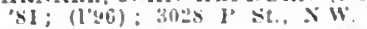

YAlitow, HARJ C. $\left(b^{\prime} 40\right)+2,1,61$;

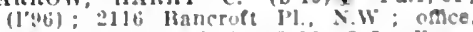
90b, i.th st. s.ll.: \$.10, 3-5: Erwer. rof. llerm., Il, c. 1 .

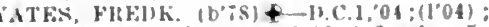
1:30, 91h st., X.W. : unth 10, 1-2, after 5: ab.

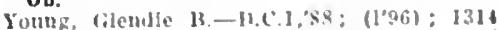
coliunbla lis.. X.W.: uflce, Bureas of l'rintinz: $: 300-4$

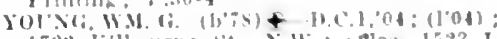

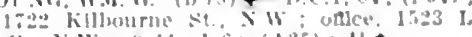

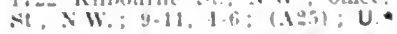

Z.M.ESkI, WM. J $\left(b^{\prime}, 1\right)+-M 1 c h .1,03$;

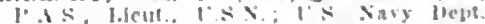

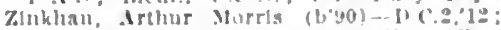

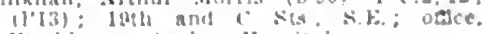
Washligton Asylum llosplal.

FOA KEY TO SPECIALTIES. ABBREVIATIONS, SYMBOLS. ETC., SEE PAGE 309 


\section{F L OR IDA}

NoTE:-The general information of this state fucindes: Medical Law, lioard of Healti, Licensing Boaldis, Medical Association, County oflcers, Assistants to the State IIentth officer, Afents of the State IBoard of Heaith, City Health Offleers, State Institutions, llospitais. Sanutoriums and charitabie Institutions.

\section{FLORIDA}

Population ( 1910 census)........752,619

Number of Counties............. 48

Number of Physicians......... 1,177

Members State Association, Dec, 3i,

1913.

408

Area of State in Square Miles....... 58,666

\section{MEDICAL PRACTICE LAW OF FLORIDA}

Law Effectire May 31, 1899, and Sections 801. 802,805 und 810 as Amended by the Legislature of 1905 and Approved by the Governor May 15, 1905.

Be it enacted by the Legisiature of the State of Fiorida:

Section 1. AIPOINTMENT: That Section 801 of the Rerised Statutes of the State of Florida be amended so as to reacl as follows :

801. APPOINTMENT OF MEDICAL EXAMINERS : The Governor shati appoint a State Board of Medical Examiners and also a State Board of IIomeopathic Medical Examiners.

Sec. 2. QUALIFICATIONS OF EXAMINERS; ORGANIZATION: That Section 802 of the Iierised Statutes of the State of Florida be amended so as to read as follows:

802. QUALIFICATION OF EXAMINERS : The State Board of Medical Examiners shall be composed of seven reguiar practicing physicians, who have been duly licensed to practice in this state; no two members shail practice in this state; no two members shail The residents of the same judicial circuit. be composed of three practicing homeopathic physicians who are graduates in good standing of some medical college recognized by the American Institute of Homeopathy.

803. TERMS OF OFFICE: The appointment of each member of each of said boards shail continue for four years from the date
of such appointment. Whenever a vacancy shall occur on any of said boards, the same shall be fliled by the Governor for the unexpired term.

804. TO ELECT PRESIDENT AND SECRETARY AND MAKE RULES : Erery board shall elect one of their number president and one secretary, and shall adopt all necessary rules for the guidance and control of their meetings.

Sec. 3. That Section 805 of the Revised Statutes of the State of Florlda be amended so as to read as follows:

805. REGULAR MEETINGS : Each board shall meet regularly semi-annually at some central and convenient point in the state to conduct examinations and grant licenses, as herein provided, and they shall give at least one month's public notice of their meeting by publication once a week in a newspaper of general circuiation throughout the state.

806. EXAMINATION: It shall be the duty of said Buards of Examiners to examine thoroughily erery applicant for certificate of qualification to practice medicine in any duction of his medical diploma from a recognized college on the following named subjeets: Inatomy, physiology, surgery, gynecology, therapeutics, obstetrics, and chemistry, but no preference shall be given to any school of medicine; prorided that it shall be the duty of the Board of Homeopathic Medical Examiners to examine thoroughly every applicant for certifleate of qualifica- tion to praetice medicine in any of its foranches or departments on the production of his dipicma from a college recognized by of his dipicmal from a coliege recognized by the American Institute of IIomeopathy on
the following sulijects: Anatomy, physiolthe following suinjects: Anatomy, physioltherapeutics, ofstetries and chemistry, and no preference shaji he given to any school of medicine. (As amended by Chapter 4419, Acts of 1895.)

807 . When the board shall be satisfled as to the qualifications of an applicant, they strail grant to him a certificate to that effect which certificate shail entitie the person to whom granted to practice medicine in any county when the same shall have been recorded, as required by Section 809 .

808. TWO MAY GRANT CER'TIFICATES ; TEMPORARY CERTIFICATES : Any two members of said board may grant a certiflcate of quaification to an applicant, and any memher of said board silall have authority to grant a temporary certiffcate to an applicant, on examination until the next regular meeting of the board, at which time the temporary certificate shall cease to be of force.

809. HECORD OF CERTIFICATE: The certiflcate provided for in the two preceding sections shail, before the person to whom it is granted shall be entitled to practice by virtue thereof, be recorded in the office of the clerk of the circuit court in the county in which such practitioner may reside or sojourn, in a well-bound book to be kept by the cierk for that purpose, and when so recorded the clerk shail certify thereon. under his offlcial seal, the fact and date of such record, and shall return such certificate to the person to whom the same was granted, and shall be entitled for such service to collect from the holder of such certiflcate the legal fee for recording.

Sec. 4. That Section 810 of the Revised Statutes of the State of Florida be amended so as to read as follows:

810. EXAMINATION FEE: The board shail be entitled to demand and receive from each applicant examined the sum of flfteen dollars, whether a certificate be granted to such applicant or not.

811. CERTIFICATES TO FORMER PRACTITIONERS: All practitioners who have been engaged in the practice of medicine, in any of its departments, in this state, prior to May 3I, 1889, shall, on the production of a diploma from a medical college recognized by the American Medical Association, be granted by the Board of Examiners a certificate of qualification, without further examination and without charge.

812. PROVISIONS NOT TO APPLY TO CERTAIN PERSONS: The provisions of this chapter shall not apply to persons who have beretofore received certificales of qualiflcation and hare recurded the same as prorided by the laws of this state heretofore existing, nor to females who follow tije practice of midwifery strictly as such. No person, except those described in this soetion son, except those described in this section, shali be permitied to practice medicine in any of its branches or departments without first haring obtained and recorded a certifiboard of medical examiners as herelnbefore provided.

\section{STATE BOARD OF HEALTH}

Hon. F. J. Fearnside, President, Palatka; Hon. C. G. Memminger, Lakeland; S. R. Mallory Kennedy, M.D., Pensacoia; Joseph Y. Porter, M.D., Secretary and State Health Officer; offlces, Jacksonvilie and Key West.

\section{REGULAR BOARD OF MEDICAL} EXAMINERS

G. I. Glover, Presldent, Monticello; Tentord. Stokes, Pensacoia; T. A. Nea1, ing, Miami; E. W. Warren, Secretary. raiatka.

\section{HOMEOPATHIC BOARD OF MEDICAL EXAMINERS}

Henry R. Stout, President, Jacksonville: Chas IV Johnson Secretary-Treasurer, Jacksonvilie; F. C. Whitaker, Tampa.

\section{FLORIDA MEDICAL ASSOCIATION} Offlcers 1913-14

P. C. Perry, President..........Jacksonvilie J. G. Dupuis, 1st V.-President.. Lemon City J. C. Davis, Jr., 2d Vice-President... Quincy J. D. Pasco, Secy.-Treas.......Jacksonvilie

\section{Councilor Districts and officers}

First District.-Santa Rosa, Escambia. Walton counties. J. Harris Pierpont, Councilor, Pensacola.

Second District.-Liberty, Franklin, Gadsden, Jefferson, Wakuita and Leon counties. Harry E. Palmer, Councilor, Tallahassee.

Third District.-Columbia, Taylor, Lafayette, Hamilton. Madison and Suwanee counties. Roy E. Chalker, Councilor, Lake City.

Fourth District.-Duval, St. Johns, Clay and Nassau counties. E. N. Llell, Councilor, Jacksonvilte.

Fifth District.-Lake, Sumter, Citrus. Hernando and Marion counties. H. C. Dozier, Councilor, Ocala.

Sixth District.-Pascoe, Hillsborough and Pineilas counties. U. S. Bird, Councilor. Tampa.

Seventh District.-Brevard, Volusia, orange, Osceola and St. Iucle counties? John MacDiarmid, Councilor, De Land.

Eighth District.-Levy, Alacisua, Bradford, Baker and Putnam counties. J. F. Ruff, Councilor, Newberry.

Ninth District-Calhoun, Holmes, Jackson and Washington counties. J. S. McGeachy, Councilor, Chipley.

Tenth District.-De Sota, Lee, Manatee and Polk counties. Y. E. Wright, Councilor, Wauchula.

Elerenth District.-Dade, Monroe and Palm Beach counties. E. E. Rollins, councllor, Ft. Pierce.

Component County Societies of the Florida State Medical Association ALACHUA COUNTY

w. H. Pickett, President.......Gainesville J. F. McKinstrey, Jr., Secretary . .Gainesvilie BRADFORD COUNTY

w. E. Middleton, President........Hampton A. H. Freeman, Secretary...................... BREVARD COUNTY

Lenn Ashley Peek, Sec....West Palm Beach DADE COUNTY

E. I. Jaudon, President ............. Miami

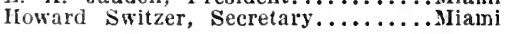
DE SOTO COUNTY

J. Simmons, President...........Arcadia if. L. Crum, Secretary.............. DUVAL COUNTY

H. Hanson, President.........Jacksonville James Knox Simpson, Secretary.Jacksonville 
Est.AMIA COLXT:

J. Turberville, I'resldent....... i ientury HII.LSBORO COLNTY

J. C. Kinisht. l'resldent.......... I'lant Clty

ii. Il Hodrson, Sceretary.......... Tampa HOLMES COLNTY

(1. C. Muton, Presldent..........Westrille

B. W. Dalton, Secretars............ Bunles JACKSON COLNTY

iv. R. Phlllipa, Presldent........ Gracevllle JEFFERSON COENTY

W. H. Walker, Prevldent........... Lamont

J. R. McEachern, Secretary.......Montlcello LAKE: COENTY

Plias. M. Ruterts. I'resldent....... I matlla

w. P. Hckeo, Secretary............. Eustis LEE COLNTY

B. P. Matheson, Presldent.......... Myers

w. B. Whkler, Secretary,........Ft. Myers LEON COLNTY

lenry E. Palmer, I'resldent.... Tallahassee

v. Cufton Moor, secretary..... Tallahassee MANATEE COUXTY

J. B. Lefingwell, Fresldent......Bradentown

H. Baer, Secretary............Bradentown MARION COUNTY

11. C. Dozler, President............. Ocala

Eugen G. Peek. Secretary.............ocala MONROE COUNT

Geo. R. Ilummer, I'resldent.......Key West

J. Yates Porter, Jr., Secretary.... Key West ORANGF COUNTY

C D. Chrlst, President.......... Orlando

(i. II. Vdwards, Secretars............ Orlando POLK COINTY

0. B. Iewls, President..........Ft Meade Harry 0 . Cox, Secretary....................... ST. JOHNS COLNTY

De Witt Webb, Presidert.....St. Augustine Fdgar Estes, Secretary........... Augustine SUWANEE COLXTY J. M. Prlce, I'resldent........... Ifre Oik
T. S. Anderson, Secretary.......Llre Oak VOLLSIA COLNTY

Geo. A. Davis, President............ Deland f. A. Klock, Secretary............ Dajtuna

\section{ASSISTANTS TO THE STATE HEALTH OFFICER}

Gainesvllle............... H. Hobbs Jacksnnrllle........................ Heck Key West.................... Yos. Purter, Jr. I'ensacola.............. W. D'Alemberte Tallahassee................ K. Taylor

Tampa.................... W. Bartlett

\section{AGENTS OF THE STATE BOARD OF} HEALTH

Vermandina.............. $r_{t}$. Humplureys ralatkis.............. Warren

\section{CITY HEALTH OFFICERS}

Hartow................... . . $\left.\mathrm{O}_{k}\right]_{\text {lesly }}$ baytona................. Itoy IJuw. Fernandina................J. Il. Horsey

Galnearllle. .................W. Lasylter

Jacksontille............... ('has. F. Terry

Koy West................ D. W J.lght

lake Clty.............. J I' Jullat

Lakeland................ II. Jave

losnn baren................ I lawe

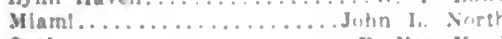

Ocala .................... V Van

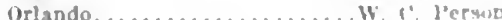

Palatka................ r. chandier

Penvacula.................. D. Nubles

yulncy................... 1'. Ilavis, Jr

Gauford................ IIther \& Miller

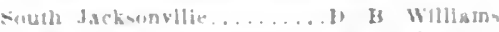
st. dusustlue .. . . . . . w I nderwood St leterobura... .. . . Wm M. Dabis Tallahaniever.

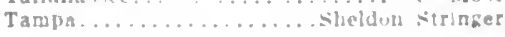

\section{STATE INSTITUTION}

Forida llispltal for the Insate, Chata

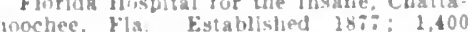
beds; Dubilc; general; H. F. Whitner suverintendent.

Jacksanville

Antracclnation Itosnital of the state Board of Ifealth, Jacksonrille, Fla. Es tablished 1 $\times \$ 9$; small-por patlents only to beds; W. G Ferriera. superintendent. confederate soldlers" Ilome, Tallesrand

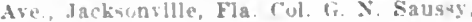
merintendent.

Dural County Isolation Hospital of the State Board of Health, Jacksonrille, Fla Established 1893: white and colored patlents; 20 beds; $\mathbf{~ L . ~ E . ~ H e c k , ~ a s s i s t a n t ~ t o ~}$ state health oficer, phystelan in charge

Miam

Iade County Isolatlon Huspital of the State Brard of Ilealth, Mlami, Fla Ls tablisherl 1905; 20 beds; James .. Jack son, asslstant to state health offlcer, physlelan in cbarge.

\section{St. Augustine}

state instlution for llea?, Dumb and Blind, St. Augustine, Fla. T. DeWltt Welsb, nhystclan in charge: H. A Walker, superintendent.

\section{HOSPITALS, SANATORIUMS AND CHAR. ITABLE INSTITUTIONS}

Century

Bonarentura Hospltal, Centurs. Fla. Es. tabllshed 1903; Reneral; 14 beds: prirate: 1. $\mathrm{s}$. Turberville, phssiclan in charge.

Daytona

Dr. Bahannon's Hospital and sanitariun, Jiytona, Ha Extablistied l904:

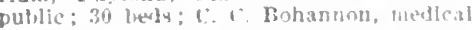
superintersent.

Dastona Prirate IIospltal, Daytona, Fla Established 1907 ; seneral: 30 heds: $i$. klock, physlclan in charge.

\section{Green Cove Springs}

Qul-sl-sana Spa and Hotel. Freen core springs, Fla. J. W. Hodies, nedical superiniendent.

Jacksonville

Hrewster Huspital, It9 Lee st., Jacksull. vlle. Fla. Established 1900; publle; for colored parients unly; 18 bels; Woman's Ifome Misslonary Seclety. In charte; Mrs. olive Webster, superingendent.

or. Iarey P. Ingers' I'rivate llospltal, Itirerside Ave., Jacksolnville, Fla, kistab. llshed 1410: prlrate: sursical only; It leods; James 11 . Ilartman, resldent physl van: Sarah II. Moore, superintendent. Chiliten's llome sinclety of Furlas st folus Are., Jacksonfllie. Fis Fostatilintim $1502 ; 25$ ireda: Wm. F. Ituss, phystelan It charäct

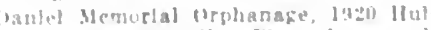
toril si, Jacksonvthe, Fla. lorena II:mes, mintron

He Situ satuaturgura, sth st and buub

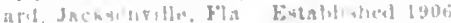

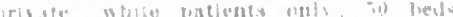

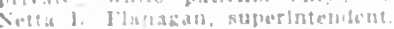

luva! fiun:y Husptal, Jeswige st, Jach. activillo. Hla Eistatiahel daice rublic

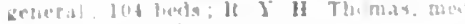

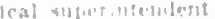

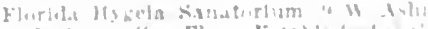
Si. Jackw millo, Fla botat: wlor ! ,

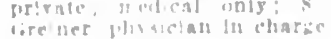

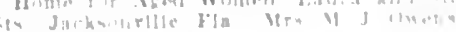

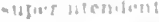

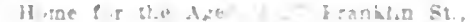
Jackacorille, Fia kini, a! 1.4)! Dut

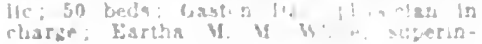
tondeni.

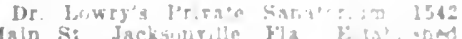

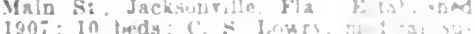
perinterulent.

wid Folks' Horre, Ifas II Itn t hi. Jack Mirille, Fla.

I'rigun Farm Iloapital. Jacksintille, Yla Evtablished 1910: 12 Imeds; M. B. Herlons physlcian In charge.

r'ropldent llospltal, Inlon and Lee Stu Jacksonrille, Fila. Kotablished 1413; prs. rate: culored only: 50 beds; Seth J Hills. V.ll. (cril.), superinenden?.

st. Luke's lluwpital, Buulerard from sth to losh St.. Jacksinrille, r7a EstabIIshed $28: 3$; Dublic and prirate: 80 beds M! Rs Vary $i$. Haker, K.X.. kuperintended st. Mars's Irphans IIome, tii Ocesn st. Jacksonfllie, Fla sisters of si. Joseph. In charge.

\section{Key West}

Jouise Maloner, 532 kiemlng SL, Key West, Fla. Established 1905; private: reneral; 35 beds; J. B. Maloney, physiclan in charge.

Cnited states Army lont llospital, Key West, Fla Estathlisted $185 \%$; army ; general: 35 beds: 1st Lleut. Vilctor F. Watkins, II.K.C. U.S. surgeon In command. Inlted States Marlne Hospital, Key West, Fla. Establisher ISt; govers. ment: Reneral: 30 beds; for benedciaries of $\because$. S Irubile Jealih service; H. M Manning, P.As., medical owier in charge.

Miaml

Florlda Kast ions: Rallway kixtension Hospital, Maml, Fla. Established 1906 prirate; general: 60 beds; malntalued by Florida Fast Cuas: Rallway Asoclstloz: Jameg .M. Jacksin physlcian in charge: Auna Dardds. matron.

Miaml Clty Hospital, Miaml, Fla Esablished 1011: an beds: John L. North. physiclan in chare.

\section{New Smyra}

Shelter Sanatorium, Dew Smrra, Ma. llawk l'ark l'o). Fastablishes 1912 general: 25 tello: Darls Fuster, resideat iurgeun; Miss Esther Kirkland, K... sis. perintendent.

Dcala

Marion Cuunty Hospital, Deala. Fla Estahlished $1 ! 13$; public: 95 rooms: MIs Vary if. Marshall, superintenden:

Orlando

Church Home and florpltal, Orlsndo, Fla Esiablisted 1895 ; mublic; 30 teds urs Maud Cumer sumerintendent.

Florida santiarium, irland. rila bis abltshew lun: prirate: feneral; 10 beuts. Irs W il lee, matron: W. It sp!re mansine

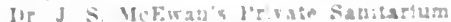
Orlando. Ha Finglistiel lull: nrtrate: 15 bients

Crlande Sandariuge crlando, Fia Fos

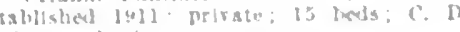
"hriat, ubysictsin.

Pensacola

lenvarola Santiarlum loarlers and le

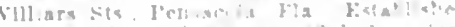

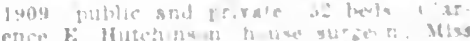
1.11 an Traw cos

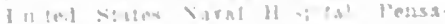

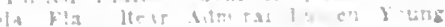
imminiman:

Pr. Orange

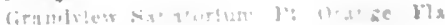

si. Augustine

liater 18 aplal. Tremertib si. se

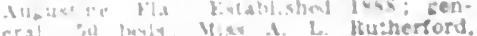

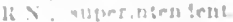

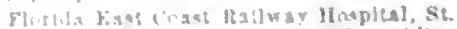

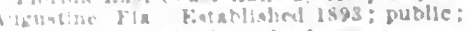
A.1 tel \& 1. Wniles. chief wurkeon. 
St. Petersburo

Aurusta Memorini Hosplal, bila Are. and bth st., s., St. J'etersturg, Fla. bistablislied I0I3; generai; 19 beds; Estluer Brown, It.N., superintendent.

\section{Tampa}

Centro Aspuriano sanatorlum, Tampa, Fla. Established I904; prlvate: Por ment bers of Fentro Asturiano; 2f inds; Constantino Fano. sujerintenlent.

contro lispanol sanituriun, Tampa, Fla. istablished 8406 ; yrisate; for members of cenero Espanol; : 31 leeds.
Cara Frye lbospltal, ltis lamar Ave. Tamu, Fla Establlshed $1900^{\circ}$; private:

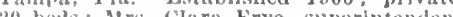

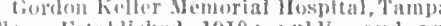
Flat. Watithished 19I0; Jublice and prt wate: 33 leeds; Wiss boulse Martia, sup IIalyeon sanutorlum, Tampa, Fla. E. tabllshed 1896; maternlty and gynecol ogy: private; 40 beds: J. I3. S. Ilolmes whysiclan in charge; Jiss M. K. I'arrlsl, I..... superintendent.

llampton's Tamba lleights Sanjtarium, 1805 Florida Ave., Tumpa, Fla. Kstablished J90I. saucer, a speclalty. "o beds: Hiram I. IJamptom, ohyslclan in charge.
Spanlsh Sanatorlum, Bay Shore, Tampa, Fla Established 1906 : private: general so beds: Jose Is. Arellanat, medical superintendent.

Trilby

Florlda Tuberculosis Siuatorlum, Trllby, Fla. Estabilshed I9I2; private; tuberculosls: I4 beds; $\mathbf{W}$. G. DeVane and II. 0 . Byrd, uhysicians in charge.

West Paim Beach

I'alm lieach sanitarlum, West Palu Beacl, Fla. Established 1012; private; 30 licds: C. II, Nerrlli, IV, $\mathbf{r}$. Mobinson and ik. 0 . Cooley, physlelans in charge.

\section{PHYSICIANS OF FLORIDA}

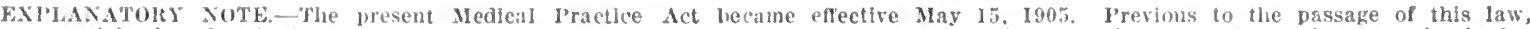
there were ditht boards of district axulners, each belur uractlcalis independent of the others. 0 wing to the incomplete records obtainable, the date of lleense is lackint in many eises. In those cilses in whlell the license date is Iacking, (lit), they are known to be lecally qualled physiclans, lut year of lleense not knowil.

KEY TO ABBREVIATIONS, SYMBOLS, ETC.

Names In capltals stgnify membership in the County soclety and state Assoclathe county society.

tion. (Dos, JoIIN). Indicates Fellowsilp in th
Med. Assn. (DOE, JoIlN\&). (h'75) Fear of blrth. Id. Theopith; L, eclectic; P-M, physloInformatlon received does of gradnition. untion.

S.-Surgeon.

Ob.-Obstetrlclan.

ObG.-Obstetrlcian, Gynecologist.

G.-Gynecologist.

Or.-Orthopedist.

Pr.-Proctologist.

0p.-Ophthalmologist.

A.-Aurist.

LR.-Laryngologlst, Rhinologist.
(1'84) Year of license.

(む) In practice before passage of present law and licensed by lling diploma or by years of practice.

(li) lilcensed but yeir not known.

(\$) Information recelved does not show Iicense.

[T.S... Tnited States Army.

M.M.C., II.S.A., Medical IReserve Corps.

SPECIALTIES ARE INDICATED AS FOLLOWS:

ALR.-Anrlst, Laryngologlst, Rhinologist.

OALR.-OphtIalmologist, Aurist, Laryngolorist, khinologist.

U.-Irologist.

D.-Dermatologist.

Pd.-I'edfatrist.

N.-Neurologist.

P.-I'sychiatrist.
US. Unlted States Navy.

I.R.C., U.S.X., Medlcal Iteserve Corps.

U.S.P.I.S., United States Public Health Service.

College positions held are indicated by alobreriated title of position, followed by key number of college. For key to colleges see Inslde front cover page.

(A1,3, 136, C4) Membership in specla Socletiós. (See Key Table, page 122.)

NP.-Neurologist, Psychlatrlst.

1.-Internist.

T.-Tuberculotheraplst.

Anes.-Anesthetist.

LD.-Laboratory Dlagnosticlan.

Path.-Pathologist.

Bact_-Bacterjologist.

WHEN THE ABBREVIATION REPRESENTING A SPECIALTY IS FOLLOWED BY AN ASTERISK ( $\star$ ) IT INDICATES THAT THE PHYSICIAN CLAIMS HIS PRACTICE IS LIMITED TO THAT PARTICULAR BRANCH OF MEDICINE; WITHOUT THE ASTERISIK, THAT HE IS ESPECIALLY INTERESTED IN, BUT DOES NOT LIMIT HIS PRACTICE TO, THAT BRANCH. THIS INFORMATION CONCERNING SPECIALTY IS BASED ON PERSONAL DATA FURNISHED BY THE PHYSICIAN AND IS NOT VERIFIABLE.

\section{FLORIDA}

ALACHUA, 610, ALACHUA

BIshop, James W.-MId.9, 05 .

Cloud, Jos. I.-Cia.5'94; (I†)

Driskell, Simon Eugene (b's8)-Tenn.8,'I2; (1'I2).

ALFORD, I50, JACKSON

LINGO, THOS, RICILARD (b'84) - NIa.',I0; (I'II).

ALLIANCE, 30, JACKSON

Dawling. Jasper Baswell (b'80)-Tenn.19, 'Il; (I'II).

Zediker, Arthur 13. (b'i3)-Neb.4,95; (1'95).

ALTAMONTE SPRINGS, 25, SEMINOLE

Randall, Chas. L. (b'4I)-N.Y.8,'64; (I'94)

(also Danville, Mich.; 1'00).

ALTHA, 100, CALHOUN

Sellers, Ernest Augustus (b'76)-Ala.2,08; (1'09).

ALTON, 25, AMITE

O'Quinn, Chas. A. (b'iI)-Ga.1,'0I ; (1'02).

ALVA, 488, LEE

Allen, Wm. Sutton (b'4I)-La.I,'68; (l'06).

ANTHONY, 36I, MARION

GILI, MILES REDACY (b'55)-S.C.1,'83; $\left(l^{\prime} 92\right) ; \mathrm{G}$.

APALACHICOLA, 3,065, FRANKLIN

FEKRIS. FRANK FENTON $\left(b^{\prime}, 2\right) \oplus-0.1$, $02 ;(1.03) ; \mathrm{S}$.

Murrow, Jos.'S. (b'72)-Ga.1,99; (1'00).

WEEMS, GEO. E. (b'81)-Ga.11,04; (1'07) ; Member Med. Assn. of Ga.

APOPKA, 4IO, ORANGE

Carroll, (ole (b'87)-Ga.I2,'I2; (I'12)

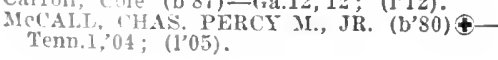

ARCADIA, 1,736, DE SOTO

BEVIS, HENRY P. (b'85) - Tenn.19,'I0; (I'I0).

CLINE, ROBT. L. (b'72) + -Ga.I, $02 ;\left(1^{\prime} 03\right)$; Pd

Dixon, James H. (col.) (b'82)-Tenn.7,'12; ( ).

Mchinney, Bungan II.-0.10,66; not in practice.

MeSWAIN, DANL. L. (b'70)థ-La.I, 99 ; (I'99)

SIMMONS, JOHN A. (b' $\tau) \oplus$-Ark.I, 05 ; (1'07); S.

ARCHER, 468, ALACHUA

RICE, SAIIL. DAVIES (b'i $) \oplus-V a .4,05$ (l'06).

AUBURNDALE, 250, POLK

Simmon, L. A. (b'50) $\longrightarrow ;\left(l^{\prime} 0\right.$ T).

AUCILLA, 500, JEFFERSON

MCLEOD, NORMAN W. (b'78)-(ra.11,05; (I'05).

AYCOCK, 75, JACKSON

GRACE, WM. HENRY (b'S1)-I.I.I,06; (1'06).

BAGDAD, 500, SANTA ROSA

Granau, Geo. Henry (b'7)-0.2,07; (\$). Turner, John Bogan (b'S4)-Tenn.5,'10 (I'II).

BAKER, I7, SANTA ROSA

McLarty, Geo. W.-Ga.5,'68; not in practice. Spears, Gus 0. (1'89)-Ga.9,'11; (l'11).

BALDWIN, 306, DUVAL

Brinson. Wm. D. (b'80)-Tenn.5,'13; (1'13). Ward, Emory E. (b'54)-Md.3,8I; (1'12).

BARTOW, 2,662, POLK

Brookins, A. B.-Ky.2,'75; not in practlce. COX. HARRY O. (',33)-Neb.6,"06; (1'II). GARRAIRD, JACOB A. (b'64)-Gá.10,'97; (1'97).
Kesnedy, Martin (b’36)-Pa.1,'68; (1十े).

IlcNeill, Iedge Wynn (col.) (b'80)-Tenn.14, 'I2; (I'12)

CEWMAN, IIEBER P. $\left(b^{\prime} 79\right)-$ Va.6, 05 (]'05)

OGLESBY, JOHN MICG. $\biguplus-M o .2,80$; (1).

Wilson, Cecil Hendry (b'88) - Ga.Il,'i3; (I'13).

WILSON, F. M.-Ky.4,'84; (1+).

BASCOM, 100, JACKSON

Bell, Wm. E.-Ga.9,'II; (官)

WHITFIELD, JOHN MARION (b'テ6)-Ala.2, '0S; (1'09).

BETTS, -, BAY

lingo, Michael Jones (b'88) - Ala.2,'I3 : (1'13).

BLITCHTON, 1,084, MARION

Bliteh, S. H. (b'55)-Ky.1,78; (1†).

BLOUNTSTOWN, 546, "CALHOUN

Brldges, Shelton S. (b'85)-Tex. 6,08 ; (l'09) Crozier, Gordon Turner (b'86) - Ga.1,'07 (1'09); Ob.

Elmore, Buena Vista (b'85)-Ga.12,0\% ; (1'0 í).

\section{BOCAGRANDE, 120, LEE}

ATWOOD, GEO. ELLIOTT, JR. (b'7 Ga.1,'00; (l'I0); Member Med. Assn. of Ga. BONIFAY, 922, HOLMES

I)ALTON, BAYLLYE WYCHLYFFE (b'83) - (ia.9,'08; (J'08).

GABLE, JOHN DAVID (b'72)థ-Tenn.1, OS ;

MARSHBURN, CLARENCE BARDEN (b'77) -Ga.II, 06 : (1'06).

BOWLING GREEN, 422, DE SOTO

Coile, Jos. Cibson (b'68)-Tenn.9,'92; not in practice; Member Med. Assn. of Ga. CRUM, IIURDOCH L. (b'73)-Tenn.9,'07; (1'0T). 
BOYNTON, I50, PALM BEACH

King. Alber? H. (6,ili)-0.5,01; (1'??)

BRADENTOWN, 1,886, MANATEE

Amold, burt (i. (b'66) 11 - l'a. 4.043 ; nht in practico.

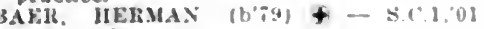
$\left(t^{\prime} 0\right.$ i) : $\mathbf{S}$.

Bonnell, Martha d. (b+1) II-111.t, 4 : sut In practice.

ALLAx, TIIOS, F. $\left(b^{\prime} 69\right)-$. Wa 399 (1'13): G.

Elkeuberry, Aaron 1. ( $\left.{ }^{\circ} 60\right)$-Ind $8,85:($

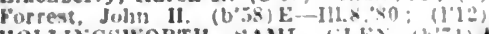

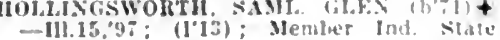
Med. Assn.

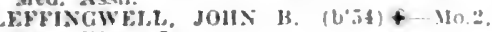
$80 ;(1$ '84): 6 .

leonard, Duncan $\mathrm{M}$.

isce Itroone c'enter. $\mathrm{Y}$ i.)

Whitaker, Furmall ic (b\%ii) - 111.4, 95 :

$\left.\left(1^{\prime} 9\right)^{7}\right)$ : OALR.

Whilapus, Israel Euas (roul.) (b'st)--Tenn.

W13: (1:13).

BRANFORD, 262, SUWANEE

Mann. John M. (b'76)-Ga.4, 10; (1'10)

Ward, Jolgle (b's?)-Ga.12,06.

BREWSTER, - POLK

Martin, John W'm. (b'80)-Mo.28,11: (1'1\%).

BRISTOL, 500, LIBERTY

Thazard, Edw. Kent-Va.6,"00; ( )

Tuten, R. H.-Ga.1,99; ( ).

BRONSON, 799, LEVY

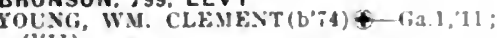
(1'11).

BROOKSVILLE, 979, HERNANDO

Brikham, lercy Herbert (b'i2)-Me.l,0l: (I'13).

Coogler, Adrian Colonna (b'st)-Valt, (0) (1'0i).

Cox Wm. II. (b'62)-Tenn.9,93: (1.94)

Fwlnn, Van Henry (b.68)-Mlch 1,41; (1.97).

Hancock, Wm. S., Jr. (b'83)-Ga.1!"1:

(1'13).

IOWRY, ROBT. ANDREW (b'5t)‡-ky.2, .5: (1'00).

Turck, Wm. C.-N.Y.6,86; not in practlce.

BUNNELL, 200, ST. JOHN

Carter Lemuel A. (b'88) - Ga.11.09: (I'11).

St. Peter, Moses (b'57)-111.1,92; (1'10).

BUSHNELL, 939, SUMTER

III HBALI, HOS('OH: CONKLING (b's.')

Mlss. 2,'12: (1'12).

Seymour, liarld Morton (1)\$I)-Tenn.ll, 09: (l’09).

CALLAHAN, 580, NASSAU

Hrewster. Wiaren Augustus $\left(b^{\prime}(t)-\right.$ - cia.l 00; ( $(\mathrm{i} 05)$.

Smlth, Curtis R. (b'65)-ria.1.94; (1'00).

CAMPBELLTON, 300, JACKSON

Smlth. S. W. $\rightarrow$ : (1t)

13ooth. Wille Is-La, 1.88 ; (1t).

PARIRISI, WM. ALIBRITTOS

Tenn. 1,09: (1'11)

Scots. Sam R. (b's1)-Tenn.19.'11: (1'11).

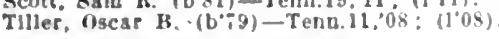

CAMPVILLE, 50, ALACHUA

Sberouse, (ieo. Washlngton (b's5) - tia.lut. 10 : (1'10).

CARLETON, -, PUTNAM

Willarl, Mary inn (b'12)-X.Y.11.93: not.In practlce,

CARR, 60, CALHOUN

Chadwlck, Jra Brown (b.51)-N J4: (1t).

CARRABELLE, 900, FRANKLIN

Hlounh liraxton 18-Ky.4:90; (1t)

Winmor, sautord srehtlald (b'a) - Il1.1,00 (1'11).

CARYVILLE, 200, WASHINGTON

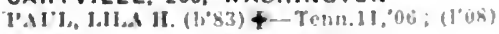

CENTER HILL, 299, SUMTER

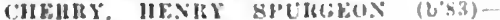
Ala.2,08: $(1,0 x)$.

Sklpworth. James J.cu $\left(b^{2} 69\right)$ - ria s,"yo (I"06).

CENTRALIA, 一, HERNANDO

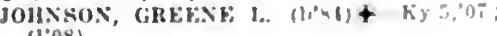
[108)

CENTURY, 1,000, ESCAMBIA

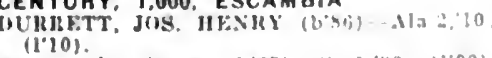

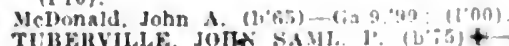
Ala. 2.02; (it).
CHATTAHOOCHEE, 440, GADSOEN

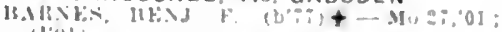
(|)

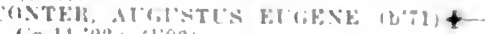
(in $11,02: 1100$

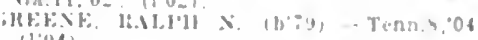

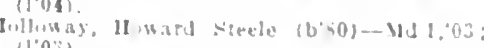

CHERAY LAKE (R.F.D., MAOISON), 50. MADISON

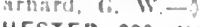

CHESTER, 280, NASSAU

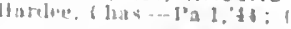

CHIPLEY, I,099. WASHINGTON

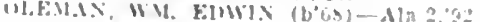
(l'(1)is), OALR

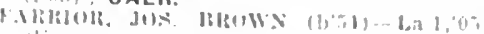

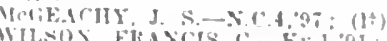

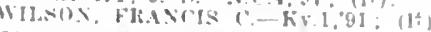

CHULUOTA, 70. SEMINOLE

Nixon. James W-M!I, 's:": (14).

CITRA, 39.4 MARION

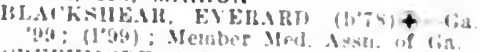

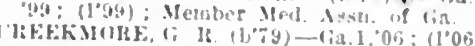

CLARA. - TAYLOR

IIarue. J.- Gat y, 1 ?

CLARKSVILLE, 400, CALHOUN

leellet, Birt H. (b'G) - lis

CLEARWATER, 1,171, PINELLAS.

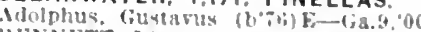

I3ENXFTT. JOS. 1\%, (b)

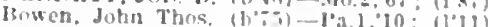

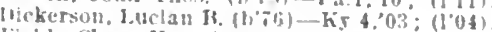

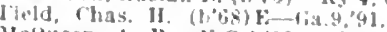

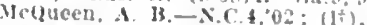

CLERMONT, 295, LAKE

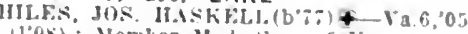
(105); Member Merl. Soc of ba.

COCOA, 6I3, BREVARD

III AIILETT, WM. I. (b'61)+-V.4:81: (1'si).

I. Incoln, Walter Jumma (b'6i)-Pa.1.90:

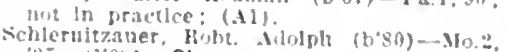
$0 . \overline{7} ;(109) ; 0$ b.

Seuffeld, John discat.

COCOANUT GROVE, 200, DADE

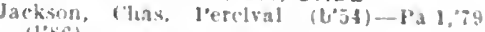

COLEMAN, 387, SUMTER

Nlsubfook, Hloxham Edw. (b)so)-Cia.11,"10 (1010)

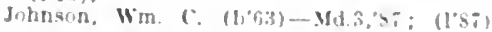

COLUMBIA, 180, COLUMBIA

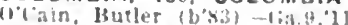

COMPASS LAKE, 10, JACKSON

COPATt, WM. M $(0,00)-1: 3,10$
CONANT, 45. LAKE

Swan. Mlire Fosicllo Worcester (bo5) -Jll.3. (1): (1's:)

CONCORO, 200, GADSEEN

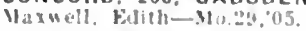

CORTEZ, 80, MANATEE

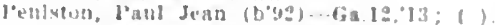

COTTONOALE, 250, JACKSON

("uleman. Albert J.-Giaso,"08: (1"11).

Harrison. Wm. II Ky.l, als: (It)

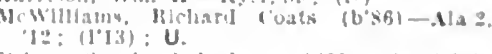

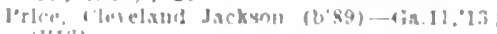

CRAWFORDVILLE, 250, WAKULLA

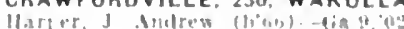

CRESCENT CITY, 677. PUTNAM

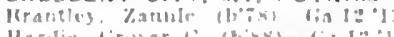

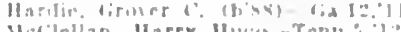

C.

CRESTVIEW, 200. WALTON

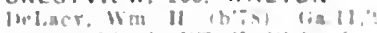

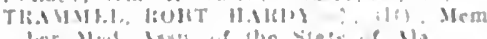

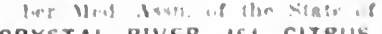

CRYSTAL RIVER, AH, CITRUB

CRYSTAL SPRINGS, - I'ASCO

l.aIr. WII. II (b;0) TCI:

CYPRESS 10R, JACKSON

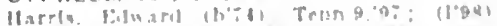

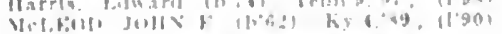

DADE CITY. 1.065. PASCO

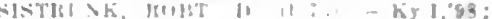

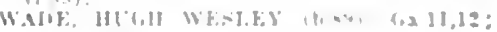
18120

DANIA, 269, DADE

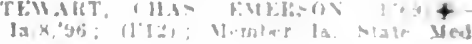

A Y, 250, LAFAYETTE

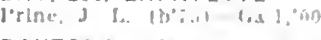

DAYTONA, 3.0B2, VOLUSIA

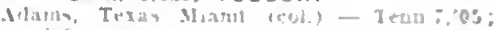

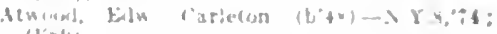

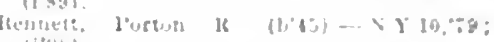

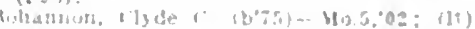

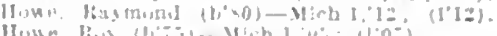

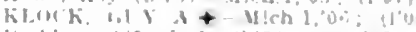

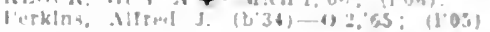

not in [18 act]r.

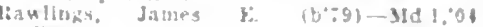

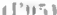

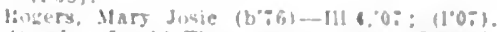

siraglan. Ihuld Thum (rol) ibou)-Tean.

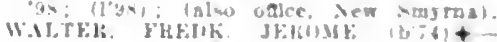

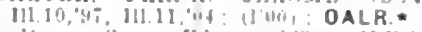

Walton, Geo, bidw (U.Gy)-Nr.10,64:

DAYTONA BEACH. 331, VOLUSIA

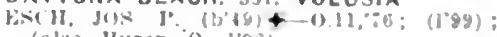
(also, lluron, () 1965 )

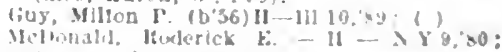

MIIIFTT, JOHN HAJJIS FORSTER (b'E) 4 Mlch I, "90: 11'(0)

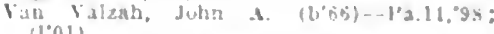
DE FUNIAK SPRINGS, 2.01\%, WALTON

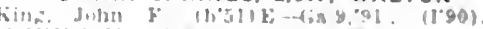

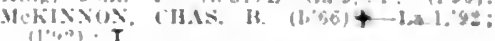

$\left.11^{n} \geq 0,2\right): T$.

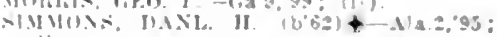

Thutrupon Charles Edwand-Oas 3,35,

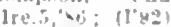

DE LAND. 2.812. VOLUSIA

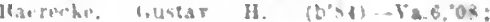

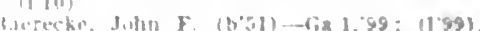

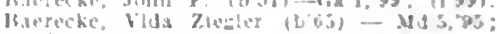
$11.05 \%$

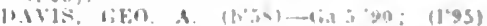

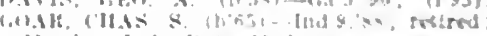
Vemiter Ind state Med. Awn

l.ancaver, cieo. W0 (b'a) vis.69 (1'+?!)

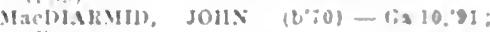
$\cos (\mathrm{s})$

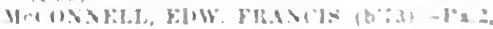

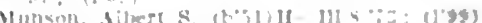

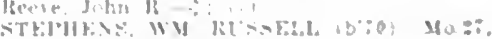

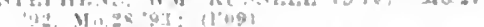
Taylir. Chester Muarne (b-1)-hy l, wo DELLWOOD (R,F,D., GRAND RIDGE). W0,

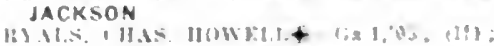
16 \& li

DELHAY. S00. PALM BEACH

a

DETROIT, -. DADE

suchls. Thu' II Y-

DOVIR. 30. HILLSHOROUGN

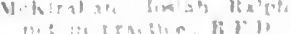

DOWLING PARK. SMO. SUWANE

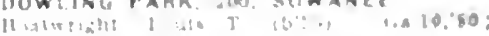

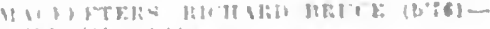

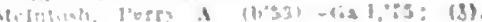

DUNNELLON 1.2:- MARION

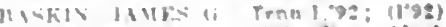

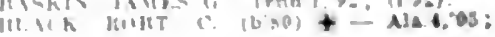


GRIFFTH, WM--MU.3,8ï; (1.01).

Luwrle, 'T'hos. L. (b's2) -D.C.3,'10; (l'10). EAU GALLIE, 329, BREVARD

CIRHEL, WM. JACKSON (b'80)£-('A.II '0S; (I'08).

EMPORIA, 50, VOLUSIA

DF I,ONG, WM. II. (b'40) -N.1.3,66; (I's9).

ESTO, 340, HOLMES

Lewis, Esker Walter (b'77)-Ala.2,01; (\$);

EUGENE, - LAFAYETTE

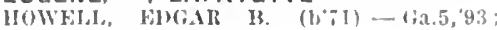
(1,9:3).

EUSTIS, 910, LAKE

Abney, Olin 1.-Ky.2,'81; (l'I3).

HANUM, IONT(OOMFISY MERIRTT (b'85) -Tenn.19'10: (1'13): Member Temn. State Med. Assn.

HUTCIHNGS, GUY (b'49) - Mlch.1,75;

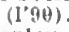

Manley, Karl (b'55)-0.6,'s5; (1'96).

McKEb, WM. P. (b'47)+-Ky.2,72; (l'89).

Reed, Francls A.-11-0.i,90; (1'0I).

EWINGTON (BRANCH P.O., JACIKSONVILLE), -, DUVAL

$$
\text { (See Jacksonrllle.) }
$$

FAIRFIELD, 35, MARION

GATRFLL, IIENRY-La.1,'98; (I'98).

FARMDALE, 179, BAY

Jenklns, Fddle Wise-N.Y.10,'s3; (1'0R).

FELLSMERE, - ST. LUCIE

Atwood, Iarold Fisher (b'S5)-Me.1,08; ( )

Conkllng, Chas. Mordecal (b'\$4)-Ia.1,'13; (1'13).

FERNANDINA, 3,482, NASSAU

Dunean, ('has. Fredk. (col.) (b'80)-Mass.6, '10: (1'11).

Galphin, Lawrence T. (b'71)-Ky.5,01; (1'02).

Horsey, J, Iouis-S,C.1,'86 (1+),

HUMYIIEYS, DAVID G.-Ky,5,96; (I†).

Waas, W. Theo-La.1,94: (I'95).

FISHERVILLE (IND. STA., PENSACOLA). - ESCAMBIA

(See Pensacola.)

FLORENCE VILLA, 20, POLK

Jewett, Mary B. (b'58)-N.Y.14,95: (1'11); not in prictice.

FOUNTAIN, 15, BAY

Pennlngton, Jlmile Lee (b'89)-Tenn.19,'10; (1'12).

FREEPORT, 800, WALTON

HUGGINS, EVANS LEWIS (b'sS)-Ga.II I2; (I'12); S.

RABORN, JOHN D. (b's0)-Miss.2.'09; (I'09).

FROSTPROOF, 70, POLK

MacArtan, Nelll Dunean (b'83)-N.C.4,09; (1'09).

Runyan, John R. (b'67)-Mo.I, $97 ;\left(1^{\prime} 10\right)$.

FT, BARRANCAS, 25, ESCAMBIA

KENNEDY, JAMES STWWART (b'5i) 4 Pa.2,'S0; Ist Lleut., M.R.C., U.S.A.; $11 \mathrm{em}$ ber Med. Soc. of State of $\mathrm{Pa}$.

MORSE, ARTIUUR W. (b'i3)-Ill.6,99;

Maj., M.C., U.S.A.

FT. DADE, 100, HILLSBORO

CHASE, CHAUNCY L. - Ky.1,99; 1 st

Lleut., M.R.C., U.S.A.

FT. DESOTO, 100, HILLSBORO

WARNER, HARRY J. $\oplus$-D.C.I,0T; P.A. Surg., U.S.P.H.S.

FT. LAUDERDALE, 1,000, DADE

KESNEDY, THOS. S.-Tenn.11, 01 ; (1'02). LOWRT, ROBT. SPEAR (b'80)\&-Pa.11, 04; (1'10).

Stanford, John A. (b.'75)—S.C.I, 09 ; (I'09).

FT. MeCOY, I50, MARION

BLALOCK, ALONZO L. (b'62)-Pa.2,'86; (1'08).

I.ISK, PERCY FRANKLIN (b's2)-Ga.12, '06: (1'06).

FT. MEADE, 1,165, POLK

COFFTE, JOS. HENDERSON (b'79) Ga.11,'10: (I'10).

Hafford, Wilbur C. (b'86)-Ky.2,'11; (1'11). Johnson, Marion Franklin (b'33)-La.1,09; $\left(1^{\circ} 09\right)$

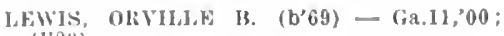
Reagln, ('alaway liarner (b'35)-0.9.77; (1"7\%)

WhLisus, Fow lack (b'iz)-ca.l1, $04 ;$ ( ).

FT. MYERS, 2,463, LEE

Armstrong, FrancIs K.-Ont.1,92; (1'12)

l3arton, CIyde Fdwin (b'70) II-I'a.9,'97;

Brecht, J. Ermest (b'42)-Mo.2,74; (1'73). (I'10).

Ilunter, Arthur P. (b'76)-Ga.1,97; (I'05).

MATH ESON, B. 1)-S.C.I, 90 ; (I†).

P'ARNHI IIEXRY E. (b'S1)-Ky.I,08; (1'08).

l'orter, Jesse 13. (b'il)-III.6,03; not in practlce.

Terry, Iarshall orlando.

(See Mintroneck, N.Y.)

Felasco, Fdward Everette (b's:) - I).('.3,'12;

WINKLFR, WM. R. (h'si) - Tenn.8,81; (l'0I).

FT. PIERCE, 1,333, ST. LUCIE

Bean. Ira loyd (b'86)-Ga.11,'12; (l'12).

Bean, Ira lloyd (b's6)-Ga.11, 12; (I'12).

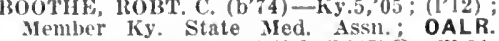

ISOEHL, CIIAS. GODFREY (b'5\%) $4-111.11$, 83; (I'08); Mrember 111. State Hed. Soc.: (2700 W. DIvision St., Clicago, IIl. ; l'99).

IROLLINS, FIGAR E. (b'T1)-Md.3,93; (L'93).

Fan Iandingliam, Wm. Ernest (b'79)-Md.4, $05:\left(I^{\prime} 05\right)$.

WHITEN, BENJ. LELAND (b'87)-(ia.11, '09; (l'09).

FT. WHITE, 329, COLUMBIA

Farnell, Ferry Cleveland-S.C.1, 12 ; (羊)

Hiddleton, Wm. F.-Ky.5,90; (安).

Whitlock, Wm. Eugene (b'87) - S.C.1,'10; (1'12).

GAINESVILLE, 6.183, ALACHUA

Ayer, Robt. B. (eol.) (b'66)-Tenn. 7,00 ; (I'01).

Bishop, John C.-Mo.i,'91; (1) ; G.

COLSOX, JAMES H. (b'66) †-IId.3,'96; $(1 ' 96)$.

DELL, JAMES MI. (b'S0)-Ga.11,'02; (l'02). DE PASS, MATTIEW H. (b'69) Tenn.8, 's9; (1'96); Or.

Dobbs, Clarence Hull (b'87)-Ga.11,'10 (l'13) : State Board of Health

Flint, Ldw. Rawson (b'64)-Mass.1,03; (teachlng).

HODGES, JAMES HARRISON $\left(\mathrm{b}^{\prime} 66\right) \oplus-$ Mld.3,'88; (1'89).

LARTIGUE, ETIENNE (b’0) - Md.4, 97 ; (l'97).

LASSITER, WILBURN (b'79) - La.1,03; (l'11).

MCKINSTRY, JAMES F., SR. (b'43) $\oplus-$ N.Y.8,'66; (1'89)

MeKINSTRY, JAMES F., JR. $\left(\mathrm{b}^{\prime} 69\right) \oplus$ Ky.1,'92; (1'92); S.

Parker, Jullus Augustus (col.) (b'77)Tenn. 7,$02 ;\left(I^{\prime} 06\right)$

PICKETT, WM. H. (b'88)-Ga.12,'11 ; (1'I1). Robb, S. L. - H-D; (I†).

SMITH, DE WITT TAIMAGE (b'80)-Ala.2,

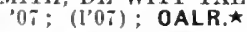

STEVENS, EDWIN LLTHER (b'69)\$-III.6, 92: (l'92); not li praetice; Member Ia. State Med.' Soe.

GARDNER, 50, DE SOTO

Baker, Frank W. (b'62) H-Ill.4,'88; (䒠)

GEORGIANA, 100, BREVARD

Chambers, Thos. H. (b'32)-N.Y.3,'55; (L

GILMORE, 60, DUVAL

Cuzner, Alban T. (b'39)-N.Y.1,'64; (1'89).

GLENDALE, 80 , WALTON

Adams, Dallas Hllliard (b'83)-Ga.12,'0s; (l'08).

GOULDS, - DADE

Teller, Robt. R. (b'56)-Ont.4,'8I; (I'I2).

GRACEVILLE, 734, JACKSON

Box, Wllmer Cortez-Ga.11,07; (1'0i).

Grace, George M. (b'51)-Ga.5,'81; (Iث).

MILLER, REDDEN LEE (b'85)-Ga.11,'i 0 ; (I'I1).

PHILLIPS, NATHAY R. (b'77)-Tenn.11, OI: (I'02)

GRAN'D RIDGE, 300, JACKSON

Battle, J. C.-Tenn.11, 06 ; not in practice.
GREEN COVE SPRINGS, 1,319, CLAY

Chalker, James LeRoy (b'84) - S.C.1,'12; (1'12)'

Chapman, hens. A. (b'85)-Ga.9,'10; (1'10). Clerke, John Wesley-Ont. I,'84; (ö).

Dunn, Berkeley Sherworl-N.Y.19, 84; not In pracllee; 26 Brondway.

Flsher, Leslie C. (b'34) - Ga.12,09: (l'09). Forde, Saml. J. F。 (b'7t)-D.C.3,'I1; (1'12). HODGES, JOHN WALTER (b'56)-MId, '92; (1'12).

GREENSBORO, 175, GADSDEN

GAIRDNFIR, 0. W.-Ga.I1,, $0 I$; (I'0I).

GREENVILLE, 751, MADISON

MIXSON, JOYCE F. (b'79) $†-(\mathrm{Ga}, 1,01$; (l'01).

PIIILIIIS, JAMES OLIVEI (b'88) -

Tenn. 8,'10; (1'10).

GREENWOOD, 400, JACKSON

BURKETT, WYATT THOS. (b'84)£-La.l, 09: (l'09).

W11lis, IR. A.- $\mathrm{Ky} .4,89$; (1†).

GRETNA, 20!, GADSDEN

Clinare, Shores Erastus (b'80)-Ga.12,08; (1'08).

GROVELAND, 200, LAKE

REGISTER, SAMI. T. (b'76)-Ga.1,06; (I'10); Member Med. Assn. of Ga.

GULFPORT, 40, PINELLAS

Robbins, Jerome J. (b'4 I) - Mich.1,'67 ; (I'03); not in practice.

HAINES CITY, I00, POLK

Grlftn, Leroy Smith (b'79)-Mo.7,'II ; (表). Sample, MartIn V. B.-Xeb.4,95; not In practice.

Sample, Thos. E. (b'75)-Neb. 5,04; (\$).

HAMPTON, 265, BRADFORD

MIUDLETON, W. E. (b'70)-Tenn.11,00; $\left(l^{\prime} 06\right)$.

TWIGGS, JOHN H. (b'70)-Ga.9,'99; (1†).

HAMPTON SPRINGS, I00, TAYLOR

KEY, FOSTER 1. (b'72)-Ga.11,03; (1'03) ; Member lled. Assn. of Ga.

HASTINGS, 399, ST. JOHN

Halloway, Wm. H. (b'84)-N.C.3,'10; (l'11).

Lattln, Chas. Andrew $\left(b^{\prime} 44\right)-0.16,{ }^{\prime} 89$; (l'89).

PADGETT, B. LUKE (b'82) - S.C.I,07; (I'08).

STANTON, GORDON (b'72) - D.C.1,05; (1'09).

HAVANA, 432, GADSDEN

KENNFDY, ROBERT LAWSON (b'88)

Id.1,'10; (I'10).

HAWKS PARK, I23, VOLUSIA

FORSTER, DAVIS $\left(\mathrm{b}^{\prime} \div 0\right) \oplus-$ Mỏ.28,'96 ; (l'10).

HAWTHORN, 324, ALACHUA

FLOYD, GEO. M. (b'81) †-Ga.11, 09 ; (1'09).

HERNANDO, 592, CITRUS

PUTERBAUGH, ADELBERT'D. $\left(b^{\prime} 64\right) \uparrow-$ Ky.1,'93; (1'93).

HIGH SPRINGS, 1,468, ALACHUA

Hodges, B. Calhoun-Ga.9,85: (1t)

Tyre, Chambers M. (b'90)-Ga.12,'11; (I'II).

HIGHWAY (BRANCH P.O., JACKSONVILLE), - DUVAL (See Jacksonrllle.)

HILLIARD, 200, NASSAU

Fuqua. Cleveland C.-Ga.18,'10: (1'10)

GOLNBERGER, HENRY E. (b' '03; not in practice.

HINSON, 100. GADSDEN

Brlnson, P. A.-Ga.I1, 01; (1'01).

HOBE SOUND, 43, PALM BEACH

SENGSTAK, ERNST P. E.

(See Jacksonville.)

HOLDER, 370, CITRUS

Blshop, B. M. (b'68)-Md.3,'90; (l'06).

HOLT, 150, SANTA ROSA

Gllchrist, J. Glenn (b'88)-Ala.2,'12; (l'12).

Iixon, Jos. Arnold (b'87) 一 Tenn.19,'11: (1'12).

HOMESTEAD, 10, DADE

Brooks, E. L. (b'69)-Ga.10,' 94 ; (1'08)

TOWER, JOHN BALLARD (b'73) @-III.6, $01 ;(1,10)$. 


\section{HOSFORO, 370, LIBERTY}

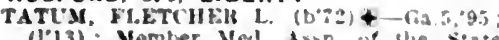
(l'13):

\section{HUDSON, 210 PASCO}

losey. J. Martín $\left(b^{\circ} 66\right)$ - (ia l, 's! (l'ss)

INTERLACHEN, 263. PUTNAM

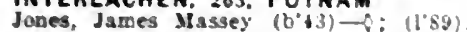

INVERNESS. 350, CITRUS

Dame. Geo. Alrab (b"52)-fis.1. 04: (104)

Millet, James $\mathrm{b}$. (b'52) - Ky.2,93: $\left(1^{\circ} 90\right)$ 6.

Reares, Horace Adams (b':3) - Tenn 11,01 ;
(l'09).

IRVINE. 30. MARION

DAVIS, JUHX I. (b'68)-Ky.4,"91: (1'92)

ISTACHATTA, 225. HERNANDO

NeKnight, S. Listen (b'B1)-S.C.1,1): (多)

JACKSONVILLE, 57,699, DUVAL NUMBER of PHYSICLAS, 160

ACKER, ALBEKT E. (b'GA) - D. ${ }^{\prime} ., 0^{\circ}$ (107): 3i Water St: otice, Masuric

ARONOVITz, SAMI. (b'si) + - Md.s." 11 (f'is): 311 w. Dural St; $9-11,4-3, ;-8$ ObG.

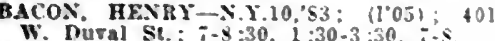

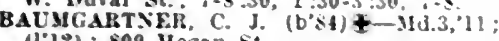
(l.12): 809 Hogsn st

BECKMAN, GEOREF ENWT (b'79)-S.C.J, 09; (101; Barnet? Bidg: : 12-3, $7-5$.

EMKI. NED CARROLL $\left(b^{\circ} / 4\right)+8-6 a .5,90$

Blick, Herbert Oetsitus (b'ss)-Ten Black, Herber Oefavtus (b'ss)-Tenn... neti Bldg; $9-10,-4,7-8$.

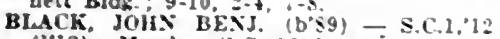
(1.13): Member S.C. Jed. Issin.; 316 E. Monroe St: once, Bay and Lalira Sts. $9.10,2-3, ;-8$.

Blake. Chas C (b'il)-Ky.2,0:; (1'0i) 530 k. 3d St: utlce, Is Hridge s: s:30-9:30, :-4. : :30-::30

BLIXX, THEODORE $1 .(680)-1-1,04:$

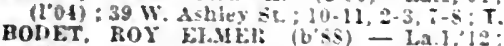
BOIET, ROY EH.Mlits (b'ss)

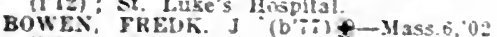
(1*03): 1400 1'ark si. : odlce. t5 W. Church St: $8-9,2-5: 5$.

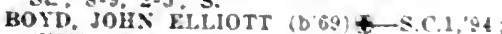
(1.99): Seminole ('lub; otlce, st. Jandes Blde.

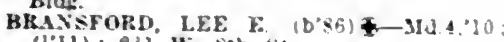
(1'Il): Ell W. sth st. (l'os): 648 W. Adam st: $8-10 . *-1$.

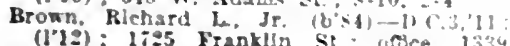
(l'12): 17:5 Frankly St.: unce, 135y Forida Are.

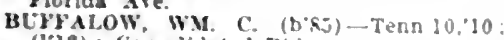
(1.12): Consolidated B:d:

Butler, James Alpheus $\left(b^{\prime}: s\right)-D(1), 00$ (l'00): 354 E. Cnlun s: : :-9, 1-4, $6: 30=$

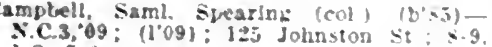
1-3, -8

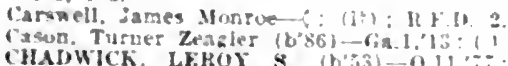

CHADWICK, LEROY \& (b'53)-0.11,

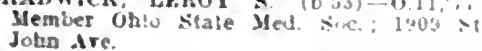

Chapell

practlce: lit E. Ist st.

ctortox: wy i (vist.

In yractice: stale lios + ont Hea!th: LD.

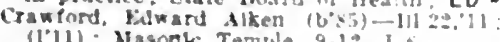
(1'11): Masonk Temb!e, 9.12.1.a

Culp, D. W.-0.14,"91: (bi) ilag Florka Are : oace 394 siruce st

ENNISGHAM, I.KETEIS W.

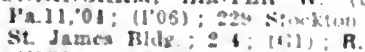

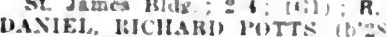

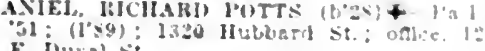

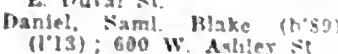

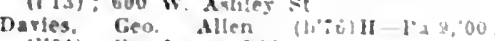
(1,01): St. damer Hog

DAF, Cistox (

Deal. Charles uran (1):3)-tiab,1!

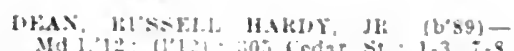

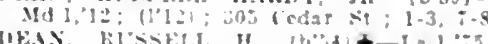

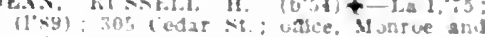

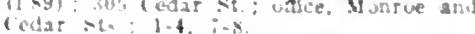

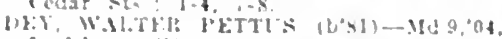

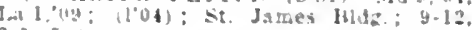

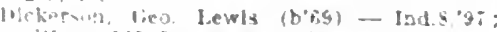

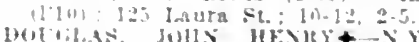

(1)

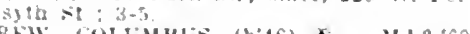

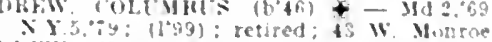

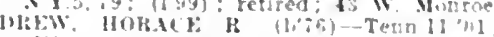

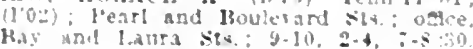

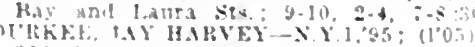

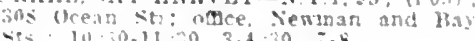

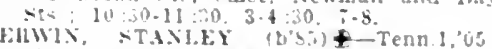

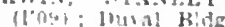

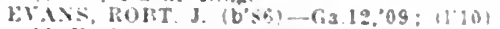
11 t. pural st, onles, 12: il bay so

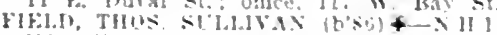

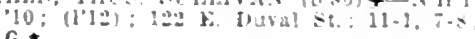
Francis. Nelson winstow $(6,73)-1$ a 6,9 ; 16" -1$): 1303$ Main

Fretand, Thus ( 1.04): :19 Market

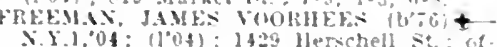

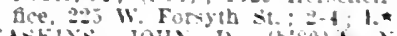

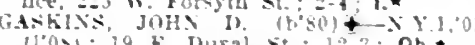

Gibson. James Copeland (b-12-0nis.

Gibson. James Copeland (b a)-Oni.5.

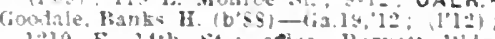

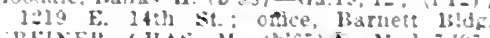

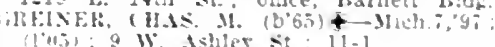

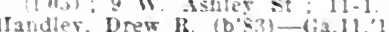

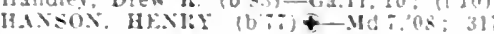

II. 10ith st. offee latwratory sidie

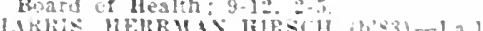

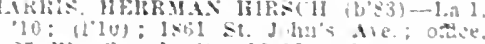

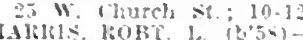

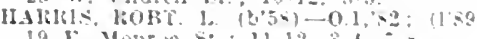

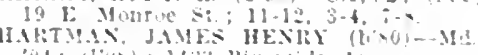

wh (19) 1433 hiverside tre

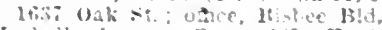

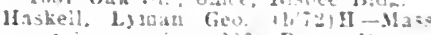

not in practice: :vev Perry s!

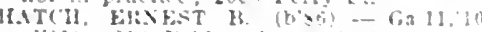

(1"11): 215 Brldae st : $30-4:$ ol, 1 ;

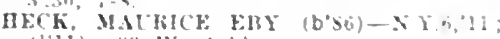
(1'11): $: 9$ W Ishes

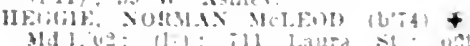

Huckman Llds:; 9,$24 ; 1 B 1)$ OALR.

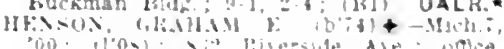

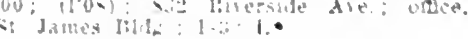

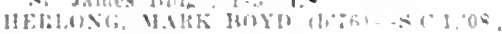
llosi; 1004 li. ditins

11:115. James keth (col.) (10\%1) X Is

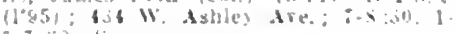
$6-7$ - 0 : 5 :

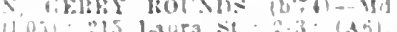

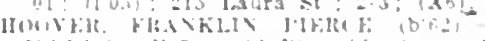

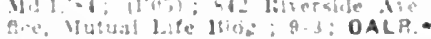

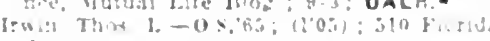

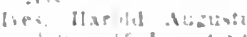

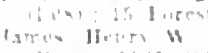

$\therefore$ in

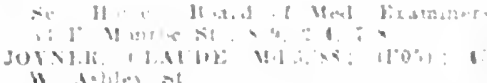

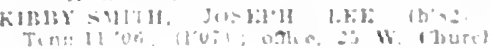

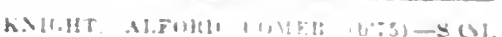
L'Eugle kidw il $-4,3$ :

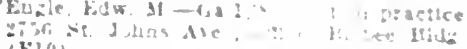

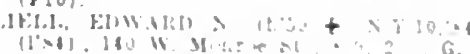

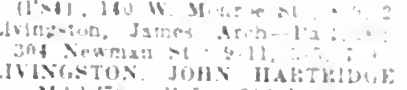

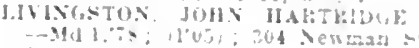

1918)

LowIRL: CHAs a

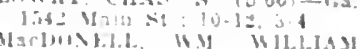

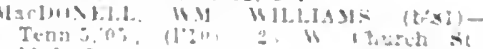
$11 \cdot 1$

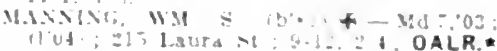
MAY KIIST I.Fir.

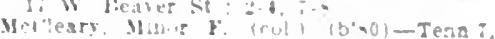
Melidis bubT H

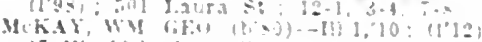

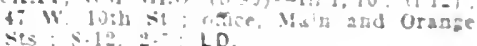
Mes: $12,-2:$ LD

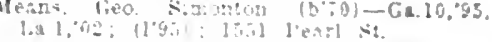

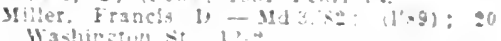

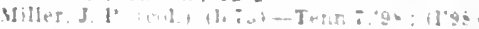

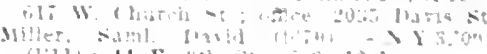

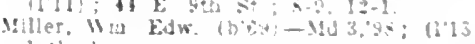

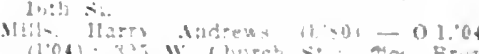

(100); 325 W. (lures s. ace Bruad

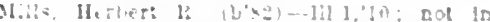

practice 1935 Warne ft osare, Latwo

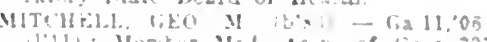

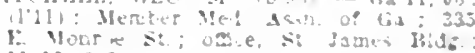

$11-12=-3$.

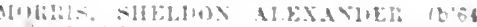

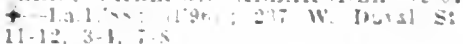

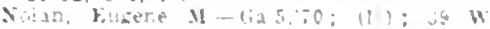

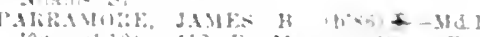

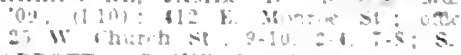
BARfOTT Alite !! $101 ;$; 11 add

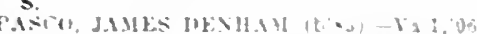

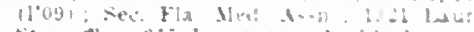

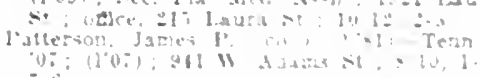

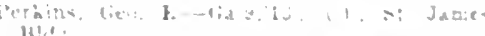

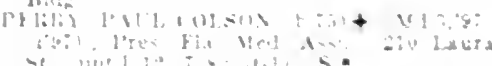

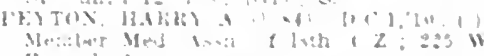
Mitions
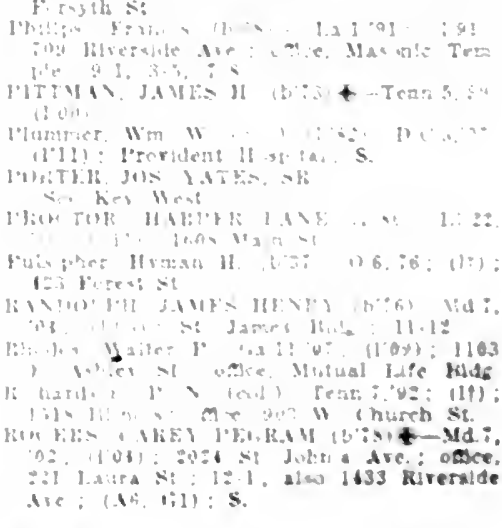
Iinss, WH. EDSON (b'70)-V-Vt.2,04

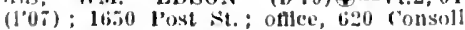
daterl Hldg. ; 1-3; Pd.

SANDUSKY, CLARESCE M. (b'न liy.4,02; (1'02); 28 W. Itonroe st.; $9-12$, 2-4; OALR. *

schell, W. W'. (col.) (b'79)-Tenn.7,65; (l'09) : 431 w. Ashley sit

Seay, Walter E. (b'2)-Ky.1,04: $\left(1^{\prime} 04\right)$ leos llighway Are

SENGSTAK, EINST l'. E. (b'i '05; (1'05); Nt. John's ant llendricks Aves. : (ofice. Ilobe sound)

Shaw, John Ii. (col.) (b'72)-1).c.3.0. (1'06); Dural and IBridge sts. ; $\$-10,1-3$, $6.8: 30$.

Sibley, Mary V. (b'48)-I11.4, $7 s ;\left(1 \frac{1}{1}\right) ; 1612$ Silver st. ; 2-6.

Slbley Vin' (1+); 1612 Silver St.; $7-4,11-2$

Slmmons, Thos. G. (b's7)-Tenn.8,'12 (1'12) iz1 lianana St.; office, is Cedar St. : $8: 30-10,12-2,7-9$.

SIMPSON, JAMES KNOX (b's6) - -Pa.1 09 ; (l'11): 230 E. Forsytl sit.; ofllec, St

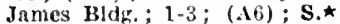

Slsson, Sallord (b’\%)-Ky.0,02; (1'11): 907 W. Adams st.

Skipper. Clarence T. (b's0)-fia.11,'13 (1'i3) : SOS W. Adamis.

Smalls, wm. C. (col.) (b'6i)-N.C.3,'yz; (1t) $; 510$, iefferson st.

Smith, Arthur Walls (col.) (b'68)-N.Y.8 $94 ;(1 ' 04) ; 600 \mathrm{~W}$. Ashley St.; ofllce Myrtle Ave. and l'elican st. $;-7-8, i-3,7-4$ Smith, Burdette (b's 2 - (ia.12,10; (I'11) 1018 E. Church St. $; 7-9,6-8$.

Smith, Claude 'IR-La.l,o0; (1).

Smith, J. llarvey (col.)-Tenn.ট,oj; (t) ; $441 \mathrm{~W}$. I3eater.

SMITH, MARYIN IHENIS (b'78) - Ga.13, 10 ; (1'11).

Smith, Mary B.-Ga.18,'10; (ま) ; 1018 L. Church st.

S.ITII, RAIPH E.†-Ga.5,'91; (1î); Mem ber fa. Mled. Assn.; 259 w. Forsyth St. Ilogan St. ; 10-4

STAPLETON, l:OBT. TAYI.OR (b'81)La.1,11; (1'12); Nember Miss. State Med. Soc.; Barnett Bidg.

STEVENS, ELLEN LOWEIL (b'64) 8 Id. 7,00; $\left(l^{\prime} 06\right) ; 2050$ Hill St.

Stewart, kdw. L. (b'tis)-'Tenn.5.'91; (1,91) 709 Hogan St. offle, Heard Bldg.; 9-19, 2-5, 7-8; OALR.

STINSON, LOUIS (b'S2)-M1.1,'11; (1'11) Dural Bildg. ; 1-3; Pd.

STINSON, w.M. M. (b'73)-Tenn.8,00 (1'02); Lakeshore Drive, Lakeside l'ark; 223 w. Forsyth St.

STOLLFXWERCK, IUASA DORMAN (b'84) (4-La.1,08; (1,09); 43 W. Ashley St.

STOLLENWERK, PERCY J. (b'43) - Va.1, '8.3; (1's9) ; 43 W. Ashley; ottlce, Bisbee Bldg. : 2-3, $7-8$

Stout, IIenry 1k. (b'43) II-Ill.4,'68; (1'89) Pres. Homeo. Board of Med. Examiners; 105 E. Monroe St.; $8-9,2-4,7-8$

TAYLOR, HLGI M.\$-Ga.11,03; (1) ; 223 W. Forsyth st.

Taylor, Jolu N. (b'49)-Mro.1, is; (1\%) ; 1016 E. Duval St

TERRY, CHAS. EDW. (b'73) 3-Ma.1,03; (1'03); 2601 St. John's Ave.; offlce, City

THOMAS, ROBT. Y. H. (b'76)-S.C.1,04 l'04); 450 E. 5th St.; office, Duval County IInspital; $0-10,3-4,7-8$.

THOMPSON, THOS. C. (b'79) $¥-\mathrm{K} r .9,03$ (I'03); 1835 Laura St.; oftice, $602 \mathrm{~W}$ Adams St. ; 8-9, 1-3, 7-8'30.

TURCK, RAYMOND CUSTER (b'-4) N.Y.5,'96; (1'0i); 1535 Riverside Are. ofice, Consolidated Bldg. $1-3 ;$; $A$, ; 00; (1'00); 204 Post St.; offlce, DyalUpchurch Bldg. ; 11-12, 2-3.

WAAS, FREDK. J. (b'81)-Md.1,'05; (1'05) ; 108 Gilmore St. ; office, Barnett Bldg. ; 2-3. Walker, Frank P.-Pa.2,'78; $\left(1_{\dagger}^{\dagger}\right)$; Julia and State Sts.

WALTER, GEO. (b'79) †-Md.1,10; (1'11) ; $325 \mathrm{E}$. Adamis St. ; offlee, St. James Bldg.; $1-3 ; 1 . \star$

Ward. Cassius A. (col.) (b'i4)-N.C.3,07; $\left(1^{\circ} 0 \pi\right) ; 722 \mathrm{~W}$. Beaver St. ; 8-9, 1-3, $6: 30$
Warl, Jolu Frank-Ga.11,07; (1'07); Barnett Bldg.

WASIIBUIIS. CLAYTON D. (b'73)-l'a.1,02 (1'10); 125 W. lseaver st. ; 9-4; OALR. Melntraub, Maurlce (b'i6)-o; not In nractlee.

White, Isham A. (b'7 $\tilde{)})-$ Teun. $\left.\tilde{7}, 08 ;(1)^{\prime} 10\right)$; (5) Dovis st.

WIICOX, ClAIRENE lbOBT, (b'79) Mllel.,04; (1'05); 1456 ('ollege St. ; of -

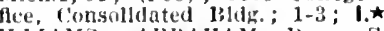

WHLLAMS, IBI:AIIAI 1). S.C.1,04 (I'89); 209 W. Ashley st. ; $9-12$

Wlilams, Frank (i.-Cia.10,'91; (1十); $30 \mathrm{~W}$ 2d St.; oftee, $\$ 8$ F. Bay st.

WILSON, Al.IIEUS KEL.LER (b'80) S.t. 1,$09 ;(1 " 10) ; 3: 3$ Forest St.; offtee

602 Cliarles St, 8-9, $1: 30-3: 30,7-8.909$

(Bacteriologlst); 1104 Walnut St.; oflnee laboratory state Board of IIealth.

JASPER, I,730, HAMILTON

l3ultard, Clifton l'. (b'85)-Ga.9,'10; (1'10)

('orbet, Jos. II. (b'78)-Ga.11,01; (l'01).

G'caln, Wm. Marrin (b'72)-Ga.11,00 (1'00)

Complins, Raymond Dean (b'84)-La.1,05: (l'05)

JAY, 100, SANTA ROSA

Stallwortl, Nielolas 'thos. (b'83)-Ga.18. '11.

JENNINGS, 480, HAMILTON

Beaty, James J.'(b'61)_- (ra.9,'93; (1'95)

Meclinton, Nathaniel-Ont.4,'65; (1'01).

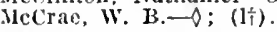

KATHLEEN, 115, POLK

MCMURRAY, II'XRY E.

KENWOOD, -, PUTMAN

Totten, Jaaies (b'44) IJ-O; ( )

KEY WEST, 19,945, MONROE

Castillo, Artuno- $0 ;(1 \dot{\dagger})$

FOGARTY, JOS. FolRAN (b'76)-N.Y.1 '98; (1'99); 227 Duval St.

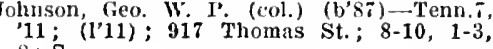
$8 ; \mathrm{s}$.

LGiHT, SAML. D. W. (b'77)-Pa.1,99 (1'04); 412 Elizabeth St.; $1-2,7-8$.

MALONEY, JOIN B. (b'65) 4 - Pa.1,'90 $\left(l^{\prime} 90\right)$; 534 Fleming St.; offlce, 537 Flcming St. ; 12-2.

MANNING, HERBERT M. (b'T8)\&-D.C.1, $00 ; 1$.A.Sur., U.S.P.H.S

NTADO, NILO C. (b'85)-Cuba 1,'08 (1'10); 608 Duval St. ; 1-2, i-8.

PLUMMER, GEO. R. '(b'il) -Ga.10,'93; (1’93); 504 Simonton St.

PORTEl, JOS. YATES, Sit. $\left(b^{\prime} 47\right) \oplus$-Pa.2, 70 ; (1'89); Lieut. Col., U.S.A., retired; Sec. State Board of Health; Duval st.; (offce, Jacksonville).

PORTER, JOS. YATES, JR, $\left(b^{\prime} 81\right)-N . Y_{1}$ '06; (I'11); Wuddell st. and Alberta Ave. office, 417 Duval St.; $12-1,7-8$.

RODRIGUEZ, BASSO E. (b'70)-Spa.1,'91 (1†)

VARREN, WM. R. (b'76)థ-Pa.1,04 $\left(l^{\prime} 06\right) ; 317$ Fleming St.; office, 621 Eaton St. ; $12: 30-2,7-8$. S.

WATKINS. VitToR E. (b'ä1)丹-D.C.2,'94; (1'96) ; 1st Lient., M.R.C., U.S.A. ; Adjutant General's Offlce.

KISSIMMEE, 2,157, OSCEOLA

(ieiger, Hugh St. Clare (b'86) - Pa.2,'11 (1'13)

llicks, Milton J.-Ga.5,60; (1'92).

Hyatt, Clinton Lee (b'81)-N.C.4,08; (1'09).

Rivers, Thos. W. (b'68)-S.C.1,00; (1'02).

Taylor, llenry H-lio.8, 22 , not in practlce.

Thomason, Frank G. (b'58)-Ga.10,81; (1'94); not in practice.

WINN, WM. I.EE (b'69) \&-Mo.28,'94; (1'06).

KUHLMAN, - DE SOTO

Keisling, Fred. ('. (b'\$3)-Mo.7,06; ().

LABELLE, 100, LEE

Weaver, Cleo Earl (b'S1)-Ind.20,'08; (1'11).

LA CROSSE, 350, ALACHUA

Roberts, J. W.-Ga.9,94; (1+).

LAKE BUTLER, 685, BRADFORD

KING, SEEBER (b'T $\tau$ )-Md.3,01; (l'02)

ONG, JOHN PONFROT (b'76)థ-Va.1,07

(1'13); Member Med. Assn. of the State of Ala.

HAINES, JOIIN E. (b'76)-Ga.11,05; (1'05).
TOMLINSON, J. I'ITT (b'73) - Ga.10,98; (1'98).

Wilson, Benj. P. (b'51)-La.3,'66; (1t)

LAKE CITY, 5,032, COLUMBIA

ANDEHSON, LEONIDAS MOSBY (b'61) (ia.5,'95; (1'36); G.

Berry, S. I - Mo.2, 65 ; (1†).

CIIAKEIt, RoY F-La.1,05; (1'05).

CHANDI,Él, ISAAC WAYNE (b'80)-Ga.11, 09 : $(1,10)$.

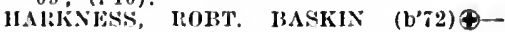
I.a.1, 97 ; (1'11).

Ives, Washington Mackey (b’77) - Tenn.5, 01; (1'01)

JULIAN, ABNER J. P. (b'59)-Md.1,'83; (1'04).

Murray, Franels A. (1'82)-N.C.3,08; (1'09)

Niblack, James L. (b'50)-S.C.1;78; (1'80).

RIVERS, DWIGIIT GILAY (b'85)-Md.1,'10; (1'J1)

USII. WAKRFN B. (b'48) 3-Pa.2,'93; (1'8i)

LAIKE HELEN, 646, VOLUSIA

Zanders, Fred. W' (b'46)-Mo.2,'75; (l'07)

LAKELAND, 3,719, POLK

BAK'TON, GEO. C. (b'53)-Pa.2,'80; not in practice; Nember Minn, State Med. Assn. in practlee; Member Ill. State Med. Soc.; R.F.J. 1.

Grittin, Jolin D. (b'88)-Ga.11,'04; (1'04).

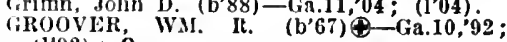
(1'92); G.

IIAIKYIE, WM. D. (b'65)-Ont.5,'89; Mem ber state MLed. Soc. of IVIs.

IIenley, Leonard F. $\rightarrow$ Ga.5,'88; (1+).

LEFFE'RS, RICHARD (b'78) - Tenn.6,'09; (1'10).

I.OVE, CICERO W.-Md.1,02; $\left(\mathrm{l}^{\prime} 02\right)$.

Maynard, Ben H. (b'66)-Ga.11,09; (1'99)

IOON, WM. BENJ. (b'70)母-Ky.5,97:

(1'12); Member Ill. State Med. Soc.

Richards, Henry Mercer (b'79)-Ga.12,09; (1'10).

Simpson, David J. (b'82)-N.C.3,08; (1'09)

SIIITIY, SAML. FREDK. (b'73) - 0.2,01; (l'01); OALR. *

Stoner, John J.-IIl.4,'80 ; ( )

SULIIVAN, ROBT. R. (b'65)-Ky.2,'92 ; (1'11); $\mathbf{s}$.

WILSON, CRAWFORD C. (b'62) - N.Y.5, S8; $(1,00) ; \mathbf{G}$.

, JOFN F., JR. (b'78)-S.C.1,05:

\section{LAISE WORTH, - PALM BEACH}

Griffin, J. Ansley (b'72)-Md.4,'06; (1'11).

LAMONT, 485, JEFFERSON

WALKER, WM. HENRY (b'i6) $\odot-G a .12$, $10 ;(1,10)$

\section{LARGO, 291, PINELLAS}

KLIR, SAML. J. (b'58)-IIO.1,'83; (l'13) ; Mer State Med. Assn. (l'0s)

KINGSBURY, GEO. C. $\$-0.9,80$ : (l'08) Nember IIl. State Med. Soc.; OALR.

LARKINS, 50, DADE

Franklin, Grover C.-Ala.2,07; (1'13).

VAN HORN, JAMES A. (b'72) (-Tenn.8, 93; ( ).

LAURELHILL, 316, WALTON

HOOTEN, WH. AHINGTON (b'74) - Ga.5 '95; (1'95).

Webb, E. Porter (b'72) E-Ga.9,'02; (1'02).

LAWTEY, 492, BRADFORD

BROWN, GEO. W. (b'66) -Md.1,'89; (1'00).

LEE, 150, MADISON

Johnston, Crowell Wim.-Ga.10; (1†).

Mickler, Walter S. (b'73)-Ga.10,'95; (l'95).

LEESBURG, 991, LAKE

Bush, Warren D.-NId.4,'93; (1†)

Butler, Peter Walton ( $\left.b^{\prime} 56\right)-G a .10,84$; not

Griffin, Lymus (b'79)-N.C.3,'10; (1'10).

Howell, Wm. H. (b'59)-Ga.5,82; (1'95); G.

Morrison, Harry K.-Mich.1,'02; (1'08).

LEMON CITY, 300, DADE

DU PUIS, JOHN GORDON (b'75) -Ky.5, '98; (l'98).

Rounsevell, Albert P. (b'45)-Ill.1,78; not in practice.

LEVON, 300, MARION

LAUGH 
LIMESTONE, I00, DE SOTO

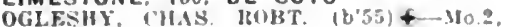
ib: $\left(I^{\circ} 90\right)$; $S$.

LIVE OAK, 3,450, SUWANEE

AIRTH, IIE\$RY F. (b'b5)-Ky.5.84; (l's?)

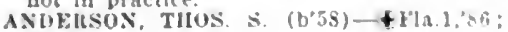

(l'S6). Chas, s. (b'6l)-Cial.200; (1'90).

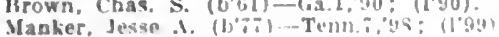

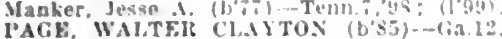
AGE: (1'13).

PRICE, J. MAIRVIS (b'81) $4-$ La. 1,04

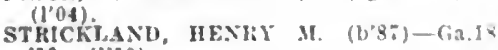

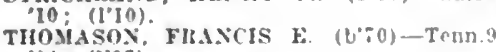
94: $(1 \circ 95)$

WRST, JA.UES WIITAKFll $\left(b^{\prime}: 8\right)+-$

Teno.s.05: (l'05)

White, WH C. (b:\%)-Tenn.11:03: 1103)

LLOYD, 351, JEFFERSON

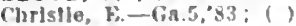

LOUGHMAN, 100 , POLK

IIolloway. C. W.-Ga.5, 9:

LUKENS, I50, LEVY

TURNEI: JAIES WITCOX (b'7s) + - la. "04: (1.04).

LULU, 200, COLUMBIA

Caines, James W. (b'63)-Ky" .97: (l'1l).

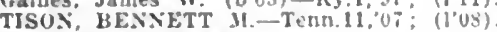

Wilt, Ded C, (b'st)-Teun.6, (0); (1012): R.F.D. 1 .

LYNN HAVEN. 300. BAY

Frecuan, Ellsha R. (b'42)-0.13,'s: : ()

MACCLENNY, 388, BAKER

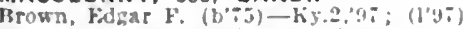

ligess. Chas. T. $(1,83)-($;a.9, 12

Strlckland, John W. (b'65)-Ga.l',99.

MADISON, 1,560, MADISON

Daris, Geo. O. (b, - G 6$)-M d, 3,03 ;(1 \cdot 03)$.

Long. Eustace $\left(b^{\prime}, 6\right)-M d .9,0.5:(1,03)$

Ituter, Lewell C. $\left(b^{2} 58\right)-0.8,59 ;(1291)$

Smith, Chandler Holmes, Jr. $\left(b^{\prime} 63\right)-\mathrm{N}$. I. 'S8; (1'92).

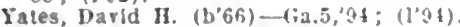

MALONE, - JACKSON

Bell, James l.ee (b'81)-Ga.9,09: (t'li).

Janiel, J. W--Gia,18,"11; ( $).$

PATTFRSON, JOIIN CliATT (1,SO)-lat 1 , '10; (1'10).

MANATEE, 988, MANATEE

GATH.S, HUBBAILU II. (b'B') - MU.3:93;

MCDUFFI:, TOLIVEl M. (b'b5)-Tenn. I9: (1'0i)

Pelot, J. C.-Pa.2,58: (1t).

MANDARIN, 1,600, DUVAL

KFNNE:IYY, GEO. I), (b'80)-Mlch.8, 04 ; $(1 * 05): G$.

MARIANNA, 1,9!5. JACKSON

BAITZEILL, NUHOLAS ALHEFT (L"T) - I. 1, $02 ;\left(1^{1} 02\right) ; \mathrm{S}$.

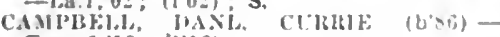
Tenn.6.12: (1'12)

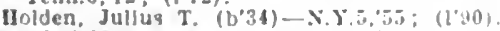

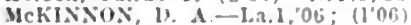

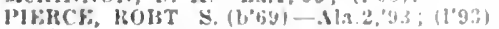

Pd.

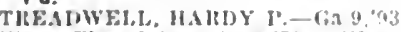

Wes,. Theophllus-(ia.6,"5y; (1'65).

MARTIN, 60, MARION

L.Indner, Carl W.-1).9:5:\%: (14)

MARY ESTHER, 6I, SANTA ROSA

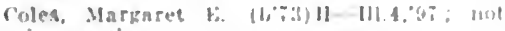
in pracelee.

MASON (R.F.D, LAKE CITY), 75, CO LUMBIA

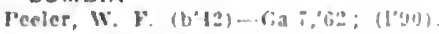

MAYO, 378, LAFAYETTE

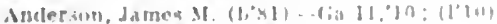

(ircen, (ivelda fred (b'sa)-lia.1.0?; $(100)$

MAYPORT, 441, DUVAL

Alsoph. Nell (b'ï)-Tum l,0\%: (100s)

MCINTOSH, 300, MARION

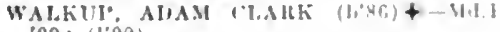$$
09:(1,09)
$$

MELBOURNE, 137, RREVARO

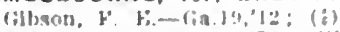

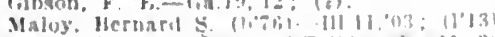

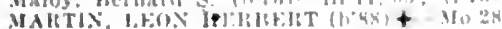
'In: (1.10)
MELROSE, 245. ALACHUA

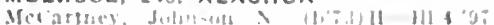

$(1,1,2)$

M.Ilae, lirank X ri3,70; (1t)

MERRITT, 60, BREVARD

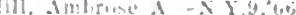

MIAMI, 5.971, DADE

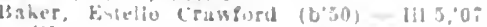
(1.1:)

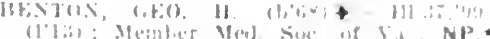

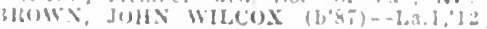
$11^{\circ}\left[\mathrm{I}^{2}\right.$

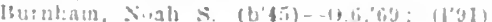

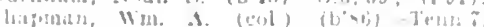
1.: (1' [i:3).

Cule, wm. J. $(6 \% 50)$-Ind 2,\%: (1'0,s)

frazler, sulnum M. (col.)-Tem i,0t (1'i) i)

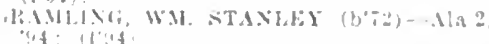

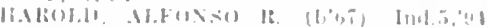

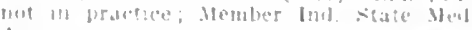

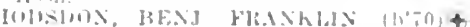

Me.1.47; III.1\}:08; (10); OALR*

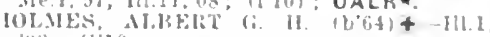
'93: (1'10).

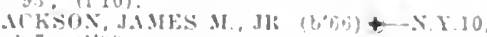

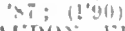

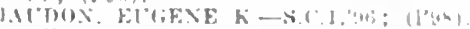

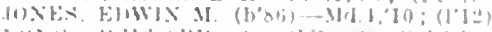

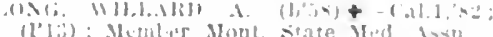

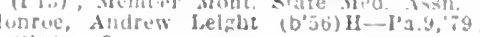
(l't)iti G

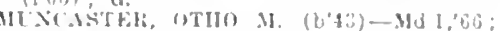
(1, I":)

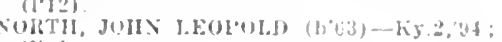
(l'is)

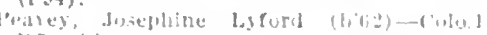
o: ; ( ).

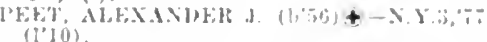

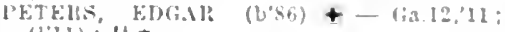
(l'11):U.*

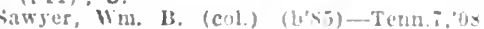
(1,0s)

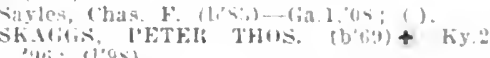

"uti : (l'9s).

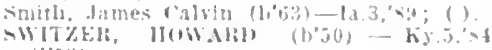

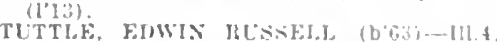
-SY (1.L2): OALR.

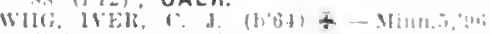

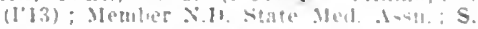

MICANOPY, 613, ALACHUA

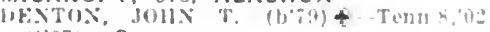

(l'0i) : G.

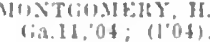

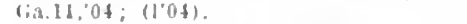

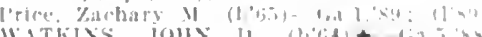

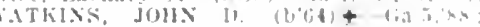
(1'0) 1 )

MICCOSUKEE, 123. LEON

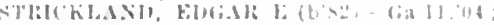
(1) 104 )

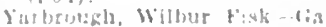

MIDDLEBURG, 340. CLAY

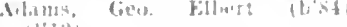

(1? 101.

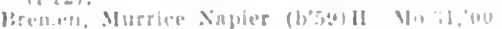

MILLIGAN, - SANTA ROSA

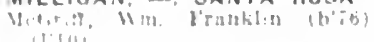

MILLVIEW, H00, ESCAMBIA

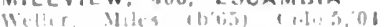

MILLVILLE, I,200, BAY

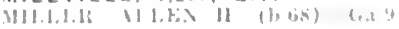

MILTON, 8:1, SANTA ROSA

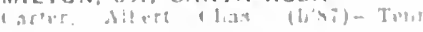

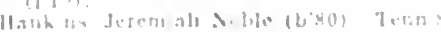

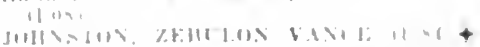

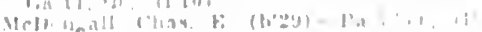

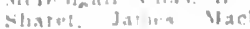

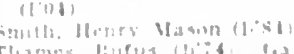

MINNEOLA, I00, LAKE

Hatton Ithis ( I th th)

MOOELLO, SO, DADE

[HF:NIS, JUIIV

MOFFITT, I20, OE SOTO

Filmuetliz. JWan ' PH. I'

MOLINO. 219, ESCAMBIA

II: TลU.

MONTICELLO, 1829. JEFFERSON

Billu, H, Hor H, W

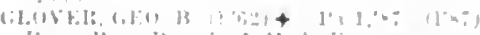

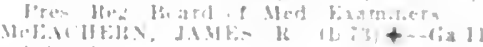

ir: (1+11)

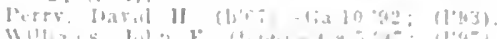

MORRISTON. 29\%, LEVY

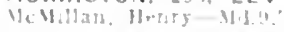

MOSSYHEAD, 25, WALTON

MT, DORA, IZI, LAKE

MT. DORA, 1,371, LAKE

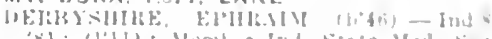

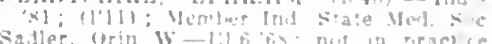
MT, PLEASANT, I30, MARSHALL

WIILLIS JUS. IIFISHFKT (b'II+-KY

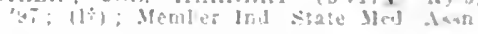
MULBERRY, 1, 118 , POLK

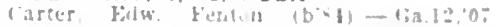

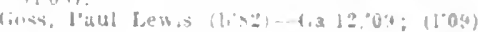
S

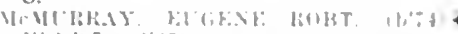

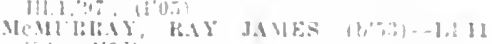
'ori: (1'05)

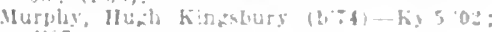
$11^{\prime} 00^{-}$

MUSCOGEE, IO0, ESCAMBIA

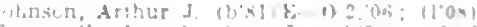

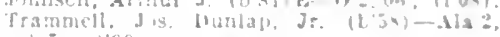

NEWBERRY. 816. ALACHUA

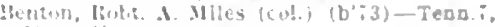

firmmete, James sutt n (b's:1-Ky 2.09 ;

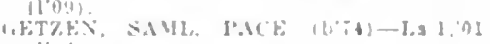
hiten

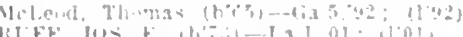

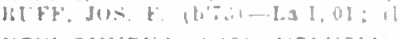

NEW SMYRNA, 1.121, VOLUSIA

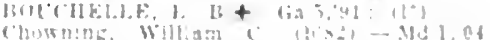
(1'mi): ob.

1 $x$. J the Ilenry 1 b.

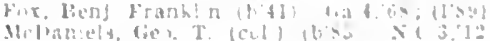
Milingelt

lime. liari! Thunas

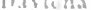

NICEVILLE, - WALTON

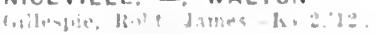

NICHOLS, 500, POLK

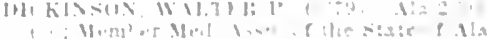

NOCATEE, 250. DE SOTO

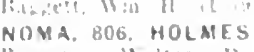

Jiamua, Wabter I) (2004:-1.2) 0

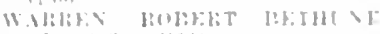

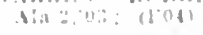

OCALA, $\$, 3 \% 0, M A R I O N$

11 NTS HYUMKI:

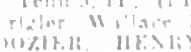

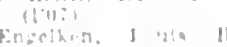

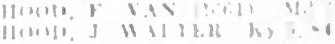

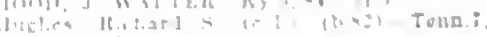

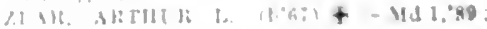

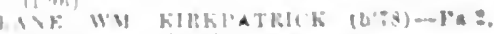
BH! (1'11): OALH *

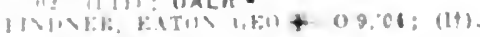


Mcclane, F. F. (b'62)-Nu.28,95; (1'09). Miltchell, Ente Carrie (col.) (b'85) Tenn $7,05:\left(1^{\prime} 00^{-}\right)$.

NEWSOM, WM. W. (b'48)-Ma.3,87; (1's9). I'ERK. LUGENE G. (b'82) - S.C.1,I0; (1'10); Pd.

SMITII, IDAN MORGAN-Va.I, II; (1t)

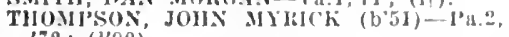
$72 ;(1990)$

WALTEHS, JAMES IIAHRY (b'84)-La.1, WATT, HAIKY FARLIN (b'85)-IH.I,12; (I'lá).

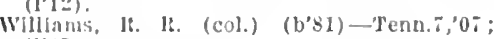
$\left(l^{\prime}(1)\right.$ i)

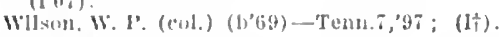
ODESSA, 90, PASCO

srygley, Elam F. (1,?90)-Tenn.5,'13; (1'13). OKAHUMPKA, 100, LAKE

Wlgeinton, Joh 1:-U.2,'73; (I⿱宀) ).

OKEECHOBEE. - ST. LUCIE

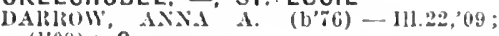
DARROW, GHAS. BOY (b'7I)†-111.22,09; (1'09); OALR.

OKLAWABA, 68, MARION

MENRY, HULIII W., Jl. \$-Md.1,91; (1) .

OLD TOWN, 100, LAFAYETTE

Goodbrel, Itobt. l,ee (b'73)-Ga.5,92; (1992).

ORANGE CITY, 490, VOLUSIA

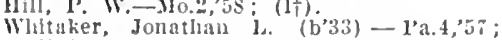
(1'ui); (Cranberry, N.J., l'y0).

ORANGE HEIGHTS, 150, ALACHUA

CUI'TIS, JOIH B. (b'J4)-MU.1.'Ty; (1'YI).

ORANGE SPRINGS, I52, MARION

l'arramore, Geo, 13. (b'b6) E-Q;(l'89).

ORLANDO, 3,894, ORANGE

Bearelall, IIarold Martyn (b's5) - Ky.1I,'0s; (l'13).

Brown, peler Lanter (b'39) - Ia.1, 64 , Mich.1, 'b6.

Callahan, Jerry B. (col.) (b'SI) -N.C.3,'0z; $\left(\mathrm{I}^{\prime} 07\right)$

CHISTS, CALTIN D. (b'78)- Ild.3,05; (1'06); OALR.

DIRANIS, INANL. EAI:I-AIa.2,'94; not in practlce.

EIVARDS, GASTON H. (b'75) (3-Conn.1, ,02; (1'09).

IIughes, Jacob 13. (col.) - Tenn. $\pi, 0 \mathrm{l}$; (l'01). INGEISOLL, IEOLT. NTEPIIENSON (b'T4) -.Ileh.1,98; (); Member lled. Soc. of Kilmer, Washington (b'3s) - N.Y.3,60 ; (1's9)

Macldox, John F. (b'45)-0.2,'T7; (l'92).

MeELROX, SILVAY (b'S3)申- IId.107 ;

McEWAx, Jolx S. (b'70) - In.6,05; (1,07); $\mathrm{s}$

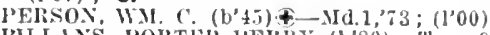
I'HLIANS. PORTER 1'ERRY (b'80) - T'enn.9. '08; (1'08).

Porter, Gico. (b'56)-N.Y.9,'s0; (1'8y)

lobinson, saml. M1-Pa.9,12,

laONEY, LAVID C. (b'55)†-Ky.5,95; () MIass,6,'11: (I'I1): LP.

WATTENSCHEIDT, CHAS_Md.3, not

in practice; Nember Mled. and Chir. Fac. of IId

WELLER, JAMES E. (b'74)-Pa.2,01; (1'13); Nember Ind. State Med. Assn.

ORMOND BEACH, -, VOLUSIA

WIITE, JOHN BLAKE

(Sec New York (ity.)

OSTEEN, 250, VOLUSIA

llutchinson, Thos. C.-Pa.9,'is.

OTTER CREEK, 62, LEVY

Turner, smith L. (b'86)-Ga.11,'11; (l'12) (l'11).

OVIED0, 220, SEMINOLE

Marshall, Cyril Justin $3-T e n n .1,07$; (1'12).

OXFORD, 325, SUMTER

Wood, Geo. W'. (b'63)-Ala.4,'05; (I'05).

OZONA. 75, PINELLAS

Whitford. Henry E.

PALATKA, 3,779, PUTNAM

Chandler, J. Cohen (b', 6 - -Ga.11,10; (1'10) Crill. Edw. S. (b'43)-0.2,'65; not in (yrus, Wu. H.-1a.1,59; (1'84); not in Frloyl, Ilayden (9. (col.) (b'80)-N.C.3,'12;

Ianpton, W. II. (col.) (b'70)-Tenn.13,05; (1.212).

Jenklns. Frederle Elmer-N.Y.10,85; (1'13); OALR $\star$

folmson, Ilerhert A. (1,79) E-Cia.9,02.

Miller, Wesley S-E-Gia.9,08; (1'08).

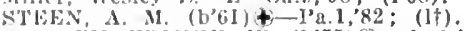

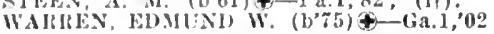

(I'(1)) : Sec. Iteg. Roard of Med. Examlners.

Welch, Geo, H. (b'59)-Ky.I.84; (1'90)

White, Wm. T. (col.) (b'80)-N.C.3,09; (1'09).

PALM BEACH, 400, PALM BEACH

Hlond, 11. C.

(see West Iralm Beach.)

Lenan, Owen II. (b'74)-Ild.3,95; (l'09).

PALMETTO, 773, MANATEE

L'row: J. $0 . \longrightarrow$ : (1†).

English, Alvin Quincy (b'81)-Ga.11,12; (I'liz).

Harrison, MacMlllar (b'86)-Ja.1,1L; (I'11). TONES, I). I. (b'54)—-Tenn.8,92; $\left(1^{\prime} 94\right)$ Nanney, Wm. Noble (b'53)-Ind.2; 78 ;

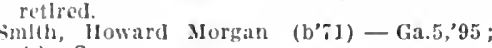
( ) ; s.

(rome Fredk. Finch-Mass.7,98; not in

Viughin, Bedford E.-Ky.2,'94; (1'l1).

PANAMA CITY, 422, BAY

(allender, James M. (b'48)-N.Y.6,'T4.

Fryer, Jesse (b's0)-Tenn.8,11; (†)

Hill, Amon S. (b'61)_Cia.5,91: (1'92).

JONES, JAMES CAlERS (b'81) \&-Ga.11, 'il; (l'11)

1.EE, WM. JOS. (b'7I)-KEy.1,93; (1†).

PARISH, 100, MANATEE

Wavidson, E. W.-Ky.1,99; (1'06).

Spooner, Doster S. (b's1)-Ga.12,03; (1'09)

PAXTON, 100, WALTON

III,L.ER, IRICHARD L. (b'53)-Ga.9,95 (l'11); Member $\Lambda$ la. State Med. Assi.

l'erkins, Ilerman (b'i5)-Mo.28,05; (1'05).

PENSACOLA, 22,982, ESCAMBIA

Abbott, M. S. G. (col.) (b'55) -N.C.3,'86 $(190) ; 601$ W. Chase St.; offlee, $i, N$ T'arragona $\mathrm{st}$

ANI)RESS, War. 1.EE (b'83)-Tenn. 8,08 (1'10); i08 N. Spring St.; office, Brent Bldg.; $9-3$

Rarnes, Wyatt. (b'S1)-Ala.2,'04; not in practice; C.S. Quarantine Station; 9-12, $1-4$.

Barney, Lee Jason (b'66)-III.6,'89; (l'10); office, thiesen Bldt.

Benn, Waller J. (b'63) - NIich.9,03; not In i) ractice.

HICKEMS'AFF, JAMES II. - Md.3,97 (1'04); 904 E. Gadsden; office, Blount Bldg. ; 9-1, 3-7; G».

Bitz, Jawrence Ben, Jr. (b's0)-1lo.34,'10 (l'13); 708 N. 9th St. ; 10-12, 2-4.

BIOCKER, LOUIS de MHLLY $\left(b^{\prime} 67\right) \uparrow$ ofice, Brent BIdg.; $9-10,12-1,3-5$.

DOLST, HENIIY (b'63)-IIl.11,'94; (1'12)

819 X. Darls St.; Nember Med. Soc. of the State of Ala.; offlee, $204 \frac{1}{2}$ S. Palafox St. ; $10-12,2-5 ; \mathrm{Pd}$

BHINK, FRITZ ALBERT (b'78) $\uparrow$-Mich.1, '06; State Board of Health Laboratory

1101 De Soto St.; $9-12,2-5 ;$ LD $\star$ *

$815 \times$ Rarcelona; office, Thiesen

Bryans, Herbert Lee (b'86)-Ga.11,'I1; (†)

BISANS, ROBT. LEE (b'64( 4 -Ga.5, 92 (1.92); $928 \mathrm{E}$. Gadsden St.; omce, $108 \mathrm{E}$. Wright st. ; 9-11, 3-5.

Crivey, J. Z. (b'4S) $\rightarrow$; $(1 \dagger)$; Spring and Gregrory Sts.

P'ALEMBEITE, CLINTON W. (b'79)-La.1 03: (1'03) ; 419 W. De Soto St.; office. 1191,2 . Palafox St.

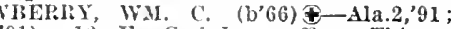
$\left(l^{\prime} 91\right)$

Diaz, Emelio-0; (1†); 405 S. Palafox St.

Fellows, James lluk (boi)-Tenn

(I'12); 400 N. Palafox St.; office, Brent Bldg. ; 9-11, 3-5; Pd.

Hannah, I'. E. (b'63)-Ga.10,'86; (1 ( $\left.^{\dagger}\right) ; 206$
IIargls, John Wulting (b'69)-Ky.1,'93 (1†); 611 N. Barcelona st.; offee, Amerlcan Natlonal Bank 13ldg.; $\mathbf{9 - 1 1}, 3: 30-5$. IJerron, James S.-Pa.1, 61 ; $\left(l_{\dagger}\right)$

IIXON, FIAANK Y'PTY' (b'74)-Tenn.5,'98; (l'06); 47 \&. Grogory St.

IIUTCIINSON, CLAHENCE E.๑-La.1,05 (l'05) ; 209 W. Do Soto St.; offce, Brent KENNEDY, STEPHEN R. MALTORY (b'78) Lat 1,03; ( $\left.\mathrm{l}^{\prime} 03\right)$; $\mathbf{k}$. I'ensacola; offce,

KILI'ATIRICK, GEO. CARLETON (b'83)Ð La.l,08; (l'08); Brent Bldg.

I0; (I'10); $815 \mathrm{~N}$. Spring; ome, Brent Bldg.; $9-1,3-5 ;$ OALR. $\star$

Magee, Astus S. (col.) (b'78) - Ky.7,'10 $\left(l^{\prime} 10\right) ; 208$ N. Reus St.; offce, 315 W. Wright st.: $8-9: 30,2-3: 30,7-9: 30$

MANELLY, R. S.-Md.9,04; (it).

Manra, Frank R. (l'76)-La.1,98; (l'03) : 202 W. Gndsden St.; once, 424 W. Jack-

MCMIILLAN, DANL. W. (b'78)--La.l,'93 ; (l'95); Old Mill Inn; offlce, Blount Bidg. M1lls, wh. Austin (b'56) - vt.2,'81; (I'90); 220 N. I'alafox St; $8-11,3-6$.

NOBLES, VELPEAU ROJ'T (b'82)-Ga.11, 13lount Blag.; $8: 30-12: 30,3: 30-5: 30$.

NOBLES, WM.' D.-Ga.11,07; (1'07); 392 N. 9th Are.; offlce, Brent Bldg.

I'hllllps, L. C. $-\mathrm{H}-\mathrm{III} .15$; (1†); $1122 \mathrm{E}$ Gadsden; offce, Blount Bldg.

I'ickens, John Jee (col.) (b'85)-Tenn.7,'11; (l'11); $144^{\circ} \mathrm{N}$. Hayne St.

PIEICE, J/YSTON II. D. (b'61)-0.3,88; (1'09); 19 E. Gregory; offce, Blount

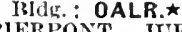

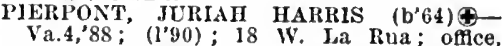
Amerlcan National Bank Bldg.; $9-11,3-6$ POLLOCK, WM. A. J. (b'70) -Ga.5, 94 (1'94); 516 N. Palafox St.; offee, $1191 / 2$ S. Palafox St.; 9-11, 3-5; G.

QUINA, MARION ERNEST $\oplus$ - La.1,05 ; (P05); Brent BIdg.

ENSHAW, FRANK G. (b'56)-La.1,79; (1'80) ; Palafox and Gonzalez Sts.; office, 104 S. Palafox St.; 9-12, 4-6.

IMPSON, HORACE LEE (b'63)-N.Y.1,'86 $\left(1^{\prime} 90\right) ; 20$ W. BeImont St.; offee, $119 \mathrm{~S}$ I'alafox $\mathrm{St}$.

Smith, Chas. V. (col). (b'69)-Tenn.7,94; Stith, Saml. (b'70)-Ky.1,94; (1'01); 1108 E. De Soto St.

Stokes, Thos. H. (b'89)-Ga.11,'12; (1'12) THOA E. Gout; office, Masonie Temple. Man.1,05; (I'06); 319 W. Gadsden St. ; ofice, American Natl. Bank Bldg.; 10-12, $2-4$

Tippins, James R.-Ill.22,12; (1'13); 119 Gadsden St., w.

Williams, H. G. (col.)—Tenn.7,'94; (1'94); 512 N. Deriller St.

PERRINE, 100, DADE

FREEMAN, MARI (b'68)-S.C.1,'12; (I'12).

PERRY, 1,012, TAYLOR

(b'82)-Ga.L2,'ll; (1'i1).

Culpepper, C. F.-E-Ga.9,'92; (l'95).

IIcliae, Alex. B. (b'59)-Ga.5,'88; (1'01).

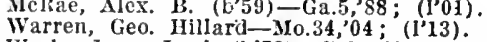

Weeks, James Louis (b'78)-S.C.1,'07; (1'08).

PICNIC, 15, HILLSBORO

Mays, James B.-S.C.1,58; (I†).

PIERCE, 150, POLK

LOTT', YOUNG CLEVELAND (b'88) §-Ky.2, '12; (1'12).

PIERSON, 250, VOLUSIA

KERR, GEO. (b'4l)థ-Pa.1,'64; (1'96) ; Member Mled. Soc. of Va.; (also Lavallette, N.J.).

PINE BARREN, 300, ESCAMBIA

Holley, John C. (b'89)-Ala.2,'12; (1'12).

PINEM OUNT, 295, SUWANEE

Blanton, Ira L. (b'86)-Ga.9,'10; (l'10).

IfcClellan, Geo. Sterling (b'90)-Ga.9,12 ; (声).

PINETTA, 200, MADISON

KINSEY, JUNIUS P. (b'72) - Mo. 7,01 ; (I'01). 
PLANT CITY, 2,48I, HILLSBORO

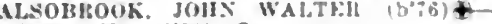

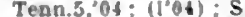

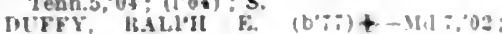

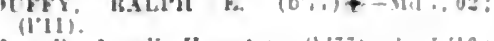

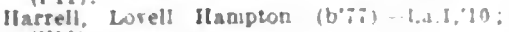

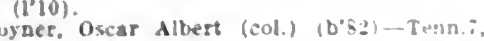
"09: $(1 \times 10)$

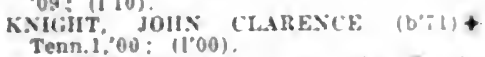
MAGUIRF, TIIOMAS CLIIR (b'a) + Ky: "0s: $(1108)$.

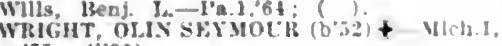

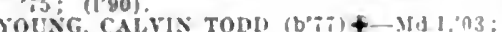
(1'04).

POMONA, 301, PUTNAM

I'eck, S. E. - H-O.I3, "i; $(1+)$

PONCE DE LEON, 200, HOLMES

Bertrem, J. Willle (b'ii)-lia.1s,'ll: (l'1l)

Lowry, C F.-Ga.9,'10.

PRINCETON, $\rightarrow$ DADE

O'BANNOX, AI.BLRT (b":t) M0.10.'11 (): Memier Mlo. Sitate Med. Aisn.; G.

PT. INGLIS, 50, LEVY

Burland, Benj. W.-que.1, 8:; (I'04)

PT. ORANGE, 200, VOLUSIA

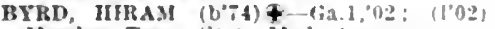

Nember Tenn. State Med. Assu.

I) UROIS, IRIRY K. (b')-XY In, i0 (1'83).

love. Wim. F. (b'70)-Ga.j, bu

PT. ST. JOE, - CALHOUN

Slutts, Baldwin S. (b'SS)-.lla.2,"09; (1"10),

PT. TAMPA CITY, I,3\$3. HILLSBORO

Altree, Roland F.-Ala.2.99; (1t).

PUNTA GORDA, 1,012, DE SOTO

Burland, Wm. H. (b'5t)-Que.1.75; (1090)

MCQLEEX, DAVID NORMAX (b'G9)-Ga.l, 02.

Stone, Geo. S. (b'6s)-Md.1, $90 ;\left(1^{\circ} 11\right)$

WHIDDEN, EUGKSF K.t-Ca.9,10; 11101

QUINCY, 3,204, GADSDEN

DAVIS. JULIUS CAESAR, JR. (b'Bn̈) +

Ca.12,09: (l'09): S.
GODARD, ROHT. FAIN (b';6)-6; 1,00 (1'01): $\mathrm{s}$.

MACK, CLIDF, C (b'81)-Md. "Of: (l'04)

scott, J. W.-III.6," $6 ;\left(1^{4}\right):$ not in iractice.

Sterens, W. S. (col.) $\rightarrow$; $\left(i^{t}\right)$.

RAIFORD, I50, BRADFORD

Farnell, WIlber W.-Ga.1,11; (

RIVER JUNCTION, 800, GADSDEN

CODARD, WM. BURSAM (b"sl) 06 : (1.08).

MCFUEN, UIARIY BERNARD (b'sij) + K5.2,09: (1'11): also Mernber $K y$, inde Med. Asisn.

RIVERVIEW, 60. HILLSBORO

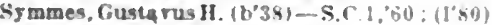

ROCK BLUFF, 80, LIBERTY

Jackson, Theophlius H. (b'3b)-C.a 6.6 (絜).

ROCKLEDGE, 100, BREVARD

Scoteld, John Oscar th'39, N. I.IO,'68: (Ii): (diso Cocoa).

RODMAN. - PUTNAM

Rosbotough. Wrn. F.CGa.1.99: (1'13)

RUSKIN, 50, HILLSBORO

Cumpman, Minerra B.-H-III.15,93: (1'11)

SAFETY HARBOR, 60, PINELLAS

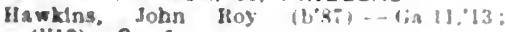
(1'13): $\mathrm{s}$.

SAN ANTONIO, 131, PASCO

Bradshaw, Johr Thomas $10 \% 01-\$ 10,36.04$ (1'11).

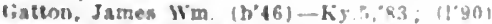

SANFORD, 3.570. SEMINOLE

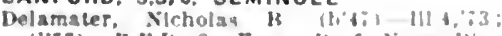

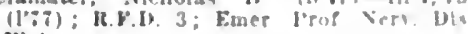
IIL. 4.

llowand, Norman de lege th'd: Io z: il $11.90)$.

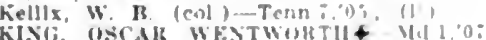

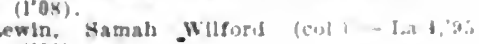
(1'08).
Mllitsl, oLIV

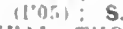

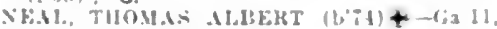
03 : (1,04)

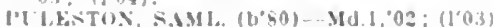

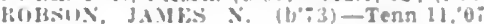
l.

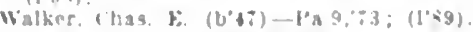

SAN MATEO. IIO. PUTNAM

Cocbrane, Joha Folnyn.

Neer Valatle Niri

SANTA ROSA. - WALTON

Neel, kilth KImball-Mich $\|, " \theta)$

Dractice.

SARASOTA, 840, MANATEE

HI'RTUS, ISCAR A

(See Albert Lea. MInn.)

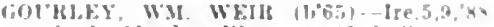

reflete: Memtrer III siate Med. Sinc

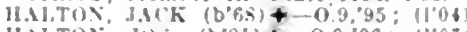

II.ILTON, J1IS. (b.81)+-0.9.06: $\left(10^{\circ}\right)$

IIOVEIS, WY. E. $\left(b^{\circ} 5 i\right)+0.1 .88:(1)$

Schultz, $y$ Wm. $(6,0)-W / 3,203 ;(105)$

Wilson, Cullen Brgant-Nla.2,06: (I'OA).

SEBASTIAN, 220, ST. LUCIE

KOSE. I).AVID (b'54)- (1'08).

SEFFNER, 295, HILLSBORO

Snarely, W. II.-O.d, SI; If'igh); nut in

gactice.

SHARPES, 25, BREVARD

Holmes, Geo, W. (b 44) E- $0.2,6 x^{*}:\left(1^{+}\right)$

SNEADS, 506. JACKSON

Foteman, W. B. $\rightarrow$ : $(1+)$.

Hudgens, Thomas Hamlin (b'35)-Ala.2,10 (l'il)

WILSOS, PERCY B. (b'7I)-Ala.2.95:

SOPCHOPPY, 192, WAKULLA

Kendall, Whllam S. (b'59)-Ga.1.85; (0)

SORRENTO, 220, LAKE

Callahan, Osmer L. (b'68)-[11.5.'11; (1'13)

SOUTH JACKSONVILLE, I, $1+7$, DUVAL

Bruson, Mary E. -l'a.i, fij: (1'05).

McYamar, Wm. Donaldson (b'69) - Pa.12 '92; (1'99).

Tomplins, Chas. Wllner $\left(6^{\prime} 66\right)-G a 1,90$ : (1.90)

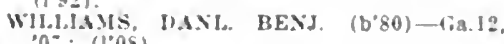
0 : : (I'0s)

SOUTHPORT, 200, BAY

TIIAMKS, JAMKS IIBIMES (b'\&4)-(i\& II $10:(1,10)$

\section{ST. ANDREW, 675. BAY}

Jansenlus, Anton J. II. $\left(b^{\circ} 46\right)-\rightarrow$; $(1 " 0$ i)

Kester, J. I. $\rightarrow$ : (1)

MITCIFl, wM. (i. (b'4t)-Tenn I:? (1'95)

ST, AUGUSTINE, 5.494, ST, JOHN

Brown, Davld Ilamillon (col.) (b'bs)

Tenn. i."98: $(1.99)$

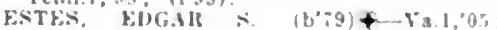

$(195): S$.

Garneth. Reuben 13. (10.3x) - V10 2.: I : not In iriactlce.

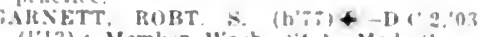
(1'13): Member Wash state Med sioc (irlnin, James Burnle (b'si) III. IIII.1. JUHA A [Cil:st's.

isce Inlury l'ark. N.J.)

dandway, Horace- H- l'a 9, 'si: (1)

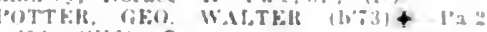
$0: 211^{\circ}(0) ; \mathbf{s}$

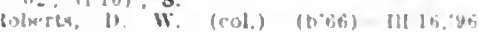

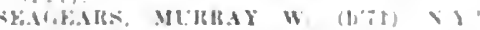
"प.": : 11.48

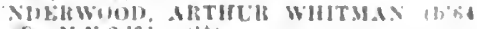
+-1 \% $8,91:$ : (11)

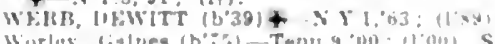

Kurleg, dialned (b a

Whe shre

ST, CATHERINE, 100, SUMTER

Urannon. Uenty (․ (10's?) h!

ST. CLOUD, 1,800, OSCEOLA

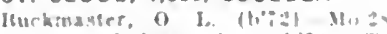

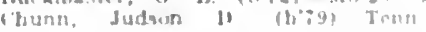

(1) (1)

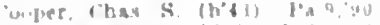

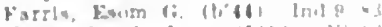

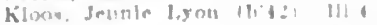

Nectaricy, Jitin 1:

Mentin

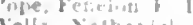

ST. LEO, - PASCO

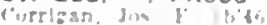

ST. PETERSBURG, $\$ 127$. PIAELLAS

ILVUKI), MI MTIS WHITL:

live liattlo (reak, Miol

Arllue, Moretong II $(1,0)-41): 00$

Barnes, Jusldidat

practice.

Chapnan, Wm Theoptsllus (col.) (t):-

chllda. Jullus $A$ (b'sa)-S r. 1 , 45 not in frartice

Cove, lollng Waison $(6 \cdot 6)$ - lif 1.81 ; nut in Dractice

Grenulaw, I Myler (lipin) Ky tol

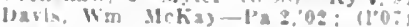

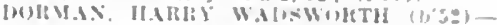

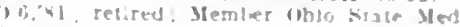
ASse.

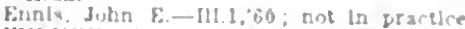

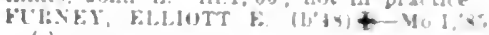

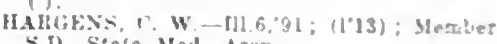
5.I). State Med Assi.

IIIrks, llobt A. ib 69)-H-II 4,92, Tena 6,

Ilulbert, (harles D. (b'70)-[1].1.02: (1\%03) Hume, J. Thompson (b'35)-Mis, s: $\left.(1)^{\circ} 09\right)$ Knowlton, Kosene Homer - Mass. 1, of : (1'13).

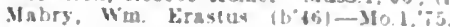

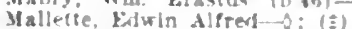

Jclver, saml. Clitord (col) (b;s)-Tenn. $99 ; "(199)$.

MInick, Wm. A. (b"54)H-Ky.1.81: retlred

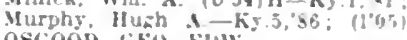

os(ioni). lika kiluw

(Siee Went somerrille. Mass

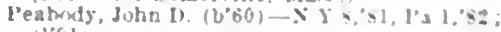
|l"G)

House, Wm. Otha (b'bk)—O J.25; \|loy).

layce, chas. rliptont

isee Ithilidelphia

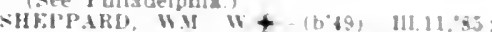
( ) Member III. State Med. Sino

Welch, Harry ( $\left(h^{\prime} h 4\right)-k y=91:$ (

Wllcox, Pranklln W: $\left.\left(0^{\prime}, 4\right)-M d: 03:(1)^{\circ} 5\right)$

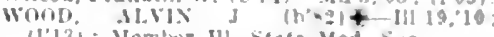

(I'I3): Memlwer III state Med. Suc.

STARKE, 1,135, BRADFORD

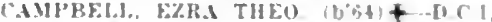
०8. : (1'0:): G.

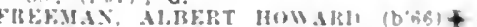
K) I, (O) : (I'OI): OALR.

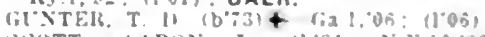

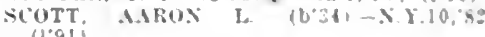
$(1.91)$

WIlls, Jolan Calvin (to"

STUART, 300, PALM BEACH

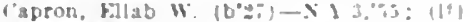

SUMMER. 36, LEVY

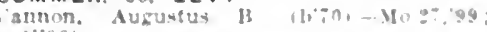
(I) 99$)$

SUTHERLAND, 100, PINELLAS

T.OLAN, I F. TEHI :

TAFT, 300, ORANGE

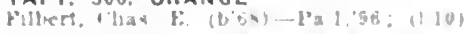

TALLAHASSEE, 5.018. LEON

Alsl.E. IIISS OS big Nit

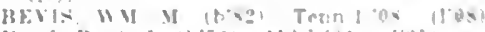

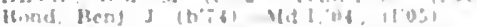

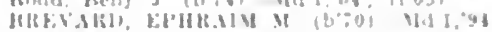

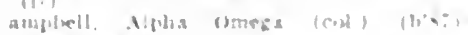

$\operatorname{Man} 6,1 \%$. 1101

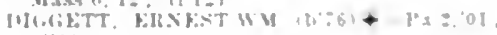
(110) 1100

(IIf)

III) \Y: 1, to, II

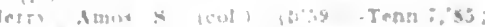

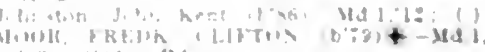

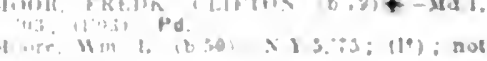

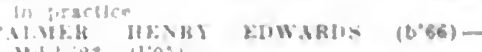
IIII $1,4: 11^{\circ} 0$ \%

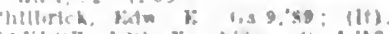

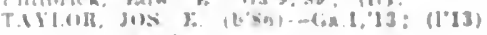
wos in wereltre 
TAMPA, 37,782, HILLSBORO

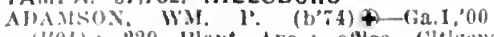
(I'01): 229 l'ant Are.; oftice, clthens lank lilde. : 10-12, 2-3:30; $\mathrm{S}$.

Altree, (iet). II. (b, 63 - IId.4,92.

11031 ta Frinklin st.

Andersou, II. Jickson (col.) - Tenn. T:97 (I)

AXllRliss, (HAbBOLKNE A. (h'84) IId.3.'09: (I'12): 41016 Franklin st. 11-12, 2-4

Avellanal, José R. (b'69)-Cuba 1,97 (1'04): 2001 Nebrasta Are; etllee, 14th st. and Fith Are.: $2-3,7-8$.

Bildwin, loolt. Edgar (b'86)-ky.2,09 (I'1:3); 200 Ilsde l'ark Ave, ontee, Mrucn-

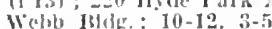

Barnes, John A.-Ga.1,91; (1'03).

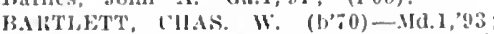
(1'94); fris. sth Ave; uftlee, 1414, ith

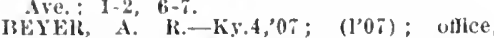
Citlzens IBank \& Trust Bldg.

MICKNELA, (iEO. FRANCIS (b'S2)-J11 $07 ;(108)$; Nember Ind. State Med

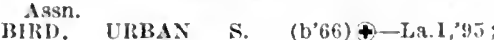
(1'95) : 702 Lafayette st. ; oflce, Cltizens lank illde; ; $\$: 30-12,2-5$; OALP.

BITZER, FAORY WEST (b'S2) $\boldsymbol{f}-\mathrm{VIT}_{\mathrm{A}} 1$ 03; (1'07); 929 s. Oregon Ave.; oflice Citizens Bank Bldg.: $9: 30-12,3: 30-5$. BIZE, IOUIS $A .\left(b^{\prime}+1\right)+-1 \mathrm{~d} .4,95:\left(1^{\prime} 94\right)$ (Gizens Jank 13ldg, 9-1, 2-4; OALR. Jlitke, C. C - Ky.2,07; (1'07); 625, ith Ave.

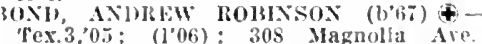
office, 6093,2 Franklin st.; $10: 30-12: 30$ 2-4.

Boykis, JoHx T. (b'69)-Ga.5.? (1'94); Tampa Bay Hotel; oftice, Curry B!dir. ; 10-12, 4-6.

CAMErON FAY A. (b'84)-S.C.1,09: (1'10); 914 Franklin st.; 8-10, 2-4.

CAMIBELL, BAVID A.-Ky.2,93; (1'06).

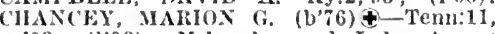
"03: (l'03); Nebraska and Lake Ares. offce, I1031/2 Franklin St.; 10-12, $3-5$

not in practlce. (1'1i) ; 2302 Florida Are.; office, 2707 Florlda Ave.: 9-12, 4-6.

Cunnlngham, claude P. II. (b'82)-D.C.3 07; (I'10); 1518 Grande Central Are.

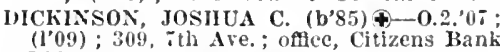
Bldg. $11-12: 30,2-4$

403 Florida Are. EFIRD, IJESTER JULAAN (b'î)-Md.1. 03; (1'05); 100 Lafayete St.; 8-10, -4, $7-9$.

Ely, Reuel Abram (b'82)-Pa.2,'10; (1'12) 909 Cleveland St.; oftee, Florida ant Zack Sts. ; 10-12, 3-5, $6: 30-7: 30$.

FAYER, HENRY II. (b'81)-Ga.12,09; (l'12)

(1004): THOMAS B.

Frago, Manuel-Spa.4,'74; and 16 th St. '85; (1'09) ; 1811, 12th Are.; oflice, 1913, 14 th st. ; $2-3,7-8$.

Glampietro, Aristide W. (b'82)-Md.1,07; (1'12) ; $917,22 \mathrm{~d}$ Are.

GIIIBERT, ELSIE MARIE MARTINSON (b'75)థ - Ill.19, 00 , 111.11, 08 ; (1'08); Jackion and c'entral Ares.; 2-5.

GILMER, BUGENE S. (b'86)-Ga.12.'09: (1'09): 2109, ith Are.

GRANTH.IY, JAMES M. (b'73) - Md.4 '\&; (l'97); 508 Azeele St.: office, $5151 / 2$ Franklin St. ; 10-12, 2-4; Ob.

Haines, Chas. W.-0.7,'s3; (l'05); $416 \mathrm{~W}$. 1.arayette St.

HAMBERLIN, SAML. T. (b'62)-Tenn.5, 8.?; (1'12); 16011/2 ith Are.

IANIBAIN. ALYA C. (b'59)-Tenn.9?'92; $(192) ; 905 \mathrm{~S}$. Orleans Are.; office, $604 \frac{1}{2}$ rranklin St.; $10: 30-12,4-5$.

Hampton. Ham.'S. (b'ss)-Ga.18, 10 ; (1'10); 1805 Florida Ave.; 8-12, $7-8$,

Hampton, Hiram J.-Ga.9, 79 ; (l $)$.
HELMS, JOHN S. (b'61) Tenn. 8.91; $\left(l^{\prime}+4\right)$; 13ay shore IHvel.; offlce, Clitizens (15.: : I:50-5: S.

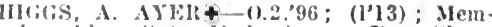
ber ldat state Mcd Assn. Hay shore 1Blvd.: offlee, Cltizens IBank 13ldg.; 9-11, $2-5 ; \mathbf{S}$.

Ilodgson, Gilbert Haven (1,88)-Mo.34,'II

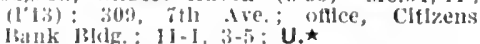
HOLAOWAY, ELLIS WHLO

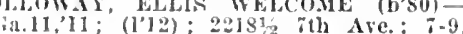
$1-3,5-4,4$

IIOHAS, JOSES R. S. (b'52) —-Ga.5,

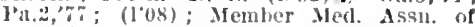
Ga.: Trimpa bay Hotel; offle 100 Lal Favetle Ave. ; 11-1, 2-4; $(\Lambda 1,6)$.

Howsley, Wm. W. (1)62)-Pa.2, 87 ; $\left(1^{\prime} 06\right)$ IIUDSON ARTHLR THOMAS (b'T2) Mo.28,'ys; (1'10); 1411 Florlda Ave; oflce, ritzens Bink Bldg.; 9-12, $2-5$, TES: $U . \star$

JlFFRRSON-Ga.11,02; $(1+)$

l'05) (b'79)-Md.1,03 (105) ; 246 Hyde Park Ave.; offlec, Gild-

Johuson

'Tenn. , 08; (1'09); 415\% I'olk' St. $1-2,6-8$.

LANCAS'TER, WI. JESSE (b'88)-Ga.12, '11: (l'11).

Larner, Leonard G.-Ill.15,95: (1 $)^{4}$.

LASSMANY, GEO. A (b'S1) + NId.3,06: Mll. : fiofid Nadison st.; $9-12$; $\mathbf{S}$.

LAWRENCE, WII. PITT $\left(b^{\prime} 57\right)$-Tenn.1. 78: (1.93); 506 Twiggs St. ; office, (It lzens lank Bldg. ; 10-12, 3-5; Pd. $\star$

IackAE, JOIIN DON.LLD \$-Tenn.I, 97 (1'06); 715 s. Orleans Ave. ; offlec, AmerMIathers, $A$. II. $-0 ;$ : (1 $\dagger$ ).

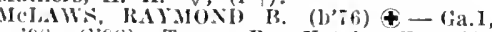
98 ; (1'9s); Tampa Bay Iotel; offce, 609 lranklin st. ; $1: 30-5 ; \mathbf{S}$.

Mills, Jolin Herman (b'71)-Pa.2,'95; not in practice; 2715 Nebraska Ave.

Miralles, Mianuel Sueiras $\left(b^{\prime} 65\right)-S p a .4$, ; 91 ; (102) : 1805, 15th St.; office, 7th

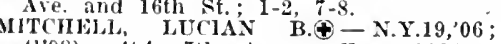
(1'08); 404, Fth Ave.; offce, Giddens Bldg. ; $10-12,2-4$.

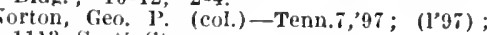
1113 Scott st.

Noto, Cosimo-Ita.12,'98; (1'06).

O'Ponoghue, John (b'63) - Mass.6,'06: (1'I2); 2005 Mitchell St.

Ol'P'ENHEMER, IOUTS S. (b'54)-Ky.4, '75; (1'94); 108 Crescent P'.; offee, Citizens Bank Bldg.; $3-5$.

rezuela y Giroud, Joaquin de la-Cuba,

liloto: J. Hernandez- 0 : (1) : 1510, 5th St. PORRO, Y ADAN, ADELBERTO-Cubal, Richardson.

(1'98); Bayshore C. $\left(b^{\prime} 49\right) \mathrm{H}-$

ROWLETT, WM. M. (b'84)-Ga.11,09; (l'10) ; 82.3 s. Orleans Are.; office, Citizens isank Bldg.; 11-12,3-5.

Sargent, S. Stratford (b'48) E-0.2,70 ; (1'90); $116^{1}, \mathrm{C}^{\prime}$ Franklin St.

SAXTOX, DAVID E. (b'51)†-0.2,83 $\left(1^{\prime} 90\right) ; 105$ W. Palm Ave.; $7-9,1-3$.

S.ATTON, JESSE J.-0.2,07; (1'07); 105 W. Palm st. ; 3-4.

SFEIYE, HHRAM HENRY (b'56)-N.Y.5, '82, N.Y.1,82; (1'02); 332 Hyde Park

Simon, fieo. Herman (b'83)-111.6,09; (13acteriologist); State Board of Health S.IOAK, J. EDW.' (b'82)-S.C.1, 07 ; (l'08); 110 E. Ross Ave. ; offce, $1016 \frac{1}{2}$ Frank: $\lim$ St.; $9-11,3-5 ; 0$ b.

SNOW, HENRY OSCAR (b'76)-Ga.11,00; $(102) ; 209$ s Delaware are.

Statford, Chas. S.-Pa.9,'87; (1

Stebbins, Henry H. (b'4i)-N.Y.10,85;

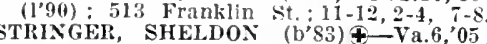
$\left(1^{\prime} 05\right)$; American National Bank Bldg.

Thomas, Arthur J. (col.) (b'66) - Ont.3,

'91, Scot,9,12,14,92; (1'05) : 810 scott St. TRUELSEN, THOMAS, JR. (b'5) †-Neb.5. Assn.; 707 ;. A St.; office, Thibbett Corner.

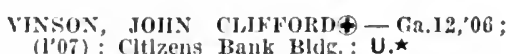

VINTON, MACK RAMSEY (b'74)-Tenn.1, 99; (i†); ('illzens Bank Bldg.

WALLACE, J. BISOWN $\left(b^{\prime} 74\right)+-$ Md.1,97; $\left(1^{\prime} 06\right)$ : 328 11yde Park Are; ontee, $7061 \%$ WEEDON, LESLW W.-N.Y.5,85; (1 $\dagger$ )

Wells, Wm. Erastus (b'i6)-Ky.2,01 (1†); 602 Amella Are.; olltce, $316 \frac{1}{2}$ Frankilin St.; $10-12,5-6$.

West, Eugene $Y$. (col.) (b'69)-Tenn. 7,92 ; (1'95) ; 817 Constant St. Wilkes, John M.-Ky.4,90; ( ) ; Glddens
lBlik.

TARPON SPRINGS, 2,212, PINELLAS

Albaugl, Andrew Phllips $\left(b^{9} 62\right)-0.9,87$;

Belelier, Irving James (b's3)-Tenn.1,09; (1'10).

Douglass, James E. (b'51) - MId.3,73; (1'02).

TAVARES, 175, LAKE

KLEISER, ALBERT HENRY (b'59) $0.13,00$.

TITUSVILLE, 868, BREVARD

IBartes, I. II.-Ga.1,'99; (1'99).

Burks, Bennette Auxford (b'84)-Mla.2, '10; (1'09)

Eulenfeld, Ludxig- $\Delta ;(1 \dagger)$

PEPl'ERS, GUX STEWART\$-NI.4,'ll; (I'12). $\left(l^{\prime} 06\right)$.

Taylor, Fred Morse (b'60)-Mlch.6,'85; $(1 \dagger)$

THOMAS, ABRAHAM FIFIELD (b'88)-Ð III.22,'12; (1'13).

TRENTON, 304, ALACHUA

CLYAT'T, ORIANDO S. (b'66) - Ga.10 ; (1'91).

Weeks, Lester Reginald (b'77)-Ga.11,'08; (l'08).

TRILBY, 289, PASCO

BXRU, HARVEY OTIS (b'85)-Ga.12,08; (1'08); T.

(1'08): T*.

UMATILLA, 283, LAKE

Guerrant, Edw. Putney (b'83) - La.1,'13 ; (1'13). ROBERTS, CHAS. M. (b'82)-Tenn.6,0\% ;

VERNON, 141, WASHINGTON

DAWKINS, N. J. (b'71)-Ky.4,'91; (l'06). Miller, G. C.-Ga.9,'10; (†).

VILAS, 50, LIBERTY

Duke, Roncie Renfro (b'84)-Ala.2,11; (l'11).

WACISSA, 45, JEFFERSON

Lewis, Butler Ormond-X.Y.8,'91; (1)

WALDO, 540, ALACHUA

Boring, Jos. Mr. (b'72)-Ga.11,02; (l'02).

WALNUT HILL (R.F.D., FREEMANVILLE, ALA.), -, ESCAMBIÄ

Watson, Albert A. (b'73)-Ga.11,'13; (l'13).

WARRINGTON, 1,301, ESCAMBIA

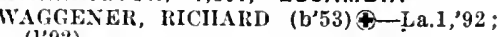
$\left(1^{\prime} 92\right)$.

WAUCHULA, 1,099, DE SOTO

CLINE. HOLDEN E. (b'81)-Ga.12,09;

DAWSON, GEO. W.-Ala.2,'94; (l'04).

Hanna, Finley Young (b'52)-0.8, 80 ;

(1'06). (1'12)

WHIGHT, YOUNG EDW. (b'67)Ð-Ga.1,

$(195)$

WEBSTER, 301, SUMTER

WATSON, WTLLIS HERMAN (b'89) Ga.1,'12; (1'12).

Wood, Stephen C.-Pa.1,87; (1'05).

WELAKA, 294, PUTNAM

Main, Danl. C. $\left(b^{\prime} 76\right)-I 11.4,{ }^{\prime} 02$; (l'09); N.

WELLBORN, 247, SUWANEE

McClellan, P. T. (b'76)-Ga.9,'10; (l'10). PENNINGTON, JAMES ELBERT, $\left(b^{\prime} 76\right) \oplus$ -Ga.11,'01; (1'01). (1'94). 
WESTBAY, 100, BAY

Hues, Geo. W. (b'62)-Ala.2,"?

WEST PALM BEACH, 1,743, PALM BEACH

Broadwell. Wllmer $\left.\left(b^{\prime} 63\right)-0.6\right)^{\prime}$ 'st: (l'9ti), Cooley, Iroy Oscar (b'sib)-Mich. 1,0y: (1'09)

Houd, Henry Cunton-XY.s.s3: (If) : (Paim Basch)

Jeterson, Thomas LeRoy (col.) (b bij)Tenn. '92: (l'0l)

KENYEDY THOYAS S $\left(b^{\circ}, 3\right)-K y=01$ $\left(10^{\circ} 02\right)$.

Yertil Chas Morton-C.5'S1: (1)

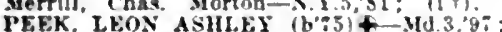
(1'07): $\mathbf{S}$

WESTVILLE, 865, HOLMES

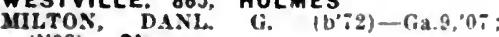
(l'OS): $\mathrm{Ob}$.

Wade, John W. (b's4)-Ga.9.'13: ().

WHITE SPRINGS, I.177, HAMILTON

Harnet, Ross Augustus (b's')-lia.l, 23 ; (t'13).

Cone, Danl. X. (b'75)-Va.1.99: $\left(1^{\prime} 00\right)$.

HOLTON, wH. JOS. (b'st) 4 -Ga.l, 11 (I'II): Nember Med. Issn. of Ga.
WILDWOOD, 329, SUMTER

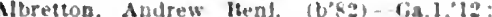
$(1$ (13)

Carter, ("lyde I (b's3)-Cia.11.04: (1'05) WILLISTON, 37I, LEVY

GOOD, JOS. MARTIN (b\%:0)-Tenn.9,98: (1'09): Member W. Va. Sitate Med. Assn.

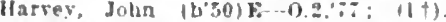

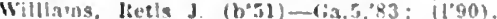
WII.IS, JESSE M. $\left(0^{\prime} 63\right)+k y .92$ (1"42).

WINDEMERE, 100, ORANGE

Stafrurd, Arthur Henry (b'sl)-Mich.ll, vis

WINTER GARDEN, 351, ORANGE

Wasls. James A. (b';6)-6;3.12,06: (1'06). lievane, James borden (b's6)-1i3.12,11: (I'II); G.

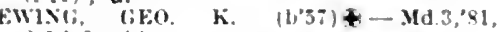
$0.1,90 ;(1)$

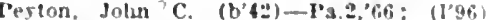

WINTER HAVEN, 375, POLK

Crump, Janes Emmet $\left(b^{\prime} \%\right)$ - Ga.9,06: (1'lo).

Jrona, Frauk Eornest (b'7)-Va.6,05; (1'07). leacock, Is II.-Pa 9 " not in practlee. lioss, John H. (b'ti)-Mt, 2,33; (1'0i).

WEXT, JAMES A. $(1,0,1+1+1,3,03:(1)$.

W'Insion, Cornellus-f; aot in practlee.

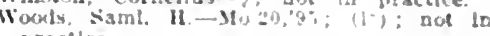
practlee.

WINTER PARK, 570, ORANGE

COFHI, CHAS. Y. (b'BS) - Neb 5,89: (1'(2).

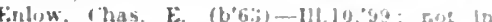
practloe.

Lltch, John Goodrleb (b'58)-X H 1,94 : no? In practice.

Trorllion, J. A. (b'63)-Tenn.6.'40; (l'0s) YOUNGSTOWN, 20, BAY

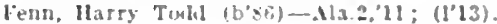
ZEPHYRHILLS, - PASCO

Kice, Wilbur 1․ (1.80)-Ni(.1,05; 1108). 20LFO, 171, DE SOTO

Frow, James [t.chard (b'\$3)-M11.:, 08 ; not In J ractice.

FOR KEY TO SPECIALTIES, ABBREVIATIONS, SYMBOLS, ETC., SEE PAGE 324

Physicians intending to take post-graduate work will fimi a list of representative schools given in the Ihysiciuns I'urchasing Imier. siee palle 1.2. 


\section{GEOR G I A}

NoTE:- The nenerat information of this state fucludes: Nedical law, lBoard of Heallh, Examining lBoard, State Assoclation, State Journal, county Oflcers, Cliy Health offlers, State Instifutions, liospitals, Sanatoriums and tharitable Instltutions.

\section{GEORGIA}

Population ( 1910 census)

$2,609,121$

148

Number of Physicians.

3,255

Members State Association, Dec. 31 1913

Area of State in Square Miles

\section{MEDICAL PRACTICE LAW OF GEORGIA}

\section{An Act}

To Abolish the Present State Board of Nedlcal Examiners and to Fistablish a Composite Board of Nedfical Examiners for the State of Georgia. To define its duties and powers; to protect the people from fllegal ind unqualified practitioners of medieine and surgery; to define the standing of a medical college; to regulate the issuing and recording of lieenses; to define what is consldered the practice of medicine; to fix fee for license; to provide for the revocation of license; to require a standard of preliminary edncation of applicants; to prescribe the penalties for the violation of this Act and for other purposes.

Secilon 1. ItEPEAL OF OLD LAW : Be It enaeted by the General Assembly of the State of Gecrgia, That from and after the passage of this Aet Sectlons 1687, 1688 1696 , 1697, of Volume 1 of Code of 1910 , creating a Board of Medical Examiners and deflning their powers and duties, be and the same are hereby repealed in their entirety. Sec. 2. BOARD; QUAIIFICATIONS: Be it further enacted that a board is hereby established to be known by the name and style of the State Board of Medical ExamIners; sald board shall be composed of ten practicing physielans of integrity and abllIty, who shall be resldents of and have been duly lieensed to practlce medleine in
thls state, and who shall have graduated from reputable medical schools and have been engaged in the active practice of their profession within this state for at least a period of five years, but none of them shall be connected in ans way wlth any medical college; said board shall perform such duties and possess and exercise such powers relative to the protection of the publie heatth and the control and regulation of the practlce of medicine in the state as shall be in this Act prescribed and conferred upon it.

Sec. 3. BOARD; HOW CONSTITUTED : shall within thirty of this Act appoint ten physicians, who shall possess the qualifications spectied in Section 1 of this Act, to constitute the members of this board. Five members of this board shall be regular physicians, three shall be eclectlc physicians and two shail be bomeopathic physicians, all to be appointed by the Governor.

The successor of each member sliall be an appointee in the same inanner.

Said members shall be so classified by the Governor that the term of office of two shall expire in one. three in two, two in three and hree in four years from the date of iImointment. Annually thereafter the govermor shall appoint two members, each of whom shall serve for a term of four years, ind these appointments shall be made so as eclectics and the original ratio of regulars, gorernor shall have power to remore from office members of the board for neglect of duty required by this Act, for incompetency or for unprofessional conduct. Any vacancy that may oecur in sajd board in eonsequence of death, resignation, removal from the state or from other ciluse shall be fllled for the unexpired term by the iovernor in the same manner. A majority of the board shall constitute a quorum.

Sec. 4. MEMBEI; OATII OF OFFICE: We it further enacted, That Immediately and hefore entering upon the duties of sald offee, the members of said board shall take the constitutional oath of offlce und shall fle the same in the offlce of the forernor of the state, who, upon recelving the said oath
of offlee, shall issue to each member a cerof ofice, shall issue to
tiffate of ajpointment.

Sec. 5. ORGANIZATION; MEETINGS : Be it further enacted. That immertiately after the appointment and qualification of sald nembers, said board shall meet president, a vice-president and a seeretarypresident, a vice-president and a seeretarytreasurer from its nembership whose sala-
ries shall be fixed and pald by the board. 111 expenses of the board shall be paid out of funds collected by the board, the remalnder to be divided equally among the members of the board. Said board shall hold two regular meetings in each year, one meeting shall be held in May or June, at such time as suits the convenlenee of graduates of medical colleges in Atlanta and uates of medical colleges in Atlanta and on the second Tuesday in octoher in the on the second Tuesday in october in the at the discretion of the president. The regular meetings shall be held at the capitol building in Atlanta and in Augusta. Said board shall adopt a seal, which must be aftixed to all licenses issued by it. The board shall from time to time adopt such rules and regulations as it may deem necessary for the performance of its dntles, and shall examine and pass upon the qualifications of applicants for the praetlce of meditions of applicants for the practlce of m
cine in this state as herein preseribed.

Sec. 6. APPLICATIONS FOR LICENSE $B e$ it further enacted, That any person wishing to obtain the right to practice medleine in this state who has not heretofore been registered or licensed so to do, shall, hefore. it shall be lawful for him to practice medteine in this state, make application to the board through the secretary-treasurer the board through the secretary-treasurer
thereof, npon such form and in such manner as shall be adopted and prescribed by the board, and obtain from the board a license so to do. Unless such person shall have obtained a license as aforesaid, it shall be unlawful for him to practice in this state, and if he shall practice medieine in this state without first having obtained sueh a license, he shall be deemed to have riolated the provisions of this Act. All applicants for a license to practice medicine or for a renewal of any such license which has been revoked shall furnish the board with evidence of good moral character. Applications from candidates to practice medicine or surgery in any of its branches shall be accompanied with proof that the applieant is a graduate of a legally ineorporated medical college or institution in good standing with the board. The board shall have the power to revoke the certificate cranted to any applicant who makes any misstatement of any material fact in his application for examination. Each applicant shall name in his application the system of practice he proposes to follow. And no person shall use the name of any system unless he holds a certificate from the board.

Sec. $i$ RECORDING LICENSE: Be it further enaeted, That before any person who obtains a certificate from said board may lawfully practice medicine and surgery in this state, he shall cause the said certificate to be recorded in the office of the clerk of the superior court of the county in which by the pose. It shall be indexed in the name of the person to whom the certificate is granted. The clerk's fee for reeording the certifleate The clerk's fee for reeording the certlfleate
sliall be the same as for reeording a deed. shall be the same as for recording a deed. The elerk shall make a report to the secre-
tary of the board on the 31 st day of December of each year of all certlficates regls. tered with him. Each applicant receiving a certificate from the board shall cause the same to be registered within thirty days.

Sec. 8. ACCREDITED COLLEGES: Be it further enacted, That said board shall be empowered by this Act to pass upon the good standing and reputabllity of any will be considered in good standing colleges sess a full and complete faculty for the teaching of medicine, surgery and obstetries in all their branches; afford thelr students adequate clinical and hospital facilities; require attendance upon at least 80 per cent. of each course of instruction; give per cent. of each course of instruction; glve aggregate of which amounts to at least 120 weeks, exclusive of holldays, of at least forty hours each week; that require at least forty-two months to have elapsed between the beginning of the students first course of medicine lectures and the date of his twenty-nine weeks of actual instruction with at least 40 per cent. of laboratory instruction in the first and second years and a minimum of 35 per cent. of clinical work in the third and fourth years; that require an average grade in each course of instruction average grade in each course of instruction a condition of graduation; that fulfill all their published promises, requirements and other claims respecting adrantages to their students and the course of Instruction; that enact a preliminary educational requirement require students to furnish testimonials of good moral standing, and that give advanced standing only on cards from accredited standing only on cards from accredited
medical colleges. Students must have attended at least 80 per cent. of the course in the last year of the college from which diploma is presented. In determining the reputability of the medical college, the right to investigate and make a personal inspection of the same is hereby authorized.

Sec. 9. PRELIMINARY EDUCATIONAI REQUIREMENT : Be it further enacted, That beginning with the session of 1913-14 each medical school or college in good standing with the board shall have a minimum preliminary educational requirement of fourteen Carnegie units. Evidence of such preliminary education shall be a certiflcate furnished by the professor of secondary education in the State University on the basis of the rating of the high schools in this state or on the basis of an examination state or on the basis of an examination
conducted by him or by some person designated by him. A fee of two dollars shall accompany each application for a certiflcate and a like amount shall be paid by the applicant for each separate subject upon which he may be required to be examined.

Sec. 10. TEMPORARY IICENSE : Be it further enacted, That in the discretion of he secretary-treasurer of sald board with the approval of the president, he may issue temporary license to an applicant which shall have the same force and effect of a permanent license until the next regular meeting of the board when sald license shall become vold. Sald license shall not be recorded. 
Sec 11 WETHOHS ANI SLIJECTS OH EXA.IISATION: lie li further enactol That exaraination of apglicante for license to practice mediclue shall he triale lyy ald mard according io the methide deremed by it to be the most practical and experlatus to lest the appllcants qual. acativens. The in uriting bisch ajpllenut shall lie desig nated by a number lnstead of hls name, that hls lidentity shall not be dlsclesed : the nuempers of the board until after the examination papers are eraded. Exumina slon shall be on the following subjects: Anatomy. physlolugs, cliemlstsy, hyitene. surgery, obstetries. eynecologs, patholizy and deamnsts.

Sec. 1:. FEEs: IBCHIUnITL: Be It further enacted. That there sliall be pald to the aecretary-treasures of sald hiard by each apslleant fur license by examination a fee of iwents lollars which shall aceonpany the applacatin. The same fee that whlch includes fee for examination fir Dermanent license; and a fee of thfy thollary permanent licease ; and a fee of tify tollars reclproclty. The Board of Fixaminers ntay reclpraclty. Jlcense wlthout examinaticn io licentlates of bonms from other states te juirlng equal or hipher gualtfeatlons, unon the same basis as such states reciprucate with the state of fieorgia. No part nf any fee la returnable uniler any clreumstances. not shall this Act be consirued as affecting or changlut in any way laws in reference to Ilcense tax to the pald by mbslclans and sumeons.

SEC. 13. POWERS OF BOARD: PROSE. CUTIOXs: Be lt further enacted. That sald board shall bave authorlty to suministe oaths, to yurnmon withesses and take testimony in all mattery relaticg to lis duties. sald board shall Issue lleense to practlce medicine in all persons who shall furnish satisfactory eridence of stialaments, and satisfactory eridence of strainments, snd ict, and the rules and regulations under the prorlstons of this $\mathrm{Act}$, snd the rules and reculations of the board. Such llcense shall be slgned by the presldent and attested by the secretars-treasurer of the lward under Its adopted seal, and it shall gire absolute authorlty to the person 10 whoul if is Issuev in practice mediclue in this state. It shall be the duty of the secretsis-ireasurer under the direcuson of the board personally or he deputy to ald the solicitory of the state in the enforcement cf thls Act, and la the prosecution of all peraons clarged wlth rio. prosecution of all pera

Sec It. REFI'SAL, TO GMANT LICENSt; HEVOCATIONS: Be it purther enacted. That sals Giard rany refuve to grant a license to practlce medicine in this atate, of may calle a licentlate's name to the remored from the records in the unlce of any clerk of court in this siate, on the follow!ng grourds, 20-w!t: The etnplayment cenve or In passing the examination prurided for In this Act, cinsletion of crime Involv. $10 \mathrm{~g}$ moral surplitude ; the practlce of mediclne under a false or assumed name tre the cine under a talse or assumed natne. "Ir the IIke. or diferent name: habltual Intemperace in the une of ardetit spirlte, narcutics or stimulants to such an extent as Incapacliate hlm for the performance of or abeting In turocurlng a criminal slocis.

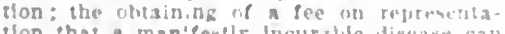
ton that a magifestly lncurable distake can be permanenty rurcel; causing the bublics tlon and circulatlon of an ardrerfimemetrs ot? any mediclne by mears wheroly the mouthly perlods of women ran le tegilatem i the

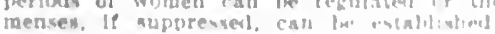

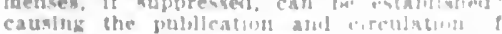

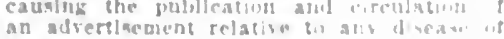
the aexusl organs: sald lmobl may ugrin

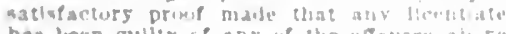
has beea gultiy of ang of the urernary atwre

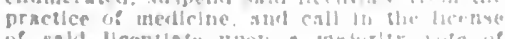

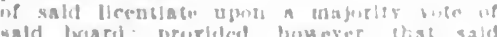

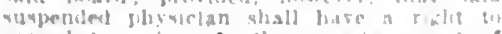
uppeal th a jury on the sugertur court of

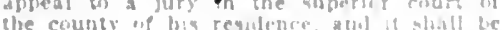

the duts ? sald in ard to juterer .n "rrang

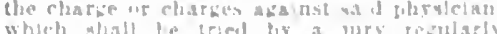
which whall te tried by a jury rezularty

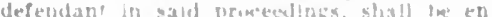

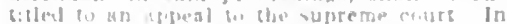

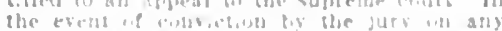

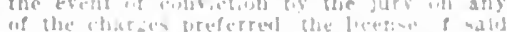

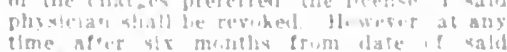

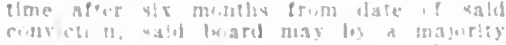

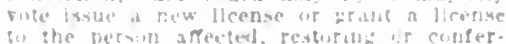

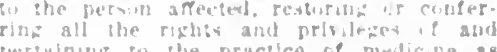
pertaining to the prartice of medicone a

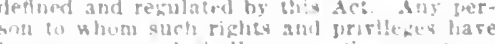
Ixwn sn restured whall pay in the smoresary. treasuser $n$ see if efenty dolliars i.n the issuarice of a new license.

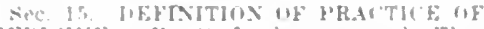
MEllitis: "No is further enacted. That the terms "patact ce of metlelne," "w prace the medicine." "pratticing mellcine" and "practice menticlne," as und in the Act. are out to the public as belng engajest withln thls state ln the diazuesis of treatmean of diseases. defects or lnjuries of human lheIngs, or the vluggesting. recommendation nt intended palliation, relief or cure of alis physleal. mental or funetional aliment of defect of any nerson, wh the intention if receiring therefor elther directly or indl. rectly ans fee, gift or compensation what recty ans fee, Rift or compensation whatthe reception, exam!nation and treatment of any person suffering from disease. defect of injury of hody or mind. or a:tachlug the tlile Mll., trh.l., Inop., Surgeon. Doctor. elther alone or in connectlon with other to h!s name Indleatire that such berson is engaged in the treatment or diarnosit of disease, defects ur injuries of human beings. if any nersin shall hollt himself out to the If any lersin shall holl himselt out to the pub diagnisis ng treatment of disease or injurles of human ledngs. "ir shall supgest recominend of presicribe any form of treat ment for the palliation, relle no cure of any phy ulcal or menta! allment ans verson with the Intention of recelsing therefor either dirertly or Inditec:ly, any lee, fift of compensation whatsoerer or shall mainsan an office fir the receptlun, examination of treatment of discase or injured luman belngs. or shall attach the t!t\}e 11.11 . Uph.D., Dop.. Surgeon, loctor. either alone or In connection wh other worda, or any other word or abbrevlation to hls name indeatre that he is engaged within this state in the treatment of ulseased. defective ne tngured human helnes, and shall not la iny of thene caseq then mossess in full porce and rirtue the law of tha siate he shall ke deemed

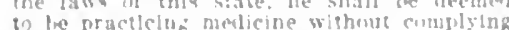
th the macticthe mate ton theres yothln: in this tot shall is construed in firnhibit coratultous surrtre to the rases of emertency nor the prastce "if church whatsoever not tin astengstils bi.

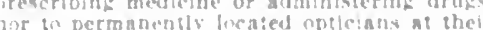
estalil whed places of bulness num preserill.

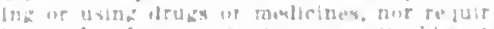

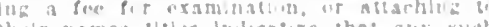

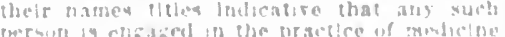

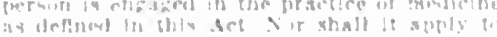

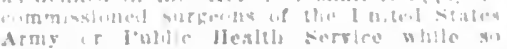

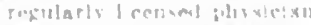

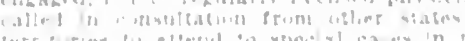

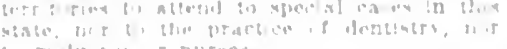

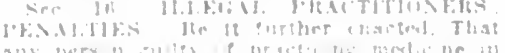

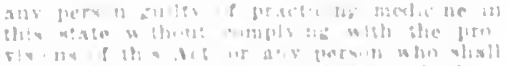

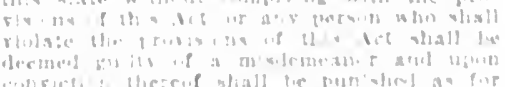

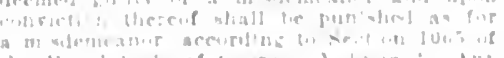

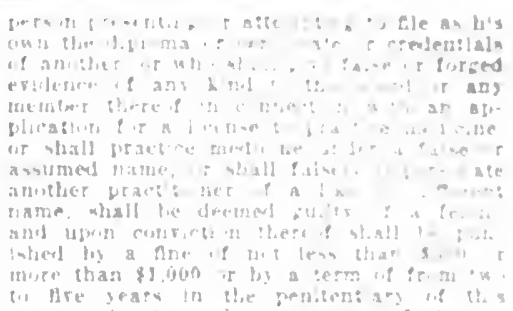

(i) Are yeapy

jon,2 of the lonal (iele of lieirala.

siec. 1\%. Le it turther enaced. Trat sll law and paris of law. n conftect with th abirived lug to 1015

\section{STATE BOARD OF HEALTH}

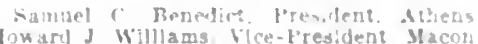
II. II I) wens sarangh Arthar [1, Luitle Thomaspille The J. Mclrtiur cordele Jadt $x$ tilantage

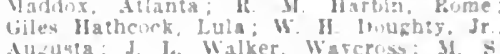
Brown, Fq. Valley; II, F II arels. Sectelary and forectior of Laburatomes. Atlanis.

\section{STATE BOARD OF MEDICAL EXAMINERS}

J. W Palmer, Presldent, Alles; A. Femming. Sce-Presluent, Wascross:

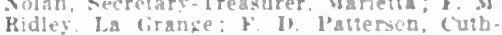
bert: N Ifetersin Thon: $\mathbf{R}$ F. Ifinman.

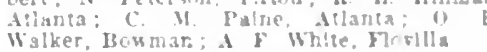

\section{MEDICAL ASSOCIATION OF GEORGIA} uffers 1313-14

Kalston Lattimnre, l'resident...... Sarannah 3 II (hason. Ist V.-Presldent... Bainbridge $\therefore$ I Poberts, ad Vlce-Presldent...Ailania Wm. C. Lyle. Secretary-Treasurer...digust.

\section{Siate Journal}

The Jucurnal of the Medleal Aserciat in if Georgia, Iugusta. W T. Lyle, M.L., kdibt

Councllor Districts and Officers

W. 1. Harman, chatrman, Commerie

Hirst Wistrict - Burke, Jenkins, sereren. Bullork, Finghan. Tatmall. Irryan, (hal. ham, Melntwh and lotherty counse

second l:atrict.-talhoun. Ibisthert Early, Bate? Meichell. Miller. Hecator

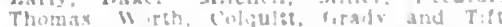

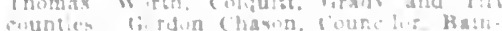
lirtdite

Thled Jotrict-Taslup, Macen. Terrell Scblev Surser labaly l.ee Webser

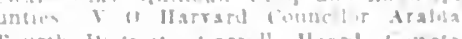

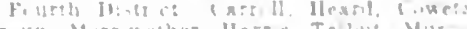

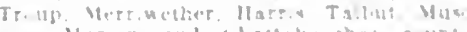

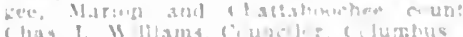

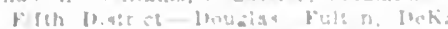

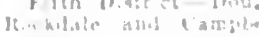

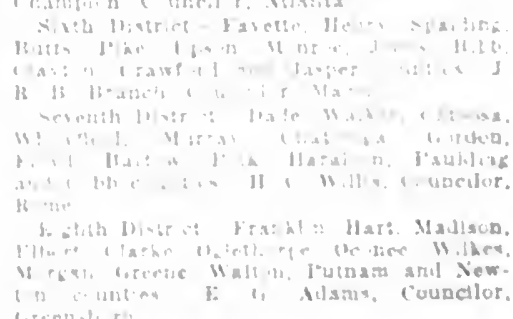


Niuth Jistrlct-Fanuln. I'nIon. Townes, liabun, fillmer, lumpkin, Whlte. llabersham, l'ickens, Jawson, Ilall, IBanks, (heroker, Forsyth. Jackson, Mllon, fwinnett and stephens countles. W. I3. II eflor, conmerce.

Tenth Distrlct.-Taliaferro, McIutflo, Lincoln, Hancock, Warren, Columbla. Washington, Gluseck. Jefferson, Itclumond, Wilklnton, Glinseck. Jefferson, Itichmond, Wilkincomellor, Mllledgulle.

Fleventi Instriet.-Ippling, Jefr lhavis, Ir. win. Cofpe, Wayne, Brooks, Clinch, Fohols, Ware, Charlton, Plerce, Cauden, dilynn, Berren, lowndes, Ben 11 ll and Turner counfles. A. (i. Idttle. Councilor, Valdesta. Twelfth Dlstrlet.-Ibodge, Emanuel, Ilous. ton, Johnson, Laurens, Ifontgomery, I'ulaskl,
Telfair. Toombs. Twiges and Wilcox countles. E. T. Coleman, Comncllor, Graymont.

\section{Component County Societies of the Medical} Association of Georgia

BALDIIN COUNTY

R. C. Swint, I'resldent..........Milledgevllle

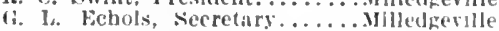
BANKS COUNT:

v. I. Lockluart, Ireshlent........... Iaysulle BAITOW COUNTY

Tanner Jowry, Presldent.......... Euluarlee

Tanner Jowry, Presldent.......... Euharlee
Iloward F. Felton. Secretary...Cartersville BE. HIL COUNT

R. M. Ware, I'resident..........Fitzerald

I. S. Osborne, Secretary............ Fitzigerild BFRRIEN COUNTY

It. N. Burch, Presidlent......... kays Mill

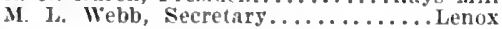
BIBB COUNTY

(Included In Macon Medical Soctety of 13 ibl County.)

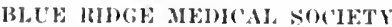

J. S. Tankersley, I'resident. ......... Ellijay

C. B. Crawford, Secretary........ iliue IRidge BROOKS COUNTY

E. L. Jelke, President............. Quitman
J. It. Mc.llichael, Secretary...... Quitman BLLLOCK COLNTY

I. E. McEachern, l'resident...... Statesboro

F. F. Floyd, secretary.............. Statesboro BLIKE COLNTY

C. Il. Cox. Presldent.......... Wayneshoro

J. .1. Byne, Secretary.........W Waynesboro BLTTS COUNTY

J. Lee liyron, Jresident.............Jackson

Ii. W. Copeland, Secretary............Jackson CALHOLN COLNTY

(Included In Tri-County Society.) CARROLL COUNTY

I. C. Grlfftes, President.......... Carroliton

Honer L. Barker, Secretary........ Carrollton CLARKE COUNTY

M. F. Mathews, President............thens

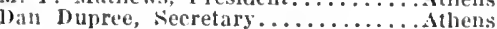
COBB COUNTY

Charles T. Nolan, President........Marietta

W. H. Malone, Secretary................. COFFEE COLNTY

John R. Smith, l'resident...........Douglas

Bascom 0. Quillian, secretary. . Willacoochee COWETA COUNTY

Theodore B. Davls, President....... Newnan

Thomas S. Bailey, Secretary............ Tewnan CRISF COUNTX

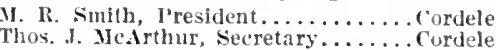
DECATUR COUNTY

F. C. Ilerring, l'resident................. Climax
Gordon Chason, Secretary ...... Bainbridge DEFALB COUNTY

W. T. McCurdy, President...Stone Mountain

C. L. Allgood, Secretary.......... Scottdale DODGE COUNTY

(Incluter? in (ocmulgee Medical Association.) IOOLY COUNTY

Edgar B. Daris, I'resident........ Byromville

Frank E. Williams. Secretary.........Vienna
H.ATLY COINTY

(Inchuled in Trl-County Soclety.) FFPINGIIAM COENTY

Whltam W. smith. I'resident.......... Clyo

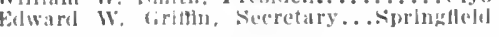
EI.HEIT' COTXTY

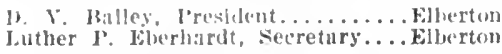
HMANEL, (OLNTI

k. E. Graham, l'peshlent.........ththnore liufus C. Franklin, seretary......... Graymont FLOI) COUSTY

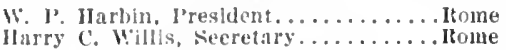
FORSYTH COUNTY

Wn. F. Jlpscomb, President...... Cumming

John If. Ilockenbull, secretary..... Cumming PIANIIIN COLNTY

George F. IBush, l'resldent..... Walnut Hil

13. T. Smith, Secretary.......... Carnesville FULTON COUNTY

S. 'T. Barnett, l'resident...........Atlanta William $\Lambda$. Selman, Secretary.......... Itlanta

(iEOLGIA MEDICAL SOOCIETY OF SAYNANAII

J. I. Iacksun, I'reshlent.......... Saramnah V. II. Bissett, secretary.............. Savannah GOHHON COUNTY

W. 13. Floyd, Iresident..........Plainville E. O. Shellhorse, Secretary............ Calhoun GILENE COUNTY

1. O. Copeland, I'lesident.....White I'lalus F. t. Adams, Secretary..........Greensboro HABERSHAM COUNTY

1.. I. Lamb, President.......... Demorest Willian $V$. Chandler, secretary..... Baldwin HALL COLNTY

13. W. Lockhart, President......... Clermont \&. T. Gibbs, secretary .......... Gainesville IIHWN COUNTY

s. J. MeElroy, President......... ocilla Gibe W. Willis, secretary.............. Oella JACKSON COUNTY

J. G. Elder, President............Jefferson

J. C. Bennett, Secretary.............Jefferson JASPER COUNTY

F. S. Belcher, President..........Ionticello

C. L. Ridley, Secretary................. Hillsboro JEFFEIRSON COUNTY

C. W. Churchill, President..........Wren

L. P. Farmer, Secretary...................... JENKINS COUNTY

1. J. Belt, President...............Millen

W. E. Iushing, Secretary.................. JONES COUNTY

B. L. White, President........ Round 0 ak Paul R. Chambliss, Secretary.............. Hray LAURENS COUNTY

J. E. New, President.............. Dexter Win. C. Thompson, Secretary........... Dublin LEE COUNTY

Wiley T. Simpson, President.......Smithville II. T. Sinpson, Secretary........... Smithville LOWNDES COUNTY

J. C. Pate, I'resident........... Valdosta MACON MEDICAL SOCIETY OF BIBB CUUNTY

Thos. H. Hall, President............ Iacon

k. II. Stovall, Secretary..............Macon MADISON COUNTY

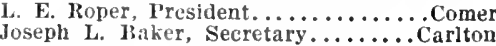
IICULFFIE COUNTY S. Gibson, President............. Thomson
B. F. Itiley, Jr., Secretary....... Thomson MERIWETHER COUNTY

Edward B. Terrell, President......Greenvllle F. P. Norman, Secretary......... Greenville MILLER COUNTY

(Included in Tri-County Medical Society.)
MONITOF ('OUTY

John F. Lancaster, Iresldent........ Forsyth John 0. Elrod, Secretary..............Forsyth MOIHTIN COLINTY

John I. Troutt, I'resident. ......... MadIson D. I), Trotter, Seeretary. . . . . . . . Madison MUSCOGEE COUNTY

G. Stewart Murray, I'resldent.... Columbus F. A. Schnelder, secretary....... Culumbus NEWTON COUNTY

Silmuel $W$. Everlt, Presldent......... Almon o. L. Holmes, Secretary.............. Covington OCMILAEE MEIHCAL ASSOCIATION-

DODGE-I'ULASII-TELFAII COUNTIES J. I. Stone, Presldent..........Ilawklnsvllle Itobert G. Stone, Secretary....Hawklnswllle OCONEF COUNTY

James T, Eleler, Presldent...... Farmlngton Willam M. White, Secretary... Watkinsville PAULHNG COUNTY

E. 11. Rothertson, I'resident......... Dallas Joseph 1. Iatthews, Secretary........ Dallas PIKE COUNTY I. A. Mallory, Presilent.......... Concord POLK COUNTY

Clias. W. Peek, Iresldent.......Cedartown PULASKI COUNTY

(Included in Ocmulgee Medical Assoclation.) I'UTNAM COUNTY

Talentine II. Taliaferro, President. Fatonton

s. A. Clark, Secretary............. Eatonton ItABUN COUNTY

Jesse C. Dover, President.......... Clayton Lester ieville, Secretary............. Rabun Gap RANDOLPH COUNTY

F. S. Rogers, I'resillent........... Coleman
Fredk. G. Barfield, Secretary...... Cuthbert RICIIIIOND COUNTY

James M. Hull, President........... Augusta

Asbury IIull, Secretary................. Augusta SPALDING COUNTY

Edwin R. Anthony, President.........Griffin

1V. C. Miles, Secretary................ Griffin STEPHENS COUNTY

Jesse E. D. Isbell, Presldent. ........ Toceoa

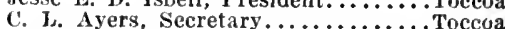
STEWART-WEBSTER COUNTIES

J. S. Wimberly, President......... Lumpkin

IV. F. IcCurdy, secretary.............. SUMTER COUNTY

Louis F. Grubbs, President.......Americus

Taylor Lewis, Secretary.............. Americus TATTNALL COUNTY

G. W. Tootle, President..........Glennville

L. A. DeLoach, Secretary...........Glennville TELFAIR COUNTY

(Included in Ocmulgee Medical Associatlon.) TERRELL COUNTY

J. G. Dean, Presldent............ Dawson

L. Lamar, Secretary................. Dawson TIIOMAS COUNTY

J. N. Isler, President..................

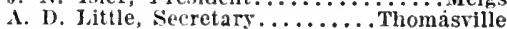
TIFT COUNTY

W. H. Hendricks, President.........Tifton

Leonard A. Baker, Secretary........... Tifton TOOMBS COUNTY

J. M. Meadows, President.......... Vldalla

T. C. Thompson, Secretary.......... Vidalla

TRI-COUNTY IEDICAL, SOCIETY-EARLYMILLER-CALHOUN COUNTIES

W. E. Saunders, President .........Arlington J. G. Standifer, Secretary............ Blakely TROUP COUNTY

Ilufh McCulloh, President.......West Point John Banks, Secretary...........La Grange TURNER COUNTY

W. L. Story, President...........Ashburn

J. H. Baxter, Secretary............................... WALKER COUNTY

J. M. Underwood, President........ Lafayette J. H. Hammond, Secretary........... Lafayette 
WHE COTXTY

3. M. Johnam, l'rusldent... WARH:N COLNT

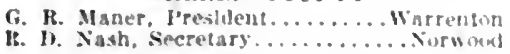
WAsHINITON COI:NT'

D. E. McMaster, I'restdent........ Tennille T. Byrun King. Secretary............. Tederilllo WAYNF COEXT

S. G. Tuten, Fresldent. ............. Jesun WEBSTER COTJTY

(Included in Stewars-Webster countles.) WhLCX COLNTY

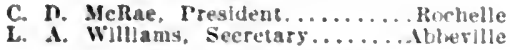
WLKES CULNTY

A. W. Simpson, Fresideut......Wushlugton Orlando s. Wood, secretary....Washingtun WORTH ODENT

v. P. Stephens, l'resldent.......... Poulan

if. C. Tlpton, Secretary.......... Poula

HEALTH OFFICERS IN CITIES OF 5,000 POPULATION AND OVER

Albang.............. J. R. De Gratteneld Amerteus................. W. Chambllss Athens.................Wedford Brown Atlanta.................. P. Kennerly

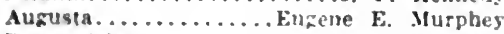
Brunswlet................. A. Mann Columbus................... J. T. Moncrief Cordele...............Mr. W. S. Tulman Dublin................... Jaul Ilarts Flberton.................. J. E. Johnson Fitzgerald.................. M. Ware Griสln.................... F. Carson La Grange................ W. Warles Macou.............. 1.. V. Notsingham Marletsa...................J. D. Malone Newman.................. A. Haney Home.................... B. Bryan Savannah.............W. II. Brunner Thomastllle................... It Ianlels Valdosta...................... Griatm Wayeross............. it. Hradley

Alto

\section{STATE INSTITUTIONS}

Stale Tubereulosts Sanatorlum, Alto, Ga. Estabilsted 1911; 58 beds: $11, i$. Para. mour. medlcal supersutendent.

Atlanta

Unlted States Pententlary IIospital, At Ianta. Ga. Fstahlished 1905; tuberculo sls; 50 beds: J. Calrin Wearer, medical superintendenc.

\section{Cave Spring}

State Schonl for tlie lieaf, care Spring. Ga. bistabllshed 1852; kenepal: : 6 heds W. T. Mekinney, phs'slelan; W. O) Con nor, super!ntendent.

\section{Hapeville}

- Stale School Heformatory Hounital. Haperllle, Ga.

Macon

Geotgla Acallemy Por the Mund. Mavon.

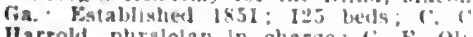
llarmold, phralelan in charge; (i. F. Oli Jhant, superintendent.

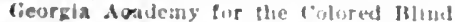

Macon, lia C. $C^{\circ}$. Haptold and Ihomas 11 .

IIall, attendinc phoslelans: prestdent brose of trustees: $1 ;$. Fimith, prealdent brard of ir

\section{Milledperille}

Genrgla stale I'enltentsary lioneral lluy pltal, Multedgeville, fia. Fivtalshishol Ings: 200 inds: (iuy L. Cumptos, plsswelan in clarge.

(Ceorela Stafe I'eulentiary Tuluerenlar Hosuital, Mllledgeville, lia. Eurtublished

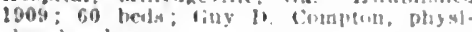
clan in charge.

Georgla state Sandarium, Millodgerllle. lia. Fintabllated 1st2: for the livane charke.
HOSPITALS, SANATORIUMS AND CHAR. ITABLE INSTITUTIONS

\section{Americus}

Amerleus and sumper rounty llomplent Barlow st. Amerleus, dia. bostulished

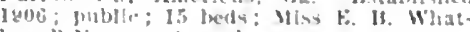
ley. II X. superintendent.

Athens

I) M. A. Rorn J'rirate Jl sultal and

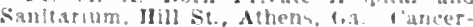
ous infections.

St. Mary's Hospital. MHurns, (ia. E.x tablished Io0t: prlvate Sanatozium Es bels: 11. II Fulliluve and J. I". l'riegent. blusicians; Mlss F. F. Slaughter, superintendent.

Allania

Mfon Villa sanltarlum, Mlinta, Fa.

Atlanta Ilospltal, 30 Crew st.. Mllanta Ga. bistahlshed 190: private: general 30 beds: Itiss Carrle Farr, It . intenuent

Atlanta sanltarium of the Seremh-Iby

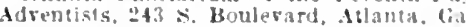
Fstabllshed lo103; private: generil: It beds; Laurin Lundy Indrews, II II., superlntendent.

battle Ifill Sanatorium. Allanta. Ga Fstabllshed 1911; public: interculosis: 80 beds for white: 7 beds for negroes: L Hollander, medical superintendent.

Dr Brawner's Sanitarlum, Itlanta, fa Fstablished 1910; privale; nerrous ant ntental: 35 beds; James $x$. Itrawner. blys siclan in charge.

Darls-Fischer Sanaturium. 27 F. I.lnden St.. Allanta, Ga. Fstablished 190: : briate 100 beds, F.. C. Mrayls. Detention llospital (small-pox) and
(n) Detention Ilospital (small-pox) and IIospital of Contaginus lolseases, 52 Col-
lege st. Atlanta, Cia. Futablished lao: publie: diphtheria and sinrlet ferer nuls

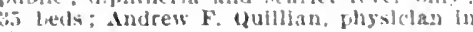
harge.

Invall's Sanaturium, :23.5 latitiol Are. Allanba, lia. J. Kichmond huvall physician in charge.

Fikin-findemith sanatorinm. at luckle St. Atlanta, lia. Fistablshed 189:; pir sale surgery and grneconlog : 20 berls Frank Bird, M.I., superintentent.

Wr. E. C. Thrash's Namamium. Atlanta. fat Fotablished 1910: ruberculosis: pri rate: 45 bells: E. C. Thrash. physlcian in charge: Mrs. S. T. Ciay. superintendent.

Fair Haven Inflrmary, 19: W. Mitchell S6. Atlauta. Fia. Established 190)? : Eett iral: 20 bels: ldorlgg B. Palmet, physician in charge.

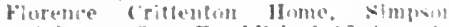
St. Atlanta, fia Fostablished 1sst: vul IIF : for fallen girls: 3il bets: Ilrs. J J). Hall, matroti.

lienrgia ltamlas Hospltal, 92 Inckio Et.

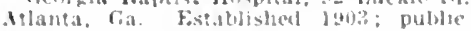
generill: 75 beds: Mrs. soghie Jones Murgan, li.i.. superinemdeds.

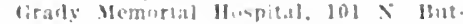

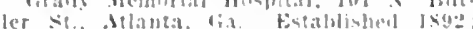

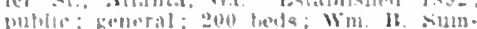

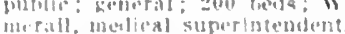

Jebrew "robans" In me, fis washingent

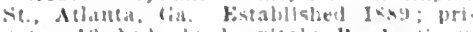
rate: 10 treste in hospltal: 16. 1. Simu

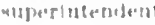

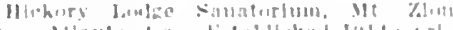

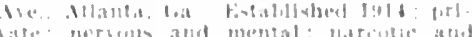

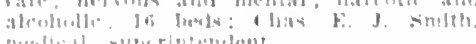

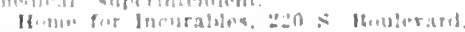

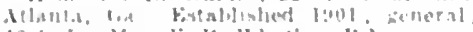

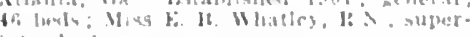
ntumbent

llum for the Friendless noul Indusirial

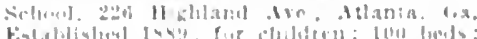

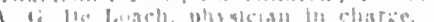

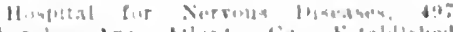

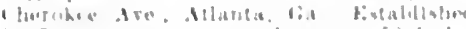

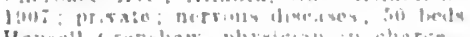

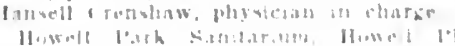

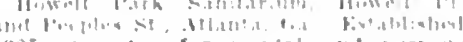

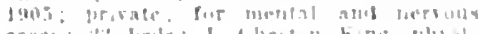

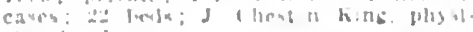
rian in rlustat

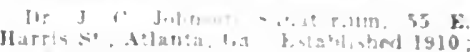

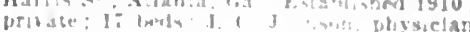

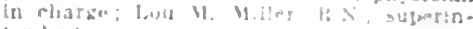
tendew:

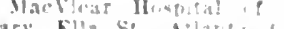

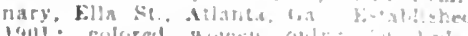
Fruma Il lanik, detan.

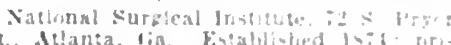

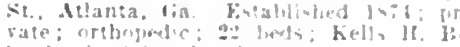
laud, plusician jn riarin.

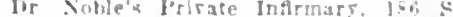

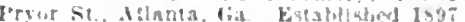

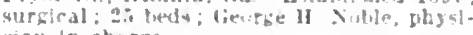

Whstetrical sariatorlum, af W: whong st.

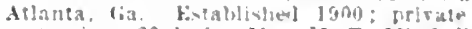
matermits: 20 beds; Mr. M. T. Mitchell. superintendunt.

lopimont sanatorium, 26: raputal Are. Mlanta, lia Fostatilinted lucis: private

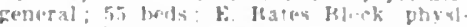
ejan [n charte: Migu V. T. Iillmer, K X. supierinterident.

Fine lidge sanitarium, 312 dustel? Bldg. Ruck siprith's Are. Iblanta, Gis. Fostablished lolo: prisnte: in trods for tubercular casea: Cieurge Brown, M.lb. suberintendent.

Red Crosy linspital ancl Trainine Schonl. Es civger st., dtanta, fia. W. I. Linzo medical superintendeut.

Robertsin-Blackman Sanitarium, I: Caplen tre. Allanta. (ia. Estabilsher

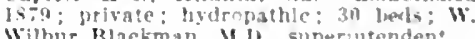
Shelering lrms a wherntendentMission, lllanta lia I'rirate: Jay gursery and emorancy home: f imis: Marion and emnräency home: 45 lmats: Marion Vabh, superintudent.

st. Ioveph Intirmary. 2of cinureland se. Illanta, lia Fotabllshed Issl: private: it heuls: k. Lowder Iteid. resldent phost. cian

bictor Sanitarlum 321 Whltelall s: Atlanta dia Estaplished 1sati berrous. narentic and alenholle: 15 beds; Vasser Wonlley. phvician In charee.

Wesley Memorial Hespleal, 190 Court

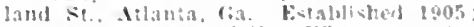
Genctal; 0 beds; Walker Whlte. superintendent

Augusta

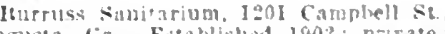
Infusta. fia Fstablished 1902; patrate

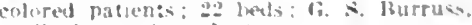
Devicul stperingerdent

Contagious lobease Hosnital, llall s: Aupista, in

liarle Maternity Home. I035 brosd St.

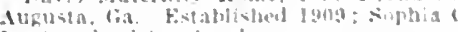
loavis, bhvilelan in tharge.

Tamat Hospital Mall st. Inzuata lia

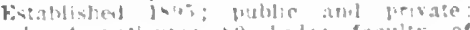

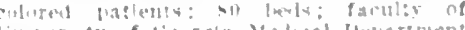

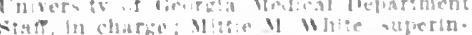
linglingent

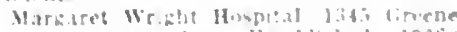

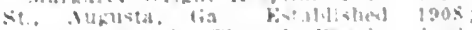

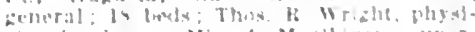
cian In rharge; Mles I II shirets, supers intementent

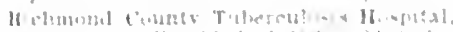

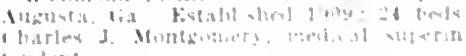

I nirersily Hentent

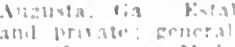

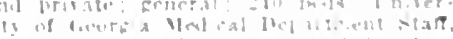

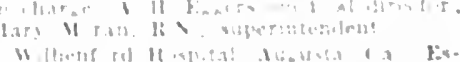

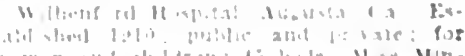

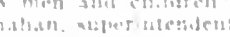

Brunowick

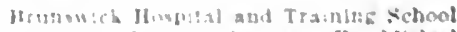

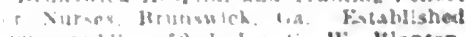

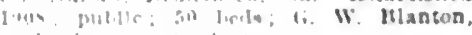

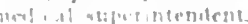


Camp Yonah

('amy) Yonah Sanatorlum, Canp Yonal, (ia. Established 1907: tubereulosis: pri vate; 20 beds; $W$. C. Bryant (Turnerville) physician in charge.

\section{Columbus}

Columbus City Hospltal, i21, lith st. Columbus, Ga. Public and private; 40 beds; Irs. Kate Fox superinteudent.

Florence Crittenton Home, Columbus, fis publlc ; for fallen and destitute women. Public :

kose Hill Sanatorium, (olumbus, fa. Established 1907: general : 12 beds: Miss I. E. Spann, R.X., superintendent.

\section{Commerce}

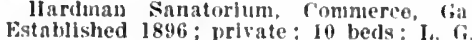
IIardman and M. F. Nelims, plissicialls. liss Nellie Chandler, superintendent.

cordele

Cordele Sanatorium, Cordelo, Ga. Fstablished 1905; privite; general ; 15 beds: Irene Thornton, M.D., superintendent.

\section{Gainesville}

Downey Hospital, Gainesville, Ga. Establislied 1912; private; general; 20 hedis J. H. Howney, medical superintendeut.

\section{Graymont}

Colenan's Infrmary, Graymont, Ga. Established 1904; private; 10 beds; Edw. tablished 1904: private; 10 bed
T. Coleman, M.D., superintendent.

\section{Grifin}

(iriftu Hospital, Grintin, Fa. Established 1903; publie: 40 beds; Miss Lucy Webb. superintendent.

Hawkinsville

Mathews' Sanitarium, Iawkinsvllle, Ga. Private; W. I. Mathews, resident physiclan.

La Grange

la Grange Sanatorium, La Grange, Ga. Fstablished 1903; prirate; 20 beds; Henry R. Slack, physlcian in charge.

\section{Macon}

Appleton Church Home, Macon, Ga. Es tablished 1868 ; private; 40 beds; for orphan girls: Eplscopal Church in for orDoor of Hope, 658 Arch St. Hacon, Ga. Door of Hope, 658 Arch St., Macon, Ga.
Estballshed $1896 ;$ publlc; for unfortunate soung women; 15 beds; Metbodlst City Mlssion in charge; I. H. Adams, attending physician; Mrs. S. B. Knowles, superintendent.

Georgia Colored Industrial Home, Macon, Ga. Eelabllshed 1899; public; 48 beds; for orphans; B. J. Bridges, superintendent. Georgla Industrial Home, Macon, Ga. Public ; for white orphans; malntained by private charities; Wm. J. Little, attending physician; A. S. Dix, superintendent.

Hephzibah Orphanage, Macon, Ga. Public; for outcast white boys and girls; 60 beds: I. H. Adams, attending phystclan Miss Bettie Tyler, superintendent.
Home for Old Ladies, Vineville, Macon, Cia. Iublic ; 6 beds; King's Daughters in (harge; Mrs. Troutman, matron.

llome for the Eriendless, Itacon $\mathrm{Ga}$ lulble; city support: Miss Eva Woodruff, matron.

Julir Parkman Jones Benerolent IIome. 512 Walnut St. Macon, Ga. Fstabllshed 1891; public: 9 leds; Christ Church in charge; w. R. Winchester, physlclan in charge.

Macon Hospital, 820 Plne St., Macon, (ia. Establlshed 1895; public; 70 berls; IV. II. Pirkle, resident physician: $0 . \mathbf{E}$ Nickles, superintendent.

Masonle llome of Georgia, Macon, Ga. Establisbed 1904; privato; for members only: general: 40 beds: J B Roberts. II. superintendent and physician: Mrs. M.D., superintendent and

leof Home, Macon, Ga. Established Roft Hoine, Macon, Ga. Established
1886 ; publlc; 105 beds; William T. Watson, Sr., superintendent.

South Georgia Conference Orphan Ilome, Macon, Ga. Establislied 1873; for the ralsing of orphans; malntained by the South Georgla Methodist Conference; 104 beds; J. $\mathbf{E}$. Wright, physician in charge; J. T. Dozler, superintendent.

Tabernacle Rescue IIome, Macon, Ga. Established 1908; for unfortunate young women: 24 beds: Tabernacle Baptist Church, In charke; Herbert Respess, atChurch, in charke; Ilerbert Respess, at-

tending

Vineland Sanitarium, Macon, Ga. Established 1903 ; private ; 8 beds; W. 1 . Rushin, physician in eharge.

Williams Private Sanatorium, Iacon, Ga. Established 1911; private: surgical only ; 20 beds; Howard J. Williams, physician in charge; Miss Mary Campbell, R.N., superintendent.

Marietta

Nolan Sanitarium, Marietta, Ga. Established 1909: private; surgery; 8 beds: C. $T$. Nolan, physician in charge.

\section{Milledgevillo}

Allen's Invalld Hone, Mlledgeville, Ga. Established 1891: private; for insane: 130 beds; H. D. Allen, physician in charge.

Pinedale

Pine Mountain Tubereulosis Sanatorlum, Pinedale, Ga. Established 1909; private; 25 beds.

\section{Red Oak}

Lee's Sanitarium, Red Oak, Ga. Established 1902 ; public : 30 beds; S. B. Lee physician in charge,

\section{Rome}

Battey's Sanatorium, Rome, Ga. Private: 14 beds; H. H. Battey, physician in cliarge.

Curry's Hospltal, Rome, Ga. EstabIsshed I907; private; 12 beds; J. W. Curry, physieian in charge.
Harbin's Hospital, Drs. R. M. and Wr. P Ilarbin, llome, Ga. Fstabllshod 1908; for surgical cases; 12 beds; $R$. M. and $W$. $P$. liarbin, surgeons in charge; Miss B. Rakellarbin, surgeons in chare

Dr. Mecall's Sanatorlum, Rome, Ga. Dr. MeCall's Sanatorlum, Rome, Ga.
Establislied 1907 ; private; 0 beds; D. T. MeCall, plysician in charge.

\section{Sandersville}

Rawlings' Sanitarium, Sandersville, Ga. Fstalllslied 1896; private; general; 125 beds: William Rawlings, physician in charge; Miss E. M. Jones, superintendent of nurses.

\section{Savannah}

Charity Hospital, 36th and Florence Sts., Savannah, Ga. Established 1893 ; general colored pationts : 30 beds; W. C. Blackman, physician in charge.

Georgia Inflrmary, 35th and Abercorn Sts., Savannah, Ga. Established 1886 . public and private; colored patients; 80 beds; C. Barrow, physician in charge: Mrs. O'Connor, superintendent.

Oglethorpe Sanltarium, Savannah, Ga. Establlshed 1907; private; 25 beds; John W. Danlel, physiclan in charge; T. P Waring, surgeon; Miss M. S. Raines, superintendent.

Park View Sanitarlum, 918 Drayton St.

Savannah, Ga. Establiahed 1900; publio and private; 75 beds; George It. White. surgeon in charge.

surgeon in charge. Savannah Hospital, Savannah, Ga. Es-
tablished I807; public and private; 75 tablished I807; public and private; 75 charge; Miss Lucy Minnigerode, superintendent.

St. Joseph's Hospital, Sarannah, Ga. Established 1875; public; 125 beds; Wm. B. Crawford, president of medical staff ; Sisters in charge.

Telfair Hospital, Savannah, Ga. Established 1886; public and private: women and children. 40 beds. Jabez Jon and Crajg Barrow, surgeons in charge; Miss Craig Barrow, surgeons in charge;
Helen M. Moir, R.N., superintendent.

United States Marine Hospital, Savannah, Ga. Established 1906; general; 50 beds; P. A. Surgeon C. H.' Lavinder, in command.

Thomasville

Thomasville City Hospital, Thomasville Ga. Established 1891 ; public; 25 beds.

\section{Valdosta}

Bellevue Sanatorium, Valdosta, Ga. Es tablished 1911 ; private: 32 beds; $G$. IJttle, physician in charge.

\section{Waycross}

Atlantic Coast Line Hospltal, Waycross, Ga. Established 1895; private; medica and surglcal; employees only; 125 beds; P. P. Lane, medical superintendent.

King's Daughters' Hospital, Gilchrist Park, Waycross, Ga. Established 1908 . publle; 15 beds; Mirs. C. E. Westcott public; 15 bed

Consult the alphabetical index if you do not have the physician's location or are unable to find his name at the address given. 


\title{
PHYSICIANS OF GEORGIA
}

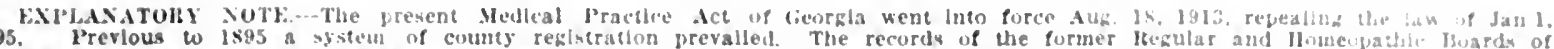

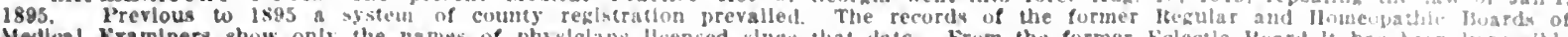

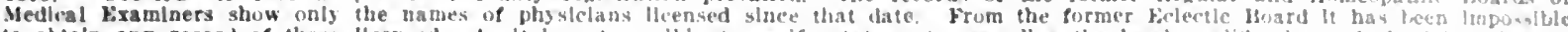

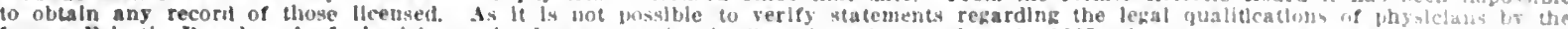

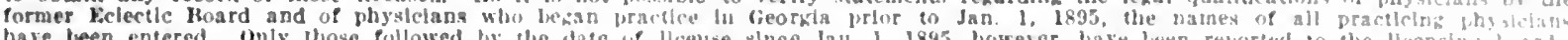

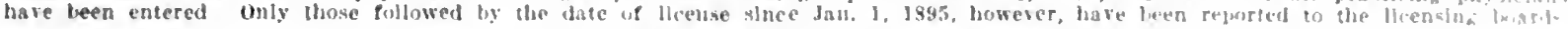

\section{KEY TO ABBREVIATIONS, SYMBOLS, ETC.}

Names in capltuls stinlfy membershlp in the County suclety and state Aswela. tlon. (DOE, JOHN).

Indlcates Fellowshlp in the Amerlcan Med. Assn. (DOE, Jollxte).

(b'-5) Year of birth.

$\left(b^{3}, 5\right)$ Year of birth. Imedic.

It, homeopath: $\mathbf{E}$, eclectle: $\mathbf{P}-\mathbf{M}$, physloMat. 7,99 , College and year of graduation. - Information recelved does not show grad
uatlon.

S.-Surgeon.

Ob.-Obstetrtelan.

ObG.-Obstetriclan, Gynecologlst.

G-Ginnecologlst.

Or-Orthopedist.

Op.-Ophthalmologist.

Op.-Ophthat

A.-Aurist.
(1'89) Year of Ilcense.

$\therefore$ In practlce betore vassage of present law and llcensed by flllng diplonin or by livirs of l'ractlce.

(1) lilcensed but rear not known.

(表) Informalion recelice itoes not show Hcense.

I.... Inited States Army.

II. is (... I. Nedleal lieserve Corps.

SPECIALTIES ARE INDICATED AS FOLLOWS:

ALR.-Aurist, Laryngologlst, Ihinologist.

OALR.-Ophthalmologlst, Aurlat, Laryngologlst, Ithlnologist.

U. - Urologlst.

D. - Dermiatologlst.

Pd.-Pedlatrist.

N. - Neurologlst.

P.- l'sychlatrlst.
I.N.N. Vnited Stales Nary.

II.I. I. I'S.N. Medlcal heserve Corps.

c.s.l.H.s. linled states putllc Healu Sermce.

rollege jositions held are Indleated by albrewated ille of posluton, follower by key numier of collcre. For key (1) colleges see Irsalde front corer pare.

(A1,3. IBi. C4) Jembernhlp in speelal sinclegler. (sice Koy Tahle, pato 1:2)

NP.-Neurologlst, T'sychlatrlst.

I.-Internlst.

T.-Tuberculotheraplst.

Anes.-Auesthetlal.

LD.-Laboratory Dlamostlelan.

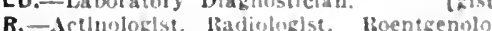

Path. - Jatholoclst.

Bact.-Bacterlologist.

WHEN THE ABBREVIATION REPRESENTING A SPECIALTY IS FOLLOWED BY AN ASTERISK (*) IT INDICATES THAT THE PHYSICIAN CLAIMS HIS PRACTICE IS LIMITED TO THAT PARTICULAR BRANCH OF MEDICINE: WITHOUT THE ASTERISK THAT HE IS ESPECIALLY INTERESTED IN BUT DOES NOT LIMIT HIS PRACTICE TO. THAT BRANCH. THIS INFORMATION CONCERNING SPECIALTY IS BASED ON PERSONAL DATA FURNISHED BY THE PHYSICIAN AND IS NOT VERIFIABLE.

\section{GEORGIA}

AARON, 120, BULLOCH

Whiteslde, James llamllton (b'87)-Ga.1,'12; (1'12).

WOOUS, WILLIAM DF LOACH (b'66).Ga. 1,'92.

ABBA, 25, IRWIN

Oorming, Andrew Cornellous (b'82)-Ga.11. 11: (1'11).

ABBEVILLE, 1201, WILCOX

FOOGE, WM. H. (b'6\%)-Ga.5,'90; (\&)

IIFISER, Wir. HEIRY (b'62)-Pa2,87 (I'08).

Maynard. J. D.-C, 5.53.

WILLIAMS, I.FOFORD A.-Ga.s.94

ABBOTTSFORD, 40, TROUP

Whle, R. Plerce-Gia.5, 'A4.

ABERDEEN, - FAYETTE

Merrlarn, SIdney Addison (b'Rt)-Tenn.19. 'II: (1'11).

ACWORTH, 1,043, COBB

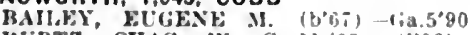

HURTz, CHAS. W. Cin.11,03: (1'03)

Jlumphrles, Wm. C, (b'6t)-tia 5'88: (2)

Smlth, Geo. W. (b'52) F-Tia.8, $16 ;$; (103).

Stroud, J. II. (b'66)-Ga.5., 88 .

Terry, H. B. (b'6) F-Ga.

ADAIRSVILLE, 751, BARTOW

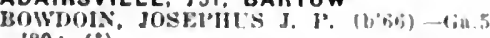

$: 89$ : (\$)

Bradiey, Jamea Wolludelle-(:a,10,'80).

Cart, W. W:-Tenn, ${ }^{\circ} \cdot 93$

Charnlee, Chas. M.-1ia.1,94: (l'95)

ADEL, 1,902, BERRIEN

Ciregury, J. M.-Ca..."93; (1.04)

shepard, Wm. M. (1, 69$)$-(ia.10,1)

TAl,1,Y. Jivit: V. Ky,1,94

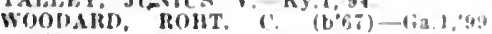
(1'98).

ADRIAN, 818. EMANUEL

Moye. Leon G. $\left(b^{\prime} 80\right) \ldots M\left(1.9,^{\circ} 04\right.$ : $\left(\mathbb{1}^{\prime} 04\right)$

knoudiree, $A$. Mannlng-1ia 1,0

Youmars, (jeo. F.-1;a.1,00:" (I'00)

AGRICOLA, 3i, GLASCOCK

Brooks, John 11.-(ia.1.81

AILEY, 306, MONTGOMERY

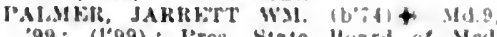

99: (1'99); I'res, state lhard of Med

Lixaminern.

AKRIDGE (R.F.D. OCHLOCHNEE), -

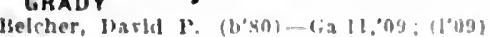

ALAMO, 249, WHEELER

FORDHAI, IAMAR PRESTON (b'80)-

(ia.11,02: (1"02)

Nelson, Trultt II.-Tenn.11,06; (1०07).

ALAPAHA. 532, BERRIEN

13J.ITIH. J. H. S.-KY.9.06: (1006)

MOORE, WH, A-GR.10,92: (t)

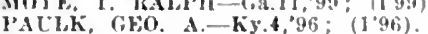

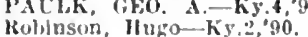

Shaw, Ifanulne franklin (b'si) ... (ia 1, l? (1'12).

ALBANY, 8,190, DOUGHERTY

bacon. A. S.-Ga.1,04; (1'04).

bacon. Walliter WInn (b'49) - X.Y.5:70

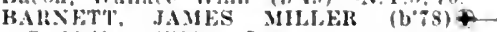
Ga.11,02; (1,02): S.

Henson, Jorman E.-Cia.11,03; (1.03)

Conk. Wim. shelley (b'st)-(ia.11,0: : (10 0 is).

DAVIS, WM. LEWIS (b'64) K-K.2,'\$6

Gullesple, John W-Ta.1,9u: not In prac

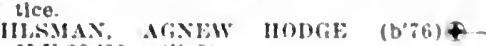
พ. $1.20: 99 ;(1 \cdot 99)$.

Keaton, John rox (b'85) - Md.1,"0i: (1'0i) U. $\star$

vew(ll. rhas. Eurene (b'83)- (;a.12,12:

(1'12).

l'orts, bilw, stegall (col.) (b"it)-N.C.3.

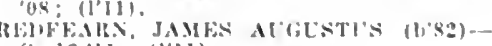
(in.12.11; (1'11).

moblnann. Hago-Ky.2.90

Sapp, F Franklln (1)'i)-Ca.12,11; (1.11)

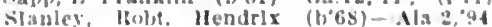

(l'05): G.

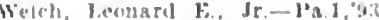

ALMA, 458, APPLING

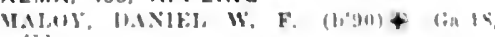
"II

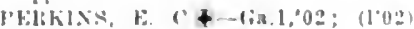

ALMON, 25, NEWTON

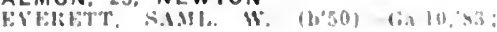

ALPHARETTA, 356, MILTON

Conart. UwCo James (lixi) dia $9: 11$, (t)

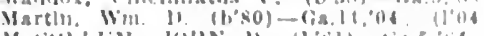

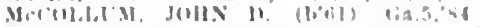

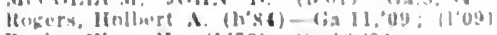

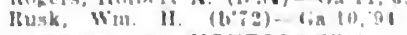

ALSTON, 100, MONTGOMERY

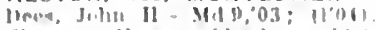

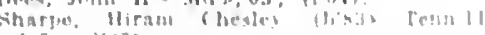

ili, (1)
ALTO, 109, HABERSHAM

larramore Wm Van Vorst (bost)-ild.I. 10 : (1'I2).

ALVATON, 20, MERIWETHER

Mann, Andrew Jackson (b'69)-Tia.9.91; (5).

AMBROSE, I00, COFFEE

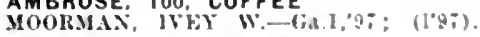

AMERICUS, 8.063, SUMTER

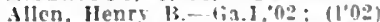

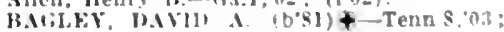
(1'09): $U$.

Bagley, Henry A. C.-Pa.16,70; R.F.D. 1

Brbson, Fugenc Jetrey (col.) -Tenn.:.9s (1'98): G.

CAT0. FRANK I.FF $\left(b^{\prime} 63\right)+$ Pa. $8 \%: S$

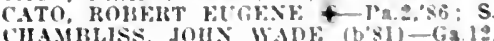

HAMHISE,

Foster, John H. (b'82)-Ga.11,10: (1'10): II.F.D. 5.

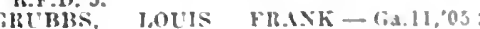
(1'05).

Ifuguley, John W. (col.)-Tenn 7,45 ; $(1.95)$.

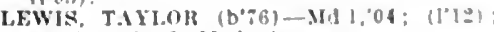

Member $\therefore$ (" Med Assn.

Logan, Nonzo-fiat,il: R.F.D.

Mathis, F. $T-k y$ 1.:5: not in prsoster.

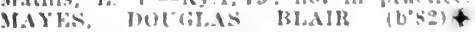

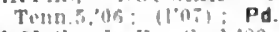

MeMath, J. F-cis.s.

Merrlit. Thomas M.a-Mil.3.

Pracher, $15 \mathrm{~m}$. $\mathrm{s}$ - is 1.29

liley, Wm. ildiven-lia 11,00

noi in practlen.

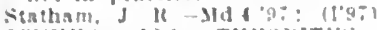

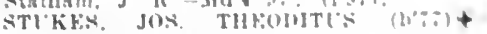

\& $(1,1,0): 11: 1=1$

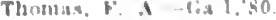

Turnar, Frank Eivell (col.) (1.43) Tean: (0): (1'0)

AMITY, 65, LINCOLN

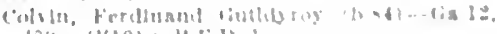

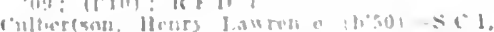$$
\text { i. (f: }
$$

AMSTERDAM. 250, DECATUH

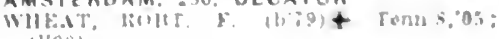
(l'oti)

ANDEHSONVILLE, 174, SUMTER

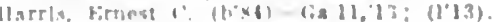

APALACHEE, IBI, MORGAN

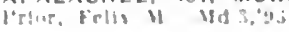


APPLING, 200, COLUMBIA

lleeks, Juhn luther (b'isu) lian, 00: (1'00).

ARABI, 433, CRISP

Cox, Tip-Tenn 5, 01) (1'01).

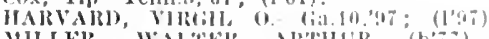

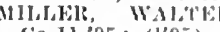

Ga.11,05; (1'05).

NIx, Wm. J.- dia.ll, 00 : (l,0)

ARLINGTON, 1,308, CALHOUN

Qulllan, Win. IIothiton (1,7!) - (ial.1 1, 07 $(100)$.

SAUNIERS, WA.TETE (I)

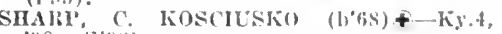

Slmmons, Patrick Cleveland (1, $\lim _{10}$

\section{ARMUCHEE, 25, FLOYD}

Grlftin, I. 11.-Tenn.9,'02; (l'02)

l'enn, Broadus Webber '(1,90)-C(a,11,13; (1'13) ; 1R.F.1). 3.

Wrlglit, A. II.-lia.5,'Tt.

ASHBURN, 2.214, TURNER

BAXTER, JAMJS IILHERT $\left(\mathrm{b}^{\circ}, 9\right)+$ Ga.11,08; (1'08).

HOUSTON. W. 11. (b'86)-Ga.12,0s: (1008)

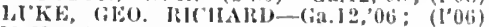
Mekenzle, fiarden c. (b's5)-Ga.11, 06 (1'00).

STOIL, WALREN I. (b'65) -Ga.j,'88 (ठ)

TUlixir,"W.1. .T. (b'6s)-(ia.5,'93; (1'93).

ASHLAND, 10, FRANKLIN

BIRISONG, JENRT WILTEIR (b'83)(iia,11,11: (1'11).

Coffer. IJenry 1). (b’si)-(in.12,09; (l’09): IR.F.1). I.

\section{ATHENS, 14,913, CLARKE}

BFNEDICT, SAMUEI, CAIDNFI.L (b’55)$0.9,78$; $(8)$; Pres. State Board of liealth 9 k. Broad 'St. ; oflee, $1061 / 2 \mathrm{E}$. Clayton St. untll 9 , $1-9$

BENEDIC'T, SAML. RAVALD (b'83)-Va.6 '08; (1'10); 127 Broad st.; offlce, 22s Clayton St.; $9-11,4-6 ; \mathrm{S}$

BLOONFIELD, JAMIES TAMACK (b'64) - ra.2,ss; (c); 116 Milledge Ave.; ofllee. II2 $1 / 2$ E. Clayton st.

Born, Mat. A. (b'72)-(ia.10,91.

BRoVN, WESTFono W. Iri.1,11; (1'11).

Canning, Gustav T-lia.1, \$1 ; (o)

CARLTOX, WM. ALEXANDER (b'4 4$)$

I'a.2,73; (2); 750 Milledge Ave.; office,

CoLEMAN, EDWARD M.' (b'63)-Ky.2,'98; (l'9s).

Conway, Wim. B.-IId.3.'69.

CRow, L. H.-Ga.9,'92.

Dunbar, stiles Il.-lia.1,06; (l'06); not in practice

Du P'REE, DANI. IULGIIES (b'83) Id. 6,$07 ;\left(\mathrm{l}^{\prime} \mathrm{C}^{-}\right)$; 794 Hancock

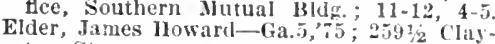
ton st.

FLLLILOVE, IIEXRY M. (b'\%)£-Va.6, "g9; $(194) ; 380$ Milleige Are.; ottice,
Southern intutul Bldr.; $10: 30-12: 30$, $4-6 ; \mathrm{S}$.

GOSs, ISILAM HAMJLTON $\left(\mathrm{b}^{\prime}, 53\right)+\mathrm{K} y .1$,

' 75 ; (5) ; 297 Handcock Are.; S.

Goss, RiLPH औ. (b'i9)‡-D.C.1,06; (1'10).

Hamilton, Wm. T. (b'67) F-lia.9, $05 ; 186^{1 / 2}$ Clayton St. ; $9-12,2-6$

Harris, Wim. 'II. (col.) (b'67)-Tenn. ,'93; (1'98) ; 446 Reese St.; offce, Norton Bidg. $9-10: 30,3-4$

Haynes, Christopher Siephen (col.)-Xi.C.3, '95; (1'45).

IIOLLIDAY, ILLEN C.-Ga,1,84.

HOLLIDAY, JAMES CARLTON (b'S6)3-5.

Munnicutt, Jolnn A. (b'3s)-Ga.5,'66; (I†); 325 Milledge Ave

IImnieuft, John A., ,Ir. (b'86)-Md.7,'11;

( ) : Siln Antonío Blikg.

JOHNSOY. OTIS IIAC'KETT (b'7T)-Ga.11, "wi: (I't5); 230 (loverhurst Ave.; office, Lampkin. Edw. 1.-Ga.9,'95; R.F.D.

MATTHEWS, MILALD F. (b'69)-Ga.I,
MeliNXEY, JOHX (IAS (b'69)-Tenn.11, [18; (1?:0!0); 275 Bater St.; offee, South ern llutual lBldg: $10-11,3-4$.

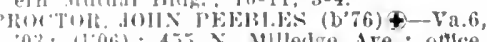
0.3: $(106): 4.5 \%$ \%. Mllledge Are. : onfere

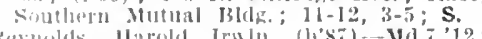

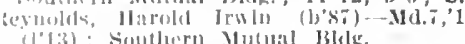

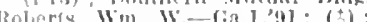

sIsk. ('RETF, NIXON (1,83)-Tenn.1,05

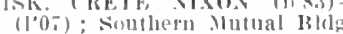

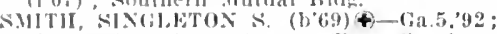
(i): 135 l'rince Ave.; offlce, Southern Ituilual lislo.

Sorrells, It. 1'.- fin.1.75

Thompson, lianclie Beatrice saunders (col.) -Tenn. $7,01:(1,02)$

WAIMIEI, JAMES PINKNEY (b'66)-Ga.1, TINA 154.839 FULTON

NTMHE OF l'IISICIANS, 514.

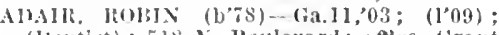
(Jentist); 518 X. Boulerard; once, lirant blilin.

T.XIS, IJENTY M. SEYMOUR (b'83)(ta.11,09: (1'09) ; 461 Euclid Ave.; offlce, (ancller julds. $9-11,4-6$.

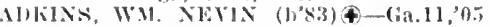
(1'05); s4 F. 14th st.; offlce, Forsyth bldg. $10-12,4-5: P d$.

Alexander, 0. R. dia.5,?3; 71 Brookline st. Allen, Wm. A. (h'62)-Ga.10,'92; (l'92); sy Kiennedy st.; $9-11,2-4$

Alley, John Alvin (b'72)-Ga.5,97; (1'97); 21 Grint l'. : 1-3.

AISTER. I.UNWIR (b'63) \$- - Y.Y.5,'88 (c); 348 Washington St.; offlee, $314 \mathrm{Em}$ plré Bldg.: $11-1,4-6$. Anderson, Fletcher f. (b'65)-Ga.18,09. (ま) .722 VV. North Ave.

Anderson, Wm. I (b'50)-Ky.4,75; 619 Edgewood Are.

ANDREWS, CHAS. R. (b'79) $\uparrow$ Ga.11,03 (1'03); 196 Cleburne Ave.; ofllce, Candler Eldg. ; 9-11, 3:30-4:30.

INDREWS, LAUIIN LUNDY (b'74)థ1). $1.1,10 ;$ (1'12); 243 south Hlvd. Itlanta Sanitarium; $4-12,2-5$.

Armstrong, Thos. Blake (b,84)-Ga.11,'13 (l'l3); Crady Memorial IJospital.

Arnole, Wm. Arthur (b'S I) - Ga.17, 0s $\left(l^{\prime} 08\right)$; $15 \mathrm{~s}$. McDaniel St. ; office, 266 Peters $S$

Arrowook, Silas W.-Ga.9,'88; I88 Hiynes St.

ASHER, WM. THOMAS (b'71)-Ga.5,'93; 532 Ponce de Leon Ave.: office, Empire life Bldg. : $9-10,3-5$.

Askam, Henry F.-Ky.2,'s0; 171 Westminster Drice; oflice, 2 . Pryor St.

Auten, William J.-Ga.9.'88; 334 Hemphill Ave, ; offlee, 80s Marietta St.

AVARY, ARCHER-Ga.10,'89; Springdale Rd. ; office, Candler Bldg.

Aren, Carl Cato (b'87) - Ga.11,'10; (1'10) ; 9 Park Ave, ; offlce, 4th Natl. Bank Bldg. lawn Station; offlee, $231 \frac{112}{2}$ Marietta St.

Ayer, (iuy D.-Ga.11,06; (1'06); 320 Capitol Ive.; offee, Atlanta Nat]. Bank Bddz Bachmann, Jean Feo. (b'75)-Pa.2,07; if Dixie Ave.; nffee, Itlanta Medical College; Irof. Physiol., Ga.5.

BAILEY, ERNEST io (b'82)-Ga.12,'12 ; (I'12): 717 Courtland St. ; office, Empire life bildg

BAIRD, IIIES BOZFMAN $\left(\mathrm{b}^{\prime} 49\right) \oplus-$ Y.10,71; (む); 105 Capitol Sq.; 9-10 BAIRD, JANES B., JR.-Ga.11,05; (1'05);

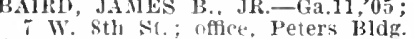

Bair(I. William Niller (b'49) —N.Y.10,77; (1'04); 56 Martetta St. ; $10-1,4-6 ;$ U. $\star$

Bak, llenry (b’46)-Aus.t, 72; 578 washington St.; offee, Empire Jife Bldg. I'rof. Mled. and F'ed., Ga.19.

Baker, Isuther P.-Ca.18,09; (\$); 272 Luckie St.; office, $206 \mathrm{~W}$. Álexander St. Ball, Emmet $i$. (b'o)-Ga.9,'94; 244 Courtland st.; offee, Austell Bidg, $9-12,1-4$; OALR. *

BALLEXFER, FDGAR G, (b' 7$) \oplus-M d . I$ 01: (1'05) : 128 Myrtle St. : office. Healy Bldg. ; $9-1,2-4$; Adj. Clin. Prof. Gen.-Urin. surg. Ga.5; U.

BALLEN(iER. WM. LEE (b'81)-Ga.11,'12 (1'12) ; 30 Crew St. ; office, 191 E. Georgia.
Barber, Iohn Neely (col.) (b'89)-Tenn.7, $05 ;\left(l^{\prime} 05\right)$; 276 Fraser st. ; oftlee, $78 \% / 2$ ‥ IBroild St. ; 11-12, 6-7

Rarke, Jutge R.-Ga.19, l'; Imperlal Hotel; onlce, Emplre Lifo Blolg.; $10-12,2-4 ; \mathbf{N}$.

Parnes, Him, lalneoln (b't2)-lig.2,84;

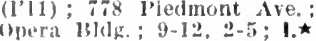

HARNE'T'T, S'TEPIIEN T. (b'71)-Va.1, 96 ; (1'49): 35 E. 1411 st. office Candler

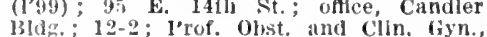
lia.to: 0 bG

Baskin, Alcinıus I1.-Ga.5,92; 27 Park St.; offle, $1061 / 2$ Whiteliall st.

BATTEY, IIUGH INYAN (b'88) क-Ga.12, 10 ; $\left(1^{\prime} 10\right) ; 81$ W. I4th St.; offlce, Empirc life lusurance Co. J3ldg.; 11-1, 4-5;

Beck, John F.-Ga.10,'39;36 W. Peachtree

Beck, John F.-Ga.10,39; 36
Sit.; offlce, 115 Marjetta St.

Beecl, Thos. Richard (b'88)-Ga.11,'13; (l'13); Atlanta IIospital.

Bell, Walter Jay (b'69)-I.a.1,91; (l'95); $3451 / 2$ l'eachtree st. ; offlee, Candler Bldg. $11-1,3-5 ; \mathrm{G}$.

Belyeu, Willlam S. (b'69)-Ga.9,91; 631 BENSON, CHAS. F., JIt. (1)62)-Ga.5,'82 ; (t) ; 251 Ponce de' Leon Ave.; offlee, 4th National Bank Bldg.; 11-1, 5-6.

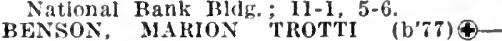
Ga.11,00; (1'00); 600 Pledmont Ave.; office, Atlanta National Bank Bldg. : $10: 30-1 ;$ ObG. $\star$

Blygers, Stephen T.-Ga.9,'81; 77 W. 10th St.; offce, 423 Marietta St.

BIRD, FRANK (b'89)-Ga.i1,'11; (1'11) 129 Courtand st. : Wesley Menorial Hospital.; wI. TROY (b'75)क-N.Y.19, 99 ; (J'99); 149 Westminster Drive: office, Atlanta National Bank Bldg. ; 12-2, $3-5 ; \mathrm{S}$.

Blackman, w. Wilbur - Ga.9,'13; Supt. Robertson-Blackman Sanltarium.

Blalock, Win. J.-N.Y.1,93; 25 W. 11 th St.

Blanton, l.ewis J.-Ga.j,'98; (I'98); 37 E. Merritts Ave.; offlce, 240 Houston 'St.

BLOCK, E. BATES $\left(b^{\prime} ; 4\right) \oplus-$ Va.1,95; (l'05); 1126 reachtree St.; offlee, Emplre Bldg. ; 11-1; Prof. Nerv. Dis and Clln. Neur., Ga.5; N

BLOSSER, ROY (b'82)-Ga.11,02, Pa.2, $06 ;\left(l^{\prime} 02\right) ; 224$ Myrtle St.; office, Atlanta National Bank Bldg.; 10-12, 3-5.

BOLAND, FRANK KELLS (b'75)@-Ga.11, 00; (l'00); 265 Juniper St. ; oflice, Candler $\mathrm{Bl}$

Boland, liells H. (b'40)-Ga.10,'87; (t) ; 72

S. Pryor St. ; 8-12, 2-5.

BOMAR, BOISE S. (b'84) - Ga.12,'08; (1'08); 533 Lee St.; offlce, 362 Candler Annex; 11-1, 5-6:30.

Bothwell, Geo. Edwin (b'78)-Ga.11,03; (1'03) ; 8 Flat Shoals Are.; offlce, walthall Bldg.

Bowen, Jolin H. (b'66)-Ga.1,94; 156 Courtland st.

Bovd, Edw. W.-Ga.5,94; 406 North Blvd. BOYD, NOXTAGUE LAFFITTE (b'82)Md.7,07; (l'1I); 580 Spring st. ; oftice Candler Bldg. ; 9-1, 4-6; U,

BOYNTON, CH.S. FDW. (b; 72$) \oplus-N . T .1$, "96; (1'96) : 707 Piedmont Ave. ; offlee, and Clin. Dis. Child., Ga.5; Pd.

BRADFIELD, JOS. H.-Ga.5,93; 501 S. P'ryor st.; offlee, 1061/2 Whitehall St.

BRADLEY, FRANCES SAGE $\oplus-N . Y .20,99$; (I'99) : $300 \mathrm{~W}$. Peachtree $\mathrm{St}$

Bragr, Eugene E. (b'7)-Ga.9.06; (1'06); 480 Ponce de Leon Are.; offlce, Atlanta National Bank Blug.; 9-5; Prof, Anat. Ga.9.

Brannon, Rebecca C. Wolfe (b'60)-Ga.9,

'95; (1'95); 356 Forrest Ave.: 9-5; G.

S. Humphries St. ; $10-2$.

Brantley, .1. P.-Ga.9,82; 606 S. Pryor St.

Brantley, James L. E.-Ga.y, 05 ; (†); 725

S. Pryor St.

Brantley, John Q.-Ga.9,05 ; 368 Grant St. ; office, Austell Bldg.

Brantley, Wm. A. $\rightarrow$; (\$) ; 68 Jett St.

BRAWNER, JAIES N. (b'76)-MI.3,'99 (1'99) ; Miarietta Rd.; offlee, Grant Bldg.; 
Hrewer, Lambert C, $\left(b^{\circ}, 6\right)-$ lia.11,01; (l'01) : 459 Luck

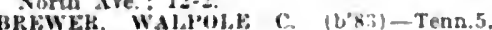

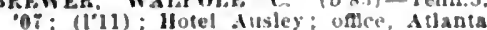
Tational bank blde: 11-1, t-6.

Hrown. Fred $\left(b^{\prime} 30\right)-\left(\right.$ ia.11.'12; $\left(1{ }^{\prime} 12\right) ; 284$ Courtiand Are: oalce, St. Justenli's inArmary.

Hrown. Georse (b'62)-Ga.10,92: (5):36 W, 14th SL: oflce, Austell Hldk.: 9-2.

BKOWX. WM. T. (b'52) + - Ra.5, ;6; 33 F.

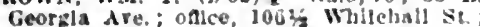
Georia $11-1,5$

Bucknell, llowand (b'it)-Ga.11,12; (1') 2$)$; 911 reachtreu sit.

Bullock, Chas, 1.-Ga.12,07; (1'0i); Matbewson lil. : nce., Nustell Hudg.

BUNCE, ALIES HAMLTOX $\left(b^{\prime} 83\right)+$ Grand Bldz.: LD.

Burney, John is. (col.) (b's6)-Tenn.7'13; (1'13): 23 Rosz st.; oftlce, 1 isto Atsurn (l'13): 23 Poaz
Ave. $8.10,2-4$

Burt, Willam J.-Ga.5,"80; 227 Furtest Are.

Bush, Guy Lawton (b'si) - (;a 11,08; (1'As) 61 Ponce de Leou l'l.; onlce, Candler Blig. ; $9-10,5-6$

BUSII, OVID BERY (b'85)-Ga.12, 0 s

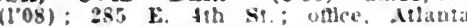
National Bank Blds.; $11-1,+6$.

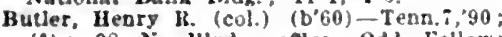
(8): 98 X. Hivd. oftce, Odd Fellows Blds.; $8-9,2-4$; Pd.

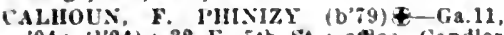
04: $\left(10^{\prime} 04\right)$ : 32 F. 5th St, oftice, Candle Blde. 8-1; Prof. Dphth. and Ciln. Dis. Blde: 8-1; Prof. Ophth. and Clin. Ois. (B1): OpA.

Calhoun, James E. (b'S6) - Ga.11,'12; (1'12) 242 E. Georgla Are.

CAMHBELL JAMES I.E ROY $\left(b^{\prime} 0\right)+$

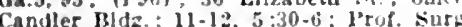
Anat. and clin. Surg. Cia.5; $\mathrm{S}$.

CAMPBELL, MOSES GATLIN (b'61) † Ga.5.94; (1'94): $1: 1$ Gordon st.; oftce Candler Bldg. : il-1.

CAYIPRELL, WM. EDWARD (b'65) Are: office, Atlanta Natlonal bank Bldg. $8: 30-1,3-5 ;(133)$; OALR.

Canady, Hullard D., Jr. (col.) (b's3) Tenn.7.12: (1'12): 29 Gammon 1'1.: of Ice, 18313 suburn Are.: 12-1.5-?.

Cannon, IIenry Grads (b'84)-Gia.11,12; (12): Cirady Memorlal llospltal.

Carmlchael, John W.-Ga.9,86; 556 Woodward St.

Carter, Baymond H. (col.) - N.C.3,0i;

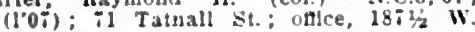
Mitchell 'st.

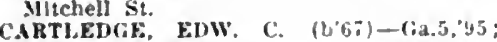
(1'95): 8i" l'eachirce Pl.: once, Cirant Hidg. : 1-3: G

Cater, Chas. Columbus, Ir. (b'86)-1'a.1,11 (l'12); 32 " $\mathrm{x}$. Jackison Si. ; oflec, 151', Auburn Are. : $9-10, \$-6$.

Catron, Isaac $\mathrm{T}$ - $-10 ., 2,45 ;(1.99) ; 322 \mathrm{X}$ Jackson st.; office, Fourti National Iank Hidg.

Caxhern, Wrn. M-Gia.11,92; (1'ys); ; 55

Marletta St. (E) : 955 l'unce do leon

Cheshire, J. Scott (col.)-X.C.3,ol; 11'01)

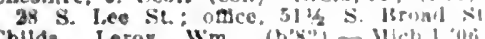

Chllds, I.erny $\mathbf{W m}$ (bs-) - Mchl, (1'08): 615 l'led

Chrlatian? Chas Jeromo-cia.5, y. ; (1'y)

jext kenberly st

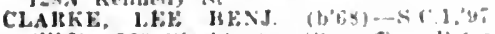

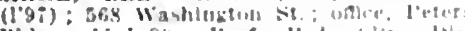

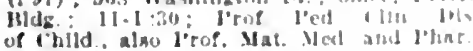
Ga.3: Pd.

Cochran, Alvert II-lia.1.97; (19z): 10

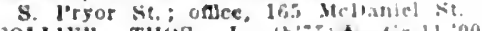

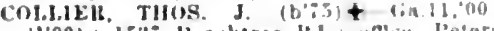
(1.00): 15:\% l'cachiree Ites

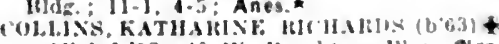

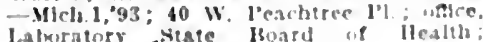
laimuratory

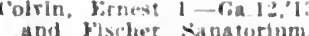

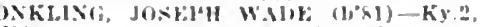
11: nui la practles; Member hy. Sita

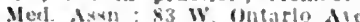

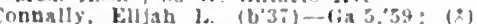

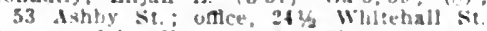
conway, John li.-Gal, st: 22: Wumlward tre.; ance, keley Instrituse.

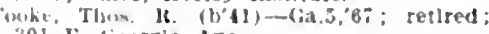
301 E fieurgia Are.

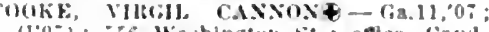
(I"0;); 330 Washlngtun st.; oflec, landlint intuex

CO[111, liko. 1), (b'54)-C;a.1,75: (II ape-

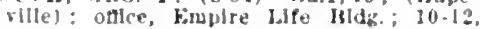
2-4: G.

Cux, Thomas H. (b058) - C;a.9,93; 905 Marl-

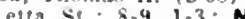

raig. Newton (b'ty)-Tenn.11,01; (l'10): 37.2 lawwn st.; once, lirand opera IBlig: : $\because-1,3-5 ;$ OAL.

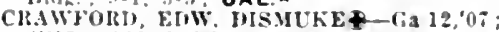
(1.07): 1:0 z., :th St.; ottice, Grant lilds: 3-2: OALR.

CRAWFOIEI), JAMES HARDEN (b'is)Cia.11, $011 ;\left(l^{\prime}(00)\right.$; 168 leachiree ('ircle: onlioe. lirant Blig: : 9-1, 3-5; OALR.

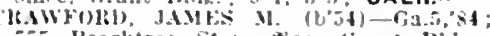

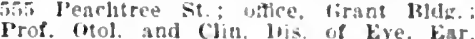
Prop. Otol and Clith. lois. of

Crawford, Thos. J. (1,58)-Ca.5,86: is

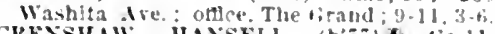
CRFSSHAW, IIANSEIL (b'T) 4 IA.11, 00 ; $\left(I^{\circ} 00\right) ; 358$ I'once de Leen Are.; of fice, Candler Bldz.; 3-5: NP.*

Crlchion, Logan M.-Nivio, $85: 680$ Pled mont ire.; onice, Peters Blid

Crist, Max Z. (b'fit)-C, 10,90. (*) : 156 Forest Are. oflce, Emptre hile lildg. :

Cromer, James Dawklns - Tenn. t, 94: (1'95); win W. Pachtree

CROSA, WW. FIUAKIIN (1,79)-Ga.12,'12 (1'12); Inman Yarts: $9-11$.

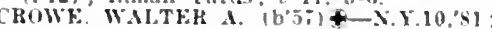
(i); 156 l.ce st.; once, Furth National Bank loldr.; 11-1: G.

crusselle, A. Cliford-tia.9,97; 17 llay. Ir)od Ire.

Cunningham. Thomas 1; (b*a)-Gia.11,92 (1'99); (1becatur); cfflce, Enure life Throat, Gá. ly

Curtis, Alfred Lee $\left(b^{\prime}: 0\right)-$ Cia.5.91; :0 w loth st: once, $35 \mathrm{~W}$. Mlichell st.

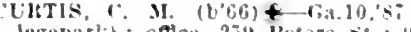

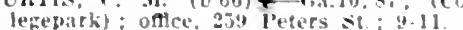

baly, l.eo 1'aul (b'st)-Ga.11,11; (1"11)

6s r. Baker st.; mince, candler Hldy. $11 ; 0-1,4-;: S$

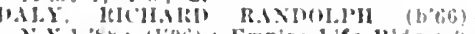

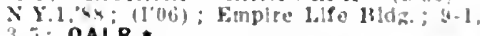
$3-1 ;$ OALR.

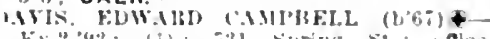

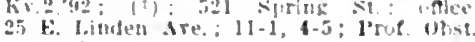
and llle dive lias

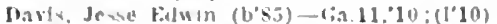

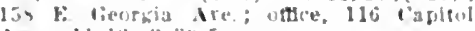

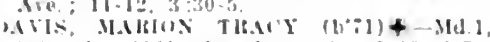

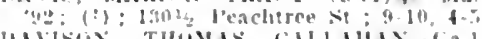

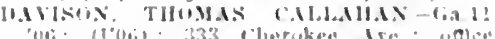

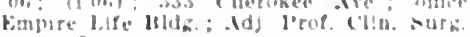
in 5

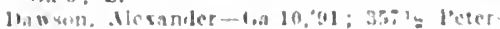

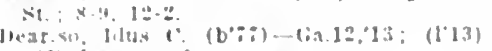

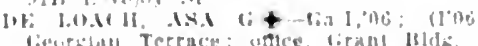

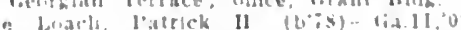

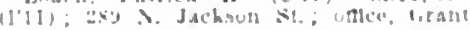
161,

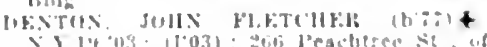

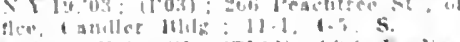

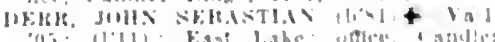
or: (1'11); E.:

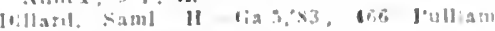

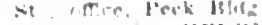

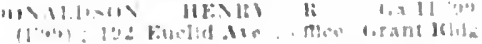

DOHSEY, JIPIS T JR (U一) Ga.10, nfice, fourth Natmat Hank Bug : 11-1 l'po? rlin. Med lian. I.

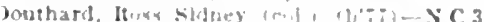

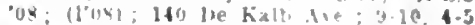
Dowd, Kenneth lirsant 12 s3 - Viali, 13; (I'13): Hatte II Sil santiartum

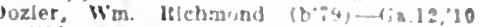

(1*10): Iragon Ilutel; utlee, The lirand: 111. I, 2- 4

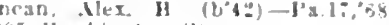

6ij., 11 ashington st.

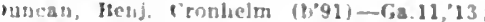

(1'13): ¿al Punce de bon tre.

I:NC. J. W. $(4,42)-1 ; 5.68 ;(2): 38$ Purse de Jeon Are: otce, Fourth Mitlonal link lbldg; $11-12: 30$, $4-3$.

(1'13): Vivirglan Terrace Hutel; oftec

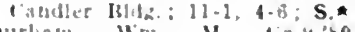

Intlatu, Wm. II. - lia y, 80 ; retlred. (iould Itldin E Emer. lerof Surg. also, urret: 1teuben is. (b.63)-G.5,"93, 130

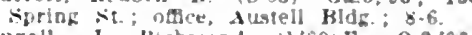
burall, J. Kichaund (t'C3) $\mathrm{E}-0.2,96$; $(1+4) ; 01$ Capltal Are.; oxce, 1064 Whitulall st.; 4-1:, 3.5.

Inuall, Ward Beecher (L8y)-Ca.l,13.

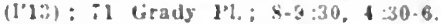

ENIRNEST, JOHN RLILFOHU (b4)

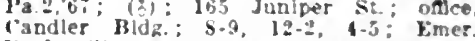
I'rof Clin. Gin., Gas: (A6); G.

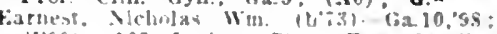
(I'09); 165 Junler St. oEce, Candler Blds

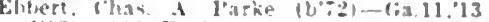
(1.13); 110 k. Cieorga Are.; Gotice, Embire life Hidz; $11-4,4$.

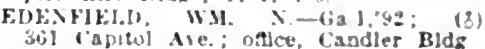

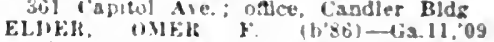
(l'oy); Milanta National Bank Bjd:. $3-1 \geqslant:-1: U$.

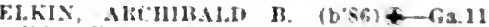
10: (I'I0); to l'ark Lane; odjce, Grand 13lug:; I1-1, + $: 30-6$

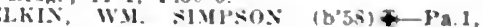
":; Cientsian Terrace; 11-1:30; Dean and l'rof. lisn. and CHn. fiyn., Ga.5: (16).

(los): thi: siring st, ualce, Fomb

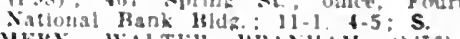

EMKHY WATKH MIRANAM $10^{\circ}, 61-$

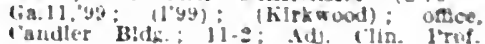
Cien.-irln. surg.. Cia.11.

Finzor, lloscoe II. (b'ss)-fis 12,11; (1"11)

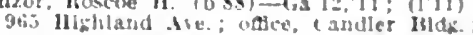
10.11.1.3: ObG.

Eskridge, Frank Iouls-6is 17,07, Ga 9,06:

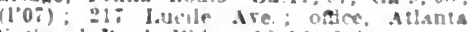

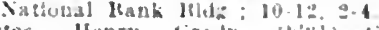

kates llenry Ciraly (b'4i) lia,11,13; $\left(1^{\prime} 13\right): 20-$ Caplen i

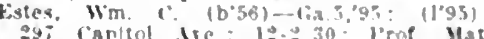
Med and Ther, i:a 19

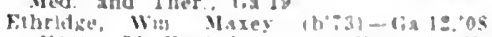
(l'ns): in bülish sre: ance. indler Annex: $11-1$

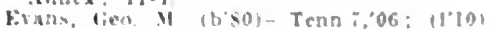

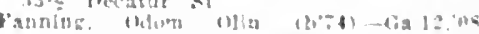

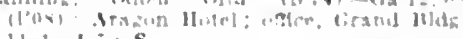
raver. lail

nimil Nin

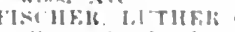

Iits. Solstis

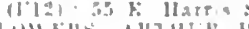

11001: irson Hute

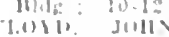

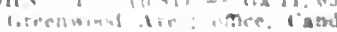

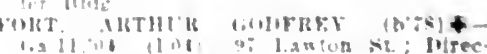

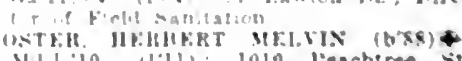

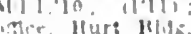


FOWLEIt, ALFIED L. (b'72)-Ga.11:99: (1'99): 16 Carnegle 10.; ottee, Candler Mldg; 12-2; clin. Pro?. Cien.-Trh. surp. (:a.5; (C3): U.

Freeman, Johin F-o; $14 \mathrm{~s}$ w. 10 th St. oflce, 302 Hemullil Ave.

F'KE, JOHN $11 .\left(\mathrm{b}^{2}+6\right)-1 \times 2,01$; (1'12) 37 Spruce St.; 1'rof. Path., Hact. ani IIyz., Ga.5.

(MANES, LEWIS MEFAIUANI) (b'- 8$)+$ Id.7,03; (I'04); 18 1'ark IAHe'; ottlo, kmplre 13lde.; 11-1, 3-4; 1'rof, Mlen Dis. and Clin. Neur., Ga.5; N.

Gardner, Grafton W." (b'30)- lia.6,61; 47 Cherokee Ave, ; 9-4

GARINER, WM. AlTTILR (1,87)-(Ga.1] 12: (1'12): P'enchtree lta.: cutuce Candler Bhdg.; 10-11, 3-4:30: NP.

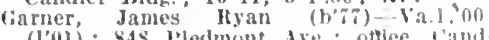
(1'01) ; 84s rledmont Are.

let Amex 11-1, 4-5, s. (iarrett, Wni.

Gault, James Thos. (b'76)-Ca.9'98; 25: $E$ Xorth Ave.; once, Inman Bidg. : 9-1, $2-6$

GEXTRY, JOHN ALLEX (b'80) \&-Va.l. '03; (); Member Tens. State Med. Assn.; Georgian Terrace Hittel: offtece, is I'ryor GIIDIXGS, CHAS. G. (b'62) +-Ya.I,'S4: 352 s. H'ryor st.; offlee, Atlanta sattona Bank Bldg; 10-12, 4-6.

GILBEItT, Wr. 1. (b'66)\$-Ga.5,'s8, I'a.2. 91: (d); $2 \times 4$ x. Wackson st.; offle Atlanta Tatlonal Bank Bldg.; 11:30-1, $4-5$

Giuffrida, Francis Jos. (1'80)-Ga.12,'10 (1'10): 15 Wholsor st.; ufflee, candler Annex.

GOLDSHITI, W.M. S. (b'70)-ra.5,? (1'42); disti riedimont Are, offce. luckle st.; I'rof. Surg. and Cun. surk. Ga.5: (A6).

Goodwy, Thomas l'ope (b'91) - Ga.11,13: (1'13); Tabernacle Intlmary.

Gordon, James T.-Cia.5, 95 ; (1'95) ;

Whitehall St. ; onlce, Immin Bldg.

GOULD, CHAS. WEBSTER. JK. (b'T3) -

111.1,01; (i'i1); 83 pruld Pl.; oftlee,

candler Rldg.; 10-1, 3-5; LD.

Grace, John T. (b'57)-Ga.1,'88; 592

Edgewood Are.; 6-8, 1-4

Graham, James Martin (b'84)—('ia.12,'12;

(1'12); $185 \mathrm{E}$. Pline $\mathrm{st}$.

Gramllng, Robt. E. (b'ĩ)-lia.18,09; (1'10); 11 W. Baker St.; offlee, Emyire Llfe Bldg.; 10-1, 4:30-6.

Green, Donald R. (col.)-D.C.3,'93; (क)

1871 is y itchell st.

Green, saml. (b'89)-0.2,'12; (1'12); 12 Alta Are.; office, Candler Bldg. ; 9-10,
$2-3,5-6$; Prof. Bact., Path. and Hist., Ga.9.

freen, Saml. H. (b'65)-Ga.5, $86 ; 106 \frac{1}{2}$ Whitehall st.

Green, Thos. E. (b'79)-Ga.9, 00; 19 Alta Are.; 8-12, 2-4.

GREER, CLARENCE BARNES (b'89) Ga.11,'11; (I'11); 151 Inighland Are. offce, State Capltol Bldr. : 9-1, 2-5; LD. GRIFFIN, EDGAR L. (b'T)-Ga.10,94; (1'94); 622 North Blrd.; offlee, Austeli

Griffith, Danl. H.-Ga.9,'11; (Deeatur) oftlee, Empire Life Blig.; 8-12. 1-4.

(iriflth, James 1.-(ia.), $93 ; 1351 / 2$ Whitehal] st.

Grizzard, Newton J.-Ga.9,'91; 305 Lee St.; offee, Atlanta National Bank Bldg. Prof. Mat. Mled. and Ther., (ia.9.

Ilall, Chas. Edw. (b'65)-N.Y.1,95; (1'95) 129 Crew st. ; offle, steiner-Emery Bldg. ; $9-1,3-6$.

Hall, James Gus (b'68)_-6.5.5.95; (1'95);

37 Miranda Ave; offlce, City Hall.

HALL, JOHN HOWARD (b'81)-Ga.11,05; $\left(l^{\prime} 05\right)$; 415 l'ulliam st.; oftce. Fourth National Bank Bldg.

Hamby, Walter B. (b'66)-Ta.5,'88: frand IBldg.; office, Candler Bidg.; ;1-11:30, 4-5:30.

Hammack, W. F.-Ga.5,88; ( ); 460 E. Fair St.

II.INCOCK, THOS. H. (b'69)↔-N.Y.1,91; (1'93); 66 W. North Ave; office, 30 Harden, Robt. DuRant (b'88)-Ga.11,11 (1'JI); 109 Greenwich Are.; Asst. Prof Anat., Ga.5.

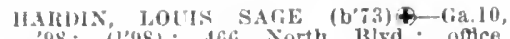

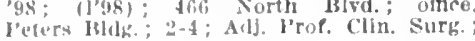
(ia.5: S.

Ilarper, Ollver Frank (b'8\%)-Ga.12,']1; Il11; : 100 N. P'ryur si.; oftlee, íandler Inzex; $9-11,3-1 ; 5$

Harrmgton, Alfred F.-(\$a.5:92: $303 \mathrm{~W}$. Feachtree St.: onjee. Cirant Bldg.

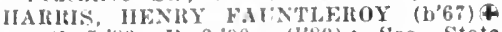

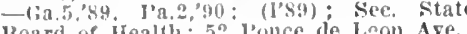
lioard of health; 52 l'once de l,on Are.
offle, state ('aphol; 1-5: (F2.10); LD.

Ilastlnks, lorne Edward (b'79) - Pa.2,'11 is Higladal Vien: 6i-s; Adj. Prof. Nat. Hed. and phar., lia.s.

IIawkins, Chas. Cilnton (b'82)-Tenn.,${ }^{\prime} 08$; (I']2); 46 Walnut st.

IIawking, lavld IBittle (b'8b)-Ga.11,13, (1'l3); $11 \mathrm{~s}_{1,2}$ kilgewood Are. ; oftee, II urt 13likf.; 9-10, 4-5.

Hawiey, Ldkar L.-Ky.4,91; 41 Orme St. office, 2311/2 Marletta st.

Hayes, Ifenry W. S.-Tenn.11,'99: (l'04) $\mathrm{N}$.

Hennies, John IIenry (b'76)-Ga.17.,06; $(106) ; 144$ Sinclair Ave.; 8-11, 2-5.

Inenry, rhas. lobt. (b'86)-Ga.12,'i1; (lii): State Board of Health. licks, Susan 11--Nlich.5,83; (\$) ; 147 Summit Are. offlce, Candler Annex.

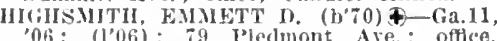
06; (1'06); 79 P'ledmont

IIII, Lyblun i. (b'80)-Tenn., 11 ; (1'11) 91 Terry st.; 11-12, 5-

HINES, JOS. HIOWART (b'78)-Tt.2,00 (l'00) : 190 W: Peachtree St.; office, (andler Bldg.; 11-1; Adj. P'rof. Clin.

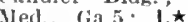

Himman, Rlehard E. (b'59) H-N.Y.9,'88, (1'93); 12: Waverly Way; offlee, $106 \frac{1}{2}$ Whiteliall st.; $\$-10,2-4$

Hollus, Arthir 6. (b'53)-Ky.2,77; 1 ('rescent Are, offlee, Empire Bldg. ; 9-1,

HOWGie, THOMAS CALMON (b'S4)-Ga.11, 08; (1'08); 759 W. Peachtree St.; offlce, Candler Bldge; 9-11, 5-6.

HODGSOX, FREDK. G. $(b, 78) €$ N.Y.1

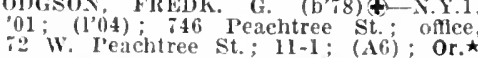
HoKE. I'eachtree St.; 11-1; (A6); Or.*

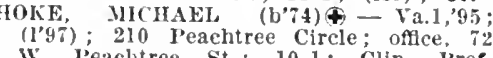
W. Peachtree St.; 10-1; Clin. P'ror Ortho. Surg., Ga.5; $(\mathrm{A} 3,6) ;$ Or. $\star$

Holbrook, Wm. Henry (b'75)-Ga.5,'98: (1'y8); 217 N. Jackson St. ; U.

Holderby, Andrew R. Roberdeat. (b'38) Ga.10,'58; (1'93); "233 Luekie

Hollander, Louls (b'82) - (ia.I1, $05 \overline{5} ;\left(1^{\circ} 05\right)$ Battle Hill Sanatorium.

Ilohllday, Benjamin F.O: 417 E. Georgia Are.

IOLLIDAY, WM. ZELLARS (b'60)llolton, Cornelius Fullmer, Jr. (b'89)Ga.11,13; (1'13) ; Grady Hospltal.

HOLTON, THONÁs J. (b'r1)-Ga.12, 09 (1'09); 86 Angler Are. : $9: 30-4$.

Hood. Hobt. L. (b'62)-Ga.10,'92; (1'90); $100 \frac{1}{2}$ Whitehall $\mathrm{St}$.

Houk, Darid M.-Ga.5,'83; 45 S. IIcDaniel St.

Ifope, Hollis Frank (b'91)—Ga.11,'13; (1'13) R.F.1). 4.

Howard, Thomas L. (b'79)-Ya.1,04, Ga.1, 08; $\left(1^{\prime} 08\right)$; 61 E. Caln St.; office, Brown-Randolph Bldg.; 8-11, 2-i.

Howell, Georgia Dwelle (col.) (b'82)Tenn. 7,$04 ; 0$ (1

Howell; Park (b'73)-Pa.2,98; (l'11); 283 Gordon St.; offlce, Carnegie Pl.

Hubbard, Thomas Virgil (b'69)-Ga.5,'92; (t) : Pledmont Hotel; $11: 30-1,5-6$.

Hughes, Talbert W. (b'86)-Ga.9,'12; ( ) 39 E. 13th st.; offlee, $16 \frac{1 / 2}{2}$. Broad St HUGULEY, GEO. P.t-Ky.4,'98; (l'98) 98 W. 11 th st.; ottice,

IHLL, JAMES L.-6a.1,89; 249 E. Pine St. ; office, $431 \frac{1}{2}$ Marietta St.

HILL, MARION MEHENRY (b'72)థ1..C.2,95: (1'97); 505 spring St.; office
Grant Bldg.: 11-1, 4-5; Prof. Ther., Ga.5.
IIUH' JOHX S.-N.Y.19,03; (1'03): 172 oftice, Candler Mldg.

II urt, John W: $\left(b^{3} 60\right)$-Ga.5,84; (8)； 580 Spring St.; offlce, Austell Bldg.; 3-4. $10-11$.

IInss, J. Frank-Ga.10,94; 450 North Blrd.; offee, $23 \frac{1 / 2}{2}$ Whitehall st.

HYTCIHNS, MILLER B. (b'64)-G-Ga.5, 86; (1'99); "The Grand; 10-1, 3-5; Adj. I'rof. Derm., Ga.5; D. $\star$

Jackson, W'm. Andrew (b'63)-Md.3,'96; (I'01); $180 \mathrm{~W}$. North Ave.; office, Fourth Natlonal Bank Bldg. : 11-1, 4-5:30.

Jaeots, Sldney Jughes (b'85); - Ga.11,'10 ; (1'10); 316 Myrtle St.

Jarnagin, Wm. C.-Va.1,72; (t); 157 Juniper St.

JENKINS, MATHEW K.-Ga.9,'91; 148 IIIghland Ave.; offlce, 227 Higbland Ave. Johnson, Allen D.-Ga.9,81; (ઠ); 114 W. Ilarris st.

Johnson, claarles H. (col.) (b'79)-Tenn. 7 ,

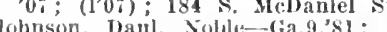

Johnson, Ilenry $B$. (b'3i)-Ga.9,87; 10 Joe Johnson Ave.

Johnson, J. A.-Ga.5,'55; 329 E. Hunter St. JOINSON, JAMES CEARENCE (b'65) $\rightarrow$ Gal.5, 87 : Peachtree Rd, : office, Hurt Intest., Ga.5.

Johnson, William E.-Ga.5,92; 188 MeLendon St. ; office, 186 McLendon St.

Jones, Alfred D.-D.C.3,00; (l'00); 126 Tatnall st.; Med. Adrlser, Atlanta Baptist College.

Joxks, AUGUSTUS B. (b'89)-Ga.11,'10; $\left(l^{\prime} 10\right) ; 96$ N. Butler St.

JONES, EDW. GROVES (b'74)-Ga.11, Tational Bank Bldg.: 11-12, 3-4; Prof.

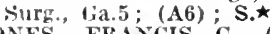

JONES, FHANCIS G. (b'86) - Ga.11,'10 : (1'10); 14 E. 14th St.; offlce, Candler Bldg. : 11-1, 3-4. (b'70)-Ga.5,91 : 326 Lawton St. ; offlee, Thlrd Natlonal Bank B]dg.

JOXES, WILLIS B. $\left(b^{\prime} 75\right)(-$-N.Y.1, 01 (l'01); 1209 Peachtree Bd.; office, Atlanta National Bank Bldg.; 10-12

JONES, Wi. TORRANCE (b'T0)థ-Ga.1 '90; $\left(1{ }^{\prime} 90\right) ; 14$ St. Charles Ave.; offlce, Emplre Llfe Bldg.; 12-1, 5-6.

Katzoff, Simon L.-Ga.9,12: ( ) : 294 Central Are.; office, 140 Peachtree st.; 11-1,

heen, Osee F. (b'90)-Ga.12,'13; (1'13): Georgia Baptist Hospltal.

Kelley. John Henry-Ga.11,05; (1'051; 57 HeLendon St.; offlee, Empire Life Bldg.

KENDRICK, WM. S.†-Ga.5,74; 286 W. Peachtree St.; office, Candler Bldg. Prof. Clin. Mled., Ga.5.

KENNEDY, JOHN P.-N.Y.5,'87; 536 W. Peachtree St.; office, City Hall.

Kesner. Geo. T. (b'63)-Ga.1,97; (l'97); 269 Lee St. ; office, Forsyth Bldg. ; $10-1$ $3-5$

Key, Claud T. (b'82)-Ga.11,'08; (l'08); 67 Inman st.

KIME. RUFUS R. (b'57) क-Mich.1, 80 : (t) Avalon; offce, Empire Life Bldg.; $12-12: 30$; $\mathrm{S}$.

(l'o5), JOS. OSCAR (b'77)†-Ga.11,05. Life Blldg.; 11-1, 5-6:S.; offce, Empire King, Aaron J.-Ga.10,95; 46 Johnson King, John H. (col.) (b'74)-D.C.3,02 (l'03) : 18 Gilmer st.

IING, J. CHESTONA-Ga.5,"95; (1'95) 65 Irowell Pl. office, Candlér Bldg. $10-11,2: 30-4$; NP. $\star$

Klausman, Marcus (b'85) - Ga.12,10 ; Annex: $11-1$ 4-6. Prof poth and clin. Nieros., Ga.19.

Knott, James J.-Ga.5,59; Knotts Station; offlce, Peters Bldg.

Lake, Wm. Fase (b's8)-Ga.11,'13; (1'13); Grady Hospital.

Lawshe, John Z. (b'56) H-N.Y.9,'83; (1'83); 150 W. Feachtree St. ; 8-10, 2-4.

LIEBMAN, JAY S. (b'84)థ'-Ga.11,'10 ; (1'10); 348 Washington St.; offlce, Candler Bldg. ; $11-1,4-6 ; \mathrm{S}$. 
Linder, John Wesley f. (col.) (b'so) Tean.7.0s: (l'0s): Brinson vrug Store.

LINDORME, ARINLD H. $\left(b^{\circ} 64\right)-$ lia.9. 98, Ga.11,03: (8): 237 (iordon st. ; once. Candler Hide: $9.1 \%, 4-6$.

I.Ingo, Wm. Bernard-Md.6,03; (l'0i): ss Cooper St. Dean and l'rot. lien surk and Oper. Gyn., Ga.19.

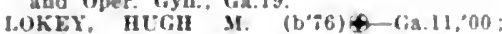
(100): 92 F. 14th St.: ofice, candlet (I) 00 ): 92 Fo, 14th St.; 0

LOXGiNo, THOSAS IICK $\left(b^{\prime 46)}\right.$ - Ga.d 70, Pa.2.82; (氵): 61 Park st.; ofle" Atlenfa Dall. Bank Bldg.: 11-1, \&-5.

Lore, Thomas D.-Ga.s."S3; is k. Falr St.

Lukens, Merrlken B.-H- $\bigcirc:\left(\mathrm{J}^{t}\right) ; \$ 5$ Ashby s.

Luning, Henry Mclninsh (b's8)-Ga.11.'10 (l'10): 55 Garnett St.: once, A ustell (1'10): 55 Garn

Madlson, James w. (col.) - Tenn.: ,9; ; (1'97); I63/2 N. Butler St.

Manahad, Mannlng W:- H-0.7,82; 28 F. Georgla Ave.; oflce, Grand BIdg.

Maner, Wm. d. $\left(b^{\prime}+4\right)-G a .11,0 L$ : (l'0I): 349 Luckle st. oflce, 431 \% Mariefta St. 9.10,3-4; Prot. Whyslol., (ia.19.

MANGET, JAMES N. (b'E2)-Ga.11,04: (l"04); 6 Angler M.; offlce, ('andler Hidg. $10 \div 30-12,4-5$

Martín, Edgar it. (col.) (b'st)-Tenu. :, (1'J0): 201 McDonough Are.

Martin. Melrllle C. fia.9,'S2; 6t Hlll St office, 328 Decatur St.

MASSOUD. MITTIY AII $\left(b^{-6}, b\right)+$ MI. 04: (J'05); 735 Ponce de Leon Ave. offce. Candier Annex: $9-12,2-4$.

MATTHFWS, OSCAR U." (b"is) \$-Ga.11, 06 $\left(l^{\prime} 06\right)$; $500 \mathrm{x}$, Jackson st. offec, Fmplre Llfe Bidg.: $11.1,5.6 ; 0$ b́. May, Wm. F.-Ga.5,92; (l'10) ; 105's

McAfee. Will am W.-Ga.9,05

Hill st.

(६); 62

Ictay, Cart Gordon (b'86)-Co $11 \cdot 10$ $\left(l^{\prime} 10\right)$ : 119 E. Gecirzia Ave, nftue. 34 Caplini Are. : $9-10,3-5$

MCCORD, JAYKS ROIEET (b'st)-Yর: "09: (l'09); 2 J'eachiree Pl.

IcDougald, James Fletcher (col.) - I, C.3 $95 ;\left(I^{\prime} 96\right): 124$ Ilouston St.

ICDougall, James (alboun (b'Re) fiall, IcFaul, James W. (b'4l)-Ga.t. row): office, 131 Marletta st

McGrew. Wm. L. (b'46)-Md.3.90: (l'0s) II: Cooper St.

McLARTY, MARVIX w, (b's)--tia 11,09 (l'09) : 94 Greensferry Ave; inle, Fourti Nat\}. Bank Bldg.; $7-9,5-7$

Mcleay. John Alex. (b'62)-I..A Н. Iluhlln, 3i. Ont.1."92; (4); Georplan Trssale ofice, 'andler Bliś: 9-11, 4 : Pro? (iyn. and Obst. Fia.19.

McMllan, Vlolet-(ia.9,'12; ( ) ; (Kirk wood): offlce, Hlllyer Trust Bld

MeltAF, VLOÝ WILLCOX (b'61) \&-Ca.5 8.5; (2): $101+$ reachtree si.; oftce, leters Hlde. : 11.1; Prof. Surg. and CHn. Surt. Hlds.: I1.1; Prof. Sur

MFHFIT, FI.ISILA IPICE: (b'85)-Ga.1" 12: (1'12); 135 Iry St.; offce, Gran Hide. : $9-1,4-5 ;$ U.

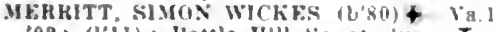
02: (l'il): Hattle Hul Sanacortum; $T$.

Mller, thas. W.-Cia.9, (0n) (l'pei); it Luckle Sh: otdce, Austel] Hog.: 10-12, $3=4$.

MILER, HAL ('UHTIS (b'8i) \&-1'a.s,09. (I'09): 83 Park st. ; ofteo, Allanta Pitl. liank ijils.

MHIJEHE, (HSCAJ I.EE (b'8̈)-(ia 11.'12 (1*12): Pletwont sianatorlum

Mis, Jaines W.-Cin.9.97;233 N. Moreland Are.

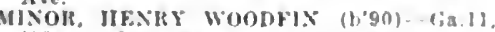
12: (1'12); Tnlernacle Innrmar

Mlichell, Jamea W.-Cia.10,R0; 187 (onklant Are, omce, Auslell islds.

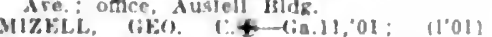

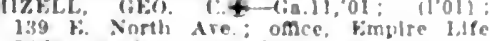
ItId: : 8-12, 3-4:30 : 1.

Monn, Pleasant leonldas-(ia.s, $19 ;$; $\left(10_{4}\right)$ 3:0 Central ire: omce, Ailania Nab] Jank Hldk.

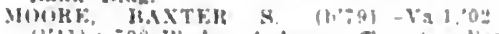

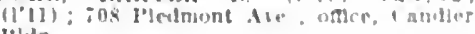

Morkan, Foblon T. $(1,60)-1$ ia $5.95:(195)$

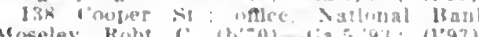

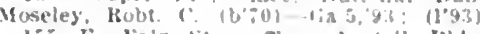
153 F. ralr st. coflce, Nustell Isldg. $9: 30-11,+6: 30 ; U$.

Notist, DAvil

(Neve ISellefuntalne, 0.$)$

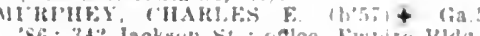

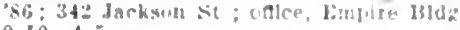
$9-10,4-3$

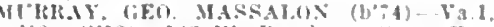
09: (1'12): 142 W. Peachtre :t; unce, Allanta ratl. Itank Rldz.

Vurrar, lirtce Emerson (b'3.3)-C, 5 ,

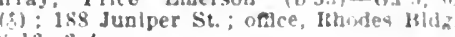
$x-12,2-1$

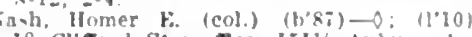
18 cllford St.; nflle, 151 th Auburn Ar NFALL, JOHN HOWAIRD (b'55) - IJ.C.3, st $\left(10^{\prime} 08\right) ; 40$ West Find Are. 8-12, 2-6.

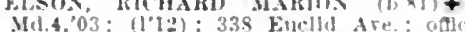

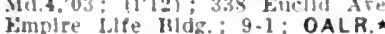

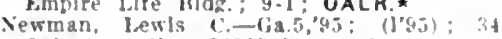
Oak sit. ; oflce, 245 h' l'eters st

Newsome, Nathan Jos. (t, 80 )- (ia 11,0 (l'0s): 115 Fast Are.

Newfon, Edwin Jorset (b'35)-La.2,58; $(1+1) ; 17 \leqslant$ I'ryor 51

Nickles, Arthur G.-lia.19,'1: :

Lake Ave ; offce, Capltol Bldg.

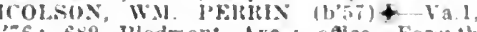
Bldg; : 12-2: (16); S.

Bldf. : 12-2: (At) S.

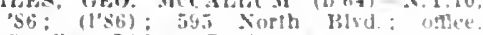
Candler Mldg. Prof. Gast.-Euter. and Clin. Med., (ia.5; $1 . *$

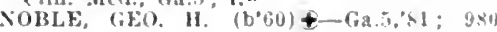

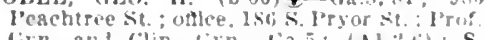

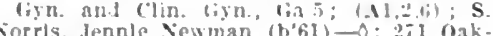
land Aic. $8-1,3,3-6$.

Corrls, Wallace W--Tenn.11,05: (1.06)

il oukland Are

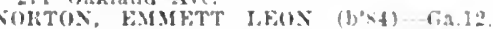

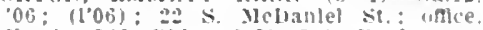
Emplre life lidg.: 9.11, 2-4; I'rus. (Iper. surk. Gial19.

GLMSTEL, JOHS COOKE (b'il)-Vi. 1,76

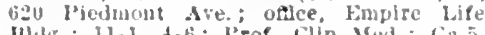
Blig. ; 11-1, 4-6; 1'rof. Clin Med. : Gat.

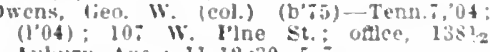
Auburil Ave. it-12:30, 5 -

онеns, Whislan-(ia.10,9\% (197); 10 IIoward st. ofte, kimplre Itse Blil.

Palne, Ciarence Mann (b'60)(ह): 381 l'ledbint Ave; offec, lirant Bliti. : 12-2:30.

Palmer, Frederick 13.-tia.10,"h3; 28.3 W Mrebell st.; oflce, Marletta st.

Palmer, Loring IR. (col.)-J'a.l, 93 ; (1'01)

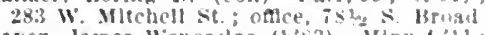
Payez, James Wencelas $\left(b^{\prime}+3\right)$ Minn. , $^{\prime} 11$

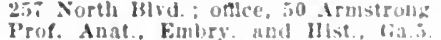

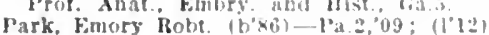

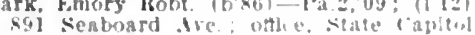
$9-5$

l'arke, bilw.

Jeachtrec st?

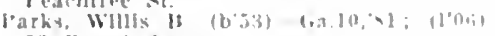
53 porest ire

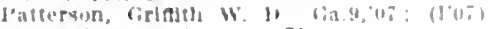
thi. Greenwoml ire; $0 b$.

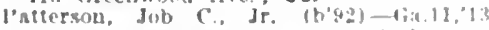
(l'li); Ciraly Memorlal llowulal

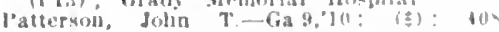

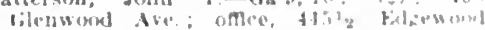
Sie

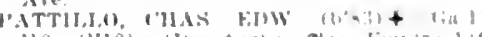

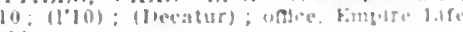
Mlisi:

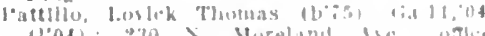

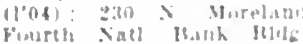

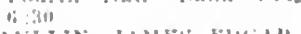

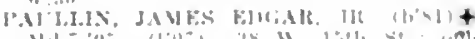

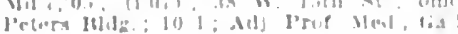
I.

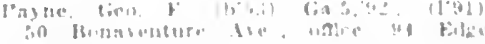

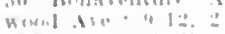

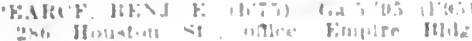

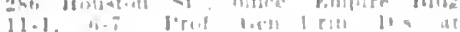
inerin.

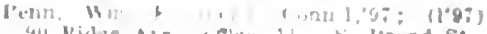

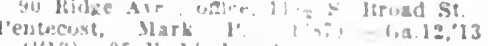
$(1 / 13): 22$, k. Laden

perry, John $\mathbb{\|}$ -

Prissox, WELIOON $\mathrm{t}+$

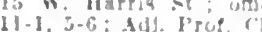

lelers, siaphen. (cul) - Tezn-

194 Pledmont Ale.

Pltmen. Jarnes fillng

(l'13): Cirady Mrnorlal Jospinal

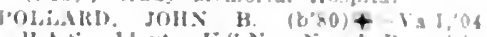

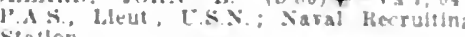
Stallon.

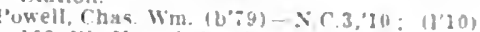

100 W: Humphrles sit.

Powell, John II. $\left(b^{\circ} 69\right)-\mathrm{Ga} .9,93 ; \quad 840$ leachtrce St.: uflce, Allania Vintlonal

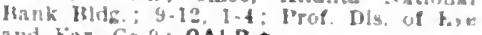
and Heilr, Ga.9; OALR.

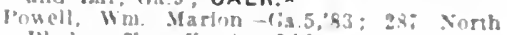

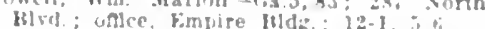

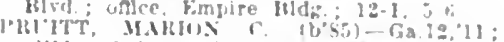
(1'11): $3: 5$ I'eachtree st.: ofluce, indler Annex, 11.1, q.

Qullllan, Andrex Flelcher (b'sh)-Ga 12,10 $(1 ' 10): 52$ 'cullege $s t$; ottce. Girand rilda' $10-11: 30,3.4$

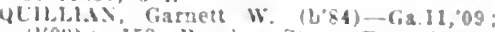
(1'04); 153 l'eeples St.; once, Peters Bldiz; 9-10, 3-5; ObG.

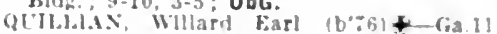
o0; (l'00); 65 l'ark Are; otsice, l'etere Iblig: : 11-1.

Razan, W'llls tugene, Jr. (b'83)-N y $1,1:$ (1"13) ; 5it Feachere St. ; udece, Allantia

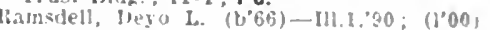
luman lider.

Medel. Homer Isewls (b'5)--Cia.11,13: (1'13): K.F.l1.

Medd, siephen C. (b's5)-Ciaje'09: (a) Arigon Hotel: once, candler Bidá; $11-3$ t-6.

IIEII, K". LOWDER (b',4 \& TA.j,'96' (1'35) : 294 Courtland Are. Anes.

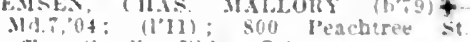
oftere. candler Indar.: S.*

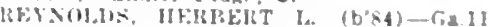
'04: (109); 494 spring St. ; once, Cand

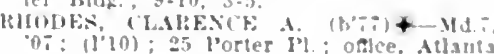
Xall. Wank Bldi: $9-10,4-6 ; P d$.

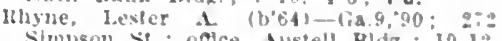
Simpon st, oftce, Austell B!dz.

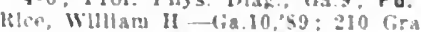

ance, $790 l_{3}$. Marletta

Itchardson, brerard [" (b'og) lia 11, 0]

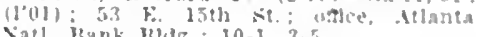
Nat1. Bunk blug.; $10-1,3-5$

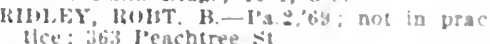

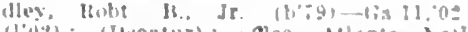
Hank Hine :-1:30: $3-3$, io): OALR

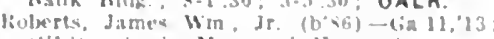

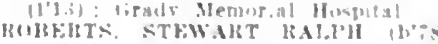

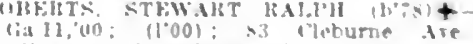

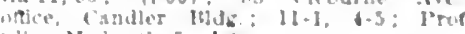
1 lin Merl. lia.5; 1.

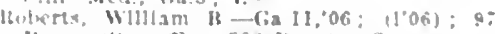
try an sis ondce, sos recatur si

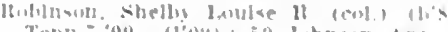

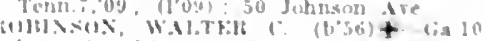
'

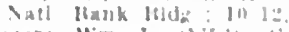

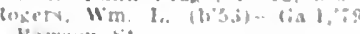

hasish $x$

oper, IIn. II (b'bi)-lin $4,04: 320$ Wast

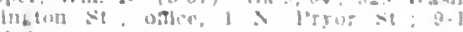

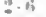

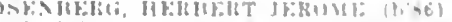

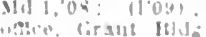

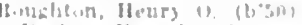

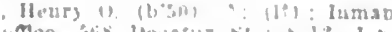

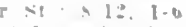

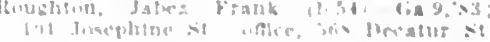

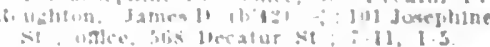

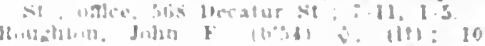

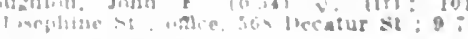




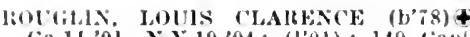
Ga.11,01, N.Y.19,04: (1'01): 149 Caple Are: oftce, Candler 13ldg.; 1I-1, 4-6 l'rof. I'hys. Dlag. lia.19.

RoS, DUNHAIt (b'66)+-Va.1, $89 ;\left(l^{\prime} 90\right)$ 921 reachtre House: 0-1; 1'rof. 1thin. Laryn. and ('lin. Dis. of bye, latr.

Russell, S. II. (col.)-Tenn.I3, OS; (寺) ; 70 IIenry st.; onlce, $2061 \%$ Auburn Ave

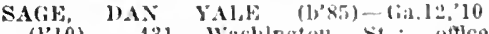
(l'lo). 4:31 Washlngton st.

Salter Freeman i,-liag, 04 ; peachtree Itd : ofllow ts st Broad St.; l'rof I'lysiol., Ga.9.

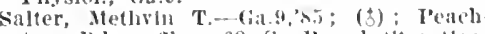
tree 14.; ontce, $68 \mathrm{~S}$. liroad st.; sec. Gia.9.

Sauls, IIenry ('llfy (l'sí) - Ga.11,"13; (l'13) ; I'iedmont sanltorlum.

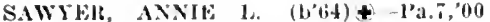
(l'01): 599 IV: I'eachtree st.: offlce (irant 13ldg.; 10-1 : 4-5.

Scott, Henry F,-Ga.t.74; 274 Peachtree st.; onlee, fits Whitehali st.

SELMAN, WM. AITTIUI (b'75) - (ia.1I, 02; (1.02); 462 North 13lvd.; oltlce, Candler 13ldg.; 11-1, 4-5: S.

Sewell, Chas. 13,-Ga.10,'s0; 126 Washington sit.

SIIALLENBELGitl, WM. F. (b'SI)

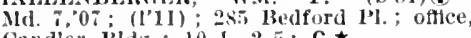

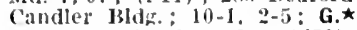

SHARl, WISFIFLI) is, (b'-0)-Ga.10,94 (l'04); 251 courtland st.; othee, 1'eter Bld

Shult', Harry 13.-Mo.24,89; 767 Edrewood Are, ; offlee, Atlanta National Bank Bldy. Silvieus, Elmer 0 . (b'iz) $1[-0.26,01$ (1'13); 14: Wellington st.

Sinkovit\%, Saml. J. (L'92)-(ia.11,13; (1'13) 423 s. I'ryor st.

Slater, Thomas II. (col.) - Tenn.7,90; 198 l'iedmont Are, once, 1281 Auburn Ave.

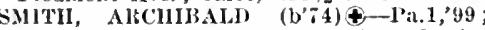
$\left(1^{\circ} 99\right)$; 314 I'eachtree St.; oftice, Empire Life kldg.; $10-12,3-4$; 1'rof. Clin. Gyn.

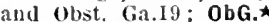

Smlth, Chas. Ephrain Jeptha $\left(b^{\circ} 65\right)-G a .10$ 97 (1'97) ; IIt. Zion Are.; It.F.D. 2; 11-1.

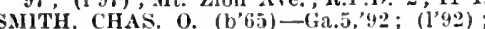
315 Capitol Ave.; office, Fourth National liank 13idg.; 11-1, :-5.

SMITH, CLAUDE A. (b' 63$) \oplus-G a .10,98$ 1.98); 565 Washington st.; offiee, City IIall; Path.

Sinith, Donald F. S. (b'75)-Ga.9,08; (市); 92 Park Are. office, Temple Court Bldg. smith, Elizabeth W.-1'a.7, 7 ; (5) ; 238 IV. Peachtree St.

Smith, ico. Waslington, Jr. $\left(b^{\prime} ; 6\right)-(i a .12$ $09 ;\left(1{ }^{\prime} 09\right) ; 246$ Houston st.

mith. Henry Marshall (b 505) - ( $\left(1^{\prime} 95\right) ; 63$ N. MIayson Are. ; 2-6.

Smith, J. Rufus-Ga.9,09; (1'09); Kimball House ; Adj. Prof. Surg., Ga.9

SMITH, LINTON (b'81)-Ga.11,02; (l'02) $63 \mathrm{~N}$. Mayson Are.; offlce, $65 \mathrm{~N}$. Nlayson Are. : 2-4.

Smitl, Marviu Farris (b'79) - Ga.11,'13; (1'13); 53 Walker st.

SMITH, THONAS HARDING (b'si)-Ga.11, '11; (1'11); 15 W. Harris St.; office, Candler Bldg.; 8-1; OALR. *

Snider, Oscar Henley (b'65) - Ga.8,'8i $421 / 2$ Decatur St.

SOMERVILLE, JOHN WILSON-Ya.1,04; not in practice; Member Mled. Soc. of Va.; 33 i Mrtle St.

SOMMERFIELD, JLLIUS E. (b'65) toffce, Atlanta National Bank Bldg.

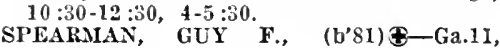
'10; (1'10); 15 w. Harris St.; office, Candler Bldg. ; $9-11: 30,5-6 ; U$.

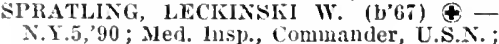
Navy Yard.

SPRATTLING, EDGAR J.-IId.3,'91; (l'99) ltremood Are.

Starnes, Wm. A. (b'73)-Ga.10,'97; (l'97); 303 Grant st

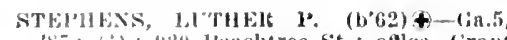
'si: (1): :00 1'eachtree st. ; onlee, (irant 13liti $11-1$.

STIPIIEXS. IRORT. GIHIER-Ga.11,05 (IPo): 337 W. I'eaclitree $S t$; oftlce, (iudller Blile.

sterts, James (d. (col.) (b'8I)-N.C.3,06.

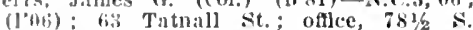
IBronal st.; $11-1,6-$ t.

STIRLAG. ALEXANDER WILLIAM (b'58)† ciot.3, so: (1'05); Fast Lake; offlce, Empire IIdg. : $9: 30-4: 30$; OALR, $\star$

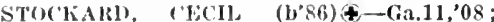
(I'08); IIf 11 urt St. ; oftlce, Empire Life

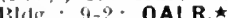

Stone, Spancer 16. (b'68)-Ill.4,91; (1'10): 26 Park Lane; offlce, Candler Bldg.; 11-1, $2-4$.

Stowe, lsanc Noel (1,'71) - Fa.9.'93; 643 Nortl 13lvel.; oftee, Allanta Natlonal Rauk Rulg.

STliICKIAL, CYRUS WARIEN (b'74) Ga.5.97; (197); 95 b. 14 th St.; offlce, 'andler 13ldy. 10-11:30; Prof. Clin. ted. (ia.5: I.

Summerall, Wm. B.-La.1,'96; (1'97) ; 190 l'alk Ave; offlec, Grady Mlemorial IIospital.

Suttles, Iolin MI. (b'49)-Ga.10,'84 ; 4s Butler sit.

STTTON, FREDK. Y. (b'78)-lia.11, 01 (1'01); 180) (leburne St.; oflce, Empire life 1 lag.; $11-1,4-5$.

Swanson, Benjamin G., Jr. (b'83) - Tenn.11, 07 ; $\left(1^{\prime} 07\right) ; 136$ Juniper St. ; office, Empire life Bldg.

SWANSOX, COSBY (b'79)-Ky.9,05: (105): 33 E. Fourth St.; offce, Empire

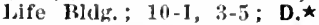

Taller, Jasper X. (b'12)-Ya.4,69; (l'10); I32 Aron Are

Taylor, Alfred G. (col.)-Tenn.7,06 (1'08); 66 Gartrell SI.; office, 221 $1 / 2$ Auburn Ave.

TAYLOR, 13LAIR D. $\left(b^{\prime} 48\right) \oplus-$ Va.1,'69 N.X.5,'T0; Col., U.S.A., retired; 755 1'iedmont Are

Thomas, Elzie B.-Ga.9,'95; 121 Park St. Proctor and Prof. Obst., Ga.9.

THONSON, JOHN DANNER (b'79) Pa.2,04; (l'04); 449 North Blvd.; office,

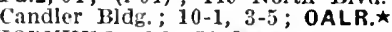

THOHNHILL, W. THOMAS (b's2)-Ga.12, '12; (1'I2); 14 w. 1'eachtree st.; office, Candler Bldg.; 10-11, 5-6.

TIIRASH, ELAIOKE C.-Ky.2,'91 ; 462 North Blvd.; office, Candler Bldg.; Prof. Dis. Chest and Clin. JIed., Ga.5.

Thurman, Joshua B. (b'5s)-N.Y.10,'86; 156 Dill Ave.

TOND, JAMES SCOTT (b'47)-Pa.2,69; (5); 607 l'eachtree st.; office, candler Blig. ; 10-2, 4-5; Emer. Prof. Mat. Med. and Ther, Ga.5.

TOEP'E1, TIIEOLORE (b'69)-Ga.11,'99; (I'49); 44 Seminole Are; office, Candler Bldg. ; 3-5:30.

Tolhurst, Geo. Monroe (b'75)-Ga.17,'08 ; (l'08); 469 W. Hunter St.

Trammell, william 0.-(ia.5,'95; (1'95) ; 39 lnman Circle; office, 503 Marietta Aré.

TRENT, POWHATAN GLOVER-1'a.2, 67 IIember Mled. Assn. of the state of Ala.; 259 E. Georgia Ave.

Truax, Florence Tilpett (l'71)-Ga.9,00, $0.2,01$; (1'00) ; 309 Atlanta Ave.; 9-12, $2-4$.

Truax, Herbert E.-Ga.9.02; 308 Atlanta Are.; I'res. Truax Sanitarium.

Tucker, Walter J.--N.Y.13,77; 92 Loomis Ave.

Turner, John Riley (b'89)-Ga.11,'12 (1'12); Grady Memorial IIospital.

Tyson, Isham S. (col.) (b'79)-Tenn. T,'12; $3081 \%$ Auburn Ave.

UICILRCII, WELBURN ARTHUR (b'82) - Ga.11.03; (1'03); 27 T Washington St.; office, Peters Bldg.; 11-1.

VANDER VEER, FR.ANCIS E. $\left(b^{\prime} 72\right) \oplus$ N.Y.3,'99; (1'10); IIotel Majestic; office, Equitable Bldy.

Van Dyke, Arthur II. (b'-0)-Ga.10,94; (l'94); 42 E. 3d St.; offlce, Grant Bldg.

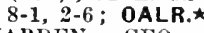

VARDEN, GEO. KENT (o'83)-0.1,05; (l'09) ; 691 1'iedmont Ave. ; offlce, Candler
Bldg. ; 11-I ; Pd.
Vaughan, Charles J.-Ga.5,'03; 210 IIIlllard st.; otnee, 246 Houston st.

verdler, Richard Augustus (b'82)-Ga.12 '08:' (1'08): (KIrkwood); offce, 350 Jackson sit.

Verdler, $W$ m. A. $\left(b^{\prime} \tau 2\right)-T e n n .8,02 ;\left(l^{\prime} 05\right)$; 490 Edrewood Are.

Vinson, Geo. A. (b'5s)-Ga.10,'8I; (t); 91 Greenwood Ave.; offlee, lnman Bldg. $9-11,5-6$

Vinson, William D. (b'60)-Ga.10,82; 57 Ponders Ave.; offlee, 790 Marletta St. ; 9-1I.

VISANSKA, SAML. A. (b'69)-S.C.1,94 $\left(l^{\prime 95}\right)$; 485 S. Pryor S6.; ofllce, Grant Bldg.; ; $11-I, 4-6$; Pd.ћ

Vryonis, Speros G. B. (b'84) - Ga.9,'12 ; Wellington Apts.; office, 140 Peachtree St. ; 9-11, 3-5.

WAGXON, BEItTLAM II. (b'84)-Ga.12,'11: (1'11) ; 186 s. Pryor St.; office, Fourth Natlonal lank Bldg.

WALDKOENIG, CHRISTIAN (b'78)-Md.3, 02 ; (1'12); Member Med. and Chlr. Faculty of ild.; 308 Whitehall St.

Wallace, Edward B. (col.)-Tenn. 7,07 (1'07); 150 Chestnut St:; offlce, $51 \frac{1}{2}$

WALLACE, JOIIN (b'82) - Ga.11,'11; (1'11) ; 21 Peachtree Pl.; offlce, Fourth Natl. Bank Bldg.; 11-12:30, $4: 30-5: 30$ : S.

Walton, Lewls P. (col.) -Tenn.7,00; (1'00); 246 Aumarn Ave.

Ward, Chas. Pelham (b'70)-Ga.10,'94; (1'94) ; 220 Gordon St. ; offce, Empire Life Bldg. ; 12-1, 5-6.

Ware, Cornellus Edw. (b'89)-Ga.11,'12 (1'12) ; 235 Capitol Are.; Grady Memorlal Hospital.

Warnock, Samuel D. (b'68)-Ga.5,'93; (1'93); 396 S. Moreland Are.; 7-11, 3-5. WARREN, WM. C.-Ga.5,90; 360 W. Peachtree St.; offlce, Atlanta National Bank Bldg.

WEAVER, JOIN CALVIN (b'79)-La.1, 01; (1'02); IIarlboro Apts. ; office, Candler Bldg.; 11-1, 5:30-6:30; Adj. Prof. Gen.-Urin. Surg., Ga.5; U.

Wearer, Reece N. (b'64)-Ga.11,01; (l'01); 8-9, $11-12: 30,5-6$

Weldon, Geo. II. (b'63)-Ga.9,'91 ; (\$) : 453 Edgewood Are.; offee, Candler Bldg. 9-12, 3-5.

West, Solomon Frank (b'71) E-Ga.9,'04 291 South Blrd.; offlce, $106 \frac{12}{2}$ Whitehali

Westmoreland, John W. (b'55)-Ga.5,'68; (t) ; 47 Logan Are.

Westmoreland, Robt. W.-Ga.5, '75;' 50 Norcross St.

WESTMORELAND, WILIIS F. (b'64)(Ga.5,'85; 50 W. 15th St.; offlee, Equitable Bldg.; 11-1; Prof. Surg. and Clin. Surg., Ga.5; $(A 1,6)$.

WILELER, AITON EVERETT (b'66) Ga.11,'99; (1'99) ; 7 E. 3d St. ; office, Empire Llfe Bldg.

Whelchel, Guy Oslln (b'88)-Ga.I1,'12 ; (1'12); Grady Nlemorial Hospltal.

Whitaker, Simon T.-Ga.9,'84; 89 Avon Ave.; offle, 525 S. Lee St.

WHITE, JOHN C.-Ga.10,89; 46 Park St. offlee, Atlanta. Natl. Bank Bldg.; 10-12, $4-5$.

White, John W.-Ga.5,'91; 511 Lee St

White, Ollver Thomas (b'78)-Ga.II, 02; (1'02); Aragon Hotel; offlce, The Grand. Whitehead, Wm. H. (b'55)-N.Y.5,76; (t); 31 White Oal Ave.; office, Temple Court Bldg. : 8-4.

Whittle, Charlton Cash (b'80) - Pa.2,'Il ; (\$)

WIGGINS, LEE WILBERT (b'76)\&-Ga.12, '08; (l'08) ; 223 Lee St.

Wigglns, Wm. Fall (b'85)-Ga.1I,'12; (1'12): $115 B$ Richardson St.; office, Atlanta National Bank Bldg

Wilkins, John G.-Ga.10,'98; (l'98) ; 497 Courtland St.; office, City Hall.

WILLETT, GEO. W. (b'68) - N.Y.I0,'93; (l'93) ; Empire Life Bldg.; 11-1, 4-6. Villiams, Andrew David (b'84)-Ga.18, 09 ; (\$) ; 581 Chestnut St. 
WIXX, DEAN F, (b's6)+ (ia.12,10 (1'10): 780 Jledmont lve.; once. Fourth National Jank Bldz: $4 ., 5$. wOLFF, MFIRXARI (b'bs) —- Va.1, R8 (8): 9 l'eachtree I'I: infec. * Inrnete

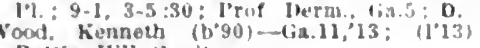
Battle IIIII Santtariun.

Wools, Paul W. (col.) (b*\$2)-Tenn.,.'0? (1'10): if Hisbee Aie.: ollice, $2021_{0}$ Butler st. : $9-11,5-8$.

Woolley, Basll M. (I'35)-Ga.5,'82; (1) ; 3 I W. Peschtrce St. $9-5$

Woolley, Vasser (b'62)-Ga.5,8t: 99 surtng St. omce. 237 whitehall st.

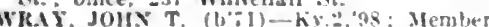

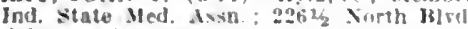
wrtght. Iuclus peatherstone $\left(b^{\prime} 3 j\right)$-ca.Il

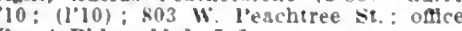
Grant Blds.: $11-1,5-6$

Wrtght, Hobt. Eimore (b's:)-lia.11,13: (1"13) ; Grady Memorlal Hospltal.

Yances, Wra. Benj. (b'67) L-Cia.9:95: 35 Cooper st.; onlce, I $\mathbf{S}$. I'ryor st.; il-1. 5. : Pr.

IAVREY, WORTH EDWIN\&-Ga.12,06 (l'06): Majestle Hotel; offlce, Empire Jife Bldg. : $11-1,4-5$; S.

relt, Otto J,-Ga.18,'11: 17 Curter St.

Young. Floyd M-Tia.9.'si: (Blue Rldge) olfice, Forsyth Isldg.

ATtAPUlgus, 360, DECATUR

CHRISTIHHIE, SAMIKL, A. I'. (blls)...

Ga.10,98: (1'4s): Pd.

Dlckens, Chas, II. (b'y0)-Ga.9,'13; ( )

ATTICA. (ATHENS P.O.), - JACKSON

Strickland. Howell cobl $\left(b^{\prime} 60\right)-$ tia.5, 90 IR.P.W..

AUBURN, 217, GWINNETY

Fowler, Thomas A. (b'is)-Ga.10,34: (c)

AUGUSTA, 41,040, RICHMOND

ALLEX, Jos. FEt-Ga.1,7;; 613 Greene St.; I'roe. Obst., Ga.I.

Armstrong, Koy M. (b'8t)-Ga.1S,11: (立) 2423 Mclowell st.; oftlce, aly Broad st. $10-12,3-3: G$

BAKEH, HIXTON J. (b's2)+Ga.l,0: BATTEI, WHATLEI W. W- Wa.1,04 BATTEI, WH.ATLE

B.ITTF:, Wy. W.-Ga.1:-3: (ङ); Wash Inston and Telfalr Sts. $x-9,2-1,8-9$

BEHXAIE, GEY TALMATHE $\left(\mathrm{b}^{\circ} 81\right)+$ (ial, $07:(100): 1298$ brosd st. : 9-10

Blanchard, C. A.-Cia.1,92: 518 N. 9tb St

BROOKS, HEXRY-Ga.1. (1'9i).

Brown, iwm, A. (cul.) (b'st-II.C.3,09 (l'10): Maguolla and inderson sis. (1'10) : Maguolla and Ninder

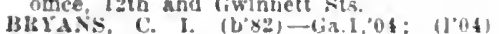

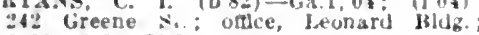
9.11, 6-7: ObG.

HHYSOX JOHT, IRWIS (h'S6)-Ga.1.09 llogy: 1120 firecue st.; uflew. Ilarrisol Bluk : 12-2, : -7 .

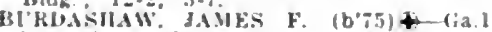
'11; (1'11): 322,30 <1. : $9-10,2-3$.

Burruss, (ieorge $\mathrm{s}$. (cul),- Tenn.,

CALLWELl. J. M.-lia.1,4; (1.47): 1316 IBroad Si.

Cleckley, H. A. H. $-0 ;(199 i) ; 1 ; i$ lirv'rue

cleckley, Marmen T.-H-1"a.9.9\%: (1'95)

COLEMAX, THOMAS D. (b'5) - I 90: $\left(1^{\circ} 01\right): 503$ fireene st.; :230-4:30 I'rof. Meil. (ia.1.

(olller. Janien Clayton (cof.) (b's:)

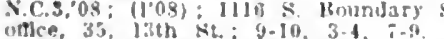

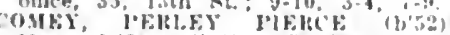
Masw. 1, :

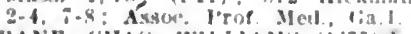

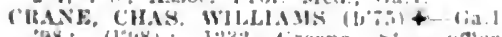

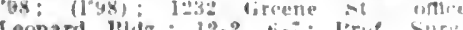

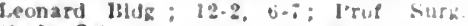
tia.1: S.

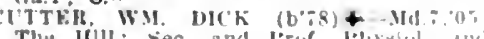
The Ifll! sec. and Irof lelysinl and Johat, lin. 1

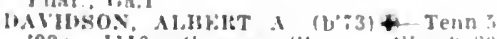
93: 116 fireene st.: unil !:3 $1+3: 30$, after :

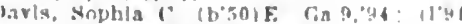
1035 Irroall st. : 0.10 .21$.

liarla, Thomas lojes $($ bow (1'11): XI9 Hroggl st.

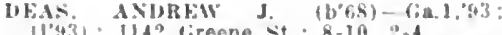

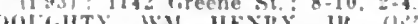

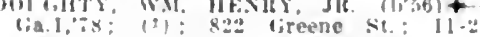

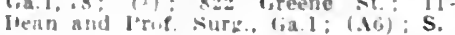

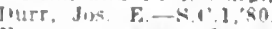

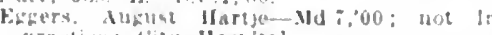
prandire: e ity hosplial.

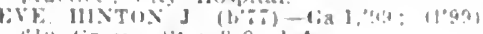
dis lireene $x$ i $89,14$.

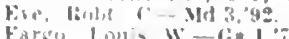

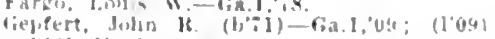

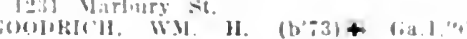

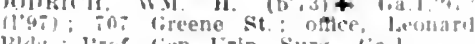

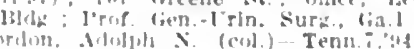

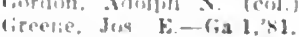

literlie. Jus k.-ria l,'sl.

lankinsus. Stephen II-Ga.1,00: (l'0u)

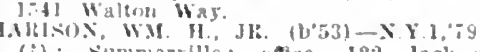

(2): Sumnertlle: onice, $122 \mathrm{Jacksu}$ Sit. ; $0-2$.

Marper. lexlus Ilenson (col.) (b'si)Mass.6.96: llog): 010 Carrie st: ontce

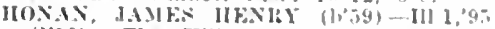

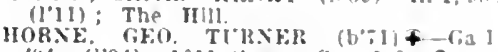
"y4; (1'94); inl1 vireene st: $1-3 ; \mathrm{s}$.

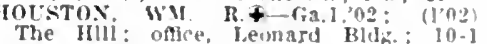
The Illl: ofte", I. Med., Fa.

IIudson, Jos. Haskeli (b.91) - Ca.1, "12 $\left(11^{\prime 2}\right): 545$ watkins st.

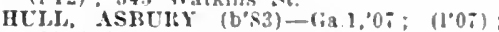
506 Telfalr st. ofice, Harrison Blif. $10-2,6-7: \mathrm{S}$

IICLI, JAMES M. (b'59)-Ga.l, 79 : (i) 506 Telfalr St, offlee, Harrlson Jldg

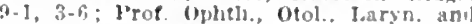
Jhin., ria.1, OALR.

Hulcherson. sidney F. (b'86) - Ga.l.1? (1'13); Augustit flly Ilospital

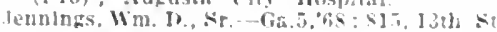

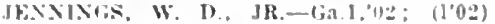
slo rawerl Are.

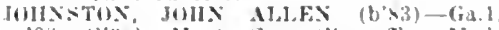

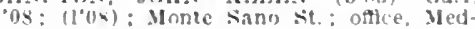
lcal Collere: Asst. Irof. Anat., Gid.i.

Joses. Thes. Walter (col.) (l,81) - D. ( . . . '12: (1'12): 1125t-2 (iwhnett st : : asil. $10: 30,65-8$

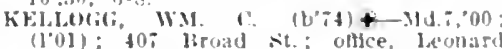

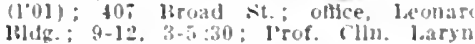
and lihn. (Fis. 1 .

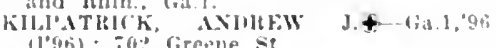

Lamar, Rlchard Vamerhory (1,a:b)- lia.

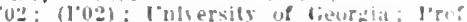
Path and Hatet., fia.j: ( $F:$

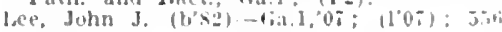
broad st.

Lethman, fieo. I1-Tha.1,og: (1999); 11ith

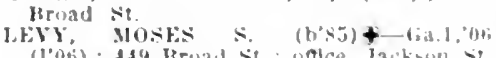

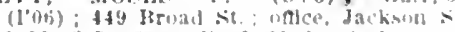
(1-11, 3-3: Aset. I"rof. Medl, dial.

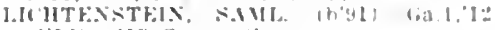

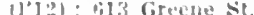

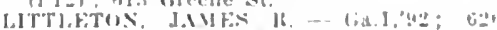
Itrial st: $8.10,2-3: 30 ; U$

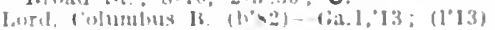

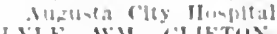

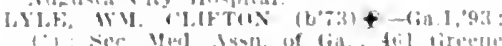

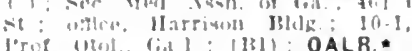

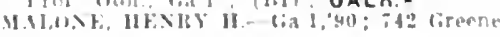

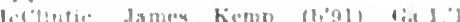

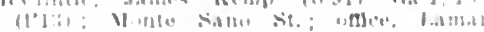

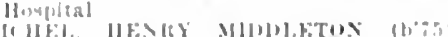

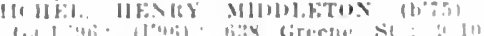

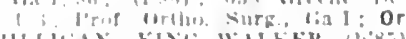

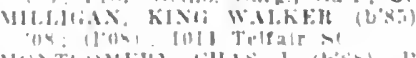

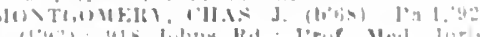

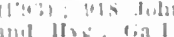

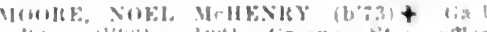

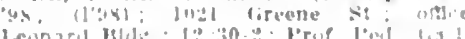
Pd.

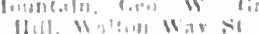

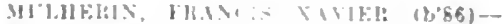
Pa.1, $11: 11,131$

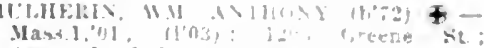

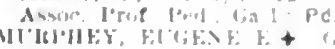

432 Telfair si : I'pise bau

vistell.

Bilythes

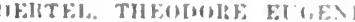

1) (..1.92; (1"b(i); 638 lire? re

n- l'sue rlen. Ophth. lial 1: OALR.

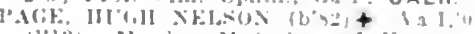

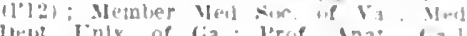

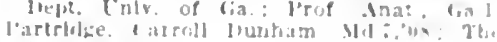
HIII Path.

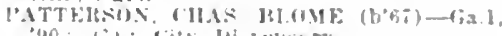

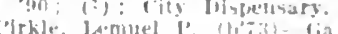

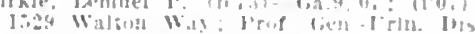
and berm., Gill: 0 bG

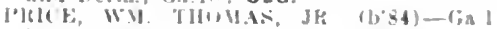

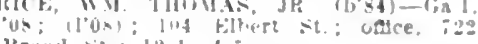
Broser $52 ; 1,-1,4$

I'ritchett, W' T. (cul.)-X.C.3,94

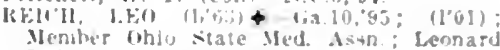
Blus:

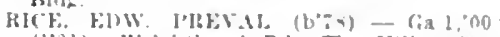
(1.01): Wrlahtberrl Rd. The HIll: onlce. leonard J]dz.: I:-2, 6-8: U.

l:OBERT. WM. H (b's9)-(;a.1,'33; (1'13) I3th anil broad st.

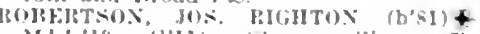

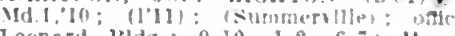

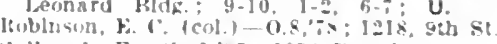

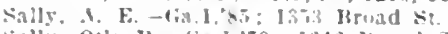

Sally, Otls H-tia I."79: 194h Hroad st

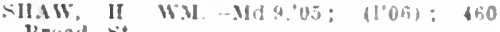
liruad st.

silser. Inild Marion

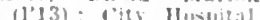

sllnann, J. H. (col)-Tenn. ., 06 : (190n)

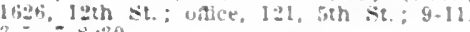
$3-\overline{3}, 7-8: 30$.

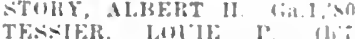

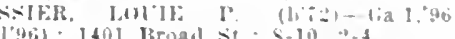

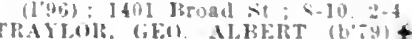
4. (103)

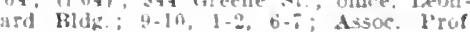
surg. (ia.i: S. " verlery, Isee Walton (b'v)-(ia.1.11 (1'11): (North tugusta. Sic): nttice, Har rlson Rlig: 12-2, i;

WAIV, ARTIITH C. (b'75)- lia 1."49:(1'y) 1100 firene st.: $8-y: 30,1-4$

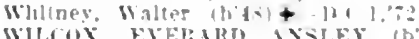

WIICOX, FVERART ANSLEY (b's5) + 3-4: Inil Irof" I'ath lia.I: s

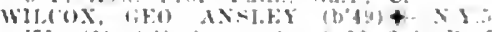

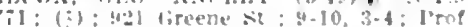
(i) 11. li3.1: G

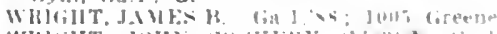

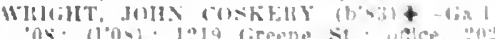

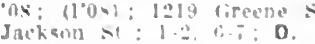

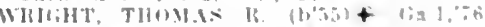

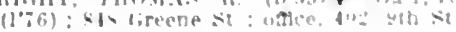
I'sue Nils: lid l:

AURARIA, 150, LUMPKIN

SHULW, WiI M. li, I,

AUSTELL. 755, C08B

liarjolt. linke :

AVALON, 60. STEPHENS

UCIITII. WW. I.

AVERA, 228, JEFFERSON

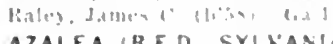

AZALEA IR.F.D. SYLVANIA), SUO SERE VEN

BABCOCK, 102. MILLER

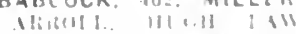

BACONTON ?YI, MITCHELL

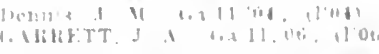

BAINRAIDGE, \$.21\%, DECATUR

Hrlill Vrab his (5) 
CHASON, JEFFERSON DAVIS (b'62)

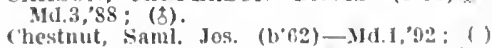

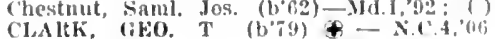
(1'08); Pd.

Cooper, C IR. (col.) - Tenn. i, 9e: (l'01). Frederick, cary 1., (col.) (b'so)-Tem. $05:(1,06)$

Klsh, l'atul it (h'si)-Mdil'13.

Toole, John E: (b'68)-VI 3 s9: (8)

BALDWIN, 280, HABERSHAM

CHANULE, W. YA.T'K-Tenn.9.96.

Willams, (ien. (C. (it.9,1:3; ( ) : li F.1).

BALL GROUND, 4.18, CHEROKEE

IIendrix, IIarion (i.-Ga.11,02; (1'02).

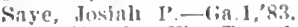

West, Tarpley W.-Tenn.1.03; (1'03).

BARGE, 80, CARROLL

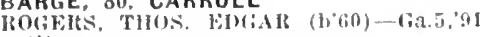
(ई)

BARNESVILLE, 3,068, PIKE

ANDERSON, J. M. GA.9, 'DT: (1'99)

Corry, dohn A. (b;i) - Ga.1, 98 ; (1'98)

Corry,

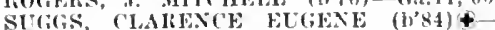

(ia.12,12: (1'12)

WIILAs, CLARENCE H. (b'83)£-Ga.11, $06 ;\left(11^{\prime} 06\right)$.

BARNEY, 303, BROOKS

Fiumphreys, Alexander S.CGa.5,'92.

Mitler, N. V.-Ga.5,?3.

Mdom, A. J.-Ca.1,05; (l'05).

Odom, A. J-Ga.1,05; ${ }^{2}$ '

BARRETTS, 80, LOWNDES

Jones, ('has. X. (1'7')-(')a.1,'98; (1'98).

BARTOW, 384, JEFFERSON

llarrey, Wm. Linwood (b'88) - Ga.1,'12;

Josey, Chas. R. (b'60)-La.1, 84 .

Thomas, $11 \mathrm{~m} . \mathrm{i}$. (h'56)-1'a.2,'is.

BARWICK, 38I, BROOKS

Lundy. I onmie Lee (b'86)-Ga.12,'11; (1'11)

SANCHEZ, SIMEON E. (b'is)-Ga.11,01; (l'01).

BAXLEY, 831, APPLING

liranch, Wills David (ia.19,13; (年)

Comas, Phllip II.-M1.1,' 82 .

Johnson, Andrew ,. - - Tenn.11,01 ; $\left(\mathrm{l}^{\prime} 02\right)$

McCrackin, Horace Clifton ( $\left.b^{\prime} \mathbf{6} 6\right)$-Tenn.11, , 03 ; (1'03).

Mercer, Jos, Eugene (b'81)-Ga.1,'13; (2'13).

Pirkle, W. C.- - (ia.1,02; (1'02)

Weaver, John L. (b'52) - Ga.5,

BEACH, 358, WARE

Findley, Cleveland W. (b'87)-Ga.12,12 ; (1'12): ObG.

McMillan, Thos. J. $\left(\mathrm{b}^{\prime} 90\right)-\left(\mathrm{Ga}, 18,{ }^{\prime} 11\right.$; (\$) Royal, Warren MicCrimmon (b'85) - Ky.2,'12; (I'12).

BELFAST, 300, BRYAN

Mc13ryde, Stewart (b's')-Va.t,'12; (寺).

BELLTON, 193, HALL

QUILIIAN, WYLY 11.-Ga.9,02.

BENEVOLENCE, 46, RANDOLPH

Binion. W, W.-Ga.5, 85 .

TAXYER, JoS. B. (b'69)-Ga.11,04; (1'04); G.

\section{BEN HILL, - FULTON}

Campbell, 1. r'arker-(ia.10,96; (1'96)

JeGee, Roy Wm. (b'88)-Ga.12,12; (1'12).

BERLIN, 200, COLQUITT

Bond, Chas. Lee (b'66)-Ga.9,'90; (b).

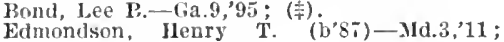
(I'12); $\mathrm{S}$.

BERNER, 10, MONROE

Smith, Benj. L. (b'i2)-Ga.9, 06 ; (1'06); R.F.D.

\section{BETHLEHEM, 209, WALTON}

ADAMS, ROBT. P. (b'7i)-(ia.1,04; (I'04).

Dela l'erriere, Edgar Eugene (b'84)Temn. 9, 04 :

Harrls, Ernest Robt. (b's5)-Ga.1,07;(1'07). BISHOP, 268, OCONEE

KENINIE, E. H.-Ga.5,97; (1'9i).

BLACKCREEK (R.F.D., SYLVANIA), 108, SCREVEN

HoCall, Chas. Polhill ('’'43)-Ga.1,'83; (1'05). L'well, Benj. F. (b'69)-Ga.1,'98; (1'98).

BLACKSHEAR, 1,235 , PIERCE

HENIPLY, GEO. 'TRACY (b's0)-Ga.12,'06;

MOOkE; WM. R. (b'Gi)-Ga.1,98; (1'9s).
OIEN JOHX WESIAY (b'85)-Tenn.1,08; MU: THOS. FLLSWOIRTI (b'76)-Tenn.1, "110: (100); OALR.

WHILA.MS, W.M. 1'. (b'67)-X.X.10,'88; (1).

BLACKWELLS, 25, COBB

Bannister, C. 1). (b'81) 一 (ia.12,08; (1'08) R.F.1). 1.

BLAIRSVILLE. 203, UNION

Berry, Thos. N.-Ua.IL, (1); (1'02)

FHWIN, F1RINK 1. (b'57)- - ia.5,'84.

BLAKELY, I.838, EARLY

ALEXANDER, WM. II.-Gin.5,95; (1'95)

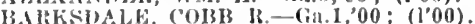

13lackitear. (ieo. IJ. (b'6s) - Ky.1,"96;

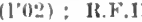

FITZGELA1D, PIILIP H. (b'80)-Ga.II $10 ;(1010)$

liand, Jos. 11. (b'56)-Ga.9,87.

Irwin. Emmett F. (b's6)-Ga.9,08,

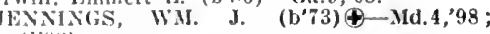
(1'98)

SIMMOX̃s, 13, K.-Ga.9,10.

STANIHFER, JACK GUY (b'88)-Ga.1,'11; (l'i1).

STANDIFER, WM. BRYAN (1)'55)

BLUE RIDGE, 898, FANNIN

CHASTAIN, JOHN BUNION (b'57)-Ga.5.

CRATFORD, C1,AUD BURTON (b'73)థ-

Ala.2, 05; (1'05); Pd.

DAYEs, JAMES MUNROW (b'60)-Ga.5,'86.

roung, Floyd M.

(See Atlanta.)

BLUFFTON, 325, CLAY

Carter, WV. T. $\left(b^{\prime} 59\right)$ - Ga.5,'84; (d)

JOHNSON, BEN TERRELL (b'89)-Ga.12, 'I2; (l'12)

Thompson, Patrick H.-La.1, 78 .

BLUNDALE, 30 , EMANUEL

CARTER, JOHN B.-Ga.1,'05; (l'05)

BLYTHE, 100, RICHMOND

13ARWICK, JOHN B. (b'50)-Ga.1,80; (b).

13EALL, Josiu A R.-Ga.1, 87 ; (o).

Shunan, Paul Anderson (b'88)-Ga.1,'12

(1'12)

TLKNER, JEJAMAR, JR. (b'7t)-Ga.1,'12; (1'12); Ob.

BOGART, 257, OCONEE

Wall, Janes M. D. (b'64)-Ga.10,'91.

BOLINGBROKE, I44, MONROE

McManus, Hugh Forest (b's6)-Ga.12,'13 (1'13).

BOLTON, I50, FULTON

Iclonald, Paul-Ga.9,02.

BONAIRE, 150, HOUSTON

Erans, Horace E. (b'84)-Ga.12,'11; (1'11)

BOSTON, I,I30, THOMAS

Friddell, Wm. F. (b'69)-Ga.10,92

Morton, Jloyd Farnest (b'84) - Ga.11,'11

Taylor, Chas. Sumner-D.C.3,'05; (l'09)

YANY, IIENRY A.-N.Y.5; 7 .

Watkins, II. L. $\rightarrow$.

Watkins, John E.-Ga.5,91.

BOSTWICK, 333, MORGAN

FAMBLOUGH, WM. MEIGS (b'72) E-Ga.9, 04.

RIDEN, CLALDE F.-Ga,10,'87.

BOWDON, 54I, CARROLL

LOVFOIN, JAMES L. (b'62) -Ga.1,'86; (ट).

Lovvorn, Robt. M.-Ga.1,'89; not in practice.

Mlartin, Frank A. (b'65)-Ga.9,'86.

IcAfee, M. F. $\rightarrow$; I.F.D. 2

SMITI, Wu. P. (b'66)@-Ga.1,91; (1'91)

WILSON, LOU1S E.-Ga.11,'03; (1'03).

BOWERSVILLE, 398, HART

Shields, IIaruld Franklin (b'81) - Ga.11,'08;

BOWMAN, 738, ELBERT

DILLASHAW, JAMES ASBURY (b'54) -

(ia.1, 89 ; (⿱艹)

Johnson, Alexamiler S.-Ga.10,'81.

WALKER, OBIE B. (b'73)-Ga.9,'93.

BOYNTON (R.F.D., RINGGOLD), 75, CATOOSA

MUR1'HY, MARION W. (b'62)๑-Ga.5,'92.

BRADLEY. 50, JONES

ANDEPSON, JOHN FRANKLIN-Md.3,'85.

ZACHIARY, JOS. D. \pm -Ga.18,'11.
BREMEN, 890, HARALSON

fook. Hamlin Collier (b'59)-Ga.9,'88.

Hutson, John A. (b'63)-Ga.5,'92.

l'hilins, Marshall K.-Ga.9,'81.

Sanford, Eugene Farmer (b'90)-Ga.18,'10

(4a.1,12; (l'10): H.F.D. 2.

Stepliens, Marshali 11.-Ga.9,93.

Willians, Benj. Franklin (b'84)-Ga.11,'10 ; (I'I0); Pd.

BRENTWOOD, 125, WAYNE

Ogdell, Danl. IIolland--(ia.5,'95; (l'95).

BREWTON, 214, LAURENS

Moye, Cecil Guy (b'88)-('十a.11,'13; (l'13).

sessoms, Wn. Clcero (b'66)-Ga.5,'92.

BRIDGEBORO, 350, WORTH

Hicks, lkeulsen N. (b'65)-Ga.1,91; (l'91)

l'ittmin, CarI shepard (b'88)-Ga.11,13: (I'I3).

Tyson, Garry C. (b'69)-Tenn.9,03; (l'08).

BRINSON, 707, DECATUR

l'ridges, Roht. L. Z. (b'71)-Ky.4,'94; (t),

BItINSON, HOMER H. $\left(b^{\prime} 78\right)-$ Ga.11,02; (1'02)

WIISNANT, BAKER (b'88) - La.1,'10: (I'12).

BRIST OL, 198, PIERCE

STEWART, ANDREW (b'75)-Ga.12,09; (l'09).

BRONWOOD, 465, TERRELL

O'NEAL, R. S. (b'87)-Ga.1,'11; (l'11).

Stapleton, Jiram-Ga.11,'04; (l'04).

BROOKFIELD, 35, TIFT

Buchan, Jos. R. (b'72)--Ga.9,'95; (\$)

BROOKLET, 36I, BULLOCH

Grooms, Thios. IaFayette (b'89)-Ga.1,12 ; (1'12); R.F.D. 1.

MCELVEEN, JESSE MORGAN (b'7 7 )-Ga.1, $02:(1,02)$

STAPLETON, C. E. - Ga.1,06; $\left(l^{\prime} 06\right)$; RATKINS, EMORY CLIFFORD (b'81)Ky, 2,07; (1'07).

BROOKLYN, 50, STEWART

Armonr, Wm. S., Jr. (b'89)-Ga.11,13 ; (l'13).

BROOKS, 200, FAYETTE

Drewry, Richard H. (b'71)-Ga.1,77.

Gable, James L. (b'60)-Ga.5,'83.

Gable, ‥ W.-Ga.5,'93.

BROXTON, 1,040, COFFEE

Lott, John James $\left(b^{\prime} 83\right) \longrightarrow 0$; $\left(l^{\prime} 10\right)$

Poer, Benj. G. (b'42)-Ga.5,'69.

RICKETSON, GEO. M. (b'67)-Ga.10,'94.

BRUNSWICK, 10,182, GLYNN

ABERCROMBIE, THOS. FRANKLIN (b'79)

$\$$-Ga.11, 03; (1'03).

Bishop, Ira N. (b'52)-0.9,74; 1316 Unton

St.; offlce, $14001 / 2$ Newcastle St

lanton, Geo. W. (b'58)-Ga.5,78; 1416 Lee St.; office, Kress Bldg. ; $9-1,3-5$.

Branhan, IIarris M. (b'62)-MId.3,'88; 803 London St.; office, Glynn County Bank Bldg. ; 10-11, 4-5.

Buggs, John W' (col.) (b'73)-Tenn. i,'98; $\left(l^{\prime} 98\right)$; 1300 Ciloucester St.

BURFORD, ROBT. E. L. (b'61) -Ky.2,'89; (引) ; 1017 Egmount St.; office, 1600 New-

castle St.; $9-10,3-4$.
Butts, Judson $\mathbf{A . ( b} 38)-$ Pa.2, $60 ; 720$ Union St.; office, $15031 / 2$ Newcastle St. ; 9-11, 3-4 Carswell, Saml. J. Tilden (b';0)-Ga.1,00; $\left(1^{\prime} 00\right) ; 1312 \frac{1}{2}$ Newcastle St. ; 9-12, 2-5.

Cate, Gustarus .V. (b'62) -.IId.3,'88; (ठ) ; 1801 Norwich St.

Christie, Alfred (b'63)-Md.3,97; (l'97): $1901 \mathrm{~F}$ St. ; office, Akins Bldg.; $10-12,3-5$. Fox, ROBT. L. (b'73) \$-S.C.1,93, N.Y.1, $96 ;(1997) ; 1000$ Egmont St. ; office, Wright Bldg. ; $9-10: 30,3-4: 30$.

Harrell, Jutian 1. (b'81)-Md.1,06; (l'0i) 713 Egmont St.; (office, Mt. Pleasant).

Jackson, Raymond Nathaniel (col.) (b'83)-

Tenn. 7,05; (l'05); 1506 Albany St. ; office 1203 Gloucester St.; until 10, 1-3, 6-8.

Mann, Thos. A. (b'77)-Md.1,'03; (l'13) 501 Darmouth St.; offlee, High School Bldg. ; 9-12, 3-5.

Nash, Ira Eibert (col.) (b'79)-D.C.3,09: (1'10); 2108 Wolf St.; office, 1308 Gloucester St. ; 8-10, 1-2, 6-8.

I'urse, Marshall Ashby-Ga.10,'90, N.Y.1,'92.

Simmons, John W., Jr, (b'80) - Ga.1, 05;

(1'05) ; 924 Union' St. ; office, Kress Bldg. :

$10-12,3-5$. 
BUCHANAN, 462, HARALSON

Ilutcheson. Bdwe 13. (b'5T)-lia.5.98.

Keld, John \$. (b'68)-Ga.5,'92.

BUCKHEAD, 384, MORGAN

Brown, Y. J.-Tenm.10,03; (l'06)

THOMI'SOX, ALVAll $16 .\left(b^{\prime} 90\right)+-02,11$.

BUENA VISTA, 1,016, MARION

Urane, Wm. A.-G. L, "st?

IInllis, Mark D.-Md.4,98; (l'9s).

Jefferson, Wesley-lia.1.'A

Mestlchael, Itobt. I.-Gia.11, 00 ; $\left(I^{\prime} 00\right)$.

Weaver, Jos. A. (b'6i)-Ga.5, 91 .

BUFORD, 1,683, GWINNETT

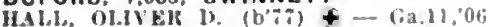
(1.06).

Huchlns, Wm, Jackson (b’si)-Gia.11,10 $\left(l^{\prime} 10\right)$.

Lles, Ilomer D. (b's9)-Ca.9,'13; ():

IR. F.D.

l)rkle, Noah 6. (h'is)-Tenn.11,9s; (1'00)

Power, Wm. W. (1) 14)-(ia.\$.'82.

Rowe, Wm. 3. (1)56)-Ga.1,85; (

Woodw ard Jos, 13 - Ga.9, 95 .

BULLAROS, 30. TWIGGS

Watkins, Ben). F. (b'S1)-Ca.9, 05 .

BULLOCHVILLE, 204, MERIWETHER

liodwin, Win. If.-Ga.5, 8 ;

Kitchers. T. Neal $\left(b^{\prime} 61\right)-K y .4,01$ (

McDonald, Jrobt. H.- Cia.12,'13; (I'13)

BURLINGTON (R.F.D., BLAIRSVILLE), 20 UNION

Bogers. Wm. H. (b'b0)-(ia.11,01: (1'01)

BUSHVILLE, (R.F.D., COMMERCE), 10 BANKS

IIAIDF., WM. P. (b'e6)-(:a.5,'86.

BUTLER, 705, TAYLOR

Anderson, karl W.-La.L,0T; not In practlee.

vdwards, Wanzle W.-Tenn.11,45: $\left(10^{\prime} 0\right)$

Ciordy, Addls Bernard (b'it)-Ga.9,'99; (俦)

BYROMVILLE, 300, DOOLY

D.INIS, ED(iAR I3.-Md.1,04; (1'04)

Watts. Wm. Jowers (b'65)-(ja.1, 89 .

BYRON, 300, HOUSTON

Cline, Geo. 1". (b'74)-Tenn.11,"99: (1'00)

smith, s. D.-Md.3,82.

Warten. Moultrge Nifred (b'80)-Tenn.5, 00 $(1,00)$.

\section{CADWELL, I54, LAURENS}

Bland, simenn D. (b'31)-Ga, 6,

Coleman. Alfred (b'8t)-Ga.12,10; (1'10).

CAIRO. 1.505, GRADY

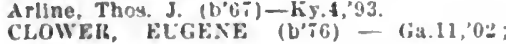
$(1,04)$.

LIXISAY, JAMES A. (b'-3)-Tヒnn.9,'9?

oliver, Win. Fo (L'81)-(;a.1, $\left.02 ; 11^{\prime} 02\right)$.

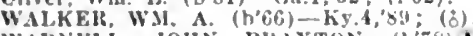

WAIELI, JOHS BHAXTON $(1,78)+$ (ia.11,00; (1'00).

CALHOUN, 1,652, GORDON

Borlers, Wr. Indrew (b'67)-Ga.5,"90

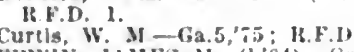

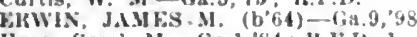

Harp. Sam. M.-Ga.1,84; K. b.I. 1

McLiIs, chis. F, (b'6i) - (9a.5,95 (1'95).

Mlils, (ieo. W.-Tenn.6,'si.

Hehards, Wim. A.-1;a.1,8; ; (\&)

Hchards, Wm. Hoy (boy)-(ia.12,13: (1'1:)

SHELIHOHEE, HVAS O. - (ia.).00

CALVARY, 85, GRADY

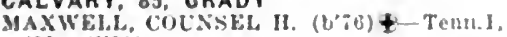
0I: (I'01)

CALVIN (R.F.D., MONTICELLO), 27, JAS. PER

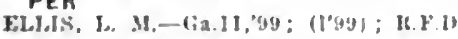

CAMILLA, 1.827. MITCHELL

Hrown, Jolun I, -Ky.4,"yI,

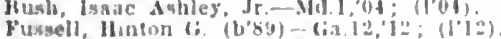

Lewis, Furreat 1. - (ias.5, $52:(1)$

Mansileld, Filiner F.-Ky.4,gn: (\$).

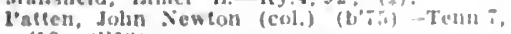
'12; (1'12).

spence, John M.-KY. I.98; (19.3)

sterensu, Clydo A. (b') -

CAMPTON, 145, WALTON

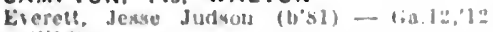
(1"12). Alonzo Thomas (b"3:) Tenn.1, 59 : rark, A

rearwoul, s. s.-Cin.s, s3: ()
CAMP YONAH, - STEPHENS

HIYAST, WM. (") (1,'6B)-Ga,10,89.

CANON, 728. FRANKLIN

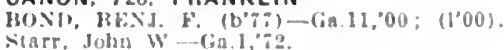

THKRELL, J(11. 1I., J16. (b'81)-(ia.11,"10; (I'10)。

CANTON, 2,002, CHEROKEE

llates, Jack M. (1,69)-7ia.10,"90; S.

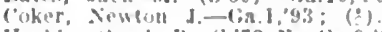

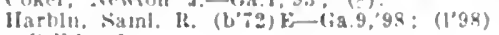

li $F^{*}$ l, 1

Turk, whu M- Ma.7,58

Willingluan, W. M-Tenn.9,'92.

CARLTON, 325, MADISON

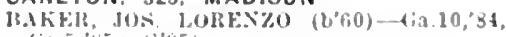

(i.1.5, $25 ;(1,45)$.

Rraifurd, I'hllip It. (b'52)-Cia.5, 80 .

leadwbler, Onule 1. (b'70)-(ia.1,92:

CARNEGIE, 40, RANDOLPH

Itugh, luther f'rancls $\left(b^{\prime}, 5\right)$ - Ga.9, 02 .

Shepard, John L. (b's6)-Ga.11,08; (l'08)

CARNESVILLE, 322, FRANKLIN

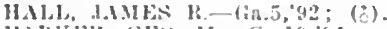

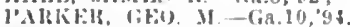

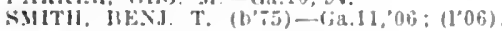

Tucker, J. H.-Gia.1, 52.

CARROLLTON, 3.297, CARROLL

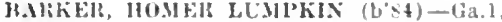

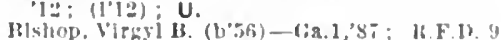

lirock. F. Maslon-6,a.1,89.

Itruck, Jefferson C. (b'58)-Tenu.5, 84

('As1', J0s. It. (b'b1)-(ia.1,'8i; Pd

Carter, J. H. M.-Cia.5,'s3.

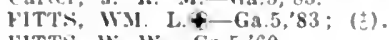

HTTS, W. W.-Ga.5,60.

rostrik, HOHT, ELLIS $(1,73)$-Tenn.6,0l : $\left(1^{\circ} 0 t^{i}\right)$.

Garst, I. C. Ilinkle-ria.11,03;

(1'03) ;

Glititus, JoHN C. (b'60)-6ia.5,90; Li.t.1). 9

firltin. ('laude (b'ss)-(;a.11;11; (1'11).

IIM,1,i'M. M. M.-Ga.5,9s: (1'9s).

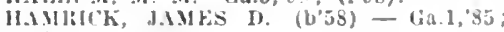

Ilantock, \$. Walter-Tia.1s,'10; ().

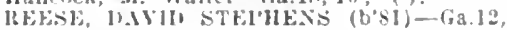
iti: (106i).

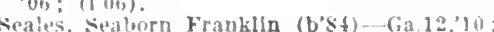
(1"10)

sheats, Thumas G.-Ga.5,'s1

West, (irover (b'81)-Cials, 10 : (1'10)

CARTECAY, 150, GILMER

Chastaln, Willer (\%--lsil.1s,11; (\$)

CARTERS, 50, MURRAY

Wontgomery, Andrew d.-lia.5,"az; (l'Bi).

CARTERSVILLE, 4,067, BARTOW

AlIIK, HOIBT, F. (b'bi) + Ga.10, (an) (")

liaker. Thos. 11.-1'all, 75

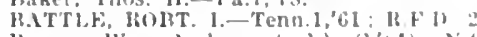

lirown, Win. Andrew (col.) (bis)-Xiva 1:- : $(1,12): G$

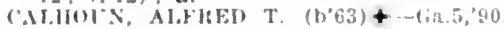

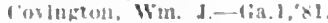

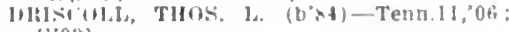
(10.6!

FELIU) H(11)

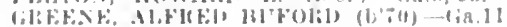
(01): $(1,00)$

Glatrix, wy. (

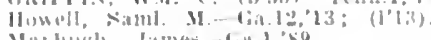

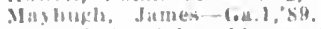

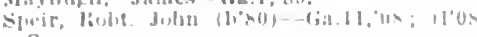

CASS STATION. IIO, IBARTOW

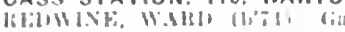

CASSVILLE, 500, BARTOW

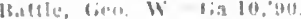

CATAULA, 50, HARRIS

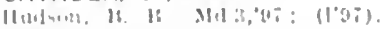

CAVE SPRING, 805. FLOYO

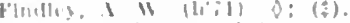

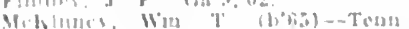

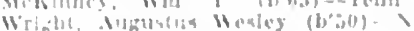

CECIL, 331, BERRIEN

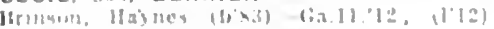

CEDAR SPHINGS, BO. EARLY

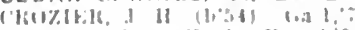

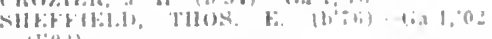

CEDARTOWN, 3.551, PULK

Mrantoril, Wm. (L't?

(H.HM.M. WM AlLES

(1'3.i) s.

(1) (1"3i3)

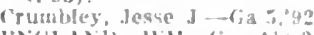

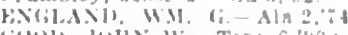

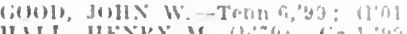

11.1.1. Ilk.

li111)kt, Jos. $\mathrm{A}+$ - lia.1, $\% 9$

l'kiki, r. W.-

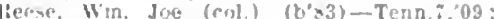
$(100)$.

Mcharifon, Fiverhard H. (b'50)-6a.l,;2; (*)

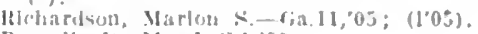

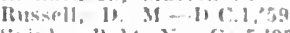

Spinks, llobt. X-Ga.5.93.

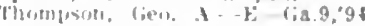

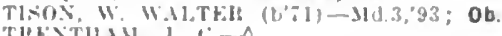

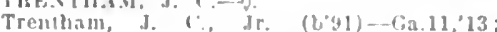
(l'13)

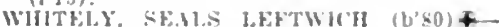

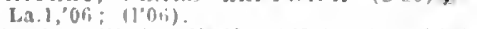

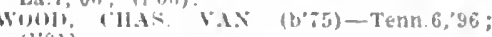
(10(11)

CENTER, 208, JACKSON

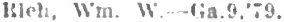

CENTERVILLE (R.F.D.

VILLE), 100, GWINNET̈T

Brown. l'eter James $\left(\mathrm{b}^{\prime} \mathrm{S} 0\right)-\mathrm{Ca} .12,08$; (Jos).

CENTRALHATCHEE (R.F.D., FRANKLIN), II9, HEARD

Wortham, Albert C. (b'is)-Ga.1,04; (l'04).

CHAMBLEE, 129, OEKALB

W.ITKIXS ANUHEW UL (b'CJ)-Ga.5,'99: (*).

CHATSWORTH, 314, MURRAY

IJulles, Jane's K. (b'il) - Tunn.9;99; (l'02).

CHATTAHOOCHEE, - FULTON

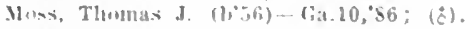

CHAUNCEY, 350, DODGE

Clark. 'has. dames (bosi)-Cia.1.89: (c).

(ollum, Useat Fredk--18a.12,07; (100\%):

CHESTER, 278, DODGE

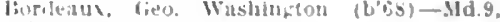

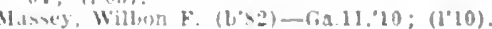

CHICKAMAUGA, 312, WALKER

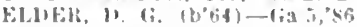

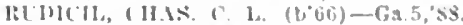

CHIPLEY, 7\$2, HARRIS

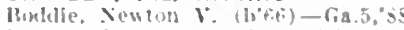

bryaut, K. W- - (ia,i, ys: (1'95).

Willints, Waleer b. (b'is)-lia., soi (i)

CHULA, 7J, TIFT

TYSUN, UM. F. + lia9.04: (1"0)

CLARKESVILLE, 528. HABERSHAM

131 li

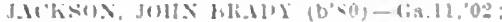

CLARKSTON, 349. DEKALB

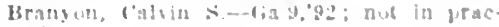

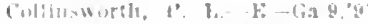

CLAXTON, 1,008, TATTNALL

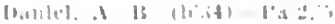

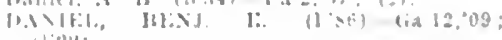

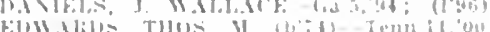

MII.LIIT BH:J rilu; III

CLAYTON, 3\$1, RABUN

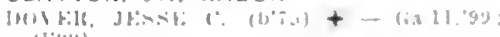

CLEM. 25, CAKROLL

CLEM

CLI RNONT 23. HALL

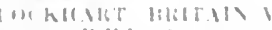

CLEVEGAND, 200, WHITE

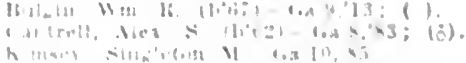

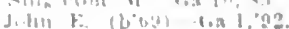


CLIMAX, 328, DECATUR

('itrer. Sibiborn 'T'- T'enIn.6,'91.

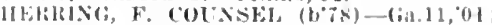
(1'04).

spormsn. Mac Crellons P'rlce (b'02)-(iis.l) 13; (I'13).

CLYATTVILLE (OLYMPIA P.O.), LOWNDES

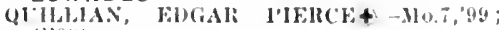
(1'99:).

CLYDE, I00, BRYAN

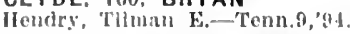

CLYO, 200. EFFINGHAM

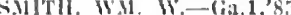

COBBTOWN, 254, TATTNALL

bowen, Humer- (ia.1,11: (\$).

Moore, Thomas (i. (b'85)-Cia.1,07; (l'0 i) lomutree, James otss (1'ss)- (ial11,13 (1'13).

STIITKLAI), 1.0HIN VAN 13. (b'sI) - Ga.l ,08: (1.08)

COCHRAN, 1,638, BLACKLEY

Forehand. Iteefer's S. (b'54)-Ga, , 'B:

ieorse, J. 1.-0.

MOHGA广, ROH'T. JACOH (b'63)-N.Y.10, 90.

T.1Y1,01, C. E. (b's1)-Ky.4,'76.

walker, thos. 1)., sr. (b'49)-15y.4, 75.

Walker, Thos. Milhart, Jr. (b'84)-Ky.2,09; $\left(l^{\prime} 10\right)$.

WIII'lis, HOI3T. 1. (b'73) - (ia.10,96;

$\left(l^{\prime} 96\right)$.
Whllams, Wm. (., Jr. (b'si)-(ia.12,11; (1'11); 1.F.D. 1.

COHUTTA. 283, WHITFIELD

Mradford, James Hlitredge (b'81i) - (ia.11.'12 $\left(1^{\circ} 12\right)$.

Hnghes, Thos. Serler (b'58)-Tenn.6,90 (1'04).

\section{COLBERT, 255. MADISON}

Jlampton, Hawkins H. (b'bi) E-Ga.9,93.

little, Saml. Boyd (b'70)-lia.10,'98; (1'ys)

McCoy, Walter 1t. (b'64)-Ga.11,'10; (1'10)

COLDWATER (R.F.D., ELBERTON), 40. ELBERT

Bond, Thos. W. (b'74)-Ga.10,90; (1'96).

GiNes, THOS. H. (b'75)-Tem.9,03 (l'06).

COLEMAN, 354, RANDOLPH

IHAll'El, THOS. F. (b'81)-(ia.1], '05; (1'05). ROGEISS

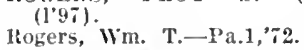

COLLEGEPARK, 2,173, FULTON

C'URTIS, C. II.

(Sce Atlanta.) DAKSoN (b't2)-Ga.10 ONTEI, JOII.

Foster, Kimsey E. (L'(1)-Ga.12,'13; (1'13)

Henley, James Thos. (b'69) - Ga.11,00; (l'00)

Lee, J. T. (b'35)-Ga.6,'60; not in practice.

Pharr, Luclus 1 '- Ga.5, 97 .

Seweli, James A. (b'69)-Ga.10,'93; (\$).

COLLINS, 327. TATTNALL

HARIRIS, JAMLS CALTIN (b'67)\&-Ga.12, 09 : (1'09)

KENAEDY, JASl'ER J. (b'61)-Ky 1,'86.

WALLING, CADOW B. (b'i0)-(ia.1, 02 ; (l'02).

COLQUITT, 600, MILLER

Baughn, Eigar B.-Md.3,04; (1'04).

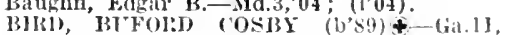
12 ; (1'12)

Busl, Elijah H., Sr.-lia.5,90 (1)

BE'SH, JAMES SHILEY, JR. (b'85)-Ga.11, $12 ;(1,12)$

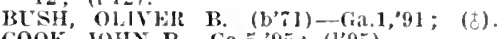

COOK, JoHN P.-Ga.5,'95; (1'95).

HAY, WAITEI colqUiTT (b'so) \& Gia.12.0s; (1'08)

Ilunter, Wm. F.-Ga.1, is.

Wilkins, Peter E.-Jid.3, 90

COLUMBUS, 20,554, MUSCOAEE

AILEN, BENd. WASHBURN (b'64)-Ga.5,

'S4; Wynnt on Pharmaey Bldg.; 10-1, 4-5.

$114 \mathrm{~N}_{2}$ Broad ist

B.ILII. TAME HAOJSON (b'69)A-Ky.1,

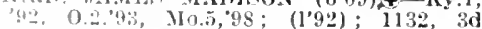
5-f. whe Masonic Temple; 8-9, 12-1. Blandfort, Wark H. (b'85)-MId.4, 08 ;
(1.09): Wymton; Office. 701,3d Ave.
13T L.LIII), W.M LEWHS (b'52) 4-Ga.5,75;

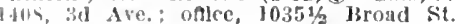
81: (131); OALR. *

('ampliell, Wim. H. (I'60)-Ky,4,'yI ; (2)

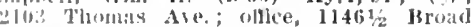
lfouse; 1]-1

(arter, Wm. Nolsun-Ky.2,07; (l'08); 8 linth st.

chambers, fiordon f. (b'r9) - Ga.11,00;

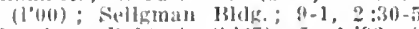

('hambers, liobt. A. (lilia)-Ia.1,'92; (1’0I)

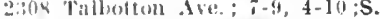

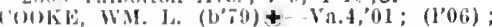
liaclne Hotel; oftlee, Masonle Temple: I:-2:S.*

(astig, Furest (:. (b'64)-ky.2,94; (1'94); (i) $101 \mathrm{~h}$ tre.

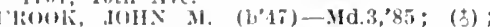

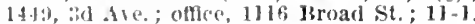
'rook, Martin (b'-7y)-Va.1,'01; (1'04); 10:3:, thi Are,; oftlee, Needham Bldg. $11: 30-1: 30,2-5$

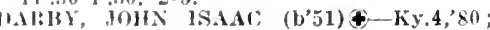
(?) : $1805,2 d$ Ave.; oflce, $121 / 2,12 \mathrm{~h}$ st. ; $11-1 \pm 3-4 ; S$.

rotTEs, WM L. (b'69)-N.Y.1,94; 212, 21 Ave.; offlee, $11401 / 2$ Broad St.

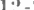

HETLR, (HAS. AMORY (b'7) \&-Ta.? (12); (1'03); 1212, 5th Are.; offlee, $11181 / 2$ Jeroid $\mathrm{st} ; 1+2-1$

Ciann, Wm. F. (b'51)-Ky.4,'88; 1715, 2d Ave. : offlec, $1713,2 \mathrm{l}$ Are.

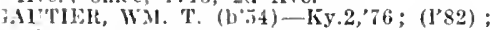
3d Are. and 11th St.; office, 1139 Broarl st. : $11-1$.

G1FAN, lRI'SSLLL I'. (b'73) \&-Ga.11,05; (l'0.i); Ilurrah Blclg.; 12-2; S.

rifithle, Tobt. I'ark (b'78)-Tenn.11,04; (1'0s); 1109, 5th Are.; oftice, Needluam Iilde. : $10-11,4-5$

JAMLSON, BENJ. B. (b'59) - Ga.5,87 ; (t); 2001 IIamilton Are.; oftice, IIasontc Temple ; $10-1$

JoHSSON, JAIIES 1f. (b'66)-Ga.30,'91; ¿3:1 Talbotton Ave.; office, Hasonic Tem1) ie ; 2-4.

McAmls. Thos. A. (b'82)-0; (\$)

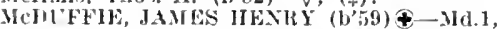
'S7; (ठ); 1515 , 2d Ave.; offlee, $11181 / 2$ Brond st.; $12-1,2-3 ; \mathrm{Pr}$

MITCIHLI, THOS, EMERSON (b'64) Tenn.5,92; (1'93) ; 402E 11th St.; offlee, Masonle Temnle; $9-12$

MONCRINF, J6HN T. (b'61) - Ga.9,'90; Affleck Ifotel; offce, 1250 Broad St.

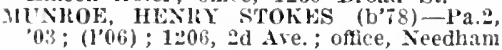
I3ldig.; 1-3.

MURRAY, GEOR(iE STLWAR' $\left(b^{\prime} ; 8\right)+$ Scot.3,01; (1'09); Wynnton; offlce, Murrah Bldg.; $11-1$.

odon, Fidelía J. (b's0)-Ga.18,'10: (1’10) : $2 i 16,2 d$ Ave.: $7-9,5-7$

PEACOCK. CIIFFORI AUECSTIN (b'86) -la.1,10; (1'10); 1034, $2 \mathrm{~d}$ Ave. ; offlce, Murrah Bide. ; 11-1.

I'rice. Thos. Blayne (b'85)—La.4,'10; (l'10) 610 Pussell st, ; 11-1, 4-6; G.

SCINEHDER, FRANCIS AJPHONSE (b'0 (4) N.Y.1,01; (1'12); Member Ited. Soc of D.C.; Wynnton; office, Needham Bldg.

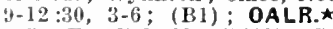

SIMS, EDWIN H (b'62)-Ga.5,'83; 1516 IBroad St.; office, 20, 12th St.; $12-2$.

Stewart, Wm Weaver (b'65)-N.Y.10,'90 1430 , 3d Are.; offlee, 15 W. 12th St. $10-1,2-6$.

Tatum, l'. A. (h'82)-Ga.11,'05; (l'05) $2517,2 d$ Are. ; office, Phoenix Bank Bldg.

Taylor, Manly L. (col.) (b'81)-N.C.3,06 (1'06); 1721, 7th Ave, ; offce, 20 , 10th St. Terry, Ernest P. (col.) (b'7s)-Tenn.7,02 (1'02); 632, 4th Ave.; offlee, $26,10 \mathrm{th}$ St. Ticknor, Doulis $C(\mathrm{~b}, 52)-G a .5,75 ; 1 \%$ Tirknor, Doughias C. $\left(b^{\prime} 52\right)$-Ga.5, 6 ; 61 , Tucker, O. B-Tenn.11,99; (l’00).

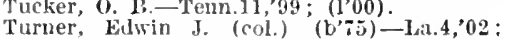
$\left(1^{\prime} 02\right) ; 508,10$ th st.; office, 6th Ave. and 10th St.; 11-2, 6-8.

Wheelis, David ir. (b'62)-Ga.10,87; 3014 Hainilton Are.

White, Alrah W. (b'88)-Ga.12,'13; (l'13). 842 Broad st.

Whitehead, Wm. F. (b'85) - Tenn.11,'08 (l'10) ; 1019, Bl Ave

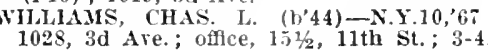

WOOLDIIUGE, JAMFS CLEMENTS (b'7 7 ) + N.Y.1,06; $\left(l^{\prime} 10\right) ; 1044$ Front St.; ollece, Mirrah Iildg. : 12-2.

wylie, Saml. John (b'63)-0.14,'87; (c) : 10102 Broal st. : 12-2, 5-6.

YoT:MAN. JAMES R. (b'75)-(3a.1,99: (1'99); 1340.31 A Ave ; offlce, $1140 \%$ Broad St. ; $11-1,4-5$.

\section{COMER, 68, MADISON}

Burckhalter, Walter M. (b'70)-Ga.1,99; (T.19) ; R.F.D.

likerhart, James G. $\left(b^{\prime}, 33\right)-\mathbf{P}^{\prime} a .4,{ }^{\prime} 54$.

(iklFFl'th, ARTHUIt J. (b'77)-Ga.1,04; $(1,04)$.

l'ower Jess w. (b’0)-Ga.9,92; (ठ).

ltol'Ek, I. 1.-Cia.5,'93.

Whel'hel, Cornellus C. (b’54)-Ga.1,'81; (§).

COMMERCE, 2,238, JACKSON

HARHWIAN, IAMARTINE G. $\quad\left(b^{\prime} 56\right) \oplus$ Ga.1,76, N.Y.10,77; (1'77).

IHARILA, WM. BENJ. (b,65) -N, Y.1, '89.

III ki3ARD, FRANCIS M. (b'48)-Ga.5, 88 ; vilus.

SA II)EIS.

LAkTUS (b'T4) - Ga.1,9i ;

SHANKLE, OLIN E. (b'80)థ-Ga.11,04; (1'04).

SHAIP', LEMUEL J. (b'62)-0.1,'83; (l'83) ;

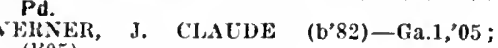
(l'05).

CONCORD, 450, PIKE

WAll.OWY; R. A.-Ga.10,84.

CONEY, 50, CRISP

GARDNER, IROHT, LEE (b'85)-Ga.12,'09; (l'09).

CONLEY, 100, Clayton

Kuglar, Robt. M. (b'69) E-Ga.9,"05; (1'05) ; Pd.

Willamson, Geo. T. (b'63)-Ga.10,'93. CONSTANTINE
114 , JACKSON

Osborne, Jewis N.-Ga.1,'98; (l'98)

CONYERS, I,919, ROCKDALE

Brooks, James Henry (b'6i) - Ga.11,'99;

Bryan, E. 1' (b'69)-Ga.5,'99; (l'97)

Guinn, Jos. Augustus (b'66)-Ga.5,'85; S.
Smith, Parlsh Stewart (b'77)-Ga.11,04

(I'04); U.

Turner, Columbus H. (b'51)-N.Y.5,'T0.

CCOKSVILLE, I00, HEARD

Cook, John D. (b'48)-Ky.2,'72.

COOLIDGE, 303, THOMAS

Crow, Wm. 11.-(ia.5,'95; (l'11).

Iones, Henry (b'70)-Ga.5,95; (l'95)

Iorris, Oscar Howard (b'75)-Ga.10,'98: (1'98).

Orr, H. W.-Tenn.11, 00 .

COOSA, 25, FLOYD

Garner, James S.-Ga.9,08.

CORDELE, 5,883, CRISP

BRADLEY, THOMAS ESBUN (b'79)-

Ga.11,01; (1'01)

DANIEL, BYRON (b'75)థ-Ga.1,'00; (l'00). EIWWARD, WALTER E. (b'68)థ-Md.4,

Marshall, Walter B. $\rightarrow$; not in practice.

IcAKTHUR, THOS. J. (b'68)-Ga.10,'94.

MeKENZIE, JOHN S. (b'66)-Ky.4,92.

Iiltchell, John J.-D.C.3, 06; (l'08).

Roherts, Henry B.-Ga.5,'82.

SIITI, MARVIN R. (b'79)-Ga.1,05; (l'05); Pd.

Thornton, Irene (b's0) - MId.5,08; (Bacteriologist).

WALLACE, F. R.-Ga.1, 79 .

WARD, JAMES A.—Ga.5,91.

WARE, FOLD (b'89) -Ga.1,12; (1'12) ; U

WIIELCHEL, ALVIN J.-Ga.11,05; (l'05).

Williams, Ralph Lee (b'87)-Ga.11,'12; (l'12).

W'HLLAMS, SIMPSON F.-

CORINTH, 147, HEARD

Webb, Lee B. (b'66) E-Ga.9,'88.

CORNELIA, I,II4, HABERSHAM

Crawford, James W.-Tenn.5,'02; S.

Field, John W. (b'73) E-Ga.9,'94.

COTTON, 290, MITCHELL

Fiuney, Wiley R. (b’59)-Ga.1,'91; (む). 
COUNCIL, 250, CLINCH

Sesslons, James H.-Cia.1,97: (1'97).

COVINGTON, 2,697, NEWTON

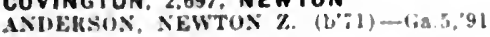
(\$).

Calvert. Fred. Clarence (b's2)-Mlch.1,0s (1'05).

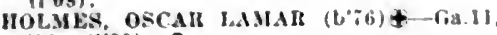
'99: (1'09): $\mathbf{S}$.

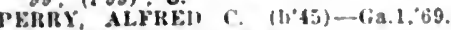

Robli, ALKk:

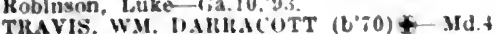

Wright, Jos. A. (b'53)-(ia.1,:9.

\section{CRABAPPLE (R.F.O., ALPHARETTA), 75}

MILTON

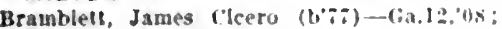
(I'0S).

CRANOALL, 220, MURRAY

Kemp. Roy Cleon (b'y2)-(ia.11,13: 11"13!

CRAWFORD, 871, OGLETHORPE

Bowen, John T,-F-Cia.9.'s9.

Fchols, Chas. C. (b'jl)-(ia.1,00; (l'v0)

Klng, Wro. Russell (b'ss)-lia.11;12; (1'12)

CRAWFOROVILLE. 688. TALIAFERRO

Beamley, Alex. HI-Ga.11,05; (1'05).

Binns, Reuben C.-fia.1, 78: (8).

RHOLES, JOIIN A, (b'b4)-Ca.1, 8 i.

CROSLANO. 198, COLQUITT

Coppage, J. M. (b'82)--lia.9, 09 : (寺).

CRYSTAL SPRINGS (R.F.D., ARMUCHEE),

5A, FLOYD

Ballenger, J. 1'. $\rightarrow$.

\section{CULLODEN, 365. MONROE}

Smith, SImeon Hull (b'5t)-Ga.11.99; (1 $\left.{ }^{* 99}\right)$.

Wrichi, James J. C.-Ga.18,'09; (

CUMMING, 305, FORSYTH

Bennelt, Wro. L. (b'73)-Ga.10,90; (l'96);

R.F. D. 7.

Bramblett, Juel Thaddeus (b'89)-Ga.9,'1I; (争)

Bramblett. Martin T. (b.53)-(ia.5,"s5: I. F.I. 1.

Bramblet, Rader H. (b'86)-Ga.9,'11; (\$).

Hockenhull, John (b'32)-('ia, 1, 55 .

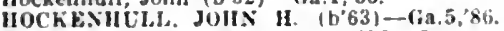

Hunter, John T.-Gia.10,89: R.F.D. '.

Hpsconb. Thos. I.-Cia.5, -5; R.k.D. 1 .

LIPSCOMis, WH. E. (b'82)-(ia.11,04;

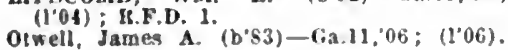

CURRYVILLE, 150, GORDON

Acree, Marlon Alblu (b'86)-Cia.1,12;(1'12).

CUSSETA. 3H. CHATTAHOOCHEE

Marpe, Frank C. (b'sb)-1ia.l, (09: (l'09).

lloward, Chas. X.-tia.l.bi: (2).

Howard, Chas. X..Jr. (b'69)-lia.1, $\$ 8 ;(8)$.

CUTHBERT, 3,210, RANDOLPH

ANIUREWS, TIUS. MLIL_LA.1, ;

HAHFIELI), FHEDK. FILENE (b'73) -

Va.1, $4:$; (1'01).

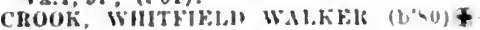

Tenn.II,08: ( $)$; Ob.

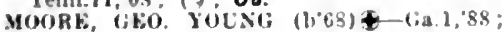
(1'0i).

Morris, James D. (col.) (b'8t)-Tenn.:,11 :

PATTHitsox, FHEDK. D.-Tenn.5."90.

DACULA, 169, GWINNETT

Hunton, Wm. T. (b'B2)-(ia.5.94.

Wilson, Henj. $v$. (b'iy)-(ia.1, ${ }^{\prime}(1) ;(1,00)$.

DAHLONEGA, 829, LUMPKIN

liead, Honer-lia.l,00: $\left(l^{\prime} 00\right)$.

DAISY, 500, TATTNALL

LL.UHISE. G. W.-(ia.1),00: $(1,00)$.

DAKOTA, -, TURNER

Rogery, Frank Willingham, Je. (b"8\%)

(it.11,13; (1'13)

DALLAS, 1,259. PAUlding

HFALL. WM. H. (1, 63$)=$ Tenn.6, \&t; U. Fu)

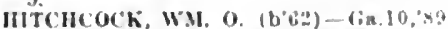

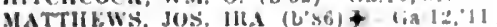

Nall, jumes baul. (bog2) - Tenn 11,0\% (1.09): 18.15. 6

Owens, Mathew i. (10033) F-tig.4."y]

ионFITSOX, EM⿻上丨 H. (b'io) Tenns, $45:$ Pd.

Simmins, Janes $\downarrow$ (b's 1$)-$ Cia.11,04
DALTON, 5.324, WHITFIELD

dul: Ilenry J. (b"is)-Aa.11,05: $(1007)$

Isroaddrlck, reco, I, (b'it)-.Tenn.?,0L: (I'ns) : If is 11

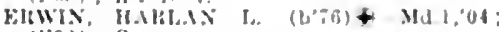
(04)

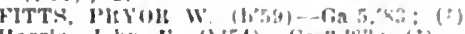

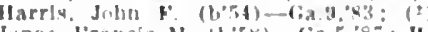

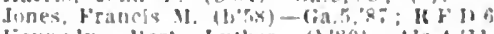

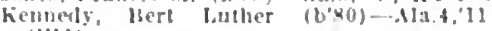
(1'll).

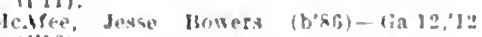

117.

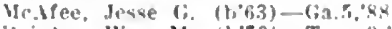

lonter. Win. M. (b70) - Tunn?

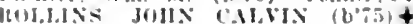

(i) : $(100): G$.

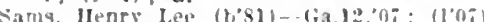

sims. Whis A. (col.) (b*3)-Tenn.13,os:

Sipede Jills II (b"ifi)-Cra.9,02

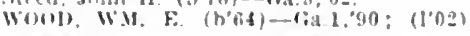

DAMASCUS (R.F.D., KESTLER), 100 ,

EARLY

Ward, L. (C-Cia.11,99: (1'99).

DANBURG, 272, WILKES

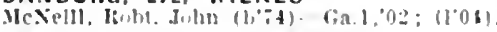

DANIELSVILLE, 323, MADISON

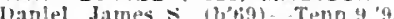

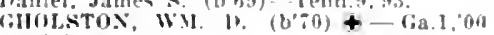

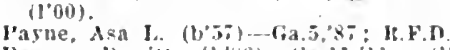

I'ayne, lewitl $\left(11^{2}+6\right)-1 ; a .11,11:$ (1'11!

Ii.F.D. 2.

DANVILLE, 299, TWIGGS

Hembrer, John Alexander (b"ig)- lia.9, 0 -

chapman, lien. F (b't5)-Ky.4.85: (b).

DARIEN, 1.39I. MCINTOSH

('lark. l'ster $\left.\leqslant\left(b^{2}\right) i\right)-0 ;\left(l^{\prime} \& 1\right)$

sterens, 3. B. (col.) (bib)-Tenn.7,ol: (1'01).

Wonds.

DAVISBORO, 589, WASHINGTON

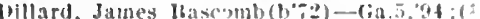

Nunn, I'utrlek í liat, 'st:

Tilylor lialul Lelan! (u's)

(l'lis): Pd.

Warthen, Wm. Ben! (b's0)-ild.1,05;(100)

DAWSON, 3,827, TERRELL

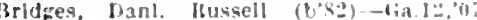
(I'0T).

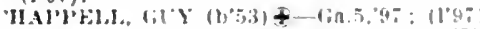

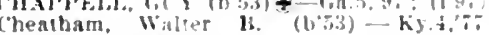

$(1+6):$ not in uractlce.

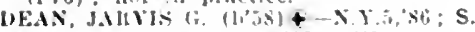

Gardner, Wm. H.-Ky,

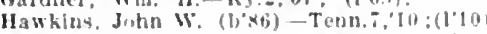

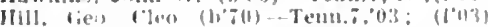

kensun, owen T. (b'titi)-las.1, 86 .

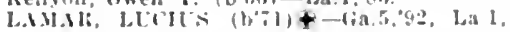

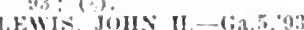

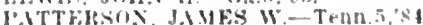

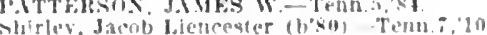

Il'Iii).

DAWSONVILLE, 179, DAWSON

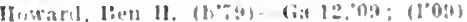

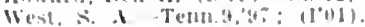

DEARING, 100, MICDUFFIE

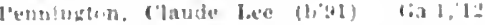

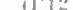

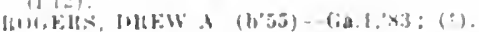

DECATUR, 2.466, DEKALB

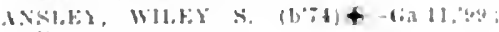

$112: 0 ! 1)$

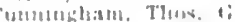

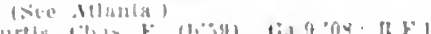

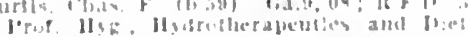

(iin's

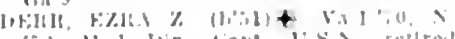

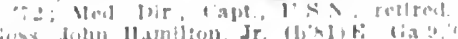

inv diotin

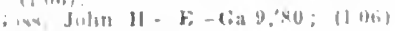

lirinl1h. |Banl. II

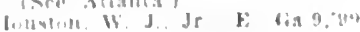

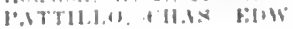

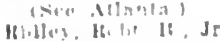

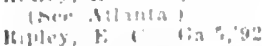

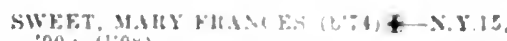

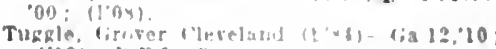

(1)10); it $\mathrm{F}$ is

DEEPSTEP, I49, WASHINGTON

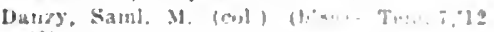

Jelfuin, Bernard Jama:

(1'12)

DEMOHEST, 760, HABERSHAM

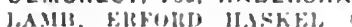

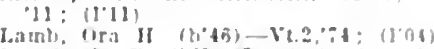

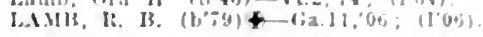

DENTON, 300, JEFF DAVIS

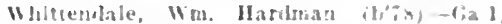
11; (1"12).

DESOTO, 228, SUMTER

sinth, Wm. Jackson (b'ti) Ky.1,"yin

OEVEREUX, 250, HANCOCK

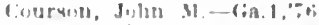

loursun. 'Thus. N- lia $10,2 \times 6$.

DEWYROSE, 50, ELBERT

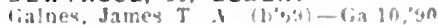

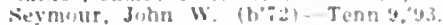

DEXTER, 550, LAURENS

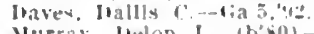

Murray, leeton I. (b's) - (ia I, Id: (I'II)

NEW, J. F.-C, 1,$00 ;(1,00)$

Tayler, Win. 13,-6an, 190.

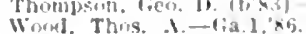

DIAMOND, I0, GILMER

Kinzey, A. I, $\rightarrow$.

DOERUN, 630, COLQUITT

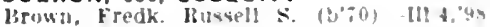

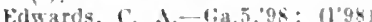

llarrell, C. B. (b*2)-ria.tos; (l'as).

Harrell, Darid B. $(1,7,3)-(; a .11,(00 ; 1100)$

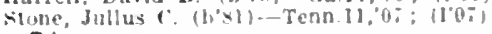
$P d$.

DOLES, 25, WORTH

Amzon (C $T$-KY4.43

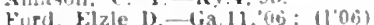

Johns. Stanley W (b)96)-6a),13; (1'13).

DONALD, I50, LIBERTY

E'rabier. Saml. H. (cul) (b'5) -Tenn.:, lo (I'10)

DONALSONVILLE, 717, DECATUR

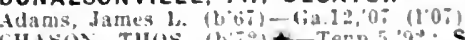

CHAsox, Tlus (b'2)t-Temp. 52 : S.

$10 ;(1,10): 0$ b

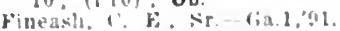

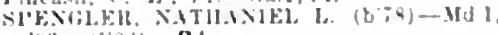
(0)?: (1'0.5): Pd.

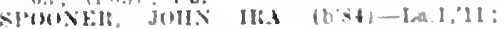
(1)!1).

DOOLING, 163, DOOLY

lober. Mouroe W. (b'ti)

DORAVILLE, IHi, DEKALB

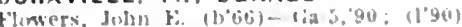

Mlller, invid li. liall's:

DOUBLE BRANCHES. 38, LINCOLN

DDUGLAS, 3.530, COFFEE

DDUGLAS, 3.550, COFFEE

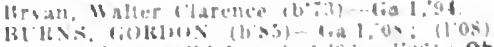

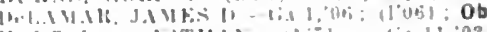

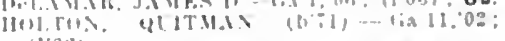

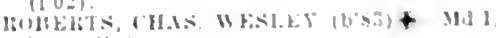

if (4)

(1) 211).

(II) I. li, bis

(1) solly

Terrell. Wm. II (bri)-tia)

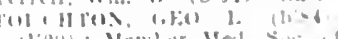

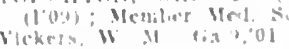

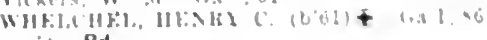
Pu.

DOUGLASVILLE, 1,462. DOUGLAS

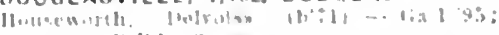

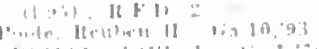

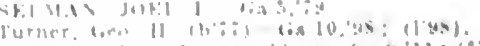

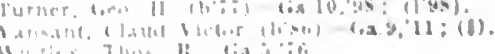


DOVER, 200, SCREVEN

Cross, Kllpatrlck (b'7i)-Ca.1,10; (l'I0)

DOVEREL (R.F.D., DAWSON), 20, TERELL

THO.MAS, LOGAN" (b'TI) \&-Ga.9,'97.

DRAKETOWN, I00, HARALSON

Fares, Benj. F.- (ia.5, 93 .

Foldlu, Wm. F-Ga.5.

IIorue, Wim. lore-Gal 12,07.

DRANESVILLE (R.F.D., BUENA VISTA), 25, MARION

Buyett, Arthur stout (b'69)-Tenn. 5,'94

DUBLIN, 5.795. LAURENS

Barkwell, Jubn I1. (b'st) -Ga.12,08; (l'08); R.F.1. I

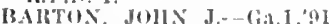

IBRILHAl, Wu. lR. (b'74)†-Ga.1,97; (l'97).

Brlght, Frank (b'66)-Tenn,9,92

CLAXTON, EDW. HURTON $\left(\mathrm{b}^{\prime} 83\right)-. M 1.9$ $05:(1,06)$

GREFi, 1;EO, F.MA.1,71.

llall, Thomas Ifartley (b'37) - Pa.3,'59. Ilodges, C. A. (b'85)-Ky:9, 06 : ( $\left.{ }^{\prime} 06\right)$

Hodges, Henry Thomas (b'60)-Ga.5,' 90 .

Jenklns, (ieo. W. ... (ial, 1,88.

Johnson, Tlysses s. (col.) (b'7t)-Temn.i, os: (I'0s); G.

Jones, H. T. (col.)-Tenn. T.,00; $\left(l^{\prime} 00\right)$

LINDER, J.MNS I. (b 48 ) $-\mathrm{Ky}, 2,73$

(1'3); R.F.I). 9

NEW, EZILA (b'60)-Ga.1,'s7 ; (১) ; G.

PAGE, JOS. M. - Ga.1, 82

Perry, Benj. D. (eol.)-Tenn.t,02; (l'02)

RUSHING, IHERHERT-Ga. L 2,06 ; (1'06)

THOMAS. I. J. (b'39)-7a.5, 82 .

THOMPSON, WM. CALHOUN (b'83)屯(ia.12."10; (l'10); G.

WALKEIR, SIINEY' (b'80) †-Ky.5, 04

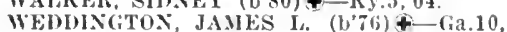
98; (l'98)

DUDLEY, 302, LAURENS

Carroll, Colgan C. (b'61)-Ga.1,78.

CHAI'ELL, ROY J. (b'66)-Ga.I, 90; (b),

"V'alker, Joshua 13. (b'69)-lld.1,90.

DULUTH, 469, GWINNETT

Chrlstian, J. E.-Ga.5,93; (1'01).

DUNWOODY, 180, DEKALB

Puckett, James IV-C(ia 10,02; (l'98).

DURAND, I00, MERIWETHER

Glenn, J. J. W.-Ga.1,52.

GRANT, N. L.-Ga.1,04; (l'04).

EAST ATLANTA (ATLANTA P.0.), 63,

FINCIIER, EDGAR F. (b'69)†-Ga.11,01; (I'0I).

Flncher, Thomas H. P.-Ga.5,'88.

EASTMAN, 2,355, DODGE

Buchan, Davld M. (b'48)-Ga.9,78; R.F.1) I

Bureh, Juhn A. (b'82)-Ga.11,09; (1'09).

CLARK, JOIN B.-Ild.3,'93.

HERRMAN, JEFFERSON D. (b'61)-Ga.I '83; (ह).

Hermann, Ferdinand Hirsch (b'90)-lat.1, 'I3; (1'13).

Thurber, Austin II. (col.) - N.C.3,07 ; (1'07). WALL, JOIIN COX (b'8z)-Ga.1 I, 07 ; (I'07)

WILKINS, ABNER L.-Ga.I1, 01 ; ('́l).

EASTON (R.F.D., ATLANTA), 15, FULTON Hope, Robt. L.- iia.9,'81

EAST POINT, 3,682, FULTON

GUFEIN, THOMAS FRELK, (b'75)-Ga.11,

12; (I'12).

Holmes, Hamilton M. (col.) (b'84)-N.C.3 10 : (l'10)

Mixon, Elijah P. (b'52)-Ga.1,'81

llixon, Fletcher T. (b'56)-Ga.1,81; (1'81).

Orerby, E. P.-Ga.10,'83

TRIMBLE, GEO. C. (b'64)-Ga.5,'88.

EATONTON, 2,036, PUTNAM

CLARK, SAMIUEL A. (b'T̃)-Ga.1,01 (l'0I).

Griffith, Eugene Frederick (b'88)-Ga, 1,11.

Howell, Geo. A. (col.) (b'81)-Tenn.7,'06: (1'06)

Pinkerton, Fvelyn R.-Ga.9,"95; IR.F.D.

Robins, Lee C.-Ga.I,'s1; R.F.D. 4.

TALIAFERO, VALENTINE H.-Ga.5,'94.

Thonas, Dennis L.-Nld.3,'92.

WEATER, JAIES D - MId 3 ; 82

Williams, Joshua S. (col.) (b;5)-Tenn.7, 1 '10)

EDISON, 841, CALHOUN

BEARD, JOS. S. (b'80) \&-Ga.11,10; (l'10).
Grifln. l'lerce Edwln (b'77) - Ga.11,01; (I'ni)

IFNKINS, ('. J.-Cia.5,95; (l'97).

kenuedy, Thus. I.-Tenn.8,87.

ELBERTON, 6.483, ELBERT

A1M.MS. FRANK I. (b'68)-Ga.10,90; (o).

MALEY WAVII) VERNON (b'80)-Ga.12, 10 ; (l'10).

Earle, claude E. (b'60)-Ma.3,'86; (l'05).

FIBLIIARIT, LU'TIER I'OI'E (b'69)

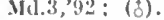

Ilulnse, (l'11)

Johnson, Albert Sldney (b'88)-Ga.11,'13 ;

(1'13). JOS. F. (b'62) †-Ky.2,'93 ;

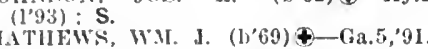

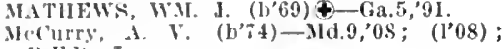
li. $\mathrm{F}, \mathrm{l})$

Moore, R. I,-Ca.b,10; ()

oliver, Alfrad st. (b'57)-Ky.4,79; (1'97).

s.MTh, AMOS CLARK (b'73) 4 -Tenn.io, (1)

II_l, MIHERT S. J. (b'61)థ-Ga.1, 86: (ह).

THOMIPON, DALLAS NORMAN (b'86)Ga.1, 08 ; (1'08).

Thomlson, James P. (col.)-N.C.3,02; $\left(l^{\prime} 02\right)$

Ward, feo. Addison (b'85)-Ga.1,'13; (1'13).

ELKO, 273, HOUSTON

Braswell, Epliraim M.-Md.4,01; (l'02).

ELLABELL, 250, BRYAN

Williams, W. J.-Ga.5,8i; R.F.D. 1.

ELLAVILLE, 672, SCHLEY

Bridges, Benj. Lymn (b'73)--Ga.5,'95; (l'95).

Jordan, Joln Rodolph (b'81)-Ga.11,02; (l'02)

Sears, Wm. D. (b’56)-Ga.9,'82.

Stewart, Luther G.-Ga.5,95; (1'95).

ELLENWOOD, 50, CLAYTON

Henry, Janies Z.-Ga.12,09; (l'09).

Sprayberry, B. M.-Ga.9,82; R.F.D. 2.

ELLERSLIE, I00, HARRIS

Ilooten, Jos. C. (b'il)-Ga,5,'93.

ELLIJAY, 659, GILMER

COX, CLARENCE GOOLSBY (b'86)-Ga.1, '10; (l'10).

Goss, NATHANIEL C, $\left(b^{\prime} 65\right)-G a .10,90$

RTSSELL, WM. V.-Ga 9'09.

TANKERSLEY，JAMES S. (b'60) $\oplus$ Ga.5 84; (†)

WATKINS, EDW. WILLS, JR. (b'76)Tenn.9,00.

Watkins, vdw. W.-0.2,'67; (\$)

ELMODEL, I50, BAKER

'Twitty, Clarence Walthall-Ga.12,'12; (1'I2).

ELZA, 50, TATTNALL

Jones, IRandolph D.-Gia.1,84; (1'99).

EMERSON, 3I6, BARTOW

MONIROE, D. 1I.-Ga.I, 00 ; $\left(l^{\prime} 00\right)$.

EMMALANE, 25, JENKINS

Deal, Benj. A. (b'85)-Ga.I,'09; (l'10).

EMPIRE, 250, DODGE

Kimberly, Lemuel C. (b'62)-Ga.9,'90.

Sinitl, Austin J. (b'73)-Ga.11,05; (1'05).

EPWORTH, 218, FANNIN

WEEKS, WM. H. (b'7I)-Tenn.9,06; (1'06).

ESOM HILL, I50, POLK

PENNINGTON, JAMES EDW, (b'59)-Ga.1, $8 ;(194)$

ETON, 307, MURRAY

Brown, Samuel A. (b'67)-Ga.9,'93.

EUHARLEE, 200, BARTOW

LOVIRY, TANNER (b'S0) $\oplus-$ Ga.11,'04;

MeGowan, Hugli S.-Tenn.11,04; (1'05).

MeGowan, Jos. F.-S.C.1,'85.

EVENS, 75, COLUMBIA

Culberson, Alfred Napoleon (b'79)-Tenn.10, 09; ( $(1,10)$

EVERETT SPRINGS (R.F.D., CURRY-

VILLE), 50, FLOYD

Gray, Robt. II. (b'64)-Ga.1,'87.

FACEVILLE, 325, DECATUR

BERRY, LOGAN D. (J'81) \&-Ga.12,'09; (1'09).

Carter, Geo. B.-Ga.5,'92.
FAIRBURN, 1,395, CAMPBELL

Camp, Ileuben Thornton, Jr. (b'88)-Ga.11, 'I3; (I'13).

Camp. Whllam R. (b'68)-Ga.5,'90; (1'90). Iarvey, Chas. I Iarry (b'84)-Ga.11,10; (1'10).

Ieard, Chas. Davls (b'82)-Ga.11,05; (1'05). Itobgood, Lemuel M.-Ga.10,94.

Lompino, John 'Thos, (b'69)-Ga.10,'93; (t). lhomason, Tohn w. (b'80)-Ga.12,'13; (l'I3) ; R.F.D. 2.

FAIRCLOTH, 45, MITCHELL

Il ammond. Jos, T._Ga.I,'83.

FAIR MOUNT, 326, GORDON

liralley, Roht. II. (b'87)-Ga.12,'13; (1'13).

Mcllan, Ilenry M.-Ga.9,01; (t).

Rogers, Robt. I. (b't0)-Ga.11,03; (l'03).

FAIRY, 10, MURRAY

Gregnry, John M. (b'i8)-Tenn.9,'04; (1'04).

FARGO, 300, CLINCH

ALILEN, GEO. OLLIE (b'72)-Ga.10,93; (¿)

\section{FARMINGTON, 300, OCONEE}

ELDER, JAIIES T-Ga.9'87.

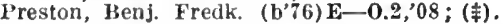

FAYETTEVILLE, 709, FAYETTE

Dixon, Robt. K. (b'84) E-Ga.9,'08.

Ldwards, James T. (b'58) E-Ga.9,'86; (1'86).

Lester, James L. (b'70)-Ga.5,94; (l'94).

Loyd, Robert C. (b'69)-Ga.5,'90.

Seawrlght, Eugene c. (b'81)-Tenn.11,04; (l'05).

Wallis, Geo. W. (b'62)-Ga.5,'86.

Ware, Jos, E: II.-La.2,'61.

FICKLIN, 211 , WILKES

Smith, I'aul Jantes (b'83)-Ga.1,'12; (l'12).

FIFE, I00, CAMPBELL

Merriam, Clarence S. (b'86) - Ga.11,10; (1'12) : $\mathbf{S}$

FINLEYSON, 232, PULASKI

Horne, Jos. Madison-Tenn.5,'95; (1'97).

Mltchell, Stephen R. (b'55)-Ga.10,'87.

Sams, James Roscoe ( (b'89)-Ga.1,12; (l'12).

Shlpp, IIenry Harris-Ga.11,02; (l'02).

FITZGERALD, 5,795, BEN HILL

Boyd, Chas.-Ga.5, 77 .

Cass, John T. (b'52) - N.Y.5,'87.

COHEN, IORRIS S.-Pa.2, $81 ;\left(1{ }^{\prime} 08\right)$

DORMINY, EDWIN J.-MI.1,90

DOR.IINY', W. D.-Ga.11,00; (l’00).

FRAZER, JOHX L. - Ky.2,'91.

FUSSELL, J. C. (b'67)-Ga.1,94.

GOETHE, JAMES E.-IId.4,92.

Haile, Thos. J. $\rightarrow$; not in practice.

Luke, James Martin Joshua (b'88) - Ky.2, '13; (1'13)

OSBORNE, LYMAN SANDERSON (b'55)Jlich.1,78; (1'98); Ob.

Roberts, L. H. (col.) -Tenn.7,03; (1'03).

RUSSELL, EDW. A.-Ga.11,'06; (1'06).

Thompson, David F.-N.Y.1,'69.'

WAKF, DUDLEY B.-Ga.1,'98; (l'98).

WARE, ROB'C. M. (b'77)-Ga.1,02; (l'02).

WHITE, T. E.-0.2,05; (1'06).

FITZPATRICK, 60, TWIGGS

Wood, Andrew J.-Ga.1,81.

FLINTSTONE, 142, WALKER

BARKER, HAMPTON MORGAN (b'76)-

Ga.12,07; $\left(l^{\prime} 07\right) ;$ also Member Tenn.

State Med. Assn.; (Alten Tark, Tenn.).

FLORENCE, 150, STEWART

Gilbert, Albert S. (b'65)-Ga.5,'89.

FLOVILLA, 495, BUTTS

Waits, W. J.-Ga.9,'95.

WHITE, ALFRED F. (b'55)-Ga.9,'92.

FLOWERY BRANCH, 373, HALL

BRICE, GEO. P. (b'60)(-Ga.5,'85

R.F.D. 2 .

Hunt, A. W.-Ga.9,89; ().

Liles, Walter W.-Ga.9,'99.

Orr, Jake Cobb (b'86)-Ga.12,'12; (1'12).

FOLKSTON, 355, CHARLTON

REYILLE, THOS. P. (b'60)థ-Md.3,' 87 ;

(6)

WILLIAMS, ADRIA

S.C.1,04; (1'09).

FOLSOM, 100, BARTOW

Bradley, Richard S.-Ga.10,'84

FOREST PARK, 173, CLAYTON

Bation, James 1?. (b'67)-Ga.11, 00 ; $\left(l^{\prime} 00\right)$. 
FORSYTH 2,208, MONROE

ALEXANDER, GEO. I.\&-Ga.5,93; (1'93) Boddle. William Flsher (col.) (b'84) Tenn 700 (

ELKOD, JÜHN 0 , (b"7i) + -(ia.11,01: 11'01)

GOOLSIBY, ROBT, C. (b'62)-Ky.4, 90

LANCASTER, JOIIN F. (b'efo)-G.5.5 83 (ङ) : U.

Ponder, Wm. leter-N.Y.I0,'85: (*).

Prischets, DeW'lt! (b'st)-Cia.11;13; (1'13)

Villlams, Guy W. (b'89)-Ga.12,'13: (1'13)

FOSTERS MILLS (R.F.D.. ROME), 25, FLOYD

Carr. R. C. $\rightarrow$; ( $\left(\begin{array}{c}o \\ 0\end{array}\right)$.

FRANKLIN, 340, HEARD

Danlel. John W.-Ky.2:?3: (1'96)

Daniel. James $16-\mathrm{K} y .2 ; 2$

IIammond, Geo. W. '(b's6̄)-Cia.12,'13; (1'13).

Mammond, Geo. W.-Ga.9,'90.

Taslor, John I. (b'50)-Cia.12,09; (1'09) H.F.D. 1.

FT. GAINES, 1,320, CLAY

CALHOU:, WM. W. (b'i5)-Tean.11,'01 (I'01).

Crozler, IBlchard T.-Cia.5,'99.

IIolmes, Chas. Piti-Ga.5'91.

Manderille, John T-Ga.5,-9

TATUM, W. J.-Ga.10,96: (1'97).

Wimberly, Wm. C.-Ky.1,89.

FT. MCPHERSON (ATLANTA P.O.), FULTON

BANTA. WILLAM P. (b"i3) \-Ky.2,"94; Capt.. M.C., U.S.S.

BRATTON, THOS. \&. (b'6s) \&-S.C.1,90 Maj. M.C. I".A

CONNOLLY, PHILIP BAIRY (b'\$6) X.Y.19,09; 1st Lleut. M.C. U.S.A.

Whlte, John w.-Ga.9,'88.

FT. OGLETHORPE (ROSSVILLE P.O.). -

WALKER

DUENNEK, MOBERT HENRY (b'S3) D.C.1,10; 1st Jlent.. M.C. U.S.A.

HARMOS, 'DANIEl, WIBWICK (b's0) \& Ya.1.03: Capt, Y.C., C.S.A.:S.

KTLBOLRSK, EDWIN D. (b'T)£-I11.6, 99: Capt.. M.C.. U.S.A.

RAGAX, CHARLES A. $\left(b^{\circ}, 3\right) \pm-D . C .1,00$; Maj., M.C.. U.S.A.

FT, SCREVEN, - CHATHAM

GWHGORY, JT'IC'S C. $\left(b^{\prime \prime} 75\right)+-V a .4,00$; Cane. Mi.C. U.S.A.

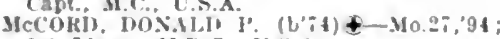
Ist Lleut., II.R.C., i:S.A.

FT, VALLEY, 2.697, HOUSTON

Brown, Mlllard s.-Ga.5,'s8.

ls rown, VlrelnIus L. (b'si)-Pa.1,01; (1'06)

IIolmes, Wm. A. (b'ts)-Tenn.i, I0: (1'I0)

Klnney, James H. (b'63) - Ga.10,'s3.

Slngleion, Oscar G. (b'5i)-Tenn.5,91: (1'91).

Whlte, $11 \mathrm{~m}$. S.-Cia.1,01; (1'01)

Woodward. Geo. Vapoleon $\left(b^{0} ; 1\right)$-Ib.c.3, $10 ;(1,12)$.

FUNSTON, 236, COLQUITT Slocumb, Clyde Buchanan (b'si)-(;a.12,
12: (1'12).

Siriplin. Mllton 1). (b'68)-ria.9,"yl,

GAINESVILLE, 3.925, HALL

BRYSON, LUCAS K. (b'ti)-Tenn.9,02; (1'00); R.F.D. I

Carter, Henry Grady (bog2) - Ga.11,13 (1'13)

DOWNEY, JAMES HENRY (b'6t) \&-Ga.5, 8i: 1100$)$.

Doyle: Хerzon A. (col.) (b'33)-N.C.3,00: (1.06).

(ienrge, Joseyh H. (h'G I) - S.C. 1,20; (3)

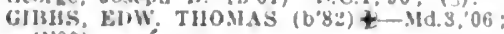

Gower, James (thas. (b'i5)-Cin.9, 08

ll am, Firnesi P. (b, 63)-L.a.1, bs; (í).

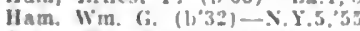

Jones, Win. Alonzo Nathanlel (b'\$3)-fia.1? 08: (l'0s): H.F.1\%. Il.

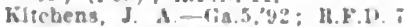

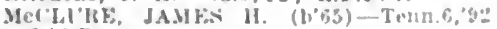
OALR.

Nisnce, A. L-l'a '6s.

Neal, linbt. L. - Ga.10, $\$ 6$.

Y'almer, Wm. A. Cia.5,

I'arla, Walter biwin (b'2)-1.a 1,94 (1'1)

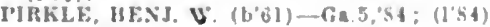

IBOHEITSON, TETER E. B. $\left(b^{\prime} 66\right)$ - GA.1. RIPUI.IH, IIENKY IATIMKR (b'79) Id 1., 0 ? : $(1,0,3)$

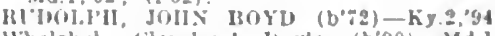
Whelchet. ('leseland liavis $\left(b^{\circ} 90\right)$ - IId.1.

whelchel, John t:-Ga.1,:83: (2).

WHITE. ALIKLIT D. (b'62)-(ia.1,85,

GARFIELD, 319, EMANUEL

Jhince, F. A-ria.l,92; (). (1'96).

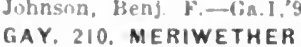

b'ennelt. V'lctor llugo (b'86) - (ia.12,'10

EI.1.1S, WM. TIELPS (b's0)-Gia.11,06;

GENEVA, 210 , TALBOT

Brouks, Slmon W. (b'63)-Cis.5,'86.

GEORGETOWN, 313, QUITMAN

Crumbley, sildney A-

(iary, liven (b'SI)-N1a.4,02; (1'02).

GIBSON, 367, GLASCOCK

Farnell, rroley Masun-Ga.1,12: (l'13): G.

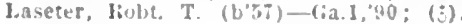

GILLSVILLE, 216, HALL

HIYAX, JOHX A. (h'bS)-Ga.1, B1.

GIRARD, 227, BURKE

Burtoly. Thoy. A-Ga.1,yl.

Herrlngton, Wm. Attlcus (b's5)-(ia.12,10 (1'10).

Mlms, Frauk (b'76)-Ga.1,97; (1'97):

L.F.D. 1.

Royal, Louls Bartow (b"is)-(ia.1,08 (I'0s').

GIRTH (ALEXANDER P.0.), 300, BURKE (handler, W. H.-lia.1, "]

GLENN, 75, HEARD

Cook, James W.-Tenn.5,'S2.

Thouassou, Wm. Edw. (b'Si)-Ga.11,11 (1'Il).

GLENNVILLE, 640, TATTNALL

WeL(1).II, LUTIIEIK A. (b'83)-(ia.11,05: (1'05)

fiross, f. R.-Gia.l, 81

IILCIIES. JOs. A. (b; 75$)$-(ia.11,02

SMITII. S. F-Ga.1,02; (1'02).

TOUTLE, (6. W.-lia.5.45: (1'95)

GLENWOOD, 347, WHEELER

Morrison, Martin (b'58)-Ca.1, 8 ?

livers, IV. 1 -Cia.5,'94.

GODFREY, 337, MORGAN

FHOREXCF, GEO. I'IEICCE (b'Sy)-Ga.I:, 11: (1'11)

GOGGANSVILLE, 50, MONROE

Thornton, lemuel $E$. $\left(b^{\prime} i t^{\circ}\right)-G a . L 1,01$ (1"0I).

GOODHOPE (R.F.D., MONROE), I5I, WAL. TON

loung, James 1. (b'it)-Ga.1, il.

GORDON, 702, WILKINSON

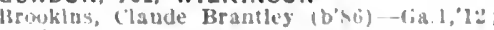
(1'l2)

Hutts, Kobt. M. (b'33)-lia.1, 58

vivans, It. Farl-Ky,9,06; (1'0<)

dee, Walter W. (b'53)-(ia.I. it

GORE, 30, CHATTOOGA

Balley, lichard A.

Kamsay. Hee-0: 1R.

Kelley, 1:. 11. (b'sl)-Gia.1, 0 ; ; (l'0i)

GRAHAM, 193. APPLING

leecher, keverlige - 0 ; (

Mareln, Saml. Wrghe (b'i, $)-$ (aia je,'ll: (1'li)

GRANTVILLE, 1.132, COWETA

1.0?

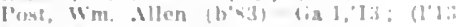

Stallug, J. II lia.", El

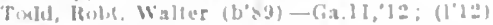

GRAY, 20, JONES

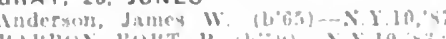

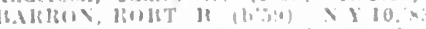

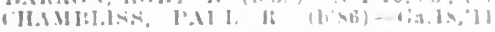

GRAYMONT, 417, EMANUEL

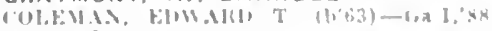

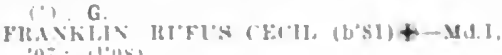

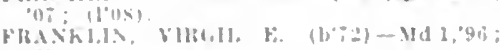
(I'vi)
GRAYSON, 278, GWINNETT

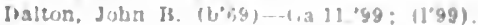

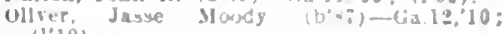

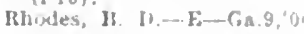

GREENBUSH, I0, WALKER

llamsey, J. I $\left.\left(b^{5} 51\right)-K y\right]$,

story. Frank A (U'st)-Teyn os

GREENSBORO, 2,120, GREENE

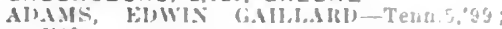
$(1,00)$

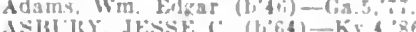

Chlsolm, Alfred Thrimas (col.) (b'is) -

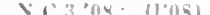

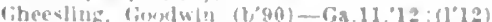

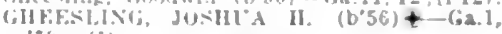
$\because 9:$ (3)

GREENVILLE, 909, MERIWETHER

(illIBEIRT, IIOHT. B. (b'81)-Ga.11.06: $(106)$

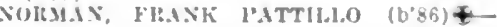

(;i) $1:, 10 ;(1,10)$

l'IXK'TUN, JuHN W+-Ra.10,"s9

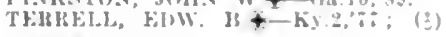

GRESSTON, 25. DODGE

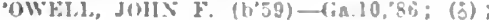
R.F.l.; G.

GRIFFIN, 7,478, SPALDING

ANTHONI, EUWIX R. $\left(b^{\circ} 52\right)+K y .2,75$

AL'STIX. WM. IIL'BERT (b'75)-Ga.12,10; (1'10).

CARSUN, MARCE'S F-IA. 'Q4

IH:WIR, NICHOLAS B. (b'34)-Ga.5,"55: l's6)

IIEWRY, T. ELLIS $\left(6^{\prime} 60\right)$ - G-G.5, $8 \%$

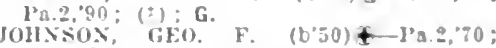
(इ): $\mathbf{G}$.

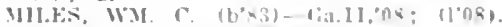

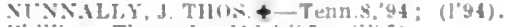

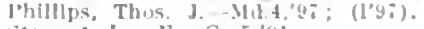

Stewart, Jos. F.-Con.s.

Trlkkl, flisiks L. (b"-1)-Ga.10,"92: Th $(1.402)$

Warren, I.Indsay (. (h';6)-Ga.1, 00; (l'00).

Wells, J. S.- E-Cia.s,

GROVELANO, 350, BRYAN

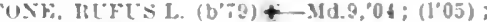
13 i I I

GROVETOWN, 558, COLUMBIA

Ibaxley, l,uy viegll (1,\%5)-(;a,1,00: (l'00). King, Walter Is. (b'ili)-lia.1,09; (1'1I).

GUYTON, 545. EFFINGHAM

I"UWERs, HLLCE, 1". (bo)-Ga.1,"95; Tarier, Hugh ls. (b"Big)-Cia.l,90.

HADDOCK, 312 , JONES

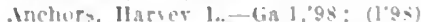

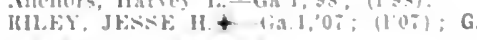

HAGAN, $78 \%$, TATTNALL

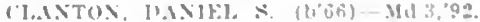

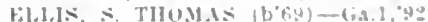

HAHIRA, 650. LOWNDES

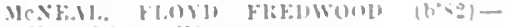

(U]TH F. J. lis 1, "49: (1.99)

HALCYON DALE, 100. SCREVEN

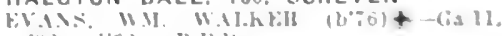

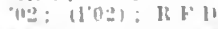

MAMILTON, 403, RARRIS

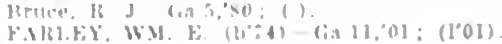

HAMR.FL, WM. E. (b. A)

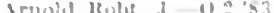

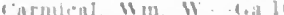

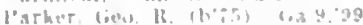

IRerdwhe. Thus W Lad

HAPEVILLE, 86.

Illanta

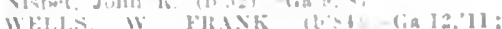

HARALSON. 17\$. COWETA

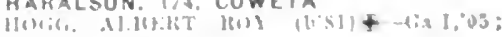

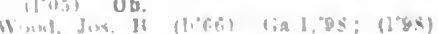

HARLEM, 36, COLUMBIA

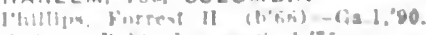

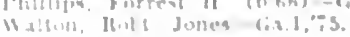


HARBISON, 383, WASHINGTON

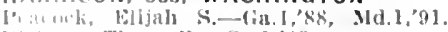

Vichers, Thes. b.-Gil, 85.

HARTSFIELD, I50, COLQUITT

lireull, I. H.- lia.10,81.

l'arsuns, James A., Ir. (1,85) - Call.12,09;

Summeriln, I. A- - lex.i, 07

HARTWELL, 2,007, HART

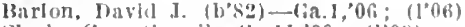

Clark. Geo, sewell--(ia.11.'99: (l'99).

llalley, Wn. Jlam (b'70)-Ky,4,93; (

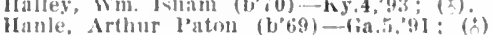

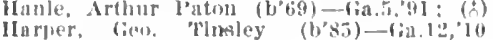

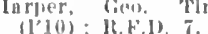

Jenklns, James 6 - Ga. 1,97 ; $(1997)$

Tenkins, Jos. I.-Lia.1,00; It.1. 1).

Iecurry, Isham L. $\left(b^{\prime} 48\right)$ - Fa.1, 71

Mclurry, W. Edgar (b'77)-Md.3, 01 i (l'0l)

'f'easley, Benager f'olumbus (b'it)-Cia.l, :00: (l'00): K.F.l.

Thornton, Henry E. (b'tiq)- riat.10,94; $(1,05)$

HAWKINSVILLE, 3,420 , PULASKI

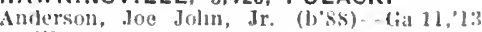
(1'13).

BROII:, FIGENE C, (b\%8)-Ga.11,00 $(1,00)$.

(roll, 0. A. (rol.) (b'70)-X.C.3, $06 ;(107)$

Jordan, k. M.- (ia. I,76.

Mathere, Iacob b. (b'-4)-Ca.5.98: (l'9s)

MATHEWS, WILLIAM A (b'62)-6a.11, M. $00 ;(100)$

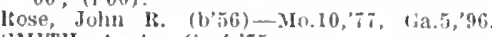
S.MITI, A. A.-(ia.4, 55

FTONE, J(HIX J. (b'4)-Ma.1,9s; (l'9s).

STONE, ROB'T. (i, JR,-lia.1, 06 ; (l'06).

Weathers, Alvah II. (1,\$6)-Gi.9, 09; (l'09)

HAYSTON, 45. NEWTON

Ilollls, Robt. Lee (b't) -Ga.5, 89 ; (d)

HAZLEHURST, 1,181 , JEFF DAVIS

Christian, John M. (b'70)-fia.1,92; (c).

cobb, John 'T. (b'66)-Ga.5,'s9.

filrtman, I'm. II. (b'84)-Ga.11,07.

Hall, John Natlson-Ga.10,'95: (1'95)

Johnson, Seaborn W. (b'59)-Ga.5,'87.

Lambert, Eljah A. (b'75)-Ga.12,09; (l'09)

Mcwhorter, 'Thomas II.-0.2,'84.
Thomason, (G. B. (1,46)-Ga.5,'82. HEARDVILLE (R.F.D., CUMMING), 100

Plrkle, Wm. W. (b'0)-Ga.5,'97; (l’98).

HELEN, - WHITE

lhillips, II 'oh Kingsley (b's0)-Ca.11,'13; (I'13)

HELENA, 890, TELFAIR

Bureh, Julius Caesar (b'88)-MI.9,'11; (III).

'Iurner, 0. W.-Ga.5,'86.

HEMP, 45, FANNIN

Ifycle, llumphrey I'osey (b's0)--(ia.12,'12; (1'12).

HENDERSON (R.F.O., ELKO), 127, HOUS. TON

Coleman, J. yavis (b'65)-Ga.5,'88,

HEPHZIBAH, 656, RICHMOND

Baxley, Wm. H.-Ga.1,'s7.

Corley, lobert Emmett (b'74)-Ga.1, 08 ; (l'08).

HEROD, (R.F.D., DAWSON), 2|4, TERRELL COLLLM. EIN (b'81)-(ia.11;'06; (l'06).

HIAWASSEE, 226, TOWNS

lolunson, James F. (b'(6i)-Ga.5,92.

Twlggs, Itobt. H. (b'5i)-Ga.1,'88.

HICKORY FLAT (R.F.D., HOLLYSPRINGS), 140 , CHEROKEE

Pettlt, John Thomas (b's0)-Ga.12,'10; (l'10).

HICKOX, 231, WAYNE

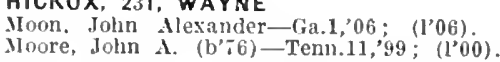

HIGH FALLS (GOGGANSVILLE P.o.),

MONROE

STEELE. WM. H.

(siee Jackson.)

HGH SHOALS, 550, OCONEE

anmel A. (b'64)-Ga.5,'98; (1'98).

Ilintial, Jun W.-Ga.5,'92.

HILLIS (R.F.D., GIRARD), I04, BURKE

Mems, Frank-ia.1,9S.
HILLSBORO, 209, JASPER

(iarland, Jolin T.-Jenn.5, 78 ; not In yrat-

IIIII,EY, CHAS. LEWIS (b'81)-Tia.l, 06 (l'o(i)

HINESVILLE, 174. LIBERTY

Hedury. Mfred I.-Cia.4,56.

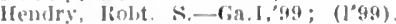

IAYTOS. THOS. S. (1,58)-1:a.10,'91

HIRAM, 254, PAULDING

INIOFISOC, JAMGS THOMAS (b'86) \& Ga.12,'12; (1'12)

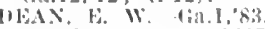

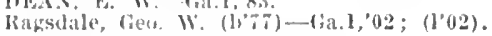

HOGANSVILLE, 1,230 , TROUP

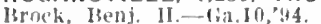

linulel, 13luefort ( $-(925,95:$ (1'95)

Fowler, Allen J- (ia.s, $85:\left(1^{\prime} 96\right)$.

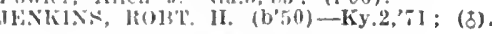

HOLLAND. 50, CHATTOOGA

llall, Fred liatt (1):81)-Temm.15,07; (1'0s).

HOMER, 228, BANKS

IIAlTIE: "TIIO NALOLEON (b'66)-6a.5, ?1: (1'94).

Inlley, James swayne (b'84) - (ia.12,'12; (I'12): G.

HOMERVILLE, 437, CLINCH

C'ulpepuer, Alexander 11. (b'60)-Ga.5,'94: (1'43).

P'arrlsh, Wm. l,eonard-Ga.1,'12; ( ).

HFAVIS, WHLLAII FARIELL (b'89)Ga.12,'11; (I'I1)

HONORA, - LINCOLN

l3urch, Alex. W.-Cia.1,'89; (ठ)

HOSCHTON, 429, JACKSON

1l.LLN, I.ISBON C. (b'62)-Ga.1,'88;

De LaPerrlere, Wm. Ernest (b'84)-Ga.11, $07:\left(l^{\prime} 0 \pi\right)$

De lalierriere, Wm. P.-Ca.1, 76.

Freeman, TaIph (J'84)-(ia.1,09; (I'09).

HOUSTON (R.F.D., FRANKLIN), 40, HEARD

l3askin, Robt. H.-I'a.2,'59.

HOWARD, 100, TAYLOR

Irrington, 'Jhos. E.-Ga.1,'83.

HOWELL, 194, ECHOLS

Hall, John Franklin (b'64)-Ga.5,90; (\$). HULETT (R.F.D., VILLA RICA), 19, CAR. ROLL

King, Rlehard L.-Ga.10,'94.

ItoBELTS, OSCAR WM.-Ga.12,06; (l'06).

HULL, I33, MADISON

'HANDLER, BETIIEL B.-E-Ga.9,'91.

HUNTSVILLE (R.F.D., DALLAS), 75 ,

PAULDING

IDEAL, 186, MACON

('hllds, John N.--ia.1,'93.

ILA, 20, MADISON

WEATBROOK, (GEO W-Ga.5'89.

WLSTlBLOK, ROBERT JOHNSON (b'7z) -Ga.1,04; (1'04).

INDIAN SPRINGS, I00, BUTTS

Elder, Eugene B. (b'75)-Ga.1,00; (l'00).

INMAN, 100, FAYETTE

('Iambers, J. A. S.-Ca.5,'92; (I'92).

Weldon, E. R.-Ga.1,'i1.

IRON CITY, 459, DECATUR

RICIIIILDSON, WM. M.-III.4, 01 ; (1'02).

sikes, James A. 1.-Ga.5,'76.

IRWINTON, 249, WILKINSON

Dugran, James H. (b'64)-Ga.10,'84; (t)

R.F.I. 1.

Parker, Wm. Harrlson (b'74)-Ga.10,97; (1'97).

Wood, 1Iubert C. (b'76)-Ga.11,00; (1'00).

Wood, Joshua s. $\left(b^{\prime} 44\right)-G a, 5,75$.

IRWINVILLE, 300, IRWIN

HICCOX, C. H.- - ;a.11,01; (1'01)

IVEY, 75, WILKINSON

Gilmore, Fbenezer T. (b'42)-S.C.1,'68.

JACKSON, 862, BUTTS

BYILON, J. LEE (b) 55$)$-Ga.5, 87 ; (t)

COPELAND, HEXRY W. $\left(\mathrm{b}^{\prime}-8\right)-\mathrm{Ga} 11,01$; (I'01)

GL'TlER, ROY A. (b'86)-Ga.12,'10; (l'10).

Jarrell. Jos. Allison (b'58)-N.Y.10,'85;

herard, Winston II. (col.) (b'7i)-Tenn.7, '08; (1'0\&).

STEELE, WiI. H. (b'io)-(ia.11, 00 ; $\left(\mathrm{l}^{\prime} 00\right)$; (High falls)
THAXTON, JOHN M.-Ga.9, 94 .

W(o)1, IA.MLS FDGAR (b'68)-Ga.5,94 (l, 04$)$

JACKSONVILLE, 450, TELFAIR

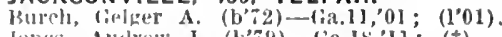

Jone's, dnelrew J. (l,79)-Cia.15.11; (\$).

Montromery, R. M.-S.C.1,'97; (I'01).

JAKIN, 622, EARLY

S.MITH, EUIY. C-Ga.11,0T; (l'0T).

JASPER, 332, PICKENS

Faulkuer, J. A.-(Aa.9,12; ().

Ientrix, John h.-Ga.11,02; (l'02).

Russell, ('lias. (: (b'73)-Ga.9,09; (\$).

JEFFERSON, 1,207, JACKSON

11\%NNET', JWASE C. (b'69)-(Ga.5,'90.

J3Ro('K, CHAS. O. (b'57)-Ga.5,'s0.

SLIIFIt, JOIIN G. (b'66)-Ga.1,96; (l'96).

Al[DONALD, EDVARD M. (b'89)-Ga.11,

l'FNlERGMASS, JAMES B. (b'51)-Ky.1, 76.

sinlti, Summer J. (b'62)-Ga.5,'86.

JEFFERSONVILLE, 740, TWIGGS

Jones, Thos. Slater $\left(b^{\prime}(64)-K y .4,87 ; S\right.$.

O'Danlel, Mark 11. (b'6I)-Ga.5,'81; (১).

Slappy, John G.-Ga.5, 75.

JENIIINSBURG, 237, BUTTS

AKIN, B. F.-Ga.9,'99.

llAll'El:, JOHN W.-Ga.9,'97.

JERSEY, 191, WALTON

Lott, Walter II. (b'80)-Ga.11,'06; (1'06).

JESUP, 1,415, WAYNE

COLAON, ILGERNON C. (b'73)-Ga.1,01: (l'01) COLYIX, JACKSON T. (b'80)-G-Ga.9,03;

CRUMIIEY, ELIAS CAMERON (b'i1) Ga.11,05; (1'05); Pd.

MOOLE, DANL. I.-Cia.5,'94.

Stow, Micollins N. (b'62)-Ga.5,93: (5).

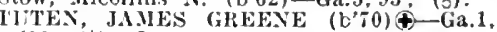
90 ; (⿱十口) ; $\mathrm{S}$.

JEWELL, 500, HANCOCK

Cason, Robt. Alurustus (b'61)-Ky.4,'86; (b).

Larl, IIerman lucas (b'83)-Ga.11,'10 (1'10).

Franklin, Remus B. (b'77)-Ga.12,'12; (I'12)。

JOHNTOWN, 30, DAWSON

Holden, Alexander $\mathrm{S}$. (b'66)-Ga.5,97 (l'97).

JONESBORO, 970, CLAYTON

ramon, 'Thos. C:-Ga.1,'83.

Cousins, James S. (b’T0)-Ga.5,'94.

Rolak, John L. (b'8:)-Ga.9,'12; ( ).

JUNCTION CITY, 225, TALBOT

Carson, Chas. Calhoun-Ga.18,'11; ().

JULIETTE, 100, MONROE

Smith, Wn. Jos., Jr.-1ld.4,03, 00 ; (I'00).

KATHLEEN, 25, HOUSTON

Story, John W. (b'71)-Ky.1,'93.

KENNESAW, 573, СОBB

Ellis, J. W. $\left(b^{\prime}-6\right)-($;a. 9,00 .

LESTFK, J. E. (b's0)-Ga.11,02; (l'02).

Usborne, Jasues C. (b'66) E-Ga.9,97;

R.F.P. 3 .

KENSINGTON, 25, WALKER

ClOWDER, MALCOLM M. (b'59)-Ga.10. '86; R.F.'.

ROGTEIt, IOS. P. (b'66)-Ga.10,90

KESTLER, 413 . DARLY

CHESHIKE, JAMES LESLIE (b'82)-Ga.11, 08: (l'08)

IEATON, I'EYTON H. (b'63)†-Md.3,88

SHEI'ARD, WH. OLVA-Ga.11,12; (1'12).

KEY (R.F.D., PIDCOCK), 50, BROOKS

Groover, J. R.-Ga.5,'76.

KINGS (R.F.D., COVINGTON), 50, NEWTON

Gibson, James T. (b'5i)-Ga.9,81; (ち).

KINGSLAND, 190, CAMDEN

Prince, Arthur Bernlein (b'88)-Ga.1,'12; (I'13).

KINGSTON, 522. BARTOW

A rnold, T. 1. - 0

Bradley, Jeflerson D.-Ga.10,'88.

KIRIKWOOD (ATLANTA P.0.), 1,226,

Daniel, Eugene Lewis (b'85)-0.2,13;

(I'13).

Emery, Walter B.

(see Atlanta.) 
lloure, Captain lluntor-lia.9,07; (1'0i) Mathews, James Chrlstoptier (b'35)-lia. $85:(2)$

Mc:Mlilan, Volet

(See Atlanta.)

Nisber. Yredk. 1'-Ca.10,94.

Verdler, Hichard

KITE, 241, JOHNSON

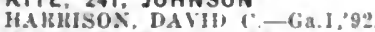

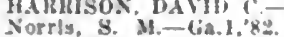

Forrls, M. M. - Ga.1,'82. Cia 1,'s9: (\$)

Teacock, Moreos D. L.

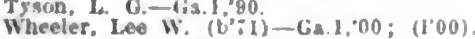

LAFAYETTE, I.390. WALKER

Cochran Geo IV - Tenn ' 68 .

COUH.TEK, IIOBERT M. (b'86)-(ia.11, 10 (1'10); R.F.D. 5 .

FAMSS, SAML iv. (b'35)-Tenn.6."8

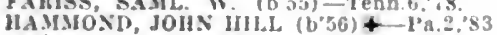
(3)

Johnston, Jasey J.-Cia.5,"95: (J'9.5)

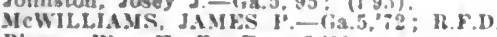

Rhyne, Wm. II. F.-Tenn.5,'po

TALI.Y, ROBT, E.Ga.5.95: (199:)

H.F.D. 3.

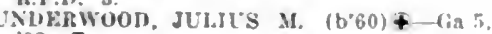
'83; $T$.

LAGRANGE, 5.587, TROUP

Allew, L. R.-Md.1,82; I6.F.n. 5

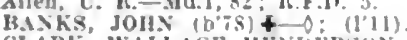

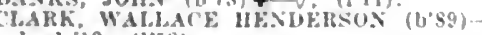
1. 1.1, 12; (1"12).

Datcher, Wm. (col.) (b'60)-Tenn.7.98 (1'99); S.

Epos, Isalah T. (col.) - N. C.3.0s: (1'96).

Gafney, wm. 1). (b'63)-Ga.1, 81 : (o): not In pracilec.

IIArdy, J. H.-(ia.1,96; R.F.D.

Justice, Baleigh A-Gia.5.89.

Lane, Isaac 11 - Gia.5, '91: (c)

LANE. JOS. E.RSEST (b'85)-(ia.11,09

Ic('all, Wru. H. (b'\$0)-Y゙a.1,05: (1'06) Morzan, 1). F. (b;s)-Cia.11,06; $\left(1^{\circ} 06\right) ; \mathrm{Pd}$ MOKGAN, WaI. E-CA.

HIMLY, FRANCIS M. (b'58)-Ia.1, 80 (3): Fres. State 1toard of Med. ExamlnRIDLEY, FRANK It., JR. (6'Rt)-Ga.11, $\theta 6$; (l'06).

RuUand, W. W-Ga $10,89$.
SLACK, HENRY HCIIST) (h62)

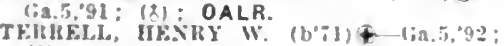
(3)

LAKE PARK, 285. LOWNDES Mlller, Thomas Elljah (b'i5)-Cia.9,"06,

Irescoti, J. P.-Ga.5.'90

LAVONIA, I,712, FRANKLIN

BOSNEI:, THOS, B.-T;a.10,9.

CORSU1: WM. W.-ra.s.

FHEFMAX, JAMES M- 18.9 .93$.

HEI.LEK, WALTEIS BAXTEK (b'85)-Ca.IL 10 ; $(1,10)$.

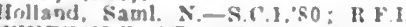

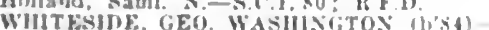

TenI. I,08: (1'08); Ob.

LAWRENCEVILLE, 1.518, GWINNETT

bizard, W: Ko-Gia.11,03: (1'03)

Hall, Beverly W, (b't5)-lia.1, 81

it. $\mathrm{V} .3$.

llinton. Chalmus (c, (b'88) … (ia.l.'(t)

Johnaron. Melslle $T$ (b'it) E-(ial 9 "a': (1’05); l'rof. Oper. and Clln. Surg., lia y

kelles. Inanle! Claude (b's 8$)-$ Tenn.I0,"10 (1" $(0) ;$ OALR.

Kells, G. S. - Cia 9.9:

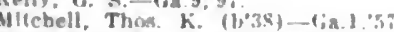

Micbell, T. K., Jr. (1, it) Cia.11,03; (1n?

LEAH, 30, COLUMBIA

Manchard. I'lerce fi, (b'sS)- lia l.11 (1'11): U

LEARY. 430. CALHOUN

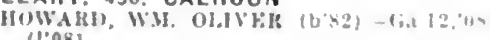
[1.03].

STHWAMT, Ji)H, C. (1, (1'10).

LEESBURG, 705. LEE

Clark. Thomas Jardeman th'sil- Ia 1, lu $(1,10)$.

Crumbley, J'one Rarrow (1,83)- ba 1,10 $(1,10) ; 5$.

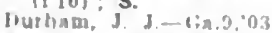

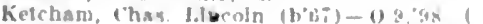

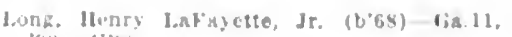
"9y: 11 "4:"

Stathau, U. W -Md, 95

LELA, 331, DECATUR

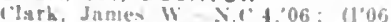

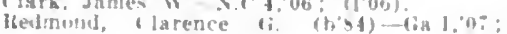
$(1,0)$

LENOX. 206, HERRIEI

Iuslln, liuj Isevlle (b'ig)--Tenn 11, Otj (1'1);)

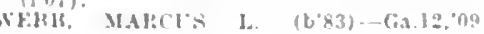
(l'():4).

LEO, 10. WHITE

kivans, Wesley k-Cia.1,'st

LESLIE, 393, SUMTER

(lawhirs. Lewla .11 (b'84)-1;a.11,10;11'1n)

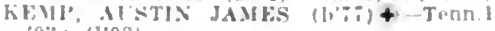
"03: (1"03)

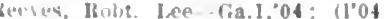

LEW. - TATTNALL

WITKINS. J. J - (ia.j, ,g].

LEWISTON, 1,200, WILKINSON

I"srker. W. II-lia.10,'81.

LEXINGTON. 545. OGLETHORPE

F'mast, $11 . \mathrm{Z}-\mathrm{Kr}$.

IEIXU1.ls, W. H. (t,il)-Ga.5.'83

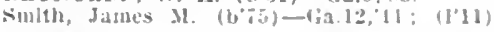

LIBERTY HILL (R.F.D., MILNER), 100 PIKE

Jarton, Jolln .t. r. $\left(b^{\circ} 56\right)-$

LILBURN, 50, GWINNETT

lijekens. 11. T.-(ia.9,'sy.

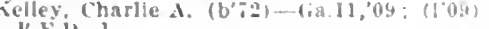

ik.j.i. 1.

Mlianlel, Ell J-Cidg'13. (1)

LILLY, 221, D00LY

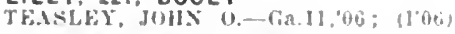

LINCOLNTON, 375, LINCOLN

('rawford, Wm. B. (b'bin)-KY.2.92; (1099)

Esles, Wm. 11. (bo-)-(ia.1.00; (100).

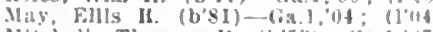

Nitchell, Thomas I', (b'tí)-(ia.1,'st.

LINDALE, 2,643. FLOYD

(1)UI.E, FHAXK-(ia.5, $\$ 4$.

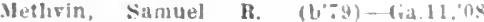
(I'0s)

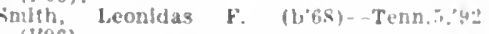

LINTON, 176, HANCOCK

lutchings, Earnest H. (bati) (iall.1. (1'13)

LITHONIA, I.428, DEKALB

liell, J. Aullson (h'81)-Ky.4,05; (1'0.i).

rarmer, Jos. A.-lia. $5,91$.

l'hllly, James ( - -6.29:13; ( ).

friblule, Jos. M1-Via.9," 95 ; J'rof. I'race uf

Med., ria.9.

Hebt. Wr. A.-Tia.9,10; (1'10)

LIZELLA, 50, BIBB

Erelerkk, (lias. ('leveland (b's)-dial.

12: (1'12).

Holley. J. S.-6a.5."s?

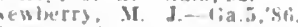

Thumas, llenry ir.-lia.5.93: t3

LOCUST GROVE, 716 , HENRY

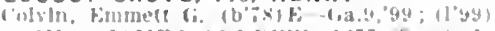

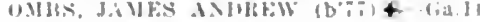

(0): (1"0.5).

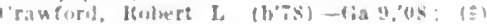

LOGANVILLE, 600, WALTON

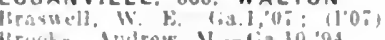

Hrowhs, Andrew M.- lia.10,"84

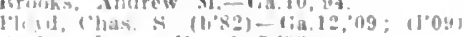

Courloy, Janies is lis ro, 83 .

LOLLIE, 37, LAURENS

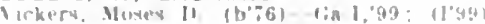

LONEOAK (R.F.D.. HOGANSVILLE), $24 \%$ MERIWETHER

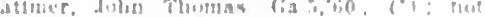

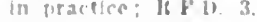

LORANE, 25, BIBB

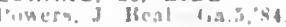

LOUISVILLE. 1.039, JEFFERSON

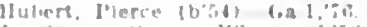

hiluent.

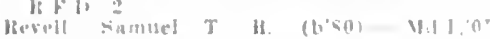

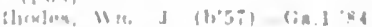

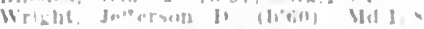

LOUVALE. 3H. STEWART

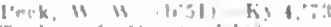

turker. it in lon
LOVEJOYS STATION 136, CLAYTON

Winlily, Janies It 1,a.

LOVETT, 165. LAURENS

IBMIIR. TUSteT IS

LOWELL (R.F.D., CLEM), 2M. CAAROLL

M.ITTHEWS, HOMER TAL I.

LUCILE (R.F.D., BLAKELY), 2S, MILLER

Husli, (harles $r$. (2 $\mathrm{k}$ )

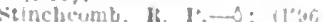

LUDOWICI. 541, LIBERTY

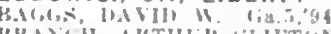

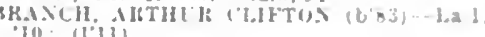
10; (1"11)

LUDVILLE (R.F.D., TALKING ROCK), 100, PICKENS

hastaln, Joln H.-. F 1ia. 30.43.

LUELLA, 100, HENRY

Nelms, J. A (b.ti) 1.9.10:83; 11-3)

LULA, 309, HALL

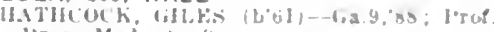

J'rac. Med, lay

LUMBER CITY, 1,195, TELFAIR

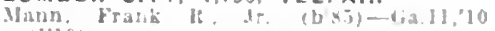

(1.10)

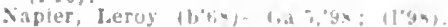

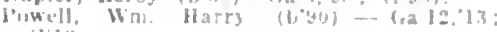

(II3)

LUMPKIN, I,140. STEWART

Bruneau, Wibler Milolib (b'seb)-Md.9.1: (1"1:)

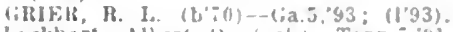

lockhart, Alleer i) (col.)-Teno-yi

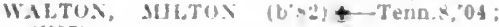
(1.05)

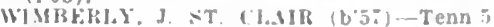

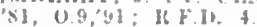

\section{LUTHERSVILLE, 349, MERIWETHER}

Irelier, Mtchatel $\therefore$ (boti)-(ia.\$, $U 2$

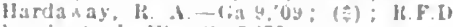

liamber?. J. W,-clia $5,71$.

lasseler, Harly J hy, $4: 04$

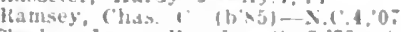

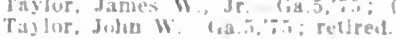

LUXOMNI, 250, GWINNET T

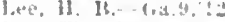

bee, Theodore 31 - 1,a.9.0S: M.FD.

LYERLY. 322. CHATTOOGA

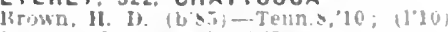

itrvant. Jus. W. hy.?

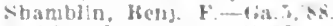

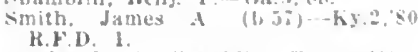

tark, Webl. Pranklin-Tenn.9,"09:

LYONS, 927, TOOMBS

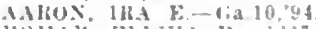

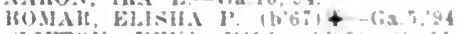

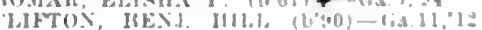

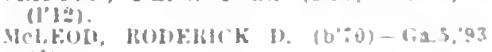

(1)

(1"04).

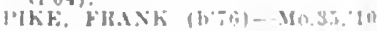

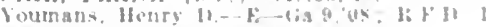

MABLETON, 300, COBB

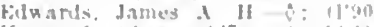

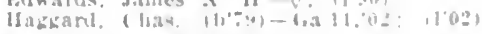

MACHEN, 160, JASPER

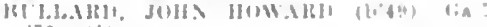

MACON. 40,665, BIB B

MACON. H0,665, BIB B

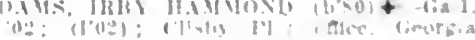

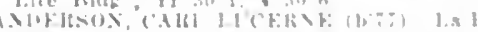

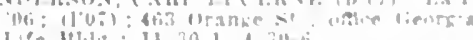

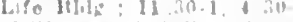

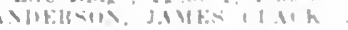

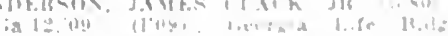

1.3

$\rightarrow \infty$

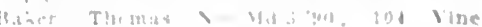

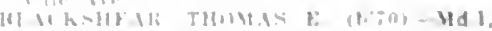

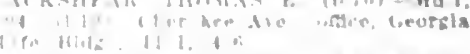

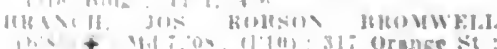

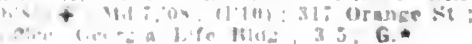


Braut, Forest Cecll-1an.1,03: not in prac tlee: st. Stanislaus collece.

Brown; lelghlon I.-Ga.1,'06; (1'06); 520 Boundary st.

BUlR, A. NOODY-Ky.4,73; 521 Forsy th Ave.; onlee, firand Hildg

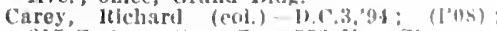
215 Cotlage St. ; offce, 552 Now SL.

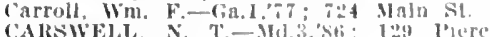

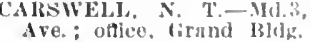

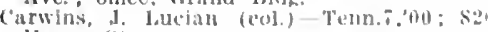
Hazey sit.

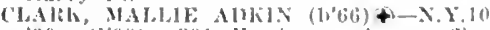
90: (1'90); 301 Hardeman Are: ollle'

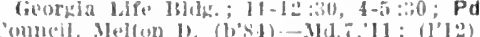

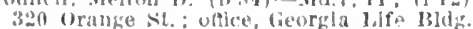
$10-11: 30,3-4: 30$

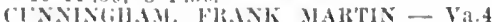
99 - 143 Jeflerson Terrace; ofllce, firand Rlug. ; 10 2: OALR.*

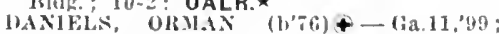
$\left(1^{\circ} 99\right): 611$ Forsylh sit.: ofllce. Americm Natlonal Bank Bildg. I1-1, 4-6; ObG

1)ELRT, HENHY PHENTISS (b) (b3) + Ga.1,88; (1's8); fift College St.; office. 673 Cherry st. : $12: 30-1: 30,5-6$.

l)wberry, T. J.-Ga.5,'85; 215 Jenkins St. oftre, $182 \mathrm{~d}, 4 \mathrm{th}$ si.

Du luid, Jos. W. (b’71)-Md.1,93; Oak Haren Are. and liansom Are.; oftce. 5721, Cherry st.

Farnhan, Hiram M.-MICh. L,95; (l'0i) 568 cherry st.

Gewinner, Napoleon f. (b35)-S.C.1,79: (8) : 803 vineville Are, : $8-9,2-3,7-8 ; \mathrm{Pd}$ Glbson, obe C-Ky.4, $44 ; 217$ College st. :

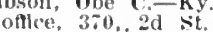

GOSTIN, HERNAIBi S \&_Id 3.03 : (l'03)

636 Orange St. : oflice, 569 Cberry st.

636 Orange

Green, ("harles F. (col.)-D.C.3.04: (1'0.) 239, 2d Are.; offle, 5.52 New st.

Green, Fustace Edw. (col.)-D.C.3, $86 ; 40$ Madison st.

GREEN, WESIEY J. (b'63)-Ga.5,'88 (太) ; R.F.l). 5 .

Greene, Benj. Walter (b'86)-(ia.1,12: (1'12); 457 Spring st.; oflice, 574 Cherry St. ; 11-1, 4-6i ; U.

IILL, TIOMAS H.†-Ga.1I,03: (1'03): Oak Haven Are.; oftlee, Grand Bldg.;

HARROLD, CHAS. C. $\left(b^{\prime}-8\right) \nrightarrow-$ Y.Y.1, 02 ; (l'04) : 206 Higli st. ; oftlce, 416,2 l st. : $1-1,3=5$.

HEIRFFOR, WILI DELAFIELD $\left(b^{\prime} 80\right) \nrightarrow-$ Id.4,03; (1'03); 3i4 Orange st.; office, Georgla Life Rldg.; $11-1,4-5: 30$.

Ilinkle, Albert Bults-N.Y.5,'89; (む) ; 559 Orange St.; offlee, 3621 , $2 \mathrm{~d}$ 'st.

HOLMES, JOIN 1'ARIM (b'85) \&-Tenn. 5 11: (1'11) : 411 Orange St.; office, Grand Bldg. : 12-2, 3-5: G.

HO1'E, E. D. Cia.5,91; 337 Adams St. Howard, H. L.-Ga.10,81; 352, 3d St.

IIURLEY, THOMAS A. (b'79)-Md.3, 04 ; (l'06) : 127 High St. ; office, Clisby Blug. ;

JACKSON, MAXE-N.Y.1,88; (t); 565

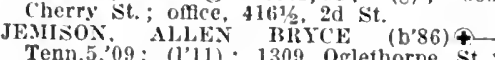
Tenn.5,'09: (1'11); 1309 Oglethorpe
oftlce, Georgia Life Bldg. : 3-5; Pd. oftlce, Georgia Life Bldg. ; $3-5$; Pd.`

JOHNSTON, FEIIX C. $\left(b^{3} 60\right) \uparrow-M 0.1,85$; (さ) ; 52216 roplar st.

320 Cephas (b'83)-Ga.11,'12 (ottice, Geortia

Keiser, John H.-E-Ga.9,92; $(100) ; 252$ Church st.: office, 2d and Cherry Sts.

Kelly, Geo. Washington (b'90)-Ga.11,11; (1'11); Grand Bldg.

KEMP, A. lIERCE (b'6S)-Ga.10,'s9; (t) $10 \mathrm{~s}$ '1 'ieree Are.; oflee, Grand Bldg.

Lee, $W$ m. G.-Ga.1.99; $\left(l^{\circ} 99\right)$; not in practiee: $461 \frac{1}{2}$, sd st.

LITTLE, WII. J.-Ga.10,'94; 339 vineville Ave. ; offce, Anterican Natl. Bank Bldg. undy, J. W. (col.) (b'75)-Tenn.7,06 (1'06); 640 Washington Are.; 8-11, 2-4,

MAIRIN, JAMES JACLSON (b'89)-Ga.II. (1'13): Maeon Hospital.

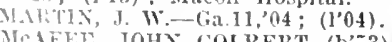

MeAFEL, JOHX COLBERT (b’3) \&-MI.4. 20: (1.0e); 330 Waslington St.; office,

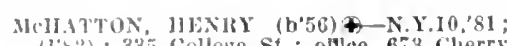
11:20) ; 335 ('ollete st. ; ollee, 673 Cherry Li: $11-12: 30,4: 30-5: 30$.

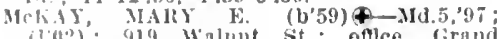
(1)

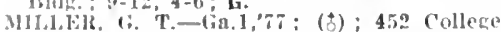
sit.; onlec, Amerlean Natl. Bank Bldg. 11-1, 3-5; G. (b'-4)-Ga.5,98: (1'98) Miller, John X. (b'it)-Ga.5,'98; (1'98) i13 Cherry

MoOHE; J.LIFA A. (eol.) - Tenn.11,'99; (1'00) ; 268 Maln $x$.

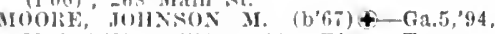
Y.10,95; (I'95) ; 110 Hines Terrace offec, Commerclal Nall. Bank Blelg.

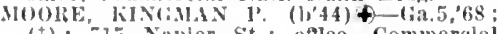
(夫) ; 71. Napler St.; offlce, Commerclal Fiti. Rank bldg.

Moore, Thos. 1", (col.)-Tenn. i,'0ï; (1'07); 121\%, 411 st.

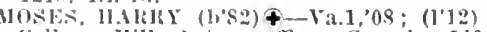
college Hill Apts.; office, Georgla Life

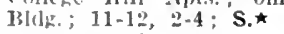

Myers, David Vance (b'86)-Tenn.5.'13 : (1): Nacon IInspital.

SFWVAN, JOHN P. (b'49)-S.C.I,69; (t) : R.F.D.

OISLEY, S. P.-Kiy,4,92; Forsyth Rd

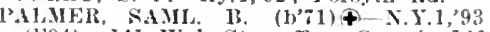
(1:94): I41 ligh St.: office, Georgla Life 13lig. : 9-1, 4-6; OALR.

larker, Abraham H.-II-0.13,'89; (†)): 207 Cotton Are.; $9-12,3-4$

Pirkle, Wm. IIomer-Ga.I1,'12; (1'12); Maeon Hospilal.

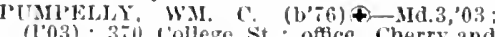
(1'03) ; 370 college St. ; offlee, Cherry and 2d Sts. ; $11-1,4-5: 30$.

MESI'ESS, HWRBELT (b's0) $\downarrow$-Tenn.5.06; (l'06) ; 134 Reinhert Ave.; offlce. Commereial Bank Bldg.; 11-12:30; 4-5:30. (b'84) 4 -N.Y.1, (09; (l'09); College IIII Apts.; ontce, Amerlcan Nati. Bank Bldg. ; $10: 30-1,3-5: 30$.

Iloberts, John B.-S.C.1,'67; (す) ; Georta Jlasonic Home.

Mobinson. W'm. MI. (b'86); Ga.1,08; 825 I'lum St.

ROtiEHS, JOS. W. (b'57)-K5.4,89; (t); Cherry st. and cotton tre.; offlee, 370, $2 \mathrm{~d} \mathrm{St}$

ROGERS, TIIOS. EDWARD (b'86) -Ga.11 10 ; $(1,10)$; Park Hotel; offlce, $3701 / 2,2 d$ St. ; $11-1,4-6$.

Ross, JAMES T.4-Pa.2.85; 363 College St. ; offlce, Ameriean Natl, Bank Bldg; OFAR, A1LEN ROBT. (b'88)-Ga.12,'11 (1'11); 722 spring st. ; $3-5$

Rushin, Walter P. - Ga.10,'S6; Lake and Fairmont St, ; office, $6561 \% 2$ Cherry St.

SELDEN, JOHN A.-Ga.1,99; (1'99); 20
2d St.; Commercial Natl. Bank Bldg.

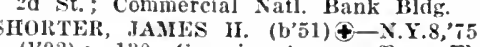
(1'92); 130 (ieorgia Ave.; offlce, The Grand; $9-1,4-6$; $(B 1,3)$; OALR.ネ

Shuften, John T. (col.)-N.C.3.92; 236, 1st Ave.; offlee, 368 llawthorne st.

SIGMAN, JOIIN MONROE (b's0) †-Ga.1, 04; (1'04); $75 t^{\circ}$ sulberry St.: office, Georgla lifé IBlde.; $10-1,3-5 ;$ D.

Speer, A. M-Ga.1,84: 31 T Walnut St.

STALLER, MAIRY M.\&-Tenn.10,92;203 High si. ; offlce, American Natl. Bank
Bidg. ; $9-1,3-5 ;$ OALR.

STOVALL, RUPERT HOPE (b'81)-N.Y.19, 05; (1'05); 290 College St. ; oflice, Georgla life Bllg.; $10-11: 30,3-4: 30$.

Subers, Jacob J. (b'38) E-Ga.7,'61; (1'58) ; 810,4 th St. ; offlce, 510,4 th St. ; $8-12: 30$,

alker, Duncan DeVane (b'86)-Pa.2,'12; Medical Sult., DIacon IIospltal; S.

WARD, JIBAI BENJ. (b'79)-Ga.12,'12; (1'12) : 303 ('hureh $\mathrm{St}$

WEATER, OLJN H. (b'73) †-Ga.5,94 (1'94): 107 ('lereland Are.; oftice, Harde man lilde. ; $11: 30-1,4-5: 30$.

WERB, FREI) IELAND $\left(b^{3}-3\right) \uparrow-P a .2, n 2$; (1'05) ; 321, 1st st.; offlce, 569 Cherry

WHIPPLE, WH. H.-X.Y.10,'S9; Washington Block.

WIILIAMS, HOWARD J. \&-Pa.2,81; 130 High St.; oflce, Wlliams Private Sanatorium; $9-6 ; \mathrm{S} . \star$
HIXUHSTEI, WEE.MS R. (b'84) †-Md.1, ' 74 ; 66 Arlinton I'l.; offlce, 610 Mulberry St. $12-1, \quad 5: 30-6: 30$.

lievrgia Life Bldg.

Worsham, H'm Eugene (b'65)-liy.4: (191): 321 Colman Ave.

W1:1(i11, JLSSE EDGAlR (b'73) - -Tenn.5, 99: (1'01): 61 Arlington 11.; offle, (ievrgla life Midg.; I1-1, 4-6; $\mathrm{S}$.

\section{MADISON, 2,412, MORGAN}

AlN.IS, WM. F. (b'67)-(ia.5,'91; (む).

IIAlRISS, IIENLY T. (b'74)-Ga.1,98; (1'9s).

Smilh. 'jhos. James-111.8,'12; not ln practleo.

THOT'TER, DENNIE DANI. (b'89)-Ga.12.

'12; (1'12).

TIROUTT, JOHN H.-Ga.1,'89.

MALLORYSVILLE (R.F.D., TIGNALL), 50, WILIKES

Ilayne, H'. I.-Ga.9,'89.

MANASSAS, 200, TATTNALL

KENNE1OY, JAMES 1. (b'68)-Ga.1,'93.

MANCHESTER, 922, MERIWETHER

Baker, Elliah L.-Ga.5,'95; (1'95).

Brubaker, A. D.-Ky.I,'80; (1'06).

Jackson, Jasper Isee-Ga.11,'02; (1'02)

Jackson, Tatum W. (b'77)-Ga.12,'09; (1'09).

MANOR, 200, WARE

Jolunson, Herbert L. (b'91)-Ga.18,'11: ( ).

LITTLE, EDGAR P.-Ga.5,'92

Pafford, Jefterson W. (b'89) - Ga.1,'13; (1'13).

\section{MANSFIELD, 589, NEWTON}

Knight, Wyatt E. (b'74)-Ga.1,'99; (1'03).

SMITII, JOIIN C. (b'50)-Ga.10,'84.

MARBLEHILL, 400, PICKENS

IICClain, M. C.-Ga.1,'s7.

MARIETTA, 5,949 , COBB

BENSON, WARREN EDGAR (b'88)-Ga.11, '11; (1'11).

Blair, Leslie Lenton-Ga.11,'11; (1'11).

onehoo, Clarence Andrew (b'91)-Ga.12, 12 ; (1'12).

Elder, Clyde D. (b'81) E-Ga.9,05. Hagood, Geo. Fellon (b'77) E-Ga.9,04;
R.F.D. :

Harris, E. L.-Ga.9,12

Johnsen, Andy E. (b'46) E-O; R.F.D.

KENIT, WM. M. (b'66)-Ga.I0,'89.

MALONE, J. D. (b'60)థ-Md.1,'84; (お).

MALONE, WILL HALE, JR. (b'90)-Ga.II,

'12; (1'12).

Moore, James M. (b'48)-Ga,1,71; (1’95);

TOLAN, CIIARIES THOS. (b'69) G-Ga.5, $92 ;(t)$; Sec. State Board of Med. Ex-

perkinsox, WM. H. (b'78)-Ga.11,'99; (l'99).

Roberson, James Kelley (col.) (b'86)N.C.3,'10; (1'10).

Simpsen, John H. (b'56)-Ga.5,'80.

Thompson, Henry E. (col.) - D.C.3, 0 ; ; (l'0i).

Yansant, Thomas J.-Ga.9,07; (1'07).

MARLOW, 100, EFFINGHAM

LANIEH, LA DESSIE H. (b'65)-Ga.1,'88.

MARSHALLVILLE, 1,082, MACON

Frederick, D. B.-Va.1,00; $\left(1^{\prime} 00\right)$

Haslan, Jake Edwin, Jr.-Ga.11, 07 ; (1'07).

Nelson, G. W.-Md.3,'82.

MARTIN, 377, STEPHENS

Bond, W. L. (b'85) - Ga.18,'09; (龸)

Clodfelter, Thomas Clarence (b'85)-Ga.11, '11; (1'11).

MAU!, 75, TAYLOR

Kajney, Boyce Tucker (b'88)-Ga.12,'13; (1'13).

MAXEYS, 334, OGLETHORPE

Bryant, Jerey (b'83)-Ga.'05.

Durham, Saml. D.-E-Ga.9,'84.

Durham, Wm. Orlande (b'69) E-Ga.9,'93; (c)

MAYSVILLE, 805, BANKS

Castellaw, Geo. Otis (b'85)-Ga.11,'13; (l'13).

DEADWYLER, MADISON P. (b'73)@-Pa.2, $97 ;\left(l^{\prime} 97\right)$.

Eberhardt, Benj. F. (b'69) E-Ga.5,'96; (1'96); R.F.D. 28 
LOCKHART, VINCENT D. $\left(\mathrm{b}^{\circ}+9\right)-$ Ga.5. (i): (8): OPAL

Underwood, Thos. G.-Ga.5.'s3.

Wuson, Capers X:-E-Tia.s.

Witson, wm. S.-F-Ga.9,91.

MCBEAN, 20, RICHMOND

Timmerman, John l'atterson (b'it)-Ga.1. O4: $(104)$.

MECONNELL (R.F.D., BALL GROUND), 12, CHEROKEE

Meclure, Geo. C.-Ga.1,01: (1"01).

MEDONALD, 250, COFFEE

MeDonald, James M. (b'45)-Ga.11,99: (1099).

MEDONOUGH. 882, HENRY

Campbell. Thomas (i.-lia.3.'il; R.F.D

Ellls, llenry Cliford (b's3)-(ia.12.06: (1.06): R.F.D. 6.

Horton. Barney E-Cia.11,00: (1'00),

MeDonald, Chas. D-1'a.2,'55.

Scott, Adell K (b'7)-fis.11:02; (1'02).

Scots. Danlel W. (b'49)-tia.5, $75:(3)$

SMTII. JEFFERSON GLLERT (b'ti) -

(29)

Tye, Kobert Lee $\left(b^{\prime} 65\right)-X .5 .10, ' 55$; (3'09): OALR.

MERAE, 1,160, TELFAIR

Born. Wade Hampton (b'ic)-Ga.11, 00: $\left(l^{\circ} 00\right)$.

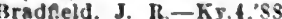

rurlow, Geo. Washlngton (col.) (b'85) Tenn.:112: (1'12): G.

Honiker, Armand h.-Ga.11,01; not In

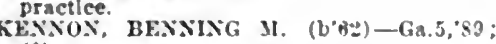
(\$).

Smlth. Ilenry J. (b'3S)-Ga.5,'b1.

MEANSVILLE, 233, PIKE

Bloodworth. Thert K. (6"66) E-Cia.9:93; (\$).

Whatley, J. 0.-Ga.10:'85.

MEARS, 73, SCREVEN

Mays, Robt. Fiward (b'91)-Ga.11,13: (I'13).

MECHANICSVILLE (NORCROSS P.O.), 54, GWINNETT

Shaw, $1 \mathrm{Wm} . \mathrm{A}$ - Ga.9.83; not In practlce.

MEIGS, 697, THOMAS

Aultman, I. R-Ga.1.'93.

Daves. Vergll C. (b'83)-Ga.12,'13; (I'13). Hollingsworth, Pryor levals-Tenn. S,"14: (1.04).

ISLER, JAMES $\mathrm{N}$. (b'jt)-Ga.10,97; (1.97). Laney, Geo. Cary (b'59) E-Ga.9, 00 ; (1'00) MENLO, 376, CHATTOOGA

JENINGS, EMMANS II. (b'69) - Tenn.9, $00 ;(1,02)$

MARTIX, GORDON F.-Ga.1,88

Wood. II. N-Ga.1,91.

MERIWETHER, 25, BALDWIN

Ilubert, Terrell E. (b'6i)-fia.1,91.

METASVILLE, - WILKES

Casteel. Lewis Ryley (b'65) - Tenn.5,'93: (1.06).

METCALF, 314, THOMAS

IIamrick, Henj. F. (b'86)-Ga.9, 13; ()

Monroe, W. A-Cialo

Watklns, Wm. B. (b'6i)-Ga.10,90.

METTER, 408, BULLOCH

JONES, HUYOHD B, (b'i4)-(ia.1.04:

(1'0t) ; $P d$

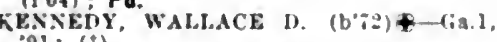
-91: (8).

SIMMONS, WALTER FLLIOTT (b'B6)(ia.1:09: (1'09)

Supler, Andrew II.-Tenn.5,'s3.

MIDDLETON, 25, ELBERT

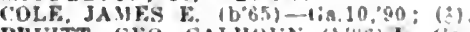

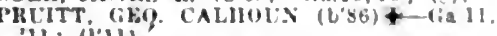
11: (1'11)

MIOLAND, 105. MUSCOGEE

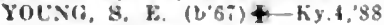

MIOVILLE, 603, BURKE

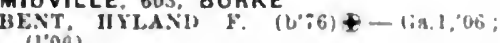
(1'00).

Lowe, Wm. Hoht (b'85)-fial1,"09: (l'09)

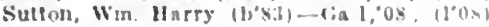

MILAN, 287, TELFAIR

Conk. dulber liend. (6:80)-(ia.1s,10: (1): KF.D. :

Johnwin. Jis. H.- 1 ; 9898 .

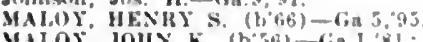

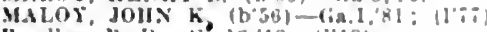

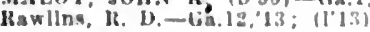

MILLEDGEVILLE, 4.385, BALDWIN

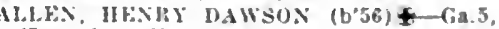

Horldice (ह) : (1:13)

13: 11131 .

Chapman, Cien. IL-Tia.5,97: (1'97).

clayton, Malcolm 10. (b'ss) - Gia.12,13

(I)

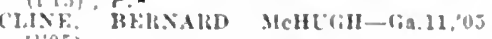

complon fuy ID (b'60)-Mld $3 * s$

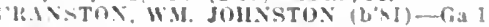

4.jacs, Win. Camphell (b'86)-Ga.12,09: (lon): Intern, Georgla state sanatorlum Pits the Insane.

EC IOLL, liEO. LEE (b'5)-lia.11, OS $(1 ! n<)$ Filsos: WH. A. $\left(b^{\circ} 81\right)+-361.9,04$

CAIUKARD, JAMES ISAAC (b'T0)-X.Y.10

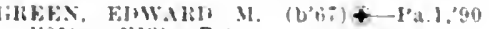

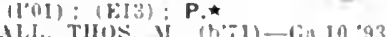

Hindran, sims seward (b'9y)-Tenn.5,00:

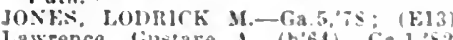

Lawrence. (iustave A. $\left(b^{\prime} 64\right)$ - fia.1:82

LITTLE, $Y$ - ALLEX (b'83)-Ga.11,05: $\left(10^{\circ} 05\right)$

1.0X6IXO, LOVIFK PIERCE - fa.11,0?

MOBLEY. JOHN W: (b'71)—(ia.1,94; (l'95)

Moran, owen F. (b'bi)-Ca.s.'ss.

PERKY, THOS, B. (b'63) - Nal 3 s.

I'RICE, JAMES ADDISON (b'8 12: $(1,12): 5$.

SWINT, BOBT. C.-Ga.1.95; (1'98)

TANER. WM. F (bos)-(ia.11,10; (1, 10$)$ Tracy, lishert Ircher (col.) (b'it)-X.t. (10): (I'10)

WALKER, X. P. (b'S0)—-Ta.1.'01; (b'01)

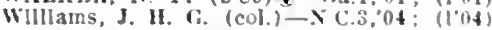

Wom. Arthur Wellesley (b'so)-Gis.12,10 (l'in): Ga. State Rord of Healu

FARBROT'GH, YOL'NG HARRS (b.2)(ia.11,05; (1'05).

MILLEN, 2.030, JENKINS

BELT, LLOYI JONES $\left(b^{\prime} 56\right)$ \& XYY,

Jo:Es, HEXRY A. (b'68) - X.2.3.92: (1'92)

KIRKENDOL, JOHSY L. (b'it)-Ga.11,0ก: $\left(l^{\prime} 00\right)$

LAXE, REMER YOLYG (bo1)-WI.3,'st

MLLKEY, ULINYEY A. (b's6)-lia.1,04 (1009)

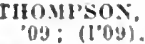

MILLTOWN, 1,247, BERRIEN

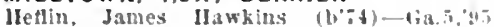
(1)

Sloan, Wim. Darde (boy)-Ga.1,10: (1'10) smith, Louls (b'os)-Cial, 06 ; $\left.18^{\prime} 06^{\circ}\right)$

MILLWOOD, 100, WARE

Chrlstopher, Alonzo E. (b's3)-Cia.j,

hirkland, spencer dtklnsfnu (b'sy)-cis id 1I: (I'II).

MILNER, 400. PIKE

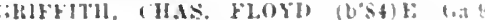

Iluckaby, A II. (b's2)-(ia.1,05: (100)

MILSTEAD, - ROCKDALE

1'urbament. [arikl Halsey (b's3)-(ia.9.'1]

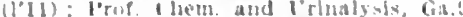

MINERALBLUFF, 338, FANNIN

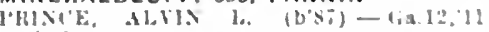
11111

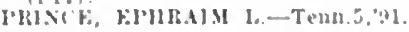

MITCHELL, 212, GLASCOCK

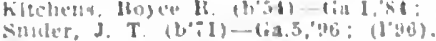

SHuler, J. T. (b०1)-(i,
MIZE, 20, STEPHENS

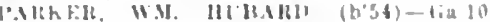

MOLENA, 398, PIKE

Astork, Wil, HIOLSTOS (lowe) lia 10

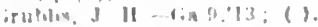

Morkish, J II -lia.s,

MONROE, 3.029. WALTON

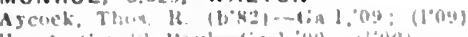

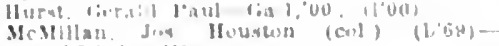
XCe 3, ve: 11091.
Sunnally, llarry B-lia 11.96; (106): S. Peaderarass, "x-lias.

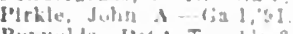

Riggliots. Petil T

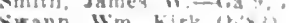

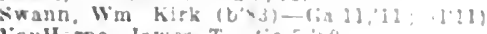

Vistlorne. James T-1ia

MONTEZUMA, 1.630, MACON

LoN.

1.tghtner, Homer 1, - lia 11, nts; 11 no

Mulliun, fredk. II - - ia 10,92

HIIIMgNos, Ills, HatT (bis)M.1. $3, \therefore 3$

Weltun, stephen ginles (cal) (b) Tenn.:09; (1'09).

MONTICELLO, 1,508, JASPER

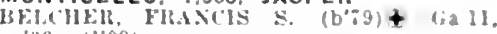

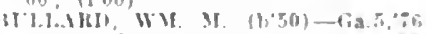

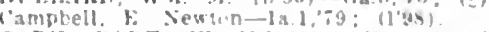

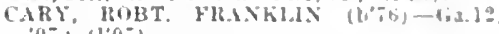
$07:\left(l^{0} 08\right)$

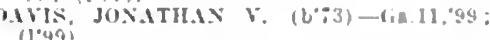
Furae, H. L. Cra.5,50; not in practice.

Turner, John s. (cul.) (b'9)--4ue.1.'10: (1'10)

MONTROSE, 50, LAURENS

Wall, Jasper Mi (b'Bb)-(ia.los

MORELAND, 312, COWETA

conch, James M. (b'shi)-Ciag.'st

Young Andrew Quige (b'b5) b-Ga.9.

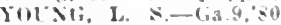

MORGAN, 302. CALHOUN

Mengan, K. Mck-Ria.M.

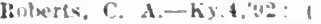

MORROW, 250, CLAYTON

Kemper, llarvey Dorman (b'a)-Ga 12,"0y

McFaul, James 11

(see Mllanta.)

MORVEN, 383, BROOKS

Clomer. 11. J.-fia.5,"95; (1.85).

leadows, C. Ib-(ia.1,93; (193); R F.I

MOULTRIE, 3,3:9, COLQUITT

('ulpepher. J li. (iald, id ()

Fletcher, Cartion Cole-lis.10,98; $\left(10^{\circ}\right)$.

Wictis, W, J,-Ria.1, 's9

Hhtheork, Cecil M. (L'ss)-1ia 1,06: (l'06).

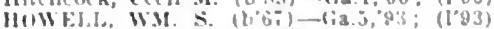

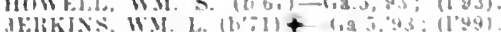

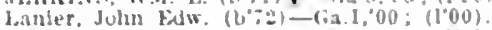

M.ANE, WM. W (1)

Mllisap, Jobn (leveland (b'sj)-livil1,"10 (1.10).

(1'13).

MOUNTAINHILL (R.F.D., BLANTON, ALA.) 50, HARRIS

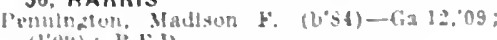

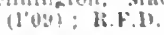

MOUNTVILLE, 226, TROUP

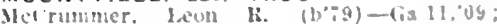
(150)

Silulers. Juln $1:$

MT. AIRY, 236, HABERSHAM

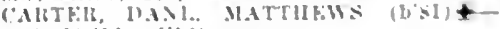

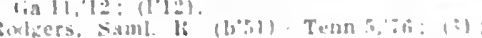

MT. PLEASANT, I00, WAYNE

Hartull, Jullan i".

RERHONG

MT VERNON 605. MONTGOMERY

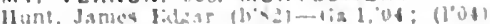

MT, ZION, 30, CARROLL

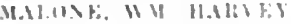

$(100 \div \div ; 00$.

MURRAYVILLE, 50, HALL

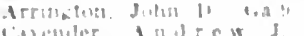

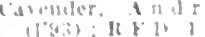

MYSTIC. 140, IRWIN

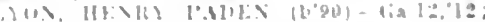
(1) $1:$ Ob.

NACOOCHEL. 200, WHITE

A.1.S. JWIM II IiA 10,93: 1198:

NAPOLEON IR.F.D. BLAIRSVILLE), 300, UNION

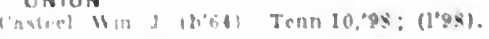


NAS.HVILLE, 990, BERRIEN

ASKlWW, I'LEASANT II. (b'72)-Ga.I, 97

corter. Donald Eitr (b,91)--(ia.11,13; (1) 13 )

CAITELI, J,A FAYETTE, A. (b'is)-Tenn.1. $86 ;($ ( ) .

vale, Jos. G. (1).53)-Ill.14,'9! ; (t).

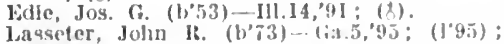
Ii.F.11. 1.

SEIMAX, fUY STOKEIJ (1,'sti)-Gat.12,08; (1'0S).

NAYLOR, 538, LOWNDES

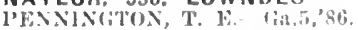

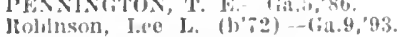

NELSON, 550, PICKENS

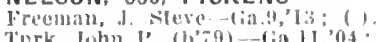

Turk, John 1'. (b'79)-cia.1 I, $04 ;(104)$.

NEVILS, (R.F.D., REGISTER), 50, BUL.

Lorille, J. C.-Ga.I, 00 ; (1'00).

NEWBORN, 475, NEWTON

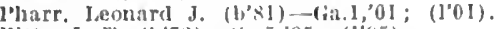

l'l(s. J. 'T' (b'72)-(its.5,'95; (J'(5)

l'orter, Joel i. (b'54)-Tenn.5,82; (⿱十口)

IVIson, 1". Jr.-(ia.11, 0I; (1'01).

NEW ENGLAND GITY (TRENTON P.O.), 139, DADE

lumpkin. 'Tlios. J. (b39)-Ga.I, 57.

NEW HOLLAND, 2,000, HALL

MAILIIS, JUIIN 11, (b'76) - (ia.1,01 (I'0I).

NEWINGTON, 50, SCREVEN

Jowning, limest E. (b'si) ('ia.J,'13; (1'13):

Pd.

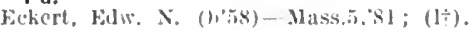

NEW LACY, 80, APPLING

Flanagln, Wley M. (b'79)-Ga.12,'12; (1'12).

NEWNAN, 5,548, COWETA

13.1I,ES, THOS. S. (b'5)-Ga.11,02; (1.02).

JAIGGE, AIUANUER A. (b'60)-Ga.J,'91. large, Joslah 1. (b'59)-Ga.5,

DAIS, THFo. 13. (b'57)-11d, 81 .

HANEL, BA.I, A. (b'82)-Ga.11,'10; (l'10) Jacksou, IIenry Bruce-Ga.18, 09 : (\$) Ii. E.1),

Jackson, James C. (b'53)-Ga.1,85; R.F.D. 1. JONES, TIIOS. J. (1,49)-1'a,, 73 ; (5).

lee, 1R. D.-Tenn.5, 06; $\left(l^{2} 06\right)$.

Itchhorter, Nlllard IL. (b'8i)-N.(..3, 09 (I'09).

I'ENISTON, l'AU1, (b'6z) †-Ga.5,'89; (c) ; S.

TLiRLR, wM. A. (b;4)-Tenn.11,'99 $\left(\mathrm{I}^{\circ} 00\right)$.

WEICH, FRANCIS IRWIN (b'52)-N.Y.5)'7

WoOnRoOF, WM. JoWE (b'82)-Ga.11 '12; (1'12)'

NEWTON, 364, BAKER

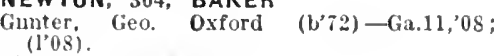

Short, B. I.-IId.6,? 92

NICHOLLS, 720, COFFEE

byer, Walter Harmon (b'89)-Ga.11,']1

(1'11). DANL. H. (b'-5)-Ga.1,00; (l’00). VINSON, SAMI. L. (b'67)-Ga.5,'95; (1'95). NONA, 350, PUTNAM

Ledbetter, Joln (b'55)-Md.3,'86; (む).

NORCROSS, 968, GWINNETT

Manldin, l'errin 0, (b'76)-('a.9,'10; (1'10) Pd.

McDinlel, T. D.-Ga.10,'88; (击).

Sinipson, 0. 0. (b'57)-Ga.5, 82 ; (t)

Walker, Wm. Powell (b'60)-Ga.10,81 R.F.D

Wingo, Absalom H. (b'51) E-Ca.9,'86; (1'91).

NORMAN PARK, 648, COLQUITT

IIall, Jos. H.—Ga.1,'89.

Tyler, F. W. $\rightarrow$.

NORRISTOWN, 87, EMANUEL

Hutchinson, Newbern B. (b'82)-Ga.12,03 (l'0s).

\section{NORWOOD, 340, WARREN}

XASH, KELBEN D. (b'53) - Ga.1, 85 ; Pryce, lithard Y. (b'il)-Ga.1,07; (l'07). NUNEZ, 174 , EMANUEL Herrington, Wm. Gordon (b'S4)-Ga.1,12;
(1'12).
OAIKFIELD, 276, WORTH

llall, Witren .I. (b'54)-Ga.5,'85.

Westhers, furry Inowden (b'84)-Ga.I2,'I2; (1'Iz).

OAKPARIK, 144, EMANUEL

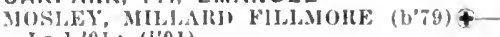
La.1,0J; $\left(\mathrm{l}^{\prime} 01\right)$.

siturkey, b́dgar 1. (b'82)-Tia.1,06.

OAKWOOD, IIO, HALL

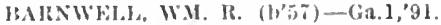

OCHLOCHNEE, 350, THOMAS

Hichreblber, John-(ia.1,'06; (l'06)

Wall. Honter A-Cia.1, 92.

Wlison, James 1.-(ia.1,'9.

OCILLA, 2,017, IRWIN

IHKENS, 11. 13.- - ia.9,02.

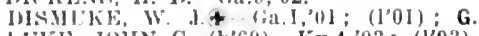

Llike, Jolix C. (b'69)-Ky.4,93; (l'93).

luke, losiat , T. (b's2)-ky,2,12: (1'13).

Melvew; Stejhen M. (b'68)-Tenn.7,'10

Me EIROY

, $00:(1,0)$

Wlllis, GABE WILAH'R (b'82)€-Tenn.9, $09 ;(1,10)$.

OCONEE, I0, WASHINGTON

(iraybill, l.coll A.-N.Y.10,'80.

ODESSADALE, I6I, MERIWETHER

Wllliams, Virgll G.-Md.3,'01; (1'01).

ODUM. 258, WAYNE

OI'M, WATTER M. (b'87)-Ga.9,'11.

OGDWN, ISIIAM K. (b'83)-Ga.18,'11.

OGEECHEE, 123, SCREVEN

Blackburn, Davld H. (b'55)-Ga.1,'91 ; (t) ; li.k.I). 1 .

\section{OGLETHORPE, 924, MACON}

lerrick, IIoward Clinton-Ga.11,02; (1'02).

GREEI, CHAS. A $\left(b^{\prime} 73\right)-K y .4,92 ;$ (t).

Stephens, John C. $-\mathbf{E}-$ Ga.9,85; not in practice.

OHOOPEE, I0I, TOOMBS

Camp, I. Abner-(ia.9,'01; (l'97).

OLIVER, 243, SCREVEN

Ezell, IIoward E.-(ia.11,'02; (l'02).

lanier, Augustus 13.-Ga.6,'60.

OLYMPIA, 200, LOWNDES

CAIEY, VICTOR FRANK (b'86)థ-La.I, 10 ; (1'12).

OMAHA, 209, STEWART

BALDWIN, JUSTIN OUSLEY (b'85) - Ga.11, ,08; (1'08) ; U.

Simpson, Le hoy J. (U'60)-N.Y.10,'83.

OMEGA, 274, TIFT

WILLIS, IRYIN (b'79)-Ga.12,'08; (1'08).

OSIERFIELD, 300, IRWIN

McMillau, Jobn Ezra (b'86)-Ga.12,'12 ; (I'12).

OWENS FERRY, 200, CAMDEN

Tompkins, Archibald (col.) (b'84)-Tenn. 7 , $11 ;(1 ' 11)$

OXFORD, 655, NEWTON

Erans, Wm. White (b'45)-Ga.1,69; (l'02)

WARI, BENJ. HARVEY HILL (b'85)(ia.12,'08; (l'08).

\section{PALMETTO, 922, CAMPBELL}

lsullard, Thomas P. (b'7I) - Ga.5,'97; (l’97). Rainey, chas. oliver (b'83)-Ga.12,10: $\left(1^{\prime} 10\right)$.

Smith, Ira E. C. w. (b'83)-Ga.11,05: (l'05).

PARROTT, 360, TERRELL

ARNol,1), JOIN T. (b'75)-Ga.1, $00 ;\left(1^{\prime} 00\right)$. MeGILL, JOII LUNSFORD (b'84)-Ga.12, 10 ; $(1,10)$

McLennan, E. P.-Ta.11,05; (1'05)

WILLIFORD, J. II.-0.8, 74 .

PATTERSON, 264, PIERCE

O'QUIN, JOHN H. (b'69)-Ga.1,'98; (l'98).

PAVO, 572, THOMAS

Brannon, John Wesley Lee (b'73)-Ga.5,'95; (1'95); S.

DALLAS, DON Q. (b'-1) †-Ga.5,'98; (l'98).

IIarris, J. Frank-Ga.9, 4

Roberts, John Iake (b'70)-Ga.5,94; (青).

Threat, Julius Barton $\left(b^{\prime} 59\right)-G a .1,87$; (ठ).

PEARSON, 558, COFFEE

CORBETT, COLONEL W. (b'71)-Ga.10,'93.

CORBETT, JOS. (b'73)-Ga.10,93.
Norris, Jesse 1; (b'89)-Cia. I,']3; (l'13); Pd. S.IITH, HENRY l'ATIUCK (b'80)-Ga.1, 06 ; (l'06).

PELHAM, I,880, MITCHELL

('lements, Janes It. (b'74)-Ga.11,01; (1'01). IIII, Wm. Stanley (b'66)-Ga.5,'92; (b).

Ic('lutn. John Wyatt-Ga.1, 89 .

Mcclun, John Wyatt-Ga.

Williams, J3eauregard (b'c1)-Ga.10,'91.

Williams, John H. (col.)-Tenn.7,02; (1'I0); $\mathbf{G}$.

PEMBROKE, 467, BRYAN

suith. Wallace Kyle (b'83)-Ga.1,08; (l'08).

STRI(KLAN1), J. O. (b'7 7 \&-Ga.11.'01: (1'01).

PENFIELD, 475, GREENE

Stajler, Jos. A. (b'67)-Ga,1,'90

Wlison, J. Flckling-Ga.9,'99.

PERKINS, 225, JENICINS

Ollver, S. V.Tia.l, T6.

IBUSHIYG, WN. EVERETT (b'75)-Ga.1, "00; (1'00).

PERRY, 649, HOUSTON

Cater, lbobt. L.-l'a.2,'88.

IIoltzclaw, Henry M.-N.Y.10,'
Ifann, Chas. legulus-J'a.2,'68.

PHILLIPS (BULLARD P.0.), - TWIGGS

lenson, Hias Jones (b'43)-Ga.5,81; (む).

PHILOMATH, 30, OGLETHORPE

Nasl, W. T.-Ga.1,'86.

PHINIZY, I00, COLUMBIA

lamsey, Wm. T.-Ga.1,'94.

PINEHURST, 45I, DOOLY

HAlRIS, V. L. (b'80)-Ga.9,'07.

LWE, JA IIES L. (b'78)-Ga.1,'99; (1'99).

PINELOG, 75, BARTOW

Banks, George Thomas (b'77)-Tenn.9,'07 ; (l'08).

PINEPARK, 50, GRADY

Kincaid, James G. (b'70) E-Ga.9,'04; (1'04).

PINEVIEW, 708, WILCOX

BliUCE, FRANCis M. (b'82)-Md.9,'04; (1'04).

Gainmage, James T. (b’70)-Ga.10,'91.

PETWAY, T1IOS. F. (b'78)-Ga.12,09; (l'09).

PITTMAN

GWINNETT

Danforth, A. R.-Ga.10.

PITTS, 279, WILCOX

Bishop, Linton lilnes (b'82)-Ga.11,'08; (l'0s)

lounlop, Thomas J. (b'59)-Ga.5,'93.

PITTSBURG, - WALKER

Madison, Pryor M. -Tenn.6,91; (l's1).

MCKOWX, THOS. D.せ-Ga.5,'85.

PLAINFIELD, 221, DODGE

SMITH, ERNEST LACY (b'75)-Ga.1,'99; (1'99).

PLAINS, 400, SUMTER

Logan, J. Colquit-Ga.11,02; (1'02).

WISE, BURR THADDEUS '(b'82) \&-La.1, 07 ; (1'08); $\mathrm{S}$.

(I'11)

PLAINVILLE, 148, GORDON

FLOY1, WM. B. (b'68) ( -Ga.5,91.

Johnson, Wm. A.-Ky.2, 86 .

POMONA, - SPALDING

CONN, WEBB-Ga.11,02; (l'02).

POOLER, 337, CHATHAM

Snow, Wm. Robt. (b'76)-Tenn.9,'08; (1'12); G.

PORTAL, 150, BULLOCH

Bowen, Andrew J.-MI.6,04; (1'08).

Stewart, James A. (b'81)-Ga.1, 06 ; (l'06).

PORTERDALE. 1,000, NEWTON

Adams, Ellis H.-Ga.5,'82.

Lee, John W. (b'41)-Ga.5,'61.

POULAN, 652, WORTH

Smith, IIenry IV.-Ga.9,99.

STEVENS, YALTER P.-Ky.2,'91.

POWDER SPRINGS, $3 I 5$, COBB

Butner, W. E.-Ga.5,'88.

Cotton, James F. (b'41)-Pá.2,'59; not in practice.

Lindley, Frank Pickens (b'90)-Ga.11,'12; 
MIDDLERROOKS. JAMKS D. (b't)

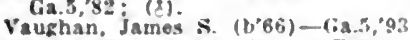

Wrisht, W. 1).-(ia.5, S4; R.F.l, 1 .

POWELTON, 100, HANCOCK

Cooper, Alex. 8.-Ga.l.'so.

PRATTSBURG, IDO, TALBOT

carter. Fomond W. (b'S2)-(ia.1,06; (1) ili)

PRESTON, 259, WEBSTER

LUXSFORD, JOHN FLETCIER (b'is)-

(ia. 1,01: (1'01).

Walker, Wm, F." (b'65)-Kr.4,8s

Wooldridge. Jurian H. (b'4I)-Tenn. 1, iti ().

PULASKI, 207, BULLOCH

Patrlck. Jekyi Zyiba (b'75)-Ga.1I,00 (l'00)

QUITMAN, 3.915, BROOKS

Cobb. M. Ifugh (cul.) (b'69)-Tenn.7, 97 :

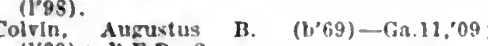
(1'09) : H.F.D. 3

Dorough, G. D. (b'f6)-ra.5."95: (1'95).

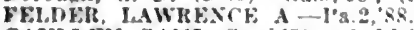

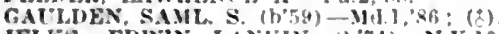

JELKS, RDWIX ILAKIN (b'7t)-X.Y.10

AIG, JAMES T. (b'66)-D.C.2.94: (1'96)

Natbews, Wallace $\left(b^{\prime} 65\right)-(; a, 5,90$

ICMICHAF, JACK R. (b'st) $\leftarrow$ Tenn.1I

Roan, James Theodore (h'53)-Ga.10,'82; (む)

RABUN GAP. 50, RABUN

NEVIILE, IFSTER (b'33; - ria.12,"11 (I'II)

RAINES (R.F.D., CORDELE), 76, CRISP Wlllams, Joron karl $\left(b^{\prime} 20\right)-1$ ia.11.13: (1'13).

RALEIGH, I50. MERIWETHER

Hatchett, T. J.-.tia.5,"91.

RAYLE, 62, WILKES

Sherrer, G. W.-Gs.1,"̈6.

RAYS MILL. 300. BERRIEN

BLICH, MEUBES NATHANIEL-MIa $\downarrow, 10$ : (l'] $\theta$ )

Burkhalter, Francls M. (b'86)-Gia 12,09 (1'09)

CLEMENTS, HENRY W. (b'z)-Ga.l,00 (1'00).

REBECCA，252, TURNER

DICKSON, WAITFH J.-Gia.11,06; (1'06)

REDAN, 120, DE KALB

Ilasty, James H.-Ga.9,"08; (食).

REDBUD, 25, GORDON

Rorders, Dennls J. (b'72)-(ia.5, 95 ; (1'9.5)

Janztord, Vester-Cia.9,"94

REO HILL (R.F,D., MARTIN), 21 FRANK. Lin

305. R-6ล 9 "19.

RED OAK, 100. CAMPBELL

lee, S. B.- I'rot. Hytro and Mech. Ther. Gia, is.

REEVES, 70, GORDON

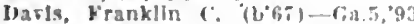

REGISTER, 300, BULLOCH

Ollir. Itenry H. (b'85)-6ia.12,09: (1'09); G

REIDSVILLE, 454, TATTNALL

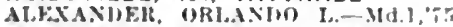

Mcrall, Fredk. Wm. $(1,70)-($ ia 1,$91 ;$ ( 1901$)$

Jogers, Danlel J. (b'ti)-Ga.., $35 ;(1253)$

RENO. - GRAOY

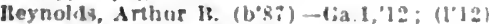

RENTZ, 275, LAURENS

HEIINCFIFIII, W. F,-Nd.9,0); ([04).

Taylor, Thos. $\mathrm{j}$-ial, $1, \mathrm{pi}$

RESACA, I12, GORDON

Fite, Berry'W (bot)-lia 10,8: $\mathrm{s}$

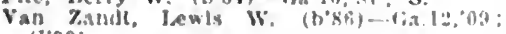
(1'09).

RESOURCE
SCREVEN

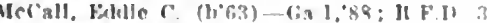

REX, SO, CLAYTON

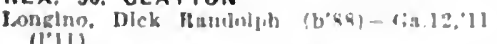

REYNOLDS, 521, TAYLOR

Bryan, Sydney Hoke (bos)-Tean 5.09: $(1004)$.

Flekllug, chas. F.-4ia 10,03

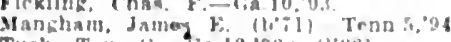

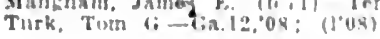

REYNOLDSVILLE, 25, DECATUR

Itrldges, E: I'leveland-hy,t,06; (1'06)

Hiler, Wm. Houslar (15'85) - Ga.11,12:

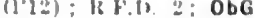

RHINE, 321, DOOGE

fussell, Thos, 11, (2:\$1)-Cia.18,'11.

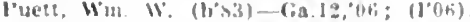

Willlanson, John Girtein (b't5)-Ga.l,"60:

H.F.l1.

RICEBORO, 60, LIBERTY

Campbell, John A. (b'85)-S.(C.1,1]: (1'13).

RICHLAND, 1.250, STEWART

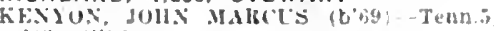

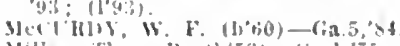

Miller. Thise is. $(2,53)-6$ -

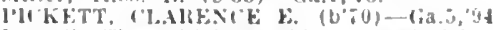

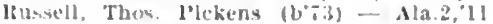
(1'13)

Slms, Walter C. $(1,42)-6 ; 1,5,9 s ;(1,4 s)$.

RIDDLEVILLE (R.F.D., HARRISON), 140 , WASHINGTON

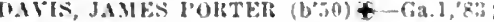
(i)

RINCON, 100, EFFINGHAM

EXILY, KUHT, MCliHEE (b':G) - (ia.11,"11 (I'11).

RINGGOLO, 398, CATOOSA

colllns, N. V. (b'si)-Ga.9, 10; (1'10)

H.IIF, H. CANTRELL (b'85) + Tenn.9,0 (l'Ii); Meuber Tenn. State Med. Mssn.

Maln, I. F.-0.14:79; (1'99).

RISING FAWN, 225, DADE

Ilidileton, Danl. Spencer-Tcan.9.34; (1'9i)

RIVERSIDE (R.F.D., BUCKHEAD), \&, GREENE

lagersill, Lucy Merrill (b*ti)-111.111,85. (1'9:2); not in practlce.

ROBERTA, 227 CRAWFORO

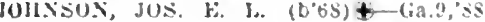

Le sueur, hanton J. (b'z) - Gib.11, $1200): 0 \mathrm{D}$

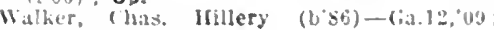
(104): $\mathbf{S}$.

ROCHELLE, 860, WILCOX

BLSAELL. VIEJJ. RANUOLIII (bod)lia.11, 11 ; (1'11)

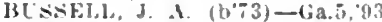

Colfe, Mark W. (b+3)-Ga.10,'s2; (c)

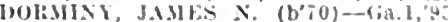

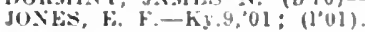

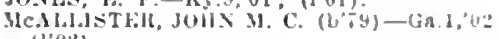
(l'0:).

MCHAL, (HAS. J. (b'bt)-MUl, N9

ROCKLEDGE, 152, LAURENS

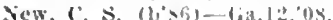

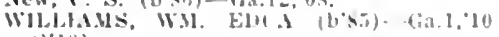
(1) 10 )

ROCK MART, I,034, POLK

Mlatir. Wm. J.-Lia.j, 's

llickle, I It - lis In"

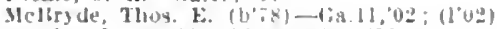

sumks, James M. (1,is)- Gis.h.

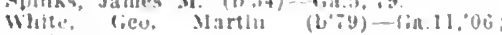
(I'06i).

ROCK SPRING, 70, WALKER

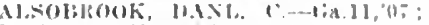

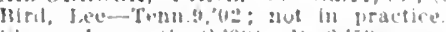

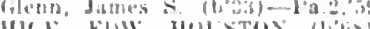

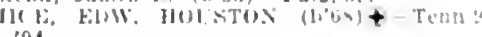
91.

ROCKY FORD, 385, SCREVEN

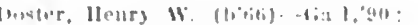

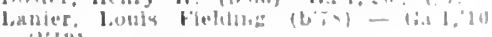
(1'!1).

FOME, 12,099, FLOYD

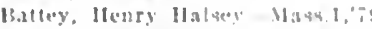

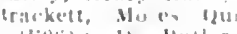

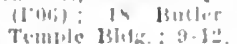

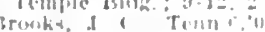

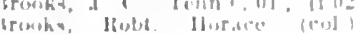

(ling)

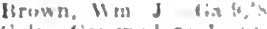

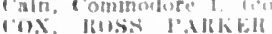

(i) int

OALR.

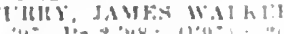

nee. rugry linevital.

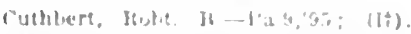

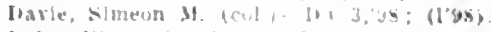

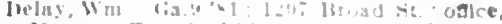

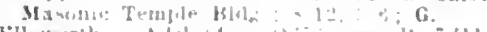

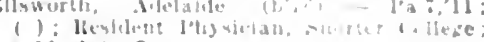

$x-10,2-4: G$

Franklin, Alliert

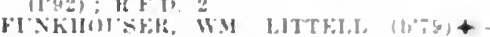

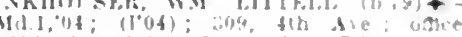

$30: 1_{2}$ IBruad S1. $10-11.2-3 ; \mathbf{P d}$

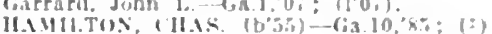

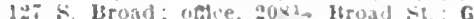

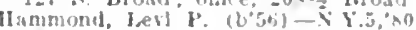

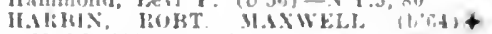

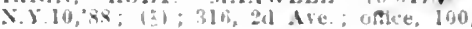

$3+1$ ite : $8-4,2=? ; \mathrm{s}$

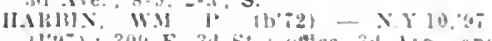

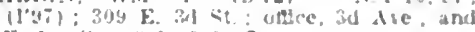

F. Int St: $5-9,2-3: \mathbf{S}$

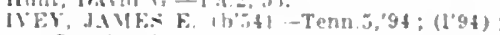

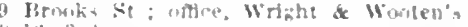

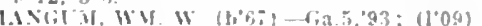

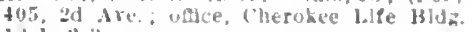

Icrall, Wanlel T, - Gia 1,":?

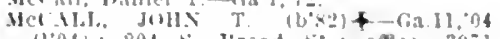

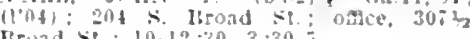
Broad sit: $10-12: 30,3: 30-5$.

campel, Alexander i. (col.)-Tenu. .96 ; (11..,

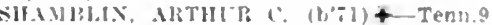

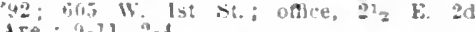
Are. "110

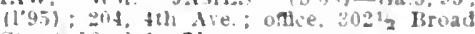
St, s-10, $=-1 ; 0$ ob

SIMMONS, HOLT, 11.IX (hes) - Tenn

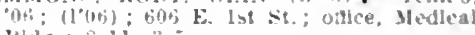
Blilg: : s. 11 .

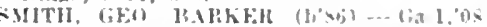

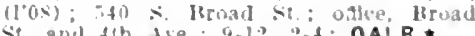

St. and the tye $9-12,4$ OALR.

TRER, IIENRY A ( $(1+3)-1$ a

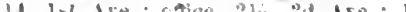

WJKER, ROBT. II. (bin) - Ga 1, \%s 300 F. a st : ntice, Medleal Whe

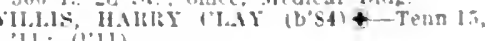
'11: (1'11)

ROOPVILLE, 173, GARROLL

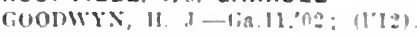

ROSCOE (R.F.O. NEWNAN), 65. COWETA

Fiwarls, Wm. It-1;a.10,9]

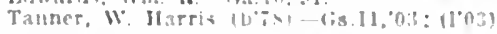

ROSEBUD (R.F.D.. LOGANVILLE). 18. GWINNETT

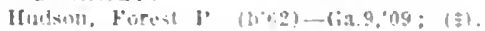

ROSSVILLE, 1,059, WALKER

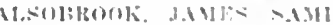

(I):(4)

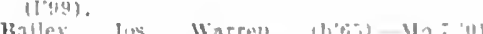

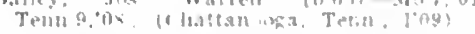

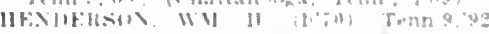

WIIllistlh, lien, y (?,

ROSWELL. H,

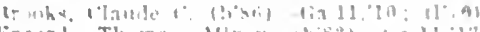

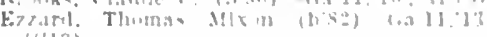

(ing)

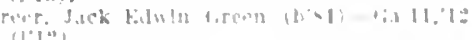

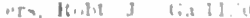

ROUND OAK. IOO. JONES

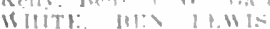

ROYSTON 1. $2: 2$. FRANKLIN

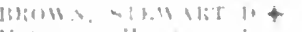

$n_{i}\left(1, n_{i}\right)$

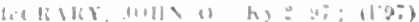

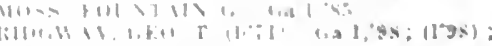

0

RUTIANO IRF.D., MACONI, - BIBE

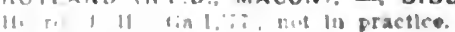


RUTLEDGE, 696, MORGAN

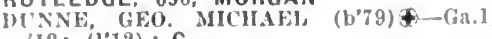
i2: (1'12): G.

POHTEL, JOLL L. (b'S?)-Ga.1,05; (1'05) spears, Wm. T.-Ga.5,'s4.

RYDAL, 50, BARTOW

Yaughan, IYm. 33. (1,55)-Cin.10,91

SALE CITY, 402, MITCHELL

Inurgrove, Allen T. (1, 75)-tia.11,06; (1'06)

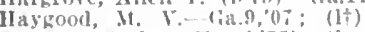

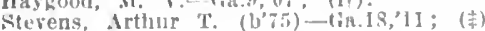

SALLACOA (R.F.D., FAIRMOUNT), 25, CHEROKEE

Bemlet, Jimes II.-O.

SANDERSVILLE, 2,641, WASHINGTON

Evans, Jullin II. (b'ti) -Tenn.t,si,

Ifarris, Euyene A.-Ga.11,99; (1'99);

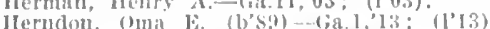

Kision, T. BYilos (b's6) f-Gia.12,11.

(III): R. B2 W. (bo9)-Ky 2,94 : (1)

Malone, (jeo. W. (hrig)-Ky.2,94; (1)
Malone, Stephen Benj. (b'is)-Ga.11,04

(lione,

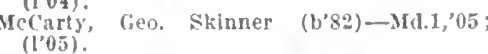

RAWLINGS, WM. (b'51)†-Md.1,75; (ะ)

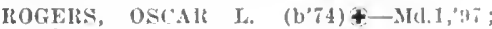
(l'98).

SAROIS, 25, BURKE

Hillis, W'm. Wyclifte $\left(b^{\circ} 85\right)$-Ga.1, 09 ; (l'0.9)

lrackley, J. F.-Gat.I, 8i; not in practice.

SARGENT, 200, COWETA

Elliott, Clitroril C. (b's8)-Tenn.9,'10;(1'12)

SASSER, 441, TERRELL

Cranford, James Robt.-Cia.5,'95; (1'94).

Cranforl, osear G. (b'66)-Micl.,'92: (1998),

DUMHAM, WM. P..-Ga.9, $0 \mathrm{~s}$

Lundy, W'm. E, - T'a.1,56.

SAVANNAH, 65,064, CHATHAM

XUMBER OF PIIYSICIANS, 113

Adams, IIenry Paul, (b'i8)-Ga.1,01-;(1'01); 414 Bolton St., E.; oflice, 14 W. Liberty

AYANT, ADNIRAL I. R. (b'57)-(ia.5,'93; (o) ; T0I Barnard St. ; 8-10, 2-4, 7-4.

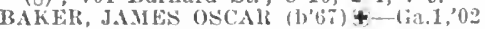

(1'02) ; 126 Oglethorpe Are, ; $9-10,3-4,8-9$.

Barr, Byrde Horton (b'76)-yich.s,

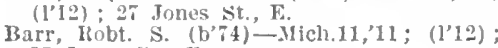

BARIOW, CRAIG (b'76)-MId. , 00 ; (l'00); 26 Liberty st.,

B.ASETT, VICTOI II. (b'TI) T-IId.7,03; (Bacteriologist); 402 E. Henry St.; office, Cly Hall; $9-2,4-6 ;\left(\mathrm{H}^{1} 1\right)$.

Blackman, Wm. C. (col.) - X.C. 3,'95 ; (1995) 620 Henry st., W. ; 8-I0, 2-4, 7-8.

Brannen, $c$. l'retorius-Ga.5, $94 ; 229$ siontgromery St

Bray, Sydnes Elsom (b'82)-Ya.4,09;(1'11); St. Josepll's Hospital.

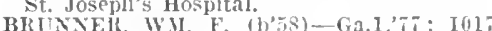
Ilobersham st.; office, City Ilall Bldy.; $9-2,4-6$

CARTEI, JANES NOTTINGHAM (h'T8) -
Tenn.5,01; (1'03); 107 Jones St., F.; 8-10. $2-4$.

C.USE ${ }^{-4}$, THOS. WM. (1) $\left.\% 9\right)+-M[d .3,09$; (l'09); 101 Henry st., E. ; office, $111 / 2$ Tork st., F.; ; 9-10, 3-4.

CIIALTOS. THOS. JACKSONF-N.X.10, '85; 220 Opletherpe Are., E.; 9-10, 3-4, CHENEL, LOCIS JULIAN (b'82)-Md.9,'04; (1'09) ; 5 Jones St., W. : 9-10, 2-4, 7-9,

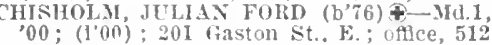
shercorn St.; 9-1.3-4; OALR.

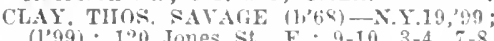
CLEBORNE, ALAX IS-Ya.1,02; (1'07) I0) 1 Gordan st. ; $1-2,7-9: S_{\text {. }}$

Clitt, Benj. Franklin (b, $6 \hat{6})-D$ C.1,08; (1'13): 218 oglethorpe Ave., W.; offee, Lilherty st.; $7-9,2-4,7-9$

Cole. Wm. A. (1,84)-Ga.1,13; (1'13); 324 Liberty St.. W.

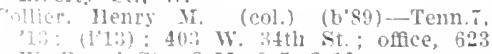
W. Br:art St.; \&-11, 3-5, 8-10;

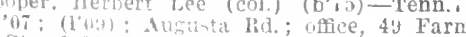

COIBIIN, MARION X.N.Y.5,91; 115 EIb-

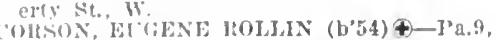
(in. $10, ?$ (1)

comints. Noalu Tilden (b'76)-Va.6, $07 ;\left(1^{\prime} 10\right)$ 11 i 1 ark Are., W. ; $: 30-10: 30,2: 30-4: 30$, $7: 30-3$.

MAWFOHE, WM. IBARIKON-X.Y.1,99; (1'99); 14 Taylor st., $\mathrm{E}$.

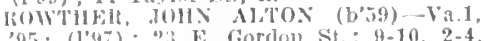

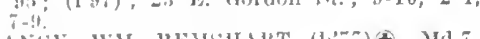

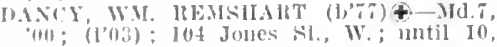
(iil) 7 (1): G.

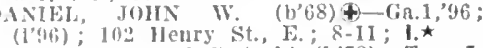
Lanlels, Bartow W. S. (col.) (b'72)-Tenn. 04: (1'04); (Woodsville); offce, 29 s. Firm st. ; $1-10,3-4 ; \mathrm{G}$.

DF CAHADE C ST, JULIEN ROAUL (b'S4) C.1.06: (1'10); tilberty st., E.; 9-1, $3-5 ;$ OALR. $\star$

Matey, David Edward $($ b'70 0 - $0.1,93$; (avaminh Ilotel; offlce, 151 Ilabersham (11.; $9-11,2-4$

W.ALDS, 1)ANI。 B. (b'83)-Ga.11,08 Elliott, Wm. II. (b'37)-Ya.l, 58 ; retired 721 Abercorn st.; ontice, iif Abercorn st. Este, Neslie W. (col) - Tenn. 7,03 ; (1'03); 546 Nieoll St.

EALEY, HOWARD TRIVERS (b'S9) - Ga.11, '11; (1'11); 5 Charlton St., W.; offec, FARMER, HOIN i.. (b'64) - Ky.4,'88; 22 Jones St., H.; $9-1,3-5.93,94 ; 5241 / 2 \mathrm{~W}$. Broid st.

Gibson. Benj. Harrison (b'86)-MI.1,09; (1'09) ; 403 E. Bolton St.; offce, 114 W. L Liberty St.; $9-10,2-3)$, -8. Gibson, Isaac A. (b'61)-(Ga.5,85; (1'98);
403 Bolton st., F.; ofttce, Provident 403. Bolton st., 1 .

Greenlear, James S.-Ga.u.'98; (1'99); 308 Barnard st.

GHIM, RANDOLPH MACON (b'82)థMI.7,08; P.A.S., U.S.T.H.S.; Marine

HIRMAN, GEO. L.-IId.6,97; 1 Henry St., E. ILARRIS, RAYHOND V. (b'80)-IId.1, 07 Heidt, Wm. T. (b'37)-Ga.4,57; not in practice; 1318 Abercorn St.

IIERIOT, GEO. W.-Ga.5, 95 ; (1'95) ; 203 W. Liberty St.

IIESSE, HERMAN WM.-Pa.1,00; (1'00): 112 E. Jones St.

IIIERS, JAMES LAWTON (b'65) —-Ga.1'89; Isemall, Everette (b'85) - Md.1,09; (I'11); $11 \mathrm{E}$. Jones St. ; $8-10,2-3,7: 30-9$.

JACKSON, JUSTIN LOWE (b'75)-Ga.11, $02 ;(103) ; 14$ W. Liberty St.; $9-1,3-5$. JOHNSON, GUSTAF HUGO (b'i1) $₫-N . Y .8$ "18; (1':9); 116 Oglethorpe St., E.; 9-10,

JONES, JABEZ (b'73) †-Ga.5,98; ( 1998$)$ : Lanneau, Chas. B. (b'46)-S.C.1,'69; (f); retired; 1107 F. Anderson St.

LATTIMORE, RALSTON (b'71)థ-N.Y.1,

4 Liberty St:, W. $9: 30-10: 30,4-5$.
LAVINDER, CLAUDE H. (b'72) $4-$ Va.1,

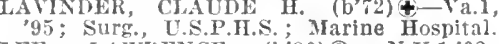

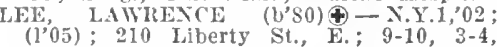
$i-8: 30 ; \mathrm{S}$.

Lee, Walter W.-Ga.1,91; 124 W. Liberty St

Leftwich, Iloyd W. (col.) (b'i6)-Tenn.14, '09; (1'11); 623 Oglethorpe Are., E. ; \$-11, Love, Philip E. (col.) -N.C.3,'96; (1'96);

MARTIN, HENRY HAGER(b'68) -0.9,'91 (1'00); 247 Bull St.; 9-I2, 1-4; (B1); MARTIN, ROBT. VINCENT (b'Tt)-S.C.I, 04; (1'04); 12 Liberty St., W.; 8-10, Maxwell, James Taliaferro (b'88)-Neb.5, '12; (): Y. M. C. A. Bldg; offlce, 8 Liberts

13 Liberty
Medinck, J. II $\rightarrow$; (

MFLUMIM, ('IIAS. II. (b'68)-Ga.1,93; (1'93); $212,32 d$ St., W. ; 9-11, 2-5.

Matdieton, Chas. Clayton (col). (b'86)9-11, 2-4, $7-4 ; 0$; $\mathrm{G}$.

MOHIRSOX, ARTHUK ALSTON (b'71) S.C.1,y4; (1'94); 1704 Bull St.; office, S.C.1,94; (l'94); 1704 Bull St.;
I 702 Hutl st.; 8-10, 2-4, 7-9; ObG.

MOLHISON, JAMES EGGLESTON (b'82)Ga.12, 08; (1'08); 118 W. Harris St. ; 9-10, $3-4,7-8$.

Myers, Wm. Jlerman (b'78)-Tenn.6,01; (1'13) ; 24 Taylor St., E.; $9-10,3-4,7-8: 30$. foltTON, GEO. M.-Ga.10,98; (1'98); 201 Oylethorpe St., W.

NORTON, WALTEIR A.-Ga.11,'03; (1'03);

105 (glethorpe St., E.
OLIVEROS, BARTOLO PEDRO (b'60)Nd.1,83; 26 W. IIarris St. ; untll 9, 3-4. OLFAl, WH. 13. (b'65)-N.Y.10,97; $\left(1^{\prime} 98\right)$;
1 I3 Perry St., W.; offlee, Union Statlon; 9-10,3-4, 7-8; $\mathrm{s}$.

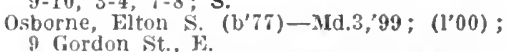
OWENS, WM. WAYNE (b'63)૯-Va.1,'85; (1'85); 124 McDonough St., E. : office,

PERKISS, MAKK EDW. (b'85)-Ga.1,'12 ; (1'12); U.S. Narine Hospital.

PHILLIPS, S. LATIMER-MId.1,85; 232 Bull St.

Plnckuey, Edward Marion(col.)-Mass.5,'78; (1'04); 524 IIall St., E.; office, 556 Bryan St., W.

PURSE, BENJ. S. (b'43)-Ga.4,70; (t) ; 18 Liberty St., w.; until 10, 1-4, 8-10 Rakestraw, Chaunzey Mortimer - 0.1,94; (1'95) ; 101 Oglethorpe St., E.

Reid, Robt. Stephen-Pa.1,'98; (1'99) ; 405 Liberty St., E.

RIGHTON HARRY YOUNG (b'81)-Md.1, 05; (1'09); 1002 Drayton St.; 9-10, 3-4, Rogers, Jesse Thos. (b'74)-N.Y.10,98;

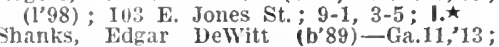
(1'13); Telfalr Hospltal.

Sharp, Winfield Kennedy, Jr. (b'81)-Ga.11, '13; (1'13); U. S. Marine Hospltal.

Member Kan. Med. Soc.; Boot ánd Sts.

Silverman, Chas.-0.8,87;113 Taylor St., E. Simmons, Alpheus B.-Ga.1,'84; Montgomery $\mathrm{Rd}$

Smith, Geo. W. (col.) (b'r5)-N.C.3,03; (l’03); 605 oak St.; offlee, 815 w. Broad St. ; $9-10,2-4,6-8: 30$.

Stone, Francis R. ( $\left.\mathrm{b}^{\prime} 36\right)-\mathrm{Ga} .4, \mathbf{6}^{\prime} \mathrm{O}$; (); 2512 Abercorn Ave.; 8-10, 5-10.

Stothart, E. J. (b'88)-Ga.1,09; (l'03); 804 Drayton St.

Stothart, James A. (b'54)-Ga.1,88; (l'88); 804 Drayton St. ; $8-10,2-4,7-10$.

Stothart, W. L. (b'77)-Ga.1,06; (1'06) ;

804 Drayton St. (1'11) ; 4 Gaston St., W.; offee, 449 Bull St. ; $8-10,2-4, i-9$.

Thomas, Mariou Russell (b'78)-Md.1,02 ; (1'02); 204 E. Oglethorpe St. ; 8-10, 2-4, $7-9$

THONISON, RALPH METHVEN (b'75)La.1,'98; (1'98); 114 Bolton St:, W. ; $9-10,3-4,7-9$.

ippins, Henry Lester (b'88)-Ga.11,'13; (1'I3); St. Joseph's Hospital. AIN, JOHN K1RKఢ-Va.1,99; (l'03); 1111 Bull St.; office, 1107 Bull St.; 9-10,

Trammell, Stella Forrest (b'75)-S.C.1,11; (1'12): 408 Abercorn st.

Tyson, C. B. (col.)-Tenn.7,'97; (1'98); 811 Gwinnett St., E.; offee, 325 Liberty St., E. Underwood, Fleming L. (b'86)-Ga.11, 10 ;

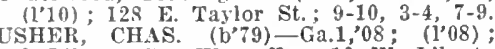
8 Liberty St., W.; offce, 10 W. Liberty St.; $9-11$; Anes.

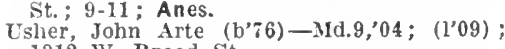
1312 W Broad St.

USHER, SHEDDIE (b'7 7 )-Ga.1,09; (1'11);

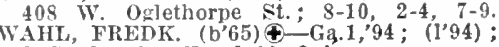
3 Gordon St., E. ; 8-10, 2-4.

WARING, ANTONIO JOHNSTON (b'81)N. $1.1,08 ;$ s. 
WARING, THOS PINCKNEY (b'Bi) + X.Y.1,92; (8); 10 W. Taylor St, 9-10, 3-4:30: (A6)

WEJCHSELBACM, JACOH (b'48)-GA.4, 80 (2) 102 Gordon st. W : 8-10, 1-4. WEINBERG, MHLTON (b'Sé) + Md a, 10 (113); Member S. C. sled. Assu.; 11 Jinnes St., E: once, if Jones St. W.: 9-1, 2.5. $i-3: 0$.

WHIE, GFo. RENVE (b'66)-XY.1,91 (1'01): : E. Liberty St. ; 9.11 ; (AI) : S.

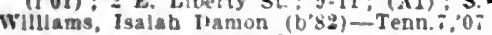
(1'0i): 2:0 k. hroad st. \&-10, 2-4, $7-9$.

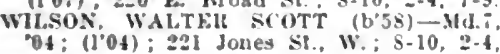
$-9$

WiNDERS, ALSTIN W--Ga.l,99; ('99) 318 Irougbton \$1., E.: $8.10^{\circ}: 30^{\circ}, 2.4: 30^{\circ}$ $i-9 ; U$.

SCARBORO, 130, JENKINS

Clifton, Benj. L.-Cia.10,\$5

SCOTLAND, 150 , TELFAIR

NR.AL, JOS. W. (b'65)-Ga.5,'89; (1'99)

SCOTT, 212, JOHNSON

Carler, J. G.-Ga.1,'52.

Conn, J. C.-Md.9;04

Fort, James Arthur (b'79)-Ga.12,08; (l'07).

SCOTTDALE, 300, DEKALB

ALL6OOD, CONUAD L. $\left(\mathrm{b}^{\prime} 96\right)-\mathrm{Ga} .11,{ }^{\prime} 12$; (1'12).

SCREVEN, 276, WAYNE

RITCH, THOS. G. (b'89)-(ia.9.' I

TYRE, JOS. LAWTON (b'86) -Ga.11, 10 ; (1'I0).

SENOIA, I,III, COWETA

Culpepper, Wailer H'lsk $\left(b^{\circ} 5 i\right)-X_{1} \mathbf{Y}^{2} .5,84$.

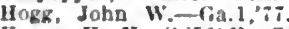

Kemp, H. H. (b'56) E-Ga.9.94.

McCrary. Wm. K-fia.10,84.

SEVILLE, 193, WILCOX

Barbour, Waller kdgar (b's5)--Ga.11,13:

Calboun, Geo. L.-Ga.9,'10.

SHACK, - CHATTAHOOCHEE

Hewell, Wr. C.-E-1;a.J." $\$ 1$.

SHADY DALE, 344, JASPER

Brown, Jos. Alonzo (b'69)-Ga.1,91

Spearman, Jathew W. (b'31)-Ga.12,11; (1'11).

SHARON, 246, TALIAFERRO

BHOWN, LA WHENCE IS. (L'G2) - Ga.1,'88:

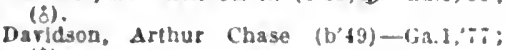

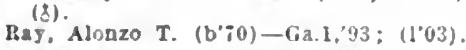

SHARPSBURG, 166, COWETA

Walls, Howard Gilkert-Ga.12,08

SHARPS SPUR, - , MONTGOMERY

Smlth, John Mell (b's5)-(ia.1,'12;

SHELLMAN, 985, RANDOLPH

Clark, G. I.-MU.3.' 80 .

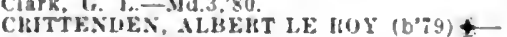
Gial1 02 : (iroy)

Ilendry, Jesse Ilomer-Ga.9,12: ( ) : K F. D. t.

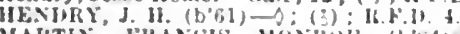

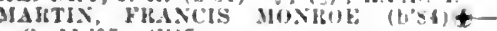
(ia.11:05; (I'05).

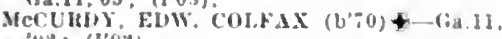
'U2: (1) 021 .

Terry, Wm. K. (b'63)-ria.5,"30.

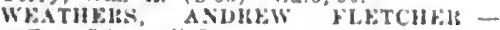
Tenn.5.'41: (1'03).

SHILOH, 250, HARRIS

Copelatu, Hend. 11.-Ga.11:00; (1'00).

Holley, dulun I. 1.a.l, "y3.

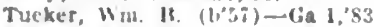

SHINGLER, 100, WORTH

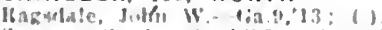

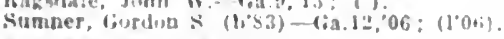
SILOAM, 300, GREENE

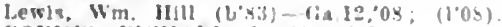

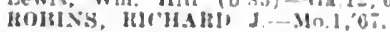

SILVER CREEK, 50, FLOYO

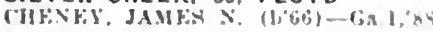

SMITHVILLE, 374, LEE

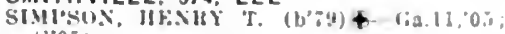
(1)03)

SIMLSON, WUR: THUS -fin.1,

sratth. Harbard lia 1,93.

SMYRNA, 599, COBB

Cotlugton, James, fielton (b'i6)-lin.1n,'11:

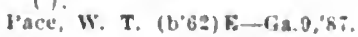

SNAPPING SHOALS (R.F.D., COVINGTON), 198. NEWTON

RANIII.: Jill, H. (b'11)-Tenn.9,99: (I'0I)

SNELLVILLE (R.F.D., LAWRENCEVILLE), 100, GWINNETT

smith, BlFaM T. Ga.9,08.

SOCIAL CIRCLE, 1.590, WALTON

Inay, dulius B3. Il. (b'68) -ky.2,'41: (2).

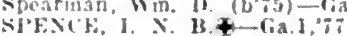

SOPERTON. 469, MONTGOMERY

Barwlek, (ieo. M.-Fia.5.95; (195)

Willams, Julun (C-Cia.11,02; (1'02)

SPARKS, 8\$2, BERRIEN

ETHMHMik, SAM1. G.-Ga.1,'S9.

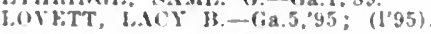

SPARTA, 1.715, HANCOCK

Brown. John Andrew (L'si) - Ga.l.0s; (l.0)

Jarden, Horace (b'is)-(ia.1, ;9

Purtam, Alex. F-Fa.2,87: (8)

Jetterson, H. 13. (col.) (b'-6)-X.c.3.05: (I'A5).

Jernigan. Chas. Sterling (b'73)-Md.4,97;

WIILEY

3T. C.-Ga.tititi

SPREAD, 370, JEFFERSON

FARNER, LCCIL'S P. (b'S1)-Ga.1,06; $\left(1^{\prime} 06^{\circ}\right.$.

SPRINGFIELD, 504, EFFINGHAM

I3rinson. S. E. - (ia.1,'s5.

GRIFIIN, FIU, W. (U:3) - Ga.1,00; $\left(1^{\circ} 00\right)$.

SPRING PLACE, 242, MURRAY

Anderson. Malcolm W. (b'8i)-Ga.8,11; (客).

SPRINGVALE, 162, RANDOLPH

lioneke, L. (C-Cia.j,st: ().

ST. CLAIR, 154, BURKE

Torbit A. W-Ga.1'ST.

ST. GEORGE, 272, CHARLTON

Purkhalter, John F', (b'\&6)-Ga.1,'11; (l'11).

WATEILS, P'IBIE TAYLOR (b"53)-0.1,'s6.

ST. MARYS, 691, CAMOEN

Thiqpen, (ialnes R. (b'69)-Ga.5,'93.

STATESBORO, 2.529, BULLOCH

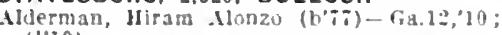
(1'10).

Brantley, Thos, Bogkin (b's3)-Ga.1,12; (1'12).

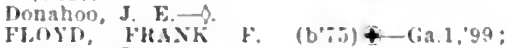
(1'99); $\mathbf{S}$.

Holland, Madisun .I. (b'60)-Tenu.5,84

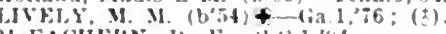

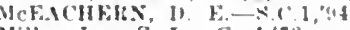

Minter Trey a. 1,-Gait 4,83; not in practice.

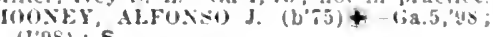
(I'98); $\mathrm{s}$.

Quallebaun. Albert Wm.-Md.3.'s9.

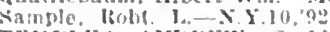

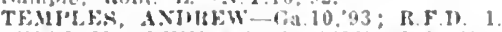
WHILIMYS, M.LIMIN W. (b'S6)-IId 1,09 ;

\section{STATHAM, 621, JACKSON}

linland. Saml. A. (b'i2)-Tenn.9.96: (l'05).

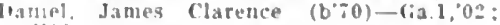
$(1002)$.

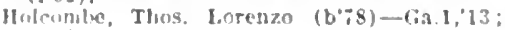

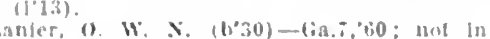

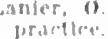

STELLAVILLE, 149, JEFFERSON

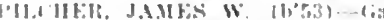

STEPHENS, 170, OGLETHORPE

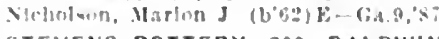

STEVENS POTTERY, 200, BALDWIN

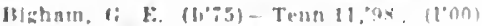

STILESBORO, 200, BARTOW

liunder R E -

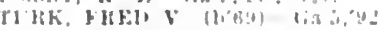

STILLMORE, 6.45, EMANUEL

H.13.111.M. 161 H1'

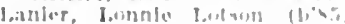

(1'0ii) 0 b.

smith. We ssimsure Jugan

$(100)$

STILSON, ISO, BULLOCH

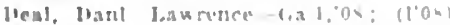

STOCKBRIDGE, 200, HENRY

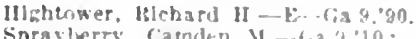

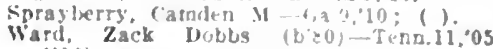
(1) 06 ).

STONE MOUNTAIN, 1,062, DEKALB

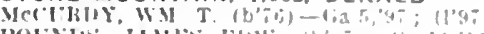

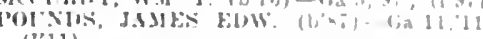
(lin)

Wells, James It. (b'72)-(;ia 5,95: (199:)

SUBLIGNA (R.F.D., GORE), 74, CHAT. TOOGA

Clensents, James Whoon-Va.t, 64; 13.K.J).

SUGAR VALLEY, 197, GORDON

Banlister, Waller lilltos (b'66)-Tena.9,05: (l, 03 )

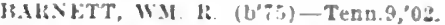

SUMMERTOWN, 125. EMANUEL

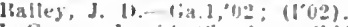
Lafrone, Bavid charlion (L'S)-Ga.l,os:
(l'04).

SUMMERVILLE, 637, CHATTOOGA

BHISANT, WILLIIS J. (b'54)-Tean.5,'s2; (乡)

Jones, Hott. I1.-Cis 1,:49; (1'99),

Lolertsul, Jan. Inizhton.

(Nighe Augusla.)

B.F.D. I.

SUMMIT, 566, EMANUEL

lowle, James W-Ga.1,:5

HOLLEY, OLIVEIS C.MA.9, 05 ; 1106'.

Lane, heondas 1', (bes)-Ga.1,92, 1'a. 'y4: (ह).

RINFr. Cl.NTUx h. (b'Ti)-Tenn.13,00: (l'01).

ltoundiree, Walter-(ia.1,99; (1'99).

SUMNER, 336, WORTH

SFASIONS, WA1TEK W. (b०5)-Ga.12,'11: (1'11)

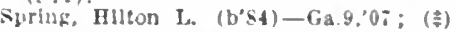

SURRENCY, 259, APPLING

Moudy. kmory dey (b's9)-Ga.11,11;

Thoma., James W. (b.83)-Ga.12,05; (1'0-).

SUTALLEE (R.F.D., CANTON), 50, CHER. OKEE

ULPden, Dasid A-

SUWANEE, 250, GWINNETT

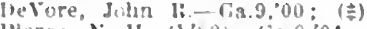

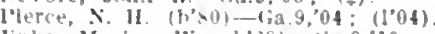

Jinks, Marlon W. (b'69)-(ia.9.10; (1'10).

SWAINSBORO, 1,313, EMANUEL

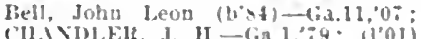

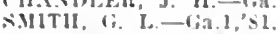

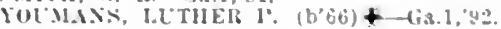

SYCAMORE, 296. TURNER

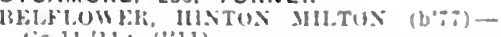
(ia.11,11: (1'11).

fll kby. Joll T. (b+s) - kyt,iz; It $\mathrm{H}^{\circ} \mathrm{ll} .1$

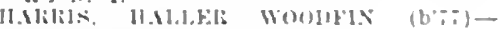

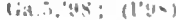

SYLVANIA, 1.400, SCREVEN

"all, Julna Calvin, Je. (b'so)-lial, o:

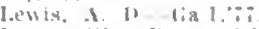

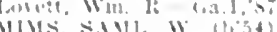

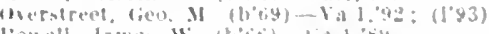

lowell. Jatrien in

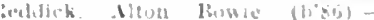

llinit

SYLVESTER, 1. 457 . WORTH

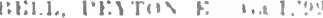

swhin. Wron.

Cringhel, Vartin

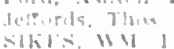

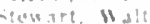

ming, 11.11 ri.t:

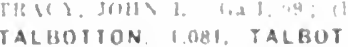

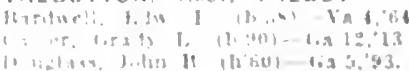


TALKING ROCK, 108, PICKENS

Uarnell, Sheruran J.-(ia.9,'93.

TALLAPOOSA, 2.117, HARALSON

Brock, Wulter 13.-Tenu, 1,'3i.

role, Alomzo I3.-Can.s.'st.

Jolus, Thos. Jifyerson (b'53) - Mli1.2, 8 : (I'0ti)

Mccurdy, Win. J-Ga.1,"8:3.

TALLULAH FALLS, 85, RABUN

for(co). I'ere"y Trant Hllekwon

Scol.9, 73, Sot. I3, 79 ; (l'ks).

TALMO - JACKSON

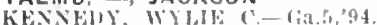

TARRYTOWN, 236, MONTGOMERY

I $\mathrm{BSY}, 11.11, \cdots$

TATE, 500. PICKENS

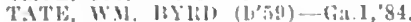

TAYLOFSVILLE, 197, BARTOW

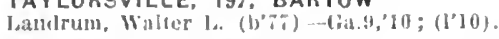

TAZEWELL, I25. MARION

Nurray, s. A.-(ia.5.')4.

TEMPLE, 711 , CARROLL

BASKIX, ('ILAS. 1. (b'(i9)-tit.5,'95; (I'b5) ;

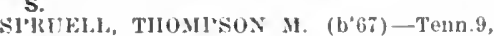
?:2; (艺).

TENNILLE, I,622, WASHINGTON

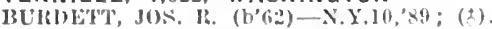

Jolner, bufurd o'veal (b'so)-Gib.12,']2; (1'1:2)

MCHASTE, D.WIH ENWIN $\left(\mathrm{b}^{\circ} 60\right)+-$ (ia.l, st: (

TROUTMAN, WAITEl: CALL (b's6)-Ga.11, 'II : (1'11):

TEXAS. 80, HEARD

Illekle, ("has, M.-Mla.2,"90.

THE ROCK, I38, UPSON

Harris, Clabborme A. (b'7s)-Cia.Iz,09: (1'09).

THOMASTON, 1,645, UPSON

Allen. II. Young (b'73)-La.1,'9s; (1'98) .

Barron. H. Aldine (b's9) - fad 11, 13: (1'13)

Barron, H. Alline (b's9)-6a.11,13; (113): (む)

King, fieo. Wiley (b’7 2)-Tenn.11,'96; (l'97).

Mckenzle, John 11. (b'7z)-Ga.11,02; (l'02).

Willans. Kirlyy S.-Cia.5,94.

THOMASVILLE, 6,727, THOMAS

AINSIOURTI, IHARKY (b'7) - Md.1,01; (l’01).

Bonchelle, Louls 13. (b'29)-Ga.1,57

Danlels, Benj. A. (b'71)-Ga.10,"97; $\left(1{ }^{\prime} 09\right) ; \mathrm{S}$.

pekle, Tlzos. ․-fia.1, 68 .

FERGUSON, $C$ 11.-Ga.1,01; (I'01).

Grey, Wm. ldw. (col.) (b'is)-I1I.19,'10; (1'12): G.

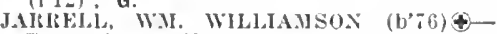
Tenn.5.'01; (I'01)

Jeukins, James Ilarvey (b'47)_-Io.2,78; (b). l.ee, Jos. E. (b'68)-Ga.5,'95; (1'95).

LITTLE, ARTHLIR JHALARD IIRHON (b's1)-Lal, 08 ; (1'08); S.

IcIntosh, Thos. II. (b'53) - (7a.5, $75 ;(1,75)$; IcIn.

Mouggomery, nanl. Chrlstoplier (b'58) -

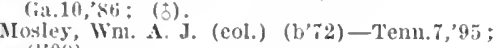
(1"09).

Palmer. Jos. B.-Ga.1,04; (I'04).

TAYLOR, ATESTIS P.'(b'49)-N.Y.5,70.

Wilson, S. II. (col.) (b.64) - N.C.3, 02 ; $\left(l^{\prime} 0: 2\right)$.

THOMSON, 2,I5!, MCDUFFIE

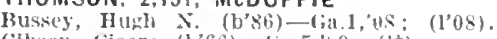

Gibson. cicero (b'66)-lia.5,'s9; (1) .

GIBSON, STRRING\&-Ga.1,79.

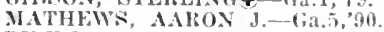

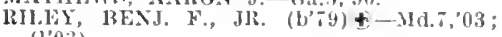
(l'03).

Ware, Ferdinand N. (b'56)-Ga.I,'s8; (c).

THRIFT, 50, JENKINS

Jones, James W.-Ga.1,"92.

TIFTON, 2.381. TIFT

BAKEK, TEOA.RD ALLEN (b'82)-Ga.1, INXNIORE, VIRGIL FRAXCIS $\left(b^{\prime} 75\right)-$

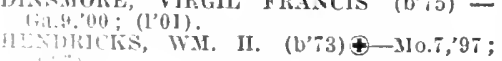
WHAS GEO WASHINGTON (b'57)Merlie. IOHX A-Ga.9,'85

IFTEKISON, AICHCLAS-Ky, 4,90

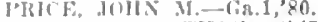

s.Mrell, wM. 'THOS. (b'76) - D.C.1.'99;

TIGNALL, 320, WILKES

lingalile, Hilias W.- -

sale, Higherson Matherson (b'71)-Ga.1, 00 (I'(1)i) ; It.F.I), I.

Wansly', Watkins Bercrly (b'84)-Tenm.9, 10: (I'10): IR. F.I)

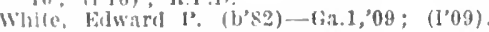

TILTON. 2:2, WHITFIELD

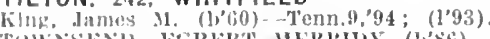

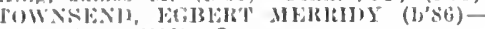
(iia.1, 12; (1'12); S.

TOCCOA, 3.120, STEPHENS

ILKS, CIAIRACE L. (b"76)-Ga.11,02; $(1,0,2)$

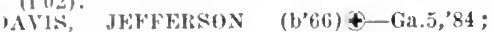

(I'Rs) Joll JIINTER (b'73) +-Ga.5,'95;

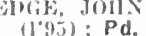

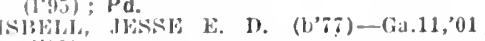
(I'01).

latimer, John Newton Franklln (eol, ) (b'75) - Temn.7,os: (l'08).

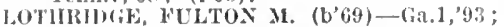
L.

, J. (b,45)-Ca, , 67 .

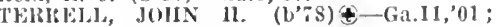
(I’01).

Young, lied-Ga.9, 08 .

TOOMSBORO, 404, WILKINSON

Mills, d. Thos.-(ia.1,00; (l'00)

(merlyy, Nicholas (b'84)-Gil.1,'12; (l'12) li. Fi, i)

Thompson, James D. (b’70)-Ga.5,'96; (1'98)

Vermilye, Wm. Gray-111.6,'34; not In praclice.

TOWNS, I50, TELFAIR

lucas, Isaac Marion (b'82)-ky.2,'08; (l'08).

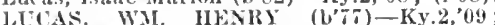

(l'12); Member Ky. State lled. Assn.

TOWNSEND, 70, MCINTOSH

Long, WInbon J. (b'75)-Ga.1,99; (l'01)

TRENTON, 302, DADE

Brock, James R. (b'61)-Ga.5,'82.

Isussey, James W. (b'50)-Ky.4,76; ().

TRION, I,721, CHATTOOGA

Mallicoat, Lester A.-Tenn.11,97; (1'98).

IIyers, John M. F.-Ky.2,'7.

TRIPLETT (R.F.D., RAYLE), 一, WILIKES liees, Ellas 13.-Ga.1, T;.

TUCKER, 57, DEKALB

Andrews, Wm. W: (b'6s) E-Ga.9, '00; (1'00).

cofer, Wm. P. (b'58)-lia.10,91.

TUNNEL HILL, 295, WHITFIELD

Brewer, Asbury II. (D'BI)-Tenn.9,0J;

Greene, Wm. J. (b'70)-Tenn.9,96; (I'0s)

TURIN, 263, COWETA

Merrill, limmett L. (b'68)-Tenn.5,90;

Storall, John C. (b'70)-Ga.5,'94.

TURNERVILLE, 75, HABERSHAM

Stribling, Garnett B. (b'82) - Ga.11,'00: ( l'OG)

TYRONE, -, FAYETTE

lones, Abran 13.-Ga.12,07; (l'0z).

TY TY, 276, TIFT

I'ickett, Frank]in B. (b'72)-Ga.1,9?; (I'9 )

lickett, lieuben Ray (b'69)-Ga.1,92

TYUS (R.F.D., CARROLLTON), 60, CARROLL

Scroggin, Abrer L. (b'T0)-Ga.1,00; (l'00). UNADILLA, I,003, DOOLY

RETLER, WM. I. (b'7T)-Ga.1, 05 : (l'05) I'ATE, REIDHFi HAMHTON (b'72)-Mld. '48; (1'99).

WOOTTEN, LOEJS 0. - Ga.5,'94.

UNION CITY, 534, CAMPBELL

Pittard, Linton Lancey (b' 86$)-M 0.34,12$; (l'12)

UNION POINT, 1,363, GREENE

Carson, II. D. (b'74)-Tenn.11,99; (I'00).

Durham, Walker Hamilton-Ga.9,i1

Fluker, Carl Barmes (b'85)-Ga.11, i1. (l'11).

FOSTER, H. CIAIY-Cra.J, 00 ; (I'00).

UVALDA, 20, MONTGOMERY

Collius, Joshua ('. (b'75)-Ga.1,'01; (l'01).

Hall, James Knox (b'- 8 )-Ga.12,'08; (I'08).
Mobley, Molt. IL. (b'81)-Ga.1,01; (1'01). () don, I) unt. I'.-Gia.9,'01; ( ),

VADA (R.F.D., FAIRCLOTH), 45, MITCHELL

I3owers. W. L.-Tenn.9,'99; (I'01).

VALDOSTA, 7,656, LOWNDES

I3mrchett, Janes F'(b'76)-110.28, 00 ; (l'11) : OALR. $\star$

Burlon, Benj. S. (b'67)-Ga.5,91.

FItELYA (I'10).

(ildlens, ('las. C.-Ga.11,07; (1'07); not in practlee.

GIIFFIN, ARCHIE $\left(\mathrm{b}^{\prime} 70\right) \oplus-\mathrm{Ky}, 4,94$; (1'34); G. (b'39)-(';2,4;01

LIT'TLE, ALEXANTHR GRAIIAM (b'69) -N.Y.10,'98; $\left(l^{\prime} 00\right)$.

I'ATE, JUL1FN CARY (b'87)†-Ga.11,'12; (1'12); $\mathbf{S}$.

QUAITTEMAN, PETER CLARK (b'84)Ga.11,09; (I'09).

Rouse, Wm. Emmett-Mo.27,93; (l'00).

Schnauss, Friedricl wilhelm (b'68)-Ga.11, $06 ;\left(T^{\prime} 06\right)$.

(1'98); OALR. *

Strlekland, Carroll C. (col.) (b'82) T'enn 7,0s. (1'08)

TALBOT, TULLX M. (b'59)-0.14,88.

THOMAS, FRANK H. (b'76)-Mi]ch.1,02; (l'02); $\mathbf{S}$.

Tllo.MAS, Jos. A. (b'84)屯-Va.6,08; (1'08); U.

WILSON, JOHIN C. (b'72)-Ga.10,'97; (1'97)

Wyche, Iilchard Theodore (b'82)-Tenn.7. '10; (1'10).

VARNELLS STATION, I00, WHITFIELD

Lacewell, John F. (b'57)-Ga.5,86; (I'07).

VIDALIA, I,776, TOOMBS

CURIRIE, MALCOLN L. (b'53) †-Md.3,'88; G.

Darby, Virgil Lee-IJd.9,05; (1'07).

IEAIIOWS, JOHN M.-Ga.1,88.

MEADOWS, J. M., JIR-Ga.1,01 ; (1'01).

MOYE, ILON L." (b'78)-Ga.11,02; (1'02).

PEACOCK, WM. F. (b'58)-Ga.1,'85.

THOMPSON, THOS. C. (b'86) 4 -Ga.1,08; (I'08).

VIDETTE, 75, BURIKE

IICCarver, Wm. C. (b'82)-Tenn.8,'10; (1'11).

VIENNA, I,564, DOOLY

BIVINS, T. F.-Ky.4,'85.

MOIBLEI, il. A.-Ga.10,'87.

Mobley, Louis W.-Ga.1,73; not in practice.

Stovall, Chas. Theodore (b'57)-Ga.5,'79; (

WHLIAIS, FIANK E.-Ga.1, 02 ; (l,02).

VILLANOW, 75, WALKER

Farmer, John J.-Ga.9, 09.

SHILLDS, JАCOB A. (b;6)£-Tenn.9,'03; (1'04).

VILLA RICA, 855, CARROLL

Boyd, J. M.-Ga.11,'01; (1'01).

E.IBRY, BALNETT LINTON (b'53)-Ga.5, 78 ; (ठ).

MARCHMAN, IIENRY R.-Ga.5,'98; (1'98).

1'OWELL, BUNA C. (b'68)Ð-Tenn.9,'92; (d) ; S.

WACO, 326, HARALSON

Herrier, John H. (b'39) $\rightarrow$; not in practice.

WADLEY, 872, JEFFERSON

Holmes, Walter B. (b'69)-Md.4,92; (l'92).

Peacock, J. Domingos (b'83)-Ga.1,'06; (I'06).

WALDEN, 243, BIBB

COWAR', JANES W.-Ia.1,'94.

Taylor, A. I. (b'66)-Ky.5,'91; (l'91).

WALESIKA, 243, CHEROKEE

loore, Russell Malcolm (b'63) E-Ga.9,85 ; (む).

WALNUTGROVE, II2, WALTON

llabry, Geo. (b'49) $\longrightarrow$.

WALNUT HILL (R.F.D., ASHLAND), 30, FRANIKLIN

BUSH, GEO. F.-Ga.11,'00; (1'01).

SEWELL, J. ROBT.-Ga.5,'93.

WALTHOURVILLE, I00, LIBERTY

Hack, Fred C.-S.C.1,'84.

Hack, Geo. Byron (b'8i)-Ga.11,'10; (l'10).

WARESBORO, 149, WARE

Ieclintock, $\rightsquigarrow \mathrm{m}$. Jay.

(See Waycross.) 
WARRENTON, I.368, WARREN

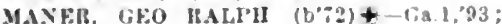
(1'93)

PILCHER, WYMAx w.t-Ca.1, $\$$ ?

RIcketson, Francls 13.-Gia.1, 8 :

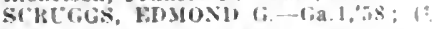

WARTHEN, 151, WASHINGTON

Mas, Ldmund T.-Md.1,85; (1'85).

Redding. C. 1).-

\section{WARWICK, 226, WORTH}

Mournoy, Harrison Cllutun (b'si)-Tenn.5. '11: (1'12).

HEYWALD, ARTHLR R. (b;0)—: $1,1,92$

WASHINGTON, 3,065, WILKES

AMASON, JAJtES k. (b'6s)-6;a,5, 44 ;

K.F.D. 2

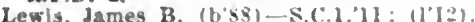

Saskus, John Gordon-fia.11,12; (1'13)

H. F, (1) 2 .

SIMISOX, ADDISOX W. (b'75)-1ia.5,9s (1'98)

SIMPSOX, HOHT. A. (b'59)-N.Y.1, 84

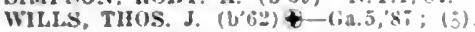

WOOD, OKLANIOO S. -

WATKINSVILLE, 483, OCONEE

Hodres, Wm. II.--ia.9,"b0.

Middlebrooks, Chester $0 .\left(b^{\prime} 35\right)$ - Ga.11, 0 ; (1'06); R. F. ()

Smith, Kobe. H, - F-Gia.9,'45.

WHITE, WM. M.-(ia.11,03; (1'03).

WAVERLY, 20, CAMDEN

Atkinson, Burwell-ia.j, TE.

WAVERLY HALL, 300, HARRIS

Bussey, Benj. X.-Ga.̌̃.'8s.

Stauford, Louis W. (b'55)-l'a.2,";

WAYCROSS, 14.485 , WARE

Bagley, J. B.-Gia.5,'yt; Miterside l'ark; oftice, Folks blig.

BHATON, JAMES J. (b'ss)-Gia.1:,0y (l'0y); 64 lated si.; oflce, bunn Blug. $\vartheta-10,4-5$.

HRADLEY, DANL. MARCLS (b'st)-Ga.J.

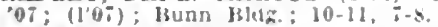

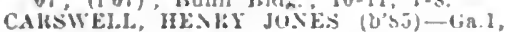
os: (1'08).

Callerell, saml. D. (col.) (b's3)-Tenn.i, "12; (1'12); ios Reynolds st. ; once, si'n l2; (l'12); $10 \mathrm{~s}$ Rejnolds st. ; utder, ding

Dodson, kichard C. (L'si)-Md.1,11; (1'13); 60 Hrunel st.

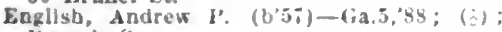
Francis SR.

FLEDISG, ALBERT (b'66)-ba.9,'44; Hichis si:; offce, Soutlers livel lildg.; J-10.

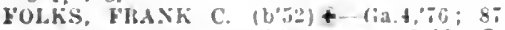
Mary st.; oflice, fix J'jans dve. 9.11: G

FoLKs, GÜSTAVI:S I. (b'5s)-hy.4,85; not in practice.

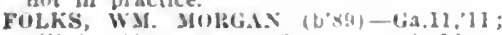
(1'11): Mary St.; ollice, Central lharmacy.

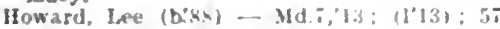
Gllmore st : offlee, Walker ihhti.; 9-11, $3-4,7-x$

IZIAAR, ROBFHTS I'OINEFT TE $\left(b^{\prime}(0)+\right.$ SC.1,89; (1'16); :" bilmore st.; onjee Bunn IBldz.; $4.19,4-5$

JOHNSON, MARVIS Y. (b'-9)+-6a.1.02

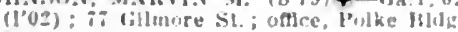
$9-10,3.1$.

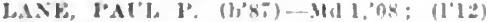
Atlantle fount In Ine llompital.

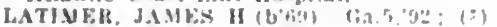
S2 ('aswill $\mathrm{xt}$ : once, Hunn Hilg ; i1) 11 ,

Lee, Samu. Fingle (b"80) Md 1.11; (1'2a) Allantlc Cosst Line IIuspital.

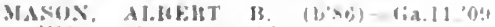

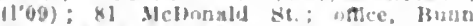
Blds: : $y-12,3 \cdot 3 ;(B 1) ;$ OALR.*

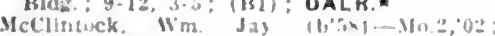
(1'10): (Warenboro): 10-1: $=4$

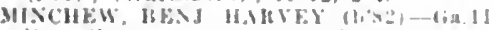

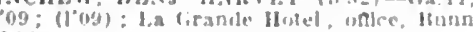
IId : :-1:, :5; OALP.

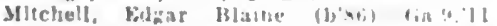

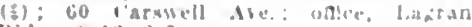
lide. : v. $1:, 2,: 5$

Relding, John II. (b's) lia lo, $\mathrm{kl}$ : (?) dlice and Isabella sex.: ualce, herldang

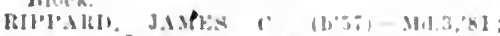

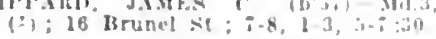

Scarlett. II. C. (col.)-Tenn.t,0: : (l’0i): 125 Iteynolds st.

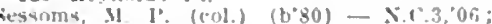
(I'0(i).

SMITI, JOB F. W. Tenn.9,82: K.F.

Thomas, Wm If (b.83) 1;2,11,09:(1,04)

Verner, folward IV. (col.) $\left(b^{\prime}, 6\right)$ - Tenn. '10: (1'10): lorallel

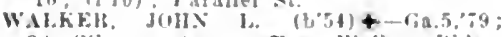
38 cillmore lie; oftce, Walker Ibldg. $y=11,3-4$.

Ward. Joht W. Ga.10,98; $(198)$; Folks klder.

Wastington, (ieneral 1.. (col.) (bifit)Tenn 7.93

Wilson, Jilmeg f. $\left(b^{\prime} 47\right)-0,6,72 ;$ not in practlce: inf lield st.; ottlce, 2 Erancis sit. WAYNESBORO, 2,729, BURKE

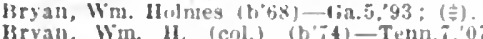
$\left.(1,0)^{\circ}\right)$.

BYNE, J. Y.- Fa.l,00; (I'00)

cox. 1" Holdoull-ria. 1,56

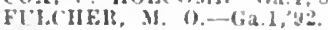

HERRINito: L l -

MACALlAS, HLGH ANGL's (b'85) \&-Ky.2

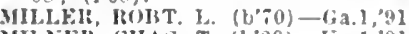

MII.NEIR. (HIS. T. (1)62)-Ky.1,91: (1991) MORTOS, HEBER JOSES $\left(b^{\circ} 84\right) \pm-(; a .1$ "09: (1"08).

WAYNESVILLE, 300, WAYNE

Gordon. Alexarder J. (b'6:)-Ga.l'ss.

WELLS (R.F.D., CARTERS), 40, MURRAY Bates, Jortan F.-Tenn.9.'id.

WESLEY, - EMANUEL

hanler, Leon 'wey" (b'81) -Ga.12,09; (1'09).

WEST GREEN, 140. COFFEE

Hall, Warren lee (1,'s9)-C(is.1,'l3; (1'13).

WESTON, 319, WEBSTER

Cleveland, James T. (b'39)-Tenn, 1, 60 .

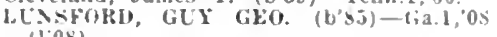
(1.08)

WEST POINT, I.906, TROP

Coar. Danl. Louis (b'G 6$)$ - X.C.3,0s: (1'0y)

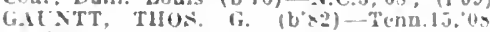
(1) $0 x^{\prime \prime)}$

Ilogg. Jarrell si-Ga.5.79.

Hogi, live?. X-La.1.45; (1"9ti)

HOLSLFY, JOS. STAFFORL (b'43) lia.l, yt; (i)

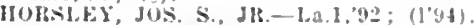

Jackson, Irthur Flournoy $(0 ; 5)-12 a .1,09$

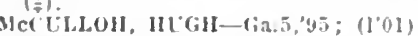

ONEAl BA

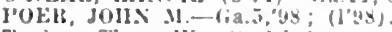

laylor, Thos, W, - lial, i,

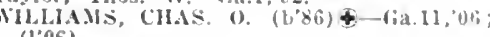
(l'06).

Willams, Madison T. (col.) (b'sl)-Temn. 11); (1'10).

WHIGHAM, 627, GRAOY

BK.IlJEl?, LEUN EIM! (b'SS)-Ga.11,11 (1'1i).

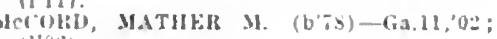
$(1+02)$.

WHITE, 20, BARTOW

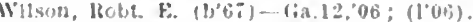

WHITE PLAINS, 407, GREENE

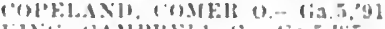

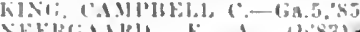

(1+12)

WHITESBURG, 315, CARROLL

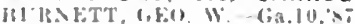

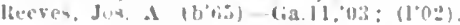

WHITESVILLE (R.F.D., WEST POINT). 126. HARRIS

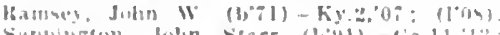

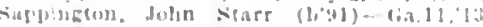
$1173)$

WILDWOOD, 23, DADE

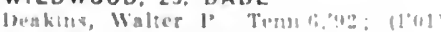

WILLACOOCHEE, 960, COFFEE

WILISSFT TIUS II (b) $\left.\left(l^{\circ} 1\right)^{2}\right)$.

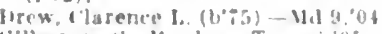

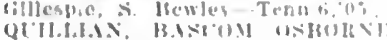

Qt?l.1.1.5: B.1.8.

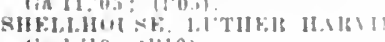

$\operatorname{lin} 1,10:$ ilini.

whllenx, deferann 11 (1).5es
WILLARD, 25, PUTNAM

WILKE.H, ElWI, I. MH

WILLIAMSON, 179, PIKE

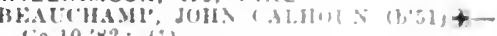

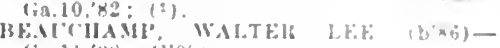
fin 11,0x: (1)0m)

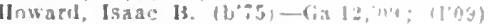

WINDER, 2.443, JACKSON

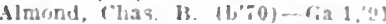

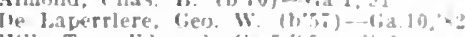

HIll, Tum Fiward-liag,

IIMLEN.

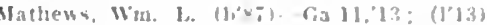

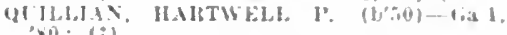

Ross. Stephen T. (b'tio)-Kr.tol

saxun. Filmund Franklin-r,a 11,03: (l'05).

WINFIELD, 25, COLUMBIA

STORY, Z. MCD. (15\%0)-1ia 1,96; (1.96)

WINSTON. I68, DOUGLAS

linenet, W. K.-Tetnit.4t. ierce, Fitw
R.F.D. 2 .

WINTERVILLE. 465. CLARKE

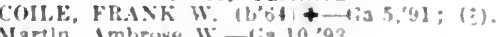

Martin, Imbrose W.-lia 10,'93.

WOODBINE.155, CAMDEN

Swift, Addising $K$. (b':-2)-Ky 4.95; (1'00).

WOODBURY, 917, MERIWETHER

Allen, Wllson Pruitl(b'sh Ga.11:07:(1'05).

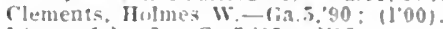

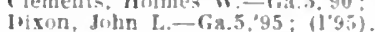

IIonten. John M-Cia.j,

Orr. Wm. Lucius (b'0)-Md.6,01; (105)

WOODCLIFF, 100, SCREVEN

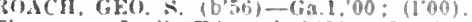

Thompon, Leslle Edmond (b'84)-Ca.l:.,12;

(1'12)

WOODLAND, 189. TALEOT

l'eeler, Julian E.-(;a.1,'s9.

WOODSTOCK, 4\$2, CHEROKEE

lBuring, James K.-lia.11,99; (1'09)

laholes, W. Oscar (b's3)-ria.9.20: (1'10).

Whitfeld, Chas E-CA 4 , DO

WOODVILLE, 250, GREENE

Wanlels, Rartiow W: S. (col.)

(see sarannab.)

Durham. John L. - ria.9, ,83.

I'urham, Win. M., Ir -1ia.9,06; (1'n6).

WOOLSEY, 162, FAYETTE

Hutchean, ilas. T. (b':4) $\mathrm{F}-$ Ca.9.99; $(1.254)$.

Wellon, folm R. Cal11,0n: (106): U.

WRAY, 400, IRWIN

H.IIRIEIR, AIRREI (b.1) - G.10.98: (1,OS).

WRENS, 616, JEFFERSON

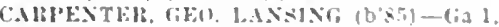

on: (l'ny).

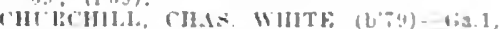
on: (1)

Aaley, Chas. II $(8,53)$ - (ia.1, <3

WRIGHTSVILLE, 1,389 , JOHNSON

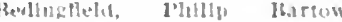

H F.'. B. B.

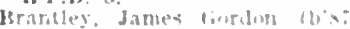

(1) 10 a

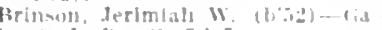

loval, 3. It - lia.

Ilinives

llarrls, Thes 1

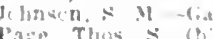

YATESVILLE, 36.6. UPSON

Julnem, B.a

YELLOW'AEEK R.F. R., EALL

30. DAWSON

YORKIILLE

PAULDING

YOUAB HAHIS: 2i TOUAS

YOLAKER : DODGE

1*n?)

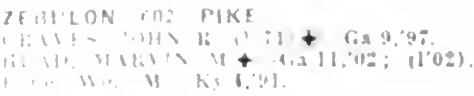




\section{D A H O}

NoTE:- The general Information of this state Includes: Medical Jaw, Board of Itealth. I3oard of Medical Examiners, Medical Associatlon, state

\section{IDAHO}

Population (1910 census)

325,594

Number of Countles...

Members State Association, Dec. 3I, 1913.

Area of State in Square Miles....... 84,313

\section{MEDICAL PRACTICE LAW OF IDAHO}

\section{An Act}

To Regulate the Iractlee of Medlclne and Surgery Wlthin the State of ldaho; and Providing I'enalties for the Vlola tion of this Act and the ltepeal

$$
\begin{aligned}
& \text { of all Other Aets in } \\
& \text { Relation Thereto. }
\end{aligned}
$$

Be It enacted, by the legislature of the State of Idalio:

Section 1. CRFATION OF BOARD: The governor of the state, within slxty days from the expiration of the sesslon of the leglslature at which this Act shall hare been passed, shall appoint a Board of Medical Fxaminers to be known and styled "The State Board of Medical Examiners," consisting of slx members, a majorlty of. whom shall never be appolnted from, nor represent, any one school of medicine, and not less than three schools of mediclne shall be at all times represented on said board, all of whom sliall be graduates of reputable medical colleges or unlrersities, in good standing, and learned and skilled in the theory and practice of medic

The terms of oftlce of the members forming the flrst board under this Act shall be as follows, riz.: 'Two members thereof shall be appolnted to serve for a period of two years, and two members thereof shall be appolnted to serve for a perlod of four years, and two members thereof shall he appointed to serve for a perlod of six years. After which all subsequent appointments shall be for a period of sIx years, and until their successors shall have been appointed and qualitied. All persons appointed to serve under said board shall, on assuming the duties thereof, make oath before a district or probate judge make oath before a district or probate judge that they are graduates of colleges or universities in good standing, giring names and fully and impartially perform the dutles of such office. These oaths shall be made in duplicate. one to be retained on fle in the offle of the secretary of said board, and one to be forwarded to the secretary of state, who shall, on receipt of the same, issue to each member appointed on said board, and complying with this section, a certificate of such appointment, under his hand and the great seal of the state; prorided, that the gorernor shall remove any member of said board who shall be guilty of any crimiual board who shall be guilty of any crimiual
or dishonorable conduct or any umprofesor dishonorable conduct or any unprofes-
sional conduct forbidden by this Act, on recommendation from the said board, made pursuant to a resolution thereof, duly autlenticated and accompanied by all the facts and testimony in possession of said hoard, on which the sald resolution is based. Vacancies occurring from death, resignation or any other eause, shall be filled by appointment ly the governor within thirty days from the time such racancies occur, and such appintee shall serre during the unexpired portion of the term of the member whose place he fills; prorided, further, that after the board shall hare been constituted and organized, no person otherwise eligible shall thereafter be appointed on said board who is not in possession of a llcense to practlce medicine and surgery in this state under the provistons of this Act.

Sec. 2. RlLFS: Sald board shall have authority to prescribe and establish all needful rules, reculations and by-laws, not inconsistent with the laws of this state or the United states, to carry Into effect the proCnited States, to carry Into effect the proMarch 15, 1909.)

Sec. 3. ORGANIZATION: Said board shall organize Immediately after appointment by electing from among its members a presillent, a seeretary and a treasurer, and shall provlde a seal and shall attest its acts under said seal. Any member of the board linder said seal. Any member of the board shall have the authority to administer oaths, testimony whenever the same is neeessary in any matter relating to its ofleial aets or duties. Sald board shall hold regular meetings on the first Tuesday in the month of April and october in each year at the capital of the state, or at such other places as the board shall designate. Speelal meetings may also be called when, in the oplnion of a majority of the said board, the same is necessary, and shall be held at such time necessary, and shall be held at such time and nlaces as a majorlty of the board may book or general book of record in which all book of general book of record in which all tions of said board shall appear in full. They shall atso keep in addition thereto a "Cash Book," in which shall appeap in detail all recelpts and disbursements of said board. They shall also keep a special reglster, containing the names and addresses of all applicants for license, tonished in the appllcation for said license. nished in the application for said license. the applicant reeeived license or was rejected, and if the applicant was rejected, it shall contain, a full statement of the reasons shall contain, a full statement of the reasons
therefor. Said general book of record, the cash book, and the speclal register, shall be prima facie evidence of all matters therein recorded, and shall be publlc records in charge of the secretary of the board.

Sec. 4. REPOR'T TO GOVERNOR: The board shall make an annual report to the governor of the state, which report shall set forth a full and complete history of all its official acts during the year, and shall also contain a true statement of all receipts and disbursements of sald board for the period so reported.

Sec 5. EXEMPTIONS FRÖM EXAMINATION: All persons, except as hereinafter prorided, who are legally engaged in the actual practice of medicine and surgery, or either of them, within the state, at the time of the passage of this Act, under the provisions of the medical act of 1887, shall be licensed without examination to continue such practice under this Act, by making applieation to the State Medical Examinin Board on suitably prepared blanks to be furnished by said board, within six months from the taking effect of this Act. The applicant shall be required to transmit with said application a certificate from the county may reside, that said applicant is a bona fide resident of the state and has recorded lis or her diploma under the provisions of the medical act of 1857 , giring date of such record. Iersons who reeeived a license under the now defunct medical law of 1897 will simply be required to transmit such license. The fee for license under this section shall be fire $(\$ 5)$ dollars and shall in each case accompany the application. Lin fulfllment of the requirements herein stated, the board shall issue to said applicant a license to nractlee medicine and surgery within this state. I'ersons for whom the provisions of this section are intended; falling or refusing this section are lntended; falling or refusing
to arall themselves of the same, shall be and are hereby subject to the requirements of Section 6 of this Act.

Sec. 6. AlPLICATIONS: After the passage of thls Act, every person, except as hereinafter prorided, desirlng to commence the practlce of medicine and surgery, or either of them, within the state, shall, Imeither of them, within the state, shall, Immediately and prior to commencing the same, make a written application to the State Medblanks, to be furnished by the board, for a license so to do. The applicant shall transmit with said application his or her diploma, together with an affdavit setting forth that said diploma is genuine, and that the appllcant is the rightful possessor thereof and the identlcal person named thereIn, and that same was obtained by pursuing the regular come was obtained by pursuing the regular course of study or examination in said institution, and settlng forth that be or she is a citizen of the United States, or has If the sald diploma has been issued by a reputable college of medicine in good standing, sald applicant shall be ellgible to examination. All applicants shall be examined in the applied branches of the theory and practice of medicine and surgery, or either of them. as those branches are taught in the reputable chartered schools of the systom of medicine to which the applicant belongs and which the applicant intends to practice, and such examination shall in all cases include anatomy, physiology, path-
ology, diagnosis, hygiene, chemistry, histology and toxicology. No applicant for license shall be allowed to practice medicine and surgery, or either of them, untll such license shall have been granted. The board shall cause the examination to be scientiflc and practical and sufficiently thorough to test the applicant's fliness to practice medicine and surgery, or either of them, and if the applisurgery, or either of them, and if the appliof all the questions submitted, said board shall grant the applicant a license to practice medieine and surgery in this state. Every appllcant for license under any of the provisions of this Act must furnish sufficlent evidence to the

All applications under this section must be accompanied by twenty-flre (\$25) dollars, which is the fee for examination under this section. Should the applicant fall to pass said examination, the fee Is not returnable. The cost of transmission to and from the board of all papers belonging to an applicant under this or any other section of this Act shall be paid by the applicant. In the case an applicant for an examination fails to pass the required examination, he or she may be reexamined after the expiration of six months, and withln one year, without the payment of an additional fee, and thereafter said applicant may be examlned as often as desired at any regular or special meetlng of the board on the payment of the regular fee for such examination. Said board may also refuse a license for unprofessional conduct, or eonduct of a criminal, immoral, or dishonorable nature.

Sec. 7. REVOCATION: UNPROFESSIONAI CONDUCT: The words "unprofessional or dishonorable conduct" as used in Section 6, or any other section of this Act, are hereby declared to mean?

First : The procuring or aiding or abetting in procuring a criminal abortion.

Second: The employment of what are popularly known as "cappers" or. "steerers" in procuring practice. 
Third: The obtalning of a fee on the assurance that a manlfestly Incur

Fourth: A wllful betrayal of the profes. slonal secret to the detrlmens of the patlent.

fifth: All advertisemeats of medlcal bus!. ness in which untruthful and lunprobable siatements are made.

Silxth: All adverlsements of any kind, of auy mediclue or means, whereby the monthly perlods of women can be regulated or the menses can be reestabllahed if supprevied. Serenth: Convlcilon of any orease inrolving moral turpltude.

Elzhth: Habltual Intemperance in the use of ardent spirits, narcotles or stimulants.

Sec 8. EXAMIXATIUNS: All questlons on the different branches of mediclne ant surgery submitted by sild board to candl dates for examlnatlon shall eliher be written or printed, or partly wrltten and printed. and the questlons on each branch shall to arranged on separate sheets of paper ani numbered consecutively.

The candidates stall be supplled with a list of the questlons on but one branch or subject at a time; after completing his or her answers thereto, he or she shall be entlied to the next list of guestlons, and so on In llke manner until said cundidate sha! have been examined in all the branche: requlred. All answers to the guestlons thrt submleted shall he In writing, on suituble paper furnisbed by the board. no candidate being permlted to furnish his or her own paper for such wrltten answers. Each llst paper for such Written answers. Each the candidate's anskers must bear the of the candidate's anskers must bear the llons, and each answer shall be numbered to correspond wlth the question to which it refers. The questlons submitted by the board to each candidate examlned, fugether with the answers thereto, shall ive hlsced and kept on flle In the offlce of the secretars of sald borard, and shall constitute part of the records of sald office.

Sec. 9. PHOCEFDISIS TO REVOKE. LICENSF: When complaint is marle to the hoard, of unprofesslonal or other contiuc: on the part of any llcentiate, under the nrovislons of the Act, merltimg a sustension. resocation. or cancellation of his license, the board shall have power to hear evidence fo plaint, and if the boarl be satlstled from the plaint, and the board be satlsted from the evidence of the justice of such complaint. in the distrlct court in and for bhe county In the distrlct court In and for the county penslon or revocation, and cancellation of auch llcense, and the ilistrlet courts of thls state are bereby rested with jurisdictlon to hear and delermine all such proceeding:s, and to suspend or revoke and cancel any Ilcense at issue in any such procectllngis. The accused shall be entlted to appear in person or by counsel st erery stape of such person or by criunsel at erery state of such complaint before the board to the hual dis. posltion of the case in the dlstrict conrt. All postion of the case in the dlstrict conrt. A
costs incldent to any such proceditis in the dlatrict court shall tre assessed by the court as the justice of the case. in the dis cretion of the courb, may reciuire.

In all such proceediogs the comb stter ney shall appear fur the buard in the dis. trlet crurt. In case the mard rofusa to Grant a liernse (1) wacsice umler this $A(c)$. the applleant shall have the rlolie il have the action of the board refusing such llcense rerlewed by, the distrleb court in and sils the county in which the merting at which the llecnse way rofused wow held. or such

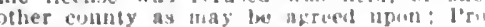
vlded, broceedings for such revlew lie listi. tuied within toll days after

sec. 10. PExAltIEs: Any permen pria tsclng medicine nnil sursery within th:s

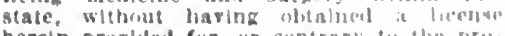
herein proviled for. "r contrary to tho pro. vlslons of thly Act, whall lee ilement sullty

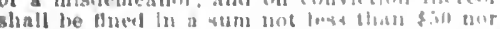
more than \$300, or loy haprisumentul in the county fail not less thin ten Hay a due more than slx monthe, or by bith sule flue and Imprlsonment. In the discroplen of thes cosurs. imprlsonment, in the discroplem "f the cosurt. each day such trerson continues to practlco medicine anil surkery, contrary to the pros. vlslons of this Act. shall cunstitute a separate offense. (Amending Secton 1350 , Mareh 15, 1809.)

sec, 11. RFCOHDXf IACESAE: Every versun recoising a llcense under thls Act shall, withit thirly daya thereafter, have the same recurfect In the oflce of the county recorder, within the county where the licen. tlate Intends to practice. Otherwlse, sald county shall hare sultaly prepared a separate "book of recorl," tu whlch all the ilcenses under this $\mathrm{Act}$, presented to them. shall lo recorded, and on the first day of Dhall be recorded, and on the flrst day of of "State Medica Framinlug Bosarl" a list of the licenses on record In hils nftice, and on nutice to hlm from sald secretary of the oflce, or of the death or removal from the county of any person whose license is on recurd therein, sald recurder shall make a note of the fact on the page containing the reeord of sald lleense, so that the records kell by sall county recorder shall correspond wlth the reenrds of hls county as kept by the secreiary of sald medical board.

Sec. 1:. LICFASES: All llcenses Issued by the board shall be numbered consecu. itrely and in the order lssued. Fach livense shall be slanel by the president and secre tary of the hord under the oftlclal seal of the boand lssulng same. Four members of the board shall constitute a quorum to transact buslness at sny regular or speclat meeting.

Sec. 13. STANIISG OF COLLEGES: The words "respectable or renutable medical college or unlversity in fonol standing" are hereby deciared to mein such mellical colleges or unisersities as are legally chartered, reputable, and in good standiug withln the
state or county where they are located.

Sec. It. DEEINiTION: Any person shall be remardet as practiclng medicine and surgery, or either. who shall advertlse In any gery, or either, who shath advertse in any the public as a physician and gurgeon. either, in this state, or who shill inrestligate either, in this state, or who shall iurestifat or diamosticate or offer to investigale or
diacnosileate any phystenl or mental allmen of any person wish a rien of reliesing the same as Is eornmonly done by physiclans of surgeons, or sugzest, recommend. prescrllie or direct, for the use of any berson. sick, injured or deforined, any drug. medicine. means or apuliance for the Intended relief, valliation, or eure of the same. with the intent of receiring therefor, either direcsis or indirectly, any fee, gift or compensatlon whatsoerer: I'rusldel. humerer, thls Act shall wot apoly to dentists and registered pharmaclsts or midwires in the legitimate practle of their respective professlomy, nor where nis feo is charked. whall present to the mard. as his or her own. the diplama of antither. or a forgen

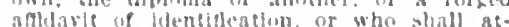

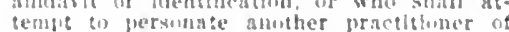
tethe ere alis

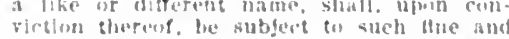
imprismment as are male nul provided by the sbatutes of the state of linho for the 'rlume of furgery'

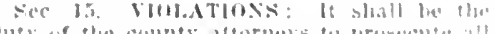

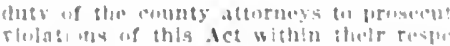

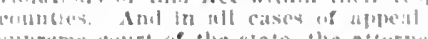
4ubreme condr of the state, the nttertacy

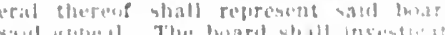

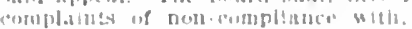

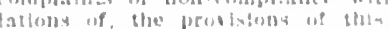

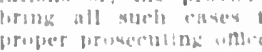

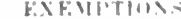

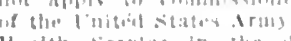

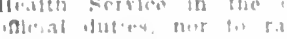

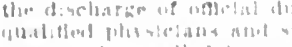

hiales. When callowl th

114. 1.190
Sec 17. CoMPE.ATIuN: Tho members of sald boarl shall tork alune to the revenues of this Act for reimbursement of

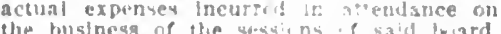
the business of the sessins of said torard, for thelr per diem allowanre, which shall unt excered the sum of flvo follary ont das wach, for each day sald bosril may xलsiton.

Sec. 18. FORMFR BOARII: The givernor is hereby empowered to recelre frum the of medleal examiners nil property aud money in hls possesulon belonging to the retary of the state Itomal tif Medical kixam. iners in be tis him avpinted inder this Act.

Sec. 19. IBEI'FAI: All cother acts and leine and surgery in this spate are hercby reprealed.

See 20. IN FFFET : Whereas, an emer. gency is herely declared to exist, this blll shall be in force and take efert frum and after its basaze and anprosal by the gorAproved on the $3 \mathrm{~d}$ day of March, 1999

\section{An Act}

To Amead Sectlons 1342 and 1350 of the Herised Codes of Idaho.

Be it enacted by the Leglslature of the state idaho:

Section 1. That Sectlon 1350 of the Idaho Rerlsed Codes be ameaded to read as fol-

Section 1350. I'ENALTIES: Any person practlcing medicine and surgery withio this state, without having chtained the fleense herein nrotided for or contrary io the provislons of this chapter, slall be gullty of a nisfemeanor, stud on conrlction thereof miscemeanor, thit wh conriction thereof dollars (slu(t). hor more than one thousand dillars $\$ 1.000)$, or be Imprisoned in the comnty jail not less than thirty (30) days. nor more than one (1) year, or be punlshed bo woth such fine and Imprisonment, in the diseretion of the court, together with the son continutes on uractice melicine and surgery contrary to the provistons uf th! engatertute a separate oftense.

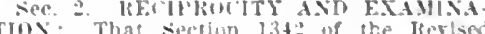
iolos uf ldaho be amonded bu read as follons:

section 1342. Suld lmart shall hare the authority wo prescribe and esiablish all reml. ful rules, regulattons and hy-lans now inCnlted states to earry inte wees the prove sions of blils elinplet. and $5,1 \cdot 9$ lwast mas. eliher with or without waminablum, wrans a licellus so any bha chan licenoed t. practice

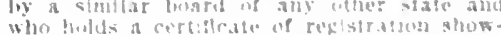

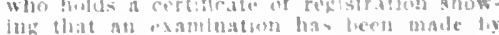

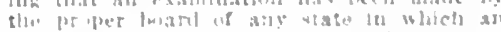

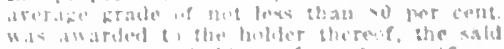
albitint and hiller of sile? certincate

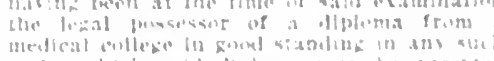
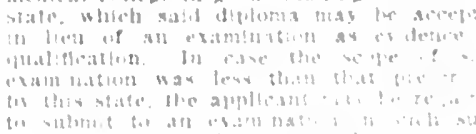

MATE BOA\&D OF HEALTH

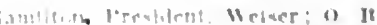

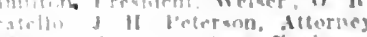
[i, idi ralk. Smetary, Bulas. 


\section{STATE BOARD OF MEDICAL EXAM.} INERS

('has. A. Dettman, P'resident, Burke; C. M. cline, V'lee-l'resident, Idaho Falls; lkusseli Truiti, Cottonwood; J. F. Serres st. dean, Waflace: J. F, schimershatl, SeeretaryTreasurer, derone.

\section{IDAHO STATE MEDICAL ASSOCIATION OHleers 1913-I4}

F. W. Withell, l'resident......... Blackfont iv: Smib vilce-1'resident............Bolse

Ed. E. Maxey, Secretary-Treasurer.... Bolse

\section{State Journal}

Northwest Mclleine, seattle, Wash. Clarence A. Smith, M.D., editor-in-chlef.

Component District Societies of the Idaho State Medical Association NORTII IDAHO DISTILCT

J. M. Fairly, President............ Orofino

o. C. Carssiw, Secretary............. Lewlston POCATELLO COUNTY

E. x. Isoherts, l'resident...........Poeatello

Jos. $Y$. 'lothier, Secretary...... Poeatello SOLTII IDAIO DISTRICT

Ralph Falk, President............... Bolse

1. L. Giase, seeretary................ Boise TWIN FALLS COUNTY

1). I. Alexander, Seeretary...... Twin Falls

\section{COUNTY HEALTH OFFICERS}

county Address

Ada.-R. E. Shurtz................ Boise Adams. - F, F. Brown............. Counell Bannock-A. II. Newton.........Pocatello Bin bham.-J. B. Daris............ Blackfoot Blaine.-J. J. Kaaf................Hailey Bolse.-G. E. Noggle............ Vian Wyek Bolnner.-M. McKinnon ...........sandpoint Bonneville.-J. O. Meliar........ Idaho Falls Canyon.-F. Il. Cole.............Caldwell

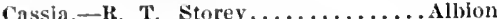
Clearwater.-J. M. Fairley.......... orofino Custer,-J. w. Kelly.................... Elmore.-B. W. Mather......Mountain Home Franklin.-G. T. Parkinson..........Preston Fremont.-1. R. Shupe............. Sugrar Gooding.-II. E. Lamb...........Wendell Kootenui.-D. D. Drennan........ Rathdrum Iatah.-J. v. ('larke............... Iroseow Lemhi - o. T. Stratton............ Salmon Lewis,-Il. M. Jones............... Pez Perce Ilneoln.-C. F. Zeller............ Slinshone Minldoka._C. H. Scott............. Rupert vez Perce.-L. J. Perkins..............ewiston Oneida.-D. C. Ray..................

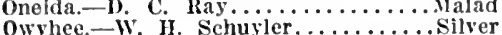
Owyhee.-W. H. Schuyler............... Silver Shoshone.-H. C. Jlowery............Wallace Twin Falls.-J. F. Coughlin...... Twin Falls Washington.-C. C. Conant.........Weiser

\section{HEALTH OFFICERS IN CITIES OF 2,000 POPULATION AND OVER}

Blackfoot. Boise............... Parker and $R$. L. Glase Caldweli....................... Robt. Cavin Coeur d'Alene.................... Hunter Idaho Falls................ R. Soderquist Lewiston................. Susan Bruee Moseow................... Clarke Nampa..................... D. Calonge Poeatello....................... $F$. Castle
I'reston..... R. Cutler and C. T. I'arkinson sindpoint................... F. Page Twil Falls ................... $\mathbf{F}, \mathrm{c}$. speneer Wallace..................... s stone Weiser...................... A. Young

\section{STATE INSTITUTIONS}

Blackfoot

Idaho Insane Asylum. Blackfoot, Ida. Fitablished 1886: public: insane: 300 leds: Georce lis ilde, medleal superintendent.

Boise

Idaho State Soldlers' Home, Bolse, Ida. Established 1905; private; general; 30 beds in hospital department; $\mathbf{F}$. $\boldsymbol{\Lambda}$. I'lttenger, physlelan in charge.

state I'rison IIospltal, I3olse, Ida. Geo collister, physletian in eluarge.

Orefine

Northern Idalo Sanitarium, Orofino, Ida. Established 1905; public; mental, narcotic and alcoholie; 250 beds; John W. Givens, physleian in eharge.

\section{St. Antheny}

Idaho Industrlal Training Sehool, st. Anthony, Ida. Established 1903; publle; general; 30 beds; F. E. Boucher, physielan; J. T. IIumphries, superintendent.

\section{HOSPITALS. SANATORIUMS AND CHARI- TABLE INSTITUTIONS} Bloomingten

Bear Lake Hospital, Bloomlngton, Ida. Establlshed 1909; private; surgery and maternity ; 10 beds; $\mathbf{L}$. T. $\boldsymbol{\Lambda}$. Hottendorf, physieian in charge.

Boise

Idaho Sanitarium, E. end of Pueblo Are., Boise, Ida. Established 1898; prirate; general; 22 beds; Mrs. Gilbert Donaldson, physician in eharge.

St. Alphonsus Hospital, Boise, Ida. Established 1895; publle; general; 125 beds; tablished 1895; publle; general; 125

Sisters of the Holy Cross, in eharge. St. Luke's IIospital, Ist and Rannoek
Sts.. Boise, Ida. Established 1902; public; general; 70 beds; Mildred Clark, R...., superintendent.

\section{Ceeur d'Alene}

Coeur d'Alene Hospital, 20 Garden St., Coeur d'Alene, Ida. Established 1905; private; general; 50 beds; John C. Dwyer, M.D., superintendent.

\section{Ft. Hall}

Ft. Hall Indian School Hospital, Ft. IIall, Ida. Established 1908; publie; general; 8 beds; Henry R. Wheeler (Rossfork), physiclan in charge; Miss Effe $\mathbf{E}$. wagar, superintendent.

\section{Harrison}

Harrison Hospital, Harrison, Ida. Estallished 1901; private; general; 15 heds; E. L. Reger, physician in eharge. Idaho Falls

Fuller Ifospital, Idaho Falls, Ida. Established 1909; private; general; 12 beds: Miss F. Alma Martin, R.N., in beds; Miss F. Alma Martin, K..., in charge

Idaho Falls General IIospital, Idabo Falls, Illa. Established 1906; 14 beds: Miss I'erry, superintendent.

\section{Kellegg}

Wardner IIospital, Kellogg, Ida. Established I883; private; general; 25 beds; George H. Kennett, physleian in charge.

Laclede

Laclecle Hospital, Laclede, Ida. EstabLaclede Haspital, Laclede, Ida. Estab-
lished 1904: private: general : 8 beds : Robert A. Allen, \$1.D., superintendent.
Lapwal

Ft. Lapwal Indlan Sanatorlum, Lapwal, Ida. Fstablished 1908; private ; N. Alley, phystelan in charge.

\section{Lewiston}

St. Joseph's Mospital, Lewiston, Ida. Established 1902; prlvate; 50 beds.

\section{Montpelier}

Asliey and Cooley Hospltal, Montpeller, Ida. Establlshed 1913; general; G. Ashley, M.D., superintendent.

\section{Moseow}

Chas. L. Gritman's Private Hospital, Moseow, Ida. Established I897; 35 beds; Chas. L. Gritman, physletan in charge. Inland Fimpire Hospltal, Moseow, Ida. carithers, physician in charge.

Payette

Woodward Hospltal, Payette, Ida. General; 10 beds; Jesse Charles Woodwar and Ira Richard Woodward, plyyslelans in charge.

Pocatello

Japanese General Hospltal, Pocatello, Ila. Established 1896 ; private; 0 . B Steely, physieian in charge; $S$.' Inukal, superintendent.

Pocatello General Hospital, Pocatello, Ida. Established 1906; publle; general ; 30 beds; Luella Francy, superintendent. Sandpoint

(ity Hospital, SandpoInt, Ida. Established 1906; publle; general; 25 beds; o. F. Page, physician in ebarge

\section{Shoshone}

Dill IIospital, Shoshone, Ida. Estahllshed 1909; private; 26 beds; Chas. W Dill, physician in charge.

\section{Spirit Lake}

Prindle Hospital, Spirlt Lake, Ida. Establlshed 1907; private; general; 15 beds; Earle S. Prindle, physielan in eharge.

St. Joe

Idaho Hospital, St. Joe, Ida. Established 1908; private for railway employees; general; 40 beds; W. C. Lindsay, superintendent.

St. Maries

St. Marles Hospital, St. Maries, Ida. Fstablished in 1913; private; 30 beds; $D$. E. Cornwall, surgeon in charge.

\section{Starkey}

Starkey IIot Springs Sanatorlum, Starkey, Jda. Established 1905; publle; health resort; 9 beds; R. S. Starkey, physiclan in charge.

Twin Falls

Twin Falls Hospital and Nurses' Training School, Twin Falls, Ida. Establisled 1907 ; publie: general; 25 beds: Ida If. Croeroft, superintendent.

\section{Wallace}

Hope Hospital, Wallace, Ida. Estab lished 1909 ; private; general; 40 beds Leonard E. 'Manson, physielan in charge. Providence Hospital, Wallace, Ida. Fstabllshed 1891; pullice 100 bells.

Wallace Hospital, Wallace, Ida. Es tablished 1890 ; public; medleal and surgíeal; 100 beds; J. Eugene St. Jean, medical superintendent.

Weiser

Weiser General Hospital, Weiser, Ida. Established 1905 ; private; 10 beds; J. A Young and S. B. Dudley, physielans in charge.

\section{Winehester}

Winchester Hospital, Winchester, Ida. Establislied 1910; private; general; 10 beds; Elton B. Rogers, physlcian in charge. 


\section{PHYSICIANS OF IDAHO}

KEY TO ABBREVIATIONS, SYMBOLS, ETC.

Siames in capltals senlfy membervlip li the County Sinclety and State dssocta llon (DOE, JOHN)

- Indieates Fellowship in tho Amerlcan Jed. Assn. (DOk, JOHXt).

(b'55) Year of lirih

inerlle. II, homeopatls: 5 e eclectle; $1^{*} .11$. physloMd. $: 09$. Collece and year uf graduation. - Information recelred does not show hrat uatton.

S.-Surzeou.

Ob. - Obstetrian.

ObG.-Obstetrlclan, (is necologitist.

G.- Cynecologlst.

Or.-Orthopedlst.

Pr.-I'roctologlst.

Op. - Ophthalmolorist

A. $\rightarrow$ I urtst.

LR. - Laryngologtst, Rh!uologlat.
(I.sio) lear of llrense.

(8) In mractloc licfure passace of present

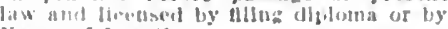
l'raclle.

(1+) Lifcened hut gear not knuwn.

(引) Informatlon recelved dives not show Ilicenste.

I.s...., Inited States Arms.

II If..., l'. 1., Medhal lleverve Corps.

SPECIALTIES ARE INDICATED AS FOLLOWS

ALR. Iturlat, laryngolog-tst, Itulnologlst.

OALR. Ophtialmologlst, Aurlst, Laryngologist, lihinoluglst.

U.-I'rologelst.

D. Dermatologlst.

Pd.-l'plliatrlst.

N.-Neurulogist.

P.-Psichinerise.

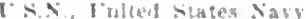

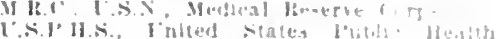
servlee.

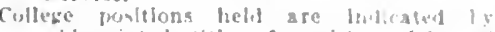

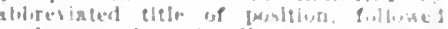
by heg loumber of crilleze bur key to rollogess ace irsilde trout cover wage

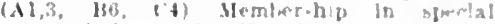

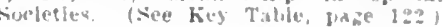

NP.- Neurolugtst, Puychatrist.

I. Interulst.

T.-Tulferiulotheraplst.

Anes.- Anevthetlat.

LD.-Laturatory Diagnesticlan.

Path. l'athingeist

Bact. - Hacterlutoglst

WHEN THE ABBREVIATION REPRESENTING A SPECIALTY IS FOLLOWED BY AN ASTERISK (*) IT INDICATES THAT THE PHYSICIAN CLAIMS HIS PRACTICE IS LIMITED TO THAT PARTICULAR BRANCH OF MEDICINE; WITHOUT THE ASTERISK. THAT HE IS ESPECIALLY INTERESTED IN. BUT DOES NOT LIMIT HIS PRACTICE TO. THAT BRANCH. THIS INFORMATION CONCERNING SPECIALTY IS BASED ON PERSONAL DATA FURNISHED BY THE PHYSICIAN AND IS NOT VERIFIABLE.

\section{IDAHO}

ABERDEEN,849, BINGHAM

Mackinnon, Malcolm C. (b'RI) - Ont. 5,09: (1'09).

ALBION, 392, CASSIA

Story. IR. Thompson (b'60)-Mo.1,'8; ; (1'99).

ALMO, - CASSIA

Sater, chester I.-M0.28,03; (1'09).

AMERICAN FALLS, 953, POWER

NOTH, RICIIARD F. $(\mathrm{t}, 79) \pm-C o l 0.5,03$; (1'05).

Wallantine, Nathantel Hay (b.8:)-Mo.34, 13 ; (I'!3).

ARC 0, 322, BLAINE

Fox, Earl Wm. (b'8\%)-Mo.28,08; (1"08).

Monroe. James-111.1.92; (1'94).

ARROWROCK, - BOISE

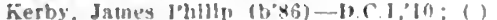

SHAw Jos. Iltilles (b's2) - $-0.1,08$ (1'11).

ASHTON, 502, FREMONT

Meacham, ('lanton Cuchber: (b' 89 ) - Tesun.î '13: (1'13).

Prlce, Ben). Andrew (b'78)-Mo.28,03;(1'01).

AVERY, - SHOSHONE

O'Bricn. Wagne I'aul (b'87) - III.11,"11" (1'12).

BANCROFT, 200, BANNOCK

SMITI, lRESELL, JAMES (b'69)-Unt.1. '42; (变); Member Utals state Med. A.ssu. BELLEVUE, 702, BLAINE

Allen, Ortila James (b'bi) - Culn.3.998 (I'01).

BLACKFOOT, 2.202, BINGHAM

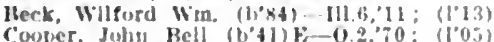

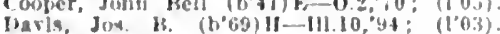
Hoover, ("layton A-ID.C.1,75: (1'99).

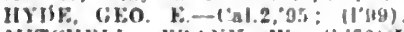
MTchH, vaNk W. (b०2)+-1).25 03: (1'03): I'res. Ida. Sitate Verl sum.

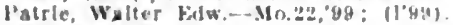

Slmmons, Ilowarcl Jackson (b'xi)- l'a.2 '11: (1'12)

BOISE, 17,358, ADA

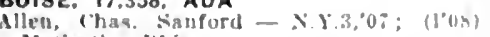
Meilariliy bils

Alen, Wm, lincoln $\left(b^{\circ} 60\right)-x$ y $t, x$ (1)

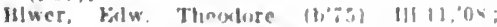
(I'II): 140: liarrison Itlud; intice, Sumba Ilide: $11.12,0.5$

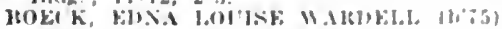

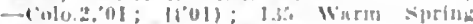
Are. oflce, 315 N, sth st.; OALA.-

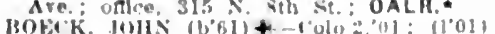

135 Warm Nurlog Are; onice. $315 \%$ sill st.: 10-12, $2 \cdot 5 ; 0$ b. lhowers, Lewls camubell (b.53)-111.1, s6;

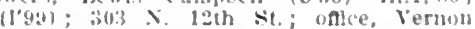
Hotel; $11-12,2-5$.

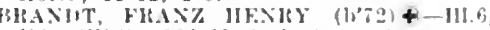

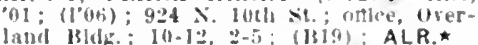

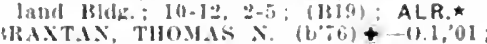

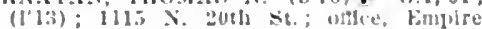
Hldg.; 10-12, 2-5; 0bG.

fallard, thas. leresford (b's2)-0nt.9.03

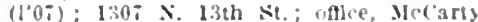
Itidg. : $1-12,1-5,7-8 ; U$.

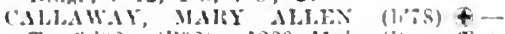

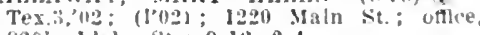
S201; Jaho st. : $9-1 \pm 2,2-4$.

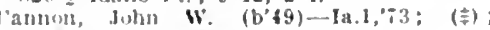
11 gay Franklln st.

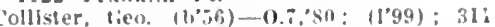
N. itli st.; ufflce, Falk Bldg.

DOSAINAOX, MALY H.I\%.IBETH JOIS STON (1,51)-0.12,41: (1,29): Inolilo

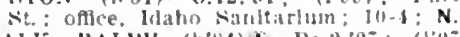

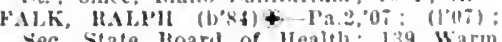
sec. State lloard of llealth: 139 Warn spring Are.: onlce, Fulk Mdg.; 2-4.

Fol:SHY. SAML. WH,COX $\{1,83\}-111,1,0 \times$ (!'!1); 910 fort st.; oflce, Uverlant Itdg. : $10-12,2-4$

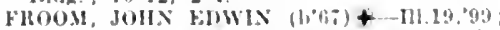
$(100)^{\prime}$; $120 \mathrm{~s}$ Jefferson si.; offlee, Holse Satiotal Hank lildg.: lo- $20 ; \mathbf{N}$.

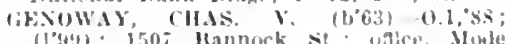
lidy. : $9: 30-12,2-3 ; \mathbf{R}$

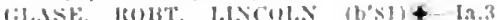
of $(1007): 1200 \times$, lath st, offlee, dwer-

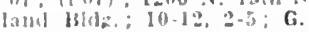

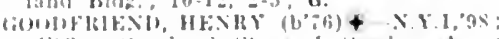

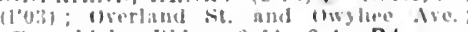

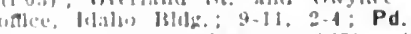

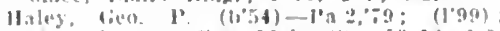
D. ioth st. : uttre, IJaho st : Ji I:2.

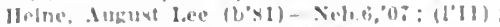

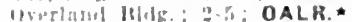

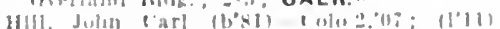

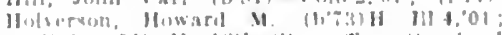

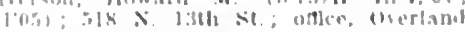
Hlle: : $1: 2,300$.

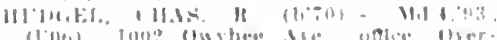

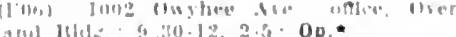

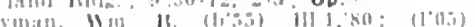

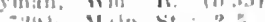

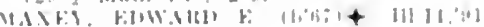

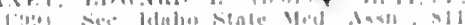

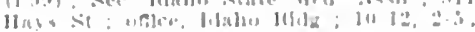
(II IH): OALH.

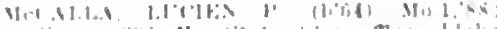

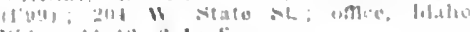

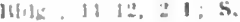

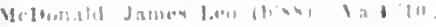

Woore, John II. (b"59)-Mlch.;.85; $(1206)$ : Irersildt.

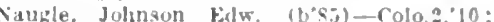
(1'11); 135 Warm sprlag Ave.; value,

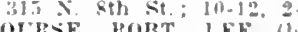

NOIRSE, RORT 1.E. (1,64)+-III.139: (1'99): 1519 Harrtson Hrd: oflce, irerland Bhls.; 10-1:2:5; (13191; OALR.

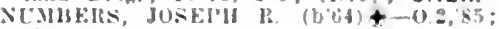
(1.9(1).

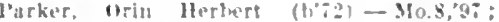

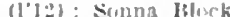

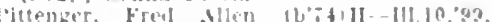
111.6.04; (805): 14. k. Jefersnn Are.;

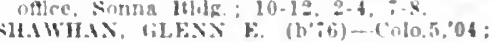

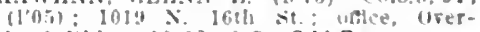
land Hille.; $10.12,2-5 ;$ OALR.*

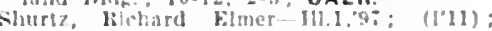

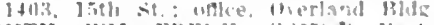

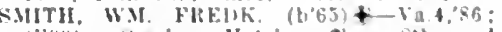
11940): (Wughee Hotel; odce. stb and

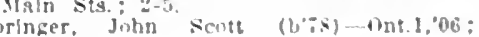
(loni): Idalus Mils.

STEWART, J.MES 1. (b'is) + I11.1,"

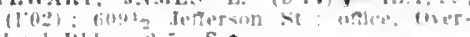
lamil lik!: $=5$.

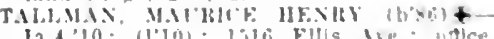

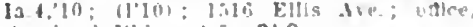
llorland lthis: : $2-5: 0 \mathrm{Ob}$.

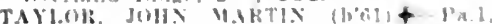

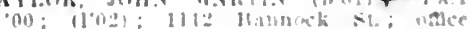
Empire llilig:

TITIS. WW \& $(119: 0)+-M i n n 1,04:$

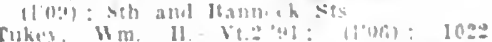

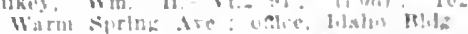

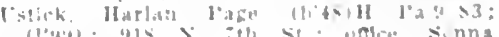

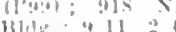

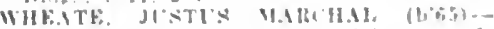

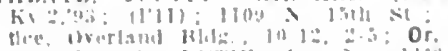

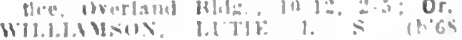

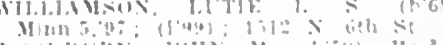

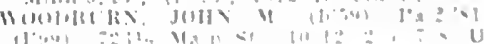
BONNERS FERRY 1.0\%1, BONAER

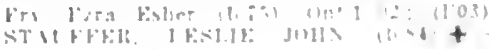

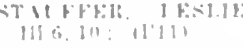

BOVILL. 650. LATAH

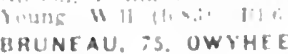

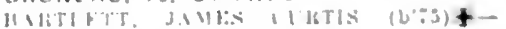
$1190.1,10,81101)$

BUHL. 634. IWIN FALLS

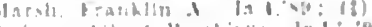
Init:3.94: relltend 
Me('IUSKY, ALBERT F. $\left(b^{\prime}, 6\right) \oplus-$ Colo.2, '06; $\left(l^{\prime} 06\right) ; 0 p$.

Murpliy, James II. (b'7s) - Tenn.9,03: (1'09)

Wetherbee, Chas. (b'69)-Mleh.7,'01; (l'09). BURKE, 500, SHOSHONE

Dettman, Chas. August-Wis.3,05; (l'06) Pres. State lionrd of Med. Examiners.

Naramore, Ilal sluerman (b;i)-1ll, log: (1'05).

BURLEY, 500, CASSIA

Coplln, Luella Cleveland (b'66)-MLleh.1,93; not in practice.

Fremstad, Jos, (b'72)-Mo.7,06: (l'13)

Loughlin, Mary (iriswold (b'73)-Ta.7,95; (I'08).

Mlnter, John Mills (b'82)-Ill.6,09; (l'10).

PATTERSON, JOIIN C. (b'80) 4 -Colo.2, 03 ; (1'03).

CALDWELL, 3,543, CANYON

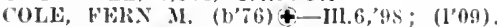
GUE, JOIIN W. (b'70)૯-1).C.1,94; (l'95): Fres. Ida. State Med. Assn.

IIENRY, JAMES M. (b'57) †-I11.11, 85; (1'00)

Iumirickhouse, John Morton (b'6I)-MA.I, '55; not in practice.

Isham, Albert F,-Vt.2,'82; (1'99).

Jolinson, Chas. T. (b'68)-Ky.2,'10 ; (1'10)

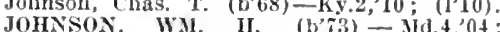
(1'10); S.

KALES, ClAFORD M. (b'7t) \&-Ill.6,04; ( )

Madden, Chas. Philip-Ky.1,05; (1'08).

Meyer, John S. (b'56)-Mo.29, 9 ; $;\left(l^{\prime} 99\right)$.

MHller, Saml. J.-Mo.20,98; (1'07)

Wright, Junlus B. ( ('’35)-Ia.1,'76; retired.

CAMBRIDGE, 349, WASHINGTON

Hopper, Simeon (b'S6)-Mo.34,10; (1'10).

Schmitz, Chas. E. (b'79)-Mo.28,03; (l’03).

CASTLEFORD (R.F.D., BUHL), 40, TWIN FALLS

Scliwarz, Theodore F.-0.1, 00; (†).

CHALLIS, 338. CUSTER

Kelley, Joln W. (b'S0)-Que.1,08; (l'11).

Kirtley, clias. L. (b'73)-Ill.1, 01 ; (1'01)

Lynn, Isaac Wesley-Ont.3,04; (I'08)

COEUR d'ALENE, 7,291, KOOTENAI

Busby, John (b'68)-Que.1,'9I; (l'99).

Cairns, Alexander-Mo.34,'07; (1'07).

borland, Max A. (b'80)-Mo.7,06; (1'06)

Dwyer, Joln C. (b'72)-Ill.11,01; (l'02).

Holden, Wru $H$ (b'68)-0.2,00; (1'09).

Hunter, Alexander (b'67)-Colo.2,'94, N.X.19, '99:; (l'99).

Shephard, John Hunt (b'79)-Ill.1,04; (1'06).

Wood, John Traverse (b’78)-MIlch.7,04; (106).

COTTONWOOD, 555, IDAHO

Orr, Wesley Frederic (b's0) - Ill.6,'II ; (1'12).

Shinnlck, John D. (b'76)-Ill.1,'03; (1'05). Trultt, Russell (b'52)-0.2,77; (l'99).

Turner, Joln WV. (b'60)-0.2,'91; (l'99).

COUNCIL, 3I2, ADAMS

Brown, Frank E. (b'70)-Ore.1,'00; (l'01) WATSON, CLYDE EMIL (b'79)\$-Md.7. 10; (1'13); Nember W. Va. State Med. Assn.

DEARY, 575, LATAH

FAUST, ROY C. (b'78)@-Ia.8,05; (1'11).

DE LAMAR, 700, OWYHEE

Farrer, Thomas D. $\left(\mathrm{b}^{\prime} 6 \overline{6}\right)-\mathrm{Mo.28,}, 0 \mathrm{I}$; (1'01).

DESMET, 500, KOOTENAI

Collard, Jonathan R. (b'66)-Pa.2,9l; (Indian service).

DIETRICH, I0, LINCOLN

Lighthall, Donald S. (b'\%) - Ont.1,01 ; (1'10).

DOWNEY, 300, BANNOCK

POND, CASPER WHIT'TLE (b'S2) Ð-Ill.6, 09 ; (1'10).

DRIGGS, 250, FREMONT

Crisler, Marcus P.-Mo.20,00; (l'06)

Keith, Ora Dell (b’33)-IIl.1,'03; (1'04)

Yountr. Juliun E. (b'75)-Pa.11,'13; (1'13).

DUBOIS. 500, FREMONT

SClioGGS, WL. P. (b'82) - Mo.34,08; (I00).
EASTPORT, -, BONNER

Slamlerk, Nathanael Lorenz A, K. (b'55) III.11,"12: (I"I1): A.A.s゙urg., U.S.I'II.S.

ELK RIVER, - , CLEARWATER

serley, Wm. 'Thumas $\left(\mathrm{b}^{\prime} 73\right)-$ Ill.11,'10; (l'i2).

EMMETT, 1.351, CANYON

C'LARK, BBRTON 0. (b'7\%) †-Mo.22,07;

UMMINGS, LOBT. N. (b'74)-Colo.5,'03; (l, 0.1$)$.

Greene, Inot. H-Mo.7,96; (I'99).

REVNOLSS, JAMES LENMON $\left(\mathrm{b}^{\prime} 78\right) \oplus$ ('olo 5,'04; (I'05)

FILER, 214, TWIN FALLS

Armes, Rubert Sylvester (b'77)-Ore.2,05; (年)

NEWBFRRY, ALFRED ASILEY (b'8I) (Colo.5.70; (1'08)

FRANIKLIN, 534, FRANIKLIN

Secrest. Wm. Boyd (b'69)-0.25,'98; (l'11).

FRUITLAND, I00, CANYON

Wright, Crispin (b'82)-Colo.5,'10; (1'11).

GENESEE, 742, LATAH

killen, Win. H. (b'66)-Ore.2,90; (l'99).

llceoll, James Macpherson $\left(b^{\prime} 85\right)-N . Y .6$, '10; (l'12).

Tuomy, Clark Francis (b'72)-Miclı.1,96; (1'09); OALR.

\section{GIFFORD, I53, NEZ PERCE}

Douglass, Arthur J. (b'66) - Mo.1,95; (1'08).

Herrlngton, James J.-Mo.10,'93; (I'99).

Watts, Fdw. E. (b'54) E-0.2,92; (1'99).

GILMORE, 30, LEMHI

l'aull, lrank Osborn (b'84)-Mich.1,09; (1'11).

GLENNS FERRY, 800, ELMORE

Davis, lenkin W.-Ill.1,93; (1'08); Ilorrison, Walter F. (b'49)-Ore.1;7; (l'13).

GOODING, 1,444, GOODING

Cary, Frank Taylor (b'79) - Ill.11,'05;

CROMWELL, JOHN HAROLD (b'76)-Mo.7,

'03; (l'10); Nember Ill. State Med. Soc.

GRACE, 50, BANNOCK

IUubbal'd, John H. (b'67)-Ill.6,06; (l'10).

GRAND VIEW, 80, OWYHEE

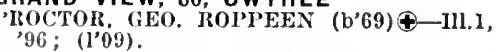

GRANGEVILLE, 1,534, IDAHO

Slusser, Carl WV. (b'77)-III.I,02; (l'04).

Stockton, Geo. S. (b'64)-Ont.4,'8; (1’99)

Warner, Willis Henry (b'76)-D.C.1, 07 : (1'12).

HAGERMAN, 308, GOODING

Fankboner, Audley $7 . \quad\left(b^{\prime} 76\right)$-Ind.8,'98; (1'09); S.

Marshail, Wm. Herbert (b'74)-Ont.3,99; $\left(l^{\prime} 07\right)$.

HAILEY, I,231, BLAINE

IILEINMAN, ERWIN W. (b'74)@-Ill.1,00; (l'02).

I'lumer. John J. (b'60)-0.3,'82; (l'99).

Raaf, John J. (b'72)-Mo.28,'98; (1'09).

WliGHT, ROBT. H. (b'81)-Mo.10, 06 ; (1'06).

HARRISON, 932, KOOTENAI

Finney, John Montfort (b'81)-0.41,'10 (l'11)

Reger, Earl Lee-Md.3,07; (l'08).

HEYBURN, 400, MINIDOKA

Gillen, Vincent R.-Ill.1,'00; (l'03)

Thompson, Willard L. $\left(b^{\prime} 74\right)-$ Ill.1,'96; $\left(l^{\prime} 06\right) ; 0 p$.

HILL CITY, - BLAINE

Bloom, Oscar Edwin (b'79)-0.41,'10; (l'12)

HOLLISTER, 50, TWIN FALLS

buckett, Walter Franklin (b'-2)-Ill.6,'94

Parrett, Wm. A. (b'65)-N.Y.5,'97; (1'11).

HOPE, 215 , BONNER

linapl, Wm. M. (b'47)-Mo.2,72; (l'03).

lloody, Chas. Stuart (b'69)-No.29,'99; (1'99).

IDAHO FALLS, 4,827, BONNEVILLE

Blevins, David L. (b'í4)-110.22,'99; (l'99) OpA.*

Bridges, Thomas M. (b'53)-Kr.4,78; (1'01).

CLINE, CLIFFORD 11. (b'83) $\$$-lll.6,'05; (1'07); S.

Coulthard, Geo. H. (b’78)-Ia.3,'04; (l'05) S.
Fuller, Sllvies S. (b'75)-Mo.35,'03; (1'07). HOLLISTER, TIIOS. CLAY (b'66) -11l.11, $96 ;(1,10)$

Kinnalrd, W'm. (b'73)-Ill.6,01; (l'01)

Mellor, John Oliver (b'81)-I'a.2,'10; (l'11) :

k. F.i. 1 .

'endleton, Grant wallace (b'64)-Colo.1,

Soderquist, Arthur Richard (b'85)-Mlnn.5,

'08; (l'08). HARRY DEL (b'75)-Ia.3,'97; (1'I2).

Wilson, Thos. C.-Mo.19,'82; (l'99).

IL 0, 209, LEWIS

I'arrish, Ifomer Coulson (b'72)-Ill.11,08 ; (l'08).

I'rice, Joslrua T. (b'47)-Md.1,'68; (1'99).

JEROME, 970, LINCOLN

l'iper, kdw. D. (b'67)-Ill.6,98; (l'08)

cimmershall, John F. (b'76) H-Ill.4,'04

(1'08); Sec. State Board of Med. Examiners.

JULIAETTA, 4I4, LATAH

K, SAMILL A. (b'76)-Mo.1,'97; (1'02);

OALR.

ICAMIAH, 324, LEWIS

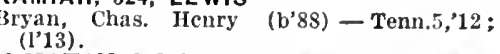

ICMAHAN, WILBER FRANKLIN $\left(b^{\prime} ; 3\right) 4-$

110.34,04; (1'07): S.

Taylor, Ell (b'55)-Ky.4,'95; (l'99).

KELLOGG, 1,273, SHOSHONE

Burgin, James Flannery (b'83) - 0.2,'08; ( ). Op.

Lindsay, Wm. Carroll (b'83)-Ill.6,'I0;

MASON, TRACY RICHARDSON

(See Wardner.)

IleCrackin, Alexander Davld

Mich., 09 ; (l'II).

KENDRICK, 543, LATAH

Hoyt, John E. (b'77)-Ill.6,'05; (l'07).

KOTIIWELL, WM. A.-Colo.3,90; (1'99).

Pd.

KEUTERVILLE, I00, IDAHO

Blake, Henry B. (b'51)- $\bigcirc ;\left(l^{\prime} 99\right)$.

KIMBERLY, 100, TWIN FALLS

DAVIS, JOS. NELSON (b'82) $\oplus-$ Kan.3 $07 ;(1,[2)$

KING HILL, 125, ELMORE

Erans, J. Wilson (b,74) H-Ill.10,01 ; (\$).

KOOSKIA, 30I, IDAHO

Verberkmoes, John Martin (b'79)-Ill.1,04; $\left(l^{\prime} 09\right)$.

Wohlenberg, Adolph F. (b'62)-Ill.11,94; (1'99).

KUNA, I50, ADA

Kerlin, Jared D. (b'64)-Mo.22,'90; ( ).

LACLEDE, 200, BONNER

Allen, Robt. A. (b'7 'T)-Ill.6,'06; (1'13)

LANDORE, 25, ADAMS

Brown, Wm. M. (b'60)-0.9,'88; (l'99).

LAPWAI, 50, NEZ PERCE

AILEY, JOHN NEWTON (b'72)థ-Pa.2 96; (1'03); (Indian Service); Ft. Lapwaí

Habel, Wm. I'. H. (b'84)-D.C.I,09; (Indian Servlce); Ft. Lapwal School.

LELAND, 150, NEZ PERCE

STONEBURNER, JOS. W.-0.2,'92; (1'99).

LEWISTON, 6,043, NEZ PERCE

BRADDOCK, ELMER GARFIELD (b'81) Md.3,'09; (1'13); also Nember Med. Soc. of the State of $\mathrm{Pa}$; $\mathbf{O b G}$.

BRUCE. SUSAN E.-Ill.10;80; (1'06)

CARSSOW, OSCAR C.-Mo.27,98; (l'06).

CLARKE, JESSIE K. (b'72)థ-Mo.22, 96 ; (1'99); OALR. $\star$

Harris, Fredk. Thomas (b'73)-Pa.2,02 ; (l'03) ; S.

Henkle, Clarence K. (b'73)-Mo.27,96; (1'99).

Hurlbut, John Fremont (b'61) -0 ; (l'02).

Inman, Lafayette (b'47)-Ill.35,96; (l'06).

MORRIS, JOHN BAKER (b'50) @-Mo.2,'74; (l'99).

Moxley, John 0. $\rightarrow$; (l'99)

NOURSE, FRANK' P. (b'52) - Ill.6,77; (l'05).

PERKINS, LOUIS J. (b'66)-1a.9,'92; (1'03). 
PUCHSFIl, EDW. (b'58)-111.1,82; not in pracflce.

Ralns, Jesse Lewts (b'7i) - Pa.2,05; (1'05): R.

SAXSING, CAMI'BELL (b'i2) †-La.1,95;

(1'12). CIIA. W. (b'55)†-Ia.3,'\$1: (1'99) STIRLING, FRiNK S.-Cal.1, '6t; (1"99) TODD, ELIZARETII A.VIE-III.9,01; (1'03) WHITE, FDGAR LEF $\left(\mathrm{b}^{\circ} 83\right) \mp-11.1 .09$ (1'11); also Mentber Wash. State Med. Soc: 's.

Whilford, (has. S, (b'55)-111.8, \$2; (1'v9)

MACKAY, 638, CUSTER

Mason, Roy karl (b'33)-Mo.34,05: (J'10) Hlchards, Francis l'almet $\left(b^{\circ} 7 i\right)-P^{\prime} a 110^{\prime} 0^{\circ}$ (1'10).

MALAD CITY, 1.303. ONEIOA

Alton, Jacub F. (b'bi)-MJch.8, 95; (L']1) Kerns, Jas. M. (b'7) - K5.5,'98; (l'99)

RAY, DAILEY C. (b':5) + Ky.5, 02; (l'03)

MARYSVILLE, 298, FREMONT

Hummell, Wllfed i.-Ia.3,'95; (1'06); 0 b.

MCCALL, 180, BOISE.

Snyder, Houston E. (b'83) - Kan.7,'09; (1'11).

MCCAMMON, 321, BANNOCK

Cooper, Geo, H.-MO.29, 05; (J'05)

MENAN, 294, FREMONT

MELTOX, JAMES KDGAR (b:1)-Mo.34,

'01; (1'09); Member III. State Med. Soc.

MERIDIAN, 6I9, ADA

DUTTON, CIIESXEY I. (b'it)\&-Colo.2, 01 ; (1'03).

Lewls, Jacob B. -0.2.'93; (1'02).

Neal, Halbert Fleteher (b'79)-Neb.5,03; (1"05).

Payne. Provo L. (b'6t)-Ky.1,'92; (1'05).

Reynolds, SamI. M. C. $\rightarrow$; (1'99); not in practlce.

MIDDLETON, 450, CANYON

DUNX, A BSEE B. (b'S3) 4-D.C.1,09; ( )

Member Kan. Med. Nive.

Hamer, John W. (b'55)-0.3,'82; (l'05).

MIOVALE, 200, WASHINGTON

Schmitz, Frank Albert (6.85)-Mo.28,09: (1'09).

Youngblood, Tecumseh S.-Mo.27,92; ( )

MILNER, 200, TWIN FALLS

Lenz, John G. (b'75) H-III.10,0L; (I'01); IIazelton; not In practlce.

MONTPELIER, 1,924, BEAR LAKE

ASHLEY, (

Guyon, kilwin r.-1).1,91; (1.99); 0 p.

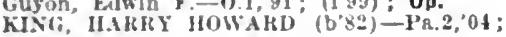
(l'05)

Poynter, D. Orr (b'J1)-I'a.11,99; (l'39).

MOSCOW, 3.670. LATAH

ADAIR. WM. A. (b'38)-Ind. 10,'83; (I'99)

ASIR.Y, JOSEIII (b'7y) + - Mass. 6,02 (1'04); $S$.

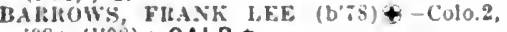
"08: 1]"08) ; OALR.

CARITIIERS. WIINER IILSTERt-III.1. C.: (l.99): $S$.

CLARKE, JAMES $\times\left(b^{\prime} 56\right)+-11.1,85$; (I'00).

GRITMAX, CIIAILLS L. (b'62) t-0.8,'20 ; (l'y9) ; S.

Leltch, Franklln M. (b"30)-Mo.5, 89; (I"12)

KAE, DAVII) F.-Ont.3,"83: (1,06)

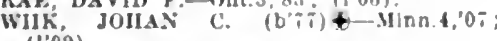
(l'09).

MOULTON, 25. CASSIA

Iloss; Saml. J. (b'51)-II1.6,76; (\$).

MOUNTAIN HOME, 1,\$11, ELMORE

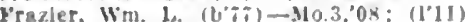

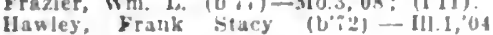

anley, Prank stacy (bia - III.1, 04:

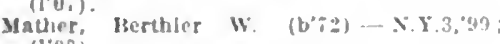
(1'00)

MULLAN, 1,667, SHOSHONE

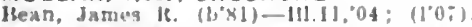

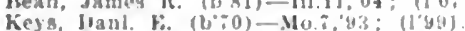

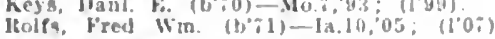

MURRAY, 500, SHOSHONE

l.esher, (ieo. S. (b"62)-1'a.1, $(40)$; (1,02),

NAMPA, 4,205, CANYON

Iheller, ow:a Ity ron $(1, ; 2)-111,19 ;:(1,0,8)$

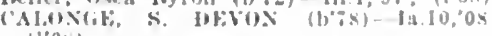
$(1,0 \times)$

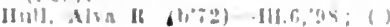

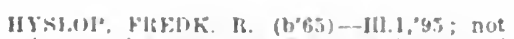
In practlice Metuber stale Med. Soc. of

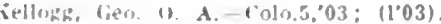

Murravi, Jou, II. (b'fin)-Ia.6,88: (I'99)

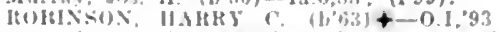

not In practlce; Member Oblo state Med isun. : Is f Ib y

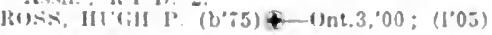

NEW MEADOWS, - ADAMS

WHTEMAN, ROIST. THEODOIRE $\left(\mathrm{b}^{\prime} 86\right)+$ Mieln. I,'(1)': (1'11)

NEW PLYMOUTH, 27\&, CANYON

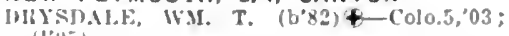

Harrls, Wm. F. (b'60)-III.11,92; not In DTArsice.

NEZPERCE, 599, LEWIS

MBOCKMAS. JAMkS (). (b'67) $\rightarrow$; not In Jractice; Member silate Med Assn. of Teris.

Jelireya, ollver Aulerson (b's1)-11.1,05;

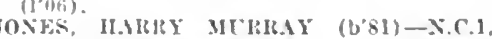
(uti; $(109)$; Member Med. Soc. of the State kelly, Joln Lee-('al.2,8s; (1'06).

NOTUS, 100, CANYON

MartIn, T. Edwin (b'S2)-III.6,'04; (I'09).

OAKLEY, 9II, CASSIA

NIFLSON, AXEI, F. O. (b'6, 8$)+-111.17,05$ (1'05).

Oldhan, Ernest Price-Ill.6, 06 : (1'0

I'eterson, Chrlstlan $\left(b^{\prime} 66^{\circ}\right)-111.5,03$; not In practlce.

OROFINO, 384, CLEARWATER

F.IIILY, JAMLS M. (b'69) †-D.C.1,'96

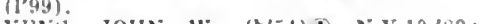

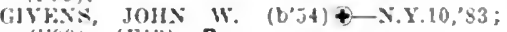
orswl1, firle W.-O.2,'08; (J'11).

PARIS, 1.038, BEAR LAKE

Conley, Aribur Dike (b'S6)--III.6,"I1; (1'12).

Hottendorf, Lewls Theodore Iuruit (b's3)$0.1,07:(1,12) ; \mathrm{S}$

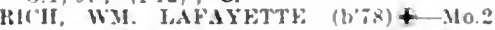
'07'; (1'13); Member I'tah vitate Med. Issu Sutton, RJchard J.-I11.2.2, 13: (1'13).

PARMA, 338, CANYON

Allen. Chas, Bradley (b; $; 4)-$ Colu.2, 05

("luen, Raymond J. (b'30)-Ia.6,01: (1'nz)

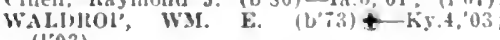
(I'03).

PAYETTE, 1.948, CANYON

AVF: OLIVEIT II. (b'65) \&-I11.1,01; (1.02).

Barton, Clark Idell (b'î)-111. $8,0 z ;$ (

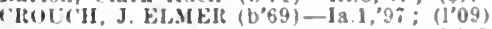
Wondward, Ira Itlchards (b'-4)-Colo.1, 97 (l'(iii) : Pd.

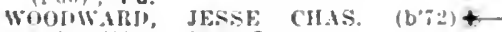
Colo.3,00; (1104): S.

PECK, 236. NEZ PERCE

l.yle, James M. (b०6)-Tenn.1,01; (1002).

PLACERVILLE, 187, BOISE

ByTl, Juntin Geo (1,xi)- II1.J1,09: (1'11)

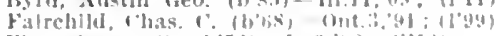

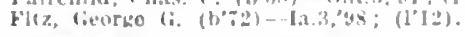

PLUMMER, 330, KOOTENA!

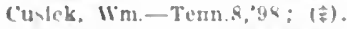

POCATELLO, 9.1 I0. BANNOCK

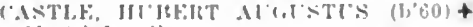

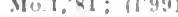

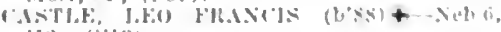

1.': $(1,13)$

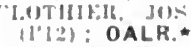

cuoke, Wim. Jlenry

llowaril, Meande

IIIIIII, WM.

(1): $\left.10^{2}=1\right): s$

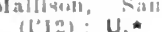

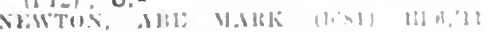

(1)1:?

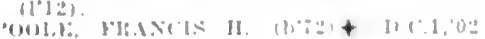

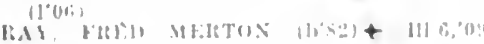

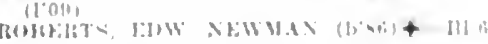

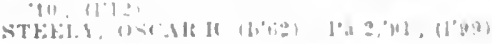

Wonlley, Ilyrum sinith. Ir. (6"74)-II1.6,09;

WhICHT, WM. A. $(1, \%+,+$ ill 1,01; (In02);

POST FALLS, 658, KOOTENAI

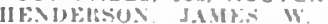

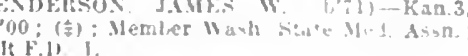

POTLATCH, 1,500, LATAH

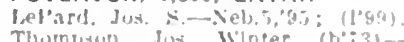

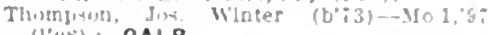

(I’U5); OALR.

PRESTON, 2,110. FRANKLIN

CANEHIID, CIIIS A.-MO5,'30

Menmer l"tah siate Med As.sn.

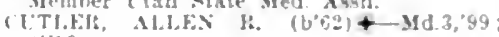
(1" 93$)$.

rimery, viuy rlinord (b'it) - Colo.2,04

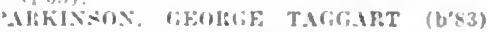

-I'a.11,'10; (I'10)

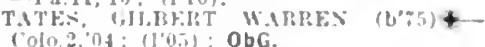

(olo.2,01; (1'0.i): ObG.

PRIEST RIVER, 248, BONNER

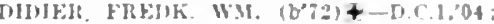
(l'I).

Llsle, IIoward cochran (b':, - 0.41,10

Mcr'arty, Elba Denton (b'is)-Mlch.1,03: (1'10).

PRINCETON, 200, LATAH

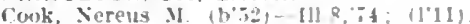

RATHDRUM, 725, KOOTENAI

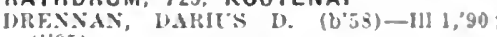
(1'05).

Wenz, Frank (t'63)-Mlch.:'89; (1'90).

REUBENS, 100 , LEWIS

(arlisle, (has. H - 111.1, his: (1'99)

lialgnard, lieo. (b'b)-I11 13,01; (1'03).

REXBURG, 1.893, FREMONT

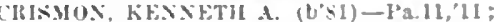

(1'12): S.

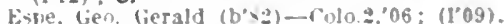

Ileine, Thumpon (i. (b'6)-MInn.3,'ss:

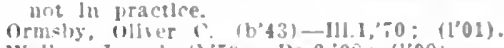

Walker, Joseph (b':y)-I'a.2,05: (l'09).

RICHFIELD, I58, LINCOLN

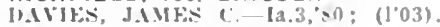

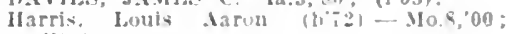
(1'(1:3).

RIGBY, 555, FREMONT

ANHEKSOX, HYRAM AYDREW (b'GS)-

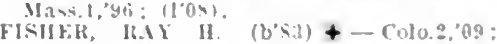
(1'0)

Palmer, Mlped Merle (b'si)-Colva, 11 : (11)

l'arton, dialen (". (b"it)-K5.4, 83 ; (1'08),

ROBERTS. 192, FREMONT

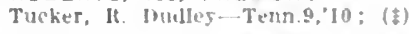

ROCK CREEK, 175, TWIN FALLS

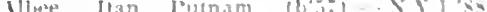

ROCKLAND. 350. POWER

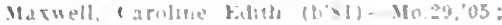

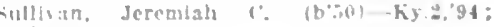

ROSE BERRY, 150, BOISE

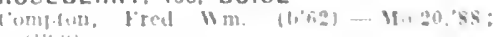

ROSELAKE, - KOOTENAI

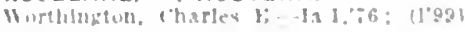

FOSSFORK (R.F.D., FT. HALL), 1,100. BINGHAM

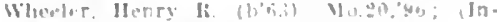

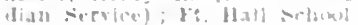

RUPERT, 297. MINDOKA

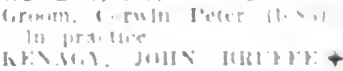

(1100)

RUSSELL, 50, LEWIS

Shrinles. WIM th (1, S

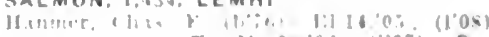

4h

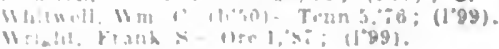




\section{SANDPOINT, 2,993, BONNER}

Jackion, Ihoscoe Neoly (b'56)-N.Y.8, 80 : (l'11); G.

Mckinnon, Malcolm (b'bi)-0nt.3, 4h: (1'06).

Page, Unes k. (b'6z)-Mo.2i,97; (l'99)

Jatterson, Eidw. B. (J)'5s)-ilich.1, sio; $\left(l^{\prime} 0 s\right)$.

stackhouse, Chas, I'. (b'71)-Pis.1l'ts; (I'09); S.

SHELLEY, 537, BINGHAM

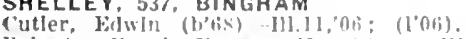

Itoberts, Frank Eiblene Kin.3, $013:(112)$.

SHOSHONE, I,I55, LINCOLN

Baugl, Horace (ireeley, (1,73)-Mo.28, (198; (I'lu).

Baugh, Wm. Henry- Io.2.9I; (1'99).

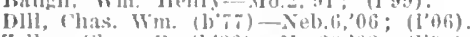

Zeller. (has. F. (b's0)-Wo.20,'03); (l'0y).

SILVER CITY, 400, OWYHEE

S('luster, Wilfrid H. (b'Js) - III.Il,'sis (1')9).

SODA SPRINGS, 501, BANNOCK

Anderson, W'm. II. (b'35)-O: (1'99)

linekley, Ellis-Tenn,6,98; (1'99).

SOLDIER, 266, BLAINE

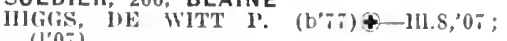
(l'0\%).

SOUTHWICK, 200, NEZ PERCE

Busey, Chas. (b'39)-Ky.1,'92, l'a.2,'93; (l'99).

SPIRIT LAKE, 907, KOOTENAI

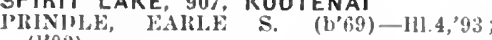
$\left(1^{\prime} 02\right)$.

Woods, Tubert B.-Ont.I, 0\%; (I'II).

ST. ANTHONY, 1,238, FREMONT

Boucher, Francis Emerwon (b'8.5)-Mo.34. '09; (l'13)

Eby, John Hobt. (b'68)-MMlun.4,'93; (1'12). Ioilis, Jesse I.-Ky.2,'9I ; (1'99).

Malotte, Karl Raymond (b'87)-111.6,'10 (I'12).

Morefleld, Allert (b'77)-Mo.34,02 ; (1'12).

West, Warren B.-Mo.1,'97; (I'99)

ST. MARIES, 869, KOOTENAI

Bennett, Walter S.-Ky. 1, 05 ; (

Cornwall, Ielos E. (b's3)-IIl.1,07; (1'09)

Gelir, Adolph G. (b'sI)-Ill.22,'0s; (1'09).

hinsolving, ('has. Johnson (b'75)-Va.6,04; (l'0s).

Leete, Herbert Nelson (b'74)-111.1,04; ( ).

Plutt, Owen I). (b'75)-Neb.5,03; (1'j0)

Smlth, Chas. 13. (b'iz)--111.11,95; (\$).

STAR, 300, ADA

Hall, Orvis I. Wm. (b'62) - Vt.2,'83; (l'99) ob.
STARKEY, 50, ADAMS

Starkey, lif(d)ard $\$$. (b'66)-Pa.2,'95; not in firatice.

STERL!NG, 75, BINGHAM

Jump, HeUry It. (J)'72)-111.6,02; (I'03).

SUGAR, 391, FREMONT

silupe, James 11. (b'79)-Mo.28, 07 ; (1'I0).

SUNNYSIDE, 20, ELMORE

Wood, Marshull W. (b'46)--H1.1,;3; (1'99);

t.leut. fol., IX.S.A., retired.

S.YYET, 150, BOISE

Sikipen, Alfred (b'59)-Ont.2,'92; (1'99).

TREFFRY, - KOOTENAI

(iarl. Ernestlue J. Hicks (b'59) - Mich.l,'s9; not in practice.

TROY, 543, LATAH

OLAON, JOHN W. (b'74) 4 -Mmn.4,00 $(100)$.

TWIN FALLS, 5,258, TWIN FALLS

ALEXANUEI, IUNCAN LORNE-Mleh.l, 03; (l'10).

Boyd, Truman Osborne (b'68)-Ky.2,02 ; (1'03); $\mathrm{S}$.

I,I CHANAN, J. ROH'T. (b'45)-Mo.2,72; retired; Member Mo. State Med. Assn.

('AlDWELI, GFO. II. (b'74) 4 -Mich.1,03: (I'13); Nember N, I). State Med. Assn. OALR:

(louchek, Ilenry Walker (b'i 00 ; ( l'03)

('oughilin, Jolın Francls (b'84)-.Md.4,'08; (1'10); S.

Medtee, James D. (b'44)-Ky.4, $\$ 2$; (l'99). Morgan, John R. (b'73)-111.6,07; (1'06).

I'ike, Walter Franklln $\left(b^{\prime}, 7\right)-C o l o .5,03$; (1'04).

s('OTT, CHAS. R. (b'78)\$-111.6, 00 ; $\left(\mathrm{l}^{\prime} 10\right)$; G.

stearns, Moses (b'62)-Mlo.1,99; (1'07).

Wallace. Wilson E. (b'63)-Mo.j0.92; ( ).

WHAYER, CHAS. DAVID (b'68)\&-Colo.2, $97 ;(1 ' 08)$.

IVlulte, John Edward (b'5s) - Mich.1,82; (l'13) ; T.

HIHESWORTII, TANDY (b;4)-0.1,00 not in practice; Member Nebraska State Med. Asill. Wilson, Hubert W. (b'70)-Mich.1,92; (104); $\mathrm{S}$.

VANWYCK, 279, BOISE

Yoggle, Geo. Elliott-Kan.3,'95; (I’08).

VICTOR, 200, FREMONT

KING, IHOBT. WASHINGTON (b'71) Colo.2,'12; () ; Nember Colo. State Iled soe.; G.
VOLLMER, 332, LEWIS

Burke, Kdw. Iawrence-111.11,00; (1'02).

WALLACE, 3,000, SHOSHONE

13.AND, CL'l'TIS (b'73) \$-Ind.8, 05 ; (1'13);

Member Mont. State Med. Assn.
HANSON, MEONARD EDWIN (b'79)€I'a.I,08; (l'08).

Nowery, (has. R.-Neb.6,02; (1'03); $\mathrm{s}$.

Nowery, Il e r bert C. (b'78)-Néb.6,07; (1'08).

Qulfley, Francls Jeo (b'78)-D.C.2,04; (I'06)

SMITI, MAX TIUMAN (b'82) (-Pa.2,06; ( 1 '10).

St. Jean, J. Eugene Serres (b'75)-Que.3, 96:; (]'99).

Stole, C. S.-Ky.4,83; (1'99).

WARDNER, 1,369, SHOSHONE

IASON, TITACY IHICHARDSON (b'74) $9-$ Ho.10,98, 111.8, 05; (1'99); (also oftle, Kellog(t).

WEISER, 2,600, WASHINGTON

Anderson, Edouard T. (b'68) - Ore.1, 98 ; (1'99): S.

('onant, Carroll C. (b'86)-Mlch.7, 07 ; (l'09) .

WDLEY, STOWELL, B. (b'66)-Mlch. 1,97 ; (1'10).

Finney, Frnest orion (b'79)-nl.11, 06 ;

Hamilton, Whlliam R. (b'66)-Ont.4,'92; (1'99); Pres, State Board of Health.

Mitchell, John Danlel (b'53)-N.Y.5,'76; not in practice.

In practice.

Nurphy, Archibald-Mo.20,'92; (I'07)

SHIILLY, CHARLES B. (b'48)-D.C.3,'79; (1'99).

Waterhouse, Geo. M. (b'60)-0.2,85, Mo.28, 99 ; (1'99); not in practlee.

loung, James Aurelius $\left(b^{\prime} 78\right)-111.11,03$; (1'04).

WENDELL, 482, GOODING

lamb, IIenry E.-Neb.6,06; (l'09)

SIIVERTHORN, JOHN RÓ $\left(\mathrm{b}^{\prime} ; 8\right)-\mathrm{Ky} .5$, 01; (I'09).

WESTON, 398, FRANKLIN

Qulck, Joy Woodney (b'75)-MIlch.1,04; (1'05).

WHITE BIRD, 400, IDAHO

Foskett, Wilson A. (b'70)-Ill.1,97; (1'99).

WILLOLA (AGATHA P.O.), - NEZ PERCE

Ilunt, Sylvester P. (b'43) $\longrightarrow$; (l'99).

WINCHESTER, 450, LEWIS

Melaughlin, Jerome E. (b'71)-Mhnn.4,'06 ; (l'06).

logers, Elton Bane (b'77)-Ill.6,07; $\left(l^{\prime} 10\right)$; $\mathrm{s}$.

FOR KEY TO SPECIALTIES, ABBREVIATIONS, SYMROLS, ETC., SEE PAGE 365

The Physicians' Purchasing Index (see page 12) is a ready reference guide to things in which the physician is interested. 


\section{L L I NOIS}

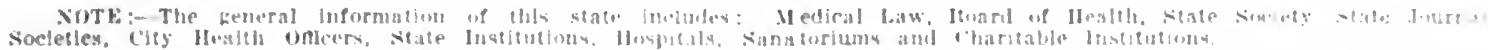

\section{ILLINOIS}

Population (1910 census) ....... $5,638,591$

Number of Counties............... 102

Number of Physicians.

10.286

Members State Socioty. Dec. 31. 1913.

Area of State in Square Miles.... 56,665

\section{MEDICAL PRACTICE LAW OF ILLINDIS}

\section{An Act}

To Regulate the I'ractice of Medicine In the siate of Illinols, and to IRtpeil an AC

Thereln Named, Approred Ipr!! 24. 1899. As Amended by Irts Ap. proved June $f, 1907$, Janu-

ary 25,1908 and $y 35$ 29,1911

Section 1. ORGANIZATION : NI DLTIES OF STATE BOARI) OF HKALTH: He enacted by the people of the state of Illlnots. represented In the fieneral Isienbly: That the state Board of Ilealth shall organize within three motiths after the shassage of this Wct; It shall procure a seal and shall rccelve Act: It shall procure a seal and shall recelve through lis secretary applications for certificates and examinatlons. The presidens and secretary shall hare the authority to admInlster oaths, and the hoard to take tes-

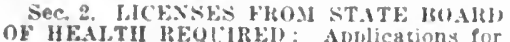
OF HF.A.TII REQLIREI): Applications for Llcense; Faminations : firaduates of Legally Chartered Medlcal colleges In lllimola in person shall bereafter hetin the liraction of medlclne or any of the braltches thereut or midwifers, in thls state without first alulyIng for and obtalning a llcense from blit State loard of IIealth to do so. Application shall be in wrlting, and shall be acrim. uanied by tho examinaton foes hereinufter specifled, and with proof that the appllcant is of gool moral character. Anplicatlons from candidates who desire to practlce medi
clne and surgery in all their branches shall be accompanter by proof that the abplicant Is a graduase of a med!cal collegt ar inst. tution In gocel standing, as mas" loe determined by the board. When the abplication aforesald has been inswected loy the buard and found to comply with the foregulng proviston, the imard shall notlfy the alubli. cant to apvear thefure is for evamination, at cant tu apvear teefore it for evamination, at

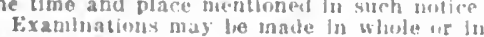
part in wrlting by the besard, altel shall be if a character suntelently atrice to test the

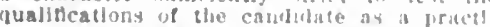
tloner. The examinaton of tluse who devire to practlce medlcine and surgery in all their branches shall cubrace those fenern! sulp.

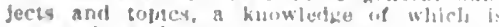
commonls and generally recpulreal of cambli. dates for the degree of doctor of inedirine by revulahle merficial collegen in the linited states The examination of shose who thasul bo prietice mlinifery yhall the of such a character as is deterintue the qualliteations of the apolicant in practice mldwifery. Tlu cxamliation of thoso who destre ti pracilc ally wher astens or sciesses of irentong liuinan ailmente who do not use medlorbses Internally of exterliblly, und whe do nith

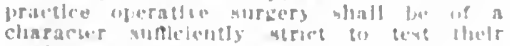
claparbor subleishely struet to tevt thelr

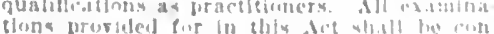
ducterl under robley and regulathons bro acribed hy tha lwarel, wheds whall burulde for a fair and wholly lmoartal mothml of

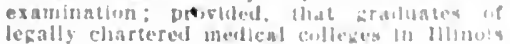

in find standing as may the determined 1,y llie bearif. maly he gramed certificales withmot "xaminations. (IN84.)

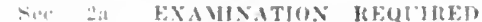

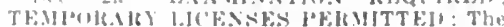
stale Buarl uf Jlealth shald require that rsory abulicans for a license on prantice mpdicine and surkery in all their hranclies. In the state of Illinois (excepting only those physarians who may he entitled to ta license under seethon $3 a$ of the act on which this Act is an umendinent) sliall present pronf satisfactory to sald loard that he is al graduate of a medicai college in gumbl standing. as mug the determineyl by the state diand of Healti, and bass, lofore said lmarit at Healti, and bass, loefore said luard, an fects and topics, a knowledge of which is fects and topics, a knowledge of which is
commony and generally reguired of candi dates for the degree of ductor of mellicine by reputalle niedical colleges in the linlou States; J'rovlded. that the state lioard of Healu may. In Its discretlon, admlt to $\mathrm{cx}-$ amination a student who has completed. in a inedleal college determined in trmal standing. the course if instruction reifuireal by ine rules of sald hoard in mellicil colleges delernined in gond standing. and wlin has passed the examination of sid college, bu has nut receired a diploma: l'rovlded, fur. ther, that the sald medical cullege shall

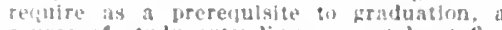
churse of study cxtending over at least ilve calendar years. Ant If said student pass the examituation of the salid lmard it may lssue (1) him a limiterl license atuhorizing hill to practice medieme and surgery in a bospital

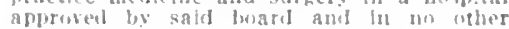

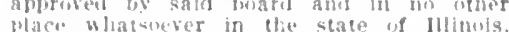
Hace Hatweber in tire state of Imimos,

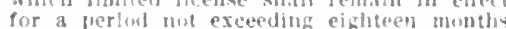

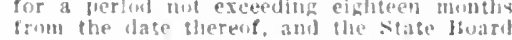
of Health may then fistue bo the asulican the regular fiemanemb license of the tinar without further examination or fee, on culldition that the anplicant prenent a diplonit from the medical college in whel he hat ruleg of the said board, prerious (1) the issuance of the limited license hereinbefore

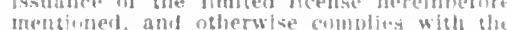
Iftmtined, and otherwhe complites with the poptirements of the lward and with the provisions of the art to
an antmelment. (1:3)

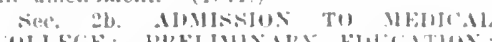

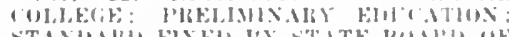

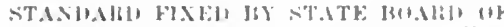

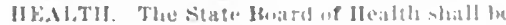

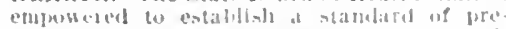

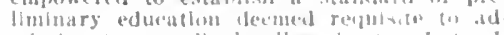

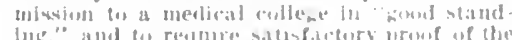

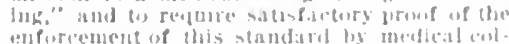

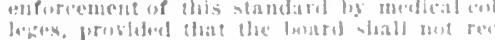

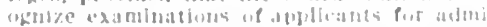

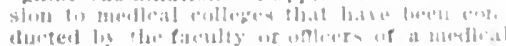

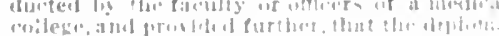

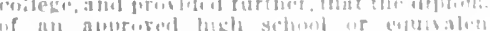

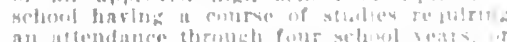

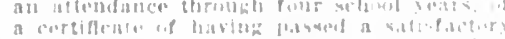

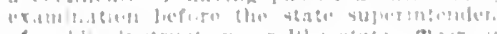

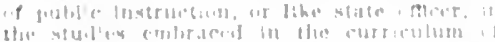

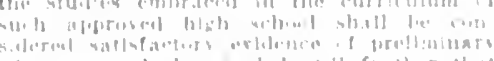

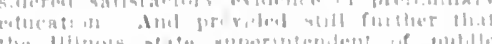

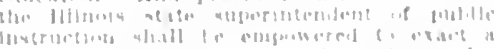

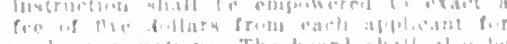

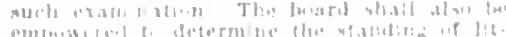

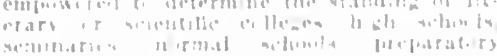

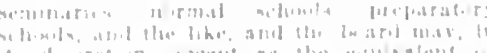

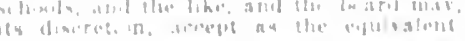

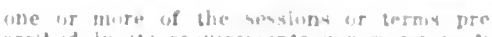

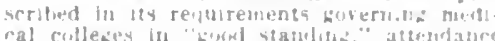

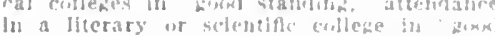
stinding." as evldenced loy a dogree fr in alal Instieution. brubling that the stand.

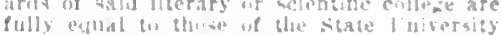
fully equal to those
of Jllingis. (lone)

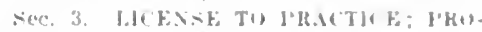

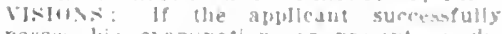
nasses his eximumation, or proments a da.

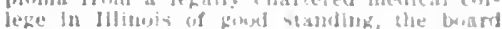

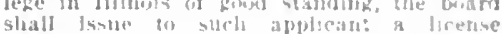

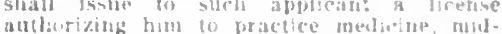

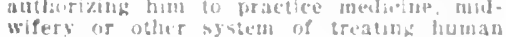
wifers (1) other system of treatmo human those who are authorized iol practice ither ststems cannob use mudicine moertally or externally or berform surzical ofreratiuds: wrovided. further, that only those whor are uuthorized to practice medleine and surbery In all their branches shall call or adrertise thenselves as plystcians or doctors; and previded, further, that those who are authorized to practice inidwifery shall not use any druz or nuedicine or atimul other than cases of labor. sidels license thall be in such furm at may be determinest ly the buard, and in aceurdance with the provisions of this lat: provited, howerer. that any wilful ritalation un the part of an applicaus of any of the rules and rezulations of the labard. gorerulng examinatong shall be sutheient cause or the anjlicant. Such certifiate shalf te simed bis all meminers of the Jusral and attestad biy all me secretary. (1sit?)

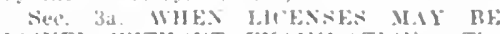
ISEIF.I WITIUIT FEIMISATIOS: The

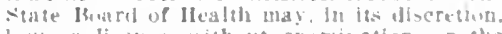

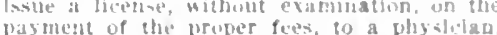
who is a graluate of a nuelival coblene in

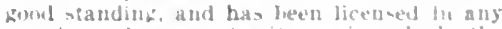
collutry, slate ur cerribrs in which the requiremeniy of medical recintration sre deened by the state hoard of Ilealal to hare

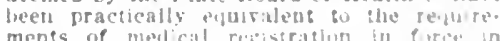
ments of medlial reibistratlon fin fure in Hllinwis. under the provtsing of the and bo

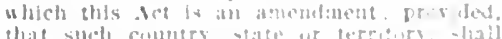

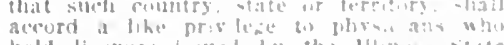

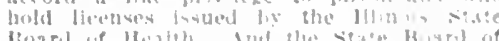

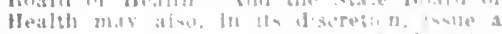

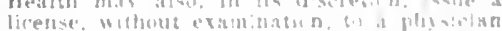

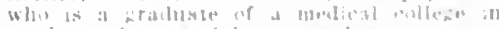

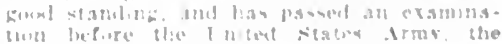

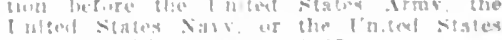

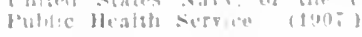

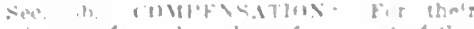

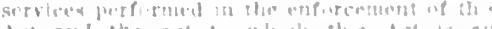

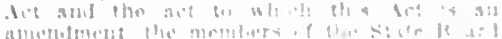
of

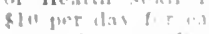

piant

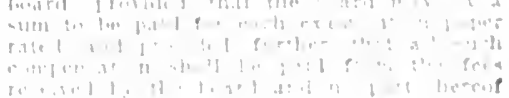

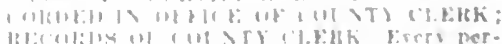

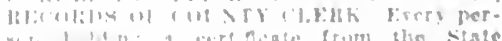

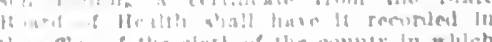

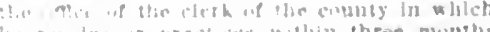

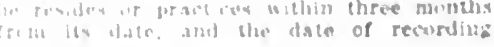


shall be endersed thereon. Until such certitleate is recorded as herein provided, the holder thereof shatl not exercise any of the rights or privileges conferred therein. Any person practicing ln another county shail record the certitleate in tike manner in the record the certitleate in like manner hin the county in which he practices. and the holuer clerk the usual fee for maklng the record. clerk the usial fee for making the record. The county clerk shali kerp. In a book pro-
veded for the purnose. a complete list of the veded for the jurpose. a complete list of the certibleates recorded ty him, with the date
of the fssue of the certitloate. The reglster of the county clerk shall be open to public inspection during business hours. (1899.)

Sec. 5. EXAMNATION FEES: The fees for examtuation and for a certifleate shall be as follows: Ten dollars for examination in medielne and surgery, and flve dollars for a certitleate if issued. Flre dollars for an examination in midwifery. and three dollars for a certificate if issued. For all other practitioners ten dollars for an examinathon and five dollars for a certifieate if Issued. (1899.)

See. 6. UNI'ROFESSIONAI OR DISIIONORABLE CONDUCT: BOARD MAT WITHHOLD OR REVOKE CER'TIFICATES; HEARING: The state Board of IJealth may repuse to issue the certificates provicled for In this Aet to Individuals who have been convieted of the practice of erininat abortion, or who have by false or fraudulent representation obtained or sourtht to obtain practice in their profession or lyy false or practlee in their profession, or hy false or have obtained or sought to obtain money or have obtainedich or sought to obtain money or sny other thing of value, or wino adrertise and other unprofessional or dishomorable conluct, and the board may revoke sueh certiflcates for like eauses; prorided, that no certiflcate shall be revoked or refused until the holder or applicant shall be given a hearing before the board. (1899.)

See. 7 . DEFINITION OF TIIIS ACT: Any person shall be regarded as practicing medicine, within the meaning of this Aet, who shall treat or profess to treat, operate on or prescribe for any physical ailment or any physical injury to or deformity of another be construed to apply to the administration of domestie or family remedies in cases of emergency, or to the laws regulating the practice of dentistry or of pharmacy. this Aet shall not apply to surmacy. And this Aet shall not apply to surgeons of the Service in the discharge of their official duties, or to any person who ministers to or treats the sick or suffering by mental or spirltual means, without the use of any drug or material remedy. (1899.)

Sec. 8. ITINERANT VENDORS : LICENSE PENALTIES: Deelared unconstitutional by

See, 9. PENALTY FOR PRACTICING WITHOUT LICENSE: Any person practicing medicine or surgery or treating human allments in the state without a certificate issued by this board in eomplianee a certificate provisious of this Act, or any itinerant rendor riolating the provisions of Section 8 of this Act, shatl for each and erery instance of such practice or violation forfeit and pay to the people of the state of Illinois, for the use of the said Board of Health, the sum of $\$ 100$ for the first offense and $\$ 200$ for each subsequent offense, the same to be recovered in an aetion of debt before any court of competent jurisdiction, and any person filing or attempting to fle as his own the diploma or certifleate of another, or a forged affidavit of identifieation, shall be guilty of a felony and on convietion shall be subject to such fine and imprisonment as are made and provided by the statutes of the state for a crime of forgery; provided, that this seetion shali not apply to physieians who hold unrevoked certificates from the State Board of Ilealth issued prior to the time of the taking effect of this Aet. (1899.)

10. ENFORCING PENALTIES; APPEIIS: Tpon conriction of either of the offenses mentioned in this Aet the cour shall, as a part of the judgment, order that the defendant be committed to the common are paid, and upon failure to pay the same
Immediately the defendant shall be committerl uniler said orier for tie first offense not more tinan thirty days, and for each sulveruent offense not more than ninety clays; provided, that either party may appeal in the same time and manner as appeals may be taken in other cases, except that where an appeal is prased in behalf of the peovle no apteal bolus shitl be required to be flled whellier the appeat be from the justlec of Whether the appeat be from the justlec of the peace or from the enunty or circult hall be suffleient in behate of the people, of the state of Jillnois, for the use of the state Board of Ilealth, to pray an appeal and thereupon alpeal may be had without hond or security. (1899.)

See. II. JUALD TO MAKE REPORT OF PlioceEIINGS: On the 30 th day of September of each rear, the State Board of Ifealth slall make a report showing all Items of recelpts from all sources and disbursements for all purposes, and all expenses incurred by the memlers of sald board, excent attorney fees, in the enforeement of the act, to which this Act is an amendment, and all compensation provided for therein to said members may be paid out of the state treasury on appropriation being made therefor by the general assembly. (1911.)

Sec. 12. REPEAL: An act to regulate the practice of medicine in the state of July 1, is 7 , and all other acts and parts July 1, 1887, and all other acts and parts repealed. (1899.)

\section{STATE BOARD OF HEALTH}

tohn A. Rolison, President, Chleago; A. Swajkart, Chicago; R. D. Luster, Granite City; T. O. Freeman, Mattoon; James J. mond: Mr. Amos Sawyer, Acting Secretary, springfleld.

\section{ILLINOIS STATE MEDICAL SOCIETY Officers 1913-14}

Charles J. Whalen, President...... Chicago A. L. Brittin, President-Elect.............. S. M. Miller, 1st Vice-President......Peoria D. F. Smith, 2d Vice-l'resident..... Freenort W. I. Gilmore, Seeretary ............ Vernon
A. J. Markley, Treasurer...........

\section{State Journal}

Illinois Medical Journal, Chicago. Dr. Henry G. Ohls, managing editor.

\section{Councilor Distriets and Offieers}

First Distriet.-To Daviess, Carroll, Ogle, Steplenson. De Kalb. Bonne, McHenry, Kane and Winnebago co

Seennd District-Wandford Ijivingston, Grundy, Kendall, 4 a Salle, Bureau, Whiteside, Iee, Putnam and Marshall counties. J. A. Marshall, Councilor, Pontiac.

Third District.-Iake, Cnok. Dis Page. Will and Kankakee counties. C. D. Penee, Councilor, rhicago.

Fnurth District.-Sehurler, Stark, MeDonough, Fulton, Hancock, Henderson, Warren, Knox, Penria, Henry, Mereer and Rock Island counties. August H. Arp, Councilor, Moline

Fifth District.-Sangamon, Menard, Mason, Logan, Tazewell, MeLean, De Witt, Ford and lronuois counties. J. W. Smith, Councilor, Bloomington.

Sixth Distriet-Madison, Jersey, Macoupin, Greene. Morgan, Scott, Cass, Brown, Pike. Adams and Calhoun counties. C. E. Black, Councilor, Jacksonville.

Seventh Distriet. Piatt, Macon, Christian, Moultrie. Shelby, Montgomery, Bond. Fayette, Effingham, clinton, Marion and Clay ette, Eunties. 0 . Coane, councilor Carlve. Eighth District.-Champaign, Vermilion, pouglas, Edgar, Coles, Clark, Cumberland, Jasper, Crawford, Richland and I,awrence countles. E. B. Conley, Councllor, Danrille.

Ninth District.-St. Clair, Monroe, Randolph, Washington, Perry, Jackson, Union,
Alexander, I'ulaski, Jefferson, Franklin, Williamson, Johnson, Massac, Pope, Saline, Ilamilton, Wayne, Hardin, Gallatin, White,
Elwards and wabash countles. Frank C. sibley, Councllor, Carmi.

\section{Component County Societies} AlMAS COUNTY KIrk Shawgo, P'resiclent........... Quincy
Ellzabeth Ball, Secretary......... Quincy ALEXANOER COUNTY

Samuel Dodits, J'restdent............Cairo James w. Dunn, Secretary...................... BOND COUNTY

E. A. Glasgow, I'resldent....Mulberry Grove
D. T. Brown, Secretay.......Mulberry Grove BOONE COUNTY

Aldin Alguire, I'resident......... Belrldere H. E. Delavergne, seeretary........... Belvldere BROWN COUNTY

D. W. Owens, President...........Mersman BUREAU COUNTY

F. B. Schroeder, l'resident.......Prineeton iI. H. Blackburn, Seeretary.........Princeton CALHOUN COUNTY

W. A. Skeel, President......... Kampsvllle J. II. Peisker, Secretary............. Hardin CARROLL COUNTY

Feison Rinedollar, President.....Mt. Carroll

II. S. Metcalf, Secretary............t. Carroll CASS COUNTY

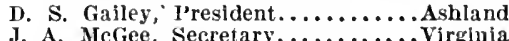
CHAMPAIGN COUNTY

T. J. Exton, Yresldent......... Thomosboro Wm. V. Seeker, Seeretary.......... Champaign CHICAGO MEDICAL SOCIETY COOK COUNTY

C. P. Caldwell, President.......... Chicago Chas. H. Parkes, Secretary.............. Chicago CIIRISTIAN COUNTY D. K. Cornell, President......... Taylorville
D. D. Barr, Seeretary........ Taylorville CLARK COUNTY

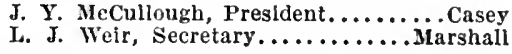
CLAY COUNTY

E. C. Park, Jr., President........... Flora
C. H. Holaday, Secretary.......... Flora CLINTON COUNTY

John Q. Roane, President...........Carlyle Leonard Niess, Seeretary............ Trenton COLES COUNTY

G. B. Dudley, President......... Charleston Gertrude Transeau, Seeretary.... Charleston COOK COUNTY

(Included in Chicago Medical Society.) CRAIVFORD COUNTY J. A. Ikemire, President...........Palestine CUMBERLAND COUNTY

N. J. Haughton, President..........Greenup

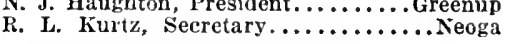
DEKALB COUNTY J. M. Everett, President........... Dekalb
Harry G. Wright, Secretary........ Dekalb DE WITT COUNTY Joseph C. Myers, President......... Clinton
C. W. Carter, Secretary.......... Clinton DOUGLAS COUNTY

Philip Herrin, President....... Villa Grove Walter C. Blaine, Secretary.........Tuscola DUPAGE COUNTY

(Included in Chicago Medical Society.) EDGAR COUNTY

W. S. Jones, President............Redmon

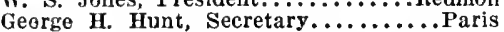
EDWARDS COUNTY

W. E. Buxton, Secretary......... IVest Salem EFFINGHAM COUNTY

E. A. Bing, President...........Altamont FAYETTE COUNTY

A. R. MeReynolds, President.........Vera Chas. H. Eldridge, Secretary............. Elmo 


\section{FORD COUNTI}

(Included in Iroguols-Ford Counts Medtcal Soclety.

FRANKLIS COUNTY

B. F. Brayfeld. I'resldent...... Chrlstopher Edgar Austin. Secretary............. Beriton FULTON COUNTY

I. I. Beatty, Presldent........... Fintrview

D. S. Ray, Secretary. GALI.ATIN COUNTY

J. W. Bowling. Iresident..... Shawneetown

A. B. Capel, Secretary......... Shawneetown GREENF COUNTY

F. x. McLaren, President........Whitehall ii. A. Chapln, Secretars........... Whitsehall GRUNDY COUNTY Chas. AlIson, President... South Whmington
W. E. Walsh, Secretary................ HAMULON COUNTY

M. C. Dale, I'resldent.........McLennsboro I. M. Asbury, Secretary........McLeansboro HANCOCK COUNTY

J. T. Jenkins, Presldennt.......... Carthage IARDIS COLNTY

W. J. J. Parls, Presldent........... Rosiclare R. If. Wulngham. Secretary... Elizabethtown HENDERSON COLNTY

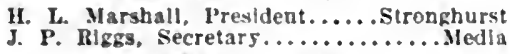
IIENRY COENTY

J. Gustafson, Presldent........... Orlon G. II. Homman, Secretary............. Kewance IROQUOIS-FORD COUNTY

N. T. Sterens, I'resildent............ Cllfton

b. W. Mller, Secretary............Gllman JACKSON COUNTY

J. W. Barrow, Presfdent.......... Carbondale

J. H. Hrablk, Secretary.......... ilurphysboro JASIER COUNTY

W. E. Franke, l'resldent............ Jewton II. J. Schmltt, Secretary.................. JEFFERSON COENTY

W. II. Gllmore, Fresident............ Vernon
C. J. Poole, Secretary............ Vernon JERSFY COUNTY A. K. Van Horne, I'resldent...... Jerseyrllle
A. M. Chenes, Secretary........ Jerseyrllle Jo DAVIESS COC'NTY

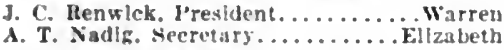
JOIINSON COUNTY

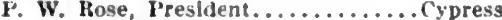

ii. J. Elkins, Secretary................. v tenna KANE COLNTY

R. G. Scott, Presldent.............. Geneva

A. Diller, Secretary............. Aurura KANKAKEE COUNTY

C. II. Leo, Prestdent............Kankakee

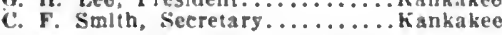
KENIDLL COLNTY

V. Ik. Frazler, I'resldent........ Yorkvllle hinuj Ilartnack, secretary.............. KNox COLNTY

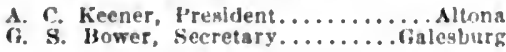
LAKE COUNTY

w. S. Bellows, I'resldent.........Waukegan

W. C. Bouton, Secretary........Waukegan IA SALLE COUNTY

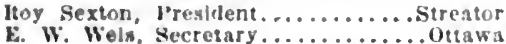
HAWR:NCE COLNTY

J. It. Itrlan. I'resldent........t. Frubelsvilto J. I3. Ifryant, Secrebary. . . . . Iaburencestlle l.kt coting

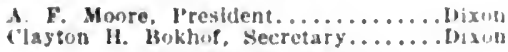
HISRISTON COLNT

B, F, Elfrink, l'resident............'llenoil Jolin Ross, Secretnry.............. Lunsiac LOt:AN (OOUTY

W. W. Coleman, I'rosident...

11 s. ovler vecretary MACON COLNT

d. x. Iandall. brealdeut.......... becntur c. F. Illdreth, secrotary.......... llecatur
MACOLPIN COLNTI

Thomas II IInH, Presldett........ Gillesple Chas. D. King. Secretary............. Gullesple MIISON COUNTY

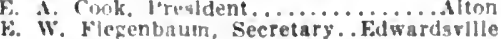
MaImox colisy

W. W. Murnn. I'resident........... Iatoka

E. C. Alrls, secretary................... MAJSH.ML-PUTSAM COUXTY

Macclarey Weeks, I'resldent......Giranville E. S. Glllesple, Secretary.......... Wenona MASON COLNTY IV. O. Regler, Jresident.......... Tason Clty IISSAC COUNTY

I. 11. Jacobs, Iresldent........... QuIncy MeMUNOLGII COUNT

Wm. W. Hentrlek, I'resldent...... Bardolph

J. Hider, secrotary............Bushnell MellF.NTY COUXTY

I1. I. Ifull, I'resident... North Crystal Lake

A. B. Smlth, Secretary.........Woodstock MCI.EAN COINTY

Whlfred H. Gardner, Presldent. Bloomington T. D. Cantrell, Secretars....... Hloomlngton MENARD COUNTT

Irving Newcomer, I'resident......Petersburg

o. P. Brittin, Secretary................ Athens MERCER COUXTY

R. I. Smlth, Presldent.......................... Wledo MONROE COUNTY

S. Kohlenback, l'resldent......... Columhla

L. Adelstwerger, Secretary............ Waterloo MONTGOMERY COUNTY

7. V. Klmball, l'resident.......... HIllshoro II. F, Bennett, Secretary...........Lltchfleld MORGAX COExTY

Albert J. Oiram. Presldent......Jacksonvllte Get). II. Stacy, Secretary.......Jacksonvllle IOULTHE COUNTY

W. P. Daridson, Iresident.......... Sulliran
Clarence W. Taylor, Secretary.... Isethany UCI. COINTY

R. E. Sterens, I'resldent......... Rocliello J. T. Kretsinger, secretary...........eal Hiver PEORIA COUNTY

F. M. Mlller, l'resldent............ Ollverla I'FHLI COUNT

Himer burch, Ireshlent......... Mu guoln Ifolla 0. Pupe. Secretary.......... Wu quoln IIATT COLNTY

W. G. McPherson, I'resldent......... I tement 13. J. Barker, Secretary............. Monticellu I'IKE; COUNTY

S. ß. Pescock, Preshlent..........Jittsfleld

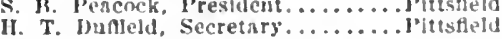
J'OI'F COLNT

J. W, lixon, l'resident..........Hartsville W. A. Sims secretary..............kosebud J'LASKI ('ITTY

1. F. Robinson, l'resklent...... J'LT:AM COLNT:

(Included in Marshall-Ibutuam County.) ITANOIJIH COUNT

w. A. James, Irestetent............. Chester L. J. Sumth. Secretary............... berey

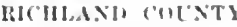

A. T. Telford, Preshlont........... they F. I1. Horner. Sectetary..............

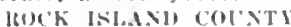

II. II. Snlvely, l'restdent, .....ltock lslan! IV. [D. Clapman, secretury............tists SAIIXE: UUT:

I. It. Empond, l'reoldent......... tinlatla

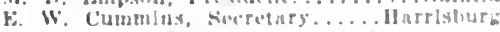

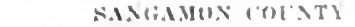

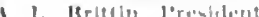

lethere

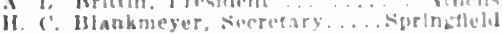

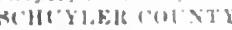

1. Wi. Itall, I'resletent.

J. S. Stulner. Sictetary Hetot in NT)

3. Hardin stounare, Mromblent. II. II Eletcher. Scertetary
SHring (in)

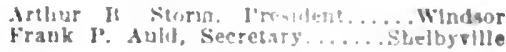
ST, CLAIR ('OT:NT)

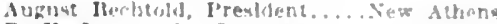
B. H. Portuondo, Secretary........ Bullerlihe STARK COLNTY

I. II. Llnker, l'resldent. . STEIIIE.STN COLNTY

F. K. Singelor. I'reslulent.

J. Sheldon Clark, Secretary.......... Freepum TAZEWELL COI:NT I

i. W. Fickler. I'reslicut.......... Delavan k. F. Kelchner, Secretary........... Delaran I'NIUN Cot:NTY

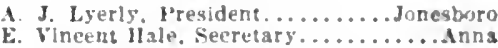
VRISMLION COUNTY

Frank if Mawn f'resident....... Rossville Solomon Jones, Sccresary......... Dapvllle W.AIBSII CUI:NT

Johu J. Melmosh, lrealdent......Mh rarmel J. B Uarwell, secretary. ....... Mth carmel WAHREX (OI:NT

J. F. McCutchan, I'resldent...........lexis ILarold M. Camp, Secretary......... Mnmouth WASHINTON COLNTI

If. Schmldt, Presldent...........Aldierllle P. B. Rabenneck, secretary........... Vashiville WAYNE COINTY

Francls Bean, l'restdent...........Falrfield o. F. Blakely, Secretary............... Firtleld WIITE COLNTI

Fells Long, J'resident. .............. Enfleld

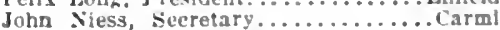
WIITESIDE COIXTY

11. 1. Pettit?, President. ............ Morrison r. J. Cunruy, secetary...........sterllng WILL COLNT:

Moysius J. Lennon, Iresident........Jollet Marion K. Bowles, Secretary............Jollet WI1.1.1 MSUN COLYTL

w. II Perr, Presldent..........Cartervlle J. G. I'armles, secretary................. WINAEBAGO COENTY

F. F. Ochsner. I'resldent......... Rockfurd Cart M. Ranseen, secretary........ Rockford WOODFORD COLNTY

F. K. Brlggs, I'resident.......... Runnoke i1. A. Mllard, Sceretary.................

\section{HEALTH OFFICERS IN CITIES OF 15,000} POPULATION AND OVER

Jlon................ Suphla Demuth

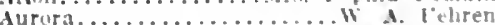

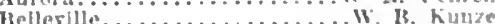
Itloomingtion

'niro..

cliteago.

lanville.

Decatur.

Fian st. Itolliv

Eldin.

Fivansiun

Freepert.

calesturaz.

Jachsolltill.

Jullat.

.1101!ne.

lak lark.

Penria.

Qutution

It whentid.

Ito.k Islanis.

siringllelel.

inthingelt

Jubn J. Fondon

Jubn S. Comoton

...W. Ii. li. loung

‥ 1. I.sndauer

.... I. It. Shuret

Me. Ndolf Flscher F. Balderstom julan ll liarelest vlew M himg ii. (i. schuesiler II Wessell. Jr Allert be sivelue iir. Vientre $h: 4$ la

Thumas 10 :

STATE INSTITUTIONS

Bosid of Administration

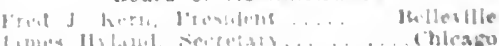

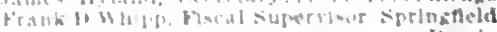

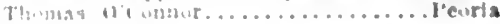
Anna

Imra State II balph I limpluer, uedical auperinsendes.t. 
Chicago

Hinois Charitable Eve nnd Enr Inflrm90.1 IV Adams St. Chlcago. EstabIlshed 1858; publle: 200 beds: Chas. T' (is rrarl, superintendent.

lllinots Industral IIome for the Bllnd Marshall Blvd. and 19 th St., Chleago. Establlslied I905; 80 beds; Wm. F. Sillultz superintendent.

\section{Dunning}

Chicago State Ilospltal, lounhing, 1II. Fstablished 1870; Insane: 2,700 heds Geo, Lubinger, M.It, ('hicago, superin tenclent.

EIgin

Figin State IIospltal, Elgin. Ill. EstabIlshed 1870 : for the Insaue: 1,700 beels kalph T. Ilinton, medical superintendent.

\section{Geneva}

State Tralnlng School for Girls, Genev a 111. Establlshed 1893: reformatory ; 512 beds; Clara Dumne, physlclan ln charge: Margaret II. Elllott, superlitendent.

Jacksonville

Illinols School for the Blind, Jacksonvlle. Ill. Established 1848; general; Geo F. Haxter, attending pliyslclan.

Illinols school for the Deaf, Jacksonville, Ill. Estnbllshed 1846 ; Geo. E. Baxter, attending physlclan.

Jacksonville State Hospital, 1201 s. Jaln St., Jacksonville, Ill. Established 1847; for the Insane: 1,715 beds: II B. Carriel, medical superlntendent.

Joliet

IIllnois Strte Penitentlary IIospltal.

Jollet, Ill. Established $1860 ; 40$ beds

J. $P$. Bensmı, physiclan in charge.

Kankakee

Kankakee State Hospital, Kankakee, III. Establlshed 1879; nervous and mental 3,200 beds; Patrick M. Liclly, physician In charge.

Lincoln

Lincoln State School and Colony, Lincoln, 111. Established 1865; . feeble minded; 1,700 beds in Instltutlon; Thomas II. Leonard, medical superintendent.

\section{Menard}

Chester State Hospltal for Insane, Menard, Ill Established 1891.220 lads Geo. K. Farrls, medieal superintendent, Southern Illinols Penitentiary Hospital, Menard, III.; 25 beds; II. C. Adderly, Chester, physician in charge.

Normal

Illinois Soldlers' Orphans' Ilome, Normal, III. Established 1865; general; 300 beds: J. K. l". Hawks (Bloomington) physician; C. W. Bassett, superintendent. Peoria

Peorla State Hospital, Terminal Station, Peorla, 11l. Established 1895; for the insane; 2,200 beds; George A. Zeller, medical superintendent.

Pontiae

Illinois State Reformatory, Pontiac, Ill. Extablished IS60; S0 beds In hospital James Kerrens, superintendent.

Quincy

Illinols Soldliers and Sailors' Home, Quiney, Ill. Established 1886; general; 381 beds; C. E. Ehle, physician in charge. St. Charles

St. Charles School for Boys Hospital St. Charles, Ill. Established 190s; general ; 20 beds; Chas. A. Potter, physician in charge.

\section{Watertown}

Watertown State Hospital, Watertown, Ill. Established 1898; for the insane: 1,510 heds; J. A. Campbell, medical superintendent.

Wilmington

Soldiers' Widows' Ilome of Illinois, Wilmington, Ill. Established 1895; 100 beds; Watson H. Curtis, physician in elarge.

\section{HOSPITALS, SANATORIUMS AND CHARI- Alton T'ABLE INSTITUTIONS}

Nt. Joierh's Hospital, Alton, Ill. Established noti.; fullic and private; 100 beds:
Amboy

Ambor IIospltal, Amboy, Ill. Established 1902) - 12 beds: T. F. Dornblaser and $\mathbf{1}$. A. Sulliran, physlelans in rlarge IIary I. Dornblaser, superintendent.

Anna

IIale Home sinnatorlum, 521 Maln St. Anna, 11l. Fstabllslied 1900; medical and surfical: 30 beds: J. I. IIale, physlcian In charge.

Argo

Argo General IIospltal, Argo, Ill. Fstablished 1912; 0. F. Scott, surgeon; Miss Marguret Tipsword, superintendent. Argo ILospltal, Argo. Ill. Kstablished 1911; lying-in: 30 beds; Mlss Rose Massoth, sumerintendent.

\section{Arlington Height} Fverpreens, Arllngton IIelghts, Ill. Es-
tabllshed 1902: private: 12 beds: Janet Gumn, physiclan in charge.

\section{Aurora}

Aurora IIospltal, Aurora, Ill. Establislıed 1Si6; general; 25 beds; Miss Jordan, superintendent.

Brightside Sanatorium, $299 \mathrm{~N}$. Lake St. Aurora, III Establlshed $190 \mathrm{~s}$; nerrous and elironic diseases; 6 beds; Garret $A$ Forton, physiclan In charge.

Old Ladles' IIome, 421, 5th St.. Aurora, III. Established 1895 ; general ; 10 beds : Nrs. Stepheu $\mathbf{P}$. Long, R.N., superintend ent.

St. Charles Hospital, Aurora, Ill. Established 1890; public; 60 beds; Franciscan Sisters, in charge.

St. Joseph Inflrmary, Aurora, Ill. Established 1911 ; private; 30 beds; Sisters of Mercy, in charge.

\section{Aviston}

Sacred Heart Hospital, Aviston. Ill. Establlslied 1905; private; 20 beds; Sisters of Charity, in cliarge.

\section{Batavia.}

Bellevue Place Sanitarium, Batavia, Ill. Established 1867; nerrous and mental diseases; 36 beds; F. H. Danlels, medical superintendent.

\section{Belleville}

Belleville City Hospital, Belleville, Ill. Established 1904; public; 40 beds; local board of liealth, In charge.

st. Clair County Farm and Hospital, Belleville, Ill. Established 1844; public: 225 beds; Frank Mandloch, superintendent.

St. Clair County Isolation Hospital, Belleville. 11l. Established 1901; public; 40 beds; Frank Mundloch, superintendent. St. Elizabeth's Hospital, Belleville, 111. Established 1880 ; private; 105 beds.

St. Vincent's Hospital and Old People's

Home, 2d and Race St.., Belleville, 111.

Established 1001; general; 100 beds.

\section{Belvidere}

St. Joseph's Hospital, Belvldere. 111. Established 1902 ; private;

Bloomington

Brokaw Hospital, Bloomington, Ill. Established 1895; pnblic; 100 beds; Miss L

J. Iustis, R.X., superintendent.

Kelso Sanitarium and Hospital, $807 \mathrm{~N}$. Main St., Bloomington, Ill. Established 1894: private; 25 beds; George B. Kelso, pliystcian in charge.

St. Joseph's Hospital, Jackson St. and Morris Ave., Bloomington, Ill. Established 1880 ; general; 150 beds; Sisters of St. Francis, in charge.

\section{Blue Island}

St. Francis' Hospital, Blue Island, Ill. Established $1905 ; 32$ beds; Sisters in charge.

Breose

St. Joseph's Hospital, Breese, III. Established 1899 ; general; 31 beds : Sisters of Charily, in charge.

Cairo

Bondurant Hospital, Cairo, 1ll. Established 1911; 40 beds; Alpheus A. Bondurant, physician in charge.

St. Mary's Infirmary, Cairo, Ill. Established $1865 ; 75$ beds; Sisters of the Holy Cross, in charge.

United States Marine Hospltal, Calro. 11l. Fstablished 1865; for seamen; 50 beds; Senlor Surgeon James M. Gassaway, III command.

\section{Canton}

Graham IJospltal, W. Walnut St., Canton, Ill. Establlshed 1909; general; 30 beds; F. W. Iteagan, M.D., president of staff; Harrlet C. ['eck, superlintendent.

\section{Carlinville}

Home llospital, Carlinville, IIl. Fstabllshed 1873; private; 10 beds; L. I. Corr, physictian in charge.

\section{Carlyle}

St. Mary's IIospital and Home for the Aged, Carlyle, 1ll. Establlshed 1911 ; publle; 25 beds; 1tev. J. B. Ilepenbrook, superintendent; Slsters of Charlty, in charge.

\section{Centralia}

Sit. Mary's Hospltal, Cenlralla, Ill. Establislied 1909; public: 40 beds.

\section{Champaign}

Battle Creek Sanjtarium, 611 University Ave., Champalgn, Ill. Fstablished 1906; 6 beds; Miss Amna Balding and Miss Inez Howel, In charge.

Julla F. Burnlanil Hospital, Champalgn, III. Establlshed 1895; general ; 65 beds : Miss Ella J. II atherly, superintendent.

\section{Charleston}

M. A. Montgomery Memorial Sanitarlum, Charleston, IIl. Established 1911; general 25 beds; Miss Francis Crabtree, R.N. superintendent.

\section{Chatsworth}

Chatsworth Hospital, Cliatsworth, Ill. Established 1902; general; 14 beds; 0 .J. Sloan, physician in charge.

\section{Chicago}

Alexlan Brothers' Hospital, 1200 Belden Ave. Chicago Established 1866; general 275 beds: Bro. Yeter Vesper, In charge.

American Hospital and Training School for Nurses, 2058 W. Monroe St., Chlcago. Established 1908; general; 75 beds; Max Thorek, surgeon-in-chlef.

Anule W. lourand IIospital of the Memorial Institute for Infectlons Dlseases. Wood and York Sts., Chicago. Established 1913 ; private; charity ; 50 beds; Charlotte Johnscu, R.N., superintendent.

Augustana IIospital, 2043 Cleveland Ave., Chicago. Established 1884; general 200 beds : A. J. Oclisner, M.D., chlef of staff: M1. Wahlstrom, superintendent

Bethel Hone for Convalescent Women and Children, 522 E. 33d Pl., Chicago. Established 1902; public; 25 beds; Mrs. W. A. Barron, superintendent.

Beulah Home and Maternity Hospital 2144 N. Clark St., Chicago. Established 1896 ; public; for erring girls; 50 beds; Wm. P. Goodsmith, physician; 0 . H. Richards, superintendent.

Bobemian Hospital 1333 S. California Are., Chicago. Established 1900; 10 beds : F. Formaneck, physician in charge.

Bohemian old People's Home and Orphan Asylum, 5061 N. 40th Ave., Chicago. Private, 40 beds; Elsa Blaska, superintendent.

Chicago Daily News Fresh-Air Fund Sanitarium for Sick Bables, foot of Fullerton Ave., Lincoln Park, Chlcago. Established 1856 ; day nursery and sanitarium. 200 beds; Mrs. Mary Gross Carrfleld superintendent.

Chicago Eye, Ear, Nose and Throat College and Hospital, 235 W. Washington St. Chicago. Established 1901 ; private; 60 beds; J. R. Hoffman, physician in charge. Chicago Foundlings' Home, $15 \mathrm{~S}$. Wood St., Chicago. Established 1871; general; i9' beds; C. A. Weirick and Harriette A. Howe, resident physicians; Frances C. Shlpman, superintendent. 
cribs: s. Josephino MeColium, house physlclan: Ftorence M. Stewart, superintendent. Chlcago llome for Incurables, 533.5 t:lll.s Are.. Chlcago. Kutabllshed 1890 ; prlsate 265 beds; F. D. Mltchell. superintendent. Chleago llome for Jewlsh Frlendless and Working (ilrts, 53.1 st and Fills Are. Chleago. Establishel 1901: Eeneral: 150 leds: May Michael. physician In cliarige: treds: May Michael, physiclan in

Chlcago Home for Jewloll Orphans, cizos Drexel Are.. Chlcago. Established 1s.4! private: 180 beds in dormitories, 20 beds in hospltal: May Michael, holise physl. clan : Leopold lleutelbaun. superintendent. Chlcazo Hone for the Friendless, 505: vincennes. Are. Chlcago. Histabtished 1859: ceneral: 400 beds: Ames $v$. Fuller. physinlan In charce: Anna Holbing, superintendent

Chleago Lomeopathle llospltal, ills. Wood SI.. Chlcagu. Established $1890^{\circ}$; pr! vate; 50 beds: Eleanor C. Gough, super. ntendent.

Chlcazo IIospital, 819 E. firh St., Chl. cago. Established 1892; general; 60 beds w. K. Mcl.aubhlin, M.i., superintendent. Chicago 1,ylng-In Ilospital and Diswensary. 1336 Tewberry Ire., Chlcago. Es. sary. 1336 Newberry Are, Chlcago, Es and Chas. S. Facon, chief obstetrlelans: and Chas. E. Kacon, chief obste

Chlcago Maternity IIospltal and TrainIng School, 231t S. Clark St., Chicato Fistablished 1897: naternlty: it heds Effa V. Darls, chlef medical ittendant.

Chlcago Municlual Tulerculosis santlartum, Bryn Mawr and N. foth Ares. Chlcago. Established 1912; tuberculosis 600 lieds: Theolore $B$. sachs, presldesu of medleal statf; Frank E. Wimg, genern! of medical stat

cuperinteudent. lum, 1932 Burling St., Chleagu. Estat. llshed 1865; private: 256 beds: $A$. C Soper, phrslclan in charge: Barbara Kebur, superjntendent.

Chlcago Orghan Asylum, 5120 South Park Are. C'nicago. Estahlished 184t public: 230 beds: Mrs. C. 11. Stocklng matron.

Chicago pasteur institule 81: $x$. Hear born si. Chleage. Fivtablivined 1xuti prliale: Antonfo lazorlo, medlcal director Chicago Pollellnic and Hospital, $2 t !$ w. Chlcago Are., Chicago. Establishe 1886 ; publlc ; 80 beds; J. W. Pease, nedt cal superintendent.

Chicago Kefuge for Girls, 5024 Indiana Are. Chlcago Estilulished isct: putilic 130 beds: Gay $K$. Durbin-lbles, physiclan 130 beds:

Chicago lest rottake, 4356 X. Kolle Are., Chleago. Fistaulishod 1901; for fallen women; 12 heds; Rer. J. Slewart Martin, superintendent.

Chleago Sunitarium, 410\% N. Arers Are Chleago Eutablished 1904 ; private; loco motior ataxia only: 10 beds: F. E. Itelchandt. physiclan in charige.

(hicago Tuberculosls Institute, Matlison and La salle sts. Chicate. irthur J. Strawson, In charge. The Fitwari sana-
torlum, Napervlte. Ilt., is a liranch.

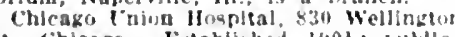
st. rhicago. Established 1:01; fuhle

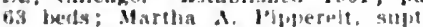
("hlldren's Memorial llomital, 735 Ful lerton Are. (hileagen, Established last ceneral; lis hesls; 13. M. Henderson. li.X wuperintendunt.

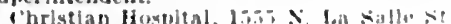

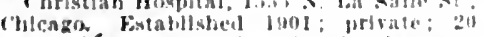

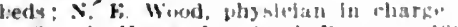

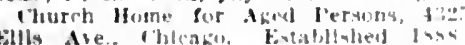

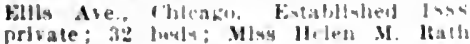
pone, sulertutondent.

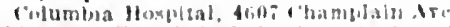

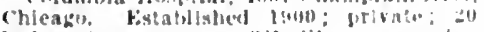

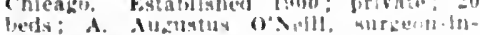

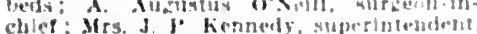

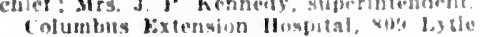

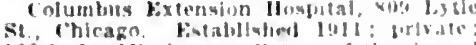
100 hedla : Misslonary sistcers of the sacted lieart of Jesus, In charke: bribull of Columbus lifuspital.

Colnmbus IIngulbal, 2600 l.ako View

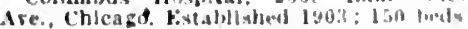
J. Hi. Murphy, surgenteln chlef: livviut ary slsters of the sacred lleart of Jestu. In claurbe: Polumbus Extens!on Hoxpital Is a bramel

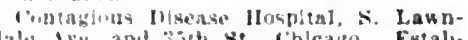

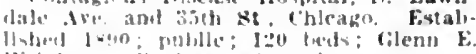

Writhe, nuedlent stujertutendent.

limk county letentlon llubital. Wimal

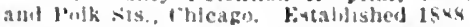
llerbus and mental: 65 bests: Haim lbaris, medical superintendent.

"imh couney Husplat, Woud and Harrl (b) sis. (hicago. Established 1866; gen eral; 1.6in beds: Wn. (1. I hayman, war

Conk county kinderhelm, Hilsseh anis 16 w well sis. rhicago. Estabilshed ly0s

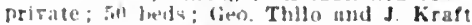
physiclins in charge; Hev. A. Schlechte sulverlotendent.

luabish latheran orphan Home. 2320 Erergreen Are. Chlcago. Fatabltslied

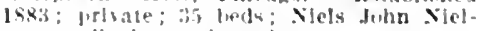
sen, metlleal superintendent.

liantsh loung I'tuple's llome, for $\mathrm{E}$ sith st., Chicago. r. sicheef, superintendent.

Eusterm Fimergency llospltal, 1065 W.

Monrue si chicago fistabtighed 1603. private; 30 luds: Jihn II. I'urtls, Jubn Buckley und E. L. leters, physlclans.

Edremere Medical llaths, isll lirvar was, chicage Fostablished 190.2 sint torium treatments only: in beds: $T$. onroy. phystoina in charate

Fugleworl Hosptial, fool fieen st.

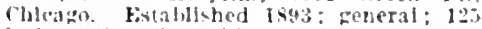
ledd: Mlas E. Wahlgren, R.X. superin-

Fungellond hearonest Hospltal, 40s

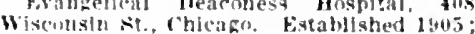
Leneral; to heds; Rev. J. H. Babernfeind superintendent

Horence Crittenton Anchorage. 261 . Indiana Are. Chicago. Falahllshed Is!l charltable matarnity heme: 17 beds; Miss loulse Indrew, superintentent.

rrances f. Wlllarel National Temperance Unspital, i10 s. Inceln st. Chlcago.

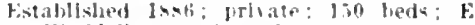

Warldell, turerlntendent.

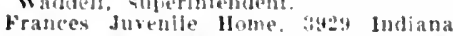

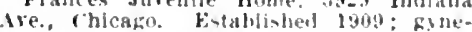
cologlcal: 14 beds: (la ra l'. selppel, ply. slclan In charte.

Fridhern llume of Hest, 11400 (rescen Are., Jorgan l'k., Thicange tistablisber 1305 ; swedlsh Hapelist houre for the aged:

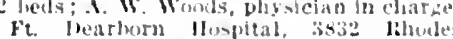

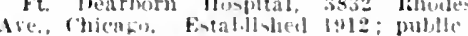

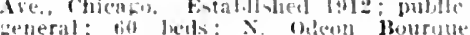
meperal: bo mols:

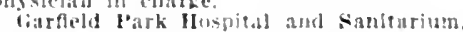

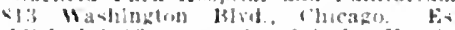

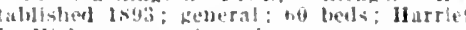
1. Hebiner, superanterdent.

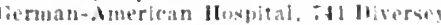

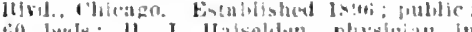

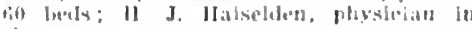
that:e

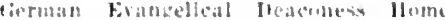
and IIspital, Morgan st. and ifth li.

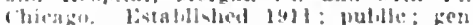

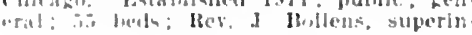
mindent.

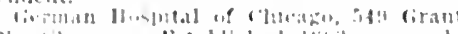

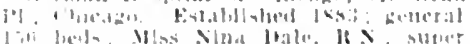

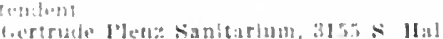

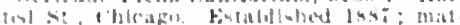

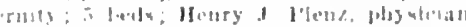

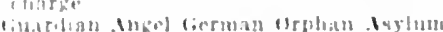

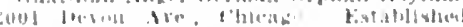

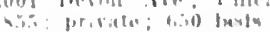

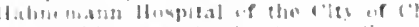

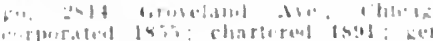

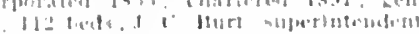

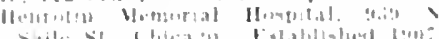

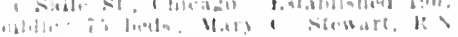

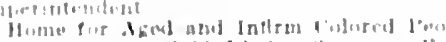

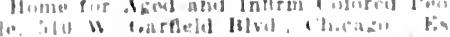

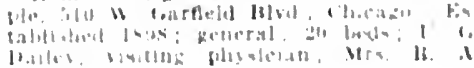

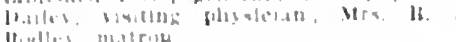

linge for $A$ inal Jo vate: 10 lword: $F$ ? at Are. and

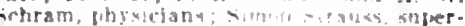
intendent.

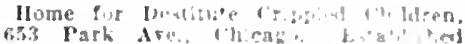
18.3; frthriedicy: ing bed

art, R.X, sujerlntentent.

llume of limal whepherrl is firent

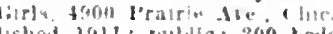

(1) bers.

IIospital of sit. Anthony de badua. W

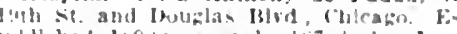

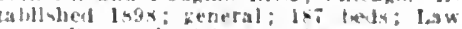
rence litan, phystelan in eharge.

House of correction and Sceleth Foner Leney Ilospltal, $\therefore$. Califurnala Are and W oth st. Phleago. Fistalllshed is:3; re firmatory; keneral: 150 beds: 1 . E sceleth. physicinn In charge.

Inouse of the fornd shepherd, 1118 firace si., thicagn. Fistabllshed 185y; reformatory; 400 heds; Filwin M. Sinith, physi cian.

Illnois Steel rompany Hosplat, ssth st. and Mackinaw Are., Yhicazo. Falablisbed 1890; prirate; "50 beds; 11. IR colver, surgeon in charge.

Irofuols Memurlat Finergencs Honptat. $23 \%$ Market it. Chicago Fstablished

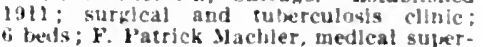
i) berls; $F$.

lsolation Ilospltal, 3tth st. and Hamlin tre., Thicasu. Evabllabed 1sy6; small por: so heds; Health deparment of elty illcago, in charce.

Jackion Park salltarium, foot of fith St., 'bleago, Established ISty general:
if heds; Hohert 1 Black, inedical superintendent.

James $C$. Klng Hume for (1ld Men, 360 F. Firtield Blid., Chlcagu Kistablished 1911 ; prirate; $\$ 5$ teds: Wllber k. Host. mhysician in charge: Harry s. Moure. aperintendent.

Japanese Mission Home, 3s.50 lake Are. Thie:age. Fisiablished 1911; public: cods: $R$. T. Takiusoto, superintendent

Jefferan lark lutyelinic and Hosplat, 1400 W. Nonreve st., Chtcazos. Established 1 to0 ; fenteral: 100 beds: Jenute $\mathbf{X}$. Kenall. li.N., sunerintendent.

lathe Shure Iluspltal, tlti late lark

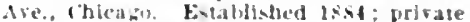

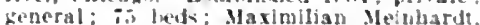
fhystcian In chorge: Miss Marle J. Siphnette, It.X. in tharge.

lakesde Ilompltal. atlo khoutes sie

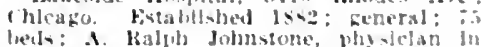
(")arge.

latke Vlow llopltat Asioclation. Itat clarenclen wre. thlcapo Fiablished 1.40s: general: provate: 50 lueds: Mlse Miratree $k$. Kane, sugherintendent

Latundale Maternlty Hupital sesa W.

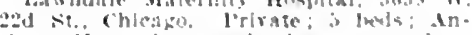
hony If souknp. mentical superintendent

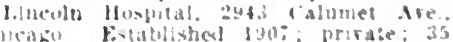

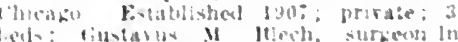

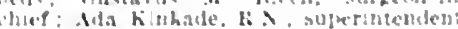
J.chle sinters of the l'wer Homa for tae

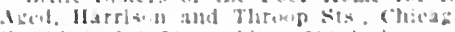

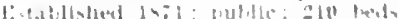

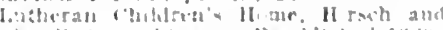

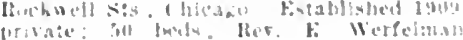

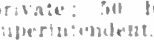

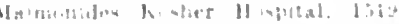

$1, \operatorname{lin} 2$

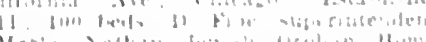

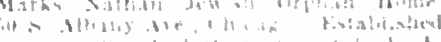

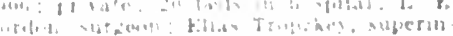

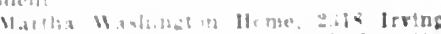

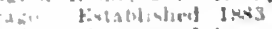

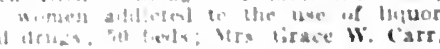

llary Thempin llinpilal of chleago for

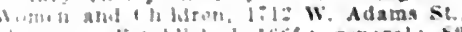

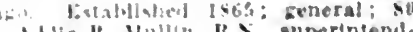
iflic it Yulle IB s superintend. 
Ifemorial Institute for Infectious IIIscase's, $1743 \mathrm{~W}$. ILarrison St., Chicago. Fstablished 1902; endowed; mulntains investigative and serum laboratory and lowspital; 40 beds; Frank Billings, presldent if boird of trustees: 1 . llektoen, direetor F. O. Jordin, chlief of serum division: Ge. dordin, chief of serum, diviston: enow. (ieo. F. Dlck, Ituth Tumielifp and 1). Glonset (Des Molnes, la.), associates: 1.. S. Manly technlcian; the dolirnal of Herey lospital and orphan Asylum. prairie Ave. and 26 th St. Chicago. Fs tabilshed Is50; private; 500 beds.

Ilethodist Episconai old I'eople's Ilome, 1117 Foster Ave., Chicago. Estublished 1898 : private; 20 beds; W. W. Ilartiman, physician in charge: Míss Isabella $A$. physician in charge:

Michael Reese Itospital, 29th $\mathrm{st}$. and Croveland Are., Chlcago. Fstablished 1567: general; 400 beds: (ieorge $L$. l'erusse, medical superintendent.

Morehouse Rest ('ure, 4859 Madison Are., Chicago. Established 1909; prirate: nervous and mental diseases; 11 beds;

National I'sychopathic Institute, $2919 \mathrm{~N}$

Clark st.. Chicago. Established 1909; private: 6 beds.

North Chicago Itospital, $2551 \mathrm{I}$. Clark St., Chicago, Fstabllshed 1906 ; general; 70 heds; Einil G. Beek, medlcal superintendent.

Northuest Side IIospital, 1625 W. Nortl Are. Chleago. Established 1903; private: 10 beds: F. Honth, surgeon in charge: Artlur $C$ Gillam, phisician.

Norweglan Lutheran Bethesda Home, 2244 Iladdon Aie., Chicago. For aged destitute.

Norwegian lutheran Children's Home, 5803 W. Irving l'ark l3lid. Chicago. Established 1899 ; private; 70 beds; Caroline Williams, deaconess in charge.

Norwegian Luthern Deaconess IInme and Hospital, II38 N. Leavitt St., Chicago, Establishtd 1896 ; public; 90 beds; Rev. H. I3. kildaht, superintendent.

Norwegian Tabitha Hospital, $1044 \mathrm{~N}$. Franciseo Are., Chicago. Established 1894; general; 40 beds; ('has. k. Noore, chief of medical statr; Bella Olsen, superintendent. old People's Home, 4724 Vincenues Are. Chiearo. Established 1873; for aged women; 150 heds: Mrs. Natalle K. Duff, R. $N$. superintendent.

Park Arenue llospital, 1940 Park Are. Chleago. Established 1901; general; 50 beds; Lonis Thexton, chief surgeon; $\mathfrak{k}$. 1 . Strorus, superintendent.

Fassavant Memorial Hospital, $147 \mathrm{~V}$ Superior St., Chicazo. Established 1880. general; 70 beds; Charlotte Christian, superintendent.

People's Hospital and Training School for Nurses, 22d St. and Archer Are. chi-

cago. Established 1897; general; 50 beds;

I. C. Gary, physician in charge.

see special dnnouncement Ads. pagr 81

l'ost Graduate Hospital of Chicago, 2400

S. Dearborn St., Chicago. Established 1888 ; general; 90 beds; Emil Ries, physician in charge; Niss J. D. Cruickshank, superintendent.

Presbyterian Hospital, W. Congress and Wood Sts., Chicago. Established 1883; general; 325 beds; Asa Bacon, superintendents.

Prospect Hospital, North and Irving Ares., Chicago. Established 1909; general; 10 beds; Isaac J. Golden, physician in charge.

Frovident Hospital, 16 W. 36th St., Chlcago. Establisbed 1891; general; 75 beds; Jeannette S. Lyon, R.N., superintendent.

Pullman Hospital Association, 11217 Watt Are.. Chicago. Established 1909; general; 15 beds; Marie Sikpberg; superintendent.

Ravenswood Hospital Association, 1917 Wilson Ave., Chicago. Establisbed 1906. smi-fublic; general; 50 beds; G. W. treen and G. N. Bussey, surgeons in chief ; Sidney K. Appell, superinterdent. Rhodes Avenue Hospital, 32d St. and general; 65 beds; Frank Deacon, medlcal superintendent.

Robert Hurns ILospital, 3807 Washington Bivd Chleago. Established 1907 : private: 35 beds; $A$. W. (iregt, physlcian in charge. Salvatlon Army Rescue and Maternity Ilospital. 1332 $N$, la salle st. Chicaro. Established 1895; for unfortunate girls: 25 beds; Anna L. Hanstein, superintenden

Sarah Morris Hospltal for Chlldren, $29 t h$ St. and Groveland Ave, Chicago. Establishel 1911; general; 125 beds; George 1. Perusse, physician In charce.

sherldan lark Ilosplial, 628 Belmont Ave chleago. Established 1912; ceueral: so heds; Robert c. Menzles, medleal superintendent.

South Chicago IIospital, 2322 F. $92 \mathrm{~d}$ Pl., (hicago. Established 1900 ; general; 50 beds; sylra bell, superintendent.

Soutll Shore Hospital, 8001-17 Luella Are. Chicago. Established 1912; private: general ; 40 beds; Miss II. B. Nelson, R.N.' superintendent.

St. Aun's llospital, N. 49th Ave. and Thomas St., Chicago. Established 1903; general; 150 beds.

st. Bernard's IIotel Dleu Hospital, 6337 Harvard Ave., (hifeago. Fstabllshed 1906: private; 172 beds; Slster Alice Burns, R.N., superintendent.

St. Elizabeth's Hospital, 1433 N. Claremont Ave. Chlcago. Established $188 \pi$. private; 175 beds.

St. Josenh's Home and St. Vincent's Orphan Asylum, 2649 N. Hamlin Ave., Chi cago. Established 1895; private; for aged Polish; 70 beds; Geo. Dohrmann, medtcal superintendent; Sisters of the

Third Order of St. Francis, in charge.

st. Joseph's llome for the Friendless, 1100 S. Jlay St. Chicago. Established 1911 ; private; 203 beds; John M. lilly attending physician; Margaret Cosgrove, superintendent.

St. Joseph's Hospital, 740 Garfleld Are. Chicago. Established 1869; medical and surgical; 125 beds; J. B. Murphy, head of surgical staff.

St. Luke's Hospital, 1431 Michigan Are. Chicaro. Established 1864; private; 300 beds; Louis R. Curtis, superintendent.

St. Mary's. Curtis, superintendent. Jackson 13lid., Chicago. Established 1895 . private; 105 beds.

St. Mary's of Nazareth Hospital, 1120 N. Leavitt St., Chicago. Established 1894; general; 225 beds.

St. Vincent's Infant Asylum and Maternity llospital, 72I N. La satle st., Chicago Established 1882 ; infants and maternity cases: 225 beds

streeter Hospital, 2646 Calumet Are. Chicago. Established 1888; general; 30 beds; Mildred R. Winans, R.N., superintendent.

Swedish Covenant Hospital and Home of Nercy, 2739 W. Foster Ave., Chicago. Established 1886 ; private: 100 beds: 0 Theodore Rolverg, surgeon-in-chlef; Rev. Albin Johnson, superintendent.

Thlich Evangelical Lutheran Orphan Asylum, 2014 Purling St., Chicago. Es tablished 1868; orphans; 90 beds; WVm. Hessert, physician in charge; Miss Minn l'feifner, superintendent.

Inited states llarine Hospital, 4141 Clarendon Are., Chicago. Established 18 ;2; general; 90 beds; J. O. Cobb, physician in chargé

Unirersity Hospital, Ogden Are., Pulask and Congress Sts., Chicago. Established 1907 ; General; So beds; Miss Mildred West, R.N., superintendent.

Vesta Circle Hospital, 218 E. 55th P1. Chicago. Established 1911; general ; 30 beds; Miss Rose O'Donnell, superintendent.

Washington Boulevard Hospital, 2449 Washington Blvi., Chicago. Established 1889 ; general; I20 beds; A. I. Bouffleur and $B$. Lounsunery sureons in

Washingtonian Home of Chlcago, 1533 Madison St., Chicago. Established 1863; for alcohol and drug addiction cases; 100 beds; W. P. Goodsmith, attending physician; W. H. Barton, superintendent.

Washlngton Park Hospltal, 60th St. and Vernon Are., Chlcago. Establlshed 1904; publle; 120 heds; C. O. Young, surgeon, superlntendent.

Wesley flospital, 2449 S. Dearborn St. Chicago. Established 1888; General; 275 beds; $\mathbf{E}$. S. Gllmore, superintendent, Sce sperial tunouncement Ads. page if

Western German Baptist Old Peoples IInme, 1851 N. Spaulding Are., Chicago. Established 1896 ; public; 85 beds; $\mathrm{H}$ Sclumidt, superintendent.

West Slde Emerkency IIospltal, $1260 \mathrm{WV}$. Madlson St., Chleago. General; W. E. Krieger, surbeon in charge.

West Slde IIospital, 1844 W. IIarrison St. Chlcago. Established 1896 ; general; 150 beds; Miss Bree S. Kelly, R.N., superintendent.

\section{Chicago Heights}

St. .lames Hospital, Chicago Helghts, Ill. Fstablished 1911 ; public; general; 60
beds; Sisters of st. Francls, in charge.

\section{Clinton}

Clinton Infirmary, Clinton, Mll. Estab-

lished 1903; liquor and drug habits; P. J. Gillen, M.D., superintendent.

Dr. John Warner Hospltal, clinton, Ill

Established 1911; general; 25 beds; Olive

1. Wllliams, superintendent.

\section{Collinsville}

Harrison Ilospltal, Collinsville, Ill. Private; 12 beds; Moses W. Harrlson, physlcian in cliarge.

Harrison Tuberculosls Colony, Collinsvllle, Ill." Established 1912; 9 beds; superintendent.

\section{Compton}

Chandler Hospital, Compton, Ill. Established 1904; general; 12 beds; $A$. W. Chandler, physician in charge.

\section{Danvers}

Dr. Parkhurst's Sanatorlum, Danvers, 11l. Established 1890; alcoholic addictlons; 60 beds; F. J. Parkhurst, physician in charge.

\section{Danville}

Lake View Hospital, Logan Ave. and Fairchild St., Danville, 11l. Established 1892; public; general; 50 beds; Mlss Iaud Northwood, R.N., superintendent.

National Home for Disabled Voluntee Soldiers, Danvllle Branch, Danville, Ill. Established 1898; natlonal home for disabled volunteer soldiers; 403 beds in hospital, 2,267 in barracks; Maj. W. A. Cochran. surgeon in command.

St. Elizabeth's Hospital, Greene St. Danville, Ill. Established 1882 ; general ; special

Vermilion County Inflrmary, Danville, 111. Established 1860; 106 beds; R. A. Lamar, superintendent.

\section{Deeatur}

St. Mary's Hospital, Decatur, Ill. Established 1875; private; 110 beds; slsters in charge.

Wabash Railroad Employees' Hospital, Decatur, Ill. Established 1884 ; gener

\section{DeKalb}

Ve Kalb Hospital and old People's Home, We Kalb, Ill. Established 1909; public; 12 beds; Edna Cunnan, general manager.

De Kalb l'ublic Hospital, 647 S. Ist St., 1) Kalb, 111. Established 1910; general; 18 beds; Jirs. Nettie M. Duncan, superintendent.

\section{Des Plaines} III.

Industrial School for Girls, Des Plalnes,

Dewmaine

Dewmaine Hospital, Dewmaine, חl. A. Dixon

Katherine Shaw Bethea Hospital, Dixon,

IIl. Established 1896; general ; 50 beds?

Elizabeth Collin, superintendent. 


\section{ILLINOIS}

Park), physiclan In charge; James Mullentack, general superlntendent.

\section{East St. Louls}

East St. Louls Contagion Hospiltal, 4000

Itlinols Are., East st. Louls, III. Esiab.

lished 1904; small-pox; public: 60 beds;

L. B. Short, medical superinterudent.

Henrletta Hospltal, isth St., kiast St.

Louls, Ill. kastabllshed Is95; general: 50

bouls, Ml. Ks M. Delong. R.N., superinfenil.

ent.

St. Mary's Hospltal, East St. Louls, III.

Established 1890: General; 150 beds.

\section{Edwardsville}

Linnwood Sanltarium, Fitwardsville. III.

Eatabllshed 1908: private: for gallstone,

diabetes and klndred cases: 10 beds:

Stepten T. Roblnson, medical superin-

tendent.

Madlson Couniy Home, Edrardsville,

Sutter, physlclan in charge.

\section{Emngham}

St. Anthony's Hospltal, Efilngham, Ill.

Elgin

Restharen Sanatorlum, Figln. Ill. Establlshed 1906; prirate; 30 beds: Mar-

gares Guenther fursheck. superlntendent. Sherman IIospital, Figin, Ill. Establlshed 18s8; ceneral; C. Irene Oterg. R.N., superintendent.

St. Joseph's IIospital, Elgln, IIl. Es-

\section{Eureka}

Eureka Hospltal, Eureks, Ill. EstabUshed 190n: general: 5 beds; C. B. Iligbs, medical superintendent.

\section{Evanston}

Eranston Hospltal. Eranston,- 111. Establlshed isqu; zeneral: 92 beds: Wm. R. Parkes, dean of niedlcal staft; Miss Allce Ruggles, superlntendent.

Grove House, Eransinn, 111. Established 1903 ; prlrate : Ior conralescents; 22 beds: Mlss F. D. Miller, K.N. superintendent. IIInols Children's Home, Eranston, III. Established 1903; putlle; general: bi beds: Dwight rlark physician in charge beds: Dwight Clark, physician In charge. Lake Shore Sanitarium, 2237 Sherman nerrous, mental and rheumatles: 16 beds; C. H. Faden, physiclan In charge.

St. Francis Hospital, Eranston. Ill. Fatablished 1900; public; 100 beds; Slsters of st. Francls, in charge.

\section{Fairbury}

Falrburs iluspltal. Falrbury, III. Establlsher 1911: jrliale: surcleal: \& beds; Jamer $H$ Langstart, ihyslclan in charge; Martba Vetters. superlatendent.

\section{Forest Park}

Cerman Old Peoples Home, Forest Park III. Fistablished 1855: general : 126 beds:

Wrm. Ma

Freeport General Hoxplial. Freeynt, III. Establlshed 1913; generai ; fil berls: J. II. Stealy, phyvleba in charge; Mry. Jara A. Niealy, sumethlendent. ara A. Elealy, sumplntendent. Esiab. llshed 1:02; public; 25 beds; Miss A. It. lengilly. B.X.. superintenulent. Se Francla Hoanlial, Freport. III. Fstablished 1840; public: 100 veds; Sisters of Si. Francis, in charge.

\section{Galesburg}

(lisleshurg llownital, fialeshurg, III. Fo. tabllshed 1st: so beds: latw ilanchette superinsentlent.

st Magy's Hospital. 239 s. Theres st.

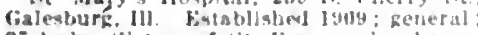
gi beds: slsters of si. Francis, in charde.

\section{Genesen}

J. C. Hammond Clis lluspitsl, (ivereste Ill. Eatabllahed 1:001: public: :11 |rey Geneva.

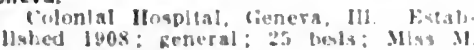
viclonalel, lix. superintendens.

\section{Godfrey}

Ieverly farm, lindrey, III Fintalinhed Isqi: home and schurl for nervolus and backiranl children: 75 leeds: W. II. C smith, medical surerintendent
Granlie City

S. Ellzabeih Ilospltal, Granlte City, III

\section{Hartis burg}

Ilarrisburg Sanltarlum. Inc. IIarrlsburg III. Fistablistied 1909: 20 beds: $C$ b Turner. prestlent.

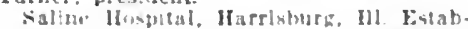

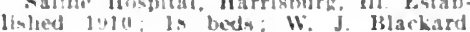
physteian in charge.

\section{Harratd}

Cotlage Hisplial, Harrard, IIL Fatab. lished I $4: 8$; general: 35 ueds; C. M. Johnsun. plusician in charge.

Harana

IIarana Hospltal. 11: x. Broadway Harana. 1ll. Established 1901; surcery 9 beds: C. M. Morrill, medleal superin tenden:

\section{Highland}

si. Joseph's Hospltal. Highland, III Fusalilished 1660; 40 beds; Slsters, In charge.

Hinsdale

Illnsdale Sanltarlum and Benerolent Association, Hinsdale, III. Established 1904: prirate: so beds; David Paulson, medical superintenden:

\section{Jacksonville}

Asioclated Charltles Tuherculosis Camp. Jarksonville, Ill. Establlshed 1911; fur inciplent and moderately advanced caser 7 beels.

Christlan old People's Home, Jacksonvlle, 111. Established 1900; private; 30 heds: Virgtule linsmore, physlcian in charke; Mrs. M. 16. Thotntery, matron.

lie. Das's Private Iluspital, $100 \mathrm{~s}$ iv. State st., Jacksonville. Establlsher 1911; surgical: is heds: J. A. Day, surgeon is charge: Miss Helen Heed, in charge.

IIome Sanatorlum, Jacksonrille, Ill. surgical; 16 beds; A. i. Kennlebrew, surgeon.

Vorbury Sanatorium, Jacksonrille, Ill. Established land: for nervous disorders $2:$ heds: Frank lorsons Sorbury, medical difector; Nibert 11. Nollear, resident jlit slclan.

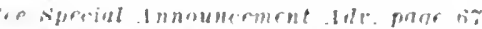

Oak Lawn Sanitarium, Jacksonrllle, III. Fstablinhed lis: : Irtiate; 50 heds: J Thompata shated, shysician In charse.

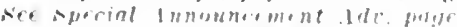

Our Sarluur's llogpital, 146 E. Siale si. Jacksonville, Ill. Eotallislied isito; Len: eral; f; heds; Sisters of the Ifoly 'Cruss. in charine.

Irassarant Memorlal IInspital, Jackson. ville, lll Established 1s75; general: 50 belv: Abyn I. Adams, M I, brewdent of stat? : Milent.

Joliet

Guardlan Angel Home, Jollep. Ill. Fs-

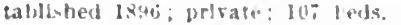

Silrer Cross II

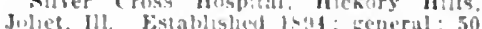

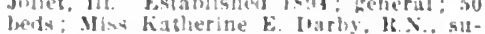
perlutemlent.

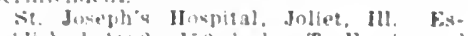

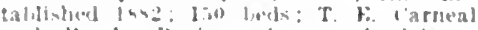
and It. L. Jirufies, hellse mysletans: cinters uf sit. Francis, In charge.

\section{Kankakee}

bimerioney IIowplfal. Kathakee, III. b inblished 1ste: lubliv: fo leds

Kensivorth

hell.lwerth santarilum, fonllworlh, Ill.

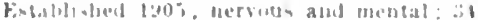

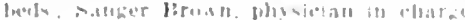

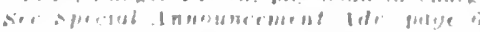
Kewance

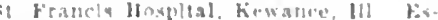

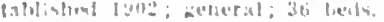

Knoxville

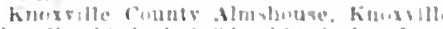

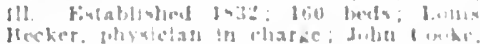

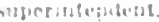

La Girango

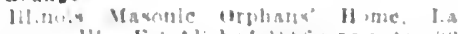

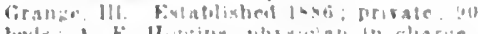

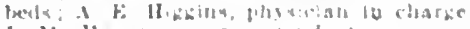
j. M llanbum. sugrentendent.

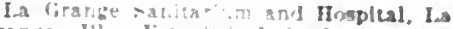

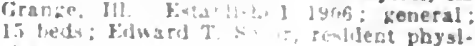
clan.

\section{Lake Bluf}

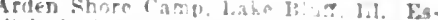

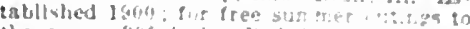

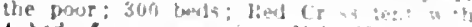
4 beds for emergen son, Reneral directir

Methodist heaconesu mrghanaze. Lahe Blut. III. Fstabllahed Isb4; metical; 1

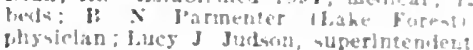
Lake Forest

Alice Inme IInapital. I'nlrersity Campus. lahe forest. III. Establluhed 1899; publle: 12 treds: Alfred C. Haren, Dhyvleian charge: Julia Jansen, suberlntendent l.ake Forest IIospltal, Lale Forest, 111. Eviablisherl 1003: nublte: tor enniaglous rases: A. C. Haren, president of medical mari.

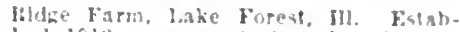
lished lil:- a brebentorlum for chlldren from of io 14 years: Is bede.

La Salle

Si. Mary's Inspital, La Salle, Ill. Ës. tablisbed ins: : Ecperal: 80 beds.

\section{Libertyville}

Corociation for the Care and Treatment of Epilewy and Kindred Cond. dons, Libertyrille, IIl Estatlished 19n: private; 16 beds: lietta cater sweeting physlcian in charge.

Lake county I'we Farm, I,ibertyille. 111. Fistablished 1<53; general: 50 berly. J. L. Taslor, medlcal atsendant: C. A. Apoles, superinteudeut.

\section{Lincoln}

Erangelical Deaconess Home and Hos plral, Linculn. Ill. Extablshel 1902: prtvale; 45 beds; Rer. C. IIotrmann, surerinterdent.

St. Clara's Ilospital, Lincoln, 11l. Fatablished Isist public: 50 beds: F. M. Ewing, physiclan in charge.

\section{Litehfield}

Holden Metsorial IInspital, Lltchtield. III Established $1913 ; 14$ beds: Iheaconeries of
M. E. Churct, In charke; Mso Mary Inoloblrs. superm:enden:

st. Francts IIospial. Llichfield, IU. Fs. tablished 1s:s; 1.25 beds: Sisters of s: trances, ir ctrarge.

\section{Macomb}

Mariena I'kelps Annex IInspiral. Ma

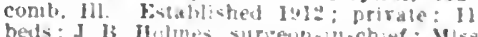

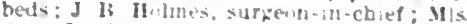

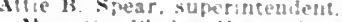

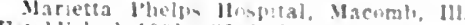
Eistablislied 1201; 30 lewls: $s$ c. Sirem nel, surgeon-in-chit: Miss Rowena b kajimond. wher:mended

Si Frances Hegpital, Vacomb. Hlt. Fa.

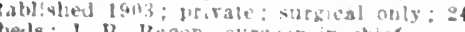
beals; 1 B. Bricon, surima-jn-chief

\section{Marion}

Marlop llocpital. Marton. Ill. Wusth

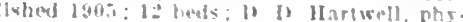

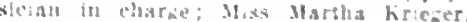
sureringerstent

Mattoon

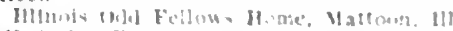

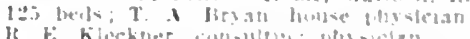

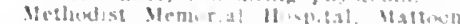

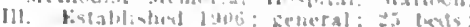

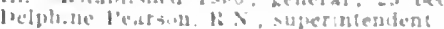

Marmell

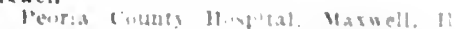

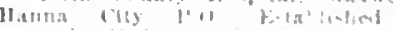

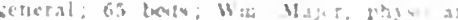
211 inditin's

Mas

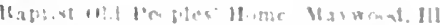

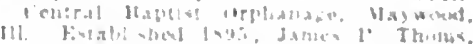

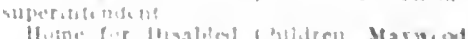

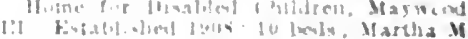


Miliord

Bumbin 1lospltal, Mllford, Ill. Estallisled 1912; medical and surgical: 10 lukt 11. 11, Junkln, surpeon; Mrs. if. I) Moline

Inline Publyc Hospltal, Noline, 111. Wistablishel 18!s; punle : 75 heds; Marguret Howney, sumpintendent

Trl. (ity saultarlum, Iollue 11l. Fstal. llshed 1!00\% prlyate; medleal and sur

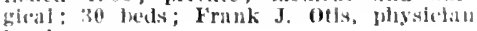
in charge.

Monmouth

Mommontl IHospital, Mommonth, 11. Es tablished I904: ceneral: 35 beds: Elliza beth l'roctor. $k$..., superlntendent.

Morris

Morrls Hospital, Norris, Ill. EstabHhed I906: Reneral: 20 leds:

Mt. Carroll

C'urroll county Poor Farm, IIt. carroll, I1l. Established 1865; 40 beds In hospltal department; W. E. Clay, plysiclan in charge.

Mt. Vernon

Equptian Hospltal, Mt. Vernon. Ill. Fistablished 1009; private; 25 heds; J. W. Hamilton, strgeon-in-chlef; IIss Anma Sawyer, superintendent.

Murphysboro

st. Andrew's IIospital. Mlurplysboro, Ill. Fstahlished 1897; general; 35 beds: Franciscan Sisters, in chare.

Naperville

Edward sanatorium, Naperville, 111. Established 1947 ; privale; tulserculosis; braneh of the Chicago Tulerculosis Instltute; 85 heds; Theodore 13. Sachs, Chicago, physiclan lin charge; Miss Whnifred Mebdward, superintendent.

Nashville.

Iiridget IIughes' IIospital, Nashyille, Ill. Established in 1910 ; Reneral; 25 beds; I. I3. Rabenneck, house physician; Mlss Dora Brydon, K.X., superintendent.

Neoga

Neoga Sanatorium, Loeust st., Neoga, III. Established 1911; general; 10 beds; Itusse1] L. Kurtz, physiclan in eharge; IIrs. M. W. liurtz, superintendent.

North Chicago

Lnited States Naval Hospltal, North Chicago, Ill. Established 19II; general; so beds.

Oak Forest

Cook County Inflimary and Tuberculosis Hospital, Oak Forest, H1l. Established $1 ! 10$; tuberculosls; aged and poor: 3,025 beds: John w'. Turner and w. A Kimmet, plissicians ln charge; James Mullenbirl, superintendent.

\section{Oak Park}

Oak Park Hospltal, Oak Park, 1ll. Established I907; general; 60 beds; Arthur Juews, physiclan in charge.

West Suburban Hospital, Oak Park, Ill. 100 beds; C. F. Humiston, president of board.

olney

Olney Santarium, Olney, Ill. Estab-
lished IS98; general; 70 beds; George T.

Weber, II.D., superintendent.

ottawa

John Stuart Ryburn Iemorial Hospital Ottawa, In. Established 1895 ; general;
25 beds; Elizateth Asseltin, R.X., super25 beds ;

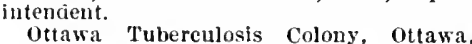
IIl. Established 1904. tuberculosis; beds; H. V. Pettit, superintendent.

Pana

Pana Deaconess Home and Hospital Pana, Ill. Established 1904; general; 12 leds; ('atherine Dockery, superintendent. Paris

Paris Hospital, Paris, Ill. Established Tus: seneral; 10 beds; Roland Hazen, hisieian and surgeon in charge.

Park Ridge

L'ark liage School for Girls, Park Ridge, Ili. Iiatah? shed $1879 ; 80$ beds; W. II. Frient, atreliding physician; Mrs. B. F could, suberintendent.
Peoria

(u) Womern, Jeorla, III. IIrs. Anna It. Fields. matron.

C.u-uperative IIospltal, Peorla, Ill, Verun Holbrook, superintendent.

buconess llome and Ifospltal, $221 \times$ clen oak Ave., l'eoria, ll. Estiblished linty; Getieral; 50 beds; Mary Melutire i. N... superlntement

Evingelical butheran linderfreund I'eoria, 1ll. Establlshed 1902; private: for delewdent and lomeless chlldren; beds, ftr. Fanel, superintendent.

Fstalisiled 1902; public; 30 beds; Irs.

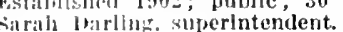

filver-IIotclikiss Memorlal IIome, Peo-

ria. Ili. Mrs. M. I. Walters, matron.

Ifome for the Friendless, I'eoria, III.

Mrs. M. F. Moslier, matron.

Ifome of the frood Shepherd, Faraday and Starr St.s., Peorla, III. Established IS91; prirate; reformatory; I40 beds; J. L. Finnell and $A$. J. Kanne, physlclans. Joln C. Iroctor Fndowment, Spring and Glentile sts., P'eoria, III. Established $1 ! 96$; home for the aged; 200 beds; $\mathrm{s}$. $\mathrm{Mt}$ Viller, lrouse physician; Miss Eleanor Coolidge, superintendent.

John C. I'roctor IIospital, Peoria, Ill. Establlshed 1882; general; 100 beds; Miss lucy .l. Breen, It. N., superintendent.

Nevins Sanitarium, 1215 Republic st. Peoria, Ill. Established 1909 ; cancer, nerrous and mental; 60 beds; 11 . Nerins, pliysician in charge.

Peorla Isolation Hospital, Peorla, Ill. Established 1900; public; 45 beds; Sandor Itorwitz, physlcian in charge; Fdward Ilasson, comnissioner of lealth; Mrs. Isaliel Voris, superintendent

I'eoria Sanitarlum, I06 N. Glen Oak Are., Peorla, Ill. Establlsbed 191I; mental and nervous diseases, alcohol and drug addlction cases; 25 beds;

cac sperial anouncement $4 d v$ page 6 ?

St. Francis' Hospital, $530 \mathrm{~N}$. Glen Oak Ave., I'eoria, Ill. Established 1877; prlvate; I24 beds; Sisters of the Third Order of St. Francis, in charge.

St. Joseph's Home for the Aged, 40\% Smith St., Peoria, Ill. Sisters of St. Francis, in charge.

Sulphur Springs Sanitarium, Peoria, Ill. Established 1909 ; mud and mineral baths: 50 beds; E. W. Oliver, physician in charge.

\section{Pittsfield}

Pittsfleld Sanitarium, Pittsfield, Ill. Established I!08; general; 8 beds; $F . \quad \mathrm{N}$ Wells, physician in charge.

Pontiac

St. James' Hospital, Pontiac, Ill.

Quiney

Blessing Hospital, 1014 Spring St. Quincy, Ill. Established 1855; general 70 beds; Miss Florence Burt, R.X., super intendent.

St. Mary's Hospital, Quincy, Ill. Established i866; public; 170 beds; Sister of the loor of 'st. Francis, in charge. $s$ t. Vineent's Home for the Aged Quiney, Ill. Established 1885; aged and inflrm; 125 beds; Jolln A. Koch, attending physician.

Red Bud

St. Clement's Hospital, Red Bud, Ill. Established I901; private; 40 beds; Sisters in charge.

\section{Rockford}

Dr. Broupliton's Sanitarium, Rockford III. Established I901; for nervous and aleohol and drug addiction cases; 44 beds; (ieo. A. Weirick, physician in charge.

ffe Npurat innouncement Adr. page 59

Crags, ('orey's Bluff, Rockford, Ill. Established 1912; chronic and nervous diseases: 12 beds; Katherine $\mathbf{E}$. James, physician in eharge.

Hodge Sanitarium and Rest Cure, Rockford, Ill. Established 1905; for chronic cases: I5 beris; E. G. Hodge, superintendent.

Jennie Snow IIome for Aged Women 525 Kent St., Koekford, Ill. Established

1907; private; Miss Carrie A. Slade, iuperintendent

Rockford Hospltal, 507 Chestnut St. Rockford, Ill. Established 1883; general; 100 beds; Mlss Elizabeth M. Wright, R.X., superintendent.

St. Anthony's Hospltal, Rockford, 11 . Established 1889 ; private; 125 beds; A C. Eakln, chlef of medical stat?; J. A. Dagnault, resident physlclan.

Dr. Wilyus' sanitarlum, itockford, III. Established 1887 as Itansom Sanltarium; nerrous and mental dlseases; 25 berls; s!dney I. Wilgus, medical superintendent. sire special Amounecment Adv. perte o

\section{Roek Island}

Bethany Home, 36th St., Rock Island, III. Established I898; for homeless children; 45 beds; $L$. O. Jalus, superintendent; Naoml Littig, matron.

St. Anthony's Hospitul, Itock Island, Jil. Established 1893; public; 50 beds; Louis Ostrom, chief of medieal staft.

Salem

Salem Hospital, Salem, Ill. Establlshed 1912 ; general ; 16 beds ; Warren R. Rainey jhysician in charge; Mrs. Ollve Webster, superintendent.

Savanna

Emergency Hospltal, Savanna, Ill. Establlshed 1s11; surgleal; 2 beds; G. W. Johnson, medical superintendent.

\section{Springfield}

Darid Prince Sanitarlum, 628 E. Capitol Ave, Springfield, Ill. Established 1867 ; for eye, ear, nose and throat treat ment; 65 beds; A. F. Prince, medica! superintendent.

Home for the Friendless. Springfield, IIl. Established 1863; public; for orphans and dependent children; 80 beds; Niss Susie Trotter, superintendent.

Isolation Hospital, Springfield, 1ll. Established 1905; public; 20 beds; Mrs. ILary I. Davis, superintendent.

Lary L. Davis, superintendent. King's Daughters Carrie Post Home, i4l Black Ave., Sprlngfleld, 1ll. Estabbeds; Mrs. Cynthia Meets, superintendent. Redemption Home, Springfield, Hl. Established 1903; for delinquent and fallen women and girls; 55 beds; MIrs. N. H. Hunts, superintendent.

springfield Hospital, Springfield, 11l. Established 1897; general; 70 beds; J. A. Hoffman, superintendent.

Springfield Open-Air Colony, Springfeld, Springfield Open-Air Colony, Springtheld,
Ill. Established 1913; tuberculosis; 25 beds; Geo. Thomas Palmer, medical director.

see special Announcement Ads: proge 7.5 St. John's Hospltal, 8th and Mason Sts., Springfield, Ill. Established 1875; private; 225 beds; Sisters in charge; Josepl C. Straub, superintendent.

St. Joseph's Home, 801 S. 6th St., Springfield, 111. Establlshed 1903; general; for the aged; 70 beds.

\section{Spring Valley}

Old Ladies' Home, Spring Valley, Ill. Established 1909 ; privale; 20 beds.

St. Mareraret's Hospital, Spring Valley.

III. Established 1902; general; 40 beds.

\section{Sterling}

Keefer Hospital, Sterling, Ill. Established 1903; general; 12 beds; Jane $R$. Keefer, medical superintendent.

Sterling Public Hospital, Sterling, Ill. Established 1910; 25 beds; Mliss Carrie Fenly, superintendent.

Streator

St. Mary's Hospital, Streator, 11l. Established 1888; publie; 40 beds; Sisters of St. Francis, in charge.

Sublette

Dr. Angear's Hospltal, Sublette, nl. Established 1910; general; 10 beds; $\mathbf{B}$. $\mathbf{H}$. $\mathrm{S}$. Angear, physician In' charge.

Sultivan

Illinois Masonic Home, Sullivan, Ill. Established 1903; general; 100 beds; George W. Pumphrey, superintendent.

Sycamore

Dr. Larson's Hospital, 'Sycamore, Ill Established 1910; general ; 15 beds; J. II. Larson, manager and chief surgeon; Pearl B. I arson, R.N., superintendent. 
Syeamore IIosplal, Sycamore, III. Established 1801 ; publlc: 15 beds.

Taylorville

St. VIncent's Ilospltal, Tastorrllle, III. Frstabllshed 1905; publle: so beds; ststers In charse.

Treaton

Trenton Inosplial. Trenton, HI. W, A. Carter, physiclan in charge.

Urbana

Champalon County Alms Ilouse Ilospital. J. J. Ilanmore, attending physiclan: M!ss Anderson, superintendens.

\section{Wainut}

Shearburn Ilosplial, Walnut, III. Es enbllshed 1898; prlvate: 18 beds: $A$. Shearburn, phýstclan in" charge.

\section{Waterman}

Waterman East Slde Hospltal. Water. man, IM. Lstabllshed 1901; geueral; is charge.
Wllkinson's Ilospltal, Waterman, Ill Es labllshed 1403: Drlrate: 6 beds: Carl II Wliklason, bysiclan In cliarce.

\section{Waukegan}

Jane Medllsier Hospltal, Waukegan 111. Listablished 1002; 50 beds: Miss $M$ J. IItll. supreplntendent.

lake Hreeze Sanatorlum. under ausplces of lahe counis Tulvercilosls institute. Wauhegan. HII. Éstabllshel 1908; tuber. culosls; 40 beds: W. H. Watterson, met]cal superlatendent.

\section{West Chioago}

Convalescent Ilome for Destltute and Cripuled chlluren, West Clateago, [1] (li. E.ll. 2); 50 beds: Miss lutule, superntendent: branch of llome for bestitut 'rippleyl 1 huldrea. Chlcago.

Wheaton

Niallonal White Cross Leanue Tuberculosls Sanltarlum, Wheaton, III. Established 1913 ; tulereulosls; 20 beds; D. C. Mould Iug (thlcage), phylclan in charge.
Winfeld

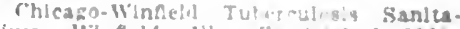
rium, Wintleld, 111 f. 3...alied 1904

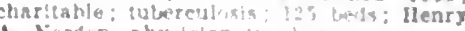
1. Sordea, physiclan in ihaphe.

Winnetka

North Shore Ileallh Pesurt. Wincelva 111. Fistablished 1901: chronir diseaves: go beds; rred C. Korats, zindical direcbop. Woodstock

Chlcago Industrial Home for Children. Wundstock, III. Estublished 1589: 50 beds: W. l". lertes, auperinterdent.

Woodslock Hospleal. Houdsuck IIt ks tabllshel 1903: zeneral: 10 beds: Hude West. chlet surgeon; Ida W. West, $4 \mathbf{X}$. superlatendent

Zeleler

Zelgler Hospltal. Zelgler, HI. Establistel 1912; general: 24 beds: J. B. Moore, medical suberiniequeat.

\section{PHYSICIANS OF ILLINOIS}

KEY TO ABBREVIATIONS, SYMBOLS, ETC.

rames In capltals slgnify membershlp In the County Soclety and State Associa. Ulon. (DOE, JOHN).

Indleates Fellowship in the American Med. Assn. (DOE, JOHNA) (D'is) Year of blth. ir homeclectlc; P-II, physlo Jear of graduatlon.

- Information recelved does not show grad untion.

\section{S.-Surgeon}

ob-Obstetrician.

ObG. Obstetriclan, Gynecologise

6. Gynecolostst.

Or-Orthopedist.

Pr-Proctologist.

0p. - Ophthalmologlst.

A.-Aurist.

LR.-Iaryngologist, Rbinologlst.
(1'89) lear of license.

(3) In practlce before passage of presen law and llcensed hy flllug diploma or by rears of practice.

(1t) lilcensed but year not known.

(\#) information recelved does not show license.

U.S.A., Linited States Army.

M.R.C., U.S.A., Medical leserve Corps.

SPECIALTIES ARE INOICATED AS FOLLOWS:

ALR.-Aurlst, Isaryngologlst, Rhlnologtst.

OALR.-Ophthalmologlst, Aurtst, Laryngologlst, Rhlnologtst

U.-Urologlst

D.-Lermatologlst.

Pd.-I'edistrist.

N.-Neurologist.

P.-Pyschlatrist.
U.S.X., Unlted States Nary.

M.I.C., U.S.X., Medical lleserre Corps.

C.S.P.II.S., Unlted Siates Putllc Health Service.

Colleze postlons held are Indicated by abtrerlated title of posltion. fullowed by key number of collese. For key to colleres see laside front cover paze.

(A1,3, I16, C4) Membership in special socleties. (See Key Table, pare I:Z.)

NP.-Neurologlst, Psychlatrlst.

I.-Internist.

T. - Tuberculotheraplst.

Anes. - Anesthetist.

LD.-Iaboratory Dlaznoctelsa.

R.-Actiuolozlst, Ladlologts, Roentzenolo-

Path.- L'athologlst.

Bact.-Hacterlolosist.

WHEN THE ABBREVIATION REPRESENTING A SPECIALTY IS FOLLOWED BY AN ASTERISK (\$) IT INDICATES THAT THE PHYSICIAN CLAIMS HIS PRACTICE IS LIMITED TO THAT PARTICULAR BRANCH OF MEDICINE; WITHOUT THE ASTERISK. THAT HE IS ESPECIALLY INTERESTED IN. BUT DOES NOT LIMIT HIS PRACTICE TO. THAT BRANCH. THIS INFORMATION CONCERNING SPECIALTY IS BASED ON PERSONAL DATA FURNISHED BY THE PHYSICIAN AND IS NOT VERIFIABLE.

\section{ILLINOIS}

ABINGDON, 464, KNOX

BELLWOOD, WM. S. (b'66) - 111.1 .95 (1.95).

BRADWAT, CHAS. F. (b'50) Ind.8,'82 (1'82)

BRADWAY, EVERETT HAWORTH (b'78) -I11.6.05: (1,05)

ROWE, JESSET-IIL 1.94: (1.94)

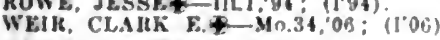

ADAIR, 300, MEDONOUGH

Hul, Edw. E. - Mo.28,06: (l'06).

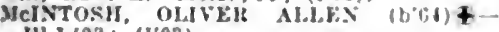

III.1, 03: (I'03).

ADDIEVILLE, 269, WASHINGTON

SCHMIIT, IIERMAN (b'i) $\$-M 0.27,95$ (1'95): OALR

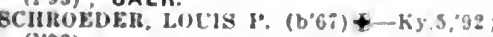
(1'92).

ADDISON, 379 , DUPAGE

Bruat, Fonll W, -Md.6."9s; (1.9y)

ADRIAN, 200, HANCOCK

SCOTT, YIRANK CISTTON (LDS) IA.10, 08; (1'09); OALR.

AKIN, 200, FRANKLIN

HERD, JUIS HMULY $(b, 40)+110:, 10$; (1'11).

ALBANY, 618, WHITESIDE

WMONI, STACY I3. $\left(\mathrm{b}^{\circ} 61\right)+$ I. 3.80 (18 89 )

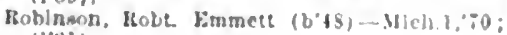
(l'8)
ALBION, 1,281, EDWARDS

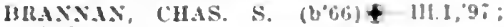

$$
\left.\left(l^{\circ} 9\right)^{\circ}\right) \text {. }
$$

MI1.LER, R01.1, S. (b'68)-Ky.2.'8s; (l'89) Moss. Harry A. (b's9)-Mo.1,9s: (1.09). MOTKR, Hoss L. (b's0)t-Mo.es,04 (1.04)

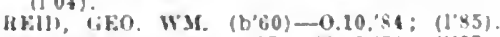

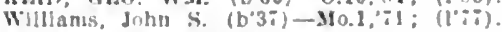
ALDEN, 135, MCHENRY

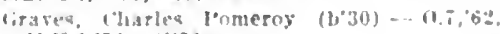
Nis?:it; (1'66)

ALEDO, 2,144, MERCER

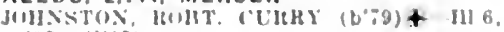
$0 \%$

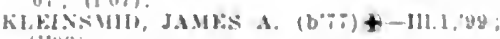
(1):0!

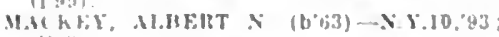
(1) $4: 31$

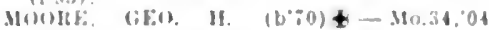

(l'04). Alт

(1.t.

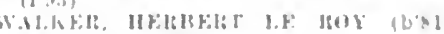
Ia 10,0$)$; $(100)$

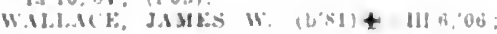
$(100)$ i

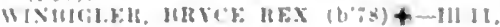
.116: 11.0(1)

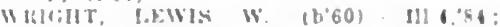
11) आ1

ALEXANDER, 200, MORGAN

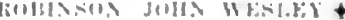

$$
\text { (1, } 00) \text {. }
$$

ALEXIS, 829, WARREN

CHOSIKK, WM. MCKLE ( ( ':J) \&-IIIII, $07:(1.07)$.

MCCUTCHAN, JAMES YIITON (b-33)Ia.1.68: (1ค\%).

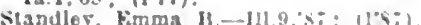

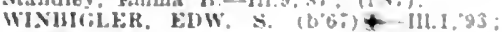
11 's3).

ALGONQUIN, 6\$2, MCHENRY

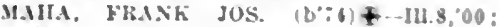

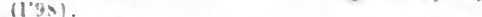

XAS(1. WM. AHLOT (b'L) $\$-111.6 .66:$

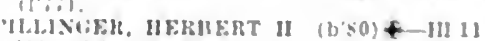
"0\&'; $\| 006)$ : OALR.

ALHAMBRA, 433, MADISON

FISH, WM. (ITTU (t'S) + MO 34.11 :

IIII) (1)

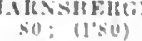

ALLENDALE, 500, WABASH

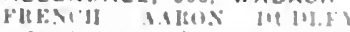

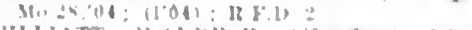

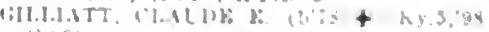

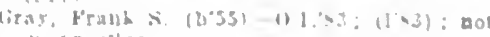
in practiee

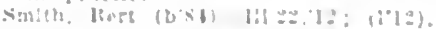

ALLENVILLE, :\$S, MOULTRIE

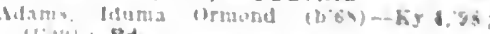

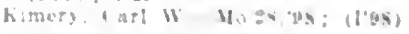

ALLEMTON, 379, VERMILION

Hardgan, Vhlidald (1) 
ALLISON (R.F.D., VINCENNES, IND.), 72, LAWRENCE.

Mesklmer, John A. $\left(b^{\prime} 43\right)-0 ;\left(1^{\prime} ; 8\right)$

ALMA, 380, MARION

IASWELL, SAMC, J. (1,74) -...Ind.9,9s: (l’08); 0 b.

ALPHA, 358, HENRY

Brown, James IIarry (6,72)-Neb,6,02; (l'04).

DANIELs, TIOS, IGH (b.54)-Ky.5, 85 ; (1'93).

ALSEY, I50, SCOTT

BOWMAN, GEO. W. (b'5s) -...to, 10,80; (l'80).

ALTAMONT, 1.328, EFFINGHAM

BAKEI, CECIL HFiH $(1,)^{\prime}(i)+-M 0.34$, 'I0: $\left(l^{\prime} 10\right)$.

BAKER, GEO. B. M. (b) (1.3) $+-\mathrm{Mo} 24,{ }^{\prime} 92$; $\left(l^{\prime} 92\right)$.

BING, FIIBERT AMSDFA $\left(\mathrm{b}^{3}, 6\right)+-M 0.34$, '06!: (l'06)

STFIN, IIENIY (b'69) +-Mo.1,'94; (l'95)

Wright, Chas. M. (b'ig)-Mo.2.02; (1'02)

ALTON, 17,528, MADISON

Bowman, l'aschall N. (b'66)-Mo.28,'99 (l'99).

Castle, Stanley (b'79) - 111.1,05; (l'05) not In practice.

COOK, EDGAl? ALLFN (1, 68$)+-111.1 \%$ 01: (1'01) ; 2621 College Ave. ; 2-4, 7-8. Daris, Chas.-Mo.2, 61 ; (1'7 7 ).

DAVIS, HOMEI WILLAI\}I (b'it) $\$-M 0.2$ ,00: (1'00); 1108 Gienrge St.; offlce, 21

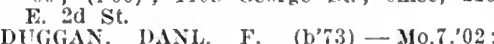
(1'02); 529 Sumnit st.; offlee, Commerclal BIdg.; $11-12,2-4,7-8$.

Enos, Edw. Wm.-11t.15,'10; (1'10); 325 E

$3 d$ 'st.

Fivos, WM. H.P-0.13,'80; (l'80); 325 E.

FIEGENBALW, JELIUS H. (b'59)-N.Y.10, 85; (1'85); ith and llenry Sts. ; oflice, 308 Belle st. ; 10-12, 2-4, 7-8.

FISCIIER, EDVI, FRFi)k. (b'82) †-Mo.28,

'10; (1'10); Judson and ('lauson sts.

FISIIEI? WALDO (b'57) 4 -Ill.1,'82; (1'82);

503 sunmit St.: offce, 120 iv. $3 \mathrm{~d}$ st.; $9-10,2-3,7-8 ; \mathrm{S}$

Fitzgerald, Robert A. (b'74)-Mo.7,04; (l'04) ; Plasl 13ldg.; $9-11,2-4,7-8$

Giberson, Oria Orton (b’81) - Mo.T,'05 (1'05); 538 E. 2d St. ; 9-11, 2-4, 7-8.

HALIMURTON, WESTLEY W. (b'53)€ Mo.1,78; (1, ;8); 200 E. 2d St.; $9-11$, $1: 30-4,7-9 ; \mathbf{U}$.

HASKELL, WM. A. (b'45)థ-Mass.1, 69 \%

(l'7 ?); rot in practice. No.2,05; (l'05) ; 531 Summit St. ; oftice, Conmercial Bldg.; $9-11,2-4, i-8$.

JOESTING, FREDK.' C. (b'78) (1'01); 1821 liberty St. ; offlce, $4 \mathrm{~W} .20$ St. ; $10-11,3-4,7-8$

JONES, FRED WADE (b'80)†-111.11,05 (I'05); 121 E. 2 d St. ; $10-12,2-5$; OALR. LEMEN, HAKRY R.\$-Mo.2,93; (1'93); 1247 W. 9 th St.; offlce, Commerclal Bldg. $10-11: 30,2-4: 30,7-8: 30$.

IERRITT, NINA POLSON - Ill.11,01 (1.02);612 Weigler St. ; 8-10, 2-4,7-8. $\left(1^{\prime} 02\right) ; 612$ Weigler St. ; $8-10,2-4,7-8$.
oore, Isaac (b'4)-MIo.2,70; $\left(1^{\prime} 94\right) ; 1501$

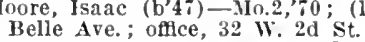

PAGEL, CHARLES W. (b' 71$) \oplus-M 0.10,96$ (1) : OALR.

PFEIFFEXBERGER, JAMES MATHER (b'i9) $\$-M 0.2,02 ;\left(l^{\prime} 02\right) ; 708$ state St. offlce, Times Bldg. ; 10-12,2-4; (A20); $\mathbf{S}$. Samuels, Geo. I. (col.) (b'84)-Tenn.7,09: (l'10); 1928 Marilla St. ; 9-11, 2-4, 7-8. Schaller, Robt. G. (b'49) -Ger.16,' 89 ; (1'90);

Q94 E. 5 th St.
SHAFF, JOHN N. (b'67) -111.1, $00 ;\left(l^{\prime} 00\right)$; 1511 Central Are.; offlce, Alton Banking and Trust Bldg.; $10-12,3-4.7-8 ; \mathrm{S}$.

TAPHORN, GERHARD (b'64) \&-Mo.2,'90 (1'90); 5th St. and Seminary Square office, 203 E. 2d St. ; 10-12, 4-6; S.

THRAILKIIL, JOHN S. (b'60) $\$$ - Io.10, '83; (1'S3); 1522 Henry St. ; oftice, Comnercial Bldg. $8: 30-10,1-2,7-9$.

an Wormer, Frank Burton (b'88) -Wis.3 (I'12): Linas Bldg.;

Wais, James Edwir (b'68)-110.10,94;
Watson, weos State St.

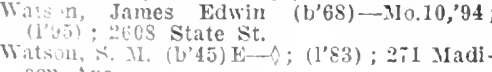
son Ave.
WLKINSOX, GLO. H. (b'68)-Mo,2,'98 (los); (Upper Niton); offce, 6 E. $2 d$ St. $10-12,2-4$

Winn, Chester A. (h'59)-IlJ.I.'89; (I'89) 641 F. 201 St. ; $9-10,3-4,7-8$.

Yorden, Frank (b'53) - Mo.2,76; (1'78) 2511 State st. ; $9-12,2-6$.

Worden, (ieo. Kent (b'76)-Mo.2,'03; (1'03) 3107 college Ave: oftce, Commerclal 13ldg. ; 9-I2, I-5 ; ObG.

Yerkes, Lathy I. (b'7t) - Mo.2,04; (1'04) Edwards and Mannling Sts.; 7-9, 1-3, 0-7.

ALTONA, 528, KNOX

FIION, CAIB]. J. (b'5t)-Ia.1,93; (1'93).

KFINEI, ALMERT CIIFSTEIS (b'73) 4

Ill.6,'It); (1'10).

ALTO PASS, 55I, UNION

(ilasco, Jesse $\left(b^{\prime}\right.$ '40) $\rightarrow$; (l'87)

IIALE. JOIIN A. (b'66)థ- Mo.24, 88

(1'88). JOEL KELIJEY (b'85)-Mo.28, '11; (1'I).

ALVIN, 3I9, VERMILION

Jonovan, Roscoe I'. (b'85) - Mo. i, $06 ;\left(I^{\prime} 06\right)$ Iloward, Geo. W. (b'49)-liy.5,

AMBOY, 1,749, LEE

WORNILASER, THOMAS FRANKLIN (b' 79 ) 4-Il1.11,08; (1'08); Nember Olilo state

SULLIVAN, EUGENE A. (b'76)థ-11.11,

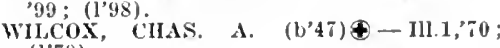
$\left(l^{\prime} 79\right)$.

ZEIGLER, CHAS. ARTIIUR $\left(\mathrm{b}^{\prime} 68\right) £-H 11.11$ 08; (1'08)

\section{ANCHOR, 250, MCLEAN}

Vaut Alstlne, (Fuy slierman (b'86)-111.6,'12; (1'12).

ANNA, 2,809, UNION

ABBOTT, EFFIE LOUISE (b'72)-111.I1, $06 ;(1,06)$

Eddleman, W. M. (b'58)-T'enn.6,'82 ; (1'82) Eddleman. Win. 1. (h'88)-Tenn.6,'12; ( ) Foster, Thos. R. (b'68)-Mich.1,'91; (1'91) GOODNER, RALPII ALLISON (b'64)-Ill.I, '88, P'a.2,'91 ; (1'88)

GREAR, D. WATSON (b'62)(-Mo.1,90; (1'90). E. VINCENT (b'69)-Mo.24,97: IALE, E. VITC

HALE, JANES I. (b'44)థ-Ill.6,'74; (l'77) Heilig, Geo. N. ( $\left.b^{\circ} 76\right)-\mathrm{M}_{0.28,02}$; $(1,03)$. KEITH, LEANDER D. (b'65)-Ky.5,'96 (l'96).

MARTIN, SIDNEY C. (b'כ1)๑-111.6,'84; (1'84).

MorRoiv, GEO. WM. (b'80)థ-Ill.11,'08; (l'08).

Norris, Saml. Brown (b'85) - 1ll.11,'08; (l'08).

Price, Jonothan-Tenn.6,'\$2; (1'82).

Rle.h, Thomas J. (b'45)-0.9,72; ( $\left.1^{\prime} 77\right)$

RITCHEY, ROMNEY MOORE (b', 6$)$-Ill. I 04; (1'04).

SABIN, FRANK A. (b'35)-Mass.2,'61; $\left(l^{\prime} 7 \pi\right)$.

SABIN, WALI.ACE EDGAR $\left(b^{\prime} 45\right) \oplus-N . Y .1$ '68; '1st Lleut., U.S.A., retired.

STEWART, JAMES C. (b'66)\&-Mo.7,'91: (l'9I).

WATERS, PHIIIP SHERIDAN $\left(\mathrm{b}^{\prime} 79\right)(-$ Mo.28,'03; (1'03) ; NP.

\section{ANNAPOLIS, 200, CRAWFORD}

Bartmess, Leonard Ernest (b'85)-11l.22. '12; (1'12).

Black, Hull M. (b'74)-Ill.22,10; ('11).

Burns, Fredk. John (b'75) H-IIl.4, 06 ; (1'06).

Davis, James E. (b'63)--Ill.1,'89; (l'89); not in practice.

Grifflth, Franklin J. C. (b'44)-0.8,'74; (1'78).

ANNAWAN, 398, HENRY

WEBER, ROBT.-111.11,'0T; (l'0T).

ANTIOCH, 682, LAKE

AMES, EDMOND H. (b'46)-Mich.3,'74; (l'84).

Beebe, Harry F.-IIl.10,'94; (l'93)

WARRINER, WINSOR W. $\left(b^{\prime} 74\right) \oplus-I 11.6$, '02; (1'02).

APPLE RIVER, 581, JO DAVIESS

BRINK, CHESTER ABRAM (b'70)-Ill.11, 93; (1'93); Menber Neb. State Med. Assn. ; Ob.

STILSON, JESSE M.-Md.6,95; (1'96).
ARCADIA (R.F.D., JACKSONVILLE), 65 , MORGAN

OBERMEYER, ALBERT EVERETT $\left(b^{\prime} 7 \overline{6}\right) \oplus$ -M0.28,'06; (1'06).

ARCOLA, 2,100, DOUGLAS

ALIEN, EIMER SIIEIMAN (b'65)†-IH.1, '95; (1'95).

BARNES, OMER FOUTZ $\left(b^{\prime}(65) \oplus-K y .1\right.$, '90; (1'90).

Johnston, Walter Scott (b'78)-Mo.5,'08;

IcCAIN, JOHN H. (b'69) $\$-K y .2,91$; (1'05).

Moser, Geo. Henry (b'59) H-Mo.5,'90;

POLK, JOHN I

(See Champalgn.)

Van Nuys, Franklln B. (b'65)-Inu.8,'89 ; (l'95).

AREA, 58, LAKE

Alverson, Geo. W.-F-Ill.8,'94; (1'95) : R.F.D.

ARENZVILLE, 518 , CASS

Crum, Geo. W. (b'48)-Mo.1,' '4; (1'78); STREUTEI, ALBERT FRANK (b'75) Ill.6,'06; (1'06).

SWO1'E, JOS. MI. (b'54)థ-Ky.2,'80; (l'80).

ARGENTA, 519, MACON

Freeman, Joel C. (b'80)-Ill.4,'03; (l'03).

THOMAS, EDW. H. (b'59) $4-$ X.Y.I,'83; (l'89).

ARGO, 100, COOK

BAICLAY, ROBT. DONALUSON $\left(b^{\prime} 70\right) \oplus$

SCOTT, ORLANDO FRANK (b'85)๑-Hll.1, $08 ;(1,08)$; $S$.

Shaw, Alfred Marion (b'80) - Ill.1,'10; (1'10).

ARGYLE, I50, WINNEBAGO

ELIISON, FIBANK EVHRETTE (b'84) $\$$ the State of lVis.

ARLINGTON HEIGHTS, 1,943 , COOK

BEST, BIUCE TAYLOR $\left(b^{\prime}, 6\right) \oplus-I 11.1,04$ (1'04).

Dyas, Webster M. (b'62)-Ill.1,'96; (1'96)

Elfeld, Edw. A. (b'68)-Mo.5,'01; (1'94).

GUNN, JANET

tuenkel, Arthur John (b'80)-Ill.11,'04; (1'04).

ARMINGTON, 327, TAZEWELL

KINSEY, ROY WALTER (b'80)-0.2,'10; (1'10).

ARMSTRONG, 300, VERMILION

HUGHES, GEO. W. (b'73)屯-I1l.17, 00 ; $\left(l^{\prime} 00\right)$.

ARPEE (NEW BOSTON P.O.), - MERCER

CRISWELL, MATTHEW (b'47)(-Pa.2,';6; (1'77).

ARROWSMITH, 366, MCLEAN

JOHNSON, LYFORD M. (b 80)-Ill.11,03 ; (l'03).

ARTHUR, 1,080 , DOUGLAS

EADS, C11AS. V. (b'71)-Mo.28,'99; (1'99); OALR.

Knodle, Ephraim A. (b'49)-Mo.1,93; (1'93). McDonald, Chas. Henry (b'77)-Ill.1,04; (1'04); not in practice.

MONROE, CHAS. WALTER (b'j6)-Ill.22, MONROE, DÓCTA ALML (b'i7)-J11.22,08; (I'08) : G.

PHILLIPS, FLOYD (b'77)-111.11,02; (l'02).

ASHIKUM, 4I6, IROQUOIS

Bemisderfer, J. Rowe (b'58)-Md.3,83;

(1'94); not ln practice.

Ernest, Wm. F. (b'58)-Ky.2,90; (1'90).

Muehlenpfordt, August-0; (1'77)

STRUTHERS, HERBERT RANKIN (b'73) -111.11,01; (1'01).

ASHLAND, 1,096 , CASS

GAILEY, DARWIN S. (b'76)-111.11,97 ;

GLEN (1'80).

IYONS, DANL.(-Mo.10,'83; (l'83).

Mekemson, Robt. N. (b'48)-Ia.1,'82; (1'93).

ASHLEY, 9I3, WASHINGTON

BERRY, SUMNER G. (b'6,5)-Ky.1,'86 ; (1'86)'

Foster, John T. (b'41)-lll.1,'68; (l’ 7$)$. 
HAGEBLSH, OSCAR JARIELL (b":8)Mo. 2,01; (I/03).

SANDFRS, CLALDF JACOB $\left(\mathrm{b}^{\prime} 82\right)-M o .34$, -66: (1'08).

ASHMORE, 511, COLES

ALLES, ORRTS THOS, (b'79) - 111.6,09: (1'09).

CARIBCO, PHESTON (). (b'62)-Ind.8,'91; (I'91).

ASHTON, 779, LEE

HREMMER, HENIR A. (b'51)†-111.12:86: (1'86).

Кrown, James $\left(b^{\prime} 31\right)-111,1,62:\left(f^{\prime} 78\right)$.

Cheadle, Clarence M. (b'bi) - 1a.9, '98; II'ys): 0 b.

PETERSMEYER, WM. (b"75)—-I11.11.98:

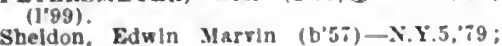
(1'79).

ASSUMPTION, 1.918. CHRISTIAA

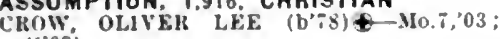
(1'03).

llarper, James kdw. (b'70) HI- Ill.10,99: (1'99)

Iloll, John F,-III.1,'84; (I'S4)

Johnson, Robt. Wesley (b'50) f; - 0.2,72;

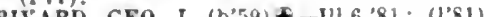

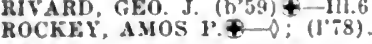

ASTORIA, 1,357, FULTON

BAXTEß, ALFRED J. (b'55) \$-Ia.1,'S0

$(1.80)$

Bonnel. Wm. Warland (b'35) $\rightarrow$ : (l' 78$)$.

BOTTORF, DANI, w. (b'59) - Mo.1,'99 ;

(1'99). (10.73)

Emerson, Edw. Paul (b73)-Mo.28,'98; (1'98).

1.0N6, JOHN POMFRE:T $\left(b^{\prime}, 6\right)$ \&-I11.10, 03 : (1'03).

Merrlil. Arabella (b'62)-Mlch.5.87; (1987)

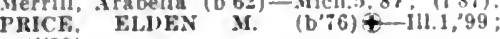
(1'99).

Toler, Thos. W. (b'70)-Ill.6,'92: (1'92).

ATHENS, 1,340, MENARD

BRITTIS, ALBHET LESLIE (b'62) \$III.1,81; (1'84).

BRITTIX, OLIVEK PERRY (b'84) †-Mo.28, 08: (I'0s).

IILL: TOLBERT F. (b'î) -111.1,96; (1'y6).

MUDD, WM. I. (b'47) -K5.2,70: (1'78)

ATAENSVILLE, 200, GREENE

Blllngs, Junlus S.-E-Mo.10;96; (1'96).

ATKINSON, 805, HENRY

CRFSS, MALTEK MEEKEK $\left(\mathrm{b}^{\prime} 60\right)-\mathrm{X} Y .5$ "93: (1'13); Member Med. soc. of State

Howlette, Geo. C.-Ill.10,'80; (1'80)

ATLANTA, 1,367, LOGAN

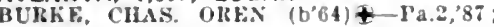

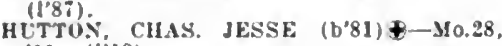

'11: (1'12). (b'55)-I11.1,88; (1'88)

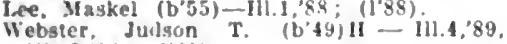
III.13,'96; (1'89).

ATWATER, 125, MACOUPIN

TROUT, W.M. A. (b'53) M0.1,91; (l'81).

ATWOOD, 659, PIATT

Abrams, James llenry (b'49)-Ill.1, 68 : (1०:8)

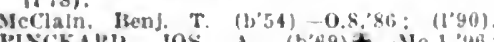

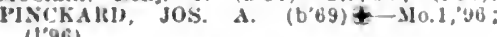
(1'96).

AUBURN. 1.814. SANGAMON

BUITTIN, KISHST HEIBBEHT (b'TA)-

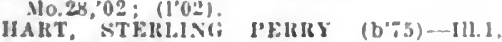

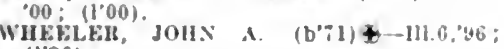
(1'96).

(1'00):

AUGUSTA, I,146, HANCOCK

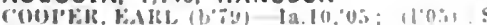

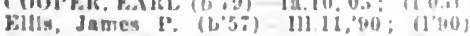

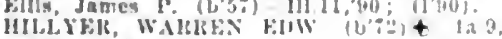
'98: (1'98)

\section{AURORA, 23,807, KANE}

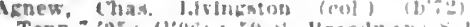

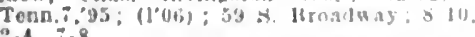

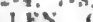

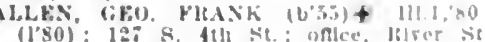
and Downer ly.; $y-12,2$; (IIs), OALR.

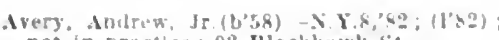
not in practice; 90 Hlackiuwk se

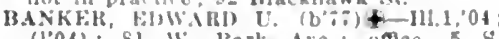
(1.04): 81 it, l'ark

Bartlett. Fred A. (i) ib) 11

$23 \mathrm{~S} . \mathrm{kg} \mathrm{Si}: 8.10,1.5$

23 S. Lake Si. : 8-10, $1-5$.

393 low 3. 11 o- -4 -

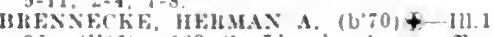
$96 ;($ f 96$) ; 123$ \&. Llneoln Ave. 15 Itronilway, 2-4, i-h: $(r+1): S$

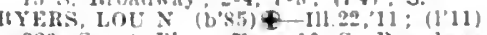
229 Grant $\mathrm{I}_{1 .}$; onlce, $10 \mathrm{~S}$. Broadway $11-12,4-4,7-3: 0 b G$

Caron. Wm. G. (b\%3)-111.1,97; (1*97); 66

X. Is roadway: $2-4, i-8$.

COLWEI, CHAS, k. (b'6t)-I11.4, $85^{\circ}$ (1'85): 150 s Lake sit. onlee, ¿3 s.. Lake St. $12: 30-2 \cdot 30,6: 30-8$

CoUGILIS, FHANCIS J. $\left(b^{\prime}, 6\right)+-111.6 .01$;

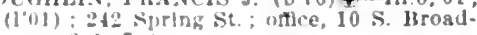

I'I Fill DAllwis DF IOS (b'6s) \&-

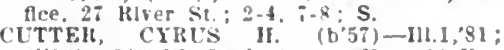

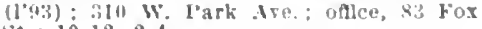
st. $10-12,2-1$

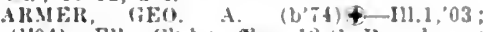
(1'04) ; Elks ('lub; oflce, 12 s. Broadway $9-12,5 ;$ OALR.

EXNEI, ROHT. STEVEXSON (b'\$3) \& III 1,$09 ;(1,09) ; 201 \mathrm{~S}$. fth St.; oftlce, 4 X. Itroadway: $2-4, ;-8: S$.

Dlenst, fieo. E. (b'us) 11-ill.14,98; (1'98) 374 Mapel Are.; office, 26 S. River St. $9-11,2-5$.

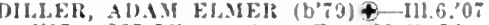
$\left(1^{\prime} 0\right.$ ) ; 225 lutherty st.: once, $26 \mathrm{~S}$. Rlrer St.: $9-12,2-5,7=9: 0 b$.

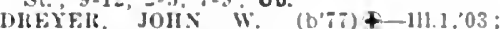
(1"03); 561 New liork st.; oftce, $25 \mathrm{~s}$. liroadiray ; $2-4$; 5

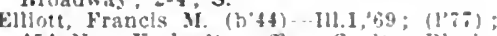
454 New lork st. : ofllce, Coulter Block; $10-11,2-5$

Encke, John J. (b'50)-Mich.1.'S3; (1'93);

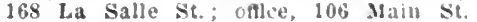
$9-12$

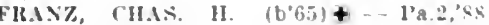
(1'89); 222 s. IAlncoln Ire.; oftce, $25 \mathrm{~s}$ Broadway; $2-4,-8.41)-0.2,75 ; \quad(1 ; 4)$ Gabel, Ilenry li. (b'4)-0.2,75; (1\%:); Garrey, John F. (b'ts)-111.1,7s:

19 S. Chestnut St. $\&-10,7-8$

GARKISON, FHEIK. FHANKLIX $(1,-5)+$ Ill.1, 04 : $(104) ; 53$ s. La salle si.

Geyer, Clarence w. (b"-8)-I11.6,01: (1.01) $350 \mathrm{~s}$. 1th st. oflce, 20 s. Broadway i $-10,2-4, i-8 ; S$

HAAN, GEO. W. (b'64)‡-111.17, $00 ;\left(l^{\prime} 00\right)$

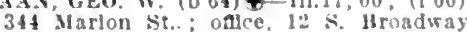

Hanna, Wm. Mc.11nue-111.1,86; (1'86),

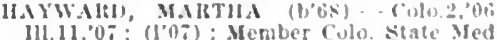
111.11,07; (1"07); Member Culo. Sitate Med Hynds, Jolun (b's0)-Mo.20.08; (1'12); 215 s. L.tucoln St. oflce, 106 Maln st. 9.12. Jacksun, Nicholas J. $(6,00)-111.16,10$ (1'12); 6 . B. Broadway ; 10-12, 2-4

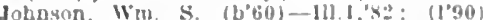
17 s. Spencer St.; oftlce, 100 Maln Sit $11-12,2-4,7-8,40$

JONRs, Wy. $\left.\left(b^{\prime} 60\right)+-111.11,94 ;(1)^{\prime} 95\right)$ 14: Maln sl. ; $9-12,2-4,7-4$

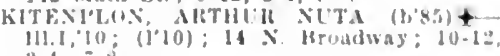
KNHIIT, WALY CAROLINH (b'49

"k2; (1.82) : siti llowner I"l. ; 1 .

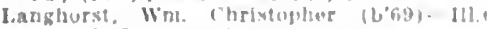
$3 \% ;(1.97): 040 ;$

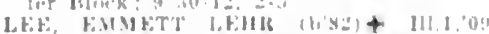

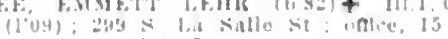

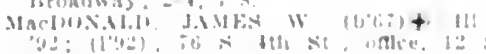

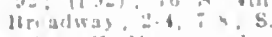

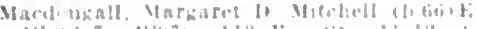

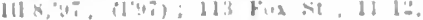

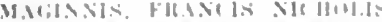

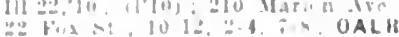

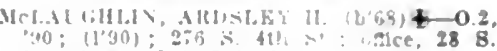
Hroadwas: $2 \cdot 4, i-x:$

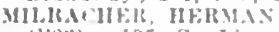

Cier 16,81:

(18. ) 13. S Llnein

Sorey, Andrew C. $\left(b^{\prime} 30\right)-1$

not in practice; 5es lafabt:

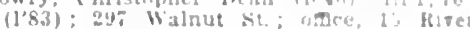
St. : $10-12,2-4$

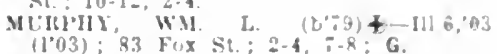

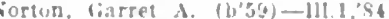

eyg X. Lake sit : P.

PARKER, ()ISSON s. (b'6i)-J, $1, " 92$ (1.93); 227 Spring st; 2-4, i-8

'HATT, JUIIN ABKAIIAM (b'Bs) क-Meh. 94: (1'94): 317 [monner 1'1.; ontee, Coul ter IH]ock; $10-12,2-5, ;-5 ;(H) ; O p$.

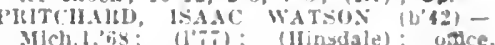
ierintle Ilock.

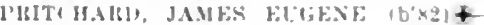
Mo.2,"1)8; $\left(1^{*} 0 \times\right)$ : Mercantile 11lock; $10-12$,

13PR (1002); 294 Liberty si. : $2-1$

REUEIR, NGGL'STLS ROLF (b':) \& Mo.2 91: (1'95): 15 s. May St.; offlce, 82 Fox st. ; 3-4.

Hice, Marrin S. (b'52) II-111.4,76; (1"76): $55 \mathrm{~N}, 4$ th, $\mathrm{q}_{0} ; 9-10: 30,2-4,7-8$

RICKEI, SUMNE!H J. (b'47) \&-III,'i1,

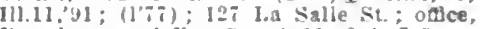
liroadreay and for st: $9-11,2-4,3-8$.

Rollins, Frank D. (b'tu)-Me.i, \$2; (1's5): (Drugzist); 119 Main st.

SClIWACHT(iFiN, (iFo, BANKER (b'84)Fis st.; $2-4, i-8$.

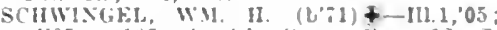

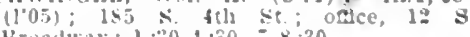

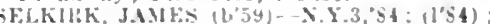
215 s. ineoln Are; once, $10 \mathrm{~s}$ Main St. $2-4,7-5$

IIEIMAN, IDAM EDW. (b'30) -IH.1, 03; (103); 425 S. tih st.; oflec, 108 OALR.

SIIEIMAN, WM. I'ALMLIR (b'63)+-IU.I, Sy; (1's9); $23 \%$ N. Lake st.

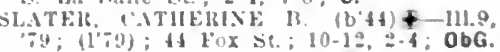

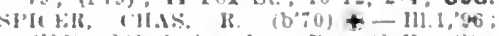
(1"96) : 201 Apring st, odice, sy for se: $\pm-4: P d$.

STLLBS, FIW, W. (b'63) +-Mo, 27,97 $\left(1 y^{7}\right) ; 207$ siemtrisy Are. omce, 106 Isaln st. $11-12,0-1,7-5 ; 0 b$

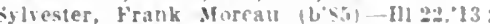
(1.13): II!kbland l'ark

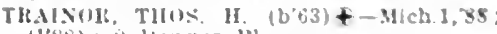
(1'SS): y lowner l't

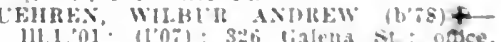

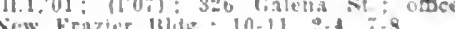

venu, Walcer T.

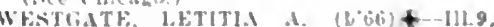

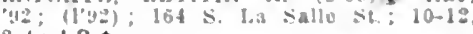
$21 ;$ LD.

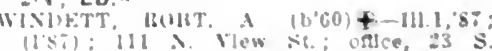
liver st: $10-11,2-4$.

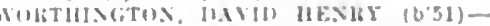

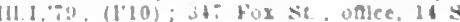
Irroalus: $\mathrm{G}$

AVA, 760, JACKSON

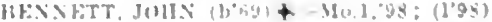

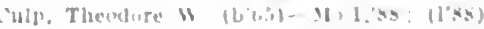

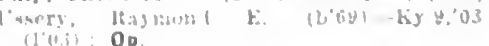
AVISTON, 39\%, CLINTON

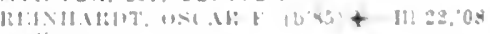

A VON. 865. FULTON

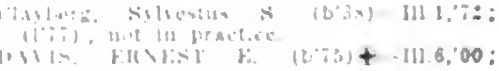

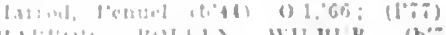

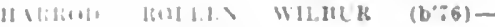


l'elrsol, Wlllard G. (b'51)-0.11,76; (1'75): R.F.i. 4

Wearer, Darld P. (b'49) Er-0.2,86; (I'86) BAILEYVILLE, 400, STEPHENSON

Carpenter, Fidwin A. ( $\left(b^{\prime} 46\right)$ - ll1.1, $75 ;(1,7 i)$ BALCOM, 9C, UNION

Granay, Thomas 1. ( $\left.\mathrm{b}^{\circ} 67\right)-110.27,92:$ (1'92) BANKLICK, 14, SALINE

Dorrls. Jos. 1. (b'5s)-Mo.7, 94 ; $\left(1^{\prime} 94\right)$

BANNER, 50, FULTON

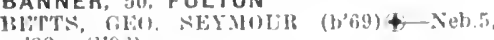

BARDOLPH, 285, MCDONOUGH

HENDRICKS, W.M. W. (b't2)+-0.3,9 $\left(10^{2}(5)\right.$.

BARRINGTON, 1.444, COOK

BICIALISOA, DAVIR HOHART (b'a3)III.1.'82; (1's2)

(IIENRS WHACHEIT,

BARRY, 1,647 , PIKE

I3EAYERS, CHAlbLES T. (b'67)†-111.6,99; (l'99)

BEAYERS, YIRGHL (h72)-111.6,98; (l'9s) COLLINS, VIETTA VOLA (bo 65$)+$ - III.II 03; (1'03); G.

Jolinsou, Chas. Albert (b's1)-Ia.10, 03 (l'03)

Iolnson, W'n. II. (b'55) - Ho.1,79; (I'84).

KAYLOR, THOS. D. (b'64)屯-Ia.9,'95 (1'95).

MAIN, RUFLY 11. (b'68)-M10.1,94; (1'94)

ICKINNEY, IOIN G.-111.1,68; (1'78).

BARTLETT, 408, COOK

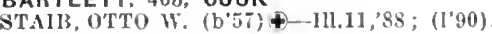

BARTONVILLE, 1.536, PEORIA

BORIX, W.I. A. (b'66) + -Tenn.9,91

wrllians, Ilerbert Lewis (b'83)-111.6,09; (l'09).

BATAVIA, 4,436, KANE

AUGUSTINE, JOIIN C.-IIl.8, '76; (l'77)

BOTIINELL, ROY S. (b'70)屯-Ill.4,90 $\left(l^{\prime} 90\right)$.

Brown, Manile Isabel (b'81)-Ill.11,'11; (l'13)

DANIELS, FRIEN. II. (b'55)-Me.1,82; (1'93); NP.

Howard, Irwil Wilson (b’78) - 0.25, 04 (l'10); OALR

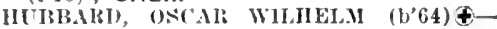
III.17,'98; (1'48).

JOIINSON, CHAS. B. (b'6i) $4-$ Ill.1,92 (1'93).

McIntyre, Annefte II.- III.22,'13; (1'13)

PATTERSON, JOHN C. (b'49)£-n1.6,72 (1'78).

SIPECER, ANNIE W. (b'59)-Ill.4,96; (1'36).

WEST, JOHX CHAS. (b'79)-Ill.I, 02; (1'02): (D2).

WHITTEN, IIARRY IIOOD (b'69)†-Ill.6 '96; (1'96); S.

BATCHTOWN, 300, CALHOUN

BERREY, ISAAC SOMERS $\left(b^{\prime} 56\right)(-10.1$

1UE 'S2; (l'S2). WM. Al.LEN (b'81)†-Mo.2,

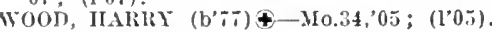

BATH. 475, MASON

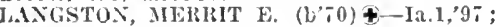
$\left.\left(l^{\prime} 9\right)^{\circ}\right)$.

BAYLIS, 385, PIKE

KUNTZ, W'SL.FY W. (b'75)€-Ill.6,05 $\left(1^{\prime} 05\right)$.

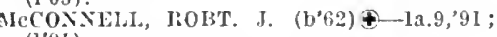
(l'a1).

BEARDSTOWN, 6,107, CASS

BLFY, GEO (b'51) 4-Pa,2,'81; (1'81)

BLEY, WALTER C., JR. (b'i)-Pa.2,00 (l'00).

CIIARLES, THOMAS GOODELL (b'87) III.6, 09 ; (1'09).

Chrhardt, Ilenry (b'53)-Mo.1.76; (1'78). c.AIR, ROY HENRY (b'十) \&-Mich.1, $0 \mathrm{I}$

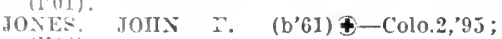
Kunz, Frank oliver (b'S3)-No.3,08; (1'13). PALALR, MARTIN J.4-0.2,'88; (1'89).
SCIIWELA THEONORE J. (b'69)-IH.I,

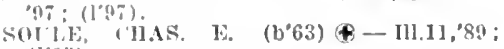
$\left(1^{\prime} 93\right)$.

BEASON, 300, LOGAN

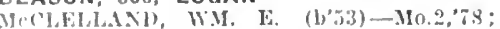
$\left(l^{\circ}, 0\right)$

BEAUCOUP, 70. WASHINGTON

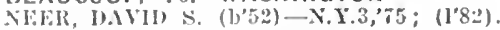

BEAVERCREEK, I50, BOND

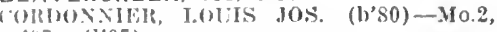
, $07:\left(10^{\prime} 07\right)$

BEAVERVILLE, 40I, IROQUOIS

REAHIIARD, JOSEP'II LAVIRY (h'72)Que.3.97; (1'06); Member Mlch. State Iled. Sac.

BEECHER, 543, WILL

Wh]ey, Mllehael R. (b'58)-Ill.1,'96: (1'96), Van Yorbls, Danl. Dewlit-lll.8,95; (l'93). BEECHER CITY, 543, EFFINGHAM

IBROOKS, HMERY WILBUR (b'76)€110.28,01; (1'01).

TINSLEY, WM. PIERCE (b'80)-Ky.2,07 ; (I'07).

BELINAP, 404, JOHNSON

Martin, Owen P. - Mlo.10,'T8; (l'78)

T'homson, Wm. (b'83)-110.28,09; (1'09).

BELLAIR, I00, CRAWFORD

Ferguson, Robert A.-Ind.4,'78; (l'78).

Kisner, Chas. II.-lnd.8,'95; (1'95).

BELLE PRAIRIE, 87, HAMILTON

L.ANT, CIIAS. 0. (b'T6)-M0.7,07; (I'07).

BELLE RIVE, $3 \mid 2$, JEFFERSON

Clinton, Johis E. (b'64) E-110.10,'96; (1'96) R.F.D,

Dulany, Isalah H. (b'3i)-- $\left(\mathbf{b}^{\prime} \mathbf{i} 8\right)$; R.F.D. KRIN(;. CHAS. H. (b'Ti)-Ky.9,04; (l'05). Neff, Iferry C. (b'66) -Mich. 7,87 ; (1'99). BELLEVIEW, 100, CALHOUN

Berry, Orland 11. (b'79)-MI0.28,05; (l'05). (6OODIN, GLO. J. (b'83)-1a.10,07; (1'09). BELLEVILLE, 21,122, ST. CLAIR

AUTEN, FRANK E. (b'63) \&-Pa.I'95; (1’97)；207 East 1) St.; office, First Natl. Rank 13ldg.; 9-11:30; 2-4:30; (B1): OALR.

Bahrenburg, Wm. (b'60)-Ill.4,'84; (l's4) 223 E. Main St.

BECHTOLD. LOUIS J. (b'48) - Mo.2,'71

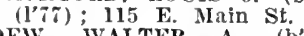

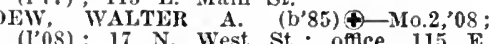
(l'08); $17 \mathrm{~N}$. West St.; offlce, $115 \mathrm{E}$ Main St. $10-11,2-4,7-8$.

DUEY, DÉLMER R. (b'84)€-Mo.2, 08 ; (l'0S); Maln and Kirkwood Sts. ; 8-9, 1-2, Eales. Irving J. (b'60)-Ill.5, 03 ,

Main and Spring Sts.

FRFIY, HARRY JOSEPH (b'84) 08; (1'08); $\mathrm{S}$.

GINY, ALLEN B. (b'47)-Mo.1, 75 ; $\left(1^{7} 77\right)$; $500 \mathrm{E}$. Ist St. ; $9-12,4-6$.

GUNN, JOHN C. (b'76)૯- $\ 0.2,00 ;\left(l^{\prime} 00\right)$ 500 'E. Ist St. : $9-12,2-4 ; 0$ p. $\star$

HANSING, ADOLPH E. (b'55) $\rightarrow$; (l'94) 621 F. Main St.; offle, Michael's Drug Store: $8-10,3-4$.

IHLCARD, GEO. E. (b'76)థ-NI0.2,97; (l'97) : $208 \mathrm{~S}$. Illinois St.; 8-9, $1-3,7-8$

Iloffman, John $\left(b^{\prime} 80\right)-110.7,10$; not in practice; R.F.D. 2.

IIUGGINS, CHAS. 'R. (b'62)-Mo.27,'92 (l'94); 517 Park Are.; offce, $101 \mathbf{E}$. IIain St.; 8-12, 4-6.

IRv'ls, EDW. M. (b'69)-Mo.1,92; (l'92) ; First Natl. Bank Bldg.

Kíssel, Andrew-Ho.1,'8I; (l'98); 2200 W. Main st.

Koht, Arthur M. (b'72)-Ind.8,'96; (l'96): St. Charles st.

WNE, WILLIAM B. (b'82)థ-Mo.34,06 (1'06); 404 Portland Pl.; offlce, Main and Sipring sts.; $10-11,2-4,7-8$.

MASSIE, JOHN GORE (b'T5)-MO-1,98 (1'98); Arery Sta., Bock Rd.; office, 1919 Ii. Main St.; $\mathrm{s}$.

OTRICH, GROVER CLEVELAND (b'84)\& Ill.11,'08; (l'08) ; $211 \mathrm{~S}$. High St. ; offtce, Commercial Bldg.; ; $9-12,2-4$; ALR.`

PORTUONDO, BUENAVENTUA H. $\left(b^{\prime} 66\right)$ (4-N.Y.1; 9 ; $\left(1{ }^{\prime} 94\right) ; 203$ Abend; $1-3,7-8$ RAAB, ERNST P. (b'59)€-Pa.1,'81 ; (1'82) 301 S. High St.; $8-9,2-3,7-3 ; \mathbf{G}$.
IRIYHIL, CHAS G. (b'59)-Mo.2,'82; (1'83) : 602 S. Jackson St.; office, 31 E. Iialn St.

REIS, HENRY, JR. (b'il)-D.C.1,00; (1'02); I21 \&. Mace St.; offlee, Maln and Spring Sts. ; $+11,2-5,7-8$.

lenner, Chas. l'. (b'81)-110.34,04; (1'04) ; 8 s. Chureh st.

REUSS, ALHERT IEROY (b'S0) \$-Mo.2 03: (1'03): 315 Wabash Are.; offce, II BOH.MTS, HLBLA? (b'52) — - Mo.1, 80 ;

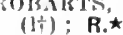

SCIIFFi, ADOLPII M. (b'5I) 4 -Ger. 16,76 ; (1'T); W. Maln and Longfellow Aves. : offle, 16 E. 2d Ave; $7-8,1-3,7-8$.

STARKEL, CHAS. H. (J'62) \$- III.1, 84 ; (l’84) : 119 S. Charles St.; oflce, $11 \mathrm{~s}$. Chureh St, ; 9-10,3-5; S.

TWITCIFLI, BENJ, F. (b'67)-Mo.10,'91; (l'91) ; 16 S. Hlgh St.; offlee, 14 s. ligh TWITCHELL, JAMES W. (b'69) $4-M 0.27$, 98 ; $\left(1{ }^{\prime} 98\right) ; 615$ East $\mathrm{A}$ St.

WANGELIN, HUGO E. (b'68)థ-MIInn.4,'91 : (1'92); 416 N. Church St.; 1-4.

WEST, WASIINGTON, JR.' (b'76)-Mo.2, '97; (l'98); 121 S. High St. ; office, $31 \mathbf{E}$. Mlain st.; $9-10,2-3,7-8$.

BELLEW0OD, 200, COOK

IOS1YN, LESLIE BURRITT. (See Maywood.)

BELLFLOWER, 394, MCLEAN

COPENHAVER, JOHN HARVEY $\left(b^{\prime} ; 6\right) \$$ Ill.11, 03 ; (1'03).

Harris, Harvey Lindsey (b'46)-Ill.1,75; (1'77).

BELLMONT, 550, WABASH

BRIAN, CHAS. FREDK. $\left(b^{\prime} 80\right) \oplus-M 0.28,{ }^{\prime} 05$; (1'05) ; S.

BRIAN, MATINA TANQUARY-Ill.11, 04 ;

BELVIDERE, 7,253, BOONE

ALGUIRE, ALDEN (b'65)@-H1.1,'97 ; (1'98). Al.GUIRE, ANNIE B. MCCALLUM $\left(b^{\prime} 68\right) \oplus$ -Ont.3,'95; (1'98); NP.

ANDREWS, ROBT. B. (b'72) $\oplus-\mathrm{H} 1.10,96$ : $\left(1^{\prime} 96\right)$.

Burt, Clarence Edward-Ill.11,'11; (l'11).

BU'TERRFIELD, WILIIS (b'48) $4-I 11.6,72$; (l'77).

DELAVERGNE， H. EUGENE (b'61)-Ia.9,

FOOTL, DANIEL E. (b'28)@-N.Y.8,51; (l' 77 ).

GANO, FREDK. F. (b'i 4$)-$ Pa.11,99; $\left(l^{\prime} 99\right)$.

ILAWKEY, WII. GEO. (b'65) - Ill.8,'98; (1'98).

MARKLEY, A. J. (b'58)๑-Ill.8,81; (l'81)

MeCRAKEN, CLARA BYWATER '(b'65)-

ICINNES, ROBT. WM. (b'57)థ-Ill.6,'84;

MITCHELA, ROBT. C. $\left(b^{\prime} 69\right) £-I 11.10,01$; (1'01): OALR.

Pluney, Ione $\left(b^{\prime} 87\right)-I 11.8,10$; $\left(l^{\prime} 10\right)$.

Stone, Chas. A.-Ill.10,77; (1'7\%).

SWIFT, ARTHUR W.'(b'60) - Mil.10,'85 ;

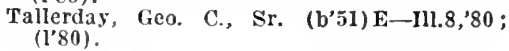

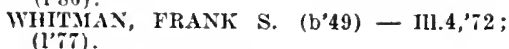

\section{BEMENT I.530, PIATT}

Fleld, Albert (b'T0)-Ill.14,04; (1'04).

MICPHERSON, WARREN GORDON $\left(\mathrm{b}^{\prime 75} \oplus\right.$ -Ill.11,01; (1'01).

Trabue, Albert L. (b'59) H-0.13,'81; (l'82).

Vance, N. Noble $\left(b^{\prime} 45\right)-0.1,68 ;\left(l^{\prime} 78\right)$.

WAID, ALBER'T LEROY-Ill.10,'99; (l'99).

BENLD, 1,912, MACOUPIN

RENNER, FREDK. ALEX. (b'78) \&-Mo.34, '06; $\left(1^{\prime} 06\right) ; \mathrm{G}$.

WN WORMER, WELLINGTON

BENSENVILLE, 443, DUPAGE

Riggins, I. Webster-Ky.2,07; (1'07).

BENSON, 362, WOODFORD

COTTON, WM. CLEMENT (b'82)థ-IIl.17, '10, III.22,'11; (1'11).

SEIDL, FERDINAND $\$-M o .7,94$; (1'94).

BENTLEY, 89, HANCOCK

SIIEETS, RAYMIOND F. (b'i9)థ-Ia.10, 08 ; (l'09). 
BENTON, 2,675, FRANKLIN

ALVIS, WALTER H. (b"ï)-M0.7,05: (1'05).

ALSTIX, EMGAR (b'69)-Ky.2,09; (1'09). BIbOWN, JOHN P. (b'43)+-Mo.1, '-8;

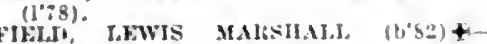
Mo.28,"11: (1"11).

llart, J. Okis $(1,-i s)-M(u .7,02:(102)$

llickman, Z. (b'46)-Tenn.1, $61 ;\left(\mathrm{J}^{\prime}-\mathrm{B}\right)$

Hudylns, Columbus M. $\left(0^{\prime} 52\right)$-Ind.2:79; $(1 ;-9)$

Hutson, Euphrales (i.-Mo, 1, is: (1'is)

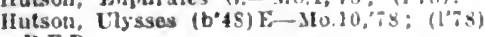

R.F.D.

Moore, Jos. F. (b'*9)--13.1,94: (1,96).

Polndexter, Kandall f. (b'62) - $111, b^{\prime}, 9^{20}$ (1'93)

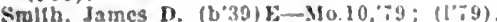

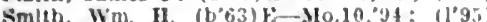

VISE, HoSEA A. (b's3)-110.7,05; (1'05).

BERWICK, ISO, WARREN

THUMISON, ELW. Is. (b'63) - IA. 1,92: (1.92).

\section{BERWYN, 5,841, COOK}

Good. (Geo. Wellington (b'88)-I11.16,08: (I'08) : (Lavergne).

HALL, WINHFID SCOTT

(See Chlcago.)

HINIS, ANXif-111.11,05: (1'05)

MacNFAL, ARTHE (b'6) $\$$-111.1, 92 (1.92).

Moe, Chester Chas. (b'84)-III.4,09; (1'00).

BETHALTO, 447, MADISON

MOOIS E, CHAS. A. (b'74)-MO.2i,'95; (l'95)

BETHANY, 859, MOULTRIE

HAMILTON, IIOWARD (b'67) -I11.11,95; (1'95)

TAYLOR, CIARENCE WM. (b'85)\$-K52.

'I2: (I'I2). JMES IUUBKT (b'61) -Ky.l. ด्: ; (I'91)

\section{BEVERLY, 100. ADAMS}

DAVIDSOS, WALTER E. (b'T5)-la.10,01;

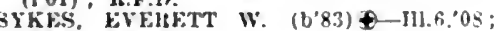
(1'08).

BIBLE GROVE, 200, CLAY

Falley, Ilichard I.-Minn.2,'sí: (l'93) ; Pd.

Shumaker, Evtralm Lutz (b'59) -0.9.'81

(1'81).

WEBSTER, F.SFER C. (b*:9) M0.34,05: (1.05)

\section{BIGGSVILLE, 400, HENDERSON}

Balles, John 1- Ia 1, :- : $\left(1^{*} ; 8\right)$

Ifenderson, Wm. I). (b'53)-0.3; ;8; (1'9)

BIG ROCK, 250, KANE

MABLON, NORMAX EDW. (b'SJ)G-H1111 08: (jos)

NASH, FIRAXK WYLIE (b'51)-N.Y.5,'87 (I'89): not In practlce.

BINGHAM, 191, FAYETTE

SHELTON, WILSON IS. + D: (I'SS)

BIRDS, 382, LAWRENCE

Indsay, Arthur llobt. (U.85) - I11.6,09 (109)

MONT(i)MERY, JOHS W. (b'76)-Ky,5,97 $\left(1^{\prime} y_{i}^{*}\right)$

THOUTT, ELIJAH $c,\left(b^{\prime} 84\right)+-M 0.7,0 \%$ (I.0i).

BISHOP HILL. 289. HENRY

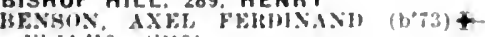
III. I1, 10: $1 I^{\prime \prime 10}$

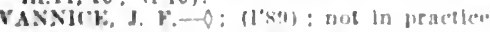

BISMARGK, 210, VERMILION

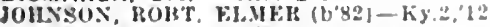
(1013): Member Ind. Silo Mel. A sai

Miller, saml Hosy-III.1,

Wultington? ico. V-III.I\%,03; (1.03)

BLACKSTONE, 250. LIVINGSTON

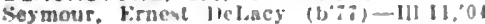
(1'04).

BLANDINSVILLE, 987, MCDONOUGH

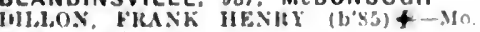
09: (1'10).

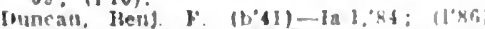

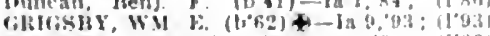

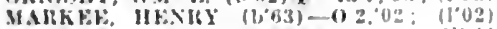

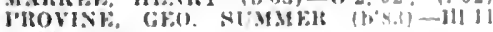
OOB: (I'Ó, BLOOMFIELD, I0\$, JOHNSON
IIALF, RICIIALI AIONZO (1'94)
BLOOMINGTON, 25.768, MCLEAN

HATI! THOS. W: $(1,0,5)+-M 0.7 .92 ;(1,92)$

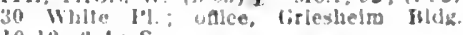
$10-1: 2.4 ; 5$

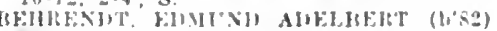

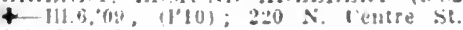

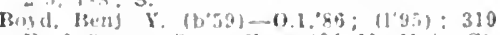

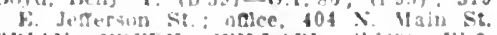

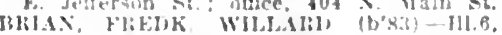

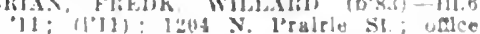

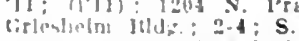

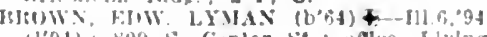

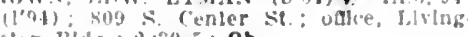
stur riki: ; $2: 30-5 ; 0$ b.

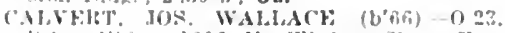

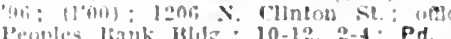

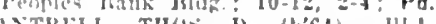

(1)

helm isidis. : $2-4$.

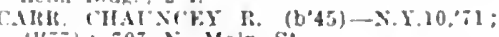
(10:3): 07 N. Main St.

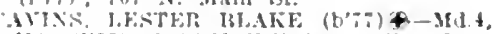
ot: (100-); $1105 \mathrm{~s}$. Fell are.; once, l'eo. ples Rank Bldg. ; -5 ; 1.

CHAl'S. rHAs. H. $(1,66)+-11.1,91$ : (1.11) : 52.2 E. (thestnut St: oftce, Grieshelm 1bldg. : 2-4.

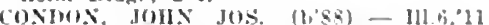
(l'll): 505 X. lioosevell Arc. offce, Peoples lbank Bldg. ; 11-12, 2-4, T-8.

COVINGTUX. ELtiFit: GRAY (cul) (b'2) f-11.C.3,99; $(1 " 46): 410$ F. Warket St.

CURI:Y, ALPIHA BHRNICE (b'69)-Ia 10 , 03: $\left(1^{\prime} 03\right)$; 107 E. Locust St.: offce, Inify Hldg:; $\mathrm{G}$.

D. COSTA. AlHEHT R. JR. (b'7z) Ill. 10, 00, Ill.4,05; (1'00); 202 s. Kooverelt Are.; oflce, Grieshelin Bldg. : 10-12, 2-5; U. $\star$

VLTEK, HORACF W. (b'59)-Yo.28,"93 (l'94); $303 \mathrm{k}$. Jefferson St. ; odlce, Durley Bldg: : $11-12,2-4$.

relts, Thomas oscar (b'09) - Mo.2s,98:

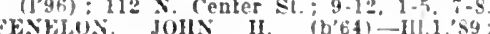
$\left(1^{\prime 45}: 311\right.$ E. Locust st.; oflce, Grles-

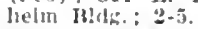

FINIE, FRANK C. (b'ts)-111.11,03: (1.03); $503 \mathrm{~F}$. Jefferson St.; offce, Ciries. helm Hldge: 2-4.

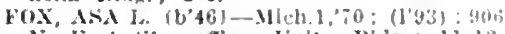
N. Fast st.; oflce, Lntty BIdg.: 11-12 rox HAIIII D. (b'-7)+-.11ch.1,03 (l.04): 905 x. East St.; onlee, Lnity Hldz:; $10-12,2-1 ;$ OALR. *

PREFIII, ASA is (1) $(1,07):$ : 04 s. Woodland dre: ofice Gisleshelm Holg.: :-4:30.

F[LWHER, JOHS WATERE (b'67)-III. 96: (lowi); fils k. Walnut st; onlce. P'eopley bank lidg.

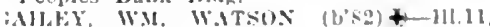
int (lot): 10: Falrilew Are.: omce lirleshelm lids: $9-12,2-5$; IIti).

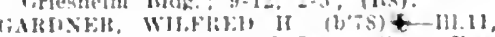
.03; ([03) : 1001 r. Jeterson si : ualce,

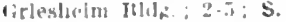

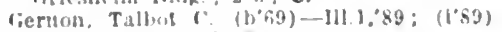

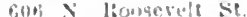

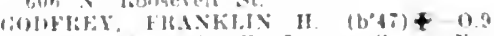

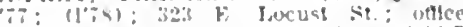
The l.Jingtum: in 1: $1: 30-1$ OALR

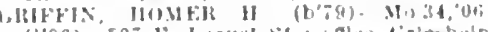

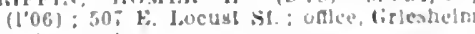
[itde : $:-1$

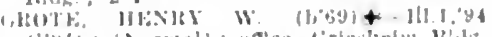

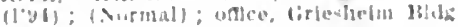

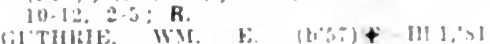

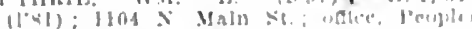
linuk IBIdg: i-i: S.

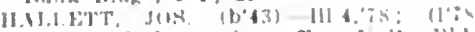

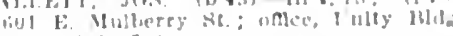

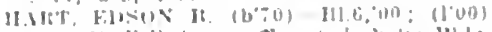

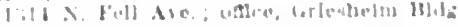

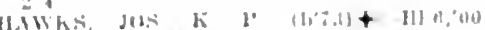

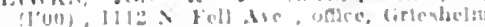
Ithd :-4: s.

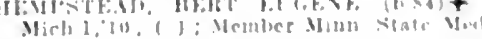
Mirl, $1,19,1$ 1 : Memler

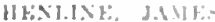

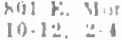

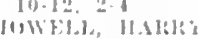

(1)il): 4l.

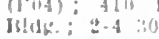

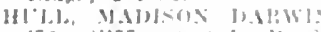

fice. Tritey Hul :

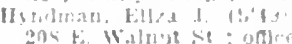

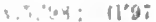

hein Bldz.

$+111 ? 04:$

कीष $\mathrm{t}$. W.2ln

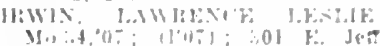

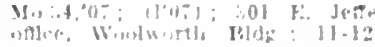

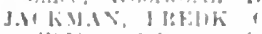

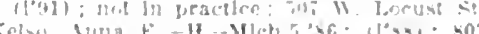
II Int?

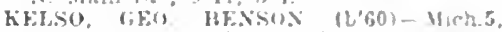

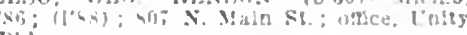
Ind

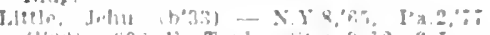

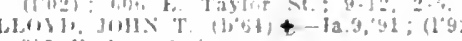

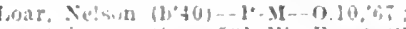

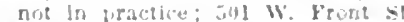

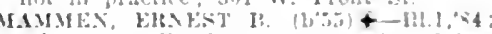

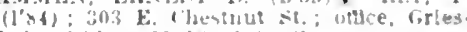
heju Mhls : 11-12,

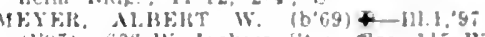

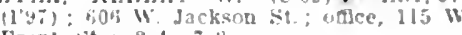
Front st. ; $2-4.7-8$.

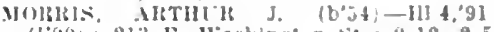
(1040); $213 \mathrm{~K}$. Wastulngtun si. : 9-12, 2-5.

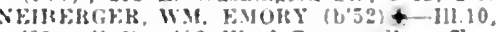
'se: (1.42): 402 w. Jeaterson Sl. ; odtce.

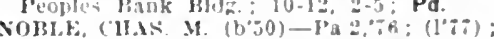
not In bractece: 1319 \%. Cirose si

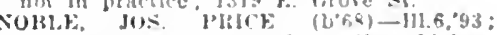

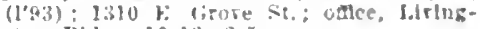
ston Inde: $10.12,0$

NOBLE, IHOBT. AYFHX $\left(\mathrm{b}^{\prime}: 3\right)+-111.6,01$ : (l०01): 1t0ij k. Washington st: oxce. Inlly' IBldz: $1: 39-5:$ S.

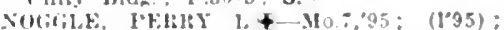
505 - State st.; onle, liriesbelm Bldz: $1-i ;$ OALR.

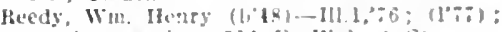
not In practlec; $514 \mathrm{k}$. Walnut s

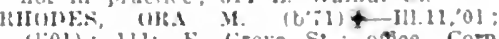
(101): $111 \%$ b. Cirote st, Omce, Corn

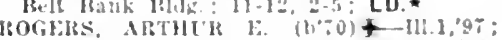

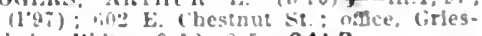
helu itda: : 9-12,205; OALR.

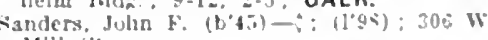
Mlll sit.

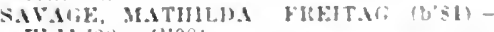

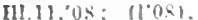

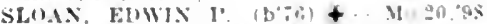

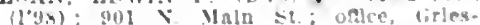
helm kidg: 2.4: S.*

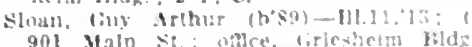

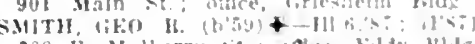

209 F. Mullerry

i1-10, 20

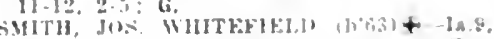

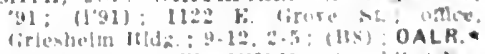

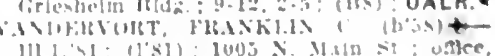

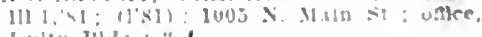

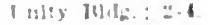

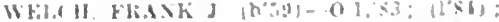

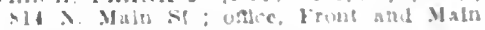
Sis. : $11 \cdot 12: 1,0 \mathrm{Bg}$.

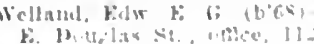

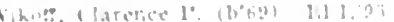

OALR. *

(inter

v(ilitis.

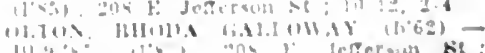
int

(i)

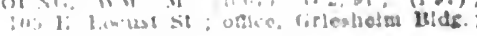


BLUE. ISLAND, 8,043 , COOK

$11.11 \mathrm{H}$, CIIAS. G. $\left(\mathrm{b}^{\prime}, 0\right)(6)-I 11.1,02$; Dollin, Haw. (b'66)-II1.11,90; (1'90) Gilian, louls Wm. (b'83)-111.11,0\%

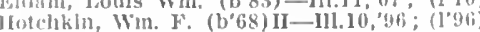
James, IRoht. Jee (b'65)-I11.10,90, 111.11

KAl1/FUAN, JACOB S. (b'53)t-Ill.1,75

KAUFFIIAN, JWSSE IZOBINSON-111.1,0

(1'07); Asst. I'rof. Surg., I11.22

Mccord, Frances-lli, $05 ;$ (I'05); (l'05) ALR.

SFIM, GFRILARD S. (b'65) + -Ill.11,"92 (l'93)

Seyforth, clarence A. (b'81)-IIl.6, 06 ; (市) BLUE MOUND, 900, MACON

MA'TTILW, JOLN B. (b'50)-Mo.10,'75;

MOFFETT, WM. T. (b'6i) Ill.1,95; (1'95). Iontgomery, Cllnton I. (b'67)-Ill.1,'95 (1'95).

BLUFFS, 766, SCOTT

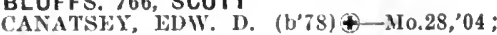
(l'04).

EVANS, CHAS. A. (b'69) -Ind.8,'96; $(1 ' 96)$

BLUFORD, 150, JEFFERSON

Taylor, Grant J. (b'68)-Mo.28,'95; (l'96). BOAZ, 14, MASSAC

SMITII, ALVIN-MO. $7,9 S$; (1'98)

BOGOTA, 90, JASPER

HAMILTON, JOHN L. (b'66) †-Mo.28,'01 (1'01).

BONE GAP, 517, EDWARDS

Kitchen, J. Edward (b'49) E-0.2,'77; (1'77) ICCORMACK, JAMIES L. (b'65)@-Mo.7, '92; (1'92).

BONFIELD, 162, KANKAKEE

YEATES, WA.-111.11,'02; (1'02)

BOODY, 275, MACON

Calhoun, Greer O. (b'56)-Md.4,'86; (l'86)

BOURBONNAIS, 611, KANKAKEE

Morel de la Durantaye, Chas. T. (b'57)Ont.4,'88; (l'91).

BOWEN, 606, HANCOCK

FOLCKEMER, IIARRY R. (b'80) $\uparrow-I 11.11$ '05: (1'05).

HUMPIREY, DAVID W. (b'7\%)థ-Ia.10, 05 ; (1'05)'

BRACEVILLE, 97I, GRUNDY

CAREY, JOIIN F. ('b'61) \$-Mo.7,'95; (1'95)

BRADFORD, 770, STARK

Chrlsman, Wm. I). (b'71)-Ill.6,96; (l'96) MITCH ELI, WW. C. (b'74) 4 -Ḿ (1'04).

Shaw, Gllman G. (b'41)-Pa.1i,'66; (1'7i)

TERWILIGER, VIOLA E. SHAW (b'71) Ill.9,'98; (1'99).

BRADLEY, 1,942, KANKAKEE

GOODWIN, ANDREW J. (b'79) \&-IIl.17, 07 ; $\left(l^{\prime} 0^{-}\right)$.

Magrúder, Noah- 0 ; (l'88).

BRAIDWOOD, 1,958, WILL

Arnold, Romus-H-Ill.4,88; (l'88)

ELDREDGE, RICHARD LEONARD (b'66) -Ill.11,03; (1'03).

BREEDS, 100 , FULTON

GRAY. WM. B. (b'58)@-I1.1,'87; (1'87).

BREESE, 2,128, CLINTON

BECHTOLD, WM. G.-MO.1,'84; (1'84)

DRAKE, WII. DAVID (b'64) 4 -Mo.34, 08 ; (1'08)

Kuhls, Frank George (b'76)-Mo.2,'98;

MORONY, JAMES J. (b'65) Mo.27,'95; (1'9\%).

BRERETON, 800, FULTON

REAGAN, THOMAS HAROLD (b'90) Ill.11,'12; (l'12).

BRIDGEPORT, 2,703, LAWRENCE

Jones, Chas. L. (b'74)-Mo.28,'03; (l'04). I.EWIS, CHAS. MARIUS (b'67)-Ind.5,'98; MANGUI, WM. ROBT. (b'72)-Mo.7,'98; SCHRADER, JOHN F. (b'68)(-Ind.8,'95; THOMPSON, JOHN RICHARDSON $\left(b^{\prime} 78\right) \oplus$ -Ky.5, ${ }^{\prime} 02 ;(1,05)$
BRIGHTON, 595, MACOUPIN

AS11, J(OIN ROSCOE (b'67)-Mo.24,80: (1) ,

IIOIBNi, TIIOMAS A. (b'58)-Mo.2,79; (1'?9).

BRIMFIELD, 576, PEORIA

lllley, Ilenry IR. $\left(b^{\prime} 48\right)-0.0,72$; $\left(1^{\prime} 77\right)$.

IKOIBER'l's, ROY J3. (b'75) - Mo.22,97 Ill.1,'09; (1'97)

TATE, LOUIS NEILI, (b'78)૯-I11.1,05; (1'05).

BROADLANDS, 480, CHAMPAIGN

DICKS, TIIOS. A. (b'67) $\oplus-\mathrm{M} 0.20,{ }^{\prime} 92$; $\left(1^{\prime} 92\right)$.

BROADWELL, 246, LOGAN

PERRY, LFWIS M. (b'36)†-Ky.2,'68 (I'78); ObG.

BROCTON, 558, EDGAR

Hale, John $\mathbf{Y}$. (b'78)-Ill.17,'08; (l'08)

HA NDLEX, CHAS. A. (b'68)-Ky.4,'94 (1'95).

KEIRRICK, IIENRY CLAY (b'60) -Ky.4, '87, Ill.1,'91; (1'87).

WHITE, JAMES OLIVER (b'59)-Ky.1,'93; (l'94)'.

BROOKFIELD, 2,186, COOK

Camp, Ella (b'71)-Ill.9,'90; (1'83).

HOFFMAN, ERNST IERMAN (b'83) Il1.6, 08: (1'08).

Winsett, clifford $\dot{\mathrm{V}}$. (b'78)-Ill.11,'05; (1'05).

BROOKLYN, 300, SCHUYLER

CAMIP, JULIAN E. $\left(b^{\prime} 58\right) \oplus$ - la.1,'80; $\left(l^{\prime} 80\right)$.

BROOKPORT, 1,443, MASSAC

ADKINS, ALBERT E. (b'59) $\oplus-M 0.1,87$; (l'87).

Young, Jolin D. (b'44)-Ky.4,74; (l'77); not in practice.

BROOKVILLE, 398, OGLE

BRIGHAM, CHESTER ROY (b'73)๑-Ia.10, 05 ; (l'05).

\section{BROUGHTON, 470, HAMILTON}

HALL, INMAN I, (b'77)-Mo.7,03; (1'03)

Organ, Jobn D. (b'46)-Ind.2,79; (1'87).

Osburn, E. Eugene (b'82)-Mo.7,04; (1'04).

BROWNFIELD, 85, POPE

FISHER, JOS. ALLEN (b'81)-Mo.34,'05: (1'05).

BROWNING, 55i, SCHUYLER

KINCHELOE, ENNIS W. (b'56)థ-Mo.1, '88; (l'88).

BROWNS, 419, EDWARDS

PARMENTER, GEO. H. (b'86)-Mo.10,'12; (l'13).

BROWNSTOWN, 4I5, FAYETTE

GREER, ALIBERT EUGENE (b'68) † Mo.27,95; $\left(\mathrm{P}^{\prime} 96\right)$

URNEY, LOAMMA E. (b'70)↔-Ind.5,'99;

Turney, Solomon R. (b'35) P-M-0.10,'79; (1:79).

BROWNSVILLE, 25, WHITE

GANN, JOS. HENRY (b'81)-Mo.34,05; (1'05)

BRUSSELS, 283, CALHOUN

LEWIS, CARL FREDERICK (b'84)-Ill.8, 09 ; (l'09).

BRYANT, 237, FULTON

AXLINE, CLARENCE E. (b'56)-Ky.4,'81; (1'91).

Harrison, Frank M.-Ia.1,78; (l'78).

BUCKLEY, 495, IROQU0IS

Bossart, Harry S. (b'65)-Pa.2,'86; (l'92). Schott, Darwin (b'79) H-Mo.5, 03 ; (1'03).

BUCKNER, -, FRANKLIN

Green, Lafayette (b'88)-Mo.7,'10; (1'10).

BUDA, 887, BUREAU

Bushee, Grant B. (b'64)-Ill.4,'87; (1'87). BYERS, EMERY MARCUS (b'72) -Ill.11, '98; (l'98).

Smith, Frank A. (b'76)-ll1.4,09; (l'10).

TAYLOR, JOHN F. (b'74) 4 -Ill.1,95: (1'95).

BUFFALO, 475, SANGAMON

Lutyens, Geo. Benj. (b'73)-Ml.11,06; (I'06).

(l'11).

BUFFALO PRAIRIE, 40, ROCK ISLAND

Marquis, Benj. Y. (b'72)-Mo.1,'98; (l’98)
BUNCOMBE, $150,10 H N S O N$

(iore, Thomas B.-Mo.7,89; (l'90)

NOBIES, CHAS. DAVID (b'80)\&-Mo.7, $05 ;(1,05)$

PICKLES, TOMM (h'53)-0; (1'89).

BUNKER HILL, 1,046, MACOUPIN

I3LFY, ROB'T. E. (b'55)-l'a.2,77; (l'78)

BLEY, LOBLR'T E., JR. (b'87)-Pa.2,10 $\left(l^{\prime} 10\right)$.

MILTON, FDWIN SPINNY (b'32)-0.30, $58 ;(1,77)$

Ilinkel, kdw. II. (b'57)-Mo.1,'82; (l'82). ROCKEFHLIER, LE MOY 1$)\left(b^{\prime} / 3\right)+-$ Ill.1, 00 ; (1'00).

BUREAU, 534, BUREAU

MCLAIN, JAMES II. (b'65) $†-\mathrm{Ky} \cdot 1,288$; (1'88).

BURGESS, 一, MERCER

Mannlng, Thos. F. (b'75)-111.11,02; (1 03).

BURKSVILLE, 25, MONROE

Kuehn, Otto M. (b'42)-Ger.16,64; (l'78); R.F.D. 1.

SCHELISCIIMIDT, ARTHUR F. (b'69)Ky.5,'92; (1'00).

BURLINGTON, 282, KANE

ROACII, DAVID C. (b'71) \&-Ill.6,94; (1'94).

BURNSIDE, 300, HANCOCK

OOMIIS, ROY R. (b'71) $\odot-$ Ia.10,'00; $\left(1^{\prime} 03\right)$

BURNT PRAIRIE, 350, WHITE

Goodrlch, Wm. Ray (b'80)-Ill.5,06; (l'07). Puckett, Alva C. (b'52) P-M-0.29,'80; (l'80).

BURTON, 106, ADAMS

LIERLE, GEO. A. (b'77)-Mo.1,'98; (l'98).

BUSH, 565, WILLIAMSON

Crawshaw, Henry (b'70)-Mo.7,'95; (1'95).

DEASON, FRANK (b'73) $\oplus-$ Mo.1,99; (1'99); $\mathrm{S}$.

BUSHNELL, 2,619, MCDONOUGH

DUNTLEY, GEO. \$. (b'79)@-Ill.6, 06 ; (l'07); OALR.ネ

Emple, Wm. Maxwell (b'88) - Ill.6,'11; (l'11).

GRIFFITH, JOHN C. (b'71)@-I11.1,'96; $\left(l^{\prime} 97\right)$

Hamliton, John W. (b'44)-Ia.3,'83; (l'81). LE MASTER, BENJ. E. (b'77) †-II.11, 04 ;

RIDER, CLEMENT J. (b'62) - Md.4,'93;

RITCHEY, GEORGE FENTON (b'84) Mo.2,'10; (l'10); Pd.

ROARK, JOHN PAUL (b'64) @-Ill.1,'89 ; (l'89).

BUTLER, 292, MONTGOMERY

Dyer, Almarian W.-0.3,'83; (1'89).

BYERTON (R.F.D., NEBO), 26, CALHOUN

Smyth, Alcinous-nil.12,'84; (1'84).

BYRON, 937, OGLE

Hall, Luther S. (b'50)-1a.1,'76; (1'93); not

in practice.

JOHNSTON, JAMES ALBA (b'59)-Neb.5, '94; (l'98)

THOMSON, STEWART CRAIG (b'70)Wis.2,97; (1'97).

Woodcock, Albert J.-Ill.1,'80; (1'80).

CABERY, 420, FORD

Mlller, W'm. M. (b'59)-Ill.1,'84; (['84).

CAIRO, 14,548, ALEXANDER

BARROWS, ROY. EDGAR (b'84)థ-Ill.6, '09; (l'09) ; Washlngton Hotel; offlce, 808 Commercial Ave.; 10-12, 1-3, 7-8.

BONDURANT, ALṔBEUS ALONZO (b50) - N.Y.10,75; (1'93); Bondurant Hospital;

BONDURANT, FLINT (b'85)๑-111.6,'09; $\left(I^{\prime} 09\right)$; Bondurant Hospital

CARY, SAML. B. (b'50)-Tenn.1,'81; (1'91) ; 612 Commerclal Ave.; 10-12, 2-4, 7 -8.

Clancy, Robt. E. (b'69)-Ky.2,'91; (l'91);

314,28 th St.

CLARKE, WM. C. (b'69)@-1ll.1,95; (l'95) 309,7 th St.; $\mathbf{1 - 3}, \mathbf{7 - 8}$.

DAVIS, HENRY A. (b'72) - -N.Y.10,96 : (l'97); 3401 Washington St. ; offlce, 612 Commercial Ave.; $9-10,3-4$

DODDS, SAML. (b'67)-Pa.2,'89; (1'89) 2040 Walnut St. ; offlce, Hallidáy Bldg. $9-12,2-5,7-8$

DUNN, JÁMES W. (b'63) $\oplus$-Tenn.5,"92 ; $(1 ' 96) ; 6$ th St. and Washington Áre. ;
$9-12,1-4 ;$ OALR. 
VIFIJS, WM. HEXKY (b'be) -10 C.2.99: $\left.11^{\circ} 90\right)$ : 300j Washlngton Ave.

cith $5-10,3-5,7-9$

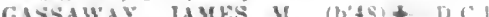

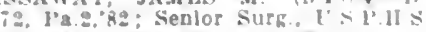

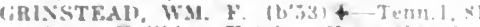
(IP2): Halllday Ilolel: once, sos form. merclal Aro.; 10-12, 1-3; S.

Hannon, Horace Blake (b',5)-(31., $0^{\circ} 0$ (1'03): aet, 9(h se: 9-11, 1-4: LD*

Harrell. Francls M. (b'55)-la.1, $81 ;(1)^{\prime} 9$ ) 811 Commerclal Are.

llart, Chas. Jos. (b'\%)-Mo.\%,10: noe in Jractlce: 1910 Joplat S

McMANLS, JAMkS M. (b\%76)-Mo., , 99 1.99): 210, Ith st.; once, sor Com menclal Aro: $10-12,3-5,7-8$.

MCNFMER, GEORGK If $\left(b^{\prime}(6)+-K y .2,89\right.$ : (1'89): 224. Ilth St.; oftce, Opera House (lock.

Nurray, John M.-Scol.5,76; (1983); 2028 Sycamore St Joll J. (b'63) HFDLEMAX, JOIIX J. $\left(b^{\prime} 63\right)$ T-Tenn.6,

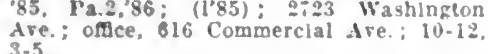

stevens, Darld A. (b'69)-111.22,03; (1'03) 809 Commerclal ire. $1-8$.

Strong, Judson K. (b'55) H-0.7,80: (1'83): ill Washington Are.

WAISH, JOIIS T, (b\%I)-Mo.4.36

29. 0 L St, oatce, 211, 20th sit.

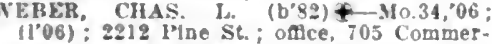
(l'06) : 2212 l'ine St.; office, 705
clal Are.; 9-12, 2-5; OALR.

WOELFLE, JAMES E. (b'i1, £-Mo.i, 97 (1'9i); 425, 28ch St; once, $702 \%$ Com: merclal Are. : 10-12, 3-4, ;-8.

YOUNG, RIPLEY MARION" (b'81)‡-D.C.3 09 ; $(110)$; 426, 19 th St. oflce, 90.

Commerclal Are.; $9-11,3-5, \div-8$

CALEDONIA, 290, BOONE

SEUERLUNI, CHAS. (b'67) \&-H1.8, 97 ; (1'9\%).

\section{CALHOUN 300, RICHLAND}

Buwers, Danlel W.-M0.28.'95; (l'95)

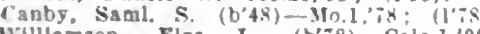

Wlllamson, Elza L. (b'78)-Colo.I, 00 (1"03).

CAMARGO, 400, DOUGLAS

HALL, ISA.AC WM. (b'59)-0.9,'31; (1'91).

WISMMAN, WILLIAM A. (b'53) \&-I'a.2,'86; $(1 " 86)$.

CAMBRIA, 648. WILLIAMSON

Rrualley, Jobn II (b'72)-Vo.7.95; (1.95).

Hurs, "Thomas J. (b'5i)-Ia.1, 94; (1's4) Pd.

CAMBRIDGE, 1,272, HENRY

CONSER, WH. HFOHY $\$-11111,0 \%:\left(10^{\circ}\right)$.

Folon. Caroline (b'il) H-lll.4, 04 ; (l'04).

EATOS, MATHLDA (b"53) $+111 \times 96$ (1.96).

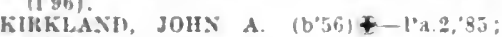

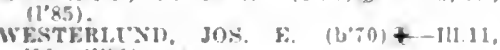
00 : (1'ys).

CAMDEN, 350, SCHUYLER

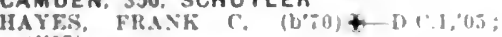

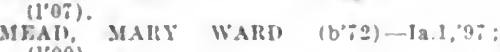
(1,00).

sead, Hchard Homer $\left(b^{\circ} 4 i\right)-I A 1,0 ; i$;

CAMERON, 23I, WARREN
ZIMMEHMAX, HH.YHY S. $\left(b^{\circ}: 1\right)+-111.5$. $36:(1 \% 97)$

CAMPBELL HILL, 497. JACKSON

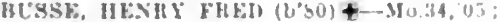
(I00)

CAMP GROVE, I00, MARSHALL

HLOI'GI, GHO. F. (6.0) + 11111.03 $(1.031$

(ill. jaMkes bo (b'in)

I.A.S., B.leut, I: S.X..

CAMP POINT, 1,200, ADAMS

H. TE.S, A.MOS I). (b.85) + III.6, 42 : (1)

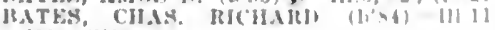
0s: (1.03).

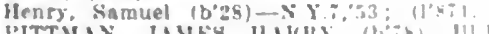
PITTMAN, JAMES IIIKII (bin) III.

SIPENC

CAMPUS, 300, LIVINGSTON

Jlelnen, Jos $\zeta$ (b'68)-III.1,95; (1.95)
CANTON, I0.453, FULTON

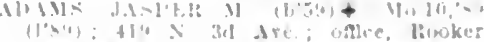

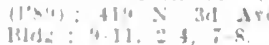

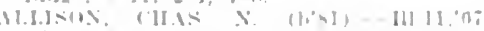

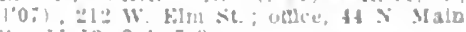
BFTTS, II II HESII

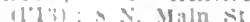

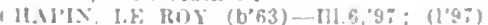
bus Vurth Are. C.: oftce, vivearingen Illa $: 1: 30-5$

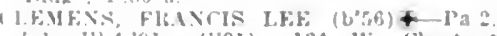

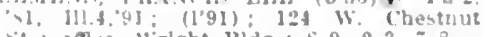
sit: onle, Wrlght Bldg: : \$-9, 2-3, 7- .

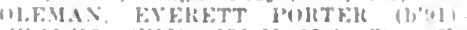
I11.11.'13; (1'13): 65h X. Ma|n Si.; ualce. It $x$ Maln st. : $2-4$

(1)EMAN, JAMES EIMUNI) (1063) +

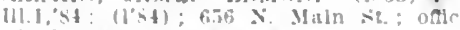
$24 \times$ Maln $x$ il: $2-4 ; \mathrm{s}$.

$11.1 \%$, THFonOIF, C. $+-\$ a 1, \$ 9 ; \quad$ (1'94) $204^{\prime}$ W. Incust Si : once, First Xathonal llank Bldg.; 9-11, 2-4.

IJirschle, Harry (irlfith (b'ss)--11l.6,'l:

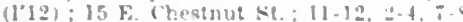

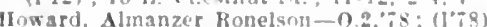

llughes, Edw. Burns $\left(b^{\prime}+1\right) \rightarrow$ : (1'78)

liandolph Block

NELSUS, F. SEYMOLR (b'74)-han.t, (1०98); OALR. *

NELSON, WM. D., JR. (b'5i)-Ml.1, 84 (1'st); 121 w. Fim $s t$.

I'TXNI, HARRISON C. (b\%

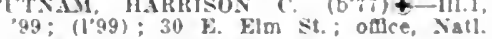
Bank H]dg. : 10-12, 2-4, i-s.

HEACAX, EWWIN W. $\left(b^{\prime} 58\right)+111.185$ (1'94): 135 Martln Are: OAce, 22 b Elin St. ; 8-4:30; OALR. *

Rulson, Leonard A. ( (b'53)--0.8,'s\&; (1'Ss) : 25, W. Vine st. ; ottce, Swearlngen Rld: UWGER, HARVEY II. (b"i0)†-Ia.1,95; $(1,9 s) ; 362 W$. Maple St.; 11-12, 2-4

RUGERS JENNIE MALI TIOMAS $\left(b^{\circ}, i\right)$ -Ia.1,98; (1'98).

SCHOLES, PAUL S. (b"̈0)—-M1.11,"98 (1'98): 372 W. Chestnut st.; offec. swearlngen Bldg.; 2-4, i-8; S.

FHALLENBERGER, WM. F. (b'62) \&-IH.I $.45 ;(1 \cdot 95)$ : 30 W. l'tue st.; offece, 32 V. Maln St: $11.12,2-4$

sulth, Floyd Albert (b's?) - I11.11,13: (I'13); $8 \mathrm{~S}$. Ma!n $\leqslant$

fmlth. James Royal (b'ss) - I11.11,12

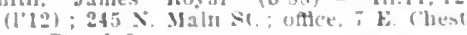
nitt st : $1-3$

STANDAIR, MPHONSO I'ERIT (b'sl) -I11.11,06; (1.06); X゙. Maln St.; ottce, $46 \mathrm{~S}$, Maln St.; 11-12, 2-4; S.

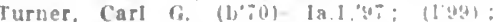
not in practlce.

Turner, Wm. 11. (b'43) (1.2.71: (1's1); 119

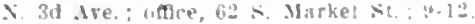
1. $-7 .-8 ;$ OALR.

THIGLER. WIIJIS TERRY (D6:) +-Ia.1,

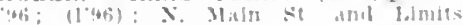

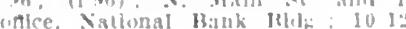

\section{CAPRON, 502, BOONE}

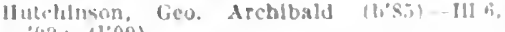

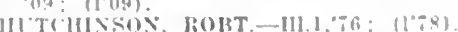

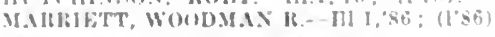

CARBONDALE, 5,411, JACKSON

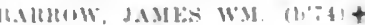

(10)!).

itrantesho

(l) 0 रो.

TII bilit

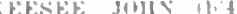

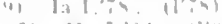

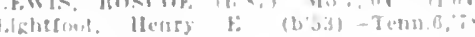

11.11)

M. K!nize

11,31

Hiller. Irom I Ol

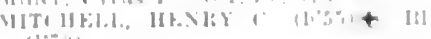
1,
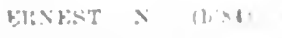

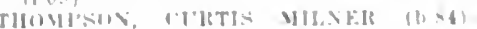

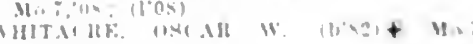
$04.110 y$
CARLINVILLE, 3IT MAT OUPIN

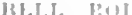

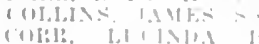

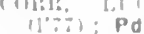

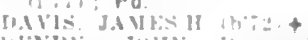

likisi, Juhi

Inakina, It, li?

llosal, Eunctie

I.ISTON, JUS HWSTWI h

(1.08)

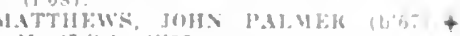

II 1, $2: x^{*}=11,921$

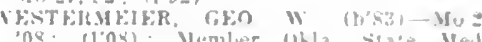
i. $\times 11$.

CARLOCK, 400, MCLEAN

(HAIMAN, ANLHEW LUCLEX (Ut:)

(1).

(I'? $(1, j)$

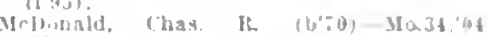
(l" $0 \nmid$ )

CARLYLE, I.982, CLINTON

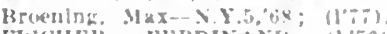

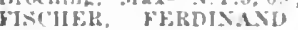

$(1, \div \div)$

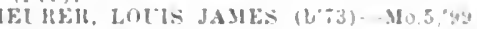
(1.44) ; Pd.

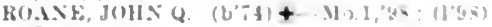
Op.

VEHXON, AEO HEYWOOL $\left(\mathrm{b}^{\prime}: t\right)+-\mathrm{K} y .5$ (1.95)

WII, (1)X, SIM[EI, H. $\left(\mathrm{b}^{\prime} 60\right)+M(1,20$ $\left(1^{\circ} 90\right)$

CARMI, 2.833, WHITE

BOYkll, JAMF' A $(272)+$ Nu. 25,99

(199).

(1)

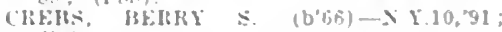

(l'y)

LFiltil, JOHX T T Y 10,91; (1'91),

Mayliew, lieason 1 lad.2, $58 ;(1,5) ; n$ s

in practice.

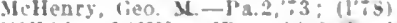

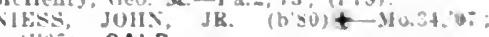
(l') : OALR

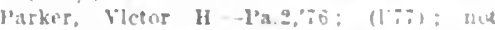
in practlce: (131)

P(XTXEY, (HAS W. (b'5i)--1a.1.9. (1) 31$\}$ : FR.INK

$03 ;(104)$

CARRIERS MILLS, 1,358, SALINE

Fuller, 1. (1.- MO.7.98; 11'98)

lirore, Rout. E. (b's6)-Mo.:-09; (l'(ng)

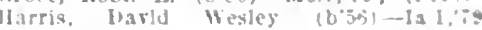

llare saml. F $\left(b^{\prime}+5\right)--$ Ind a se; $\left(l^{\circ} \leq 0\right)$

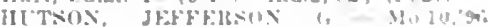
(1"y,i)

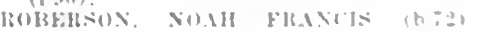

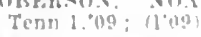

CARROLLTON, 2.323, GREENE

HIHIS. IIUKS HUW

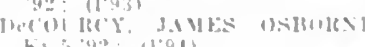

his 5011941.

FUHRMAXX, Jus JoחX+Ma34,05 Ir. VALIR, 1.EOS IRI) JONATHAX (b'SO) remo ion (100)

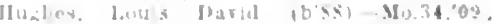

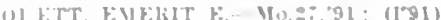

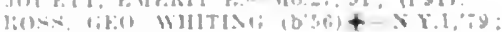
(n) 0 : 0

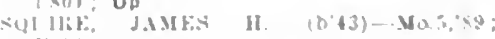
$\mid 1 \cdot 4 y)$

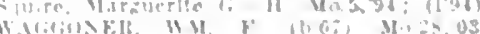

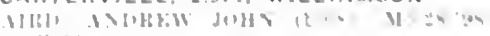

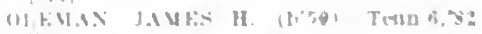
iा?isis

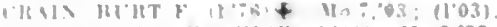

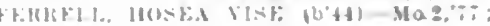

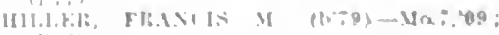




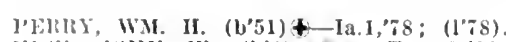

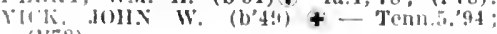
(I'T)

CARTHAGE, 3,000, HANCOCK

ISI.HNUEK, WII. (1,83) + -Ia.10,'04; (I'04)

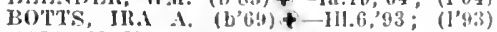

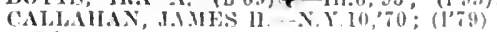
Pd.

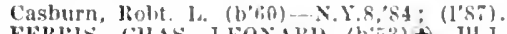

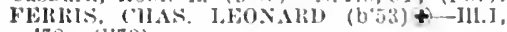

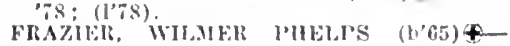

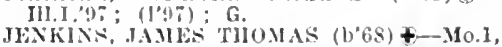
JENKINS IA

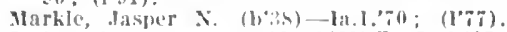
I'AlR, SAML MARION (1,62)\&-Ia.9,97 $(1,9-1)$.

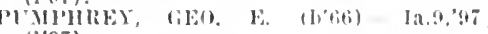
(1'97).

\section{CARTTER, 25. MARION}

HOLT, IUTHER (b'62)-MO.2,'St; ( $\left(1^{\circ} 8 \pi\right)$.

CARY STATION, 650, MCHENRY

Theobald, k'rank John.

(See Chlcago.)

CASEY, 2,500, CLARK

loygl, hiyne Bishford (b's4) -.. III.1,0s; (l'08).

1BRCCE, WM. WAIJIACE $(1,41) \pm-0$ (1'80).

IIarrls. Cyrus Munsou (b'72)-Ind.8,'96; (l'09); 0 p.

Heywood, Cyrus F. (J'44)-Ill.1,'68; (1'is). JOIINSON, LESTER II. (b' 69$) £-I I .17,05$;

Mecl'LiOUGH, JAMES Y. $\left(b^{\prime} \$ 2\right) \oplus-K y \cdot 2$,

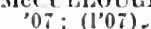

Stolt:, Wm. II. (b'54)-Mo.1,90; (1'90).

young, Wallace (b'45)-Ill.6, '5; (1'78); not in practice.

CASEYVILLE, 6I3, ST. CLAIR

BALTON, ALBELT I,EE (b'83)€-Mo.28, '11: (1'11).

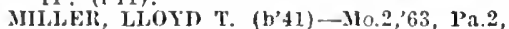
'64. No.1,79; (1'7); not in practice.

CASTLETON, 200, STARK

Neill, Chas. Wells (b'84)-Ill.22,'09; (l'09).

CATLIN, I,000, VERMILION

ALLISON, O'TIS WOOD $\left(b^{\prime} 76\right) Ð-I 11.1,05$; Boggess, John Wesley (b'43)-Ill.6,70; (l'80). RICHARD A. (b'64)†-Ind.8,'90; CLOYD,

Colyer, J. R.-0.1,'8s; (1'93)

Runyon, Thomas H.-Pa.2, 55 ; (177).

Turner, Joln W. (b'39)-Ore.I, $i 2 ;\left(I^{\prime}{ }^{\prime} 6\right)$.

CAVE IN ROCK, 306, HARDIN

Clement, John M.-Tenn.6,'98; (1'99).

GREGORY, WM. G. (b'64)-111.1,91; (1'91).

Qullin, John N. (b'5l)-Ia.1,'84; (1'84).

CEDARVILLE, 377, STEPHENSON TIONPSON, SMITH C. (b'51) $₫-$-N1.1,72 ;
(1'Ti).

CENTERVILLE STATION, 25, ST. CLAIR

Renols, Wm. II.

(Sce East St. Louls.)

CENTRALIA, 9,680, MARION

ALMSTRONG, JAMES W. $\left(\mathrm{b}^{\circ} 56\right) \oplus$-Ind.8, '85; (1'S5); OALR.*

BRANN, HAROLD W. (b'84)€-Mo.34,06;

BROOMER, EMANUEL (b'54)-MO.1,'80 ;

(I'81).
BROWN, RUDOLPH H. (b'79)-Mo.7,02 ;

DIRHL, OTTO DARWIN (b'76)3-Mo.27, '99; $(1$ '49).

Dunn, ('has. N. (b'51)H-H1.4,'78; (1'-

Dunn, Helen S.-H-Ill.4,'is; (1'80); not

in practice.

Fyke, Edgar Ellis (b'Cs) - Mo.T,'89; (l'89); not in practice.

MILTON (b'i5) - Mich.1 'I2; (l'12) SPd. '01; (1'02); S. MO.28, $10 ;\left(1^{\prime} 10\right) ; \mathbf{S}$

Half, Frank W'ilford (b'88)-111.6,'11 ; (l'1z).

II.114 L, JOHN CARROLL (b'S6)屯-H.6,'10; HALIAY, JOHN C.

Haney, James II. (b'63)-Ill.6,'97; (1'97).
KLSEL. ITIII'S PETER (b'85)\&-Mo.34, '20: $(1,10)$

Marshall, Chas, I'ope (b'56)-Ill.1,'81 (1).82); not in practle. In. $2 x, 10 ;(1,10)$

Plasiman, Walter Frederlek (b'si)-I11.11, 'Il: (1'11).

Rive. 'Thes. Warren (b'72)-Mo.1.97; (1'97) RICHARISON, WM. I). (b'51) 4 -Ia.I, 78 ; $(1,-x)$.

STOKER, WM. A. (b't4) - $0.1,85$; (l'85) LRIBAN, ROBT. OLIVER (b's3) f-Mo.7, $07 ;(1,07)$.

willams, Ilarry otto (b'73)-Mo.z,'98;

HISON, IISRRY E. (b'82)థ-Ia.10,0I (I'0I); Ob.

CERRO GORDO. 869, PIATT

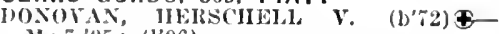
.10.7,95; (1'96).

Inulley, Errwin F. (b'87)-Ill.4,12; (l'12).

TLILA, JOSIIUA G.-Mo.10,80; (1'85).

GASTON, MARY ADELAIDE (b'79) $\downarrow-$-HI.9, $02 ;(1,02)$

LAMB, JAMES G.ARFIELD $\left(b^{\circ} i 8\right) \downarrow-111.1 \mathrm{l}$, $03 ;\left(1^{\prime} 03\right)$.

CHADWICK, 700, CARROLL

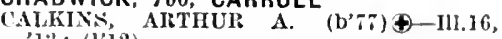
IIARTFIEL' (1'12).

III. 39,$09 ;$; (1'03).

CHAMBERSBURG, 208, PIKE

Iluher, Fred 11.-Mo.34,06; $\left(1^{\prime} 06\right)$.

CHAMPAIGN, 12,421, CHAMPAIGN

BENNETT, CLFAVES M. (b'70)Ð-I11.11, First 950$)$; 1902 W. Park Are.; office

BRANYAN, HUGO (b'85)-III.4,09; (I'09)

111 W. Church Are.; 11-12, 2-5, 7-8; $\mathrm{S}$.

Burwash, T. N. (b'55)-Mo.1,78; (1'78); not in practice.

Carues, Harry II.-Ia.4's8; (l'99).

Cogswell, Geo. E. (b'49) II-Ill.4,73; (1'87) ; 204 W. Green St.; offce, 51 N. Nell St.; 9-11, $2-4$.

AIG, CASSIUS M. (b'57)-0.1,82; (1'83) ; 616 W. Hill Are.; office, Illinols Bldg.;

9-12, 1.5; OALR. $\star$

DALLENBACII, JOIIN C. (b'81)\&-Pa.1, W. Church'St. ; $10-12,2-4$.

DAYIS, CHAS. S. (b'66) $₫-0.2,90$; (l'90) ; 212 W. Springfield St.; oftce, i9 Main st. : S.

OODS, JOS. C. (b'64)-Ill.6,'s9; (l'90) ; INCH, JAYES H. (b'70)థ-IId.3,95; (l'95); 101 N. Elm St.; offlce, nilnols Bldg. GRAY; WM. L. (b'66)\&-Ia.9,91; (l'91); Bldg. ; 11-12, 2-4; S. $\star$

(1.-Il.4,'80; (1'80); not In GULICK. CLYDE D.

(See Urbana.)

Haley, Henry A.-H-Ill.10,'82; (1'86) ; 402 Tovirch St.

HON W, WM. M. (b'71)-Ill.14,99; (l'99) ; $305 N_{\text {. Willis }}$ st.; office, 55 Nell St.; $9-12,2-5$.

Howard, Ifartwell Carver (b'29)-0.3,'50; (l'77); 1508 w. Green St.; offlce, 206 N. Randolph St. ; 8-11, 1-4; T.

JOIINAON, CHAS. B. (b'43)†-0.1,72 , $\left(l^{\prime} 7\right) ; \% 18$ w. Church st.; offee, Kariher

KARIHER, MARRY CLLLEN (b'79)-III.I, 03; (I'03); 710 W. Church St.; offtee, Kariher Blas

KIRRY, DARWIY (b'83) ક-III.6,07 ; (1'07) ; 604 E. Jobn St.; offlce, Illlnols Bldg.; $10-12,2-5$.

RATZ, EDWIN A. (b'44)†-Pa.1,69; $\left(l^{\prime} i T\right) ; 403$ S. 13th St.; office, 9 N. 1lth

LatPoon, Clint A. (b'80)-Ill.4,07; (1'09) ; Karilier Bldg. LYONS, JENNIE $\left(b^{\prime} 69\right) €-H 1.9,00$; $\left(l^{\prime} 00\right)$;
Illinois Blds.

MANDEYILLE, JOHN DRAKE (b'44) - III.1, '75; (17T); not in practice; 701 w. Astive.

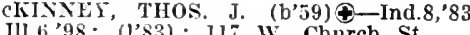

MHLLER, LEO C. (b'82)థ-III.11,06: (1'06); 501 N. Randolph St.; offlce, First Natlunal Bank Bldg.; 10-12, 2-4.

MINER, ELLLN + -12.9, 82; (1993); $209 \mathrm{~W}$ Wureka st.; offlce, Ilinols kldy.

NEWCOMB, CYIRS F (b'70) \& Ill.11,04: (1'04); 1311 W. Inlil st.; ollace, Illínols Bldg.; $11-12,2-5 ; \mathrm{S}$.

OSHORNE, JOHN WILLIAM (b'78)-IIL.1, Illinols Bldg; ; 9-12, 2-5.

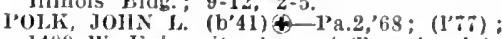
1409 w. Vulversity Ave; (olfice, Areota).

Reeves, Jolin Trumbull-Ia.9,'91; (1'y1); 203 Universty Ave.: 10-12,4-6; ob.

Replogle, Peter S. (b'48)-Ill.8, 74, Ill.4 92; (1'77); 107 iv. Unirersity Ave.; office, $80 \mathrm{~N}$. Nell $\mathrm{St}$.

Ilce, Gordon W. (b'6s)-Mich.1, 03; (1'03) 305 N. 22 d st.; offee, lirst Nutional Bank 13Id!.; $9-12,1: 30-5 ; 0 A L R$.

SCIOWENGERDT, WII. L. $\left(b^{2} 72\right) \oplus-M O .1$, 97; (1'97); 301 L. Untversity Ave.; office, lllinols Bldg.; 2-5.

ECKER, WM. V. (b'77)甲-III.11,06. (106); $1006 \mathrm{~S}$. I5th St.; offce, Illinols Bldg. ; $9-11,2-5 ; \mathbf{S}$.

(1'072, STRAUT' W. (b'67) - M.I,93; (1'93); $107 \mathrm{~s}$. Nell $\mathrm{St}$; offlce, Illinols IBIdg.; $10-12,2-5 ; \mathrm{S}$.

S'EARS, CHAS. H. (b'73) - Mo.27,97; (1'97); 1403 W. Unlversity Ave. office,

WALL, ALBERT S. (b'61) $\oplus-0.9,90 ;\left(l^{\prime} 90\right)$ 411 W. HIII St.; office, First National Bank Bldg.

(1'03) HARLOW V. (b'76)-Mo.2,03 (103); $1005 \mathrm{~S}$. 15th St.; offec, IIIInols Bldg. ; OALR. $*$

Wood, John II. (b'43)-Ia.1,78; (1'78); 505 S. Elm St.; $10-2$.

ZORGER, ANNIE L. (b'65) - Mo.10,'94; $\left(l^{\prime} 94\right) ; 602$ Green St. ; office, 5 Maln St.; 9-12, $1-5$.

ZORGER, WM. H. (b'60)๑-IR.1,'86; (l'86) ; 602 Green St.; offce, 5 Main; 9-I2, 1-4. CHANA, 317, OGLE

ROE, MALCOLM C. $\left(b^{\prime} 42\right)-0.4,72$, Ill.8, 78; $(178) ; \mathrm{Pr}$.

CHANDLERVILLE, 950, CASS

BOONE, HOWARD B. (b'71)Ð-Ill.6,'97; $\left(l^{\prime} 97\right)$.

Boone, Nathaniel II.-Tenn.1,60; (1'82).

Eversole, Garibaldl (b'59)-Ml.11,'87; (1'89). RANKEN, JOHN G. (b'64)థ-111.11,'95 (l'95).

CHAPIN, 552, MORGAN

FOUNTAIN, JAMES HARNEY $\left(b^{\prime} 58\right) \oplus$ III.1, 81; (1'81).

ROBERTS, FRANCIS A. (b'70)-0.8, 00 ;

Smith, Luclen (b'75)-Ml.1,99; (1'99).

CHARLESTON, 5,884, COLES

Barnes, Finis E. (b'72)-Mo.10,03; (l'03). Bisson, Walter C. (b'74)-Ill.10,'03; (1'03). BISSON, MLARTIN W. (b'77)Æ-IlI.10,02: RAIG, ROBT. П. (b'73)-Ky.4,00; (1'00)

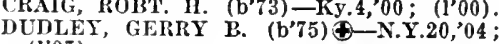
$\left(\mathrm{I}^{\prime} 0 \bar{i}\right)$.

Greer, Chas. E. (b'74)-H-Ill.10,'98: (1'98); $\mathbf{s}$.

IKNAYN, NICHOLAS C. (b'68)Ð-Ill.6,

' Lambert, Curtis Allen (b'46) - $0.9,71$. (1'91); OALR. *

Iscan, Wm. H. (b'66)-N1.10,'91; (l'92). IONTGOMERY, JOHN T. (b'52) Ð-III.6,

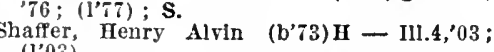
(1'03).

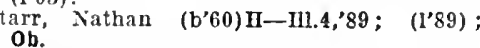

TRANSEAU, GERTRUDE HASTINGS (b'78) $\$$-Mass.7,04; (1'07).

WALKER, GRÁNVILLE M. (b'38) $\rightarrow$; (1'78) Christopher C. (b'50) - Md.1,8I; (1'88).

CHATHAM, 6E6, SANGAMON

BRADLEY, IIILTON M. (b'64) \&-Yo.27, $92 ;(192)$

PIMI, EIGENE JUDY $\left(\mathrm{b}^{\prime} 82\right) \oplus-\mathrm{M} 0.28$, '10; (1'10). GEO. E. (b'68) - 0.9,'92;
(I'92); Pd. 
CHATSWORTH, 1.038. LIVINGSTON ELI.INIFU UOI), CIIAS. $Y$. (b"5s) $t-111.3$

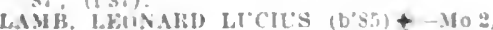
10: $(1$ '10): $\mathbf{S}$

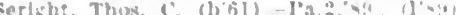

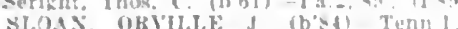

(l'13): Memlet Mo. Siate Med. I

CHAUNCEY, 100, LAWRENCE

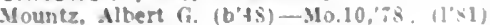

CHEBANSE, 555. IROQUOIS

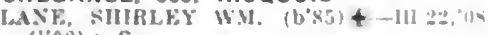
$(108): s$.

contance, II S.F-Mo.10,'sl: (1's:-3)

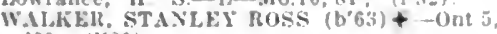
\$9: $(1 ' 89)$

Watson, Wm. II. (b't4)-III.I,75: (1'i7).

CHENEYVILLE, IIS, VERMILION

KLOTZ, OSCAK 1". (b',5) $+-111.1 \%, 05$ $(1 \% 06)$

\section{CHENOA, 1.512, MCLEAN}

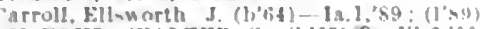
UU FOUR, WILTER 6;. (b'65) \&-11.6, 00

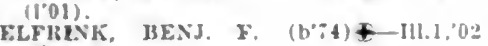
(]'02).

Monroe, James A. (b'42)-Ill.1,64, X.Y.10, "69: (1'99).

IICF: FLI VESTAI (b'b0)f-kis.'9t Ky.5:96; (1'96)

CHERRY, 1.500, BUREAU

(T"II,FOYLE, THOS. F. (b'ii)-111.6,"03; (1'03).

CHERRY VALLEY, 600, WIN:JEBAGO

KLONTZ, CIIAS. EDW $\left(\mathrm{b}^{\prime} \mathrm{SO}\right)+-111.6,05$ $(105)$

VOOPARD, WILLS J'. (b'js)-111.11,"94: (1'94).

CHESTER, 2,747, RANDOLPH

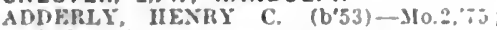

(1'79): U. URFE, ALRET E. (b'61)\$-MO.5,"S5: (1'85); 0 o.

nOFFMA., GFO. (b':1)—-Mo.7.96; (1'96).

JAMFs, WM. A. $\left(6^{\circ} 54\right)+-M 0.2,81 ;\left(l^{\prime} 81\right)$; ALR.

MackFizis, Wy. R. $\left(b^{\prime} t t\right)+-11 \mathrm{ch}, 1,70$ (1*i).

YANDFLL, MARLEY (b'84) - Mo.34,11

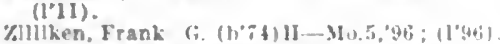

CHESTERFIELD, 36\%. MACOUPIN

Crouch. Joah Allen (b'64)-Mo.1.96 $(1 \circ 96)$

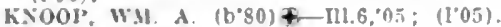

CHESTNUT, 350, LOGAN

KIKBY. WH. II Ғ-III.6,7:; (17i).

CHICAGO, 2,185,283, COOK

NUMHEH UH I'HYICIANS, 4.713.

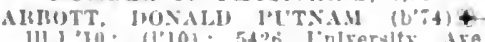
111.1, 10 : $(1,10) ; 54: 6$ indversify dre, umce, $122 \mathrm{~S}$. Jilehlgan Are.

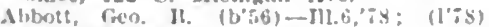
Jell s. Wabah Are.

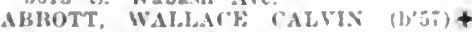

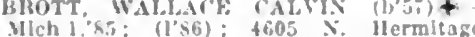
Are. : once, 4:53 k. liarenswom! l'ark.

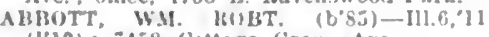
(1'12): it58 Cottage firore Ave

Albrtt, Wlison Ifunin (b"3)- Il1.11,01

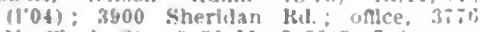
X. Clark st. : $9: 30-11,3: 30-5,7-3$.

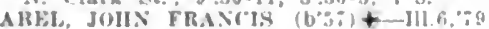
(179); 5200 Indlana Aro.; unlee, 3501 $\therefore$ state St.

ABkL, THKonoh: r. F. $\left(b^{\circ} 69\right)+111.18$,

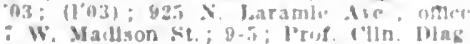
W. Malll

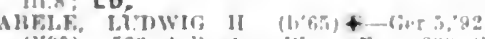

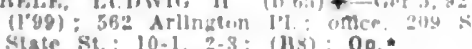
Siate St.: $10-1,2-8 ;$ (11s); 0 p.

Ullchacl Ifecre llosultal.

Mchact Reose lloxplat

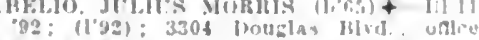

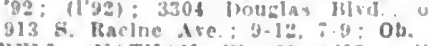

AHFL, XATHAY W-Mo.2:291: Corlland st.; ofleo, 1901 \& Mest st.: 9-11, $;-9: \mathrm{G}$

AIFINASN HFNRY W $\left.(1)^{2} 80\right)+-111.1$

at. Hugo (b-3) ll1.13,10 (1 19), la?

I.Incoln Ire.: 6,8 .

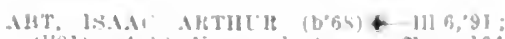

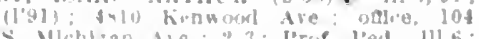
(1) Min: $\mathrm{Pd}$.

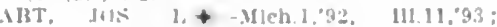

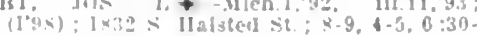
: :31): 151

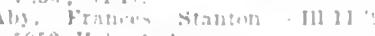

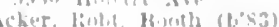
fiosk cinnty IIospltal.

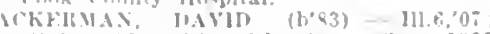

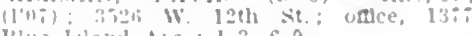

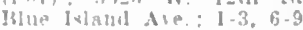

cres, l.oulse $\left(b^{\prime} 58\right)-111.9,90 ;(191) ; 3157^{\circ}$

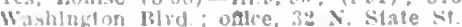
$11-1$

MIIII, S.11)1F 13.1Y (b'70)-Yeb.6,0: (1'02); s;0 F. 33th st. : 10-12; D.

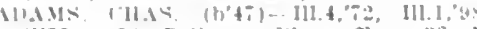
(1\%): 33 Bellerne $11 .:$ once, $32 x$ Idams. Thas $5-11-110 \% 81 ; \quad(1 \times 9) ; 32$ MiNis, (iF.1).

(See Kenosha. WhIs.)

Mlans, Geo. T. Cooke- On! 2, "82; not in practlce; 6.50 lush st.; ontce, $305 \mathrm{~S}$

Mllehlgan Ave. Indla (b'87)-Mi.11,12
Idams, Mabel India (1'12); Mas s. Mlehlgan Are.: Anes.

ADAMS, NATHANIFL HOMEIR (h\%1)

IPark: ince, los X. state St. 11-1: N.

aller, llenry I. (b'79)-Md.9,03: (1'10): 2300 W. Taylor st. (b'28) - Md.1. "5९:

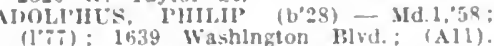

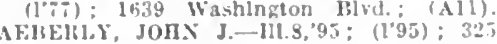
Fugenlo St.

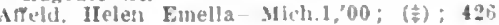
liarry ire.

thner Chas Inuiv (b'6) - 111.8, 13: (1'13); $3: 35$ W. Surth abe

Alistrom, James peter (b'8:)-111.8,'12: (1'I") : fis3: IIarvard A

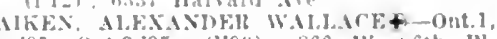
95 , Ont.3,95: (1'95); 860 W. 4 th I'l. Iisenutadt, Facek Albert $\left(h^{\prime} 90\right)-111.11,12$ (I"12) : $20(18$ IV. $122 \mathrm{~h} \mathrm{st.}$

Altchlson, F'lorence $x$. Hamlifar (b'56)Masas:s2: $(196)$ : 903 Buenal Are

MTkFo rils stasisy (1, -3)-Pa.I. of: (1'11): Gibso sherlatan Ril

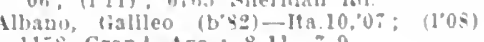

l1.is frand Are.; 8-11, ;-9

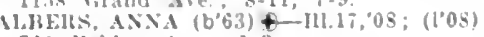

$\because 23$ Hellen Are.; 1.3

Albert, Albert \&. (b's0)-11l :34, $11 ;\left(l^{\prime} 13 i\right.$

l:olt inrmal iro.

M.18IR.CIIT, CHAS. A. (b'tii) +-111.11,-29

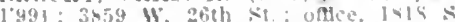

IIalsted st. : 1 .

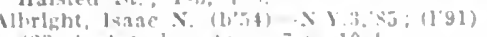

tion Arsestan Are; $7-10-1$

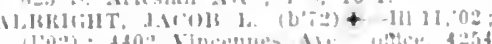
11001: 180: Vimeenses A1

Indliana Are :

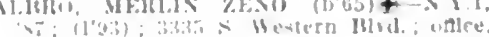

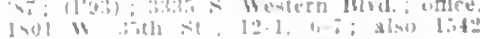

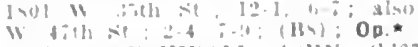

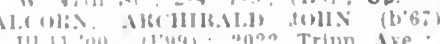

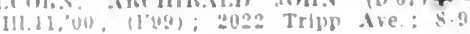

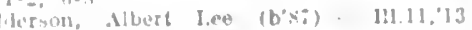
(1"1:3) weth mol wearborn situ.

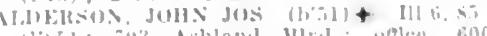
1].

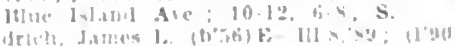

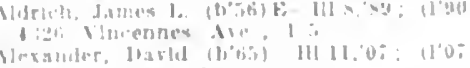

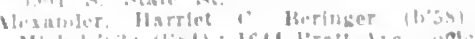

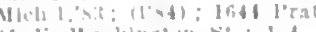

1. k: Wavhngton st. : 1 t

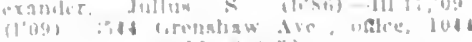

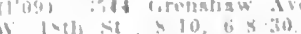

Iflert. lucincla Marsh $\left.10^{\prime} \times 0\right) \quad 11119,0.3$ (I)

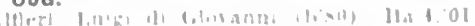

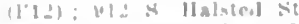

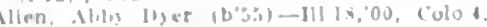

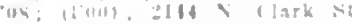

MILES AIIIII I:

$+-11128,09$

Allen, fince lime

filiz 1,1

(1.9i):

illen, Thus

$5=21$ ken

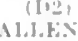

(l'si;)

vewport Are y. 11 .

Anat. 111.20: $\mathbf{S}$.

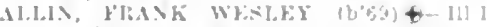

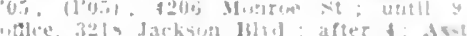
lorof Mid. IH. 1: (1,a): Pd.

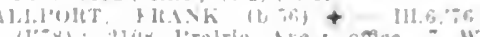

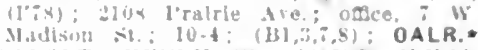

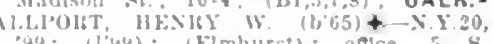

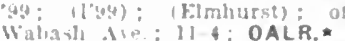

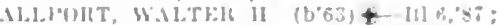

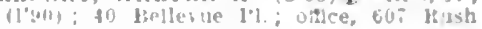
si: 10)-12, ; : (\$13).

AI.MK, IIFIMAXX EARH.IRT (b'bi)

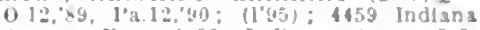
Are ofle, taju Iudlana Are.; $3+5$.

Armtz, Louls Ferthand $\left(b^{\prime}, 6\right)-111.11,04$; $\left.11^{\circ} 04\right)$; 131: \& llarding Are astre, $395 \%$

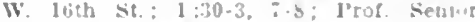
Ulust., 111.16; 0 b.

Nlt. Sieo. I.zdulg-I11.11,05: (1.05); 1333 D. llark rit.

M.VAILE MANLEL (b'-3) - $111=3.04:$ $(1,04): 3150 \mathrm{~N}$. Clark si.; untl $9,1.2$,

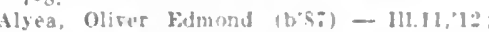
(113): $533 \leqslant$ IInlsterl sit.

Imiera.' ciaml. (b'it)-(ier.10,99; not in practice; Children's Memorlal IIospltal Isvil: l'ruf. EIfer. Med. 111.1; (11:, Ft) Pd.

AMEISU, GRO CIIRISTIAX (b.5) $\left.111.10,02,111.11,04 ; 10^{\circ} 2\right)$; 136 S. I1am-

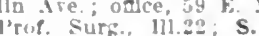

MHRSON, W3. li. (b'69) - I11.10,90

IIl.11,01; (logu); iog X. I entral Ave.; oflce, 3354 Madlson st. : $-2,3,8.8$

INES, JUIX G.-Ma.1, 'si; (1's); 1412

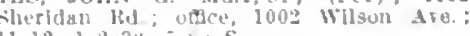
$11-12,1-2: 30, ;-5: 5$.

Anda, Thurwald - Ill.14."96: $\left(1^{\prime 96}\right) ; 530$ Iacnolla Are; until 9, $5-5$; ottce, $59 \mathrm{fo}$ Van buren sit: $11+1$.

IXIFISON, DAVII $(11 \%)+111=2,14$ (1"10): 3fol 11: 12 h s. ; $10-12, ;-9$.

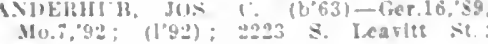
$9-11,:-$

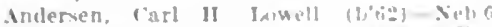

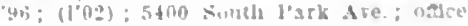
$159 \mathrm{X}$ siate st. : $1-\overline{5}$.

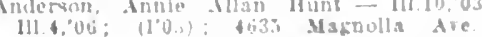
10. 1 .

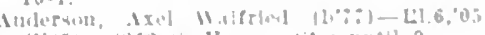

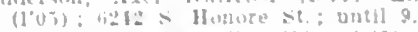

Indersin, (arl 11 111.13,04: (1)3) : 10:3 helimate dies

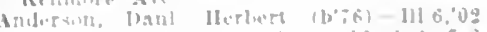
s

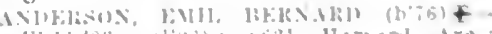
$11111,03:$ (103); wizl llarishl. Nre

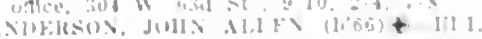

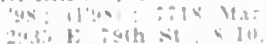

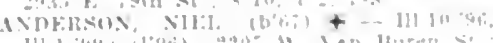

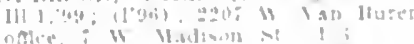

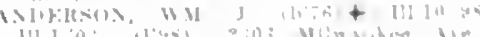

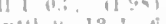

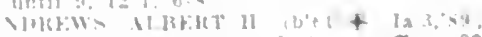

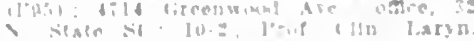

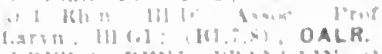

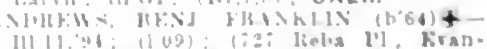

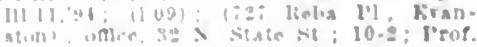

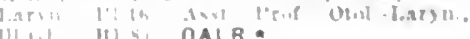




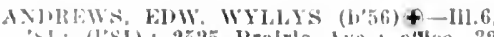
(1'si) ; 2525 Pralrle Ave : oflice. 32 state st.; 12.1; Prof. Surr. and riln. Siurg, $111.6 ;(45,7,13)$ : $s$.

ANDREWS, FRANK TIYIO(Ol (b'58) +

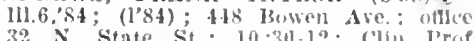
fivn., Hlit: $(12,1)$ : 0

Andrews John D. (h'54)-111.6, ' 8 : (1'78)

(188s sherldan lid., Evanston): offee, 323 kinzle st.; 9-12, 3-5.

ANDRENS, JoIN JAMF $(1,79)+$ Quo.1

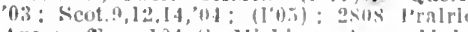
Are. ofler, 104 s. Mlchlyan Are : $11-1$. ObG.

Andrews Wells - Ill.1,ie: (170); 421 s lloman Are.; $8-9: 30,1-3,6-8$.

Anscher, Herman (1'63)-111.8.90; (1'90):

1549 W. Chlcaco Ave.; until $9, \dot{i}-9$.

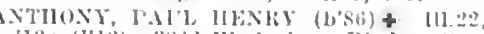

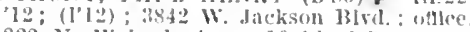
$222 \times$. Wulash Ave.; $10-12,2-$

Antisdale, Edw'n S. (b'61) - Mich.1,90. (1'98); 5403 Woodlawn Ave.; oftlce, $25 \mathrm{l \%}$. Washlington St.; 10-12, 2-6; (138)

Anway, Jos, D. (b'48)-N.Y.1,'75; (I'92) 323 F. 43 d St. : $10-12$ AlFELBACII, GEO. LFONARD (b'85)-
I11.6, 10; (1'10); \$25 Center st.; olllce, 3166 dincoln Are.; 4-5, 7-9; S.

Appelget, Eugene B. (b'46) - Mo.14,'80. not in practlee; 3544 Ellis Are.

Appleman, James Ilenderson (b'86)-Ill.4, 11; (I'[1); 201 E. 37th St.; 9-11, 7-8;

Appleman, John Sherman - N.Y.10,85 (l'92): (New Albany, Ind., l'97): 5906 sheridan Rd: ; $12-2$.

ARKIN, MOKMIS LLE (b'82)\&-111.1'11 (1'12); 2701 Evergreen Are.; (1'4); Path. ARMSTRON(, ENW. KENT (b'80) - Ill.11

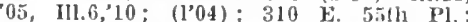
office, 5501 Pralrle Are.; 2-3; Pd.

Armstrong, Jay L. ( $\left.\mathrm{b}^{\prime} 77\right)$-Ill.11, 04 ; (l'04); 775 S. State St. ; 10-12, 4-6.

Armstrong, Jeremiah Frank (b'7t)-Ill.11, '12; (l'12); 1924 W. Jake St.; 10-12,

ARMSTRONG, JOIN B, (b'4t)-La, 2,69 (1'83); 4905 Washington Blvd.; office, 32

Armstrong, Walter Waldo (b'87)-Ill.16,'13; (l'13) ; 6037 Harper A下e.

ARNOLD, EDMUND MAX (b'-6)£-111.11, 08; (l'08); 5544 S. Ashland Are.; $9-1$ I, $2-4,6-8$.

ARNOLD, MARTIN B. (b'35) - $0.2,64$ : (1'Ti) ; 7037 Eggleston Ave.; office, 9151 Erle Ave. : 9-11, 3-5.

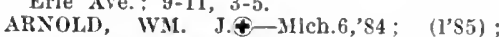
$448 \mathrm{~N}$, Normal Parkway; 8-9:30, $1-2: 30$,

Aron, Matthew J. (b'85)-111.22,09; (1'09); 4800 s. Ashland Ave.

Aronson, Julius-III.16,'13; ( ) ; 1313 Turner Are.

Arzt, Geo, Edw. - Ill.22,'12; (I'12) ; 1654 Are.

ASHER, HARVEY COMBS (b'83)-Ill.6. AsIIVORTH, JOHN $10-111.16,06 ;(1,06)$ $500 \mathrm{~S}$. Robey St.; office, $2827 \mathrm{~W}$. Madison St. ; 7 -9

Asplnall, Noritas $\mathbf{B}$.

(See Plymouth, Ind.)

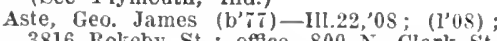
3816 Rokeby St.; office, $800 \mathrm{~N}$. Clark St. ATHERTON, JASI'ER LEROY (b'i9)-IIl.8, 12; (1'12); $502 \mathrm{~S}$ West End Are.

ATKEISSOS, JOIN EUW H. (b'i 4$)$ Tenn.5,97; (1'98); 1954 ilitwaukee Are. $2-4,7-8$; Anes.

Atkinson, Thos. Geo. (b'70)-Ill.22, 05 . (1'05); 1826 sunnyside Are.; Prof. Neur., Ill. 22

Atwood, Albert H. R.-Ill.16,'06; (1'06); 5209 Washington BLrd.

ATWOOD. R. JAY (b'65)-III.6,'90; (1'13) 32 x. State st.; ; Prof. Olol., Rhin. and l.aryn., 11l.G4; OALR.*

Aluld, John M.-Ia.1,'S0; (1'90); 5 S. WaAimand, Sanif. H. (b'万4) H-Ill.4,'s4; (I'S4) ; Whithington 5 t.; 11-1; Prof. Mat. Med.,
IIl.4.
AVEKT, FLMLK k. (b'74)‡-111.11,00 ; (100(1) : 2914 Washington Blyd.; offle

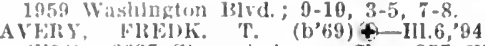
(1'94): 6637 Stewart Are. : oflice, 357 W (1i1): OALLR.

AXIISON, JOHN M. (1)T1)†-I11.8, 00, III.6?,04: (l'98); 840 N. laramle Ave. offee, 600 N. $48 \mathrm{ll}_{1}$ Are.; $2-3,7-8$

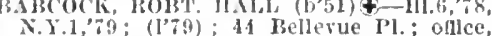

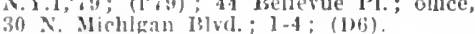

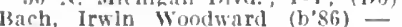
(I'12) : st. lonke's Hospital.

BACHEILA, CERH V. $\left(b^{\prime}-4\right)$

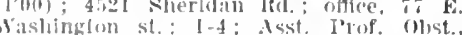

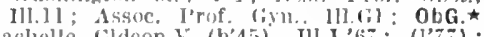

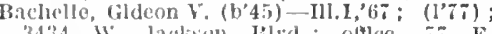

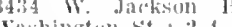

IBachrach, Jullus-Ill.16,12; (1'12); 1618 Bachrich, millus

Barneister, Theodore, Jr. (b'7fi) II-Mich.5, 00; (l'01); 4041 $\times$. Keeler Are. ; $2-4$,

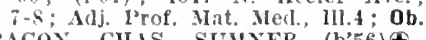

BACON, CIIAS, SUMNER (b'56)థ-I11.6, '84; (1'85) ; 2156 ' Sedgwlck St. ; 2-4; Prof.

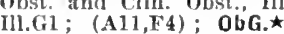

Bacon, Earl Z. (b'43)II-Ill.4,'S5; (1'86) ; 6420 Normal Blvd.; office, 357 ' W. $63 \mathrm{~d}$ St. : 8-9, I-3, 7-8.

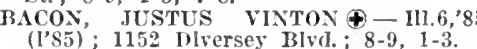

BACON, MARTIN WRIGHT€-Mich.1,75: (1'78); 7321 Princeton Are.; offlee, 6857 Wentworth Ave. ; 1-3, i-8; S.

BAER, ALMERIN WEISTTER (b'62) IIl.1,89; (1'89); 5500 Cornell Are.

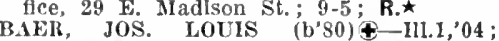
(l'05); 4755 Forestrille Ave.; office, 104 S. Mlchlgan Are.; 2-3:30; ObG.

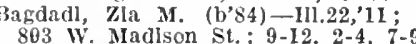

BAGLEY, HLNRY PATTERSON (b'76)Ill.11, 05 ; (1'05); 736 W. Madison St. offce, 31 i. State St.; $10-1$

Bahl, Wm. Ilenry (b'72)-Ill.11,04; (1'04); 3849 Langley Are. ; 2-4, 7-9; U. *

BAIER, JOHN G. (b'61)-Ill.14,'05; (1'05); 2001 'sedgwick st.

Bailey, E. Stillman-II-Ill.4,'78; (1'78); 6222 Woodlawn Ave.; office, 22 E. Washington St.; 1-4; Prof. Gyn., Ill.4.

BAILEY, GEO. TROY (b'64)\&-Ill.6,94; $\left(1^{\prime} 94\right) ; 656$ E. 45 th St.; offtce, 39 S.

LAILEY, IIARRY BRAWLEY (b'a)Bll.1,02; (l'05); 228 S. Robey St. 5 Winthrop A re.; office, I08 N. State St.; $8-9, \quad 4-6: 30$.

BAKER, BENJ. G. (b'82)-Tenn.10,'11; A.A.Surg., U.S.X.; Member Tenn. State Med. Assn.; Nary Recruiting Station.

BAKER, EDW. IIALL (b'62)థ-111.17,04, a.1,08; (l'04); 5436 University Are. office, 29 E. Madison St.; $9-12$;

aker, Fredrica R. (b'65)-111.4,'95; (1'95); 4457 N. Paulina St.; $8-10,4: 30-7: 30$.
BAKER, HENRY IJESTER (b'70)૯-111. '98; (l'98); 3860 University St.; 8-10, $3-4, \quad i-8 ; S$.

Baker, Wh. Edw. (b'72)-111.11,02; (1'00); 1758 W. Lake St.; 10-11, 3-4, 7-8.

BAKER, WI. EVAN (b'63)屯-111.13,04 ; $\left(l^{\prime} 04\right) ; 225$ N. Lockwood Are.; 8-9, 1-2,

BAICERZAK, ANTHONY (b'72)-III.17,09; (I’09) ; 2643 Crystal St. ; office, 1053 MIlwaukee Ave. ; $9-12,2-5,7-9$

BALDRIDGE, 'SAMIL. T.' (b'62)-Ia.3,'87; (1'92); 5259 S. Halsted St.; $8-9: 30,1-2$, after

Baldwin, Theo. H.-N.Y.9, 75 ; not in practice; 817 Dakin St.

Balhatchett, Thos. J. - Ill. I,'91 ; (1'91) ; 6253 Dorchester Are.; 9-11, 5-6, ;-8.

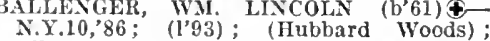
N.Y.10,'86; (l'93) \& (Hubbard Woods);
office, 31 N. State St. : 10-5; Prof. Laryn., oftice, 31 N. State St.; 10-5 ; Prof. Laryn.,

BALXINGER, JOHN RALPH (b'75) $₫$ Ill. $1,{ }^{\prime} 00 ;\left(1^{\prime} 01\right)$
$12-2,7-8 ; \mathrm{S}$. 13ambenek, John Damascus (b'81) - Ill.6, 08 ; (l'08) 1533 W. superlor st.

BAMBEIRGER, ARRIE (b'8i) \&-Ill.1,00; (1'09); 4439 \$. Mlchlgan Are.; offee, $32 \mathrm{~N}$. Stalo

Bamberger, Geo. Washington (b'80)-IIl.11, '04; (1'04): 432 E. 50th ['],; offlce, 239

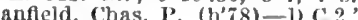

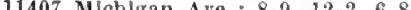

BARAT, STEIHEN S. (b'67) + $-111.5,03$

(I'03); T011 Euclid Ave.; offlce, 9154: Commerclal dve.; 9-12, i-8; also $15 \mathrm{~F}$. Washlngton st.; $3-5$.

Marber, Frank A.--11i.8,78; (l'84); 110. L. $63 \mathrm{~d}$ St.; $9-11,3-5,8-9 ; \mathbf{0 b}$.

Barber, Gideon Iannlng (b'43) H-Ill.I5, '94: (1'94); 1514 E. 65th St.; 8-11, 2-5,

Barbour, Fred. Leaworth (b'84)-Ill.11'11. (1'12); 6101 Woodlawn Ave.; offlce, 1230 E. 63d St.; 10-12, 4-5, 7-8; LO.

Barcal, Edw. J.-Ill.6,'03; (1'93); 8936 N. KIrby Ave.

Barclay, Metellus Rowan (b'67)-Md.1,'89; (l'91); 36 L. Walton Pl. ; 1-3; LR.

Barclay, Wm. A.-Ill.5,'97; (1'97); 3935 W. Monroe St.; offlce, 1553 W. Madison St.; $1-4,6: 30-8 ; G$.

BARKER, ClAARENCE DRYDEN (b'80)Ill.11,'04; (1'04) ; 5838 Ontarlo St.; oftce, 4051 iv, North Ave.; 8-9, 2-3, $7-8$

Barker, Clarence F. (b'52) H - Ill.4,'80 ; $\left(1^{\prime} 80\right)$; 3942 Ells Ave.; 8-9, 1-2, $6: 30$ $7: 30 ; \mathrm{s}$.

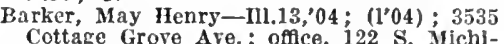
gan Are.

Barker, Milton Reed (b'59)-Ill.10,90, Ill.6, 01; (1'93) : 32 N. State St.; 11-1; (also office, Cox BIdg.; Wilmette; 8-10, 2-4).

BARLOW, LOUIS N. (b'61) $₫-\mathrm{Hl} .6,{ }^{\prime} 85$; (l'85); 4608 Vincennes Ave.; offlce, 3035 Indlana Ave.; $3 \cdot 5,7=8$.

BARNARD, HAYDEN S. (b'66) (- IIl.1,'89 ; $\left(l^{8} 89\right) ; 4033$ Vlncennes Ave.; offlce, 2600 Wallace St.; 1-3, 7-8; G.

not in practlce. 1909 Harrison S, (l'97): 1977 Ogden Are.

Barnes, Florence L. -II-III.15,03: (1'03) : 6150 Kenwood Ave.; 2-5; office, Marshall Field Bldg.; 9-11:30; G.

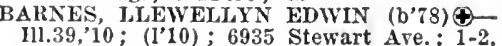
$7: 30-9$.

BARNES, WALTER STEELE (b'69) $\oplus-$ office, 29; E. Madison St.; 11-1; Asst. Prof. Gyn., mll. 6 ; $\mathrm{S}$.

BARNSBACK, JACOB LESTER (b'78)Ill.11, 03 ; (1'03) ; 4315 Forrestville Ave.; office, 4259 Cottage Grove Ave.; 11-12, $2-5,7-8$.

Barnum, Wm. Truman-Ill.11,'03; (l'03) ; 5843 Winthrop Ave.

BAROTHY, ARPAD M. (b'il) †-Ill.1,'94; $\left(1^{\prime} 99\right)$; 7619 Garrison Are.; office, 29 E.

Madison St.; $9: 30-5$.

ARR, WM. ALLEN (b'58) €--111.1,'92; (l'92) ; 3824 Jackson Blvd.; office, 32 ... State St. ; $9: 30-1$; Prof
Ill.G2; (B8); OALR $\star$

BARRETT, CIANNING WHITNEY (b'66) (-Mich.7,95; $\left(l^{\prime} 96\right) ; 446$ St. James Pl.; offce, 32 N. Śtate St. ; $1: 30-3: 30$; Prof. Gyn. and Clin. Gyn., 1ll.11 ; Prof. Gyn., III.G1; (A1,11)

BARRETT, FRED THORNTON†-III.11,06; (1'06) ; 2516 E. 74th St.; office, 9154 Commerclal Ave.

BARRON, ANNIE ESTHER (b'72)†-Ill.11, '02; (l'03): 3216 Douglas Blvd.; offce, $90 \mathrm{~L}$ W. 12th St.; until 9, 12-2, 6-8. (1'12); $851 \mathrm{~N}$. Albert (b'75)

BARRYTE, EVAN LUCIEN - Tenn.11,97; (1'98); 2104 Belmont Ave.; 8-10, 2-3, 7-8. Barstow, Rhoda Pike (b'52) H - Ill.4,'88; (1'88); 4317 Irving Park Blrd.; until $9: 30,11: 30-12: 30,6: 30-8$.

Bartells, Henry W'm. Fred (b'63)-Ill.1,'85; (l'85); 4823 Champlain Are.; offlce, 15 E. Washington St. ; 11-4.

Bartholomew, Anna. Joulse Lanb (b'62)Eranston); office, 32 N. State St. 


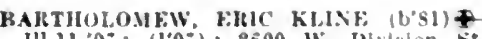
III.11, $0:$ : (1"0:): 2600 W. Ilviston st. $9.10,1.3,7-8: 30$.

RARTIOLONEW, JAMFS KI.EKXER (b'63)-Mlcb.1,'si: $(1,8 i) ; 50 \% 8$ italmoral Ave: ouce, 1225 . $\mathrm{x}$. ishland ive.: $1: 30$ 3. $7-8$.

Harlete. Frank kalser (b'si)--I11.1,12; $\left(l^{\prime} 13\right)$ : 1332 Congress sl. : (14).

Bartz, Nicbolas B. (b\%0)-ILl.1,93: (1'93); (1:8 W. Finmond Are. Oak Park); odle, 39 W. Idans tit.: 9.5.

liaklnd, Nathanlel Isadour (h'91)-Ill.11, '13: (1'13); 1822 \&. Halsted St.

BASS, GEO. F. (b'55)4-Vt.2, 's? : (1'82) 9896 Ewing Ave, oflce, 9549 Ewing Are. $8: 30+10,2-4, i=8$.

Bass, Luiber a. (b'\$5)-Ill.1,'80; (1'30): 11206 MIehlean Are.; 9-11, ;-9.

Bassett, Chas, F-H-H1.10;79. 5921 Indlana Are.

Bassett, Susan A. (b'42) F-111.8.'84 1832 S. Sawyer Are.

ISASBOE, I'ETER (b'it) \$- I11.11, 97 (1'97) (2207 Colfax St., Eranston) : of fle, 15 F. Washington St. : $1: 30-3: 30$ : Assoc. Prot. Med., 111.1: (k:1,4, ki); NP. BATES, MOKLEX DA COSTA $(b,-2)+-$ I11.1,'96: (l'96): 39 S. Contral loark lilvil onte. 3530 W. Monroe St.: $:-3,7-7: 30$.

HAEER, ALGLST HARVEY (bS3)--111.1, "10: $\left(10^{\prime} 10\right) ;: 100$ Semlnary Are. : untll ".

BAEGHER, ALBERT HOWARD (b'S3) III.1,09; (1'10); 6233 Ingleslde Are.

Baughman, Danl. Sparks (b'8i)-Ill.22.'11 (l'1); Cnlted Siates Marine Inspltal.

BAUM, WM. L. (b'67) \$-Pa.',8S: (L'88) gan ire.; $9-1$; Prof. Skin and Fen. Dis. III.63; (C3,0,7, Ft); D.

HA UMANN, FREDK. (b'6, $\$-111.11,01$ : (1.01): Congress Ilotel; offce, $31 \mathrm{X}$. State St.: Prof. Syph., $111.16 ; U . \star$

BACMGARTH, HERMAN R., JR. $\left(\mathrm{b}^{\prime} 68\right)+$ Wis. 2.98; $\left(l^{\prime} 98\right) ; 2000$ W. Chlcago Aiv. 1.2. $7-8 ; A L R$.

Baumrucker, otlllle olga Zelezny (b'80)III.I,03; (l'03); 3856 W. 96th St. ; 10-12, 6-8.

Baumrucker, otto-Ill.23,05; (l'05); 3856 W. $26 \mathrm{th}$ St. : $10-12,7-9$

BACK. FMIL FRE IK J1k (b'ts) fice, 3147 Iogan Ilvd.; $1: 30-5,7: 30-9$; ALR.

BALTI, CARI, O.- $-11.13,96 ;\left(1^{*} 90^{\circ}\right)$ : 4\$3\% Winthroo are: ofice, $140^{\circ} \times$ State st: 9-12.

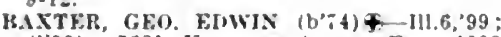
(1'99): 5621 Kenmore Are.: once, 4603 Brodway; 8:30-9:30, $4-6 ;$ Pd.

Beach, Geo. L. - II-III.4,'83; (1'33); 738 Calitornla Terrace.

REARI, CHAS. IIKADY $\left(\mathrm{b}^{\circ} 55\right)+-\mathrm{Ky}, 2,75$ (1'85): $1019 \mathrm{k}$. tsth St. oflce, $15 \mathrm{k}$ Washlngton st.; $9-1$; (B4, E. E) ; Op.

Beard, Guy Falw. (b's0)-III.b, 10; (I'10); 1206 Waveland Ne.: T.

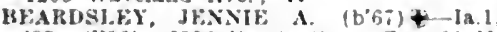
95: (1'56); 6500 l'eorla st.; office, 31 s. state St. $1: 30-3, \quad ;-8 ; S$.

BHATOX, HIXUAY AI.F.X (b'so)-111.1 $05:(105): 2373$ c. clask st $12-3,6-3$

Beatty, Bllzateth-H-111.15, 01; " $(101)$; 235 F. $51 \mathrm{st} \mathrm{St}$

Heaullette, Jis. Wilbur (b"so) ‥ III 2,33 ; $(1,13):$ 1824 Hilue Islanel tie

Beaudry, John S.-N.8.10,"8\%; $(1990) ; 010$ I'rinceton Ire.; untll 9, "::30-3:30.

Bechlel, Itaynond b. (b'\$6)-III क, 08

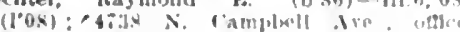
Hotel ia sille.

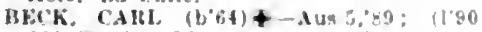
Gol Dernlug I'l.; oftice, 10.3 sitato sit 2-1: (A13, F) : 5 .

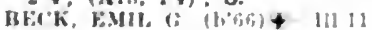

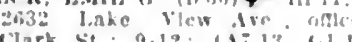

Clark ki. :-12; (Ai,13, (1.1) \$

HECK, Jus. $\therefore\left(b^{\prime}, 0\right)+111.11,95:$ (195) 2isl c. Clark st.: oflce, ios i statc

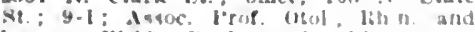

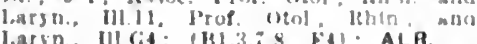
larsn., Ill Cit: (111.3.\%, F1): ALA. W lath Bt.: Asst. Irof. Derm. III.22.

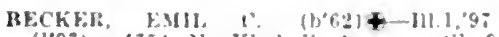
(l'9i); 4.54 s. Klmuall Are.; until $12: 30-2,6: 30-8$

BECKFI, Flisik C.-.Ind 8,'9i: (l'9s)

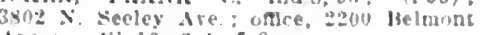
Ale: unt11 10 o-

Itecker, Jolnn (b'29)-I11.1,65; (1'7i) ; 1243 Weit fond is

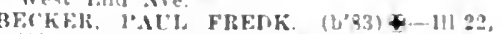
(4: 11.07); 2240 larrateo sl.: once, asos 1.inculn ive.: 1-2. i-8.

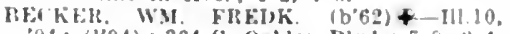
9: $(1,94) ; 324$ s. Oakley Bltd.; $;-9,3-4$ i-s; 6 .

Beckwlth, Fdwin Burt (h's)-I11.15,0?: Ilos): 8030 rmerall Ave. oflce. Masonle Temple: $10-3$

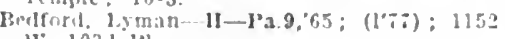
IV. $10311 \%$

Beecher. lieo. Xisin (l,si) 113.28.10 $11^{*} 101$ : Imsurance Exchange Blds.; unti feeclier, Sand F-IIl.16,06; $\left(1^{\prime} 06\right)$; (Den(lst); gul $\mathrm{x}$. State st. OAlce, Jasonlc Temule : $9-5$.

Beecher, Wrn. I.-III.6,"01; (l'01): 4503 Winthrop sie.

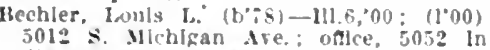
diana Ave: $1-3,6: 30-8$.

Beck, Wm. (i--I11.23,"04; (104) ; 3623 Plne Grove ire: offce, 21 N. Wabash ire. $0.12,2-5: 0$ p.

BFERS, BHRTLAM RORT (1'S3)-III.11, 0.8: (1'08): $450 \mathrm{x}$. Kluball Are.; once, 4006 I.lncoin Are.

Beers, lilla Filla (b'67)11-Ill.t,97; (1'97) lith W. 35th st.; 8-9, 12-3, 6-8.

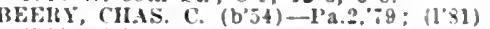
454t Mlcligan Are.; once, 1.33 Wabash lie.: 9 -11, 2-4.

MFESON, BENJ. B.IRKER (b'83) - 111.11,

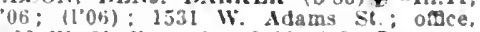
s02 W. Madlison st.; 9-12,6-8; D.*

Beeson, strother J. (b"53)-111.1,"ss; (1'99): 15.31 W. Idans st.; nflce, stl: W Madlson st. $9-12,2-5, i=8$.

BRHRENDT, ALFXANDER $\left(b^{\prime} \div 6\right)+\longrightarrow$ : (1'34); $5629 \mathrm{~s}$ Mllchigan Are, oftce, 32 X. State St.; $10-1$.

BEHREXDT, ALTHCK J. $\left(\mathrm{b}^{\prime} 65\right)+-111.11$, 91: (1'91): 2026 Fowler St. ; untll 9, $12-2.6-7: 30 ;(\mathbf{A} 12)$.

Behrende, Geo. Jos. (1, 33$)$ - Ill.28, 05 $\left(l^{\prime} 0.8\right) ; 4136$ W. North Are ; 1-3, 7.R.

BEIFEII. ALBERT IIENIS (b'SI)-MA. '07: (l'0s); 3304 (alumet Are: oftce. $104 \mathrm{~S}$. MIchligan Ave.; $11-1 ;(\mathrm{D} 2) ; \mathrm{Pd}^{\star}$

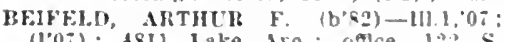
(107); \$S11 Lake Are.: oflce, 1:2

Mchlgan Are.; $1-3 ;(\mathbf{F}+) ; 1$.

MEILSTEIY, FREDK. W. (b"7i)-1116:99. (l'94); 5200 Loumls St ; oftce, 5059 s Ashland Are

Bein, Alfred (6,5) 111.11,9; 1195$) ;: 100$ Alice l'l

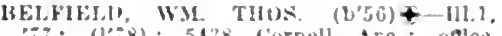

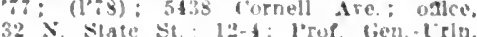

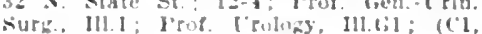
Siurt. I U. U.

lielith. Ilford in

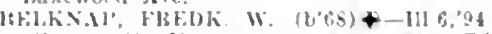

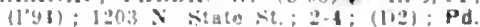

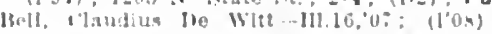

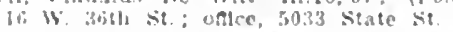

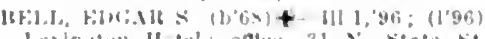

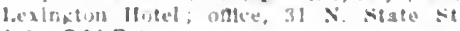
I: OALR.

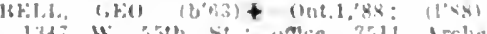
1.167 W s5th st.: umie, $3 \% 11$ Irrlaer

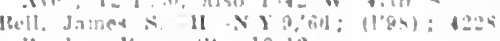
II b.un lituren sit : 10.12.

liwll, damm simwart tho

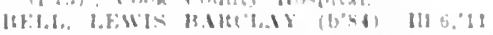

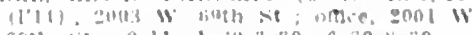

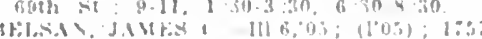

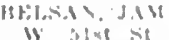

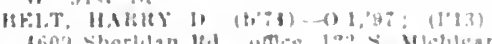

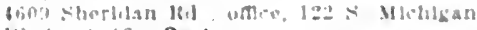

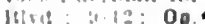

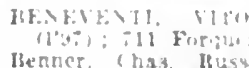

(105) Thas. Iflesw.

Benuet, Jolig l'. (b०in)

21 b. Van Inuren

It:xit Wi II

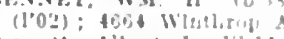

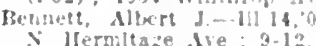

Bennett. Win. ilos alus

oxio llene is orth a a $9-11$

renuley liuts liussell (t)

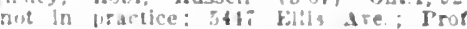

Lat, III 1; (ri)

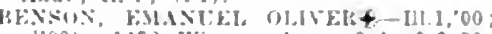

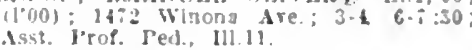

Bensun, Fredk $\times$ 305,15 E. 215t \$1 ; 8.9, $1-2, \div-3$.

(b.5)-II1.5, 43 (1'.99)

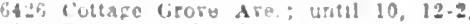
afier : iflec, 3035 Indiana Ire; 10.12

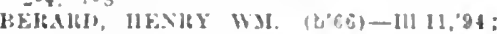

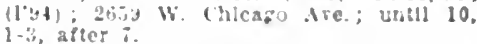

Berg, Ole H.-IH.11, 20 ; (\$); 1101 X. CallPornla tie.

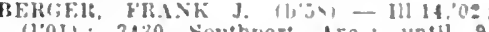
(101): 3430 Southport sre; until 9

REHGE, GINTAVLS FHEDK, (b'6:) 111.1,97: $\left(1^{\circ} 97\right)$ : 4511 Dorer St: otlce, 3001 Liacolr Are, $9-10,8-4, ;-8$

BERGEI, JOHX MILTON (b'33) \&-III.11, W. Madison St.

BERGIERON, JOS. Z. (b'C4)\$-III.1,89 (l.kg); jli kosene st: : ottice.

Mergeron victor A-lil. f, ALR.

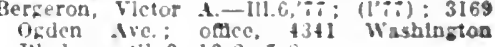
Blrd. ; untll 9, 12-2.

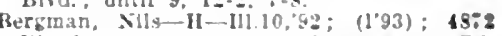

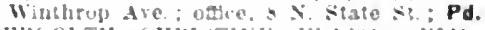

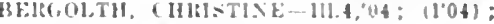

Bergstrom, Enoch Aiot-lll.s, 'gt; (t'94): i5t9 Coles st. : $9-1 \%, 1=3$.

[BEHGSTROM, victulit CALLA A-n1.1 03: (1'03) : $5330^{\circ}$.N. Clark st. : oclce, 108 $x$. Niate si.

Irerkoulte, Jos (i.-l'a 11.07; (1'0i): 3246 Wishlngtun Blvil : OAlce, 1003 s. IIalsted st. 111-", 5.s: U.

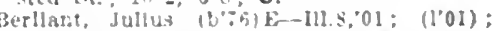
1146 W. l2th st. unth 10, l-2. 6-s.

kermingham, Fugene Emact $\left(0^{\prime} 80\right)-I 1 !-11$

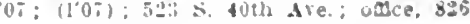
S. i.caritt st

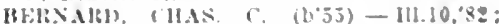
(1's2): jom Magrulla Are.; omce, 2000 N. Haisted st: 1 -2. :- : Op.

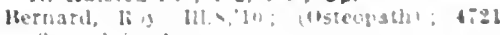

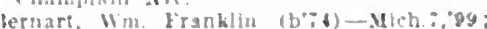

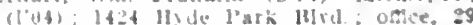
t. Mudlson si.; b-i: U.

lhersharde, Ilarry heruard (b'st)-1:16,09:

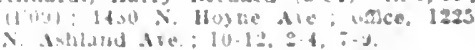

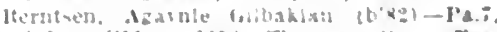

(1.11); 3iso

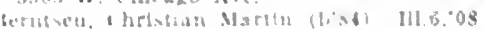

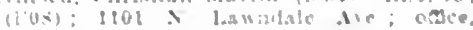

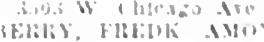

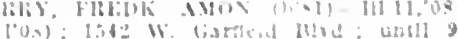

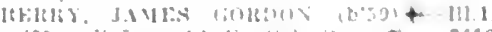

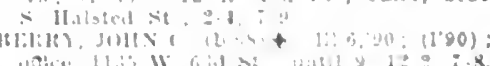

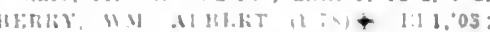

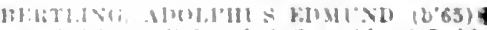

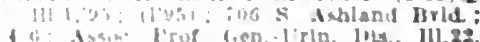

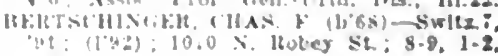


Bertschinger, Lcua Honegger-Swltz.7,'91; (192) : 1010 N. Robey Nt.; $10-11,4-5$. 13eseler, John Francis-Ill.16,'0s: (l'0s) : 5659 S. Mlchlgan Ave, otlle, 3000 E. 7914

Besharlan, Jolin H.-111.1,'82; (I'S2); 3258 Prulrie Are: 8.9 1-3, है-5: OpA

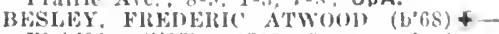
111.6,'94: (1'05): 4515 Greenwood Ave. offec, I04 S. Michlgan Ave; $2-4 ;$ Assoc.

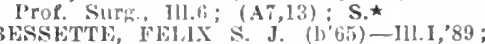
(1's9) ; 26,57 W. 3sth St.

Bethel, Mary Wright Thomas-111.0,92 (1'92) ; 3032 Lake l'ark A ve. : 2-

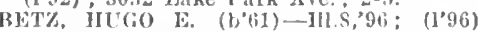
5500 S. Halsied St.; $9-12,6-9$

BEVAN, ARTIUR ISEAN (b) (10) †-Ill.1, 837; (1"42) : 2917 Mlchlgin Ave.: ottlee, 122 S. Miclugan Are.; $2-4$; Irof. Surg. III.I; $(A 5,6,12,13,(3,7,71,4) ; \mathrm{S} . \star$

Berins, Nathan Sldney (b'84)-1ll.6,'11; (1¹); 2449 s. Dearborn St.

BHXFRLEN, AR'THUR LFWIS (b's9) + 111.11,'12: (1'12); 1936 Belmont dro.

BEYERLEIN, LOUIS J. (b'5s) $4-111.13$,'99 ; (1'99): 1936 Belmont Are $: 8-10,1-3, \pi-9$ BLANKINI, ANTHONX, (b'60) -Aus.7, 88 ; (l'99); 3207 Indlana Ave.; 8-10, 6-8.

Blbb, Merwyn R.-Ill.13,02; (l'02); 2900 S. State St. ; $9-11,2-4$, after 6 .

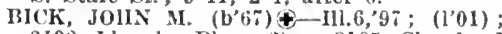
2100 Incoln Pl.; ottice, 2105 Ćleveland Ave, ; 1-3, $7-8$; (Ji) ; ALR.

Blckerdike, 1Rlchard J.-H-111.14,'98; (1'99); 5669 Forest Gion Ave.

BIEHN, JOSHI? FAVIL (b'79)-Jll.6,'01 (l'01); 5444 Lakewood A re.; offle, 4753 E. Ravenswood Park; untll $9,5-7$.

BIESENTIAI, NAX (b'32) \&- $-111.11,04$; (1"04); 4953 Forrestville Ave.; offlce, 309 E. 47 tl St. : $I-3,7-8$.

BIGEIOW, FREDK. E. (b'70)-IIl.1,97 ; (l'97); 5239 lingleside Are.; 8-10, 1-3, 6-8; oftce, 4259 Cottage Grove Are.; $4=5$.

Billg, Adolf (b'62)-Ger.10,'92; (1'96) ; 1131 Michlgan Ave.; 8-9, 1-2, 7-8

BIILIG, GEO. W. (b'7 01; (1'98); 2041 Byron; offlce, 4016 Lincoln Ave. ; 1-3.

BILLINGS, FRANK (b'54) $\oplus$ - Ill.6,'81; (1'82); 242 E. Walton St.; offlce, 122 S. IIlchlgan Ave.; 2-5; Prof. Med., Ill. I; (D6, E4, F2,4).

Bllings, Rebecca Rhoads--1ll.9,'99; (1'99); 3322 Walnut St.; 8-10, 2-4, $7-9$.

BILLINGSLEA, CHARLES C. $\left(b^{\prime} 78\right) \oplus$ Md.1,00; Capt., M.C., U.S.A.; Central Depot.

BNGLEY, M. ARISTA $\oplus-$ Ill.11,'98; (1'98) 804 Milwaukee Are. ; offlee, 730 Christiana Ave.

Binkley, Iohn T.-0.1,'83'; (l'83) ; 5470

East End Ave.

BIRK, JOHN WILLIAII (b'74)-Ill.11,0I; (l'11) : 4645 Malden St.; oftlce, 4602 Kenmore Are.; also, 139 i. Clark St.

Bisanz, Ralph F. (b'82)-Ark.1,09; (1'II) ; 3214 Montrose Are.

BISCHOFF, IIENRY A. (b'62) Ill.6,'89; (l'89); 859 Oakdale Ave.; until 8, 4-5; office, $1900 \mathrm{~S}$. IIalsted St.; $9-10,1-3,7-9$.

Bisdon, Fredericus Augustinus (b'58)I11.1,'11; Intern, St. Lukes Hospital.

Bisdorf, Math. H. (b'S1) -Ill.16,06; (1'06) ; $3121 \mathrm{~N}$. California Ave.; $1-3,7-8$.

Bishkow, Isadore Edward-Ill.11,'11; (1'11); 1240 S. St. I,ouis Ave ; office, $3158 \mathrm{~W}$.
12 th St.; $10-12,3-6$.

BISHOP, ARTHUR I. $\oplus-111.6,98$; (1'98); 5541 Kemmore Are.; office, 'Virginia' Hotel; until $9,1: 30$

Bishop, Rufus W. (b’59)-Ger.1,'82; (1'83) ; Calumet Club; offlee, 140 N. State St.; $10-1,2-5 ;(C 3,6,7) ; D$.

Blshop, Minnie Ridgerray (b'61)-Ill.4,'89;

(l'89); Chicago Beach Hotel.

Bishop, Seth Scott (b'52)-Ill.6, 76 ; (l'80) (1726 Ridge Are., Eranston); offlee, 31 $\mathrm{x}$. State St.; 10-4; Prof. Otol. and Rhino. Laryn., Ill.8; ALR.

Bissell, Wirne W'n. (b'86) - Ml.1,'11; (1'11) ; Cook County Hospital.

Birlns, Burton Wayne (b'i6) E-Ill.22,'04 (1'04) ; 2227 Madison St.; 11-12, 3-5, 7-8;

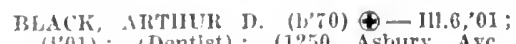
(1'01): (Dentist); (1250 Asbury Are." 1, Ack, G. V.-111.6, $89 ;\left(1^{\prime} 78\right) ; 4549$ Oaken wald Ave. $10-12,2-4$.

BI.ACK, IROB'T. AI,FIET ( (l'05); Del Irado IIolel; Proe. I'ed., Ill., Gi3; (1)2)

Black, Wm. Letcher (b'68)-Pa.1,'9s;

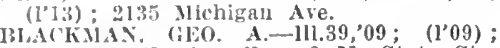
Blsmarck 1lotel; office, 8 N. State St. ; $3-6$

Blackmarr, Frank llamiln-111.4,97; (1'97) 1:439 Kinbarl Ave, offlce, 22 E. Wash$8-9$.

BIAC'KWOOD, ALFXANI)ER L. (b'62)11.4,'s8; (1'88); 9128 13altimore Ave. ; ottice, 3004 F. 921 St. ; 1-3; also, 9151 Commerclal lie.; Prof. Mat. Med., 1ll.4. Blahnlk, Karel Bartholomae (b'86)-Ill.6, '11; (1'11); 1901 W. 47 tb St. ; 10-12, 2-4, $7=9$

Blair, Chas. Patton (b'83) - Ill.11,'12; (1'12); Cook County Ilospltal.

BLAIR, JAMES H.-Ill.8,'97; (1'97) ; 804 Oakwood Blvd.; offlce, 3900 Cottage Grove

BIAKE, JOS. M. (b'75)-Ill.1,03; (l'03) : 712 W. 31st St. ; offlee, $2 y$ S. Dearborn St. : $2-3$.

BIANCHARD, WALLACE (b'4s)--III.6, '69; (1'77); 943 Whlson Ave.; offlec, 15 E. Washlngton St. $9-12$; Asst. Clln. Blanchard, Wm.-Ill.14, 05 ; (1'05); 2014 Os good St.

Blanchet, Lawrence (col.) (b'80)-La.4, 09; (1'12); Provldent Hospltal.

Blanck, Ellse w. S. (b'57)-Ill.9,'90; (l'92);

I1140 Mlchlgan Blvd.; 2-4.

BLANCK, ERNEST C. - Ill.16, 07 ; (1'07) ;

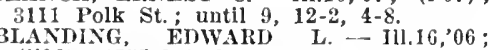
(1'06) ; 475 Winthrop Ave.; 10-I.

BLATT, MAURICE IAMM (b'79) $\&$ - Ill.1, '03; (l'04); 5356 Mlchigan Ave.; offlee, 31 N. State St.; also 309 F. 47 th St.

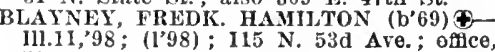
Ill.11,98; (1'98); 115 N. 53d

BLECH, GUSTAVUS M. (b; 0$) \oplus-M 0.28$, 94; (1'98); 3717 Indiana Ave.; offlce, 104 S. Michigan Ave, ; 3-5; S.

Blesse, Fredk. A. (b'88)-Ill.4,'13; ( ) ; 2832 Prairie Ave, offlce, $3118 \mathrm{~N}$. Clárk St.

BLEWETT, WII. I.-Ont.1,90; (l'90); Lexington Hotel, office, 1800 Wábash Are

BLOCH, LEON (b'79)@-IIl.1,03; (1'04) 1010 Ashland Blrd.; office, $32 \mathrm{~N}$. State St. ; 4-5; Asst. Prof. Med., Ill.1.

BLOCH, MAX EMANUEL (b'73)-Ml.11,'00 ; $\left(1^{\prime} 00\right) ; 3906$ N. Hoyne Ave.; 8-10, 1-3, $6-7: 30 ; \mathrm{U}$.

BLOMGREN, CHAS. EDWIN (b'70) $\oplus$ 1-2; office, 3203 ; 5400 Lakewood Ave. Bloomingston, Francls E. D.-H-Ill.15,00 (1'02) ; 6132 Kenwood Ave.; 10-12.

Blouke, Milton B. (b'62) H-Ill.I 0,$85 ;\left(l^{\prime} 86\right)$; 2907 Washington Blvd.; office, 22 E. Washington St. ; $1-3$; S.

BLUE, ROBT. B.-I1l.6,04; (l'04) ; 6117 Langley Are, ; ofllce, 15 F. Washington

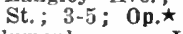

Blumenkranz, Louis (b'88) - 111.6,'10 (1'10); 8819 Houston Are.; offlce, 9154 Commercial Ave.

Blunt, Arthur I. (b'54) E-Ml.8,'88; (1'88) ; 4043 Prairie Are.; offlee, 9 W. Harrison St. ; $9-5,7-9$

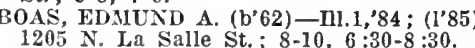

Bobzin, Edwin C. (b'82)-Ill.14,03, Ill.16, '06; (l'04); 208 E. Erie St.

Bockius, Frank B. ron Eisen (b'48)-111.6 72 ; $(1,78) ; 4657$ Wilson Are.; office, 1967

Milwauke Are.; $12-3,8-9$.
BODDIGER, CHAS. E. + -Ill.11,93; (l'93) ; 2801 Archer Ave.; office, 1801 S. Ashland Ave. ; $7-9$.

Bodman, Edward Whitney-Ill.1,'07; $\left(1^{\prime} 07\right)$ : 1519 N. State St., office, 125 E. Chicago Ave.

BOE, ALFRED N.-Ill.14,'03; (1'04); 946
Boehm, Chas.-N-111.8,95; (l'95); (Hlghland ' Tark); oflce, 3839 N. Avers Ave. $\tau-9,2-6$.

Bnerlin, Ifenry 'T. (b'62)-111.13,'00; (1'00) 4553 Lymail $\Lambda$ ve. ; offlec, 8 N. State St. $9-12,1-5$

BOETTCHER, IIENRY R. (b'66) $\oplus-111.4,00$, Ill.13,'96; (1'90); 6336 Ilarvard Ave. S-10, 7-8: ollice, 15 W. Waslungton St. ; 11-1; (Iit) ; OALR.*

Botfenmeyer, Geo. E. (b'72)-111.22,11. (1'11) ; 3801 Alta Vista Terrace; 1-3.

Bogart, Leon Maxwell (b'87)-111.22,'13; (1'13) ; 1501 W. Harrlson St.

Boguszewsk1, Stantslaus-Ill.17,'05; (1'06) 8709 Commerclal Ave.

BOHART, WM. 11, (b'68)-Ill.1,'91 ; (1'91) IIollendlen Hotel; offlce, 300 W. $63 \mathrm{~d}$ St.; $11-1,7-8 ; \mathbf{S} . \star$

BOHMEL, OIAV (b'69) †-Ill.11,'04; (1'04) ; 1304 W. Ohio St.; 1-2, 6-8.

Boles, Eugenle Ferguson (b'72)-Ill.16, 09 ; (l'09); 2558 w: Chleago $\Lambda$ ve.

BOIES, HENRY M. (b'79) $\oplus-111.16,10$ (l'10) : 2558 W. Chlcago Ave; $8-10,5-7$ : 4801 W. IIarrtson.

BOLOTIN, JACOB W. $\oplus-111.22,12$; (1'12) 3328 W. 12th St. ; offlec, 1726 W. 12th St. ; 6-8; Asst. Prof. Med., Ill.16 ; I.

Bonthlus, Andrew (b'80)-II1.6,09; (1'09); 11213 Curtis Ave.

BONTHIUS, FREDK. A. $\left(b^{\prime} 74\right) \Theta-111.6,02$; (1'02); 11055 Michlgan Ave.

Boodel, Jolun Cullen (b'90) -IIl.6,'13; (1'13) ; Intern, Mlchael Reese Hospltal.

Bookwalter, Carl Ferdinand (b'79)-MId.i. 10; (ま); 2601 Pralrle Are.

Boomer, Paul C. (b'68)-Ill.6,'92; (1'93) ; 3130 Indlana Are.; 2-3, 7-8.

Boon, Alfred Henry (b'88)-nl.6,'II ; (1'11): St. Luke's Hospltal.

Boone, Jesse F.-Ill.4,'12; (1'12); 9119 Commerclal Ave.

(See Evanston.

Booth, Frank Hulburt (b'60)-Ill.1,'85 ; (l'85); 1627 w. North Ave.; untll $9: 30$;

BORCHERT, ROBT. LAMBERT (b'88)Ill.11,'10; (l'12) ; 5045 Lincoln Are.

Boren, John WWm. (b'87)-Ill.6,'12; (l'12) ; Cook County Hospital.

Borges, Davld G. (b'78)-Ill.11,04; (l'04); 6601 Washington Ave.; offce, 6602 Wash: ington Ave.; 2-4, 7-9.

BORLAND, LEONARD C. (b'62) - Ill.1 '87; (1'87) ; 2525 Smalley Ct.; offce, 209 S. State St. ; $1-4 ; U$.

Boros, Salamon (b'86) -Ill.16,'12; (l'12) ; 1401 N. Western Ave.

Borrelll, Wm. F. (b'79)-Ill.8,'05; (1'05) ; 1634 W. 69 th St.; untll 8; after 4.

Borucki, Felix M. (b'50)-Rus.4,'74; (1'90);

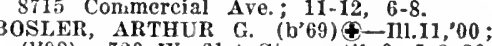
$\left(1^{\prime} 98\right) ; 720$ W. 61 st St.; until $9,1-2: 30$ $\tau-8$.

Bostick, Ida May-Ill.4,07; (l'07) ; 225 W. 72d St.

BOUFFLEUR, ALBERT IRVING $\left(\mathrm{b}^{\prime} 64\right) \oplus$ Ill.1,87; ('1I) ; 2449 Washington Blrd. (A13) ; S.

BOUGHER, WM. SHERMAN (b'67)@Ill.16,'08; (1'08); 6342 S. Green St. : office, 6304 S. Halsted St.; 12-1, 4-5, T-9. Bourque, Norbert Odeo-Ili.14,04, Tenn.1, 07; (1'08); 3832 Rhodes Ave.; 8-10, 2-4. Bousfield, Midlan Othello (b'85)-Ill.6,'09; (l'09) ; 4623 Langley Ave.

BOWE, EREDK. OTTO (b'78)€-I1.6,03 (1'03) ; 3000 Belmont Ave.; 2-4, $\tau-8$; ObG BOWEN, CHAS. F.-Ill.1, 89 ; $\left(1^{\prime} 89\right) ; 3535$ W. Congress St. ; offlce, 32 N. State St.; 2-3.

Bowers, Chas. Edward-E-Ill.8,98; $(1,98)$; $3802 \mathrm{~N}$.

Bowers, Wm. Baldwin (b'76) - Ill.6,09; (1'13) ; 4221 Prairle Are.

BOWES, LEON M. (b'78) $\oplus-$ IIl.I,'03; (1'03); 6031 Circle Ave.; 10-12, 7-8; LR.

Boyd, Jay-Que.1,'87 ; (1†)； 4347 Oakenwald Are.

Boyer, Eugene Radford (b'85)-Ml.11,'12; (l'12); West Side Hospital. 
Bosnton. Chas E. (b'60) H-Ilt.4,91; (l'93) (333 Lake st.. (Oak l'ark); once, I59 State st.; 3.5: ALR.

Boynton, John II.-II-I'a.9.'80: (l'86): 1328 †. I. Sialle St. oace, Chicago siavings Hank $\mathrm{B}$ Idg.

Hoynton Wim. Falson (b"i2)II-III.10,"9s (1'95): 3t4 Englewood Ave. onlce, $22 \mathrm{k}$ Washligtan St.; 3.5 ; Ad. "Prof. Ophth. III.4: OALR.

BOZINCH, MATTHEW F. $\neq$ - Hus.6,90 III.22.'12: (1'95): 1036 N. Hoyne Ire. offe, 815 IIlwaukee Are. $8: 50-11,6-9$ $33 \mathrm{th}$ st.: office, $1653 \mathrm{~W}$. $35 \mathrm{th}$ S

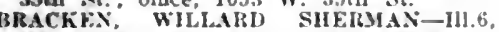
02: (1.02): 5007 Grund B!vd; once, 104 S. Inchlon Are.: 1-4; OpLR.

Bradley, Allen Marshall $\left(\mathrm{b}^{\prime} 69\right)-$ II.22,10: (1'10): 4148 W. Marrison St.; 8-10, 1-2. $(110): 414$

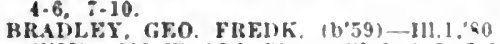
$\left(1^{\circ} 82\right) ; 800$ w. $121 \mathrm{~h}$ St. : untll $9,1-3, i-9$ Bradley: Wm, Hurace (b's3)-111.11,10

(l'10): 3958 W. 12 th St. 2-4, $;-8:$ S. S. State St; $9-11,2-4,7-9$.

Bradwell, James B. (b'-5) II-III.4,02 (1'02): 4624 Lake Ave.: offce, $29 \mathrm{E}$ Yladison St.; 11.2 .

Mladison St.; Il.2.
Brads, Ellzabeth Nell-Ill.9,00; not in

practlce: 3229 Flournoy St.

Brady, Geo. Peck (b'til) II-IIJ.10,'90; $\left(1^{\prime} 90\right)$ : 5324 Drexel Ave, untIl 9, 1-3.

Braham. Jullan Alfred (b's4)-111.11,09: (1'09): 3556 Gladys Are.: oftice, 2958 W Van Buren St.: $2-5, \quad i-9$.

Brams, Wm. Alexander (b'90)-II16,'I2: (1'12): 2035 Potomac Are.

Branen, Frank (b'67) H-I'a.9,91; (l'92) : 2339 w. Monroe St.; oftce, 32 '. Sitate St. ; $12-1$.

Brasher, Mllis C. (b'65) Fr-III.8.'s9; (1'89) 404 Vincennes Are.; 10-12, $1-5$

Braude, Benj. (b'8i)-[1].1,09; (l'09): 827 S. Ashland Blvd.: oftce, Til Fuln St. (l'05): 827 Ashland I'trd.; NP.

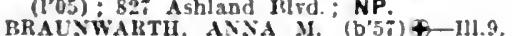
86; (l'86): 3119 South Fark Are.; oflce, i. Madlson St. : 10-12.

BRAWLEY, FRANK ( $\left.\mathrm{b}^{\prime}, 5\right)$ - I11.11, 02 ; (1'02): :211 Cramdon Are.; oftlce.

Madlson St. 10-4; (I3 $1, \overline{1}, 8) ;$ OALR.* Carmen Are

BIFAKSTONk, BENJ. II. (b'7/)-III.1.99: (1'98): 3716 I Douglas Bird. offec, $32 \%$

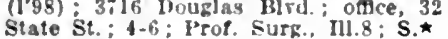

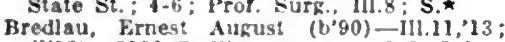
(l'13): $5100 \mathrm{~s}$. Western Ave.; $1-3,7-8$. Breeden, Roy Fred (b'90)-I11.11,'12: (1'12) St. Mary'a IIospltal.

BREM YRMAX IFWIS WINE (b'ii) I'a.2,00; (100i): 520; Washlngton Are. Brendecke, Idolph Carl (b' 16)-III.I1, 86 : (1.88); 1200 W. Madlson St.: 12-2. Brennan, Denals F. (b'64)-11!.6.'86: (l'86) 5660 \&. II Ilsted St. : $10-12,2-4,7-8$.

BREXXFMAX WM, LLMER (b'63)

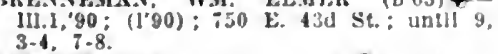

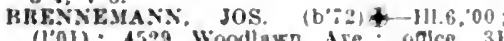
(1001): 4529 Woodlaxn Are. odice, 3 III. 6 : (1)2): Pd.

Rrenza, Syliester II. (1,8i)-I11.22,10: (l'10): 4608 \&. Ashland Are.

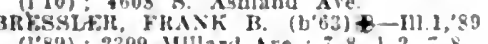
(1'89) : 2309 MHlard Are. : $7-8,1-2$.

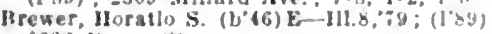
6623 verry st

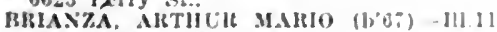
92: (1'92): 2758 dackson Mlvis: odces Masonle Temple: 1.3: OALR.

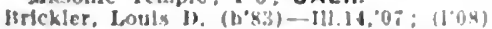

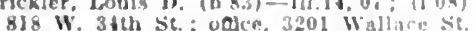
$7: 30-8: 30$.

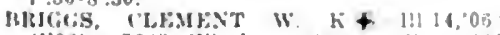

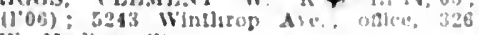
W. Madison St.

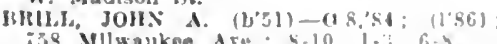
i3s Mllwankee Aro ; $10,1-3,6-4$.

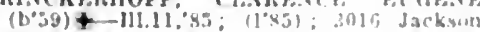

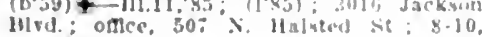
III
$1.2,6.8$.
Itrlney, Wm. F. (b'69)E-I11.8."97: (1'99) 1900 s. Kedale Ave: $10.12,7-8$

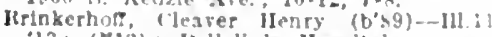
13: (r13): Pollelinle Hovyltal.

Irrinkerbor. Wm. C. (bo 61$)-111.11 .80$ (l's9): 1129 l'ratt Hivd: once, is5 w Mallsop st. : $10-1,2+$

HSLEN ANDREW 3.-I11.6,95: (1'95) $223 \mathrm{k.} \mathrm{HCtl}$ St. ; oflce, 4656 Indlana Are. $10-12,3-4, \quad i-8$.

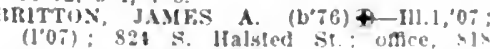
cilpla IN.: (1)2).

Itrlk, In Joln-F-111.8,01: (1.29): 1210 truad, Hents

Mllwatikec Are

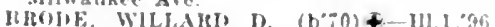

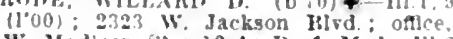
W. Madtson st.: 12.4: I'ro?. Med., Ill.22 (IB) ALR.

IROELI, ALHERT C. (b'64) \&-III.6, $\mathrm{SG}$ Irook. Iyman-3lo.28,'99; (1.99); 2100 W. lirlaton St.

Bronke, Flrmen C.-F-Pa.1:,66: (1'38)

Brooks, Geo. I. (b'-8) H-III.10, 01: (1'01): 5435 Greenwond Are.: unt]1 9, 6:30-7:30: once, $32 \mathrm{x}$. itate st.; $1-3$

Brooks, James Firnest (b'82) - 111.8, 10

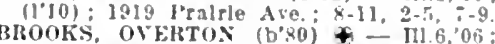
(1.06): 2001 Clereland Are. oftce, 54 S. Tearborn st. : 11-2, 4-6; $\mathrm{S}$.

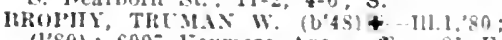
(I'SO): 6007 henmore Are.: once, si F. Madison St.

BROUGHAM, EDWAIN J‡-111.6, (I'87) : 1739 X. I'ark Ate. once, 16. W. Chlcago Ave : 10-12. S-10.
BRoUHLET RALII JULIN

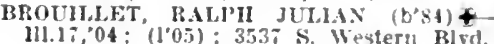
oflce, $3: 95$ Archer Ave.; 1-3, 6:30-5:30 S.

BHOWER, DANI. IR. $(1, \div \downarrow)+-111.1,02$ I002); (Wllmete); onlce, lot s. Mlebl BROW AT, ACE BARI.OW $\left(\mathrm{U}^{\prime} 69\right)+$-Ill.4, 96. I11.11,03; (1096): (Winnetka): oftce 1.5 F. Washington st: : $1-3$

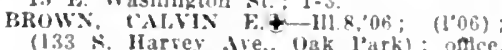
(133 \&. Harrey We. Oak l'ark) : once 203 N. Kedzle Aie.; $1-3,6: 30-\$ ;$ S. Warren Ave; oflce, 125 Ifonore sit; 8 - 10 $2-5$.

brown, Earle Godfrey

(l'13): Mercy Hospltal

HOWN, FAki, J. (b'61) + -I11.16.03 (1'03); 6708 Southport Are; once, $;$ Madlson St. : $10-4$.

IROWN, FWWARD MILTON (b'0) + J11.6 32 x. State st: 1-3: Assoc. I'rof Clin surg. Jll.11; S.

HIOWX, EDW:ARD VAJ, LAPHAM (1) Fi)

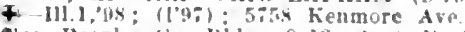

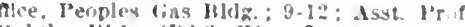

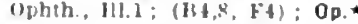

Itrown, Fldello Fletcher $(2,60)-111.14,96$,

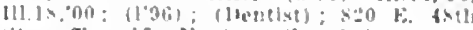

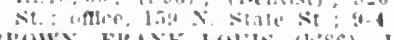

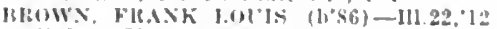
(1.12):351) W. Harrbon st.; 12:30-1.30

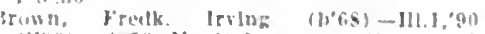

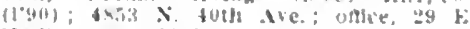
Mallsons $>2$ : $10-1$.

Broun. Cied. Juduan (bisill - 11114,97 (I"3): $330+$ W. Madlson 51 ; 913,2

Hrown, lien. J.ekuy (b78) II I11.10,"99

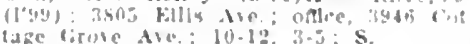

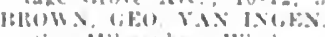

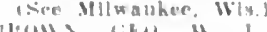

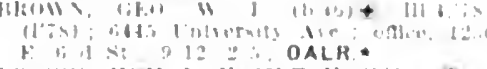

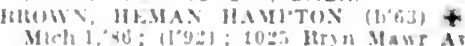

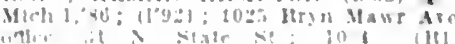
OALR *

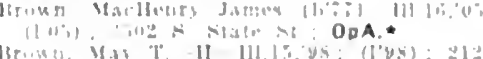

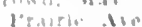

BH()WX, MOKFA MUHERT

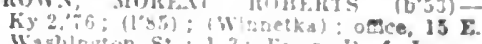

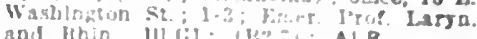

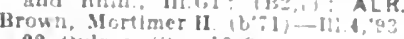

22 Qulncy it: ; $10-2$.

Brown, Halio Crlsoman

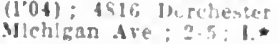

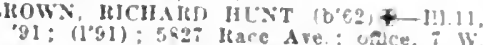
Madison St.: $11-3$; Arst. Jrof Clln. Ioaryn. thln. and oinl. H11.11; (H1, i): OALR. BHOWN, SANGE $\left(0^{\circ}, 52\right)$ - Y Y 10, (1'si): 1heullworth): odve, : S. Wabash Irrown, stanles Lee (b's5) -III.6,00: 1100) 13420 Gntarlo Are: once, 13309 Erlé

A130W: WM. CLLP (D'66) - $11.14 .95:$ (1'95): 432 x. I'ark Ave: 9-12, 1.5: OALR

BROWN, WM. D. H.-III.14, 02 : (1'02): (230 \$ Tatharlne Ni., La Grancel: offce, I0s X. State St.; 10-1, 2-4

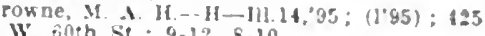

Brownstein, Iberward $(6 \% 9)-$ I1].11.02: Bruce ; 1242 S. Albany Are ; 10-12, 1.3.

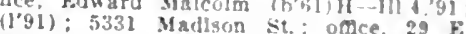
Madison Si, $1-3$; I'rot. Theo and I'rac.

BRLCCKEW, MАTTHEW WW $\$-11111,05$ (1.06): 3845 I'olk st. : oflce, $335 \mathrm{~S}, 40 \mathrm{th}$

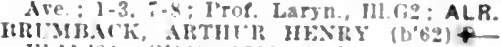

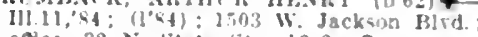
onte, 325 siate st. $12-2 ; 6$.

Rrumund, liledrlch A - II1.6\%99:

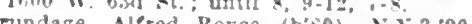

not in practlee: 62os valls Are.

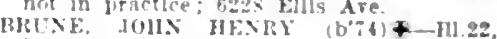

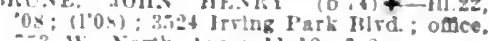

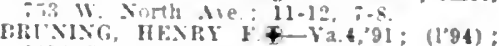
2004 lioscae [B]

Iirumo, li!ovama! 13. (b"a)-Ita.:,00; (1'03) ; 11: Lostoe st.; culde, SI2 X. Ilesrborn

Brunswlek, Fodmund Lewly-I]1, :12: (I"13);

BIB YAN, CLAIFATE: H $\left(\mathrm{b}^{\circ} 65\right)+-111.1,59$ :

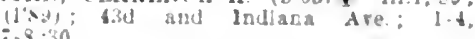

Bryan. Juhn C.-III.1, :7: (1":9): 3536 Sherldar lid: (Ft).

HRYIXT, HAMRI HMANTEI, (D'Bt) III. 1,09; (l'09); j490 Wasblngton Ate. $4: 30-5: 30$. $5:$; ottce, $1: 2$ s. Mledigan

IBIIGF, J.MMES CHAS. (1058)-111,92: 11'10): Masomle Temple, $2-1$.

Huchan, Edw. James -111.11,06; ("12); 110 Itriat I.l.

Buchas, John It. (b't6)-N.Y.5,:2: (1":;) 1:10? Fark lie: matl $9,1=2$

Bucluanan, Charles Jlenry (b"si)-111, :6:

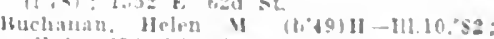

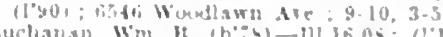

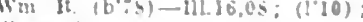

lucliliniler, Jacob lichier (b'si) - - III 6, 11

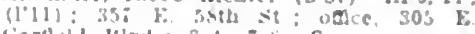

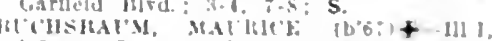

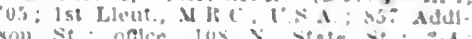
son se : oflece. Iux

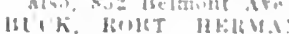

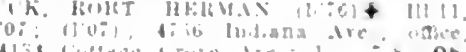

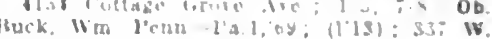
651451
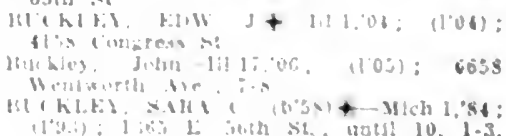

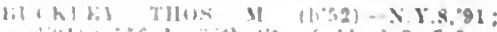

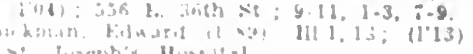


Buckner, Wim, A-1ll.13, 00 : (l'00); 3433

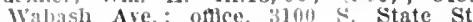

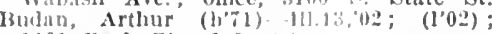

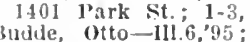
St.; oftee, 3100 s. Mlchigan Are.; 12-2,

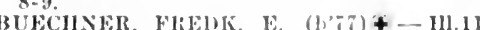
0I: (1.01); 20.40 Logan 13lrit.; oftlce, 659 Cortinnd st.; $2-1, i-8 ; s$.

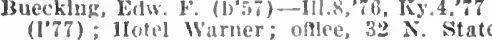
(I'77); llotel Warner; oftlee, $32 \mathrm{~N}$. Stat

BUFildil, WM. EMMETT (b'69) †-III.5, 04, Ill.15,06; (1.04): 3758 sheffleld Are. once, 64 k. Van IBuren st. : $10-5$

Buettner, A. loulse (b'5i)-111.11,94 $(1 ' 95) ; 4721$ lieacon $S$

Buffum, loseph lloward-II- N.Y.9,73 (1's0) ; $15 \mathrm{~F}$. Wishlungt on St. ; limer. Prof. Ophih. ind otol. IIl.

BUFORI, COLHWAN GRAYES (b'2) 111.6,94; (1.04); 141 Surf st.; ofllce, 122 S. Mlelilgan ase: after 10: Asst. Clin. prof. Surg. III.1; (A13); S.

BUHLIG, WALTER HEIMAN (b'T6)†Ill.6,03; (1'03); 5533 Unlon Ave.; oftee, $31 \mathrm{~N}$. State St. ; $2-4 ;(\mathrm{F} 4)$

Bullen, Clifford (b's0)-11i.s, 07, 111.11, "0s; (l'07): 4800 Washington Ave.; of flee, 4801 W. Madlson st.; $1-3,6: 30-8: 30$. BUNDESEX, HERMAN NEHS $\left(b^{\prime} 82\right)$ t 447 E. 60th St.; also 6258 Champlaln 4 . E. 60th St.; also 6258 Champlaln

BUR13AC1I, WM. M-III.6,05; (1'05); 2025 Ilowe Are.; offle, $555 \mathrm{~W}$. North $A$ ve. $9-10,2-4,7-8$.

BURCKY, W. F. (b'53)£-11t.11, 89 (1'89) ; 6641 s. 11:1sted st.; until 9, 12-1, after fi: Pd.

BURDICK, ALFRED S. (b'6 i) \&-Ill.1,91 (l'91) ; 2148 Giddlngs $A$ ve.; offlce, 4739 Ravenswood Are.: 10-12, 1-4.

BURDICK, GORDON G。 (b'63)†-III.6,90 (1'90): 1600 Sherwin Are.; oftice, $; \mathrm{w}$ Madison St.; 9-5; 1'rof.' Phys.-Ther. $111.8 ; 1 . \star$

Burgess, Sarah F. K.-N.Y.14,'74; (1'81); 2004 W. Van Buren St.

BURGNER, BLAXCUE A. (b'74)-III.22 $10 ;\left(1{ }^{\prime} 10\right) ; 626 \mathrm{~S}$. Western Are. ; 8-10, $11-12$

Burke, Gordon (b'S6)-II1.6,'13; (!'13) Mlchael Reese Ilospital.

BURKETT, SLSIE L. (b'75) †-I11.13,05 (1'05); 5211 Washingt on Hivd, 10-12, G BURKIIOLDER, CHAS, AUGLSTUS (b'86) -Ill.1,12: (1'12); 6355 Inglestrie Ave. BUKKHOLPER, JACOB F, (b'61)-Ont.6, 108 N. State St. also, $1105 \mathrm{E}$. $63 \mathrm{~d}$ St. Prof. Ophth., Ill.8; (BS).

Burland, Saml. C. (b'50)-Que.1,'7T; (l'96); 3148 W. Congress St. : 8-12, 2-4, $;-8$.

Burmaster, Paul (b'67) II-111.4,'95; (1'96) 546 Surf St.; oftice, $35 \mathrm{~S}$. Dearborn St Burmelster, Wm. Henry (b's2) - Mllch.1, 07 (1'12); 312 S. Ashland Blvd, office, 122 III.11.

Burnett, Wesley Edward (b'S4)-I11.11,'10 (l'10); 3556 Rhodes Are.; office, $2842 \mathrm{~S}$ State St. : 9-11, 3-5, 7-8:30.

Burns, Don Dewitt (b'75)-1a.8, 06 ; (1'12) 1940 Nelson St.; office, 3935 W. Chicago Are. : $10-2$.

BURNS, PETER THOS. (b*64)థ-11l.6,'91 (1'91); 1034 S. Leavltt St.; 8-10, 6-8

BURR, ALBERT II. (b'50) \&-Ill.6, 81 (1'81) ; 1265 Columbia Are.; oftice, $32 \mathrm{~s}$. State St.

BURROUGIS, WALLACE MCMLRRAY (b'71) $€-111.6,93$; (1'93) ; 1528 N. Falrfield Ave. : 8-9, $2-3,6: 30-7: 30$.

Burrows, Danl. E.-IIl.16, 00 ; (1'00) ; 3562 Forest Are.; offlee, $3221 \mathrm{~S}$. State St. $10-12,2-4,7-10$

BURRY, JANIES —-Ill.6,75; (1'79); 5430 East View l'ark: offlee, 208 S. Lal salle St.: $10-12:(\mathrm{Al})$

1.UIIIASH, HENRY J. (b'54)థ-Que.1,'79; 1341; 4342 Sheridan Rd.; office, $29 \mathrm{E}$

Busch, (ieo. C. (b'-3)-I11.1,'99; (1'99); 842 lrrin tark Bird.: 2-4; 0 b.

(1's9) 1644 164 E. (b'65) \&-111.9,'s9;
IH'SHNLL, CHAS. IIENRY (b'60)

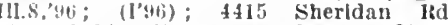
offlce, ligt Wilson Are; $2-5: 30 \div 0$ obG. 01: (1'01): 1 100 S. Avers Ave.; office 211 W. $21 \mathrm{st}$ st. ; $7: 30-9,3-4$

I31 SSEY, (iNO N. (b'65)+-II1.1,93: $(1+45) ; 4543 \mathrm{~N}$. IIermltage Are.; oftice riting

SNELH. CLARK A. (b'70)せ-IIl.11, (100); $420, \mathrm{~N}$. Winchester $\Delta v e . ;$ office, Butler, Frank A. (1'63)-111.6,'90; (1'91) it: 27 Wentworth Are; offlce, 8 N. State t.; 10 -

Intler, Frod 0.-111.22,'12; (1'12); WashInd on l'ark IIospital

Butler, ('eorge E.-111.14,09; (1'10); 2925 Shefiteld Ave; oftce, 29 L. Madison st. $9-3$.

BL'TLLR, WM, JOS, (b'72) $\oplus-$ III.I, 94 (1'94); 3220 W' lackson Blvd. 6-7:30 ofllee, 7 Madison St.; 12-1; jean and Prof. Pefl. and Med.. Ill.2: (D2); 1.* B) T'T liEo. BASSETT (b'76)-Ill.6, 00 ; C. G1.st st. ; $1-3,7-8$

Butterfleld, Forrest Russell (b'79)-III.11, 05; (l'05) ; 486 E. 31st St.; until 9, 2-4,

3341 Oscood st.

Butts, J. Baptist-Ill.11,98; (1'98) ; retlred; 6389 Nordica Are.

BUTZOW, ARTIUR Mt. (b'74)-11l.1,99;

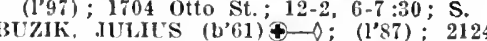
N. Kedzle Are. : oflee, 1175 Milwauke
Ave.: 8-9, 1-3, -8; Ob. Ave.: $8-9,1-3,7-8 ; 0$ b.

XYFOR1, HENRY TURMAN (b'53) † -

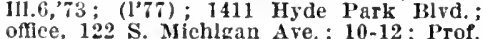
Gyn. and Clln. Gyn., Ill.11; (A2,6,7, 1i) ; G. $\star$

Byle, Archle S. (b'85)-111.15,09; (1'09); 3102 Flournoy St.; offlee, 3203 IIarrison St.; $11-12,3-5,7-8$.

BYRE, JOHN IIENRY (b'41) (-Ill.1,74; 6-7:30.

BIRNE, WMI. DAVID (b'61)Ð-II.1,99 ; (1'99); 7120 Yale Are.; office, 153 W. 69th St. ; 2-4, 7-8:30; OALR.

BYRNES, FRANK†-Hi.1,94; (1'97) ; 454 Melrose St.; office, 3203 N. Clark St.; 2-4, 7-8; Prof. Surg., III.8; s.

Byrnes, Peter-11l.16,06; (l'98); 3844 N. Ridgeway Ave.

Cabbell, Herbert G. (b'87)-Ill.I6,'12; (l'12) ; 3441 S. State St.; $9: 30-1: 30,3: 30-8: 30$

Cadwell, Ernest (b'72) H-Ill.15,97; (l'97) ; 6606 St. Lawrence Ave.; office, $557 \mathbf{E}$. 6 th St.: $8: 30-10,1-2,6: 30-8$

CAHILL, ELLIZABETH II. (b'75)-Ill.22, 09 ; (1'09): 4501 Racine Ave.

Cahlll, Thos. A.-E-Ill.22,04; (1'04) ; 1457 W. Garfield Blvd.

Cain, Jos. D.--Ind.9,97; () ; 825 Garfield Blvd.

Caird, Alexander (b'44)-Mll.8,'96; (l'96); 1637 W. Monroe St.; G.*

Caldwell, Chas. (b'41)-Mass.1,67; (1'80); 3339 Calumet Are.: 9-5.

Caldwell, Chas. E. (b'51)-Ill.1,77 ; (1'78) ; 5016 Jefferson Ave.; office, 3904 Indlana Are.; 9-11, 7-8:30.

ALDWELL, CHAS. PETER (b'56)€-IIl.6, 'T6, Ill.1, 7 ; $\left(1^{\prime} 78\right)$; 4427 Nichigan Are.; $2-4,7-8$.

Caldwell, Francis C. (b’50)--Ill.11,'83; (1'83); Windsor-Cllfton Hotel; office, 35 S. Dearborn St.; $1: 30-5$.

Caldwell, Fred Cornellus (b'85)-Ill.1,12 ; not in practice; $1163 \mathrm{~L}$. 54 th st.; offlce $35 \mathrm{~s}$ Dearborn $\mathrm{st}$

Caldwell, Hanna L. (b'69)-1ll.s,'04; (I'04) 5306 Aberdeen St.

Callantlne, Blythe Jackson (b'85)-Ill,1,'13 (l'13) ; 'St. Luke's Hospltal.

CALLAWAY, WM. L. (b'69) \&-N10.28,97 (197) ; 3015 Warren Are.; offce, $32 \mathrm{~N}$

State St.; 1-2; Prof. Inter. Mied., Mll.G2. Calvert, Geo. S.

Calvin, Wm. John, Jr. (b'sî)--1ll.5,'11 ; (1'12); 4843 W. Van Buren St.; 1-3, 6-8; ObG.
Cambourn, Stephen A. (b'63)-Ill.6,97 ; $\left(l^{\prime} 97\right) ; 5101$ Wentworth Ave.; offee, 5103 Wentworth Ave.; untll 9, 1-3, 7-8.

Cameron, Anson M. (b'74) lI - Pa.9,00 (l'01); $851 \mathrm{~N}$. State St.: aflce, $32 \mathbf{N}$. Pd.

ameron, Don Franklln (b'89)-Md.7,'13; (l'13); St. Luke's llospltal.

Camfleld, Bradford Allen-Ill.8,88, Ill.1,94, Aus. i, 10; (l'89); 501 Belmont Ave.; offlee, 140 N. State st. ; 2-4: OALR.

Camodeca, Demetrlo-Ita.10,81; (1'03); 712 Taylor St

Camp, Chas. D. (b'44)-Ill.1,70; (1'79) ; 1726 W. Monroe St.; untll $10,4-7$.

Campbell, Allert F.-N.Y.6,'86; (1'86); 12 th and Central Sts.

Campbell, Allce T. F.-H-Ill.4,'85 ; (I'85) ; 5704 Dorchester Are.; 10-12.

Campbell, Amos W. (b'49)-Ont.4, 80 ; $\left(1^{\prime} 92\right) ; 40 N$. 5th Ave.

CANI'BELL, GLACE ANARIETÐ-I1.9,99; (l'99); 3301 Washington Blrd.; 1-3 ; (D2) ; LR

CAMI'BELL, JAMES TWEEDIE (b'65)\&Ont.1,'89, N.Y.10,'89, Eng.15,'90; (l'90);
4621 Woodlawn Are,; offlee, 77 E. Wiash-

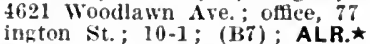

CAMPBELL, JOHN YRÁNKLIN (b'64)Ont.4,'86, Seot.9,12,90; (1'91); $856 \mathrm{E}$. 65 th st.; offlce, $32 \mathrm{~N}$. State St.; 9-1; OALR. *

CAMPBELL, JOHN GAIIEY (b'69)(Ill.6,'96; (l'96); 7143 l'rinceton Are. offee, 6914 Wentworth Are.; 4-6; Pd.;
CAMPBELI, WM. A. (b'70)-0nt.1;92

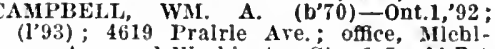
gan Are. and Washington St.; 1-5; ALR. *

Canavan, John Ladlslaus (b'87)-Ill.6,'09; $\left(l^{\prime} 09\right) ; 3700$ Wallace $S t$.

CAPPS, JOS. ALMARIN (b'72)๑-Mass.1, 95; (1'98); 2532 Pralrie Ave; offlee, Prof. ised., Ill.1; (D6, F4) ; I.‡ ; Assoe. Carberry, Francls Vlncent (b'90)-Ill.11,'13 ; (1'13); 3800 Pralrle Ave.

Carey, Danl. J.-Ill.11,95; (1'95) ; 3644 Ogden A ve.; 8-10, $7: 30-9$.

Carfora, Alfonzo (b'81)-Ita.10,05; (l'09); 815 S. Halsted St.; office, 949 Polk St.; 12-2, 6-9.

Carlsen, Haldor (b'84)-IIl.8,'13; (l'13) ; 4904 Grace St.

Carlson, Mabel Rosina (b'89)-IIl.11,'I2 ; (1'12); 5744 Carpenter st.; 1-3, 7-9; Pd. Caron, Walter (b'76)-Ill.i1,'05; (1'05); 4300 W. Madison St.

Carpenter, Estella Clark (b'67)-Ill.16,'03; (I'03); $2212 \mathrm{~N}$. Western Ave.

Carpenter, Francis E.-IIl.16,03; (Y03); 2212 N. Western Ave.

Carpenter, Geo. Henry (b'70) H-Ill.15, 05 : (I'05): 225 N. 1'ine Are.; office, $27 \mathrm{E}$. Jonroe St. ; $9: 30-5$; N.

Carpenter, Jessle Drew-Ill.11,'03; (1'03) ; 2060 Flournoy St.

CARPENTER, JOHN HENRY (b'65) 1820 W. 'Harrison' St.; 11-3:30; R.

CARR, JAMIES GRAY, JR. (b'T6)-Ill.6, '02; (1'02) ; 3923 Gladys Ave.; office, 2201 W. $22 \mathrm{~d}$ St.; $9-10,1: 30-2: 30,7-8 ;$ (F4).

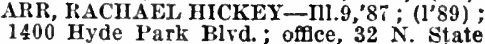
St. ; $12-1$.

Carroll, Henry C.-Ill.11,99; (1'99); 4100 Indiana Ave.

Carroll, Wm. Bayard (b'78)-Mlich.1,'80: $\left(1^{9} 90\right)$; 4421 Fulton St.; offce, $120 \mathrm{~S}$. State st. ; $9-5 ; U$.

Carson, Clayton iv. (b'60)-Ml.1,'84: (1'\$4) South Shore Country Club; office, 766 Oakwood Blvd.

CARTER, ALBERT HOWARD (b'84) - Ill.16, 06 ; (1'06); 2206 Campbell Park; office, 1161 w. Harrison St.; 3-5, 7-9; 's.

Carter, Frank 0. (b'74)-1ll.16,04; (1'04); 4643 Winthrop Ave.; offlce, 120 s. State St. ; $9-5: 30$.

Carter, Richard W.-Ind.10,93; (l'93) ; 2829 Nichigan Ave.; office, 2200 S. State St. $9: 30-11,1: 30-3,7: 30-9$

CARTER, THOS. AIBERT (b'80)@-III.8, 10; (1'12); 919 Wellington St.; offee, 852 Belmont Ave.; $3-5,7-8 ; \mathrm{S}$.

Carter, Wm. (b'70)-Ill.14,04; (l'05); 3600 
CARTWIIGIIT, FMOR LOHP (b'83) III.6,12; (1'12): Nesley IIospital.

Cary, Fugene (b'8;)-111.1:12; (1'12); 190 b. Chestnut st.

C.IRY, FRANK (b'5i)+-111.1, \$2: (1'83): 2536 vralrlo Are: once, $104 \mathrm{~s}$. Mlchlgan Are. : $8-10$.

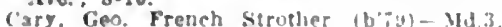
-06: (1*13); 1213 E. 53d St.; under, 31 D. State RL: $9.10,4 . f_{0} ; U . *$

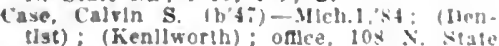
Ilst); (Kenllwor!h); oflce, 10x $\mathrm{X}$. Siate
St. 9-5.

Case, Edw. Norrell-III.1,83: (1'92) : 2042 Dayton Sit. Case, Heary w. - H-I11.4,91: (1'91): 3129

CASk, JAMES THOMAS.

(see Ilattle rreek, Wleh.)

CASEDY IHFXEY I. (b.63)-111.4,03: (1'03)；3034 Mlchlgan Aro.

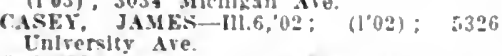

CASIERS, PAUL (b.68) \& - N. Y.10,93: (1'94): 4 is Champlain Ave

CASPIAS, PASCHAL G.t-H1.13,04: (1'04); $1404 \mathrm{~N}$. Kedzle Are.; once, is E. Wash. Ington St: : 8.10, 4-8.

Cassedy, Géo. Washlngton (b'66)-III.16. '00, 111.11,0s; (1"00); 2000 Webster Ave. oflee, 1862 Mllwaukee Are.; $1-3,7-10$

CASSELBERR Y. W. EVANS (b.5s) Pa.1,79; (1'83); is30 ('alumet Are. : offlce, 15 E. Washlngton st. $9-1 ;$ Fmer.
Prof. Lary. and Hhln. Lli.6; (B1,2,i) Prof.

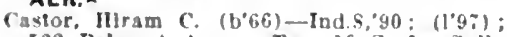
522 IRelmont Are, oflice, $19 \mathrm{~S}$. La Sallé

Catheart, Wm. F.-Jll.11.06; $\left(1^{\circ} 06\right): 1610$ X. La Salle St. : oflce, 5453 Winthrop Ave. Caltern. Chas. (b'6\%) - Ill.14,09; (I'11): 2450 Southport Are.; $8-10,5-8$.

CAVANAlGH, JOH A GERNON $\left(\mathrm{b}^{\prime}, 9\right)+$ Ill.11,04: (l'04): 3167 Plne Grore Are.: otice, ithl. Madlson st. ; $9: 30-2$; Prof.

\section{ALR. *}

Cayley, Frank Jos. (b'86)-111.11,13; (1'13):

('azler, Marlon H.-Ill.1, 80 ; (l'92) ; 6950 N. Ashiand Ave.; oflce, 547 Wastington Bird.: $10-12$

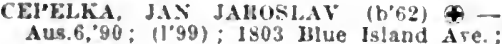
$8-11,2-6$.

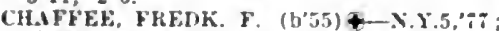
(1'96); 6331 Klmbark Ave. oftce, 6245

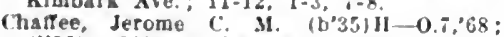
(l'96); 3406 Archer Are.; onlce, $59 \mathrm{E}$. Van Buren St. : $9: 30-11: 30,1: 30-5: 30$.

CIALLENGER, IIESTEH J - III.23,06, III.11,07; $(1,06): 235 \%$ W. Sorth Are.
1-3, $6-8$ LR.

CHAMHERLIN, RARNEY H. (b'62)-III, 8\%; (1.85); 2855 Washlnkton Hird. ; untll $9,12-2,6-7 \cdot 30$

Chamberlln, feorne Montgomery $\left(b^{\prime} 44\right)-$ IIl.1.66; (1.92): 4t:5 Irexel Blrd.: oflce, 3031 Iniliana Ave, $9-11$.

Chamberlin, llarry $\mathrm{X} .\left(b^{\circ}: 9\right)-111.160^{\circ} 04:$ (1'0t); 3 it shefield Ave; oflce, 209 S. Sitale st.: $9: 30-12$.

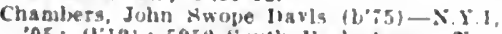
03: (I'12) : 5952 South l'ark Ave.: onlee, 4126 s. Inaled st.:9-12.2-5, : $30-8: 30$.

Chamlee, siml. It. (b'32)-1al, 81 ; (1): 36

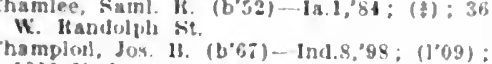

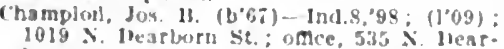
$1019 \mathrm{x}$. learborn st. once, $535 \mathrm{x}$. llear

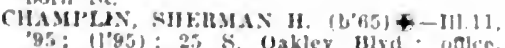
9.5: (I'95): 25 \$. Oakley [3wd.;

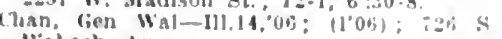

Waluah tie.

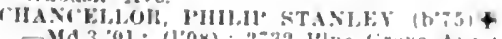

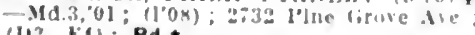
(II? 14); Pd.

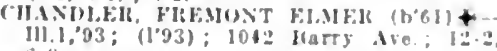
is. 8 .

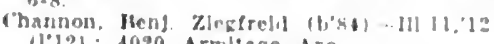
(1.12): 4020 Armitage Are.

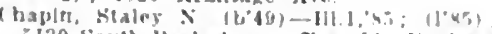

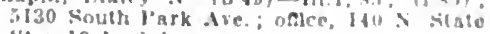
sit: $10-1,2-1$.
CIIAI'MIX, MRANK AMOS (b':a)-Mo.27,

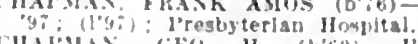

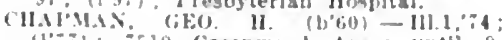
(17): 510 Grecnwoud Are.: until 9;

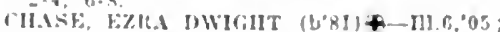

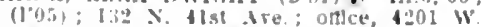

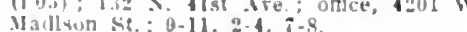
(hise,

hase, Martion list (b's6)-Ill.b,'12: (1'12) Wewley Howpltal.

(hatiset, Frank (678)-111.11,07; (1007): ints toth Are: ntutll $9: 30,6: 30-9$; l.aryn. III Gi2.

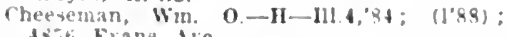
taiti Fivans tive

(limer Franklin Snow (b'61)-111.11,89: (I"wi): (Murgan l'ark): oflce, 69 W Washige on אi. 12-2. rlikfy, IIf.

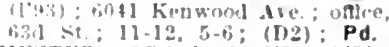

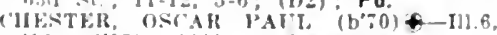

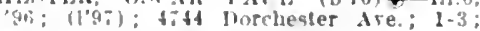
Assi. I'rui Med. III.6: 1.

CHEW, Jo1T, $11+M d, 1,63 ;(1 \% 7): 1223$ Astor st. :-3, 7-8; Pres. and kmer. l'sof Med. Mll (i).

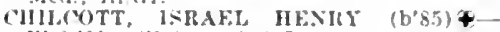
111.8,05; (1'09); 1645 Bryan Are. : oflce. Chllds. A. S. - II-III.4, (1'84); (w!)-

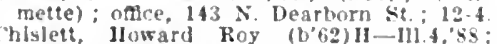
(1's9): 3604 Grand Ilvd ; 11-1; Prof. surg.: 111. 1 ; S.*

Chloupek, Elto i. A. (b'74)-111.11,"n9: (l'99): 16.2. Jlumbolat RItr.

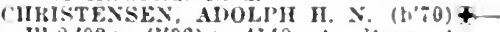
III. $: 02 ;(102) ; 4140$ Armitace Are.

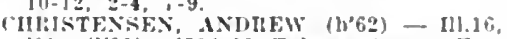
01: (1.01); 4704 $\mathrm{x}$. Talman Are ; offlce,

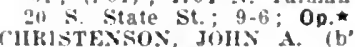

IIHstrssos, Johs A. (b'i2) f-lll.11. sioc. : 917 Belmont Are.

Chrlisenson, Peter Jos-111.16,04: (1"0); si: Albany Are.

CHRISTIF, EIMLNIt-gue.1,82; (1's2): $11: 3$ s. Central l'ark 13ird.; office, 2000 W. $22 d$ sı. ; 1 :30-2:30

CIIHITIF, ELKONORE F.-II1.9,94: (1.94);

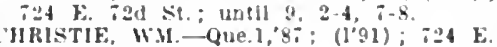
i2d st.; 2-4, i-s.

ihrlatotferson, kiw. Albert (b'si)-11l.11. 12: (1*12); Cook County Hosplial.

Chrlstoph, Carl Henry (b's9) - III.6.'12: (1'12); 3662 Mllolgan Are.

CHILSTOH, ELGENE OTTO (bEl)-(ier.5:85; (1'85); 366: Mlehlgan Are. ; i-s HIPCII, ARCIIIRALD (

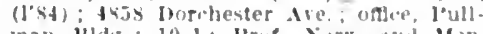
Inan 13ldg.; 10-1; Y'rue Surr. and Meo IIS., III, $6 ;(\mathbf{E} 1,4) ; \mathbf{N}$.

hurch, James Luther (b:83) IJl. (105): 1419 Morse Are.

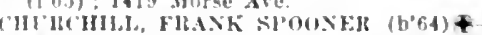
Mass. 1.'(0): $\left(1^{\prime} 92\right) ; 1259 \mathrm{~N}$. State sit. 11-12:30; A $4800^{\circ}$ l'rof. l'ed., 111.1: (D)!. 2) : Pd.*

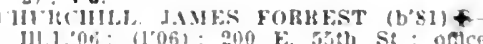

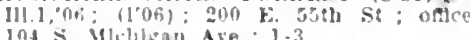
104 is Mlolikan Ave; $1-3$

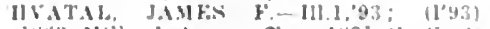

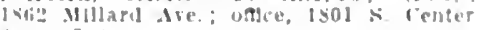

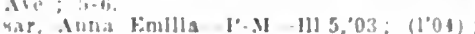
hivi He onth

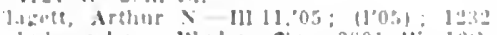

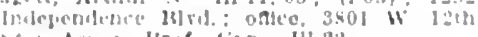
to: A Aves I'rot lisn. Iil a:

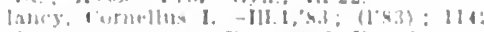

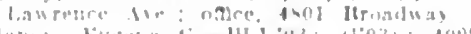

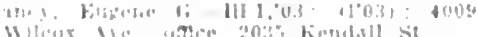

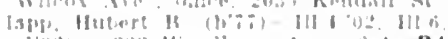

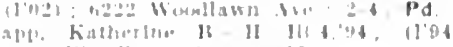

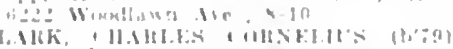

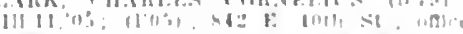

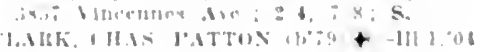

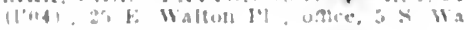

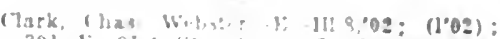
301 r: Fils:

Clark jlith y-

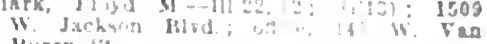

Huren st

Hark, Jacol, wirnde!l

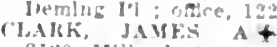

al:o Mllaril A

2020,11 ilst St: i.2; ALR

EIAIRK, IHNXIE U I ALS

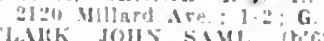

(I.

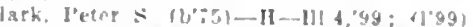

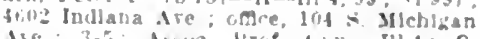

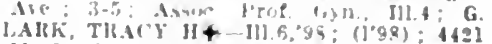
vi. I'auliua st: ontre, f50i Rarenswood Ave ; 1-:2:30, i-8: G.

Clark. Win Arthur (b's2)-Maas. I, 11: Marligon si; $1-4 ;$ Or.

(lark, Wm. liefi -11-1) Estes Ale.; S-10, 2-4, '-9; odtce, 1735 Greenleat is

clarke, James funn!nalian $(20<5)-111]$ 13: (1'13); (cock lourey Hovital

Clarke, Ward Greene-Ill.1,52: (1'82); 1415

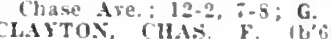

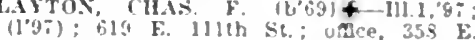
$115 \mathrm{th}$ St: $1-3,7-8 ; \mathrm{S}$.

clears, Jos. Pastick (bs1-IIls, CI.FFr, (ISCAR (b-3)

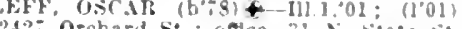

-42. Orchard St ; otace, 31 X. Siate st.

Clegg, Chrlstuna scott (v'60)-las,9: (19:); 823 Sherldan Ka.; 10-12, 1-4, i-s:

legr, Joslah W. (b'59)-Ia.1,96: (1996); (Dherden Rd :-9:ALR.

III.6, $02 ;(1002)$; 0156 Erans Are. : 9-11.

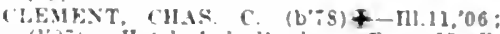

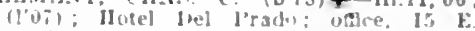

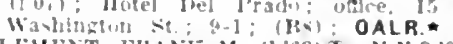

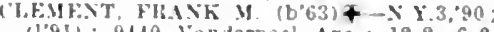

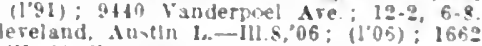
w Madlson st.

Cleveland. Chas. Wm (b's) - III 11, ns

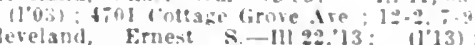

si. Fillzabeth's II ospital.

('lereland, reo. Henty (b'6:)-M!ch l, s': (1)9i1): 3540 W. Monrue S:

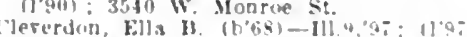

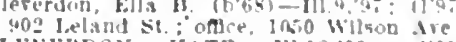

LEVERDOS, KATE - 111.1305 (120 (10): Leeland sis ; orlce, 1050 Wilson Are

Thit, Frank Selli (bas)

("luer, I"aul Mltchell- IH 4,0\%: (100) : $3: 16$ l'rairle tre : once, 3019 indlana Are 11-12.34, - 5 ; Adf l'rue chat, 111 4 s

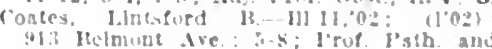

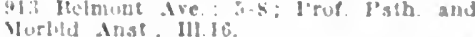

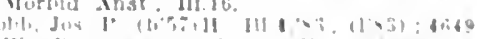

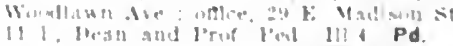

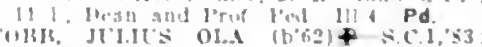

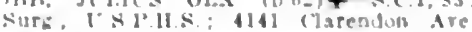

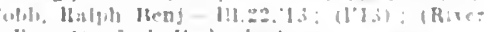

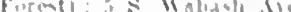

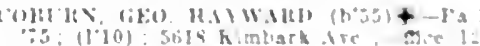
$\because 5$ : $(1+10)$ : stis hmbark

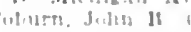

Pain lerow W

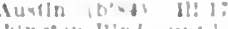

"11:- kenjer lio

II Intexth

darimation 11 led

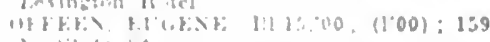

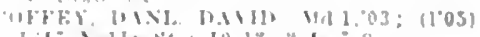

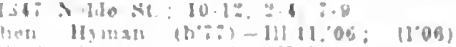

Hoaldi liovartucht, ilts II all. 


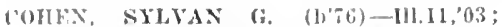
(1.03): 4025 sherluan lkd : otlce. 15 fo Washlington si.; $41^{2}$.

Cohn. Edwin Arthur $(1, ; 6)-111.1 \%, 09$ (1'09) ; 4345 Forrestrllle Are.; $2-5, \%=8$ COIlN EMANUEL I.- - III.22,'I2; (1'12) $2724 \mathrm{~W}$. birlsion sit.

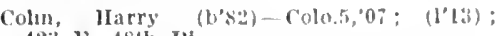
$42: 3$ W. 48 th I'l.

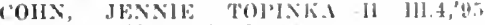
(1'95) ; 542 W. North Ab

Colin, Jos, siml. (b) sti)- 111.11,'10: (l'In) 1240 S. Si. Louls Ave, ottlce, $315 \mathrm{~S}$ W

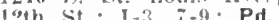

Cohmhelm, Fra-swltz.s, $0: 3 ; \quad\left(1^{9} 07\right) ; 1301$ Oakley Blval; offle, li25 N. Áshlind ive.

C(1)be, selma Olga (b'si)-11l.11,'12; (1'12) not ln praetlee: 2217 it dith st.

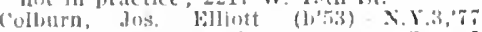
(I's.3); 6031 Madlson Ave; ollee, Is 7. Wathington St. 1 1-4; (13S)

COL13Y, 13EN.1. IOIR (b'50) - Ill.1.84: (It84); $25 \mathrm{~N}$. Walnut Ave, offle, 5 N Wabatsh . Ire.; a Iso, 15.3. W. Madison: 1-"3. Cole, Alfred I. - II-N. Y.9,76; (1'88); 1822 Mleligan Are.

COLE, ALV1X VEKXON (b'68) \$-Ill.6,93 (1'03); 4207 Vincennes Are.; once, 2602 Indlaria ive. $10-11: 30,3: 30-5$.

Cole, Henry Travers (b'70)-H-III.4,94 (l'98); 6011 Woodlawn Are.; ofllec, 8 s. State st.

Cole, Ivory s.-0.11,69; (1'84); 3403 W Monroe st.

Cole James Jos, (b'- 's) - - 1ll.6, 03 ; (1'03) 51 1. 59th St.; offee, 5 E. Garfleld livd. $9-11, \quad \mathrm{I}-3,7-9$.

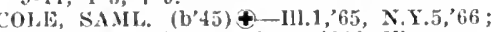
(1'86); not in practice; 4920 Vincennes Ave.

Coleman, fien. Ilowell (b)\$4)-- IIt.1, I3 (l'13): I'reslosterlan lIospisaI.

colluiN, W. FRANKL1N (b'3s)-Ont.5,

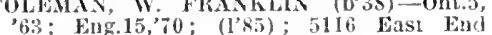
Ave.; offle, is E. Washlngton. St. ; 10-3; I'rof. Oplnth., Ill.G3; (B8); OALR. COLIN, GEO. \UGUST (b'8I) \&-Ill.17,'03; (I'04); 20 I3 Lawrence Ave.; office, 409 Wells ist. ; 2-4, 7-9.

collier, Clinton C.-II-111.10,04; (l'04) 2451 E. -2 l St. : offlce, 32 N. State St. 1-2: Adj. I'rof. Thin. and Laryn., Ill.4.

Collius, clinton 1). (b'66) H-III.4, 89 , Ill.1,

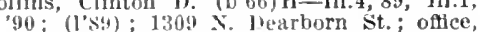
I0s state st. $9-1$; I'rof. Skin and Yos N. State st.

Collins, Hranels iugustine (b'88)-Ill.6,'11; (l'I1) ; $6312 \mathrm{~s}$. Oakley Are.

Collins, Helen w. (b'-10)-Ill.15, 00 ; (l'00) ; 331 \&. Garfleld Blvd. ; 10-12, 1-5.

Collins, James 'l'. (b'78)-Ill.1, ${ }^{\prime} 02$; (l'02): 1151 W. Garfield Blvd. ; 4-6, $7-9$.

COLLINS, IORIN C. (b;6)-Ill.6,00; (I'00); 820 Edgecomb Pl.; offlce, $15 \mathrm{E}$. Washington St.

colliss, IRtive G. (b'59) $4-111.6,85$; (1'85); 5157 Michigan Ave.; office, $505 \%$ State St.; until 9, $12: 30=2: 30,6: 30-8: 30$.

colver, Harley Ross (b'74)-Ill.1,04; (1'04); Illinois Steel Company Hospital.

COLWELL. NATILAN PORTER $\left(b^{\prime} ; 0\right) \Phi-$ mette); offlce, 535 X. Dearborn St.

collBs, FRANK BURR (b'79)-Ill.6,05; (l'10); 3034 tlichigan Ave.; 1-3, 7-9; Pd' Combs, Helen H.-0.13,'85; (l'96); 4711 Frans Ave.; offlce, $220 \mathrm{~S}$. State St. ; $9-4$. Comerford, Edw. J. (b, T4)-111.14,'09; (\$); 239 S. Lineoln St.; 1-5; S. $\star$

CONKI.IX, ALI'E I. \&-Ill.9,97; (1'97): 2949 Iogan I3lud.; offlee, $32 \mathrm{~N}$. State St. ; 10-12; Prof. Gin., 111.22; G.

COSikt, THos. I. (b'59) (l'S5) ; 2256 Kedzie Blval.; ottice, $32 \mathrm{~N}$. State st.; 2-6; Prof. Surr., IIl.ge; S.

Conley, Willard Thos. (b's5)-Ill.6, 1:; Merey Hospital. Conlon, Andrew A. (b'62) - N.Y.10,'85;
(I9s); 4433 Broadway ; 3-5.

(ONXER, ELSPETH M. (b) 65$)+-111.13$,

comad, Albert Everett (b'69)-1l.4,'95; Albert Everett (b'6
IIalunemann Hospital.

Conrey: Ceorge Asbury-Ill.8,'12; (l'12) ; $3 \mathrm{~L}$ L. 11 th Pl.; oftice, 11122 Michigan Are.: $8: 30-10,1-3,-8: 30 ; 0$ p.

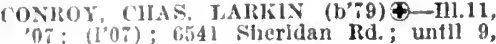

Conroy, whil Huckler (L'71) - N.Y.19,'9? (lens) : 119 \&. Leavlil St.; offlee, $31 \mathrm{~N}$ slate st.: 1-5.

coNlaOy, THOS. FRANCIS (b'65)

$9 t i ;(1.96) ; 1521$ Sherwin Are. converse, bummd D. (b's3)-Ill.6,'“

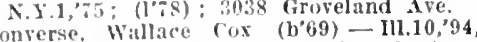

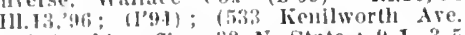

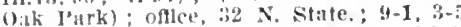

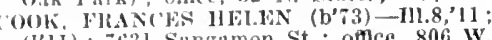
(I'li) : 7631 Singamon St.; offee, $806 \mathrm{~W}$. -01l $\mathrm{Si}: \mathrm{I}-3,6-8$

lódk. Allert (b'65)-N.Y.5.9I. not in practice; Steinway Irall.

not In practice; Steinway Mall, 538 \&. Wabash Ave.; 11-1.

rook, J. II. Vennlsón (b'69)-IIl.1,'94; (1'94); 2130 \&. Wabash Ave.; offee, 3000 S. Moligan Ave. : 1-9.

Cook, Jyman Ios. (i)'s5)-Il1.11, '13; (1’13) ; Augustana Hospital.

Cook, Saml. LeCount (b'sï)-IIl.11,'13: (l'13): 6028 Aherdeen st.

Cook, Wllber Danl. (b'63)-Ill.4,00, 111.11 '09: (1'03); $6 \mathrm{~s}$. Winchester Ave. ; offlee, 59 E. Midison St.; 12-2, 4-6; OALR.

COOKE, HAROLI) IVAN A. (b'7t) \&1la.2,04; (l'09); 736 E. $63 d$ St.; ofllce. 200. Śtate St.

('nons, Wm. 1'. (b'2 - -Ill.14;01; (1'n]); 5424 East Vie
Sitate St. ; $10-4$

(ooper, Chas. P. (1)'82)-Ill.8,'06; (1'06) $3344 \leqslant$ Stale st.; $10-12,2-4,6-8: 30$

(O)'LANI, NoRMAN (b'78)-IIl.11,08 (I'0x); 6902 N. ('lark st.;

'OPELAND, Wu. LOWhY" (b'51) \&-Que.1 72; (1'69); 3148 Warren Ave.; offlce, 2 E. 'Washingtoll St.; 12-2; Prof. Anat. III. $22 ; \mathrm{U}$.

(ORBETT, MATTHEW - Ill.11,90; (1'90) 2314 W. 12 h St. ; $10-11,7-8 ; \mathbf{G}$.

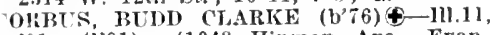
01: (lo1): (1043 Hinman Ave., Evanston 0 . Stace, 32 N State $9: 30-4: 30$; Asst. Prof. Gen.-Irin. Dis., Ill.G3; (C3, Asst. Pr) : U.

Corcoran, Filward Angustine (b'74)-III.11, 02; (I'02);3159 W. Jackson Blvd.; un til $9,1-2,7-9$

CORCORAN, KATHERINE W. (b'71)-Ill.11 02 ; (l'02) ; 3154 W. Jackson Plrd. ; offlce 3159 W. Jackson Blvd.; until 9, 2-3, 7-8 CORE ATBERT $s .\left(b^{3} 49\right) \oplus-$ Ill.1, 79 (I’s0) : 4301 cottage tirove Ave.; 10-12, ORLETT, THOS. G. (b'68)-N.Y.6,'9n : (l'92); 5843 Ceylon St.; nffice, $15 \mathrm{E}$ Washington st. ; 12-2.

'ornelius, $\operatorname{Iax}$ C.-Neb.6.'95; (1'95) ; 4801 Calumet Are, offlee, 366 E. 4ith St. $9-11,1-3,7-9$

CORNELI, FDWARD TYMAN (b'83) Ill.1,10: (1'10); 122 S. Miehigan Ave. $11-\mathbf{I} ; \mathbf{O b G}$.

Cornell, John W. (1';6) H-Ill.4, 00 ; (1'00) 4636 vincennes Are. ; $8-9,1-2,6: 30-7: 30$ Aij. I'rof. Inat., Ill.t.

Cornell, Mary Clagett (b'68) H-Ill.4, 01 ; (l'01); 4634 Vincennes Ave.; 8-9, 1-2, $6: 30-7: 30$.

Corper, Harry John (b'84)-Ill.1,'11; (l'12); 275l winur ive. Office, Sprague Me morial Inst., University of Chicago; (F4) CORW1X. AR'THUR HILLS (b'64)(4-III.1, 90 ; $(1,90) ; 3531$ W. Monroe St.; offlce, 15 k. Washingt on St. ; 9-I ; Prof. Laryn. Ill. (i2 ; (Bi) ; ALR.ネ

Corwin, Chas. T.-Ill.6,06; (l'06); 3035 Indiana Ave, ; $12-2: 30,6-8: 30$

(ORY, EDWIN V. (h'73)-IIl.6,96; (l'96) 5243 Ellis Ave, 1-3.

costain, T. Edward (b'62) H-11l.10,'92 $\left(1^{2} 93\right) ; 4459$ Berkeley St.; office, $29 \mathrm{E}$ IIadison St. ; 1-3; I'rof. Anes., Ill.4.

COSTELLO, CHAS. A. $\$-111.1,01$; (1'01)

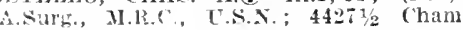
plain Ave.; office, 1255 Indiana Ave. $10-12,7-3$
COTTRELL. THOS. (b'83) - Il.17,'06: (1'06); 607 Wriglitwood Ave.; offlce, 800 Y Clárk St: $9=10,1-2,6-8$.

COTTON, ATFREO CLFVELAND $\left(b^{\prime} 4 i\right) \$$ Ill.1, '78; (1'78); 3218 W. Jackson Blvd.

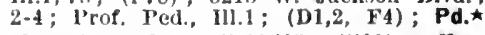
Cotion, J. Arthur-Ill.13,'97; (I'99); offlce, 33 W. 22] St. ; $9-11,2-4,7-4$.

COLCII, MAIS CATHEHIN (b'90) $\oplus-$ Mass. í: (1'13); Member

Soc. ; $255 \mathrm{I}$ N. Clark St.; P.`
(onrlenay, Gordon Trevor (b'8i)-Ill.6,08 $\left(l^{\prime} 08\right) ; 746$ L. 47 th St.; oftce, $106 \mathrm{~S}$. Mlehigan Ave.; 9-11, 4-5, 7-8.

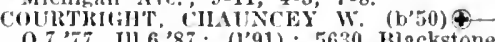
$0.7,77$, Ill.6,87; (L'91) ; 5630 Blackstone Ave. i intil s

Cousin, Jos. B. (b'54)-Mo.7,'91; not in practice; 234 F. 51 st St. ; $10-10$

COUSINS, JOIIN A. (b'79)-Ia.10, 05 (1'09); 2478 orchard Ave.; offlee, 403 S. State St. ; 10-12, 1-5.

Covert, Jennje Muzzy-11l.8,07; (1'07) 4909 Broadway.

Cowan, Lee-Mo.22, 06 ; (V'12); Illinols Charitable Fye and Far Inflrmary.

Cox, James Francls (b'83)-Ill.1,'09; (1'09) ; 725 S. 40th Ave.; untll $9, I-3,7-8: 30$.

Cox, Mattie Estella (b'62) H-IIl.4, 03; (I'03); 2720 Magnolia Are.; G.

Cox, Roy Herndon (b'79) - Ill.1, 02 ; $\left(1^{\prime} 02\right)$ 1005 N. Clark St.; office, Maller's Bldy. ' $9-12,7-8: 30$.

COX, S'TEPHEX W. (b'59)-111.1.89; (1'89) 2914 W. Jaekson Blvd.; office, 32 X. State St. ; $12-2$.

Coy, Albert E. (b'58)-Mlch.1,84; (l'89); 6211 Lexington Ave.; offlce, $5 \mathrm{~N}$. Wabash

Ave; $9-12,2-5$.
CRAIG, ALFX ANDER RIGIITER $\left(b^{\prime} 68\right) \oplus-$ Pa.1,93; not in practlce; Nember Med. Soc. of the State of Pa.; 9 Chalmers Il. See. American Hedical Ássociation; offlee, $535 \mathrm{~N}$. Dearborn St.; (B1).

Craig, Augustus L. (b'53)-Ill.1, 78 ; (1’78) 3919 EIlis Are.; offlee, $37 \mathrm{~W}$. Van Buren $\mathrm{St}$ Craig, John Games (b'65) - Mich.1,91; (l'91) ; 5858 S. Halsted St. ; $1: 30-3,7-8: 30$ 00; (l'01); 5434 Winthrop Ave.; office, $31 \mathrm{~N}$. State St.; $7: 30-12,2-4$.

CRAMI, ARTIIUI J. (b'72) $4-W l s .2,06$ : not in practice: 7332 Union Ave.; offlce, $535 \mathrm{~N}$. Dearborn St.

Crane, Milo A.-Mich.7,07; (1'09); 4155 Grand Blvd.

CRANSTON, WM. BRUCE (b'76)-Ill.8,'04; (l'04); 6240 Cotfage Grove Ave.

Crapple, WVm. (b'8S)-11l.8,'13; (l'13) ; 849 Taylor St. : 8-12, 8-9.

Crary, Eva E.-H-Ill.4,'95; (1'95) ; 3412 W. 62d Pl.

CRASS, EDGAR WELLS (b'73)-Ill.23,'06 (l'06) 6453 Lakewood Ave.; office, $39 \mathrm{~S}$. State st.; 9-5.

Craven, Wm. C. (b'47)-0.11,73; (1'97) $455 \mathrm{~W}$. Chicago Ave. $9-12,2-4,7-9$.

Cravens, Thos. R.-Ill.13,'97; (1’97); 4648 W. Sunnsside Are.

Crawford, Byron E. (b'73)-Ill.22,'11 : (1'12); 2006 Howe St. ; offlce, 36 W. Ran-

dolph St. ; 4-7; Op.
Crawford, John F. (h'88)-Ill.5,11; (1'12) ; Phodes Are. Hospital.

Crawford, Ralph B.-E.-H1.8,'82; (l'87); 222 E. 56 th St.

rede, Wm. Ifenry-Mich.1,04; (l'04) ; 242 . N. Central Park Ave.; office, 3937 Fuller. ton Are.

Creely, Wilmer Roberts (b'83)-Ill.8,'09; (1'09) ; 176 N. Clark St.; 10-6; G.

('RIS'T. JOS. CARY (b'62)-1ll.6,87; $\left(10^{\prime} 00\right)$; 5214 Kimbark Are.; tflce, 1203 E. 55 th st. ; $1-2, i-8$.

Crittenden, Alden Larue (b'83)-Ill.1,'12 (1'12); Cook County Hospital.

Crocker, Fredk. Sargent (b'70)-Ill.1,'97 $\left(l^{\prime} 97\right) ; 31$ N. State St. ; (B1).

CROFT, ALBERT JOS. (b'75)-III.II,'06 (l'06): 1931 W. $22 d$ St.; offlce, $2159 \mathrm{~W}$ $22 d$ St. ; $9-10,1-2,7-8: 30$.

CROFTAN, ALFRED C. (b'71) Ð-Ill.4,'96; Ill.11,98; (l’96) ; 4907 Madison Are.; of -
fice. Field Alnex Bldg. ; 2-4; (E4, F4).

fice, Field Annex Bldg. ; 2-4; (E4, F4);
CROFUT, MARTHA MARIIL - ni.11,07; (l'07); (Maywood); offle, $15 \mathrm{E}$. Washington St. 
Croker, James Niomian-III.1.'80; (1'81) : 5317 S. Wabash Are. : oAlce, 1 k. 22d St. untll $5,12-3,7-8$.

CRON1X, JOHN JAMF, -11.11,06: (1'06) chlcago a re.

crooks, Fred Itasmond (b*\$3)-111.11,"12 $\left(1^{\circ} 12\right): 1005$ X. Crawford Are. : 1-3, i-8.

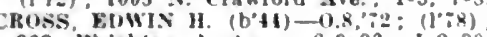
922 Wriphewood Are.: $8.9: 30, \quad 1-2: 30$ $6-i: 30$.

Crossey, Elljah llockhold-111.6,02; (1'02) a9 k. Madison sit ; 10.1

CROW. JOHX 5. (b'63)-111.1,01: (1'01) 6700 8. Green st.; 8-9, 12-3,7-8;06.

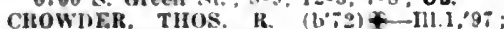
(1.97): Quadransle Club; oflce, Puliman (19): Quadrabgle Club; odrce, Pullman Blug: : 9-12, 2-5; ( 14$)$.

CHOWF, THOS. STAXI.EY (b'66)-MII\%, '96: $\left(t^{\circ} 96\right)$; 5458 Magnolla Avo.; oftce, 1121 N. State St. : 1 -6: NP.

Crowley, Wm. If. (b'67)-111.1,96; (I'96)

303 S. Halsted St. : $9-11,1-3$. $i-9$

CROWLE WY. SIMON (b'\$5)-11. 6.03 (1'09) : ofnco, 31 $N$ state St. 10-12 (1'09) i onco, 31 $\mathrm{N}$. Sitate St. ; 10

also, 1225 . Ashland Are. :-4, 7-3. ologist): 3759 (irand Itrd: oftce, 8 : State sit. : 10-4: L0.

croy, Clayton (hurchll (b;0)-la.1, 98 (I'athologlst) : 3759 (irand Bird.; offlce 8 x. Siate st: $9+3: 30 ;$ LO.

Crum, 1'hllip A,-III.4.96, JII.1,00: (1'96): 3304 llumboldt Are.; 8 -12.

Crumpton, Robt. C. (b'86)-IL1,1,11; (1'11): st. Luke's llospital

CUBBIXS, WM. ItOBT. (b'it) $£-111.6,00$ : $\left(1^{*} 00\right): 5139$ Lalrersily Are.: ottice, 29 r. Madlson St.; 10-12; Asst. Prof. Surg. III.6 : l'ro?. Surg. lli.t3: (A13, F4): S. CELBEHT MH.O HFHMAN (b'85)-11.6. 10 : $(1 \cdot 10)$ : 10301 Walden l'arkway; of fice, 1840 w. $103 d$ St.; $\$-9,2-4,7-8$.

CUIRFRTSO:- CAREI (b'il) $4-11.6,98$; (1'98); 35 : $^{\circ}$ Adams st.; oftice, $105 \mathrm{~N}$ State St. I :30-3:30; (Ft): Asst. I'rof.

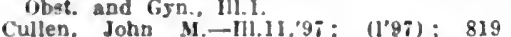
Iadependence Bird.; oflce, $1160 \mathrm{~W}$. Taslor St; $2-4, i-8$.

CULFEK, CILAS. M. (b'it)-III.16,02 (1'02); 1057 Grand Ave.; $8=10,1-2,6-8$ Culver, Forest E. (b,it) 11 -IIll 10,03, Ill.4, 03: (1103); 91: Belden Are; 3-4, 1-3.

Cummins. Erwla Jephtha (b'st) - I1.6, 12 (I'12); 251k Waslinton Bird

Cummings, Henry T.-Ill.11,03; (l'03): 439 F. 35 th St.; once, 3035 Indiana Are. : 439 F. 35th St.; office, 3035 Indlana Are. $10-11,4-3,7=9$.

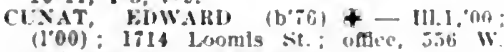
isth st. ; $9-10,12-2, f-8$.

Cunltte. Rolut. A.-III.6,05; (1.06): :2I0 Vale Ave.: offce, 20.516 .531 St. : $8: 30-$ 9. $3: 30-5, i-8$.

DNINCHAM, DANI. II. $\left(6^{\prime} 64\right)$ - $\mathrm{Pa} 2$ $32: x$. State st. S-6: also, 3158 Jacksin Iird.: 12-2

"unningliam, Firson Mllls (lopis) - Inel s Ge: (1'02): (Vandalla, Hich., l'J 2728 Flournoy st.

('unningham. Jos. Louls (b'78)-I1!.11,0 (1'07) : I201 Belmont Are.: $9+11,1.3,7.8$ ("unninghan. Norral M. (b'- $\$$ )- II1.13,"no:

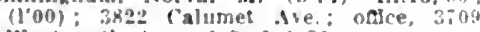
Wentworth Are. : $1-3,6,-8: 30$

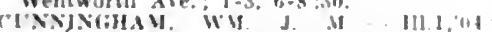

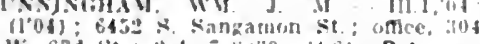
W. c3d st.: $2.4 . \div-170 ; 11,1 ; 0$.

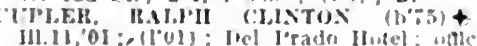
2as. W. 24th si.: 2.4. T.8.

Cueney, brank lichard $(b)-5)-111.11,01$ (1): [63] Wintona tre.

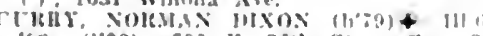
(1): $(102): 700$ t: 36 th st. oflec. 31

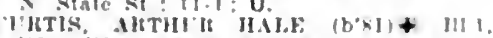

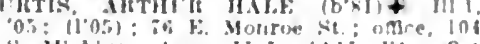

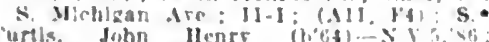

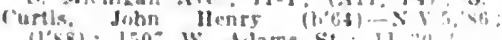
(1'sk): ligo: W Alams st. : Il :

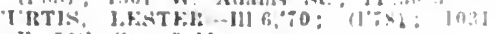
b. soth st.: 9.11

curlla. Whllur $\mathrm{F}$ (b's) 930: Cotlage firore ire : $5.9,1$ -
CIRTIS. W. HINCIRHE (b'30) - III.23,05: (1"05): 3218 thodes Are. ; omce, 3265 (cot tage firute Are: I-2. $5: 30-i:$ (II) : Pd.

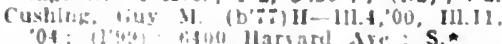

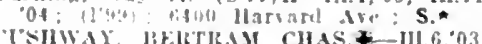
(1"04): 201 W GIst PI.: ouce, 304 W (i⿱⺈⿻コ一心]

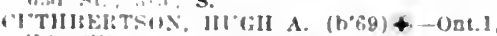
94: (1"64): 6i24? Woullawn Ave? \&:30-10 $+-5, \pi-4: A L R$.

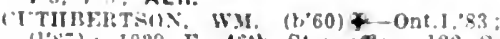
(1'x): 10ะ9 E. 46ith St.: ance. 122? Micligan tre: $1: 30-3: 39: G$.

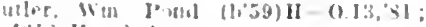

filtit IItzel tre

I'TRERA PETER (b'6f) \& - I $12.12,49$ (1'yi): 6.022 Wintlirop Ave.; ontee, tyt thitwatike Ase.

"raja, leo Matther 111.11.'11; (1'12); 16.in W. 1sih St.: 2-4, :-9:S.

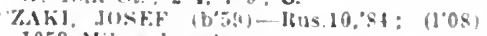
1053 Nilwanker Nre.

(zolbe, kwall Il. (b'5) $\rightarrow$; (l.99) : 9217 w $19 t \mathrm{~h}$ St: office, 2138 W. $191 \mathrm{~h}$ St.; 9-12

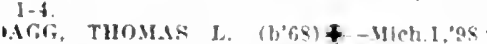
(1.03) : 5\$t2 East Vlew I'ark; once. D. Siate St. : $(+2,4)$ : Anes,

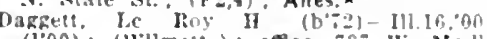
(1900): (Wilnette); offec, 73i W. Madlson st.: $9-3 ;$ S.

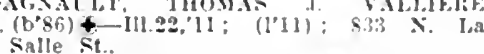

IiIII. STExNING (bosi) \&-111.11.90; (190): 2029 Plerce Are.; 12-3, 5-7

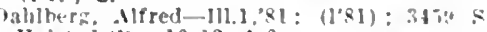
Halptei $\leqslant$ : : 10-12, $4-f$,

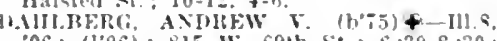
06 : (1.06): 815 w. figth st. : $6: 30-2: 30$ affee, south shore Himpital $10-12$.

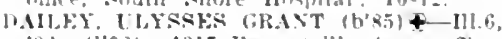

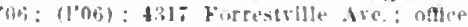
; E. 36th il.: 12-2; $\mathbf{S}$.

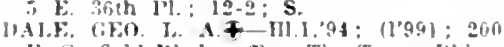

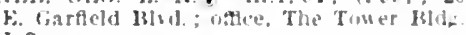
$1-3$.

Wale. Ilenry C. (b'60) $)-111.8,84$; (I's4) ance, tint Fuans Are.; 12-3.

bale Philip Marshall (b'83)-Ill.,'12

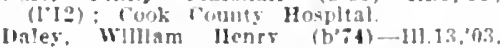
Il.11,09: (1'w3): 442.2 Washington Hive

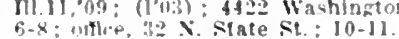

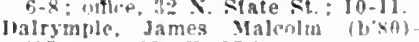

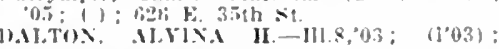
titi Indlina Are.

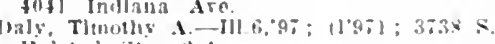
Iialsied st. : $:-1$

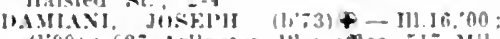

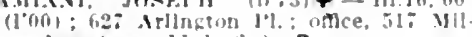
waukee Ale.: II-I. B-8: R.

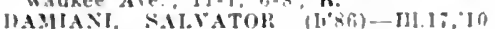

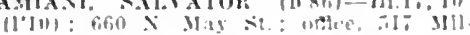
Watuke ils

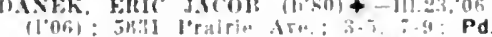

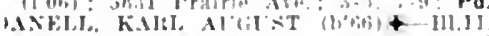

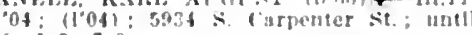
$9,1.3,7 \cdot 8$

barche. Nexander louls (b'st)-Ill.22,"1s 11 $1: 31: 2020$ Fretumblt st

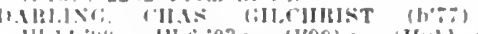

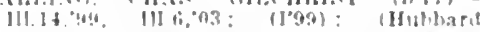

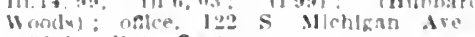

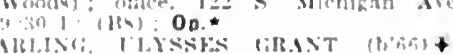

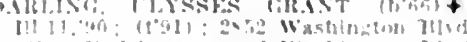

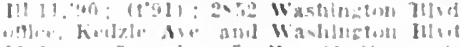
I1. 12 . $11111=\mathrm{N}$

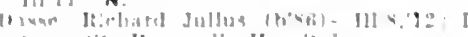
torst si leopharil's Hewntsa

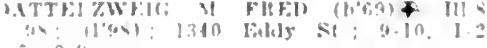

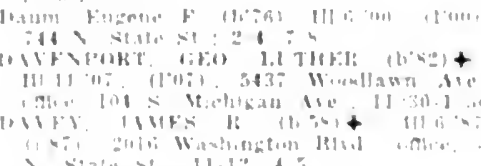

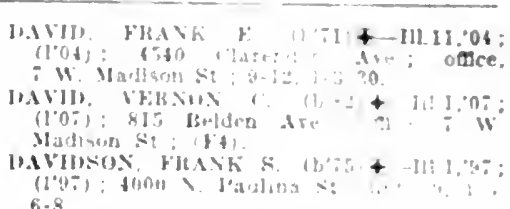

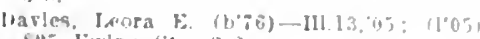

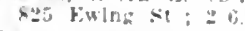

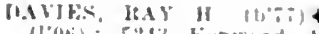

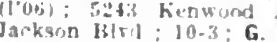

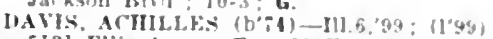

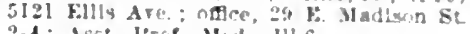
2-1: Asst. I'tof Mrd, III 6 .

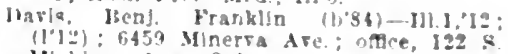
Illohlian Are : $2-4$

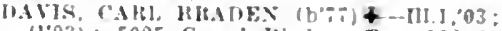
(1'03): 5025 Grand Hird: riflee, $122 \mathrm{~s}$ Michigan Are. 2:30.4:30; Asst. Mrnt surp. III I: (A7, I3,F4): S.

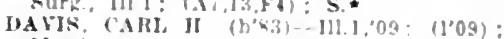
Member Med. Sirc uf Wis: I'resbstetian IIospieal.

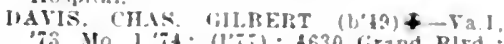
73. Mo. 1.7i: (17i): 4530 (irand Blrd.:

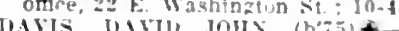

(l01): (11)

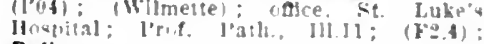
Path.

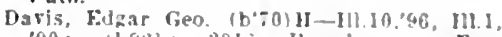
108: $x$. State st : 9-1; Assoc Proe. Skto and Yen Dls., III.

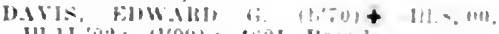

Ill.11, ily: (1'9y): friol Broalway,

D.IVIS, FFF.I V $\left(h^{\prime} 66\right)+-111.9,91 ;\left(1^{\circ} 92\right)$; $2311 \mathrm{~N}$. Clatk sh: 10-12; oflce. $32 \mathrm{X}$ State st.; 3-4; (1)2): ObG

Alis, H.MII I $\left(\mathrm{b}^{6} 65\right)+-$ Rus.t.91:

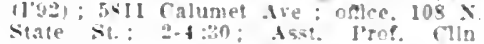
paych. Ill.11: (r.4): NP.*

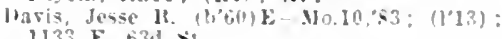
1133 E. क. क. 2

DAVIS, JUH. FIBAXKLIN(boij)-111.11,"10: (1'10): 919 Ibanont Ire.; oflce, 45; irel. mont ire.

DAIS, JAHX SITDOER, ( (1.53): 9029 Exchange Ire. onlee. y189

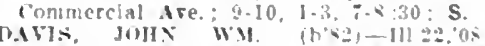

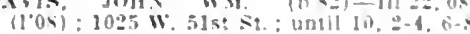
[harle, Jos. Jnb-IIl I Nij; (1's6); Hitel Mor

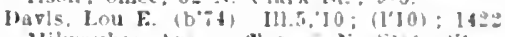

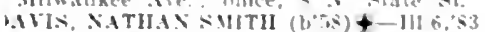

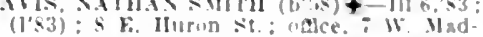

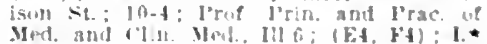

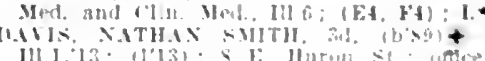
III. 1,$13 ;(1,13): \&$

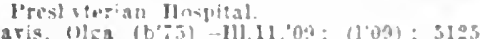

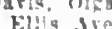

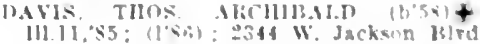

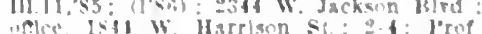

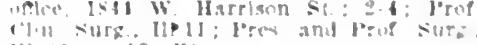
III 1:2: 1.113, , 11

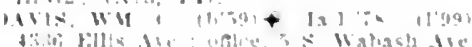
10.1.

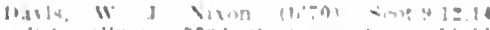

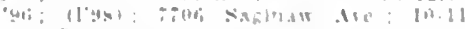

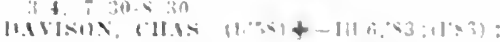

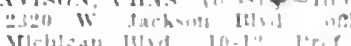

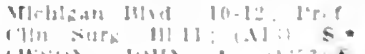

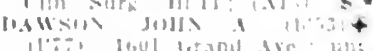

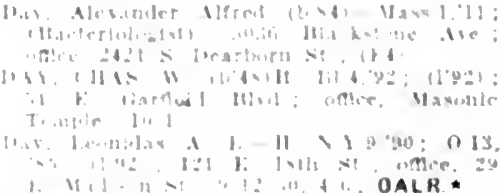


Lewis Jolnson $\left(b^{\prime} 70\right)-111.22,10$ : $10)$; 3015 Wilson Ave. office, 3400 Itawrence Ave. : $2-4,7-8$

leachman, $T$. Whlson (b'68) II I11.4,95 14.45) ; 3548 Carroll Avc.; oftee, 140 N. Dearborn St. : untll 6

DHACON, FRAXCIS (b'6) 1 - 111.11,04 (I'04); 464 E. $32 \mathrm{~d}$ St.

Delsey, Cornella B. (b'65) il - 111.4,"9.5 (l'95); 4581 Oaken

$N$ sitate sit. : 10-1.

de liey, Ilenry Bernar(Ius (b'b $\left.b^{2}\right)$-III.I, $A 9$ (l'sif); 1143 Ashland Islvd.; once, 1606 W. I2th st. ; $1-3$

De 130er, Win. (b'78)-111.14,06; (1'0i) $2431 \mathrm{~N}$. Maplewood Are.; othce, sol Mh watuke Ave ; $10-12,1-3,7-8$.

lwoker, Alole' (b'58)-Ger.20,81; (1'89) 432 Ibuena I'ark Terrace.

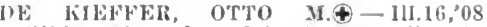
(l'0s); bis ('hamplain Are.; untll y: 30 Non-1'harmacal Ther, Ill.16; obg.

Dekoven, 13ernard (b'76)-N.Y.1,04; (I'04) 3259 Douglas Blvd.; offtce, $1315 \mathrm{~S}$. Hal sted St.; $10-12,3-5,6-8$.

DE LEE, JOS. BOLIVAR (b'69) 111.6 ,

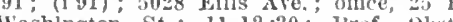
III.6; (AII); ObG.`

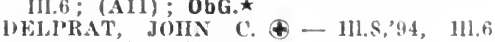
03; (1’94); 634 E. 5 Ist St. ; ofllee, $15 \mathrm{~F}$ Washington St. : $1-3$

DENCKER, (IIRISTIAY I’, K. $\left(b^{\prime} 67\right) \oplus$ Ill.1, $00 ;\left(l^{\prime} 09\right) ; 4200 \mathrm{~N}$. Hermitage $A \mathrm{ve}$. offlce, $2007 \mathrm{~N}$. Ilalsted St.; $12-1,7-8$ Asst. Prof. Med., Ill.1.

Denison, F. Lyman, Jr.-I11.17,95; (1'92) 17 W. Garfield Bivd.; I0-I2, 6-10.

DENXEY, JAMES A. (D'57) - $0.10,79$ (1'91) ; 547 W. Jackson Blvd.; 9-12, 2-5.

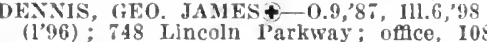
(1966); 748 Lincoln Parkway; off
N. State St.: 3-5; (D2); ALR.

DENNISON, ALBER' EUGENE (b'69)I11.I,'95; (l'95); 1926 S. Lawndale Are. 4-6; offlce, 1358 S. Ashland Ave, ; $9-10$ $2-3,-8$.

DePondrom, Theodore Edward (b’52)-Ia.6 86; (1’90); 22 F. Delaware Pl.

DEREBEY, CHRISTOS A. (b'57) $\oplus-111.6$ $97 ;\left(1^{\prime} 97\right)$; 4125 MIontrose B17d.; $8: 30$ $10: 30,1-2,7-8 ; \mathbf{G}$.

DERN, HFNRY JOS. (b'75) (-Ill.1,98 (l'00); 6845 Central Ave.; office, 9127 Commercial Are. ; $8-10,1-3,7-9$.

De Rosa, Roce - 111.22,'13; (1'13); 809 Blshop St.

De Roulet, Alfred (b'75)-Mo.24,'99; (1'03) 6620 Kenwood Ave.; offlce, 15 E. Washing ton St.; 1I-3; Clin. 1'rof. Gyn., 111.8; G.

UESSER, ABRAHAM LINCOLX-III.I1,'11; (1'11); 1525 Park St.; offlce, 141 I Nil waukee Ave, : 11-12, 2-4, 6-7:30

De Stefano, Jos. (b'64)-III.1,'89; (l'89) 844 Ewing St. ; 9-12, 7-8.

DE TARNOWSKY, GEO. (b’i3) \&-111.6,'00 : (I'00); 4221 Kenmore Ave.; offlce, $455 \%$ Broadway ; 4-6; also 31 N. State St. ; 2-3; (A13); S.

DETLEFSEN， FREDERICK (b'61)-Ger.1, 90 ; (1'91); 1 S46 Eddy St. ; offlee $3027 \mathrm{~N}$. Ashland Are. : $9-10,1: 30-2,7-8$.

DETWEILER, EDWIN S. (b'58)↔-Ill.1,'88 (I's9); 4531 Sherldan Rd.; offlee, $31 \mathrm{~N}$ Slate St. ; 9-11.

DE VAULT, ASA NATHAN-III.I1,'00; (1'99) ; 310 S. Hamlin Ave.; until 10, 7-8 office, 22 E. Washington st. $10: 30-1: 30$

DEV1NE, EDW ARD J. (b"i9) $₫-111.22,09$ (1'09); 6812 Center Are.; offlce, 7301 Vincennes Rd.; 2-4, 6-8.

Dewar, Hugh M. (b'70)-No.26,91; (I'09) 5701 S. Michigan Ave.; office, $5751 \mathrm{Ml}$ diana Are.; also, 6200 Cottage Grove Are.

Dewey, Katherine Weller (b'68)-111.1,'12; (I'13) ; 1531 Adams St.

DEWEY, RICHARD (b'45) - Mich.1,'69; $(176)$; Member State Med. Soc. of Wls. Physician-in-Charge, Milwaukee Sanitarium, Wauwatosa, W'is.; l’01); office, 15 Washington St. ; $11: 30-1$; (E1,4,13);

De Witt, Lydia Maria (b’59)-Mich.I,'98; (Pathulegist); University of Chicago;
DEWLT\%, OTTO J. (b'76)థ-Ill.I1,04; (l'01): 4001 Mllwaukee Ave; until 9, Dimols, Lambros (b'81) AM(ONI), ISADOHE HERNHARD (b'T3) lia. 10,94; $\left(1^{\prime} 98\right) ; 1305 \mathrm{~N}$. Hoyne Are.; ick, (ieo. Frellk. (b'81)-Ill.1,'05;

1?2 $S$ inclugan Ave: $(1,2,4)$.

DIKER, WHIWARD WOODARH (b'84)థ$111.1,08 ;\left(I^{\prime} 0 S\right)$; (54I N. Nimwood Ave. Oak l'ark); onlee, 422 N. 1'ark Are.; $1-3, \tau-8$.

rickerson, sipencer Cornellus - - Ill.1,01 I'(1) : 602s Alerdeen St.; offlce, 3101 State St. ; 8-9, 2-4, 7-8.

DICKINSON, EMMA I. IBENHAM (b'54)†

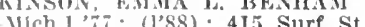

DICKINSON, FRANCES $\left(b^{\prime} 56\right) \oplus-111.9 ; 83$; (1.83) : 415 sure St.

Dickson, (ctly 13.-111.4,'86; (1'87) ; 4240 W lackson IBlid.; oflee, 2257 W. Madison St. : $8-9,1-3,7-8$.

IIISON, WM, F. (b'56)丹-Ont.3,82 : l'93) ; 6331 Woodlawn Ave.; ofllce, 32 N. Stale St. ; 12-1; G.

I) ickson, Wm. IIarrison (b'82)-Mich.1,'II not in practlee; 3130 Forest Ave. Dicosola, Frank (b'89)-Ill.11,'12;
740 Independence Islvd.

(l'12) ;

Diederlch, Victor P. (1)'87) - Ill.1,'11; (1'11) ; 4159 Grecnview Ave.: offlce, 104 s. Michigan Are.; also, 3166 Lincoln Ave. : $2-4 ; \mathrm{S}$.

DIEFENDERFER, IAROLD - Pa.1, 94 ; (I'99); 7150 Euclld Are.; oflce, $104 \mathrm{~S}$. llichisan Ave. ; $9-10,2-4$

Dlenst, R. CarI (b'86)-Ill.4,10; $\left(1^{\prime} 10\right)$; 907 Fullerton Ave.

DINSHORE, WALTER HARRIS $\left(b^{\prime} 57\right) \oplus$ Med. Assoc.; 943 Lakeside Pl.; office, 31 N. State St.

DINWOODY. JOHN A. (b'66)-Ont.3,90 (1'9I) ; 4137 Ellis Ave. ; offlce, 31 N. State St. : $1-3$.

DISBROW, ERNEST D. (b'58)-III.1,80; (1'04); 6231 Kenwood Are.; untll 9, 1-4, $6-8 ; \mathbf{o b}$.

Dittmann, Geo. C.-Ill.11,02; (l'02) ; 729 Belmont Ave. ; until $9: 30,12: 30-2,7-8: 30$.

DOANE. PHILIP SCHUYLER $\left(b^{\prime} 72\right) \oplus--$ III.1,95; (l'96) ; 1427 N. State St.; o
104 S. Michigan Are.; I-3; (A1I).

Doblja, Franciscus-Aus.3,'94; (1'07); 1225 N. Ashland Ave.; offlee, 1164 Milwaukee A re. ; 8-10, 1-3, 7-9.

DOCKERY, MCIAEL F. $\left(b^{\prime} 60\right) \oplus-I 11.1$, 91; ( ) : Member Mich. State Med. Soc. 1947 Jackson Blrd.

DODD, OSCAR (b'64) -III.11,90: (1'90) (1419 Chicago Ave., Evanston; 8-9); of flce, 31 N. State St. ; 1I-1; (B1,4,8) ; Op. DODDS, ROBT. (b'56)థ-III.6,90; (1'90) 3931 'Drexel Blvd.; offlce, 3946 ' Cottage Grove Ave. ; I0-12, 4-6; (A11); G.

Dodge, Chester C--H-lll.1,'82, Ill.10,'87; (1'87) ; 125 N. Sacramento Ave

Dodge, Rufus Emerson-H-Ill.4,"99: (1'03) 625 Groveland Park; offlce, 3300 Cottage Grove Are. ; 1-3, 7-8.

DODS, GEO. D. B. (b'61) -111.11,95; (1'95); 3335 W. Jackson Blvd.; until 9 , $2-3,6: 30-7: 30$

DODSON, JOHN MILTON (b'59)థ-III.1, 82, Pa.2,'83; (1'89); 5806 Blackstone Ave, office, 21 E. Washington St. : $3-5$; Dean and Prof. Ped., Ill.1; (D2, F1,4). Pd.

DOE, ANDERS-Norw.I,78; (l'82) ; 3040 Logan Blrd.; offlce, 1203 Grand Ave. $9-10,3-4,7-8$.

DOEDERLEIN, THEODORE J. (b'72) (Ill.11,94; (1'94); 5713 Kenmore Are. : office, 25 E. Washington St. 10:30-4; also, 743 Fullerton Ave.; (AII)

DOERING, EIMUND JANES (b'54) \&III.6,'T4; (I'81); Chicago Atbletic Club; offlce, 81 E. Madison St.; $2-4 ;(A 11)$. (I'01); 3631 Wrightwood Ave.; 12-1, $6-7: 30$.

Dolan, John Edward (b'82) - Ill.11,'08; (1'08); 1447 Wilson Are.; office, 800 Diversey' Parkway; ntil 8, 1-4, T-8.
Domecho, John-111.17,09; not in practlce; 15 Honore St.

bonaldson, ollver II.-IIl.11.94; (l'94); 6200 Kenwood Ave, oftlce, 1344 F. $63 \mathrm{~d}$ St. : $9-12,2-4,7-8: 30$.

DONKLE, IUCICS B. (b'77) \$-111.11,03 (l'03); 5135 Ingleside Ave. ; offlce, 1558 S. Wabash Are. ; 3-5, 8-9.

DONLON, STEPIIEN EDW. (b'64) \&-Ill.I 95; (1'95); 3819 Wilcox St.; offlce, 4000 W. Ilarrlson St.: I :30-3, 7-8:30

Donlon, Thos. IIenry' (b'72) - Ill.6,'10; (l'12); 3947 w. Madlson St, ; offlce, 31 N. State St.

Donohoe, Chas. T. (b'72)-111.16,'10; (1'10) ; 621 N. Waller Ave, omce, $222 \mathrm{~N}$. Wabash Ave.; $1: 30-2: 30,7-8: 30$.

Donoran, Chas. Andrew (b'81)-Ill.8,'05. $\left(1^{\prime} 05\right) ; 5101$ S. Ashland Ave.; 7-8.

Donoran, John S.-III.39,09; (\$); 647 E.

Doodokyan, Yeprous Martin (b'73)-Ill.11, 08 ; (l'08) ; 3252 S. Halsted St. ; office, 323 I Emerald Ave. ; $9-1,3-7$.

Dooley, IIarry Jos. (b'88)-Ill.6,'11; (1'12); 1239 S. Californla Are. : offlce, 4000 Harrison St. ; 2-3, 8-9.

Dorchester, Chas. O.-E-Ill.8,'94; (l'94) ; 2317 Cleveland Ave; 12-2, 8-

(b'64) Soc. Blvd.; office, 7 W. Madison St. Jackson Obst., Ill.8; (A11); ObG.

Dorn, Gay (b'54)-Ill.6,'83; (l'83); 6238 Dirchester Ave. ; 7-8.

ORNBUSCH, HENRY W. (b'60)๑-Ill.1, '83; (1'83) ; 1848 N. Keeler Ave.; offlce, 4200 Armitage Ave.; 8-9, 1-2, $7-8$

orsey, Hugh P.-lll.22,'13; (l'13); 3050 Warren Are.; offee, 204 S. Kedzle Ave. Dosef?, Dosu (b'82)-Ill.1,09; (l'09); 4743
Washington Blvd.; offlce, $139 \mathrm{~S}$. Halsted St. : 11-5; $\mathrm{S}$.

DOSTAL, FERPINAND EDW. (b'81)థIll.11,'05; (1'05); 1161 W. 18th St. ; 8-10, $6-8 ;$ offlce,
$10-12,2-3,842$

Doty, Maurice F. (b'65)-Ill.11,'95; (1'94); 562 N. Plne Ave

DOUGHERTY, WM. BYRNE $\left(\mathrm{b}^{\prime} 79\right) \oplus-\mathrm{Ml} .11$, 06; (I'07): 1542 Cornella Ave.; offle, 3401 N. Paullna St.

DOUGLASS, FRANK GERALD (b'86)థofflce, 304 (I'10); 7657 Stewart Ave.; $\mathrm{St}$.

Douglass, Robt. Lee (b'85)-Tenn.7,10 ; (l'10); 3638 Forest Ave.; untll 12, 2-4,

Douglass, Roscoe L. (b'80) - Ill.39,'10; (1'10); 10220 Parnell Are.; 8-10, 2-4, 7-9. DOWDALI, GUY GRIGSBY (b'75) $\oplus$-I1l.11, :00; (l'00); Chica

Downer, Chas. L. (b’58)-Ill. I,'84; (1'85) ; 800 S. Claremont Ave.; $9-12$,

DOWNES, ARTHUR W. K.๑-IIl.4,03; (1'03) ; 3103 Cottage Grove Ave. ; 2-4, 7-9. DOYLE, THOS. F. (-III.1, 04; (I'04); 8940 Cottage Grove Are. ; $8-9$; offlee, 9250 Cottage Grove Ave.; 2-4, 7-8.

Dracass, Fredk. (b'47) E-Ill.8,'86; (l'86) ; 320 4. 61st St.; 9-12, 2-4.

Drais, Lawson-0.1,69; (I'92) ; 3844 Elmwood Are.

Drake, Clarence St. Clalr (b'70)-Ill.10, '90; (I'91); 2758 Washlngton Blyd. ; offle, City Hall; 9-5.

Orammis, Louis (b'68)-Ill.16,'10; (1'11) : 563 W. Taylor St. ; 10-12, 2-4, 7-8.

DRAPER, OTTO G.-MO.I,'98; (l'98); 607 Fullerton Parkway.

Dressler, Florence Grant (b'68) P-M-Ill.5, '00; (1'00); 4324 Gladys Are.; 10-2.

DRISCOLL, JOHN J.-Ill.1,91; (I’91); 6408 Yale Ave.; 7-10, 2-4, 7-9.

Driver, Wm. A. (b'76)-Ill.17,09; (l'09); 3536 Prairie Are.; office, 3300 S. State St. ; also, 1472 Larrabee St.

DROZDOWITZ, THEODORE (b'67) \&-Ill.1, '97; (I'97); 1656 W. 12th St.; 1-2; office, 804 Milwaukee Ave.; 6-7:30 DRUECK, CHAS. JOHN (b'73)-1ll.6,'96;
(1'96); 438 E. 46th St.; 1-3; Pr.

trummy, Anthony Mathias (b'86)-Ill.6,'13; (1'13); Cook County Hospital. 
DHYDE: WM. FIEACIS - IIII],00; $(1 * 00): 14 \pm \div$ Dearboru St. oflce, 1900 Addlson Are: $8-0,12.2,6-8$

DUDLFY, EMIIIUS CLARK $\left(b^{\prime} 50\right)+$ N.1.8:75; (1'78): 1545 Astor St. oftce $122 \mathrm{~S}$. Mleblgan Ave: I2-1; I'rof. Grn.,
III.6 and III.(i1: (A2, 11.13$)$.

DUFk, (iCI C. (b'55)-111.11.9: (1.9i) 4316 Malden St. : 8-9, 12-2, 6-8.

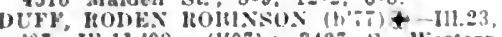

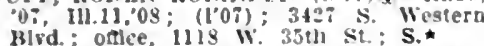

Dumeld. Allce Virginla-H_-11.4,99;(1299)

Dumeld. Allce Vit: ${ }^{2}$

Duffy, Hugh John-III.11,11: (1'iI) : 1037 Belden Are.: oflice, $6: 40$ Sherldan lid. untll $9: 30,2+4,7-8 ; S$.

Duket, leter '1'" (b'65)-[1].4.93: (1'13) 1016 Wilson Ave; orthe, Gibbons $\mathrm{Hldg}$ $9-12,1-5$

DENAVAN, 1.0ts W., (b'66)-I11.6,92 (1'93); 1142 Indlana Ire. offec. 4304 S. Mlchlgan Are. $11-12,3: 30-5, i-8$.

DUNCAN, ADELAIDE (b'65) Q-111.9,'95: (1.95); 6058 Kimbark Nc. : offce, $25 \mathrm{k}$ Washlington St. : $10-1$; (I31); OALR.

Duncan, Darld-H-III.4, 8 ;: (1'ST): 3331 Walnut St. untl $9,6-8$; onlec, $39 \mathrm{~S}$. Siate St. : 11-4.

Duncan. Sarab B.-111.4,93: (1'93): 7739 Inlon Are: : 2-4, i-s.

DUNCAN. WM. F. (b'52)-111.1, 81 : (l's1) 6058 Klmbark Are. oflce, 31 State St. 12-7.

Dunláp, (ieo. Wendell (b'84)-Ill.1,13 (1'13): Presbyterian IIospltal.

DUNX, FIIZABETII IIOIKINS (b'6i) + III.9, 94 ; (1'94); 4760 Iake Park Are.; of fice, 15 E. Washlngton St: (FI).

Dunn, Maude J. (b'70)-III.14,05; (l'06) 122 S. Mlehlgan Are.

bunn. Roland J. ( $\left.{ }^{\circ}, 5\right)-111.1,97:$ (1'9s) i16 Independence Rlrd.: 11-12; oflce. 600 Independence Rlvd, $11-12$; onlec.

Dupuls, Thomas Athur (b'-4)-Ky.1.02 (1'09): 1060 whlsun Are.; office, 3759 Shempld Are.

DVORAK, WEXCKSLATS JOTX (h'63)III.1.96; $(1,96)$ : 2510 purner Ire.

Drorsky, Bohumir J. (b'80)-111.11,02: $\left(l^{\prime} 02\right) ; 1800$ Flsk St

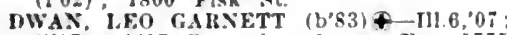
$(107): 417$ Greenvlew Are: oflce, 17 wllam Ave. : 1-3, i:30-8:30

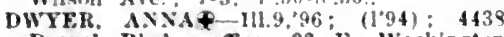
Drexel Blrd. : ofice. 22 k. Washington St. : $1-2$.

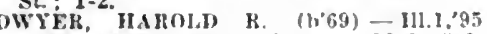
$(1 \cdot 95): 2328$ Clereland Are $12-2,5-8$

liwyer, Harry Jos. (b'89)-Ill.11, 12: (l'12) Mllwaukee Are: 10-12, 2-4, :-9: Ob. 1)wyer. J. Glllman (6'92)-111.22,'13: (1'13) 551 Grant 11.

DYAS, FREDK. GEO, (b'73) III.6,04: (l'04): Asst. Prof. Surg. and Clln. Surk:
III.11; 1132 F. isth St.; onlec, $32 \mathrm{X}$. state st. : 11-1; (A13).

Dyche. Cieo. Boyd (b०12)-111.6,'97: (1'9i) 4935 Dorchester Are, onlec, 104 s. Mlch gan Are. : 1-3: Asst. I'rof. Med. IIl.f.

Earle, Fdwin Grafram (bob)-111.11,91 (1'91): 2549 N. Clark st.; onlce, 159 $\mathrm{A}$ state $\mathrm{St}: \quad 1-3$

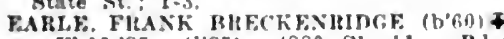
-Ill.11,85: (1'85): 4880 Sherldan IM]. once, 22 \%. Washington

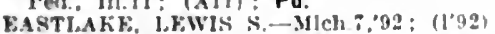
4754 Charuplaln Are: once, 407 kith ije. $8-9: 30,7: 30-9$

Faston, sildney "Ilarria $\left(h^{*} 90\right)$ 111.1.13 (1'13): Cook County llospltal.

raton, livid it (b'4)-111.6.82: (1083) 3147 Indlana ire.: $8-8,1-2 .=8$

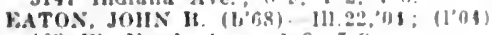
403 W. North Abe: 1-3. 7.8 .

kiberhatdi Waldemar $(1,93)$ (1'96) : 3360 W. Jackwn ltwil

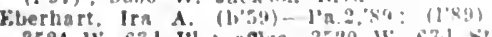

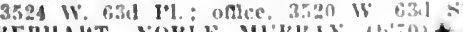

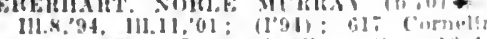
Are: unce. i W. Madison st. 12-4 1"rof. Fhys. Ther., H118; R.

HCKk, AliNiM r. k. $(6 \%+1)+1111,03$

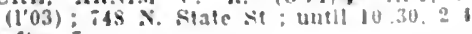

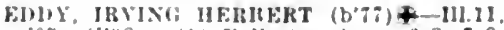
03: (1'0) 3 ): vit Fullerton Are.:-3, $;-8$

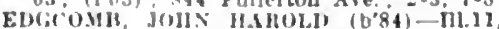
06: (1"06); :158 W. Jackson B|rd. 2-1. $:-4 ;$ Junlor I'rof. Surg. Ill.s.

Edison, Saml. M-I11.11,06; (1"06); 916 Aldikon Ale : onde, $534 \mathrm{~W}$. Nurth Ave; $1-3,:-5: 30$

Edmondson, fillbert W:-Ky.5.8:
3350 hinmore Ire., $8-12,1: 30-5$

(1'98):

EDWHIIS, ALTHLIR HOBIN (b'Gi) th

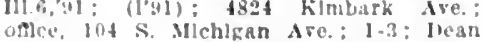
and I'rne. J'rin. and I'rac. of Med. and

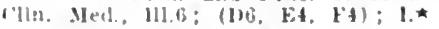

rolwarls sineman (bok) ill.1,93; (1+); llupel Ilulland.

F(1.1., 11.1N1. + 111.1,81; (1'\$1) : 2!0R Iroher we.: $8=10,1-1$

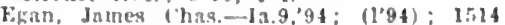
Montrose Blid.; onle, 1119 Wllson Ire. $10-1,3-5, i-5: 30$

ECAX, WM. J.- J11.11,05: (1'05); 2034 S tnion si: offlec. $250 \%$ Areber Are. 10-12. 2-

Fghialan. Setrak (i.-Crer.1.99: (1'09) ; 5505 s. Ilalsted St.

Ehlers, [गul F. F. (b,56) F-I11.8, $86,111.1$ $90:(1 ' s 6): 2059$ Relmont Aie.

EIIRMANN. FRFIV. J. F. (1) 93; (1'93) (327 s. 5th Are. Ia Crange) offce, $205 !$ W: $21 \mathrm{st}$ St. ; 1-2. $7-8 ; \mathbf{S}$.

Elchman. IIarrey F. (b'80)-IIl.22,'10 (l'l0) : 5. $\mathrm{N}$. Clark St. 08: (l08): 5027 Berteau Are.: oflce, 4019 Mllwakiee Are.: 2-4. 6-8: R.

Eidherr. Edw. I.-Ius.:S6: (Chemlst); H4I X. Winchester Are.; LD.

Elcenmann, John C.-111.6.97: (1'97): 5011 Blackstone Ave, ; $8: 30-10: 30,1-3$.

Einarson, Benedlct-Mllch.5,'82; I11.11,90; $\left(1^{\prime} 90\right): 535$ W. $63 d \mathrm{st}$.

HIENIILATI, DANI. NATIAS (b'6i)† I11.6.'91: (I'91): 4840 Woodlawn Ave. oftlce. 31 v. State st. ; $\mathbf{2}-\mathbf{4}$; Prot. Surg. and Clln. Surg., Ill.11: $(\mathbf{A} 7,13, \Gamma 3,7): S$.

FISENUIRTH, JACOH" IEONARD (b'sO) - Il1.11,04: (1'04): 1832 Hammond st. office, $1733 \mathbf{x}$. Ialked st. $1-3,7-s ; \mathbf{S}$.

EINENSTAEITT JOS. (b'85) (1'09) : 3330 sont

EISEXSTAFIUT, JOS SPIRO (h०85) F

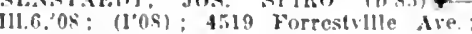

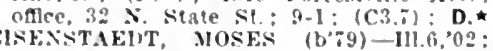
(1'02); 4521 Forrestulle Arc.: offce, as F. Madison St. ; y-12, 1-5.

EISFNSTAET, SOLOMON (b'67) + 111.1 $90 ;\left(1^{\circ} 92\right) ; 4613$ VIncennes Nic.; once i W Madison st. : $1-3 ; T$.

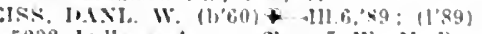

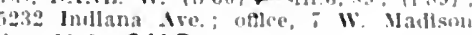
Si.; 10-1; OALR.

Fkstrom, John F. (b'82)-111.1.09: (l'09) 1138 Brytu Mawr Wre: $2-4$;-S.

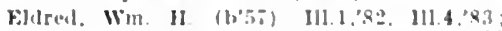

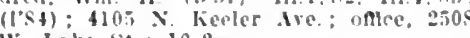
w. Lake st. : $10-2$.

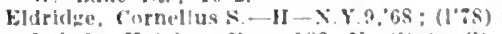
Lakola Ilotel: ontee, I3R N. Siate st. $0.11,2.4$

Elfrlnk, Mlanche Mayes (b'ia)-111 2a.'la: (1'13): 6141 lniversity Are.: onle, 2? f. Minrene sis.

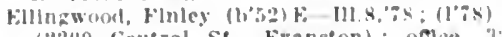
(20) (entral St, Fyanston); oftce, 3. sente si : $1: 30-3: 30$

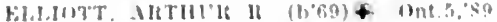

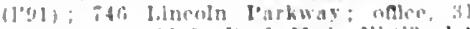

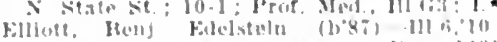

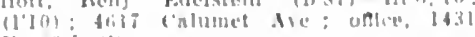
F. notil st

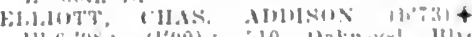

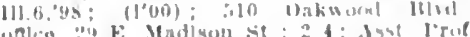
Iol ill 6 : (1) 1 .

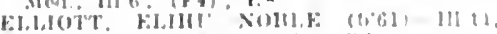

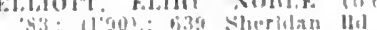

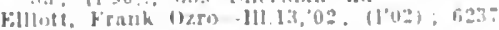
Inglealule Ale

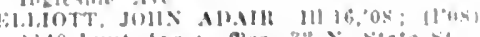

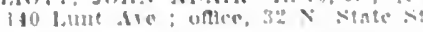

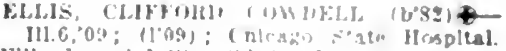

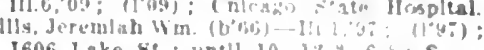

1606 Lake st. : untll 10.

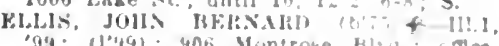

$15 \mathrm{k}$. Wanhingin st

kllis, John Jaydud (bise

4luI Brinadway.

Ellsulu, Ilerel olin

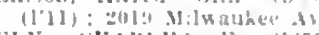

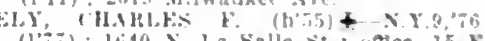

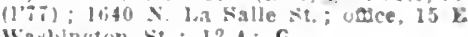
Waslington st.; 12.1: G.

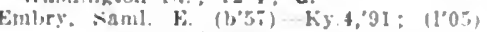
$4 i 0 \mathrm{~N}$. Hockwell se.

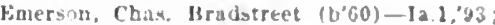
(l'12): 374 rilmworl tie: $6-9 ;$ G.

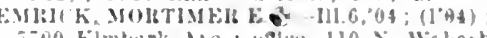

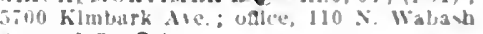
Irea ; 1-3; S.

FNGFILHERTEOS, FEHDINANI) (b62) + 111.23, $07 ;(1.07) ; 6$ N. II chigan Are. $12-1$.

Fingls. llenry r.-0.23,"9i: (1.9i); 1470 N. I'aullna St.

ENGEJ NICL11) IS IR $\left(\mathrm{b}^{\prime} 64\right)+-111.1, " 96$ (1"9;); iol w. 4ith st. $;-10,6-8 ; \mathbf{S}$

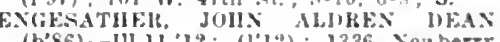
(b'\$6)-I11.11,12; (1'12)：1336 Newbers

Fingland, Fredk. II. (b'55) l'-M-II1.5,"96: (1'9i5); 694 l south l'ark Are

ENiILKR, VICTOIR I.t-\$10.2,06: (1'06): $525 \%$ : Clark St.

Enlow, Harry RIsIng (b'-s)-111.1,07: (1*0S) ; $420 \mathrm{St}$ James V1.; otlce. 36 W. Randolph Sit. : $9-6$.

FNIS, MATIIDA OLSOS (b'65)-III.8, 02; (I'02); $10 \$ 59 \mathrm{~s}$ State st.; 9-11. S.9: $\mathbf{N}$.

Enrlght, Wm. J.-I11.23:06: (1'06); :00 W. liarfleld Hivd: oflice, $1600 \mathrm{~W}$, Carfeld Blvd.: untll $8: 30,3-5, ;-9$.

Eppsteln, Ralph Morris (b'81)-111.22,'11: (1'11); 3336 w. 26th st: 10-12, 1-3, $i=9$.

Fpstein, Wm. Geo. (b'Af)-111.11,10: $\left(1{ }^{\prime} 1 \theta\right)$ : 6604 Woodlawn Are; once, i25s 8 . Halsterl st.; also. T001 Porchester Are

Erlckson, Charles Adolyh $\left(b^{\prime}, 6\right)-111.22,10$ :

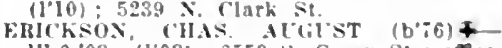
III 6.03 ; $\left(1^{\prime} 031 ; 6.59\right.$ \&. Green st: offle. 24js Wentworth Ave.: 10-12, $3-5, i-3: 30$.

Erickson, Pontlus I.-III.S, 10; $\left(\mathrm{l}^{\prime} 10\right): \mathbf{2 0 5}$

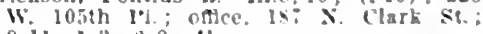
$9-11,1-3,4-8 ; U$.

kirstling. Kirnst (bo6)-I11.14.05: (1.06) $341+$ Beach Are. : 8-4.

Fach. Wn. W. (1),6)-111 16,06; (1'06):

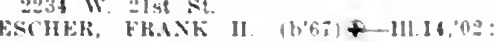
11"02): 3013 Washington B1rel; onlee, 1553 II. Madisom sis: 12-2, 6-5.

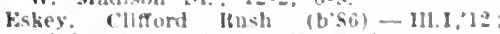
(1'12): cok comty llospltal.

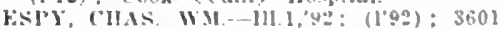
Imilage ire, ; until :4, 1-2,6-8. Eitheredes, Vaute lee (tis)-I11.8.11: (1'1:3: 131\% Irvmg loark Rlvo.

Fistaive, Irthur Itarrete (b\$6)-111.6, 0 ; : $(100)$ : 42as Indlana No.

Fians, Havld \& (10':\$1 11t.1.98: (1"99) sIf $x$ learmirn st. odlec, 54 W. Jack. sun Hivel.

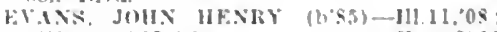
$(100): 1196$ w II IIrrtan

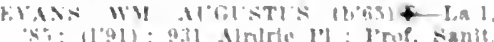
sinemo 1110

Evert. Fredk K. II- 11110,88

ati Center

Eicretl llenry II (1)

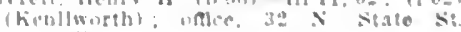
y $1 ;$ L. H.

forlban, Ifarzuerle fiverlle - III fo:

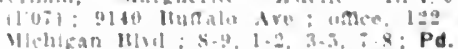

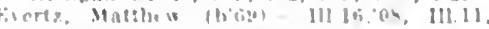

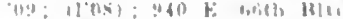

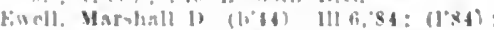

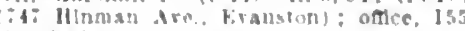
(lark $21 ; 10.8$ 
EHING, JOHN 13. $\left(b^{\prime} 56\right)+$ NIth.7,, 86 : $(190) ; 2301 \mathrm{~W}$. Madlson 5 t. ; $8-10,2-4$,

kzekiellan, Sennacherlb V: (b'68)-111.1,95: (l'95); 1337 Washington Blyd.; $8-8 ; N$ Faber, Ixaul J. - Ill.6.90; (l'y(0); Bright. Houso; oflce, $i \mathrm{~W}$. Madison st.; $10-12$ $3-5$.

Falr, Fred F. (b'83)-111.6, $05 ;$ (I“05) 940 W. 58th St.; oflice, 5451 Halsted st $8-10,1-3,7-9$.

FAITH, THONAS (b' (1'94): 6945 ientral ive. offle $31 \mathrm{~s}$ state st.; 10-1; also, 9119 Commercial Ave, Prof. Oplitle., 1ll.fi4; (131, 7,8

Falh, Victor sofus (b's!)-Ií.1,'13; (1'13): st. Joseph's Itaspltal

FALKEIt. WM. HENHY + III.1,02; (I'R2) 4433 irexel 13lscl: ofllce, $1041 \mathrm{r}$, 630

Falls, Fredk. Howard (b'85)-1II.1,10: $\left(l^{\prime} 10\right) ; 750$ Lincoln I'arkway; 8.9, $5-6$, $7-10: 0 b$.

FAITERMIYER, JACOB (b'75) - - III. 22 10: (l'10): 4030 x. Paulina st.; ottee 1909 T.incoln Are.

PANTS, BlEINARD (l'74)\$-111.11,99:

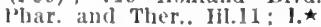

FARA. FRANK JOIN (b'81) \&-111.11, 05 : (1'05)；3341 W: 26th St.; 8-10, 3-5; Asst. Prof. Med., Inl.16.

FARLANDET IVENEI ERIC (b'SO) I1l.14,09; (1'10): 3135 Irving Park 13lvd.;

PARLEY, ROGEIt T. - Ill.5, 91 : (l'01) : 5530 Dorchester Are.; offce, 1381 E. 55th st. '07'; (I'(14); 54 is Lakewood Ave.; oflce, 14 IV: Wishington St.; $9-4$.

Farnluam, Harry Itathbun (b'99)-Ill.6,'I3 (1'13); 1214 Itosedille Ave.

Farnum, Edw. J.-E-Ill.8.'89; (1'89) ; 5659 Mignolia Are, oftice, 29 E. Madison St. $12-3: 30$.

FARQLIIALSON, HENRIETTA M.-III.9, '00; (l'00); 4635 V'incennes A re.; oflice, $15 \mathrm{~F}$. Washington St, ; 10-1; 0 p.

Farr, Albert Laucance (l, 49)-Ill.1,80 (l'S1): 3915 Pine Grove Ave:

FAIRLIL, T'ATRICK J. H. (b'64)థ Ky.1,92; (l'99) : (608 Flm St., Winnetka) offee, $32 \mathrm{X}$. State st.; 10-1; $(\mathrm{B1}, 7)$

OALR. *

Farrinzton, llarrey (b'72) $\mathrm{H}-\mathrm{Pa} 9,96$ (1'00): 5000 Dorchester Are.; offle, 5 S Walbash Ave.

Fash, Martin 17. (b'63) H-Ill.10,'96: (l'96) 2832 Warren Are.; offle, $2358 \mathrm{~W}$. Madi son $\mathrm{St}$ : $9-10,1-4,7-8$.

FAILKNER, LOU1S $\$-111.10,96 ; \quad(196)$

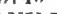

FAYILL, HENRY P.AIRD (b'60) §-111.1, "83; (1'94) : 78 E. Elm St.; office, $122 \mathrm{~S}$. Mtehigan Are.; 2-5; I'rof. Clin. Med. Ill.1 : Prof. Nled., Ill.G1; (E4, F4).

Fay, Michael J.-Ky.1,95; (l'94); 909 Dakin St.; office, $32 \mathrm{~N}$. State St. 1-3.

Feasler, Chas, H. (1,81)-111.17'04: '(I'09): 4226 wilcox Ave; offee, 2758 W. Madi son st.

FEIGEN, PHILIP II-111.22,07; (l'08); FEINGOLD, TEON (b'-5) (l'99); 2502 N. Clark St.; $12-2,6-i=30: \mathrm{s}$ Feinstein, Benj. I.-111.22,'13 ; (I'13) ; 1314 x. Claremont Are.

FELDSHER, ISRAEL (b'73) -111.22,'08 : (l'08): 635 W. 12 th st.; $9-11,2-4,7-9$ Felker, stephen sewall E-Ill.8,94; (I’94); 113 x. Francisco Are.

Fellows. Antoinette K.-111.15,'96;
4958 Blackstone Ave.; $9-12,5-7$;

Fellows, C. fiournee (b'63) H - 111.4, 8 . (1'89); 4820 Kenwood Are.; Office, $22 \mathrm{E}$. Washington st.: 9-1; 1'rof. Ophth. ant Otol., IIl.4; OpA.»

Fellows, Uarie A. (b'69)-111.11;99; (1'99); 10 W. 47th St. ; $1-4,7-8$

FILNIEE. SAII T.-111.1,'91; (l'91); 1645 Ii. Garfield Blyd. FLTEASTEIN, BENJ. (b'68)-Ill.11,95;
(1'05); 2328 Milwauke Are; 8-10, 1-3,

Feliman, A. Wm.-Ill.16,96; (l'96); 5262 W. Wonroe st. ; oftice, 2159 W. $22 \mathrm{~d}$ St.
Felts, Ilarvey Austln (b'85)-IIl.6,'13; (1'i3); N'esley Hospltal.

Fonn, lieo, Karl (b'90)-III.6,13; (l'13) st. l,uke's Hospltal.

Fenn, Thomas Legare-N.Y.1,82; (l'8i) 306 F. 4 t3d St.; $2-4,7-5$

E'enwlck, Lonls .1.' (b'58)-N10.28,98; (1'98) 4662 s. State St. ; 8-10, $12: 30-2,7-8$

F'erguson, Alexanter Donald (b'86)--Ill.11, '12; (l'12) ; 4619 Grand I3lrd.; office, 32 N. State st.; $4-6 ; \mathrm{S}$.

crguson, Allan Jiarvey (b'84)-Ill.4,'13; (l'13) : Hahnemann Ilospllal,

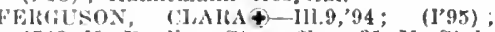
4548 N. Iaulinil st.; ottlee, 31 N. Stale St.; 12-2; Prof. 1'ed., 111.22.

Fercuson. Fre(lk. II, (b'71)-11.16, 06 (106): 2434 Linden $\mathrm{F}^{\mathrm{P}} \mathrm{l}$.

FEIRTISON. ROY RALI'IT (b'78)†-III.1, 0.3: (l'03); $3923 \mathrm{~N}$. kecler Are.; 2-3,

Fernow, John A. W. (b'63)-Ill.11, 01 (1'01): 24⿴囗十 Mllchigan Are.; offee, $7 \mathrm{~W}$ Madlson St. : 11-4.

FEllNIT\%, GTSTAY (b'44) - Ky.4.'sI (1's.3); $125.5 \mathrm{~N}$. liobley St.; 8-9, 2-3. Fetherston, Ellw. B.-III.11,'93; (1'94); 4200 N. I'aulina St.

Fleldlurave, Alfred-111.8,'12; ( ); 1834 W Adams St.

FINLAY, EPHRAIM KIRKJATRTCK (b'70) \&-Man. 1,93: (1'95): 4818 Forrestrille Ave.; oflce, 30 N. Michlgan Ave.; 9-1; OALR. *

Finegan, Thomas Francis (b'88)-111.6,'10 (l'19); 6114 Rhodles Ave

Flnkelberg, Itose (b'i2)-111.8,08; (1'08) 39 S. Menari Ave. : 9-11, 3-5, 7-9.

Finkelstein, Iulian is. (b'87)--IIl.16,'13 (1'13) ; 1322 N. Rohey St. : 9-10, 1-2,7-9) Finn, Wm. H.-Ill.11,97; (197) ; 3035 Indiana Are. ; 10-11, 3-5, 7-8

HISCIIER, CHAS. F. M. (b'81)†-Ill.11, 07; (I'07); 1922 W. Chicago Ave.; untl 9, 1-3, T-8; Prof. Physlol., Ill.16.

Fischer, clement (b'85)-111.11,'12; (1'12)

800 s. Oakley Blvd. 8-9, 12-2, 8-9.

1902 S. Kedzie Are.; office, 802 W. 12th St.; $10-11,1-4$.

Fischer, Oscar G. (b'81)-111.11,03; (l'03) 1902 S. Kedzie Are.; office, 802 W. 12th St. ; 1-3, 6-8.

FISCHER, WALTER D. (b'78)†-Ill.1, 04 $\left(l^{\prime} 04\right)$; 830 Oakdale Are,; offce, $301 \mathrm{~W}$ Chicago Are.; 12-6; S.

FISCHKIN, EDW. A. (b'62) $\$$-Ger.1,94; (l'95); 3037 I.ogan Blvd.; office, $32 \mathrm{~N}$ State St.; 3-5: also, 1225 N. Ashland Ave.; 9-12; Prof. Derm. and Syph., 111.22 ; $(\mathrm{C} 3,6,7) ; \mathrm{D} . \star$

FISCINIAN, EGON WALTER A-III.1,06; (l'06); 6310 Magnolia Are. ; uffice, $602 \mathrm{~W}$

Fish, A. Sirvester (b'63) H - Ill.14, 96 : (1'96); 4021 N. Harding Ave.

Fish, Eleanor E.-1ll.8,'10; (l'10); 919 S Bishop St.

FISH, HENRY MANNING $\oplus-111.4,00$; (l'06); Wiudermere Hotel; office, 29 E. Madison St.; $9-1$; $(B 1,8)$.

FISHBEIN, MIORRIS (b'89)↔-Ill.1,'12 ; (I'12); 535 N. Dearborn st.

Fisher, Arthur Haeberlin (b'86)-Ill.1,'12; (1'12) ; 5 E. Garfield Blrd.

HISHER, ERLE FRANK-111.8,'12; (1'12) 1902 Irving Park Blvd.

FSHER, FREDK. ALFRED $\left(\mathrm{b}^{\prime}-6\right) \uparrow-111.1$, 01; (1'01); 1257 Addison St.; office, 1609 Fullerton Áve. ; 9-10, 1-2, T-8; S.

FISHER, GEO. CARL (b'75)థ-111.11,99; (1'99); 2136 Indiana Ave.; 11-12, 4-5, i-8; ú.

Fisher, liart Ellis (b'86)-Ill.4,'12; (1'12): 3518 Broadway; office, $421 \mathrm{~S}$. Marshffeld Are. : $9-11,2-4 ; s$.

FISHER, JOHN (b'51)Ð-Ill.11,'87; (l'87) ; 441 Belden Ave, ; 2-3, 6:30-7:30; Prof', Nied., Mll.G1.

Fisher, Ludwig J.-Aus.6,'06; (l'08) ; 3711 W. $26 \mathrm{th}$ St.; office, 1801 S. Ashland Ave. Fisher, lichard C. (b'48)-D.C.4,'y0; (1'95) 4744 Dorchester Ave.; 10-3.

FISHER, ROY GATTX (b'83)-II1.11,09. 4241 Sheridan Rd.; offlce, $32 \mathrm{~N}$. State St. 11-1; Prof. Ophth., Ill.G4; OALR.`
FISHEIt, WMI. ALBERT $\left(\mathrm{b}^{2} 59\right)-$ Mich.1, office, $31 \mathrm{~N}$. State St. : $10-1$; I'res. and Prof.' Ophth., Ill.G4; (131,8); OALR.

F'Ishnan, Louls B. $\left(\mathrm{L}^{\prime} 66\right)-\mathrm{M} 0.27,97$ (I'04) 1427 Wicker I'iurk Ave, oltlce, 848 W. 14 th st. $8-10,2-4$.

Flsk, Itoscoe liaby (b'86)-Ill.11,'12; (1'13); Augustana Ifospital.

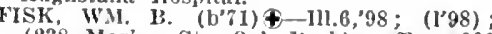
(23s Marion St., Oak l'ark); office, 606 s. Michigan Ave.; 10-12.

FISKE, DAYID (b'72)థ-1ll.1,00; $\left(\right.$ I' $\left.^{\prime} 00\right)$; 25 E. Walton Pl.; offlee, 25 W. Washlng-
ton St.; $9-12$; Assoc. P'rof. Otol., 11l.Gi; $(B 7,8)$; OALR.ネ

FISKE, GEO. F. (b'60)థ-Conn.1,'83: (l'86) ; (Lake Forest); offlce, 25 L. W'ash. ington st.; 9-12; Prof. Otol., 1ll.til $(\mathrm{B} 1,4,5, i, 8) ; 0 \mathrm{pA}$.

FITCII. AIBERT F-III.17,02:(1'03): 123 S. Winchester Ave.; offlce, 5io W. Iladlson St.; 8-7

FITCH, WAL'TER M. (b'62) - Ill.1, 85 ; (l'85); $1728 \mathrm{~W}$. Monroe St.; 1-4.

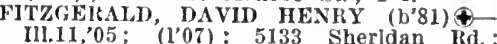
until $9: 30,12-2, \quad 8: 30-9 ;$ once, 5201 Broadway; 10-12, 2-4, 7-8.

Filtzerald, James Merlin (b'70)-IIl 16, 08 . (1'09) : (Riser Forest); offlce, 8 N. State St. : $9-5 ; P_{.} \star$

FITZGIBHOX, GARILTT $4-$ III.1, 89 : (l'99); 701 S. Sacramento Are.; office, 108 N State St.; 10-12.

ITZMAURICE, JA MIES W. (b'60)-IIl.1, '89; (1'\$9); 747 S. Oakley Bird.; office, 2876 Archer Ave.; 7-9, 12-2, 7-8:30.

Fitzpittrick, Ernest Hugh (b'63)-Scot.9,12, 14,86; (l'94); (Pontiac); oflice, $108 \mathrm{~N}$. State St. ; 9-12, 1-3, 5-7.

FItzPatrick, Gilbert (b'73) H - Ill.10,96 (1'96); 114 E. Walton Pl.; office, $122 \mathrm{~S}$ Michigan Ave.; 10-1; Assoc. Prof. Obst.,

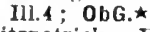

Fitzpatrick, Henry Perkins (b'68)-Ill.1, '96; (l'96); 6031 Eberhart Ave.; oftice, 220 S. State St.; $9-4 ;$ D. $\star$.

Fivey, Robt. E. (b'62)-N.Y.3,'87; (l'99) 1245 Early Ave.; office, 339 S. Wabash Ave. FIANACAN, BARTHOLONEW F. (b'70)-
IIl.11,98; (1'98); 436 E. 49 th St.; $2-4$,
$7-8$.

FLANNERY, ROBT. EMMETT (b'84)€III.11,06; (l'06); 1301 N. Maplewood Ave. ; office, 2014 North Are.; 1 1-3, ;-9. Fleek, Bernice A.-IIl.4,13; (1'13); 3126 Calumet Ave.

LEMING, JAMES LOUIS (b'72)థ-III.1, 03; (1'03); 3756 W. Chicago Ave.; 1-2, 7-9; Assoc. Prof. Med., IIl.22.

Fleming, Saml. Clifton (b'86)-1ll.11,'13; (l'13): 2043 Cleveland Are.

LETCHER, HENRY STEPHEN-III.23, 0 $\left(1^{\prime} 0 \pi\right)$; Wellington Hotel; $9-12,1-3,7-9$;

Fletcher, John Rice (b'64) - MId.3,'91; (l'93); (Winnetka); office, 32 N. State Ill.G3; (B 1,7$)$; ALR.

Flinn, Chas. C.-E-Ill.8,'01; (l'01); 3232 Park Ave.; office, 1514 S. Kedzie Ave.; $10-11,3-4,7-8$

Flinn, Elmer Holmes-Ill.8,05; (1'05) ; 1514 S. Kedzle Ave.; office, 3168 Ogden Are.
Flint, Edw. N.-Iil.11,'87; (1'02); 419 Belmont Ave.; office, 322 State St.; also 9037 Conmercial Ave.

Flood, Geo. E. (b'56)-Mlch.2,79; (l'93); 6300 Jackson Park Ave.; offlee, $127 \mathrm{~N}$. Dearborn St. ; 10-1, 2-4.

Flood, James , Ramsay (b'38)-Pa.2,66; (1'77) ; 5414 East Vlew Park; 9-12.

Flood, John $\left(b^{\prime} 50\right)$ - Ill.8,'73, Inl.1,'89; $\left(l^{\prime} 7 \mathrm{i}\right) ; 3348 \mathrm{~W}$. Monroe St.

Flynn, Helen B.-Ill.11,'06; (I'06); 5610 is. Peoria St.; $5: 30-7: 30$.

Foelsch, Alwert 'J. (b'76)-Ill.8,98; (1'99); Foley, James Lennon (b'90)-Mo.34,'13; (l'13) ; 6337 Harrard Are.

Foley, Jos. F.-Que.3,'04; (l'09) ; 9829

FOLEY, THOMAS PATRICK (b'82) $\oplus$ III.6, 68 ; $\left(l^{\prime} 08\right) ; 1256$ S. Kedzie Ave.; office, 32 N. State St.; 1-3.

Fomon, Saml. - Ill.11,'06;' (l'06); 5155 Prairie Ave.; offlce, 1575 Ogden Ave. 
Ford, Francts r. (b63) II - Mllch 5,90 (1'91): (Clyde): once. 2sil ('ottsgo Grove Are: : 1)-5; I'rof. Inat. III

Forkin. Wr I? $\left(\mathrm{b}^{\circ}, 6\right)-111.11 .03 ;(103)$ Monalinock lijock.

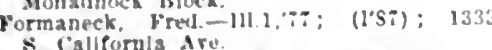

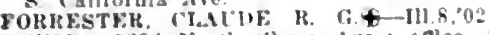
(102): 1936 North shore tre.: onlce. Pin ORIR.sT: jos

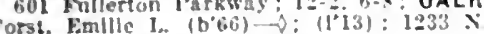
orst, Fantlic 1. $\left(b^{\prime}(6)\right)$

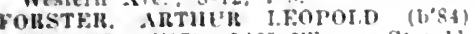
I11.11.07: $\left(1^{0} 07\right): 146.5$ Whona st: $11-$. A.6, i-8.

Portier, Geo. Snow-Ill.11.07; $\left(10^{\circ}\right)$; 3906 Lake lark ire.

ForTIx, WM. HK.sR (b's0)-Ill.11.08 (1'08); 124t s. Sawrer Are.

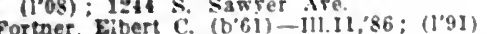
3242 indlana Are. $2-4,7-9$

rose Indlana Are. ${ }^{2-4}\left(b^{\circ} 66\right)+-111.1,96$ (1'98): 3213 Kimbark Are.: once, 1504 (198) 3213 Kimbark Are.

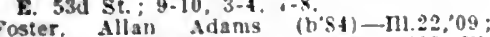

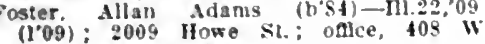
North" Are.: 8.10

Foster, Fred P. (b'5s)-Ill.22,09: (l'09) $169 \mathrm{w}$. Chlcago Are, ; 41 , 2-5.

Faster, Jobn M.-11-III.4, 83 ; (1'84) ; 1043 ' S. Seeley Are.: oflce. $357^{\prime}$ W. $63 \mathrm{~d}$ 'St.

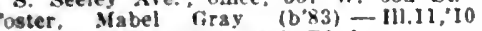
(I'10): 3600 Irving Park Blvd.

Toster 3600 Irving Park Rivd. $(1 ' 6) ; 5542$ Dorchester Ave.; o.sce, $32 \times$ (1'7) : 5542 Dorchester Are.: O.Ace, 32
Slate St.; $10-4$; Prof. Mat. Med., Ill.4 Ob.

POSTER, ROBERT H.-Ont.3,96; (1'04) 900 W. Madison St: 10-12, 2-5.

Humer. Chester watson (b's6)-111.11, 13 (l'13): Finglewood Maspltal.

YOUSEIC GEO, G. (b'69)\&-I1L. 10,96 ; 111.6 04: (1'95); 4313 Irvlug l'ark Blod.; 2.t.

COWLER. ALFJED HLGII (b'7)-11l.1 (04: (1.04): I1122 Esmond St; offce, 2101 Morgan Ave. ; $8-9,4-6,7-8$.

Howler, Clarence Taylor (b'85)-X.Y.15 fowler, Clarence Taylor 2009 Jrring Jark Bird.

Fowler, Earle lHloodgond (b'84)-Ill.l,'I0 (1'10): (209 S. Oak Park Ave., Oak Park): oflce, 31 X. State St.; 9-12; OALR. *

FOWLER, EDSON BRADY (b'65) \$-H.6. 96; (1'96); 3339 Indiana Ire.; onlec. - 1 .

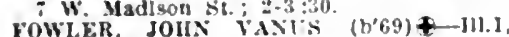

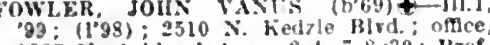
1225 x. Asbland Are.; $2-4,7-8: 30$; I'rof.

fox cIlAs. MARvis (b'-8) \& Ill.6,01: (I'01) 5461 Mlackstone ire.: onlere 25 E. Washington st.: 1-s; I'rot. Surg lil. $63 ; \mathrm{S}$.

Fox. Fdw. Francls-H1.11,'11; (1'11) : 1222 . Pw. ire.: 11-12, 2-4, $;-8 ; 0$ bG.

dre. Paul Chrlstopher (b's6)-111.1.12 (1'12); Mlehael Iteeso Hosplial.

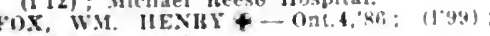
6432 Mherva Are

Fraln, Adnah K.-Wlch.4:-3; (1.95); 13320 Woodlawn Are.: $8-1$.

FRANCIS, (HAS. HOKACE (b'T1) +-III.8 91; (l994): 912 Jrring lark Hird: of nce, \% F. Wasblngton St.: 10-4: Jroif. (1),lith. Ill (61: (B8) : 00.k

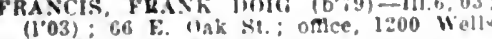
st. $\sin 7 \cdot \pi: S$.

FRANK, IHA (1077)+-111.11.99: (1'45) 17if Grand Blvil.; onlee. 101 s. Mrlilean Are.; 11.1, 4.5: (131,i): ALR.

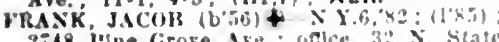

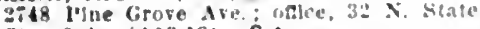
St. : 2-4: (A12,13): S.*

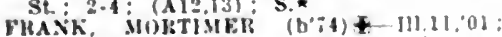
(1.01): 5ti3 Ellls Are: onco, $11 \mathrm{X}$. State

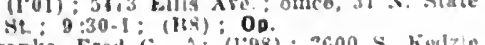
Franke, Fred $\left(C-0 ;\left(1^{\circ} 98\right): 2600\right.$ s. kiedzio
Are.: 12-1, 2-3, $6: 30-8$.

rankel, Rugene-swlezi,96; (l'a) : 1250 Turner dre.

FILANKFNSTEIN, victok S. (bon) umcr. $3:$ Y. state

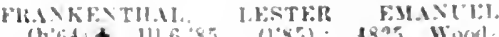
$(646+111.6,85,1185): 1825$ Worm

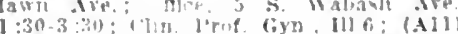

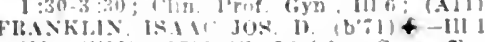
01: 11.011: 1701 W. InItslon st: onle $1 \% 03$ W. IV vinn st. $8-9,8-4:-9$

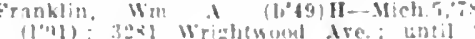
Aritis

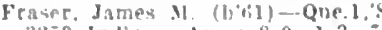

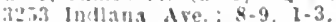

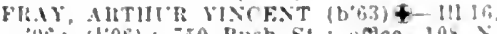

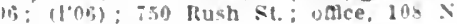
State st. : $10-0$

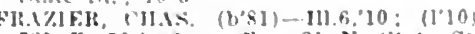
31 F. snit st.; unce, 31 x. State St In $: \div 0-12: 30: 5$.

EH.IZIER. HAIIOLI) I. (b\%s)-J11.1,01 (1.02): 5820 La salle s?: oflce, 4024

Frazin, Sathinlel Danl. (b'\$9)-11t.6.'11 (1.11): 3118 Wen?worth Are.

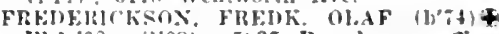
III.1.fo:; (100) : 5437 Brnadwas; onlce. $2 \pi 31$ <. Clark st.: 1-3, i-8.

FREFYIX. ARTHT'R $R$. (h'59)-I11.1.85: (los): (Dentise): (IInsdale)

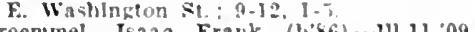

Freentmel Isaac Frank (b's6)-
(1'ng): Chlcago state Hospital.

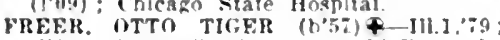
(1'81): 81 k. Eilm St.: oflce, 25 k. Wavh Ington St: 9-3: l'rof. Jaryn. and Rhle Ill.6l: Assoc. Prof Laryn. and Mtol. III.1: (B2,7): ALR, *

FRFESE, ATTHIR WM. (b.84)P-JI11. 09: (1'09): 2749 prances l1.; offce, 1968 Mllwalkee Are.

PREXCH, LOTIS CI.ARK (t':8)-I11.17 $05:$ (1'05): 4003 sheridan Rd.; offec French. Walleht R. (b'58) I - 0.13,'so : (1'?0) : tit: Gladys Are.

FRFACII, WII.RII MAYXAIB $(1,76)+$

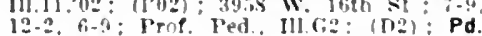

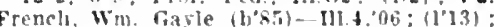
3] I' line Grore Ire.; oflce, Hallers HIdz: $10-2, t-i$

FRFN7, Wu. D.-I31.6:91; (1.91): 4008 I.Incoln ite : $8-10,2-4,6-8.98$, not in practlce:

Frev, Arthur farfleld $\left(b^{\circ} \$ 3\right)$ - III.6.11 $(1,12): \sin \mathbf{N}$. Clark sit.

FHCK, ANDERS (b'b8) \&-Swerl.2.'9n

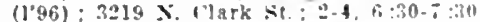
Frtek Walier Cairin (b-al)-11l.1b.0 $(100): 2751$ w. Jthl st. : 2-t. $6-4$

FIIIII

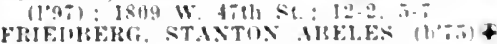
III 1.97: (109); t!67 Washinitum lirk

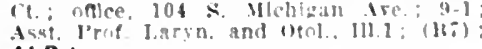
Al. R.

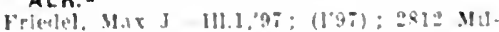
katuhio Ire. Iforman J. (1) (l丷12): s15 x. sarramento Hed: omen $235 \%$ firans ive : $1-2,-3 .-411$

VII)

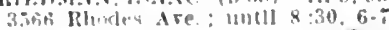

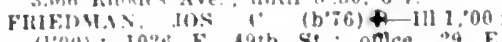
(1'01) : I02t) E. tath si : nalce, Alatllsill

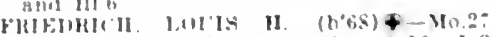

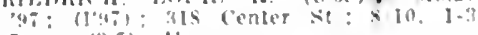

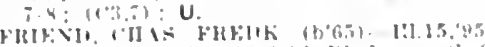

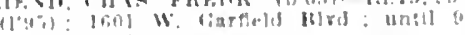
$12.130,9.4$

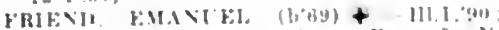

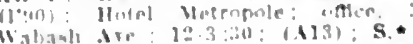

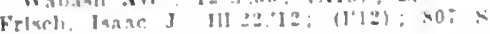

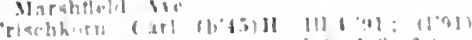

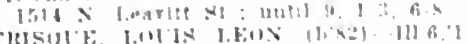

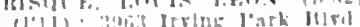

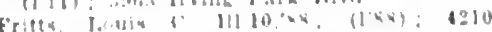

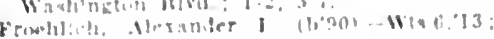

Tolim. 1 is d $1: 1$

$111 ;$

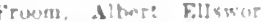

(1'si) : 5ing ith ire

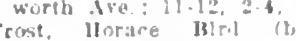

(1104): 5351 Vazmolla

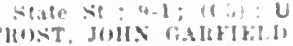

(10:) 6.002 s. Ilalsted st

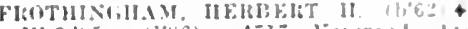

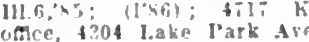

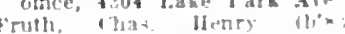

$(107): 2047$ \& Mllohan Ave

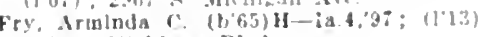

$122 \therefore$ Mlehigan Blrd.

Fry. John l.ewis $\left(b^{\circ} \times 2\right)-1116$, II: (1'12) $4 \times 05 \times$ hicdrle Are.

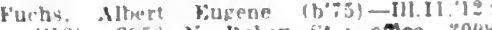

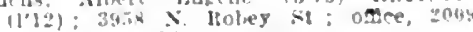
Irrlas lark [i]ri.

Fuchismann. Murrav Maury - I11.11.11: (l'll): 45n $\mathrm{X}$ Winchester Aro; ofle 2000 W. Jivision St.

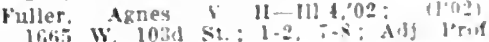
Ind., III. 1 : Pd.

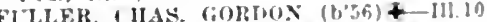

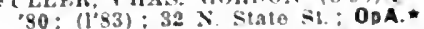

FlLLFI, WILIAM (b'st) 4 - III.L, $8:$

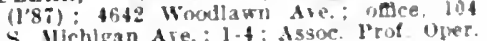
S. Michlgan Are: $1-4$ : Assoc.

FLLTOS I,LL H. - III.5,02: (1'02) $445 \%$ Ashland Are: until $9,3-5$.

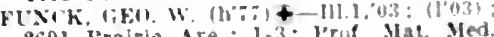
2601 Irairie Are. $1-3$; 1'ruf. Mat. Med. and Ther., I11.16;

Funk, Teil Fugene (b's:)-111 29,'13; (1't:i) 4900 Thomas St.

Funk, Wm, Hernard (bois)-111.23:0\% กt. 11:'10:

Funkhouser, Oscat Brunk (b'\$6)-111.11. unkhouser, Oscat Brunk (b's6)-111. 1.3, $7-9:$ Irot. Med. IMag. III.s.

l-3.

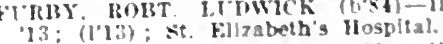

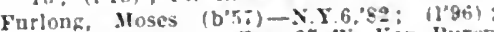
909 inch st once, 36 W. Fin Buren St: $:-6$

Furman, Roht. (b'63)-N.Y3.'89; (1'95): $530 \mathrm{r}$ Kenmore Ale.

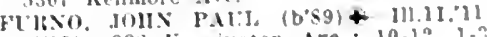
111): 335 Kensington Are.: 10-12, 1-3. hi-s: $\mathbf{s}$.

Furno, Marcis (1)62)-Ita.1,ss:

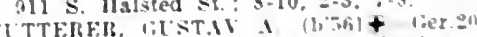
[TTERFI, 1, ST, Fulleron l'arkway

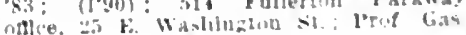

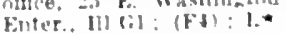

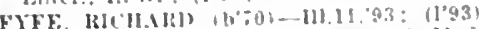

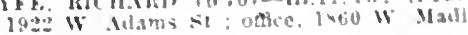
son si: $1.4, ;-$

lidarde Frel Whllams (bs:)-11]1.89 11.13i: I'reshyterian llospltal.

(iabel. Finma $11-111: 00: 1100):=55:$ I Clark St : 9-4

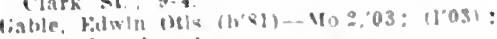

G1:- 1.ambley Ale (1'40)

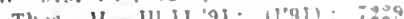
a Vintess sis.

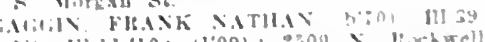

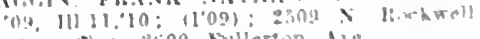

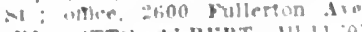

III. ITTU MIIF:RT-

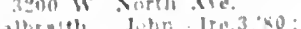

lersirie we

callatlier. IIram Y

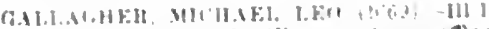

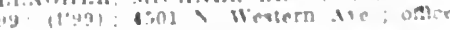
- 11 metert is

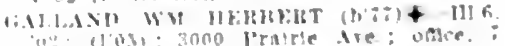
II Vad!an $\$$ : $12:$

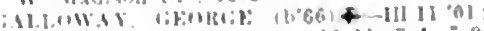

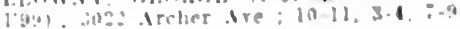


Thos. Cyrus - Ill.1,'I2; (1'12); unty Hospltal.

Benj. Phtllp-Ill.16,08; (1'08) 484 Farragut Are.

(AMBLE, WM. ELLIOTT (b'60) -IIl.1, "86; (1'92); 2802 Washlngton BIrd. offlce, 31 N.' State St. : 9-2; Assoc. F'rof. Clin. Ophth., Ill.11; (B7.8); OALR. *

G.IMMAGF, ARTIUR EDISUN (b'81) lil.8,06; (l'06) ; $5755 \mathrm{~N}$. Clark St.; oftlce. 6405 N. Clark St.; $3-5,7: 30-8: 30$; Junlor l'rof. CIln. Surg., 11l.8; $\mathrm{S}$

G.SNLVOORT, ANDREW (b'7t) $\nrightarrow$ - IH.I, 03: (1'03) ; $10559 \mathrm{~S}$. Wabash A wo, offlco. 11054 . Mlehigan Avo ; $12-2,6-8$

(iarabedlan, Garabed Arshag Zacar (b's8) Ill.1.13; (l'13) ; 1917 Wllsm Ave

(ARARI, WM. TAY (b'-5) $\$-111.10,03$ (1.03); 560 Arlington Il.; omce, $22 \mathbf{E}$. Washlugton St.; 3-5; Adj. Prof. Hyg. and Sanit. Sclence, I11.4; $\mathbf{R}$.

(:IRINNER, EDWIN J.\$-Spa.4.'8: (1'80) $1222 \mathrm{~N}$. State St.; oflce, $15 \dot{\mathrm{F}}$. Washing ton St. ; $10-1,2: 30-4: 30 ;$ (B8): OpA.

ciarliner, Frank II,-II-IIl.10,'s2; (I's3)

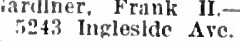

G.IRDNER, GEO. AIBERT (b'68)-Ill.11 '03; $\left(l^{\prime} 02\right) ; 1449$ E. 66th St.: offec, 1401 E. 66 th St.; $9-10,1-3,7-8 ; \dot{T}$.

GARDNER, IRWIN A. Ill.11,04; (1'04) 2321 S. State St. ; $10-12,2-4,6-8$

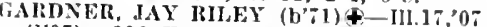
(l'07) ; 326 E. 51st st. ; $11: 30-3,6: 30-8$ GARDNER, STEIIA MAY (b'67) 99; (l'99); 5652 Race Are. : oftice, 31 N. State St. ; 1-3 : Asst. Prof. Micros. and Chem. Dlag., Ill.11; (F4).

GAREN, DANA II-Ill.6.92; (l'92); 6318 S. Green St, ofllce, 6300 S. Halsted St. ; GARRACIUA

Ill.11,01 ; (1'01) 628 SANCIS (b'73) क3035 Inrliana Arc.; also 31 Rd.; offce. $12-2 ;(\mathrm{B} 1,8)$

Garrlty, James (b'79)-Ill.1,'04; (1'06); (Oak Iark); offlee, $3959 \mathrm{~W}$. Madison St. ; $1-3,7-8$.

GARTIN, CHAS. NEWTON (b'90) P-IIl.8, '12: (l'12) ; 1568 N. Hoyne Ave.: office, 41 st St. and Ashland Ire.; 9-11, 1-2; also Fisher BIdg. 4-6.

Garry, Andrew Cosmas (b'78)-Ill.1,01; (l'01); 6000 Sherldan Rd.; offlce, 1002 Wilson Are. ; 3-7.

GARY. ISAIAFI CLARK (b'58) @-III.6, $89^{\circ}$ (1'89) ; 22d St. and Archer Ave; $12: 30-2$,

Gates, George Francls (b'86)-IIl.8,'13; (1'13); Columbus IIospltal.

GATES, PETER F.(-Ill.13,'03; (l'03) ; 3024 Irring Park Blrd.; 8-9, 1-3, 7-8.

Gates, Wm. S.-1ll.6,81; $\left(l^{\prime} 83\right) ; 4540 \mathrm{~N}$.

atewood,

Presbyterlan Hospltal.

GATEVOOD IFE CONTE (b'89)

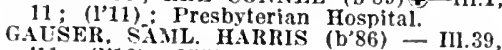
11; (1'12) ; 2559 W. Diviston St. ; offlee, 2634 W. North Are.; 2-4, $7-9$.

(iAY, ROPT. JAMES (b'77) $9-111.1,02$; (l'02) : $122 \mathrm{~S}$. Michlgan Ave. 1-3.

Gazda, Ios. A. (b'81)-111.22,'13; (1'13) ; 10721 S. La Salle St.

GEARIN, JOHN JOS. (b'85)-III.11.'08 ; (l'08) ; 4310 W. Jackson Blrd.; offlec 4003 W. Madison St.

GE.ARON, FRANK EMMETT (b'81) -IIl.11, '09; (1'09): 3158 N. Sawser Ave.; 10-12, $2: 30-4,6-7: 30$.

Gecr. Wm. Edw.-III.14,02; (l'02) ; 5620 N. Ashland Are.

Gehl. Wm. Henry (b’91)-Ill.8,'13; (l'13); $170 \mathrm{~W}$. North Are.

GEIIRMANN, ADOLPH (b'68)థ-IIl.6,'90 ; (1'90) ; 3815 Ellis Are. ; offce, 31 N. State St.; 9-5; Prof. Hyg. and Bact., IlI.11 (F4) ; LD.

GEICER, ARTHLR H. (b'78)@-Ill.11, 00 : (1'99) ; 554 Fullerton Parkway; offlee, 32 State St. $2 \cdot 30-5$; ALR, *

iviger, Louls Francis (b'70)-III.16,06 ; 5024 Broadway; offle, 209 S.

ieiderman, Fredk. H. (b'7t) H-Ill.10,00 ; (1'00); 760s Bosworth Ave.
Genlus, Arthur E. (b'68)H-Ill.4,92 ; (1'92) ; 4556 Woodlawn Are.; office, 23

Genlus, Richard M. (b'65) II-Ill,4,?2 $\left(1^{\prime} 92\right)$; 4804 Greenwood Ave.: offlee, $23 \%$ W. Ciartleld RIvd.; $9-4$; also 539 E. $341 \mathrm{~h}$

ENTIES, MARRY WFRNICKE (b'66) t Scot.5,'88; (1'92); 5131 Kenwood Ave. Genlry, 1 ivm. lane $\mathrm{Ct}$. enrge, Edgar J. (b'63) II-IIl.I0,'90, Ill.4, 05; (1'91); 4358 Lake Park Are,; offee, $110 \mathrm{~N}$. Wabash Are.: $9-1,2: 30-5$; Prof Ophth. and Otol., III.4,; OpA.*

Gerhard, Walter Bertram (b'83)-Ill.11,07 (l’07): 4047 Sherldan Rd.: offlee, 1203

Gerkins. James Jos. (b'80)-Ky.2,07; (苂; 1016 ircenleaf Are.

GERMAN, WM. II. (l'55)-Mlch.6,'83 (1'84) : 10918 Prospect Ave. ; 8-9, 12-1:30, $5-7: 30$.

GERMER, JAMES W. (h'72) \$-nl.6.'00 (l'99); 2535 Orchard st.; once, 2574 IIncoln Ave. ; 1-3, 6-8.

GERSTLFY, JESSE' ROBT. (b'86) †-Ill.1, 09 ; (l'09) ; $4235 \mathrm{~S}$. Mllchigan Are.; offlce, 29 E. Madison St. : $12-1$; Pd. $\star$

Gessing, James $i$. (b'68) $\mathbf{H}-I 11.14,97$ (I'97); 1618 Humboldt Blvd.; 8-9, 1-3, $6-7.30$

Gethner. Max Peter (b'84-Ill.11,'11: (1'11) 2235, Potomac Are.: $10-12,2-4,7-8: 30$. (l'85); 1146 Independence Blvd.; offlec, 59 E. Madison St.

Glalloretl, Vlncenzo (b'6i)-Ita.10,92 (1'04); 1010 W. Harrison St.

Gibbons, Mary D.-H-Ill.4,'88; (1'92) ; 3543 Walnut St. : 8-9, 1-3, 6-7.

GIBBS, JOHN PIIIIIP (b'62)-Ill.13,'05 (1'05) ; 2750 Fullerton Are.; untII 9, 1-2, 6-8.

GIBBS, SEWARD P. (b'6i) $9-I 11.14,95$ (l'95) ; 748 Fullerton Ave.; offlce, $108 \mathrm{~s}$. La Salle St.

Gibson, Harold Kenneth-Ill.6,'98; (l'98) ; 5235 Greenwood Are.; offlce, 31 N. State St. : $12-1: 30$

Gibson, John Y. (b'51)-D.C.1,79; not in practice ; 1210 Grand Ave.

GIER, MARK AILEN (b'77)-Ill.16,09: (l'09); 347 S. Homan Ave.; offlee, 4401 W. Harrison St. ; 9-10, 1-2, $6: 30-8$.

Gleraltowski, Chas. Peter (b'72)-IIl.17,'04 (l'05) ; 804 Mllwaukee Ave.; 1-2, 6-8; OALR.

GILL, JAMES CORNELIUS (b'65) $\uparrow-$ IIl.1, fice, 104 S. Michigan Ave.; $11-4 ;$ Assoc. Prof. Med., Ill. ; Assoc. Prof. Neur. and Psych., III.G1; (E4); Pd.

Gill, John G. -lill.1,'97; (1'97); 4123 Ellis Are. ; office, 32 N. Clárk St.; $9-1,2-4,6-8$. GILL, JOHN JOS. (b'72) $€$-III.6, 05 ; (I'05) 5 i08 Harper Ave. ; 3-4, 7-8; (D2); Ob.

GILL, PERCY WALKÉ (b'81) -III.17, 08; (l'08); Windsor-Clifton Hotel ; 12-2,

GILI,AM, ARTHUR C. (b'72)(3-Ill.1,'00'; (I'09) ; 1612 Milwaukee Ave.;

GIllies, Duncan 'Reld (b'68) - Ill.1,00 : (l'01) ; 6056 Mlchlgan Are.

Gillmore, Emma Wheat (b'67)-Mich.1,90 ; (l'98); 6517 Kimbark Ave.; oflice, 1230

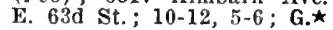

GILTMORE, ROB'T. TRACY (b'67) $\uparrow-111,6$, 92: (l'92); 6517 Kimbark Ave.; office, 1230 F. $63 d$ St.; also, 30 N. ilichigan Ave.; Asst. Clin. Prof. Gyn., Ill.6 ; (A11, F4) ; G

Gilman, John Ellis (b'41) H - Ill,4,71; State 'St.: 1:30-4:30; : offlce, $159 \mathrm{~N}$. Med., IlI.4.

GILMAN, WM. T. (b'61)-Ill.4,96; (l'96); 2300 Indiana Ave.; 8-10, 5:30-7:30; of fice, $15 \mathrm{~F}$. Washington $\mathrm{St}$. ; $1-2$

GILMER, THOMAS LEWIS (b'49) क-III.12, 'S5; (1'85) ; 3220 Lake Park Ave.; offlce, People's Gas Bldg.; 9-12, 4-5; $\mathrm{S}$.

GILMORE, WINFIELD S. (b'49) $\$$-Ind.2, '79, N.Y.10,'85; (1'98); 7214 Woodlawn Ave.; office, Ti05 South Chicago Ave.;
Gindele, Geo, Wm. (b'73)-Ill.11,10; (1'10) : 2735 W. $43 \mathrm{~d}$ St.
GINo, VINCENT (1,7i)-Ita.12,02; (1'03) ; 317 'N. Central l'ark Are.; offlce, $019 \mathrm{~S}$. IIalsted St. ; $9-12 ; \mathrm{ObG}^{\star}$ *

Ginsburg, Joshua-N.X.5, ;8 ; (1'88) ; 1022 S. Ashland Blrd. ; 12-2; offlee, $603 \mathrm{~W}$. 12 th St.; 8-10, 2-3.

Grard, Mary Augusta Brown (b'36)-111.9, '83; (1'83); 818 k. 51st St.; 10-5.

Glafke, Wn. IIarley (b'86)-111.6,'11; (1'11) : 1400 F. $53 d$ St. ; omce, 122 S. Mlchlgan Ave : $1: 30-5$.

GLASER, GEO. M.A-Ill.1,'92; (l'92); 3149 S. Morgan St.; untll 9, 12-2, 6-8.

Glassman, I.eon (b'85)-IIl.11,'13; (1'1:3) ; 572 W. 12tlı St.

Gleitsmann, Fmil (b'66) II-Ill.14,'90; (l'96) ; 847 Lill Ave. ; 8-10, 5-8

Genn, Edw. Andrew (b'84) - Ill.11,06: (106); 7 W. Madison St.

FRED L. (b'72) ๑-Ill.11,'96 $\left(l^{\prime} 96\right)$; 533 N. PIne Arc. :
48th Are. : $9-10,7: 30-8: 30$.

Gnadlnger, Emma Katherłne - Ill.15,'10 ; (l'10): 221 E. 44th St.; offlec, 64 E. Van Buren $\mathrm{St}$.

GOEBEL, GUSTAVUS ADOLPHUS $\left(b^{\prime} 63\right) \oplus$ -Ill.22,11; (1'12); 628

Goetsch, Gustaf AdoIf (b'70)-Ill.1,'98; (1'98); (Oak Park); offlce, 31 N. State St. : $4-6$.

GOETZ, FREDK. A. (b'53)-Ger.14,78; (l'90); 1640 N. Irving Ave.; ofllce, 1574 Milwakke Ave, ; 8-9, 1-2, 7-8.

GOETZINGER, CHAS. F.' (b'75) - - -Ill.11 05 ; (1'05); 3535 Armitage Ave. ; 8-9, 3-4, $7-8$.

GOING, ZENAS II. (b'48)-Ill.1,74; $\left(1^{\prime} 78\right)$; 4642 Indlana Are.

Golbeck, Carl Henry (b'89) - Ill.11,'13; (l'13); 55I Grant Pl.

GOLDBERG, JOS. BENJ. (b'75) $\oplus$-IIl.1, 02 ; (1'02) ; 3200 Douglas Blvd.; office, $739 \mathrm{~W}$. 12th St. ; 10-12, 6-8.

Golden, Carrle-E-Hi.8,'89; (1'89) ; 3000 Armour Ave.; 9-11, 1-4.

GOILDEN, ISAAC JOHN KING $\left(b^{\prime} / 2\right) \oplus \rightarrow 0$; (l'97); 2238 W. North Ave.; $3-7 ; 5 . \star$

GOLDEN, JOHN FERDINAND $\left(b^{\prime} 80\right)(-$ Ill.6,03; (I'03) : Mercy Fospltal ; office 104 'S. Irichlgan' Are.; 2-5; S.

Golden, Sol S. (h'83)-Ill.22,'13; (l'13) : 1233 N. Oakley Blvd.

GOLDENBURG, MICHAEL $\left(b^{\prime} ; 9\right) \oplus-111.23$, '05, Ill.11,'08; (1'05); 4641 Vincennes Prof.; Ophth., IIl.16; (B8); OALR. *

GOLDSMITH, ALEXANDER AARON (b'78) (4)-Ill.6'01; (l'01); 5242 Indiana Ave. offlce, 29 E. Madison St. ; 2-4; Prof. Dls.

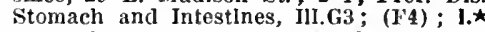
GOLDSPOHN, ALBERT (b'51) -Ill.1,78; (l'83); 2118 Cleveland Ave.; offlce, 2120 Cleveland Ave.; 2-4; Prof. Gyn., Ill.G3; $(A 1,11) ; S . \star *$

GOLDSTINE, MARK TWAIN (b'77) offlee, 32 N. State St. ; I-2; (A11).

GolEMBI0WSKI, JULIAN J. (b'77)-Ill.11, 03: (1'03); 1165 Milwaukee Ave.; 1-3,

Goltz, Julius A. (b'52) E-Ill.8,'87 ; (I'87) ; 11324 Michigan Ave.; $8-10,12-2,6-8$.

GOOD, ROBT. HOSEA (b'73) -11l.1,02; (1'02); (River Forest) ; office, 7 W. Madison St. $; 9-12: 30 ;$ Prof. Rhin.,
otol., Ili. $22 ;(\mathbf{B} 1,7,8) ;$ OALR.

COODKIND IIAURICE LOU1S ${ }^{-}$- X.1, 89 . (1'90); 2900 Indiana Ave. ; 5-6; office, 31 N. Státe St.; $1: 30-3: 30$; Prof.'Med. and Clln. Med., Ill.11; (E4).

Goodman, Jacob (b'88)-Ill.6,'12; (l'12); 3137 Douglas Blrd.

Goodner, Geo. W-Ill.6,69; (1'\% $)$; not in practice; 2606 Wallace St.

GOODSNITH, HEBER M.-III.11,'S7 ; (1'87) ; 4649 Beacon St.; offlce, 32 N. State St. $10-12$

GOODSMTH. WM. P. (b'59)(4-IIl.1,'83; (l'84); 4526 Beacon St. (b'69)-III.6,03 (I'03); 934 E. 75 th St. ; offlee, 7466 S
(I) Chicago Ave.; $10-12,7-8$.

GOODWIN, HENRY FRENCH, (b'63)-I1l.11, 00 ; (I'98); 6021 Woodlawn Ave.; office, $108^{\prime}$ N. State St. ; $11: 30-12: 30$. 


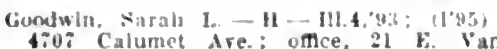
Huren sit.: : 9."

Goone, $11 \mathrm{~m}$. N. (b'85) - 111.11,12; (1'13) 1900 W. DIrislon st, S-10, 12-2, i-9:

ObG.

Arthur Horace (b'63) II-III.4.8: $(1 ' 88)$ : $\$ 58$ X. La Salle St. $8-9,1-3,7-8$

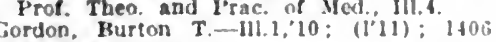
N. Harniln Are.

GORDON, LOUTS ELFVEH (b'76) $\theta-111.1$ 97: (1'97): 1493 8. Mlllard Are: nflle sted St, : 10.12, 5.:; ALR.

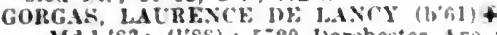
-Md.1,83: (1'85); 3720 lyorchester Are. oflce, E. 5ith st. and Jake I'ark Wo. once, E. Sith st. atid lake ratk Nie.

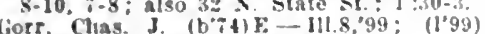
Gort, Clas. J. (b"it)

Gorr. Chas. Wm. (b'is)-I11.1,03); (1'03) 1256 Eariy Are, offce, 605 Belmont Are

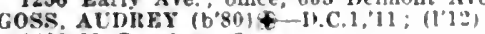
$1423 \mathrm{~N}$. Dearborn $\mathrm{St}$.

Gosa, Geo. W. (b'70)-M1ch.9,'99; rellrul 1027 Buena Are.

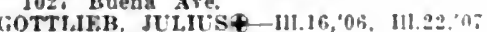
(lot): 9154 Commerclal Are.; $8-10,1-3$ $6-8$

Gould, Casslus W.-N.).6,:2: (㰻: 1361 X

La Salle St.
GOULD, HAROLD vOGT (b'89)-I11.11,'12 (1'12): 5301 Broadway; 1-3. ;-9.

could Henrletta-III.11,01: (101); 1615 W Jackson Blrd. ; oftee, 31 ;. State si.; $9-5$ GOWEX. GUY AUBREY (b',5) क I11.6,96 (I'96): $28 \% 0$ Pralrle Are.; oftice, $502 \mathrm{~V}$ 26th St: $12-2,7-9$; (1)2)

Gras, Vena Cordle-II-III.4.04; (1'04) 1340 Siewport Are. : 2-4, 7-5

GRABLE, ELMER EDGAIt (b'61) -111.14 09 ; (1'10); 2348 N. Western Ave. : untli 11, 1-4, after 6

GRABOW, PAUL F. (b'69,-111.11,02: (1'02): 2349 Seminary Ave: once, 2405 7 . Haisted $5 t$. $2-3, ;-8$.

RALE, IAARRY SEAHIES (b'83) Ill.1,08: (1'08): 1337 Fargo Are : ofthce. III.Gi; (B1.8, Fi): Oo.

GHADY, WM. PO-Ill.1,02; (1'02) ; 645 Cottage Grove Are.: 9-11, \$-6, $7: 30-9$.

GRAHAM, ARCHIE' J. $\left(\mathrm{b}^{\circ}, 03\right)-111,11,02$; (1.02): $6306 \mathrm{~S}$. Malsted St. : 11-12, 1-3.

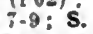

GRAHAM, DAVID WILSON (b'43) X.Y.10,72; (1'7i); 700 Graceland Are 8-9, 6-: : office, is E. Washlngton s:. 12-1; Clin. I'rof. Surg., III.1; (A13, Fl $\mathrm{S}$.

Grabam, Earl Bruce-D.C.1,0J; (1'0J) : 5200 W. Madlson St.

GRAIHAM, FVARTS AMBROSE (b'83) \&offce, 15 F. Washlngton st. $\left(\mathfrak{r}^{* 0+t)}\right.$ : S.

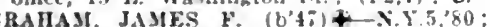
(1.81): 822 Oakdale Are.: uneill 10 , afier 3 . HAIIA JOHV ALFllE $\left(\mathrm{b}^{\circ} 80\right) \uparrow-111.1$. 02: (1.02); 536 Deming Pl.: ottce, $32 \mathrm{X}$. Stale St.: $3-5$; Prof. Path. and Itact. III. Fil: $\mathbf{S}$.

Grabmann, Emest $\boldsymbol{F}\left(b^{\prime}: 1\right)-[11.10,01$ (1"01); 6343 s. Halsted st.

Ciralczunas, Andrius I. $(1,70)-111.1 \%, 0$, (1.01): $3310 \mathrm{~s}$. Halsted st.; $;-10,1-2$, b. 10 .

lirannt, Carl Theolur (boid) - Ia $1.4,3$ $\left(l^{\circ}: 3:\right) ; 31$ x. Silate $81 .: 9-4$.

(iIsANT, JOS. F.-Ky.2.90; (104); (28) Stanley Sit. Viranutun): onlee, zy E. Madison Sie : $y-3$

CißANT, MARCALET STOL':II $(6 \% 2)+$

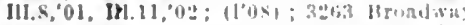

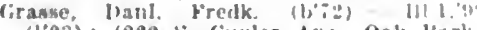
$(1093)$; 1222 s. Cuyler Ive, Oak l'ark once, sos W: Mrillwon st. $11.3,7.3$ (13): U.

Graves, firace A-E- $-111.80^{\circ} 01 ;\left(1^{\circ} 01\right) ; 1$ i 40 lirake Are.

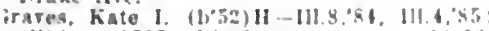
(1'84); 500 Hackstome Are: 10-12. 6.7:30

IHAVE, NATHAXIEI, A-111.8, $40 ;\left(1^{3}, 1\right)$; Ciraves, lolllp abernethy (1,;0) - lil $23,01$. Ill.11,0!; (1004): ("30 S. Kentlworth iro. Ill.11, "0:; (1"04); (\$30 S kentworth Iro.,

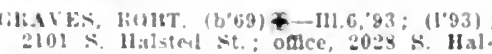
sled Sil. : $10-12, \vec{i}-8$.

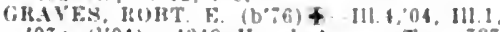
07: (l004): 4:49 llazel Ire.; uflce, 737 Sherldan lid.: $10.12,3$ Pd

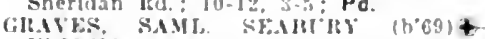

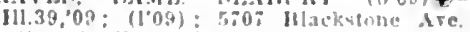
nalce, 25 k. Waslington si: $9.1 \%$ i-f Cray Addle F. F (1,50) ll li1.15,93

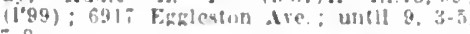

GHAY, AlLEX IV $\left.\left(b^{*} 39\right) \mp-I 1\right] b_{0}, 6.4$ $(10 \%) ; 0213$ Wavalagton Ibrd: 10.12

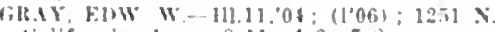
Alalformit Ire; 8-11, 4-6, i-8.

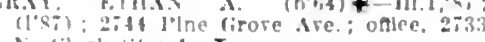

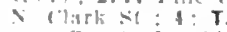

Cray ripant j (b'j4) 0.294 (1.95): (1) 15 :

$691:$ Ficpleston Are. unt1l $3.5=-4$

Gill, IHIT.IP M. $\left(b^{3} 69\right) \mp-111.1,93$ (I'\$3); 43.it $x$. Rothey St. $8-9,2-3,8-9$ iray. Wm. Karg $110 \%$

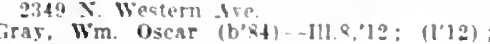
this Grand Are.

CRATBEAI, JAMES $(1,7,3)+111.11,07$ (I00\%): $: 101$ Xormal Ase. offee. 500 w $691 \mathrm{~h}$ st $=9.10,3=5$, i.s.

Grayston, lesse Trott (b.89) - 111.11,13 (1'13): $02 \mathrm{~S}$. Ashland 131.d.

CiRFAVES, JOS A-III.11,04: (1.04); ค3! Rush St.: nffce, $516 \div$ llearborn $\mathrm{St}$ $10-12.3-6,7-9$

Creen. Abraham (hester (boti) Jll. in (1'10) : 2119 w. Sorih Are ance Itid $\rightarrow$ Boner si.: 9-11,3-4.6-8

FRFFN, FREDK R. (b-in) \&-III.6.99 $\left(l^{\circ} 98\right)$ : not in practlee: 19 (halmere $P$ l. anice. 3.35 . Dearbnrn $\mathrm{st}$.

GREES, GEO. WIILARD (bof) F-MIrh. 92: (1.92): 4.537 N. Whaheater Are.

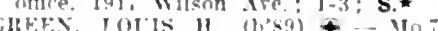

(lin): ilts Ashlanal Irt

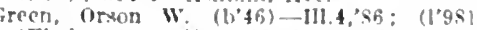

(Elmhurst); oflce, 39 s. I.a sille St

GRFES, TIOMAS STEHIIEX (BRE) III

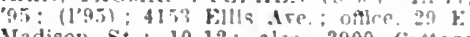
Iradisnn St. : $10-12$; also. 3900 rottaci

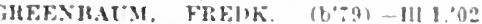
(1'02): 63\% s. sangamon st.; oflee.

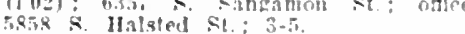

Greenbanm, Gen. Jien. (h.8.s)-111.6.09

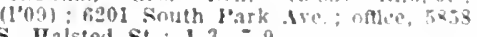
S Malsted si. ; $1-3, \div-9$

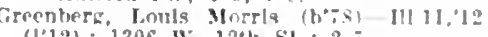
$(1212): 1306$ W 12011 s1 : $: 20$

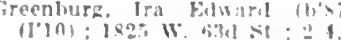

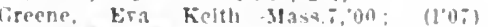

60t? Fast Fnd Ire

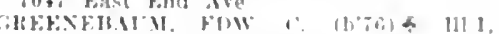
P: (197):3505 Indlana Are.

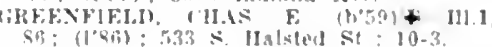

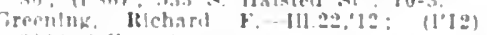

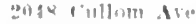

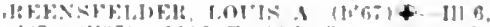

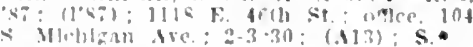

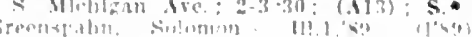

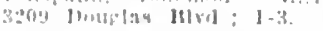

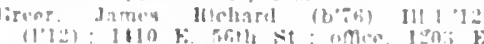

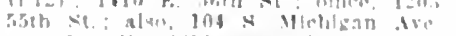

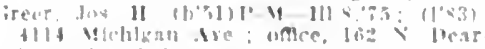

lirira si : is of

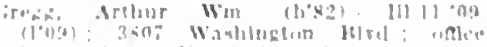

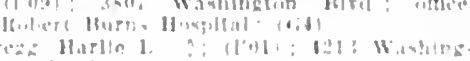
111,il!

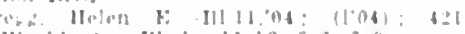

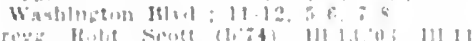

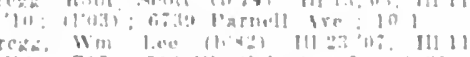

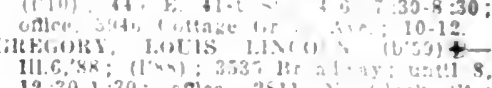

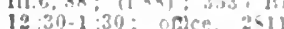

4.6.

Gresens, llemnan

lie. $1231=$

firltix, ruing Ju:

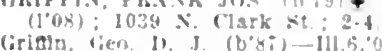

2020 Indians ire. Calumet Ave : 8.9, 2-1

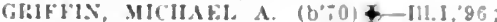

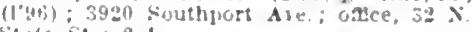
GIHFITH, (HARIES HYPON (b'so)111.17,10; $(1,10): 3763$ southnort sie. $\vec{i}-2,3-5 ; i-9$

GRIFITHS, KVAN IISARY MATGOMERY $\left(b^{\circ} 2(1)+11111.09:(1 \circ 09): 4500 \mathrm{~W}\right.$. IIas. $2.4,8-9 ; 5$.

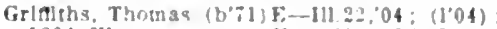

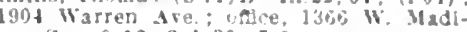
Son St. : 9-12, $2-4: 30,7 \cdot 9$.

RIM LLYSSES J. (b'65) ₹-111.1.91 $(1 ' 91) ; 133$ N. Lonckwood Are. : once, 31
N. State St. ; 10-1; I'rof. (otol., lthln. abd

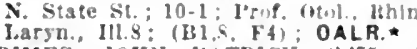

GRIMES, JOHX INTRICK $(6 \% 5)-111.11$,

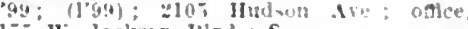

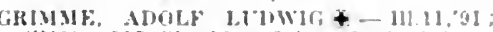
(I'9!): 807 sherldan IRd : 11-12, 3-4.

Grimmer, Artbur HIll (b'it)-Ill.406: $l^{\circ} 0(i) ; 4 t 2$ E. 3tth St.; once, $5 \mathrm{~s}$. Wabash Are : I1-3: Adj l'rof M.11. Med. III

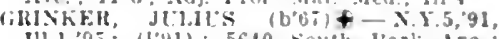
Ill.1,95; (I'91); 5640 south I'ark Ire. offce, 32 . State st. : 10-1; Asst. l'rot. clin. Nent Ill.6; Jrof Vers. and Ment. (iroenendal. John 11.-I'.-M - I11.5,04: (1'04): 321 x. Arteaian ise; once, 2317 Walnut St.

Gronlund, Iyron C. s. (bs9)-111 t.'12:

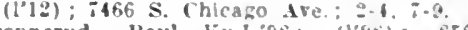

Gronnerud, I'aul-Ky. 1,95; (1'93): $\$ 56$ Sherldan Rd. oatce, 31 N. State St.

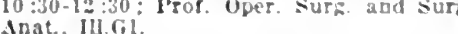

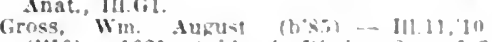
(1'10); 1021 Ashland 1:1rid: 5.?. 1.3 i-s.
Crosser. Edw. Wm, (b":3) H $111.10,01.111 .1$ 02 . I11.4,05; (1001); 1056 W. Chicabo

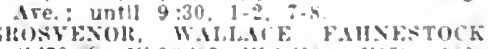
$\left.\left(b^{6} 70\right)+-111.10,45,1111.00\right)(1095): 10.3$

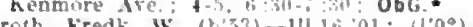
232s Warren ire; once, 59 t. Madison

(ift)TIt, wy. F- - 111 l6,04: (1.04): 3345

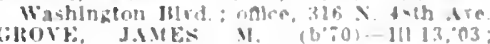
(1.03); 14t Foster we: $1: 30-20$ i-8: Op.

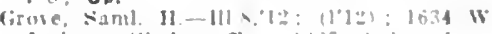
Jackson libll:

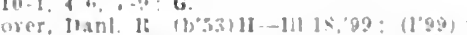

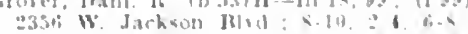
cirulitue, timll 11 b anto Imulana lie oftco, $130 x$ siste

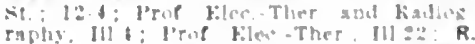

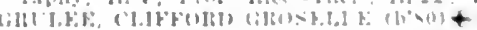

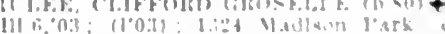

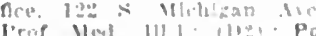

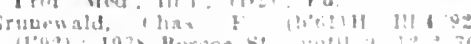

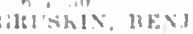

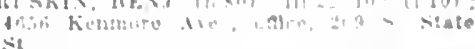

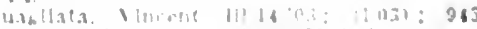

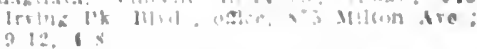

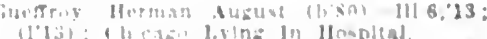

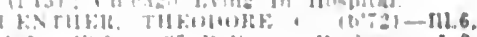

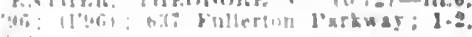




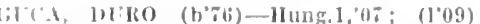
I7.3. S. Halsted St, $9-1], 3-5,7-8$.

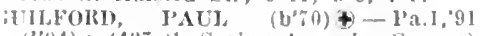

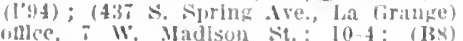
OALR. *

Gullatume, Vrank-II - 111.10,90; (1'90) $4.54 \mathrm{~W} .27 \mathrm{th}$ st. $3-30$, 1 .

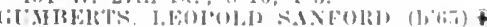

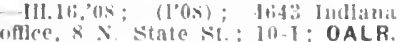

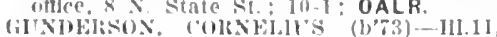
ot: (1'04); 2 soo lifersey Iiral. ; untl

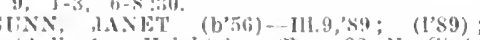
(Arlíngton Ileights); onlee, $32 \mathrm{~N}$. State St.; 11-1.

Ciunn, Nell Mackay (b'83)-Ill.6,'11; (I'11) 7208 Ellls Are.: ofllee, 10900 Michiran Are.; 10-11, 1-2, $6: 30-8$

liunn, Wm. Parker-111.11;07; (1'07); 6459 Cottage Grove Ave.

iunther. Theodore John (b'87)-Jll.1,'11; (1'11); St. Luke's Ilospltal.

(inney, Belle R.-II-111.15,'97; (1'97) ; 6854 Wentwortl twe. $8-10,4-7$

Gustlne, Franklin I.-La.1,'s3; not in praetlce; 511 Roscoe St

Haas, Archibald-11l.8,'82, Ill.I1,86; (1'82) 2003 x. Western Are. 9-1, 4-6

HAAS, RAOUI, R. (h'79)-I11.10,03, Ill.6, 06 ; (103) : 1144 Independence $131 \mathrm{rd}$. offlce, 535 S. HIalsted St. ; $10-12,2-4,7-9$. Ilabenicht, John ( $\left.b^{\prime} 40\right)$-Aus.5,'64; (1'90); HDS S. Ridgeway Ave :8-10, 2-4, 7-8, IADE, FRED

Hadley, Horace A. (b'65) P-M-MIll.5, 89 ; (1'89): $2823 \mathrm{~W}$. Jacksou Blyd.; untll : $12: 30-2$, after 6.

ILAEJERLIN, JOIIN BENJ. (b'T̈)Ð-HI.6, 00; (1'00) ; 6553 Perry Ave.; offlee, 5 E. Garileld Blvd.; 1-3; $\mathbf{S}$

HAEFFNER, ALIFF'T W. - Ill.11,06 ; $\left(l^{\circ} 06\right) ; 4022$ W. $22 d$

HAERTIER, AUGUSTUS G. (b'55)-III.6, 83; (l'S3); 4919 Sherldan Rd.; offec, W. Jladlson St.; $1-3 ; \mathbf{O b}$

HAEUSLEIR, ANNA' M.-Ill.11, 03 ; (l'03) ; $3510 \mathrm{~W}$. ('hicago Ave.; until 10, 1-2, 7-9. Hagan, James H. (b'63)-1a.6,90; (1'97); 5357 N. Clark St.

Hagedorn, Peter-H-Ill.4,'91; (1'91) ; 2343 Wentworth Are: 1-3, 6-8

HAGENS, GARRETT J. (l,69)‡-III.6,'91 (1'93) ; 6517 Stewart Are,; office, $7207 \mathrm{~S}$ IInlsted St.

IIAGER, DANL. S. (b't33)-I11.8,98, 111.1. 00 ; $(198) ; 3653 \mathrm{~N}$. Crawford Ave. ; office, 7 W. Madison St.; $12-2,7-8$

Hager, Saml. Nead $\left(b^{\prime} 63\right)-0.1,85 ;(1 ' 98)$; 40 3 Kenmore Are.; office, 29 E. Madlson St. : : :30-1; Asst. Prof, Ophth., Ill.G1 OpA.*

IIAGEY, JAARIY H.-Ill.6,'98; (1'99) ; 7033 Yale Ave.: offce, $4191 \mathrm{~S}$, Halsted St. also, 800 w. 78 th $: 10-12,1-3$.

Iralght, Wm. D. (b'66)-I11.5, 10 ;

1551 Milwauke Are.

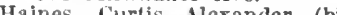
(I'10); 3594 ILilwaukee Are. ; 1-3, 7-9

IIalnes, Frances Edith (b'82) - Neb.5,13, (): Mary Thompson Hospital; Pd.

H.INES, WALTER STANLEY $†-$ III.6,73; (l'82); 1401 W. Adams St.; office, Rush Medical College; I'rof. Chem. and Ther., ill.1.

Hair, Charles H. (b'70)-Ill.I6,'10; (l'10); Ás. Crawford Ave.;

AISELDEN, HARRY' J. (b'70)—-IH.11. 93; (1.93); 819 Diversey Blrd.; office, 741 Dlversey Blyd.

HAKANSON, ALFRED (b'66)†-Neb.5,90; (1'90) ; 1442 Bryn Mawr Ave.; 32 N. State St.; $4-6 ; 0 A L R . \star$

Halbert, Ilomer $V$, $\left(b^{\prime} 58\right) \mathrm{H}-111.4,87$ (1'Si); 4719 Kenwood Are.; offlce, 22 E Waslington St.: 9-1; Prof. Theo. and Prac. of Med., Hill.4.

HALEY, RICILARD $€-11.1,90 ;\left(1^{\prime} 90\right) ; 2456$ IV. 3stlı St.

IIaley, Wm. F.-H-Ml.10,'89; (I'90); 2857 Wileox Ave, ; 8-9, 4:30-i; office $140 \mathrm{~N}$

HAIJI, ALFRED IARVIN (b'63)Ð-IIl.6, shail (lielits Annex; $9: 30-12: 30$; Prof.

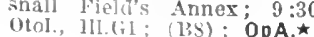

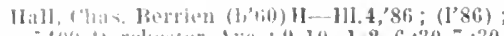

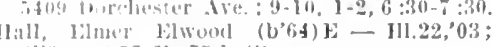

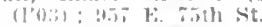

II.ILA, filo. C. + Ill.8,'88; $\left(1^{\prime} 88\right) ; 3249 \mathrm{~s}$ Wialbish Are; oftlee, $3102 \mathrm{~S}$. State st.

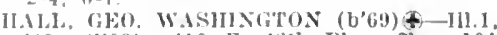
43: (193): 416 E. 4 tith Plo : ontce, 104

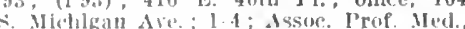
III.1 : (E.t)

11:all. James M. (eol.) (1,85)-Tenn.7,13;

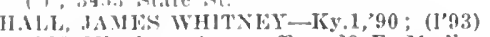
3512 Mienlgan Ave; offce, 29 E. Madlson Sit.: 9-11.

HALL, JWASE T. (b'48)-111.4,91: (l'91): $64: 34$ Kimbark Ave, offlce, 32 x. Slate St. ; $3-4$.

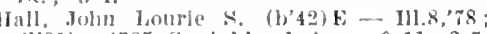
(1'8I): 4735 S. Asliland Ave.; 0-11, 2-5,

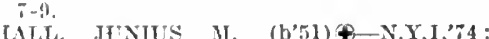
$(177)$; 31 Waslulugton $11 . ; 8-9: 30,2: 30-4$,

Hall, Maule (b's4)-Ill.1,12; $\left(l^{\prime} 12\right) ; 1423$ s. Mlchigan Ave.; offlee, St. Luke's Hospilal; Anes. $\star$

Irall, Herritt Walter (b'84)-In.22,'10 ; (l'10): 5759 Broadway.

Iall, Win. Fo-nll.1,'78: (1'79); 618 Groveland Park; untll $8: 30,11-12,4-5$

IILLL, WINFIELD SCOTT $\left(b^{\prime} 61\right) \oplus-I l l .6$, 'ss: (Berwyn) ; office, 2431 Dearborn St, 9.4: Prop. Physiol., Ill.f.

IIAIOWAY, ISAAC IIOWF (1,75) 7 I11.11,'11: (1'12); $165 \mathrm{~S}$ W. Lake St. ; unt11 $9,2-4,6-8$.

HALPERIN, GEO. (h'81)—-H1.1,'05; (1'05) 3200 Douglas Blvd.; $1: 30-3,6: 30-8 ; 1 . \star$

IIALSTEAD, ALBERT EDWARD $\left(b^{\prime} 68\right) \oplus$ Ill.6,'90; (1'91); 5528 Woodlawn Are. office, $31 \mathrm{x}$. State St.; 2-4; Clin. Prop. office, 31.5 . State St.; $2-4 ;$ Clin. Pro

HALORSON, HERMAN JOHN (b'Ti) Ill.22,'12; (1'12); 4655 valden St.; office, 1048 Wilson Are. ; 2-5:30.

IAMIPYTRGER, WALTER WILE (b'81)↔fice, $104 \mathrm{~S}$. Michigan Are.; $3-4: 30 ;$ (F2 4) ; $1 . \star$

IHAMIL, FDWIN-III.1,88: (1'88) : 2901 Warren Ave.: 12-2, 6-7:30; (F4)

ILAMILI, RALPH C. (b'76)-IIl.1,02 (I’03); (Winnetka); offce, 15 E. Wash Ington St.; $1: 30-3: 30 ;(\mathrm{Et}, \mathrm{F4}) ; \mathrm{NP}, \star$. not in practlce; $800 \mathrm{~S}$. Malsted St. ; ( $\mathrm{F}^{2}$ 4).

IIamilton. Edwin S. (h'90)-Ill.1,'13; (l'13) Cook County Hospital.

IHAMITTON, JAMES M. (b'68)†-III.1,05. (1:55); 1452 Addison Ave.; offce, 2572 Lineoln Ave.; until 9, 12-3, 6-8.

Haunilton, Robt. C. (b'47) P-M-0.10,'82 (1'sT): 69,?27 $s$. Ashland dre.

IAMILTON, ROBT. I. C. (b'65) $€-\mathrm{ml} .5,93$ (1'96) ; 723 Relmont Ave.; office, 1004 Sedpwick St.: 8-10, 6-8: LR

Hamlln, Wibur Grafton (b'70)-Ml.16,06 (1?06) : 839 Wilson Are.: $10-12$, I-5.

HAMMETT, ALBERT C. $\left(b^{\prime} 71\right) \notin$ - Jich.1, $97 ;\left(1{ }^{\prime} 97\right) ; 4113 \mathrm{~N}$. Kedvale Ave.; office, 4200 Irving Park Blvd.; until 10, 2-4, $7-8$, Hammond, Francis Peery (b'79)-Ill, 6 , 13 (1'13): Cook County Hospital.

HAMNOND, HERBERT R. (b'69)‡-Ill.1, 94: $\left(1^{9} 95\right)$ : 1552 W. 12 th St: $3-5,7-8$ HAMIOXN, JABEZ DEAN (b'60) \&-III.1 '85: (1'84); 77 E. Congress St.; 9-11:30 HAMMONI, JAMES LLOYD (b'71)-Ill.11 99 ; (1'98); (Wilmette); office, $29 \mathrm{E}$ Madison St.; $9-12,2-5$.

HAMIOND, WALTER CHAS. (b'88)

Ill.11,'11; (1'11); 737 Sheridan Rd.

Hanchett, Reuben C. (b'62)-N.Y.15,'84; (1'12) ; $4350 \mathrm{~W}$. Madison St.; office, $29 \mathrm{E}$ Madison St. ; 2 -4.

Hanenck, Tames Monroe (b’77)-Ill.22,'10 ; $\left(1^{\prime} 10\right) ; 4759 \mathrm{~W}$. North Ave.

Hancock, Jos. Lane (b'(i4) - Mll.6,'88; (1'88); 5454 University Ave.; 3-5. IV. 12th, Lou1s-Ill.6,07; (1'07); 1159 Handlin, Danl. Wm.-Ill.S,'12 ; (l'13) ; 14 Bishop $\mathrm{Ct}$.
IIANDSHAW, ANNA MORGAN - III.9,93 $\left(1^{\prime}, 93\right) ; 30$ s. Ked\%le Ave.; offec, $29 \mathrm{~F}$ Madison st.; 11-12.

II.ANELIN, WM. RENJ. (b'80)\$-I11,11,06 (1'06) ; 1237 Johnson st.; offtee, $32 \mathrm{~N}$.

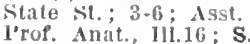

Ilanford, Chas. Worcester-C.Y.5,91; (1'91): 3602 latke l'ark Ave.; oflee, 68 W. WashIngton st.

Ilanks, Mary Elizibeth (b'62) II-Mass.5,97; (l’98); 27 Bellevue Pl. ; office, 22 Is. WashIngton st. ; $11: 30-2$; Adj. Prof. Med. Gyn., 111.4; G

lanmore, Fredk. C. (b'83)-Ill.8,06; (1'n6) 659 W. 31st St. ; unt11 $9: 30,12-2,6-8$.

Ianselı, Lua Grace Showalter - III.8,09: $\left(l^{\prime} 09\right) ; 15 \mathrm{k}$. Washlngton St.

Hinlsen, Frank E. (b'84)-I11.8,06; $\left(1^{\prime} 06\right)$ 4441 Mllwaukee Ave; office, 4 \%́l4 MIIwaukee Are. ; 9-12

IIANSEN, GEO HENRY (b'63)€-III.1,96 (1'96); 2501 Smalley Ct.; office, 803 Milwaukee Ave.; 1-3, 7-9; ALR.ネ

Iansen, Iohn Harrey (b'87) - MI.11,'13 (1'13); Englewood Hospital.

HANSEN, OSCAR L. (b'70) - Ill.1,97; (1'98): Member State Med. Soc. of Wis.: 4742 Rernard St. ; offfee, 3400 Lawrence Ave. : $1-4,7-8$.

HANSIIUS, JOHN WM.-II.I1,'01; (1'01) 2338 N. Kedzle Blvd.; 5-6; offce, 2294 Milwaukee Ave. ; 1-2, 6-8.

ILANSON, HALVOR C. (b'81) \&-Ill.1, 03 ; Washing $1-3,7-8 ; 0$; '13; ()$^{2}: 2013$ Walnut St.

Ilardle, Robt. (b'78)-IIl.1,01; (l'02) ; 1928 S. Springfield Ave.; offce, 3638 Ogden Ave. ; $1-3,7: 30-8: 30$

HARDIE, THOS. MELVILLE (b'62) Ont.1,88; $(1 ' 90) ; 4947$ Lake Park Ave. 7); ALR. $\star$. Washington St.; 9-12; (B2,

Hardin, Roy 43d St.

IIARDON, ROBT. WALLACE $\oplus$-Mass. 1,93 (1'93); 5406 S. Michigan Ave.; offce, 31 N. State St.; 3-5; Prof. Surg., I1l.G3; (A12); S.

HARDT, HARRY G. (b'76)€-MI.1, 00 ; (l'00); 730i Emerald Ave.

HARGER, JOHN ROSS (b'76)థ-Ml.1,06 $\left(l^{\prime} 06\right)$; 3918 W. Monroe St. : offec, 32 N. State 'st.; 8-9, 12-1, 7-8;

Hargis, Edw. L.-Tenn.5, 06 ; ( ) ; 5125 Kimbark $A$ re.

HARGREAVES, OLIVER C. - Ill.6,04 $\left(1^{\prime} 04\right)$; 4304 ' Lake Park Ave.; until 9, $1-3, i-8$.

Harkness, Carleton A. (b'81) H-Ill.10, 04 ; (1'04); (IIIghland Park); offce, 29 E. Vadison St.; $9-1,3: 30-5 ;$ Adj. Prop. Physiol., Ill.4; OALR.ૌ

Harlan, Lee Henry-III.17,'10; $\left(1{ }^{\prime} 10\right) ; 2840$ S. State St.; 10-12, 2-4, 6-9.

IARMISON, FRANK B. (b'70)థ-II.I, 96 $\left(10^{\prime} 9\right)$; 63 E. 36 th Pl.; office, 202 E. 35 th St. ; 2-4, 7-8.

H.ARMION, HENRY (b'63) $\oplus-\mathrm{Ill}$.10,'89; (1'89) ; 825 Milwaukee Ave.; I-2, $7-8$.

IIarms, Franz Ifeinrich $\left(b^{*} 75\right)-111,1,10$. (1'10); $4800 \mathrm{~N}$. Western Ave.; 6-8.

HARNISCY, F. CURT $\left(b^{\prime} 60\right) \oplus-$ Ger.14,'90; (l'91) 1850 Eddy. St.; office, 209 S. State St. ; $10-12,2-3 ; 0$ p. $\star$

Harpel, Wm. Franklin (b'56) H-Ill.4,05; $(1,05) ; 4557$ Indiana Ave.; until 8, 6:30$8: 30$; Prof. Physiol., Hist. and Embry., Ill.4; $T$.

HARPER, JOHN ERASMIUS $\left(b^{\prime} 51\right) \oplus-$ Y.5,78; (1'82) : 5459 East End Blyd. offce, 159 N. State St.; 9-12, 2-5; Emer. Prof. Ophth. and Clin. Ophth., Ill.11; (B1); $0 \mathrm{p}$.

HARPOLE, WINFIELD SCOTT (b'65)-Ill.6, 25 E. Washington St.: 11-1.

HARRIGAN, CORNELIU'S PRENTISS (b'63) $\rightarrow$ N.Y.10,85; (1'93); 2316 W. 12th St.; $10-12,7-9$.

Harrington, Raymond Regan (b'90)-Ill.6, '12: (1'12); 6337 Harvard Ave.; oflice, 6559 Cottage Grove Ave.

Harris, Andrew Fuller (b'56) H-Ml.4,'84; (1'84); 6106 Princeton Ave.; until 9, 1-2, 
HAKRIS, FIEELK, GILLETTK (10:-4) Ill.11,99: (1'93); 6il: Wumllnun Are.

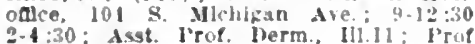
Derno., III.G2: $\left(C^{2}, i\right) ; 0$.

IIarrls, James $X$. Ind.18,0-; (l'OS)

3ith Se.

HAHMS, LouIs J. $+-11111,06$; (l'0ti) 1539 ; Oakley Are: $10-12,3-5,:-9$.

larris, Jyudun benny (b'ss)-III.11.1? (l'12): Unlverslly" llowpltal.

HARIS. MAI.(1)M LA SALLE (b"62) † III.1,82; (1'st); l208 licarborl dre otice, 25 F. Washlngton st. : $12: 30-3: 3 n$ Sec, and I'rot. Surg., Ill. (il) $(\mathbf{A} 5,6,12,1:$ C3, : F4): S.

Harris, Norman Macleod (b'i0)-Ont. J,"94 not in practlce: Inlverslty of Chicaño: Asst. Prot. Bact. I1].I; $\left(F^{\prime 2}, \mathbf{t}\right)$.

Farrison, Caivin W. (b':2)-111.13,01, 111.11,

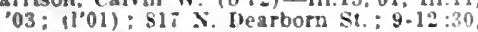
$1-2: 30,7 \div 9$.

llarrison, Kdwin Marrlott (b*4)-M, 19, 0 " III.16,04, I11.22,09, Ill.S,'12: (1'0s) ; 590 . Mapnolla Are: : otlee, jo s. Wabash Ave. $10-4$.

Uarrisin, Mary Fllen (b'50) - H11.2:.09 (1'09); 420s Berkeley Are.

HARILSON, WALJACE KASSON (b'tS) † 111.8, 77, 111.11.'st; (1"7s): 1244 X. State St. : office, $159 \mathrm{X}$. State St. : $3-5$

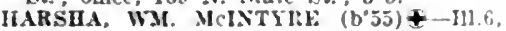
83: $(1 ; 9): 4201$ Grand Rlru.; offce, 31 $x$. State St.; 1-4; I'rot. Surg. and Clln. Surg., II.11; (A13); $\mathrm{S}$

HARSHA, WM. THOS. (b.84) - III.6,0s (1.08): 932 F. 4th Are.: a.tice, $31 \mathrm{~N}$ State st. : 1-5.

Hartlgan, Fugene J.aurence (b'82)-11l.6, 09 (1'10); 8945 Dauphin Ave.: onlie, 9215 Commerclal Are, ; also, City Hall.

Iartigan. Mllchael 'F. - Ill.16,03;

Ilo6 N. Paullna St

Hartman. Alfred (b'69)-Ill.10,'98. I11.4, 05 $\left(1^{\circ} 98\right) ;$ it18 Bond Are.; offce, 9154 con merclal Ave. : 8-9, 1-3, ;-8.

Hartman, Jos. M. $-\left(1^{\prime} 93\right) ; 5533$ เ. P

lina st. : offce, 1757 W. 4 th St.

HARTMA:, WM. W. (b'6i) A-Ill.1.92: (1'92): 5043 Kenmore Are.; ofle, 5606 Winthrop Are.: $3: 30-5: 30$.

HARTMANX, FikDK. STEELE (b.62) \& III.1.'85; (1.86); 3537 Jackson Blrd.; offlce, 600 Blue liland Are, $1-3,7-8$; (F4)

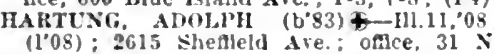
State st.; $9-j ;(1,1,4) ;$ R.

HAItTCNG, HFNIR (bis) + - $11.11,94$ (1"96) ; -22 lliersey Parkway; offce, 2615 Shemeld lie : $1-3,-\cdots: \mathbf{0 b G}$

ITAHEY, ANIREF MAGER (b'GS) \& 111.11.93: (1'94); (La(irange) : oflice, $\$ 35$ IIlchigan IVe.; $8 \cdot 12,1-5 ; 5$

Harrey, Ilasil C. H. (b;5)-Ont.1,3s a not In practice; 1545 E. 61 st St. ; Assoc. Prof. Anat.. I11.1; (F1).

Harre", Chas, $\mathbf{2}-\mathrm{H}-111.10,{ }^{\circ} 86 ;(1,89) ;: 26$ sherldan lid.; ance, $63 \mathrm{~W}$. Handolot "st.

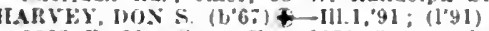
3023 F. $91 \mathrm{st}$ st. onlee, 9154 Comnercial Are. : $9-10,1-2: 30,-8$

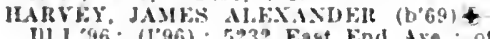
tice $25 \mathrm{~K}$ Wailug East Find Ave

IARVE\%, IROHT. H. (b'68) + - HI.6, (1'94): 2100 ('alumet Ave

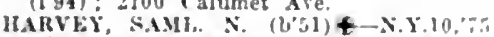
$\left(1^{\prime} 93\right) ; 1534 \mathrm{r} .66 \mathrm{th}$ st, : oftce, $7032 \mathrm{Jach}$ son rark Are : $8-10,1-3,7-8: 30$

IJarvey, Wro. S.-111.4,83; (1'85); IIonrise Hidg.

Harwond, Shas. B. $(2 \cdot 74)-[11.1,0.5)\left(10^{\prime} 051\right.$ 4301 Dover si.

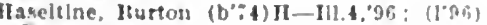
Hotel Sherman: once, 122 \& Mlchlan Ave: $10-1$ : l'rof. Ithln. and laryn., IIIt: OALR. *

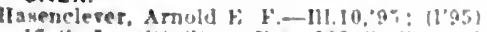

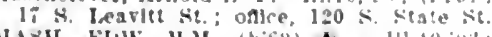

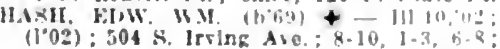

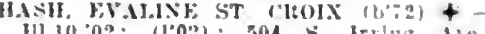
111.10,02: (1'02): 304 s. Irvlng No.

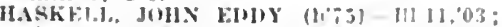
(1'03) : 50 F. 5lat st, : omce, 31 y state

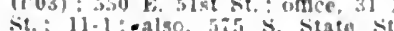

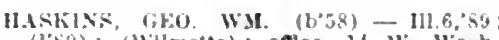
(l'si): (Wilmetto); otice, if w. Was tugton st: $9-5$

Hass, liew. Albert (bai)-Hl.11,'11: (I'11) 6618 1'erry Are.; offce, 6057 Caluruet

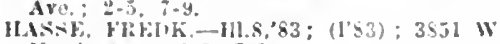
North dve. ; $1-3.7-9$.

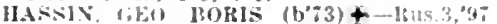
(102); II: s. Marshneld Aie.; $4-10,7 \cdot s$

Ifatteld, lien. A-111.4,"70; (1'22); 1221 k

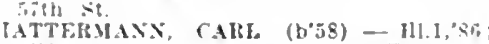
(1's6): 2311 x. Sawyer Are : oflce, 2035

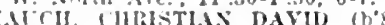

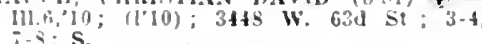

Hawes, John Ford-0.1,91: $\left(1^{\prime} 04\right) ; 1024$ W bi.d si.: untll 10,1-3, ;-9. II awk Iortimer Capsy-1'a.12,96: (1'97)

Hawhins, James Jengldas (b'82) - -111.22,09: (1) 10 ) 5925 $\rightarrow$. Michlgan Are; otice, 1201 E. 55 th $5 i$

Hawkinson, Oscar (b'7)-111.11,06: (1006) 500 W. Clicagn Ale; NP.

HAWIEL, CLAIK W. (b'5t) -111.1,85 (l'b6): (ha (irange); ofllce. - W. Mallson St. :-4; I'rof. Ophth., Ill.G3; (Ji, s) OALR. *

HAIVIF, GEO F, (b'4) - N.Y.1,6.5 (l'84) : 800 Windsor Ale.; office, 5 s. Wa bash Are.: 2-6:30; Prof. Laryn., Hil. (B1) ALR.

HAWLEY, JOS. R. (b':1)7-I11.6,93;(1'93) : 3120 talumet ire.: once, ? $\mathbf{W}$. Madison St. $; 9-11,12-2 ; 1 . \star$

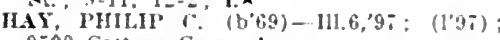
9500 Cotage Grure dre

HAYDR: Al'STIX ALBERT (b'SI) $\$$

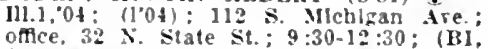
office, 32 : OALR.

HAYDEX, DANI. BERSARD (b'-8) $\oplus-$ D.C.2,04: (1"0t); 150: Blrchwomi Are. oftice, $122 \mathrm{~s}$. Michlgan Are.; 9-12; (Bi): $A L R$, *

HAYDEX, EDWARD (b'-1)-I11.14,07, I11 $2:$ os: $\left(10^{\circ}\right)$; 305t Fastirond Are: office. Champlain Bldg.: 12-2; OALR.

llayes. Darl. Francis (b's) - 111.5,'12: (1'12) Mercy Hospita!.

Hayes, bdwin II. (b'to) II-HLt.'s; (Ist) 272 Lineoln Blrd, ; ottice, $159 \mathrm{X}$. Sitate st. $11-12,1-5$

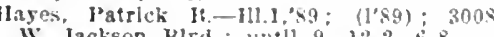

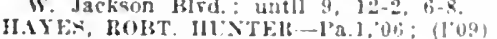

1142 Lawrence Are: $9-12,1-3$,

II.AFOIS, FRNEAT L. $\left(b^{\circ} 65\right)+-\mathrm{X} \times 1,90$ (1120): $2301 \mathrm{~W}$. Monsoe st.; otice. $15 \mathrm{~K}$ Wasbington st: $2-t$.

IIAYMAN, I1181 11. (b'59) + - 111.1,86 alon, 5 s. Mabash die.: $11: 30-2: 30$

Haynes, Cella M (b+4)E-O.,7; (1\%a) 3540 s. llearlmern se. $5-x ; G$.

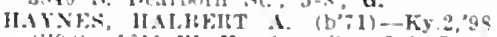

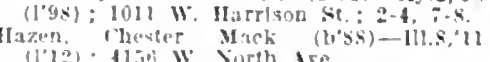
11"121: Alip W: North tre

HFACUL, EDWABI MURTON (b\%6) \&

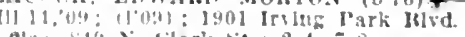

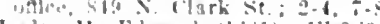

Healy, II Eduard (b'a)-lli.6, $0:$; (1'09) H.il. Wi

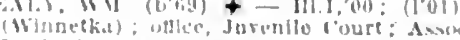

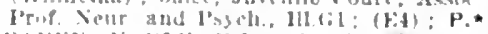

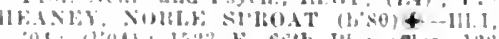

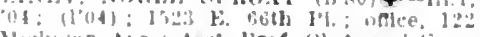
Murlagan dice Anst l'ror. Obst. and lign. III 1: $111 ;: 066$.

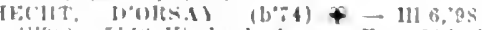
(lob): :11: Kinihark Ire ; umee, 104

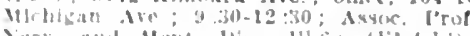

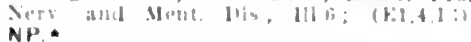

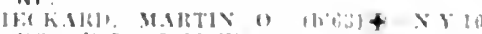

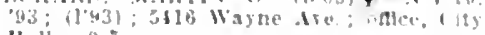
llall: 0.5 .

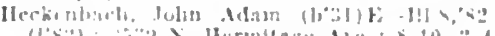

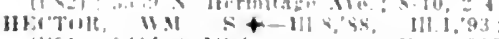

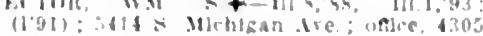
lirand Jist: 4 :

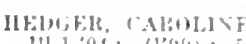

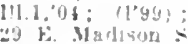

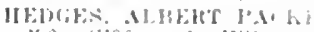

(31): (1.90): 10 - W11

Herlax, leking i - 111

6 ith st. ; rith

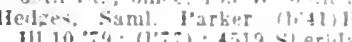

III. 10,$79 ;(1 ; 7) ; 4019$ sherilan lat?

1048 Wilnon Ave.; $x-10,=4$

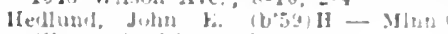

$(1.43): 5 i 51^{\circ}$ liowibe st.

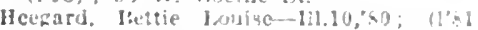

lrito $\$$. Ja salle $=t$.

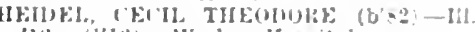
1:: (l'I:): Westey II uspital.

Helifner, Aluion lienry (b'st) - I11 1, 12 (1'13) : Augu-tana Rirsultal.

HEIXYK, AMUE I"ATL $\left(60^{\circ}, 0\right)+-116,960$

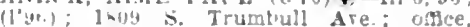

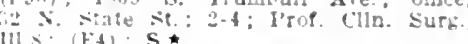

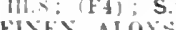

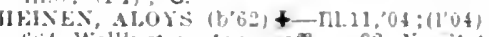

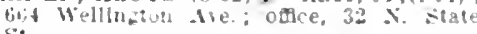
St.

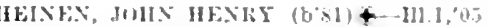
(1'65) : 731 W. North Are: Untl 9. 1 -

HEINTZ, EDWARD LOCIS $\left(\mathrm{b}^{3}-4\right)+-111.11$ $01 ;:\left(l^{\prime} 01\right) ; 1856$ WF. Chicago Are. ; $2-3$

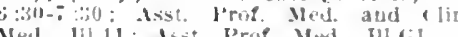
Nel., III.11; Issio Jrof. Med., Hil.(il.

Helnt., Julin E.-F-Pa.2, 89 ; (L'04); 1034 E. $4 i t h$ st

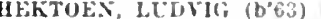

(1's9); sot In practlce: 5803 Blackstone Are, oflice, 174: W. Ifarrison st.: I'rof. Fath., 111.1: $(r \neq,+4)$

Held, Wm- - Ill.16, 02 ; (1'02); 5511 Higsins Are.: 11.1:; OALR.

Heldring, Carrie Elsle - 111.16,"07; (1'0\%) 1503 X. Clark st.

HELDHIXG, FAHIICICS LEO JOHX +-H1.8 $98 ;\left(1^{2} 97\right)$ : 1509 X. Clark st. odlce, $3^{2}$ State St.

HFLLERKANIT, FRANK J. (b.0) — HI.11.

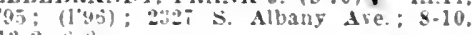

Heller, (has-111.13,"9; $\left(19^{*}\right) ; 437$ F. $31 \mathrm{si}$ ㄴ. : $111-3$

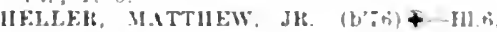
12: (1'12): 3033 Armltage Ale: 11-t 6.30- 2

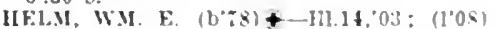
$1446^{\circ}$ Jacksun Hivi.; OAlce. 8000 W. Masi son st. ; 10-12, 2-4, $7-8: 30$; Asst. Frot Ned., Hil.22.

HELMHOLZ, HF.NRT FREI (b*2) Ild.'0h; (1'09); (1630 Ishland Ale. Fivanston); ottlee, lu4 S. Michiban dre.

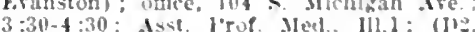
F.4 : $: P d$

Helw!g. Alin lieo, (b'st)-111.11.06; (1'06) 1950 harralee $\mathrm{st}$ : : undl 9. 1 .

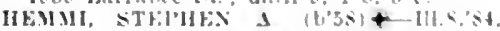

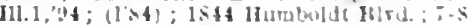
1.2.

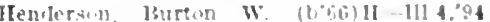

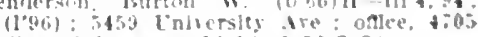

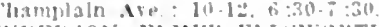

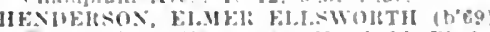

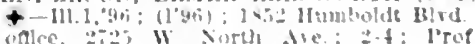
surg, $111.45 ;$

llenteranes.

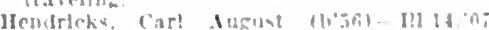

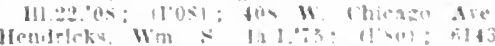

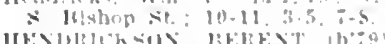

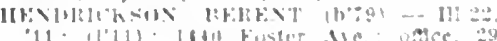
11: kl11]: Illl rust

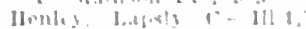

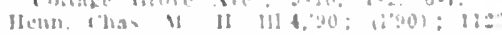

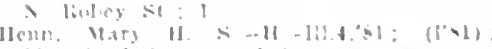

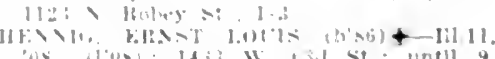
Af

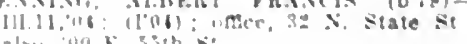


Isabel II. Darenport (b'58)(1'91) ; 5348 Lakewood Are.

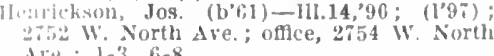

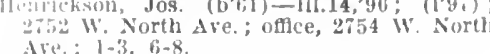
Ihentinkreld, Ifenry John, Jr. (b's8)--111 'lis: (l'13) : st. Anthony's llospltal. agot s Halsted st. $9-11,2-4,7-8: 30$

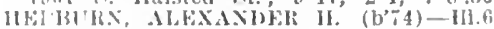
$\therefore$ ilulsted st. 1 - $2,7=9$

Hent

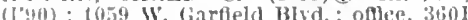
s. Hulsted St.; $1-2,7-8$; $\mathrm{S}$.

IILRB, ISAIBLLAA COLER $\uparrow-111.9,92$ $\left(I^{\prime}(3)\right.$; 5740 Maryland Ave.; (A21, 14); Anes. $\star$

HERIST, ROHT. HARKY (b'Ti)\&-1H.1, '(0); (l'00) : 13lackstone IIotel; office, 32 X. State st.; 10-2; Asst. Prof. Urol.,

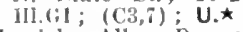

Iferrlek, Allen Duane (b'71) - Ill.23,06; $\left(I^{\circ} 06\right)$. $315 \%$ N Alhland Ave, 9-1, 6-8 IERHCK, JAMES MRYAN (b'61)థ-111. '88: (1'88) ; 242 E. Walion I'I. ; oftice, 122 s. Michigan Ave. $1: 30-3: 30$; Prof. Med. III. 1 ; (D6 $\mathrm{F} 2,4) ; 1 . \star$

Iferrick, Nlinerva $\left(b^{\prime} 61\right)-111.17,07 ;\left(l^{\prime} 07\right)$; 1918 S. St. Louls Ave, ; 2-4.

Herriman, Elbridge A. '(b'34)-0nt.4, 60 not In practice; 632i Grcenwood Ave.

HERRIMAN, WILFRED D. $\oplus$ - Ont.3,91 (l'y3) : 6327 Greenwood Ave. ; office.

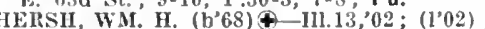

4341 w. Wan Buren St. ; offce, 2056 W. Jackson Blvd.; $10: 30-12,7-9$.

HERSHFIELD, ALEXAN'DER SANDOR (l's1) \& Ill.6,06; (1'06); 3722 W. 12th st. : $9-10,12-1,4-5,7-9$.

Hertel, Louls Is - Ky.1,93; (1'93) ; 3000 (iroveland Are.; untll 10, 2-4; office, 486

b. 31st St.; 10-12, 5-8.
Mervey, Wm. Eugene (b'82) - 111.8, 11 ; (I'11) ; 6850 Fullerton Ave.; 10-12

IIERZ, KARL (b'60)£-Aus.5,'84; $\left(1^{\prime} 84\right)$. 2128 Cleveland Ave.; 11-12, 4-6.

Herzfeld, llerman S.' (b'71) - Rus.2,'96: (1'09); 1432 N. Hoyne Are.; office, 1574 Hilwaukee Ave. ; $10-1,2-4,7-8$; D

Iferzman, Morrls H.-IIl.16,99; (1'99); 3412 S. IIalsted St.; office, 971 W. $18 \mathrm{th}$ St. $10-12,7-8 ; 0$ b.

IIERZOG, MAXIMLIAN (b'58)€-0.1,90; (1'99); 3152 Cambrldge Ave.; offlce, $5 \mathrm{~s}$. Wabash Are. ; $9-5$; Dean and Prof. Path., Bact. and Hyg., IIl.8, ; $(\mathrm{F} 1,2,4)$; LD.

Heskett, Stanley F, - P-1I-III.5, 8 ; ; (1'87). 6824 Lowe Are.; until $9,12-2,6-8$

Hess, Edward Fredk. (b'89)-11l.11.'11; (1'12); 2238 Dayton $S$.

IIess, Emory Lelloy (b'85)-111.6,09; (]'09) ; 4800 W. Chicago Ave. ; 3-5, 7-8; s.

HESS, FREDK. ANDREW $\left(\mathrm{b}^{\prime} 51\right) \notin-$ - III.1, 73 (1'7) ; 1433 Belle I'lalne Are.; offlce, 526 W. Division St. ; $1-2,6-8$.

RS, JULJUS H. (b;6) \& $111.6,99 ;\left(l^{\prime} 99\right)$; tie.; $2-3$; Assoc. Prof. Clin. Med., 111.11; (I) $)$; : $\mathrm{Pd}$

HESSERT, WM. (b'71)†-111.6,92; (1'92); 547 1'ullerton Parkway; $12-2,6-7: 30 \vdots$
Assoc. 1'rof. Surg., 1ll.Gi; $(\Delta 7,13, \mathbf{1} 4)$;

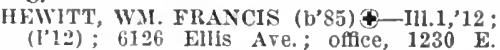
$63 d$ St. $2: 30-4: 30,7=8 ; O b G$.

IIES LIASN, CHAS. J. (b'60) - Ill11,90; (l'90) ; 1436 Hood Are.; offlee, 6205 Broadway ; 8-10; also $5 \mathrm{~S}$. Wabash Ave.; $12-1$.

HEIM, ALBRECHT (b'62)£-Ger.14, 87 ; (197) : $1702 \mathrm{~N}$. I salle St. Madison St.; 1-4; Prof. Neur. and 1'sych., MH.22; (E4); N.ћ Prof. Neur. and Psych., Hibbert, Geo. A.`Il1.11,93; (1'93); 6751 Emerald Ave.; offlee, 2901 Wallace St.; $10-11,2-3: 30,7-8: 30$.

HIESTER, ALYIN C.-I11.1,'80 ; $\left(1^{\prime} 80\right)$; 3552 IV. $22 \mathrm{~d}$ St.; office, 3625 W. $22 \mathrm{~d}$ St.; 9 $111: 30,7-9$.

Higrins, John I. (b'70)-Ill.1,'96; (l'96); $444:$ Archer Ave, ; $7-9,2-4,7-9$; Pd n, John (b'72)-Ill.16,02; (1'02);

Hiklewrind, 1-5. Herman E. (b'36)-Ill.8, '77; (1'Ti); 3320 S. Dearborn St.; offlce, 775 $0-12,2-5,7-8$
HIJI. Armlna Sears (b'i1)-III.11, 06 ; (1'06) as.2 Washington BIvd.

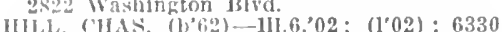
Kimbark Ave; oftee, 6301 Coltage (irove Hit, FuOBY

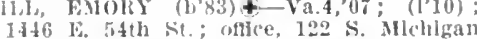

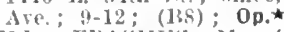

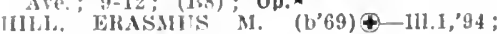
(199) ; 618 S. (Iccero Ave, intil 9, 2-4,

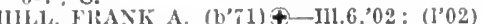
7454 Harrard Are.; offlce, 6914 Wentworth Ave: $3-5$.

Ifll, Geo. Mortimer (b'71) H-111.4,97; $\left(l^{\prime} 02\right) ; 1233 \mathrm{I} .53 \mathrm{~d}$ St. ; 8-10, $6: 30-7: 30$; nfflce, $32 \mathrm{~N}$. State $\mathrm{st} ; 2-3$.

Hill, Vernon-Hll., 03 ; (1'04); 1827 Adams t. ; offle, 1860 W. Madison St.; 10-12,

2453 lrake Henry J.-Ill.11,99;

(1'99) ;

HILENEYER, WM. A. (b'75)€-Pa.2,96; $\left(Y^{\prime} 97\right)$; 6403 Ingleside Ave.; offlce, 630 Cottage Grove Ave.; $10: 30-12,4-5,7-8$.

nuLLS, DAVID SWEENEY - III. 6,98 ; (I'99); A.Surg., M.R.C., U.S.N.; 6547 Kilmbark Ave.; office, $106 \mathrm{~S}$. Míchlgan Are.

H1lls, Lester llarper (b'85)-n1.6, 09 ; (1'09) ; 5616 Calumet Ave.; office, 340 E. 58th

Hilton, Etta R. (b'67) P-N-MII.5, 05 ; (1'05) ; 511 N. Central Ave.: 2-6.

IIILTON, GEO. V.-Mleh.2,76; (I'88) ; 6327 Woodlawn Ave.; ofllco, 1230 E. 63d St. $11-12,3-5,7-8$

Hilton, Jos. Jacobson (b'89)-IIl.6,'13 (l'13) ; Michael Reese Hospital.

Hilton, Robt. A. (b'61) P-M-II1.5,04; (I'04) 511 N. Central Ave.; office, 116 S. Michigan Ave.; 12-5.

Iimmelmann, Harry C.-Ill.22,'12; (1'12); S

Hinchlon, Timothy Richardson (b'83)-Mll.6, '08; (l'08); 1159 W. Garfleld Blvd.; until $9,1-3,7-9$,

Hinckley, Don H. (b'78)-Ill.16,09 ; (1'09): 3816 Langley Ave.; office, 3918 Cottage Grove Ave. ; 9-12, 1-5.

Hingston, James West (b'58) H-111.4,'82 ; $\left(l^{\prime} 82\right) ; 6237$ Greenwood Ave.; offlce, $5 \mathrm{~S}$ Wabash Ave.; $2-5: 30$; ObG.

Hinman, Rlchard Franklin (b'74)-Mll.8,'12 (1'12) ; $4611 \mathrm{~N}$. Western Ave.; offlce, 15 N. State St, ; $12-5$; G.

(1'04) office, Tower Bldg.; 1-3. A

Hinshaw, Levi E.-H-Ill.18,02; (1'02) : 3152 Wralnut St.; offec, 1513 W. Madison St.; $10-1 ; \mathbf{N}$

Hoag, Chas. A.-H-Ill.10,'91; (l'91) ; 6362 ulinerva Ave.; office, 25 W. Klnzie St.; 1-3.

IOAG, JUNIUS C. (b’58) †-III.6,'82;(1'82) 4669 Lake P'ark Are.; 11-12, $6: 30-7: 30$;

(A11); Ob.

tice ; 5733 Midway Park.

Hobbs, Chas. I.-IIl.1,96; (1'97); 2349 S. Central Park Are.; office, 2140 S. 40 th Ave. ; until 8, 7-8.

Hobbs, Fredk. Janis G. (b'67) - Il1.4,'03; (1'03); 6242 Ingleside Are.; offlce, 3506 Indiana $\mathrm{Are.}$

Hobbs, John 0.-111.6,72; (1'78); 2349 S. Central Park Are.; office, 3625 w. $22 \mathrm{~d}$ St.; $2-3$.

Lillan Raywham (b'68)H-nl.4,04, (1'04) ; 4035 Indlana Ave.; 8-2, 6-8; G.

Hobson, Sarah Matilda (b'61) H-Mass. 5 , 90 (1'92); 5215 Blackstone Are.; 2-3; oflce, 22 E. Washington St.; $10-11: 30$.

HOCHREIN, GEO. W. (b'79) †-NI.6,06 ; (l'06) ; 4101 Prairie Are.; office, 104 S. Michigan Ave.; $2-6$; $\mathbf{S}$.

Hodgens, Isaac Walter $-\mathrm{Pa} .2,{ }^{\prime} 94$; (1'99) (Wilmette); offlce, $35 \overrightarrow{\mathrm{S}}$. Dearborn St. Hoeffel, Adelaide Doolittle $\left(b^{\prime} 67\right) \mathrm{H}-111.4$, ObG.

HOELSCHER, JULIUS H.థ-I11.6,'85; (1'85) ; 4506 Sheridan Rd. : 7-8; office, $15 \mathrm{E}$. Vashln ston St. $3-5$.

Hoffman, Harry 'Pichard (b'87)-111.1,'10 (l'10); 2141 Humboldt Blvd.; offlce, 1856 W. North Ave.; 11-12, 7-8.
HOFFMAN, IRA ELMEIR (b'82)‡-III.11 "09; $\left(l^{\prime} 09\right) ; 1120 \mathrm{~W}$. W. Jacksol lilvd. 11-12, 1-4.

llot?man, John R. (b'65)-111.6,'91 : (1'91); (W'Ilmette); office, 31 N. State St. ; 3-5; Sec. and Prof. Ophth., H1..(i4; $(\mathbf{B 1} 1,8)$; HOFF.LAN, IOUIS ('EO (b'87)-II1.6,'10 : Incllana Ave, also $32 \mathrm{~N}$. State St.; $9-12$, I-2:30; OALR, $\star$

HOFYMANN, BERNARD T. (b'74) $€-11.22$, '12; (1'12); 1249 Montana st. ; oflice, 1521 Fullerton Ave. ; 1-3, 6-8.

HOFFMANN, FRANK FRED (b'78) †-III.8, office, 3117 Logan Blvd. ; 12 :30-2, 6 :30-8;

Hoffstadt, John Phlllp-Ill.8,'12; (1'13) 3212 W. Addlson St.; office, 64 E. Van Buren St.; $10-5$; $\mathrm{N}$. HOFMANN, IIENRY (b'85)-Ill.6,'10;(1'10);
6400 S. Ashland Ave.

IIofrichter, Jos. (b'87)-Ill.6,'11; (1'11): 2728 S. Central Park Ave.; 8-10, 2-5, 7-9.

GAN, STEPHEN CLEMANT-III.22,'12 (1'12); 3658 Wentworth Ave.

HOGAN, TIIOS. ALDHELM (b'77) †-MI.1, '03: (1'04); 932 Alexander P1.; offec,

OGLUND, EIIL J-1116,05: (1'05) (W. 63 d 6139 2-4, 7-9.

Hogue, Hal Wyman (b'90)-Ill.6,'13; (1'13); Cook County Hospital.

HOIBY, CHAS. OSCAR (b'76)థ-I11.1,'02 ; 2500 Kedzie Blvd.; $9: 30-11,7-9$; 's.

HOIT, JAMES DE WITT CLINTON (b'42) Mo.1,85; (1'85); 4020 vincennes Ave.

IOLIBERG, EDMOND A. (b'83)-I11.6,07 ; (1'07); offlce, 2749 W. Division St.; also 343 S. Dearborn St.; 11-1.

Iolcomb, Dayton Barrett (b'70)-Ill.5,'10, 111.8,'12; (1'11) ; 5600 Dorchester Ave. offlce, 108 N. State St.; 9-5.

Holden, Edw. B. (b'67)-111.1,89; (1'89) 2443 S. Kecler Ave. ; 10-12, 6-7:30

Holderread, John-Mo.7,'81; (1'81); 2227 S. Wabash Ave.

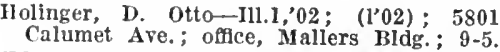
IOLINGER, JACQUES $\quad\left(b^{\prime} 65\right) \oplus-$ SwItz.1 92; (1'92) ; 617 Fullerton Parkway; offee

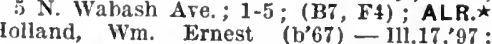
(1'97) 5533 East End Ave.; offce, $32 \mathrm{~N}$ State St. ; $10-1$.

Hollatz, Herman-Ill.22,'07 ; (I'08) ; $\mathbf{5 6 5 6}$ Higgins Ave.

Holleman, Peter W. (b'60) - Mich.1'89. (1'89); 126 E. 11ith St.; until 9, 12-2,

Hollen, Henry Bronson-Ill.10,'02, 1ll.4,'05 ; (I'03) ; 830 Leland Ave.

IOLIENBECK, FRED DRURY (b'63)†III.1,'95; (1'96); 1548 Estes Are.; office, Obst. Ill. G1 St.;

Hollle, Albert 0. (b'81)-n1.22,'11; (1'11) $1000 \mathrm{~W}$. Madison St.

Ifollson, John H.-H-Ill.18,02; (l'02) ; 2851 Elston Ave. ; 8-9, 1-2, 7-9.

HOLLISTER, MARY C.૯-M1.9,'82; (1'90) 22 E. Washington St.; $9: 30-1: 30 ;$ (B8) Op.

Holm, Anna S. Wlndrow-Ill.11,01; (1'01) $2419 \mathrm{~N}$. Halsted St. ; 2-4; Ob. , OLMBOE, ANTON T. H. (b'5i)\&-I11.11, '86; (l'87); 1045 N. Sacramento Ave.' $2: 30-4$; Prof. Ortho. Surg., 111.8.

Holmes, Bayard (b'52)-111.10,'85, Ill.6,'88; (l'85) ; 813 E. 40 th St.; office, $108 \mathrm{~N}$. State St.; $3-6$; (E4) ; S. $\star$

HOLMES, BAYARD, JR. (b'79)థ-Ill.1,04; (l'04); 843 E. 40th St.; office, 77 H. Washington St. ; $3-5$. HOLMES, EDW. M. Ф- Ill.11,'03; (1'03);
3726 Ogden AVe.; 11-1, 7-9.

Holmes, Herman R. (b'71)-111.22,'13; (1'13) ; $27 \mathrm{E}$. MIonroe St.

HOLMES, PHILIP HENRÝ-II.11,03 (1'03); 342 W. 65th St.

HOLMES, RALPH R.-Ill.11,06; (1'06); 458 w. 61st St. 
HOLAES, RIJULPII WIESER (1):0) —

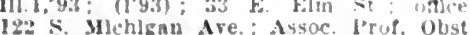
122 Mlehlgan Ave.

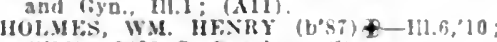
(1'10): $2431 \mathrm{~s}$, hearlorn st

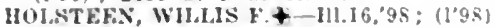

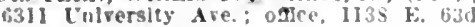
St. : $8.9,1-2, \div-5$.

Holton, Elizabeth S.- H-IIl.9.83; (1'85) not in practlce; f 423 stewart dbe

Holzman, Fredk. ('has - III.8,12: 51: N. Albany Are.

Homman, Grace lalne (b'6) - Ill.11,"11 (1'12); Cook Counts Hospltal.

Iunaker, Geo. T.-Mo.2s, 00, III, 1, $03 ;\left(l^{\prime} 05\right)$ 1526 W. $103 \mathrm{~d}$ St. : 1-2. $7-\mathrm{S} ; \mathrm{S}$.

Honberger, Frank H.-H-III.4,90; (1.90) 441 Oakwood Blvd.; $8.9, I=2$, t tj- 7 ; J'ros. Obst

Honnold, Fred clifton (b'72) - Mll.1,96 (l'96); 4517 Beacon St.: oace, Fisher Bldg.

Hood, Calvin T. - Ill.11,'85; (l'SJ); 2959 Wasulngton Bivd.: 8-9, I-3

Hooge, Ludwlg F. (b'64) H-H1.10,"s9, Hl.11. $03 ;(1 ' 9 \%) ; 1054$ E. 75th St.; 9-11, 1-2, i-9.

HOOK, FLISHA 1. (b'57)--111.1,89;(1'89); 2706 S. kockwell St, offlce, 2600 W. Fullertion $\triangle$ re.; ObG. Hook; Harrlet A. (b'6)-Ill.1,05; $\left(1^{\prime} 06^{\circ}\right)$;

HOOPER, HENRY' (b'44) -Mass.1,69 $\left(1^{\circ} 7\right) ; 1210$ Astor st.; untll $9,12-2,5: 30-$ i Emer. Prof. Obst., Ill.GI

HOÓVER, MEIRRITT 0 . (b'71) -III.16, 05 (l'05) : 1342 N. Rockwell ši. ; ottce, 1536 Grand"Are: i-2, i-8.

GOPKINS, CAROLINE. B. (b'iz)-Ill.9, 97; (1'97); $\mathbf{4 2 4}$ Sherldan Rd.; until 9, 5-7; oalce, 4557 Broadway; 1-4.

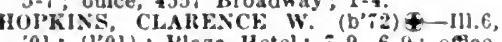
01 ; (l’01); Hlaza Hotel; $i-9,6-9$; oflce, 323 W. Kinzle St. ; $9-1,4-6$.

Hopktos, Porter W. (b's0)-Ky.5, $0 \pi$; (l'08) :

$235 \mathrm{~W}$. Washlngton se

HOWKHK, CLARENCE COWLES (b'85)IIl.6,'10; (l'II); 9949 Longwood Hlrd.; ofice, La Salle St. Statlon; 10-12, 2-4.
Hormann, Wm. F.-E-11l.8,03; $\left(l^{\prime} 03\right) ; 1319$ W. Adams St.; $9-12,1-4$.

llorn, Albert Triplett - Mid.3,04; (1'04): 6231 Vincennes Are.; oflice, 3044 Went: worth Are.

Horn, Amandus Max (b'6i)-IIl.8.'12;(l'13) 2 i30 N. Clark St.; $8-10,2-4,7-8: 30$

linrning. Vlctor Helmer-III.8,'I2; ( N. Claremont Ave.

HOHNSBY, JOHN ALLAN (b'c1) \&-Mo.2, '80; (1'95); 64 K. 36th I'l.; office, Tower Bldg

IURUVITZ, DAVID Al.FHED (b'84)-IIl.I, 08: (1'08); 1521 Mlllard Ale.: oflce, 209

S. State St, 1 1-3; ObG.
HORSTMANN, FRANK M-IIII1,04:(1'04): not In practlce: $725 \approx$ Central l'ark Ave. Prof. l'byslol., mi.8.

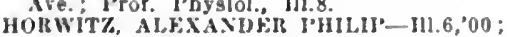
(1.00): 212 E. 45th St.

Hotchkin, IBenj. L. (b'52) HI-111.10,89 (1'89): 5522 Kennure Ave.; ofice, $7 \mathrm{~W}$ Mallsón St.; $12-2$.

HOTTINGEI, "EITWIN STAUFu (b'84)

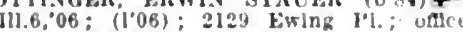
$108^{\circ} \mathrm{x}$. Sitate st.; $10-12,3-5,7-9$.

Houghton, Estella Lorton-111.9.'99

6602 Wentworth ive.: OALR.

Houston, Henry $\left(b^{\prime} 66\right)$ - Ill. 8,0 ,

1637 is Madlson st. 2.5

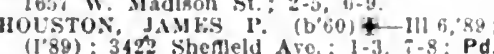

Hoveden, Loulse Marshall (b'09)-Ill.14 09; (1"09); 2525 W. Harrlson st. ; 10-1: $2-5,7-8$

HUVbY, CIAlla A. (1) 55$)-111.5,03:(1003)$ 325 Turner Aro, $10.12,2.4$.

$\left(b^{\circ} 64\right)+$ $11.12,2.4,7.8$.

Howard, Frank J.lneoln (b'to) -111.16," 9 , $\left(1^{\circ} 96\right)$ : foak lark): onlce, $3001 \mathrm{~W}$. Lalke Sit. : II $-3, ;-9$.

HWW AHD, fiKo HKRHEIT $\left.\left(b^{\circ} ; 0\right)+-I\right] ! 11$

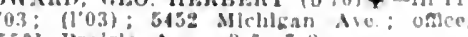
5001 I'ralrie Ave; $3-5, \quad$ i-s

HOWE, HAIRUTE: A. $\left(b^{\circ} 50\right)+$
Huwe, Hest loal - Ill x.08: (1'08); 1133 Uowe, walter : oflce, $32 \mathrm{~N}$. State sit. mant Hosplat

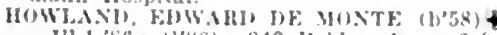
-I11.1:\$6: (1'46): 843 hulden Are, $6-8$ orlere 31 X. state it: $2: 30-3: 30:$ S. (1.0y): "Tivi W. Madison st.: $8-9,12.2$

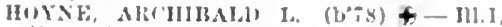
04: (1.04): 4145 Indlaua Ave.; Offec, $3:$ N. State st.: 2-3; D.

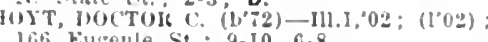
166 bugenle st. : 9-10, 6-8.

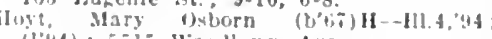
(1'44):5.5 Womllawn Are.

lloyt. Wu. Welles (b'5)-Mass.1,01 (1"01); 431+ loke lark Ave; onte, 12:

Irynlewleckl, stephanus $c$ (boi)-ius. o6: $\left(l^{\prime} 09\right)$; 3637 Wrlghtwood ire.; uflce. 1318 w wivlslon st

Hubbard, (chas. F. (b"i4)-I11.15,"99; (l"49): 5961 West Find Ave; oftce, $\mathbf{W}$. Madlson st. ; $10-4$

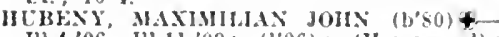

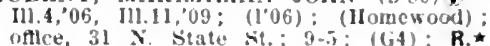
IIuber, Jos. M. (b,5)-Ill.4,06; (1,06); 3023 Broadway; once, $800 \mathrm{~N}$. Clark st.; $11-1,7-8$.

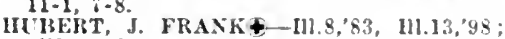
(l'83); 6820 inlon Ave.; I-2, i-S.

Hudson, Harry Hackney (b'90)-Ill.6, 13: (1'13); Wesley Hospltal.

ILESTIS, ARTHUH (b,79)-H1.16,06; (1.08): $505 \%$ l'ensacola Are.

HulTaker, Thos, s. (b'5s) H-III, , s4; (l's4); 414 Ellts Are; oltce, 769 E. 39 th St. $10-11,3-4, i-8$

Hugrard, Timothy S. (b'S0) - 111.22,09; $(1,10) ; 4616$ Yilden Ave.

Huggins, Robt. V.-0.13,91: (1993) ; (Oak

Park); office, 36 W. Randolply st.

Iughes, Enos J.-Ia.1,"tj, Mich.1,'86; (1'-i): 5320 Dorchester ire

ILCIIES. THOS. (b'66)t-I1!.6,"9z: (l'92) 3652 Wallace st.: $9-10,1-3,7-8$.

Ifulett, Ralph WI]son-Ill.4,09; (l"09); 1532 VInccnnes Ave.

Hulett, Sidney Fo-H-III.4,76; (l'7\%) : 4532

VIncennes Are, i-s, I-2, 7-8.
LILI. CHAS. WILHLK (b'67)-I11.23,06;

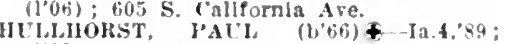
(l'97): 6960 N. Ashland Are. untll 9. $2-4,7-8$

ILITGES. JСOK $k$. (b-2) - - $111.6,00$; $(1,00): 5041$ S. Asliland Ave.: 12-1,6-7; (1)

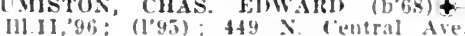
III.I1,94: (1"95): $449 \mathrm{~N}$ (cutral Ave. 111.i1; S.

II 44 X. Central Ive.

IINAMANX, ARTHII ]". (b'68)-I11.13

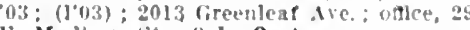
r. Mallson st.; $9-1: 00$.

Hunt, Goo. C.-Ill.1, a.: (1's.s) ; $93 \%$ Foster No. onlee, ilty lla!l.

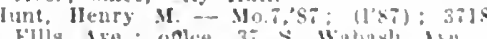

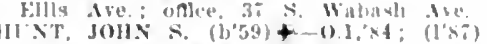
130 Englewood Are, ; 1-2, :-8

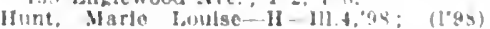
Ifyle l'ark liotel.

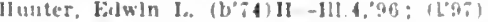

Ilotel Winclermere: onlce, 1:2

lve.: 1-3: All J'rof Surt. III

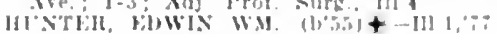

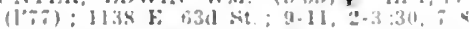

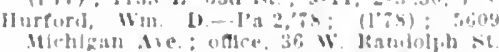

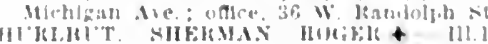

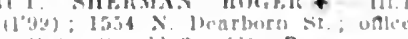
$3: 5$ sitate sit: i1-2 $(1+1) ; 0$.

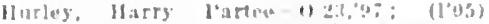

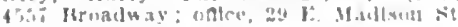

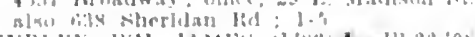

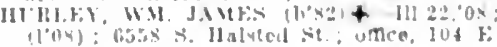

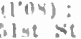

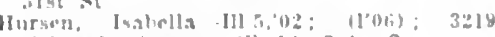

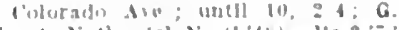

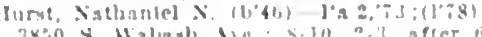

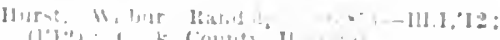
llurbali, Iretier li il: W. lath $=$ i
Iuston, Hussel] Itagin

$(1,13): 4501$ Thromas 5 :

II. Monoe

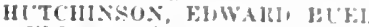

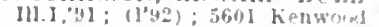

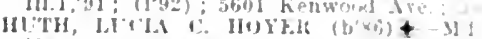

os: (1'13): Member state Mend

W'ls.: 54:34 Lexlngton Are

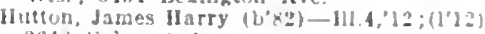

2 tite Calumet Ave.

IIIE, IIAIJ L. (b6hi)

ISIE, KATHFHNE IFMISET - III 13

62. (1'02) : 3941 W. Irulne l'ark Blod

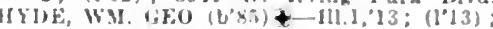
goog lruing l'ark Ihlud.

WWA.L. CIIAS. WM. (b's0)‡-III.23,0" I. $230-3 ; \mathrm{S}$

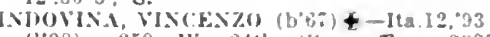
(1.98); 259 W. 2th st.; oflce.

INGALS, FIHIRAIM FLETCIEH (b'48)

Ill.1.71: (1'76); 5.540 Woodlawn Are. office, $104 \mathrm{~S}$. Mícblam Are.: 9-12: Pros. Dis. of the Chest. Iaryn and otol. 11l.1: $(132,3,1, F 4)$; ALR.

Ingersoll, Jowell F'-1I-IlJ.4,96; (l'96)

416 W. Glst Ill ; untll $9,12-2,6-8$

INGHAM, CECIL (b'80)-Ill.6,06; (l'06) 1844 Canalport Ase.; 1-5; Oftice, 205 : Niste $-1,12-1$

106 - I1].14, $05 ;(105)$ HISI, IIFIR ELCES $9+11,6+8$

01: (loj)

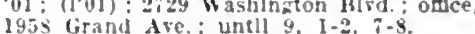
MONS ERNEST EDWARD (b\%-7)-IIL1. "03; (1'04): 302 s. Ashland Blsd.; oflce 122 s. Mlchlgan Are.; 1:30-4: Asst I'rof Med., III.I; $($ F., $) ; 1 . \star$

Irwin. Bermard J. I). $\left(0^{*}, 30\right)-X .1 .751$ Brig. Tien. I'A.A. retlred: 32 E. Invlston

(1), John Louls (15'60)

(Maywood); uttee, 52 W. Huron St.: 2-4 (i)

lsiacs, Chas. F. (b"7:)-Ill.6,04: (100

ISACS, I.EWIS J.H HI.11,94; (1'94): 2729 W. 3sth St.

ISENAS, JWBEXCE LEE $\left(b^{\prime}-9\right)+-I d$ "Ub- (l.09) Chicago lleach llotel. omce. :2 $\mathrm{Y}$ - state $\mathrm{St} ; 1-3: \mathbf{S}$

IsIIA in, Gro. S. $\left.\left(\mathrm{b}^{\circ} 59\right)+-111.6,84 ;(1)^{\circ} 5\right)$ $1340 \mathrm{X}$. Silate $\mathrm{St}$.

Ishmael. Usiar Filgle (b'S3)-Il1.11,0s

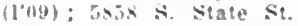

Izakowltch, Jarry-IlI.22,12: (1'12); 9534 W. Nurth dre.

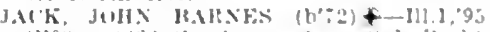

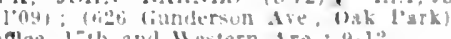

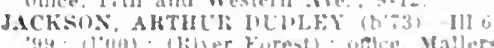
"

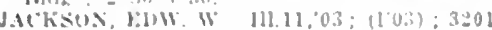

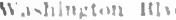

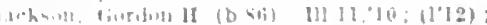

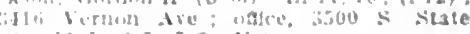

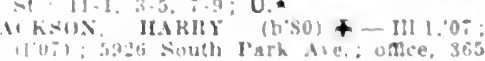

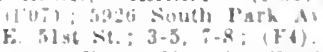

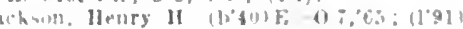

1.0.3iste

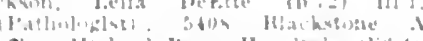

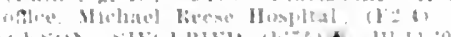

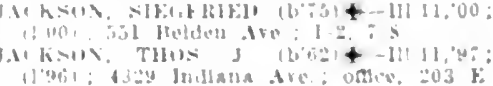

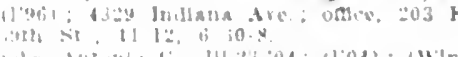

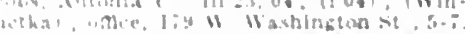

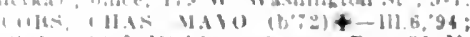

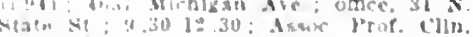

Ortho. surs, 111.11: (119): Or.*

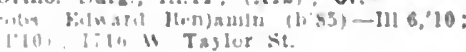


Jacobs, Frerlk. Caspar (b's8)-111.6,'12 (12); 1342 Wellington s

Jacols, Gustave I. (b'70) $\mathbf{E}-111,22.04$ (104) ; 1526 W. Mallsom; [0-12, 2-4

JACOISA, HARRY LQWNART $(1,65)+$ Ill.11,03; (1'03); 6,657 \&. Ashand Ave. JACOHS, Joll MAlTIN, JR.-I11.17, 03 Ill.11,06; (1'04); 2224 Irving 'iark Blwl. $1-3,7-8: 30$.

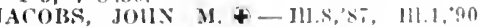
(l'si); 1342 Wellington st.; until

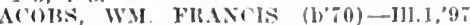

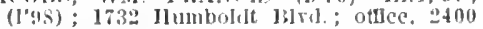
IV. Vorth ive

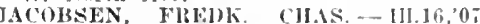

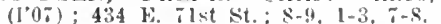

Iacobson, Alfred lredk. (1,79)-Ill.t, 05 (l’05); 1156 W: tistli st.

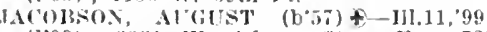
(l'99): 2931 W. Nolams st. oftlee, 725 s. Kella Ave : 9-10,1-3, 7 - s :30.

Jacobson, IItirris Alnsworth (b'87)-I1I.11 '10; (l'10); 1301 W. 14th st.: office, 123 S. Illalsted St.: 10-12, 2-5, $7-9$

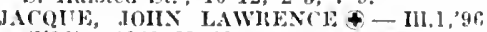
(l'96) 1362 N. Iloyne Ave. : offlce, 5. Wabasi

(F4). Fred K. (b'69)-111.22,'13; (l'13)
ames, Fre $44 f i 3$ Woodlawn Ave.

TAMFS, HARRY 1DAVID-111.23, 0 ; ; (l'07) 31 N. State St. ; 9-12; Prof. Ophth., 1ll.G James. Jizzic Ollve (h'72)-Ill.22,'13; (l'lis) 4463 Woodlawn Ave

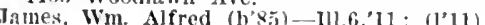
4125 W. Harrlson St.; office, 440 W.

Iamleson. John Knox (b'73)-I11.11, 07 (1'99); 1108 W. 59 th $\mathrm{st}$

JAMPOIIS, MARK (b'81) - Ill.6, 06 ; (l'06); 3838 Grand Blrd.: offlee, 106 Michigan Are.; $2: 30-3: 30$; (D2) ; Pd.

Janson, Sar: A-III 1 03 ; (1'03): 906 N. Kerlzle IIvd.; office, 29 F. Iadison St.

JAQUES, WM. K. (h'59) (4-IIl.6,'87.; (1'87) 4316 Greenwood Are.

ared, Fernon Meadows (b'si)-Ill.4,'12 (1'12) ; 3113 Cottage Grove Are.; 8:30 $9: 30,2: 30-4: 30 ; \mathrm{S}$

Jaros, Jos. Francis (b'84)-I1l.6,'12; (1'12) ; Cook County Hospital.

IAY, FRANK WEBSTER (b'68) P-Ill.1,'90 ; (1'90); 2510 Indiana Are.; offce, $31 \mathrm{~N}$ State $\mathrm{St} . ; 10-12$

JEFFERIS, RENI. GRANT (b'51) \-Ky.1, '87: (l'ss); 1414 N. Robey St.: office 1572 Mllwanke Ave.; $8-9,3-4,6: 30-7: 30$ EFFERSON, FREDK. A. (b'69) $\uparrow-111.1,95$ (1'95); 648 Oakdale Are.; ofllce, 5 S Wabash Are.; $1: 30-4$.

Jeffries, Willard Guy (b'81)-III.6,'06; (1'06) ; 5300 Blackstone Are,; offlce, 29 E. Madison St. : 11-1.

Jenney, Frank I. B. (b'69)-Il1.11,90; (l'9i) : 5001 Blackstone Are.; offle, 169 v. Nichigan Are. $9-12$.

Jennings, Janies A.-II--Ill.8,97: (l'98) 311 S. Sacramento Blrd.; office, 3638 Ogden Ave.: 8-9, 1-2, 7-9.

JENS, OTTO F. (b'69) $\$$-Ill.16, 01, Ill.17 '02; (1'01): 3400 Fult on st.; oftice, 2207 W. Van Buren St.; until 9, 1-2, $7-8$.

Jenson, James (b'7)-Ill.22,'11; (l'11): $3 \$ 02 \mathrm{X}$. Clark St.; office, $220 \mathrm{~S}$. State St.

Jenson, Wm. A.-Ill.22,'12; (1'12) ; 3802 N. Clark St.: office, $17 \%$ N. State St.

Jentzscl, Ernst (b'69)-Ill.S, 01 ; (I’01) ; $3 \$ 46$ Elston Are.; 12-2.

JENTZSCI, RICHARD (b'63) §-O; (1'9i) $15 \mathrm{~N}$. Willow Are.; office, $10 \mathrm{~N}$. Western Are. ; $1-6$.

JERN, JOIIAN II. (b'73)థ-Ill.6,04; (1'04) Menuber State Med. Assn. of Minn.; $75 \%$ w. 79 th St.; $2-4,7-9 ; 0$ bG

Jeths, Rikus A (b'68)-1ll.5,03; (1'03) $\$ 353$ Belmont Arc.; office, 2351 Belmont Are. $8-10,12-2,6-8$

JETT, GEO. A. (b'72)-Ill.1,'93; (l'93) ; 740 Washington Blrd.; 9-11, 3-6; offlce, 31 N. State St. : 1-2.

11 WELL, EARL BOWEN (b'82)€-III.11 l'07); $440 \mathrm{~S}$. Dearborn St.

Jincira, Frank F. (b'86)-Ill.39,'11; (1'12) 2553 W. 2 Ist Pl.; offlce, 19 th and Leavitt
JII"\$0N, N(1ITON w. (b'65) $\$$ - IIl.6,'89; (1'89); 4310 Indlana Are, 7-9, 2-4. (I.i) 2utI st.; 8-10, I-3, 7-9; Asst. 1'rof. Med. 1II. $22 ; \mathrm{S}$

Mroch, Francls Wm.-IIl.16, 06 ; $\left(\mathrm{l}^{\prime} 06\right) ; 533$ W'abasli dro.

Tobling, Tames $1 \mathrm{~V}$-.-Tenn.10,'9i); ( Jatbolo(glst); Micharel licese Ilospltal: $\left(F_{2}, 4\right): P$ Ioffee, Wm. (1's0)-111.1,04; (1'04); 342: louglas IBIrl.; offlce, 1301 s. II tulsted St. $1-3,6-8: 30 ; A L R$

Jolianun, Jacoh Baha (b'72)-Ilo.34,04; (l']11): 11, in practice 733 N. la sialle.

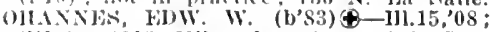
(I’0s); zols Milwauke Ave.; 1-3, 7-8; $\mathrm{Obg}$

OILANNES, II HNRT C.\$-Ill.23,05; (1'05) Johamues, thilip C. W. (b'7(b)-Ill.6, 00 (1'99); 1201 W. 69th St.; untll $\delta, 12-2$

oln Adelliert Allen (b'56) - Ill.6,'98; (l'98) (Oregon); othlce, 6240 Cottage Grove Are. OIIN, FINDLWY D. (b'71) $\oplus-$ Ml.1, 03 ;

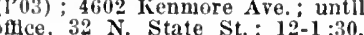

Johns, Chas. Grant (b*9)-Ill.16,10

$133^{3}$ s. Austin Ale.: after 6.

Tohnsen, Nicls J. B. (b'52)-Den.1,79 (l'89); 2458 w. Forth Ire.; until 9 $1: 30-2: 30,7-8$

Johnson. Arthur Green (b'84)-Ill.11,'10 (l'10); 5000 S. Ashland Are.; until 9 $12-1,7-9$.

OIINSON, AIfISTA E.-IIl.5,97; (I"97) 922 Noble st.

Iohnson, Chas. Henry (b'84)-Ill.22, 08 ; (1'08); $131 \mathrm{E} .111$ th St. ; unt11 9, 1-2, $7-9$. olmson, Edw. Richard (b'82)-111.4,06 (l'06); 1233 s. Wabash Are.

IOHNSON, FRANK SEWARD (b'56) Ill.6,'81; (1'81) ; 2521 Prairle Ave. : 10-12 Dean and Emer. Prof. Med. and Clin

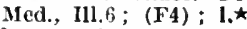

Iohilson, Grover Frman (b'85)-Ill.11,'10 (l'10); 1158 W. 59ih St.; 12-2, 7-9.

cohnson, lames Andrew (b'83)-Ill.6,'10;

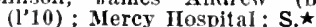

Johnson, John Frank-Ill.16,03; (1'03) 3417 W. North Are.; 2-4, 6:30-8:30 OALR.

Johnson, Jos. H. S. (b'56) H-N.Y.17,'83, Ill.4,84; (I'84); $1518 \mathrm{~N}$. Washtenaw Are Johnson, Levi o. (b'41)-Mich,1.'68; (l'97) 4848 State St. ; 10-12, 2-4.

Johnson, Margaret C. Boosing (b'58) HIll.14,'96; $\left(l^{\prime} 96\right) ; 1518 \mathrm{~N}$. Washtenaw Ave.

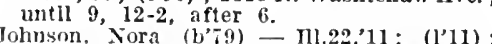
3650 Ogden Are.; offle, 29 E. Madison, Johnson, N. La Doit (b'69)-Ill.11,97; (l'97); 3536 W. Monroe St.; offlee, $209 \mathrm{~S}$ State St.; $1-5$.

Johnson, RezIn I'ritchard, Jr. (b'72)-Tenn.9, 97 ; (198); $600 \mathrm{~S}$. Crawford Ave.; office, 5 N. Wabash $\Lambda$ re. ; $3-6$.

Johnson, Virginia Marguerlte (b'89)-111.15, 13; (1'13); 1518 N. Washtenaw Ave.; $2-4,6-8$

JOIINSON, WARREX (b'79) $\oplus-$ Ill.11, 09 (1'09) ; $3201 \mathrm{~W}$. North Are, ; 2-3, $7-8$

Johnston, Chas. Herbert (b'51) P-M-0.10, '85; (l'85); 1752 N. Kedzie Are.; offlce,

\section{(1'12); 3822 W. Chicago Ave.}

MOHSTON, JOUIS CAMPBELI (b'87)Ill.6,'11; (1'11); 3270 N. Clark St. ; 1-3,

JOIYSTON, THEODORE(-IIi.8,05; (1'05) 3550 S. Iloyne Are.; offlce, 3511 Archer Ave.

JOHNSTONE, A. RAIPII (b'65)థ-Ill.11, '87: (1'90) ; 4319 Greenwood Ave.; offlce 3410 Rhodes Ave.; 11-2.

JOIXNTONE, MARY M. S. (b'70)†-Ill.9, 99 ; $(1$ '99); $1703 \mathrm{~W}$. Jackson Blvd. ; 2-4' (D2)

Jolinstone, Norman Arthur (b'66)-Ill.11, '96; $\left(1^{\prime} 06\right) ; 820 \mathrm{~N}$. State St. ; offlee, $32 \mathrm{~N}$. Clark St.

JOHNSTONE, STUART (b'54) $€$-m.11,'86; State St. ; 1-5; Prof. Gyn., Ill.8.

Jones, Caroline Allen-Ill.22,'05;
JONISS, CIIAS. HIWIN (b'51) $\$-0.9,74$, N.Y.10; $60 ;(1.85)$; 327 X. Plue Are. ; 8-4, $12-2,7-8$

Jones, Jirid Janeson (b'83)-I11.11,'11; (1'12) ; 2403 W. Chleago Are.

JONES. HALOLI) ELIDEE (b'83) $\$-111.0$, 09 ; (1'09); 1724 F. 54 th St.; 5-6, $7-8$; office, 122 S. Mlclilgan Ave.; 11-1.

ONES, IIUGII OWFN (b'75) $+111.6,02$ (l'02) : 2441 Inilana Are.; offlce, 802 W. 31 st st. ; $2-4,7-9$.

JONlis, IAY GLEN (b'84)-111.0,11; (l'11) ; 3359 " N. II Ilsted st.; 1-3, T-8.

Jones, Jos. J.-Mich.1,'90; (1'94); 818 l:. 90 th $_{1}$ st. ; 8-10, 3-4, $7=8$

Jones, lueslle W.-I11.10,'97; (1'97); 300 s JONES, MAIGARF'T MAY (b'76)-Ill.11,'03 (l'03) ; 625 L. 63d St. ; offlce, 32 N. State

JoNHS, NARTIN 1 .

(sce Oak Park.)

Jones, Mlontague J.-0.1,71; (1'7\%) ; 6408 Grecnwood Ave.

Jones, M. Estelle-Ill.15,'99; (1’99); 816 F.

Jones, llobt. T.-I-IIl.8,98; (1'98) ; 6359 S. Haisted St

(1'08) IRussell Arthur (b'84)-111.22,'08 (1'08); 3904 Cottage Grove Ave. ONES, THOMAS GOODMAN $4-I 11.8,12$
(1'12); 1156 W. $63 \mathrm{~d}$ St.

JONES, WALTER CLINTON (b'74) $4-$ Ill.6, Washlngton 'St.; 2-3; (A13) Offe,

IORDAN, Glio. THOMAS (b'76) $\$-11.6$, 05; (l'05); 4335 Mlchigan Ave.; offee JOSEPHSON, VICTOR (b'62) $\oplus^{\prime}$ - Ill.11,'94 (1'94); 1339 S. Kedzle Ave.; offce, 1021 W. 14 th $\mathrm{St}$.

JOURD AN, AIBERT F. W.9-Ill.14,06 (1'07) ; 3132 N. Ashland Ave. ; offlee, 3158 N. Ashland Ave. ; $9-10,2-3,7-8$.

Joyce, Paul Vincent (b'84)-111.11,'12 (l'12) ; 2104 Washington Blrd.; office, 3134 Montrose Blrd. ; 3-6, 7-9.

Joyce, W'm. M. (b'75) -Mich.7,'97; (1'97) ; 6123 Indlana Ave.; offlee, 300 E. 61 st St. $8-10,2-4,7-8$

Joynson, Harry Bromllow (b'64)-Md.6,'97 (1'97)'; 1254 Elmdale Ave.

uhl, Erik (b'86)-1ll.8,13; (\$); $212 \mathrm{E}$. Ontario St.

JUIINKE, LEO ANTONY (b'82)-Ill.6,'10 (1'10); 3720 Herndon St.; offlce, 3166 Iincoln Ave. : 3-5, 7-8; ObG.

Kallke, Charles ${ }^{2}$. ${ }^{2}$; (b'70)H-Ill.4,'94; (1'94); 3147 Calumet Are.; offce, $32 \mathrm{~N}$ State St.; 10-12; Prof. Surg., I11.4; (A13);

KAHN, CHAS. (b'74)-III.6,'97; $\left(1^{\prime} 97\right) ; 1100$ W. $63 \mathrm{~d}$ St. ; $2-4,7-8$.

(1'98): (10-1. State

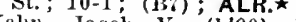

Kalin, Jacob V. (b'90)-111.6,'13; (1'13):

KAHN, MAURICE (b'76) 9 -Md.6,'03; (1'03) ; 5545 Prairie Ave.; offlce, $4627 \mathrm{~S}$. Ashland Are.; 9-10, 2-3, 7-9.

KAIN, OTTO LEONARD (b'80) Ð-Ill.22, 909 S. State St. ; $1: 30-3,6: 30-8: 30 ; \mathbf{S}$

KALACINSKI, FELIX (b'74) $\$-$ Ill.11,98; (1'98); $1024 \mathrm{~N}$. Robey St.; $9-10,1-3,7-8$ KAIES, JOHN DAVIS (b'64) $\oplus$-Mass.1,'8i'; (l'88); 1356 N. State St. ; office, 7 W. Iadison St. ; 10-1, 3-5.

Kales, John W'., Jr. (b'84)-Ill.22,'10 ; (1'10) ; 3400 Lawndale Are.

KALLIONTZIS, coNSTANTINE P. Greece 1,00; (1'04); 2506 N. Kedzle Blvd. offce, $140 \mathrm{~N}$. State'St.

Kamplain, James (b'61)-Mo.7,91; (l'91) ; 919 W. 63d St. ; 8-10, $6: 30-9: 30 ; \mathbf{D}$.

KAN, AILEXANDER M. (b'82) (-Ill.17,'06; (l'06); 1514 S. Kedzie Are.; offlce, 2067

W. 12th St.; 2-4, 6-8; Pd.
KANAVEL, AIIEN BUCKNER (b'74)甲Hll.6,99; (1'99); 5136 Kimbark Ave. ; ofllce, $31 \mathrm{~N}$. State St.; 1:30-2:30; Asst Irof. Surg., 111.6; (A5,7,13). Kane, Louls Matthew (b'84)-Ill.6,'12 ;
(l'12); Cook County Hospital.

KAPLAN, MAURICE ISADORE (b'88) \&Mo.2,'10; (l'13) ; Member
Assn. ; 3819 W. 12th St. 
KAPSA, PAUIJA: ROSF" (b'86)-111.11.,09

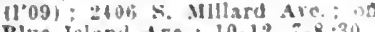

KARA, Jolls MATTILW (b'si) - HI.1 $10 ;(110): 1913$ \&. Halsted st: $: 9-1 \%$ 3-5, $:-9 ;$ Pd.

KALKLMAX, ATIIA REGISAIS (b'in)

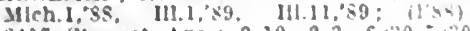

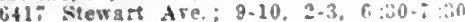

KARST, FREDK. A (b'33)-1ll t, ${ }^{2}:\left(1^{\prime}, i\right)$ (Wilmelle) : oflee, $32 \mathrm{~N}$. Clark st.; 11.

Kaster. Thomas J. (1,", 5$)-111.1,01:(1,02)$ 3614 S. Ilamilton Ire. aftce, $1 \pm n: 5$

-asasnskl. Jacoh (b'be)-Md.3,

2001 ‥ Oakley ire.

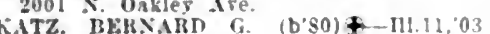

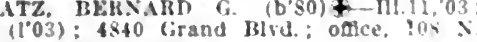
State St, : $1: 30-3: 30: \mathbf{S}$.

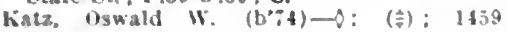
spruce $\mathrm{S}$.

Kaufruan, Adam Fmory (b.56)-111.1, \$5 (185): 1338

KAUFUAXX, GLSTA I,EOXALD (b'S3)-

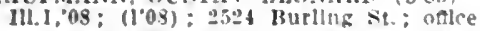
Cay. Abbott Elllott (b'3)-111.11,99; (1'99) 2133 I'ark Are.: 10-1,5-7:30; S.

Kearney, James Francls-111.11,05:

225 W. Gartleld Mlrd.

Kearney. Jos. M. (b'i4)-111.1,97; (1'9i)

5300 S Racine Are.

KEARSLFY, MARY JFANX'ETTE (b'6:

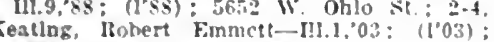
2501 Logan Hird, oftce, is k. Wash: ington $S t:$ : 3-5: S.

KEATING, VINCENT J. (b's4)-I11.22.09: (1009): $411 \mathrm{~S}$. Western Are. oflce, 600 S. Western Are. : 10-12, 1-3. - : .

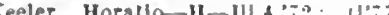

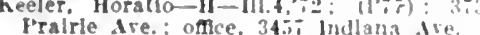

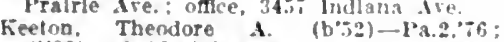
(1':2) : $559 \%$ Edgewater Terrace; nffice. 1002 Wilson Are: 1-3.

Kelth, Alrin Nelson--IIl.11,53; (1's3) : 1521 Irritog Fark IHIr!.

Kelleher. Mlchael W. (b'56) -X.Y.10,85: (I'85): $00 \mathrm{~S}$, Clcero Are: 10-11 i-S

heller, Darld Ilenry (b'6i) not in practlce: 5442 East vlew Park
not offce, Insurance Frchinge.

KELLEY, JOIIN E.DW. (b*2) - $111.0,0$, (I'05): 46:1 M!chlaran Are.: oflce. 12 E. 33 St.: $\mathbf{S}$.

KFILEY, THOMAS H. (b'\$1) \&-III.I, 0 ? (1.03): i301 kenwoud Are.: oftlee. jo01 v. 75 th $\mathrm{S}$. $; 1-3,7-8 ; \mathbf{S}$.

kellogr, Chas, S.-F;-0.2,"81: $(1 \cdot 82) ; 12.06$ F. $46 \mathrm{th} S t$.

Kellogr, Helen Reynolso-111.9.'s6: (1's6): 652 Croveland l'ark: 1-j.

KFLLY, JIMES W, (b\%-t) क- $111.1,00$; (1.00); 159 L. 11lth St.

KEILY, JOS. A. (b'p0) _.Jlch.1.98; (1"99)

36 W. 35th St.: 8-9, 2-i, $i-8$

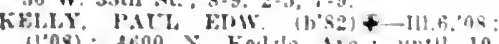
(1'08): trioo $\%$. Kellale die.: mill 10 , $2-4 ; s$

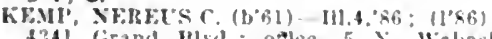
4341 Cirand Hul.: ortlee, $5 \mathrm{x}$. Whash Ire. 1-3: OALR.

KEXI)ALL, JWHX HEE (b'39)-Ky.1.08 (Teachlng): Momber Ky state Med Ason 2245 ('ampbell I'ark.

heaned5, Elw. T. (b'is)-\$11.5,05; (100.) $140 \%$ Menard Are.; onlce. $20 \mathrm{~s}$ sian St, : almo $505 \mathrm{~N}$. Sangamon sit

henny, Ilenry Hanilal $(1,46)$-Ire, $3,0:$ (I'io): 4 w. Dlrision st.: $2-4, i-k$

hensingion. MII Iotonar) (1, tii)-111 11,41 (1901): 630i Wondlawn Are.: 10-12. $4-1$

kent, James Tyler-11-0:. 1 , M०.5, (l'00): (Eranseon): oflec. Ins $x$ sitate

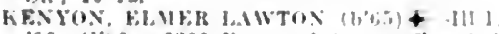

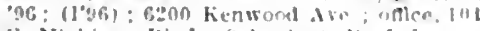

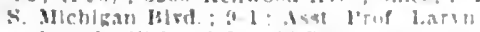

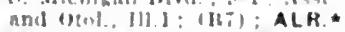

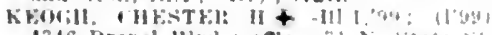

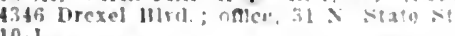
10.1

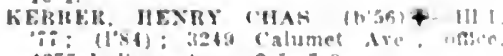

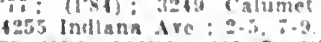

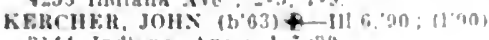
314 Indlans Are: $1-6 ; 36$.

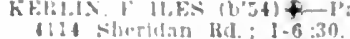

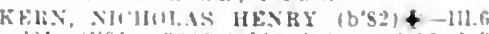

of: (I0f): $3: 3:$ Awhland Ave ; in, l-s.

hritli EILIS KIl:k

(see thak l'athi

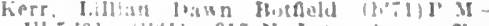
$115,01: 11911$ : $315 x$. Lotus ive. : ance

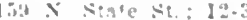

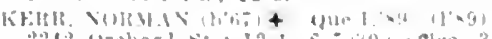

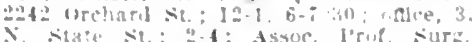

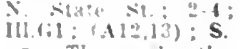

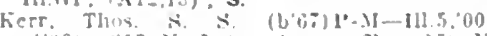

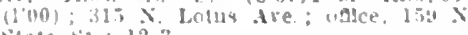

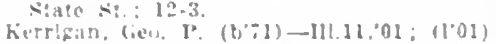
liati liarine Are. oftce, 6901 s. Halsted

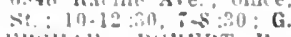

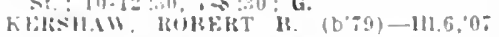

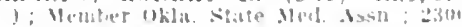
Calumet Atre.

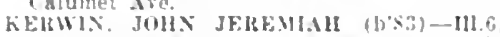

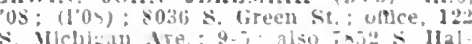

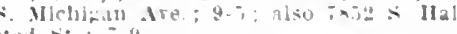

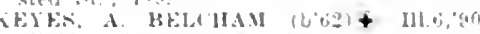

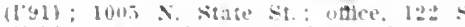

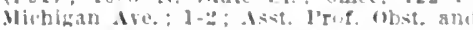

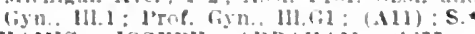

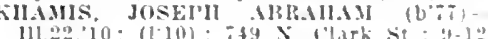
111.22

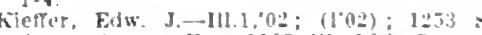
Arers Ave : antce. 1103 W. 10ih st.

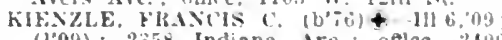
(1'09): ass Indiana Ire.; oftlce, zfoo Wentworth Ire. ; $2-4,3-8: 30:$ Pd.

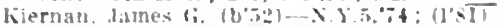
loft l'rar are: oftice, 11 N. Staie si. $10: 30-1: 50$

KIERLLFF, LTDWTG

algo Indiana Are; 0.7

kiles, John Earl (b's)-111.22,13; (1'13) ; Alexian lirothers' Iluspital.

Kilgore, Joln $11-0.3,5:(1.04) ; 364$ k:

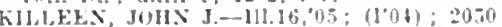
W. Izth St. Offlee, 104 S. Michigan Ire. $11 \cdot 2$.

Kimball, (cecelia P.-llt.,01: (l001); fill

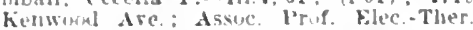
and Radiograpliy. 111.4.

KIXCHD. JHIS HERBERT $\left(\mathrm{b}^{\circ}: 0\right)+$ IHII 03: (101): $4553 \times$. livbes st. $1=2: 30$,

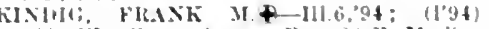
H4: Wondlawn Are, ofllec, 2 E. Madlson in. Alphonsus rincent $\left(b^{2} S 3\right)-$ Ill.11.09

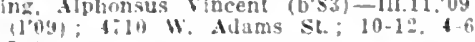

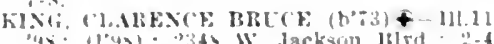

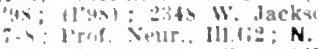

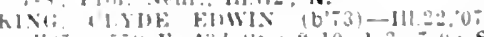

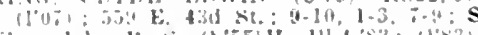

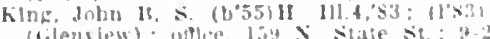

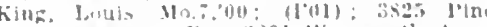

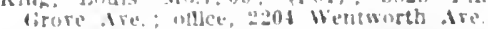
king. laxued benedice (b'it)-Mass 1,00

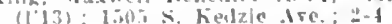

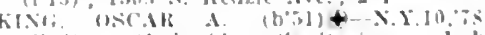
(I:A) (1.akesfle sunltarlum, labe liarera, Wis : l'00! : nalce, i W Madisen

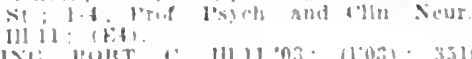
livi: livil

W

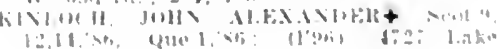

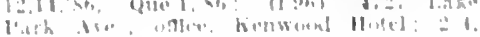

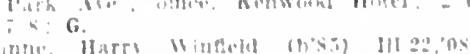

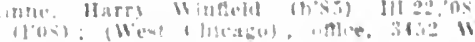
Van lisurela

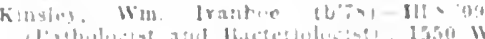

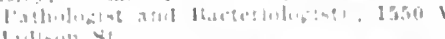

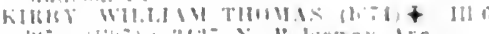

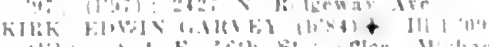

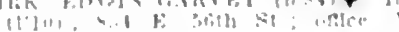

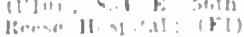

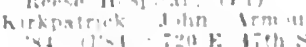

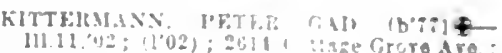
111.

k.tice. Hlcharil D. (b'bs

hlTZINi: Flikin

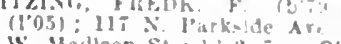

w. Madlann st: $12,2,0$ : 0 .

Kjellberz, A. Eru

Miveligan Are.

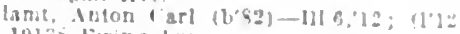

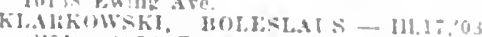

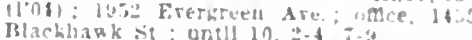

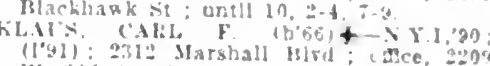
11. agd sit. $:-1 n, 1-3, \div-9$

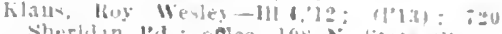

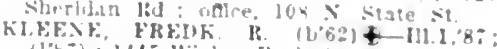
(l'4i): 145 Wirker Jark Are, 1, 1.1.8: whe bol Whatike Are: $9-11$

\section{BI! : OALR.}

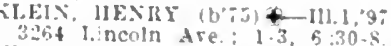

Wabash Are. Asst. I'rof if Mel, lll (il.

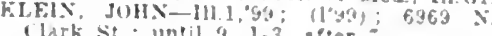

Clark st. until $9,1-3$. after

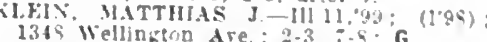
KLFIX, SIDYEY (b'50)\&-111.1.05: (1005):

$25: 3$ I'rairle Are. : oflce. 302 F. 5lst St. 1-3. :-8; Pro?. Senlor Gsn. Ill.16.

Kleinhans, Jos. IB.-II-III.4,03; 3901 Cotrage Gruve Ire.

KLEISIEIL. HENRY H. (b'69) -11.2,00

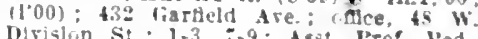
Dirision S

KI.EMPTIER, DIETRICHA - RUS.2.03 (1'09) istio Milwauke Ave. : Asst Prol. Yed. III.I6.

KLEITGEX. ARTIP CHAS + -III.6, 0 : (I'02): 903 W Garfield Bird.; odce, sot Klinck, John IIClellan (b.36)-Mo.ss:05: (100i) III W. Cbicago Are. S.11 kline. Foin (b'iso)-111.1,"s9, X.1.10,90 (l'so) $3 \times 62$ Fark Are $\$-9$ after $i$

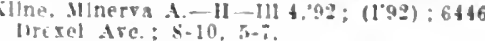

Kline. loy $11 \mathrm{~m}$ (b'a3)-I11.8.13; (1'13): $130 \%$ X. toth $\leqslant$.

Klinetup. Arthur $r$ (b'6s)H-II.1\%.9 (T"a) : batit kuvalle Ire: ofte,

Kllnetop, ihas. W' (5'63) H-111.15,'94 (1"94): 4:13 VIncennes Are.: ofleo, : N. State sit: : $1-6$.

kluow, Frank C (b'sl)-111.16,0:; (l"0:) 355 be?mont Are.

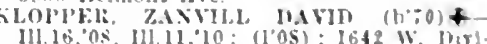
(1) $11,10:(1042 \mathrm{~W}$,

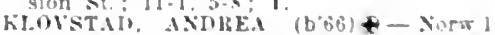

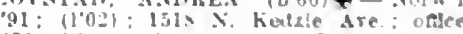

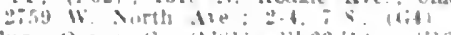

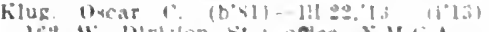

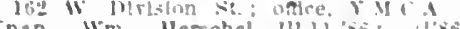

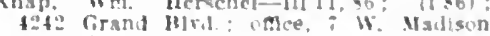
i : $10.1: 2$

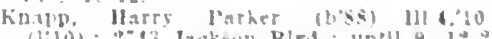

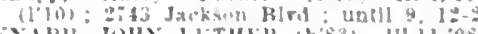

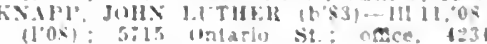
Irmltase Ire.

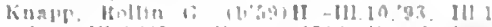

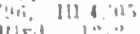

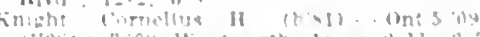

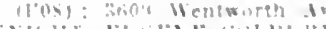

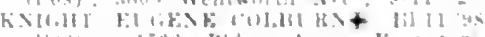

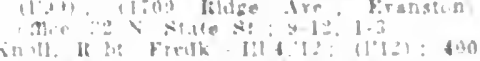

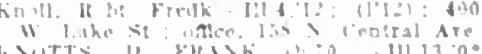

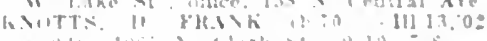

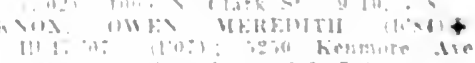

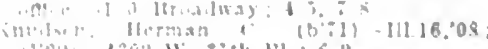

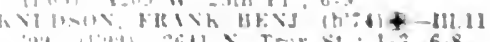


Koliak, Misraell Wm. (b'Bb)-H1.11,13; Cook (rounty letention IIospltal.

huch, Edw. I'.Mo.1.'81; (I'81); 5238 Cornell Are.; oflce, 1540 F. 53d St: $9+12$, $2-5$.

Koeliler, Gottfried-III.6,02; (l'02); 2700 Klmball Ave.; until y:30; onlec, ('ity llall; Pd.

KOFIIIFR. GI'STAY (1) 66$)-$ Ger.20.,95. (1'99):550 onkdale Ave.; oflce, 8.4 W (l'99): 550 Oakdale Ave.
Forth Ave. : $y-10,1-3, \tau$

hoehn, John w. (b'63)-1a.3.85; (1'86); 3733 Indiana Ire.; onlee, 31 X. State st.

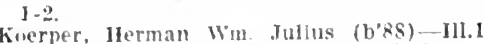
10. (l'12): Cook county 1108)ltal!

Koessel, rhedilore C.-L-111.8.96; (1'96); 1:006 Nurtil Jark Are, otthe, 108

Stite st.

OESCLEL, KARL, KONRAD (b'79) Aus. '05: (1'08) : 5626 lorcliester Ave

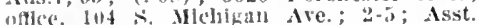
['rof. Med., 111.1: (F2,4).

livester, charlotte Margaretha SekJer (b'î) -111.11,07; (1'07); 1644 W. Congress St. KOETHE, AÁRON C.-Ill.8, 00 ; (l'99) ; 3313 W. Nortli Ave: : offtce, 1658 W. Clileago Ate. ; $2-3,7-8 ; \mathbf{S}$.

Kofoed, lianson Jullus (b'70) - 111.16,'13; (1'13) : 1845 (irand Are.

hohlbamer, Fredk. W-.Mo.1,90; (1'90); 150 Iocust $\mathrm{St}$.

Kohn Fredk. A-Ill.1,04; (l'04); $1914 \mathrm{~S}$.

Ashland Ave. : $9-11,3-5,7-9$.

Kolin, Isadure Fimil (b'89)-Ill.11,'12;(l'12) ; 1511 (iarfleld Blrd.; offlce, 4101 W. 12th st. ; $8-11,4-6$.

Koler, Louls C.-III.10,'s8; (l'Ss) ; 2243 Trlpp Are.; 9-11, 1-3, 7-9.

Kolar, Edw. E. (b'71)-Ill.1,93; (l'93) $2601 \leqslant$ Trumbull Are.

KOLISCIIER, GUSTAV (b'63) - -A US.7,'86 (1'99) ; Chicago IBeach Ilotel; office, 108

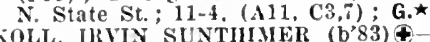

KOLL, IILIN SUNTHIMER (b'83)€-III:1, 07; (1'07); 6900 Euclid Ave.; office, Koller charles (b'53) E-Ill.8,81; (l'81) 1847 Clereland Ave.; untll 9, $1-3$, after 7 . Konzelmann, Andrew (b'53) - Mo.28,99; (I'99) ; 1959 w. Chlcago Ave. ; $8-9: 30,2-3$,

Ó-8.

ONZFLMANN, OTTO W. - Mo.2s,99; $(1+99)$
$\mathrm{l}-3,7-\mathrm{T}: 330$.

Koons, John Edwin-Ill.16,05; $\left(I^{\prime} 05\right) ; 2295$

Mllwaukee Are.; 8-9, 4-5, 7:30-9.

Koppnagle, Saul A. (b'64)-III.8,90; (l'92)

$2450 \mathrm{~W}$. Chicago Are. : 1-4, 7-9.

KOIB, MELVILLE CHAS.-III.8,96, 111.11, 07 ; $\left(1^{\prime} 96\right) ; 124$ N. Franklin St. ; office, $59 \mathrm{E}$. Madison St. ; also, $1553 \mathrm{w}$. Madison St $: 1-2,7-8$.

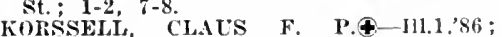

(1'86); 5609 Indiana Ave.; offlce, 5502 (1'86); 5609 Indiana Ave.; offlce
Indiana Ave. ; $10-12,6: 30-8$;.$\star$

KOSITCHEK, SOL BERNARD (b'86) Mich.1,09; (I'10); 3263 Aldine Ave. office, 3202 Lincoln Ave. ; 10-12, 2-4, $7-8$; $\mathrm{S}$.

Kossakowskl. M. P. (b'53)-Mich.6,84; (1'84); 1908 W. Division St. ; offlee, 1535 W. Division St. ; untll $9,2-4,7-9$.

Kostrzewski, Mieclslaus J.' (b'90)-Ill.22,'12; (1'12) ; 1533 W. Superlor St.

Koursoumis, Constantine John (b'87) - Ill.11 '13; (1'13); 1628 Warren Ave.; 4-6, 8-10 KOWSKY, JULIUS FRANZ (b'77) †-IIl.23 KOZENY, BESSIE FRANCES (b'79)-111.22 08; (l'0S); 1441 w. 18th St. ; I-4; 6-8; G. KOZLOWSII, JOSEPH F. (b'70) $4-I 11.13$ 01; (l'02); 4800 S. Ada St.; offlce, 1540 W. 4 th st.

,AFFT, JACOB CARL (b'74) †-N.Y.8 99 ; (l'01) ; 3038 Palmer Sq. ; offlee. 1856
w. North Are. ; $11-\bar{i}$; Pd.

KRAFT, OSCAR H. (b'72)థ-N.Y.6,96; (I'96); 2600 Hanpden Ct.; office, $25 \mathrm{E}$. Waslington St. ; $9-1$; (B1).

Kraft, Sigurd IIerbert (b's8) - Ill.11.'12; (l'I2) - so0 Diversey Parkway.

TRAMER, CARL FREDK. C. (b'72) $4-$ 111.11.09; (I'09); 1903 Belmont Ave. Henry' (b'80)-Ill.22,'12; (I'I2)

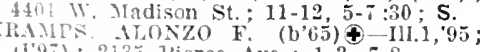
(197); 2135 l'ierce Ave, ; $1-3,7-8$.
Kramp, Joln W.-11t.1,98; (1'99); 2135 b'leree Are; $10-12,7-8$.

Kranz, Frank' J. (b'79)-Ill.10,05; (l'06) ; 20Is Thomas st.; ofllce, 1401 W. IIuron $10-1 \mathrm{I}, 1-3,6-8$.

lirasi, Jolnn Chas. Mattuew (b'91)-Ill.11, (l'13) : 3745 Douglas Blvd.

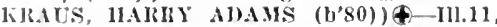
$06 ;\left(l^{\prime} 06\right)$; 4518 Drexel Blvd, ; offlee, 108 N. State St.: 11-4; (C3,7); U.»

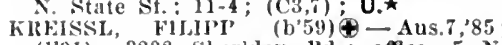
(1'91): 3202 sherldan lid.; offlce, 5 N. Wabash Are. $11-1,2-$

HIs., 111.8; (C's) ; U.` 4811 slueridin IRd.

Kress, Lauretta Lby (b'63)-Mlleh.1,94; (199) ; $32 \mathrm{~N}$. State st.

KRFTSCHMER, IIERMAN LOUIS (D'79) -Ill.6,04; (1'04); 2218 Clifton Ave. offlee, 29 E. Madison St. ; $12: 30-5$; (C 3,7 , F4) ; U.

KIEU'SCIIER, I'IIIIIP HEINRICH (b'83)KREUSEIR, TIFODORE ANTHONY (b'65) -IIl.1,97; (l'97); 2152 Montrose Ave.

KliEYE, 1'AUL (b'51) 8-III.8,'83; (I'83) 721 Brompton Ave, ; 8-10, 2-3:30, 6-8. krleg, Julius A. 'T. (b'64)-Ill.22,'11; (I'13 2147 Mllwaukee Are.; 8-10, 2-4, $7-9$,
Krleger, Wilhelm Wmil (b,77)-11l.1,03; (l'05); $1260 \mathrm{~W}$. Madison St.; 1-5.

IROGII, CLARENCE A.-IIl.1,04; (l'04) 1638 N. Fairfield Are. ; office, $2757 \mathrm{~W}$ 1638 N. Fairfleld Ave.
North Ave. ; $2-4,7-9$.

KROHN, WH. OT'TELIBEIN (b'68)థ-II.6, $05 ;\left(l^{\prime} 05\right) ; 62 d$ St. and Kenwood Ave.
office, 29 E. Madlson St. ; 10-1, 3-4: NP. office, 29 E. Madlson St.; $10-1,3-4 ; N P$. Kröll, Sarah A. (b'71)
2736 W. Jackson Blvd.

Kropacek, John Anthony (b'88)-Ill.4,'12 ; ( ) ; 2736 W. $161 \mathrm{~h}$ St.

KROST, JOSEPII (b'60)-I11.1, 81 ; (l's1) 4738 Dover St. ; office, 32 N. S'tate St. : 1-5.

KkOST, ROBT. AGEDIUSA-III.6,05 (1'05); 5650 Prairie Are.; oftice, $300 \mathrm{E}$ 61st St. ; Prof. Ped., Ill.G3; (1)2); Pd.

KRUEGER, ARTHUR H. R. (b'83) ()-Ill.11, 06 ; $\left(l^{\prime} 06\right) ; 2209$ W. Chlcago Ave. ; 1-3,

Krueger, Edw. Henry - Ill.8,12:

41 st $S$ t. and Ashiand Are.

Krueger, John H. (b'80)-III.14,'09, III.8,'12

(l'13); 855 N. Parkslde Are. ; 2-4.

Krueger, Jullus H.-H-Ill.4, 87 ;
9134 Erie Ave. ; $8-10,12-2,6-8$;

9134 Erie Ave. ; 8-10, 12-2, 6-8. (1'87) ,

Kruk, Geo. Jos.-Ill.11,'04; (I'04); 1750 W. 18 th St.

KRUMHOLZ, SIGMUND (b'71) (†)-N.Y.19, 99; (l'01); 4729 Forestrille Are.; office, 104 S. Nichigan Ave.; $1-3$; (E4); NP.

KRUSEMARCK, CHAS. '(b'54) $\$$-III.1, 79 (l'79); 2136 Indiana Ave.; office, $132 \mathrm{E}$.

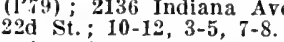

Krygier, Anna I.-Swltz.4,'96; (I'97) ; 825 N. Leavltt St. ; $8-11,7-8 ; G$.

KRYGOWSKI ANTIIONY९-III.10,'94, Ill.13, '96, Ill.4, 05 ; (1'94) ; 2854 N. Racine Are.; until $9,12-2,6-7$.

KRYSINSKI, CONSTANTINE S. (b'87)III.15,'09; (1'09); 2042 N. Robey St. ; offlce, $11.15,09 ;(1 ' 09) ; 2042$ N. Robey
1149 W. Chicago Ave. ; $7-8,2-4$.

Krzeminskl, Ignatius J. (b'73)-Ill.17,'01 (l'01); 836 Milwaukee Ave.; 10-12, 3-6.

KCBAlA, STEPILEN F. (b'78)-Tex.2,10 $\left(I^{\prime} 11\right)$; 4101 W. 21 st Pl, ; offlce, 3959 W. 16 th St. ; $2-4,7-9 ; \mathrm{G}$.

KUBICEK, ALBERT C.-III.8,'99, Ill.11,01 : (I'99); $1654 \mathrm{~S}$. Clifton Park Are.

Kucera, Jerome Francis (b'77)-Ill.11,08 (l'07); 321 S. Whipple st.; untll 9 , 12-1,

Kuehne, Wm. R.-Ill.16, ${ }^{\prime} 00 ;\left(\mathrm{I}^{\prime} 00\right) ; 1247$ George St.

KUFLEWSKI, WLADYSLAW A. (b'70)๑Ill.11,94; (I'94); $1368 \mathrm{~N}$. Robey St. ; $10-12.8: 30-9: 30 ; 0$;fice, 1800 W. 18th St. ;

4330 Drexel Blrd. ; 8-9; office, 31 , State St. ; 1-4; LR.

KUH, SYDNEY (b'66) ₹-Ger.10,90; (l'93); 4330 Drexel Blvd.; office, 31 X. State St. 9-12; Assoc. Prof. Med., III.1 ; Prof. Neur. and Psycl., III.G1; (E1,4, F4); $\mathbf{N}$.
KIHN, LEIROY I'IHLII (1,79) \&-III.11, 05 ; (1'05) : 3000 Wilson Are; offlce, 1120 w. 35tl St.; $9-\mathrm{I} I ; \mathrm{S}$

Kóuhn, Orlá k. (b'78)-Ill.8,04; (l'04); 2701 $N$. Kedzle $\Lambda$ ve.; offlce, 1520 W. Madlson

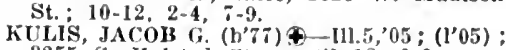
3255 S. Ilalsted St.; until i2, 6-9.

Kunz, Emil (b'48)- $\bigcirc\left(l^{\prime} 91\right) ; 650$ Briar Pl. $1-2,6-7: 30$.

Kunz, Robt. W.-Ill.17,04; (I'04); not in practice; $4137 \mathrm{~N}$. Paullna St.

KUNZ, SYLVAN (b'68)\$-111,1,9I: (1'91) 533 Diversey Blvd.; offlce, 32 N. State St. ; KUITZ, CIIAS. J. (b'72) $\$-111.6,98 ;\left(\mathbf{l}^{\prime} 99\right)$; 4136 Pralrle Ave.; 12-2, 6-8; ALR.

KURZ, HENRY GIROVEIl (b'83) -Ill.22,00 ;

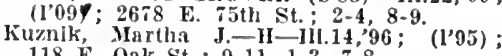

118 F. Oak St. ; 9-11, 1-3, 7-8.

uzn!k, Maxlmllian-Ill.11,03; $\left(l^{\prime} 03\right) ; 118$ E. Oak St. ; 12-2; I'rof. Phys. Dlag. and Dls. Nerv. syst., Ill. 16 .

Kyes, Preston (b'75)-Md.7,00; not In pracExper. I'ath., Ill. I; (F1,2)

Lacey, Geo. W.-Tenn.7,04; (I'04); 3640 Forest Ave ; offlce, 3671 S. State Śt. (1'7); 3201 Calumet Ave.; offle, 31 N State St.; $1: 30-3: 30 ;$ (D2); Pd.

LACKNER, JULIUS ERNEST (b'87)-Ill.1, 10 ; (I'10); 3201 Calumet Are. ; offlce, 5 S. Wabash Ave. 1 1-3:30; ObG.

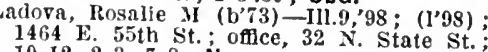
$10-12,2-3,7-8 ; N$.

LaForge, Alvin' Wilfred (b'88)-Ill.4,'11, Ill.11,13; (I'I2)； 3169 Groveland Ave.; NP.

LAFTRY, THOMAS DOWNS (b'73)-Ill.11 99; (l'99); 16 N. Kedzie Ave.; 8-10, 4-6: Junlor Prof. Surg., IIl.8;

(l'79); 417 IROScoe
St.; office, 812 Dearborn St. ; 10-12.

l.agorio, Frank Ambrose (b'84)-Ill.6'11: (1'11); 416 Aldine Ave.; offlce, $812 \mathrm{~N}$. Dearborn St.

(1'02); 10841 S. W. (b'79)-Ill.11,'02; 11100 'S. Mlehigan Ave.: 8-10, 1-3, office

Lalrd, Susan Fairfleld-11l.4, 05 ; $\left(1^{\prime} 05\right)$; AKEIFYER St.

02: (l'02); 1627 Ilumboldt Blvd.; ofllice, 2405 W. North Are, ; 1-3, 7-8:30.

Lamb, Chas. WV. (b'79)-111.16,10; (I'10) 3326 Walnut St.; offlce, 323 w. Kinzle

Lambden, Frank W.-H-Ill.4,'95; $\left(1{ }^{\prime} 95\right)$; 4037 N. Paulina St.; 8-9, 7-8:30; office, 800 N. Clark St. ; 10-2.

Lambert, Jos. S. (b'67)-IIl.6,'93; (1'93) ; 528 W. 67 th $^{2}$ Blvd.; offlce, 6358 s. Halsted St. ; 11-1, 7-8.

Lambert, Schuyler Colfax (b'76)-Ill.1,'10 ; LA MOTHE, ELZEAR (b'71)-Que.3,'96 ; (1'07); 607 Rush St.; offlce, Nichlgan Ave. and Washlngton St.; 10-1; Assoc. Prof. Ophth., IIl.8; (B8); OALR. Lampe, Henry G.-Ill.11,01; (l'01); 1611
W. Jackson Blvd.; office, 1820 S. Halsted St. ; $9-11,1-3,7-8$.

Lamping, Thomas J.-Ill.1, 01 ; (1'01) ; 128

N. Sacramento Blvd.

Lampkin, Herbert F. (b'84) - Ill.15,'08; (1'08); 2629 E. 74th St.; until 9, 6-8;

LANDAU, BENJ. G. $\rightarrow-I 11.11,04 ;$ (1'04); 3812 Indiana Ave.; offlce, 6202 Cottage Grore Ave.

Grore Ave.
LANDAU, DAVID RALPH (b'75)(-Ill.11, '03; (1'03; 4959 s. Ashland Ave.; I-2, $7-9$; (I'99); 5000 Cornell Ave, ; offlce, $25 \mathrm{E}$. Washington St.; 9-I; (B8, F4).

Lang, Henry W. '(b'76)-Ill.11, 03 ; ( $\left.\mathrm{l}^{\prime} 03\right)$; $2054 \mathrm{~W}$. Chicago Ave. ; $10-11,1-3,6-8 ; \mathrm{G}$.

LANG, JOHN IJCHAEL (6) III.11,00 ;

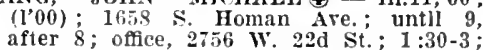
Asst. Prof. Clin. Gyn., Ill.11; Prof. Gyn., Ill.G2.

LANG, JOHN MILIS (b'65)@-III.1,95; 6; office, 31 X. State St. ; 2-4; ObG. 
Lance, Pauline $\mathbf{F}_{\mathrm{a}}-\mathbf{H}-111.15,00 ; \quad(101)$ : 1833 W. Madison st. untll $9,1-\$, 6-830$.

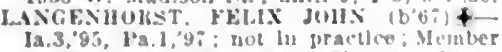
la. State Med. Sice: $\$ 143$ Sheridan H.

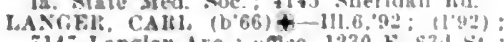
714 Lingley Are. : uflce, 1230 r. 63a sit. 3-4: S. *

IANGSIALE, HU)W: B. (l, Xit) 08: (1'08): Lakeslile Horjultal: Ob.

I.anskl, Jacol (b\%9)-Tenn.6,"06; $(1 ' 10)$ : 1021 W. lith $S t$

LAPHAM, AXXA ROSS-111.9,9m; (1'sm) ¿55 Bowen Ave. ( $(5:) ; 0$.

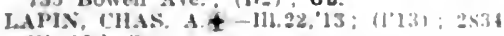
w. $12 \mathrm{th} s \mathrm{st}$.

LaPorte, Jacob-111.17,07; (1.06) ; $437 \mathrm{~s}$

Wood Si.

LAKKIN, O. ELGENE (b.55)+-1116."St (1'98): 1239 Gladys Are:; oftice, 1159 Late Park A re : $2-3$

LARKIS, WM. RIPHAFI (b;9)-111.11,0s: (l'08): 1443 S. Central l'ark Are.: oftce. 3538 Ogden Are.

Larrlson, Glen David (b's8)-111.15, 13; (1'13): $301 \mathrm{~W}$. Chlcago Are.

larken. Edward IL-IIl.39,11: (1"13) : 4305 W. Fullerton Ave.

Larsen. Lewls $0 .\left(b^{\circ} 80\right)-\left[11.22,12 ;\left(1^{\prime} 12\right)\right.$; 425\% Armltage Ave. $1-3,7-9$

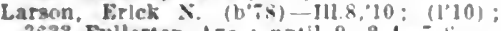
3633 Fullerton Ave p pritl 9. 2-t, $7-8$

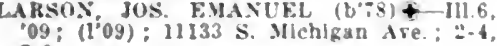
$7 \cdot 9$.

LATHAM, VTDA A. \&-111.9,95; (1'95); 1644 Morse Are. 9-5; LD.

LATIMER, HESRY HOKACE $(6 \cdot 54)-118.8$ 85: (1'\$5); 2728 Haddon Are, $\$-9,1-2$. LTIE

3133 Fillerton Are.

IATZ, PE'TE J. $\left(b^{\circ} 60\right)-111.18,96,111.16$. 99; $\left(1^{5} 97\right) ; 31$; Wilsconsin St: once, $20 \%$ S. State St.: $11-2$.

La vien, Jack Halph (b'89) - I11.11,12: $\left(1^{*} 12\right)$ : Conk County Mospltal

LAVIN, JOHN M. (b.62)-111.1,01; (1'01): $1656 \mathrm{~S}$. La salle St.; office. $32 \%$ State St.; $11: 30.1$ : also $62 \%$ inveriey lorkway: $2-3,-8 ; 5$.

Lawhon, Wm. M. (b'67)-Mo.28,98: (1'98): $1311 \mathrm{~N}$. Dearborn St: offlce, 31 W. Man-

dolph st.
Lawrence, Gerald l'elrce (t'sh)-111.1,13: (1'13): Chlldren's Memorlal Hosplial.

Lawrence, M. B. (b'36)-111.10,89: (1991); 6435 S. Ashland Are.

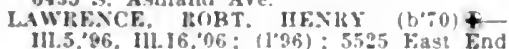
Are, once, 6218 Kimbirk Are; 10.11 . 1-6; 0 b.

Lawson, Louls K.-II1.6.55; $(185) ; 4130 \mathrm{X}$. Clcero Ave; $8.9,2.3,8-8$

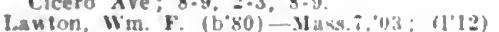

3413 ('alumet Are. onlee, 3123 s state.

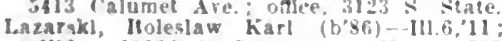
(I'Il): 11826 S. State si. aftce. 11703 Mlchigan Are : 10-12, 2-4, -9 .

leach, Mllerd irthur-ills, 11; (1’13): 6.8 f. E.Im St.

I.eaf, lluch Mark (b'81)-111.6.11: (1'11):

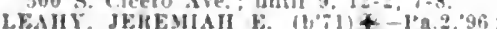
(1"96): 4337 Mlehigan Ave. onlec, $232 \mathrm{~K}$ 4.3d st. : $2-3,7-9$.

Leahy, Thoma Maurlee McFarland $\left(h^{\circ} \times 3\right)-$ III.1, 10: (1.10): 3006 W. II

harlif. (") Yrankl!n-11 ill. 6.1 W. Elm sit. omce. 14 W Washlughi Sil: $4-3$

Learlit, Herbert Autron (1, kb) 111 15.'13: (I'13i: isot liogen Are.

Learits. Sheldow (b'si) III I:7: (17i) 466: Lake l'ark Are. : $P$

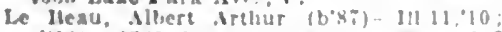

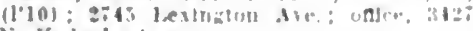
$\therefore$ Kedrale tre.

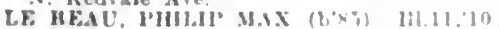
(1010): $\$ 03.8$ Irving l'ark lilud : 1.3.?

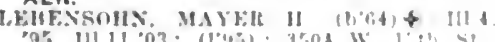

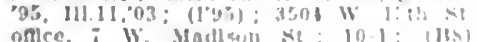
OAlice, :

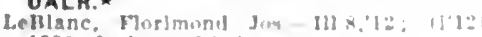

1539 Jackwn Jirit.

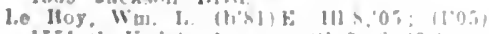

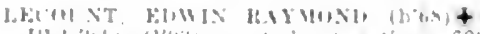

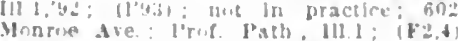

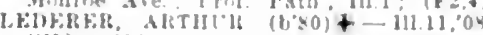

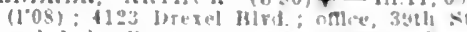

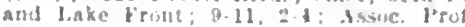
Hy. and Sanl?. Sclence, MII,

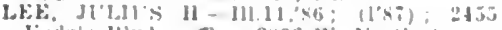
kerlale liva ; once, 2802 w Vorll dre.

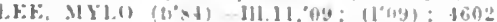

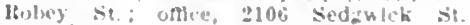
FE, NEWTON DEFOE (b.83)-111.11.08 LEE, NEWTON DEFOE (b33)-111.11,08;

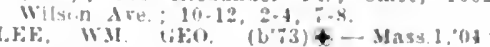
(1.05); 1251 Wilson Are.: odsce, 15.5: Broaduay: $8-10$; Asst. I'rot. Ubst. and liyil., 111.1.

latelle, fieo, T. (b'60)-111.11.91; (1.61) is site site $; 1-3$.

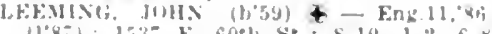

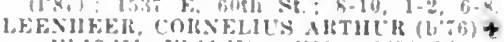
-111.13,01. H11.11,09: (1'01); 9431 I'lewsant Are. utice, 32 X. State st.: $9-1$; (IBQ) : OALR. *

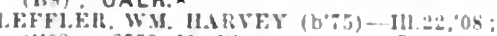
(1005); $2753 \times$. Western Are. ; $7-8.1-3$,
$7-9$.

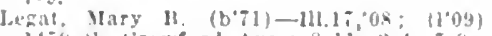

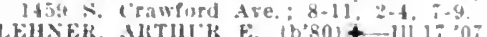
(1)0

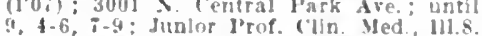

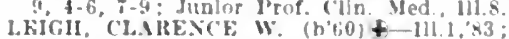
(1'85); 4053 sherilan lid.; oftce, $108 \times 3$ State st.: $11-1: \mathbf{T}$.

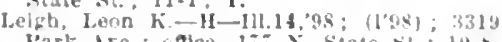

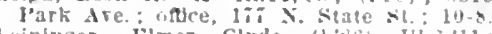
beininger, Fimer clyde $(1,26)-11.0,11$; (1'11) 39 E. Ollo st: $1-3,7-9$. $1521 \times$ wood St:

Leipold, Win. C. A. (b't2)H-111.1",96:

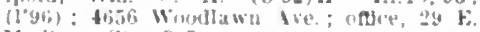

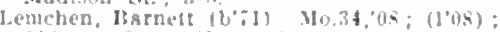
Chleagn siate llospltal.

lemke, Albert R-111.11,99: $(1992) ; 32 \mathrm{X}$ siate sit.: 3-6.

Lemard, Formellus 1arken -111.11,95; (1045) : 21 is W. Zuth St. 4 - it,

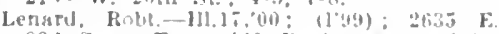
83d St: offlce, strio Burley ire.: $9-10$, 2-3, ;-8; 0 b.

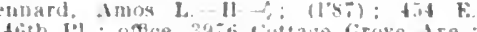

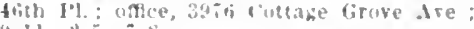

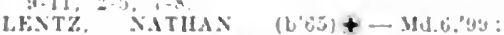

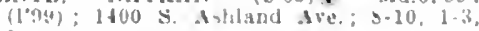

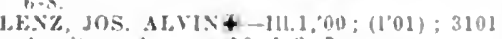
Irnitage ire : $10,1-3$.

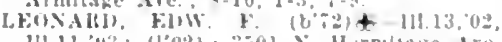

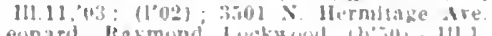

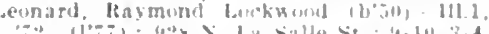

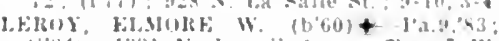

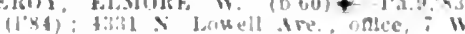

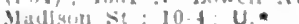

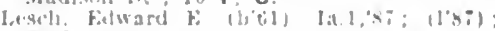

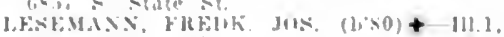

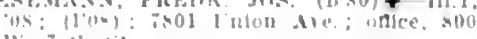
II Fill

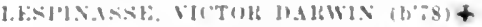

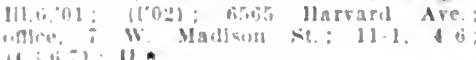

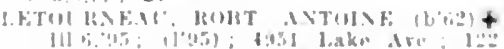

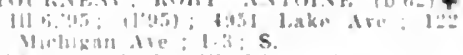

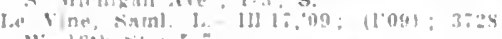

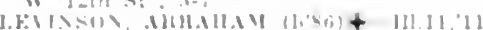
1111,1100 W Tal it $\$ 1$

L(") (1)

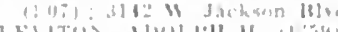

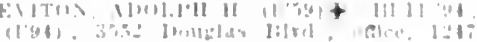

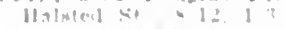

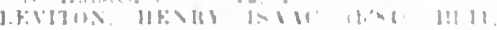

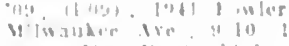

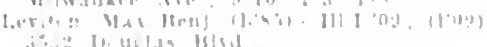

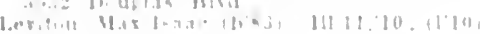

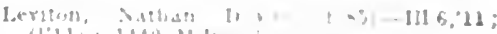

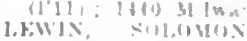

(1) $\{$ की

EWIStil fHLII

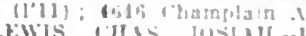

1900 carrill dre ditil

LEWIS, (IYJUE ALSTIN

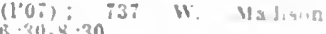

LEWIS, DFAN HE WITT

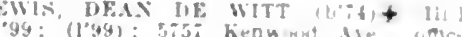

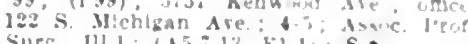

Surg, I11.1; $(A 5, \overline{1}, 13, \% 1,4) ; \mathrm{S}$.

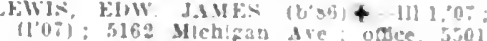

Aloil: \$162 Mleh! gas?

lewls, (ien. indrew (m) (b):

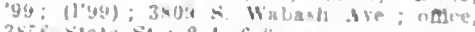

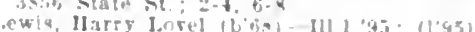
(11:1lside): odace. Itis $x$ siale si : 10-5

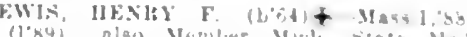

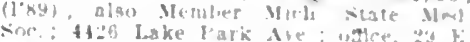
Mallion st: 1-3; l'rut lasu, III (A11) $O b G$.

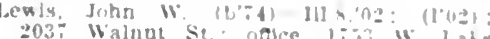

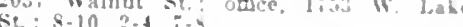
cewlo, Leonard W. (b'73)-Tenn : 64 (l’99i; 116.5 lirsud Are: once, 3e01 State st: 2 -

LEWIS, THOMAS HKXIR $10 \% 2+-116$

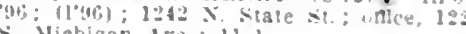
$\therefore$ Michigan Are : 11-1.

towla. Thromas whliams (b) (6) - Va 1,9 ; (1000): fits Kenmore Ire offee, is Wa-hington St.: also, 105; Wiloru ise. and 4537 Iroadway

l.ewis. Wm. Herry (1, 82$)$

$1006 \mathrm{~s}$. Nanzamon s?

rivis 0 r val. $(1.06): 312 \%$ w. I2th st athe $3 i \mathrm{y}$ siate si. 10:30-12: isst. l'rof. 1hys Diag, 111.11

JEWKE. (ITTO W. (L66)-111 5, 49: 11901 234 S. Kedzle litrd. :-5 - 9.5 Path.

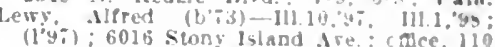

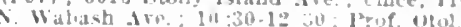
iij. 1 : $13 \%$ : ALR.

I.e\%ania. Jus Ellas ib so

J'rovident Ilospital.

l. linka Jolun $k$, (bis) - 11 . lis: iv $191 \mathrm{~h}$ S

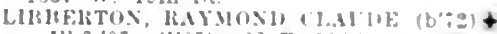

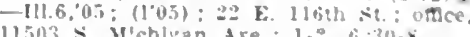

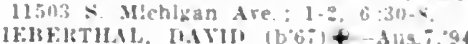

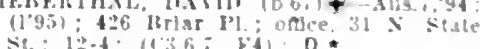

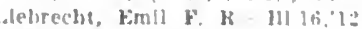

Ulirlutiona Are.

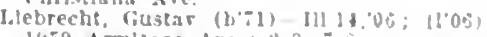

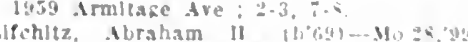

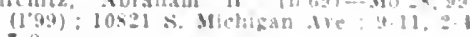
i. 8

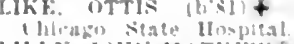

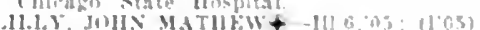

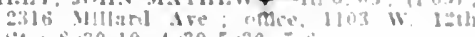

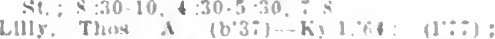

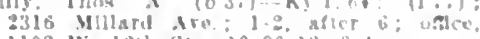

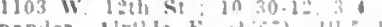

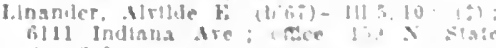

sir : $9 \cdot 8$

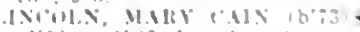

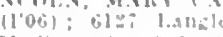

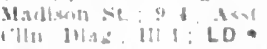

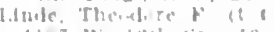

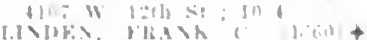

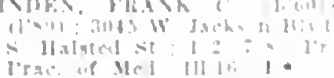

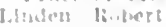

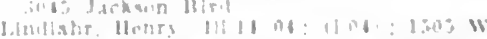

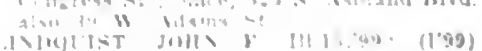

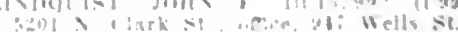


LINDAAY, JOIIN CLAREN(E (b'63) $\rightarrow$ X.Y. Y, $90 ;\left(l^{\prime} 90\right) ; 4834$ P'ra

flce, 108 S. State St. : 11-4. '08; (I'08); 419 Belden Are; oftice, 521 inebarger, Isaac B. (b'7s)-I11.6.02; (1'02) 2052 Dayton si

Link, rlaude Allen (b'79)-111.11,09; (I'09) $1623 \mathrm{WW}$. Vall 1 suren St.; $4-12,2-5,7-8$. Linn, Emma Wolcott (b'66)-111.22,'10 (1'10) : 25.51 N. Clark S

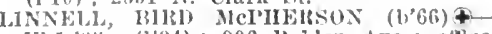
IIl. 1,$\left.93 ;(1)^{\prime} 94\right)$; 900 lseilden Ave.; othec Mit N., ill.1; (F4).

linsol., John xienry (b'S6)-111.1,'12; (l'12) Cook Connty llospltal.

J.ipinska, sophle-Ill.16,07; (I'07); 2200 IV. North Are.; offee, 902 Milwaukee Ave. ; $9-12,2-4$.

Lipman, W'm. II-I11.1I,04; (1'04)； 449 N. biel st. : $7-8$.

Jppnianu, Iewls S.-111.22,11; (I'13) get18 Taylor St.

Lipscomb, James W. (b'57) H-1ll.10,02 ; (1'02) ; 3050 W. Madison St

LIPSHULCH, GEO. U. (b'80)-111.14,06 (1'06); 920 S. Ashrland Bird.

1.1ska, Anton $\left(b^{3} 70\right)-111.16,09$;

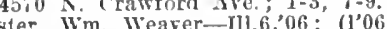

$\mathrm{S}$. iralsted $\mathrm{St}$ : untiil $9,12-2,7-9 ;$; 1546 W. $63 \mathrm{~d}$ St.; Ob.

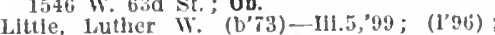
1328 Schubert Are.; offee, $5 \mathrm{~S}$.' Wabash Ave.

Little, Nelville C. K--111.5,05; (1'05); 1328 Schubert Ave.; offlce, 5 \&. Wabash Ave. LITTLE, ZACK J. +- M11.11,01; (1'01) 611 S. State st. ; 9-5; Prof. Bact., 111.16. Littlejohn, James Buchan-Scot.5, $92 ;\left(1^{\prime} 97\right)$ (Osteopatis); (Lake Bluff); oftlce, $159 \mathrm{~N}$. State St.

Lituejolinn, 3. Martin (13'67)-Ill.18,'02, 111.15 '04: (Osteopath); (Lake Blutf); office, 159 S State St

Lltvin, Abraham (b'68)-N.Y.10,96; (1'97); 835 Milwaukee Ave.; 1-3, 6.8.

Livingston, Margaret Máry (b'65)-I11.8,09 (1'10); 1739 Wells St.; 10-12; office, 550 Belmont Are.

LOBDELL, EFFIE I.-Ind.10,91 (1'92); 1555 న. Clark St.; office, 22 E. Washington St. ; $1: 30-5 ;$ ObG.

(b'89)-I11.11,12 (1'12) ; 3508 Lake Park; offce, $569 \mathrm{Ew}$ ing St.

IOCKHART, THERON D.-Ont.3,'96; (l'99) ; 1209 W. Garfield Blvd.; 12-2, 6-8.

LODOR, CHAS. HOWARD $\left(\mathrm{b}^{\prime} 58\right) \oplus-\mathrm{Pa} .1$ '82; (1'83); 3136 Indiana Ave.; until 9 $12-2,5-7 ;(\mathrm{E} 4) ; \mathrm{N}$.

LOEB, LUD'WIG MANNHEIMER $\left(b^{\prime} 78\right) \oplus-$ Ill.1, 00 ; (1'00); 4529 S. Michigan Ave. offlce, 122 S. Michigan Are.; $2: 30-4 ;$ Asst. Prof. Med., IH.I.

LOESER, WILHELM (b'76)థ- III.6,05; (1'05); 2317 Roscoe St.; untll 9, 12-2, after 'ALEXANDER (b'46)(-Aus.7,68; (1'82) ; 4354 Indlana Ave.; 2-4.

Loewe, Gilbert Mtartin (b'89)-I1l.11,'12; (1'12); Michael Reese Hosplat.

Loerenberg, Louis A-III.22,'12; (1'12) 1005 S. Paulina St.; office, 1356 S. Center St.

Loewinger, Ernest A. (b'84)-I11.17,09; (1'09); 1858 Grand Are. ; 9-11, 5-8.

Lomer, Gilbert Demnis-No.28,01 ; retired 5002 Sheridan Rd.

rofgren, Carl A. (b'69)-I11.11,02; (1'02) ; 1166 N. Clark St. ; $8-10,3-5,7-8$

LOFTON, FREDK. A. (b'T3) \&-Ill.13,'01; (1'01); 6425 Stewart Ave, offle, $449 \mathrm{~W}$ 63d St.; $1-3,7-8: 30$

I.OGAN, WI. H. G.\&-I11.22,'03; (1'05) ; 29 E. Madison St.

Lomas, James Ashton (b'69)-Ind.10,98; (1'96) ; 123 E. Erie St.

LONG, CHAS. HOPKINS (b'63)@-Que.1, 88; (188): 054 Union Also l'0s); Prof. Ear, Nose and Throat, Mll.G3 OALR.ネ

LOONIS, EDW. BEACH (b'48) - -Vt. $2, \% 0$; $\left(1^{\prime} 89\right) ; 3833$ W. Ntonroe St. ; offlce, $15 \mathbf{~ E}$ Washington St.; 1-4; (F4).
Lorrh. (ico. Joln (b'74)-Yl1.11,01; (I'03) ; $1800 \mathrm{Wl}$. (hicago $A$ ve. ; 1-3, 7-8; R Lorenz, I,ylu Iuzerne (b's8)-IIl.11, 12; (1'12); 4759 Broadway; 11-12, 3-5, 7-8. (1'?4): 2818 Miliard Ave, ; oftce, $1800^{\prime} \mathrm{All}$ mort St. : $9-12,6-8$

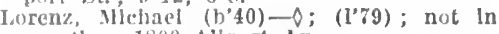
practlec; 1890 Aliport Ave

romixs, 1. 18130w' - Q que.1,83, Eng.11, 15.'s; (1'xu); 502 sheridan lid.: $7-8$ millce, 31 $x$. State st.; 9-12, 3-4:30 Asst. X'rof. (1lin. Ophth., hil.11; (131,8)

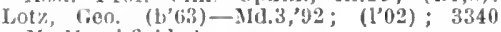
x. Narshneld Are

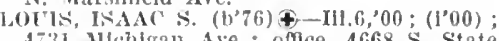
4731 viluhigan Are, ; offee, 4668 s. State st. : $9-10,1-3,7-8$; also, $31 \mathrm{~N}$. State $\mathrm{St}$; $11-12 ; \mathrm{Pd}$.

LOUNSBUHY, IBENJ. F. (b'Ti) - b-III.6,07 ; $(107) ; 2503$ W. Jackson Bird.; offlce, 2501 in. Mtonroe st.

OVE, RAMTOND STANLEY $\left(b^{\prime} 84\right)+$ Mr.b, 09 ; Menber Kan. State Med. Assn. OOVWWLL, (11AS,

60.58 Wentworth Ave.; untll 8, 12-3, after $\tau$; offle, $122 \mathrm{~S}$. Michlgan Ave.

LOVEWVLL, (MAS. IIUBERT (b'72) nfflec, $5500 \mathrm{~S}$. Halsted St. : $1-3, \tau-9$.

Low, Jos. II.-H11.10,'88; (1'97 ); 4147 Drexel Bivd. ; office, 3019 Indiana Ave.; 8-9, 1-3; Assoc. Prof. Theo. and Prac. Med., Mll.4 LOWELI, ADELBERT DCI. $(\mathrm{b}, 63) \oplus$ - III. '89; (I's9); 6966 N. Clark St.

Lowenthal, Albert A. (b'74) - M11.11,95: (1'95); (Kankakee); offlce, 39 W. Adans St.; $11-2$.

LOWENTIAL, LOUIS (b'38) \&-M11.10,79 ; (1'79); 1262 W. $103 \mathrm{~d}$ St.; 7-9, 12-5.

OWER, FRANK SUITH ('b'82)-III.16,'10 22 E. Washington St. : $9-5$.

LOWRY, NELSON H., JR. (b'86)-I11.4,'10 ; (I'10); 514 Belmont Ave.; offlee, 929 Belmont Ave.

Lowry, Robt. H.-E-Ill.8,'93; (I'93) ; 16

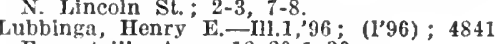
Forrestille Ave; $12: 30-1: 30$.

in practice; $2457 \mathrm{~N}$. Albany Ave. Lucas, Argancy I. $\left(\mathrm{b}^{\prime} 87\right)-$ Tenn.7, 11 ;
(1'13); not in practice; 2457 N. Aibany

Lucas, David E. (b'66)-r11.11,'99; (1'98); 3338 W. Adams St.; $3-4, \tau-8$.

LUCAS, WM. A. (b'74)-0.1,96 ; ( ) ; 3517

Flournoy St.
Lucas, Wm. Mt, (b'44)-0.1,'80; not in pracUCK 458 W. $63 \mathrm{~d}$. ,0I; (1'01); 815 Oakdale Ave.; 1-3, $7-8$; NP.

Luckhardt, Arno Benedict (b'85)-nll.1,'12;

(I'12); 1423 E. 62d St.

11516 S. Michigan Ave.
Ludwig, Alexander E. (b'78) H-III.10,'0I ; (1'01) ; 3209 N. Ashland Ave.; until 10, 1-3, 6-8; U.

Ludwig, Chas. H. (b'50)H-Ill.4,75; (1'88); 1 i21 Berteau Are. ; 2-4, 7-8.

LUDWIG, HERMAN' M. '(b'50)థ-Ill.8, 84 ;

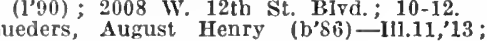

Lueders, August Henry (b'sb)

LUEHR, EDW. (b'63)€-Ill.1,'92; (I'93) ; 9141 Houston Ave.; 8-9, 1-3, 7-8

LUKEN, MARTIN GIRARD (b'82) - - III11, '06; (1'06) ; 2418 Kímball Ave.; office, $1549 \mathrm{x}$. Irving Ave.; $1-2,7-8$.

LULL. RICHARD H.-IIl.1,'83; (l'83) ; (Oak Park); offlce, 2003 Roseo St. U. Halsted St. ; $1-3,7-9,01$; (1'01) ; 6356 LUNAK, CHAS. J. (b'75)-111.23,'05; (1'05) ; 3756 w. $26 \mathrm{th}$ st

LTNDGREN, ALBERT THEODORE (b'T7)I11.I, 07 ; $\left(1{ }^{\prime} 07\right) ; 5125$ N. Clark St. ; offlce,

Lundgren. August ; E.-111.22, 05 2757 W. $22 \mathrm{~d}$. St. ; 8:30-9:30, 2-3, $7: 30-$ $8: 30$

Lundgren, Sven Adolf (b'58)-M11,10,'83; (1'84); 1656 W. $63 \mathrm{~d}$ St.

Lunn, A. E.-I11.22,12; ( ) ; 803 W. 31st St. Luria, Adolpho-Ill.11,95; (1'95); 3611 Lexington $\mathrm{St}$
Lurie, (iottlieb A-Kiy.9,04; (1'04); 1616 S. Centrai Park Ave; offce, 1804 Blue Island Are.

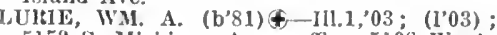
5153 's. Michigan Ave.; offlce, 5108 Wentworlh Ave.; also 104 F. 51 st st. ; 1-3, 4-6 Wor
obs.
Lusk,

Lusk, Perry Gilbert (b'87)-I11.1,'13; (l'13) ; St. Anthony's IIospital.

Luttenberger, John (ieo. M. (b'63) - MI0.2S, 06; (1'06) ; 1467 Merwyn Ave.; oflee,

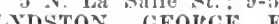

MDSTON, ('EOIRGE FRANK (b'58)ФN.Y.10; 79 ; (1'81): Kelswood Ilotel; of -
flce, 32 N. State St.; 1-5; (C3); U. $\star$ LYNAM, TIIOS. P' (i)'67) $\uparrow-111.1,00$ : (1'00); 3914 W. Nonroe St.; office, 3959 W. Wadlson st.; $8-10,3: 30-5: 30,7-8 ; 0 r$. LYNCH. 1DANL. J. (b'70)-I11.1,96; (1'96); 6157 Broadway; 9-11, 3-4, 7-9.

IYNCII, FRANK WORTIINGTON (b'i1) 4 -Nd. 5,$99 ;\left(l^{\prime} 06\right) ; 1450$ E. 51 st $\mathrm{St}$; ; of flce, 104 Nlichlgan Ave.; 11-1; Asst. I'rof.

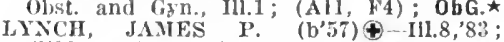
(1'83); 3210 Indlana Ave.; office, 3035 Indlana Ave.; $9-10,1: 30-3,6: 30-8$.

Lynott, Thomas Frank (b'55)-N.Y.5,86 ; (1'92); 4522 N. Racine Ave.

LYNWOOD, WHIL ANDERSON†-M11.23, 07 ; $\left(1^{\prime} 0 \pi\right) ;$ iI00 Stony Island Ave.; 8-9, 3-4,

Lyon, Edw. A. (b'71)-III.1,96; (1'96); 6253 Eills Ave.; office, 6238 St. Lawrence Ave, YON, HOWARD $N$. $\left(b^{\prime} 66\right) \oplus-\mathrm{lll} .4,88$; (1'88); (Wheaton); offil

Lyon, Jamès Harrey (b'52)-Mich.1,78; (1'82) ; 4357 Calumet Are.; until 9, $12: 30-2$, $5-7: 30$.

LYON, PAUL TIFFY (b'78)@-III.6, 03 ; (1'03) ; 1640 Rídgeway Ave.; office, 3625 W. 22 d St. $; 1-3,7-8: 30$.

Lyons, Edw. Waish (b'86)-Ill.6,09; (l'09); 6118 vincennes Ave.; offlca, 3046 Wentworth Ave.; $3-4,7-8 ;$ ALR.

LYONS, JOHN ALEX. (b'53) ๑-N.Y.8,89 ; (1'89); 6848 Anthony Ave.; 1-3; (A1,11);

Lyons; Paul D. (b'84)-Ill.6,08; (1'08); 6844 s. Centre Are.; offce, 6744 Parnell Ave.

Mabee, Melbourne (b'77)-IIl.6,'11; (l'11); 3100 Wentworth Ave.; offlee, 2204 Michigan Ave.

IacARTHCR, ROBT. D. (b'43)(4-Que.I, 67; (1'77); 1164 N. Dearborn St. ; 8-9, Emér. Prof. Derm. and Syph., Ill.Gí.

MacCRACKEN, WM. P. (b'61) (4-Ill.4, 87 ; (1'87); 1142 E. $46 \mathrm{th}$ St.; office, $32 \mathrm{~N}$. state St. ; 1-3.

NaCDIARMID, IESLIE FREDK. $\left(b^{3} 84\right) \oplus-$ Ifl.11,09; (1'09); 164 N. Asliland Blvd.; offlce, Chicago Sarlngs Bank Bldg.; 1-3, 4-6: Junior Prof. Med., III.8; $\mathrm{S}$.

MacDONALD, CHAS. (b'70) - III.1, 00 ; (1'01) ; 951 E. 65th St.; until $8,5: 30-7$; office, 3101 Wallace Ave. ; 2-4, 7-9.

MacDOXALD, EDWARD v. (b’59)థoffice, 31 N. State St.

MracDonald, John H.-111.16,'98; (1'98) ; 3100 W. Congress St.; until 9, after 7 . IIaCDONALD, PETER S. (b'36)థ IHI.1, '61; $\left(1^{\prime} 7 \tau\right)$; 2829 Indlana Ave.; 1-3.

MACDOWELL, GEORGE ALONZO (b'72) $€$ -I11.1,'96; $\left(1^{\prime} 96\right) ; 3824$ W. Adams St. : office, 2337 W. 12th St.; 9-9:30, 1-3, $6: 30-7: 30$.

IracFarlane, Wm. Allan (b'52)-Ill.11,'90 ; (1'91) ; 2137 W. Taylor St. ; offtce, 2310 Ogden Bird. ; 8-9, 1-3, 7-8; G.

Nach, Geo. F. (b'84)-I1l.22,09; (l'09); 4048 W. Van Buren St.

Machler, Francis P. (b'80)-D.C.1,'10 ; (1'13); $23 \mathrm{~N}$. Market St.

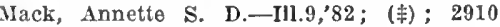
Warren Are.

Mack, Burton WiIson-Ill.11,'03; (I'03) ; 4156 W. North Ave.; after 10, 6-7.

Mack, Mary K.-IHl.15,'94; (l'94) ; 4827 Washington Blvd.

IACK, MHLTON HOWARD (b'68) †-0.1, $92 ;(1 ' 99) ; 6224$ Kimbark Ave.; offce, 7
wV. 'Jradison St. ; 9-1; Prof?' Dis. Stomach and Intestines; 'Ill.22. 


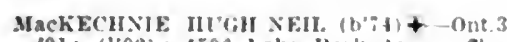
$01:$ (1'09): 4506 lake Park lire. offce, fW. Madison St. : 1.3: I'rof. Sur., 111.8: S.*

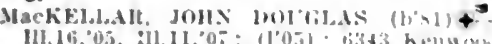

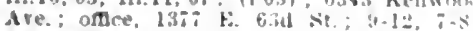

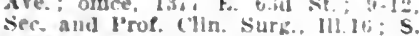

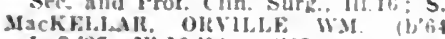
Ia.3,87, 11. 16,04; (1983); $13 \%$ F.

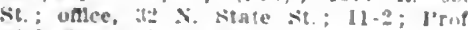
Aldi. Surg.. 111.16 ; S.*

MACKEY, ARTHI'H YOLTWN+-Ind.S.91 (I'32): 34:01 sluenteld Are; 1:30-2:30

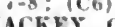

MACKEY, CORNELICS D. (b'60) - N.Y.H '89: (I'yl); 45: I'ralrie Ave.: s-10, 2-4 omce, 1213 s. Wabash die.

MACLAY, OTIS IIAHIYY $(6,3)+-1119,01$

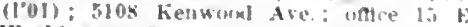
Washington St.; 1-5: (15); ALR.*

Maclean, Malcolm 13. (b'y) - IIt tios (1'08): 550.5 Iniversilv lve, ontere Watiash Are.: 10-4; OALR.

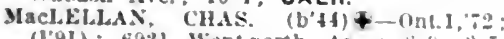
(1'91); 69:2 Wentworth Ale: : $i-9$.

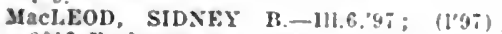
9017 Exchange Are : uttce, 215 (Commerelal Are. : 9-12, 2-4, $i=5$; $\mathrm{S}$.

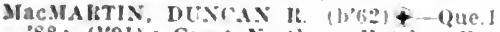
88: (1"91): Great Northern llotel: unce. 90 W. Jackson Mlvd.; 1:-1; Assoc. l'rof

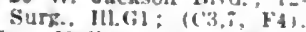

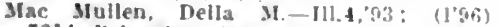

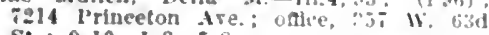
St. : $9-10,1-3, \quad ;-8$

MACNAMAKA, JOHI R. (b'63) - -111.11, 37 . (1'88): 7336 Princeton Are, oflice

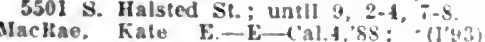
Mackae, Kale E- E-C (al.A,'s

MAYY. IIENRY COVINTOS+ XY.10.97 (1198) : 5111 Blackstone Are, once, is $\mathrm{k}$. Madlson St.; 10-4.

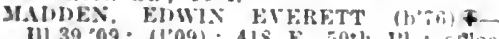

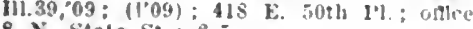

(1)

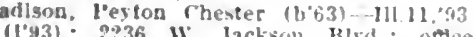
(l'y3); 2236 W. Jackson HJWd.; ontce

Madison. Wm. Darks (b92)-Ja.6,12: in tern, Finglewood IInsptsa.

MAFFT, WM. T.-1II.16,03; (lo3); 1611 w. Chicago Are.

Magee, Ira Jos. (b'89)-111.6,'13: (1.13): $29 \mathrm{th}$ and Groveland Ase.

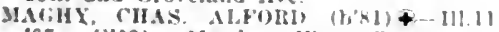
05: (1003): Member llow state Med Soc, : 1049 Dakin st: OALR.

Magnus. Idolph Marlnlus (1,'-6i)-111.6.11 (乡): 200 E. 22d st.

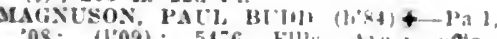

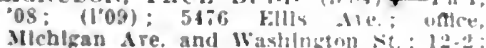
also, $4126 \mathrm{~S}$. Halsted St.; 3-5; S.

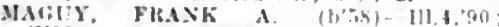
(1'90): 11500 S. Michlgan Ave, ; $-9,12-2$.

Maher, Loretta hatherine-I11.11.11; (1'11); 3323 Fournoy sit.

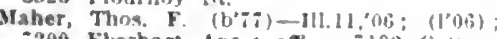
i200 Eberhart Ave: offce, $\div 102$ rentage (irove 1re: : $8: 30-9,1-3,7: 30-x: 6$.

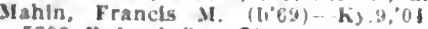

3300 Pederal $\$$ st. 0 b.

MAIONFY, GFO WW (1) (1'93): Tol Gordon Terrace; onten, What gan Blird Bleg: 1.5; l'rof. Ol, heth III. GI: (BS) ; ODA.

MAIIONEY JOIIX J. (tre2) lll 6.03 (I'03): 6053 s. if alsted st: inter, 32 ? state st: $8: 0$.

MAI, HEHMIS $\left.\left(b^{\circ} 66\right)+-111.11,90\right)$ (1'90) ; 435 W. North Are: onlce. 32. State St. : $4.6 ; \mathrm{U}$.

Majeskl. Wenzel (1'4t)-1118.81: (1'81)

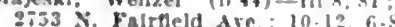

Majom, Montoe A. (b'es)-Tentin : an: (1'96): 6652 s. Whabash Are: inlce, tint? S. Stite st $9.12,2-5, \div$

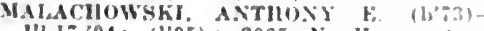

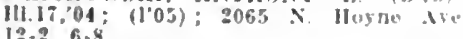

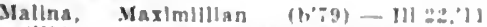

(1011): 131: W. Chleage ire; $9-11.1$.

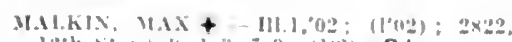

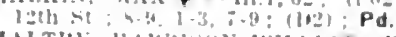

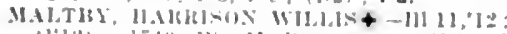

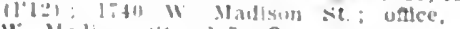
11 Madisern st.; 1.5: 0r.

Maltese, Antunis-110.10.03: (1'08); 315 Maltman, lames Fishor (b'if) $11-111.4,04$

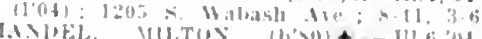

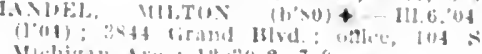

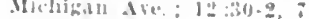

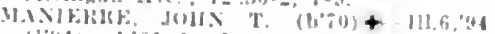

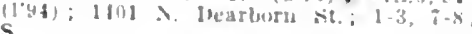

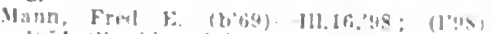
Whit sherdan led.; unlee, lto st hear tiren st.:

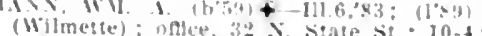
(ISS): OALR.

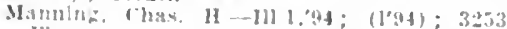

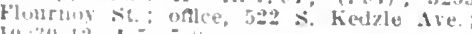

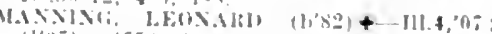

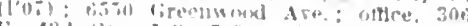
E. $43 d$ Ato; 1-i, T-8; Adj. Prof. Obst, III. 1: Ob

Minougian, krlkere M. (1, $>1)-111.11,11$ (1'il) colmmlas nompral.

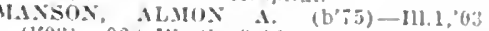

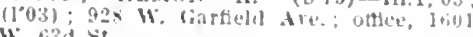
1.. liad st.

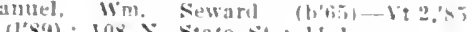

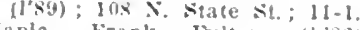

taple, Frank Fulton (bsij) Ill. I, 13 (1'13): Mlexjan Brothers' Hospltal.

Marcusson, Win. Berlnger (6,61) - Ill. 1,85;

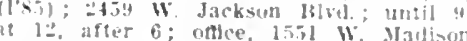
s. ; $f$; ; Jrof. of sure. III.

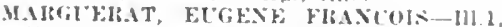
105; (1'95); 212 s. Ifoyne Are : 4-11, ti-s

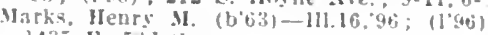
143.1 E. 5. 5 . S

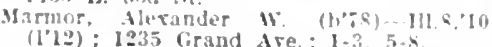

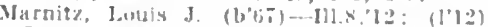

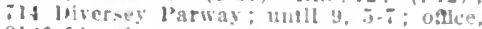
3ltif Lincoln lie.: :-1.

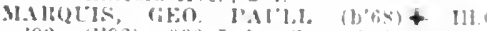
30 ; (1'92) : 999 Lake shore lirive: onlec ALR:

Marrs.

(1'12): Wreske Addiam

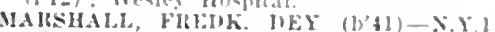
'(6), Mich. 1,65; (106): 417 s. Centul

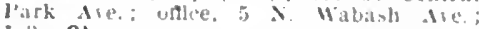
i $-3 ; 0$ b.

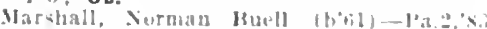

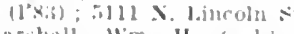

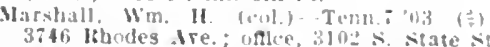

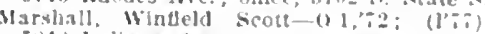
josti Indiana Are.

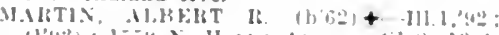

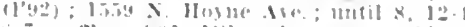

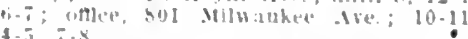
Martin, Ellswith o (bot) II-111.10,

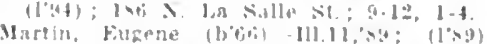

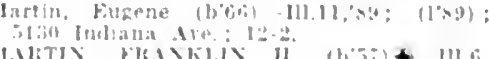

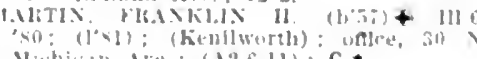
N

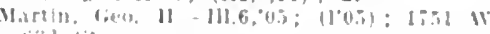

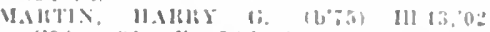

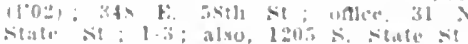

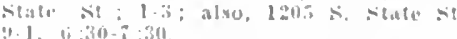

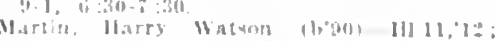
(1'12); :20.4 II Madloun sit

Martio, Lutan Marshall (b;0)-111.1,03:

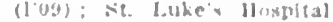

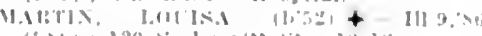

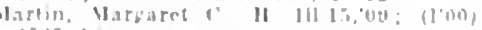

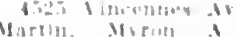

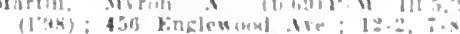

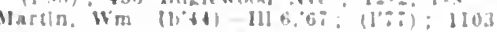

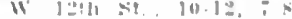

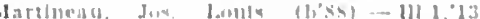

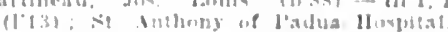

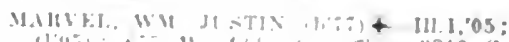
(1) tuin, III G:

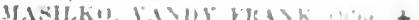

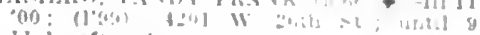
II-1, alter

Masmo Frask lirant

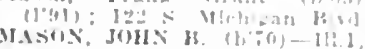

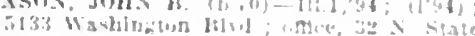

lisumination

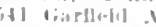

Matin, Janes firans:lle-1a 9,$94 ;(194)$ :

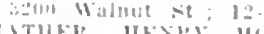

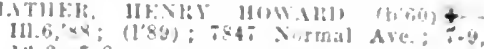
$1:-2 .:-9$

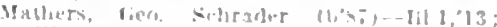

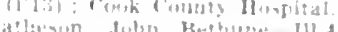

Maller's Bldg.

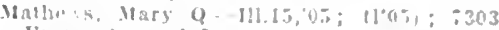

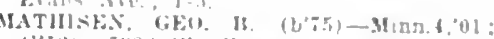

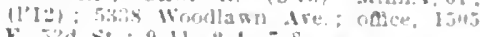
k. sid st : $9-11, \ldots-4,7-8$

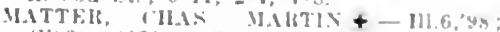

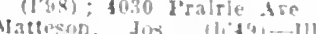

$-7116,-3:(12 \pi):$

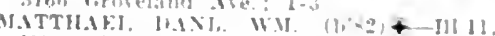
09: (1'ug): Member lua. Sitate Mevi.

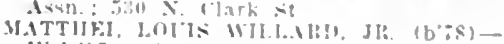
S-10, 12-2, h-s:s. Matrhed l'hil p arl

x rlark st.; $11-1$

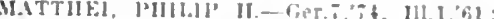

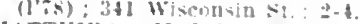

MATTHE, MALEI, VAKIF (b'83) +

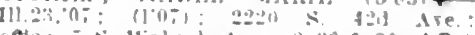

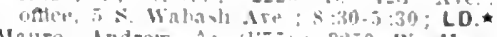
Mnuro, Andrew-A; (106); 3250 Wr. Mon. rine st.: Pd.

Maron, Mary Yan Alsten $(1,+14)$ H-In.15.

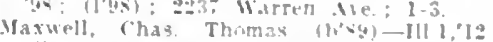

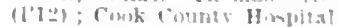

Vaxwell, Wm. slerling-1) 1?91: (191):

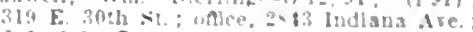
2-4. 4 -5; 6

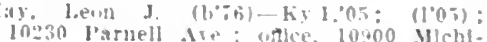
mail ive.

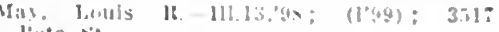
liets sit

Naser, Juhn Itenry Vat.02; (1'14: :5163 l'rairle tie.: inlop, sols and Harrison

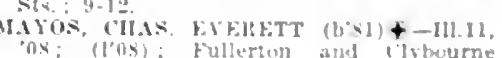
Ave : S. ${ }^{\star}$

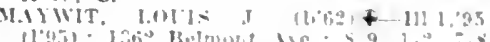

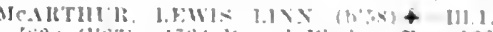

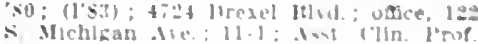

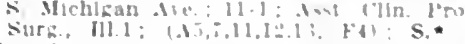

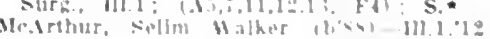

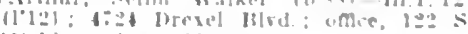
Vichlizan die: 11-1.

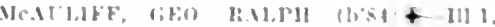
11: 1'111: alid k: tith st.

(1)

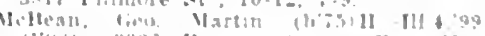

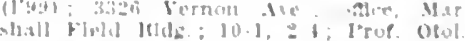
III t: OALR.

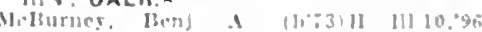

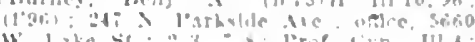
G.

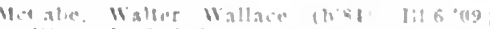

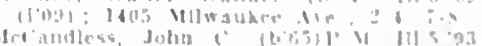

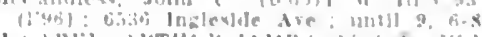

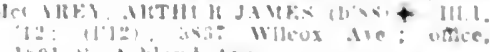
lonj st Aliland dir

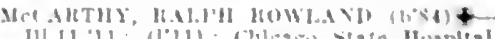

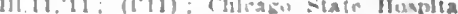

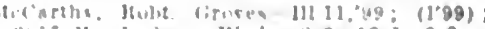


Mec(arthy, Wh.-Que.1,67; (17) ; $1520 \mathrm{~W}$.

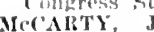
Mass. 'I0: (l'13); $4800 \mathrm{w}$ Madson st. $11-12,1-4,7-9$.

Mecmulina, lose E.-Mlch.1,90; (1’90) 4000 Cottage Grove Ave.: at $11,2-5,7-8$.

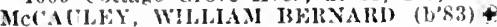
IIl.10: (1'10): 1740 Greenleaf Are: Junlor l'roe. Surg., 111.8.

MC('IAVE, ARTILI WRIGIT $(\mathrm{b} ; 2) \oplus$ 111.6,00; (1'01) ; 1509 E. 66th St.; offlce 29 s. l.a salle'st.; $9-5$

Met'lidiY, WIJBLR WALLACE (b'67) + -II.6,'89; (1'99); 165 W. 47th St. ; 12-2 6-8. ICCLCLLAN, Cla Clark st. : $9-10,3-5,8-9 ; \mathrm{G}$.

Mec'lellan, John Haneock (b'76)-I11.1,11 (l'11); 1225 E. 54 th St. ; oflce, $32 \mathrm{~N}$ State St.; also, 1203 E. 55 th St.

Icclenathan, Luclan Ford-Ill.4,'13; (1'13) IIahnemann IIospital.

Mc('LINOCK, ROY WIITE $\left(b^{\prime} 7 \bar{t}\right)-11.13$ 04 (l,04): $4=0$ Brondway ; office, $402 \mathrm{~s}$ Ilalsted St.; also, $5 \mathrm{~N}$. Wabash ive.

MeCLINTON, NELSON F. (b'74) $\uparrow-M 1$-M. '08: (l'11): Member Mich. State Med. Soc. ; 625 F. 63d St. ; offle, $32 \mathrm{~N}$. State St. : $3-6 ;(C 3,7) ; U . \star$

(b'85)-Mo.2,'12 (1) 1358 Fulton st.

(b.85)- $110.2,12$

Mc('lurkin, John C. $\left(b^{\prime} 40\right)-N$ Y. Y.10,'万1; $(178)$; not In practice; 6151 Greenwood
Are.

McCollum, . James Leslle (b'55)-Ill.6,'89 (1'92); 3119 Fulton St.:

McCollum Janet Long-III.17,'96; (1'97) 3119 Fulton St.

MCCOLILM, SALLY JOSEPHINE (b'60) 午 $-111.17,98, \quad$ Ill.9,99; (1'98); 1712 W. Adams St.; office, 29 F. Madlson St. $10-12,2-5$.

Mccollahy, Mary R.-Nich.1,90; (1'90); 8666 Vincennes Ave.; 12-2

McConnell, Carl P. (l)'74) H-Ill.14,98 (1*98); (Hinstale); office, 14 W. Wash-

ington St.; 9-4.
McConnell, John $\quad$ w. $-I l 1.11,00 ; \quad\left(l^{\prime} 00\right)$; $2055 \mathrm{~N}$. Spaulding Ave.; oftlce, $3500 \mathrm{Arm}$ itage Are.; until $9,2-4,7-9$.

McCormick, Chas Aifred-Ill.17,'98, Ill.11, 99 ; (1'98); 4210 Wilcox Are.

IcCormick, Francls J. (b'76)-111.16,09 $(110) ; 2857$ W. Van Buren St.; 11-1, $6: 30-8: 30$.

McCornick, Roht. Seth (b';9)-111.10, 03 ; (1'03); 566 Alliwaukee Ave.; offlce, 540 Iilwakee Are. $9-12,3-8$

IcCornell, James Elliott $($ b'; $;$ ) $\rightarrow 111.17,09$ : (l'09); 3221 S. State St. ; 2-4; U.

(l'09); 3221 S. State St.; $27 \%$ (I'85); IIccoy, John Cresap.

MeCREIGIIT, SAML. LUTHER (b'49)-Ill.1, '85; (1'85)'; (311 Wesley Ave., Oak Park); office, 32 X. State St.; 10-12; (B8). IcCuaig, Wm. J. (b'60)-Que.1, 86 ; $\left(1^{\prime} 90\right)$;
S08 E. 51st St. ; offlee, 32 N. State St. ;

MeCULLOLGH, CAMVIN G. (b'62) \&-0.3 83: (1’91) ; 4601 Vincennes Arc.

MCCULLOLGH, JOHN R. (b'3J)-Ill.11, '83; (I's3) ; 2302 W. Adams St.; office, Iasonlc Temple; $11-3 ; \mathbf{G . \star}$

McDERMIID ANDREW (b'54) - Ont.1,79; (1'42) ; 6325 Greenwood Ave.; (A11); Ob.

NicDermott, Lee Chas. (b'88)-D.C.2,13; (1'13): P'oliclinic Hospital.

McDonald, Alex. F.-I11.10,97, Ill.1,98; (1'97); 2227 Park Ave.; 8-9, 6-8; office, 22 E. Washington St.; 1-3; Prop. Mat. 22 E. Wash

Med., Ill.4.
McDonald, Elizabeth Josephine-Mo.28,04; $\left(l^{\prime} 07\right) ; 5743$ Prairle Are.

McPOXill, JAMES H. (b'51)థ-Ill.6, 76 (1'83); 13248 Brandon Ave : 12-1; Ob.

MeDONALD, MARION BERTH.A-Ill.22, 11: offee, $32 \mathrm{~N}$. State St. ; 1-2.

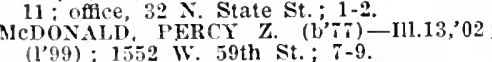

MCDONELL, ELIZABETII JENNIE-Ill.16, 08; (1'05); 2106 W. 35th St.; Ob. McDonowh Frank J. $-111.16,06 ; \quad\left(1{ }^{\prime} 06\right)$;
$13 \downarrow$ S. Waller Ave.; $7-9$.
Mclowell, John Win. (b'70)-D.C.3,98; 1'99) ; 3518 ('alumet Ave.; offlce, 3100 state st. ; 8-10, 2-4, $6: 30-9$

Melowell, Wm. C-ra.9,78; (1'93); 854 Fullerton Ave ; $7-9,2-4$.

ICDOWEll, Wir. I). (b'62) क-111.11,01 (i'01):726 S. Oakley Blyd.; 12:30-2, cDowili. WM. STEWART $9-111.6,91$. (l'a1) : 6527 Normal Ave.: offlee, $6304 \mathrm{~s}$ llalsted St. $0-10,1-2,7-9 ; \mathrm{S}$.

ICEACILELN, WUNCAN BILOWN (b'7c) t $-111.16,06,111.11,07 ;(106) ; 3229$ Cot tage Grove Are, offle, 842 W. Garlleld
Blvil.; 10-12, $7-9$; Asst. Prof. Anat., IIl.16.

MCEACIIERN, WILHELMINA C. (b'69) Ili.13,'05; (l'05); 9229 Cottage Grove tre.; l'rof. Embry., Ill.16; Asst. Prof. inat., 111.22

McEnery, John Chas. (b'69)-Ill.1,97 ; $(1907) ; 925$ Center st.

McEvers, Albert Wdwin-111.22,'12; (1'12) 1148 S. Mlchlgan Ave.; office, $1205 \mathrm{~S}$ Wabash Ave.

ICEWF., ERNEST LEWIS (b'67) - 111.1 97 ; (1'97); (1793 Chicago Ave.. Evanston); offlee, $25 \mathrm{E}$. Washington St. ; 10 - Asst. Prof. Skln and Ven. Dis., 11l.1.

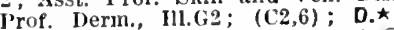

McFWEx, MARY (IILUTH (b'72) \#-111.9, $98 ;(198)$; (1703 Chicago Avenue., Eranston); office, 25 E. Washington St.; 2-3; Asst. Prof. Clin. Gyn., Ill.11; ObG.

lcFall, llose C.-Ind.4.'38; (1’96); 3021 Indlana Ave.; offce, 2912 Indiasa Are.

IfcFatrich, (ieo. W. (b'i0) E-IIl.8, 92 Masonic Temple; 1-4.

McFatrich, James B. (b'62)-Ill.8,'84, 111.4 1: (1'84): 1362 Astor St.; office, Ma sonte Tenple, 2-4

ICGARRY, CHAS. PATRICK (b'82)-Ill.11, 10: (1'10); 1355 Granville Are.

McGarry, Helen Amelia O'Sullivan (b'84) -J11.11.'10; (1'10); 1355 Granville Are.

McFidUGHEY, JOIIN A.-Ill.6,'83; (1'84) 4800 (irand Bivd. : $11-12,3-4$.

MCGEE, HARRY R. (b'78)-Ill.6,'09; (l'09) ; 1810 Wilson Are ; $1-3,7-8$; LR.

MCGIRBON, WALTER PETER ( $\left.b^{\prime} 71\right)$ 111.4,'98; (1'9s); 5339 Dorchester Ave.; ALR.

ALR. James Palmer (b'56)H-0.7,'84; (l'89): 4553 Forrestrille Are. : 10-12.

IcGill, Joln A. (b'44) H-0.7, 84 ; (1’90) 4938 Drexel Blvd.; offce, 2003 Indiana Ave.

McGinnis, James W. (b'53)-Ill.1,'83 ; (1'84) not in practice; 6404 S. Peoria $S t$

MCFONIGLE. THOS. C. (b'6i)-Ill.6.98; (l'98): 5725 S. Peoria St.; office, $5505 \mathrm{D}$ Halsted St. ; $1-3,7-8$; LR.

IcGOVAN, JOHN D. (h'53) \&-Mass.1,'S5 (1'89); 623 Oakwood Blvd.; office, 28 స. Market St. ; 11-1.

MccowAN, MICHAEL J. (b'70) \$-Md.4, 98; (1'98); 714 N. State St.; 1-2, 7-8. CGrath, Mlchael H. (b'55) H-Ill.1,'80; state St.; $9: 30-12: 30$.

MeGREGOR, JOHN D. - H1.1,'91; (1'92) 2736 W. Congress St. ; offec, 32 N. Clark St. ; $12-2,-5-8$

McGRoRY, IOS. JAY (b'72)(-Ill.8,'96 lll.11,08; (l'96) ; 3921 Grand Ave.; 12-2, $6-9$.

Mefuigan, Hugh (b'i4)-Ill.1,08; (1'10); 5405 Freenwood Are.; office, 2

Dearborn St. ; Prof. Pharm., 11.6 (1,10): 1625 Grace St.

McGUIXX. JAIIES J. (b'74)-Ill.11,01 (l'01) : 5850 Kenmore Ave.; offlce, Mich: jgan Boulerard Bldg. ; 2-4; Clin. Prof. Surg., 111.8 ; Assoc. Prof. Surg., Ill.22; S. McGuire, Desmond Francis (b'88)-Ill.11, '13; (1'13); 1200 Beldon Are.

McGLIRE, JOIIN W. (b'68) $\oplus$-MId4,'94; (1'99) ; 7424 Evans Are. ; 9-10, 6-8.

McGuire, Michael Francis-Ire.2,'11; (l'12) 748 Garfield Blrd.; office, 5453 S. Halsted

IfcGuire, Walter Geo.--Ire.2,'11; (1'12) ; 748 Garfield Blvd.
Mc(iulre, Wim. Aloyslus (b'88)-III.6.'12; shington Blvd.

McHugh, Francis Thomas-1ll.8,'11; (1'11); Cook County Iospital.

McHUGH, JOIIN A. $4-$ Ill.13,'01; (1'01) : $2102 \mathrm{~s}$. St. Louls Ave, offlce, 3437 Ogden Are. : 1-3, r.

NeHugh, M. Geo.-Neb.6,'00 ; (1'01) ; 3600 Irvlng l'ark 13lrd.; 3-4, $7: 30-8: 30$.

McInnes, Ifae Harrlson Dillard (b'89)-

III.15,'12: (1'13); 2066 Harrlson St.

IleIntyre, Chas. J. ' (1,58) -0nt.3,'84; $\left(l^{\prime} 84\right)$ :

$488 \mathrm{~N}$ Sacramento $\mathbf{3}(\mathrm{vd}$.

MeINTYRE, GFo. (b'74) $b-111.17,04$; (l'04) ; 4602 $\mathrm{N}$. Robey st.

McIntyre, John-Ill.16,13; (l'13) ; 23 Honore $\mathrm{St}$.

Mclver, Mlalcolm L. (b'76)-Ill.8,12; (l'12); 3805 S. Washtenaw Ave.; office, 2456 W'. 38 th St. ; 9-12, 6-9.

MeKEe, CIIAS. WM. (b'54) - Ky.1,'86 ; (1'89); 1110 S. Sacramento Blvd.; 1-2,

IClEE, JOS. FENNELL (b'68)-Ont.1,'94; (l'08); 5134 I'ensacola Ave.; oflice, 4400 Mllwakee Are. ; 9-10, 2-4, 7-8; S.

MCKRE, WAITER CONWAY (b'87) क$111.11,10 ;(1,10) ; 5258$ Kenmore Are. oflice, 1144 Byrn Mawr Ave.; 2-3, 7-8.

MCKENNA, CIIAS. HUGH (b'75) $4-I 11.1$, 03; (l'03); 577 Hawthorne Pl.; oflce, McliENA, CHAS. MORGAN (b'78) III.1,05; (l'05) ; 2404 N. Clark St.; until $9,5-6$; office, $108 \mathrm{~N}$. State St.; 1-2; $(\mathrm{C} 3, \mathrm{~T}) ; \mathrm{S}$.

McKenna, Michael Joseph-Ill.1,'82 ; (1'82) ; 4432 I'ralrie Ave.; office, 4647 S. Halsted St.; until y. $12-3$.

McKENZIE, DUNCAN (b'73)\&-IIl.17, 08 : (1'08); 5062 Lincoln Ave.; until 9, 12-2 $7-9$.

McKlilip, Matthew H. (b'47)-Ill.6,79; (Veterinary Surgeon); 4420 Grand Blvd. offlee, 1639 Wabàsh Áve.

McKINLEY, JAMES JOS. (b'78) ๑-I11.6,10 $\left(1^{\prime} 10\right) ; 800$ w. 78 th St.; 5-9.

MCKINLEY, JOII FRANK (b'57) Tenn. 7,$79 ; \quad\left(1^{\prime} 97\right)$; 5420 Corn

offce, 29 E. Madison St,; 12-3. 11 ch. ${ }^{\prime} 83$,

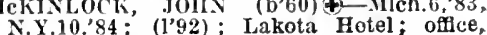
N.Y.10, 84 ; $\left(1^{\prime} 92\right)$; Lakota

$32 \mathrm{~N}$. State St.; 11-1; G.
McKInney, James Robt.-Ill.22,'12 ; (1'12) ; Western Ave and 63d St.

MCLAUGHLIN, ALBERT W. $\oplus-0.1 . ' 80$; (1'82) ; 9038 Houston Are. ; offlce, 9139 Commercial Are. ; 8-10, 1-3, 7-8; S.

Mclaughlin, Eugene F.-N.Y.10,'85; (l'93); $22 \mathrm{~N}$. Ilermltage Ave.; offlce, 735 W. Madison St.; $9-1,2-5,7-9$.

McI.AUGIILIN, GEO. L.-Ill.1, '00; (l'99) : 3355 Douglas Blrd. ; offce, 1759 w. 21 st. McIAUGHLIN, JOHN J. (b'58) $4-N . Y . S$, 79; (l'89); 4327 Evans Ave. ; Office, 608 W. $26 \mathrm{th}$ St.; until $9: 30,1-2$, after 7 .

McLAUGHLIN, WARREN BASTIAN (b'86) -111.6,'12; (1'12); St. Luke's IIospital. 811 E. 49 th St.

MCLEAN, GUY MARSHAIL $\left(b^{\prime} 70\right)(9-0.12$, '92; (I'92); 11104 Indiana Are.; office, Arcade Bldg.; 10-12:30, 2-7.

Arcade Bldg.; $10-12: 30,2-7$.
MCLEAN, JOHN (b'37)@-IIl.1,63; (l'77) ; 623 E. 111th St., Pullman; S.

McMahan, John W.' (b'70)-Ind.9,'97 ; (Earl J'ark, Ind. ; ['99); office, 302 E. 35th St: 3400 Prairle Ave.; 11-2, 5-6.

MCNICHAEL, ORVILLE WINTHROP (b'67) Ф-Ill.4,'90; (1'91); 3939 Clarendon A re. : offee, 25 E. Washington St. ; 12-3; Assoc. office, 25 E. Washington

Medillian, Paul Duncan (b'77)-Mo.2,05: (1'07); $816 \mathrm{~N}$. Dearborn St.; 1-3, 7-8

McMullen, Clarence James (b'90)-IIl.11,'12 (1'12); Cook County Hospital.

McNURTRY, TILMALAN E. (b'68) @-III.1, 99 ; (1'99); 6111 S. Ashland Ave.; until $8: 30,1: 30-3$, after $8: 30$

IcNamara. Francis WV. (b'67)-Ill.6,'89: (1'89); 3457 S. Michlgan Ave.

ICNEALY, RAYIIOND WM. (b'86)-Ill.11, 10; (1'10); 4802 Indiana Ave.; office 4254 Indiana Ave; 3-5, 7-9.

MeNEILL, SAML. J.' (b'75) $\oplus-\Pi 1.1,03$; (1'03) ; 4707 N. Paulina St.; office, 4802 N. Robey St.; 3-4, 7-8:30. 


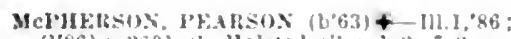

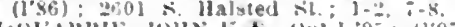

McuUAllik, Jilx K. Unt. $95 ;(195)$

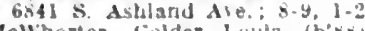

Mcllhorter. Golder louls (b'x)-111.1.13 (1'13); presbyterlan lluspltad.

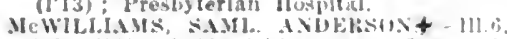

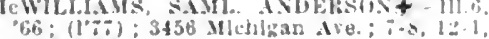
$5: 30-6: 30$.

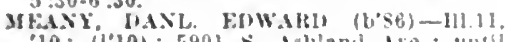
10 : (l'10): 5901 s. Ashlanel Ave; until 9, i-3, i-s; oflee, 24063 lyman sit.

MFisy. Jolix J-111.11,00; (1.99); 370 W. Cblcaso Ave ; $1-2, \overline{-}-5$

Meany, Thos kduard (b'sj) - 111.2., $0 !$ (1"ug) : 218 Balrul ats

Meath, August II. (b'liz)-III.1.'Ks: (l'ss): 305 "s. llalsted si: $10-12,2-4, i-9$

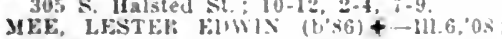

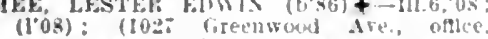
Central and Wilnutle dies., WiImette) also $31 x$. Stute st.; Asot. I'rof. Ther. III. 2.2.

MEEHAY, MARTIS G. (bij) - $111.10^{\prime 2}$ $(1 \circ \$ 5) ;$ 1341 5. Halsted S:; 3-11, 1-3,

seek, Juhn w. (b'5s)-111.1, \$1; (1"81); 2234 Washlnaton Mlid.; othle, : Hoyne Aro; 3-5: S.

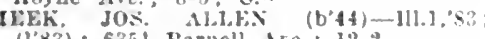
(1'83); 6351 Parnell Are.; 12-2.

Meents, Walter Itowaril (u'si)-M.\&,0

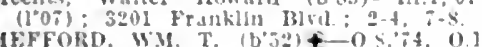

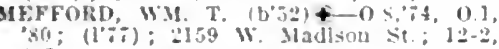
3-i.

Melers, Darld Fulward (b'S4) - Ill 22,'10: $(1 \cdot 10): 3320$ W. $12 \mathrm{th}$ st $;-4,7-\mathrm{Pd}$

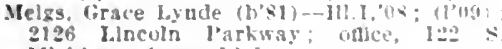
2126 Innculn l'arkwa

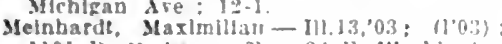
1101 l'ran die.; uftice, 22 k. Washington St. ; $10-1,4-5$

Meicher. Saml. H. (b'2S)-X.H.1,31; (1'73);

not in practice; 2327 Jackson Fivd.

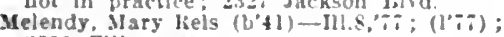
3 in Ellls Ave.

Melendy, Lobt. A-111.t,"06; (1'05); 3751 Fills Are; onlce, 3401 iofsage firore

Are: 11-1, i-s: Adj J"rof. Surg, Ml.4.

AHLISG, NkLs (HIISTIAN (b'2) \&oflice 3201 Armitage ire.: 2-3, 7-s; (Ft).

MEIJINGER, IERBEIT VICTUL.

(see Whlmetle.)

MELOY, WM. W. (b;3)-III.1,97: (1'97): 6302 Kenmore Are. office, 31 i. State st. ; $3: 30.5$.

MEX(1.EWSKl, MIGISTA Fo JUHXSONt -I11.5.99; $\left(l^{\prime} 97\right)$; thit Noble st.

MENCIEWSKI, STFHILX WITOLI (b'6o) t-III.5,02: (1'03); 924 Noble st.; untu 8. $1-3,6-8 ;$ Pd.

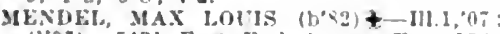
(1'07); 5431 East find Are; odlce, livi:;

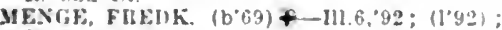
$25 \mathrm{E}$. Washington St; $10-1$; Prop. Iaryn. and Ithln. Hi.6; (lti): ALR.*

Mencersen, tien. K. - I11.22,0y: (\$): 2550 Smatley" (ct.

Meragle, Saml. (i. (b'49)-['a.1,69: (l'93) 59th st nnel cottage liruve -lve.

is.

Mennle, Amnle M.-III.1\%,01; $\left(1^{\circ} 02\right) ; 16$. Robey St.

Merizies, Hobt. Camplell (b's1)-Ill.1,0i;

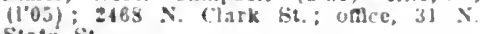
State St:

Merbitz, Martin llenry (b'si) - I11.6:11: Garlleid Hord.; 1.3, :-5: 0 bG.

Mercer, Aupustus is $\left(b^{\circ} t^{\circ}\right)-11 i^{\circ}, 01$ (1'02): 19.60 rirand Ate.: $9.11,3-7,7$

Mercereau, rarence W. $\left(b^{2}, 6\right)$ - Ill. 8,78 (1'89): 4954 Mllwaukec Ave.

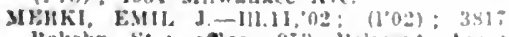
llokebs St.: once. 953 irelmont tro. $10-12,5: 30.8$.

Merrell, IIenry Hudson $\left(b^{\circ} 65\right)$ - III.14,9i ;

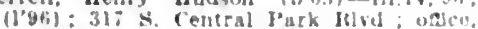

3152 Warron Ave: $10-11,2\}-4$

Merrll, Julla lijer - Ill y. 24

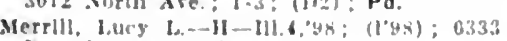
brexel Are, intll $9,2-3,6,30-8$.

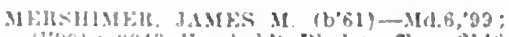

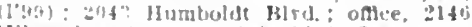

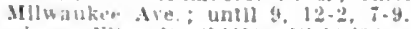

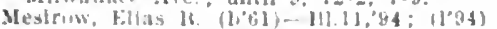

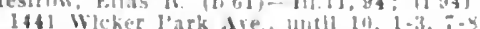

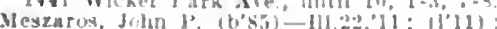

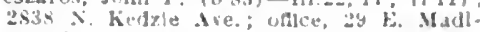

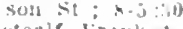

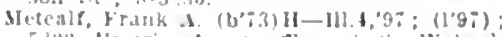

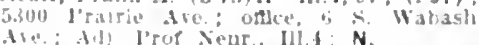

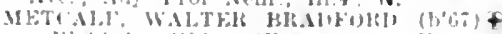

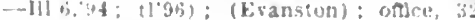

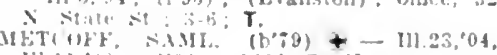
li1.11,09: (1004); Je00) S. Homan dre. f-5:30; oftee, ild3 libe loland Are.

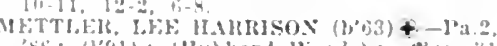

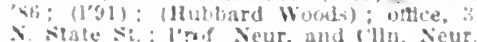
III ilate si: ; lorit

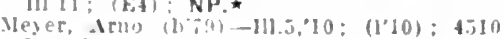
Pralrle Are: onlce, 1si $\therefore$. Clark st. $10-4$; U.

Meser, Baithazar d. (h's0)-Nurw.l.7

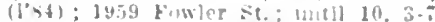

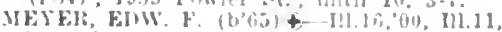

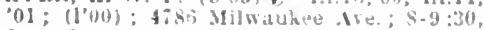
$1-\because, \quad$ i $-5: 30$

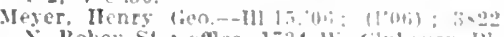

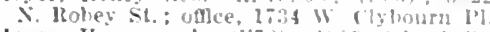
Meyer, Herman-3: (1) Meger, Julli

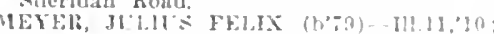
(l'10): 1259 if. it? st.; whell $9,1-3$

Meyer, Ota, Ernest-111.1;.07: 11'0i): (4:0n J. Park Ire, Gitk I'ark); o*tce, 39 W. Dilang st. ; $9-6$.

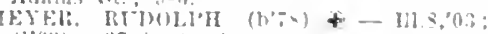

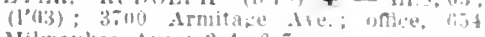
Milwanke Are.; $0-4,6-7$

Meyer, Wm. II (b'in) U.1, (los; (ln3): 901

Meyer, Wn. John (b\%d)-II1.11.07: $\left(10^{\circ}\right.$;

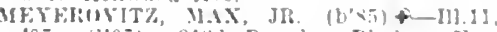

07: (1"07): 3lab Domplas Flvel. oller?

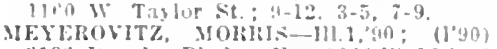

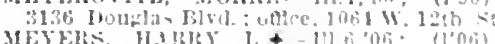

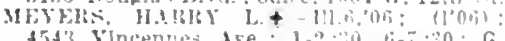

45t3 bincennes tre 1 and

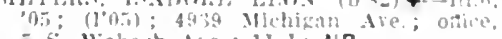

IS. Wahath in : 11-1: NP.

Megers. Juhn 0 - Il1:, 12: (1’13) : 2335 Ful-

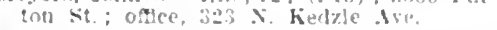

Mlohael, Herman whis (1)-

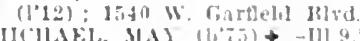

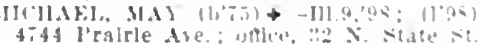

(1) : Pd.

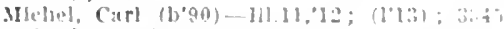

Millet

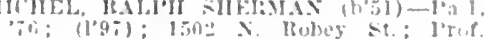
lnter Med., mitio

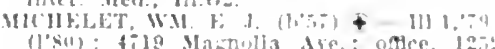
(1's(1) 4 ilg Mannolia di

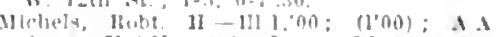

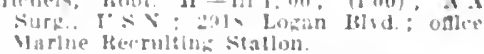

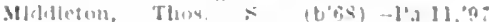

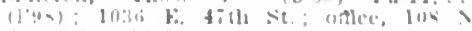

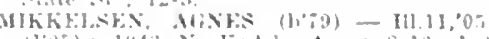

(10) ; $1: 43$ S. Kedzlo Ave, R.10, 1

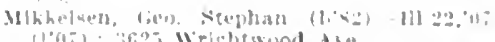

(1)

H1 K....

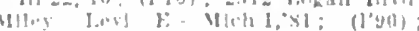

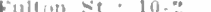

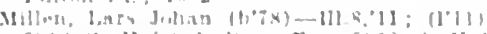

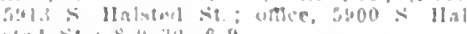

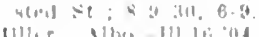

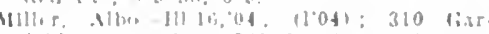

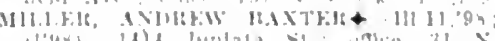

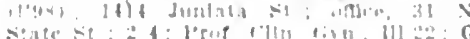

Miller. Hernirel (b); (i) - Il].11,00; (100)

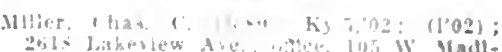

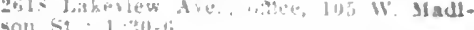

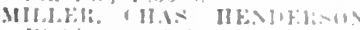

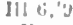

roflen.

11

MII,LER

(l'ofi)

Montroge Ave: 11-1:

MILLH, HEY $p$

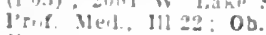

Miler, bis. J. 2 - lli.1i.

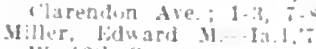

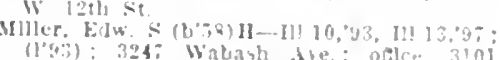
S. Nige st: $2-1, i-6$

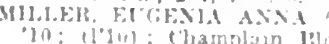

D.

MIII.Fil, rizO II

gion Klomald Ave

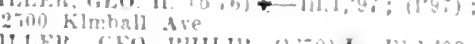

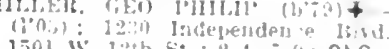

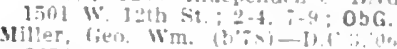

365: columet Ave : $4-11,1$.

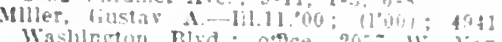
Buren $=1$; 7 (1)-2:

Miller, llarry $k$ is

923 Belmone Ave. nace, li $x$. Iear-

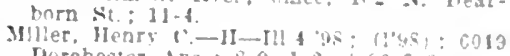

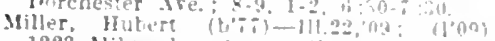

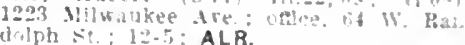
dilph : $12-5 ; A L R$.

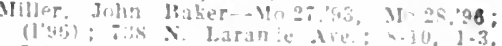

Miller Juhn Willtam (bat)--I11.6.11

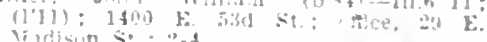

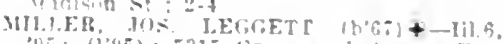

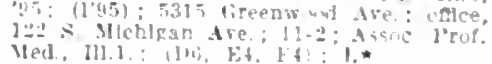

Miller, loal Mrin (bin)-111.12,12:

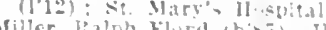

Ifller. Falph Flust $(b+5)-111.409 ;(1 \cdot 30)$

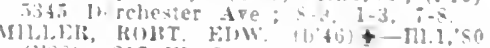

(1'ss): 217 w. $31 \mathrm{st}$

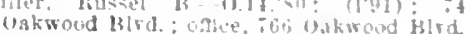

y-5.

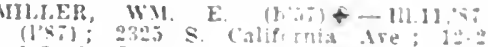

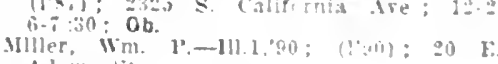
Allimis si:

Mills Cormeling $F$ (b't - Mlch $1 \%$

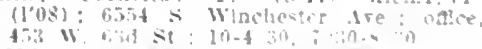

Misis, litrick

1101):

lotrage lirube Ave

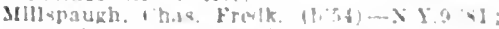
mot in proctice: 5taf roust biew loark Avt

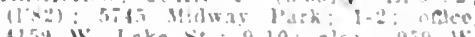

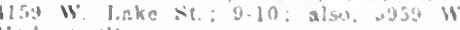
Madison st.

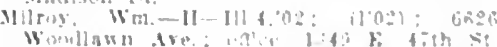

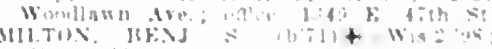
(1)1211: 3010 tat

Mnke. Jacob Joln 10 ,

3 rajulla. Sintrat re

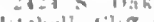

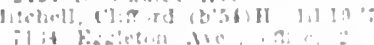

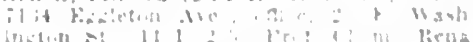

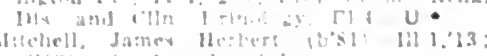

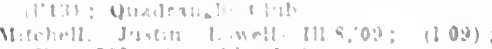

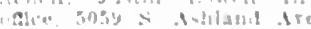

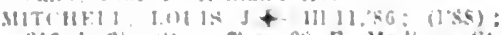

219 l.aftin st : oftor ay r. Madsson st

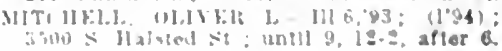




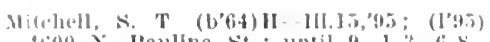

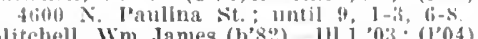
Mitehell, Wn. Janies (b'82) 11l.1,03; (l'04) Cirove

Mltzenniclier, Mraham (1)'88)-111.11, $1: 3$

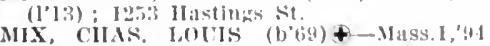
(1'94): 532 I (ireenwond Are. anter, 104

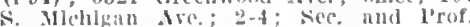
Ioly's. llag, H1, 6 ; (lid); N

MZE, HAIt AX EIICAli (1'68) +-111.10 95; (1':5); t201 Kenwnod Ave.; oflec $105 \times$. State st. : A-6; Obg.

Mizen, orinda K.-E-Lil.s, $46 ;$ (196) ; (331 lorel Ave.

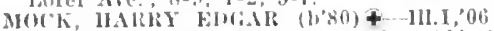
(l'0i) ; 350.2 W. Alams sis ; ntllee, 122 s.

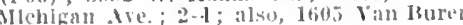
st. $S_{*} \star$

Ioe, Feo... II Ill.10,03; (1’93) ; 421 i Washligton H|r.l. : $10.12,1-3,7-8$

MOEL, LL, FREDK. W. (b'79)-111.6, $\theta 6$ $\left(I^{\prime} 06\right) ; 5: 58$ s. Ilalsted st.; $1-: 3: 30,7-8: 30$ Moeser, Ralph \&. (b'S4) - II o.35,'10; (l'13) 3338 w. 64th Yl. ; Yrof. Anat., Mo.35. Moessner, Fredk. It. (b'76)-IIl.6,01; (1'0-1) 28 - Archer Ave, ; $9-11,1-5,80$; 3843 Cottage lirove Are.

voje, llerman A.-111.14,07; (1’07); $413:$

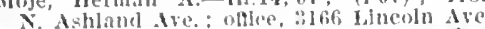
MOLDENIIACEL, GUSTAV II. (b'74) 4 Ill.11,00; (1'00); $1554 \mathrm{~W}$. Chicago Ave $8-9,1-3,7-9$.

MOLliFNIIIER, W.Y. J. (b'8I) †-111.11 $06 ;$ (I’06); 4035 W. Jorth Are.; 1-3, $7-9 ; 5$.

Molinarl, Alberico (b'76)-Ita.9, 03 ; (1'13) 1200 McAlllster I'l, : $8-10,1-3,7-8.30,48$

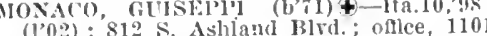
(1'02); 812 S. Ashlant

Monico, Pasqualé (b'63)-Ita.10,90; (1'06) ; 901 S. II Insted St. ; offle, I03I W. I'olk $9-12,4-7$

MOS AIIN, JMIIAS J. (b'75) - J11.11, 04 (l'11); Member Wyo. Slate Med. Soc., 62. F. $63 \mathrm{~d}$ st. ; offlec, $32 \mathrm{x}$. State; $3-6 ; \mathrm{S} . \star$ MONASI, DAVII F. (b'71) $\mathbf{f} \times \mathbf{X}, 133$ (l'46); 4735 Michlgan Are.; $11-12,5-6.460$ Greenwood Ave.; oftlee, linlversity of (')leago.

Monroe, (ifo. G.-Mich.1,78; (In0) ; 1230 E. 63 st. offlec, 1449 F. 69 th st

Montezuma, Carlos (b'66)-Ill.6,'s9; (l'96) 3135 South Park Are; office, 7 W. Madison St. ; 12-2.

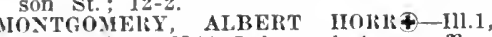
07 ; (1'07); 6344 Lakewood Ave.; offlee, 6205 Broadway; 2-4. $7: 30-9: \mathrm{S}$.

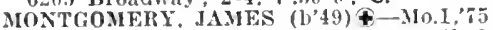
(l'91); 1508 N. La Salle St.; until 9 after 4

MONTGOMERY, LISTON IIOMER (b'4s) † -Ill.6,71; (l'7); 1416 N. Iearhorn

MovTGOMER 'WM. A. D. (b'60)-ont.x, 'S1: (l'86); 5001 Sheridan Rd.; offee, 7 S1; (1'86); 5001 Sheridan

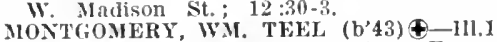
'71; (1'\%); (1107 Michigat Ave., Evans ton); oflce, 22 E. Washington St.; $9-I$ (BS); OpA.

loody, Addrian I. (b'54)-Ill.6,'82; (1'82) 6210 IIarper Ave. : 1-5

MOODY, ADELBERT MONTAGLE (b'84) Ill.1,10; (l'10); St. Iuke's Ilospital; (F4) LD.*

TOORE AIJFED NEWTON (b'73)థ MOORE, CIIS. R.4-111.1,94; (1'94); 2113 Alice 1'l. ; $2-3,7-8 ; \mathbf{S}$.

Inoore, Edw. E.-N.H.I,'84; (1'97); (1203 Ashland Ave., Wilmette; $8-10,7-8)$; of flee, 1142 Bryn Mawr Áe. ; 2-4; Pd.

Hoore, Emma IL.-I11.9,97; (1'97); 6314 Stony Island Ave.; (D2): Pd.

Moore, Ermest S. (b'69)-I11.11,03; (l'03); 2434 Orchard St.

MOORE, FLOYD B. (b'6 6 ) $\oplus-111.6,89$; (1'89); 11157 Waft Are.; offlee, Areade Blrlg.; 8-9, 1-2, $7-8$

$100 \mathrm{RE}$, FRANK DONALDSON (b';0)屯1I1.11,99; (1'98); 800 S. Oakley Blvd. ; surg., 111.22; Asst. Prof. 'Surg., Clin. surg., I11.11; s.t
Mnore, Harohl II. (1)'90)-Hll.11,'12; (t'13); Dugustalua llospital.

Ioore, Jolin Milton-Que.1,93;

4702 cirancl lilvel. ; 11-12, 4-7.

Moore, Iosiald, Iohn (b's6)-111.1,'12; (1'1:5)

wot lin practlee: 550t Cirenwood Ave

11rore, Malleom T. -111.11,85; (1'85); 4332 Kedvale Are: $s-10,6-8$.

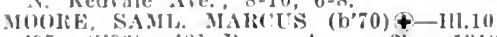
65: (1'96) : +21 liarry Ave; oftlce, 1310

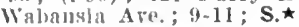

Moore, Vletorla MeLaren (b'84)-111.8, 09 (1.0i) ; $417 \mathrm{~F}$. 6ith St. ; ofllee, $702 \mathrm{E}$ 6id st.

Molt F, WI,LAs-III.f.,90; (l'90); Drexel Arms llotel offlec: 32 N. State st. : $1-3$. toore, II. Elles $(1,50)-$ III,23,06; $(1206)$ $4600 \mathrm{~N}$. Racine Are.

IOOLFIIEAD, FItEDK. IIItOWN $(1,65) \oplus$ 111.1, (16): (1'06): (Dentist): ( $\$ 03$ lin wood ive onk Park): offlee, 122 s. Mirligan Ave.; $10-12,2-4$ : (14).

IOUIILAI, EDW. I. (h'64) \$-ILl.1,90 (190) ; 35i a ackson Blvd. ; onfee, 31

MOORIIFAD. JAMES J. (b'61) \&-11.1, 95 $(195) ; 6058$ S. Halsted St. ; $1-2,7-8$.

MORAN, FLIZABE'TH FORD (b'63)-I11.17, 4.5: (1'05) ; 857 Wilson Ave.; 8-10.

MORAX, TAME HENRY (b'7i)-111.6, 09; (109): 8656 W. North Are. ; 8-9:30, I-2 $-8: 30$.

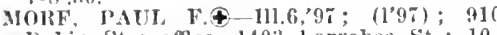
bakin St.; offlee, 1403 Larrabee st. ; 10 11, $;-8 ;(\Lambda 13) ; s$.

Morfan, James J. (b'63)-Ill.6,'88; (1'91) 29 E. Madison St. : 10-11.

MORGiN, WM. ENW (b'58)-Ill.6,82 (1ndiana Indiana $\mathbf{A}$

MOLGEXTHA, GEO. (b'62) क-N.II.1,'88 (1'85); Chicago Beach llotel; offlce, 104 \$. Michigan Ave, : $(\mathbf{B} 3,7)$; ALR.*

Morlan. IIalfori J. (b'80)-Mo.34,05; (1'05) Wellington IIotel; offlce, $31 \mathrm{~N}$. State St. 5-8: Prof. Jaryn., Hll. (:2,

MORRILL, ASIILEY BAKER (b'84) $9-$ Mass.1,11: (1'12); 4558

MORRILL, L. FIANC (b;66)థ-Ill.9,'9I (1'91); 121 \&4 Stewart Ave.; 10-11, 3-5 $7=8$.

Morrill Louis Grant (b'79)-Ill.6,'13; (l'13) St. Luke's Irospital.

Iorris, Abraham Lear (b's2)-Ill.8,'12 ; (1'12) ; 6254 Wentworth Ave.; 10-12, 2-4 $6-8$.

Morris, Robt. N. (b'60)H-I1l.4,'89; (l'94); 4517 X. Ashland Are.; offlee, 7 W. Madison St. ; $2-6 ; \mathrm{S}$.

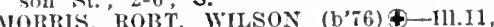
, 02 - (1'03) : 4335 Greenwood Ave. ; offlce, 4301 Ellis Ave; $1-3,7-8$.

Morris, sampson . Iames (b'84)-111.22,'10

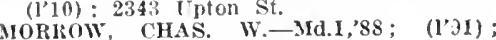
6337 Dorchester Ave.; 10-12, 5-8.

MORSE, ELIZA R.†-IH.9,'88; (1'91); 814 E. $42 \mathrm{~d}$ St.; until $10: 30$; offlee, $15 \mathrm{E}$. Whington St: 1-3.

MORTON, EDW. CAMPBELL (b'67) Ф$111.6,88 ;$
$1-2 ; 30,7-8: 30 ; 0 b$.

MORTON, FRANK ROY (b'80)థ-Ill.11,'01 ('01); 4338. Sheridan lid.; offlee, 801 Wells St. ; I-3, 7-8; S.

MOKWITZ, SAIIUEI, MORDECAI (b'86)Ill.I,'II; (l'11) ; 2538 Division St. ; offec, 2424 Division St. ; 2-3, 8-9; Pd.

Moses. Jack Jesua (b'86)-Ill.22,'10 ; (l'10) 4457 Vincennes Ave,; offee, 603 's. Hal' sted St. : $I-3, \tau-8 ; \mathbf{S}$

MOSHER, GEO. WWARNER (b'78)థ-Ill.1 05 ; (1'05); 1368 E. $53 \mathrm{~d}$ St.; office, 104 S. Michigan Ave.

loss, Chas. Taylor (b'86)-Ill.6,'12; (1'12) Iichael Reese Hospital.

Moss, Danl. B. (b'i2)-Mlo.1,96; (l'04); 5738 IIonroe Are.; offlce, $54 i$ Jackson Blvd.; 9-12, 2-5.

MOSS, E. BRL'CE (b'83)@-1ll.22,05; (l'05); 3540 W. Jackson Blrd.; offlee, 447 N. Kedzle Are.; 3-5, 7-8; Assoc. Prof. Surg., Ill.22.

MOSSER, ROBT. (b'69) -Ill.11,'08; (l'08); 1732 N. Halsted St. ; 8-9, 1-3, 7-8.
Moth, Morris J. (b'53) H-Ill.4,90; (1'90); 54.3 5. 34 th $\mathrm{Nt.}$; offlec, $32 \mathrm{~N}$. State St. $3-5 ;$; l'rof. Mat, Med., Ill.4.

llott, Joln w.-lli.1,83; (1'77); 1067 Alnslle St.: 8-9; ofllec, 104: W'llson Ave.; $9-12$

MO'TYR, 'JIOMAS IRA.

(See ()ilk rark.)

MOULDING, WHOU CARPLNTER (b'50) $-111.23,06, \quad 111.11,09$; (1'06); 3336 VV. Monroe st.; ofllee, 508 \$. Dearborn st. $12-2$

loulion, Fugene A.-III.4,06; (1'00); 839 Wellington St.; until $9,6-i: 30 ; \mathrm{S}$.

MOWRY, AIBEEIT EARL (b'73) 4 -Ill.6, $98 ;(198) ; 3505$ Indlana $A$ ve. ; 12-1, 7-8; $(\mathrm{C} 3,7) ; \mathrm{U}$.

Mover, Gertrude Bilger (b'82)-IIl.8,09: (l'09) ; $1955 \mathrm{~W}$. Monroe St

MOYER, ILAROLI N. (b'58) $\uparrow-111.1,79$

(1'79); 5455 East End Ave, ; offlee, $31 \mathrm{~N}$.

State St.; $2-4: 30 ;(\mathrm{N} 1,4, \mathrm{~F} 4) ; N_{*} \star \star$

Moyer, Rápl Emerson (b'82)-1ll.8, 08 ; (l'08) ; $1955 \mathrm{~W}$. Monroe St.

MUCINIC, ADOLPII MAUICE (b'75) 6111.11,11; (1'11); 1305 S. St. Louis Ave.

MUEJIER, AN'TON D. (b'63) —-H1.5,'96; (1'96); I854 W. I2th Hivd.; office, I008 S. Haisted St. ; 8-10, $3: 30-7: 30 ; 0$.

IUELLER, EDW. WM. (b'80)థ-11l.1, 02 (l'04); 3401 Southport Ave.; untli 9 $1-2,7-8 ;$ LR.

Itueller, Frank Louis-Ill.11,95;

(l'95) : 4406 N. Clark St.; until 9, 12-2.

IIUELLER, FREDK. (b'71) $\oplus-$ A us.7,'96 Stale St. : 10-12, 2-4; Prof. Ortho. Surg. Stale St.; 10-12, 2

MUELI,ER, GEO. (b'67)థ-Ill.1,'94; (l'94); 2024 I'ierce Are.; offlce, $209 \mathrm{~S}$. State St. $3-4 ;(\mathrm{F} 1) ; \mathrm{S}$.

MUELLER, LOUIS A. (b'74)-Ill,1,99 $(1,99) ; 4613$ N. Robey St.; 12-1, 6:30-

MULDOON, JOHN, J. $\quad\left(b^{\prime} 64\right)-I 11.6,94$; (1'94); 1212 N. Dearborn St.; 8-10, MULLAN, EUGENE A. (b'49)థ-1'a.2,74; (1'7i) ; 1811 W. 21st St.; until 10, 4-6.

Mullen, Michael C.-111.11,'94; (1'94); 5900 Wentworth Ave, ; 1-3, i-9.

MULLEL, FRED HERMAN (b'86)-III.8,'09 ; (1'09) ; 2575 Emerald Ave.; 8-10, 2-4, 7-8. IIunch, Frolk. Elmer-Ill.6,07; (l'07); 757 W. 79 th St. until $8: 30,1-3,7-8$.

I UNDT, GUSTAFE HENRY (b'83) (-Ill.22

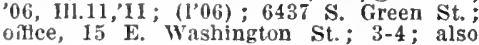
6300 S. Halsted St. ; $10-11: 30 ;(B I)$; OALR. *

Ilunson, Leonard J.-Ill.16,'06; (l'0ß) ; 1331 N. Arteslan Ave.

IURDOCK, EZEKIEL P. (b'45)-Ill.1,80 ; (1'80); 1824 Washington Blvd.; 4-6. ILurphy, Belle B. (b'i1)-Ill.16,'10; (l'10); 3134 Rhodes Are.; 4-6

IURPHY, CHAS. T. (b'72)థ-N.Y.10,95; $\left(l^{3} 97\right)$; 6433 Mlinerva Ave.; offce, $1105 \mathrm{E}$. $63 d$ St. ; $2-4,7-8: 30 ; \mathrm{S}$.

Murphy, Cornelitus Augustus $\left(b^{\prime} 6 \pi\right)-N . Y .13$ 98 ; (1'04); 2001 Warren Ave.; offlee, 9055 Commercial Ave.

MURPHY, DANL. E. (b'71) $-111.6,01$; (1'01): 2226 Semlnary Ave. ; offlce, 1624 Fullerton Ave. ; $9-10: 30,1-3,7-9$

MURPIY, EIAM TUR EER (b,76)థ-Ill.11 08 ; (1'08); 2356 W. Van Buren St.; offlce, 32 N. State St. ; 4-6.

Murphy, Frank T.' (b'78)-Ill.11,02 ; (l'02): 4242 W. Jackson Blvd.; office, 4259 W. Madison St. ; 2-4, 7-8.

MURPHY, JOHN BENJ. (b'57)-Ill.1,79; (l'80); 3305 S. Mllchigan Ave.; offlce, 104 S. Michigan Are.; 2-4; Prof. Prln. and Prae. Surg. and Clín. Surg., Ill.6; $(A), 5,6$,

ITURPHY, JOHN JOS. (b'82)-Ill.11,'11 ; (l'11); 4742 Calumet Ave.; offles, 6901 S. State St.; 12-4, 7-9:30.

Murphy, Patrick A.-Ill.11,05; (1'05) ; 1923 W. Garfleld

Iurphy, Ralph Dollahan (b'87)-IIl.11,'12; (1'12); 1446 Jackson Blvd.; OALR.

Iurphy, Robt. Cornelius (b;79)-111.8,'12 ;

(l'12) ; 114th St. and Homan Are.; offlee, 718 W. $63 \mathrm{~d}$ St. ; 11-1, 6-8. 


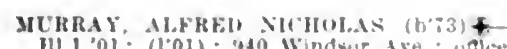
111.1.01: (1'01); 40 Wiadie' dve : unter 95 F. Wahlington st. : 11) 1? ;

MURRIY, MICHAEL, Y-III L,9I: (1"31) MUR.lY, HCUAET,

Murray, Wm. K.-Ill.6,95; (I'gs): $61+$ Woodland I'ark; once, 29 k. Madisur st. $11-1 \%: 30$.

Musgrave. Georre James (b'06)-In.4:01 (10is. Mllchizan Ire.

MUSSELMAX GEO. HFERY (b'S2) - III II 09: (l'09): 314 Sherldan Hd.; oflce, 1603 Brosules

MYERS, CARLFTON \&. (b,79)-HII1, 03 (1.03): $059 \mathrm{~S}$. Halsted St, I-2, i-S:30

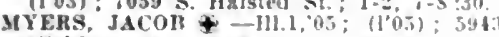
Illchican Are.; oflce, 456 W. Gid st. $9-10,2-6,7-3$

Iyyers, Iouls M. $\left(b^{\prime} \$ 6\right)-111,6,10 ;(1 ' 10)$ 1722 W. $121 \mathrm{~h}$ St. Hud.; offce, 1001 s P'aullna St.; $11-1$.

MYERS, WILSOX ALEXXYINER (1,83) III.1,12; (1'12); Mlagel Reese Hosplant. Nadeau. Oscar Fugene (b'ss)-II1.1,13: (l'13): Oscar Fugene (b's

Nadler. Benj. M.-III.22.12: (1'12): 3.54 W 16th St.

sadler, WaJter Herman (b'ss)-Ill.6,'13; (l'13); Cook County Hosultal

SAFFz, EDWIYł-111.1.93: (193): 2904 Archer Are.: $8-9,12-1$.

NAFEL, JOIS STEPHAN $\left(b^{\prime}-t\right)+-[11,11$ 98: (1'98) : ill S: Central l'ark Are. 8-9, :-8; once, $5 \mathrm{i}$. Wabash Are: $11-1$

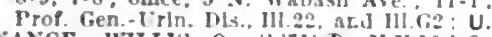

XANCE, WLIS O. $\left(b^{\prime}, I\right)+-X .10,43$ (1'93): 5213 Kenwnorl Are ; oflce, $32 \mathrm{~N}$ State St; 10-1; (I11,8); OALR.*

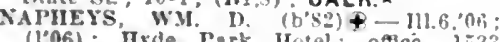
(1.06): Hyde Park IIotel: nftice, is.33 llvde Park Blrd. 12-1, :-8; NP.

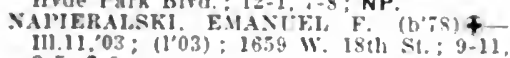
$3.5, \div-9$.

Napper, Boss Anthony- Kr zan: (1'?l)

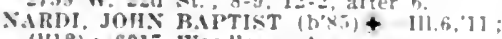
(1.12); 6017 Woodlawn ire.

Sate. Rarmond Jesse-111.1, 92 : (1.92); 724 E. 46 th St.; 9-3.

NATHANSON, FRANK LAI'IS (b'81)-

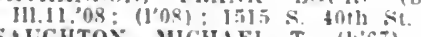

NAECHTOE, MICHA.1 T $\left(h^{\circ} 67^{\circ}\right)-111.11$ 94: (1'94): 323 F. Jlst sit.

Neft Enery Bowers (1,41)-111.11,13 (l'13): 3410 Rhomp Are.

Nell, John Alexander (b'79;-I11.22,'10 $(10): 1858$ W. Idamis st

Velli, Sewman $\left.1 h^{\prime} \$ 1\right)-I 11.22,04$; not In

practlce: 3203 S. Clark st. (834. Cuyler dre., thak l'ark): once. 31 N. State St.: $1-4$.

Nelswanger, Chas Sherwoul (b'st)-111.1\% $98 ;(1,99): 22 \mathrm{~F}$ Washlugton $\mathrm{Si}: 8-1$.

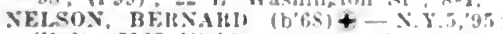
(196); 5123 Michlgan Ire.: $1-3,6,-8$

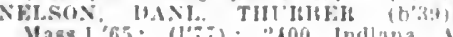
$10-1=:(A 1): G$

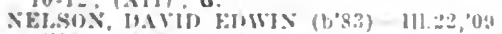
(1"09): 5335 w. Thleago Nie.

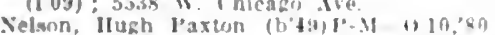
$(1.86): 1650$ W. Jackson HIrd.; $8-4,1: ;: 50$. $2: 30,6,8$

Vielson, James A. $\left(b^{\prime} 68\right) \rightarrow 0:(196):: 363$ is pirlsion sit.; $9+10,3-5,-7-8$

NHLSOX, MI'JARI, - III.13,03, 111.11, "ค1

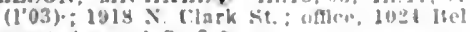
ment ire : $1-3, i-0$.

NEISON NATHANIR, C. (b's) ObG.

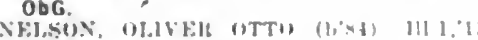

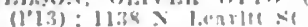

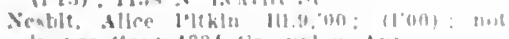

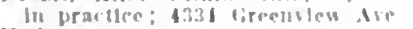

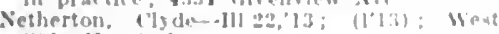
side IInsplial.

NELMANS, rMAs $\left(\mathrm{b}^{\prime} 60\right)+11130,04$

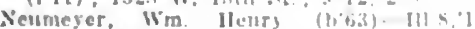
(1"13): "2134 Wawnlanel ate

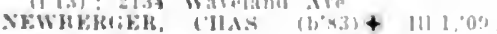

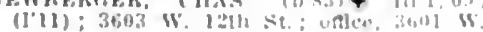
lith st. : $3-5, i-5 ; 0$ b.

Newell, Amos J. (b"3.i)-111, 1,92: (1042)

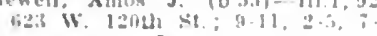

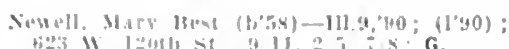

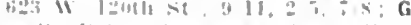

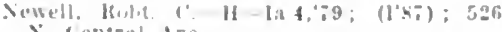
entral Ari

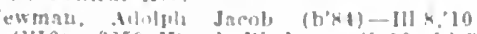

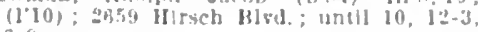

Newman, John Lewls (b'si)-111.11.09:

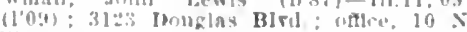
Weslern . Il

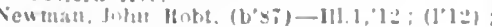
st louke's Ilumplial.

NEWTOS, HERMIN C. (b'ib)-111.60, (1) 05):" (Deulist): 2134 Indiana lie is Niclabls, chas. l.yman (b'73)-0.2,4., III 1 , "ak: (1'4i)); j115 Pralrle Ire

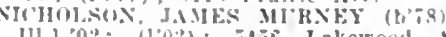
111.1, $02:\left(10^{\circ} 2\right): 5435$ Lakewoml Are. nafe. \i31 Bryn Mawr Are; 10-12, 4-6. $7: 30 \cdot 9: 30$.

NiCHOLAON, IBOSCOF M.IX (b'87)-Coln.5. 05: (I'] ) : 45.31 Sherldan Rd.: oflce, II S. Mlloligan Ire.: 10-12: N.*

Nickersol, Fdw. J.-Ia.1, (I'90); Arllng. ton Hotel; oflce, 25 W. Madison

Nekey, Barbara Marle $(i, a f j)-I l l .11,12$ (1"l:): Cook rounty Hrepltal,

NicuLal, JUH. LF(ixAlil (b'81)-111.11.

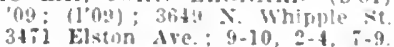

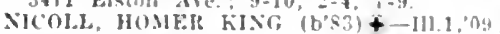
(l'09): 4919 West Find Ire.; uitice, $122 \mathrm{~s}$ Mllchiman Are.: 4-6.

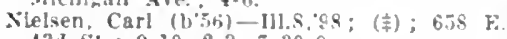

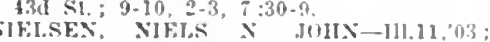
(1.03) $2002 \times$. hedzie Are.; untll $9: 30$ $12-2, ;-8$ Nemeser (ien. Beekman (b'84)-III.11,09:
unt in prartice; 1512 Melrose st.

NILES. Fllw. (6'84)-III.1,0\%; (1'07) ; 4722 Slles, John Whiting (b'51) - N.Y., "56: (17i): 4:22 Winthrop lve; oflee, 353 w. "uisislon St: 12-\#, i-s

Nilssion, Martin Morris (b's)-1ll.6, 13 (1'13): 25It I'rairle It

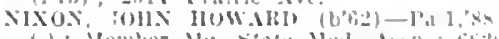

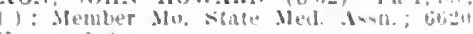
ketwoml die.

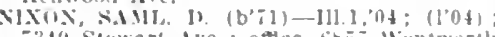

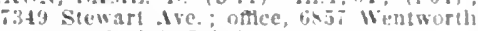
Are.; $9.11,2-1,7-8 ; 30$.

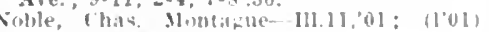
731i lecorla sit.

soble, sarah I. (b9i9)-111.5,05: (1'0.5)

if Koss ite

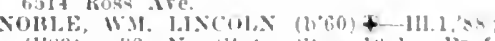

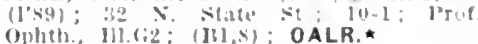

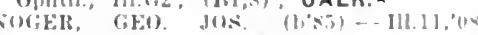
(los) : 2sje Rome Ave.

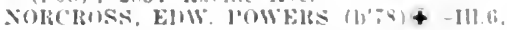

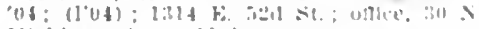
Mllablean ire

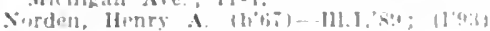

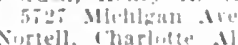

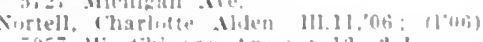

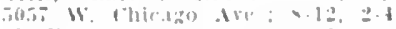

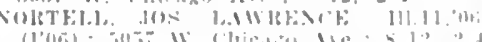

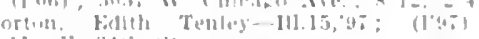

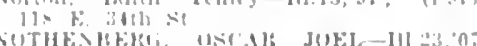

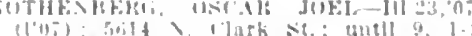
(I). OALR.

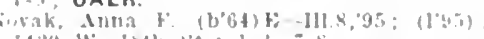

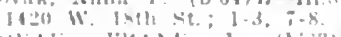

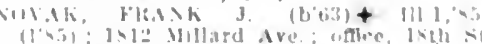

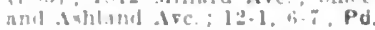

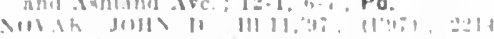
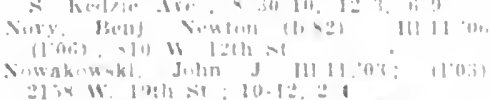

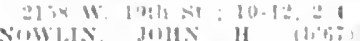

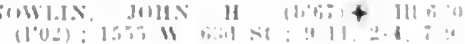

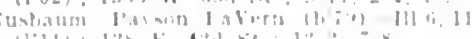

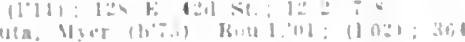
lowinalis $\mid 1:$ : 1

Sinte Wm Yrom

N lienthern \&
Oake. Wh $\mathrm{Th}_{3} \mathrm{~s}$ Inston hing 23.8

Oakes, lam. Nilen (b)

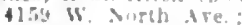

oberman, Abrallam Max

O'BILEX, IHAS. I.

1539 IV Congres

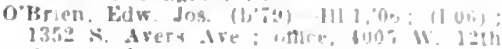
13, s. Arers Ire: antre, tyon II. J:m

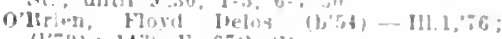

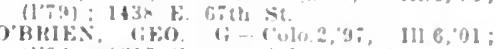
110\%1: 9215 cummercial ire? $8-10,1-3$,

0'Mrlen. J. Hugene-111.5,05: $(105)$ : $950 \mathrm{k}$.

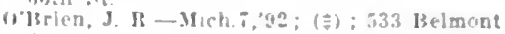

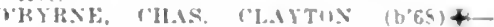

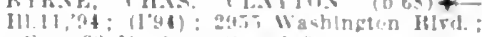

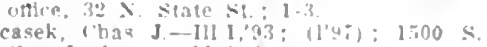
Crauporil Are.; 11-1, k-4

uchs, siml (b'if)-ill-2:13: (1'13): 53 x. Wonl st. : ofle, 1426 Miliaukee die. unit a. $4-5.7-9$

G(IISTH AIKERT JกHN (b'58) - HII,

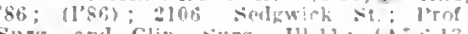
Ft); $\mathrm{S}$

OCHSNER, ENW II $(b / f)+-111.2,94$ $(194): 2038$ Lane $(? .:(1,12,13, \% 4)$.

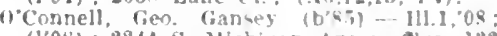

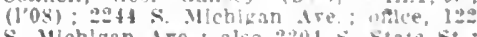

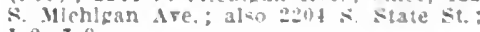
$1-2 . ;-S$

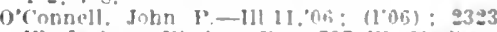
W. Jackson IRlsd.; uace. 37 W. Madlson

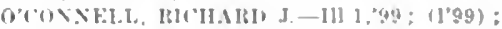

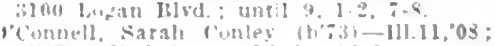
$\left(l^{\circ} 0 \times\right)=31$ hO L

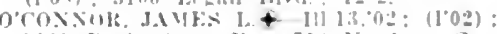
jotl Ibush si : ofice. 7lu Xiate st.

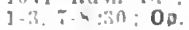

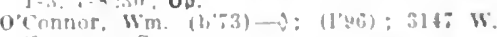

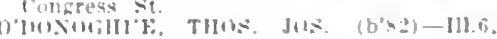

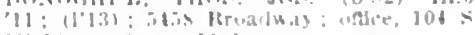
Vlichioan ine : 11-1

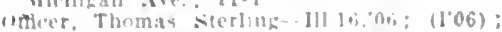

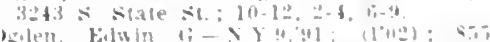

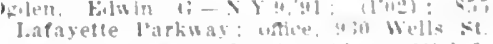

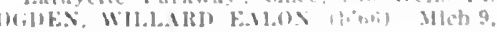

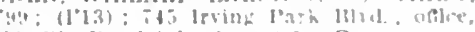

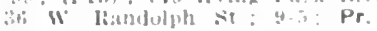

nilarra, Wm. Vi. (bot)-1ti.ti.st; (!'so) lis le larame IFe : unel

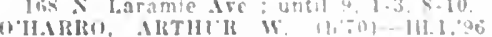

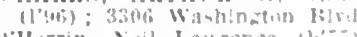

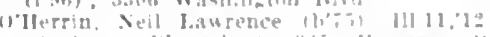

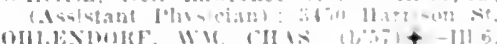

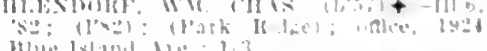

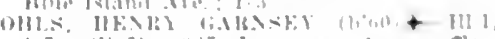
i: (1)

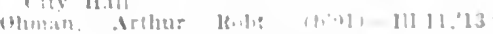

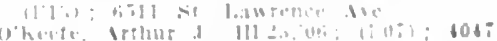

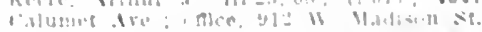

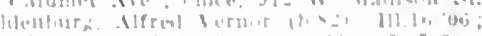

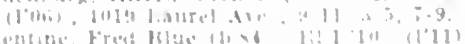

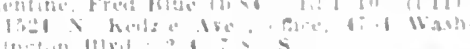

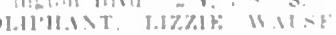

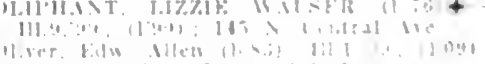

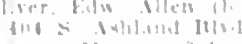

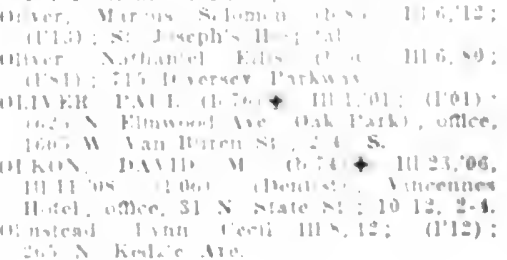


Ol.MSTED, WM. IR.-(3nt,6,03; $\left(\mathrm{l}^{\prime} 03\right) ; 302$ ‥ Ashtand Btvd.; oftce, 1200 Blue Island Ave.

Olsen, Adolph IIans (b'69) -0 ; (1’98); (Oak I'ark); ottec, 1705 W. Mtadison St.; $9-10$, $3-4,7-8$.

Olsen. Figll Thorbjorn-D.(1,04; (1'0T) 1956 Humboldt Blyd. ; until $8: 30,6-8$

OIALN, MIRIE A.@-IIl.9,91; (1'91); 1358 N. learborn st. : 10-1.

Otson locar (i. (b'C1)-Ky.I,93: (l'93): 555 N Clark st. oftce, 159 N. State St. 1-3. 11.12 . C. (b'75) \$-111.11,'99; (I'00) 4359 Pralrio Ave, offle, 31 N. State St. : $12-1$

OLSSOX, OLOF (b'66)-Ill.I1,05; (I'05) ; 11106 indiana Are.; oflice, 41 E. 111th St. $8-10,1-3,7-9$.

o'llalley, foln Gibriel (b'88) - 111.11,12; (1"13): Mterey Ilospltal.

O'MALLEY, THOS. J. $9-I 11.11,96$; (1'96) ; $168 \mathrm{~W}$. North Ave. $; 8-9,2-3,7-9$,

Oneal, oren (b'59)-0.8,79; (l'95) ; 4454 (ircenwood Ave.; office, $37 \mathrm{~S}$. Wabash Ave.

O'Nell, J. Howard F.-lll.17,'04; (1'04); 5919 Calumet Are

O'NEILL, A. AUGÚSTUS $\uparrow-3 t o .9,90 ;\left(l^{\prime} 94\right)$; 4327 Drexel Blyd.; oflee, 4607 Champlaln

Ave, also, $31 \mathrm{~N}$. State St; 4-6; S. (l'10); 4449 Erans Are.

O'NEILL, FUGENE JOHN (b'86)-III.6,'11;

(1'11); 6429 S. Halsted St. ; 2-4, 7-9.

O'NEILL, JOHA W. $\odot-111.1,92 ;$ (1'92) ; 2800 . Clark St.; $4-6$

Opre, Ilarry E. (b'79)-111.22,'08; (1'09); 62 is Chainplain $\Delta$ re.

ORCUTT, DWIGHT CHAPMAN (b,72)థ$111.11,01 ;$ (I'99); (IIubbard Woods); offlee, 7 W. Madison St. ; 9-2; $(\mathrm{B} \tilde{i}, 8)$

OALR.

OLIVER SAML. (b'74) $\theta$-Ill.1, 95 ; $(102)$; $(729$ N. Oak Park Are., Oak Park) : offlce, 32 N. State St. ; $9-2 ;$ Sce. l'rof. Skin and Ven. Dis., Ill.1; (Ć2,3,6, F4, Gi); $0 . \star$

Ormsbs, Wm. Bert. (b'7 1 )-Pa.9,'96; ( ): $1640^{\circ} \mathrm{N}$. Clark st.

ORNDOFF, BENJ. H. (b'81) \$-Ill.22,'06; Washington st.; 1-3; I'rof. Hematology and l'atli., I11.22.

Orr, John Foster (b'59)-Ont.4,'86; (1'90); 4456 Cottage Grove Ave.

Orsinger, Fredk. Leo (b'52)-IIl.5,'02 ; (文) ;

331 S. Wlnchester Ave. ; 9-1, 7-9.

ORTH, DANL. ADAM (b'72) ९-III.1, 96 ;

(I'96) ; 3319 Washington Blrd.; office, 209 S. State St.; also 1958 W. Chicago Ave.
orTu, wat. S. (b'64)@-Ill.1,90; (l'90) 628 Wrightwood Ave.; $6: 30-7: 30$; offle, 5 S. Wabash Ave.; i0 :30-12:30.

osbaldeston, Julian Turner (b'59)-Mich.8 '01; (l'02); 322 E. 25th St.; 9-12, 2-4,

(1'95); 2862 N. Clark St.; $10-12,2-4,7-9$; offlce, 350 N. Clark St.

Osenbaugh, John - Ill.18,'01, 111.15,04; (l'02); 468 N. Halsted St.; 2-5.

OSGOOD. LUTHER JAMES $\left(\mathrm{b}^{\prime} ; 6\right) \oplus-I 11.6$, 03; (l'03); 6450 - Stewart Ave.; office, 456 W. 63 d St. ; $1-3,7-8$; Asst. Prof. Med., ill. 6

O'SHEA, DAVID (b'5T) †-Ill.1,'S3; (l'83) 3605 Ellis l'ark; until 8, 4-6; office, 1724 S. Ashland Ave. ; $10-1: 30$

OSHER, JUL1LS C. (1'75) Ill.11,03; (l'03);

2148 X. Sanyer Ave. ; oflice, 159 N. State St.

ostllng, Carl August-Ill.1,04; (1'04); 5850 W. Chicago Ave.

Otis, Margaret Ruth (b'75)-Mich.8,'05; (1'08); 6322 Lniversity Ave.; 10-12, 2-4, $6-8$.

Otradovec, Jos. Henry It.-Ill.1'01; (l'0I) ; 7235 Union Ave.; oflice, 357 w. $63 \mathrm{~d}$ St. ; $9-11 ;$ (F4).

OTTO, ENW. J. (b'52) (-11L.1,'89; (l'88) 538 Demin

Otto, jos P.-Ill.6, 73 ; (1'T) ; 10138 Ewing Ot10, Julius-Ill.6,76, Ill.1,75; (I'77) ; 4100 W. Nortl Ave.; offee, 8 N. State St.; OUfIITOX, CHAS. M. (b'62) $९-I l l .1,84$; (1's.t); $5+10$ liosalie Ave.
Overall, Geo. Whitfleld - I'a.2,75; (l'02) ; (()ak l'ark); offlce, i W. Madisoll St. $10-4$.

Ovitz, Eruest (iayleart (b'85) - 111.6,'12: (1'12) : Sherldan l'ark Ilospital

WEN, ROY LAFAYETTE (b'70)-111.I 01; (l'02); 725 W. 43d St.; until 9 $12-2,6-8$.

WE.S, JOHN FDWIN (b'36)6-Pa.2,62 (l'77); 2127 'ralrie Ave ; offlee, $15 \mathrm{E}$ Washingt on st. ; 11-1, 4-4:45; Emer. 1'rof.

Surg. and (liu. Surg., Ill.6; $(\Lambda 5,13)$.

(l'91): 2816 Logan Blvd.; offce, $1522 \mathrm{~N}$. (1'91) : 2816 Logan Blvd.; offlce,
lRockwell st. : $1: 30-3,8-9$; ObG.

Oyel, Albert Nélson (b'7s)-Ill.1,05; (1'05) 2816 Logan Isird.; oftlce, $2513 \mathrm{~N}$. Kedzle Blvd. ; $1: 30-3,7-8$; ALR.

oyen, Henry M.-III.13,0s; (1'03); 4862 Warner Ave.

Packard, James Wrlght (b'68)-Ill.11,'10 ; (1'10); 4259 Wentwerth Ave.; 2-4, 7-9. Packard, Robt. Goodall (b'86)-111.6,'12; (1'12): St. Luke's Hospital.

lackard, liollo Kirk (b'8 $)-111.22,11$; (['12); 447 F. 60th St. 'ncyna, Vletor (l'80)-IIl.13,04; (l'04): 932 Alexander PI. ; offlee, 16 s. Market. '91); (l'91); 3622 S. Michlgan Ave.; offlce,
S. 106 S. Míchlgan Ave.; 1-3; Asst. Clli l'rof. obst., Ill.1 ; Prof. obst., 1ll.G.3 (AI1) ; ObG.

Paesler, Nlary $-0 ;\left(l^{\prime} 99\right) ; 1156$ W. 59th St. AGANO, AUREIIO $\left(b^{\prime} 80\right)-1$ ta.I0

PACANo, RALPH (b'i9) $\bigcirc-$ Ita.io,'06; (1'0-); 831 w. I'olk St.; $8-9,6-10 ; \mathbf{S}$

I'age, James M. -E-D; (I'87); 138 N. State St. ; 9-1.

aine, Josephine Ir.-II-Ill.4,04; (1'04) 4731 Lake Park Ave, oftce, 22 E. Washington $S t$; 10-12.

Palmer, Albert E.-Ill.1,'85; (l'85) ; 2658 Seminary Ave.; until 9:30, 1-2, 6-7:30. Palmer, Thos. D.-Ill.6, 67 ; (l'77);

Pamment, Harry Glil' (b'85) -Ill.1,'13; (1'13) ; Presbyterlan Hospltal.

Panter, Judson Carey (b'50)-Ill.1,'70; (1'93); 145 N. Clark St. : 9-11, 2-4

I'apageorge, Geo. C. $\left(h^{\prime} 76\right)-$ Greece 1,97 $\left(\mathrm{I}^{\prime} 03\right) ; 2000$ W. Madison St.; office, 824 Blue Íland Ave. ; 7-11, 4-8.

Papailiou, Gregory A.-Greece 1,'97; (I'01) ; 3500 W. Congress St. ; office, 776 w. Harrison St.; $9-12,2-9$; also $535 \mathrm{~S}$. Halsted. PAPIK, CHAS. (b'84)-111.8,"08; (l'08); 17 E. 61 st St.; offlce, 5860 S. State St. ; $2-4$. PAPIK, EDW. (b'79)-Ill.8,'08

2901 wallace St.; $1: 30-3: 30,7: 30-9$.

Papot, Grace Elltott (b'66)-Ill.1, $04 ;\left(l^{\prime} 04\right)$;

3808 Lexlngton Are.

Paradine, Danl. James-Ill.8,'11; (l'11) ; Cook County Hospital

PARDEE, LUCIUS CROCKER (b'68)CIll.6,94; (l'94); 751 Lincoln Parkway ; office, 15 E. Washington St.; 10-3; Assoc. Prof. Derm. and Syph., Ill.G1; $\left(\mathrm{C}^{\prime} 2,6\right)$; D. $\star$

PARK. ABRAIIAM S. (b'81)-Ill.17,'08; (l'08); 1145 Washington Blvd.; offles, $108 \cdot \mathrm{N}$. State St. : 2-5.

Park, Andrew James-Mass.1,'52; (I'88); 731 E. 50th St.

'ark, samuel J. (b'82)-Ill.11,'06; (I'07)

4143 Berkeley Ave.; oflice, City Hall.

Parker, Alonzo McKinstry (b'76)-nl.22, 09; $\left(l^{\prime} 09\right) ; 5300$ Washingt on BIv

PARKER, CHAS. AUBREY (b'G $)(-I I I .1$, 91; (1'91); 3418 Fulton St.; oflice, $7 \mathrm{~W}$. Madison St.; 9-11; Asst. Prof. Anat. and Madison St.; $9-11$; Asst. Prof.

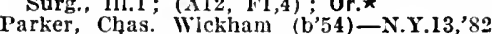
Ill.1,93; (I'92); 6820 Perry Ave.; until 9 , after 5 ; office, $9 \mathrm{~S}$. La Salle St. OALR. * Parker, Harley $\left(b^{\prime} 74\right) \mathrm{H}-\mathrm{Ill} .15,95$; $\left(\mathrm{I}^{\prime} 95\right)$;
654 W. Garfield Blvd. ; offce, 31 N. State St. ; $9-12$.

Parker, Luke Wesleyan (b'84)-N1.8,'12 (l'12); 6116 S. Ada St. ; $9-11,2-4,7-9$. ARKER, MARY URNER

PARKER, RUPERT MERRILL $\left(b^{\prime} 70\right) \Phi-$ Ill.6,96; (l'96); 5536 Mlichlgan Ave. office, 7 w. Madison st. 'arker, Thomas James (b'65)-Ont.6,'92; (l'11) ; $6 \mathrm{~N}$. Dearborn St.; oftlce, $127 \mathrm{~N}$.

'AlkES, CHAS. H. (b'72) 9 -Ill.1,'97; $\left(l^{\prime} 97\right) ; 1910$ lincoln $\Lambda$ ve.; oflee, $32 \mathrm{~N}$. State St. ; $12-2 ;$ S. $\star$

l'arkyn, Herbert A. (b'i0)-Ont.5,'92; (l'92) ; 3500 Ellls Are.; oftice, $140 \mathrm{~S}$. Dearborn St. ; 10-3.

I'ARUW'SKI, STANLEY W. (b'73)-IIl.22, $05 ;\left(1^{\prime} 05\right)$; 3043 W. $22 \mathrm{~d}$; untll $10: 30$,

l'ARSCIIF, THOMAS WM. (b'80)-Ill.1, 03: (l'03); 3743 Pino Grove Ave. ; oftlce,
3954 Sheridan Rd.: $9-10,4: 30-6: 30$, $8-9: 30$.

Parsons, Fredk. If. B. (b'68)-Ill.15,'95; (l'96); 11109 Fairfleld Ave.; until 9, 12-1, $5-7$.

Parsons, IIarry-II-Ill.4,'80; (l'82) ; 4457 N. Hermitage Ave. ; untll 9, 1-3, 7-9.

Parsons, John (b'46)-D.C.2,70; (1'99); not in practice; 1505 E. 60th St.

PARSONS, WM. (b'43)๑-IlI.1,74; (1'78); 4524 S. Mlelilgan Ave.; office, 741 W. 47 th St. : $9-10: 30,3-4$.

Patejal, James (b'85)-Ill.6,'11; (l'12) ; Michael Reese Hospital.

PATERA, EDIV. G. (b'75)@-Ill.11,03 (l'03); 1318 Independence Blvd.: offlee, 1809 roomis St.

PATERA, FRANK JOS. (b'6I) 9 -Ill.1,'83 (l'83) ; 154 N. Parkside Ave.; oflice, 1152 N. Ashland Ave.; 12-4, 6-8.

PATRICK, HÚGII TALBOT $\left(b^{\prime} 60\right) \bigcirc-N . Y .10$, '84; (I'86); 1428 N. State Parkway; offce, Nerv. aud Ment. Dis., Ill.6; Prof. Neur. Nerv. aud Ment. Dis., Ill.6; Prof. Ne

l'ATRICK, ZORAH ExON-Ill.1,72, N.Y.10, 77; $\left(l^{\prime} 77\right) ; 625$ Woodland Park.

Patterson, Franklin (b'69)-IIl.10,'97; (l'97) : 3012 Eastwood Ave.

PATTERSON, JAMES $\left(b^{\prime} 80\right) \oplus-$ Ill.1,'11; (l'L1) ; 5810 Drexel Ave. ; offlce, 6158 Cottage Grove Ave. : $7-9$; also 7 W. Madlson St.; $11-12: 30 ;$ (F1); Or.

PATTILLO, RICHARD STARR (b'70) Man.1,95; (l'96); (Wllmette); office, 15 E. Washington St. ; 9-4; Prof. Ophth. Itl.G3.

PATTON, DAVID H. R. (b'67) @-Md.1,'95, Md. 4,96; $\left(1^{\prime} 96\right) ; 119$ E. 23d St. ; ofllee, 2204 Michlgan $\Lambda$ re. ; 10-11, 2-3, $7-8$.

Patton, Frank Rauch (b'86)-Ill.11,'13: (l'13); Mercy Hospital.

I'A'TON, JOS. MeINTYRE (b'60) $\odot-N . Y .5$, 82; (l'82); 336 S. Hoyne Ave.; until 9, $12-1,6-7$; offle, 108 N. State 'St.; I-4; Prof. Med., Ill.11 and IIl.G1.

Patton, Leigh Klumb (b'87) ;-nl.11,'13; (1'13) ; 336 S. Hoyne Ave.

Paul, Phillp D. (b'49) H-Ill.4,'84, Ill.15,'95. (I'95) ; 4649 Sheridan Rd.; offee, $31 \mathrm{~N}$. State St. ; 8-6.

Paul, Robt. Dorland-ont.5,07; (l'08); 120 E. 36th Pl.; office, 128 E. 33d St.

Paulin, J. Frank-E-Ill.8,'94; (I'94); 783 Milwaukee Are.; 12-2, 6-8.

PAULSON, ADOLPH THEODORE $\left(b^{\prime} 71\right)-$ Ill.22,'05; (1'05); 3000 Diversey Ave. office, $2201 \mathrm{~N}$. Californla Ave.; 2-3, 7-8. PAULSON, DAVID (b'68) $\$$ - N.Y.10,94; (I'99); (Hinsdale); office, $32 \mathrm{~N}$. State St. Pauly, Michael H. (b'68)-Ill.16,'98; (l'98) 6600 Loomis St.; offlce, $6310 \mathrm{~S}$. Ashland

Ave.; I-3, $7-9$.
PAVIIK, O'TTO STEVE (b'74) $4-I l l .6,04$; $\left(l^{\prime} 04\right)$; 1900 Millard Ave.; offee, 801 Milwaukee Ave. ; $10-11,2-3,7-8 ; G$.

PAYKE, DOUGLAS AMOS (b'57) -Md.3, '87; (l's8); 5557 Winthrop Ave.; office, $25 \mathrm{E}$. Washington St. ; also, $24 \mathrm{~N}$. Wabash Ave. ; 9-4; Assoc. Prof. Ophth., Ill.8; (B8); ; OALR. *

Payne, Jesse David (b'66)-Ia.1,'87; (l'09) ; 3834 N. Ridgeway Ave.; offlce, io S. La Salle St.

PEACOCK, ALBERT (b'62) N.Y.6,'91 ; (l'91); 1442 E. 55th St.

Peake, Marle McGarvey (b'65) - Ia.4,'00; (l'00) ; 3240 Lake Park Ave. 233 F. 47th St.; 8-9, 2-4, 6-7:30.

Pease, Jerome F. (b'48)-111.1,93; ( ); 4704 Magnolia Are. 


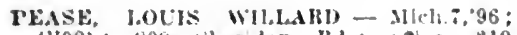
(1"08): $>09$ sheridan B.1.: ant.e, "19 IV. Chilcago Ave.

Pech. Albert (b'5)-111.6,00; (1'00)； 4040 Pralrle Are.; offee, 3904 Indlana Are.; $3-5,7-8: 30$.

PFCIVAL, JOS. P. (b'66)-Nob.t,"9ti ; $11^{\circ} 11$ 2552 S. Ilamiln Are.; oftce, 2tith si. and I. awndale Are, 10-12: I'rot.

Hent. Dls., III.16; (F.13) : NP.

PFCK, AUEIHEIT H. Assuclate FellowII1.1,91: (I)entlst); 1431 Bello Flaine Ave. : oflace, $10 \mathrm{~s} N$. State st.

Peck. Comfort rolsun $\left(b^{\prime}+6\right)$ - N.l. x.r.10,79: $\left(1^{*} 9 b^{6}\right)$ : (llighland l'ark); of flee, 158 is: Ontarlo st.

PECK, DAVID BHLLING $\left(b^{\prime} \div 8\right) \neq-$ IIL.6. p5: (l*05): (Highland I'ark); odlce, 152
W. Ontarlo St.

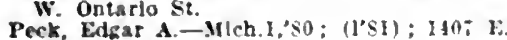
53d St. : otte. 3055 italumet Are. ; $10-1: 2$ 1-4. $7-9$ : OALR.

PECK, WESLYY HAMILTON (b.63)

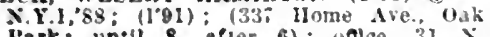
Yark: until 8, afler 6); unlce, 31

PEKARDT, KATF F. (b'60)-Ill.6, $s 5$

PECKARDT, KATE, F. (b'60) IIl.6, s:, III. 4 ; '\$9 : OALR.

Pelro, Frank L. (b'39)-rt.2,66; (1'7i): 4536 Greentew Ave.: 10-12.

PENCE, CLYDE, 1) (b'is) $t-111.11$; $\left(1 y^{*}\right)$; 1810 s. Homan lve,; ottlce, 3itis O-den Are.: 8-4, 3-4, i-8.

PEXNINGTON, JOUX RAWSON (h'5s) क IId.1,87, Ky.1,'91: $\left(1^{*} 93\right) ; 933$ Alrdrie I'l ontee, 3I $\mathrm{X}$. State St.: 10-1, 4-5; Prof. Rectal Dls., III.GI; (A4): Pr.

Pennoyer, Nelson A. (b'49) H- Pa.9,:0 11'9\%): (1'ennoyer Sanltarlum, kenosha, Wis., 199 ) : omce, 22 F. Washington st. 2.4

Penrlce, Henry M. (b'63)-Ill.11,03: (1'03) ; $3926^{\circ}$ Folk st.: office, 134 S. ia Salle st

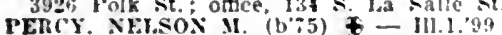
(1'10); 2256 Lincoln l'ark, W. ; oflce, 2100 $(1+10) ; 2256$ Llncoln lark, W. : offlce, 2100
Sedewlek St.: 2-t; Assur. Prot. Clin. Surk. Ill i1: (113): S.*

PEREKIIAN, JOHN SAID $\left.\left(\mathrm{b}^{\prime} 6\right)^{-}\right) \neq-111.1, \mathrm{~S}$ (1"88): 2600 Indlana Ave; 8-10, 2-4,

Perklns, Eirnest Della (b'5, H - III.4 III. I, 01; (1'01) ; 459 W. 621 St. : unt!l 19 , 2-4, :-8.

Perklns, Orrllle Juan (b'49)-X.10, $\mathrm{F}$ (1'91): 046 Egzleston
Van Buren Si.; $9-5$.

PEIKISS, STANIKY REIHEX (b'sl) -

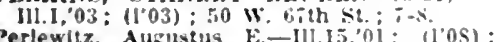
Perlewitz, Augustus Fa-Ill.I5,01: (l'0s) 4645 Lirans Are.: $8-10,2-4$

Periman, Adolph X. (b'-2) $\mathbf{E}-113,8,95:$ (1'95); 1339 S. Troy st.; 8-4. I:-1, at. ter :

Perlsteln, Saml. (b'83)-111.6, 07 ; (1'07); 2938 W. North tve.: $2-4,6-8$

PERRILI, IIVISG $\left(\mathrm{b}^{\circ} 85\right)+-111.1,10$ : (1'10): 1517 Bltchwood Ale.; oftlee, 32 Xे State st. : 12:30-3:30.

Pepuse, fieo louls (b't) - 111.16, os (l'0s); Michael IReese Hosfiltal.

Peter, Robt. (b"59)-1'a.2,'81: (1"98); 4450 s. State St.; $4: 30-11,1: 30-3: 00,6: 30-8$ Peterman, (ieo. F.lmer $\left(b^{2} i 1\right)$ - III.23,

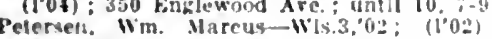
\$849 Velmont ive.

Peterson, Albert II orton $\left(b^{*}, \hat{r}^{\prime}\right)-1 \mathrm{a} .10,01$; 11.06t: 958 wrightwoul tie ; $10-1: 3-3$ $\because-8$

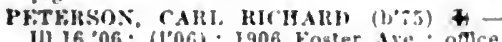
M96.06; (1'06): 1906 roster Al

peterson, kmma ll. Sallshurs $\left(b^{\circ}-8\right)-1 a .10$, "03: (1"0ti): 958 wriglitwom Ave.

Feterson, Jos. Nlonzo $(1,4)-11128,05$;

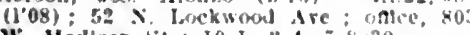
w. Márison sit.; 10-1. : -4. ;.8:30.

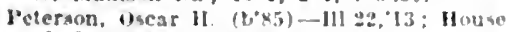
oi inrrection Howllal.

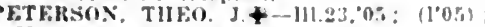
$3 \pi 30$ Fullerton Are.

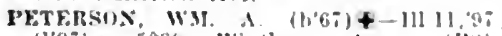
(l'9:): 503! Whithrel Ave: (iiv):
OALR.

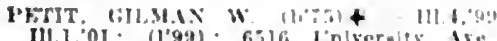
onde. : w. Madison si. : 1.t.

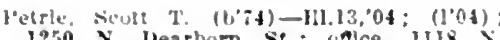
$1250 \mathrm{x}$. Dearborn St; ualce. IIIS Francisco Are: $8+12$.

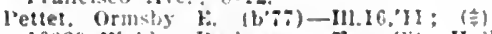
10339 Walden Parkway; oflce, ("ity Ilall FTTIT, JAMES WhIY.

(See Ottawa)

I'felfer. Flwarl rlias. (b's:) - Ill6,13: (I"13): Jexian bruthers" llostultil

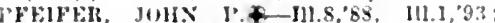
(1"90); $15 \div 2$ Jllwaukeo Are.; 10-11, 1.2 - 8 .

l'fellfer, Chas.-ll1.1.09; (1"99); 920 W. Madison St: $11-12,2-3$.

"lielps, tugene Talmadge-I1.1,12; (1'12) 6.sit champlall Are

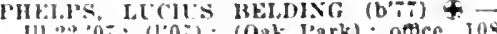

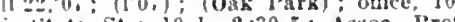
Wol.t lalu. and I.aryn. Ill.22; OALR.

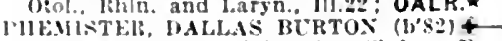
III. 1,04; (1.05); Linlrersity Club: offlce, 122 S. Mlchlian are; $3-5 ;(A 13,54)$ :

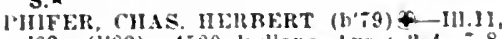
02: (1.02): 500 Indlana dre.: $2-4, i-8$

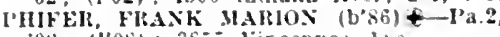
l'hllips, Robt. M. (b'63)-111.22,'ll 300 s. Clcero Are.

IHILLIPS, conNEIILS J. क- III.], 90 $(190)$; 301 W. Garfleld Blrd.; $1-2$, after 3

I'lillips, feo. S. (b"55)-I'a.:2, 80 ; ( ) ; 65.5 Cotsage Grore die.

IHII.IPS, HEXKY A. - III.8, 1 : (1'3T) 2159 W. Adams st.; oftuce, 516 W. Madison St: $9-11,1-3$.

l'hlllips. John D.-N.Y.6,"is; (1'ss); 7li E. 42d St.

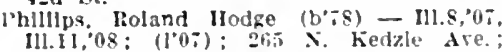
10-12, ;-9; Clln. Prot. Med., Ill.K.

l'HI'I'S, LELAND HLDORL'S (b'st) Mich.1,08; (1'10); 4.33; Lincoln tre. offee, $32 \mathrm{X}$. Staté St.; 11-1, 3-5, ;-S Pd.

l'ickerlll, James Thos.-111.6,92; (1.92) : 401 Lincoln Are.: oftlee, 1 its Wilson we. : 3-5, $7: 30-8: 30$.

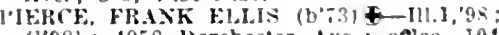
(l'98); t95s lorchester ive.; onlec, I0s S. Mchizan Are.: 1.2; $\mathrm{s}$

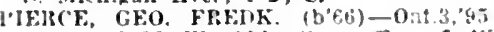
(1'95): 3538 W. Ohlo st.; nftce, ; W.

Madlson St : $10: 30-I 1: 30,7: 30-9: 30$.

vierce, Ina Mighell

PIFIRE SORVAL HARVEY (b'63) III.11, $85:$ (1'86); 13i E. Thicago Are: offle, 22 E Washington st. : I0-1, $4-5$ Prof: Otol.

vierron, Jos. J. (b'55)-111.11,93: (1'93)

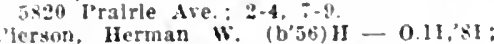
(193): 1309 Astor st.: once. 116 s Mlihlean Aie.: 10-1.

l'H:THOWICZ, STFIHES ROMAX (1):3) -III.11.95; $\left(1^{\prime} 98\right) ; 213 t$ Plerce Are S. Ashland ive.: I'-2, fi-s; I rof. Vet

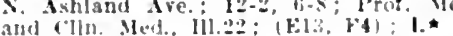

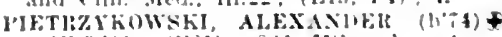

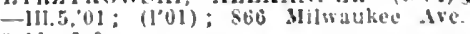
9-11,, $9-9$.

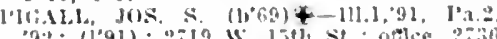
Grilen dre.; 1-2, i-s; Irof Inter. Mel. lil. 1 is

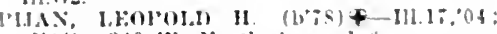

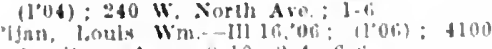

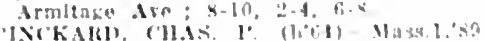

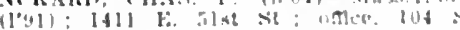

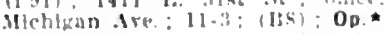

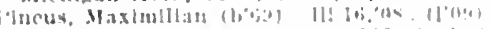

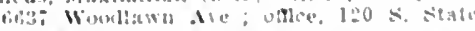

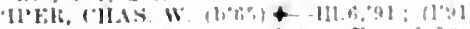

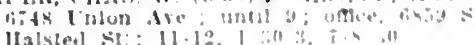

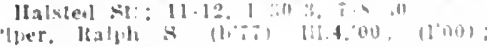
$17 \% \mathrm{x}$, wite st

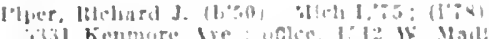
son sit.

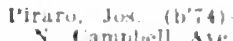

(1"03); 1217

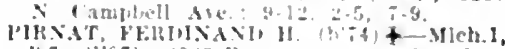

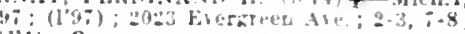
(ri) : $\mathbf{S}$.

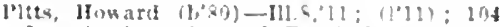

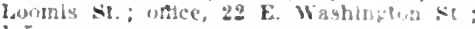
$1-5$.

l'ils, Jay Fredk- $11114.04: 14^{\prime} 04$

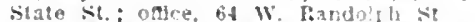

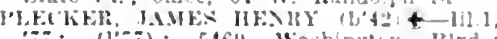
ii; (1\%i); 546y Washingtort Bird. $10-12,2-5$

["lenz, Henry John $\left(b^{\circ} \times\right)-1116,210:\left(1^{\circ} 10\right)$

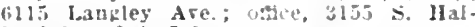
Sterl St: $2-4,7+9$

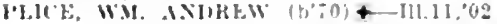
(1002); $759 \mathrm{~S}$. Californa Ave, once, $\mathrm{W}$ Madison St.; I-2; LR.

llumbe, Edw. o. (b'3n)-1.a 2.69: (1'55): 358 E. both St.; odtec, 300 S. Learbom si. : $8-10,+10$

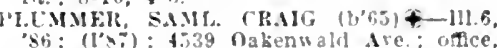
25 E. Washlugton St.; 10-11; Clin. Pro?. Surg., lil.t: $(.1$ i, 13$)$ : S.

l'ofill.s. J.1Cob (b'55)-I11.6,"89: (1's9)

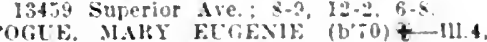

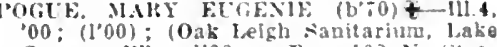
Geneva, Wis. l'061; otlce, $108 \mathrm{X}$. State st.; (E13) : NP.

POHL, CARL MATTHAS $\left(b^{\circ} 79\right)+-111.1^{203}$ (l'03) : $: 33$ N. Slenard Are.; once, 5801 wi. Chleago Ave

rOKORAEY, FRANK J. (b'9) P-II.11, 03: (l.03); 1501 s. Craw ord Ave.; 8.10 , $2-4,8-9$.

POLKEY, HLYUI JAMES-III.1.03; (1'03) 5100 Sheridan Rd.; ottce, II:s Arfyle st. $\mathrm{S}$.

ollach. Paul (b'61) II-I11.25.95; (1'95): $1115 \mathrm{X}$. Rinbey St: $\mathbf{N}$.

POLLOCK. HARBY LOCIS (b'it) P-III.11, 4: (l'96): 846 Wareland Are.; ortice. ALR.

PULIOCK, LEWIS JOHS (b'.5) +-111.11 06 ; (1'06); 15 K. Waslington st.; (Et F): NP.

0l.l.o(k, WM. JoHx (toil) - I11.8.01 (1.01): 2at Iowa st.: oftice, $2100 \mathrm{w}$. 111.8 .

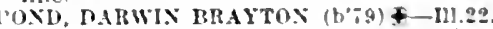
07 ; $(107) ; 4345$ I.Incoln Ave.: $2-4, ; .9$

bolc, Geo. w. $(10,59)-k y 1.05: 1199)$ 3931 Drexel st.; offce, 122 s. Michlgan Hird.

Fope, Edw. Ira (b'52)-Mn 2'al: (l'SI): titl w. Klnzle St. untll 9, I2, 5-8. $\therefore$ Ilalsted st.; oace, it W. Washlngton St. : 3-5.

3orges, Irring A. (b's2)-111.11,03; $\left(1^{\circ} 03\right)$

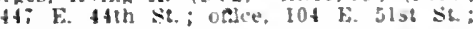
$1-3, \quad-8: 30$.

Purt. Irwin A. (6.33)-111.11,07: (1.05)

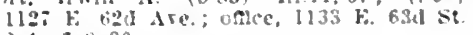
$2-4,7.5 .30$.

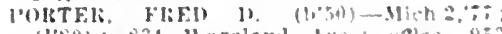

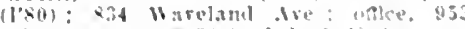
Helmont tre : क:30-4, $1-2$

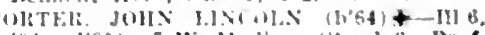

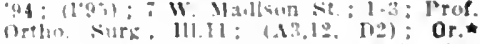

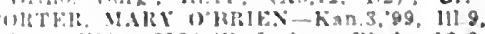
"11: 11021: 3134 15. Jacksuls lisd: 1:-2

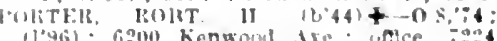
Hinto

(1)

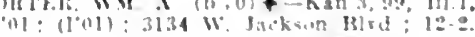

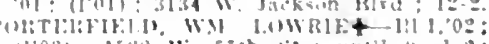

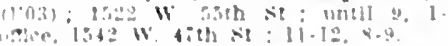

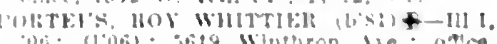

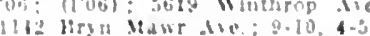

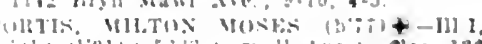

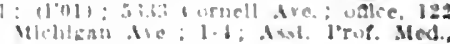

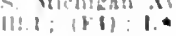

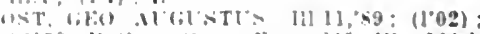

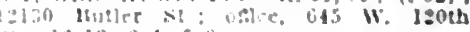


Hoste, GFo. WASHINGTON, Jh. (1'84)†

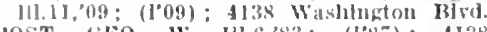
I'OST, (iko. W.-IIl.6, \&3; (1'87); 4138 Washington Blve; oflee, 4159 W. lake

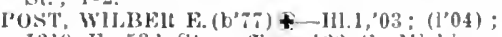
1219 F. 531 St. : offlee, 12.2 s. Mllelligan Ave. ; $11-2$; Asst. I'rof. Med., 111.1; (Ft); I."

POTTER, IIOLI,IS lELMEIR (b'S0)†-III.1, 08; (l'0s); 722 Sherldall IRAl. ; oflce, 122 s. Mlchlgan Ave, : I-5; $\left((11,4) ; R^{\star}\right.$ *

Potter, Jokoy Calkins (b'so) - Ill.16, 07 III.J, J8; (1.07): 4403 kilston A re.

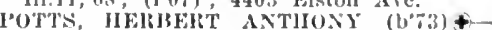
111.6,01; (1'01); 142 Junlata st.; offlee, 1336 Atorse Are.; nntil I0, i-s; also $31 \mathrm{~N}$ State St. ; $3-4: 30$.

Poulsen, Jull us Wm.-IH.14,05; (l'05) ; 2446 N. Callfornla $\mathbf{S t}$; oftlee, 29 E. Madison St. ; also, zxtis pullertom Are

Powell, John lt.-tia.5,'95; (l'95); 4624 Vincennes $\mathbf{A r e}$; offlee, $31 \mathrm{~N}$. state $\mathrm{st.} ; 4-6$. POYNTON, IBOHT. A. (b'65) $\uparrow$-N.Y.IS, 91 (l'00); 760 Bond ive.; oftice, 9154 Com nerelal Are.; $8-10,1-3,7-8$.

PIRAFTORIUS, (i. CIIABERT (b'62)-Ta.I 83; (1'84); 5540 Way'ne Ave.; oftlce, 75 W. North Avo.; 9-10, 2-3, 7-8.

Pratt, Edwln llartley (h'49) H - Ill.4,73 (l'77); (722 IInman Are., Fvanston); of flce, 32 x. State st. : $2-4$,

PRATT, GEO NATILANIEL, JR. (b'6)Ill.10,97; (I'07); 4119 Kellmore Are. ; of flce, 5 S. Wabash Are.; $11-2 ; \mathrm{S}$.

Pratt, tieo. P'eyton (b'8s)-Ill.1,'13; (I' 13$)$; Cook County llospltal.

Pratt, Harry I'reston - Ill.14,92; (1'95) 3106 Waluut St.; oftle, 36 S. State St.

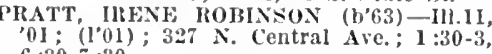
$6: 30-\pi: 30$

Pratt, Roscoe Wellington (b's9)-Ill.11,'I1; (1'12) ; 185.5 ('hase Ave.; 1-3, 7-9.

PREBLE, ROITT. HRUCF $\left(\mathrm{b}^{\prime} 66\right) \uparrow-\mathrm{Ll}, 6,9 \mathrm{I}$ (1.91): $1518 \mathrm{~N}$. Hearhoru st. $30 \mathrm{~N}$. Michlgan Ave.; 2-4; Irof. Med. Ill.6; (106, F4); I.

'rentis, l'ercy 1. $\left(b^{\prime} 70\right)-0.7,93 ;$ ( ) ; 5433 w. Ohlo St

PRFXDERGAST, JOSEFH (1)'66) -111.1, 94: (1'96); 3201 l'ark Are.; 1-3, 7-8;

PliESCOTT, FYA (b'66)-Ill.11,'03; (1'03) 226 S. Hoyne Ave.; I-3; G.

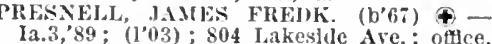
4601 liroadway ; 4-6.

Prettyman, Chas, W. (b'53) - N.Y.1,'88; (1’91) ; 4l39 Indlana Are.; 10-12.

PRIBY,, HLGO Y.-Ill.1,99; (l'98); 5429 Ingleside Are.; offle ${ }^{2}, 162$ '. Dearborn st. ; $12-3$.

Price, Arthur Edgar-Ill.1,97; (197); 4811 Lake Park Ave.; oftce, 1:5 W. Jackson Blvd.; also, 542 W. Van Buren st.; $3-\overline{5}$.

Price, James Itussell - Ill.14,'96; (1’96) 6309 Wentworth Are.; $8-10$,

PRICE, OSCAR J. (b'45)-Mich.1, tic; (1'7) prince, (reo. Washington (b, 7 (l'08) : 3502 s. State St. : $9-12,2-8: 30$.

Prlnty, James A.-Ia.4,'82; (1'88); 4611 sheridan Rd.

PRITZKER, I.OLIS JACOH (b'67) \$-Ml.6, 91; (l'91) : 2548 N. Kiedzie l31rd.; oftlce $539^{\prime}$ N. Kenzie Blid. ; 2-4, 7-8; ObG.

Proctor, (ilenn J. (b'si)-Ill.16,'12; (1'12) ; I315 Rosedale Are.; offlce, Goddard Bldg.

PROMIISKI, ILEX.INDER J. (b's8)-111.22, Il; (l'I); 1911 s. Kedzie Are.

Propeck, Jos. W.-E-Mo.10,'8
lI33 W. Randolph St.; 10-4.

1133 W. Randolph St. ; 10-4. (l92); 2723 Logan Blvd.; office, 1050 IIilwauke Ave.; 10-12, 3-5, after 7 .

Provost, Win. Y. (b'39) - Y.Y.8,77; (l'86) ; 4157 Indiana Are.; 9-12, 7-9.

Pruyn, Chas. P. (b'54)-Ill.1,86; (1'86); 4326 Greenwood Are.; oftice, 108 N. State PI"KEY, MALRICE VICTOR H. (b'79)Ill.16,10; (1'10); 3535 Reta St.

PLGII, CH.AS. F. (b'65) \-IIl.I,'91 ; (l'91) : $3221 \mathrm{~W}$ Washington st.; office, $400 \mathrm{~S}$
'TIRCLI, MICHAKI, J. (b'78)-IH.22,I2 $\left(1^{\prime} 12\right) ; 800 \mathrm{~N}$. Cliark St.; oftlee, I3I5 N.

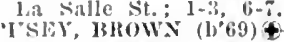

W'a.I,'92: (1'98) Oplith. Ill.6: ( 34,8, E4 14$): 30$

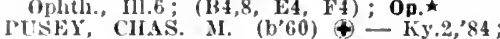
(1'86): CllAS. M. (b'60) - Ky,2,8

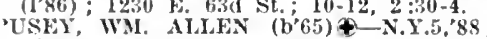
(1'32)'; Treasurer Amerlcan Medical Assoclation; (512 (ircenwood 131)d., Fvan ston) ; oftle, 7 W. Madison St.: 10-12 Prof. Derm., Ill,11; (C2,6, F4, G1) : D.*

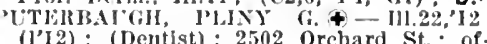
(1'12); (Dentist): 250

PUTHEY, LUIS AMMON (b'81) \&-I1l.11 10; (1'10): 503 N. $52 \mathrm{~d}$ Are.; ofllec, $515 \pi$

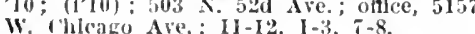
I'utram, Ida 13.-II-ILI.15,97; (1.97); 4316 Gladys Ave. ; $3: 30-6$.

IUTY, W.Y. EDW. (b'83) $\oplus-111.22,08$ (l'08) ; I 852 IBlue Island Ave.; Asst. I'rof Med., Ill.16; Asst. Mrof. Med, and P'hys. Dlag., I11.22

PYNCION, FJUIN (b'52)థ-0.2,73, 0.1 $36 ;(1+85) ; 5010$ S. Mlehlgan Ave.;

QUALES, NILES T. (b'31) $\oplus$ - III.I,'66; $\left(1^{\prime} 77\right)$; 195 I Fowler st. ; $7-8,12-1: 30,7-8$ quenzer, John Fred-H-III.18,0I; (1'0I) ¿is Lincoln Ave, intl1 9, 1-2; 7-8. Quigley, Wm. Jos. (b'86)-111.1, 13; (l'13) Cook County ILspital.

Quille, Maurlce J., Jr.-F- Ill.22,0. ; (l'0.5) 502 Claremont Ave.; offlce, 236 S. Center QUINF, WM. ENW. (b'47) $\oplus$ - Ill.6,69; $\left(l^{\prime} 78\right) ; 3160$ Indlana Ave.; offlee, $31 \mathrm{~N}$ State st.; 1-3; Dean and Emer. Irof. Me(I., Ill.il: (E4, F4).

QUINLAN, W.M. W. (b'67) $4-$-N.Y.I,9I (I'93); The Lessing Annex; office, $29 \mathrm{E}$ Madison St.; 11-1; Assoc. P'rof. P'ed. Ill.Gl ; (D2); Pd. Quinn, John J.-Md.4,03; (1'05); 442 GarQUIN, LEONARD CARDINAL (b'83)Ill.1I,'09; (l'09) ; 4453 Irving I'ark Blvd. offlee, 4226 Irving Park Blvd.; $3-5,7-8$ :30;

QUIN WM ALOYSILS (b'69) -Ill.II '94; (1'94); 3014 W. Jackson Blyd. ; offlce, 122 S. Michlgan Ave.; 9-12; (C6); D.* Quirk, Frank J. (b'69) E-111.8,95; (1'95); 5503 Washlngton Blvd.: offlee,
itadlson st.; $10-12,2-4, \tau-9 ;$ U.

QLIIRK, JAMES P. (b'69)-Jll, '91 : (1'91) 4742 W. Monroe St. ; office, $4003 \mathrm{~W}$. Madison St. ; 3-5, $7: 30-8: 30$.

RAASCH, WM. H.-Ill.22,'13; (l'13); st. Elizabeth's IIospital.

RABE, OTTO JOHX (b'83) $\pm-111.6,09$ $\left(l^{\prime} 09\right) ; 5302$ Ellis Ave.; office, 901 F 5ith St. ; 2-4, $7-8: 30$.

Rach, Enill Arthur (b'79)-Ill.11,06; (l'06) $5753 \mathrm{~S}$. Morgan St.; office, 3901 Wenworth Ave.: $11-12,3-5,7-8$.

Radesinsky, Antonio (b'6 6 ) - Aus.7,94; $\left(l^{\prime} 45\right) ; 3505$ W. 26 th st.; $8-9,1-3,6-8$.

Ratp. Alexamler Berkley (b'80)-Pa.2, 05 (I"05) ; 1748 Taylor St.; 12-2.6-8.

RAGER, NORA $\oplus-M o .30,00$, Ill.22, 09 ; (l’00); 129 S. Central I'ark Are.; office, Wasonic Temple; 10-12; also office, 155: W. Madison St:; 4-6; OALR.

Rahe, Albert (b'86)-Ill.22,'13; (1'13); south Shore Hospital.

Ituhling, Leo. IIenry-IIl.6,'06; (l'06) ; 6738 S. Simganon St.; offlce, $6802 \mathrm{~S}$. Ifalsted

Rainey, Iames M.-0.2,93; (1'00); 136 W. Lake st.

Raithel, John Adolphus (b'70) E-IIl.S,'96; (1'96); 631 Wrightwood Ave.; 2-4, 7-8.

kandall, Kay R. (b'81)-Jll.1,'13; (1'13) 2301 W. IIonroe St.

Ranes, Annie R. (b'70)-Ill.17,03; (1'03); 2329 Cleveland Are.

Rankln, Arthur Bennett (b'84)-0nt.I, 06 : (l'0s); 1360 Fulton st.; Prof. Anat.,

RANNEY, THOS. POLTOCK (b'8L)-Ill.6, $05 ;(1 ' 05) ; 6538$ Woodlawn Are.; office, 1230 E. 63d St.; $2-4,7-8$

RANSMEIER, ROBT. E. (b'7i) †-Ill.6, 01 ; Garfield Blvd, ; $1-3,6: 30-7: 30 ; U$.
Ranson, Stephen Walter (b'80)-Ill.L,07 ; $\left(10^{\circ} 07\right) ; 1511$ E. 6ith St.; offlee, $2431 \mathrm{~S}$ bearborn St.; Prof. Anat., Ill.6; (FI). Rasclike, Emll II. (b'68) II-I1l.4,06; (1'06) (La firange); offico, 5969 South Blvd.

Rasmussen, Alols Christlan-II-Ill.10;89 ; (l'00): I826 $\mathrm{N}$. Franclseo Are.

RASMUSSEN, INGEBORG (b'58)-H1.9,'92 (1'92) ; oftice, 23 Blshop St.; 9-11; Pd. F. 530 St.: Oflce, 5233, Lake Park Are. 10-12.

Ratlije, Fred Conrad (b'82) - Ill.1,05: (1'05); 7657 Vinlon Ave.; offlee, 6233 s. IIalsted St. ; $10-12,2-4,7-8$.

RAILINGS, ISAAC DONALDSON (b'69)( Itawllns, 63 ; (l'93); Dept. of Ilealth ; 9-5. (1'04); (Hinsdale); offlce, $122 \mathrm{~S}$. Michlgin Are. ; $12-2$.

Re, Nleholás-s; $\left(l^{\prime} 86\right) ; 1162$ W. Polk St.

Rea, Ira H.-III.I3,98; (1'98); 374 E. 61st

Rea, Robt. II. (b’78)-Ill.I,'03; (l'03); Cook County Insane Asylum.

Reading, Arthur H. (b'63) F-Ill.8,86 ; (1'87); 6444 University Are.; $8-10, ;-9$.

READING, EDGAl MEAD $\left(b^{\prime} 52\right) \dot{\varphi}$ Hli.s, $7 \pi ;(1 ’ 84) ; 6416$ Kenwood Ave.; offlce, 29 i. Irison St. ; 4-6; I'rof. of Neur. III. 8 ; $\mathbf{N}$

Reading, Rose M. T. (b'66) E-111.8,'86. $\left(1^{\prime} 86^{\circ}\right) ; 6444$ University Ave.; 8-10, 7-9.

REDDEN, EDWARD $\mathrm{N}$. (b'79)-IIl.17, 09 (1'09); 5939 Mliway; office, 2358 W. Lake St.

REIPIELJ, HAROLD IIAMITTONФ-III.23, '07, Ill.8,'12; (1'07) ; 562 Oakwood Blvd. Junlor l'rof. Ther., Ill.8.

1024 , IIN.1,'83; (1'83);

REFD, CHAS. BERT $\left(b^{\prime} 66\right) \oplus-111.1,87$; (1'8i); 3748 Slieffleld Ave.; untli $9 ;$ of flce, 31 N. State St.; 10-1; (AlI); ObG.
Reed, Chas. IIerbert (b'66)-Ill.16,08; (l'08); $139 \mathrm{E}$. Ontario St.; 9-12.

Reed, Dudley Billings (b'78)-N.Y.1,08 (l'12); 5548 University Are.; office, Chicago Iniverslty; II :30-1.

leed, Torrance (b'90)--Iil. I1

Tenrotin Memorlal Hospital.

EEDER, WM. GEO. (b'78) †-I11.1,'03; (106) ; (Wheaton) ; offce, 25 E. Washington St. ; 9-1; Asst. Prof. Oto.-Laryn.,

Reese, Jos.-0.1,84; (1'86); 841 W. Garfleld B1 rd.; $1-2,7-8$; office, 6300 S. Halsted St. ; $11-12,2: 30-3: 30,8-9$.

Reeves, John H.-E-Il1.8,'96; (1'99) ; 4801

I a flin St.; $10-12,7-8$.

Refer, Chas. Nlbert-iI-Pa.9,'86;

12 Balrd Are.

Rejo, Florence Wing - Ill.11,04; (1'04); RFICHMANN, MAX (b;65)@934 Mlexander Pl.; offlce, $5 \mathrm{~S}$. Wabash Ave.; 9-12, 2-5; R.

REILLY, IOS. (b'48) 4 -Mo.2,72; (1'77);
4922 Kenmore Ave.; office, 4328 Union Are. : $2-4,8-9$.

REIMCHE, ROBT. CLIFTON (b'79) $₫-I 11.1$, REINHARDT, IIENRY G. W. - $211.1,97$ (1'97); 2656 I Logan Blid.; office, $1225 \mathrm{~N}$. Ashlanil Ave.; 8-9, 6-8; Prof. Forensic Med., Ill.8.

REINHART

ENHART, MAURICE DAVID (b'T3)Id.9,09; (l'09); 901 w. 12th St.; $9-12$, $1-3,6-8$

EININGER, EDW. E. $\odot-I 11.10, ' 38 ;\left(1^{\prime} 88\right)$; 704 S. Oakley Blid.; offlce, 29 F. Madison St. ; $1-3$.

Reinseh, Herman-Ill.22,'12; (1'I2) ; 4641 REIS, GEO. WM. (b'71) -Ill.13,04 $\left(1^{\prime} 04\right)$ : 3247 Armitage Are.; $9-10,1-2,6-8$. REITERMAN, CHARLES (b'51) - -Ia.3, 73;

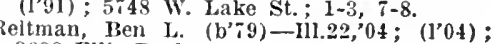
3628 Ellis Park.

Remington, Geo. Albin (b'79)-Ill.22,05; (1'05); 2208 Wabash Are.; 10-9:30.

REMMEX, NILS E. (b'63) - Ill.11,'87; offlce, 31 N. State St. ; 10-1; (B1,8); Op ; RFALD, Jos. THOS. UBOLD (b'7 ;

Ky.2, 05 ; (1'05) ; 6000 Prairie Are. ; offlce, 5040 Cottage Grove Ave.; 10-12, ;-8. 


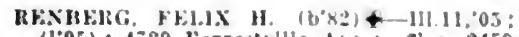
$(1 \cdot 05)$; 7 :29 Forrestulle die

Wentworth Ale: $3-?, 6-7: 0$ Alce. 2459

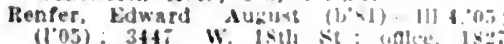
Hlue Island A re.: $5 \cdot 8: 30: U$.

Renn, Thos. Hulert (b'il) - Ill. I I, 9?: (t"04) 1849 S. Sawser Are.; oatce, 1759 is. 2lst St. : $1=2: 30,7=8$

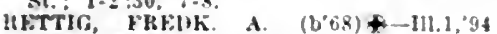
(1'94): 2026 Oszood st. : 1.

lietzer, Robt.-Cer.14,0 I: not in practlce

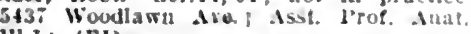
IIL. I: (FI).

veulter, Franz (1,"15) II-111.14.95; (1'95) 2943 X. Ilalsted St.; S-10, 1-4.

REYNOLDS, ARTHCi R. $(6054) \$$ N.Y.10 $76:(183)$; 148 lirexel litrd.: onlce, 13x

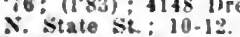

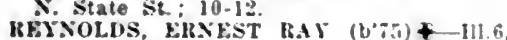
00: (1'00); 6615 Wentworth ire.; once. 153 W. $63 \mathrm{~d}$ SL: $8 \cdot 10,3-5, ;-8: 30$.

IReynolds, Henry' James $\left(6^{*} 52\right)-\mathbf{X}, \mathbf{Y}, 10,75$ (1'\$3): 2013 r'ralrle Aie.: odice, 15y $\mathrm{X}$ Stale st. : 1-3.

Reynolds, Horace D.-0.8,92; (1'95) : $\$ 39$ Oakdalo Are.; ofice, 39 W. Adams 5

REYTOLIS, JAMES EDIN. (b'0) - ind 9 35. III.1,91: (1'85): (Melrose Hark). ontce, 101 i S. Oakley" Blid.: 2-5: Assoc. l'rof. Ginn. Ill.22: S.

KEZA.KA, GEOHGE W. (b'69)†-111.1.93; (1'93); 2357 s. Central l'ark Arc.: $2-4$

RHODES, JOHN EWWIX (b'51) t-111.1, 85 : (1'8i): 1338 k. 58 th St.: utice, 128 s. Illchigan Are.; 9-4: Assoc. Prot. Laryn. and Otol. III.1; (I:,, 0$):$ LR.

Rlach. Thomas James-111.11,11 Chlcago state Hosplial.

RIBIEECK. WM. A. (b'si)-111.6,"0\%; (100i) 16201 Hatrison St. Oak Park 5969 South Iird. : $i-3, i-i: 30 ; P d$

Hicard, Tennsson J. (b'70)-111.39.'11; (1'12): 5204 Broadway; oftce, $209 \mathrm{~s}$. State St: $9-5$.

RICARDO DAXI. F. $\left(b^{\prime}, 3\right) \mp-111.14,04$ II1.11.05; (104): 333 E. 60th st.; offlee 15 E. Washingtón St. $1-3 ; \mathrm{S}$.

RICE, ERI PERRY (b'59)-I11.1.89; (1'88) 2315 W. Jackson Hird.; untli 8, atter

Bice, Ethel-Iil.13,02: (102); 158 W. Chtcago Ave: otlce, Blarshall Fleld Bldg.

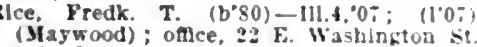
2-6:0

Rice, Imas I'ryor (b's9)-[11.11,13; (1'13) United States Public Icalth service Hos pital.

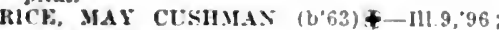
$(1996)$ : 5526 Hiackstone Ave, :5-7; ofice I2 E. Washlngton St.; 1 -

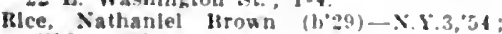
(l'96): 360 k. Garfleld blid.

RICH, KATHKRINE HRANEHW†-11.11, 01: (1'49): 500 Dirersey larkway; otlice, $108 \mathrm{~N}$. State St: 11.12.

RIchards. (ieo, k-11-III.4, $79 ;(1,-9) ; 63$

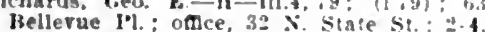

Rlehards, Henry $c(6,89)-111.11 .04 ;(104)$ 6739 Jnosworth Ave.; oatle, 209 s. Siate Sit: $10=6$.

Rlchardson, Delmer lbatton (b'6s)-0 1,"9t: (1'95): 4406 Gircenwrod Are.: andere, 476 \$. Siate St. : alsn, If St. Tlark st.

Rlehardcon, Frank If. (1, 66$)-111$ is, $(0)$ (1'01): (bentlat): ILa firange): once, $3:$ $X$ Stiate St.: $9: 30-4: 30$.

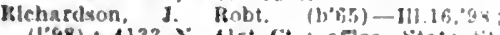
(l'98) $4133 \times$ Hst Ct. : offe, state st. and Jakkson Btrd

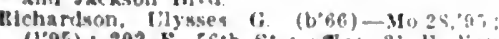
(1'95): 202 5. $36 \mathrm{th}$ st: oflce, 21 5. $1 \mathrm{an}$ Buren St: : -6 .

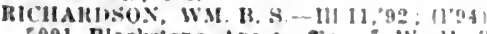
5001 Blackstone Nre.; unce, W. Wall hon St. : 1 -3.

Rlchberh, klulse 0.-III.15,08; (104); :2:? Calumet Are.

MCIIIA. SILAS T. $(1052)+$ Ind 8 111.6.'09: (1.y2); 7i20 Jerncelen Air odle, 5659 Wentworth Ale.; 3 $1.2,30$ $6: 30 \div \div: 30$.

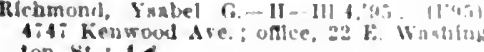

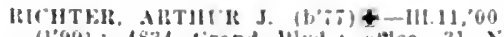
(1.99): AS34 lirand Hivd.: ondace, $31 \mathrm{~N}$ State st. : $3-5$.

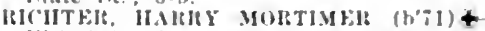
111.11,"4f: (1"94): 5748 suth I'ark Are. once, Niesley lloxpital; 10-12; Asst. I'rof

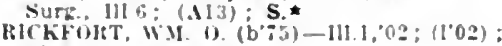

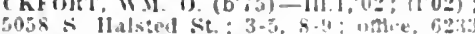
s. Halsted st.: $1=1,6: 30-8: 0$ bo.

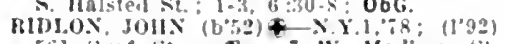
561 surf st. ofice, W. Madlisor st. a. I1: $(\Lambda 3) ;$ Or.

ItIjath, 'Paul Cole (b'5)-Pa.2, 00 ; (1001)

metog lthodes dre. (109): 1517 Roscoe Blvd: odce, 3sit lierteau ire : $9-11,2-4,-5$

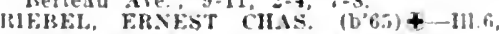
"00: (1.00): 63ro stewart Ale.; orec, 302 II. (13) St.: $10-11,7-8 ;(113)$ : S.

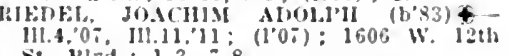
St. Hisd: 1-3. :

liks, r.MII (b'6i) t-Ger.1s,'89; (1'95): 4419 Circenuond Are. : once, $32 \mathrm{~N}$. State

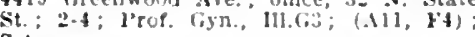
S.

Rles, Cay K. vurbln-X.14,92; (1'93): 4419 Greenwood Are.

RIFSE, BFINHIITT i. (b'65) $t-111.6,87$ (1'89); 5164 S. Mlchigan Are, oflce, 182

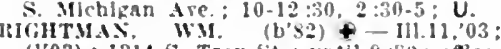
(I'03); 1314 s. Troy St.; until $9: 30 ;$ odece. $\$ 49$ W. $12 t h$ St. : 10-11:30, 2-3, $\%$. . .

mley, Fletcher Tarls (1,54) - $01,7:$ Grand Ave, Milwauke, Wis. ; $1-12,2-5$; lowy).

RIIti FI.OYD BURKE: (b'\$t)-111.1.08: (l'08); ft0t Magnolla Are.; oftec, $122 \mathrm{~s}$. Mlchlgan Ale: $10-1 ;($ Fi)

IHEY, JOHX ATGCSTINE $\left(\mathrm{b}^{\prime} \mathrm{B}^{\circ}\right)+-111$, 9.: (195); 3214 (ulversity Are: $9-10$,

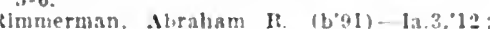
(1'13): 2551 ×. Clark st.

linderspacher, farl otto (b'89)-111.1.13: 11'13): Conk ('ounty liospital.

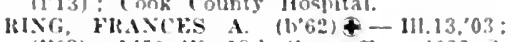
$\left(1^{\prime} 03\right): 1450$ W. ISth st: omce, $2622 \mathrm{~s}$ Lanndale Are: $8-10,2-1$.

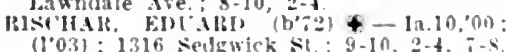

Itterbouse, krnest victor (1, iti)-illi01. (1'01): 3146 Warren Are ; $1-2,6-7$

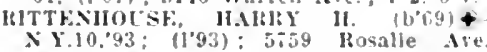
io-10.93: (1'93): 5.59 Rosalle Nie.

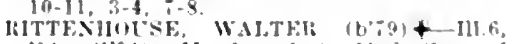
of: (1'04): Memler state Med.
wla : 6159 somh Park Are. Pd.

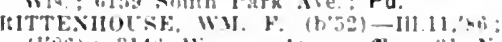

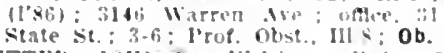

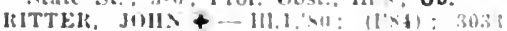
Vologato ble

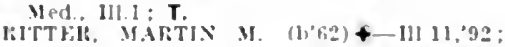

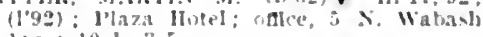

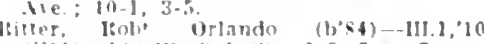
(1)il): lex W: (0:1k st : 1-3, $7-3 ;$ Or. litze. Jilan Mlam (1,:1)--111.6.11; (I'11) 62:- Si lanwrence Are.

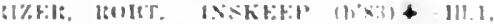

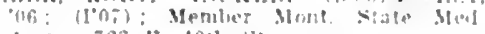

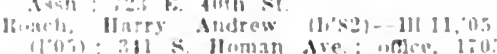
(1) 11 a

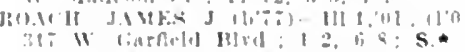

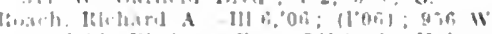

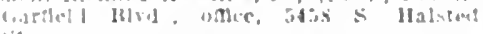

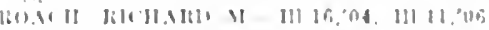

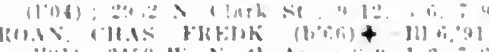

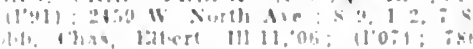
Milwanke it

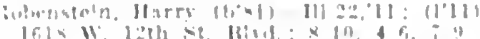

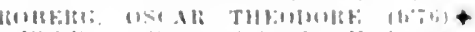
III 1."045: (12101). 3412 A keeler lie
IalkRts, lik, J

$12.5111+-111.10 .96$

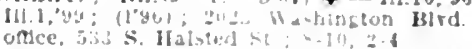
HOIELTS, RIIL GIE:

11: (1.il): 1130 Weil

leolierts, Thos. dillmore

(1'y4); 814 i: 420 is:

liolertsun until $9, b$

60: 1105$): 3195$ M11 n auke ise

Itobertion. Arthur Throma-111.22,"1"

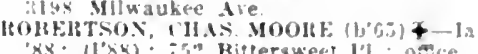

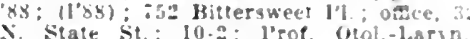

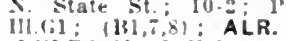

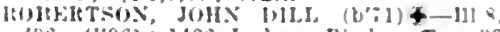

(21): $(1 \cdot 96) ; 1422$ Jacksnn I3|rd.; offce, 32 l'rot. Surg. and cin. Surz., I11.8: $\mathbf{S}$.

libertann, Wm. II-II1.8,01; (101): 3940

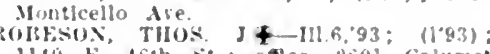
1140 b. toth st. : office, 2601" Calumes Ale.

Hobin. Saml. Mortlmer (b's3)-111.11,04

(1.06): 1139s. Ashland Blrit ; odice, 1314 $\therefore$ Jefferson st.; $12=-2,5 ; 0$.

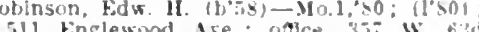
st. : $8: 30-10: 30,1-3,6: 30-5: 30$

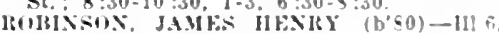

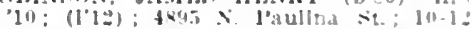
nftce, $112 x$ stople st. : 1.t, i.

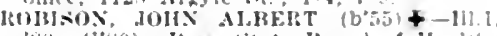

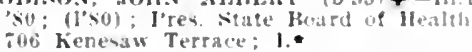

Roblee, l.enard klelil-ill.1.12; (1'12); 522 liryant Ave.

lRoche. Micharl Ambrose (b'8;)-11.6,'12: (1'12) : Conk county llospital.

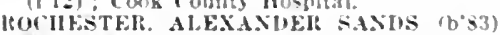

+-l'a 2,06: (1'11): Member Ohwo state

Med Assn. Metropole Hotel once,

iv. Madison St. 10-1, 2: H OALR.

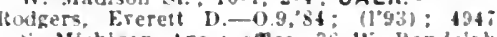
$\rightarrow$ Michlgan Are; omce, 36 w. Kandoiph MUtUR, CHAS. CODFIFI.

(See rt. l'ierce, Fla.)

liochrla, G. Fodward (b'6t)-Mheh.s, 90 ; (†) : 5011 Grame lilid

ROFHKS, HENFIHCT WES(OTT $(\mathrm{b} 59)+$

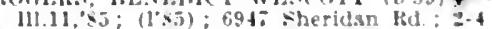

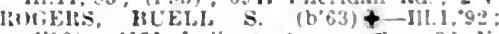

$\left(1^{*} 92\right): \$ 151$ ludlan
state st. $1-4: U$.

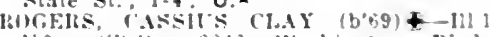
(6) $(1246)$ : 3240 Washlnaton Btrd $111: 2: \mathrm{s}$.

R(MERS, IINI. WESTON (bo6)\&-1116 (44: (1.94) : 540 l'rsirie lre : ntice, -204 $\therefore$ ilchlon Ire.; 11-1.

lingers, lda Wright (b'60)-111.4.84; (1's4)

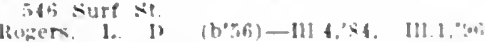

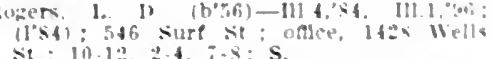
si: 10-12, $2-7.8: S$.

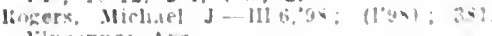

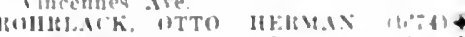

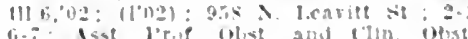

III is ObG.

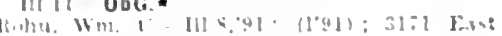

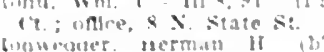

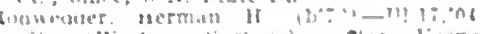

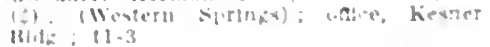
Itoland samuel rissen 11,261150 lintere renj

nut in jerattion

lbulutek. Ilarrs

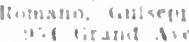

1:1111:

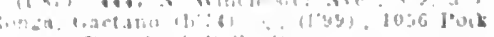

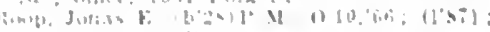

(1) BIT PII.IZ1 II

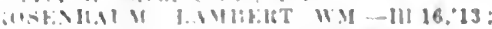


Rosenterg, Maurlce II.-F-Ill.8,94; (I'94) 3 fio.t Indlana Are.; olllece, los N. State Sit. : $11-1$

HOSFXELATT, SOL (b'75) $\oplus-111.39,09$,

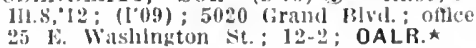

llosenblum, l'hllip (b'90)-111.6,'l3; (l'13) Allchael lleese llospltal.

ItosfxB1.UM, SAML. M. (b'69)-(ier, 1,90 (1'94); 1364 N. llobey St.; 6-7:30; ofllce, 31 N. State St.; 11-1.

ROSliNow, EDW. CARL (b'75) $\$-1 ! 1.1,02$ (1'03); 5804 Blackstone Ale.; oftlce, 12: S. Ilchligan Ave.; 4-5; Asst. Prof. iled. III. 1; $(1 ; 2,4)$.

Rosenzwelg, Geo. K. (b's1)-11!.11,08 (l'08); 1358 W. 12tli st.; $9-12,1-9$.

Rosenzweig. L.ouls (b'83)-111.11,'06; (I'06) 4943 Forrestrille Ave.: oftlee, 309 F. 4 itl St. ; $10-12,1-3,7-8 ;$ ObG.

Ross, Bermard M-E-O.2,'82; (I'82) ; 1331 v. Dearborn S't. ; offlce, 35 's. Wearborn St.

Ross, Colln Kenneth (b'85)-III.8,'11; (1'11); $220 \%$. Hoinan Ave

ROSS, JOIIN BARTLETT (b'71)-Ill.23, 05 ; (l'05); 2030 Irvlug l'ark Blvd.; until 9. $1-3,7-8$.

ROTH, ALBERT ALEX. (b'74)-I11.11,05 (l'05) ; 933 Ashland Blvd.; oftice, 1325 Blue Island Ave.; 10-12, 2-4, 6-8.

Rotl, Arthur E.-IĹ.13,01; (1,99): 1137 E. 72d St. ; offlee, 21 E. Van Buren St.; $10-5$. ROTH, CHAS. R. (b'7T)థ-Ill.6,06; (l'06) 1419 Granrllle Ave.; oftice, $3 \mathrm{l}$ N. State St.; 9-11, álso, $6405 \mathrm{~N}$. Clark st.; 1-3,

ROTH, JAMES IIENRY (b'68)థ-III.1,'96; (1'96) ; 2612 S. Mlllard Ave.; offce, 1664 Blue 1sland Ave.: $9-11,2-4,7-8$.

ROTH, JOS. A.-Ill.13,'05; (l'05); 1054 N. Ashiand Ave.

ROTH, 1.EO IR. (b'80)థ-111.17,03; (l'03) ; 137 S. Halsted St. ; 3-5, 6-8.

ROTHSTFIN, THOR. C.-Swed.2, 97 ; (1'98) ; 6500 Green St.; oftice, 122 S. Mlehlgan Ave. ; 2-4; I'rof.' Med., Ill.1; (F2): N.

ROTT, OTTO ... (b'83) +-Pa.2, 08 ; (l’10) Member olilo state Hed. Assn; $10 \mathrm{~s}$ Y Member

ROUBADEAUX, IAVELLE B.-Ind.5, 97 (l'05); 1037 wellington Ave.; office, 2804 Lilueoin $A$ Ye

ROWAx, CHAS. Jos. (b'T4) $\$-I 11,1,98$. (1'99); 725 Independence Blvd.; office, 122 S. Nichlgan Ave.; 4-5; Asst. 1'rof. Surb. III. $1 ;(\mathrm{A13}) ; \mathrm{S}$.

ROWAN, I'ETER J. (b'47) $\oplus$-Ont.1,70 $(1,7) ; 1211$ W. Adams St. $1-3, i-8$

Rowell, Lawrence W. (b'i1)-Ill.1, 00 (I'00); (Western Sprlngs); offlce, $159 \mathrm{~N}$ Stute St. ; 2-6.

Roy, Davld G. (b'6S)-111.15,'04:

$\left(l^{\prime} 04\right)$

7259 Emerald Are. : 9-12, 2-5, i-9.

yce, Wm. Sylvester (b'62)-Ml.11,07 $(197) ; 3240$ Lexington st.; offlce, $32 \mathrm{~N}$ State st.; $3-5$; also, $2359 \mathrm{~s}$. Kedzie Arc. $2-2,7: 30-8: 30$

Rozenka, Geo. W. (b'69)-Ill.1,'93; (l'93) 100 W. 19 th St. : 11-19

Rozunski, Mlehael (b'73)-Ill.8,'12; (1'12) 4744 S. Paulina st. : $8-10,12-2,6-8$.

Rubel, Maurice J. (b'75)-Ma.7,01; (l'02) 4337 Grand Blvd.; office, $32 \mathrm{~N}$. State st. ;
4-6.

RLBIN, GEO. (b'75)—Ill.11,98; (1'98) 5031 S. Michiga Are. ; offee, $32 \mathrm{~N}$. State St. ; $2-5$.

(l'00) W.I. II. (b'78) \&-I11.6, 00 $\left(l^{\prime} 00\right) ; 5233$ Greenwood Ave.; office, $25 \mathbf{E}$ Washlngton St. ; $3-5$; I'rof. Obst., I11.22; ObG.

Ruckel, John F. (b'60) II-Ill.10,'86; (l'97) ; (1) office, 9207 Commer-

$12,1-5,7-8$

RED, ANTHONY (b'62) $\mathbf{\uparrow}-I 11.6,91$; (1'91); $535 \times$. Central Ave ; $2-4,7-8$

(1) ; Memler ia. State Med. Soc.; 1900

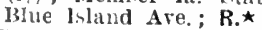

RLDN1CK, FRED (b'74)€-111,11,05; (1'05); 2007 Milwanke Ave.; $8-9,1-3,6-8$. RUDOLP11, LOL'1S (b's6)-111.6,'11; (l'11); $1214 \mathrm{X}$. Pobey st. : $9-10,2-3,7: 30-9$. RUEIL, MAX C. (b' 1734 Fullerton Ave., Evanston); office,

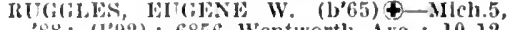
88: (I'92) ; 6856 Wentwortl Ave.; 10-12, t-8; Op.

GR IVT E (b'64)-111.13,04. $\left(I^{\prime}(14)\right.$; 1234 Granvlle Ave.; offlce, 6405 N. ('Inrk st. ; $1-3,7-8 ; G$.

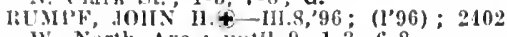
W. North Are; untII 9, 1-3, 6-8. UNELS, JOHN F. (1,49)-Ky.4,79 (l's1); 1037 Webster Ave.; 8-9, 1-2, $6: 30$ $\because: 30$; Pd.

Runyan, Ilermau C. (b'78)-Ill.1,06; (1'07); 5010 Dlckens Ave, intll 10, 12-2, after 7 . RUILRT, RICH.1lil) l6OOT (b'82) 12; (1'12); 1610 Jackson 13lvel.; I'rop. Anat. and oper. Surg. III.(;2: S.

Rupert, W'm. Inall (b'82)-III.4,08; (l'08) 326 N. Central Are. ; 8-10, 4-8; offec, 30 W. Randolyh St. ; 11-3

Rupp, Wm. A.-III.6,00; (l'02) ; 6155 champlaln Ave.; offec. 736 F. $63 \mathrm{~d}$ St.

Rusco, Ralph M.-H-111.4,'01; (l’01); 5747 Calumet Ave.; untll 9; offce, 32 N. Clark St. ; 12-6.

Rusl, Eugene Alphonsus (b'84)-Ill.8,'12 ; (l'12); 3000 E. 79 th St. ussell, Dennis P.-Ill.1,'90; (1'91)； 3147 W. Congress St.; office, 3158 W. Tan Buren St. ; 2-4, 7-9.

lusscll, Jannes V.-Ill.1,'94; (l'95); $1508 \mathrm{~W}$. 20 th 'St. : 8-9, 2-3, $7-8$

Russell, Jos. L.-IIl.I6,02; (I'02) ; 4004 W. 12 th St.

Russell, Jos. Weston (b'76) P-M-III.5,'04; (1'04); 355 E. 26 th St.; office, 73 W. 430 St. $10-11,7-8$

Russell, Marion Ousley-H-Ill.4,'90 ; $\left(l^{\prime} 90\right)$; 361 E. 57th St. : 12-4.

RUSSELL, SAMI. JOS. (h'70)థ-Ill.11,'04 ; (1'02); 5950 Nornal Blyd.; offlee, $15 \mathrm{E}$. Waslington St.; 4-5.

(IVlllow Sprlncs) $440 \mathrm{~S}$. Dearborn St. ; $10: 30-12: 30$.

(b'61)-IIl.1,96; () ;

1438 Washlngton Blvd.

uthenberg, Erich B.-Ill.1,'90; (1'90); 614 York Pl.; offce, 3057 Seminary Ave.; $11 \cdot 12,7-8$.

Que.1,82; (l'82) CLARENDON (b'54) $\oplus-$ $8-9, \mathrm{I}-3,7-8$.

RUTKAUSKAS, ANTIIONY KAZIS (b'72) -I1l.11,06; (l'06); 2338 S. Leavitt St. ; $9-11,3-5,7-8 ; T$.

Rutkus, Susan Aldona-Ill.11,'11; (1'11) ; 1976 Canalport Are.

RUUD, HEIGA (b'60)-nl.9,'89; (1'89); 4124 Clarendon Are.; offee, 15 E. Washington St.: 11-1.

RTUS, CANUTE WALTER (b'80)-Ill.11, 09; (1'09); 2647 Erergreen Ave.; offlee, 34.03 Fullerton Are.: until $10,1-3,7-9$; Asst. Jrof. Surg., 11i.22.

Pyan, Albert Freeman (b'86)-Ill.6.'13; Cook County Hospital.

Ryan, Davld Alex.-111.23,06; (l'07) ; 3859 Orden Are.

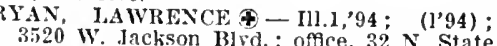
St.; 2-2:30; Prof. Suro, 11l.22: (A13, F4).

Ryan. Wm. S. (b'69)-111.1,95; (1'95);

1221 E. $62 d$ St.

RYDIN, CARL G. S. (b'74)థ-III.11,02; (1'02) : 902 Addison st.; ofluce, 953 Belmont Are.: 2-4, $6: 30-8$.

RYERSON, EDWT WARNER $\left(b^{\prime}, 2\right) \oplus-$ Mass.1,97; (1'99) ; 743 Lincoln Parkway; office, 122 S. Michlgan Ave.; 9-11; Asst. Prof. Surg., Ill.1; Prof. Ortho Surg.,

S.ACIS, TIIEODORE B. (b'68) T-Ill.11,'95; (1'9.5) ; 41 S. Central Park Are.; offlce,

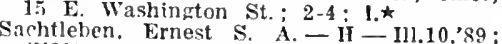
(l'89); 1634 W. Garffeld Blvd.; until 9 3-6: offle, 2843 Areher Are; 12-12:30,

SADLER, LENA KELLOGG (b'75) \&-I11.19, 06 : (l'0\%); (122 $\mathrm{x}$. Sheridan Rol., 11ighland Park); office, 32 N. State St.; $12-3$; $\mathbf{G}$.

SADI.ER, WM. SAML. (b'75) \$-M1,19,'06 ; (l'ni); (122 N. Sheridan Rd., Highland Park); office, 32 N. State St. ; 12-3; Prof. Phys. Ther., Ill.G.3; S.

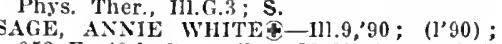
958 E. 40 th St.; office, 32 N. State; $1-5$.

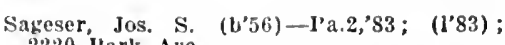
2220 J'ark Are. 1579 Mllwakce Ave, ; $8-10, I-3,7-9$

SALAMSON, MAX JASON (b'68) \&-Ill.1, 04 ; (1'94); 2039 Fowler St.; 8-10, 1-3, $6: 30-7: 30$

SA1,NGER, DAVII) - Md.1,94; (1'95) 31 N. Stnte St. ; $10-1,2-3 ;(137,8) ; 0 p$. Salinger, llarry (b'83)-111.16,12; (1'12); 2538 N. Sacramento Ave. ; of

Wabash Are. ; 8-9, 4-5, 6-8,

Sallnger, Samuel (b'84)-Ill.22,'06; (l'06)
5627 I'ralrle Are.; olflce, 59 F. Madison St.; $5-6$.

Sallnger, Simon F. (b'61)-Pa.12,'97; (1'97) ; 817 S. Marshflicld Ave.; offle, 1659 I'olk Sit.

SALISBURY, JEROME MENRY (b'54) $9-$ I1l.1,78; (1'79); (Wheaton); Asst. Prof. Chem., Ill.1.

Salk, lobt. Salem (b'89)-Ill.11,'13; (1'13) ; Michael Reese Hospltal.

SAIMMON, CHARLES SIGMOND (b'84)Ill.6,08; (I'08); 6401 S. Green St.; offlce, 1600 w. $63 \mathrm{~d}$ St.; $1-3,7-9$.

Salopoulos, Nlcholas-Greece 1,'90 ; (l'99) : 748 Blue Island Are.; offlee, $143 \mathrm{~N}$. Vearborn St. ; 10-12.

Sammls, Wm.-Ky.1,75; (1'82); 3503 Beach Ave.; oflce, $208 \mathrm{~N}$. 5th Ave.

SAMUELS, MALRICE WOLFE (b'84)Ill.11,08; $\left(l^{\prime} 08\right) ; 2617$ Leland Ave. ; offlce, 401 W. North Ave.; until 10, 1-2, 7-8.

Sanborn, Ida M. (b'67) E-Ill.8,'98; (l'98); St. : 4-6.

SANDAHI, ABEL P. M. (b'87) \&-Ill.16,'11; (l'11) ; 3350 Seminary Ave.; office, 5333 N. Clark St. ; 1-4, 7-8; Ob.

SANDAHI, JÓS.--11l.16,06; (l'08); 3350 Seminary Ave.: 8-10, 2-4

SANDBERG, CARL ERIC (b'69)-IIl.22,08 ; (l'08); 1001 W. 59th St.; untll 9, 1-3, SANDBERG, KARL F. M. (b'55) - Norw.1

'81; (l'82) ; 2850 Logan Blvd.; 1-3; S.

Sanders, Audley owenton $\left(b^{\prime} 78\right)-111,1,11$; (1'12); 3713 Grenshaw St.

SANDEliS, JOS. (b'61)-Ind.8,'84; (l'95); 5619 lrving Park Blvd.; until 9, 1-2, 7-8. SANDSTEDT, GUSTAF EDWIN $\left(\mathrm{b}^{\prime} 76\right)$ की IIl.14,'07; $\left(l^{\prime} 07\right) ; 3162$
$8: 30-9: 30,3: 30-4: 30,7-8$.

SANDUS, ESTHLR ELEANOR (b'71) $\oplus-$ Ill.16,'06; (l'06); 1638 Farragut Ave.

Sandy, 'Thomas H.' (b'74)-Ill.13,01; (1'01); 4258 Wilcox Ave.; offee, 5 N. Wabash Ave. ; $11-1$

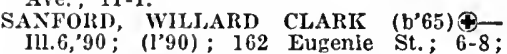
office, 31 N. State St.; 11-1; $\mathrm{S}$.

SANTEE, HARRIS ELLETT (b'64)(4-Pa.1, 92; (1'92) ; 2S06 Warren Ave.; untll 9, $4-7$; Prof. Anat., Ill.16 and Ill.22; (F1);

NRHEIM, RORT. IK. (b'80)-Ill.11,05; (1'10); 3234 Pierce Are.; office, 3407 W. North Ave. ; 2-4, 7-9.

SARNOFF, ISADORE (b'79)-Ill.16,'10; (I'10) ; 1102 S. Ashland Blvd.; offle, 2405 W. 12 th St.

Sasko, llelen B. Molnar (b'75)-Ill.11,'03 (l'03) ; 1849 W. 51st St. ; 9-10, 2-3, 7-9.

Sasko, Martin Pavel (b'73) - Ill.11,'12 ;

(1'12) ; 1849 w. 51 st St. ; 10-12, 1-3.

SASS, MARJA DOWIATT (b'71)@-Ill.9,'96; $\left(1^{\prime} 96\right) ; 5208$ W. Harrison St. ; offece, 1725 w. 18 th St. ; 10-12, 6-8.

SATTLER, 'HHLIP (b'48)-Ill.1,'81; (l'81) ; 3239 Orden Are.; office, 105 S. Dearborn St. ; until 9 , after 4 .

SAUER, IHEXRY EDW (b'68) -111.6,96: (l'96); 1415 N. State St.; office, Marshall

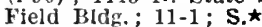

Sauer, Louls Wendlin (b'86)-Ill.1,'13; (1'13); Children's Memorlal Hospital.

SAUNDERS, ANNETTA AYERS $\left(b^{\prime} 61\right)-$
I11.14,96, $111.13,97$, Ill.18,'99; $\left(1^{\prime} 96\right) ; 919$ Ill.14,'96, 11l.13,'97, Ill.18,'
N. La Salle St.; 10-12; G.

SAUNDERS, C11ÁS. B. (b'65)-Ill.14,'96, Ill.13,'97, Ill.18,99; (1'96); 919 N. La Salle St.; until $9,12-2,6-7 ;$ obG.

SAURENHÁUS, ERNST (b'59) $\oplus$ - Ger.10

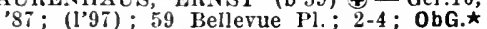
Sawyer, Alvah Lewis (b'80)-Ill.11,'13; (1'13); 4915 West End Ave. 


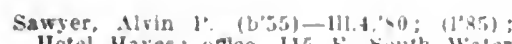
llotel Hases; onlee, 115 k. Suuth liater st.

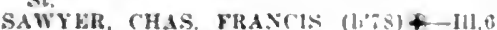
04: $\left(10^{\circ}\right)$ : 3142 South I'ark Aie,; ntlce, 129 E. 33d St.; $3-3 ; S$.

Samrer Eugene w. (to3i) I1-111.t. (1992): Hotel Hnyes: once, 7155 Vincennes Are.: $10-12,1-4$

Sax, Arhur $0 .-11-111.4,97$; $(1.97) ; 65$ fir Yale Ave, : 1-3, :-8.

SAYKE, CHAS. Eliv. (b'69)-Ill.15,9t Ill.11,97; (1'94); 3903 kills Are: onled T W. Madlson St. : $1: 30-3 ; \mathbf{S}$.

SCELFTH, CHAS. F. (b'*2)-111,1, $90^{\circ}$ (1"96); $34+4$ W. Jackion lird.: $9-4$

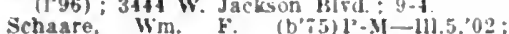
(I02): 1433 Clifton lark Are.: oflce 95: W. Isth st.; 9-t; Asst. l'rot Surt. III. 22.

SCHACUTER, JOSEPH V.-III. 1n, 99 ; (I'99) 1535 W. North Ave. untll $10,1-2,6-2$.

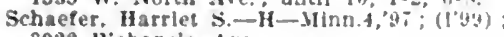
3022 Wabansla ire.

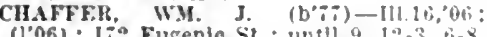
(d) (I’94): 1526 N. Spaulding Ire. : 8-9, I.2, (1’94); 1526 X. Spaulding tre.; 8-9, 1.2. $6-8$

SCHKLL, CHAS. P.-III.11,05; (1'05); $1: 00$ W. Chlcago Are ; $1-3, i-8$

SCIEMHS, FRAXK H." (b'69) +-111.1, $9:$ $\left(1^{\circ} 93\right) ; 2450 \times$ Sawyer Are.: othee, 1543 W. Dirlalon St. ; $10-11,3-4$, ; -8

SCHEXKELHFRGER, I'ETEK C. (b'TS) + IIl. 4,03: (!'03) : 52 Gialt Ave.; oflle, 32 X. State St.; $10-4 ; \mathbf{N}$

Bcheuerman, Chas. S. (h':5)-111.16,02 (1'02): 1321 Peferson Are.; oflce, 15 F Washlngton St. : 9-4.

SCHILLER, IIELIODOR $\left(b^{\prime}, 1\right) \mp-A U S .5, \cdot 4$ (1'03): 5042 Drexel Blrd.: oflee, 29 b. Madison St ; I-3:30

Schlndler, Frank \$ - I Il.11,9; : (1'93) : 1306 McAlloter PJ.; once, 606 Iilue Islaud Ave. : 2-4, i-8:30

Schlrding. Wm. I. (b'72)-I11.1,34: (1'9t) (Palatine); once, I:4 $x$ State St. ; $2-5$.

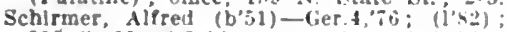
81 s. Marshfleld Are. ; Offlce, 1604 litue Island Are.

Schlrmer, fiustar (b'55)-(ier.4,'82; (1'5i);

1102 S. Ashland I1rd.; $1=3$

SCHLAMEK, HENRY $Y^{\prime}$, (b'56)-111.1, (1'92): 1229 Montana St. ; offlee, 1513
Fullerton Are.: 8.11, 2.4, 6.8.

schlaplk, Alexander $\left(6^{\prime} 8,3\right)-111.23,00,111.6$. "0S: (l'06) : 1325 Turner Are.: I-2, B-s. Schllerbach. Then. L.-NY.10,85: (I'si) not in practice 65 . Normal dre.

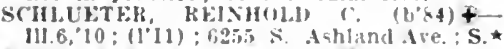
SCHMALCH, GEORFE (b'BG) + Tier.13,"92 (1'02); 6127 S. Green Si : onice, 32 X Stale St.; $1-3 ;(\Lambda 11) ;$ ObG.

Schmeling, Max' (h'47)-111.1,83; (1'97):

1502 Wells St. ; $0-11$.

Schmidhoter, Max (b'81)-111.16,'13; (1'13)

lits Belle plalne Ire.

Schnildl, Charles (b'ï)-Ill.39,10; (1'10) $1405 x$ Harding Are. inlee, 3504 W North Are. $8: 30-9: 30,1-3, ;-$

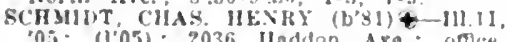
ro: (1'05): 2036 Iladdon Are.: onfer. 2103 W. Diviston st. : 3-4, i-8

SCIIMIDT CTAS. J,HOP()LI) $\left(\mathrm{b}^{\prime} \bar{i}\right)+$ III.11,08: (1'0!4): 654s 8 . Ashland

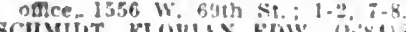

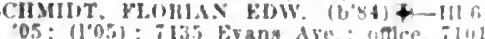

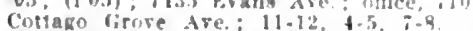

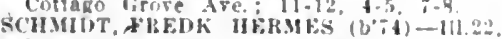

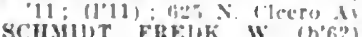

SCHMIIT, FREIOK W. $\left(\mathrm{b}^{\prime} 62\right)+-1116.85$ (1'85): 13614 Indlama Are ; K.10, 11-12

schmlat, Karl IIerman (b"8t)-111 f, 11 ;

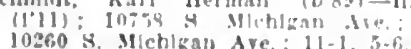

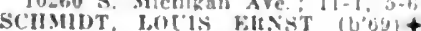

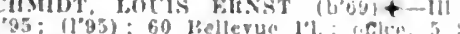

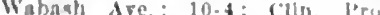

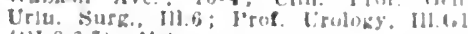
$(1 \cdot 1,3,0.7): U . *$

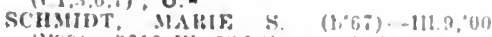

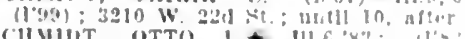

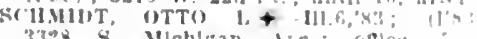

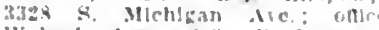

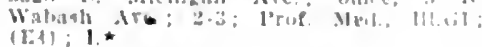

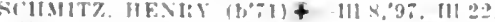

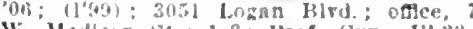
W. Madisen st. ; 1-3; I'rof. Gyn., Ill:2:

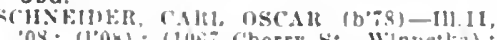

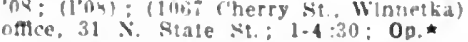

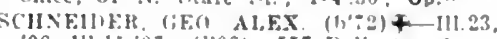
'0f, 111.11, $0 ;:(1006) ; 557$ Fullertn dve. schnelder, lichard U (bosil-111.14,0\%:

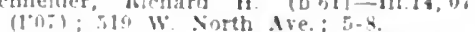
SCHNEIOEI, SAML $N$ (b'sa) \&-III.10, So: (183): At: Fullerton Ave: oflce 22 E. Washington St.: 1.3

celineider, Wm. John (1,83)-Neb.ti,10 (1'10): 1021 Pralrie Are.: ofice, 3900 cottage lirore Are ; $11-3,7-8$.

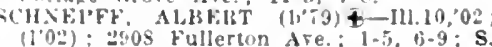

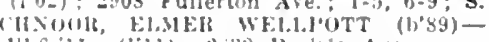
111.6, 11: (111); 24:3 I'ralrle Ave.

schoch, Lennard F. (b'ti) II - Mo.s, 90 (1'yii); (C.1k l'ark); ontce, 3152 Warren Are : $8-9,1-2: 30, ;=8$.

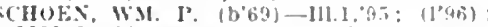
3218 Le Joyne Are, once, 20 : West ern Are.; $3-5,7-8 ; S$.

SCIOE.XBFRO, ALBFHT JOHS(t'fs) + III.11,99; (1'99); 4521 Beacen st.; offlee. 2432 Lincoln Are. : $2-3$, i-8; G.
chnenfeld, Chas. Jos.-111.6,9y; (1'98): 4736 lndiana Are.

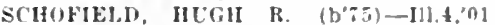
(1*01): Memtrer state Hed. Sioc. of Wis. 2814 Groveland Are.

Scholes, I.ydia (: ( (b'5t) $\mathbf{H}-111.15,4,4) ;\left(1^{\prime} 96\right)$ : $31: 1$ Washington Bird.

Scholler, Alphonse E. (b'7)-111.22,12; (1'12); 1035, X. Western dve.; $9-11,2-5$,

Schols, Fred Ir. (b'il)-IM.n."10; Axsistant Plisilelan: fien W. 3ith st.

SCHOLTEN, FRYEST R. $\left(b^{\prime} 6^{-}\right)+$-Ger I:. "93: (1'92); 5010 Vincennes Ife.; (filce, $32 \mathrm{x}$. State st.: $2: 30-5$

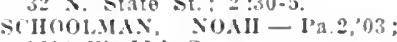

(1'03,3) :

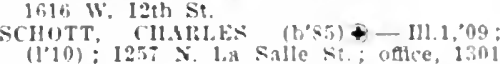
N. Clark St.: 1-3. $7-5:$ Pd

SCIIRAFER, VICTOIR LITL (b'Ts) + Rกu. 1,01, Ill. 23,'04. II1.1,07; (1'04); 3300 Jonulas IBlyd: $1-5,7-9$

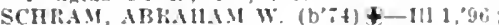

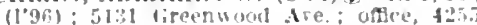
Indlana Aie.; $1: 30-3: 00: 0$ o.

SCIIRAM, DAVID i. (U'ot) - II!.5:0 (l'0(1); t5is l'ratile tie.; oftlee, $31 \mathrm{X}$ State St: $1-3 ;\left(1 y^{2}\right): 1$.

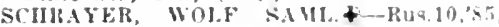
111.13,"00; (1'93); 927 Noble st.; untul

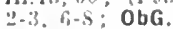

Schreider, Theidore II. $\left(b^{\prime} f, n\right)-111,1,01$ (I.91); H401 Pralrio Are.: $3-5$.

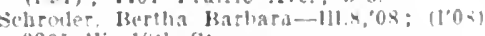
t2001 IV. 18th s

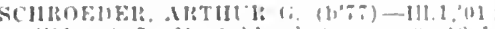
$(100)$
$6-3: 5$

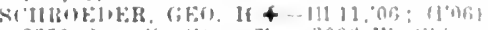

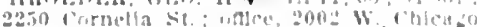

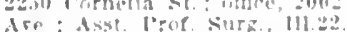

schroeder, Juhn Firlo Sixtus $(60,8)-1112$

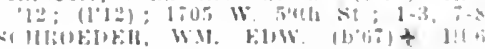

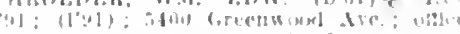

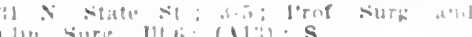

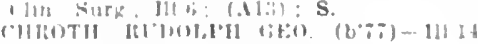

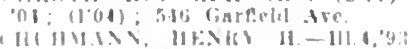

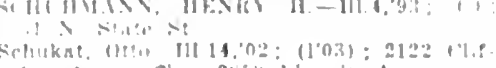

('ll till

(1)

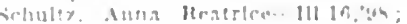

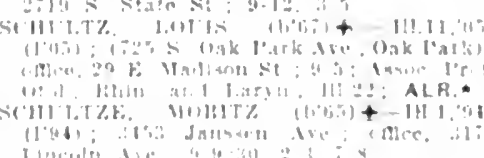

Scliulz, Irthur $y$

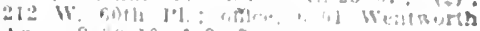

Schulz, otion llenry (Lin)

4040 Lincul: Are.: 1:-

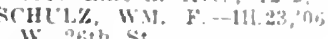

STIIIIZE, I.EONIH1)

(1.05); 135 \&. Ilamlin 1

S.hulze $1 \mathrm{~m}$ ('l)

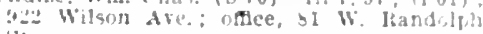

Schupmann, whert (b'62)-310.5,97; (l'ys)

2011 Fremont Si ; offee, 156 (7ytoum ise ; $9-10,1-3,7-3$.

Schurmann, Martin luzuat (boni)-111.8 09: $\left(1^{\circ} 09\right)$ : 1765 Shemleld Ars.: $2-3,7-8$ Schussler. IIugh K. (6'76)-111.6,03, I11.13 37; (1"97); +121 kenmore Ar

chussler, Waltet Iichard (b.64) F-111.8 89: 11891; (Orland): otsce, $410 \mathrm{~s}$ Dearborn s:? : 12:30-2:30

SCHWAR. I.ESIIE W. (b'65) +-111.11 .96$ (1'90): 4311 vinomes Are : until $8: 30$; odfee, Hok coitage firote Are.: 10-11, Ob.

hwandt, Emll I-III.1,8S; (1.90); It23 Chwandt, Emll 1-Ill,'ss; $(190) ; 1$ t25 schwartz, Nifred John rhas.-Ill.11,0\%; $\left(1^{\circ} 05\right) ; 2111$ Clereland Are.

Schisarti, Elmer Ellsworth (b'66)-Ill.16, 11: (1'11); (wilmetle): otice, $39 \mathrm{~s}$.

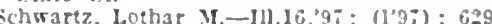
Siratford ll.; once, $39 \mathrm{~W}$. Adams 'si:

Sehwartz, Wllliam Augustus (b'85)-III.6. 'I1; (1'11); 1466 Weniworth Are:; 1-3,

SCIIWARZ, LEIGH FWING (b'69) †-I11.6

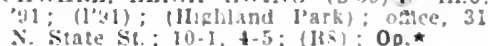

schwarzel, Fredk. M. (b'it)-111., 11: (1'11); fit?r, siewart Are; oflce, Audl(1) rlum Blito : $91-5$

Schweers, Fredk. Mi-1'-11-I11.5,"03; (I'03) : $24: 33$ lacine lre.

senfleld, (has. J. (b'as)-Mll.11,0I: (1.01) : 6420 Anthuny ire : ottoe, $15 \mathrm{k}$ Washington 5 t. ; $1: 2: 30-4: 30$.

ont, Henry (b'71)-Kent.3.93; (1'09) ; 6159

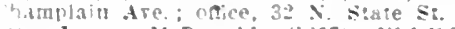

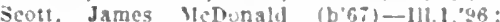
(1'b6); 1161 w. Van Juren si.;9-12, 1-3,

7.8. Lancasier F.-N. Y.10,'sz:

435 Cireenciew Are.

ait laura lironatm (b69) - 111.29.08: (l'os): 324 stanley Terrace: oftce, $116 i$ 15. ban liuren St.; $1-3$.

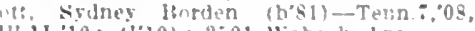

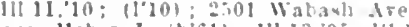

ars, lleber J. (b'61)-I11.13,05. 111 11,06:

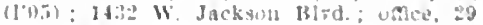

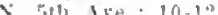

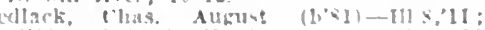

(1'11): 2145 S. Ilaring are: Alce, a

E. l)earburn

Ëllis o

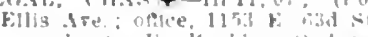

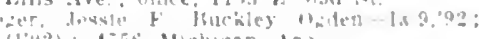

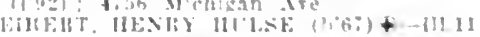

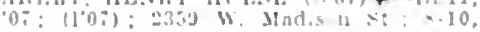

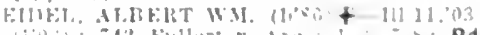

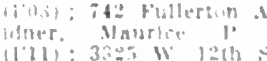

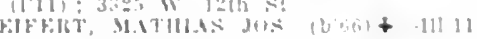

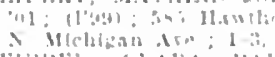

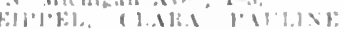

111
are.

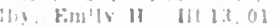

OALR.

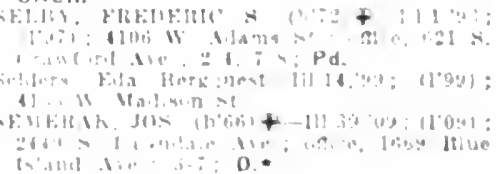




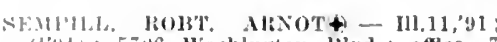
(1':01): 506 Washlngton lisd.; offlee, II. Mindison St.;

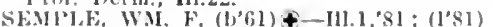
703 Melrose st.; oftec, 843 Belmont dre. 1- 78 .

Senate, Arehte Samuel (b'79)-Tenn.7,04: (l'o?) 5122 s state st. $0-100-4=$ SENX. FMANUE1 JOHA (b'69) + - Ill. 3. (1.93); 39 E. Achller st.

SEN WI. $\left(b^{\prime}, 6\right)+-11.1,00 ;\left(10^{\prime} 00\right)$ 124 Astor st.; olllee, 2i V. Wilshinger St. $: 1-3:(6, \pi)$

SEI'PLF, BDW, (a. (b'74)-111.23,01, 111.11 '06: (1'04); 4214 Cillumet Are.; oflde' 6.901 \&. IJalsted st. : $1-3,7-9$

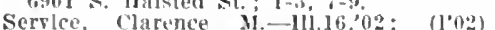
5 sis Everett Ave, oftce, 1164 E. 55 th st.

Servlss, Climena-H-IIl.4,'96; (I'96); 803 Sherldan Rd.; $10-12,2-4$,

SEUFEIRT, EDW: CONSTANT (b'73) $\uparrow$ 111.11,'93; (1'93); 244. N. Kíedzle 13lyd. offlce, 1173 Milwauke Are, $2-3,7-8$ I.

SEVILLE, FIEDERIC $\left.b \cdot\left(b^{\prime} 6\right)^{-}\right)+-I 11.11$ 95 : (l'95) ; 3360 W. Monroe st.; ottlee, $22 \mathrm{E}$ Washington $\mathrm{St}$.

Sesmour, Mars A. (b"38)II-ill.4,82; (1'82) 1513 N. Waslatenaw Ave. : -10 .

SHARAD, AlTIUL M. (b'68)€-111.11,94; (1'94); 1610 W. 12th $\mathrm{St}$.

SHACKLETON, WM. HLSWORTH (b'82) †III.6.09; (1'09); 6030 Vincennes Ave. office, 32 N. State St.; 3-5; S.

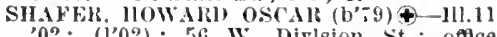

02; (1'02); 56 W. Dirlsion st.; office,

1200 N. Dearborn

Shaffer, Mary I.-1'-.11-111.5,'ss; (1's8) 6248 irexel Are.

HAFFE, TESPER $\left(\mathrm{b}^{\prime}(64) \oplus-\mathrm{Il1.9}, 96\right.$ (1'96) ; 2258 N. Cintral Park Ave.; oflee, $32 \mathrm{~N}$. State St. : $3-4: 0 \mathrm{~b}$.

SIIAFFNER, PIHLIF FRANK (b'85) †-III.1 09 ; (1'09); 811 Drexel Square; offlee, 31 N. State st.; 10-1, 2:30-4:30; D.*

Shallenberzer, Jamies Nelson (1, (6i)-Mo.28, 97 ; (l'97); 764 Oakwood Bled.

Shallenberger. John $F$, (b'79)-Il1.22, 07 $\left(l^{\prime} 0 \bar{t}\right) ; 120 \bar{t}$ E. $53 \mathrm{~d}$ St.; office, 766 Oakwood Blva.

SIAMBALGH, CLEVELAND JAMES-111.8, '11; (1'11); 7000 S. Green St. ; offlee, 6903 S. Ifalsted St. $; 2-4,7-9$.

SHAMBAUGH, GEO. ELAIER (b'69)†-Pa.1 $95 ;(1 ' 97) ; 5317$ Greenwood Ave.; office,
122 s. Jichlgan are.:9-12: Assoe. l'rof. Lary. and Otol., Ill. 1 ; (B2,5, $\bar{i}$, F1) ALR.*

SHANAIIAN, BENEDICT F, (b'71) \&-IH.8. $97 ;\left(I^{9} 97\right) ; 404$ S. Asliland Blrd.; office, 160.5 W. Van Buren $S$ t

Shanahan, Thos. P.-Ill.1, T7; $\left(1^{\prime} 76\right) ; 1$ E. $22 d$ St. ; $2-4$.

SILANS, Jos. (b'S2) - 111.5,'10; (1'11) Iifi W. Dirlsion St.; $9-11,1-3$, i-s; $\mathbf{G}_{\text {. }}$ HANos, CllAs. G. (b'84)£-111.39,'10 Madison St.: $9-4$

SHAPIRO, HIYIAN B. (b'T7) क-MII.1,03 (l'03); $1300 \mathrm{~S}$. Troy $\mathrm{St}$; office, $1000 \mathrm{~s}$ raulina St. ; $10-12,1:: 0-8, i-9$

hare, Geo. A. (b'81)-111.22,'08; ( ) ; 191? W. Adams st

Sharkey, Nary E.-Ill.16, 0s; (1'09) ; 2107 Grand Ave.; 9-10, 6-7:30.

Sharp. Chas. E.-N.Y.6.88; (l'97); 2534

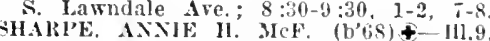
91; (1'91); North Side Iospital.

Shaver, Eva S.-II-III.14,03; (I'04); 545 W. Oak St.

Shaw. Siremba-Ill.1,'82; (1'82); 1539 W. SILY) (1'12): 2607 Potomac Are. : 10-12, 7-9: SIIEARER, CHAUNCEY T, (b's4) '11; (1'11); 812 Diversey Parkway; 2-3,

Shears, Jessie E. H.-II-111.4,'S4; (1'89) Liaknta Hotel.

SHEETS, YALGHN LEE (b'69)£-III.22, 2,41 Washington Blvd.; of fice, 5 . F. Mindison St.; 1-3; Prof. Phys.
Shetrerl, deamette M. (b'79)-Neb.6,'12; not la practlce: 2573 N. Clark St.

Shekerjian, Ilofakim 13.-111.14,07;

14.3 N. Lat Nalle st.

Sheldon, Harlath loanl. - Ill.8,'10

$\left(l^{\prime} 08\right)$

3459 walmot st.

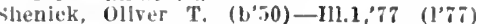
1754 W. Allams St.

sheppard, Jouis relos-Ill.11, 00 ; $\left(1^{\prime} 00\right)$ T331 W. Jinekson livd.; 12-2, 6-8. $1315 x$ Western Are; $8-10,12-4,8-9$; onles s.iz Milwakee Ave.

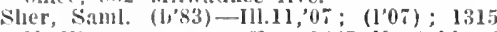
N. Western Ave; offle, le:s N. Ashland Sherin, We'sley Horley (b'75)-I11.11,98 (1':9) ; $50: 21$ l'ralrie Ave.; until 11, 3-5,

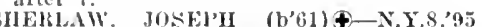
(1'es); office, 7001 Normal Ave, ; until $y$ $12: 30-2: 7: 30-9$

Sherman, Clare Arthur (b'80)-111.22,'11 (1'11); 4307 W. Madison St.; offlce, 4 ; 39 il. Vin Bureu sto

SHERIHLL, JOS. JOHNSTON (b'79)-III.11 , 03 ; (1'03); 753 littersweet I'l.; offtce, 32. N. State st.; also, 402 s. Halsted st llumbolelt klid.; otflee, Cook County Hospital.

SIIEKWOOD, PHANCIS BOREIRTA $\left(b^{\prime} 62\right)$ t -111.1,'s8; (1'88); 3508 W. Ilarrlson St.; stile st. : $10-1$.

Shiley, Douglas A.-N.Y.10,'72; $(195) ; 2125$

shoemaker, Claude E.-H-HI.10,95; (1'y5) 524 W. Van Buren St.; also 400 s. Jth Ave ; : : :30-6:30.

SHOLL, HAIKY EARL-III.4,06; (1'06) ; 4700 Broadway ; offlee, 1002 Wrilson Ave. Short, Nathan Green (b'5) - Ill.4,06 HULTZ, LOUIS A.

(Seo kockford.)

SHUTAN, MARY (b'82) - - Ill.1,09: (1'09) 4942 W'ashington P'ark P'l.; office, $29 \mathrm{E}$. MIadison st.; $11-12.30$

Sidali, Ernesto (b;3)-Ita.10,01; (l'11) 947 'Taylor St.; 8-10, 1-3, 6-9.

SIDWELI, CLAItENCE EDW. (b'Ti)‡oftice, 1433 Claremont Ave, Monroe St, SIEBEL, JOIN EDW., JR. $\oplus$ - III. $6,0 \overline{0}$ (l'07); 960 Nontana St.; offlee, 2402 lineoln $A$

Sieber, Franeis A. (b'41)-IIl.1,83; (1'83) 4327 Michigan Ave.; oftlce, 35 S. Dear born st. $4-4$

Slegel, Abraham Mlorris (b's6)-Ill.6,'13; (l'13); $92 \bar{T}$ S. Irving Are.

SIEGLER, WM. JOS. (b't4)£-I11.11, 10 ; SIEMINóvicz, WLADHMIII J.' (b'59) - IId.3, '93, Ill.11,95; (l'94); $4105 \mathrm{~N}$, Avers Ave. Sietsema, Ebel (b'81)-l11.14,07; (1'09) 6972 Fullerton Ave.; 9-11

Silverman, Jacob 1). (b'i5) - 111.14,04 (1'04); 1227 N. Crawford Ave.; offlce, 1002 blue Island A ve.; $10-12,2-4,7-9$

MMIONS, CIIAS. A. $\oplus$ - Ill.6,96; (1'96) 4703 Prairie Ave, ; oftee, 2725 S. State St. ; 8-9, $12-2,6-7$; and
St.; also, 501 E. 43 d St.

SIMIONS, GEORGE II. (b'52)£-111.4,'82, 11l.1,92; (1'99); 4217 Kenmore Ave.; of fice. $535 \mathrm{~N}$. Dearborn $\mathrm{St}$; ( $\mathrm{F} 4)$.

simmons. Howard L.-H-Ill.10,'9i; (1'97); (612 Kenilworth Are., Oak P'ark); office,

Simmons, Lloyd H. (b'89)-Ill.11,13; Chicago lyilt-ln Hospital and Dispensars. Simmons, Margaret E.-Ill.9,'91; (1'93); 1518 W. Madison $\mathrm{S}$

SIMON, LUDWIG SILYERMAN (b'70)€offlee, $31 \mathrm{x}$. State 47.3 Forrest

SMIOND, JAMES PERSONS (b'78) $\oplus$ Ill.1,07: not in practice: Nember ind. State Med. Assu, ; Northwesteru University Medical School; Assoc. Prof. Path.

smoss, CHAS. J. (b'43)-N.Y.3,67; $\left(l^{\prime} 7 \overline{7}\right) ; 4412$ Indiana Ave.; until $8: 30$, $12-2,6-7$.

SIMPSON, BURTON J. (b'T0) $€-M 11.1,00$; Halsted St.; $2-3.69$ th
SIMI'SON, ELMER E.t-111.6,94; (1'94); 6562 Stewart Are.; onlee, 6340 s. IIalsted

SiMPSON, FlRANK Ellw, (b'69) - I11.6, 96 ; (197); 542 liush St, ; offlce, $59 \mathrm{E}$

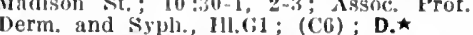

SINCElk, ENIL,-Ky,2,"74; (1'81); 3424 Ithodes Ave.; $2-4$; ottee, 25 W. Madison St.; 11-1.

SINCEHE, MAL'LICE B. -N.Y.10,'88; (1'88); 3424 lihodes Ave; $2-6$.

Sinclalr, James (i. (b'55)-111.11,88; (1'84); 3455 Cottage Grove Ave ; $10-11,5-\overline{7}$,

Slmelair, Jardine frank (1)'T9)-III.23,07. $\left(l^{\prime}(0)\right.$; ; 11 . Superlor St. ; oflee, $8 \mathrm{~N}$.

singley, Chas. Clary (b'57)-J'a.2,'81; (l'si); 4959 S. Mllehlgan Ave.; office, 21 E. Van Buren st.

Sinkler, Saml. (b'7 7 )-Ill.22,'08; (l'08); 939 S. P'aulina St. ; 9-11, 2-4, 7-9.

SIPPY, RERTRAI WELTON (b'66)๑-III.1, 122; S. Michigan Are.; $1: 30-5: 30$; Prof.

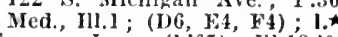

Slssman, Isaac (b'6i)-1ll.13,00; $\left(l^{\prime} 00\right) ; 858$

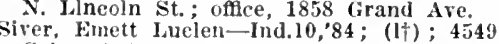
calumet Ave.

SKEBEISKY, JAMES W. (b'82)†-111.6, 07; (1'07); 9039 Commerclal Ave. ; 8-10,

Skiles, IIngh P. (b'51)H-III.4, 80 ; (1'80) : 2340 W. Monroe St.; offce, 32 N. State

kleba, Leonard Fredrlek (b'91)-Ill.8,'13; Intern, Jefferson Park Polyclinle Hospital. Slade, Louls Vida Bronson (b'79) $\mathbf{H}-$ Cal.5,

SLATER, GEO. F.-Ind.10,'96; (1'97) $: 6201$ South Park Are.; office, 6240 Cottage

Slavik, Edward Frank (b'89)-Ill.11,13 ; (1'13): 4119 w. 21st. 1l.; offce, Illinois Charitable Eye and Ear Infrmary; OALR. $\star$

SLAYMAKER, SAML. ROBT. $\left(b^{\prime} 64\right) \oplus-$ Ill.1,92; (1'96); 3017 Wasblngton Blrd. ; office, 2.5 K. Washington St.; 1-3; Assoc.

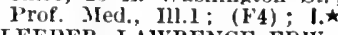

SLEEPER, LAWRENCE EDW. (b'77)-H11.6, 1201 E. 55th St.; 2-4, 7:30-8:30; ALR. Slinde, Arthur Christlan (b'81)-Ill.6, 09 ; (1'09); 4700 Racine Ave. ; offlce, 800 Belmont Ave. ; 1-2, 7-8.

Sloan, Ralph C.-H-Ill.10,'99; (1'99); not in practice; 6235 Ellis Ave.

Smale, Wm. If. B. (b'68) N Nich.8,91; (1'06); 4444 Sheridan Rd.; 5-6, 7-8:30. SIIALL, ARTHUR ATWELL (b'T3) $\$-0$ - Ont.1, 95 ; (1'02) ; 32 E. Division St. ; office, 32 SIALL, CHAS. PORTER (b'63)Ð-Me.1, '89; (1'92); 4741 Greenwood Arre; offlee, 7 W. Madison St.; 10-4; OALR.
Smalley, David Arthur (b'76)-1ll.14,05; $\left(1^{\prime} 05\right) ; 4$ w. Ontario St.

SMEDLEY, JAMES E. (b'55)\&-Mich.1, '90; (l'90); 911 N. La Salle St.; 8-9, $1-4$, after

SMEDLEY, NATHAN JAY (b'63)థ-Ill.6, $87 ;\left(2{ }^{\prime} 87\right) ; 3730$ Ellls $A$ ve.; $6-9$, after 8 ; office, 629 Wells St. ; $9-10, \mathbf{1}-\mathbf{4}, 7-8$.

Smejkal, Harry Jerome (b'81) - nil.23,'07, office, 3200 W. 26th St.; $9-10,11-1,3-5$, $7-8$.

Smiley, Hiram-H-0.13,'85; (l’85); 7834 Ilawthorne Ave.; until 10, 12-2.

Smith, Alfred K.' (b'43)- ; (1'87); 2142 J'ark Ave.; 9-11, 2-4.

Snith, Andrew L. (b'68)-Ill.1,96; (l'96) ; 3809 S. Wabash Are.; office, 3518 ' S. State St. ; 2-4, 7-9.

Smith, Charles Edw. (b'87)-Ill.11,'11; (l'I1) ; 1957 Adams St.

smith, Chas. W. (b'54)H-Ill.4,'83; (l'11); 1128 Fullerton Are.

SMITH, EUGAR A. (b'76)-Ill.6,'99; (1'98); 6311 Woodlawn Ave. ; 9-11, 2-4, 7-8.

Smith, Edwin H. (b'63)-Que.1,'84; (1'86) ; 6 î30 Lafayette Are.

SIITH, EDWIN M. (b'61)థ-Ill.6,'86 ; III.G1; (A12); S. 
Smlth. Emmet 1. (1)"His)II-111.10.'SS, 111.11, -93: (1.89): 5 it9 lorchester ive; unce, ; W. Madlson Sh: 2.5

SMITI, ENI'Y L., $\left(b^{\circ}, 55\right)+-111.10,23 ;(1 ' \times 3)$ 319.2 Washlnglon Hlru. : omce, 31 3 sinte Si.; $12: 30-2: 30 ; 0$ b.

Smith, Frank F-LII.22,13; (1'13): St. Filizabeth's Ilospltal.

Smith, Frank Leroy (b'8t)-Ill.6,08: (I'0s) 2500 N. Kedzle 131rd.; ontee. $4354 x$ Kedzle ilrd. : $2-4,7.8$.

smith, Franklln l'avld (b'85) -.Mllol. ', (19) [iniversity Hoepltal.

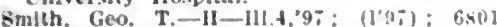
Perry Are.; once, 456 w. 63d st.; 1-:

MITH HENRY IRE(IINAl, - 11, 3006 (l'0i): 3401 \&. State Sit. : $10-2$.

SMITI, HIKAM JAY (b'sa) $£-111.11,0$; (l"07): lvunnlng.

Smlth, James Lawrence (b's2)-111.11,04 (l'04): 2403 Catalpa $\mathrm{Ct}$; oflce, if 11 Randoiph St.

smlth. Jennle F.-H-III.10:79;

2011 Sedgwick st. untll 10 .

Smith, Jos. A. (b'S0)-III.22,09: (l'10) gosi w. Jackson lil rd. : $;-9,1-3,7-8$.

Smith. Julla Holmes (b'39)11-ill.10::$\left(I^{\prime} i \tau\right) ; 226$ Wisconsin St.

Smlth. Leslle Dutcher (b':(i) - 111.5, 04 $\left(1^{\circ} 04\right): 37$ S. Wabash are ; 12:30.4.

SMITH, LOUIS DANI. (1)'sy) क-111.111 (111): 1000 x. Oakley it

state St.; $9: 30-4: 30$; U.

Smlth, Paullne selby-11-I11.4,04; (1004) 6219 (ireenwood Ave ; 1-3.

Smlth. Hehard S. (col.) (b'a3)-D,C.3, (0t (1"10) $2525 \mathrm{~s}$. State st.

MITU, ROHT ABERCIGMBIE (b'so) I11.1,03: (l'03); 809 sherida.

Smlth, Robt. Louls Irrine (b'8i)-111.1, l: (l'13): St Luke's IIospltal.

Smlth. Wm. Bowman $\left(b^{\prime} 84\right)-111.1,12 ;\left(1{ }^{\prime} 12\right)$ Cook County Hospltal.

SMITH, WILLIAM CIESTER (b'80)-Ky.2, 04. Ill.11,13; (1'10); 2701 W. 22d st. oftice, 209 S.' State sit.: 10-12.

Smlth, Wm. H. F. (b'46)-I11.1,'s4; (1's6) 1604 S. Michlgan Are. : 9-12, 6.5

Smlthles, Frank W. (b'79)-Mich.1.04: $\left(1^{\prime} 04\right) ; 122 \mathrm{~S}$. Mlchigan Are

SMITI1, JOS. P. (b.62)+-I11.]."88; (1'88)

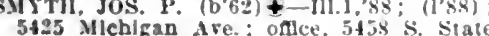
3425 Mlchlgan
SL: $2-4,7-8$.

Snlder, Kandolph F. (h's8)-IIl.t, I3; In tern, Rhodes Arenue Hospital.

Snoddy, Lot (b'53)-1'a.2, $80 ;(1 \cdot 91)$; 1125 I'ralrle Are.; oflice, $32 \times$. Sitate s.: $1-3$. Snow, Robe, L $-1 I-I 11.4,92 ;(1.92) ; 4423$ Indlana Are.

SNow, RUTH VAIL $\left(b^{\prime}, 6\right)+-111,1,04$

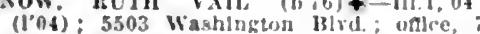
(1'nt): 5503 Washln

SNYDACKER, HUANEEL F, $\left(b^{\prime}, 0\right)+$ IIL. I1,98; (1.97); (Kenllworth): utlle. 31 S. State st. : $9-1$ : (118).

Snyder, (has, strong (b':1)-1'a $1.4 t$ (108): 5126 sherldan Hd.; offce, los st Ita Salle St.; $9-11$.

Snyder, Omer $(-11-11-111.10,84:$ (1'85)

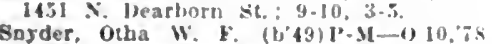
$(1 * 8)$; 404 fireenwoud Are, ; aflce, 17 N. State St: $9-5$.

Snyder, I'hllo b. (b'\$4) :-Ill.22.'10: (1'12) 1618 W. (hleaso Are.: I'rof. of Junlor fiyn., 111.16.

Snyder, lloncue F. (b'74)-111.5,01: $\left\{1^{\circ} n !\right)$ $3423 \mathrm{~W}, 62 \mathrm{~d} 1 \%$; once, $17 \% \mathrm{X}$. Sitate st.

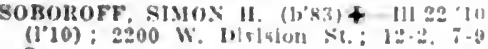

Sochat, 1.eon-111.11,11: (1'11): 210s 10 Ninth Are.

SOLOMOS, CHAS. Hr.str $(1,50)-I 11$, 08: $\left(l^{\circ} 08\right)$ : oflec, $1045 \mathrm{X}$. Ahland Are. $1.3,7.8 \cdot 30$.

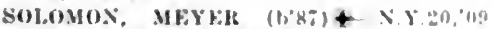
$(12)$ : 1317 \& Kedzle Aie. S.10. is? $\because .9:(E I): N P$.

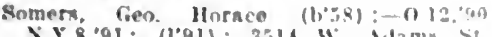
omce, 30 (

somers James 11 (b.6.) - III S.

1355 . I s salle st. 8.10 , ti

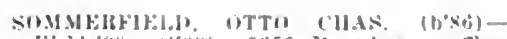

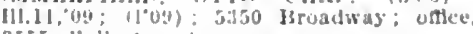
3 sis rullerbon ire.

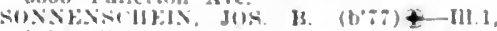
02: (1'02); 5535 Mlichigan Mre.: 9.12 ;

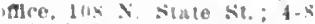

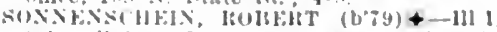

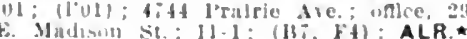

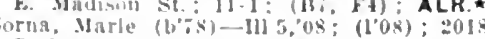

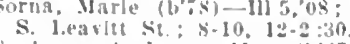

sulup. Inthing M. (bit)-Ill.22,06

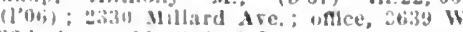
221 sit. ; $11,2-4,6=$

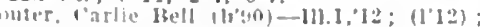
link County Ilusplat.

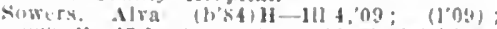

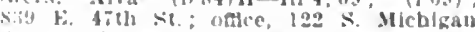

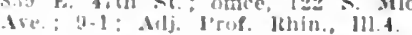

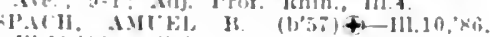
[11.11,:3: (1'š); $662 y$ Harvard Ire.

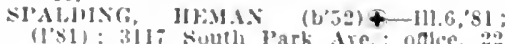

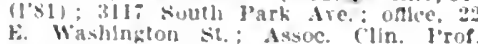
Med., III.1.

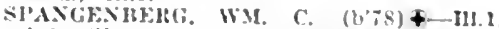
02: (1'02); 1032 IJrersey l'nrkway; 1-3. vangler, Falth Futher (h'\&t)-111..'l! (1'11): Clicato state IJospitil, Junnlnt spare, Aristoph (b'.2)-1'a.11, $98 ;(1,99)$ 3146 Denglas Rlvd; omce, 1504 W. Tay lor St.; 1-3, 6-8.

Sparlng, Ellis 11--11-111.10,'st; (1's.) 7017 Stewart Are.; untll 9, $1 \pm-3: 30$.

Sparrow, Hannah steele (bot) E-Mlls.8\%

(1'87) ; 9125 Frle Are. ; until 10, $12: 30-4$

SIATZ, MAXIMIIAX (b'81) †-I1].2, os (1'08) : 1015 s. Western ire: oflce $0=$ Ozden Ave. ; 10-12, 6:30-s:30; Axst. Prof.

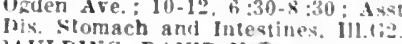

SPAULDIXG, DAVID N. + V.2, $1:(192)$ 810 George St.; odtce, $37^{2}$ iv. Chlcago Are: : 10-2, 5-6:30

SPEFD KELLOGG $(1, \% 9)+-111.1,04$ (1) Wlehlgan Are : $1: 2-1: 30: S_{0}$

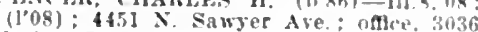
Irring Park Biv(1: : 10-12, 3-5, i:30-9.

spencer. Geo. Jos. (b'i)-111.11,0s; $(1.0 \mathrm{~s})$ AHI Park Are

PFNCFR, NOIRINE DEVRRE-III.S'0s $\left(I^{\circ}(18) ; 4451\right.$ N. Sawyer Are.; oflee, 3030 Irving l'ark Bird.; 1-3.

Spengler, Albert C.-11l.1.02; (1'02); 2046 l'leree Are.

sperry. Chas. C.-111.6.'7t; (1\%3): 30:5 Indlana Are. intll 9, afier $;$. no

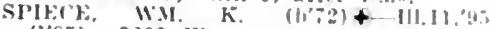

(I'95); 2926 Warren tre onhe 24 b

Madison St, lo-1.4-6: (BS) : OALR

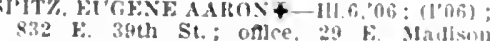
832 F. 39th St.; oflce. 29 k. Malfimin

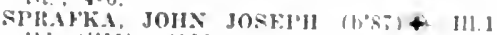

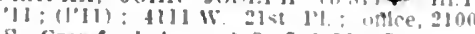
S. Crawford Ave: $1-3,8-8: 30: S$.

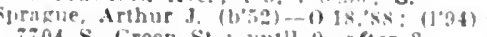

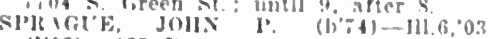

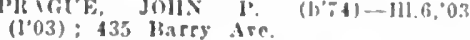

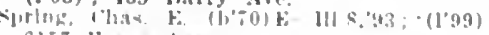

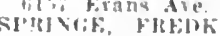

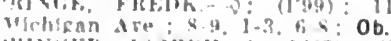

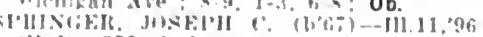

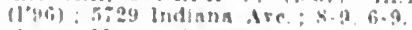

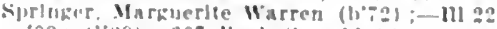

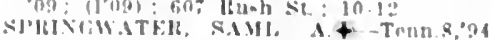

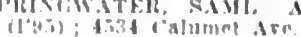

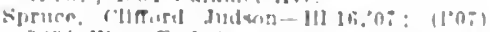

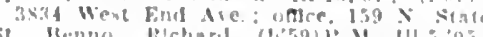

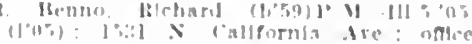

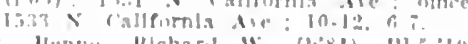

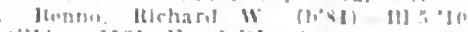

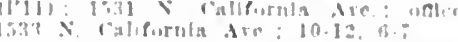

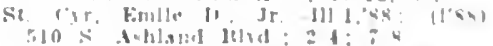

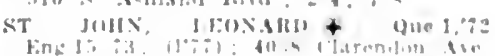

(I)

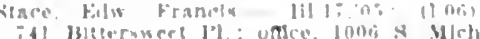

In:m Nic
STARKABI, WU, Ht, UIY $(6,8)+$

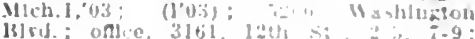
ObG.

Stahl, Folw. I. (b"5.3)-111. 1, :3: (1'8\%)

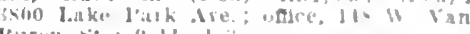
BIII rith

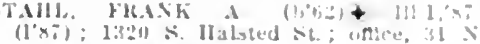
State SI.: (Ail).

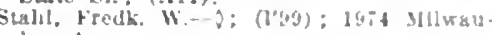
kive Ave.

Siahl, Joln lien. A.-111.1, $95 ;$; (1'yi); 1320 Thateal sic

(159): $1311 \mathrm{~s}$ soringteld ire

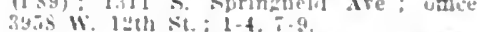

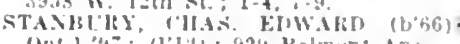

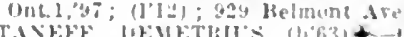

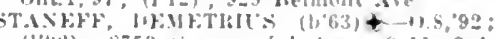

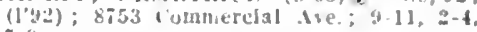

Stanforcl, Mary Fllzateth-l'-M-III.J."9; (1.97): 321 Xormal l'arkway; unlee, 453 W. 63d st. ; 8-12.2: 2:30-4.

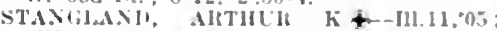

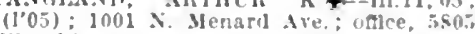
11. ( htcano tre.

Stanton, Juhn E. (1'73)-11i.1.99; (1'99); 3542 Fluurnoy sit: oflce, 3109 W. Har rlsun St: $1-3, \pi-9$.

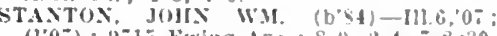
(1'06); 9715 Eswing Are ; 8-9, $-4,7-8: 30$.

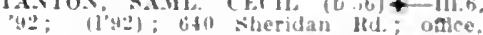
$335 \times$. learlorn st.; $8-11$; also $159 \mathrm{~N}$. Siate st: $2-5$

Stapler, Andre 1.evpold (b's2)-111.22, 12: (1'12); 1060 Wilsun Ire.: 10-1:, 6-9; office, Mallers Hidg. : $t-5$.

Siark, Oswald Geo. (b'st)-IIl.1,11; (1'11):

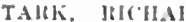

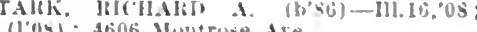

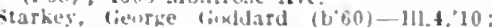
(1'10): 5412 Ihoreliester Are; oftice, 1133

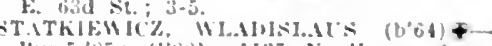
lius.5, 85 : (P'is); 1137 X. Hogne Are:

sTrillss, wM. (i. (1.65) $+-111.6,95$ : (1'yt): (320 loke St. kivanston): onice, $108 \mathrm{~N}$. state st. $11: 30-1 . \quad(113):$ NP. hearns, $11 \mathrm{~m}$. Marlon (b's(i) H-IIt.10,'80 (l'su): (kenllworth); onle, 22 tiash Ington St: : 4-1, :- Fimer. I'rof. Ithln. aluil laryn. I114: ALR.

STERI, MAXL ATKIXSUX KING (bos) uttce, $31 \mathrm{x}$. siate st. $10-19$ true clin. Surg. 111.11: (.113); S.

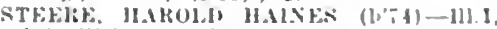

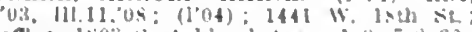
oflice, isos s, Avlland Are : $1-3,7-\$: 30$ ? S.

Stees, Marle denn-111.17,25: (1'45): 7363 X. Avlsland Ave: $10-3: 30$

stefanskl. Jis. Adrlan $(6, n 6)-$ III 15,09 (1'09): stus sulwertor two; \$ 11, :-9

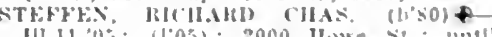
III.11.04; (1.05); 2000 llowe sb; unt -30, $:-9:$ ObG.

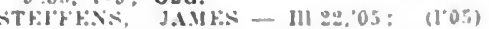
6xas Wasilngton ledrd.: oftec, 1959 firand Ire $=9.11,1-3,-9.9$

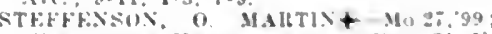

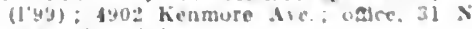
Siste st, : $=4$.

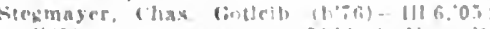

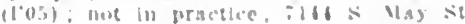

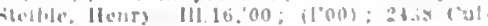

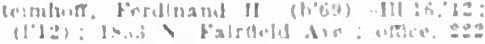
Walma we; b-s

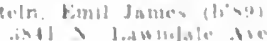

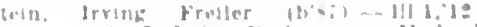

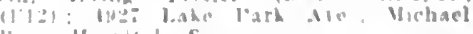

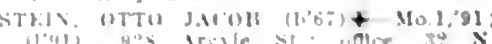

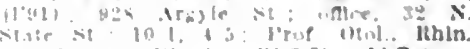

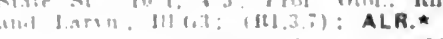

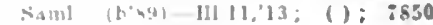

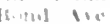


STL1NEL, 1,EO (b'83)-III.I6,06, Ill.11, 07 (1'06); 1814 S. May st.; 8-9:30, I-2, $5=6: 30 ;$ offlce, 182

stenhouse, Anelia foodrich-1I-Ill.4,84; (1's5); 7142 Fmerald Ave.

Stem, Eil NATHAN-lil.11,07; $\left(1^{\prime} 07\right)$ : 1811 w. 4 in st.

Stephanl. Alfred II.-Ill.1.'s6; $\left(l^{2} S 6\right) ; 5902$ W. Frie St.; once, 1958 w. Chlcago . Wre. Stephens, Chas. N.-H-Ill.10,'96; (1'96) (Libertyrille); 2232 Milwaukeo Avo.

STEPIIENSON, IBOH'T. a'BECKETT (b'i4) (f-1ll.1,03; (1'03); 902 leland Are. $7: 30-9$.

STEPHENSON, WILIAM $(1,56)$ (t)-N.Y.1 s0; Col., Mi.C., U.S.A.; Federal 13ldg.

sterl, Alexander" (1'38)-X.Y.5,66; (1'76) 7.3 W. Yan Buren St.; 9-11. 6-7:30

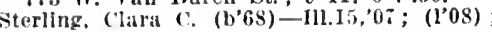
660 t limbark Ave.

Stern, Iavid II.-E-N.Y.13,'82; (l'82) 4718 Calumet Are.; offlee, 333 s. Dearborn st.

Steller, (ieo. A. (b'53)-Ill.13,'96; (1'96) ; 751 E. 75th St. ; 9-12, I-4, 7-9.

Steltauer. J. Lewis-Ill.11,01; (1'02); 5 s. Wabash Are.: 3-5.

STEVENS, CHAS. A. (b'71)†-Ill.6,99; $\left(l^{\circ} 99\right)$; 1019 W. 59 th st. ; $1-2: 30,7-9 ; \mathrm{S}$. stevens, Lerman Camplell (b'78)-Ill.1,'13 not in practice; University of Chlcago. STEVENS, JOHY YOSRURG (b'51)-111.8, 's5; (1'91); 100 Loomis st.; offlee, $32 \mathrm{~N}$. State St. ; $1-6$; Sec. and Prof. Ped., Ill.s ; Pd.

Stevens, Karl Ivan (b'88)-Ill.8,'12; (1'13); Park Avenue Hospltal.

STEYENSON, ALEXANUER FRANCIS (b'72) \$-Ill.1,98; $\left(19^{\prime} 99\right) ; 1205 \mathrm{~N}$. State St.; offlee, 104 S. Michigan Ave.; 1112:45: also, The Rookery, 1-2; Asst. Prof. Med., Ill.1 and Ill.GI; (F4).
STEVENoN, FRANK H.-Ill.1,04

9904 Ewing Are.

Sterenson. John A. (b'70)-Ont.5,'94; (l'94) 1658 W. Chicago Ave.; 9-10, 1-2, 7-8.

Steward, Francis M.-E.-0.2,76; (1'77) ; Steward, Francis Mird. ; 8-6.

Steward, Oscar Scott-E-0.2,'82; (l'84); 931 uargate Terrace; offee, 39 W. Adams St.; $9-6$.

STEWART, ALLAN EDGAR (b'73)థ-Ont.5, '98; (l'01); 724 Independence B1rd.; offce, 31 S. State St.; 1-2:30; Assoc. Prof.' Surg., ill.22:S.

STFWART, ANDREW - Que.1,83, Eng.11, '84: (1'85) ; $140 \mathrm{I}$ W. Adains St.; $12-1$ :30, 7.8: offce, $236 \mathrm{~S}$. Racine Ave.

STENART, EDWARD S. (b'61)-111.6,'92; (l'92); 4821 Vincennes Ave.; offlce, 128 1.. $33 \mathrm{~d} \mathrm{st}$

Stewart, Frank Jackson (b'75)-Ill.13,'03; (1'03); 324 E. Garfleld Blvd.; office, 8 N. State St. ; 11-8.

STEWART, HARRY JOHN (b'74) †-IIl.11, '97; (1'97); (47 I N. Oak Park Ave., Oak l'ark); office, 4200 W. Lake St.; I-3; S. 35 thewart, Robt.-Ill.1, 95

STEWART, WELLINGTON T. (b'64)థIll.11,93; (1'93); 1311 Pratt Ave.; offlce,

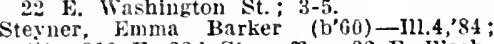
(声) ; 319 E. $22 \mathrm{~d}$ St.; offle, 22 E. Wasb-

STILLIANS, ARTHUR WM. (b'7I)†-Ill.11, 99: (1'00): 4556 N. Paulina St.; offce, - iv. Madison St.; $3-5 ;(C 6) ; 0 . \star$

Stillman, Loran A.-E-Ill.8,'91; (1'91);

4714 Chamulaln Ave.; 7-8, 7-8; office, 304 S. Wabash Are.; $10-1 ; 5-6: 30$

Stinnette, Shelby E.-111.4,'13; (); 5959 Calumet Are

STOBER. ALVIN MARTIN (b'79)థ-Ill.11, $01 ;$ (1'01); 3213 Greenwood Terrace; 2-4,

Stockslager, Saml. oliver (b'50)-N.Y.10, 75 ; reltred. 833 wilson Are.

STOCOL, JACOB B. (b'5I) $€-15.28,99$; $(199) ; 3217$ S. Morgan St.

STOKES, W.I. F. (b'68)థ-1ll.1,97; (1'97); $18 . i 2$ Clifton Park Are.; until

Stol, Sebastian (b'69)-Ill.1I,92;

83 : s. Winchester Are.

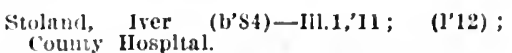
STOLL, JOHN 1. (b'6I) —-Ill.1,85; (1'90) : 1103 \&. Ashland Bblvd.; $1.2: 30,7-8 ; 0$ b. tonc. Clara-Ill.22,12; (1'I2); 1934 W. İth St.

stone, Fellx 13. - Ill.4,02; (1'02); 3123 I'ralrie Ave.; 8-10, 1-3, 7-8

Stone, Fordyce Homer" $\left(\mathrm{b}^{8} 87\right)-111.15,11$; (l'II) 1958 wilson Ave.

stone, Willis c. (b'54)-111.1,'84; (1'84) 5 I. W. 56 th Place.

STOKCK, WHLllM $\left(b^{\prime} 66\right) \oplus-[l l .11,01$; (1'01); 5414 Drexel Ave;

Storer, John (b'61) H-Ill.4;89: (1'98) ; Hyde l'ark Ilotel: oflce, 108 N. State St. 10-4.

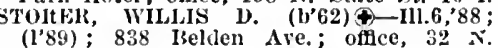
State St.: $1-3$

STOREY, CHALILS A.๑-0.12,'82; (l'86) 2822 s. Michigan Ave, oflce, 29 E. Mlauison st.; 11-1.

Story, John Wesley, Jr. (b'87)-Ky.2,'12 (); 3545 Indlana Ave.

Stolts, John H.-H-Ill.10,93; (l'93) ; 3721 Grand Are. ; 8-9, 1-2, 7-8.

STOTZ, (IIARLES FREIK. (U'T2) (-1II.11, 98; (1'98); $2603 \mathrm{~N}$. Sawyer Ave. ; offlce, 1954 Milwaukee Ave, ; $2-3,7-8 ; \mathrm{S}$.

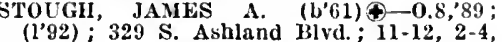
$7-8$

STOWE, HERBERT MARION $\left(b^{\prime}, 4\right) \oplus-$ Ill.1,'96; $\left(l^{\prime} 9 \pi\right) ; 4355$ Oakenwald Ave. Asst. Prof. Obst., Ill.6; (A11); ObG. Stoweli, Harry E. ' (b'85) - Ill.39,'I1 ;

STOWELL, JANIES ' H. (b'54)(4-11.6, 81 ; (1'81); 2633 Indiana Ave.; offlee, $31 \mathrm{~N}$ State $5 t^{\prime} \cdot 1-3 ; 1 \star$

Stranberg, Walter Leonard (b'85)-111.6,'11; (1'11); Wesley Hospltal.

Stranges, Giovannl-1ta.10,04; (1'07) ; 533 Milwaukee Ave.; offee, 746 S. Halsted St. trass, Herbert Willls (b'86)-lll.6,'10; (1'10); 7500 Cottage Grove Ave.

STRATEN, HUBERT-III.15,'94, Ill:18,'95; (1'94); 1114 Loyola Ave.; I-4; ObG

Stratford, Henry Knox-E-Pa.17,65, Ill.8, '88. not in practice. $236 \mathrm{~N}$. Ylenard Ave. Strauch, August - Aus.7,'98; (1'04); 4617 Kenmore Are.; offlee, 4557 Broadway, I1-12; Pd.

STRAUS, DAVID C. (b'82) $\oplus-I I 1.1,07$ (1'07); 949 Hyde Park Blvd.; 2-4; (F4)

STRAUS, IRVING J. (b'68)@-Ill.11,96 (l'96); 3640 Cottage Grove Ave.; 9-10,

STRAUSS, ALFRED ADOLPH (b'81)-Ill.1, Wabash Ave.; 11-1.

STRAUSS, FLETCHER LOUIS (b'76) Iil. 1,$97 ;(1,97) ; 925$ E. 62d St.; offce, 235 S. State St.; $9: 30-5$

Strauss, Jerome Frank (b'89)-Ill.1,12 ; (1'12); Mlchael Reese Hospltal.

STIAUSS, SIDNEY (b'7S) $\oplus$ - Mass.I,04; $\left(1^{\prime} 04\right) ; 5039$ S. Mlchigan Ave.; $3-5$; Asst. Prof. Med., III.1; (F4)

STRAWN, JULIA CLARK 9 -Ill.4,'97, Ill.11, offce, 22 E. -Washington St.; 10-1; Assoc. Prof. Gyn., Ill.4.

Stream, Anthony Jos. - Ill.23,'06; (1'07) 2025 S. Western Are.; 8-10; 6-8:30.

Street, Richard H. (b'74) H-Ill.4,'98; (1'98); 4509 S. Michlgan Ave.; office, 32 N. State St. ; $10-1 ; 4: 30-5: 30$; Assoc. Prof. Rhin. and Laryn., Ill.4; LR.

STREICH, EDWIN $\Lambda$. (b'76)-Ill.11, 01; (1'01) ; 5505 S. Ashland Are.; until 9 $12-1,7-8$.

STRINGFIELD, C. PRUYN (b'66) $\oplus-\mathrm{m} .6$, '89; (l'89); Grand Pacifle Hotel; office, IIl W. Jackson Blvd; $10-6$

TROMRERG, JOS GIDEONO-Il1.23,07 (I’07); 4857 N. Robey St.; 10-1, 7-8.
STRONG, SAIIL. BENJ. (b'78) ${ }^{2}-111.8,06$

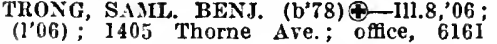
Broadway.

STROUSE, SOLOMON (b'82)@-MId.7,06 ; (l'I0); $4901 \mathrm{~S}$. Mllchlgan Ave; office, 104 S. Michigan Are.; 11-1; (F4); 1.*

Struble, James R. (b'50) E-IIl.8,86; (1'86) ;

(Lyons); offlee, 2757 w. North Ave.

$2-4,7-8$.
STRUKH, CAR1, (b'6I) $\oplus-$ Switz.7,86 ; (l'86); (Mclleury); oftice, 32 N. State St.; $10-12$

STUBBS, JAMES E. (b'38)-Pa.1,64; (1'77); 3203 South Park Llyd.; office, $108 \mathrm{~N}$. State St.; 1-4.

STUBBS, J. CHASE (b'65) - Ill.6,'89 ; (1'90); 1905 S. Millard Ave.; 6-7:30 office, $2026 \mathrm{~W}$. 21 st St. ; $10-11,3-5$

STUBENRAUCII, GEO. JACOB $\left(b^{\prime} 72\right) \bigcirc-$ Ill.I1,'10; (1'10)； 4025 Milwaukee Ave.; 2-4, 7-8;

Stuhr, Walter Anthony (b'80)-Ill.6,'10; (l'10); 410 Briar 1'l.; offlce, $2733 \mathrm{~N}$. Clark st.

STULIK, CHARLES A. $\quad\left(b^{\prime} 60\right) \oplus-$-Il.1,'94 ; (1'94); $1108 \mathrm{~S}$. Winchester Ave.; untll 9 1-2; offlce, 1658 W. 21st St.; 11-12, 5-8. STUPNICII, NIKOLAY J. (b'50)-Rus.4, 's2; (l'82); $3109 \mathrm{~S}$. Norgan St.; 8-12, 5-6.
stusser, Sami. (b'88)-111.11,'12; (1'12); Cook county Hospital.

SUKER, (GEO F. (b'69) -Mich. I,'92; (1'02); 946 Wilson $\Delta v e$; offee, $25 \mathrm{E}$. Washington st. ; $9-1$

Suldane, Joln Anthony (b'85)-Mo.34, 10 . $\left(1^{\prime} 10\right) ; 2444$ wilcox Ave.; offee, $748 \mathrm{~S}$ Halsted St.; $2-4,7-9$.

SUlLIVAN, PATRICK A. (b'66)-Ill.1,97 (1'97) ; 3001 Washington Blvd.; office, 32 N. State St. ; 1-2, 7-8; Prof. Clln. Surg., Ill. 16 ; $\mathrm{S}$.

Sullisan, Ralph Chas. (b'87)-1l1.1,'12; (l'12); 5249 Washington Blvd.; $4201 \mathrm{~W}$ 12th St. ; $9-12,2-4,7-8$.
1

SULLIVAN, THOS. J.' (b'57) $\oplus$-Mllch.1,80 (l'87) ; 4709 S. Michigan Ave.; 1-3; Prof. Surg., IIl.G3; $s$.

SULTAN, GEO. (b'61) (-M-Md.4,93; (l'93) ; 3325 W. 12th St.; office, 1226 S. Halsted St. ; $5-8$.

UMMERS, PORTER WHITEFIELDO-IIl.8, 12; (1'12); 2001 Fullerton Ave.

SUPPLE, ARTHUR BLAISE (b'87)-Ml.6, 09 ; (l'09) ; 6152 St. Lawrence Ave.; offlee. 132 E. $22 \mathrm{~d}$ St.; 8-12, 7-9.

Sutcliffe, Harrison Willis $\left(b^{\prime} 72\right)-$ ml.1,95, Ill.10,'92, Ill.11,'94; (1'95) ; 4618 Clarendon Ave.; offlce, 72 W. Adams St.; 9-1.

Sutter, Rose Irene - Ill.i1,'11; (); 2800 Washington Blyd.

SUTTON, L. FRED $\oplus$-Md.3,06; (1'06); 2136 Wilson Ave.; offee, 32 N. State St. also $433 \mathrm{~W}$. Chicago Are.

Swalm, John C.-P-M-Ill.5,04; (1'04); (Wilmette) : office, 1060 Wilson Ave.

SWAN, CHARLES F. (b'52) $\oplus-0.1,75$; (1'77) ; 7251 Jeffery Ave.; offce, 9139 Commerclal Ave. ; $8: 30-9: 30,12: 30-2,7-8$. SWAN, CHAS. JOS (b'64) (-) m.4,'90, IIl.6,'09; (1'09); (1818 Hinman Are., Eranston); Offle, 15 E. Waskit

Swank, Clyde Ware (b'64)-Hll.1,90; $\left(l^{\prime} 90\right)$; 5042 Sherldan Rd.; offlce, 140 N. State
St.; $2-3: 30$; also 426 W. Division St.; $6-8$.

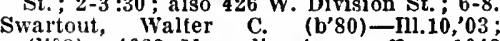
$\left(l^{\prime} 03\right) ; 4622$ Magnolia Ave.; offec, 1048 Wilson Are.

Swartz, Albert E.-Ill.11,95; (1'96); 3701 W. 12th St.

Swartz, Katherine Haage (b'61)-Ill.17,'96; (1'99); not in practice; 629 Stratford $\mathrm{Pl}$ SWARTZ, THOMAS BENTON (b'55) $\oplus$ 111.6,'88; (1'89); 3716 Lake Park Ave. offlee, 31 N. State St.; 12-1.

Swarz, Geo. (b'70)-Ili.8, 12; ( ); 3350, 12 th St.

Sweany, Francis Leaverett-Ind.8,'81; (1'93); office, 63 W. Randolph St.; $9 \cdot 8$

Sweek, Wm. Oscar (b'85)-Mo.34,12; 1456 W. Monroe St. ; Asst. Prof. Bact. and Clin Path., Ill.8.

SWEENEY, JOHN I.(4-NId.6,'98; (1'98); 257 W. 47 th St.; until 10, 2-5, 7-9. YEENEY, JOHN STEELE ( ( $\left.^{\prime} 77\right)$

Sweet, E. C. ' (b'46) H-Ill.4,'84; $\left(1^{\prime} 85\right) ; 1650$ W. Monroe St.; offee, $159 \mathrm{~N}$. State St.; $12: 30-3$.

SWENSON, CARL G. (b’56)(4)-Ml.1,91 (A13, F4): $\mathrm{S}$.

Swift, Charles Henry (b'81) - Ill.1,10: (l'10); 5632 Maryland Ave. 
SWIKT, WM, J.MK.S (1078)-111,1,04; (1'06); 603 Arllugton I'l.; ontee, Insurance Fixchange lileg. : 12-1.

Swindle, Kotert Norrls-I11.11,06; (1'06) $35 \%$ E $115 \mathrm{sh}$ St. untll $9,5-\pi$

SZFKELY, LOUIS ( 9320 Cottage Grove Aie.; 8.10, 2.4, i.s.

SZOPIXSKI, ALOYSIOIS-111.11,06; (1'06) 1001 W. 32d St. : unth 10.

SZUMKOWSKI, LEOXIRI) S. (b'SE) III. 22,11: (1'11): 175i W. North Ave

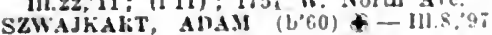
111.11,03; (1'yi) ; 3535 W. Dirersey Ire. omce, I363 X. Ashland Are.; 11-12,6-9 Pd.

Tale, Wm. A-P-M-O.10.'\$2; (l'st); 5150 Are. : 2-4, 7.9 .

TALBOT, EUGENE SOLOMON (b'ti) +

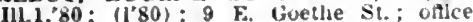
II.1,80; State St: $9-12,2-5$; I'rot. Stomalology and bental Surg., IIl.8.

TALBOT, EUGEXE SOLOMOX, Jl, (b'st) -111.1,10; $\left(t^{\prime} 10\right): 1449 \mathrm{~N}$. learborn st. ottce, I29 S. Mlchlkan Bird.

Tallerdas, Geo. C., Jr. (b'St)-I1.22,06 (l'06): $150 \mathrm{X}$. Austln Are.

TALLMAN, ELIHU D. (b'5t) M MIch. 1, 82 (I'83); 738 W. 8 ith St.; 8-9, 1-2, $7-8$.

Tallman, Wm. Lewis (b'58)-N.Y.10.'\$1 ; Mlchlian Are.: 10-1.

Tandy, Henry (iordon (b'bt)--Scot.9,12,15,

8:? (I’91); 915 IIIwaukee Ave. : $9-5,7-9$

TANSEY, ELMER E. (b 64) \$-Ill. ,95 (1'95); 2902 E. 79 th St: $8-9,11-1, \vec{i}-8$;

Taraba, Frank J. (b'St)-Ill.5,'10; (l'10) 3326 I.lncoln Are. : 2-4, i-9.

Taylor, Cora E-H-O.13,'84; (1'84) ; 6356 Stewart Are.; offce, 22 E. Washington 8t: 7-8, 1-3.

Taylor, Edwin A. (b'63)-I11.15,'95; (1'95) 335 Englenood Are, 8-10, 7.8 ; oftec

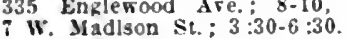

Taylor, James H.-Ill.1,05; (l'05) : 3041 W. Madison St: until $8: 30,3-5, i-9$; offce, 32 N. State St.; 11-1; Prof. Hist. III. 16.

Taylor James Mltchell (b'48)1I-Mfo.5,69 (1'78) : 825 k: 42d St; once, $15 \mathrm{~K}$. Wash ington St.: $11-4$.

Taylor, Lllian Ethel (b'75) - Ont.1,06: (l'10); (Winnetka): offlce, Stale and Washlngton Sts.; $9-5$

Taylor, Wm. Ilenry (L' 6 (6)-I11.8,04; (1'04)

4650 X. Kedzle A re.: 2-4, $;-8$.

Tearnan. Rasmod Arthur (b'86)-Mass.1, I2; ( ) : 2043 (leveland Ave

Tedtman, Gustare (b'64) H-I11.14,97; (1'97) ; 3650 Grand Blrd.; onlee, itt s. State St: : 9-8.

Teetzell, John K.-Ky,1,92; (声); 6113 Kimbark Ave.

Tenney, Alonzo C. (b'33) H-III.4,95: (1'95): 6548 lafayelle Are.; untll 8 ; oflce, 122 s. Mlchlpan Bl rd.: $1: 30.5$

Terry, Junlus (b'41)-\$0.1,61; (1'87): 400 Weluater Ave.

Test, Annabel Cleveland (6;7)-111.9.95: (l'93); not in practlce; 4620 Greenwuod Are.

TEST, FREDK. CLFVFIANT (b'69) \&

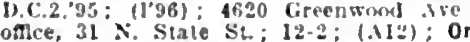
oflce, 31 N. Stale St. : 12-2; (.II:); Or. TETLR, DANL I'. $\left(b^{\circ} 66\right)+-114.4,89$ Tetrer, Heury $\left(0^{\circ} 78\right)-111.22,08 ;\left(1^{\circ} 04\right)$ 2328 s,Central l'ark Are: onlce. Isol

Thayer bdwaril J-Ili.1.93: (1.93): Vullerton Are.

Thayer, Morrls D. (b'83)-III.39,'10 ; (l'10) II35e Mlchloan Ave.

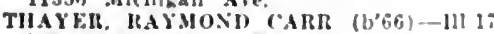
02: (1'03): 1451 Parragut Are.; onle.

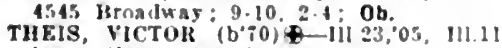

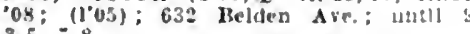

Theohald, Frank John (b's:) - 111.11.06 (l'06): (Cars stallon): umce, 7 W Mad TIEOOBAI.

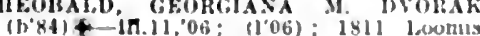
Sit ; $10-12, ;-8 ;$ OALR.

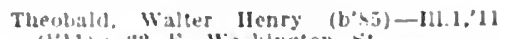
(1'11): 2:2 k. Waslilugton sit. Themlore, foplstanthe $(5,-9)$ - ifreece 1,02 $(104) ; 20 y$ E. 55th Fl.; otlce, $140 \mathrm{X}$ siate sit.

THFATON, Jolls $\left(b^{\prime} 65\right) \neq-$ III.1.'91 (19]): 1:40 l'ark Are.; 9.12.

Thllo, licurge $11 .$, Jr.-Ill.1.99: (1'99): 35.0 . Kolin" Are,; onice, 2000 W. bivicion se.

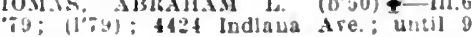
$1 \cdot 3, \overline{3} \div ; \mathbf{G}$.

Thumas. Chas. carroll (L'80)-111.4,06

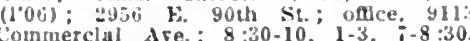
Thomas, II arold E.-II-III.4,03; (1'03) its Bueva Are. Ill.6,03: (1.04): 6530 Unisersity Are. oflce, 31 N. Siate st.; 11-12; (A12) otalce, $31 \mathrm{~N}$. State St.; 11-12; (A12) TIUMAS, HOMER M. (b'58)-Ill.1,'32: (l's): 12 \$. Mlichlgan Are.

Thomas, Juhn II.-Ky.2, $90 ;\left(I^{\prime} 91\right) ; 3047$ Harrard St.; oftsce, 3528 Ogden Ave.

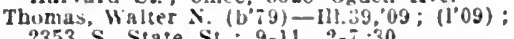

Thomas, Wesley II.-IIt.10:95; (1095): 3036 liroadxay; until $9,7=8$.

Thoms, Wm. Allen-III.S,11; Illlnols Steel Company IIospital.

Thome, Arthur 6.-H-Ill.10,83; (l'83); ¡26 Oakuale Are.; oflice, 2038 Lincoln A ve. : $8-4,1-2,6-8$.

Thometz, Anthony M. (b'7I)-Ill.1,95: (1'35): 1106 if 55 th St. $1-2,7-5$.

THOMETZ, FRAXCIS I'ETER (b'85)-IIl.11, "us: (1.08) ; $2132 \mathrm{~W}$. 12th St.; ofllce, 2001 w. 2lst st. : $2-3, \div: 30-8: 30$.

Thomesz, llarry Michacl Hubert (b'89)III.1,11; (I'I1);2132 w. 12th S

THOMI'SON, ALVIS (b's0) - Ill.11,"12 (1'12): 43 w. Dlvision st.

THOMYSON, ELMER GIBSON (b'8 $)^{\circ}-$ Ill.2., 10 : (l'10): 1432 N. Robey St.

Thomyson, Frank 1. (b'-il)-lil.16."ul (1'99); 536 Addison Are.; oftice, $20 \mathrm{~s}$ State st. : $9-t^{\circ}$

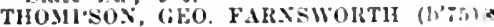
-II1.1.99; (1'99); 35:6 W. Van Buren St: oftice, 600 Blue Island Are.: 1-3: Asst Pro:. Surk and Clln. Surg., III.11; Prof. Gyn., Ill.(i2; (AI3); S.

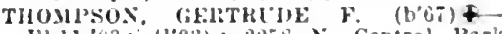
111.11, $03:(1.03): 2258$ N. Central rark Ave. oflce, $32 \times$. State St. $3-4 ;$ OALR.

Thompson, Herlert lelkoy (1)'33)-illt,08; (loos): \&23 Hyde l'ark blid.: ottue, 22 E. Wasblugton St. ; 2-5; OALR.

Thompon, Jenuie Lind (b'is)-111.11,98 $\left(1^{2} 48\right) ; 501$ w. $60: \mathrm{h}$ st. ; 8-10,6-8, Thompson, l.ewis It. (bs3)- kyt,o A.surg., L.S.P.H.S., Marine Hosplial.

Thompson, lidlan Marcelletto $\left(b^{\prime} i t\right)-$ Ill.4. 09: (109) ; i022 coustance

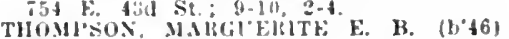
t-0.s.45: (1.98); Member Ariz. State lied. Assn. ; tiso r. 334 s:

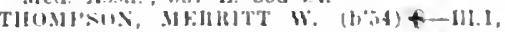

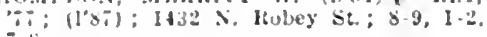

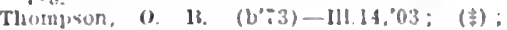

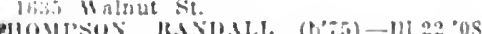

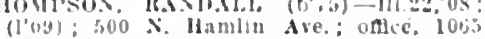
Madiun st. : $10 \cdot 3,5 \cdot 8$.

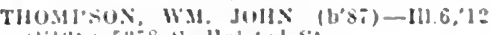

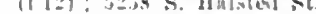

TIJOMISON, WM, MCH.WAIX $\left.(1)^{\circ} 6 \mathrm{~N}\right)+$

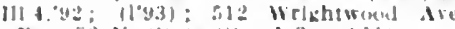

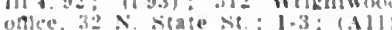

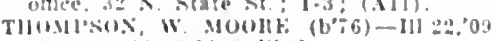

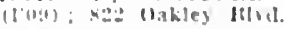

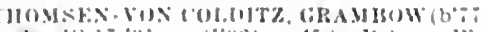
$+111.18,01:$ (1902)

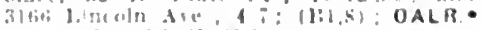

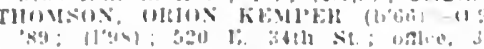
$x$ sinic si: $1: 90-3$

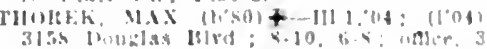

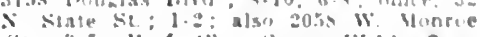

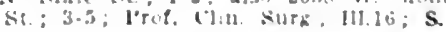

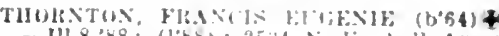

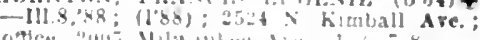

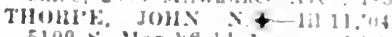
5100 s. Marsbfted .

TIOI:SriAdLI, K.IIt.

$000(102), 111.1$

122 s. Mlchlgan Are.

Tlumston. Timm Jhy John-lil.2

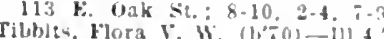

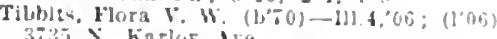

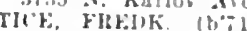

341 W. Munce st once. $31 \mathrm{~s}$ state

St: 1:30-3:30; Prot. Dis. of the Ches: a:d Cliu. Med. III II: I.

TIEKEN, THEOIU)

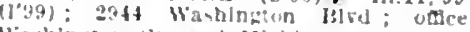
Washlngton sit. and Illchlgan Are; $1-4$ Assoc. 1'rut. Med., 111.1: 1.

TILIOTSON, HAHHY THLUEAC (L'62)111.11, 85: (1'56); 30511 , fth St : 6.8 Timblin, Wm. Sianley (b\$9)-IL.1, 13; $\left(l^{\circ} 13\right)$ Michael Recie Joyglal.

TIMERIAN, HARRIS $E$. $\left(b^{\prime} ; i\right)-I ! 1,00$ (l'vo) : 1840 A Selison st. ofte, $3175 \mathrm{Lin}$ culn Are; 10-11, 1-3, ;-8; $\mathrm{S}$.

Timmer, Wm. I. (b-18)-III.22,11; (1'12) 1213 S. Arers Are.

LOCIS JACOB (b':9) P-Ya.2,05 (IIi) : 2046 Le.Moyne St. : 6-y; (F4)

TIK, MOKLIS 1.-III.2,12; (1'12): 1300

isciorth Are.

ISCHART, PIERRE J. (b'71) M Mich. S. Halsted St.; $9-11,:-8: 30 ;$ also $140 \mathrm{~N}$ State St. : $3-6$.

Tirus, Miton Rennett (b'5s)-X.Y.5.:1 (1'93): 112 X. Callfornia Are. otice, 1065

TITZEL, WALTER RANDOLPH (b'65) 10054 Ewing Ave.: $8-9,1-3, ;-8$.

TIXES, RICHARD JOS. $(6 \% 4) \&-111.1,95$ (1’35); Hotel Yerropole : ottice 104 Michléan Are.; 10-2; (Bi,s): OALR.

Tolvey, Wills G. $\left.\left(\mathrm{b}^{\circ}, 5\right)-I 11.6,05 ; 1105\right)$

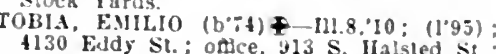
$\$ 130$ Faddy St. ; ottce, $913 \mathrm{~S}$. Il Ilsted St.

TOBIAS. GEO. J. (b'60)-I11.11.'s5; (1's5) (Wllmette); offce, los N. State st; 10-4 N.

NOD, JAMES FORREST (b'4l)-XY.10 63: (1'7) : tilso Ingleslde Are.

TOELLER, JOHN JOS $\$-111.11,07$; $\left.11^{\circ} 0 \mathrm{~T}\right)$ 4iol Liticoln dre.

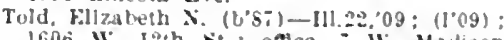
1 rioo W. I2th st: odlce, "W. Mauison St. ; $4-6$.

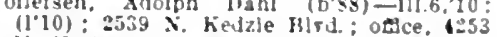

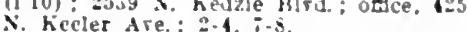

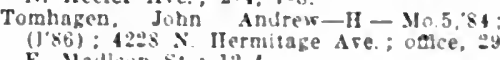
E. Madlsun s: : 12-4.

Tomliagen, laurs sommer $\left(b^{\circ} 63\right)-111.11 .03$ (1.03) : 4a:s \& Hermliace Ire.

Tompkins. J. Ellzahesh-111. 13,96: (1'96) 321: liroreland Are.: $3-10,2-5$, omce. W. Kandolyh st.

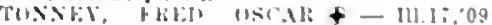
(1.04): $300^{\circ} \times$ Marul Wasbiubon si also licalsh lept. laber a)ory, lliy Hall?: LD.

Toneli, Pico. Thomas $(2,36)-11128,12$ (1'12); 3201 Franklin 16rd

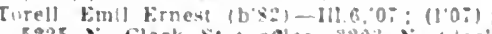
$3925 \times$. Clark st. oflce, $\$ 003 \times$ t lark

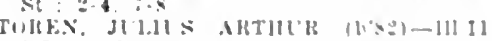

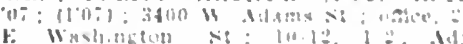

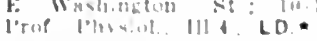

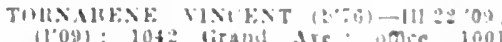
(1'09): 10t: lirand I

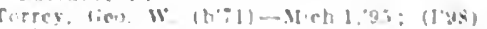

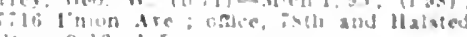

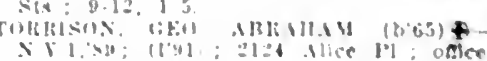
\$1 State s:

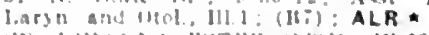
TIII, Jull I J. Fot 


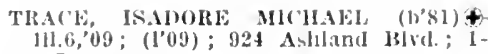

Trafelet, EmI1 Thomas (b'79)-111.15,'I1; (1'12): 3959 W. 26th Ave.

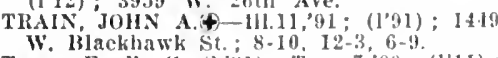

Trapp, Fredk. (:. (b's1) - T'enn 7,og; (1'1I) ;

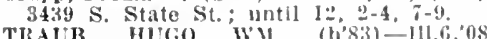

(l'08); 521 E. 34 th St. : offlce, 4301 Ellis (108); 521 E. 34 th

Trasls, Andrew; loot $111.8,12$; (1); 3013 P'ralirle Ave.

Treadwell, (chas. Ilmmphrey (l'il)-Ill.13, '05; (I'0.5); 6220 Rosalic Ave.; 4-6, 7-5.

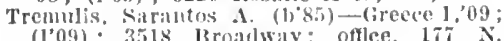
(l'09) 3518 Jroat

Trenchard, Joseph-1Il.6,93; (1'93) ; 2624 Indlina Are, ; 6-9, 12-2, 6-3

TIIICE CIIAS, D. (b'72)-D.C.3,'y0: (1'03) 5427 s. learborn st.; oflce, 2902 S. State st.; $9-12,3-5,7-9 ;$ G.

Tracer Sidney' Nertou (b'86)-Ill.11, 10 ; (1'10). "I 800 clifton 1'ark Ave.: office, (l10) 1800 Clirton Tark Ave.;

Trombly, Frank Fillion (b'83)-111.6, 09; (1'09); 3904 Areher Ave : 9-12, 2-4, 7-9.

TROSTLER, ISADOR SIMiON (b'69) Neb.5,'04; (1'07); 615 Garfleld Ave,
offlce, St. Joseph's IIospltal; 9-12, 1-3, i-8; R. $\star$

Trout, Elizabeth H.-Ill.9,'84; $\left(1^{\prime} 85\right) ; 200$ N. Lockwood Are.; N.

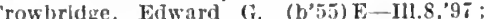
(1'97); (Lombard); office, 29 E. Madison St. : $9-12$.

Trudél, Jos. L. O-E-E-Ill.8,93; (1'93) ; 7 ;25 Shernan Ave.; until 9 , after 7 ; offlce, 35 S. Dearborn st.; $9-1,2-6$

Truman. Mlexander S.-Mlch.1,72; (177); 1016 W. 69th St.

Trumbull, Elizabeth-II-I11.15,'99; (I'99) : 6911 llarvard Are.; 9-10, 4-6.

Turholka, Louls s. (b'75)-Ill.15,01 ; (1'05): 1352 ז. Aslland Are. ; 8-10, 7-9.

TUCKER, GEO. WILLARD (b'72)-Ill.11, 08 ; (1'09); 225 Honore St. ; $3-5,7-8$.

Tucker, Geo. W. (b'57)-Ill.1,'s1; (l'80) ; 435 S. Irving Are.; oftlce, 2158 Harrison St.

TUCKER, HENRY STEVENS $\left(b^{\prime} 53\right) \oplus-I 11.8$, 79 ; $(1,79) ; 451$ K. $42 d$ St. ; office, $159 \mathrm{~N}$. $79 ;(1,79) ; 451$ K. 42 d St. ; office, 159.
State St.; 1-4; 1'rof. (iyn., Ill.22; G.

TUFTS, FRANK S. (b'72)థ-Ill.13,00 I11.11,03; (1'00); $806 \mathrm{~W}$. 78th St.; office, S10 W. 'Tsth St.; 8-9, 2-4, 7-9.

Tull!s, Alexander ( $\left.\mathrm{b}^{\prime} 56\right)-111.16,09,111.11$ '11; (1'09); 1027 bakin st.

TUNNICLIFF, RUTH $\left(\mathrm{b}^{\prime} \mathrm{T} 6\right) \oplus-111.1,03$ (1'03) ; 6018 stony Island Ave.: offiec, 1743 W. Harrison st. ; (F2,4); Baet.

Turbin, Louis M. (b'57) H-Ill.10; 91 ; (1'91) 6011 Calumet Ave.; office, 64 W. Randolph St. ; $9-5$.

Turek, James Charles (b'75)-Ill.1,95 : (1'95) : $2501 \mathrm{~S}$. Millard Are. : 9-10, $7-S$.

TURLEY, FRANCES C. $\left(-111.9,95 ;\left(1^{\prime} 95\right)\right.$ 5344 Rosalie Are. ; offrce, Michael Reesé Hospital ; (G4) ; R.`

TURNER, BYRON SEAGER (b'63)-Ill.6, '37; (1'87); 6226 Langley Are.; office, 4300 Indiana Ave : 10-12, 3-5, 8-9.

Turuer, Gus Burton (b'8i) - 111.6,'12; (1'12); St. Luke's Hospital.

Turner, Ilerbert Alcenia (b'85) - 0.25,'07; $\left(1^{\circ} 07\right) ; 3658$ S. State St.; 11-1, 3-5,

TURNER, JOHN W. (b'80)-IIl.6,'08; (1'08) ; 1854 Addison Ave.

TUTEUR, EDWIN B. (b'66)£—Pa.2,90; (1'91); 4559 Greenwood Are.; office, $31 \mathrm{~N}$ State St. ; $3-6 ; 1 . *$

Tuthill, Jos. D.-E-111.8,'s1; (1'99); 3947 Flournoy St.: $8-9,1-3,7-8$.

TYNINGS, OLIVER $\left(b^{\prime} 54\right) \oplus-M d .1, T-t$ (1'01): 932 Wilson Ave.; office, 31 N. State St. ; 10-1 ; Prof. Ophth., Otol.,
and Laryn., 111,G4; (B1,8) ; OALR.

-Ier, Aldora 1.-111.9,'85; (1'85); 1434 Bryn Jawr Ave.; 9-10, 2-4.

“ER, HARYEY AINSWORTH (b'69) 1,'89; (1'90); 4610 Racine Ave.; offlce, n., In.G1; G.
Tyallu, Frank Fdward (h's3) - Ill.17,07: (l'08): 4.15 Washlugton Blvd.; offlec, 4501 W. Lake st.; 8-10, 2-3, 6-8

Tyrrell, Adelalde iliry (b'62)-Ill.11,09; (109); 1715 W. 67 th st.

cllerick, Chas. A. (1)'58)-111.1,93; (1'93) 28 North I'ark Ave.; office, 304 S. Wabash Are, ; $3-5: 30$.

Cthman, Jenry Jolınson (b'81)-Ill.1,'12; (1'12) ; l'resbyterian IIospital.

Lnger, August 11. (b'68)-Ill.11,92; (1'92); 642 Barry Are.; oflice, $8 \mathrm{~N}$. State St. unseth, Mraguus A.-Ill.1,93; (1'93); 4056 Mintin $A$ ive

Unsicker, Robert (b';0)-Ger.2,98; 919 la Tamble St.: office, $5 \mathrm{x}$. Wabash Are.; $1-5 ;$ LD. $\star$

I'rheim, Jacob L.-E-IIl.8,'91; (1'91) ; 2839 W. Division St. ; $8-9,1-2,7-8$.

VAIILTEICI, JOHN RUDOLI'fi (b'64)111.1,'99; (1'98) ; 732 Addlson St. ; office, 2000 N. IIalsted St.; $9-11,3-5$.

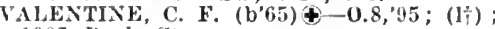
1007 IRush St.

Valentine, James C.-H-Ill.4,'87; (1'87) 2340 Pralrle Ave. : 12-I, 4-6.

Vallely, Johu Linton Jos. (b'71)-111.6,'10; (1'10) ; 117 S. St. Louis Are

rau Arsdale, Fred. A.-Ill.13,02; (1'02) 2258 S. Wabash Are.; 8-10, 2-4, 7-9

FAN BENSCHOTEN, WM. CROWELL $\left(b^{\prime} 70\right) \oplus-111.6,96$; $\left(1^{\prime} 96\right) ; 6516$ Kimbark Ave. ; oftice, 1230 E. 63d St. ; $9-10: 30,5-6$ vance, James St. Clalr (b'82)-ill.6,'10 (1'13); 1201 N. Clark St.; 2-5, T-9.

Yan Dellen, Alfred Lubbert (b'87)-111.6, '10; (1'10); 1434 S. Ashland Are.; 1-3,

VAN DELLEN, ROBERTLS L. $\left(\mathrm{b}^{\prime} T \mathrm{~T}\right) \oplus-$ I11.4, $01,111.11,{ }^{\prime} 0$

YAN DE ROOVAART, JOHN F. (b'T1) $\oplus-$ III.6,'96; (1'96); 203 E. 113th St.; 1-2, ranpooz

(l' Rel (b'43) - Ill.6,'6s;

(17) ; 4318 Prairie Ave.; 1-3, 6-7; G.

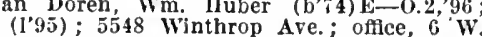
Randolph St. ; $10-5$.

VAN DYKE, GEO. H. (b'64)(-Ill.6, '91 (1'97) ; 1525 Hastings St. ; 3-5; office, 3415 Van Buren St.; G.

van Dyne, Anna L.-H-Ill.4,05; (1'05) 624 W. 59 th St. ; 8-10, 6-7:30.

$\checkmark$ an Hoesen, Elizabeth Nell (b; 73$)-111.11$, '09; (1'09); 6404 Harvard Ave.; office, 29 E. Madison St. : 9-12, 4-6.

YAN HOOK, WELLER $(\mathrm{b}, 62) \notin-I 11.11,85$. (1'85) ; 7124 Coles Ave, ; oflice, 31 N. State St. ; $2-3 ;(A 13, F 4): S$.

AN HOOSEN, BERTHA (b'63) (4)-Mich.1 88 ; (1'92); 4845 Calumet Are.; offlee, 32 N. State St. ; $2-5$; (F4) ; G.*

Van Horn, Ansel L.-111.4,07; not ln practice; 306 E. $43 d$ St. ; (G4)

Van Tuyl, Harry I.-111.6,'98; (l'98) ; 1222 E. 61 st St. ; offlee, 1230 E. 63 d St. ; 9-12, $2-5$.

Van Valkenburg, John LeRoy (b'T0)-N.Y.8, 95 ; (I'96); 31 N. State St.; 2-6.

VAN WINKLE, JOHN W. $\left(b^{\prime} 50\right) \oplus-N . Y .5$ 'is; (1'92); 6958 N. Ashland Ave.; 11-1,

Van Zandt, Garrett (b'56)-Ill.1,'83; (1'83); 2339 W. Adams St. ; offlee, 1705 W. Madison St. ; I2-2, 6-8.

Vasumpaur, Jos. -IIl.1,'94; (1'94); $3237 \mathrm{~W}$ $22 d$. St. ; $7-9,12: 30-2,6-8$.

Vaughan, Elmer E.-H-Ill.4,'89; (1'89); 2235 Fremont St. ; 8-9, 7-8; office, 22 E. Washlngton St.; $1-3 ; \mathbf{S}$.

vaughan, Phillips C. (b'67) - Ill.1,'88, N.Y.I0,89; (1'88); 3618 Greentiew Ave. offlee, 2772 Lincoln Ave.; 2-4, $7: 30-8: 30$. AUGIIAN, ROGER THROOP (b'78)థIll.1,03; (1'04); 4610 Ellis Ave.; oft
31 N. State St.; $4-5 ;(\mathbf{A 7}, 13, \mathbf{F} 4) ; \mathrm{S}$.

vaupell, Henry Harrison (b'76)-Ill.1,97 (1'97); 228 N. California Ave.; offlce, 2801 W. Lake St.; until 10, 12-2, 6-8.

VAUPELL, WNI. R. (b'61)-Ill.11,94 (l'97); 3335 W. Jackson Blvd.; until 9,

Veit, Jos. Louis (b'i1)-Ill.11,'95; (1'95); $1953 \mathrm{~W}$. Jackson Blrd.; office, $1860 \mathrm{~W}$ Madison St.; I-4, 6-8.

VENN, AUGLSTUS E. (b'65) - Pa.1,93;
Venn, Chas. II,-Ill.1,76; (1'80); 877 Mllwaukee $\Delta$ ve.; until $9,2-4$, after 8 .

Venn. Walter T. (b'7) - III.11, $02 ;\left(l^{\prime} 02\right)$; (73 Fox St., Aurora); office, 31 N. State St. ; 4-6 ; l'rof. Derm. and Syph., Ill.16. "erdenlus, John Jacob-111.6,09; (1'09); 7042 s. Carpenter sit.

VERMEREN, CYRILLE + - $111.14,98$; (1'98) 620 Grace St.; office, $108 \mathrm{~N}$. State St.: $3-6$.

Vernon, Ilouston Wingale (b's0)-III.17, 08 ; (1'08); 6657 Wentworth Ave.; 8-10, 12-I, 6-8; Obg

VIERS, JOHN WESLEY (b'77)-Ill.1,03 ; vllas, Chas. If. (b'46) Il-I11.4,73; (1'77); not lu practlce; 2811 Cottage Grove Ave.; Emer. Prof. Ophth. and Otol., Ill.4.

Vlncent, Mlary L.-1llch.1,75; (1'76); 5519 kenwood Ave.

TOLET, JOSIAH CLAIIE (b'82)థ-Ill.6, '10; $\left(11^{10}\right) ; 7855$ Normal Ave.; 1-3, 7-8;

Vloran, Raoul L. (b'83)-111.16,'10; (1'10) ; 1601 S. Kedzie Ave, ; until 9, 3-5, 7-9.

Vitullo, John Marinelll (b'85)-Ill.11, 10 : (1'10); 752 De Koren st.; 8-10, 4-8. Volicos, John N. (b'66) H-IIl.14,'96; (1'96) 501 Cass St.; $9-12,1-4$.

YOLINI, CAMILLO $\oplus$ - Ita.10,'85; (1'88); 2929 Washington Blvd.; office, 923 S. Halsted St. : 3-5: Clin. Prof. Surg., Ill.8. roN BOENIGK, WM. (b'7t) Int.14,09; $\left(l^{\prime} 09\right) ; 3059$ Montrose Ave.; until $9: 30$,
$1-3, i-9$.

VonDaacke, Louis (b'60)-Ill.14,'03; (1'04); $1622 \mathrm{~N}$. Californla Ave.; untll 10, 2-5, $7-9$. ON DER HEYDT, KOBT. (b'75)థ-111.11, Park); office, 25 E. Washington St. ; $9: 30-$ $1: 30$; Assoc. Prof. Ophth., Ill.22; (B8); Op.ネ

Von Kotsch, Rudolph Helnrlch (b'70)111.15,'99; ; $^{2}\left(1^{\prime} 99\right) ; 446$,

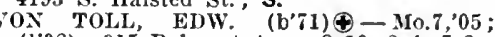
(1'08); 915 Belmont Ave.; 8-10, 2-4, 7-8. on Velsen, August F. (b'61)-IIl.16,97; $(1 \cdot 97) ; 1818$ Newport Are.; 9-5.

OA WEDELSTAEDT, BISMARCK $\left(\mathrm{b}^{\prime} 70\right) \oplus$ 2-4, 7-8; ÁLR

VonWerder, Artbur (b'41) $-\Delta ;\left(1^{\prime} 89\right) ; 2111$ N. Maplewood Ave.; $9-11 ; 2-4$.

VON ZELINSKI, WALTER FRANZ (b'82) $\oplus$ -III.8,08; (I'08) ; 4759 N. Rockwell St.; offce, 4811 Lincoln $A$ re.; $1-3,7-9$; S.

Vopata, W'm. J. (b'80)-ill.11,'04; (1'04) 1801 W. 47th St.; unti1 $9,11-12,2-4,6-8$. VORSANGER, ROSA૯-Il1.11,03; (1'03) 2354 Milwaukee Are.; $7-9,12-1,6-8$.

Vreeland, Clyde Emerson (b'87)-III.1, 11 (1'12); Cook County Hospital.

TREELAND, FREDK. D. (b'72) (-III.23, 05; (1'05); (Greenwood Inn, Evanston) offce, 15 $4: 30-5: 30$.

Vrettos, Andrew (b'7i)-Ill.8,'11; (1'12) ; Wachowski, John Geo. (b'80)-111.11,'02 ; (1'02) ; 4800 Loomls St.

Waddell, Lottie Anna-Ill.8,'09; (1'09);

WADE CHAS. ALBERT (b' 65 S. State St. (l'91) : 3218 W. Jackson Blvd. untín 12-2, 8-9; Prof. Ped., IIl.8; (D2); Pd.

WAGGONER, JONATHAN ELISHA (b'75)Ill.8, 02, Ill.6, 04 ; $\left(1^{\prime} 02\right) ; 4740 \mathrm{~N}$. Eberly Ave.; ofllice, 4395 Elstón Are.; $12: 30-3$,

WAGNER, CARL $(-$ Ger.10,'91; (1'91); North Ave. Park, West; offlce, 125 W

Wagner, Carl B. (b'76)-Ill.17,09; (1'09) 160 Eugenie St.; offce, $31 \mathrm{~N}$. State St. II-6; Clin. Prof. Ophth., Ill.8; Prof. Ophth., III.G4; OALR.`

WAGNER, CHAS. B. (b'66) (4-IIl.6,' 88 ; (1'88); 2144 Clereland Are.; 1-3, 7-8; G WAGNER, GUY WATTS (b'73) $€$-IIl.6,'99; (1'99); 1336 Argyle St.;
Clark 'St. ; 1-3, 7-8; ALR.

WAGNER, HENRY E.(4-lli.11,95; $(1995)$; 2424 Armitage Ave.; 1-2, 6-7?

Wagner, Rudolph (b'i i)-Ill.8,'10; (1'10); $4 \mathrm{~W}$. Ontario St.

Wahlberg, Karl Wm.-Ill.1,'12 ; (1'12) ; Cook County Hospital. 
Walte, Robt. A. (b'T)-W's.2,02; (1'12) 12145 siewart Are: $\% 12,1=5$

Wald, Olander E. (b'os)-ill.11,9s; (1'02) $1346 \times 1$.a Salle si: $\mathrm{S}$.

Walden. Walter (b'70)-1 - 11.6,96.

1211 k. 5:d St. :-8: N

Wales, Remnald C. (b's3)-III. '0s: (1'0s) 913 E. 6ะd S:

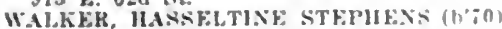
-111.993: (1093) : (Eranston): onlece, 29 Y. Madison Si.; i0-12, 1-4

WALKER, WEKHERT (b'67) - - 12, घ? (1॰93): (Green Iseat Inn, Eranston); of fle 29 E. Madison st. : 9-1; (1B1.8)

WAIKER, JAMES W- $111.6,93 ;$ (1'94) 1504 E. 53d St. : $9 \cdot 10,2-3$.

Walker, John Warren - 1ll.1,'St: (1'St) :212 Washington Blrd.

wilker, Marle winchell (b'5)-111.4, 99 (l'ag): 806 Lakesile l'

WALKER. ROBT. J. (b'il) \&-111.1,94

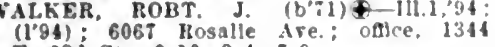
E. 63d St.: $9-10,2-4,7-9$.

WALKER. SAML. JOHXSON (b'67) \&-111.6, 93: (1'94): 670 Lincoln Parkway'; oflce, $125 \mathrm{~K}$. Chicago Are. 11-1; Asst. Cllu Prot. Med., III.1; Prof. I'ed., III.GI; (102)

walker, SIdney-Tenn.6.84; (1'St); 413 WInthrop \&

WALKER, SYDNEY (b'st) \&-Ill.1,10 : (I'10): 29 F. Madison

WALKER, WM. IENRY (b't0)†-III, 1,00; (1'00): Hotel Hayes: offlce, 6253 Ellls Are. : $9-10,2-4.7-8$.

WALKER, WINFIYLD $\mathrm{s}$ ( (v'61)-111.1,86; (1's6) : 2738 Racine Are.; until $9: 30$, $i-8$. Wall, charles Delamere (b'7)-Ill.11,00; $(1,00) ; 518 \mathrm{~S}$. Central l'ark Are; oftlce, Clty Irall.

wall. Clarence II.-III.11,04; (l04); 319 W. 5lst St: once, 31 \%. state St

WALI, FRAXK J. A.-lil.16.04: (1.04) 4431 S. Halsted St. ; offce, 4133 Wentworth Are.

Wallace, Geo, B. (b'56)-Ind.4,7; ; (1'8 7 ); 3631 Shemld Are.; oflce, 81 k. Madison St. : $1-5$

WAILACE, JOHX R.-I11.8, 90 ; (1"92)；200; live Island Are, ; $9-10,1-3, i-8$

WALLACE, WALTER S. (b'52)-Ia.1, 'is; (1'96): 3903 Llncoln Are: office, 3901

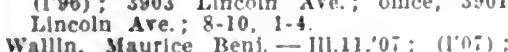
Wallin, Maurlce Benj, - Ill.11, 07 ; (I'0i);

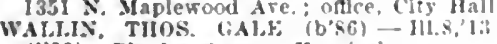
(I'I3): Rhodes Arenue llospltal.

WALLIXG WHAOLGHIY (b'4s)-Kу. GS: (l'9i) : 127 Drexel BIvd.

WALLNER, JOHX S. I-III.17,06; (1.04): 1158 Diversey Jarkwas; oflce, $2804 \mathrm{LIn}$ coln ire.

walls, Cbas Bruce (b.5i) H-III.10,94: (1'94): I60I Greenleap Ire.; oflce, 22 F. (194): 1601 Greenleaf Are.

Washington SL: $9-12 ; G$.
WALLS, FRAXK XAVIFR (b'69) + Ill.f. 91; (1'91): 4616 Fill Are. ofice, 31 v. State st.: 2-3:30: Clin. Irut i'ed. III. $6:(\mathrm{D} 2):$ Pd.

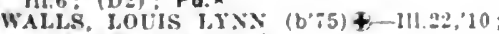
(1'10); Virzinla IIotel.

Walpert, Hernard E. (b'76)-111.,03 (103): 8747 Commerclal Are.: $8-10,1-3$ $7-2$; Ob.

Walab, liarry Fowln $($ bas) $-111.22,10$

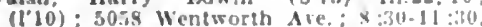
$2+1, \because 8: 30$

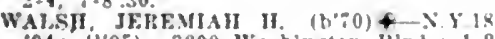
94: (f'95); 3200 Washlngton lilri.: 1-2 7.8: Assoe. Hrof, Sure, 111 $k$ : S.

walter olim Minroe (b'-4) Ill. (1'12), 4002 W. 26th st. 10-12, 9.

WAI,TER, WILL $\left(b^{\circ} 67\right)+-$ Mrh 1.92 (1'96): (150\% Human Are. Fonngting) once, 122 \$. Michlean Are. : (IBI, S Ft) Onl.

werers.

alfers. Sidney W, (bot)-II) \&, os (li)

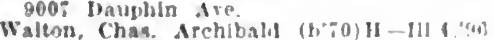
(t.96): 6630 Kenwond Are: onde, 1230 ค. 631 St. : $0-11,1-3,7-8$.

Wanicek, Edw. Mathlas (bo I11.11:93: (1'9\%): 1232 8. Sawyer Are

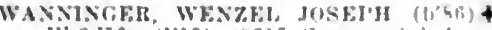
-111.63."10: $\left(10^{\circ} 10\right): 4215$ commerelal Are.

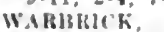

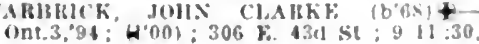
$2.5, \% 8:$ ALR.
Ward. ('bas W (b'5s)-111.1, $6:$ : (1's8):

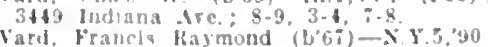
Wart, Frapcla kaymond (b'6i) $\rightarrow$ Y.3.90 born sit.

Warl, lieo A-111.1,03: (1.03); Ist2 W. Alams si, : once, if W. Washingtur st. Fard, Jihn H.-ll1.1\%,08; (1'08): $3165 \mathrm{~W}$

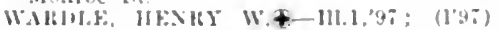

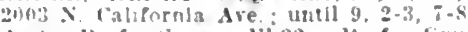
Asst. l'rof surg., lli.az; l'ref. Gyu. III $\mathrm{r}: 2$.

WAllF: HAMRY ALFANDFR (b'5) \& 111.1,98; (1"9s) : 838 ('ass st.; oflce, sos X. State St : $1-2: 30, i-8 ; G$.

WIIE, LYis (17i): 421 brexel Blrd.; offlee, $22 \mathrm{~b}$ Waslilamon st: $9-12,1-3 ;$ (HR); OD.

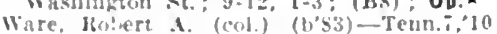
( ) 3734 Wabash ive.

WARI.OE, THWMAS-II1.1,91; (1'92) ; 2323 N. Kedzle 1blvi.: offlce 2421 W. North

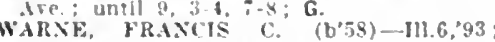
(l'93): i\$39 Kimbark Ire.; office l23s E. 75 in St.: $9-10: 30,1: 30-3,6: 30-8$.

Warne, (:eo, B-11-111.15,97; (197); it? Oakwood Blvd.

Warner, Abraham I. (b'61)-IIl. I.'st (l'8t): $32 \times$ state St. ; $8-11$.

VARNFi, ANTIIONi KIMMEL (b'63) + Md.1,85; $(1,90) ; \$ 55$ Grace st. ; offlce, 1056 Belmont Are, $10-11,6-8$

WAKXEK, ALGLSTL'S S. (b'65) $\$-111.6$. $9.5:(1,95)$; 3236 W. Polk St.; 2-3.

Warning, O. F.-111.16,05; (1'05); 3125 w 15 th St. ; offlce, 2300 w. 12th si.: $2-6: 30$ also $8 \mathrm{X}$. State st.; $9: 30-12: 30$.

Warren, Fimma J-lli.9.93: (1.93): 32.25 Fllis Are, ; oflce, 629 Wells St.; $9-10$, $1-4, i-8$.

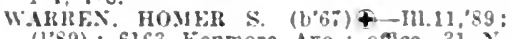
(1'39); 6163 Kenmore Are: oflce, $31 \mathrm{~N}$ State St.: 1:30-4; I’rot. Clin. Surg., 111.20 Assoc. Prot. Surg, 111.22: Path.

Warren, Wm. T. F.-111.3, 0 ; $\left(1^{\circ}(0,3): 232\right.$

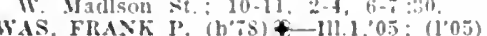
$10559 \mathrm{~S}$. State St.: nntice, 10900 Michlgan Are.: $9-10,2-4,7-5: 30$

wAs, joll w. (b'55)-Mich.1,78; (l's1) : 13 E. 111th St.; 1-2. 7-8.

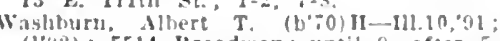
(1'y2) : 5514 Itroadway; unil 9. after 5. W.SHBL'W , JAMES MURRIY (b'3) + $111.6,99:(1 ' 99)$; 18 Hellevue Il.; offec,
?2 F. Washlngton st. 2-1; Asst. I'rot, Med.. Ill. I.

WASk. Jos A (b'-3)-111.8,05; (1'05) WASkA, Jos, A. $\left(b^{\prime} 3\right)-111.8,0.7$

Wnskow, Otso (B.-Ill.i1,02; (1.03); 5901

Waterhouse, Clins, F. (b'60)-1'al, 190 ; (1'92): Court llouse.

WATERMAX, ALONZO IIIGBFF (b'so)+

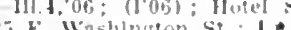

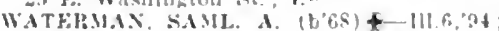
(I's); 7815 Wimecona Are.; $8-10,3-5$,

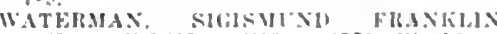
(b'7!)-111.6.05: (1'05) : :-5, wathm: tin MUd. : o

1 2, :-s; T.

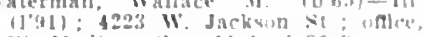
II. Madisnn st: 11.1. 6:20-s.

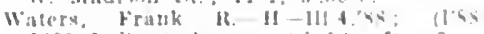
tsoo Indiana Ire; unt!l 10, after Ilce, $32 \times$. sinte si: $1-2$

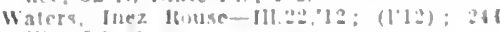

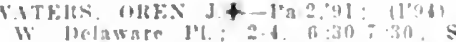

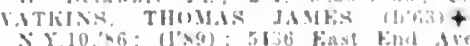

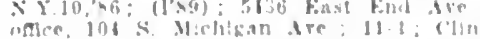

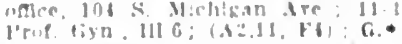

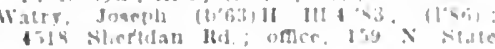

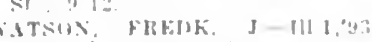

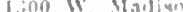

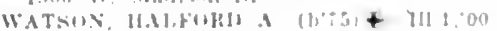

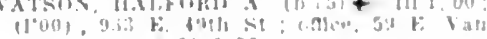
lusen $x:$ : $\$: 300.30$.

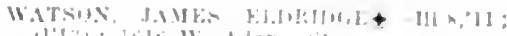
Walts, filde W Alars.

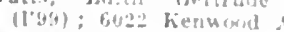

$111+38:$

W.ATS, fi WII.B:H?

II. $6 \pm t h$ si

Wi i cill st.

(1.04) FHaNk

siate st. : $2.4 ; 0$.

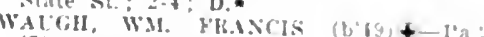

il: (l94): 6.t0: Iralrie be. orlce

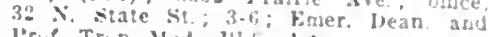

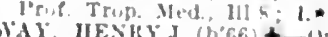

3501 Jack J. $\left.\left(b^{\prime} 66\right)+-1\right)$ (nt. $92:\left(l^{\prime}, 2\right)$

3501 Jackson 13184 : unce, $206:$ W. 1D

WA1. JAMES P. (b'62) \&-111.11, bi: (l'si)

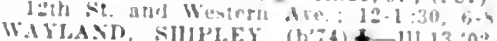
$\left(1^{\circ} 0-2\right): 5512$ ludiana Ire. orlee z Garfeld It|rd.: $y-10,1.2,-8$

WF.ATHEKFORN, HRINKIIN A-1111,95

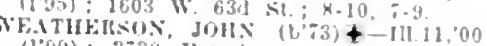
(199): 3.39 Prairie Ave. odlce, s Wabash Ave.; 3.5; (Ft): Asst. Wrof Med. 11l.11.

WEAVKR, GEO IIOWTT (b'66) + III

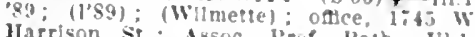
Jarrison St.; Assoc. l'rof. I'atb., III 1 Ino, $\mathrm{F} 2, \mathrm{~s}$.

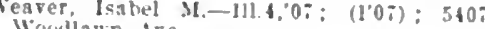

Wearer, Leonard Wehster (b'sG)-111.29,'12; (1'12); 1001 Townsend st

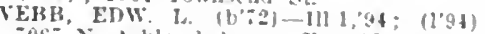
jof: 5 . Ahland die. odce, 1 to lireen leat Are.; $9-10,2-4$,

Webb. Wm. J-Mich.1, $3:(19 t) ; 1053 \mathrm{~N}$ Arers Are, oflce, 333 w. Division st thitll 9. aller 1

WFIBER, BLNNCHE EDITR-III, 13 , 111.11,03: (102): \$712 Jirerel Blid: once, 5. E. Malison st ; 3.5 .

ljto clenlake Are.; omce, $30 \%-2$ Lincoln

Weber, Alfred A-Wus.785; (1998): 9756 Belmont AFe, odce, 145 B Blackhair St.

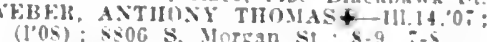

Weber Ewald (b'b4)-I11.22,10; (1'io)

WFHER, S.ML. I. $\left(b^{\prime} 61\right)+-x$ I.1.Ss $(1,91) ; 4336$ (irand litid. once, $32 x$

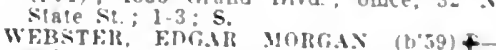
$0.3,84 ;\left(18^{\circ}\right): 6640$ Wondlawn Are.; of

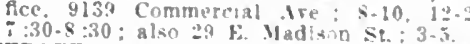
WFBSTER (iE) WAsHINGTON in's; III.

WEBsTFI8, JOHX ("-Vas 1, $0 ;$; (1\%) intio Winthrol ol

WEISTER, JUHX CI.IRFAT' (b'b3)

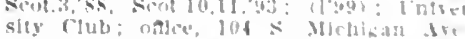

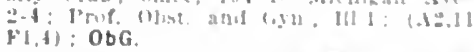

WEHTH:H, JOH

WFisTy : S.

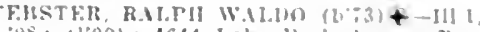

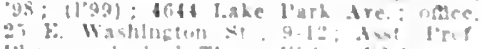

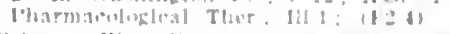

Weliver, Wm Henr 1060 W $\mathrm{ch}: 5$

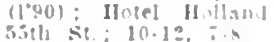

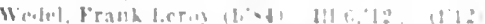

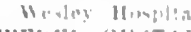

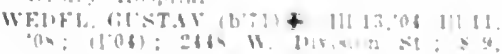

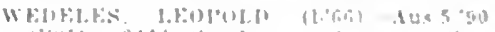

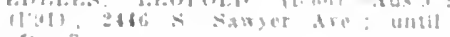

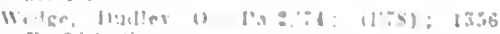
F. fieth 5 t

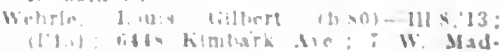

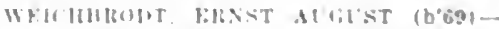

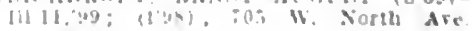


Well, Carl A.-Ill.11,87; (l'si); 634 Barry

Ave. Untll 9, 12-2, 6-8.
Well. Harry Nathan-Ill.6,07; (l'07) ; 135 ; v. Western Ave.

Well, Jerome Jacob (b'02)-Ill.11,'13; 634 Barry Ave.

Wellhart. Catherine E--II-Ill.10,82; (1'82)

3709 Ells Are.; $9-10,2-4$.
WEINBERGER, CARL, FREDK. (b'i3) III.1.07; (1"07); 5401 Indiana Ave.; of Velnlander, John-111.1,91; (1'91); $1805 \mathrm{~S}$. Welabash ire.

WEI16, CLAS. F. (h',0)甲-Ill.6,94; (1'05)

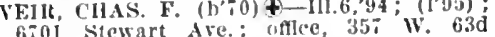
6.01 Stewart Are: : lfflce.

Welrick, ("lement $\lambda$. (b'52) II-111.4,76; (I) : $15 \mathrm{~S}$. Wood St. ; offlce, I553 W. Mandison st.; 8-9, 4-5, ;-8; also $29 \mathrm{E}$. Madison St.; 11-1; 1'rof. Mat. Med., Ill.4.

WFIS, Allitillson Are.; offlce, $32 \mathrm{~N}$. Stre : St.; $9-12 ; 1 . \star$

State St.; $9-12$; 1. ^ $\left(b^{\prime} 61\right)-111.11,94$; (Iध9): 223 N. Sacramento 13lrd.; offce, 1200 w. Madison St. : 9-I, 3-7:30.

Weiskope, Merman C.-lil.6,00; $\left(1^{\prime} 00\right) ; 601$ Belden Are.; 6- 7 ; office, 627 Diversey
Parkway; 3-5, 8-9.

Weiss, Jozua S.-IId.6,03; (1'03); 1756 W. Division St: until 10 , after 7

WEISSHRENNER, RICHARD FREDRICII (b's5) + -111.10;10; (1'10); 3600 Irving (b's5) +-1ll.10,'10; (1'10);
Park Blvd. ; 8-10, 1-3, T-9.

WEISSLOPF, MAX A. (b'74)(111.1,'96; (I'96): 1014 S. Ashland A re.; $10-12,7-9$. Weissman, Abraham J.-E-1ll.s,'94, Ill.1, 57; (1"94); 1106 S. Ashland Blvd. ; 9-12,

Welch, James-H-Ill.10,'95; (1'04)； 5445 Ellis Are.: offle, $545 \mathrm{I}$ S. Halsted St. E-10, $1-3,6: 30-8: 30$

Welch, John Thomas-H-Ill.10,'01; (1'01) 5445 Ellis Are.; offee, 32 N. State St.; 12-1; Adj. Prof. Theo, and Prac. Med. IIl.4.

Welcker, Henry c. (b'61)-Ger.14,'90; (l'y0); 170 W. North Are.; 3-5.

Weldy, Frank Ionroe (b'S8)-Ill.11,'12; (1'13): $\mathbf{5 6 2 4}$ w. Chicago Ave

WELFELD, JOS. (b'74) $\$-111.17,99$; (1'98) ; 208 s. Hamlin Are.; offce, 209 S. State St. ; $12-6 ;(\mathrm{C} 3,7)$; U. $\star$

Wells, Alnia Fuchs-Mo.30,'97; (l'98); not In practice: 012 Margate Terrace.

WELLS, EDWARD FRANIILIN (b'53) (4) $1-2 ;(\mathrm{F} 4)$ : $1 . \star$

WELLS, HARRY GIDEON (b'75)@-AsSOCLate Fellow-Ill.1,98; (l'99); $6025 \mathrm{~K} / \mathrm{m}$ bark Ave.; office, University of Chicago; Prof. Path.. Ill. I; (1)2, F2,4).

WELLS, WM. H. (b'53) \$-Ky.2,83; (l'94); 3367 N. Clark St. ; 9-10, 2-4, $7-8 ; G$.

Wendt, Alfred Carl (b'87)-1ll.6,'10; (l'10) $2 \overline{7} 46$ logan Blrd.; office, 3627 S. IIalsted St. : $10-12,2-4$

Wentworth, Jesse LeRoy (b'84)-Ill.22,'Il (l'11); 1310 George St. ; 2-3, 6-8; ALR.

WERELIUS, AXEL F. W.(9-Ill.I1,02; (1) 03$) ; 6725$ Constance Ave.;

Werinuth, Arthur Wm. (b'90)-IIl.11,'12 (1'12) : 4070 Broadway; office, 3933 Broad way; $1-3,6: 30-8$; Ob.

WERMLTH, WM. CHAS. (b'63) 0 -Ill.11, '89; (l's9); 4070 Broadway; offee, 31

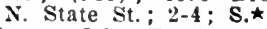

Werner, John Harris (b'74)-Ill.22,'II; not in practice; $173 \pi \mathrm{W}$. Monroe St.

Wernicke, Henry Oscar (b'87)-111.1,'11; (1'11) : $1533 \mathrm{w}$. Congress St.

WERNICKE, OSCAR G.-Ill.1,'89; (1'89); 1533 W. Congress St. ; office, 606 Blue 1533 W. Congress St.; offlc

werth, Stephen S. (b'- 8 )-111.23, $05 ;\left(l^{\prime} 05\right)$; 6949 Sheridan Rd.; ofluce, 209 S. La Sallé St.

WESCOTT, CASSIUS D. (b'61) -111.1 '83; (1'83); 1360 F. 58th St.; office, 22 F4) ; Op.

Wescott. Iuman I.-II-Ill.10,'98; (1'98); WESENR

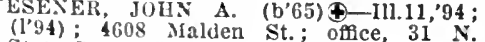
State St.; (F4).
WTSLLY, A1,LEN A. (b'56) \&-111.6,'87; (1'85) : 3149 l'rairio Are.; oflce, 3102 State St. ; $10-12,4: 30-5: 30,7-8 ;$ 's.

West, Alleert M.-H-ll1.10,'04; (1'04) 1867 S. Ilamlin Ave.; offlec, 4000 W. 12th St. ; $10: 30-12,2: 30-5,7: 30-9$

West, Lester Charles (b'86)-Ill.22,'10: (1'10); 3935 W. 26 th St

west, Stephen Gano-lli.1,90; (l'92); 31 S. State St.; 2-5.

West, Sylvester A. (b'7 7$)-I 11.8,{ }^{\prime} 12 ;\left(l^{\prime} 12\right)$ 454 Mllwakce Ave.

WEST, WI. ISUTIER (b'76)-111.11,06 (1'06) ; 4230 W. 25 th Pl.; offec, $31 \mathrm{~N}$. State St. ; 10-1; OALR.ћ

WESTEISS(IILLT', FIRANK II. (b'63)Ill.1.95; $\left(l^{\circ} 95\right) ; 1667$ llumboldt Blvd. $1-2, \pi-8$.

WESTMAX, CARI, (b'68)क-I11.8,'98; (l'99): 514 l)eming $\mathrm{I}^{\prime} \mathrm{l}$; ofllee, $108 \mathrm{~N}$ State St.

Weston, liw. I3. (b'46)-Ill.1,73; (1'77) 300 E. 33d st.; offlce, People's fias Bldg. WHHERIA, WM. W. (b'49) क-Ill.6,'85 Wetrcl, Toblas H.-N.Y.16,'S2; $(1 ' 90) ; 2006$ s. Sfate St. : $9-11,2-5,6-9 ;$ U.

WHALFN, CHAS. JOS. (b'68) $\oplus-11.1,91$ (1'91) : Pres. 11l. State Med. Soc.; 4603 N. Paulina St.; until $9,7-8$; office, 15
E. Washington St. ; $3-5 ;$ Prof. Med., lil.8; (Bi) ; LR.

Whalin, Oscar D. (b'65)-Ill.1,'90; (l'92); 6056 Kimbark Are.; 10-4

WIIAMOND. ALEX. A. (b; 71) -111.1,96 (1'96): 4359 Washington Blvd.; office

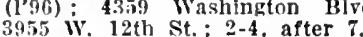

WHAMOND, FREDERICK GORDON (b'64) †-D.C.1,08; (1'09); 3953 W. 12th St.; 8-1, after 7 .

WIEATON. CLARENCE L. (b'73) N.Y.10,96; (l'96) ; 2738 Pine Grove Ave. oftee. 2733 N. Clark St. ; 9-10, 2-4; T.

WIEELER. ALONZO M. (b'71) -Ill.1,'97;
$\left(l^{\prime} 97\right): 3856$ Flournoy St.; offlce, 22 E. Washington St.; 3-6.

wheeler, Fredk. A.-Ill.s,'85; (l'85); 915 F 42d Pl. ; until 10, after 5 ; offce, $8 \mathrm{~N}$ State St.: $1-5$.

Wheeler, Geo. E.-Ill.39,09: (1'11) ; 611 Wrightwood Ave.; offlce, 8 N. State St.

WHEEI,ER, RALPH H. (b'63) $\oplus-111.8 . ' 89$ (1'90); 4900 Sheridan Rd.; office, $8 \mathrm{~N}$. State St.: 8-fi: S.

WHEELOCK, WARREN OVERTON (b'80)Ill.11,12: (1'12): 312 s. Ashland Blrd. office. 220 S. State St.; 12-4.

WHERRITT DAYID HENRY (b'71) III.I.'02: (l'02); 4017 Sheridan Rd.; office,

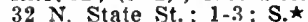

Whetzel. Frank F. (b'58)-Ind.4,78; $\left(1^{\prime} 92\right)$ 5241 Cornell Are.; offce, $236 \mathrm{~N}$. CrawPord Ave.; 10-12.

Whipple. Inhn A.-II-Ill.14,95; (1'95); 2601 S. St. I,nuis Are.

WHIPPLE, LEWIS ALIEN - Ill.22,05; (l'05): 1959 Grand Ave.

Whipple, Myron T.-0.1.93; (1'37) ; 6432 kenwond Are.; 9-11, 2-4.

Whipple, walter B. (b'83) - Ill.22,'04; $\left(1^{\prime} 04\right) ; 8 t 1 \mathrm{~S}$. Halsted St.

WHISE, MEICHIOR (b'69) $€-$ II.8.'92. Ill.1,'93; (1'92); 1618 Humboldt Blyd. offlce. $1257 \mathrm{~N}$ - Western Are.; 8-9, I-2, 7-8: Prof. Obst., Ill.16: (F4) ; Ob.

WHITAKER, WM. B. (b'75) क-Ill.1,97 (1'97): Lexington Hotel ; office, 32 N. State St.: $4-6$.

White. Annie H.-H-Ill.4.'96; (1'96); $5 \pi 37$ Kimbark Are.; 8-10, 5-7.

White. Edward Wm. (b'84) - III.11,'10 (1'10) : Alexian Brothers' Hospital.

White, Edwin Clay (b'88)-Ill.1,'13; Presbyterlan Hospital.

White, Elmer T. (b'61) H-0.7,'83; (l'95) 233 E. 47 th St.; offce, 7 W. Madison St. $12-1: 30$.

White, Geo. N.-Ky.1,81; (); 8920 Exchange Are.

WHITE, GILBERT J.9-III.8,'86; (1'86); 5534 Cornell Ave.; office, 104 S. Mlchlgan Are.; $10-12,1-4$

White. Harvey A. (b'38) E-0.2,'82 ; (1'83) ; 2917 Fulton St.

White, James R.-Tenn. 7,97 ; (1'98); 5908 S. Michigan Are.; office, 3558 S.' State St. ; $9-11,2-4: 30,7-8: 30$.
WHITE, MARIE LORINE†-IIl.9,'92; (l'93) 6024 Woodlawn Ave.: $8-10,6-7: 30$; of fice, $32 \mathrm{~N}$. State St.; 11-1; G.

WIITE, MARY BLAX́CII (b'60)-MIch.1. 98 ; (1'99); 3807 Grand Ilvd.; offce, 32

Wilte, Sarah Marquerlte (b'83)-Ill.11,'12: (l'12): North ('hleago Hospital.

White, Wm. Edgar (b'84)-D.C.3,08; $\left(l^{\prime} 08\right)$ $5136 \mathrm{~S}$. State St. ; $8-10,12-2,6-8 ; \mathbf{G}$.

WHITE, WM. S. (b'64) \&-IIl.10,88; (I'88) (Hinman and Greenwood Aves., EvansWhitehead, Lella $\mathbf{E}$ - Washington St. : 11-3. IV, Ontarlo St. ; \$-6.

WHITFIFLD, GEO. W. (b'60)థ-III.6,'87; (l'87); 5332 Harver Are.; ofhee, $25 \mathrm{~K}$ Washlngton St. ; $10-4$; (B7) ; LR.

Whltford, Grace Ionls Ruare-II-Ill.4,'04 (l’04); 457 Englewood Ave.; office, $29 \mathrm{E}$ Madison St. ; 1-3.

Whitford, Henry E. (b'59) E-Ill.8,81 ; (l'81); (Ozona, Fla.); othlee, 29 E. Madlson St. ; $1-3$; U.

Whitmer, Lawrence Wells (b'59)-Ill.11. 92; (l'92); 4717 N. Paullna St.; offlce 864 Aldine Ave.; 3-6:30; OALR.

Whitney, Alvin Herbert (b'78)-Ill.17,04: (l'04); 2000 W. Van Bureu St.; 10-11, $4-6,7-8$.

WIBORG, HANS B. (b'56)-Ill.1,'93; (1'98); 1503 W. Jackson Blvd.; 9-12, 2-5.

WICK, WM. J. (b'67)-Ill.1,'90; (1'97) 2141 W. Montoe St. ; office, 31 N. State

Wickensimer, John (b'86)-Ill.22,'13; (1'13) ; Bridewell Hospital.

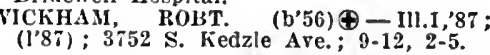
WICKS, SETH (b'79)๑-Ill.II, 03; (l'03) 1207 'Wilson Ave.; until 10, 3-5, 7-8:30.

WICKSTROH, ALBERT M. $\left(b^{\prime} 72\right) \oplus-111.11$, 06 ; (1'06); $1205 \mathrm{~N}$. La Salle St. ; office, 1001 Townsend St.; 2-4, $7-8: 30$.

Widner, Jos. E.-N.Y.I8,'90; (I'94) ; 4232 N. Karlov Ave.; 5-8.

WIEGNER, PAUL GERHARD (b'T0) $\oplus$ Rus.6,'98; (1'07); 3337 S. Morgan St. ; 8-12, G-10.

WIELAND, FRANK (b'69) - Ill.15,'96; (l'96); 4443 S. Michlgan Ave.; until 9, 7-8; office, 122 S. Michigan Áve.; 3-5; Prop. Theo. and Prac. Med., IIl.4.

WIENEKE, CLARENCE HENRY (b'90)( Ill.11,'12; (1'12); 1009 N. Sacramento Ave. : $10-12,7-8$.

WIENER, ALEX. C. (b'6I) $\odot-G e r .14, ' 86$; (l'91) ; 841 Grace St.; office, 32 N. State
St. ; 2-5: Sec. and Prof. Surg., IIl.G2; (Ai2); $\mathrm{S}$.

WIWKSEN, THEODORE MARTIN $\left(b^{\prime} 78\right) \multimap$ $111.8,06,111.11,08 ;\left(l^{\prime} 06\right) ; 2703$ N. Clark WIGGIN, TWING BROOKS (b'65) $९-$ III.II, 66; (l'86); 442 E. 4 Sth St.; until 9 , after Diag., Ill.11.

wilcox, Earl E. (b'86)-Ill.4,08; (l'08) ; 5453 S. II alsted St. ; 11-12, 7-8.

wilcox, Helen B.-111.15,93; (1'99); 6307 Unirersity Are.; office, 1153 E. $63 \mathrm{~d}$ St. ; $8-10,2-4,6-7$.

IVILD, THEODORE (b'34) $\oplus-$ Ill.1,'65 (1'i⿱ ; ) 532 Aldine Ave.; 8-9; offlce, 801 Mllwaukee Ave.: 2-3.

WILD, TIIEODORE, JR. (b'74)Ð-III.I,'98 ; (1'9S) ; 2453 orchard St.; offlce, $32 \mathrm{~N}$. State St. ; $2: 30-4 ;$ also 801 Milwaukee Ave. ; $10-1$; DALR. *

wilder, Geo.' J.-Mich.1,77; (l'84); 341 Enzlewood Are; until $8: 30,1-3,6-8$. 942 Alexander Pl.; offlce, 7 W. Madison St. ; 2-3; Prof. Ortho. Surg., Ill.16.

WILDER, RUSSELL MORSE (b'85) $\oplus-$ Ill.1,12; (1'12); Presbyterlan Hospltal. WILDER, WM. HAMLIN (b'60) $6-0.1,84$ (l'91); 5811 Kenwood Ave.; office, $122 \mathrm{~S}$. Michigan Ave.; 9-1: Prof. Ophth.,

Wilgus, James lisingston-Ind.8,96; (l'96) 5749 Calumet Are.; office, 108 N. Dearborn St. ; 10-5.

Wilkenlnh, Margaretha-Ill.8,'95; (l'95): 2023 N. California Ave.

Whlkins, David W.-H-Ill.4,97; (1'97); 547 Aldine Square. 


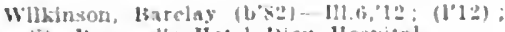
st. liernaril's llotel bien llaspital

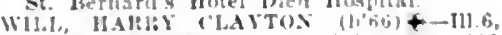

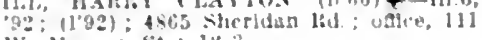
Whlaril, Mancli W. (1,66) - Mo.2:91:

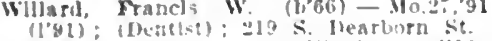

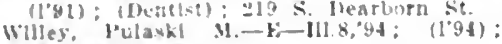
181 F Fulton st.

whuams. Allce 11. (b'6s)-M1d 5, 41; not in

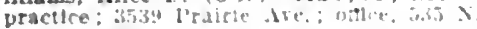
Dearborid st.

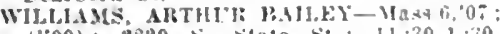
1109): 28:9 $\$$. state sit.; $11: 30-1: 30$,

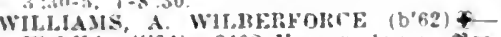
II1.6.94; $(1 \cdot 94)$ : 3403 Vernon Ale.; otsce, $\$: 55$ S. State St: $2-5,6: 30-8: 30$.

Williams, Chas. I. (b'6t)-Ill.11, (13; (1'11): $4 i 40$ w. $63 d$ St.

WILLIAMS, DANL. It. $\left(b^{\prime}, 0\right) \notin-I 13, f,{ }^{\prime} \& 3$ :

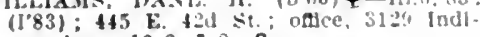
and Are.: $12-2, ;-8 ; s$.

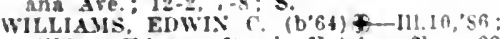
(1'86): Chicago lieach llotel; oflce, 22 F. Washlogton St. : 1-4; ObG.

WILLIAMS, FVEIIETT JFXSOS (b'8I) 4 III.6.06: (1'06): 4001 Greenrles Are. untll $9,2-5,7-8$.

WIILIAMS, JAMES B.-1'a.1,'s0; (1'85);

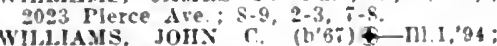
(1'96): 541 Fuller:on l'arkway; $12-1,6-5$ : (F4): A.

WILIAMS, JOHN F $\left(r^{\prime} 37\right)+-111.5,65$; (1'i:): 311 Center si : 10-1.

wlllams, Lucas R.-111.1, T5: (l'ii); 455

Wrlahtwood Are.

Wriahtwood Ave. $\rightarrow$ (\$) : $2120 \mathrm{~W}$. Van
Wlilams. Maud $\mathrm{C} \rightarrow$; Bureb st.

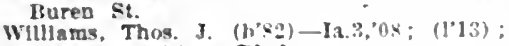
this S. Michlian Blrd.

Willams. Thos. Hamilton (h'fi) - 111.10, 86 ; (1's:): $5506 \mathrm{~W}$. Ontarlo St.

WIHLMS, WM. (b's2) \&-111.11, "ns: (1'ns) 1115 Bryn Maxr Are. ; 10-12, 1-5. 7-9. whllams. Wm. Carrer-0.6,92; $(1,92) ; 20$

WILLIAYSOS, CHAS. SPENCER (biz)

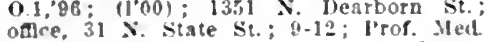
and Clin. Sled. Ill.11; 1'rof. (ias.-Fnter. III.G1; (F) ; i.

Wullanson, John Clement $\left.\left(b^{\circ} \times 4\right)-11\right] .1 I$ 12: (1'12): ("hlcago Lying-In IJusiltal. willlston. Saml. Wendell (b'52) - Conn.1.'so not in practlce: 50:3 Dintchesler Are.

WILLITS, IHA I. (b's.) + - I11.11, 05: (1.05): 536 Rush st.; 0Atce, $70 \mathrm{~N}$. Chark St.: $1-3, \div-8: U$.

willson, thas. (;-Wis.2.96; not in prac llce: 1fot; Jackonn Jird: oflee, 39 s Ia salle $S t$

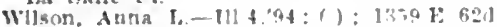

Wilson, Arthur W.-III.8,03: (1'03): 1340

Madison Park.

wilson Franklin saml. (h'-2)-H1.11,11. (III) Franklln Saml. (tr. (1'11): 1.32 Wa Jison St. Jarkson 4 -

Wlison. James lee (b's5)-Ill.1,12; (1'12): Cook County Ilosgltal.

WIISON, JAMES WM $(1,70)-111.11,03$; (I"03): 6100 s. Halsted st.; $4-11,1-2$,

HILs(1), JOLI,

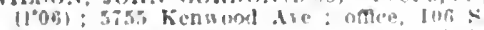
Michlean Are; 3-5; Jrone Utol. 1116 Michlesin Are : $3-5$

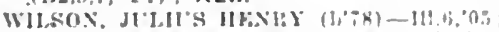

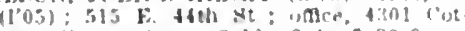
tage dirore Ave: $8.10,2.4, ;: 30.9$.

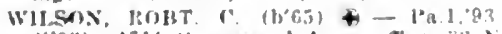

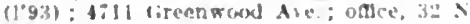
siate it: 11.1

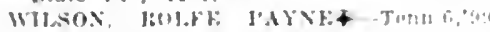
(1): Member Tenn. Site Mled divn

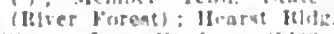

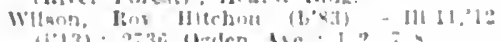

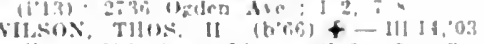

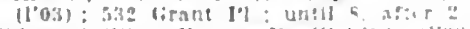

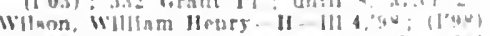
Wlan, Whlinm Herts. II IIl 4.

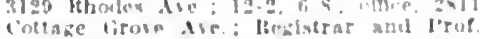

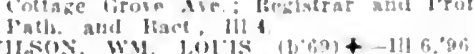

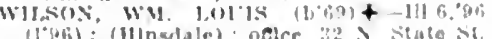
(]$^{\circ}(0, b): c^{(1)}$
Winan, E.lw: Clark (bej)-111.11, "59: siate st: 1 Rowalle Are.

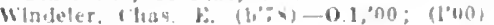
tivebiage Blite.

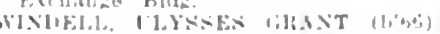

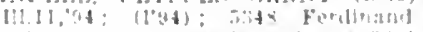

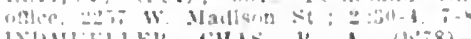

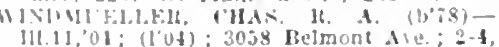
i-a.

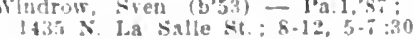

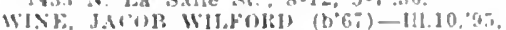

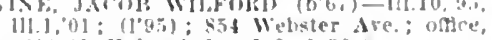
$2: 200) \times$. Halsted sit.: 1-2, b:30-5

Winer, Intu king (b'62)-111.1, 84 : (1" 4 ): 150 dacust st. : once, s00 $\rightarrow$ Clark sit. $9-10,4-1,7-8$.

Wumble, walter Fritz (bss) - 111.1,13; (1’13); 2001 X. Callfornla Are.

Wune, ihas. Walter $(1,7-7)-111.11,0: 4$ (bif) ; 3255 walnut st.; once, lok siate si.: 10-: : U.*

Winner, l'eter Saul-I11.22,12: (1'12); vagle Ave and lrring lark lird.: 9-11, $3=b^{2} ; \mathbf{N P}$.

WIXNER, SAML. S. (b'8t)-I11.22,09: (1009); 3345 W. lfith st; oftce, $805 \mathrm{~W}$ Madlson St.; $3-5,7-9 ; U$.

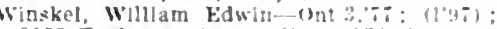
9023 Exchange Are; onlew, 1.4 Commer

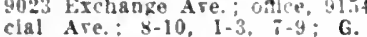

WIat Are, 8-10, I-3, $7-9 ;$ G. 09; (1'09): 5538 W. Clilcago Ire.; 8-10, 2. 4. $7-9$.

WISTERS, wM. THOS. $(1,66)-111.11 .02$; (1)02) 4149 W. Monroe ti.; oltice, ito St. ; $9-7$.

Wlpper, Otto (b'69)-111.8,']0; $(110) ; 941$ lidgecomb IPl.

Wippern, Adolphus G. (b'6s)-X.Y.I.92: (1'95); (Rlverslde); offce, $32 \mathrm{X}$. State St.: 2-6; I'rof. Oplith. and t)tol., II. (it.

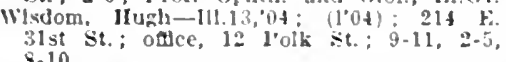
$8-10$

Wisely, Allen Newton, Jr. (6'-3)-III.1,'13; (l'13): Michael leese ijospltal.

WISNIEWSK!, FLAN(IS F. (b't)-111.2.,

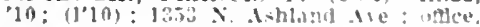
1868 Mllwalke Aie. $10-12,-1, \div-9 ; \mathrm{G}$ Wisslg, slmon to $(1,-3)-111.11,05 ;(105)$ : 1759 w. 18 th si.; $10-12,8-4,6-0$

WISTEN, WOSINA $R,\left(b^{6} 6 z\right)+111.11,04:$

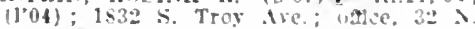
-tate st. : $8-11,7-4: 30$.

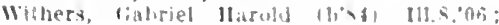
(1'0b): (1.ake Furest): otlice, is X. Siate

WiTKOWSKl, 1.F, JOS. (b'82) $\neq-1116,0 \%$ : $(1007) ; 1724$ W. Asth st.

Wlle. Wm. 1.-111,2:13; (1'13); s3: x. levinire are

W0511.

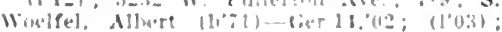
not in practico: $1101 \mathrm{~F}$. ofth st

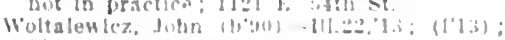
14:as clareont Ine.

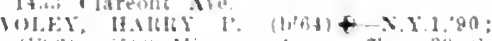

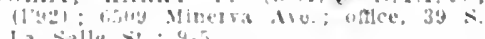
W.3 Nalle : : 9.5 11004): 11.1 Fullerton Are : $4-12,1-3,79$

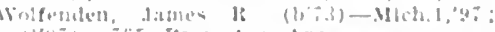

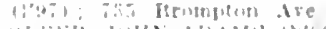

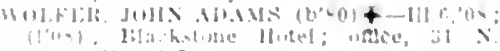

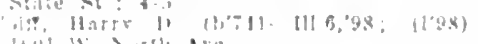

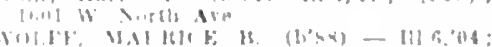

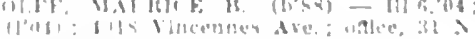

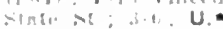

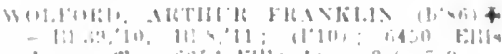

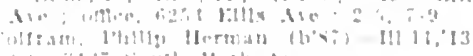

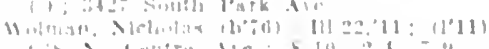

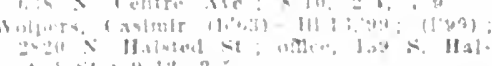

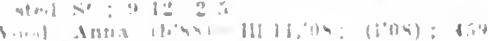

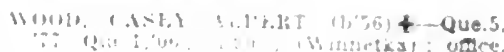

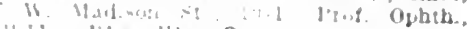

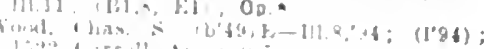

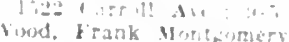

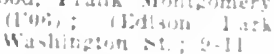

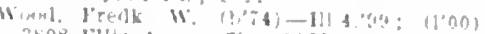

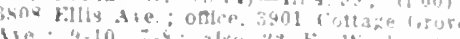

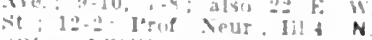

Wen1), 1.1.5. 12 No Nub shore Are; offoc, $10 \mathrm{x}$.

coul, leonard Saml. - I11.4,13; Intern, Hobnemann llovwltal

Wum!, Nathan New-111.1,90; (1*31): 1555

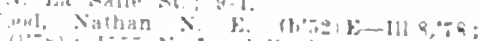

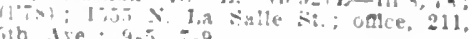

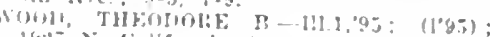
after \&. Callformia Ave : intil \&. $2-3: 30$,

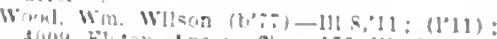

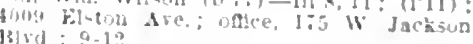

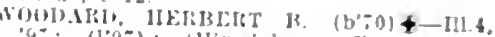

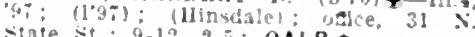

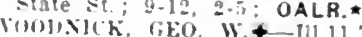

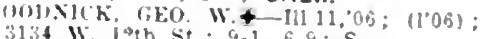
3134 W. I th st. ; $9-1,6-9:$ S.

Woodrnt, Ilolland cecll (b's:)-111.1,13; (1'13): If53 l'ark Are.

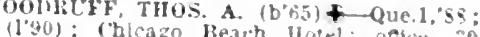
$x$ Hichon ation, 30

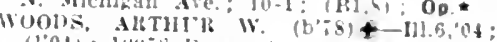

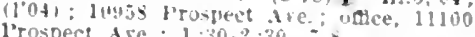

WOOHS, BEITT LESLIF TAYIOR (b'82)ofrce, $209 \mathrm{~s}$ - vitate st. : $12-4$.

Wrock. Jiand Hueston (b'je-111.11'13 (113): Illinols Cbarlable Eye and Ear Intirmary

Wondward. (barles (b'45) E-O 2.:9: (1'so); 2209 11. Madison st. : $9.11,2-5,7-9$

Woodward, Clara li (b'b)-I!1.16,10:

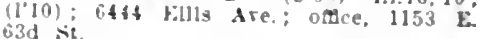
tisd it.

WOOMWORTII, PICMER MORTOX (b*51)-

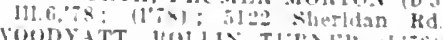
I1. ston): once, lnis shempier st.. Kran $5: 30 ;$ Ast Irot Med. Ili. Are 3:300

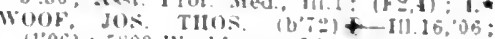

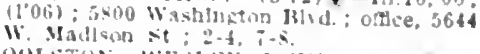

111.11.05: (1003) :3 state st.: $1: 1: 30 ; \mathbf{G}$.

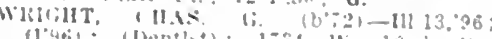

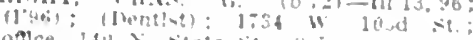

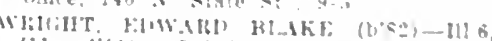

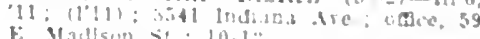
f: Malloegl st: $10-1:$

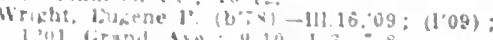

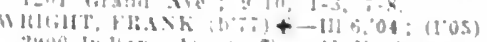

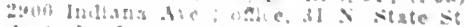

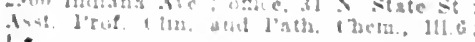

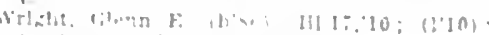

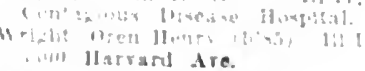

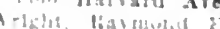

b.elatel livo

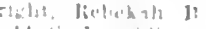

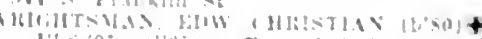

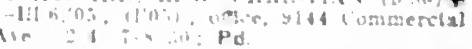

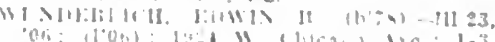

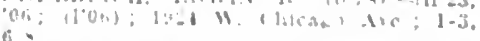

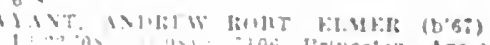

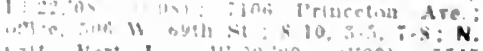

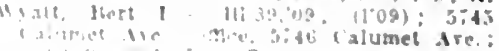
G. 


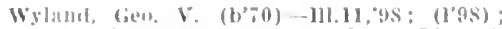

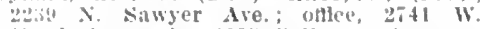
North Ave.: : also 3235 Fillertom Al.

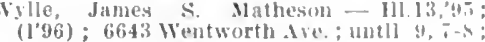

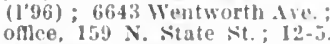

WYXEKE, (ikHIAIDT ERSN (b's2) III.22,08; (l'08); 3944 W. Vin Buren St. : onlec, 706 s. Inneoln st.

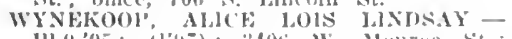
111.9,95: 11'0.5); 3406 W. N1mroe oftce, 32 N. State st. $12-1,3-4$ Pd.

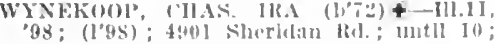

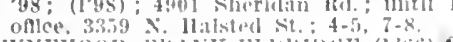

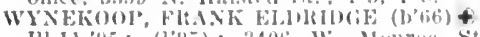

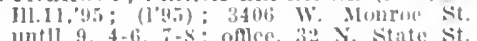
unt11

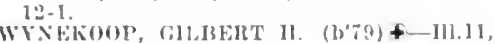
$06 ;$; $\left(\mathrm{I}^{\prime} 06\right) ; 4500$ sheridan Iid.; $3-5,7-8$ : S. $*$

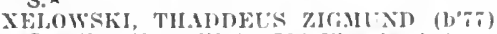
+ 111.11,03; (l'03); 72s Waveland Ave. onlce, 1053 inlwanke Ave.; $11-12,7-9$; ( $\mathrm{F} f$ ) : $S$.

Yanipolsky, Itehecea Mirlan - Ill.11,0h:

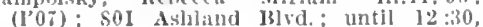
$6: 30-8: 30$

YAltios, HACHELIAS S.-1'a. Z,'94; (l'94); 800 S. Ilalsted st.; $s-4,6-7$; Assoc. I'rof?

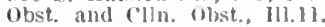

Yates, Geo. F-III.I,'s: (I's8); 6445 S Halsted st. : $10-12,4-15$

YHAKFL, WHLIAM K. (b'65)--11.11,99; $\left(1^{0} 02\right) ; 4207 \mathrm{X}$. Keeler Are.; $8-9,1-3,7-8$. Yeck, frltz ("arl-lll.I, 03 ; (1'03); 3265 Oglen Are : 8-9:30, I-3, $7-9,-9)+-I I, 6$, YERGER, CHAS. FIRANCIS (b'T9) \pm -IIl.6, 136: Belmont Ave : $2-3,7-8 ; S$.

Yorks, Wm. K.-II-III.15,00; (1’00); 5906 E. CIrcle Are.; untll 9, I-3, 7-8.

YOUN(, ALBFN (b'61) —-111.6,'89; (1'89); 4232 N. l'aullna St.; ottice, 1810 Wilson Ave. ; $4-6$.

Young, Annie M. (b'58) II-III.4,'89; (1'89) 2248 Idneoln Are, ; 4-11, (i-8: OALR.

Young, Earle Montgomery' (b'si) - Ill.1,'12 (1'13) ; 628 Belmont Are.

Young, $, d w, V . J .\left(b^{\prime} 85\right)-111.17,10$ : (1'10)

1400 Dlversey l'arkway; $10-12$, 5- 5 ; offlce, 953 Belmont Are. $1-3,7: 30-8: 30$.

YOUNG, GEORfiE 13.†-11d.1,87; surg. U.S.P.H.S.; ('ity llealth Commissioner 711 Gordon Terrace; offlce, clty Hall YOUXF, JOSEIMINE FSTABROOK (b'6T) † Ili.9, $96 ;$; (1'96); 5718 Dorcliester $3-5,6: 30-7: 30$; Asst. I'rof. Med., Ill.I ; (1) 2 ).

YOUNGEIS, CIIAS, BENJ $(b, 5) \mp-I l l .6$, 02; (l'02) ; 9557 S. Winchester Are. offee, 15 F. Washington St. : 2-4; ALR.

YOUNT, JOSEPII STERLING (b'67)-Ill.1, "9.3; (1'94); 6243 Drexel $A$
w. 63d st. ; $10-12,3-5 ; s$.

YUDELSON, ALBERT BERNARD $\uparrow-\mathrm{ml} .6$ 06: (1'06); 4539 Indiana Ave. until 9 7-9; offlce, 7 W. Madison St.; 11-1.

YTSKA, ADAM L. (b'-6)-I11.22,'10; (1'11); $1749 \mathrm{~S}$. Malsted St.

ZABOKRTSKY, JOS. (b'74) - II.11,01 (1'01) ; 2531 's. Lawndale Are.; office, 31

Zahn, Benj. J. '(b'6s) H-Ill.10,00; (I'00) ; $4550 \mathrm{~N}$. Oakley Ave.

Zahorik, Alris il.-Ill.23,'06; (l'06) ; 1846 s. Ashland Are.; offlee, 1339 S. Ashland Ave.

Zaleskl, Jos. P. (h'73)-Ill.11, 00; (1'99); 4649 s. Ashland Are, $9-10,12-2,6-8$. ZAI'FFE, FREN CARL '(b'73) $4-11111,96$; State 'st.; 4-6); I'rof. Oper. Surg., Ill.22 $(\mathrm{G} 1,4) ; \mathrm{s}$

Zaremba, Frank (b'58)-Ill.8,03; (1'03); Zeh, Jos. Wm. (b'3)-Ill.22,09; (1'09); $4642 \times$. Kenton Are.

Zeigler, L. C. H. E. (b'49) $\longrightarrow$; (1'99); 2135 Ilichigan Are.; offce, 8 S. State St. Zeisler, Erwin Paul (1'88)-Ill.6,'12; (1'12) ; Michael Reese Hospital. ZEISLER, TOSEPH (1,58) †-Aus. 7,82 x. Miehtgan Are.: 10-1, 2-4; Prof. Skin and Ven. Dis., III.6; (C2.6); U.ネ

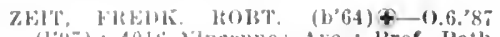

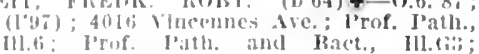
III, (i) I'Tuf. I'ilth.

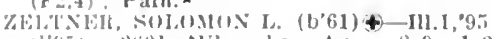

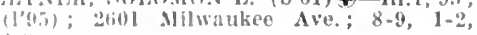

\%.mer, stanley cillum (b'83) - 111.1,13; (t'13); st. luke's ifospltal.

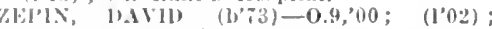
3154 Douplas blvil.

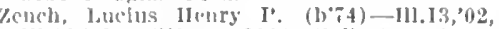
111.11,11; (1'02); 3014 rullerton Are.; unt $11,30,12-2,7-5$.

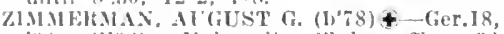
99: (1'0(i); C'nlverslty (lub; oflce, 32 N. State si.; ; $2: 30-4 ;$ S. *

Zimmermann, Jean Turner (b’i]) - Ia.1,'97 not In prictice; 110 s. Morgan St.

Zlus, Lewlit E.--111.17,98; (1’98); $183 \mathrm{~N}$. ('lirk St.

Woelirlaut, (ieo. Guido (b'79)--Ill.11,'02 $\left(l^{0} 0\right.$ i) ; 56 I Melrose st. ; until $9,2-4,7-8$ Zuelalke, Frank J. (b'86)-11l.8,'10; (1'10); 2752 Pelmont Are, ; 9-10, 1-3, $7-8$.

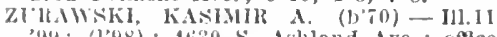

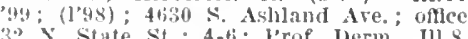
$(\mathrm{C} 3, \mathrm{~T})$.

CHICAGO HEIGHTS, 14,525, COOK

Boyer, John S.

(siec trete.)

COHD, (11.L. F. (b'61) t-IIl.1, 00 ; (1'01). 31 , 16 th st.; oftce, 171 I West End Ave.;

'OLiNGT, ALI'HON I. (b'85)-Ill.22,'10; (I'10)

MONALDSON, IIENITY BAILDWELL (b'80) -Ill.bi, 09 ; (l'09); 1637 Oak St.; office, 229 E. 1 th St. ; 1-3, $7-9$.

Fegan, Gco. R. (b'66)-Ill.1,00; (1'00): 1tiol West End Ave.

GILEETT, NEWELI. CIARK (b'80)-Ill.6, (97; (1'08); 12 Oak St.; office, 8 Illinols ORRELl, TALBOT J. H. (b'72)థ-III.11, '01; (1'01); 82 E. 16th St.; $11: 30-12: 30$,

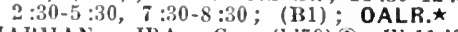

IIAISHAN, IRA C. (b'79)—-III.11,04; (l'04); 98 W. 15 th St. ; offlce, 78 lllinols
St.; $10-12,2-5,7-8$.

KLINGLER. ELLIS GISE (b'76)-I11.11, 02 ; (1'02) ; 1417 Otto Blrd. ; 10-12, 1-3, $7-9$.

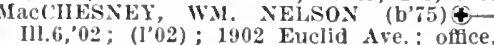
111.6,02; (I'02); 1902 Euclid Ave.; office,

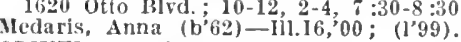

OLIVER, NELSON EUGENE.

(Sec Thornton.)

PNNENBOIt(, ARTHUR HERNAN (b'80) Ky.2, 04 ; (1'04); 1562 Schilling Ave.; of fice, Flrst National Bank Bidg.; 9-11, Bobbins, Wilfred D.-H1.6,84; (l'84); 163 T Oak St.; office, Odd Fellows' Bldg.; 2-4, Oak S. ; office, Odd Fellows Bldg.; 2-4, i-3: Anes.

-Ill.1, $75 ;$ GUSTAVLS FRANK (b'48) -Ill.1,75; (1'75); 1623 Aberdeen St.; office, 78 illnois st. ; $1-2,7-8 ; \mathrm{Pd}$.

(I'90); 1600 Aberdeen St. ; office, 17111 West End Ave., 10-12, 2-4; G.

SPENCER, RICHARD V. (b'79)-Mo.20,07; (l'11) ; 1445, 5th Are.; 10-12, 2-5, 7-9. STRAND, MARTIN屯-III.1,96; (1'98); 80 Illinols St.

SLILIYAN, CHAS. PETER (b'85)-II1.6,'I2 ; (1'12) ; 1537 Vincennes Are.; office, 1635 West End Are.; 3-5. 7-8

CHICAGO LAWN (IND. STA., CHICAGO), OOK (Sec Chicago.)

CHILLICOTHE, I,85I, PEORIA

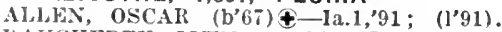
DAEGHERTY, JOHN W. (b'i4)£-III.I,00; $\left(l^{\prime} 00\right)$.

Field, Laura B. $\longrightarrow$; (1'78); not In pracKELLY, J'ATRICK H. (b'63)€-III.I,'92; (1'92)

Thomas, IIarry Y.-1ll.11,06; (1'06)

THOMAS, ORA F. (b'52)-IIl.6,78; (l'78).

WEAVER, JOHN-MO.5,'79; (1'79).

CHRISMAN, I,193, EDGAR

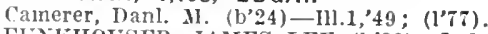

FUNKHOL'SER, JAMES LEE (b'83)-Ind.8, $05 ;(1,06)$

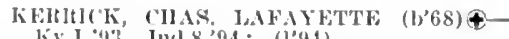
liy. I, In, Incl.8,94; (1'94).

S.'OTT, OTTO H. (l)'Ti) \& 0.3,'98; (l'98). CHRISTOPHER, 1,825, FRANKLIN

13KAYFIFIII, BENJAMIN F。 (b'61)-Ky.1, '92; ( (1'92)

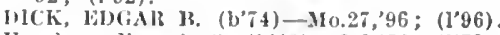
Ilarrlson, Francls $0 .\left(b^{\prime} 46\right)-0.2,78 ;\left(1^{\prime} 78\right)$. I.ITTLL, 1'dith MOORMAN, IIOWAID (b'69)†-Mo. t, 06 ; (l'06).

Willls, Albert (b'81)-110.7,04; (1'04).

CICERO, 14,557, COOK

Alstrom, Ernest Fredk. (b'83)-Ill.8, 09 ; $\left(l^{\prime} 10\right)$; 1330 s. 4sth Ct. : 10-12, ; -9.

Coopersteln, Jos. (b'84) - I11.11,'09; (1'09) ; 1401 S. 51 st Ave.

IInn, otto W'm. (b'85)-111,8,'12; (1'13): s2d I'l. and $52 \mathrm{~d}$ - Ave

Hooul, Addie Clark-1li.16,01; (1'99).

IIt)ON, JACOB J. (b'69) †-III.I6,02, Ill.11, 03; (1'(2) ; 5147 W. 25 th St.; $1-2,6-8$.

kotallk, Frank Jos. (b'89)-ni.11,13; (l'I3); 5209 W. 25 th St; (l'10) ; 2300 s. ('lecro Ave

Luce, Fredk. A. (b'56)-Ill.II,'92; (1'92) ; Melatlen, James Claude $\left(b^{2}-7\right)-I 11.16,09$; (1'09); 2937 s. 48th ct. $9-12,6-9$.

Ostrowskl, Florlan Geo. (b'87)-IIl.11,10: (1'10); 5106 W. $22 d$ I'l.; office, $2910 \mathrm{~S}$. 4sth Ct. : $10-11: 30,2-4,7-8: 30$.

Palmer, Chas. Nelson (b'54) - Ill.1, 80 ;

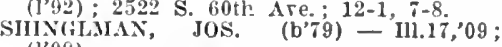
(l'09).

SLADEK, BOHUMIL $\left(b^{\prime} 70\right)-$ Ill.11,92; (1'92); 5002 W. 30 th St.; offlce, $2215 \mathrm{~S}$. ilna, Bretislav Lidumll-Ill.11,'11; (l'11); 5539 W. $22 d$ St.

\section{CISCO, 400, PIATT}

Graves, Brlnsley C. (b'52)-Mo.1,85 ; (1'85).

HATILAWAY, ROHT. MEREDITH (b'82)Ia.6,"09; (l'09).

CISNE. 373, WAYNE

Bryant, Lawrence K. (b'76) - Mo.28,'99; (1'99).

HANCOCK, WALTER ADDISON (b'71)-

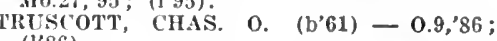
(l's6)

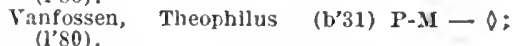

\section{CISSNA PARK, 652, IROQUOIS}

IIack, Edmund Carl (b'88)-Ill.8,'11; (l'12). ROBERTS, WM. ROSS (b'73)€-Ky.1,94; (1'94).

\section{CLARENCE, 200, FORD}

Brown, John Bernard (b'i6) - Ill.17,'02: (l'02).

CLARKSBURG, 120, SHELBY

Humphreys, Andrew Jackson-0; (1'78).

CLAY CITY, 837, CLAY

Boyles, Elijah Warren (b'36) - Ill.1,'62; $(177)$; not in practlce.

CREWS, CHAS. IIUBERT (b'80)†-Mo.28, '08; (l'08).

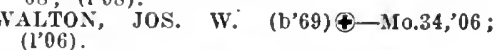

\section{CLAYTON, 940, ADAMS}

Briggs, Robt.-Ill.1,'69, N.Y.10,'75; (1'77). Darison, T. A.-1a.I,'76; (1'77).

Dodd, Frank Clark (b'69)-Ill.i,'00; (l'00).

GARNER. WM. A. (b'60)£-Ia.I,'85; (1'85).

Parker, Henry J. $\left(b^{\prime} 45\right)-M 0.1,70$; (1'78).

PETERS, LEMUEL PINCKNEY (b'78) $\uparrow$ Ia.10,05; (1'05).

Wallace, Thos. A. (b'61)-Ill.14,'99; (l'99). CLEONE (R.F.D., MARTINSVILLE), 27, Morrill, Seth T, (b'59)-Ill.1,87; (l'8ï). CLIFFORD, 800, WILLIAMSON

EVANS, CLAUDE MONROE (b'80) $\oplus-$ IIO.34,09; (1'09).

CLIFTON, 634, IROQUOIS

LEBET, FLAVIU $\left(b^{\prime} 77\right) \oplus-$ Que.3,'02 ; (1'04).

STEYENS, NATHANIEL T. (b'63)€- 
CLINTON. 5,165, DEWITT

BABCOCK, MILTOS J. (b'3)-Il]4,06: (l'06).

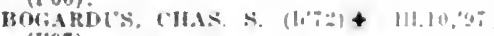
(I'97)

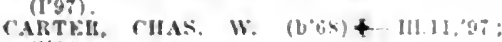
A

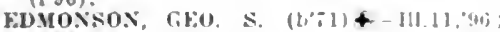
$(1 \circ 96)$.

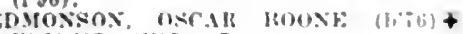

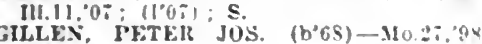
ILLEN.

GRAHAM, SAML. I. (b'\$5) $+-111.1,9$ $(1,8 \div)$.

MYERS, JOS. CIIAS, (1) 58$)+-0.9,80$ : (list).

PRICE, HARMOE ELLSWOETH (b: $02.05: 1105)$; 6 .

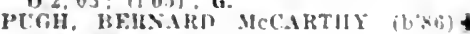

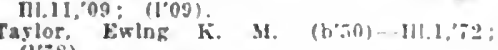
TI0

$\left.(1)^{\circ} 83\right):$ OALR.

WII, COX, JOHE M. (h'th)-111,6,79; (1'69) S.

CLYDE (CICERO P. O.), 500, COOK

Yord, Franels $C$.

(See (hlcago.)

Motls, Marle A. (b's1)-111.28,07, 111 11, 1: (l'0i)

COAL CITY, 2,667, GRUNDY

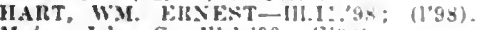

Major, John C.-111.1,00; (]'oul.

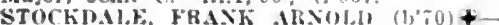

Neb. 203 : $\left(I^{\prime} 04\right)$.

COAL VALLEY, 190. ROCK ISLAND

MYEIS, WM. $F$, (b'bi) +-Ky, l, "Y2: (1'93)

COATSBURG, 262, ADAMS

Lamber, John IR. (b'68)-Ill.I,'s9, ''a.1,"40 (I'sy).

THIPL" CHFFORD INGIBAM (1): Colo.5, 10; (1'11).

COBDEN. 988, UNION

Blanchard, John A. (b'53) F-0.2,75; (103)

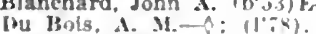

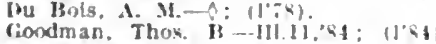

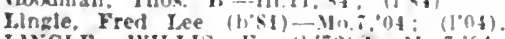

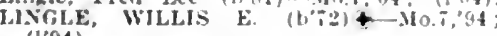
(1'94).

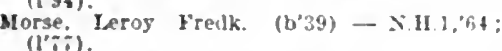

COFFEEN, 980, MONTGOMERY

BARRI, FHEHK. W. (b', G) $+-110.2,02$;

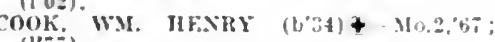
$(1,7)$.

Hendrix, John T.-Ia.1, $\% 8:(1 \% 8)$

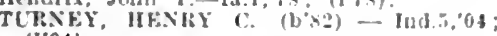
(I'04).

COLCHESTER, I.445. MCDONOUGH

HARRISUN, IBIICE, ASIITUN $\left(\mathrm{b}^{\prime} 86^{3}\right)+$ III. J1, $09:$ (1'09).

RETH, OLIVEl JAY (b'67) - Ia.9,'91 (1'9\%) : ODA.

Slookey, Pespasian (ti.5)-Ia.1,82; (1985)

COLETA, 300, WHITESIDE

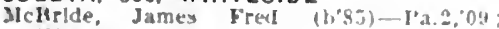
(l'09).

COLFAX, 965, MCLEAN

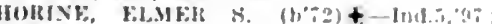
(1'9i).

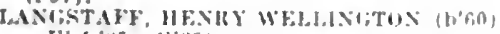
- III.4, $x:$; 11,$8 ; 1)$

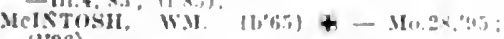
$\left(10^{\circ} 9\right)^{\circ}$.

SU1.T'T\%, TIIAS (h'bf)- [1] 1,00: (1'00)

COLLINSVILLE, 7.478. MADISON

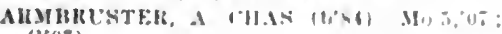
$(1,0 \%)$

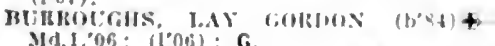

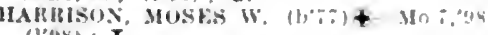
$(1,9 \times): T$.

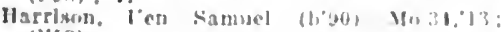
(1'13).

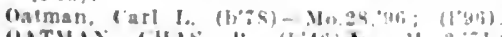

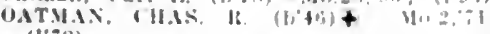
$(1 ; \%)$.

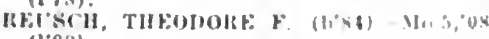

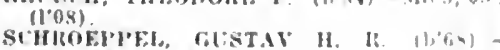
M(1).8.92:-11'02).

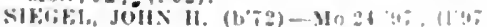

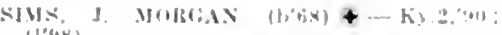

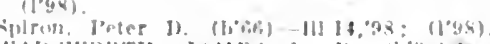

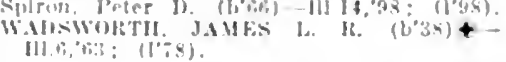

COLLISON, I50, VERMILION

"amplull, Jus. Houard (b":;) -111.11,02: (1) $D=1$

COLONA. 217, HENRY

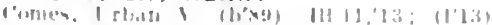

COLUMBIA, 2.076, MONROE

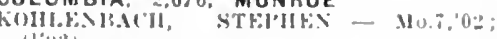

(1) $1,-3)$.

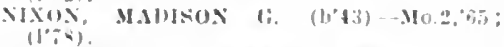

KrSt, WM. J. (b'74)+-110,296; $(1290)$

COLUMBUS, 134, ADAMS

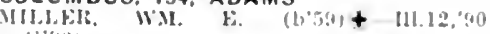

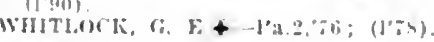

COMPTON. 387. LEE

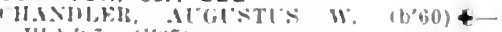

III. $\rightarrow=$ (lox

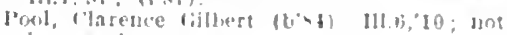
In practice.

CONCORD. 160, MORGAN

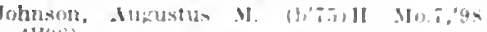
(1'48).

COOKSVILLE. 332, MCLEAN

Mahon, Wilson H. (LO, E-MO.10,80;

(I'DI)

06: (1.06).

COOPERSTOWN, 200, BROWN

snyder, James k'lwin I1!.2.2,"): : (1'1:

CORA, IOO, JACKSON

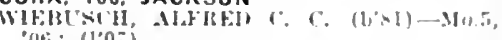

ofi ; $\left(10^{\circ}\right)$.

CORDOVA, 324, ROCK ISLAND

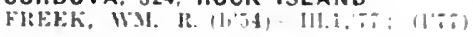

CORINTH (R.F.D. THOMPSONVILLE), I0I,

\section{WILLIAMSON}

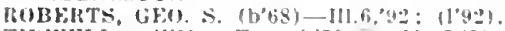

TIIWELL, IIS. T. (b'79) + $110.5,01$; (I'02).

CORNELL, 536, LIVINGSTON

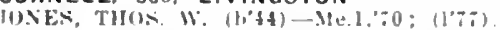

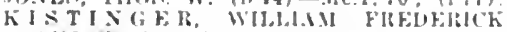
(b.8)+-111.11,11: (1/1).

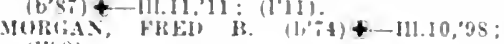

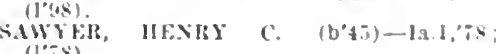
$(1,2 x)$.

COTTONWOOD (R.F.D., OMAHA), 150 ,

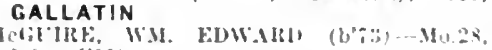

"99:; (1'99).

COULTERVILLE, 9\$7. RANDOLPH

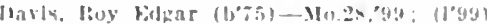

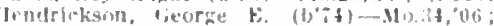

$(100+1)$

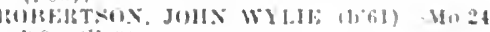

(A?): (1'm!y)

COWDEN, ZII, SHELBY

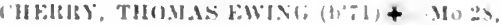

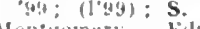

Ionfiromery bilna lougluery $(b 0<0)$ -

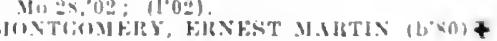

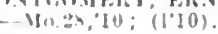

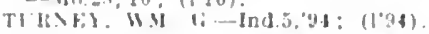

CHAI3 ORCHARD. 200, WILLIAMSON

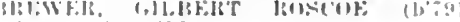

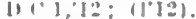

CAEAL SPRINGS, 936, WILLIAMSON

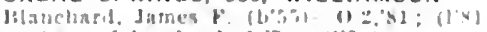

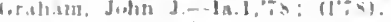

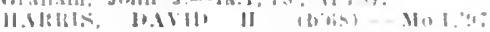

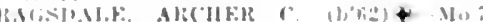

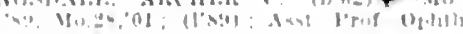
I1, $111 \mathrm{~s}$

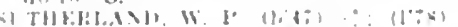

CHESCENT CITY, 3H. IROQUOIS

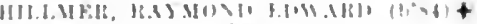

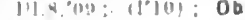

MHari, libin D, Hin,

CRESTON, 323, OGLE

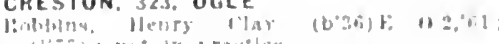

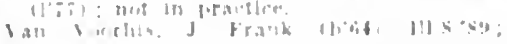

CRETE, 840. WILL

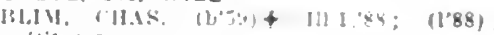

isienger

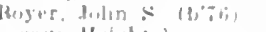

dengler.

(1.20).

CROPSEY, 250, MCLEAN

"ANTHF, IIEILUSFIRT

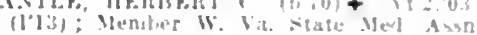

CROSSVILLE, 5\%4, WHITE

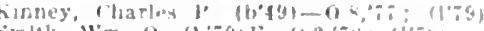

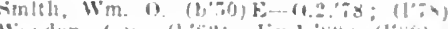

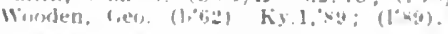

CUBA, 2,019, FULTON

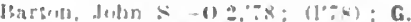

Huan, hate k. Armotrong-1'a.i, 06 ; $\left(1^{\circ} 0-\right)$ not in practlce.

Markland. Wm. I'. (b'33) $\rightarrow\left(1^{\prime}, x\right)$

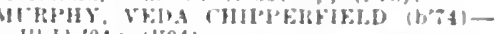
III.11,04: (1"04).

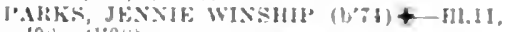

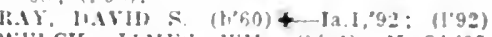

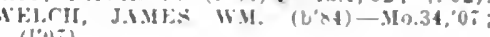
$\left(l^{\circ} \mathrm{U}_{i}\right)$

CULLOM, 900, LIVINGSTON

leuklna, Ins, 1. (b) 56$)-I I-I 11.10,99:\left(I^{\prime} 49\right)$

l'KHEI.EL, HIRAM M. (b'5)+-0.2,94 (1) in th

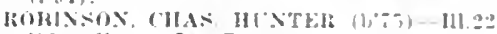
"I0: (1'10): OALR.

CURRAN, 123, SANGAMON

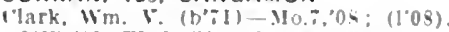

'OWDI. FREIELICK I'TXIU. (sice sprlnafleld.)

CUSTER, IIO, SANGAMON

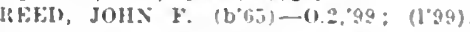

CUTLER, 324, PERRY

SMITH, JAMES W. $\left(6^{\circ} 54\right)+-M 0.1,81$

CYPRESS, 311, JOHNSON

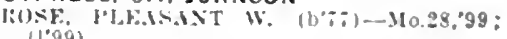
(1099).

mith. Frank S- Ky.1.22: (I.9?).

DAHINDA, 250, KNOX

BEIYOIBJ, IRIIIJARL J. (b'-0)-IHI, L": $\left.(1 \cdot 3)^{\prime}\right)$.

DAHLGREN, 654, HAMILTON

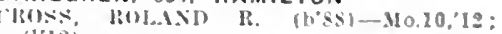
$(1,12)$.

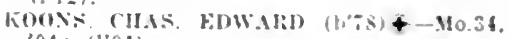
of: (lol).

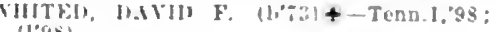
(logs).

DAKOTA, 250. STEPHENSON

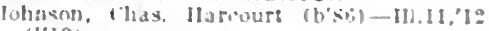
(1'13).

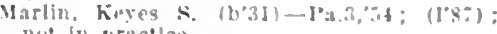
IIut in fractlee.

DALE, 26, HAMILTON

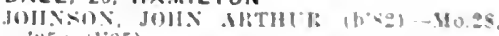
U5: 11005$)$.

DALLAS CITY, 1,288, HANCOCK

Patlersin, Wh. Madloun (l)

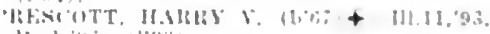

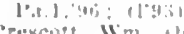

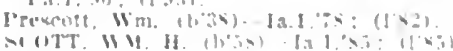

DALTON CITY, 500, MOULTRIE

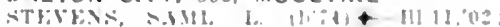
(1.0:-1)

Wll

DANA. 300, LASALLE

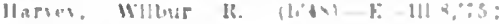

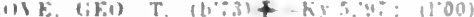

DANFORTH, H09, IROQUOIS

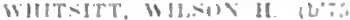

$11 ! 1.01$

DANVERS. 700, MELEAN

(IS: WII AlIUUIISMITII $\left(\mathrm{L}^{\prime}: 0\right)+-$

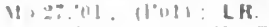

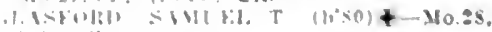

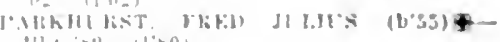

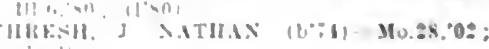


DANVILLE, 27.87I, VERMILION

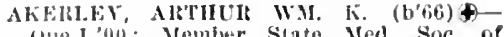
(vic.1, Natlonal llome llospital.

A ruckle, Alphonso Taft (1,54)-111.1,'86: rbuckle, Alphonso Taft (b)

BABCock, HENHY STKANAHAN (b'69)f Mleh.1,yI ; (1,y1); $110 \div$ Hobinson St. onice, Temple Bidg.; 10-12, 1-3, 7-8; $\mathbf{S}$

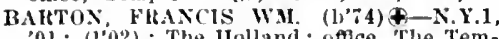
01 ; (1 02$)$; The IIolland; offec, The Temple $11-1: 3-4: 30 ; S$

BAUMGAIDT, FIEEK. AUGUST (bois) $\oplus$ -111.11,04; (1'04); 859 k. Main St.; oftce. Batm B]d : 11-12, 2-4, 7-8.

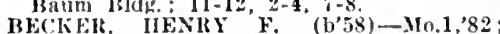
(1'97): The IIolland; oftlee, The Temple 1]-12, 2-4, 7-8; Anes.

Blrd, John C. (b'69)-Mo.20,00; National Home.

Brandt, Ernest II. (b'68)-Ill.16,'05; (I'12) 34 line st.; oftce, Baum Bldg.; 10-12,

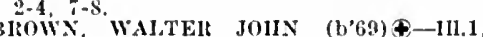
$91 ;(191) ; 331 / 2 \mathrm{~N}$. Vermilion St. ; $10: 30-$

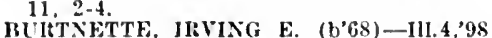
(1'98); 519 W. Madison St.; offlce, Danlels Bldy.

CASS, GFO. THAYER (b'i1)-I11.22,07; (I'07): 109 Vermilion St.; $10-12,2-4,7-9$ Chaffee." Johı A. (b'68)-Ind.s,'97; (l'02); $705 \mathrm{w}$. Falrchild St.

CLALK, ELBEIT E. (b'66)థ-0.1,'92 (I'94); 115 lilbert St.; office, The Tem ple: $9-12,2-5 ; 0 A L R . \star$

CLEMENTS, ROBT. (b't)-111.6, $05 ;\left(1{ }^{\prime} 05\right)$ 935 Walnut St.; office, 101 E. Main St. $10-12,2-4,7-8$.

CINCI, JOHN HOUSTOUN M. (b'62) $\oplus$ Ore.2,96; $\left(l^{\prime} 97\right) ; 439$ Franklin St.; offce Adams Bldg.; 10-12, 2-4, $7-8$; Pd.

cline, Corles Belford (b'72)-0.2,97: (1'97) 15 W. Madlson St.; offlee, 114 E. IIain St. Cochran, WM. A. (b'50)-0.1,73; (l'83) ; Nitlonal flome.

COOLEX, ELMFR BURT (b'Gi) क-III.1, 89 (1'89); 112 Pine St.; offee, The Temple, $10-12: 30-2-4: 30$

CRIST, 0TTO H. (b'78)Ф-Ill.6,'06; (l'06) 1302 E. Maln St.; oftice, 2009 E. Main St. : $10-12,1-3,7-8$.

DAIE, A. ERNEST (b'81) $9-111.60^{\prime} 07$ $\left(l^{\prime} 0 \%\right) ; 014$ s. Vermilion St.; oflice, Temple Bldg. ; $10-12,1-4,7-8 ; \mathrm{S}$.

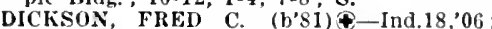
$(1,06) ; 505 \mathrm{~N}$. Vermilion St.; offlee, $221 / 2$ W. North St.; 10-12, 1-3, 7-8; U.* Dlxon, Wm. C.-No.24,95; (l'95); s07 Fairchild st.; office, 16 F. Main st.

Dowxs, HENTY B. (b'59)-.110.7,98:(1'98) 222 Logan Ave, ; offlce, 130 . Vermilion St.: $U$.

DOWXS, MAGGIE YELTON(b'67)-Ia.9,'93 (193); 222 N. Logan Are.; office, 130 \% Vermilion St.; 10-12, 2-5.

Edens, Geo. (b'51) 1I-IIl.4,79; (I'79) ; 203 N. Jackson St.: $5-9,12-2,6-\pi$,

EVANS, CHAS. I1. (1, 75$)-111.17,05 ;\left(1{ }^{\prime} 05\right)$ $11 \%$ 1/2 E. Main St.; 10-12, 2-4, T:30-9.

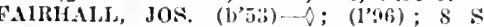
Gilbert St. ; office, 1. 0 . O. F. IIdg.

FAIRHALL, LEO V. (b'so) - III.11,'06 (1'06); 1101 Logan ire. ; oftlee, 1. 0. O. F BIdg. ; $10-12$, $1: 30-4,7-8$.

Falls, Chas. W. (b'60)-Ill.11,'85; (1's5) $610 \mathrm{~N}$. Ilazel st.; office, Temple Bldg. $9-11,2-4,6: 30-7: 30$

FISHEI, JACOB G. (b'55)-III.1,'01; (1'01) $405 \mathrm{~W}$. Harrison St.; oftice, Baum B!dr. $11-12,1-4 ; \mathrm{Pd}$

FRENCI, TRUMAN P. (b'51) - Ind.4,'is (1'is); 1203 Sherman Blid.; office, 11: F. Vermilion Si.; 8-11, 2-4, 7-8; G.

GERETY, wa. FRANCIS (b's3)-ill.11.'0s (l'os); 12. Payne Are.; oflce, $219 \mathrm{~W}$ Harrison $\mathrm{St}$.

GIEESON, BEXJ. (b’T) - - III.1,02; (1'02) 1006 N.' Walnut st.; office, Temple bldg.; 9-12, 2-5; (B1); OALR.

GLIDDLF, AN.YL 1VES-Mich.1,94; not GIIDINEN. STEPHEN C. (b'r0)-Mich.1. '94, (1'94); $422 \mathrm{~N}$. Yermilion St.; office, Temple Bldg.; $1: 30-4: 30,7-8 ; \mathrm{S}$

GLY, J011: H1LTOX (b'60)-111.1,'86; Daniels Blde. ; $11-12,1: 30-4$
IIarper, Cieo. MeC.-Ind.8,97; (1'97); $151 / 2$ Normilion St.

II'AFILI), It.1YMOND L. (b'79) --III.10, 03: (1'03) : 424 N. Walnut St.; oflce,

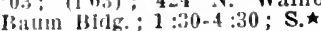

Inwles, Chas. j. K. (b't2) II-Ill.10,84; (1's6) : 321 N. Vermillon St.; offlce, Mling. ; 8-10, 1-3, i-8.

HOFFMAN, CHARLAS JATILK (b'75)O.9.96; (1960); 1106 Cliandler st.;

Ilole Melvin I,eo (b'88)-11.6,'11; (l'11); 423 N. Ilazel St.; ottce, The Temple: $4: 30-12: 30,4-6: 30,7-8$.

HOOKER, IIE.TR $\mathrm{x}$ FROST $\left(b^{\prime} 81\right) \oplus-111.6$, 08: (I'08); 317 Franklln St.; office, Baum Bldg. : 10-12, 2-4, $7-8$; S.

IIOWARD, MOIHDLAI I. (b6i)-0.13,91; $(1.91) ; 10$

HL YOLFY, JAMES B. (b'80)\&-J11.11,04: (1'04): 16 N. Main St.; office, Temple Blelg. ; $10-11,2-4,7-8$.

Jacolis, Geo. Clinton (b'80)-111.22,08; (l'0s) ; $1133 \mathrm{~N}$. Walnut St. ; offlce, $156 \mathrm{~N}$. Vermilion St. ; $10-12,2-4,7-8$;

JONES, SOLOION (b'72) $\oplus$ - Ill.17, 02 ; (1'02) ; $604 \mathrm{~S}$. Buehanan St. ; offlce, The Temple; $10-12,1-3$.

JoNEs, STEPHEN W. (b'51)-0.1, 78 ; $\left(I^{\prime} 78\right) ; 409$ N. Vermllion St.; office, Baum lBIdg. ; $10-12,1-5$.

I.ANDALFR, SEWARD L. $\left(b^{\prime} / 6\right) \oplus-111.1$, 01 ; (1'01) ; 9 W. Madison St. ; office, The Temple; $10-12,2-4$

LENHART, cHAS. WM. (b'72)-Ky.2,'11; (1'12); $101 / 2$ N. Vermilion St.; 10-12, $1: 30-3: 30$.

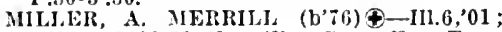
(1'01); $1222 \mathrm{~N}$. Yernill on St. ; offlee, Temple Bldg. ; $1: 30-4 ; \mathrm{S}$.

o'Ferrall, Itobt. L. (h'61)-111.1,'85; (l'89); 318 Gilbert st.; office, I. O. O. F. BIdg. ; $9-11,1-4: 30$

O'IIA YER, JOHN W. (b'49)-0.8,'82 ; (1'82) $458 \mathrm{~N}$. Jackson St. ; office, $116 \mathrm{E}$. Williams St. ; $7-8,1-4,7-8 ; \mathrm{G}$.

PFItIIGO, FRED A. (b'6 $\left(1^{\prime} 98\right) ; 415 \mathrm{~N}$. Hazel St.; offlce, Daniels BIdg. $1-4$; S.`

POLAND, BENJ. I. (b'54)-Ga.5,'95; (l'83)
RATIBLN. JA.IES CORBETT (b'81)-I1l.8, 09; (1'09) ; 1100 Logan Are.; offlee, Tenple 'Bliler. ; 2-4; G

REACAN, THEODORE (b'65) - I11.1,'93; (l'93); 814 walnut St. ; office, Baum Fidg.

Redmond, T'leo. IB. (b'46)-Ind.4,75; (1'83) 126 Warr!ngton Ave.; offlee, $2 d$ and Varrington Are. : $7-9,1-2,5-8$.

Ross, Iliram Earl (b'88)-I1l.6,'11; (1'11) 409 Chandler St.; office, Daniels Bldg. $2-4,7-8$.

SATTERIEE, ALBERT ROBINSON (b'67) क) $2-4,7-8$

SCOTT, IRA JOS. (b’て2)-Ky.4,01; (l'09); s.6 F. Fairchid st. ; $7-9,1-3,7-8 ;$ OALR. STEELY, GEO. (b'70)-Mass.6, 05; (1'05) 801 N. Vermilion St. ; office, The Temple 11-12, $2: 30-4 ; \mathrm{S}$.

TENNERY, WILLET R. (b'72) $\odot-0.19,05$; (1’05); 7 Inlmois Ave.; 11-12, 1-3, $7-8$.

Vogt, A. Wm. (b'56)-Mo.1,'84; (1'85); 116 Gakwood Ave.

WAITON, THOS. E. (b'62)\&-Ky.1,'89; (l'89); $317 \mathrm{~N}$. Walnut St.; offee, Baum Weaver, Archibald Carlton (b'86)-0.6,'11 ; National llome.

Webb, Wm. J. (b’59)-0.14,'84; (l'85); 306 W. Nortl St.; office, Odd Fellows Bldg. : $9: 30-11: 30,1: 30-4$

Wendle, Floyd G. (b'82)--Ill.10,'04; (1'06).

WILKINSON, CHAS. E. (b'69) 8-Pa.1,95; (1'95); 1611 N. Vermilion St.; offle, Temple Bldgr.; 11-12, 2-4; ObG.

Williams, lames Robt. (b'58) - Ind.8, 85 ; $\left(l^{\prime} 96\right) ; 1026$ Walnut St.; office, $1021 / 2 \mathrm{~W}$. Irain St. ; 9-12, 2-5, 7-8.

WILLIAISON, GEO. L. (b'63)-Mo.1,93 (I'93); $521 \mathrm{~N}$. Vermilion St. ; office, Temple Bldg.; $1-4 ;$ S. *

WILLIAMSON, JAMES II. (b'72)(-Mo.1, 98; (1'98); 1 Virginia Ave.; offee, Temple Bldg. ; $10-12,2-5$.

WINSLOW, EDWIN L. (b'65)-0.12,'92 (197); 507 Warrington Ave.; office, Baum

\section{AVIS, 484, STEPHENSON}

WILSON, ABRAHAM ASHLEY $(1,70) \oplus$ I11.6,'94; (1'94).

DAWSON, 574, SANGAMON

MAYES, WAHL GAITILLD (b'85)-Mo.2, 04; (l'04); ObG.

\section{DECATUR, 31,140 , MACON}

Adams, Fred. Mlllard (b'73)-Ill.6,'01; $(1+)$; Decatur IIotel.

ANDERSON, FRANK M. (b'60) $9-0.1,82$; $(1,99) ; 616$ W. Whlliams St. ; office, Powers BIdg. ; $10-12,2-4$.

Bachmann, Arthur Simon (b'84)-Ill.11,'07; $\left(1^{\prime} 07\right) ; 967 \mathrm{~N}$. Morgan St. ; 2-6.

BACHRACH, BENJ. (b'78)-Pa.2,02 ; (l'03) ; 731 W. North St. ; office, Bachrach Bldg.; $10-12,2-5 ; U$. Ball, John Wm. (b'79)-Mo.28,'02; (l'02) ;
1512 N. Water St.

BARNES, LYNN MOORE (b'73) $€$-Mass.1, Title and Trust Bldg.; 10-12, 2-5.

BARNES, WM. (b'60) 9-Mass.1,'87; (1'89) ; 500 W. Main St.; office, 152 E.' Pralrlé St. ; $2-3 ;$ S.*

BELI, WI. H. (b'72) (-Ill.1,93; (l'93) ;

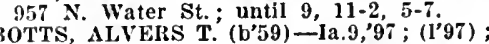

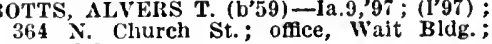
$8-5, \quad \vec{i}-8$

BOURNE, NATHAN L. (b'73) 9-Mo.28,03; (1'03); 904 W. Decatur St. ; offlce, Title and Trust Bldg. ; 10-12, 2-5; OALR. *

Bridgman, Danl. Addison (b'32) - N.H.1,'66 ;

$\left(l^{\prime} 77\right)$; not in practice; $1107 \mathrm{~W}$. Water St.

BROWN, EVERETT J. (b'65) @-Ill.6,'88; (1'89); 600 Powers Lane; offlce, 134 W. Prairié Are.; 10-12, 2-4.

BUFFINGTON, CLINTON G. (b'59) -Mo-1, '81; (I'83); 601 W. Williams St.; office, Powers Block; 8-11, 2-5.

Powers Block; ('-11, 2-5. 385 Central Ave. ; office, 137 N. Water St. ; $9-11,2-4,7-8$.

BUSTER, HARRY CRYDLON (col.) (b'81) -Ill.6,'10; (1'10); 318 S. Broadway; offlee, Powers Bldg.; 10-12, 2-4.

Buxton, Thos. Chas. (b'75) - Mo.7,04; Powers BIdg. ; 9-12, 2-5.

CHANDLER, HARRIET MARCH DAY (b'69) -IlI.11,02; (1'02); 233 S. Edward St.; offce, Walt Bldg. ; 2-5.

Chenoweth. Albert (b'48)-111.1,72; (1'77) CHENOWETH, CASSIDY (b'48) @-IIl. 1,69 ; (1'7t); 540 N. Edward St.;

CHENOWETH, WM. J., JR. (b'71) ९-0.1, '96; (l'96); 427 w. Whlliam St.; office, 129 E. William St. ; 11-12, 1-4, 7-8.

Childs. Chas. F.-Ky.1,'92; (1'92); $135 \mathrm{~N}$.

Main St.
CLARK, LEWIS H.-0.2,68; $\left(1^{\prime} ; 8\right) ; 555 \mathrm{WV}$. North St.; offlee, Walt Bldg.; 10-12, 2-4. CUSSINS, JAMES S. C. (b'5i)-IIl.1,77; (1'77); 464 W. Decatur:

DIXON, WII AI.LEN (b'65) - Ky.1,92, Ill.17,'95; (l'92); 1586 N. Water St.; of fice, Walt Bldg.; $8: 30-11: 30,1: 30-4: 30$.

DREW, ALBERT M. (b'49)-0.9,73; (1'77) 1428 N. Main St.; offlee, $139 \mathrm{~N}$. Water St.

DUDLEY, FREDK. J. (b'58) \$-I1l.10,94; (1'94); 1795 N. Churc

Eberly Kar! Coulson (b'87)-Mich.1,12 (l'13); 451 w. Marion St.; offece, 134 W. (l'13); 451 W. Marion

FISHER, JAIIES C. (b'58)-IIl.1,89; (1'89); 612 W. Macon St.; office, Title \& Trust Blag.: OALR.

FITZPATRICK, MARTIN WM. (b'74) Ill.1, 03; (I'03) ; 418 E. Eldorado

Foster, Alva Curtis (b'4i) - Mo.7,82; (l'82); 961 N. Union St.; office, Walt Bldg. ; 9-12, 1-5.

GARBER, CIAARA ALICE (b'72)-Ill.4,02; (1'02) ; 1164 W. North St. ; offlce, Powers Block; $9-12,2-5$.

GRINES, EILEN F. TAFT $\left(b^{*} 48\right)($-Pa.7. '76; $(1 ; 9)$; Wait Bldg. ; 10-11:30, 1-6; G.* Heffernan, Irichael Thos. (b'71)-Tll.1,01; (l'01) ; 1377 N. Main St. ; office, $1021 \mathrm{E}$. William St.; 10-12, 2-5. 
Hell, Henty 16-111.1'8: $(1987) ; 712$ b Decatur st. oflce, $836 \mathrm{~N}$ Water si

HLDHETH, CHAS, EUWAHD $\left(\mathrm{C}^{2}+1\right)+$ Tenn.1.09: 11'09); slso Mlenter sitate Yled. Soc of Wls; Walt lide; : S.

Hiillgoss, Erasmus J". (b'53)-Mo.1\%s $(1 \% 8) ; 893 \mathrm{~W}$. Wood St. : oftece, $102 \mathrm{k}$ Main St. : 8-12, 3.5

JACK, CECIL MCKEF $\left(b^{*}, 6\right)+$ Mich I, 0 ? (100) 45I W Macon St. oalce, 134 it Iralrle Are: : $10.12,2.4$

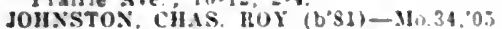
(1'05): 216 livision St.; odlce, Tille A (1205) 216 Division

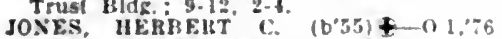
(l'sl): 421 W. Maln st. : otlce, Tlile Trust Bldg: 9-11, 2-1; $0 \mathrm{~b}$.

Kennedy, Clyde IP. (b'56)-0.1.80; (1'88) loss S. llilnols St; oalce. Title \& Trus Bldg. : $10-12,3.5$

Kibble. Hamilton (arlos (b'45)-Mich.1 $66:(1 \circ 7)$ : 156 Merchant St

Lauerman, Archibald Wm. (b85)-I11.1.'12 (1'12): Wabash IRallroad Employes" Hos. plial.

Lee, Levl M.-Ky.2,'I: (1'7\%) : nut In practice: $1615 \mathrm{~N}$. Water st.

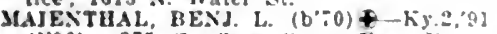
(1'96): 375 s. Crea st. odice. Howers BIdz: : 10-12, :-4

Mccarty, Chas Ellas (b's:)-III.11,03: (1'03): $217 \mathrm{~S}$. Water St.

McCl.ELLAND, ChafRECE F. $\left(b^{\circ} \times 3\right)+$ III.6.07; (1'05) : $\$ 50$ W. North St. : onice. Hilikikln Bank Hide: 9-12 -5: ÓALR.

JCCLEILAND, SILAS E. $\$-111.1$. W (184): 904 w. WHllam St. oftlce. Millt kin liank Bldg: : 9-12, $2-5$; OALR.

MClAVID JESSE TAYLOR (b'i) + Mo.28, 04 : (1'04): 35.5 W'

sclean Chambers A. (b'32) - - o.i (1\%8): 221 Central Are.; oflce, $215 \mathrm{Cen}$ tral Are.

MERISEATUER, TYLFR (bi5)-1'a.2,99; (1'99): 547 s. Webster st.; oflce, Powers (1'99) : 547 s. W'ebstel

MLLER, JOII T. (b'a) †-S.C.J.96 (1"96); 853 W. Wood St.; oftice, l'osers Bldg.: 9-12, 2-4: S.

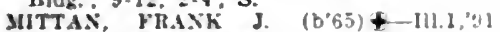
(1091); $119 \times$. Edward St. ; onlce, l'users Bldg.: $9-11,2-5$

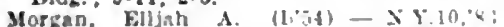
(I'83); not In practlce; 521 $x$ Main si.

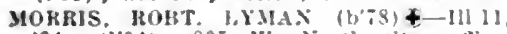
04: (1'04): S05 W. Sitrell sh.: othice, Powers Hide.: 10-12, 2-4: U.

MYER, NOAII D, (b'43)-0.1,72; (1':) $1831 \times$ church st.; offce, Wait $\mathbf{k l d g}$ $9.12,2-5, \quad i=9$

PARRISH, MHLVIX P. (b.6) + 111.,95: $(196): 121 \times$. College St.; orlce, l'uners Bidg, $1-5:$ S

Pasley, Birckner H. (b:38)-0.3,65; not in practice: 147: 16. Macon St.

POLLOCK, MILTUN I) WIT (b't3) +

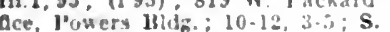

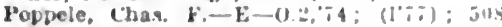
W. Vurth sit.

Poupele, Oubri A- - $111.15,01 ;(101)$ : sijs W. North si

RANDALL, JOHN $\times\left(b^{\prime}+n\right)+-1 / a$ as 1 , di" (107): 860 11: Willams ste; inlce, is a:? Hug. : $9-12$.

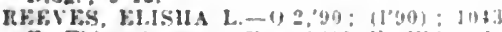

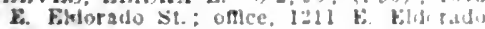
St. $10.1 \pm 1: 30: 3: 30$

Rowdrbush, itunsey tranklln $(1,22)$ - Ilf it

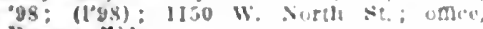
powers loly.

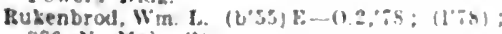
$320 x$. Maln st.

RLSSFL.I, BH:

Russell, Minnlo A

zens liank Hlals.

Byan, wm Joland

Fentun litinck.

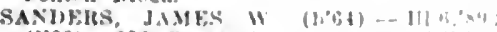

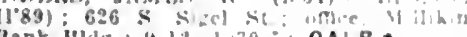
Ilank Hor : y-1: J 30 : : OALR.

SANDERS, MOHT \%INK (b'S III II!

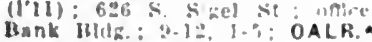

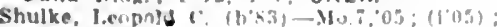
1721 k. Shangamou se

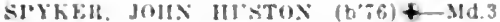

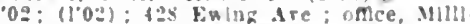

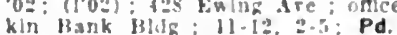

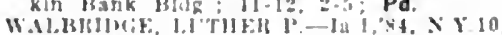

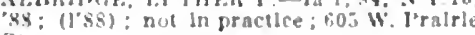

Walston, Hobt. I. (b'5i)-I11.1,66: (17ii) $422 \times$ Main st

West. Chas F. (b)', 1) ll-111.10.98; (1'38)

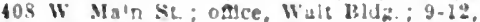
2-4: OALR.

Wesl, (ieo. W.-F,-0.2,89; (1'83) : Park 1!! : onlee, Bachrach Blat:

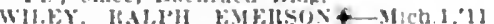

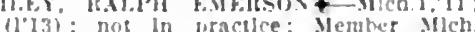
stute Med. Sinc; 1078 F. kildorado st.

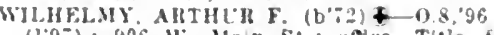
$(197)$; 906 W Man St: oftce, Title \& Trusi HId : 10.12, $2-4, i-8$,

Wisehart, I) Smbll-0.1,79: (179); 1032 F. Eldorado St. nflice, 111 in E. Eldotado wOOT, CHAS MARTIX $\left(b^{\prime}, 5\right)+-M i c h .1$, 99: (1'99); 432 s. Union st.; Ance, .111likin Bank Bldg.: $10.12,2.5: \mathrm{Pd}$.

wond. Howard it (b', s) H-Tenn.5.'se (1'89): $1406 \times$ Edward st.: office, 120 $\$$ Water St. $10-12=-1.7-8$

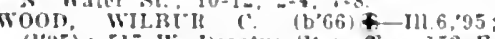
(1'45): $51 \%$ W. lecatur St: oflce, $132 \mathrm{E}$ Pralrle Are : 11-12:-4:S

WOODWAIL, ChatTON E. (b's3) + HIL 06: (1.06); $950 \mathrm{X}$. Water St.; 10-12, $2-5$

YARELI, OSCAR (b"is) †-Mo Ma Trust Hlds, 9-12,2-5; OALR.

rockey lim. M. (b'68)-Ill.1, 91 : (l'95) $1+45$. Water St: ontce, 5t0 $\mathrm{E}$. Hildorado $S t$

DEER CREEK, 298, TAZEWELL

('HAMMAN, CAMI'BELL Me'G. (6'68)--III. I

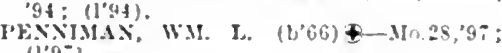
(1'9\%).

DEERFIELD, 400, LAKE

DAVIS, CIIAS. JOIISTOS $\left(b^{\prime}, t\right) \mp-I 11.1$, 02; (I0:3).

Knaak, Theo. I. (b'\$3) II-IH.4, \&:; (1'83).

DE KALB, 8,102, DE KALB

ANDERSOS, STODLAI:D L. $\left(\mathrm{b}^{\prime}, 5\right) \mp-I 1 ! \mathrm{L}$, $96:(1,96)$

ADGI.EY, JUYI ANTIIONI (b.53) -

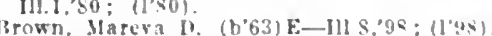

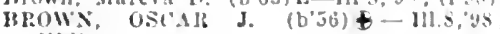
$(1,38)$

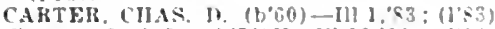
("henes, Carl l. (bot) II - I11.10,02: (1'02)

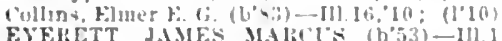
E)

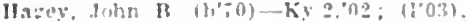
JOHNSUN, THOMAS AlTIICL" (bos) IIIII!: U1!I]; S.

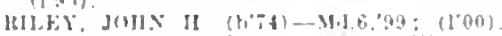

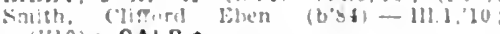
(1'10); OALR.

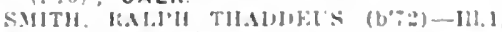

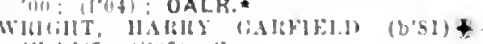

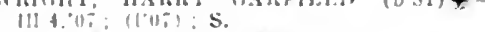

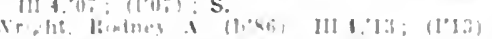
DE LAND, 5N3, PIATT

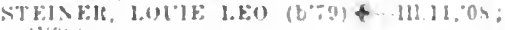

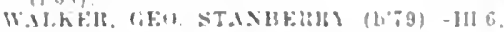

DELAVAN, 1,173, TAZEWELL

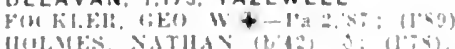

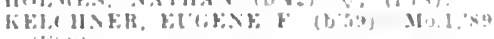

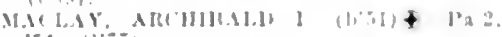
Mition

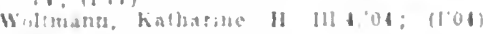

DENVER, 200, HANCOCK

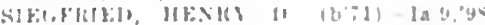
(I':AM).

DEPUE. 1.339, BUREAU

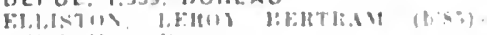

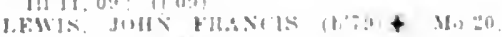

DE SOTO. 644, JACKSON

IIUL:SL, UST AIS $(2 \%, \mathrm{O})+-1$

DES PLAINES, 2,348, COOK

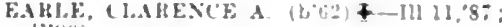

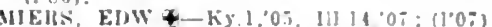

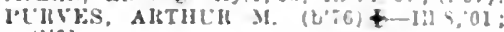
(1.01).

DEWEY, I50, CHAMPAIGN

WONOYAS, SAMI. D. (U'S3)-M, :05 (1,0:3).

DEWITT, 300, DEWITT

llonker, Henty K. (b':5)-[11.10,03: (1'03)

DEWMAINE, 900. WILLIAMSON

SPISIXIS. ANIUREW WILTON (COL) (b'69) - II!. I1,05: (1.0\%)

DIETERICH, 493. EFFINGHAM

claf: Jah Clinton (b'36)-Ia.l.'95; (1'96). Munn. Jutn lvm. (bs)-Mo.34.03: (1,05). II! N. THOS. J (b't5)-I11, s1; (1'83).

KERSIISER, JOS. L. (b'5S)-Mo.2:,92:

DISCO, 100, HANCOCK

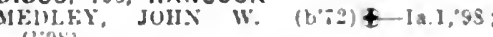
(I.98).

DIVERNON, 1.519, SANGAMON

Juhnson, Simeon Il. $\left(b^{\prime \prime}+1\right)$ - III.11."9S

Mathew, Ererltt S. (b'62)-Mo.:,85; (1'85).

DIX, 200, JEFFERSON

CLARK, THONAS ALLEX $\left(\mathrm{b}^{\circ} ; 4\right)-M O .31$ '04: $(1,07): 0 \mathrm{O}$.

DIXON, 7.216, LEE

lalrd. Hobt. Is. (b'St)-JIL.t, 08 ; 1108

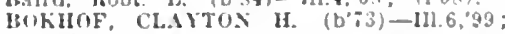
( 1.93$)$

Frizelle, Clifonn H. (1,6s)-Ia $1.89 ;\left(1{ }^{\prime} 64\right)$

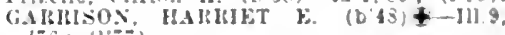
Grees, saml. II (b'42)-Ky. 2.89 : (l'90). IVE. CLISTOX II. (b66) + - III.6, (1':4).

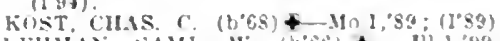

I.HMAX, SAML. W. (6.66)

I.ESACE, CIIAS. A. E (b'72) $4-111.6,97$ (1'G): (B)E); OALR.

MOORE, AMO FOSTER $\left(\mathrm{b}^{6} 6 \mathrm{6}\right)+-310.27$

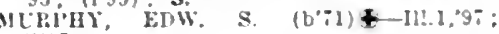

(1)ES:, EDMLND B. (b65) - II1.6, 90 : Il'40). WM. R (b'69) - IH11.01:

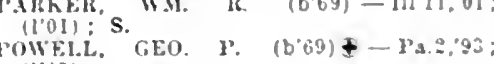

$(1,45)$.

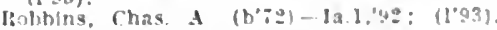

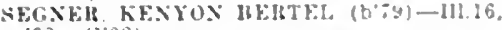
'0?: (1'08).

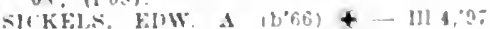
$(1+a): S$.

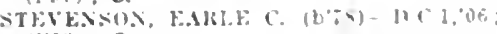
(1'13): $\mathrm{S}$.

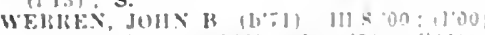

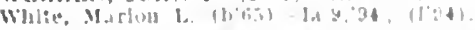

DOLSON IR F.D. MARSHALL), 79. CLARK MAII.0W, JUIIN W. (b'39) - Uich I,:-: (1:83).

DOLTON, 1.869, COOK

Thomven, (arl II-1116.,00: 1100)

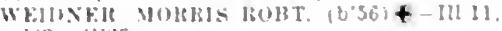
DONGOLA, TOZ, UNION

lusbroma. fien W--4) 10.53: (1.83)

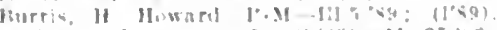

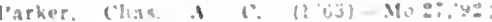

DONNELLSON, 10S, MONTGOMERY

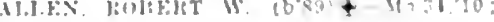

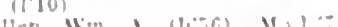

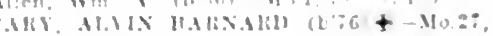

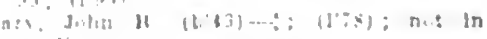
DONOVAN. 450 , IROQUOIS

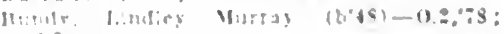

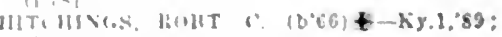
(1. a) 
DORCHESTER, 102, MACOUPIN

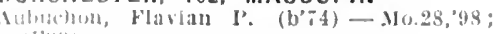

DORRISVILLE, 1,184, SALINE

liarger, kpliralm $\rightarrow$ (b'te) - Mo.27, Mcrormack, Iooney (1'65)-Mo.7,,98; (1'95). DORSEY, 60, MADISON

KEITCINEL, FRE1). WM. (b71)-.110.27, ; (l'98)

DOWNERS GROVE, 2,60I, DUPAGE

I3L1313, WALTEK S. (b'74) +-111.11, (98: (l'os).

Bolilue, Jos. O. (h'62)-IIl. I:, ,00 : (1'02)

Chills. Colvin Burr (b'85)-Ill.6, 09 ; (1'09).

lllhe, (has. $11,-11-111.4,95 ;(1,95)$.

l.eech, Thos. F. (b'40)-1'a.2, $66 ;\left(1^{\prime} 98\right) ; \mathrm{S}$.

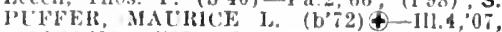
III.11,09; (l'07); Op.

DOWNS, 300, MCLEAN

WILIAMS, EDW. C. (b'74) $1-0 ;\left(l^{\prime} 99\right)$.

DUBOIS, 35I, WASHINGTON

NEUDECKER, LOUIS A. (1'65) \&-110.1,96. (1'36).

DUNDAS, 225, RICHLAND

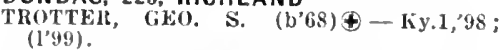

DUNDEE, 3,000, KANE

lBumstead, James E. (t, 48$)-111.6,80 ;(1 ' 80)$.

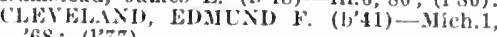
$68 ;(1,7 \%)$.

Diftinbaugh, Wm. Audrew-111.4,'12; (1'12)

Hlimun, Nibert W. (b'45)-111.10,'

KERCII, IIARRY E. (b'68)థ-111.10,'92; $(19-1)$

ETERSEN, IIEINRICH F. W. (b'54)‡-

ROI3FITS, WM. CLYDE (b'82)\&-Ill.4,06 ; $\left(I^{\prime} 0 \%\right)$.

\section{DUNLAP, 157, PEORIA}

Allen, Walter II. (b'60)-Mo.28,'97; (1'97).

SIMPSON, OTTO WALCOTT (b'76)-IIl,22,

Zook, Erle Will (b'73)-III.1,95; (1'95).

DUNNING (IND. STA., CHICAGO),

COOK

$$
\text { (See Chleago.) }
$$

Lisor, Graham McAllster (b'88)-Mo 28, '11; (1'12); Chicago state Hospital; NP.* Selwell, Harry Stephenson (b'85)-11l.11, '13; (l'13).

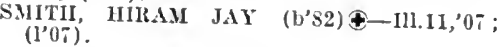

DUPO, 433, ST. CLAIR

('ooper, Nevadla $($. (1)'b8)-Mo.28,'02; (1'03)

ARXER, BARNEY JOS. (b'83)-Mo. 7,08 ; (l'0s) ; $S$.

DUQUOIN, 5,454, PERRY

ADLES, MAX (b'67) 4-Mo.1,'98; (1'99) Boeheim, Julius John (b'65)-30.27,'95; (1395)

BROOKINGS, CHAS. M. (b'68)-Mo.1,98; (l'ys)

BURCH, ELMER J. (b'64) †-Ia.1,'86 ; (1'86); G.

Carr, Martin C. (b'50)-Mo.1,'76; (1'12). DAGGETT, ARTIILR W. (b'79)-Mo.34, 08 ;
(l'08).

Dunn, D. Winton (b'52)-Mo.10,90 : (l'91). GILLIS, FRANK P. (b'54) 4 -N10.1,76

I,EIGII, JAHES T. (b'57)-MO.1,'82; (1'82)

1'OPE, ROLIAA D. (b'69) \&-D.C.1,'97; (1'98)

DURAND, 671, WINNEBAGO

IINS, FRANK J. (b'64) †-Ill.1,97; (1'97)

Roberts, Clas. A. (b'84)-Ill.22,09; (l'09).

DWIGHT, 2,156, LIVINGSTON

BARR, CYRUS H. (b'54)Ð-111.6,'82 ;

BROWN, FREDK. WILLIARD $\left(\mathrm{b}^{\prime} 81\right)-111.22$

'11; (1'12); G.

Dondanville, Flosd Ierrelle (b'83)-Ill.4, '11; (䒺)

HAMILTON, CIIS. L. (b'58)@-Mo.1,'80 (1'95)

lieeley, Milton R.-III.1,'86; (1'86); not in

MACGREGOR, JOHN ANGIER (b'73)-

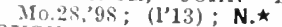

OTGITUN, JAMFS HENRY (b'82)థ$111.13: 0 \% ;\left(1^{\prime} 0 \%\right)$.

Reynolds, Peter I. (b'68)-111.1,'94; (1'94) (‡).
EAGLE, 10, SALINE

Wialuen, Chas. W. (b'73)-Mo.7,"09; (100). EARLVILLE, I.059, LA SALLE

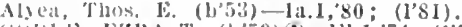

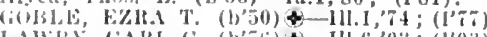

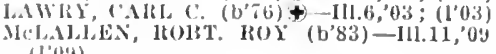

['ierce, pranklln E. (b'cio) - $111.14,97$

(1'm).

W11.1\%, FRANK A. (b'60)థ-Ill.1,"88;

(1.88); 0 p.

EAST ALTON, 584, MADISON

'ence, C'hats. Newton (b'67)-Ill.12,'89;

EAST DUBUQUE, I,I53, JO DAVIESS

leller, Augustus 1hillip (b'86)-Ill.22,'10; $\left(I^{\circ} 10\right)$.

LEWIS, ULYSSLS S. (b'66)థ-11.1,96; (bys)

EAST LYNN, 300, VERMILION

VANDOLEN, "RAYMONI) FLEMING (b'8t) $-111.6,11 ;(1 ' 11)$.

EAST MOLINE, 2,665, ROCK ISLAND

Baruing, Lewis Daniel (b'S $\$$ ) - Ill.11,'11; $\left(1^{\prime} 12\right) ; \mathrm{S}$.

CHAIG, ALEXANDER (b'83) - l'a.2,'12;

DONAllOO, CHAS. E.-Ia.10,03; (l'03).

LOAi, JLDSON I1. (b'70) \$-M0.27,96; $(1,36)$.

OYE, HLNIY JAY (b'81) †-Mich.1,05; (I'0y)

Soule, Earle A. (b'76)II-IIl.4, 01 ; (l'01).

Taylor, Lvander Iom (b'80) - Ill.4, (l'03).

EASTON, 400, MASON

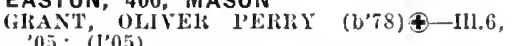

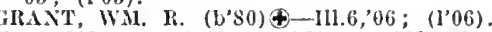

HANSON, MARTIN WARNLR (b'79)屯1Il.16,08, 111.11,'09; (I'08)

EAST PEORIA, 950, TAZEWELL

HOPIINS, FREI GiRAN' (b'71)@-Ill.1I 05; (1'05); Member State Nled. Soc. of Vis.

STIERS, FREDK. LOREN (b'75)(-Mo.2, 03 ; (1'03)

EAST ROCKFORD (IND. STA., ROCKFORD), - , WINNEBAGO

$$
\text { (See Rockford.) }
$$

EAST ST. LOUIS, 58,547, ST, CLAIR

ADA.IS, GEO. C. $\left(b^{\prime}, 0\right) \oplus-M O .7,98$; (l'ye); 233 Collinsworth Ave.; OALR. APLEWHITE, LEE D. (b'T3)-Mo.7,98; (1'y8); 1740 College Ave.; office, 229 '́ollinsville Are. : 9-11, 2-4, $;-8: 30 ; \mathrm{S}$

ARBUCKLE, NILLARD FLLLIORE (b'83) 9 -Mo.2,09; (1'09); Memuer Mo. State Med. Assn.; Hotel Illmo; oftlce, Murphy 13!dy. ; $10-1$; (B33) ; ALR. *

Aszman, Max (b'65) H-Mo.5,90; (1'90): 245 Collinsville Are.

Aszruann, Artlux Max (b'86)-Ill.4, 10 $\left(l^{\prime} 1 \theta\right) ; 1003$ St. Louis Ave. ; office, Coloma Bidg.; $10-12,2-5,7-8$.

Arery, Claude A. (b'78)-Mo.28,03 ; (l'03) 5.S. V Veronica Ave.

Baldwin, W. S.-1ll.16, ${ }^{\prime} 0 \tau$; $\left(1^{\prime} 0 \tau\right) ; 926$ E. Broadway.

Barker, Ioy F. (b'84)-Mo.28,07; (1'07). 2600 Market Are.; offlce, 2700 State St.; $9-11,2-4,6-8$.

Bluitt, Lyman B. (col.) (b'66)-Tenn.7,'90; (1'92) 613 st. Louls Ave.

BOTTOM, EMIITT H. (b'73) $\$-M 0.2,97$; (1'97); 1235 Gaty St. ; offee, 222 Collinsville Are. ; $9-11,2-4,7-8$.

BOYD, TULLIE YAN' (b'82) - Mo.34,'10 (l'10); $22 \mathrm{~S}$ Collinsville Ave.; office, Ifurphy Blug. ; $10-12,2-4$; S.

Bromley, Cerilda Niswonger ( $\left.b^{\prime} 60\right)-111.9$ 91; (193) ; 2 Coddlngton Pl.; office, 661 N. 33d St. ; $9-12,2-5$.

Butler, Jacob (b'50)-Ind.2,78; (1'78) 559 N. 13th St.; offlec, 1327' Missouri Are. ; 9-1, 2-5; G.

Cables, Henry A. (b'69)-Mo.34,03; (1'04) ; 529 Washington Pl.; offlee, Cahokia Bldg. ; $10-12,3-5,7-8$.

CAMPBEIA, RICHARD L. (b'68)థ-Mo.2, "00; (l'01); $523 \mathrm{~N}$. 12 th St.; office, 222 Collinsville Are.; 9-11, 2-4, 7-8.

CANNADY, EDW. WYATT (b'-3)థ-Mo.2 '02; (l'02) ; 422 Columbia Pl.; office, 339

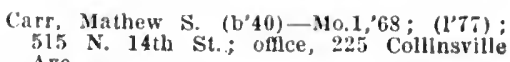
CULBEIRTSON, ORA J.

(b'77) †-Mo.34, 02: (l'02): Coloma Hag

de Haan, Adrlan fohn (b"87)-Mo.2,10; (1'10) : Illluols State Trust Co. Bldg.

De IIaan, Henry J.-Mo.1,'84; $\left(1^{\prime} 84\right)$; Ill1nols State Trust Co. Bank IBldy.

Doyle, Martin R. (b'40)-Ky.1,85; (1'85); St. Louls Are, and 10th St.

Dwyer, Iohn W. B.-Mo.1,7\%; (1'81); 523 Collinsville Ave.

ISSELE, CHAS. EDW. (b'71)-Mo.7,05; (1'05); 209 S. 4 th St. ; $9-10,1-3,7-9$.

therton, J. C. $\left(b^{\prime} 57\right)-M 0.7,94 ;(1,94)$; 1204 Collinsville Ave.

ANS, FLORENCE L. (b'75) @-Mo.28, 06; (1'06); 3004 Forest 1'l. ; offlce, $111 / 2$ N. Main St. ; $2: 30-5 ;$ LD.`

FAIIBROTHER, IIENRY CLAY (b'45) Mo.2,72; (1'77); $500 \mathrm{~N}$. 10th St.

FOLLON, JOEL J. (b'62)థ-Mo.1,87 ; (1'87); 1041 state St.

FOLLON, ZEPHANIAH S. (b'62) 6-Mo.1. $87 ;(1,87) ; 1041$ State St.

UULIIAM, JOHN H. (b'72) ๑-Mo.27,95; (l'95): 515 Washington St.; offlce, 513 MIssourl Ave. ; 11-12, 2-3, 7-8.

GILLIS, HUDS'ON B. (b'82)-Mo.7'0 (1'07); 227 Collinsville Ave. : 8-9, $3-5,7-8$ Glass, Miles M.-111.1,86; (1'86); 1044 Plgrott St.

Gundlach, Geo. M.-Mich.1,'87; (1'88) ; 1326 St. Louls Ave; $9-10,2-3,7-8$.
UNX, FRÉl). HENRY (b'82)-Mo.34

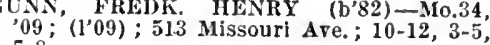
$-8$

HAGARTY, THOMAS (b'65) - Mo.7,96 ; (1'96); 25 Ridge Ave.

HARNEY, LOUIS G. (b'79) -I11.6,03; (1'03); Murphy Bldg.; 1-3, T-8:30; S. $\left(l^{\prime} 9 \pi\right) ; 514$ Mlssourl Ave. ; 8-10, 2-4, $7-9$;

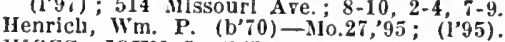

HIGGS, JOHN I. (b'59)-Mo.1, 85 ; (l'85); 2713 Bond Ave. ; offce, 2745 Bond Ave. ; $8-10,3-5,7-8$

HILL, CHÁS. EDGAR (b'76)థ-M०.34,02 ; (l'02); 2734 Bond Are.; office, Colomá Bldg.; $9-10: 30,2-4,7-8$.

HOUSII, ATO C. (b'73)-Mo.1,'99; (1'99) ; 1473 Belmont Are.; S. $\star$

IIulick, Geo. O. (b'76) E-Mo.10,02; (l'02) 1412 St. Louis Ave.; $7-9,12-2,6-8$.

Iunter, Thomas Gerald (b'77)-D.C. 3,07 ; (l'09); 520 E. Broadway; until 11, 2-4, after 6 .

Killene, IIarry Franklin (b'83)-0.2,'09; (1'09); 1730 N. 23d St. ; 2-4, 6:30-8.

King, Isaiab Iorace (b'85)-Tenn.7,08; (l'09).

kirsch, Francis (b'62)H-Mo.5,'90; (1'93) 225 Collinsville Ave.

NEWITZ, OTTO W. (b'81)థ-Mo.2,'05 (l'05); $1332 \mathrm{~N}$. $13 \mathrm{th}$ St. ; office, 541 Collinsville Are. $9-10,7-8$.

LE GRAND, DÁNL. W. $\left(b^{\prime} 70\right) \oplus-M 0.2,01$ (l'01) ; 463 N. 25 th St.

LILLIE, CHAS. W. (b'48) $\uparrow-M o .24$,'88, , 40 th St.; office, $\mathrm{I} 2 \mathrm{~d} ., \mathrm{Mo.7}$ and $\mathrm{Mo.10} \mathrm{T}$.

JINDER, LOUIS J. (b'75) \$-Mo.10,98; (l'98) ; 1301 St. Clair Ave.; office, Collinsrille and St. Louis Aves. ; 10-11, 2-3, 7-8;

LIPPERT, JOHN (b'65) $\oplus-\mathrm{Mo.10}, 04$; (1'04); 1556 St. Clalr Ave.; 10-12, 1-3, 6-8.

TTLE, EDGAR H. (b'72)థ-Mo.27,'00;

ITTLE, FINIS COLEMAN $\quad\left(b^{\prime} 72\right)$ -
Mo.34,06; $\left(l^{\prime} 06\right) ; 3322$ E. Broadway; $10-12,2-4,7-9$.

LITTLE, IIOMER M. (b'70)๑-Mo.27,00 ; $\left(l^{\prime} 00\right) ; 1623$ State St.

LITTLE; ROBT. M. (b'65)థ-Mo.2,'99; (1'99); Arcade Bldg.

LITTLE, ROLLA E. (b'8 (1'06); 403 Collinsville Ave.

Ludwigs, Gustav Anton John (b'78)-Mo.2, 07 ; $(107) ; 312$ N. 16th St.; Anes.

McBrien, Alfred A. (b'68) - Mo.7,98; (1'98) ; 331 Collinsville Ave.

IcBrien, James G. (b'63)-Mo.7,'99; (1'99) ; 622 N. 10th St. 


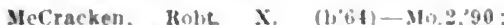

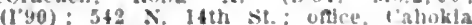
IHldg: $9.11,2-4$.

Mclonough, kobt. (:.) (b'st)-Mis., 08 (1'0s).

MCNARY, WILHERT FRANCAS (1+\$3) + Mo.28,09: (l'09): 403 Collinsulle Are: 9-11.2-4, .3.

McQUILIAX, AIBERT I3, (b"S0)+-MO. 03; (l'03): 242f Virghla H.; oflce, agth and Hond Are.; 9-11, 2-4, -8.

Mesirow, Maurlce Fllas (b'82)-111.11,07 (1.0\%): Maurlce fllas (b's:)-Mill.11,0 polltan Bldg. : $8-12,1-3,6-8 ; 0$ bG.

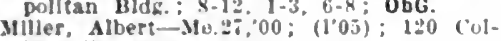
linsrllle Ave.

MOFII.ER, CIIAS 1. (b'63)-Mo.1,'87 (1'94); il 1/ N. Maln st.; $8-11,4-5$

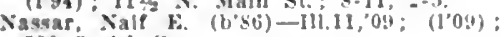
520 s. Ith si

Niemlller, August II.-0.1,75; (l'79)

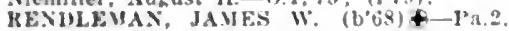
94; (1004): 333 X. Itth st.; unlce, 2.2 Colinsville Are. $9-11,2-4, i-8$.

Renols, Wm. H.-it.2,6t; (1'ii): (centervllle Stalion): 1200 isth st.

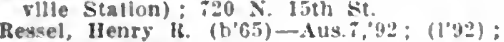
229 Collinstlle Are

RIVES, ALRERT F. (b'75)-MO.34, 0 t ; (l'06); Jurphy lildz.

Hyan, John J. $(1,+4)-M 0.10,78 ;(196)$; 626 Missonti Are

SHORT, LEIUEL HYKD (U'83)-Mo.31.'06: (1'06); $613 \mathrm{x}$. 24th St. ; offlec, Josejhlne

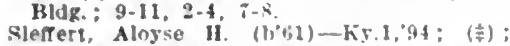
2601 Kidge Ave. : nftre. 500 . 2 .

SKAGGS CHAS SYLYKTHK $\left(b^{\prime}-8\right)+$ Mo.28,03: (1'03) : 17.75 college Ave. office, $300^{\circ} \mathrm{s}, 4$ th st.; $9-10,1-3,7-8$

Smith, Chas. A. (b'6s)-Mr).2s, 11 ; ( ) 1501 Douglas St.: offee, 22.7 Collinsvillo Are.: 10-12, 2-4, :-4.

smith, Harrey s. (b'if)-Mo.27,99; (l'49) 753 a Collnsrille Are.

Smlih, Henry D. (b'72)-M/n.28.98; (1"9s) 1531 k. Broadway; oflce, 25 Collinsllle ive.

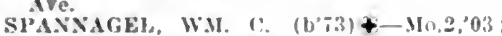
(1'03): nftice. Iatid collinsille Are. $10-12,2-4,7-9$.

SPITZF, EDW. C. (b):5)+ Mo.2,02 (102): 424. 5 . IBldg.: 9-12; Op.

Stanton, luarley libson (1)

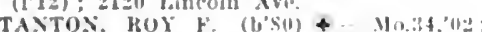

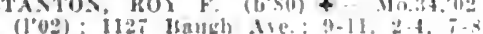

Siate Joseph fobralm $(1,96)$-Miehs, 96 $(196)$ : 335 Colliastlle Ire.; 4-11, 2-4 7.9 .

STEVEXSON, WAITER HMYS

(see Si. iomls.)

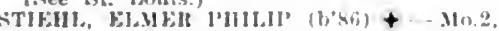
08: (1'0s) : Murphy Melis.

Sine, Ira Allen (b'81)-Mn.3t'l.: (1.13) 621 Vennsylvania ire.

stines, Thoinas Irring (b, 88$)-313^{3}, 11$ (1'1i) ; 2302.1 state st. ; onlce, SI0 Trend(III) : 2302A State Nt. ; once, SI0 Trelld

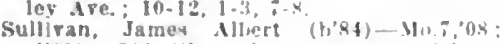

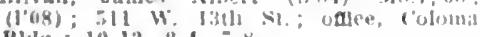
Hhlo: : 10-12, 2. 1, -

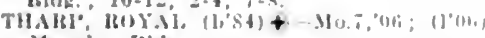
Murphy bils.

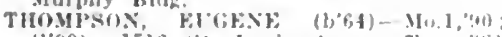

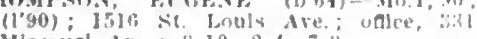
Minwonet Are, ; $8-10,2-4, i-!)$

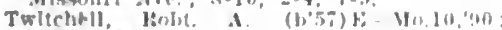

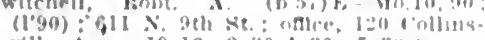
vlle ire : $10-12,2: 50-4: 30,7: 30-6$.

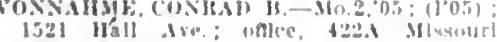
Ave: : $y=10, z-4,:-x: S$.

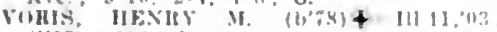

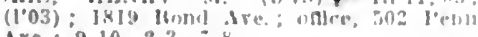
Ave.: $9-10,2-3,7-8$

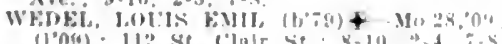

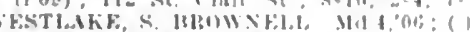

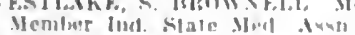

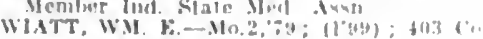
linswlile Ave.

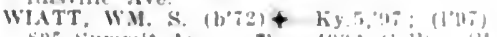

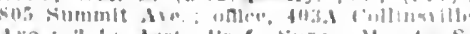

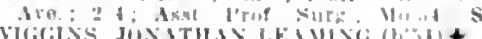

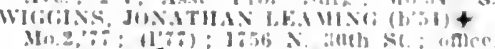

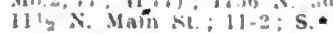

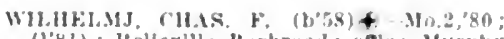
l's1); Hellevllle lsuckroal; oftce, Murphy Itld; : $12-2,-8 ; 5$.

WH.HEI.MJ, WALTBil $(1081)+$ Wo.34,0t

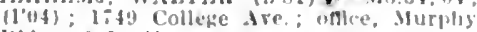
lilug: $: 9-1 ; U$.

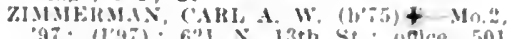
Ifisurt $621 \times 13 \mathrm{t}$

EDDYVILLE, 145, POPE

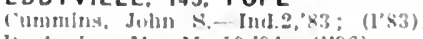

Jenl, J13. 11 - $110.10,94$; (1966).

EDGEWOOD. \$19. EFFINGHAM

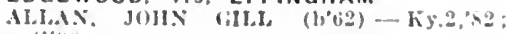
cicott. James R. $\left(b^{\prime} 40\right)-0.8,63 ; \quad\left(1^{\prime} 70\right)$ : (1)ruginlst).

EDGINGTON, 80, ROCK ISLAND

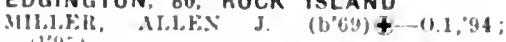

\section{EDINBURG, 9I8, CHRISTIAN}

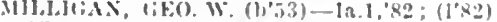
NF, F, IRA E. (b"a)t-110.34,04; (1'04):

kecfy, Sulomon I. (h':9) F-0.2,70; (1'7);

STOKES, CAMHBELA A. (b'59) +-(1.2,82: (1.82).

\section{EDISON PARK, - COOK}

Wood, Frank liontgoulery.

(see (hlirago.)

EDWARDSVILLE, 5,014, MADISON

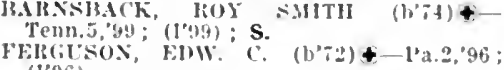
$(196)$

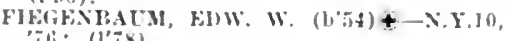

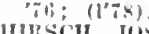

(1.99).

watman, ("hrlstopher Jorenzo (b"i) - Mo.2S, '94): (1"99)

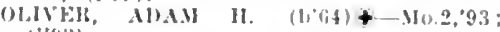
(1,93).

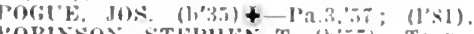

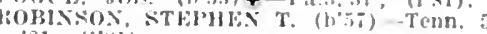

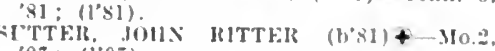
oi: $(1,07)$

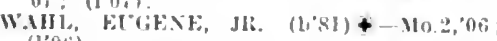
(l'oti).

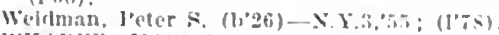

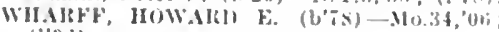
(1'D)ii)

Whart", Howarl T. (1,fi)-D: (1\%

EFFINGHAM, 3,898 , EFFINGHAM

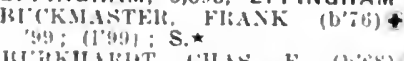

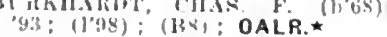

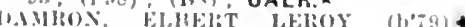
lo,

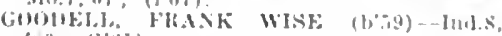

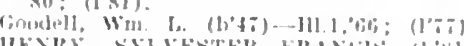

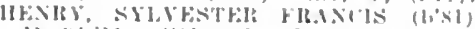

M10.34:11; 11'11): OALR

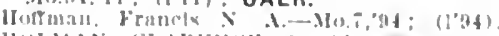

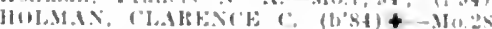
[11]; $(100,1):$ LD.

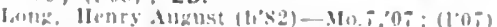

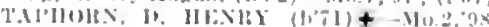
(1.98); ObG

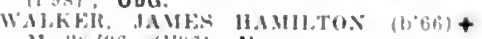

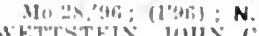
WETTSTHIS. JUIIS I. It. (1):D) + III:-

EICHORN, 8, HARDIN

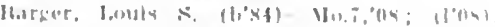

ELBURN, 775, KANE

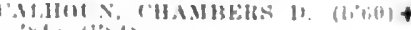

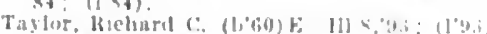

EL DARA, 195, PIKE

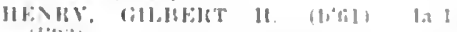
[I"!i:?

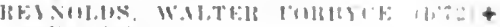

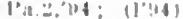

ELDORADO, 3.566, SALINE

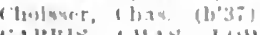

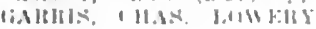

11: (1,13)

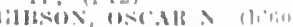

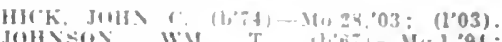

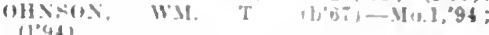
11 (1)

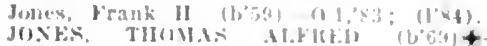
M0.2:97: (1,0); OALR.

Jatham, saml W. (1, =

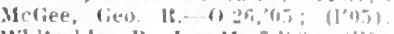

Whlteslde, 13. I. Mr "tok: (100)

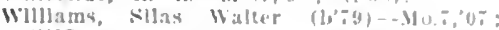
$\left(1^{\prime} 0 i\right)$.

ELDRED, 241, GREENE

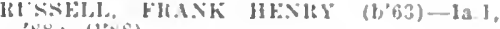
$88:(1285)$

ELGIN, 25,976, KANE

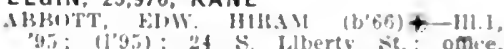

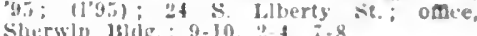

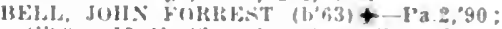
$(1090) ; 1 ; \times$. (hannlng st. ; unlee, fountilin sif.: 9-10, 2-4, $-5,30$

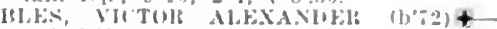
Colo. $2.95 ;\left(10^{\prime}\right)$; Member Jic. Siate Med. Assn. State Hispital.

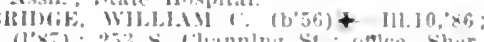

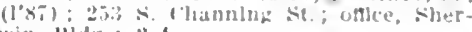
win Hidg.: $2-4$.

Brown, frank N. (b'45)-H 8., 33 ; (1's3); ass Chlcago it.

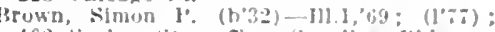
402 surlng si. : once. smirling Bidg.

Brown, $16 m$. s. $(1,69)-311,11,94:(1045)$. 258 Jeferson Are.; oflce, sgurling Isldg. : S.

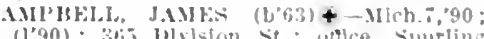

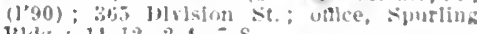

roldz: 11-12, 2-4, :-8,

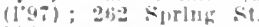

bobbins, Geo. s. (b'5t)11-111.10,01; (1'01); 364 Chleagn st.

luterlnger, llenry W. (b'6゚)11-111.10,96: (1'yti) : 1'ti Ternyson st.; ottice, 161 Cblcaro st. ; $9-11,2-4, ;-8$

FrILL, F. W. (b)

Figln state Ilonilal.

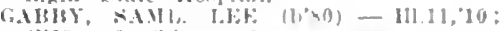

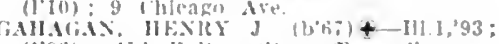
(1"93): ilo kulton st, once, sherman bldg. $9-10,2-4,7-5: 30$.

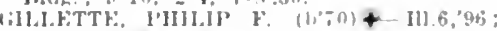

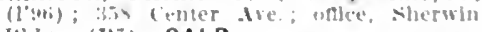
IHWF ; (1si) : OALR.

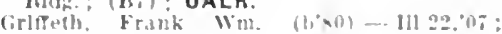

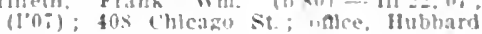
Is!du, ; 9-11, 3-6, ;-8

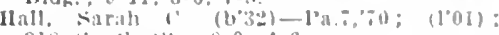
31s suth st.: $\$-9,+-6$

11.IWIEY MAX (1):9) Ind.9.04:(1'10): Figln siate loosplal: NP.*

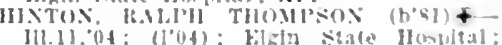
( HiBi: NP.*

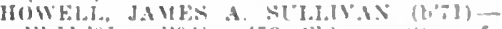

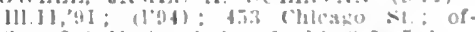

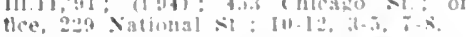

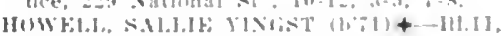

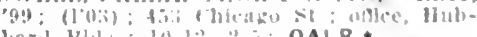

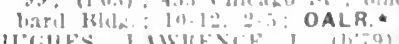

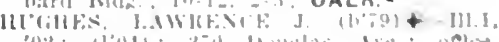

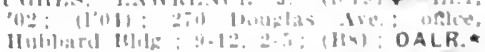

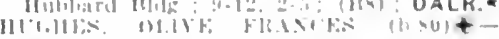

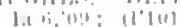

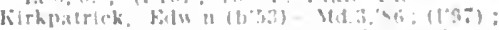

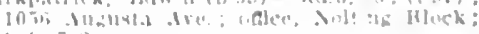

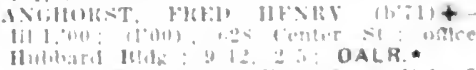

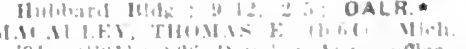

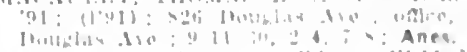

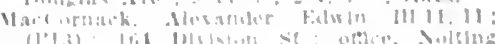

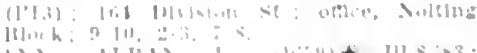

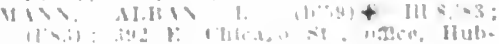

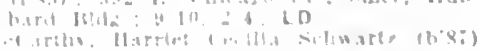

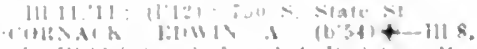

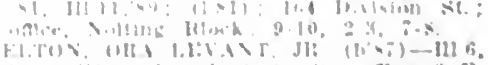

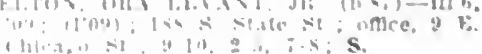




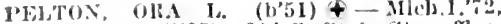
X.1.10,74; (1'85); $214 \mathrm{~S}$. State st. ; oflce. 9. E. Chicago St, $9-10,2-4 ;$ S.*

1. (loc). nol chlcuro st. ofllee, 47 spurl(l'06) : 20l chlengo st.; of

Ing Block; 10-I1, 3-4, i-8. Postle, James M. (b'fil)-Mleh.I, 8 ; IRATT, HOWARI L. (1,50)-Jll, is (I'78) : 266 Chlcago St. ; $7-8,1$ I $-3,6-8$ thoe Albert J.-Ill.1,71; (178); 63 Grove Are.

liUPliRT, GEORGE FREDERICK (b'72)-

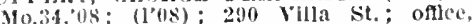
165 Cilicago Si.; $9-11,2-4,7-8$.

coltlit, Ifoward kennetl (b'88)-1!I. I. "13; (1'13); I28 N. Gifford st. ; ollice, Solting lilock; $1-4,7-8$

S(IINLIDER, (;EO. I. (b'66) $\uparrow-M l l c h .1,89$ (1'89) ; $56 \mathrm{~N}$. Chamnlnt st. ; offlec, 163

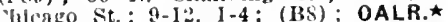

SCIIITMEIER, FRLIK. CONLAD $\left(\mathrm{b}^{\prime}, 2\right) \oplus$ III I, 02: (1'02) : 820 Spriug St.; offlce, Illi.1,02; $\left(1^{\prime} 02\right)$; 820 Spriug St. * ottice

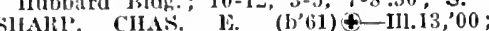

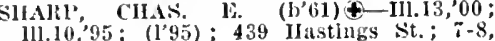
$1-2, \tau-8$.

SISSON, CIIARILS 1. (b'73) 6 -IH.11,'99 $\left(I^{\circ} 99\right) ; 486$ ('hlcago St.; oftice, II ubbard Blits.: $9-10,2-4,7-8$.

Truper, John (;. (b'53)-Ill.1,'82; (l'83) 116 Collere St.; oflce, 162 Chleago st.

TOBIx, JoHN R. (b'77)-IIl.1,01; (l'01) 439 South St.; offlce, IIubbard Block: $9-11, \quad 3-5, \quad i-8: 30$.

TRULL, JANE CROMIRIE (b'71)-111.8,05 (l'05); Hubbard Block; 10-11, 2-5, $;-8$

Tyrrell, Plerce (b'29) $\mathrm{H}-0.2,66 ;\left(1^{\prime} / 8\right) ; 1$ s. Chipel St.; ottlce, Hubbard Bldg. $10-12,2-6$.

Vaill, Ellas J. (b'68) E-111.8,94; (1'94); $31^{2}$ Lake St. ; $9-10,2-4,7-8$

Van Doren, S. H. (b'52) E-Ill.8,'78; (1'78); 23 S. spring St.

WARD, HARIEETT B. (b'6I) \&-Ill.4,'96 (1'96) ; 322 Chicago st.; otfice, is $\mathrm{Du}$ Page St.; $10-11, \ddot{3}-4,7-8$

West, Hugh H. (b'70)-IH.10,98, Ill.13, 00; (l'9s); :2 Hill Ave. ; oftce, Spurling l3ldg. ; $9-11,2-4 ; \mathrm{N}$.

WITTHAX, ANTHONY G. (b'76)-Ill.6, 05 (105); Elyin state Hosnital; INP.»

ELIZA (R.F.D., MUSCATINE, IA.), 68, MERCER

Mckelves, Joseph D. (b'i1)-111.1,95; (1'95).

ELIZABETH, 659, JO DAVIESS

Hagle, Franklin Eugene (b'86)-Ill.11,11; (1'11).

NADIG, ANTON T.\$-Ill.11,02; (l'02)

ELIZABETHTOWN, 703, HARDIN

Fowler, Francis II.-Tenn.5,'96; (l'96)

WILLINGIIAM, IADFORD II. (b'i4)-Ky.5, '9i ; (1'99).

ELKHART, 650, LOGAN

Taylor, Chas. B.-Ky.2,'81; (l's1); not in practice.

TAYLOR, GEO. GWIN (b'i5)\&-Mo.7,'97 ; (1'97).

WOODWARD, JOS. T. (b'71)-Ind.8,'94; (1'94).

ELKTON (R.F.D., OAKDALE), I50, WASHINGTON

JACK, ROBERT B. (b'62) - Mo.28,'98; (I'98) ; Ob.

ELIKVILLE, 732, JACKSON

CHAMNESS, CLYDE JAMIES (b'S8)-III.22, '10: $\left(\mathrm{l}^{\prime} 10\right)$

Walker, Ered C. (b'79)-Ill.22,10; (1'10); S.

ELLERY, 50, EDWARDS

Merritt, Nathaniel P.-E-0.2,'7\%; (l'Ti).

ELLIOTT, 350, FORD

THOMAS, VICTOR DARWIN $(\mathrm{b} ; 6)$ \&Ill.16,02; (1'02); (A21); S.

ELLISGROVE, 252, RANDOLPH

Beare, John Wm. (b'81)-Ill.4,'07; (1'07). Boldt, Henry M. (b’51)-110.1, '79; (I'79). ELLISVILLE, 732, FULTON

CLTTS, ABRAM C. (b'67) $\$-$ III.1,93; (1.93)

ELLSWORTH, 300 , MCLEAN

THOMPSON, ORRIS MARTIN $\left(\mathrm{b}^{\prime} / 8\right) \boldsymbol{F}$ HI.1I,08; (1"06).
ELMHURST, 2,360, DUPAGE

MLLI'OR'T, IIFNIY W.

(Sce Chlcago.)

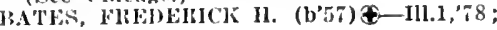

(ireen, Orson W

(sce Chlcago.)

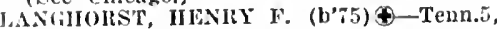
97 : (1'98).

MARQUARDT, FDT. W. (b'76)-Ill.1, 01 ; (1'0I).

(Oslrorue, ltiy R. (h'82)-Ill.22,'12; (1'12)

ELMIRA (R.F.D., TOULON), 75 STARK

INliEl, LUTIIER M. (b'67)-Ky.4,'95 (1'95); R.F.D.

ELMWOOD, 1,390, PEORIA

KEMI', ('LAILNCE IIONER (b'T0)-Ill.1, '94; ; (l'96)

CONG, IIARLAN W. (b'69)Ð-Mo.1,98; N.Y.19,04; (1'98); R.

OITON, DAVID HOLMES $\left(b^{\prime} 80\right) £-I 11.11$

Zoll, Edw. C. (b'62)-Ia.9,'98; (l'98)

EL PASO, I,44I, WOODFORD

OORDOX, liOBT, EAILI (b'72)థ-Mo.1,93; (1'93); Op.

iunn, Iatlock T.-0.1,'85; (l'85)

IENDERSON, FRANCIS HAROLD (b'31) - I11.15,05; (1'05).

ICHOLS FRED COLMAN (b'82)๑-Mo.34, 05; (1'05).

ELSDON (IND. STA., CHICAGO), COOK (See Chicago.)

\section{ELVASTON, 400, HANCOCK}

ADERSON, SAMIL. DUFF (b'66)-Mo.20, $08 \cdot(\mathrm{P} 11)$

RUNYON, CHAS. A. (b'61)-Ia.1,'84; (1'84)

ELWIN, 86, MACON

Leslle, Jos. $\left(b^{\prime} 38\right) \longrightarrow$; $\left(l^{\prime} 77\right)$; not in practice.

ELWOOD, 250, WILL.

GILBERT, ALSON R. (b'74)-Ill.6, 01 ; (l'0I).

HOOD, WILLIAN TAYLOR $\left(\mathrm{b}^{\prime} 48\right)-0.2$ '84; (1'91).

EMDEN, 500, LOGAN

BARRINGER, BERT MONTROSE (b'67) $€$ Ill.17,04; (1'04).

EMINGTON, 65, LIVINGSTON

Richardson, Bertram Arthur-Ill.11,'07 ; (I'07).

EMMA, 176, WHITE.

Bozarth. Finis E. (b'54)-Ind.2,'81; (l'81) Wylie, Francis W. (b'67)-Mo.7,'98; (1'98). ENFIELD, 927, WHITE.

I.ONG, FELIX 4 -Mo.10,'81; (l'81).

Rodgers, Horace L. (b'41) - Ind.2,'83; (1'83) (I'98); OALR

WILLIS, OMER M. (b'76)-Mo.7,'98; (1'98)

EPWORTH, 25, WHITE

Allen, Wm. Andrew (b'48)-Ill.1,74; (l's8)

EQUALITY, I,I80, GALLATIN

Bonrland, Isaac Newton-0.9,'S3; (l'83)

Ferrell, Grover C. (b'86)-Ill.22,'12 ; (1'13)

Gordon, Luclen Winslow (b'58)-0.9,'80; (1'80).

Harris, Monroe (b'70)-Ill.6,'09; (l’09).

WOMACK, JAMES A. (b'60)-Tenn.6,'84; (I'84).

ERIE, 768, WHITESIDE

FosTEl, ADIN H. (b'65)-Ia.10,'05; (1'05). LA ILEE, ROBT. E. (b'T4)థ-Ky.4,94; (1'98).

Magill, J. T.-E-Ill.8,92; (1'92) ; R.F.D.2.

MCENTIRE, E. JOE
(l'95).
ESSEX, 475, KANKAKEE

Allison, J. Wallace $\left(b^{\prime} 53\right)-0.8,77 ;\left(1^{\prime} 83\right)$.

ETNA, 100, COLES

STRICKI.ER, CLARENCE A. (b'56)థ-Ky.2, $79 ;\left(l^{\prime} 84\right)$.

EUREKA, 1,525, WOODFORD

BANTA, CHAS. FRANKLIN $\oplus-N . Y .10,84$; (l'91).

CRAWFORD, NAPOLEON B. (b'39)N.Y. 10,$64 ;\left(1^{\circ} 7 T\right)$.

HIGBY, CLAUDE B. (b'68) - Mo.27,96; (1'98).

NICKEL, FRANK WMI. (b'84)-Ill.11,'10 ;

I'AGE, JOHN FRANKLIN (b'55)@-Minn.3,
EVANSTON, 24,978, COOK

AlJXANDER, WM. GRAHAM (b'71) 0 III.6,04; (l'04); 2040 orrington Are. : oftec, I 604 Chlégo Are. : $9-10,3-5$.

ANDREWS, BENJ. FRANKLIN.

(See Chlcago.)

Andrews, John 1).

(see Chlcago.)

BAIRI, MAlY BRoOKS (b'74)\$-Ill.11, 03: (l'03): Avenue House.

HAJDELSTON, STEPHEN VICTOR (b'68) (-Pa.1,95; (1'99); 614 Clark St.; of-

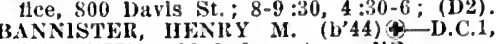
' 1 ; ; (1'7); 828 Judson Ave.; NP.

Barrows, Ransom Mooro-Hlch.1,77, 11.4 , '84; (1'84); 1303 Chlcago Ave.; 8-10, 2-4, $6: 30-7: 30$.

Barry, Geo. Fravel (b'75) Il-Ta.9,02; $\left(1^{\prime} 02\right) ; 1640$ Ch

$2: 30,6: 30-7: 30$.

Bartholomew, Anna Louise Laub.

(See Chleago.)

BARTHOLOMEI, ROY W. (b'77)-III.10, 00; (1'00): 2109 Sherman Ave.; offec, 1947 Maple Ave.; 2-4.

BASSOE, PETER.

(See Chicago.)

Bishop, Seth Scott.

(See Chicago.)

BLACK, ARTIIUR D.

(See Chicago.)

BOOT, GEO. WM. (b'70)థ-Ia.8,'93, Pa.1, 98 ; (I'02); 2302 Hartzel St. ; offlee, 800 Davis St. ; $9-11$; (also 122 S. Mllchigan Ave., Chicago; 4-5) ; (BI,7) ; OALR. *
Bragdon, Merritt C. (l'78); 1709 Chizago Ave.; 8-9, 1-2, 5-6. BRAYTON, SARAH H. (b'50) $\oplus-N . Y .35,75$; (l’83); 1637 Chlcago Ave.; 8-10; Pd.

Butler, Arthur De Lyons (b'79)-Ill.6,'09: (l'09); 1726 Oak Ave.; 8-10, 2-4.

Clajp, Eben P.-Ill.4,'82; (1'82); not in practice.

LARK, DWIGHT F. $\left(b^{\prime} 78\right) \oplus-I l l .1,03$; (l'02); 1423 Judson Are.; office, Century BIdg. ; 8-9, 3-5.

Clyde, Harry E. (b'75)-Pa.11,'99; (l'00) 913 Forest Ave.; offlee, 529 Maln St.; $8: 30-10,1-3,7-8$.

Cook, Wm. Wesley-0.10,'82; (I'S6) ; 2012 Sherman Are.

CORBUS, BUDD CLARKE.

(See Chicago.)

DAKIN, FRANK CARYL (b'68)-N.Y.1,'90 : (l'92) ; 1134 Hlnman Ave; 8-10, 6-8.

DANFORTH, WM. CLARK (b'78) $9-111.6$, 03; (1'03); 1620 Hinman Ave.; 8-9, 1-2;

Diamond, Peter Thos. (b'73)-IU.23,'04 ; (1'04) ; 2754 Exing Are.

DODD, OSCAR.

(See Chleago.)

DOERANN, AUGUST FREDK. ( $\left.b^{\prime} 80\right)-$ IIl.17, 06, Ill 11,'10;

Edwards, Frank H. (b'72)-Ill.10,'95, Ill.1 01; (1'95); 2719 Sheridan Rd.; 10-12.

Ellingwood, Finley.

(See Chicago.)

Ewell, Marshall D.

aulkner, Elmer Ellsworth (b'61) H-Ill.4,

'89; (l'05); 1939 Sherman Ave. (l'06); Central Bldg.; 8

(See Chicago.)

Gable, John Emmett (b'67) - Ill.4,09; (l'09).

Garnett, Isabella Maud-Ill.11,'01; (1'01); 1916 Asbury Ave.

GOLTRA, JOHN NELSON (b'59)†-N.Y.l, 87; not in practice; 1612 Hinman Are.

GRANT, JOS. F.

(See Chicago.)

HARDER, HERMAN P. (b'68)@-IIl.6,'97; (1'97); 910 Hinman Ave.; offlce, Rood Bldg. ; $8-10,1-3,6: 30-8$

HELMHOLZ, HENRY FREDERIC.

HEMENWAY, HENRY BIXBY (b'56)कIII.6,'81; (1'80); 701 Davls St.; 8-9:30, 4-6.

Henderson, Wm. C. (b'6z)H-Ill.15,'97; (1) ; 1908 Central St.

Hinkle, Abbie A.-H-Ill.4,'87 ; (l'87) ; 1039 Maple Ave, offlce, Main St. and Chlcago Ave.; 8-10, 1-2:30, 6-8 


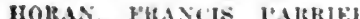

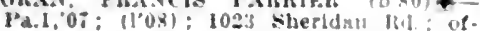
flce, Ceniury Itidg.; $\$-10,2-3$

JONES, WALTER CLIXTOX.

thee Chicazo.)

KAIPRIMAN JoHx ADAM (ling +

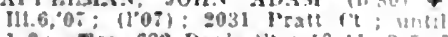
1.2: ofke, 63ะ mavis st.; 10.11

KALFMANS, GUSTAV w. (b.50) 90 ; $\left(1^{\circ} 90\right)$ : si3 hinman Ave. $6: 30-\div: 30 ;$ Pd.

6:30-::30: Pd.

Kelly, E. D.-Ill.10,

ient. James Tylor

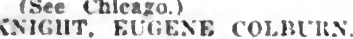

(See Chlcago.)

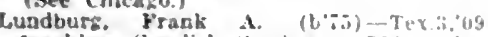
teachlng. Swedish Seminary; int urrine ton Ave.

Mann, Win. B. $(2 \cdot 33)$ P-M-111.5.90; : 119: 1370 Ashbury Ave

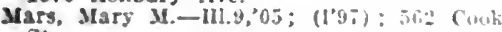
St.

Marshall, Nicholas IR - Ill.1, 60; (17\%): retlred: 1139 Bidgo Ave

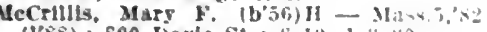

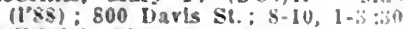

MeEWri, ERIHST LEWIS

(See Chlcaro,)

MeRWEN, MAIIY GILRUTII.

(see Chicazo.)

METCALF, WALTER B.

(see Chicazo.)

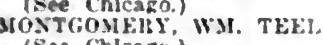

(See Chlesgo.)

O'XEIL. WM. E. (b':9)-III.I1,02; $\left(1^{\prime} 06^{\prime}\right)$ 1422 Eimwood Are.: omce, soo vavis sit. $9.10,1-3,7-8$.

OWELEI PALL OCTAVIIS (b'a) + Id : 99 : (t.01) : 1892 Sher

flce. Unlrerslty Bldg, $11-\mathrm{I}$.

Paden, Chas. M.

PSRKES, WM. ROSS $\left(b^{\prime} 6.9\right)+-11.1,92$

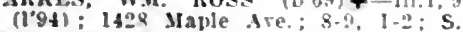

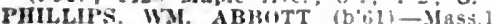
'8: (1'89): i21: Mlchizan Ale ; orlce, 1601 Chlcago Are.: 9-10, 1:30-2:30.

Porter, Addison Grane $(b ; n)-3[0 .-9 b$

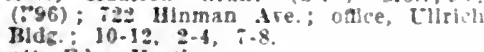

Prats, Ejw. Hartey.

(See Chlcago.)

USEY, WM. AI.L.E.

(See Cblcago.)

Race, C. W-0.6.95; (1005): 529 Main st 8.9, $12: 30-1: 30,6: 30-: 30$.

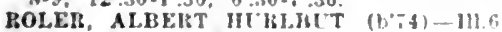

BOLER, ALBEIRT II HLACT (b-a)-11.

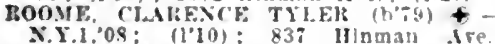

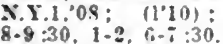

Ruderador?, Oscat I.-111.8,12; 11'13); 809 MaIn St.: $11-1 \%, 2.4$

RUVIII, YAX C.

(See (hicazo.)

SCHWARTz, HOLLIX (b':a) - Ill., 04 (1004): 1326 Washington sit; onice, tjet

Scolt, Russell Auans $\left(b^{\circ} 56\right)-1116,15$; (1'i4): Evanston Howpltal.

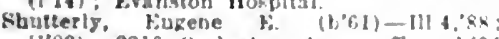

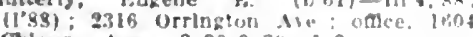
Chleaco Are.: $8: 30.9: 30,1.2$.

Sprouse, Jennle ilenn $(1,09)-111.9,40$ (1'9:): 2133 sheruan Nie.

STEAts. W31.

(see Chicrzo.)

swa., CIIAs Jus

(see (hlesin).)

Switrer, Chas II-H-III. I4," 89 : (I"gu) 1323 Ehmonod Are.

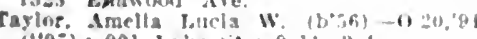
$(1.98): 901$ like si : 911.21

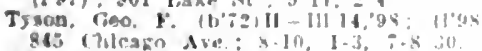

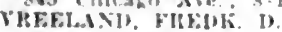

(sice (hls amo.)

WALKEI, HASSEI.TISF STHIIIF,

(Sine (lilengo)

W.IKEH. HFHHFIT

(Bio (bicazo.)

WH.TER, WH.1, I"

(see (hicazo.)

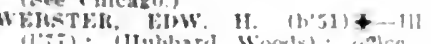

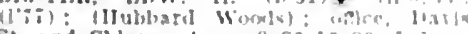
$\mathrm{SL}$ and Chicago Ire.; $8: 50-10-30 \% \mathrm{o}$

WHIT:, WM-

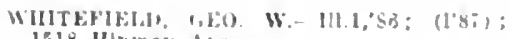
151 L Ilthoma tio

WOOLAKI, HK:HAH:1:T B

tsee thirazo

W(W)

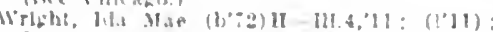

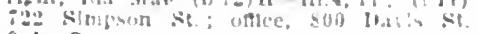
3.t: G.

EVANSVILLE, 562, RANDOLPH

MEYHE, FIRIXT'/ \&. (b"US)

$(10 .,)^{-10}$

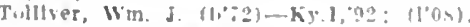

EWING, 3I\%, FRANKLIN

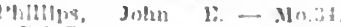

I: F.D. 1.

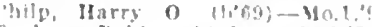

II $F$. Hol.

EXETER. 201, SCOTT

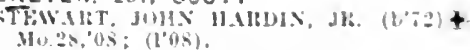

-itewart, John 11.. N5.-111.1.90; (17\%)

FAIRBURY, 2.505. LIVINGSTON

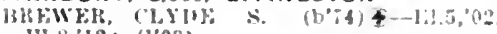
111.8, 12: (1'03).

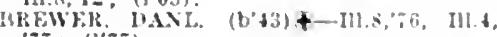
$7 \%:(1+17)$

Johnson, Heam E. (b's)-Vi: 1, a ; iloll

1.IXISTALF, JAMVE IIATZILJ. (b'83)+

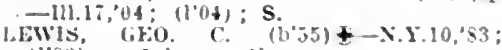
(l's3) not in practfoc. ITIs: NEWrT

Thatcher, dilen ח. (b'fi) Y:-111.8,96; (1'97).

FAIRDALE, 200, DEKALB

Fan Foorhls, Juhn l'bllip-E-O 206 ; (1"is); not in practice.

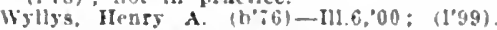

FAIRFIELD, 2,479, WAYNE

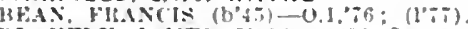

BIAKEIY, JAMES TIIOS, (b, 31$)$ - ilo.2s, 'ीf : $(1.06)$; S.

BLAKELY, OSSTELLA FITCH (b's 0 )II0.28,08; $\left(11^{\prime} 03\right) ; 00$.

กabls. Wm. II (b':1) - Ia 1,79: (1;9).

Hall. Neat J. (1), 1$)-110,29:(199)$.

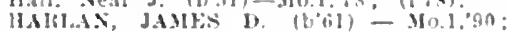
(1'90).

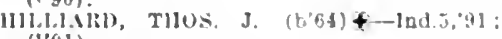
(1'91)

Matthews, Wm. Clarence (bit)-Mo.10.1:;

not in practice.

S111.FY, WM. ( (1):5)-Mo.7.91: (1'd) storemeiz, Guy $x$. (b'63)-1102, $25 ;(1 \times 5)$

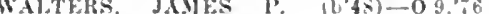
(I'ii).

FAIRHAVEN (R.F.D., THOMSON), 30. CARROLL

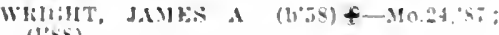
(I'SS).

FAIRLAND, 250, DOUGLAS

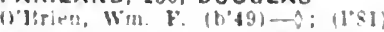

FAIRMOUNT, 347, VERMILION

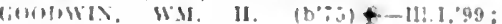
(1) 92 )

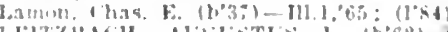

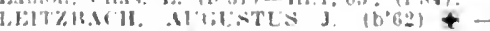

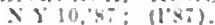

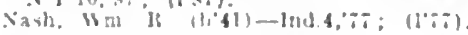

FAIRVIEW, 6000, FULTON

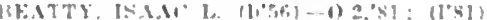

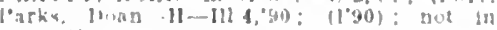

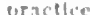

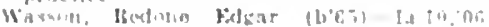
$11.6 \%$,

TANCY PRAIRIE, IOO. MENARD

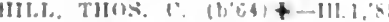

FAIIINA, 800 , FAYETTE

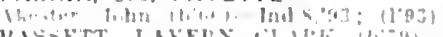

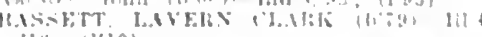
"11): $(1,10\}$.

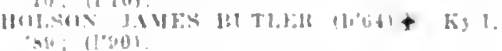

FARMER CITY, 1.103, DEWITT

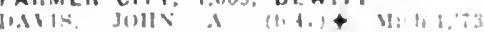

(1): 41

1.1TT1.ห.1011

an: $(1, x)$

sclniru, Mardatl

$(1 \div ; y)$

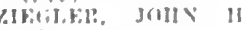

(l) 0,1
FARMERSVILLE, 533. MONTGOMERY

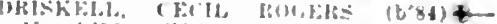

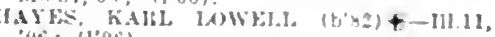
(10\%: $(1,00 \%)$

FARMINGDALE, 80, SANGAMON

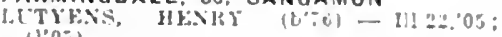
(1). 03$)$

FARMINGTON, 2.421, FULTON

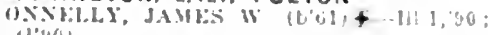

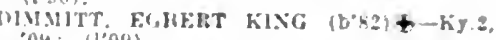
os: (l'03)

rlack. Wm. D. (b'83)-111 क, 12: (1'121.

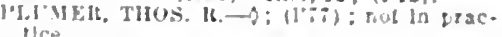

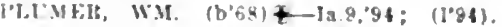

FAYETTEVILLE, 28, ST. CLAIR

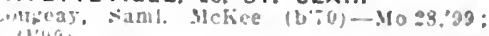
$11^{\prime} y 31$.

FERRIS, 300, HANCOCK

('asburn, Alfred l.eslle (b's3)-Kan 2,06: (1) 0 n)

Kelly, Inalr $\left(b^{\prime} \cdot 6\right)-18.10,02:\left(1^{\circ} 04\right)$.

Thornber, James Mathew $\left(b^{2} 0^{\circ}\right)$-la 9.92 ; (I); not in practlee.

FIATT, 300, FULTON

T.IYIOR, NLFXANUELE H. (b'82)-M 29.

FIDELITY, 211, JERSEY

Krwin, A. Duuglas-No.1,83; (I'Si)

FIELDON, 227, JEPSEY

Birewsler, Hert MarJon (b's2)-Ma.,05: (l'0j).

kirans, (has. W. (b'63)-U1.1,'ŝि; (1'S6).

FILLMORE, 500, MONTGONERY

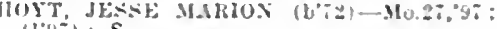

$(1.97) ; \mathbf{S}$.

Short, Hiram S.-E-0.2:73: (1":5).

FINDLAY, 827, SHELBY

lisklus, Alram Walter (b'72)-No.2s,'99; (1.99).

liregury, (bas. Sumner $\left(b^{\prime \prime}\right.$ 't) - Ia.9,"96; $\left(1,4 x^{\circ}\right)$

Yauzey, (ieo. W-K5.5,93; (1'93).

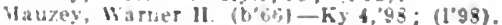

FISHER, 700, CHAMPAIGN

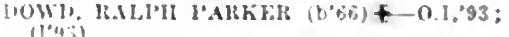

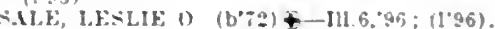

FISHHOOK (R.F.D. BAYLIS), 122, PIKE

KOWM.A, WW. F. (1) 59$)-1 \mathrm{a} .10 .00$ : (100).

FITHIAN, 309, VERMILION

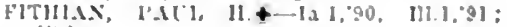
$(10,30)$.

foml, lieo, $11-F-0.2,35 ; 11 ; 5)$

FLANAGAN, 600 , LIVINGSTON

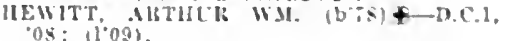

Inn, Julin

FLAT ROCK, 840, CRAWFORD

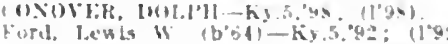

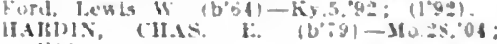

(1'04). H1.NII \&. (b'33)-K5 \&.83; (1's3):

OALR.

FLORA, 2.70\%, CLAY

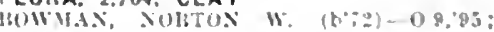
(1095).

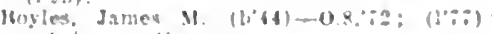

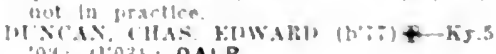
10:1: 11031: OALR.

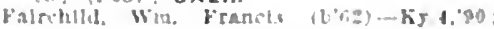
(I.)

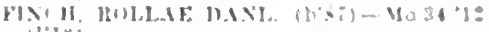
ता I I

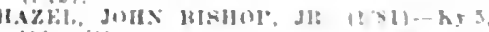

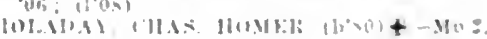
(II) ili,

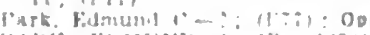

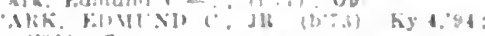
(1.05): 00.

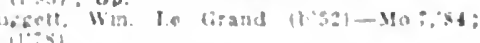

LLORIO (R.F.D. HENNEPIN), 100, PUT.

NAM (1, CLOSSMOOR. Sa. COOK

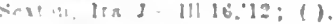


FOOSLAND, 250, CHAMPAIGN

(O)LWKLL, JOIIN BRENER (b'T3) - III.I, , 02 ; $;(1,02)$

Yorke, Frederick II. (b'50)-Ill.1,'S5; (I'85), FOREST CITY, 320, MASON

llill, Columbus C. (b'-2) -Ia.I1),01; (1'01). P'AUL, LINW. W. (b'55)-Ill.1.'84; (1'S4). FOREST PARK, 6.594, COOK

Dacosta, saml. N. (b'72)-Ill.22,'13; (l'13).

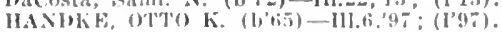
Huber, otto Clats-111.22,'12; (1'12)'; I'rof.

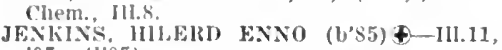
MASSLOW, WM. C. (b'66)£-III.13,02; (I'02).

McNil, Albert Gordon-Ill.s,12; (l'13).

MeNett, Clarence 1.loyd (b'79)-111.11,03; (1'03).

Von Bernauer, Julius- 0 ; (1's2); 528 does Plalues Are.

FORREST, 962, LIVINGSTON

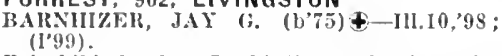

Falr(hild, keuben J. (b'it)-Mich.9.00; (\$) : $\left(1^{\prime} 00^{*}\right)$.

FORRESTON, 1,200, OGLE

AKINS, JESSE C. (b'69) - IJ o. 28, 99 ; BROW', ROYAL OSCAR (b'74)-IIl.1,03; (l'03) : OpA.

OVEIIFIELD, WALTER W. (b'68)-IIl.1,90; (1'90).

FORSYTH, 200, MACON

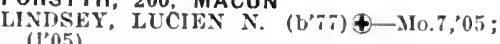
(I'05).

FOUNTAIN GREEN, 250, HANCOCK

Barr, John A.-Ia.1,'55, 1'a.2,77; (1'7i).

Bouseman, A. W. (b's 1 - Jo.2s,'10; (1'10).

FOWLER, 164, ADAMS

HAXEL, CHIRISTIAN C. (b'68)-Mn_25,'91; (1'91).

FOX LAKE, 400, LAKE

BERGII, MARIE SWANSON (b'75)

FRANKFORT, 550, WILL

Hass, Emll $6: T-0:\left(I^{7} 78\right)$

HEDGES, WALTER VIACENT (b'86)-Ill.4, -07; $\left(\mathrm{I}^{\prime} 0 \bar{T}\right)$.

FRANKLIN, 696, MORGAN

ELDER, J. MARSHALL (b'69) £-Ind.5ั,'96; $\left(l^{\prime} 96\right)$.

METCALF, FREDERICK H. (b'62) $\$$ - Ill.6,

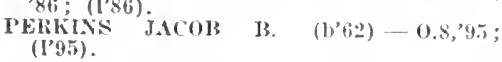

FRANIKLIN GROVE, 900, LEE

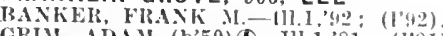

GRIM, ADA.I (b'50)—-11.1,81; (I'81).

Smlth, Webster C. (b'41)-Ill.1,85; (1'85).

FRANKLIN PARK, 683, COOK

Dodge, IIarold F.-Ill.1,'90; (l'90)

May, Lomis Fredk. III.I1,'95; (1'95)

FREDERICK, 300, SCHUYLER

McElroy, Wm. T. (b'5t)—IIn.2,'T2; (1'92).

FREEBURG, I,397, ST. CLAIR

Fox, Fredk. B. (b'7 ' 2$), M 0.34,06 ;\left(l^{\prime} 06\right)$.

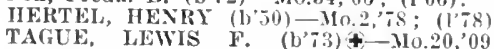

TAGUE, LI

Tegneier, Chas. I. (b'7 6 )-No.7, 06 ; (1'06)

FREEPORT, 17,567, STEPHENSON

ARNOLD, BE.J. ABNER $\left(\mathrm{b}^{\prime} 66^{2}\right) \mp-I 11.1$, $95 ;\left(1^{\prime} 95\right)$; $85 \mathrm{~N}$. Galena Are, oftice, 162 Stephenson St.; 10-12, $2: 30-5,30 ; \mathrm{S}$.

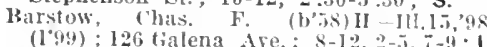

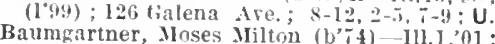
(1'01); 14 Harlem Are.; office, Tarbox BIdg. : 8-12, 2-5.

BRST, CHAS. LORTON (b'79) \&-IIl.1,04; (1'04); 181 Foley St.; office, $y_{5}$ steplienson st.; 11-12, I-4, - -8. Best, Elmer Howard (b'64) - 111.1,'88; (l'91); 26 S. Galena Are.; offlee, Mackay BROCKHAUSEN, BERNHARD ERP $\left(b^{\prime} 45\right) \oplus$ -II 4,69; (1'99): I 43 Rentonl st.

Bunsen. Aligust B. (b'30)-Ger.10,53; BURNS; 49 Blackhawk st.

12 Prospect. (1'96) ; Bldg.; ll-I2, Terrace; office, Wilcoxon
I3urwelt, Ho, F. (b'61)-1a,3,85: (1'85): 127 Jefferson st.; offlec, 122 stephenson St. ; $11-12,1-3,7-9$.

CLAIRK, JOIIN SHELDON (b'75)—-III.6, , 03 ; $\left(\mathrm{I}^{\prime} 03\right)$; 76 stephenson st.; ; $; 2$ $1: 30-5: 30$; (B8); OALR.

COLLINS, WM. THOMAS (b'83) - - II.6, 09 ; (1'09) ; 82 Douglas Ave,; oflce, 95 Stephenson $81 . ; 11-12,2-4,7-9$.

DIESTELMEIVR, EIW. A. (b'S2) †-I11.17 '10; (1'12); it lieaver st, ; oflce, 156 Stcphenson st.; $8-9,10: 30-12,2-4: 30,7-9$ (l'81): 124 West st.

Grant, Jolm Joseph (b'86) - N.Y.19,'11 (l'11): 812 x. Gialena Ave, office, 116 Stellieison St.; $10-12,2-4, \%-8 ; \mathrm{S}$.

HARLAN, NOAI' ROI'T. (b'80)థ-Ill.6, 09 ; (1'09) ; $431 / 2$ I Beaver St.; offlee, 97 stephcuson St. ; 11-12, I-3, 7-9.

Ilayes, IRobt. F. (1,32)-Pa.1,58; (1'77) not in practice; 46 Carroll St.

IIEWETSON, SARA E. (b'70)థ-0.25,98 (l'12); 210 stephenson St, ; II-12, 2-4, 7-8 HOLKE, THEOI'III J. (b'66)£-Mo.2, 99 $\left(l^{6} 99\right)$ : 195 Pleasant st.

HUTCHINS, LINDA KRAPE (b'63)†-111.9,

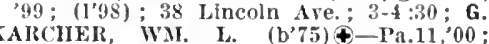

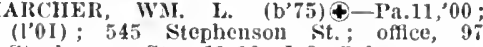
Stephenson St. ; 11-12, I-3, 5-6.

LEAVI, CUTIIBERT JOS. (b'76) †-III.11, '09; (l'09); 473 Stephenson St.; offlce, 65 stcplsenson st. : $10: 30-12,3-6$.

MEASE, DLPUYTREN C. L. (b'61) †-IIl.1, '84; (1'84); 568 Stephenson St.; office, 192 Van Buren St.; OALR.

MORRISON, HUCH E. (b’ 70$)-$ Ill.10,'91 (1'91) ; 151 Foley St.; offtce, 127 Stephenson st. ; 10-1I, 2-4, $7-8$.

PECK, W. BUCKLEY (b'74)-IIl.1,97 (1'37) ; 74 Stcphenson St.; office, Hcttinger Blug: $11-12,2+4,7-9$

PETTEPIECE, THOMAS ARTHUR $\left(b^{\prime} ; 6\right) \oplus$ -Ill.11,'10; (1'11) ; 85 N. Galena Ave.; 1'HHLIPS, NELSON C. (b'78)థ-111.11,07; $\left(I^{\prime} 0^{-}\right)$; 228 Jefferson st.; offlce, 110 Stephenson st.; 11-12, 1-4, 7-8.

POLIN(i, JANIES' ALONZO '(b'66)૯-IIl.6, 93; (1'93); $\$ 29$ Stephenson St.; offlce, old Colony Bldg.; 11-12, 2-3.

RIDEOIT, WM I. (b'69) †-Ia.9,92; (1'92) : 38 Prospect Terrace; office, Tarbox Bldg. $9-12,2-5 ;$ (BI) ; OALR

ROSENSTIEL, MARY L. (b'79)Ð-Mich.1. 04; (1'05); 204 Stephenson st.; otflice, 88 Cherry St.; $10-12,1-4,7: 30-9$.

Shar, Robt. Henry (b'7 7$)$-Ill.11, 01 ; (1'01); 428 West St.; offce, 137 Steplenson St. $10-12,2-5,7-9$.

Shelly, Emanuel Ely (b'82) - Ill.5,04: (1'04); 222 S. Galena Are.; office, 65 Stcphenson St.; 10-12, 2-4.

SMITH, ALDEN E. (b'60) - Ill.10, 84 (1'85); 229 Carroll St.; office, 126 Stephenson St. ; $10-12,3-5,7-9$.

SMITH, DOMER GHEEx (b'66) $\$$ - l'a.2. 99; (1'99); 58 Clark Are.; offlce, 94 Stephenson St.

SNYNIR, KARL F. (b'75)థ-Ill.6, 02 ; $\left(1^{\prime} 02\right) ; 296$ Stephenson St.; offlce, $9 \dot{4}$ Steplenson $\mathrm{St}_{\text {+ }} 1-4 ; \mathrm{S}$.

STEALY, JEREMIAH H. ( $\left(\mathrm{b}^{\prime} 59\right) \oplus$ - Pa.2,'82; (1'89); 242 Stephenson St.; offlce, 97 stephenson St. : 10-12, 1-4; $\mathrm{S}$.

STIVER, ROLAND J. (b'58) - Ill.1,'89; (1'89); 85 Stephenson St.

STIYER, WM. B. (b'50)-Ill.1, 78 : $\left(l^{\prime} \div 8\right)$ : 121 N. Galena Ave. ; oftice, 85 Stephenson St.; $10-12,1-3$.

TOREX, EDGAR J. (b'58) - N.Y.5,'90; (1'95): 57 Lincoln Are.; offlee, 118 Stephenson St.; $10-11,3-5,7-8$.

rOIGT, LOUIS G. (b'i5) - N.Y.19,00; (l'00) ; 9 Park Ave.; office, 87 Stephenson St.; 9-11, 2-4, ;-8.

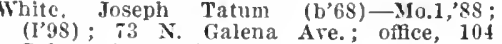
(I'98); 73 N. Galena Are.; office, 10.
Galena St.; $1-5,7-8$.

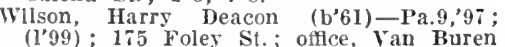
St. and Galena Are.: $11-12,2-5,7-9$.

Witt, John Desha (b'it);-Ill.4,06; (l'06); 32 Pine St.; offlce, 101 Galena St. ; 10-12,

Wood, Edwin Owen (b'85)-Ill.1,'12; (1'12). FRENCH VILLAGE (E. ST. LOUIS P.O.),
I.000, ST. CLAIR

I,ANE, EDW. II. (b'74)-Ill.4,98; (1'98).

FT. SHERIDAN, 1,575, LAKE

'ORTEI, IAALI'II \&. (b'75)£-Ill.1,97

FULLERSBURG (R.F.D., HINSDALE), 700, DUPAGE

Rudorf, Paul-II-H1.4,85; (1'85).

FULTON, 2,174, WHITESIDE

Clendenen, (ieo. W. (l,44) E-Ill.8,'84; (1'84).

DURKEE, WILIIAM IIENRY (b'68)€-Ia.9, 97, III.11,04; (1'07); Pd.

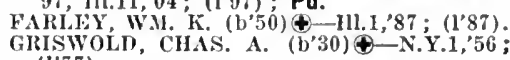
(1)

ARRISON, CHAS. N. (b'64)థ-III.14,03;

HEESINKVELI, HENRY JOIN (b'59)థ SCHMALIN, HANNAII NICHOLS $\left(b^{\prime} 63\right) \oplus$

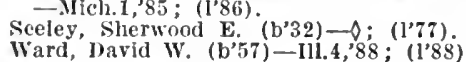

FULTS, 80, MONROE

Maeys, Alvin II. (b'91)-Mo.10,12; (l'13).

GALATIA, 745, SALINE

EMPSON, M. D. (b'56)-Mo.1,'82; (1'82) ; IR.F.D.

GARIISON, AUI)A (b'76) - Mo.28,09; (T?09)

Gratton, Phillj) D. B. $\rightarrow$; $\left(1^{\prime} 75\right)$; not in JoHNSON, THOS. M. (b'6i)-Mo.27,95; (1'96)

GALENA, 4,835, JO DAVIESS

BENCH, EDIVARD II. (b'72) †-I11.6,'98 ; (1'98).

Cleary, Mlchael II.-II-0.13,'78; (1'78).

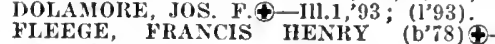
PLEEGE, FRANCI
No.34,09; (1'09).

IIOFFMAN, COLEMIN L.๑-Ia.3, 03 ; (l'03). LOGAN, RAY EVAN (b'88)-M1.11,12; (1'12).

MILILER, WMI. H. (b'82)†-Ill.6,07; (1'08).

SMITH, WM. A.-Ill.6,97; (1'98).

GALESBURG, 22,089, KNOX

Augerson, Clara Klopsch (b'75)-Ill.1,04; not in practice; $998 \mathrm{~N}$. Seminary St.

AUTER, MILTON H. (col.) (b'79) \$-D.C.3, BAIR: (l'05) ; 142 Laurel Ave.

(1'95): 1287 I Broad St. $10.24,94$ of Galesburg Bldg.; 2-5; S. $\star$ oftice, Bank

Ballard, John A. (b'42)-1ll.6,'68; ' (l'04); 927 N. Broadway; 9-10, 1-4.

BARTLETT, JOIIN DONNINGTON (b'80)Ill.1, 05; (1'05); 475 W. North St. ; office, Bank of Galesburg BIdg.; $10-12,2-4 ; \mathrm{S}$.
BIRNINGIIAM, THOMAS F. (b'77) Mich.1,04; (1'04); 591 N. Prairie St.;

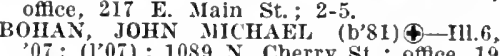
; 1 (107); $1089 \mathrm{~N}$. Cherry St.; offee, 19 BOWER, GEO. STUART (b'69) †-IIl.6,'94 (1'94); $515 \mathrm{~N}$. Chambers St.; offce, $306 \mathrm{E}$. Main St.; $11-12,2-5$

BRADLEY, WN. O'R. (b'61)థ-N.Y.6,'83 (1'92); $347 \mathrm{~N}$. Pralrie St.; offlce, $151 \mathrm{E}$. Iain St. ; $10-11,2-4$.

BRYANT, JOHN HOWARD (b'76) $4-111.6$, 03; (1'03); 451 N. Cherry St.; office, 306 E. Main St. ; $10-12,3-5,7-8 ; \mathrm{Pd}$.

CHALNERS, GEO.'S. (b'45)-0.10,78. (1'78); 701 Day St.; offee, Court House; $10-12,2-4$

Cooper, Elias S.-Pa.2,77; (1'77); 159 E. Forris St. 98; (1'98); 135 W. Tompkins St.; office, IIolmes Bldg.; 9-12, 2-5.

COWAN, JAMES E. (b'49) - Ill.1,74: (1'78); 736 N. Kellogg St.; office, Main and ('humbers sts.; 11-12, 2-5.

Dickinson, Francis C. (b'69) H-11l.10, 93 . $\left(1^{\prime} 93\right) ; 343$ N. Broad St.; offlce, $207 \mathrm{E}$. IIain St.; 2-4.

Drake, Franklin Jos. (b'69) II-I1l.10,95; not in practice; $529 \mathrm{~N}$. Kellogg St.

Early, Ralph Orr (b'79)-111.1,01; (1'06).

FINLEY, CLYDE ALEXANDER (b'77)@offlee, 151 E. Main St.; $10-11,2-4 ; S . \star$ 
FRANINL: FIW IRI) C. $\left(\mathrm{b}^{\circ} 69\right)+-111.1 .69$ (1'99) ; 545 X. Brond si.; ualce, 300 ह. Main St. 11-12. $2-4$.

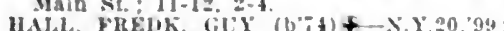
(1'99): 624 E. Loses st.; once, 300 t: lain st. 11-12, 2-4, :-5.

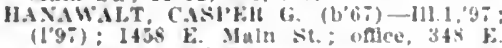
Jalo st.; $1-3,7-5 ; G$.

Harrls. Wm. T. (b't1)-Mo.5.'ss; ( )

lleller. Delnom Ieroy (1,s(i) - 111.1.11

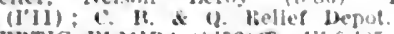

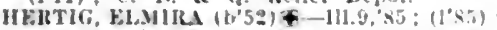
$1195 \mathrm{x}$. Kellog: st.; once, $300^{\circ}$;. Mal st. : 10-11, 2-5.

HOKRELL, CHAS. I. (b.51) +-111.11, $\$ 4$ $\left(l^{\prime} s t\right): 1112 \times$ Broal St; othce, $234 \mathrm{k}$ Maln St, $10-12,2-5,7-8$.

Ilumphrey, A. 1: (b"39)-X.Y.32,58: (1'78)

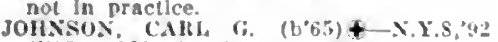
(1"93): 200 . Chambers sit: ontce, $300^{\circ}$ F. Main St: $11-12,=-4$

Lambert, Luclan S. (b'42)-0.9,69; (1'7i) $35 \%$ N. Academy St; onlce, 12 Min s? 2-5: OALR.

LANGENDERFER, VICTOR LEO ARTHTR (b'84)-Mich.1,09; (I'11): 129 Seldun St; oflce, C. H. \& Q. Depot; 1-12.

Law, Mobt. I. (b,40)-1a.1, $73 ;(1,7) ; 10 \mathrm{k}$ Maln si

LOXGBHAKE, GTY A. (1,'2)-I11.1.9: Mialn Sit. : 11-12, 2-4.

Luster. Geo. L. $\left(6^{\circ} 53\right)-$ Ia 1,$74 ;(1,7)$; 7 ine $\mathrm{N}$. Iiroad St: oftee, Main st. $2.4,7$

MALEI, GFO. ELZKAll $\left(\mathrm{b}^{\prime} 69\right)+$ III.11, 10 ; (1"10) : 516 S. West st.; offlee. $134 \mathrm{~F}$ Maln st. : 9-12, 2-4, $7-3 ; S$.

MALEY, WILLIAU H. (b'Gi) + -711.1. $(197): 422 \mathrm{~N}$. Cherry st.; ollce, $139 \mathrm{E}$. Main $S t ; 11-12,2-4, ;-8 ; 0 b$.

MATHKXY, RALlH C. (6'5s)+-111.6,"91 (1'91); $1030 \mathrm{~N}$. Broad St.; oflec, $306 \mathrm{~F}$. Maln Si: $10+12,2-4$.

MeCLANAHAX, W.M. S. (b"5)-III.1, 83 (1'83) : $862 \mathrm{X}$. Cherry st; unce, zty $\mathrm{E}$ Maln st.

MNER, CIARENCE JENININGS (b'bt) + Ilinn.4,91: $(1 ' 93) ; 634$ k. Losey st. ofitce, $23 \vec{t}$ E. Maln st.; 9.12, 2-5: OALR. MORRIS, EWING VAN DARIAX (b'58) + III.1,S4; (1'84); 60 N. West sit: uflce 339 : Maln Si.

MUNDY, HOMER FRANK (b.83)-111.8,'11; (1/11): $229 \mathrm{X}$. Seminary st. ance, ComInerclal Block.

Murchison. John C. (b'75)-Mo.24,95; $(1.98):$ :50 $\mathrm{x}$. Kellige $\mathrm{Nt}: 1$.

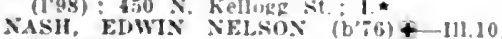

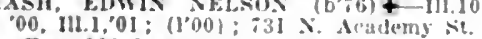
office, 306 Main St.; 11-12, $2-3$

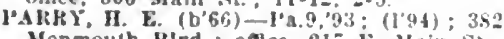
Monmouth Blvd.; once. 217 is. Main st.

PERCY, JAMES F. (b'64) + N.Y.10:86; (1'88): 593 E. Losey" st. ofice. 14: Cherry St : $1: 30-5 ;(A-11):$ S.

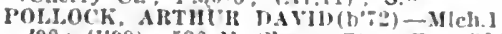
$99:\left(I^{\prime} 99\right): 536 \mathrm{~N}$. ('herry st.; nffee, 300 k. Maln st: $9-11,2-5:(\mathbf{F t}) ; \mathbf{P d}$.

f. Maln st, 9-11, 2-5: (Ft); Pd. Ky.11:09: (1'10): \%25 N. I'rairle st. oflce. 243 to. Mals st : $11-12,2-t,:<;$

ilce, bella M. (b'it)-Mich.1, (14: (1'si) $1030 \mathrm{~N}$. Rroad St: oflice, 204 F. Maln St. : $11-12,2-4$

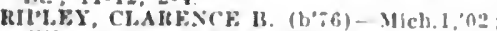
$(1004): 502 \mathrm{~N}$. Isroad st. oflce, $204 \mathrm{~s}$ Maln-St.; 11-12, 2-4, i-8

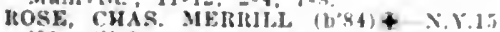
09: (1'13): Galenturg (Inb; unce, 14 ? S. Cherry 8t: $2.5 ; \mathrm{S}$.

STOTTS, ARTHUI FIRANIAN $(1,05)+$ Ya.11,99: (1'99): 1129 s. I'ralrlo st once, 306 r. Maln si. :-5; S.

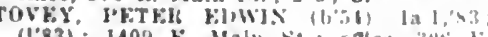

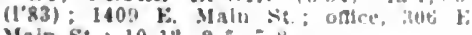
Main St. $10-12,2-3, ;-x$

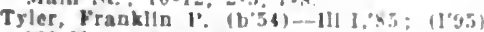

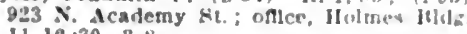
$11-12: 30,3-8$.

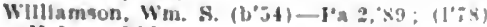
Holmes Hils.

W11.sox, IIt)1:ACF I. $\left(\mathrm{b}^{\prime} 61\right)+-111.1 .85$;

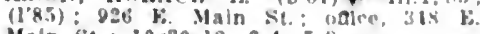
Maln sit. : $10: 30-12,:-4, ;-8$

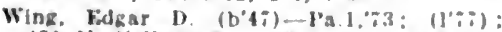
$470 \times$ Kellogz st.; once, Holnea Itllg. : 9.11. 3.6.
GALVA, 2, 498, HENRY

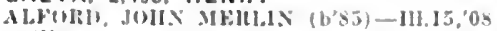
(I'us)

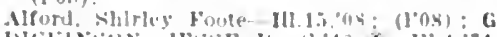

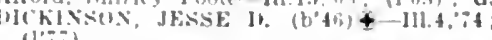
$(1 \div 5)$.

linthel). Henry I). (b'68) Ky, 240; (l'06).

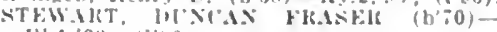
111.1.00: (['010).

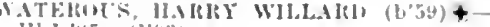
111. I, \$5; (1"43).

GARDEN PRAIRIE, 200, BOONE

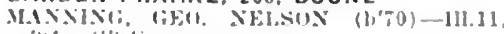
"If: (1"it).

GARDNER, 946, GRUNDY

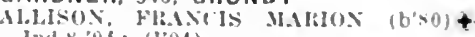
Ind.x, "1) i; (I'04)

Fll.F.F, EHLAX G. $\left(b^{\prime}, 5\right)+-111.6,208$ (I"g)

MeMs.X. W.M. $(1,3 s)-9 ;(1 ; 8)$ : nut In juractlee.

GARRETT, 500, DOUGLAS

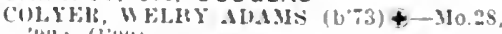
SIATH: (1'4:1), OWES M. (b'62)-111.11,95; (I'45).

GAYS, 400, MOULTRIE

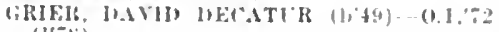
Hardinger, (1'\$6i)

\section{GENESEO, 3,199, HENRY}

Carman, fred W". (b'5s)-111.10.'s2; (1'sos)

Flujerrell, Larry Bacon $\left(4^{\prime} 70\right)-11.6,04$ (los).

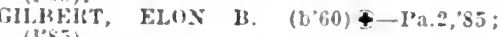
(1"S5)

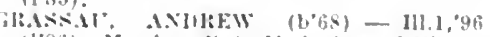

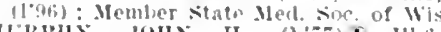

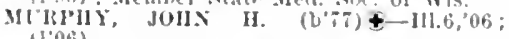

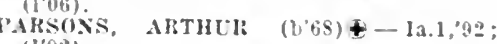
(1.9.3)

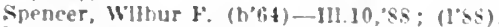

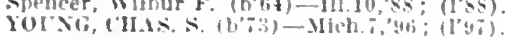

GENEVA, 2,451, KANE

Hlackman, Francis H. (b'to)-111.6?:0 ; (1) $\%$ )

Blackman, Julia C. $\left(b^{\prime} 4 s\right)-111.9,71 ;\left(l^{\prime}: 7\right)$ not in practice.

Cory, Joln 11. (b'.2) F-N.1., Ts: (1'02) Ibunn, Clara (1\%3)-111.11,03; (1'0\%)

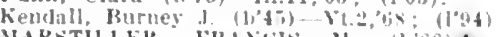
MAKSTILIEL FHAVCIS M. (b66) + III.10.9, ; (1"05).

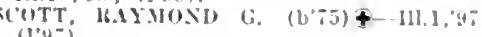
$(19 \%)$.

Warlswith, Ilenry 1'--Ill.1, s9; not in practice.

GENOA, 1,257, OEKALB

AI:TIS, THOS. N. (b'62)-Michs, 91 (I,?:0)

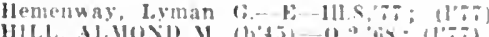

Mols 111 4. $0.7 ;(1 \times 1)$.

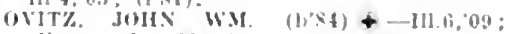

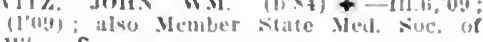

\section{GEORGETOWN, 2,307, VERMILION}

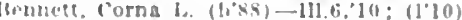

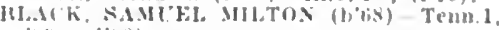

$40,(12:+3)$

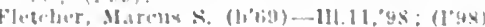

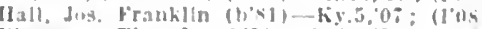
"lonman. Ther It. (b'il) Ind 4,7s: (l'is Sulth, Fimer II (lidis) Ind $x$ 'Sig: (I'gs')

GERLAW, 65, WARREN

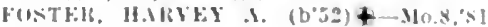

GERMANTOWN, III, CLINTON

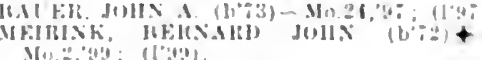

GERMAN VALLEY, 250, STEPHENSON

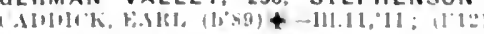
GIBSON CITY, 2.086, FORD

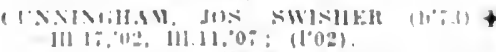

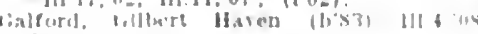
$(100)$

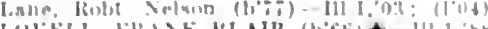

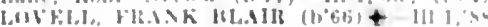

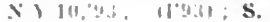

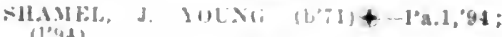

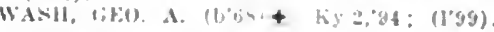

GIFFORD. 500, CHAMPAIGN

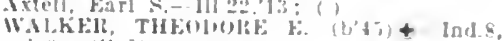
'No; (1'x2)

GILBERTS, 250, KANE

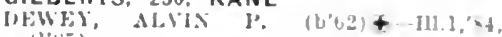
(1S.)

GILLESPIE, 2.261, MACOUPIN

IHFNX, I.EUNAHD HALLECK (b"87) Ilo.2, $99 ;\left(1^{\prime}\right)(4)$.

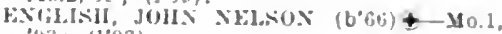
$43 ; ; 1093)$.

11.11. TII)S. H. (b'60)-111.1.'St; (I'8t)

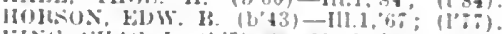

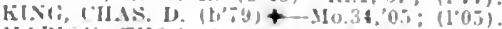

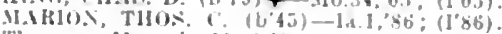

Thonas, Marvel-Mlo.1,'st; (1'a); nut in practicet'

GILMAN, 1,305, IROQUOIS

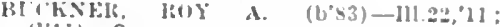
(l'1): $\mathrm{S}$

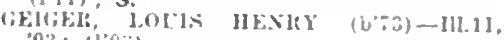
MCKEXZ1H, HOHT, E. $\left(\mathrm{L}^{\circ} \mathrm{B}\right)$ - Mo.2.99; (1.99)

Meser, Karl Allert (L'sf)-Ill.11,0s:

MHLEl, DAVID WARIREN (b'Jf)-Ha.

GILSON, 300, KNOX

BEFCHFI, (HIS. KUWIX (b's0)£-111.6, $0.5:(105)$

GIRARD. 891, MACOUPIN

IBLIALARI), FIG.SEST EIIVIS (b'bJ) - Mo.34. 10; (19)

(1)Wan, Kolt. S. (b'33)-Mo. 2fij; (I's6).

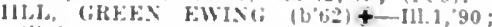

(IIs)( (t).

MITHEH.L, RORT JAIBIS (b+3) +-III. $71 ;(1 ' 9) ;$ OALR

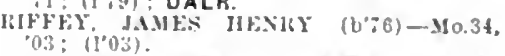

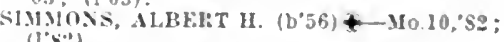

GLADSTONE, 433. HENDERSON

IITTU, BUYLIE ILON (b'S?) \&-1a.10,06:

GLASFORO, 409, PEORIA

larnes, Mllen C. $\left(b^{\prime}, 5\right)-111,1, s s$ : (l'ss).

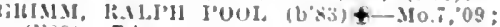
(l'09): Pd.

TOHILKA, K.MLL T. (b':2)t-30.,'06: $\left(I^{p} 0_{i}^{*}\right)$.

GLEN CARBON, 1.220, MADISON

MANitE, WII. F. (b'-3)-MO.25,01; (1'03).

GLENCOE. 1.899. COOK

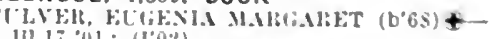
111.17.01: (1.02)

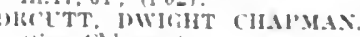

(ITrus

(1'01); Ob.

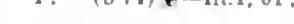

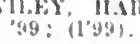

GLENDALE, 35. POPE

Handolph, llenty Feret (h's3)-Mo.,0s: (I"ON).

GLENELLYN. 1.763, DUPAGE

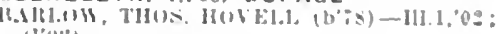
(I"(1)-1).

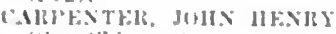

(sece chleato.)

budley, Lewis Walten (306)-III 6,93: (1) ins),

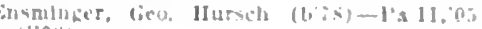

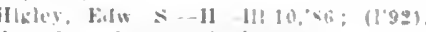

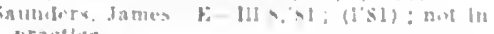
practlece.

GLENVIEW, 630, COOK

King. Juhn II:

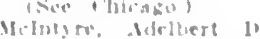

(1.94). GODFREY, 68, MADISON

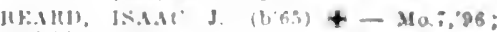
(1. $9(i)$

जITII. WM. II $\left.0^{\circ}, 1000\right)+$ N.1.8.59. 
GOLCONDA, 1,088, POPE

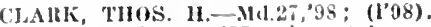

cullum, J. Theo. (bii) -0 ; not in practlee.

Lawrence, bant_- Ia.l, $78:(1,78)$.

McCoy, Henry W.-1a.2, 64 ; (1;7).

AcCoy, Henry W. (b'4t)- (1, 78 )

Simlth, Jolnn R. (1)+11)-1'a.2, 64 ; (1'7).

GOLDEN, 750, ADAMS

115COX, CHALMblis li. (b'75)-Ia.1,97; $(1997)$.

WIIIAY, THOS. R. (b'45)-1a.1,78; (1'78).

GOLDENGATE, 345 , WAYNE

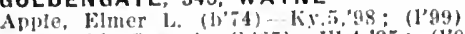

AcDonald, Geo. A. (1)'65)-111.4,'95; (1'97)

Trego, Jerome j). ( $\left.\mathrm{b}^{4} \mathrm{~s}\right)-\mathrm{D}$; $(1,78)$.

GOOD HOPE, 550, MCDONOUGH

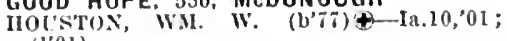

Stocking, Adella Lodoska (b'64)-Ia.9.92; (l'92).

GOREVILLE, 554, JOHNSON

Benson, Yewton J. (b'48)-Ky. 2, $\% 5 ;\left(I^{\prime} 7 \pi\right)$ Benson, Newton

Fly, Jesse J. (b'46)-Tenu.6,'78; (1'78).

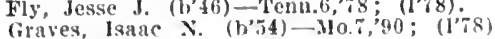

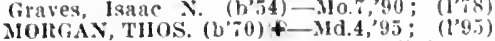

Thornton, Alfonzo D.-111.22,'l3; (I'13).

GRAFTON, I,1 16, JERSEY

WAlNEK, FRED G. (b'7i) $4-.110 .34,06$; (l'06).

GRAND CHAIN, 490, PULASKI

Doty, Monroe (b'4i)-Tenn.s,'S6; (1'86)

TAIR, A UGLSTUS WILLARD (b'05)

Mo.28,98; (1'98); G.

GRAND DETOUR (R.F.D., DIXON), 300 OGLE

Pankhurst, James (b'45)-l11.1,6s; (1'ii)

GRAND RIDGE, 400, LA SALLE

IVES, AUGUSTUS $\left(\mathrm{b}^{\prime} 55\right)$ - N.Y.10,'78 (1'82).

(1) James $S-0,78 \cdot(1,78)$.

S.ITII, WII. E. (b'78)\&-111.1,04; (1'0-4)

GRAND TOWER, 873, JACKSON

BAYSINGER, MILLALD W. + Mo.1,'s3,

N.Y.5,'91; (J'91)

GARDISER, ClIAS. D.-Ky.5, T; $(179)$

GRANDVIEW (R.F.D., DUDLEY), 205, EDGAP

Mosley, dllen k. (b'45)-O; (1';s).

GRANITE CITY, 9,903, MADISON

BAKER, JUIIN WILLIAII (b'87) \$-Mo.34,

11; (1'11).

BINNEX, ROBT. IVEBSTER (b'72) \&-Mo.2, $97 ;(1.97): S$.

BRASDES, liENRY AliGST (b'87)-Mo.2, '12; (l'12); Memuer Mo. State Micd.

COWAX, GEO. RUTLEDGE $\left(b^{\prime} 56\right)+-M 0.2$ 84; (1's6).

Darmer, leslie lorse (b'88)-Ilo.2,'13; (1'13) DAVIs, WM. TIIOS. (b'sl) - Mo.28,'10 (l'10).

Erwin, Geo. B. M. (b'62)-Mo.28, 00 ; $\left(1^{\prime} 00\right)$

G.
Gardner, Frank Fredk. (b'S2) - Ill.1,'11; (I'12).

GRAYSOx, wM. F. (b'72) $\oplus-M o .7,9 s$; (I'98)

GRAYSoN, WM. H. (b'\$6)є-Mo.7,'83 (1'83) : $\mathbf{G}$.

KING, BENJ HARRISON (b'80)\$-Mo.2s, 04 : (1'04)

LUSTER, ROBT. D. (b'\%9) Mo.34,03; (1'03).

NIEDRINGIIAUS, RALPH E. $\left(b^{\prime} \tau\right) \oplus$

Mlo. 6.98 . (1,00)

REUSS, HARRY PIERCE $\left(\mathrm{b}^{\prime} 88\right) \oplus-110.2$, 10; (1'10).

SCHREIFELS, LEONARD $\quad\left(\mathrm{b}^{\prime} 66\right) \oplus-\lambda \mathrm{I} 0.7$ '99; (1'99).

SCHKOEDER, HUGO C. (b'85)-Ill.4,'09 (1'09).

SMITH, WII. REMESES (b'68)-Mo.27 95: (1'95); Pd.

Stoycheff', Alexauder D. (b'\$1)-Ill.8,'13; (1'13).

TIEODOROFF, CHRISTO (b'ī)‡-Mo.2, TLLIE) FREDK. EDWIX (b'68)-Mo.27,

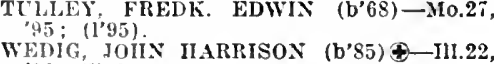

Woods, Alexinder (b'45)-Mo.2,73; (1'78) ZOLLER, CHRISTIAN II. $\left(b^{\prime}, \tau\right) \oplus-M O . \bar{t}$ 03; (1'06)
GRANT PARK, ZI2, KANKAKEE

CARR, OHCLTT YATIIAN (b'69)\$-III.16, $98 ;(1,9 S)$

Ferree, Geo. l'erry (b'65)-Pa.2,'92; (l'09). Van Horne, Geo. W. (b'48)-Ill.6,'75; (l'77).

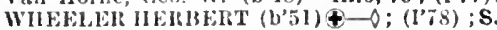
GRANTSBURG, 300 , JOHNSON

WALKEI?, IIARTLEY W. (b'73)\&-MI.4, 95 ; (l'95)

GRANVILLE, I.391, PUTNAM

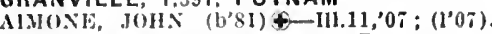
WELKs, Mac('LAIREY (b'71)\&-III.6,02 $\left(10^{\prime} 02\right) ; S$.

WIISOY, IIWNRY MASON (b'88)€-Ill.11, 'Il; (l'11).

GRAYMONT, 120, LIVINGSTON

II HSLINE, HARVEY L.-Ind.5,'04; $\left(l^{\prime} 00\right)$. GRAYSLAKE, 720, LAKE

Clark, Wm. N. (b'69)-Ia.1,96; (I'96):

G.
PALIIEL, JOIIN M. (b'70)-IIL.11, 01 ;

snAFl'ER, EDW. F. (b'58) 4 - Ind.9,99; (1'89).

GRAYVILLE, 1,940 , WHITE

ALLISON, IIUGII OUITMAN (b'83) $\&-$ Ho.28, 09 ; (1'09) : Pr.

FElRRE, ('IIS. EDWIN (h'58) - Ind.5 05; (1'13); Member Ind. State Med. Assn.

GREEX, ERNEST A. (b'i2) - Mo.28,'98; (1'38).

KEACis, CrILS s. (b'63) $\oplus-$ Mo.1,89;

Jarlin, Illram B. (b'8l) $\mathrm{E}-0.2,05$; (I'05).

GREENBUSH, 140, WARREN

I'ITTMAN, S.AML. YI. (b'63)-IIL.1,'88; (I'SS).

GREENFIELD, $|| 6 \mid$, , GREENE

BLLGER, CIIAS. OLIVER (b'80) \$-III.1I

Clement, Franklin A. (b’50)-Mo.2,73;

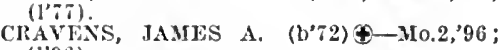
(I'96).

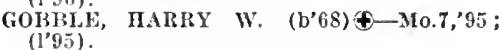

GREENUP, 1,224, CUMBERLAND

BROOKILAR', JOS. C. (b'76)-Mo.7,'03: (l'03).

HANCOCK, CLINTON J. $\left(b^{\circ} 66\right) \neq-0.1,97$ (l'97).

HAUGHTON, NICHOLAS J. (b'79)↔-Mo.7, 05: (l'05).

GREEN VALLEY, 400, TAZEWELL

FINK, GEO. D. (b'68)-Md.3,'95; (1'95).

KEILET, FRANKLIN ELLIS $\left(b^{\prime} 55\right)-K^{\prime} y_{4}$, 95; (1'95); S.

GREENVIEW, 92I, MENARD

BOWMAX, WM. TOWNZEN (b'74) $8-I 11.11$ 06 ; (l'06).

ELDRIDGE, FRANK PARIS (b'53)-Ill.1, $78 ;(1 ' 92)$.

HAMIL, CIISS. (U'53)๑-III.1,84; (I'84).

GREENVILLE, 3,178, BOND

CARTMLEL, IIARRY D. (b'79)థ-Ill.6,'05; (l'05)

CIARK, EDW. SPENCER (b'79)Mo.2,06; (1'06).

COOP' BEDFORD F. (b'65) $\uparrow-$ Tenn.5,'88, Mo.24,'92: (1'92); S.

EASLEY, WM. T. (b'5\%) Q-MO.7,'83; (1'83) ; OALR.

KEITH, ARCHIBALD M. (b'70)\$-Mo.7, 08; (1'09)

LUZADER, KATIIFRINE BELLE (b'72)\&111.4,06; (I06); G.

Matney, wm. D. $\left(b^{\prime} 40\right) \mathrm{E} \longrightarrow$; $\left(1^{\prime} 78\right)$; not in practice.

Poindexter, Don Y.-Mo.27,'98; (I'98).

Polndexter, Emmett P.-110.1,74; (1'77).

Ravold, IIarle L.-H-Ill.4,0I; (I'01); not in practice.

TAUGHT, HEZEKIAH MARTIN (b'57)Ky.2,'82; (1'82)

VIlSON, JEREMIAH C. (b'60)-Mo.7,'83; (l'83).

GRIDLEY, 900, MCLEAN

ADAMS, EDWIX MI. (b'7T) $\bigoplus-$ Io.28, 01 ; $\left(l^{\prime} 03\right)$

Aylin, Chas. H. (b'69)-Ill.6,'93; (l'93).

MOATE, THOS. (b'7)-IIl.6,97; (1'97).

Taylor, John A. (b'50)-N.Y.10;75; (1;7).
GRIgGSVILLE, 1,262, PIKE

IIARVEY, LUTIER JACKSON (h'51) 4 Mo.2,75: (1'77).

LOVELESS, IIARIX CLAYTON (b'76)Mo.7,04; (1'04).

SKINNER, WM. O. (b'48) $\oplus-$ Pa.1,74; $\left(I^{\circ} 77\right)$.

WATSON, THOS. M. (b'51)-0.2,74; $\left(1^{\prime 77}\right)$; OALR.

GROSSDALE (BROOKFIELD P.0.), I,III, CoOK

Jradford, Theron-Ind.1,49; (1'92).

Brown, Surali A.-IIl.9;'75; (1'78).

GROVE CITY, I19, CHRISTIAN

STAILES, MELVILLE WRIGHT (b'50)NIO.2,'84; (I'84).

GURNEE, I50, LAKE

YOUNG, IIIRAM O. B. $\left(b^{\prime} 73\right)-I 11.1,96$; $\left(1^{\prime} 96\right)$

HAGARSTOWN, 125, FAYETTE

STANRERY, AIBERT RUSSEL (b'75) 6 Mo.7,09; (1'09).

HALLSVILLE, 100, DEWITT

Mcluean, Chas. Thos. (b'58)-M0.3,'79; (1'79)'

HAMBURG, 335, CALHOUN

Vaughn, James R.-Ja.9,'94; (1'94) ; not in practice.

Werner, August Anthony (b'83)-Mo.34,'11; (1'11).

Willams, Bluford H.-Ia.1,78; $\left(l^{\prime} 78\right)$; not in practlee.

HAMILTON, 1,627, HANGOCK

Jlan, James W. (b'81)-Ia.10,02; (l'02) Mliller, John $A:$ (b'55)-Ia.1,81; (1'84). Runyan, Westey claude (b'86)-Ia.10,07:

Taylor, J. C. (b'72)-Ja.9,'99; (1'99).

HAMMOND, 500, PIATT

Lewis, Tullls Blaine (b'81)-Ill.15,07;

MCNUTT', JOHN H. (b'70)-Mo.1,95; (1'95).

Noe, Osear D.-H-Mo.5,'78; (l'78).

HAMPSHIRE, 900, KANE

Olms, Frank A. (b'75)-Mich.1,'95; (1'95).

REID, CILAS. P. (b'48) $₫$-III.8,72; (1'77).

HANAFORD, 20, FRANKLIN

Jixon, Thomas E. (b'83)-II1.22,'12; (1'12).

Elckelmann, Wm. Henry (b'87)-Ky.2,10; (1'10).

HANNA CITY, 300, PEORIA

Gillette, Arthur Ernst (b'78) - III.6,08; (1'08).

HANOVER, 785, JO DAVIESS

BOOTS, FRED. WARNER (b'78)-Ia.3,04; GOLLOBITH, EDWARD FRANK" (b'86)III. 11,08 ; (1'08).

HARDIN, 654, CALHOUN

PEISKER, JACOB HERMAN (b'86)-MIo.28, $10 ;\left(l^{\prime} 10\right)$.

HARDINVILLE, 50, CRAWFORD

Shipman, Everett M. (b'74)-Ky.5,00;

HARMON, 200, LEE

Henry, W'm. (b'39)-III.1,70; (I'78).

LUND, JOHN MAYHUE (b'80) (1'08).

HARRISBURG, 5,309, SALINE

BLACKARD, WM. JAMES (b'70)-Mo.2, 08 ; (l'08).

(I'0S); ObG.

CAI'EL; ObG. V. (b'66)-Ky.2,93, Mo: (1'94).

cumMIXs, EDW. W. $\left(b^{\prime} 78\right) \oplus-M 0.34,06$;

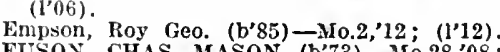
FUSON, CHAS. MASON (b'73)-Mo.28,08; (1'08).

HART, FRANCIS M. $\left(b^{\prime} 71\right)-M 0.7,03$; (1'03).

Ledford, Geo. (b'60)-Mo.24,'88; (1'89).

LEHMAN, DOUGLAS ARCHER (b'85)@Tenn.5,09; (1'10); OALR. *

Lockwood, Kathyrn Habermel - Ky.8,'08;

not in practice.
McTAGGART, WALTER (b'62)-Ta.1,'84;

Milchell, John W. $\rightarrow$; $\left(l^{\prime} 87\right)^{\prime}$. NYBERG, ROBT. BURDETT $\left(\mathrm{b}^{\prime} 79\right) \rightarrow \mathrm{MO} 34$,
05; (1'05).

Ozment, Emery Lee-Mo.7,'06; (1'07). 


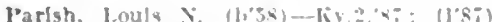
Ruse, sames II (b'ts)-Ind:a's: (1'78)

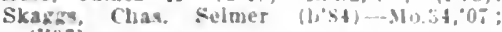
$\left(t^{2}(1 i)\right.$.

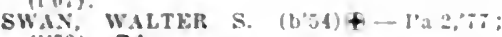
(1':8): $\mathbf{P d}$.

THOYPSON, HERBERT I. ( 03: (I'03): Pd.

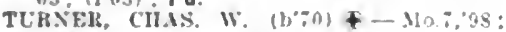
(1'9s).

HARRISTOWN. 153, MACON

Plerce, Jolin Robt (b'"3)-110.2S,97; (1997).

HARTSBURG, HOO, LOGAN

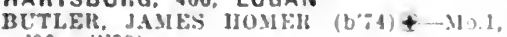
"99: (1'99).

HARTSVILLE, I5, POPE

DIXOX, JAMES W-IA.J,SQ: (I'91).

HARVARD, 3,008, MCHENRY

Blanchnt, Illuy W: (b'32)-Mass.2.'5t; $\left(\mathbb{1}^{2} \div 9\right)$.

GODDARD, CHAS. $W .\left(b^{3} 37\right)+-111.6,82$; (1'86)

Groesbeck, John W. (b'38)-I14.1, 'C, ; (1'7\%); not in practlce.

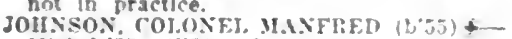
Mllch $1, \because 5:(1 ;-8): S$.

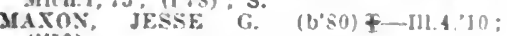
(1'10)

MCIANE, GEO. AIRERT (b'75)-IM.11.06 (108).

PECK. CHAS C (b-0)-II1 4.95: (1:36) SCIIMID, HENRY JOHN (b'75) £-III.S, 09 (1'09).

SFELYE. NORMAN LEE (b'TS) \&-MHII 03: (1'03): (Wond tock): OALR.*

HARVEL, 396, MONTGOMERY

KIITON, WEIDUN BlANCII (b'SO) IBI.8, 0 i; ( 1 '0s).

HARVEY, 7.227, COOK

AITKES, AKTIL'1 NORLE (b's3) \$-ML.1 '10: (1'11).

Blals, John Wm. (b"76)-Ill.1s,00; (1'w6); S. Fouser, IIlram-1!1.4, $8 b^{\circ} ;(1$ 'ss).

MORSE, MchoNE (b'59)+-Mich l, \&3:

NORLE, THOS. A (b'se) \& Ont.1.99: (IP92): $\mathrm{S}$.

Rose, Marle F.-H-WII.4.96; (1'99).

Sterenson, Layard Taylor (b'-2) - III.11,9s: (1'92)

HAVANA, 3,525, MASON

COREY, FREHK JOHNSOS (b'79)-rH.1 03: (1'03): OALR.

Hall, Wrn. II. (b'40)- - 2:00; (1"i:)

Harmison, Davld $C$. $\left(b^{\prime}+1\right)-1$ - $1, \cdots(1)$

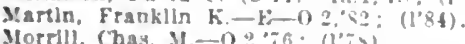

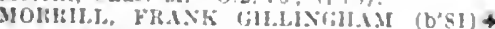
-I11.6,08: $\left(10^{\circ} 0 \times\right)$.

Servoss, Archibald G. (6.65) - Pa.2.Se; (1'86).

STEELF, WM. A. (b'Bi) \&-M10.29.96 : (P96): OALR.

STLBFORACUR, CHAS. HFNHY (U'SO) Md. $\left.\%, 0 \% ; 110^{\prime} 09\right)$.

HAZEL DELL, 160, CUMBERLAND

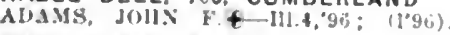

HAZELHURST, 61, OGLE

MePHEKSON, "HAS. W. (b'b1) + -111.1.'\$2 N.Y.5.87: (1'82)

HEATHSVILLE (R.F.D., FLAT ROCK), 22 CRAWFORO

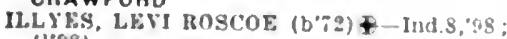
(11.98).

HEBRON, 644. MCHENRY

BAILEY, "IIIMLFS WHITSEY $\left(6^{\circ}: 4\right) \uparrow$ III 1:00: (1,01)

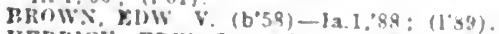

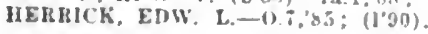

HECKER, 187, MONROE

Eckert, Aifred Fred (b's0) - M10.31;'10 (1.10).

Kleas, John T (b'69)- Mn 2,05: $11^{\circ} 05$

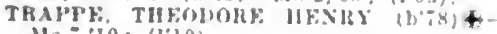

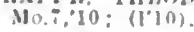

HEGEWISCH (IND. STA., CHICAGO), COOK (sive ( l)ichasu)

HENDERSON, 200, KNOX

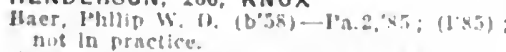

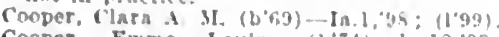

Conper, Eusad Loulse $\left(b^{\prime}+4\right)-1$ in 10,03 (I03).
HENNEPIN 523, PUTNAM

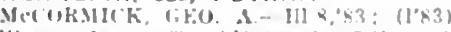

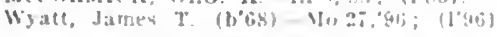

HENNING, 500, VERMILION

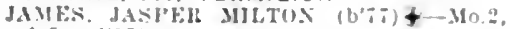

$05:(1,0: i)$

HENRY, 1.687. MARSHALL

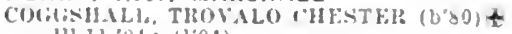
- II1.11,04: $\left.11^{\circ} 04\right)$.

CBOMWEL, EDW G. (b',6) +-111.10,96,

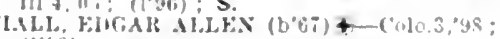

(1'as).

WEM JESAE ACGUSTINE $\left(b^{\circ} 5.2\right)+$ Mo.10,st; (1'84).

HERMON, 150. KNOX

BRIWNING, AITHUR L. (6'62) - Ia.I, $\$ 9$ : (1's?)

HERRICK, 618, SHELBY

krunk, Chas. H. (0.25)-n11.1,65; (1'07).

11:11, Astaley J.-0.22.93; (1"93)

sollls reorge stluer (b'yl)-Mo.2s,0s. (l" (0)

HERRIN, 6.86I. WILLIAMSON

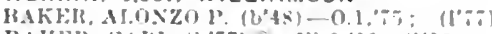

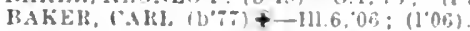

BAKER, LESTER WADE (b'Sti)-\$10, i, 09 (1109)

Baker, Allles D. (b"53)-0.1:5: (1'7).

Black, James Taylur (b'8)-Mo.6.09

BOILES, DALLAS S. (b'ii) t-Mo.2,01

BROW', COLLMBLS (b'68)t-Mo.1.98 (1'05)

Ford, Nim. H. (b'7)-M0.7:98; (1'98).

GAITHER, WTLLAM ROEERT (b's5)III.1.10; (1's0).

MCRFAH, FRANK CLAY (b'8I) -JIL.1,10 (1'10)

SANDERS, D.LIL. WEBSTER (b'Bn) - Mo.7,

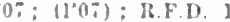

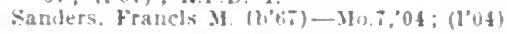

HERSCHER, 500, KANKAKEE

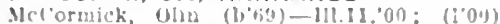

XELAIS, (HAS. O. (6"it)-\$10.34.00; (106)

HERSMAN, 200, BROWN

ASII. JOIIX (: + Ky.1.96; (t'98).

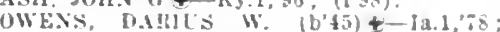

$\left(1 \% x^{*}\right)$; nut in vractice.

HETTICK, 306, MACOUPIN

Brandom, Harry (b'32) $\rightarrow$ : (

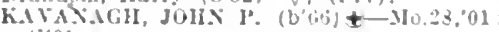
(1001).

HEYWORTH, 68I, MCLEAN

TIRNER. FHANK (b'6s)-IJ1.1, '03; (1'93).

WAKEFIELI), FR.SK I. (b'66)-XY.10, 410): $(1.30)$

HICKS, 87, HARDIN

JUISEK, JAMFS TRACEY (b'79)-Mn, Z,'09. (1'0!)

HIDALGO, 190, JASPER

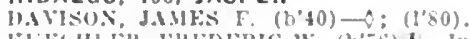

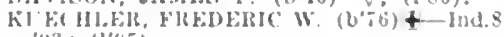
$4: 3:\left(1^{2} 95\right)$

SAITTA, CHE LAWIENCE (b'84) -

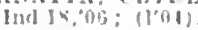

HIGHLANO, 2.675, MADISON

HWHYTT, WM. WASHALTON (b'56)Ja $1, \because ;(1,-8)$.

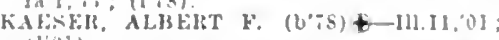
(l'o!)

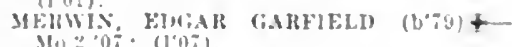

TIMHTTS, JOSES D. (695)-110.1, s1: (l'kl).

Wirth. Jullua (biti)-la. 2, J0; (l'is)

HIGHLAND PARK, 4.209, LAKE

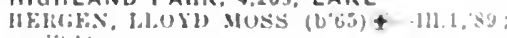
$1{ }^{1}: 011$

bocher. Chas

(sue (litcaso.)

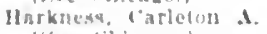

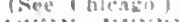

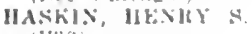

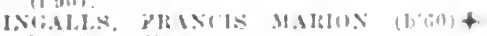

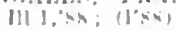

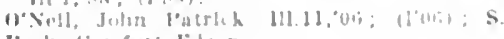

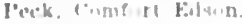

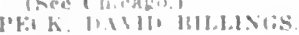

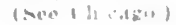

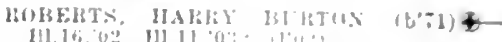

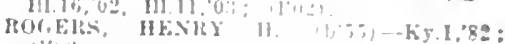
SIIIIEK, I.FAS KEILLOW,

S.MIII.KH, I.E.SA

Allitill, WM. SAML.

(seo rhleagos.

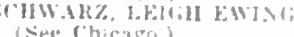

SHEIDON, AIIHET K. (6:\%) (1) (1): 2)

HIGHWOOD, 1,219, LAKE

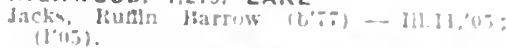

HILLSBORO, 3.\$2\$, MONTGOMERY

BRIIN, LI)TIS SILIFSTEI: (L'T) Мu 2,02: 1105.

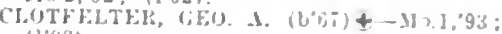
(I) $\left.{ }^{2} y 3\right)$

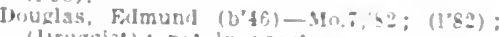
(lorugingt) : not ln practice

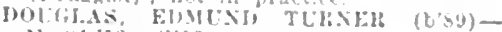

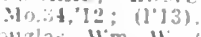

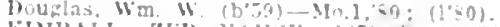

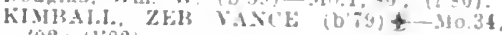

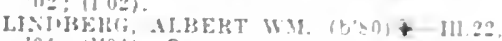
of: $\left(1^{\prime} 04\right): G$.

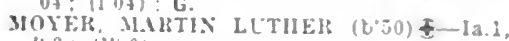
$30 ;(1200)$

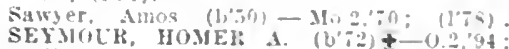
(I'!U!).

HILLSOALE, 400 , ROCK ISLAND

TACKETT, WALTUS (b\%) - M. 250 (1)0\%).

HILLSIOE, 600, COOK

Lewis. Harry Lotel.

ste ('bicasn.)

HILLVIEW, 309, GREENE

Lewls, James J $(1, \because 2)-310,25,09:(110)$.

HINCKLEY, 66I, DEKALB

CASE. JUHS 1.0VELL (b'SO $\$-30.34,04$

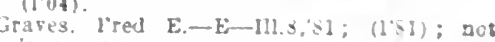

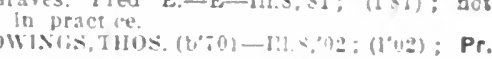

HINOSBORO, 550, OOUGLAS

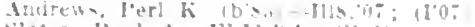

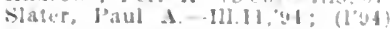

HINSDALE, 2.451, DUPAGE

Barber, (Ora Mabel (b.aI)- l'a. listutant l'hsician. Hasda!e sanital

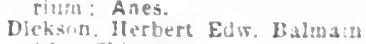

(siee Chicazi)

FIBEFIAN, IRTIILR B.

Isice clicas

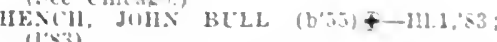
(1.283)

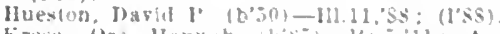

Kress, (oral Hamah ibso-lo, il As-

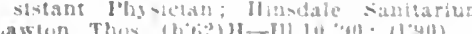

Meconnill. larl í.

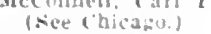

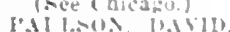

(sive (lifeasa)

Y'sulocm. Mary W- $111.4,96$; 1'92).

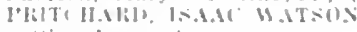

(sice durnes)

hathis. Iseny lewis.

(siee ibucago.)

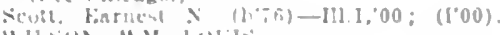

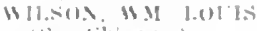

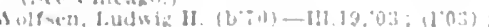
OALR.

HOF FMAN, 50, CLINTON

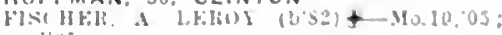
(1'(1)

HOLCOMB, 100, OGLE

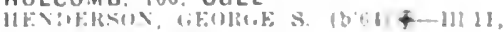
$\because 4.11: 41$

HOLDER, 125. MCLEAN

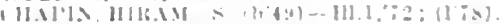

HOMER, 1,086, CHAMPAIGN

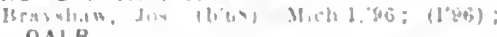

FALRT

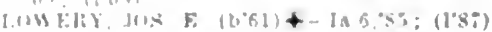

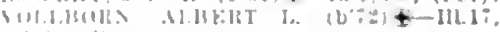


HOMEWOOD, 700, COOK

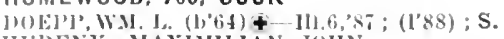
HIBESY, MAXIAHHAN JOHN.

(see chlcago.)

WHAHTON, JAMES F. (b'82) \&-111.4, 05 (l'05) ; Adj. l'rof. 'I'heo, and l'rite. Med. 111.4 .

HOOPESTON, 4,698, VERMILION

AI)SIT, JUA. S- III.10, $: 90 ;\left(I^{\prime} 91\right)$.

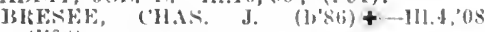
(l'0s).

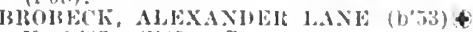

ky:2,'s5; (1'85); S.

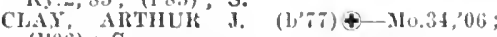

(l'06); S. (1'3I); (IBI) ; OALR

HAZEI, JOHIY IBISII()I' (b'f!) - Ky, 5, 's3 $\left(l^{\prime}, 46\right)$

ligles. Joln $A .\left(10^{2} 38\right)-0 ;(1 ; 8)$

JOINSON, JIXLES ]". (b'J(i)-I11.1, 85 (1'85).

JONES, H.FILOY (b'(63) —-W0.1,88; (1'95) MeCAUGHEY, IROBT. STANTON $\left(\mathrm{b}^{\circ} \mathrm{a}\right)+$ III.1.02; (l'03).

MCCALUIIEY, THOS. CORWTN (b'4I) Ill.1,6s: (l'93).

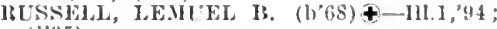
(1'45).

HOOPPOLE, 125, HENRY

l'elly, liay llumbert (b'SB)-Ill.11,13: (1'13).

HOPEDALE, 600, TAZEWELL

Harman, Clarence $\left(b^{\prime} 75\right)-\left(3.3,98 ;\left(b^{\prime}\right) 20\right)$

KEYNS, ItOI'T. 11. (b'0)-1a.1, 's3; (1'83)

HORD (R.F.D., LOUISVILLE), 50, CLAY

Anderson, James $\rightarrow$; (l'is).

Gladson, II. II. (1)'49) - Ho.7,'84; (1'78).

HOSPITAL (KANKAKEE P.O.), 2,500, KANKAKEE

CLAIL, SAMUEI, NIE (b'81)Ð-111.15,05 III.11,09; (1'05); (E 4$)$.

FISH, DRULY IEIG] (b'85) \&-Mo.34, 09 (l'il).

Jacobs, Wilhelnina-1ll.1, 0 ; ; (1'05).

ItEAI), CIIAS. F. (b'76)\&-11l.1,01; (1'01);

HOOKS, JAMES THONAS (b'7i) \&-Hll, 10 ; $(1,10)$.

SINGER, HAROLD DOLGLAS (b'5)

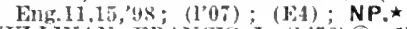

SUILIVAN, FRANCIS J. $\left(b^{\prime} 76\right) \uparrow-111.1,97$; (1'97).

HOYLETON, 451, WASHINGTON

GREEN, GEO. A. (b'7 7$)-110.7,06 ;(1,06)$

Klostermann, Louis J. (b'7) $11-$ Mo.5, 98 ; (1'98).

HUBBARD WOODS, 300, COOK

BALLENGER, WH. LINCOLN.

(See Cblcago.)

DARLING, CIIS. GLLCIIRIST.

(See Chlcagn.)

METTLER, LFE HARRISON.

(See Chicago.)

ORCUTT, WWGHT CHAL'MAX

(See Chlcago.)

WEBSTER, ENW. II

(See Eranston.)

HUDSON, 400, MCLEAN

Johnson, John O.-E-0.2,'87 ; (1'87)

HUGO (R.F.D., OAKLAND), -, DOUGLAS

Willams, Aratus C. $\left(b^{\prime} 45\right)-0 ;\left(l^{\prime} 78\right) ; U$.

HULL, 54I, PIKE

Carder, Lce C. (b'58)-Ia.1,91 ; (I'92).

SPERRY, IIERBEIT C. (b'63)-Ia.1,96 (I'01).

STEVEXS, WALTER S. (b'84)-Mo.10,'12; (1'12) ; LD.

HUMBOLDT, 319, COLES

DEANE, FRANK JI. (b'69)†-Ill.23, 06 ; $\left(l^{\prime} 06\right)$.

McDougle, James-Ill.1,'77; (l'77).
MORGAN, CHAS. E. (b'69) $€$-11.6,02; (l'02).

HUME, 800 , EDGAR

Layton, Clifford 1haymond (b'8i) - 111.2:2,

Wilson, Chas. P. (b'79)-Ky.2,04; (l'04).

HUMRICK, I00, VERMILION

P.ROWN, ROBT. A.-0.1, 84; (1'01)

Graliam, Tliomas B.-Ill.1,79; (1'79).

HUNT, 235, JASPER

Gettinger, Martin L. (b'58) E-Mo.10,'80

Martin, Lewis (b'59) E-0.2,'94; (1'94).
HUNTLEY, I,000, McHENRY

III(ifilNS, ALTON J. (b70)-IL.17,08; $\left(l^{\prime}(0,5)\right.$.

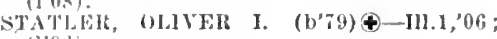
(1'0ii).

HUNTSVILLE, 250, SCHUYLER

Ilester, Fredk. (1, 68)-Ia.1,'95; (1'95).

HURST, 600, WILLIAMSON

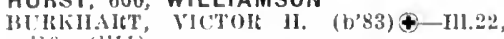
ili; (l,II).

HUTSONVILLE, 722, CRAWFORD

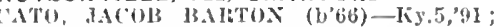

(1'93)

Eatou, Wim. (b'38)-Ill.1,'67; (l'76) ; not in mactice.

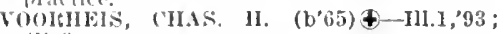
(l's,3).

ILLIOPOLIS, 849, SANGAMON

WU(iNE, HICHALI) D. (b'76)-MO.1,99: $\left(1^{*}(3) ! 3\right)$

MAYE, JOHN WM. HNWIDDIE (b'52)kу十, $76 ;\left(l^{\prime} 78\right)$

ILL'OC'KSON, HOMEI: BILYANT (b'81)II $0.31,10 ;(1,10)$.

INA, 484, JEFFERSON

C'TLLI, GEO. OSCAI: (b'85)-Mo.28,08; $\left(l^{\prime}(0,)^{\prime}\right)$

HAIPLit, AV(il'sTLS DEFO (b'81) II0.2S,'10; (1'10).

INDIANOLA, 500, VERMILION

MCNUT"T, JAMES CAITSON (b'78) - Mo.2 05 : (l'05).

ODBEIT, FRANKLIN N. (b’う̄)-Pa.2,'80 $(1,80)$.

WORTHINGTON, RICHAILD R. (b'52)-0.1, '74; (1'78)

INDUSTRY, 463, MCDONOUGH

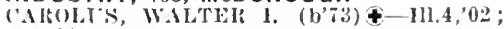
$\left(l^{\prime} 02\right)$.

strung, Fdwin Itilymond (b'90)-Ill.4,'13; (l'13).

INGRAHAM, 200, CLAY

Jayne, Wm. J.-Ia.1,'79; (1'79).

KNOWLES, HENIY BIAINE (b'85)-Mo.34 '11; (1'11).

Lewis, llarry overton (b'84)-Mo.28,'08; (I'08).

IOLA, 375, CLAY

C'ItUSE, CAIL, V. (b'73)-Mo.28,99; (1'99) Finch, Amos $13 \rightarrow$; (lit); not in practice Holson, lialpli R. - Ky. 1,91; (L'91).

llockman, Frank (b'79)-líy.5,06; (官).

IPAVA, 749, FULTON

SNIVELY, CHAS. D. (b'75) 4 -Ia.1,97; STOOI'S, PElili H. (b'63)థ-11.1,'86 ; (L's6).

IROQUOIS, 500, IROQUOIS

WEST, JOHN FIANK (b'80)£-III.22,'10 ; (l'10).

IRVING, 223, MONTGOMERY

CANAIAY, HOBT. N. (b'79) \&-Mo.34,02; (I'02).

Fullerton, Pierce J.-Mich.1,'79; (l'98)

PAKKHLL, W. VHCENT (b'5i)-Ho.10, 78; (17.6)

IRVINGTON, 223, WASHINGTON

Klostermann, Geo. Wm. - H Mo.5, 0 ; ; ( $\left.\mathrm{L}^{\prime} 0 \mathrm{~T}\right)$.

ISABEL, 225, EDGAR

COML"TON, SILAS MELVIN (b'7T)-Ind.20, 09; (13); Member Ind. State Med. Issin.

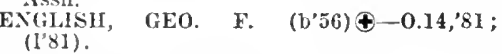

ITASCA, 375, DUPAGE

Schroeder, (ieo. Fred. C.-Ill.6,'05; (l'05). IUKA, 364, MARION

Birbee, Merle.

(See l'aducah, ky.)

Carneal, 'Thos. Edgar (b'85) - Ill.8.'13; (1'13)

Finn, Walter L, (b'75)-Mo.1,99; (1'99).

IVESDALE, 600, CHAMPAIGN

HICKS, SAMIL. J. (b'63)-0.9,'90; (1'90).

RICKETTS, MARION M. (b'it) क-Ill.22, 11 (l'11).

JACKSONVILLE, 15,326, MORGAN

ADAMS, ALBYN LINCOLN (b'65) $€-I I 1.8$, S6, N.Y.1,'89; (1'90); 871 W. College Are. ; offlce, 323 W. State St. ; $9-12,2-4$; (B1,8); OALR. *
BAliEl, KIVIN F. (b'42) $4-111.6,67$; (l'87) : 350 W. State st.

BAITLETT, AVIELILS T. (b'30)-III.1 62, Mo.2,7I; (1’7); not in practlce; $1215 \mathrm{~W}$. College Are.

BAXTEE, (iEo, lill: (b'71) - Mo.1,99; (1'99); 820 W. College Are.; offlce, Hopler I3lde. : 2-:: Pd.

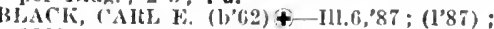
1302 W. State St.; offlec, Ayers lBank Blulg.; I :30-4; (Ai) : S $\star$

130WF, EinW. (b'73) \&-Ill.1,97; (l'98); St, $, 11-1,3-5$

BHAllEY, (iEO, It., (b'69) $+-110,28,97$ $(1,97)$; $314 \mathrm{~W}$. College Ave. ; $9: 30-11,2-4$,

CAIRIIL, HENIBY 1. (b'63) $\oplus-H .6,{ }^{\prime} 88$;

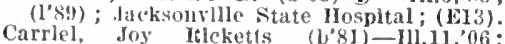
$\left(\mathrm{l}^{\circ} \mathrm{O}^{\circ}\right)$; not In practlce; Jacksonvllle State IIt)spital.

Clamplt. Louis H. (b'to)-Ky.5,'84; (l'84); 839 W. Norih st.

eb (b'49)-1a.1,97; (l'97): COLE, CHAS. \&. (J'79) $\$-111.6,03 ;$ (I’03) : 234 w. College Ave.; 1.

Cranc, Wm. W. (b’51)-0.1,75; (1'78); 223 W. College Ave. ; 8-1I, 2-5

ROLCII, ELMEIT L. $\left(b^{\prime} 69\right) \oplus-$ Mo.1,'91; (I':1); Ayers Bank Bldg.; 10-12, 2-5;

NAY, JAYES ALLMOND (b'69) \&-Mo.7, $90 ;\left(I^{\prime} 90\right) ; 844 \mathrm{~W}$. North St.; offlet, OAY, JOHN ELYSSES (b'82) \-110.28, 08 (1'10); $3101 /$ E. State St. 4-11 DEWEY, GRACE (b'63)-NÍd.7, 03 ; ( l' $^{\prime} 03$ ) 1123 iv. State St.; offce, 610 iv. State Dinsmore, Geo. F. (b'66)-Ky.1,94; (l'94) 303 W. College Are.

INSMORE, VIRGINIE (b'53)థ-H1L.9,'89. ( $\left.\mathrm{l}^{\prime} 89\right)$; $303 \mathrm{~W}$. College Avc.; $9-\mathrm{II}, 3-5$.

Dollear, Albert II. (b'76)-Mo.34, 04 ; (l'04) 806 s. Diamond St.; office, Ayers Bank BIdg. ; 2-4; (E4).

Doying, Enma X-Ind.8,01; not in practice; $921 \mathrm{WW}$. Grove St.

DUNCAN, WM. PERCY (b'78) -IIl.6,03 ; (l'03) ; 356 E. State St.; 11-12, 2-4.

(1'96); Jacksonvllle State Hospltal : NP.

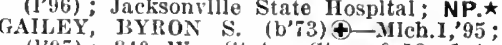
(l'97); 340 W. State St.; 9-12, 1-4; OALR.ネ

GRE(OORY, ABRAHAW ROYDEN $\left(b^{\prime} 78\right)(-$ Mich.1,07; (1'10); 825 S. East St. ; office 326 W. State St.; $9-12,1: 30-4 ;$ ÓAL. HAIRGROVE, JOHN WHTLOCK $\left(\mathrm{b}^{\prime} 56\right) \Theta$ Mo.1,'85; (1'87) ; 339 E. State St.; 1-4; S. $\star$

Hamilton, J. W. (b'5 $)-M o .1,80 ;\left(I^{\prime} 81\right)$; 610 S. Kosciusko St.

ARDESTY, TULLY O. (b'69)-Mo.27,'96; $\left(l^{\prime} 96\right) ; 7$ Duncan Pl.; offlce, 336 W. State St. ; $10-12,2-5 ; \mathrm{S}$.

HASKELI, HIRAMI ABIFE (b'62) - Ill.6,

, R.F. 2 .

Tenn. ‘,97; (l'02); 323 w. Morgan 2 $9-11,2-5 ; \mathrm{S}$

KING, ALLEN MASON (b'76)-Mo.28, 02 ; (l'02) ; $812 \mathrm{~W}$. State St. ; offlce, 323 w. State St.; $10-12,1-5,7-8$

State St.; 10-12, 1-5, 7-8,
LOWE, CHAS. REUBEN (b'79) $\oplus$ Mich.1, '11;(1'12); Jackisonville State Hospital; P. MeLin, Thos. Garfleld (b'82)-III.11,'10; (l'10) J Jacksonville State Hospltal.

MILIIGIN, JOSEPHINE $\left(b^{\prime} 60\right) \&-N . Y .14$, '89; (l'90) ; 1123 W. State St. ; offlce, 610 W. State St. ; 10-12, 4-5.

MYER, JAMES FITZWILLIAM (b'71) La.1,03; (1'10); $331 \frac{1 / 2}{1}$ W. State St. office, $333 \frac{1}{2}$ W. State St. ; 9-11, 2-4, 7-9; ObG.

NORBURY, FRANK PARSONS.

(See Springfield.)

FoRRIS, FRANK A. (b'82) $\oplus-111.6,03$; (1'03); Paclic Hotel; offlce, Ayers Bank BJdg. ; 11-12, 1-5; S.

OGRAM, ALFRED J. (b'58) $\oplus-0.6,{ }^{\prime} 83$; (I'83) ; 1106 W. Iafayette Are.; offlee, 326 W. State St. ; 9-4.

l'atchen, Clayton C. (b'64)-Mo.7,'92; (l'92) ; 304 E. State St. ; 9-12, 1-4.

IITNER, THOS. J. (b'42) $\oplus-$ N.Y.1,'69; (1'78); 1437 W. College Are.; offlice, 215 w. College Are.; $9-11,1: 30-4$. 
PONTICS, MINEIISA RLAII $\left(\mathrm{b}^{\prime} \mathrm{m}\right)+$

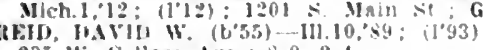
23\% W. College A tie.: 5 . 9 - 4 .

Sanford, Gea Hoyt-Mich I, fiv: ( In pracllee : 17 w. rillege st

SII'S, FHAXEE, (b'49) $\$-0$ :

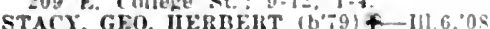
(108): $1106 \mathrm{s.Clay}$ Are; once, Huph (los): 1106 \& Clay

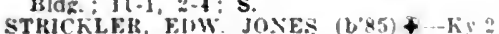
07: Asslstant Physlclan. Jucksonvile State IJospltal; Member Ky. Stuic Med Asan

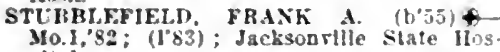
pltal.

THOMPSON, PFRRY C. $\left(b^{\prime} 50\right)+-I 11.1$. 83 (1'83): Iist W. College Are: ofly IV. State St: $10-1 \geqslant, 3-6$.

WAKEIX, THOS. I. $\left(b^{\prime}+2\right) \neq-111,1$, fis (17i): 321 s. Maln S6: oflce, $319=$ Maln SL; $s=9,1=2, i \cdot z$.

WEBSTEH, GEO. OMilit-Mu.34.04 (1'04); 352 Collego Ale.; oflce, Aler: Bank Bldg: 9-12. 2-5.

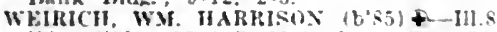
09: (1.09); ist4 S. MaIn St: o otce, 34 . W. State SL: $8+10,2-4, i-8: S$.

Tharton. Jos. E. (b'at)-la.b, 98 : (logs)

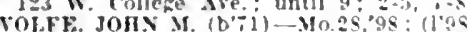

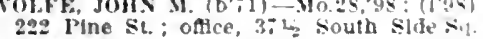
$9-12,2-5$

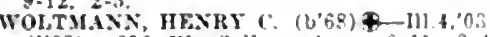
$(1,03): 216$ W. College Are.; 9.11 .2 .4

JACOB, 35, JACKSON

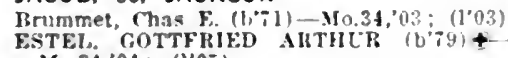
Mo.34.04; (l'05).

JAMESBURG, 25, VERMILION

Ras, Danl. V. (b'65)-la.1,'92: (l'92)

JAMESTOWN (R.F.D., POCAHONTAS), 150 CLINTON

IIotiw. Fred E. (b'73)-IIo.2:,9s; (1'99).

JANESVILLE, 300. CUMBERLAND

HARWOOD, CLARENCE HCGII (b'SZ) + KY.2,10; (1'10)

JEFFERSON (INO. STA., CHICAGO), COOK (SEe Chlcago.)

JEFFERSONVILLE, 237, WAYNE

HILLIAMD, WAVID ALEX $\left(b^{\prime}: 2\right)+-M 0.34$ 02: (I'02).

JERSEYVILLE, 4,113, JERSEY

BARSETT, ALIEX A. (b'30)-Ky.2,:3 (1'iz)

Harry, Edw. I. H. (b.3s)-111.1,60:(17\%)

not in practlce.

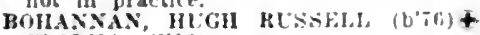

Bll.17:04: (l'05). Francis (b's0)-.110.7.0s Bray.

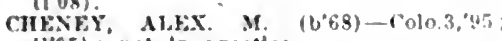
$(1 \cdot 95)$ : not in practice. (l'95): not In practlce.
boyle, Eredk. Murray (b':5)-Mll.11, of
(1'03).

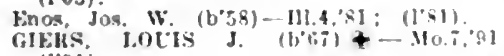
(1.91).

GLEHHILL, IIFAH HOIBT, $\left(b^{\prime} f(\theta)+\right.$

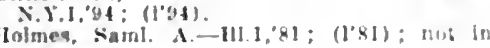

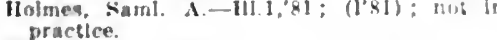

II practice.

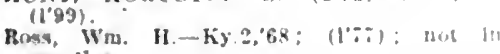
practlce.

Shote. A. K-Mo 3,69: (1\%7)

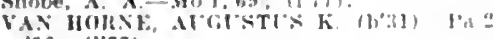
sh: $(1 ; 7)$

Wakgoner.

JEWETT, 366, CUMBERLAND

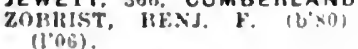

JOHANNISBURG (R.F.D., VENEOY) 100 WASHINGTON

Klostermann, Alwill 1.-Mo.5,06: $11^{\prime}(b)$

JOHNSONVILLE, 225, WAYNE

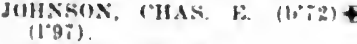

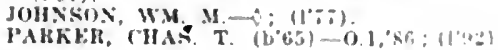

JOHNSTON CITY. 3.248, WILLIAMSON

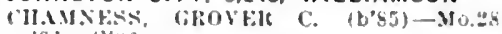
$\left.0 r^{\circ}: 1100\right)$

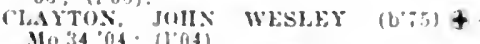

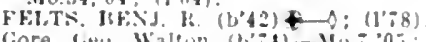

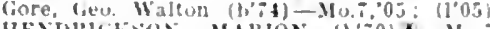

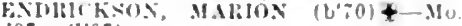
$28 ;(1.9 i)$

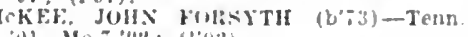

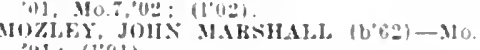
"41: (1०91)

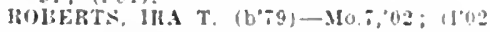

JOLIET, 34,670. WILL

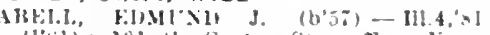

(1's1): 201 \& Cunter St.; once, lound Mild. : $111-12,2-4, \quad i-8$

hidwin, llerbert h. $\left(b^{\circ} 57\right)-111.6,83$

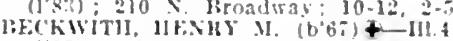

(1)9i): 325 Huell Ave, ottice, Harber I!!dg: $10-12,2-4$

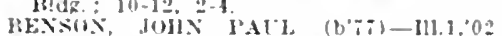

(1.02): 1is $\mathrm{x}$. Center st. "oftlce, state I'enitentiary.

HWWEs, MIRION K. (b65)-1119,94

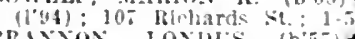

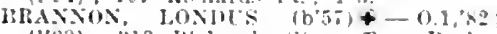
(1's3); \$13 Hichards st: oftec, Rarbé lidit.; $10-12,2-4, i-5$

Brinckerhor, Erank Erwin $(490)-$ Ill.1I, 13: (1'13): 203 (thleaso $x$

LIXE. IAMES A $\left(b^{\prime} 60\right)+-$ X.1.3, 86

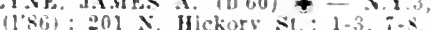

Cohenour. Vincent Jacob (6,73)-11l.6,01 (1"01): 311 Tulon st.; ciftlee, 924 collins -1. $2-4,7-6$.

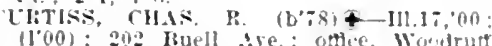
Hldz: $10.72 .-1, \cdots: U$.

('TIIIX, MARTIX W. (b52)

(1'92) : Natlonal Bank Plde

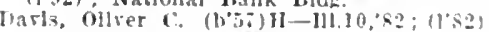
the Richards st.; OAlle, 323 Jetfersun st. in $-12, \cdots-4,-8$

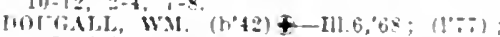
$30 \%$ inton si: : $8-1$ ?

FLIIRED, CIIAS C. (D't9) \&-I'3 275

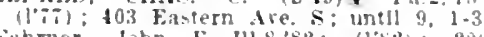
Fahruer, John-E-III.S, $82 ;(1-2) ; 200$

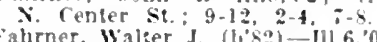

-16 oneldat 9-12, 2-4 $\approx-3$

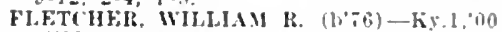
(1001); Natlonal bank Bllt.; 2.4 .

Flecer, Howard Norton (1,89)-III.11,12 (1.12); 210 (ampbell st.; ntice, 113 is Jefrerson st. : $10-12,2-4, ;-8$.

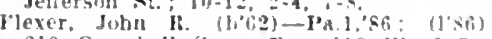
210 Campbell st. ualce, 113 W. Jetrer sun St: 2.4 : $: 8$

Folk. Julius is (b'45)-1116,69: 110 in practlee; 11 Favern die

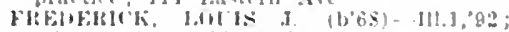
(1) ; ins Herklmer Si

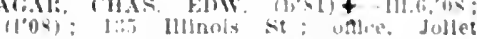

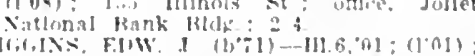

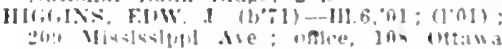

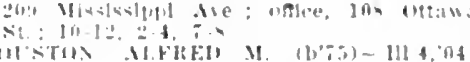

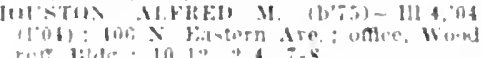

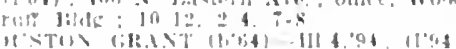

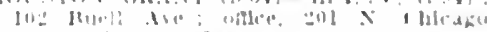

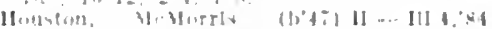

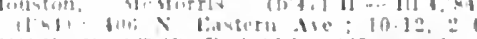

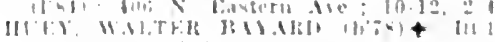

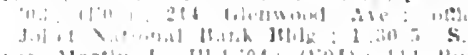

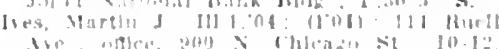
1 1. : s.

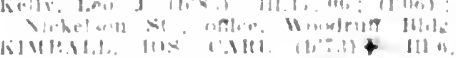

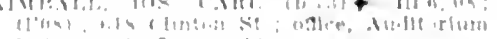

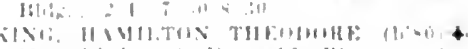

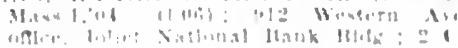

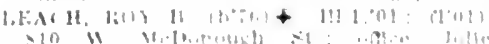

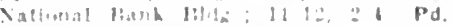

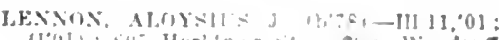
1101); d11; llerh!nte in a Wirdrut lidg.:-1

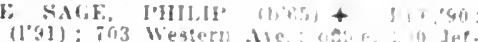
ferson st. : J1)-12 "z t

MrGis:is, "IIII.J)

(l'(10): :200 liardner

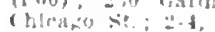

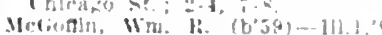

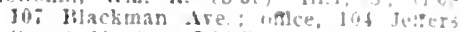

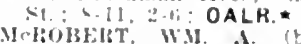

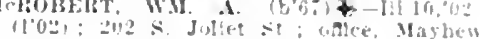

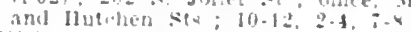

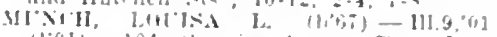

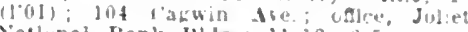
Natumal Fank Hlele: I I-1

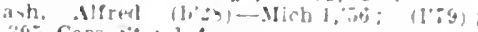

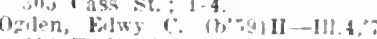

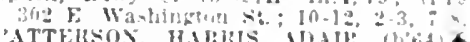

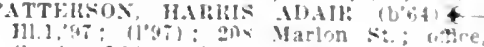

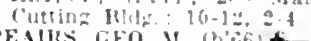

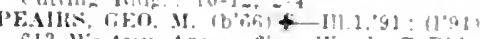

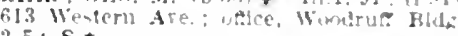
$2-5:$ S.

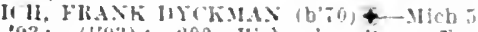

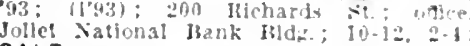
OALR.

RICHAR.

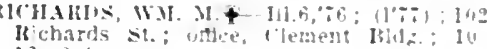

ROBERG, FREDK. FMASLFL (b'<214

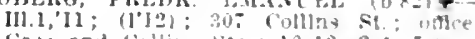

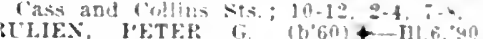

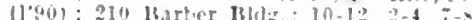
sarrela, IIerman Louls (bis)-111.11, 1? (t) flo rollins si

schuessler. Auzustus Win. (b'si)-111.11,08 (105): 11 i

soluessler, Henry li-lli.11, ye: (I*9s) $602 L_{2} \times$. Illchory Si: anjce, Hilctory and Exchange sts: $10-12, \cdots-1$

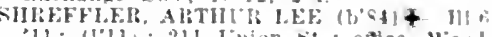
11: (1'11): 211 Thion :t.; oflce, woul rutr Billz; : $2-4: S$.

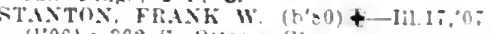

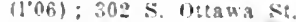

STREX, E.lR1, R. $\left.(1)^{\prime 3}+-1111,99: 1109\right)$ 30 sterling Are; oalee, Womlruf Bha

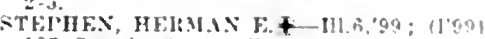
105 Cazmin the.; oftlie. 207 letrersou si $2-4$.

stephens, dennle farr-111s.s., 111.4:

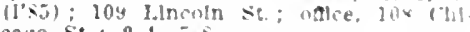

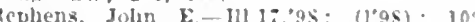
lindholn si: ome, $10 ;$ : Ortana

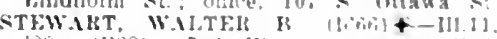

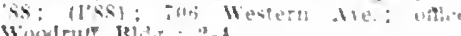

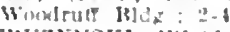

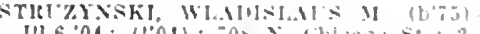

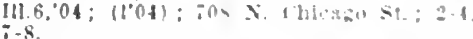

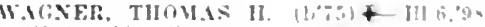

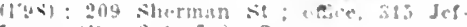

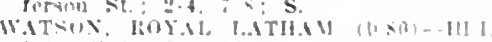

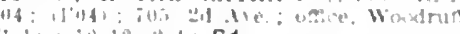
liuls: it is \& $1: P d$.

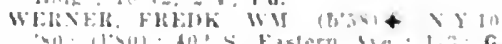

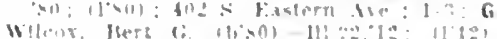

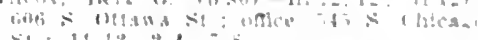

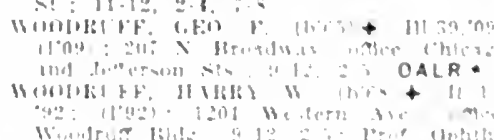

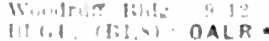

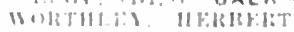

JONESRO1RC. I.169, UNION

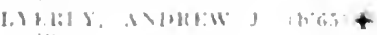


SANIPERS, KARL D. (b's0)-Mo.22,'0S; (1'08). Wm. G. (b'53)-Jud.s,82; (1'82) ; Whilte,
D.

JOPPA, 734, MASSAC

Uutchluson, Robt. W. $\rightarrow$; $\left(l^{\prime}, 8\right)$; not in practlce. TILS, W. (b'72)-Mo.7,98

(l'98).

TUCKER, CHAS. ENW. (1)'68)†-Mo.t,'92 (1'92).

\section{JOY, $5 \mid 6$, MERCER}

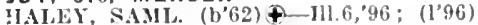

JUNCTION, 300, GALLATIN

Versblumer, WM. C. (1)67)-IH.1,96; (1'96)

KAMPSVILLE, 506, CALHOUN

Lumley, Zoda I\%. (b'82)-Nt0.2,05; (1'05).

SKEFL, W. A-Mo.7,91; $(1,91)$

Woltmann, Fredlerlck-III.4,03; (1'04).

KANE, 521, GREENE

FEYITY EDW W (b'61)-I11.6,'85: (l'85)

FolEMÁ, CLAUDE BERNALD-Mo. $7,9 \tau$ (1'97).

PROCTOR, EDWIN G. (b'55)-M(1.3,'82; (1'82).

KANEVILLE, I50, KANE

IIARDY HIRAM TENNEY (b'38)\&-N.H.I, 66 ; $(1,77)$.

KANKAKEE, 13,986, KANKAKEE

rustrong, Chas, A. (b'68)-J11.10,96 (lag) ; 39 S. Wearborn Ave.; offlce, 274 E. Court St. ; $1-3,7-8$.

BADGER, PAUL RAYHOND (b'7)๑-H1.1, $04 ;(105)$; 10 Matn st. ; $7-8,2-4,7-8$.

Banks, James llarvey, (b'60)-Ja.9,'92; III.I1.97; (l'92).

Bedard, Uiric A. (b'66)-Hll.1,94; (l'94) 3 Il S. Indiana Ave.; offlce, 138 Scbuyler Are.; $1-4, T-8: 30 ; \mathbf{N}$.

Bergeron, Eugene D (b'59)-1116,'81. (1'83) ; 705 Cobb Blvd. ; offlee, $226 \frac{1 / 2}{2}$ Court St. ; $11-12,2-5$

BROWN, JOIIN ARCHIBALD $\left(b^{\prime} ; 0\right) \oplus$ Que.1,93 (1'93) ; 464 Station St.; oflee, 175 Court st.; $I-4,7-8 ; S$.

Brown, Vlolet Palmer-Ili.9,98; (l'98) ; 464 E. Station St.; offlec, 175 Court st. Anes. $\star$

BUNDY, JAMES A. (b’57) $\oplus$ - Ia.I,'85; (l'85); 119 Harrison Are.; offlce, $2421 / 2$ Court st. (1'05); 395 Harrison Ave.; office, 178 Court 395 Harris

CARON, TELESPHORE E. (b'65) †-que.3 "91; (1'96) ; 249 Dearborn Ave.; offlee, 212 Merchant St. ; $7-9,1-3$.

Carroll, Elizabeth D. (b'80)-Ill.11,'10 ; (1'10); State Hospltal.

CHAFFIX, CIIAS. PROWSE (b'\%3) $111.23,06:$ (1'06); Powell Bldg.; oflice, 292 Court St.; 10-12, I-4, 7-8; G.

Conk, Walter C. (b'Si)-0.1,'03; (1'13): State Hospital.

CORICS, HOWARN I. (b'68)థ-Pa.12,'92; $\left(l^{9} 94\right): 247 \times$. Indiana Ave. ; office, 206 s. East dre. : $10-12,2-4, i-8$.

Deppe, Arthur H. (b'88)-Illo.2,'I0; (l'11) ; Kankakee State Hospltal.

Eshbaugh, Aaron S. (b'59) II-Ill.4,'86 (1's6); 130 S. Rosewood Ave.; offlce, City Xatl. Bank Bidg. ; 11-12, 2-5, 7-8.

Freemmel, Harry Jos. (b'83)-Ill.11,'12: (l'I2); Kankakee State Hospital.

GAGNON, ARTIIUR L. (b'i4) \-IIl.I, 00 (1'00); $5 \mathrm{I} 6 \mathrm{~s}$. Chicago Are.; offlee, Cobb (l'00); 516 s. Chicago Are.

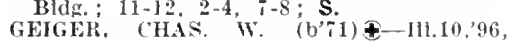
Ill.11,04; $(196)$; 949 Chicago Are. ; ofthe Cobb Bldg.; 9-1:, $1: 30-4: 30$; Prof. Otol. Rhin. and Laryn., Ill. G. 4 ; $(\mathrm{BI}, 8) ;$ OALR.

GERNON, JOHN H.૯-Ill. 1,$72 ;(1 ; 7) ; 241$ S. Chicago Ave.; offlee, 144 Court st. $0-11,2-4$.

Gollmar, Arthur 11. (b'-2)-Ill.1, 00 : (1'00) 37 s. Indiana Are.

Greenman. Ernest Nelson (b'85)-Pa.2,'I2 (1.12): Cobly Bldg.

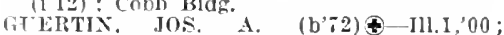
(I.01) ; 205 Wildwood Are.; offlce, Cobb litd : $1 \mathrm{I}-12,1-4, \mathrm{i}-\mathrm{s}$

I1 amllton, Edwin C. (b'60)-0.3,85; (1'93) ; 321 learborn Ave. $7-8,1-3.6-8$

Hamilton, Fredk. C. (b'70)-Ill.6,'93; (1'93)

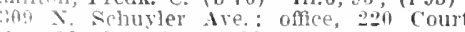
$10-12,1-4,-1-8: 30$
110) I'SE, ARTIILR N. (b'66)-H11.1,93; (194); 327 Indlana Are.; offlee, Bank Bldg.; 10-12, I-4, $;-8$. KLLLY; I'ATRICK' M. (b'60)๑-Mo.2,'92 ; (t'92): State llospltal.

LEE, GEO. HARVEY-III.8,'83; (1'85); 161 Chicago Are. : oflce, Cobb $13 \mathrm{ldg}$.

LOCKWOOD, CIIAS. RICHARD $\left(b^{\prime} ; 6\right)-$ Ill.11, 02 ; $(1,02) ; 125$ N. Greenwood St. ; ollice. ('ity Natl.' Bank Bldk. ; 9-12, 1-4.

lowenthal, Allert $A$

(Sec Chleago.)

MURHAY, WARILFN GARFIELD (b'82) \& $0.25 .^{\prime} 06 ;\left(l^{\prime} 08\right)$; State IIospltal.

O'LOUGHIIN, WANL. JOS. (b'80)థ-I11.6, 04; (1'05); $25 \%$ N. Schuyler St.; offlce, 175 Court St.; 9-12, 1-4; OALR. *

Phelps, (r. II. (l,58)-I11.11,'85; (1'85); 210 Greenwood Ave.

PRATT, ELCEN C. (b'84)-Wis.3,'08; State Hospltal.

kiley, Wm. Ilenry (b'87)-111.1,'I2; (1'12): Cobb Bldg.

ROY, JOS. HERCULE (b'61)๑-Ont.4, 86 ; (1'92); i45l E. Court St.; offlce, 177 E. Court St. ; $8: 30-9: 30,2-4$.

SCOBFY, ALFRED W. (b'68)-Ill.1,95; (1'97); 641 Chlcago Are.; offlce, Granger Bldg. ; $10-12,1-3$.

SMITII, CHAKLES F. (b'50)థ-0.9, $7 \mathrm{~s}$ (l'78) ; 859 S. Chicago Ave.; offlce, Bank Bldg. ; 8-10, 1-3, 7-8.

SMITII, CHIS. KENNETH (b'83)-Ill.11, 06 ; (l'06); 859 S. Clicago Ave.; oftlce, City Natl. Bank Bldg. ; 10-12, 1-3; R.

SPENCER, ORSON BAILEY (b'45) 0.7 ,68: (l'7): $162 \mathrm{~N}$. Dearborn Ave.

URAN, (l'7): $162 \mathrm{~N}$. Dearborn Ave. (l'78) ; 341 pearborn $\mathrm{st}$; offlce, $1881 / 2$ Court St. : $7-9,12-3$

WAY, SPENCEIR J. (b'51)-IIl.1,72; (1'77) ; 256 schuyler St. : $8-9,1-4,7-8$.

MILKINSON, JOHX RAYMOND (b'77) Ill.4,'11; (1'11); 795 S. Wildwood Ave. : office, 130 East Ave.; 10-1 I :30, 3-5.

WIISON, ERNEST G. (b'84)-Ind.18,06 (l'06); 248 Dearborn Ave. ; offlce, I96 Court St. ; $9-12,2-5,7-8$.

WILSON, WM. IIENR' (b'59)-1a.1,88 (1'94) ; 877 chieago Ave.; offlce, City Natt. Bank Bldg. ; 10-12, 2-5; OALR. $\star$

KANSAS, 945, EDGAR

EPPERSON. JOIN CLIFTON $\left(b^{\circ} 49\right) \$$ Cal.1.'82; (1'86)

Hite, Jos. F. (b'58)-Pa.1,'85; (1'92).

Ickifiti, ROY H. (b'81)-Ill.23,06; (l’06).

Roberts, James B. (b'75)-Pa.1,02; (1'03).

KARBER'S RIDGE, 300, HARDIN

Vinyard, Silas $\left(b^{\prime} 76\right)-K y .2 ; 09 ;\left(l^{\prime} 09\right)$.

KEENES, 220, WAYNE

DULANEY, WM. A.-Mo.34,'05; (1'05)

KEENSBURG, 405, WABASH.

LOVELLETTE, IIARKY R. (b'69)-Ky.5,'93; (1'93).

MANLEY, RICHARD SABINE (b'79) Colo.5,05; (l'06).

PARMENTER, B. (b'81)-Mo.28,'09; (l'09). KEENVILLE (R.F.D., KEENS), 75, WAYNE Melton, Nathan W.-E-Mo.10,'S3; (1'83).

KEITHSBURG, I,5I5, MERCER

Allen, Joln S. (b'51)-Ill.4,77; ( $\left.{ }^{\prime} 77\right)$

CHILDS, AUGUSTINE BEN (b'80)థ-Ill.1, '08; (i'08).

COE, TRUE DELOSS (b'60)(-III.1,'84;

Willits, Azro P' (b'50) $\longrightarrow$; (l's1).

KELL, 300, MARION

ALVIS, EDW. C. ( ( $\left.{ }^{\prime} 71\right)-M 0.7,05$; (1'05).

SIMMÓN. JOHN ALVA (b'81)-Mo.28, 07 (l'0T); Ob.

KELLERVILLE, 75, ADAMS

BROWN, ELWIN OTIS (b'83)†-IIl.22, 09 ; (1'09)

KEMPTON, 500, FORD

Gilborne, Henry B.-H-Pa.9,'72; $\left(l^{\prime} 77\right)$.

KENILWORTH, 88I, COOK

BROWN, SANGER

(See Chicago.)

BROWN, SHERMAN-N.Y.1,02; (1'12) Menber Med. Soc. of the State of X. Y. Case, Calvin $\mathrm{s}$.

(See Chieago.)

riscoll, Katheryn T.-Mass,6,0i;
Ererett, Henry II.

(See Clicago.)

MARTIN, FRANKLIN II

(See Chlcago.)

SNYUACKEI, FHANUEL,F.

(Sec Chlcago.)

Stearns, W'm. Marion.

(See Chlcago.)

TOL1, IUUY' B. (1,75) $+-111.10,97$;

WHKFIR, HERBEITT.

(See Chlcago.)

KENNEY, 600, DEWITT

COLE, BLRT R. (b'84)\-Ky.2,09; (l'09)

CRAIt, WM. M. (b'57)-M0.1,87; (l'87).

KEWANEE, 9,307, HENRY

'aser. Clycle 1. (b'89) - Ill.11,'13; (1'13).

COFFix, ('IIAS. ALBERT (b'79)†-ILI1, 04 ; (l'05).

('OLE, WM II. (1,36)-N.Y.8,73; (1;7).

DUNCAN, GEO. 13. (b'54)-Ill. I4,'96; (1'96).
FISCHER, HAYDN LYLE, (b'84) - 111.6 , 03; (1'09); $\mathbf{S}$.

HEAI'S', WARIEN T. (b'79) \$-Mo.34, 06 ; (1'06)'

HEFIIN, II. NELSON (b'64)థ-Mlnn.5,'95;

HOFFMAN, GIDEON H, (b'71)థ-0.6,'98; (1'00); $\mathrm{S}$.

HOHMANN, WM. DANL. (b'67)థ-Md.4,

LowE. FriNCIS o. (b'61)-H11.11,'86; (1'86).

MANKIX, FRANK D.-0.2,93; (1'95).

MCDERNOTT, PETER J. (b'72) ( 9 -Ia.3, 04 ; (l'05).

MELAIK, HATTIE B. (b'68)-Ia.9,97;

NOREN, GUNNER P, (b'68)\$-Ia.9,'98;

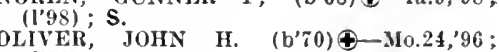
OLIVER

O'Malley, Wm. H.-Ill,11,'93; (l'98).

Pratt, Sidney G. (b'79)-Mo.34,06; (1'06) : not in practlec.

SMIILEY, FRANCES M. (b’6I) $\oplus-111.1,7 y$; (l'81).

STEWART, HARRY J. (b'68)థ-Ill.6,'93; (1'93). (l'99).

\section{KEYESPORT, 670, CLINTON}

MECKMANN, ERNEST (b'69) \&-Mo.1,9i; $(199)$

Ou Conb, James Wllson (b'72)-Mo.28,05; $(1,05)$.

Ducomb, Mirza Phillip-Mo.28,05; (1'05).

KICKAPOO (R. F. D., EDWARDS), 200 PEORIA

ROLLINS, GEO. E. (b'62)థ-Ill.1,'84; (1'92).

KILBOURNE, 400, MASON

ROOT, JACOB W: (b'45)@-D; (1'78)

KINDERHOOK, 370, PIKE

DECHOW, PHILIP HERMAN $\left(b^{\prime} 77\right) \oplus-$ Ia.10,06; $\left(1^{\prime} 07\right)$.

Gose, Chas. Jones-Mo.1,'99; (1'99); not in practice.

Penlck, Mark (b'36)-E-0.2,'65; (1'78).

KINGSTON, 305, DEKALB

BURTON, EDGAR CURTIS (b'83)-Ill.6, ; $(107)$

\section{KINMUNDY, 997, MARION}

CAMIERER, JOHN DOUGLAS $\left(b^{\prime} 57\right) \oplus-$ Ill. 1 , 80; (l'80).

MILLER, 'IUGO (b'64) -Mo.24,'95; (I'98). SONGEK, FREDK. S. (b'74) $4-M 0.27,97$;
$\left(1^{\prime} 97\right)$.

KINSMAN, 350, GRUNDY

ICGocy, Jos. A. (b'76)-Ill.11,04; (l'03)

KIRKLAND, I,000, DEKALB

REEDER, (;RANT S. (b'85)-Ill.1,11; (l'11).

Spiers, R. B. (b'45)-J11.8,78; (1'78).

KIRKWOOD, I,008, WARREN

ALLEN, JAMES I. (b'62)-Ia.1,'90; (1'97).

(hickering. Geo. A. (b'86)-Ill.11,'12; (1'13).

MCCLANAHAN, JAMES M. (b'50)-Ill.6. $74 ;(177)$.

KNOXVILLE, I,818, KNOX

BECKER, LOUIS (b'64)@--11.6,'88; (1'89). Giles, Henry Wyley (b'61)-Ia.9,'95; (1'95). H.RMS, ARTHLR H. (b'80)-Ill.1,04; (l'04). TIOMSON, THOS. W.-Ill.1,03; (l'03). 


\section{LA CLEDE, 200 FAYETTE}

LA CLEDE, 200 FAYETTE (1'96).

LACON, 1,495, MARSHALL

Bradford, A. Wre. (b'74)-I11.11.95: (1'65)

Eberleln, Fredk. Walter $\left(b^{\prime} 60\right)-111.1,86$; (I'86).

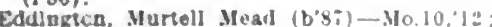
(1'12): ObG.

FDDINGTON, ROYAI, LACEI+Mo.".8 $00:(1,00): S$

POTTS. JOHX W. (b'45)-0.2:?1: (17i).

LADD. 1.910, BUREAU

BUTI,ER, J. P. (b*54) $+111.4,90 ;(1 ' 92)$.

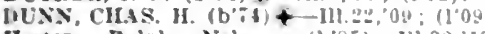

Hesier, halpb Nelson (b's5)-III.22,'13 (1'13).

O'Shay, Franklın J. (D'62)-111.1, $\$ 9 ;(1 ' 92)$

LA FAYETTE, 300, STARK

BRAND GEORGE JACKSON (b'86) — III. 17:10; (1'10).

LA GRANGE, 5.282, COOK

BROWX, WM. D. H

(Seo Chlcago.)

Carey. Warren (b'49)-Ill.1,'83; (1'83) Dey, Wm. Frederick Imrie (b.82)-Ont.1.

EHRMCAN. FREDK. J. F.

(See Chlearo.)

GUILFORD, PAUL.

(SEOChlcago.)
HARVEY, ANDREW MAGFF.

(See Chlcazo.)

HAWLEY, CLARK W.

(See (rileago.)

IIgeins, Arthur E. (1,69)-111.1.'96; (1'86)

Lemon. Wllls S. (b'Ts)-Ont.1,05; (l'09)

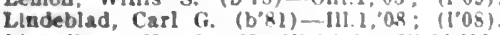

Llewellyn, H. S.-II-III.4."2, III.In,"93;

MCCLURE, CHAS. F. (b';2)-Pa.1,99 $\left(1^{\prime} 99\right): \mathbf{R}$

Morgan, Ricbard Hasward (b'8I)-Mlch I loren: (1'12).

Raschke, Emil H.

(See Chlcago.)

Alebardson. Frank M.

(Seo Chleago.)

SECOR, EDW, THOMAS (b'84) + III $2:$ OS: (1.08); NP.

SLAY'AK. WIJHELMIN $\left(\mathrm{b}^{\prime} 84\right)+$ III. 10 : $\left(l^{\circ} 10\right)$.

Sterens, Fred W.-IU.I1,06: (l'06).

LA HARPE, 1,349, HANCOCK

ASU, JOHS C (b'68) +-IIL.1,99; (I'99)

BFACOM, DANI. FISIELI (b'6I)-111.I,94 (1.94).

Buhrmaster, Edw, w. $\left(b^{\circ} \times 0\right)-M 0 . ;, 05$; (1'05).

Dennis, Farl Bently (b'i4)-Tenn.5,0l, IIl.23,05: (1'05); G.

Martln, Isaac M. (b'53) II-IIl.4,"3I: (l'8l)

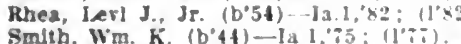

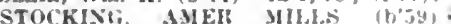
IJI.11,"10: (1"II).

LA HOGUE, IIO, IROQUOIS

lockwood, I. O. (b't9)-la.1,'so; $\left(I^{\prime} 90\right)$ not in practlec.

LAKE BLUFF, 500, LAKE

Littlejohn. James Huchan (see Cblcagn.)

Litlejobn, J. Martin.

(See Chlcago.)

LAKE CITY, 200, MOULTRIE

loesch. Geo, Edw (1,63)-Ky?.42; (1'9.1)

LAKE FOREST 3,340 , LAKE

Conulletse, Wllliam F: (b'32) $(2,05)$

III. 4.4,

$(195)$

SKE:, C;EO, F

(See (hlessu.)

French, firo. ti, $\left(b^{0}, 0\right)$, o $1, \because$ to $\left.11 \%:\right)$

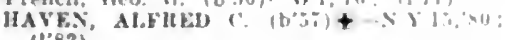
(1'82).

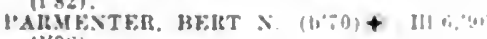
(1.88).

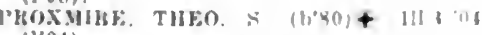
(1'04).

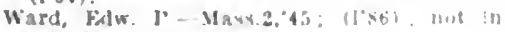

practlee.

Withors, liabrle! Harold.

(see ihlcaro.)

LAKE FORK, 100, LOGAN

IDenlouI], l.e. I. (b)
LAKE VILLA, 330, LAKE

TM.HOTT, CIIAS. W. (b'51) - HII.'S $(2,83)$.

LAKEWOOD, 82, SHELBY

Eddy, James H. (6.63)-III.11.89: (1.89).

Foose. ('asper Hartman (b'i3)-Mo.34, 05 (1005)

LAKE ZUR!CH, 304, LAKE

WMIIINGTUN, AJGERNON

$\left(b^{\circ} 82\right)+-111.29,12 ;\left(1^{\circ} 12\right)$

LAMOILLE, 576. BUREAU

HEMSISLIBG, JOS. L. (b'4)-1a 4, is \{l's?

WIMAN, LOUIS II. (L"Ti) $\$-$ Ind 8,04 (1'04).

LANARK, I.175, CARROLL

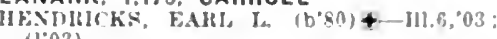

PACKARD, THOS. I. (b'65) - $111.1,95$ (1'95) Wales, Ilbers H. (b'66)H-I11.10,'8., 111.13.

LANCASTER, 200, WABASH

Brines, Fred Ilarrison $\left(b^{\circ} \$ 0\right)$ - III.11,'II; (L'11).

LANE, 200, DEWITT

DEAN, GF, ALMARION (b'T8) 05: (1'06).

LANSING, 1.060, COOK

Potts, Wm. Anthony (b'79)-W's.3,08;

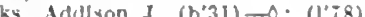

LA PLACE, 250, PIATT

Hunsaker, Curtls Arthur (b'87)-Ill.11.08; (l'0s).

WILHLMY, ORVILLE (b'8t) t-M0.28, 0 ; : $0 \%$ )

LA PRAIRIE, I82, ADAMS

IIUSE, JOIIN FILFDK. (b'79)—- MO2."96 I"(0)

LAROSE, 200, MARSHALL

EALTMA., JOEI. A (b":9)--III.2,"10 (I'10).

LA SALLE, 11,537, LA SALLE

Burke, Ednund Joseph (b's)-Ill.1,13 (I'13); SI7, ith st.; once, $163 \mathrm{Mar}$ quelle st: $2-\bar{y}$

BLKKF, I'ITRICK MLRICE (b'54) +

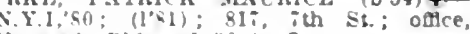
Neustadt BldF. : I:30+4; S.

CROWLEY, JOHX FRIXClA $\left(\mathrm{b}^{\prime} 68\right)$ \& III.11,00; (1'00): 536 Gooding st.; once, 603 , Ist st.; 9-10, 2-4.

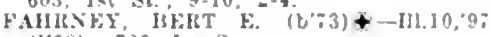
$(1.38):-30$, Ist St

FRASER, WM. II. (b'39)-Que. I, $6 \tilde{a} ;\left(l^{3} i\right)$ 655 , 5th St: ottre, 131 Marquette st. $10.12,3.5 ; s$.

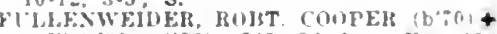

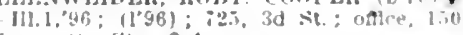
Mariquette St. ; $2-1$

MFIVES WAITES WOOD $(1,5)+$ III. 11,03: (1.03): 660 Huch

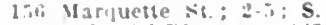

G'TIMIN, FItED A. (b'2) +-111 1.96

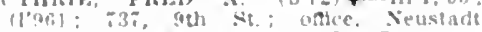
11410 9.10 .

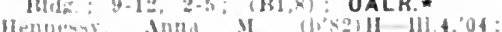
(I'n)

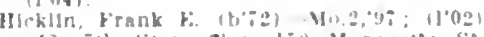
ato, ith st: udo, dio Marquatse si Q.12, $1-5, i-8$

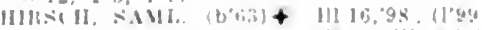
Maclejewsil, Follx J $11, \times 41,111.22,11$

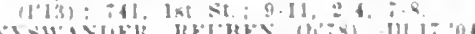

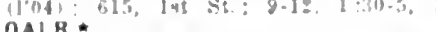
OALR*

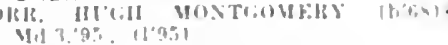

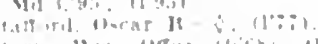

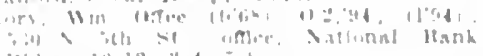

$1311 \mathrm{~L}, 119 \cdot 12 \div 1 \div$

LATHAM, \$29, LOGAN

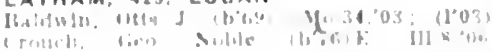

LAURA. 105. PEORIA

DATIHERGNE. COOK

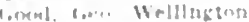

Sien lownon
LAWRENCEVILLE, 3.23\% LAWRENCE

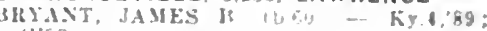

ONXF'TT, JAMES EUIING,THS G62, Ind I1,33; 11'83)

COOLEY, EVFRETT M.-KY.l "39

French. Zebs D. (b's:)-la $1, b^{\prime \prime}$

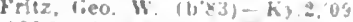

(iORINOS, HALH L.

rOKF, VIAS. I'. $\left.\left(b^{\circ} 90\right)+-1111.05 ; 1105\right)$

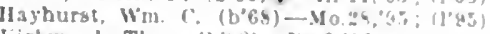

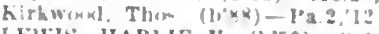

I.F"WIS, IHARLIE V. (b'J0)— $40 ;\left(L^{\prime} S 0\right)$

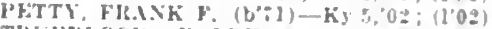

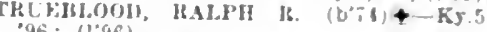

LEAF RIVER, 507, OGLE

HOWFRMAN, HC'(;M L. $\left(\mathrm{b}^{\prime} 74\right)+-11 \mathrm{4}, \mathrm{O}^{\circ}$ (1'9:)

KRETSINGER, JOSIAH T. $\left(\mathrm{b}^{\prime} 43\right)+-\mathrm{Y}$ Y 10 , (T)

LEBANON, 1.907, ST. CLAIR

BHISRY. ROY CIIFFORD $\left(b^{\circ} 86\right)+110.34$,

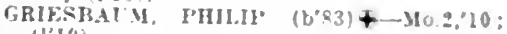
III Io)

SCRTGis, JOHA B. (bei) - Mo.7.98;

$\left(l^{\prime} g(x)\right.$; nor in pracrice.

LEDFORD, 599. SALINE

OZMEST, FREEMAN H. (b'B3)-\$O.:09: (l.09).

LEE. 300, LEE

HEDIUER, IHAVT
III.6,09; 11.09\%.

LELAND, 800, LA SALLE

CHAPMAN, WM. E. (b'05)-III.,04;

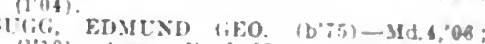
(l'io): Assoc. I'ru?. Seur., III.29.

LEMONT, 2.284. COOK

(auldwell. Earl Wm. (b'S3) - IIS, 11; (1'11)

Lealyy, Juln J. (b'6.3)-M1.1, $85:\left(1^{\prime} 965\right)$.

Ludwl., John B. (b'66)-I11.8,'93; (1'93).

LENA, 1,168 . STEPHENSON

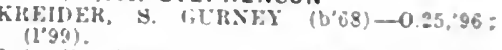

leltrell, (has F. 1b93)-Md 3.82: (1'33). S.ILTEI, ALLES (b'64) +-111.11.,93: (133)

LENZBURG, 463. ST. CLAIR

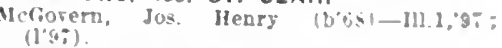

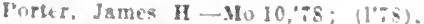

LEONORE, 500, LA SALLE

SICKI.EY, FHEI) L. $(6.66)+$ HLI:,04; (l'04).

LERNA, 396, COLES

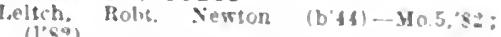

ANATTA, HABIS BRINCOE (b\%i) Ind $a, " P b^{\circ} ;\left(I^{\prime} y_{0}\right)$.

LEROY, 1,702. MOLEAN

BUNNFT, JUIIN Y $\left(b^{\prime} / 3\right)+-10 d .5,96$ :

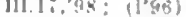

keys, Thumas w. (2035) la 1,:8; (1.3):

not in practice.

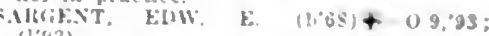

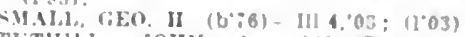

TrTIIIIL, JOIIX A (bos) + IA 3,51 :

LEWISTOWN, 2.312, FULTON

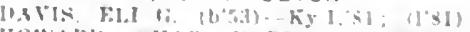

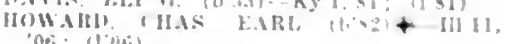

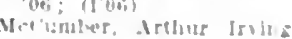

(1)

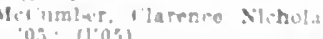

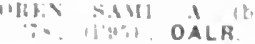

OH, OALR.

OALR.

OALR

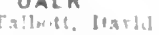

LEXINGTON, I, J1R, MCLEAN

Ibul| $F$ Varil

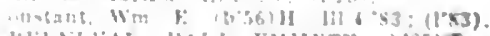

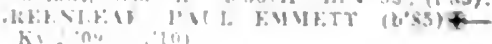


11.1MALRS, LEWIS JOS. (b'7i) - -111.11, 02: (l'02)

I'erry, Herbert B. (b'59)-Ill.16,'96; (1'96i)

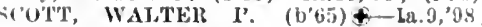
(l'98)

WILLIAMSON, WM. T. (b'64)-Ky.2,'86; $\left(l^{\prime} 88\right)$

LIBERTY, 499, ADAMS

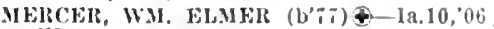
(l'06).

LIBERTYVILLE, 2,000, LAKE

CIIUIKC'IILL, AIFIKED H. (b' $/ 3) \uparrow-111.6$, 99: (I'09): OALR.

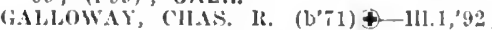
(I’92)

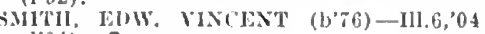
( l’04); Op.

Stephens, chas. $\mathrm{N}$.

(Nee (lalcago.)

SWEETIN(i, GETTA CATER (1,72)MInu.4,01 ; (l'02); not in practice.

TAYHOK, JÓIN HINCOLN (b'65)t-Ill.1 94; (1'94).

LICKCREEK, I00, UNION

Bird, Edwin E.-MIo.7,03; (l'03)

Gourley, Andrew J.-Ky.1,'90; (1'90).

LILYLAKE, 100, KANE

TAYLOR, RALPH C. (b'69)†-111.11,'97; ( I'97).

LIMA, -, ADAMS

PAIKEIt, FIANK B. (b'72) †-1a.9,'93; (1'95).

LINCOLN, 10,892, LOGAN

ANDFIESON, BERTHA OLIVE (b's3)Kan.2,'11; (1'11) ; 226, 3d St.; oflice, $502 \frac{1}{2}$ Broadway ; $8,8: 30$.

BRADHUHN, BENJ. P. (b'65)€-Ia.1; y (I'0I); 445 N. Unlon St. ; oftlec, 510 'ekiu st.

Braucher, Alma Filzabeth (b\%58) II-IIl.15, '95; (1'95); not in practlce; 227 lincon Ave.

Brown, Ifenry B. (b'51)-Mo.2,76; (1'73); 402 Delaran St.; oftice, 315 Broadway; S.

CAIDWLLL, CIIAS. BURR (b'79) Mo.34,05; (1'05); 861 S. State St.; 8-9. $1-3 ;$ NP. $\star$

COLEMAN, WM. WAITER (b'75)-Mo.1 '99; (l'99); 229 Kickapoo st.; offlce, 123 N. Kilckapoo St. ; $9-12,2-4$.

cosBr, 111kAM I. (b'ti) $\oplus-111.1, \mathrm{~b}^{\prime}$; (1'89) ; $5161 / 2$ Broadway.

Elthng, Kathryn Hardenberg (b'80)-Kan.2, 11; (1'14); Lincoln State School and Colons.

EWING, FRANK M. (b'57)థ-Pa.2,'s2 (1'84); S. Logan St. ; office, 315 Broadway; $10-12,2-5$.

GAFFNEY, EMERY C., JR. (b'84)\&IIl.4,05; (1'05); 124 N. Logan St. ; 1-5,

IIAGANS, FRANCES MARION (b'81)屯III.11,05; (l'05); 400 Broadway; office, 100 logan St. ; $9-11,2-4$; Pd.

HOUSER, F $\mathrm{RANK}$ C. (b'58)-III.8,'87; (I'89) ; 221 N. Logan St.; offlee, Hanger Bldg. ; $8: 30-12,1: 30-5$.

Houser, Wm. W. (b'3\%) E-0.2,59; (l'8 6 ) ; 405 Kickapoo St.; offlce, 610 Broadway 8-12.

LEONARD, THOS. II. (b'77) F-111.22,04: (l'04); Lincoln State School and Colony.

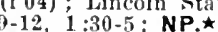

MENDELSOIIN, JACOB J. (b'89)థ-I11.22 12; (1'12); 861 S. State St.; offlce, Lincoln State School and Colony; 8-12, 1-5; NP.

MONTGOMERY, CALVIX CARLIN (b'68)† -Mo.2,"00 ; (1'02) ; 202 College St: offlce. Broadway and Kickapoo Sts. : 8-10, 2-4

OYLER, HARRY S. (b'T0)థ-Mo.27, 01 . (I'02); 135, 1Ith St.; office, IIanger Bldg.; $9-11,2-5,7-8$. ; office, IIange

I'ugh, Meredith D. (b'7) H - Ill.10,'01; (l'01) ; 620 Broadway; 9-12, 2-5.

keed, Chas. C. (b'51)-Ill.1,78; (1'78).

REMBE, CHAS. (b'56)†-Mo.1, $7 \mathrm{~s} ;(1 ; \mathrm{s})$

115 Pulaski st.

Lewis T. (b'75) H-Ill.4, ${ }^{\prime} 02$; $\left(l^{\prime} 02\right)$;

coria St.; offlee, 402 Broadway.

worke. s. Ellen' (b'67)-Ia.9,'96; (I'99)

Jathrin St.; offce, Gresheim Bldg. ; G.

ARAENT, ALGERSON M. (b'57) क-
LISBON, 300, KENDALL

connaway, Norman W. (b'z2)-Mo.7,06: (l'I I (0).

LITCHFIELD, 5.97I, MONTGOMERY

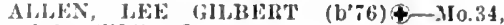

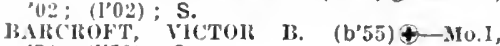
HE.XYTT, HARIR F. (b'71)\&-111.8, 05 $(1,95)$.

Benneti, 1klchard $\mathrm{F}$ (b'30) $\mathrm{E} \rightarrow 0 ;\left(1^{\prime} 8 \pi\right)$

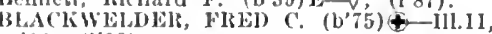
$00 ;\left(I^{\prime} 00\right)$.

IBLckweller, James F. (b'41) - 0.8,'64; $(1,77)$.

COLT, JOIIN IDENISON (b'40)థ-0.6,65; (1, $(1)$; $\mathrm{S} . \star$

,il. RGSS WM. (b'88)†-Mo.34 IOHNSON, (UAS. W. 4 -I'a.2,'72; (I'86)

SIHLEI, GEO. ALIBFHT (b'62) \&-Que.1,

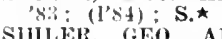

SHIJER, (EO AL, AELT, JR. (b'86)(que.1.'10: ( $\left.\mathrm{I}^{\circ} 10\right): \mathrm{S}$.

SNELI. MYRON WERSTER (b'\%1) \&-PR.Z, $48 ;(1 \times 1,7) ; \hat{S}$.

WIIJIAMS, T. W. $\left(b^{\prime} 55\right) \rightarrow$ II0.10,79; (l'80)

LITERBERRY, 100, MORGAN

OR'TUNF, HANNIBAI, CLAUDE (b'72) 4 Ilo.34,05; (1'05).

LITTLETON, 36I, SCHUYLER

Jowell, ('hauncey W. (h'86)-III.6,'11; (1'11).

Justus, Wm. F.-Ta.1,92; (1'93).

LITTLE YORK, 334, WARREN

IIIFTT, ALVA (b'6̈6)-111.11,'05; (1'0.5).

JEWELL, NERIT S. (b'74) - Ky.4, 98 ; (I')8).

LIVINGSTON, I,092, MADISON

HAGER, WHLLAM FRANCIS (b'8I)థ110.28, 08 ; (1'08).

obert, F. C. Wm. (b'62)-Mo.10,'90; (1'90).

LOAMI, 481, SANGAMON

(XAIDNE1, NATHAN B.๑-ML.1,'89; (1'89).

llagll, Saml. Rufus (b'90)-Ill.8,'13; ( ).

willcockson, IIardin (b'51) - Mo.10,'so (1'80).

LOCKPORT, 2,600, WILL

Bacon, Chas. H.-Ill.6,'62; (l'zi

Courtney, John F. (b'61) H- Ill.10,94: (1'9t).

Kingston, Filwood A.-11l.11,03; (1'03).

I'addock, Walter R. (b'73)--Ill.6,'96; (i'96) Schoop, Fredk. W. (b'49)-Ill.6,77; (l'77) LODA, 660, IROQUOIS

BOUE, THLS. NEWTON (b'37)-Ill.1,66; (1'78).

HEWINS, CHAS. F

LOGAN (R.F.D., CHRISMAN), 24, EDGAR

HUFFAKER, COLUMBUS (b'72)-Ky.2,'05; (l'05).

Slaughter, James P. (b'43)-Ky.4,78;(I'79)

LOMAX, 150, HENDERSON

EMIIRSON, WH. JESSE (b'68) †-III.1,'ss ;

(1'88).

King, Stephen J. (b'60)-Ky.5,'85; (l'85)

L00MIS, DEWITT-111.22,'12 ; (1'12).

Russell, Orange H.-Ia.1, 66 ; (I'88); not in practice.

LOMBARD, 900, DUPAGE

KOBISK, FREDK. B. (b' 78$)-111.16,06$; (1'06).

Oleson, Rlchard Bartlett (b'70)-Ill.6,93; (l'93); S.

Trowbridge, Edw. G.

(See Chicago.)

LONDON MILLS, 650, FULTON

ESSEX, CIARESCE RAY (b'\$1)€- $\$ 10 . \overline{6}$, $05:(1,05)$.

HESSE, PAUL IIENRY (b'73)-111.22,'08; (l'08).

LONG POINT, 284, LIVINGSTON

Turner, Guy F. (b'76) …Y.Y.19,'99; (1'99)

LONGVIEW, 300, CHAMPAIGN

RATTS, RINEHART P. (b'54)-Ky.1, 66 ; (I’ 78$)$.

LOOGOOTEE, I90, FAYETTE

owen, Calmer C.-I1-III.10,'90; (1'92)

LORAINE, 349, ADAMS

GOSSARD, GARY THOMAS (b'7) $\$-M o .2$ 08; (1'08).

HEDRICK
(I'91).
LOSTANT, 500, LA SALLE

GOU1, GEO. SYLVANUS (b'68)@-111.1, S'96; (1'07). '88; (1'90).

LOUISVILLE, 670, CLAY

lurgett. Warren E. (b'65)-Ky.1,'86; (1'97). ('ampliell, (jeo. Washington (b' 85 ) - Tenn.6, '09; (I'10).

Dllluan, John V. (b'69)-Mo.1,99; (1'99).

(ilBSON, ELIJAH l. (b'50)-Ky.5,78; $\left(1^{\prime} 80\right)$.

Lauchner, Henry S. $\rightarrow$; (I'82)

Steely, Benj. F. (b'8l)-Ky.5,07; (1'08).

STELLY, GHO. W. (b'75)屯-Mo. 7,99 ; (l'99).

LOVEJOY, 1,500, ST. CLAIR

Thomas, James Ilenry

(See sit. Louls.)

(b'84)-Ill.16,0 '0 ; (1'08).

LOVINGTON, 1.300, MOULTRIE

Douvovan, Jeremlah D. (b'36) -Ky.2,'68; (I'83).

Gregory, Lyman T.-I11.1,'83; (1'83)

Hoover, Walter K.-111.1,'88; (1'88).

McNahon, Curtman (b'85)-Mo.7,07; $\left(l^{\prime} 07\right)$.

LOWPOINT, I50, WOODFORD

llouck, Ross M. (b'58)-III.1,'82; (l'82)

LUDLOW, 305, CHAMPAIGN

BOYU, EDW. GEORGE (b'78)@-Ill.22,08; (108).

LYNDON, 500, WHITESIDE

POWELI, CURTIS F. (b'76)-Mo.27,'98;

LYONS, 95I, COOK

Balley, Charlotte Kent (b'77) - Ill.8,'10 ; (1'10).

truble, James R.

(See Chlcago.)

MACEDONIA, 285, HAMILTON

Bradford, James Alexander (b'84)-Ky.2,

10 : not in practlce.

CARLTON, HENRY OLIVER (b'82)-Mo.34,

Hunt, John T. (b'44)-Ia.1,78; (l'78)

Johnson, John H. $\left(\mathrm{b}^{\prime} 20\right) \longrightarrow \mathrm{o}^{\prime}$; $\left(\mathrm{l}^{\prime} 78\right)$.

Sims, John Milton (b'60)-Mo.7,'95; (l'08).

MACKINAW, 859, TAZEWELL

Allen, (ico. Stewart (b'67)-Ill.1,'02 ; (1'03) ;

Dentlst.

FAST, IIARIY DeWITT (b'7T)థ-Ill.11,'06 ; (1'06)

Kllby, Edgar E. (b'71)-1a.1,96; (1'96)

Illler, Cynthia A. (b'45) H-Ill.4,'84; (l'84)

MACOMB, 5,774, MeDONOUGH

AIAIIS, AITHUR R. (b'70)@-Mlch.1, 00 ;

ADANIS, DAVID S.P-Ia.10,'00; $\left(1^{\prime} 00\right)$

ALIEN, SAMIL. S. (b'83) (4-Ind.18, 06 ;

(1'08); OALR.*

III. 6,$81 ;$; $(1,85) ;(A 1)$

pavls, Jos. H. (b'76) E-Ill.8, 01 ; (l'01)

DRAKE, ARTHUR KNOWLTON $\left(b^{\prime} 72\right)-$

IARTMAN, WM. MICHAEL (b'80) - III.1,

HERMETET, JOHN W. (b'72) ४-Ill.10,'96 ;

HOLMES, JOS. B. (b'71) $\oplus-111.11 .94$; (1'94).

ENKINS, BENJ. D. (b'68)థ-I11.6,95;

KNAPPENBERGER, GEO. EMMETT (b'84) -IIl.1,09; (l'09).

KNAPPENBERGER, HENRY (b'51) (-Ill.1, '81; (l'81)

MINER, EIIZABETH R. (b'67)థ-Colo.1,

RUNKLE, G. DARIUS (b’79)£-Ill.6,03 ;

(1'03)

Russell, Samuel-Ill.1,81; (l'81)

RUSSELL, S. FRANK '(b'77)\$-IIl.1, 01 .

(l'01)

SCHRADER, EDWIN FREDK. (b'78)-Ill.11, 07 ; (l'07)

STREMIEL, SAMI. CALHOUN $\left(\mathrm{b}^{\prime} 63\right) \oplus-$

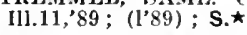

$M A C O N, 900, M A C O N$

Hughes, Albert L. (b'61)-IIl.1,'88; (1'88)

MIII.ER, CHAS. A. (b'75) $\oplus-111.11,02$

PIUMMER, OSCAR F. (b'i1)-Mo.7,03; (1'03). 
MADISON, 5,046, MADISON

IIAMM, MALFRED (b'is) 7 - M $0.31,05$ : $\left(1^{\prime} 03\right)$

HAHLIX, JEL COLLISS (b'86)-Mo.28,

KISRR. CHAS. R. (b'66)+-0.1,95: (1'9s). SEEBOLI, JOIS: L. (b\%1)-Mo.10,9s; (l'05).

MAEYSTOWN, 200, MONROE

WIIIEL.MJ, ALGI'ST 1:-MO.27:95; (1.95)

MAGNOLIA, HOO, PUTNAM

VRANKLIS, WELIINGTON A (b;3)

Neb. 6.'96; 11'12).

SIMMONS, WM. A.\$-MO.28, 05 : (1'05).

MAHOMET, 600, CHAMPAIGN

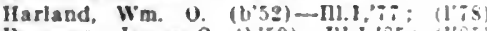
learman, Jamea $0 .\left(6^{\circ} 59\right)-111.1,85 ;(1 ' s, 5)$ wison. Chas. T. C ( $17 \cdot 1)-0.5,90 ;(190)$

MAKANDA, 400, JACKSON

A(iNEW, FRASK M. $\left(\mathrm{b}^{\prime} 40\right)-0.1,1,2,0.9$, 66: (1'ii).

Thompson, Alberb Jaurenen - Mlo.;,9s; (1'95): $\mathbf{G}$.

MALDEN, 490, BUREAU

KILGOLR, GUY GODLFY (b':2)\$-ILI.IA. 03: $(103)$; $\mathbf{G}$

Wickersham, louls L. (b'59) - I11.1,82; (1'93); (I'rinceton).

MALTA, 800, DEKALB

HABTON, LOUIS E. $\left(b^{\circ} 60\right)+-1 a .3,86$; (1'8:).

MANCHESTER, 480 , SCOTT

Knox. Wm. T. (b'52)-Mo.I,"96: (1'96).

WEIS, J. WM. (b'50)†-II1.4, T2; (1'7s)

MANHATTAN, 400, WILL

Bakez, Yary I.01lse-Ill.9,'8:; (1'8i).

BRANNOX, liEO H. (b'63)-Ку.5, 89:

KRSSLER, ARTHLR G. (b'75) \&-H1.1\%,03; (1'03).

WILAS: FVA MCrI.FNAHAX (b'0)tIll.9,94; (l'95).

MANITO, 900, MASON

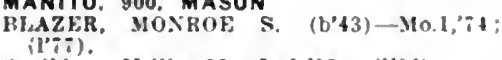

('aulkins, Nellle M--Ia.1,'92; (l'94); bot In practice.

Neles, John B. (h'35) $\rightarrow$ : not in practlce.

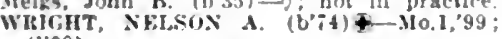
(1'99).

MANLIUS, 225. BUREAU

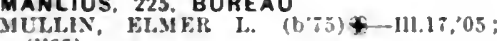
(1'05).

MANSFIELD, 750, PIATT

CILAMPIOS, JOS. Y. (b'5i) $4-111.1,85$ : (1' 98 ).

Huckln, Franklln Roscoe (1,85)-111.1,11; (1'11).

l'allerson. Newell (b'38)-0.1,70; (1'78);

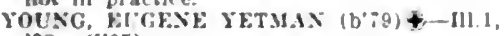
03: (1'05).

MANTENO, 1,200, KANKAKEE

Desbols. Phlllipe (b'79)-Que.3,04: (1'l2). GUICK, JOHX MAYYARI (6,6) + -III. 91: (1.91).

THOMAS, HCSSE1LI. Y. (b'R3)-Ky 2,'ln; (1'10).

MAPLE PARK, \$00, KANE

Henderson, Curlls-Ill.22,12; (I'12); S

MAPLETON, 135, PEORIA

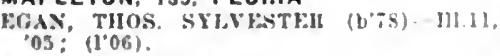

MAQUON, 473, KNOX

KNOWLES, GIL.HERT L. $\left(b^{\circ} 4 t^{\circ}\right)+-H 1.1$, '81: (1'81).

Jong, James I: (b'03)-MO I, Ss; (l'A,

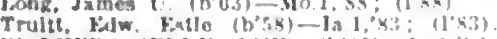

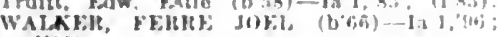
(1'96).

MARENGO, 2.005, MOHENRY

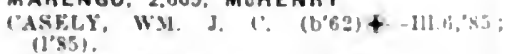

CUnTISA, ROZFI. M. (b'56) - - 1111,2, Jll. 10, $85:\left(I^{\circ} 84\right)$.

FonH

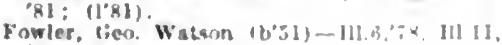

owler, lieo.

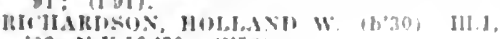
(1). $51.10,70 ;(1,4 \times)$.

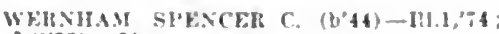
( $(17 i) ; 0 b$

Wuolward. Helle Soward-JIl t, \&2: (I's2) no: in iracellee

MARINE, 685, MADISON

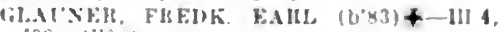

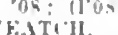
II"SN): ODA

MARION, 7.093, WILLIAMSON

HAKVR. RIIIHFIX I., JR. $(0 \% 0)+-M O I$ (14; ; 11.911$)$

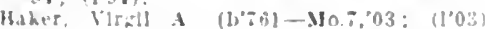

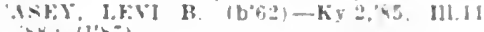
FwWirus Aloszo y (b'69)-Tenn. 94; (1.91)

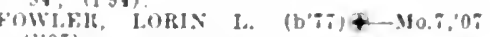

GlllFoplk, JUIIN M. (b'75)-Mo.28,05

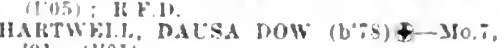
(1): llori).

Hudson, Theodore $\left(\mathrm{b}^{\circ}\right.$ (5) $)$ - Tenn.1, 68 (I'Di)

Fudson, Zach. (b.83)-Mo.; $07:(2,07)$

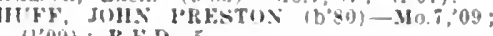
$\left(l^{\prime} 09\right)$; IB. F. D. 5

Mclronald, Martin M. (b'+3)-Mn 1,79: $(1,79)$.

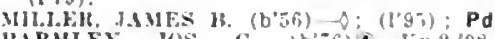
lARMLES, JOS. G. $\left.10^{\prime}: 6\right)+-k y, 2,08$ : REJD, W3. EDW. (b'il) \&-W1s.3,12: (I'I2).

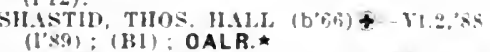

WILKER, ISAAC CECIL (b'il) $\$-30 . j$,

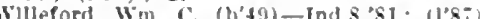

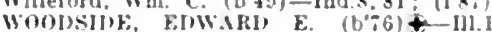
05 : (1.05) : OALR.

MARISSA, 2.004, ST. CLAIR

('AMI'REL, JOS. H. (U'53) - MO.I,'SO $(1.80)$.

llays, Geo. Rlchard (b'i0)-Mo.24, 96 ;

leslurio, $11 \mathrm{~m}$. Wilford (b'79)-Mlo.2, 05 ; $(1,05)$

Mendonsa, Lawrence A. (b's1)-Mo.t, $00^{\circ}$ : (l'06).

Treed, James 16. (b'51) 11-111.10.86; (1'86) Wlison, Jullus M. (b'ti) $-0.1,73 ;$ (17i)

MAROA, 1.500, MACON

Crocker, Geo. I.. (b'56)-I11.9,97; (1'97): not in practice

MCLEAN. WM. T. (b'5S) +-1]1.'SI: (I'SI)

Wood. Charles i. (b'2)-I11.6,94; (1'95).

MARSEILLES, 3,500 , LASALLE

BI.ANCHARL. MILTON EBF.X (b'52)--0.2

$78,111.1,94 ;(1,78)$.

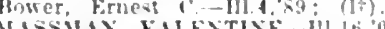

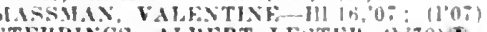

STEHBITCO, AIHERT LESTER $\left(\mathrm{b}^{\prime}: 0\right) \$$

STHIHLTT, WM. STOKEs (b6i) - M1.L,'94

WHIJl(K, ALBERT J. $\left(b^{\prime} 76\right)+-I 11.10,99$; (l'03).

MARSHALL. 2,500, CLARK

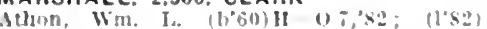

(

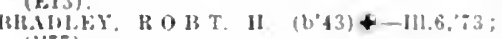

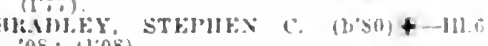
$08 ; 1108)$

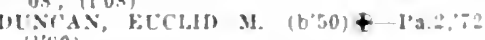
$(1,00)$

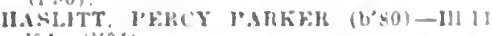
of: $\left(1^{\circ} 04\right)$

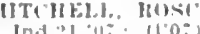

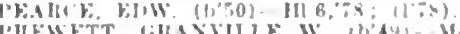

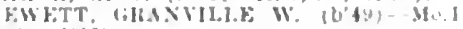

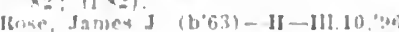

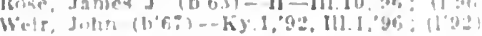

ind In preaclice

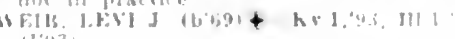

MARTINSVILLE, 1.800, CLARK

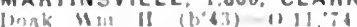

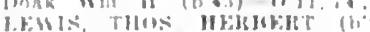

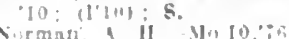

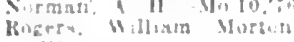
ilitis

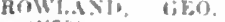

$(32)-k 5 \cdot, 76:$

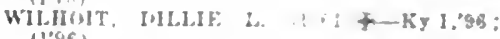

(1.96)

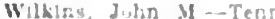

MARTINTON, 400, IROQUOIS

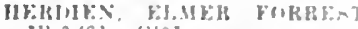

III.6.01: (1.01)

MARYVILLE, 739, MADISON

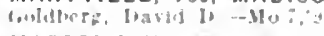

MASCOUTAH, 1.812, ST. CLAIR

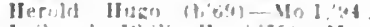

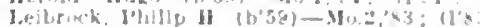

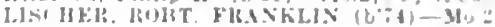

int: 1100t)

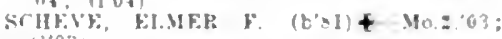
$10_{0} 0: 31$

MASON, 500, EFFINGHAM

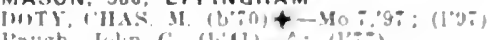

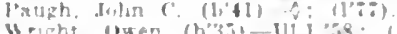

MASON CITY, 1.890, MASON

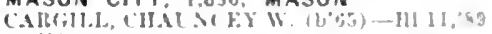
$(1+x)$.

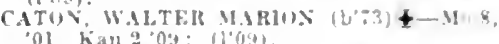

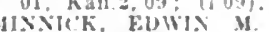

$\left(b^{\prime}, 0\right)+-111.1 .57$

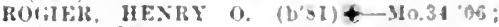

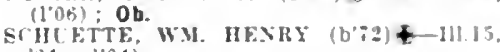

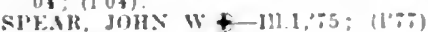

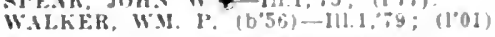

MATHERVILLE, 300, MERCER

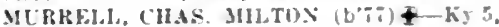
103: (1'12).

MATTESON, 600, COOK

Galbraild, Jubb. Georto (b'63)-I11.1:,99: $\left(1^{\prime \prime} 04\right)$.

HFRCLIES, CLAREXCE ARAVILLFE III.03,0t; $(107) ; \mathbf{S}$.

MATTOON, 11,456, COLES

IBAKEI, JAMEN 1, (b':1)+-Ind.18.06

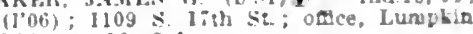
BId 2.; 9-10, 2-4. Woos (b'65)-Mo.10,03: (103); (Osieupath); 12 k. Broadwas: of Hce, 1;00 Broadway; 9.12, 1.6.

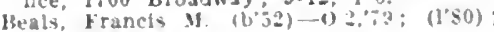
liold charlevbun s.

BEI.1. FINIs E. $\left(b^{\circ} 54\right)+0.1,30 ;(1 ' s 3)$ : $130 \pm$ Rroadway: : $-5,1-3$.

Boaz. Chas, (b'5t)-Ill.10, 90 ; (1'g1); $9-11,-4 ; 0$.

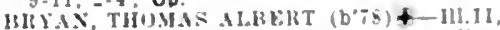

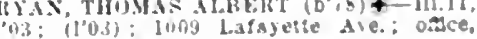

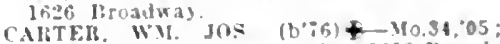
(1"05); 15 S. lith st. ; unce, 1613 Brosd. way 0 - 5

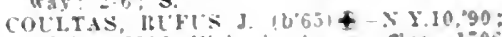

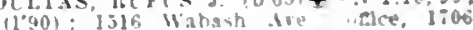
IBroadway; 9-1 $2-3$; OALR.

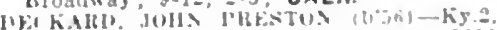

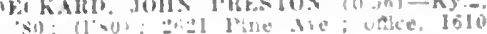

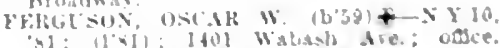

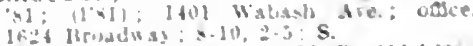

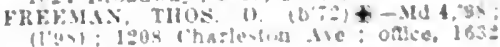

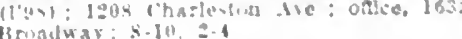
Hronas

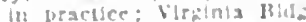

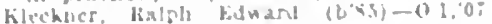

(1) (14)

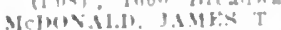

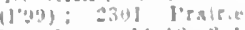

Rrualway; $11 \cdot 12 \pm=1$

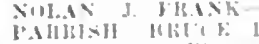

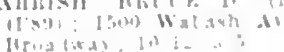

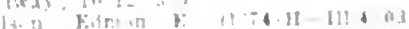

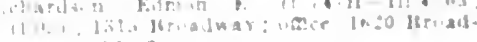

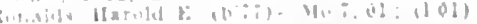

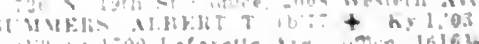

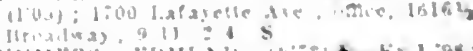

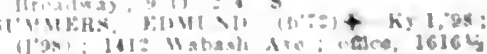

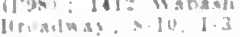


VOIIT, CHAS. I3. (b'74)థ-111.11,00; (1799); 1705 Iafayette St. ; offles, 1702 liroudway; 9-12, 2-5; (131, 8) : OALR.»

WALACE, WN. G $\left(h^{\prime} 84\right) \notin-M d .7,0 ?$ (l'i1): 2704 'ralrio ive: otflce, linilley 13ldir.; $9-11,2-4$.

MAUNIE, 300, WHITE

Giltner, Plillp C. (b'67)-Ky.2,89; (1'33).

MAYWOOD, 8,033, COOK

Clendenen, Irving (b'46) E-IH. $8,{ }^{\prime} ; 6$; (l's0) Colpman, siml. W. (b'74)-111.5,96, Il].13, $98:(1,96)$.

CROFIT, MATTIIA MAIILI.

(See Chicago.)

llarper, Mary Mckibben (b'73)-Mlli.1,99; $(1 \times 0.3) ; \mathrm{S}$.

Ilowe, Albert 0.-I11.13,98; (l'9S) : (bentist)

Irwin, John Louis.

(See Chlcago.)

JOSLYN, LESLIF BURRITT (b'86)†-III.6, 10; (1'10); (Bellewood).

Lovejoy Walter C. (b'67) H-1ll.10,91 ; (l'91).

Matter Orson Eugene $\left(b^{*} ; 2\right)-I 11.10,96$, III.11,04: $(1,98)$

Perry, Jos. II. (b;74)-Ill.13,'04; (1'04).

PETERS, JoHN (b'89)-IIl.22,'12; (l'12) ; $\mathrm{s}$. PICKARD, WM. S. (b'59) †-III.6,'86; (l'87).

Rlce, Fredk, T.

(See Chlcago.

ROBERTS, HAROLD H. (b'72) $\oplus$-III.6, 02 ; (l'02).

Rounds, Clara W.-III.S,04; (l'04)

SCOTT, WM. F. (b'69) \&-n1.1,'92; (1'93)

Sturm, Arthur 18. (b'74)-Ill.1,'99; (l'99).

Swan, Vandaller N. (b'48) - Ia.1,77; (l'99)

Taylor, Geo. Gordon (b'70)-I11.6,02; not

In practice.

\section{MAZON, 600, GRUNDY}

Gllborne, Henry B.-Ill.10,'01; (1'03).

Worley, Luther F. (b'58)-M0.1,87; (1'87).

MCCLURE, 300, ALEXANDER

DUNCAN, CLYDE EARL (b'89)-MIo.28,' 11 ; (l'11).

\section{MCCONNELL, 175 , STEPHENSON}

Kerr, Geo. A. (b'76)-Ill.16,'I0; (1'10).

MCHENRY, 500, MCHENRY

FEGERS, CHAS. II., SR. (b'46)-Ill.6,'79; (1'79).

Mueller, Arnold F. (b'86)-Wls.3,'08; (I'08)

NYE, NICHOLAS J. (b'71) Q-Tenn.8,'99 (l'99).

STRUEH, CARL.

(See Chlcago.)

WELLS, DAVID G.-II1.11,'98; (I'98).

MCLEAN, 680, MCLEAN

Donovan. Ophlus Poston (b'79)-Mo.7,'03

(l'03). CHTTER, CHAS. W. (b'7) (l'03).

Tenbrook, Andrew (b'53)-Pa.2,76; (1'83).

MCLEANSBORO, I,796, HAMILTON

AXDERSON, CYRU'S II. (b'69)€-Mo.1,'98 (1'98).

ASBURY, ISAAC M. (b'48)-0.2,73; (1'77)

BOZARTII JAMES ANDERSON (b'83) Mo.28,'07; (1'08).

DALE, MÁRTON CARROL (b'50)-III.6, '74; (1'7i); Member Ind. State Med. ASsn. HENRY C.-Ind.13,'83; (1'83)

HALE, HENRY, EMORY SYLVESTER (b, 73$)$-IIl.6, '0S; (I'08); OALR.

HALL, WM. W. (b'61)-II1.1,83; (1'83)

HASSETT, JAUES JEROME - Ill.1,'90; $\left(I^{x} 90\right)$.

Holt, Geo, W.-Ky.2,76; (I'86)

JOHNSON, CHAS. WILSON (b'73)-Mo.28, 99: (l'99).

NATION, PARIS M. (b'7 $)$-Mo.i, 04 ; (I'04).

Pemberton, Fannie-H- $\rightarrow$; (l'86)

Woodson, John C.-Pa.2,53; (1'80).

MECHANICSBURG, 4I7, SANGAMON

HILL, JOHN H. (b'66) -Ill.1,'94; (1'94) RIDDLE, HANILTON RUSH (b'41)-III.1, ,

MEDIA, 300, HENDERSON

MELOAX, JOS. F. (b'70)-MO.28,"97; (1'97)

RIGGS, JOHN PATTISON (b"44)థ-III.1I,
MEDORA, 444. MACOUPIN

Erwin oliver P'. (b'62)-Ifo. 1,87; (1'87).

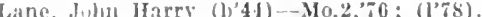

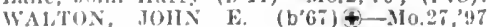
$\left(I^{\prime} y\right) ; 0$; Ob.

MELROSE PARK, 5,000, COOK

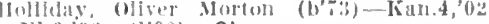
Ill.6, $060 ;(1,06) ; 0$ b.

IIUMMElAND, KAll, S. (b'62)Ð-Ill.I6 $08:(108)$

KIONKA, J'A L'L B. (b'71)-I11.8,"93; (1'93)

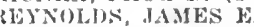

(see ('hicago.)

SHOCKLY, FEO. CU1TIS (b'72) $₫-N$ Neb.5 $02 ;(1 ' 01) ; \mathbf{N}$.

certuno, Louis Abbott (b'83)-Ill.22,'11 (1'II)

MELVIN, 700, FORD

BOSIIlis, HOR.T'IO X. (b'72)\&-IH.1,'95 (1'95).

MENARD, 50, RANDOLPH

Farrls, Geo. Kuapp (b'70)-Mo.34,'06; (l'07) MENDON, 627, ADAMS

AUSTIN, ADELBERT MOITON (b'80) Mo.2,04; (1'04)

KNAIP, 'DAVID M. (b'70)ד-Ia.3,96; (1'96).

Slgsbee, Wm. (b'28)-Vt.1,'52; (1'87).

MENDOTA, 4,000, LA SALLE

Cook, Chas. E. (b'59)-Ill.6,"81; (l's1).

COOK, EDGAR P. (b'70)థ-Ill.6,'95; (1'95)

CORBUS, JOIN CLARK, JR. (b'6I)-Ia.3 '84; (l'85).

EDWARDS, JOSEPH W. (b'32)థ-II.1,'54 (l'7i)

IIARRIS, OSCAR P. (b 70$)-I l l .1,02 ;\left(l^{\prime} 02\right)$

IIDONALD, WM. BROWN (b'65) ४-Ill.15 10 ; (1'11)

MCINTYRE, ARTHUR CECIL $\left(b^{*} 72\right) \oplus$ Ill.11,02; (l'02).

MEREDOSIA, 95I, MORGAN

ESTES, R. LOGAN (b'76)-III.11,03; (l'03). NEVILLE, FRANCIS A. $\$$-Ky.5, 87 ; $\left(1{ }^{\prime} 87\right)$. Nevllle, Lois-Ill.9,'94; (1'96).

METAMORA, 758, WOODFORD

BARTH, HENRY NICHOLAS (b'85) -Ill.6 09; (l'09); S.

KNOBLAUCH, JOS. I. (b'67) ๑-Ill.6,'93 (1?93)

\section{METCALF, 600, EDGAR}

FRANTZ, DANIEL W. (b'68) -M-M0.28,'03 (l'03).

Glick, Orral E. (b'73)-Ill.4,01; (l'01)

Honn, Sami. Henry (b'53)-O; (l'78).

METROPOLIS, 4,655, MASSAC

IIELM, JAMES A. (b'57)-Tenn.6,85, Md.4 92; (1'89).

IILLER, ANDREW E. (b'71)థ-0.1,00 ; (I'00)

ORR, JESSE A. (b'46)-0.2,78; (l'78)

STEWART, GEO. A. (b'63)-Ky.4;89; (l'89)

TROVIJIJION, CARLES E. (b'67)-Mo.7,'91, Mo. 28,'98; (1'92).

TROFILLION, MILO H. (b'65)-Mo.7, 92 ; (1'92); Pd.

WALBRIGHT, GEO. W. $\left(b^{\prime} 65\right) \oplus-K y .4,90$; (l'90)

Wallace, James Henry (b'77)-Ill.11,08; (l'08)

Willis, John T. (b'49)-Ind.2,'73; (1'77) not in practice.

MIDDLEGROVE, 200, FULTON

DEHM, CHAS. H. (b'68)@-Ia.1,97; (1'97) MIDDLETOWN, 1,200, LOGAN

GUTTERY, WM. VINCENT $\left(\mathrm{b}^{\prime} 50\right) \uparrow-\mathrm{M} 0.2$ '81; (I'sí).

SHEARL, JAHES M. (b'77)屯-Mo.28,'05; (l'05) ; Op.

MILAN, 727, ROCK ISLAND

EDDY, WARNER L. (b'69)4-IIl.1,'92; (l'92).

WIGGINS, GEORGE A. (b'61) \$-Pa.I1,'86 ; (I'88); G.

MILBURN (R.F.D., WADSWORTH), I50, LAKE

JAMISON, HOMER E. (b'58)-III.11,'91; (1'94).

MILFORD, I,700, IROQUDIS

GREEN, AUSTIN L. (b' 0$) \oplus-I 11.6,07$; (l’07). GREGORY, JOHN H. (b'74) - I11.1,96 ; (l'96).
IIALL, O.IAR OAlKLEY (b'58)-IIl.6,'79; ( $\left.1^{ \pm} 83\right) ; 0 p$

JUNKIN, IIOMER 1)AVII) (b'84)థ-IIl.22,

I 0 ; (1'10); S.

MILLCREEK, 221, UNION

Brown, Wllson-Mo,1,78; (1'78)

Ilellig, ollver M.-No.28,45; (1'95)

MILLEDGEVILLE, 800, CARROLL

Mcl'kerson, Irobert (b'44)-III.1,71; (1'77)

RUNNFLS, 13URGET (b'Ti)屯-III.4,05;

SWORW; IIOWARD RUSSELL (b'80)ÐIII.11;10; $(1,10)$.

MILLER CITY, 65, ALEXANDER

DICKEIRSON, ORVAL MLLCHER (b'81)I'a.2,10; (1,10).

MILLERSBURG, 417, MERCER

OHAVER, MAT'IIEW, (b'73) - Ia.10,'02 ; (1.02).

MILLINGTON, 286, KENDALL

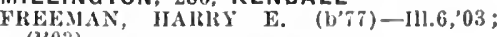
$\left(l^{\prime}(03)\right.$.

MILL SHOALS, 700, WHITE

FIASCOCK, ELMER NEWTON $\left(b^{3} 79\right) \oplus$ II0.34, 05 ; (1'05).

Greene, Mlliton S. (b'56)-Ind.2,'81; (1'81).

IIendershott, Lynn W. (b'50)-Ia.1,8I (1'84).

Marlcle, Robt. H. (U'40) -0 ; (1'96)

MILLSTADT, I,140, ST. CLAIR

Dlesel, frover John (b'85)-Mo.7,06; (l'06)

Rodemich, Geo. l'hillp (b'72)-Mo.28,'08; not in practlce.

ROSE, FRED (b'70)-Mo.7,'92; $\left(l^{\prime} 92\right)$

Schmidt, Waiter John (b'82)-Mo.7,'10 :

TEGTMEIER, EDWARD H. (b'78)Ð-Mo.7, 01 ; (1'01); ObG.

MILTON, 330, PIKE

Allen, Chas. Isham-Ill.1,'66; (l'78); not in practlce.

Doss, Judson Irwln (b'58) E-Ill.8,'80 ; (l'80)

JOHNSTON, FRANK (b'73) $\oplus-$ Mo.1,'97: $\left(l^{\prime} 97\right) ; 0 b$.

MINERAL, 339, BUREAU

Brown, Saml. L. (b'41)-0.8,'84; (l'85); not in practlce.

MARTIN, BERTRAM A. (b'70)-Ill.6,'93 (1'93).

\section{MINIER, 800, TAZEWELL}

Blackburn, Geo. M. (b'44)-0.11,69; (l'80)

Holmes, Edgar Rea (b'64)-Ill.11,'87; (l'87).

McLAUGHLIN, SAML. M. (b'73) $€-0.2,99$ (1'99).

ROST, JOHN FREDK. W. (b'82) †-Ill.1I $06 ;(1 ' 06)$.

MINONK, 2,070, WOODFORD

Evans, Perry M. (b'30)-Ill.1,70; (1'77).

MILLARD, HOMER A. (b'67) ๑-Ill.4,'90;

MORRISON, WINFIELD SCOTT $\left(b^{\prime} 80\right) \oplus-$ Ill. 4,'05; (l'05).

WILCOX, FREDK. W. (b'64) $\oplus$-Ill.1,'86 ; (l'86).

MINOOKA, 500, GRUNDY

BRINCKERHOFF, JOHN J. (b'69)-Ill.11, 'Q7; (1'97)

COAD́Y, JOHN JAY†-Ill.22, 07 ; (1'07).

Forrest, Benj. Frankiln (b'58)-Ill.l,'83; (l'91).

Searles, Josephine D. (b'49) - Ia.9,'97; (i'96).

MITCHELLSVILLE, 200, SALINE

Hart, Ezra (b'75)-Mo.7,'03; (l'03).

MODESTO, 299, MACOUPIN

KENNEDY, JOHN ALBERT (b'81)-Mo.34, 07 ; (I'07); Op.

PEEK, EVERETT J.-IIl.22, 07 ; (l'07).

MODOC, I90, RANDOLPH

CHURCH, HARRY S. (b'81) -Mo.34, 06 ; (1'06).

Sheppard, Archibald C. (b'78)-Mo.34,'00 ; (l'99); not in practice.

MOKENA, 500, WILL

SEARLES, FRANK WESLEY (b'52) (-111.6, 77 ; (1'10); Ob.

MOLINE, 24, I99, ROCK ISLAND

Abel, Nellie Evelyn Hager (b'80)-Mo.10, 13: (l'13) ; 1514, 30th Ave.; offlce, Reliance Bldg.; 10-12, 2-4, 7-8.

ARP, AUGUST H.๑-Ia.4,"82; $\left(1^{\prime} 82\right) ; 718$, 5 th Ave.; offle, $508 \frac{1}{2}$, 15 th st. 
BKAL, ALIEKT MLTON $(b, 58)+-1$. 6.94

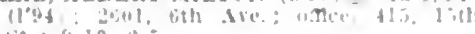

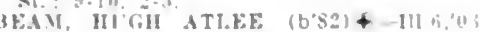
(1'12) : $151 \%$. 15th st. : nnce. K.aibil

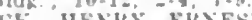
$06 ;(1,0$ i): $000,16 \mathrm{th}$. 1 re

IB

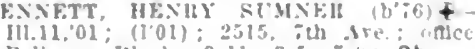
Rellance klock; $9.11,3,0,0$, ob.

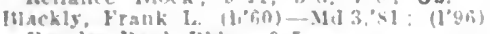
l'eonles llank Bhlig: ?-

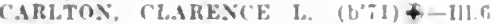
03; (1'03); 8452, 18th Are; ontce, sti Si and Isth Are?

Dalles, orear S. (boxy Ia 1,95

(1995) : not in practlce: $920,160 \mathrm{~b}$ st.

MONDAXVILIE, MARTIS S. (L'TE) + III.I 04: (1'04): 184t, l4th st.; nftce, 403 13 th St.: 11-12, 2-4, i-8; 5

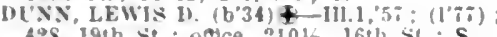

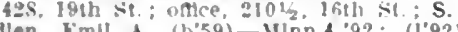

Edlen, EmIl A (b'59)-MInn.4,92: (1'92)

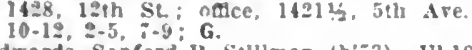

Edwards Santond I". Stlllman (b'73) - III.19. 99 ; (1'99) : not la practlce : $1213,15 \mathrm{~h}$ St. Freeman, Darld Barnard (b'86) - 1a.3,10 (1'10): i17, 14th St.; oftce, 1330, ith ire.: $10-12,2.4,7.8$

Gardner, Frank 11. (b'64)-111.11.93: (1'94) 1816, 6th Are.; oftce, $30 \pi, 15$ th St.; $8=10$, $1 \cdot 3, ;-8$

Hansson, XIls (b'66) - Ill.5,"9s; (1'98): Peoples Bank Bldg.

HAUBER(, GEO. IIVIN (b'83)-111.6,'11 (l'12): 2002 , 14th St.: office, $\$ 031 / 2$, 15 th St. $10: 30-12,2-4, i-s: s$.

HSMAN, WILLIS T. (b'-3) - Ill.11, 04 (1'04): $2015,15 \mathrm{th}$ St.; oflce, $1219 \% 2,5 \mathrm{~h}$ Are. $2-4,: 9 ; s$

KERIS, EDW. L. (b'66) - la. $3 ; 89 ;$ (1'91) : \$42, isth st. notice. hern'a BIds

KOILER, ARYIN E. (b'73)-III.11,98, (1'98): 1212, ith Are.; offce, Kern's

EIPOLD, ARTHUR TIIOMAS (b'st) + 2.3,07: $\left(l^{\prime} 0 \pi\right) ; 2110,5$ th Are.; office. 4261/2, 5th Are.: 11-12, 2-4, -8

McCanon, Wallace C (b"36)-Ia.1,80; not In practlce: 1515, 1ith St.

IEYER, ROIST. C J. (b'65) - $0.12,41$ III.1,92; (I'91); $18152_{2}^{2}$. 3d Are.; offlce, Sklnner Annex; $10-11: 30,2-4,7-x$.

MIller, Loulse X. (b'61) U-III.4,95; (I'95) 314 , 16th si

MYERS, JAMES r., (b'56) - 111.1,83; (1'83); (2926. Jth Are., Rock lsiand): oflce, 12926, 5th Are., Rock lsiand)

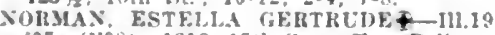
07 ; $(108)$; 1213,15 th St, ; oftce, Rellance Bidg: $2-5$.

Oakley, Pobt W. (b'55)-111.6,02. (1'02) 1316, 15th St, ; oflce, 50142.15 th st. 2.4 , i-s.

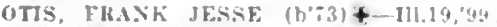

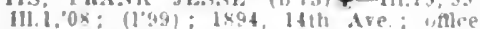
Trlocity sanitarlum: 10-12.3-i $\mathrm{S}$.

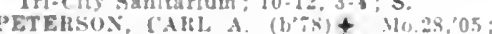

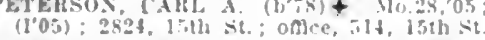

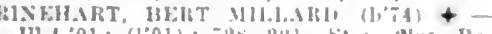

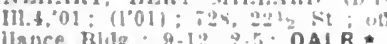

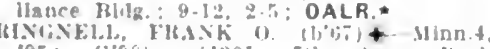

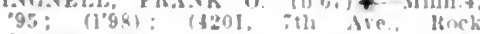

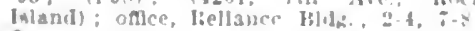

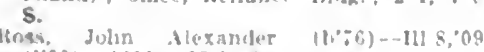
1109): $4 \geqslant 123,17 t 1$, :

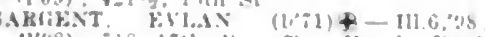

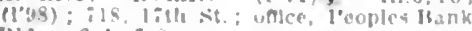
Blig. ; $2-4,8.4$

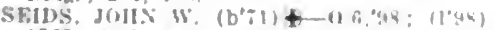
1523, 1:th Are onles, Heliance Halk $11-12,2 \cdot 4, i, s$

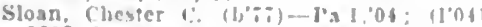
1300 , ith Are once, 52lts, lith si

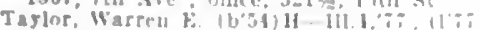
not in pracpire: 15e9, fath sfo

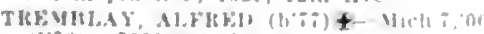

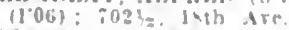

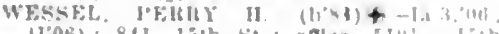

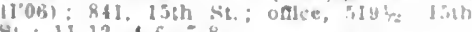
St. $: 11-12,1-6,7.8$

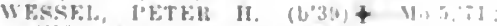

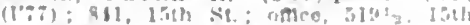

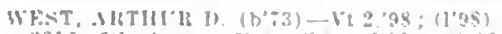

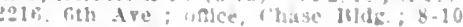
$1.3: 30$, fi $: 30-4: 30$

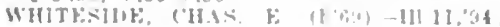
(l'94): 2403 bith Are : Ace, skinter

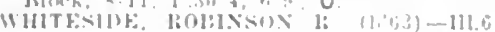

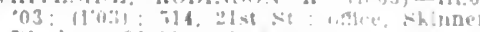
Iyleck

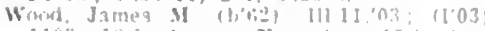

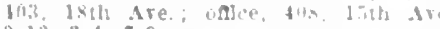
II) : $: 2 .-1, \quad i-9$

Wyland, Jonathan Mllton (l)'s, ta $3 . x 6$ ire

MOMENCE, 2,201, KANKAKEE

BTPTT, A.BFHT S. (b'BS)+

Gunn Margares M. (b'on)-Ill.4,0s; (l'0s).

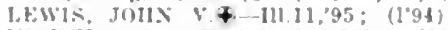

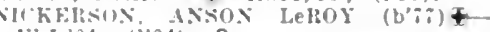
$111.1 .04 ;(1.04): 5$

SHIRSTS, CLALDE. F. $\left(\mathrm{U}^{\prime 69}+-111.6,96\right.$ $(1.96)$

MONICA, II9, PEORIA

IICKS, WM. W $\left(\mathrm{b}^{\circ} \cdot 6\right) \mp-111.19,05 ;\left(1^{\prime} 05\right)$.

MONMOUTH, 9.128, WARREN

BALL, R. M. CHALLES (b'31)-Mo.1,:9; (l'si).

BURGESS, CHAS. 0. (b'6)-IIl.11,03: (1.03).

CAMIP, IAROLD MINLOVE (b'S5) —-111.6 '09: (1'09); LD.

FBERSOLE, JOS. R-III.4. "88: (1'88)

Glragoslan, Vahan H. J. (b'7̂์ $-111.39,09$ (1'09).

CIKAHAM, RALPH (b'05) - III, 1,$00 ;(1,00)$

Ilollidas. Wm. S. (b'50)-Kyt't: (1'ti)

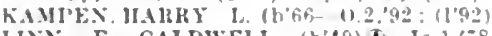

LINX E CAIDWELL $\left(b^{\prime} 19\right) \mp$-1a.1, is:

IcCleary, Ralph B.-11-I11.4, ;8; (1'

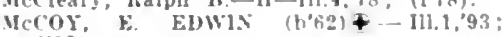

MCMILLA:, BOBT. C. (b'63)-1114:05: (1'05).

MTCHELL, EDH. I.†-III.I:\&2; (1'S2)

MITCHELL, FosTHE $\left(\mathrm{b}^{2} 6 \mathrm{~b}^{\circ}-111.1,03\right.$ (1!03).

PATTOS, ADELMA (iEO (b'U9) - - 9,'92: (1'92): $\mathrm{S}$.

SIERRICK, CHATYMEY (1) 58$)+-$ MO.1 '81: (1'81): S.

(XKRicH, CHAs. Ib. (b'7t)+-I11.15.99; (1'99); OALR.

WEIOLS, WM. H. (h'H1) +-IH.11.97: (1'9:)

Whters, frank (has (b's?) 111.11,"12

MONROE CENTER, 250, OGLE

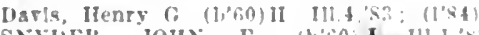

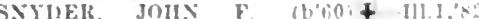
(1'82).

MONTICELLO, 1.980. PIATT

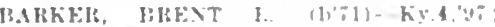

$(1998): 00$.

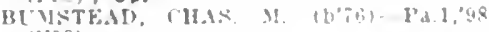
(los)

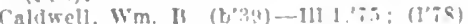

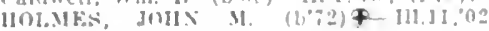
(1.02)

knute, Jepheha D, - II-III \&.83: (1's5)

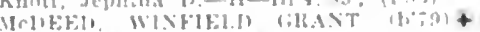
III 6,01. (I'n) : OALR.

MONTROSE, 347. EFFINGHAM

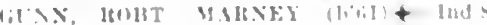

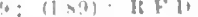

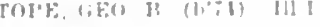

MORGAN PARK, - COOK

$$
\text { (Sere I'hlcagh }
$$

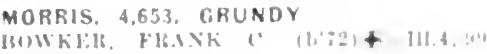

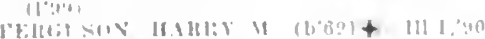

Plicin som

(It(0)): OALP , II $11 ! 1,0$

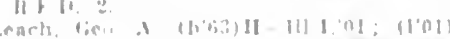

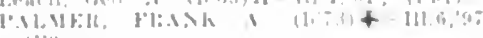
1139

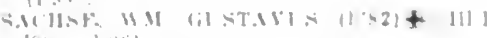

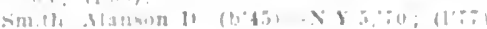

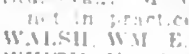

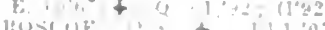

MORRISON, 2, \$10, WHITESIDE

FITZIFIR.1III, IIIATh

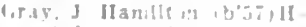

1" it in prawt?

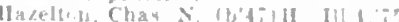

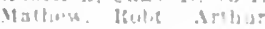

$311.181 \mathrm{~T}$

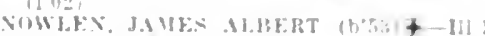
PETITT, HFKLFKT I.EIR

$11111 \cdot \theta_{r_{i}}(1)(16)$

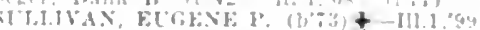
(I'ye).

MORRISONVILLE, 1,126, CHRISTIAN

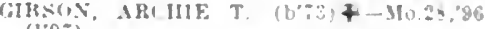

SFATON, rIAS $\|+111.1202 ;(103)$

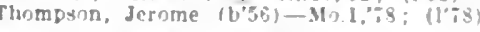

MORTON, 1,004, TAZEWELL

Darlson, Margaret (b'6.5)-111 4.00; $11^{\circ} 00$ MeMILIT HOWAM) (LARENCE $\left(b^{\circ}, 4\right)+$ $-111.1 .0 \%:(100)$

YODFR, HENRY LEE (b'i2) - M0.1.9?: (1'99)

MORTON GROVE, 1,100, COOK

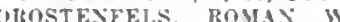

I11.14, "113: 1103$) ; 0 \mathrm{O}$.

MOUND CITY, 837, PULASKI

Grimin, Alonzo T. (co)1.) (b'8:-D.C.3,04 (1'08).

Hargan, John $\mathrm{F}$ (b'rt) - ky 2.2.91: (1'91)

HITUESON, BFILENIFX SFYMOLR

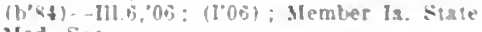

Nathls, John $B \quad\left(b^{\prime} 40\right) \rightarrow\left(l^{\prime}: 0\right)$

WESE.NBFH, WM. ROBT + Tenn.5.12: (112).

Willard, simon (bo59) -Ill.5, 'st; (1's4).

MOUNDS, 1,686, PULASKI

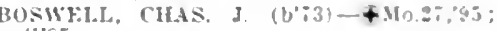

HCRSON, OTIS TALMAGE (b'i) +-Mo.2S, 09 : (1.09).

L.SLIF IMFN FRANK $\left(\mathrm{B}^{\prime}-9\right)+-1115$. 03: (106): Member lnd. Slate Med Ass SF.ALY, SAML. T. (col.) (U'S5) + Tenn. : (119:) (1002)

MOWEAQUA, 1.513, SHELBY

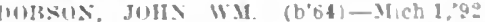
$(1.03): 00$.

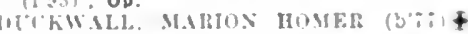
111.1\%:65; $110+0$

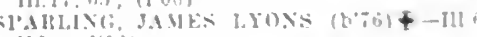
-10: 1610$)$

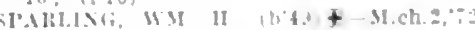

MT. AUBURN, 463, CHRISTIAN

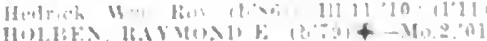
(1) 11]

NT. CARMEL, 6.934. WABASH

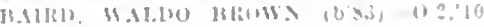

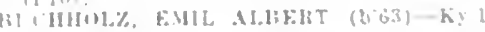

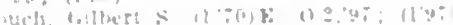

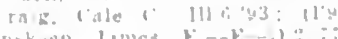

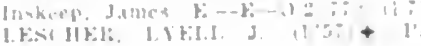

nivitis 1001

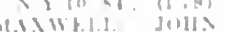

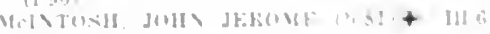

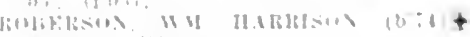

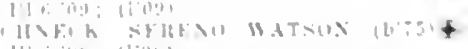

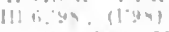

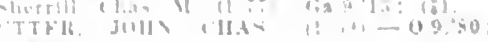


MT. CARROLL, 1,759, CARROLL

('LAY, WALTER E. (b'69)-Mo. T,97 ; (l'07). C(LEIIOU1t, SAML. I'. (b'75) 4 -III.14, 09 : (1'99); $\mathbf{S}$.

Cormany, James Wilson (b'49)-0.9,73; not in practlce.

Greely, 1)ustan M. (b*3.1) F-0.2,59; (1'77)

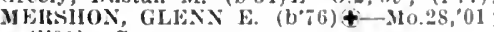
(I'0I) ; $\mathrm{S}$.

Mershon, Jos. Ingram (b'84)-111.11,12; (l'1:2).

METCALF, IFXIY s. (b'5:) -Ill,6,86 $(1 \times 6)$

RICE, ROIAIN 13. (b'67)-Ill.5,'s9; (1'90). IRINEOLLAI:, NELSO

Wood, Heuben 1H. (b'53)-111.4,96; (1'96).

MT. ERIE, 299, WAYNE

IOOHER'T: EIMWA EI.MO (b'S3)-Mo.34, $07 ;(1,07)$.

Slueldon, Matthew II. (b'53) $\mathbf{k}=0.2,76$; (1'T8).

WILKIX, W. ERNEST (b'80)-Mo.28,04; (l'04).

MT. MORRIS, 1,I32, OGLE

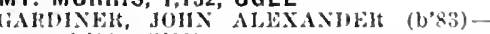
(Ont.1,11: (1'12).

HANES, WM. W. (b'6I)-0.10,'83; (1'83)

Mecosh, Geo, B. (b'57)-Ill.1,'80; (1'83)

I'RICE, CIIAS. J. (b'76)-111.4,00; (1'00) OALR.

MT. OLIVE, 3.501, MACOUPIN

ALILN, OMA 16 FRANK-IH.1,00; (l'00)

Ambrose, leslle Eugene (b'89)-IIo.10,'il (1'12).

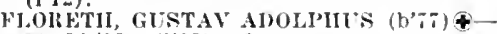
Mo.34,03; (l'03); 0p.

MT. PULASKI, I,5 II, LOGAN

Bullard, Francis B. (b'50)-Ill.1, ;8; (1'77) CONNELLY, GEO. SULIVAN (b'79)థMo.28,09; (l'09).

HOPPING, OLIVER P. (b'70)-IIl.17,'96, Mo.1,97; (1'97).

colan, Émanuel Cross (b'53)-Ill.1,78: $\left(I^{\prime} ; 8\right)$.

Rlgg, James R. (b'73)-Ia.1,9s; (1'98);

RYMAN, HERBERT DICKENS (b'78)థKian.3,07; (l'08)

VAN HOOK, HEXRY M. (b'79)థ-Mo.34,

MT. STERLING, I,986, BROWN

ALLWORTII, EDW. C. (b'5i)-111.16,98; (1'98).

DEARIBORN, CHAS. BARTLETT (b'68)థI11.1,'90; $(1,90)$.

Dearborn, Henry Jonathan (b'65) - Ill.1,'88 (l's8).

FowLER, WM. C. (b'61)-Mo.1,'87; (l'87).

MeGANE, RAYMOND CIIS. (b'85)Mo.34,'11 : (Y'11); G.

PETERS, DANL. R.' (b'76)-Ia.10,'06 ; (1'06).

Thompsoll, Geo. L. (b'49)-Ia.9,96; (l'96)

MT. VERNON, 8,007, JEFFERSON

Arendale, Lillian A. (b'S9)-Wis.6,'13; ()

Davis, Henry Levl (b'-8)-Mo.34,06́; (1'06)

EDMONDSON, EDW. EVERETT $\left(b^{\prime} 76\right) \uparrow$

Mo.33,'06, IH1.6,'09; (l'09); OALR.ネ

FOSTEK, THOMAS " JEFF'ESSON (b'7I) No.34,03; (1'03)

Frost, Arthur Mck.-Ind.5,'88; (l'88)

GEE, HARL L. (b; 74$)$ 4-Ho.2,98; (1'98)

GILMORE, WILBLR HAWLEY (b'98).

Pa.2,03; (1'04); Sec. Ill. state Med. Soc.; $\mathbf{R}$

GREEN, EARL (b'61) - -Y.Y.10,'84; (1'84). Greer, Virgil David (b'89)-Ill.1,'13 ; (I'13) HALL, ANDY (b'65) \&-I11.6, $90 ;(1,90)$.

HALL, CIIAS. WESLEY (b'SO)-Tenn.5, 00 N.Y.19,01; (1'03).

HAMILTON, JAMES W. (b'71)-Mo.28,

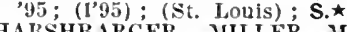

HARSHBARGER, IILLER M (b'75)థ Mmn.5,02; (1'13); Memuer Siate Med.

Levick, Alfred T. (b'46)-Ia.1,'76, IIo.I,'83 ; (l'85); Ob.

MAXEY, MOSS (b'73)-Mo.1,97; (l’97).

MITCHELL, JOHN H. (b'50)@-Ill.6,74; $(1,7) ; \mathbf{N}$.

MORGAX, LEWIS C. (b'61)-Ind.13,'86;

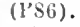

Newton, J. H. $\rightarrow$; (l'T); not in practice.

Peavler, II ugh-Tenn. 6,85 ; (1'85)

I')(1LE, CHAS. JUDSON (b'74)-Mo.28,00 (l'ini)

R. (b'54)-Md.3,'80; (I'S0)
SMITI, ROBEIT IBUSSELL (b'70)-Mo.34, $0 \% ;(1,0 \pi)$

SITTYL, OKVEL AMDISON (b' 72$)-M 0.28$, (1): ; $(109)$; Op.

Swift, 11. Maxey $(b, 60)-$ Ind.5)'95; (1'95)

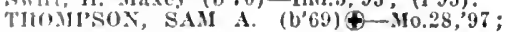
$(1,97)$

TH'1'EH. (;FO. (b'71)-Ill.6,99; (l'09);

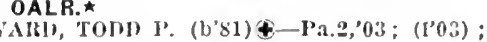

WATSOx, WALTER (b'51)థ-0.1, 65 ; (l'i) ; not in practice.

WIITLOCK, JoIIN TIIOMAS (b'60)† $110.1,90 ;(1,90)$

MT. ZION, 470, MACON

Jacoly, Aruold Leon (b'86) - Mch.1,'io;

MAY, SIIFFFIF R. (1,'59)@-Ia.1, 80 ; (1'80).

MUDDY, 40, SALINE

31)ND, IBO13T. GIKAY (b'78)-Mo.7,09: $\left(l^{\prime} 09\right)$.

MULBERRY GROVE, 7I6, BOND

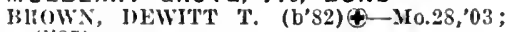
$(10 \%)$

GLAStiow, HDW. A. (b'70)๑-Mo.27,'99; (1'99).

IIutchinson, $\mathbf{W m}$. B.-0.8,65; (1'78); not in practice.

I'oludexter, Jos. S.-Ia.1,'80; (l'80).

MULKEYTOWN, 250, FRANKLIN

WINNING, CHAS. CRAIN (b'86)-Mo.10, 11 ; (l'12)

MUNCIE, 400, VERMILION

MIICIAEI, OSCAR WILLART (b'75)Ind.8,'98; (1'98).

MURDOCK, 350, DOUGLAS

ICKINNEY, I. NEWTON CIIAS. $\left(b^{\prime} 71\right) \$$ Ill.I 1,'02; (l'02); Op.

MURPHYSBORO, 7,485, JACISSON

CARTEI, ALBERT R. (b'69) $4-M 0.1$,'95: (l'95).

DANIEL, HARRIETT M. $\oplus-I l l .4,06$; $\left(l^{\prime} 06\right)$; G.

ELLIS, IRA W. (b'58) †-Ind.8,'83; (1'89). ESSICK, RAYHOND BROOKE (b'85) $111.11,08$; $(1,08)$.

GRIZZELL, CHAS. C. (b'59)-Mo.1, 89 ;

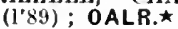

IIORSTMAN, HESRY G. (b'68)†-Mo.1, $95 ;(1,95)$.

HRABIK, JOIIN II. $\left(b^{\prime} 86\right) \oplus-$ Ill.11,12 ; (1'12)

MINNER, LOLIS A. (b'61)-Mo.t,'98, Pa.2, $00 ;\left(l^{\prime} 98\right)$

MOLZ, CHAS. O. (b'72)థ-Mo.1,98; (l’98) ; S.

ORMSBY, OSCAR BURTON $\left(b^{\prime} 76\right) \oplus-$ Mo.T,'97; (l'97)

Post, Chas. A (b'74)-Pa.2,'99; (l'99).

Risellng, Chas. E. (b'67)-Mo.1,'93; (1'93)

ObG.
ROTH, HEXRY HERIIAN (b'75) - Ill.17, '00; (I'01); OALR.

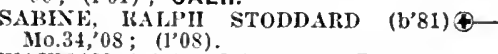

WAYMAN, IOUIS ROY (b'79)థ-Mo.7,'09; (I'09); G.

MURRAYVILLE, 450, MORGAN

ELDER, JOIIN KENYON (b'72) $4-$-Ill.5,'9t $(1,9 i)$.

Mateer, Chas. A. (b'67)II-Ill.4,'96; (1'96)

SPENCER, JOHX H. (b'67) - Mo.10,'92; ('’92).

Waters, Chas. Edwin (b'73) - Mo.7,'08; (l'09).

NAMEOKI, 200, MADISON

JOHSSON, Fl'ANK O. (b'T⿰)-Mo.28, 02; $\left(l^{\prime} 03\right)$

NAPERVILLE, 3,449 , DUPAGE

Bell, J. A.-II-Ill.4,79; $(1,78)$; not in

CLANCEY, JOHN II. (b'65)€—Ill.11,'97 ;

MARTIN, WISFRED B. (b'TT) -Ill.I1,'0I;

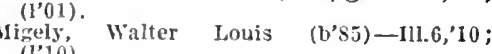

$(1,10)$

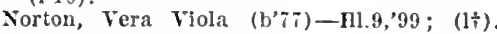

RIKLI, ARTIUR RICHARD (b'7T)\&-Ill.1, 08; (1'07); $\mathrm{S}$.

loogers, James Bailey (b'si)-Tenn.5,'10

Schott, Ira John (b'60)H-Ml.4,'87; (l's7).
SIMISON, FLGENE GRANT (b'65) $€-111.1$, 92 ; (1'93).

Trultt, Luliff Jawrence (b'7 7$)-$ Pa.0,98; $\left(\mathrm{l}^{0} \mathrm{O}^{\mathrm{i}}\right)$

Truitt, Wm. Joln (l,'6ï)-Ill.4,'89: (l'93). NASHVILLE, 2,135, WASHINGTON

Bahrenburg, John 1'. (b'38)-110.5,'79 ; (1'79).

CAR'THR, WM. D. (b'37)-Ill.1,62, Ill.6, 60; $\left(l^{\prime} 92\right)$.

Krumsiek, Wm. E. (b'60)II-IIl.4,'91 ; (l'92). RABFNNECK, I'AUL 1BENJ. (b'86) \&II0.34,12; $\left(1^{\prime} 12\right) ; \mathrm{S}$.

SCROEIEI, SHMON I'ETER (b'61)Ð-Ky.5, '87; (1'88).

TIOUTT, JAMES J. (b'44)థ-N.Y.5,72; VEKNOR, RICIARD E. (b'46)-0.1,76; (l'80).

Vernor, Roscoe Conkllng (b'82)-Mo.34,'09; (I’09).

NAUVOO, 1,020, HANCOCK

BOIt'T, JOHN ALEX. (b'63) $4-19.9,92$; (1'92).

IIAGGHTT, WALTER M. (b'58) @-Ia.1,'87 ; (l'8\%); OpA.

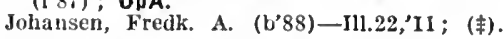

NEBO, 520, PIKE

Dinsmore, James WV.-Mo.7,'96; (l'96).

POLLOCK, JOIIN ROY-IIO.28,04; (1"04).

NEOGA, 1,074, CUMBERLAND

HI(ILER, SHERMAN EDWIN (b'83)\&Ill.6, 07 ; $\left(1^{\prime} 07\right)$.

Dougherty' Geo. F. (b’55)-Mo.10,'80, Mo.28, '94: $(1,80) ; 1 . \star$

Doutherty, Geo. Pltzer (b'87)-Mo.28,'11;

KUIt'T\%, RUSSELL L. $\left(b^{\prime} 70\right) \oplus-M 0.7,93$, Ky.1,'93; (l'93); S. $\left(\right.$ l' $\left.^{\prime} 31\right)-$ D.C.2,'66 ; Ragan, Gillum Taylor (

NEPONSET, 600, BUREAU

IBISHOI', ELLIS IIENRY (b'72)๑-Ill.8, '05; (1'05).

PRIESTIAN, JOHN L. (b'57) (-Ill.6,'81; (I'81).

NEVINS (R.F.D., PARIS), 34, EDGAR

FEIRGUSON, WiI. M. (b'61) - Pa.2,'83; (l'85).

NEWARK, 600, KENDALL

IIAR'TNACK, INNUD (b'74)(-III.39,'10 ; (1'11) ; Op.

Langum, Hanson I. C.-Ill.14, 04 ; $\left(1^{\prime} 05\right)$.

Sweetland, Nelson L. $\left(b^{\prime} 43\right)-111.1,67$;
(l'77); Pr.

NEW ATHENS, I,I3I, ST. CLAIR

BECHTOLD, AUGCST F. (b'77)-Ill.11,'99; (l’99).

KRAENIER, JOHN N. (b'59)-Mo.24,'92;

Nolan, John Alonzo (b'64)-Mo.2,'04; (1'04).

Power, Julia (b'70)-0.2,07; (l'07).

NEW BADEN, 1,372, CLINTON

EDWARDS, FRANCIS M. $\left(b^{\prime} 76\right)(-M 0.7$, '98; (I'98).

Huwatcheck, Frank G.-Mo.28,'99; (1'99).

NEW BEDFORD, 250, BUREAU

WILLIAMS, SAML. E. (b'66)-Ill.11,'93; (l'93).

NEW BERLIN, 690, SANGAMON

Fulton, Leo Wm., Jr. (b'82)-Mo.34, 06 ;

MCMILLAN, J. CHAS. (b'73) - Mo.1,98; (I'98).

Wiley, Lewls D.-Ky.2,'87; (1'93).

NEW BOSTON, 7I8, MERCER

LYTLE, CHAS.' F. (b'74)@-Ia.1,97; (1'97).

IcIntyre, Louis Leroy $\left(b^{\prime} 79\right)-$ Ill.6, 07 ; (l'07).

NEW BURNSIDE, 369, JOHNSON

Ballance, John W. (b'71)-Ill.1,'96; (l'96).

Glass, Alonzo-M 0.27,'97; (1'97).

LA RUE, HENRY D.-0.9,' 11 ; (1'81).

Mizell, Wm. R. (b'40)-0.9, '74; (1'7).

NEW CANTON, 575, PIKE

Gilbert, Geo. A. (b'64)-1a.1,90; (l'90);

McCOMAS, GEO. U. (b'58)๑- $\rightarrow\left(1^{\prime} 88\right)$

RAINWATER, JAMES H. (b'58) $4-\mathrm{I}_{0} .1$, $89 ;(1 ' 89)$.

NEW COLUMBIA, 160 , MASSAC

Iobley, A. 'T.-Ky.1,'80; (1'80).

NEW DENNISON, 30, WILLIAMSON

BURNS, J. ERSKINE-Mo.7,'02; (1'02). 
NEW DOUGLAS, 499, MADISON

Helper, John (', (b'58)-0.2,81: (1'35).

McKINIFY, GLY HESEMIB (b's) +

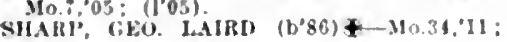
(I'II):

NEW HANOVER, 40, MONROE

Lark, Wiverard T, (b's0)-Mo.34, 02 : (1'02).

NEW HAVEN, $5 ! 4$, GALLATIN

MARSFTT, JOHX (hobi)-MO.2S, "SR; (1'98)

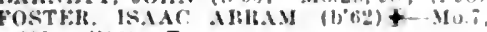
'91: (1'91); T.

NEW HEBRON (R.F.D., ROBINSON), 100, CRAWFORD

MOHLFR, GKO. C. (b'52)-MO.5.94; (1'94).

NEW HOLLANO, 397, LOGAN

KendaIl, Wm. Eugene (b'84)-111.22,"13: (1'13).

P.INE, W, IITHR (". (b'66)-III.1,95; (["95).

NEWHOPE (R.F.D., GALATIA), 17, SA. LINE

Lasswell, Thos. R.-Ia.1.'A4; (I'\$4),

NEW LENOX, 216, WILL

H.AICIAY, CHAS. K. (b'79) \$-111.1.04: (1'04).

NEW LIBERTY, 100, POPE

lewls, Etlat K.-E-0.2,93: (1"93).

Lewis, Mary A-E-0.2,90; (1'91).

NEWMAN, 1.264, DOUGLAS

Calvin, James $W$. (b'29)-II1.1, 56 ; not in practlce.

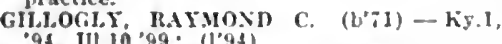

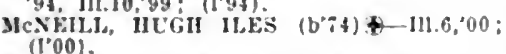

Rutherford, Cyrus (h'50)-Pa.l,7:; (1'7).

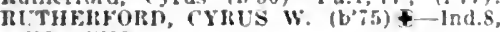
$99:(1,99)$

Wagner, John M. (b'i)-N.Y.10,78; (10\%).

NEW MINDEN, 245. WASHINGTON

EIIICII, KAILL WALTEK (b'84)-Mo.', 09: (1'10).

NEW PHILADELPHIA, 300, MCDONOUGH II. VR.SS, ALIBERT (b'75) \&-111.1,01; (1'01).

NEW SALEM, 260, PIKE

A.IDIEW, HARLY IB. (b'22)\$-\$10.1,96; (1'99).

NEWTON, 2.108, JASPER

IBooker, Carroll (b'58)HI-Mo.5.'84: (1'84): not in practlce.

HUHTON, ELMII: \&. (b'65)-0.2,91: (1'91). Yluhlan, Cieo. Kolland (b"80) - I11.1,02; (1'02); not in practlce.

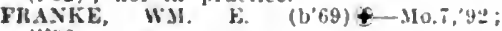
(1'y2).

Itnman, Henry s. $\left(b^{+47}\right)-1$ a.1.78: n`is).

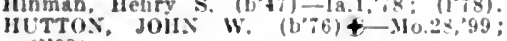

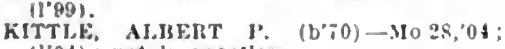
(1) 04 ): not In jractlee.

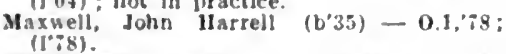

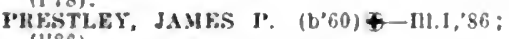

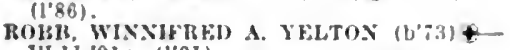

III.11.01: (1.01).

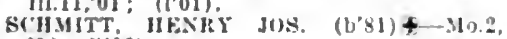

WAL: (1'09), XOMMAX C. $(1,76) \mp-0.1,04:$ (I'0).

NEW WINDSOR, 473, MERCER

EMERSON, E.WW. 1.. (b-4)-111.1, 81 ;

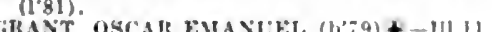
GIRANT, OSC

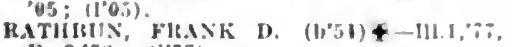
I'a.2:"8: $(1,7 \%)$

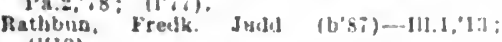
$\left(1^{\circ} 13\right)$.

Hathbiw, Cico. Lawrence (b's4)-III.1, "1:?;

NIANTIC, 800, MACON

IIall, Nlonzo H, (6.59)-111.11,85: (1'4.1)

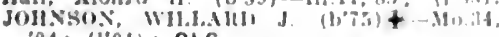
04 : llo 1$) ; 0$ OG.

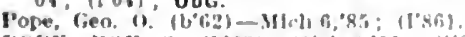

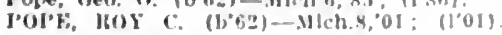

NILES CENTER, $700, \operatorname{COOK}$

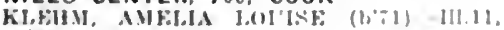
$02:(1202)$

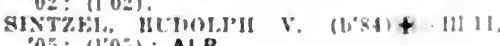
03 : $(10.0)$; ALR.

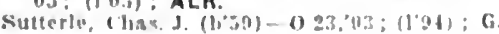

NILWOOD, 401, MACOUPIN

MOHBil, JAVII) AlTIL] (b'33)

M(0.28, $10 \%$ : (1,0\%).

NOBLE, 618. RICHLAND

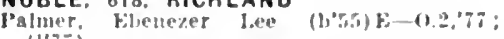

$(1, \cdots ;)$

almer. lien, 0. - $\rightarrow$; $(1 \% 8)$.

iandervoll, Jugh M., Jr. Mn 1,20 : (1'sd)

Shafer, Jow. $1^{\circ}\left(b^{*}+1\right)-0,2,07 ;\left(1^{\circ} 07\right)$.

NOKOMIS, 1.872, MONTGOMERY

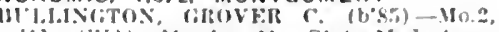
'11; (1'11): Metnlier Mo. Siate Menl. Avarn.

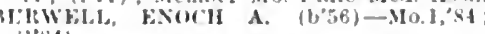
(1) $x+$ ).

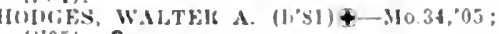
(1.05); 00 .

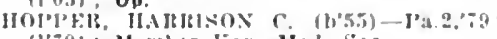
(1'79); Member Kan. Med. Soc.

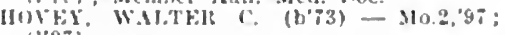

IIWI. MIJIRI IIOLIOWA (b8i) +

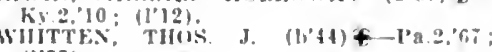

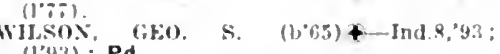
(I'y3); Pd.

NORMAL, 4.024, MCLEAN

(ilGTE, HF.KKY W.

(sife fitoomlugtur)

Me(onM]ck, Fkm (

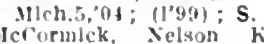

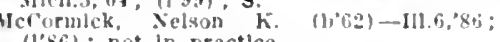
(l'si); not in practlce.

Parker, Jacol) J. $\left(b^{3}(6)-0 ;\left(1^{4} 78\right)\right.$; not in

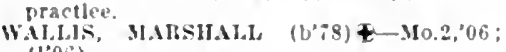
(I.06i).

NORRIS. 1,000, FULTON

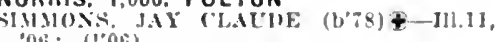
oni: (l,0Bi)

NORRIS CITY, 1.055, WHITE

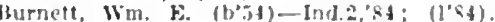

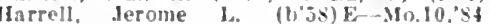
(I's $\$) ; 0$ p.

IJarrell. Wm. 11. (b'58)-111.1,92: (1'42)

IIart, loel A (b's) la, 1, $85 ;(195)$.

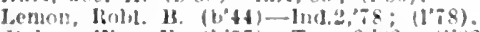

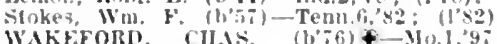
$(1,9 i)$.

NORTH CHICAGO, 3,306, LAKE

BLIDIF AlFORI EUIV

111.6, 0s; (1'0S); Ob.

("onnell, James i (1);0)-nll.fi,0t: (1.09).

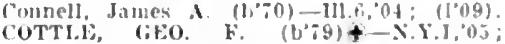

l....., lleut., Is Naval Trainbu

statlon, Great Iakes; S.

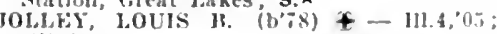
$\left(1^{\prime} 05\right)$.

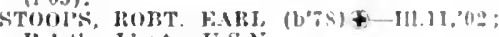
I'.A.S.. I Jeut., I.S.S.

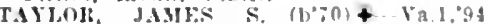
surg. Jleut. (ommander, I".x. X. Nabl Tralulug statlot.

NORTH CRYSTAL LAKE. 689. MCHENRY

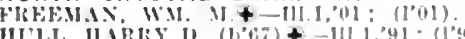

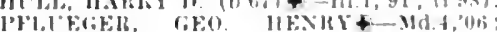
(1'13).

NORTH HENDERSON, 200, MERCER

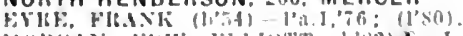

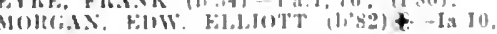
0.5; (l, (0,5).

NORWOOD PARK (IND. STA., CHICAGO). -. COOK (sine inleaga.)

OAKDALE, 150, WASHINGTON

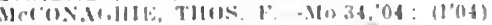

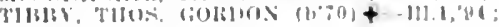
$11^{\prime}(4)$.

OAKFORD, HOO. MENARD

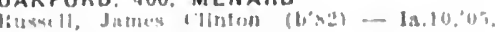

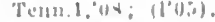

OAK FOREST, - COOK

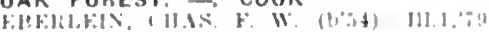

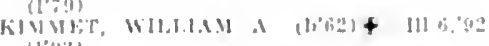
$11 \% 1 \div: 1$.

OAKLAND, 1,139, COLES

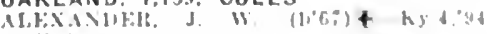

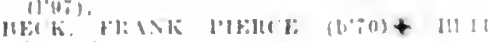

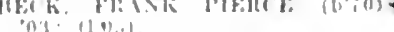

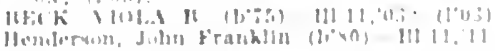

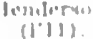

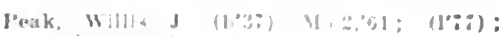

OAKLAWN, 287, COOK

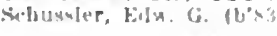

OAKLEY, 100. MACON

Clark kilmer $\mathrm{B}$. $\{1,70\}$ T

MU.MS, NITHANIEI, II.

(siee ( hlogen )

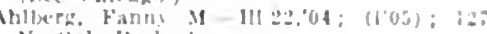

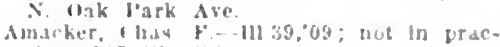
thro: it Wimalline Abe

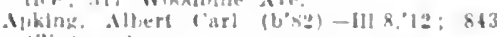
illonton ine

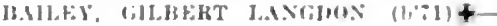

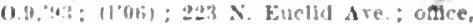

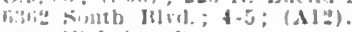

Joarl\%, Nichralas B.

(Sice ("lilrapon)

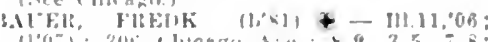

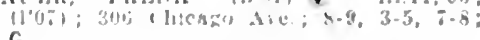
G.

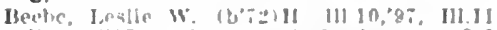

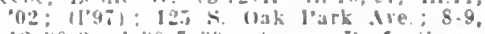

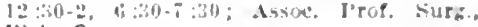
III $t$; $S$.

Jinnet, fohn 1 .

(site (hlcagnj)

Berkey, llarvey Mllan-111.22,13; (1'13); Oak l'ark lloipltal

Blackivell, F. 1.-Md.1, ${ }^{\prime} 05$ : not In practlce.

H.OT:T, ANXA KILAWORTII $(1,02)+$ $111.9 .97 ;(197)$; I04 \$. Oak Park Are. 4-ti; ObG.

lb) gnton, rhas. E

mave rhicagon.

(sice inlcago.)

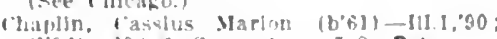

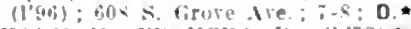

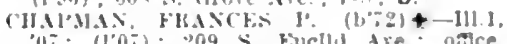
Latie st and buclld tre s-1: LD. cunker, Guy I'arke (b"is) II - III.4,03; (1'03) $10 \mathrm{~s}$, Fanklln ire.; once, $1 \geq 0$ X. Oak l'ark ibe.; :-5; Adj. Prol. Ophth.. HI.4; OALR. *

converse. Wallace Cox

(see iblarato.)

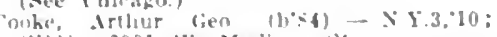

(1"l1); fio0l W: Madison st

Copland. Wm. II $\left(\mathrm{b}^{\circ} \mathrm{c}(1)-\mathrm{X} \mathrm{Y} \cdot 10,83\right.$;

(1"yo) : 12: korest ine.

(are (jocago,

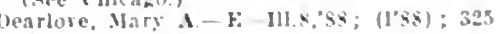
x. Grove Ave.

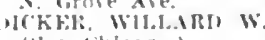
(siee inllago.)

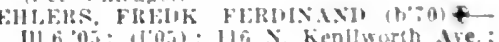
III:- LR

FISk. WM. I3

(sios (litenzos)

rouler, fiarte hloodgoml.

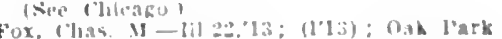

llowplial: S.

Carrlit, James.

(Aise Clulongo.)

lionethe liuvtal A

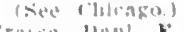

orthse, llatal p

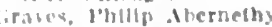

(sice (hleaso)

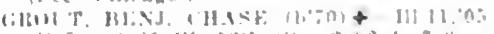

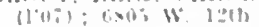

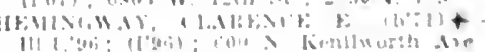
$11-1=12 \div: 06$.

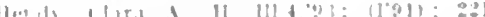

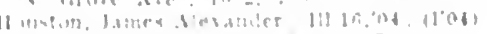
at 2 Ilarrey lie :

II i.irt. I ratik I the in

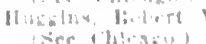

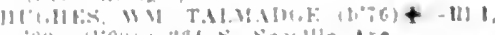

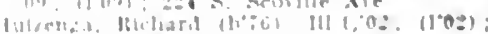

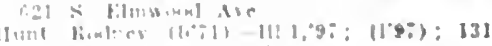

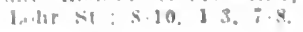


ACK, JOHA MARNES.

(see ('hleago.)

10NES, MAHTIN 1), (677)+- 111.1. (1.99); (offlec, $4401 \mathrm{~W}$. llarrison st., (h) eago, and 4159 W. lake st.)

KERR, LidLS KIRK $\left(b^{\prime} 75\right)^{+}+-1116,00$ (1'00); I63 N. seovtle Ave; $11: 300$ offle, 640:3 take Ni $4-6$; (allso, 3 I $N$. State st.. ('hichlgo

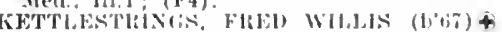
-111.1, 19: (1'45); 43\% X. lirove Are.;

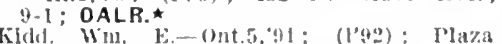
Ilotel.

KIRKWOOH, ROBT. CARNAIAX (b'ts) + I'a.2,0s; (1"13); Member Jud. sitale Med Assn. : 6802 South Btvd. ; 4-6, 7-8.

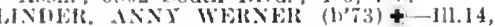
(12, III.22,03; (1'03); New Misonic Temple.

LOEWY, AR'THYIR (1'67) $\nrightarrow-111.11,89$ (1'90); 235 Marlon St.; offlce, Lake and varlon sts $8=9,2=4,-8$

luff, Emlly M. (b'63)-I11.4,94; (194); 326 Chlcago Are.

LULL, RICHARD H (See Chlcago.)

Lyon, John Bates (b'79)-111.1,01: (104) (271 Forest Ave., 1iver Forest): office Franklin Ave. and Iake St. ; 8-9, 2-3, $7-8$ S

Mathews, Allen A. (b'53)-Ill.1,79; (1'92)

429 Clinton Are, until $9,2-4$

ICCREIGHT, SAML. IUTHER.

(See Chlcago.)

Meacham. Win. Chas.

(See Chlcago.)

Meyer, Anna K.-Ill.13,04: (l'04); $101 \mathrm{~N}$.

Oak Park ATe.

Heyer, Otto Frnest.

(See Chlcagro.)

Moore. Harry Walter - 111.16,06; (1'06);

6000 Chlcogo Aro, 8-10, 1-3, $7-8$

MOOREHEAI, FIEDK. BROWN.

(See Chicago.)

MOTTER, TIIOS. IRA (b'72)థ-III.10,97, III.1,'99 ; (1'98); 224 x. Kenilworth Ave.; 8-9, 7-8; (office, 122 s. Mllchigan Ave. Chicago ; 2-4); S.

NEEDHAM, FRANK STEWART (b'TT) Ill.23,05, Ill.11,08; (1'05); 332 IVisconsin Áre. : $3-4,6-7: 30$

NEILL, wit. J.

(See (Chicago.)

NELLES, JAMES EDW. EARLE (b'84) 11l.11, 07 ; (l'07); Member Wyo. State Med. Soc.; 1038 'S. Cuyler Ave.

Noe1, Jos. R. (b'72)-Pa.2,'94; (1'95) ; not in practice; 139 S. Grove Ave.

OLIVER, PALL.

(See Chlcago.)

Olsen, Adolph II

(See Cbicago.)

ORMSBY, OLIVER SAMI.

(See Chicago.)

orerall, Geo. Whitfle]d.

(see Chicago.)

PARMELEE, ARTIIUR HAWLET (b'83)-

III.1,11; (1'13); Member Minn. State Med. Assn.; 233 Clinton Ave.; offee, 7140 Madison St. : 9-11, 2-4.

PECK. WESLEY HAMIITON.

(See Chicago.)

I'HELI'S, LUCIUS BELDING.

(See Clineago.)

Pierce, Chamncey Merrill (b'85)-111.6,'08; (1'08) ; $824 \mathrm{~S}$. Humplurey Ave.

POORMAX, CIIAS. WALLACE $\left(b^{\prime} ; 3\right)+$ III.11,03; (1'03); 460 N. Oak Park Ale. ; offlee, 12; $\mathrm{i}$. Oak Park Ave.; 8-9, 1-2, i-s.

POTTKR, WALD E. $\$$-III.11,00: (1'00): 503 N. Grove Ave.; offlce, 100 Wisconsin Ave.; $8-9,2-3$

POTTHOFE, ERNEST WM. (b'Ts)£-111.1, 02; (1'02); $1132 \mathrm{~S}$. Austin Are. ; until 9,

$2-3.7-9 ;(C 6) ; D$.
RIBI;ECK, WM. A.

(See Clicatyo.)

ROBERTS, THOS. ELMER (b'65) †-III.10, 88, Ill.1,97; (1'88); 320 N. Euclid Ave. : office, 132 ₹. Oak Park Are.; 8-9, 2-4. 3ose, Cameron Afred (b'sI) - Ill.11,07; ameron Alfred (b'sI) - III.

1Vm. L. (b'65) H-I11.10,91; (l'91) 349 Xurth Rivu.; office, 120 工. Oak Park Are: $:-9,1: 30-3,7-8$.
SAYAIF, ROIST, GARF'IELD (b'81)-Ill.11, 115: (1'05); Oak l'ark Are. and IIarrlson

Schorli, lecollard $\mathbf{E}$

(Sive Chiferigo,

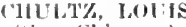

(see Chleago.)

clmmons, Itowara L,

thee (hlearos.)

SKIILS, IAMES H1 HER'T (b'85)-111.1,10: (1'10): The Groveland.

S'TEW.ART, IIARRY JOIN

(See Chlcago.)

Storke, Whert Frencl (b'68) - 111.4,90 (1.92) ; 405 Forest Ive.; oflice, 151 Lake -i) $0,5, \pi-8$

Tebliefts, Frank' M.-111.11,'85; (1'85) ; 514

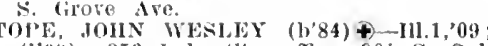
(1'0s) ; 350 lake st.; ofllee, $001 \mathrm{~S}$. Oak l'ark ive.

AN 1)ELALICE, IAJES WARREN (b'69) †-111.1,93; (1'93); $155 \mathrm{~N}$. Ridgeland Are.; 1-2; Asst. Prof. Med., 11l.1; (I)2)

VAITiHAN, IIERIBERT GANES $\left(\mathrm{b}^{\prime} \mathrm{i} 4\right)-$ III.1,01; (1'01); 615 N. Scovllle Ave. offlee, 6403 Lake St.; 3-6; Assoc. Próf. Ifed., III.22.

ON DER II EYDT, ROBT

(siee Chicago.)

Wanderer, Arthur Enll August (b'91)III.1I,'12; (1'12); 414 S. Lombard Ave. Vilktnsoll, Lucette (b'59)-111.9,'94; (1'94) 427 s. Ridgeland Ave

WTLLARD, WM. G. (b'65) \&-Ill.10,'86 Ill.1,9s: (1'89): 428 r. Kenllworth Are. oflce, 132 N. Oak Park Ave ; 8:30-9:30, 4-6; ObG.

OAKWOOD, 450, VERMILION

Snider, I'm. 'Thos. (b's8)-Ky.2,'10; (l'10) ; Pd.

WILLIAMS, EDWIN GORDON CULBERT-

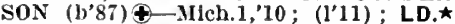

OBED (R.F.D., MOWEAQUA), I6, SHELBY LYON, GEO. ELMER (b'79)†-I11.11,'02; (1'02).

OBLONG, I,482, CRAWFORD

HENRY, GEO. HERBERT (b’ 78$) \oplus-I 11.6,10$; (l'10).

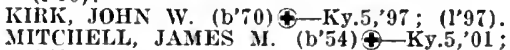
(1'01).

OCONEE, 293, SHELBY

Littlejolin, Lewis C.-O.1,'85; $\left(l^{\prime} 92\right)$

Patterson, John W. (b'67)-Ill.11,'93; (1'94)

ODELL, I,035, LIVINGSTON

Bannister, Thaddeus 0 . (b'33) -N.Y.5,'56 $\left(l^{\prime} 77\right)$; not in practice.

Larsen, Robina Henry (b'69) - Ill.4,'94 (l'94); G.

Tombaugh, John L. (b'79)-Ill.6,03; (l'03)

พVELCH, M. M.-Ia.9,'96; (1'96).

ODIN, 400, MARION

Fyke, John J.-E-D; (I'98)

SMITH, SAML. A. '(b'68) $\oplus-$ Ill.17, 04; l'04).

O'FALLON, 2,018, ST. CLAIR

Bechtold, Herman Theodore (b'53)-Mo.1, ' 80 ; (I'80); AL.

Cleveland, Aurelia Puderer (b'83) H-Mo.5, '05; (1'05).

HAVEN, WILLIAAI WALTER (b' $\% 9) \oplus$ Mo.28,09; (1'08).

Pierce, Clarence E (b'72)-110.2,03; (l'05). TRIPPEL, EDW. (b'88)屯-Mo.34,'12; (1'12)

OGDEN, 500, CHAMPAIGN

HAIRIS, J.MLS F. (b'52)థ-Ky,1,77; (1'83).

Lutz, Gustay A.-Ill.4,'12; (1'12).

OGLESBY, 3,500, LA SALLE

Beadles, Chas. H. (b'67)-111.1,90; (1'90). Cox, Edward Frank (b'83)-I11.22,'10; (1'10). CRESSMAN, RALPH G. (b'80)£-Ill.8,'05; (l'05).

OHIO, 600, BUREAU

ALLEN, DAVID WMI. (b'69)-Ill.8, 03 ;

HOW'ARD, WM. E. (b'64)\&-Mo.7,'90 N.Y.10,'98; (1'91). O'MALLEY, JOS. MICHAEL (b'80)థ-

OHLMAN, 200, MONTGOMERY

HUBBARD, ISAAC GEO., JR. $\$-M 0.34,07$ (l'07).
OKAWVILLE, 579, WASHINGTON

HEWLEY, IOUIS ANIHEW (b'83) \&-Mo.34, $10 ;(1,10)$

MelLWAIN, JAMES (b'43) - N.Y.5,68; $(1,7)$.

Mcllwain, James, Jr. (b'71) - M0.27,'94; (I'94).

IOOS, ROBT. C. (1)57) $+-\mathrm{MO}, 10,84$; (1'84).

OLIVE BRANCH, 50 , ALEXANDER

Caldwell, John $\mathrm{F}^{2}$. (1)'5i) -Teun.6,'90; (1'90). OLIVER, I00, EDGAR

MARTIN, JOIIN WESLEY (b'82)-Mo.28, 07 ; $\left(l^{\prime} 0 \pi\right)$.

OLMSTED, 288, PULASKI

CAR.IKER, OS(AN (1)'81)૯- Mo.7,08; (1'08).

OLNEY, 5.01I, RICHLAND

Foster, Martin D.-0.2,'82, 111.4,'94; (1'82). FRITSCIILE, WM. H. $4-\mathrm{Ky} .2,93 ;(1,93)$. HORNER, HAIR, H. (b'78) $\$$ Pa.2,02 $\left(l^{\prime} 02\right)$.

MARTIN, IRA NEWTON-0.2,06; (1'06).

Rowland, Elbert (b'32)-N.Y, ,'58; (l'83).

Spaln, James w. (b'31) $\rightarrow 0.9,72 ;(1,78)$.

TELFORD, ALEXIS T. (b'72)\&-Mo.1,'96; $\left(1^{\prime} 96\right)$.

Thompson, Wm. A. (b'45)-0.1,78; (l'78)

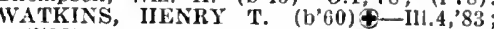

(l'83).

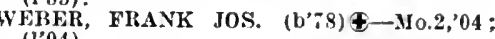
(l'04),

WEBER, GEO. T. (b'68) $\oplus-\mathrm{M} 0.1,{ }^{\prime} 94$; $\left(1^{\prime} 94\right) ; \mathrm{S}$.

WEBFR, JAMES AUGUST (b'87)-Mo.34, '12; (1'13); Member Mo. State Med. Assn. WEBER, J." CORNELIUS $\left(b^{2} 75\right) \oplus-M 0.1$ 99; (1'99).

OMAHA, 586, GALLATIN

Braun, Wm. E.-Ia.1,78; (1'78)

IIarrell, James C.-Pa.17,;0; (1'-8)

Johnson, Frank-Mo.28,02; (1'02).

OMEGA (R.F.D., KINMUNDY), 84, MARION

Sinith, Thos, J. (b'39) - ; (1'04).

ONARGA, I,273, IROQUOIS

Baker, Nellie M.-Ill.11,'05; (1'05)

HEMALA, RICHARD (b'63) †-Ger.11,'88: (l'90); $\mathrm{S}$.

Morgan, Frank R. (b'79)-Jll.4,05; (1'05)

Palmer, Ira F (b'45) E-0.2 ;

SHAWL, JOHN L. (b'66)-Ill.4,02; (l'02).

ONEIDA, 589, KNOX

HUNTER, CHAS. W. (b'69)-Ill.1,'94; (1'94)

STEIVART, ALEXANDER F. (b'68) 9-Ill.1,

'94; (1'94).

OPDYKE, 300 , JEFFERSON

Ilenderson, Marion D. (b'68) - Ind.5,'95: (1'95).

Hontgomery, Martin V. B. $\left(b^{\prime} 3 \pi\right) \rightarrow\left(l^{\prime} ; 8\right)$

Williamson, Thos. B.-Mo.10,06; (1'06).

OQUAWKA, 1,010, HENDERSON

EADS, COLEMAN J. (b'66) - Ky.2,'90

KAUFMAN, CLOID E. (b'79) §-Ill.10,03; (1'03)

Noyes, Frank A. $\rightarrow$; $(178)$; not in prac-

tice; R.F.D. 1.

ORANGEVILLE, 400, STEPHENSON

DALY, JOHN NELIIS $(b, 70)(-11.1,95$;

(1'95). (I'85); S.

ORAVILLE, 160, JACKSON

HOUSE, WALTER WILSON (b' 78$)-M 0.7$ 08 ; (1'08)

OREGON, 2,180, OGLE

BEVERIDGE, JAMES M. (b'67)£-II!.11, '98; (1'99).

Cottlow, Benj. A. (b'i1)-Ill.4,'92; (l'92).

John, Ádelbiert Allen.

(See Chicago.)

ROE, JOHN BENJAMIN (b'72)-Ill.8, 95 (l'95).

CHNEIDER, LEO ELMER (b'78)(-Ill.1,

'01; (l'02). (1'02).

ORION, 655, HENRY

Andreen, Frank Godfrey (b'82)-Ill.11, 0 i : (l'07).

GUSTAFSON, JOS. ANSLEY (b'73)-Ill.11,

LONG, H. HORACE (b'40)-Pa.2,'68; (1'78) 
ORLANO, 366, COOK

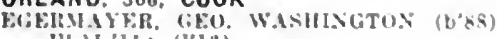
- III.11.11: (1"1:2)

Kimbrough, Marie A-III. II,99: (193),

Schukxler, Waller likhard

(See (ílcairo.)

OSCEOLA

(R.F.D.

NEPONSET), 55. STARK

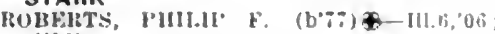
(1'06).

OSKALOOSA (R.F.D.. LOUISVILLE), 100. CLAY

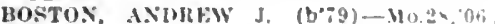
(1"06).

OSWEGO, 726, KENOALL

DRKW, THOS. 16. (b'75) †- 111.11, : : (1'9i)

Van Deventer, A. Fo,-III.6,"63; (1'7;

WRISHEW, IEWIS JHROUL (t)

III.22,"12; (1'12); S.

OTTAWA, 9,535, LA SALLE

BLLE, WM. S. (b'G) O-Ind Is, (1), (l'is) OALR.

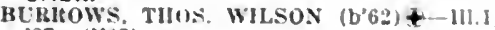

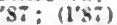

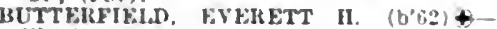
III.1,'84: $(1 ' 85)$

CLUNE, PIIIII" J. (b'68) $\$$-Que.l, (1'00)

EVESSE:, HAKOLD O. (b'68) \&-111.21, 94 (1'94) : (BI) : OALR.*

FREAI, WM. YHINE.IS (b'Ti) \&-111.15,"03, (l'03)

GARLINGTON, JESSE M. (b'45)-MO.J,'69 (1'90): OALR.

Hatheway, Elnathan P. (b'58)-IIl.1,95: (1'95).

UERZOG, ALBERT $5 . \quad(b \div 6)$-III.11,99; (l'99); OALR.»

Hubbard, Argal E. - IH.22.'I2: (Asslstam Physlcian) Otlawa Tent Colóny

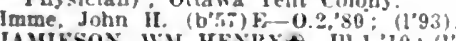

JAMIFSON, WM. HEXISY III.1, 10 : (1'10)

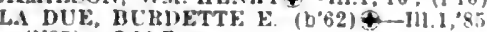
(1'85): OALR.ネ

MILLIGAN ELLA FITCH $\left(0^{\circ} 63\right)+-1119$, "84: (1'93).

PAIMER, ENOS E. (b'66) \&- I11.6,'90 $\left(I^{\prime} 90\right) ; S$.

PARK, SAML. E. (b'83) \&-11.4,09: (l'09).

['ETTIT, JAMES WIIKY (b'43) \&-Ky 4,73 ni.1,'st: $(1 \% 6):$ comce. $31 \mathrm{~N}$. Stale st. Chlcago) : $T_{0} *$

PettIt, Roswell Talmadge-III.1,'13: ().

PJKE. WM. A. (b'73) - Ili.i,96: (1,96)

RORERTS, ALBFItT JAY (b"i2) +-illi," 9 " (1'9\%).

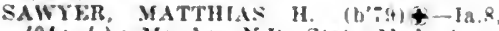
04: (); Member $X$ u. State Sled. Assu.

Smurr, Thos. A. (b'3i)-Pa.2,62; (1'78).

Smurs, Thos, A. (b3i) (1\%:9); $\mathbf{S}$.

OTTERVILLE, 179, JERSEY

Vandre, Chas. A. (b'59) E-0.2,'82; (1'\$2)

OWANECO. 365. CHRISTIAN

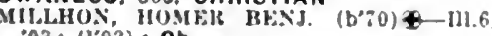
$03 ;(1,03) ; 00$. TANKEISLLYY GEO. ANIJEIESON (b'si)-
Ia.10,08; (1.08).

OZARK, IIO, JOHNSON

Blanchard, J. Ezra (b'7l) E; -0.2,95; (1'95)

PALATINE, I,144, COOK

MLACK, JOS. L.-1I1.10,'03; (1.93).

Schlrdlng, Wm. P.

(seo (ulcago.)

Slarck, Carl A. (b'su)-III.J1.'04: (1'04).

PALESTINE, 1.399, CRAWFORD

IKEMIRE, JOHI AXIIS

04: (?05)

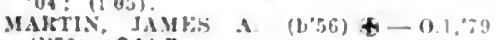
(1'79): OALR.

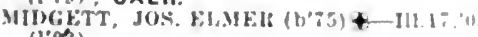
$\left(l^{\circ} 03\right)$.

Taylor, Orlando 4: (b'63) - III.11,93; (1'9:3)

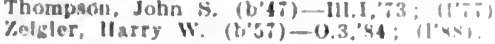

PALMER, 299。CHRISTIAN

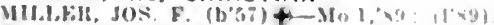

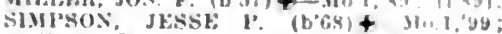
$\left(I^{\circ} 02\right) ; \mathbf{S}$.

PALMYRA, 873, MACOUPIN

'IRLM, ELWIX W. (b'i6) + Vu:B, $(100)$

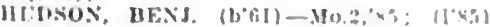

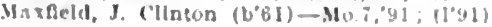

McMAIION, MaliTIN (b's) $4-$ Mo.l. M: (1'85) ; $\mathbf{N}$

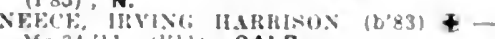
Mo. 3411: (1'11): OALR.

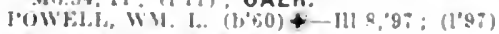

PALOMA. 100, ADAMS

MCIXTOSII, JHESE II $(1, \div 2)-M 0.25,95$ (1"95): 0 b.

PANA, 6,053. CHRISTIAN

Reatly, Fileanor (un3)-111.15,45: (1'45) Hechtold, Eredk. Wm. (b's) - Mo.9.0s (I'0s).

HELGEs, WaITEK $\left(b^{\prime} / 3\right)-$ Mo.27.97 (l'ai).

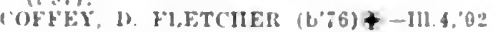
(1'12) : OALR.*

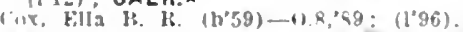

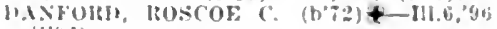
$1 l^{\prime}\left(90^{\circ}\right)$.

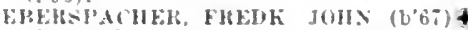
Y Y.10,97: $\left.(1,9)^{\circ}\right)$

Lorton. Thos. S. (b'3i)-ML:"10; $\left(b^{\prime} 10\right)$. MILLE.1t, JOHX IIENRY $\left(0^{\circ} 55\right)+\mathrm{Mo} 1,80$

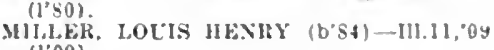
(l'09).

SIIEIWOON, WILLOUGHBY WM. (b"5)-

111.4,"08; (1'09).

PANAMA. 708, MONTGOMERY WILCOX. INAAC OLJVER (b'85) + MO.28
"Oi; (107).

PAPINEAU, 162, IROQUOIS

I.ILE., fiEO. J.-111.11, 00 : (I'00)

PARIS, 7,664, EDGAR

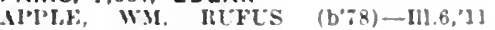
(I'11).

B.UM, ZACHARY T. $\left(b^{\circ i}\right)-0.9,: 00$

IHIILNAN, WM A (b'48) - $0.9 \cdot 75$

(1,

LINTON, BERTHA J. (b':2)申-H1.9.99 :

Conk!ln. Winered Fo. (b'ib) H - $111.4,02$ : (l'02)

Davls, floyd M.-Ky.4,s9; (l's9)

Dill, Jos. M. Foulke-X.Y.1.96: (1'96); not In practlce.

DORRIS, NFTTIF, ACSTIX MLRPII (b76) 4-Ky.2,05: (1'05).

EVIxGF, Jolt. W. (b'52) -Inds, 86 $\left(\mathrm{l}^{\prime} 86\right)$ : It. F. D. 2.

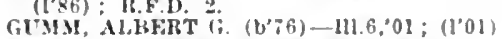

H.NILORA. WM. IHERMAN (b's4)-HI.4. 09 (1'10).

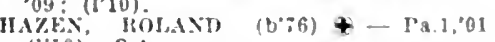

(1'10); S.

HII, Cien. K, Mcclellan (b'63)-I11.11,98 (1'99); OALR.

Ilor, Weller II. (b'v9)-0.1,96: (l'96).

HUNT, GEO. H. $\left(b^{\prime}+1\right)+-0.13,82$; (I's 2$)$

Jenklas, Jeroy $0 .(b \div)-30.10,-8,111.13$ Jenklas,

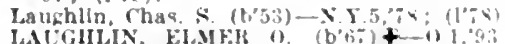

I. ITGIII)

IIXK, PHANCIS M. (1',9)-[11. $1.01:\left(I^{\prime} 01\right)$

Iydlek, Frank D. (b'60)-Mleh 1,$80 ;(190)$

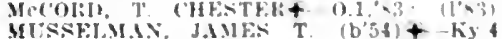
$79: 1179)$

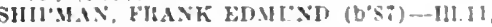

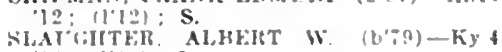
(O) $(104) ; s$

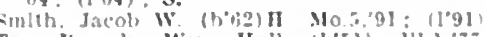

Ten Hrocek, Wm. II $(1,7)$

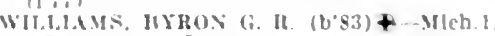
"1) ; (100s); LD。*

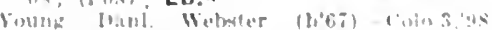
$111+, 4:(1+9 s)$

\section{PARKERSBURG, 238, RICHLAND}

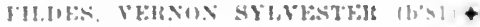

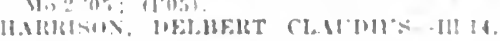
0\%: (100\%)

PARK RIDGE, 2.009, COOK

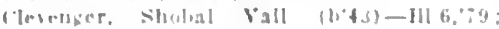
$(10 \% 3) ; N P . *$

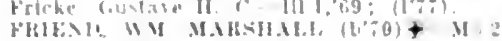

aps, 1100,0$)$

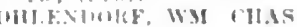

(Sine ( hlonet)

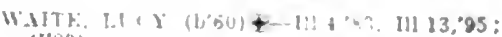
(1'83)

$35:(1,37)$

PATOKA, 67\%, MARION

II uilspech.

(1,3:)

MITIEFIN

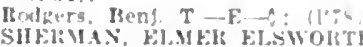

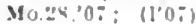

PATTERSON, 200, GREENE

Fureman, Jus, - E-O-O.2,65: Uractlce.

PAWNEE, I,399, SANGAMON

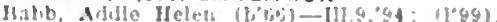

Crald James Alexander (b'of-Mo 2,01: (1'0).

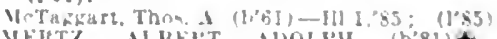
MEISTL, ALBFIST MONLH (b'BI) Nich.1, 09 : Il']

F.K (11.: WM. (65\%) + K5 2,91; $\left(1^{\prime} y=2\right.$

PAWPAW, 800, LEE

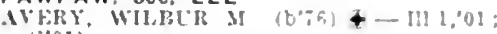
(1'01)

rowell, John C,-I11.1,91; (['91).

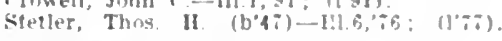

PAXTON, 2,912, FORD

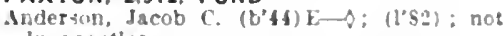

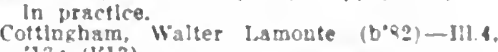
$13:\left(I^{\prime} 13\right)$.

MIXNA FRAIK $\left(b^{\prime}+8\right)+-$ M1.:5 $(I S 3)$ : OALR.

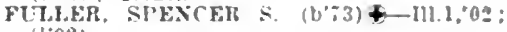
(1002)

HFSTHR. FITENE k. (b?i) \& 02.99

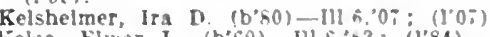

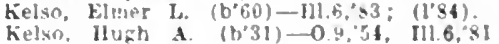
(I's;): not in practlce.

Norderling. Karl A. (b'5i)-Ill.11,'si: (INA); not In practlce.

WYILE, S.IIL. YI. (b.53) +- III.6.78:

AYSON, 465. ADAMS

G.ABRIEL, EUIF: J \&-Mo.;,91; 11911.

PEARL, 842. PIKE

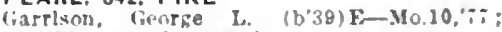

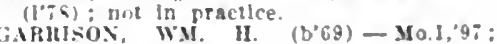
(1.97).

THIRMAX, FRANCIA MARION (bog)+ IIO.2S, 0 i; 1104$)$.

PEARL CITY, 485, STEPHENSON

IIooker. ("has I. (b'58)-MI.1, $\$ 6$ : (1's6).

WOKRE, JOIIN if (b'65)-111.10.95: (1.95).

PECATONICA, 1.022. WINNEBAGO

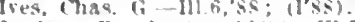

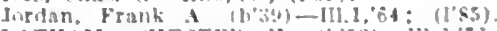

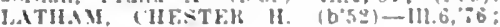

$(1 \% \pi)$

Parker, Harry $C\left(b^{*}:\right)-1116,11$; (111).

PEKIN, 9.897. TAZEWELL

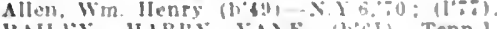

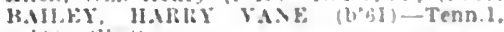

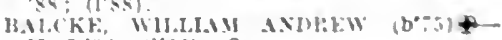

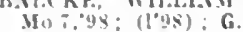

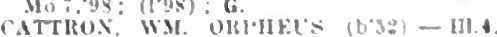
churchll, Harsey J. (b 19) HI-J11 14,23: $(1,3) i$

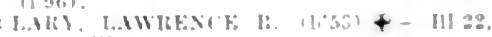

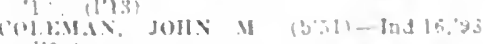

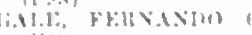

(1) 0 ;

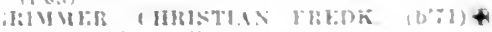
Vich 1, 111; 11001

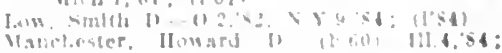

(I) औt)

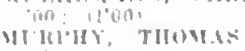

$1+-11111$.

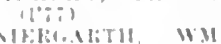

(1) $93 i$

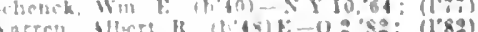


PENFIELO, 300, CHAMPAIGN

Cleteher, John OLls $(1,8 \mathrm{~J})-11 \mathrm{~s} .22,12$; (I'12): S.

PEORIA, 66,950, PEORIA

NISMBEI? OF 1'HYSICIANS, 156

Abbott, Whllts L. (b'58)-Ill.8,89; (I'89) 404, 6th Are.; omce, 3 II $\mathrm{k}$. Adrams it. $9-12,2-5$

ALLISON, WM, RUSSE1, (b'ti3) +-111.] '86; (l's6); 600 Fayette st.; oftle, con tral Natlonal lBank 13lak.: 10-1\%, 1-4; D

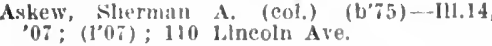

Ayleswroth, William llarrlson (b'54)-

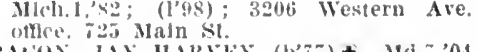

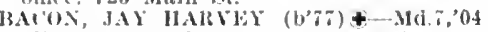
(I"04) : 202 Columbla Terrare; offlee, Central bank Jldg.; 11-12:30, 2-4, $7: 30-$ $8: 30 ; 5$.

BAKLR, IAMES MONROE (b'65)-0.2,92 ; (1"94); 420 Peorla Are.

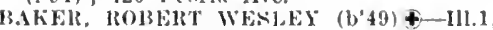

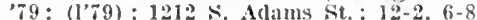
Baldwin, Frank Eugene (b'75)-I11.1,97 $\left(l^{\prime} 97\right)$; 311 N. Perry Ave.; oflce, $725,2 \mathrm{~d}$ Ave.

BARBOUR, LDW. F. (b'69)\&-Ind.5,'99; (l'99) ; 515 N. Gilenn oak St.; oftlee, Jefferson Bldg.; $11-12,2-4,7-8 ; 0$ b.

Barker, Alexis B. (b'72)-0.8, 92 ; (l'95): $102 \mathrm{~N}$. l'erry si.

BASCON, 11ENi广 M. (b'53) \&-Ill.4,73; $\left(l^{\prime} 7\right)$; Nlagara Ilotel; oftice, Nayer 13Idg. ; S. *

BELIINGEA, WILLIAM H. (b'70)థ-111. '95; (l'96) ; 104 la Salle Are.; offlce, 301 Main sit. ; 10-12, 1:30-4:30.

BRADLEY, EDWIN II. (b'61) 4 -Yt.2,'91; (1'92); 112 lligh st.; offlce, Woolner Bldg. ; 9-12, 1:30-5; (B1) ; OALR.

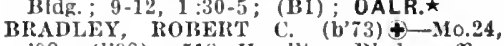
98; (1'98); 518 IJamilton Mlid.; office $129 \mathrm{~S}$. Jefferson $\mathrm{St}$; $11-12,2-4,7-8 ; \mathrm{U}$.

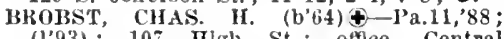
(1'93); 107 High St. : office,

BlROCK, GEÓRGE WILLIAM (b'78)-Ill.6, '10; (1'10); 1201 Terninal Station; offlce, I'eorla state llospltal.

BROWN, JAMES L. (b'41)๑-0.1,'68; (1'6); IIS, ith Are. : offlee, $100 \mathrm{~S}$ Adams St. ; 1 -3.

Burby, John E. (b'70)-Md.4,95; (I'97) ; 800 N. l'erry Are.: offlce, 120 N. Adams St.; $8-12,1: 30-4: 30,7-8 ; U . \star$

BURHANS. LFVI ALDEN (b'73) 4 -III.6 08: (1'08); 432 Main St.; 11-12, 2-4; ObG.

BURNILAM, ALONZO FESTUS $\left(b^{\prime} 53\right) \oplus$ Ill. 1,$78 ;(178) ; 300$ N. Elizabeth $\mathrm{st}$. $9-12,2-5 ; N$.

CAMPBELL, JAMES EDW. (b'71)-111.6 08 ; (l'08); 805 Lincoln Ave.; 11.12,

Cauble, Willss R. (b'66)-Ill.1,'88; (1'88);

$129 \mathrm{~S}$. Jefferson St. $11-12$

COIIN, EUGEN (b'75)†-M0.28,'98, I11.6, '06; (1'98); Peorla State Hospltal; (E13)

COLLINS, CLIFFORD U. (b'6 6 ) $\oplus$-Ind.5, '91, Mo.27,'92; (1'91): 624 Glen Oak

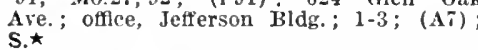

Collins, John Haskell (b'66) - Ill.22,08 (I'08) ; 1327 S. Adams St.

COOLEY, IVM. M. (b'79) - $\rightarrow-11.6,03$ (l03); $1212 \mathrm{~N}$. Monroe St.; oflce, Jefferson' Bldg. ; 11-12, 2-4; $\mathrm{Ob}$.

COOPER, JABAS FENIMORE (b'53)-Md.3 '80; (1'82); 415 Barker Ave.; offlce, 423 Main St.; 10-12, 2-4

CORCORAN, ALBERT L. (b'69)-Ill.6, '92; (1'92) ; 103 Moss Are.; offlee, 1501 Maîn St.; 9-10, 1-3.

CORY, WALTER BENNETT (b'7 $\tilde{\jmath})$-IIl.11, '01; (1'02); 116, ith St. ; offlce, Jefferson Bldg. ; 9-12, 1-5.

Cotton, J. Allen (col.) (b'68)-Ill.13,'97; ('’9-); $712 \mathrm{~N}$. Jefferson St. ; 8-9, 2-4, 6-8. TTTER, WM. W. (b'81)థ-Pa.2,06 ; 1607 Knoxville Are.; offlce, JefBldg. ; $2-4 ; 1 . \star$

EIJIS L. (b'68) $₫-M 0.28,96$; (I'gf): $406 \mathrm{X}$. Glen oak Ave.; offlice, 123 s. Arams st.; $10-12,2-4$
DAV1S, FRANKLIN S. (b'69)†-Ill.10,93 (1'93) ; 712 Hamilt on Mlyd.; 8-9, 1-3, 7-8 Mr'klisux, MERCER (b'76) Mo.28, 08 (1) : 00 Adams st. ; $10-12,2-4,7-8$

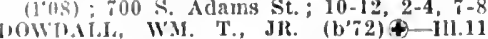

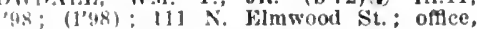
Woolner 13lds. $11-12,2-4 ; \mathrm{Pr}$.

1) 1 NE, JOS, FRANCIS (b'80)-III.1,03; (I'03): 716 IIamilton St.; offee, Jetfer-

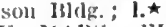

WU MAls, El, W'T C. (b'83)-Mo.2,06: (1'06); 217 N. Maplewond Ave.: oftlee, 102 s. l'erry Ave.: 1-3, 7-8. S.

I) MARS, RIVTS A. (b'49)-Pa.1,77; (l’i); 17? Maplewood Ave.; offlee, 102 S. lerry Are.; 1-3, $7-9$.

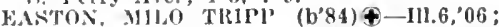
(l'0ti); 216 Cooper Sl.; offlce, 604 Maln

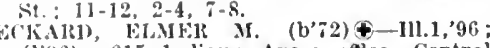
(I"96); 615 Indiana Ave. offlee, Central Natlonal bank Bldk.: 11-12, 2-4.

Ficter, WM. I3. (b'69)†-Ia.9,'98; (1'99) ; 1110 racifle Ave.; offlee, $2913 \mathrm{~N}$. Aclams

wider, l3rice lloward (b'48)-Ind.4,7s: (l'i8); 1222, 21 Ave. ; offlce, Woolner Bldge $9-11: 30,2-5$.

Ellioti, John ifltion (b'30) - Mo.8,'90 (1.91); not in practlee; $127 \mathrm{~N}$. Underhill Are.

FAlNUM, CHAS. GEO. $\left(b^{\prime}-4\right) €-111.1,01$; (1'01); 216 Parkside Drive; offlee, Jefferson Bldg.

FINXFLI, 7OS. J. I. (b'68) - $\mathbf{K y} 4, \mathbf{y}^{\prime} 98$ (l'98) ; 403 II urlburt St.; offlce, 437 Ifain

St. : 11-12, 2-4.
FLOYD, TIONAS $\left(b^{\prime} 72\right)+-K y .1,97$; (1'98); 208 Ellis Ave.; offlee, Woolner Bldg: $9-12,2-5$; OALR. *

FOERTEK, ADOLJH J. (b'75) - - $111.8,01$ (l'99); 657 Moss Are.; offlce, $110 \mathrm{~N}$ Ionroe St. ; 10-4

GARRETT, EMIIETT A. (b'80)-Ill.11,02; (l'02) ; 220 Cooper St. ; offlee, 422 Main St. : $10-12,2-4,7-8$.

GELDER, EDGAR EARI, $\left(b^{\prime} 78\right)(-P a .1,02$; (1'03) : Peter Apartments : offlce, Jefferson Bidg. ; 11-12,2-4: ObG. $\star$

GERZFMA, FRANZ (b'62) $\oplus-1 \mathrm{~A} .1,93$; (1'93); 2223, 7th Are.; offlce, 731 Lincoln Ave. ; $2-5,7-8$.

GILTLSPIE, TIIOMAS WALTER $\left(\mathrm{b}^{\prime} 69\right) \oplus$ III.1,'96; (I'98); 1005 Jackson St. ; oflice Jefferson Bldg. : 11-12, 1-3.

GREEN, ROLIAYD LESTER (b'75)థMo.7,98; (1'98); Fay Hotel ; offce, 415 S. Adlams St. ; 11-12, 2-5, 7-8.

HAMILTON, ANGELINA G. $\left(b^{\prime} 72\right) \oplus$

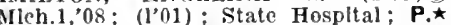

IIANLY, HARRY HAMIITON (b'78) III.10,00, III.6,'10; (1'00); 600 Fayette St. : offle, Jefferson Bldg. $1: 30-4,7-8$.

HANNA, ROBER'T A. (b'68) (-Ia.9,'94; St. : $2-4 ;$ S. *

llarrison, John R. (b'58)-1a.1,92; (1'92); 721 W. Meclure Are.

Harrison, Iflfe (b'66)-Ill.2,'11: (l'11) ; 2106 S. Adams St. office, 919 Lincoln Ave ; $10-12,1: 30-4,7-9: 30$.

HASSON, EDW. (b'76) \&-III.1,99; (1'99) 407 Knoxville Are.; offlce, Jefferson Bldg. ; $11-12,2-4,7-8$

ПAYES, CLARA EDNA (b'84)థ-Ill.11, '12; (l'12); Peoria State Hospital: NP' Adams $\mathrm{St}$.

HINCKLE, WM. A (b'76) -III, 03 ; (1'03) ; 212 N. Parkside Drive; ofllce, Jefferson lilig.; 11-4.

Holbrook, Yernon Dayton (b'76)-Md.4,02; (1'05); 122, 4th Ave.

IIORWITZ, SANDOR (b'67)థ-Mo.1,'95 (1'95); 410 S. Bourland St.; offlee, Mayer Bldg.; $9-11,2-4,7-8$.

HOUGLAND, WALTER L. (b'6)-Mo.34, 05 ; (l'05); 323 Bradley Are.

Howell, Wm. G. (b'62)-Pa.1,84; (1'99) ; $1025 \mathrm{x}$. Jefferson; office, Masonlc Temple. IUBER, JOS. EMIL (b'67) $\uparrow-11.6,10$ (1'10); 1114 Hamllton Blvd.; offlee, Wool ner Bidg. ; $10-12,2-4 ; 1$.

JAMES, PETER FRANKLIN (b'82)థ 111.22,10; (l'10); 2106 S. Adams St.

JOHNSTON, WILLIAM ADAMS (b'60)Pa.1,'82; (1'82) ; (Dentist);
Helghts); office, Jefferson Bldg.
KANNE, AlOYSIUS, J, (b'64) Mo.2, ferson Bldg: $9-12,2: 30-5$; OALR. $\star$

KEIRI, IRO13'T A (h'57)-Ill.1,81; (l'82) : 1218 II amlition Ave.; office. Jefferson lildg. : 11-12, 2-5; S.

KInneli, Wu. Ennls' (b'49)-0.2,76; (1'78) offlee, 802, 4th Ave.; also, Masonle Temple, $10-12,2-4$.

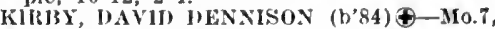
07 : (l'07) ; Jefferson Bldg.; U.

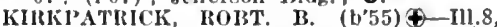
$76:(1 \cdot 77) ; 609 \mathrm{~N}$. Jefferson Ave.; oftlec, Woolner lidig. : $10-12,2-4$

KNAr'I', ALFRED A. (b'68)-Ill.1,'91 (l'91); 1800 Columbia Terrace; Offlce, Jefterson Bldg.; $10-12,2-5$.

KOCH, WESLEY' ALFKED (b'76) \&-nl.11, 01; (1'01); 613, 14th St.

KRAFFT, HEXIRY LOULS $\left(b^{\prime} 85\right)$ - (1).11, 09: (1'09); Peorla State IIospltal; NP.

Lang, Francls Ferdinand (b'85)-111.8,'12 (1'12); 1329 S. Adams St.; 10-12, 2-4,

LEVITIN, EMII, ZOLO (b's0) \$-Ill.11,05; (1'05); $1610 \mathrm{~N}$. Maclison St.; offce, Jetferson Bldg. ; $10-12,2-5$; NP.

Iewls, Robt. kinest (b'69)-Mich.1,'91; (1'91); not in practice; 201 North St.

LIMMER, GEO. I. (b'66)-Mo.8,'88; (l'94); Nlagara Hotel; offlce, Obserratory Bldg. ; $10-12,2-6$.

Longhridge, Samuel o. (b'38)-Pa.2,66, N.Y.1,'70; $\left(1^{\prime} 7 \overline{6}\right) ; 113$ N. Bourland St. ; offlec, 3031/2 Main' St. ; 10-12, 2-4.

MAGEE, HARLY BAYNE (b'82)-Pa.1,08; (i'10); 203 Bradley Ave.; offlce, Woolner Bldg. ; 8-10, 2-5, 7-8.

Major, Wllliam (b'73)-Ill.11,01; (1'05) ; 2416 S. Adams St.; offlee, 3028 S. Adams St. ; 11-12, 2-4, 7-8.

MARCY, HILTON S. $\left(b^{\prime} 54\right)(1)-11.6,78$; (I'81); $716 \mathrm{~N}$. Jefferson Ave.; offlce, Woolner Bidg. ; $8-9,2-4 ; 0$ b.

Martin, Leonldas B.-Ill.1,'68; (1'77) ; 610 Morton St.; office, 305 Main St.

MeBROOM, ELAM ROWLAND $\left(b^{\prime} 77\right) \oplus$ Ill.22,08; $(l, 08) ; 120$ S. Adams St.

McIlVAINE, TIIOS. M.(-III.1,81; (l'81) ; 213 North St.; offec, 516 Main St.; 2-4,

ICMAHAN, JOHN PAGE $\$-I l l .1,83$; (1'83); $105 \mathrm{~N}$. Elizabeth St.

Melxner, Fred Morris Frankfort (b'84)Ill.6,'11; (l'11); 1111 N. Monroe St. ; 911, 7-8; offlee, Jefferson Bldg. ; $2-3 ; \mathbf{O b}$. (I'00); 201 W. Armstrong Ave.; offle, (l'00); 20I W. Armstrong $\mathrm{A}$.

MELOY, MARGÁET BABCOCK (b'78)III.11, $00 ;\left(10^{\prime} 00\right) ; 201$ W. Armstrong Ave.; offlee, Woolner Bldg. ; 11-1, 2-4; G.

IERCER, WHEDON WORLEY (b'81)Ill.11,'08; $\left(l^{\prime} 08\right)$; State Hospital; NP.* (l'04); 106 Glen Oak Ave.; NP.*

MILLER, CHAS. M. (b'54)-I11.1,'81; (l'81); 107 V. McClure Ave.; offlee, 1800 Knoxville A ve.; $10-12,2-4,7-8$.

miller, Chás. Wm. (b'80) - Mich.1,08 (1'10); 1709, 1st Are.; offlce, 801, 1st Ave. ; $11-12,2-4,7-8$

MILLER, SUNINER M. (b'73)๑-Ill.6,99 (l'99); 407 Knoxville Ave.; office, Jefferson Bldg. ; 1-4; S.

Morgan, Johanna Wilhelmina Bauer (b'50) -No.5,84; (1'84); not in practice; 717 Starr St.

Nevins, Herbert (b'59)-Cal.5,91; (l'98); 1215 E. Republic St. ; offle, Nevins' SanItarlum.

NYSTKOM, ELMER EDIVIN (b'84)-Ill.6, 09; (l'09) ; $1830 \mathrm{~N}$. Jefferson St.; offlee, 424 Main St. ; $2-4$.

OLIVER, ELBERT W. (b'74) - Mo.27,93 (1'95); 219 N. Glen Oak Ave.; office, 215 N. Adams St.; $9-4 ;$ Or.

PAGE, THEODORE H. (b'75)-IIl.1,97 ; (l'98); 411 Moss Ave; offlee, HeraldTranscript Bldg. ; 9-12, 2-4; OpA.ネ

PAINE, JAMES CLAUDE $\left(b^{\prime} 74\right) \oplus-111.6$, '98; (I'98); 2721 N. Adans St.; offlee 2719 N. Adams St.; $10-12,2-4,7-8$.

Parker, Donna M.-H-Ia.4,'88; (l'88) ; 519 N. Monroe St.; office, Masonlc Temple; $10-12,2-4 ; \mathbf{G}$. 
PARKER, GLORG: (b'7) $+-113.6,02$ (1'02); $97 \times$ : Cnlversity

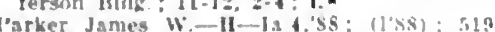

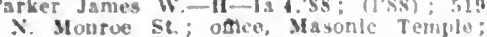
10.12, \$-4

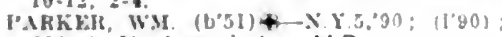
216 \$. Majlewuml si; ALR.

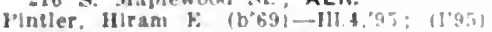
311 indlana Are.: onlce, 415 \& Adam St. : 9.4: U.

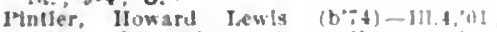
(lioi); 615 Allantle st.; ofleo, Wuolnet Bldg: $10.12,1: 30-4$.

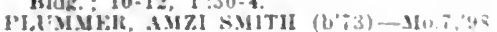

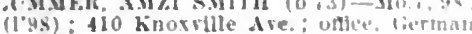
(1'48): 110 knorrlle Are.

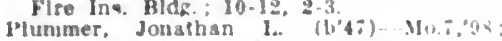
(18s); 1313 Main st, onlee, 1315 Main st.

HOLLOCK, JAME.S KINTA-Pa 1,0 (I'It): Peorla siate Hospltal: P,

rowell, Vance M. (b'bi)-Ky.t.94; (1'84) $1315 \times$ Jefierson lie: umce. Idams St. : 9-5.

Prewett. (ieo. D. (b'61)-Mo.1, "90: (I'90): 408 Oakland Ire. : offce. $2623 \mathrm{~s}$. Adam st. $9 \cdot 12,2-4,-4,4$,

PIICE, WAITEK J. $($ b'T1) $+-111.1,95$ (1'95)

ROHEHTS, JOHN C. $(6.61) \mp-11111,8$ (I'37): 103 High SI.: attce, Jetsersol

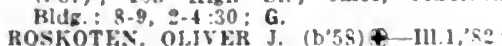
(1.82); il W. Armstrong Are.; often 301 \&. Adams St. : $2.5 ; U$.

KITHERFORD, LESIIF (b, 79$) £-111.1 .01$ (1'01): 15i Maplewood $\Delta=e$ : : oflce, Ief ferson Bldz. : $2-4$

Schuar, Henry L-Ia.9,'98; (l'98) ; (iram Vlew prive: oftice, $216 x$, Jeffersion Aie.

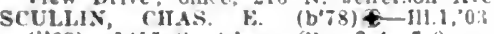
(1)03): 1415 s. Adams st. : 2-4, i-8.

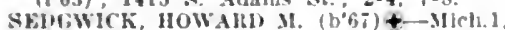
$90:\left(I^{2} 89\right) ; 922$ Knorvile Ave; ottce, '90: (I'89) : 922 knorvill

Shepperd, James II. (col.) (b'65)-Tenn.i,

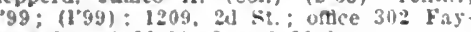
e.té St. : $8: 30-10,2-4,6: 30-8$

SHOLL, J. RFX (b'80)-IIl.10,04: (I'04) 204 Randolth Are.; once, $111 \mathrm{x}$. Jefferson st.; $9.12,2-4$.

SHORT, WAHE H. (b'6s) + 111.10,'98:

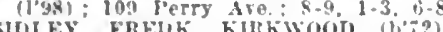

SIILEY FREIK. KIIKWOOD $\left(\mathrm{b}^{\circ}: 2\right)+$ Ill. 10,97: (1'9i): to4 Barker Ale.;
Jefferson Bldg. : 10-3; (II); ALR.

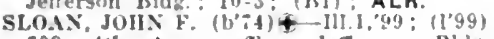
609 th tie oflce, Jefferson Bldg. 11-is, $2 ; 30-4: 30$.

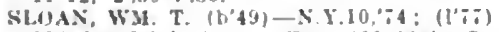
204 Kandolph Ave; offer, 4:0 Main st 2-5; S.

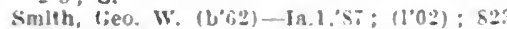
Hizelow Ire; uflice, 333 s. Alams si. $8-4$.

Spaliting, Leonard II (b't5)-Mld.1,69: $\left(1^{\prime} 81\right) ; 805 \mathrm{~N}$. Jerterson Ave.

Sprague, Ioyal T. (b"53)-X. Y. 5, ;6; (1's2) not in praeslec: $2 ! 11 \times$ Jerterson Ave

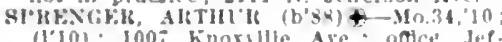
fervin Bilg. : 2.i: U.

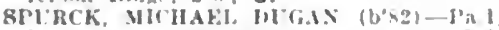

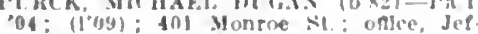

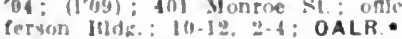

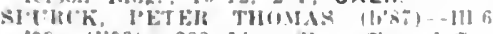
09: (lo9): 223 L.lnn si: onlloe, Juter son Mlle; 10.12 . 2.4, i- 8 .

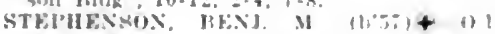

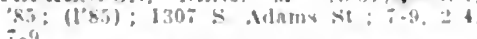

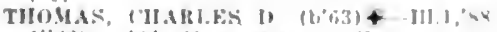

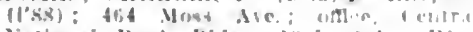

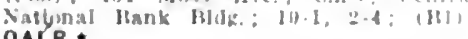
$O A L R, *$

TOALSOX, JAMK:A J (1,

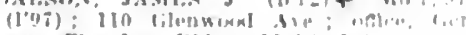

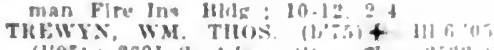

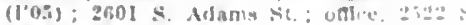
diamý sie

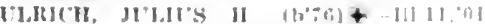

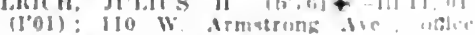
510 Valn St: :- i; S.

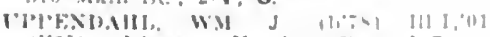
11001); Nasara Hutel; ugder, Jertersut IHIg. : 11-1: :1; s.

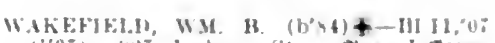

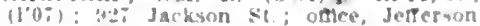
Itld: ; : $4 ; 0$.

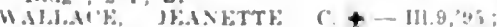

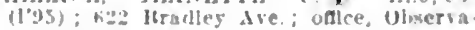
tury laldi: ; 10. I:2, 2-4

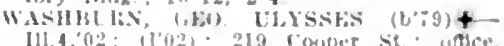
$111.4,02 ; 1102): 212$ ('orble

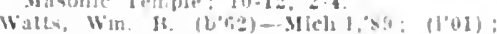

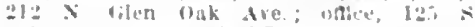
Nlams M: 1.5, OALR.

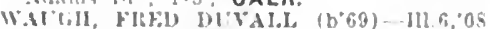
$(10 x)$ : 10w $X$. Madison Are, odlee, 125

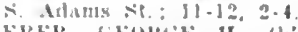

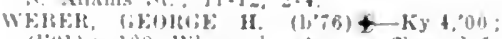
(101); 10s Wlscunsin Ave.; oatice, JerPersun lilig: 1-3; S.

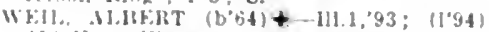
II Knuxvilie twe; onlce, Jefrerson bldg. $\therefore-4 ; 5$.

Wolmer, Euln Alexander (b'al)-III, y.;

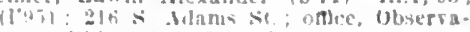
atory bilk: $: 1-3,-5 ;$ G.*

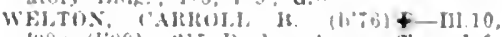

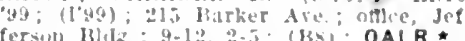

Whitluck, Merle II. (L's3)II- III $4,00^{\circ}$ (l"0is) : Jefierson Bldit

WLEs, I'ETEA (b'bi) + Ma.24.96; (l'09)

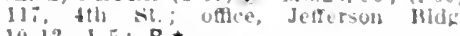
111. 12. 1-5: R. *

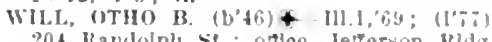
$9-1:($ : 11$)$

WHLIAMS. WRICHT C. $\left(b^{\prime} R 0\right) \pm-0.9,0.3$; (1०04): $40 \%$ hrorville Ave. umce. Je? ferson Bldg.: 1-4; (BI, x): OALR.

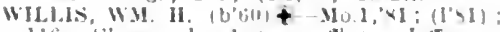

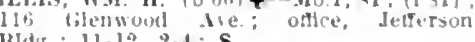
Blikg; $11-12,2-4 ; \mathrm{S}$.

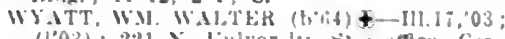

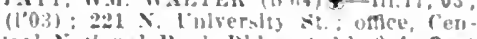
Iral Sablunal Bank Bldz; $y-12,2-4 ; 0 p . *$

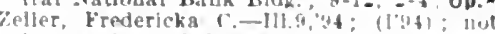
in practice: $1008 \mathrm{D}$ Maln st.

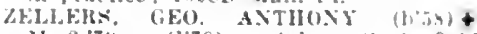
Yo.2, iy; (1'79); (also surinstleid) (1.13):P.*

PEORIA HEIGHTS (PEORIA P.O.), 582, PEORIA

J)HXSTUX, WHALAM ADAMS

(sere l'enria.)

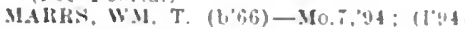

PEOTONE, 1,207, WILL

Ifolahaver, Frank Arliur (bia)-111.17,09;

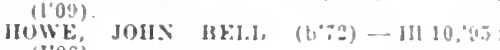
(I'36i).

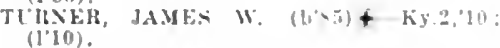

PERCY, 1,033. RANDOLPH

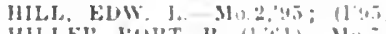

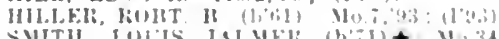

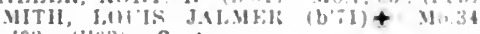
03: (1'03); Op.*

PERRY, 6\$9, PIKE

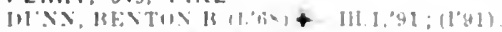

PERU, 7,98 b. LA SALLE

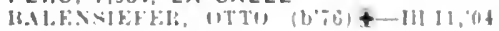

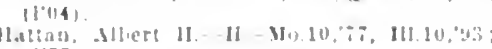

$(1 \div 3)$

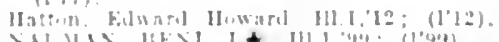

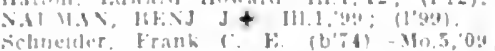

(1)??)

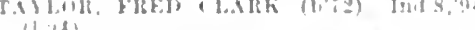

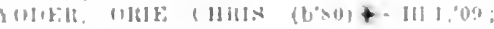

PESOTUM, 430, CHAMPAIGN

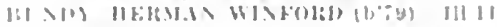

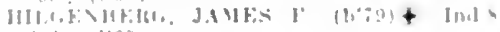

PETERSAURG, 2,38\%, MENARD

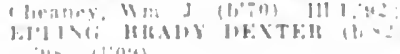

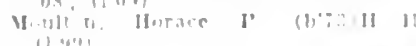

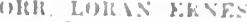

+1 Ia.0:

WIITLEY, JAYk:

(1) 1:1 1::1:

WH.KISS, II b. 11 h, II

PHILO, 725, CHAMPAIGN

JESTER, IS(IIT. EIW I,E.

(91i, : 11 'sonj

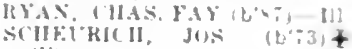

(1.4TS)

PIERRON, 240. BONO

IIAWIITUN, RUIST ALUIZO

Mo:-4,01, Mo.7,04; (1'04).

PINCKNEYVILLE, 2.722, PERRY

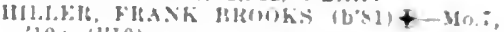
$10 ;(110)$.

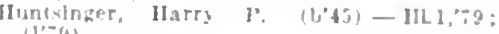

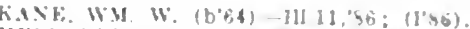

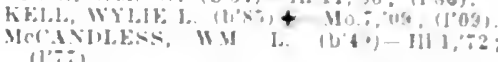
$(1 ; \cdots)$

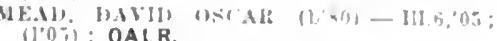

OALR.

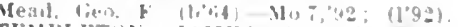

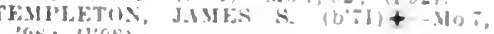

PINKSTAFF, II0, LAWRENCE

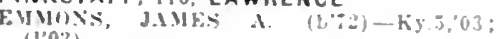
(1,03).

PIPER CITY, 850, FORD

l)e Mendozs. Arthur Huriado (b'bl)-Ill :.3. 05 : $\left(l^{\prime}, 05\right)$

Mellen. (harles s, (10.50)-11].11,03: (1003).

TIEKEx, JUHX D. $(455)+-110.0,79$; (1'79).

Willanson. Carl syleman (b'2:i) - 111 29, 10 ; (1'10).

PITTSFIELD, 2,095, PIKE

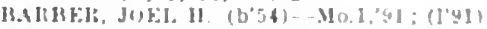

not in practice.

luley, Luciux A. (b':2) E-O 2.:45: (1.95)

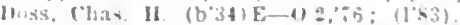

IIalpio. John C. $\left(b^{\prime} 5 i\right)-310,2,33 ;(133)$;

Itit in practlce.

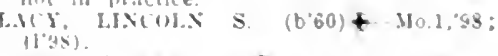

l'ringle, jolin

(vive Sit. Iouls, Mo.)

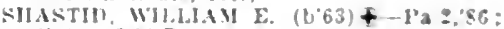

(1'?1); OALR.

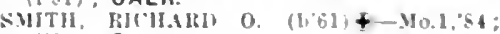
(I'S I) : S.

WLLLS. FHANK ×. (b'6s) +-111.10,93; $\left(I^{\prime} 95\right)$.

PLAINFIELD, I.019, WILL

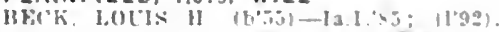

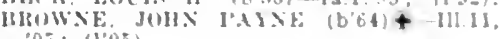
$05 ;(1,05)$

Unens, Juln C.-. Y 15, s1; (1.83).

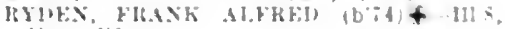
(0), (1.00).

PLAINVIEW, I50, MACOUPIN

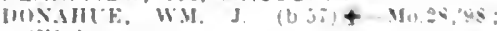
(I"is)

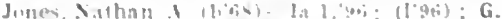

PLAINVILLE, 300. ADAMS

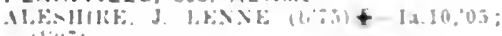

PLANO. 1,627. KENDALL

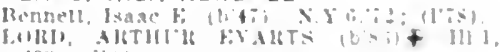

on: 1100 ,

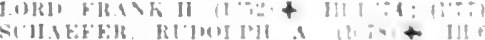

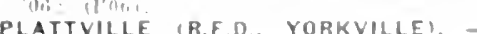
KENDALL

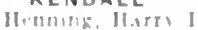

PLEASANT HILL. S:B. PIKE

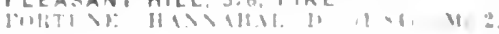

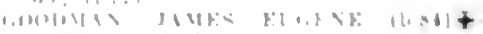

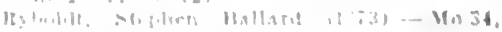

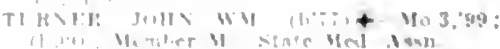

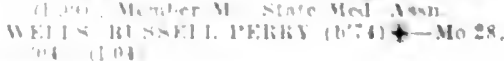


PLEASANT MOUND, 200, BOND

YAIVIIN, ('ILAS. WALIO) (b'SI) 09 ; (l'09).

PLEASANT PLAINS, 625, SANGAMON

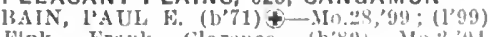

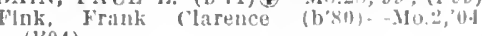
(l'04).

PLYMOUTH. I,000, HANCOCK

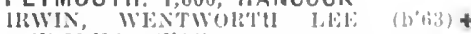
II1.I1,98; (I'98).
IeDaniel, Thos. J. (1,60)-111. 1, $66 ;\left(1^{\prime} \times 8\right)$; not in practice.

Tuck, Wm. 0.-III.6.91 ; (1'11)

Wade, law. II. $\left.\left(0^{\prime}, 6\right)-0\right), 03 ;(1003)$.

POCAHONTAS, 7\%9, BOND

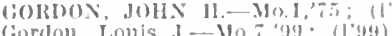

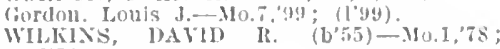
$\left(I^{\circ} 78\right)$.

POLD, 1,828, OGLE

1BEAli), LISLLIE A. (b'60) - I11.6, 89 ; DONALDSUN, WM. BURNS $\left(\mathrm{b}^{\prime} 53\right)-$-Ill.6,

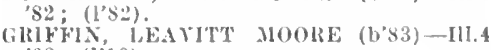

'08; (l'10). SAMUEL D. (b'5̃) †-I11.5,'86

Inks, Frank Emerson (b's2)-111.11,'12: (1'12); 0 b.

Krebbs, Jacub Irvin $\left(b^{\prime} 57\right) \sim$ Ia.3,'86: (1'90) Powell, Clinton E. ( ( '73)-MU.27,'y7; (1'97). POMONA, 150, JACKSON

STEARNS. CLAU1UE ADAMS (b'S5) Mlo.28,'I I ; (l'11).

Stearns, Willis-IIo.7,91; (l'91)

PONTIAC, 6,090, LIVINGSTON

Baker, John Iowen (b'37)-11!.1 ,60; (I'75) BAWDEN, FRANK C. (b'7) $\$$-IIl. 1,02 $\left(\mathrm{l}^{\prime} 0: 2\right)$; $\mathrm{S}$

Colbourne, John Antony (b'62)-Ill.6,'94 (l'94)

CROClikR, FIETCIER L. $\left(b^{\prime} 66\right) \oplus-0.9$,

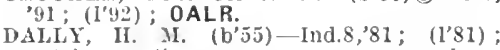
not in practice.

DALY, VICTOR MACKAY (b'67) 4 -Sec.3, '92; (I'94).

DURKEE, ALVARO C. (b'71) \&-Ill.1,'01;

(l'05).

(See Chicago.)

JOHNSOX, s. CUIRTS (b'69)-Ind.8,'97 (l'06)

King, Richard Irring (b'70)-Ill.s,'09; (l'09). Long, Chas. H. (b'50) H-Ill.10,78; (1'78).

MARSHALL, JAMES A. (b'61) 6 -Mich.7,

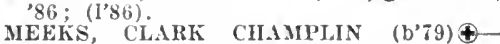
Ill.1 1, 05, III. 17, $05 ;$ (1'05).

MIDDLETON, ALONZO B. (b'76) $\oplus$-Mo.28, '98; (1'98); (B1) ; OALR.*

MTCIIELL, JAMES M. (b'69)†-Ill.1,00 (l'00); OpA.

Pearson, Jas. J. (b'55)-Ky.1,81; (1'78); G Pearson. Norman (b'80)-IIl.6, $01 ;\left(l^{\prime} 01\right)$

ROSS, JOHN (b'67)—-III.1,94; (1'94)

scouller, John D. (b'36)-N. T.6,'70; (''81)

SCOULI.ER, JOHF D., JR. (b',5) -Ill.1

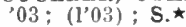

STITES, JOHX゙ J. $\left(\mathrm{b}^{\prime 2} 26\right)-0.2,50, \mathrm{Va}, 2,60$ (1'78); not in practice.

YOUNG, JOHN GLENN (b'79) †-Mo.28,'06 $\left(l^{\prime} 07\right)$.

\section{POPLAR GROVE, 350, BOONE}

MAKKLEY. GEO. WASIINGTON (b'69)Ill.17,'03; (I'04)

PORT BYRON, 642, ROCK ISLAND

Block, Wm. S. (b'50)-Vt.2,'86; (l'90); not in practice.

BRUNER, JAMES M. 0. (b'59)థ-Ill.11,'87 (l'87).

Johnson, Henry W. (b'54)-Pa.9,'82; (1'92)

Lyford, Wm. Haines (b'36) - Ill.1,59; $\left(1^{\prime} 77\right)$; not in practice.

POTOMAC, 800, VERMILION

BUTZ, JOIIN EDW. PREBLE (b'49) 111.1, $75 ;(1 \% 8)$.

COSSAIRT, WM. S. (b'69)థ-I1I.1,00 ; ( 1.00$)$

JYINALL, JAMES MATTHEW (b'84)†IH. 11,10; (l'10). OALR.
PRAIRIE CITY, 818, MCDONOUGH

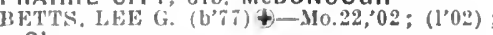
$\mathrm{Ob}$.

lirehier, Wm. Leed (b'32)-Ill.1,59; (1'77)

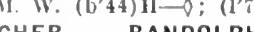

loulas Sami F-MIo.1,83; (I'85).

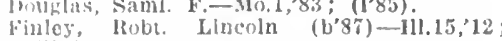
(l'12).

LYONS, JAMES M. (b'57)-MInn.2,'88; (1*01)

PREEMPTION, 250, MERCER

SFYLER, IAMES H. $\left(\mathrm{b}^{\prime} 42\right) \notin-1$ 'a.1, 68 ; $(1,1 \%)$

PRENTICE, I55, MORGAN

IIARIRIS, DOI'(BLAS NEBRASKA $\left(\mathrm{b}^{\prime} 54\right)+$ 1to.18,'87; (1'si).

PRESTON, I0I, RANDOLPH

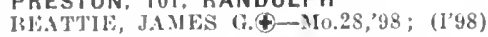

PRINCETON, 4,131, BUREAU

B.IRUETT, CIHS. CYRUS (b'73)\$-III.1 (1):; $\left(l^{\prime} 02\right)$

IMLACKBURN, MATTIEW II. (b'61)4Ia.3,'S9; (1'94); S.

Downer, Abner Geo. (b'56) H-N.Y.9,'82; (1'8:

OLIVER 3. (b'T0)-I11.6,'98 :

GARWOOD, JESSIE I'IERCE (b'58) †-Ia.? 'S8; (1'93).

GTSWOLI), WM. CARTER (b'39) -0; not in practice.

Hickman, IIomer V. (b'68)-No.28, 01 ; (I'0I).

KALLL, WM. M. (b'33)-N.Y.5,'55; (1'78); not in practice.

KELI,ER, WM. (b'42)-Mo.7,'84; (1'84).

LINABEIY, WAI. L. (b'59) -I11.11,'83;

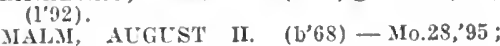
(I'95).

Nix, Milton Arthur (b'81)-Ill.6,'10; (l'10) OWENS, ALFRED E - (b'5i) $4-I l l .6,283$ (l'83).

Owens, IIattle M.-Pa.7,'92; (1'93).

Schenk, Ernest J. (b'30) $\mathrm{H} \rightarrow$; (l'83)

SCHROEDER, FRANK BERNARD (b'76) Ill.15, 09; (l'09); OALR.

SCO'T' CHAS. C. (b'67)-Ill.1,'91; (1'91).

S'TEELE, IIENRY D. (b'69) \$-Ill.6,92 ;

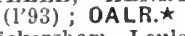

Wickershan, Louls I.

(See Malden.)

PRINCEVILLE, 735, PEORIA

Haney, Franklin H. (b'78)-Ill.22,09: ( I'09)

Henson, Earle E. (b'87)-Ill.22,12 ; (1'12)

WIICOX, COLLIX H. (b'64) $\oplus-111.1$, b $^{\prime}$ (I'88); G.

PROPHETSTOWN, 1,350, WHITESIDE

INCE, EDW. ARMSTRONG (b'49)-IIl.4 JOHNSON, ABRAHAM L. (b'65)థ-Ill.1 OHNSON,

Mosher, James H.-N.Y.8,67; (1'77).

SMITH, SIDNEY ALBERT (b'85) $\oplus$-Ill.11 ' 10 ; (I'10); ALR.

TASCHER, JULIUS H. (b'64)-IIl.8,'91; (1'91); OALR.

PULASKI, 592, PULASKI

WHITEAKER, WM. J. (b'72)-Mo.28,'00; (I'00).

PUTNAM, 250, PUTNAM

Stipp, James H.-Ill.1,'79; (l'81).

QUINCY, 36,587, ADAMS

BAKER, WM. HAYDEN (b'70)-N.Y.1, 96 $\left(l^{\prime} 97\right)$; 1636 Jersey St. ; offlce, wells Bldg.; $10: 20-11: 30,2-3$

BALI, ELIZABETH BROWNING $\left(b^{2} 82\right) \oplus-$ Ill 11;07: (l'07); 648 ohio St, $2-4,7-8$. Barstow, LeRoy P.-Ill.1,'96; $\left(1^{\prime} 96\right)$; not in practice; 24 th and Locust Sts.

BECKFR, HARRY E. (b'69)-Ill.4,05 $\left(1^{\prime} 05\right) ; 237$ N. 8 th St. ; $10-12,1-3,7-8$; G.

BEIRNE, HENRY PETER (b'72)--Y't.2,'93 (1’94); MusseIman BIdg. ; 8-10, 1-3, $7-8$

BITTER, J. W. EDW. (b'62)-III.12,87 (l'87); 829 Washlngton St.; i-9, 12-2,

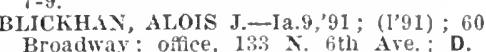
BL0OMER, JOS. H. (b'79)-IIl.1,'06; (l'08) Mercantile Bldg.
BRENNER, FRANKLIN TIIEODORE (b'71) III. I,95; (l'95); I452 Vermont st.; of 1lee, Mercantlle Bldg. ; 7-9, 1-3, 7-9. Buchanan, lobt. F. ( ( Ilst); 5ist/2 Maln st. ; 9-12, 1 -5.

Bullett, Josephus Granderson (col.) (b'69)'l'enn.7,'C2; $\left(\mathrm{I}^{\prime} 10\right) ; 920$ Chestnut St. : $9-11,2-5,7+8$

I3urch, (ieo. W. (b'66)-Ia.1,90; (1'90);

$5281 / 2$ Hampshire St.
CENTER, CHAS. DEWEY (b'69) 9-Ill.1, 94; (1’95); I67 I IIampshire St.; oflce, 94; (1’95); I67I IIampshire St. : offce,

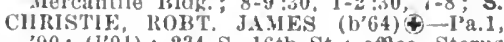
$90 ;(1 ' 91) ; 234$ S. 16 th St.; ofnce, Sterns

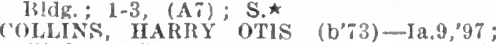
(1'97); 645t/2 Itampshire St. ; 8-10, 1-3, 6-8.

Crandall. Orson II. $-0.2,57$; (1'89) ; not In EAREI, JOIIN WM. (b'69)\$-III.1,95: (l'95); Sterns IIIdg.: $9-12,1-5 ;$ OALR. EIILE, CIIAUNCEY F. (b'66) \&-III.6,'95; (1'99) : Soldiers and Sallors' Home.

ERICSON, CIIAS. E. (b'79)૯-III.I 1,04 ; (1'04); $205^{1 / 2}$ N. $81 \mathrm{~h} \mathrm{St.;} \mathrm{offlce,} 8$ th and IIampshire sts. ; $7-9,1-4,7-8$.

GERMANN, MELINIA C. KNAPHEIDE $\left(b^{\prime} 63\right)$ क-111.12,'86; (l'86); 1231 Maine St. ; 8-9, $1: 30-4, \pi=9$

Githens, Wm. K. (b'63)-Ia.9,'91; (1'91) ; not in practice; 1228 Vermont $\mathrm{St}$

Green, Henry Lee (b'57)-Pa.1,80; (l'06); $604 \frac{1}{2}$ Naine St. ; $2-7: 30$,

IRWIN, GRANT (b'65)-Ill.12,86; (l'86); $8081 / 2$ Maine St.; offee, $8081 / 2$ Malne St. 8-10, 2-4, 7-8; Pr.

JACOBS, ROB'T. H. (b'66) †-Kÿ1,'94; ('95); SoldIers' Ilome.

JOHNSTON, O'TIS (b'37)-Ill.12,'89; (1'89) ; 1476 Hampshire St.; office, 241 Wells Bldg. : 1 3, $7-8$.

KIDD, ALLEN EDW. (b'76)€-M0.28,'05; (1'06); 1441 Hampshire St.; offlce, Wells Bldg. ; $9-12,1: 30-4: 30$; OALR, $\star$

KNAPHEIDE, WM. S. $\oplus \rightarrow$ Ill.12,'89, N.Y.8 $90 ;(1 \% 89) ; 224$ S. 12 th $\mathrm{St}$; offlce, $63 i$ Malne $S t$.

KNOX, THOMAS B. (b'72)-Ill.11,'02: (l'02) ; 534 N. 8 th St. ; offlce, Mercantlle Bldg. ; 8-10, 1-3, 7-8.

KOCH, JOHN A. (b'74) †-D.C.1,97; (1'97) ; 330 N. 8th St. ; untll 9, 1-3,7-8; $\mathrm{S}$.

Konantz, Orion Frank (b'79)-Pa.2,05: (l'13) ; 1667 Hampshire St.

LANDON, DAVID M. (b'53)-Ia.1,77, Mo.1, 79; (1'77); Soldiers and Sailors' Home. Llesen. Anna M. (b'66)-Ind.10,97; (I’97): $1302 \mathrm{~N}$. 10th St. : 9-10, 2-3, 6-8

LIT'HFIELD, HAR'T FLORINGTON (b'83) -Ky.2,09; (l'11); 8th and Madison. Sts. ; $7-9,12-3,6-9$.

McNeill, Charles (b'66)-Ia.9,'97; (1'97); $428 \mathrm{~N}, 6$ th Are.

MEYER, AUGUST WM. (b'63)-Ia.10,04;

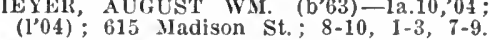
MLLEN, WM. A. (b'72)ष-Ia.1, 96 ; (1'96) : 805 N. 5 th St. ; $9-11,3-5,7-8: 30$.

MILLER, J. ESTILL (b'71) †-MId.4,93; (1'95); 1836 Main St.; office, 400 Jerse. St. ; $7-8,1-3,7-8 ; 5 . \star$

MONTGOMERY, EDMUND B. $\left(b^{\prime} 58\right) \oplus-$ Pa.2,78; (l'79); 1461 Vermont St. ; offlce 132 N. 8th St. ; $8-9,1-3,7-8 ; \mathrm{S}$.

NICHOLS, ASA BURTON (b'72)-111.4, 95 $\left(l^{\prime} 95\right) ; 800$ N. 6th Ave.; $10-12,2-4,7-8$; Pd.

NICHOLS, HOSEA JEFFERSON (col.) (b'70)-D.C.3,'99; (1'99); 819 N. 8th St.; $8-10,1-3$

NICKERSON, LEVIN H. A. (b'51) $\oplus-\mathrm{Pa} .1$ '74; $\left(1^{\prime} 7 \%\right) ; 120 \mathrm{~N}$. 18th St. ; offce, $501 \frac{1}{1 / 2}$ Hampshire St. ; $8-9: 30,1: 30-3$.

PEARCE, WARREN FREDK. (b'85) $\oplus-$ Ill.11,08; $\left(l^{\prime} 08\right) ; 1235$ Broadway; 8-9:30, $1-3,7-8 ; 5$.

PENDLETON, FIED. MILFORD (b'59) Ill.1,'83; (l'83) ; 1455 Vermont St. ; office, Stern Bldg. ; 9-12, $1: 30-5 ;$ (B1) ; OALR.* FEIFFER, CHAS. W. $\left(b^{\prime} 75\right) \oplus-1 a .10,{ }^{\prime} 02$
$(1,02) ; 429$ S. 8 th St. : $8-10,2-4,7-8$. REIFEERT, MARION F. (b'72)-Ia.9,97; (1'97); 6451/2 Hampshire St.; 9-11, 2-5, 6-8.

REIFEERT, WMI. J. F. (b'70)-Ia.1,95 $(195) ; 808$ S. Sth St. ; 8-10, 12-2, i-8. 
RICE, 3011. ก. -0.2,78. IH.1,98: (1'78): 400 Jersey st.

Rlchandson, Eihsl Harriet $\left(b^{\prime}: a\right)$ to- 110.10 99: $\left(1^{\prime} 00\right)$; 835 Cedar st. $10.12,1.3$ 6-:

Schmids, Wm. G. -Mo.1,91; (l'9:); 1130 state st. :- $-5,12-2,6-8$.

SCHILLAX, OHE FRANK (1) I11.11."05: (1.05): 505 x. 8ih St. ; $1: 30-4$ -8 . 5 .

SILWGo, KIRK (b'7) - III.l.,03: (1'03) 1643 Jerses Sh: oftce, Stern $1 \mathrm{ld} p, ; 2.4$ ShAGHTER, THERON HALT (1)'SB)Mo.2,12; (1०13); Member Mo. Slate Med issn.

SNIDFR, w. FIRINK (b'68) - KY.5."89 (I's9): $39 s$ Cherty st. : Pd.

Stannus, Fdwin F. (b'83)-In.10,05; (1.0i) 1201 Malne St.; ndtce, $601 \frac{1 / 2}{1 l a m p s h i r e ~}$ St: $11-12,1-3, \% .5$.

Stelner, David [i. (b'60)-Ia.1,86: (l'a6) $931 \mathrm{X}$. 5th St. : omec, $2321 / 2$ X. 5 th sL. $9-10, i-3, i+8$

STINE, DiNi. Gish (b'83) - Mass.1.11 (I'11); 1211\% Jersey st.: odlce, Wells Mldg. : $8+9,1+3,7-8$

Strohl, Harley M. (b'78)-I'a.31,98; (logs) $132 \mathrm{X}$. 25th St. omce, $629 \%$ Hampshlre St: $0-12,1-3 ; U$.

Toole, Earle H. (b'75)-II1.10,97; (1'9i) 239 N. 5th St. : oflec. lirown Bids.: 10 12. $2-5,--8: 30 \vdots U$.

Trader Wm. Arthur (b'86)-Ill.22,09 (1'09); $18 \$ 24$ Brondway: OALR.

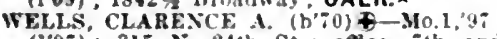
(19:); $315 \times$. 24 th St. nflice, ith and Hampsblre Sts. : 9-10, 2-4, 7-8; Anes.

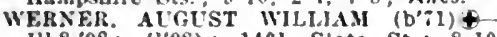
111.8,98: (l'98): 1401 Slate St.: 8-10,

Whipple, Alfred A. $\left(b^{\circ} 45\right) \mathrm{H}-0.2,76$, III.4, 80: (1'80): $10+\mathrm{X}$. 5th St.: onice, Well Blde: $8.9: 30$ 1. 3 . $i=8$.

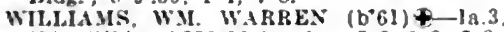
84: (1'94) : 1250 Malne St ; 8-9, 1-3, 7.8; S.

Wolfe, Wm. s. (b'78)-Mo.34,02; (1'03) $138 \times$. 12th St. $9-10,1-3,7-8$

Woods. Reuben-N.Y.10,66; (1) 14$): 14=0$ Vermont St. : offce. Wells Bldg.

TIMMERMANX, ERNST (b'\%6)-Mo.2.97 $\left(f^{\prime} 97\right) ; 312 \mathrm{~s}$. State St.; once, 63214 (J'9t); 312 S. State St.;

ZJMMERMAXN, WM., JR. (b':3)-Mo.2,97; (1'97): 812 state Si.; onlee, 632 1' Malno St. : $9-1,2-4,7-8$

RALEIGH, 338, SALINE

Glasscock, Gen. W. (b'63)-Mo.24,89; (I'89) KANE, IHOBERT LEONIDAS (b'81)-Mo.34. "10; (1'10).

RAMSEY, 769, FAYETTE

Farthlng, Edgar W.-llo.27,94: (1'94).

HAYES, LOUIS HODD (b'85) \&-Mo.28,0 : (1'11)'

Stat, Edmund P. (b'69)-MIo.1,95; (1'95).

"AN" V'RANKEN, GEO. R-Mo.1.89"; (1.91)

RANKIN, 800, VERMILION

JIfiTTT, FLEMMING L. (b'73) - Ill.11, 01 : (1'01).

Veterson. Martin Itarld E. (b'80)-111.11.06 (1'06).

RANSOM, 400, LA SALLE

HARWOOD, DORSEY A. (b'T0) $\$-11111$, 106; (1'06).

TRALOOR, CLAREXCE ALFRED (L'84)III.6, $10:\left(11^{\prime} 10\right)$

RANTOUL, 1,384, CHAMPAIGN

ALPERS, J. H. (b'36) $\rightarrow$; (1'78)

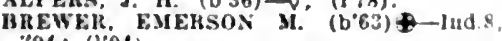
"96: (1"94).

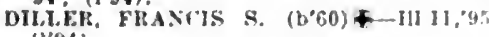
(1'94).

Jonoyan. Wm, r. (h'80)-Yo.7,03: (1'03)

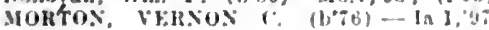
(1'97).

RAPATEE, I3I, KNOX

Ronneberz. Wesles (ieo,-III. 4,9ti: (I'9G)

RARDIN, 230, COLES

CHABTHËF, SABL. Al,ONZO (bibb)- () $\theta$ 01: (1'01).

RARITAN. 931. HENDERSON

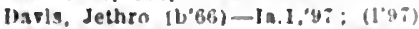

NoRIIS, JFESE; LOT $\left(b^{\prime}, 6\right)+-111=2,10$; (1'10).
RAYMOND, 881, MONTGOMERY

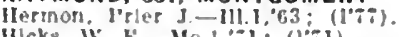

Hicks, W. F-310.1, $71 ;(1 ; 1)$

KENTON, JAMKS R. (b"0) - $40.24,99$ (I':99)

MERCK, WM. HAISEl (b;0)-Mo.27. Neymour, Jarnes Ih. (b'59)-0.2,83: (1'83).

RED BUD, 1,240, RANDOLPH

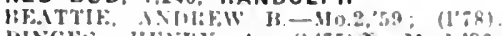

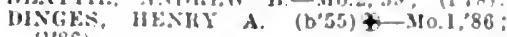
(1'86)

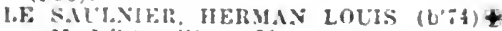
-IIn.1, "98: (1"9R); 0 b.

SkELY, WM J. (b'32) 0 ; (1'si)

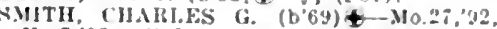

K5.5, 92 ; (1'92)

REDDICK, 400, KANKAKEE

MAMIUX, FIMER D. (b':8)-111.29,'10; (l'10).

Sralth, Samucl G.-III.4,9; (1.94).

REDMON, 275, EDGAR

JONEs, WM. S (b'63)+-KY.1.403; (1.93)

Rowe, Chas K Pa.l, $\mathrm{k}$ : (1)

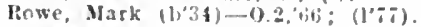

RENAULT, 241, MONROE

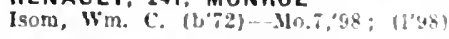

REND, 14, FRANKLIN

STONECIIHER, JOSHLA C. $\left(b^{\prime} 5 i\right) \downarrow$

Colo. 5,09; (1'10).

REYNOLDS, 367, ROCK ISLAND

Marston, Ernest L. - Ill.1,'88:

h.F.1). 1

MOORE (1' $\left.86^{\prime}\right)$.

Moss, Harid Currie (b’13)-Tex.10,03; (1'13).

RICE (R.F.D., PINCKNEYVILLE), 10, PERRY

HOLMAX, THOMAS A. $(1,+t)-111.1,70$ $(1 \circ \% 8)$

RICHFIELD (R.F.D., PLAINVILLE), 80 ADAMS

Ilouse, Chas. R. $\left(b^{\prime}+7\right) \rightarrow 0$; $(178) ;$ not lit practice.

RICHMOND, 700, MCHENRY

FOSTEK, WALTEß E. $\left(\mathrm{b}^{\prime}, 6\right) \mp-M i c h .1,00$ (l'01).

STRENG, WM. HENRYA-II1.22, $07:\left(l^{\prime} 0{ }^{\prime}\right)$

WARD, SAML. It. (b'42) \$-D.C.2.6s $(1,78)$.

RICHVIEW, 366, WASHINGTON

WHTE, JAMES F.-O.1,74; (l'i;)

RIOGE FARM, 1.110, VERMILION

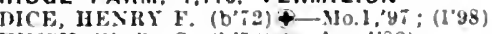

HINSHAW, D. C. (b'5s) - 0; (1'82)

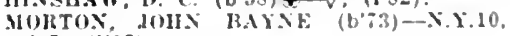
'yi: $(1,97)$

Plerce, Jos, Cooper-II1.11,06: (1'06).

Swalm, l'atrick H. (b'+9)-O; (I'\&2).

RIDGWAY, 1,054, GALLATIN

COMBS. (GEO. W. (b'38)-1).8,:9: (1':5).

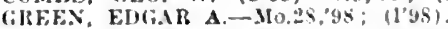

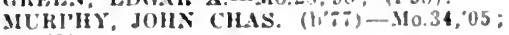
(1'0j).

Hiley, Wm. II. (b'56)-0.2," $>0$; (1'80).

RIDOTT, 180, STEPHENSON

Hoag, EdW. J. (b'60)-III.1,84: (1'84)

RINARD, 100, WAYNE

YOUNC, JOHA L. (b'68)-M0.34,05; (1.05)

RINGWOOD, 300, MCHENRY

IIEI'HI'IS, WH, - Teun.S,99, 111.17,00: (1'ay)

RIO, 300, KNOX

(nx, Julun Nell (b'5i)--0 1:, 89 : (1'91)

RIPLEY, 298, BROWN

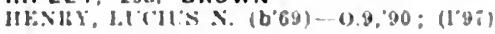

RITCHEY, 90, WILL

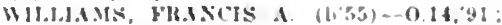
$11.91)$.

RIVER FOREST (CHICAGO P. O.), 2,456, COOK

(inlil, tenlpls lland.

(sin (IIteraso).

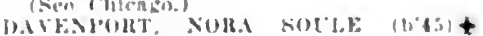

$111.4, \times 9:(1 \times 93)$.

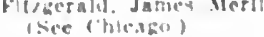

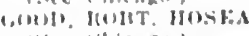

(sire ithicagu.)

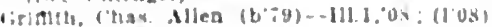

JA'KSON, ARTHEIS INTHES

(Sine (hilcago.)

Lyon. Jubn Bales.

isen Oak l'ark.

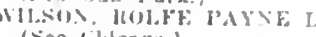

(Ree lhlogano.)

RIVERSIDE, 1.702, coOK

Congdon, J. L-I11 1, 65:

H H. WOOH, CHAS. W.

(1'96): $\mathrm{S}$.

OHR HARRY DERHOS

(T): U.*

$\left(1^{\circ} 94\right)$

Wippern. Idulutus o

(see clicabo.

RIVERTON, 1.911, SANGAMON

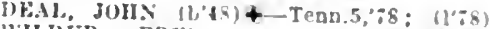

WIIBLR, FRKi) M. (b'i6)-Mn, 2,03 ; (1'03).

ROANOKE, I.311, WOODFORD

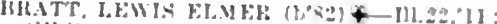
110

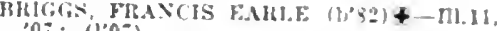
i: $\left(10^{\prime} 0 i\right)$

ROBERTS, 446, FORD

ANDEHSON, MARTHA (b':1) - -111.9,"98:

COLTEAT, JOHS A.FFED (b'36, III.22,11; (1'11).

ROBINSON, 3,863. CRAWFORD

Allen, Arthut Woodson (b'sl)-Mo.zos;

Bussard. Francls M. (1);3)-0.2,:3; (1t)

not in practlce: R.F [t. 4

CARLISLF, JONAS W. (U'68) +-I11.5,97 $(1,97)$.

DAVIS, CHAS. I.LDYEY (b'84)-Mo.34,08 (1'0s): ALR.

IPLNHAM, FRINK (b't3) 4 -III.1.'s:

FIIELAICII, ISAAC I. (b"6i) $4-0.9,73$;

LINAiY NATHANIEL F. (b'50)‡-Ky.2, I.UWF. ILSEY I.YMAX (b.80) -I11.1,05: (1) 0 i)

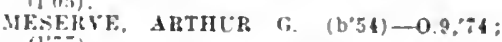
(1) 7 ).

SEWLIX, LE ROY (b60)-Ky.I.'91: (1'21).

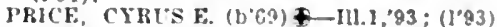

R.FFERTY, HERPERT 5 . $\left(b^{\prime} ; 8\right) \neq$-Ind.S. '95, ra.2,94: (1'98): $\mathbf{S}$

AFFETI THEODURF $x$. $(b+5)-0.1$ $69:(1 \% 7): G$.

schmidt, Gustar F. $\left(b^{\circ}: 9\right)-$ m.1:006 (l'0s): U.

ROCHELLE, 2,732, OGLE

HESIINEL.. GEURGF E. (b'65)\$-IILA 'R5: (1'S5): OALR.

'IOWFi.l., FR.INK G. (b'bi) $\$-111.1,39$; (1's9).

Jlederich, Jos!e Kennedy-II1.11,01; (1.01). HI.E, ELMEK C. (b'72)- $1114,96:(196)$ JIIISTON. ROHT. SHERWOON (b:2) $111.1 \%, 04:(1705)$

KITTLKK, WALTER ECHENE (b०月)

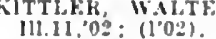

III.I1.02: (1'02) III.11.09: (1'0s).

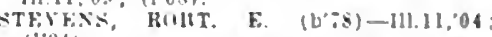
$(100+1)$

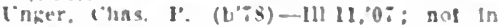
practice.

ROCHESTER, \$4, SANGANON

liell. Jaméw Marshall $\left(b^{\circ}: 6\right)$ - Mich.l: $\because$ (1':a) not in noctlee.

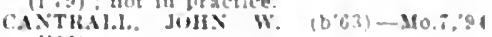
(I') 3 ).

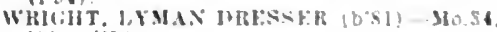
$02 ;(1,0 \div)$

ROCK, 35, POPE

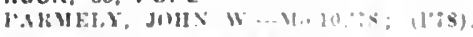

ROCKBRIOGE, S8B, GREENE

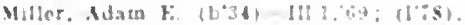

Wind. "lacule ('rouland (bis) - ind 00,0 : llosis.

ROCK CIYY, IIA, SYEPHENSON

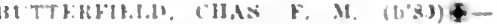

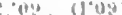

HOCKCREEK, 25, HARDIN

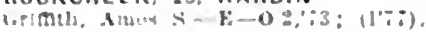


ROCK FALLS, 2,657, WHITESIOE

ALLEX, STEPIIEN A. $\left(\mathrm{U}^{\circ} 72\right)+-111.17,(04$; (1'05); OALR.

miv, EITEEST L. (b'61)+-111.1, 87 ; (1'87).

FISYE, (CLALEACE MAXFIEL) (b'6)-

III. 1, 02; $(1,02)$ : (Sterling).

scott, freeman J. (b'6:) II-III,4,88; (1'Ss).

ROCKFORD, 45,40I, WINNEBAGO

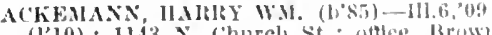
$\left(1^{\prime} 10\right) ; 1143$ N. ("h

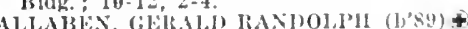

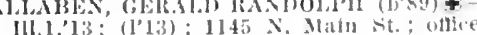
Nasconle Temple.

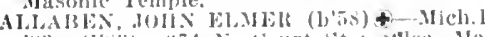

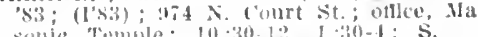

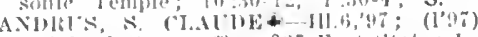
62. L'ark Ave, offlee, 327 East state ; 1-4. Arnold, Whilard "

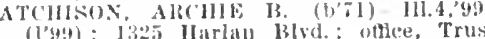
(3) $10-12$ 2-4 $7-5$

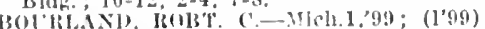
314 apoleon st. oftce, Win. 13rown IBldy Boyd. Whlliam is $\left(\mathrm{b}^{\prime}+1\right)-111,10,20$; (1'82)

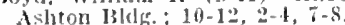

Brooks, Frank ( $\left(1^{\prime}(10) ; 413,7\right.$ th st. ; 2-3, 7-8

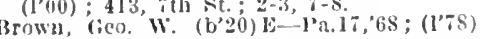
907 Killurn Are.

Brown, lorinda (i (

Brundage Joses S - Ill.1.83; (1'91) ; 1035 W. State St.; offlce, Ashton Bldp

rurdlek. Ward P'almer-I11.8,'12;

(1'12) ;

308 E. State St. w $\left(b^{\prime} 58\right)-111.6,86$

(1'91): $405 \mathrm{~s}$. 3d st.; offlee, Trust 13ldg. (10-12, $3-5,7-8$.

CATLIN, SANFOItD R. (b'i1)-Mass.1, 97: (198); 14 N. Main st.; offle, CLAR, ELBERT JUDSON (b'4i)-111.6, '71: (1's0); 119 Oakwood Are.; 9-12.

CRAVFORD, CIIAS E. $4-$ Ind.13,'84; (1'S9); 624 N. Court st.; offee, state and Main Sts.

CULHANE, THOS. II. (b'68) $\oplus-111.1,90$; $\left(1^{\prime} 30\right)$; $1003 \mathrm{~N}$. Church St. ; oftice, '1025 S. Maln St.; 8-9, 1-4, $7-8$.

CUNIIGHAM, WM. IAItIY (b'82) III.22,09; (1'i0); 407 W. State st.; 1-4; G. I)agnatult, J. Alphonse-IIl.22,'I3; (l'13) st. Anthony's Hospital.

DAY, DLDLEY WATSON (b'82) †-Ill.1, '06'; (l'0s); 1615 sichool st.; ofice, Rockford Trust Bldg. ; $2-4$

Dunn, Elisha C.-E-0.16,'s8; (1'90); 819 W. State st.

DUN, HUHAE BOASEY (h'78)€- Ill.8, "06; $\left(11^{\prime} 06\right) ; 620$ N. Court St.; office, 419 IV. State St.

FALIN, ALLEN CHANCELLOR (b'67) 111.6, '9.4; (1'94); 622 W. State St.; $2-4$. (1'05) ; 325 E. State St.; $10: 30-12,2-4$, Wallace-X.10'85. (1'85). 2007 , Slain 'st.; offtee, Dr. Broughton's 2000 s. Min

FITCII, W.I. II. (b'43)†-IH.6,'68; (1'78); 849 N. Main St.; office, Masonic Temple; $8-10,1-4 ; \mathrm{S}$.

Ford, Otho M. (b'81)-Ill.22,'08; (l'08) $1059 \mathrm{~W}$. State St.; $2-4,7-9$

PLANCES(II, BIAGio (b'83)-I11.22,'11 (I'11); 1001 S. Main St. (b'59) - -111.10, 'S3; (1's) ; 1303 \%. State St.; oftice,

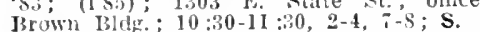

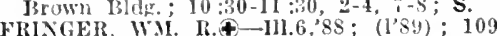
Sheridan St.; nffice, Wllliam brown Bldg. $9-11,1-4 ;(\mathrm{B} 1,8) ; 0 p . \star$

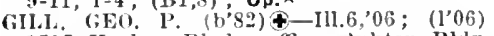
1517 IIarlem Blrd.; office, Ashton Bldg. $2-4,7: 0-8: 30 ; \mathrm{S}$.

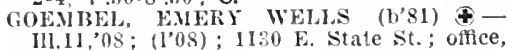
404 E. State St. ; $1: 30-4$.

GREEN, JOIN A. (b'8I) -11l.6.'06; (I'06) 818 N. Court St.; office, Wm. Brown 13ldg.; 2-4, 7-8. II. NFORD, FRANK W

1I.AT'II.' WILLIS GRANT (b'69) Ð-Ill.1,

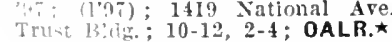

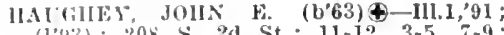
OpAL.

Ileckman, Irvln J. (b'61)-I11.11,95; (1'95) 327 L.' State St.; $8-10,1-3,7-8$

IIFL.M, WALTEIt B. (b'59) \&-111.6, 84 (I's5): 400 N. Church st.; offee, Wm Brown Bldg.; 11-12, 2:30-4.

111.l, FllAXK KNIGITT (b'5i)-N.Y.975 $\left(1^{\prime} 77\right) ; 32 \pi \mathrm{N}$. Court st.; offlce, Trust Bldr. ; 10-11, 2-4; G.

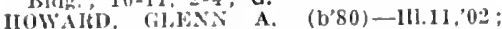
(1'02) ; 1124 s. Court St.; offee, Matsonle Temple.

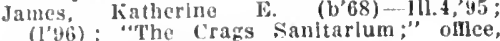
(1'y6): "The Crags Sanitarl

KEITI, DALWIN MILLS $\left(\mathrm{b}^{\prime} 67\right) \oplus-$ Belg.1

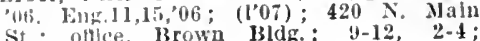
St.; onlice, 13 .

kile, lay l'urter (b'84)-Ill.11,'13; (l'13);

1106 . Mtaln st. H. $\left(b^{\prime} 55\right)+-111.6,80$ (I's0):527 Fisher Are.; onlee, 266 Maine st. ; $10-12,3-1$

KINUER, 1ROSCOE G. W. $\left(b^{\prime} 75\right) \oplus-111.11$ 01; (1'01); 1201 School St.; office, Brown I3) lg.: $10: 30-12,2: 30-4$

KINLEY, THOMAS FULTON (b'i1) t 1105,14 th Ave.; $2-4,7-8$.

LICHTY, PANI. (b'45) 4 - Ill.6, 71 ; (l'77)

$129 \mathrm{~s}$ d $\mathrm{d}$.; ; otfice, Masunic Temple.

LOFGREN, EMII (b'74) $4-111.6,01 ;\left(l^{\prime} 01\right)$ $14: 1,4$ th

Lundholm, Jos. Sebastian (b'91)-Ill.11,'13; (1'13); $609 \mathrm{~S}$. 4th St

laas, Elizabeth C. (b'64)-Ill.4,94; (1'94) 212 N. Wyman st.; 10-12,3-5; G

MAIKLEY, PAVL L. (b'61)\&-111.6,'86. (1'si); 1322 W. State St.; offlee, Trust Bldg. ; $1-3$.

MAIKLEY, ItOBERT WM. (b'72)-Ill.6,'98; (1.98); 1220 E. State St. ; office, Trust l3ld 5 : $2-5$.

MeDowcll, fieo. W-II-IIl.4,'89; (l'89) $831 \mathrm{~N}$. Church St.; oftice, Brown Bldg. $10-12,3-5,7-8$.

MILLER, THOMAS NUNAN (b'49)\$-111.6, '80; (1'80); 1304 W. State St.; MOORE, HOMER' FRANK (b'85)-Ill.6, , 10 : $\left(11^{\prime} 10\right) ; 957$ N. Court St.; office, Brown Bldg, : 10-12, 2-4, 7-8.

JOYET, CHAS. WASLEY (b'67)-IId.3,95 (1'95); Ashton Bldg.

NORDWALL, CHAS. OLOF H. (b't1) Neb.6,06; $\left(1^{\prime} 06\right) ; 524$, 7th St. ; 11-12, 2-5,

NYMAS, CARL Y. $₫$ D.C.1,03; (1'04) $11-12,2: 30-4,7-8$

OCIISNER, EMIL (b'79) $\oplus-$ Ill.11,09; (1'09); 423,7 th St.; office, Lundberg

OCHSNER ERNEST E. (b'68)†-II1.1,96 ; (1'98); 1537 E. State St.; office, 424 E. State St.; 11-12, 2-4, 7-8.

O'DONXELI, WM. J.-IIl.22.'13; (l'13)

OLSON, OLOF ALFRED (b'71)-Ill.15, 08; (I'9s) ; 119 Gardner Ave.;

P.11K, WI. E. (b'74) \&-Pa.11,99; (l'99) $1246 \mathrm{E}$. State st.; office, Lundberg Bldg.; $2-4,7-8$

PATTISON, HARRY AIRCHIBALD ( $\left.\mathrm{b}^{\prime} T \mathrm{~T}\right) \oplus$ Ill.10,'04, Inl.11,'10; (1'04); 1030 Ridge Are.; uffice, T'rust Bldg.; 19-12, 2-4.

PEARMAN, ARTIIUR COLTMBIA $\left(\mathrm{b}^{\prime} 84\right) \oplus$ -Ill.1,10; (1'10); 1403 Harlem Blva.

ENYIMY, DAYID BARTON (b'6i)

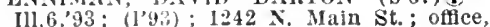
Trust 3 idq $11-12,1: 30-3 ; \mathrm{S}$.

PORTEL, JOII RICE (b'87) \$-111.6,'11. (1'11); $1135 \mathrm{~N}$. Court St.; office, $302 \mathrm{~W}$. State St.; $9-12,3-5 ;$ LD.*

RANSEEN CAR1 WATTHEIV (b'79)-Ill.11, $05 ;(105) ; 905$, th Are.; office, 402 , 7 th St. ; $2-4,7-8: 30: S$.

RANSOM, WHLIOT LELAND (b,52)-111.6, cedy Robt. Aaron (b'81)-Ill.22,'09 (l'1i); 516,7 th St.

RICHINGS, HENRY (b'40)‡-N.Y.5,'64; (l's0); Nasonlc Temple; $2-4,7-8$.
Hogers, Harrison ltoss (b'85)-111.1, 09 ; (1'10) ; 1019 N. Church st.; office, 'Trust I3ldk. ; 8-12, 2-9.

Rosers Nathanlel Curtls (b'82)-1'a.1,07 (100i); $1141 \mathrm{~N}$. Chureh St.; office, Trust Bldg; ; $10-12,2-4, \quad ;=8$

BUNUUULT, GMANUEL MATTHEW (b'78) +-11.22,05; (1'05); Nember Nont. State Med. Assn.; lundberg l3ldg.: 2-5. (1'06) ; 808 Garfleld Ave.; offlee, 'T́rnst 13ldg. : $11-12,2-4$.

SIILITZ, LOUIS A.-Ill.4,92; (1'02); 630 v. Malu St.; oftle, Itockford Trust Bldg. $9-12,1: 30-5$; (also 31 N. State st.

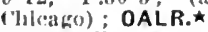
smith. Ilalley A. (b'88)-Ill.22,'13; (1'13);
Itockford Hiospital.

STARKEY, HORACE MANN (b'51)Ð-111.6, 78; (1'78); 1229 s. Church St.; offce,

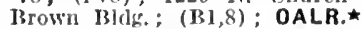

Sullivan, Harry A. (b'88)-Wls.6,13; ( ); 32 . longwood

IIIBETTS, INEMUEL $\left(b^{\prime} 42\right) \oplus-N . Y .10,67$. (l'ii); $\$ 34 N$. Maln St. ; OALR.

GITE, JOHN E. $\left(b^{\prime} 64\right) \oplus-111.1,00 ;\left(l^{\prime} 99\right)$

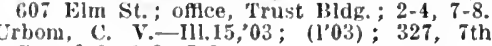
St. $8-9,1-3,-8$.

HLKEIt, ClIAS. A. (b'i2)-111.10,96; (l'97); 630 *. Church st.; oflee, Masonic Temple; $10-12,2-4,7-8 ; s$.

Walters, Hamlin J. (b'50)-0.9,75; (l'82); $322 \mathrm{~N}$. Court St. ; offce, $116 \mathrm{~N}$. Maln St.

WEIRICK, GEO, ALBERT (b'62)क-Ia.6 '85; (1'08); 1925 S. Maln St.; office, 2007 S. Main St.; N.` WEL. ANNA - Mich.1,06; (l'07); 1215 , $2-5$.

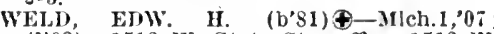
(1'08) ; 1512 W. State St.; offlee, 1512 w. State st. : 10-12, 2-5.

Weld. Fredk. J. (b'59)-Ill.1,84; (1'84) : 1228 N. Court St.; offlee, $401 \mathrm{~W}$. State; $9-11,2-4$.

WILGUS, SIDNEY D. (b'22) (3)N.Y.6, 95 (1'10); Wilgus Sanltarium; (E4,13); NP.* Winn, chas. S. (l,63)-11l.6,98; (l'97); $10-12,2-5$.

WISN, GEO. L. (b'51) †-Ill.6,76; (1'82) 5.34 lockton Ave.; office, Elcamba Bldg.; $10-12,2-1$.

Young. John Roseoe (b'51) E-0.2,'88 ; 1135 W. State St.

\section{ROCK GROVE, 175, STEPHENSON}

SAUCERILAN, MARTIN M. (b'49)-Ill.1, '81; (1'81).

Walton, James Carlssle $(6,67)-0,3,91$; (1†) ROCK ISLAND, 24,335, ROCK ISLAND

ASAY, JOS. E. (b'66)†-0.8,92; (1'92) $2-4,7-8 ;$ OAĹR

Banta, James Dudley (b'81)-Kiy.2,09; (); Best Bldg.

BELYHARDI, CARL (b'43)థ-Ger.1,67: (1'7T); 1728, 5th Ave.; offlce, People's National Bank Bldg. : 9-10, 3-4

BERNHARDI, CARI OSCAR (b'80)@-IIl.I '02; (1'02); ;06, 18th St.; offlee, People's Bradford, Eli II. (b'61)II-IIl.10,86; (1'92) 602,18 th St. ; $8-9,1-3,7-8$.

Burkhart, Hada M. (b'74)-Ia.9,98; (1'98) 723, 22d St. ; offlce, Best Bldg.; 6-8:30. ConEGYS, Jos. P. (b'65)థ-Pa.2,91 $\left(l^{\prime} 92\right) ; 1903,6$ th Are. : offce, Best Bldg.

(l'99): 1720, ith Ave.; office, 1718, 7th A re. : ' $10-12,2-4,7-8$.

Crooks, W.M. A. (h'72)-Ill.4,99; (1'99); Robinson Bldg.; (E13).

DART, RALPII (b'80) \$-111.1,03; (l'03) ; 2435, 8th Are. : office, Best Bldg.; 10-12, $2-4,7-8$.

Davenport, Frank Noble (b'85)-111.6,'10 ; (1'10) ; 4209,6th Are.

Davis, Colbert Smith (col.) (b'81)-1ll.6,

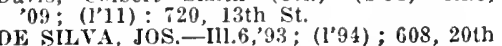
DE SILYA, JOS.-Ill.6,93;

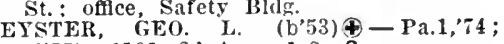
$\left(1^{\prime} 7\right) ; 1109,2 d$ Ave ; $1-3 ;$ S.

FIRST, FRANK H. (b'7i)థ-Ill.1,97; (1'97) ; 1115, 20th St.; office, Robinson
Bldg.; 11-12, 2-4, i-8. 


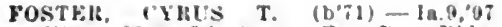
(1'9s): 2208, ith Are: omce, liest Bluk.

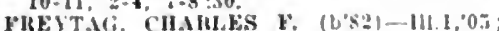
(1105): 900 , is/h sto; ofles, liest ridid. $10-11,2-4,7-8$

IIall, I3. Y. (b'53)-Ky.4:7i: (l'80): 1218 is 2d Ave. : OALR. *

HAIL, SIIRLLEY H. (b'bl) - Ia.3,'92 (1'92): 608, 30th st.: ofice, loublisor Istde

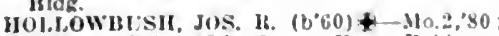
(I'sI): 838, 23d sit. oace, Rolinsin bldg.:2-4, $:-8 ;(A i): S$.

Jones lien! k- hy. Si; ( ).

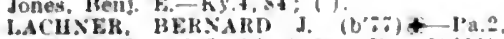
$06 ;\left(10^{\circ}\right) ; 181 \%$, 6h Are ; oflce, 1901 s 2d Are. $2.5, i-8 ; S$.

MLLER, ROB̈T. B. ( $\left(0^{\circ} 83\right)-$ Ky.1, $07:\left(10^{\prime}\right)$; I:19? 2d Are.

Moore, Nelvin Merrin (b'69) - III.1,"95; (1'95): $305 \%, 20$ th st. : $2-4,7=9$.

MUELLER. ALBERT VICIUIUAS (b'St) †

III.6.07: (I'08); 550, 261h St. odce,

Krobinson lidg.: 10.12, 2-4, ;-8.

MYEIS, JAMES F.

(see Mollne.)

'Hern, Mlchael J. (b'7) $\rightarrow 111.1,04$; (l'04)

$328 \%$, 20th St.; $10-12,2-4, i-8$.

Olson. John (b'7)-Mlo.28,06; (l'07): 540 , $161 \mathrm{~h}$ St.

OSTIKOS, I,OUIS, JR. (b't4) \&-Mo.1,99; (101): 1037. 21 st st. office, People's Paul Frank 1). (b'6) H-Ia.4, 86 ; (1'8i);

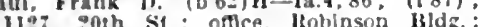
10.ii 20 th 51 .

petrle, Marleita Bechtel (b',1)-la.10,01

(l'0if); $\$ 100$, ith Are.; ofthe, Best bidg.

Reed, Cors I. (b'58)-111.4,84; $\left(1^{\prime} 84\right) ; 1920$, th Are.

RINAELL, FRANK O.

(see Molline.)

ROCHOW, CAHI, J. F. (b'TT) $\$-111.1,03$ (l'03) : $8231 / 2,202 \mathrm{~h}$ st. ontice, liest lihdg. 9.12, 2-4. $:-8$ : OALR.

SILA, sT. EI.MO MORGAN (b'70) + -la.9, '92: (1'92): $336,19 t h$ St.: offlce, 1829, th

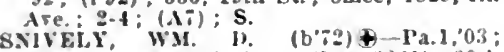
(I01): 1116. 161h St.; otfice, $3261,2,202 h$ St. $:-3, i-8$.

SOUDERS, JOHX CI.OYD $\left(\mathrm{b}^{\prime}, 2\right)+-1 \mathrm{a}, 3,3$, (I'04); 920 , it/2 St.; nflce, Hest Bidg. $10-11,2-4,7-8$.

stoeker, Alfred (b'69)-Mo.28,00, IH.11, 04 (1'00); 1610, 18th Ave.; untce, Best Bldg. $9-11,2.4,-1-8$

WIILIAMS, AHTHE! k. $\left(b^{\prime}, 6\right)-11.6,02$ : (loz); offce, 32., 19th s!.; 10-12, 2-4, i.8. Austin L. -1a.1, $80 ;\left(l^{\prime} \mathrm{s} 0\right) ; 1025$. I'th

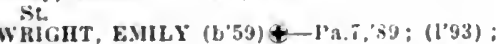
$621,23 \mathrm{~d}$ St.: oalce, Satety Jidis.: $\$-10$.

ROCKPORT, 20\%, PIKE

Gay, Emina ron Greyerz (b'is)-Mo.2s,05:

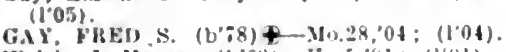
Welch, J. IIarrey (b'68)-Ky,i, (U1; (1'01).

ROCKTON, 1,000, WINNEBAGO

COCILRAS, BAKL, IB(IKT $\left(b^{\prime}, S^{\prime}\right)-111.22,08$ : (I'OS)

COLE, K.METT, J. (b'5L)-III., $96 ;(1997)$ : Member Stale Med. Soc. of Wis.

Mellen, WhIIs A. (b'ti)ll-III.,i3; (1'83).

\section{ROOOHOUSE, 2,171, GREENE}

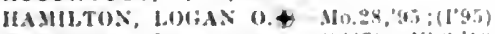
llawthorne, lloy Orway (h'si)-lli in, lis; ( $(1,13)$.

Iank, Itaylesw It. (b'52) h-0.2,73: (1'76).

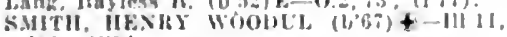

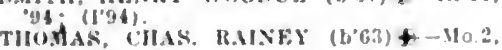
"8\%: (1.8\%).

ROSCOE, 500, WIN:E BAGO

Ilarizell, Ilarry Wallace-111.11,12: (I'1:1)

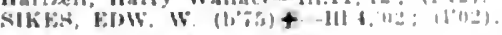

ROSEBUD, 30, POPE

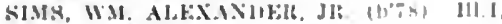
02: (l'02).

ROSE HILL, 229, JASPER

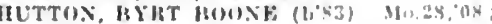
(I'08); G.
ROSELLE, 350, DUPAGE

HOHMANI, GEOHGE IH.XJ. (b'81) - H G OS: $\left.11^{\circ} 0 \mathrm{~S}\right)$

ROSEMOND, 300, CHRISTIAN

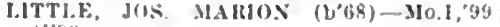

ROSEVILLE, 1.014, WARREN

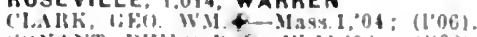

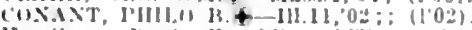

Ifanthon, Iters. Franklin (b'3s)-19.1: bi:

(1;i) ; not in practlee.

Pltiman, Wu. E. (10\%9)-III, 1,85: (1's5).

Tallaferro, Lavid M.-1'a.2,33; (107); not

in practice.

ROSICLARE, 609, HAROIN

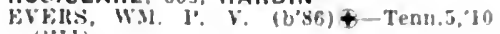
(I'II).

I.ARIS. WM. J. J. $\left(b^{4} 53\right)+-T e n n .6,8:$ : $(1,2,2)$

\section{ROSSVILLE, 1,\$22, VERMILION}

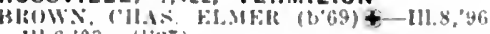
III.6.03; (1.:17)

Geruand, John K.--Mleh.1,31: (1"34)

MASON, FRAXK M. (b'66) $+-11.6,94$ (1"94): S.

Wllsun, Saml. 18. (1,59)-Ky.2.'81; (l's1).

ROUND KNOB, I50, MASSAC

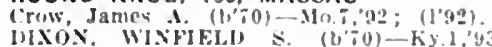
(l'iti)

ROUND LAKE, 182, LAKE

IAITIS, FILEDK. HFXIKY (b'\%2)-III, 99 $\left(1^{\prime} 93\right)$; Member Mloh. stale Mled. Sic

ROYAL, 70, CHAMPAIGN

WOTTEil, GEO. MLIHA (b'76)-Mo.28, 03 ; ( $\left.\mathrm{l}^{\prime} 03\right)$.

ROYALTON, 357, FRANKLIN

THUISNTON, CIIRISTOLHER M. $\left(b^{\prime} 50\right)+$ Kiy.4; $; 0 ;(1 ; 7)$.

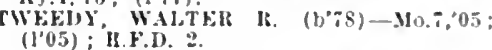

RUSHVILLE, 2,422, SCHUYLER

HALL, A.IOS WHLLIS (b'ti) $+-M 0.1,86^{\circ}$ (1'sti)

Courtrlght. Chas. 0. (1)'7)-11t.8, :9; (1's0)

CVIBFHTSON rkill H.S111 (b's3) \& III. 6, 06 ; (1'06); Pd.

Finch, Thos. (b'2l)-s; (l'is); not in practlce.

Fleming, c. Warshall (b’a)-\$10.6.06; (1'06):

H.ARVY, WHLLS FREI) $\left(b^{\circ} 62\right)+-\mathrm{Ia} .1,97$ (1'9)

Moencli, Frealk. (b'70) F- $0.2 .45 ;(1095)$. Iunson, Henry $0 .\left(b^{\prime} 6 i\right)-H 1.4,90 ;\left(t^{\prime} 93\right)$ G

SClikxck, Mrros c. (b'73)-Ia.1,95 $\left(l^{\prime} 9.5\right): \mathbf{G}$.

scotT, TIlOs. W. (b+8) 1 -Mo.l, $8 t$

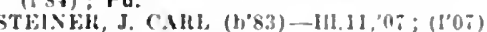

RUSSELLVILLE, 257, LAWRENCE

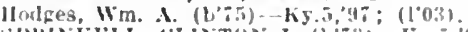
I'IIXKkLL, CLIXTUX J. (b',3)-Ky, (I'0)

RUTLAND, 1,100, LA SALLE

E.XIl:N, WM. O. (b, 11$)+-11,11,40,(17 \%)$

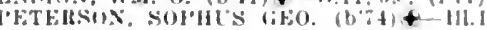
$\because 1 ; ;(14 i)$

SADORUS, 450, CHAMPAIGN

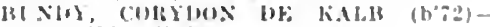

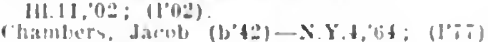
inea in uractlece

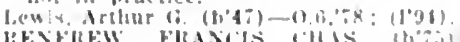

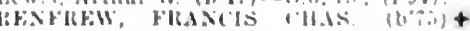
$11,4,113 ;\left(10^{\circ} 03\right)$.

SAILOR SPRINGS, 388, CLAY

Slure Nudrew J.-

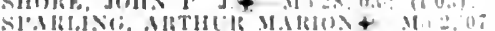
(1०0\%).

SALEM, 2,663. MARION

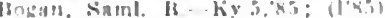

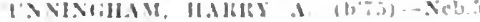

$08 ;(1,9): 0 b$.

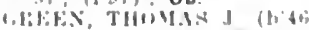

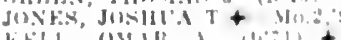

(1.as) Somes llackiner

(1):- (1).

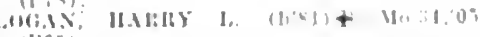

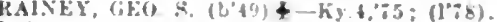

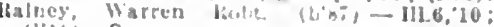
(l'10): S

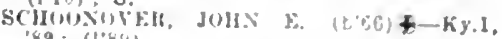
$9 ;(1.83)$

SALISBURY, II3, SANGAMON

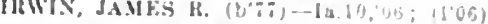

SAMOTH, IHO, MASSAC

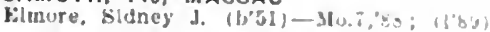

SANDOVAL, I,563, MARION

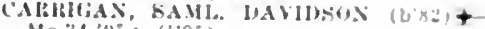
"1lo.34,03; (1.03)

Downey, 6. W- $(1 \% 5)$; not In practce

LDHICK, HOHERT ("OAWAX (b'o)

111.11, 1:; (1'13).

SANDWICH, 2,537, DEKALB

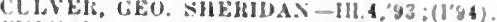

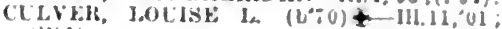
(l'01).

THUM SON, WHALLD ASTHOSY (b'8:)$111.4,10 ;(1,10) ; 0$ oG

TLISEI, VRANKLIN A (b'G6) - -III, 'ys: (1'44)

Wormley, Giny J-III.1.93; (1'93); OALR.

SAN JOSE, - MASON

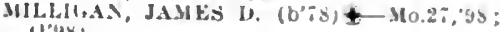
I'3x).

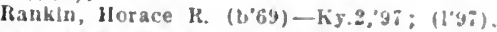

SAUNEMIN, 400, LIVINGSTON

CUSS, USMAN A. (6.67)+-I11.6,97; (1.6\%)

IRGSS, CHAS. F. (b55)-11.1,'81; (1'81).

SAVANNA, 3,691, CARROLL

HCIRTUX, HILHAKL C. $\left(b^{3} 13\right)-111.5,78$ : co'TKiL, GEO. HENKY $\left(b^{\prime}: 3\right)+-310.34$ 03 ; $(1,05)$.

GRAY ALEXINUER (b'68)-111.1, \$9:(1'99)

JOIISUS, GEU, W. (6'43)-Jich. 163. Mass. 1,$65 ;$ (1's3).

LXNES, JAMES DUKE (b'69) - OtR3, 01; (1'01).

Malurey, Lother II. (b'5i)-III. 's4; 11'54).

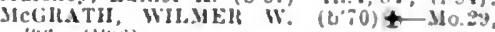

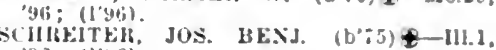
$96 ;(1 " 46)$

SAYBROOK, 784, MCLEAN

WUWXS, JAMFS N. (U'5t)-0.7'S0: (l's0).

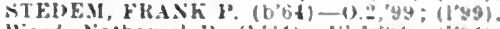

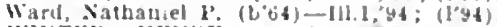

WISTHL, HENHY A. $\left(b^{\circ}+3\right)+-11.1,73$ (1":3)

Wouley, Elljah (b'43) H-H.t,'s0 : (l'so).

SCALES MOUND, 468, JO DAVIESS

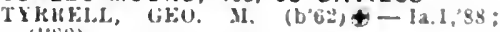
(l'SS).

SCIOTA, 238. MCDONOUGH

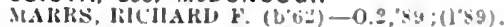

SCOTTLAND, 400, EDGAR

JEXXIAGis, J. FHA.TK (b'70)-0,3,'y4: $(1, y)$ ).

SCOTTVILLE, 301, MACOUPIN

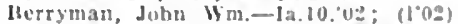

W.U.TUN, W.U. H. $(6,3 y)+1$ - is

(1'is) th

wo.t. TIIU.s. I1. $(669) \pm-M 0.34,0.3$ (l'i) $\left.; t^{\prime}\right) \mathbf{T}$.

SEATON. 326, MERCER

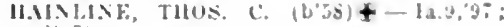
$(1+4)$

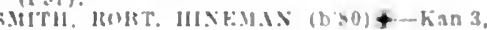
U.): (1.11).

SEATONVILLE, 1.370, BUREAU

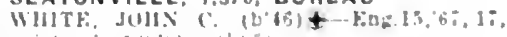

SECOR, 3\%3, WOOOFORD

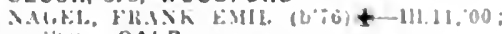
(1'?:1): OALR.

SENECA, 1,100, LA SALLE

(1) L.THE, WIIIUIR EIUIS (b.93) III

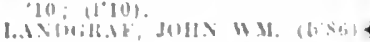
(1'0):4).

SERENA. 150, LA SALLE

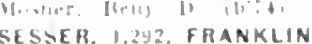

SESTER. I.392, FRANKLIN

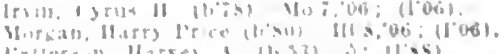

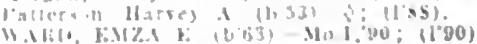

SE WAHD, 100, WINNEBAGO

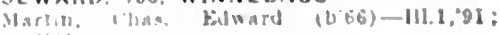


SEYMOUR, 220, CHAMPAIGN

HADUE., JOHN M. $\left(b^{\prime} 42\right) \rightarrow$; (1'Zs)

IIARTlick, HOUIS EUGENE (b'79)

111.6,'10; (1'10).

SHABBONNA, 100, DEKALB

Brewer, Edwin Jason (b,it)-111.11,01 (1'01).

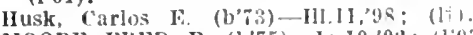

MOORE, FIED. B. (b'75)-1a.10,02; (1'03

Rogde, Jacob (b'86)-Hll.6'10: (l'10)

York, Herbert A. (1) 44)-111.6.66; (1'77).

SHANNON, 700, CARROLL

MAY OFAIID FRANCIS (1,81)-HI.22, '04 (l'09).

MLLEli, RORT. C. (1)'70)-Ill.11,'8i ; $(1.8 \%$

SHATTUC, 75 , CLINTON

O'NEAL, URVIL (b'83)\&-No.34,'10; (1'10)

SHAWNEETOWN, 1,863, GALLATIN

BOWLING, TOHN WI. (b'62) $₫$-Ia.I, 87 (1'87).

CAPEL, ALONZO B. (b'68)\$-.110.34, 02 (l'02).

Grattan, Wm. T. II.-Mo.7,'97; (1'97).

SIELMAN, PALL (1'75) 9-Mo.7,'88; (1'98)

SHEFFIELD, 1.008 , BUREAU

MARSIIALI, JOHN R. (b'72) \&-I11.1,96; (l'97).

SPRAGUF, THEOPIIILS $\left(b^{\prime} 46\right) \oplus-111.1$ 70; (1'78),

SHELBYVILLE, 3,590 , SHELBY

AUII, FRATK IARKINSON (b'75)屯-

Mo. ¿s, 03; (l'03).

birins, F. 1'-0.9;'81; (1'83)

BKOWN, OLIVER CLINTON (b's8) \$-111.4,

'11; (1'12); OALR.

EDJY, WII. , (b'57) †-111.11,85; (1'85).

llullek, Chas. II. (b'88)-0.2,'II ; (1'12); G

Mlzell, Adolph G. (b'/1)-111.1I,'97; (I’97).

MONROE, HENRY E. (b'75)๑-0.1, 99 ; (1'99).

Rhoads, Geo. W. (b'31)-Pa,2,66; (1'78).

THOMISON, THEO. (b'72) $\oplus$ - Ill.1,97;

(1'96). practice.

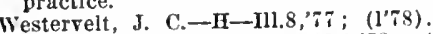

Wllson, Win. G. (b'27)-Md.1,52; (1'i 7$)$; not in practice.

SHELDON, I,143, IROQUOIS

BUND $x^{*}$, JOS. E. (b'55)-Ja.I,'83; (l'83).

BUNDX, JOS. E. (b'55)-Ja.1, 83 ;

SEEVER, CHAS. WILBER (b'80)థ-11l.22,

09 ; (1'09).

wOOD, IIENRY W. (b'62) †-0.I4,'9I ; (I'9I).

\section{SHERIDAN, 485, LA SALLE}

BOWER, REUBEN W. (b'39)-Ill.6,70;

CARR, JESSE WASSON (b'67) $1-111.15,99$; (l'95) ; Pr.

SHERMAN, 150, SANGAMON

SMITII, JOS. HENRY (b'76)-No.34,'12 ; (I'12); 0 b.

SHERRARD, 906, MERCER

SMITH, NERVI H. (b' 76$) \oplus$-Neb.6, 02 ; (l'04); 0 b.

SHIPMAN, 392, MACOUPIN

BOBZIS, RANDALL R. (b'76)-Jll.17, 06 ; (l'05).

KERRELL, JOS. L. (b'56)-Mo.I0,'89; (l'89).

SHIRLAND, 100 , WINNEBAGO

Savage, Saml. Micajah-Ia.3,06; (l'07).

SHIRLEY, II9, MCLEAN

SUMNERS. EDW. (b'78)-Ill.4,'04; (1'04).

SHOBONIER, 306, FAYETTE

CHHLS, TRALL BENNET'T (b'58)-Mo.7, '89; (i'89).

GRIMES, ROLLO JANES (b'75)-0.2, 03 ; (l'03).

Pollock, ostrander C.-E-0.2,'82; (1'82).

SHUMWAY, 29I, EFFINGHAM

IIAUMIESSER, GLO. J. L. (b'58) ๑-Ia.I,'81; (l's1).

LORTOS, SAML. CLIFFORD (b'79)-MO.28, $06 ;\left(I^{\prime} 06\right)$.

SIBLEY, 550, FORD

ABSHER, ALLEN ALBERT (b'69) @-Ill.11, ?

CASNER, INDREW JAMES $\left(b^{\prime} ; i\right)(-I 11.22$,
SIDELL, 800, VERMILION

RAIMWIX, HERS('IEL EDW. (b'32) I1.1 $1.05 ;\left(1^{\circ} 06\right)$

HHLW: (ARL C (b'80)-II1.17,06; (l'06)

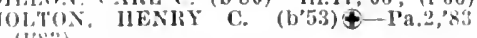

SIDNEY, 600, CHAMPAIGN

L.AWSON, JOS. M. (1)'J8)థ-Mlch.1,85 (l's5).

IIANES, MAME 1. (b'7.1)-Mo.2S,05; (1'07)

SIGEL, 308, SHELBY

Frost, Thomas G. (b'40)- 0; (1'78); not in practice.

Ilelick, Ilenry II. (: (b'84)-Ill.22,'I2;(1'I2). SILVIS, 1,I63, ROCK ISLAND

('HAPMAN, WM. DAY (b'83) \&-Mo.2,08; (l'08)

Ilansen, Andrew Clinton (b';0)-Ill.6,02 (l'03)

Rankin, James Fdward.

(See Watertown.)

SIMPSON, 16I, JOHNSON

liERLEY, MLLES J. - Ia.1,'88; (I'89); R.F.1). I.

Kerley, Thos. B.-Ia.I,'88; (l'89).

SIMS, 399, WAYNE

HXON, JANES EDMOND (b'80) - - Ho.34 02; (1'02).

SMITHBORO, 30I, BOND

Crawford, (ien. B.-O.1.'69; (1'90).

SMITHFIELD, 420, FULTON

EWAN, JOBT. THORNTON (b'77) †-III.II 04: (I'04)

vewberry, (Geo. W. (b'44)-1a.1,83; (1'83)

Newberry, Geo. W. (b'7 14 -Ia.1,96; (1'96)

Watson, Chas. 0. (b'70)-la.I,97; (1'97).

SMITHSHIRE, 250, WARREN

Calverl, Otho S. (b'80)-MO.7, 06 ; not in

practice. PHILIP ERASMUS (b'82) Mo.:28,10; $\left(1^{\prime} 10\right)$.

Tinsman, Lewis 1.-Ill.1,'86; (l'88)

SMITHTON, 380, ST. CLAIR

Bock, (iuslarus G. (b'58)-Mo.2,'82; (l'82). STOOKEY, JOUN DAVID (b'87)-Mo.2,10 (1'10).

SOMONAUK, 630, DEKALB

Carr, Clarence Thomas (b'78);-Ill.15, 0? (1'02);0b

K'AIER, JOIIN M-Mo.I8,'86; (1'87)

Ieacham, Wm. Chas. (b'86) - Ill.11,'10 (1'10).

SORENTO, 1,018, BOND

CHITTUM, JASON D. (b'6I)-Ia.9,'91

Duncan, Wesley wllson (b'40)-Mo.10,78; $(1,78)$; not in practice.

Everett, Ernest Anthony (b'83)-Mo.34,'06 (l'06)

SOUTH ELGIN, 5I5, KANE

STRUVE, CARL P. (b’78)థ-Jll.6,'04; (l'04)

SOUTH HOLLAND, 1,065 , COOK

Walroord, Gerrit Wm. (b'76)-Ill.11,'02 $(1 \times 2)$.

SOUTH WILMINGTON, 2,403; GRUNDY

IIUISON CIIAS. D-Ind.8,96; (l'96).

TERRANDO, Jos. S. (b'72)-Ita.13, 03 ; (l'04).

SPARLAND, 459, MARSHALL

Royce, Emery E. (b’i1) H-nl.4,'98; (l’98) SPARTA, 3,081, RANDOLPH

Boynton, Chas. Qtls (b'75)H-Mlo.5,'97 $\left(l^{\prime} 9 \pi\right)$.

GAULT, HUGH L. (b'46)-Mo.2,'80; (l'80) MeKEE, HENRY T. (b'5s) 4 -Mo.1, 84

tevenson, B. J. (b'73)H-Mo.5,98; (l'98).

Sterenson, Nerin G. (b'7I) H-Ill.10,95; (1'95).

WEIR, JAMES WALLACE (b'50)-Mo.I,'82 ; (l'S2).

Weir, Wm. Foster (b'83) -.Mo.7,'09; (1'09)

WYLIE, WALTER 1. (b'75)-IIl.15,'97; (1'95).

SPEER, 100, STARK

WULMOT, CLAUSON M. (b'79) £-111.11,04; (I'04).

SPRING BAY (R.F.D., PEORIA), 100 ,

WOODFORD (l'96).
IICHHOR
SPRINGERTON, 418, WHITE

Artin, Arsen S. (b'72)-Ill.6,'99; (1'99).

CHEMELNS, GEO. L. (b'68)-Ia.9,'y5; (1'96).

IIunter, Chas. T. (b'39)-Tenn.6,78; (1'78).

SPRINGFIELD, 5I,678, SANGAMON

NLMBER OF PHYSICIANS, 110.

A.MANT, IIALRY (b'S0) †-Que.1,'10; (1'I0); 1048 N. Ttl St.; oflee, $731 \frac{1 / 2}{E}$ E. North (irand Ave.; 2-5, $7-8$

ARMSTRONi, WHLER J', (b'60)-0.7,'85; (I'86): 824 S. 61h St.; office, $616 \mathrm{E}$

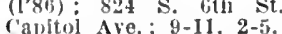

ASTHAUER, ÁIBERT GEO. (b'79)-111.I1, $09 ;\left(l^{\prime} 09\right) ; 529 \times$. 6 th St. ; oftlee, Reisch

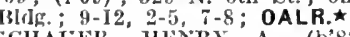

ISCHACER, IINTRY A. (b'82)-Ind.18, 06; (1'06); 629 N. Rutledge St. ; offlce, Relsch I3ldg.; 2-4, 7-8; S.

B.IBCOCK, (IIVEK E. (b'57) \&-110.2,'79 $\left(1^{\prime} 80\right) ; 1100$ S. $2 d$ St.; offlee, $728 \mathrm{E}$ Capitol Ave.; 9-10, $2: 30-4,7-8$.

BAIN, WALTEL GLLVIN (b'76)๑-lll.6. 05; (1'05); W. Grand Pl.; offce, St John's JIospital; $9-2$; LD.`

JBARER, AlCHIE W. (b'67)-Mo.28,'99 (1'99); j01 Black Ave.; oftice, Myers HIdg. ; $9-11,2-5,7-8$.

Bartlett, Edw. Pinchon (b'42)-Mo.2,70 N.Y.10,75; $(1,77)$; 514 E. Capltol Are. BAXTER, ALBERT ĆRUM (b'80) †-Mlch.I, '07; (1'07); I418 Holmes Ave.; offlee, Leland Bldg.; $9-12,2-4, \pi-8$.

Bellin, Leo. Max (b'87)-IH1.11,12; (l'12) 14 th and Carpenter Sts.; offce, $1330 \mathrm{E}$. Carpenter St.; 9-1I, 2-4, 7-8.

BERNAII, FAII, LAWREXCE (b'85) Ill.6, $09 ;\left(1^{\prime} 09\right) ; 701$ N. 6th St. ; offlice, Jllinois Natl. Bank Bldg. ; $2: 30-5,7: 30-9$. BERJY, RILAND DILLARD (b'55) \&-0.1 79; (1'80); 219 S. Walnut St. : office, $2271 / 2$ S. 5 th St.

BLANLIFXER, HARRY C. (b'77) $\oplus$-Ill.6, 05; (1'05) ; 855 S. Lincoln St.; offlce, 6th and Monroe Sts.; 9-11, 2-4:30.

BOWCOCK, (IAS.' M. (b'58)థ-Pa.2,'82; (l'82); 1058 N. 6th St.; offece, 5th and Washington Sts. ; 9-11, 2-4.

BULLARD, ROBT. IRVING (b'77)-Pa.I, 03; (l'05) ; 524 E. Capitol Are.; 9-12, $2-4 ; 0 p$.

COLBY, CHAS. P. (b'75)-Pa.1,'03; (1'03) 800 'S. Tth St.; offlee, 524 E. Capitol A re. : $9-10,2-4,7-8$. COMPTON, CIIAS. W. (b'76) - Ind.9,'00

CONLIN, GLADSTONE CONMAN (b'90)IHch.1,'12; (I'I3) ; 723 Capitol Ave.; 9-I1,

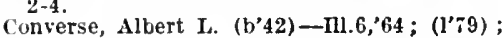
not in practice; $1346 \mathrm{~N}$. 8th St.

Conway, James S. (b'48)-Ia.I,'79; (1'79). COWDIX, FREDK. PUTNAM (b'84) Mo.2,'I0; (l'10); $8081 \frac{1}{2}$ S. 5th St. ; office, $3201 / 2$ S. 5th St. ; 2-4, 7-8; (also Curran). Darldson, Thos. Warner (b'64)-Ia.9,'92; $\left(l^{\prime} 92\right) ; 401 \mathrm{~W}$. Vine St. ; offce, $101 \frac{1 / 2}{2}$. 5 th St. ; $10-12,2-4,7-8$.

OEAL, DON WES'T (b'79)(-I11.6,04 ; (1'04) ; 210 W. South Grand Ave.; office,

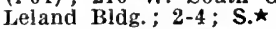

DEAL, JOHN FRANCIS HENRY (b'85)థ111.6,'I1 ; (1'II) ; Leland Bldg.; 10-12, $2-5$ EICIMLNN, OTTO H. (b'76)థ-Mo.2,02 (l'02); 411 E. Capitol Ave.; offce, 5th and W'ashington Sts.; 2-5.

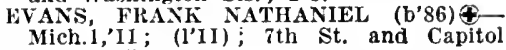
Ave. ; 2-5.

EVANS, HARRY A. (b'87) - Ill.22,'12 (1'12); 2317 S. 10th St.; offce, $517 \mathrm{E}$ Capitol St. ; $10-12,2-4,7-8 ; \mathrm{S}$.

FLETCHER, FRANK D." (b'79) $\$$-Ill.1,02. (1'02); $915 \mathrm{~S}$. 5 th St.; offlce, Leland Bldg.; $10-12,2-5$.

Ford, Noel Bertram (col.) (b'78)-Tenn. 7 . 06 ; (I'08); 1611 E. Jackson St.; offlce, 63I 1/2 E. Adams St. ; 2-5, 6-8.

FRAZIE, CALVIN A. (b'63)-Ill.10,'8T: (1'8i) ; 1003 S. 7th St.; office, Leland BIdg. ; 9-10, 2-4, $7-8$.

FRENCH, GEO. MARION (b'79)-Ill.II, 01 . (l'01) ; 715 E. Cook St. ; office, Court of (l'01); 715 E. Cook St. ; O

GODFREY, EDWIN BRLCE (b'81) £-0.9, 09; (l'09); 526 W. Monroe St.; office, Myers Bldg.; 10-12, 2-4. 
Gordon, Noel B. (b'31)-Mo:35: $\left(l^{\prime} ; i\right)$ : 1513 W. Gorernor St. Wtice Wonre st: $9-12,2+4:$ OALR GRIFFITH, HEN HAIIET $(1,1)+-111$

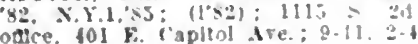
GRIFHTS, THOS. HOTSTON LuW + Tenn.9.03: $\left(1^{\circ} 07\right)$

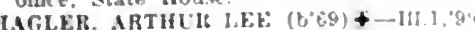

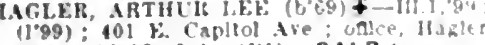
HIdz: : 10-12, 2-1; (1:1); OALR.

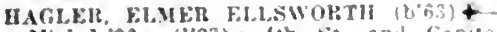
Meb.1.90: (1"93): 4th st. ant (apt: Aro: 10-4: (HI); OALR.

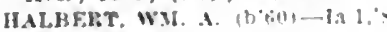
Mjers Itldz.

IIAfMOS (IIAs FliEDK (b"s3)+-Mo? "10: $\left(1{ }^{\prime}(0): 1934\right.$ s. fith st. : on

Ilenderson, Janses $\mathrm{F}$; (eol.) - 111 6, 33 ; (1'43) 412 F. Adami si

HENKEL, HERRERT H.AHYY (1)'QG) + III.6,1I: (I'11): 1129 S. 2d st.; altice, 5th and Monroe sts.

Illckman, Cornellus w. $\left(b^{\prime} 56\right)-0.2,84$ $(187): 136:$ II olmes Are.; otace, Ferzu son Bldg.; 8.I2, $2-6$.

IIOIMBYRG, CIOARA FNMIYNAS (b';s)III. 4, 03 : (I"03): 401 F. Capitnl 5 : : Ace. 305 Myer3 Bldz.: 9-11, 2-4, ;-3

Hulett, Granville A. (b'59)-llh.6,'st: (1'st) 1131 s. Qd st.: oflce, Bth and Washlum ton Ste.

JAMES. AlIDISON C. (bo3) - I11.1.8n (1.81): 1203 s. Sth St, oftce, 12012 S 6th st. : $9-11, \pm-4, ;-8$

JAMES. HARRY LOREXZO (b's5)-III n."11 (1'12); 304 E. South Grand Blrd: anlce 1224 S. 6th st. : 9-10, 2-4, i:30-8:30,

KELLI, JOHN w. (b'63) ₹-111.6,9; ; $\left.11^{\prime} 9 ;\right)$ 1218 S. 6th St: 0tlce, 405 S. Gth st. 1-4, $;-8 ; \mathrm{S}$

Ketchum. Fred G. (b'64) H-111.4,93; (t'03) ils E. Scarrett sl.; oftce, Leland blar $9-19,2-5$.

Kirg, John A. (b.53) - 0.2.83; (1'55) Jyers IIIdz; \$-10, 2-4, $7-8$. Kinnear, Theron James (b'76)-111.6,"04 Rldzley lank Bldg: $10-12,1: 30-3: 30 . ;-8$

KNLDSOX, THEOLORE JAMES (b'63) \& III. 5,$95 ;(194,1) ; 1400$ llolnes A leland Annex; 10+12. 2-4; $\mathrm{S}$.

KREIDER, GEO NORI.E $\left(\mathrm{b}^{\circ} 56\right)+\mathrm{N} \mathrm{Y}^{\circ}$ '80: (1'80): 522 E. Caplrol Are. ( 1 i)

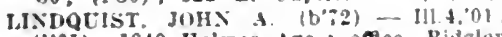
(1'0I) : 1349 Holmes Are. : once, Ridzley Natl. Bank Bldz.; 9-11, $2-5, \tilde{2}: 30-9: 30$.

Unday, Wachel T.'(b'43)-0.9,69; (1':-) Go3 S achel $\mathrm{T}$ : of ce, t2t E. Edwards St.: 8-12. $1: 30-6$.

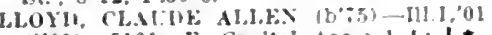
(1'01): 5122 E. Caultol Ire.; 1-t; I."

Jocklb; Giri ll $(b " 60)+-111.1498$

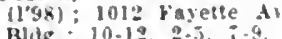

MTTHEWS: ELIZABFI $(t) 11) \uparrow-1119$. 90: (1'91): 631 s. 4th st.; ontlee, vid

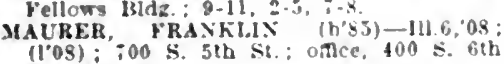

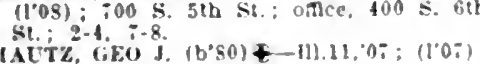

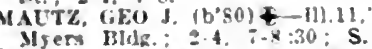

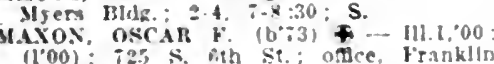
l.le inde.

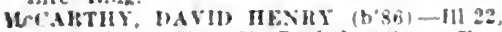
'12: (1'12): $1321 \times$ Rutledga Nt. : nfles.

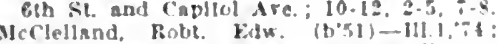
(1\%:- not In practlce: 1401 Inuell isn

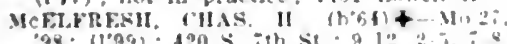

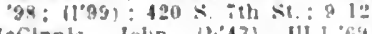

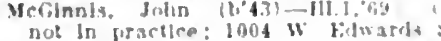

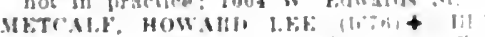

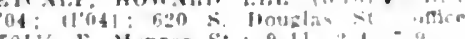

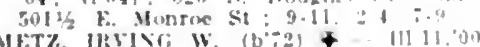
$\left(1^{\circ} 00\right): 503$ w. Solsth lirand in ance

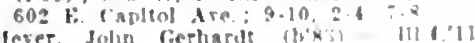

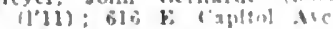

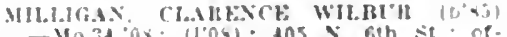

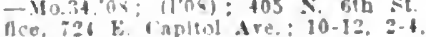

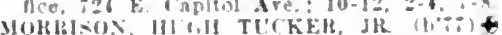

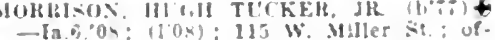
Ace, 1.0 !and I3ld: : 9-11, :-4.

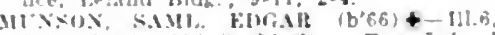

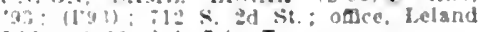
Bid: : $5-10,2-4,7-5 ; T$.

Wyers. Harry ibert (b.90)-n1 11:13:

(1)3). Ni. John's Huspltal.

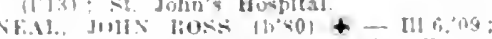

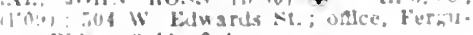
son 13112: $9-11,2-4$

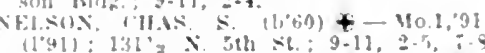

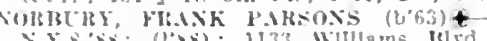
D. 1:30-3:30) (Also Arer's Bank B!d Jackwrille; $11-1,2-4):($ Fi.13); NP.

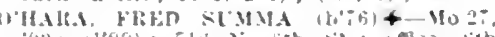

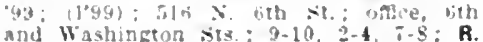

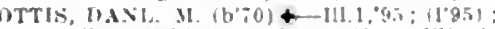
50, E. Wasbington st. adce. Ilumol

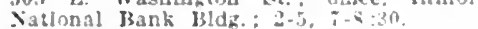
owE. M, MUN f. (b.2) $+\cdots 1114.94$

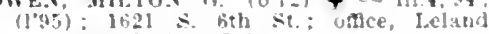
Hldz: $9-10,2-1,7-8$

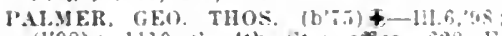
$(1 \circ 9) ; 11\} 0 \mathrm{~s}$ th st: offce, 6.25 $\mathrm{k}$ Cantlol Are.: 2-4: T.*

IATUS, CHAs. Id. $(6, \% 9)+-11 \mathrm{ch}, 1,0^{\circ}$ [l03): Ift: leland Ire. unce, ith st. and Capltal Ave.: 2-5: S.*

I'FICK. NINLS S. (b'65)-Ill.6.91; (1'91) 945 S. 5th st. nalce. h2s E. Capltol Are, 9-6: OALR.

(l,03); :09 W. Grand $d r e$. Natlonal Rank Bidz.

PRINCK, IITHER k. (bot)+-X.5.: (17): 502 S D si ; otice, 623 E. Capltol Are. ; $9-6 ;$ (B1); OALR.

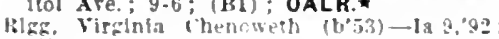
$(199) ; 1516$ s. 5th sit. $9: 30-11: 30$. $4: 30$.

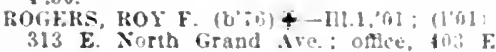
Cantul Are: 9- $12,2-4, i-8$.

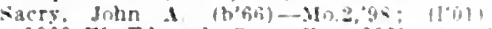
1909 W. Edwards St.; oftlce, $2201 / 2=0$

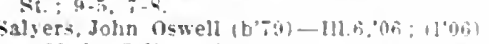

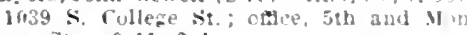
roe Sts. ; $9-11,2-1$.

scholl, Wade H. - 111.22,13; Intern. s: John's llosuital.

Slmon, Edw. F.-I11.4.02; (10021: 1001) s 11 th 5 .

SORGATZ, GEO, FHEDK. $(1,+3)-111.6,11$

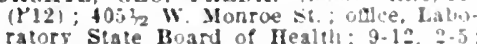
ralory

\section{LO.}

SOLTHWICK. IAIRY II. (b's3)-1'a.,, 10 $(1 \cdot 10)$ : Jeland Hldz.

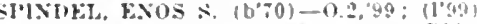

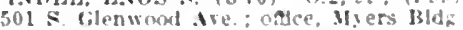
$9-11,2-1, \pi$

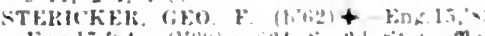

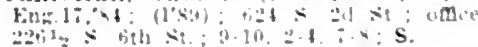

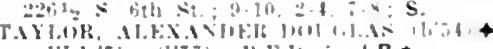

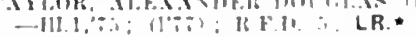

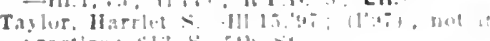

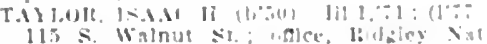

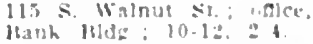

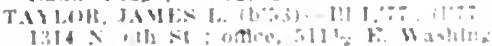

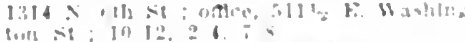

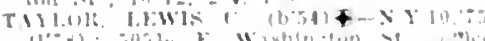

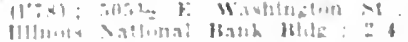

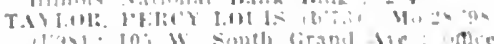
ables Jafunal Jas:k Mas

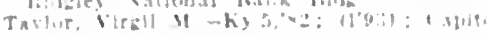

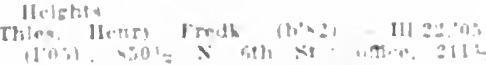

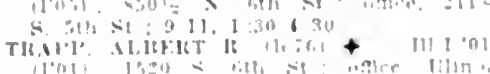

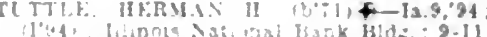

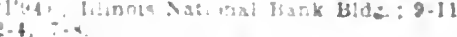
be

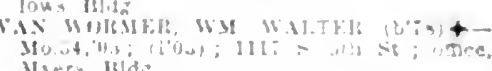
ओgor Ho Ha:

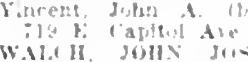

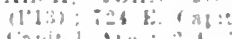

10:0

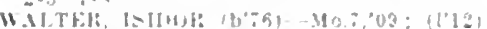

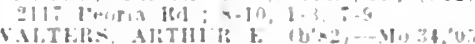

I'1)

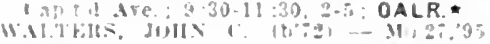
G.

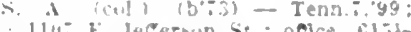
F. Washington st

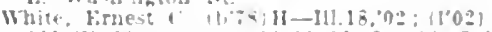
iol 16 Munace $5 i$ : $10-11: 30,2-4: 50,7-5$.

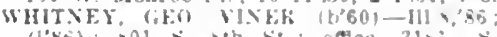

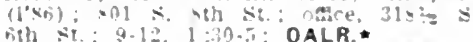
Wileur, J. I. M 2,$60 ;(1)=21)^{2} \mathrm{~S}$ 5th 5

Word, Jay Them (b'83)-111.11.0\%: (10\%):

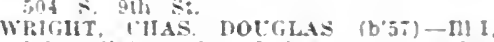

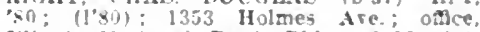
Illnols National Bank Bld-; 9-11, \$-4.

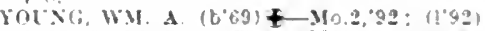

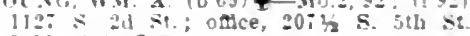

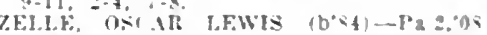

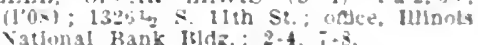
Vational Kank Mldz.: $2-4$

inee leotia.)

SPRING GROVE, 250, MCHENRY

H'RLONG, JOHX C. (D'B)-IM." (1'91)

SPRINGVALLEY, 7.035, BUREAU

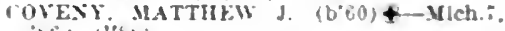

FRIYKI.IX, JกIN HEIBBERT (b's) III. 1.92: (1.92): S.

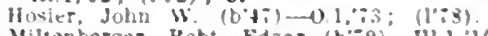

Miltenberger, Kobe Ed-ar (b:-9)-II!, 10 : HOHAS. JAMES JOS. (b"i6) \&-111.6,"05 $\left(1^{\circ} 05\right): S$.

Rathben, isac IIale $\left(t^{*} 50\right)$ - II1.1, is:

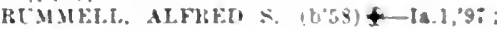
$11^{2} 96$

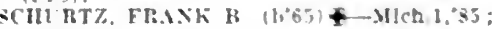
(l'si)

ST. ANNE, 1,065. KANKAKEE

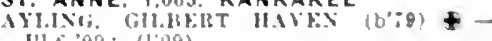
lil a,p?: $\left(1^{\circ} 08\right)$.

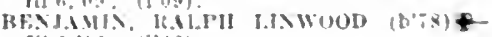

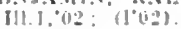

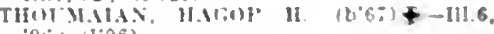
(1.06).

ST. AUGUSTINE, 300, KNOX

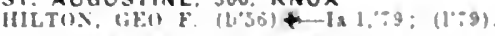

ST. CHARLES, 4,0\$6, KANE

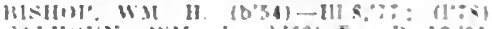

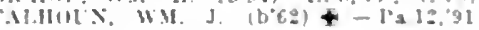

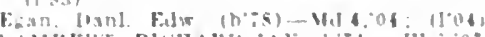

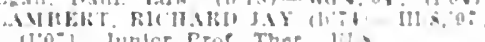

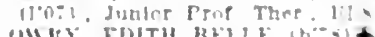

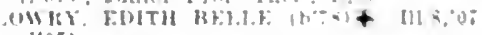
$\left(1^{\circ} 0 \pi\right)$

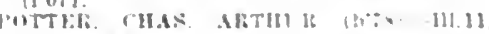
"112: 110021 .

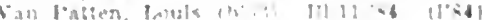

SY OAVIO. 1.000. FULTON

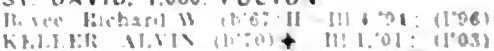

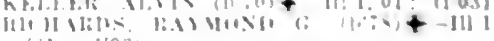

ST. ELMO. 1.227. FAYETTE

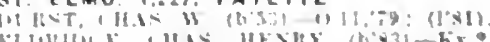

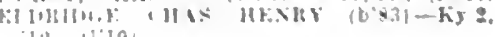




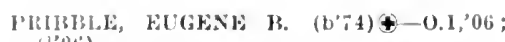
(l'oti)

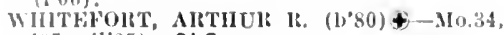
'(1): (1'05); ObG.

WIITHFOHT, WM. J. (b'5) $t-110.1$, $9 \mathrm{~s}$ (l'g8),

ST. FRANCISVILLE, I,39I, LAWRENCE Alell, Anson T. (L,59)-Ky,5,95; (1,95).

IBIIAN, JOIIN R. (1, 0$)+-110.28,99$ (l'99).

leeds, II arry M.-0.1,79; (I'8I).

Medurray, Robt J. (b'53)-0.1,78, 111,6,'s5 (1'78); G.

ST. JACOB, 534, MADISON

(OLILIS, JOIIN A. (1,60) †- Mo.2,02; $(1,0: 2)$.

(villit, cllss. G. (b'\%) $\$-M 0.27,97$ (l'yi).

ST, JOSEPH, 775, CHAMPAIGN

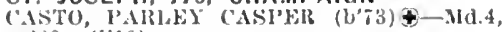

1)ALTON, ARTHLI JOIIN (b'83)\$-Ia.10, of: (l'0S); OALR.

huappenberter, T. (;allard (b'83)-Ill.11 '06; (l'06).

ST. LIBORY, 328, ST. CLAIR

IIEEI Y, 0l.1VER J. (1)'72)-MI0,2,97; (l'99)

ST. PAUL (R.F.D., ST. PETER), 80, FAY ETTE

DNLF, DAVID IIARRISON (b'85) \&-III.22, 09 ; (l'09) ; $\mathrm{S}$

ST. PETER, 3I3, FAYETTE

DALF, JOS. W. (b'82) †-I11.22,'10; (1'10) S.

STE. MARIE, 450, JASPER

BLOWN, GIOYLR CLEVLLAND (b'S4)† II $0.28,05$; (1'05).

KIBLEli, OLA ALOLPIIUS (b'81)-Mo.7 06 ; (1'06).

STANFORD, 525, MCLEAN

(AVINS, STANIX TIIUS. (b'74)-Md.4,03; (1'03).

IERRMANX, ENWV. R. (b'69) \&-I11.14,'06, III.17, $07 ;\left(1^{\prime} 07\right)$.

Wright, saml. I3. (b’50)-Tenn.I,75; (1'7).

STAUNTON, 5,048, MACOUPIN

Aver, Ulysses Grant (b'68)-Mich.1,0I ;

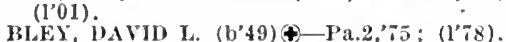

IIUNTER, ARCIIBALD ILARIYY ( Ilo.34,'02; (l'09).

MCBIIES, WM. L. (b'65)-Mo.7,'98; (I'9s); Prof. Surg., ilo. 7 .

PATTEIRON, JOII S. (b'66)థ-Mo.7,04; (l'04).

VAN METER, FUGENE R. (b'84) $4-M 0.2$, 05; (l'05); $\mathrm{S}$.

Wehr, Solomon F. (b'34) E--Pa.14,'62; (l'is).

STEELEVILLE, 708, RANDOLPH

Armbruster, Henry G. (b'5i) H-Mo.5,'SI; (l's1).

Bollinger, Edward-Ill.17,'00; (l'01)

ROBEITSON, THOS. (b'59) \-Mo.2,'8i ; (l'si).

Whorowskl, Fredk. A. (b'66)-Ky.5,'97; (l'98).

STEGER, 2,161, WILL

BLIN, CHAS.

(sec crete.)

MOORE, MARY TILAIR COURTNEY BROW' (b'84)-I11.4,05: (1'05)

MIRI'II, LEA MARION (b's5) $\pm-111.6,11$; (l'11).

STEFLING, 7.467, WHITESIDE

BEAIID, CHAS. G. (b'75)£-Ill.6,01 ; (l'0I); $\mathbf{S}$.

BRODRICK, FRANK w. (b'/2)§-Ill.11, '97; (1'95); (B1); OALR.*

Carolus, Wm. B.-II-Ill.4,'S8; (I'88).

CONlRoY, FliANCIS JAMES (b'85)-lil.1 I, '10; (1'10).

Dillon, John II. (b'79) H-Ill.4,03; (l'03)

FRYE, CLARENCE MAXFIELD.

(See Rock Falls.)

llill, Morris Jasper (b'42)II-Ill.10, 'is;

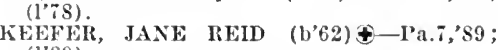

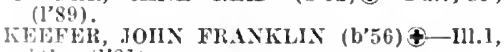
(1; (1'81).

aml. S. (b'53) H-11l.4,'s0 ; (l's0)

Noah H. $\left(b^{\prime} 50\right)-0.2,77 ;\left(1^{\prime} 77\right)$.

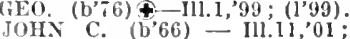

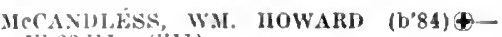
III.22,11; (l'11).

I'AKJiR, CHAS. E. (b'70)@-IH.II, 02 ; (ए'(1).

Plitis:, WM. IILLHOUSE (b'78)థ-H1.6,

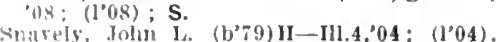

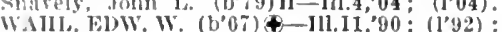
B.

STEWARD, 500, LEE

Durlu. James M. (b'6i)-Ill.4,89; (l'89).

Kinball, Geo. W. (b'66)-Ill.11,02; (l'02).

STEWARDSON, 720, SHELBY

HOLMFS, WM. F. (b'67) †-IHI.1,97; (l'97).

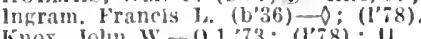

Ḱnox, Joln W- $W .1,73 ;(1,78) ; U$.

I'HIFEI, JOIIN N. (b'48)-Mo.2,78; (1'78).

STILLMAN VALLEY, 400, OGLE

HEEBL: ARTIITR II. (b'71)屯-III.16, 04 ,

111. II,05; (1'01); ALR.

IIAMET', J1ALOLD (b'76)↔-I11.11,'II ; (1'11).

STILLWELL, 250, HANCOCK

IIanson, Fred A. (b'80)-Ill.22, 09; (1'09).

STOCKLAND, 155, IROQUOIS

MONTGOMLIY, CARL. S. $\oplus-$ Ill.17,03; (l'03).

STOCKTON, 946, JO DAVIESS

KAA, NIEI,S ANDERSON (b'65) \$-Ill.11, 02: (l'02).

SMITH, I. CARSON (b'60) $\oplus$ - Ia.1,'84; (l'84).

STIFFORD, THOS. J. (b'60)↔-I11.I,'89; (l'90).

STONEFORT, 500, SALINE

IBlackman, Saml. J-Mo.27,96; (1'97).

(iroce, R. V. O; (l'83)

lohnson, Fredk, F.-I'a.2,'60; (l'80).

Osburn, Thos. J. $\rightarrow$; (I'T).

Osburn, Wn. G. $\rightarrow$; (1'83).

st. Jolın, B. F. - ; (1'7i)

STONINGTON, I,II8, CHRISTIAN

BIBRIY, JAMES IROY (b'82) - Ill.22,'1I ; (I'II) ; ObG.

Brldqes, Wm. T. (b'60)-Mo.l,'88; (l'88).

SALING, WII J. (b'65)—-Ky.2,92; (l'96).

SIIORT, W.I. T. (b'72)屯-Mo.27,97; (1'97).

STOY, 488, CRAWFORD

BROOKS, ALAN GOODWIN (b'80)థ-MId.1, 06: (1'0S).

STRASBURG, 526, SHELBY

Ilsser, Fredk. W. (b'63)-Mo.2,'86; (l's6). Schroeder, Fredk. W. H. (b'83)-Mo.28,'11; (l'Il).

STHPIIENS, OLIVER Z. (b'70)థ-H1.6,04; (l'04).

STRAWN, 400, LIVINGSTON

Kilemme, J. J. (b'6S)-111.11,90; (I'90); Pd.

Salisbury, Wm. W.-H-111.4,78; (1'78).

STREATOR, 14,253, LA SALLE

BRONSON, F. ILOYD (b'83) - Ill.6,08;

$\left(l^{\prime} 0 \mathrm{~S}\right)$; $40 \mathrm{I} \mathrm{N}$. Vermillion St. ; office, 304

Main St. ; 11-12, 2-4; Pd.

CIART, JOHN EDW. (b'85)థ-Ill.11,07 ;

$\left(l^{\prime} 07\right) ; 223$ E. Main St.; 2-5, 7-8.

CONlWY, DAVID S. (b'60)+-Mllch.I, 83 .

(1'87); $115 \mathrm{~W}$. Kent st. ; oftlce, 103 Main

St. : $2-4$

DICUS, GEO. ALLEN (b'63)£-Ill.1,'90; (1’90); 609 E. Broadway; oflice, 221 Main St. ; $2-5$.

DORSEY, MICHAEL F. (b'73)థ-Ill.1, 00 ; (l'00) ; 301 S. Park St.; offlce, 112 E. Iain St.; $1: 30-4$.

HIGINBO'THA. CIIAS, J, (b'79)-Ill.4,07 (1'08); M. W. Jack Bldg.; 8-12, 1-6.

HILL, HARRY C. (b'69)\$-Ill.I,'94; (l'94) I1s, Fth st.; office, 303 Main st.; $9-12$, $1: 30-5 ;$ OALR. $\star$

IIolland, Ora D. (b'53)-Ky.5,79, N.Y.10, ' 80 ; (I'81); 101 W. Wilson St. ; ollice, Main St. : $2-4$.

Howe, Lyston D. (b'S0)-Ill.11, 03; (1'03) ; $506 \mathrm{~N}$. Sterling St.; offlce, $201 \mathrm{E}$. Main St. ; $10-12,2-5, i=8$.

LESTER, HARRY S. (b'خ1) - - Ia.3,'9S;

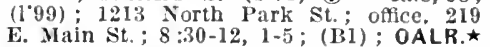
Maras, Peter E. (b'85)-Ky.2,'11; (\$); 1512 N. Otier Creek.

ICCORD, ARTHUR NELSON $\left(b^{\prime}, 0\right) \mp-$ Ill.22, 08 ; (1'08); 311 W. Stanton St. office, Leroy Bldg. ; $9-11,2-4$.
PERISHO, EIFY FIBERT (b'74)థ-III.11, $97 ;\left(l^{\prime} 97\right) ; 111 \mathrm{~W}$. Wllson St.; ofllce, 221 Maln St. ; 2-4.

l'OWFIIS, ('GEO. J. (b'83)-111.11,05: (l'05); 401 Mionroe St. ; oflec, $220 \mathrm{E}$.

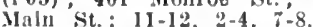

PI'IRCLLL, ALIBEIR'T CHAS. (1)'80) P-III.I, 05; (1'05); 305 s. Monroe st. ; oftice, 305 F. Maln St. : 2-4, $;-8$

QUILLIN, IAIVIRENCE JACOB (b'86)-IH.6 10 ; (1'10); 210 S. J'ark St. ; offlee, III F. Maln st, $2-5,7-8 ; \mathbf{S}$

RLNO, CIARENCE G. '(b'72)†-Ky.2,'97; (1'98); 215 Maln St.; 2-5, 7-8.

RI('IIARDS, FLIEN A. (b'67) $4-111.5,97$; (1'97); 201 F. MaIn St.

SCIIUIRT, CARI, $\left(\mathrm{b}^{\prime} 76\right)-M 0.27,00 ;\left(1^{\prime} 00\right)$. 216 s. Bloomington St. ; oltec, 201 E. Maln St. $10-12,2-5,7-8$.

Schurtz, Ieuben (b'51)-Mich.1,76; (1'86) 214 S. Bloomlngton St.; office, $201 \mathrm{~F}$ Main St. ; $2-5$.

SFATON, ROY (b'68)థ-III.6,'94; (1'94) ; $30 \mathrm{~s}$ s. Monroe St. ; offlce, 305 E. Maln St. ; $2-4 ; \mathrm{S}$.

Willams, Edwin E. (b'37) $\rightarrow$ : (l'93)

WILSON, GEO KISSICK (b'79)\$-Mlch.I, 07; (l'08); 205 E. Brlage St.; offec, 307 E. Main St. : 2-4.

(1'02) IINA MI. (b'65) \&-Ia.10,0I

STRONGHURST, 762, HENDERSON

BOND, EDWIN EVERETT (b'86) $\oplus-I 11.6$, $09 ;\left(10^{\prime} 09\right)$.

IIARTER, ISAAC F. (b'5I) - Ia.1,77;

(l'77). (1'99); Op.
IARSHALL, HUGH L. (b'73) $\odot-M 0.28,99$; (l'99).

SUBLETTE, 300, LEE

AFGEAR, BENJ. HORACE SMITH (b'TI) -Ill.17,00; (l’99); S.

SUGAR GROVE, I00, KANE

McNalr, Francls M. - Ia.1,'93; (1'93); R.F.P.

MOORE, ALRLIT W. (b'61) - II1.11,93; (1'93).

SULLIVAN, 2,621, MOULTRIE

DAVIDSON, WMI: P. (b'7I) $\oplus-\mathrm{Ky} .4,97$; (1'97); S.

Gaskill, lienry Allen (b'47)-Ia.10,'90; $\left(1^{\circ} 90\right)$.

Johnson, Stonewall (b'63) $\rightarrow$ Mo.5,'87; (l'87)

KESSLER, GEO. BRINTON (b'64)€-Md.1, '90, Tenn.10,'99; (1'07)

LAWSON, JOHY FOUROSE (b'78)(111.11,'06; (1'06)

Lucas, Jos. A. (b'64)-Mo.7,'99; (1'99).

SCARBOROUGII, WALTER E. (b'80)" $0.28,04 ;(1,05)$.

STEDMAN, W. E. $\$-K y .1,80$; (l'80).

WILYIAMSON, ORA MONROE (b'8'i)$30.28,07$; (1'07).

SUMMERFIELD, 337, ST. CLAIR

POOS, GROYER II. (b'84) $\oplus$-Mo.7,'05; (1'05); Op.

SUMMER HILL, 142, PIKE

AITON, MARY J. HENRY (b'65)థ-Ill.9, 01; (1'0I).

SCHWARTZ, GEO. W. (b'47) - Mo.2,73; (1'78).

SUMMUM, 200, FULTON

GOODWIN, PERRY B. (b'78) (-Md.3,04:

(l'05); Ob.

ONION, EMORY OIJVER (b'78)\$-Ia.10, 06 ; (1'06).

SUMNER, 1,412, LAWRENCE

Bosart, Jacob M. - 0.9,'67; (1'78).

Dale, Wm. R. (b'54)-Ky.2,'77;

not in practice.

DEAN, NOAII (b'i9) (-1a.10,07; (1'07).

Gideon, David Clark $\left(\mathrm{b}^{4} 48\right)-0.2, ' 73$, Mo.28, $07 ;(1,77)$

GREEN, WENDELI IRVING (b'83) $\oplus-$ Мo.28,'07; (1'07).

HOCKMAN, BENJ. FRANK (b'65) $9-0.1$, 93; (1'94).

IcDowell, James 0. (b'43) F-0.2,74; (1'77).

Turner, otis M. (b'69)-0.2,'98; (l'99).

SUTTER, 50, HANCOCK

Young, John G. (b'72)-Ja.9,'95; (1’95).

SWAN CREEK, 150, WARREN GIIFFITH, BENJ. A. (b'44) $†-\Pi 1.8,78$; 
SWANWICK, 75, PERRY

CLELAXD, JAMES S. $\left(\mathrm{b}^{\circ} 7\right)+-$ IO 1."98; (I'9s).

SWYGERT, 40, LIVINGSTON

Coomes, Asa (b'5I)-III.1I,'st; (l'Rt); not in practlce.

SYCAMORE, 3.926, DEKALB

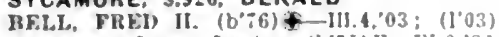

Blagten, Alunzo Dexter (b'5i) r-Ill,s, Sb: $(1,86): 0 b$.

BROWN, CHAS. 1\%, $(6 \cdot i)+-$ N.1.6,76: (1:75).

Ecbert, James K. (b'64)-IIl.I.'s6; (J's6)

FVANS, ISAAC S. (b"is)-111.22,06; (1'06)

IARSOS, JONATIAS M. $\left(\mathrm{b}^{\prime} 63\right)+-111$ 1 03 ; (1'05)

Munn. Marshall Curts (b'59) - III.5,"4.3, Ky.5.95; (1'95).

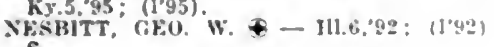
$\mathrm{S}$.

VESBITT, JOHX IB.-III.6,'9i; (1'9i).

Okerstrom, Albert (b'-1)-lll.11,05; (1'05) : not In practlce.

TABLE GROVE, 544, FULTON

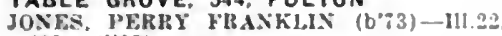
$00^{\circ},(100 \%)$.

WEIKEK, CIIAS. JONES (b'3 2 ) -I11.6,09 (1'09).

TAFT, 300, PUTNAM

Vawghan, Whllard lobt (b'87)-Ill.11,'12 (1'19).

\section{TALLULA, 860, MENARD}

IIGHTI.:, GEO. AILEX (b'69) \&-Ia.1,96

VALF. Ky, i,04: (1'04).

TAMAROA, 910, PERRY
MAILLOW. JAMYS T. (b'59) \$-MO.I,' 86 ; $\left(1^{\prime} 86\right): \mathrm{Pr}^{2}$

WARD, F. M. (b'56)-Mo.I,79: (1'79).

WOLFF, MFERY W, (b'69) - Mo.28,"98 (1'99):

TAMMS, 350. ALEXANDER

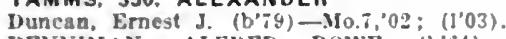
PENNIMAN, AIELED ROWE (b'b t)D.C.4,95: (1'95).

TAMPICO, 807, WHITESIDE

HOKN. ARCIIE S. (b'SO) $\$-111.11,03$; (1'03): $\mathrm{Op}$.

HORXER, CHARLES PERRY (b'i3) \&-III.6, 99: (l'99).

TERRY, IIARRY ALFRED (b'\%)†-Mo.2, 04; (1'04).

TAYLOR RIDGE, 75, ROCK ISLAND

ECKIIARDT, PKTHK (b"59) - III.1."96: (1'9i).

TAYLOR SPRINGS, 380, MONTGOMERY

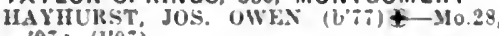
$07:(1109)$.

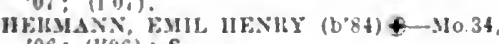
06 ; (l'06) : S.

TAYLORVILLE, 5.446, CHRISTIAN

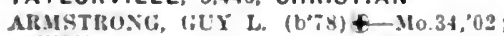
(1'02).

BARR, DORWIN JHLOSS (b'56) -0.2.'90; (I'96): OALR *

CAHIOLL. C'EHIIS L. (b'36) - Mich.2 i0: $(10 i \bar{i})$.

coltsilu, inst. K. (b'40) - Mo.2, $6 \%$ (1?i8).

Dorman, M. I.-Ky.1, 75 : not in practlce. Plrey, John Jacob $\left(b^{\circ}+1\right)-\$ Y .10,019$

FlKAZF,1. WM. 11. (b'60)-Mo., ,94: (1'91) HEHIMAN, SAML IKCK (b'82) †-JI.l 09: (1'09).

KleIn; Grover Cleveland (b's4)-111.1,"1: (l'i3): li. $\left.\mathbf{F}^{\prime} \mathbf{1}\right)$. 6 .

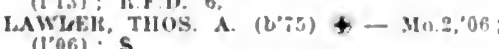
cacham, lieo. T. $\left(b^{\circ}: 0\right)-111.1 \cdot 93 ;(1 \cdot 93)$

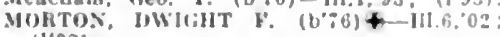
(l.02).

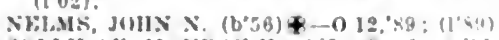

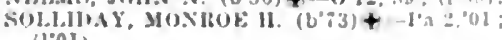
(1.01).

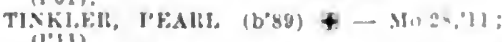
(1) II).

TLhNik AlHkl:T FRAXKLIX (b'iz) + Mo.2., 05 ; $(1105)$ : $\mathrm{S}$. (1'03).
TENNESSEE, 250, MEDONOUGH

Talor, Hus (tren (b'88)-111.11,12: (1'13).

TERRE HAUTE, 175, HENDERSON

HuckIns, Jamroy HOY't (1,8K)-In 6, 09: (1'10)

TEUTOPOLIS, 592, EFFINGHAM

WEISFNHUM, FIWAHU ALGIST (b'82)\& -Mo.34, 193 ; II"l09.

TEXICO. 10, JEFFERSON

l'arker. Wm. K. (b'51)-Ia.1, 93 ; (I'92)

simmons, ("hat Dasld (1,83)-Mo.28,"09:

110001 : ene in practlee.

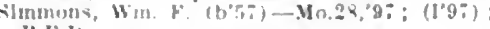
K.F.I.

THACKERY, 200, HAMILTON

Jotramel, kiljal Y. $(b ; 3) \rightarrow O ;(1 ; 8)$.

THAWVILLE, 350, IROQUOIS

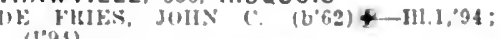
(I'DS).

THAYER, 1,012, SANGAMON

ALUFISION, ARTII'IL SFIMOLR (b\%O) T -II1.8.045: (I'06).

THEBES, 717, ALEXANDER

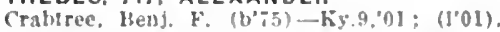
Phelps. Wm. A. (b'54)-Ky 1, \$4: (1"8t)

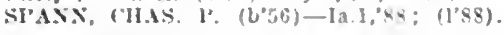

THOMASBORO, 350, CHAMPAIGN

EXTOX. LUC'Y A. (b'7) $+-111.9,01$ : (l'01):

not in practlce.

FXTOX, TIIOS.J. (b'b0)-111.8,90: (I'90)

Kelso, CurtIs FImer (b'81)-J11.11, 05 ; (1'05) not ln practlce:

THOMPSONVILLE, 573, FRANKLIN

Carter, Narquis D. I. (b'ts)-Ind 2, 68 : (1'78).

Johnson; Wm. I.ogan (b'69)-Mo.1,97; (199i): OALR

Karns, Thos. H. B. $\rightarrow$; (1'78).

THOMSON, 600, CARROLL

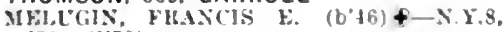
(1): $(1,-9)$.

SACNEls, MNRY A. $(1079)-$ Ia.10,02: (I'04).

THORNTON, 1,030, COOK

OIIVEIR, NELSON FLCENE (b'Ji) $\leftarrow$ HI.1,'s0; (1's3): (chlcago Helghts).

TILDEN, 77\$, RANDOLPH

Wrake, Jlolly T. (b'66) -Ky, 1,98; (I'98).

Stanley, Zeph (b's2)-111.11,10; (1'10).

TIMEWELL, 219, BROWN

IIVIS, FLOHEX FRED $\left(v^{\prime} S 0\right)-I 11.11,05$; (I.05).

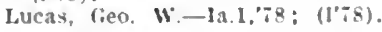

TINLEY PARK, 400 , COOK

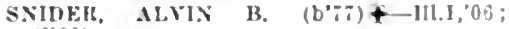
(I'06)

TIOGA, 300, HANCOCK

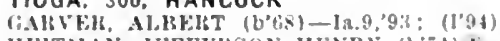

HEITMAN, JKFFERSON HENRI $(b ; 4)+$ Mo.28,99; (1'99).

TISKILWA, 1,000, BUREAU

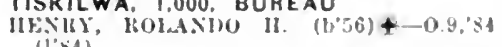
(1's4).

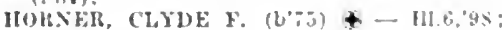
$\left(l^{\prime}(9 x)\right.$.

Kltlerman, fredk. H. (676) - III.11,02:

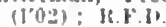

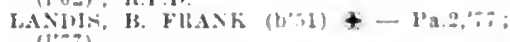
$(1,7 \%)$

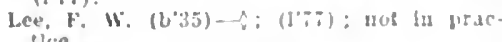
slce.

TOLEDO, 900, CUMBERLAND

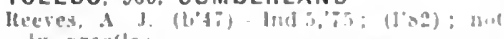
In Drantles.

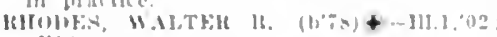
(1) 1$)=1$.

SWTII, WII I.ETER $\left(b^{*} 33\right)+-11111,06$

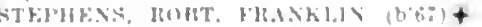
Ki: $5,: 4 ; ;(1 " 0 y)$

TOLONO, 950, CHAMPAIIIN

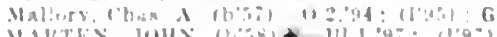

TOLUCA, 2.407, MARSHALL

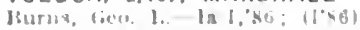

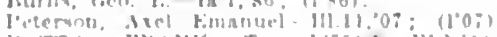

lotTs, FHAN T. $(\mathrm{b}, 5)+-111.06$

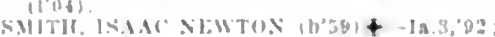
$(1,1 ;: 2)$
TONICA, 497, LA SALLE

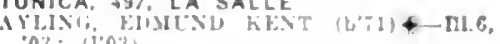
0.3: 11037

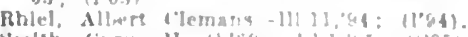

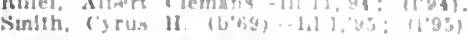

TOPEKA, 130, MASON

Mlankenabuld, John

(I'90)

TOULON, 1,208, STARK

HFHFILIL, CLYLE $\{t ; 9\}+-M 1,01$

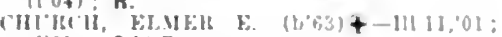
(1'01); OALR.

Hall. Waller T. $(1,40)-$ Ia 1,$69 ;(1 \% 5)$.

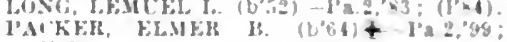
(1.99).

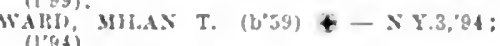
$(1,84)$.

TOWANDA, \$50, MELEAN

HOUNE, (H.AS. I.KSTEL (U'83)-III \&2,09: (1) 09 )

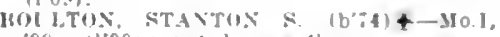
"99: (1.99); not In practlce

Roberis, C. IB-Mo.:2, 90 ; (1'96).

TOWER HILL, 1,010. SHELBY

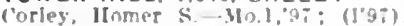

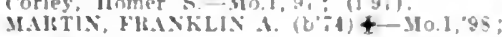
(I.98).

TREMONT, 768, TAZEWELL

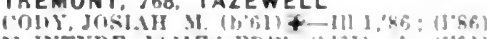
MCINTYRE, JAMEs LNW: (b'GI) $\rightarrow$; (I'GI) TRENTON, 694, CLINTON

HC'TRCF:SS, THOS. (1,69)-II1.1,"93; (1"93). ARTFil, WM. A. (1) 66$)+0.8,92 ;(1.93)$. NIFSS, LEONAKL (b'-S)-Mo.2,13: (I'12); OALR.

TRILLA, 260, COLES

COOK, ROBT. CAI.VIX (b'82)-KY.2,09:

(

THIUMPH, 150, LA SALLE

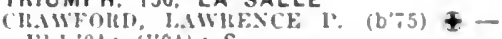
III.1,04; (1004); S.

TRIVOLI, I50, PEORIA

ILLCMEK, JUHX .1 \$-Ia.1,'s9; (1'39).

TROY, 1,447, MADISON

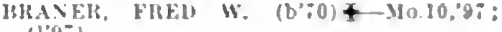
(I) 97 ).

BROW: JOSEFUT'S JLSTLS (b'33)

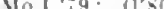

IOI.MEN, CIIAS. F. $(b \% 5)+-M 0.70 \%:$ $\left(\mathrm{I}^{2} 0 \mathrm{i}\right)$

TROY GROVE, 289, LA SALLE

Mayor. IIarry E. (b*5)-1a.10,"00; (I"06).

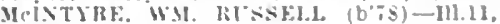
09; (I'08).

TUNNEL, HILL, 150, JOHNSON

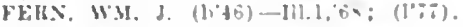

TUSCOLA, 2.453. DOUGLAS

HLAIXF, WALTEL (") (b'6s) +-1'a.1.96: (l'96i).

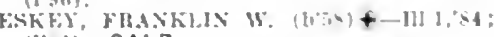
(I':4); OALR.

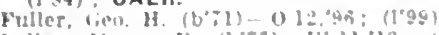

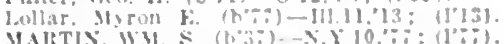

RFIT, JMIIS LEE (b'35)-0.5S, III.

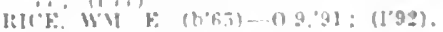

ULLIN, 6J0, PULASKI

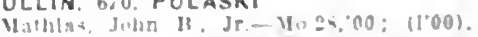

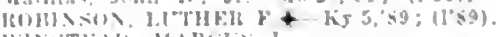

IIISTTRIII. MAISTS L

UNION, 322. MEHENRY

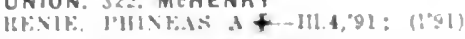

UNIONVILLE, - MASSAC

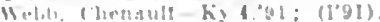

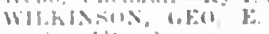

UNITY, 150, ALEXANDER

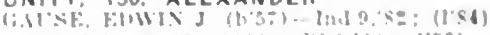

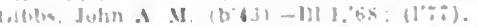

UPPER ALTON (ALTON P.O.), 2918. MADISON INCE IITUI

URBANA, 8.245, CHAMPAIGN

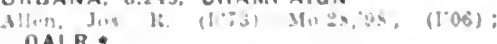
OALR.

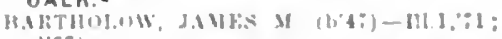
(1:7i).

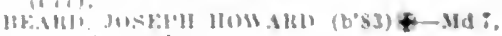
$( \pm ;\langle 119\rangle ; 1.0$ 
IBLTRES, WM. FRANKLIN-II1.1,82; (1'81). DAV1S, F. G. (b'69) - Io, 7, 91 : (1'91).

Dillon, Wm. (b'49)-0.1,'s2; (1'82); not in practlce.

Fugate, John T. (b'30)-Mo.1,58; (1'78): not in uractlee.

GUlick CLYDF D. $\left(b^{\prime}-6\right)+-11111.02$; (1'02); (also ofter, Firut Nittional bitnk IBlelg., ('hampalen)

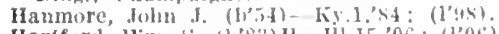
Har(ford, Wm. \&. (b,83) H-II.15, 06; (1'06i) IJN1)LEY, NLSTIS II, $(1,56)$ - $0.8,2$, $(1,80)$.

Landley, Mahlon (b'33)-D: (1'78).

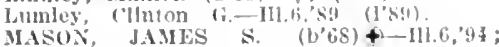
(1'94)

MHLFI, HokATHo W. (b'65)-P'a.1,'89; $(1.89)$

Munsell, Wllbert Watkins (b'78)-Ill.4, 01 : Nichols, chas. A. (b'65)-Ky. 1,'96; (1'96)

U. SMII, ELIJAH S. (b'56)-111.10,96, I11.4 "05: (1'96); OALR.

STANLEL, OTIS ORION $\left(\mathrm{b}^{\prime} 64\right) \pm-111.6,06$ $\left(l^{\prime} 06\right)$.

VAN HOREN, CHAS. L. (b'57) —-I11.8, 81 ; (l'81).

YANTIS, DAVID E. (b'70)†-IH.11,02 (1'02),

UKSA, 123, ADAMS

Curless, James W.-Ky.4,81; (1'81); not in

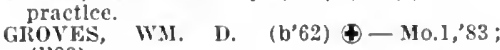
(1'83).

MITCIIELL, JAMES A. (b'54)-Ia.1,81; (1'81).

UTICA, 1,500, LA SALLE

ETZBACII, JOS. F, (b'80)-Ia.3, 05 ; (1'06) GEEN, JAMIES S. ( $\left.b^{\prime} 70\right) \uparrow-M d .4,96 ;\left(1^{\prime} 96\right)$ LELAND, KMBBLL, W,-111.8,'79, 11.1,'92 (l'79).

\section{VALMEYER, 400, MONROE}

Liesen, Francls H.-Ind.10,97; (1*9s)

MILLER, JOHN P. (b'79)†-IId.4, 06 ; $\left(1^{\prime} 06\right)$.

\section{VANDALIA, 2,974, FAYETTE}

Bassett, Geo. MI (b'49) $\rightarrow$; (l';8).

GREER, GEORGE (b'51)-Mo.I,'82; (1'82).

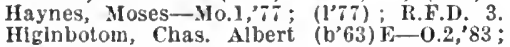
(l'83).

Mattes, Rlchard J. (b'67) P-M-Ind.5,'96 ; $\left(l^{\prime} 96\right)$; R.F.D. 3 .

MOREY, LOTHARO L. $\left(b^{3} 56\right) €-0.10,81$, Ind.5, ${ }^{2} 82:(1 ' 81)$.

ROSE, WALLACE EDSON (b'i 8$) \uparrow-I 11.11$, $09 ;\left(1{ }^{\prime} 09\right)$.

SMITH, HENRY D. $\left(b^{\prime} 54\right)-0.2,80$ : $\left(l^{\prime} 80\right)$.

WIILIAIS, ASA L. T. (b'70)屯-M0.27,93; (1'98).

VARNA, 403, MARSHALL

Park, Geo. S. (b'59)-Ill.8,'83; (l'84)

SCHWAMBACH, LOUIS (b'79)థ-I11.22. '10; (1'10).

VENICE, 3.718 , MADISON

LEE, JOHN E. (b'75)-Ia.10,'02; (1'02).

SCOTT, JULIEN W. (b'62) 4-Mo.24,'88; (1'89).

SCOTT, RALPH B. $\left(b^{\prime} 65\right) \oplus-\mathrm{I} 0.24,98$, (1'98).

VERA, 125, FAYETTE

MCREYYOLDS, ALBERT RAY (b'i4)£Мo.i, 02 , M10.34,04; (l'04).

VERGENNES, 342, JACKSON

TWEEVY, JAMES ROY $\left(b^{\prime} 80\right) \mp-110.7,05$; $\left(l^{\prime} 05\right)$.

VERMILION, 325, EDGAR

KILLGORE, JOS. GRANT (b'66)-Ky.1,'88;

LYCAN, HARRY (b'73)-No.27,99; (l'99).

VERMONT, 1.118, FULTON

BOY'TON', LLOYD $\checkmark$. (b'-9)-Mo.34,06; $\left(l^{\prime} 06\right)$.

BUNCII, RODNEY J. (b'80)\$-Mo.34, 06 ; $(1,06) ; s$.

HAMH'TON, CHAS. H. (b'68)-0.2,94; (1'94)

IIccurdy, Columbus (b'44)-0.2, 13 ; (l'78).

I'AlKER, IEDWIN S. + III.6,'85; (1'85); G

Taylur, Benjamin- $\rightarrow$; $(1 ; 8)$.

VERNON, 333, MARION

MURFIY, WALTER DEAN (b'8\%)£--Ill.11, 'I0; (1'10).
VERONA, 300, GRUNDY

BI'C'IILR, IACOHB C. (b'56)-0.1,78; (1'89). VERSAILLES, 524, BROWN

IBrlgea, IIcury (1,54)-Ia.1, 80 ; (l'80).

Scauland, sluney W. $\rightarrow$ : (l'80) ; R.F.D.

Wlllams, Hugh 7 \% (b'59)-Mo.1,95; (l'95).

WILAN, JOSLPII FRANK†-In.28,99;

Wilson. Sllvey J.-Ia.I,'88; (1'88).

VICTORIA, 400, KNOX

MON'TGOMER Y, ROB'T. CLYDE (b'S3) III. 8,$11 ;(1 ' 12)$.

OIRE, BEATTRICE, CARPENTER (b'T9)థ Ill 2., 0s: $\left(1^{\prime} 08\right): 0 \mathrm{p}$.

TEWART, ROIBET ILARDY (b'81)- H11.22, 'II: (I'II).

VIENNA, 1,124, JOHNSON

BHLWN, AT'STIN I. (b'68) \&-Mo.27,'92; (192).

bIKES, HOMER JOSHUA (b'87)-Mo.28, '10; (1'11); $\mathrm{S}$.

Ilart, James 1). (b59)-Ia.1,85, М[o.7,'89; (1'85); not in practice.

MeCAIL, ROBT. MARION (b'47)-Ky.2, 76 ; MCCALL, TIIOS. E.\&-Ky.1;93; (1997).

VILLA GROVE, 1,830, DOUGLAS

GILMER, CLINTON, H. (b'66)-Ky.1,'88:

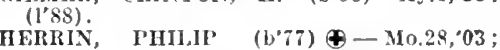
$\left(1^{\prime} 03\right)$.

Nlegrath, Henry- $\rightarrow$; (1'7T)

MILLER, JAMES M. (b'64) - Mo.34, 05 (1'05).

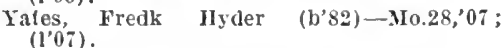

VILLA RIDGE, 500, PULASKI

RIFE, WI. CHRISTOPHER $4-T e n n .5, ' 94$; (1'94).

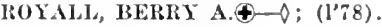

VIOLA, 760, MERCER

ICCLANAIIAN, VICTOR A. (b'69)Ð-Ia.9 '94; (1'95).

MILES, WALTER (b'68)†-IIl.1,98; (1'98).

VIRDEN, 4,000, MACOUPIN

BLUNK, SANFORD NILTON (b'î)థIII.11,11; (1'11).

Botkin, John W. $\rightarrow$; $\left(l^{\prime} 78\right)$.

Boyer, John (b'43) H-O; (1'79)

BRITTEN, W.I. A. (b'66)-110.27,95 (1'95).

Lockwood, Edw. K. ( (b'70)-No.27,'95; (1'95). IIORGAN, THOS. WYNN (b'78)€-111.1,00

(1'00).
MOTIEY, ELLIOT RECTOR, JR. (b'73)1a.1,'97; (1'97)

MOTLEY, ERYEST GRAGG (bs 79$) \oplus$ Mich.1,07; (1'07).

Shrlver, Wm. A.-E-0.2,7l; (l'77).

Spaulding, Davld L. (b'38)-N.Y.13,'75; (1'87).

\section{VIRGINIA, 1,50I, CASS}

BLACKBURN, WM. R. (b'67) †-Mo.28,'98; (1'99).

Day, Harry Levi (b'72)-111.10,99; (l'99).

HUBIBARD, CHAS. M. $4-0.2,71$; (1'78).

LYLES, ALBERT R. (b'61) †-Mo.7;90; $\left(1^{\prime} 90\right)$.

MerEE, JOHN A. (b'73)థ-Ill.4,96; $\left(l^{\prime} 96\right)$ Snyder, Joln $\mathrm{F} . \mathrm{O}$; (1'01); not in practice.

WAGGONER, 270, MONTGOMERY

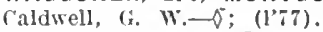

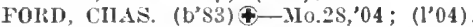

WALDRON, 295, KANKAKEE

WORSTALL, SAML. A. (b'5T) - Pa.2,'82; (I'97).

WALNUT, 900, BUREAU

HOP'KINS, SAMILEL W. (b'66) \&-Pa.1,95 ; (1'95); $\mathrm{S}$.

SHEARBLKN, ARTHLR P. (b'62)†-III.10, 92, $\left.111.4,05 ;(1)^{\prime} 93\right)$

SNADER, GEORGIA ILAYHALI $\left(b^{2} 63\right) \oplus-$ III.14,'99; (l'99); G.

WALNUT HILL, I60, MARION

Wayman, Benj. F. $\rightarrow$; $\left(l^{\prime} 78\right)$; not in practice.

WALNUT PRAIRIE, 100, CLARK

Rynerson, Barnett A. (b'52)-Ky.2,'91; (l'92).
WALPOLE, 125, HAMILTON

WHLIIS, JAMIES J. (b'82)\&-MLo.7;09; (1'09) Willams, Jos. S.-Mo.1,84; (1'87).

WALSHVILLE, 169, MONTGOMERY

IIAISER, OTTO (b'73)\&-Mo.1,'99; (l'99). WALTONVILLE, 250, JEFFERSON

Jelfrles, John W. (1, 44)-No.10,79; (1'78) Torrls, Ollice I' (b'43)-0.8,71; (1'78). ROIBNSON, JANES WIISON (b'i4) -Mo.28,

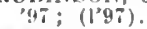

Wells, James Walter (b'79)-Mo.28,06 : $\left(1^{\prime} 06\right)$.

\section{WAPELLA, 500, DEWITT}

lavis, Yesseltus (b'59)-0.6,"82; (l'82).

Jomes, Joln IBranson-111.11,'05; (1'05).

WARREN, 1,327, JO DAVIESS

BUCKXAM, ALVAN FLLCH $\left(b^{*} 36\right)$-Me.I, (3)

GMLLA, ALFONZO C. (b'68)-Vt.2,'89; ('P1) OALR.

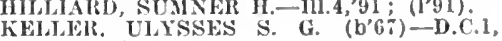
95: (1,98)

RENW'WICK, JOS. CLYDE (b'81)-III.1,04; (I'04).

WARRENSBURG, 503, MACON

MELTON, WM. ALEXANDER, JR. (b'63) - 111.6,$)^{\prime} 96 ;(1,96)$.

Rea, Aiberilna Loulse (b'78)-WWls.2,'10; (l'11), James Thompson (b'63)-Wis.3,'08; (1'10).

\section{WARSAW, 2,254, HANCOCK}

EDWARDS, RALPH T. $\left(b^{\prime} 72\right)-M I . T, 04$;

IIoward, Florence Amelia (b'58)-1a.10,'05; (1'05); not in practlce; R.F.D. 1

Johnston, J. Laton-II-III.10; 91 ; (1'92) .

Matzke, Saml. E. (b'72) H-Mo.26,'97; (1'97).

Miller, John-1a.1,'95; (1'96).

Warner, (has. O. (b'30)-Mio.2,'63; (l'77).
WINNARD, WELIINGTON L. (b'6i)屯III.10,'90; (1'90); G.

WASHBURN, 703, WOODFORD

Irela nd, Frank B. (b'71)-Ill.8,98; (1'98).

TWEDDALt, JA II E S (b'32) \&-Ill.1, 69 ; (1'7\%).

WATT, BENJ. N. (b'54)-Ml.1,84; (l'84).

WASHINGTON, I,530, TAZEWELL

BENNET', U. PRESCOTT (b'69) \&-Ill.11, 90 ; (1'89). GoT', WM. A R Y EL (b'74)Ð-Ill.10,01 ;

MANSFIELD, WILLIS A.-I1].6, 84 ; (l'84). (1'95).

WATAGA, 600, KNOX

GILES, WM. NELS ON (b'58)-Ia.9,'98; (1'98)

Miner, Hazen H. (b'67)-M1.13,'97; (l'97).

WATERL 00, 2,091, MONROE

ADELSBERGER, LOUIS $\left(b^{\prime} 62\right) \oplus-M o, 2,84$;

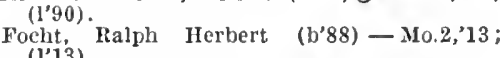
(1'13).

FULTS, JACOB C. (b'61)-Mo.2,'85; (l'97). (1'78).

PAUTLER, NICHOLAS B. $\left(b^{\prime}\right.$ '2) '93: (1'93) JOHN S. (b'61)£-Mo.2,'83:

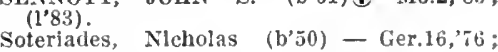
(1'78).
VOGEL, FREDK. GEO. (b'68) $\$-M 0.34,06$; VOGEL,

WATERMAN, 450, DEKALB

Atherton, Wm. Kaymond ( $\left.b^{\prime} i 7\right)-111.22,08$; $\left(1^{\prime} 08\right) ;$ not in practice.

GREELEY, PAUL E. N. (b'75) $€$-Mich.5. ,00, Ill.1, 01 ; (1'01); Anes.

WILKINSON, CAIL IIIXSON (b'70)屯I11.22, 04, I11.11,'05; (1'04).

WATERTOWN, 525, ROCK ISLAND

ATHERTON, CLESSON C. $\left(b^{2} 78\right) \pm-111.16$ '05, Ill.11,'10 ; (1'05); NP,`

(i'06). WILSON INIRT $\left(b^{\prime} 85\right) \oplus-0.2,08$;
DYER, (l'08); NP.* $07 ;\left(l^{\prime} 07\right)$.

Ford,' Walter Ari (b'87)--n1.8,'13; (l'13).

GAMBILL, WM. HENIYY (b'81) $\rightarrow$ Mich.1,10; 


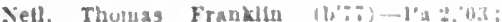
(1'12). Tankln, Jatres Kdw. (b'6s)-In9.41; $\left\{1^{\prime} 9 \mathrm{si}\right.$

U. 0 : : $(10 \%):$ NP.

WIXsulk, HIIHIR!)

WATSEKA, 2,476, IROQUOIS

Blssell. Hobark Henry- III 1,'99: (1'9:4)

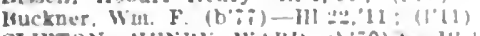

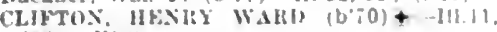
os: $170 x)$

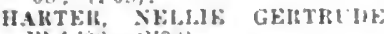

lli.t,ox; (lopit

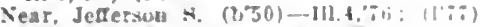

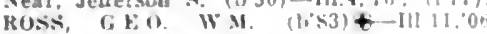
(l'06): OALR.

WATSON, 330. EFFINGHAM

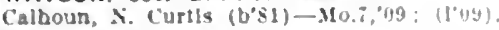

WAUCONDA, 500, LAKE

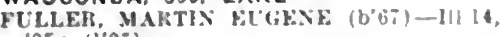
$05:$ (1.03).

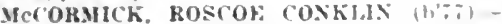
III.11,08; $(1,0 \mathrm{~s})$; Ob.

Wells, Chas R. (b'4t)-Mlch.1, ito: (l'si): not in practice.

WAUKEGAN, 16.069, LAKE

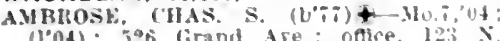
Genesee St. $9-11,1: 30-3: 30$, ti- $7: 30$.

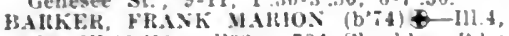
02 , Ill.11,03; (1'02); 734 sherldan lid. $02,11.11,03 ;\left(1^{2} 02\right) ;$
office. 119 Clayton st. : 10-12, 2-4; S.

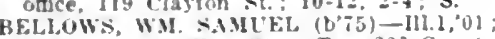
(1.01); 116 s. West St. ; oflee, 220 County SL: 2-4, T-S; OALR.

BOLTOX, WM. C. (b'65) +-Ill.6,83; (1'89) 912 sherldan Rd.: uflce, 123 No. Genesee St. : $4-11: 30,3-5: 30,:-9 ; \mathbf{N}$.

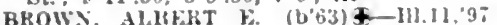
(1'96); 422 West St.; ottlce, $115 \mathrm{~s}$. Genesce st : $2-4,7-2$.

ClALBOE, ALFEL HANSOX $(6 ; 8)+$ III.11,11: (1'11): 1312 Mcillster Avo. ottice, 125 Washingtou St.; $9-11,2-4,7-8$

DANIELS, C II A S. k. (b,5)-111.1,02: (1.02): 112 Clayton st.: otlce, 213 Gen-

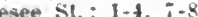

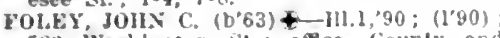
532 Wastington St.; oftice, County and Washington Sts. : 2-4; S.

Gavis, KDW: FoRD (b'6t) \&-11.1." 40 ; 191) 530 stcele Cr: once.

Kd. Thos, Haldi (bo-ig)-11.6, i3; (l'13) $123 \times$. Gevesee St.

GOLKLIY, FIEL IANT\% (b'7)\$-11111, 03: (103) : 425 Hickory St.; oalce, 214 Washlugton' $\mathrm{St} ; 10-11,2-4, ;-8 ; \mathbf{S}$.

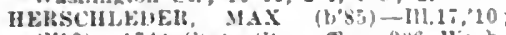
(I'10); litt state st. ; oflce, 2Ub Wash ington St.

KAlowsky, Moklis Jos. $\left(b^{\prime} i l\right)+-111 . \$ 3$, '01: (l'0l): M020 Mcillister si.; ollice, Genesee ami Washliston Sts. : 10-11, \&-4.

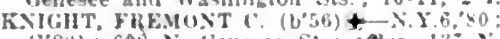
$(180) ; 608 \times$ iencsee St, once, $137 \mathrm{x}$ ienesce st.; $1-4,7-8 ; \mathbf{S}$.

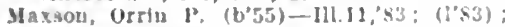
not in practlce.

lesblt, Hobt. H. T.-H-III-,96; (1'96); 902 illielt ire.

pearce. Herclral (1967)-111.11,"y6; (l'at) sos Jullan S: ; othre. 203 Washingtun st $10-12,2-1$.

l'earre. W. W, (b'sy)-1H.11,'s5; (1'as) nus in practice.

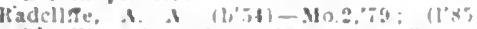

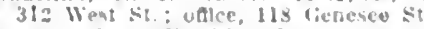

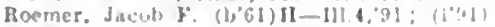

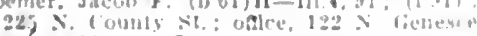

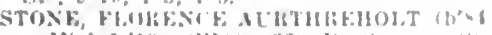

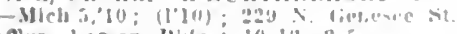

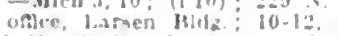

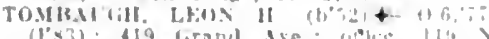
Cicnesee sit. : 1-4, i-s.

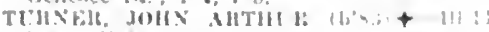
00: (1.05): $620 \mathrm{~S}$, louml

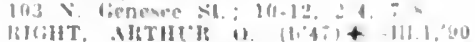

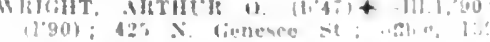
1. emeste sit: 1 - 4
WAVERLY, 1,538, MORGAN

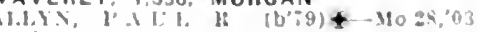

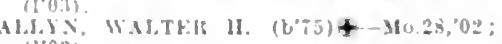

$(1.021$

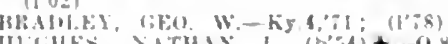

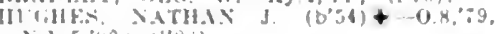

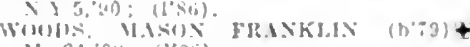

II:34,0K: IJOA)

WAYNE, 150. DUPAGE

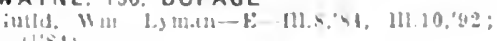
11 I' 1

WAYNE CITY, 620. WAYNE

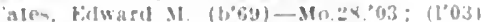

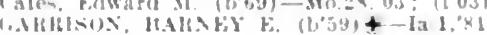

(1':2): Ob.

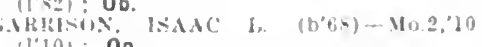
110 ; $10 p$.

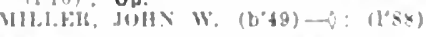

WAYNESVILLE, 528, DEWITT

Honoran, Comellus J. (b'il)-Mo.7,93;

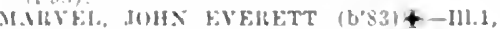

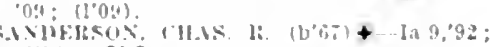
(1'92); ObG

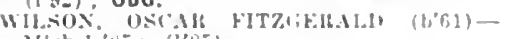

II!ch.1, S5: (1'85)

WEDRON, 200. LASALLE

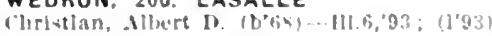

WELDON, 687. DEWITT

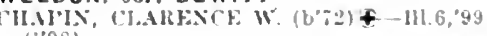
H.IHbil, M'THFR MIITIS $\left(b^{\prime}, 2\right)+$ III.11,04; $(1,04)$.

WELLINGTON. 300, IROQUOIS

SISTI.K.K, A. UTTO (b's3)-KY.2,10; (1'10)

WENONA, 1,486, MARSHALL

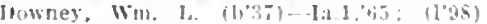
nut In prartice.

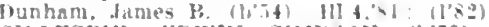

GILLESPIt, HDWIX SHISOS (b'9)-

III. $\left.1.07 ;\left(10^{\circ} 0\right)^{\circ}\right)$

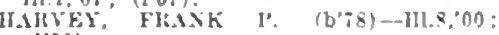

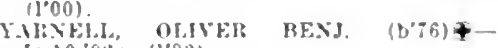
I.10, $102 ; \quad(10 \geq)$.

WEST BROOKLYN, 300, LEE

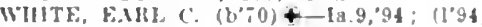

WEST CHICAGO, 2,378, DUPAGE

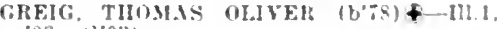
(1'03)

Jaberwod, Paul Nonzo (b'8:)-111.6.'11 (1'2:)

ISHERWOOD, THOS. (i, (b) - $1111, \times 3$ (1's5)

Kinne, Harry WInfled

liee Chicago.

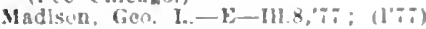

WEST END, 30, SALINE

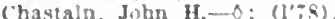

J.amont. (has. Leruy (b'so)-Mo 10, l: (1, I:2)

WESTERN SPRINGS, 1,046, COOK

Hohwedler. Herman il

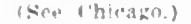

katel], h.twrence w

(Siee I hicago.)

WESTERVELT, 180, SHELBY

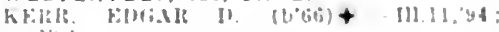

WESTFIELD, 1,100, CLARK

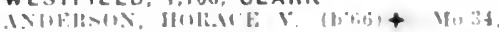

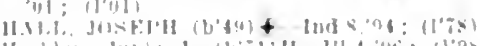

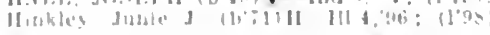

WEST FRANKFORT, 2, 11. FRANKLIN

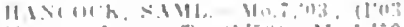

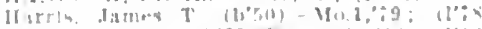

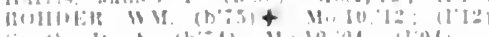

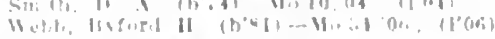
WEST HAMMOND (HAMMOND. INO [O O I g.84, COOK

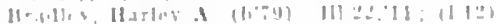

WFST JERSEY (R.F.D. TOULON). 100. STARK

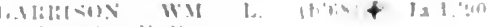

WESY LIBERTY, 214, JASPER

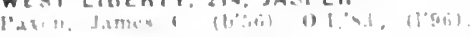

WESTON, I91, MCLEAN

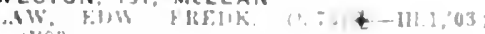

WEST POINT, 2Z\%, HANCOCK

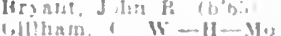

WEST PULLMAN IIND. STA. CHICACOL,

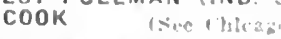

WEST SALEM, 725, EDWARDS

HITTUY WI L COSO

$(1,+0) ; 16 k$

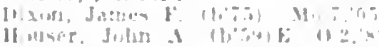

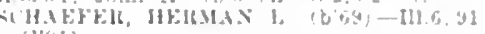
$11 \times 31\}$

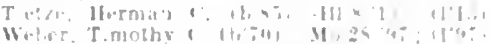

WEST UNION, 450, CLARK

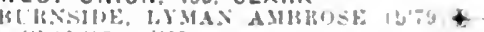
111.11, 0\%, ; 11051

WESTVILLE, 2,607, VERMILION

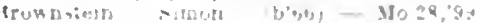

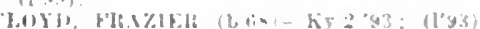

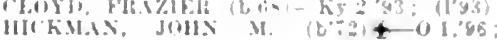

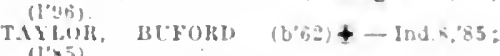
(1'85).

WEST YORK, 300, CRAWFORD

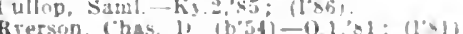

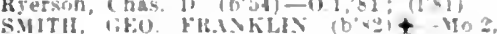
$10 ;(1,10) ; \mathrm{G}$.

WETAUG, 218 , PULASKI

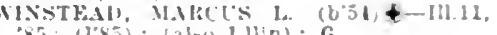
'85: (1"85): (also (lin): G.

WHEATON, 3.123, DUPAGE

B] anchard. Frances Carothers $\left(b^{\prime \prime 50}\right)-111.9$ 85 ; $(1 \div 6): G$.

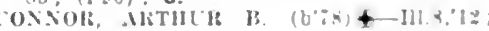
(1'12).

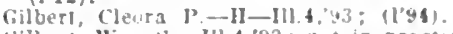

filluert. Wm. S.-Wll.4.93; not in practice

l.10X, HUW IKL

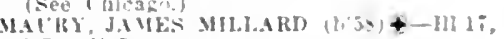

UELKL, EML KARL HEIXRICU $\left(\mathrm{b}^{\circ} 3\right)+-$ Ha.:.04; $(1 / 10)$

Kasch, John Henry $(6 \% 5)$ - III 4:05: 1104). REEDEH, WM. GEOU.

(see (bicazo.)

S.ASH KY, JEROME HFAR

(Nice (hicago.)

WHEELER, 255, JASPER

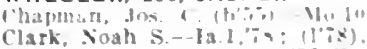

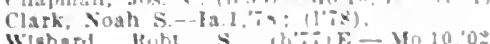

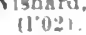

WHEELING, 600, COOK

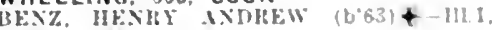

WHITEFIELO (R.F.D., HENRY), 25, BU. REAU

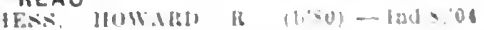

(l'ut)

WHITE HALL, 2.834. GREENE

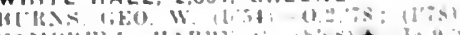

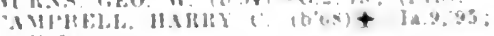

(1):1:

(II)in. Hr:MRY

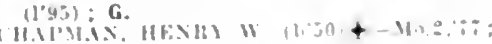

1):3,

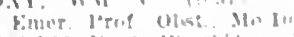

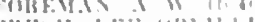

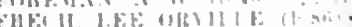

(I' [19]

Mi: H, Hil

WHITE HEATH, 200, PIATT

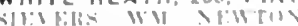

WILLIAMISFIELD, H:, KNOX

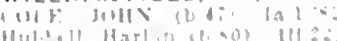

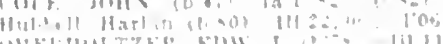

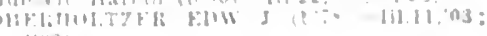

WILLIAMSVILLE, 600, SAMGAMON

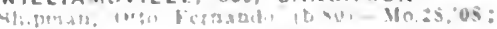

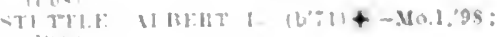


WILLISVILLE, 1,082, PERRY

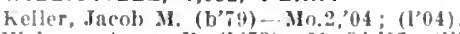
Wolever, Aaron I. (b'73)-Mo.34, 07 ; (1007) WILLOW HILL, 444, JASPER 1BERSS, SIMON 1'. (b'61) + Mo.1,"81 (1'3I).

HU'TTON, THOMAS I.LE (b'78)‡-M0.28, '08; (I'08) : S.

WILLOW SPRINGS, 150, CCOK IUST, JOHN WM.

(see ('hlicho.)

WILMETTE, 4,943, COOK

Barker, Milton liced.

(see (hicagho.)

MHOWEIR, WANI. MOIBERT'S

(see I hivigo.)

'llilds, A. s.

(sece ('hicago)

COLWHA, NATHAN POLTER.

(see (hicato.)

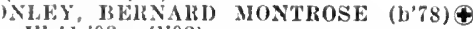
- II. I, 03 ; (l’03).

Conley, Hinnic Agnes Illuch-Ill.9,01; (1'0I).

Conrad, R. W. (L'68)-N,X.10,'98; (l'98); 807 ('entral Are.

Daggelt, Le loy II.

(See Chleago.)

AVIS, DAVH JOHN.

(See Chlcago.)

FARIELL, "ATIICK J. I.

(See ('hleago.)

HAMMOND, HAMES LLOYD

(Sce Chicago.)

IIASKINS, GEO. WM.

(See Chicago.)

IIECIIT, MANNE CIIAS. (b'83)థ-III.1I 07 ; $\left(\mathrm{l}^{\prime} 07\right)$; Pd.

Ilodgens, Isaac Walter.

(sce Chlcago.)

Hoffman, John $\mathbf{R}$.

(See Chlcago.)

KAIST, FREDK. A

(Sce Chicago.)

LOWER, FRANK SMITH.

(See (Chieago.)

$M A N N$, WH. A

(See ('hicago.)

MEE, LESTER EDWIN.

(See Chlcago.)

MELLINGER, IIERBERT VICTOR (b'79) -I1I.1,06; $\left(\mathrm{I}^{\prime} 06\right)$; (32 N. State St, Chi cago); $\mathrm{S}$.

Hoore, Edw, E.

(See ChIcago.)

PATTILLO, RICHARD STARR.

(See Chicago.)

Schwartz, Elmer E.

(See Chicago.)

Searle. ('laude H. (b’73)-Ill.1,98; (l’97).

SEGSWORTII, JOIIN, JR. (b'66) - Ont.1 '94; (1'95); $\mathrm{s}$

SMITII, CHAS. GEO. (b'67) 4-Ill.14,04; (l'04).

STOLI, BYRON C. $\left(b^{\prime} 51\right) \oplus-111.8,73$; (107it,

Swalm, John C.

(See Chicago.)

ToBlas, GEo.

(See Chicago.)

Trask, Fredk. Marquand-N.Y.10,'75; (1'84).

WEA VER, GEO. HOWITT

(See Chicago.)

WILMINGTON, 1,450, WILL

Carlin. Chas. John-Ill,4,'12; (1'12).

CASSINGHAM, MARSHALL (b'41)థ-Ill.1, $75 ;(1,76)$

CURTIS, WATSON H. (b'49)థ-N.Y.8,'73 $(1,78)$.

SAMUELL, DILLARD ESTEP (b'Ti)-111.11 08 ; (l,08).

WELCH, WY. B. (b'88)-Ill.4,06; (l'06).

WINCHESTER, 1,639, SCOTT

BOWMAN. CHAS. STUART (b'86) (4-Mo.28 ,09: (I’09).

BREFGLE, GEO. C. (b'59) - 111.11,88 (1'89)

DAI, LEWIS R. (b'66)-Mo.28,'97; (l'97).

TCKMAN, JOHN WESLEY, JR. ('b'83) \& 111.11,0s: (l'0s): ObG.

FLETCHEli, HUBERT H. (b'72) †-Mo.28, 'C4: (1'49); Prof. Med., Mo.10: OALR

MINFI, JAUES (b'35) 6-Pa.2;61; (l'87). O'Reilly, Wm. MI. (b'8I)-MIo.2, ${ }^{\prime} 07$; (l'07). STRAIHT, GEO. M. (b'5T) - Ia.1,'8I (1'81).
WINDSOR, 866, SHELBY

DONOVIN, JOHIN H. (b'67) - Mo.1,89;

IHlsilieck, Wm. Franklln (b'46)-Ill.1,'72;

stoki. ARTILI H. (b'71)-Mo.28,'98: (I':919)

\section{WINNEBAGO, 500, WINNEBAGO}

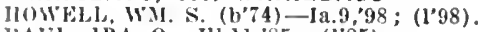

I'AU1. IRA O.-Ill.11,'85; (I'85).

WINNETKA, 3,168, COOK

I3: rrohl, Ila Marie Lalro-N.Y.20,'07; (l'08)

BR()WN, ALICE BARLOW.

(Sec Chicago.

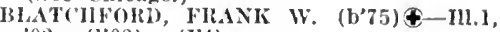
'02: (l'02); (I'4)

Brown, James Morcau (b'7 (1)99).

BHOWN, MOHEAU ROBERTS.

(see Chlcago.)

Darragh, Eimiston.

(see Clileago.)

FAIRRELL, PATRICK J. H.

(see Chicago.)

Fletcher, John Rice.

(see Chlicago.)

HAMILL, RALIII C.

(see chicago.)

HEAI, Y, WM.

(sice 'Chlcago.)

Jacobs, Antonia C.

(See Chícago.)

Kovats, Fred C. $\left(b^{\prime}, 76\right)-111.1,00 ;\left(1^{\prime} 00\right)$

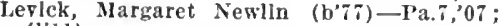
(l'11).

Macracken, S. Gordon (b'69)H-Ill.4,'94; (l'94)

MKKELSEN, EDW. MCHAEL $\left(b^{\prime} / 2\right) \oplus-$ 11].11,08; $\left(l^{\prime} 08\right)$; $\mathrm{S}$.

SCIINEIDER, CARI OSCAR.

(sce Chicago.)

Taylor, Lillian Ethel.

(See Chicago.)

White, Persis-111.9,'94; (1'95) ; not in practlee.

Wildman, Henry G.-N.Y.1,80; (l'87)

WOOD, CASEY ALBERT.

(See Chicago.)

WINSLOW, 500, STEPHENSON

Bucher, Claude Farl (b'83)-Ill.6,'12;

BII'I2), PAIIL, JULIEN (b'76)థ-IIl.1, 0.3; (l'03); Pd. Saucerman, Iohn W. (b'37)-Ill.1,'63;
$\left(l^{\prime} 7 \%\right) ;$ not in practlce.

Wills, Geo. II. (b'\%2)-Ill.1.'00; (l'00).

WINTERROWD, 23, EFFINGHAM

Drake, Le Roy (b'85) E-Ill.8,'06; (1'07).

WITT, 2,170, MONTGOMERY

AlAMS, JOHN WILSON - Tenn.1,'98 : (1'38).

BURNS, W. IRVING (b'55)-Vt.2,'96, N.Y.6,

Gruenewald, Julius (b'57)-Mo.1,'91; (l'96).

LOCKHART, CHAS. II. (b'71) - Ifo.1,98; (1'98).

WOBURN (R.F.D., GREENVILLE), 250 , BOND

CIIURCII, OSMON CHARLES $\left(b^{\prime} 74\right)-$ Mo.28,'10; (1'10)

WOLF LAKE, 75, UNION

CIANILE, EUG'ENE-MO.7,'04; (l'04)

WOODHULL, 692, HENRY

CARISON, CARL W. (b'70)థ-IIl.1,03; (l'03).

Cowles, Geo. Henry (b’i1)-Itl.1.'96; (l’96) DRENNAN, GILBERT D. (b'76)థ-Ill. 6,02 ; $\left(l^{\prime} 02\right)$

Lowry, Nelson Horatio (b'47)-Ill.4,'72;

Taylor, Edw. D. (b'76)-Ill.1,03; (l'03).

WOODLAND, 450, IROQUOIS

DOWSETT, CHAS. HORACE (b'81)-Ill.6, 08 ; (l'08).

WOODLAWN, 3|5, JEFFERSON

Sutton, Roscoe E. (b'86)-NIo.10,'12; (ま).

Watson, James H. (b'46)-Mo.T,81; (1'7).

WOODRIVER, 1.500 , MADISON

Gotischalk, Edw. D. (b'79) - Mo.34,'06;

(I'06). (l'04).

WOODSON, 257, MORGAN

JONES, RALPH ROY (b'74)-Mo.28,'05; $\left(l^{\prime} 05\right)$.

Miller, Geo. W. (b'42)-Mo.1,71; (l'78).
WOODSTOCK, 4,331, MCHENRY

ANI) ERSON, Hiw. V. (b'4S) - Ill.1,71; (1'77).

BACCIS, CLYTE FIRANKLIN (b'86)థIll.11,'II ; (1'12); $\mathbf{N}$

I3lankner, Fredk. (b'59)-Mo.27,96; (1†) ; (bentlst).

FRANCIS, HORACE MONTAGUE (b'83)๑HII.I, $06 ;(1,07)$

HY, JOIIN E. (b'79)-Ill.4,04; (l'04) ; OALR. ^

Hoesley, Ienry Pranklin (b'86)-Ill.8,'13; (l'13).

McAuliffe, Elwin Iouls-Ill.1,'82; (l'83) ; not In practice; R.F.I.

SHEIYE, NORMAN LEE.

(siee IIarvard.)

S.IITH, ADOLI'H B. (b'79)థ-111.1,06; (1'06)

Thon, Harry Chas. $\left(b^{\prime} 78\right) \rightarrow$; (l'99).

WEST, W.M. HYDE (b'85) $\$$-III.4, 11 ;

WINIMUELLER, EMIL (b'69)థ-III.1,94; (1'94).

WOODWORTH (R.F.D., MILFORD), IROQUOIS

LCKE, CYRUS V. (b'75)-Ill.17,'99; (l'99).

WORDEN, I,082, MADISON

DORR, CHAS. F. (b'80)-Mo.34,'03; (l'03).

Hanson, Frank (b'65)-Ill.1.'88; (I'89).

WRIGHTS, 200, GREENE

ROYAL, ANDY-IIO.28,'02; (l'02).

WYANET, 950, BUREAU

ROBINSON, FEINANDO C. (b'37)-IIl.1, 63; (1'77).

THUVIIAUER, JAMES D. (b'75)-Hll, 197 ; (1'97).

WYOMING, 1,506, STARIS

IIENSON, JOHN GEO. (b'84)థ-III.22,'08: (1'08).

Holgate, James R. (b'41)-I1l.1,'69; (1'77).

King, Robt. N. (b'64)-Ky.4,'98; (1'98).

McMACKIN, CURTIS C. (b'58)-Mo.1,'95; (1'95).

Morse, Newton B. (b'38) $\rightarrow$; (l'78).

Wead, Alma T.-Ia.1,'95; (1'95).

WEAD, JAMES S. (b'67)(†-Ia.1,'94; (1'94).

XENIA, 634, CLAY

BRYAN, JOS. LYMAN (b'81) $\rightarrow-M 0.34,06$; (l'06).

CAMPBELL, GLEN STEWART (b'83) Ky.2,08; (1'08).

Campbell, Frank C. (b'72)-Ky.2,'96; (1'97).

I'armenter, Jacob A. (b'35) - Ill.6,'67; $\left(1^{\prime} 79\right)$; not in practice.

Thompson, Thos. W. (b'57) - Ill.1,'84; (l'84); not in practice.

YALE, 200, JASPER

WATTIEWORTH, JAMES R. (b'72) Ky.5,'02; (l'02).

YATES CITY, 603, KNOX

IIensley, IIerman J. (b'63)-Ill.1,'87; (l'87). IENOIIER, JAMES A.๑-Ia.1,94; (l'94). YORKTOWN (R.F.D., TAMPICO), 50, BU. REAU

BOHNETT, ENNOS (b'66)-Ill.8,'99; (l'99).

Sheldon, John K.-Tenn.11,04; (ま).

YORKVILLE, 43I, KENDALL

FRAZIER, FRANK R. (b'72)(-Ill.1,'95; (l'95).

LEESON, ERNEST . E. (b'72)-Ill.11,'94; $(l \dagger)$; Hember State Med. Soc. of Wis.

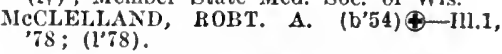

YOUNGSTOWN, 100, WARREN

HOORNBEEK, NATHANIEL B. $\left(b^{\prime} 54\right) \$-$ IIl.1,'81; (1'81)

ZEIGLER, 500, FRANKLIN

IIOORE, JOHN BEVERLY (b'84)థ-Ill.1,

'10; (l'10).

SHEEKER, WALTER W. (b'81) $\oplus-0.2,05$; (l'05).

ZEARING, 70, BUREAU

Rohde, Max Spencer (b'84)-MId.7,12; ( ).

ZION CITY, 4,789, LAKE

BIILMEYER, GEO. MCCLELLAN (b'63)థIII.1,'97; (1'97).

Blanks, John Harrlson (b'66)-Tenn.6,'91; (l'04); not in practlce.

La Rose, Noah J. (b'51)-0.2,'85; (l'05).

Ruby, Wilber Olan (b'58)-Ill.4,'84; (l'09) ; not In practice. 


\section{INDIANA}

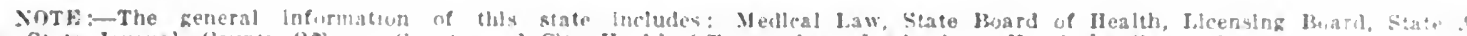

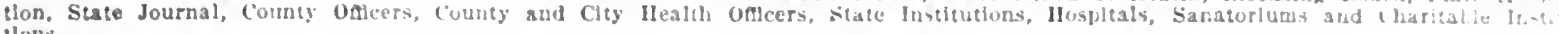
tJons.

\section{INDIANA}

Population (1910 census).

$2,700,876$

Number of Counties. .

Members State Association, Dec. $3 i$. 1913.

Area of State in Square Miles.

MEDICAL PRACTICE LAW OF INDIANA

Law of 1897 with Amendinents of 1814 , 1901 and 1905

\section{An Act}

Regulating the Practlce of Medlcine, Surgery and Obstetrles, I'rorlding for the Issuing of Llcenses to Practice, Proriding for the Appointment of a siate Board of Hedical Registration and Examina

ton and Defning Thelf Duties.

Defnlng Certain Mlsuemeanors and P'roviding Penalties, and Repealing all lows in conRepealing all lows in Conaict Therewth and $\mathrm{Ce}$ -
iain Icts Therein spectled.

[H. 226, Approved March 8, 189:.] [Act 139i, p. 225.]

Section 1. LICESSE REQLIHFD: BC It enacted by the General Assembly of the state of Indlana. That is shall hereafter be unlawful for any person to practlce mediclne, surgery or obstetrics in thls siate without frat obtaining a license so to do, as herelnafter provided.

Sec. 2. EXASINATION; IPPIICATIUN: FEFS: CERTIFICATE: Mfser this law gres Into efrect any person desiring to begin the practlce of medicine, surgery or obstetrics in thls state shall procure from the state Hoard of Vedical Iteglstration and ExamHoard of Viedical lieglstration and ExamInation a certilcate that such person is enbery and obsterrics in the state of Indiana; and in order to prucure such certifleate the alplicant shall subnit to the state buard of Nedleal Regastration ard Fixaminatlon hls diplona, with an anluarit setting forth the the and number of terms, duratlon of each term, applicaut was reçuired to be in atiend. ance at aaid schonl in order to complete sald course of study, and that the anlint is the course of study, and that the aningt lis the verson to whom buch diploma was lssued. such appllcatlon shall be accompantion toy the same county ln whilch the applicant resldes. stating that the upplteant is the person named in the accompanylug dipluma and apullcation fur a certificate. Nll diplow mas recelved by the trard shall be returned to the person ow ming satne, and for fature to return any dijlema bo its lawful owner withm a reasinalole time tro speretary if withm a reawnable time tro sucretary if damages in tlie sum of twenty-tfre dollars (825)? Such ajplleant shall pay to sabl boarl the sum of ten dullars isiol at the tline of maklng such applicatiun. N11 persolls who nere practicing medicfie, surgers and obstesricy In the srate of Indiatia in

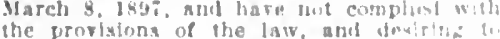
continue the same, shall. on or before July entitled to do w by presenting th the siate Hoard of Medical legintration and kixmiantion the llcetso possessed by them at the time of the passage uf thly lis liatlier with an andarit that they are tho tanal Imasevsors of the same. and the two his inen. thoned thereln, and surlt afoluent thalf bias the tlme of making ruch application. The buard shall thereupon Isute to such appllcant a certificate, whlch when presented in (untitle the holder to a llcense to practice medicine, surgery and obstetries in the state of Indiana. In the event of an applicant for 3 cerbitrate from the State lsosed of Medical liegistratuol and Exatination shall present a dolomal forn a medical college whlch la nol recognized as maintaluing a suffeiently likh graife or standarel of medical mlucasion as defined and fixed in the records of the buard. the alplleant shall have the prlollege of being examined as to his cuallilcatlons to practice medicine, surgery and obstetrics in fuch manner as the board shall proviste, and if he shall pass an examination satisfactory to the bnard he shall recelre a certiflcate the same ga if he had presented a satlisactory diploma and other evidences and qualio. cations for the praclice of medicine. But if he should fail to pass such examination he shall be permitted to submit to another examination whin twelre montha from the tlme of the first examinallon. He shall pay to the slate Board of Medical Reglstration and Examinallon the sum of twenty-tire dollars $(\$ 25)$; provided. howerer, that payment of sald sum of twenty-flre dollars $(\$ 25)$ of sald sum of twenty-fre dollars (\$25) of failure at the first or any subsequent of failure at the first or any subseruent
eximlnation. And provided furtier, that If such applicant shall fail to pass the examination preserithed by such IBoard of Medical Registration and Fixamination he shall have the right to an appeal to the circuit or supreme court of the proper county reupiring such board to show cisuse why such applicant should not in leriaitterl to practice medicine. suryery or olstetrica lis tha state of Indlana, on the anplicant giring a state of Indiana. on the afplicant giting a by the cnurt. Ho secure all costs of suit by the cnurt. to secure all costs of suit IIIm. On the receift of the certifleate tis the applicant from the State lsoarl of lled ical lieglstration and Fixamination the appl cant shall. on the presenta:ion therpof to the clerk of the countw in which be resldes. recelve from the county clerk a licenna to practice medfelie, surpory and ohstetrfe

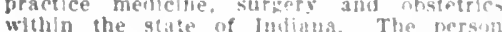
withn the state of Imithus The frersuth county clerk tifty $(-i$,$) cents is his fece$ for fsillug and recurding visch fleenve ss

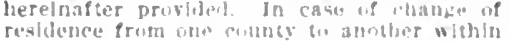
thly state the hibler of is physlctall's license shall oblaln a new lowno in the county where lie frofused to reable by fling with

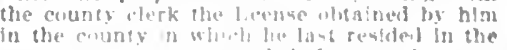

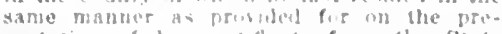
sentabiens of his cerliflcate from tlies state

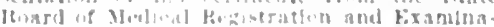
ifon. and tlies clerk shall wath htm a new

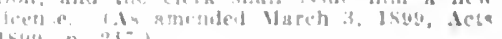

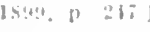

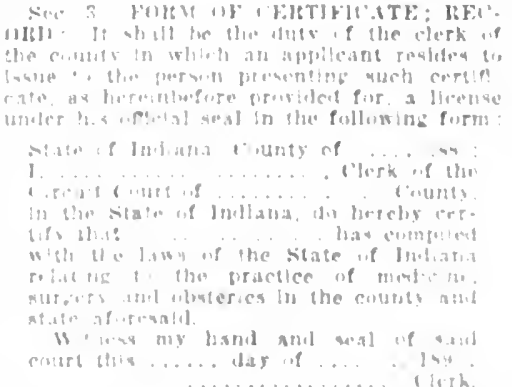

The county clerk whall enter on reconil the name, aze, flace of hirtla, address, wchisil yystens of medicint to which sald abtlitunt sulucribe (i) anil verlfy l,y osib befre sul clerk all adularlt concerning such iacts.

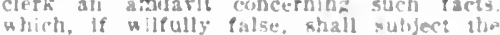

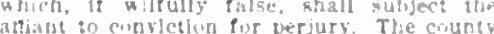
clerk shall (urnish annually, on the lsi day of January. to the state joard of Mledica Rectstration and Essminatlon, on bisuks furnisteel by said burarl, a duplloate list of all certiticates recelred and licenses fsoued by him during the preceding year. and what Include thereln the daie of isve of sain the verson recelv]ng the same.

Sec. 4. AINOJTMENT OF BOALU withln thirty days after this law grees ist: effect it shill be the duty of the gorerurit of the slate of Indlana (") appoint a siate Foard of Medical Kezlsiration and Examina. tion. composed of fire (5) member, who rears, one for three years and fite for four years, and thelr successors for a term rif tour years each. No school ot syatem of medl. cloc shall hare a majorltr reprecenta:lon ol such hoard. sald bnarl aball be nunpartisan, and not more than three shall be nembers of any one pollifeal party. The gorcrnor shall select members of sald Board fron reputable phyalclans in this state who are craduates of any colleze of medlcine of rond repute; prorided, that a professis of ceacher in a medical college shall te apvolnted as a memlier of such board: nro. rided further that each of the four schols or systems of medlelne hartng the lariset numerical reprenentation in the state whall hare at least whe representaine on said bord should a racancy cocus in wald bo art by death, resigmation, remoral, or otherwise. all the racancy frum she ochml or system entisled to regresentation by rirsue of such sacancy. The Envernor shald bate ponter t.

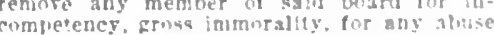
of hls offelal puwer. or ins other fuml caust. and may till ary racoucy shus werationed lis appointment. Any jersin apininted in all any racancy on surb bord. Whether ices therwlse, shall hold sol the uncroltent irrm of the nember whose blace he fo abrintom to fllt.

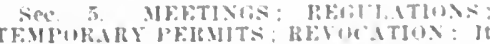

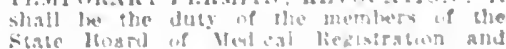
Fixmination to mede in line cliy of Indian. apolls in thirts days weer ther arpmintrant and oranalen by the elert we of a bestedent.

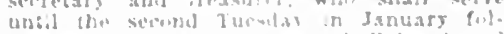
liwing. and ther wheren ro -hald be ciecimi oil the sec 111 Tupata: 'n Jabuary annus

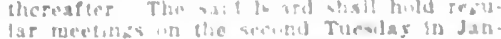

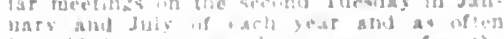

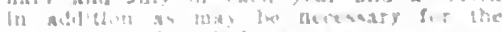

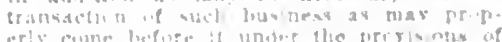

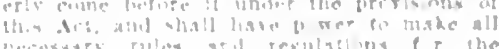
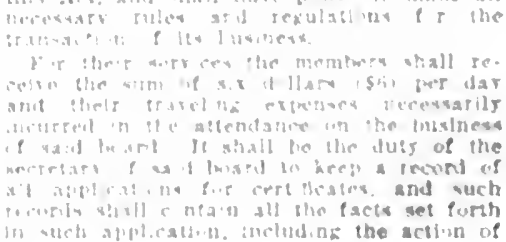
ward thereon, and shall execute all of said board, and the secretary shal ired and flfty dollars $(\$ 250)$ Jer annum, to be paid from the funds of said board, and said board may employ a clerk and fix lis salary at not more than five hundred dol lars $(\$ 500)$ per annum.

It shall be the duty of the treasurer of sald board to pay quarterly all moneys recelved by the board to the treasurer of state. which moneys shall be credited to a separate and vermanent fund for medical reglstration and examination, which is hereby created. All moneys so pajd to the treasurer of state shall remain and be a separate and permanent fund for the mantenunce ination. The sald board sliall, by its president nnd secretary, from time to time, cerdent und secretary, from time to time, cerexpenses incurred by the said board, including salaries and per dlem of the members, and the auditor shall issue his warrant for the same. which shall be paid out of the fund so established for the maintenance of the sald board; provlded, that no order shall be drawn by any state officlal on any other fund than the above named fund for any salarles of the board incident to the administration of this Act.

The treasurer and secretary of said board shall each give bond in the sum of five thoussand dollars $(\$ 5,000)$, with sureties to be approved by the governor, which bonds shall be flled with the auditor of state. The mem-
bers of the State Board of Nedlcal Registrabers of the State Board of Nedlcal Registration and Examlnation are authorized to administer oaths in matters relating to the discharge of their official duties. The State tion is charged with the duty of enforeing this Act, and It shall be the duty of the prosecuting attorney, on the complaint of the board, to prosecute any violation of this Act.

It shall also be the duty of the grand jury of the proper county to investigate all violations of this Act and return indictments therefor in proper cases, and it shall be the luty of the prosecuting attorney to prosecute violations of this Act by information whenever a proper affdavlt is filed by any one, as in other cases of violations of the Iaw; or to prosecute offenders before the justice of the peace in proper cases.

The State Board of Medical Registration and Examination shall, from time to time, establish and record in a record kept by them for that purpose a schedule of the ininlmum requirements whlcb must be complled with by applicants for examination for license to practice medicine, surgery and receire such license. The said board shall also, in like manner, establish and cause to be recorded in such record a schedule of the mininum requirements and rules for the recognition of medical colleges, so as to keep recognition of medical colleges, so as to keep
these requirements up to the average standard of medical education in other states. ard of medical education in other states. in such schedules of requirements in any year after the month of January of such year, nor shall any change be made to affect students theretof effect, or that shall record shall be at all times open to examination by the public, and the said schedules of requirements, after they hare been established aud recorded, and all changes made therein, shall be printed in clrcular form and mailed to all medical colleges in the state, and shall also be furnished to any person on application. Said board shall not, in the establishment of the aforesaid schedule of requirements, discriminate for or against any school or system of medicine, nor shall it prescribe what system or systems or of the colleges, universities or other educational institutions of the state.

It shall have power to make and establish ili necessary rulcs and regulations for the ciprocal recognition of certificates issued cother states, and to prevent unjust and arbitrary exclusions by other states of have fulfilted its requirements. When an application for a certificate is made and a shall be the duty of the State Board of Itedical liegtstration and Fxamination to determine, on the evidence presented, whether siploma rightfully belongs to and was cortiticate person making application for that issed medical coltaudard of medical education conformin to that flxed by the State Board of Medica Registration and Fxamination, and whether the application otherwise conplies witl the rules of the boara.

If these facts are sliown by competent evldence it shall be the duty of the state Board ssue al and secretacy, and under its offlclal seal, stating that the person applylng for such certiflcate and possessing such diploma is entitled to and possessing such diploina is entitled to a license to practice medicine, ana; provided, said application shall be fled prior to January 1, 1905; and provided, further, sald applicant shall have, prior to January 1, 1901, matriculated in a reputable medicai college in Indlana, maintaining a standard of medical education conforming to that fixed by sald board, and shall liave graduated from sald college and recelved his Except as last above provided, no certiflcate shall be issued to any person whomsoever shall be issued to any person whomsoever
until he shall have satisfled the sald board that he has graduated at a reputable medical college as in this section set forth, maintaining a standard of medical education as above prescribed, and shall have passed before sald board a satisfactory examination as to his qualifications to practlce medicine, surgery and obstetrics. Such examination and on the same terms and conditions as are provlded in Section an of sald act, approved March 8,1897 , but the applicant shall proved March 8,1897 , but the applicant shall the time he fles hls application, the member of the board who shall conduct his first examination in materia medica, therapeutics, theory and practice of

The hoard at its discretion may authorize the secretary to issue a temporary permit to an applleant for the interim from date of application until the next regular meeting of application until the next regular meeting of
the board. The State Board of Medical Registration and Examination shall have the right to review the evidence on which a license has been obtained, and lif it shall be found that a license has been obtalned by Praud or misrepresentation the board may revoke such license. The board [may] refuse to grant a certifleate to any person addicted to the use of liquor or drug hablt to such a degree as to render him unflt to practice mediclne or surgery.

If any person holding a license under the provisions of this Act shall be guilty of any of the above enumerated acts or shall have procured a certiflcate or license by fraud or misrepresentation, said bnard may, after notice and hearing, revoke any license which has heretofore been or may hereafter be on which such license has been or may be issucd.

A speciflc written charge, verified by afflavit, must be presented to the board, making definite and speciflc charges of such board shall thereupon fix a time and place for the hearing of such charges, at which the person charged may appear and defend against the same. A copy of such charges, together with a notice of the time and place fixed for the hearing, shall be served on the before the time set for the hearing of the same. If, after such hearing, the board
rerokes such certificate and license, such rerder shall be by said board entered on its order shall be by said board entered on its
record. A copy of such order of revocation, certified by the secretary of such board. shall be by it at once delivered to the clerk of the circuit court of the county in which
such license was issued, and such clerk shall such license was issued, and such clerk shall record the same on the margin of the record of such license. If the board shall refuse above stated it shall enter such refusal on its record, together with a statement of the grounds for such refusal. An apjeal nay be taken from the action of the board to the circuit or superior court of the county til which such license was issued In case of revocation, and to the county where the apvlleant lives in case of refusal of a certiflcate, on the licensee or applicant fling with the clerk of such court, within thirty days from the entering of such order of revoca ion or refusal by said loard, a rood ani sullicient bond in the sum of two hundred dollars $(\$ 200)$, to be approved by said clerk. to secure the payment of costs of such aparainst him the appeal be determined of the clerk to notify the said board of the flling of such bond, and said board shall thereupon forward to said clerk the charges, together with a copy of the order of revocation, where there has been a revocation, or the application for a certlficate and a copy of the order of refusal where there has been a refusal to grant a certificate. The clerk of said court shall thereupon docket th same as a cause pending in sald court. Salk verifled charges shall be treated as a complaint. The accused may plead to sald charges and issues may be formed thereoll as in any ciril case, and the same shall cuit court. It shall be the duty of the prosecuting attorney of the clrcult court to which sald county belongs to appear in auch which sald county belongs to appear in such
case aud represent the board. The only case and represent the board. The onls
finding and judgment in such cases shall be "Guilty" or "Not gullty," the same to be rendered separately as to each of the charges. If the finding and judgment of the
court be "Not guilty" as to each of sald charges, the same shall be by the clerk of sald court certified to sald board, and it shall thereupon make an order setting aslde its older of revocation, and forward to the clerk of said court a certified copy thereof which shall be entered on the margin of "Guilty" of any of said charges be awarded "Guilty" of any of said charges be awarded in said case, the costs of such proceedings of ten dollars $(\$ 10)$ shall be taxed therein in favor of the prosecuting attorney, and the order of revocation made by said board shall be and remain in effect. During the pendency of such appeal the accused shall not be Where the appeal is $\mathrm{from}$ a refusal to grant a certificate the same shall be beard on the a certificate the same shall be beard on the
application and certlfied copy of the order of refusal without certified copy of the order of refusal without any other issues; the same to be tried by the judge of said court, who
shall, on his finding, enter a judgment that shall, on his finding, enter a judgment that the facts may require, and on auch order the clerk of such court shall issue the proper license showing thereln the authority by which it is issued, and shall report the same ney shall represent the board in such appeal, and if the court shall refuse the license judgment shall be entered against the appllcant for costs, including ten dollars (\$10) fee for the prosecuting attorney. Appeals from the judgment of said court may be
prosecuted to the supreme court as in other civil cases, elther by said board in its own name or by the applicant or holder of such license or certificate, where the judgment may be against him. No fees other than against sald board in any event. Where the applicant shall appeal from a refusal to grant a certificate the cause shall be dockgrant a certificate the cause shall be dock-
eted in the name of the applicant against the eted in the name of the applicant against the amination. Where the license or certificate shall have been revoked the cause shall be entitled The State Board of Medical Registration and Examination against A. B. (the 11, 1901.)

Sec. 6. MIDWIFERY: All persons practicing midwifery in this state, and who have practiced it for ten years last preceding March 8, 1897, and desiring to continue the same shall on or before July 11, 1899, make application to the State Board of Medical Registration and Examination by submitting an affidavit, fully attested, giving the name, age, residence, the length of time during which, and the place or places at which the 
applleats has been engaged in sich prartice. and tho special education if ary is hich the anpllcant has recelred for sucl. prictice. applcant has recelred for such menctice. the amdarit of two freetoliters, duty nt tested. that the applicant is kuown tis them as the persun applying for a certifleate to practice nuldwifery, and that such alplicant has heen engaged in the artive prictiec of of such liractice ero the lust tern (10) years prevlous to the pastage of thits $A$ c. we such application and the bayment of one dollar (\$1) the State Hoard of Medical Hegistra. (\$1) the State Hoarid of Medical Heghtra: plleant a certincate which sliall, whet nrepllcant a certincate which sliall. Whet nreso a license to practlce midwlfery in this state. All persons desiring to enter in the practlce of midwifery in this state after this law goes into effeet shall present is the State Board of Medical Reglstration and Examination their diplomas, duly aftested, and procured from an obstetrical school of such standing as shall be recognlzed and determiled by the board. Such applicant shall pay :o sald board the sum of fire dollars
(\$5) at the tlme of maklog such alipliea(\$on: at the tlme of maklpg such alplieaexamination in midwifery as the board may require and pas a fee of ten dollars $(\$ 10)$. Such evidence of qualiscation being satis factory to the board it shall Issue a certift. cate eutltiling the holder to a llcense from the elerk of the county in which the aDpllcani resides, which llcense shall enitile the holder to practlce midwifery in this state. The llcesse thus isued shall conform to ali requirements of reglstration imposel nn phy requlrements of reglstration Imposed $\mathrm{nn}$ phy-
slclans' IIcenses in Sectlon 2 of thls Act and shall be subject to revocation for the same shall be subject to revocation for the same
cause as prorlded In Section 5 in case of IIcense to physicians. (As amended March 3. 1899. Acts 1599, D. 252.)

SeC. : EXEMPTIONS: RECIPROCITY PRACTICE UNDEIR PRECEITOK: VIOLA Tloss: Nothing In this $A$ ct shall be (so) consirued as to dlacrlmlnate agalnst ans school or system of mediclne, or to prohiblt grafultous services In cases of emerrency, or to the adminlatration of famlly remedles. This Act shall not apply to any commissloned offcer of the luited States Army. vavy or Publlc llealth Service In the discharge of hls oflal duties; not to any charge of hls offclal dutles: not to any to practlce in the state or territory in whlch to practlce in the state or territory in whlch
he rosides, when In actual consultation with a legal practitloner of this state: nor to any physlclan or surgeon reslding on the forder of a nelghtoring state and duly authorized to practlee under the laws thereof, whose practlee extends into the limits of this atate: provided that such practitener shall not open an office or appisint a place to meet patients or recelve calls within the limits of to prerent medical students from practiclng medlelne and gurgery under the immedlate abul direct supervisions of a licensed physiclan for a limiterl perixd of two yeary: provlded, however, that the sald student had not pracliced medicine, writery or ohstetrlcs prlor to the passage of this .les; in the evell of the anount of the sald student thas prac tlced medicine, surgers o, ribstetrics shail to deducted frim satil turn senrs herein then. thoned: and in no crent stall the kaid stis.

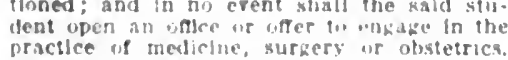
Any person rlolatung any of the firorialung of thls seetion shall be deernest zulley of it mis themeanne, anil wh ennvictlong shire of ahall subject the offenter ton ane of mol lewy than twenty. Are dollars (\&Es) nor thork than tw 3, 1899. Act 1599, 8. 253.)

Sec. 8. DEFINITION: To open an inte for such purpose or to antwinge to the sub lic in any way a readituess on bratere medleine In any county of the mate is to pre-

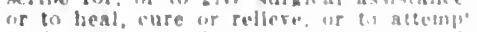
lieal, cure or rellere thoue sutfertho fru lajury or deformltw. of dllacase of mint

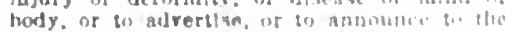
public in asy manner a readiness or nbillsy to heal, cure or relleve those whu inng the nufierlng from infury or deformity or dle

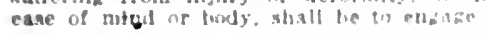

the firtatice of mediclne withln the trimants: of this int: provided. that nothtne in this Ict shali lie construed to apply to or limis in any runtuer the manufacture or sale rif bir brictary neeticines. It shall also te re. karteol ts practseing medicine wlthin the

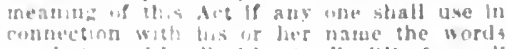

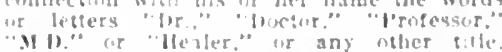
word, lettor or designation intending in imple of dentatiale hitn or her as a prace? loranches: Drurided, that this. Ict shall not loe conatrued in aliply to mon-ltineramt op. ticians wiul are ai this time cngaked in, or who nay hereafter engage in the practice of mptometry in thls state nor to profes-
sional or other nurses. In charg!ng any person in an addarlt. Intornation or in dictruent with a riolation of shis law by whout license it shall be sumelent to charge that he did, on a certaln day and in a certaln county. engage in the pracuce of

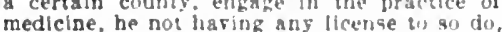
medicine, he not having any license th so do, ular facts concerning the same. (As amended March 11, 1901 .

Sec. 9. PEXALTY: Any person who shall practlce mediclne, surzery or obstetrics In this state without having a license duly deemed pully of a misdemeanor, and on conviction therens slial! the thed not less than twenty-fle dnllars (\$25) not more thas two hundred dollars $(\$ 200)$.

Sec. 10. REPEAL: All laws and parts of laws in conflct with this Act are hereby repealed, and also an act entitled "An Act gery and Obstetrics, prorlding for the issuing of license to practlce, defining certain ing of license to practice, defning certain misdemeanors and proriding penaltes," apthereto be and the same are hereby repealed. Approred March 8, 1897 .

Additlonal Sec. 3. ANNLAL REPORTS : Three thousand $(3,000)$ coples of the annual report of the board to the gorernor shall be printed In the same manner as the report the State Board of Health: and the printing and statlonery of the board shall the pald out of the printing fund (Add
and amended Narch $1 \mathrm{I}, \mathrm{g} 901$.)

didditonal sec. 4. LIMITED CERTHFCATES: The sald board may grant limited certfficates which shall authorize the proper clerk to lssue to the bolder therent a license to practice osteopathy only. Such certificate shall be issued on the same terms and cont shait be issued on the same terms amd cont ditons as others, except that the applicant therefor shall not be required to pass an examination In materla medica. nur shall the required to conform to the standarif fixed by sald board as to Instructlonx In materia medlca, but such college shall so confurm in all other branches of lastruetfon. Such lip to adminlster or preserite of use un nowe

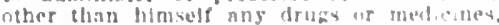
and any such adninfseration, prescription no and ans such adminlstration, preserimtion no

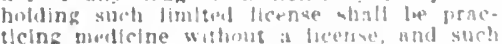

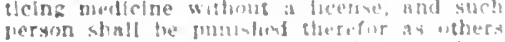

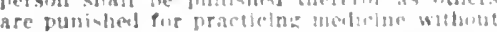

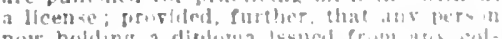

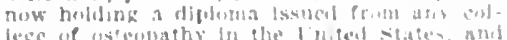

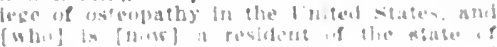

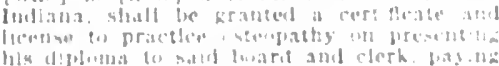

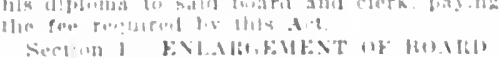

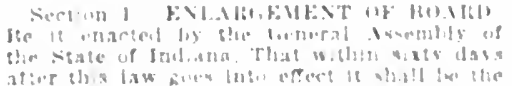

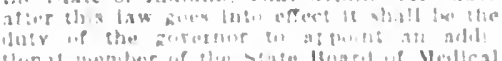

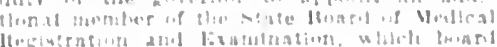

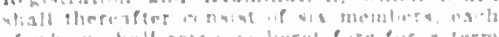

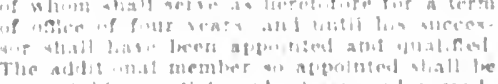

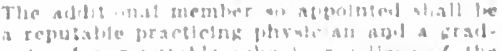

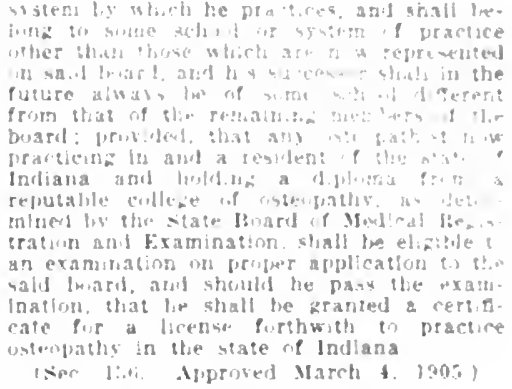

STATE BOARD OF HEALTH

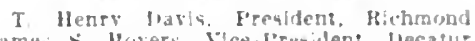
James s. lloyers, vice-l'swilent beeatur

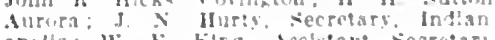
apolls: w k king. Ieslutant sectetses Indiananolls.

STATE BOARD OF MEOICAL REGISTRA. TION AND EXAMINATION

W. A. Spurkeon, President, Muncle; James 16. Dinnen, rt Wiyne: $s$. F. Smelser, Rlchmond: 31 . 'anfeld, Frankfort: John $y$ spaunhurst, D.U. Indianapolts; W. T. Gott Secretary, irawfordarlle.

INDIANA STATE MEDICAL ASSOCIATION Oncers 1913-14

Ianes I. Salb, Presldent........... Jasper $\because$ b. Stone, Ist Vice-f'resident...... Shoales r. H. I.inthlcun, of $r$ - President...ransille Clas. Wotkh, id Vice-I'resldent...Farmand

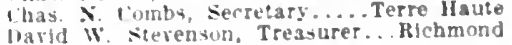

\section{State Journal}

Journal of Indlana State Medical Associaifun, it. Was

\section{Councilor Districts and Dffers}

Chalrman, W. R. Oarldsun, Fransrllle Secretary, Chas $\mathbf{x}$. Combs, Terre Haute.

First District. - Vanderburg, Warrick, Spencer, rike, litbson, loses and rerry countles.

second plstrle: knox. sultiran, Grene. owen Monroe. Hariess atid Martin counbles. Thirt batrlet - rawford. Dubols, law

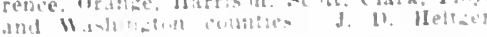

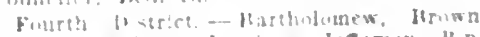
Lecatur Jacksom, Jemninga, Jesersum, Hap

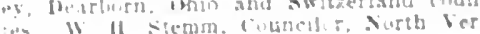

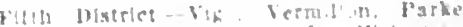

lat and J'uenam tuntes Jas Welasteil

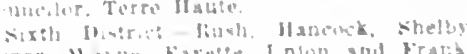
flenry. Whye, Fayelet. T alm and
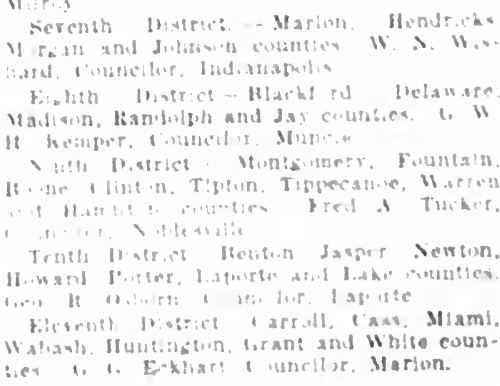
Twelfth Dlstrlet-Adams, Allen, Whltley, be Katb, Noble, Steuben, Lagrange and Wells countles. E. Morgan, Councllor, Ft. wayue.

Thirteenth Distrlet.-St. Joseph, Flkilurt, starke, yarshall, Koselusko, l’ulaski and Fulton counties. A. C. MeIonali, Councllor, Warsaw.

Component Societies of the Indiana State Medical Association AOIMS COUNTY

II. F. Parrish, l'resldent...........Monroe

s. I. Ilotrmann, secretiry......... becatur ALLEN COLNTY

(has. IR. Dancer. I'resldent......Ft. Wayne G Yan sweringen, secretary......t. Wavne BARTHOLOMEW COUNTY

II. I1. Kianman, I'resident....... Columbus

E. U. Wood, secretary........... Columbus BWNTON COUNTY

Ward A. Smlth, l'resident........ otterbcin II. G. liloom, Secrotary.............oxfor BLACKFORD COUNTY

George II. Dando, President....... Montpelier Chas, d. Sellers, Secretary....IIartford City BOONE COUNTY

Clancy Bassett, President........Thorntown Max A. Arinstrong, Secretary.......Lebauon CARROLL COUNTY

C. C. Crampton, Iresident.......... Delphi

W. R. Quick, Secretary............ Delphl CASS COUNTY

Nelson w. Cady, President.......Logausport

G. I. Miller, Secretary .......... Logansport CLARK COUNTY

C. C. Crum, President.........Jeffersonville

I. N. Ruddell, Secretary........Jeffersonville CLAY COUNTY

II. II. Young, President............Brazil

F. C. Dlley, Secretary............................ CLINTON COUNTY

M. T. McCarty, President.........Frankfort

A. G. Chittick, Secretary........... Frankfort CRAWFORD COUNTY

F. R. Gobbel, Presldent........... English

G. B. Hammond, Secretary.......... English DAVIESS COUNTY

o. K. Mckittrick, President.......Plaluville

H. C. Wadsworth, Secretary..... Washington DEARBORN゙-OHIO COUNTY

o. S. Taquith, President....... Lawrenceburg

Edward R. Wallace, Secretary.......Aurora DECATUR COUNTY

C. F. Kercheral, President...... Greensburg

It. II. Thomas, Secretary.........Greensburg DEKALB COUNTY

J. W. Thomson, President..........Garrett

Wm. F. Schumaker, Secretary.............. Butler DELAWARE COUNTY

Dwight M. Green, Presldent..........Muncle

H. D. Falr, Secretary................ Muncie DU BOIS COUNTY

Louls Iukemeser, President.....Huntlngburg

Eugene A. Sturm, Secretary..........Jasper ELIKART COUNTY

E. E. Ash, President.............. Goshen

Janes A. Work, Jr., Secretary.........klkhart FAYETTE COUNTY

J. H. Clark, President......... Connersville
o. P. M. Ford, Secretary...... Connersville FLOYD COUNTY

II. B. Shacklett, President...... New Albany

W. J. Leach, Secretary......... New Albany FOUNTAIN-WARREN COUNTY

F. H. I'lgh, President........ Williamsport

A. M. Sullivan, Secretary.............. Attica FRANKLIN COUNTY

I. i. IIull, President........... Oldenburg

E. II. Glaser, Secretary.............. Brookville FULTON COUNTY

Taylor, President......Rochester Seeretary...........Rochester GIBSON COUNTY GHBON COUNTY

Wm. G. Hopkins, President......Ft. Branch A. L. Ziliak, secretary........... Princeton
GIRANT COUNTY

(i. 1). Jimniall, Presldent...........Marlon F. Johnson, Seeretary.............Marion GREENE COUNTY

13. F. C'lambers, I'resident............ Lyons t. 1i. Mason, secretary...........Bloomfleld IIAMILTON COUNTY

1. A. IBond, l'restdent...........Westfleld Cieo. Ilaworth, secretary............. Nobiesville IIANCOCK COUNTY

Stewart Slo('um], I'resident.......Fortvillo (arl W. Mefaugliey, secretary.....Greenfled ILARILISON COUNTY

Frank F. Wolfe, I'resident......... Corydon Wllliam E. Amy, Secretary......... Corydon IIFNDIHICKS COUNTY

Wim. II. Terrell, President........PIttsboro

Wilson T. Lawson, Secretary........ Danville IIENRY COUNTY

H. W. Macjonald, President.... New Castle

W. C. Van Nuys, Secretary...... New Castle HOWARD COUNTY

I. M. Knepple, President...........Kokomo chas. J. Alams, Secretary............Kokomo HUNTINGTON COUNTY

R. Q. 'Taviner, Presldent........Huntington F. B. Morgan, Secretary.........Huntington JACKSON COUNTY

J. M. Shields, President........... Seymou L. B. Hill, Secretary................. Seymour JASPER COUNTY

Edward C. English, President.... Rensselaer II. D. Gwin, Secretary..........Rensselae JAY COUNTY

J. E. Nlxon, President...........Portland Geo. V. Cring, Secretary...................... JEFFERSON COUNTY

II arry S. IIatch, President...........Madison Fred C. Denny, Secretary.................... JENNINGS COUNTY

W. H. Stemm, President....... North Vernon John H. Green, Secretary...... North Vernon JOHNSON COUNTY

L. L. Whltesides, President........ Franklin R. W. Terhune, Secretary.........Whlteland KNOX COUNTY

Chas. W. Benha!n, President......VIncennes

Hubert D. Mccermlck, Secretary..Vincennes KOSCIUSKO COUNTY

C. F. Thomas, President..........Leesburg

F. J. Young, Secretary................llford LA GRANGE COUNTY

William H. Short, President....... La Grange

A. A. Wade, Secretary............. Howe I.AKE COUNTY

J. W. Jddings, President............. Lowell

E. M. Shanklin, Secretary........Hammond I.APORTE COUNTY

D. A. Buck, Presldent............ Laporte

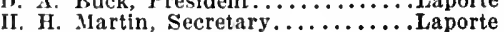
IAWRENCE COUNTY

J. C. Kelley, President................

F. S. Hunter, Secretary................... MADISON COUNTY

S. C. Newlin, President...........Anderson

Etta Charles, Secretary.............. Alexandrla MARION COUNTY

C. E. Ferguson, President...... Indlanapolls

Arthur E. Guedel, Secretary... Indianapolis MARSHALI, COUNTY

L. D. Eley, President.......... Plymouth MARTIN COUNTY

H. W. Shlrley, President........... Shoals

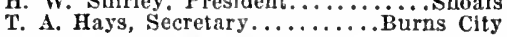
MAMI COUNTY

II. E. Line, Fresident.............. Chill
I. A. McDowell, Secretary . . . . . . Peru MONROE COUNTY

J. E. Inzadder, Presldent.......Bloomington C. C. Stroup, Secretary......... Bloomington MONTGOIIERY COUNTY

J. L. Beatty, President...... Crawfordsville F. A. Dennis, Secretary....... Crawfordsville
MORGAN COUNTY

II. II. Dutton, P'resident..........Paragon

II. C. Itobinson, Secretary........Martinsville NOBLE COUNTY

F. IV. Black, I'resident............Igonier

W. F. Carver, Secretary................lbion OIIIO COUNTY

(Included in Dearborn-Ohio Counties.) ORANGE COUNTY

R. E. Baker, Presldent............... orleans

II. L. Mller, Secretary............... West Baden OWEN COUNTY

G. I. Mitcheli, 'resident............Quincy

Allen Plerson, Secretary................ Quinencer PARKE-VEITMILION COUNTY

II. E. Washburn, I'resident......... Clinton PEIRY COUN'TY

Earl R. Snyder, President............Troy Wm. H. Nuelchl, Secretary........ Tell (Sty PIKE COUNTY

S. It. Clark, President..........Petersburg

E. S. Imel, Secretary............Petersburg PORTER COUNTY

i. R. Douglas, Presldent....... Valparalso D. J. Loring, secretary......... Valparaiso POSEY COUNTY

Chas. Arburn, Presldent.........Wadesvllle Edwin Rinear, Secretary.............. Vernon PULASKI COUNTY

Wm. Kelsey, President...........Monterey C. E. Linton, Secretary..............Medaryol. lo PUTNAM COUNTY

W. M. Mrchaughey, Presldent.... Greencastle F. Ilawkins, Secretary..........Greencastle RANDOLPH COUNTY

J. H. Moroney, President........Wlnchester C. L. Botkln, Secretary ............Farmland RIPI,EY COUNTY

Bine Whitlatch, Presldent........... Milan H. G. Nelson, Secretary............................ RUSH COUNTY

W. S. Coleman, President.........Rushville L. M. Green, Secretary ............ Rushvillo SCOTT COUNTY

o. C. Murphy, Presldent.........Scottsburg SHELBY COUNTY

James E. Keeling, Presldent........Waldron

Mot is Drake, Secretary......... Shelbyville SPENCER COUNTY

Saml. P. Gwaltney, Presldent........Mldway

H. Q. White, Secretary........Grand . Vlew ST. JOSEPH COUNTY

A. C. Bartholomew, President.... South Bend W. H. Baker, Secretary.........South Bend STARKE COUNTY

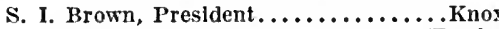

J. I. Denaut, Secretary..............Hamlet STEUBEN COUNTY

P. N. Sutherland, President.........Angola

o. H. Swantusch, Secretary................... SULLIVAN COUNTY

Robt. H. Vancleave, Presldent..Farmersbur James B. Maple, Secretary......... Shelburn SWITZERLAND COUNTY

John Paxton Ward, President........Vevay Robert Marquils Copeland, Secretary...Vevay TIPPECANOE COUNTY

R. M. Campbell, President.......... Lafayette Earl Van Reed, Secretary........... Lafayette TIPTON COUNTY

S. M. Cotton, President..........Goldsmith W. F. Dunham, Secretary............. Kempton UNION COUNTY

Garrett Plgman, President........... Liberty W. A. Thompson, Secretary............ Liberty VANDERBURG COUNTY

G. C. Johnson, President......... Evansville

C. A. Hartley, Secretary........... Evansville VERMILION COUNTY

(Included in Parke-Vermilion.) VIGO COUNTY

Chas. N. Combs, President..... Terre Haute o. 0. Alexander, Secretary..... Terre Haute 
WAISASI COUNTY

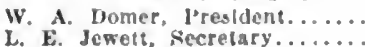

Wallash WAIREX COUNT

(Included In Fountaln-Warren Counties) WARRICK COUNTY

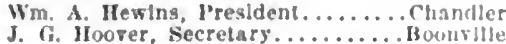
WASHINTOS COUNTY

Claude H. Paynter, Secretary. Campbellsburs WAYXE COUNT

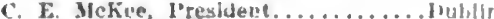

J. J. Whallon, secretary.........jilchmom WELLS COUNTY

I.ouls Sererin, President.......... Mlutition WHITE COUNTY

Guy R. Comn, Presldent.........Montlechlo Grant Goodwin, Secretary............ Monticello WHTLEY COUNTY

J. Wro. C. Scott, Iresldent..........Jecla X. I. Kitheart, secretary..... Columbla cliy

\section{COUNTY HEALTH COMMISSIONERS}

County Aldres.

Adams. $\rightarrow$. M. Mtller............. Decatur

Allen.-E. M. Van Ruskirk............ Wayt. We

Bartholomew.-J. II. Morrison....Hartavll!

Benton.-D. F. Mavlty............... Fowler

Blackford.-Famuel Hollts.... Hartford City

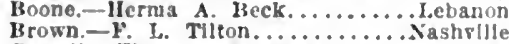

Carroll.-Thos. A. Kearns................ Flora

Cass.-John P. Nilcodemus............... Fansport

Clark.-W. Marshall Varble....jettersonvill

Clay.-Clinton $C$. Sourwine............. Brazll

Cinton.-C. A. Zinn.............. Frankfort

Crawford. $\rightarrow$ C. n. Luckett........... Engllsh

Dearborn - $T$. Fagaly........

lecatur. $-\mathbf{D}$. $\mathbf{W}$. Weaver............. Greensburg

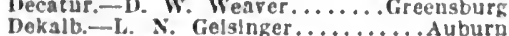

Dekaware. - Ifugh $\boldsymbol{d}$. Cowing............... Muncle

Delaware. - Hugh d. Cowlng.......... Mluncte

Folkhart - J. A. Snapp............. Foshen

Fayette - R. II. Filliott........ Connersville

Foyd.Chas. W. Mclutyre.... New Albany

Pountaln.-C. C. Wert............... Covington

Franklin.-John 1 . Iucas........ Brookvllle

Fulton. - M. 0 , king............... Hochester

Gluson.-Aivis L. Zlliak............ Princeton

Grant-Geo, G. Rlehardson...... Var Buren

Grant-Gene-Wm. B. Cravens...... an Buren

Ireention. W. D. Sturderant......... Noblesville

Hamilton.- J. D. Sturderant..... Noblesvllle

Harrison. -William laniel .......... Corydor

Hendricks. - Wrn. J. Hoadley........ Janrille

Henry.-D. S. Wilgelns........... Castle

Huntington-C. W. Fry............ Kuntiugom

Jackson.-D.J. Cuminings........ B i rownstorn

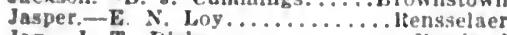

Jay.-J. T. Dlekes................ Tortand

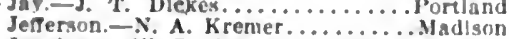

Jennlncs. - W. L. Krenter................ Kadlson

Jennlngs. - W. L. Grossman.... North Vernon

Johnson.-Oran Irovince ....... Franklin

Kosclusko.-16. I. Ilines............Warsaw

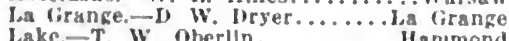

Lake. $-T$. W. Oberlln.......... Hammond

Laporte. - J. W. Snyder.......... Milibhan City

lawrence. $-F$. S. II Iunter...............

Madlson. - T. J. Siephenson.............apel

Marton.-Harry s. Mackey....... Indianapolls

Marstiall. - L. 1. Eley..............1ymouth

Martin:-charjes Fo stono.............. shoals

Mlami.-Johin F. Yarllng............... Ieru

Monroe-Flutcher fiardner .... ilimomington

Mostgomery - H. W slamond. Cratufurderll. Morgan.-lieo. H. Hreedlove.....Martinstlle Newton.- L. M. limtrey............ kentland

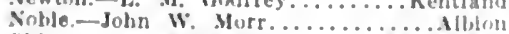
ohlo. $\rightarrow$. A. Stevensun...................

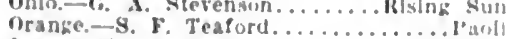

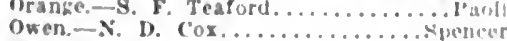

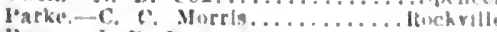

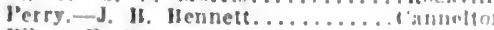

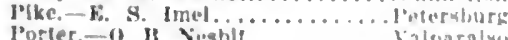
l'orter. - o. It. Niesblt.

Powey:-It. L. Hardwick Numb ingum

l'ulaskl. J. J. Thomas.

Wiramac

Jutnam. -J. M. Klug.......... firencarth

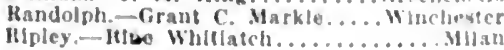

liush. Frank 11. Tireen.......... ltushvllle Scott_-J. I'. WIlson............. Scottsburg Shelby.-J. Wtllard Pirrish.......shellyville spencer-1). $v$. Mc.lary.............Dale

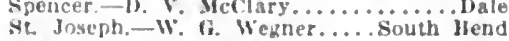
starke. W: C. Schwler.............Knox Steuben. - W. H. Lane............. Angola

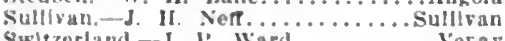
Swltzerland.-J. 1'. Ward............ Veray Tupecanoe.-16. M. Campbell....... lafayette Tulon.-W. $k$. Dunham........... kempton Inlon.-F. T. bubers..............lberty Yanderburg.-M. J. Compton.....Evansville Vernttlon. - Danlel s. Stronk........... Dana Wigo.-F. W. Shaley......... Terre Haute Wabash.-6. .1. La salle........... Wabash Wurrick-Walter Wrablngton.-Chas. W. Murbly.........Salon Wayne-J. E. KLug............ Richmond Weils.-A. W. Brown.............. Blution Whlte-Girant Goodwln ..........Montlcello
Whitley.-F. V. Nolt....... Columbla Clty

\section{HEALTH OFFICERS IN CITIES OF 10,000} POPULATION AND OVER

Anderson................... A. Long East Chlcago......................... Ilerskovitz

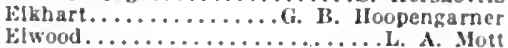

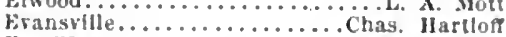

Fl. Wayne.................. A. Crull

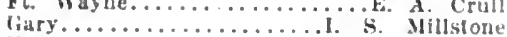
Ilammond.................... Millstone Indangton................. F. Frost

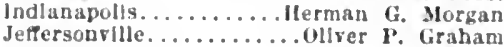
Kotomo.................... J. Martin Lafayette................ D. HIIIs Lapurte.................. W. Ross

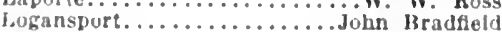

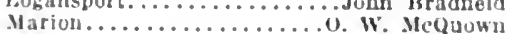
Michlgan ciry............. Whitefld Howers Mishawaka.................... Dreach Muncle................. Herman s. Bowles New Albany.................. B. Shacklet P'eru..................... Malsbury South Bend.................. B. Berteling Terre Haute.............. B. W. Morteling Vincennes.................... H. Caney

\section{Evansvilie}

\section{STATE INSTITUTIONS}

Southern Indiana llospital for Insane. Evansille, Ind. Establlshed 1883; 510 beds; C. E. laughlln, medical auperintendent.

\section{Ft. Wayne}

Indlana school for Feeble Minded Youths, Ft. Wayno, Ind, Established is.9. yublle; 1,300 beds; Geo. s. Hllss, M.l., superhitendent.

\section{Indian apolis}

rentral Indlana IInspltal for Insane, Indismapolls, Ind. ristablished 1848 1.tios buds: fieorge $F$. Fifendarter, physl clan in cliarge and supertukenture. lullana virls" school, Intlanajolls. Intl. Fistabllshed 1907; jublle; correcetlonal and educational: 290 bedis; kuno. shat sexslons, superlntendent.

Imblima sichoed for the Illind, Indlan. suolls, lant ristublished isti; publle.

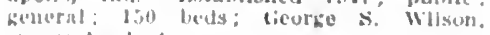
superintendent.

Indland state siboul for the lines.

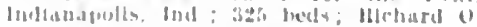
Jolnsern, bugerintendeut.

Indiana Woman's I'rison, Inellanaudle linl. listaflented lstig: bublle: reforth Martha J. Sulth. phystcian: timtly F. Horstles, superistendent

Jeftersonville

lestinan Itefermatury, Jeforsumbly.

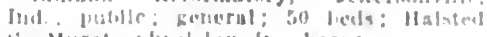
- Murat, misalidan in charge.

Knightstown

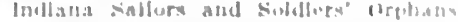

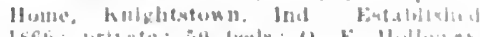

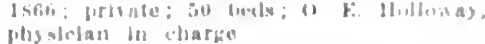

Lafayette

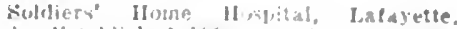
Ind. bistallislued $1650 \%$ : mulild ; 150 berls:

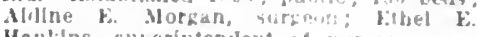
Hankins, suberintenilent of thirsoci

\section{Logansport}

Sorthern Inullara Hosplial fur lusinc.

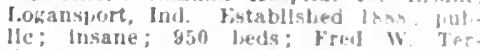
finger, medical sunerintendent.

\section{Madison}

sioutheastern Ifospltal for the Insinte. Madison, Ind Fistallshed 1510: 1.100 bedv: H. J'. Jusse, medlcal sibjerin. terudent.

\section{Mlchigan City}

Indiana llospltal for Insane Crininals. Mhohfzan r'Jty, Ind. Fstabllshed I909: publle; nerbous and mental; 155 beds: James $W$. Mllthan, medical superintendent.

Inclana Siate Irison Hospltal, Michlgan C'lty, Ind. Fistabllshed I8:9; publle: kereral; is berls; Itaul k. Bowers, phys?. clan in charge.

\section{Neweastle}

Indlana bllage for Filleptles, Ner. castle, Ind. Established 1905; 218 beds:

W. C. Van Nuys, medleal suberintendent.

\section{Piainfield}

Indiana Boys' School, Plainfleld, Ind. Fstabllshed 1869; publle; general; Krnest Cooper, physlclan In charge: Guy C. lianna, superlntendent.

\section{Richmond}

Eustern Indlana llospltal for Insane, Easthasen, Mchmond, Ind. Fotablished 1889; fublic; nerrous and mental: s.?0 beds; Saml. Fo. Smlth, medical superlntendent.

Rockville

Indlana state Tuberculosis Ilospital, llockrllte, Ind. Fstabllshed 1911; publle: tulserculusis: I00 beds: W. A. Gekler, medlcal superlntendent.

\section{HOSPITALS, SANATORIUMS ANO CHAR. ITABLE INSTITUTIONS}

\section{Alexandria}

Alexandrla Hospltal, Alezandrla, Ind. Fstabllshed 1.993; private: Eeneral; 20 beds; L. F. Schmauss, physlcian in charge.

\section{Andersen}

Madison County Inflrmary. Anderson. Ind. Established 1834; public; 60 bels: Benjamin II. Cook, phyglelan in charge lidward k. Thomas, superintendent. st. John's Ilospltal, Inderson. Ind Fstalllshed isq4; prlvate: tio heds: sis. ters of the lloly" ("ross lin chare"

\section{Anoola}

steuton Connty Infirmary infola. Ind. Fistablishod lsos: publdo: on loeds: Thos. J. Crevl, whisletan In tharge: John Inspaugh, superlntendent.

\section{Bedford}

Hivlford rify Hoypllat. Bedford. Ind Fostabllsled 1908: publle: in heds: Mllso Fornes; superintendent.

Beech Grove

it. Franele llouplal, lieach lirore, Ind.

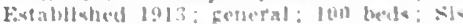
ters of sit rialuets in wharge

Bloomington

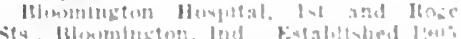

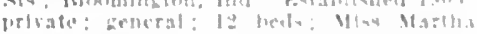
M Jameson. II $\mathrm{Y}$, suberintendent

Bowling Green

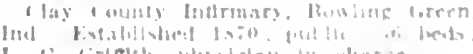

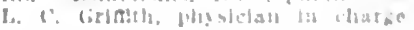

Brazul

tingline singlih llowplent, Itrazll, lud

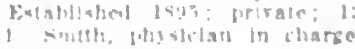

Centerville

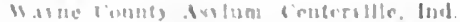

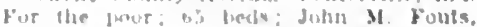

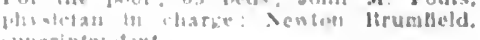
nuperintesictent 
Charlestowa

Clark County Ioor Asylum, Charlestown. Ind Established 1854; public: 30 heds; J. T. Carr, superintendent.

Columbus

Columbus Sanitarlum and Surglea llospital, Columbis, Ind. Establlshed 1900 ; private; 20 beds.

\section{Connersville}

Fayette Sanitarium, Connersville, Ind. Established 1903; pullic: general; 15 beds; G. L. Brown, superintendent.

Crawfordsvilie

I. I. Culver Unlon Iospltal, Crawfordsrllie, Ind. Established 1902 ; publie; 15 beds; Mabel R. Van Auker, R.N. superintendent.

Dr. Stackiouse Sanitarlum, Crawfordsrlle, Ind. Establlshed 1912; Frank Stack house, physiclan in charge.

\section{Danville}

Private Hospital, Danville, Ind. Es tablished 1912; 6 beds: Lewls W. Armstrong, physician in charge.

\section{Elkhart}

Elkhart General Hospital, Elkhart, Ind Establlshed 1913; public ; general 65 beds; Miss Agnes Moloney, superintendent.

\section{Evansville}

Boehue Farm, Eransville, Ind. Established 1910; public; tubereulosls; 75 beds; C. A. Hartley, superintendent.

City Isolation IIospital, Evansville, Ind. Fstablished 1907 ; public; smallpox: 79 bed

Crescent Sanitarlum, Evansvllie, Ind Established 1898; prlvate; 18 beds : $A$. if. Hayden and J. W. Phares, physlclans iil charge.

Dr. Hollinger's Sanitarium, Eransville, Ind Establlshed 1893; private; alcohol ind 25 beds; I. C. Hollinger and drugs; 25 beds;

Protestant Deaconess Home and Hospltal, 604 Mary St., Evansville, Ind. Established 1892 ; public and private general; 50 beds; E. Linthicum, chier of medical staft.

St. Mary's Hospltal, Eranswllle, Ind. Establlshed 18\%6; publle and private; 100 beds.

United States Marine Hospltal, Eransrille, Ind. Established 1892; public: general: 32 beds; I. E. Werry, physician in charge.

Walker's Sanitarium, Evansville, Ind Established 1894; private; general ; 30 beds; Edwin Walker and

born, surgeons in charge.

\section{Frankfort}

Falmer's Hospital, Frankfort, Ind. Established 1899 ; private; 18 beds; Robert Alice M. Brown, superintendent.

\section{Franklin}

Drs. Prorlnce's Private Hospital, Franklln, Ind. Establlshed 1912 ; pricate; surgical only ; Drs. C. and 0. A. Province, physlcians in charge.

\section{French Liek}

French Lick Springs, French I,ick, Ind. Established 1850; public; health resort; hotel; 600 beds.

\section{Ft. Wayne}

Allen County Infirmary, Ft. Wayne, Ind. Wm. Enslen, attending pliysician.

Allen County Orphans' Home, Ft. Wayne, Ind. Established 1895; 60

rayer, physician in charge. Hospital. Ft. Wayne, Ind. Established Hospital. Ft. Wayne, Ind. Established 1908: public; 12 beds; Drs. Van Buskirk

and F. A. Crull, physicians in charge. Ft. Wayne Lutheran Hospital, 3020 Fairfleld Are., Ft. Wayne, Ind. EstabH. Dued 1904; public; general; 100 beds superintendent

Ft. Wayne Orphans' Home, Ft. Wayne Ind. Fstabllshed 1884; 100 beds; Reformed Church of U. S. of A., in charge; P. Ruf, superintendent.
Ft. Wayne Itescue IIome and Mission, Ft. Wayne, Ind. Established 1902 ; pub11c; 30 bedis; G. I. Cooper, superintendent. Ilope llospital, Ft. Wayne, Ind. EstabUshed 1878: public, general; 75 beds: IIles $F$. I'orter, surgeon in chlef; MIss A. R. Forter, surseon in

st. loseph's liospital, Ft. Wayne, Ind Fstablislied 1869; public; 100 beds; The Poor Handmalds of Jesus Christ, in charge.

it. Rochus IIospital, Ft. Wayne, Ind. Established 1900; public; tuberculosis : 10 beds; The loor IIandmaids of Jesus Christ, in charge.

\section{Garrett}

Sacred lleart Ilospltal, Garrett, Ind. Established 1903; publlc; surgical and Gary

Gary General IIospital, 805 Van Buren St., Gary, Ind. ; Established 1911; public ; general; 34 beds; Mlss Margaret $\mathbf{E}$. l'rltchard, superintendent.

Indlana Steel Company Hospital, Gary, Ind. Establlshed 1910; private; 167 becls; Ira Mlitlmore and James Burry, chlcago, physiclans in charge.

Nercy Hospital, Gary, Ind. Fstablished 1908 ; public : general ; 150 beds MIss Dorothy Phelan, R.N., superintendent.

South Side St. Antonio Hospital, Gary Ind. Established 1911; private; general: 10 beds; Antonio Giorgi, medical superintendent.

Goshen

Ash IIospital, 110 W. Lincoln Are., Goshen, Ind. Established 1903; private; surgical: 5 beds; E. E. Ash, surgeon in charge

Becknell Hospital, Goshen, Ind. Established 1890: private: general; 7 beds : Irvin J. Becknell, physiclan in charge. Goshen City Irospital, Goshen,
Established 1913; public; 25 beds. Hollugsworth Hospital, Goshen, Ind. Private, 4 beds; A. S. Hollingsworth, physiclan in charge.

Kauffman Hospital, Goshen, Ind, Established 1900; private; 7 beds; Anna G. Kraege, superintendent.

\section{Greencastle}

Putnam County Infirmary, Greencastle, Ind.

\section{Greenwoed}

Craigs Inc. Sanatorium Ideal, Greenwood, Ind. Established 1913; private; mineral baths; 40 beds; J. A. Craig, physiclan in charge.

\section{Hammond}

St. Margaret's Hospital, Hammond, Ind. Established 1898; private; 200

\section{Huntington}

Huntington County Hospltal, Frederick and Charles Sts., Huntington, Ind. Established 1913; 15 beds; Miss Ethel Jackson, R.N., superintendent

\section{Indianapolis}

Alpha Home, 2002 Darwin Are., Indianapolis Establlshed 1893; public : I5 beds: Mrs. E Corington, superintendent. Dr. Clark Robbins' Sanitarium, 1229 Washington St. E., Indianapolis. (See Mooresville, Ind.).

Colored Orphans' Home, Indianapolis. Day Camp of the Woman's Improvement Club, Brightwood, Indianapolis. colored women; 7 beds; Mrs. Lillian Thomas Fox, president.

Faith Home, 1523 Southeastern Are.. Indianapolis. For repentant erring girss; liev. A. I. Kilburn, superintendent; Mrs. II. E. Kilburn, matron.

Florence Crittenton Hospital, $1260 \mathrm{Chi}$ cago St. Indianapolls. Established 1893. maternity cases; public; 20 beds; $\mathbf{H}$. F. Beckman, physician in charge; Miss Grace C. Reed, superintendent.

German General Protestant Orphan Home, Indianapolis. Established 1867 ; private; Samuel M. Roes, superintendent.

Hartwig Kalicy Assembly for Aged and Aflleted People, 252l Chestnut St., Indlunapolis. Fstablished 1899 ; reestablished 1008 ; private; 30 beds; Mrs. Ella Hartwly Kalley, superintendent.

Ilome for Aged and Friendless Women. $1731 \mathrm{~N}$. Capltol Ave. Indlanapolis. Established 1867; public; 40 beds; A. I. wilson, physician in charge.

Indiana Home Ilospltal, $1127 \mathrm{~N}$. IHinols St., Indlanapolts. Estab! Ished 1905; private; general; $\boldsymbol{i}$ beds ; Arthur G. Doty, medilcal superintendent.

Indianapolis City Irospltal, 1000 Coe St., Indianapolls. Established 1850; puhlic; general; 500 beds; John WV. Sluss, physlclan in charge.

Indianapolls Free Tuberculosis Colony, Indianapolis. Fstablished 1908; public : 17 beds; Aifred Henry, physiclan in harge.

Indianapolis Maternity Home, 152I Southeastern Ave., Indlanapolls. Established 1909; private; 10 beds; Mrs. Marie Wires, R.N., superintendent.

Indianapolis Orphan Asylum, 1107 E. Washlngton St., Indianapolis. Established 1851 ; public; 150 beds ; Miss Carrie Threall, superintendent.

Indianapolis Pasteur Institute, $224 \mathrm{~N}$. Meridian St., Indianapolis. Established 1909 ; private; H. S. Thurston, medical superintendent.

Joseph Eastman Hospital, Delaware and Vermont Sts., Indianapolis. Fstablished 1885; private; general; 30 beds; Jos. Rilus Eastman, physiclan in charge. Leach Sanatorium, 524 W. New York St., Indianapolis. Private; 50 beds; $L$. T. Leach, physician in charge.

Lincoln Ilospltal, 1101 N. Senate Ave., Indianapolis. Fstablished 1909; public; colored; 25 beds; Amanda Rogers, supt Marion County Asylum for the Poor, Haughville, Indianapolis. Established 1860; 265 beds; George W. Braman, superintendent.

Marion County Juvenile Detention Home, 28 W. North St., Indtanapolts. Established 1906 ; 21 beds; Marie IIaslep, risiting physician; Susanna J. Pray, superintendent.

Marion County IVorkhouse, Indianapoiis. Established 1884; public; general : penal ; 208 beds; Thomas L. Sullivan, attending physiclan; J. T. O'Connor, superintendent.

Methodist Episcopal Hospital and Dea. coness Home, Indlanapolis. Established 1908; prirate; 135 beds; J. McLean Moulder, medical superintendent.

Mt. Jackson Sanitarium, $3127 \mathrm{~W}$. WashIngton St., Indianapolls. Established 1903; private; health resort; 40 beds; Thos. J. Dugan, house physician; Chas. E. Cliff, superintendent.

Nathan Morris Home, 923 S. Meridian St. Indianapolis.

Neurouhurst, Dr. W. B. Fletcher's Sanatorium, $1140 \mathrm{E}$. Market St., Indianapolis. Established 1888; private; nervous: 50 beds: Urbana Splnk, house physictan; Mary A. Spink, medlcal superintendent.

See Special Announeement $A d v$. page.67 "Norways" Sanatorium, 1820 E. 10th St., Indianapolls. Establlshed 1898; private; for nerrous and mental cases; 30 beds; Albert E. Sterne, medical director: Chas. D. Humes, house surgeon. See Special Announcement Adv. page 61

Protestant Deaconess Hospital and Home for the Aged, $200 \mathrm{~N}$. Senate St., Indianapolis. Established 1895; private; general; 126 beds; A. L. Marshall, M.D. superintendent.

Robt. W. Long Hospital, W. Michigan St., Indianapolis. Fstablished 1912 ; public; acute cases; 100 beds; controlled by Indiana University.

Runnel's Hospital, 522 N. IIllnois St., Indianapolls. Establlshed 1890; private; chronic diseases and surgical; 25 beds; o. S. Runnels, M.D., superintendent. and Illinois St., Indianapolis. Established 1881 ; private; all cases except contagious : 250 beds; Sisters of Charity, in charge. 
Stewnre Sanitarium, 100 X Luitol tie. Indlanapolls. Fistablishacl lonto private: alcoliol and drute addletion: 25 beds: J. B stewart, physlclan in iharge. Dr. Ward's Sanitarium, 722 lidtana Are., Indlanapolls. Establlshed $190 t^{\circ}$ prlfate; 25 beds; Joseph II. IVard, niedI cal superintendent.

\section{Jeffersonville}

Jeffersonsllle Detention Hospltal. Jef fersonvllle, Ind. Fistabllshed 1850; wub lic; 20 bets: Jos. Zuerner, Jhgsiclan Mr. Monroe, superintendent.

Jeffersonvillo Orphans' Jome, 832 Melis Are. Jeffersonrlle, Ind. Estalilinher! 18:6; frirate: for dependent chlldren 12 beds: F. M. Wells, physlctan in old Ladles Home, Jeftersanrllle,

ulletta

Marlon County Asylum for Incurahle Insane, Julletta, Ind. Established lain. publle: mental; 200 beds: $\boldsymbol{H}$. $\mathbf{s}$. P'otter medleal superintendent.

\section{Knightsville}

Clay County orphanage, kulghtsvilte

Kokomo

Dr. Edgar Cox llospltal, Kokomo. Ind Established 1903; private; surglcal; 6 beds: Edgar Cox, physlclan in charie Good Samaritan Hospltal, Kokomo. lid! Established 1012; conducted by fisters of St. Joseph.

\section{Kramer}

Mudlavla, Kramer, Ind. Established 1889: private sanltarlum: general: 200 beds: Geo. F. Butler, physiclan In charge

\section{Lafayette}

Detention Hospltal. Lafayette. Ind Kstablished 1902; publlc: for smalluor cases only: 35 beils; $R$. J. Bataft, super intendent.

Lafayette Home Hospital, Jafayette. Ind. Fistabllshed 1895 : pubile and urlrate; ceneral: 50 beds: F. F. Knerht K.N. superintendent.

Ola Peoples' Home, Jafayette, ind. Lstabllshed 1906; prlvate: aged women only: I0 beds: Margaret Watson, matron. it. Anthony's Ifome, Iafayette, Ind Fistabllshed 1903; pullic: 60 beds: Slsters of st. Francis, In charge.

St. Ellizabeth's Hospltal, Lafayette, Ind Established 187t: vublic; general: 200 veds: Slsters of St. Francls. In charge. st. Joseph'a Orphan Asylum nd Manual Labor School, Lafayette, Ind. Fisual Labor School, Lafayette, Ind. Fsbeds: M. I. Ialry and I. C Arnett, physiclans; Rev. J. A. Seimetz. superintendent.

Tippecanoe County Chlidren's llome Lafayette, Ind. Fostalllabed lssh; public: 73 teds: Lilllan Janeway, super Intendent.

Wabash Valley Santarium. Lafasette. Ind. Histabllshed 1906; private: medical and surglcal: 30 beds: Floyd Addison Loope, sulrefintendent.

\section{La Porte}

Holy Famlly Hospltal, Ia Porte, Ind beds.

\section{colongen}

Whllams Hospltal, lebanon, fnd. Fos. tabllshed 1903 : mublic: tonera!: 12 heds Milss Mao billo simirus, It.N., superJntend(7)t.

Linten

Freeman rity llumpital, Iintors, In! Fstablised 1913; public: Eeneral: Its berls.

\section{Logansport}

Cass county lufrmary Lapansimert

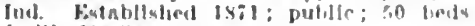
J. M. Midain. sumerintemlent.

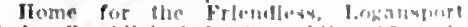

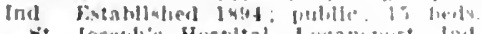

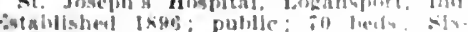
Futablishen] Ix

\section{Madison}

Jembs's Sanltarium, Undlson, Ind

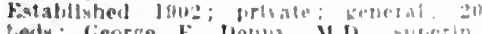

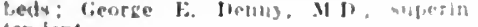
tentent.
Klng' I la ubliters Hospltal, 112 Presty. terlan die. Mad!son, Ind. Establishect 1 1599; publle; general: 10 beds; Mlss Lora belle ituser, Ki.t.. aliperinterdent.

\section{Marion}

(irant County Jlospltal, Marlon, Ind. Established (gon). Wublle and prisate: general: 2h leds: Marion Whiten, supt

\section{Martinsvilie}

Marnard's sanltarlum, Martinsrille. Ind. Fortalistied 1888; publle; 40 beds. II J. IInkle, physlclan In charke.

tolonial Mineral sprlags sanatorlum, Martinswille" Ind. Fistablished 1906 : publle: $8: 5$ beds: G. Breedlove, physlclan II charge: 5. V. Mitcliell, nanager.

Ilighland Mineral Springs, Martinsrille.
Ind. Fstabllshed 1 sy3; private Frank Maxivell, physlcan in charge.

IIII] House sanltarfum, Martínsille. Ind. Fstablished 1905; publlc: 48 heds. F. (C. Itobluson, higslcian In charge.

Ilome lawn IIIneral springs sant. tarium, Martinstille, Ind. Fitabllshed 1.590: publlc; so heds: Robert Ezbert physician In charge.

Martinsrille sanitariun, Martinsville. Ind. Fstabllshed 1892; publlc; 100 beds: v. v. Green, physician in tharge

Satlonal Sanitarlum, Martinsille, Ind Established 1895: public: 70 beds: H. II Sweet, physlclan in charge.

\section{Mexico}

Mexlco Old Folks Home, Mexico, Ind. Established 1893; prlvate: for aged drunkards; 14 beds; Inna Waggoner. ination.

Mexico oryhans' Home, Mexlco, Ind. Estahlished 1892; prlvate; 45 beds; (;. Evans, superlntendent.

\section{Michigan City}

Si. Antheny's Ilospltal, Mlchlgan CIty, Ind. Establlshed 1904: publle; 50 beds; Slsters of st. Thonas in charge.

\section{Mishawaka}

St. Joseple Jospltal, Mlshawaka, Ind. Fistibllsbed 1910: pulilic: to beds: Poot Hand Malds of Jesus Chrlst, In charge. Mongo

Mongo IIospital. Mongo. Ind. Prirate: general: 12 beds: . (5. tirubs. II 1 . superintendent.

\section{Mooresville}

1)r. Clark Robbins' Sanitarium, Moore rlle, Ind. Established 1880; private for cases of plles only; it beils: $s$. lincald, pitysiclan in charge; branch in Indianapolis.

\section{Muncle}

Jlome Ilospltal, Ituncle, Ind. FistahIlshed loni; prlvate; surglcal: 10 beds cien It dulrews, surgent in charge. IIr. MIX IIospital. Murcle. Ind. Es tabliwhet long; private: general; 25 beds 1. M. Mix phystelan in charge; Mist Agnes Iuckler, sume'rlntendent.

Ifuncle Hospltal. Muncle, ind. Fatab Ilshenl 1s92; private: 15 heds: Wn. I Whitney, medical superintendent

\section{Nappanee}

l'rle IIosplal, Nappanee, Ind. Fotal

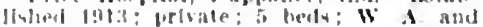

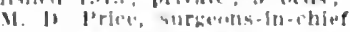

\section{Nutional Military Home}

Ilusplat, Murlon liranch for llisalim Vuluneter suldlers, Sational Milltary

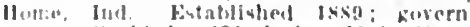

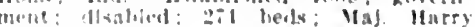
viller, surgetiots.

New Albany

Cormedia Vemorial Mrphang IInte. Som

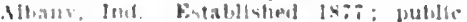

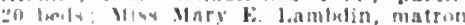

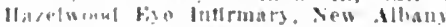

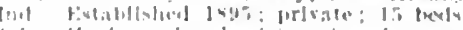

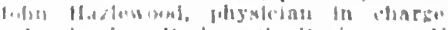
Dostund lork sunitarlum. Non

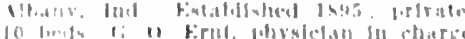

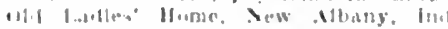

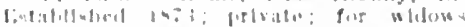

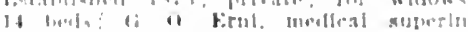

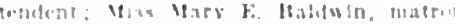

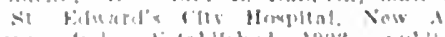

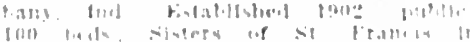
phater

\section{Noblesvillo}

IJarrell Hospital, $x$ gth st., Nubles rille, Ind. Fitabllobed 1 sng; publle and prlinte: Lemeral: 22 heds; s Harrell, physlolan in charge.

\section{North Vernon}

Walnut Struet IIosplial, 2! Wathut St. North Vernon, Ind. Established 1900; prlvate: surgical: 3 beds: If. II Stenum, physlclan in charge.

\section{Paoli}

Orange fonuty Poor Asylam. I'asth

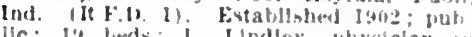
clare londley, physiclan

\section{Pennville}

I'rovident Hospltal, I'ennrille, Ind. Establlshed 1905: publlc; surglcal: 12 beds: C. F. Caylor, surgeon: Ilss Hallie Koons, It.... sumerintendent.

\section{Peru}

A. II. Kalbfelsch santaflum, Peru Ind. Establlshed 1901; prlrate; 10 beda A. Kaldwin. playslelan In charge. Slaml County Asylum. l'eru. Ind. Fistabilvied 18: : public: general: Feru Hospltal Astoclation, l'eru. Ind Established 1912: general; Mlss Id Beyer, superintendent.

Wabash Employees Hospltal, Peru, Ind Established I884: prisate: 40 beds: trard II. Girlswold, physlclan in charge.

Piymouth

County Infirmary, J'ymouth, Ind Es tabllshed 185\%; pullic: 50 beds: $1 \mathrm{Wm}$ Frles, sunerintendent.

Julla Work's Wrphans' IJome, Plymouth. Ind. Fistalilished 1857; publlc; 200 beds N. B. Asplnall, physiclan in charge Julla llork, superintendent.

Plymouth sanatorium and Hospleal. I'lymouth, Ind. Estalllshert ISE:; prI vate; for alfohol and druz addiction cases: 30 beds: $\mathbf{N}$. B. Aspinall, phrslclan In charge: 1 . L. Baxter, manazer.

\section{Portland}

Jay County IIospital, Fortland, Ind Fstablished 1905: nuhllc: 10 beds: MIs I. M. Garard, K.... superintendert.

\section{Princeton}

Princeton Sanatorlum, Princeton, Ind Establlshed 1907: gencral and maternit cases: prlvate: 25 lieds: It. S Anderson, uhyslelan In charge.

\section{Richmond}

II ome for the Friendless. ItIchmond, Ind. Fistablislied 1869: publle: maternity: 20 teds: Aurella Thomas, super

Margaret Smith Home for Aged and Inflrm Women. Itlchmond, Ind. Estab. llshed lsws: prisate: l2 heds: Melville F. Johuston, physlcian in charge: Mrs surface, matron.

licid Venurlal Hospltal soring Grore. Itichmond, Ind Extatishell 1905: public Hal prisate: general: i.j perts Francey

IVimaliann Hospltal Rucheoser Ind

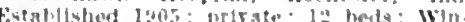
theles shafer, phigstclas in charge

Rome City

huclup santertum. thome rity. Ind

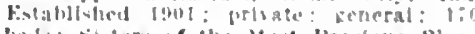

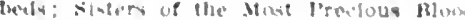
in vhale; li loulskamp mediral director.

Rushrille

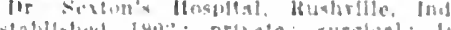

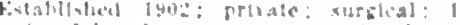

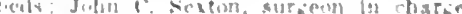
Sellersbura 
South Bend

Foworth Ilospital and Training School, Sould IBend, joublic : general; 60 beds: llugh M. Mifler. imetical director: Margaret I'arker, super

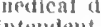

ntencient.

South Bend Isoiation IInspital (St. Ioseph's County Intirmary), South Bencl Ind. Hstablished 19I1; publle: smatipox only; 1: beds; J. 13. Bertellng, phystclan in churee.

South lBend Tubereubsis ('amp), South Bend. Ind. kstabltshed 1908: mublic: I bend, Ind. Estalitined 190s; julite; beas; W.
Intendent.

St. Joseph Iospital, South Bend, Ind. Established 18xz; prlvate; feneral; 100 beds: sisters of the lloly ('ross, in charge.

Spencer

(ierman Mineral Springs Sanatorium Spencer, Ind. Fstabllshed 1890 ; private health resort; 1: heds; predk. W. Denkewilter, physletan in charge.

Sullivan

R. H. Crowder Memorlal Hospltal, Sull van, lnd. Established 1913; prirate; 12 beds: J. R. Crowder and G. D. Scott, jilysicians hil charge.
Terre Haute

Florence Crittenton Home, 1923 Poplar st., 'Terre llaute, lnd. Established 1907 ; maternity cases and erring giris ; i: beds: 0 . F. Fink, pliysician harke; Lilth Flsher, sujerintendent. Irose Orphau IIone, 'Terre Hawto. Ind. listailhshed I8S3; 100 beds; F. G. Alden, uperintendent.

st. Ann's orphan Asylum for Girls, Terre Haute, Ind. Slsters of Irovidence, in charge.

St. Anthony's Hospital, Terre Haute, Infl. Fiallished 1882; general ; 200 beds. Inton Hospital, Terre Haute, Ind. listabllsiled I 895 ; general; 75 beds Chas. N. Combs, M.D., superintendent. VIgo County Poor Asylum, Terre Haute Ind Established $1867^{\circ}$ public I00 beds: $\dot{A}$. D. Weeks, superintendent.

Valparaiso

chrlstian IIospital, Valparalso, Ind. listallished 1906; public; general; 25 beds; Miss M. Irummond, superintend. ent.

Vincennes

Bowers Sanatorium, 217 N. $3 \mathrm{~d}$ St., Vincennes, Ind. Established 1913; prirate; general surgery; 20 beds; Eugene Bowers, physician in charge.
George Knapp Santtarium, Vlucennes, Ind. Lstablished 1898; private; for eye, ear, nose and throat treatment; 40 beds: Geo. Knapp, physician in charge.

Good Samaritan Hospltal, VIncennes, Ind. Established 1808 ; public; keneral; 35 beds; Fulth Willis, superintendent.

Knox County lnfirmary, Vincennes, Ind. Established 1870: publif: 35 beds; Chas. S. Bryan, physician in charge; $A . J$. Buley, superintendent.

Knox County Orphanage, Vincennes, Ind. Established 1891; public; 55 beds; Chas. S. Bryan, phystclan; Minnle Hannah, matron.

P'resbyterian Hospltal, Vincennes, Ind. Fstabllshed 1905; private; 10 beds; Withelm T. ron Knappe, physiclan in charge.

Wabash

Wabash County Hospital, Wabash, Ind. Established 1905; publlc; general; 15 beds; Miss Rosa Thomas, R.N., superintendent.

White's Manual Isabor Institute, Wabash, Ind. Established 1852; for dependent children; 200 beds; Jiewellyn Harkness, superintendent.

\section{PHYSICIANS OF INDIANA}

EXI'LAXATORY NOTE.-Names marked $\$$ are those of physiclans licensed by the Indiana Board of Medical Registration and Examination but whose certiflcates liare not been fled with county clerks or who, following a change of residence, have not fled their old certlficates for exchange in the counties in which they now reslde.

\section{KEY TO ABBREVIATIONS, SYMBOLS, ETC.}

Names in capltals signify membership in the County Soclety and State Association. (DOE, JOHN)

- Indicates Fellowship in the American Med. Assn. (DOE, JoHN\$).

(b'75) Year of blrtil.

[medic. í homeopath; E, eclectic; P-M, phystoInfor, College and year of graduation. uation.

S.-Surgeon.

ob. - Obstetrician.

ObG.-OIstetrician, Gynecologist.

G.-Gynecologist.

Or.-Orthoyedist.

Pr.-Proctologist.

Op.-Ophthalmologist.

A.-Aurist.
LR.-Iaryngologist, Rhinologist.
( $\left.\mathrm{r}^{\prime} 89\right)$ Year of llcense.

(t) In practice before passage of present law and licensed by filing diploma or by vears of practice.

(1) Iicensed but year not known.

(末) Information recelved does not show license.

U.S.A., United States Army.

M.R.C., U.S.A., Medical Reserve Corps.

SPECIALTIES ARE INDICATED AS FOLLOWS:

ALR.-Aurist, Laryngologist, Rhinologist.

OALR.-Ophthalmologist, Aurist, Jaryngologist, Rhinologist.

U.-Urologist.

D.-Dermatologist.

Pd.-Pediatrist.

N.-Neurologist.

P.-Psychiatrist.
U.S.N., United States Nary.

M.R.C. U.S.N., Medical Reserve Corps.

U.S.P.H.S., United States Public Health Service.

College positions held are indicated by abbreviated title of position, followed by key number of college. For key to colleges see inside front cover page.

(A1,3, J6, C4) Membership in special Societies. (See Key Table, page 122.)

NP.-Neurologist, Psychlatrist.

I.-Internist.

T.-Tuberculotheraplst.

Anes.-Anesthetist.

LD.-Laboratory Diagnostician. [gist. R.-Actinologist, Radiologist, RoentgenoloPath.-Pathologist.

Bact.-Bacteriologist.

WHEN THE ABBREVIATION REPRESENTING A SPECIALTY IS FOLLOWED BY AN ASTERISK (*) IT INDICATES THAT THE PHYSICIAN CLAIMS HIS PRACTICE IS LIMITED TO THAT PARTICULAR BRANCH OF MEDICINE; WITHOUT THE ASTERISK, THAT HE IS ESPECIALLY INTERESTED IN, BUT DOES NOT LIMIT HIS PRACTICE TO, THAT BRANCH. THIS INFORMATION CONCERNING SPECIALTY IS BASED ON PERSONAL DATA FURNISHED BY THE PHYSICIAN AND IȘ NOT VERIFIABLE.

\section{INDIANA}

ABINGTON (R.F.D., CENTERVILLE), I30, WAYNE

Neek, Marcus I.-Ind.9,'95; (1'97) ; not in plactice.

ACTON, 400, MARION

Boone, Byron II. (b'65)-Ky.1,94; (1'97).

Swails, Jeremiah Arthur $\left(\mathrm{b}^{\prime} 71\right)-I 11.17,99$; (1'00).

ADAMS, 378 , DECATUR

TREMAIN, MHTON ALVIN (b'76)€-Ky.5,

Webb, Wm. H. (b'26)-0; (l'95); not in practice.

ADVANCE, 4i6, BOONE

Burk, Thos. P. (b'45) $\rightarrow$; $\left(l^{\prime} 9 \pi\right)$.

Fill, Wm. D. (b'52)-0; (l'97)

Hal, Stephen A. (b'64)-Ky.1,'94; (1'97)

Iramilton, Iohn A. ( $\left.\mathrm{b}^{\prime} 36\right) \mathrm{E} \longrightarrow ;\left(\mathrm{l}^{\prime} 9 \pi\right)$.

AKRON, 1,000, FULTON

Case durustus $\left(b^{3} 32\right)-0.1,57 ;\left(l^{\prime} 04\right)$

FelT, Petry Iawson-N.Y.20,'04; (1'05)

Hosmban TVilis E-E-Ind.11,92; $\left(1^{\prime} 97\right)$.

Jolinston, Aaron- $\downarrow ;\left(l^{2} 97\right)$.
ALAMO 209, MONTGOMERY

GIIFF'TH, JAMIES BARTON - Ind.8,'99. (1'0I)

Sparks, Joseph Tyndall (b'53) $\rightarrow$; (1'97).

ALBANY, 1,289, DELAWARE

Burris, saml. O.-O: (l'97)

Dowell, Iohn A.-0.2,81; (1'9s).

LeFavour, Jos. $\left(b^{2} 50\right)-0 ;(1+)$; not in practice.

POWERS, UIJSSES GRANT $\left(\mathrm{b}^{\prime} 65\right) \oplus$ Ind.8,94: $\left(\mathrm{i}^{\prime} 9\right.$ )

VANDFRRITG, JAMES M. (b'69) \$-Ky.1 $98 ;(\mathrm{l}, 98)$

ALBION, 1,213, NOBLE

CARVER, WALTER F. (b'66)£-Ind.10,'92 : (l'9i).

GREEN, WM. T. (b'55)-111.1,'80; (1997).

HAYS, JOHA W. (b'41)-0.1,72: (1'97).

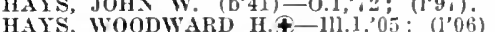
S.

MILLER, BENJAMIN E. (b'46)-0.8,'71; (l'97)

MORR, JOHN WV. (b’70)-Ind.10,'94; $\left(l^{\prime} 97\right)$

ALERT (LETTS P.O.), 206, DECATUR

Vorton, Thomas J. (b'70)-Ky.I,'95: (1+)

Wood, Chas. (b'80)-Ky.2,07; (1'07).
ALEXANDRIA. 5,096, MADISON

Beardsley, Edmond J. (b'61) H-Ill.10,'86 ;

(1'04). ETTA (b'60) $\oplus-$ Mo.37,'95;

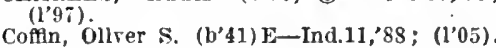
(iibson, John J.-Ont.5,93; (1'97)

HALL, JOS. F. (b'58) \&-Ind.8,'81; (1'97).

KELLER, FRINK G. (b'68)-0.1,91 ; $\left(\mathrm{l}^{\prime} 97\right)$; G.

Mercer, Andrew Barclay (b'54)-Mich.1,'84; (I'99).

OT'To, ANTHONY E.-0.1,'83; (1'97).

Schaefer, Augustus R.-0.2,'81; (1'97).

SCHIIAUSS, LEONARD F. $\left.\left(\mathrm{b}^{\prime} 67\right) \oplus-\mathrm{l}\right) 1.1$ 97; $\left(1^{\prime} 08\right) ; S$.

(b'59) \&-111.1,'85; (1'98).

WILSOS, OLIVE A. CHAS. (b'60) $\$-111.9$

$91 ;()$.

ALFORD (PETERSBURG P.O.), - PIKE

Dukate, John S. (b'25)-Ky.2,57; (1'97).

ALFORDSVILLE, 200, D'AVIES

BURRESS, BERT OVERTON (b'77)-IIl.17, '05: (1'07).

Hedrick, John T. (b'49)-O; (l’97). 


\section{ALGIERS, 100, PIKE}

Gray. Elwood (b'- 8 ) - Ind 9, 01 : (1'04)

HARRIS, R. W-Ky.1:9:; (198;

LOGAN, ALSTIS It.-Ind.9,0); (10)1

ALQUINA (R.F.D., CONNERSVILLE), 111 , FAYETTE

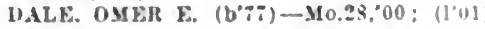

ALTO (R.F.D. KOKOMO), 40, HOWARD

Schrock, Joslah J.-0.6,'87; (1.98)

ALTON, 161, CRAWFORD

MYERS, JOSEl'IITS $\left(6^{\circ}, 0\right)+-k y, \cdots$ (1'9\%)

\section{AMBIA. 359. BENTON} RA.ilA1.1. EDWIS E. (b'65)-II1.1,9"

AYloR, WALE II. (b'a)-M0.24, 04 $(1.04)$.

AMBOY, 521, MIAMI

Baldwin, Verne k-111.15,04: (I'04)

Haltey, Wm. H. (b'65) E-0.2,91: (1'yi)

RESLFR, PRANCIS LEE $\left(\mathrm{b}^{\prime}, 5\right)+$ Inds

04: (1.04).

AMO, 500, HENDRICKS

Summers, Harves C. (b'49)-0.I, Ts: (1'9i)

White, Wm. H.-Ind.8,82: (1'97).

ANDERSON, 22,476, MADISON

Armington, Cbas. 1.-Ind.9, $\$ 6$; (1'9i) ; $1220^{\circ}$

Maln Si.
Armington, John Charles-Ind.S, 02 ; (l'02) : Únlon Bidg.

Atberton, Romeo M.-Ill.4,'81; (193i); not In practlce: $215 \mathrm{~W}$. th st

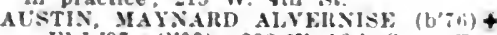
-III.I."9:; $(100) ; 238 \mathrm{~W}$. 12th St, ; ofllce, Lnlon Bldg.: 9-10, 2-4; S.

Boyden, Wilber $\Lambda$. (b.62)-Ind.9, s; ; (1'02) 1300 Merldian st. : $9+12,2-4: 0 b$.

Brock, Farl Ernst (b'85)-0.41,10:

Union 1 ild 2 .

Unton lidg.
Buxton, Albert J. (b'59)-0.3,97: (1'01).

Buxton, Albert J. (b'59)-0.3,97; (1'01);
(bitlenden, Edgar W.-Ill.6,"94; (1'9:) 1108 Central Are.

Chittenden, Geo. F.-Ky.2,3.1; $\left.\left(I^{2} 9\right) ; 1120\right)$ Central Are.

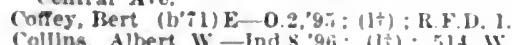
131h Albert W. - Ind.s.96: (1) : 514 W.

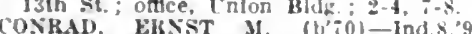

(1†): 2124 Merldan st.; oftice, L'nion Hidg. : 2-4. $;-8$.

COOK, BESJ. HARVEY (b'5s)-Ind.s, 85 (l'9i); 630 w. I2th st.; untll $9,3-5,:-8$ Cummins, James 1.-Ind.í2, 89 ; $(1,00) ; 316$ w. lith $\mathrm{St}$.

Diren, Chas. E. $\left(b^{*} 51\right)-0.9,74$ : (1'97); 123 W. 12th St.: $9-11,2-5,3-9$

biven, John \&. (b'83)-1'a.1, is: (1'13): 110 W. 8th st. ; Pd.

FATTIC JoHX B. (b.62) + 0.1.84: (1'9:) 227 W. Sth St; oftice. 315 Ĺnlun Mlds.

GANTF, IIENTY WASHINTTON (b'86)-

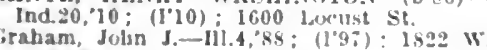
lith st.

Hammond, John II-IIl.4's: ; (I'9;); 2131 Vetcher st.; ofice, I uilon Bldg.

Harter, Jacob II. $-0_{\text {: }}\left(1^{t}\right)$ : not in prac Ilce: 24 W. $13 \mathrm{th}$ st.

HAKтни, WM.

Jaugh, John A. F.- ind.8, 81 : (1†); 208 W. Haugh, Joh

Hockett, Georze H. $\left(\mathrm{b}^{\prime} 83\right)-111.15,,^{\prime} 10 ;\left(1^{\prime} 10\right)$; $138 \mathrm{w}$. 9th st.; onre, Cnlou IHig.: 2.4 $\because-8$.

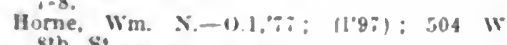
Sth st.

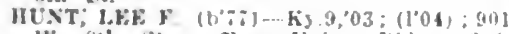
W. sith si.; oalce, I'nlon isldg: ; $2-1$ $7-8 ; 8$.

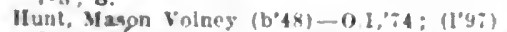
122. Juckwon st.; onler, liberal life Blds.: 10.11, 1.4

Janies, John II - Ind s, 81 ; (1.13)

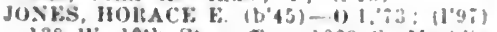
138 W. 10 th St.; oftice, $1029 \mathrm{~s}$. Merldian St. $1: 30-3: 30,:-8$.

J0N 1029 (te $(100): 310$ W. 12th ste

Kintle, Fred. Nllert (b'25) - Ind 20.83 $(\mathrm{l}+13)$

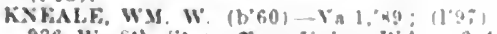
$936 \mathrm{~W}$, sth st.: once, Inlon kidis.: 2.4

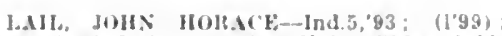
439 W. IIth st.; offee, I.nion BIdg, ; $9-11$ 1-4, i-9: G.

Iong, James A-Ky 2.92: $(100) ; 131 \mathrm{~W}$

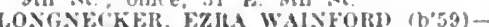
$0.1,84 ;(1.9 \%) ; 404$ Madison Ire. : 8:30$0.1,84 ;(1025)$

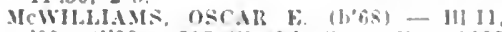
99 : (l'99) : 325 w fith sit; offlee jont Merlular si ; j-4, $i=8$

MEISTEIL DORIS $(6 \% 8) \sim$ Ind 18,07 (1'0s): Merldian st, : oflce, Manning 1slk. Merson, L'berto H.-O.13,86: (I'9i); 1107 Jackson st. : nfice, L'nilon Bldk.

MILEY, ISAIAH (b'45)-Ia.1.75; (1'9i); 2323 F. J.ynn st.; onlee, 2303 Columbus St $=-4 \cdot 30$ - $1-3, i-8+30$

MILF, W'FIR M. (b'85)-Pa.2.'10: (1'11) 323 5. Lynn st; oftec, Culon Hddg. I-4, :-9

MHler, Aibert W.- o.2.'82; (l'97): 930 Meridlan st.

Miller, Fllzabeth - 0.2.91; (1'9i): 930 Merlulan it

Mnor, (ieo. W. (col.) (b'83)-Ky.:.08: $\left(l^{\circ} 08\right)$ : oftce, 1415 Meridian st.; 8-9,

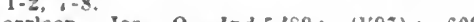

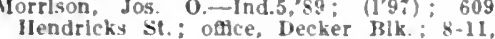
llendrlcks

NFWLIS, STANLES C. $\left(b^{\circ} 56\right)+0.1,81$ $\left(1^{\prime} 9 i\right) ; 106 \mathrm{~W}$. 8th St, $9-11,2-4,7-8$.

roRIIS, SAML. COBB (b'69)-0.9,'94 $\left(I^{\circ} 02\right) ; 426 \mathrm{~W}$. 12th St: offlce, I6 W 10th St.; 10-12. 2-5: (B1); OALR.

O'Nelll, Thomas J.-(b'S2) - Ind.S,'04: (l'05) 1103 Meridian st.; oflce, 511 W. loth st. $2-4 ; 5$.

PERCE, BEXJMMIX H. (b'3s)-Ind.4, 3 (1.97); 1037 Meridlan st, 9-11, :-4, ;-9 Quickel, Daniel S-0.8,94: (1†): 2002 s Maln st.; office, liritith Block; $9-10,2-4$,

Ueynolds, Marshall F. (b'S6)-Tenn. $0^{\prime} 10$ : (1'12): 151\% sherman St.

Sears, dlbert 11.-111.4,90; (1ค97); 139 W

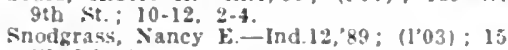
II. 9 th $\mathrm{st}$.

ST(J)IDHD. JAMKA M. (U'TS)-ind Q, 02 (l'05); 914 W. bth st.; offlce. L'inlon HIdg.: $9-11,2-4,7-8$.

Tracs, F. Is, $-\infty ;(1+) ; 120 \quad$ W. 13 th st. oftice, inlon rild

Van Xuys, Darld HI-13a.2, $54 ;(1+) ; 1309$

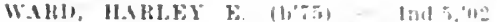
(102): I I 0 Cedar st.; oftce, 1023 w $16 \mathrm{th}$ s?. $8-10,2-4,7-9$.

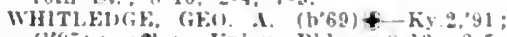
(l'y); onice, tonlon HHg, : s-12, $2-5$; DALR. *

WIIIIAMS, CHAS. F-Ind.S, $82 ;$ (197): 151 W. 13 tb st.

Willams, John Hartholomew (h'5x) l'-MInd 5,$85 ;\left(10^{\circ}\right) ; 35 \mathrm{~W}$. 11th st. : onlee, rnlon bldz.: :-1):30, $1: 30-4: 30$, ;.s.

WI1.1.1MS, $1.1^{\circ}$ C1.1. ()TTO $\left(b^{\circ} 5+\right)$-Ind.s.

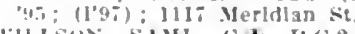

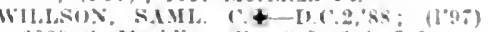
2003 s. Meridian sit: $\$-9,2-4$,

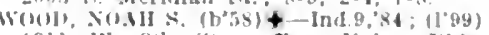

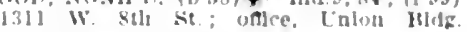
I (1.-1:2. 2-5: AI.16.

ANDERSONVILLE (R.F.D., RUSHVILLE) 348 , FRANKLIN Moralf. Henty ("arter (b'si)-Ky :.'13; (I'13)

ANDREWS, 957, HUNTINGTON

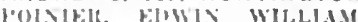

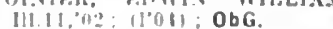

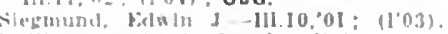

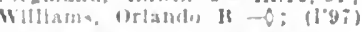

ANGOLA, 2,510. STEUBEN

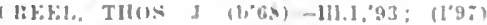

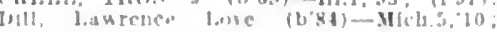
1101

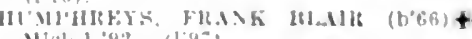

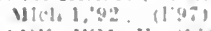

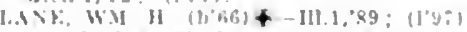

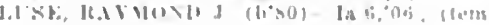
lorary lermle, 13

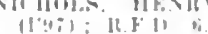

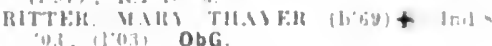

SITHF.ILI.AI),

VIIVAX $(6 ; 0)-$ Mleh.

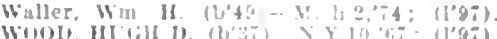

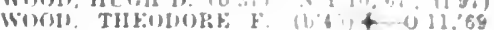$$
\text { (lig:) }
$$

ANNAPOLIS (R.F.D.. BLOOMINGDALE). 200, PARKE

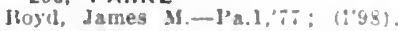

ARCADIA, 990, HAMILTON

HIKL, JUS, I.EWls (b'6i) + - Ky 1,2 ? (1.92).

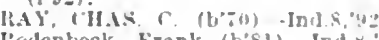

Iirdenbeck, Frank (b'81)-Ind 3, 04 , (1'05)

ARCOLA, 375, ALLEN

(ilock, C. Marlon (b'/6)-Ind.10,03; (1'03)

ARGOS, 1,088. MARSHALL

Could, Saml. W. (b'39)-Ill.1:70; (1"9:).

Kendall, John T.-Ind.13,'85, I11.1, $86:(1 ' 98)$.

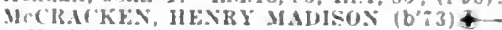
Ky.2,0\%: (l丷09)

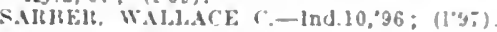

ARLINGTON, 400, RUSH

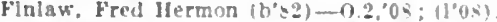

HAlTK, ALBERT G. (b'\%)-Ind.8, 05 ; $\left(l^{2} 05\right)$.

ARMSTRONG, 50, VANDERBURG Wilhelmus, Wm. M. (b'81)-Ky.11,03:

ASHBORO, 175, CLAY

Moss, James K. (b'59)-Ind.8, $85:\left(\mathrm{b}^{\prime} 97\right)$; Pd.

ASHLEY, 639, STEUBEN

Cunnlnghan, Harley L. (b'61) - Mich.8,94; (1.9i).

Iarnelle, Terence E. (b'69)-Ind.8,"92; $\left(l^{\dagger}\right)$.

Shepherd, Zephanlah W. (b38)H-III. (京)。

herrow, Whllam E. (b'55) E-Ind.11.85; (I'OS)

ATHENS, 159, FULTON

STISSON, ARTHL'U ELGENE (b*9) $\mp-$

Ind.9.,03: (1.03).

ATHERTON, 300 , VIGO

Nichols, John A. (b'56)-Ind.8,91; (1'90).

ATLANTA, 876, HAMILTON

I311.1.S, LEISOY F. (b'79)-Ind.8,04: (1'04)

Mcluanlel, Franklin $b^{\circ}$ (b'sl)-Ind 18.06 ; (l'0 0 (i)

Muler, Henry D. $\left(b^{\circ} 51\right) \rightarrow$ : (1'9i).

ATTICA, 3,335, FOUNTAIN

BE(KETT, CLLTUN (i. (b'it)-Ind 8,05; (1'05)

BOLLIXG, LOEIS A. (b'6i) + Mo.:"9z

(1.00)

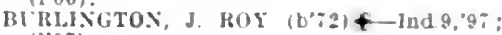

C.IF, MARVIX THLMAX (b'43)-Mlel. $\because 0 ;(1997)$

FIXNFY, CHARLES J. (b०59)-123.8,\$\$; (1' 9 * $)$.

IIOLLEY, ALBERT C. (b"3)-III 4.96 (1'9i).

KFIASE:

OALR.

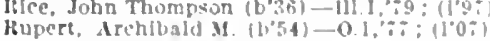
got in praclloe

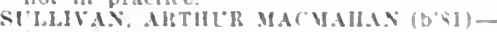
Ind. $20.09:$ : (100)

ATWOOD, $\$ 00$, KOSCIUSKO

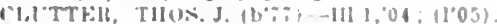

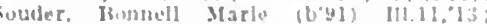
$(1+13)$

AUBURN, 3.919. DEKALB

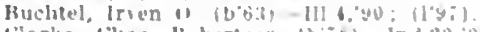

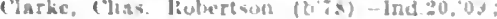
(I'us); 5 .

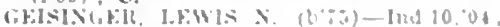
$(100,0)$

III.

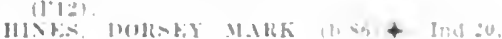

III)

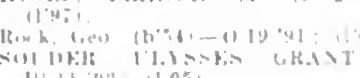

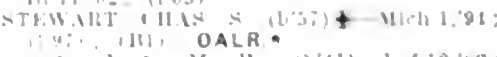

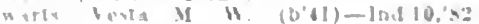

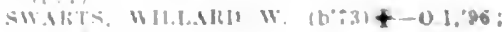




\section{AURORA, 4,410, DEARBORN}

IBON1), IIALC I. (b'59) \&-0.I, $82 ;\left(19^{\prime} 97\right)$. IIFAY, W.1. ( $\left(b^{\circ}+1\right)-0.9,70 ;(197)$.

IIOANES, ELIA SULIIVAN (boris)-0.8

'96: (I'98)

IAC'KON, JOIN MARTIN - Imt.8, 05 ; (1'05).

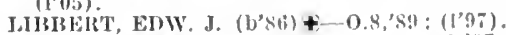

Marshall, Charles corley (b'it) i).1, 97 (1'05).

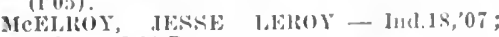
(1'07): OALR

SUTTOE, HAlRIEY II, $(1,, 2)+-0.1,76$, la.3.7.

TREox Julles iv (h's0)-0.1,03: (1'03)

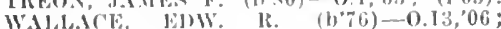
(1,06); OALR.

AUSTIN, 4I0, SCOTT

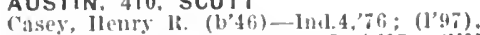

simple, James M. (1,'sI)-Ky.4,07; (l’07)

AVILLA, 579. NOBLE

IALONEY, FIRINCIS C. (b'44)-0.11,66 (1'97).

VHAZFY, WILLIAM M. (b'65)‡-Ky.I,9I; (1'9\%).

AVOCA, 500, LAWRENCE

Stout, O. II, (b'64) ]'-M lnd.12,9I; (1'99).

AZALIA, IIO. BARTHOLOMEW

DeLONG, ORVILLE, A. (b'b7)-Ind.5,'9I; (197).

BAINBRIDGE, 449, PUTNAM

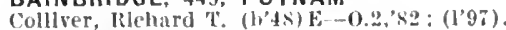

Conn, Wellman 1).-Ky.4,'93; (1’98).

CUlix, JoIN F.-Ill.1,80; (1'97).

Moore, Alexander H.-Inl.s, 81 ; (1,0).

BARGERSVILLE, 75, JOHNSON

Comer, Jonathan F.-Ind.8, n4: (l'04).

Flemlng, Ilarry cilbert (b'78)-Ind.8, 05 . (I'05).

Tresslar, Jaeob f. (b'63) E-Ill.8,'81; (1'98).

BARNARD (ROACHDALE P.0.), 118 , PUTNAM

NEW, YANCEY N.-KYy.1,93; (1'97)

BATESVILLE, 2,15I, RIPLEY

Abbott, June-E-0.2,, 2 ; (1†).

Coomes, II. Jos. (b'60)-Ky.4,92; (l'97); ObG.

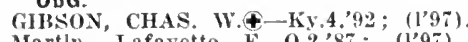

Martln, Lafayette-E-0.2,87; (1'97).

Sams, Nalcom I. (b'7)-Ky.1,01; (l'07).

Ziteke, Jos. X. Di: (l,07).

BATH (R.F.D., COLLEGE CORNER, OHIO), 125, FRANKLIN

Johnson, Ward A. (b'59)-0.19,'89; (1'97); R.F.D.

BATTLE GROUND, 443, TIPPECANOE

BIDDI.E, FIRANK MOLRIS $\left(\mathrm{b}^{\prime}, 74\right) €-\ln d .10$ $95 ;(1,97)$.

Throckmorton, ora F. (b'67)-Ind.9,97; (l'00).

BEAR BRANCH, 80, OHIO

Elder, John R.-Ky.l,'05; (l'06)

BEDFORD, 8,716, LAWRENCE

CAREY, HARRY KEYSER (b'T6) †-Pa.l, 98; (l'13); also Member Med. soc. of the state of I'a.

DUNCAN. JAMES B.ศ-Ky.L, 79 ; (1'97).

Ellison, W'm. Thomas (b'49)-N.Y.10,75; (l'97).

EMHRY, CHARLES H. (b'67)Ð-Mich.1,'92 ; (l'97); OALR

Frceland, John T.-Ky.1,'86; (1'97).

fardner, Jos. (b'33) -Ky.2,'61 ; ( ). (l'97).

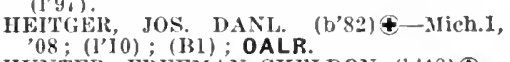

HUNTER, FREEMAN SHELDON $\left(b^{\prime} 48\right) \oplus-$ $0.1,76 ;\left(l^{\prime} 97\right)$.

MATTOX; N. EILIS (b'81) - Kiy.2,'12; (l'12).

MCDONALD, ARTHUI J. (b'60)€-Kу.4, '82; (l'97). ELIJAH E. (b'64)-Ky.1,'88;

NORMAN, OLIN BERTRAM (b'8I)๑$0.6,09 ;(1,11)$.

PEARSON, JOHX ROYER (b'76)@-Ind.8, PERḰINS, EDW. L. (b'7t) - Ind.8,'98; (l'98).

RARIDAN, CHAS. E. $\left(b^{\prime} 56\right)-K y^{+} .1,80$;

SIIORT, RICHARD BEASON - Ky.1,9I, SIORT, RICHARD; B
N.Y.19,99; $\left(1^{\prime} 97\right) ; \mathbf{G}$.
AIMIPSOX, MOLREL, E. (b'82)-Ky.5, 07;

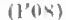

YOLI, ILARVIX (b'49)-Ky.2,77; (1'97). BEECH GROVE, 568, MARION

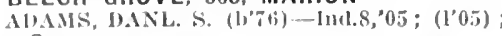
$\mathrm{S}$.

BT"ThER, RAYMONI) AIERED (b'85) †Ind 20,08 ; $\left(1^{\prime} 0 \mathrm{~s}\right)$.

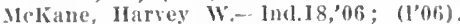
spleer, James W. (h,53)-0.8,78; (lyz). BELLE UNION (R.F.D., COATESVILLE), $1 / 0$, PUTNAM

Moser, Wm. A. (b'7?)-Ind.8,03; (I'03).

BELLMORE, 320, PARKE

MARTIN, ALONZO (b'iL)-Ia.I,'78; (l'97) I'RARE, REEYE C. (b'(i2)-Ky.I,'9I; (1'97); LR.

Shonkwiler, Francls Marlon (b'76)-Ky.4,

BS; (1.98); R.F.1). I; G.

BENNINGTON, 127, SWITZERLAND

Ilootan, Lorenzo (b'TI)-Ky.4,07; (l'08).

BENTON, 175. ELKHART

Liyler, Wm. B. (b'46)-O; (I'97); not ln praclice.

BERNE, I,3I6, ADAMS

FRAN\%, EIRNEST (b'65)-III.4,93; $\left(1^{\prime} 97\right)$; OALR.

IONFS, DANL. DAlILY (b'II) $€$-III.6,'09;

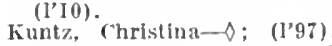

RJUSAER, AMOS (b'69)-III.10,97: (1997) SCHFNl, ('IIAS. II.-Ind.12,'94; (1'97).

BICKNELL, 2.794, KNOX

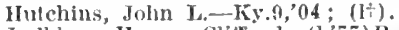

Judklus, II arry clitpord (b, $0 \% ;\left(\mathrm{l}^{\prime} 07\right)$

KFASINGEI, W.I. E. (b'55) - Ky.I,'85; (1'97).

Sherwood, Benj. M. (1'56)-Mlo.1,89; (l’97)

STALEY, TIIOS. M. (b'79)£-Md.4, 03 (1'03).

BIG SPRINGS (R.F.D., ZIONSVILLE), 50, BOONE

Mefee, Jos. A. (b'57) P-M-Ind.5,'83; (1'97). BIPPUS, 350, HUNTINGTON

Biggerstaff, James T. (b'53) -0 ; (I'03)

PERRY, IRA E. (b'73)凹-Ind.8, 05 ; (1'05).

BIRDSEYE, 439, DUBOIS

Garland, James Monroe (b'79)-Ky.2,'io ; (l'11).

Gobbel, Jos. F. (b'76)-Ky.1,'02; (I'03).

JFFFERS, ALBERTUS-Ky.L,'07; (1'08)

Smith, James II. $\rightarrow$; (1'01).

Walls, John W.-Ky.4,90; (1'97)

BLOOMFIELD, 2,069, GREENE

Cook, Peter I1.-0.9,'83; (l'97).

cook, THos. Rol (b'78) 4 - Ind.9, 03 ; (l'03).

CRAYENS, WM. ROTTT (b'68)థ-Ky.1,'92, Ind.9,'96; (1'97)

GRAY, JOHN W. (b'39)-Pa.2,64, N.Y.10 $67 ;(197)$.

Jennings, Caswell H. (b'7I)-Ind.8,'95; (1'97).

MASON, ELIAS R. (b'73)-Ind.9,'05; (l'05)

NORVELI. HORACE V. (b'39)-o; (l'97).

YAN SAND'T, FRANK A. (b'77)-Mo.29,'99; $(1,02) ; 0$ p.

BLOOMINGDALE, 528, PARKE

IIester, Laura M.--Ind.8,98; (1,00).

Hester, Robt. F.-Ind.8, ${ }^{, 99}$; (I'01).

Morgan, lobt. R. (b'64)-Ind.8,'97; (]'97).

WOOUARD, MATIEW FOSTER (b'71)Ind.5, $00 ;\left(\mathrm{l}^{\prime} 00\right)$.

BLOOMINGTON, 8.838, MONROE

AKIN, RAYMONI ALVA (b'82)-Ind.20,'08;

BATMAN, FIRED IIENRY (b'78)-III.I, 04 ; $\left(\mathrm{I}^{\prime} 05\right)$.

BOBBITT, JAMES DOUGLAS (b'84)-H1.1

CUIJiER, WNITER N. (b'76) $₫-\mathrm{Ky} .2,00$; $\left(l^{\prime} 00\right)$.

Farr, Alexander C $\rightarrow$; (I'9 $\mathrm{i})$

Gardner, Fletcher (b'69)-Mich.1,91 ; (l'00). Gardner, Incy Woodward (b'68)-Mich.1 $92 ;(1,00)$.

HARRIS, C. EDW. (b'76) $\oplus-$ Ky.4, 97 . (l'97): $\mathrm{s}$.

,03; (1,03) : S.

HOLLAND, S. SiEs EDWIX P (b'-6) Ind.I8,'06 ; (I'06); OALR. ^
Ifolland, Jhlly, (". (b'40)-0.1,69; (1'97). HI'T'('IIS, 'ILA, I'. (b'72)-N.Y.8,97: not In pracllce; Member state Med. Soc, of Wis.

livoch, Edw. Wm. (b'82)-I11.I,'1I; not in practloe.

LUKAl)EE, JOIIN E. (b'70) - Ky.1,'92; (1'97).

MYEIR, MERTON DORR (b'70)†-Ger.I4 02; Sec. and Prof. Anat., Ind.20; (FI) Rhinehart, Darmon Artelle ( $\left.b^{\prime} 87\right)$-Ind.20, "I3: (l'13); not ln practle.

Rogers, ollo Floyd (b, 2 2)-Ky.2, $00 ;\left(1{ }^{\prime} 0 \mathrm{I}\right)$. Rogers, Robt. C. (b'70)-Ky.2,93; (1'97).

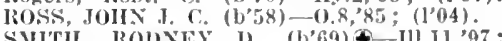
S.ITII, ROHNEY D. (b'69)—-I11.I1,97; (l'97).

Spencer, Alexander C.-Ind.9,83; (l’98); R.F.I). 9.

STROII', ('HAS. C. $\left(b^{\prime} 76\right)-I 11.1,00 ;\left(l^{\prime} 01\right)$ $\mathrm{U}$.

Tourner, Frank F. (b'59)-Ky.9,'99; (1'99).

TOURNER, JOHN 1'. (b'54)- (l'97).

Ward, Janes $6.0 ;\left(l^{\prime} 97\right)$; R.F.D. 7 .

WHETSELI, LEON F. (b'80)-Ky.4,03; (I'03).

WITTSHIRE, JAMHS W. (b'71)-Ill.10,96; (1'98)

WOOLERY, HOMER-Ind.2I,'07; (1'07).

BLOUNTSVILLE, 200, HENRY

GOIRI)N, VIIRII (b'89)-Ind.20,'I2; (l'I2).

BLUEGRASS (R.F.D., GRASSCREEK), I00, FULTON

Abbott, IIarrlson B.-Ind.12,'91; (1'97).

BLUFFTON, 4,987, WELLS

BROWX, ASA WILLIS (b'7 $\tilde{)})$-Ind.18, 06 ; (1'06)

COOK, LLZERNE H. †-0.1,85; (1'98),

DICKASON, FIANCIS M.-0.2, 99 ; (1'99).

FULTON, GEO. F. (b'55)-0.9,'78; (1'97).

FULTON, JOHN C.- 0 ; (1'97).

GOODIN, SAMUEL A. $\triangle$; (1'01).

HATFIELD, ISAAC N. (b'56) - Ia.3,'84: (1'97).

MASON, LEONIDAS (b'3 $)-0.1,72 ;(1 ; 97)$. MCKINNEY, JAMES W. \&-O.3,'98; (1'98). Mlch.5, 08; (l'08).

METTS, FIFD A.૯-Ind.10,'98; (1'98).

REDDING, JOIHN I. (b'76)థ-Ind.8,04; (l'04).

SEVERIN, JOUIS (h'70)-0.9,'99; (l'00).

SIIOEMAKER, SAML. A. $\left(\mathrm{b}^{\prime} 66\right) \oplus-$ Ind.8, '98; (1'98); OALR.ネ

SPAULDING, LEANDER A. - 0.1,7\% (1'97).

\section{BOONVILLE, 3,934, WARRICK}

DE FOREST, DANL. A.-Conn. 1,58 ; (1'97). FORD, WM. I. (b'59) - Ky.2,94; (l'97): OALR.

HoOVki, J. GUY-Ind.9,04; (l'04)

HOOVEK, PETER N.(-Ky.1, $81 ;(1,00)$.

Howard, Thos. M. Ky.4,78; (1'97).

INGLE, SHERMAN KEMLO'

(See Evansville.)

MARTIN, CHAS. FRANKLIN (b'86)-Ky.11, ,08; $\left(l^{\prime} 08\right) ; \mathbf{G}$.

MeCoy, T. I. $\rightarrow$; (l'97)

MIILS, WM. HENRY (b'52) $\oplus-0.1,80$;

(l'97)

RHUDY, W. W. (b'7I)-Va.4,'95; (l'I2)。

ROBINSON, WALTER P.-Ky,4,04; (l†)

SAMIPLES, J. TILDEN (b'㣙-Ky.1, 07 ; $\left(l^{\prime} 07\right)$.

Shaul, Monroe-Ky.1,'83; (l'97) ; R.F.D.

Spradiey, Norman M.-Ky.4,90; (1'97).

WILSON, I'ALL EDGAR (b'87)-Ky.2,'I3; (1'13).

Wright, Thos.-Ind.13,'83; (1'97)

YOUNGBLOOD, ELI L.-IIl.10,94; (1'98).

BORDEN, 425, CLARK

Hall, Walter A.-Ky.5,'04; (l'04)

Stalker, Benj. F.-Ky.2,';3; (l'97).

Stalker, C. Homer-Ky.5,'0I ; (I'04)

Stalker, James Bodine-Ky.2,'98; (I'99).

BOSTON, 122, WAYNE

CIAWSON, JOS. C. $\left(b^{\prime} 76\right)-11.17,0 j$ (1'06).

Meek, Jos. B. (b'53) $\longrightarrow$; (l'97).

Rife, John J. (b'41)-0.8,'69; (1'97).

BOSWELL, 814, BENTON

Atklnson, Chas. W. (b'78)-Ind.8,'03; (1'03).

FLACK,
OpA.

HPA. Ind.20,'11; (1'11). 
BOURBON, I,163. MARSHALL

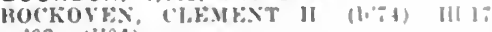
03: II'nt)

Rockovt:, SLNE MAllus - 11111,04 (1.03)

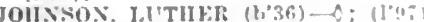

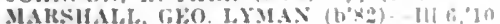
(1'11).

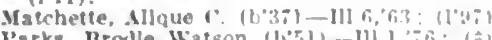

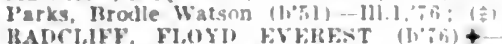
MADCILIEY, FI,OXI) H.

BOWLING GREEN, 336, CLAY

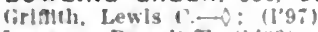

Lemmon, Brande Fo (b'ko)-Ky.l, RS; (l'ns)

BOXLEY (R.F.O.. SHERIDAN), 175, HAM

ILTON

MeNurtry, Thos. J. - In I 4, :

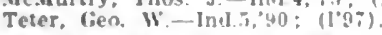

BOYLESTON, 150, CLINTON

Thorpe, 1. Xolin (b'is)-Ind.8,05; (1'0.3)

BRADFORD, 200, HARRISON

Boston, (has. II. (b'64)-Incl.3.'57; (1'97).

BRAZIL, 9.340, CLAY

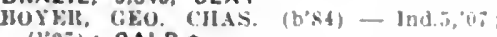

(I'0i); OALR* *

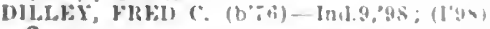

S.

ELIOTT, HARRY (b'Ts) $£-$ Ind.8.'b

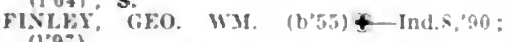

(1'8i)

Hawklns, Robt. W. (b'72)-Ind.8.95; (1'95)

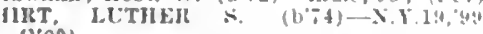
(1'00).

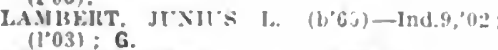

MLXclt, HExUY L. (b'79) —-Ind.8,05

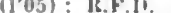

Sall, dibert Ilayworm- 0 ; $(195)$; not In practice.

NTSSBI, FREUK-Ind.8,91: (1'9-).

Ollver, Jacob 13. (col.) $-0:(199 \pi)$

ORR, W.M. H. (b'69)-Ky.294; 1197

JELL, HARK MILTON (b'90)-Ind.20,']" (1')3).

RAWHEY, JAJES A. (b'0) - H1.18,04

S.ITH, JACOB F-Ind.9, S6; (1'9;)

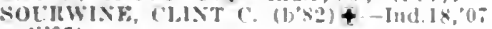
(1,0:)

SOLRWIXE, JOHX I), $\left(b^{\prime} 52\right)+$ Ind.9,?6

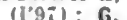

WIILIAUS, I.EWIS I. (b58) - Ky.t'A

YOIN98, MELVIN 11.-Ind.8.92; (1'98).

BREMEN, 2,008, MARSHALL

Chenoweth, Albert C. (bi: -111.4 .08$

DF, (l'08). RASOMONI C. (b'i6)-D.C.4 (100: 11091 .

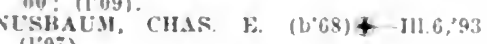
(1.9i).

TripD, l'ranklln-f: (1'G9) : not In pracilce.

BREWERSVILLE, IS0, JENNINGS

ADA.IS. S. 11. (b.33)-O: (1'97).

BRIDGEPORT, 400, MARION

JEXNISiS. WM. I. (b'63)-X.Y.5.'B8 (1'gij)

roke, (has. (b'5i)-Ind.8,79: (199i).

BRIDGETON. 250. PARKE

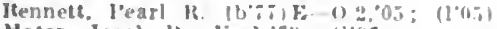

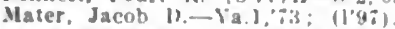

BRIGHT (R.F.D., HARRISON, O.), 128 DEARBORN

Lidule, John $16-(0) 1,200$ : (1'97).

BRINGHURST, 400, CARROLL

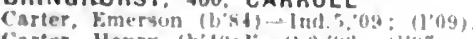

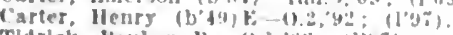

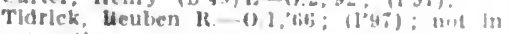
practice.

BRISTOL, 335, ELKHART

Aliken, Prelk. Wixer (b'6)-N.Y.l, GK

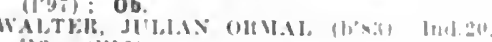
1.: (1) (12).

BRISTOW, 150. PERRY

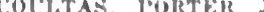

(1.09)

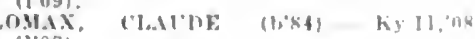

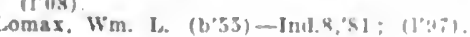

BROAD RIPPLE, 770, MARION

Cole, Mllert VI.

(see Intliamanolls.)

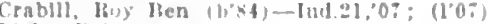

Ligbt. Rotht.

(See Indlanapolls.)

slinger. Baymond Ilenry (b'si) Ind Is, 0: $(100 ;)$

BROOK, 1,067, NEWTON

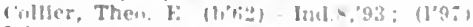

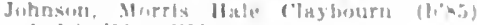
Inil "il $011: 11011$.

I'arklsin, Wallawe II - Ind 8,04: (1'04).

BROOKLYN, 572, MORGAN

Spmer. Julu sellers Ind.s,ol: (1'011.

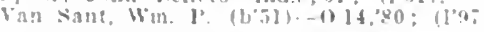

BROOKSBURG, I50, JEFFERSON

llurat, dames I.=-1) 1.'KI: (1'0,5).

BROOKSTON, 907, WHITE

Bruckwis, chas. Jesse (b'ss)--I'ag,'l] (1)1])

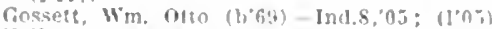

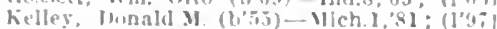
liarlden. lawrence Mrailty (b'sol-Ind:a 12: (1012)

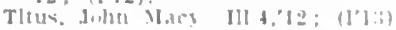

BROOKVILLE, 2,169, FRANKLIN

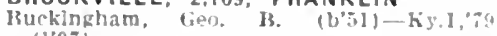
(1'97).

Garrigues, Israel Dayton (b'aij)-0.1, $11971: 0 b$.

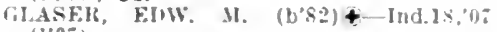
$\left(l^{\prime} 0\right.$ - )

Pattersnn, Eran 1. $(653)-0.8,78 ;(147)$

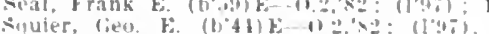

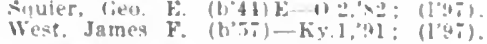

BROWNSBURG, 876, HENORICKS

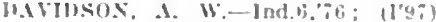

lingeman, kdw. Loarel (b'si)-Inden,'le (1'12).

M.IEII, JOHA LEONARI) (b'51) \$-0.1 sMITH, THOS. G. (b'64)-InI.9.4\%; (1.97) BROWNSTOWN, 1,492. JACKSON

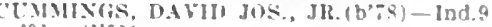
ol ; (l'0])

IIFLIFIR, FRFD. (b'68) +-K5.I, $98 ;(1989)$ Zaring, l'hllip L. (b'60)-Tenn.5, 93 ; (l'04) BROWNS VALLEY, 120 , MONTGOMERY kilmore. Homer H. (1)'-9)-Ind S, 0:3; (I"0:3) not In practlce.

Odell, Jacub I. $\left(b^{\prime} 52\right) \rightarrow$ : $\left(l^{\prime} 00\right)$

BROWNSVILLE, 300, UNION

Bradley, Janes Tayior (b'-2) - Tenn.6, (1'04).

Sherman, Wm. C. (b'62)-0.9,85; (10i)

smith. James $1-0:(1 ; 5)$.

BRUCEVILLE, $\$ 00, K N O X$

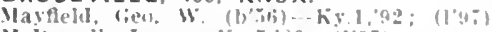

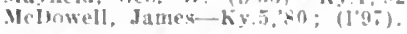

BRYANT, 469. JAY

Glentzer, Madionn A. (b'fl) $\mathrm{F} \rightarrow$; $\left.1 l^{\prime}: 4\right)$

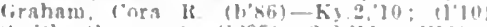

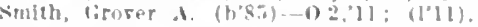

BUCK CREEK, 250, TIPPECANOE

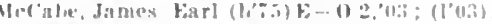

BUENAVISTA, 50, MONROE

Gliphant, leeter T

BUFFALO, 100, WHITE

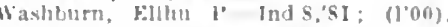

BUNKER HILL, 668, MIAMI

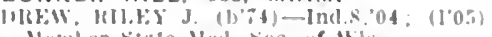

Memiser state Buol soce os Wis

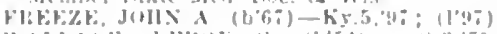

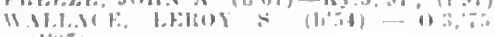
$\left(l^{\circ}\right) i$

BURKET, 400, KOSCIUSKO

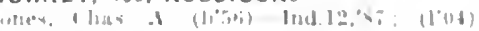

1R. 111

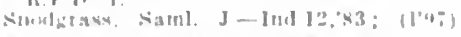

RURLINGTON, 800, CARROLL

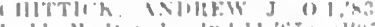

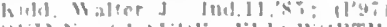

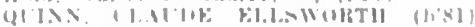

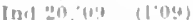

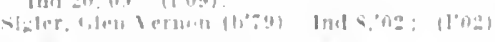

BURNETTS CREEK. 790, WHITE

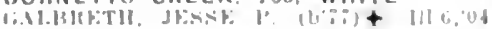

(1) (1)

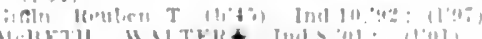

BURNEY, 200, DECATUR

II arrial.

'orier, biw

BURNS CITY, 200, MARTIN

11. Y.:

BURNSVILLE (R.F. ELIZABETHTOWN)

60. BARTHOLOMEW

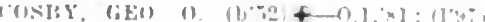

BURROWS, I50, CARROLL

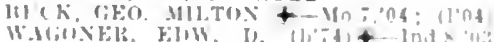

(I'03).

BUTLER, I.818, DEKALB

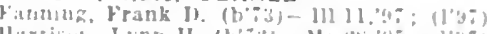

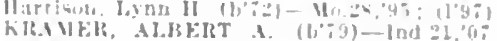
hit? $110 \%$

SHIMAKER, WILILUY F. (bust-1) 3

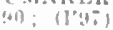

BUTLERVILLE, 400, JENNINGS

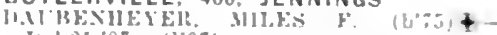
(1) CABORNS (R.F.D. MOUNT VERNON), 67,
POSEY

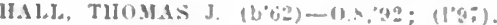

CADIZ, 209, HENRY

fiarreti, Ubediah H. (b'Tn)-ind. 5.83 $13 \mathrm{si}$

IIESS, FRANK C, (4.50)-11 1, $11 ;\left(1^{4}\right)$.

CAMBRIDGE CITY, 2.23\%, WAYNE

IBOYL, IUWKICE, IB. (b'5.) $4-0.3$, 'SI

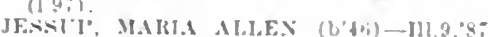
$(1 \div \div)$

LITTELI., WILI.S R. (bibl)-0.1,

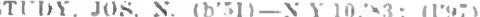

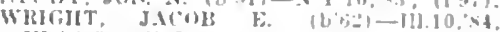

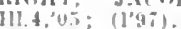

CAMOEN, 357, CARROLL

KENAEII, CHAS M+ IndS, 05 ; $(1003)$

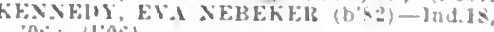

KITCHELL, JACOB F. $\left(t^{\prime}: t\right)+-\operatorname{Ind} 8,02$ $(100) \div 1$.

If-1 1 :

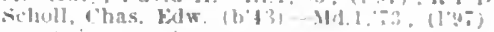

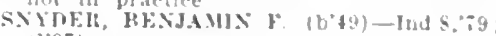

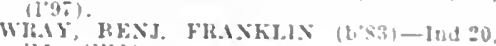
'11: (1'11).

CAMPBELLSBURG, 666, WASHINGTON

I'AYNTER, CILIIF, H KY 4.06: (I06)

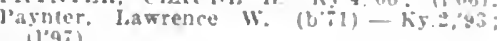
(1) 9 i)

CANNELTON, 2, I30, PERRY

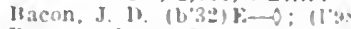

lienneti, James 13. (b'ti)- (lis:

Conner, Inills s. (b'sl)-kytor; (l"ar)

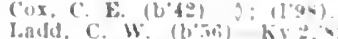

Werling, Millard $r$ ib $(1 \div \div)$

CARBON, 493, CLAY

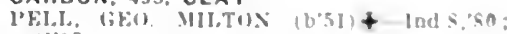
$(1 \div 91$

Van sandt, Wm. H-Im!s:00; 119i).

CARLISLE, 850 , SULLIVAN

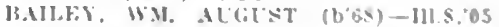
II thi $U$. U.

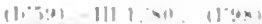

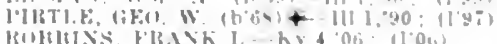

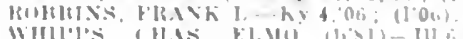

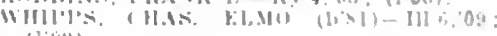
(1) II!)

CARLOS, I50, RANDOLPH

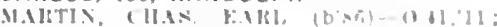
(1'1: 11

CARMEL, 626, HAMILTON

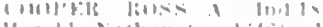

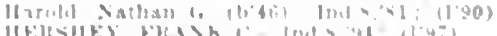

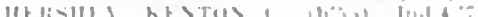

CARTERSBURG, 253. HENDRICKS

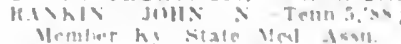

CARTHAGE, 8;3, RUSH

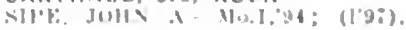


CASTLETON, 194, MARION

13irket, Cbas. Theo. (U'59) - Jnd.16,'91; (l'04)

Marsli, John A. (1,8:) -Ind.20,09; (1'09)

CATARACT, 190, OWEN

MCQUEEN, WII. (1)'79) $\$$-III.I4,'06; (1'09).

CATES, 200, FOUNTAIN

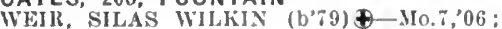
(1'12).

CAYUGA, 9 II, VERMILION

BUTLEI, WM. F, (b'57) -Ind.8.95; (I'95),
DAIROCH, SAMI, C. (b'80) +-III.I, 03 ; (I'04)

DARROCH, WM. PAXTON (b'56)£-Ky.I. 7\%: (l'9s)

FLAUGIEIR, EDW. A.-Ind.8, 83 ; (I"97).

CEDAR GROVE, I85, FRANIKLIN

Cramer, Carl Paul Rafael (b'69)-0.2,'10; (l'11).

Mayfleld, Chas, Eugene (b'81)-Ky.1,05; (I'05).

CELESTINE, I30, DUBOIS

Coble, Peter L $\rightarrow$; $\left(l^{\prime} 97\right)$.

CENTER, 300, HOWARD

Noland, John W. (b'56)-Ky.I,'82; (l'05).

CENTERPOINT, 4I4, CLAY

HINCH, GILBERT R.-O.I,97; (l'99)

RENTSCHLER, IFWIS COURTNEY (b'8i)

-Ind.20'I2: (I'I2).

CENTERVILLE, I,0I9, WAYNE

iruley, Limer N. (b'63)-0.2,9I; (l'03)

not in practice.
FISHER, WM. THOMAS (b'72)-Ind.18,06; (l'06).

FoUTS, JOIIN M. (b'7I)-Ind.9,'98; (l'98)

Gabel, Harrison (b'4I) -Ind.9,80; (I'97).

CENTRAL, 40, HARRISON

BAHR, MAXWELL A.

(See Indianapolis.)

Dean, Menry K.-III.6,62; (1'97).

Hays, Danl. W. (b'54)-Ky.4,'S5; (1'97).

CHALMERS, 513. WHITE

Morrls, Wllbur B.-Ky.2,'98; (I'98).

CHANDLER, 147, WARRICK

HEWINS, WM. A. (b'5I) $-0.9,78$; (1'97).

Iagenheimer, P.-Ind.8,80; (1'97)

CHARLESTOWN, 864, CLARK

Bottorff, Chas. M.-Ky.I,'88; (1'97).

Jones, Cadwallader-Ky.2,78; (I'97).

MARSHALL, THOS. JAMES '(b'83) $₫-K y .2$,

'10; (temporary permit,'I3) : S.

Taggart, John E. (b'36)-Pa.2,'60; (1'97);

R.F.D. I.

Work, Wm. F.-0.2,75, Ky.2,'87; (1'04).

CHARLOTTESVILLE, 459, HANCOCK

JOHNSTON, WM. R. (b'67)-0.1,91; (l'97).

Smith, John T.-Ind.8,'80; (1'97).

CHELSEA (R.F.D., LEXINGTON), 45, JEFFERSON

ICKEAND, ROBT. A. J. (b'75)-Ky.1,'04; (1'05).

CHESTERFIELD, 285, MADISON

NEWHOUSE, JOHN T. (b'48)-Ind.12,'90; (1'97).

CHESTERTON, I,400, PORTER

AXE, ROSS HARRISON-III.1 I, 04; (1'05)

Von Osinskl, Jos. $\rightarrow$; (l’97).

WILTFONG, CHAS. O.๑-Ill.11,0I; (1'01).

CHILI, 250, MIAMI

LINE, HONIER E.-Ind.10,'05; (1'06)

CHRISNEY, 524, SPENCER

BAKER, CLARENCE S.-Ky.4,06; (l'06).

BEAN, ALBERT M. (b'56)-0.2,'85; (I'97)

Beuser, PhIllip-Ky.2, 00 ; (I'9

Heuser, Phlllip-Ky.2,'00; (I'97).
Walters, Linsey 0.-Mo.7,99; (1'00).

CHURUBUSC0,870, WHITLEY

BRIGGS, JESSE HOWARD (b'80)-IIl.I,'03 ; (l'03).

CRISWELL, JOHN F. (b'45)-Pa.2,'79; (l'98).

FRANKS, OTHO PIERCE (b'î)-Ind.I0, '04; (1'04)

MAGERS, FRANCIS M. $\rightarrow$; (l'97).

Morrison, Thomas Ray (b'37)-Ind.10,84; (1'03).

CICERO, 990, HAMILTON

Havens, Edw. D.-Ind.8,'03; (I'03)

IING, BERNARD A.-Ind.8,'05; (I'05)

KING, BERNARD A.-Ind.8,'05; (I'05).
Mendenball, Alonzo B.--0.8,'65; (I'97).

Stout, Henry H.-Ind.4,'TI; (1'97)

TOMLINSON, CARLTON H. (b'69)-Ind.8, $\left(I^{\prime} 97\right)$.
CLARKSBURG, 454, DECATUR

Jeall, (has. M. (b'54)-0.8.,81; (1'97).

CLAIK, PROSSEll ELWIN (b'84)\$-Ind.20, 0!); (I"0y).

SmIli, John L. - 0.8,77; (1'97)

'IIOMAS, WM. El)GAR' (b'78) \$-Ind.8,01 (I'03).

CLARKSHILL, 463, TIPPECANOE

ALLFN, HIIBIRT' I'AKL (b'83)-InI.20,'1I (I'11).

Bartholomew, James Nelson (b'52)-0.1,82; (I'10)

MUGG, IIFNRY M. (b'75)-Ind.8, 02; (l'05)

Ware, Wm. II. (b'48) $\rightarrow$; $\left(l^{\prime} 04\right)$.

CLARIKSVILLE (R.F.D., NOBLESVILLE),

160. HAMILTON

Camp, Wm. E.-Ind.8,96; (l'97).

CLAY CITY, 1.213, CLAY

Asbury, Wm. H.-0.1,75; (1'97); not in practlee.

Brown, Archle S. (b'76)-Ind.8,'04; (l'06),

Freed, Martln A.-Ky.2,'82; (1'97).

Hille, Joevl $\mathrm{A} \rightarrow 0$ : (1'97): not in iractlce.

YANDIVIER, HENRY R. (b'69) \$-Ind.8,

$98 ;$ (I'98)

Wolfe, Christopher H.-Ky.4,76; (1'97).

CLAYPOOL, 408, KOSCIUSKO

LANDIS, WM. CARLE (b'80)-Ill.8,07;

MURPHY, SAMUEL CASPER $\left(\mathrm{b}^{\prime} 85\right) \Phi-$ Ind.20,'10; (I'I0)

CLAYTON, 497, HENDRICKS

Irooks, Mathlas WV $\rightarrow$; (l'03).

Gilbert, A. K.-0.I,77; (1’97).

JONES, RJLUS E. (b'78)-Ind 8,0I : (1'03)

REYNOLDS, D. MONROE (b'77) $\oplus$-Ind.8 '00; (]'0I)

CLEAR CREEK, 100, MONROE

Morrls, Oliver M. (b'69)-Ind.9,97, Ind.20, “08; (1'05).

Simmons, Wm. D.-0.2,'88; (1'05)

CLERMONT, 205, MARION

Ferris, Justus C. (b'77) E-Ind.17,'06; (l'06).

Ruse, A. 0.-Ind.9,0I; (1'00).

CLIFTY (GREENSBURG P.0.), 287, DECA-

CRAWFORD, GEO. S.-Ind.4,74; (1'97).

CLINTON, 6,229, VERMILION

Ashley, Chas. W. (b'82)-Ind.8,05; (1'0,5).

Beeler, Frank McHarry (b'87)-Ky.I1,'08 (l'08).

Bogart, John H.-MIch.I,'68; (I'97).

Gerrish, Wakefleld D. (b'79) - Ind.8,02;

(I'03).

Murray, Alan Butler (b'65) - N.Y.I,'90;

(l'I3)

Ragan, Chas. E. (b'8I)-Ind.18,'06; (I'06)

Heese, Geo. B. II CC. - 0.22,93; (1+i).

Salarogllo, Annlbale (b'73) - Ita.19,'98; (l'08).

SHAFF, DEWITT CLINTON (b'69)థ-Ill.I, $07 ;(1908)$.

(l'07).

FASHBURN, HENRY EVANS (b'84) Ind.20,'10; (l'10)

WHITE, ISSAC D. (b'72)-Ind.8.'04; (1'05)

Whlte, Chas. M.-Pa.2,76; (1'97).

CLOVERDALE, 624, PUTNAM

IIURST, EVERETT M. (b'T4)థ-Ill.11, 00 (1'00).

PRESTON, JOS. I. (b'5I) -Ind.4,7 7 ; (l'97).

Prichard, Walter K. (b'60)-0.9,'82; (l'97).

CLOVERLAND, I55, CLAY

PIERCE, HAROLD J. (b'82)-Ind.8,'05; (1'05).

COAL BLUFF, 600, VIGO

Rowe, Thos. C.-N.Y.S,'66; (l'97).

COAL CITY, 300, OWEN

YOCUMI, BOAZ (b'68)-Ky.4,'93; (1'00).

COALMONT, 150, CLAY

ASBURY, W.I. D. (b'74) $\pm-\mathrm{Ky} .2,04$;

ARD, HARRY H.-Ky.4,'98; (]'04).

COATESVILLE, 472, HENDRICKS

HOPE, CHARLES F. (b'6T)-Ind.8,'96; (l'99); 0 p.

HUNT, STEPHEN (b'45)-III.I,'8I ; (1'97).

Ill.6,'97; (1'98).

COLBURN, 300, TIPPECANOE

WAGONER, HOBT. H. (b'i6)-Ind.8, 03 ; (1'03).
COLFAX, 801, CLINTON

Coon. Hiram J.-Ind.8,81; (1'97).

LAMIBEUT, ISAAC C. $†-K y . I, 99 ;(197)$.

Milburn, Jos. C. $\rightarrow$; $\left(l^{\prime} 97\right)$.

schuck, John Ifenry' (b'i3)-Ky.5,'89; (l'97)

Webster, James (:. (b'29)-N.Y.5,64; (1'97)

Wlsehart, Wm. H.-Ind.9,97; (1'98)'

COLUMBIA CITY, 3,448, WHITLEY

GIRISIIAR, FREDK. G. (b'53)-0.6,75; CISISIER 0

(b'st) - Jass. I

KITIY AIT, NATHAN I. (b'51)-0.1,81 (1'97)

Lawrence, Isalah E. $\rightarrow$ N.Y.10,69: (1'97)

LINVILL, BENJ. I'ERRY (b'81)-MIch.1, '09: (I'II); $\mathbf{S}$.

LINVILL, DÁVID S.\&-Mich.7,'86; (l'03),

McClure, Wm. Ilenry Harrison - 0.1,'75; (1'97).

NOLT, ERNEST VERLIN (b'84)†-MI.I $08 ;(1 ' 09)$

SCHUMAN, OLIVER V.(-Ill.6,89; (I'97). SOUDFR, CARL LAWIENCE (b'70)థ-

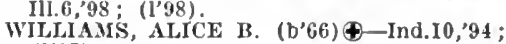
(l'97)

COLUMBUS, 8,813, BARTHOLOMEW

Arnold, John Wm. (b'52)-Ind.9,85; (l'97). Ind.4,76, N.Y.10,'80; (1'97).

Banker, Wilson T.-Ind.8,'79; (l'98).

ВENHAM, JAMES W. (b'68)-Ky.4,'96 ; (1'02).

Bracken, Lawson E-H-Mo.5,03; (1'03).

BUTLER, WM. H. (b'46)-Ind.8,'99; (1'97)

CLOUSE, BERTHA ANNE (b'68)-Ill.9, 00 ; $(1,00)$

FITZPATRICK, BART-0.1,'82; (1'97).

Francls, E. T.-Ind.8,75; $\left(1^{\prime} 97\right)$.

GRAHAM, PAUL, C. ' $\left(\mathrm{b}^{\prime} 79\right)$ - Ind.8,'03;

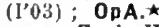

Hauser, Zack H.-O.I,'66; (1'07).

HAWES, JAMES K. (b'74) - Ky.5,'98: (1.98); Pd.

N.Y.I0,'84; $(1,97) ;($ A21).

RAMMAN, HERMAN H. (b'72)-Ky.1, 03 ; (l'03).

KIRKPATRICK, ALVA M. (b'74)-0.I,'89;

IrCoy, Edw. LeRoy (b'8I)-Ind.20,08. $\left(l^{\prime} 08\right) ; U$.

MARSHÁLL, DAVID J. (b'65)-Ky.2,'9I ; (1'98).

McCOY, GEO. T. (b'46)థ-0.9,'82; (l'97).

YORTON, FLETCHER D. (b'53) $€$-Ind.4 '77; (1'97).

Oldham, George L.-Ind.9,'98; (1'97).
RFYNOLDS, (;EO. E.-Ind.8, 81 ; (1'98)

REYNOLDS, (:EO. E.-Ind.8,8I; (1'98); S. $\star$

Shane, Thomas A.-H-0.13,'81 ; (1'97).

SUVERKRUP, LOTTA RUTH ARWINE (b'69)-Mich. I,'90; (1'97).

VORIS, SAML. II. (b'46)-Pa.2,70; (1'97)

Wisner, Wm. E. (b'32)-0.8,70; $\left(\mathrm{l}^{\prime} 97\right) ; \mathrm{Pd}$

WOOD, ELMER U. (b'71) థ-0.1,98; (1'99).

Vright, Appleton F. (b'6I) - Ind.9,'85:

(I'97); (also Taylorville).

COMMISKEY, 150 , JENNINGS

MATTHEWS, DENNIS W. (b'80)-Ky.5,'03 (1'03).

CONNERSVILLE, 7,738, FAYETTE

Booher, Irvln Edwln (b'83)-Ky.2,'I3 ; (l'13)

Carlisle, P. G.-Ind.9,04; $\left(1^{\prime} 04\right)$.

Chitwood, Frank A. (b'47) $\longrightarrow$; (1'99).

CLARK, JEDLA HLSSEY (b'68)\&-Ind.8, $95 ;(1 ' 0 \mathrm{I})$.

DILLMAN, LURTON D. (b'45)-0.1,78; (1'97)

ELLIOTT, ROY H. (b'78)-0.9,'01; (l'02)

FORD, OLIVER P. MORTON (b'64) $\uparrow-0.1$ '89; (l'89).

GORDIN, STANTON E. (b'70)-Ill.10,'96; (l'9T).

(1'97).

Hoag, James H.-Ill.4,'83; (1'04).

Johnson, James H.-III.I0,'95; (j’05).

Ludwick, Verner D. (b'64)-0.9,89; (l'97). IOUNTAIN, JOS. R. (b'7I) $\$$-Mich. I, 98 ; (1'99)

Porter, Wm. J.-0.1,'90 ; (1'04).

Rice, John S.-N.Y.I0,'66; (l'05)

Smith, Birna Richle (b'73)-Ky.2,03; (l'I0)

SPILMAN, FRANK J. (b'73)-0.1,97; (1'00)

Tyrrell, Alexander $\mathrm{D} .-\mathrm{E} \rightarrow$; not in practice. 
CONVERSE, I.I64. MIAMI

IBROOKIE, MU(SEI: W. (U8\%) + - III 6, 08 (l'08): $\mathrm{Ob}$.

rondon, Wm.s. (b'66)-Mo.10,40: 11r1

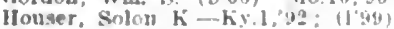

himbali, Merlulth iaton $\left(b^{\prime} \mid 6\right)-1,5,-4$ (1'9i)

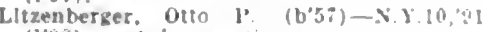
(l'9s) not in practice. 'L; (I'II).

COPE (R.F.D., MARTINSVILLE), GI, MOR. GAN

Wllllams, Keylon II.-Ind.S'Si: (l'gi)

CORNETTSVILLE (R.F.D., PLAINVILLE) 85. DAVIESS

JEXKIXS. JAMES MORTON (b'bl-ky. 91 : $(1,00)$

Telford, Percy Kenward $\left(b^{\prime} s i\right)$ - Ind $: 0,11$ (1'11).

CORUNNA, 318, DEKALB

Allln, John IIerbert (b'62) Ont.3, $\left.96^{\circ} ;\left(l^{\prime}\right) \mathrm{s}\right)$ BROWNE, FRANCIS STANLEY $\left(b^{\prime}-2\right) \leftarrow$ Ind.8, 03 ; (1'03).

CORY, 304, CLAY

James, ollier (b'4l)-Ind.4,7\%: (1'9:). FEAVER, TIMOTHY M. (b'il)-III.1:,05 (1'06).

CORYDON, 1,703, HARRISON

AMY, WM. E. (b'80)-Ky.1,"03; (1"03)

BOTTORYF, JOUN C. (b'66) -Ky.2,'st $\left(I^{\prime} 9 \%\right) ; \mathbf{S}$.

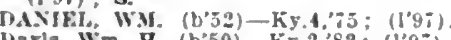

bavls, Wm. H. (b'50)-Ky.2,82: (1'9i).

Funk, Zachary T. (b'ti)-hy.1, i6; (1'9i)

not in practlce.

llabermel. Clara L. (b'58)-Q; (l'90)

Martin, Geo. F. (b'59)-Ky.5,'84; (1'9i).

Neely, Isasc L. $\left(b^{\prime} 56\right)-K y, 1,82$; (1'97)

WOIFF, FTANK F。. (b';6)-Ky.1,97; (1,04)

WOLFE, ZFLOTL' C. (b'55) - KY, I, SI (1'97).

\section{COVINGTON, 2,069 FOUNTAIN}

Buckuer, Jacob $H^{\prime}$ (b'49) $0.1,74 ;\left(l^{\prime} 37\right)$

COGGINS, CHAS. IS-O.1,76; (1'9;); 1t. r.D

IIIKS, JOHX R. (b"71)-Ind.9,03; (l'03)

LAMBRIGHT, SIMEON (b'63) - $0.22,9$ ? (cemporary permlt,13): Memler ohl

MYRRS, COLUMBE'S L. (b'49)-111.1,73 (1'98) ROWLAND, GEORGE (b'10)廿-Mlch.1,65,
$0.1,66$ : (1.97).

SPIXNIXG ALVA L. (b'66) Ind.R,91; (1'04): OALR.

WERT, CHAS. C.-Ind.8, 03 ; (l'03).

\section{COWAN, 200, DELAWARE}

WILI.IAMS, JOHX HI. (b's0)-0.3, 07 ; $\left(1^{\circ} 09\right)$ Marsball. Reuben $\left(b^{\prime} 40\right)-0.9, \div 6 ;(1 ; 9)$

COXVILLE (ROSEDALE P.0.), 450, PARKE

Wheat, Wallace W.-0.2,'99; (l'99).

CRAIGVILLE, 200, WELLS

UAVENPORT, E. P. $\rightarrow$ : (1'3i)

CRANDALL, I33, HARRISON

13AKEK, GUY D. (b'86)-Ky.2,'10; (1'10).

CRAWFORDSVILLE, 9.371 , MONTGOMERY

BARCUS, VAUL J. (b'62) \$-0.1.' (1.9\%): $\mathbf{S}$.

BKATTY, JAYES L. (b'39) -0.9,'81; (1'97) CARY, NATHANIEI. AUSTIN (b'8 ) Ind.18,06; (l'06): S.

CIESHNT8, GEO Y.-111.1,00; (1'05)

COOKSEY, THOMAS LYNCH $\left(\mathrm{b}^{\prime}, 0\right)-0.9$ $97:(13)$

Cowan, Edw. H. (b'46)-(1).73; (1,y)

HAVIUSON. JESSE (1.9:).

LFNNIS, FRED A. (b',6)--Ind.8,98 (1.95); $\mathrm{T}$

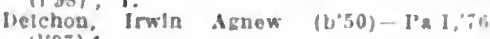
$(1.97) ?$

liewey, Ceo. W. $\left(b^{\prime}+5\right) \cdot 8 ;(1,97)$

Halson, Chas. C. (b' ( 3$) \mathbf{E}-111$ s, 80

K.Y.J. $\$$.

E.XSMINGE

CTTR J

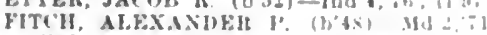
$(10 \%)$

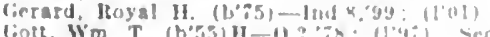

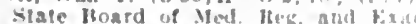

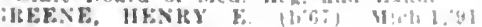
(I'9): OALR.
(iHF'FII, NAITHA F H. (b'(3)-I'a.

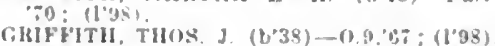

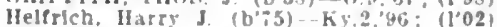
HUTCIHNlis, HENJ. FHANK. (1, (ii) -0.1, (1)

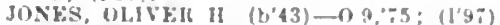

Keegan, Enoch W. (b'36)-111 1.61: (1.97)

Iagne, Preston $M$ (b'2:) $\rightarrow$; $(1, i)$; not in practlce.

luen, John S. (b'059)-111.1,44, (1998)

RAMSEY, GEO. P. (b'6)-Ind.9.00; (101)

Rlley, Chas, (b'6:) - $0.2,94$; (l'99).

MSTIXF, WARHEX HEXRY ('53) 4

S Y.10,7\%: (109:)

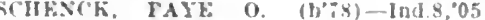
(l,05).

SIGMOND, MARVEY WOHTH (6\%1)

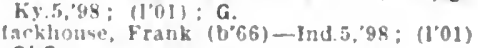
ObG.

SWIXK. WI. GRAY (b'60)-Mo.24,'92 $(1,95)$

SWOPF, ALSTIX A. $\left(b^{\circ} 68\right) \mp-$ Ind.8, 98 (1,00)

Taylor, John X. (b'51)-Ind. 4:76; 1 19:

Tliney, Wm. Defaux (b'il)-Ja.lt,is (1'9i); not in practice.

l'tter, Joseph A. $\left(b^{\prime}+i\right)-0.13,280 ;\left(l^{\prime} 8 i\right)$

wILIAYS, GEO T (bo5) + - Ind 8 (1'04).

CROMWELL, 520, NOBLE

liants, John (b'32) E-O.2,72; (1†)

NIE. JOHX HAMITON $\left(b^{\circ}(i)\right)+$ Ind 8

TCCKER, HENRY G. (b"39) -0 : (I'9i).

CROSS PLAINS, 1,988, RIPLEY

Mlller, Reuben II $-0.1, ; 6 ;$ (I'9;)

RYA., ('HAS. D. (b':-Ky.1,03; (1'03 OALR.

CROTHERSVILLE, 1,038, JACKSON

Adslr, W'm. K. (b'82)-Ky.2,10; $\left(l^{\prime} 10\right)$

Ipplegate, Geo. $\rightarrow$ : (l'98)

Butts, II bert P.-Ky.2,'95; (1'97)

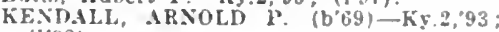
$(1 \cdot 98)$.

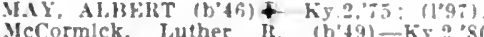
(1".4\%): Anes.

CROWN POINT, 2.526, LAKE

lBackstone, John $\mathrm{K}$. (b'f2)-Ky,2,95: (1097)

MHANON, GEO. WWIGHT (b'61)+-IIJ.6. S6; $\left(l^{\prime} 9 i\right)$.

FARLEY, ARCIJBAI) 11. (b* $(1,05)$

GIRBS, JAMES C. $\left(\mathrm{b}^{\circ} 5 \mathrm{H}^{\circ}\right)+111.10, \mathrm{~s} 6$ $\left(l^{3}(9)\right.$

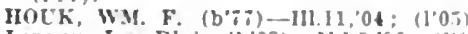

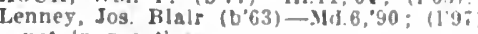
not in practlce.

Schedell. Wm. I. $\left(b^{\circ} 55\right) \rightarrow 0:\left(1^{\circ}:\right.$ i)

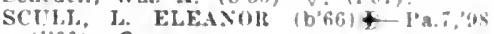
(100): $\mathrm{G}$.

CRUMSTOWN, 120, ST. JOSEPH

Broun, Jacob R. (b'23) $\rightarrow$ : (1"9i): not in practlce.

CULVER, 810, MARSHALL

IARKER, EDW ERYEST $(4 \cdot 70)+$ Ind.S, 98: (1'04): ObG.

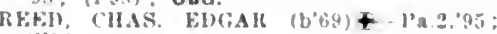
(1'19)

Stevens, Ahram F.-O : $\left(I^{\prime} 9 \vec{i}\right)$

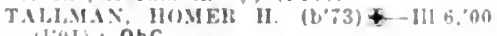
(1\% I): ÓbG.

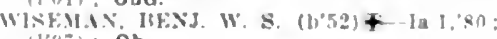
$(1 \% \because): O B$

\section{CUMBERLAND, 310, MARION}

Amlirose, I'ryal C. (b'B3)-Ky $1: 3 ;$; (l'01)

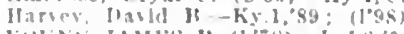

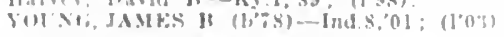

CURTISVILLE, ISS, TIPTON

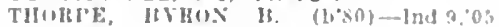
$(1,0)$

CUTLER, 160. CARROLL

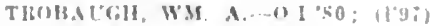

CYNTHIANA, 610. POSEY

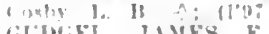

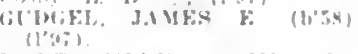

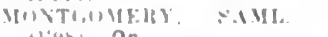

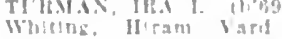

DALE, 583, SPENCER

Mrsant WiHts

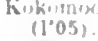

Med $1.31:$

(1'3i).

(I"g)
(1).IA

DALEVILLE, 624, DELAWARE

Hrandon, Winfleld \$ (b'st) - Iuds, $\left(I^{2}+3\right)$

Kllogre, frank T. (b०66)-Ind \&.98; (1'03)

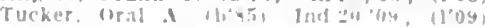

DANA, 748, VERMILION

IIFFX, PLELK. (i. (b'S2) - KY.I,OZ

KEYk.s. OTIS M. (b', (b)-Ky.1,:":; (1'9i).

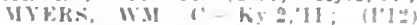

I"IITCIIHTT, GIOVEH 'C. '(t'85)-Ind.20,

trong. llant. S. (b'-8) E-O z,os: (1'0s).

DANVILLE, I,640, HENDRICKS

IMMSTIONG, LOUIS W. (b'75) -MId.

UARKI, JOEL, TALLOH - YY10:00 (1'Q\%).

BAHKKL, THOS It +-Ind.9,01: (l.01).

(;RIMES, JIY IIAHOLI (b'i) (temporary permlt.'13)

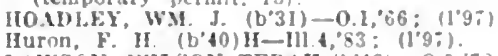

LAWSON, WHSON TERAI (L'9)-0.98 (1'9i).

O'Brien Bertrand M.-M0.6.03: (1'03);

vifiworl CHAS. A-Ky.1,03: (1'04)

WHITF, CIAS. A. (B.45)\&-III.,"il; (19:)

DARLINGTON, 780, MONTGOMERY

Kendall, Cares w. $\left(h^{\prime} 68\right)-K y .5,98:(1 \cdot 98)$

I'FACOCK, NOLMAX k. (b'33)-IIIII,"97; (1'97)

Robe Ray-Ind 18,06 ; (1'06).

DAYTON, 690, TIPPECANOE

MCBIUI)

Molter, Thos. S. ( $\left.b^{\prime 3} 3\right) \mathbf{E} \longrightarrow ;\left(l^{\prime} 9 i\right)$,

Vesblt, Wm. S. (b'56)-Ky.1,87; (1'97).

DECATUR, 4,471, ADAMS

BE.IVFIS, SETII D.t-III.1.'86; (1'97).

HOYEHS, JAMES S. (b'52) +-Md4, 82 I'a $2,53:(1,96)$.

Burns, Eillzabeth viola (b'68)-I1.11,02; $(1 \times 1:)$

rlark, ('has. S-0.2.91: (1'9i)

('lark, D. D. - Ind.10,"91; (1'9i)

COSTELLO, HEXIY F. (b'62)-0.3,'S6: (1'9î).

Coverdale, Earl G.-II1 1.02: (1'03).

coverdale, Jonas s. (b'49j-Ind., 51 ; (1.9\%).

HUFMAXX, STERLIS; PETEK (b'St) Ind $20 ; 12 ;$ (1'12).

Keller. II. E.-Ind.I2,94; (1'97)

MIILLK, JAMKS M. (16) -O 1, $86:(199:)$ OALR.

SMITI, WALDO k-0 25, 68 : $\left(\mathrm{l}^{\prime} 06\right)$

THOMAs, l'HLI" HFlR $(\mathrm{b} 60)+-n ! 6$. ST: (1'9i)

DECKER, 800. KNOX

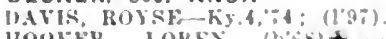

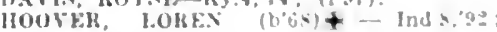
(l'0I).

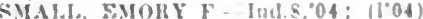

DEEDSVILLE, 125, MIAMI

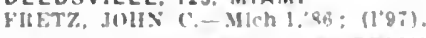

DE GONIA SPRINGS, 30, WARRICK

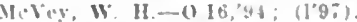

DELAWARE, 250, RIPLEY

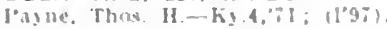

DELPHI, 2.161, CARROLL

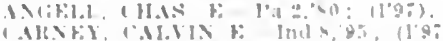

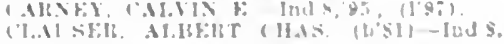

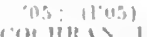

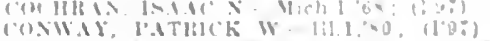

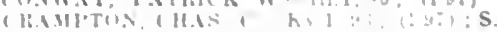

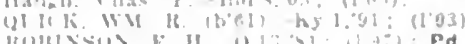

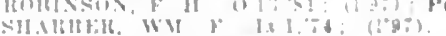

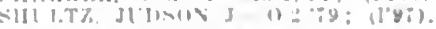

DEMOTTE, 1;3, JASPER

HHWITT, HONH:H

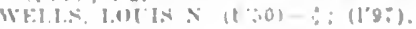


DENVER, 900, MIAMI

Mlllkan, Jahe\% II. (1,59) II $0.1,84 ;(197)$ Newell, Jay W. (b'58)-Ky, 1,80; (1'97)

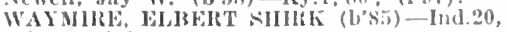
I 0; (l'10).

DEPAUW, 150, HARRISON

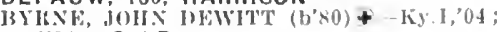
(I'0I); OpLR.

DEPUTY. 300, JEFFERSON

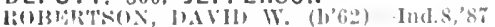
(I'0\%).

DIAMOND, 1,070, PARKE

Benell, ('hals.-Mul.s,'sil): (l'ar)

DILLSBORO, 425, DEARBORN

ION(i IlULl

(1'04).

SII\% FHEFTWOOH, $11 .+-0.1,89:$ (1'97)

Sale, James II.-O.I, T0; $(1.97)$

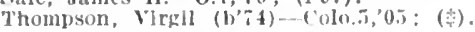

DONALDSON, II0. MARSHALL

Oyler, Wm. A. (b'49)-O; (1'04)

DOOLITTLE MILLS, 76, PERRY

J3rown, lieo. W.-O; (l'99).

DREWERSBURG (R.F.D., HARRISON, O.),

75, FRANIKLIN

Jertenshaw, Thos. F. (b'42) $1-0.2, ' 66$; (1'97).

DUBLIN, 704, WAYNE

FACKLFR, VOLNEY NEVIN (1r'72)

Ind $2 l^{\prime} 0 \pi$ : (1,0

YcKEE, CHAs. L. (b'67)-0.2,99; (l'99)

Wallon, (ieo. F. (b'73)-Ind.5,01; (1'03)

not in prictice.

DUBOIS, 100, DUBOIS

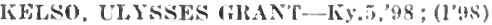

DUDLEYTOWN (R.F.D., SEYMOUR), 75 JACKSON

NILES, JOIIN H. (b'SI) \&-Ky.2,'10; (1'12)

DUGGER, 1,226, SULLIVAN

BEDWELL, THEOPHIIU'S S. (b'58)--Ind, $80 ;\left(1^{\prime} 97\right)$.

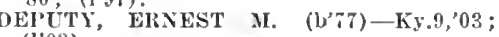
(l'03)

DEliEs, FRED MORTOX (b'88)-Ind.20 '11; (l'11).

GILL, IRA J. (b'68)-Ind.I7,'03; (I'03).

DUNKIRK, 3,03I, JAY

GAIBER, ERWIN C. $-0.25,05$; (1'06).

Lytle, Joln S. Scot. $3,{ }^{\prime} 80 ;(1,97)$.

MURRAY, DONNILATT (b'70)€-Ind.8,94; (l'9i).

Selvey, Saml. S.-0.9, $69 ;\left(l^{\prime} 97\right)$.

DUPONT, 300, JEFFERSON

Lewis, James $F$ (b'56) - 0.1,75: (l'9

I,ewis, James F (b'56)-0.1,75; (1'97); (l'9i).

DYER, 545, LAKE

CHEVIGNY, JOS. A. JULES (b'72)-Que.3, 95; (1'02).

EARL PARK, 609, BENTON

IBUNDY, CLYIIE T. (b'84)-III.11,'09; (1'10).

IcCaslin, Carl N. (b'i6)-Ind.8, ${ }^{\prime} 02 ;\left(l^{\prime} 02\right)$.

Mevatian, Jolin Wum.

(See Chleigo.)

EAST CHICAGO, 19,098, LAKE

Baker, Jelunie (b'63)-Ill.5, 08 ; (I'10).

GIVEX, HILTON AIE (b'88) - Ill.6,'11 (1'14)

GOLDBERGER, SOLOMON MAXWELL (b'86) $\$-111.11 .08 ;\left(l^{\prime} 11\right) ;$ Chicago and Forsythe Aves.; office, First National Bank BLdg. $9-12,2-4,7-8$.

Ilale. Raleigh Peter (b'83)-Ill.6,'08; (l’08)

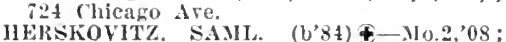
(l'09); Chlcago and Melville Aves.; otfice, 3432 Michigan Are.; $8-10,7-9$

JOHNS, DAVID RICHARD' (b'85)-111.22, '10: (1'13)

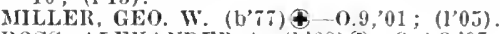

ROSS, ALEAAXDER A. (b'6s) $\$$-Ont.3,'97; (I'00).

SCHLIEKER, ALEXANDER G. (b'68) \&Ill.6,00; (1'99) ; 713 Chicago Are.; ofllce, 715 Chicago Are.; 2-4.

SPEAR, ROBT. (b'68)-Ont.3,97; (l'97); s06 Chicago Are.

Townsley, Frank Livingston (b'is)-111.11, '09; (l'12) ; Calumet Bldg.; 8-10, 1-3, 7-8. Walsh, IIarry F. (b'73)-Ill.6,'98; (1).

EAST COLUMBUS (COLUMBUS P.O.),

BARTHOLOMEW

CHNE, (KEO. F.-KY,2,93; (1'01).
EAST ENTERPRISE, 150, SWITZERLAND Hall. Wirley .I. (l'sO)-Ky,1,07; $\left(1^{\prime} 07\right)$.

EAST GERMANTOWN, 302, WAYNE

Fill,F, A.MGS F. (b'69)-0.2,96; (l'97).

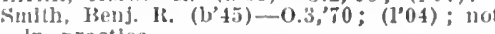
In practlce.

EAST HAVEN (RICHMOND P.O.), WAYNE

JAC'KSON, ELBER'T W. (1)'S7)-Ky,2,'12. (1'12); Nember liy. sitate sled. Assu.

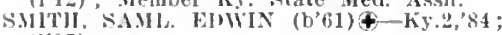
( 1297 )

WIKENS, MAIYY-Ind.18,06; (1'06).

EATON, 1,428, DELAWARE

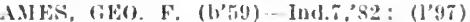

ATKISAN, JAMES M. (b'63)£-Mli.1, '93: (1'07) CIIAS. J. (b'72) $\$-0.9,00$; (I'00).

ECONOMY, 375, WAYNE

LOOP', $\triangle \mathrm{U} B \mathrm{BREY}$ L. $\left(\mathrm{b}^{\prime} 74\right) \oplus$-Ind.8,'99;

EDEN (R.F.D., GREENFIELD), 100, HAN COCK

FEILELI, JWSSE E. (b'80) - Ind.8, 03 (1'03).

EDINBURG, 2,040, JOHNSON

Baker, Jacob V. (b'68)-Ky.5,'98: (1'99)

Blee, Lon C. (b'7I)-N.Y,10,97: (1'9

Bland, John A. (b'38)-O.8, 6

Middleton, Joln I'lios. (b'62) - 0.1,90 (l'98).

Myers, J. Porter (b'55)-Ky,4,98; (1'98)

White, Wm. If. (b'50)-Ill.4,9I; (1'97).

Wricht, Waiter Waldo (b'83)-Ind.20,0s; (l'08) : LR

\section{EDWARDSPORT, 670 , KNOX}

REFVE, JOS. I. (b'37)-Ky.2,'81; (1'97) Ind.18, $06 ;$; (l'06).

EKIN (R.F.D., ATLANTA), 175, TIPTON

Ross, I. H. O; (I'97).

ELBERFELD，438, WARRICK

Jenson, R. A.-Ky.1,'84; (1'97)

Brown, Leander-Ky.1,90; (1'97).

Grim, Simon (b'49) $\rightarrow$; (1'97).

KISTER, GEO. H. (b'T1) $\oplus-\mathrm{Ky} .2,97$; $\left(1^{\prime} 02\right)$

ELIZABETH, 238, HARRISON

BILRLY, FIRED, JI. (b'81) - Ky.1,08; (1.08).

IVEAYER, AMZI (b'73)-Ky.1,04; (1'04)

Winders, Iyman C. (b’45)- 0 ; (1'97); not in practice.

Wolpert, Wm. I. (b'59)-Ky.4,'86; (l†).

ELIZABETHTOWN, 350, BARTHOLOMEW IACKSON, CLOU1) II. '(b'76) - Ky.5,'03; (l'03).

Redman, Lonzo H. (b’ 74$)-K y .2,98 ;\left(l^{\prime} 98\right)$ ELIZAVILLE (R.P.D., LEBANON), 100 BOONE

Tucker, Jesse E. (b'70) E--Ind.5,'95; (1'97).

ELKHART, 19,282, ELKHART

I3arwick, Saml. O. (b'63) E-0.2,'94; (1'98) Indiana and Steriing Aves.; office, 119 W. High St. : $9-11,2-4, \tau-8$.

BASSLEI, CARI, IRCHARD (b'86)-Ill.11, 09; (1'11) ; 521 Riverside Drlve; office, Monger Bldg. : 2-4, 7-8; G.

Baumgartner, Atbert J.-0.8,94: (1'98).

BENHAM, FRANK ADELBERT (b50)Mich.1,74; (1'04): 505 Garfield Are. offlee, $109 \mathrm{~d} / 2$ Marion St.

Bower, Chas. C. (b'50)-Pa.1,77; (1'97). Carper, Andrew J.-Ind.I0,'82; (1'97). DEWEY, FRED N. (b'64)屯-Mich.1,92 $\left(1^{\prime} 99\right) ; 127$ N. 5th st.; office, $117 \mathrm{~s}$. Main. Hekelman, Fredk. C. (b'36)-J'a.3,60; (l'97);219 S. 2d St.; offlee, 118 W. High. 94; (l'97) ; 219 s. 2d St.; office, $118 \mathrm{~W}$ Irigh St.; $10-11,2-4,7-8$. Eiser.buiss, Chas. N1. (b'70) - Ky.1,92; (1'97); 210 Marion St.; office, 117 Marion St.

ELLIOTT, LOYD ALBERT (col.) (b'85)Ill.11,'1 : (1'11); 115 W. Franklin St. Fisler, Albert L. (b'45)-Pa.9, 11 ; (l’97) :
325 Lexington Ave.; office, 327 Lexington Ave.

FLEMING, CLAUDE F. (b's0)\$-Ill.1, 03 ; (105); 1200 Marion

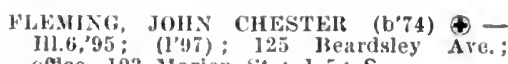
once, 123 Marion st.; $1-5 ; \mathbf{S}$.

TiNk, Cllas. W. (1'(i3)-1ll.1,87; (1'97) 000 E. Jackson St.; oltlec, 102 N. Muln sion $1: 30-$

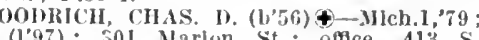
(197); sol Marlon st, offee, $413 \mathrm{~S}$ Main sit.; 9-11:30, 2-5:30; OALR.

Ilagenbuugh, Fimer J. (b'64)-0.19,05; (1'06); 731 Lexlugton Ave.; office, 416 Maln st.

Iavenslein, Geo. W. (1'66) - Ill.11,'93: (l'97) ; 817 Marlon st.; oftlee, 123 Harrlson St. ; $1-4,7-8$.

HAYWOOD, CHAS. WESLEY (b'70) $\oplus-$ N.Y.9,94; (1'04); 344 W. Jackson St. office, Monger lildg; $10-11,1-4,7-8 ; R$.
Ietsler, Orrie I. (b'71)-0.2,96; (I’97) : $4291 / 2$ s. Main st.

HILL, JOHN CURTIS (b'80)-111.17,03: (l’04) ; 710 Kilbourn St.; oflice, 124 Lexington Ave.; 1-3; OALR.

Holdeman, Eugene" (b'74)-Ind.8,97; (1'97). IIOOPINGAKNER, GEO. B. (b'59) $\oplus^{\prime}$-Ind.8 '82, 1'a.2,'88; (1'97); 509 Marion st. :

IOOVER, ENOS MUSSER $\left(b^{\prime} 70\right) \uparrow-I 11.11$, "06: (l'06); 201 Garfleld Ave.; offlce, 128 W. Franklin st. ; $2-4,7-8$.

Iuklil, Hannah Luella (b; 1 ) - Ill.11,99 (l'09) ; 212 Harrlson St. ; 2-4, 7-8; ObG.

KUHN, BENJ. F. (b'69) $\oplus^{\prime}$-Ill.8,'97; (1'99) ; 126 s. $2 d$ St.; offlee, 300 S. Main St.; $1-4,7-9 ; \mathrm{S}$.

Leib, Alfa R. - o. $t,{ }^{\prime} 86$; (I’97); not in

LOCKWOOD, REUBEN L. (b'58)-0.7,'88 ; (l'97); 901 S. $2 d$ St.; Office, $4011 / 2 \quad \mathrm{~S}$. Main St.; $8-11,1-5,7-9 ;$ OALR.

Markel, Ivan Jaules (b'86) - I11.1,'11; (l'13); 124 W. Franklln St.

Mast, Jacob Creston (b'68) - Mlch.7,'94; (1'97) ; 303 High St. ; offlce, 305 S. 3 i St. Mlles, Franklin-Ill.1,74, Ill.6,75; (1'05). MILLER, SAML. T. (b'83)-III.6,'10; (1'12); 206 Garfield Ave.; office, 111 Marlon St. $1-5,7-8$.

MURPHY, ROBT. M. (b'60)-Mo.22,'89, Pa.2,'92; (l'00); 326 Vistula St.; office, 4 II S. Main St.; $9-11: 30,2-4,7-8$.

NoRRIS, ALLEN ANSON (b'76)థ-111.1, '06; (l'06); 401 Marlon St.; offtce, 415 Main St.; $2-4,7-8$

Randolph, Frank (b'65)-Mlch.1,'92; (l'99) 636 W. Franklin St. ; office, Monger Bldg. 2-4, $7-8 ;$ OALR.

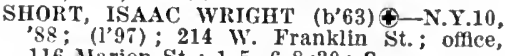
116 Marion St. ; $1-5,6-8: 30 ; \mathrm{S}$.

SPOHN, GEO. W. (b'57) €-0.1,'87; (I'97); Franklin Beardsley Are.; office, $130 \mathrm{~W}$ STAUFFER, WALTER " (BI); OALR. * IIl. 6,04; (1'05); 659 strong Ave.; offlce, 121 Marion St.; 1-5, 7-8

STAUFFT, IHANNAH OPHEIIA (b'68)థMich.1,02; (1'03); 3041/2 S. Maln St. ;
$1-4: 30$.

ORK, JAMES ANDERSON, SR. (b'45) 1-4, i-9;:ObG.

WORK, JAMES ANDERSOY JP (b'83) office, Monger Bldg.; 11-12, 2-4:30, T-8; G. WORK, PAUL BARTHOLOMEW (b'85) llich.1,11; (temporary permit,'13) : 306 Division St.; offlee, Monger Bldg.; 8-10, $2-4,7-9$.

ZIMMHIMAN, ERASTUS R. (b'76)Ave : 2-4, 7 -8.

ELLETTSVILLE, 676, MONROE

HARRIS, OLIYER K.-Ky.4,'96; (I'97),

HAlRIS, WALTER W.-Ky.4,'89; (l'97).

l'resley, Isaac N.-Ind.15,'85; (1'97).

ELLSWORTH, 50, DUBOIS

Whittinghill, Benj. F, (b'44) - ; (l'97).

ELMDALE (R.F.D., CRAWFORDSVILLE), 50, MONTGOMERY

Olin, Levertt W. (b'5̃1)-N.Y.1,'80; (1'97). ELNORA, 961, DAVIESS

Adkins, Onan Chas. (b'7 7 )-Ind.18,07 : ('’07).

(l'13). 


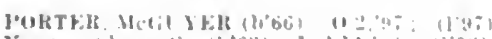

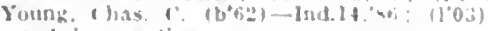

In fisactlon.

ELWOOD, 11,028, MADISON

Adalr, Cosh (lins)-Ky.1,91; (199;) $1531^{2}$ Maln Ni.

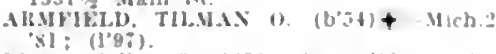

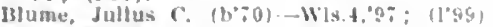

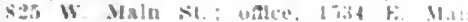
St: $9-12,2-6,3.9$

Cotton. Carrol i, (h'6i)-Ky.,291; $\left.11^{*}:\right)$

$119 \%$ s. Anderson st.

plek, chas. (i. (b'66)-1a.9,95; (1'9y)

lederer-Hene Iluck.

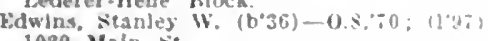
1020 Man sit.

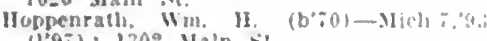
(1'97): 1309 Maln $\mathrm{il}$.

Jessup, Juhn T. $(6+9)-$ Ind.4, 33 ; (1:4) not in practice.

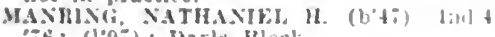
76 : (1.97); Dark Hock.

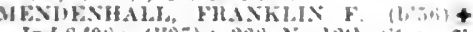

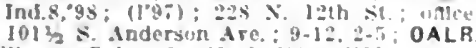

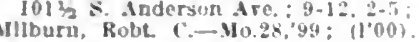

Mott, Luther A. $\left(b^{\prime} ; 1\right)-$ U.i3, $(00$ : 12i: South A $\mathrm{si}$.

Newconer, Cirant $v$. (hobi) Ind?. ol $(1 \circ 99): 608$ s. Indersen st.; onlce", i.ed erer-hene Hock: 111-32, $3=-;-5$

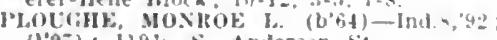
$\left(19^{\circ}\right): 11925$. Anjerson si.

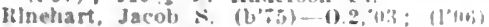

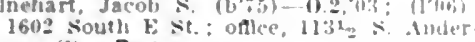
son St.; Pr.*

HLXIX: (HANIULER FRFSTON (b"a)-

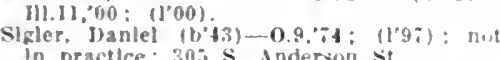
In practlee; 305 s. Andersoli st

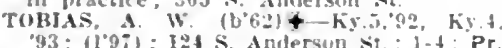
93: $\left(1^{\circ} 9:\right)$ : ILt S. Andersun si.: $1-t ; \mathrm{Pr}$

EMINENCE, 238, MORGAN

kelso, kimer $\mathrm{k}$ : (b'63)-Ind 8,91; (1"17)

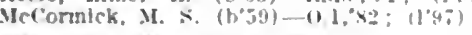

ENGLISH, 383, CRAWFORD

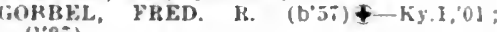
$(1.8 \%)$.

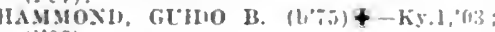

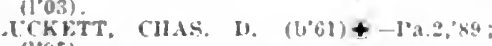
$\left(1^{*} \varphi_{i}\right)$.

EPSOM (R.F.D. PLAINVILLE),
DAVIESS

125.

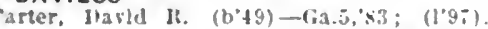

ERIE (BEDFORD P.O.), 20, LAWRENCE

Butler, Wm. (C. (b')-

ETNA GREEN, 431. KOSCIUSKO

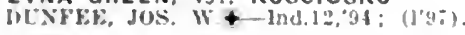

EUREKA, I50, SPENCER

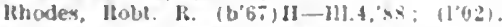

EVANSVILLE, 69.647, VANDERBURG

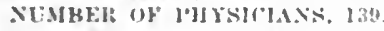

Alexander, liuth (b'85)-l'a.i,"by: (1'12) Southern Indiana Hosplial for the Insane.

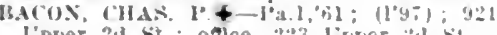

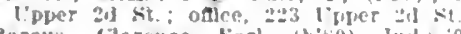

Barcus, clarence biarl $\left(\mathrm{b}^{\circ} 80\right)$-luds 03 (103): 3122 loper ad 51 .

แ10.MAs, J(H.

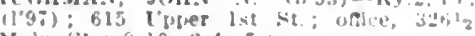
Maln S: : R-10, "-A. i-s

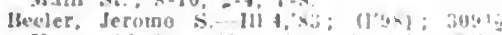
Ipper "d si, oflce, 3a and Malr; -10 I-1:Pe.

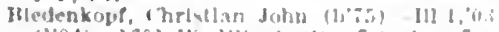

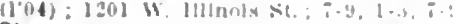
ob.

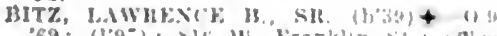

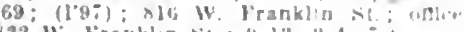

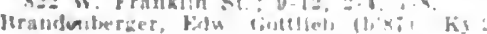

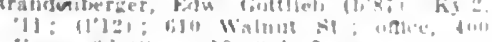
\bijet

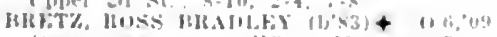
(impurary permile:lis) Mamer T.Bu

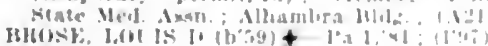

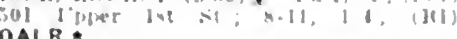

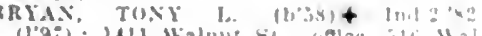
(1'9i): bll Walume sio tuflco, illi ilat

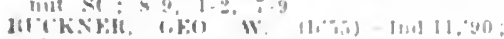
$(1, i):=10 \mathrm{lnh}$,i
AIX, IDANL H+-Ky, 1,93: (1295): 1111 ining

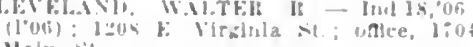

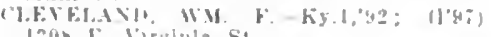
Izhn L. Virdinla St

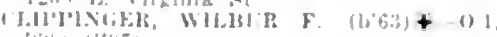

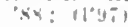

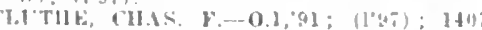
Fintein ilve

Linwomal Are.

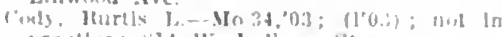
mantlo: s] W. Indlana st.

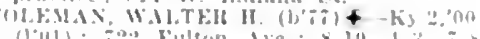

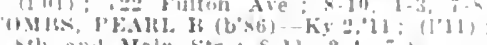
th and Maln sis: $5-11,2-4$.

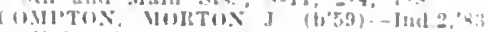

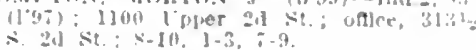
(anmelly. Jish Jullan

Ibealcomesa IInopllat.

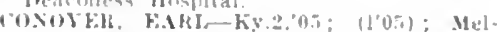

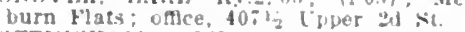

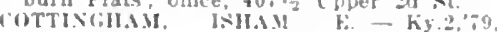

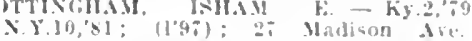

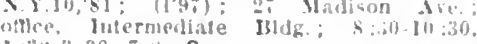
$1: 311-3: 30, \bar{i}-\mathbf{S}: \mathbf{S}$

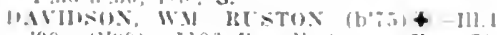

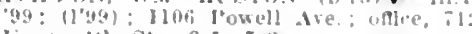
inier th st. $3-5, \quad i-5$

nals, Flbivivi l.kWls

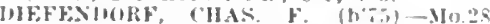

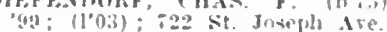

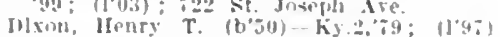

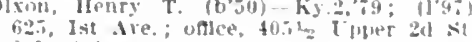
$8-9, \ddot{2}-4$

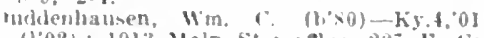
(1.02); 1913 Maln st.; onle, 200 F. Co

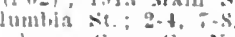

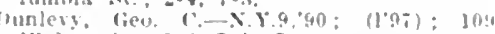
Walnut $51 .: 1-3,7-8 ;$ S.

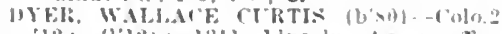

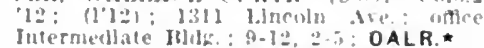
EIrRICIT, WM. \&. (t) 'Ds: 1lo9): 429 Marenswom lve: otter.

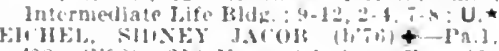

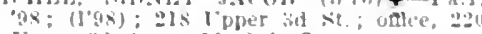

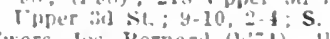

bwers, Jus. Hernard (10-1)-ill 1, (1) (1'10)

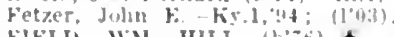

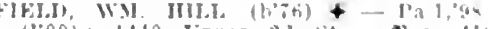

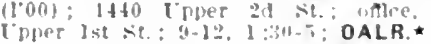

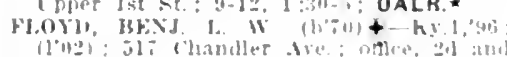

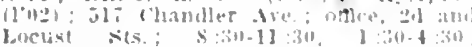
LALR'.

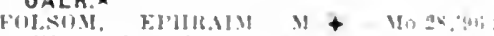
(1001) : 12:4 chandler Are; unce, Womb lle?g: : 1-: : Pr.

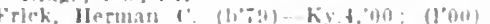
219 Warhlng(on Are, whice, $20 \%$ J. til

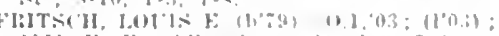
I111 fo Franklln si. \& 10. 1-\$. PIITSII, WM A (1) $1,+1 ;(195) ; 619$

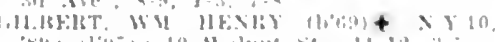

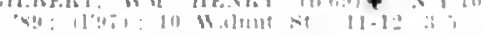

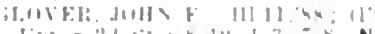
henescks di

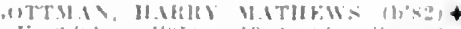

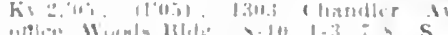

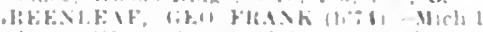

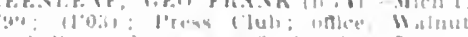

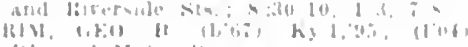
Hil and Wain $\times 10$

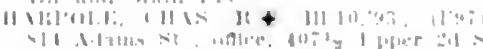

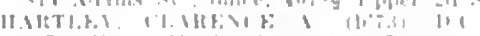

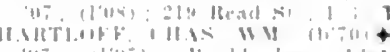

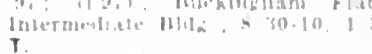

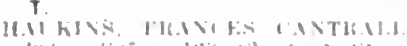
$\operatorname{ll}\{1,0\}$ Anes.

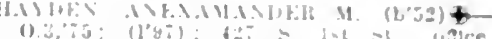

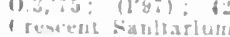

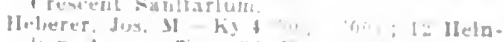
leen ile ; wase. 32

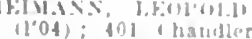

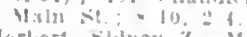

IIterlers, slumey z- Mllh l, as

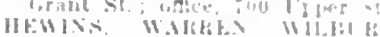

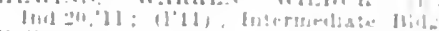

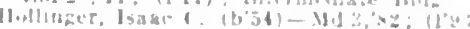

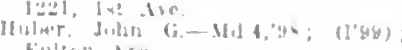

Fontom dit

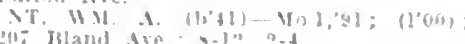

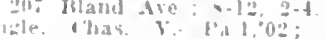

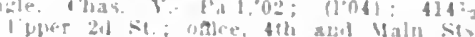

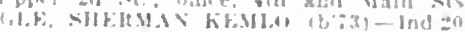

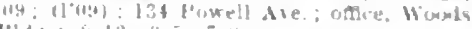

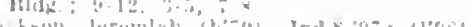

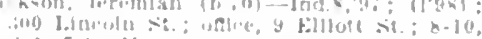

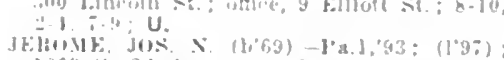

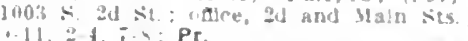
11. 2 4. :- Pr. Pr.

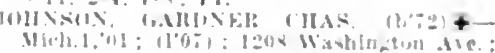

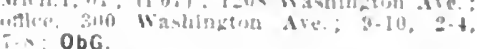

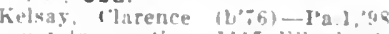

and In practice: 1117 lllewels st

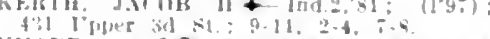

KNAPr. I. J \& Tenn 6,93 (I9i) 218

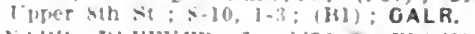

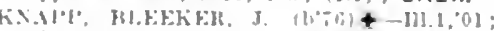

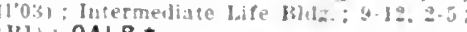
(Ii) ; OALR.*

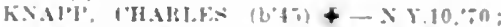

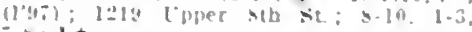

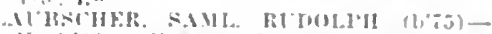

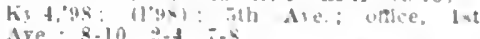
Ire.: $8-10,-4=7,-4$

1.MVIIIJX, "HAS k. (b'5is) + $0.9,75$ : Imilana Iuaglabl for the Iname: (1:3); P.

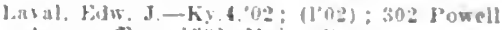

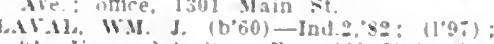

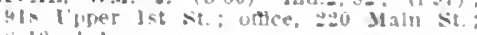

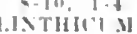

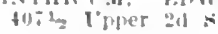

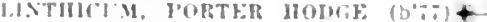

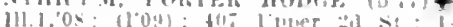

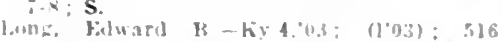

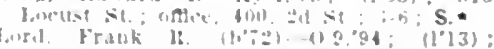
(Inmlueres: "the, stabe Huphal for Inathe: NP

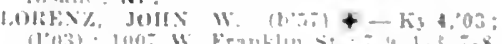

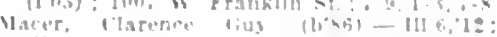

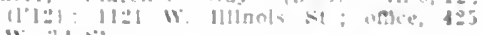

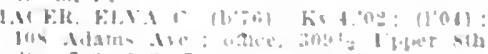

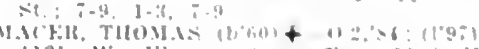

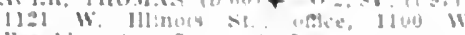
Franklin st. $\div-4$.

年

le(l.liskls, Jus o $19 \%+x y 10$

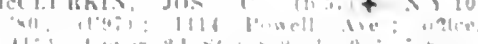

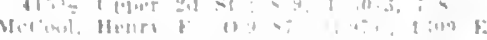

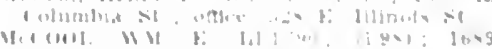

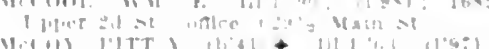

14.30 loper at Ne. Mice. 201 is Ma:n

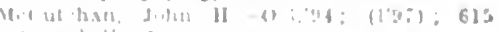
(1)

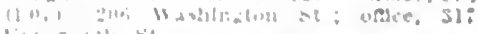

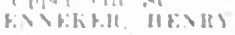
- Kis :.95: 


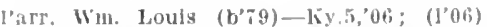
408 Llne St.; oflce, fay Mín si. $10-12,2-4,7-5$

l'aterson, A. 1R.-Ky.1, $02 ;(1 ' 05) ; 722 \mathrm{st}$ Joseph st.

['eckinpaugl, Geo. I3. (b',5) - 0.1,'82: (199); 610 Waluut st.; once, 400 T"uret zd St.; 8-10, 1-4, 7-8.

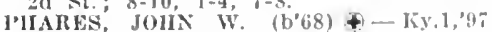
(1'07); 1023 Inlverslde Ave, olthe, 20 Walnut st.; $9-10,3-4$.

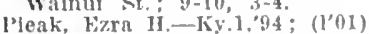

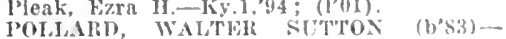
Ili.11,11; (1'12); 514 S. $2 \mathrm{~d}$ st. ; uffere, 415 s. $2 \mathrm{~d}$ st. $; 9-10,1-3,7-8$.

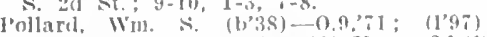

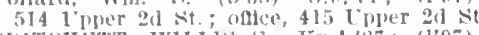
l'BITCHLTT, WIIIS s.-Ky.4,8 ; (1'97) 814 Washington Ave; offlce, $332,2 \mathrm{~d}$ Ave kalston, W11. ('. (1)'19)-Ind.2,73; (l'97) 614 Ipper 4 th st.

WAVDI, MARCUSt-Tenn.8, 00 ; (1'01) : 426 Grant St.; ofltce, 223 llain St. ; 10-12, 2-5; (Bi); OALR. $\star$

16-12, 2-5; (IBI); OALR.ћ 718 Baker Ave.; $8-10,2-4,7-9$.

718 Baker AVe; 8-10, $2-4,7-9$.
HHTZ, PAUL CIIAlRIES $\left(b^{\prime} 75\right) \oplus-11.1,98$; (1'99); 903, lst Ave.; offee, American Trust Bidg.; 2-4; S.

loosli, BENONI S. (b'69) - Ky.4,94; $\left(1^{\prime} 97\right) ; 26$ E. Pennsylvanla st.; oftlce. 24 F. lennsylvanla St.; $7-9,1-3,7-8$.

ROTIlROCK, MHLSON W.' (b'7z)-Ky.1, 04 (I'04); 612\% Fulton sit.

ROYSTER, WMI LUTHER (b'83)-Ky 9,06 (l'06) ; 618 Riverslde Ave.; offlce, Woods Bldg: $9-12,2-5,7-8$

RYERSON, ESTIIER ANNE (b'64) Ill.11, 03 ; $\left(l^{\prime} 07\right)$; Member Ia. State Med. Soc.; Woodnere; NP.

Sinders, James M. (b'57) - Tenn, 8, 00 ; (I'04); 721 IIarriet St.

Schellhase, Fredk. Wm. (b'4l)-Mo.5,80 (1'97) ; 922 Main St.

Schuyler, I'eter 11ry-M1ch.1,62;

122 Uiper ith St.; $10-12,4-8$.

Seltz, Chas. I. (b;7)-Pa.1, 99;

(1'97);

Smith, Alexander C. (b'46) - Ky y.8,'98;

(l'98).
STORK, JOHN WESLEY $\left(b^{\prime} 71\right) \oplus-K y .1,95$; (I'97); R.F.D. 3.

TAYLOR, FUGFNE C.-Ind.8, 03; (1'03) 1200 Cherry $\mathrm{St}$.

TAYLOR, THLODORE H.థ-0., , 82 ; (1'97) ; 719 Upper 2d St.; oftlce, Woods Bldg. ; $8-10,1-3,7-8 ; G$.

'TEPE, GEO. W. (b'71)Ð-Ky.5,93; (1'97); 611 Chandler Are.; offlee, 306 Divislon St. : $9-10,1-3,7-8$.

THOMAS, JAIIES (b'61)€—Ky.4,'94; (1'97).

Tully, Lee H. (b'69)-Ky.4,'90; (1'98); 1113 Washlington Ave.; office, 307

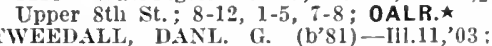
(l'03); 812 W. Indiana St.; offlce, 826 w. Franklin st. : $8-10,1-3,7-8$.

VARNER, GEO. W. (b'62) $\oplus-\mathrm{Ky} .1,{ }^{\prime} \mathrm{S} 6$; (l'97); $90 \pi \mathrm{W}$. Franklin St.; offlce, 1002 W. Franklln St. ; $i-9,1-3, i-8 ; \mathbf{S}$.

VER WAYNE, EDW. J.-O.3,'97; (1'97) 516 Line St.; offlee, 325 Walnut St.

VIEII E, C. H.-Mo.5, $76 ;(197) ; 18$ Mary St. : $8-10,7-8$.

VIEHE, ROBT, WV \&-Pa.1,05; (l'07) : 420 Waslington Ave.; offlce, $50 \%$ Upper 1st st. : $1-3,7=8$

WALKER, EDW1N (b'53)†-Ind.2,74, N.X.5,79; $(1,97) ; 712$ S. 4th St.; 2-4: (A1,6, C3); s.

WARTER, PHILIP A. (b'it)-Tenn.5,00; (l'00); 31 sladison Ave.; office, $427 \mathrm{~s}$. $3 d$ St. ; 11-12, 3-4, 7-8.

Weever, John B; ( $1-3,7-8$.

WELBORN, JAMES YORK (b'73)—-Mo.27, 99 ; (1'99) ; 400 Chandler Are.; offlce, 712

S. 4th St. $2-4 ;$ S. ${ }^{2-4}$
Werry, Leslie Edward (b'83)-Ky.2,'13; (1'13); United States Marine Hospital.

Whitinghill, J. I. - Ill.35,'96; (l'97) ; R.F.D. 2.

Wilde, G. O.- $\diamond ;\left(I^{\prime} 09\right) ; 4$ Lincoln Ave

'ilson, Arthur Henry (b'76)-Ind.18, 07 ;

$\left(I^{0} 07\right)$; 5 Lincoln Are. ; 8-30-10, 2-4, 7-8;

DALTON (b'72)-Ind.8,'94; $\left(\mathrm{l}^{\prime} 97\right)$; Columbia St.; $\mathrm{s}-10,2-4,7-8$.
Wilton, Isalih (b'46)-Ind.13,83; (1'97); ut: Lower 20 st.

Witling, Anthony $\cdot$ P. (b'53) - Рa.2,79; (l’97); 625, 1st Ave. ; $2-4$.

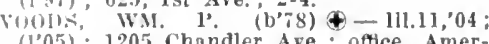
(l'05) ; 1205 Chandler Ave.; office, AmerIcan 'Trust 13ldis.: 2-4: S.

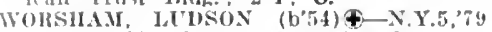
(1'97); 608 Adams Ave.; offlee, Furniture IBlelg.: $8-10,1: 30-3: \mathbf{S}$.

leck, (has. Waller (b'84)-111,6,'11; (1'12) 300 frant $\mathrm{St}$; $9-11,1-3,7-8$

Yongue, Win. Johnston (b'89)-Ky.2,'13; st. Mary's ilospltal.

YOUN, GFo. M. (b'55)-l'a.1,83; (1'97) Stratford; offlce, $416 \mathrm{~S}$. 1st St. ; 8-10, 2-4; S.

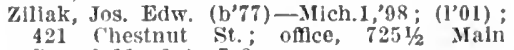
St, : $9-11,2-4,7-8$.

EVERTON, 150, FAYETTE

IITCHFL, FRANK IELAND (b'72) Ind.9,'03; (1'03).

EXCHANGE (R.F.D., MARTINSVILLE), 70, MORGAN

Wharton, J. 0.-Ind.4,77; (1'97).

FAIRBANKS, III, SULLIVAN

BLAND, HERBERT E. (b'73)-Ky.4,98; (1'98).

Julian, Edw. T.-Ky.1,'91; (1'97).

FAIRFIELD (R.F.D., BROOKVILLE), 200 , FRANKLIN

Linegar, John M. (b'62)-Ky.4,'94; (l'97).

Preston, Abraham lincoln ( $\left.b^{\prime} 60\right)$-Ind.8, '84; (1'97).

FAIRLAND, 513, SHELBY

SNIDER, IOHN W. (b'45)-Ill.1,'70; (l'97) STRICK1ER, STETHEN L. (b'53)-0.2,79; (1'97); G.

WELIS, M. M. $千$-Ind.8, 01 ; (1'03)

FAIRMOUNT, 2,506, GRANT

Brown, Chas. Newton-Ill.8,'97; (1'90).

HENLEY, GLENN (b'70) $\oplus$ - Ill.17,'99. $\left(l^{\prime} 00\right)$.

IIOLLIDAY, DANL. A. (b'59)-Ky.1,'93; (1'87).

HOLLIDAY, L. D. (b'84)-Ind.8,'05; (l'05) Horton, Caleb John - Ky.1,96; (l'05); R.F.D. 21 .

Seale, Jos. P. (b'76)-Mlch.1,'99; (1'99).

FALMOUTH, 175, RUSH

IREA, CHAS. L. (b'59) -0.1,'84; (1'97).

FARMERSBURG, 1,115 , SULLIVAN

Bennet, Jonathan H. (b'44) E-0.2,72; (1'97)

McGrew, James E.-Ind.6,77; (1'98)

OLH'HANT, JACOB THOMAS $\left(\mathrm{b}^{\prime} 80\right) \oplus$ Ind.8, 05 ; (1'05)

VAN CLEAVE, ROBT. H. (b'53)థ-Ind.2, 79; (l'97).

Housmyer, Chas. C.-E-0.2,'04; (1'06).

FARMLAND, 907, RANDOLPH

BOTKIN, CHAS. LEANDER (b'78)€-Ind.8,

04: (1'05); OALR.

Botkln, Thos. W. $\rightarrow$; (1'97).

CLRRENT, ORPHEU'S E. (b'71)-Ind. 8,97 (1'97); OpAR.

N1XYON, JOHN-0.1,82; (l'98)

Nixon, John Sater (b'87) -Ind.20,'12; (1'12).

FAYETTEVILLE, 125, LAWRENCE

Allen, Edward F. (b'38)- 0 ; (1'97); not in practice.

FERDINAND, 827, DUBOIS

KNAPP, YICTOR (b'57)థ-0.1,81; (1'97). SCHRIEFER, ERNEST EDW. $₫-\mathrm{Ky} .2,06$; (1'06).

FILLMORE, 180, PUTNAM

AMICK, CHAILES LEONARD (b'85)-Ky.2, $11 ;(11)$.

BASTIN, JOEL Y. (b’59)-Ky.l,'87; (l'97).

FINLY, - HANCOCK HAWK, EDGAR ALLEN (b'79)-Ind.9, 05

FISHERS, 188, HAMILTON

Black, Vinton G. (b'74)-Ind.5,09; (1'09)

Heath, J. P.-Ind.4,79; $\left(1^{\prime} 97\right)$.

Lyle, Arthur W. T.-0.1,68; (1'97)

SCHERER, SIMON P.

FLAT ROCK, 400, SHELBY

SHAW, CLÁRENCE W. (b'; 6$) \Phi-0.1,01$; (1'06).

Wertz, Edw. R. $\rightarrow$; (1'02)
FLORA, 1,386, CARROLL

I3rown, Nathaniel F. (b'49)-O; (1'07)

IBIUUAKER, ELIAS IIAIRY (b'80)-Ind.8 $05 ;$ (1'05)

(ALILANE, MARSHAI, D.-Ind.8,'02; (l'02) Cook, Andrew J. (1, 5, 1$)-0.2,84 ;(1,97)$.

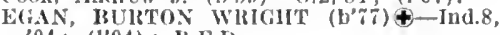
04; (I'04); R.F.I)

IIorner, Blanche (b'88)-Ind.20,'10; (1'10) ; ObG.

KEARNS, TIOMAS ALBEHT (b'78) $\oplus-$ Ind.8, 04 (1'04).

IYYNS, FRANK P.-Ind.8,81; (1'97).

1'ETER, ISDW. L。 (b'61) 4 -Ind. $8,{ }^{\prime} 89$; (1'97)

ETERS, THOMAS D. (b'85)-Ind.18, 06 ; (1'09)

Shirar, Lewls $\left(b^{\prime} 60\right)-0.2,01 ;\left(1^{\prime} 02\right)$.

FLORENCE, 240, SWITZERLAND

TO1D, IIENRY J. (b'83) +-IH.6,'07; (1'08) Langsdale, J. M. IV.-O.1,74; (1'97).

FOLSOMVILLE, 4I0, WARRICK

Barnett, Warrick (b'82)-Ky.2,'11; (1'11)

Williams, Quincy I,-Ky.1,'94; (1’9i).

FONTANET, 521, VIGO

Newlin, Edgar Oriel (b'76) - Ind.5,04; (1'05).

FOREST, 300, CLINTON

Duncan, Saml. O. (b'67)-111.1,96; (l'97); R.F.D.

OLIPHANT, IXOMER N. (b'80)-Ill.17, 08 ; (1'0S)

Suhre, Edw. F. (b'69)-Ind.9,'97; (l'98).

FORTVILLE, 1,174, HANCOCK

HERVEY, SAML. IV. (b'65)-Ind.8,'87, 0.1, 91 ; (1'98).

IeCORD, CILÁS. E. (b'70)-Ind.8,'95 ; (1'97)

SLOC'M, STEIVART (b'68) $\oplus$ - Ind.9, 00 : (l'00).

Wibam, Saml. I.-0.I, 79 ; (1'01)

FOUNTAIN CITY, 448, WAYNE

IUFF, OLIVER N. (b'52)-Mich.1,78;

GRIFFIS, WM. T. $\left(b^{\prime} 47\right)-0.2 ; 71 ;\left(1^{\prime} 97\right)$.

FOUNTAINTOWN, 455, SHELBY

Lowden, John $\left(b^{\prime} 49\right)-0.2,78 ;\left(1^{\prime} 97\right)$

Miller, Ephraim B. (b'65)-Ind.8,'97; (1'97)

Nave, 11. E.-Ind. 17, 05; (1†).

FOWLER, 1.491, BENTON

COOK. CLARK (b'53)-Ky,1,81; (1'97); S

GREEN, NELLIE E.-
LE SAGE, ARTHUR (1'97); (1,04).

MAVITY, DAVID EVERETT $\left(b^{\prime} 70\right) \oplus-$ Colo.3,'92; (1'97).

Morehouse, James L. - 0.3,'97; (1'01); LR.

FRANCESVILLE, 729, PULASKI

Ives, Raymond Judson (b'85)-Ill.4, 08 ; (1'10).

Sharrer, Frank Leslle-Ill.11,'06; (1'08).

Sharrer, John C.-Ky.1,80; (1'97).

FRANCISCO, 407, GIBSON

SWAN, DUDLEY H. (b'68)-Ky.5,00: (1'00).

FRANKFORT, 8,634, CLINTON

Andrews, James (b'46) H-0.13,'80 ; (l'00) : G.

Bergen, Edw. D.-I11.10,90; (1'97)

BOULDEN, MELVILLE F. (b'69)-I11.17. 03 ; (1'03) ; G.

Bowers, Valentlue-Ind.9,80; (1'97)

BROWN, GEO. W.-Ill.1,66; (l'97).

Canfleld, Moses S.-E-0.2,73; (1'97).

CHITTICK, ARCHIBALD GOLDING (b'83) -Ind.18,'07; (1'07).

CHITTICK, CHARLES (b'49) (-0.1,76; EDMONDS, OSCAR W. (b'61)-0.3,'86;

Endicott, Clayton A. (b'81)-Ind.21,'07; (I'07); R.F.D. 9. JENKINS $\left(\mathrm{b}^{\prime} 64\right)-\mathrm{Ill} .1$, $90 ;\left(1^{\prime} 00^{\circ}\right)$

GARD, OLIVER-Ill.1,'69; (1'97); not in practice.

HADLEY, JAMES WILLIAM $\left(b^{\prime} 73\right) \oplus-$

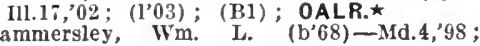
(1'99).

Hill, Clarence--Ind.8,'98; (1'98).

Johnson, John M. (b'58) P-M-ind.26,'94; (l'98). Frank Collett (b'63)-111.6,'89: Jones, 
McCAITY, MLTON T. (b'63)-1nd 9.02: (1'03): OALR.

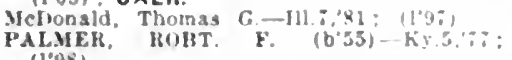
(1.98).

Kuddell, Benson-Ind 8,00: (1'04)

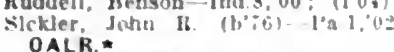

SIMS, STEPHEX HEFCHER (b'fH)-III.] '84: $\left.\left.(1)^{\circ}\right)^{\circ}\right)$

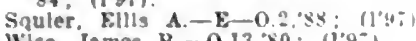

Wise, James $\mathrm{B}-0.13 .80$ : (199)

Zinn, Chas. A-Ind.9.97: (1197)

FRANKLIN, 4.502, JOHNSON

Byers. R. S, (D'52) - Ind 8.80; $11^{\prime} 9:$

DIII, John W. (b'13) H-111ch 5,79: (1'03)

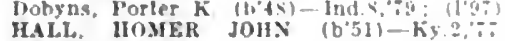
(1'yi) : Ob.

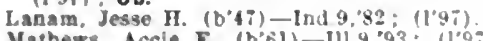

Mathews, Accle E. (b'61)-111.9,93: (1'98) (l'12).

Ott, Lymen E.-1'a.2.82: (195): not in practlce.

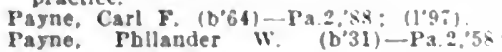

(I'97).

Payne, Roscoe W. (b':2)-N.Y.10,96; (1,97)

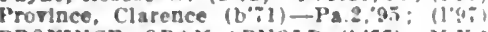

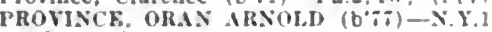
02: $(1102)$

RECORDS (1.9i)

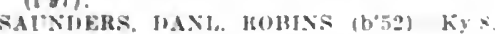
MiLice. (l'A9). BARNETT (b'36)-Pa.2,'6i: (1.97).

WHITESIDES, LINDSET L. $\left(b^{\prime} 60\right) \mp-k y, 2$ 83, 13.11,09; (1998).

Wood, Joseph" Jones (b'St)-Ind.20,'10: (1'10).

\section{FRANKTON, 936, MAOISON}

French, Wm. J.-0.8,79; $\left(1^{\prime} 9 i^{\circ}\right)$

PECK, J. L. WERSTER $\left(b^{\prime}, 0\right)$-Ind.5. 95

Wright, Cyprlan B. (b'62) -Ind.8.88: (1'88)

FREDERICKSBURG, 27I, WASHINGTON Cook. Wm. Henderson-ky.1,95; (1'04).

Deweese, Geo. W-O; (1'9:).

Halston, Alanzo 11. (b'60)-Ky. '97: (1'05).

FREEDOM，285, OWEN

Branham, Jonathan-: (1'03)

HAZEL, JAMES T. (b'69)-K). 5:00; (1'02)

Plew, John II.-E-0.16:'S0: (1'04).

FREELAND PARK, 300, BENTON

Beaty. Gran: S. KK.5.'97; (1'04).

FREELANOVILLE, 500, KNOX

For, Rlchard H, (b'68)-Ky.1,98: (1'98)

Mebowell, Leonldas C:-Ky.5, $; 9$; $\left(1^{*} y^{7}\right)$.

FREEMAN, 10, OWEN

L) vingaton, John J. (b.5.) E-Ind.11,'sl (1'9i).

\section{FREMONT 694, STEUBEN}

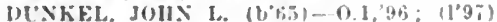
MOORE, (HAS A (1), 11$)-11,00 \vdots(100)$. WALE, ROBT, LAVEHS (b'i)-IH.11,0i $\left(1^{\prime} 0^{\circ} i\right)$.

FRENCH LICK, 1,803, ORANGE

DILLLNGE, JOS. R. $\left(b^{\prime}, 5\right)-K y, 03$; (I!03):0 0 .

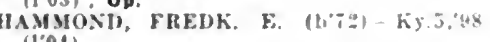
(1'04).

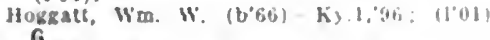

WOWBY, WM. ATW001 $($ b'80)+ $+11.6,10$ : (1)12).

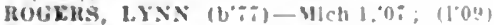

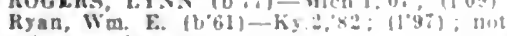
In practice.

Senerf. John II. $\left.(1)^{\prime} 54\right) \rightarrow$ : (1'yi)

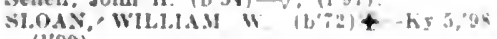
(1.93).

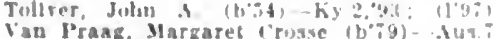
0o: not in practice.

FRITCHTON (VINCENNES P.0.). 50.

KNOX
"HUIBCII, LEE O. (b\%)
(l'OS).

FT, DRANCH, 1,182, GIBSON

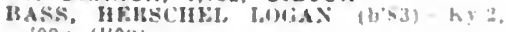
"rench. W, w, (b.31)-Va 1:79; (19yi)
Huklas. WM 4. H161-XY10, мй[н]:

(1.00)

FT. RITNER, III, LAWRENCE

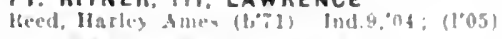

FT. WAYNE, 63.933, ALLEN

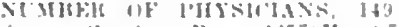

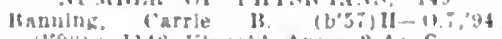
(1095): 11th kincald Ale. :-4: G

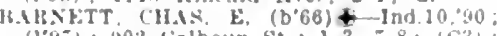
$\left(10^{\circ}\right) ; 002$ Calthoun st.: 1-3, :-8; (c) U.*

Haruett. Walter Wygn-Ind.10, $66^{\circ}$; $(1964)$ iti liroaluay.

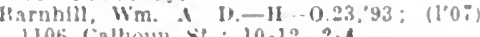
IIntio Calt

Itarry, (ien) A - E $\rightarrow 0.2,05 ;(1 ' 05) ; 194]$ rantleld Are.: $5-9,1-3,6 ;-4$,

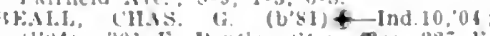

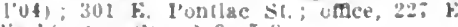
Washington si: $1-3, \pi-8$

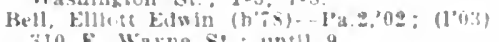
310 E. Wayne S?: untl 9.

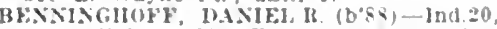
11; (1'11); 1009 E. lewls st. o otice ohin and $F$ l,ewis sis.

BICKEL, JUIN E. (b'is) - - 1nd.8,9; ; (1'9i); 506 E. Lellald st. ; $:-8: 30,12+2$, Blackstone, Wm. 13. (b'po)-Ill.6, $84 ;\left(1^{\prime} 0 t\right)$ : Blackstone, Wm. B. (brot-m.6, 1 ; Wot)

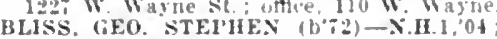
Yember Mass. Med. Soc.; Indlana schel for Feeble winderl: P.*

BLOSSER, MLAINE ANINEEW (U'81)otice, 626 Harrisun st.

H,OSSE.16, HOWARD V. 309 W. Maln St. $1.3,7-8$.

BOLMLI, HALFH M-Ind.10,05: (I'05)

1t, нers, Jesse W. (6.82)-0.2,0.: (1'08) 1315 Wells St.; oftce, Shoat Rldg. $1-3: 30.6-8$.

HRIG(IEMAN, HENBY OTTO 16'80)-111. 03: (1.04); 711 Pairfleld Avo,; oftice.

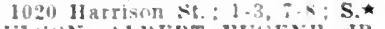

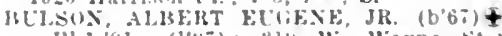
-111.1,91: (10:): $21 \%$ W. Wayne st. 10-4: l'rus. Onhth., Ind 20 : (B], OALR。

Calvin. Jeswie Carrithers (bob)-111.9.45: (199): 235 W Wayne st. 10-12, 1-3.

"ALVIX WAKHEN W. (b6) + 111.1.45:

carrada, clement do (b'so)-inds.of (1.04): 2620 Fox Ave

Canada, Jonathan Eiverett (b'as) Ind.:0.

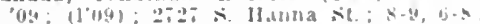
oftce, liat be lierry st. : $:-1$

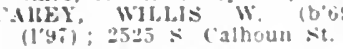

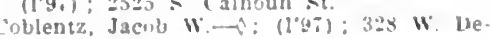
wald $x$.

CHCLL, ERIC A (b'a) + HO 26,97

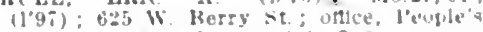

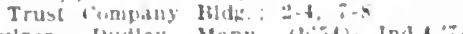

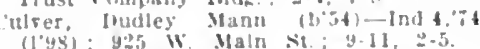

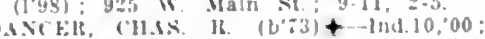
(1'00): 905 ialformia Ave. ance, 20s Ii. Herty sit: : $2-4,7, x$

De La Ruhl, Whilam $(6 \cdot 56)--1$ nd $: 0$, is: $\left.\left(1, y_{i}\right): K . B^{2}, 1\right)$

worhyshire, lauella Ickinley-Ind 10,'ss:

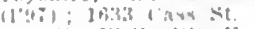

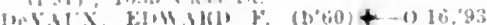

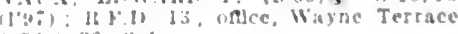
$x: 30-3: \div 0,: 2$

lings. Wu $11-h)$ tyt: $\left(1 y^{2}\right)$; $1: 0$ W

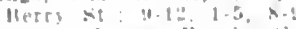

binnen, James rrank (b.83) -lus :0,06

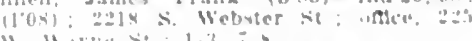

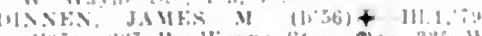

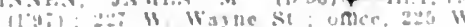
is.

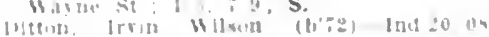
(liva).

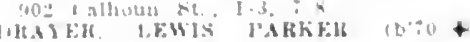

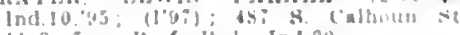
1! 3. - . l'rul lioul Ind 20

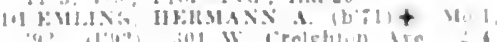

Eberhard, Freals

(1'12): A Arthus in il

blerly har! Got?

Ellitirith

illarrion

Mist:

REILISH, CAISTS H

(l'yi): 2535 \& Heluter sit; ont

Berfyst.

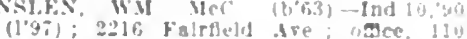

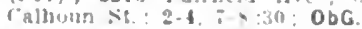

Falr, C. S Ind 10.9t; (1'ui); tot in prac Icte long Ilanna st.

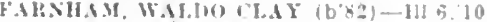
(1'13); 21 E. Creighton Are.: 11-1; :-4.

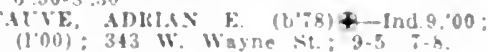

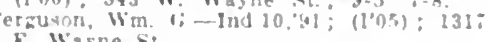
f. Wayne s:

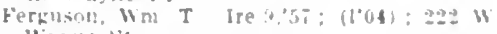
Wasne si:

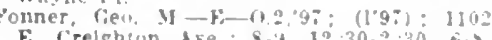

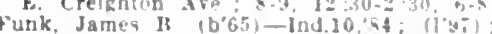
1112 sit. distegh Blod: velce, 119 W wing st.

IAMTISER, I.EO I. (b'82)-MU.4:0: $\left(1^{\prime} 10\right):$ :20 Old Fort Pl.: once, Shoan

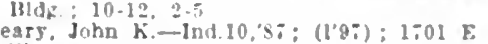
Wayne st Collpln, John II-Mich.1,02; (1'06); $218 \mathrm{E}$

GLOC $\mathrm{k}$. HOMYR E. (6.7) + Ind.10,03: (1005); 1015 Lake Are : otmce, $930 \mathrm{Cal}$. louts st. : 9-12. 1-4: OALR.*

GOBA, BE.THAE-Ind.10,0.7; (1'05); 339 16. Berry st

Goheen, Charles M (b5\%)-Ind 10, sz:

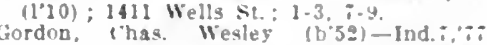
Gordon, (has Wesley (b32)-Ind... $10-11,3-4$

GRANOY, CHAS. CIANCY (b'S5) - III. , '11: (1'11): sil Wildwood st. : R.

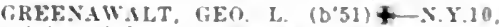
"s0: (1"yot): 501 E. Wagne st.: 12:30-3, $6: 30-8$. iriebel, llerman G. (b's2)-1nd.10,02: (iRoss. Wy oTro (b"il)-1nd.10,93:

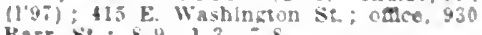
Barr st. : 8-4, 1-3, i-s.

Ifamiltinn, Allen 1604$)$ XY. 102: (105): 337 W. Waspe st. : 1-3, i-4

IJanaway, Nellle Jabe (b'sy) - Ind a0,do (1'10): Indiana school for Feeble Mlnded Youths.

Hardman, Walter E. (D'it)-Ind.8,?50. (1.39)

Harrod, John-E-0.2.8:; (1.00): 214i Ifanna St: $1-3,6-8: 30$ : $\left.11^{\circ} \%\right): 634$ E Wastingtion st.

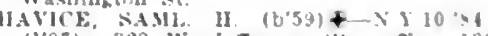

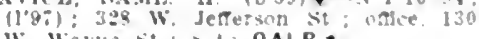
W. Wayle st: " t: OALR.

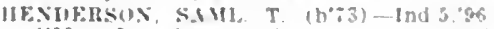
(1'00): Hroadway and scoth dre : -10 .

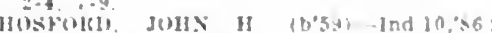
(i10): 295 W. lewald st, : ace. Kanget 13lis

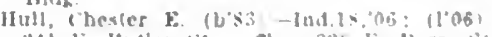

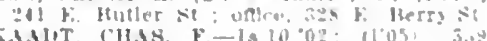
hidlit, chiss. Fo

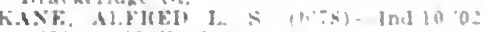
1103 : 253 W. Wasino

kell. prank

solt 1"alhoun st. : 1

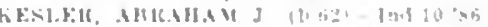

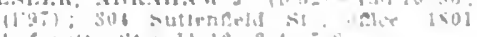

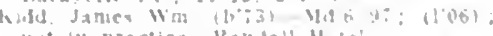

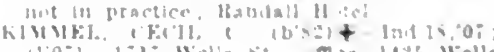

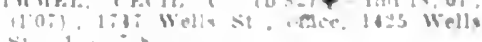

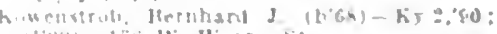

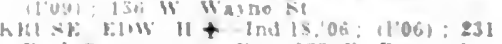

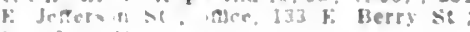


Jadd, Franklin Barton (b'65)-Ia.1,88;

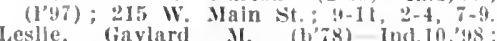

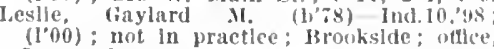
liass illock.

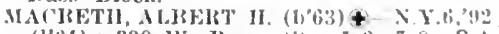
(l'01) ; 339 W. Borry st.; I-2, i-8; S. 93; (1'97); $: 339$ W. Berry sit. : $1: 30-3:: 30$;

Mart\%, Chrlstion (b'53)-Ill.4.82; (1'4i); 207 k. Crelghton Ave, othe, $117 \mathrm{~W}$ Jefferson st. $7: 30-9,1-3,7-8$.

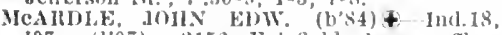
07: (1'07): 2l5t Falrfleld Ave; offles, 2205 - Calhomi st. : 1-3, 7-8

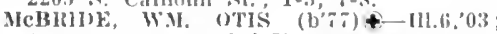
(femporary jrermit,'13); Nember state Med. Soc. of Wls. ; $609 \mathrm{~W}$. Wayme st. ottice, zis Washlugton Mivi., W.

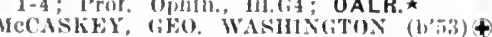
- I'a.2,77; (198): $409 \mathrm{~W}$. Main sto flee. [hysiclans, 409 W. Main St.; of fice, Physiclans' Defense 13ldg.; "2-4; I'rof. Mral., Ind.20: 1.

IcCausland, John W. (b'58) - 111.1,79; $\left(1^{\prime} 9 \pi\right) ; 506$ F. Wayne Si.; nttre, Lewls and Lafayelte Sts.: 8-9, 1-3, 7-8.

MCEVOT, JAMES BEITRAND $(1,74)+$ Ind.10,96; $\left(\mathrm{I}^{\prime 97}\right) ; 1906$ Lafayette oftice, 1801 Lafayefle st. : $2-4, \vec{i}-8$

MCHUGH, MAMFS E. (b'67) †--1nd.10,:13; (l'ai); 2214 Thomas St.; oftice, llolton and E. Creighton Ares.; $8-9,1-3,7-9$.

MCKEEMAN, IROI3T. I3. (b'i4) $\downarrow$-Ind.10 97 ; (1'00); 20:0 Broadway ; oftwe, 133 E. Berry st. : 10-12, 2-4.

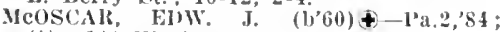
(†): 120 w. Jelferson St.; 1-3, $;-8$

IETCALE, DEAN (b'82)-W'W.3,'11; (1'11) ; 1333 Calhoun St. ; $1: 30-4,7-8$

Netls, A. H. $\rightarrow$; $\left(\mathrm{l}^{\prime} 9\right)^{-3}$; not in pratice;

Mikesell, Arthur I. (b'68) H-Ill.10,92; $\left(1^{*} 97\right) ; 214$ Washington Hlrt., F.; 8-9,

MORGAN, ELMEl E (b'61) (1'97); 342 E. Washlngton Blvd.; 8-9, I-3, 7-8; Pr.

Morgan, Mary Fnıma (b'70)-I11.11,00 (Asslstant Physlrlan); X.M.C.A. Kidr.

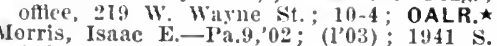
Morris, Isaac
Calhoun St.

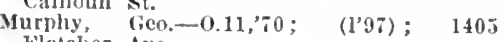

Fleteher Atre.

IESCHANG, CHAS. C. F. (b'60)†-Ind.10 '82; (1'97); 130 W. Lewis St.; uffec, 108 W. Jetterson st. : $1-4,6-4 ; s$. Ogle, John J. (b'47) E-IIl. 8,$90 ; \quad\left(l^{\prime} 97\right)$;
1243 Huestls Avc.

PHILLIPS, AI'OLLOS F. (b'65)-Ont.3,'95; (1’97) ; 915 Rockhill St. ; oftice, 506 Calhoun St. : $8: 30-12,1: 30-5,7-8 ;$ OALR. PORTER, MILES FULLER, (b'56) $\$-0.1$, '78; (l'97); 207 W. Wayne St.; offlce, Prof. Surg., Ind.20; (A1,6,7); S.ネ

PORTER, NILES FULLER, JR. (b'8 Mass.1,'11; (1'11); 207 W. Wayne st.

offle, Physiclans' Defense Bldg.: 2-4.

PULL1AM, JOIN MATTHEW (b'71) 1).C.1,01; (1'05) ; 2724 Broadway;
Shoaff Bldg. ; 10-11, 2-4.7-8; NP.

RANKI, JOHN' W, HENRY (b;0)\&-Pa.2 96; (1'97) ; 3112 Beaver Ave. ; oftce, 207 W. Washinglon Blrd. ; $9: 30-12,1: 30-4$;
OALR.

RAWLES,

Ind.10,05; (1'06); 3131 Fairfleld Ave.; afle, $40^{\circ}$ Cathoun 4131 Fairfield Ave

Ray, Herbert A.-Ill.6,07; (I,07); 325 E.

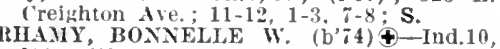
'98; (l'04); 1115 Garden st.; offle, Einpress Theatre Bldg.; 8-12, $1: 30-5,7-8$; LD.

RICE, WILKIE BENJ. (b'82)-I'a.2,10; (l'12); 1101 E. Pontiac St.; $1-3,7-8: 30$. IOSENTHAL, MAURICE $1 . \oplus-0.1,90$;

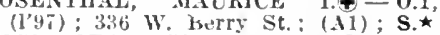
ROSS, GEO. ALBERT (b'57) †-0.13,79; $\left.\left(1^{\prime}\right)^{7}\right)$; New Haven Are.; oftice. Physi'inns' Defense Bldg.; $7: 30-8: 30,1-3,7-8$.
ROTHSCHILD, CHAS. Jos. (b'sI) ROTHSCHILD, CHAS. JOS. (b'8I) †-
Mlich.1.05; (1'06); $516 \mathrm{~W}$. Washington Blycl.; office, People's Trust Bldg.; 2-4, Ob.
HuhI, Wm, 1), (1556)-Ind.5,78; not In practice: II.F.I).

Schermerhorn, 1. J. (b'90)-Mìch, I, 12 ; (temporiry permit, 13$)$ : Sillumltz Hlde.

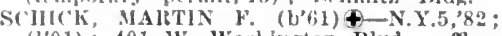
(1.01); $401 \mathrm{~W}$. Washington Blvd.; office, (p02 Calhoun St. : $1-3, \tilde{i}-\mathbf{S} ; \mathrm{S}$.

Sclll L.ING, JOHN-Mo.7,84; (1,97).

SCIINEIIER, AIA.M LAWREACE $\left(b^{\prime} 72\right)+$ -Ind.10.98; (1'48) ; 1503 E. lewls St.; oftec, 702 F. Lewly st.; $1-3,7-5$ SCIIRAIFIR, W. FllANK (b'68)- Ind.10,'94;
$\quad\left(1^{\circ} 97\right) ; 109$ W. ('relghton NFe; onlce, 131 F. Berry sit. : 0-11, 2-5: Pr.

Schulz, Adolph F.-II-0; $\left(1^{9} 97\right) ; 1421$ I3roadway.

Schulz, Fredk. J. (b'78)-Mlch.5,'02 ; (1'02) ; $14: 1$ l3roadwity ; 8-19, 1-3.

Shutt, John II-O; (1'97); not in practice. Sohn M.-D; (1.97)

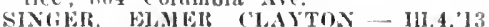
(I'13); Ft. Wayne limlheran IIosphtal.

SLED1), SAML. D. (b'55)-Ind.7,78; (1'97) 134 bouglas st.; oftice, 902 Cathoun st. 11-12, 1-3, $7-4$

SMTH, ERNEST DON (b'74)-Ind.10,96; (l'97); 629 I'utman st.; office, $11 \%$ W' Wilyne St.: $2-4,7-8$

Smith, Nelson B. (b'62)-Ind.10,'82; (1'02); 321 k. Pontiac st.

SQUIRES, JAMES W. (b'55) †-Mich.8,'92 ; (1'97) ; 1633 W. Main St.

Stametz, Zeanlin 1I. (b'72)-Ind.10,95: (1'97); 815 Harrison St.; 11-12, 2-4, $7-8$;

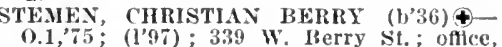
Shoaff Blde.

Stemen, (ieo. B. (b'59)-Ind.10,'82; (l’97) ; 1162 W. Main st.

STOLER, ALBERT E. (b'80)థ-Ind.10,'03 ; (1'03); I205 Fulton St. : I1-12, 2-4, 7-8 STUDER, GEO. IOS. (b'83)-Ind.18, 07 ; $\left(10^{\prime}\right)$; 1011 llanua St.; ottlce, 624 Cal-

hotn St.; 2-4, '-8.

318, 2d St. ; $7-9,1-3,7-8$.

Sutton, Sylrester F. (b'68)-111.15,95; (1'03); 2536 Maple $1^{\prime} 1$

TALYOR, THOMAS LACY (b'79) \&-Ind.20, "08; (l'08); Indiana school for Feeble Minded Youths.

Thain, Geo.-0.1,'91; $\left(1{ }^{\prime} 00\right)$; W. Main St.

Thimiar, J. Wiley (b'84)-111.22,'11; (I'11)

$1303 \mathrm{~F}$. Lewis St. ; $2-3,7-8$

Tinkham, Melrin W. ( $\left.b^{\prime} 65\right)$-Ind.10,92; (1'97); 1604 Wells St.; office, 723 Clinton St. ; $10-11,2-4,7-8$

Titus, Elton L. (b'80)-Ind.8,02; (1'02) ; 1123 Columbia Ave.

Tl't's, PIIILIP S. $\$$-Ind.18, $06 ; \quad\left(l^{\prime} 06\right)$;

UNI)EHWOOD, EIVWIN II. (b'T1)\&-IIl.4 YAN" (l'05); 2610 Broadway; 1-3, 6-8. lnd.10,02; (l'02); 1853 Broadwa offlce, 8 Lau Bldg.; 10-11, 2-4, $7-8$.

Yan Hummell, Quincy (b'43)-Pa.I,'64 (l’97) : 1230 Spy Run Ave.; 9-3.

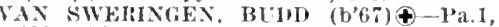
'88; (1'97); 208 Washington I3lvd., W. (- vivent

Ind.10,'03, 1'a.2,05; (l'03); $633 \mathrm{~W}$. Wayme Ind.10, 03,1 'a

WALLACE, J. CLIFFORD $\left(\mathrm{b}^{\prime} 75\right) \uparrow-I n d .10$,

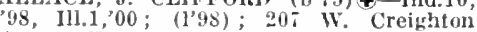
Ave.; office, People's Trust Bids.; 10-1I, $2-4,7-8$.

WEAYER, BEN. PERLEY (b'T 112; (l'03); 1104 W. Wayne St.; offlce, I'hysichans' Defense Bldg. ; $2-4,7-8$.

Wells, Henry 0. (b'65)-ky.1,'ss; (1'05); 404 Old Fort Pl.; offlce, 229 E. Berry st. ; $4-12,2-5,7-8 ;$ D.

Henger, Noah R.-1).8,80; (1'97); $1006 \mathrm{Cal}$ houn St.

WHEELOCK, KENT KANE (b'5)థN.Y.10,80; (1’yi); 1020 IIarrison st. 9-3; OALR. *

WHERY, MARY A.†-Ind.10.82; (1'97) 404 E. Berry St.: $9-3: 30 ;$ G.

WHERX, WH. P.-Ire.9,60; (1’97); $404 \mathrm{E}$. Berry' St.; offce, 1302 Calhoun St.

ZEHR, NOAH (b'82)-0.6,08; (1'08); 319 IV. Williams St.; offiee, 916 Calhoun st.:
FULTON, 296, FULTON

DHEI,MAN, FIRAKKLIN C: (b'79)-IH.11,04; (l'05).

Morrls, J, M-0: (1’97)

IRICHAIBDS, JOHN (1)"35) - ; (1'yT).

GALENA, 200, FLOYD

IAYIS, CHAS. I'. ( (h'60)-Ky, 2,81; (1'97)

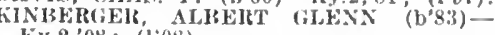
Ky. 2,$08 ;(1 \circ 08)$.

Leuthart, Chas. P. (b'73)-Ky.I, 01 ; (1'04)

GALVESTON, 658, CASS

COIRNELI, J. FIA NK $\left(\mathrm{b}^{\prime} 70\right) \oplus-111.11,02$; (1'02)

LOOP' ZU1NGLESS, U.-Ky.1,82; (l'97). MIILEIt, IIAIREY II. (b'T1) $4-\mathrm{K} y, 4,97$; (1'98).

Ross, Robt. II.-Ind.8,79; (1'97)

Smith, John S. (b'55)-0.1,'82; (1'97).

GARRETT, 4,149, DEKALB

CLEVEXYGI, JAMES ALLEX $(1,60)-$ Tenn. $1, ' 88 ;(1, y \pi)$

Hutchinsol, Francls Howard (b'82)-Md.3, 11 ; Asslistant Physleian.

Kesler, Alonzo A.

KING, FliANK A. (h'80)-111.I1,02; (l'04). $\left.04 ;(1)^{\prime} 04\right)$; S.

Powell, John' F.-Ind.8,97 ; (l'99).

Strouse, Johnson 1". (b'59) $-0.12,87 ;\left(l^{\prime} 97\right)$.

Thomson, John $k^{\prime} .\left(b^{\prime} 50\right)$-Mich.1,75; (1'97).

'IIOMSON, JOHN WM. (b'86)-I11.1,09;

(1'11)

Yarian, Henry O. ( $\left.\mathrm{b}^{\prime} 73\right)$-Ind.10,98; (1'99); not in practice.

\section{GARY, 16,802, LAKE}

ALEXANDER, WM. F. $\left(\mathrm{b}^{\prime} 57\right)+-0.2,91$; (l'04); 700 I'enlisylvanla St.; oftice, 690 Broadway.

Andrus, Abner 11. (b'62)-0.3,'86; (1'09); Jefperson St. ; oftics, 527 Broadway

ARTIIU1?, W.Y.' R. (b'68)-D.C.3,90; (1'12); 1911 Washlngton St.; oftice, 1615 Washnington St.: $2-4,6-8$.

Blumstein, David Barnett-Ill.11,04; (I'13) ; 1328 Broadway.

BOARDMAN, CARI S. (b'79) - -Pa.1,04; (l'09); 6th and Yan Huren Sts. ; offlec, 522 Broadway; 9-12, 1-3:30, 7-8; OALR.

Bourbakl, Peter (b'r2)-lireece 1,95; (j; 700 ('onnectlcut St.; office, 1200 Broadway.

Church, Wm. B.-E-0.2,66; (1'12).

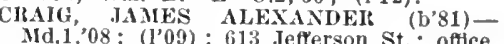
652 Hroadway.

DE LONG, CHAS. ALANSON (b'73)-IIl.1, 05; (1'06) ; 602 W. 5th Ave.; office, Flrst Nat. Bank' Bldg.; 11-I 2, $2: 30-7$.

EYANS, EDW. EVERETT (b'75) $€$-Mich.7, 00 ; (1'08); 600 Adams St. ; office, 515 Broadway; $1-5,7-8$.

Faulds, Mable C. Lawrence (b'81) $\rightarrow$ Ill.23, 06; (1'09); 708 Broadway; 10-12, 3-5,

Fauldis, winfield S. (b'72)-111.23,06:

(1'07); 708 Broadwas; 9-11, 2-4, 7-9.

GANNOS, (;EO. WILFKED (b'79)-Mleh.1, '10; (1'11); Ridge lid. and Maryland st.; offle, 475 Broadway; $8-9,11-12,3-5,7-8$.
GIORG1, ANToNio (b'61)

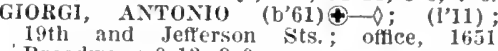
Broadway : 9-12, 3-9.

GREENE, GEO. S. (b'85)థ-Mleh. 7,97 ; (I'10); 724 Tyler St.; office, 800 BroadWay ; 8-10, 1-3, 7-8; S.

420 , 4-19. Jifice, 542 Broadway; Iol'l,

(l'97); sth and San Buren sts. ; offlce, 469 Broadway

HOSMER, HARKY M. (b'79)\&-Pa.1,04; (1'98); 520 Van Buren St. ; offlce, 522 Broadway; $1-3, \tau-8 ; \mathbf{S}$.

Julien, Wm. Floyd (b'75)-Ill.1, 00 ; $\left(l^{\prime} 00\right)$; 664 Broadway.

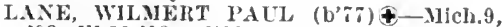
03, Ill.11,08; $(1,08) ; 176$ Anbridge Ave. office, 688 Broadway ; $9-10,2-3$.

Lawrence, Caroline Carle (b'69)-Pa.7,'94; (1'12); 6th Ave. and Jefferson St.

Loar, Laban T. (b'60)-Ky.4,91; (1'99); 1001 Cleveland St.

LOEBEL, MAURICE A. (b'82)-Ill.I6,'12;

(1'13); 658 Broadway; 8-10, 5-8; OALR. G, CHAS. IOPKINS.

(See Chicago.) 
MeMICHAFI, FR.XK J. (b'st)--Mich 1,0 (1'09): loch Are. and lomserselt sit.

MERRITT, FEINK WALLO (b'S2) III.11, 0:: (lil): Gary Hospltal.

METCALF, JOHX FEQGES: $\left(\mathrm{b}^{\prime \prime} 0\right)+11111$, 99: (1'08): 615 Van liuren st.; Ottlee. 583 Broadway: $:-4,7.8$

Mlllstone, larael Sansl. (b'63) 11.to."no (1'09); 801 Jefferson sit: unce, 1114 Broadway: $8-11, \geq-4$

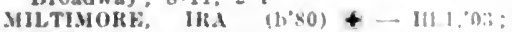
(l'0:): Gary Unspltal.

NESBIT OTIS HURGESS (b\%1)+-llls, 02: (1'02): l'pof. Ther., 111.22.

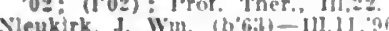

640 Adams St.

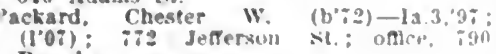
Rroautway.

Paf, Geo, Ellsworth (b.84)-Ind.20.08 (1'08); 502 Broadway; :-4, :-5.

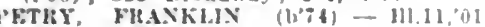
(Y0s): Tolleston.

Prentiss, James IJ. F. (b'5s)-Ind.19.' $94^{\circ}$

(1'9i): 800 Tyler sit: offee, so0 Broal (19i) : 800 Tyler Sit: offlee, \$\$00 Broat way: $8-10,1-3,:-8$.

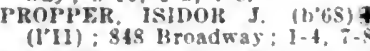

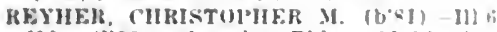
'06: (l'06); Security Bldg.; $11-12,4-4$ Pd.

SCHAIBLE, ERNST I.FNXOX (h'\%)Mleh.l,0R: (l'0s): 537 Jacksem st oøle, 710 Broild ay : 1 -3, i-4

SKEEN, IARL DONOVAX (b'st) + Nelo.j, 08 ; (1018); Rroadway: $9-11,1-3,--5$

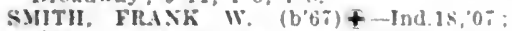
(1007): 32 Harrison st. ufree, ribit

Brondway: $9-10,2-4 ;-9$

STAWICKI, JOHS l'ALl, (h's0)-IH.1l, 0R: $(1 / 10):$ It2R Broadway.

TFMLLIX, THEOIORE L. (b"-9) - Pa.2, (104): 801 Madlson St.; offle, $60 \%$ Broad way: $1-3,6-8: \mathbf{S}$.

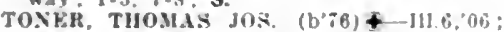

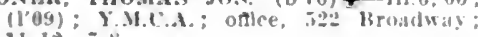
$11-12, \because-8$.

VHILAXK, GROVKR IAWRENCE, (b'si)

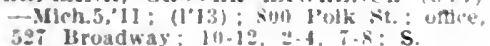

Watson, Jos. C.-Ind.4, 4 : (1'4i); 2113.

loth Are.
WHIT F, WM. JEs, $(1, \div 2)-111.1 \%, 02 ;$

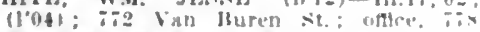
Broadway: $8-10,2-4$, h-s.

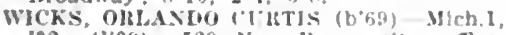
02: $\left(1^{\prime} 09\right)$; 529 Van Buren st. oflec, 60: Hroadway lio-19, a-t, ;-y: ObG.

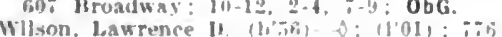

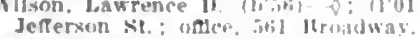

VARIRNCTON, (HAS, WklB (b;i) t-

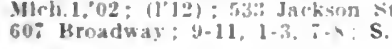

GAS CITY, 3,224, GRANT

CONIKY, L. H.-1).J2, X3: (1'S5).

Unrne, Browe s.-0.1.45; (1002)

logh, Juhn $w$ - Ind.12, 8 - (1001)

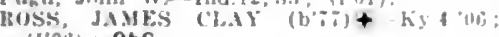
(I"Oib); ObG.

\section{GASTON, 638, DELAWARE}

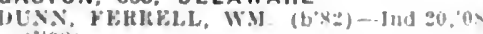
[1'0s,

Vastes, Wm. T.-Ind.s, : 1 : (1"9s),

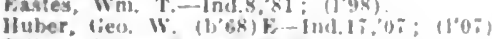

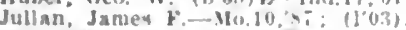

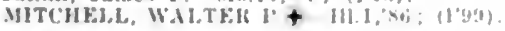

GEETINGSVILLE (R.F.D., SEDALIA), 75. CLINTON

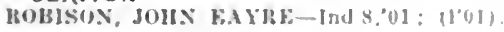

GENEVA, 1,140, AOAMS

ASI"Y. 1I. M. $\rightarrow$ : (H")

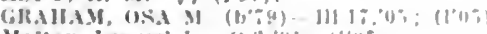

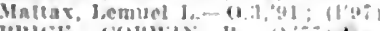

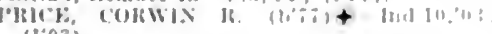
(1.03).

GENTRYVILLE, 383, SPENCER

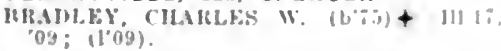

GEORGETOWN, 331, FLOYD

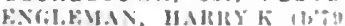

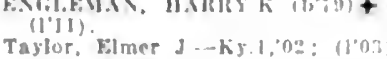

GESSIE, 159, VERMILION

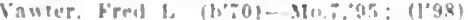

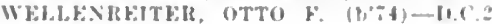
01; 11.101

GILEAD, I60, MIAMI

Hrower, Jowidh-1).2,"is: (195); not In

practice.

Wrebam, J. W. (b'+8)-A; (1'9i)

GILMAN (R.F.D., ALEXANDRIA), 400 MADISON

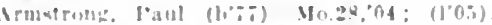

GILMOUR, 200, SULLIVAN

Javi*, Juhn W. $\left(b^{\prime}(x)-8 ;(1.02)\right.$.

GLENN'S VALLEY (GREENWOOD P.O.), 50, MARION

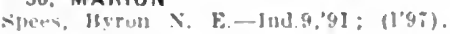

GLENWOOD, 266, RUSH

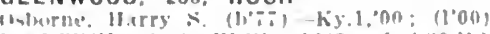

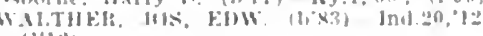
(1'1:2)

GLEZEN, I00. PIKE

HYTHE, WY. T.PA: (1'9i)

GOLDSMITH, 227, TIPTON

'ITTUN, STANIEY M. (1,7)- Ind., 05

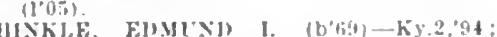
(l'gi).

GOODLAND. 1.105. NEWTON

lasser Clarence (D. (b)'79)-Wk.206: $(1006)$

Clymer, heever (b'3:2) F- $02,58:\left(1^{*} 99\right)$.

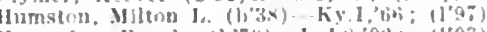

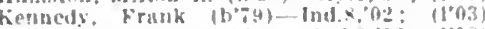

Kimneman, John (i. (h'6s) Inds, 'Ps: (I'9s)

GOSHEN, 8,514, ELKHART

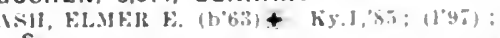

SHKXELL, IHVIX J. (b'46) + Ind.t, 5 ,

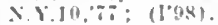

ork, J(IIX MlKERT (b'-4)-()nt.3,'9J; $\left(1, b^{2}\right)$

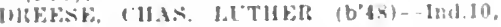
21: 18.95

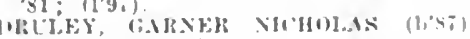

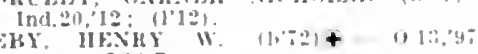

(1'05) : OALR.*

Fomands, summer A. (b'-1)-IH.I, 96 : (1) (1)

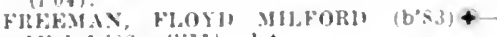

Ulch.1,05: (1'11); 1.*

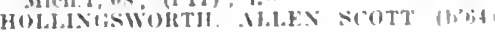

$0, \cdots, 0(1,0)$

ILW

(1,ii)

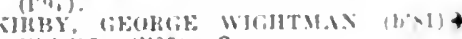

$111.1,(1.5:(1 \cdot 0.5): S$.

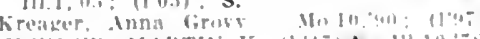

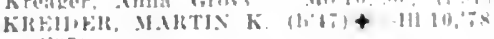

11971

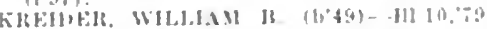
$11 \div \div): 0 D A$.

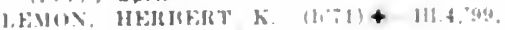
111 11,01; 110111 : $\mathbf{s}$.

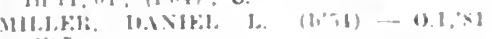
$(1,16 ; 1)$

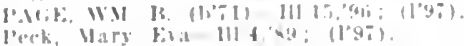

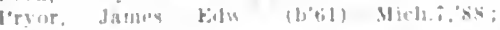

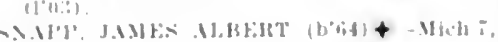

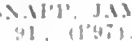

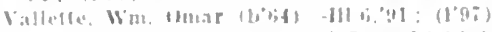

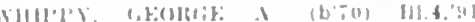

(1,u)

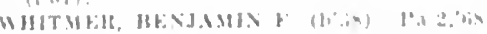

$11,0,10$.

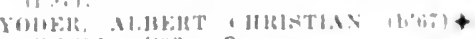

$111.1,02.1103): \mathbf{S}$.

GOSPORT, 776, OWEN

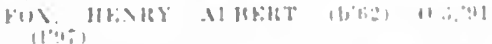

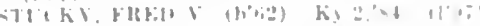

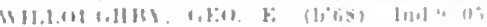
1100.10

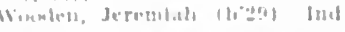

KIRAND VIEW, 735, SPENCER

STI TH:YIIIE, NTHYHH:N W

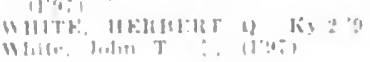

GRANTSBURG, 200, CRAWFORD

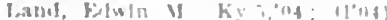

GRASSCREEK. 200, FULTON

silumber, Joel $k$ bul at:?

GRAYSVILLE, 75, SULLIVAN

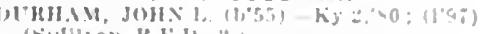

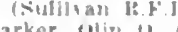

GREENCASTLE, 3.790 , PUTNAM

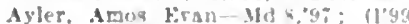

Harraby boma Jenririgion (bojo)-111 Arrativy Fin

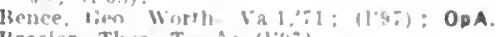

Ibraster, Thus, $T$ A : $(1 * 4:)$

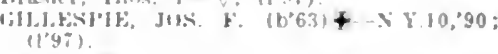

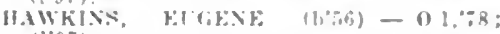
(1'97)

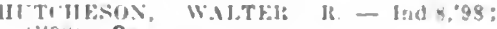
$11 \% 9 \times) ; 0 p$

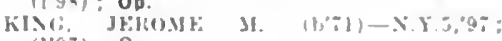
$\left(l^{\circ} \theta_{0}\right): \mathrm{S}$.

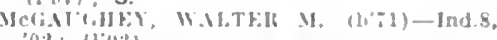
(1): $(1 * 1) \geq 1$.

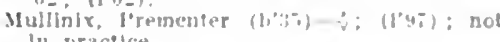
In practice.

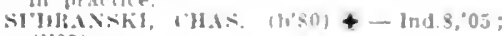
(1"05)

Town. salem 13.-. 1ll.fo, bs: not in practlce.

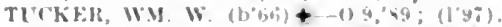

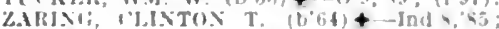
$(\ln x)$

GREENFIELD, 4,448, HANCOCK

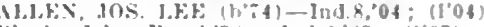

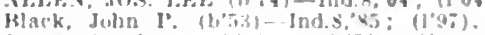

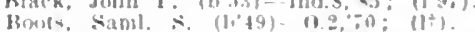

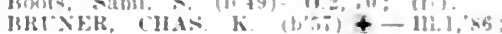
$\left(1^{\circ}\left(6^{-}\right): S\right.$.

Bruser, Mary 1. (bo5is) - 111 9, $85 ;(1995)$.

CIHHS, (HAS, MI1, $($ b', 3$)-$ Ind.9,00 (1'iii)

(ir)my, I,nual B. (1,js)-Ind.s,"90; (1'95)

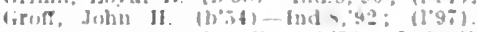

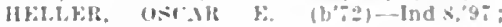
(1) (1)

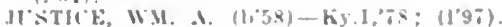

laarmore. Jamev if. $(1,39)-1 a, 1,07 ; 1197)$ : not in practice

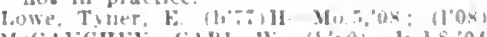

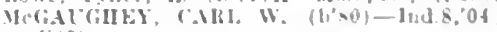
(I0j).

Moure, J. Wollen Mo.10, ss; $(I+s 9)$; not in prartlce

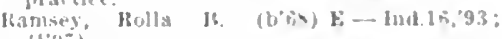
प्रतs

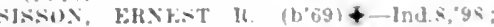
(1'4a)

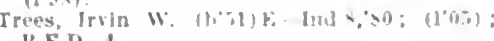
It F.I.

GREENHILL (R.F.D., OTTERBEIN), I70, WARREN

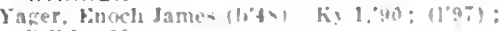

GREENSBORO, 250, HENRY

Shammur. Jos. H - Ind $\because, 0 \%$ : (I'B)

GREENSBURG, $5 .+20$, DECATUR

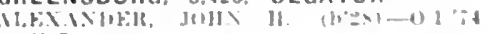
$(1,0 \div)$

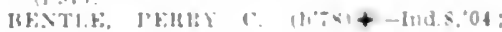

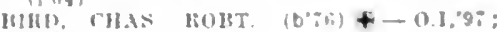
(1)isi).

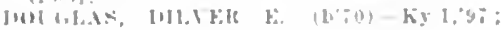
$11.0 \% 1$.

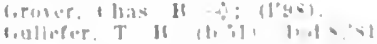

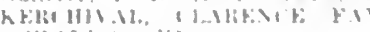

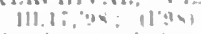

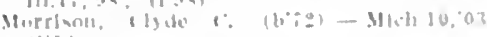
(1'0.s)

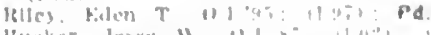

kneker. Jevan 11 al.

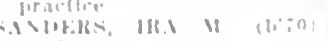

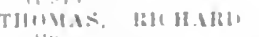

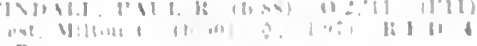
Pr

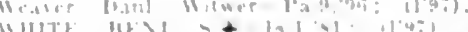

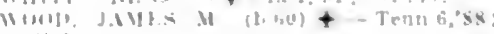

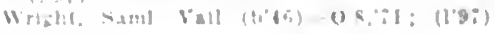


GREENS FORK, 379, WAYNE

lierr, James I). (1'64) F-Ind.8,'98; (t'98)

Neft, W. Webster-O; $\left(1^{\prime} 97\right)$.

GREENTOWN, 1,166 , HOWARD

Coralt, Amos A.-Ill.1, $19 ;(197)$; not in practlee.

Frecman F. kiarl (b's1)-Ill.15,08; (l'0s)

MILLER, IIEXIRY 1.-KY, 1,'83; (l'97)

Murray, Saml. T. 0 ; (I'yi); not lu practlee.

JETERS, DAX1. C. (b'39)-Ky.1,91; (l'97)

POWhil, FL.MER I\%. (h'62)-Ind 10,'84; (l'97).

GREENVILLE, 227, FLOYD

W'llilam, Wm. IR.-Ky,2,81; (1'98).

GREENWOOD, 1,608, JOHNSON

('OX, LLNAFORI) l\%. (1,83)-lnd.2I, 07 $\left(l^{\prime} 07\right)$.

CRAIG, JAMES MIBER' (l, 71$)$-Ind.8,'94 (1'97).

Malloy, Jay S.-Ind.19,?66; (l'01); G.
MeAlpin, loobt. B. (b'69)-Ind.8,02; (l'02). Sheek, Danl. W. (h'i1)-lnd.8, 03 ; (l'03).

GRIFFIN, 275, POSEY

Brydon, John $\mathbf{F} \rightarrow(1,97)$

Iurphy, C. F.-Ky.4,'94; (1'97).

GUILFORD, 200, DEARBORN

JALIOTT, JOHN C. (b'80)-Ky.5,'06; (l'06),

GWYNNEVILLE, 200, SHELBY

Wlitslilre, Roland Aubrey-0.2,'94; (l'04).

HAGERSTOWN, 936, WAYNE

('anaday, Nathan F. (b'45)-0.7,70; (1'97).

DEARDORFF, OLIVER MORTON (b' Ind.20,'09; (I'09).

Stotelmyer, Chas, 1. S. (b'59)-MId.1,'92; (1'97).

Thurston, Ell H.-0.10,70; (1*97)

HALL, 200, MORGAN

Bradley, John S.-Ky.4,98; (I'0I).

Jones, lloward C.-Ind.4, 7 ; (1'97).

HALO (R.F.D., SALEM), 25, WASHINGTON Bradshaw, A. E.-Ky.1,;8; (l'97); not in practlce.

HAMILTON, 625, STEUBEN

CAIIERON, JOHN FRANKIIN (b'55)-Ill.1, $80 ;\left(1^{*} 97\right)$

RANSOM, GLENN DEWEY (b'84)-Mich.1, '13; (temporary permit,'13).

HAMLET, 579, STARIKE

ABNER, JOHN R. (b'58)-Ind.12,84; (l'97)

DENA [T, JAMES L.-Ill.1,'96; (1'97).

HAMMOND, 20,925, LAKE

Beaver, Thurman Ross (b'88)-Ind.20,'10 (l'11) ; 251 IIohman St.

BOLIN, JOHN T. (b'82)థ-Ky.2,'10; (l'12) O. K. Bldg.

BUCHANAN, WM. AUSTIN $\left(b^{\prime} / 1\right) \oplus-$ Tenu.1,'99; (l'02); 590 S. Holmman st.; $8-9,1-3,6-8 ; \mathrm{S}$.

CAMṔBELI, CYRUS W. (b'50)-Ind.8,'88; (1'97) ; 36 Ruth St. ; offlce, 179 S. Hoh man St. ; $9-10,1-3,7-8 ; \mathbf{0 b}$.

CHIDLAW, BENJ. WALTER (b'79) - 0.9 04; (1"05); 387 S. Hohman St.; offlee, Commercial Bank Bldg. ; 10-12, 2-4, $7-8$

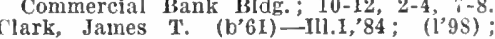
Hotel Carleton; offlce, 139 State st.

Farrer, George W. (b'50) -Ind.4,75; (l'97)

FOX, FraNCIS H.-Pa.2,02; (l'04); Iáson St.; offlee, 575 S. Hohman St.; $9-10,1-3,7-8$.

GLSON, EDMOND A. (b'72) - 0.19, 05 ; $\left(l^{\prime} 06\right) ; 20$ Carroll St.; offlee, State and Hohman Sts. : $2-5,7-8 ; 0$ b.

GRAHAM, JOS. ALLEN' (b'T 7 ) - Ont.5, 04 ; (l'08).

Greiner, Karl (b'71) H-Ill.10,'92 ; (temporary permit,'12) ; 52 Warren St. ; offlce, 109 Citizens Bank Bldg. ; 2-4, 7-8.

GROMAN, HERMAN C. (b'82)@-Ill. I, 07 ; (l'07); 28 Rimbach Are.; offlee, Groman Bldg. ; 9-12, 1-6.

HOFMANN, ANDREW (b'78) - Ill.1I,09 (1'11) ; 552 E. State St.; office, 641 Hoh-

man St.; 1-4, i-8.
HOWAT, WM. FREDERICK $\left(\mathrm{b}^{\prime} 69\right) \oplus-\mathrm{Pa} .1$, "92; (1'97); 832 Hohman St.; office, 57 IIohman St.; 2-4, 7-8.

Jackson, I Iorenzo D. (b'49) - Ind.5,'s9; (1'97); 525 Hohman St.; 3-i

Jackson, Mary E. (b'51)-Ind.5,'s7; (1’97).

JENELT, BENSON MUNDY (b'so) 4Soc.; 91 williams St.
JOHNSON, CLARENCE ARTIIUR (b'80) $11.1,10 ;(1 ' 13)$; Member Mo. State Med. Assu. : 456 May S't.; offlce, 697 Calumet sit. : $9-11,2-5$.

KiLl, LUKE H. †-Ill.11,99; (l’01) ; Flrst Natl. Jauk Blde.

Kiepert, Andrew Edw,-111.16,05; (毒)

Leedy, ('has. V. (b'68)-NId.4,96; (l'04); (00) S. Ilohman st.; oftlee, Rlmbach Block: $9-12,2-5,7-8$.

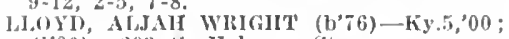
$\left(l^{\prime} 00\right) ; 203$ s. Hohman st.

MEATON, ONIS $0 .\left(b^{\prime} 84\right) \$-K y, 2,10$; (I'I0); 627 IIohman St. ; $2-4,7-8$.

NEIK, IIENRY G.-Ill.10,92; (I'97).

Illkesch. Wm. Henry (b'80) - Mo.34,'13: ( ) ; O. K. Bldg.

MILKR, ALBION JOIIN (b'71)-III,13,98; (l'03); 866 Calumet Are.

VILLER, (FEO, FNOS (b'82)Ð-H1.1,07 $\left(\mathrm{l}^{\prime} 09\right) ; 442 \mathrm{May}$ st.; oflice, IIammond Hhlg. : $2-4,7-8$.

OBFILIN, TIOS. W. (b'75) - Ill.6,98; (l'98); 47 Warren Are.; olfice, $575 \mathrm{~s}$. IIohman St. : 2-4, $7-8$; Pd.

Oder, Edwin Elmer-0.s, T5; ( ).

OSTROWSKI, RONUALI ÓTILLLLO (b'80) 4-Ill.11,'08; (1'08); 715 State Llne St.

SIMANKIJN ELDRIDGE M. (b'75)-Ind.8, '02: (1'03) ; 14 Iruth St.; offlce, 549 S

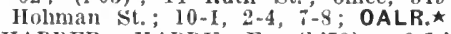

SHARRER, HAIRY F. (b'73)-0.1,96 ; $(1 \cdot 97) ; 797 \mathrm{~S}$. Hohman St. ; offlce, Cltlzens Bank Bldg. ; $2-4,7-8$; S.

Smlth, Andrew Wm. (b'88)-Mich.5.'12; (temporary permit,'13); 32 Doty St.; S.

Van de Walker, James G.-E-D; (1'97) 712 Johnson st.

Vaughn, Martin (b'36)-0; (l'98).

WEIS, WM. D. (b'73)థ-Ill.22, $04 ;\left(l^{\prime} 04\right)$ 641 S. Hohman St.; 2-4, 7-9.

WIIITE, IIUGH JAMES (b'79)€-Ill.6, 06 ; (l'10); 11 Mason St. ; olflee, 563 Hohman St. : $2-4,7-8 ; \mathrm{S}$.

YOUNG, ALVA A. (b'81)-Ind.9,'05; (l'05); 85 State St.

HANNA, 400, LAPORTE

CRAWFORD, EDWARD $F$. W. $\left(\right.$ b $\left.^{\prime} 69\right) \oplus$ Mich.7,'94; (1'97).

HANOVER, 356, JEFFERSON

Burdsal, Chas. A. (b'50)- $\longrightarrow$; (1'97)

Green, Wm. E. (b'5I) E-0.2,94; (l'98)

HENNING, CARL (b'79) 4 - Ind.18, 06 ; (1.06).

HARDINSBURG, 254, WASHINGTON

Nay, Frank Alexander (b'82) - Ky.2,'09 (1'09).

McPhecters, John S.-0.8,'60; (1'97); not in practlce.

HARLAN, 600, ALLEN

ADAMS, HORACE E. $\rightarrow$; (1'97); Pd.

Swift, Clarence F.-Mich.1, 77 ; $(1+)$; not In practice.

Thompson, Wilson H. (b'75) - Mo.27,99; $0.8,0 \mathrm{I} ;\left(\mathrm{l}^{\prime} 05\right)$.

HARMONY, 1,020, CLAY

I'ALM, WII. (b'82)-Ind.8,'05; (l'05).

HARRISTOWN, 85, WASHINGTON

Oatley, Joln Harrison $\left(b^{\prime} 30\right)-0$;

not in practice.

HARRODSBURG, 400, MONROE

Holland, Deward J. (b'78)-Ky.1, 07 ; (1'08)

HARTFORD CITY, 6, 187 , BLACKFORD

CLAPI'El, MANFORD M. (b'63) †-Ill.6,'90 : $(1,97) ;$ OALR. $\star$

COREY, CHARLES W. (b'64)-Ind.10,'87: DAYISSON, HENRY C. $\left(b^{\prime} 42\right) \notin-I n d .4,7 \mathrm{I}$; (1'97)

DEWEES, ROY E.-Ind.12,'97; (1'97).

Dodds, Thos. C. (b'75)-0.2,'98; (1'06)

HACHAT, FERNANDE IDA JULIA (b'90)Ind.20,'12; (l'12); G.

Hollis, Ella Allen ('b'58)-Ind.8,'90; (1'98). HOLLIS, SAIIL. (b'52)-Ky.1,' 79 ; (1'98)

HOLLIS, WM. ALLEN (b'78)థ-III.11, 02 ; (1'02): OALR, $\star$

Scott, Wislon $\mathbf{L}_{\text {. }}$ ( (b'53)-0.10,83; (1'97) SELLERS, CHAS. A. $\$$-Ind.10, $04 ;(104)$ Pd.

SELLERS, JOHN (b'44)-Ind.8,'88; (l'97).
SEXAUER, CHAS. F. (b'58)-0.6,'84, Md.3 $94 ;\left(l^{\prime} 98\right)$
HARTSVILLE, 358, BARTHOLOMEW

IBECK, FlA VIUS J. (b'63) - Ky.1,'90; (1'97) ; Pr.

Blddlnger, solomon W. (b'33) E-0; (1'97) ; I.F.1)

Morrlson, James H.-Ky.1,93; (1'97).

HATFIELD, 200, SPENCER

('I,ACKMAN, JOIIN CIAY (b'81)-III.I0,04; (1'04)

Glemn, Fred $\left.C(1)^{\circ} 80\right)-K y .2,08 ;\left(1^{\prime} 08\right)$

HORLOM, LEO. W.-Ind.8, 94 ; ' (1'97).

HAUBSTADT, 500, GIBSON

MARCILANI), VICTOR II. (b'62) \&-Pa.2,'84;

$(1.97)$.

PETITHAN, JOHN WM. (b'76)-Pa.2,03; (1'03).

HAYDEN, 375, JENNINGS

CIIAMM, GEO. W. (b'81)-Ky.2,'05; (1'05). HAYSVILLE, 200, DUBOIS

EIFEIT, ELMER EIRNEST (b'84)-Ind.18, $07 ;\left(I^{\prime} 07\right)$.

HAZELWOOD, 100, HENDRICKS

Wrlght, Fredk. Newton (b'78) E-Ind.17,'05; (1'0):

HAZLETON, 648. GIBSON

ARTIUR, IIAMILTON M. (b'72)-Ind.8,'98; (l'98); OALR.

GUIGEL, IIARRY B. (b'77)-Ill.11,04; (l'05).

Loudin, Ernest B. (b'70)-Mo.28,'00; (l'01).

HEADLEE (R.F.D., IDAVILLE), I00, WHITE

Morrls, Geo. M. $\rightarrow$; (1'97).

HEBRON, 821, PORTER

BLOOD, ROSCOE P. (b'80)-111.6, 06 ;

Edmonds, Finos A. (b'50) $\mathrm{H}-\mathrm{l} 11.10$, 86 ; (l'98). (l'97). HECLA (R.F.D., COLUMBIA CITY), I50,

SCOTT, JAMES W. C.-Pa.2,'80; (1'97).

HEORICK, 75, WARREN

Hicks, Louls C. (b'77)-Ind.8, 03; (1'03).

HELMER, 150, STEUBEN

Denman, Robt. D. (b'75)-Ind.18,'05; (1'97) ; G.

HELMSBURG, I50, BROWN

Wllliams, Iyron If. (b'54)-0.1,79; (1'05),

HELTONVILLE, 600, LAWRENCE

CAIN, JASPER (b'77) -Ky.11,'08; (1'08).

Faublon, James-0; (1'97).

Martln, Robt. E. (b'69)-Ky.1,'92; (1'97). WOOLERY, PERRY (b'69) $\oplus-\mathrm{K} y .4,97$;
(l'G 7 ); Pd.

HEMLOCK, 300, HOWARD

DEWEES, LEANDER-Ky.1,'94; (1'97).

HENRYVILLE, 402, CLARK

ELROD, STEPHEN B. (b'73)†-Ky.5,'98; (1'98).

Prall, Ezra-Ky.1,98; (1

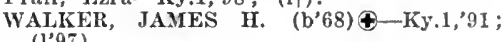
(1'97).

HILLHAM, 150 , DUBOIS

Line, Wm. A. (b'44) $\rightarrow$; (l'97).

HILLISBURG, 300, CLINTON

CRIPE, DANL. E. (b'50)Ð- (1'98); G.

HILLSBORO, 528, FOUNTAIN

BOUNELL, E. G, (b'71)-Ind.8,95: $\left(1^{\prime} 97\right)$

Faulkner, Albert S. (b'70)-Ky.2,'93; (l'97).

Songer, Frank-Ind.8,'91; (l'97).

HILLSDALE, 207, VERMILION

Mack, Erastus-0; (1'97)

Swayne, Jap F. (b'87)-Ind.20,'13; (l’13).

HOAGLAND, 300, ALLEN

Morris, Elmor E.-E-0.2,02; (l'03).

Smith, Jos. L.-E-0.2,78; $\left(1^{\prime} 97\right)$.

Smlth, Willard 0.-E-0.2,01; (l'0I).

HOBART, I,753, LAKE

BRINK, CALVIN CLARK (b'84) P-Pa.II, '10; (1'12).

Bulhand, Cyrus J. (b’54)-Ia.1,77; (1'05); Op.

FAULKNER, CLARA (b'64) - Ill.8, 01 ; FRIEDRICH, LOUIS M. (b' 73$)-\mathrm{Ky} .1,02$; (l'03).

MACKEY, DWIGHT (b'84) - H1.22,09; (l'I1); LR.

Irackey, Richard C. (b'52)-I11.8,'83; (1’97). 
HOBBS, 200. TIPTON

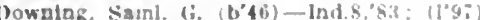

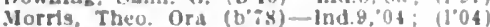

HOLLAND. 300, DUBOIS

REST, YHEl11K. C $\left(b^{\circ} 6 i\right)-0.8,91 ;\left(1^{\circ} 05\right)$

Rust, Wm. F.-Ky.5,'59; (1'9i)

HOLTON, 350, RIPLEY

Cor, Jacob G.-Ind.8, 92 : (1.8\%)

loltox, cIlAs. E. $\left(b^{\circ}-8\right)+-k 39,06$ (I.0\%)

lioberts, Jeremlah-0: (1'9i)

HOMER, 130, RUSH

Bamett, Danlel Fommett $\left(b^{\prime}, 5\right)$ - Meh 1,07: (1'09).

HONEY CREEK, 182. HENRY

AIFOIR, HOXFORI I) H:NIS (b'86)-111 20 11: (temporary permlt,"13): Member III. Med. Soc.

Eaglerth, Jasper T. (b'53)-Ind.5,":9:(1"9i)

HOPE, 1,223. BARTHOLOMEW

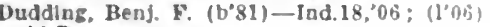

ALR.

Kent, Cornellus V.-Ky.4,73: (1'9i)

Norlon, Wm. J. (b'64)-Tenn.10,94; (1.9;

Reed, Lew/s D. (b'63) - Ind.9,90: (1'9i)

REGANXAS, ELGEXF, G. (b'53)-Ind.9, Sh

(I'98) : OALR.

HORTONVILLE, 200, HAMILTON

Aldred, John A-Ind.S:79; (1'97).

HOUSTON (R.F.D.. FREETOWN) JACKSON

ACKEIMAN, CHAS. L.KY.9,03; (1'03)

Conner, Thomas Elmer-Iod.S, 05 ; (1'05).

HOWE, 800, LAGRANGE

WAIF, ALFRED AINSWOKTH (b', 3 ) Mich. :09; (1'11); OALR.

WAOE. YRAXK C. $\left(\mathrm{b}^{\prime}: 5\right)+-$ Mch.7.00 (1'00); Pr.

\section{HOWELL, 2,000 VANDERBURG}

COX, I)AVID A. (b'65)+-0.1,90; (1'9i); S Freenan, James Francls-Fing.1, 75 ; (198) HECSLFH, ERNST H. C. (b'32)-D; (1'9i) KNAPL, HENKY CYIL-Mo.34, 02 ; 1103 sutler, Chas. Culley (b'S9)-Ind.20,10

HUDSON, 390, STEUBEN

llamllton, Frank C. (b'4i)-Ind.10,'ss $(1.97)$

KIMSEL, ALVA J. (b'3i) +-0.9, $36 ;\left(10^{\circ} 9 i\right)$

HUFF, 40, SPENCER

Allenbsugh. E'nter E. (b'b1)-0.8,'s8; (l'97); Ob.

HUFFMAN, 20, SPENCER

Dyer, Abram Smlth $\left(b^{\circ} 50\right) \rightarrow$; $\left(1^{\circ} 9 i\right)$.

HUNTERTOWN, 400, ALLEN

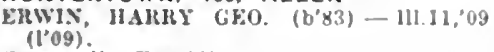

(ireenwell, Franklln (i,-0.6,76; 11.97)

Houshton, Lloyd-X.1.6,65; $\left(19^{\circ}\right)$; not In practice.

HUNTINGBURG, 2,464, DUBOIS

(jengelbach. Krnest F.-O.2,' $\times 1$ : (1'97)

KNAP', IIEXRY CLAY (b'68)\&-Ind.18. '00: (I'07): OALR.

LUKFMEYHI, EIWW, G.-Ky.4,85: (1'9i)

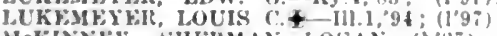
MCKISNEY, SHEHMAN LOGAN (b'si)Ky.2,'12: (l'12): S.

ACHWARTZ, CHARLES W. $\left(b^{\circ}, 0\right)-K y .2$ STBINKAMI", RMII, F-KY.2,03: (1"03).

HUNTINGTON, 10.272, MUNTINGTON

lieck, Wm. K.-Ky.1,'92; 11'031; 30 ltorthe St. : oesce, $314 \mathrm{x}$. Jeffersun sit.

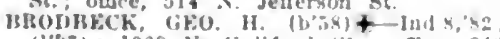

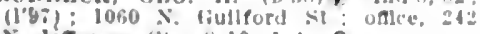
X. Jeterson st. : $k-10,1-4 ; 0 p$

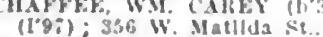

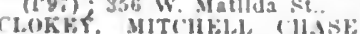

Ky.8,98: (1'98); 340 Matilu

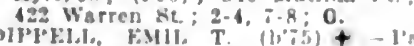

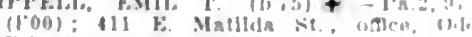

Fellow lllock: 10-1'z, i-8: 1."

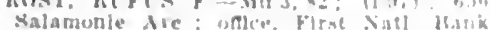
Jilis:

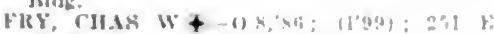

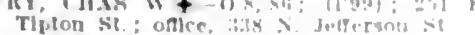

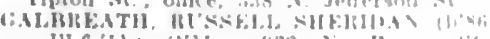
-111.6. 11 : (1'11), !3:2 $x$ 11!
CoOL, (11As. II $\left(b^{\prime} 60\right)+-111.1,83:\left(1^{\prime} 97\right)$ $35 \%$ E. Franklla st. ; once, $405 \mathrm{~N}$ Jenter

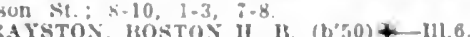
75 ; (199;): 64t $\mathrm{x}$. Jetrerson st.; oflce, $310 \times$ Jererson St. $9-12,1-4$. HAYSTON, CHAS, b-(1):81; (J'97) 312 W. Thiton si. ; aflce, 13 r. Market se

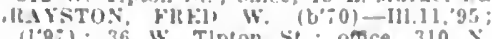

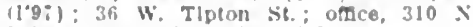
beftervon st. : 8-10, 2-4, $;-8$.

lili litos, WALLACF s. $\left(b^{\circ} 78\right)$ \& 111.6 , 04; $(1.07) ; 303$ E. Narket St ; I-3; S. *

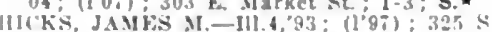
Jefferson st; onlce, First Xat. Bank IBdda.

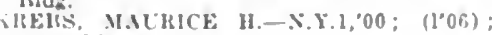
Hoos Bldg.

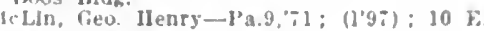
Market St.

VURGAX, FRANK B. (b'69)-Ind.8,9"; 11991: 582 kitua Ave.: oftice, 41: $\mathrm{X}$ Jefterson st. : 10-12, 2-4, ;-8.

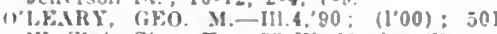
W. State St. : office, $3: 3$ W. Market si.

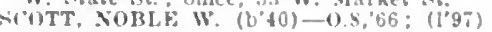
504 H. Market St,

IIAFFER, AHNER H. sh! $\times$. Jetterson St.

$1155^{\circ} \mathrm{x}$. Jefferson $\mathrm{s}$. fervon St. ; $11-12,1-4,7-8$;

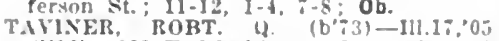
$\left(1^{\prime} 06\right) ; 239$ E. Washington St. : oflce, 42 Warren St.; 8-10, 1-3, :-9.

Tlromas Mareus H. (b"76)-Ind 9.97: (l'01)

WIIITII CUARLES I (b'62)-Ii1. $\left.\left(l^{\prime} 9\right)^{7}\right): 23 L$ Frederlck st.; oflce, $2 \mathrm{k}$ Market St. $10-12,2-t ; S$.

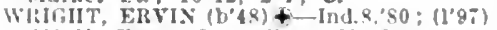
W0 $\mathrm{X}$. Cherry st. ; oflce, $420 \mathrm{X}$. Jeffersol Sit. : $7-8,2-3$.

Yingling. Danlel (b'39) $\rightarrow$; $\left(1^{\prime} 97\right): 930 \mathrm{x}$ Warren St.: oflce, $420 x$. Jefferson st. $12,1-4$.

\section{HURON, 197. LAWRENCE}

Selfrldse, Wr. T.-K5.2.94: (1'11)

HYMERA, 1,515, SULLIVAN

SIIIRY, CIALOE W $\left(\mathrm{b}^{\prime}: 3\right)+$-111.1:,03 $1104)$

I'lew, Geo, F. (b'58)-Il1.1,76: (144)

THRALLS, CHAS. IIIHAS" (bo') III. 03; (1'04).

IDAVILLE, 500, WHITE

IISNIIK, HORACK, K. (1153)-08, (1'97)

Itelf, Chrlstian W.- $-02,01:$ (1'02)

Wilkerson, llattle I. (b'60) J'-M-ind.1:91 $(1 \cdot 9 i)$

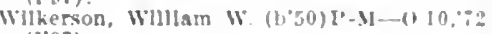
$\left(1^{\prime} 9 i\right)$

INDEPENDENCE, 500, WARREN

Innes, Thos Boyd (b'tit) Ky"lo"

Michael, (has, W. (60.5)-Ind.9.9:; 13951

lloveberry, Isaac A $\left(b^{\prime 3} 33\right) \rightarrow$; $(129 i)$.

INDIANA HARBOR, 7,000, LAKE

A.SSI.K: HOIST. (b'

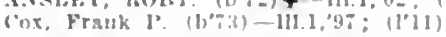

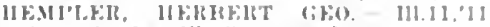
(1) Member [1]. Siate Med. S

III (10:3)

Kary", Marcus ofuis (b'86)-M0.20:11;

(1) (itil) (1):3) + Ind.9,05; (1005).

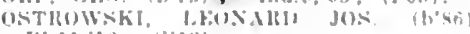

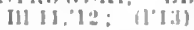

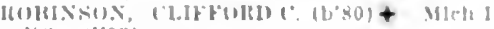
(1): (1'03)

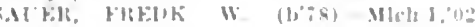
(I0)

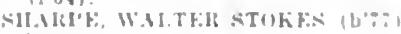

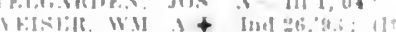

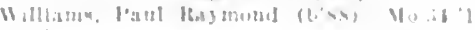

INDIANAPOLIS, 2333.630. MARION

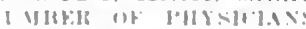

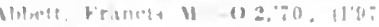

lighrt blish rim

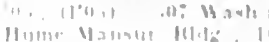

bolt, Manis llit:

$1(85) ; 922$

lendrulb, kranz $k$

$\therefore n \geq\lfloor n\rfloor$.

versily tre.

Ohlo Si ; y.1: a :30-7, OALR.

dams, Jusegili II Is - 10.16 ;

Sol'ta Trmina me

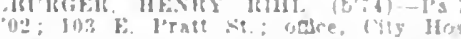
plial; l'ruf. Pasth., lud 20: (F10); Path. Nexander. dames T.-Md2: is: (1'8i); 830 Merlullati Sit.

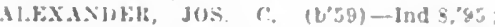
(1.95); 122 S. Nisbama st. ; ofoce. Nen lon ("laypool Irdge: $10-12,2 \cdot 4,7-8$.

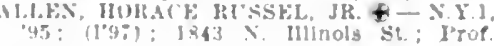
Ortho. Surg. Ind.20; Or.*

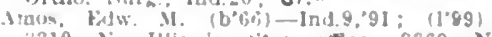
$3310 \mathrm{x}$. Illibols st. unce, 3369 y

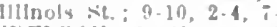

A.NDFilsox, lus a-ind 8.9.; (1'9i) 1:211 l'rospect sit ; unce, Newton Claypool Mllt. : $10 \cdot 12$, : 1. :-8

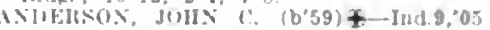

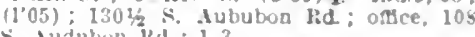
A dudubon lid. : 1 -3.

Andrew, Virgil k-lad 5,90; (1002); 3940 lionkworm ine.

Inthony. F. (;rove-Ind.5, $99 ;(1997)$; 141 I'drk Nie.; oflace, Newton Clayposl Ilda. Inthony, James IR. (b'44)-0 1.:4, (1.9:) 13ll College Are.; oflce, 1809 Coilege live -9 i- $=9$

Irmlstesd Henry Watson (b'6s) - Tenn (14: $\left(10^{\circ}\right)$ : 1116 Cornell Ire.; 10-12, sh. Mary Ella-IIL.11,03; (1’01); Lemcke lidug. : N.

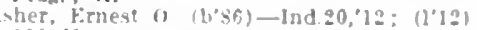
$105 \mathrm{X}$ s.nate dre, ottee, Indlana In versly schowl uf IIed : 10:30-11:30; 0b.* ukins, falvin liupert-D.C.3,94; (1.05): 1427 lofumbla Ale; onde, 1564 Coluratis lie.

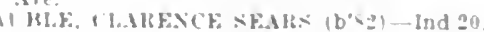
'1:: (1"12): 2t19 Kronkuble die : ontce.

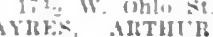

(1); igt0 Talbot Ire. Ualce, Newton (1a) mol bldy: 9-12. bafoli, Harrlet

liadders, Ara (arl (b'90)-Ind 20,$13 ;(1,13)$; l'rotestant Deaconess Hoopltal.

Hadger, tharles leona (b"6)-ind :0, 11 (1'I1): a3ng $x$. New Jersey st.; once. 1401 Bellefontalne $\mathrm{x} b ; 9-11,2-4, i-4$

MaIl, MAXWFL, I (bot4) + Ind 8,86 $\left(I^{\prime} 9 x\right)$ : (central); " "fre. Central Hospltal for Inssue: P.

M.)KFl, Wy FRANKLIX (b's3)-Ind:0, 11: (l'11): 220 liendrick J11

laldwin, lien, $\left(\mathrm{C} \rightarrow\right.$; $\left(l^{\prime} y ;\right) ; 3190$ North. nevtern ile.

lillenger, How ard (has, (hsi) - Ind :00,1! (1'II); Methmist llospllal.

lalllnger. Osear 1. (b'as) - III 16:04 (1'10); 929 \& senale Are; oace, sto II Worth st : $9+11,=-5$, i-9

Barker, Joha l: - Ind 9,00: (1.03): 2145 shelly st ; oftce, s3i Virsinda Are.

Harker, Mary A -Wlst.9o; (1.00); Esic

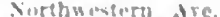

llarmm, (has. F. (b'6) lut 16.93: 11"9:) roos l'arkway die, adlec. Hulituag Hels

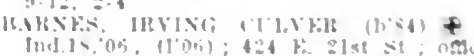
lon z: Market si: $91,3-3,: \because U$.

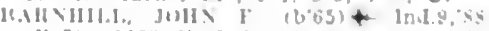

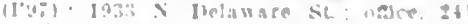

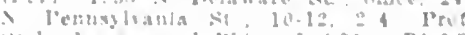

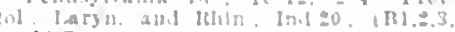
ALR

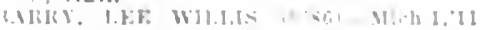

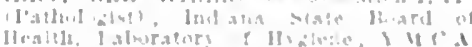

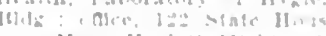

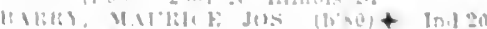

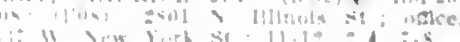

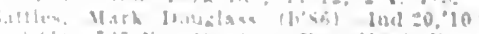


HLASLLY, TIOS. J. (1'S1)+-Ind.18,07; (1'07); Newton Claypool bldg. ; $11-2$.

HECK, WI. S.-Ind.s.'8s; (1'97); nut in practlce 1831 $\mathrm{x}$ Merlum st.

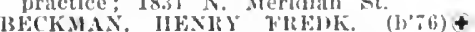

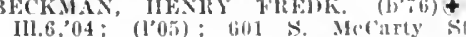

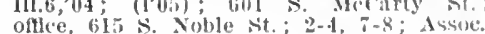
I'rof. Mbst., Ind.20; 0 b.'

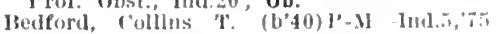
(1'97); 2203 13roaldwaty; olfhe, fenton Claypool 13lig.: $:-10,2-4$

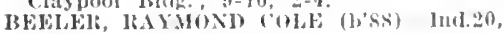
12; (1'12); 2I34 Talbott Ave, alluce llume-dansur bldg.; 10-4; R.

BERATER, IOS MARTIN (b"bi) +0.1 93: (1967): 1349 Mallson dre

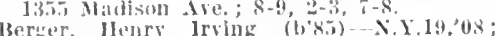
(tos)

Berner, Lollis fo-Inds.'0l; (l'0l); $110 \mathrm{~b}$ fleasant st.: oltce, 1415 shetby st.

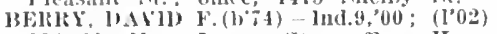
826 $\mathrm{N}$. New Jerses St.; offlce, IImme

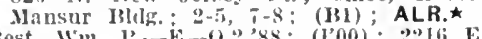

(ance $1-3,6-8 ; G$.

1-3, 6-8; G. 3036 v. Wishington st.

Biebinger, John-f (1'97); 312 F. Washlington st.

Blgger, lichard F. (b'6l)-Ind.s, $8 \pi$ : (l'9i) 524 Whklle Drive, Woolrutf Pl.; offlce, 520 Massinchusetts Ave. : $2-2: 30.7-7: 30$.

IBirchfleld, dames W. (h'61) - lnd.9,'98 (l'98) ; 2328 E. 10th st. ; offlee, $2326 \mathrm{~F}$ I3OAZ, 70HX JORl) iN $\left(b^{\prime} 76\right)+$-Ind.9, 95 ; $\left(l^{\prime}\right): 240 \mathrm{~W}$. New York st. ; offlce, New-

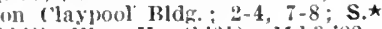

Boblitt, Wm. lI. (b'til)-Md.3,82; (1'97) $226^{\circ}$ F. 13th st.; offlce, Indiana Pythlan islelg.

Bolender, Clarence s.-Ind.17,03; (I'04); 1940 Bellefontaine St.; office, $1110 \mathrm{E}$. 1940 Bellefontaine St, ; office,

BONN, IIARRY KRAYLOR (b'86)థ-Ind.20, '08; (l'08); 2210 Central Ive.; offlee, $33 I^{\prime}$ N. Delaware St. ; $10-2,7-8 ; \dot{U}$.

Boran, Filen Vance ( $\left(1^{\prime} 98\right) ; 4 \div \div$ E. Washington St.

BOWER, 10HN V. (b'50)-Ind.8, 80 ; $\left(1^{\prime} 97\right)$; 5355 Fall Creek Are.

Bowers, lsaac H. - 0.13.'96; (I’98) ; 215 Jefferson Ave.

BOWMAN, GEO. WASHINGTON, JR.-(b'89) -Ind.20,12; (l'12); 901 Wrlght St. ; offlee Newton Claypool Bldg.; 10-11, 2-4, 7-8; U.

Boyer, James Mueller (b'63) - Ky.1,95; IV. Washington St.; $9-11,2-5,7-9$.

BRAYTON, ALEMRERT WINTHHOP (b'48) †-Ind.8,79; (l'98); 2125 Broadway. offce, Newton Claypool BIdg.; $10-12,2-5$ offlee, Newton Claypool BIdg.; 10-12, 2

Prof. Derm. and Syph., lnd.20; (C2);
Brayton, Frank Alembert (b'90)-Ind.20,'12; (1'12); Newton Claypool Bldg.

Brennan, Fdward J.-N.X.6,'̌1; (I’97) ; 438 N. Capitol ive.

Brenner, Ivan Frnest (b'87)-Ind.20.'13

(I'13); Protestant Deaconess Hospital.

Briggs, John J. (b'82)-Ind.18,'06; (I'06) ; 33:3 Park Ave.; offlee, 804 N. Illinois

Bive $1-2.80,7-8$.

(l'0-) (l’97); Merldian Life IBldg. ; $9-12,2-5$.

BR11/l, JAMES H. (b'43)-0.9, 72; $\left(1^{\prime} 97\right)$

Brocking, Ernest R.-ind.8,02; (1'02); 309 E. Wyoming St.; offlce, 417 E. Wc Carthy St.

Brown, Benj. A. (b'66)-Ind.8,'8 2530 Station St: $8-9,2-3,7-8$

BROWN, EDWARD A. (b'73)థ-lnd.8,'9s (l’98); 1519 Pleasant st.; offlce, HumeMansur Bldg.; $8-9: 30,2-4,7-8$.

BROWN, KARL T. (b', 7$) \oplus-$ Mo.28,'99: (l'03); 651 F. $32 d$ St. ; 2-4; S. *

Brown, Wm. Ellott - Mich.1,95; (1'98): 357 Indiana Ave.; offlee, $1125 \mathrm{~K}$. Senate Are. S. J.

Brubaker, Elmer H. (b'68) - Ind.5,'96; $\left(l^{\prime} 97\right) ; 122$ E. Ohio St.; $9-11,2-4,7-8 ; \mathbf{G}$.
Bryson. liachel Amna-Ind.5, $89 ;\left(\mathbf{l}^{\prime} 97\right)$ Bryson, liachel Amma-
932 Massachusetts Ave. buehler, Eugene - Ind.9,98; (l'99); 3525 fan Hhitg.

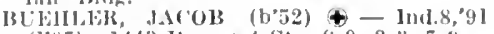
$\left(l^{\prime} y \overline{7}\right) ; 1443$ l'rospect $s t . ; 8-9,2-3, i-9$

131 H.1, J0HN 1I.-Ind.8, 03 ; (1'05); 225 E. Michlean st. oftlee, 1222 le. 130 st.

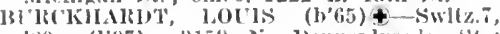

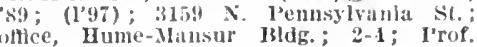
once, Hume-

Obst., Ind.:20.

I3urris, Charles-Ind.8, $04 ; \quad\left(l^{\prime} 04\right) ; \quad 527$ Annes sit.; otthe, 242 W' 13 h st.

BUltis, liLZA WYA'T (b'74)-Ind.8,03 (l'03) ; $3333 \mathrm{~W}$ W. Nichlgan st.; offlce, 2608

W. Wichlgan St, ; $10-11,2-4,7-8$.

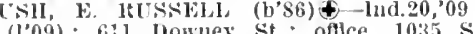
(Tlog) 6il Downey st.

Butt\%, Rose..' Plscator-lnd.8,01; (I'01); 2 il W. Nlehtgin st.

Bye, [Benj. F.-lill.19,96; (1'95); $1935 \mathrm{~N}$. Senate ive.

CA1BAIZER, CHAN. LAWRENCE (b'8I) Ind.20, $08 ;(1,08) ; 429$ W. Mlchlgan St.; offlce, Willoughby Bldg.; $12: 30-2,7-8$ Anes.

Caln, Clias. Masters (b'83) - Ind.20,09 (l'09) ; 3470 Kenwood Ave. ; oftlce, llume-

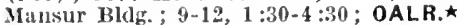

Caldwell, otls Álexander (b'35)-Ind.20,'10; (1'10); 12 Vlemna Apts.; offlce, Newton Clay pool Bldg.

Camphell, lootla W. (b'55) 1'-M-0.10,79; (1*99); 3916 College Are.; offlce, State Llfe Bldg. ; 9-4; G. *

Canaday, James W. -Ind.8,01; (l'02) ; 1602 1'rospect St.; oftice, 866 Virginia Ave.

Canlleld, Benton Y.(b'64)-Ind.9,'90; (l'97): 866 Fletcher Arc.; offlce, 209 E. New lork St.; $9-11,2-4$

CARAWAY, SAML. H. (b'66) $+-0.1,93$;

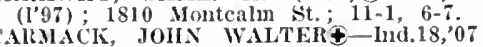
(l'07) ; 2419 E. 10 th St. ; $10-11,2-4, i-8$; Ob.

Mlison, LOUIS o. (b'53) - Ind4, 77 ; $\left(l^{\prime} 97\right) ; 941$ Congress Are.

CARTEk, CIIAS. A. (b'63)-Ind.8,'87; (l'97); $309 \mathrm{~N}$. Tacoma Ave. : offlee, State House.

Catlett, Marshall Burr (b'88)-Ind.20,:13 (l'13) ; Protestant Deaconess Hospital.

CHAMIBEIRIN, CAMERON (b'79)↔-Ind.8, '02; (I'02); 3215 W. 10 th St. ;

CIIAPPELL, RAL1'II S.\&-Ind.8,'04; (l'04) ; Termlnal Bldg. ; 11-12:30, 2-4.

CHARLTON, FIEOK RANKIN (b'73)屯 Ind.8,'94, 1'a.1,'96; (l'97); The Cambridge ; office, Hume-Mansur Bldg. $10-12 ;$ Clin.
Prof. Gen.-Urin. Surg., Ind.20; (C3); U CIIRISTIAN, (*EO. IR.- - Ind.8,,$^{\prime} \overline{7} ; \quad\left(\mathrm{I}^{\prime} 00\right)$ 1449 I'rospect St.; offle, 1110 I'rospect St. : $10-11,2-4,7-8$.

Christlan, Wilmer F. (b'71) - Ind.8,'96; $\left(\mathrm{l}^{9}\right): 1624$ N. Delaware st.; offlce, Lemcke Bldg. ; $9-11,2-4$.

Christie, J. Preston (b'82) -Ind.18,07; $\left(l^{\prime} 0^{-}\right) ; 1306$ E. 10th St.; office, 1204 E. 10th St. ; $9-11,2-4,7-8$.

Clark, Andrew J.-Ky.1,'80; (l'97) ; $624 \mathrm{x}$. New Jersey si.

CLAlK, EDMLND DOUGAN (b'69)థSt. ; office, Hume-Miansur BIdg. ; 11-12,3-4 Sec. and Clin. Prof, Surg., Ind.20; S.

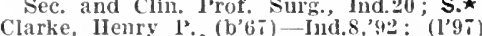
312 E. Washington st.: $9: 30-11: 30$. Clarke, Wm. Bralles (b'4s) - Ill.10,'84 (I'97) ; 1529 $\mathrm{x}$. Illinois St. ; 8-10, 2-4.

Clayton, Chas. II.-Ind.8, 02 ; (1'02); 2305 Brookside Are.; offlce, United Bldg.; 1-5. $\tau-8$

ClFiENGEl, WII, F. (b'-1)£-Ind.8,94; (197): 1626 Tilbott Ave; office, Yewton Claypool Bldy.; 9-1, 2-5; (B1).

CLINE, LEWIS CURN (b'J1) \&-Pa.2,79; (1'97); 5404 Central Ave; office, Willoughby Bldg. ; 9-12, 2-4; (B1,3) ; ALR.* Cloud, Laura Jennlngs (b'55)-Ind.5,'85. $\left(1^{*} 97\right) ; 712 \mathrm{~N}$. Illinois St. ; 1-5; G.*

COBLE, I'AUL B.-Ind.9,'05; (I'05); 1933 N. Delaware St.; offlce, Pennway Bldg. 9-12,2-5; ALR. $\star$

Coble, Ralph R. ( (b'79)-Ind.8, 05 ; (1'05) 711 E. 27 th St.; offlice, $2701 \frac{1}{2}$ College Are.
Coffln, Orlatudo S. (b'57) F-Ind.11,'83; (I'03) ; 1552 k. 10th st.; $9-11,2-4,7-8$.

(OLE, ALBERT MAYNARI) (b'70) \&-

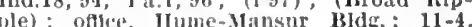
(Ci); R.

Collfer, Susin $\mathbf{~}$ :-Ind.12,94; (1'98) ; 2235 lienwood are.

('OMBS, GEO), W.--In(I.8,'84; (1'97) ; 2734 Sutherland Ave; ollice, l'ennway Bldg.; (A4); Pr.

compton, ('has. Benton (b'89)-Ind.20,'13 ; (1'13); Clty Ilospltal.

Compton, loshua A.-0.7,66; (l'97) ; office, 5448 k. Washlugton st.

Conger, Chas. Walter (b'72) - Ind.8,98; (198); 1712 l. 10th st.; offlee, 840 Massachusetts Ave.; $3-5,7-8$

Conger, vilzabeth s.-ind.8,'97; $(1,97) ; 1714$ I. 10th st.; oftlce, 840 Massachusetts Ave.

Conley, Jos. I,eo (b’89)-Ind.20,'11; (l'11) ; 1617 F. Ohlo St.; office, 2443 E. Washington st. : $8-10,2-4, \bar{i}-8$.

Conner, Haskett. Lynch (b'84)-Md.7,'10; (l'11); $3241 \mathrm{~N}$. New Jersey St.; offlce, Newton Claypool Bldg.; 11-12, 3-5; $\mathbf{S}$.

Conner, Wm. H. (b'63)-1).C.3,'94; (I'12) ; $2321 \mathrm{~N}$. Capltol Ave.; 8-10, 1-3, 6-8. Converse, Ray Vletor $\left(b^{\prime} 75\right) \mathrm{F}-111.8,01$;
(1'02); $3338 \mathrm{~N}$. Illlnois St. ; $9-11,2-4,7-8$. COOK, CHAS. J. (h'67) $€$-Ind.8,'94; (l'04); 2405 Ashland Ave, offlce, 958 E, Washington St.; $10-12,2-3,7-8 ; \mathbf{O b}$.

COOK, GEO. JAMESON $\$-\mathrm{Ky} .1,66$; (1'98) ; $1726 \mathrm{~N}$. IIlinois St. ; offec, Hume-Mansur Bldg. ; (Af).

Cook, Hathew. D.-Ind.8,'91; (1'97)； 1843 Thalman Ave.

COPEIANI), SAML. JAMES (b'78)థ St.; offlce, 1647 Lexington Ave. ; 2-4, 7-8. COTTINGHAM, CHAS. E. (b'68)-Ind.8,'95 ; (1'04); 2142 Broadway; office, Board of (l'04); 2142 Broadway; Offlce,
Trade Bldg. ; 1I-12, 2-4; NP.

Colty, Wm. R.-Ind.17,05; (l'06) ; 1236 N. west st.

Coulson, Sewell B. (b'78)-Ind.9, 03 ; (1'03) 1440 S. New Jersey St.

CURTNEY, THOS. E. (b'68) ๑-Ind.9,'92 (l'97); 3034 N. Delaware St.; offec, Indiana Pythian Bldg.; $2-4$.

Cox, Clifford Larl (b'89)-1nd.20,'12; (1'12) ; $200 \mathrm{~N}$. Senate St.; offlce, Deaconess Hospital.

Cox, Homer Wlckliffe (b'85) - Ky.2,'12; (1'12); 220 W. 20th st.;

Crans, James T. (b'41) - lnd.9,'86; (l'98); 2810 Martindale Are,

CREGOR, FRANKLIN W. (b'T3)@-Ind.8, 94; (1'97) ; Pennsylvannia and Ohjo Sts. office, Iume-Mansur Bldg. ; 9-1, 2-4; 0 .

Cropper, Eva A.-Ind.10,'83; (1'97); 312 E 13tl St. oflice State Llfe Bldg.

Crow, Cluas. R.-Ind.16,'92; $\left(1{ }^{\prime} 97\right) ; 1226$ N. Illinois St.

Crum, Fredk. E.-Ind.18, 06 ; (l'06); 877 W. 29 th St:; office, 2820 Clifton St.; $9-11$, 2-4, 7-8; Pd. Culloden, Wm. G.-Tenn.5,'99; (l'99); 2439
X. I'ennsylvannia St.; offce, Newton Claypool Bldg. ; $10: 30-12,3-4,7-8$.

Culver, Thos. II. (b'52) E-Ind.11,'86; (1'86) $227 \mathrm{X}$. Lllinois St. ; $i-9,1-3,6-8$.

CUNNINGHAM, JOHN M. $\oplus$ - Ind.4,04; (l'04); 2327 N. Meridian St. ; offle, Willoughby Bldg.; 11-12, 2-4.

DAGGY, BENJ.' THOS. (b'85)-Ind.17,'08; (lo8); 704 N. Capitol Are. $;$ N.

Daniels, lismeralda A.-Ind.4,76; (1'99) ; 1322 ollver Ave.

Davenport, Hilbert Fenton (b'74)-Ind.20, 08, 0.2,'99; (1’99); New Commercial Hotel.

DAVIS, JOHN QUINCY (b'74)-Ind.8,'99; (l'00) ; 122 E. Ohio St. ; office, Rauh Bldg. Asst. Prof. Gyn., Ind.20.

Day, Clark E. (b';6) P-II-Ind.5, $01 ;\left(l^{\prime} 01\right)$; Illinois St. ; 1-3, 6-8; Ob.

Dean, Michael F.-Ind.18,07; (1'07); 711 Shelby St.

DE HASS, THOS. WARREN (b'5T) $\oplus-0.1$, '83, N.Y.10,'88; (1’97); 2152 Meridian St. office, Hume-siansur 'Bldg. Asst. Prof. Clin. Med., Ind.20. 


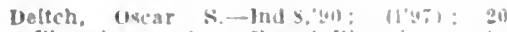

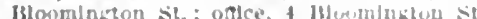

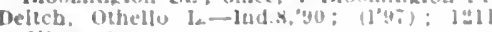
Olliver ive

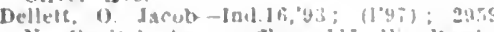
X. [ajlfol Ave: Uttec, 11j W. Wash Ington st:

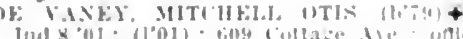

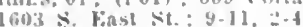

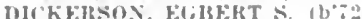
(l'13): Member 111. state Med E. 16 h S

1) 6it $b$. listh sit.

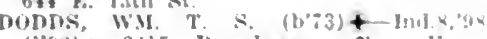
(1'95); 2415 Brualway; omen, llume Mansú Blde: $9-12,2-1 ;:$

Dorlge, Wm. A-Ky, Senate Are.

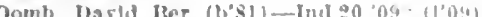
639 Madlsun tro: unce, $31 \mathrm{~W}$. Ohitu sit

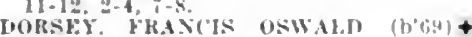
N.Y.1,96; (1.99); 121: X. New Jerney st.; once, Hume-Mansur lidg.; 11.1 Assoc. I'rof. Meal. Ind.20.

Doty, Arthur G. (b*3)-M/ch.11,00: (1"0) $1] 31$ \$. rapltol Are.; $8-4$, ti:30-8:30

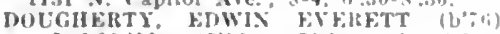
-Ind.20,10; $(1,10) ; 30$ th and flifton

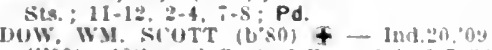
(l.09): 4 sth and central sis. ; $-4,6--30$ (l丷09); tsth and Central sis, ; $-4,6-700$ Mowd, Frank T. Inds.

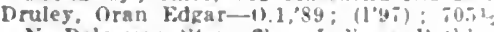
$X$ Delaware st. : oflce, Indlana ibubau Bids.

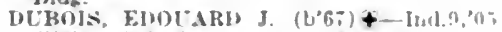
(105): 238 k. 10 th st, : nflce, state late Bldg.: Bact.

Duckworth, James Wesley (b'90)-Ind.20, "12: (1'12); Hume-Manisur IHde: 1]-3. UCix, TIIOS, J. \& Ind.8. n1: (1'01) 953s ir. Washington st.; oftec, atin W. Wiashlngton St.

Dunbar, Colln V.-Ind.15,"06; (1"(bii) : 261: X. Cayltol Are.: offee, Hunde-Mausur Bidg. : $11-1,3-4, ;-5:$ Pd.

Dunlary, Ira F. Ind.8.83; $(197): 1.94$ DUXNIS, I.EHMAN M. (b'xt) + Inil. 20 08: (1.08): 1547 Roosevelt ive : $3-4, i=8$

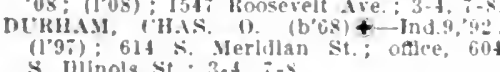

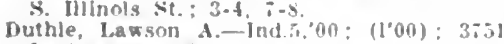
l'ark Are, once, Newton Claypool Blug. $1: 30-3 ;$ U.

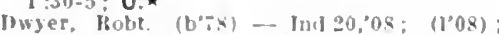
$1333 \times$. Olney st. ; uffle, IIme-Mansur I3Idg.

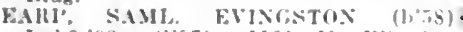

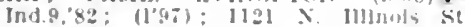

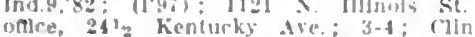
oflce, $2 \mathbf{1}^{2}$ Kentur

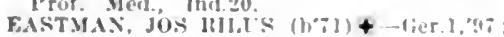
(195): $331 \mathrm{x}$. Delaware st.: I'rot. Surg, ind.20; (1), (3)

EAsTMAX, THUS, MARKEI (h'6) Ind.9.93: (1.9:); 4150 Washlngen His. oftce, l'ennway 13ldg.: 1-3: l'lin. I'rof C.yn., Ind $20 ;(x)$

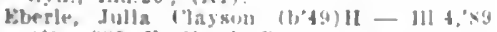
(\$) : \$39 F. North st.

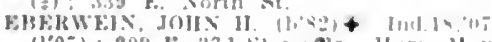

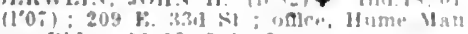
aur IBlug: $11-12,2-4 ; S$

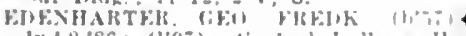
Ind.8:96; (1.96); 1'pltral Imbllat Hual tal for limane: (E13)

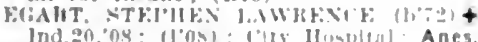

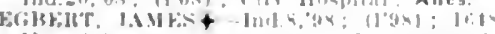

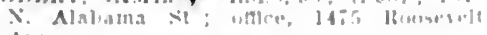
Ale.

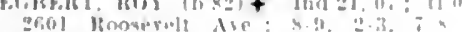

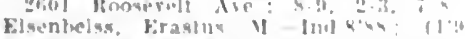
abi X Delaware si

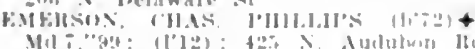

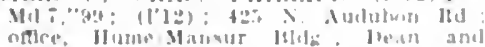
liros Mol. Ind : 20 : I.*

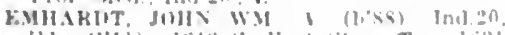

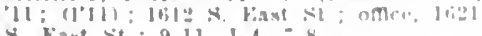

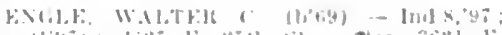
(1) \#th st: $4-9: 40,2-3 \cdot 30,6 \cdot 30-7: 30$.

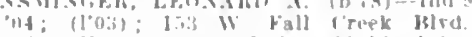

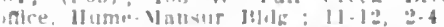

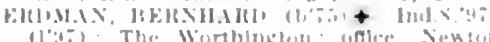

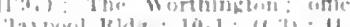

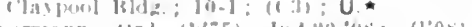

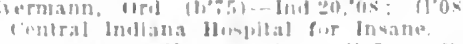

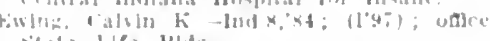

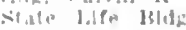

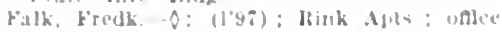
$1 ! 11_{2} \leqslant 1111$ nols sit.

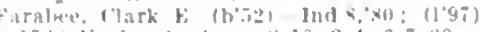
ling senate dre.; $8.10,0-4,6-7,30$

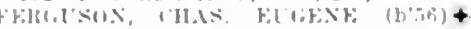

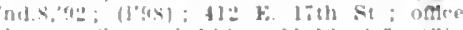

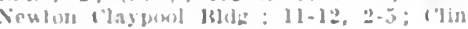
l'rof. 1ltist. Ind:z0; ObG.

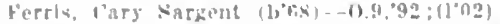
324 k. Walnut st. omlue. Terminal Blug.

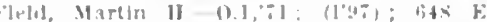
st. Clutir si.; ontere, itt k. st. Clair st.

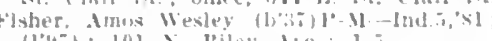

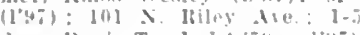

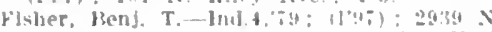
New Jersey +1 ; unter, i:s W. Sew lork st.

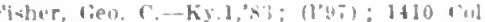
lege Ave

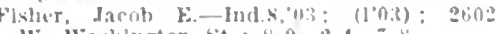

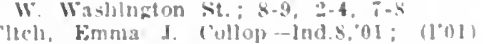
$911 \times$ Merldian st.

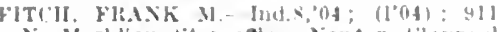
$x$ Merldian sit; oftce, Venton l'laypowl lidig: : $2-3 ; 0$ b.

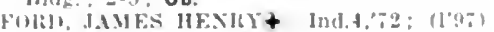
The Colonnade: oftie. Vewton claypont

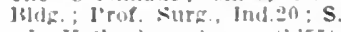

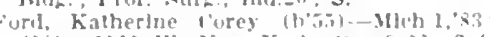
$(1 \div): 1111 \mathrm{~W}$. New Yurk sit. : 9-11, 2.1

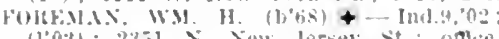

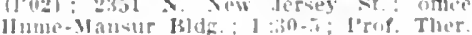
Int) $: 0: 1, *$

roprer, iucle Gahrlelle (h'se) Ind:0.'12

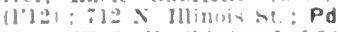

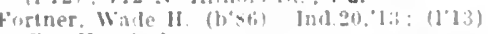
Iliy Hospltal.

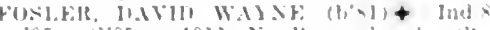

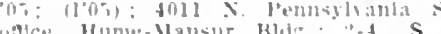

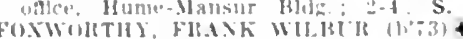

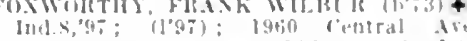

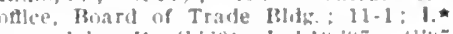

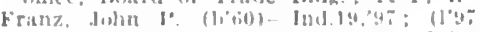

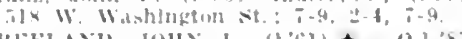

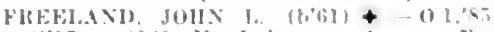

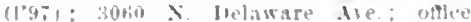

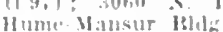

Falenwider. Homer lase (1,-3) Indsent (100\%:

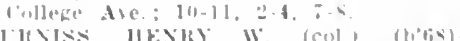

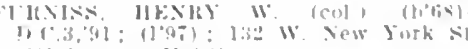
(Mlnlister in Malii)

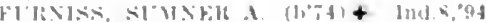

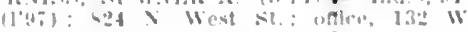
lin Juth si: 111-11. 2.4. i

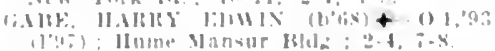

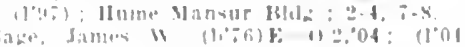
abot simus w $\left(1, \frac{6}{6}\right)$

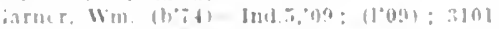
l: linll 81 : $10,3-4$,

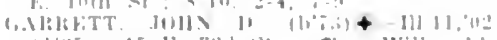

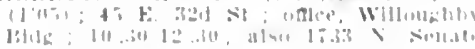

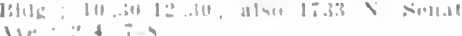

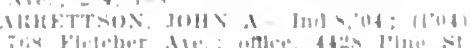

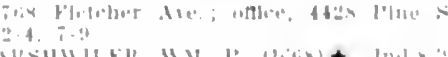

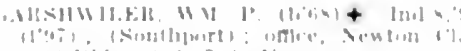
(1)

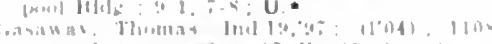

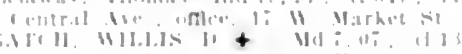

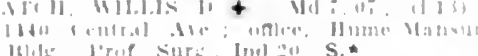

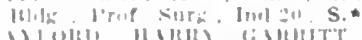

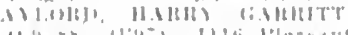

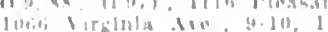

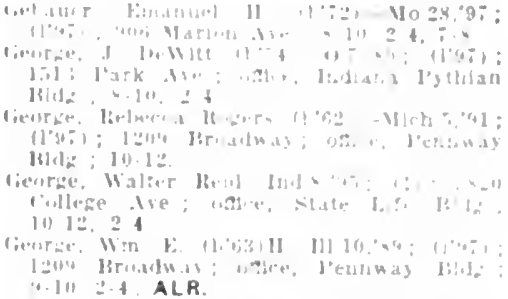

"Al1, B.t. ALR.

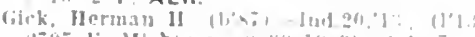

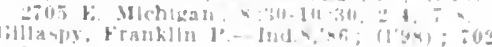
Jasuell Are

allevple, Wm lismer (b"3ri) - Ind 4,01 ;

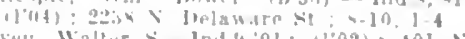

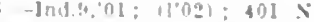

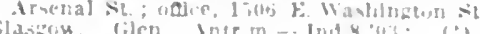

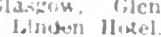

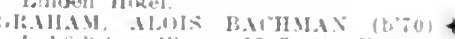

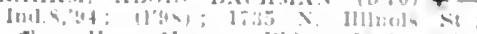

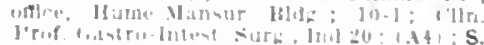

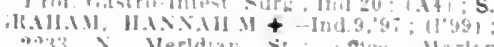

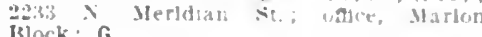

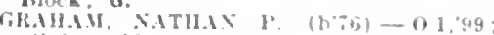

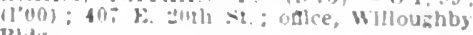
lild

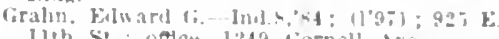

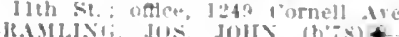

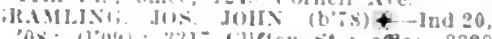

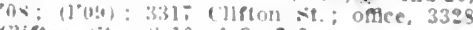
clifton st. : $:-10,1-3,7-9$

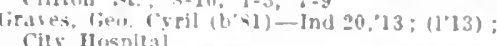

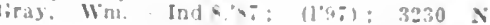

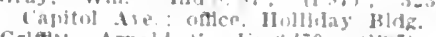

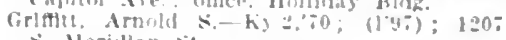

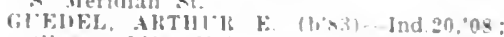

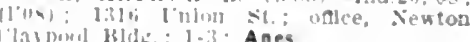
l'lay poul klak:; $1-3$ : Anes.

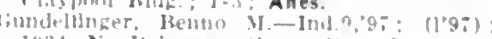

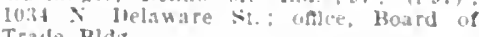
Tracle Blda

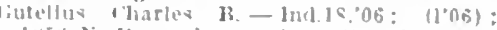

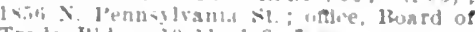
Trate lidit: :

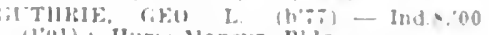
(l'(1) : Hunk-Mansur Blde

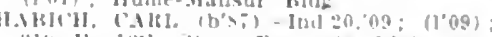

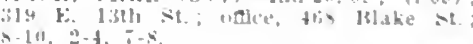

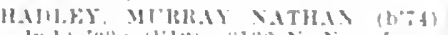

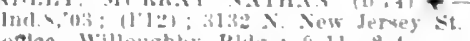

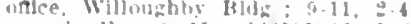

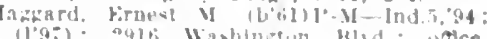

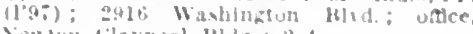

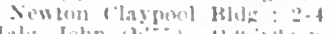

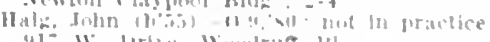

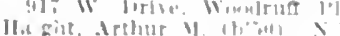

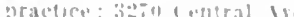

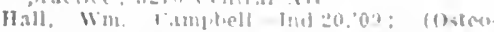

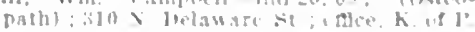
Bath :

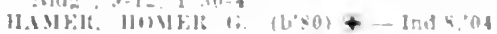

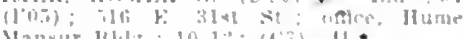

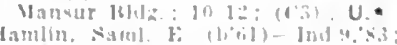

(1100)

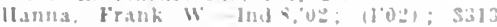

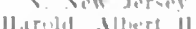
trout itre

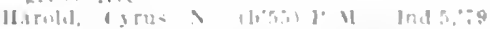

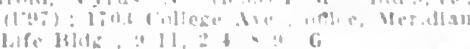

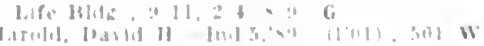

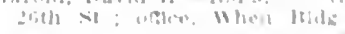

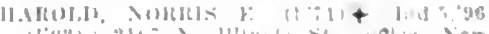

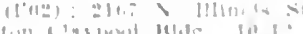

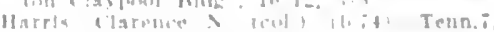

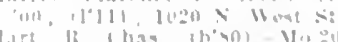

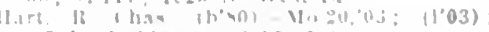

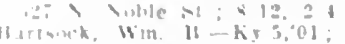
4 -rise ive

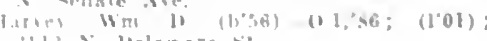
11: i Jelanare st. 
HISILT, MAIHETTA - Mlch.I, $83 ;$ (1997): onlice, 2005 College Ave. ; $3-5$.

IIATFIELD, SIOXEY J. (b'80) —-K5.5, 02 ; (l'03): 2304 Stuart St.; nftice, I'ennway Bldg.; ; 9-10, 2-4; Asst. 1'rof. Gin., Ind.20

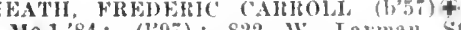
Ye.1,84; (1'9i); 822 W. Iayman st. office, Newton Claypool Bhlg.; $10-4$; Cllm

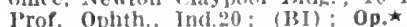

IIEINIRICHS, IIARRY H. (1) 81$) \mp-$ Ind 9 , '04: (I'04); 1011 13roadwny

Helmen, Harry Wim. (h'82) - Ind.2n,'I3: (l'13): Indlanapolis Clty IIospital.

Helmlng Herman Augustus (b's0) - Nlch. I 04. (195): 1130 s. Wast st.; offlee, 1126 S. Wast St, $9-11,2-4,7-8$.

IILAING, 'THEODOLE' W. (h'65)-Ind.8. si; (1'9i) ; $1136 \mathrm{~s}$. Fast st.; offlee, 1126 s. East st. ; $8-10,2-4,7-8$.

Helwh. Edw. C (b's4)-Ind.20,08; (1'08) 3017 N. Delaware st.

Hendricks, Alfred 1I. (1)'82) - Ind.20,'08 (1'08); 462 W. I2th St.; $8: 30-10: 30$,

HENDIHICKS, ROLLIN G. (b'78)-Ind.9, 03 ; (1'03); $21 \% 1 / 2 \mathrm{~N}$. Inmols St.

HENIT: ALFRED + -Ind.18.'07; (I'07) 2319 N. I'ennsylvanla St, ; office, Board of Trade Biddr.; II-12:30, 2-4.

Ileskeft, WHbur C. (b'58)-Ky.I,'86; (l'97) 46 Greer St. ; 10-12, 2-4: OALR.

Hesler, Geo. F. (b'49)-Ky.1,'82; (1'03) 6316 Iselfontalne St. 8-10, 2-4, i-8.
HETILLINGTON, ARTIUR MITCHEL IFTIEPINGTON, ARTIUR MHTCHEL York st.; oftice, If une-Mansur IBldg. $10-12,2-4 ; 5$.

Hickman, Waiter Fredk. (b'8s)-Ind.20,'12: (l'I2) : 834 Marion Are.; omce, 49 I E Mllchlgan St.; 2-4, i-8.

IIheksol, Fred Earl (b'83)- Ind.20,09; (1'09)

Hill, Albert Arthur - Ind.19,97; (1'97); 3334 Central Are.; offlce, Indiana Pythlan Bldg.

IIltt, Thomas S. (b'46)-0.3,'73; (1†); 429 N. Delaware st.

HOAG, WM. I. (b'59)†-N.Y.I,'84; (I'98) ; 2627 w. Washington St.: $8-10,1-3,7-8$.

HOBBS, ALICE LODICA $\oplus$ - Ind. 9,96 $\left(1^{*} 97\right)$; $5228 \mathrm{E}$. Washington St.; 1-3.

liobbs, Guy Fulton (b'85)-Ind.20,'II; (I'11) $3025 \mathrm{~N}$. Western Are.; $2-4,7-8$.

HODGES, ENW. FRANCISథ-Mass.1, 77 ; $\left(1^{\prime} 02\right) ; 2$ W. New York St.; Emer. Prof. Obst., Ind. 20

HODGES, FLETCHER (b’ 8 ) - Mass. 1,02: $\left(1^{\prime} 03\right) ; 2$ W. New York St. ; $2-3,7-8 ; 0 b$.

Hodgin, Everett $\mathbf{E}$. (b'71) P-M-Ind.5,'96, Ind.8, 01 ; $\left(1^{\prime} 97\right) ; 2645$ College Are. office, State Life Bldg.; 11-12, I-4

Hollingsworth, Albert A. (b'i9)-Ind.8,05; (l'05) ; 3916 E. Washington St.; 8-10, $2-4,7-8$.

Hollingsworth, John S. (b'65)-Ind.8,93; (1'96): 1258 Ollrer Are.: $8-9,1-2,7-8$.

Holmes, Benj. F. (b'49)-0.9,'80; (1'01) 221 W. 28 th St.

Holmes, Claude DuVall (b'80) - Ill.1,'12 (temporary permit,'13) ; 403 Beville Ave.

Hon, Amzi W.-Ky. 2,92; (1'04); 4131 College Ave.; offlce, Indiana Pythlan Bldg. : $9-11,2-4: 30 ; 0$ bG.

HOOD, TIIOS. COLWIX (b'60)†-Pa.2, 84 (1'00): 1149 N. Meridian St.; office, Newton Ćlaypool Bldg.; 9-12, 2-4; Prof. Ophth., Ind.20 ; (B1); Op.*

Hoover, 'Iohn E.-Ind.8,'81; (1'97); 2004 Central Are.; office, Indlana Pythian Bldg.

Hornaday. Henderson F.-Ind.9,83; (1'98); 133 W. 16 th St.

HOSKINS. WALTER D. (b'î)†-Ind.8,'94; l'9i, ; 3241 Central Ave; office, Newton Claypool Bldg.; 11-12, 3-5': Pd.

IIosman, Fred L. (b'ti) E-Ind.25,98: (1'98) ; 2258 Martindale Are.; offlce, 1325 E. 23d St.; $10-12,2-4 ; 5$.

IIU) (17) : $3015 \mathbf{N}$. Illinois St.; $1-3,7-8$

E, IOIN W. $\left(b^{\prime} 60\right)-0.9,86$; (l'04) Talbott Are.: office, 2150 Central
Houser, flames A. (b'47)-0.10,'86; (1'97) 16 t'4 l'ark Ave, offled, Indhana Pythlan

IItGIIHS, JAMES K. - Ind.I8,06; (1'06)

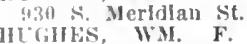

Mroilles, WM. F. $\quad\left(b^{\prime} 71\right) \oplus-1$ - Ind.8,02

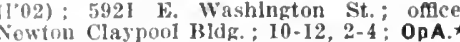
Intulse, Ilarrlson Bonlam (b'88)-Ind.20,'I2 (1'12) : 2629 Northwestern Ave.; 10-12, $\because-4,7-8$

Hulsizer, Elmer E.-Ind.9,88; (1\$) ; 2270 N. Dearborn St.

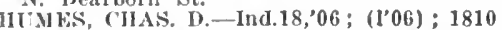
E I 1 ih St. offlce, "Norways" Sanatorlum. Irummons, Ilenry L.-Ind.8,'02; (1'03); 713 N. West St.; offlce, 653 N. West St. ; 8-10, $2-4,7-8$

Hurd, Harry Clark (b'74)-0.9,02; (appll callon pending,'13); College of Mísslons. IIUHTY, JOHN NEWWELL (b'52) $\$$ - Ind.8 '86; $\left(1^{\prime} 97\right)$; Sec. State Board of Health; House; Prof. Hyg. and Sanit. Sclence, Ind.20.

HUTCHESON, HENRY A-Ind. 8, 03 ; (1'03) 52 Hamllton Are, ; office, 2206 E. Washington St.

HITCHINS, FRANK FRAZIER (b'T0)Ind.8,92; (1'02); 507 N. Delaware St.

Iypes. Francls Elsworth (b'86) - - ind.20,'13 (l'13); 108 N. Senate Are.

Jacks, James R. (b'52) - Ind.11,'89, Mo. i,'98 (1'04); 2725 E. Michigan St.

JACKSON, GUSTAVUS B.-Ill.1,02; (1'06) 3140 N. Delaware St. ; offce, Pennway Bldg.

Jackson, James Wllliam (b'80) - Ind.20,10 (l'10); 6I4 N. East St. ; 11-12, 2-4, 7-8.

JACOISS, HARRY A. (b'80)€-Ind.8, $0 \mathrm{I}$ (l'0I): 214I N. New Jersey St.; offce,

JAEGER, ALFRED S. (b'74) †-110.1;99 (1'99); 1858 Talbott Are.; office, Newton Claypool Bldg.; ObG. $\star$

JAMESON HENRY (b'48) - N.Y.10,71 (1'97); 962 N. Pennsylrania St.; omee Hume-Mansur Bldg. ; 10-11, 2-3.

Jay, Nanuel (b'47)-Ind.8,'90; (1'11) ; 2366 Engllsh Are.

Jeffries, Kenneth I. (b'80)-Ind.8, 03 ; (l'03)
$302 \%$ Talbott Ave.; office, 609 Virǵinia Ave.

Jeter, Frank-E-Ind.16,'91; (l'97) ; 2230 w. Mrlchigan St.

JOBES, NORMAN FMMETT (b'71)-Ind.8, 97; $\left(1^{\prime} 00\right) ; 3426 \mathrm{~N}$. Meridian St.; offlee, Terminal Bldg.: 10.11, 1-3; Assoc. Prof. Surg., Ind.20; s.

Johnson, Robt. Carson (b'82) - Ind.5,'08, Ind. 20,09 ; $\left(l^{\prime} 08\right)$; 106 N. Senate Are.

JOHNSON, WMr. F. (b'81) $\begin{gathered}\oplus-\text { Ind.18, } \\ \left(l^{\prime} 06\right)\end{gathered}$ offlce, Hume-Mansur Bldg, 12-1.

Johnson, Wm. H.-Ind.4,'iT:' (I'98) ; Stuart and Roosevelt Are.; offlce, 2348 Station St.

JOHNSTON, SAML. ANDREW (b'76) $\underset{\text { I }}{\oplus-}$ Ind.8,'02; (1'02); 1334 Central Ave.
offlee, Hume-Mansur Bldg.; 9-2; ALR.

ones, Edw. F.-Ind.5,'98; ; (1'98); 111 Udell St.; office, 2818 Culfton St.

Jones, Homer I. (b'65) - Ind.8,'93; (l'98) $2 I 66$ N. Capitol Are.; Indiana Pythian Bldg. : I1-12, 3-5, 7-8.

Jones, Oscar Ind,

Jones, Porter M.- (b'58)-0.16,'95; (1'9i) ; 108 South Capitol Are.

Jordan, John S.-Ind.11,87; (1'97) ; 939 W. 2 th St.; office, 159 F. Market St.

KAHN, DAVID I. $\left(\mathrm{b}^{2} 66\right) \oplus$ - Ind.9,97 $\left(1^{\prime} 9 \mathbf{i}^{2}\right) ; 1839 \mathrm{~N}$. Meridian St.; offlce, $10{ }^{7}$ E. $22 \mathrm{~d}$ St. ; $10-12,2-4,7-8 ; G$.

Kakaza, Theodore Miasiza (b'78)-Ont.1,07;
(III); 1034 W. 26tl St. office, 807 Blake (I'1

Karstetter, Wm. B.-N.Y.5,84; (\$)； 1937 IV. $29 \mathrm{th}$ St.

Kast, Marie Barbara (b'89) - Ind.20,'13; (1'13) ; 1309 English Are.

Katterhenry, Edw. H. (b'i4)-Colo.3,97; (1'98); 2946 Laurence Are.; office, Odd Fellows Bldg. : 10-12, 2-4, $7-8$; U.

KEENE, THOS B. VICTOR (b'8I) \&-

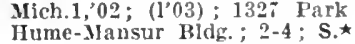

Keeney, Stanfleld II. - Ind.9, 00; (l'98) 843 Fletcher Are.; office, 511 Prospect St.; also Hume-Nansur Bidg.

Keller, Amella R. (b'i1)-Ind.9,'93; (l'93): 3527 Bellefontalne st.; office, Indiana P'ythlan Bldg. : 2-4: I'rof. P'ed., Ind.20.

Keller, Martha E.-III.4, 84 ; $\left(1^{\prime} 06\right) ; 523 \mathrm{~N}$. Alabama St.

KLLLY, WALTEIS F. (b'74) †-Ind.18, 06 ; F. Washlngton St.: $8-10,2-4,7-8.06$.

KFMPEIt, 1RO13T. J. (1'79) - Ind.20, 08 ; (1'08); I $49 \mathrm{~N}$. Inghland Are.; offlce, New York and Noble sts. : 9-10,2-4,7-8; s

Kendrew, Thomas ( $\left.\mathrm{b}^{\prime} 72\right)$-Ind.5,09: (1'11) 1817 Nowland Are.; office, When Bldg. $9-12,2-5$.

KENNEDY, BERNAYS (b'72)†-Ind.8,98: (l'02); 1030 N. Pennsylvanla St.; offece,
Ilume-Mansur Assoc. I'rof. Gyn., Ind.20; G.

Kennedy, Saml. A. (b'32) N. Tacoma Ave.; $10-11,1-4$.

KENNEDY, TIIOHAS C. (b'B2)-Ky.1,'83 $\left(1^{\prime} 97\right) ; 2610 \mathrm{~N}$. Illinois St.; offce, IIumeMansur Bldg: $10.12,2-4$.

Kerr, John F.-Ind.8,02; (1'05) : 1307 E.

KETCHAM, JANE MERTILL (b'80) $\oplus$

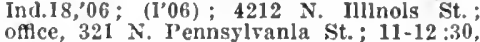
$3-5$.

Keyes, Paul H. (b'80)-Ind.8,'01; (1'02) ; 2449 Pierson Are.

Kilgore, Byron (b'82)-Ind.8,05; (l'05): 923 N. West St.; office, 925 N. West St.;

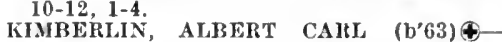
Ind.8,88: (1'05): I232 Park Ave.; office, Willoughby BIdg.; 2-4; Clln. Prof. Med., Ind. 20.

Kincald, John Clarence-Ind.17,'06; (1'06) : 1414 E. Ohlo St.; offee, Odd Fellows Bldg. King, Abraham

King, Wm. F. (b'74)-0.25,98; (1'98) : 2156 N. Pennsylrania St.; office, State House. KIngsbury, John Kaylor (b'85) - Ind 20,09 (1'09); 129 S. Ritter Ave.; offce, $5462 \mathrm{E}$ Washington St.; 8-10, 2-4, 7-8.

Kirkpatrick, James B.-0.1,79; (l'99) 218 E. 19th St.; office, Newton Claypool Bilig. ; G.

(1'03) EDGAR F. (b'80) —-Ind.8,'03 E. $22 \mathrm{~d} \mathrm{St} \cdot 2-4,7-8 \cdot \mathrm{Pd}$

KItchen, John Mr. (b'26)-N.Y.5, $46 ;\left(l^{\prime} 00\right)$; Itchen, John M. $\left(b^{\prime} 26\right)-\mathrm{N} . \mathrm{Y} .5$

KITCHEN, W. BURRETTE $\left(b^{\prime} 73\right) \oplus$-Ind.8 03: (1'03) : 1812 Park Are.; office, The Pennway; $10: 30-12: 30,2-4$; G.

KLEIN, FRANK C.-Ind.8,03; (l’03) ; 1309 Spruce St.; offce, 911 Vlrginia Ave.

Knert, Leonora E.-Ind.8,98; (1'04); 560 Lexington Are.

KNOX, EDWIN S.-Ind.8,'95; (1'97) ; 1406 Fletcher Ave.; offlce, 1404 Hoyt Ave.

Knue, Geo. Francls (b'84)-Ind.20, 09 ; (1'09); 655 E. 25 th St.; office, $9501 / 2 \mathrm{~S}$. Meridian St

Kohlstaedt, Geo. Wm. (b'90)-Ind.20,'12 ; (1'12) ; 1206 Evison St. ; offlce, 2174 MIadison Ave. ; $8: 30-10: 30,2-4,7-8$

KOLMER, JOHNं૯-Pa.2,94; (1'97) : 1626 Central Ave.; office, Board of Trade Bldg. $10-11,2-4 ; 5 . \star$

Koons, Geo.-Ind.8,02; (1'02) ; 22 W. Washington St.; office, $22 \mathrm{~N}$. West $\mathrm{St}$.

Kuebler, Luke Wm. ('十'87)-Ind.20,09: $\left(1^{\prime} 09\right) ; 454 \mathrm{~N}$. Rural St.; 8-10,1-3,7-8. Kurtz, Fred B. (b'79)-I11.11,02; (1'04); $10-12,2-4,7-8$.

Lambert, John A.-Ind.9,'91 ; (l'97) : 2420 N. Alabama St.; offee, Traction Terminal Bldy.; $2-4 ; O b$.

Lameroux, Scott T. $\rightarrow$; (1'01) ; 3571/2 E. Washington St.

Landon, Lewis C.-O; (1'97) ; 24 N. Arlington Ave.

IANGDON, HARRY KEMPERథ-Ind.8,'99; $\left(1^{\prime} 00\right)$; 1710 Talbott Ave.; office, Newton Claypool Bldg.

Lankford, Jos. Fredk. (b'85) -Ind.20,09; (l'09); 1830 S. Fast St.

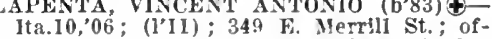
fice, Newton Claypool Bldg. ; $2-4,6-8 ; 5 . \star$ 
Larkln, Kernard John (b.81)-Mo.34.12 (1'12): 3028 Washington BIrd.

Larway, John L.-10.2."98; (l'01); 2154 N Jelaware st.: oflce. Reserre ioan I.ito Ins. Co. Bide

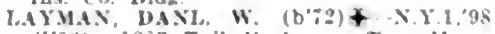
(I"98): 1803 Tallobi Ave. : imce. Mumb

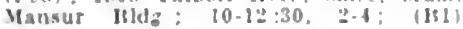
ALR.

Leach, Loon T. (b० T6)-Ind.s.01: $(1 \% 00)$ $1322 \times 2$. Mersdian St; ouce, 338 w. Yew link St.

Leak, Saml. O.-IIL.17:97; (1'03) : I751 W Morris St. : once. 1211 Itelsner $S t$

1.eatherman, A. 1.- X.1.1,93: (1'94): 1531

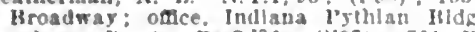
Leathers. D. A.-Pa.286 (1'97): 701 F IIth St: office, 1021 collece Are

I. F.E, DAVID FI.ETCHE (195): 2255 Central Are.; omce, Wlli oughby IIdg.

Leetb, Moses Cortez-Tenn.6.95: (l'9i)

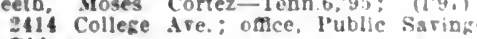
2114 College Are.; otlce, Public Sariag
Rids. LIONARD, HENRI S. (b\%t) (1\%01): isl6 Ashland Ave, once, $703 \mathrm{~F}$ 19 th St: $9-11,2-4,7-8: \mathrm{S}$

LFWIS, JAMES R. $\left(\mathrm{b}^{\circ}, 8\right)$-Ind 8,$01 ; 11^{\prime} 011$

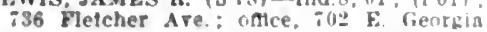
St. $9-11,2-4$, i-s,

Lewls, Lawrence Aldrddge (b's) - Ind 20 11: (1'11): 738 Indlana Ire.; offlce, titi $\therefore$. West st

LIGHT, MASON B. (b'\$5)-Ind 20,10 (I'10): College Are, and $63 \mathrm{~d}$ st

Llebt. Robt. C. $\rightarrow$ : (l.95); (Broad Mipple) unce, State Life BIdz.

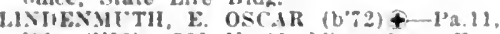

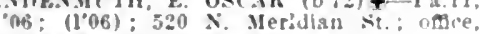
Hume-Mansur Bldg. $10-12,2-5 ;$ Prof Iherm. and Elec.Ther. Ind.20: (GL) : D.

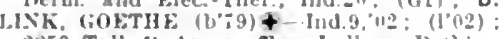
M850 Talbolt Are. oflce, Indlana Pythlan

Bdg. 2-4: Skst. Irot. Fyn., Ind 20 ; S.

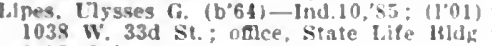
9-12, 1-4.

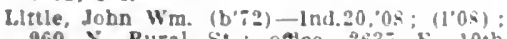
$\$ 60$ N. Rural St.; once, 2635 E. 20 th

lituer, John II.-Ky.1,76; (105): 24. S. Toble st.

Lochbead, John M.-Mo.5,94: (I'01) : 1202 x. Fennsstranla st.

LOIRMANX. HFiliy-I'a. $200 ; \quad(100)$ : Crawfordsville kd.; onlce, Jewton Clay pool Is]de.

LONG, JOHX B.-Ind.9,'82; (1'97); it w

New York $\mathrm{St}$.

Long. Robt. W.-X.Y.10,69; (1'97): 121 \% fentral Ave: office, 312 k. Washilngton

Sivg. WM. H. (b'st) -Ind 20,0s; (2008);

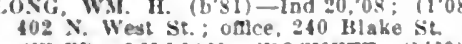

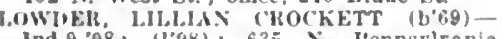
Ind.9,"98; (1'95); $635 \mathrm{~N}$ I'ennsylvania Si: : omce. I'enaway IHdg.: 11-12, 1-1 OALR.

Lowe, Geo, Eillsworth (b'it)-Mo.5, 03 ; (103): 1567 College Are.

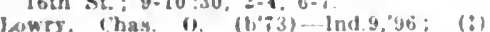

weyt thas. Washlngton st, once, $2-15$

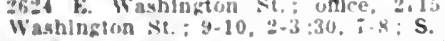

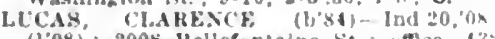
(108): 200s Mellefuntalne st. ; unce, 32 W. North St.: 10-12,2.4.

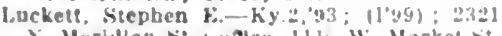

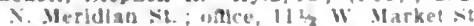
lodwly. Oscar liennen (l, so) -Ind 20,"10 (1'10): Fourala siluare.

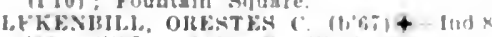
92: (1'40i): 2229 \&. Washlogtun st 8-8, $1: 30-3, ;-8$.

lutz, lienrge w-(1.1,70; 1109$) ; 118$ แ Mafket st. ontce. Tis Indland l'ythuan [H]ls.

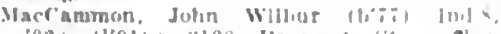

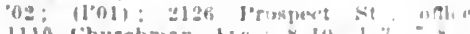

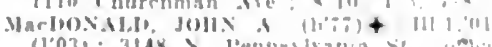

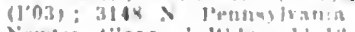

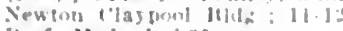
Irof. Medl., Inif an

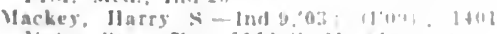

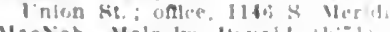

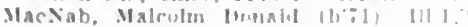
(\$): 1927 X. Nerlulan st
Madsen, Marg- Ind10.9I: (196i): 116

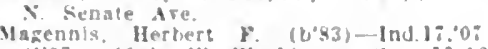
(1'0i): Hosts W. Washington st.: 10.12. $2-5,7 ; 0$

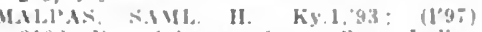
2102 - Valiana st. otice, Indlana 1'siblain Midg: $10 \cdot 12,30-3: S$.

Manchester, Jerume J_- vita, an: (1.97) 5t: lark Are; omee, $331 \mathrm{z}$ ह. Washing ton st.

Manker. Frank k.-Ind.R, S4: (1'97): 124 IV. Washlugton st.

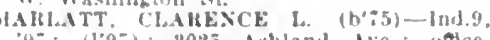

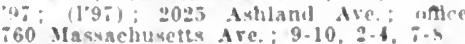

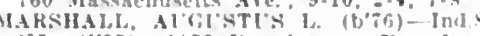
05: (1.05) : 1950 Jhroadway; once, bea coness IIospital.

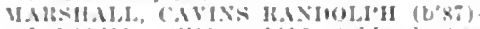

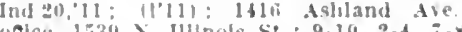

"Alce, 153! X. Illlnols st. : 9-10, 2-4, ;-

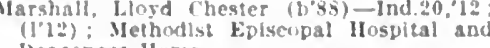

Martlu, kirgent 11-N. Y. N9; Asslstant l'alliologlst. Ceniral Indluas Hospltal for Invane 11 i F. 220 Si

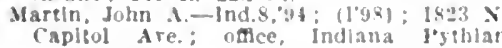
lildg.

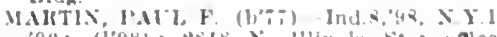

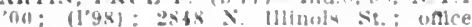
llume-ylansur 13lde $11 \cdot 30.1$ in.30-4

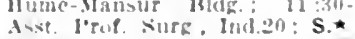

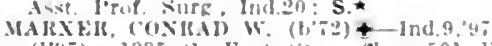

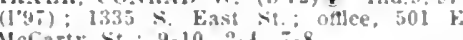
Nerarty st. : 9-10, 2-t, i-8.

MASTERS JOIIN L.OLIS (b'59) + - Ky.4

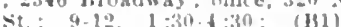
OALR.

MAXWELL, AILISON (b'+8) + - $0.9,76$

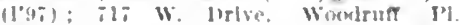
offce. Pennway ladg.; 1-3; l'ro?. Med. $\ln 1.20$

MAXWLL, LESLIE IIOWE (b's)-Ind.20

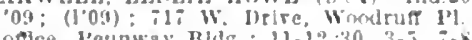
otice, l'estnway Bidg. : $11-12: 30,3-5,7-8$ jimukslde ire.

Ma5o, Wm, R. (b'6i)-Md.1,90: (1'01); 715 X. Alahama $x 1, ; 9-12,0-5,7-8$.

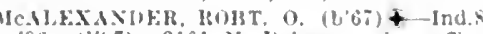
$96:\left(10^{\prime}\right): 2101 \mathrm{~N}$. Delau aro $\mathrm{Si}$ : (Iftce $320 \times$. Meridlan st. : $11-12,3-5 ; \mathrm{S}$

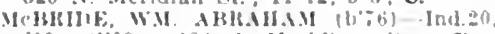

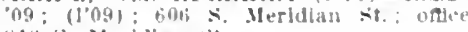
$x+1$ s. Meridlan $\therefore$.

MCCARTY, PEKLEE W.-Ind $\mathrm{S}^{\prime} 04:\left(\mathrm{I}^{\prime} 04\right)$

2020 W. Washingion St: odlice 2019 W Washington st. $9-10,2-3,7.8$

McCarty, Wm. T-Iads, 85 ; (103): ltios s. Kast St, oftce, 1900 \& Hast st.

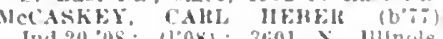
Ind.20,0s: $\left.11^{\circ} 0 x\right)$ : 3tiol No lilinals st oftice, American central Life Mldg. : 10 $12: 30,1: 311.4: 30 ;($ H1): ALR. *

Ucrhesnog, Wm. (i,-Ind.9, $9 s ;\left(l^{\circ} 9\right)$ : state life lilig

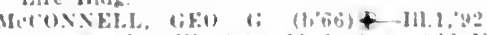

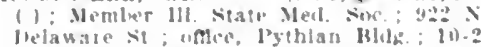

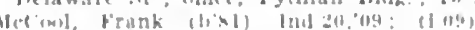

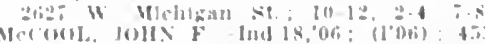
$x$ Arumal ire once, lois v Wawh

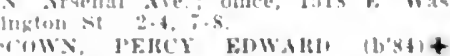

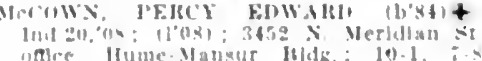

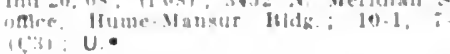

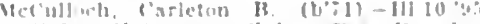
(1)

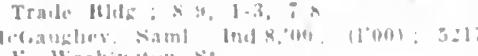
b. Wxahngtill $\leq 1$

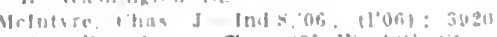

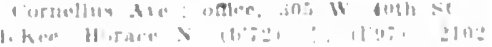

llentiditat

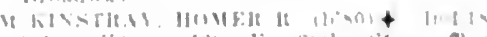

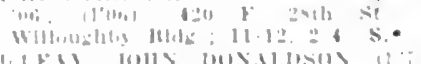

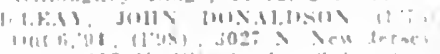

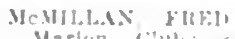
Marten ("ist,

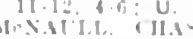

$(1 \cdot 9 \times): 524 \mathrm{~F}$.

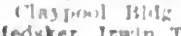

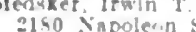

Merulenhall. Wm

"2003 8 . Michlear

pastern Ase

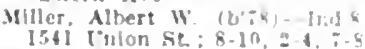

Miller, Donald L (b G 6 , M!ch $: 1$ (1'12); 1353 Rlesner ti:

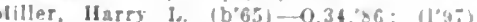

\section{i.i. $x$ Capliol are}

Mllier, Harrey Wave (b's4)... Ind 20,12. (I'12); Indlanapulis Cily Hoipltal.

Mllier, J. Inon (b'ol)-Ind.20,0\%: (I'0.5): 310 Broaluas; nace, eobs central Are.

Wher, Minn N (b'i) Ind $20,12:$ (I'12): I'rotestant licacunesy losplai.

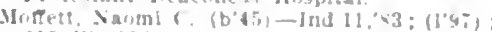
619 is $12 \mathrm{~d} \times \mathrm{t}$

MOL.T, WM. F. (b.5)+ Ind $3.9 \%: 119 \%$

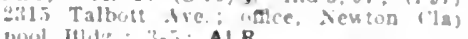
[u) IIIJ: : 3-5; ALR.

MOURE. HAWVEV MlWMS + InIS.

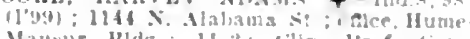

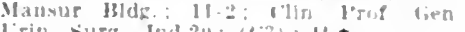

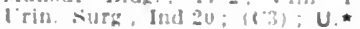

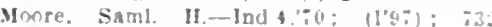
Fletcher Are. : nace. 302 Virglna ire.

Morgan, chas. A-Ind s,02; (l'02): 4730 F. Washington St: otlice, tias F. Wash. ington St.

MURGAX, MERMAX GIUTER (b'85)+ Ind.20,09; $(10 \%)$; 2505 ×. Lllinols si riflee. City Hall:

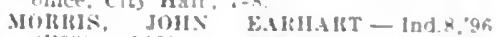
(!०OS): 1401 s. Eas st.; oflee, vidi Fellows Midg. : 2-t; Asure. I'ru? surz Ind:an: S.

MUIRISIX, FHANK ATHOS (bo0)t Willoughb lildg.: 12-5; Prur. Ophab. Ind.20; (111): 0D.*

Morrisul, James i'halmert (b'82)-Ky.2,06; (1"11); 15 ! W. I'rats s?.; oftce. 210 indiana Are. : $2-4, ;-\infty$

Morrisun, John Foster (b.34) N.1.3, a1: $(108) ;$ tad sit. and college Are.

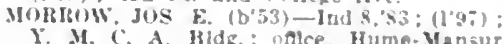
Bide. : in.1. $:-2$ : U.

MOSCIIELE, JIUS(O) D. (b"7s) +-Ind.A 02: (1'02); 2521 ientral Are: otfee

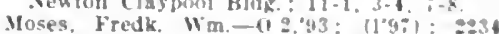

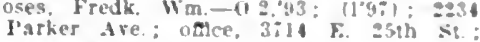
$10-12,=-1, \div-8 ; U$

Mottler, ciulliord Indleg-0.9:00; (100) 304 . Illinols st.

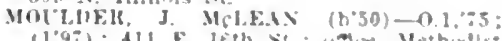
$1197)$ in E. lith si : winte. Methiulls II nspital.

Mozingo. Arvine karl $(10 \times 0)$ - Ind 2013 11'13): Nethollos Bulsmpal IIosplial and leaconess Jlome

MIELLEK, LIIIIAN B.TRIARA (b'S5)-

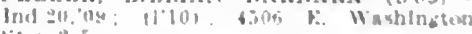

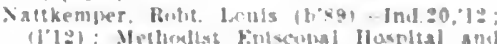

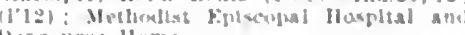
leacunese Honde

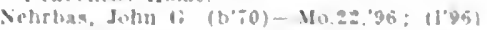

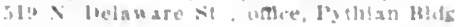
- t

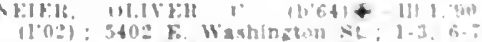

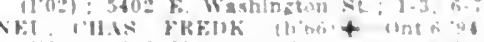

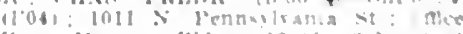

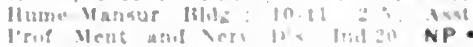

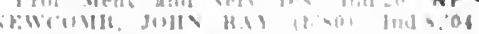

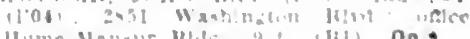

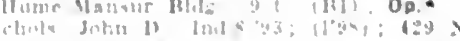
linnosilanis at.

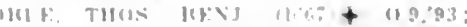

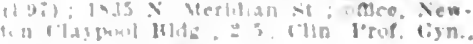
Ind -1) : 11: :

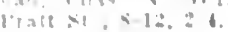


Norwe James R, (b'75)-0.12,488; (104) 3005 Ruckle st. oftice 318 indiana Arte Norrel, Jolin W:- $0.6,98 ;\left(1^{\prime} 03\right) ; 5.30$ Senate Ave : offlee, 318 Indlana Ave. Norris, Wm. Newell ky.494; (1'97); 721 King A ve.; office, 2438 W Mlehigan s

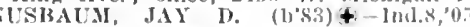
(1'05); $1920 \mathrm{~N}$. Nerjdan St.; oftlce, lumeMansur Bldg.

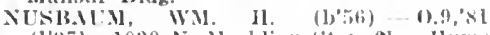
(1'y) ; 1920 ... Mlerldian st.; oflece, HumeMansul Bldy.

o'Brien, Wm. M. (b'69)-Ky.1,92; (1'04) 1230 Central Are.

O'Dell. Harry (t's 5 - In(1.21), 1:3; (1'13) : Indianabolis Clty llospital.

O'Dell, Tlinmas A. (1'65)--9a, 10,94; (1'00) 3406 Ronsevelt Ave, otflce, 2423 station St.; $8-10,2-4,7-8$.

Ogle, Albert A. (b'07)-Ill.10,9s; (1'0.5) 973 widdle prlve. Woodruty l"l. ; ofllce, malana Tythe $(b, 91)$;

Methodist Fipiseopal lrospital and liea

coness llome; HOLLID.M (b's9)--Ind.8 '8I; (1'05) ; $1912 \mathrm{~N}$. Merldian st.; oftlee, 422 N. Delaware St. ; $11-1$; Prof. Surg., Ind. 20 ; S.*

Orahood, doh, D. (b'55)-Iud.8, 84; (1'84) 1892 Hlllside Are.; offlee, 1702 lionserelt Ave.

Orders, Clark E.-Ky.5,07; (1'08); 859 W. Osborn, Wells II_-IIl.10,99; (1'99) ; 2464 I'ark' Ave.: offlee, $9 \mathrm{~N}$. Meridlan St.

Osenbach, Wim. (b'66)-ind.9,96; (1'97); 1130 l'ark ite.; office, lsoard of Traile Blilg. : 9-12, 2-5; S. *

OTTINGER, Ross C. (b'83)-Ind.18,0 ; ; (1'07); 3301 Central Ave, office, Newton Claypool Bldg.; $12-2,7-8,30$.

OUTLAND. EIDAR M. (b'61)-Ind.5, 90 ; $\left(1^{\prime} 97\right)$; 2138 N. Delaware st.; office, Newton claspool Bldg.; 9-11, 2-4.

OVEMMAX, FREIK YALE (b'Ti) office, Hume-NIansur Bldg.; 9-1, 2-4 (B) : ALR. $\star$

PADGETT, EVERETT E. (b'79)†-IIl.1,05 (1'05) ; 2355 College Ave.; oftice, IlumeMlansur I3ldg.; 9-12, $2: 30-4$; S.*

PAGE, LAFAYETTE (b'63) $\oplus$ - Ind 8,88 ; $\left(1^{\prime}\right)$ i) : Mosewell; offlee, Hume-Mansur Bldg. : 9-12, 2-5; Clin. Prof. Otol., Laryn. and lihin., Ind.20; $(B 1,3)$.

PANTZER, IIUGO OTTO (b'58)†-Ind.8, '81; (l'97); 717 Iriddle Drlse, Woodruff Pl. ; oftlce, Hume-Mlansur Bldg.; 2-4;

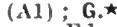

Pape, Edw. A.-Ind.21,07; (1,07) ; 1212 Oliver Are.; offlee, 1210 oliver Ave.

PARKER, IIARRY CALDWELL (b'77) offlce, IInme-Mansur Bldg.; 9-12, 2-4; Clin. Prof, Ophth. 1nd.20: $0 \mathrm{p} \star \star$

Pasley, Harry Walter (b'84)-1n(1.20,09; $\left(1^{\prime} 09\right) ; 3043 \mathrm{~N}$. $111 \mathrm{in}$ is $\mathrm{St}$.

Patterson, Amos W. (b’39)-0.1,66; (1'97) ; i17 N. Alabama St.; $9-10,2-3$.

Peachee, Harrison- 0 ; (1,98): 31 Butler Ave.; offlee, $101 \mathrm{~W}$. Morris St.

PEBWORTII. AUBREY C. ( $\left.\mathrm{b}^{\prime} 7 \vec{t}\right)$-Ind.9,05; (1'05); 1228 Reisner St.; office, $1625 \mathrm{~W}$ Morris St.; 11-12, 1-3, 7-8.

Penclleton, Geo. H.-Ind.9, Talbott Ave.; offlce, 217 W. 18th St

Pennington, Walter English $(1,88)$-Ind.20, '13; (1'13); 142 E. Ohio st.; offlce, Hume-Mansur Hldg.; 9-12, 2-5.

Per Due, C, Ioland (b-74)-Ind. 9,9(1'03); $200 \mathrm{~N}$. Alabama st. ; ottice, Indiana Pythian Hldg. ; 8-11, 1-5; D.*

Petersdorf, Gustave Adolphus ( $\left.b^{\prime} 76\right)$-Ind.s, '98; (l'99); 518 J'arkway Are.; office, 1103 S. Fast St. ; $11-12,2-4,7-8$.

Pettijohn, Blanchard B. (b'it)-ind.8, 01 ; (l'01); 458 Blake St.

PETTIAOIN, FREDK. L.-Ind.8, 96 ; (1'9i) 2423 ('entral Ave.; offlee, 2460 ('entral Ave. Pettijohn, Otto B.-Ind.4, is; (1'9i); 1114 N. 1llinols st.; office. 458 Blake st. PFAFF, JOHN ALFRED-Ind.8,98; (1'04) $61 \%$ E. 24th St.; offlce, Newton Claypool Bldg.; Asst. Prof. Gyn., Ind.20; G.

Ind.8,82; (1'97); 1222 N. Penusylvania St.; offce, Newton Claypool Bldg.; 2-4;

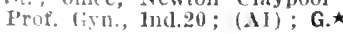

DEAFTLI, (IIAS, A. (b'T2) \&-0.1,93; $\left(10^{2}\right)$; IS4 $\mathrm{N}$. l'ennsylyanla st.; onlee. xenton Claypool 13ldg.; 9-12, 2-5; (181); OALR

P’ink, Jullus -Ind.8, 00 ; (100) ; 620 W. Mlohlyan tre.

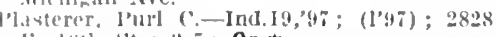

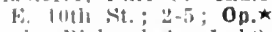

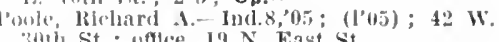
(l)

$82 ;(1+47) ; 660 \mathrm{E}$. 220 st

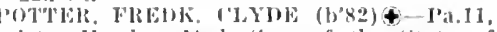
'II!: Member sted. Soce of the state of Jil.; (pathologist); ('entral llospltal for Insiate ; $\left(\mathrm{F}^{\prime} 1(3)\right.$

POTTER, 'THLODORE (b'61)—-0.1,87; rlaspol 13ldg.; 11-12, 3-5; Clin. I'rof. Yed., Ind.20.

Potts, John Franklin (b'64)-Ky.4,89; (1 t) $1608 \mathrm{~W}$. Morris St.; offle, 1626 Howard sit. ; $8-9,2=4,7-8 ; \mathrm{S}$.

I'runk, Isyron Fletcher (b'66)-l'a.2, 96 ; $(1966)$; 1549 liroadway; offlee, 157 N

I'tunk, Danl. II. (b'29)-0.2,'56, Ind.2,'76 $\left(1^{\prime} 98\right): 1549$ 13roadway; office, $9 \mathrm{~N}$. Illinoís St. ; $y-11,2-4, \pi-8$

l'urman, saml. 13. (b'62) - Ind.19,'9

$940 \times$. Orlental st. ; 1-3, 7-8

l'uryear, dames otway-Ind.17,06; $\left(1^{\prime} 06\right)$ 1222 E. 16th St.; office, 1564 Columbla Ave.

Rawlings, James V. (b’59)—IId.3,'87; (1†) 2965 Cornell Are.; office, $915 \mathrm{E}$. 30h st

REED, JEWETT VILIEROY Ild.i, 04; (1'06); A.A.Surg., I.S.N 3:3:1 Rrokle St.; oftice, Hume-diansu 13ldg.; 11-12, 2'-4; Asst. Prof. Surg.

ind.20;

T. (b'78)-Ind.18,06; (1'06)

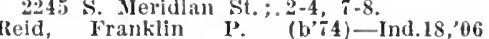
(I'06): 2245 s. Merldian st.; $2-4,7-8$.

Reisler, Simon (b'87)-Ill.22,'11; (l'11) ; 657 W. 30th St.; offlee, 257 W. Washington st. $10-12,2-4,6: 30-8$.

REPASS, ROBT. E. (b'82) †-Ind.18,06 ; (l'06); 150 Maple kd., W.; offlee, HumeMansur Bldg.; $12-2, \tau-8$.

REYEIR, ERNEST CIIAS. (b'64)-Ind.8,'8́ N.Y.10,'89; (1'97); $1801 \mathrm{~N}$. Capltol Are. office, Newton Claypoel Blilg.; N.

Rhodes, John M. ( $\left.b^{\prime}, 7\right)-N 0.27 ; 99 ;\left(1^{\prime} 99\right)$; 728 s. West St. ; $8-9: 30,1: 30-3,6-8$

Richards, Karl Taylor (b'76)-N.H.1,00 not in practlce; 1656 Central Ave.

R1(KETrS, JOS. W. (b'83) —-IId.1, 09 ; (1'12); 3201 Central Ave.; 11-12, 3-5, $7-8$.

RIDGEIVAY, ORA WASHINGTON (b't8)Ind.20,09; (1'09); 16th and New Jersey Sts. ; $2-4,7-8$.

Ridpath, Henry WV. (b'58)-Ind.9'84; (l'9i) not in practice: $1815 \mathrm{~N}$. New Jersey St. Riftle, Raymond Ernest ( $\left.b^{\prime} 87\right)$-Ind.20,'11; (1'11) ; 450 E. Vermont St.; 9-11, 2-4,

Rimmelin, Marie T.-Ind.5, $06 ;\left(l^{\prime} 06\right) ; 1530$ s. East st. ; $8-10,2-4,7-8 ; 0 \mathrm{bG}$.

Rinker, Earl Bailey (b'90) - Ind.20, 13; (1'13) ; Jethodist Hospital.

IITTER, CALEB L. (b'54)-0.2,79, Ind.8, '83; $\left.(1)^{\prime}\right)$; 1118 Oliver St. ; office, Newton Claypool Bldg.; $9-10: 30,2-3$.

ROBERTSON, T. FRAXK (b'66)-Ind.8,95 $\left.\left(1^{\prime} y\right)^{7}\right) ; 65$ ' $\mathbf{x}$. Ritter Ave.; offlee, $2313 \mathrm{E}$. Mlehikan St.; $8: 30-10: 30,2-4,7-8$

ROBINSON, PAUL F, (b' 88$)$-Ind.8, 0., $\left(1^{\prime} 05\right)$; 3137 I'ark Ave.; office, $114 \mathrm{~S}$. Noble St. ; 11-12, 2-4, i-8.

Roller, Clias, W. (b'i9)-Ind 17,06; (1'06); 2605 shelby st.; oftice, 1437 'shelby st. $9-10,2-4, i-8$

Root, Chas. C.-Ind.8,01; (I'01) ; 402 x. Mleridian St.

Rose, kinmet E. (b'80)-1nd.8, 03 ; (\$); 1121 Naomi st.; office, 1869 Shelby st. ; 8-10, $2-4,7-9$

R0S. D.IVID (b'65)—-Ind. 8,95; (l'97); 1730 Broadway; offlee, $143 \mathrm{~N}$. Mleridiun St.; 11-12, 2:30-4; Assoe. Prof. Surg.,

ROW, GEO. SANL $\left(\mathrm{b}^{\prime} 66\right) \mp-0.9,90 ;\left(1^{\prime} 95\right)$ 2027 N. Delaware St.; office, Indian
Pythian Bldg. ; 9-11 :30, 2-4; (B1); Op.
LOW N. lllinols st.; oflee, $538 \mathrm{~N}$. Pennsylvanla st. isearburn learborn sit.

linbusls, Guy W'm. (b's1) - Ind.20,'13; (l'13) 1726 , Washington st : $8-9,2-4,7-8$. UNDELI, KALI, IBAYMOND (b'87)7-9): Anes.

Runnels, (Orange Scott (b'4i) II-0.7,71 (1'97): $1100 \mathrm{~N}$. Meridian St.; oftlee, 522 $\mathrm{N}$. unnois st.; $8-10,2-4$

Runnels, Scott 'Clark (b'82) H-Ind.18,07 Mich.5,08; $(107) ; 1100 \mathrm{~N}$. Meridlan'st.? oftlee, 522 N. 1llinois St.; $8-10,2-4$.

Runnels, Sollis-II-IIl.10,'87; (1'98); 121 E. 13th St.; olflee, I'enmway Bldg. ; 8-10. 2-4. $7-8$.

Rutledge, Carl W. (b'79)-Ind.8,03; (1'03); 1215 Kentueky $A$ ve. ; 10-12, 1-2, 6-8. Saalman, James Elmer-Ky.5, $06 ;$; (107) ; 2541 Shelby St.; offlce, 2543 shelby" St. Relsner St.; oftee, 1218 Relsner st

RCHAEFER, ; Coffee, 1218 Reisner St. (b'69) ४-Ind.8,90, N.Y.1,92; (1'98); 1838 N. Mlerldlan St. ; offee, 1208 Mádison Ave. : $2-4,7-8$; P'rof. Ther., Ind. 20

Schenck, Foss (b'80)-Ind.8, 02 ; (1'02) 344 N. Arsenal Are.; office, Unlon Statlon I3ldg. ; $2-4$

SCIIERER, SIMON T. (b'65)-Ind.9,91: (l'97); (Fishers); office, Indiana I'ythian 13ldy. ; $19-4 ; 1 . x^{2}$

SCHNECK, LUELLA M.-Ind.8,95; (1'97) : $320 \mathrm{~N}$. Illinois St.; $10-12,2-4$.

SCHNEIDER, ANTHONY J. (b'5) \&-Ind.8 98; (1'98); 1666 S. Meridlan St. ; offle, 1664 S. Merldian St. ; 8-10, 2-4, 7-8. SCIIWEITZER, ADA ESTELLE $(b, 72) \oplus-$ Ind.18,'07; (1'07); 1205 College Ave;
office, 122 State House; $8: 30-11,12: 30-5$; Baet.

Selfres, John G. (b'84) -Ind.20,08; (1'08); 1434 Rembrandt St.; offlce, 212 Stewart

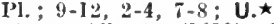

Seaton, Albert (b'80)-Ind 8,'04; (1'04). 40 th st. and Keystone Ave.; office, Meri dian Life Bldg. ; $9-12,1-5$.

Seaton, Guy W.' (b'73)-Ind.8,98; (1'98); 1123 Oliver Are.

egar, 1ouls Herold (b'90)-Ind.20,'12. (1'12); Methodist Eplscopal Hospital and

Deaconess Hoine.
Seiberth, Jacob (b'74)-Ind.8,'04; (1'04) ; 21 Lexington Flats.

SESSIONS, S. KWNOSHA 4 - 111.9,93. $\left(1^{\prime} 9 \bar{i}\right)$; Industrial House.

Shaffer, Geo. Henry (b'43) - Ill.10,82 $\left(1^{\prime} 06\right) ; 1706 \mathrm{~N}$. Senate Are.; 8-10, 1-3. Sharp, Jos. E. (b'73)-Ill.22,'12; (l'12); I54S N. llinois St.; $8-2,7-9 ; 0$;

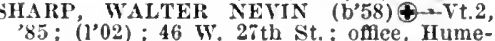
Mansur Bldg.; $10-12,2-4 ;$; (B1) ; $00 \star \star$ Shelburne, Wm. Thos. (b'5i)-Ind.8,"89; $\left(l^{\prime} 97\right) ; 846$ W. 27 th St.; offlce, State Life Bldg.; 9-12, $1: 30-5$; OALR.ネ

Sheridan Aaron J. (b'80) - Ind.18,06. $\left(1^{\prime} 06\right) ; 1207$ íexington Are.; offlee, 727

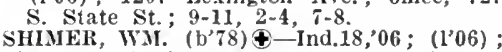
1116 X. Capitol Are, office, State House. Shipp, Augustus Clyde (b'79)-Ind.20,'12; (1'12); $2518 \mathrm{~N}$. New Jersey St.; offlce, Senate Are, and Market; $9-12,2-5 ; L D$.

SHIPP, FLOYD NICHOLSON (b'78)-Ind.9, "03; $\left(1{ }^{\prime} 04\right)$; Delmar Flats; office, Newton Claypool Bldg.; 11-1, 2-4, 7-8.

Siersdorf, Theo. N. (b'77)-Ind.18, 06 ; not in practice: 1140 E. Market $\mathrm{St}$

Sigler (ieo A. (b'46)-N.Y.10,75; (1'97) 1915 Ni. Illinois St.; office, Newton Claynool Bldg.; $10-12,2-4$.

Simpson, Wáde Emmett (b'78)-Ind.8,03; (I'03); 923 S. West st. ; $1-3,7-8$.

SLUSS, JOHN WM. (b'67) - Ind.8, 93 (1'98) ; City Hospital; offlee, Newton Claypool Bldg.; 4-5; Assoc. Prof. Surg. Ind. $20 ; \mathbf{S}$.

SMILEY, ORYALL (b'81) $\subsetneq-0.6,08$; (1'09) 143 W. 35th St.; office, Newton Claypool Bldg. ; $12-4$; D.

Smith, Alexander C. (b'49) E-Ind.11,81; (l'00) ; 5 N. Temple Ave.; 8-11, 2-4.

mith, Andrew .1.-Ind.9,86; (1'03); 4501 $\aleph_{8-4}$ Arsenal Are.; offee, $506 \mathrm{E}$. Morris St.; 


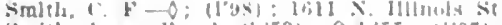
smlth. Isace frank (b.53)-0.6,7: $11.9-1)$ Mite

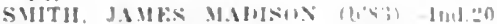

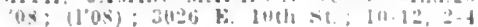

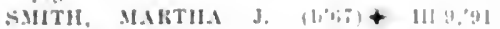

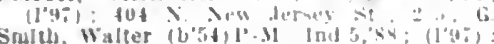

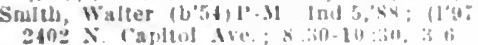

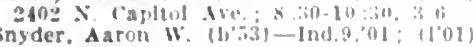

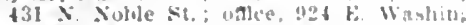
Lon SL; $\$ .10,1 \cdot 4,7-\$ ;$ OPLR.

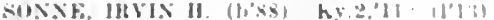

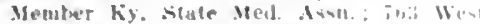

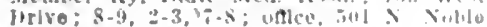
Sit. : $10.12,4 \cdot 1 \%$

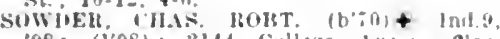

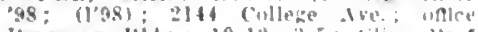

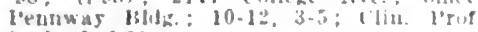
llod. Ind.20

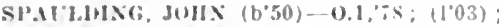

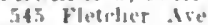

SIEYCEL, MAYITY J +-Ind.9.96: (J'97) 3604 \&. Washlngton st. oflce, 2719 r. Washlngton S?.

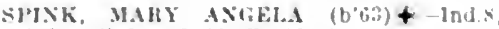
Si: (194): 1140 k. Market sis: 111-1:

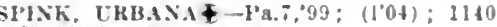
F. Market St.

spmrgeon. Leota $(1, \$ 3)$-Ind.20," I ; (1'12) $2043 \leqslant$ Meridian st.: onde. 13:s s. Merldlan St.; 9-11, - -

Sputh. Carl Broslus (b'84)-Ind.20,12;

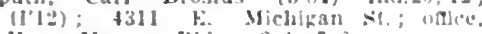
llume-Mansur Mldg. ; $2-4,-3-8$

siatord, Chas. A.-Ind.5,'89; (197); $223:$ $x$ Vew Juriey sit

Stafford, Lindley Hastlngs-Ind.5, $07 ;\left(1^{\prime} 0{ }^{\circ}\right)$ 3054 Central Are: unice, 425 F. 3ntl si

Stalker, John Morton (b"s2) - Ky, , 06 (I"11); 510 k. 21st st. : 2-4.

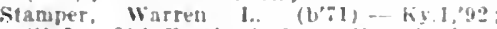
(107); 314 r. Sorth st.; ontce, lyllian HIde: : 12, 1-5.

Stark, John Raynond $(1,90)-$ Ind.a, $2: 1:$ (1'13) ; 1641 Central Ire ; $10-12,2-4$.

STEPIIENSON, CHESTHIS E. (b"i)

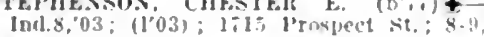

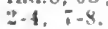

stephenson, Jolun r. (b'b3) - Inuls.tig; $(1,4 i) ; 20 \pm 5$ t: loth st.; $x-10,2-4 . ;$ ob.

Steplensun. Ora I.-Ind.8.91; (1'03) : 91: X. Fiast it.

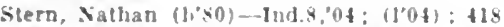
F. joth si.: ontee, sol Fint Wayne ire. $9-11, \div-1, \div 8$.

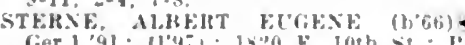
Ger.1.91: $(195):$ 1.20 k. I0th nt.

Ment. нn! Verv. Iris. Ind.2n; NP.

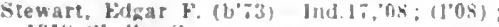
1818 silgelby si

stewart, filsle liertrutes $(1, \%)$-Minnt, 0 : not la pitactlce: 1 i Wurthlugton si

iewart, frank $(:-1\}), 96 ;\left(l^{2} 9 i\right) ; 1-30 \times$

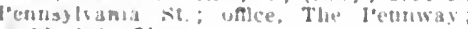
$10-12,2-1 ; 0 b$.

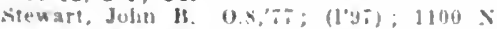
t'apleol Are.

Siewart, John 11.-Inds,0\%; (1045); 20 bit

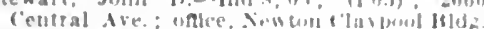

sicuat, Wn. It.-III.t,

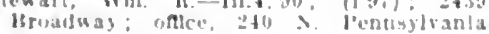
Sit: $10.10,3-5: A L R$

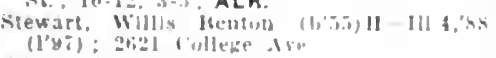

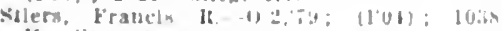
ILamllon fre

STI1,LEN J11: 11 $(1,511)+-1190 \%$

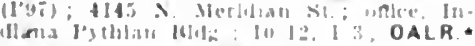

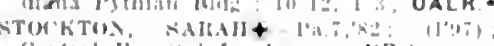
central Himpitial Por Iusall NP.

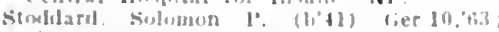

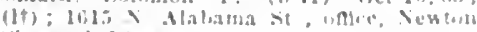
llasgmel Hhle: II

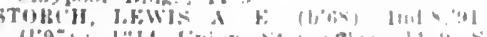

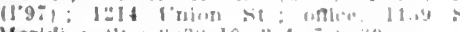

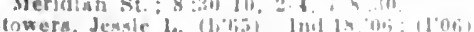

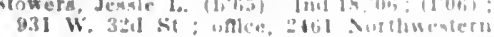
Are.

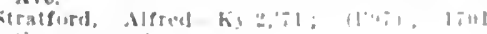
iommerce Are.

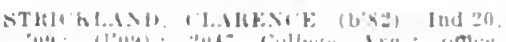

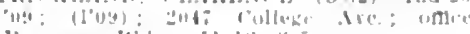

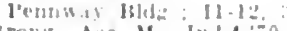

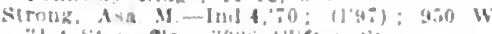

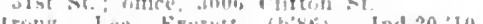

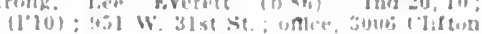
t170): 11 , 31 st

stuckmeyer. Wm. E-InlIs'of; (Jonf);

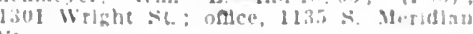
$\therefore i$.

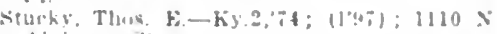
Alaliama st

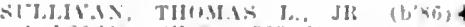

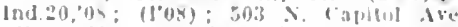

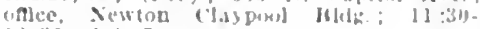
$1 \geq: 30 ;:-4=-8$.

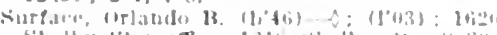

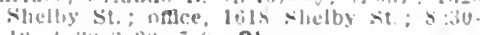
I11, 1 :201-;:311, $i-6 ; 0$ b.

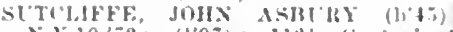
X.Y.10,72; (1'9i); 11:L Centeal Are orten, 154 E. Market $x 6 ; 10.11,2-3$

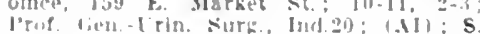

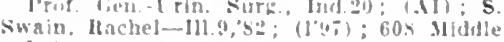

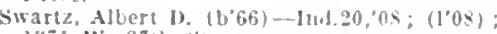
1:TI W. 2ith se

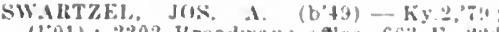

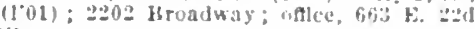

Talbost. John H. (b'51)--Indt:

llt k. 2lat st. oflce, luion station: $-t$

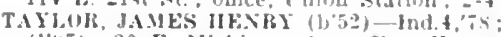
(I'y); 20 E. MJchlFan st. offlce. HumeInd. $\geq 0$.

Tearue, Albert k.-- 0.2.'92: (1097): 110 I. Cenate tre.

Teague, Mable M.-Iod.16,93; (I'4): 110 $\lambda$. sinale ire.

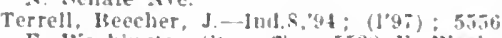
E. Washlugton sit ; once, $552 \mathrm{k}$. Washington st.; $\$-10,2-4,7-5$

Telet, Jacub 1'- Ind.5.,06: (1'06): 500 x Shentelil Are, : vifice, 2617 W. Mllifma St. ; $10-11: 30,2-1$

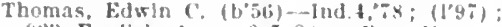
923 English Are.; 6-7;31); nttce, Newton Clas pool lilug. : $11-12,2-1$

Thompson, kugene $(-1-1040 ; 1197) ; 15.4$ v. Naliama st.

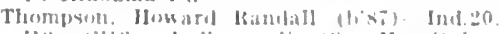

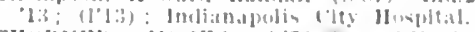

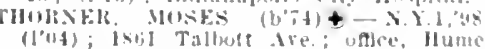

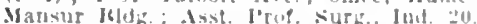

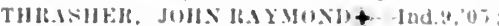

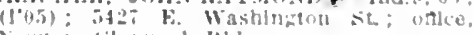
Xewton ilayporil Hald

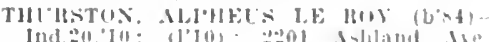

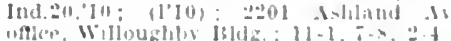

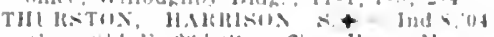

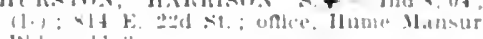

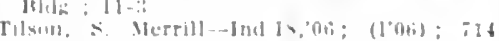

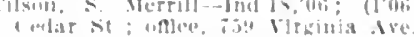

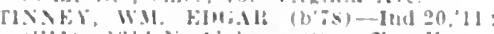
(1'12); Jä x. Nahama st.; once, Hime.

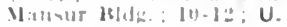

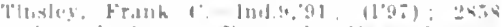

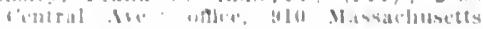

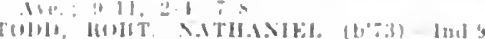

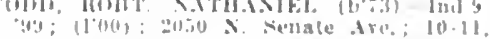
$1 \therefore ;$ NP.

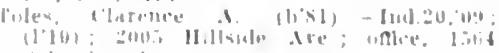
(1)

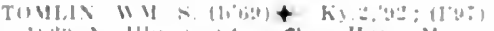

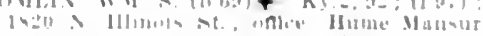
Imis 111 I \& IMI ALR.

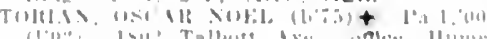

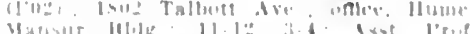

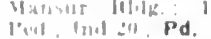

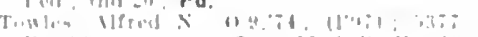

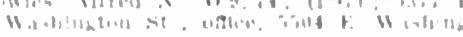

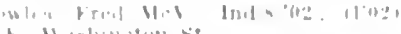

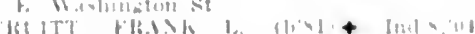

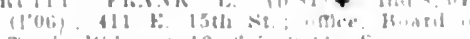

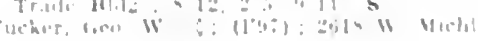
finn :

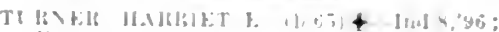

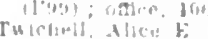

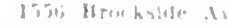

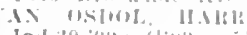

Ibuaril of Trude bis].

Moard of Tride Bit.

Merlilias

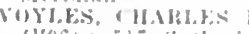

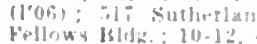

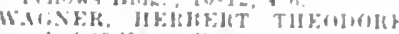

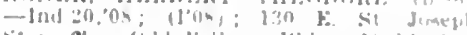

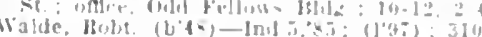
r. inth sit

WAIES, FinEST de WHIFE $(1,-3)+$

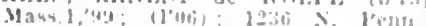

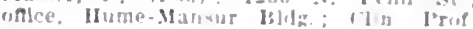

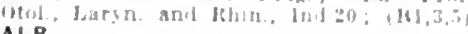
ALR

WA.KFIR, HISK \& -111,0\%; (10\%):3011

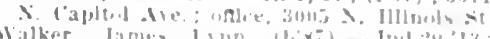

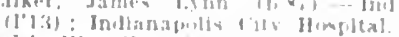

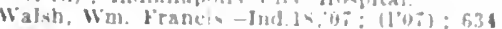

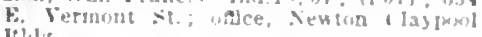
Iili]z.

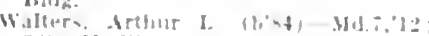

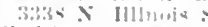

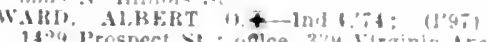

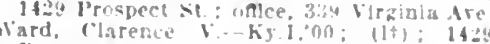
Frospect sit: office, w Fletcher lie.

WIRD, CI.IY I. (b'ris) +-Ind.6, 15.55 Hruadway, onlce, 259 Virgiala Are. $9-21,2-1$

ard, Jus. 11-Ind.5,2: (1997; 2920

Warfel. Fredt. $i$, (b'a) Ind.5, $05:$ (1)05)

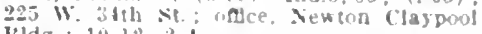

Waterman, Luther Hans (1,301-0 1,:53 aob In practice : (laymal Joted: bor WATHIS, l.ATHIC

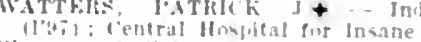

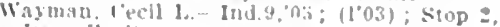
lianvilje line.

Wukley, Hetram (1,701-1) 1.04: not in

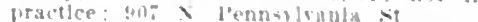
Webb. bigar Clinte (b:3) - Ind 20.13. (l'is) : lerutestant leaculues Huspital.

webb, Jolu W.-III 10:04: $(105): 11: 0$ F. Washluztun st, wace, 3906 F. Washing ing st.

Wecusler, Hyman-InII, s3; $11011 ; 4 ; 3$ W.

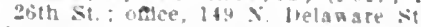

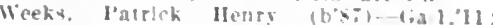

Central Indiatta IImpital for Insane.

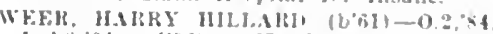

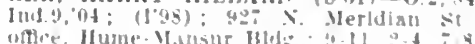

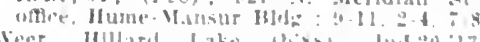

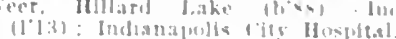

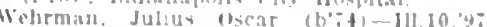

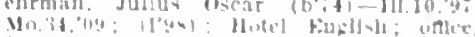

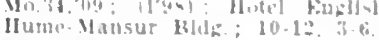

Wril., H.1

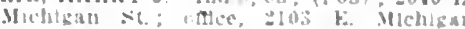
St. : 2-3. :

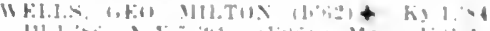

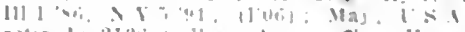

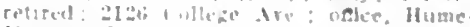

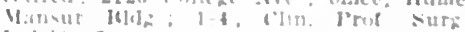
[n] : 21 : $\mathbf{s}$.

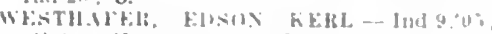

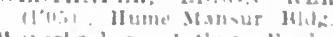

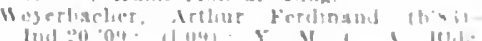

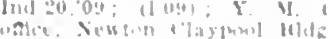

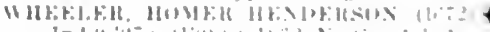
- Ind s.

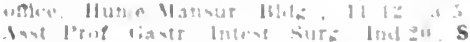

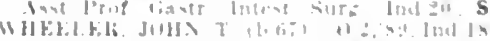

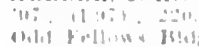

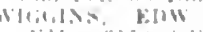

(1)11:311:10110,0

Inds.00

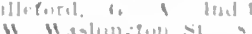

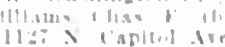

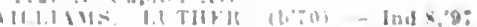

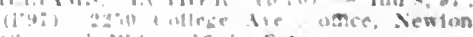


Willamson, Alvls A-Ind.8,'98; (1'98); 446 W. 30 th st. offlec, Newton ('laypool 13lith. miliamson, if. N.-1nd.8,80; (1'05); 10.5 $2-4, i-8$.

willis, Edward A. (b'74)—Mlch.1,02; (1'05) of:5 college Ave.; once, IInme-Mansur Bld $10: 30-12: 30,2: 30-5 ;$ (131); OALR.

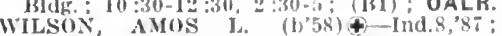
(1'97); $15 \% 0$ N. Capitol Are.; onlce, Odd fellow's Bldg.; $11-1,2-4,7-8$

wilson, Chas. A. (b'56)-0.1,79; (1'95); 510 W. 41 st st. ; Or.

wilson, ('has. L. (b'31)-0.6,'54; (l'97): 524 k. 25ith st. Or.

Wlson. lames steredith - 111, 1, s2; not $\ln$ practice: tan x. leenesylranla st. (F1). winter, Carl G. $\left.-0.2 ; 93 ;(1)^{\prime}\right): 3759$ ('entral Are. office, it wo ohio sit.

whlter, rmil G. $0.2,07$, Ind.20,08; $\left(1^{\circ} 0 \mathrm{~T}\right)$ Whiter, Emin a. $0.2,07$.

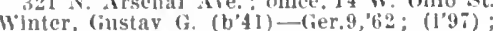
1201 Ollve st.

W'shard, Ernest E. (b'75)-Ind. 8,$00 ;\left(1{ }^{\prime} 00\right)$ 5514 Tnlsersity Are.

WISHARD, WM. NILES (b'51)†-Ind.4, '74 o. 9,76 ( $\left.{ }^{\prime} 97\right)$, 2050 N. Jelaware St. offlce, Ifume-Mansur Bldg.; 10-12; l'r

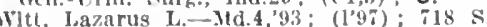
Illinols st.

Wood, Geo. (C.-Ind.8.81: (1.97); 866 W. 29 th St.; office, 2865 Clifton St.; 10-11. $2-4,7-8$

Wood, Geo. W. (b'79)-Ind.20,'08; (1.08) 866 W. $291 \mathrm{~h}$ St. ; office, 2865 Clifton St. $10-11,2-4,7-8$

Woodard, Nathan D, (b'49) P-M-Ind.5.; 79 $\left(1^{*}\left(y^{2}\right) ; 1942 \mathrm{~N}\right.$. Pennsylrania St. ; oftce, Tesston clavpool Blug.; 9-12, 2-4.

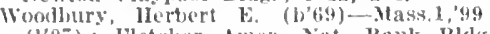
(1'07); Fleteluer Amer. Nat. Bank Bldk. Woods. Chas Edwin (b,88)-Ind.20,'10 (1'10) ; 408 s. New Jersey st. ; offlce, 216 Virginia Are.; $10: 30-11: 30,3-5,7-8$,

WOOLS, CIIAS. SAML. (b'78) $\$-111,1,00$

(105): not in prictlce; 3051 N. llinol St.; Assoc. I'rof. IIyg. and Sanit. Science, ind.20.

Woodworth, llenry A.-F-Ind.17,03; $\left(1^{* 04}\right.$ ) 235 E. V'ermont st.; office, Hume-Mansm Bldg.

WOOLLEN, GREEX $v \cdot\left(b^{\prime} 40\right) \uparrow-N \cdot X^{\prime} 10$, 65; (1'02); not in practlee; $48 \mathrm{~W}$. $21 \mathrm{st}$ St.: offlce, American Central Idfe Bldg.

Woolien, Herbert Milton (b' $\left.\mathrm{b}^{\prime} 5\right)$ - Ind.8, 04

$\left(1^{\prime} 04\right)$; 1719 \& Pennsylvania st. office. American Central Llfe Bldg. ; $9-4$.

Wright, Frank M. (b'58) E-Ind.11,89 $\left(1^{\prime} 00\right)$; 1315 E. 10 th St. ; office, $1120 \mathrm{~B}$ 10th St. ; 2-4, $7-8$.

WRIGIIT, JOS. WU. (b'8 (1'11); 2246 Ashland Ave, office, HumeMansur Bldg.; 10-12, 2-4; ALR.ネ

Wylie, Bruce MI.-Ky.2,94; $\left(1^{\prime} 04\right)$; not in

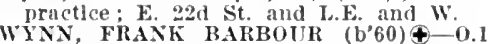
'85; $\left(1^{\prime} 97\right): 140$ S N. Alabama St.: office, Newton Claypool Bldg.; 10-12, $2-4$; Prof. Med. Diag., Ind.20.

Wysong, Geo. T.-Ind.18,07; (1'07); 1528 Woodlawn Ave.; office, 853 Virginia Are. Young, Mllchael Arthur (b'58)-Ind.8,'91 E. Washlngton St.; 9-11, 2-5.

INDIAN SPRINGS, 250, MARTIN

GILKISON, JOHN S. (b'76) - Ky.5, 05; $\left(I^{\prime} 05\right)$.

INGLEFIELD, I50, VANDERBURG

BEGLEY, BAXTER (b'56) $\oplus$ - Ind.2,'76; (1'97)

INWOOD, 300, MARSHALL

Bell, John F $\rightarrow$; $\left(l^{9} 97\right)$; not in practice.

Klzer, James 11.-1a.1, 87 ; (1'97).

IRELAND, 275, DUBOIS

JOHNSOX, LEE B. W.-KY.5,'85; (1'9i).

Stewart, Omer Hall-Ky.5,0 07 ; (1'07).

JAMESTOWN, 690, BOONE

BOLNELL, THOS. A. (b'48) $\rightarrow$; $\left(\mathrm{l}^{\prime} 9 i\right)$. Brent, Newton I. (b'45) - Ky, 5, 5 ; ( l'00)

Finch, Albert M. (b'52) -

JOIISSON, THOS. B. (b'82) \-IId.1,06

Irichard F. (b’55) - Ind.9,'s1; (1997) JASONYILLE, 3,295, GREENE

'thos. A. (b'73)-Ind.8,03; (]'03) B. - - Ind. $8,01:(1,01)$
GOODWI, ATRL1, (b'83) 4 - Ill.6,09: (I'0!n).

Jilxon, W'm. II. (b'53)-0; (1'97).

Osbon, Guy Geo. (b'78)-MI0.28, 03; (l'03). 'adgett, 'T. Irwin ( $\left.\mathrm{b}^{\prime} 62\right)-\mathrm{k} y .5,89$, Ind.4. '06; (1'98)

JASPER, 2.196, DUBOIS

('isper. John (b'82)-liy.2,04: (]'05)

CAsl'kR, Jos, FHAN('IS (b'8 8 )-Ky,2,10; (1'12).

UGSELL, ANDHEW F. (b't4)-Ky.1,07; $\left(1^{\prime} 07\right)$.

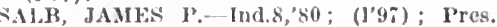
Ind. State Med. Assn.

SAI.B, LEO A (b'86)-Ind.20,'08: (1'08). STULI, EUGENE A. (b'79)- Ky.1,04; (1'05)

JEFFERSONVILLE, 10,412 , CLARK

13aldwin, John II. (b'76)-Ky.8,97: (1'97): 425 E. Maple St.; offec, 344 Sprlng St. $8-10,2-4$.

Bruller, Emory W. (b'41)-0.9,'67; (l'97); 213 Wi. Court Asc.; 8-9, 2-4

COIIEN, DAYID (b'82)-Ly.9;03; (l'04);

1415 'spring St. ; oftice, 408 ' Spring St. : $9-10,2-3,7-8$

liU, CLAUIE C. (b'78) - Ky.5,01 (l'01); 811 E. Maple St.; office, 418 Spring St.; $8-9,1-3, i-8$.

Ficld, Davld L. - Ky.2,'65; (击); 222 E. Naple St. ; $7-9,1-3, i-9$.

FLYNN, NDWARD N. (b'67) - Ky.5,97 (l'97) ; 119 Court Are.; office, 459 Sprlng St. ; $8-9,1-3,7-9$.

FUNK, AÚSTIN (b'74)థ-Ky.2,00; (l'00) : 404 spring St.; $9-12,1-3, \tau-8$

RAHAM, OLIVER P. (b'66) - Ky.2,'90 (l'97); 628 Maple St.; office, 418 Spring

INĆOCK, ClAS. FREDK. C. (b'67)\&offce, 327 spring St. ; $8-9,2-4, i-9$.

Hazard, Sami D.KY.2, $88 ;(1997)$.

IIOWLAND, WM. VICTOR (b'46)థ-0.6,

'7; (1'02); Howard Park; 9-9.

Jackson, sarah C.-Ind.9,'91; (1'97).

Lewis, Benj. $\rightarrow$; (1'03)

Loomis, .t. (b'20)-0; (1'97); not in practice. Iead, Arthur Ross (b'87)-Ky.2,'11; (1'11) 213 w. Court Are.

MURAT, HALSTED S. (b'82) - Ind.20,'10 (1'10): Indiana Reformatory.

PEYTON, DAVID C. (b'60) $\oplus$ - Ky.2,'86 (1'97); 418 E. Chestnut St. ; office, 311 spring st. : 2-4, 7-8,

(lit, ISAAC N. $\left(\mathrm{b}^{\prime} 5 \pi\right)-\mathrm{Ky}, 2,81$ (197); 343 spring St.; 8-9, 1-3, 7-9.

VARTLE, WM. MARSHALL (b'7 01 ; (1'03); Court Are. and Spring St.

WELLS, FRAXICIS M. (b'59) - -Ky.2,'82; (1'98); 401 Spring St.; offee, Switow Block.

Zuerner, Jos.-Ky.2,'78; (1'99).

JESSUP, 150, PARIKE

Towey; James T.-Ind.8,'i9; $\left(l^{\prime} 0 \pi\right)$

JOLIETVILLE, 350, HAMILTON

RAINEY, EVERETT AMBROSE (b'76)†-Ind.20,08; (1'08)

REDUEN, THOS. OLIVER-Ind.8,'92; (l'97). JONESBORO, 1,573 , GRANT

BAKNE'T', JOHN T. (b'57) - Ky.1,'82 (l, 97$)$.

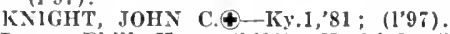

Lucas, Philip Horne (b'89)-Ky.2,'13; (1'13).

JONESVILLE, 2I3, BARTHOLOMEW

Irvine, Wm. T. (b'55) - lnd.9,01; (1'98):

Jones, John H. (b'60) E-0.2,'91; (l'00).

JUDSON, I4I, PARIKE

PRICE, GROVER CARLISLE (b'88)-Ky.2, '09; (1'13).

JULIETTA, 75, MARION

PAYNE, J. H. (b'53)-Ind 9,86; (1'97). OTTEl, BENJ. S. (b'i4) \& - Ind.18, 06 ;

KEMPTON, 600, TIPTON

Cooper, Joln-lnd.5,'84; (1'97)

DUNHAM, GROYER ('-Ind.18, 06 ; (1'nb) DUNHAM, WILBUR F. (b'82)€-Ind. I8, 06 (1'06).

Ferguson, James Harrey-Ind.8,02; (1'02). Gossett, Lucy A.-0.2,'86; (1'97).

Ploughe, Martin T. (b'61)-Ind.9,98; (1'98).

Pugh, Jefferson-Ind.4,'i4; (1'yi).
KENDALLVILLE, 4,981, NOBLE

COYNEl, $\triangle L$ LEITT G,-0.9,'89; (1'9i).

GARDNER, CYILĆS ALVIN (b'75)థ-IL.I, $\left.02 ;(1)^{3} 03\right)$.

GIIBBEIT, JOS. LORAIN (b'44)Ð-N.Y.10, coonwix, columbes B. - Ky.1,94;

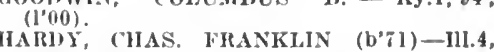
95: $\left(l^{\prime} 97\right)$.

JOHNTONE, DONAIS DINNIE (b'84)Mleli.1, 08 ; (l'11)

IRING, IIIRAM O. (b'50)-NICh.2,76; (l'97)

Nunk, Cleorle Erwln (b'84)-0.2,'12; (1'13); not in practice.

PERKINS, FIRANCIS M. (b'89) -Ind.20,'11; (1'11).

silook

Teal, Geo. A. (b'57)-111.1,'82; (1'97).

WIILIAMS, HAROLD OTIS (b'89)-Ind.20, $13 ;(1 ' 13)$.

I'Ilson, Darid C. (b'44)-0.2,73; (1'9i); not in practlce.

KENNARD, 449, HENRY

Weaver, Chas, A. (b'71) -Ky, 2,07; (1'08)

KENT, 110 , JEFFERSON

WHITSITT, SCHUYI.EIt A. (b'69)£-Ind.8, '97; (1'99).

KENTLAND, 1,209, NEWTON

GodPrey, Luman M. (b'29) HI-Mich.3,75: (1.97)

Iathews, w. Curtlss (b'85)-ky.2,'11;

MeCail, lllchard C.-Ky.4,75; (l'97).

Van Kirk, Geo; IIIram (b'79)-III.11,05 : $\left(1^{\prime} 05\right)$

Westcott, Jos. B.-II-Ill.10,'90; (l'97).

KEWANNA, 728, FULTON

Armstrong, IIerman I.-0.1,'81; (I'01).

Washburn, John M. (b'67) - Ind.8,'95; (l'05).

KIMMELL, 300, NOBLE

LANE, CAIRLOS D. (b'83) - Ind.8,05: (1'05).

KINGMAN, 535, FOUNTAIN

CUTHBEIT, FRED S. (b'76)థ-111.11, 05 ; (1'08).

RATCLIFF, A. LONZO (b'72)-Ill.17,'05; $\left(l^{\prime} 05\right)$.

KINGSBURY, 250, LAPORTE

HENDERSON, ABBY MAY (b'79)-Colo.2, '12: (1'13).

ENDERSON, ROBT., JR. (b'80)-Colo. 2, 07 ; (1'13).

Webster, Ben (b'i8)-D.C.2,00; (1'09).

KIRKLIN, 699, CLINTON

Bowers, Burton E.-Ind.9,'91; (1'97).

Hart, M1llo Forest (b'82)-Ind.20,09; (l'09)

sount, Wm. Chalmers (b'i9)-Mi.11,05; (\$)

KNIGHTSTOWN, 2,008, HENRY

Barrett, Max Culbertson (b'89)-Ind.20,'13;

Barrett, Omar H. (b'60)-0.1,'84; (l'97).

CALL, EARL B. (b'85) $€$-Ind.18, 07 ; (l'07)

Cress, Joln B. (b'47)-Ind.4,74; (1'97).

Drake, Flavius J. (b'52) - Ind 8,'81; (1'97). (1'11).

Iolloway, Olin E. (b'56)-Ind.8,'81; (l'97).

IIcGarran, $\mathbf{W m}$. B.-0.3,'63; (1'97); not. in REES, OMAR H. (b'67)—-Ind.8.'00;

Winston, Leonldas V.-N.Y.10,'66; (1'97).

KNIGHTSVILLE, I,08I, CLAY

THORTON, FELIX G. $\rightarrow$; $\left(1^{\prime} 97\right)$.

KNOX, 1,644, STARKE

BELL, HARRY LEE (b'77)-Ill.22,"08;

BROWN, STEPHEN I. (b'48)-Ind.4,'75; (199.)

Schwler, Wm. C. (b'68)-Ky.4,'92; (1'97).

WHITE, DANL. 0. (b'61)-Ind.19,'96; (t).

KOKOMO, 17,010, HOWARD

ADAMS, CHAS. JOS. (b'83) —-Ind.18,'06 (1'06); 1223 W. Mulberry St.; offlce, 314 N. Washingt on St.; 8-8.

ANDERSON, THOS. B. (b'64) - Pa.1,'91 (1'13) ; $328 \mathrm{~W}$. Jefferson St. ; offlee, 215 W. Walnut st.; G. 
CARNELLKY, JAMKS II $(19 i 0)-H 11,02 ;$ (1.06): 1214 W. Mulherry st.; oflce, 21: W. Mulherry st : $1: 30-5,-5$

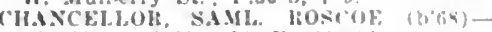
III.I, 89 ; (I"4); 32 k. Markland Nve: 1-4, i-s.

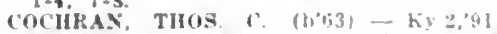
$\left(19^{\circ}\right)$; $1111 \mathrm{~W}$ Walnut st: unlet, $20 \%$ il Mulberry sit. : 1 - $3,7-8$

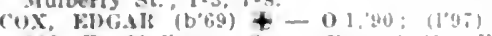

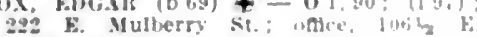
Mulberry St: $1-4,7-8$. (b.85) H-I11.4, 1 :

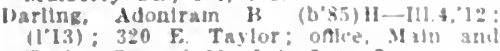
Taylor Sts. : 9-11, 1-4, i-s: S.

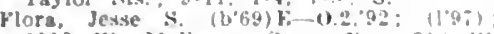
1002 W. Mulbery si inice, $21 \times$ w Walnut st.; 9-9.

rederlek. Geo. W--0.1.85; (1.97); lumt it pracilleo.

Gart, Janues o.- - 0.1,75: (1.9:); not lit practlee: $\$ 12 \times$ Maln is

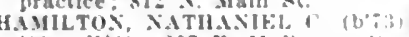

00 : $(1001) ; 207$ k. Mulherry st. : $:-t$

HAKRISON. WM. - Inds, $96 ; \quad(1,7):=3$ x. Maln st.

Hatfleld, Wm. A.-Ind.12,45; (1.5x).

llolcombe, A wuray W. - $111.15,93 ;(195)$ $323 \times$. Main $\mathrm{St}$

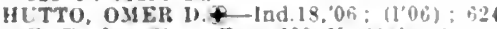
E. Tarlor St. offle, $200 \mathbf{x}$. Malu st

Johnson, oltrer M (b'7s) E- IIIs, 07 $\left(l^{\circ} 08\right)$; $314 \leq$. Webster st. oftce, 117 W. Sycamore st. : $9-12,2-5, ;-9$.

Kemp, ollver 10-Ill $11,9 s ;(199) ; 71 \times x$ Main St. oftce. IIF W. sycamore st.

KXEPILE, IAIAR R. (b72)-lnd.s? $(104): 514 \times$. Washlngton.

lung. Bruce DeWlt! (b'ss, - Ind.20,'13; (l'i3): 218 3 W. Walnut st.

MARSIALT, GEO DEXTER (b':Ind.9,04: (1"04); 1011 F. Taylor si? flce, 129 is w Walnut st.

Iartin, Ross (hristman (b's s)-Ky.2,'l?

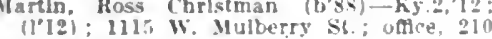
(1) Mulberry st. Mulbery

MAKTIX, WM. H. (b'62)-Ind.10.'s: $:\left(1 y^{\prime}\right)$ $1115 \mathrm{~W}$. Mulberry $\mathrm{st}$ : ottce, giv W. Mul berry $\mathrm{St} ; ; 2-4: 30, ?=9$.

MARTIX, WM. J. (b'69) + Mo:.03 $\left(l^{\prime} 06\right): 1216 \mathrm{~W}$. Waluut st, oflce. ili $\mathrm{k}$ Mulberry St.; $8: 30-12,1: 30-5: 30$

Masfleld. Marcellus (b'66)-Ky.1.9\%: (1'00); 610 W. Walnut st.

McCLUKG, WM. H.-Ind.s, $8 ;$; $(19 i) ; 514$ McClUKG, WM. H.-

McDonald, Cella s. (b'bej) P-.M-Ind.5,03; (1'03): 918 X. Maln st.; $9-11,-5$.

McXes], Geo. I. (10;i)-0 2.98; (1.93) 632 S. Union st.: onte, 12212 E. syca more St. : $8-11,1-4$.

Melner, J. Aaron-Mn, 34, 115; (1'06); Maln St. Miller, lewis (C-Inil $4: 0 \%(107)$

Yoore, Fmma it-l'a 9 i: (19\%); not in practlce.

plekactlce. jons

$321 \times$. Broadway.

Ilamey, John Willson (col) (b'89)-Tenn."12; (1"12); 1002 X. Kenneds st.; ofter 908 : Cnlon si : $-11,2-4,-4$

STIILER, RCSSELI, IIIIII" (1) 831 III.1,09: (1'12); 6.? W Mulberry si omre, Courtland lltork; $9-11,3-4,7-4$. (l'03); 61t W. Taslor st : oflue, s. Mali

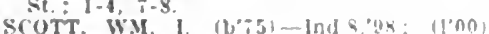
415 W. Sycamore st; calce. 111 k. Mul lersy st. : I.t.

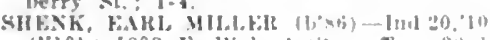

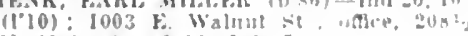
N. Maln st.: 9-11, 1.1, ;.

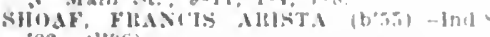
\$2: (1'ys).

SMITH, IUIIARD H - Ind \&, SO: (1.97)

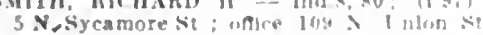

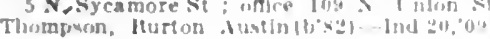
II'ny).

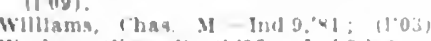

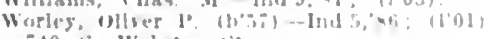

ito $\$$. Webster st

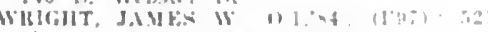

$\therefore$ Maln
KOUTS. 750, PORTER

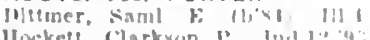

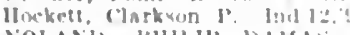

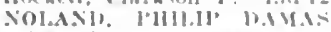
\$2, III 11,01: (1.4:).
KRAMER, 200, WARREN

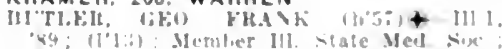
l'rot Ther and I"rev. amb (Inn. Med. III $\div \cdots ;$

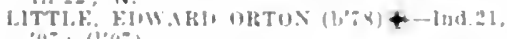

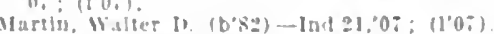

KURTZ, 200. JACKSON

kern. Frank Weaver (b'so)- hy 11,0 ,

\section{ACONIA, 82, HARRISON}

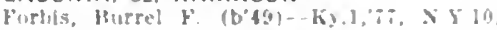

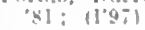

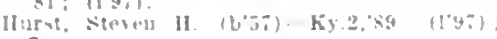
Op.

\section{LACROSSE. 125. LAPORTE}

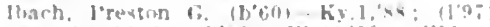

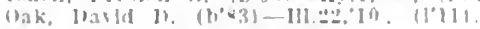

LADOGA, 1,148, MONTGOMERY

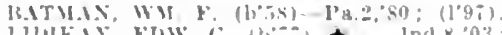

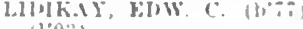

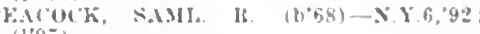

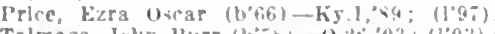

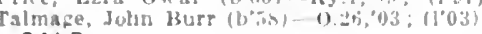
OALR.

LAFAYETTE, 20.081, TIPPECANOE

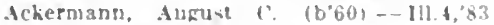
$(195)$ : II $55 \mathrm{~N}$. I2th $\mathrm{st}$ : once, $213 \mathrm{X}$ th st. : 10-11, 3-5, 8-9.

IINETT, IIETT (AMIBELL+-InU.IS, $07 ;(100) ; 1402$ Columbia st.; uflce, Masonle Temple ; 1-t. $7-8$.

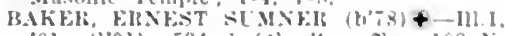
01: (1201); $534 \therefore$ sil 5 : : oflce, $103 \mathrm{X}$ 6sh st. : $8: 20-10,1: 30-1, \div$.

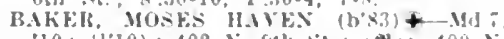

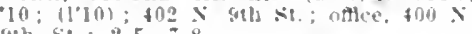
ath 4 t. $2-5,7-8$.

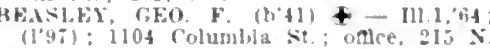
sth sit. : untll $9,1-4$. :-8

Irown, Wm. W. C.-D; (1's): 1106 X, 1:th st.

BYERS, W.II.TEIK MORJISOX (b.83) Ind i, ne: (l'0s): Kiver lid.: anlce. Wa-

CAMLBELA, IOUT. M-Inil.s, 03 ; (I'43)

103I hartord sit: $1-4$, i-9

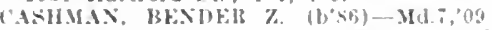
(1'13); 402 in oth st: ontce, 400 : in $-1:=2: 5$.

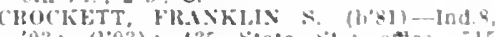
103: (l.03); 435 state 51 : oflce, il: colunbla si.: 1-4. :-x: U.*

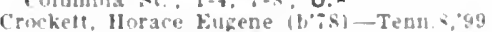
(1'0,i): 515 Columbla se

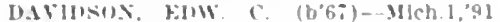

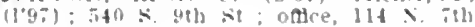
St: : 1-t, :-8

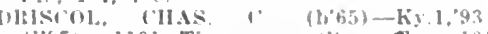

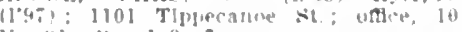
x. kith it $: 1-3$,

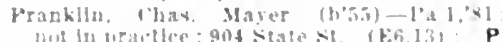

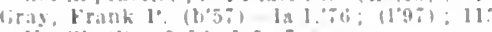

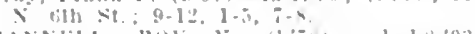

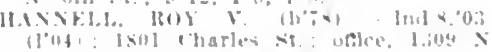

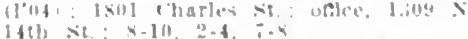

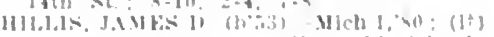

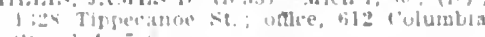

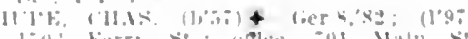

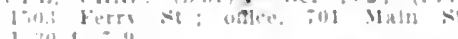

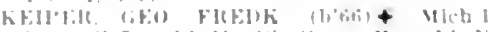

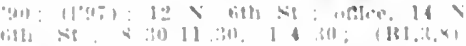
OALR.

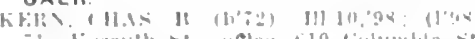

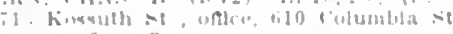

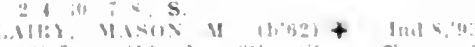

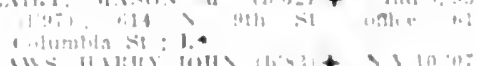

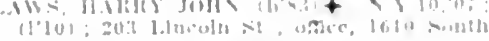

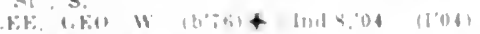

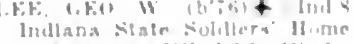

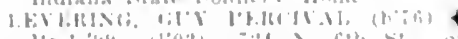

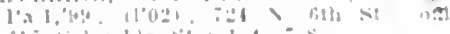
giti inlumb si: is
Jitewil. Jish

(1"8:): 911

loder, lesikin! ly

$1: 1^{1 / 2}$

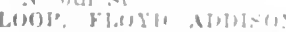

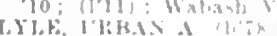

130 i Morton

$1 .+7.4$

Icrlelland, Donalid rias

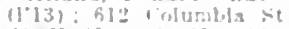

McM.MHAN All

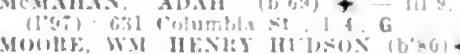

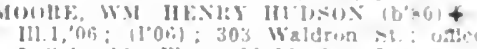

5 Colmenbla Flais: 10.12, $2-1$.

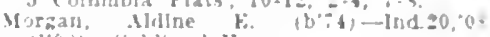
(1) 0 a) : Snldlers' llume.

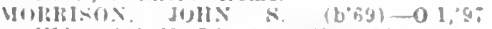
(100); f:1 5 ith st; odie, 523 rolum lita st.; $1-4, i-h$.

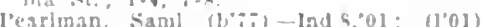

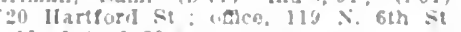
11, 1-4, $6: 30 \cdot 4$

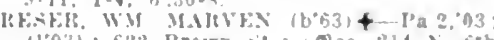

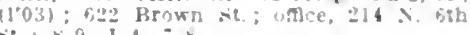
St $x-9,1-4, i-5$.

$+-\ln I 8,0 I ; \quad(10 I)$ :

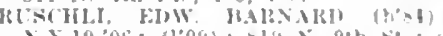

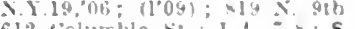

SCHAIBLE, FMIL (beit) - N Y 10,8y

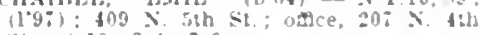
sit. $8-10,2-4,7-9$.

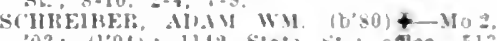
0) 3: (1004): 1143 State st.; oflce, 513 Columbla si : $9-11,1-5, i=4$

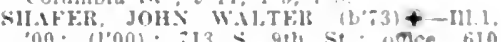

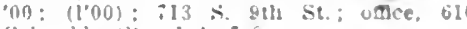

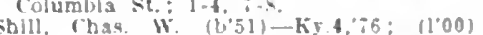
it: Soutb st.; otlce. $5 \% 0$ Columbia st

Smith, john y. (b+4)-I114,59: (199): 116 Bromn st.; once, $214 \mathrm{X}$. oul st: 10-11.

MITI, I.ICIAN W (b'a) - Inds:05: (105) : Soldiers Home siatlon

Spark. Mltkon W (cul.)-Ks:95: (It)

SWEZEY, IIBKY $\$$ (b) ('01): 61: Wyandotte Are, once, 606

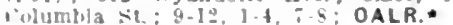

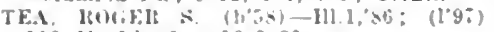
$103 \times$ Sth st.; $10-3: 30$

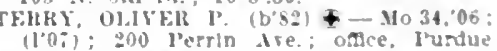
niverslty: $:-4$

Test, Frastux - Ind $1: 93 ;(199)$; not in practice.

THOMI'SON, FRINK R. $\left(t^{\prime} 60\right)$ $(194) ;=4 \times$ :

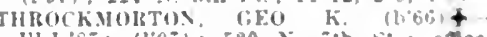

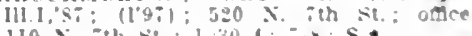

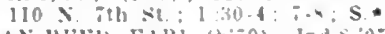

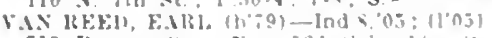

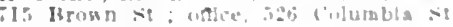
$1: 30-4: \div-8$

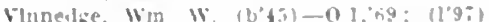
725 fill st ; oatce, 515 colunibls st

W.

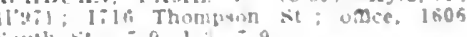

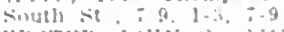

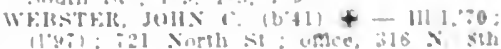

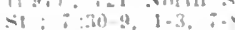

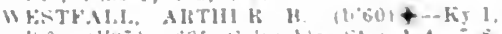

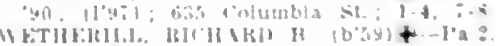

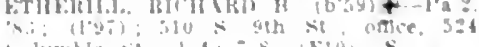

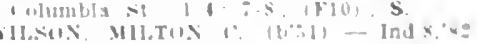

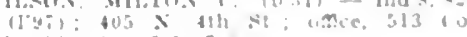

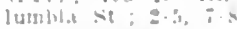

LA FONTAINE, 683. WABASH

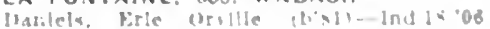
il'ons?

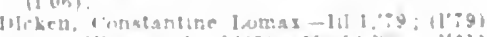

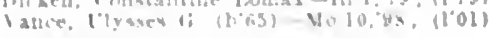
LAGRANGE, $1.82 \%$ LAGRANGE

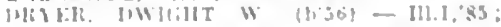

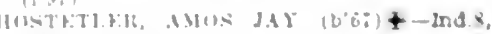

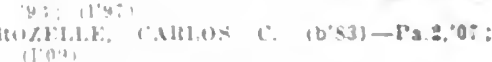




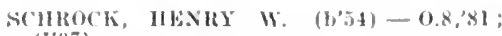
$\left(I^{\prime}: 17\right)$.

SCHROCK, STEWAIT H. (1,82)-Ind.I8 $06:(1,06)$

sIIOIRT, W.i. II. (b'44)£-Meh.L,'69 (1'97)

WYATT, ANDREW R. (b'55)‡-Ind.5,'8t: $(197) ; S$.

LAGRO, 463, WABASH

Hloomer, Frank H.-O.I,73; (1'04)

Hlgglus, Jesse I3raxton (b\%8)-Ind.10,01: (1'04).

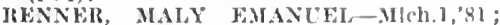
(1'07).

LAKE, 450, SPENCER

(rowder, R. II. (b'65)-Ky.t, 06 ; not in prastlee.

HF: 'TAR. GEO. 13. (b'TI)-Ky, K, 04 : (1'04) JOLISY, JOHN CFAINS-Ky. I'S: (1'9i).

LAKETON, 528, WABASH

Wells, Wm. Y.-Ind.4,'73: (1'97).

Wllson, John I baris (b'60) - Mo.22,'96: (1'11).

\section{LAKEVILLE, 227, ST, JOSEPH}

IIow, John T. (b'73)-Ill.4,'97; (l'02)

Wiseman, Chas. S.-Ind.10,05; (1'05).

LAMAR, 50, SPENCER

MHDCALF, NOIRMAN I. (b'85) +-0 ; (1'II)

LANDESS, 200, GRANT

Siaunders, Jesse k.-Ind.26,'95: (1†)

LANESVILLE, 290, HARRISON

MEYER, OSCAR IR. (1,'82)-Ky.1,07; (1'08).

Teaford, IBenj. J.-Ky,2,02; (1'08).

LAOTTO, 350, NOBLE

ISH, FTHAN A. (b'7i)-Ill.22,09; (1'10).

LAPAZ, 270, MARSHALL

SIIIILEY, JOHY B. (b'62) - Ind.12,95; (l'0.)).

LAPEL, 1,045, MADISON

Fisher, John M. (b'45) $\longrightarrow$; (1'97); R.F.D. 36.

IRInne, John Isaac (b'87) -Ind.20,'09; (l'09). Stanford, II. H.-Ind.8,'94; (I'97).

STEI'IENSON, IIIOMAS J. - III.17,'98: (l'99).

LAPORTE, 10,525, LAPORTE

ANNIS, FBEIR I4. (b'60)†-IHI.I, 81 ; (l'9i) 205 IRumely St.; offlee, 718 Michigan Are. I0-12, I-4, 7-9.

HOWELL, BO CARR $\left(\mathrm{b}^{\prime} 69\right) \uparrow$ J11.11,'95 (1'04); 202 Main st. ; $8-10,1-3,7-8: 30$

BUCK, DEXTER A. '(b'70) 4 -II ich, $1,{ }^{4}$ (l'05); 1002 Harrison st. oftice, 07 Maple Are. ; 10-12, 2-5, 7-9.'

BURIESON, CHAS. EIERY (b'73)€-Jll.6 04; (1'06); 1010 Mlchigan Ave.; office, 708 Jetferson Ave.

Ehrlich, Herman K.-Ia.1,72; $(197)$; not In practlee; Maple Are.

FAIRGHLR, JAMES H.-Ill.10, 03; (l'06); 807 , lelferson Are.

JONF,, ROBT. BENJ. (b'84)-Ind.20,'09 ; (l'09) ; 1107 Jefferson Are.; 11-12, 2-4 $7-9$.

L.ONG, HARRY II. (b'62)£-I11.1,93; (1'97) 9 I 2 Indiana Are.; $1-2,7-\delta$

Joomls, Clias. (b'6-) - (ia.5, Madison St. ; offlee, 806 Maple Are. ; $8-10$ $1-4, \quad 7-9$

MAR'TIN, HARVEY H. (b'7I) £-IH1.10,'95 ; $\left(1^{\prime} 97\right) ; 806$ Maple Are.; $\mathrm{S}$.

MERT $Z$, IIENRY o. (b'84) - Ind.20,'0s (l'08); 806 Maple Ave.

Meyer, Johann II. Wm. (b'53)-Ill.1, 76 (1'03); 1001 Jaekson St, offlce, 708 Jefferson' $\mathrm{St}$.

OSBORN, GEO. R. (b'75) $\oplus-\mathrm{IH} .11,06$ (1'06); 811 Vichigan Are.; offlce, 805 Jef ferson Ave. : $8-9,1-3,7-8: 30$

ROSS, WILBUK WESLEY (b'T) - Jll. 6 , "08; (1'10) ; 810 Madison st.; 1-3, 7-9.

SIIEDD, HLGH BAYLOR (1,83)-JIo.34,'12 ; (lemporary permit,'13): Jember Mo. state Med. Assn.

SIMON, ARTHUR R. (b'86)€-Ind.20,'08; (1'0s): I003 laple Ave,: office, 806 Japle Ave.; 1-3, 7-8; OAĹR.

SMITH, MILTON S. (b'61) $\oplus-$ Ill.10,'96; (148); 810 Michigan Ave.; 9-4; (Bi) OALR.

SLTHERLAND, ORIANDO I. (b'60)807 Jetterson Are.
THOMISON, HAIRY JOHN - Mass. 94: $(105) ; 706$ Mathle Ave.; oftce, 707 Maple ive. : $10-1 \%, 1-4,7-8: 30$.

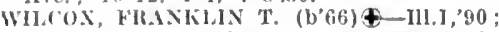
(1'97); 1116 Indlana Ave.; offlee, 808 Inple Ave.; $1: 30-4$.

LARWILL, 400, WHITLEY

THANANT, IEWIS W. (b"ïI)-Ind.8, 04 ; (l'04).

LAUD (R.F.D., COLUMBIA CITY), 250. WHITLEY

Ricluards, Joln (1,3:5)-0.2,'71; (1'07)

S'TI(KLEIR, IBFE.I. FIRANKLIN (b'85)In(l.21), I1 ; (1'II)

WHITL, SAML. R. (b'58)๑-Ind.10,'86; (1'97).

\section{LAUREL, 503, FRANKLIN}

Glfford, Saml. A. (b'55)-0.I,79; (l'97).

Gregory, Henry (b'5I)-0: (1'9i); U.

Mayfled, Cllford Hill (b'75) - Ind.18, 06 ; $\left(l^{\prime} 0 b^{\prime}\right)$.

\section{LAWRENCE, I20, MARION}

RATLIF', JUTHER II. (b'67)థ-Ind.8,'96 (1'97)

Records, R. Saml. (b'70)-Ind.9,'91; (1'97).

LAWRENCEBURG, 3,930, DEARBORN

Bateman, Wdward B.-Ind.8,95; (1'05).

Collns, Samuel H. (b'51)-0.9,'76; (1'97)

WWYER, HAlRRY H. (b'69) II - 0.13, 89 (1'97); S.

Emmert, Edward J. (b'il)-0.9,95; (1'98)

FAGAIY, AITHUR T. (b'T0)-0.9, 93 (1'97).

JAQUITI, ORVILLE S. (b'72)థ-0.9,97; (1'97).

MUELLER, FRANCIS M. (b'73)†-Ky.2, $95 ;(1 ' 99)$.

SMITH, GEO. FOSTER (b'75)-0.9,97; (l’97).

Walter, Charles Albert-0.9,93; (1'97).

LEAVENWORTH, 690, CRAWFORD

DEEN, HENKY H. (b'76) $\oplus-\mathrm{Ky} .5,06$; (l'06) ; OALR

Klmes, Danl. W. (b'50)- - ; (l'99).

LEBANON, 5.474, BOONE

ARMSTRONG, MAX A. (b'84)-Ind.20,'I1 (1'II).

Baker, IIerbert I. (b'81) II - Mo.5,'04 (1'04): Pd.

BAIL, JANES R. (b'68) \&-Ind.8,'9I ; (1'97)

Bearen, Leslle Moss (b'78) - Ind.20, 08 (1'08)

BEC $\mathrm{K}$, HERMA A. (b'80) - Ind.8, 04 ; (1'04); $\mathrm{S}$,

Bennington, Amos M. (b'38) $\rightarrow$; (1'97); R.F.D. 13 .

BLACK, JAMES H. (b'il)-Ind.I8, 06 ; (l'06) ; OALR. *

Coons, Henry $\boldsymbol{x}$. (b’33) H-IH.4,'83; (1'97) G.

Higgins, otis C. $\left(b^{\prime} 76\right)-J 11.10,00:\left(l^{\prime} 00\right)$.

Hurt, Geo. K. (b'4i)-Ind.8,'8I; (1'9i).

Jones, Alfred B. (b'5 5 )-Ind.8, ${ }^{\prime} 87$; (1’97).

Orr, Janes P. (b'31) $-0.2,60,0.1,65$; $\left(\mathrm{I}^{2} 05\right)$.

l'orter, John R. (b'49) $\rightarrow$ : (l'9i)

SCHLI,T\%, GUY A. (b'72)- Ind.8,00; (l'00)

smith, Carter 11. (b'35)-Ill.1,73; (1'97).

SAITII, De LASKIE (b' $千 3)$ - Ind.8, 01 ; (1'0I).

Turner, Thomas S. (b'63) E- $>$ : (1'9i).

UMBERIIINE, (HAS. 1). (b'62) 4 -I11.1,'85 ; (1'97) ; R.F.D. 9

VAN NUYS, MARY M. (b'61)-Jll.9,'9i; (I'9\%).

WILLIAMS. WM. H. (b'68)థ-Ind.8,97; $\left(l^{\prime} 00\right) ; \mathrm{S}$.

LEESBURG, 401, KOSCIUSKO

FERIIJR, PIERRE G. ( (13,66) \&-Ind.8,'94; (1'97) ; $\mathbf{0 b}$.

THOULS, CIAS. E. $\left(b^{\prime} 74\right) £-I n d .10,00$. $\left(l^{\prime} 00\right)$.

LEESVILLE (R.F.D., FT. RITNER), 125 , LAWRENCE

SMITH, SPENCER W. (b'56)-Ky.2,82 : (1'97)

LEIPSIC, 60, ORANGE

COLGLAZIER, GRANVILLE G. (b'79)
LEITER'S FORD, 200, FULTON

SLONAKEIR, CLEMEST I.EE (b'75)-Ind.8, 03; (1'03).

LENA, 340, PARKE

Silles, Jay-0.25,ys: (]'04)

Welel, John A.-Ind.9,'83; (1'97)

LEO (R.F.D., GRABILL), 300, ALLEN

IOSTETLER, MENNO 11. (b'82)-0.40,'11; (l'II).

LEOPOLD, 1,200, PERRY

TAYLOR, JOIH liLLSWORTH $\left(\mathrm{b}^{\prime} 69\right) \Phi-$ II0.7,99, III.11,08; (1,09).

LETTS, 200, DECATUR

Clark, Thos. J.-0.2,74; (1'97).

LEWIS, 225, VIGO

Crulkshank, Orrls G. (b'61)-Ind.9,98; (1'99); Pd.

Fonte, Ziba H. (b'24)-N.Y.5,47; (l’97)

(IIF'WS, CIIAS, C.-Ky,4, $82 ;\left(l^{\prime} 97\right)$.

LEWISCREEK, 90, SHELBY

l'ERRY, CHAS. H. (b'75)-Ky.5,'96; (l'97).

LEWISVILLE, 446, HENRY

BAITI,ETT, CLAUDIUS G. (b'55)-0.1,77 ; (l'yi).

Blalr, James B. (b'82)-Ky.2,'10; (1'11).

IFMAREE, CHESTER (b'86)-Ind.20,12; (1'12).

LEXINGTON, 325, SCOTT

Lothrop, Alonzo H. (b'41)-Ky.1,'76, Ky.4, $34 ;(1,37)$.

Matthews, ('has. B, (b'72) - K5.1,94:

(1'98); Pd.

LIBERTY, 1,338, UNION

BEARI), EVERETT RILEY (b'7I)-0.I, 97 (1'97).

DUBOIS, FRANKIIN T. $\left(b^{\prime} 70\right) €-N . Y .19$, 99 ; (l'04).

EGOLF, HARVEY MARION (b'56)@-Ind.8, 81; $(1,97)$.

Phares, Omer P. (b'55)-0.3,84; (1'86).

PIGMAN, GARRETT (b'58) $4-N . Y .10,83$;

HOM1'SON, WILI, AMBROSE (b'75)€Ind. 20, 09 ; (1'09).

LIBERTY CENTER, 35!, WELLS

GARRETT, FRANK W. (b'55)-Ind.8,'82: (l'9i).

LIBERTYVILLE (R.F.D., VERMILION, (LL.), 40, VIGO

SIIPLEY, CLARK LEE (b'82)-Mo.7,'08; (l'12); Member Kan. Med. Soc.

LIGONIER, 2,173, NOBLE

BIACE, FRANK W. (b'72) $4-N . Y .10,97$; $\left(1^{5} 98\right) ; \mathbf{S}$.

CLAPI, FRED. RAYHOND $\&-111.1,03$; (1'04).

FRANKS, WM. H. (b’41)-IIl.1,74; (1’97).

LUSE, HORATIO 1). (b'74)-111.4,'11; ( )

SIIOBE, WH. A (b'56) (1'97); G.

Wlneburg, Louis Peter (b'79)-Ill.8,09, Ill.14,'08; (1'13); OALR.

LINCOLN CITY, 140, SPENCER

Barnett, David C. -0 ; (1\%)

Crafton, Owen T. (b'74) $\longrightarrow$; (l’99).

LINDEN, 556, MONTGOMERY

Elliott, Joln W. (b'62)-Ky.2,'97; (1'00).

Rhea, James o. (b' 65$)$-Ind.s, $\left.02 ;(1)^{\prime} 03\right)$.

Shotts, Henry R.-Ind.4;77; (1'03).

LINNGROVE, 250, ADAMS

IICKEAN, THOS. J.-Ind.S, 05 ; (1'05)

LINNSBURG, 25, MONTGOMERY

Riley, Frank H.-Ind.8,'02; (1'02).

LINTON, 5.906, GREENE

Anerman, Chas. E.-Ia.I,'87; (1'06).

BERNS, PETER C., JR. (b'72)-Mio.1,97 (1'99); also Member III. State Med. Soe. Cravens, Elmer R. (b'62)-Ky.1,88; (1'97). CUSTER, ANDREW TENNYSON $\left(\mathrm{b}^{\prime} T 2\right)+$ Ind.20,08; (1'08).

FJEETYOOD, BRLCE (b'Ti) - Ky.I,OL: (1'01).

HYDE, LOREX A. (1)'T0)-Ind.8,97; (l'02)

MASGANA, EMANUEL P.-Ky, 2, 98 ; (1'99). I'orter, Geo. C. - 0.2,'03; (1'04)

Quillin, saml. N. (b'72)-Mo.27,99; (1'01). ROSE, BISHOP A. (b+49)-0.1,75; (1,97). SHERWOOD, ELMER T. (b'59)-Mo.1,'82; (1'96). 


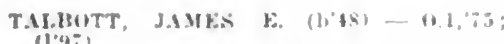

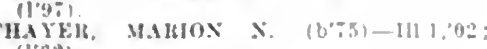
(1'0?).

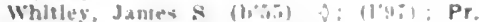

LINWOOD, 123, MADISON

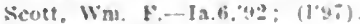

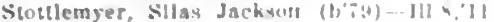
(1'11).

LIPPE (R.F.O.. WADESVILLE), 20, POSEY Mlller, W'm. H.-Indis,"01; (I't)

LITTLE YORK, 193. WASHINGTON

Jerron. Thos. W- $-6 ;(109) ;$; nut in prar

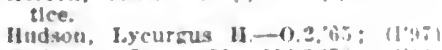

P'lukston, James M-MU.3: is: II'nt!

LIVONIA, 197, WASHINGTON

Perree. Isaac-Ky.1, sII; (1'9i)

STBPHExSON, LEWIS E. (b) + Ind,

10.03: (105): Metuber Kati. Mit

LIZTON. 224, HENDRICKS

HESDHICKS, JOHS LEWITT-Ind LS,'(10i (1'06).

LOGANSPORT, 19,050. CASS

Baker, Ira J. (b.33) - ; : (1'97) ; 201; Mlght St. : offee, $403 \%$ Broadway

BALLARD, CHAS. ANSON (b'82)-111.11. 07 ; $(10 \%)$ : Member 111. State Med. Sur 323 ve Market st.

BARNFIEL, JOHN HLMES $\left(b^{\prime} 64\right)+-P^{\prime}$ a ? "86: (1'97); 505 Broadway: 1.4.

Mradfeld, Benjamln liean (b'io)-1lich 1 7t: (1'95): 816 k. Market St. : nnce, 315

3A St. $9-12,1-5,6-8$ G.
BRADFIEL, JOHN CHAS. (1) 79 - Mich 1 , 03: (1'04): 705 North st. : oftce, 205 $3 \mathrm{~d} \mathrm{SL}: 2.5: \mathrm{S}$

Burkley. Howarl W. ( $\$ \times 0)-1+4 s, 00$

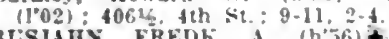

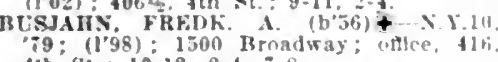
4 h' st. 10-1\%, 2-4. 7.8.

CADY, NELSON WAKNER (b'50) + NY10 "7i: (1'9i); 1108 Market st.; nalce, 606

Broadway 9-11. -4. i-s.

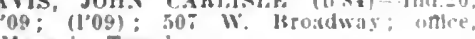
Masonlc Temple.

lownes Jasper A (b.53)-0.2,85: (199) 312, ilth St. : office, 413 , thi s:

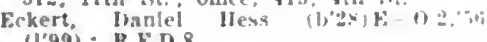
(1'99) : R.F.T.8.

(II,RERT, JAMES L. (b'T(1) - $11.1,4$ (1997); 117,11 th $\mathrm{st}$; oflce, 421 , t11 st. :

Hall, Joseph

(n)

in practice.

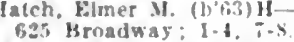

HERMAXN, FRAXCIA J. $97:\left(19^{\circ}\right): 114$, thl st.

HESSLER, RORT. (b'b]) + - Ind $=$, [1] (1'98): $2000 \mathrm{HIlgh} \mathrm{St}$

HETHERISGTON, JOHIN 1 . (b'th) $11=2.00$

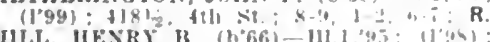
HLL, HENRI H. (b66)-111.199: (1) 2-1: OALR. *

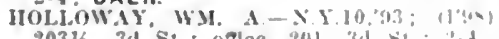

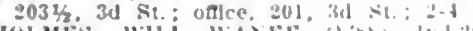

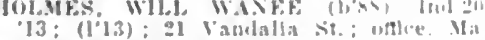

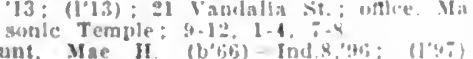

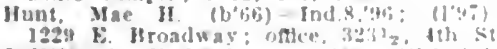

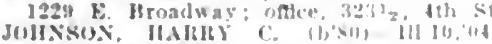
(1'04); 2015 Broadway; utre, 320 Purth St.

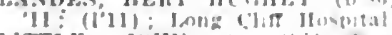

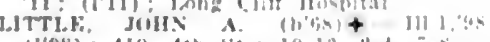

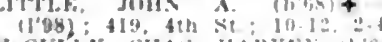

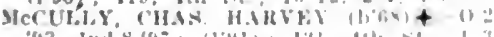

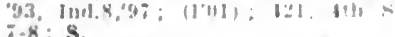
$7-8 ; 5$

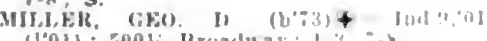

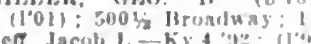

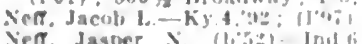

vief, Jasper sit

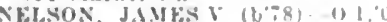

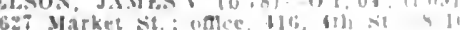

$1=3,0.9$
0.9

Nicodetnus, John l'hlly (1) sol lund ts oti (rleary: Francls T. (b'is)-Tenn.1.998:

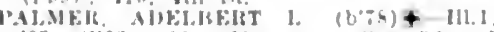

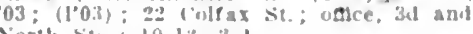
North sto : 10-1:2 :

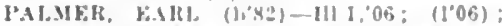
Vorthern Indiana llosultal por livane.

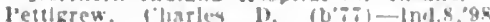

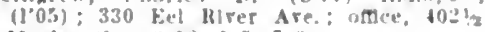
Market st, 9-12, 1-5, i-s

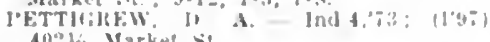
40? 1 Market $\leqslant 1$

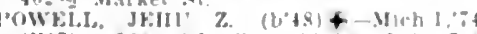

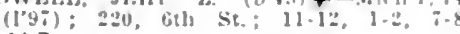

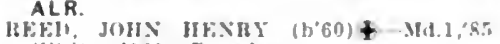
(1'y2) : $410^{2} / 2$ Brondway.

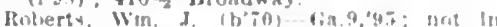

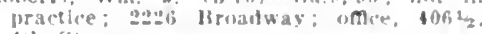

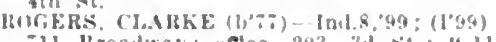
ill lirnadway: oflce, 203, th st.: $4-11$, $1 \cdot 30-4: 30,8-8$.

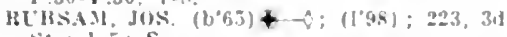
st.: $1-5 ; \mathrm{S}$.

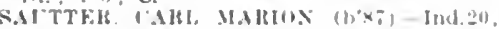
'11: (1'll): Northern Hosplial qur the Insane

Shultz, Harry 11. (b':2)-Ind a:03: (1'03): iIs k. Market st.; mre, tio. 4th st. $2-5,7-S:$ ODLR.

Shullz, Jolin II. (1)'43)-0.2.72; (1'97)

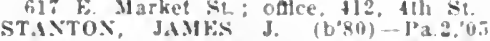
(1'03); 703 Broadway; oflice, Masonic Temple.

Stewart, James Wilson (bos) - Ky.4, ij llasonic Temple: $10=-\hat{\mathbf{S}}$.

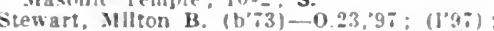
1308 Jllgh St.; nftice, $30 \mathrm{~s}$, 4 th st., $-4-7-8$

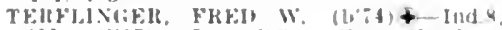
02: (1'05): Longeliat: uftce. Northers Indliana Hospltal for Insane; (E.13). rHows. (HAs, Ia (b'tis) - Inds, i: $(196)$ : Burlingion Bd.; urtce, 415, th

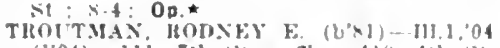
(1'04); 111, ith st: natled, 419, th st.

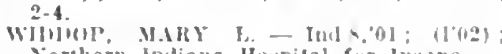
Xnthern Indiana Hospital for lasare

FILE, WM. LOKNE (b'\$1)+ Unt.5, US (l'10) : Iouniclit: oftce, longelifr Hos liltal: $P . \star$

LONDON, 200, SHELBY

Rubnsh, Thomas Robert-Inds, is: (1'yi).

LOOGOOTEE, 2.154, MARTIN

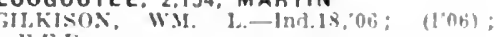
18 r.11.

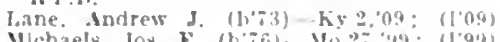

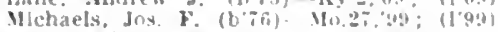

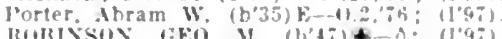

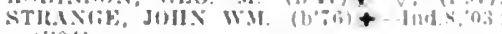
(lot)

THI Kis

LOSANTVILLE, 325, RANDOLPH

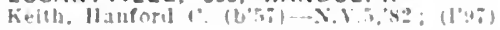

LOWELL. 1.233, LAKE.

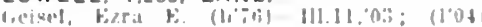

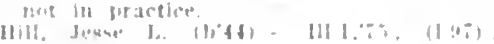
lin 11

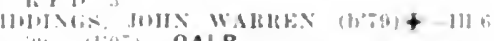

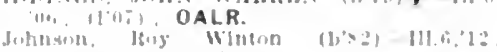

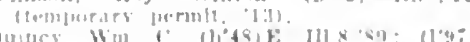

LUCERNE, 230. CASS

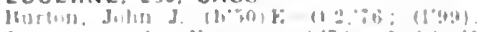

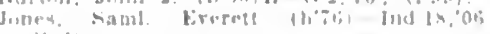

LYNN. 91\%, RANDOLPH

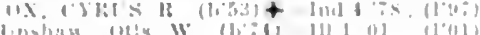

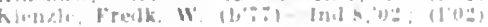

LYNNVILLE, 297, WARAICK

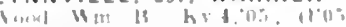

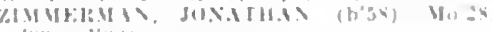

LYONS, 94., GREENE

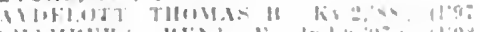

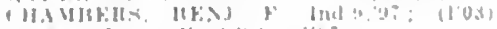

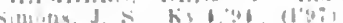

MACE (R.F.D. CRAWFOROSVILLE), 310,

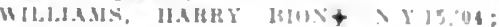
(1'11)

MACY, 320, MIAMI

CAHTHE, JIIINEAS

(19)

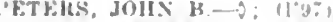

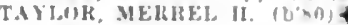

(109).

MADISON, 6.934. JEFFERSON

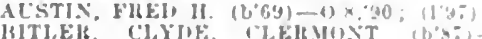

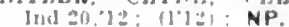

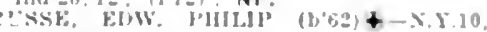

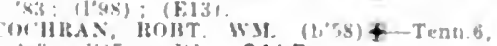

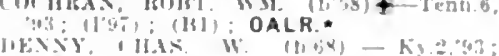

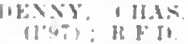

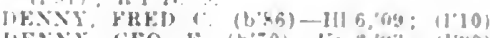

IIFANY, (:EO, bo (b'T0)-ky

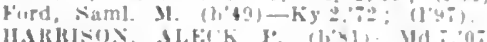
(I' $10 \%$. P*

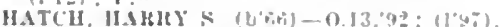

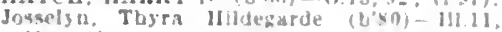

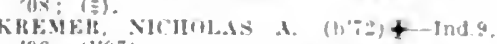

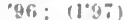

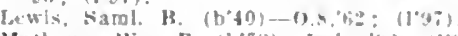

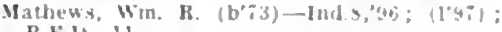
R.r.11. 11.

I'etro, lienj. L. - 3; (1'G:

Kains, (ieo, $\left.w,-(1)^{0}\right)$

STEWART, JOSAS (1.13) - X.1.,20: $(19 \pi)$

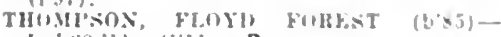
Im1 :0, $11:$ : (1'11!: P.

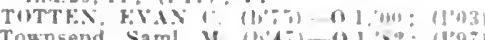

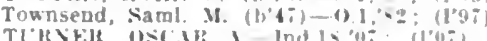

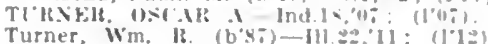
IS.T.R. 1:.

MAGNET, 100, PERRY

IHIPDerdan, John II (b'ti) - $:$ (1'0.5)

MANCHESTER, 350, DEARBORN

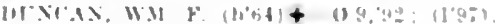

MANILLA, 400, RUSH

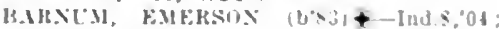
11041.

Rarnum

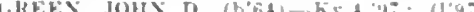

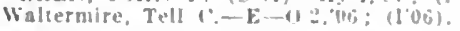

MAPLES, 150, ALLEN

MYFiRS, ISASE XY (b'BA-lud.?'? $\left(\mid y_{0}\right)$

MARCO 300, GREENE

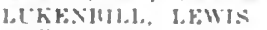

(l'00)

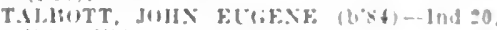
11): (1'11).

MARENGO，686, CRAWFORO

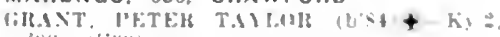

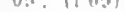

MARIAH HILL, 100. SPENCER

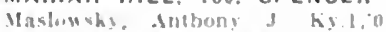

MARIETTA (R.F.D., SHELBYVILLE), 210. SHELBY

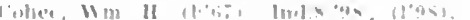

MARION, 19.359, GRANT

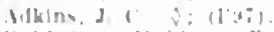

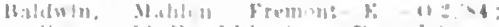
(1)

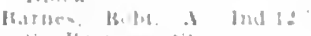

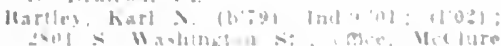

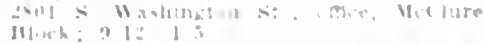

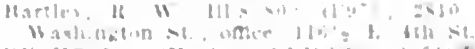

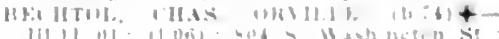

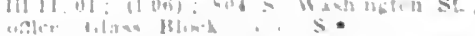

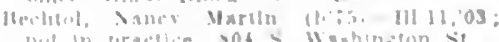

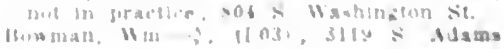

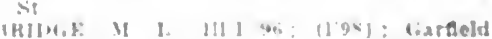

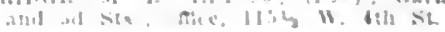




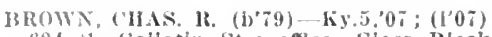
624 s. Gailiatin St.; office, Giass Block; $9-11,2-5,7-8$.

lirundige, Sainl. P.-0.1,'72; $\left(1^{\prime} 98\right)$; sth and Alams sts.

Bryan, Lorenzo D. $\left(\mathrm{b}^{\prime} 46\right)-0.14,78$; $\left(\mathrm{I}^{\prime} 00\right)$ $1822 \mathrm{~s}$. Washington $\mathrm{st}$; ; oftce, lifles Block: OALR.

CAIIERON, VICTOR V. (b'75)†-MIA,4,99 (1'99); I I $\mathrm{N}$. Nebraskia St. ; offlee, $4081 / 2$

Cariwrlght, IIary 1.-Ind.12,84; (1'97) ; $21 \mathrm{I}$ E. $2 \mathrm{~d}$ st.

DALE. PERNHAM C. (b'i1)-Ind.8, 93 (l'97); 609 W. 4th St.; offlee, 3d and Washington Sts. : 9-11, :-4, $7-8$

DANIFLS, (iEO. R., IR.--Ind 8,00 ; ( 100$)$

$116 \mathrm{~s}$. East st. ; oflice, Wlgher liock ; 2-5 Danleis, Welch V. (b'60) E-0.2,88; (1'97) 1204 S. Adams st

DAVIS ALRERT T. $\left(b^{\prime} ; 6\right)$ - Ind 8, 04 (1'04) : Colonial St. : oftice, Glass Hiock. Bavis, Fmlly J.- $\mathrm{I}^{\prime}-\mathrm{H}$-Ind.I2,92; (1'04); $2225 \mathrm{~s}$. Gallatin St.

Davis, (ieo. W.-E- 0.2,'80; (1'98); 419 W. 5 th $\mathrm{St}$; ; oftce, $408 \frac{1}{2} \mathrm{~S}$. Washington $\mathrm{St}$. DAYIS, OLIVER HORTON (1)69)-Ind.8 94; (I'06); Cecillan Apts.; offlee, Glass Block : 11-12, 2-5, 7-8.

ECKHART, GODLOVE G. (b'82) †-Pa.2, 07; (1'08); 203 S. Adams St. ; offlee,

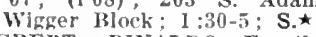

EGBERT, RINALDO E. (b'4i)-Ili.1,7I $\left(t^{0} 07\right) ; 203$ North $\mathrm{E}$ St.; office, 1536 spencer Are.; $9-12,2-6$.

ESHLEMAN, LINDLEY H. (b'70)†-Ky.I 96 ; (1'97); $2923 \mathrm{~S}$. Washington St.; of flce, $2923 \frac{1 / 2}{2}$ S. Washington St. ; $7-9,1-3$, $7-9$.

FANKRONER, WM. A. $\left(\mathrm{b}^{\prime} 61\right) \oplus-\mathrm{I} 11.1,91$ (l'97); $703 \mathrm{~W}$. 4th St,; offlce, $116 \frac{1 / 2}{\mathrm{E}}$ ith St.; 10-12, 2-5.

Fite, Calvin H.-Ind.26,97; (\$); $3746 \mathrm{~S}$ Washington St.

Fowler, Ada A. (b'58) H-Ill.4,'89; (1'91) 822 W. 4 th St.; offlce, 116 W. 3d St.

MAMILTON, ASA A. (b'50)-Ind.4; 72 ;

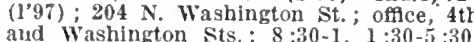

HARROLD EDWIN O. $\left(\mathrm{b}^{\prime} 76\right)-$ Ill.1, 02 (i'02) ; Mecca Club; offlee, 4th and Washington Sts.

Houser, James A.-P-MI-Ind.12,'95; (1'97) $605 \mathrm{E}$. Grant St. ; offlce, $1111 / 2 \mathrm{E}$. 3rd St. 8-12, 2-6.

JOHNSON, JAMES EDW. (b'72)-IIl.1,97 $\left(1^{\prime} 97\right) ; 609$ S. Boots St.; office, JIarion Block; 9-12, 2-5; (BI) ; OALR.

Jones, Chas. H. (b'80)-Ind.8,03; (1'03) Glass Block.

KHMBALL, GLEN D. (b'70) - I11.1,92 (1'97); i15 N. Nebraska St.; offlce, $408 \frac{1}{4}$ S. Adams St.; $2-5$.

Lewis, Miles J.-Pa.II,97; (1'97); Cecilian: offee, Fifth and Adams Sts.; 8-10, I-3,

LOOMIS, JOHN F. (b'64)థ-0.8,'90; (1'07) 1001 W. 3d St.; offlce, When Bldg.; 8-10 $1-3,-i-8$

MAURER, JOS. (b'75)-Tenn.1,'01; (1'02) 614 S. Washington St. ; 9-4; OALR.

ICKAY, JAMES D. - Ont. 3,$95 ;\left(1{ }^{\prime} 97\right) ; 1521$ S. Boots St.; office, Webster Block.

Mckay, John Blake-Ont.3,04; (i’05); 1521 S. Boots St.; offlee, Webster Biock. MCQUOWN, OTIS W. (b' 60$) \oplus$-Ind.8, 00 (1'02); $408 \frac{1 / 2}{}$ S. Adams St.; 2-4, $7-8$. OVERMAN, CHAS. J. (b'66)-Ind.8,96 (1'97); 2 $708 \mathrm{~S}$. Washington $\mathrm{St}$; ; offlce, Iroquois Block; $10-12,2-4, i-8$.

Iroquois Block; $10-12,2-4,7-8$.
POWELL, NETTIE BAINBRIDGE $\left(b^{\prime} 68\right) \oplus-$

Iich. 1,92 ; (1'97); 615 Whites Are. ; $2-5$ Pd.

Priest, Frank A.-IIl.4,'98; (1'98); 636 W. $2 \mathrm{~d}$ St.; office, Glass Block; 8-10, I-3, $7-8: 30$.

Shanahan, Alva A.--Ind.26,'94; (1'97); 1626 W. $2 \mathrm{~d}$ St.

SHIVELY, MARSHALL T, -0.1,74; (1'97)

Race and 6th Sts.; offlee, $1151 \frac{1}{2}$ W. 4th St.

Siddons, James $0.0 ;\left(l^{\prime} 9 \pi\right) ; 204$ S. Boots office, Glass Block.

Andrew D. (b'43) H-0.23,'92; (1'97) in practice; $524 \mathrm{E}$. $31 \mathrm{st}$ St odrtas, David B.-P-II-O.4,'78; (l'97);
Jonesboro Pike; office, Mirquette
Studiey, Jos. W. ( $\left.b^{\prime} 50\right)$-Ind.8,81; (1'97) s. Alnms St.; offeres S Washington St. Sutton, Henry 1.-Ind.12,97; (1997); 1529 Sinencer Ave.; oftlce, 1533 Spencer Ave. Thomas, Willam T. (col)—Ky.7,97; (1'97) 514 F. Cirant st.; offce, 22113 E. 4th si. THOOK, EDWIN. MI $\left(\mathrm{b}^{\prime} 63\right) \uparrow-$ III.1, 92 (l'y9); Colonial; offlce, Iroquols Bidg. 9-12, $1-4,7-9$.

Wail, M. I. -II-Ili.4,81; (1'09); 633 W. 4th st. ; offlce, (ilass Block.

Webster, Klery Channing $-\mathbf{E}-0.2,68$; (1'97): Giass Block.

Williamis, Davld A.-E- $0.2,90 ;\left(I^{\prime} 97\right) ; 224$ W. 4th St.; office, Glass Block.

ILLIAMSOY. HARRY-Ind.8,"92; (I'01); Colonial; office, Glass Block.

MARKLE, 820, HUNTINGTON

FISIIER, MARYIN F.-Ind.20,08; (1'08)

Jolinston, Robt. Gray (b'86)-Hich.I,'il; (i'13).

Filander, Wm. J.- $0 ;(199 \pi)$

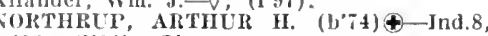
04 ; (1'04); 0 b.

MARKLEVILLE, 250, MADISON

Conner, Davld Neison (b'76)-Ind.20,10

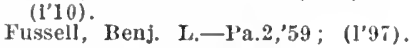

MARSHALL, 334, PARKE

WARREN, BRADFORD (b'8I)-Ky.5,'06 (1'13); Member Ky. State Hed. Assn.

WELLS, ISAAC F.-Ind.9,'95; (I'99).

VILIIAMSON, AIVIN A.\$-Ind.S, 98 ; (1'97.

MARSHFIELD, 300 , WARREN

Trent, John Henry (b'46)-X.Y.8,'76; (i'9i).

MARTINSVILLE, 4,529, MORGAN

BOTHWELL, CAMDEN GROVER (b'87) Ind. 20,13; (1'13).

BREEDLOVE, GEO. B.-Tenn. 6, 00 ; $\left(l^{\prime} 00\right)$ Carter, James $\left(b^{\prime} 43\right) \rightarrow$; $\left(1^{\prime} 97\right)$

EGBERT, ROBT. HITE (b'84)@-Ind.20, '09; (l'09).

GREEN, ELIJAH V. (b'49)-Ind.4,'76 (1'97).

Hendricks, Walter E.-0.1,78; (1'97)

IIENSON, THEODORE (b'54)-Ind.8,'81. $\left(I^{\prime} 97\right)$.

Hinkle, James S. (b'59)-0.1,8I; (1'01).

Kennedy, Danl. $r^{3} \quad\left(b^{\prime} 45\right)-0.2,70 ;\left(l^{\prime} 97\right)$

MAXWELL, FRAXK R.-Ind.8,'95; (i'98).

MAXWELL, JOIIN II.-Ind.8,97; (1'03).

ROBINSON, FRANK C. (b'76)-Ind.8, 02 . $\left(l^{\prime} 02\right)$.

ROBINSON, H. C.-Ky. 2,'72; (I'97).

SANDY, WLLIAU JOHN $\left(\mathrm{b}^{\prime}-4\right) \oplus$-Ind.8, , 00 ; (i'03); LR.

SWEET, EDW. It.-0.1,'90; (1'97)

SWEET, OTIS AUSTIN (b'i8)థ-Ind.8, 03 ; $\left(l^{\prime} 04\right)$.

Tilford, Benj. W.-Ind.8,81; (1'97).

MARYSVILLE, 150, CLARK

Smith, Thomas MI. (b'82)-Ky.5,06; (1'06).

MATTHEWS, 688, GRANT

Dawson, Chas. Francis $\left(b^{\prime} 60\right)-M d .4,92$; $\left(1^{3} 02\right)$

Greenleaf, Hannibal A.- $Q$; (l'97)

Wharton, Wm. L. (b'51)-Ind.8,82; (l'97).

MAUCKPORT, 279, HARRISON

MATHYS, ALFRED (b'80)థ-Ky.2,09; $\left(1^{\prime} 10\right)$.

MAXWELL, 400, HANCOCK

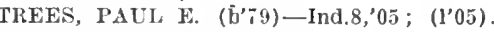

MAYS, 200, RUSH

Lord, J. Levi (b’58)-Ind.8,82; (1'98).

MCCORDSVILLE, 301, HANCOCK

BENYETT, EDWL .I. (b'67)-Ind.18,'06; (l'06)

MECCA, 1,200, PARKE

Erans, Ererett Horton (b'64)-0.13,'95; (l'97).

MECHANICSBURG (R.F.D., MIDDLETOWN), 175, HENRY

Hoppes, Gilbert Austin (b'90)-Ind.20,'12: (1'12)

MEDARYVILLE, 7/0, PULASKI

Hackley, Robt. Pythian-Ky.I, 00; (1'00).

Jones, IIlorace G. -Ind.8,'86; (1'97)

Jones, Jay-Ky.1,93; (1'04).

LINTON, CHAS. E. (b' ( $\left(1^{\prime} 04\right)$.
Stone, I eslle Lewls (h'87)-Ili.11,'12; (1'13). randament, Waiter Thomas $\left(b^{\prime} 87\right)$-Ind.20, $12 ;\left(I^{\prime} 12\right)$

MEDORA, 675, JACKSON

CUMMINGS, DAVID JOS. (b'45)-0; (1'96)

MeNllian, James P. ( $\left.\mathrm{b}^{\prime} 43\right) \rightarrow 0 ;\left(1^{\prime} 97\right)$.

lRoss, Meivilie (b'87)-Ind.20,'11; (1'11).

MELLOTT, 372, FOUNTAIN

KERR, ALVIN ROBT. (b'82)-Ind.20,'I0 ; (i'10)

Parker, John-O; (I'99).

MEMPHIS, 200, CLARK

REYNOLDS, JAMES M.-N.Y.10,85; (l'97),

MENTONE, 728, KOSCIUSIKO

Bennett, IIerbert E.- $0.3,79$; (l'01).

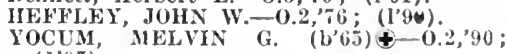
(I'97).

MEROM，521, SULLIVAN

BOONE, FRANK C.-KY.2,93; (l'0i).

Brown, Lemos L. $\rightarrow$; (1'97)

MILES, JAMES (b'67)-0.1,97; (1'9i).

PARKER, J. J. $\left(b^{\prime} 72\right)-K y .9,00 ;\left(1^{\prime} 00\right)$

Stoddard, Orren (b'43)-Ind.8, 86 ; (1'97).

MERRILLVILLE, 209, LAKE

IDDINGS, HOMER L. (b'52)-Mich.2,'76: (I’97).

METAMORA, 588, FRANKLIN

Allen, Irvin 0. (b'65)-Ky.4,'98; (1'98).

CUP', MILLALD F. (b'58) † 0.1,82;

$\left(1^{\prime} 97\right)$.

METZ, 275, STEUBEN

SWANTUSCH, OTTO H. (b'83) $\uparrow-I n d .10$, $05 ;(105)$.

MEXICO, 500, MIAMI

Rendel, Chas. F. (b'76)-Ind. 8,05 ; (1'05).

MIAMI, 300, MIAMI

MILLS, EDWIN A. (b'61)-Mo.27,99; (1'99).

Shoemaker, Iames B. (b'84)-0.13,'10 (1'10).

MICHIGAN CITY, 19,027, LAPORTE

BLINKS, EDW. GUSTINE (b'69)૯-MI.4, 93; (1'97); 6th and Washington Sts.; $8-10,1-3$.

BOWERS, JOHN WHITEFIELD (b'7L) Mo.27,'99; (1'99) ; 814 F'ranklln St.; ontice, 8 I6 Franklin St. ; $1-3,7-8 ; \mathbf{U}$.

BOWEKS, I'AUL E. (b'86) $₫$-Ind.21, 07 ; (1'07); State Prison.

BOWERS, ROSE ALEXANUER (b'83)Pa.7,09; (1'12); 2221/2 W. 9th st.; 2-4, $7-8 ; \mathbf{P}$.

DRESCHER, MARENA L. B. (b'76)-Ill.9, 90 ; (1'98); not in practice; $2002 \mathrm{E}$. Michigan $\mathrm{St}$.

Fads, Thomas L. (b'50)-D; (1'97); 831 H'ranklin st. ; 9-12, 4-9.

EBERHARDT, WERNER (b'72) $₫$-Switz.5, "99; (1'03); 119 E. 6th St.; OALR.ネ

Farres, Shickry (b'87) - Il1.8,'12; (1'13); 4291/2 Franklin St.

KASDORF, GEO. CHAS. (b'71)屯-N.Y.8, 0T: (l'08).

KERRIGAN, JOHN J. (b'56) - In.11,94 ; (i'04) ; 409 Washington St.; I-3, 7-8.

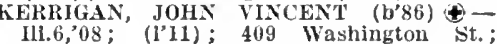
$3-4 ;$ S.

KILLOUGH, AIMEE R. (b'78) (--III.22, 09 ; (temporary permit,'11); 713 Franklin St. 10-11, 2-4, 7-8; Pd.

KRUEGER, EMIL OTTO (b'85)↔-UIch.I, '08; (temporary permit,'13); Member Mich. State IIed. Soc.; I21 E. 4 th St.

LEDBETTER, JOHN NELSON ( $b^{\prime}$ T 2 ) Mo.7,'96; (1'99); Ledbetter Block; $2-5$.

LEEDS, FRANK R. (b'73) $₫-111.4,99$; (I'04); 808 Franklin St. ; $8-9: 30,1-3,7-8$; LR.

MARTIN, FRANCIS V. (b'64)Ð-Mich.5,'92 ; (1'97) ; 132 W. 8th St.; offlce, 124 W. 8th St. ; $7: 30-9,1-3,6: 30-8 ; \mathbf{S}$.

MILLIGAN, JAMES W. (b'59) - Ill.1,89; (1'05) ; 210 W. 9th St.; offlce, State Prison.

Reed, Anne Isabel IIurphy (b'86)-Mich.l, 09 ; retired; Park Row.

REED, NELLIE MALYINA COLE $\left(b^{\prime} 85\right) \oplus$ -Mich.1,09; (1'11); 516 Pine St. ; office, 209 E. 5th St.; $2-4,7-8$. 


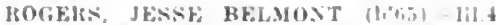

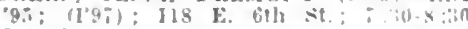

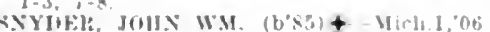

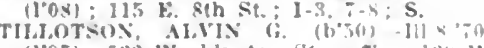

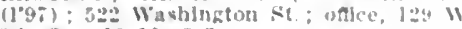
(ith st. : $10-12,3-5$

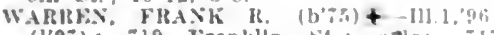
(l'9i) : 19 Franklln st:

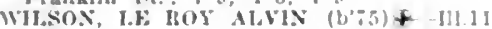
99: (199): 201 k. 5ih St.; i-s, 1-3.

MICHIGANTOWN, 395. CLINTON

HAMILTOS, ALEXANDHA (b'65) - Ind 04 : (1'04).

MIDDLEBURY, 600, ELKHART

FAlAFE, MOSES A. $\left(b^{\circ} 66\right)+-$ Md 4.93 $\left.\left(1{ }^{\prime} 9\right)^{\circ}\right)$.

TETERS, RENJAMIN F. $\left(\mathrm{b}^{6} 60\right)+\mathrm{I}^{2} \mathrm{a} .2,50$ (l'9i)

MIDOLE FORK (R.F.D., FOREST), 100 CLINTON

Morrlson, Owen A. J. (b' (l'9i).

Ihlsteman, Alden Clufton-Ind.8,03; (1'03) : OALR.

MIDDLETOWN, 1,174, HENRY

1'alnter, Berryman 11. (b'50)-Ind..., 33 $(190 ;)$

Stoute. Chas MI (b'64)-Ind 5,91: (1'yi)

Stoute, Chas. M. (b' 64$)-$ Ind

Wallace, Geo. W: (b'66)-Ind.8, $95 ;(1997)$

WATEIS, SAMI. C. (b'61) —-0 3, sI (1'9i).

Wllson, John 13.-III.6,"92: (J'99)

MIOWAY (R.F.D. CHRISNEY), 80 WPENCER SAMI, Y'ERY (1)'6n)- 0.2. 94; (1'97).

MILAN. 557, RIPLEY

MCCLURF, J JASSF W. (b'b5) - KY.5.9s Ind.8,04: (1'98). I'ATF。 JOHS ROBERT (b'67) - Ind.9,'9i;

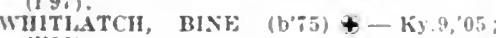
(l'05).

WHITLATCH, IRINAi Alo'FDO (b'SI)Ky.2:11: (i'11).

WHson, Florence M. Olmsted. (See Troy.)

MILFORD, 814, KOSCIUSKO

Benson, Wm. O.--IIl.15,00: $\left(1^{\prime} 00\right)$

I'OTTER, JOHN k. (b'68) £-ind. 8 , 94 (1'97); OPA

STOCKHERGER, EMANTEL ; (1.97)

YOUNF, FORKEST J. $\left(b^{\prime \prime}(6)\right.$ \& Ind.IS, 0 i (1'0i).

MILLERSBURG, 428, ELKHART

HARPEH, WALTEK Q. KY.I, 48 ; (1'01)

SIDERS, W: BEIBT (b':5)-III.11, $0 t^{\prime}$; (1'06).

MILLGROVE, 250. BLACKFORD

McFarland, John Fo,-III.4,05: (1.9i).

MILLHOUSEN, 211. DECATUR

Jauman, Nicholas $\left.i:\left(b^{\prime} 6\right)^{\prime}\right)-0.2,04:\left(1^{\prime} 05\right)$

ilass, Jazob Cressy (b'3) - ky.u, 0 i

$\left(1^{\circ} 0^{-}\right):$Pd.

MILLTOWN, 586, CRAWFORD

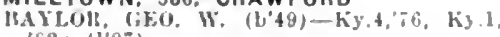

JoHisos, JESS J. - Ky 1, 0:3; (1'03) .

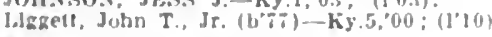

MILLVILLE, 200, HENRY

TU1, J, JOHN A. (b'66)-KY.I,01; (1'11)

MILROY, 750, RUSH

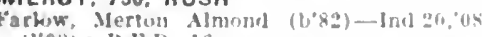
(1'08) : 1C. Y.D. 16

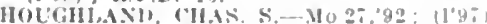

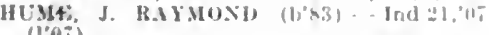

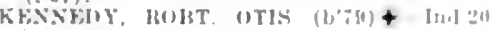
$13:(1013)$

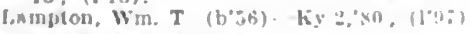

MILTON, 60I, WAYNE

Boark. ('has. I $(1,20)$ - [ud R, 0 s:

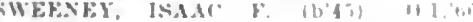
(1) 9 i)

MISHAWAKA, 11,886, ST, JOSEPH

Hall, Fidmunds Jus. (1, 63$)-11111,(06)$ $1 \%$ MIII $\$ 1$

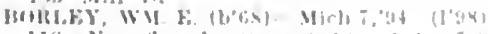
OALR.

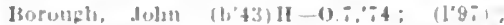

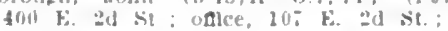

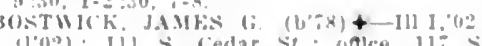
1102) II s redar st utlee, $11 \%$.

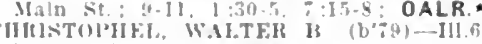
(192: (1.09); 702 \$. Malu St.; 2-4, 7-s. Cheldiahy, rennls-Ind.10,"02; (1'03); s0s

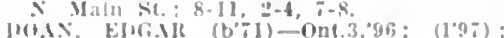

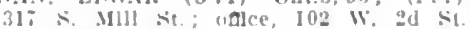
10.11, 2-4

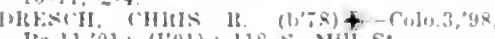

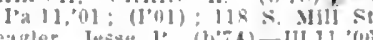

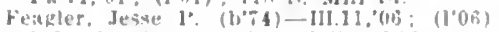
int 11 . 3d st. : oflec, keller Hidm.:

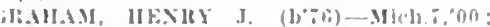
(1'04); 534 W. 21 st.; oflce, 112 W: 21 irene, Jamies $18-0 ;(196) ; 113 \mathrm{~S}$. Maln

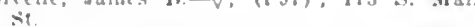
Hollendorit, Henry C. (b'70)-Ind.8,95;

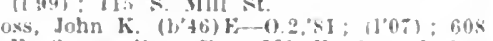
k. Cirove st.: uftice, $109 \mathrm{k}$. Seconel st. $8-11: 30, \quad 2-9$

SEMMAY, JOSE'll B. (b'64) - Ind $\$, 00$ (1'01) 101 E. the $\$ 1,1-3, i$

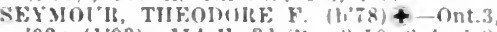
02: (1.03) ; 1It k: 3d st.; s-10, 2-4, 6j-s VAS RIF, I,EO PATI, (b 85) + III.6,'11 (l'11); 315 s. Tayles st. ; s-10, 2-4, $7-8$ :

\section{MITCHELL, 3.438. LAWRENCE}

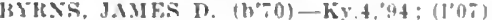

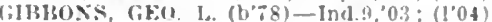

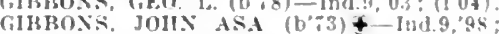
$\left(l^{\circ} 98\right) ; T$.

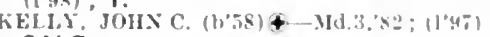
OALR.

AIEIWOOIN, WAI,TER C. $\left(b^{\circ}\right.$ ai) + Tenn.. 1) 1: (1"03); Ob.

MODOC, 26I, RANDOLPH

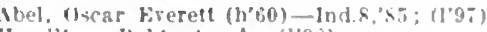

il anillion, Bolts. A. $\rightarrow$ : (1'92)

Kelll, k, F, Flnd.8,97; (1'97).

MOHAWK, I50, HANCOCK

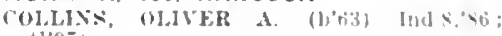
$(139)$.

MONGO, 2I5. LAGRANGE

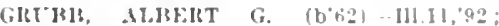
(1.9i); S.

MONON, 1,18S, WHITE

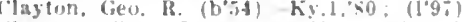

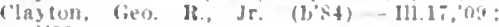
(1) 091

HEAGiA.

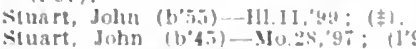

MONROE, 334, ADAMS

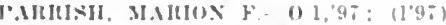

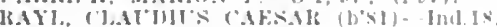
Men:; (1'06); $\mathbf{S}$

MONROE CITY, 630, KNOX

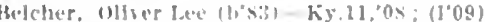

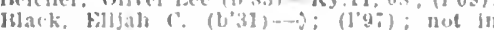
uracticte.

Cillmure. 1.anls Leomard-0.2.99: (1'99)

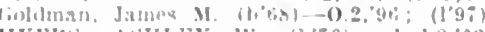

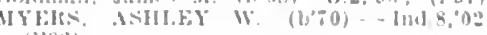
$(1,0) 2$

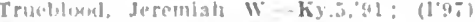

MONROEVILLE, 910, ALLEN

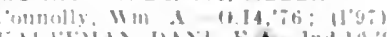

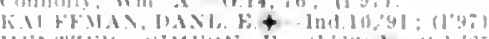

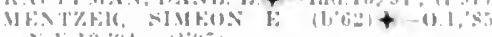

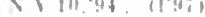

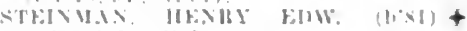
Ind 18,"1): 11"0;

MONRUVIA, 400, MORGAN

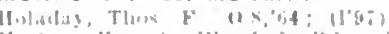

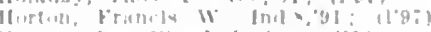

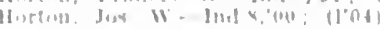

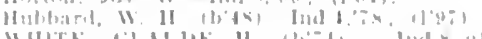

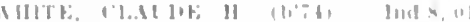

llusi: S.

MONTEREY, 260, PULASKI

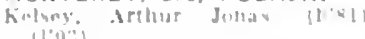

IIII 1

hiti.:ets II II
MONTEZUMA, 1.537. PARKE

Pronley. liufian

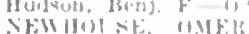

(1"01)

liecelder, Jis.

MONTGOMERY, 5II, DAVIESS

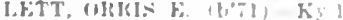

MONTICELLO, 2,168, WHITE

("OFFIS, lil'Y He (6'it) Ind

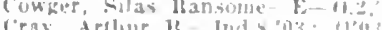

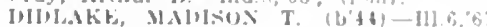
$(1 * 97)$.

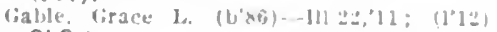
ObG.*

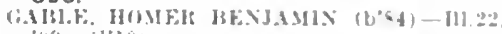
(09): $\left.11^{\circ} 10\right)$.

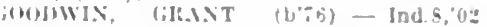
(1)02)

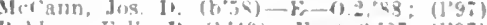

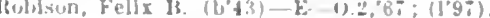
MONTMORENCI, 325. TIPPECANOE

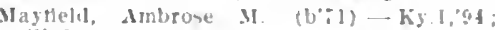
$\left(1^{\circ} 00\right)$.

MONTPELIER, 2,786, BLACKFORD

DANIIO, GEO II. (b'O'S) + - 111.11, 05 ; (1'05) LR.

Emshwller, Marion A (b'tig)--1nds, $\left(1^{\prime} 03\right) ; \mathrm{G}$

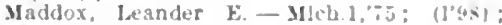
not in iractlce.

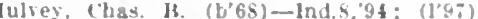

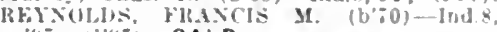
(97: 1190$):$ OALR.

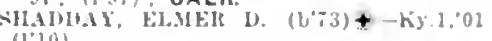

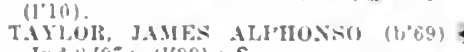
Ind $8.97:\left(1^{\prime} 99\right) ; \mathbf{S}$

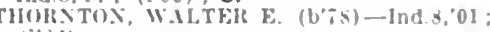
(lion).

MOOREFIELD, 94, SWITZERLAND

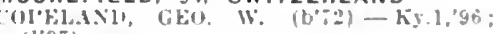
$\left(J^{2} D^{3}\right)$.

MOORELAND, 455. HENRY

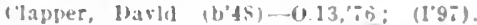

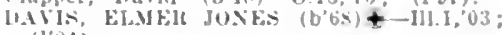

HAUMUNI), M.ART H. (b'tig)-Mo.33,06; (1'10).

MOORES HILL, 424, OEARBORN

CH(IL, (EE). E. (b'6s)-Tent1.6\%,93; 11'12) Memher Ky State Med. Isin

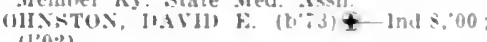
$(1,03)$.

\section{MOORESVILLE, 1,608, MORGAN}

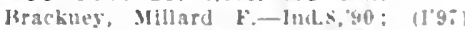

llylton, dilen Jackson-Ind : "1); 1101

kincald, simpson $b$, (b's) E Ind.11, st: $(1,97)$.

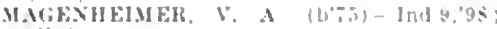
(1,ys).

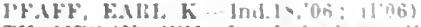

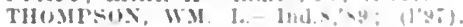

MORAN. 200, CLINTON

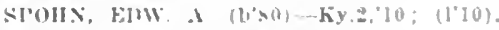

MORGANTOWN. 66 $i$, MORGAN

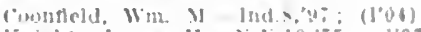

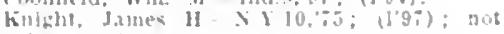
In praction

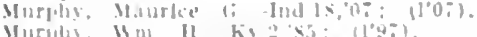

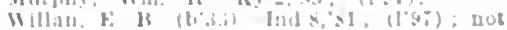
Lin lisactiee, If Fil

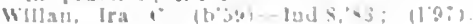

MOROCCO. 927, NEWTON

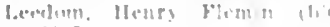

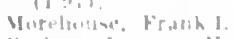

kercher. I.a mand Ilets

Tritivi

MORHISTOWN. 62?. SHELBY

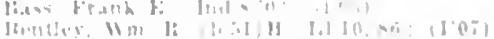

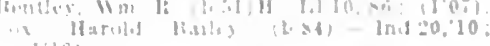

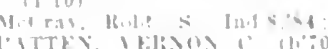

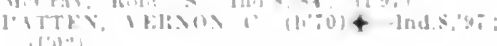

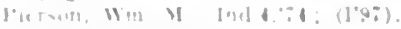


MT. AUBURN (R.F.D., EDINBURG), I20, SHELBY

Furd, Walter M.-Ky.2,'it; (1'97).

MT. AYR, 23I, NEWTON

Martlu, John T. (1'6i]) II-III.4,'95: (1'y!1) : G.

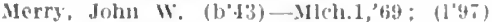
MT. CARMEL (R.F.D., BROOKVILLE), I42, FRANKLIN

Lucas, Johm Wi, (b'8I)-lud.18,07; (l’07).

MT. ETNA, 148, HUNTINGTON

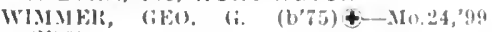
(l'(t) ).

MT. SUMMIT, 300, HENRY

Cioodwlu. Wis. Westoby (b'3?) - Mleh 1, thi. (1'4i)

MT. VERNON 5,563, POSEY

IBARIRTT, COMMOUULE

(1'01).

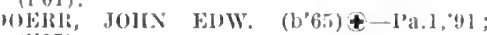

Eimmlek, Thomas C. $(1,72)-0.1,9 \pi ;(1997)$

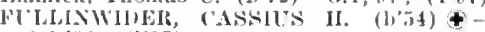
0.1, $83 ;$; $(1.97)$

Il a rdwlck, Robt. I.-MIo.1,'86; (l'97).

Jaslings, Wm. E. (b'71)-Jlo.2,97; (1'00).

KI.EIN, ARNO (b'S6)-1'a.:'11; (l'11)

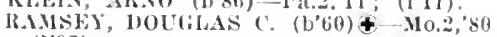
(l' 197$)$.

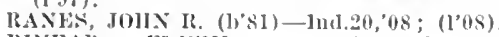
RISElR, EUWIX O. (1'bi)-0.1, 90 (l'01).

SLGG, IlENRY H. (b'66)-NI0.10,90; (l'97) WELCH, DAVII WALTER (b'48)-Ind.13, $36:(1,9 \pi)$.

MITING, ILYSSES G. (J'69)†-Ky.2,?i (l'97); OALR.

Wllson, Robt. Ernest (b'67)-0.9,'96; (l’97) R.F.D. 8

MT. ZION, 300, WELLS

IOIRRIS, TIIOMIAS-Ind.7, 83; (1'97).

MULBERRY, 850, CLINTON

Bonham, David M.-E-0.2,75; (l'97)

Earhart, Isaac S. (1'40)-0.1,66; (1'97).

Kent, John A.-Ill.17,'02; (l'03).

lioons, Mlonroe T. (b'49)-N.Y.8,7s; (1'9t)

undt, Alfred M.-I'a.2,'81; (I'97).

MUNGIE, 24,005, DELAWARE

ANDREWS, GEORGE R. $\left(\mathrm{b}^{\prime}, \mathrm{i}\right) \oplus-1 \mathrm{nd} .8$ 97 ; (1'9 $)$ ) llome Hospital; 1-4; S.

Bacon, Casper L.-0.23,'96; (1'98); Johnson Bldg. ; $2-4,7=9$

IBALL, CLAY A. $\$$-lnd.18,06; (l'06) ; Vatet

BALT, LUCIUS L. (b'J0)-X.Y.6,'89; (l'97) Minnetrlsta Blvd.; office, Kinbrough $13 \mathrm{lk}$. $8-10,1-3,7-8$

BELL, JOHN NELSON-0.1,'88; (1'y i) ; D. IBERRY, NOAII 1). $0 ;\left(I^{\prime} 00\right) ; 603 \mathrm{Wr}$ Main St.; office, $107 \frac{1 / 2}{2}$ S. Mulberry St.; 9-11,

IBOWLES, HERMAN S. (1, 78$) \$-0.1,02$ (I'05); $324 \mathrm{X}$. Vine St. ; offee, $310 \mathrm{E}$ Washington St.; $10-12,2-4$

Bowles, Thos. J. (b'36)-0.1,'67; (I'97) 310 F. Washington st.

BTCKLIS, GEO W. (b'50)థ-X.Y.10,;9 $(1 \cdot 97) ; 525$ E. Main st.; $8-10,2-4,6-8$.

Bunch, Fredk. Layman (b'86) - 111.8,'07 (1'08); $512 \mathrm{~S}$. Ilulberry st. ; offlce, 21: s. Julberry St.

Bunch, Rollin H.-E-Ill.22,04; (1'05) 122 Elm St. ; office, 261 Jolnson Blk.

('ECIC, AARON A.-0.1,'86; (l'97); 1022 Kirhy Are.

Cofiman, John S.-0.2.'92; (I'98) ; $2011 \%$ N. Irice, Walnut and liownd sts. (1'9i): 206 S. IIigh st.; office, $210 \mathrm{~s}$ Iligh st.

rick, I'eler B.-0.2,74; (ま); $1081 / 2$ E. Idans sit.

DlELIM, HOWARD (b'5) - Ind.18, 07 ; $\left(1^{\prime} 07\right) ; 713 \mathrm{~N}$. Mulberry $\mathrm{Ne}$

Ellis, Edwin W. (b'50)-Ind.5,'80; (1'99) not in practice; Neely Blyd.

FistH, GUSTAY WM. (b's2) \-1nd.20,10 (l'10); $119 \frac{1}{2} \times$. Jefferson St.; office, Wysor Jidg. ; 10-12, 2-5, $7-8$

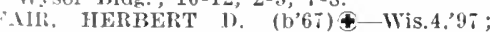
(lio) ; 2811 s. Jefterson St.; offlce, Vatet lsidd.; $10-11,2-4,7-8 ; 0$ bG.

FINHAR, ERASTCS S. (b'45)-1nd.10,'92; $\left(I^{\prime} 9\right) ; 1026 \mathrm{~W}$. Power st.
FHAKS, HAMHTON 1'. (b'49) 'Sey: N.Y.5,88; (l'04); 1202 S. Jelfer son sil.; wifico, $108 \frac{1}{1 / 2}$ E. Jackson? $8-9$ $11-12, \quad 1-3,7-8$

FliAlek, ('ILAS.-Ind.4,7\%; (1997); 1015 A st., Whltey.

(irant, Wu. I. T. (b'-5) - Ky.5, 00 ; (l'02) 4251 S. Walmut st. : $7-9,2-4,6-8$

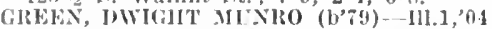
(l'04); 6020 Ashland Are. Klversile, olltec, $124 \mathrm{~W}$, lackson st.; $9-11,2-4$.

GIREEN, FARIE \&. (l,83) - Ind.I8, 07 (1'07); 329 K. Gilbert St.; oftse, 124 W latcksoul st.; $9-11,2-4,7-8 ; S$.

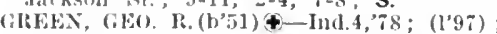
223 N. Itm St.; oftlce, 126 W. Jackson

Gregg, Elijah H. (b’53)-0.16,'87; (1'97); 219 W. Iloward st.

Hastimgs, Aaron H.-II-Ill.4,'87; (I'01); $3111 / 2$ E. Malu St.

Irayden, John 1I.-Ind.12,'S5; (1'97) ; (Bethel l'ike) ; R.F.D. 11.

IILL, FRANK EDWIN (b'62)\$-0.1,'40 (l'98); 215 W. Jackson St.; office, Vatet lildg. ; $10-1 \mathrm{I}, 1: 30-3,7-8$.

I1orn, Wm. Cornelius-0.9,80; (1'97); 1101 In practice: $619 \mathrm{~s}$. Councll 'st.

Ilouscman, liate (b'57) E- $0.2,97 ; \quad\left(l^{\prime} 94\right)$;

C. (b'58) †-Ky.4,'y4: Adams st.; 2-4.

KEMI'ER, ARTIIUR T. (b'T0)-Ind.8,'97; (1'97): $112 \mathrm{~W}$. Adams st.

KWAI'ER, GENERAI, W. H. (b'39) N.Y.8,65; (1'97); 116 W. Adarns st. offlce, 112 W. Allams St.; Emer. P'rof. Hlst. of Med., Ind.20.

Larimore, Jos. D.-0.1,'6S; (I’97) ; $1322 \mathrm{~W}$ Stl $\mathrm{St}$.

Leech, Garrett Davld (b'48) - N.Y.10,75; (丰); 486 IIoyt Ave.; 8-8.

MANX, ELI 13. (b'55)-Ky.4,'82; (1'97)

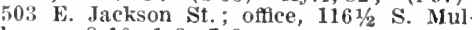
berry: $8-10,1-3,7-8$.

MARTIN, CHAS. AUGUSTUS (col.) (b'66) -Ky., 01 ; (1’02); 1109 Jackson St.

Iartln, John S.-H-O.i,'83; (1'97); $324 \mathbf{E}$ Alams st.

MILLIER, CIIAS. E. (b'69)థ-0.9,'98; (1'98) 917 E. Main St.; offec, 315 S. Jefferson St. ; $9-12,1-4 ;$ (131)

Miller, Jos.-Ind.26,'94; (1'97)

IIX, CHAS. MELVIN (b'-3)屯-N.Y.20,02 ; loLlor, Wul J (b'72)' (1’01); $310 \%$ S. Mulberry St. ; $2-4,7-8$.

(T01); 310 $/ 2$ S. Mulberry St. ; $2-4,7-8$.
Iorrow, Benj. B. (b'72) $\mathbf{E}-0.2,97 ;\left(\mathrm{l}^{\prime}\right)$

1621 w. Jackson St.; offee, $1241 / 2$ s. Walnut. ; $10-12,2-4,7-8$.

OWESS, OWEN WALTER (b'69)-Ill.10 '97; (l’01); 220 W. Jackson St.; $9-10,2-3$, $7=8$.

Payton, Lewls (b'51)-Ind.12,'83; (l'97); 323 r. High St.

'OLAND, ULYSSES G. (b'65) †-Ind.8,'95 $\left(1^{\prime} 97\right) ; 303$ E. Washington st. ; office $120 \mathrm{~N}$. Jetferson St. $8-10,1-3$.

I'olk, Fimer E. (b'64)-Ind.5,'86; (1'97); 1507 W. Jackson St.

QUICK, JAMES MONROE (b'-1) \&-Ind.5, 98; (1'98); 201 liverside Are.; office, vatet Bldg.; OALR.ネ

QUICK, JOIIN CORNELIUS (b'62)థ-Ind.5, '86; (I'97); 4:1 S. MuIberry St. ; office, 114 E. Howard st.; $10-12,2-4,6-8$.

IBEA, CLARENCE G. (b'80) \&-Pa.2,04 ; (1'04); 4:20 E. Charles St.; office, $610 \frac{1}{2}$ S. Walnut St.; $9-10,2-4,7-8$; LD.

Reasoner, Osiner I.-Ky.1, $76 ;(197) ; 1191 / 2$ E. Charles Nt.; oftice, Bishop Block.

Rickard, Clandia A. (b'48) $\longrightarrow$; $\left(1^{\prime} 97\right) ; 1315$ S. Madison st.; Ob.*

Rickard, Wm. A.-0.2,79; (1’97); $1315 \mathrm{~S}$ Madison st.

ROBINSON, MICHAEL (b'て2)-Ky.1,04; (l'04) ; $329 \mathrm{E}$. North $\mathrm{St}$

Searcy, Geo. II.-0.1,'91; (I'97) ; McCulloch Blvd.; office, Fatet Bldg. ; 8-9, 1-3, $;-8$.

Shields, Fdgar A.-Pa.2,80; (1'97) : 416 E. Adams St.; oftlce, Patterson Block.

Silvers, James Monroe-Ind.8,'04; (1'05) 805 iIacedonia Are.

S31TH, CHAS. W. (b'57)-0.1,'94; (1'97); 1329 E. Main St. ; office, Vatef Bldg.: Pd. Smith, Isaac M.-0.16,78; (I’03); Jones Block. sinlll, Wm. (b'43) $-0 ;\left(l^{\prime} 97\right) ; 114$ N. Martin $s t$.

SPICKEMMON, IIARIR R. (b'i4)-III.11 '98; (1'99); 122 N. Mulberry St. ; 1-4, 7-8 SIURGEON, ORVIhlW E. (b'76)-Ill.1, 02 (1'02): 107 riverslde ive.; offce, 2151/2 1. .lackson St.

SI'URGEON, WM. A. (1,'52) \&- - Ind.5,'75; (1"y7); I'res. Sitate lhoard of Med. Reglstration and Exam.; 322 E. Charles st.; offec, 2151\% E. Jackson st.

STEIIILAS, WALTER (HAS, (b'T9)Ind.20,'13; (1'13); 601 Blrchwood Are. oflce, valet BIds.

Surler, Alva claude (1,'il) - Md.4,'95: (1'97) ; McCullough Blrd.; oftice, $416 \frac{1}{2} \mathrm{~s}$. Walnut st. ; 9-8.

TINIAL, EDWARD) F. (b'69) \&-Ind.8,' $\theta$; (l’01); $423 \mathrm{~W}$. Jackson St.; ofllce, Wysor Block; 9-12, 2-5; OALR.

THACY, JIlIUS ROSS (b'87)-Ind.20, 09 (lo9); 332 W. 9 th st.; offlce, Union lildg.; $9-11,2-5$.

TlRENT, ISAAC N. (b'54) - Ky.I,'81, N.Y.1,'87; (1'97); offlce, 1081/2 E. Jacksoll St.; $\mathbf{S}$.

VINTON, AIRTHUR E.-Ky.4,'98; (l'98); 600 W. Charles St.; office, 107 Vatet Block; ;-12, 2-4, 7-8; OALR

WADSWORTH, WM. W. (b'63)-0.1,97 $\left(l^{\prime} y_{7}\right)$; 306 E. Jackson St.; offlce, Kimbrough Bldg.; $9-11,2-4,7-8$.

Wenz, Wm. A. (b'72)-Ind.8,'94; (I'99) 920 Woodlawn Ave.

Whitney, Emma A.-0.7,86; (1'97); 515 S. Council sit.

Whitney, Wm. D. (b'52)-N.Y.6,'74; (1’97); 515 Council St.

Wickham, Julia Anna Siegfried (b'57) EInd.16, 91 ; $\left(l^{\prime} 05\right) ; 120$ E. Seymour St. ; $2-5 ; \mathrm{G}$.

\section{NAPOLEON, 520, RIPLEY}

COX, IAFA'YETTE T. (b'68)థ-Ind.8,'92; (l'97).

Heath, Earl Eugene (b'80)-0.41,'I0; (1'11).

Hicks, John C.-0.10,'67; (l'97).

NAPPANEE, 2,260, ELKHART Cripe, Earl Jerome (b'80) - Ind.20,'10 ;
(1'10).

UEFIRES, HENRY J. (b'61)Ð-111.1,'88 ; (1'97)

INKS, CIIAS. A. (b'76)థ-111.11, $02 ;\left(l^{\prime} 02\right)$

INKS, JOHN S. (b'48)-Ill.11,'84; (1'97)

I']ICE, MELVIN DELBERT (b'71)-Ind.8, , 00 : (l'00).

PIRCE, WILLARD A. (b'6i) -Ind.8,'95; (1'97).

slabaugh, Janey Saml. (b'74)-Ill.15,'09: (l'09).

\section{NASHVILLE, 354, BROWN}

Tilton, Frank Lewis (b'74)-Ind.8,'02; (l'03).

Tilton, Raymond M. (b'82)-Ind.8,02 ; (l'03).

Turner, James A.-Ind.8,'98; (1'98).

NATIONAL MILITARY HOME, 2,289, GRANT

Braunlin, Walter Albert (b'85)-0.41,'11.

Braunlin, Wm. Henry (b'82)-0.9,'04; (l'13).

HILLER, IIARRY (b'67) $\oplus-$ Ind.8,9I: (1'04).

Poters, Chas. Edwards (b'88)-0.40,'12. (Government Servlce).

NEBRASKA, 150, JENNINGS

CASE, WM. W.-Ia.1,'86; (1'98).

NEEDHAM, 200, JOHNSON

Hannahan, Johu Henry (b'63)-Ky.1,'93; (1'00).

NEEDMORE, 125, BROWN

l'rather, W'm. Elisha (b'40)-D; (1'97).

NEW ALBANY, 20,629, FLOYD

Alexander, Stephen C. (b'79)-Ind.8, 03 (1'03) ; $1716 \mathrm{E}$. Shelby St.; offlce, $801 \mathrm{E}$. lith St. ; $9-10,1: 30-2: 30,7-8$.

Appleman, John Sherman.

(See Chicago.)

Ashabranner, James A. (b'61) E-0.2,99; (l’99) ; 509 E. Spring St.; 1-3, 6-9

I3AXTER, JAMES W. (b'73) Ky.1, 03 ; (1'03); 417 E. Spring St.; 8-9, 12-2, $7-8$. BIRT, Jos. E. - Ky.5,'97; (1'03); 1308 Spring St. ; $8-9,12-2,6-8$. 


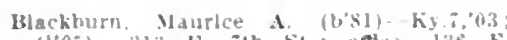

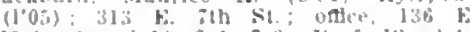
Maln st.; s-10, 9-4, 7-9: I'rut. l'bystul. ky.i.

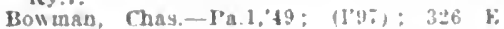
3d st.

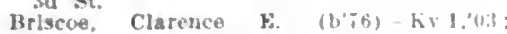

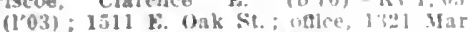
ket st. $-10,1-3,7-8:$ Anes.

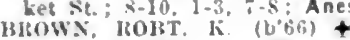

(1.08): 315 k. Spring 51 .

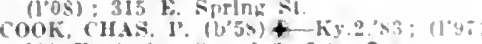

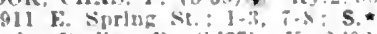

Darls, indley (bo (bi) - K $3,2,92$ 342 Vinceunes st.

FASIJEY, FIIHI IP. (h.47) + (llai): 6.2 F. Spring st: i.

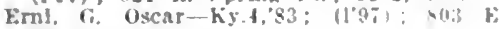
sth st.

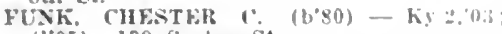
(1'05) : 139 surlag S

Gaddle. Edmund R. (b०0)-Ky. $, 0,2$; (1:): 511 state st.

Gatterer, John A. (1, :3)-Ky.1. Ati; (1'0ri) 329 Bank st, $8-5,1-2,6-8$

HARUS, Robr. W. (bou ky, $\left(1^{\circ} 95\right)$ : 1923 kikin Ave, once, fibl lin cennes st.; $10-12, ;-8$.

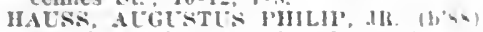
Ky.,11: (1'I2); 1009 k. Mirchet st ontce, 315 Pearl st:; 8-10, l-2. - ; ; S

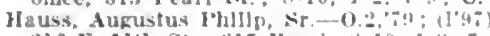
216 F. 11th St. ; 315 l'earl ; s-10, $1-1,7-9$ HARLWOO, FELIX W. - ky, no; (1,03) 111 Rank St,

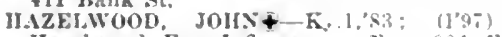
IIazelwood Eye Infirmary ; ofthe, $904 \mathrm{E}$ Intn St.; S-12; OALR.

Hazlewood, Varnes (b'Bti)-Ky.中, 13 i : (1'13) 904 E. Jaln St.

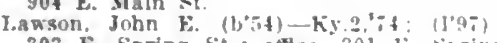
303 E. Spring St.; offtce, $301 \mathrm{k}$ spring si.

LFACH, WAITER J. $\left(b^{\prime}\left(f_{2}\right)+k y .97\right.$

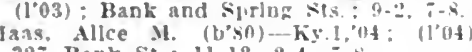

IcFall, Hetlie M.-K, 5,$05 ;\left(10^{\circ}\right) ; 41$ incennes st.

MCINTYKE, CHAS. W. SR+ KY:S:; (1'9:); 601 Vincennes 5 t.

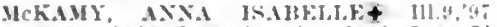
(1.9i) ; 1109 F. suring st.: 10-2. i-n: ob SOORE, WM. (b51) - Ky.2,84; (504) ${ }_{207}$ w. Suring st. Q.11, i-s.

NEELX, AlONZO S- - Ky.1,04; (1) ; 1808 E. Ouk st, ; oftce, Vinreguté and spring Sts. : 9-12, 1-3, $\quad-8 ; \mathrm{Pr}$

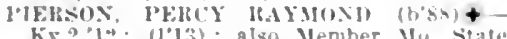

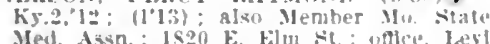
Bldz.: $s-9,12-1, i-x ; S$

locers, Sherman T. (b'bi) $k-0.2 .87$

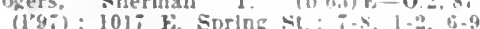
HLTHEKFOHD, HULEKT \&. KY I.SB (1'99) 119 F. Sprlng: 10-12, :-

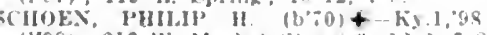
(109): 216 W. Market s. .

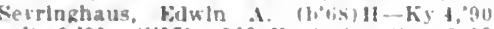
1.9.9?:91: $(197) ; 500$ r. sirlnz st.; $9-10$ $=4,7-8$

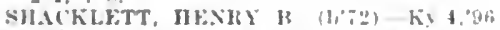

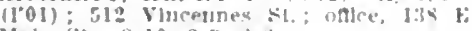

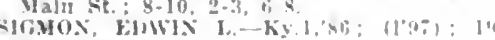
bank st.

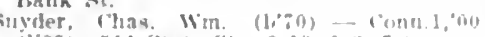
(1'05i : 514 state sit : 8-10, 1-3, - -

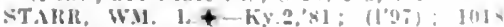
r. Surlng se

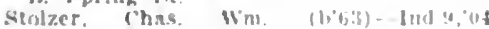
(1.05) : 401 state si

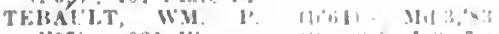

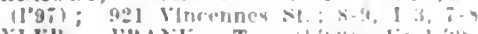

TYLKL, HHANK T, Hall hi l, 'll (I"0s) 1406, borling si

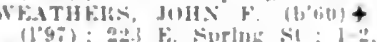

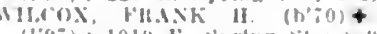

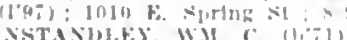

MINTAS

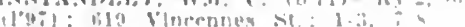

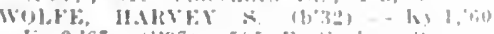

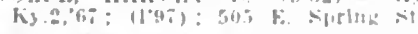

NEW AMSTERDAM, 134. HARRISON

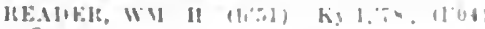

NEW AUGUSTA, 300, MARION

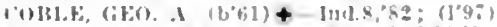

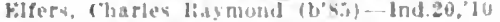
(1)

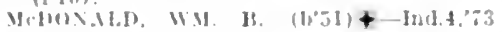

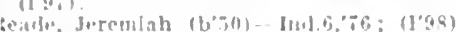

NEW BELLSVILLE (R.F.O.. MOUNT LIB. ERTY), 100, BROWN

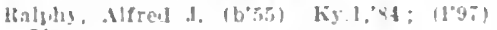
Ob.

NEWBERRY, 455, GREENE

Hamilton, (cuiths $C$ (b'st)

Hamllun, M luther lb'ten 0.2.03; (1'03).

NEWBURG, 1.097. WARRICK

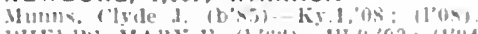

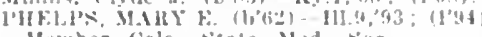
Member Colo. siale led. sice.

Taylor, I'ninn T. (b'54)-Ky.5,9s: (1.99)

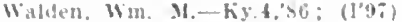

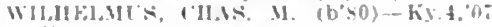
(1'III.

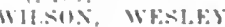

Ind 4,73

I.F. IP. 1 :

NEW CARLISLE, 612, ST, JOSEPH

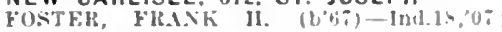
$(1,0 \%)$.

Wiavnlek, Jos, R- Ia.3,'S2; (1'97).

NEWCASTLE, 9.446, HENRY

Applesate, (his. 1! KY 1,01 ; (1'n!)

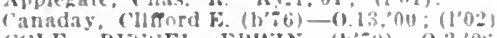

COIF, BLSSE EHWIX (1)"6)-0.3, 0 ; (1) 121 .

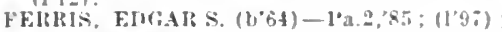

(III); OALR.*

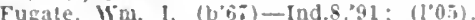

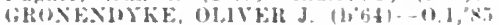
$(1,1 \%)$

Gronendyke. Thonas $W$. $\left(b^{\prime} 40\right) \rightarrow$ : $\left(b^{\prime} y\right.$ ) HARDEST: JONATHIX C. $\left(b^{\prime} 49\right)$-ind.s '80; $(1,9 i)$.

HATT, JULILS E. $\left(b^{\prime} 6^{0}\right)+-$ Ind.8,02 $(1+(0)=3): S$

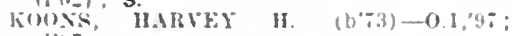
$(1,4)$

LFE, HOSCOE: L. (b'St)-KY.2,10; (1'10)

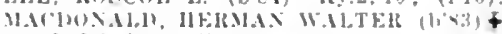
Ind.?20.419: $\left(11^{\prime} 04\right)$

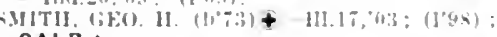
OALR.*

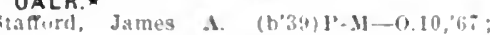
$\left.(1)^{2} \%\right)$

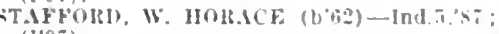
(1"97)

Thumpon, dehn F, - $0.7,75:(199)$

Val Mathe, cassiz's E. (b;o)+-0.9.

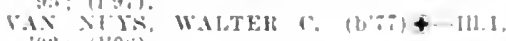
, $02:(1,040)$.

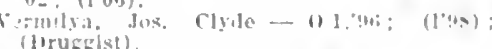

Wayman, John C.-lnd.5, is: (1'40)

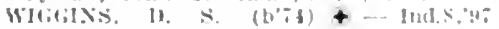
$(1,0): S$

NEW CORYOON, 210, JAY

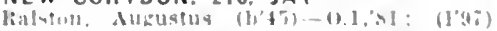

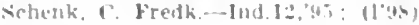

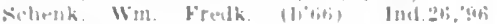

NEW GOSHEN (R.F.D., SANDFORO), 150. VIGO

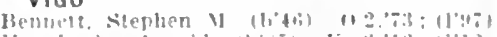

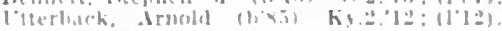
NEW HARMONY, 1,229, POSEY

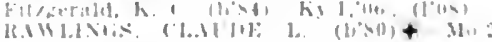

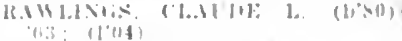

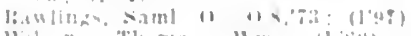

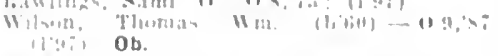

NEW HAVEN. 1.038. ALLEN

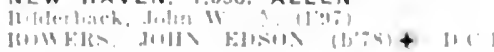

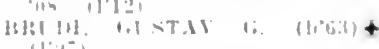

G lark Hathe lud a

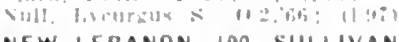

NEW LEBANON, IOO, SULLIVAN

NEW LISBON. 187. HENRY

NEW LONDON, I50, HOWARD
NEW MARION, 225, RIPLEY

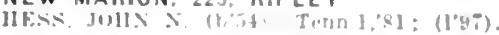

NEW MARKET, 33\%, MONTGOMERY

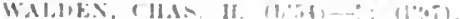

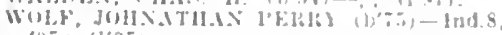
$05:\left(10^{\circ} 05\right)$

NEW MAYSVILLE, 102, PUTNAM

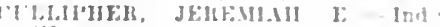
(1) 031

NEW MIODLETOWN 145, HARRISON

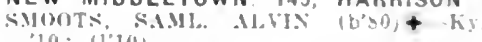
'10; (1'10).

NEW MT. PLEASANT (R.F.D., PORT. LAND), 125, JAY

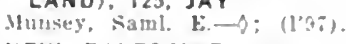

NEW PALESTINE, 450, HANCOCK

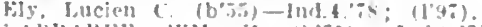

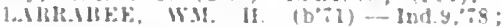

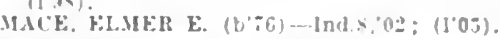

NEW PARIS, 400, ELKHART

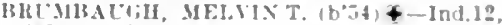

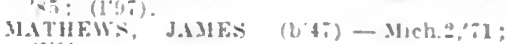
(1)

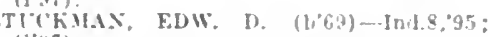
$\left(1 W^{\circ} 9 i\right)$.

NEW PHILADELPHIA, 100, WASHINGTON

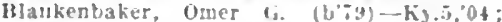
(I'04).

NEW PITTSBURG (R.F.O., RIDGEVILLE), 160, RANDOLPH

YcFarland, Norman-A; (1.9;).

NEW POINT, 341, DECATUR

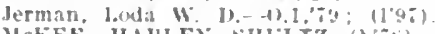

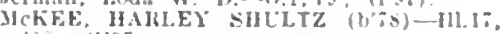
(0): $(1,07)$.

NEWPORT, 732, VERMILION

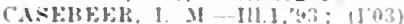

Hall, Metrin L. (b'ti)-XY 10,76 ; (1'97)

NEW RICHMOND, \$64, MONTGOMERY

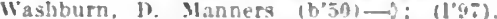

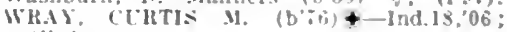
(l')

NEW ROSS, 296, MONTGOMERY

Bronaugh, (has. T. (boit) - Ind.s, st: $(196)$.

Edunitield, beo. W. (1.t1) $-0.9,72$;

HOBHS; URINE ALHRRT - KY.4,90: (I'06)

Menefee, Wm. $x$ (b'sis)-111.1,95; (I'04).

NEW SALEM, 200, RUSH

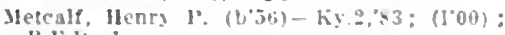
IR.F.11. I.

NEWTON STEWART, 90, ORANGE

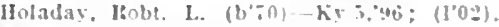

NEWTONVILLE, 150, SPENGER

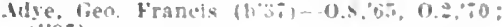
(1)

(1), (1)

NEWTOWN, 3|2, FOUNTAIN

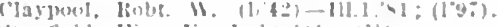

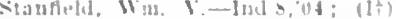

NEWVILLE (R F.D., BUTLER), 210, DE. KALB

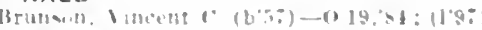

NEW WASHINGTON, 268, CLARK

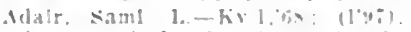

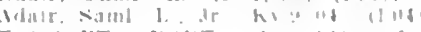

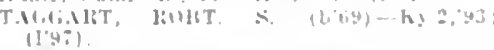

NEW WAYERLY, 300, CASS

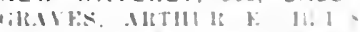

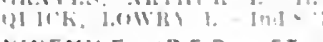

NINEMIL

ALLEN

NINEVEH, 300, JOHNSON

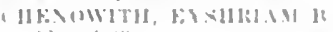

Ind $\mathrm{s}$

NOBLESVILLE, $3,0 \% 3$, HAMILTON

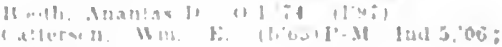

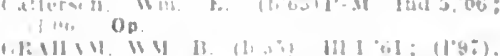

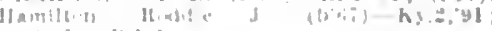


Hanna, Julian E, (b"71) - Iud.8,05: (1"05) $\mathrm{ObG}$

IIarrell, Madison H.-Mo.5,00; (l'00).

Harrell, Saml. (b'69) H-Mlch.5,'93; (l'97) IAWORTI, GEO. I) (b's6)-In(3.20,'I I (l'11).

II AWORTIL, MLLTON C. (b"51)—-Ind.4, i7 $\left(l^{\prime} 0 \pi\right)$

Loehr, Edgar C. (b'50)-0.1,7I; (I'97).

Mlchael, Addlson (b'59)- 0 ; (I'03); OALR. I'ETTIJOIN, ORLANDO 13.- Ind.4,'T4 (1'97).

Smith, Thomas J. (b'44) Ind. f, 72, Ind.6. ; $75:(1997)$.

Sturdevaut, Joel Dixon-Ind \& 04 : (l’05).

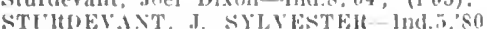
(l'02).

TIOMISON, IIENIKY HERJERT (b'\%) $110.2,05 ;(1,05)$

TLCKFR, FRENK. A. (b' $\left(l^{\prime} 97\right)$.

Whecler, Mrinda M.-Ind.15,'85; (l'97).

NORMAN STATION, 175, JACKSON

Coble, Albert II. (b'55)-Ill.1,83; (1'99).

NORTHGROVE, $3 I 6$, MIAMI

Mallott, John D.-Ind.8,"98; (l'99).

NORTH JUDSON, 1,143, STARKE

FNGLERTI, PERRY O. (b'T4)-Ky.1,'96 (1'96).

FISIIER, AIBERT-Ind 9,04: (1'04).

NORTH LIBERTY, 681, ST. JOSEPH

Fish, Clyde M. (b'7s)-111.22,'10; (1'10).

Moore, Allen-Ind.10,'80; (l'97); not in practice.

Sprague, John S-Ind.8,05; (1'05).

NORTH MADISON, 860, JEFFERSON

CHRISTIE, JAMES H. (b'49)-0.8,70 (1'9\%).

COPELAND, CHAS. C. (b'64)థ-Ky.2,'89; $\left(l^{\prime} 97\right)$.

Funkhouser, Ralph M. (b'8\$)-1nd.20,'12; (1'12).

NORTH MANCHESTER, 2,428, WABASH

BAISBAT(IH, GEO. DANL. (b'-9)-Ky.9 04: (1'04).

BEAMAN, ZERA MERRITT (b'80)థ-

Ind. I ,'06 ; (1'06).

Cottrell, Asher Raymond (b'81)-IIl.1I,'12; not in practlce.

Cottrell, Laura Murphy (b'81)-Ill.11,'12; not in practlce.

Ginther, David-0.2,91; $(1,9 \pi)$

GROSSNICKLE, GEO. W. (b'si) - Mich.I, 09; (1'10).

Harding, Geo. W.-Mlch.1,'86; (1'97)

HOLLOWAY, EIIMA G. (b'74)-III.4, 04 ; (l'0t); ObG.

KITSON, FRANK S. (b'70)4-111.1,95; $\left(l^{\prime} 97\right)$.

Holler, Leo W. (b'73)-Kan.3,05; ()

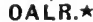

SHOEMAKER, GEO. L.-Ill.10,'91; (1+).

Wrlgbt, Shelby-Ky.4,'82; (1

NORTH SALEM, 569, HENDRICKS

ROYER, ELMO RAY (b'75)-Ind.5,03; (l'03).

Wlsehart, Oscar H.-Ky.1,'98; (l'98).

NORTH TERRE HAUTE, 150, VIGO

HEBBLE, DAVID W. (b'69)-0.3,90; (l'97).

Nelion, Seth B. (b'48) $\rightarrow$ : (l'97)

NORTH VERNON, 2,915, JENNINGS

Firsich, Balthasar $\left(b^{\prime} 46\right)-\triangle ;\left(l^{\prime} 98\right)$.

GREEN, JOHN HARVEY (b'86)-Ind.20, 1I: (1'11).

GROSSMAN, WM. L.-H11.17,07; (1'08).

ICAULIFFE, DENNIS LANE' (b'65) $€-0.9$,

MITCHEL, WALTER J. (b'62)-0.1,84; (1'97).

RICHARDSON, WM. H. (b'53)-0.1,75, N.Y.10,78; (1'97).

STEMII, WH. H. (b'61)థ-0.1,'s7; (l’97) ; $\mathrm{S}$.

NORTH WEBSTER, 400, KOSCIUSKO

1. yons, James H. (b'63)-Mich.1,'84; (1'97).

OAKLAND CITY, 2,370. GIBSON

Ashby, Willard B. (b'78)-Ky.9,05; (l'05). IVm. L. (b'49)-0.2,84; (I'06) Geo. C. (b'04)-Ind.8,79; (1’97); N

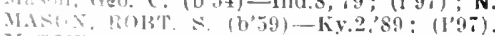

MeGOWAX, JOHX W. (D'54)屯-Ky.2,81; $\left(\mathrm{l}^{\prime} 0-\mathrm{T}\right)$ lteld, Hornce W*, (b'52)-0.10,81; (走). SMITIL, WM, II, (b'70) -Ky, 1,93; (1'99). Trusler, I.eslie Solon (b'53)-Ind.8,'83 $(19 \%)$.

OAKLANDON, 353, MARION

lineer, Chas. J. (b'75)-Ind.8,01; (1'01).

OAKTOWN, 608, KNOX

Ilalze, Joshua I. (b'81) - Ky.I,'07; (l’07) Johnsion, Marlon A. (b'54)-Pa.2,'81 (1'99).

Llsman. Saml. J-O.I'72: (I'97)

sprinkle, Welcome B. $\left(b^{\prime} 55\right)-K y .4,76$;

Troul, liohert Edw. $\rightarrow$; (l'04).

OAKVILLE, 200, DELAWARE

Walterhouse, Harrison K. (b'79)-Ind.8,'04. (l'04)

OATESVILLE (R.F.D., LITTLES), 60, PIKE Atklnson, Edw.-Ky.I,'98; (l'98).

OCCIDENT (RUSHVILLE P.0.), 25, RUSH HOWEN, JOS. F.-Ind.8,97; (1'97).

OCKLEY, I50, CARROLL

Bard, Chas. Blanchard (b'88)-Ky.2,'12 ; (声); $\mathbf{O b G}$.

ODON, 1,064, DAVIESS

ANDERSON, JOHN W. (b'54)-Ky.1,'81; $\left(1^{\prime} 97\right)$.

BOWMAN, IRA E. (b'81) - Ind.20,'10; (1'10).

Culmer, Geo. F. (b'25) $\longrightarrow$; (1'97); not in practice.

E MOTTE, JEROME (b'69) - $0.1,96$ (l'97)

JIedrlck, Wm. H. (b'39) $\longrightarrow$; (l'97).

Lane, Allen K. $\left(b^{\prime} 43\right) \longrightarrow ;\left(l^{\prime} 97\right)$; not in practice.

RANKIN, TIIOS. B. $\left(\right.$ b'50) $^{\prime}$-Ind.8, 80 (1'97).

OLDENBURG, 956, FRANKLIN

MULL, PIIILIP LEE (b'72)థ-Ky.1,'98; (1'98).

OLIVER, 100, POSEY

Shutt, Lewls C.-E-0.2,89; (1†).

OOLITIC, I,079, LAWRENCE

DOLILNS, CLAUDE (b'80) - Ind.I8,'07; (1'07).

Iclahlan, Oliver (b'55)-0; $\left(l^{\prime} 97\right) ; G$

Ray, Geo. Carroll (b' 6 i $)-\mathrm{Hll} .22,08$; (l'0S).

ORA, 250, STARKE

Parker, Albert-P-M-Ind.12,'95; (l'01).

ORANGE (R.F.D., GLENWOOD), 179, FAYETTE

Phlllips, Wm. Robt. (b'78)-Ky.1,05; (l'05) SIPE, RICIIARD W. $\left(b^{\prime} 40\right)$ - Ind.4,75 (1'97).

OREGON (R.F.D., MARYSVILLE), 82, CLARK

Carr, Francls M.-O; (I'9T).

ORESTES, 420, MADISON

Cook, Joel-O; (1'97).

Honver, Rufus Albert $\left(b^{\prime} 72\right)-I 11.8,12$; (1'12).

ORLAND, 500, STEUBEN

Gondale, Albert Wilford (b'73)-N.Y.6,07; (l'09).

Samuell, Walter A. (b'79)-Ill.8,06: (l’13)

Smith, Arthur Hiram (b'62)-Ky.1,'98; (I'05)

Smith, Marle R.-H-IIl.4,'94; (1'99).

ORLEANS, 1,367, ORANGE

BAKER, ROBT. F. (b'61)-Ky.2,'92 ; (l'99) Laughlin, Edmund D. (b'2i)-N.Y.10,72, $0.9,68 ;$; (1+).

PATTON, WIIBUR H. (b'69)థ-Ky.4,96; (l'97).

RITTER. THOS. B. (b'5I) $-\Delta ;\left(\mathrm{l}^{\prime} 97\right)$

STEWART, OSCAR H. (b'60) $6-0.13,85$; (1'9\%).

OSCEOLA, 23!, ST. JOSEPH

Prouldit. Louis (b'76)-Ind.8,02: (1'02).

OSGOOD, 1,169, RIPLEY

Brenton, Theodore M.-0.9,02; (1'97).

FREEMAN, EDW. D. (b'53)థ-0.I,7 ;

(l'97); (Bl) ; 0p.

Harlan, Earl (b'72)-0.1,'98; (l'13)

Larabee, Gilbert Brown (b'85)-0.41,'II (1'11).

NELSON, HARRY G.-0.1,06; (1'0T)

TOWNSEND, REECE C. (b'67)-0.1,90; (1'98).

\section{OSSIAN, 66I, WELLS}

DYAK, EDWIN W.4-Ind.8, 04; (1'04)

('orreli, Andrew G-Ia.3,75; (1'97)

Nowman, Miles N. (b'43)-lá.1,70; (1'97)

FibotiRx, DAVID c. $\left(b^{\prime} 78\right) \downarrow$-Ind.10,02; (l'02).

OTISC0, 218, CLARK

Cortner, Sldney Grant (b'70)-Ky.2,07 : (l'07)

OTTERBEIN, 652, BENTON

CHENOWE'TI, OSCAR U. (b'76)-111.1,01; (l'01).

Leaming, Lewls M. (b'73)-III.1,95: (l'97) .

SMITII, WARD A. (b'65)-Ky.1,92; (l'97).

OTWELL, 300, PIKE

ABBOTT, CIAKENCE (b'71)†-Ky.1,'98; (l'98).

De Mott, Wm. M,-0.8,71; (I'97)

Godwin, John W. - : (1'99).

OWENSBURG, 450, GREENE

BERESFORD, GEO. B. (b'63)-Ind.1I,'87 ; (l'97).

Moore, Chas. C. (b'66)-Ky.4,'91; (l'91).

OWENSVILLE, I,237, GIBSON

Emerson, Ralph W.-E-0.2,'98; (1'98).

Goodwin, Lorauza D. (b'62) $\rightarrow$; (Y'08):

R.F.I).

Lockhart, Thomas L. (b'70)-0.2,99; (l'00).

MONTGOMERY, JAMES R. (b'79) - H1.11, $04 ;\left(1^{\prime} 04\right)$.

1ONTGONERY, MARTIN A. (b'75)-Ky.2,

Strlekland, Karl S. (b'80)-Ky.2,07; (1'07).

Willams, John M.-0.2,81; (1'97).

OXFORD, I,0I0, BENTON

BLOOM, HARVEY G- $-0.9,95 ;\left(1^{\prime} 97\right)$

LAIRD, DEIBERT HARRISON (b'85) Ill.1,11: (1'13).

I.EE. ROBT. ESTES (b'66)-Ky.I,'90; (1'99).

PALMYRA, 252, HARRISON

BOPP, IIENRY W. (b'81)๑-Ind.18,'06 ; (1'06).

BULLEIT, LORRIEN L, (b'88)-Ky.2,'12 ; (1'12).

Finley, Jolin F. (b'47) $\longrightarrow$; (l'97).

PAOLI, I,278, ORANGE

BOYD, CHAS. I. (b'54)-Ind.8,'81; (1'97).

Horton, Jackson Davld (b'60)-Ill.11,'84; not in practice.

LINDLEY, LABAN (b'46) - Mich.2,70 (l’97)

LINGLE, SAML. L. (b'67)-Ky.2,91; (1'99).

Pray, Frank M.-Ind.9,00; (1'00)

TEAFORD, SCHUYLER F' (b'73) - -Ky.5, 98 ; (1'04).

PARAGON, 409, MORGAN

DUTTON, HAYES H.-Ind.9,'04; (l'05).

Farr, Lirlah H. (b'46)-Ind.4,77; (d'97) ;

Kennedy, John (b'33) $\longrightarrow$; (l'97)

PARIS CROSSING, 380, JENNINGS

BANISTER, REVEL FRANCIS $\left(b^{\prime} 84\right)-K y .2$,

GADDY, ORVILLE E. (b'47) $\oplus-0.1,72$; $\left(l^{\prime} 97\right)$.

PARKER, 800, RANDOLPH

BAINARD, PLINY C. (b'68) 9 -Ind.9,'01 (l'01)

Kramer, Jos. A. (b'74)-Ky.11,'08; (1'08).

Rogers, Aaron G.-O; (l'97).

PATOKA, 657, GIBSON

ARTHUR, MARTIN L. (b'76)-Ind.8,'98 (I'05).

RTHUR, SYLVESTER IRVIN (b'63)థMo.34,07; (1'09).

Davis, Wm.'T. (b'41)-Ind.9,'98; (1'05).

PATRICKSBURG, 400, OWEN

KENNEDY, ALBERT C. (b'74)-Ind.8,'98 (l’99).

Richards, Renos H. (b'67)-Ind.9,'03; (1'03)

Richards, Saml. D. ( $\left.\mathrm{b}^{\prime} 40\right)-0 ;\left(1^{\prime} 97\right)$.

Williams, John A. (b'46)- $\rightarrow$; (l'99).

PATRI0T, 340, SWITZERLAND

Beck, Condie B. (b'74)-Ky.1,'93: (l'03)

Searcy, Benj. ‥ (b'73)-Ill.17,98; (1’98); OpÁ.

PATRONVILLE (R.F.D., ROCKPORT), 50, SPENCER

ADYE, CLARENCE H. (b'T0)-Ky.4,'94; (1'9\%).

PAWNEE (R.F.D., LADOGA), -, MONTGOMERY

Young, Dudley-0; (l'9i). 
PAXTON, 164. SULLIVAN

WALTEHS, COATAEY B (U\%, - Ind: O? (1'02)

PEABOOY, 60, WHITLEY

Hader, Siaml. I1.-II-[1!.10,9?; (1'n0).

PEKIN, 350, WASHINGTON

Green, Wm. Louls (b'-1)-0.6,00; (1'0)

PENCE, I50, WARREN

WHIlams, Kobb. J. (b,:2)-I11,6,01; (

PENDLETON, 1,293, MADISON

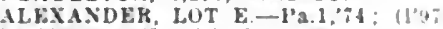

BROW YHACK, OHLANDO W', (1) (b)-1'a 1 .

$67:(1,9 i)$.

COB) JOIIN WALLACE (b*5:) - Ky ? ?":

Lewls, Walter H. (b't9)-Wa.1,7i, (1'9:)

MARTINDALE, HOHACE C. - In] , $0{ }^{\circ}$; (1'0:).

SPARKS, WM. RILEI (b'S')-Ind.00,0\% (l'0S)

Stove. Prank L. -Ind. 5; if; (1'9i).

PENNVILLE, 800, JAY

Bloxsome A. W. (6',1)-1nd.8,97; 1104$)$

CAYLOR, CIIS. F. (b'0)+-ky 1,03 (1.97): S.

hall. Wills $3 .-0.12,93 ;\left(l^{\prime} 97\right)$

HESTAND, HARLEY J. (b'81)+-1nd Is, 06: (J'06).

Mason, Saml-ind.4:3: (1'9i)

PERKINSVILLE (R.F.D., ANOERSON), 318 , MADISON

GAREETSON, WM. M. $\left(b^{\prime} 00\right) \mp-I M d s, 32$ : $\left(19^{\prime}\right)$.

Mcnonald, Vergl] Gwinn (b'86)-Ind 20), 10: (1'10).

PERRYSVILLE, 650, VERMILION

Barnes. James A. (b'46)-0.1, i5; (19i): not in practice.

JOHXSON, WM. A. (b'33)-[1],1:;10:(1'10)

Loomis, Edwin C $\rightarrow$ (1'9s)

Sanders, Frank E. (b'i i)-1nd.8,92: (19i).

PERU, 10,910, MIAMI

A.NDHEWS. ELLIS II. (b'0)-Ky.1,01 (1'0I): 172 W. 3d st.: office, s Wahash

trmsirong, $1 \mathrm{~m}$ ' $\mathrm{k}$

Ewing St

Baldewn Clarence 1 (1)" (1:02); Kalbfelsch Sinltarlum; -10 , - $=30-10$.

Bogrs, Miston M. $\rightarrow:(197): 81 \mathrm{E}$. fith st

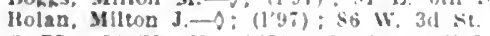

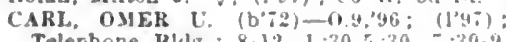
Telephone IBldg: : 8-12, $1: 30-5: 30,7: 30-9$

Carlson, Edward A st. atce, $11 \%$ w (1) 101 ;

Eikenberry, Benl, Franklin (b'69) 11 - Ill. 96: (1.95) ; 20 W. bih st.; onlec, Brownell Hluk.: $8-10,1-3,:-8$

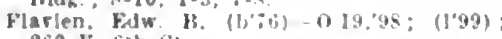
$\$ 60$ k. bith st.

CHISWOLD, ElW H. $\left.(1)^{\prime} 54\right) \downarrow-M \cap 20,91$; (1'97): 105 w $34:$; nflce. Teleplune IHIdz: :-t. S.

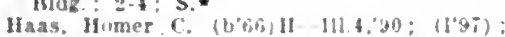
mi W. आ sit.; untce. Telephone MJg. 8.10, $2-1$.

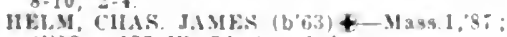
(1002): 153 w. 3d st: 1-1

Jordan, recll $(1608)$-Mich.5, $04 ; 110011$

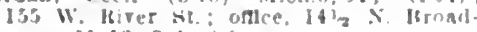
way: $11-12,3 \cdot 1,8-8$.

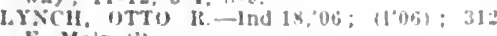
E. Main sit.

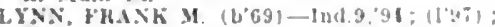
Schinoll Mde.; s:30-11, 2-t, ; ;

Malsburs, Jacob' () (b'G5)-ky, 1, $90 ;(190)$ :

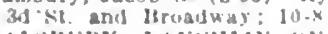

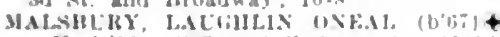

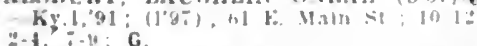

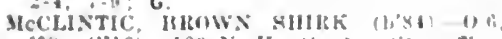

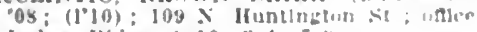
bukes Md: y-io, $2-t, i-y$

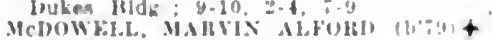
Ind.80,11; 11.11); 336 W.

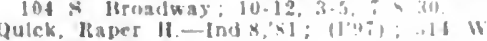
ith'sit.

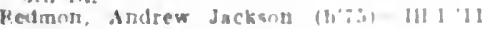

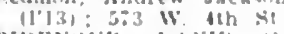

RIIF, Nith, livill

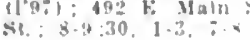

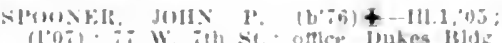

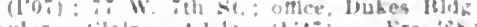

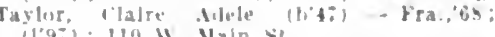
(1'9): 110 II llain si.

Van fiundy, "lyole lingers (b'xi) 11!.11,1?: (1'12): Wiabash Fomployeen Ilumptral

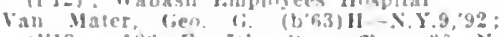

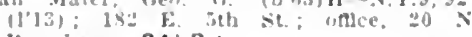
Breselin a OAR."

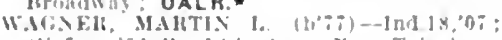

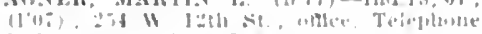

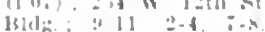

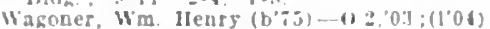

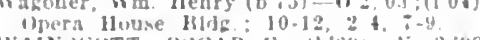

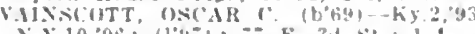

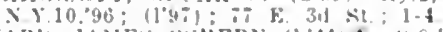

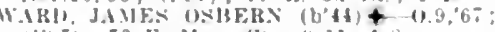

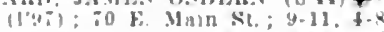

Willyard, Warren 11. (b'bi - ky.1,0\%:

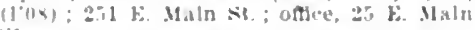

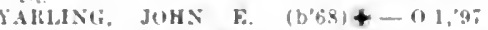
(1097); 132 k. Main st.; vffuce, $35 \mathrm{~F}$.

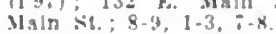

PETERSBURG, 2,170, PIKE

MASINGEK, THOMAS IV. (b'st)-Ky.1, 'X0; $(197)$.

Hurger, John R.-1'a.2,95; (1"97)

Hers, ollrer .1-Ind.401": (1,01)

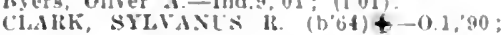

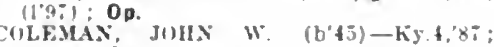

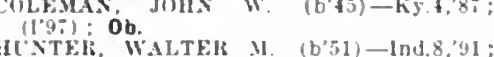

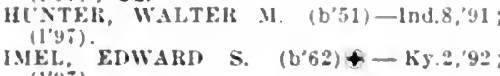

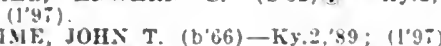

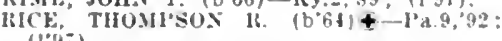

RI'HARINOS, FVERETT W (b'T)-

Ind.18,06; ( ) ; Memher X.M. Med. Sic

PETROLEUM, 75, WELLS

MUItIIS, (;FO). B.-Ind.18, 06 ; (1"0h)

PHILADELPHIA (R.F.D., GREENFIELD), 182. HANCOCK

13ell, John $x$ (b'39)-Md.1, \&4; (1'9i)

PIERCETON, 817, KOSCIUSKO

IEEllY. CH.A. F. (b'70)+-Mich., 97 : $(1,4 i)$

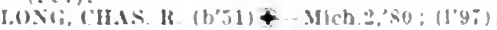

Mclirew, Wm. H.-L-III.5,'2; (l'01).

PIKEVILLE, 75, PIKE

Corn, Nathanlel Ky, s: (l'yi).

PIMENTO, 100 , VIGO

Jolsun, James is. (b't2)—; (13i)

PINE VILLAGE, 352, WARREN

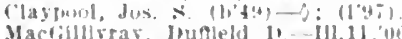

$1,0(i ;)(106)$.

Simls, James .1--ind.s, 69 ; (I03)

PITTSBORO, \$08, HENDRICKS

Frencli, Juhn $x$-1nd.8,83; $(197)$; not !n beractices.

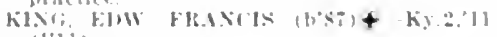
(1'11)

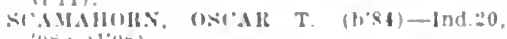

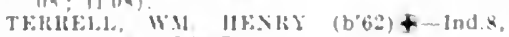

(n:A: II?:Ma): OALR.

PLAINFIELD, 1,303, HENDRICKS

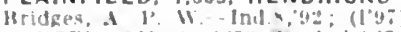

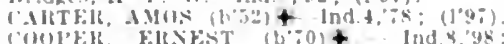

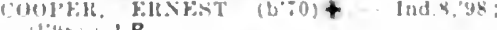

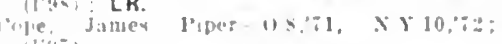

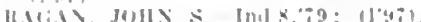

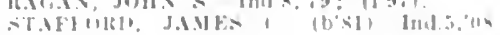

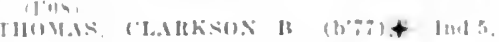
(t):- : (I'0:)

PLAINVILLE, 300, DAVIESS

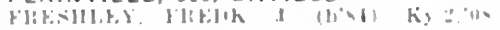

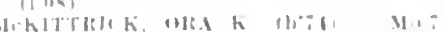

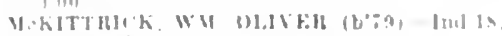

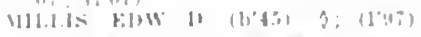

PLEASANT LAKE, 600, STEUBEN

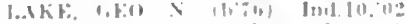

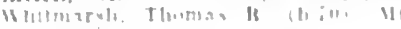

PLEASANT MILLS, 200, AOAMS

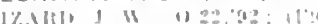

PLEASANTVILLE, 250 SULLIVAN

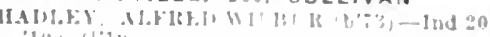

Jackin. Jilin II

$(1,(5) ;)$

PLEVNA

ARD

(R.F.D., GREENTOWN), $3 \%$

PLYMOUTH 3.838 MARSHALL

lopinall. Virllas $H$ (1)'5n

iotelee, Ifis 11 Washirigtiols

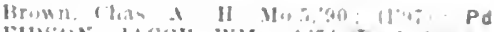

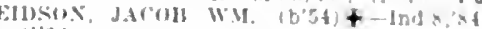
$(1+1): 2)$

F.1.

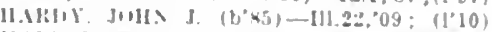
HOLTZLNDOHF', CHAS. F, (b'6s) + Ind.8,95; (1.9i)

Kaszer, Jacrb (b'55)-I11.11.86; $\left.\left(1^{\prime 4}\right)^{*}\right): 1 *$

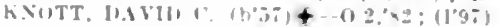

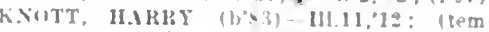
jurary permis. '131: Nember 111. Siate Med. son. 1.OIRX

Martin, John S. (h'36) II-MIch.5.78: 11.4 I'RESTON, HOWARD P-I11.10'

Sinith, John W. (b'5)-Fa.2.:?: (1097)

STEIIIFSS, R. ("LAREN"E- MOI.93 (1'9\%)

POE, 100, ALLEN

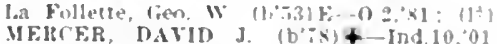
(1'02).

POLAND, 160, CLAY

Bartholnmew, Newton B.-F- : (19:).

Lew1s, feo. $r$. (b'60)-Inds, 98 : (1"gi)

PONETO, 308, WELLS

IUfman, Darid $C$. $\left(b^{*} 55\right)-0.9,78:(1 \cdot 97)$.

PORTER, 52\%, PORTER

Theorell, John J-H-III4,95; (1'93)

PORTLAND, 5,130, JAY

Brown, II V. $\left(b^{4} 10\right)-0.3,22:\left(1^{\circ} 95\right)$

CH.INF., (IR.INT (b'65) + 0.1,96: (1'07)

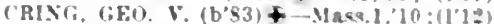
NICKF.s. JUHS T. (b'5s)—-Ky.l, $\$$, (1'9:)

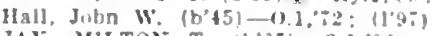

JAY, MIITOX T $\left(b^{\circ} 6:\right)-0 i, 90 ;(19:)$ (1)i OALR.

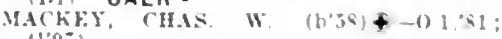

Vetzer, Blocadus $S \rightarrow$ : (Ins) : R F II

Mincks, Francls II.-H-

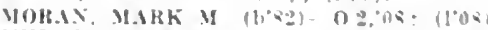

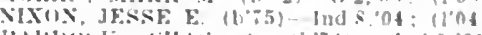

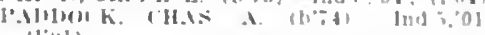
(1)11].

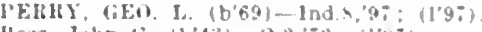

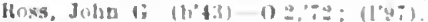

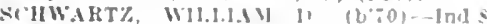

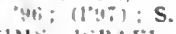

OALR.

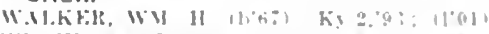

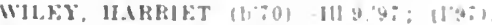

POSEYVILLE, 780, POSEY

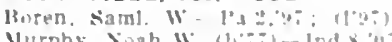

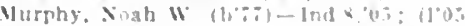

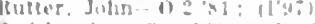

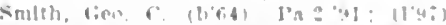

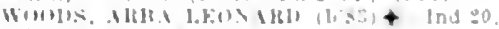

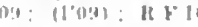

PRAIRIE CREEK, 232. VIGO

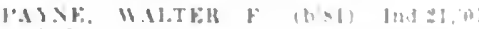

(lin

PRAIRIETON, 300 , VIGO

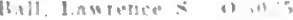

lirshe THW I Itwinl

UII IYUSTWF J1111

PRINCETON. 6, 488 , GIOSON

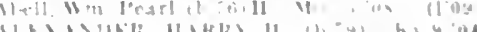

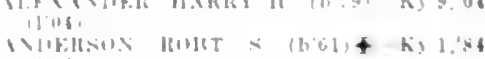

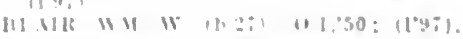


1Brazelun, Osborne Turner $\left(b^{\prime} 87\right)-0.2,12$; (1,In).

ISROWN, A. I. O : (1'97).

IBURTON, AlBERT li. (b'50)-0.1,82 (1'9\%).

critclifield, John s. (b'56) - Ind.11,87: (l’98).

CUSIIMAN, ROBT. A. (b'76)-Ind.8, 02 ;

(1002).
Ilollingswortl, Marshall I'. (b'62)-Ind.8, 91: $\left(1^{\prime}, 07\right)$.

Ifudson, oliver L. (1)30) -0 : (1'97). 10,69 ;

KFEI)I.

(1'37). Chambers M. (b'32) - 0.1,60; (1'96): not in prictice.

MAXAM, FIRANKLIX IT. $(1,50)$ \&.Y.10, $77:(1,97)$.

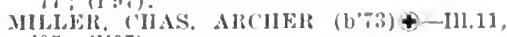
$65:(1,07)$.

MORRIS, JOIN I. (b'69)†-I'a.2,'96;

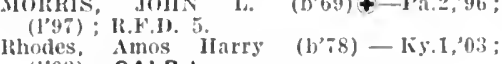

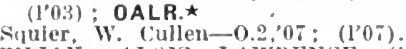

ZIJIAK, ALOIS LAWREACE (1, 13$)+$ Mllol.1,9S; (1'99); S.

PROVIDENCE (R.F.D., BARGERSVILLE),

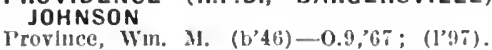

PT. ISABEL (R.F.D., SWAYZEE), 200 , GRANT

Langston, Elgar-0; (1'97)

VIGUS, CHAS. I3.-IMl.s.'95; (1\%).

PUTNAMVILLE, 204, PUTNAM

IIORN, A HOS' II.-Ya.1,'s:?; (1'97).

PYRMONT, 125, CARROLL

CARNEY, JOHN R. (b'80)-III.1, '02 ; (1'02).

QUAKER, 50, VERMILION

Saunders, Jones Lindsey (b'\$1)-II1.1, 04 ; (1'12).

QUINCY, 300, OWEN

McDonald, Darld IIume (b'32) - Ky.2,'55; $(1,9 \%)$.

MITCIELL. GEO. LUTHER (b'84)-Ind.20, 12: (1'12).

WILLIAMS, F. A.-Ind.8,'89; (1'00).

RACCOON, 100 , PUTNAM

summers, Willam F. (b'66)-Ky.2,'94; (1'9T).

RADLEY (R.F.D., JONESBORO), 75, GRANT

Davis, Nathan Farmer-Ind.26, 67 ; (1'03).

James, Chas. S.-Ind.12,93; (1'00).

RADNOR, I50, CARROLL.

Snyder, Elmer Dallus (b'65) - Ky.4,92; (l'97).

RALEIGH (R.F.D., LEWISVILLE), 160. RUSH
SMULLEN, CHAS. L. (b'64)-Ind.8,'89;
(l'97).

RAMSEY, 100, HARRISON

GLENN, IAFAXETTE (b'6 6 - Ky.5, 03 ; (1'03).

\section{RAY, 250, STEUBEN}

IIcTaggart, Duncan (b'62) - Mich.8,'94; (licensed Mich.'00; P. O. Kay).

REDKEY, 1,714, JAY

Conner, Norris F. (b'58)-0.2,79; (1'97).

Golngs, JIartha Allen (b'34)-Ill.10,'81;

MARKLEY, HENRY W. (b'72)థ-Ky.5, 01 ; (l'01).

MILLS; CASSIUS C. $\left(b^{\prime} 61\right) \oplus-0.1,88$;

Pierce, John S. (b'64)-Ind.26,94; (1'97).

Rosenkrans, liarvey R. (b'72)-0.8,98; (I'98).

REELSVILLE, 200, PUTNAM

IIcClure, Chas. A.-Tenn.1,'99; (1'99).

REG0, 75, ORANGE

Kochenour, William P. (b'48)-Ky.5,'84; $\left(I^{\prime} 97\right)$.

\section{REMINGTON, 982, JASPER}

BESSER, E.IIL (b'69)-I11.10,99; (1'99).

Landon, Hanuibal (b'41)-0.3,65, Pa.2,66 ; (1'97).

RAINIER, ALFRED P. (b'79)-Mo.i,'03; (l'03).

RENSSELAER, 2,393, JASPER

EN(ILISII, EDW. C. (b'bi) $4-I 11.1,95$;

GWIN, MERLE D. (b'79)థ-Ind.8,05;
IIF.MIIHI.l, FRANCIS II. (b'72)-Mo.29, 9s: ( t.0I).

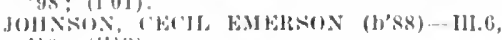
iti; (1'is).

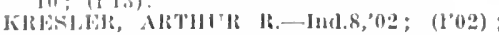
LR.

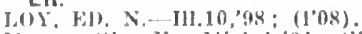

Hoore, silas 11 - -llich, 1, 64; (109).

WANIIBLRS, IRA N. (b'64)-Ill.1,00; (1'0)( $)$.

REYNOLDS, 377, WHITE

liusli, Ernan A. (1,8:2) Inet.5, 03 ; (1'03).

schoflele, lioht. K.-Mcl.6, $48 ;(1998)$.

Williams, Nlfred ('arson (b'89) - Ind.20,'12; (I'lis).

RICHMOND, 22,324, WAYNE

ANIJiRSON, WARRE.: W. - Ind.10,95; (1'0:3).

Bally, lico. 1).-Int.4, '61; (1’97); not in

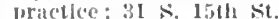

IBANON, FRLEMAN K. (1,85)-Ind.20,11; (1+1); Eastern lindiana liospilal for Insillle.

H.0Nล0.I, IOIN C. (b'72)-Ky.1,00; (1.00); 111 N. stlu st. ; $8-9,1-3,7-8$.

I30NII, CHAS. S. (b'56)\$ N.Y.10,'83; (1'97); $112 \pm$. 10th st.; $8-9,12-2,6-8$; (I)6)

IBUND, S. EHGAl (1)'76)-Ind.5, $04 ;\left(I^{\prime} 04\right)$; $21 \%$ N. 9 th St. $8-10,2-4,7-8 ; \mathbf{N}$.

BRAMKAMI, ALIAN ILWIS (b'73)థ0.1,99; (1'02); i s. 8th st.; $T-9,1-3$, (i) $: 30-8 ; 5$

BICIIE, FREIL. I'. (b'81) - Ky.2,05 (1'05); 133 s. 5 th st. ; $8-10,1-3,6-8$

I3ULLA, HORA S. (1, Ti) \&-0.9,05; (1'05) ; 10 th and South $A$ Sts.

IBURCHA.M, IIENRY C. (b'60)-Mlch.1,'89; (I'97); First National Bank 13ldg.; 8-9, $2-5,7-8$.

CHURCIILL, EDWIN R. (b'75)-Ky.4, 03; (1'12); 21122 South $\Lambda$. St. ; offlee, second Vational Bank Pldg.

COLBURN CLAKEYCE P. (b'59) $4-0.9$

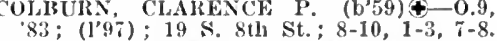

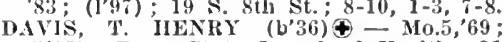
(I'97); Pres. State J3oard of Ilealth; 21 S. 8th St. ; $7-8,1-2,6-8 ;$ Pd.

Duffin, Chas. E. (b'80)-KKy.1,03; (l'05); 322 N. sth St.; office, Colonial Bldg.; $9-11,1-5,7-8$.

Dunham, Frank If. (b'73)-0.13,'99; (1’99).; 41 N. 16 th St.; 8-9, I2-2, 6-8.

FWING, UIYSSES B. G. (b'63) $\uparrow-0.1,84$; (1'97); 72 S. 12 th St.; office, 11 S. 8 th St. ; $9-12,1-4 ;$ (B1); OALR.

Foster, James T. (b'73)-Pa.12,'00; not in practice; 1226 Maln St.; offlice, Union station.

GENTLE, I.UKE M. (b'64) - Ind.8, 90 ; (1'97) ; 52 S. 8 th St.; 8-10, 1-3. 7-8.

Grosrenor, Elmer B. (b'61) - 0.13,'82 ; (197); 770 National Rd., W.; office, 713 Main 'st.; 9-12, 2-5; OALR.

Main St.; 9-12, 2-5; OALR.
GROSVENOR, JULIES JOHNSTON (b'89) AROSVENOR, JULILS JOFHSTON (b'89)
-Ind.20,11; (l'11); 770 old National Rd., W.; offlce, 713 Main St.; $7-9,1-3$, i-8; Pd.

IHarold, Frank L. (b'78) P-MI - Ind.5,04; (1'04) ; $27 \mathrm{~N}$. 10th St.; $8-9,1-3,7-8: 30$.

HAXS, GEO. R. (t'79)థ-0.6, 02 ; (l'03) ; 1411 south A st.; office, 931 Main St.; 9-11, 2-4, i-8; OALR.

HOPKINS, ROBT. R. (b'44)-Q.8,68; (1'97) $110 \mathrm{~N} 5$ th St.; $7-8,1-2,6-8$.

HUFFMAN, WM. G. (b'69)-0.6,'96; (1'97); 28 N. 6th $\mathrm{St}$.

HUNT, GEO. BEAM (b'82) - Ind.20,'10 ; (1'10): $201 \mathrm{~N}$. Fth St.

JOINSTON, MELVIILE FREEMAN (b'58) (4-N.Y.10,86; (1’97); 103 N. 10th St.;

KING, JAMES E. (b'56)甲-0.1,'84; (1'97); 24 S. 9 th St. ; $8-9,12-1,7-8$

Kinsey, Jos. H. (b'66) P-M-Ind.5, 88 ; (1’97); 124 N. 8 th st. ; $7-9,1-3,6-8$.

KRUEGER, FREDK. WM. (b'-8) $₫-0.9,03$; (1'05) ; 45 S. 7 th St. ; 8-9, 1-3, 7-8.

Luken, John H. (b'46)-N.Y.10,66; (l'97); 1725 Main St.

MARKEY. EDW. BONDÐ - N.Y.20,06; (temporary permit,'13) : Member 0 . State Hed. Assn. : 127 X. 10th St.: 2-4; S.* MARKLEY, STEPHEN C. (b'72)-0.1,'98; (l'99); 34 S. Th $S 1$; $8-9,1-3,7-8 ; 0$ Ob. MARYLL, CHAS. (b'64)†-Pa.2,91; (1'97)
Menleuhat, Elwln H. (b'69)-Ind.18,06; (1'(16): 19 S. Tth st. ; $8-9,1-3,7-8$. MISENHR, WAITER I.-Ind.5,01; (l'01). MORROW, R(O) DARI,INGTON (b'84) $†$ Incl.18, $07 ;\left(I^{\prime} 97\right) ; 23$ s. 8 th St. ; $8.9: 30$ $1-3,7-8$.

MORROW, SIIRAII I. (b'4i)-0; (1'97); 27

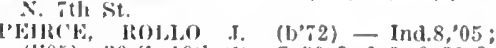
$\left(l^{\prime} \theta i\right) ; 30 \mathrm{~s}$. 10 th st. : $7: 30-9,1-3,6: 30-8$.

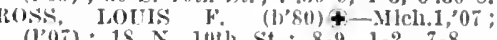
Rusk, Anua F; (bin st.; 8-9, 1-2, 7-8.

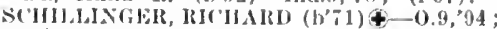
(1'97); 118 N. 8tl St.; $8-9,1-3,6-8$.
(1)

SM BLSER, SOLOMOX (i. (b'80)-Ind.8, 0 ; ; $(1+) ; 51$ s. 8 th St.

STEVENSON, DAVII) WM. (b'66)†-III.1, 99: (l'97); 408 S. 15th st, ; offlce, UnIon NIIURs'Tos Bank Bld.; 8-12, 1-5; OALR. (1'97) ; 225 N. 8tl st. ; 7-10, 1-4, 6-8:30; NP.

Walls, Jolu A. (b'49)-Ind.5,'84; (1'97); 21 S. 10 th st

WAMILLR, JOIIN M. (b'54)థ-0.9,94; (1'97); $100 \mathrm{~N}$. Tth st. ; until $9,12-2,6-8$. Weist, Ebenezer l'adlock (b'73)-Ind.9,"03; (l'03) ; Colonial J3log.

WHALLOS, ARTHUR TAMES $\left(b^{\prime} 86\right) \mp-$ o.41,'11; (1'13); 224 Main st. ; $8-9,1-3$, $6-8 ; \mathbf{G}$

YENC'ER, MARTIN WASHINGTON (b'71) -Ind.9, $97 ;\left(l^{\prime} 97\right) ; 22$ N. 14th st.; $9-12$, $1-3 ; \mathbf{G}$.

Zimmerman, Wm. W. (b56)-0.13,'88; $(1397) ; 46$ \$. ith St.

RIDGEVILLE, 1,302, RANDOLPH

IILLIKIN, CLARENC WM. (b'81) lnd.20,'08; (1'08); Member Arlz. State Hed. Assn.

Schenk, (ieo. II. (b'75) E-0.2,02; (l'02) ; S.

Wallace, John IIanlfold (b'78) -Ind.8, 03 ; (1'05).

RIDGEWAY (R.F.D., KOKOMO), 18, HOW. ARD

Martin, Amos A.-Ind.8,'96; (l'97).

RIGDON (R.F.D., FAIRMOUNT), 200, GRANT

Ford, Karl Bernard (b'78) - Ind.9,04; (1'04). McTuruan, Michael J. $\rightarrow$; $\left(I^{\prime} 9 \pi\right)$.

RILEY, 550, VIGO

BRUNKER, JAMES W. (b'58)థ-Ind.8,'84; (1'97).

OUPUY, CHAS. M. (b'67) $\oplus-\mathrm{Ky} .4,94$; (1'97).

RISING SUN, I,5I3, OHIO

COWEN, LEWIS C.(b'48)థ-0.1,74; (l'01).

LLFERS, JOHN (b'52)-0.9,78; (1'97).

IIANSELL, ('EO. IIART (b'65) $€-0.4 h^{\prime}, 10$; (1'11).

IIarris, Fred Halsie (b'86)-0.41,'10; (I'II).

STEYENSON, GEO. AITKIN (b'37)-Ill.1, 65 ; (1’97).

RIVER VALE, 91, LAWRENCE ANDREWS, JOIIN IREID (b'71) - Ky.1,'92 ;
(1'97).

BLLLITT, THOS. W. (b'49)-0.8,'74, Ky. '55; (1'97).

\section{ROACHDALE, 849, PUTNAM}

COLLINS, CLEMEN'T C. (b'T0)థ-Ky,2,'92; (1'9i).

tanley, Logan-Ind.4,';6; (1\%)

STROUBE, CHAS. N. (b'69)థ-Ky.2,'97; (l'97).

\section{ROANN, 447, WABASH}

Kldd, Gideon P. (b'47)-Ill.6,'74; (1'98).

Kidd, James Gordon (b'89) - Ind.20,'13; (1'13).

Whitson, John S. (b'6i)-11l.1,95; (I’97); G.

ROANOKE, 699, HUNTINGTON

Gordon, Baltzer L.-0.2,'91; (l'97).

KEMP, JOS. W. -Ind.8,91; (l'97).

KOONTZ, SYLVANIS (b'44) - Ind.10,' $\$ 4$; (1'99).

Murray, Lucien E. (b'53)-Ill.1,'80; (1’97).

ROCHESTER, 3,364, FULTON

Bitters, Franklin Pierce (b'52)-Ky.1,79; (1'87).

BOWMAN, AARON I. (b'76)-Ill.17,08; (l’07). 


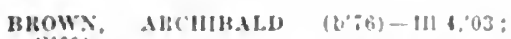
(1.09)

Clymer Sewton J. (b.3i) 1:-0.2:4; (1'g(s)

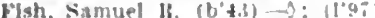

GOELD, CHAS R. (b'39)-0.1.'4: (l'4i).

Hul, lico. A. (b, 65 ) -Ind 9.95 ; (l'gs)

IIII. $W \mathrm{~m},\left(\mathrm{~b}^{\circ} 32\right)-1 \cdot \mathrm{a} . \mathrm{s}^{\circ} 65 ;(1 \cdot 97)$

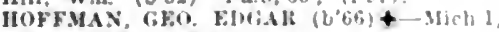
.93: (1'9s) : NP.*

King, Mllo o. (b'68)-111.1.'96: (1'96).

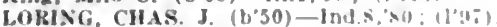

SHAFYR, WISFIFLA \&. $\left(6^{\circ} 52\right)+-(1,2$, st $\left.\left(1^{\prime} 9\right)^{\circ}\right)$

TAYLOK, HAKLFY W: (bo7)- [M! s, (05 (1'05).

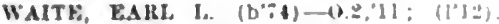

ROCKFIELD, 300, CARROLL

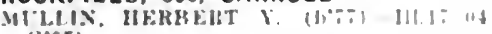
$\left(I^{\prime} 05\right)$.

ROCKLANE, (R.F.D. FRANKLIN). 95, JOHNSON Chas. (b'62)-0.1,'s!: (1'9:)

Wadsworth, Chas. $\left(\mathrm{b}^{\prime} 62\right)-0$.
ROCKPORT, 2,736, SPENCER

HAUMGAEITTEK, "TTU CHAS, (b"3)

Siwltz: :97; (1'99)

Dalley, James M. (b+12)-0.1, $99 ;(14 i)$

EIIRYAY CALDEK D-III.10,00: 1100$)$

Fhrman, F. D. $\rightarrow$ : (l'9i).

Hackleman, Francls M. (b'\$)-0.2.7l (1'9i).

llartkon, E. I. (

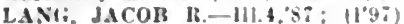

LANG, SHIRIAY CIIAS. (b'80)-III.11, 05 (l'05).

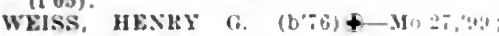
(1'99): Pd.

Whlte, Arhur-Md.1,"5t; (1'9;)

ROCKVILLE, 1,943, PARKE

BLOOMER, JOS. If. (b'\&I)-IH. 40 ; : (1"0i)

COLLINAS, THOS. JKASE Ind.

GEKLER, WALTER A. (b'st)-Ind.Is, 0 t; (1 $\left.0 \theta^{\circ}\right): T_{*}$

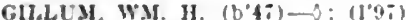

MHler, Rlchard Jaxper (b'85)-III.11, 10 Intern, Indiana state Tuberoulusis How pltal.

MORHIS, CHAS. C-Pa.2,"i: (109)

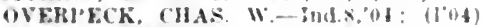

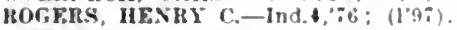

STEVESS CIUK I (b'si)-111.'1: (1'13): Indlana siare Tuberculosis ins pltal: "T."

SWOIE, RAYMOSI, E.-Inds, 0u; (1, II ALR.

ROLL, 125, BLACKFORO

IIAHIOLD, JOHIN H.-Ind.J0,'SI: (1.9.)

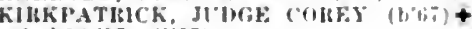
nd. $18,0 \% ;(100)$.

ROLLING PRAIRIE, 440, LAPORTE

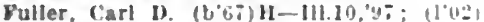

Macl'herson, (Thas. II. (bofi)-Ill.20.'li:

MARTIN, JACOH STEWART (b'3?) (1.9i).

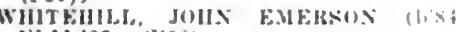
III. 11,02:" (1008).

ROME, 254, PERRY

LEE, JOII U. (6.5\%)-Ky.1.85; (1.5)

ROME CITY, 450. NOBLE

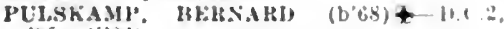
Y0: (1'04)

\section{ROMNEY, 200, TIPPECANOE}

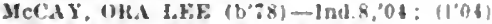

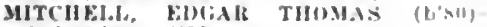
In1.80,0x: $\left(l^{\circ} 08\right)$.

Simlsun, Jelut frank $(1,50)-111.1$ - I: $11: 40)$

ROSEDALE, I,I66, PARKE

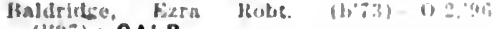
(1"Y:); OALR.

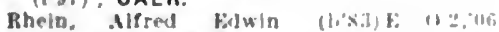
III.11, $A$ il: (1)0ii): Ob.

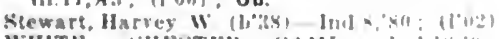

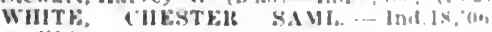
$\left(10^{\circ} 0(B)\right.$

\section{ROSELAWN, 228, NEWTON}

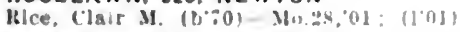

ROSSVILLE, B77, CLINTON

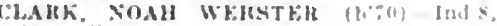
04: (1'04),

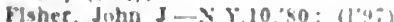

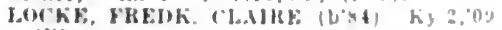
(I'09).
ROYAL CENTER, 909. CASS

Foutz, Ilavid X.- $\rightarrow$ : (l'g?!)

WEY, WOXNEI,L RA(idX (b"is) - Ind,9,04:

$$
\left.\left(I^{\circ} 0\right\}\right) \text {, }
$$

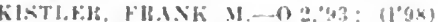

ROYERTON. 300. DELAWARE

MAXKYHLI, THOMAS J.-1).16,"90: (109i).

RUSHVILLE, 4.925. RUSH

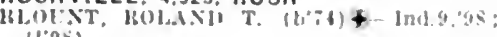
(1)as)

colkills. WM. S. $\left(b^{\circ}, 6\right)+$ Ind.8.03: (1.03)

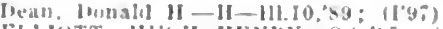

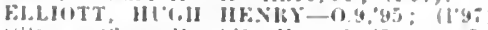

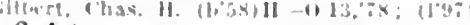

$0 \mathrm{pA}$

GMEFX, YHANK H. (b\%5)+-Ind $8: 37:$

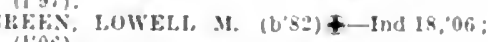

HAKLFVAx, FlKANK (;. (b'39)-Ind.9, $\therefore \div:(1,0) ;$ OALR.

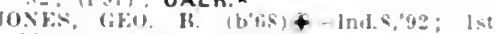

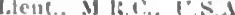

Lewls, Jolun 1:- II III.J0,95; $\left(1^{2} 4\right): 0$ p.

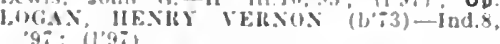

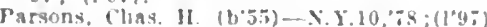

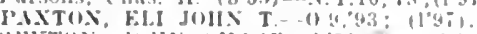

EXTOX, J111. (H.SE $(1, .69)+10.1,2$ (1'9i): I'rof diantro-lutene sur $\operatorname{lnd}: 0:$ S.

SMITH, WM. C. (b'o, $)-0.1,21 ;(196)$

smish, Wm. H. (b.33)-0.6\%"6: (1,

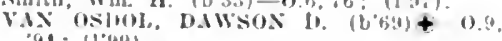
$31 ; 11.491$.

WOOIE, E, EW, I.-Ind.\&, $\$ 8 ;\left(I^{\prime} 97\right)$.

RUSK, 300, MARTIN

MCAdams, Lee (b'50)-KY.1,'s1: (1'9i)

RUSSELLVILLE, 443, PUTNAM

IBltow, John W.-hy.",s0, Ind.s.41; (1'9i)

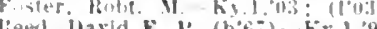

lieet, llavid E. I". $\left(\mathrm{b}^{6} 66^{\circ}\right)-\mathrm{Ky} .1,98$; (1"04).

RUSSIAVILLE, 298, HOWARD

Hark. Hownal C.-0.2, $04 ;(1004)$

Kemp. (ien.

MILLEK AITHCH HESIIEKSON (6.8)lud.8.,03: (1'03)

Ollar, Martin l.-0.1.75; (l'9\%).

SALAMONIA, 169, JAY

('hew. Wm. A.-Ind.1:.93; (1'97)

Hutchinson, James . 1.-0.. 68 ; (l'Q8); not In practlce.

Kldder, John J. (b'70) E-0.2,"96; (1'96),

SALEM, 2.283, WASHINGTON

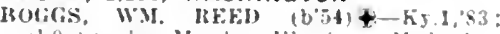

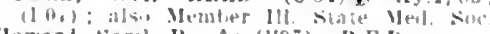

Howard. Saml. B. $\rightarrow$; $(197) ;$ IR.F.I).

kelles, james $r$ -

Jlichell, James J.-Ky.2.86; (1.97): not in practile: : R.F.I, 3

Mitchell, John lsaac Kv.t,06: (l'oii).

Murplyy, Chas. W. (b'si)-ky z:i!. Ind.s.

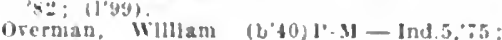
(10,1)

laynter, Horace M. (b65)(1'02).

luberts. saml. A.-ky.2.82; (1'at)

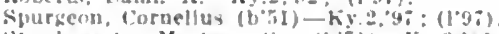

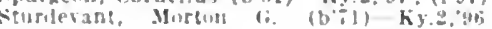
$(1,1 \%)$.

Warman, A. Preston (bs3) - Ks.2.'1? 11. 131.

II:? :)

SALINE CITY. 350, CLAY

dianzz. Iikeluard- $\theta$ : (1'vi).

SALTILLO, I62, WASHINGTON

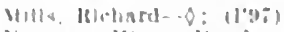

Se'yman IIIram $r-\theta ;([\uparrow)$

SANDBORN, \$4, KNOX

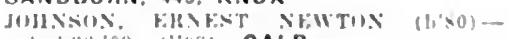

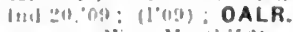

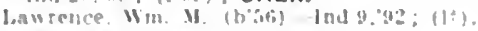

SANOFORD, 250, VIGO

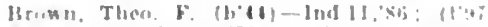

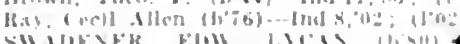

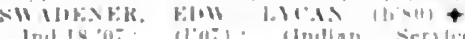
I II) IS, $10 \%$

SAN PIERRE, 400 , STARKE

Sill. Win $\left.J(8)^{\circ}: 0\right)$ VId $3: 90^{\circ}:(1,00)$
SANTACLAUS, 70, SPENCER

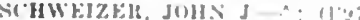

SANTA FE (R.F.D., NORTHGROVE), 130.

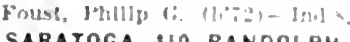

SARATOGA. HIO, RANDOLPH

SIATH.L:L

$\left.\left.(1)^{*}+\right)^{-1}\right)$

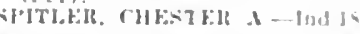

SCHNELLVILLE, 200. DUBOIS

PUISENS, MOHMII MH.I.K

$3.9 .0 .3 ; 1103)$

SCIPIO, 200, JENNINGS

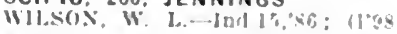

SCIRCLEVILLE, 250, CLINTON

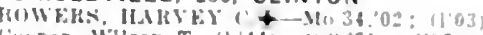

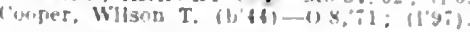

SCOTLAND, 200, GREENE

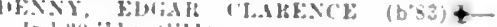

Inil:"11; 11.11).

SCOTTSBURG, 1,659, SCOTT

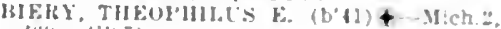

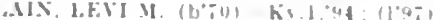

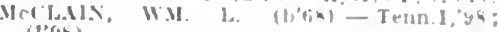

III 1111

all kili

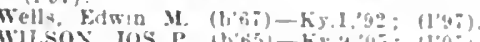

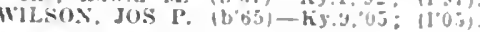

SEOALIA, \$00, CLINTON

WHITE. BAKCl.W 6. (b:3)-Ky:1,02: $(1.03)$

SEELYVILLE, I,I88, VIGO

CAKMICLAEL, CLYDE S. (bii)-Ind S, $05 ;(1205)$

IOC'KS, THOS. (HAHLTON (b:1) + Ind. I8, $07 ;$; $(100 \%)$

SELLERSBURG, 676, CLARK

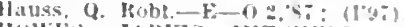

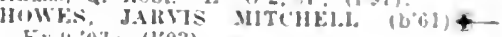
Ky:s, $0: 3:\left(l^{\prime} 03\right)$

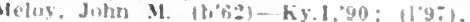

SELMA, 350, DELAWARE

Jump. Chas, A. (b'so)-Ind.Is:ab; (1006).

JLMI'. SIML. GILHEKT $\left(\mathrm{b}^{\circ}, 2\right)$-Ind 5,09 ;

SELVIN, 200, WARRICK

liarrison. Harry Morion $\left(b^{\prime} s^{\circ} j\right)-K y, s^{\prime} 10$ : (I'Il)

springstun, ('has, $5-K y+94 ;(1 * i)$.

SEYMOUR, 6.305. IACKSON

"ARTEIR, JAMES H. (b'As) $1-K y .979$;

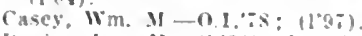

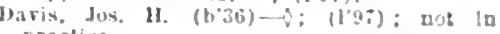
practice.

GFRIRISH, MILLABL) $r,\left(\mathrm{~b}^{\circ} 36^{\circ}\right)+-1^{2} 3.1,31$; (19i)

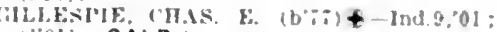

(01): OALR.

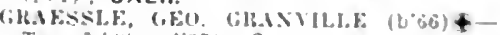

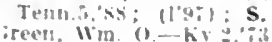

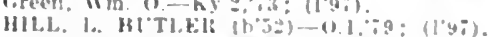

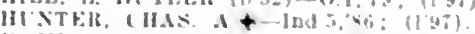

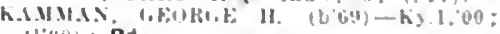

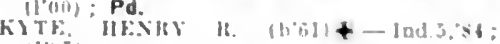

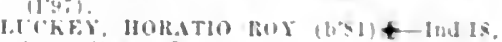

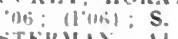

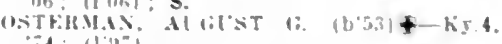

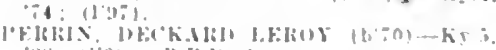

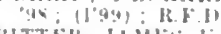

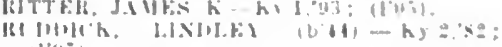
(1)

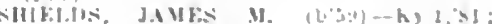

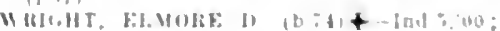
(1)

SHADELAND. 30, TIPPECANOE

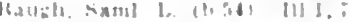

SHARPSVILLE, :00, TIPTON

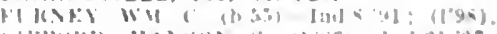

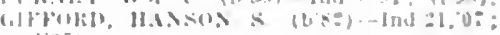

SHELEURN. 2,03S. SULLIVAN

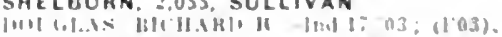

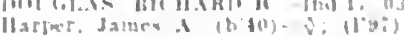


MLIPLE, TAMLS HRIAN (b'79)-111.1,02: $(1,102)$

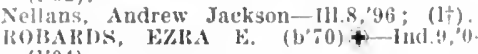

(1'04).

(l'05)

SHELBY, 300, LAKE

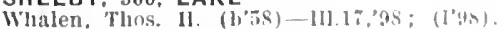

SHELBYVILLE, 9.500 , SHELBY

Alams, ovicl L.-lnd.R.'94; (I'ai)

CARTER, IATIRA (

G.

Clark, Rolu. F. $(1,5,3)-0.1,91$; (1'01).

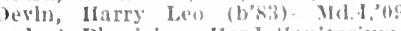

dent Plysician, linrd sanitarim.

ORAKE, MORIS $\left(b^{\prime}, t^{\circ}\right)+0.1,81$

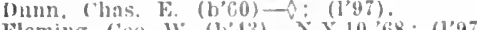

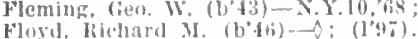

GREEx. TIOMAS (i. (b'65)-Ky.1,89; $(1,97)$.

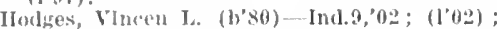
$u$.

INLOW, GEO. I. (b'74)-Ky.1,97; (1'97): IR. F, (1), 6 .

Keeney IBayard G. (b'76)-0.1,02; (1'02).

KENNEIY, SAMI. (b'67)-Ind.8,91; (1'97)

KEXNEY, WM. H. (1,75)-Ind.8,03; (1'03); S.

Linrille, Elbert C. (b'79)-Ind.8,04; (l'04); R.F.I. 1

Licas, John N. (b'46)II-0.13,73; $\left(1^{\prime} 97\right)$. 02 ; (1'02)

PARRISII, J. WILIARD-Ind.8,'96 ; (1'97).

PHARES, IIENRY E. (b'70) - Ky.5,'9 (1'98).

RAY, FIRANKIIN F,-Ind.8,'90; (l'97).

Sammons, Leslie C.-H-Mo.5,99; (1'99)

Shlmp, llarry A.-Ind.18,'06: (1'06)

TIndall, Chas. A. (b'G7) E-0.2.'87: (1'97)

Tindall, W. W. (b'7)-0.2,03; (1'03).

SHELDON, 200, ALLEN

Iurray, Dudley E. (b'83)-111.11,'06; (1'06)

SHERIDAN, 1,768 , HAMILTON

Davenport, Isaac W.-Ind.8,'81; (1'97)

Gipe, Walter Wm. (b'85)-Ind.20,'13; (1'13)

JOHNSON, PAUI S, (b'79)థ-Ind.8, 03 ; (1'04): $\mathbf{N}$.

McKenzle, Lawson W. (b'78)-Ind.8,01 :

$\left(1^{\prime} 04\right)$. Alonzo Clark (b'79)-Ind.8,03;
Newby, (1'03).

Newby, John C.-Ind.8,'80 ; (1'97)

Reck:John L. (b'82)-Ind.20,08; (l'08).

YOUNG, EDW. M. (b'69)-Ill.17,06; (1'06).

SHIDELER, 200, DELAWARE

PHIPI'S, CHAS. E. (b'73)-Ill.17,'05; (1"06).

SHIPSHEWANA, 500, LAGRANGE

FASH, SAML. MI. (b'64)-0.12,'8s; (l'98) (I'04).

\section{SHIRLEY, 1,519, HANCOCK}

Shrout, James Wesley (b'T) E - Ill.8,'97;

Wilson, Ralph (b'70)-Ind.9,'96; (1'98).

SHOALS, I,0I5, MARTIN

FREEMAX, GEO. M. (b'67)-Ky.1,'90: $(1,9 i)$

LONG, EDW. E. (b'68)థ-Ky.4,97; (1'97)

SHIRIEY, HEXRY W. (b'\$2)థ-0.1,78; $\left(I^{\prime} 97\right)$.

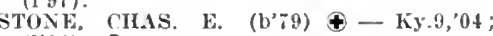
(l'04); S.

SIDNEY, 400, KOSCIUSKO

WARVEL, JOS. L. (b'65)-IH1.4,95; (1'97).

SILVERLAKE, 493, KOSCIUSKO

Amiss, James M. (b'52)-Ind.8,' 80 ; (1'9s).

J.eckrone, Ira (b'69)-Ill, I,96; (1'98).

Sherbondy, G. 1V. - (1'05).

Shock, Algie H. (b'83)-Ind.20,'II ; (l'11)

SILVERVILLE (R.F.D., WILLIAMS), 75, LAWRENCE

Hornocker, Slmon D. (b'33)-O; (1'97).

SILVERWOOD, 50, FOUNTAIN

Keller, J. C.-111.5,95; (1'97).

SIMS, 250, GRANT

IIaines, Howard C.-E-Ind.I1,'85; (1'97).

Tichenor, James B.-Ky.2,'93; (1'97).

SMITH VALLEY (FRANIKLIN P.0.), 90, DOHSON

DEWITT RUSH (b'71)-Ill.10,96;

SMITHVILLE, 400, MONROE

Kentling, Jos. (b'6)-Ky.2,00; (1'00).

SOLSBEIRRY, 200, GREENE

l)em, Fredk. Saml. (b'S1) - Ind.9, 04 ;

SOMERSET, 306, WABASH

livodrllck, clayion E. (b'75)-Ind.8,05:

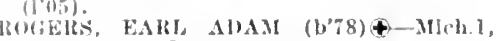
(1) ; (1'02); G.

SOMERVILLE, I00, GIBSON

Null, Calvin 1. (b'5) Ind.8,91; (1097)

SOUTH BEND, 53,684, ST. JOSEPH

BAER, SAML. W. (b'61) - 111.17,06; (lo6) $5: 4$ S. Carroll St.; offlee, J. M. Sindebaker IsIdg. ; $9-12,2-4,7-8$

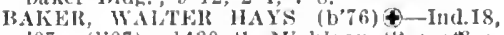
$07 ;\left(1^{\prime} 07\right) ; 1439$ s. Michlgan st.; ofllce, I. .I. Stullebaker Bldg.; 2-4, 7-8.

Barber, Albert F. (b'6S)-Ont.5,'92; (1'97) 550 W. 2 d St.; offlee, Cltlzens National Bank jildg. : 9-12, 2-5, T-8; OALR. *

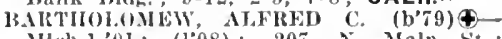
Mleh.1,01; (1'08); 207 N. Maln sit.; 10-1:, I :30-5; (B1,8); OALR. *

BERTELANG, JOIN I3. (b'60) $\uparrow-0.9$ '83; (1'97); 215 s. Taylor St.; office, 228 W. Colfax Ave.; 2-4, i-8.

Boram, Alla Kesler-0.2,05; (105); $137 \mathrm{~S}$. Micligan St.

Boram, llarry Blshop-0.2,'05; (1'05); 137 S. Michlgan St.

Borlsowicz, Nicodemus G.-Kus.4, 89 ; (1'97).

BORLEY, EDGAR R. (b'72) \$-Mich. 7,98 ; $(100): 435$ N. Lafayette St. : oflice, J. II. studebaker Bldg.

BOSEXBURY, CHAS. SEARLES $\left(b^{\prime} 7 \pi\right) \uparrow$ Ill. 1,$03 ;\left(I^{\prime} 06\right) ; 1055$ Woodward Ave
office, 103 N. Lafayette St.; 2-4, $7-8$.

Boswell, Andrew J. (b'55) - N.Y.10;90; (1'02); 715 Rex St.

BOYI-SNEE, HARRY (b'69)€-Ill.I,'89 ; (1'02) ; Kunstmann Apts.; offlce, Jetferson Block; $9-11,1: 30-4: 30$.

BUTTEHWOKTH, CHAS. M. (b'66)థ-0.1, 89 (1'97); 522 S. Mllchigan St.; office, 334 Jefferson Bldg.; 2-4.

334 Jefferson Bldg. ; 2-4.
CAIVERT, ALVAH iv.-Ill.14,06; (1'07); Nember 111. State Med. Soc.; 523 E. Monroe St. $10-12,2-4,7-8$.

Calvert, Robt. II.-0.1,69; (1'97); office, II S. Jlleligan St.; 8-10, 1-3.

Cannon, James H. (b'56)-Mo.I,'81; (1'99); 224 N. Maln St. ; $1-3,7-8$.

Cassidy, John - Ill.I, 68 ; (1'97); 1202 Michigan Ave.; oftlce, 307 W. Jefferson St: $9-10,2-3$

Chaffee, Walter D. (b'65)-Ill.4,'s7; (1'02); 116 E. Marion St.; offlee, Jefferson Bldg. $9-10,2-4,7-8$

CLARK, STANIEY A. (b'7 7$)-I l l .4,98$; (1'02); Indlana Club; offlce, J. MI. Stude-

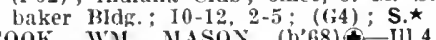

Cook, WM. MASON (b'68)@-I1l.4,'98; N. Main St. ; 10-12, 2-4, 7-8:30.

coOPER, HÁRRY LINFORD (b'87) COOPER, HARRY LANFORD (b's7) Crowe, Harry II. (b'62)-Va.6,05; (1'12) ; 208 N. Nain St. ; $2-4$

CRUMIACIER, CHESTER BLAINE (b'83) I11.6, $05 ;$ ('05) ; 219 E. Indiana Ave.: DEAN, EDWIX R. (b'65)-Pa.2,90; (1'99); 323 W. Wayne St.; offlce, Dean Bidg. ; $2-5,7-8: 30$.

De Forest, Danl. F. - Ind.8,'95; (1'99) ; Amerlcan Trust Bldg.

DEGDALE, RICHARD B. (b'68)థ-I11.1, 92 ; (1'92) ; $825 \mathrm{E}$. Waslington St. ; offlce,

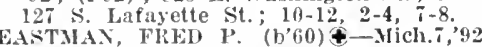
(I'97); 330 s. Main St. ; 2-4, $7-8$.

FEARS, JOHN IIAROLD‡-0.25, 03 ; $(104)$; I23 s. Willians st.

FINK, IIEXRY A. (b'56)-111.6,88; (1'97): 720 s. Michigan St.; vfflce, 231 S. Michlgan Sit.; $10-12,2-5,7-3$.

Freyermuth, Emil G: (b'כ̃) H - Ill.4, 80 ; (i,04); $509 \mathrm{~S}$. Carroll St.; office, $304 \mathrm{~s}$. (104); 509 S. Carroll St.; office

GALLOWAY, ULYSSES G. (b'66) \&-Ky.I, '93; (198); I216 S. Mlehigan st.; offlee, Dean Bldg.; 2-5.

GAMMACK, ALEXANDER PENROSE FORBLS (b'67)-Scot.1,'s9; (1'11); 836
GIISTER, ARTHUK EDMLND $\left(b^{\prime} 8 \%\right)-$ $111.4,10$; (1'12) ; $311 \mathrm{~N}$. Emerick st.; of flce, J. M. Studebnker IBldg.; 9-11, 2-4, 6-8.
rilsh, John L. (b'60)-Mlch.1,84; (1,01): oftice, J. M. Studebaker Mlikg.

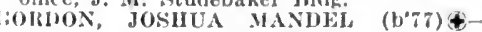
$111.22,09 ;$ (l'11); also Member 111. State Med. Assn.; 235 S. Mlchlgan St.;2-4; 7-8. (1'93); $116 \mathrm{~S}$. Taylor St. Oftece 103 , lafayette St.; 9-12, 2-4; (131,8); OALR.

IIANSEL, CIISS. li. (b,74) \$-II.II,97:

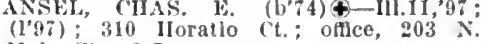

Maln St, $2-5$. WHLLS (b'58)-Pa.2,81; (1'97) ; 511 N. Maln St.; oftlce, 136 N. lafayette St. ; $2-4,7-8$.

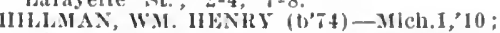
(I'I1) ; 1043 I'ortage Ave.; offlec, Jefferson lldg. ; $2-5,7-8 ; 0$ bG.

llughes, Geo. Alvin-Mlch.1,82; ( ) ; 407 S. Maln' St.

Kilsey, Perclval fiates - III.6, 64; not in practlec.

KHAMER, SAML. I. $\left(b^{\prime} 49\right) \$-I 11.1,79$; $\left(1^{r} 97\right) ; 429$ S. Michlgan St.; offlee, 217 KNAPP, ARTHIR 'LFROY (b;8) $₫$ - 111.6 , '12; (1'12) ; 710 I'ortage Ave. ; offlce, 1326 S. Mlchlgan St. ; 8-10, 1-4, 7-9.

LNT, EDWIN J." (b; 70 - Ont.5,92; (1'97) : 107 North Shore Drlve; offlce, J. M. Studebaker 13ldg.; $9-12,2-5$; (B8).

4INDQUIST, NILS S. (b'75)-II1.4,99; $\left(l^{\prime} 99\right)$; $231 \mathrm{E}$. Duvall Ave.; offlce, $228 \mathrm{~W}$. Colfax Ave. ; $2-4,7-8$.

Lockwood, Francls W. (b'67)-Mlch.1,02; (I'03); $504 \frac{1 / 2}{2}$ E. South St.; office, $230 \mathrm{~S}$. Mlehlgan St.

Martin, Edwin Allen (b'72) - Ind.18,06 ; $\left(1^{\prime} 06\right) ; 317$ S. Maln St.; 2-4, 7-8.

McKinstry, Wm. B. (b'70) $-0 ;\left(l^{\prime} 05\right) ; 2105$

Mishawaka Are.; untll $9,2-4,7-8$

Mishawaka Ave; untll 9, 2-4, 7-8.
IcNamara, Danl. W. (b,63)-Mo.27,94: (1'97); 318 S. St. Joseph St.; offlce, 22. S. Mlchlgan St. ; $10-12,2-4,7-8$.

Miller, Allen G. $\left(b^{\prime} 35\right)-0 ;\left(l^{\prime} 97\right) ; 721 \mathrm{~F}$. Sanple St. ; $9-12,3-8$.

MILIER, IUGH M. (b'78) $\oplus-111.6,02$; (l'05); $518 \mathrm{~W}$. Washington St.; offlce, 135 S. Lafayette St. ; $2-4$.

F. $\left(\mathrm{b}^{\prime} 66\right) €$-Ont.5,'89; (1'97); 928 Riverside Drive; office, 30. W. Jefferson St.; $2-5,7-8$.

MONTGOMERY, HUGI T. $\left(\mathrm{b}^{\prime} 49\right) \oplus-111.6$, 75; (l'97); 209 S. Maln St.

MOORE, EDWIN PERCY (b'70)థ-Pa.1,93; (1'97); 328 N. Mlchigan St.; offlee, J. M. 'Studebaker Bldg.; 2-4, $7-8$.

Murray, Helen Lennox (b'69)-Ind.18, 06 ; $\left(l^{\prime} 06\right) ; 507$ W. Washington Ave.

IIERS, CORNELIUS H. (b'53)-I11.4,77; $\left(1^{\prime} 97\right)$; 719 W. Washington St.; office, 201 N. Maln St. : $9-10,3-5$.

Myers, Edgar Harrls (b'82)-Ill.4,'06 ; $\left(l^{\prime} 0 \tau\right)$; $724 \mathrm{~W}$. Colfax Ave.; offlce, $201 \mathrm{x}$. Main St. ; 8-10, I:30-3; S.

Neifer, Frank J. (b'59)-0.2,'84; (l'03); 231 S. Michigan St.; $10-12,1-4: 30,7-8: 30$. OLNEY, THOS. A. $\left(b^{\prime} 70\right) \&$-Ill. I, 92 ; $\left(l^{\prime} 05\right)$; 413 La Mont Terrace; office, Jefferson Bldg.; 2-4, $7-8$; S. $\star$

Owen, Mary Willing (b'72)-Ill.4,'96; (l’06); Portage Are., R.F.D. 4 ; office, Jefferson Bldg. ; 2-4, 7-8.

OWEN, WM. LEONARD (b'77) $\oplus-111.4,06$; $\left(l^{\prime} 06\right)$; Portage Ave., R.F.D. 4 ; office, 208 Jefferson Bldg.; $10-12,2-4,7-8 ; 0 \mathrm{~b}$.

Powers, Francis Jos. (b'74)-Ill.6, 08; (1'11) : Dean Bldg.

RENNOE, CALLIE A. (b'68) - Ill.I,'92; (1'97); 504 Columbla St.; offlce, 234 s. Uichigan St.

SEXSENICH, ROSCOE LLOYD $\left(b^{\prime} 82\right) \Phi-$ Ill.1,'05; (1'05); $216 \mathrm{~S}$. Main St.; oftice, J. II. Studebaker Bldg. ; 2-4.

SHANKLIN, ROBT. CLARENCE (b'81)Ill.1,'05; ( $\left(l^{\prime} 06\right)$; Indiana club; office,

II. Studebaker Bldg.; 9-12, 2-5; D. $\star$

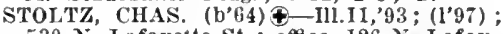

$530 \mathrm{~N}$. Lafayette St. : office, $126 \mathrm{~N}$. Lafay-

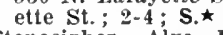

tonecipher, Alva E. (b'63) - Pa.12,'88; (1'03); $711 \mathrm{~N}$. Nichigan St, ; offlce, 105 16. Washington Ave.; 9-12, 1-5, $6: 30-8$. STRANZ, LEO VICTOR (b'68)€-I1l.I8,'96; (l'05); 519 Cleveland Ave.; offlce, $40 \%$ Chapin St.; $9-11,2-4,7-9 ; 0$ b. 


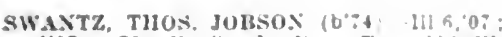

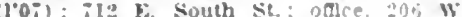
Jefterson st.: :-4, :-8.

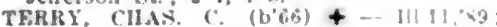
(10\%)

Ialayetle st: $: 4$

I.afagetle st.: 2-4.

Lafasetle st.

TRATER, PERR C (b'sio

(1013): 203 $x$ latayelte it

Whin 1,11

ucker, Marls W.-Ky lis

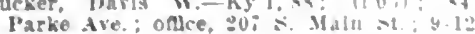
$2-4: 30, i-s: 4$

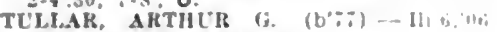
$\left(1^{\circ} 00^{\circ}\right): 133$ S. Lafayette st.

VAN PELT, MYAN T. (b'G3)+ IMI 10 $\left(1^{\circ} 03\right)$ : 231 S. MJelligan St. 10-1?

SARIER, CHAS. EMMITT (h'St) Michl 09 (1'11): 312 W. Wayne st. ; aclce, 30. S. Hllctigan st. : $11-1 \%, 1-3$

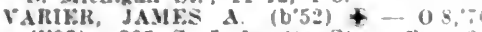
(19.9): $305 \mathrm{~S}$. Latayelte St; 0.ller. 30 S. Michlgan St.: 10-1:, 2-4

VICKrRY CHAS. IR, (b'71)-111.4, 01

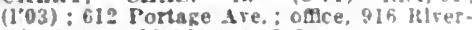
slde Drire: $10-12$, g-4, $1-8$.

- STO He

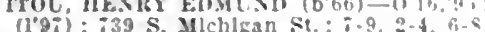
voN BARANor oscar - Hung i, 'no (103): 229 S. Chapln st

WAGER, FARL P'. (b\% + I11.11,"1) $\left(1^{\prime} 0^{\circ}\right): 426$ Lamoni Terrace: offce, 2. W. Colfax Are. : 2-4, 7-8

Wabl, Geo. F. (bi5)-III.I.'s2; (199); 520 Cottage Grove Are.

WARWICK, CIARENCE A. ( ( 93: $\left(l^{\circ} 0 \%\right)$; 505 Inalne Are, onlee, Lean Bldz: ; 9-11, 2-5, $;-8: u$.

WEGNER, WU. GODFHEY (b'T2) + -III11, 98: (1'95): 616 E. Washington Are. offce, Jefferson Bldg.; 9-10, 2-t, :-

white, Milton Perus (b'51)-nil.6.'s0; not in practlee; 1093 Rirerside Drise

WICKHAS, WM. A. R. -0.2," 80

J. 3. Studebaker BIdg.

SOUTH MILFORO, 350. LAGRANGE

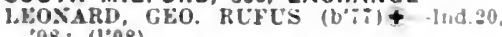
08: (1.08)

NEWMAS, HARMER M. (b'60) IH.1, NA $\left(10^{\circ}\right)^{\circ}$.

\section{SOUTHPORT, 352, MARION}

BARNES, ARTHLR L. (b.6.) - Ind 8 , gh (1.97).

Curry, Thos, W.-Ind.8,'55; (1'97)

Garshiller, Wm. I"

(Sec indianapolis.)

SOUTH WHITLEY, I,I76, WHITLEY

Albertson. Chas. Stuart-Ind.8,05: $110^{\prime}$,

EBERHAII), ELI L. (b'5i)

EBBERHALID, ELI Lo $\left.\left(b^{\prime} 5\right)^{\prime}\right)$

IETZGER, OWEN E. (b'82) —-MCh. I, ON (1.08).

Sowers, J. H. $-0.8,80:\left(1^{\prime} 05\right)$

WEHSTER, MONROE W. (b) 51 ) - III. 1,82 (1.20).

SPARTANBURG (R.F.D. CRETE), 302, RANDOLPH

MORGAN, THOS. W. 0.12 .93 : 1197 ).

SPENCER, 2,150. OWEN

COX, NATHANIEL D. $\left(b^{\circ}+2\right)$ - Ind $(1,8 i)$.

Denkewalter, Fredk. Wm. (b't3)-In!, at

GANTz, THOS. (b'40)- $\rightarrow:\left(l^{\circ} 9 i\right)$

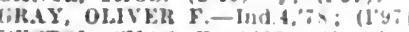

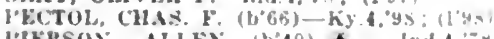

I'IEISON, ALLES (b) + - Ind $\left(10^{\circ}\right) ; 00$

klce, Wm. II-Ind.8,' $\$ 2:(19 \%)$

SIOWN, JOHS XHLON

SPENCERVILLE, 300, DEKALB

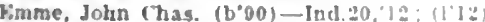

Shook, Hen\}. 0.-0.9:03; (1'03)

SPICELAND, 622。 HENAY

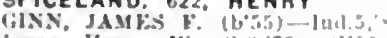

Juacs, Heury W-0.8, $75: 11000$

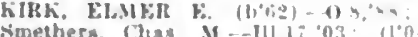

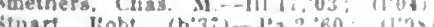

SPRINGPORT, I56. HENRY

Ticen, W. W:- Ind.is, "uri, (1'06,

SPURGEON, 250, PIKE

B.SKER, J.SBLE S - Ky 4,01: 11'041

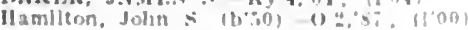

Harrlwin, Janes a
ST, ANTHONY, I50, DUBOIS

BICIIAJ, OILILI, A. (b'ö) IRISA

'83; (1'9:).

ST. BERNICE, 130, VERMILION

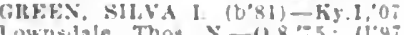

$(1,0:)$

Xewton. John T, (b't5)-ill.i,:9: (1'9i)

ST. CROIX, 80, PERRY

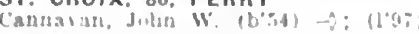

ST, JOE, 391. DEKALB

Bow mat1, lluratn W, (b.49)-0.11, it

lake, Julin Henrs-Ind.Is.0 i (ion)

schlisser, Walter karzer (biss) - ind.20, 1.: : $(1,12)$

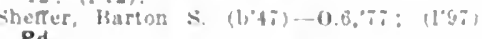
Pd.

ST. JOSEPH (R.F.D.. ARMSTRONG). 40. VANDERBURG

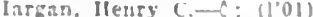

ST. LOUIS CROSSING. 300, BARTHOLO. MEW

smith. Wm. A. (b'65) -Ind.9.9s; (1.99)

ST. MAGDALENE (R.F.D. HOLTON), sO, RIPLEY

Kremer, Yredk. M. (b\%:0)-Ind $4,9:$ : (199i)

ST. MEINRAD, 538, SPENCER

IAMES, NICHOLAS A. (1,'S2)-KY z'UA $\left(l^{\circ} 04\right)$.

ST. PAUL. I, 050, DEKALB

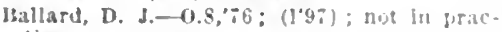
tice.

Bell. John Wesley (b'69)-Ky.1,'92: (1"05) lloward, rrancls it. (b'40)-0.8,64: $11^{\circ} 9$ )

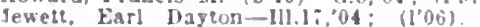

MAITZ, ("EO JAMISON" (b'bi)-0.1,91;

(1'13): Menber Oblo State Med. Soc.

ST. PHILIP (R.F.D.。 MT. VERNON), 75. POSEY

llenderson, Saml. F-Ind.2.'99; (1907)

ST. WENDELLS (ARMSTRONG P.0.), 200. POSEY

FICCKS, CARI $\rightarrow$; (1'9S).

STANFORD, 100, MONROE

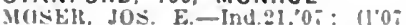

STANLEY (R.F.D., ELBERFELD), 20, WARRICK

TAYLOK, LON \&. (b'79)-Ky, 2,0S: (1'03).

STAR CITY, 500. PULASKI

stephens, Henry ("lay-Ind.I2, 85 ; (19")

ivashburn, Geo. W- C.2.94; $11^{\prime 4}$

STATE LINE, 194, WARREN

LAKIX, ALSTIS

STAUNTON, 746, CLAY

VHACH, JATHCK H, (b'62) + - Ind . YI (IDOi)

STENDAL, 250, PIKE

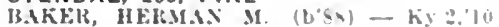
(1'12)

stork. John Ilenry-ky.1.'ss; (199:).

STEWARTSVILLE, 300, POSEY

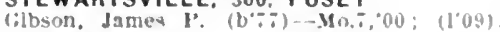

STILESVILLE, 400, HENDRICKS

HLCKS, LEOLA YHANKLIS (b't) + Ind.8,01; $\left\{1^{\prime} 03\right.$

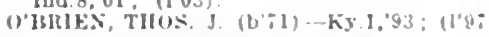

STILLWELL。200, LAPORTE

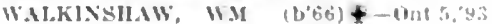
(I.)

STINESVILLE, 497. MONROE

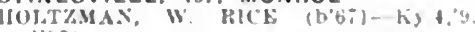
(1'gi).

STOCKWELL, 300, TIPPECANOE

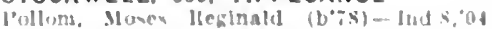
$(1,05)$

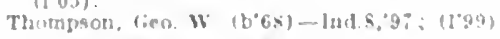

STRAUGHN. 23\%. HENHY

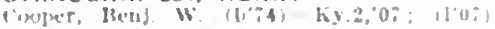

STRAWTOWN (R.F.D. CICERO), B? HAMILTON

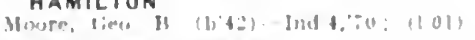

STROH. 500. LAGHANGE

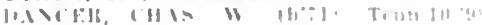
(10):3)

SULLIVAN 4.II3. SULLIVAN

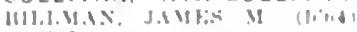

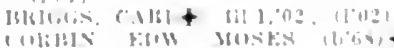

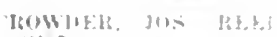

1)-Iil.1.9: :

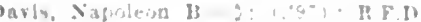

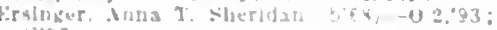

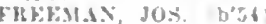

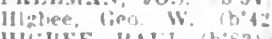

llinkle. Jamet is (tos)

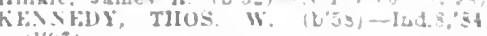
(l'yi)

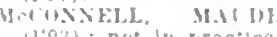

surphy Jukn biactic

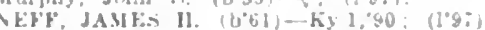

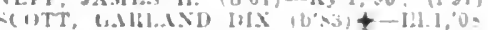

Meraher 111. stano Med. Sonc.

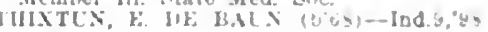
(1.98).

THOMBON, WM.TER $x \quad\left(b^{2} 64\right) \mp-1111$ Sis: $11^{\prime} y$ i)

Tollsver, Mulun I' $-: \therefore(1 \% 9$ :

SULPHUR, 20, CRAWFORD

Abell, Gilbert II. (b'\$4) $\rightarrow$ : (1.99)

SULPHUR HILL (R.F.O., WALDRON), 150 . SHELBY

schooley, Wm. A $01,183:\{100\}$

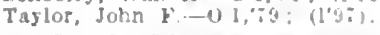

SULPHUR SPRINGS, 209, HENRY

Pos?, Burtun 0. (b'b4)-lad.s,'35; (1'si).

SUMMITVILLE, 1.38\%, MADISON

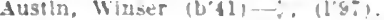

Gart. Jesse l?. $\left(b^{\circ} b^{\circ}\right)-0.20^{\circ}$;

OALR.

OALR. SETH HLCO (2) (lous).

MOBLEY, LEWIS F. $(0: 5)+-$ LDU.8, U2: ( $\left.l^{\circ} 02\right)$

WHITE, ERAXCIS W--Ind.5:89: (1.9:)

Whlte, John ifm. (b'51)-lnd.J's9; (199i).

SUNMAN. 35.3. RIPLEY

rletcher, (has. Fredk. (b'3l)-Ky 1,08: (1 0 os

NFWroRTI, CHRISTIA-0.1,83: (199:)

ROBISOS, WILBCIT $0.1,00^{\circ}, 10^{\circ} 0^{\circ}$

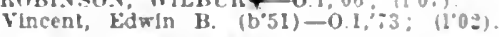

SWAYZEE, 836, GRANT

Anderson, Brmma-Ind 1:.96; $11^{\prime 9}$

Anderson, John $\left.T \rightarrow \longrightarrow:\left(b_{9}\right)^{\circ}\right)$

Hlswkins, Zed. T. (bei) E- 0.293; (195).

Hesuner. W. S. - Ind 1:.91; (1001)

SWEETSERS, 333 , GRANT

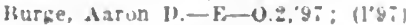

Buroker, Jacob 1'-Ind.12,97: $110 \pm 1$

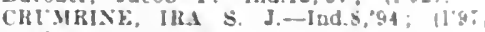

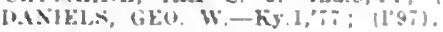

SWITZ CITY, 600, GREENE

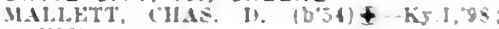
(1.9S).

SYRACUSE, 1.379, KOSCIUSKO

BOWSER, JOHN HOWAIRD (b'0) -lads,

- $55:(1.97)$

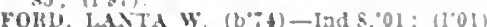

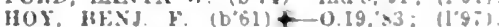

Iloy. Cllford Ray (b'ss)-Ind.20,13: (1'13)

TAMPICO (R.F.D. BROWNSTOWN), 1 \$0.

JACKSON

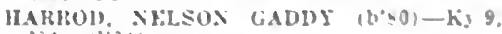
O4: $(104)$.

TANGIER, 300. PARKE

Irrlce, Wm. S. (b'At) $\rightarrow: 11^{\circ} 9$ :

TASWELL, 200, CRAWFORD

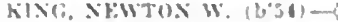

Kubtis, John it ti: (199i).

TAYLORSVILLE, 500, BARTHOLOMEW

Wright. Apritecus $\mathrm{B}$

(S.)e tislumbus

TELL CITY, 3.369. PERRY

1.1 TH:. W.IITH:I:

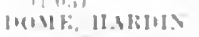

malbis. " II! '

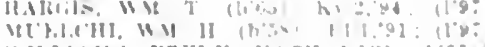

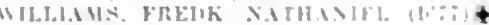
Ki! :."11: (1'I1).

TENNYSON. 3II, WARAICK

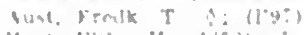

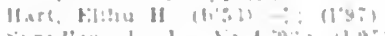

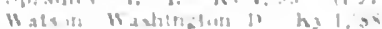

$\left(I^{4} 45\right)$. 
TERHUNE, 150, BOONE

'urdy, Jos. C. (b'54)- 0 ; (1'97)

TERRE HAUTE, 58,157, VIGO

NUMBER OF PHYSIC1ANS, 112

ALFXANIOER, OLIVER OSTIROM (h'Si )

IIleb.1,99; (1'10); 621 I'oplar st.; 9-10 $2-4,7-8$

Raker, Wm. I1. (h'5s)11-111.4,'s2; (1'47) 225 S. 5 th st. ; $8-10,1-3,7-8$

Balurldge, John 1i. (b'40) $\mathbf{E}-0.2,73 ;\left(l^{\prime} 97\right)$ not in practlce: 1630 lafayette Ave.

Baldrldge, Odus I.eever- $-0.2,02$; (l'02)

lith st. and Maple Ave.

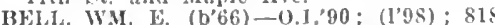
Walnut st.; oflec, 621 I'oplar St. ; 8-10, $2-4,7-9$.

BEHNIHEIIER, MERMAN L. (b'68) +-0.1 49: (1'99); 322 s. 4 th St.; oflice, 4 th $\mathrm{st}$ and Wabasli Ave. ; $9-12,2-4,7-8$

BETINA, DENN1S A. '(b, 76$)+-111,16,07$ (1'10); 1206 \&. 13tl St.; offlce, 13 th St and Wabash Are.; $9-10: 30,2-4: 30,7-8$.

BOIIN, JULIUS CIIAS. (b'76) 4 -Mo.:, 01

(lo3): $1522 \mathrm{~S}$. Center St. oftice, 1634 S. ith' St. $9-10,2-4,7-8$

BOOR, MYroN A. (b'72)屯-Ind.8, 94

(1'9s) ; 1207 s. Center St.; offlce, Swope Block: $2-4: 30 ; \mathrm{S}$.

BOL'I, i AV1D W. (b'81) $\oplus$ - Ind.18, ${ }^{-}$ (1'0 7 ) ; 1627 Poplar St. $8-10,2-4,7-8$.

BREAKS, ILTHER ZWIGLE (b'79) + 1]1.1,01; (l'03); $1142 \mathrm{~S}$. Center St.; ollice, Terre IIaute Trust Hidy. Op.

Cahell, Abram L.-D.C.3,95; (1’07); I607 Oak St. : oftec, 624 Wabash Ave.; $9-10$, C.

CAFEEE ANOS II. (b'65) - Ind.9, 00 (l'05); 1301 N. 9th St.; offlec, S69 La fis ette Ave. : $10-12,2-4,7-\$: 30$.

CAFFE, BENNET Y. (b'75) †-Jll.1,99 (l'04): 815 Maple St.; $7-9,2-4,7-8$.

CARIFATER, GEO CHFSTEH (b'85)Ind.20,'11; (1'11) ; 1024 s. Fth St.; offlce, $2 d$ and Halman Sts.; 8-10,2-4, $7-8 ; \mathrm{S}$. N. 14th St.; office, I218 Wábash Nie. N. 10:30, 2-4, $7-8 ; U$.

COMBS, CIIAS. NATHAN (b'79)థ-Ind.8 03: (1'03); Sec. Ind. State Med. Assn. 1510 S. Center St.; offlce, $128 \mathrm{~s}$. 6 tl $\mathrm{St}$. $2-4$; (421); Anes.

COMIS, MALACHI R. (b'63)€-Ind.8,'85 (1'97); 523 N. 7 th St.; office, 660 N. 6 th St. $; 9-10,2-4,7-8 ; \mathrm{S}$

Compton, Fredk. Saml. (b'64)-Ind.13,'85. (1'97): not in practice: $1330 \mathrm{~s}$. Tth st. covalitios, GEo. CU1RTS (1),81) Ky.2,11; (1'11); 329 S. 15th St.; offee 12 th St. and Wabash $\Lambda$ ve.; $8-10,2-4,7-8$ COOK, JOHN H. (b'81) †-0.9, $96 ;\left(l^{\prime} 06\right)$ 1331 Sycamore St.; office, $437 \mathrm{~N}$. 13th St. : $9-11,2-4,7-8$.

COOPER, JAMLS A.-Ind.2,'51; not in practice.

CRAPO, GEO. W: (b'52)£-0.1,75; (1'97) 1500 S. 6th st.; offce, 311 Poplar St. $8-9,2-4,7-8$.

CRAWFORI, WM. G. (b'S3) - Ind.20, 08 $\left(l^{\prime} \theta 8\right) ; 2220$ N. 7 th st. ; offlce, 603 Ia fayette Ave ; $9-11,2-4,7-8$.

pavis, Wn. S. (b'65)-0.1,90; (1'99) ; 1503 $\mathrm{N}$. Center St.; offlce, $34 \frac{1}{2}$ S. 4 th st. $9-11,2-4,7-8$.

Dees, Harry Edgar (b'82)-Mo.28,'08; (1'12) ; 13 th and Locust Sts.

Donnelly, James Edw. (b'72)-Ill.1,'01 (1'01); 1360 Maple Ave.; office, Swope Bldg. : $10-12,2-4,7-8$.

Irrake, Thos. G. (b' 36$)-111.1,62 ;\left(1^{\prime} 97\right)$; R.F.D. 1 .

EDWARDS, CIIAS. H. (b'59)-0.8,'85 (1'97) ; 460 N. 7 th St.; offle, $301 / 2$ S. 7 th

ELLIOTT, JAMIES (b'83) $\oplus$ - Ind.8, 04 $\left(l^{\prime} 04\right) ; 1218 \frac{1}{2}$ Wabash Ave; $9-10,2-4$,

English, Iames Plaster (b'54) - Ill.1,79 (1'00); 1701 N. 9th St.; office, 927 Beech St. ; $8-9,12-3,7-10$.

Farman, Frank Lee (b'84) - Ind.20, 08 ;

(1008): St. Anthony"s Hospital.

INi OTTO E. (b's2) f-Ind.8, 05 ; (1'05)

660 N. fth St.; offlee, $6831 / 2$ Main St. $-11,2-5, \quad T-8:$ OALR

J. DELBER'T (b'-1)-Ind.8, 00 1132 S. 8th St.; office, $1100 \mathrm{~S}$

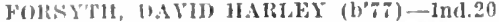
'04. (l'04) - I526 s. 9 th St. : offlce, $7 I^{2}$ II liman st. ; $9-11,3-5,7-8$

Fortune, James L. (b'80)-Ind.8, 03 ; (1'03) 214 N. 12th St.; oflice, 13th and Poplar St.s.; $8-10,2-4,7-8$.

Frued, John Fillas (b'88)-I11.6,'12: (l'13) 2124 C'leveland Are.; oftlce, 869 Lafayette Are $9.11,2-4,7-8$

Fits?, Jos. A. (b'78)-Ind.8,"00; (1'00) 1245 Maple Ave; 8-10, 2-4, 7-8.

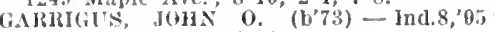
(1'05): $1705 \mathrm{~N}$. $8 \mathrm{th} \mathrm{St}$.

Gerstmeyer, ('has. P.-0.1,67; (1'97) ; 15 S. 81 h st.

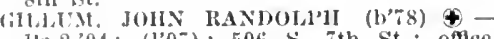
I'a.2, $04 ;(1,07) ; 506$ s. 7 th St.; ofllee swoje 13lock; $9-12,1-4$

thlover, wimer E. (b'54)-Ind.4,78; (1'97) 1201 N. Sth St.; ofllce, 124 S. Tth St. $7-10,1-4,6-8$.

Ilatiley, IIarvey (b'78)--Ind.8,'03; (l'03) ; G 77 6th

IIAHE, UAVID JONES (b'76)क-I11.1, 05 (l'13); 1115 S. 4 th St.; office, 806 s. itl $\mathbf{s t .} ; 9-12,2-5,7-9 ; \mathbf{s}$

Hauck, Jos. H. (b'74) E-0.2,'99; (l'99) 1202 Lafayctte Ave. ; 8-10, 1-3, 7-8.

ILWITT, JOIIN HFATII (b'83)-Ky.2,'09 (l'09); $1103 \mathrm{~N} .4$ th st.; offlee, $1305 \mathrm{~N}$ (lit)

Iursey, Vlrgin (a. (b'90)-Ill.22,'13 St. intliony's liospital.

HUTCHINGS, BYRON NERLE (b'79) Ind.8, $03 ;\left(l^{\prime} 03\right) ; 1546 \mathrm{~S}$. Center $\mathrm{St}$ oftlce, $1218 \frac{1}{2}$ Maín St.; 2-4; G.

JWNKINS, WILBUR O. (b'61)†-0.1,'84 Hante" Trust Bldg. ; $9-9: 30,2-4,7-8$.

JETT, FRANK IIUBELT (b'T6)-D.C.1, 05 (1'05); 1139 N. 9th St.; office, Swove Block; $2-4,7-8 ; s$

JOIINSON, GEO. TIIOMISON (b'84)Ill.1,0s; (l'10); $1411 \mathrm{~S}$. Center St. ; ofnce Terre Haute T'rust Bldg.; 1 1-12, 2-4

Joslin, De Ella Brown-0.2,99; (1'99) $1925 \mathrm{~N}$. 8th St.; 2-4; G.

KNOEFEI, AUGUST F. (b'80)థ-Ky.2,'03; (l'03): 626 Walnut St.; office, Trust Bldg: $2-4, \pi-8 ; 5, \star$

IKUNKLER, JOS. (b'82)-Ind.18,07; (1'07) $301 \mathrm{~N}$. 18tl St.; offlee, $4011 / 2$ N. 4 th St. $8: 30-9,2-4,7-8$.

KUTC1I, MEL,CHERD HEIMER (b'74) -

LA BIER, CLARENCE R. (b'73)-Mo.28, 98: (l'99) ; $928 \mathrm{~N}$. 7 th St.; offlce, 1124 $98 ;\left(l^{\prime} 99\right) ; 928$ N. 7 th

LARKINS, EDGAR L. (b'55)-Ind.4, 78 (l'98); 321 N. Tth St.; offlice, 1231 Wabash Ave. ; $7-9: 30,1-4,7-9$.

Laughead, James T. (b'52) $-0.1,77 ;(1,97)$ 826 N. 9 th St.; offlce, 44 S. $101 / 2$ St. $8-12,1-5$.

LAYMAN, ERNEST IV.--IIl.4,99; (I'99) 2230 N. 10th St.; offle, Swope Block - $2-4,7-8$

Lee, Thos. L. (b'49) $\rightarrow$; (l'01) ; 31 \% N. 5th St.

LOVE, JOHN ROBT. (b'69) - Ill.17,'00 (1'01) ; 1601 sth Are.

LUCKETT, LUTHER P.-Ky.2,'91; (1'97) 818 S. ith St.; offlce, McKeen Bldg. $9-12,2-5,7-9$

Lynch, Chas. F. (b'86)-Ill.8,'13 ; (temporary permit,'13) ; 1624 S. 4 th St.; office, 324 s. 3d St. $=10-12,2-5,7-8$

HAGUIRE, IAMES BERNARD (b'83)Ill.11,07; (1'10); 15th and Locust Sts. $8-10,2-4,7-8$.

MCALIISTER, EDWIX B. (b'68)థ-Ill.1, '94; $\left(1^{\prime} 97\right) ; 31$ S.' $131 \mathrm{~h}$ St.; offlce, 1230 Wabasi Ave.; 2-4, 7-8.

MCBRIIE, EARL CLARENCE (b'74)థKy.2, 07 ; (1'07); 18th St. and Wabash

IICCALL, JAMIES, JR. (b'70) - Ind.8,97; (l'09); Mckeen Bldg. ; 9-12, 2-4, 7-8.

ICCARTHY, FRANK GEO. (b'81)-Ind.20, 09; (1'09) ; 719 Sycamore St.; office, JcJolnston, Willard E.-Ind.2, 99 (1,98) 118 N. Sth St.; office, 10 s. 12th St. $1: 30-4, i-s$

Medley, Wm. Winfleld (b'74)-Ont.1,05 (I'06); N. 8th St.; offlce, Rea Bldg. ; $9-10$
$2-4$. $-8 ; 0$ bG.
MILIFR, DANiL。 B. (h'76) $\oplus-111,1,03$; (1'05): 119 \&. 17 th St.; oftlce, $1227 \mathrm{~S}$ ifth $\mathrm{St}$.

MILLER, DANL. TUCKER (b'86) †-Pa.I, 99: (l'09); 1006, 7th St.; offlce, Rose Dlsjensary Bldg.; 9-11, 2-4, 7-8; U.

MITCHELL, ALBELT MLIVIN (b'89)Ky.2,'13: (temporary permit,'13) ; 81 s. 17 th St.; oftlce, 6 th and Tlppecanoe Sts.; $9-10,2-4, \quad i-8$.

Modesitt, James A.-1nd.8;79; (1'97); 1467 s. 11 th st.

IOt)HHAI), THOS. W. $(1,56) £-$ Ind.6,'76 $\left(l^{\prime} 98\right) ; 118 \mathrm{~N}$. 8th St.; offlec, 10 S. 8th St. ; $1: 30-4 ; \mathbf{S}$

MULLIKIN, IILGGII M. (b'77) \$-0.9,'03 : $\left(l^{\prime} 01\right) ; 2016$ N. 8th St.; offlee, 1121 N. 7 tl. st. : $8-10,2-4,7-8$.

Neale, Edw. M. (b'57)-Ind.2,84; (l'97); $3171 / 2$ Wabash Ave.

N]BLACK, EART, S. (b'70)€-Mlich.1,05; (l'97); 1038 N. 8th St.; offlce, $705 \mathrm{Elm}$ St.; untll $9,2-4,7-8$; Anes.

Patton, Benj. F. (b'67) I'-M-Ind.5,'03; (l'03); 2015 X. 25th St.; offlce, 1510 Beech' St.

Pavy, Chester Arthur (b'82)-Ind.20,'11; (1'II) : $1629 \mathrm{~S} .61 / 2 \mathrm{St}$.; offtce, Ist and Vorhlse sts. ; $10-12,2-4,7-8$.

IORTLI, ALBEIT GAKFIELD $\left(\mathrm{b}^{\prime} 80\right)+$ Ind.20, 99 ; (1'09); 1364, 8th Are.; office, 19 th and Locust Sts. ; 9-10, 2-4, 7-8.

price, Robt. F. (b'59)-0.1,'86; ( ); $2210 \mathrm{~N}$.

Price, Robt. F. (b'59)-0.1, 86 ; ( ); $2210 \mathrm{~N}$.

reese, Forrest Leslie (b'85)-Ill.11,'08;

RICE, SPENCER M. (b'55) 4 -Ia.3,'79; (l'98); 644 Oạ St.; offce, Rose Dispen-

sary likg.; S.
klchmond, Wm. B. (b'76) - Mich.I,99; (l'00);425 S. $61 / 2$ St. ; offle, Rose Dlspensary Hldg.; $2-4,7-8$.

licker, Jos. W. $(b, 80)-0.1,01$; not in practlce; 1509 S. Center St.; offlee, Jaboratory London Packing Co.

Itoberts, Jos. D.-Ind.11,'81; ( ) ; 1st and

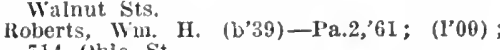
714 Ohlo St.

SCHELI, WALKER $\left(b^{\prime} 56\right) \oplus-0.9,78$; (1'97); 615 S. 6th St.; offlee, Rose Dispensary Bldg.; $8-9,2-4,7-8$.

Schott, Edw. J. (b'75)-Ill.4, 04 ; (1'05) ; 917 , Tth Ave, office, Terre Haute Trust Bldg.; 8-9, 1-4, 7-8.

Scovell, Joslah Thos. (b'41)-Ill.1,'67 ; not in practlce.

SHAFEI, JAMES SAMI. (b'83)-Ky.2,09; $\left(l^{\prime} 09\right) ; 2348$, 3d Ave.; $\tau-9,1-3,6-8$.

SHALEY, FREDK. IV. (b'58) \&-Hll.1,'84; (l'97) ; 664 Mulberry St.; oftleę, Swope Block; $8-9,2-4,7-8$.

Siner, Francis 11.-Ind.9,'84; (l'99); 13 Maple Ave.

Smick, Cassius M. (b'53)-0.9,'81; (l'97) : 1020 S. 4th St.

Smith, Elijah W.-Ind.11,90, Mo.28,93; $\left(1^{\prime} 97\right)$

Smith, Harry Chester (b'85)-Ind.20,'09; (l'09) ; 1212 N. 10th St.; offlce, Rose Dispensary Hldg. ; $9-11,2-4,7-8$; $U$.

Spellbring, B. F.- $;(197) ; 1628$ S. 17th SPIGLER, OTTO R. (b'75) $\oplus-\mathrm{Ky.5,02}$ (1'02) ; 1620 Ohio St. ; office, 344 S. 13th St. $9-10,2-4,7-8$.

Spotswood, Edmund T.-Ill.1,'5I; (1'97) ; not in practice.

'TEPHENS, MADGE PATTONP-Ind.8, '95; (1'96); Nember Tenn. State Med. Assn. E Edgewood Grove; offlee, Rose

Stock, Louis K. (b'53) E-0.2,'82; (l'02); 324 s. $3 \mathrm{~d}$ St.

STUNKARD, THOS. C. (b'61) - 0.1,'85; (1'97) ; 201 S. 6 th St.; offlce, 515 Walnut St. : $9-10,2-4,7-8$.

TABOR, FRANK A. (b'72)-Ind.s,'98; (l'98); 398 Kent Ive.; office, 10 N. 14th St. , $9-10, \tilde{2}-4,7-8$

Thompon, Horace H. - 0.13,'89; (1'98); 1740 N. Sth St.; 8-10, 2-4, T-8.

Thomson, Gilbert J.(b'-5)-Ind.8,'05; (l'05); $25^{1 / 2}$ S. 5th St

UIMIER, DAVID R. (bi1) क- Mo.28, 01 (l'01); 2306 N. 10 th St.; office, Rose Dispensary Bldg.; $9-11,2-4,7-8 ; \mathrm{S}$ 
VAX CLFAVE, MACHICE H. $16 \%$ H - IH. IJ, 00: $\left(11^{\prime}(00): 505\right.$ \&. th st.

Waters, Moses II. (b'3j) H - N 14.45 ; (loi); i2s Maple Are.: once, hose dis: penary BId: : $y-10,1-3$.

penary Bldz: : y-10, 1-3. (1.9\%) 1504 s

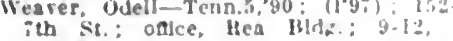

OALR.
WHISTHIS, JOS. H. $\left(b^{\prime} ; 0\right)+-0.99^{\prime}:$ : (1297): $1438 \mathrm{s.}$ bit st, aftce, l2s. fith si: $: 9-10,2-1 ;$ S.

WEIR, LDW. A. (b67)-\$ ass. 1.93; (1.93) Member veb. State Med. Isil : Tetre

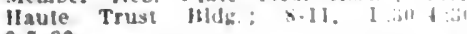
$6-\%: 50$.

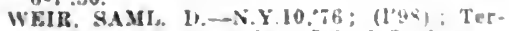
WEIR AAMIs. 1;WIEIEMANX, FRANK F. (b'rz) + IIh.1. 94; (1'93): 1530 s. 6ith st.; once, Huse blspensary 'Bldg: $9-10,2: 30-5$.

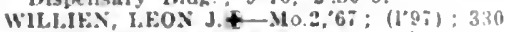
x. Tth St.; offce, 6il Chestout St. : 8-9. I.t; $S$.

WII.IFE, WM, F, $\left(b^{\prime} 35\right)-I n d x \cdot 4=$ (1'9s); 114 Proplar st. : oftce. Roso Inj: (1'9S): ht Poplar st. 0 nce.

WOUIMIIR, ROBT. ILE, (b'ti)-Tenn 5,

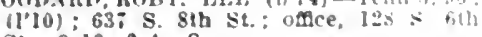
st. $9: 10,2-4: 5$.

WORKFIL, JOXATHAN P. (b't)-l'a. 6i: $(199):$ H10 X. Centre st. : ultlce. 20 S. ith St.: $9-1$; (B4.8); OALR.

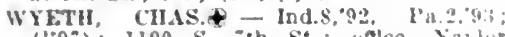
(1.9i): 1100 s. ith St.: unlce, Naylur

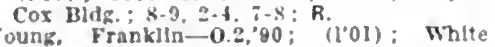
loung, Franklln-0.2,"90
Bld. : 8-9:30, I-3, $:-8$.

roYsi, STEPIIEN J. (b'29) - $-1,51$ : (1'97): not in practice: bt5 131 -

TUNG, juLILS RLDOLPII (b)'-8) + MIII.

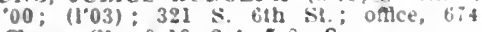
Cherry si.: $9-10,2-1, \pi-8:$ s.

ZARING, FHIRTT T. (

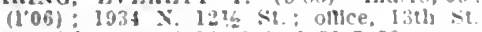
and 8 ih Are.: $8-10,2-4,6: 30-7: 30$.

THAYER, 200, NEWTON

Tate. Wallace Weston $(2 \cdot 0)-\Pi 1,13,0:$ (1"0:s).

THORNTOWN, 1,508, BOONE

Artustrong. Chas, Hoy (b'7t) H-Mn. (1'9\%).

BASSFTT, CLANCY (679) - Ind.IS,0: (l.0i).

Brown, EIt L. (b'ti) E-0.27s: (1'si)

Davis. Darld B. $\left(b^{\prime} 38\right) \rightarrow$ : (1'95)

Masters, Luella M. (beth)-X.Y.15."yl: (L'99)'

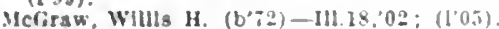
Owsley, Ciuy Mannerlag-Ky.2,05; (1'06).

SHIELIS, JA10IB s. (b"65) - Ind s.4 (l'Bi): OALR.

TIOSA, 150. FULTON

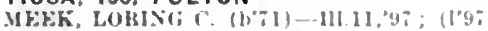

TIPPECANOE, 400. MARSHALL

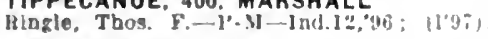

TIPTON, 4,075, TIPTON

HCRKHARIT, ARTHIH E.ILAKST (b"ai) $+\ln (9.90 .08:(100)$

WCKEY, A.DDHEW S. (6"50) - Ind.9,"s! :

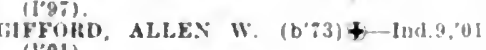

(IRISHAW, HARBY E. (b'83)-IIU.9, $(1,9 i)$.

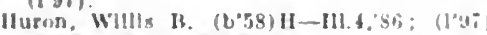

MCKEF, WM. EIWIS (b०0)-Ky,5, (I.97):

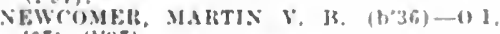
$08: 8\left(19 y^{3}\right)$.

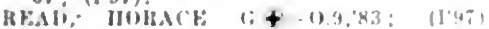
( 3 J)

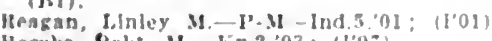

llecubs. Rob: M. hy 2,93: (1'97)

lloads, Anna F. ( $\left.\left.b^{\prime}+2\right)-8:(1)^{\prime}\right)$

Trosslder, James Trelur-Min.2p,

Treasider, garah F, - Mo. 25,$433 ; 11^{2}$,

TOBINSPORT, 300, PERRY

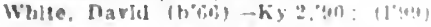

TOCSIN, IIS. WELLS

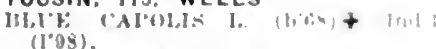

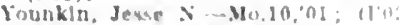

TOPEKA, 430, LAGRANGE

HII.IFIISAVI, III $\left(10^{\circ},\right)^{\circ}$.
Heed, C. Whlard (L'12)II-III.10,6i: (I'yi): not in practliee.

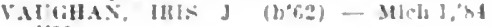
('99).

TRAFALGAR, 400, JOHNSON

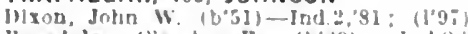

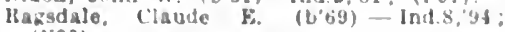
(1'00).

WILLAS. CARL Fo (b"72)-0.1,97; (1'95)

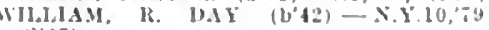
$\left(l^{\circ} 97\right)$.

TRINITY SPRINGS, I03, MARTIN

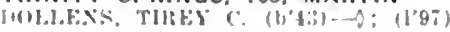

TROY, SIO, PERRY

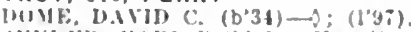

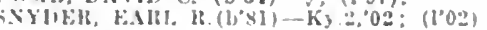

Wb. Florence M. Olusted (bo9)-0.21. (1):- (1"11:-): (HIan): G

TUNNELTON, 235, LAWRENCE

Mallock, II ustǫn J. (b'80)-Ky.l, 05; (l'05).

TWELVE MILE, 200, CASS

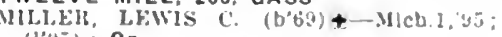

(1):i); 0 p.

TYNER, 200, MARSHALL

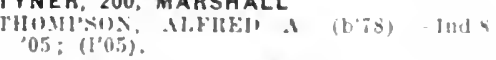

UNDERWOOD, 125, CLARK

Houghland, II. E. II $\rightarrow$ : (l'si)

UNION, 200, PIKE

Hatfleld, lienj. F. $-0.1, s: ;$ (1'9i).

UNION CITY, 3,209, RANDOLPH

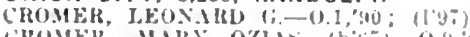

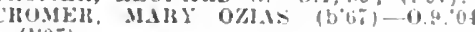
$\left(l^{\prime} 05\right)$.

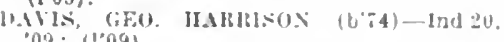
LETRICK, IIERBERT WELLYSN (b'SS)0.2.'10; (I'10).

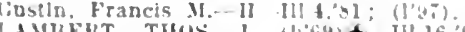

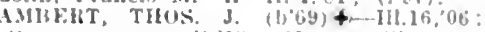

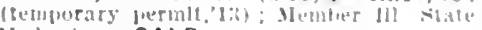
Med Soc, : OALR.

Nufrsinger, Henry-0.2, $x$ : $(1: 0)$

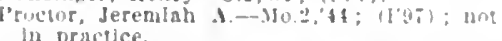
In practice.

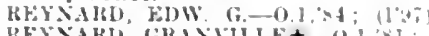

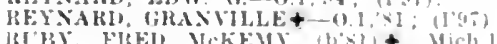

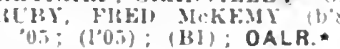

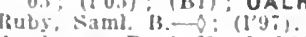

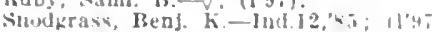

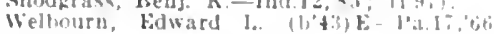
(1'3i).

Zeller, H. F, - 0.1,"05: (1.01)

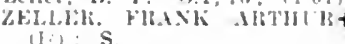

Zeller. Wird Clinton-0.25,"4i; (It)

UNIONDALE, 189, WELLS

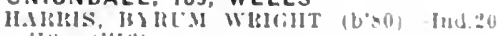

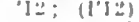

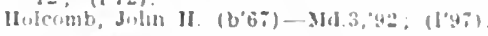

UNION MILLS, 500, LAPORTE

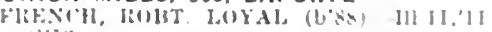

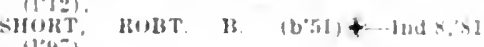

UNIONVILLE, 100, MONROE

Frilch, Jus, $Q$ : $(1: 1 \%)$

UPLAND, 1,080, GRANT

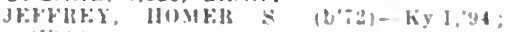

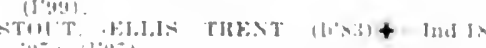

111: $(1,11 i)$

\%.

(

URBANA, 300, WABASH

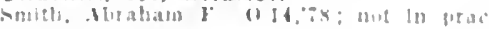

UTICA, 400, CLARK

VALEENE, 100, ORANG

SALE Juhn II $(1,311)$ -

M-Ibinahi, Juh (bit) his?

VALLONIA, 473, JACKSON

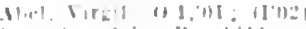

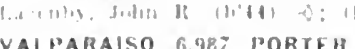

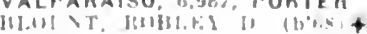

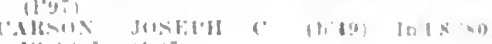

III i, : : $11+i 1$.

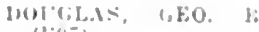

$+-111.4,01:$

(10i)

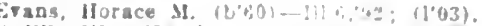

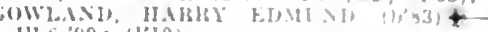

111.6.,03: (1'D0)

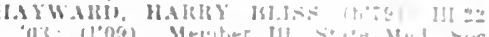

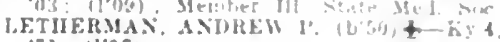
iI: $(1,97)$

Lewls, Eoren E. $\left(b^{\circ} 82\right)-\operatorname{lnd} 18,0^{2} ;$ iloi)

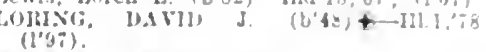

MT('HELI, HILEl), WM (b'-8)-I:1,20,03 (1) 10$)$.

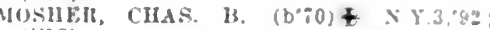
(1'23).

EARIT, OTIS HTIR,ESS

(see tiary.)

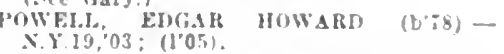
mise, Joint. II. (1,

juractice.

OALR.

OALR.

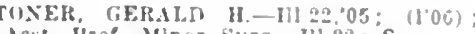

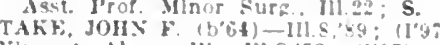

Vincens, Alonzo W- III.8,-2; (195).

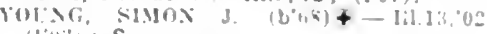
(I'):3): S.

VANBUREN, 1,189, GRANT

nerbyshIre. John FA-III.1,03; (1'01).

HCIALUSON. GLO. ri. (b'to)-lad 5.05 : $(1.05)$.

TONEY, JUHS M.-IDd.8,00; (1'01).

VEEDERSBURG, $1.75 \%$, FOUNTAIN

KIRK, EIIIITT W. (b)it)-Ind9: ÜJ (l'05).

McCOLD, CARL BYRON (b's3)-Ind.20,05 ;

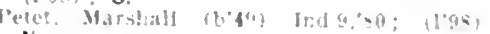

ROS. W.ILTER

(lias)

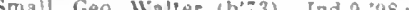

VELPEN, 250. PIKE

TAYIOR, INAL.E.-Ky.5,113: (1.03).

VERA CRUZ, 133, WELLS

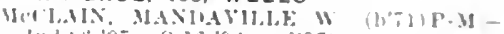

Ind:-6.9. $0.16 .905: 1195$

Warner, Willam-0.14,"is: 1

VERNON, 453, JENNINGS

HAYTIF. DMVID N. (U'TA

VERSAILLES, 486, RIPLEY

Beckelt, lien). T-Imd."

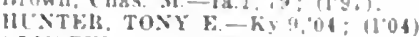

OLMSTED RLSSEL T. $(6,50)-0.1 .79$ $\left.(1)^{\circ} 9 \%\right)$

VEVAY, 1.256, SWITZE?LAND

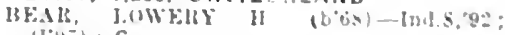
$(1,4), G$.

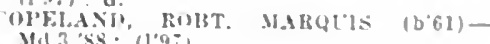
Ma. 38 : $(1.96)$

(III)A J J

S.IITH.

$(13 i)$.

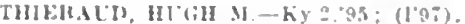

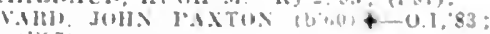

$(1,25)$

VICKSBU:G, 50, GREENE

(ule, W. H. - Inds.so; (I'9i)

VINCENNES, 14.895, KNOX

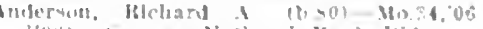

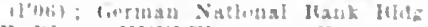

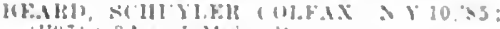

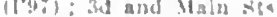

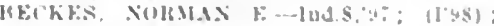

Hisluon lunck.

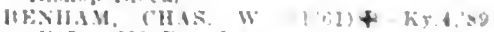

(1.9)

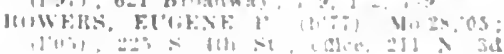

सा $21,8:$

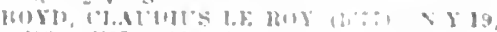

$0.8: 0.3): 114=0$

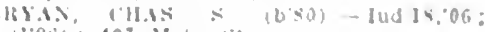

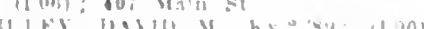

as it

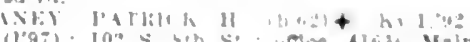

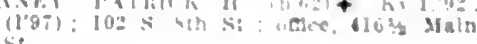


CARSON, SAML. J. (1;,0) - Ky.5,98; (l'0l): 104 E. Inortiand Ave.; ottice, $2 d$ and lortland Ave $\mathrm{S}$.

CCRTNER, MYRON i. (b's9) $\$$-ind.20'Il : (1'11); 1047 1/2 Fairgrumas st.; 10-12, 2-4, (111) Ś

DAVENPORT, WM. II.-I'a.2,'s1; (l'97); 319 N. 7 th St.; $8-10,1-3,7=9$

De lriest, Asa $13-1$ - Ind,2, 74 ; retired : 721 13 roadway

DOWNEY, LOI'IS J.-IO.2,02: (L'04).

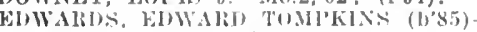
Ind.20, In: (1'10); 421 liart st

Fairhurst, omar-110.28,99: (1'02)

FRIG(;E, EINWARD IIENIRY (b'78)-Pa.2, 11: (1'12) ; 3 W. Locust St. ; offlce, $221 \frac{1 / 2}{2}$ Irain St. I $0-1=3,4, i-8$

FT:NK, VANCE A. (b'82) $₫$-Tenn, 1,09; (1'12); 511 Bunton St.; office, La Planté lilde.; $9-11,2-1: 5 . \star$

Glenn, Marlon (b'70)-Ky.1,02; (l'03); not hin metice: Nilus

GRIFFITII, BENJ, 13. (b'61)-Ky.6,'82, Mo.1, '84; (1'09); 408 barrett St.; ontlee, Ia Plante Iildg. ; $4-5:$ (151); OÁLR.

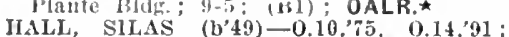
(l'97); not in practlce; $1022 \mathrm{~N}$. 9th St. (l'97); not in practlce ; $1022 \mathrm{~N}$. 9th St.
IIELD, HENRY W. (b'70) $\oplus-0.1,94$; (I’9 ') ; 613 Busseron St. ; $7: 30-9,1-2,7-8$. Jessup. Robt. B.-N.Y.10,83; (I'97); not in practice.

JONES, JOIIN GLOVER (b'78)-Ind.8,04; (I'04) ; 567 Perry St. ; offlce, $117 \mathrm{X}$. 5th st. $10-12,2-4,7-8$.

King, Ossian H. (b'86)-Ark.2,'11; Intern, (co. Kuap Sanitarium.

INAPI, $\triangle D A M$ B. (b'62)-Tenn.6,'9I; (1'97); 408 Broadway ; offlce, 402 Broadway; OALR. *

KNAPP, GEO. (b'60)๑-Tenn.6,'92; (l'00); 410 Broadway; offlce, 4 th and Broadway; (B1): OALR *

LESCHER, EDWIN R. (J'82) -4-Pa.2,'08

MAXEDON, THOS. H-Ky, 5,87 (l'89)

MAXEDON, THOS. H.-KJ'.5,'87; (l'93).

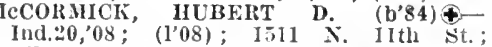
offlce, 16 s. 2d St. : $y-11.2-4,7-8$

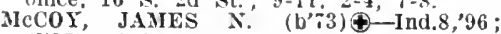
(1'97); 1122 Broadway; ofllce, $1261 / 2 \mathrm{~N}$ ith St. : 10-3: R

McDOWELL, JÁMES D. (b'74)-Ky.5,94; (1'97) ; 110 N. 7 th st.; 8-10, 2-4, 6:30-8. Ickowen, Thos. J.-N.X.10,82; (1'97); S. 4 th $\mathrm{St}$

Moore, Feuben G.-0.8,61: (l'9i) : Bos-

Woore, Feuben G.-0.8,61; (l'97); Bosworth Helghts; office, 221 Main st. ; $10-12,2-4 ; P d$.

Parrett. Harry M. (b'68) - Mo.27,97; (1'05) ; 823 Hart St. ; offee, $4091 / 2$ Iain St. ; $9-12$, $2-5,7-8$.

Pielemejer, Edw. F. (b'64)-Ky.1,94, Ky.5, '95; (1'99); 315 N. 5th St.; offle, 518 Maín St.

I'RATHER, SAML. A. (b'r4)థ-Ind.8,'05; (1'05); $16061 / 2$ N. 2d St.; $10-12,2-4,7-8$. RIISEY, JOHN P. (b'62) $4-0.1,89$; (1'9i); 606 J Haln St.; $8-9,2-5,7-8 ;$ 'S. RICHARDS, DAVID HAYDEN $\left(\mathrm{b}^{\prime} ; 0\right)-$ - Ind.9, '03; (l'03); 1125 Perry St.; offlee, 418 Main St. ; $8-11: 30$, I-5:30; ÓALR. *

SCHMADEL, JOS. W.-Ky.2,96; (1'97); 7 Main St.

Smitb, Wm. F.-0.2,'86; (l'97) ; 224 N. 2d

Soll. Bldg.

STEWART, CLARK E.-KY.1,97; (1'98).

Von Knappe, Wilhelm T. - $;(1997)$.

Von Tress, Edw. C.-Ind.8,'83; (1;97)

Williamson, Almira Bever-0.2,'81; (1'97) ; 430 N. 3 d St. ; $8: 30-5 ;$ G. $\star$

WABASH, 8,687 , WABASH

BENT, FRANK HOMER (b'79) \$-Ill.11,'06 ; (1'06); Member Neb. State Med. Assn.

Blount, Rufus F.-Ill.6,'65; (1'97); not in practice.

Brady, Thompson R. (b'43) - Ill.1,'69; (l'97).

Burke, George H. (b'63)H-Ill.10,'98;

OMER, WALTER A. (b'72)\$-III.I1,0I (l'01). IE()TSER, BERVIA A. (b'60)-Ind.8,'90;

IEWETT, LAWRENCE EMIIETT (b':3) Ind. 18, 06 ; $\left(1^{\prime} 06\right)$.
Jordan, Loran W: (b'53)-111.4,'83; (1'98);

OALR.
Jordan, Mlnnetta C. Flinn (b'68)-Mich.5, "11.); (1'0) : G.

king, clifford Henry-Ill.1,'81 ; (1'97).

I.A SALLE, GILASRT M. (b'70)-III.4,'95;

Moore, Perry G. (b'45)-0.8,'66; (1'97).

Nurphy, David S.-Ind 12,90; (1'00)

Ogle, Hercules $\left(b^{\prime} 44\right) \rightarrow 0 ;\left(l^{\prime} 99\right)$.

'earson, Eison Dorwin $\left(b^{*}+2\right)$ - Ill.4,'99 (1'99).

IIOLTY, RIOYD OTTERBEIN (1,84)Ind.20,'12; (1' I2)

MiTIf, I.OLIN W. (b'65) $\oplus$ - Pa.1,93;

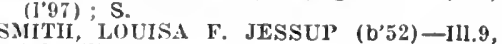
'82; (I'97)

Stewart, Jolin W, G. (b'61) H-I11.4,'89 ; $\left(1^{\prime} 97\right)$.

THOMPSON, NOAH HOWARD (b'7I)-111.1, '94; (1'97); S.

WILSON, JAMLS $\left(\mathrm{b}^{\prime} 65\right) \oplus-$ N.Y.10,'90 ;

WADESVILLE, I,000, POSEY

ARBURN, CHAS. (b'58)@-Ky.I,89; (1'97). IILLER, WM. LOUIS-Ind.8,'01; (l'01); R.F.D. 23 .

WAGONER, 100, MIAMI

Tamsey, Saml. G.-Ind.4,74; (It) ; not In practice.

\section{WAKARUSA, 859, ELKHART}

SENSENICH, AARON S. $\left(b^{\prime} 49\right) \oplus-111.1,71$; (I'97).

WAGNER, SAML. CHAS. (b'75)-Ind.8, 03 ; (I'03).

Fyland, Hyron Jay (b'83) - Ind.18,'06, Ind.20,09; (1'09).

WAKELAND (R.F.D., MARTINSVILLE), 30, MORGAN

Retts, John P.-Ind.8,'01; (l'04).

WALDRON, 400 , SHELBY KEELING, JAMES E. (b'67) $4-$ Ind.8,'91 ;
(I'97).

IcCain, Thos. J.-Ind.8,'80; (l'97)

RANDOLPH, DANL. FITZ (b'54)-Ind.8,'88; (I'9) ; ObG.

Shrout, Wm. 'Y'-E-Ind.I6,'9I; (1'98).

Washburn, Harry Augustus $\left(b^{\prime}, 3\right)-$ Ind.8, $97 ;\left(I^{\prime} 02\right)$.

WALESBORO (COLUMBUS P.0.), 148, BARTHOLOMEW

Carmichael, Wm. T. (b'43) - Ind.5,'85; (1'98).

WALKERTON, I,003, ST. JOSEPH

UENAUT, MATTHEW S. (b'63) $\oplus-I 11.1,97$; (I'98).

MIRANDA, WM. FRANLKIN (b'51)-0.1, '77; (l'98).

Neville, Rephaniah-0; (1'97)

Tracy, Stephen P. (b'53)-Ill.4,'86; (1'01).

WALLACE, $\| 6$, FOUNTAIN

CAPLINGER, CHAS. ARTHUR $\left(b^{\prime} 61\right) \oplus-\emptyset$; (I'02).

APLINGER, THEOPHLLS PARVIN (b'80) Ind.18,'07; (1'10).

\section{WALTON, 579, CASS}

AMPBELI

$\left(1^{\prime} 05\right)$

CARPENTER, CHAS. D. (b'49)-0.1,72; (1'00).

Dutchess, Chas. P.-Ind.6,'76; (1'97).

Hattleld, James F.-0.1,'97; (1'97),

WANAMAKER, 21I, MARION

Brown, Corydon S. (b'58)-Ind.9,'82; (l'97).

WANATAH, 573 , LAPORTE

Fisher, Wyman H.-Ill.6,80; (l'97).

PRICE, JESSE D. (b'72)-Ky.4, 00 ; (I'06)

WARREN, I,I89, HUNTINGTON

BLACK, CLAUDE S.IITH $\oplus$ - Ind.8, 05 ; (I'05).

BONIFIELD, WM. D. (b' 62$)-0.1,88$ (1'97)

Crandel, Thos.-E-0.2,'69; (1'97); not in practice.

Edgington, Benj. F.-Ind.12,'89; (1'97).

LAYMON, HENRY E. (b'67)-Ind.8,'97;

(l'97).
(I'98).

WARRINGTON, 300, HANCOCK

TITLS, CIHAS, (b'71)@-N.Y.10,94; (1'97).
WARSAW, 4,430, KOSCIUSKO

ANGLIN, GEO. W. (b'74)†-Ill.6,'05; (l'05). liurket, Calvin W. (b’38)-0.1,'66; (1'97); not in practlce.

Byler, James M.-H-Ill.4,76; (li)

DUBOIS, CHAS. CLIFFORD' (b'78)@-0.1, '06; (l'07).

IIINES, W. L.-Ind.10,92; (l'97)

OWARD, C. NORMAN (b'75)๑-D.C.I,'98; (1'07); OALR.

11utt, Ellswortli A. (b'66) 11--La.4,03; (1'05); D.

MeDONALD, ANGUS C.†-Pa.1,92; (1'97). Milice, Anna-Ind.12,"87; (1'97).

l'ownall, Emma-Ind.26,96; (l'00)

Reynolds, Norman Leslie (b'73) II-Ill.I5, 05; (1'11).

Rleher, Jacob D. (b'67)-Ill.4,'96; (1'97).

SHACKELFORD, TIFFIN J. (b'55)-Md.3, $82 ;\left(1^{\prime} 97\right)$.

Sinlth, James S. (b'45) P-MI-0.10,80; (1'97). WASHINGTON, 7,854, DAVIESS

boner, Geo. IV. (b'78)-Ky.5,'06; (I'06); OALR. *

('LARK, JACOE W. (b'42)-Ky.2,70; (l'97) UEFFENDALL, WM. B. (b'63) H-Ky.L,' 91 ; (1'97).

DONALDSON, AUSTIN I. (b'73)-Ind.8,'03; (l'03).

Goshorn, Noal Jefferson $\left(b^{\prime} 48\right)-0.1,74$;

HERR, IIENLY (b'65) 3-0.9,'94; (l'97). IIolder, Union H. (b'63)-Ind.8,'95; ( $\left.\mathrm{I}^{\prime} 00\right)$. IOLLINGSWORTH, ERNEST $\left(b^{\prime} 76\right)-\mathrm{Ky.2}$, 98; (1'01).

Jones, John N. (b'46)-Ill.I,'67; not in practice.

MAY, VANCE (b'66)-Ky.2,94; (l'98).

McPHERSON, SOLOMON L. (b'59)@-Ky.I,

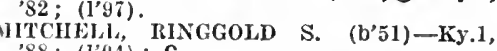
'88; (l'04); G.

PARR, GEO. 'L. $\left(b^{\prime} 47\right)-K y .2,74$; (1'97).

RANG, AHTHUR AUGUSTUS (b'8 Ind.20,'1I; (I'1I); $\mathrm{S}$.

SCUDDER, CHARLES P. (b'59) $\mathbf{0}-0.9,81$ (I'9i).

Sellman, John P. (b'74)-YId.3,96; (1'10)

SMOOT, DORA BROOKS (b'62)-Ind.8,'92;

SPINK, THOMAS FRANCIS (b'65) (9-0.9, 01; (1'02); U.

WADŚWORTH, HEILMAN CURTIS $\left(b^{\prime} \tau 8\right) \oplus$ -Ill.1,09; (1'12); S.

WILLEFORD, GEO.' W. (b'47)@-111.6,74; (l'97).

ILLEFORD, RALPH WALDO (b'83)YENNE, CHAS. H. (b'59)@-0.1,'84; (l'97).

WATERL00, 1,167 , DEKALB

BEVIER, FRANK (b'51)- $0 ;\left(l^{\prime} 97\right)$

BIROUGHTON, FRANK (b'60)-111.1,84; (I'97).

DARBY, A. BIRON (b'39)-0.2,63; (P97).

Schurtz, Espy Kerl (b'79)-Ind.I8,'07; (l'07).

showalter, Jos. Edwin (b'63)-0.12,'93: (''98).

WAVELAND, 676, MONTGOMERY

BALL, THOMAS ZOPHER (b'67)๑-Ill.I.

95 ; (I'97)

Kleiser, Arthur J. (b'62)-Md.3,'85; (1'97)

TRAUGHAN, KENT K. (b'57)-Ind.4,'78; (1'97).

Straughan, Walter L. (b'79)-Ind.8, 02 ;

AVERLY, 130, MORGAN

Benliam, Jobn F.-0.1,'90; (I'9T).

WAWAKA, 400, NOBLE

SYMOURE, CALVIN A. (b'74)-Ind.4,'76; $(1996)$

WAWPECONG (R.F.D., SWITCH), 205, MIAMI

KRATZER, EUGENE F. (b'77)-Ind.8,'03; (1'03)

WAYMANSVILLE, IIO, BARTHOLOMEW

Banks, Wm. H. (b'38)- $\rightarrow$; (l'97).

MARIS, JOHX I. (b'80) 6-Ky.5, 03 ; (l'03) ;

WAYNETOWN, 734, MONTGOMERY

BOUNNELL, HARRY M. (b'68)-Ky.2,'93; (l'97).

HAMILTON, ALBERT N. (b'48)-0.9,'71;

Hurt, WM. J. (b'50)-Ill.1, 73 ; (I'97). 
WEISBURG，125, DEARBORN

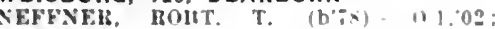
(1"04).

WEST BADEN, 746, ORANGE

ARTHUR, FIED IIFLIBYRT $\left(6^{\circ} \cdot 3\right)+$ hi

BOYD. CLAREXCE E. (b'i9) - hy, 5,02 (1'02).

NOWDEN, CHAUNCEY W. $\left(b^{\prime} 80\right) \downarrow-K y .4$

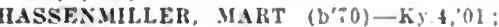
(1'01).

MILER, HENDEHSON I. (b'55)-Ky,a, 03; (1'04).

Ritter, John A. (b'59)-Ky.2,74; (1'97).

SHARP, HARIKY C. (b'6?) - K5.2,93: (I'98) : S.

WEIDNER, CARL, JR. (b'S6)-KY' 2,03; l’athologlst, West Baden Siprings II Inpital

Member Ky. State Med. Assn.

WESTFIELD, 670, HAMILTON

dllen, Wm. P.P.M-Ind 5:95; (l'9i)

RALDWIS, LINCOLN J. (b'60)-Ind.8,98 (1'98).

BONI, ARCHIRAIAD ILRERT (b'80) + Ind.20,'10: (1'10).

CARTER, LARUE D. (b'80) - Ind.8,04: (1'04).

FODREA, ZERI II. (b'56)Ð-NICh.1,'ss ; (1'97).

llunt, Alfred T.-I'-31-Ind 5.91: (l'03).

WEST LAFAYETTE, 3,867, TIPPECANOE

Bowen, Maurice II. (b'61)-0.6.'84; (8'96) not in practlce.

Isl'RKLE, JOHN C. Ind.IE,'06;

$\left(l^{\circ} 0\right.$ bi)

Pd.

DAVISSON, CARL VINTON (b'S1); Ind.20, '08: (l'08).

Hiner, Fredk. T. (b'54)-Pa.2,7i: (1'9i).

LOFIAND, WM. A. (b'64)-III.I,'89; (1'02)

MOFFITT, WM. R. (b'49) -Ind.8, 79 ; (1.9T).

\section{WEST LEBANON, 6\$2, WARREN}

WALE, HARRY WILFOKD $\left(b^{\prime} ; 9\right)-I 11.6,02:$ (I'13): also Memuer III. State Med. Sinc.

Johnson, Earl Emerson (b'S5)-Mo.35,'11: (1'11).

McInnls, Mary E. (b'55)-110.23,94; (l’97)

STEPHENSON, RICHARO (b'6i)-M0.28.

'98; $(1 ' 98)$; Op.

WEST LIBERTY (R.F.D., GREENTOWN),

60, HOWARD

Ware, Chrlstopher II. (b'4)-Ind.471: (I’9i).

WEST MIDDLETON, 200, HOWARD

MURRAY, FKEDK. NICHOLAS (b'82) Ind.20,09; (1'09).

WEST NEWTON, 300, MARION

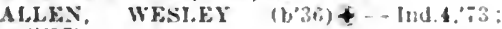

IcCaskey, Geo. Hadden (b'8i) -Ind.20,'11;

(I'11).

WESTPOINT, 300, TIPPECANOE

ROWLAND, CALVIN L. (b*2)-Ky.5,00: (104).

TUBBS, GEO. RILEY (b'i5)-Ky.5,'00 : (1'06).

WESTPORT, 675, DECATUR

Burroughs, James I'.- ; (1'97)

Hause, Wm_-E-0.2,65: (1'gi): not in practice.

Relley, Jobn II. S., Jr. (b'78)-Ind.8, 04: (1'08).

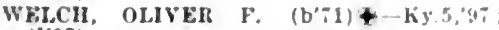
(1) 97 )

WEST TERRE HAUTE, 3,083, VIGO

lBelt, Mlebard $\left(b^{\circ} 48\right) \rightarrow$; $\left.\left(1^{\circ} 9\right)^{\circ}\right)$.

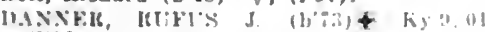
(1'02).

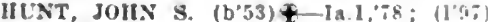

Mapes, WHmet L. (b'68)-Ind 9,$94 ;(105)$

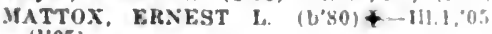
(l'03).

SIIANKIJN, VERNON A. (b'81) + Ind I '08: (l'06).

WESTVILLE, 503, LAPORTE

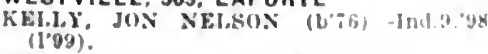

WHEATFIELD, 357, JASPER

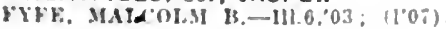

WHEATLAND, 400, KNOX

Henrickun, Ilatrdin M. (b'sii) - Ky.z:ll: (1'Il).

TADF, FILLAS H. (b'78) -Ind 8,05: (l'05) WOOI, HOHT. STANTON (b'3)-ind.8,05 (1'0J).

WHEELER，200，PORTEF

OOBBINS, ALLEN OTHO (b"70)-IHI.1:,03: (I'04).

WHEELING, 110 , DELAWARE

Tultle, John R. $\rightarrow$; (l'9i).

WHITELAND. 343, JOHNSON

Dally, Geo. W. (b'36) -0 : (1'03)

PHIPI'S. DAYID L (b't3)-Ky.1.92: (1'yz)

TERIIIXE, HLFLS WEHSTER (D'66) Ky, $, 01:-11.98)$

WILLIAS, LUCAS I'. V'. (b'62)-KF.I, 83 (1'06).

WHITESTOWN, 800, BOONE

B.ITTLE, I'ERIS Is. (1)'66)-Ind.8.95

Mullkan, Harrls W.-Ind.5,'S4; (I'9i).

Taslor, Oscar S. (b'72)-Ind.8,'95: (1'97).

WHITE WATER, II2, WAYNE

Jones, A. II. (b'69)-Ind 12,94; (1'98).

WHITING. 6.587, LAKE

DEWEY, EDW. LC'C1AN (b'6S) —-IH1.16, 04: (I'05).

DOOLITTIE, RERTRAM U. (b'80)ÐInd.10,05: $\left(l^{\prime} 05\right)$. Marshall (b'79)-Ill.8, 10 : $(1,10)$.

HOSKINS, GEO. H. (b'72)-III.6,'98: (!'98)

KOHR, THOMAS $W$. (b'42) -N.Y.5,84 (1'98).

IAAER, ARON J. (b'il) - Ill.8,93: (1'97)

PUTNAM, WILLIAM E. (b'61) \&-III. I, 89 (1'9i).

WILKINSON, 500, HANCOCK

GIBBS, EARL BAY (b'S1) - Ind.18,07 $\left.\left(l^{\prime} 0\right)^{2}\right)$

Jullan, Janies P.-Ind.5,'91; $(1997)$.

WILLIAMS, 350. LAWRENCE

MCFARLIS, JOIIS T. (b'67) \& Ky.2.94 (l'9i).

WILLIAMSBURG, 350, WAYNE

GRIFFIS, VIERL C. $\left(b^{\circ} \$\right.$ \& \&-Ind.18, 0 (1'07).

HELM, WM. N. (b'46)-0.2,7I; (1997)

WILLIAMSPORT, I,2\$3, WARREN

DE IANCEY, SIIELDON S. $\left(b^{\prime} 60\right)-$ III. s2: $\left(l^{\prime} 94\right)$.

PORTER, GÉ. S. $\left(b^{\circ} 70\right)-I 11.1 \pi, 01 ;\left(1^{\prime} 02\right)$ PU(iIl, FLORIN H. (b'61)-IIl.1,02 ' (1'02) WINAMAC, 1.607 , PULASKI

COLLINS, ILOSAID PHILIP (b'85)Ind.2n:11: (1'1I).

Marshall, Eilw. Humphrey (b'86)-Pa.1,12 (tenuporary permlt,'13).

MOSx, WM. C. (b'74)-III.I,99; (1'99).

Thunas, Juhn J. $\left(b^{\circ} 56\right) \rightarrow$; $\left(1^{9} 97\right)$

Thomas, Ray F, - Ill.17,06: (1'07).

THOM!SON, (IEO. WARREN $\left(\mathrm{b}^{\circ} 49\right) \mp$ Ind., 73 , 141.1,89; (1'99).

TIOMI:SON, WM. И. $\left(\mathrm{b}^{2} 44\right)+$ Mlch 290.

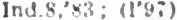

WINCHESTER, 4,266, RANDOLPH

Hosworth. Mlichard (b'32) - Mllch.l, ${ }^{\prime}, 5$ (1? 90$)$; not In practlec.

(HB:NOW'TH, FORHFST A (b'gs) -0.1, $a_{0 \rightarrow}(1, g i)$

Eirans, Jus J. $(1,40) \rightarrow$; $\left(l^{\circ} 9 \pi\right)$

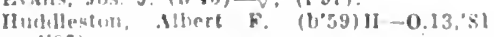
$(1,94)$

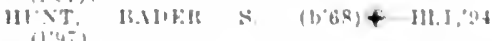

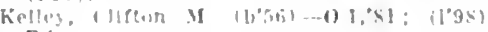

Pd.

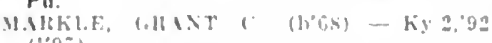

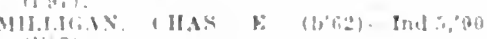

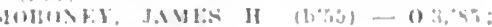

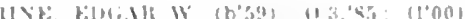

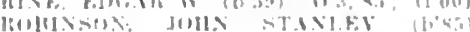

In!?

WINOFALL, 899, TIPTON

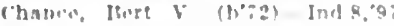

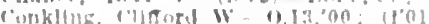

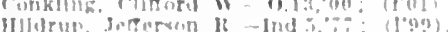

LONCFELLOW, THOS $W+-$ Ind 9.93:

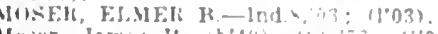

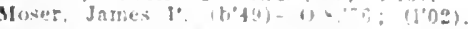

WINGATE, \$6, MONTGOMERY

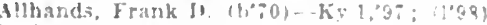

blckerson, Jamen II: (boj3) b: - O b b, $(1,3 i)$

WINSLOW, 932, PIKE

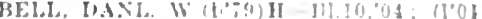

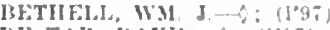

DE TAR UIVII $A$ (1)

IRELAWI, IENO. L. "(b'58) Ind 8,$82 ;(1997)$ MCGLASSUN, THOS I1-ky 4.44; $\left(1^{2} 98\right)$.

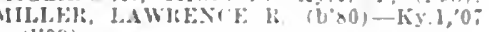
(109)

Whaley, leonard T. (b's9)-ky.2,12: (1'le).

WOLCOTT, 873, WHITE

BLICKEYSTAFF, ALGCSTLS J. (b':2) - Ind. 21.0\%: $\left(10^{\prime} 0\right)^{-}$

Smltb, Jullan A. (b'a)-Ia.1.90; (1'05).

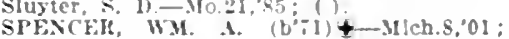
(102)

WOLCOTIVILLE, 627, LAGRANGE

BROI'(HTOS, FORBES II. (b'4)-Ind.8, 74: $(1,97)$.

FOSTER, JOHN HARVEY-III.1,00 ; (1'01).

R.ABICK, JOHX E. (b'si) \pm - Ind 10,05: $\left(1^{\prime} 05\right)$.

WOLFLAKE, 450, NOBLE

LUChFY, JAYLS E. (b'65) - Ind.8,92: (I'03).

WOODBURN, 300. ALLEN

Retts, Albert P. (b'6\%)-D.C.2.89; (l'9i).

Lueders. Albert G. (b'76) II-Mo.5,'98: (1'98); not In practice.

MOSER, EDW: (D'74)-Ill.4,05: (1'06)

WORTHINGTON, 1,732, GREENE

BEATY, WM. H. (b'52)-0.8,'76, Ky.1, 90 ; (1'97).

CLIFFORD, JOS. W. (b'63) - 6a9,95: (I'03)

DAVIS, WM. M. (b'il) - 110.28.99; (1'99)

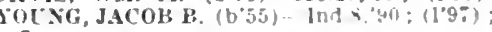
G.

WYATT, 200, ST, JOSEPH

Kuhn, Leslle A. (b'- $\$$ )-M1.16,05: (temporars permls,'13).

YEDDO, 203, FOUNTAIN

IrondeIn, Iamer II. (b'42) $\rightarrow$; $\left(l^{\prime} G i\right)$.

YEOMAN, 180, CARROLL

IIICKMAN, (IIAS. C. (b'T3)-IDd.8,0:: (1203).

YORKTOWN, 1,100, OELAWARE

Downing, Jonathan IS. (b'+4)-Ind.4; is; $\left.\left(I^{\prime} y\right)^{2}\right)$

DOWNINT, J. FRANK (b'4t) Ind 5,97 ; $(1, y)$.

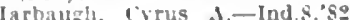

"HUTIT, CIRL HIOTON (b's-Inds (0): 11.03$)$.

YOUNG AMERICA, 500, CASS

Gray, Indrew J-IndL.'97: (1'9;)

Lybrook, lanlel Edar (b's4)-ind :0,'10: (1'in)

TBUH)OK, WM. F. -KY.1,"99: (I’9S).

YOUNGS CREEK, 75, ORANGE

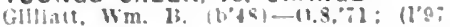

YOUNGSTOWN (RILEY P.0.), 110, VIGO

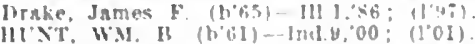

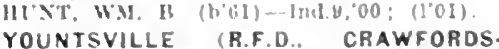

VILLE), 130, MONTGOMERY

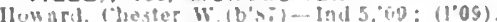
ZANESVILLE, 300. WELLS

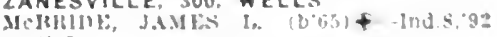

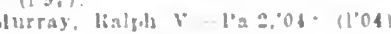

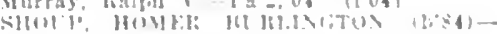

ENAS, 10 F D. NEBRASKA 92 JEN NINTS

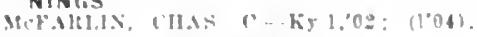

ZIONSVILLE. B40. BOONE

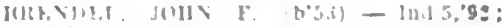

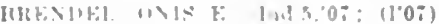

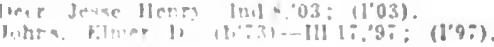




\section{OWA}

NoTE:-The general information of thls state Includes: Medical Law, State Board of Health and Medical Exaniners, State Medical Soclety, State fournal. County ofleers, City Health offcers, State Institutions, Hospitals, Sanatoriums rnd Charltable Institutions.

\section{IOWA}

Population ( 1910 census)

$2,224,771$

Number of counties.

Members Stato Society, Dec. 31. 1913

2,000

Area of State in Square Miles..... 56,147

\section{MEDICAL PRACTICE LAW OF IOWA}

Chapter xril, Tille xil. Code of the Practlce of Mediclne.

Seetion 25\%6. HOARD OF EXAMINERS : FXAMNATIONS : CERTIFICATES: The State IBoard of Medical Examiners shall consist of the physicians of the State Board of IIcalth, and the secretary of the Board of Health shall he secretary thereof. It shall hold regular. meetings in January and July and special ones as may be necessary, due notice thereof being given, at which it shall discharge the dutles contemplated by this chapter. All examinations shall be in wrlt lng, each eandldate for examination in any sehool of medicine being giren the same set of questlons corering anatomy, physiology. general chemlstry, patholngy, surgery and obstetrics. In materia mediea, therapenties, obstetrics. In materia mediea, therapenties, a set of questions shall be used corresponding to the school of medicine which the applicant desires to practice. The examlnation papers. when concluded, shall be marked on the scale of 100 , each candidate for examination first to pay to the secretary of the board a fee of $\$ 10$ therefor. The average required to pass shall be fixed by the board prior to tlie examination. Each applicant shall, on obtalning an order for examination, receive from the secretary a conficiential number which he shall place on his work when completed, so that the board. in passlng thereon, shall not know by whom it was prepared. Ill matters connected therewith shall be fled with the secretary and preserved for flre years as a part of the records of the board, during wisleh time they shall be open to public inspection. If the examination is satisfactory to three members of the board, It shall issue its certifleate, under jts seal signed by its president, seeretary and not less than three other members, who may, in the absence of the others, act as an examining board, and the different schools of medleine represented in the Board of Health shall be represented in sald number. This certifieate, while in force, shall confer on the holder the right to practice medicine, surgery and obstetries, and be conclusive evidence thereof. In all examinatlons nuade or proceedings had pursuant to the provisions of this chapter, any member of the board may administer oaths and take testimony in any manner authorized by law. Any one failing in his examination shall be entitled to a second one, wlthin three months thereafter, without further fee. If any persons shall, by notice in writing, apply to the secretary of the board for an examination or a reexamination, and it falls or negleets for three months thereafter to give him the same, he may, notwithstanding any provision of this chapter, practice medicine until the next regular meeting of the board withunt the required certificate.

THE CERTIFICATE; REC(ORi). Every certiflcate issued under this chapter sluall show whether it was granted on examination or diploma, and the school of medicine the holder praetices under. He shall, before engaring in the practice of medieine, file the same for record in the offlce of the recorder of the county in which he resides. who shall record it in a book provided for that purpose, which record shall be open to public inspectlon, and for which scivice the recorder may charge a fee of 50 cents, to be pald by the certifleateholder. The same record must be marle of the certifleate in any county to which the the certifleate in any county to which the
holder may remove and in which he proposes to practice.

Sec. 2578. REFUSAI, OF CERTIFICATES ; liEVOCATION: The Hoard of Medical Examiners may refuse to grant a certlftcate to aminers may refuse to grant a certificate to any person otherwise qualified and shatl physicin who is not of good moral charaeter, or who solleits professional patronage by agents, or who proflts by the acts of those representing themselves to be his agents, or who is guilty of fraudulent representations as to his skill and ability, or who is guilty of gross unprofessional conduct, or for incompetency, or for habitual lntoxication or drug labit; or if the certifleate has heen granted on false and frandulent statebeen granted on false and frandulent statements as to graduation or length of prae-
tice, the Board of Medlcal Examiners shall, to safeguard the pubic health, revoke the certiflcate in the manner herelnafter set forth. Before the revocation of any certificate issued by the State Board of Medical Examiners the licentiate shall have been afforded an opportunity for a hearing before the board. At least twenty (20) days prior to the date set for such a hearing, the secto the date set for such a hearing, the secretary of the State Board of Medical Examiners shall cause a written notice to be personally served on the defendant in the man-
ner prescribed for the serving of origlnal ner prescribed for the serving of origlnal
notice. In civil actlons. Said notice shail contain a statement of the charges and the date and place set for the hearing before the board. If the party thus notified fails to appear, elther in person or by counsel at the time and place designated in sald notice, the hoard shail, after receiving satisfactory evidence of the truth of the charges and the proper issuance of notice, revoke sald certificate. If the licentiate appear either in person or by counsel, the board shall proceed with the hearing as herein provided. The board may recelve and consider affidarlts and oral statements and shall cause stenographic reports of the oral testimony to be taken, which, together with all other papers pertaining thereto, shall be preserved for two years. If three members of the board, present at the hearing are satisfled that the present at the hearing, are satisfled that the licentiate is guity of any of the offenses the revoeation of the certificate the holder thereof shall not practice medicine, surgery or obstetrics in this state, for such times as the State Board of Nedical Examiners may determine. Any person aggrieved by any ruling or order entered under the provisions of this Act shall have the right of an appeal to the district court in the county where the alleged offense was committed, on giving notice to the Board of Medical Examiners of such appeal withln twenty days after the such appeal within twenty days after the entry of such ruling, order or judgment. Upon giving said notice, the original com-
plaint, affidarits, depositions and a duly cerplaint, affidavits, depositions and a duly cer-
tifled transeript of eridence taken upon the hearing before the State Boari of Medical Examiners shail be by the secretary of said board, certifled to the clerk of the district court of the county to which said appeal is taken. Said appeal shall be triahle at the next term of court in tise county to which said appeals taken conrening not less than ten days after notice of appeal is served. The appeal shall be heard and determined upon the affidarits depositions and eridence so transeribed and such further eridence as either party may offer. The provisions hereof shall apply to all cases not actually tried upon appeal at the time this Act goes into effect.

Sec. 2578h, UNPIROFESSIONAL CON1)UCT DEFINED. The law as it appears in Section 2578 of the supplement to the code, $190 \%$, is hereby amended by adding thereto the following:

The words "gross unprofessional conduct" as used in this section are hereby deelared to mean:

1. The procurlng or alding or abettlng in procuring a criminal abortion.

2. The employment of what are popularly known as "cappers" or "steerers" ii procuring practice.

3. The obtaining of a fee on the assurance that a manlfestly incurable disease ('an he permanently cured.

4. A wilful betrayal of the professional secret to the detriment of the patlent.

5. Any advertisement of medical business in which untruthful and improbable tatements are made.

6. Any advertisement of any kind, of any medicine or means, whereby the monthly periofs of women can be regulated or the menses be re-establisbed if suppressed.

7. Conviction of any offense involving moral turpitude.

8. Wilful neglect of a patlent in a critical condition

9. Accepting any fee for service as a than such as is allowed by the court, or that the court is made cognizant of.

10. The splitting or division, or agreelng to split or divide, any fee or charge paid or to be paid on aceount of any operation performed or to be performed, upon any patient, with any other person for any serries performed or agreed to be performed, or in any consideration of such other person accompanying, bringing or referring to hlm accompanying, bringing or referring to hlm a patlent for any treatment or operation, or on account of such other person assistoperation without the knowledge and consent of the patient or the person having the patient in charge or the patient's admin. istrator or exeeutor in the event of the patient's death.

11. Knowingly misstating the cause of a cleath in a death certificate except, where an exact statement would render the physician liable to suit for libel, or subject

Sec. $25 \% 9$. DEFINITION ; EXEMPTIONS ; MIDWIVEs: Any person shall be held as practicing medicine, surgery or obstetrics, or to be a physician, within the meaning of this chapter, who shall publicly profess to be a physician, surgeon or obstetrician, and assume the duties, or who shall make a praetice of prescribing or of preseribing and shail publicly profess to cure or heal; but it shall not be construed to prohibit students of medicine, surgery or obstetrics, who have had medicine, surgery or obstetrics, who hare had not less than two courses of leetures in a medical school of good standing, from preor gratuitous service in ease of emergency, nor to prevent the advertising, selling or preseribing natural mineral waters flowing from wells or springs, nor shall it apply to sure the pulic Health Servi Arm, Navy, nor ians or midwin the Board of Examiners a certificate permitthe Board of Examiners a certificate permittobstetries without a diploma from a medical school or examination by the board, nor to physicians, as defined herein. who hare been in praetice in this state for flve consecutive 
years, three sears of which time shall have been in one locallto ure to fllug lrescrlptlons by a reglstered liharmaclst, nor to the advertsing and sale of patent or proprlatary melicines.

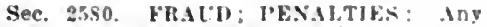
person who shall present to the Boarl if Medical Firaminers a traudulent of false diploma, or one of whleh he is nut the rlightful owner, for the purbose of bropuring a ceriffeate as hereln provilud, or shall flle. or attempt to flle, with the recorder vit any county la the state the certifcate of innther as bls own, or who shall falsely persillate atty one to whoin a certiflcate has leen sranted ly such boat. or shall pratice medicine surgery or obstetrics in the state medlcine. surgery or obstetries in the state recond the certiflcate herein required. and record the certlflcate herein regulred, and
who is not embraced in any of the excepIons contalned in this chatiter, or who cun. Inues to practlce medlcine, surgery ir obstetrles after the rerocation of his certiflcate, Is ruilty of a mistemeanor. and, in than $\$ 300$, shall be fined not lest prosecutlon, and shall stand committed if prosecution, and shall stand committed in the county jall untll such fine Is pald: and thoever shall flle or attempt to fle with the
recorder of any county in the state the correcorder of any county In the state the cipparty to whom it was granted or jssired erased, and the clalmant's name inverted, ot shall flle or attempt to flle with the llosed of Medical Examiners any Palse or forged afflavit of Identlfication. shall be cullty of forkery.

Sec 2581. ITINERANTS; FEES; PEX. Aitiks: Every physlclan practlelng mediclne. surgery or obstetrles, or professing no attempting to treat, cure or heal diseases, allmeats or injuries by any mediclne. appliance or method, who by hlmself azent or employee goes from place to place. ir from house to house, or place to place. nt from adrerlisements sollcits rersons to meet hin for professlonal treatment at places other than hls fiffice at the place of his resldence, shall be consldered an ltinerant physleian: and any such Itinerant physlesin shall, in addition to the certiflate elsewhere prorlated for in this chapter. prome from the State Board of Merlleal Examiners a license as an itinerant, for which he shall pas to the treasurer of state, for the use of the state of lowa, the stum of $\$ 250$ per annum. on payment of this sum. the secretary shall lasue to the anplicant therefr a lleense to practlce withln the state, as an Itinerant physiclan, for one year from the date tbereof. The bord may, for satisfactory reasons, refuse to jswile such llcense, or may cancel such liernse on satifictory evldence of Incompetency or grose immorality. Any person practlcing medlcine as an itinerant phyalelan, as hereln defined, wlthout having procured such lleense shall the mullty of a miademeanor. anis on confletlon thereot shall be fined not less than $\$ 300$. nor more than 8500, and costs, and shall ho eommltted to the cousty jall untll such fne is pald: provlded howerer, that nothing hereln shajl we construed in present any physician ntherwlse legally gualifed from attending patlents in any part of the state to whem he may lin called In the regular course of huslness, or In consultation with rther physiciang.

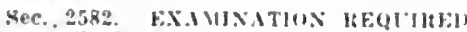
From and after Jan. 1. 1894. alf peronns be anning the practice of medlclne in the vat of Iowa muat submit to an "ramination os set forth in this chapter, alde. In addituon thereto, shall prevent illulumas frum modteal colleges recognized ay in gomel standlug lo the state licarl of Medlcal Fixnmblers, ant all versons recelving thelr diplomas siblive quent to Jan. I. IS:19, shall proment erideue of harlug attended four full enurwis of stud of nut less than twenty-six weeks earh, m (wo) of whlch shall have lwen hilver la an! one rear. The stalu llowal rif Mulleal ks aminers shall examlso tho graluatey of 140 medical debartinenty of the state l nisurs ts

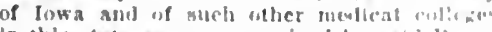

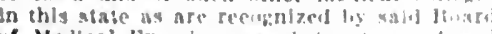

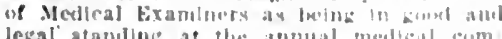

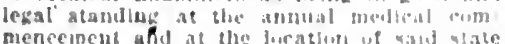

unlrerslty and other inedical colleges re. apectively.

Section 1. RH'lltocity: That sectlon two thousand, the hundred and elghty-two (2582) uf the cralo bo and tho same for lowing :

(a) I certiflcate of replatration showing hat an examinatlon has leen made by the proper bard rif any state, on which an aver age grade of not less than seventy-llo (75) wer cent. Was awarded, the holder thereof having been at the time of sald examination the legal possessur of a diploma from a medleal college In good standing in this atate, may be accepted, in lleu of cxaminathon, as erldence of yual!flcation, but in case the scope of said examination, was less than the scroce of said examination was less than that prexcribed by this state, the applicant may he refulsed to slibmit to a supplentental been covered.

(ii) A certifleate of registration. or license ssued by the proper board of any state, may les accepted as eridence of qualification for reglstration in this state; provliled, that the bolder thereof was at the lime of such reflatration the legal possessor of a diploma lssued los a medical collece In cond standing Insued ly a medical collece ln gond standing In this state, and that the date thereut was
prlor to the legal requlrement of the cxam. nation test in this state. The fee for such eglstration shall be fifty dollars $(\$ 50)$

(c) Applicants for reglstration under the provisions of clauses " $a$ "and " $b$ " of this scction sliall make proper application upon forms furnished hy the brard and flle salte vecretary of sald board. If the credentlals of the applicant are complete and roxular. the secretary shall lssue a temporary permit authorizing the sald ajplicant to practlce in lowa during the period interrening betweer. the date of flling his application and the date upon which the bond authorizes or refuses the issuance of a permanent certiflcate, hut not more than one such nermit hali he lswued to the same applieant. The temporary permit hereln prusidel for shall arply noly in apulicants for a errtiflcate under reclprueal agreentents with other

Sec. 2. If by the laws of any state, or the rulings or deeisluns of the approprlate ofncers or boards therent. ally burten. nbligia tion, requirement. distualifleation or disabully is put on rhysicians rezistered in this atate or holding diplomas from medical col. leceg in thls state which are In good stanis ing therein, affecting the right of said nhrs! clans to be registered or adinitted to pracilco n sabl state, then the same or like pur dens, oldinations, requirements. dispuallften. don or dlwability shall be fut rin the registration in this state of physicians pezistered

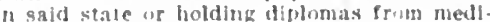
cal colleges situated lhercin.

Alproved Itarch 15. A. I lant.

- Is amonded by the ruanty-serenth Gen. eral Asxembly, thapter for.

\section{STATE BOARD OF HEALTH AND MED} ICAL EXAMINERS

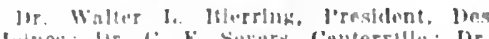
Mnines: lir, li F sevirs centerrille: Irr

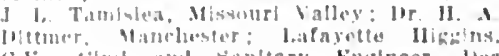
cte iful and sanitary Englneer, les

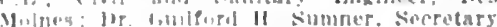

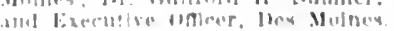

IOWA STATE MEDICAL SOCIETY IInTor re 191:-11

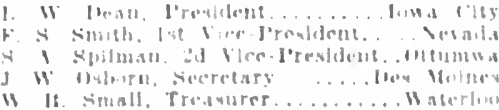

State Journal

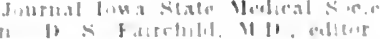

Councilor Districts and offeers

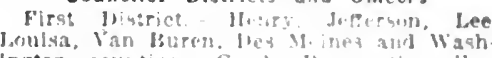
Ington courities. C. I H... Cs. licuncllor, Washlngtron

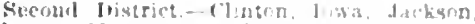

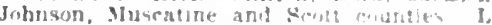

Dean, Cruncliar, Jisua l'ts

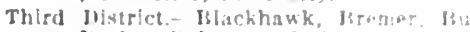
chanan, imeler, Detanar", buburat, Jranklin, Wright and llardin countes.

Fourth listrict.-Allamakee, Cercu ciopifi

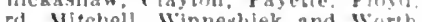

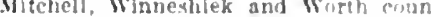

Fifth Ibistrict-- Renton, Cedar. Cirundy Junes. Jinn, Marshall and Tama cumntles i. H. Crawford, Counclior, Celar Raplels. wixth Instrict-Jaris, Jusper, keokuk, counters. II. r. Fischiach. Cruncllor Ilbla. Serenth listrict-Dallas, Madison, Marn, lolk. Stroy and Warren countses. J. W. Cokenwer, Councllor, Jes Molnes.

Elghth Wistrict. - Niang, Appanonse Wayne, Clarke, Jecatur, Fremint, Lucas, are. Itingabid. Taylor and l'nlon countle

Ninth liktrict. - Adalr. Sudibon, Cass, Guthrle, llarrionn, Mills, Montgomery, lotta wattarnie and shelly counties. A. L. Brooks, Councilor. Audubis

Tenth Dlstrict.-Palo Alto, Pocahontas, Winnebago, Bonne, Calh un, Carroll, Craw ford. Emmet. Girene, Hamilton, Hancock Humboldt, hossuth and Webster cuunties. I. J. Kenuffe, Councllor, Algona.

Elesenth listrict.-Buena Vista. Cheroke, Clay", Dichinson. Wa. Lyon, Jonona. G'Itren. Osceola. Mymouth. Sac. Sloux and Woodburs countlies. F. C. Moorehead, coun cilor, ha Grore.

\section{Component County Societies of the low} State Medical Society

AINIII COLNT

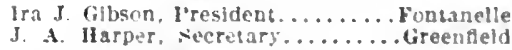
AlDMS COLXTY

F. P. Amdor, l'resdlent............ Carbon ALLAMAKEE COLXTY

I. C. Crawfort, President.......... Waukion f. Wominger, Seeretary.......... Waukon

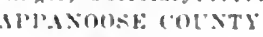

C. I. Tillmont, Presldent........ Centerrille

II. A. Ilarrls, secretary. ....... Centerville ALDITHA COLNT

I’. James, I'resident.......... Audubom BE.STON COLNTS

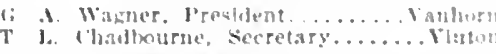
BI.ACKIIWK COLNTY

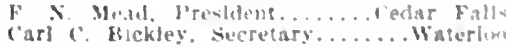

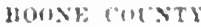

llark innes, l'remblent.

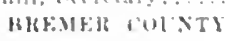

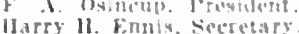

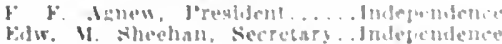
IIIFAT SISTA CUINTH

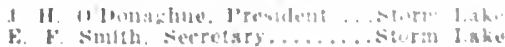
M.TI.l: 1010)

"aul le. Jurrolgho l'requlese.

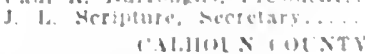

$$
\begin{aligned}
& \text { Midrary. I'ronddent }
\end{aligned}
$$

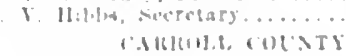

1 . B.S (11:0T)

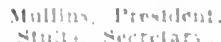


CEIDAR COUNTI

I. W. Byrnes, President........... burant

I. II. IIoffinan, Secretars............ Tipton CERRO GORDO COUNTY

C. C. Stockman. I'resident......Mason City

S. A. O'brien, Secretary..........Mason City CHEROKEE COUNTY

T. I. Iong. I'resident.......... Cherokee

I. 13. Cleaves, Secretary........... iherokee CIICKASAW COLNTY

1. D. Melinley, Iresident.......... Lawler

I. E. Gardner, secretary.... New ilampton C $\mathrm{L}, \mathrm{AY}$ COUNTY

If. Porter Wert\%, President..........spencer

1: 13. Snyder, secretary.............Everly ('TAITON COLNTI

11. II. Clark, I'resldent...........MeGregor

J. D. Brownson, seretary........... Monolla CLINTON COUNTY

11. C. Moffett President.

A. Smith, Secretary................ JALIAS-GUTHIIE COUNTIES

A. P. Free. l'resident..................... Perry DAVIS COUNTY

Roy Swinney, President............Troy

H. C. Young, Secretary........... Bioomfleld DECATUR COUNTY

I. S. Coontz, President....... Garden Grove DELAWARE COUNTY

M. E. Dittner, President.......... Colesburg

E. J. Wlntenburg, Secretary...........Delhi DES MOINES COUNTY

C. H. Magee, Presldent..........Burlington

Julia M. Donahue. Secretary..... Burlington DICKINSON COUNTY

G. L. Atkins, Presỉdent...........Snperłor

C. S. Schultz, Secretary............. Spirt Lake DUBUQUE COUNTY

H. T. Walker, Presldent......... Dubuque

A. M. Ioes, Secretary ............ Dubuque EMMET COUNTY

M. E. Wllson I'resident.......... Esthervllle

i. E. Bradley, Secretary.......... Estherville FAYETTE COUNTY

Walter H. Fox. Presldent.........Waucoma

T. $\mathbf{N}$. Walsh, Secretary............. Hawkeye FLOYD COUNTY

Chas. J. O'Keefe, President.... Marble Rock

Chas. 0 . Yenerlch, Secretary....... Rockford FRANKLIN COUNTY

w. R. Arthur, Presldent..........Hampton

J. C. Powers, Secretary.............. Hampton FREMONT COUNTY

H. J. Piper, Presldent.......... Randolph

A. E. Wanamaker, Secretary....... Hamburg GREENE COUNTY

G. W. Kester, Presldent....Grand Junction

Benj. Hamilton, Jr., Secretary......Jefferson GRUNDY COUNTY

1. H. Thielen, Presldent.....Grundy Center

J. A. Uran, Secretary..........Wellsburg GUTHRIE COUNTY

(Included in Dallas-Guthrie Counties) HAMILTON COUNTY

C. J. Christiensen, President.........Jewell

Forest F. Hall, Secretary...... Webster Clty HANCOCK COUNTY

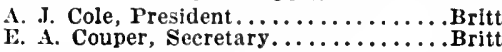
HARDIN COUNTY

Frank Siedenburg, President..........Alden

Wm. E. Marsh, Secretary................ HARRISON COUNTY

H. A. Cobb, President............ Dunlap

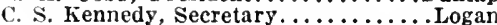
HENRY COUNTY

D. S. McConnaughey, President.... Wayland HOWARD COUNTY

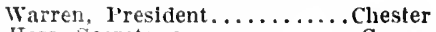

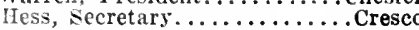
HUMBOLDT COLNTY

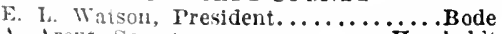

A. Arent, secretary............. Humboldt
IDA COUNTY

1. I. IBifty, I'resident........Battle Creek IOWA CounTy Tas. F. Noe, Presiclent............. Amana JACKSON COUNTY

I. N. Loose, Presldent..........Maquoket o. Ristine, Secretary.........Maquoketa JASPER COUNTY

I. Koeper, Presldent.............. Baxter iI. P. Engle, Secretary ............... JEFFERSON COUNTY J. v. Bean, I'resldent...........Fairfleld JOIINSON COUNTY C. S. Chase, Presldent........... Iowa City
Kella w. Stewart, Secretary..... Iowa City JONES COUNTY

A. G. Hejinian, President.........Anamosa

Thos. M. Redmond, Secretary..... Monticello KEOKUK COUNTY

C. B. Taylor, President........ What Cheer

J. A. Dulin, Secretary........... Slgourney KOSSUTH COUNTY

Judson Laughlin, President......... Ledyard
E. C. Hartman, Secretary........... Algona LEE COUNTY

John R. Walker, Presldent.......Ft. Madlson
E. G. Wollenweber, Secretary...... Keokuk LINN COUNTY

R. B. Hasner, President......Cedar Raplds Jennings Crawford, Secretary... Cedar Raplds LOUISA COUNTY

F. A. Hubbard, Presldent, Columbus Junction

S. J. Lewls, Secretary........ Columbus Clty IUCAS COUNTY

3. B. Robb, President ........... Russell LYON COUNTY

L. L. Corcoran, President...... Rock Rapids J. M. Crowley, Secretary......... Rock Raplds MADISON COUNTY B. D. Little, President.......... Patterson MAHASKA COUNTY

II. Chiloress, Presldent.......... Oskaloosa

A. C. Spurgln, Secretary........... oskaloosa MARION COUNTY

J. M. Weiss, President...........Knoxville

c. W. Cornell, Secretary............ Knoxpllle MARSHALI COUNTY

F. P. Lierle, Presldent........ Marshalltown Ralph E. Keyser, Secretary.... Marshalltown MILLS COUNTY

F. IT. Agan, Presldent...........Glenwood

James M. Donelan, Secretary........Glenwood MITCHELL COUNTY

I. A. Hanson, President............. Osage Guy A. Lott, Secretary.........

J. A. Thomson, President......... Onawa MONROE COUNTY

C. A. Jenkins, Presldent.............. Albla

T. R. Jackson, Secretary. . . . . . . . . Albia MONTGOMERY COUNTY

L. A. Thomas, President......... Red Oak Velura E. Powell, Secretary........... Red Oak MUSCATINE COUNTY

E. K. Tyler, President...........Muscatine

w. H. Johnston, Secretary........... Muscatine O'BRIEN COUNTY

W. C. Hand, President ............ Hartley J. B. Sherbon, secretary............ Hartley OSCEOLA COUNTY

F. S. Hough, Presldent............. Sibley F. P. Winkler, Secretary...................... PAGE COUNTY R. J. Matthews, President.......... Clarinda
B. S. Barnes, Secretary........ Shenandoah PALO ALTO COUNTY Edw. D. Beatty, President.................. Crallard PLYMOUTH COUNTY W. T. Shepard, President..................... Mars
POCAHONTAS COUNTY

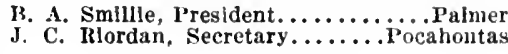
POLK COUNTY

Granville $\mathrm{N}$. Kyan, I'resident....Des Molnes . F. Duhlgg, Secretary......... Des Molnes POTTAWATTAMIE COUNTY

Frank T. Seylert, I'resldent..Councll Blufts

rant Augustine, Secretary..........Minden POWESHIEK COUNTY

P. F. Somers, I'resident......... Grinnell RINGGOLD COUNTY

J. H. Goad, Presldent. ........... Ellston Sam'l Balley, Secretary....................... Ayr SAC COUNTY

J. C. Iwerson, President............. Early SCOTT COUNTY

. H. Schroeder, Presldent........ Davenport Secretary......... Davenport SHELBY COUNTY

S. II. Walters, Presldent........... Irwin

Herman Bocken, Secretary............. Harlan SIOUX COUNTY

F. J. McAllister, President.........Hawarden

A. F. De Lespinasse, Secretary... Orange City STORY COUNTY

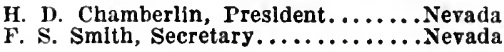
TAMA COUNTY

E. R. Smlth, President............. Toledo
A. A. Pace, Secretary........... Toledo TAYLOR COUNTY

H. F. Dunlavy, President..........Bedford

C. M. Paschal, Secretary............... Bedford UNION COUNTY

J. W. Fry, President............................

T. V. Golden, Secretary........... Creston VAN BUREN COUNTY

G. R. Neff, President.......... Farmington Edw. W. Pahl, Secretary................... WAPELLO COUNTY

E. G. Barton, Presldent......... Ottumwa John $\mathrm{F}$. Herrick, Secretary........... Ottumwa WARREN COUNTY D. P. Judkins, Presldent.......... Indianola WASHINGTON COUNTY II. C. Terry, President........ Brlghton WAYNE COUNTY

K. R. Huff, Presldent........... Linevllle
B. S. Walker, Secretary.......... Corydon WEBSTER COUNTY

W. W. Bowen, President.........Ft. Dodge G. Baldwin Palmer, Secretary..... Ft. Dodge WINNEBAGO COUNTY

H. F. Thompson, President........Forest City WINNESHIEK COUNTY

H. H. Thomas, Presldent.......... Decorah

Harriette B. Amy, Secretary......... Decorah WOODBURY COUNTY

P. B. McLaughlin, Presldent..... Sloux City Chas. P. McHugh, Secretary.... Sloux City WORTH COUNTY

L. G. Hewitt, President......... Northwood
E. H. Dwelle, Secretary........ Northwood WRIGHT COUNTY

R. D. Bernard, President..........Clarion E. D. Tompkins, Secretary...............

HEALTH OFFICERS IN CITIES OF 5,000 POPULATION AND OVER

Boone.................. A. Healy Burlington .............. Wehman Cedar Falls.............. L. Hearst Cedar Rapids................ Anton Tlusty

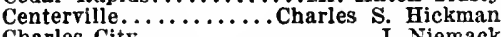
Charles City................... Niemack Clinton.................. R. Sugg Creston ............ W. Fry

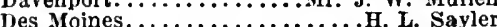

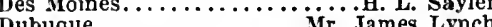

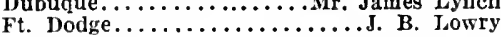


Ft. Madison:

Girlnnell.

Jowa Clis.

Meokuk......

Mason City.

Muscatine.

Oelveln.

Otrumwa.

Sloux Clty

Waterloo.

Webster City.
II (avey in F E Ilaris Tharles A. Dimuno $\because \because$ I. I. Ierle b. C: Echterasch chas. S Irelevis ..J. A. Iful H. W Coursho . Furreat liall

Ame STATE INSTITUTIONS

lowa siate College Mosplial, Ames. lowa. Established 1884; for studens only; 15 beds; C. G. Tilden, phystclan.

\section{Anamosa}

Reformatory Hospltal, Anamosa, Iowa Fstablutied 1874: prifiate: general: :beds: T. C. Gorman, physlcian in charge.

\section{Cherokee}

Cherokee State Hospital, Cherukee. loxa. Established 1902: for the Insane 1,100 beds: M. N. Voldeng. medleal superintendent.

\section{Clarinda}

Clarinda State Hospital. Clartuda

Iowa Established 1855 ; pulilic: for the Insane: 1,160 beds: Max F. Wilte, M.I. superintendent.

\section{Counell Blufis}

Iow School for the seaf. Councl Bluft, Iowa. Establlshed 18is: publlc: deal: 300 beds: A. P. Hanchett, physl clan in charge: Henry W. Rothert, superIntendent.

\section{Daveapert}

Iowa Soldiers' Orphans' Home. Daren port, lorra. Fistablished $1865 ;$ F. J. Sesslons. superintendent.

\section{Eldor}

Iowa Industrial school for Boys, El dora, Iowa. Fstablished 1868; 500 heds: W. I. Kuser, superintendent

\section{Ft. Madisen}

Iowa State Penitentlary Hosplial, Fe Madlson, Iowa. Fistabllshed 1849; gen ral: for prison Inmates: 30 beds; J. W and Austin F. Phllpot, nhyalclans in charze.

\section{Glenwood}

Iowa Instltution for Feeble. Minded Chll dren, Glenwool. Iowa. Fistabllabed 19:6 public: feeble-minded: 1,100 beds in dormitory: 60 beds in hospltal: George Magridse, medlea! superintendent.

\section{Indepeadence}

Independence state Iloupltal, independ ence. Iuma. Establlabed 1 kig: publle for the Insane: 1,22: beds: W. I'. 'rum backer. medical superlntendent

\section{lowa City}

State Culreraly Humeopathlc llospltal. lowa Cliy. Iowa. Lisiablisherl 1s:-in: pub lle: general: 50 beck: T. l. IJazard M.D. amperintendent.

State linlterslty llosplial lowa fliv. Iowa Estabilsted fsio: publle: conersi: 200 beds: I. W. Dean. "neullral Alrectur Jasephine Creelnian, M.I, sulintutend enc.

\section{Kaoxrllte}

staic Ilusplial for Inebriates, hinox

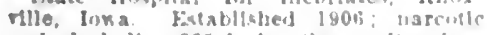
and alcoholle: 225 leets: licorge flunolume medical suprinterdent

\section{Markhalltewn}

lowa Soldlers JInme Ilengultal Mar

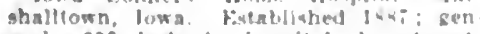
eral: 200 leets in hospltal inpartment

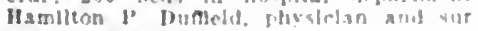
sern-in-chle?.

Mitehellville

Induntrisl sichnol sue tilrts. IIR lindl

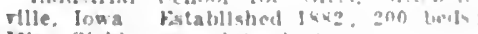
Wi*a sickle, superlntendont

M1. Pleasant

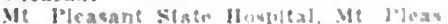

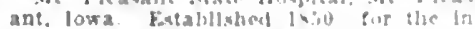

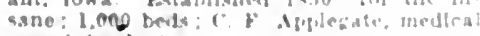
superinienden?

\section{Oakdale}

Stato sumatoriun for the Treatmen: of

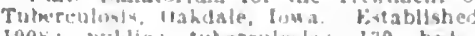
I9ns: public: iuterculouls: 130 beds II. Scarbopolith, merllal suberintend enil.

Vinton

Juwa f'ullege for the HInd, Vintons.

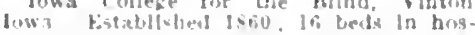

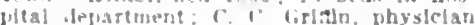

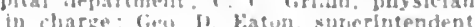

\section{HOSPITALS, SANATORIUMS AND CHAR.}

ADEI ITABLE INSTITUTIONS

Scott Sanatorlum. Ndel, lowa Estab. Ished 1904: nrliate: general: 10 toels: Wialter E. Scott, Dbyislclan In charge.

\section{Akron}

Ikron Private Hospltal, Ikron, lowa Albia

herr. physlclan in iharpe.

Albla Hospltal, Albla, Iowa Eutab. llshed 1908: prlvate: general: 15 beds: R. P. Mhler, pbyslclan in charge.

Algona

Nzona Ifospital. Algona lowa Estab lshed 1907: private: surgloal: 10 heda M. J. Keneflck, surgenn In charge.

Alt

Alta Ilospltal, Alta, luwa liplvate 2 bods : J. W. Mortson, C. H. Johnson

\section{An amosa}

Mercy Hospltal, Anamosa, lowa. Fatalllshed 1893: general: 35 hets: con. ducted by sisters of Mercs; A. G. Heflnlan. surzeon In charge.

Andrew

Jackson County Poor rarm. Andrew Atlantle

Atlantlc Hospltal, Atlantle, Jowa. Facablished 1903: private: Feneral: 25 beds: $r$. W. Whider, prezldent of medlcal stan: Mlss C. Lears, R.N. superintendent.

\section{Bloomfleld}

Bloomfleld llospltal. Mloomfeld, Iowa Establlshed 1873: private: Eeneral: 2f beds; Eldjah shelton. physlclan In charge. Boone

Eleanor Moore Hosultal. Boone, Iowa batallished 1900: mbllc: general: 3ileds: Mlss louella Hristol. R.X. super. intendent.

\section{Burlineton}

Burlington Jospltal, Kurlington, Iows bistabllstred 1895: puthlc: 65 beds: Miss (' keeler, superintendent.

fies Molnes county foxptsouse and $\mathrm{I} s \mathrm{y}$ lum, Iturllngton, Iowa. KF.W. 3. FulIlr; l:0 beds: il A Vorwerk, whyslelas In charge: $k$ w dlevander, sumerthsendent?

Meriog flosgltal, Jurlington, Jowa. Eotabllwhed 1093; fiublle: 30 beds

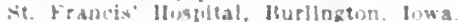
Futabllshed iscib: urirate: reners!: io biends

Carroll

Si Anthony"a llowplial. Iafroll, lowa

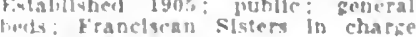
Cedar Rapids

Merry Ifospltal. Certar Itaplda. Ions

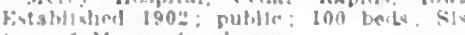
bore of veres. In eliager

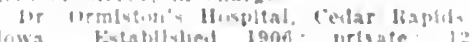

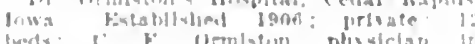
lineds: "

rbas:

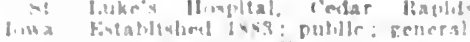

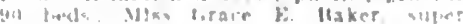
inforident

Craterville

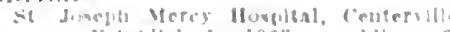
lowat Fontallebel 1903 publle. one

Chariton

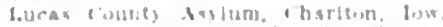

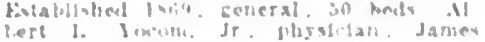

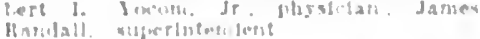

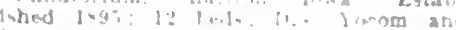

Charles city

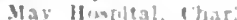

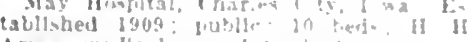

Amon. medtral suberlnterders

Charlotte

Clinton courty Powr Fam?. I hasl it

lowa. Fistablhshed Intil: publye : to teet

w. $r$ kndist, JP. sugerlaterident

Charter Oak

rharter rak llospltal, iharter oak

lowa Fistablished 1911: frirate: ien.

eral: 6 beds: G. S. Waterhouse, plys clan In charge.

Cherokee

Cherolee sanltarlum, ('berokee, Iowa Establlshed 160\%: privale: cancer: I5 beds: H. C. Seaman, physlcian la charge Hornstironk Medical and Surgteal Hos. witsl. (herokee, Jowa. Fistubitshed 1902 public; general; 10 berls; F. II Horal: public; reneral; 10 beds:

crook, Jhyslclan in charge.
Dr. H. B. Cleaves, Hospltal, 1024 Main sit. Cherokee. Jowa. Establuhed 1912; pritute: medical and surgteal: beds.

\section{Clarinda}

lburwell liosplal, Clarinda, Iowa. Establlshed 1906: publlc: surzery: herls: T. F. Powers, surzeon in charze Kennelworth Hospltal, Clartnda, lowa
Estabilshed 1.698; private; Reneral: 30 beds: 1). 11. Kilingworth, physlelan in charge

\section{Clear Lake}

Clear Lake Houpltal, Clear Iake, Iora Established 1911; 10 beds.

\section{Clinton}

Agatha Hospltal, Clluton, Iowa Establlshed 1859: yubllc; general: 60 teds Martetla Tsnder. R.N. superintendent. st. Joseph"s Jercy Hosplul, the and Jackson Sts. Clinton. 10\%a Established 1892 : nolvale: zener

colfax

Colfax Ceneral IIospltal, Colfax. Iowa Established 1912; prirate; sunclesl: s Cappellar. superlnterdent

Colfax Rest Home, Colfar, lowa Fx. tablished J905: pritate: as peds: C. It porter, nhyslcian in bisree.

vletorla sanatorlum, Colere lowa. Fixtablished isot: jeneral: in iveds: Flor. eure Hewn shertwen. rhyslelab in charse and superintendent.

Couneil Blunts

thrlstlan llome Orphanaze, Council

Rluts, Iona. Kiablinhed 1ss:; publle: 1. beds la chiltremis berls in denartment for anteted chlldren and aced wormen: 13 beds In hosplial department: 11. IR. leizen, superintendent.

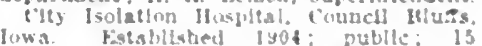

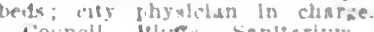

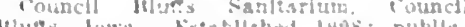

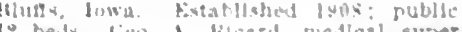
Intendents

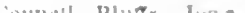
llwhed goon: public 60 jecty in seners?

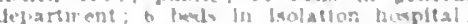

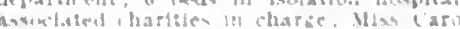

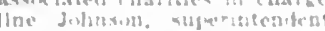

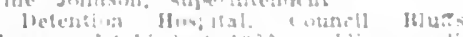

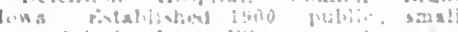

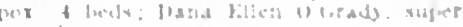
utendent

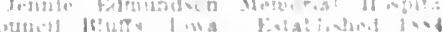

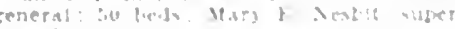

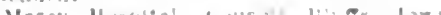


Creston

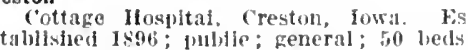
Lella Given, superintentent.

Inity Hospitaf, freston, lowa. Prrlvate; 50 beds: i. W. Reyuolds, $0.1 \%$ Coakley, J. iv. Fry jhystclans in charge; II charge;

Davenpert

(vok llome for the Friendless, Divenport, Iowa. Wstabllshed 1852; prisate for aged wormen: 25 beds; Misa E. I Meacham, superintendent.

Darenport IIospital, Davenport, Iowa. Istablished 190s; prirate: 38 beds: Sarah Foulks, diysucian in charce.

Pejevary Ilome for Old Farmers, Davenport, Iowa. Fstablished 1892; private Mrs. I. II. Nutting, superintendent. Merey liospital, Davenport, Iowa. Establlshed 1867; generaf: 250 heds; H. 1 Braunlleh and Georpe F. Decker, medicai offlers: Sisters of Mercy, in charge.

Si. Luke's Ilospitai, Marenport, Iowa. Estatilshed 1895; puhlic; general; 40 beds: Martha Oaks, R.N., superintendent. St. Vincent's IIome, Darenport, lowa. Estabilshed 1895; private; for orphans ; 175 beds.

\section{Denison}

Denison Hospital, Denison, lowa. Estatblished 1907; public; general, nerrous and mental: 22 beds: Mlss Constance Barsfield, R.N., superintendent.

\section{Des Molnes}

los Molnes Detention Hospital, 14th and St. Joseph Sts., Des Moines, Iowa. Estabished 1902; public; smail-pox patients only ; 31 beds; II. I. Sayler. physician in charge; I. i. Carr, superinsician in

Des Hoines Home for Friendiess Children, 2018 High St, Des Moines. Iowa. beth $J$. Cook, superintendent.

Des Moines Sanatorium, 1603 E. 9 th St., Des Moines, lowa. Estabitshed 1909; cancer cases; private and public; 20 beds; II. B. Stine, medical superintendent.

Health Ilaven Sanitarium, 1305 l'leasant St., Des Molnes, Iowa. Fstablished 1912 ; general; I0 beds; Burt F. Bliss, superintenderst.

Iowa Children's Home Society, 2340 E. 9th St., Des Moines, Iowa. Established 1590 ; public; 30 beds; James W. Cokenower, president of medical staff; Rev. A. T. Burneti, superintendent.

Iowa Methodist IIospital, 1200 Pleasant St. Des Mloines, Iowa. Establlshed 1902 , public: 250 beds: Willard $\mathrm{T}$. Graham, physician in charge; Esther Pearson, superintendent.

Mercy Iospital, 4th and Ascension Sts. Des Moines, lowa. Estabilished 1893; public; general; 130 beds; Sisters in charge. Retreat, 28th and Woodland Ave., Des Moines, Iowa. Established 1905; prirate nerrous and mental; 45 beds; John C. norvous and mental; 45 beds;

See Special Announcement Alv. page 68 Walston Hospital, 846 Sixth Ave., Des Ioines, Iowa. Established 1900; private general; 18 beds; Edwin Brainard Waiston, physician in charge.

Dubuque

City Detention IIospital, Dubuque, Iowa. Estabished 1900; contagious diseases : publie; 30 beds; Charles Palen, medical superintendent.

Dubuque Rescue Home, Asbury Rd., Dubuque, Iowa. listablished 1896:" ma ternity; 10 beds; Mrs. Ada E. Rockrell uperintendent.

Finiey IIospital, Dubuque, Iora. Es tabished 1890; public; 54 beds; Miss Alice E. Isaacson, R.X., superintendent.

Home of the Friendless, Mt. Pleasant Are., Dubuque, Iowa. Established 1874, private; 44 beds; Miss Masters, superintendent.

II ouse of the Good Shepherd, Dubuque Established 1902; private; refor sods; M. J. Moes, physician sisters of the Good Shepherd in charge. Limgurthy Eve, Ear, Nose and Throa Intirmary, ioth and Bliff Sts., Dubuque, lowa. listatillshed 1910; prirate; eyo, ear, nose and throat; 12 beds; Mrs. Anna lianh, matron.

st. Anthony's Ifome for the Aged, Dubuque, Iowa. Fstahllshed 1898; prirate; 30 hesls: Sisters of Mercy, in charge.

St. Francis IIome, Dubnque, Iowa. Estahitshed 1905; private; for the aged. 300 beds; conducted by Sisters of St Franeis.

st. Joseph's Merey IIospital, James St. nuburue, Iowa. Establlshed 1879; general; 200 beds; Sisters of Mercy, in

St. Ioseph's Sanitarium, Dubuque, Iowa Estabilished 1895; prlvate; nervous and mental; 300 beds; Sisters of Merey, it charge.

St. Nary's Orphan Home, Daris Are. Dulbuque, Iowa. Estabtished 1878; private. 186 beds: J. J Brownson, medieal superintendent.

\section{Eagie Grove}

Eagle Grore Hospital, Eagle Grore, Iowa. Established 1908; private; general 10 beds; W. C. McGrath, medical superintendent.

\section{Eldora}

Hmergency Hospital, Eldora, Iowa. Es tablished 1896: surgical only ; private: 20 beds; N. C. Horse, medical superintend-

Wheeler Sanatortum, 1334 Edgington Are., Eldora, Iowa. Established 1908; general: 25 beds: N. C. Morse, M.D. superintendent.

\section{Elkader}

Clayton County Hospital for Incurables, Fikader, Iowa. Established 1898 ; pubilic, 75 beds; I. I. IIulverson, superintendent

\section{Esthervilie}

Escherville City Hospital, Estherville, Iowa. Established 1908 ; public; general ;
8 beds: Miss Joseph A. Roberts, R.N., superintendent.

\section{Fairfield}

Jefferson County Hospital, Fairfleld, I0wis 1912 ; public : general: 25 beds; Miss Amy Beers, superintendent.

\section{Forest City}

Forest City Hospital, Forest City, Iowa. Established 1913; prirate; general; 22 beds; Thomas Lucast, medical superintendent.

\section{Ft. Dodge}

Benedict Home, Ft. Dodge, Iowa. Established 1882; private; industrial and reformatory ; 20 beds; Woman's Christian Temperance Union, in charge: Geergia W. IeClellon, superintendent.

Boulder Lodge Sanatorium, Ft. Dodge, Iowa Established 1901; private : tubereutosis; 20 beds; J. W. Kime, physician in charge.

Eye, Ear, Nose and Throat Hospital. Ft. Dodge, Iowa. Established 1906; prirate; 6 beds; W. F. Carrer; physician in charge.

German Lutheran Orphanage, Ft. Dodge, Iowa. Established 1901 ; private; 11 beds; Dr. Herman Rose, physícian; Aug. Hemann, superintendent.

St. Josenh's Merey Hospital, Ft. Dodge, Iowa Established 1909 : private : 50 beds: Sisters of Mercy, in charge.

\section{Ft. Maćison}

Atchison, Topeka \& Santa Fe Railway Hospital, Ft. Madison. Iorra. Established 1888; private; for railroad employees; 70 beds.

Saered Heart Hospital, Ft. Madison, Iora. General: 50 beds; conducted by Sisters of the Third Order of St. Francis. Grinnell

Grinnell City Hospital, Grinnell, Iowa Established 1908; general; 12 beds; Miss I. E. Ginn, R.N., superintendent.

\section{Guthrie Center}

Harrison Surgical Hospital, betreen 4th and 5th State St., Guthrie Center, Iowa. W Harrison, physician in charge.

\section{Hampton}

Potrers \& Osborne Hospital, Hampton, Iowa. Estabilished 1908; general; 14 beds; J. C. Powers and C. F. Osborne, physicians in charge.

\section{Hartiey}

Hand Iospital, Hartiey, lowa. Established 1909; prirale; generat; W. C. Hand, physician in charge,

\section{Hawarden}

If warden Hospital, Ifawarien, Iowa. Established 1911; private: 6 beds: $F$ J Ilcilister and $A$. J. Meyer, physicians in charfe.

Ida Grove

Conn Hospital, Ia Grove, Iowa. Established 1905; private; surgical; 25 beds J. F. Conn, physician in cliarge; Ruth G. Whitney, superinteudent.

\section{Independence}

Buchanan Hospital, Independence, Iowa Estabisised 1900; private; 10 beds; Robt. k. Buchanan, surgeon in charge.

McClernon Ilospital, Independence, Ia. Established 1912; pubilic; 12 beds; Mary A. McClernon, superintendent.

lowa City

Nerey Hospital, Iowa City, Iowa. Es tablisiled 1870; Sisters of Charity, in St. Joseph's Sanitarium, Iowa City, Iowa.

lowa Falis

Eilsworth Hospital, Iowa Falls, Iowa. Established 1902; public; 35 beds; Margaret M. Stoddard, superintendent.

Keokuk

Birge Benerolent Union Home, Keokuk,

Iowa. Estabilished I894; public; for

women and thildren; 20 beds; Mrs. Mabel Schroeder, superintendent.

St. Joseph's Hospital, Keokuk, Iowa. Established 1887; general; 40 beds.

U. C. Graham Hospital, Keokuk, Iowa

Established 1901; general; 30 beds ; Miss

Mary C. Jackson, R.N., superintendent.

\section{Lansing}

Lansing Hospital, Lansing, Iowa. Es-

tablished 1913; private; general; 8 beds;

J. G. Saam, medical superintendent.

\section{Mars}

Le Mars Hospital, Le Mars, Iowa. Established 1905 ; pubile; 14 beds; Jeanette Larson, R.N., superintendent.

Le Mars Mosher Hospital, Ie Mars,

Iowa. Estabiished 1912; private ; 6 beds;

A. H. Mosher, physician in charge.

\section{Manchester}

Parkview Hospital, Manchester, Iowa. Established 1911; public; general; 25
beds; A. C. Murray, R.N., superintendent. Maquoketa

Iowa Sanatorium, Maquoketa, Iowa. Established 1904; generai ; 25 beds ; L. K. Bobo, physician in charge.

\section{Marshailtown}

German Evangelical Deaconess Home and IIospital, Marshalltown, Iowa. Established 1914; general; 40 beds; Rev. Rest, superintendent.

Mercy Hospital, Marshalltown, lowa. Established 1903; private ; 30 beds ; Sister Mary Angelo, superintendent

Singleton Hospital, Marshalltown, Iowa. Estabilshed 1902 ; private; 10 beds; E. M. Singleton, physiclan in charge.

St. Thomas Merey Hospital, Marshall-

town, Iowa. Established $1903 ; 45$ beds.

\section{Mason City}

Detention Hospital, Mason City, Iowa. Established 1901; public; 20 beds; C. A. Trevett, superintendent.

Park Hospital, 6th and Washington Sts., Mason City, Iowa. Established 1909 ; general ; 75 beds; Effe E. Moore, R.N., superintendent.

Story Hospital, Mason City, Iowa. Es- 


\section{Missouri Valley}

MIssouri Valley IIospltal. Mlswarl Val ley, Iowa. Yatabllaherl 1895: prltate. I beds: Crorl Helse, whystclon lo thir:

\section{Museatine}

Hellerue Hospltal, Museatine, Inwa k, tablished 1904: publle: 20 beds: A. Weaver and J. 1. Kleln, pliysleitats Benjamin Hershey Memorlal II ispital.

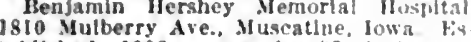
1810 Mulberry Ave.. Muscatlne, Iowa Fis

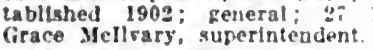

Mrs. Fllabeth Fershey lutheran or hans: Home, Muscatine, Iowa. Estab IIshed 1894: 40 beds; Kev. II. Iteinemund superintendent.

German lutheran Old Jeople's II ome Muscatine, Iowa. Fatablished 1s96: prt vate; 30 heds; Rev. II. Reinemunil, super Intendent.

Old Ladles' Home, Muscatlne, lowa. Establlshed 1893; private: 6 bels: Mar garet Guy, superintendent.

\section{Nevada}

Iowa Sanitarium, Nevada, Iotra. Es tabllshed 1899 ; Reneral; 10 bets; C. W Heald, phystclan in charge

Iowa Seventh-Day Adrentist Isspelathon Sanitarfum, Nevada, Jowa. Fistat. lished 1900: private: 50 beds: C. W Ileald. medical sujerintendent.

\section{Now London}

Cook's Private Hospltal, Yew London. Yowa. Established 1908: prirate: sur gical; t beds; C. F. Conk, surgeon it charge.

\section{Odebolt}

Odebolt IIospital, Odebolt, lowa. Hs tablished 1911: general: i heds: f. If Crane, medical superintendent.

\section{Ogden}

Ogden Hospltal, Ogden, Iowa. Vstak lishes 1811; general; 6 beds; Fillen John lishes 1811 ; Renera

\section{Osage}

Willlam Woods Hospital, Osage, low Established 1801; general; f beds: li. I Whitley, surgeon in charge.

\section{Oskaloosa}

Abbott Jlospital, Oskatoosa, Jowa. Es tabllshed 1906; General: 35 lweds: C. A Ibbott, M. W. sujerintendent.

Oskaloosa Hospital, Oskaloosa, Iowa Established 1908: kencral: 25 beds; 13 strohmeler, superintendent.

Oskaluosa Merey IIospllal, Oskaloosa,

lowa. Establlshell 190 : private: 10 berls:

B. G. Williams, medical superintemient.
Ottuma

chomu llompital, 2d and College Sta. ottumwa Jow: Eutablishol isg4: $\mathrm{gCn}$ oral: so herls: lilkabeth Trotter. superinterident

(Ittuntwa Inotatlon IIosultal. Otfunusa. Jowa. Fotnblulued 1855: publle: 1.5 heds 3. A. Ifull. Whysletan in tharge

sisters of llumllity of Mary IIospltal. ottumwa. Iessa. Establlshol 1914; Fen eral: 4 ib beds.

Postrille

lostrille IIospltal. I'ostrile, Iонл. Fs. tallikher 1909: private: 10 beds: 1.1 schmblt, physlcian In charge.

\section{Red Oak}

lowell sinool for Rackward and Men tally Hepletent Children, Ifed Oak, Iowa bitablished 1903 . edicatlonal: 50 veds: Velura F. Powell bhystan ln chinese.

\section{Rack Valley}

Rock Valley IInopltal, Rock Valley, Iowa Establlshed 1908: prtate 12 beds. F. J. Ilulzenga, physletan in charge.

Sayler

'olk County Hospital for Insane. Say lor, Jowa, Jes Molnes J'. O. Eutahilshed 18.9: 121 beds: A. S. Price, plisslctan in charge: Wm. McHone, superintendent Sheldon

Cram's Hospltal, Sheldon, Iowa. Estab Ilshed 1900: prlvate; 12 heds; Frederlel W. Cram, physletan in charge.

\section{Shenandeah}

Shenandoah City Hospltal. Shenandoah. Iowa. Fstablished 1905; public: 10 heds J. F. Atdrich, jhyslcian in charge

\section{Sloux City}

Florence Crittenton IIome and Mater nity Hospltal, Sloux City, lowa. Establlahed 1 sup: public and private: 35 beds A ches Elchelberger, niystelan in charge Jean s. Cole, superintenden:

German Lutheran Iospital, 2ith and plerce sits., Sloux City, Jowa. EstahIlshed I895; public; general; 44 beds Mary F. Ludy, superintendent.

Samaritan Hospltal, 17 th and Pleren Sts. Sloux City, lowa Kstablished is:a. publle; general; 65 beds; Mrs. N. I'almiulst, superintendent.

st. John's Lutheran IIospltal, Siou cit. Jomn's Lutheran Hospltal, Sloux City, Jowa. Fistablished 1910; put

st. Joseph's Mercy IIospltal, sloux City. lowa. Fstablished 1590; private; 251 beds: Slsters of Mercy, in charge.

st. Vincent's Hospltai, Sloux City, Iowa bistabllshed $190 \pi$; nublte: generil: il heds.
Sloux Rapids

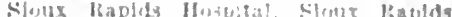

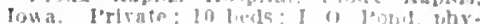
flclan in phareo.

Spencer

Clay county llosplal, sifel *er, froma. Fistablished 1810; rubltc.

Storm Lake

Storn Lake Irouftal, Sitnrm lake, Inwa. I'risate: 20 beols; F. F. Smlth and J. II

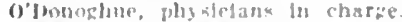

Swallum Hospital, Storm labe, Iowa. Fstabllshed 1910; general; is beda: J. A swallum. physlclan in charke.

Stuart

Crosby Hospltal, stuart. lowa. Fistablluhed 1909 : pulille: 10 teeds: I. F irosty", whysiclan lin sharge.

Toledo

IInme Medical and Surglcal Inhrmary, Tolelo, Iowa Fotablished 1530; general 15 bedls; F. IR. Smlth, rhyslelan in charge Tuberculusts Hospital. Toledo, Гока. Entablished 1913; treatment of indlans: tulerculosis: 75 beds.

\section{Washington}

Washington County IIospltal, Washlag. ton. Iowa. Kstablished 1912; publle: general: 25 beds; Fllzabeth Finley, superintendent.

\section{Waterlo}

St. Francls Ilospital, Waterloo, lowa Established 1906; surglcal unly; prirate F beds; J. A. Jerger and Grace Jerger. physlcians in charge.

Synodlcal I'resbyterian Irospltal. Water too, lowa. Hstabllshed 1904; publle: 36 beds: Minerva Wilson. superintendeat.

\section{Waukon}

Allamakee Countr Insane Asylum, llau kon, Iowa. Public; 25 beds; Oliver A Ilixon, superlnterdent.

Home Hospitat, Waukon, Iowa. Fstab. lished 1912; jrirate; generaî: 10 beds: Otto 0 . Srebakken and Clark Willson Rominger, phystelars in charge.

Waveriy

St. Jusegh's Merey IIospltal, Wareriy

Jow 4 . Fisblisited 1904; Inublic; Is bedw Webster

st. Joseph's Mercy Ilowltal, Wehiter. lowa. Fistablistied 1903: publle; 40 beds. Wheatiand

lonald Metlean Memorial Hospltal. Wheatland, lowa. Established 1901, wi. rate: 3 berls; J. $s$. lean, Jhysuclan in charge. 


\section{PHYSICIANS OH IOWA}

Names In capitals slgnify mentershly in the County Soclety and State AssoclatIou. (DOk, JOHN).

- Indleates Fellowship In the American

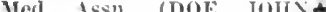
(b'75) lear of birtl. II, Lomeopath; F, eclectlc: P-M, physloIId.7, 09. Collegre and yeas of graduation.

Infornation recelved does not show graduation.

S.-Surgeon.

Ob.-Obstetrician.

ObG.-Obstetriclan, Gynecologist.

G.-Gynecologist.

Or.-Orthoredlst.

Pr.-Proctologist.

Op.-Ophthalmologist.

A.-Aurist.

LR.-Laryngologist, Thinologist.
KEY TO ABBREVIATIONS, SYMBOLS, ETC.

(l's9) Year of lleense.

(1) In practice before passage of present law and llecused by flling dlploma or ly years of practlee.

(1†) Llcensed but year not known.

(t) Information recelved does not show license.

I..S.A., United States Army.

I.K.C., U.S.A., Medical Reserve Corps.

U.S.N., United States Navy.
M.R.C., U.S.N., Medical Reserve Corps.

U.S.P.II.S., Unlted States I'ublic IIealth service.

Collere positions held are Indicated by abbrovlated title of position, followed by key number of college. For key to colleges see inside front cover page.

(AI,3, B6, C4) Membershlp in specla societles. (See Key Table, page 122.)

SPECIALTIES ARE INDICATED AS FOLLOWS:

ALR.-Aurist, Laryngologlst, Fhinologist.

OALR.-Ophthalmologlst, Aurlst, I,aryngologlst, Rhinologist.

U.-Urologist.

D.-Dermatologlst.

Pd.-Pediatrist.

N.-Neurologist.

P.-Psychlatrlst.

NP.-Neurologlst, Psycblatrist.

I.-Internist.

T.-Tuberculotherapist.

Anes.-Anesthetist.

LD.-Laboratory Dlagnosticlan. [glst. R.-Actinologist, Radiologist, HoentgenoloPath.-Pathologlst.

Baot.-Bacterlologlst.

WHEN THE ABBREVIATION REPRESENTING A SPECIALTY IS FOLLOWED BY AN ASTERISK ( ) IT INDICATES THAT THE PHYSICIAN CLAIMS HIS PRACTICE IS LIMITED TO THAT PARTICULAR BRANCH OF MEDICINE; WITHOUT THE ASTERISK, THAT HE IS ESPECIALLY INTERESTED IN, BUT DOES NOT LIMIT HIS PRACTICE TO. THAT BRANCH. THIS INFORMATION CONCERNING SPECIALTY IS BASED ON PERSONAL DATA FUR NISHED BY THE PHYSICIAN AND IS NOT VERIFIABLE.

\section{IOWA}

\section{ACKLEY, 1,244, HARDIN}

BREIMAN, ELBRIDGE MAXWELL (b'71) †-Ill.I,'99; (1'98); G.

MILLER, JOHANNES' JACOBUS $\left(b^{\prime} 75\right) \oplus$ Jll. 6,'99; (l'99).

Potter, Isáac L.-Ia.3,7 I, Ill.6,77 ; (1'86).

RABE, FREDK. LOUTS $\left(b^{\prime} 52\right) \oplus$-İa.3,'92 ; (1'92).

THORNTON, JAMES WM. (b'74) $\oplus$-Neb.6, 99; (1'99)

AOAIR, 900, ADAIR

MAYNARD, JAMES H. (b'73)థ-III.I,'99; (l'39).

POWEI, PRESTON (b'67) - 111.11,'89; (l'99).

Sammons, Stewart Andrew (b'iI) H-Mo.5, '98: (l'05).

ZOOK, ABRAHAM JAMES (b'/2)‡-Ill.1, $97 ;(1 ' 98)$.

ADEL, 1,289, DALLAS

Barkalow, Derrick G. (b'38) - Ia.I,'84; (l'85). $\left(l^{\prime} 00\right)$

SCOTT, WALTER E. (b'64)థ-Ia.6,9I ; (1'91).

AFTON, I,014, UNION

JOHNSON, ELTON MAYRANT (b'T0)

Ia.3,'97; (1'97).

LAUDER, JOHN W. (b'50) $\oplus-$-Ia.3,'74; $\left(\mathrm{l}^{\prime} 86\right)$

AGENCY, 322, WAPELLO

MCELDERRY, DONALD (b'74) - Ia.3,08; (I'08).

REED, CHARLES SUMNER $\left(b^{\prime} 70\right) \mp-\mathrm{Ia} .6$, $02 ;(1,02)$.

AINSWORTH, 408, WASHINGTON

ALCORN, WM. LFMUEL $\left(\mathrm{b}^{\prime}, 7\right) \mp-I \mathrm{a} .10$, 04: (1'04).

LAIRD, ALLISON JARDINE (b'58)-N.Y.5, $87 ;\left(l^{\prime} 8 S\right)$.

AKRON, 1,130, PLYMOUTH

KERR, JOHNSTON H.\&-Neb.5,04; (l'08).

ALBERT CITY, 26I, BUENA VISTA

BRIDGE, BARTON B. (b'il)-Ont.5, 00 (l'00).

WERNER, CARL A. ANDERSON (b'72) Neb.5,'98; (1'01).

ALBIA, 4,969, MONROE

AYERY, THOMAS J.-Mich.I,'89; (l'94).

ESCHBACH, HENRY CLAY (b'56) $₫$-Pa.1 '83; (l'si); $\mathrm{S}$.

GANTZ, SUE B. (b'68)-Mo.30,97; (1'98).

GRAY, SAML. THOS. (b'66) (-)-Ia.3,' 89 ; (l'89); $\mathrm{S}$.

GUTCH, THOS. ERNEST (b'T4) $\$-10.28$, 98 ; (1'9s).
Hlckman, Solomon R. (b'7I)-Ia.I0,'06; (l'06)

HYATT, CHAS. N. (b'70)-Ia.9,'95; (l'95) JACISON, TAYLOR RICE (b'70)@-Ill.1I $97 ;(1,907)$.

JENKINS, GEO. ALLEN (b'79)-Mo.27,'01. (1'0I).

MILLER, ROB'T. PUMPHREY (b'68)Mo.26,'94; (l'96); S

Porter, Henry Clay (b'63)-Ill.I,'90 ; $\left(l^{\prime} 90\right)$. POWELL, BURKE (b'74)-Mo.27,'99; (1'98). POWELL, CHARLES B. $\left(b^{\prime} 49\right) \oplus-0.2,70$, Ia. $I,{ }^{\prime} 82 ;(1,86)$.

ALBION, 457, MARSHALL

Callison, Cyrus O. (b'81) - Colo.2,'11; Doty, Clarence Hays (b'80)-Ill.II, 03 ; (I'II).

Mantle, Wm. B. (b'73)-Ia.10,'02; (l'02).

ALBURNETT, 250, LINN

Allen, Paul Edward (b'83) H - Ia.4,'10 ; (l'10).

Daris, J. L. $\rightarrow$; $\left(l^{\prime} 90\right)$.

ALDEN, 699, HARDIN

Darid, Jos. W. (b'4I)-Ill.1,'69; (l'92)

JOHNSON, JONATHAN, JR. $\left(b^{\prime}, 6\right) \oplus-\mathrm{Ia} .10$ 02 ; (l'02)

SIEDFNBURG, FRANK $\left(b^{\prime} 80\right) \uparrow-111.11,07$. (I'07); Member Ill. State Med. Soc.

ALEXANDER, 262, FRANIKLIN

ROCKWOOD, MERLE CLINTON $\left(b^{\prime} 79\right) \oplus-$ Ia. 3, 08; (l'08).

ALGONA, 2,908, KOSSUTH

CRETZMETER, CHAS. H. (b'77) $\oplus$-Ia.3

FELLO (l'01). CLAY D. (b'67) $\oplus$ - Ia.9,'92; (l'92). WASER, WALTER (b'70)-Mo.27,93; (l'93).

IIARTIAN, EVERT CLARENCE (b'82)Ill. 6,08; (l'09)

KENEFICK, MICHAEL J. (b'6I)๑-Ill.I, $92 ;(1 ' 92) ; \mathrm{S}$.

Rohner, Frank James (b'82) - Ia.3,'12; (l'12).

Seeley, Frank T. (b'46)-Mich.1,74; (1'86).

Sheetz, Chas R. (b'51)-Ill.1, 82 ; (1'03)

Tribon, Francis Lewis (b'64) H-Ia 4,93 . (1'93).

ALLERTON, 862, WAYNE

Bullis, Wm. L. (b'44) E-Pa.14,70; (1'87). Duden, Wm. H. (b'3I) H-N.Y.9,70; (1'87). Everett, Burres S. (b'44)-Ia.1,71; (1'87). Parker, Bernard Barney (b'89)-Ill.1I,'12;

(1'12).

ALLISON, 495, BUTLER

BURROUGHS, PAUL R. (b'82)-Ia.3,'06 ; (l'06); Ob.

Hazlet, Édwin A. (b'64) H-Ill.10,97; (1'97).
ALTA, 959, BUENA VISTA

ELLYSON, CHAS. WRIGHT $\left(\mathrm{b}^{\prime} 78\right) \oplus-\mathrm{Ia} .3$, 05; (l'05).

Hadden, George (b'44)-Minn.3,88; (l'92);

Op.
JOHNSON, CHESTER H. (b'85)-Ill.4,'06 ; (l'06).

MORRISON, JOHN W. (b'78) @-Ill.1I,'04; (l'04).

ALTA VISTA, 356, CHICKASAW

HASTINGS, JOHN CHAS. (b'75) -Ill.I, 02; (1'02).

HASTINGS, PATRICK HENRY-Ill.11,05; (l'07).

ALTON, 1,046, SIOUX

GLEYSTEEN, RICHARD J. (b'8I)-IIl. I,'05 ; (l'07).

Miller, Henry Edw. (b'5I)-Mo.7,'95; (l'95).

ALTOONA, 438, POLK

Carter, Wm. H. (b'39)-Mo.10,80; (l'87).

LANG, CORVU'S CONSIL (b'70) (1-10.7, '93; (1'93).

ALVORD, 283, LYON

Blair, Saml. Ellsworth-Ia.3,'94; (1'97)

AMANA, 621, IOWA

HERRMANN, CHRISTIAN H. (b'49)-Ia.3, '81; (l'86).

NOE, CHAS. F. (b'76)@-Ia.3,98; (l'98). SCHADT, FREDK. CONRAD (b'85) -Ia.3, 'I0; (1'10).

Winzenreid, Chas. Jacob (b'33)-Ill.1,66 ; (l'86); not in practice.

AMES, 4,223, STORY

Adamson, James Edw. (b'77) - Ia.6,04:

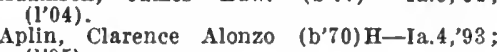
(l'05)

Brown, J. Alvin (b'47)-Ia.3,76; not in practlce.

BUDGE, BEN GARFIELD (b'80) - -Ill.6, 09 ; (1'10).

BUSH, EARL B. (b'84)-Ia.6,'08; (l'08).

DYER, BENJAMIN GEORGE (b'66) \-Ia.6,

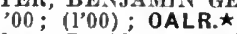

Edgar, Darld Wm. (b'47)-Ill.1,'74; (l'87). GHRIST, DAVID M. (b'65)థ-Ia.9,'98; (l'98).

GHRIST, JENNIE G. (b'70)-Ia.9,'98; (1'98)

Granger, Ernest F.-Md.4, 03 ; ( ).

Hackett, Andrew Roy (b'78)-Ia.6,'12 ; (l'12).

Lynch, Leslie James (b'48)-Ia.I,'79; (I'86) ;

not in practice.
Maxwell, Adelbert Bertel (b'63)-Ill.10,0I, Ill. 4, $05 ;\left(1^{\prime} 01\right) ; 0$ PA.

Proctor, Clark M. (b'72)-Ill.I,97; (l'98). Templeton, Henry M. (b’48)-Ky.4,77; (l'86).

Tilden, Chas. Geo. (b'72)-Mo.27,'99, Ia.6, '00; (l'00). 
ANAMOSA, 2.983, JONES

Darts, John lienry (b'60)-Mase. J, OA: As slstant Pbystelan.

bruct, samuel (b'44)-1a.1, $\because 4 ; \quad\left(l^{\prime} 86\right.$

GORMAN, THOMAS CONNER $\left(b^{\prime}: 3\right)+$ I11.1.97: (1197)

HFJINIAN, AIAM G. (b'63) $+-111.1,93$ $(1.96): \mathrm{S}$

HUNTER, WM WYLE (b'SS) ₹-1a.3.86 $(188)$

Joslln, James M. D. (b'4i)-la. 1, is: (1's6)

KING JOHN EZRA (b'65) -la.3,"9: (1) (1,00)

Slgworth, Harrtson w. (b'36) - 111.1,63 (l's0): not is practlce.

ANDREW, 307, JACKSON

LITTLFFELD, SAML, MILTON (b'60)III.1,'\$4; (1'86).

ANITA, 1,118, CASS

Adalr, Gael Myerly (b'85)-Ia.6.'09; (1'09)

BEAVER, CHAS, VERNON (b'si) + Mo.18 85: $(1+86)$.

BECKER. ROTAL ALGUST (b'8i)-1a.4 10: $(1 ' 10)$.

CAMPRELL, HOWARI ELMER $\left(b^{6} 6.5\right)+$

N.Y.5,"91; (1'94).

ANKENY, 445, POLK

PATTERSON, CHAS. FULLER (b'68)Ind. 10,'98: (1'98). SPAULDING, HOMER LAWRENCE ( $\left.b^{\prime} 64\right) \$$

\section{ANTHON, 635, WOODBURY}

Caules. Francla Patrick (b'83)-Neb.6,"10 (\$)

Stlliman. Wayne L. (b'73)-111.11,02: (1'02)

APLINGTON, 448, BUTLER

Blackmore, Hartlet Norelssa - 1a.3,05 (1'05).

ROLFS, JOHX A. (b"69) -1a.6,04; (l"04)

ARCADIA, 390, CARROLL

GARTIN, THOMAS MARTIN (b'78)-In.3 O 07 : (1'0i)

ARCHER, 35!, O'BRIEN

Klely, Michael D. (',B0)-\$cot.3,"85: (1'98)

AREDALE, 100, BUTLER

Wickman, Herman J. (b'8) - Ia.3,06: (1'06)

ARGYLE, 60, LEE

lanes, Paschal Fidward (b'79)-1a.10,00 (1.00).

ARLINGTON, 678, FAYETTE

Ayer, 0. 0.-Ia.1,76: (1'87)

Bower, curtls E. (b"81) H-IL.4,02: (I'02)

Rrown. Gates M. (b'73)-Mllch. 1:99: (l'0i)

ARMSTRONG, 586, EMMET

KNIPE, JAMES B. (bo 1$)$ - $111.11,04:\left(10^{\prime} 01\right)$

Robinson. Raymond Eurene $\left(b^{\prime} 90\right)-M o .21 \%$ (13): ( ).

WEST, GEO. HUMPUREУ $\left(b^{\prime} 69\right)+-111.0$ 03: (1"03): OALR.

ARTHUR, 215, 10A

PATTERSON, SAML. TANNER (b'85) Yeb.6.07: (1007).

ASHGROVE, 50, DAVIS

Selman, Thos. J. (b'53)-12.1.73; (1'86)

ASHTON, 518, OSCEOLA

CADWALLADRR, JOS. MAXWFIA (b'83)-

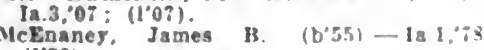
(1'86).

ATALISSA, 220. MUSCATINE

HUTLER HALPH ADOLPIIIS $\left(b^{\prime} 86\right)$ * IA.3,12: (1'12)

Thesebrough, Saml.-XY.3:89; (1'89)

ATKINS 200, BENTON

Thomas, Clsde Earl (b'83) -1 a 3,"13; (1'13)

ATLANTIC, 4.560. CASS

Becker, Fredk. Jacol (b'BS) 11-Ia A Bei, Pa.9:87: (1.87).

BLEK, CHAS. H. (b'70)-111.6,"06: (1"0h)

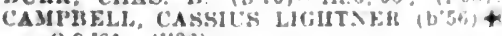
-0.9.81: $\left(1^{\circ} 86\right)$.

年 $\mathbf{S .}$

limmble, H. Anderwan-Mo.i.n\%: 110\%

(iRAHAM. WILHAM FRAVK (b'5S) 111 '80: (1'87)

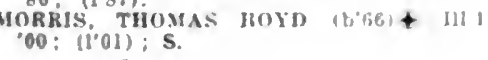

IULLINS, ULYSSLS SIMISON (b\%il)111.1.95; 11.95$)$

FOLLOCK, DAVIN KIHK (b'78) - Ia.lo

03: (1'12): Member III Stale Med Soc

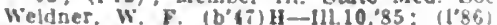

Wilder, Agnes Hoss (b"73) H-111.4,9: (1'97)

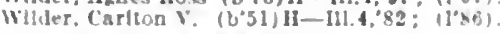

ATTICA, 110, MARION

Arllne, Wrn. II. (b' 66$)-$ la 1,69: (1'8i).

AUBURN, 399, SAC

Barrs, Patrlck Jos. (b'bi) - Ia.3,9l: (1'9I)

lobes, Henry Lawrence (b'0)-ia.3," 9 ": (113).

AUDUBON, 1,928, AUDUBON

BIOOKS. ALFRED LEROY (b'58) -III.

.83; (1.8\%).

CHILDS, RATFORD F.T-Nieb.5.'97: (1'97): LR.

Fulsun, John M. (b'65) H-II1.10.96; (1'96). "IY, GEO ALBEBT (b'81) f-IA.3, 11 :
(1'i1).

AUGUSTA, 100, DES MOINES

Hansphy, 'rank P. (b'63)-la.3,8s: (1'88\},

AURELIA, 625, CHEROKEE

Bates, Firnes! Guy (b"81) - Ia.6.'13: (1'13)

Eddy, Alfred H. (b'0)-I11. 16 : (1'97).

l'utrets, Geo. Fredk. (b'B4)-Ia.3, 89 ; (1'39)

AURORA, 287, BUCHANAN

BISSELI, BURT G. (b'69) $\mathbf{x}-11111.07$; (1’08).

AVERY, 560, MONROE

Montsomery, C.A. (b'50) $\mathrm{E} \rightarrow$ : (l'S6)

PEPPLRS, AUSTIX W. (b'78)-Mo.28, 02 (l'08).

AVOCA, 1,520, POTTAWATTAMIE

BAUMEISTER, CHAS. F. (b'72)-M0.9\%,"9: (1.98)

EMMERT, DORSEY F. (b'64)-Pa.2,91; (1'91)

SPAULDING, GEO. ALBERT (b'6i) \&-18.3,

AYRESHIRE, 337, PALO ALTO

MORTON, ELMER FLLSWOHTU (b'7̈ + Ia.9.'98; (1'98).

BADGER, 212, WEBSTER

Turner, Wm. R. (b"84)-In.6.08; (l'08).

BAGLEY, 488. GUTHRIE

HCXII, HUEI) WILSON $\left(b^{\prime}: 0\right) \mp-110.29,97$ (1.9s)

IRINTLE, JESSE ALVA $\left(b^{\prime}, 6\right)+-1 \mathrm{~g} .3,01$ (l'0l).

BALDWIN, 229, JACKSON

Cillmore. John k. (b'39)-Ia.1.67; (1'87)

GHIFIN, FRANK L. (b'33)-1A.3,05: (l'05).

BANCROFT, 830, KOSSUTH

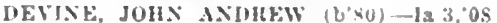
(l'08).

Sartor, Plerre (b'i1)-nl-ati: $11^{\prime} 96^{\circ}$

West, Geo. T. (b'ij)-D; (1'sti)

BANGOR, 40, MARSHALL

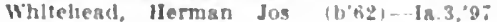
(1.9:).

BARNES CITY, 307, MAHASKA

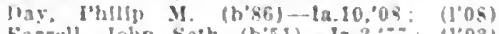
Farroll. John seth (b.51)-1a.3,7;: (1'93)

BARNUM, I5\%, WEBSTER

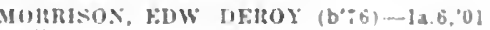
(l'01).

BASSETT, 130, CHICKASAW

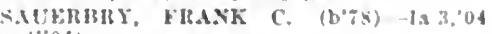
(1'04).

BATAVIA, 560, JEFFERSON

lialdrifie, John II -IA.10"04: (1'04)

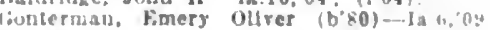
(1.09)

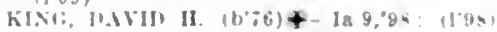

BATTLE CREEK, 52\%, IDA

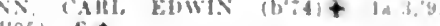

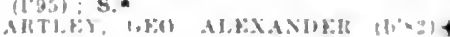

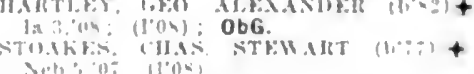

BAXTER. 527. JASPER

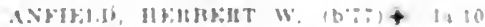

$03: 1100$ i)

11: 11,111.

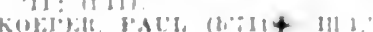

BAYARD, 339, GUTHRIE

Coover, W. A-H-II!.4, 2 (1102) (1" $\$ 9)$

THOMLSOS, WILLLAM

'8: 11'94)

BEACON, 623, MAHASKA

RC'AX, JOHN ARTUCR (b':I)-M0.29, 00 $\left(1^{\circ} 00\right)$

BEACONSFIELD, I48, RINGGOLD

('arr. James Aroscoo-Ja.6.0\%: (1'0\%)

BEDFORD, 1,883. TAYLOR

Ahrens. Haries (t'6)-14.1:.03; (1.05): OALR.

Archer. Alra A. (b'55)-Mo.22,95: (1'95)

Besuchamp. Jos. W. (b'31)-la $1, \because 6 ;\left(l^{\circ} b 6\right)$.

DLNILIV, HENKS F. $\left(b^{\circ} 45\right) t-30.1,71$ : (1'x6).

Dunnlaz. MHo BenJ. (b"3) - Ind 8,95: (1.96).

PASCIAL, CLAYTON M. (b'54)-1a.1,75: (1'si): ALR.

standley, Josech I'erry $\left(b^{\prime} 68\right)-K y .1 .89$; (1"89).

BELLE PLAINE, 3,121, BENTON

cook, steghen is. (6.33)-18.1, 8 ; (1.86): not in practlce.

Cox. James B. (b"42)-1a.1.85; (1"86).

Mc.Inrrls, James (b"36) - I11.1."72; (1"86)

Iurcls, Albert J. (b'4) I-II.4,63; (1'86): not in practlce.

Snitkay, Chas. 3. (b"i4) H-Ia.4, OI: (l'01).

VINCENT, WM. A (b'4) —- II.1,91: (13*6).

WIILIAMS, JAMES A. (b'65)\&-IH.8,'95: $(1.95)$

YAVOISKL, GEO. WM. (b'\$3) - IA.3,05: (1"05).

BELLEVUE, 1,7\%, JACKSON

IIENYISON, JOHS CHASE (b'66) \&-Ia.3, 1.1XKE. FDW. ALBEIT (b"\%2) \$-KJ.t. "0I (I"0?) A.MYI., E.M.ME.

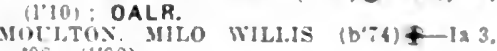
-9S: (1.9S).

BELMOND, 1.224, WRIGHT

MCBUISEL, GEO. FRAVK (b'69) f-IA. MYFL, HEXRY EDW. (U.: - 111.6.03: ( $\left.10^{\circ} 03\right)$

STEVLIS, FRANKI.I A ICLSTLS (b'63) -X.Y.6, 90 : $(1 \% 91)$.

BENNETT, 243, CEDAR

CHAPMAN, HORACE HAY (b'33) — IA 3 , 01: (15"02).

ROIRIG. JOHN GEORGE (b's3) $\neq-1$ a.3, 09 ; (1.09)

BENTON, 191, RINGGOLD

LANIHS, FRANK HF.NYL (b:3) - MO ?: i: $(1.97)$

BENTONSPORT, IAI, VAN BUREN

Boon, Hob! Leonand $\left(b^{\prime}, 00\right)-1111, ' s 0$ : $1 l^{2} 92$

Schee, James II (b'60)-la.1,\$1: (1'56).

BERNARD, 95, DUBUQUE

shlelds. Iuncan chartes ib'bil. Mieb.1.95: (1'95).

BERWICK. 75, POLK

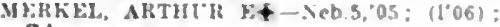
Pd.

BETHLEHEM (R.F.D. RUSSELL), ;5, WAYNE

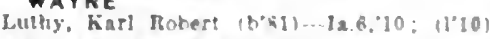

BETTENDORF, 909, SCOTT

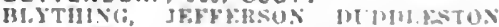
$\left(b^{\circ}-6\right)+1111,00 ;(1 \circ n): S$.

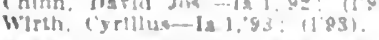

BIRMINGHAM. 5\%, VAN BUREN

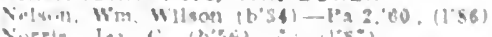

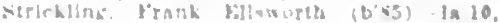

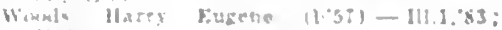

BLAIRSBURG. 2J1, HAMILTON

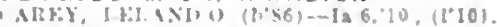

RLAIRSTOWN. S32. BENTON

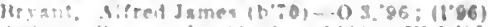

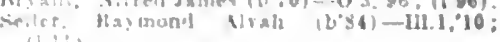


BLAKESBURG, 344, WAPELLO

Fielman, Ralpil Jackson (b'8i)-1a.10,'0s (l'10). TAJT, MLEXANDER M. (b'51) - Ja.9,

TORIRECE, IAIRIS 1'. (b'4 4$)+-10.10,76 ;$ (1'86).

BLANCHARD, 408, PAGE

JOHNSON, WALTER CONWAY (1, Ia. 8,09 ; (1'09).

l'ruitt, George i. (b'51)-0.1,77: (f's6).

lobb, labt. Worth (b'6)-Ia., (it: (l'id)

BLENCOE, 283, MONONA

Iacy;, (Geo.--la.1,'8:3; (1'87)

BLOCKTON, 648, TAYLOR

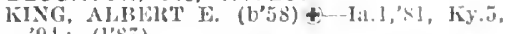

MALOY, JOIIN THOMUSON $\left(b^{\prime}+1\right)+$ M10.27,92; (1'93).

MHIJT, IIIIJ) IIAGANS $\left(b^{\prime} 67\right)+-M 10.27$, '93; (1'93); OALR.

Terrill, Jay S.-M0.22,'06; (l'06).

BLOOMFIELD, 2,028, DAVIS

BliAUCHAMI", KDWALD D. $\left(b^{\prime} 60\right)-I a .1$, $82 ;(1,87)$.

CRONK, CLIAS. H. (b'61)-1: I0, 00 ; (l'05) CRONK, CLARA I, KEMBEL (b'63)

Ia.9, $92 ;\left(1^{\prime} 93\right)$;

Guernsey, Paul Francis (b'87)-Tenn.5,'13 (l'13).

HEAIY, CONDA C. (b'62) $\oplus-$ Ia.1, 89 (1'89).

Shetton, Amanda I. (b'50)-Ia.1,'92; (1'92) SIIFITON, CIJAS. DALTON (b'76) \$-Mo.t '99; (1'00); S.

Shelton, F. J. (b'32)-0.8,76; (l'86).

shreve, Menj. F. (b'41)-Ia.1,75; (1'87).

SWINIEX. JOSIAH (b'57)-Ia.1,'88; (1'88)

IOUNG, IIENRY CLAY (b'69) \&-Ia.9,9I ;

(l'91); S.

BLUE GRASS, 223, SCOTT

Wandeveer, W'm. Ira (b'59) II - II0.5,'93; (l’94).

BODE, 419, HUMBOLDT

YOLLUI, EDW. OSCAR (b'80)-Ia.3,'08

WATSON, EDWTN L. (b'64) - Ill.11,'89; (1'96).

BONAPARTE, 597, VAN BUREN

Blackmer, Benj. P. (b'39)-Ia.1,78; (l's '7). CRESAP, ROGER N. (b'57) $\oplus$ - Mo. 8,'85; (l'92); OALR.

Whiteley, Jos. IIall (b'81)-Ill.11,'07; (l'09).

BONDURANT, 287, POLK

PORTER, LEROY "VALISTINE (b'T2)

Ia.6, $00 ;\left(l^{\prime} 00\right)$.

BOONE, 10,347 , BOONE

BASSETT, LEMUEL, A. (b'67) - Ill.1,'96 $(1,96) ; 328$ Benton St. ; office, 12I6, 4th St. ; $10-12,2-4 ; \mathrm{S}$.

Buell, Wm. C. (b'61)-Ia. 7,85 ; (l'86)

Conley, Henry Caroll - Mid.1,'85; (1'86);

$819 \frac{1}{2}$ Story St.

CRARY, ARCHIE W. $€-$ Ia.3,06; (l'06); 624 Story St.; (B1)

Cruikshank, Roswell D. (b'78) - Ill.1, 05 ; $\left(l^{\prime} 05\right) ; B o o n e$ Natl. Bank Bldg.

DEERING, ALBERT B. (b'74) $4-111.6,98$ $\left(1^{\prime} y 3\right) ; 410$ Boone St.; office, 802 Story St. ; $I-4,7-8$.

Doyle, John W.-Mich.1,'88; (l'08) ; s10, 8th St.

HARPEL, KATE STEVENS (b'6T)-Ia.6,02 (1'02) ; 702 Story St.; 10-12, 2-5.

HFAI,', MAUIICE ARTIIUR (b'75)-IH.6, 03; (1'03) ; 813 story st.; 2-4.

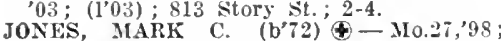
(l'1I) MARK C. (b'72) - Mo.27,98;

Boone' National Bank Bldg.

hinight, Samuel Edmund (b';2)-Me.I,'92; ('II).

Lyle, Franklin H. $\left(b^{\prime} 49\right) \rightarrow$; (1'86); $823 \mathrm{~W}$ $2 d$ St.

MYRRS, EDW. MORRISON (b'-2)-Ill.6,'00; (1'02) ; 604 Carroll St.; office, 722 Story St. ; 2-4, 7-8.

PEO, EVALENE E. (b'65) ๔-Ia.3,'93; (1'93) ; 8tli and Greene Sts. ; 2-5.

ROVE. GEO. D. (b' 45 )-Me.1, 68 ; (l's6) 321 Boone St.; ofluce, 722 Story St. ; 2-4,

TANGR, GEO. HENRY $\left(b^{\prime} 66\right) \uparrow-111.11$, 92 ; (1'92); 600 Benton St.; office, 815 Story St.; $10-12,2-6$.

TPDEGRAPF, CHAS. LOUIS (b'88)-1a.3, 12; (1'1:2): Boone Natl. Bank Bldg.
WALKEK, JAMEN ( $\left(\mathrm{b}^{\prime} 70\right) \oplus-\mathrm{Ia} .3,98$ (1.98); ت11, 4th si,; oftlce, $812 \frac{1}{2}, 8$ th

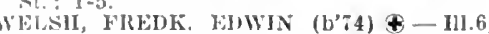
'03; (l'03); 1210 Story St.; offee, 8111/6 Sitory St. ; 2-5, 7-8; Pd.

Whitaker, lken Tallman (b'85)-I11.6,'l2; ( )

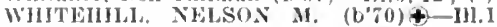
97 ; (1'97); 126 Tinma st. ; olthee, Boono National bank Blug. 2-4; $;-8$.

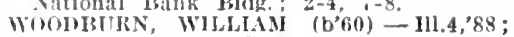
(1'88) ; 428 slory St.; offleo, Boone Natl. liauk IB]lli.; I0-12, 2-5, 氵-8; OALR.

BOUTON, I50, DALLAS

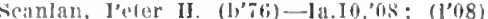
BOYDEN, 364, SIOUX

lirik, Milber (b'5I)-Ill,1,'84; (1'86).

stoelır, Gustare Ilewellyn $\left(b^{3} i \pi\right)-$ la.3, 09 ; $\left(I^{\prime} 03\right)$.

BRADDYVILLE, 283, PAGE

II.ATIIORNE. IOOBT. ACHESON (1,60) Neb.5, $01 ;(1,01)$

large, Adin F. (b'53)-Ia.1,'84; (1'86).

BRANDON, 200, BUCHANAN

Jiyde, Merrill James (b'55) - Mich.I,'T6 (1'87).

Ward, Everett C. $\left(b^{\prime} 76\right)--1 a .3,07$; $\left(1^{\prime} 07\right)$.

BRAYTON, 137 , AUDUBON

KOOI, IVA. ROSCOE (b'69) - Mo.22,'92 (1'92).

BREDA, 374, CARROLL

Bookhart, Edw. WV. (b'80)-Neb.4,06; (l'06) Jones, Uriah C. (b'43)-la.6,'83; (l'87).

BRIDGEWATER, 365, ADAIR

CIIAPIIN, ROI3'T. RICHARD (b'69) 111.1,94; (1'94).

Reed, William Ilenry (b'75) - 111.11,05 (l'13); Member Neb. State Med. Assn.

BRIGHTON, 776, WASHINGTON

Hosh, Geo. Warritte (b'53)-Ill.1,'79; (l'86) (1'08).

PARKS, WII. S. (b'59)-Ia.3,85; (l'86).

TERRY, MARCUS CLAUDE (b'44) (-Ill.1, 99 ; (1'86)

BRISTOW, 291, BUTLER

Appleby, Geo. W.-111.6,'85; (1'87).

RFEVE, DELOS N. (b'69)-D.C.1,96; (l'98).

BRITT, I,303, HANCOCK

Brewster, Calvin Orville (b'81) - Ia.4,'09

BURKE, THOS. A. (b'83)-111.22,'09; (l'09) COLE, A. J. (b'54)-Ill.1,'83; (1'86)

COUI'ER, EDW. ALEXANDER (b'62)-11l.1, 90 ; (1'95)

BRONSON, 100, WOODBURY

Glann, lioy Carlton (b'78)-Ia.8,05; (l'05)

BROOKLYN, 1,233, POWESHIEK

Barker, Alfred Herbert (b'60) H-la.4, 9 '? (1'93).

BUSBI, CHARLES D. $\left(b^{\prime}, 0\right) \oplus-M 0.27,97$ (l'y-)

Busby, Isaac N. (b'39)-Ill.8,'87; (1'86)

Landis, Albert C.-1a.6,'88; (1'87).

RINGENA, ENGELKE JANSEN (b'78)Ia. 3,$08 ;(1,08)$.

SIMLRAL, FRED ERNEST (b’-8)-IIo.3,09; (l'09).

BRUNSVILLE, -, PLYMOUTH

Ilsworth, Clande G. (b'85) - Wis, 3,'II (1'13); G.

BUCKEYE, 140. HARDIN

BOWIL, LOLIS LEE (b'79)†-Ia.3, 05 . (1005)

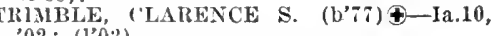
BUCKGROVE, 87, CRAWFORD

Teske, Carl (b'49) - Ger.8,70; (l'87).

BUFFALO, 456, SCOTT

TEUFEL, JOHN CARL (b's0)Ð-Ia.3,'04 : (1'04).

BUFFALO CENTER, 753, WINNEBAGO

DOLMAGE, GEO. FRAYCIS $\left(\mathrm{b}^{\prime} 79\right)$ \&-Ia.3, 09 ; $\left(\mathbf{l}^{\prime} 09\right)$; $\mathbf{S}$.

EIEL, HAN'S EDW. (b' 76$) \oplus-$ Ia.9,99; (1'98).

BURLINGTON, 24,324, DES MOINES

Boatman, ollyer W. (b'79) - Ia.10.'03; (1'03) 1414 Pine St.; offlce, Tama Bldg.; $9-11$ $2-4,7-8$.

Bolding, Wm. R. (b'43) H-Neb.3,'84; (l'91) 620 Iowa St.; offlce, 317 N. Main St. $8-5$
('AMPRELL, BENJ, FRANKIIN (1)74) Ia.1,97, 111.6,'04; (1'97); Nember Mass. Med. Soc.; 1213 smmmer st.

CIILGRHN, G. Al'THI'R (b'65) $\$$-Minn.4 92 ; (l'92); 500 Norlh st.; olthee, $4061 / 2$ Jeflerson st, ; 10-12, 2-5; ( $\mathbf{k} 13)$.

Dixan, John Wesley (b'64)-ont.3,'90; (1'91) 815 N. 4th St.; office, Tana Blag.; 2-4.

DONAHLE, JULA MAUIE $\left(\mathrm{b}^{\prime} 6 \pi\right) \oplus-I l 1.9$, 92 ; (1.05); 420 Washington St.

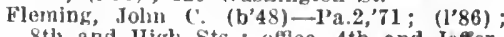
8 th and IIigh Sts.; offlee, 4th and Jefferson sts. ; 2-4.

FRANTZ, ('ILAS. I'FTEI (b'7I) †-III.6,"00 ; (1'02) ; 729 N. 5lh St.; offlce, 4th and Jefferson Sts.; $9-12,2-4 ;$ OALR.

Guenther, Edward (ieorge (b'76) $\longrightarrow$ Ky.5,"98; $\left(l^{\prime 98)} ; 1503\right.$ Mt. Ileasant St. ; office, $615 \%$ Jefferson st. ; 9-II, 2-4, 7-8.

IIoliday, Joshuil W' (b'46)-Ja.1,'69; (1'86) 8:3 1 . 6th St.; offlee, Tama Bldg.

llopklns, Alfred Grant (b'39) - Ill.11,90; $(190) ; 616 \mathrm{~N}$. Mlain st.; oftlce, 203 . Tefterson St. ; 10-5.

HUNT, ERNEST A. (b'76) - Ill.11,'98 (l'98); $114 \mathrm{~N}$. Woodlawn Ave.; offlce, $4 \mathrm{lh}$ and Jefferson Sts.; OALR.

KARNEY, ROY FOSTER (b'82)థ-I11.6, 07 (l'11); Member Ill. State Med. Soc. I:330 S. Main St. ; $9-11,2-4$.

K'nney, George Jackson (b'68)-1a.3, 88 ; (l'94) ; 806 N. 3d St. ; offlee, Garman

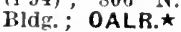

KOCH, FRED F. (b'78)-Mo.7,'01; (l'01) 715 S. Garfleld Ave.; offee, $5031 / 2$ Jefferson St. ; $10-12 ; 2-5,7-8$.

KRLECHBAUM, HORACE T. - Ill.6,'08; (l'08); 515 North St.; offlee, lowa State Bank Bldg.; 10-12, 2-4.

LA FORCE, EDW. FRANCIS (b'73) Ill. I, $00 ;\left(l^{\prime} 00\right) ; 1112$ N. 4th Ave.; offce, Iowa State Bank IBldg.; (B1); OALR.`

Lawhead, William E. (b'56) -Ia.1,'82; (1'86) ; 119 S. 6th St. ; offlce, Tama Bldg. ; 9-12, 2-5, 7-8.

LEIPZIGER, HENRY A. (b'59) \&-N.Y.10 '81; (1'84); Member Med. Soc. of the State of N.Y.; 901 N. 5th St.; office, 306 Washingt on St.; $2-4 ; \mathrm{S}$

Little, George B.' (b'51)-Ill.1,73; (l'86) 316 S. 8 th St.; offlce, $4051 / 2$ Jefferson St.; $10-12,2-4$.

Lunbeck, Danl. W. (b'53)-0.3,78. N.Y.10,

'90; (l'86) ; Tama Bldg.; 10-12, 2-4. '89, Pa.1,'9I ; (1'89) ; $123 \mathrm{~S}$. 8th St. ; office, $3 d$ and Jefferson Sts.; 10-12, 2-4:30; S. McKitterick, Nathanlel M. (b'57)-111.1,'80; (1'86) ; 537 Summer St.; offle, Parson Bldg.

MILIIGAN, WILLIAM WRIGHT (b'66)Ia.3,'97; (l'98); 130 S. Central Ave.; offle, 4th and Jefferson Sts.; 10-12, 2-4;

HOERKE, ALBERT CHARLES (b'67) \&Ill.8,96; (1'96) ; 903 N. 6th St.; offlee, Carpenter Bldg.; $10-12,2-4,7-8$.

NAUMANN, PHIL C. (b'61) - Ia.3, 87 ; (l'86); 1601 S. Central Ave.; office, $3201 / 2$ N. 4 th $S t$.

Nixon, Samuel E. (b'49) H-Ill.4,74; $\left(l^{\prime} 86\right)$; 1001 Maple St.; offlce, Parson Bldg.

PATTERSON, JOHN NORMAN (b'64) Ont.5,90; (1'98); 929 N. 4th St.; offlee, 310 Washington $\mathrm{St}$.

Ransom, James Johnson (b'39)- $71.1,63$; (l'87); not ln practice; 421 S. 5 th St.

Reppert, Phillp A. (b'59)-Ill.1,03; (l'04) ; 811 N. 8th St. ; offlce, 422 Jefferson St. $10-12,2-4 ; \mathrm{S}$.

SCHAEFER, PALI, H. (b'79)థ-III.11, 02 (i'02) ; 2110 S. Main St.; offlee, Carpenter Bldg. ; $10-11,2-4 ; 0$ b

SHERMAN, ALBFRT WILLIAM (b'61) IIeh.I,'89; (1'89); 501 S. Garfleld Ave. ; offlee, Iowa State' Savings Bank Bldg.: $10-12,2-4$; S.

Smith, John Wesley (b'69) - Mo.28,'03 ; (I'03); 922 S. 8th St. ; offlee, 2081/2 Jefferson St. ; $10-12,2-4,7-8$

Stelnle, Henry F. (b'6 6$)-$ Colo.3,'90; (1'91) ; 1000 S. 8th St.; office, lowa State Bank Bldg.

STRONG, ARTHUR CHURCHILL (b'82)Ia.3,09; (1'09); 201 Spring St.; offlce, lowa state Bank Bldg.; 9-12, 2-4; OALR. 


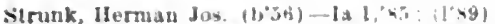
1009 s. Central Ave: onfce, Jusia stato liank Bha.

strunk, Mary- 0 : $\left(1^{\circ} 90\right)$

STETSMAN CA11! (b65) + 111.6, 93: (1993): 103 Woodlawn Are $x$ : oftce lowa state Savings Mank lihdk. : 2-5.

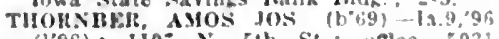

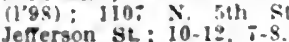

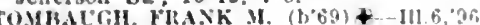
(1'99): 851 Franklin st.; otce, Tama (1P99): 851 Frant

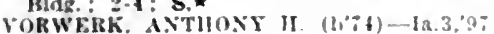

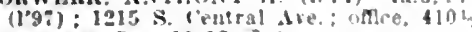
Jefterson St. $10-12,2.4$

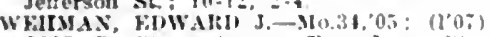
1105 S. start Are. oftlce, lown stat Bank Rlug.

WOOHRERT, ERNEST 1. (b\%0)-[11.10,91 (1'96): 613 X. ith St.: ottce, 306 Wash Incton St.; $10-12.2-1$.

Young, Henty Byrs (1,51)-111.5, is: (1'sb) loy $\mathrm{s}$ ith $\mathrm{st}$ - antce, $310 \mathrm{~s}$, th St: 10-4; (BI.8); ODAR.

Zalser. Albert Charles (b'-3) - M6.:9: (1'9:); 408 High st. : onter. 34 ams Wish Ington Sts.: 10-12, 2-4.

\section{BURROAK, 495, WINNESHIEK}

Emmons, Wullam Henty (b'68) - Ill.1.92: (1'92).

\section{BURT, 495, KOSSUTH}

("lapsadule, John fint (1).85) - 12.3,'12:

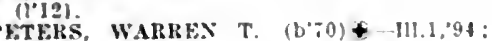
(1.91); $s$.

BUSSEY, 669, MARION

Anderson. Wilbu: J. (1568)-111 1,'94: (1'94) ICCLIRE, ERSEST (l'03).

BUXTON, 5,000, MONROE

Carter, Edw. Alberl (b'sl)-la.3, $0{ }^{\prime}$ : (1'0i) $0 \mathrm{~b}$.

Crose, John R (b'55) - : (1'sib)

Larsen, Wru. Wallace (b'st)-1a.3.'13: (1'13). MATER, ROY VINTOX (b's6) - Ia.3,10 (I'10)

Mult, James (b'il)-Ia 6, $40 ;$; (l'9i).

CALAMUS, 270, CLINTON

an Pattea, Clyda Lewlle (b.8.) - 1114.11 (春).

CALEDONIA (R.F.D., MOUNT AYR), 25. RINGGOLD

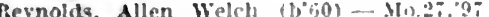
$(1 \cdot 97) ; 0$ b.

CALLENDER, 321, WEBSTER

Arent, Adolph (b':3)-111.1.95: (1'95)

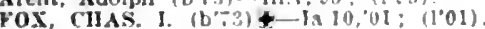

CALMAR. 849, WINNESHIEK

Elllngsen, Elling II. (b'02) F-111.8,9s: $\left.11^{\circ} 98\right)$.

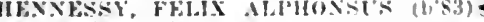
-13.3, 0 : : $\left(1^{\prime} 07\right)$.

\section{JOTHB,}

CALUMET, 242, O'BRIEN

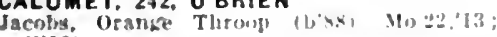
(l'13).

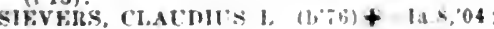
(1'04).

CAMANCHE, 629, CLINTON

Luse, Malph Frank (b's.i) la 3,'12; (1'T2)

CAMBRIA, I20, WAYNE

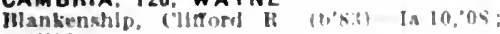
(1'08)

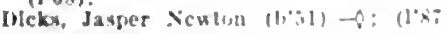

CAMBRIDGE, 696, STORY

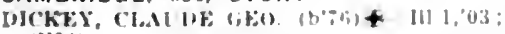

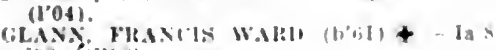
"98:" (1.98).

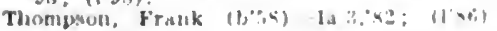
not ill practlce.

CANTRIL, 413, VAN BUREN

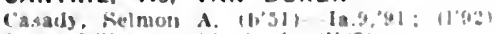
Jonew, Wlley $A$. (b't1) $\rightarrow$ : (1'xi)

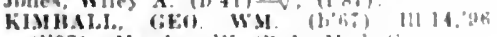
(1'97): Mernlwer III Stalde Wort

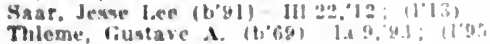

CARBON. 246, ADAMS

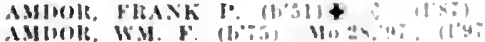

CARLISLE, 392, WARREN

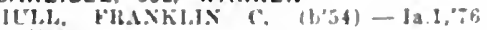

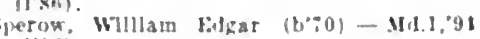
(1"96)

CARROLL, 3,546, CARROLL

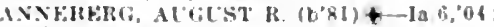
(i) 0 (1): 0 big

Itoyer, intun John (b'6s)-W14.2,00; (1'05)

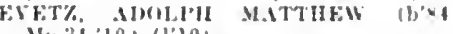
Mo..3:10: (1'101

OO'Kl.EY, ALEET S. $\left(b^{\prime} 55\right)+$ - N.Y.,80 $\left(1^{\circ} 9 x\right): 0 b$

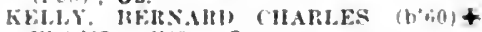
HII. 4,$2 ;$; (1,93); $\mathrm{S}$

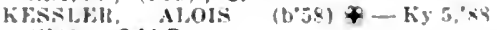
(I) (र) : OALR

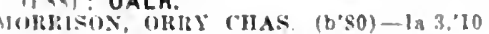
(1010)

I'A. 1100his: op

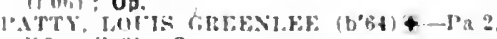
$33: 10^{\circ}(19,1): 5$.

MIIthY WAYK McKNIGHT (b80) + 111.1,05: 1l'091: S.

paulding, Chas. W. (b०h3) E- III 4, 85 (1'si).

CARSON, 640, POTTAWATTAMIE

l'ershall, klnes EwIng $(1,34) \rightarrow$ (I's9)

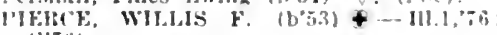
(1'7(i)

SIIFFER, CALI, I. (b'72)+-1a 303 (l'0'3)

CASCADE, 1,268, DUBUQUE

lane, James $P$. (b'79)-Neb.t, 06 ; (1'06)

I.FONAIRD, FREJK. SYlVESTER (b's0) $\rightarrow$ Mo.34,08: (1'0.8): S.

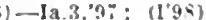

CASEY, 735, GUTHRIE

lluncan, Wm. Thos. (b"it)-111.14,95, Ia.6. $99:\left(I^{*} 96\right)$.

MAIISBY, FLILA 1'. (b'52) - 1a.1,7\% $\left(1^{\circ} 86\right)$.

Van Puzer, Wru. Hoy (b'85)-Pa.,12: (I'12).

CASTANA, 364, MONONA

CIXCIIES, WM. WHANON (b'6i) \&- hy.l,

$0.2,88$, III.17, $40 ;$; 1 '90)

CEDAR BLUFF, 100. CEDAR

Vouman, Win. (i,- F-l11, ; , : $:(1,86)$

CEOAR FALLS, 5,012, BLACKHAWK

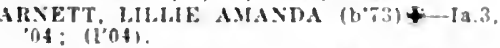

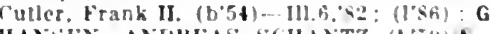

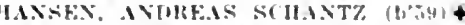

la 4,98; (1.93); OALR.

HE.IIST, GEO. HIIV. $(1,78)+$ IJ3, 04

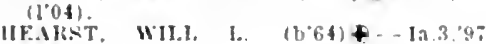

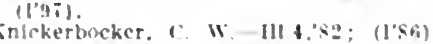

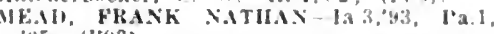
(15: (1"93).

III.ARKI, WM (:) (1)59)+-13.3,8: $(1,8)$.

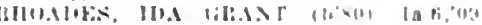
$11^{*}(34): 6$

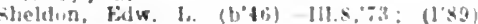

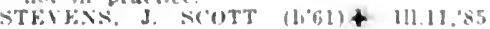

Therman, Firnews J. (b'a) - l"a 2,04; 1105$)$

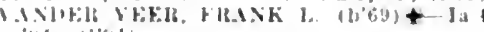

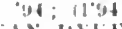

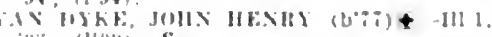

Colle: (l'03): $\mathbf{s}$.

aut (i) Juractice

CEDAR RAPIDS, 32.811, LINN

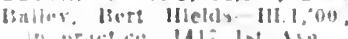

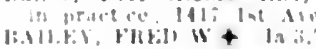

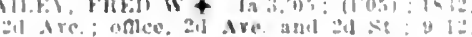
i. 404 (III): OALR.

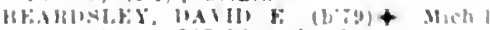

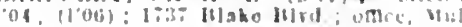
lin

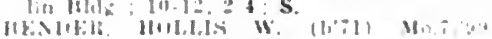

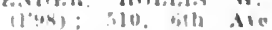
Mile: $101: 3.3 \%$

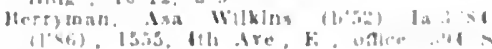
loith $21.81: 13$

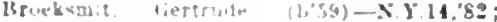

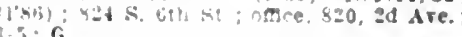

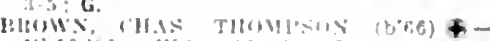

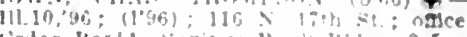

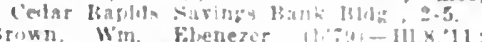

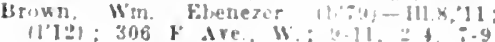

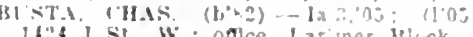
armichael. kuzene $\left(b^{\circ} f, n\right)$ II - la a ond lloli: Julln lild.

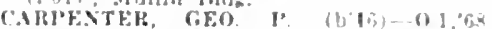
(1'86): 521, 3d Ire.: nalce, socurity

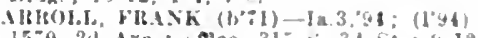

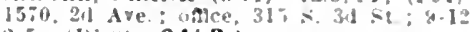
2-5: (131,*): OALR.*

(lidls, Edward layson (16"5) H- III + 03 (1'03): $150 \pi$, Ist ire ; $11,2.4,7+9$

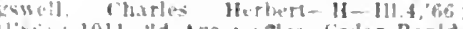

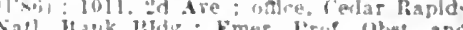
this of thllidren lat: 0 bc. is. of thidren, Ia.t: ObC.

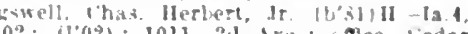
'02; (l'02); 1011, al dre: allec, ledar $1: 30-3$

uns. IIarold Ruswell (b'89)-1'3.:.'12 (I'12); Kitoball kldz.

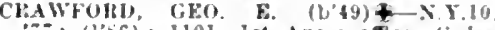
7:: (1's6): 1101, Ist Are. oftce cedar Baplds Savings Bank Bldg: : 10-11, 2-4.

CHAWFOHI, JEXNISG (b's3)-Md., 09 11'09); 1250, tih ire: offe. iedat Itapida Sarings Hank lidda.; $10: 30-12$ - -4, i-s: U.

(RAWFORI, J. IXYX (b'3)+-Pa.1.97 (1'97); 1266, 31 Are.: onlee Cedar Raplds sarlon Bank Bldt: a-t. S.

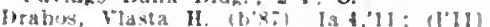
reda: Kaplds saving Bank Islus:; 10-1:.

Firskine. Arthur W. (b'85)-3Id. ${ }^{\circ} \circ s_{;}\left(I^{\prime} 13\right)$

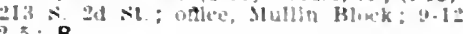
$2-5: R$.

Finer, ryrus (b.54)-191,88: (1'56): Securlly Bldg

filzicerald, $w_{m}$ (b'35)--I\$.3,36; (l'ss): 5ex. Ist Are., W.; uflce, Jim Hirak: 9.11

FKExch, (IIAS H. (b"i) Mo.,04

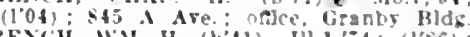

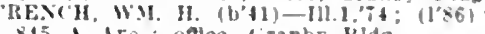
845 A Are: offce. liranth lidg

Gifford, Nhere hirby (b; 6 - -ine bo:

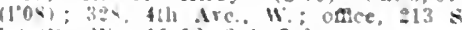
Ist 5 ?. II: $11-1 \div, 2-1,8$.

Hamblum, Julur (b'i)-Jal, $96:$ (1'96): 1941, Ist Are, oftec, Vultin Hidg: 9.11 , -4:5

ISNFI, IEOBT IBMI (b'st)\&-III 1,05 (I'l0); 350 s. lith st; oflce. Cedar

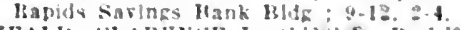

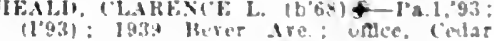
lapils savings ltank IHd: : 10-12, :-1 s.

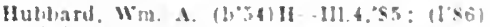
1035, 2al Are: ontere. Cedar kapids sar lage liank lih!s

llubliell, Хен

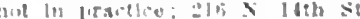

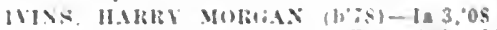

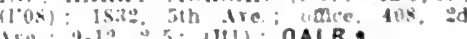
Ire: 1-12. 5; $11111 ;$ OALR.

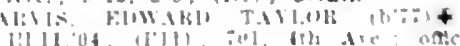

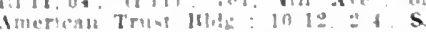

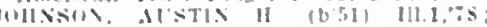

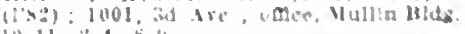

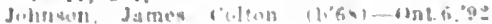

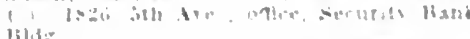

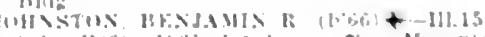

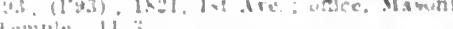

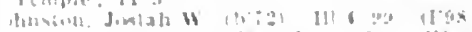

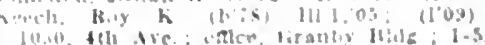

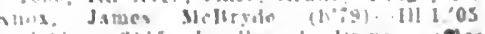

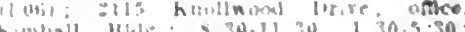
OALH.

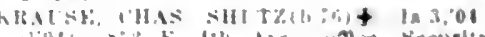

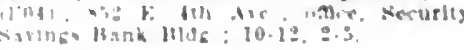


KREJSA, OLDRICII $\left(13^{\prime} 75\right)+$ - Ia.3, 01 ; (l'01); 816 S. 9th st. ; oltice, llasek Bldg. liubela, Louis Franklín (b'8i) - Ill.11,'12; Asslstant 1'hysiclan; Granby Bdlg.

Ladd, Fredk, Gains (b'66)-1a.9,91; (1'y1) $21 \%$, 2 d Are, W; ; office, Ios, 3d Are. W Lindley, Thos. II. "(b'45) $\mathrm{k} \rightarrow$; (1'89); not in practice: 123 $\mathrm{s}$. 16 th st.

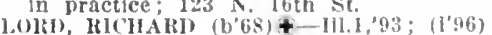

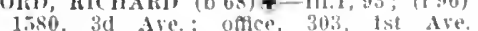
$1080,3 \mathrm{~d}, \mathrm{~A}$

Loy, Jacob (b'28) E- 0.2,53; (1'86); not In practice.

MacLaughim, L. E. (b'83)-Ga.1,07; (1'12) 1508 , 1st. Are.

MANION, PATIICK HENRY (b'64)\$-IIl.1, 90: (l'90): Iiontrose IIotel: offlce Girnuby 13ldg.; $10-12,2-4 ; G$.

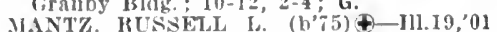
(1'03): 1545 Park Are., E.; offce, Granby (103) : 1545 Fark

itconkie, James J. (b'35)-0.3,64; (1'88) ; not in practlee; 209 , Ist Are.

H・ONKIE, WHLIS ALLEN (b'65)-N1ch.1 's9; (l's9); 1636, Ist Ave. ; office, 209 , Ist Ave. : 9-12, 2-5, $6-8$.

Hontague, Everett Ia Dew (b'72)-Mo.2 01; (1'03); 125, 26'th St.; offlee, Kenwood Park.

MOHRISON, WESLEY JONES (b'70)-Ja.3, 93 . Pa.1,94; $\left(1^{\prime} 94\right)$; 857 , 3d Are.; offlee, 93, Pa.1,94; $(194) ; 85 \pi, 3 d-8$.

408, 2d Ave. ; 9-12, 2-4, 7-8.
Munden, Kalph Edward (b'8í)-Wls.3, 09 ; (1'09)': 100 , 1st Are., W.: $9-11,2-4,7-8$

IIURPII, JAMES JOS. (b'76) - Ia.9,'98, X.Y. 19,03 ; $\left(1^{\prime}, 98\right) ; 603,3$ d Are., E. ; $8-10$ $3-4,7-8$.

l:urray, Fredk. G. (b'74)-Ill.I, 00; (l'03) : 1829 B Ave.; office, Kimball Bldg. ; 10-12, $2-5 ;$ Pd.

FAL, EMMA JEWEL (b'78)-Ia.10,02: $\left(l^{\prime} 02\right)$; 112 I'ark Ct. ; offlee, Masonic Tem-

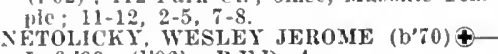
Ia.6,96; $(1996) ;$ R.F.D. 4.

FEUZIL, WM. JAMES (b'86)-Ia.3,0 ; (1'07); 603, 3d Are.; OALR.

ormiston, Calvin Ford (b'45) E-Ill.8, 90 ; $\left(l^{\prime} 90\right)$; 514,1 st St., W. ; offee, 127 S. Ist

olVEN, $8-12$, W. $^{-7}$ Fow. (b'62) $\oplus$-Ill.I, 89 ; (1'89): 1753 C Are., E.; offlce, 301 , Ist Ave, ; $9-12,1+5 ;$ ALR.

Paxton, Flmer Grant (b'69) -0.25,'96:

(l'09); 2714 , 1st Are., E. 111.1,01; (1'02); I978 B Are.; offle Security Savings Bank Bldg.; $9-11,2-4$. Security Savings Bank Bldg.; $9-11,2-4$.
I'FEIFFER. IIARRY EAHL (b'79)-Ill.6, 05; $\left(l^{\prime} 0 \%\right)$; I9II, 4th Are.; offlce, Security' Sarlng's Bank Bldg.; 10-12, 2-5, 7-8; $\mathrm{S}$.

POORE, ALVIN BRAINARD $\left(b^{\prime} 52\right) \oplus$ N. Y.5,79; (1'83); $829,2 \mathrm{~d}$ Ave.; office

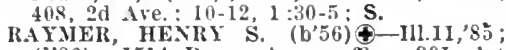
(1'86); 1514 Bever Are.; oflice, 301, 1st Are. ; $9-11,2-4,7-8$. (1'12); Ifullen Bldg.

Riggle, Frank P. (b’ 75$)-I a .10,00$; (1'00) liranby Bldg.

RISTINE, JOHN M. (b'4i) $(1,76) ; 1026,2 d$ Ave.; offlce, Kimball Bldg. ; $10-12,3-5$.

RT'ML, WEXTZLE $\left(\mathrm{b}^{\prime} 67\right) \oplus-\mathrm{Ill}, 6,91$ (l'91); 806, 5th Are.; office, Kimball Bidg. : $9: 30-11: 30,2-4$.

SAFLEY, AGNES ISABEL (b'75)-Ia.3, 04 (1'04); 1504, 2d Are.; offlee, Kimball

Bldg.; $10-12,2-5$.
SHELDON, BENJ. L. (b'77) $4-111.1,02$; (l'03); 1449 Berer Arc.; offlce, Security Savings Bank Bldg.; $11-12,2-4,7-8 ; \mathrm{S}$

spencer, Wm. Henry (b's0)-Ill.Il, 04 (1'09) ; 1979 B Ave. : offlce. Granby Bldg spicer, S. S. (b'52)-Mo.2, ${ }^{\prime} 3$; (1'86); 3d Are. and $2 d$ St., II

STANSBURY, GEO. W.-1a.3,'83; (1'86) 422 , th Are., $1 \%$; office, ith Are. and

STASBLRY, JOHN ENGER (b'89) †-1a.3, 11; (1'11); 422, ith Ave.; office, Security sarings Bank Bldg.; 10-12, 2-4 Chas. Casper (b'T)-Ill.11,04 III C Are., W.; OALR. $\star$

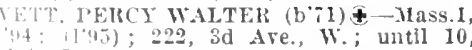

TAYIOK, WALTËL SIIEITWOOD (b'73)Ilo.28.'y!9: (1"99); not in practlce; Memher Fll. State Med. Soc.: $900 \mathbf{E}$ Ave., W. Titfany, Deforrest E. (b,7I) HI-Ja.4,"93: (1.96): 1 731 liever Ave; offlee, Cedar kapids Salings Bunk Bidg.; 1 5; OALR. an Duzer, Francis Henry (197); $118 \mathrm{~s}$. 2d St.; oftce, 127, 3d

vol'AHL, KUDOL'H A. (b'80)థ-Wls.3, ,05; (1'12); 12I, 4th Are., W.; Member Wis. State Med. Soc.

WALKEIt, ILARIKY LEWIS (b'63) )-Pa.2, '89; (l'96); 1800 B Ave, ; office, Klmball Ildg. : 10-12, 2-4:30; (BB) OALR. * WEBH, MARTHA SUL $\left(1^{\prime} 97\right): 224$ S. 5 th St

WHTMORE, CLARA BFATRICE (b'73)Ia.3,03; (I'03); Kenwood Park; office, Kimball Bldy.

Woodruff, Lewis Foster (b'62)-Ia.3, 90 (1'86); 1617, 24 Are.; offlee, Kimball Bldg. ; 10-12, 2-4.

\section{CENTER JUNCTION, 199, JONES}

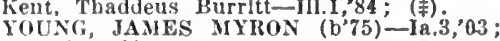
(1'03); Ob.

CENTER POINT, 802, LINN

MANAHAN, CHAS. ALBERT (b'85) †-Ia.4, '08, Pa.2,09: (1'08)

Newland, Mark A. (b';0) H-Ia.4,92; (1'02).

Yost, Chas. C. (b'74)-Mo.7,98; (1'98).

lost, Francis M. (b'31) - ; (1'98).

CENTERVILLE, 6,936, APPANOOSE

BAMFORD, ELMER E. (b'66)థ-I11.1,'90; (1'95); S.

BLACHLEY, TRACY W.๑-Ml.6,07; (1'08). BOWEN, CHAS. PARK (b'67) $\oplus-$ N.Y.10, 92 ; (1'93).

GEORGE, ABEL R. (b'78)-Ill.11, $00 ;\left(1^{\prime} 00\right)$. IIARRIS, WAYNE ADELBERT (b'8I) Ill.11,04; (1'04); $s$.

HEATON, ELBEH'T ELLSWORTII (b'71)屯 -Ia.1,'96; (1'98).

Heflin, Ánna Fay (b'67)-Mo.10,'11; (I'13) ; not in practlce.

IICKMAN, CHAS. STEPHEN (b'83)†Ill.6, 09: (1'09).

JAMES, CHAS. STEPHEN $\left(b^{\prime} 70\right) \uparrow-M o .20$,

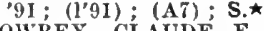

(b'77) $-M \circ .20,02$ (1'13) ; also member Wyo. State Med. Soc. McFARLAND， JOHN (b'54)- Ill.10,'87; (l'87). WM. BELLUS (b'79)థ-Mo.20 MILLER, WM

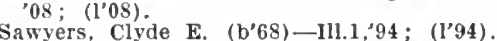
SAWYERS, JOHN LAZELLE (b'56) †-Ill.6, $78 ;\left(1^{\prime} 86\right)$.

Scott, Wm. M. (b'40)-Ia.1,'6I; (l'87).

SEVERS, GEO. FILLMIORE (b'58)-1a.6,'87,

O.2,89: (1'89); N. (l'09).

YP, WILIIAM WARD (b'73)థ-Ia.3,'95;

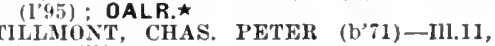
'01; (I'01).

CENTRAL CITY, 558, LINN

Adams, Ernest Marlon (b'68)-Mich.1,'94; WOODBIRIDGE, WARD (b'49) $\oplus$ - Ill.I,'8I ; (I'86).

\section{CHARITON, 3,794, LUCAS}

Barnes, Theo. (b'62) E-0.2,'08; (l'98).

Baskin, Chas. Llewelyn (b'83)-Mich.I, '12; (1'13).

Boynton, Frank H. (b'66) H-Ia.4,'88; (l'88)

BRITTELL, CHAUNCEY LEE (b'82) - Ia.3, $0 \% ;\left(1^{\prime} 07\right)$

Dougherty, Barbara E. (b'68)-Mo.22,92; (1'95).

Dougherty, Bernard F. (b'60)-111.11,'89 ; (1'95).

Elrod, Chas. F. (b'48)- 0 ; (l'\$6)

Guteh, Roy Clark, (i)'s8)-iro.28,'10 $\left(l^{\prime} 10\right)$.

Mcklveen, John A. (b'35)-Ill.8,'72; (l'si). SAUN, FRED ALLEN (b'59)-Ia.6,'87 (1'89) ; OALR.

STANTÓN, JOHN H. (b'61)-111.1,'92; $\left(l^{\prime} 00\right)$.

STANTOX, THEODORE P. (b'53)థ-Ill.1, $79 ;(1 ' 86)$.

STOKIE, DAVID Q., JR. (b'74)-IIl.1,01; (1'01).
TIIROCKMORTON, JHANNETTE FRANC (b'83) @-Ia.10,07, Neb.5,'10; (1'07). THROCKMORTON, TOM MORFORD (b'52) -Pa.2,77; $\left(1^{\prime} 8 \%\right)$.

YOCOM, ALBLKT LEE (b'55)థ-Ia.I, 86 ; (1'86).

OCOM, ALBERT LEE, JR. (b'87)-Hl.Il 09 ; (1'09); S.

CHARLES CITY, 5,892, FLOYD

Amos, llenry H.-1a.7,88: (J'89).

Brackett, Anson R. (b'55)-0.1, 80 ; (1'8i).

Coolldge, James (b'59)-111.1,'80 ; (1'92).

Hummel, Edw. P. (b'73)-Ill.11,00; (l'00).

Klinetop, Warren Bassett (b'59)-I11.15,95: (1'05).

KOBEI, AUGUSTUS FREDK. $\left(b^{\prime} 74\right) \oplus$ Va.6,01, Ill.6,02; (l'11); Member 111 . State Med. Soc.

McCRAY, WALTER R. (b'75) $†-111.11,00$ : $\left(1^{\prime} 00\right) ; 0$ bG.

MINER,' JAMES B. (b'69)-Mll.4,94; (1'98). NIENACK, JULIUS (b'60) 4 - Ger.7,91; (l'96); $\mathrm{s}$.

overfleld, Elner Ellsworth (b'61)-Ia.3,'88; (l'88).

Parker, John Leon (b'70)-Mlch.1,99; (1'01); S.

RAMAGE, CMARLES (b'66)థ-Scot.3,'87 ; (l'03); OALR.`
SEYMOUR, WM. HENRY (b'65)థ-Ger.I '98; (1'98).

CHARLESTON, 400, LEE

Davis, Andrew J. $\left(b^{\prime} 45\right) \rightarrow$; (l'86).

CHARLOTTE, 356, CLINTON

Schmitt, Adolph Otto (b'78)-Ia.3,08; (1'08).

SCHWARTZ, R. F. (b'83) $\oplus$-Ill.11,06; (1'06).

CHARTER OAK, 734, CRAWFORD

Hill, Geo. Ray (b'Ti)H-Mo.5, 04 ; (l'05).

HUBER, SHION A. (b'81)థ- Neb.6,'08; (l'08).

IcWlllams, John J. (b'60)-Ill.1,'83 ; '87)

CHATSWORTH, I3I, SIOUX

ROLAND, CHAS. LEE-Neb.6,95; (1'06).

CHELSEA, 507,. TAMA

BENEDICT, BYRON IRVIN (b'83)-Ia.3, $07 ;(107)$.

LSON, COMMODORE PERRY (b'60)(1). (I'II).

CHEROKEE, 4,884, CHEROKEE

BEACH, LENA ALICE (b'78) 9-Ia.3,'01; (1'01); (E13).

Bryan ivm. Alfin (b'83)-D.C.I, 0s; (1'09). BURLIXGAME, JOHN HENDERSON (b'48) †-111.1,78; (1'86).

CIEAVES, PRENTISS B. (b'79) 4 -Mlch.1, 02; (1'03)

CLEAVES, ROYAL L. (b'44)†-Mass.1,'69 ;

HALL, CLARENCE H. (b'7 7 )-Pa.11,04;

HORNIBROOK, EDW. (b'38)థ-Ont.4,6I ; (l'86).

HORNIBROOK, FREEMAN HARDING (b'78) IIOWARD, WM. ARTHUR (b'77)†-I11.6,

LONG, THOMAS LEE (b'74)-Ia.3,05; (l’05) ; (EI3).

Pritchard, Millard F. (b'53) $\rightarrow$; (1'86).

QUINN, CHAS. FULLER (b'59)€-Ia.8, 96 ; (1'96).

RUSSELL, RO

(l'1I); NP. Clarence-Ill.8, '06; (l'06)

Seaman, Roy Clarence-Ill.8,'06; $\left(l^{\prime} 06\right)$ -
VOLDENG, MATHEW NELSON (b'63) lll.11,87; (1'87); (E13); NP.

WATSON, GEO. LEWIS (b'59)-Ia.9,'97; (1'97).

WESCOTT, LE IROY ANDERSON (b’2)Ia.3, 01 ; (1'01)

CHESTER, 266, HOWARD

CLARK, I.ESLIE WILLIAM (b'86) \&-Ia.3, 09; (1'09); Member S.D. State Hed. WARREN, CLARK LEROY (b'T0)-IIl.I, ,97; (1'97).

CHILLICOTHE, 181, WAPELLO

RAMBO, DATIN T. (b'74)Ð-Ia.1,97; $\left(1^{5} y_{i}\right)$. 


\section{CHURCHVILLE, 75, WARREN}

Maber, Thomas Aurustine-1a.3,06; $\left(1^{\prime} 06\right)$ CHURDAN, 667, GREENE

Cressler, Frank Ernest (b'78)-11I 6.'04 $(1.04)$.

lobr, Oscar C. (b':3)-Mo.2k:96; (1"thi)

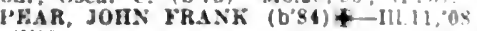
(I'i1).

\section{CINCINNATI, 1,335, APPANOOSE}

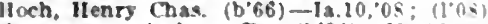
sterenson. Arthur P. (b'84)-Mo.2?, 0 ; (1'0i).

stephenson, W. H. (b'52)-Ill.8.83: (1's:) Sturdirant, John $\left.M\left(b^{\circ} 66\right)-I_{3} 1^{\circ} \mathbf{s}^{\circ}\right)$ (I'Bi).

CLARE, 299, WEBSTER

Oorsey. Thorzas James (b'\$5) - - Ill.b.'l0 (1'11).

CLARENCE, 662, CEDAR

NICOLL, DAVII T. $\left(b^{\circ} 6 b^{\circ}\right)+1116.6^{\prime}(9)$ (1'98).

Smitb, John Edw. (b'it)-III.1,00; (1'00)

CLARINOA, 3.832. PAGE

UARK, FRANK H. (b'7i)-111.11,03

(I.03)

FAIREXS, FTASTIS TALBOTT $\left(\mathrm{b}^{\circ} 35\right)+$ Mo.1,81; $\left(1{ }^{\prime} 8 \%\right) ;$ OALR.

lsher, Wm. Clark (b'\%0)-1a.3.93: (l'93)

00 .

hillingsworth, Danlei II. (b'63)-1a.6.8s: (I's3).

klng. Frank L. (b'60) H-0.13.88: (1'05) LEADER, PACLINE M. (b'67)-1a.3.94 (1'95).

Mack!n, M. Charles (b'66)-Md.4;'91, IIl.10 93: $(1 \cdot 95)$ : NP.

MATTHEWS, ROBT. JOHN (b'is) 98: (1'02): OALR.

OHLYACHER, JOS. C. $\left(b^{\prime}-4\right) \neq 111,1,01$ (1'03).

PHILLPS, WM. CHAMBERS $\left(b^{\prime}(5)+\right.$ 111.11,03; 11051 : s

PWER. THOS. ENWIN $\left(\mathrm{b}^{\circ} 50\right)-1101$ 81: (1'86): $\mathbf{S}$.

Sellards, Jos. W. (b'i5)-la fi.c0l; (l'0l) SUERMN, ALVA MATNABD $\left(b^{\prime}-5\right)-$ IIl.17:01: (l'03). Danl. (b`90) - 1a.6. ${ }^{\circ} 09$ (1'09).

WITTE, MAX E. (b'39) + Ja.3.81; (1'86) (E:13).

CLARION, 2.065, WRIGHT

HERNARD, RASSOM IIRII'S (b'S2) +-111.1 O : : (1.09).

BEST, ELMER ELLSWORTH (b'58)

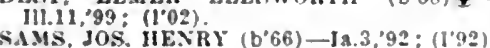

SAMS, JOS. MENRY (b'66)-Ja.3,92: (1'92) 99 : $\left(10^{\circ} 00\right)$.

CLARKSVILLE, 895, BUTLER

DAY, WW. E. (b'63)-la.3.02. (1)002)

SiRIPTCRE, JAMES LEVI (bo)-Ia.3,

Taylor, Morrison A. (bo5i)-1a.4,"9:; (1'9i)

CLEARFIELD, 625, TAYLOR

BROWX, JOS. WESIEY (b"ai)-la 3,05 (1"03).

MCCALL HARRY ERXEST (b'i5) - IA 3 ¿03: (j'03) ; OALR

Reed, Darld W'm. (b'6i)-Ia.9,"it; (l'12)

CLEAR LAKE, 2.014, CERRO GORDO

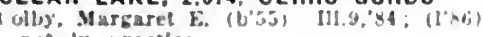
not in pracelce.

vHLL.IPS, ALBIN B. (6.6) - 111.6.02 (1)02)

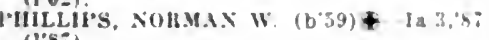
(1'si).

Scanlon, yranklin Tuglor (1; 79$)$ - Tenu 19 , 10: (1)12).

wills, Therdore Alan (b'a b) la 4:10 (1)ios.

wright; Charles boural (u'bl) la s,'so (1"9s).

Wright, Jane Iurusle Nolntush (bes) ba.3. 98: (I'ys): $\mathrm{G}$.

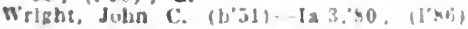

CLEGHORN, 186, CHEROKEE

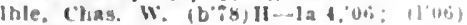

CLEMONS, 213, MARSHALL

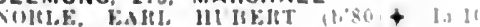
ODSi (10.03).

CLERMONT, 310, FAYETTE

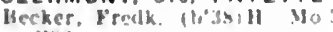

$(1,86)$.

IERRY, HCIAHD I" - que I, 'A
CLINTON, 25,577, CLINTON

Allen, II. D. $\left(b^{\circ} 50\right)-I I 1.6,74 ;$ not lu prac

Anderson, Marlon Ellsworth (b'sa)-IIl.6

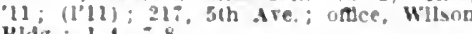
Hide. $1-4, ;-8$

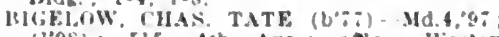
(1095): 315, th Ave. oalce, Weston lliok: 9-1: 1-5; OALR.

Blunt Arthur w. (b'54) H-11l.10:78: (1'is): 323,5 th Are. : $9-10,2-4, \quad:-8$

hOYI, bRANK HUTSAM (b'79)-I11, 01 (I'03): Member III. State Med. Sioc.

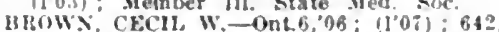
$5 \mathrm{~h}$ Are. onlee, Weston Block; I:30-1

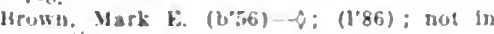

fisactice. THOS, BFATTY (b"2)\& Iil.10,97; (196): Lapayette In : uflce, Howes Block: 9.12, 2-4; OALR.

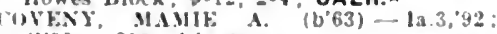
(1092): 319 , 4th Are.

EVERHART, ROBT, ह. (b'60)-las, 82 :

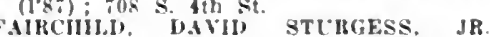

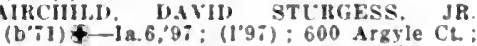
atice, Wilson Mlikg. 1-4: (Ai): $\mathrm{S}$.

FAIRCHITD NAVID STIRGESS, SR.

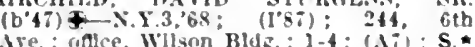
cruber, Carl (h'55) II-IIli, 86 : (1'8i); 213 Id St. : $8-10,1-3$.

HOFSTE'TTER, GEO, (b'58)£-I11.1,'s?: (1'si) : Lyons P.

HOHEXSCHUH, FRAXK A. (b'75)-Ia.3. 00: (1'00): 434, I0th Are.; offce, 223 5th Are. : $9-12,2-5,7-8$

IILDSON, JESSIE BLANCHE (b;0) la.3,0s: (l'08); Agatha Hospltal; Member Med. Soc. State of Ira.

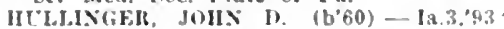
(1'93): 1101 Camanche Ave.; offee, Toll lilock: $2-3$.

Jaenlcke, A(tolph (b'34)-Ger.20:79; (l'\$2): iot s. fith st.: antce, 213,5 il we.

J.IE.NICKE, KI'RT (b'\$3) - Ia.3,05: (1'05) 704 S. 6th St.; offec, 213.5 th Are.; 9-12 - - : 0 .

IIRUA.; MARION S. (b'66)F-I11.11,01 (101):600, ith Are, offce, Corlln Block $10-12,2-4$

KFFFE, FIANK MII.Fs (b'79)-I11.11,04: (1'0i); 806 \&. 34 sis: otfice, Wlison Hlock: 10-12, 2-4. hellogg. Chas. $F$. (b+t) -4 ; (1'86); not in practice.

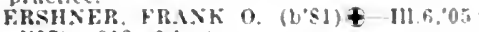
(1"0\%): S12, 6th Are.

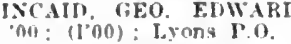

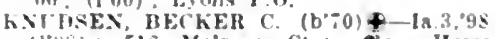
$\left(l^{*}, 5\right): 516$ Melrose $C t$; office. Howe Hock: $2-4$

l.ambert, Chas. Curtl-Mil.6,01: (I'01): 1: S. Od St. in practloe.

l.S.TIAN, JOS. CLEMENT $\left(b^{\circ} 69\right)+-111.1$ '91; (l'01): 5th Ave and Blun Itd.; natce. Lankan Hidg: : $:-4$

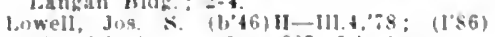
52: bith Are.: uflec, 22:, Bill Are

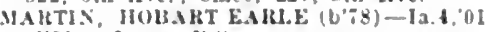
(l'01): Lyons I'. I).

MAITINIAL, EDW. LOWH (b65)NICh 1,94; (1'9t): 34t, sth Are. nnce

MILLEIS ANSON TURES("E) (b'a)- 111.11 04; (10.7); i:6 s. ith st. ofice, Mals st - i, ons in.

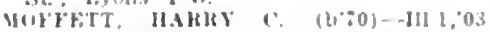

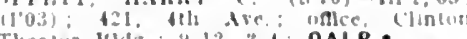
Theabr Has: $y+12, z-1 ;$ OALR.

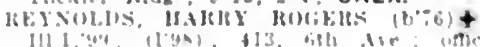
II. wes islus

It) de?. Walter Murne H III.10,99; (1'ba)

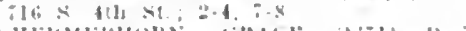

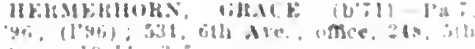

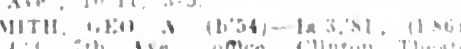

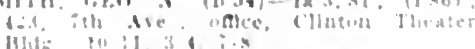

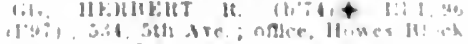

WALLIKER, WILBI I II (L":) - -IH.II

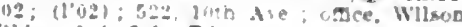
Hlde; $1-4 ; 8 ; \mathrm{Pd}$.

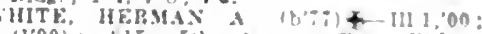

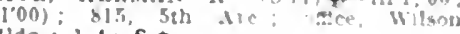
Hids. : 1.1 ; S.

Hemenkay, Frank A. (b'4)

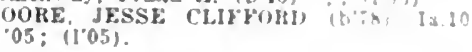

CLUTIER, 186, TAMA

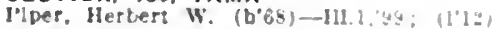

COGGON, 47I, LINN

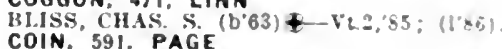

Johnson, Wm. Garteld (l'09)

king, dlled H. (b'51)-0: (I'85)

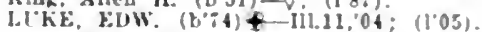

COLESBURG, 27I, DELAWARE

IITTMLY. M. E. (b'62)-111.4.35; (1'86)

Wlson, Fred C. (b'6s)-Ia.3,95; (1'95).

COLFAX, 2,524, JASPER

A.ISEACII, ROYAL BILENWOOII (b'8t)

III.8,"09: (I'09): Ob.

HOYI, FRASK ELMER (b'68) 1a.3,93: $(1 \cdot 93)$.

Corsellus, Jeptha $C$. (b'37) $-c:(1 ' 56)$.

Hawk, Wm. W. $\left(b^{*}+3\right)-1 a, 1,80^{\circ}$; (l's;); not in practice.

lotier. Clarence M. $\left(b^{\prime} 7 b\right)-1 \mathrm{a} .6,01$; (1'01) SIIERBON, AMOS (b'-3)-Ia.30: (1.10). SHERBON, FLORENCE BROWY (b'70) Ia.3,"04: (1'04).

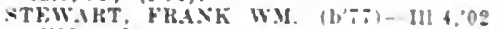
$(1002): 00$.

Turner. Alice B. S. (b'39)-Ia.1.' 8 t

TIRNER, I.EWIS C. S. (b'36) - Ia.1,8: (1"85); OALR.

Welrick, Harry A (b'65)-0.2.65; (1's8)

Weston, Nums T. (bo4)-Ia $5.98 ;(1098)$.

Velt, Ot? J.-Ra.15:11: (1)

COLLEGE SPRINGS, 626, PAGE

llones, John M.-13.3,"90; (l'90).-Mo.18,"93:

j)arles,

lictlsmonds, saml. Erskine (b'3:)-0.9,:7; (l'บ1).

COLLINS, 52I, STORY

Graham. Geo. Wurren (b'ig)-Ia.6.0.5 ( l'05)

knepper, Norman willson (1"54)-X.Y.S,'s:

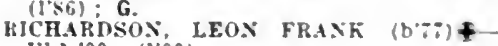
III.1,00: (1,00),

COLO. 463. STORY

liLAXX, ARTILK IERALD - Is. (1.95)

lioodenow, sidney Bartlett (b's:)-la.3,09: $\left(\mathrm{l}^{\prime} 0 \mathrm{~g}\right)$.

Ilostetier, John IIull (b's6)-III.6,'10; nil In practlee.

IOSTETTKH, JOHX IRVIXE (b'35)-III 6 'S0: (I's6).

COLUMBIA, 200, MARION

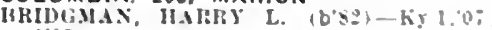
(1'0:)

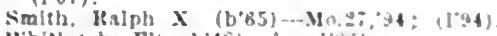

Whitlatch, Fil (b'ts)-8; 11 (15).

COLUMBUS CITY, 375, LOUISA

J.EWT, SAML JONES $(b: 0)-1101.96$ (1'y(i): Ob.

COLUMBUS JUNCTION, 1,185. LOUISA

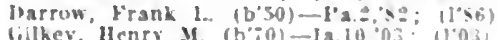

lillhey, llenry il

HIHAli, FH.I.

\section{$(1,93)$}

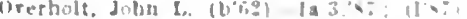

lence. James Wna. (b'; $)$ - ia 10.0

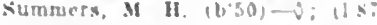

CONESVILLE, 347, MUSCATINE

ENTIINII. HARII 11. 16621+ IA 80.01 :

CONRAD, 5\$9, GRUNOY

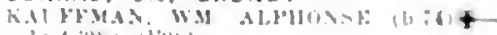
Ia tan: $\{1, y=3$.

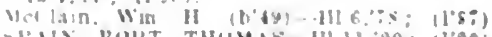

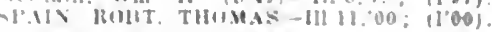
CONWAY, 2BJ. TAYLOR

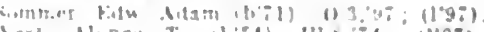

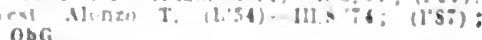


COON RAPIDS, 1.084, CARROLL

llenry, Chas, Willís (b,54)-111.1,84; (1'86).

WOLPE, CHANNING KLMER (b'-8) III.6, 03 ; $\left(1{ }^{\prime} 03\right)$.

COOPER, 150, GREENE

Knowles, Joseph K. (b'45)-Ill.1,'69; (1'86). CORNING, 1,702, ADAMS

MINIER, FREIL, (b'75)-MO.34,11; (l'12). BRYANT, CHARLLS It. (b.5)-Ill, 6,79 ; (1'87).

HAWLEY O. 18. (h'79)-MI0.22.06: (1'06).

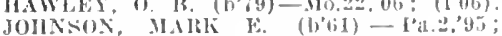
$\left(1^{\prime} 96\right)$.

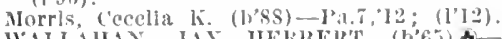

WALLALAN, JIY IIEKRERT (b'65) Мo.7, $97 ;$; $(1,9 \pi)$.

CORRECTIONVILLE, 893, WOODBURY

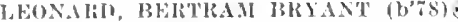

Iat.:, 08 s: $\left(l^{\prime} 08\right)$

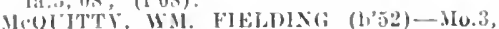
; 9 : (1'si)

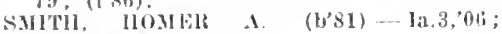
(1'06i): OALR.

CORWITH, 455, HANCOCK

BUSIIBY, AIONZO L. $\left(\mathrm{b}^{\prime} 66\right) \uparrow-\mathrm{Il} .11,91$; (l'ys).

Van lyke, James A. (b'59)-1ia.3,'86; (1's6)

CORYDON, 1,669 , WAYNE

Booth, Allce Fillen lsurtoll-Ill.9, 00 ; $\left(\mathrm{l}^{p} 00\right)$

Broek, Wm. 13radley (b'01)-Ill.11,86

(1's9) ; (1)ruggist).

MlccoY, JOS. N. (b'59)-Ia.1,'82; (l’01)

SOLLENBARGER, GEO. HAI'TLEX-Ill.11, 98: (1'98).

WALKER, IBENJ. S. (b'it)-Ia.10,00; $\left(1^{\prime} 00\right)$.

WALKES. WI. (8. (b'79)-Ia.10,02; (l'02).

COULTER, 198, FRANKLIN

Everson, Giustare Adolf (b'85) - Ia.3,'10: $\left(1^{\prime} 10\right)$.

COUNCIL BLUFFS, 29,292, POTTAWATTAMIE.

Ash, Wm. Ldw. (b'90)-Neb.6,'13; Nercy lfospital.

BARSTOW, JAMES 11. Ia.1,80, X.Y.I0 '84: (1'86) : 221 s. 6th st.; I'rof. Applied Ther Neb, 6 ; ( 1 is)

BELINGLR, FRANK EARL (h'T) Neb.6,00; (1'00); 318 0akland Are.; of flec, 614 Broadway: 11-i2, 4-6; S.

Bellinger. Fredk. $\quad F$. (b'00)-N.Y.3,80 (1'\$6) ; 616 Broadway ; 8-10, $2-6$; G.

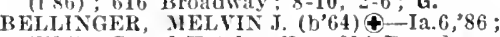
(1'86) ; Grand Hotel; office, 614 Broadway. BELLINGER, SNITH W. (b’t)-Neb.5, '04; (l'05) ; 405 Oakland Ave.; office, 614 w. Broadway.

Benjamin, Herman Paul (b'85)-Yeb 6,09: (1'09); First Natl. Bank Bldg.

(l'09); First Natl. Bank Bldg.
Bower, Chas. II. (b'55)-Pa.2,'85; (l'89) ; McPherson Are, ; oflce, Sapp Block; 8-10, $\mathrm{I}-4,7-8$.

ClAAVER, GE.AN D. (b'84)-Neb.6,n9: (1'09) ; 620, lst Are.; offlce, 23 S. Fth St. : 8-10, 2-5.

CIEAYER, J. IHARVEY (b'56)-2Id.1,80; (1'89): 23 s. ith st

COLE, JAMES HAMVEY $(b, 70) \notin-$ Ill.11, OLE, IAMES HANVEY (b' 60$) \notin-$ Ill.11, 125 Pearl St. ; 8-10, 2-5, 7-8.

DEAN, FRANK WHLSON (b'63) \&-MIIn.4, '90; (I'91) ; 424 Oakland Are.; offlce, City' National Bank Bldg. ; 9-12, 2-5; (B1,18, 31) ; OALR.ネ

Engle, Carl yon (b'54)-Ger.1,76; (1'90)

Ericksen, Christine S. (b'75) -Neb.5,03; (l'03) ; Elder Court; office, 131 P'carl St. ; $10-12,2-4,7-8$

Green, W' W. Niason (b'74)-Neb, 6,01 (1'01); 201 N. Ist $S t$ : office, Shugart Bldg.; 11-12, 2-4, 7-8.

Hamilion, Harriet Spera (b'69)-Neb.6,'12; (\$) ; 348 Iawton Terrace.

Hanchett, Alfred P. (b'52) H-Ill.10,78 : (1's6); $120 \mathrm{~S}$. 6th $\mathrm{St}_{\mathrm{t}}$; offlce, City Natl. Bank Bldg.; 11-12, 2-4. S.

Hanchett, Wm. Mldicken (b'81) II-Pa.9, '08; (1'08); 120 S. 6th st.; office, City '08; (l'08); $120 \mathrm{~S}$. 6th St.; office, City

II awkins, Eumet L. (b'si) - Neb.6,'12; () (20) Lawton Terrace.

IPNESSY, ALRERT V. W. (b'84)†-Ia.3, Xational Bank Bldg.; $11-12,3-5 ; 7-8: 30$;

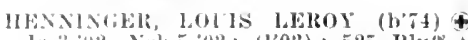

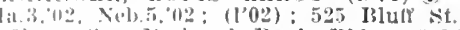
office, 'ity Nattomal Bank Bldg.; 9-1: $(1319) ;$ ALR. $\star$.

HIIA, IIALMERS ALEXANDER $(1,79)+$ -Iil b.07: (l’09) : 3 Flder Ct. office,

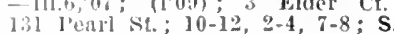

Ilollingsworth, Nellie F. Waelde (b'86)1'a.F," 0 : (1'I2) ; 409 Oaklind Are.

IIontrach, Wh. I'cter (b'62)-Ill.11, 61 ; (1') I) : 608, Ist Ave. ; I-4; S.

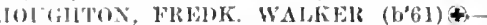

N.Y.1,83; (1'87): 203 Park Ave, office,

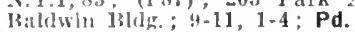

IWNNINGS, IIENRY b. (b'60)థ-Ia.I,'82; (1:8\%); 201 , 3d St. ; omee, 125 Pearl'st.; 10-12, 2-4; 1'rof. Surg., Neb.6.

VACRAE, DONALI, JR. (b'T0)\&-Mich.1, 91; (1.91): 809, 5th Are; offlee, Clty

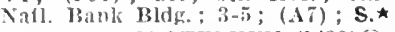

U(ATEF, JOIN STEPHEN (b'88) \$-Nel.6, 10: (Ii1) 100 9th St. offlee, City Na (fonil liank Bldg.; 11-12, 2-4.

Necolm, Cyrus B. (b'54) - Mo.18, 83 (1'86): office, 11 S. 1st St.

MERRITT, EDWIN ATKINS (b'81)क-

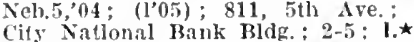

MITCIELL, ADDA BOWERMAN ( $h$ '68)-

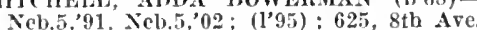
Neb.5,91, Neb.5, 02 ; (l'95): 62., 8th Ave
Moth, Robt. S. (b'81) II-Ill.4,05; (l'10) 417 S. 1st St.; office, Shugart Block; $11-12,2-4,7-8$.

O'KEFFE, MATHEW EARI, (b'79) कNeb. 6,06; (1'06); City Natl. Bank Bldg. Reichenbach. Henry A. (b'75) -Neb.5,'01: (1'06): 106, 4th St.; offlce, Clty Natl. Bank Bldg.

Reller, Wm. Edw. (b'64)-Ill.4,'85; (1'90); 830,1 st Ave.

Ricard, Geo. A. (b'75)-1ll.13,05; (1'05); 420 W. Broadway.

RICE ROSE HAMMOND (b'66)-Neb.5,03 ; (l'03); 625,5 th Ave.; offlce, IIcriam Block? $3-5$.

Rollins, Chas. A. (b'64)-0.1'82; (l'89) 201 E. Broadway.

sanders, John Aloyslus (b's 4 -Neb.6,'11; (1'13); Sapp Block.

SEYBERT FRANK T. (b'59)-ra.2,81 $\left(l^{\prime} 86\right) ; 534,1$ st Are. : office, 532,1 st Are. $1-3 ;($ E13).

Smith, Sydney H. (b'79) $\rightarrow$ Neb.6, 09 ; (1'10) 242 N. 2d St.; office, $630 \mathrm{~W}$.'Broadway $10-12,2-5,7-9$.

Snyder, Melanchthon Braham (b'56) IIMich.5, $8 \pi ;\left(1^{\prime} 8 \pi\right) ; 121 \mathrm{~S}$. 7 th st.

Snyder, Susan MeGlaughtín (b'60) IH Mieh.5,87; (1'87); 121 s. ith St.

TINLEY, MARY LOUISE $\left(b^{\prime} 69\right) \uparrow-N e b .5$, '95; (1'95); 331, 9th Are, ; offee, Baldwin Block; 9-12, 2-4.

TINLEY, MATHEW ADRAIN (b'T6)Neb.5,02; (1'02); 919,6 th Are.; office Baldwin Block; 11-12, 2-4, $7-8$.

Tobey, Saml. D. (b'37)-Mich.1, 60 : (l's7); not in practice; $803,3 \mathrm{~d}$ Ave.

TREYNOR, VERNON LAWRENCE $\left(b^{\prime} 66\right) \notin$ -Ia.3,91; (1'91); 811, 3d Are.; office, 13aldwin Block; 10-12, 2-4.

TUBBS, RAY BURNEY (b'79) - - $111.1,01$ (1'03); 545 Willow Are.; office, City National Bank Bldg.; 11-12, 1-4; Pd.

VERPOOKTEN, M. H. (b'48) †-Belg.4, it; (198); not in practice; llember Wyo. State Med Soc. : $135 \mathrm{~S}$. Main St.

Warner, Merle Frank (b'83) - Neb.5,'07: (1'08) ; 1120 Arenue $B$; offlce, 208 X. Sth St. ; $10-12,2-4,7-8$.

CRAWFORDSVILLE, 322, WASHINGTON

HUSTON, S.1.13. W. (b'-5)-Ia.3,03; $\left(l^{2} 03\right)$.

LEASE, NIMROD JAMLS (b'70)-Ti.3,'92; (1'92).

CRESCENT. 375, POTTAWATTAMIE

ROBERTSON, ANDREW ALEX. (b'8 $)$ Neb. 5,01 ; (1'01).

CRESC 0, 2,658, HOWARD

Almond, Elizabeth A. (b'68)-111.4,94; $\left(1^{\prime} 94\right)$.

CONXOLLY, WLLIAII (b'61)‡-M11.1,8? (1'86); OpA.
DALY, WM. THOMAS (b'72)థ-Ill.6,99 ; $\left(l^{\prime} 00\right)$.

IIESS, W31. CLARENCE (b'74)£-Ill.11, $01 ;(1,01)$

JINUEIRLEE, JOS, WENCEL (b'T5) (la. 10.03 ; (l'03); OALR.

KESEEL, GEO. (b'56)+-Ill.1, 85 ; $\left(l^{\prime} 86\right)$; $S . \star$

PLUMMER, GeO. A. (b'79)-Ia.10,02 ( 1202$)$

koome. (has. D. (b'43)-11l.1,'iI; (1'86).

CRESTON, 6,924, UNION

BARBER, OLIYER S'TLLLMAN (b'T5)€-

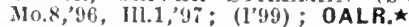

Beatle, Chas. Anilrew $\left(\mathrm{b}^{3} 76\right)$-Ill.4, 03 ; (l'03) : $\mathbf{S}$.

IBEATY ALFX.NOER STEELE (b75)111.10,03; $\left(1^{\prime} 05\right)$.

CHIL, HAL AYGUSTAN (b'79)-Jll.1, 01: (l'05) ; OALR.

COAKL.EY, GROSER C. $(1,84) \&-\mathrm{Ill}, 6,{ }^{\prime} 04$; (l'04).

COAKIEY, JOSHUA W. - Ill.8,'83, Mo.^8, $93 ;(1 \times 8 \pi) ; \mathrm{S}$.

COAKLEY, OHLO ELBERT (b'80)屯No.28,01; $\left(\mathrm{l}^{\prime} 05\right)$

FKY, JAY WORTI (b'75)-Neb.5,97; (1'97) GOLDEN, THOMLS V. (b'87)-Neb.6,10; (1'11).

GREEN, RALPH EDISON (b'78)-Ill.1, , $00 ;(1,06)$.

Gregory, Iloss II. (b'70)-Ky.I,'93; (1'94); not in practice; 132\%, 36l Are., N. EITH; WILFRED KENNEDY (b'71)

Mrebonald, John (b'65) E-Ia.7,'86; (1'86).

NYERS, ANOS J. (b'54)H-Ill.4,79; (1'86);

Norton, Harlow M. (b'33)-Ia.1,'74; (1'86) ; not in practlce.

REYNOLJS, JOHN W. (b'75)†-Mo.8,'98, (1'98) OALR.ネ

(1I. SCHIFFERI

Stanley, IIorace M. $\left(\mathrm{b}^{\prime} 80\right)-\mathbf{M} 0.22,{ }^{\prime} 0 \mathrm{~T}$; $\left(l^{\prime} 07\right)$

\section{CROMWELL, 208, UNION}

REED, MOSES BRADFORD - Ia.1,'88 ; (l's8).

CUMBERLAND, 522, CASS

BARNETT, REU LEE $\left(b^{\prime} 79\right)(-\mathrm{Ia} .3,07$ $\left(l^{\prime} 0 \pi\right)$.

WEAVER, ADAM (b'66)ङ-Mo.7,92; (1'92); OALR.

CUMMING, 200, WARREN

Cochran, Aaron Lenuel (b'75) - Ia.10,02 ; $\left(1^{\prime} 02\right)$.

CUSHING, 254, WOODBURY

BLLLOCK, ALFRED II. (b'73)-Ia.8,'00 ; $\left(1^{\prime} 00\right)$.

Summers, Martin Perigo (b'82)-Hll.1I,08; (l'08).

CYLINDER, 129, PALO ALTO

WOODBRIDGE, JAMES WARREN (b'T0)Ia.1,'93; (1'93).

DALLAS, 250, MARION

Lindsay, Vernerd Thorne (b'80)-Ia.10,05: (l'05)

XPLE,

Pitts, Francis Uarton (b'CT) - Ia 0,01; (l'01).

DALLAS CENTER, 769, DALLAS

BUTTERFIELD, EDWIN J. (b'79)-III.11, 03; (l'03).

CIHLES, JESSE HENRY (b'92)-Ia.10,'03 ; (l'03).

CRILEY, BEXTON H. (b’50)(4-Pa.2,'71; $\left(l^{\prime} 8 \pi\right)$

DANBURY, 558, WOODBURY

Creswell, W'm. I. (b'78)-Ia.8,03; (l'03). IIURPHY, GEO. W. (b'59) †-Ia.3, 88 ; (l'88).

Murphy, John Jos. (b'86)-Neb.6.'11; (1'13).

DANVILLE, 203, DES MOINES

Giese, Geo. F. (b'50)-Pa.2,'75; (l'86).

Thomas, Wellington Amos (b'58)-N.X.13, '91; '(1'11).

DAVENPORT, 43,028, SCOTT

Allen, Larned Van Patten (b'87)-Ill.1,'12 (application pending,'13); 11 Oak Lane: office, Central office Bldg.; $10: 30-12: 30$ $:: 30-5: 30$. 
M.LE., WM, 1. -1a.3, DI; (12wi, 11 03k

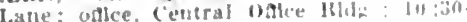
$12: 30,2: 30-5 \cdot 30: \mathrm{S}$.

Anderson, Fredk. Fugene (b'it - la 3, to

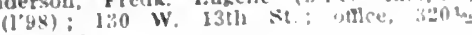
Brady St.

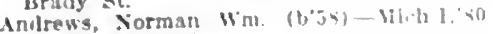
(1.0s); Box 270

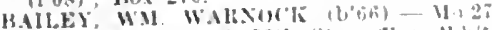

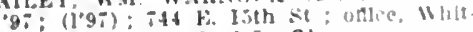
aker Huls: 10-12, 2-5: 0 b.

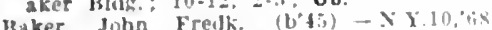
(lio): litl liranil die.: unter, Whitath. Ii] $d x^{2}: 10-12,2-4$

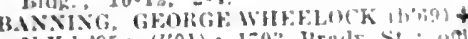

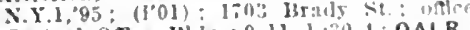
Central once lilds: : 9-11, 1:30-4; OALR, (I'91): Schmitt 1tdg.; 11-12,2-4

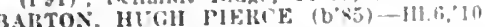
(l丷io): 120 yount st. onler, l'utram (1) 10$): 102,3-5: 30$.

Bawden, IIenry 1...-1a..., \%3; (l'si); not in practlce.

Benadom. Willism Albert (b'79)-III to, 10: (\$): 1103 Leonard St.

LESDIXFS, I'ETEK ALFSRD (h\&1) III. 1,05; (1.05): 112

ence lane Block: $S$

Bowman, Edw. S. (b'6s)-1a.3.33; (1'93) 637 Kirkwood Blyd.; once, Central Ofle Bldk.: $11-12.2-5$.

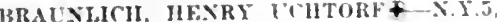

'83: (l'S6): $1040 \mathrm{~W}$. 4th $\mathrm{st}$

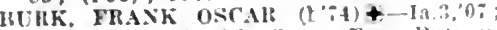

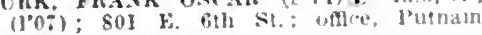
BIdg.

Inurkhart, danes R. - la 9." MeManus Bldg.

Hyrnes. Thomas-la.3,93; $\left(19^{\prime} 3\right) ; 510 \mathrm{X}$ Ulncoln Are.

Campell Maggle Annette-111.15,05: (I'10) ; 1411 I.e Clalre : 8 ; $8.9,2-4$.

camplrell, Win. Elliotl (b'57) - Ill.t5, 05: (1) 10$)$

rantwell, John Malzell (b'7) - In.3.0! (fol): itl f; 14th st: oftce, Jutuam Bldg: $10-12,3-5: 0 b$.

Carmlchael, lienj. F.-la.3,73; (1'sh); not in practlice.

CARXEX, ROSCOE J'ATRICK (b'St)-MO.34 11: (1)121: 1615 Farmam Si.; iftce. Securlty Bidie: 11-12.: :-6

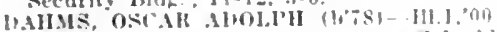
(100); 1430 W: 18th St.: oftlee, schmldt Bldip.

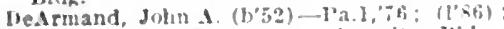

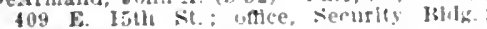
$9-11,2-4$.

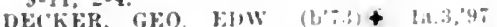
(197): 742 Brady 5 i.; uthce. Central Once Bldg. : 2-5; $\mathrm{S}$.

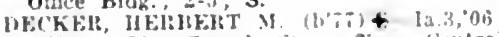

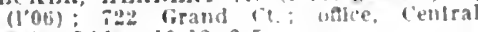
once lildg: $10-12,2-5$

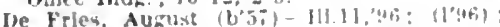

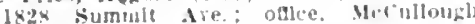
IBlde.

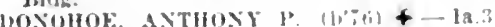

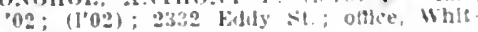
aker $131 \mathrm{dg},: 12-1,3-5$

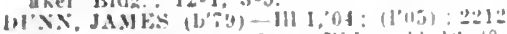

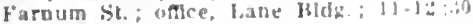
$3.5: 30,-3-\mathbf{P d}$

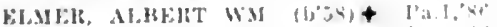

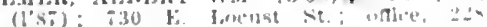

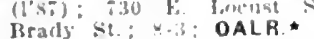

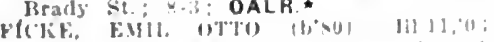

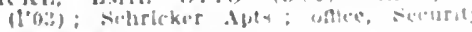
Hal: : 9 10, 2.4

Foley, Walter Bilwatrl (1, (1) 3 ) : 30ti 4161611 .

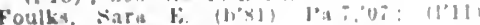

Foulks, sart fo.

Gl,

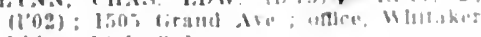
Hluke: 12-1, :-6.

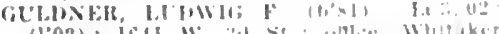

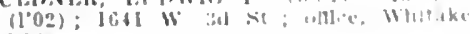

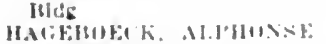

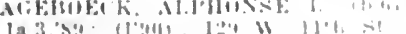

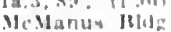

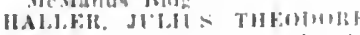
Mu., $05: 110.01$, 1:2i) Mrati

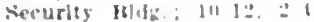

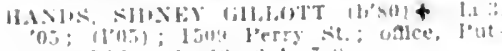

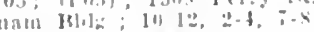

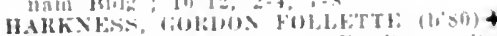
- lat.3.0

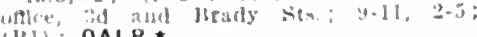
(131): OALR.*

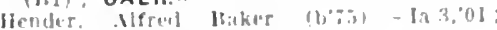

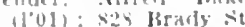

loeple. Jlenry (harles (b'tio)H-1ut,':

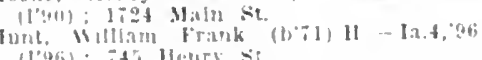

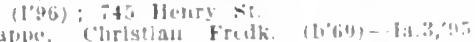

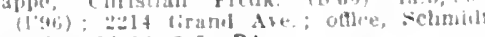
Hhl ; 10-12, 20-5: $0 *$

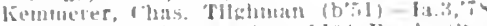
(listi): not in prasticen: 1104 brads st

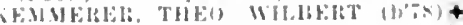

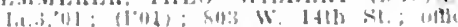
U.,.

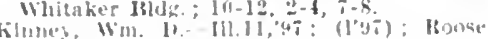

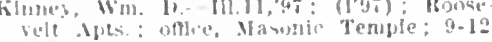

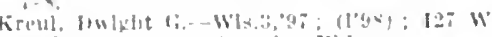

Ith si, ofthe security lidip

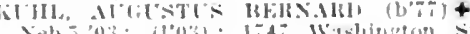

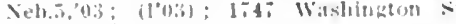
$\because: 30-1,12-2,10-8$

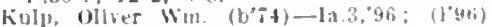

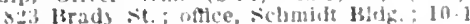
$2-5$

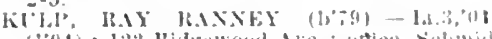

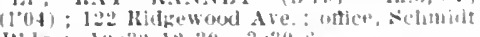
Blilh. $10: 30-1=-30,3: 30-4)$

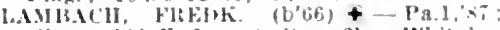
(1'40); f:4 E. Locust st.; oftere, Whitalier Hilly. ; 10-1:, 2-4.

umdley, charence $r$, (J,55)-111.1, $45:(1 \times 3)$ :

1514 brady sit. aftlce, Dintue Bhlp.

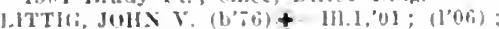
$30 !$ colleze lie. Oftie, J'tinam Ridg $1=1 ;$ (BI) O OALR, *

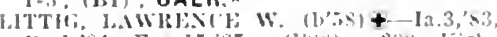
J'a.1,84. Eng.15.87; (1'ss); 2:is Kirhword Blve; odlee, Intnam Mldir. 10-12. $\because-5 ;(1:) ; S$

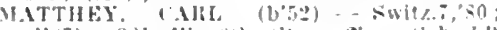
(I) bul : 10-12, 2-4.

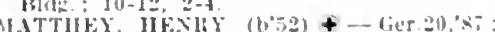

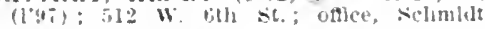
Hidg. ; $10.12,21$

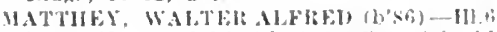

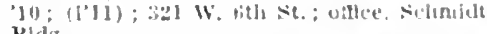
Hidg

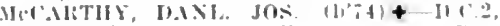
"49: (109): ios College Ale: other.

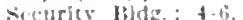

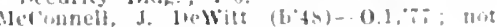
in practlee; to39 lirmil Ne.

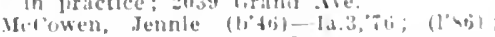
, 114 E. 1 th $51, ; 1-1,2-4$

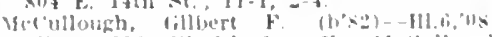

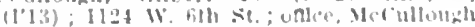
IHW

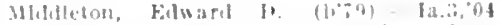

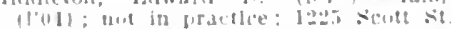

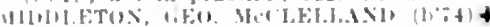

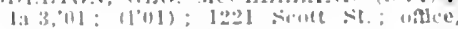

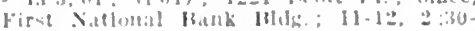
t:洲: 5 .

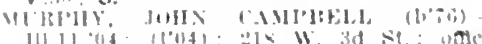

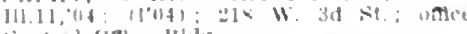
ientral cimine Bumb.

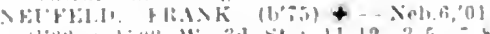

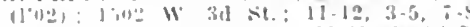

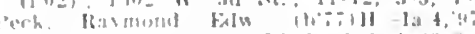
(1.

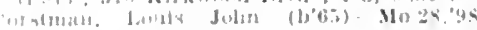

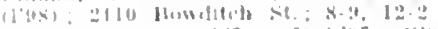

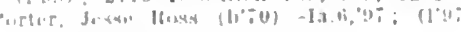
.1]: Itr,aly sit

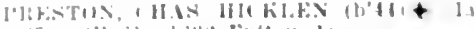

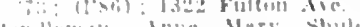

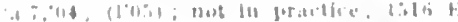

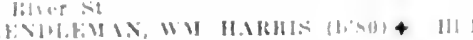

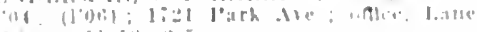
11. 1\% $111: 2$

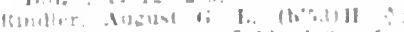

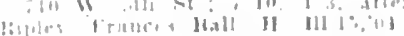

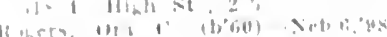

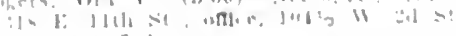

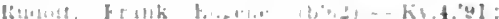

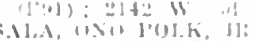

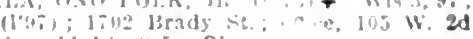
St: $11.1 \%,: 5,0$ b.

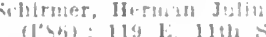

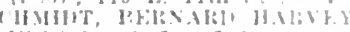

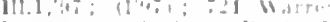

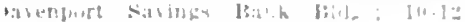

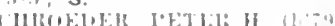

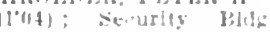

Anes.

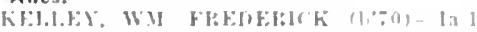

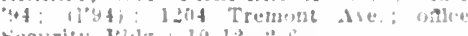

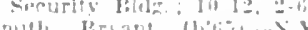

brantece: lawama firms.

prictice

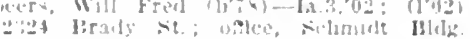

$111-12,2: 310-5: 30$

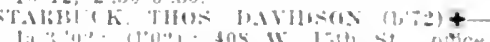

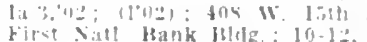

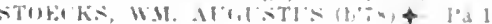

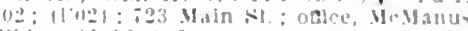

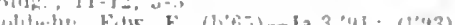

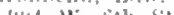

struple, Llnton Wi (b'b, ll la.t,

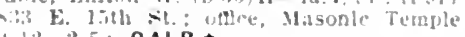
it 12, $2-5 ;$ OALR.

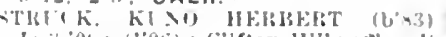

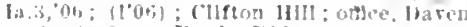
OALR.

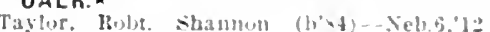

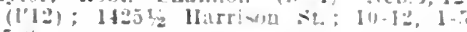

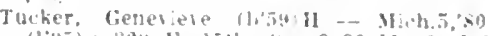

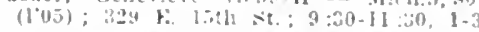

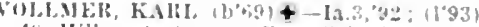
4 linlerent Ale

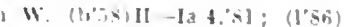
una in practice: 140; Rrandy st

WELEH, IACOH SIFWEIT (1)

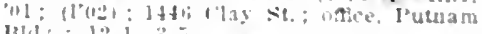

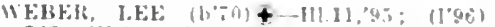

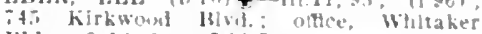
H]LL:; 9-1:2, 1-5; OALR.

DAVIS CITY. 489. DECATUR

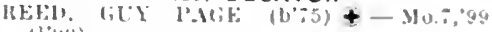

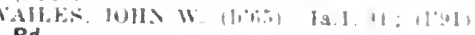
Pd.

DAWSON, 275, DALLAS

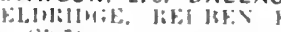

(l'si)

DAYTON, T17. WEBSTER

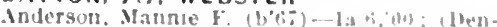

tist!

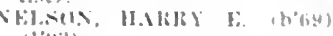

loulghan

DECATUR, 3II, DECATUR

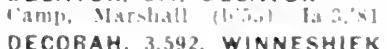

III IIAIEHIF,TH, IIITTSIUIR

$10 \mathrm{a}, 11901$; la.3. Al, Fa

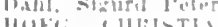

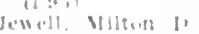

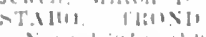

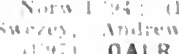

THill: OALR.

Ting a

DEDHAM, 335, CARROLL

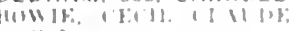

OEIP RIVER t6: POWESWIEK

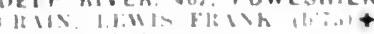

(1'U.1): OALR.

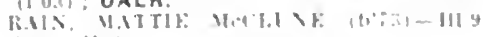

moloce it 11,103115 
Grimes, Francls S. (b'33)-N.Y.10, ${ }^{\prime} 62$; $\left(1^{\prime} 33\right)$

(;UNN, ROSS FHVIX (h'82)-Ia.3,'I] (1'11).

DEFIANCE, 411, SHELBY

Meyers, Valentine J. (b'7 $)$-Ia.10,02; (I'02).

DELHI, 375. DELAWARE

WINTENBUIR, E, J. (b'75)-Ia.3,0(1'07).

DELMAR, 548, CLINTON

MC(ORD, ELIAS S. (b'68)-Ia.6,"94; (1'94).

ICMLEI, EUGENE (. (b 58$)$ - la.1, 80 ; $(1,00)$

DELMAR JUNCTION (DELMAR P.O.), CLINTON

Jacobs, Thos. Dana (b'81)-Ia.3,'13; (1'13). DELTA, 728, KEOKUK

liusby, Wm. ]. (b'59) $\mathrm{y}-I 11.8,88$; (1'89).

PIERCY FlREN FRANKII (b'8'

Ia.6, 07 ; $\left(1^{\prime} 0 \tau\right)$.

Stlrlen, WVn. IV. (b'81)-Ia.10,00; (l'05).

DENISON, 3,133, CRAWFORD

13ON1), I. IAFAYETTEA-III.I, 70 ; (1'86),

BRANXON, PATIICK J. (b'76) $€$-Ia.8, 04 ; (I’04).

CARIR, CIIAS. W. (b'65)†-Ill.1,'90; (1'90).

Coon, Louls Montrose (b'63) - Mo.7,98; (1'98).

Holke, Henry J.-Mo.1,80; (1'96)

Iseminger, Wm. (b'37)- (l'8i); not in

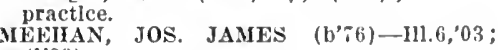
(1'03).

Plimpton, Robt. Pearson (b' $/$ I) II-Ill.10, 00 ; (1'02).

Toon, Jouis 13. (b'71)-Ky.1,'93; (1'93);

IVRIGHT, WM. T. (b'56) 4 - Mlch.I, 82 : (l'S7).

DENMARK, 400, LEE

Hancock, Chas. (b'34)-Mich.I,"58; (I'87). 1'ATCIIN, IIORACE J. (b'83)€-Ia.6,'10; (1'10).

SIOAT, WM. ELGENE $\left(b^{\prime} \pm 2\right) \uparrow-N . Y .8$, -73; $\left(\mathrm{l}^{\prime} 86\right)$.

DENVER, 224, BREMER

Murphy, IIarry W. (b'6i)-Ia.3,06; (1'06).

DERBY, 326, LUCAS

Mitchell, T. B.-Ill.11,84; not ln practice.
NIBLOCK, GEO. F. (b'71)-Ill.11,00; (l'00).

THROCKMORTON, ROBT. FREDK. $\left(\mathrm{b}^{\prime} 69\right) \oplus$ -I11.11,'92; (1'93).

DES MOINES, 86,368 , POLK

NUMBER OF PHYSICIANS, 254

Aborn, Claud Elmer (b'86) - Pa.9,'08; (1'08) ; 648, 15th St.

Alden, Fredk.-Ia.4,'U6; (l'06); 3417, 6th Are.; offlee, 3707,6 th Ave.; 11-12, 2-4, i-8; $\mathbf{s}$.

Aldrich, Stewart W.-H-0.7,74

(l'93) ;

IV Grand tre.

Allen, Lowell Edw. (b'68)-1a.3,97 ; (l'97) ; 619 Walnut St.; $9-5$.

Amos, Andrew Raymond (b'58)-Ill.1,'82; (l'93) : Ridge Rd.; offlce, Equitable Bldg. ; 9-5; (B1) ; OALR.

ANDERSON, ALBERT A. (b'58)-111.1,'82 ; (l's6); 1833 E. 9th St. ; office, Capital City Bank Bldg.; $11-12,3-5$.

ARMSTRONG, MARGARET (b'83)-Ia.6,'10 : (1'10); 1122, 25th St. ; offlee, Securities Bldg. ; 11-1, 3-5; Pd.

BAILEY, JOH '1VM. (b'82) - Ia.3,05. (1'05); :18, 33d St.; office, Citlzens Bank Bldg. ; $9-5$; OALR. *

Bair, W'm. Medill (b'56)-Mo.22,'86; (l'90) ; 1122,6 th Ave.

BAKER, WALTER EUGENE (b' 76$) \oplus-I a .6$,

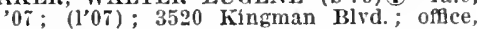
Citlzens Bank Bldg. ; 11-12, 3-5.

Bartrutf, Chas. Henry (b'88) - Ia.6,'I3; (l'13): Mercy Hospital.

Beck, James W.-Ia.3,'8I; (1’87) ; 3iI4, 4th

RIERRING, WALTER LAWRENCE (b'68) -Ia.3,'92; (l'94); Pres. State Board of Rd.; office, Equitable Bldg. ; $11-1$; (F5);

I.` ${ }^{\star}$ THOS. PARSONS $\left(b^{\prime} 63\right) \oplus$-Wis.2,

(I'02) : 1060,31 st St.; office, Flynn BIdz: $10: 30-12: 30,3: 30-5: 30 ; \mathrm{S}$.

Bonnell. Frank Sumner (b'S4)-Pa.2,'13: (1'13): lowa Methodist Hospital.
I3OOKEIR, ARTHUR J. (col.) -IIl,6, ${ }^{\prime} 06$; (l'08); 10II Crocker St.; offlce, 413, 6th Ale

IITR(HAM, TIIOS, A.†-Ia,6,06; (1'06) ; lst lieut., M.R.C., U.S.A.; (Ft. Des Molnes); ofnce, Fquitable Bldg.; 10-11, $2-3: 30: \mathbf{R}$

'allahan, ]3ernard Jos. (b'65)-1'a.2, 00 $\left(1^{\circ} 00\right)$; not 11 practice; 510,8 th St.

'ARSON, ANDROS (b'63) $\oplus$ - Ill.1, 00 : (1'90); 292: Iittand st.; ofllce, 25 th and University sts. ; $10-12,3-5$.

'hamberlain, Lowell II. (b'76)-Pa.2,00: retired; 3829 (irand Ave.; offlee, 6 th and Park sts

hapman. IRobt. Updegraph (b'51)-IIl.6,'88, Ia.6,'92; (1'92); 1110,25 th st. : 10.12, $2-4$

Chase, Frank W'lbur-Ill.1,'74; (l'91); not In practlce; 613 Walnut $S t$.

Chrỉsinger, W'm. II. (b'49)-Ia.1,93; (1'97) 1631 Capitol Ave.

Clement, Charles Y. (b'74)-I1l.14,'04: (l’05); 718, 18th St.; office, 52l Locust St.

Clift, Guy Ernest (b'81)-Ia.6,'12; (1'12) I353 E. Grand Ave.; offlce, Police station. Coffee, Percy Elmos-Ill.4,03; (\$); Grand and Park Lane; office, Davidson Bldg.

Coffee, Wm. O.-Mo.1, 81 ; (1'97); 8th and Walnut Sts.

Coffln, Lonnic Alfonso (b'90) - Ia.6,'13; (l'I3) ; Iowa Methodist Hospital.

COKENOWER, JAMES IVINFIELD (b'53) -Ia.1,77, Ky.1,'80; (1'82); 1002 Forest Ave.; office, Utica Block; 11-12, 3-4; (Ai); Or.

Coleman, Jennie May (b'68)H - Ia.4,'98; (1’98); 3514, 2d St.; 1-5.

Collins, Chas. Melvin (b'67) P-MI-Ind.5 "97: (I'97); Utlca Bldg. ; 9-12, 2-5, 7-8.

CONDON, JOS. REDIOND (b'81) $4-I 11.6$, 08; (l'09); 1218 Pleasant Ave.; offce, Flynn Bldg.; 10-12, 1-5; (F5).

CONKLING, WVILBUR SCOTT $\oplus-$ Ia.6,'97 ; (1’97) ; 1003 Penn Are. ; office, Capltal City Bank Bldg.; S.

COOK, CJARENCE PERCY $\left(b^{\prime} 71\right) \oplus-$ Colo.2, 'I1; (l'98); 1427 Woodland Ave.; office, Utica Bldg.: 9-12, 1-4; OALR. *

Cook, Roscoe E.-Ia.10, 03: (1’03); 525 W. $3 \mathrm{~d}$ St. ; office, $505 \mathrm{~W}$. Locust St. ; 8-11 :30, 1-5:30.

Cross, Frank W. (b'72)-Ia.3,'04; (l'04); 335 E. 5 th St.

CROWLEY, DANIEL FRANCIS $\left(b^{\prime} ; 8\right) \oplus$ Neb.6,06; (1'07) ; 648 Harwood llive offlce, Flynn Block; 1I-1, 3-5; (F5).

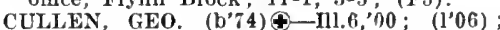
532,40 th St. ; offlce, Hippee Bldg.; 11 $12: 30,2-4 ; S$.

DAVIS, JOHN GRAHAM (b'82)థ-Ia.3,'06 (1'06); 1337, 8th St.; office, Equitablé Bldg.; 10-12, 2-5.

Daris, Willis H. (b'53)-Ia.I,'79; (l'86) Florentine Apts.

DeFord, Wm. H.-Md.3,'83 ; (Dentist) ; 3925 Cottage Grove Are.; offlce, Flynn Bldg.; $10-12,2-4 ;$ (A2I).

DENNY, THOS. COLLINS (b'87) (-Pa.2, '12; (1'I2) ; 1400, 19th St.; offlce, Flynn Bldg.; $9-5$.

De I'ew, Clarence Chauncey (b'76)-Ill.14, 99; Assistant Physician; 1924 Arlington Ave. ; office, Utiča Bldg. ; $9-5$

De Pew, Henry H.-H-Ill.10,87; (l'86); Utica BIdg; $9-5$.

Dickinson, Dwlght W. (b'59) H-Ia.4,'84 ; (1'86) : Med. Dir., Commodore, U.S.N., retíred; 1213 Pleasant Ave, offlee, Knlghts of Pythias Bldg.

DIEHL, CHAS. ELLSWORTI (b'61)-Ia.3, '93; (1'93); 631, 42d St. ; offlce, Utica Bldg.

DOANE, GRACE OTTOLEE(b'91)-Ia.6'13 (l'13); 831, 4th St.; office, Equitable Bldg.

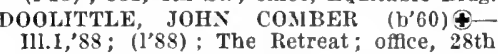
and Woodland Ave.; NP.*

DOOLITTLE, RUSSELI COMIBER (b'86)Ill.1,'11; (1'12); 28th St. and Woodland Ave.; NP. *

DORR, EDW, ELISHA (b'63)@-1a.3,'s9 (1’90); 3302 University Ave.; offlce, Citizens National Bank Bldg.; $9-12$; (F5).
DOWNING, JAMES MRTHUR (b'87)-Ia.6, 09; (1'09); N. 6th Are.; omce, Equitable Bldg.; 8-6; OALR.

DIIIIGG, THOS. FRANCIs (b'78)థ-Pa.? 02: (1'02) ; 4205 Greenwoot Drive; office. Fleming lidg.; II-1, $3: 30-5$; (F5)

Dunlap, Asbury w. (b'52)-1a.6,'89' '(1'89) 1774 J.yon St.; offlce, 422 E. 6th St. 9-12,3-5.

Dunlap, Mary L. (b'56) E-Ia.6,'87; (1'88) : not in practice; $\mathbf{k}$. 6th and Grand Ave DUNLAl, WALIACE ASBURY (b'79)-Ia.6 03; (l'03) ; 1175 W. 2 I st St. ; offlce, $422 \mathrm{E}$. 6th st.; 10-12, 3-5; Pd.

DUNN, MABEL (b'70)\&-Ill.9,'96; (l'97); Fleming Bldr.

Durkee, Raymond Wilson (b'70)-Ill.1,'95: (1'95) ; 1211 F. Grand Are.; 10-12, 1-4, $7-8$; Ṕd.

ELDER, JOHN WILHELM (b'90)థ-Ia.6 12: (1'12): 1343 Buchanan St. offlce, Equitable Bídg. ; $11-12,5-6,7-8$.

Elllott, Wm. J.-la.9,'98; (1’98); 603 Caulder St. : office, Davldson BIdg. ; $8-12,1-5$.

ELY, FRAXCIS ARGYLE' (b'7e) 98; (l’98); 1611. 8th St. ; offlce, Cltizens National Bank BIdg. ; 10-12, 3-5; (F5). FAY, OLIVER JAMES' $\left(b^{\prime} 74\right) \Theta-$ MI.11, 02 ; (1'03) ; Equltable Bldg.; 11-12, 2-4; (A\%, 55) ; S. *

Fellows, Jos. Thos. (b'62) - Ind .5, 90, MIo.28, '98: (1'90): 614,9th St.; office, 4 th and Wainut Sts. ; 9-12, 2-6.

Eellows, Feubén F.-Mo.1,'97; (1'91); 323 Walnut St.; office, 4 th and Walnut Sts.

FIFLD, AIRCHELAÚS G. (b'31) ९-0.3.'54 N.Y.1,'64; (1'86); not in practice; 1303 , 13 th St.

FIELD, GEO. ALFRED (b'72)๑-0nt.3,98 : $\left(1^{\prime} 98\right) ; 1303,13$ th St.

Findley, John B. $\left(b^{\prime} 49\right) \rightarrow$; (l'86) ; 61 Walnut St.

Findley, Park Alphonso-Ia.6,'95; (1'96) : 617 Walnut St.

Finlayson, Danlel W. (b'47)-Mich.1, 75 , N.Y.10,80; (1'87); Walnut St.; offlce, Century Block; 11-12, 3-5.

FIANNERY, JOS. JEREMIAH (b'77) $9-$ Ia. 6, 00 ; $(1,00)$; Equitable Bldg.

Flelschman, Abraham Geo. (b'89)- Ill.11, '12; (1'I2); 749 E. Walnut St.; offlce, Citizens' National Bank Bldg.

FOULK FRANK ERASTUS (b"80)-Ia.3 04; (1'04); 1631, 9th St. ; office, Equitable Bldg. ; $10-12,3-5$.

Fountain, Chas. B. (b'62)-Ia.3,'91; (1'91) : not in practice; 4539 University $S$ t.

Franklin, Chas. L. (b'83)-Ia.6,08; (1'08) 651,36 th St. ; offlce, S. and L. Bldg. $10-12,3-5$.

Gadd, Edson E. (b'69)-Ill.8,'03, Q.2,'97; (l'97) ; 716, 16th St.; offlce, Century Bldg.

Gatchel, Margaret Morrell (b'74)-Ill.9,'99: $\left(l^{\prime} 00\right) ; 1074,26$ th St.

Gibson, W'm. H.-E-Ill.8,03; (1'06) ; 1421 , 25 th St. ; office, Century Bldg.

Glew, Percival Bainbridge (b'89)-Ia.6,'13; (l'i3); Iowa Methodlst Hospltal.

GLOMSET, DANL. JOHNSON (b'81) $\oplus-$ Ill.1,11; (Pathologlst) ; 1235, 3Ist St. $(\mathbf{F 2}, 5)$.

Goodrich, Alíce Amelia (b'52) - Ia.4,'89: (l'89) ; 1304 E. Grand Ave.

GOODRICH, JOS. ALBERT (b'72)@-III.6 05 ; (1'05) ; 1345, 9th St. ; office, Cltlzens National Bank Bldg.; 11-12, 2 :30-5; Ob. Graeser, Bernard N. (b'37) - Il1.4,78 (1’87); 1516, 31st St.

Graham, Chas. C. (b'59)-Ia.3,'84; (l'86) : 3418 Cottage Grove Ave.

Graham, Willard T. (b'63)-0.1,'86; not in practice; 740 , 17th St.; offlce, Iowa Methodist Hospital.

Gray, Ella M. (b'61) P-M-Ind.5,'93; (1'93) ; 1314 High St

GRAY, HOW ARD D. $\left(b^{\prime} 76\right) \rightarrow$ Ia. 3,$00 ;\left(l^{\prime} 00\right)$ : 1136,20 th St.; offlce, Fleming Bidg.

Green, Chas. C. (b'46)-Ia.1,75; (1'95) ; 830, 15th St. ; 9-12, 2-6.

GREENMAN, JOHN W. (b'74)థ-Ia.9,'98; (1'98): Member Neb. State Med. Assn.; Hippeé Bldg.

GRIMES, ELI (b'68) †-Ia.3,97; (l'97) 1308. 9th St.; office, Fleming Bldg. ; 11-12, $3: 30-5$; (F5).

Guild, Wm. Alva (b'79)-Ill.10,03; (1'03) ; 950 , 19th St.; offlce, Utica Bldg.; 10 $12: 30,3-5$. 
Ciunn, John Alexander (b' +9$)$-Nich 1,75 (1"91): 130 i IIIgh St.

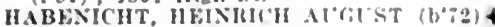
-I11.19.99: (1'06): 20I". 97th s! ; nthee, flynn bidz: $10.12: 30,3-5: 30: \mathrm{s}$.

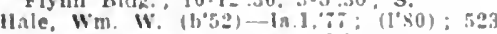
locust st.; once, 820, isil st.: 10.12. 3.5.

Haumer. Thos. R.-Ind.5.'s] : (1'xis) : 1720 ath st.

Ilarbach, Jucy M. Busenbark (1,63) HI

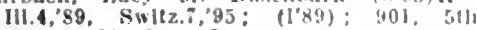
st.: 11-12, \$-5: G.

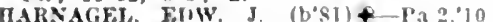
(l'10): 1151 W. 28 th st.: once, bigutalite Bldg, $11-12,1: 30-4: 30: 5 . *$

IIAKSFD, CALVIS WALDO (b\%9)--Ia 3 06 ; (1'06): 5 th and Waluut sto.

II atch, Nllce II. Iumphrey $\left(b^{5} 6,5\right)-$ Ia 4 95; (1.95); 1025,811 St.; oflec, Grumt lilock

HAKE., EDW. II. (b'3\$) -0.11,'66; (1'86) ; 813, 6th Ave.

Hedges, Wm. Marry (b;3)-Mo.;,10: not In practlce: 9 th and locust $\mathrm{st}$.

IILI. GERSIIOM IIYOF, $\left(b^{\circ}+6\right)+-1111$, it (1'86); 693, 3Ist St, oftice, Fqultable Rldg, 2-4; (EIS, F5); NP.

IIII, Julla Ford (b'86)-Ia.6,'13: (I'13) 693, 3ist St.; office, asth St. and Womland Are.

Hobbs, Saml. W. (b;6)-1a.3,01: (1'01) 1149,28 th $\mathrm{St}$.

Holloway, Chas. F. (b'69) H-Ill.10.'93: (1'93): 675 Harwood Drive; once, Flynu Block.

Hock. 03: (1'03) ; 1602, 23d St.: office, Fleming Bldg: $9-5$; OALR. *

HECKIXS, HORACE SEAVER (b'64) Ia.10,"93: (1'03): 1401, 20th' St, : offce. Century Bldg.: 10-12, i :30-5: G.

Hughes, John Ituan (b"55)-Ia.6,93; (1'93) 219 E. 5th St.

Huntoon, Gardner A. (b'it) II - la.4'96 $(1 \cdot 96)$ : 1086, 25th St: omce, 2410 Unlveralts

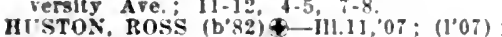
632,39 th St.; oflce, Equitable Bldg.; 10 $12.2-5 ; U$.

IITCHINS, ARTHUR C. (b'64)-Ia.6。'05 (105): i 309 , fih St.: offce, Fleming

Hutchlnson, Eileanot Mcialr (h's)-Ia.b. 13 ; $\left(l^{\circ} 13\right) ; 403 \mathrm{r}$. IIth $\mathrm{St}$; ofice, Captal ('Ity Bank Plilg.: $10: 30-12: 30,3-5$

Jacobson, David Jackson (b'3i)-Ia.6,'13: (1'13); Methorlat IIospltal.

JEFFER ŚN JAMES AIVIX (1)'il)-Wis 3 11; (I'12); 1322 Day St.; once, $64.9 t$ St: $10-12,3-5,7-9$.

KHT.I,EIER, THOS. $₹,\left(b^{\circ}(5, i)+-1 a .3,78\right.$

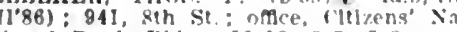
tlonal Rank Juldz: 10-12, $2-5,-8$

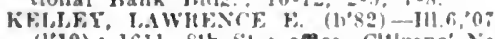
(1'10): 1611, sih st, attee, Clelrens'

Cennedy, Francls [ravld (1) 90$)-1$ a. 9,13 Kennedy, Francls ravild

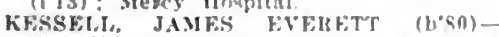

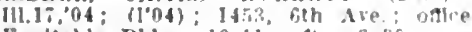
Fquiliable Rldk.; $10-11$, after 3

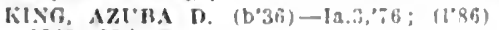
1143, $27 \mathrm{th}$ st.

Kirkpatrlck, Robt. S. $\left(b^{\circ} 50\right) H-$ Ia.4'so

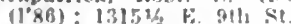

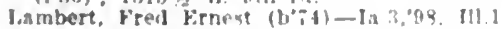

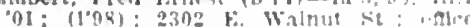
117 Walnut si

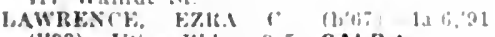
(1993): I"ticr Mldz. 9.5; OALR.*

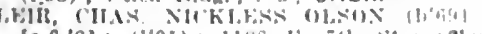

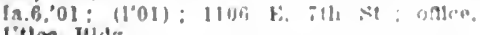
Ittion Illik

l.elins. Ilenry rlas (b'34). Mut.

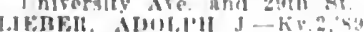

locust sit.

I.1NCOL. SIMUN F. $\left(b^{\prime}, A\right)+-1111.02$

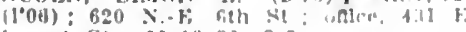
l.ocust St. : $11-12: 30$.

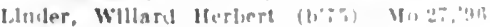
$\left(1^{\circ} 98^{\circ}\right)$; 1337 Washlugen Are

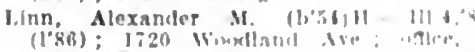

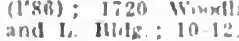

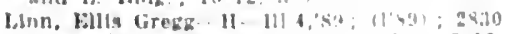

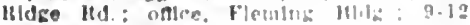
$1.5:$ OALR.

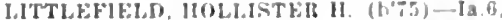
10 : $\left(I^{\circ} 10\right): 1169,9 t 1$ st :

6th Are. : 9-12, 3-5, 7-p: ObG, - 19.4.89

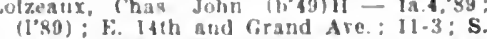
I.OSH, CI,IFEOLD Whi, COME (b's4)-ia.6, 05: (1'05): 1290 I.aurul st.: ofice, 8 . and T. Blag.

J.OWFIby, OSCAR w.Y. (b45) F-Ia.1,73 (1'86): 280 israttleboro ive, nnce, 517 Wulutt St. : $0.12,2-5 ; G$.

1. YNCII, RORT. J. - III.6,06:

(I'0 05$)$ : Futultable Bldg : 11-1, 3-6.

MAILF, WM. WARItEN (h'65)-0 2,92 (1'92); 805, 18th st.; ofnce, Fleming l3ldg.

MAITIS, JOHN WALTFR (b+81) -III.6 $0.3 ;\left(10^{\prime} 03\right): 1625,7$ th St. ; oflee, Hinpee Bidr.

MARTIX, SIDNFI DFAN (b'87)-Ia.6,'I] (1'11); Fleming Bldg.

MASCI, RIFFAFIE - Ita.10,'90

(1'08) 1313 Dunham Are.

Mathews, fillis Filsworth $\left(b^{\circ} 74\right)-0.40,09$ (l'11): 1736 E. Grand Avo.: offce, 401 F. 6th St.; $10-12,2-5, ;-8$

MAXWEI. JOHX" p. (b'52) \&-1a.1,81 (l'86): Hippee Bldg.

Mccanon. Frank Wallace (h'60)--1a.6.'83 $\left(l^{\circ} 86\right): 56$ th and Yew York Are.; offce 42] I.omust St.: 9-3.

ICCARTHY WITON W. (h'12)-Ia.6'94 (1'93): 3i03 Forest Ave, nffice, Flemlng Bldg.: 1]-12, $3: 30-5 ;$ (A7)

McCartney, Wm. Henry - II - I11.10.04 (l05): j114 w. 10th St. ance, CHea Bldg.

MCKITRICK, JOIYX FRANKIJN (b'75) Illch.7.99; (l'00): 2941 Rutland Ave. aflce, Flynn Bldz.: 11-12, $2: 30-5: 30$

MFANFA, IFNYA I.FOTA (b'71) \$-Ia.6 97 (l'97): I2II Pleasant St.: oftice. Sc curities Bldg.: 1 1-12:30,3-5.

Mendelson, Ralph Waldo (b'8s)-III.6.'1I A.A.Surg. U.S.X.; Nary Recrulting Statlon.

MFNDENHALI, NELRERT GRAVER-Ia.6, $07:\left(1{ }^{\circ} 07\right): 2954$ F. $13 \mathrm{tb}$ St. : oflce Teachout Ride.

Mesvenger. IIarrlett F. (b*59) H-Ia.4.'90 (1098): 2800 Unirerslty Are.

Mlller. Sam! (bs?)-In.6,12: (1'12): 406 E. 6th Are

MINASSIAN, HAROOTY'NF AYEDIS (b'6i) \&.N.Y10,87: (1'93) : 715 Clark St

Ilnkler Turr Carlose (b'o5) E-IIIs'94 (194): U0th and Vandalla Rd.: offce. Ilawkere Bldg.: 10-5.

MOIUIFE, ROY ROHT. (b.81) + -I11.11.04 (1"nt); 12ง?, l3th st.: nalce, cltlzens Nallonal I3ank Hlak.

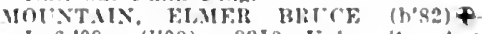

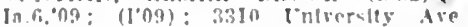

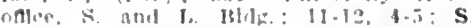

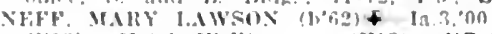
(l'gS): Holel Wellugfon: (k.13): NP.

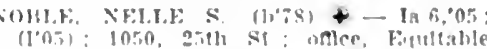
$111.15: 11-3.4-5:$ G.

(1)

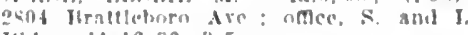

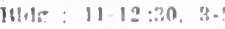

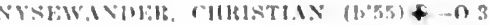

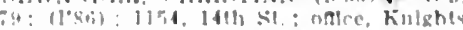

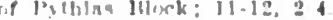

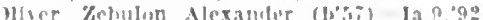
(1.92): 134 \& *: 20th in: oflos, 131$\}$ (1)

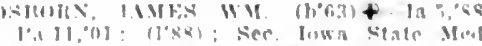

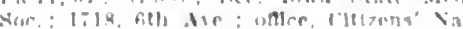
tlonal liank lllig: 11 la 7.5 s.

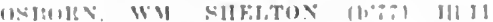

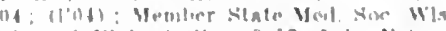
Dith and Walnut sta: 9.12. 1.4 N

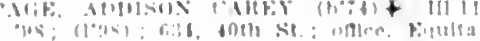

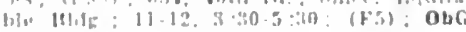

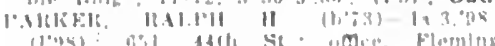
llule (1., OALR *

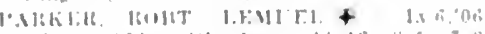

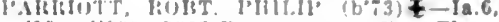
98; (log) : 3305 forea: Ave; omce, Flyna (11) 1 (1)

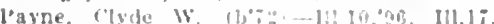

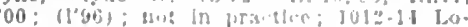
cust st

l'ayne, Ira lean $(1,55)-1$ a 3,"40, N i.jo, 86; (1'86): wot lin uractloe; 1950, afth

PHARSOX, WM. WII.S(1) (1)69) - M!Ml, (n)

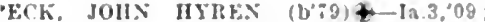
$\left(10^{\circ}\right)$ : $739,45 \mathrm{~h}$ it ; oftce. Equitable

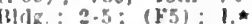

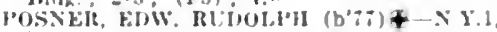
03: (1003): Hotel VIctnrla: odtce. Clts. zens Xatlonal liank IHdg: $11-12,3-5$ $\left(5^{\circ} 5\right)$

post, Carl Mark (b'79)-la.0,13; (l'13); Mercy Hospltal.

POTTEIL, HOMFIl ('URTIS (b.34) -0.2, 5.5: (1'8fi): 1135 l'leasant 8t: : oftsce. 510 Walnut st. : $10.12,2.4$

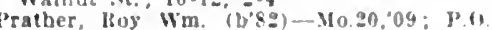
Mox, 843.

Press, llarry Baron (b'86)-la.6,'0s: (l'08): 1307 Venn Ava.; oftce, $223 \mathrm{~W}$, Loust St. : 10-12, 2-5, after 8:30.

PRICE, ALFRED STIRGUS (h'80)-Ill.11, "04: (I'04); 639, 36th St. : office, Cittrens" Natlonal Bank Bldg.; 11-12, 2-5.

PRIESTIEY JAMES TAGGART (b'52) क Pa.J, it: $(186)$; 3407 Grand Are.;

Reynolds. Albert C. (b't2)-Ia.5,10; (1'10): 1414, 26 th St: $9-12,2-5$.

Rice. Ulysaes Augustus (b'13)-1a.:, 89 : (1'86) ; 405 F. lith St: U

BOCKAFELLOW, JOHY CHESTER (b'i2) - la.1.94: (l'98): 2427 Forest Drive: office, Equltable Bldg: : $\mathbf{S}$.

ROSENBLADT, FRITZ (b':5) \$-1a.3,04: (l'0t): 100ti, 20th st: once, Hippee Bldg: $11-12,2-6.5$.

Rowat, Harry Lew1s (b'-g) H-Ia, 04 (1.04) : 1900 lork st. of ce, 500 E. Locust St.; $3.6,7-8 ;$ OALR.

Royal. rieo. (b'54)II - X.Y.9.'82: (l's6) 1334: 6th Are.: oflee, 5th and Walnut Med. and Ther. Ia.t.

lloyal, Malcolm A.H-Ia.4,06: (1'08): (iood Block.

BCSSELI, JOHN (b'79)—-Ta.6,10: (1'10) 907 Walker st.; oflce, Teachout Hidf: I1-1, $3-5: 30,7-8$.

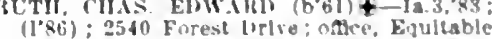
Hlik. ; 11-12, $2-5:(A 1,5) ; S$.

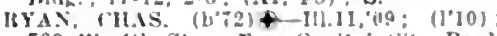

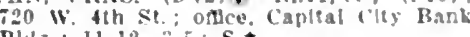
B112: $11-1 \%, 3+5 ;$ S.

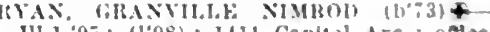
III. 1.95: (1.98); ItII Capltol Are : oftsec Capltal flig Wank Hag.: (F゙5).

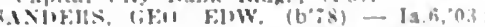

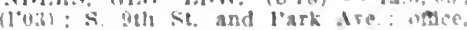
filca isleg

INI)

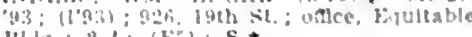
$11112: 2-4:\left(F_{1}\right): \mathbf{S}_{0} *$

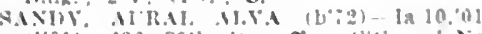

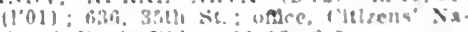

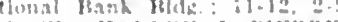

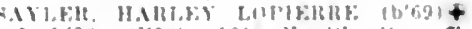
1n $13,98: 1194): 101 ! 4$ r: rith

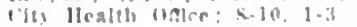

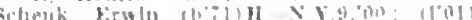

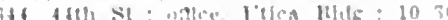

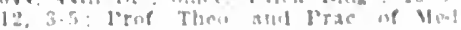
Ia $1: 0$

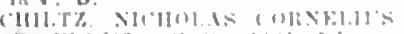

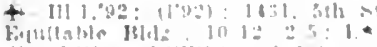

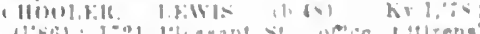

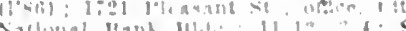

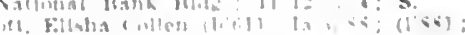

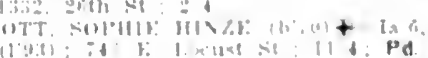

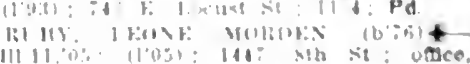

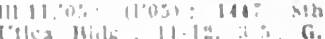

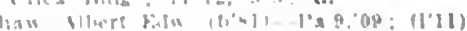
1.0. II and 
sheldon, Andrew C. $(1,+1)-19.7 .76 ;(1 \times 5)$ oftlee, 6th and lowust sit.

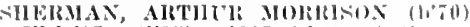
III.1,95; (1'95); 4237 l'lea 4 ant sit.

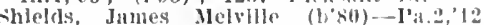

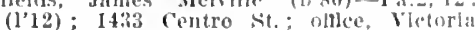
ILtel: $8-6 ;$ OALR *

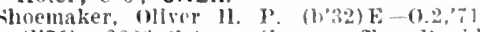

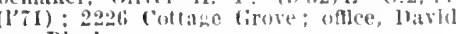
son Biock.

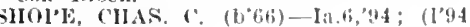
29 th 5 t.

SHORE, FRANCIS k. V. (1)ti3) +-Mllu.l, 86: (['Sti): 210, 3ith st.; offlee, (F Wal nut st. $9-12,2-5 ;$ OALR.

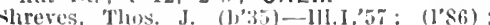
$153:$ E. Grand Are, ; ontere, 5of F. Loenst st. ; $2-5$.

SLOAS MILTON GHANVILIL (b'4S)

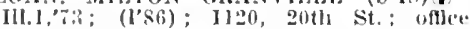
Cltizens' National Bank Blug.; $\mathbf{R}$.

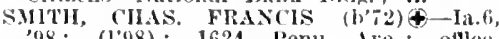
98 ; (1"98); 1624 P'enil Aro.; ofllee. Flynn 13ldg. : 11-12, 3-5; S.

SMOUSE, IIIVID WILSON (b52) - -Md.1 '76; (1'81i): 2323 Grand Ave. offlee. Knights of Pythias Bldg.; $\mathrm{S}$.

S.MOTSE, WM. OSCARt-Ia.6,01; (l'01) 1054 , ibih St.; oflec, Knights of r'ythis. Bldg. ; $11-12,3-5$; at 8 .

Snearly, Geo. E. (b's0)-Ill.22, 06 ; (l'10) 1054, 13th st. ; $9-4$.

SPATES, CIIAS. BANE (b'65)-Neb.5,'91: (l'98); 2406 Kingmin rivd.; offled Equitable I3ldg. : 10-12, 1-5.

STEEISMITI, FRANK RAY (b'74) 4 -Ia.6 01: (l'01) ; Flynn Bldg.

STEINDLEL, Mitidi $(b ; 4) \$-A u s .7,02$ (1'10) ; 706, 15th St. ; offlee, Flymn Bldy. (F5) : or.

STEVENSON, WM. (b'58) - Ia.6,94 (l'94); 1502, 22d St.; offlce, s. and I. Bldg. ; $9-12$, $2-5$.

STEW $\left(1^{\prime} 97\right)$; Florentime Block; offce, ith and Locust Sts. : 11-12, 3-5; G.

STINE, MILO B. (b' 79$)$-IIl.22, 04 ; (1'09) 1603 E. 9th St.

Stockdale, Benj. Andrew (b'65)-Ky.l,'9l (l'93) ; 525, 41st St. ; office, Utica Bldg.

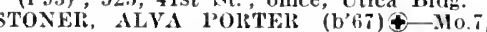
91; (l'91); 1 422 , I0th St. ; office, Equita '91; (l'31); 1422, 10th St.; offlce,

STRAWN, JOHN THOS. (b'81) $₫$-Ill.1, 09 (l'11); Woodlawn Are. and 2sth st. office, Equitable Bldg. ; $10-12$; (FJ).

STUART, RICHARD IóUIS (b'á3)-Ia.1 74 ; (l'si); 2500 Cottage Grove Ave. ofre, $\left(1^{\prime} 97\right)$; not in practice; sec. State Boir of Ilealth and Med. Examiners: $1216 \mathrm{~F}$ Grand Are.; office, 1007 Des Moines st. Grand Ave. ; office,

Tanner, Willis Canon (b'61) - Mo.20,98 $\left(l^{\prime} 98\right) ; 1350$ w. 27 th St.

Taylor, Lola Dell (b'78)-Ifd.5,'09; (1'09) $541,43 \mathrm{~d}$ St.; office, 1422 Locust St.; 11 $12,2-3 ; \mathrm{G}$.

Taylor, Simeon Lafayette (b'72)-Neb.5 $08 ;(1,09) ; 541,43 d$ St.; oflice, 14221.0 cust St. ; 1-4; S

Thornton, Jolın McKlnney (b'47) II-0.1, 73 (1'90); not in practice; $402 \mathrm{~W}$. ith $\mathrm{S}$ THROCKMORTON, TOM BENTLEY (b'85 $\Phi-P^{\prime} a .2,09$; (1'09); 618, 38th St. ; office. Equitable Blde.; 11-12, 2-5; (F5)

TURNER, MATTHEW IINCOLN (b'65) Ind.8,96; $(1 * 96) ; 814$, 17th St.; office, Equitable Blds.

TYRRELL, JOS. WALTER (b'-2) $\$-I a, 6$ 00; (l'00); 6th St. and Furest Are. office, 310 Walnut St. ; $11-1,8-5$.

UNGER, DAVID-Neb.6,'06; $\left(\mathrm{l}^{\prime} 06\right) ; 404 \mathrm{~F}$ 6 th St.; office, 528 E. Locust st.; I0-1: $2-4,6-8 ; U$.

VAN WERDEN, W. (b'63)-1ll.1,'95; (1'85); Victoria Hotel; offlce, Equitable Bldg.; $11-12,2-5 ;(15) \cdot S$

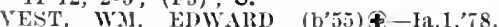
Pa.2,80; (l's ) ; Victoria Hotel; office, Euvitable Bldg.; 10-12, 2-6; S.

WALKER, CHAS. CLIFEOR', (b'so)-la.6

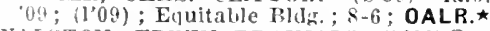
Y.ILTON, EDVIN BRAINARD (b'68)\&-
Ware, dames liati

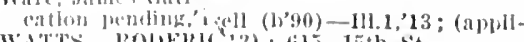

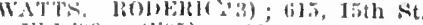

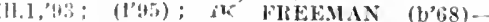
Flemlng l3ldg. 75 , ith St. ; offec.

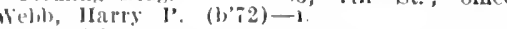
114) stl st. "11.10,96; (1'96) Welce, Andrew II.- lin.6,95

Walnut St. ; ollce, Flym Bld ${ }_{f_{1}},\left(l^{\prime 95}\right) ; 520$ Teingart, dulius Silaw (1)'81)-?

(1'13); Hllpee I3lalg.

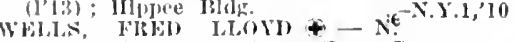
(l'y2); Jrown lpt.; olltce, L.Y.10,'s8; Blolif: 11-12, 3-5. Fuitable WELITON, IILUH FILALR (b'70)

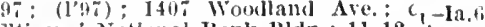
Citizens" Natlonal IBank 13!dg. ; 11-12, Efflec, (F5) : S.

VELPTON, MARTILA ANNA (b'79) \& III.1,10: (1'12); 2840 University Are. ottlee, 2101 University Ave.; 11-12,3-5; G.

WHRTS, CILAS. MARTLL(b'T6) $\$-I a .3,02$ $\left(l^{\circ}(12) ; 1050,35\right.$ th st.; offlce, Equitable

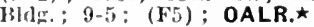

WESTOS ROBT ALIHAELS $\left(b^{\prime}-9\right) \oplus$ Mo.28,03; (103) ; 4311 II arwood lirive: office, Fleming 13lock; 10-12, $1: 30-5: 30$; U. $\star$

WIIIIIER, CHAS. M. (b'69) †-N.Y.6,'96; (l'09); $321,42 \mathrm{~d}$ st.; offlee, Securities Bldg. ; 11-12, 2-4; Pd.

WILF, FRANK ARTHUR (b'86)-Ia.3,'09: (l'09) ; Fquitable Blig.; OALR.

WIII, FREDK. JAMES (b'59) †-Ia.3,'83 (l's6); 4114 Greenwood Drive; offlee, Fquitalle Bldg.: $8-5$.

WILLETT, IIARKY CUSHMAN (b'GI)Ill.1,'94; (l'04); 3007 University Ave. offec, Equitable Bldg.

Willson, Mordecai Myers (b'65) - Mich.7.'89. (l’05); Good Block; office, Fleming Bldg. $10-12,2-5 ; \mathrm{G}$

WINNETT, EDWIN BASON (b'84)-Ia.6, $12 ;\left(l^{\prime} 12\right) ; 1231,15 t \mathrm{~h}$ St.

WINTERS, O. G.-N.Y.I0,'88; (l'07) ; 904, 5 th St.; office, Park anil 5th Sts.

wirsig, Árnold o. (b'81)-Ia.6,'12; (l'12) 914,5 th St.

WOODS, HUGH BECHTEL (b'7)-Ia.6,03: (1’03): 3624, 6th Are.

Woodward, Harry IIall (b'63) E-1a.6,'s: (l'88).

Wright, Charles Iarkin (b'64) E-la.6,'85: (1'86); 21st and Stanton Ave.

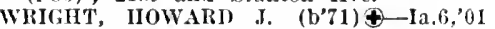
(l’01); 1602 Irigh St. ; oflice, $S$. and $L$. Bidg. : $10-12,2-5$.

Tates, dieo. Spurgeon BaIshazaar (b'91)la.6,'13; (1'13) ; Mercy IIospital.

YOUNG, GUS BROSS (b'81)-Ia.6,'04 $\left(l^{\prime} 04\right) ; 913$, 5th St.; office, Equitable Bldg. ; $11-1,3-6 ; \mathbf{R}$

YOUNG, PHILIP GOUVNEUR (b'78)कIa.6.'08: (l'08) : 1049, I6tb St.

DE SOTO, 356, DALLAS

IBrewer, 3rartln T. (b'72)-111.1,96; (1'98). DEWITT, 1,634, CLINTON

Burke, Thos. Jerome (b'75) - Ill.11,'99 (l'90).

I.YON, HORTON (b'65)(4-Ill.1,96; (l'96) OALR.

Scanlan, Maurice (b'75)-Ill.1,00; (1'00)

Waggoner, Melanethon Rhyersee (b'90) Ia.4,13; (1'13).

Waggoner, Melanctlron R., Jr. $(b ; \tau) H-$ Ill.4,'96; (1'96)

Waggoner, II. k., Sr. (b'38) II-11l.4.'71 (I's6)

Wafgoner. Mortimer Clement (b'6t)H-Ill.4, 'ST; (1'87).

DEXTER, 767, DALLAS

SHERMAN, BENJ. HARRY (b'79)థ-Ill.6. 04 ; (l'04).

WTNSELI. FRANK F. (b'68) - Ia.9,95 (l'95); OpA.

DIAGONAL, 509, RINGGOLD

Carlisle, Glenn M. (b'75)-Mo.27,'01: (l'01) Christy, Wm. D. $\left(\mathrm{b}^{\prime} 46\right)-0.3,78 ;\left(\mathrm{l}^{\prime} 86\right)$.

Jessup, Artbur E. (b'69)-Ia.3,'95'; (1'95).

TALLEY, I.OLIS FRANKLIN (b'82)-III.S $07 ;(1 ' 07)$.

DICKENS, 255, CLAY

RRLCE, JAMLS HLGII‡-Ill.4,06; (l'ne)
DIKE, 286. GRUNDY

Corsant, James C. (b'74) - Ia.3,00: (l'00) flett, Wm. Telson (b'75)-I11.11,00 $\left(l^{\prime} 00\right) ;$ ObG.

DIXON, 198, SCOTT

HAFolis, WM. SIIERWOOD - Ia.3, 00 ; (1'00).

DOLLIVER, 107, EMMET

"OLEMAN, HAYMONI C'LAIRE (b'89)1a.3,12: (1'12).

Mereness, IIerluert layton-Ja.3,98; (1'98).

DONAHUE, 64, SCOTT

ullivan, Iawrence F. $\left(b^{\prime} 80\right)-I a .3,04$; (1'04).

DONNELLSON, 337, LEE

S.MTI, WALIEIt ALBERT (b'77)-Ia.10, TIIO

02: (l'02), IRA FARWEIL (b'73)-Ia.10,

\section{DOON, 58I, LYON}

Brott, John Fredk. (b'7T)-Ia,6,97; (1'97) Thalmers, Francls Edw. (b'74)-Ont,1,04;

Dal MRHESTER, 90, ALLAMAKEE

DOUX; James Jos. (b'70)-Ill.6,'98; (1'99).

McCI'PS LEANDO, I,000, VAN BUREN

Pollock $)$. TIIOS. G. (b'51) $\oplus$ - Ia.1,78;

DOUGHL, Roseoe (b'82)థ-Ia.10,'05; (l'05).

Aberg, II

DOW cIT enry H. (b'74)-Ia.3,'98; (l'98).

Potter, Joy, 462, CRAWFORD
(l'93); On,

Rowe, Frank

Dows, 892, ? 0 Noyes (b'74)-Ia.3,06; (l'06).

Georle, Jos. (lowright

KELLOGG, OI ,'7I) -..Ill.1,'95; (1'95)

Mulnix, James isON ARZA (b'7I)Ð-II.1,

Schnug, George

(1'10). (b'52)-Ia.1,78; (l'86).

DRAKESVILLE, 24 .

JENNINGS, JHOS. 9, DAVIS

NEWLAND, ELMER? B. (b'43) - Ia.1,73;

DUBUQUe, 38,494, DL REE (b'79)-Ia.10,04;

ALDERSON, JAMES IBUQUE

Beach, Helen Junkins $\left.\left(\mathrm{l}^{\prime} 98\right) 64\right) \rightarrow$ Ill.6,'91; not in practice; $1183 \mathrm{i} ; 10-12,1-3,7-8$.

BECKER, WMI. LOUIS - (b'77) $\rightarrow$ Mass.5,'03 ; $\left(l^{\prime} 00\right) ; 1157$ Iowa St. Tocust St.

BIGELOW, ISAAC S. " (b'72) $\$$-Ill.6, 99 ;

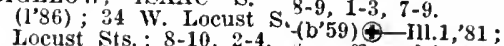

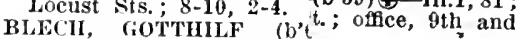
(1'95); 120 Seminary St.

BLOCKLINGER, ALBERT $\mathbf{B}^{\text {(2) }}$ - Ger.4,'87; '94; (1'94); 14th and Loo (b'66) (4)-Ia.3 BOOTHBY, JAMES M. (b'5, iust Sts.; office, $\left(l^{\prime} 86\right)$; Bank \& Insurance 41)-Mich.2,76 ; (1'86) NICHOLAS (b'54 (l'86); 1024 Iowa St.; 8 :')-Ia.4,'85; BRiOWNSON, JOLN JOS. (b'57 30-11, 1-3:30;

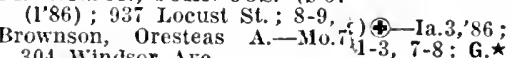
304 Windsor Ave.
costello, wi. EDW. (b', $96 ;(1,06)$;

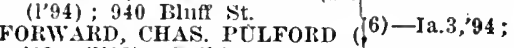
'12; (l'12); Welhi and W. 5t $\left.\mathrm{b}^{\prime} 89\right)-\mathrm{M}_{0} .2$, Fosselman, Alois Nicholas (b'85) Sts. ; 8-9, (application pending,'13); $2,-M 0.7,10$; Fowler, Joun W. (b'59)-Mich.1,124 Couler

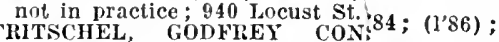
(b'80)屯-Ia. 3,$02 ;\left(l^{\prime} 02\right) ;$ Mer $_{\text {STANTINE }}$ State Med. Assn.; 256, 11th St. 1 iber Neb. ,11: (I'11); 1020 Bluff St. ; of Locust St.; $1-3,7-S ; S$. St. ; of $) \oplus-$ Ia.3, GOODMAN, LEO ALBERT (b'87)-
(1'12); 1057 Main St. ; 8:30-10 -I11.6,10 i-8:30. $(197)$; 999 lowa st.; oflice, 256, i-Pa.2,96 : ÓALR. 


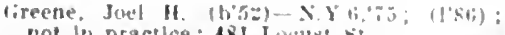

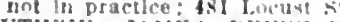

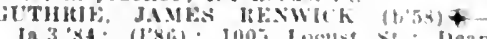
Ia.3:34: (l's(i): 1005 locust st.: lean and l'ruf, lisn la.3: $\mathrm{S}$.

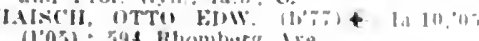
(1'0s) 594 llhomberg 1 rom

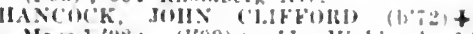

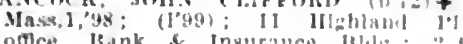
oflce, liank \& Inqurance lilit: : (Ai): S.

IIAPLE, FIAXC1S AEFIEL (b\%) \&-Ia.3 05: (1'0.5): 104h aml [ilurt Sis: OALR. IIFLES, JUII HAJTST (b') fit. 00 : (1'03): 2035 Comler Ave.: omes. :11i Couler Are: : unill 9.2-1. $: 30-4$

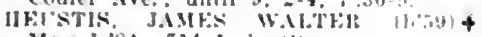
Mase I, $84 ; 314$ Irula st.

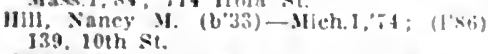

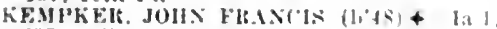
\$5: (1'86): 1425 lowa xt.

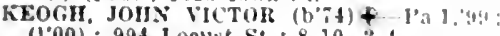
(1'00): 994 Jocust St. : R.10, $2-4$

KTLLEEX, MaRY A. $(\mathrm{b}-3)+M ! c h .1004$ (1'04) : 883 bluft St. : (A*L) : R.

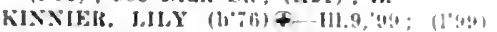
257 13th St: $9-3 ;$ OALR.

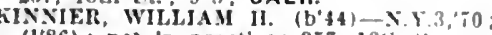
(1'86); not in practlce; $25 \%$, 13 ih sit.

L.INGWORTIY, HENITY GI,OVEIR $\left(6^{\prime} 80\right)+$

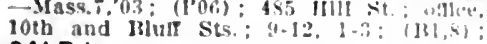
OALR.

I.EWIS: EUGEXF RICHARDS $(\mathrm{b} / 7)+$

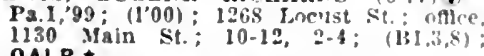
OALR. *

LIADSAY, SAMI SERASTIAN (b'fï)X.Y.10,91; (195); Ilank \& Insurance Bidg.

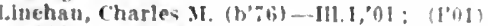
2090 Couler ive, : $9-10,1-3,7-s^{\prime}:$ s.

Linehan, Lewis Jns. (b'SR)-Tenn s.'12: (1'13): 501 Ithomberg Are.; oftce isis Main St.

LINEUAN, MATHIS DANI. - Mo.7,00 (1'06): jezs Main st.

LOES, AXTHOXY MICHAEI, (b'81)+ 111

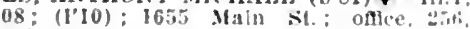
11 th st.: $8-10,1-3,7-8: 0 b G$

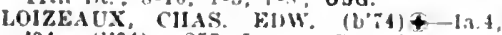
"04; (1'04); 855 Lncust St.; $7-t^{\prime \prime}, 1-3$.

Maculte, Jolin E. (b70)-Ia.3,93; (193) 333,15 th sit.

JcCLLLOUGII, MAITHA A. (b\$5)-Wis.3, 09: (1'11); Metuber siate Merl. Soc. of Wls.; \& W. lth st.; ontlee. Hank \& in. surance H/dg.; 10.12, 2-4. $i-x$.

MCFLIRE, CIARENTE AMUROSF (b's:) Mo.7,09: (1'11): 1230 Main Sit, : $8: 30-11$ $1-3,6: 30-8$.

MEHIHOP, CIAARENCE W.IHREN (U'T2)Mich.1,93; $(100) ; 10 \% 2$ Locicust st. offlce, 256,1 ith $>$ it: : 10.3

MEYERS, FIRINK WM. (1, $\% 3)+-11.11$ 99; (1'99); 2006 Jack.4n Sit.; K-?, 1-3.

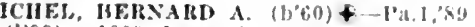

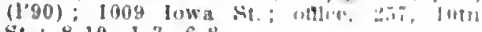

MINGEs, (iEORGE (b"55) $+-\mathrm{N}$ Y.10,78

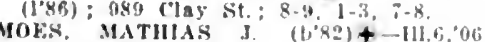
(1'06); 901 locust st. : ofrec, Temple llat Rldk : $8-10,1-3: 30: S$.

Sitzache. Inober Fred (b'29) - II1.1, "i

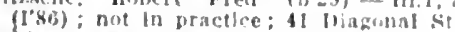

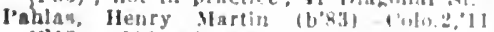

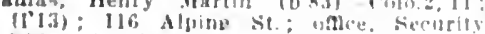
lileg: : 10-12, Alling st

IXI,ks: (IIAS. (1) 79$)-1116,02:(102)$

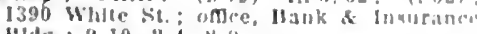
Hhlg.: $9-10,2-1, x-11$

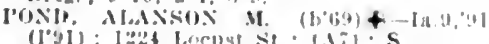

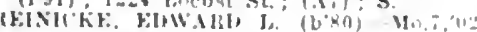

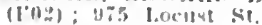

llowan, Jus, Jamey $(1,75)$ l'a 1, $102:(100$ in

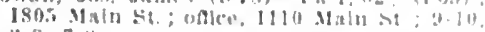
$2-3,7 \cdot 5$

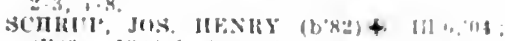

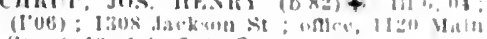
Si, $: 1111,1-3,7 \cdot 8 ; S$.

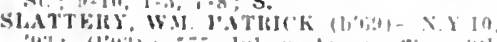

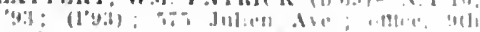
aul laturt sis:

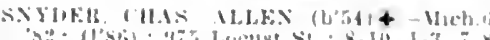

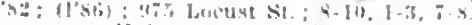

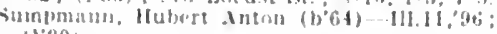
11 00 1.

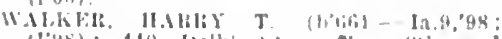

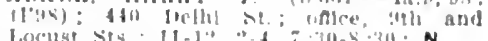

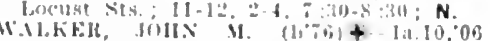

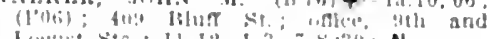

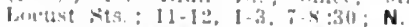

White, Vifw llarrey (b)

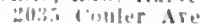

Wielanu, Frauk W: (1,5f)-111.1.88: $(1.90)$; 1:303 iouler Are:; $:-8,1-3, i=3$.

DUMONT, 550, BUTLER

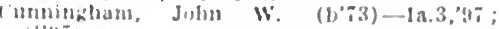

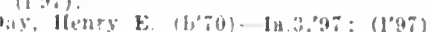

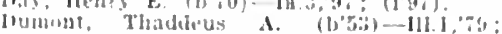
(I'si).

DUNCOMBE, 418, WEBSTER

Hell, "las. I'lltrorl-la.1,"98; (1'98)

Thompis], Juhn (b'63)-l!ne.1,92: (1'95).

DUNKERTON, 276, BLACKHAWK

Buckmaster, lialeligh Ankrey $\left(b^{\prime}-(i)-111.6\right.$, 03 ; (1'03).

DUNLAP, 1.155, HARRISON

COHH, HE.NLY A.IHUN (b'SO)-111.11.02:

Ilazlet. Andrew II. (b'35)-0.2, lngersoll. l'errs (i.-11-Ia 4,05; (10.5).

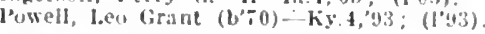

DURANGO, 100, DUBUQUE

MAlliti, ANIOIEW L. $\left(b^{\prime}, 4\right)+111.6,98$; (I'DS).

DURANT, 720, CEDAR

Buls, Willis Cliffurd (b'56)-1a.3,'s5; not in

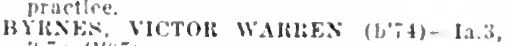
$\because \div ;(1 ; 4)$.

Irrin, James (b'soj-0.1,09; (l'lo).

DURHAM, 100, MARION

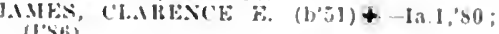
DYERSVILLE, 1.511, DUBUQUE

Ilersieln, Wim. Jos. (b's3) III.22,04 (I'13).

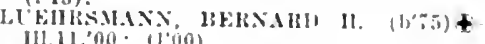

Mucller, Emil k,-IH.6,04; ([06).

DYSART, 906, TAMA

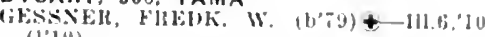
$(1 \% 10)$.

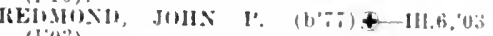
(103).

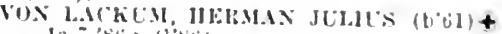

- Ia.7.86; (1's6).

EAGLE GROVE, 3.387, WRIGHT

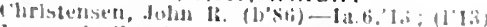

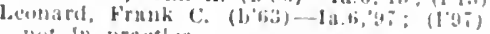
not In prantle.

Mclillti, WM. CYHEs $\left(b^{\prime} 62\right)+-111,6,91$. $(1,41)$.

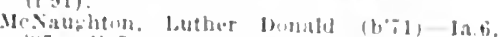

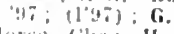

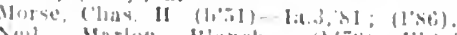

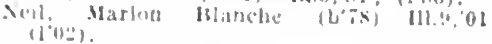

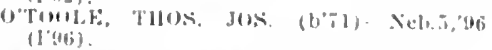

EARLHAM, ;49, MADISON

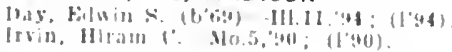

EARLING, 323, SHELBY

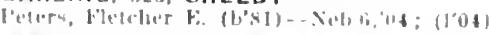

EARLVILLE, 552. DELAWARE

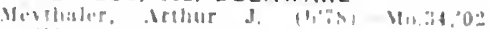
(1) 0$):$

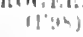

EARLY, 500, SAC

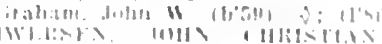

EAST PERU, 37I, MADISON

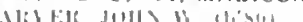

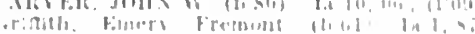

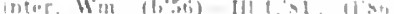
EAST WATERLOO (WATEMLUO 1.0.). -
IILACKIAWK

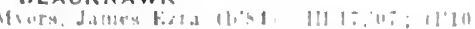

EDOYVILLE, 1.085, WAPELLD

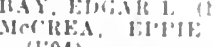

(1"04).

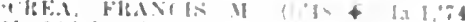

stilili

$+13.3 .04:$

ANIF, FHE

EDGEWOOD, 555, CLAYTON

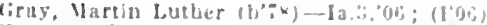

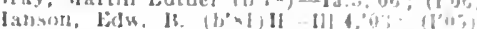

Pd.

ELBERON, 336, TAMA

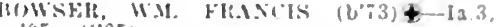

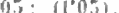

Wheten, Ferilnatud F. (biat) - Ia.3.6\% 1]'11:4

ELDON, 2.024, WAPELLO

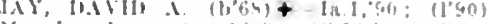

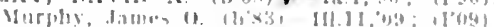
sawyers. silveqter llarlan (b'61)-III.1.85 (1.8.

ELDORA, 1.995. HARDIN

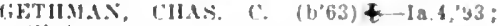
$(1,4+3)$.

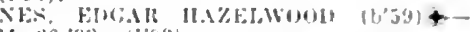

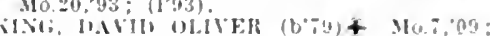
(I'0y).

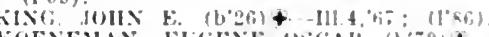
KOENEMAN, ELGENE USCAK $\left(\mathrm{b}^{\prime} 70\right) t$ III.11," $\$ 9 ;(1093)$.

MAISH, WM. EI.MEK (b'66) 1 -Ia.3,91; Mrolist,

$\left(1^{*} \mathbf{s}^{\circ}\right)$; $\mathrm{S}$.

shefleld, libchard $11 \rightarrow:(198$ i)

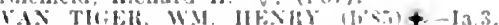

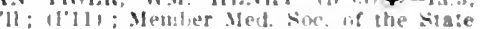
uf Wis: $\mathrm{S}$.

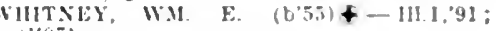
$\left.(1+3)^{\circ}\right)$.

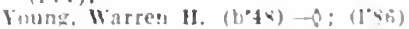

ELGIN, 56.1. FAYETTE

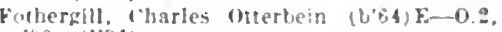
$90 ;(1,9.1$

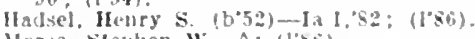

Ilorve, slephen w $\rightarrow$ : $(1 \cdot 85)$

Trezina bart lienry (bsi) - Ill 4,11 (1'13) : Pd.

ELKADER, 1,181, CLAYTON

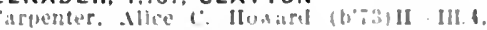
00 : ( 1002$)$

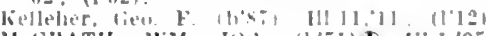
Mefilitu, WM. Jos. $\left(b^{\prime}, 1\right)+-11.1,95$ $(1,95) ; \mathrm{S}$.

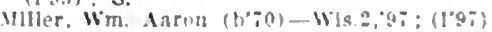

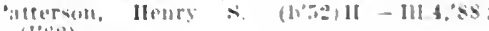
(l'ks).

ELKHART, 132, POLK

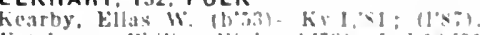

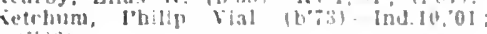
(I'i):?

ELK HORN, 400, SHELBY

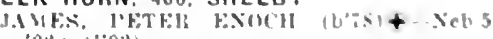
no:-; (1, 0:3)

ELKPORT, 210. CLAYTON

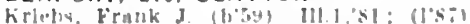

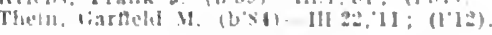

ELLIOTT, 328, MONTGOMERY

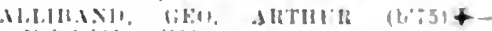
Nolno, of: 1108)

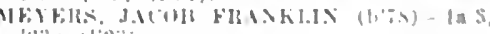
"11:3: 11'0:il

ELLSTON, 205, RINGGOLD

H,11! I IUES II 11 -

GALR.

ELLSWORTH, 406, HAMILTON

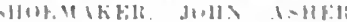

LMA. BU:. HOWARO

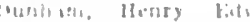

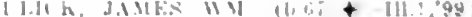

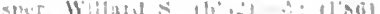

ELVIRA IH.F.U., LOW MOOR). 3I, CLIN. TON

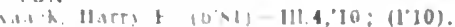


ELWO0D, 167, CLINTON

MCKENZIE, IIERBERT MARCUS $\left(b^{\prime} 51\right) \downarrow$ III.1,'74; (1'86).

ELY, 161, LINN

I.1WRY, NOHBERT J. (b'79)—-I11.11, 02 ; (l'02).

EMERSON, 478, MILLS

Prlest, W. A. (b'44)-0.9,'72; (l'S6)

Stuart, Altert 13. (h'81)-Nebi, 5, 04: (l'04).

rates, Iorace Cluton $\left(b^{\prime}, 8\right)-10.10,08$. (1'08).

EMMETSBURG, 2,325, PALO ALTO

CRETZMEYER, FRANK X-Ia.3,06; ( I'06)

Hennessy, James $\left(b^{\prime} 75\right)$ - Ia.10,06; (l'06).

o'Brien, Thos, Mloyslus (b'60)-No.7.91 (1'91).

POWEKS, HENRY A. (b'48)†-Ia.3,'82; $\left(1^{\prime} 86\right)$.

Van Gorden, Jesse Leland (b'75)-Ia.3,'01 ; (l'01).

Walker, John 1. (b'44) H-Ill.4,'81; (l'86) EPWORTH, 520, DUBUQUE

Harwood, Geo.- (1'86); not in praclice. ICNEILL, ALONZO L. '(b'57)-IIl.10,'95 (l'95).

REYNER, FRANKLIN (b'\$1)@-Ill.1,75; (1'87).

ESSEX, 776, PAGE

Okerlin, Oscar Whlliam (b'74)-Ia.4,05 $\left(1^{\prime} 05\right)$.

Parker, A. W. (b'55)-Ia.1,81; (1'87)

R.F.D. 2.

PARRIOTT, CIAAS. CLARENCE (b'62)Ia.6, 89 : (1'99).

prichard, Geo. Winthrop (b'79)-Neb.5,08; (l'10).

ESTHERVILLE; 3,404, EMMET

ANDEISON, ALBERT (b'61)-Ia.3,'90 (l'90) $; \mathrm{S}$

BACHMAN, EDSIL W. (b'54)๑-Ia.3,87; $\left(1^{\prime} 8 i\right)$.

Barber, Frances Adams (b'66)-Ia.4,'11; (I'I1); OALR.

BIRNEX, CLEANTHUS E. (b'73)థ-Ky.1, '93; (1'93)

BRADLEY, WILLIAM EDWIN (b'65)థIll.1,92: (1'92).

Staggs, Wm. Andrew (b'55) H-Ill.4,'89 $\left(1^{\prime} 89\right)$.

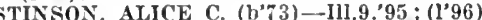

WILSON, MAURICE EDW. (b'69) $)$-Ia.3, $97 ;(1,97)$.

EVERIST, 500, MARION

REITER, ALFRED E. (U'สT) - Ia.3,'0I; (l'01).

EVERLY, 392, CLAY

Haverstock, Arthur Davld (b'84)-Minu.5, 09 ; ().

NYÝER, GREELEY B. (b'60)-N.Y.10,85; $\left(1^{\prime} 90\right)$.

EXIRA, 787, AUDUBON

JACOBSEN, ROBT. ANDREW - Ia.4,'94 (1'04).

NEWLON, JOHN CHARLIE (b'56)థ-Ia.1, '80; (1'91); OALR.

Rendleman. I. M. (b'38)-Ga.5,60; (l'86).

RILEY, JOHN (b'50)£-Ia.3,'80; (1'86).

EXLINE, 660, APPANOOSE

DAVIS, CHARLES, MORGAN (b'84)-Ia.6, '11; (l'11); U.

Sturdirant, Lawrence J. (b'63)-Ia.1,'88 ; (1'88).

FAIRBANK, 618, BUCHANAN

BOTHWELL, CLYDE D.๑-N10.7;07; (1'07); Pd.

YOLLOY, EDW. (b'72)థ-IIl.6,04; (1'04).

Murphy, Jos. H.-Ia.1,'82; (l'86)

WARD, GRIFFY B, (b'5i) - Mich,1,80; (I'87).

FAIRFAX, 225, LINN

Dvorak, Jos. Frank (b'75) -Ill.1,'99; (l'99). FAIRFIELD, 4,970, JEFFERSON

Bateman, Chas. B. (b'7)-Ia.10,04; (I'04). BEAN, JOHN Y-N.10'68; (1'86) (1)

CARPENTER, MARCELLUS C. $\left(\mathrm{b}^{\prime} 5 \mathrm{i}\right) \oplus-$

Ill.1,'S2; (1'88) , $\$ 4 ;:(1,89)$

onner, Warren H. (b'55)-Ia.4,'93; (l'93.)

Dunkel, Geo. Kasper (b'79)-la.3,05; (1'05)

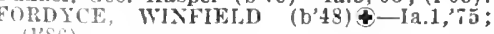

Gantz, Byron Noble (b'61)H-IIl.4,85; GAVIER, JAMES STHWART $\left(b^{\prime} / 2\right) \oplus$ III.1,00: $\left(I^{\prime} 00\right)$

GiRovi, Fill (i. (b'73)-Ia.9,96; (l'96).

HAGVE, ALBFHT SMLLE $\left(\mathrm{b}^{\prime} 72\right) £$ - Ia.9 $97:\left(1^{\prime} 97\right)$.

AMES, LOIA DOCGLAS (b'82)-I11.6,06 (I006); $\mathrm{Pr}$.

Myrick, Fllel Grant (b'69)-Ia.10,04; (I'04). Sloall, Nelson A.-N.Y.15,'88; $\left(l^{\prime} 00\right)$

TALLMAN, CAMERON C. (b'i5)-IIl. 1,00 . (1'03).

FARLEY, 676, DUBUQUE

BERRY, JOSEYH TOWER (b'73)屯-MIch.1 $06 ;$; (1'11).

Callahan, Danl. Andrew-Ia.1,'97; (1'97).

KEARNEY, CHARLES A. (b'69) †-Ia.3, '98; (1'98).

HerMaN, RICHARD CHARLES (b'82)థIa. 3,10 ; (1'10).

FARMERSBURG, 259, CLAYTON

Brandt, Glenn A. (b'76)-Ia.10,01; (1'01).

FARMINGTON, I, 165 , VAN BUREN

KIRKPATRICK, WI. J. (b'62) $\oplus-\mathrm{I}$.I.1, 87

(1'88) WOTT W. (b'74) -Ia.10,00: (l'00).

MOTT, WM. H. (b'74)屯-Ia.10,'00; $\left(l^{3} 00\right)$.

PAISLEY, CHAS. L. (b'66)-Ia.4,'91; (1'91).

FARNHAMVILLE, 332, CALHOUN

GREEN, WM. H.'(b'74)థ-Ia.6,03; (1'03).

FARRAGUT, 431, FREMONT

Battey, Percy Betterman (b'88)-Neb.6,'11 (1'11).

Coleman, Harry L. (b'66)-Ill.1,91; (l'91)

FARSON, 100, WAPELLO

HENRY, CLXDE A. (b'73) - -Ia.9, 97 (1'97).

FAYETTE, 1,112, FAYETTE

Baker, Frank Leroy (b'77) $\mathbf{H}-\mathbf{I l l . 4}$, 04 ; $\left(l^{\prime} 04\right)$.

(1'86).

McLean, Roy A.-Ia.3,'06; $\left(l^{\prime} 06\right)$.

Parker, James Donaldson ( $\left.b^{\prime} 68\right)$-Mich. 1 '92; (1'92).

FENTON, 211, KOSSUTH

LOGAN, FREDK. W. (b'73)థ-Ia.3,'01; (l'01).

FERGUSON, 127, MARSHALL

COWGILL, FRANK WILBUR (b'82)థIa.6,'10; (1'10).

FERTILE, 207, WORTH

Peterson, August John (b'75)-Ia.3,01; (l'01).

FINCHFORD (R.F.D., JANESVILLE), II0, BLACKHAWK

Davis, Frank Curtiss-Md.7,'99; (1'03).

Evenson, George A. (b'59)- ; (1'98).

FLORIS, 300, DAVIS

BAKER, HOWARD N. (b'81)థ-Ill.4,'05;

PARKER, WALLACE WM. (b'73)Ð-Mo.20, '96; (1'98).

FLOYD, 332, FLOYD

GRIFFIN, WILLIAM LEIGHTON $\left(b^{\prime} 85\right) \oplus-$ Ia.s,'10; $\left(l^{\prime} 10\right) ;$ Pd.

FONDA, 978, POCAHONTAS

DOWER, THOS, J. (b'66)-Ia.3,'96; (l'96). PATTERSON, ALPHEUS WOOD $\left(b^{3} 85\right) €-$ Ia. 3,$08 ;\left(1^{\prime} 08\right)$.

PATTERSON, MICHAEL FRAMPTON (b'57)

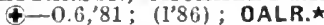

Whitney, Chas. Rufus (b'64)-IIl.1,94 $\left(1^{\prime} 95\right)$

FONTANELLE, 789, ADAIR

GIBSON, IRA JAMES (b'84)-Ill.22,'09; (1'10).

MCDERMID, PIERRE (b'i6)屯-Ill.1,98; (1'98)

Sweet, Hartford (b'i6)-Ill.11,'04; (I'04).

FOREST CITY, I,69I, WINNEBAGO

IIansen, Otto A. (b'65) H-Ia.4,'96; (1'96).

IIBISH, HARRY R. (b'60) †-Ia.3, 83 ; (1'86).

Lucast, Thomas (b'69)-Wis.2,98; (I'12); S.

THOMPSON, HARRY FRENCH (b'69) Ill. $1,{ }^{\prime} 94 ;$; (1'94); 0 b.

VESTERBORG, PEDER HANSON $\left(\mathrm{b}^{\prime} 60\right) \oplus$ -Ill.1,'92; (1'98).

FRANKVILLE (R.F.D., POSTVILLE), 100,

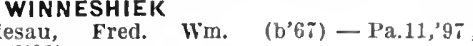
(1'02)
FRASER, 537, BO0NE

Shafer, Almon S. (b'58)-Ia.3,'89; (1'89).

FREDERICKSBURG, 558, CHICKASAW

JOHNSTON, EDW'IN N. (b'69) †-la.3,95; (1'95).

REICH, LOUIS PIIHIP $€$-Ia 10,03 : (l'05)

TAYLOK, LOUIS M. (b'62) - Ill.10, 84 ;

$(1,86)$; not In practice.

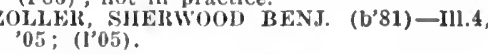

FREDERIKA, I49, BREMER

SHUMATE, C. FRANK (b'70)—Mo.28,'98; (l'12).

FREMONT, 501, MAHASKA

COMBE, LOUIS ABEL ( $\left.\mathrm{b}^{\prime} 70\right) \oplus-110.34,03$; $\left(1^{\prime} 03\right)$.

Krout, Jacob B. (b’ǒ6)-Ia.1,'86; (l'86).

FT. DES MOINES, - POLK

BURCHAM, THOS. A.

(See Des Molnes.)

Loosbrock, Joln F. (b'89)-Neb.6,11;(1'13)

FT. DODGE, 15,543, WEBSTER

ACHER, AIBERT EDW. (b'78) - Ind.8,'05; (1'06); 708 N. 16th St.; offlce, First National Bank 13ldg.; 11-12, 2-5.

ALTON, WILFRED EU'GENE (b'73)-IIl.10, 96: (l'96) ; 5161/2 Central Ave.

BATES, WM.' RUSSELL (b'63) - Mlch.1,91; (1'92); 317 N. 14th St.; offlce, Flrst National Bank Bldg.; (B31); OALR,

BELT, ANDREW LINCOLN ( $\left.b^{\prime} 61\right)-I a .3$ '90; (1'92); 226 N. 13th St.; offlce, First Natlonal Bank Bldg.; $2-5,7-9 ; S$.

BOWEN, WILLIAM W. (b'69)-Ia.3,95 (1'95); 628 S. 12th St., S. ; offce, $600 \frac{1 / 2}{2}$ Central Ave. $2-4,7: 30-8: 30$.

CARVER, WILĹLAM F. (b'69)(-Ky.5,"93 $\left(l^{\prime} 93\right)$; Eye, Ear, Nose and Throat Hospltal ; 8-5; (B31).

CHURCHIL,, CHAS. HIRAM (b'58)\&, Member Neb. State Mied. DE JoNG, CONRAD (b'71)థ-Ia.3; 97 (1'04); First Natlonal Bank Bldg.; 11-12, $2-5 ; S . \star$

EVANS, ROBT. (b'57)-Mlch.7,'88; (l'91); 530 S. 12th St. ; office, $6001 / 2$ Central Ave.; $11-12,2-4 ; S$.

GARRETT, JOHN MILTON (b'69)@-Mo.27, '92, N.Y.10,'96; (l'92); 1133 Park Blvd.; office, Doud Block; 10-12, 2-5, 7-8.

KIME, JOHN W. (b'55) @-Ia.3,'83; (1'85) ; 26 N. 7th St.; I. $\star$

Kime, Sara A. P. (b'58)-Ia.3,'82; (1'86).

LOWRY, JAMES DAVID (b'76)థ-Ia.3,01; (l'01); Oleson Block; 11-12, 2-4, 7-8.

ICCREIGHT, ARTHUK HENRY (b'66)IIl.1,97; (1'97); 625 S. 12th St.; offlce,
St. Joseph's Mercy Hospital; 2-4, 7:30St. Jo

MULRONEY, CHAS. H. (b'75) $\oplus-I 11.1,00$; $\left(1^{\prime} 03\right)$; First National Bank Bldg. ; $1: 30-5$. NELSON, JOHN S. (b'61)-Ia.4,'88; (1'88); 635 , I0th Ave.

OLNEY, FLOYD B. (b'51)-Ill.4,81; (l'86) 1610, Ist Ave., S.; office, West Mason Bldg. ; 2-5.

Paige, Chas. H. (b'56)-N.Y.5,80; (1'86).

PALMER, GEO. BALDWIN (b'T1) $\uparrow-I 11.10$, 99; (1'99); 1021, 2d Ave. N.; offlee, 5161/2 Central Are.; 10-12, 3-6; Ánes.

RISTINE, HARLEY G. (b'38) §-Ill.1,69 ; (1'86); Oleson Block.

ROSE, HERMAN (b'55) $\uparrow-G e r .8, ' i 2$; (1'95); Schaupp's Block.

Russell, Edmund Darld (b'67)-Ia.3,'96 ; (1'96); $516 \frac{1}{2}$ Central Ave

SAUNDERS, CHAS. J. (b'62)థ-Ia.3, 85 ; (1'86); 1108, 4th Are., N.; offce, Flrst National Bank Bldg.; 2-4.

Schultze, Fred. Pitt (b' $\left.{ }^{\prime} 8\right)-P a .2,{ }^{\prime} 02 ;\left(l^{\prime} 02\right)$; Oleson Bldg.

SEYMOUR, FRANK E. (b'52) †-Ia. 3,79 ; (1'86); 6261/2 Central Ave.; 9-10, 1-3. STUDEBAKER, JOHN FRANKLIN $\left(b^{\prime} \tau 4\right) \oplus$ -IIl.4,06, Ill.11,08; (l’08); 1333, 3d Are. N. ; office, First National Bank Bldg. ; 2-4, :30-8:30.

WAKEMAN, ALLIE HOYT - Ia.10,01; (l'01): 912, Ist A ve., N. ; office, oleson Block; $10-12,2-4,7: 30-8: 30$; G.

WILDMÁN, MURRY-Ia.4,06; (1'06) ; First National Bank Bldg.

FT. MADISON, 8,900, LEE

Baker, Chas. Orrin-Mich.1,78; $\left(1^{\prime} 86\right)$.

Bishoff, Mark L.-Mo.20,02; () ; S.ネ 
CASEY, JOS, MOXTGOMERI (WOT) MII. BR: (1'S8) 110.34,11: (1'1:3)

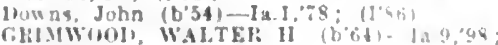

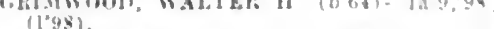

KAST: WM. CHAS. $(2 \%)+19.10 \% 3$ :

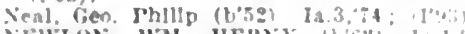

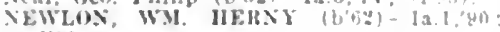
$(1,90)$

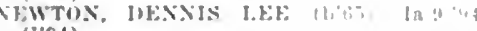
(I'94).

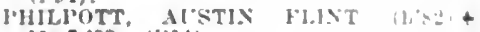
Vo.7,03: (l'04).

I'UHLPOT, JOHS w. (b'56)-Vta.st: (I'S6).

POWERS, MARION R.IY (b's9)-1A3,10 (1'10).

PHCE, ELWYX DF.NE (bos5)- Iก 2."10 (1'13): Asst. Surgeon, Santa Fe llusilinal

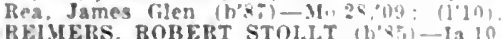
EIMERS, ROBERT ST

MCHMOSD, ALIBERT CAREY (b'34+ 1a.9.98: (l'98).

IRSR, John J,-Is.1.85; (1'87)

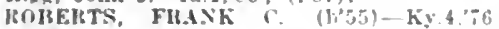
$(1 ' s 6)$.

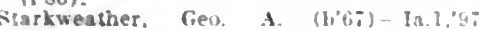
(19\%).

THAVERSE, ISAAC W. (b०71)-1a.9.93; (l'93).

WAHER, CARL WM. (b'/9) - 111.1,02 (1.05): $\mathrm{s}$.

WAHLER, CHARLES FREDK. (b'50) IA.1.:8-: (1'87): $\mathbf{P d}$.

WIHRFR, MALRICE (b'58)- 0 : $(1,864$

WALKER, JOHN RILEY (b'75)-Ja.10,04 (l'04)

GALT, 250, WRIGHT

Potter, Wm. (D.66)-ont.3,'92; (1'94)

GALVA, 357, IDA

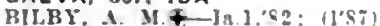

YARSSWORTH, DAVID W. (b'51) Ia.3 '85: (1'85)

CRT'BB, MERRILL WORTH (b'85)-III 11 '12: (1'12).

GARDEN CITY, 200, HAROIN

Pines, John Andrew (b'í)-Colo.2.'ll (1) 13 )

GARDEN GROVE, 6II, DECATUR

COONTZ, JESSE S. (b'75) - Ia.10,'03:(1'03)

ION WM. EDWIN (b"il) I - IA, (1'9i).

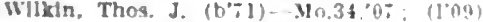

GARNAVILLO, 342, CLAYTON

HTI)EK, JOS. W. (1,81)-Ta.10,05: (1'0.1)

GARNER, 1,028. HANCOCK

Bemls, Geo. Arthue $\left(b^{2} 84\right)$ - Ia.3.0n; (1'ng)

Fraser, Jefferson F. (b'b3)-III.11, '91 ; (1'91)

HIchler, Jerman A. (b'65)-O I

GARRISON, 438, BENTON

CARLE, FRANK C. $\left(b^{\prime}, 3\right)+-1,3,04$ $\left(1^{\prime} 04\right)$

\section{GARWIN, 423, TAMA}

raunder brank $T$ (b'ti) H - Ia 4.01. (I'OI)

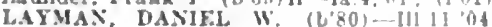
(I'04).

GENEVA, 199, FRANKLIN

SIBERTS, PRANK I. $(1,20)+1,3,04$ (1'04).

GEORGE, 608, LYON

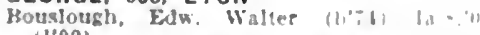
$\left(I^{\prime} 00\right)$.

MCKIXSEY, OLIVEH H, (b'63) - -InI क w (1॰93).

GERMANIA, 436, KOSSUTH

Wurtzer.

(I'12)

GIBSON, 100, KEOKUK

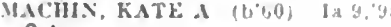$$
\text { G. }
$$

MACHIS: MHLJH:L

$(1,90): \mathbf{N}$.

CILBERT, 235. STORY

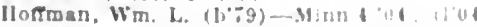

GILBERTVILLE, 200, BLACKHAWK

GILERTVILLE 2OQ BLACKHAWK (1'0J):

GILMAN, 430, MARSHALL

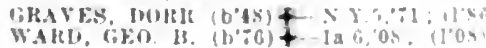

GILMORE CITY, 689, POCAHONTAS

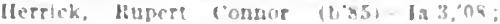
(1)

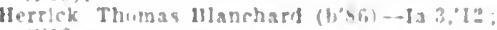
(I.12)

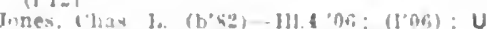

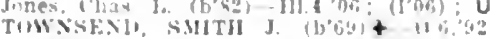
(1'9:2).

GLADBROOK, 869, TAMA

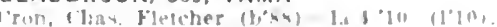
Melinwell, Gilbert thompon (b') la $b$. $11+6,3)$

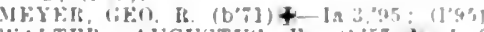

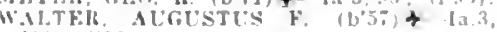
'A:2: $(1 ' s 6)$.

GLASGOW (R.F.D., FAIRFIELO), 100. JEFFERSON

BISUI ( IRL S -IA O.94 (I04)

GLENWOOD, 4,032, MILLS

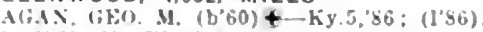

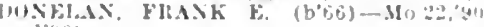
$\left(l^{\circ} \div 0\right)$.

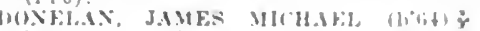

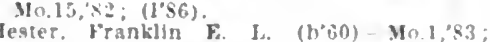

ester, Pranklin F. I. $\left(b^{2} 60\right)-\mathbf{M} 0.1,83$;

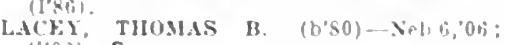
(1.06): $\mathbf{S}$.

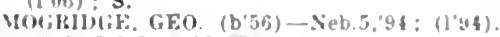

MOOX, ROY $\left(b^{\prime}, 3\right)-10.3,03 ;(1,03)$

l'limplion, Wm. Nerrll (b'69) 1 - $111.10,96$ : (1) I): OALR.

SIDWELI. LAWREXCF T. (b'\$3)-Neb.s, .08: (1'08).

sward, Martu l'aulus (b'st)-Neb.5,11; unt in practlce.

GLIDDEN, 850, CARROLL

Deshler. Jordan J. (b'5i)-Ild.3,80; (1'S6)

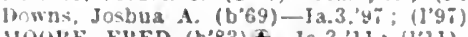

MOORE, YKED (b'83) —-1a.3,11; (1'31).

GOLDFIELD, 618, WRIGHT

'ENINGHAM, ALBBET STEYESS (b.55) III. $1, s^{\prime} y_{;}\left(l^{\circ}+40\right)$.

PEPP'ERS, JOHN LEWIS (b'il) t-Ia.10, (102; (1'02).

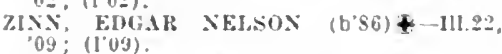

GOODELL, 240, HANCOCK

Marek, Jos. Edir. (b'86)-1'al. 2,0s; (l'08)

GOWRIE, 829, WEBSTER

ERICSSON, CHAS. MFLVIN (b'2)-1as, $05:(1003)$

lundvisk, Arthur W. (b':s) la.3,0z: 1102

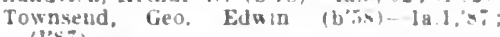
(1'Si).

GRAETIINGER，556, PALO ALTO

HESSION, l'ATHCK J. (b'63)-191,'s: (1) 48 )

Nase, Thorles? T. (b'b2)-1a 10,00: (1'00).

GRAND JUNCTION, 1,012, GREENE

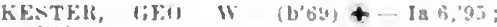
(10.).

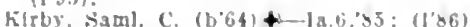

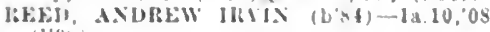
(1'0)

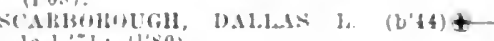
B. $1,: 11 ;(1,80)$.

GRANDMOUND, \$28, CLINTON

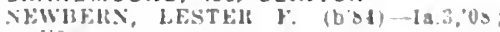
(1).03)

Wille, Utto Vletor (b's3)-Ia 3,'1!; (1'12)

GRAND RIVER, 333, DECATUR

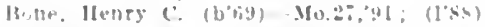

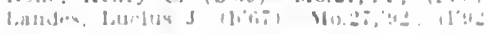

GRANDVIEW, 374, LOUISE

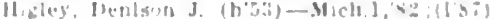

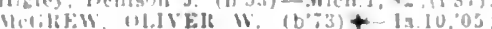
(1.0.0)

GRANGER, 225, DALLAS

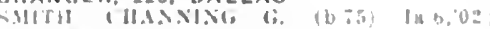

GAANT, 162, MDNTGOMERY

(1) (1)?

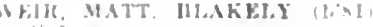

GHANVILLE, H00, SIOUX

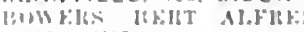

$0 \% ; 10010$

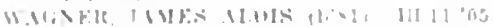

GRAVITY, 475. TAYLOR

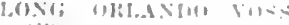

$131.96 ;$

Real Li i $\mathrm{TH}$.

Stanloy fredk l. (L'D

GRAY, 148, AUDUBON

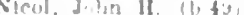

GREELEY, 383, DELAWARE

Kresensliy, Wialie? Wh. I

(1?10)

GREENE. 1,150, BUTLER

H.rneY, Varillay COMnelhas

"all, Merlyn Bubb (283)-1a.3.'11: 117

lirum, Jamex Warner (b'82)-iac.'11

(1'li)

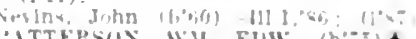

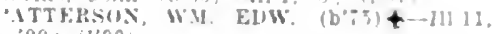
Co: $; 1$ (1) 00$)$

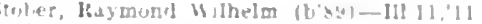

GREENFIELD, 1,379, ADAIR

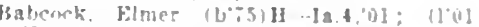

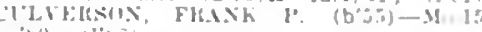

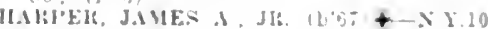

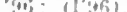

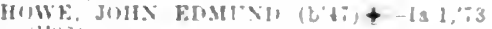
(1) 86 .

Humer, Warten lee (trit-Nebriot

HI:05). H1MAM H. (b'6i) $+-11111,01$

(i'0i)

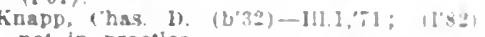

not in practice.

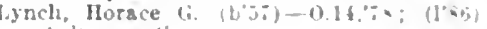

not in gractsce

MACRIE, JAMES GILBEBT $\left(b^{\circ} S 5\right)+$ W $10 ;\left(l^{\prime} 1: 2\right)$.

GREEN MOUNTAIN, 100, MARSHALL

STRAIN, JOHS FINLEY (b'Q IA.Y... (1'ys).

GRINES, 733, POLK

M.IKER, LEWIS E. (b':3) —-13.6,"9": (I)

PEACOCK, ABRAHAY LEO $\left(\mathrm{b}^{2} 54\right)+1 \mathrm{t}, 3$, $993,1 \mathrm{l}, 6,96$; $\left(1{ }^{\prime} 96\right)$

GRINNELL, 3,036, POWESHIEK

Mlss, EUlwin (C. (b'39)-111.1, $85 ;\left(130^{\circ}\right) ; 0$.

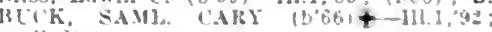
$(1, y+2)$.

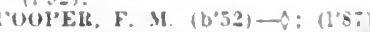

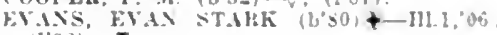
$\left(I^{\prime} 08\right): T$.

H.1RIBI: "I.INT

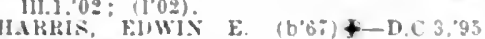
$\left(I^{\prime}(4.5) \div \mathbf{N}\right.$

I.ACDER, CLARK H.IS (DSt) +-1.3.

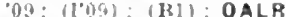

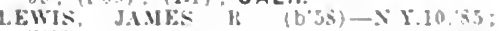

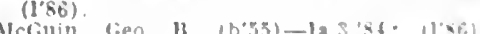

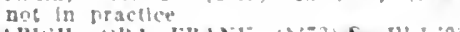

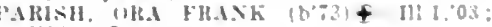
$(10,3): \mathbf{S}$.

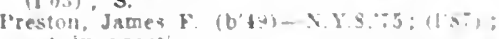

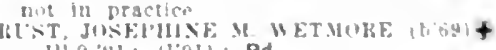
- III.91: (1.91): Pd.

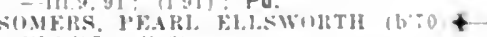

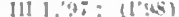

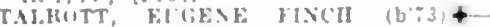

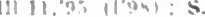

ODA

GRISWOLD, 949, CASS

('IIISHULS. IGI)EHII $\mathrm{K}$

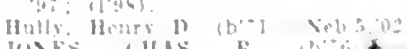

J"I.

GRUNDY CENTER, 1.354, GRUNDY

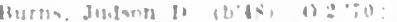

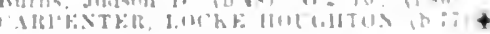
- 111 1 04 . lint

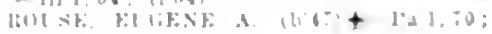

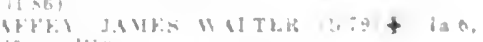

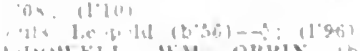

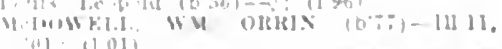

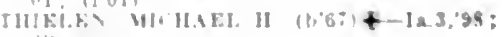


GUERNSEY, 143, POWESHIEK

('hase, Albert 1. (b'80)-la.10,07; (l'0て). GUTHRIE CENTER, I,337, GUTHRIE

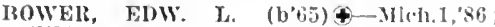

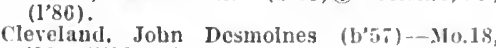
$92 ;$ (1'92); D.

CRAWFOLD, DAVH AGNEW (1,64) $£$ Ia.1,83: (I'91); (1B1) ; OALR.

HARRISOY, JOS. WILEY $\left(\mathrm{b}^{2}-2\right)+-1 \mathrm{a} .3$ $96 ;(196)$; $\mathrm{s}$.

TIIOMLS, CIARENCE I. (b'SI)-Ia.3,05: (I'05).

GUTTENBERG。1.873, CLAYTON

BEYER, AITHLR EDWH (1, 23$)-111.11,01$ (I'01): $\mathbf{R}$.

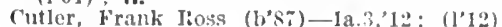
DUFFIN, CILS. W, (b'56) $\oplus$ - III.1.'81: $\left(1^{\circ} 86\right)$.

HALBUR, 147, CARROLL

(CONION, CIIARLES M. (b'82)-Neb.6,06: $\left(1^{\prime} 06\right)$.

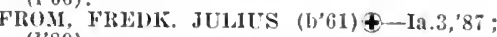
(1'89).

HAMBURG, 1,817, FREMONT

Bogan, W. L. (b'51)-Ia.1,74; (l'87).

Dalbey, Eugene T.-MI0.18,93; (1'93)

llayes, Ifezekiah-Ia.9,98; (1'98).

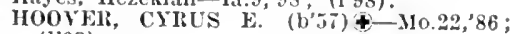
(1'93).

Jolly, Arnold (l,'61)-Ala.2,'85; (1'94).

MURCHISON, KENNETH (b'ה)-Ia.3,03; (l'03)

Richards, Emmett Earl (b'70)-Mo.2,98; (I'98).

SPERIT, WADE (b'61) क-Mr.22, 95 (1'95).

Swiggart, Nanl. W. (b'31)-Mo.2,'69; (l'S6). Sykes, lloy W. (b'i6)-III.1, 02 ; $\left(1^{\prime} 02\right)$.

WANAMAKER, AMBROSE E. (b'66) \& Mo.20,97; (1'97).

HAMILTON, 39I, MARION

DANIELS, WM. HARRISON (b'83)-Ky.2, '10; (1'12); Nember Wyo. State Ned.

Faivre, Mathew J. (b'31) $\rightarrow$; (1'86). Groenawalt, Nibertus G. (b'69)-Ky.1,'93;
(l'9s).

HAMPTON, 2,617, FRANKLIN

ARTHUR, WM. 1:ICIIARD (b'78)-Ia.3,'07 ;

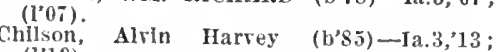
(1'13). Geo. Addison (b'35) II-Ill.4,'74

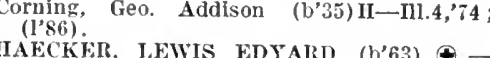
IIAECKER, I.EWIS

Ill.1;'94; (1'95). Pa.1, $92 ;(1,86)$.

Hoxie, W'm. E. (b'69)-Ia.3,'98, Inl.1,99; (1'98).

Knowles, Myrta M.-1a.3,96; $\left(1^{\prime} 96\right)$.

LONG, WAITER KLINGEMAN (b'7 7 $111.6,06$; (1'12)

OSBORNE, CLAUDE F. (b'67)-III.11, 00 (l'00).

Powers, Jos. CLINTON (b'68)£-Ill.1, 97; (1;97).

ST, ĆLAIR, FRANK E. E. (b'77)£-Pa.2, 04; (I'04).

HANCOCK, 250, POTTAWATTAMIE

Stevens, Albert S. (b'61)-Pa.1,91; (l'91).

Stevens, John F. (b'56)-Ky.2,94; (l'08).

HANLONTOWN, 129, WORTH

Cross, Geo. B. (b'78)-Ill.10,'01 ; (1'02)

Jones, Jolin R. (b'53) E-0.2,'78, Ill.8,'82 ;

HARCOURT, 247, WEBSTER

Lundvick, Eric J. (b'64)-Ia.6,'04; (l'04).

HARLAN, 2,570, SHELBY

BISGARD, JAMIES A.૯-Neb.5,94; (I'94).

BOCKEN, HERMAN (b'86)£-Neb.5,'11.

Cobb, Élliott A. (b'43)-0.11,68, N.Y.10,

;is.

Conk. Elihu L. (b’39)-Ia.1,'î, Ill.11,'85; $(1,86)$

MOORE, EDWIN AUgUSTUS (b’2)థ-

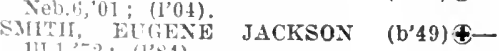
$111.1, \therefore 2 ;(1 ' 84)$.

Famatia, Clarence Fisher (b'87)-Ia.4,'12; $\left(1^{\prime} 12\right) ; G$
HARPER, 232, KEOKUK

Adrian, Frank-1I-1a.4,04; (l'04).

T'1lmanns. Carl Sanil. Gordon (1)'83) Y10., $2,0^{-1}:(1,08)$.

HARPERS FERRY, 297, ALLAMAKEE

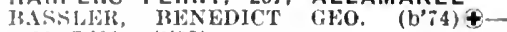
Uก. i,, $01 ;$; (i’01)

HAKRIS, 239, OSCEOLA

('A1)Y, CHINTON COLNAX (b'69)૯-Ia.6. , $00 ;(1,00)$

Palyhium, James Blaine (b'83)-Ia.3,09; (I'09).

HARTFORD, 100, WARREN

Hooper, saml. F. (b'66)-1a.10,04; (1'04) Sturman. EIden Cromwell-Ia.l,97; (1'97).

HARTLEY, 1,106, O'BRIEN

'oleman, Francis J. $\left(\mathrm{b}^{\prime} 68\right)$ - Ia.8,'97, X.Y.fi.'s9; (1'97); OALR.

COXAWAY, JOHN W. (b'60)థ-la.5,'85, (l's6).

IIAND, WY. C. (b'7)థ-Ill.6,06; (l'06) ;

PITELI'S, CIIAS. F. (b'81)-Pa.9,07; IIFRIBON, JOHN BAYARD (b; 6$)$-Ia.3, '04; (1'04) ; OALR.

HARVARD, 125, WAYNE

HINK1.E, GE0. W. (b'49)-Ia.1,'i5; (1'8i). HARVEY, 346, MARION

'ascoe. Irvín J. (b'85)-Ill.22,'10; (l'10) ; OALK.

HASTINGS, 393, MILLS

CIIRISTY, EDGAR (b'81) $\oplus-$ Neb.5, 0 i ; (1'07).

HAVELOCK, 24I, POCAHONTAS

HEATHIIAN, FRANK E. (b'71)-1a.9,'95; (1'95).

HAWARDEN, 2,107, SIOUX Doolittle, Marshall Erwin (b'5I) H-Mo.3,

ICAILISTER, FRED J. (b'7t)థ-Ia.3,02; (1'02); $\mathrm{s}$.

MEYER, ALBERT JULIUS $\left(b^{\prime} 83\right) \oplus-K y .2$, '10; (I'11).

Palmer, Clarence Elmer (b*85)-Ia.4,'12; (1'12). Will Aerions (b58)-Iil.1,'80; (I'82); G.

HAWKEYE, 510, FAYETTE

WALSH, THOMAS NELSON (b'65) $\oplus-$ Que.1,'92; (1'93)

HAWLEYVILLE, 140, PAGE

ELIIOTT, JESSE D. (b'52) - Ia.1,'82; (1'87).

HAYESVILLE, I50, KEOKUK

Grimes, Chas. Oscar (b'73)-Ia.9,'95 ; (1'95).

HAZLETON, 444, BUCHANAN

GARARD, JUSTUS CORBLY (b'73)€IIl.11,'05; (1'05).

HEDRICK, 978, KEOKUK

IIENRY, REX VALE (b’75)-Neb.6,01; (1’01).

Lawson, Fred E. (b'75)-1a.10,00; (1'98). Lewis, Edgar Chas. (b'67)-Ia.4,91; (1'95). MCLAUGHLIN, WM. HENRY (b'63)థ1a.3,87; (l'94).

Porter, James Arthur, (b'86)-Ill. 6,'12; (l'13)

HENDERSON, 240, MILLS

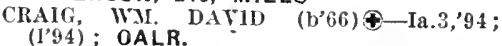

Cowdy, Augustus S. (b'46)-Mich.2,'II ; (I'96)

HEPBURN, I10, PAGE

West, Wm. Walter (b'75)-Ia.9,98; (I'98).

HESPER, 200, WINNESHIEK

Worth, Fordyce (b'31) E-IIl.8,'70; (1'86).

Worth, Louisa D. (b'50) E-III.8.'79; (1'88).

HIGHLANDVILLE, 150, WINNESHIEK

HEXOM, JOHN DANIEL (b'79)-1a.3, 05 ; (105).

HILLSBORO, 325, HENRY

IIowe, Jaines M. ( ' $\left.^{\prime} 70\right)$-Ia.3,'97; (l'97).

Jiarr, Harvey E. (b'57) H-Ia.4,'82; (1'86).

HINTON, 329, PLYMOUTH

ROBIBINS, JESSE HOWARD (b'70)--1a.8, '95; (I'95).

HITEMAN, 2,000, MONROE

MAGARIAN, SENNACHERIB MALCOLY (5'80) 1 -Md.4,05; (1'08).
MAIREY, WILLIAM JAMES (b'78)-IIl.22, '10, (l'12).

Wortl, Craig-No.3,'06; (l'06).

HOCKING, 800, MONROE

SNY11)R, RALEIGI RUSSELI (b'85) Ia.6,'08; (I'08).

HOLLAND, 168, GRUNDY

IBurroughs, Saml. Edw.-N.H.1,'74; (1'86).

HOLLY SPRINGS (R.F.D., HORNICK), 27, WOODBURY

Flageolle, Jos. W. B. (b'88) - Ia.8,'09; (l'10).

HOLSTEIN, 936, IDA

BRANDT, GEO. CARL (b'76)థ-11.6,05;

CRAN1, GEO. II. (b'68)£-Ia.3,'96;

crank,

Kelling. Jouís Francls (b'74) - Mo.7,'98; (1'98).

PUTXAH, CMESTER LIOYD (b'86)-Ia.3, '12; (1'12).

Walker, John Tllgham (b'47)-Ill.1,73; not in practice.

HOLY CROSS (R.F.D.̈ NORTH BUENA (4), DUBUQUE (I'05).

HOMESTEAD, 300, IOWA

MOERSHET, WM. (b'65)-Ia.3,'88; (l'88).

HONEY CREEK, 87, POTTAWATTAMIE

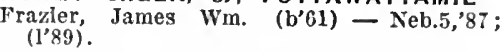

HOPEVILLE, 103, CLARK

Mulcahy, Arthur R. (b'72) - Ind.8,96;

HOPIINTON, 797, DELAWARE

cummings, Louís F. (b'61)-1a.3,84 ;

(180) 0 b.

, David Lewis (b'78) -Mlch.1,06; ( (1,90)

HOPNICK, 245, WOODBURY

FLENTJE, ROBERT $\left(b^{\prime} 80\right) \oplus-M 0.34,06$; (l'12) ; Member. Ill. Statc Med. Soc.

HOSPERS, 58I, SIOUX

de Vogel, Balthazar Johannes (b'46) Neth.1,'68; (1'86).

Galman, James John (b'72)-Mich.7,'97 ; (1'99).

HUBBARD, 568, HARDIN

BRUBAKER, JOHN FRANCIS R. (b'59)థMd. 3.' 85 ; (1'94).

LIVENGOOD, J. T. (b'55) $\multimap$; $\left(I^{\prime} 86\right)$.

REED, JOS. EMERY (b'75) - Ia.10,'06 ;

HUDSON, 372, BLACKHAWK

ACMIILAAN, EDWIN C. (b'77)-IIl.4,03 ;

PYIES, RICHARD H. $\left(b^{\prime} 79\right) \oplus-1 a .10,02$; (1'02).

HULL, 658, SIOUX

Maris, Gerrit-Ia.3,'06; (l'06).

WIRKMAN, DIRK JOHN (b'67)(-Mich.1, '92; (1'92).

HUMBOLDT, 1,809, HUMBOLDT

ARENT, ASAPH (b'í7)-Ia.3,'98; (1'98)

CODDINGTON, JAMES KEEL (b'72)-Ia.4, O0: (1'00).

DOAN, HENRY C. (b'55)థ-MIich.1,'84; (1'87).

Miller, Albert Douglas (b'88)-Ia.3,'12; (1'12).

HUMESTON, 1,006, WAYNE

Arnold, lsobt. R. (b'47)-Ia.3,7T; (l'8i).

Ateculloch, Geo. (b'48)-Ill.1,'73; (1'87).

McGulre, Carlton Monroe (b'63)-Ill.1,9I ; (1'91).

IcGuire,

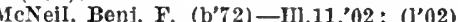

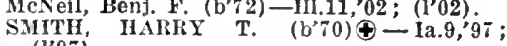
$\left(l^{\prime} 9 \pi\right)$.

HUXLEY, 336, STORY

MORSE, ARTHUR B. $\left(b^{\prime} 62\right) \oplus-I a .6,03$; (1"03).

HYNES, 500, MONROE

BONE, MERLE (b'85)(†-Ia.3,'07; $\left(l^{\prime} 07\right)$.

IDAGROVE, I,874, IDA

CONN, JAMES ENMETT $\left(b^{\prime} 67\right) \uparrow-I a .3,92$; (I'92); S. 


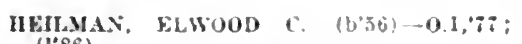
$\left(l^{\circ} 86\right)$.

IIEILMAN, ERNEST SIMI (b'ig)III.1,01: (1'01); OALR.

HOVLIHAX, THONAS JOS. (1, i5) ก1.1.02; (104); S.

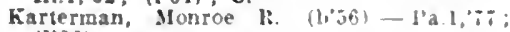
karternan,

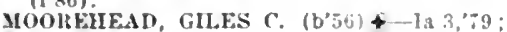

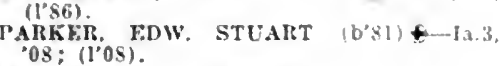

IMOGENE, 34I, FREMONT

Allen, Sherman A. (b'32)-Mo.18, $83:\left(l^{\prime} 95\right)$

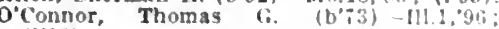
(1'96).

INDEPENDENCE, 3.51\%, BUCHANAN

AGNEW. PREN. F. (b,id) + - I'a 2,02 : (I'03): ALR.

Allen, Wm. Géo. (1,59)-111.4,'10: (1'11)

Bain, Fred Halph-1a.3,95; $(1,95)$; not in practice.

HUCHANix, HOBT. Eu(60) $(1,-14)+111$. 's3; (1'91); $s$.

Butz, lobte c (b's5)-Pa.12.07; 11'12); S, CRUMRACKER, WM. PUIJOCK (1,5) $0.1,82 ;\left(1^{\prime} 02\right) ;(\mathrm{E} 13)$; NP.

Femlng, Margaret Amanda (bois)-ont.3 94: (1"08).

IISUSAY, IHAREY

Fia.3.06: $\left(\mathrm{L}^{2} 06\right)$ NDSAY, SAYH CONSEIA, (b'2 2$)-0.6$, MCGREADY, JOS. HLGH $(1 \cdot 2)+-11111$, $96 ;(1,93) ; \mathrm{S}$

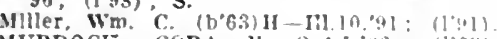

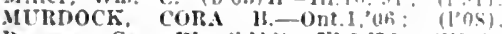

Ramsey, Geo. W. (b'45)-Ill.1,76; (1'94):

SELI.S. BENJ. B. (b'80)-1a.3,05: (1'0

SHEEHAS, EDW. M. (b.79) \&-Ill.6.05;

(l'05),
SHELLITO, AMOS G. (1690) —-Md.3.82;

Woodrur, Carollne F. Bromiki-Mast.5.q4;

(191).

INDIANOLA, 3,283, WARREN

Nlden, Geo. H. (b'-9) H-1a.4, 02 ; (1'02).

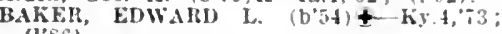

(l'86).

Buttertleld, Hosabell A. (bry)-Ta.10, 0 ; ; (1'0i).

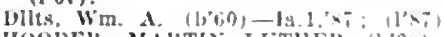

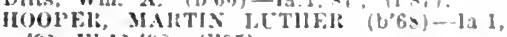
'91. I11.11, 98 ; (l'95).

Humphrey, Howard it, (b88) H-Jat, 95 ; (1'95).

J'DKLS. OLYYER 1'. (b'70) + fa 1,95, I11.1,95: $\left.1 l^{\prime} 9.8\right)$.

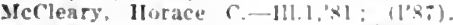

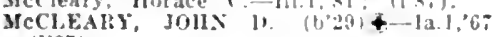
(1'85).

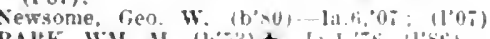

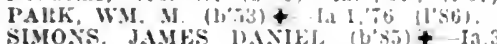

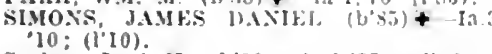

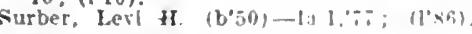

INWOOD, 595. LYON

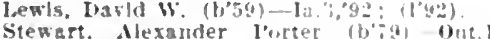

Stewart, Ne
'0.5: $(105)$.

IONIA, 298, CHICKASAW

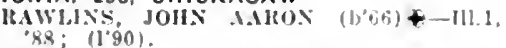

IOWA CITY, 10.091, JOHNSON

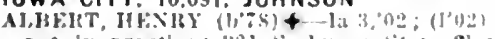

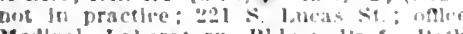

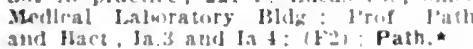

Haumann, louts (b'sol-a r.1,0I: not in practlce: Indsersliy Howpleal: Amat. I'rif Hed,', Ia.3.

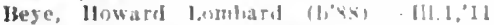

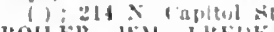

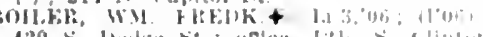

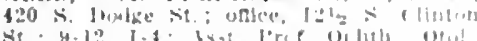

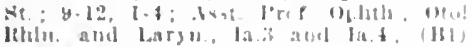
OALR.

Itolstal, Hamllen Imo (b)

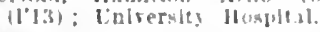

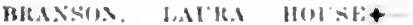
(1's6) 12 s. Sumnla st:

5. rllnton st. 111-12, 1.t: G

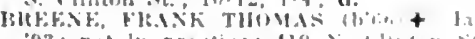

'93: not his prantice: 119
BROW not ln practlec: 510 s. Johnton st.

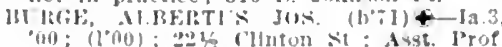
surg., Ia.3 and Iat; $\left(A^{0}\right): \mathrm{s}$.

lbwater, Wm. le ('lalre (1)

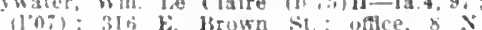
cInton: I'rof. Ophth. Ias; OALR.

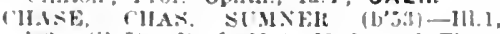

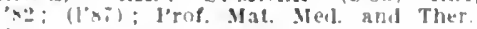
l.t...

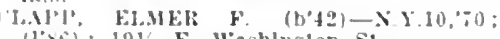
$(1 \times b j): 191$ E. Washlngton st

ingewell, John Wilkingon - H.-la 4,06:

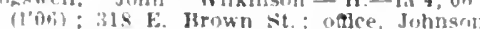
Comnty sarlnge Bank Mldg.; I'rof, Obst. and Cyn., Ia.t; ObG.*

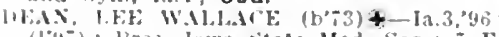

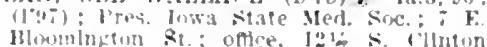
st. : 11)-12, I-3; Prof. Ophtlu, Ja.3; (B), T.S) : OALR.*

monoran, Wm. Henry (b's2)-1a.3.07: (1007); $1002 \mathrm{~F}$. College st. : oflce, Johnson

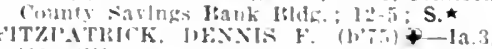

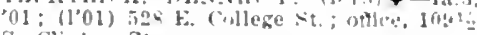
S. Clinton Si.

GRANT, CLAS NHAEFYER (10,-20-1a.3.

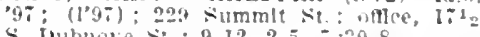
rover

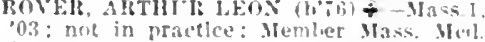

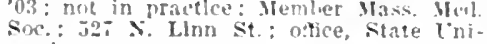
sersity.

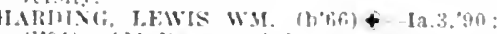
(1'94): 404 llasenport st.

Hazard, Theodore J.incoln (1) b1) H-Mich.1.

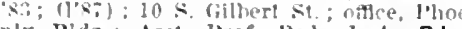
nlx Bldm. Aset l'rop. ped.' la.4: Pd

HF.UH, UIRY KITHINA (b)

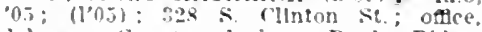

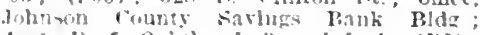
ist. 1'rof. Opisth., ia.3 and 13.4 ; (IBI) ? op. *

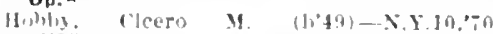
$(1 \cdot 5)$ : not in practlce; $524 \mathrm{~s}$. Jolnson

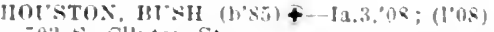

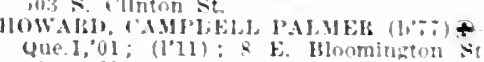
uftce. Inir. llu pital: l'rof. lifer. Med. la. $3 ;\left(F_{2}\right) ; 1 . \star$

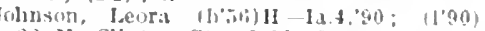
2.2 $\times$ rlluten st.; $9-11,3-5$.

KE(BE, EkSRT T. (1005) + - Ia

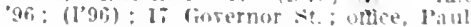
lielen lsidg: : 9-12. 1-3.

Keller, Feorge Eulzar (bos) - Ia.3,10 (1'1n): Johnson Counts Bank Bldg.

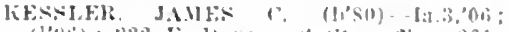

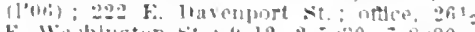

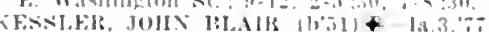

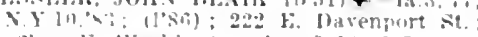
nthe. W Washeton st: $9-12,2-\overline{3}$

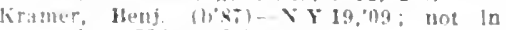

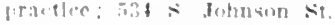

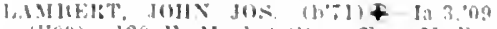

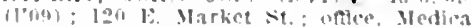

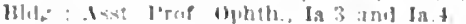

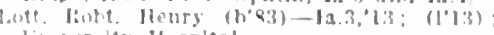
linsority Hocpleal

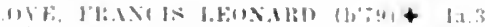

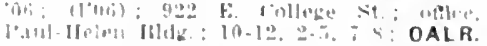

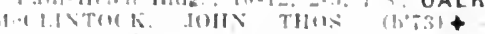

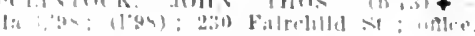

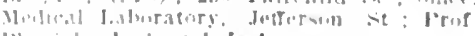

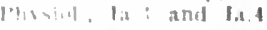

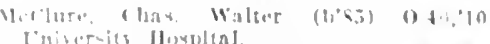

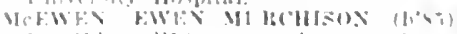

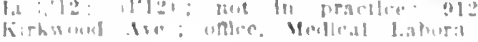

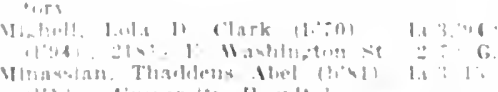

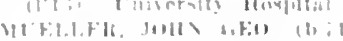

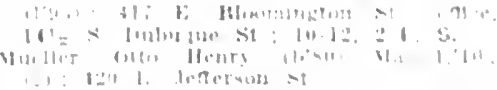

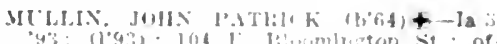

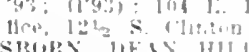

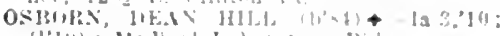
(I'III) Mediral Lalurat. Birt

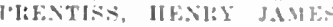

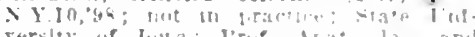
lati: ( $\left(\mathrm{H}^{\prime}\right)$ ).

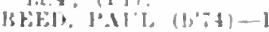

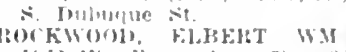

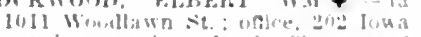

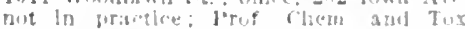

l.t.3 and la.t

leshrbacher, Wm. Mar bor) - latel?

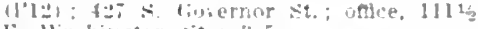

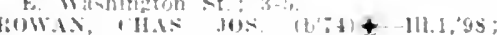

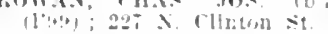

(10, sii)-Y.Y1.11:

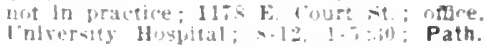

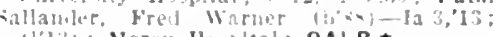
I'I31 Nerey Ilw-[ntal; OALR

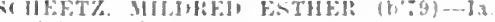

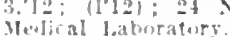

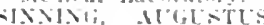
$(1,05)$.

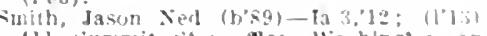
11] sumnit st. : oflce 113ohlngtut and Inhurue sis.; 10-12,2-4

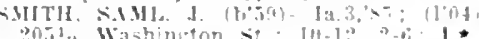

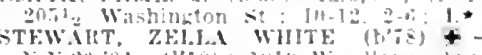

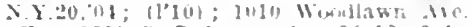

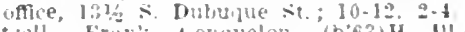

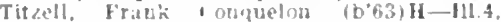

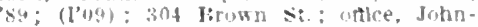

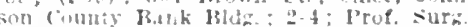
I:t. $; \mathrm{S}$.

Titzell, Ify smith (b'6)--1a \&.'T0; (1'13): sut Isruwn st. notlee. Johnson ciunty lank IHId - : 10-11, 3-5; Pd.

AIENT. jos i (hol) - la $3990^{\circ}$

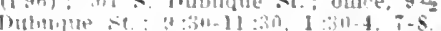

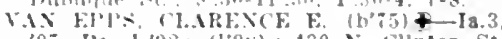

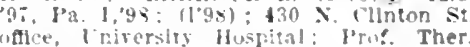

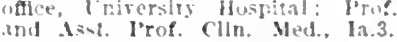

cilland, lonsce H.-la t."17; not in prac tlee: !ht lowa ire.

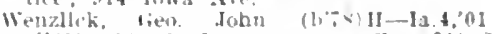

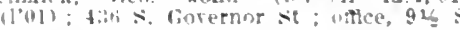
liulumare st.

WTITES, WM. RORT. (D'69) --13.3,95

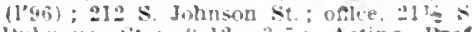

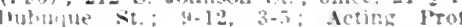
SUIH. I. I.3.

IOWA FALLS, 2.797. HARDIN

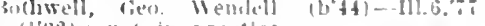

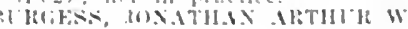
ln 3,$40 ;: 11094$

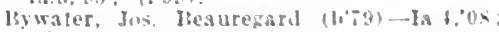

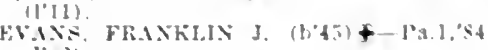
$(1, \cdots)$

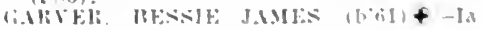

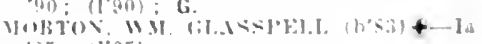
10:- $10^{\circ} 051$

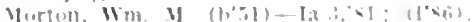

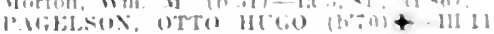
$($ inon

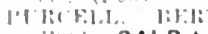

II':S) OALR.

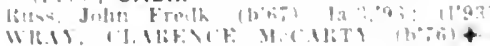

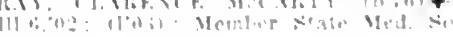

RRETON. 63I. SIOUX

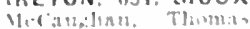

AI.1., FIRELK

IRWIN. 2Z8. SHELBY

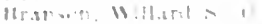

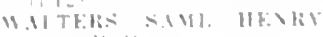

JAMAICA. 379. RIUTHRIE

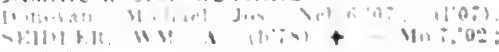


JANESVILLE, 269, BREMER

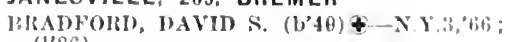
(I'S(i).

JEFFERSON, 2.477, GREENE

HAACK, JOIIX ROLAND (b'83) †-III.t, 11 ; (I'12).

BIAKE, CIJAS. WFSIFY-Ia 3,98: (1998) WEAN, FRFI MARQ. (1'67)-IH.11,82 (1'92); ОрА.

FNFIFID, CHAS $(1,43)+\ldots$ - Y, 70 . (1'87): (BI); OALR.

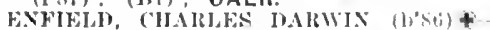
Ili.1,09: (1'10).

FRANKIIS, GEO. Wu. (1,76)+-Iato,98; (l'9s): $\mathrm{G}$.

IIMIITON, BEN.I. CIIAS. (b־9)-1a.1,'82; (I'?0)

HAMHTUN, HENJ. CHAS. JR. (b's6) III.6." 09 : (I.11).

H(1)T, LUCIUS FRANK (b'58) \&-111.4,'89; $\left(l^{2} 89\right)$.

YOUXi;, WM. M. (b'57)-Ia.1,81: (1'si).

JESUP, 697, BUCHANAN

IOYNT, MARTIN JOIIN (b'7s)\$-Ia.3,05; (l'05).

SIIMER, FRANK ELMER (b* 05: (l'05).

JEWELL, 941, HAMILTON

CIIRISTENSEN, CIIRISTEY JINSEN (b' 64 ) \&-Ia.3,'02; (1'02).

Slater, Ernest W. (b'7)-Ill.6,06; (1'06).

JOICE, 300, WORTH

GUTIIRIF, JAMES KUYKENDALE (b'87) क -Md.3,'12; Member W.Va. State Med. Assn.

JOLLEY, 250, CALHOUN

IAIONEY, ARTIIUR PAUI, (b'82)-Neb.6, '10: (['11).

JORDAN, 25, BOONE

Allen, Frank Hervey (b'74)-Ia.3'98; (1'98).

KALONA, 466, WASHINGTON

Klsor, Frank Hays (b'65)-Ia.3,'95; (1'95); not in practice.

STUTSMAN, ELI EDGAR $\left(b^{*} 82\right)-0.40,10$; (I'I0)

WOLFE, JOS. HERBERT (b'84) $\$-0.40,10$; (1'11).

KAMRAR, 262, HAMILTON

CLARAUGII SYLVESTER LOUIS (b'56)Ky.1,'87; (1'9I).

KANAWHA, 398, HANCOCK JUDD, ADDISON I. (b'63)-Ia.I0.'02;

Keeney, Wm. R. (b'48) -0; (l'86)

IKELLERTON, 503, RINGGOLD

Camp, Americus (b'69) $\rightarrow$; (l'86).

Harely, John M. (b'69) E- Mo.10,96; (1'02).

Owen, James Bllss (b'86)-Ky.2,10; (l'l1).

WAIKFR, CLAUDE M. (b'74) - Mo.7, '98; (1'98).

\section{KELLOGG, 610, JASPER}

Hackett, Janies Francis (b'50) H-Ia.4,89; (1'S9).

I.elsman, Bismarck-Ill.1,'90; (1'91).

YOOD, ROLLIN WEBSTER, (b'85)€-Ia.3, '10; (1'10).

KENSETT, 360, WORTH

GRAESER, HARRY BERNARD (b'75)Ill.11,'9s; (1'98).

Irelan, Henry II. (b'70)-Ia.10,'04; (l'04).

KENT, 158, UNION

IIUFF, LEOMAN DUSTIN (b'84)-Ia.6,'10 ; (l'10).

KEOKUK, 14,008, LEE

Allen, Bundy (b'87)-Mo.7,'12; (1'13); 201 N. 6th St.; oflice, 6 th and Yain Sts. $\mathbf{S}$. ARIENTROUT, CORAL RAY (b'-8) Ia.10,04; (I'04); 2008 Grand Are.; offlee, Y.M.C.A. Bldg.; S. $\star$

Bailey, Benjamin F.-H-0.7,60; (1'86); 422 Concert St.

Barr, G. Walter (b'60)-Pa.2,'84; (1'90) ; not in practice; 813 Blondeau 'st. Bertratn, Pauline' (b’75)-Ia.1,90; (l'90); $2 \times$ N. 5 th St.

BHOWX, WM. FRANK (b'83)-Pa.'05; (I'0J); 3IS N. 5th St.; $2: 30-4,7: 45-9$;

Browne, filsurn (l'69)-Ia.9,'93; (l'95) ; not in practice.
CIARK, OLIVER THADDEUS (b'82)-Ja.6, 09: (I'0:3); Blondeau St.; oftlce, $105 \mathrm{~S}$ :3r :5t.; $10-12,2-4$.

Cotfey, Lee Matthew (b'79) - Mo.2,03; (l'iu) : 700 MaIn st. ; $2-5$.

(1)IRTII(IIT, II.IRIRY LFF (b'76)-Ia.10, (1) l; (1'01); I129 Franklin St. ; ollle.e. til Maln st. : $2-4: 30 ; \mathrm{S}$.

lowees, Frank l.eroy (b'82)-Pa.9.'1I;

(l'II) ; 425 Morgan St. ; offee, $6161 / 2$ Main st. ; $10-12,2-5$.

bickson, John l', (b'63)-Ia.3,'88; (l'88) l228 Jark st.

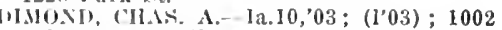
Orleans st, : offce, $13 \mathrm{~N}$. ith St.

DORSLIX, FRAXI R. $\left(b^{\prime} 58\right) \oplus$-Ia.1,'81; (I'90): Ti2 Orleans Are.; offlce, Dorsey I3!dg. : $2-5 ;$ Pd

DOREYY, TRANK BIINN, JR. (b'88) In. 3,'12; (1'12); 712 Orleans St. ; office, Dorsey Bldg.; 2-5.

Fegers, chas. Il.. Jr. (b'73)-ra.9,'95; $(1+25): 126$ s. 7 th St.

Fegers, Robt. Hubert-Ia.10,06 ; (application pendiug,'I3) ; $126 \mathrm{~S}$. Th St.

Flournoy, Stacy (col.) (b'79)-Tenn.7,06 (l'08); $1103 \frac{1 / 2}{2}$ Maln St. ; 8-11, 3-6.

FULLER, FRANK M. (b'67) †-Ia.9,'97. (l'97); 217 Iligh St.; offce, 29 N. 5 th St. ; $10-12,2-4 ; 0 \mathrm{~b}$.

Gaunt, Perry Dale (b'82) - Ill.15,'06

(l'07); 1903 Maln St. ; 10-12, 2-5; G.

Gelser, Mary L. (b'7I) - Ta.9,'95; (1'95). 1823 Johnson St. ; $\mathbf{G}$.

GILFILLAN, BRUCE LOCK (b'83)-Ia.10, '08; (l'08) ; $317 \mathrm{~N}$. 4th St.; offlce, $6211 / 2$ Maln St. ; $10-12,2-4,7-8 ; U$.

GRAY, IIENRY ARTHUR $\left(b^{\prime} 73\right) \uparrow$-Ia.I, 95 , Ia.10,'00; (l'00); 510 N. 4th St. office, 729 Main St. ; 2-5.

HALL, GUY JEROME (b'78)-Mo.7,'09 (l'11); 702 Des Moines St.

IIANSON, EDW. M. (b'68) † - Ia.9,'92; (l'96) : 716 Fulton St.; offlce, $404 \frac{16}{16}$ Main St. ; OALR. $\star$

Harter, Wm. J. (b'i4)-Ia.10,'02; (1'10); 19 th St. and Grand Ave.; offlee, 30 N. 4 th St.

HOGLE, WILLIAN MILO (b' 74$)$-Ia.10, 01 ; (1'01) ; 604 High St.; oflee, 601 Main St. $2-5: S$.

HOLMES, WILSON w. (b'68)4-Ia.9,92 ; (l'92); 829 Orleans St. ; offlce, Young Meu's Christian Association Bldg. ; 10-12, $3-5,7-8: 30$.

HOWE, LYSLE C. $\left(b^{\prime} 7 \tau\right) \oplus-I a, 10,03$; (1'03); 721 N. 14th St.; offlce, Young Mcu's Christian Assoclation Bldg.; 10-12, $2-4,7-8$.

HTGIIES, ALONZO B. (b'57)-Ia.1,97: (1'97); 1116 Timea St. ; offee, 30 N. 5tb St.; $2-5.4$ CHARLES ALBERT (b'66) $9-$ Mo.I,93; (l'00) 1102 Timea St.; office, Estes Bldg. ; $10-12,3-5$.

उENKINS, GEO F. (b'42) $9-$ Mo.1, $6 \pi$; (l'86) : 629 High St.

Kinnaman, Clarence H. (b'70)-Ia.9,'99 (1'86); not in practice; 1614 Orleans St. Kinnaman, Horace A. (b'47) - Ia.1,'82, Pa.2,84; (1'86); 629 Fulton St.; offlee $20 \mathrm{~N}$. 5 th $\mathrm{St}$.

LAPSLEY, ROBERT MCKEE (b'T0)థ-Ia.I, '90, Ill.1,'91; (l'94) ; 303 Morgan St. ; offle, Foung Men's Christian Association Bldg.; 10-12, 1 :30-4; (B1); OALR. $\star$

Narrley, fieo. Raymond (b'f8)-Mo.t,09;

(l'II); 513 Concert St. $u$

PEASE, TRANCIS W.-Io.5,'83; (l'Br); 412 Franklin St.; office, $102 \mathrm{~N}$. th St. $10-11,2-5$

RANKIX, WM. (b'7z)-Ia.10,03; (l'03) Member Ill. State Med. Soc.; 303 N. 5th St. ; offlce, $400 \frac{1}{2}$ Main St.

Roseberry, Francis M.-Ia.1,97; (1'98); 1606 Iain St.; 10-12, 2-4; G.

Sherlock, Wn. Paul-Ia.10,0s; $(1,08) ; 18$ N. 5 th st.

SMITH, FRED C. (b'74) $\$$-Ia.9,'98; (l'98); 310 Main St.: $10-12,2-4,7-8$.

Tate, Francis M. (b'30)-0.2, 57 ; (1'86) ; not in practice; $122 \mathrm{~N}$. 7 th $\mathrm{St}$.

WEDEL, JAMES R. (b'70)-Ia.1,97; (l'97) ; 1220 High St.; offlce, 17 N. 4th St.: $9-1 \overline{1}, 1: 30-3: 30,7: 30-8: 30$.
WILSEY, AIBEIRT ROSS, (b'73)-Mo.34, 02; (1'10); Member IIo. State Med. Assn. ; 5th and I'alm Sts.

MOILFNIEBEIR, ERSEST GEO (b'78)Ia.10,04; $\left(1^{\prime} 04\right) ; 613$ Fulton St. ; office Young Men's Christlan Assoclatlon Bldg. ; $2-4$.

KEOSAUQUA, 1,009, VAN BUREN

('raig, James Alexander (b'71)-Pa.2,'95: (1'96).

Russell, Charles R. (b'71)-Ia.9,'98; (1'98). IILEMAN, ELAME EMMETT (b'66)\$ Ia.1,'98; (l'93).

KEOTA, 988, KEOKUK

Dings, Samuel (b'58)-Ta.1,89; (1'89).

ROZ, ADOJI'llUS JOIN (b'75)-Ia.9,'96; (1'96).

Gray, Clara, (b'68)-Ia.1,'96 ; (l'96).

insdll, Iyman R. (b'65)-Iá.6,'94, Mlch. I0, $02 ;(1,94)$.

Mulhern, Janes Wm. (b'66)-Mo.27,'92

PERSHIXG, FRANK O. (b'67) - (l'02-Ia, I,93; (l'93) : Member Inl. State Med. Soc.

Rlchardson, Jonathan F. (b'36)-Ta.I,'64; (l'86); not in practlce.

Trumbauer, Chas. A. (b'70)-1a.9, 97 . (1'97).

KESWICK, 32I, KEOKUK

Harlan, Chas. Davis (b'79)-Ia.3,01: (1'01)

NEGUS, ALVAH (b'65) (-Ia.3,'06; (l'06).

EGUS, CORA WEBER (b'67)థ-1a.3,06 ; (1'06)

KEYSTONE, 412, BENTON

DUNSIIEE, JAY DEE (b'82) (-Ia.3,'08; (l'08).

KIMBALLTON, 27!, AUDUBON

SOE, PEDER (b'61)-Ill.10,'93; (1'93).

KINGSLEY, 977, PLYMOUTH

CODY, WM. ELLSWORTH (b'88) \$-Ia.3 '11; (l'11) ; $\mathbf{S}$.

IECHTY, EŔREST JOHN (b'79)-Ia.6,05; (l'05).

Walcutt, James R. (b'55)-Ky.5,'83; (1'86)

Wendel, Benj. F. (b'77)-Ia.8, $06 ;\left(1{ }^{\prime} 06\right)$.

KINGSTON, 50, DES MOINES

NEWBERRY, ARTHUR D. (b'67)-Ia.1,98; (l'98).

KINROSS, 142, KEOKUK

CASHMAN, CHESTER FLOYD (b'81)\$Ia.6,'08; (l'08).

KIRKMAN, I80, SHELBY

SABIN, ALBERT EDW. (b'74) -Ind. 8,97 , Ill. 1,$99 ; \quad\left(l^{\prime} 00\right)$

KIRKVILLE, 299, WAPELLO

Abegg, Wm.-Ia.3,'85; (l'86)

KEPLER, JOHN C. (b;7)-Ia.1 0,05 ; (l'05); G.

MlcCune, James Harold-nl.1,74; (1'87).

KIRON, 207, CRAWFORD

Garner, Wm. A. (b'78)-Ill.4, 05; (1'05).

KLEMME, 306, HANCOCK

IISSMAN, WALTER FRANK (b'80)-Ia.3 08; (1'08).

Zinn, Geo. (b'65) P-M-Ind.5,'97; (1'98).

KNIERIM, 220, CALHOUN

KENNEDY, WM. CLARENCE (b'86) \$-Ia.3 $12 ;\left(l^{\prime} 12\right) ; 0 p$.

KNOWLTON, 190, RINGGOLD

WATSON, ELBERT J. (b'7T) $9-M O .22,04$; (1'04)

\section{KNOXVILLE, 3,190, MARION}

ALDRICH, LINUS IRA (b'67) $\oplus$-Ia.3,' 88 $\left(l^{\prime} 88\right)$; not in practice; Member Minm. State Med. Assn.

ANIES, EDW. RICHARD (b'70)-Ill.4,'96 ; (1'96) ; OALR.

BAILEY, IDA IIOLSON (b'61)-Ia.4,'98; (1'98); G. (l'86), JOHN TINSON (b'53) $4-0.1,81$ CARY, LEE WINFIELD (b'84) (- HIl.11, '10; (1'12).

CORNELL, CORWIN SHAFFNER (b'86)Ill.1,13; (l'13).

CORNELL, CORWIN W. (b'49)థ-Ill. , ‘1: (l'86)

DOхоноE, GEORGE (b'75)†-Mass.1,98; (I'06); (El3).

FINARTY, JOS. W. (b'47)@-Ia.1,'7; IARRINGTON, CHAS. M. (b'72) $9-I 11.10$, $99 ;(1 ' 99) ; G$. 
Mllser, Geo. Wm. (b'72) H-lll.10.9'; (1'99) MULKY. CAllL (b'7) \&-lll.10,99, III.1. 100: (1'99).

TRMMER FRANK MHLFll (b's6)-lll.6 09: (1'09); Member III. State Med. Soc. whISS, JoH's M. (b'79)-111.1.03; (1'04) WRIGHT, JOHX RORT, (b'si)-KJ:"13 (I'13)

KOSZTA, I00, IOWA

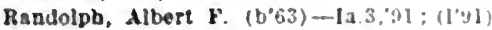

LACEY, 50, MAHASKA

Rartlett, Geo, Eilton (b's3)-Ill.1,0s; (l'0y)

LACONA, 517. WARREN

cruzen, John Lewls (b'-5)-Ill.4.'9.t: (l'00) HATFIELD, GEO. EBFR (b'68)-IIl. (I'98)

LA CREW (R.F.D. WESTPOINT), HO, LEE Wittlch, Cora (b'6i)-Ia.9,97: (1.97)

LADORA, 260, IOWA

A LtiUSTINE, JASI'ER L. (b'68) -1a.3,93 (1'93) : $\mathbf{S}$.

LAKE CITY, 2.043. CALHOUN

Chamberlin, Asa W.-Ky.t,76; (187),

llull. John F. (b'75)-1a.3,98: (1'98)

kautman, Frank E. (b'63)11-Iat,9: $(1 \circ 9)$.

McCRARY, DELBFRT W', (b'68)--Ia.3, (1'93).

ScYay. Melrin Joslah (b'83)-111.s, I2 (1'13) Morgan, Cbas. Henry (b'79)-la.3,01
(l01).

Pray, Glibert L. (b'75)-la.j.'97; 11'97)

LAKE MILLS, I.214, WINNEBAGO

loalager, Norman o. (b'; 3$)-111.11,0:$ (1.02).

Helgeson, Peter A. (b'69)-Ia.1,91; (1'91) Herm, Gilbert Gullickson (b'69)-ill.4, 04 (1'04).

KAASA, LAWRENCE JELS $\left(b^{\prime} 30\right) \$-1 a .3$ '10: $(1$ '10).

LAKE PARK, 552, DICKINSON

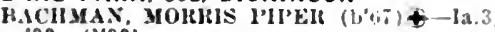
00 ; $(1,00)$.

HIHLOCK, WM. E. (b'1)-Ia.3,01; (1'01)

LAKE VIEW, 514, SAC

Speaker, Everelt Flmer (b';6) H-Ia.4,9; (1'97).

LAMONI. 1.541, DECATUR

GREER, BERTIIA ALLEN (b'55) -Y 97: (1'97).

IILLS, HENR' MONROE (ด'ว2)-III.1,00 $\left(\mathrm{l}^{2} 00\right)$.

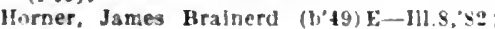

(1's7): ObG.

LAMONT, 57I, BUCHANAN

'iarker, Wm. Isaac (b'64) H--111.4.'91; (l'91)

LAMOTTE, 288, JACKSON

Henneger, Wm. Andrew (b'si)-Ia.3,"0s (1'08)

Stueller, John C, (b'65)-Mn., , igy: (1'001

LANESBORO, 268, CARROLL

HAKT, WH. EIW. (b'0)-III.11,03; (1'03)

LANSING, I,542, ALLAMAKEE

bavls, John iv. (b.37)-D.C.2, 60 ; $\left(I^{\prime} \$ 6\right)$

l.ytle, Carl C. (b'79)-1a.6,03: (1'03)

SAAS, JOIIN GLSTAV (b'81) III 1,0, (l') 3 )

THOHNTON, JOHS HENHY (b'4t) III.1, 79: $(1.86)$.

\section{LAPORTE CITY, 1.233. BLACKHAWK}

Alt. Roy Culnay (b'86)-1'a.2,13; (1'1:").

Cascaden, John Harold $\left(\mathrm{b}^{\prime}\right.$ i8) - Ont.3, 04 (1'06).

spley Clarence Oscar (b'\$2)-111.11,"I0

(I'II) $; \mathbf{s}$.

plelus, frobi. B. (b'74)-111.1,03: (1'04

Pivber, Geo. W. $\left.\left(b^{\prime} 34\right)-111,10, \because 7 ;(1)^{\prime}\right)$

LARCHWOOD, 434, LYON

IMLTSCLAW, ZACHAKY TAYl,OH (b'1:)

- Ia.3,81: (1'86)

LARRABEE, 158, CHEROKEE

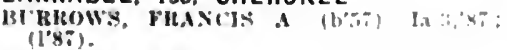

LATIMER, 378, FRANKLIN

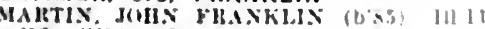
12: (1'12): OD.

LAUREL, 179, MARSHALL

ATTON, CHARIEX WIIHC:

|a. 3,10: 1110$)$
LAURENS, 817, POCAHONTAS

Carroll, Jos. M. (b'49)-Ia.3,79: $\left(1^{\prime} 86\right)$

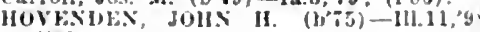
$(1,98)$.

NILSSOX, Fl!FDK, COITXELILS (b'83) 111.6, $0 y^{\circ} ;$ (1'11)

Tlee, Claude Haber (b'80)-Ill.4'12; (1'12)

LAWLER, 601, CHICKASAW

MCKINIFY AIEXANDEH W (b'iti)

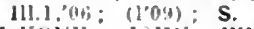

MckoNk, JOHN WM. (b:3)-1a.3,"40: $\left(1^{6} 97\right)$.

LAWTON, 138, WOODBURY

lelpard, Bennet A. (b'81)-la.8, 08 (1'05).

LE CLAIRE, 690, SCOTT

JOHNSON, CECH, CORWIS (b'Ti) \&-IIIII, $01: 11$ : $(12)$

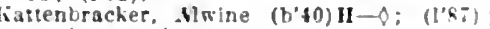
not In practice.

SKINNER, FREDERTCK CENII (b'73) la.4,9s: (1'04): G.

LEDYARD. 222. KOSSUTH

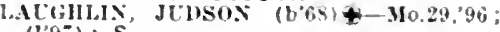
(1'9i): $\mathrm{S}$

LEEDS, - WOODBURY (Nee Sloux cliy.

LEGRAND. 338, MARSHALL

Erans, Mark M. (b':')-111.1,99; (l'99).

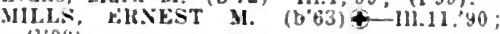
(1.00)

LEHIGH, 928, WEBSTER

Fivans, Chas. I'. (b'63)E-111.8,91; (l'91)

(ilBsux, Gro. G. (b'73) \&-la.6, $4 \mathrm{~s}^{\prime}$; (l'gs)

Jones, James D. (b'67)-Mo.25, 96 ; (1'y6)

heallng. Wm. W: $\left(b^{\prime} 7 t\right)-I 11, t^{2}, 04:(168)$

I'aul, Geo. (b't $\rightarrow) \rightarrow$ : (l’90)

LEIGHTON, 200, MAHASKA

YBE.V(IA, JACOH JOHX (b'8i) \&-111.6 11; (1'I2).

LEMARS, 4,157. PLYMOUTH

BELLAIRE, ROY FBANK (b'\$4) \&-Mo.34,

CLAKKL, FLOYD SWEETLAND (b'75) I'a.11,00: (1'02).

Cole, Thomas Edw.-H1l.11,'90; (1'92)

FETTES, JANES M. (b'79)-Ont.3,04:

MAMMEX, G. HEXRT (b'72)\&-111.1,94: $\left(l^{\prime} 94\right) ; 5$.

Mosher, Arthur H. (b'59)-111.1,'S2: (]'S6)

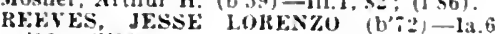
96 ; (1'96)

Kichey, Mllton w: (1,53)-Ky.1,76; (1's6)

SIIEIAKI, WM. T. (b'65)-111.4, $85 ;\left(l^{\prime} 86\right)$

Wlld. l'eter K. (b's0)H-1a.t,03; (1' 133$)$.

LENOX, 1,274, TAYLOR

BE.NETT, THEOPHILUS W. (b'53)-la.1 "7; (1'S2)

ALPWELL. JAY S. (b's1)-Mo.22.04; (1'10): OALR.

Cash, Wim. Jenry (b'72)-[11.11.06; (1,06) Hamilton, Simion Mllo (b7i)-ia li), 02 (I'0)

ACHOGGS. JAMES PAXTOX (b:50) \&-Mo.2 Q2: (l's6).

LEON. 1.991, DECATUR

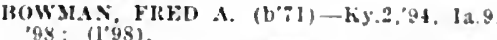

BERT L. (b'il)+-I11.1,'96: (1'96)

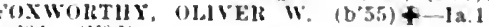

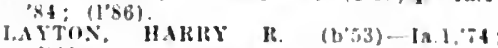
I'T'ULEL, CI.ARE H. (h'3:)-111.6.07 (1'0)

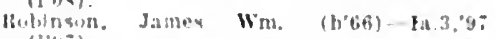

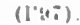

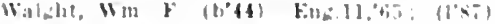

LE ROY, 185, DECATUR

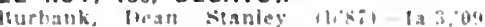
(1.0.)

LESTER, 24A, LYON

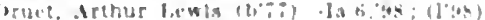

LETTS, +33. LOUISA

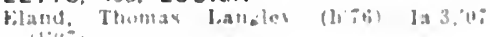
IIU:

LEWIS, 603, CASS

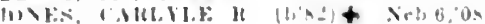

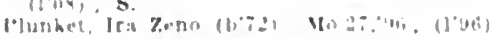

LIBEHTY CENTER, 80, WARREN

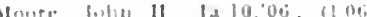

LIBERTYVILLE, 300 , JEFFERSON

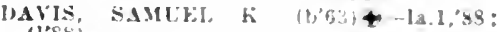

STEIHE

(l's(b).

LIME SPRING, 498, HOWARD

IIISAIVA (IIS. BIIL"

(I'13)

'LIMMER,

LINDEN, 315. DALLAS

PESNINGTOS, ORVHILE J \&-1a6,06: (l'0t)

LINEVILLE, 600, WAYNE

LINEVILLE, 600, WAYNE

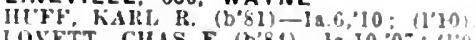

l.OVETT, CHAS. E. (b'8t)-1a.10,0z: (10i)

l.trett. Isac 31. (b'69)-Ia.?.91; (10yl).

Nye, $B, 1$ - Mo.22,00; (1's:;).

LINN GROVE, 500, BUENA VISTA

Van Ness, Chas. S. (b'it)-0at:ot (1'0i).

LISBON, 846, LINN

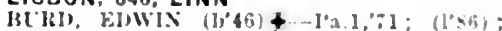
0 p.

GARDNER, JOIIN R. (b'75) -Ia.3.99: (l'95).

L.ee, James A. (b'49)-Ia.3."-3; (1'S6)

YORK, NATHAN ALBERT (b'66) +18.3 00 : $\left(1^{*} 98\right)$

LISCOMB. 354, MARSHALL

Marl)le, learl leonidas (b'72)11-Ia.4, 49 'a.8, 06 ; (1'99).

LITTLEPORT, I66, CLAYTON

Hrown, James C. (b'i3)-Ill 22,11 : (1'12

LITTLE ROCK, 47I, LYON

RALEIGH, ROSWELL R. (b'65)-Mina 5 '94: (1'94).

SMITI, FERDINAND JAMFS ENDRES (b'62) $+-1 \mathrm{a} .3$, , $^{\prime}$; $\left(\mathrm{l}^{\prime} 87\right)$ : (15).

LITTLE SIOUX, 390, HARRISON

Bock, John Jay (b'7)-111.11,06; (1'06).

(cutler, Roy H. (b'st)II-Mo.5, 0 S; (1'0s).

LIVERMORE, 578, HUMBOLDT

BOWE.S, JoH. J. (b, 6$)^{\prime}-1 \mathrm{a}, 6,00 ;\left(1^{\prime} 00\right)$

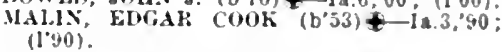

LOCKRIDGE, I50, JEFFERSON

SHERLOCK, I'ETER JACKSON (b'S4) Ia.3,'10; (1'10).

LOGAN, 1,453, HARRISON

IIANSES, HAXS (b'is); Neb.6, 05 : (l'05)

KENNEDY. CILARLES S. (b'68) - Neb.6,02:

STHARXS ROBT. JAMES (b'85)-Neb.5. 10 ; (1'11)

WILJIAMS, D.tVIn (b'66) - Neb.5,?4: $(1+25)$.
woon.

(l'\$6).

LOHRVILLE, 674, CALHOUN

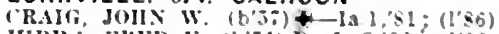

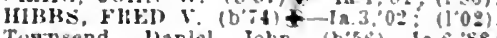

Tuknsend, Naniel John (b'5t)-ia.6, 85 (l'87).

LONE TREE, 782, JOHNSON

IAY GEO. I.EWIS $\left(\mathrm{B}^{\circ}: 0\right)+$ IA 3.25

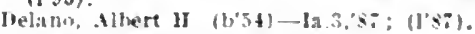

LONG GROVE, 225. SCOTT

Nawell, lien. Bancros: (b'64)-Ill.1.'s3: (IST)

LORIMER, 643, UNION

IYIES. KIDW ( ) (b'G6) \& Ia.3.'94: (1'94)

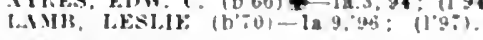

LOST NATION, 523, CLINTON

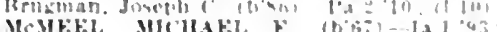
(1'y3).

LOVILIA. 552. MONROE

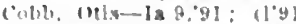

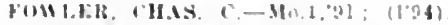

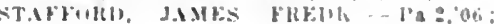

LOWDEN. S84. CEDAR

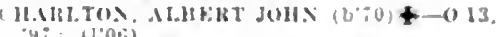

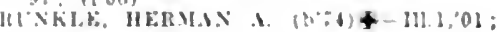
(101).

LOWELL. 125, MENRY

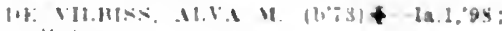


LOW MOOR, 253, CLINTON

loungs, Daniel lewis (b'65)-1a.6,95; (l'95).

LUCAS, 666, LUCAS

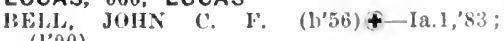

("rosion, Thos. $\left(1 j^{\prime}+6\right) \mathrm{F}-0$; (l'sij).

LUTHER, I30, BOONE

Cooper, Thaldeus Constantine (b'r9)-Ill.6,

'I'? (1'12).

LUVERNE, 501, KOSSUTH

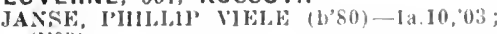
$\left(l^{\prime} 03\right)$.

spooner, Alexander 1. (b'(i) In.9.'92 :192).

LUZERNE, 160, BENTON

Krum. Francls litherney (b'65)-Ma.9, 08 (1'I1).

LYNNVILLE, 370, JASPER

Quire, Austln Flint (1,'-2)-Ia.10,01; (l'01) quire, Frank Edw. (b'68)-Ill.1,9\%; (1'92) LYONS, 5.799, CLINTON

$$
\text { (See Clinton.) }
$$

LYTTON, 200, SAC

Blalr, Fred Leroy (b'79)-Ia.3,05; (l'05).

MACEDONIA, 357, POTTAWATTAMIE

BFSORE, WALTER NCKAY (b'74)-Ia.3, '9s; (l'9s).

Borghim, Francis I. (b'79)-Neb.6,0\%; (1'03)

Stempel, finde L. (1035)-D; (l's6) .

MACKSBURG, 197, MADISON

Coltrane, Marion B. (b'85) $\rightarrow$; (l'si)

Wallace, Chas. M. (h'71)-Mo.22,08; (l'08)

MADRID, 1,191, BOONE

Brown, Ernest ( $\quad$ (b'67) II-Mich.5,'93 (1.93)

EARWOOD, FI)(YAR (h's)-Ia.6,'l2; (l'12) Farr, Herman s. (b’53)-1a.3, 81 ; (1'86).

Farr, Herman

Rogers, Arthur II. (b69)-Ta.3,95; (1995). $04 ;(1,04)$

Sturgéon. Quincy A.-Ky.1,83; (1'86).

MAGNOLIA, 3I1. HARRISON

Cutler, charles kdward (b'5I) II-0.13,78

HANSox, FRANK II. (b' 66$)-N e b .5,02$; (1'02).

MALCOM, 377, POWESHIEK

WILCOX, DELANO (b':2)-Ill.1,99; (]'99)

WIl.COX, VINTON s. (b'48)-Ia.3, 44 (1'86).

MALLARD, 331, PALO ALTO

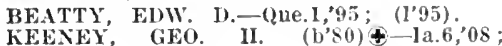
(l'08).

MALOY, 127, RINGGOLD

King. Thomas Wayne (b'81) -Mo.22,'05 $\left(1^{\prime} 0 \pi\right)$.

\section{MALVERN, I,I54, MILLS}

CAMPBFLL, SAMUEL A. (b'50)£-Ia.3 $75: \quad\left(l^{\prime} S 6\right)$.

Cunníngham, Michael A. (b'89)-Neb.6,'13;

PARSONS, IRYING USHER (b'66)

N.Y.10,93: (l'94).
RUSH, WEAVER ALIUS (b'82)థ-Neb.5,

USII, WEA

SCOT'T, JAMES R. (b'59)-Ill.4,'85; (1'86).

MANCHESTER, 2,758, DELAWARE

BRADLEY, HARRY MERIRT'T (1.69) I.1.1,94; (1.02)

BURXS, THOMLS JOHN (b'78)-Ia.3,'03; (l'03)'

lijers. Bert H. (b'75)-Ia.6,'11; (1'11).

DITTIER, ERNEST G. (b'69)'-111.10,'95 (I'95).

Dittmer, Henry Aaron (b’38-Ill.4,84; (l'86).

JINUSAY, JOHX JACOB (b’5)-N.Y.IO '83: $(1966) ; 0 p A$.

May, John A. (b'64) H-Hll.10,90; (1'92)

Terril, Aaron B. (b'43)-Ia.3,'81; not in practice.

MANILLA, 875, CRAWFORD

Trable Walter E. (b'80)-Ia.8,04; (l'04). Jalus B. (b'55)-Ia.3'82; (l'86). nivell Sidney (b'86)-Jio.34,'12;

firallam, Jumes Harlow (b’53)-Ia.10,01;
MANLY, 346, WORTH

lBoody, Frank Dwlght (b'66)-Ill.6,'90: VETI i, SOREN S. (b'81) $\oplus$-Ia.s, 09 (1'09).

MANNING, 1,434, CARROLL

CARLII, AMOS WALTER (b'79) $\uparrow-N$ Neb.5 $02 ;\left(1^{\prime} 03\right)$.

(b'49)-Aus.7,73: (1'86)

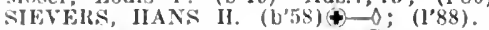

WIJLIAMS, ROR'T. R. (b'49) †-111.1,76 ;

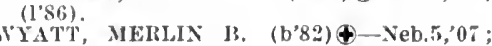
(l'0s); R.

WYATT, ORRIN WM. (b'80) $\uparrow$-Neb.5,09; (1'10)

MANSON, 1,236, CALHOUN

Freeherger, Sarah Myrtle-Ia.4,97; (l'97).

MLILAHKi, IIUtiI .I. (b'65)屯-Ia.3,'89 (l's!').

SIDAKLI, WM. T. (b'51) \$-Ill.6,78; (I'sT).

Yolum, IIenry (b'43)-Ill.6,72; (l'86).

MAPLETON, 1,100. MONONA

GILINSIIE, MAMILTON S. (b'75) 4 Neb.5,9s; (1'38).

IIANSEN, NELSON I. (b'75)-Ia.8,03: (1'03).

Itequillen, Chas. Walsh (b'86)-Ia.3,'13: (I'13).

Waterlouse, Geo. S. (b'70)-Ia.3,95; (1'95)

Wheel'r, Nellie May (b'67)-Ia.8, 0 i (1'07).

MAQUOKETA, 3,570 , JACKSON

Avery, Alonzo Mollt-Mlass. 1,'77; (1'87) ;

BOPO, LACY KINDRED (b'61)-Ky.2,'89; (1'85).

BOWEN ASA B. (b'42) $\downarrow-$ N.Y.3,'68 (l'86).

BOWEX, JESSE C. (b'81)-Il1.11,06; (1'06) Carson, James A. (b'44)-Ill.4,'81; (1'86); not in practice.

CARSON, LOC1S B. (b'73)-Ill.4,92; (1'94) IOIINSOX, FIRANK F. (b'70)-111.8,97: (l'97); $0 \mathrm{p}$.

L.OOSE, DAVID N. (b'55)థ-Pa.I,'7 ; (l'so

LOWIVI, ROSA ELLEN (b'67)-Ind.8,'94; (1'y4).

LOWWER, WM. (b'65)-Ind.8,'94; (1'94);

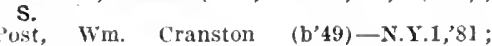
(L'95).

RIGGS, LINDES LaRELA (b'68)\$-Ia.I0, 04,1 'a.2,05; (1'04)

RISTINE, JAMES OSCAR (b'66)-Ia.3,96 ; (l'96).

Ritter, Joln Franklin (b'69)-Mich.1,'95; (1'95).

MARATHON, 532, BUENA VISTA

DELAHUNT, JOS. (b'60)థ- Ont.I,'80; (l'92).

Gallagher, Pierce (b'53)-Ia.6,'86; ( ('86).

Kelley, Thos. J. (b'68)-Ill.1,'01; (l’98).

MARBLE ROCK, 480, FLOYD

Haynes, Eli B. (b'2T) E- (l'86).

O'KEEFE, CHARLES J. '(b'73) \&-Ia.6,'95; (1'95).

W'ilson, Carrel A. (b'7 7$)$-Ia.10,01; (l'01).

MARCUS, 896, CHEROKEE

Joynt, Michael Francis (b'83) -Ia.3,'l0 ; (1'10)

Kllox, Thomas 'Clifford (b.84)-Ia.3,'08; (l’08).

Loomis, Frank E. (b'60)-Ill.1,'9l; (l'yl).

MARENGO, 1,786, IOWA

BIOWN, ERIE N. (b'63) - - Ia.3,'88; (1'90).

CIROW, IRA NEISON (b'81) \-Ia.3, '08; (1'08).

Edds, Wm. II. (b'39) H-0.7,65; (l'87) ; not in practice.

ribson, Altert E. (b’tiI)-0nt.5,'si ; (l'si) HENDERSON, EDRAR BRENTON (b'72) Ia.3,04; (1'04).

MARION, 4,400, LINN

CARHART, WAI. GARRETSON (b'T4)Mich.1,04; (l'0 $)$

Christie, Orvil Burl-Ia.3,'91 ; (l'91)

Christie, Orvil Burl-Ia.3,'9l; (l'91).
CREW, ARTHLR E. (b'75) $4-1 a .4,02$; (1'02)

Hindman, David R. (b'32) H-Pa.6,'5i ; (l'86).
Ia Grange, John Wesley (b'49)-111.1,'77;

Woorliead, James (1'50) II-Ia.4,93; (1'93). MUIRHEAD, GEO. SAFLEY (b'68)-Ia.4 $91 ;\left(1^{\prime} 91\right)$

Naftzlger, Armand-Ill.17,'04; (1'05).

SIINNEI, FRANK S. (b'72)४-Ill.1,'97; (1'97).

MARNE, 266, CASS

THO.HI'SON, CLAUDE E. (b'86)-Ia.6,'08; (l'08).

MARSHALLTOWN, 13.374, MARSHALL

Angelsberg, Anton (b'54) II- 0 ; (1'87); 110 N. 3d Ave. ; 8-12, 1-8.

Battin, Iames Franklin (b'69)-Ia.4,97 ; $\left(l^{\prime} 97\right)$; 109 S. 9 th St.; office, 35 W. Main Si. ; $8-12,2-4$.

BOUCHER, FRANCIS HENIY $\left(b^{\prime} 55\right) 4$ Pa.2,75; (1'86); 208 S. 3d Ave, ; 8-9 11-12, 3-6, $7-8 ;$ LR.

Brady, Thos. C. '(b'72) $\rightarrow$; (1'87)

CHESIRE, MATTHEW U. $\left(b^{\prime} 70\right) \oplus-I l l 1$, 97 ; (1'97); Masonlc Temple; 10-11, $\mathrm{I}-3: 30 ;$
$\mathrm{HOATE}$

CHOATE, CORA WILLIAMS $\left(b^{\prime}, 2\right) \oplus-111.9$ "96; (l'06) ; 808 W. Maln St.; offlce, 102 E. Jain St.; $9-12,1-4 ;$ G.ћ

COBB, EDWIN (b'85)-1a.3,'I1; (1'11) 6 N. 5 th St. ; offlce, Masonlc Temple;

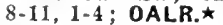

CONAWAY, AARON C.๑-Ill.1,00; (l'06); 30 F. Maln St.

CONAWAY, ALPHEUS BARTS $\left(b^{\prime} 49\right) \oplus$ $0.2,75 ;\left(1^{\prime} 87\right) ; 30$ E. Main St.; $9-11$,

Davil, Wilbur F. (b'60) II-Ill.4, 81 ; (1'86) ; 4, 2d St.; office, Fremont Block.

DFVINE, WINFIELi) S. (b'54) $\uparrow-$ Ia.3,'87. (1'87) ; 312 N. 1st St.; offlce, 8 E. Maln St. ; 9-12, 2-5.

DUFFIELD, ILAMLTON PRICE (b'45) Ill.1,70; (l'86); Soldiers' Home; 8-12.

FRENCH, ROYAL F. (b'83)-1a.3,'09; (l'09); 1001 W. State St. ; offlce, Masonlc Temple ; 9-12, 1-4; (B1); OALR. ^

Gillette, Ellzabeth 'Speers (b'52) H-Ill.4. '89; (1'39); 306 E. Main St.; 10-12, 2-4,

HANSEN, ROBT. R. (b'83)-HI.I1,07 (l'09); 418 Park St.; offle, Masonic Tem-

HANSON, PAULINE MYERS TOWNSENDE -Pa.7,95; (1'95); $205 \mathrm{~S}$. Center St.

HARRIS, GEO. WASHINGTON (b'53) Ill.1,86; (l'87) ; 31 W. State St.; 11-12,

Harris, Grove Walton (b'81)-Mo.34,'94; (l'05).

Ilermance, George Earl (b'88)-Ia.3,'12; (l'12) ; 206 W. Church St.; office, $30 \mathrm{~N}$. Main St. ; $10-12,3-5,7-8 ; \mathbf{S}$.

JOIINSON, GEO. MONROE $\left(b^{\prime} 75\right) \oplus-I l l .1$, '0I; (l'0I); 409 N. 4th St.; offlee, Masonic Temple; $2-4,7-8$.

KEYSER, RALPH EMMERT (b'81) Ill.6, 06 ; (l'11) ; 212 E. State St. ; office, Masonic Temple; 1-5, 7-8.

KIBBY, WM. BECKFORD - Mass.1, 82 ; (l'88).

Lamb, Enoch (b'36) - Ind.4,70; 406 W. Church St.

LEFFLER, EDW. G. (b'59)๑-Ia.6,'86 ; $\left(l^{\prime} 86\right)$; 31 W. Main St.

'94; $(1,94) ; 307$ Park St.; offee, Masonlc
IIERLE Temple; $9-12,1: 30-5$; OALR.

LYNN, ARTHUR RAY (b'83)-Ia.3,05; (l'05) ; 408 N. $3 \mathrm{~d}$ St.; office, $132 \mathrm{~W}$. Maln St.

MERRILL, NELSON (b'63)థ-Ia.3,93 * (1'93) ; 305 W. Main St.; offlce, Masonic Block; 11-12, 2-4, $7-8$.

Mighell, Norman E. (b'62)-Ill.1,'84; (1'87) ; $708 \mathrm{~W}$. Church St. ; office, Tremont Bldg. ; $11-12,3-5$.

Newell, Harris Andrew (b'79)-Ill.6,09 ; (l'10); Jowa soldiers' Home Hospital. NICHOLS, HENRY H. (b'68)-Pa.2,96 ; (1'96); $114 \mathrm{~N}$. Center St.; offlce, 2 E' II ain St.; $2-4,7-8$.

Parne, Wm. C.-0.6,53; (1'86).

Pence, Lawrence Waldo (b'75)-Ia.3,98; (l’98); 522 N. 3d St.; oflce, Tremont Bldg.

Reed, Benj. Hopkins (b'70)-Mo.10,'03; (l'il); 401 E. Main st. 
SINGLETON, ELSTACF: W. (btit) +111.6 91: (1'92); 104 S. th SL; ottce, 111 k. Ciurch St: (H1); OALR.

TIdd, Charles II. $\left(b^{\prime} t^{\circ}\right) \rightarrow 0.1, \because 3 ; \quad\left(1,8 b^{\circ}\right)$ 309 ‥ 4th st; odee, IF W. Maln st. $10-12,2-5, \div-9$

WOOD, PERCY R. (b'62)+-Mich. I (1'93); 9 Maln St.; 9-12, 2-4; OALR.*

MARTELLE, 178, JONES

WHISLAXD. JOHX (ito. (b'66)-Mo.24 "92; (1.92).

MARTINSBURG, 285, KEOITUK

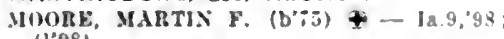
(1'98).

QUIXX. EDWAIDD (b'56i) \& Ill.1, 63 ; (l'ati)

MASON CITY, 11,230, CERRO GORDO

I3lmey, Clarlus Contuclus-111.1,'it; (1'so) : not in practice.

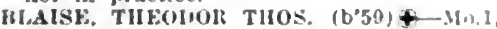
'87; (1'si) : 119 X. Superlor Aie. : ompe. Flrst Yatlonal bauk IIdg.; $9-12,-5$ FoA.

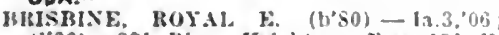
$\left(1^{\circ} 06\right) ; 331$ Rlver Ifelghis: odice, $13 i$ i State St, : $10-12,1: 30-5,:-9: G$.

cillLSON, FRANK G. (b'80)+-111.6,03 (1"03).

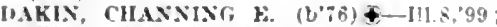
(1'00): $610 \mathrm{~N}$. Washlugtot st. oflce, 1092 s. Maln st.: 10-12, 2-5; S.

ItKANT, WJ. J. (b'69) \& - Mleh 1,02

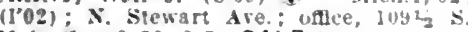
Maln st: $9-12,2-5 ;$ OALR.

ECHTERNACHT, ALTHLR CHAS. (b) Ia. 3,05; (l'05); Member state Med. sou

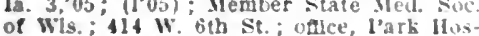
of Whis: $41+$ W. 6ith

FGLOFF, WM. JACOL $\left(b^{\circ} 63\right)+-111.4,36$

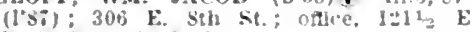
State St.; $10.12,3.5$.

FAKIELJ, VINCF.NT A (b'OC)-H1, 01

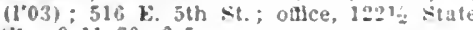
st. $9+11: 30,2=5$.

FITZIDTKICK MATHEW JOS (b's5) 111.6,09; (1'11); 12.2 W. sth st.; onlee l'ark Ilospltal; 9-12, 1-3.

HOAG; HALBY MARTIN (b'0)-I'a.2,'yt (1'96): 948 s. Suverlor si ; oftree, First Satlonal Hank Blde.; 9-1, 2-j: D.

Holman, Henry D. (b,, 6$)$ II - Ia $f_{,}^{\prime} 0 z$ (I'03)

HUBBARD, CIESTER W: (1, $\left.f_{6}\right)-I 11.11$ 01: (1'0i); 801 N. Main st.; oftce, First National Bank Holg.; 9-12, 2-5.

1.0.6. WM. k.16Ekst (b'1) - I11.11,99 (l'ys) : l'art Hosplial.

MAKSTOX, CHAS. JEALEL (b\%0)-II1.1 93; (1'93); $\div$. Stewart Are ; oflce, Kirst Nathonal Bank l3ldz.; $9-10,3-5$.

Mason, Stella May (b'61)-I11.4,93; (1"93) Mason Hank bldr.

MelOONALD, JAMF' ro. (b'67)-1a.9,93 (1'33); 315 x. Mlchlgan Ase ; unce, 2216 F. Silate si: 1-4; Pd.

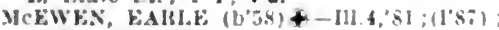
$316 \mathrm{X}$. Wasbington Are, ; uflce, lith s Jaln it. : $10-11: 30,2.4$

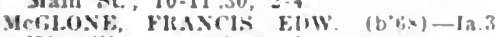
95: (1'95); jo1 $\mathrm{x}$. Washlanton si.; uffec Century lilock; $10-12,2-4 ; 5$.

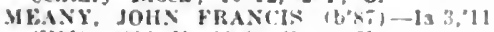
(1'11): 604 $x$, Maln , it.: onlce, century

MCRIHY, Fis (I'01): $115 \$$. Maln si: ahlece, ['ark IIom vllal; 10.t; (BI): OALR.

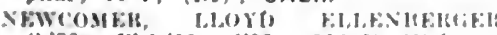

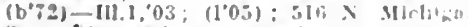
St.: once, Gth and Washtuktrom Kits.

vicola, IR.I I. (b'bI)-la.l, ob; (l'vej); 31 S. Adams st

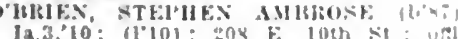

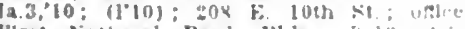
OALR.

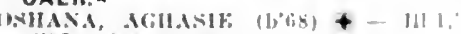

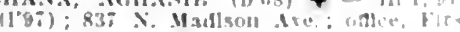
Satlonal liank lbldz: 9.12

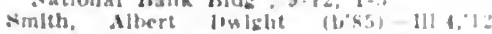

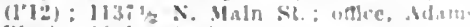
lllock: $10.11 \% 30$ i 30 -

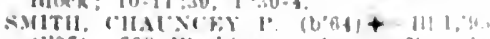
(19i) : ios Wawhlngton d Main

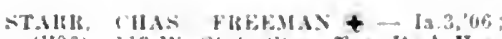
$\left(1{ }^{\prime} 06\right)$; $113 \mathrm{~W}$. State st.; oqlce, rark llospltal.

STEIRS: WILLIS L. (b): 1$)-111.1,94$

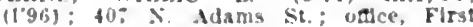
Natlonal liank loldg.

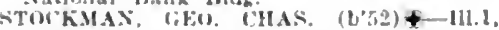

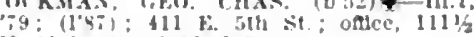
N. 31 aln $21 ; 9-12,1-5$

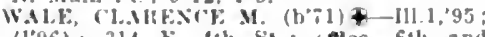
$\left(1^{\circ} 96\right) ; 314$ k. th Sit.; attce, $6 \mathrm{th}_{\mathrm{s}}$ and Washlugton Sty.; also l'ark Hospltal; $10-12,2-6$.

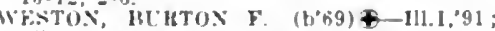
(1'91); $810 \mathrm{X}$. Adams st.; odce. Flrst National Ibank lthlg.; 10-12, 2-5.

wheeler, Arthur LeŔoy (b'51)-I11.1,"5 (1'86): pot in practlce; 214 Adams Are.

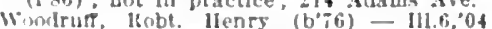
(1'11); 5011/ $x$. Main St.

MASONVILLE, 282, DELAWARE

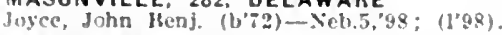

MASSENA, 490. CASS

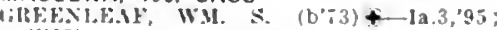
$(1 \cdot 05)$

"FXUITTE, HARRI IIAEI.TON (b'86)1a.6,"09; (1'09)

MAURICE, 290, SIOUX

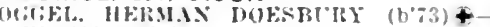
III.1, $00:(100)$

MAXWELL, 754, STORY

Hatcher, (has. F. (b"i) F-1a.6.'8s: (1'ss)

lefrey. John A. $\left(b^{\prime} \$ 1\right)-1 \mathrm{~d},,^{\prime}, 81 ;\left(1^{\prime} 86\right)$

$100 R$, J'ETER (b'5s) + Ia.3, R1; (1's')

Trotter. Wm. M. (t's1)-Mo.34, 06 ; (1'11)

MAYNARD, 382, FAYETTE

liaker, John F.lmer (b'sf)-1a.3, '08; (1'08)

MCCALLSBURG, 309, STORY

Mills, llanl. Guy (b'bi)-Ia.3,96; (1'96)

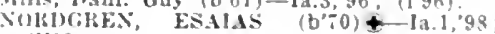
(I'9s).

MCCAUSLAND, 106, SCOTT

Ityerly, Andrew J. (b'b'1)-Ja.3,'s: : (1'se) not in practlce.

ath. Edwin Nexander $\left(b^{\prime}, 5\right)-12.10,204$ $10+1$

MOCLELLAND, 134, POTTAWATTAMIE

Mesire, Nbert Jetroy (b'b0)-1a.3.05;(1'05)

MCGREGOR, 1,259, CLAYTON

clark, Allie M. (1, i2)-1a.3, 02 ; $\left.11^{\circ} 02\right)$

'LARK, IIENIRY H. $\left(b^{\prime}+b\right)+-I 11,70$ (1's6).

Miles, lsaac lloyt (bo5)I1-111.10,"4s; (1"8x) it. $\mathbf{k}$.it.

sclubter, Fllzabeth Iloyd Phelps (b'69)III.4.04: (1'04); not in uractice.

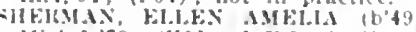

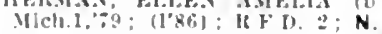

THOMA. WM HAlblil $(6,9)+-1111$ (1):- $\left.11_{102} 02\right)$

MCINTIRE, 487, MITCHELL

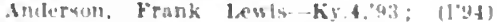
MECHANICSVILLE, 817, CEDAR

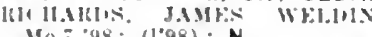

M0.; $98 ;(1.98) ; N$

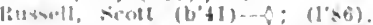

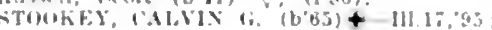
11":⿱艹⿰氵) 1

MEDIAPOLIS, 858, DES MOINES

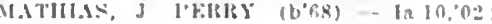
$(1+1)=1$

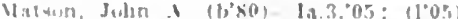

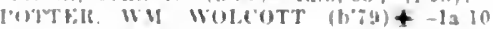
'ali: Il'not)

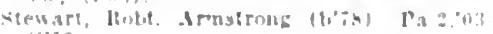

MELBOURNE, 423, MARSHALL

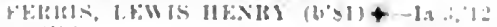

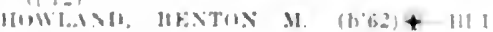

NELROSE, 459, MONROE

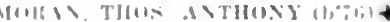

MELVIN, 193, OSCEOLA

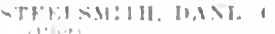

MENLO. 382. CIUTHRIE

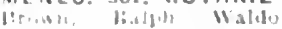

MERIDEN, 216, CHEROKEE

Mauer, lien. Aifrel (b)" il - Ia, i, 12; (1"12).

MERRILL, 520, PLYMOUTH

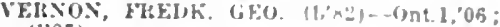
$(1.07)$

OJ.COTT, W. E[CIENE $\left(b^{\circ}=5\right)+-1 a 3,10$ (1'10)

MESERVEY, 193. CERRO GORDO

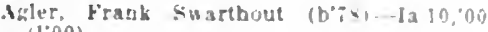
(I.00)

MIDDLE RIVER (R.F.D., DEXTER), 30 , MADISON

Camsey, Alexander (b'5i) - Ia.1, 86 : $\left(1^{\prime} 86_{j}\right)$.

Knefuer, Joq. John-Fra.6, "ki: (I'ge)

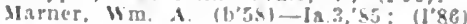

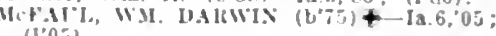

MILFORD, 575, DICKINSON

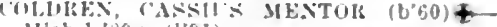
Mch l, s9; (1.91).

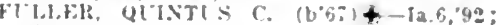
(1) $(1) ; S$.

MILLERSBURG, 258, IOWA

AMIK K, 1.0UIS BLHTUN ( $\left.{ }^{\circ} 81\right)+-111.20$ '05; $(1 ' 12)$; S

MILO, 519, WARREN

Illckman, Mack $\left(\mathrm{b}^{\circ} \cdot 6\right)-1 \mathrm{a}, 100^{\circ} 06 ;$ : (1'06)

l'rice, l'erry Franklle (b'i3) F- la.6, 55 ;

Taylor, Ira Curts (b'7t) W-0.2,9i: (1'9i).

MILTON, 9I3, VAN BUREN

Ilkins, rerry Lee-la.10,"01; (1'01)

Atkins, Walker W, (b'53)-1a.1,8i; (1'8i); $\mathrm{Ob}$

Foluards, Eldridge sbarp $\left(\mathrm{b}^{\prime 39}\right) \rightarrow$; (1'\$s) : not in practlee.

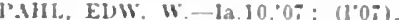

stevhenson, Chas Vurris (b's5)-Ia.10,00 (1'0i)

MINBURN, 388, DALLAS

Tinchlit, Jatues (L'-9)-1 a 10,05; (1'0.5).

MINDEN, 423. POTTAWATTAMIE

A1 1:ITISE, GLANT $(0,73)+-13.3,00$ : (1.(Ui)

MINGO, 2\$6, JASPER

Aruer. lember Colurado $\left(b^{\circ}: 1\right)-310.396$ (listi).

MISSOURI VALLEY, 3.187. HARRISON

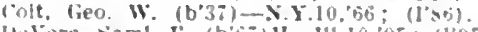

le Vore, saml. I. (b'6)11-111.10,95; (1'95).

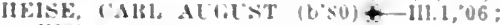
(I.0s)

slilley, do Rlegel (host)-11.6,11: ().

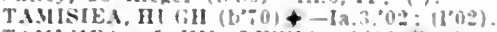

TAlISIFA JUIIN LEWIS $\left(b^{\prime} 66\right)+-12.3$ 'afi: (1'96)

White, Abner-F-la.1,s0; (1'8i); not in Praitice.

MITCHELLVILLE. 869, POLK

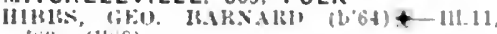

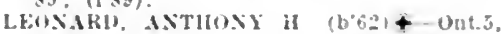
"03: (1'03)

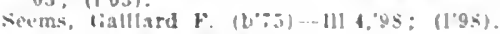

MODALE, 387. HARRISON

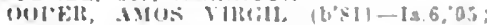
$(1,051)$

WII,TSE, KIWW W (b'61)-NCb.3,93; (1.93).

MONDAMIN, \$20. MARRISON

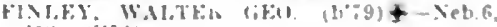
o:?: (1'0.3)

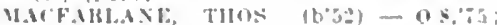

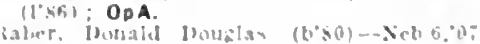
(li"i)

MONMOUTH. 221, JACKSON

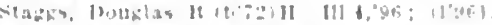

MONONA, 792, CLAYTON

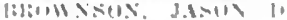

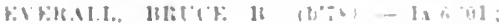

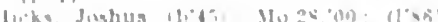

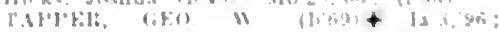
(1), (i).

MONFOE, BON. JASPER

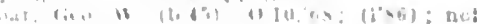

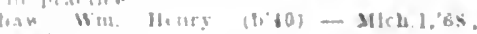


S.MTII, FIDAK J.E MOYNE $(1,66)-1 \mathrm{~b}, 6$, , $00 ;,\left(1^{\prime} 00\right)$

TAYLOR, JOHN LEAlANI) (b'i4)-Ia.3, $02 ;\left(I^{\prime} 02\right)$.

MONTEZUMA, 1,172, POWESHIEK

BARG, Fllas (b'78)+-lier. 1, 0)?

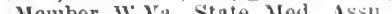

IVG

Kloos, John Ruchdeschell (b'90)-Ia,6,'Is ; (1'I3): ObG.

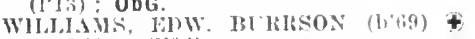

IO.J., $99 ;\left(1^{\prime} 98\right)$

MONTICELLO, 2,043, JONES

MIITK. WII.IS A. (b'.54)--111.1,'78:

(l'sfi).

P'uleston. Fred (1)'65) - 1a.3,01: (l'01) ; D

KEMMONI, THOS. M. (b'78) +-111,6,04 (1,04)

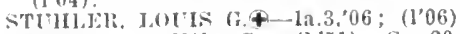

THOMAS, J()IIN G. (b'51)-Ger.20,78; (I'86).

MONTOUR, 383, TAMA

MONTOUR, 383. TAMA

Corns, Win., "Ir. (b'i4)-Ia.6, 00 : (100). III.9.97; (1'9s); not in practlce.

Southwick, Wm. Warren (b'86)-Il1.22,'13: (l'13)

MONTROSE, 708, LEE

BUCK, EHW. MORTON (b'65) †-Ia.9, '96:

MOORHEAD, 366, MONONA

ICDA1PF, CIIAS. WEBSTER (b'61)-Mich.1, $88 ;$ (I'8s).

IcDade, Mary Amma K.-Mich. 1,92; (Assistant 1'hysician).

MOORLAND, 137, WEBSTER

Farlow, Chas. Troy (b'S4)-1Y0.7,'10; (1'12) ; not in practlce.

MORAVIA, 682, APPANOOSE

DAY, WM. R. (b'67)-Ja.10,'01; (l'01).

fray, John F. (b'-3)-Ia.3,02; (l’02).

Harris, Wm. (b'85) - Wis.3,'12; (1'12)

LICH. GEO. D. (b'72)-ilo.28,99; (1'05)

SIAYIN, CHAS. THOMAS (b; -2$)-110.28$ 04; (1'04).

MORNING SUN, 897, LOUISA

Graham, Dilles 1. (b'66)-111.1,90: (1'90)

IIcClellan, Wm. Stewart (b'66)-Ill.1,94 (1'94)

smyth, Wm. R. (b'66)-Ia.9,'96; (l'96).

MOULTON, 1,233, APPANOOSE

DOWNING, WH. L. (b'62) $\oplus$ - Ill.1,'86 $(1,90)$

PRINTZ, LDW. T. (b'57)-Hl.11,'84; (l'87)

SELLERS, MOSES Y. $\left(\mathrm{b}^{+} 39\right)-\mathrm{Ia} .1,80$ (1'86)

Ware, îm. F. (b'68)-Ia.10,00; (l'00).

Ziegler, David Stirette (b*51)-Tenn.6,'91 (1’91); not in practice.

MOVILLE, 552, WOODBURY

DEWEY, WM. 1H. (b'56) †-Ia.3,'84; (1'86)

Hipple, J. W. (b'56)-Mo.10,'81; (1'86).

STOLLEY, J. GEO.†-Neb.6, 05 ; $\left(1{ }^{\prime} 06\right)$

MT. AUBURN, 228, BENTON

Ilainen, Frank Salatblel-Ill.22,'13; (I'13)

MT. AYR, I,646, RINGGOLD

B.IILEY, SAML. (b'5I)Ð-Ill.1,79; (1'86)

HANNELLY, MICHAEL FREDK. '(b'74)-

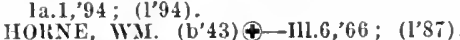

HOHNE, WM. (b'43) \&-IIl.6,66; (l'87);
LESAN, CASSIUS TRUE (b'74)-Ill.1,97; (1'97)

SCHMALTZ, WALTER FRANKLIN (b'S3)-

Neb.4,'10: (l'10).
SMITH, FRANKLIN CHAS. - Ky.5,'93; (1'94).

White, John H. (b'48) E-0.2,'7s; (1's9).

MT. ETNA, 125, ADAMS

SWEET, HOMER L. (b'45)Ð-N.Y.13,69, Ill.1,97; (1'87).

TWINING; EDW. T. $\left.\left(\mathrm{b}^{*} 44\right) \oplus-\mathrm{I}\right) \oplus, 6,67$ (1'ST).

MT. PLEASANT, 3,874, HENRY

IILIEN, LOUIS' BOYD (b*58) - Ia.1,'80; (1'98).

APLEGATE, CHAS. FRANKLIN $\left(b^{\prime} 65\right) \oplus$ N.Y.10,90; $\left(11^{\prime} 94\right)$; (E13).

Blackburn, Ella (b'66)-Pa.7,98; (1'12)

'arlson, Clara (b'85)-Ia.3,'10; (1'10).

(arter, Chas. W. (b'52) - ; (1'36); not in iractice.

J-I11.1,02; $\left(1{ }^{\prime} 0 \tau\right)$

arr, 1I. 11.- Tt.1,55; $\left(1^{\prime} 86\right)$; not in prac-
GEESLKA, oTTO A. $\left(b^{\prime} 54\right) \oplus-1 a .1,78$; (1'93); OpLR.

(illWIILAN, JOMER J. (b'68)-Ja.9,96; (l'9ii).

IIHUANIES, JOHANYES (b'82)-1a.6,'13 ; (1) 13 )

IIOIAND, JOII ELISWORTH (b'62)N.Y.10,90; (1'90).

laird, lohn W', (b'71) II-I11.4, 00 ; (1'00). LUSENGFll, WM. S. (b'67)屯-Ia.3,90; $\left(l^{\circ} 90\right) ; S$.

l'ltcher, Alfred o. (b'43)-Pa.6,'67; (1'86).

l'ltcher, Jonathan Jay (b'82) - Ill.4,06; (1'13)

Smith, Geo. R. (b'53) 11-Ill.4,'80; (1'96)

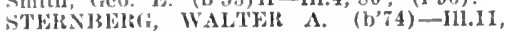
$01 ;\left(1^{\prime} 01\right)$.

STEVART, WM. LLOY') (b'86)-1a.3, 07 ;

Who7). Michael IHenry (b'\$4)-Ill.11,'11; (1'11)

MT. STERLING, 232, VAN BUREN

'Toben, Ilussell D. (b'6i) -Ia.9,97; (l'97).

MT. VERNON, 1,532, LINN

Baird, Chas. Glenn (b'S3) - Mo.34,'12; (1'12); OALR.

('arson, Geo. Albert (b'64)-I1l.1,'90; (1'90). ('IAWEORD, ALEXANDER (b'58) 4-Ill.1,

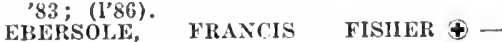
Md.7,06; (l'0S); LR.

HILL, MLLVIN W.(b'5I)๑-Ia.1,'8I; (1'86).

Hogle, Geo. W. (b'60)-0.9,91; (1'91).

11OG1E, KATE A. MASON $\left(b^{\prime} 59\right) \uparrow-I 11.9$ '85; (1'89).

Lott, Editli Stockton (b'\$6)-Ia.3,'13; ROBINSON, JOIIN BLAIR (b'53)థ-III.4, $79 ;(1 ' 86)$

WAUD THOS. SMITH $\left(\mathrm{b}^{\prime} 50\right) €-\mathrm{K} y \cdot 1,91$; (l'91).

IVolfe, John D. (b'61)-Ia.3,'89; (1'89).

Wolfe, Thos. L. (b'69)-Ky.1,'91; (l'91).

MURRAY, 796, CLARKE

Irmitage, Geo. Ira (b'72)-Ia.9,'97; (1'9i)

Freel, Cécil O. (b'69)-Ia.1,97; (1'97).

MUSCATINE, 16,118 , MUSCATINE

AI'PEL, FREDK. LYONS (b'81) †-Ia.3,'03 (1'03) ; 812 Mulberry Ave. ; office, Hershey Bank Bldg. ; 10-12, 2-4, 7-8.

BEVERIDGE, THOS. F. (b'66) - $4-\mathrm{Ky}, 1,91$. (1'91) : 1505 Mnlberry Ave.; office, $200 \mathrm{~b}$ 2d St. ; $10-12,2-4$

BRAUNIFATH, EIIMA L. (b'59) †-Ia.3 '81; (l'86); 703 E. 6th St. ; office, 112 E. $2 d$ St. ; 2-5.

Braunwartl, Sarah Jane--Ia.3,76; (1'86).

Clapp, Arch Burwell (b'80) H-Ia.4,02 (1'02) ; 507 E 8th St.; office, Hershey Bank Bldg. ; $9-12,2-5 ;$ OALR. *

DEAN, IIENRY IIUNSON (b'36) $\oplus-N . Y .1$ 61; (1'86); 128 E. $2 d$ St. ; $9: 30-11: 30$, EVERSMEYER, BENJ. ERNEST $\left(b^{\prime} \div 5\right)-$ Ill.11,05; (l'05); 311 E. 6th St.; offlce, German-Ámerlcan Bank Bldg.

Fulliam, Edward B. (b'58) E-IIl.8, 79 . $\left(1^{\prime} 86\right)$; $407 \mathrm{E}$. Front St. ; office, $229 \mathrm{E}$ E. 2 d $(1,86) ; 407$ E. Front

St. ; 8-10, 2-4, 7-8.
Fulliam, Jeff Davis (b'66)-Ill.8,'87; (1'87); 311 E. Front St.; offlce, 301 E. $2 \mathrm{~d}$ St.

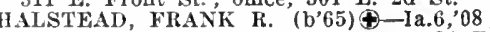
$\left(l^{\prime} 08\right)$; $1101 \mathrm{E}$. Front St. ; office, $124 \mathbf{E}$ 2 d st.; $10-12,3-5,7-9$.

HEIDEL, GUSTAVE A. (b'72)-Mo.7,'97; $\left(1^{\prime} 97\right) ; 401$ W. $3 d$ St. ; offlee, GermanAmerican Bank Bldg.

HUSTED, HORACE LEE (b'83)థ-Ia.3,'09; $\left(1^{\prime} 09\right) ; 104 \mathrm{~W}$. 5th St.; offlce, GermanAmerican Bank Bldg.; $9-11,2-4,7-8$; Americ
OALR.

JOHNSTON, WLLIAM HOWARD (b'84) -Ia.3,'10; (l'10); Oakland Drlve; office Hershey Bank Bldg.; 10-12, 2-4; (B1) OALR, *

KLNG, ELBRIDGE H. (b'43)Ð-Nich.2,"70 $\left(1^{\prime} 86\right) ; 417$ W. 4 th St.; Offlce, 510,6 th St. : $10-12,2-5$.

ILEIN, JOHN LEONARD (b'73) †-Ia 3,97 (1'97) ; E. 2d St.; offlce, German-American Bank Bldg. ; 10-12, 2-4, T-8.

I.ezotte, Geo. I. (b'56)-II1.1,'81; (1'86) ; 304 E. 3d St.; offlce, 108 W. 2d St.; 10-12, $2-5,7-8 ;$ OALR. $\star$

LITTLE, FREDK. H. (b'55) \&-Ja.3,79: $(1 ' 86) ; 108$ W. 5 th St.; office, German American Bank Bldg.; 10-12, 2-4.
Morkan, James W. (b'54)-Ia.1,84; (1'88); 518 Woodlawn St.; offlce, German-Amer!call Jank I3ldg.; $10-11,2-4$.

NOHTON, WM. SHEPllRD (b'67)-Kan.3, 'i) 0 ; $(1,00)$; 410 I'ine St. ; office, Flrst Natlonal Bank 13ldg.; 10-12, 2-4, 7-8.

OHVBit, Al'rHIlt IAUES (b'71) क-III.1, $96 ;\left(I^{\prime} 96\right) ; 316$ Walnut St.; offlce, 204 H. $2 \mathrm{~d}$ st.

IIMLT, FHEDK. E. (b'70)-Ia.9,91; (191); not in practlce; 314 W. $3 \mathrm{~d}$ St.

TEIN, S. G. (b'61)థ-111.6,'89; not In practlce ; $501 \mathrm{~W}$. 2d st

T YLE1, EDW. KING (b'59)-Ia.3,'82;(1'87) ; $3 \mathrm{IO} \mathrm{W}, 4 \mathrm{tl}$ St. ; ofllce, $126 \mathrm{~W}$. $2 \mathrm{~d}$ St. ;

WEAVER, ARTIIUR JOIIN (b'65)-III.8,'95 ; (1'14); 200 W. 6th St.; offlce, 213 Iowa Are. ; $10: 30-12,1: 30-5$.

MYSTIC, 2,663, APPANOOSE

FENTON, WILLAlBD JOSHUA (b'8I) Ia.10,04; (1'04).

IABAGH, NICHOLAS W. (b'80)థ-Ia.10, 04 ; (1'04).

Lugar, Laurell Lavergne (b'89)-Ia.3,'12 ; (1'12).

Walles, Joslah S. (b'48)-Ia.1,89; (1'89).

NASHUA, I,I02, CHICKASAW

GOODALE, IEON HARVEY (b'63) †-I11.4,

MCDANNELL, JOHN (b'70)Ф-Ky.1,'91; (1'97).

STUART, PERCY ERNEST (b'77)\&-Ia.3, 00 ; (I'00).

NEMAHA, 165, SAC

liehrens, Geo. Wm. (b'83)-Ill.22,'09; (1'11).

NEOLA, 926, POTTAWATTAMIE

DOYLE, JOS. M. (L'65) - Ont. 4,'93; (1'93).

Lowrey, Jos. H. (b'58)-0.13,'83; (l'87)

Seward, Guy (b'74)-Mo.28,'02; (l'05).

NEVADA, 2,138, STORY

BOWERS, HENRY WOLFFE (b'82)థColo.5,'09; (1'10).

CHAMBERLIN, H. DEWEY (b'48)-Mlch.1, '76; (1'86)

CONER, FRANK HOWARD (b'66) Ill.11,'98; (l'98).
Ieald, Chas. Wesley (b'76)-Ill.19,06 ;

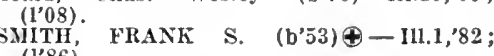
(1'86)'

Soper, Caleb P. (b'6I)-N.H.I,'83; (l'86).

WARNER, ERVIN WM. (b'78)๑-Ia.10,06 ; (1'06).

Wiusett, Benj. Franklin (b'61) H-Ill.10, $85 ;(1 ' 91)$.

NEVINVILLE, II5, ADAMS

Iiller, Chester Arthur (b'75)-Ia.10,02; (l'02); $\mathbf{G}$.

NEW ALBIN, 588, ALLAMAKEE

Gable, Edw. James (b'67)-Ia.1,'96; (I'96).

Park, Paul Archibald (b'84)-Ia.4,'10: (1'10).

NEWBERN

(R.F.D., LACONA), 65,

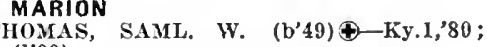
(l'90).

NEWBURG, 200, JASPER

Abbott, Clifford John (b'70) H-Ill.4,'03 ; (l'09).

NEWELL, 728, BUENA VISTA

BROOKS, JAMES MILES, (b'57) $\oplus-I 11.11$,

FOLEY, FRED. CHAS. (b'68)@-I11.1,94; (1'94); OpA.

\section{NEWHALL, 225, BENTON}

Bradley, Carl Leroy (b'85)-Ia.3,'11; (1'11). (I'86).

NEW HAMPTON, 2,275, CHICKASAW

B.BCOCK, AMOS (b'44)-Ill.1,'68; (l'86)

FALLOWS, HOWARD DANL. $\left(b^{\prime} 83\right) \oplus$ Ia.3,'05; (l'05) ; OALR.ネ

FEENEY, FRANCIS S. (b'76)-I11.11,'98; (l'98).

GARDNER, PAUL E. (b*73)€-1a.3,'96;

IANDON, OREN MORRISON (b'54) Ia.3,'82; (l'86).

SCHILLING, NICHOLAS (b,68) $\$$-Neb.6, $96 ;(1,97) ; S$.

CORPEY, JAMES F. (b'66) †-Mo.28,'98; (1'98). 
NEW HARTFORD, 482, BUTLER

EVANS, JOHS C. (b'6i)-la.3, $9: 3 ;$ (l'93).

Pelleller, Dyro II. (b'80)-Ill.11,00: (l'08).

NEW LONDON, 1,144. HENRY

COOK, CARIOLL ELGKNE: (b०:5) \$-111.1. 97: $\left.\left(l^{\circ} 9\right)^{\circ}\right)$; 0 .

Lessenger, Lirnest J. (b'8i) - la 6,'13; (1'13): 6

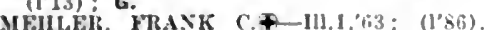

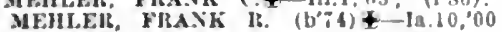
(1'00).

SKELTON, WM, BARTON (1.81)-Mlch. 04: (): Meraber Med. Soc. of the state of I'a.: : $\dot{\mathrm{S}}$.

VAX AISDAII, GARRETT M. (b'58)Ind. 8,84; (1's9).

NEW MARKET, 673, TAYLOR

JOILN, GOMER (b'68) †-Ia.10,00; (l'11): Member Mo. State Med. Asin.

KITCHEX, WARRE. A. (b'63)-0.7,90 (1'91).

McCOLM, CHAS. W. (b'66)-Ja.1,92: (1'92).

Wallace, Rlchard-0: (1'92).

NEW PROVIDENCE, 246, HARDIN

Felt, Garnett Smlth-H-Ia.4.07; (1'0i).

MABEE, CURTIS OSCAR (b'ii) \&-OLT.5, '85: (I'8S).

NEW SHARON, 1,122, MAHASKA

HAITWELL. SAML. WILLAIBD (b'S2)IA. 3,06: (1'06): NP.

Phlllips, Forest Odessa (b'S2)-IIl.1,10 (1'11).

Phllllps, Jesse 11. $\left(b^{\prime}+2\right) 11-11.4 .97 ;(197)$.

RYA., JOHX GASTON (t'S3) - lil.1,10; (I'13).

Wallace. Chas. E. (b'58)-0.9,'s4; (l'S6).

NEWTON, 4,616, JASPER

BFSSEH, EDW: FHANCIS (b'75) $₫$-III.11, 00 : (1'00).

boyv, Cils. E. (b'69)\$-Md.4,92, 0.12, 92; (1'93).

Brers, Heury V. $(1,47)$ F-0.2.75; (1'86).

ENGLE, IIARRY (b'72)\&-Ia.3,98; (I'98):

ENGLE, IIARRY

Engle, Ierry (b'43)-M1ch.1.'il; (l'8i); G.

Gorrell, Jos, R. (b'36)-X.Y.6,59; (1'85):

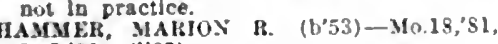
Ia.7., 89 ; (1'87).

Hardlng, Mary R. (b'38) -0 ; (l’86).

HILL, JAMES CIIARLESWORTI +-11.1 , 'C5: (l'03).

MINSHAW, SYLVE.STER NSHAW, SILYF.STER ELLSWORTH (b'6) -Ia.6,'12; (l'12) i - Ia.4,07: (l'0i)

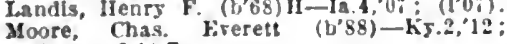
(1'12): OALR.

Slaght. Nellle (b\%: -III.15,04; not In practice.

SMFAD, CARROLL C. (b'54) -111.1,'80:

SMEAI); LESIIE I. (b's2) $¥-\mathrm{Ill} .6,03$; (l'03).

NEW VIENNA, 188, DUBUQUE

A BELS, JOS. I. (b'i8)-MO.T.00; (I'03)

NEW VIRGINIA, 396, WARREN

Bellinger, Vlctor Eirroll $(6,80)-1 \mathrm{a} .6,13$; (l'13).

Fee, Richmond M. (b'63)-la.1.98; (l'85).

NICHOLS. 396, MUSCATINE

Carl. Frank $F^{\prime}$ ( (u'60)-la.3,'86: (l'86).

MUR.XCH, VIHGIL ORIN (b's5) -1a.3,'20 ; (I'10).

NOOAWAY, 323, ADAMS

Morgan. Wm. (ivo (L'66)-1Il.1.91; (f'91) WOILEY, WILLAM IIAMMOND (b*7)กl.4,00: (1'02).

NORA SPRINGS, 983. FLOYO

Banton. Oscar Jerman ( ( ' 86$)$-la.3,12: (I'12)

Burnes, Erasmus-1a.1, $87:$; $\left(1^{\prime} 87\right)$.

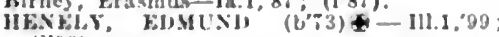
(1'98).

Rhodes, Frank (j. $(1, ; 3)-$ la.10,00; $\left(l^{\prime} 06\right)$

NORTHBORO, 197, PAGE

THOMISUX, JUHX HUIT. $\left(b^{\prime} 68\right)-K y 1$, '92: (1'22).

\section{NORTH ENGLISH, 848, IOWA}

Coxe, Juhn IB. (b'54)-Ja.3, 80 ; (1'88).

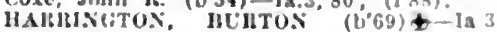
$97:(198)$

IIIS: JACOL (b's2)-1a.3.04: (1.04).
NORTH LIBERTY. 350, JOHNSON

Von Steln, James $b^{\prime}$. (b'51)-0: (1'87).

Ware, Matthlas (b'83)-Ia.3,'12; (1'12)

Young, Mlller-Pa.2,:33; not in practlce.

NORTHWOOD, 1,264, WORTH

INEILE, ELMER IINMAN (b'04)Z 111. B.,99; (J'01).

IIFWITT. LELAND GRANT (b'60)-III.1, $92 ;$ (l'93).

117.11), CHAS. ADDISOX (b'6L)-12,3,88: (1'8s).

SANDFits, rIIAS. WILLAHO $\left(\mathrm{b}^{\prime} 60\right) \pm$ 111.1:84; $(1+86)$.

loung, Ernest Raymond (b'iz)-111.10,'00 (I'01).

\section{NORWALK, 315, WARREN}

Brown. Fletcher Emory (b'6t)-III.1,91; (1'91).

willet. Chas Austin (b'i6)-Ia.6,02: (1'02).

NORWAY, 479, BENTON

SIMPSO., CIIAS. F. (b'73)-III.11, 98 ; (I'98)

NUMA, 659, APPANOOSE

HLRT, ULYSSES L. (b'65) †-M0.18.92; (l'92).

DAKDALE, 50, JOHNSON

Runyon, Will Darrow (b'86)-Ja.3,09: (I'09) : I. *

GCALHOROLGIT, IIERBEIT $V .(6 ; 6) \uparrow$

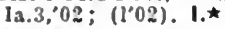

OAKLAND, 1.105, POTTAWATTAMIE

Alexander, Thos. C. $\left(b^{*} 69\right) \rightarrow$ (l'87).

CLAKK, MREEDA M. (b'73) $4-111.4,99$;

GILES, GEO. CLIFTON (b'69)£-Ont.5, 93: (1'95).

Perkins, Ilolla W.-Mo.28,05; ('06).

Smlth, Ralph Geo. (b'6s)-Ont.5,'93; (l'93).

OAKVILLE, 389, LOUISA

Ditto, Iichard C. (b'73)-Ja.10.03; (1'01).

Murray, T. H. (b'61)-310.t,98; (l'13); G.

OCHEYEDAN, 595, OSCEOLA

ELY, WM. EDW. (b'GI) -Mllh.1,S5; (I'8\%).

HAMITON, ROYAL GRAYES (b'to)-III.1. 92 ; (l'sí).
(l's6).

\section{ODEBOLT, 1.283, SAC}

Crane, kdw. H. (b; $;)-$ la.3, $04 ;(1,04)$

(iroman, August (b'56)11-lll.10, 8 ; (1'si). Sebern, Richard C. (b'\$1)-Ia.3.04: (1"04). Selby, Robt. Wllson (h's(j)-Mlch.1, ${ }^{\prime}$ l:; ( ) OELWEIN, 6,028, FAYETTE

Baker. Iichard Clarke (1,61)-La.4:90: (l'90).

Cole, James F.-Ia.3,'si; (l'si).

Conney, Chas. Jos. (b'-2)-la 3,95: (1*95). Kennedy, Ellzabeth smith (b,79)-1a.3,01;

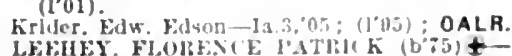
III.11,02; (1,02)

Mclerlt, (has. s (10's 0$)-K y .209:\left(l^{\prime} 09\right)$.

O'Connor, John B. (6,5)-1a.3,96; (色)

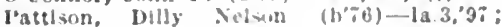
(l'9i)

I'attlson, John T-Cia.l, 90; (\$)

lablnaon, Whisant k. (b't6) - Ia.3.'93; (1०93)

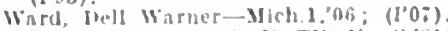

WissoM, (itolicit NATHAN (b'si) III.11,0\%: $(109): S$.

OGDEN, 1.298. BOONE

('lark, (hax. Bryau (1'72) - la.3,93; (1'94).

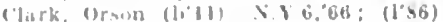

l'lark, (1ron Whisney (16:3)-111.11.00;

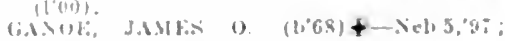

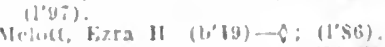

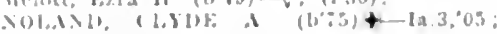
(1) (1) ; 0 o.

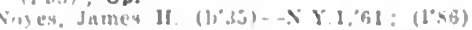

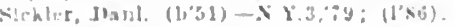

OLDS. 163. HENRY

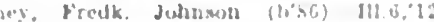
(1'12)
OLIN. 659. JONES

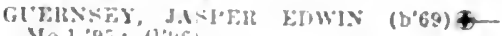
POHT. $195 ;(1.45)$

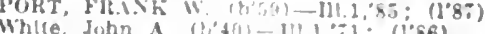
WHIT: SFWA KI (t)

OLLIE. 289, KEOKUK

MCKINNIS, CHAS. (1, \% ]

chrelner, (bas. (l’g8).

ONAWA, 2,026, MONONA

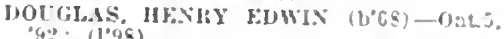

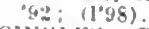

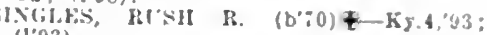
(1'33).

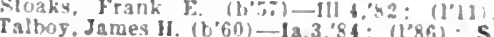

THOMSON, JOHN ALIEN (b'\%) L IA 8 , ot: $\left(l^{\prime} 0\right.$ i)

Young, ("llitord lim. (b's6)-la.4,11; (1'11). ORANGE CITY, 1.374. SIOUX

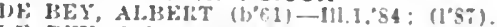
IIE BFI, JOHN GLIRALD (b'83)-Ia 6, 10: (1)

DeLEIIXASSF, ADOLEII FRKUK. HENIK -Ia.3.01; (1'01)

Ogfel, 11. 1.-111.6.,67; not In practlce.

Stadt, Henry M. (b'70)-Mn. 7,$93 ;\left(1^{\prime} 93\right)$.

ORIENT, 373, ADAIR

130WkBS, ARTIL'R S. (b'78) -111.1,03; (1'03).

TINSMIX, ELGEXE (b\%4) \$-1a.10,03: (l'03).

OSAGE, 2,445, MITCHELL

Barrelt, James W. (b'5t) H-Int 4,79: (1'90).

HANSE., MACHCE A. (b"i3)-Ind.9,95; (l'98).

ITTLE, EISXEST HARTI.FY (b'ซ8)-IIL.11, $02:\left(l^{2} 03\right)$.

OWEN, WM. ROY (b'Ti)-Ia.4,03; (1'03); Ob.

Sarre, Louls (b; $;$ )-Ind.9;01; (l'01)

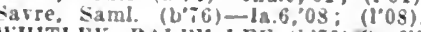

WHITLEY, R.ALII LEE (b'7i) -III. 1.98; (l'98); S.

WIG(iNS, CHAS. CARPENTER (b'63)111.10.89; (l'\$9).

OSCEOLA, 2,\$16, CLARKE

Irmistrong, Gev. T. - 1a.1.:35: (1'86)

belrout, siephen I:-11-110.5,'s0: (1'86)

Rulibaugh. Wn. IR. (b'58)-1a.6,92: (l'92).

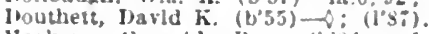

llarken, Conreld hes (b'st)-123,0z: (100).

IJwlenkeck, Huber Lexls $\left(b^{\prime}\left(0^{\circ}\right)\right.$-Ja.3,00; $\left(t^{\prime} 00\right)$.

l'arrlsh, Wm. O. (b'39)-Ia.1,65: (l'\$6).

sells, Franklin Wesles (b;0)-1a.6,96: $\left(\right.$ l'$\left.^{\prime} 96\right)$. S. 5 .

Wa!l. Thos. M. (b'44)-Ja.1, 67 ; (l'si).

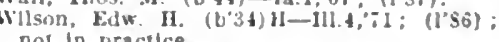
not in practice.

OSKALOOSA, 9,\$66, MAHASKA

ABLOTT, CIIITIS MCGL'STL'S (1.69) + K., 1,$93 ;(1093) ; S$.

labluwin, (lare C: (699)-Ia.3,04: $\left(1^{\circ} 04\right)$ : nut in practice: R.F.D.

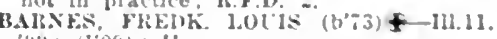

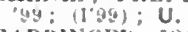

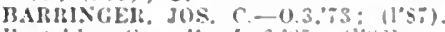

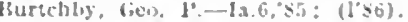

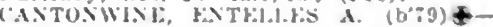

I11.6.'02: ( $\left.6^{\circ} 02\right)$; OALR. *

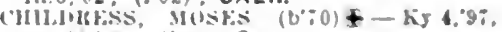

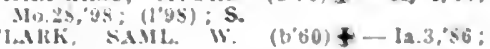

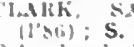

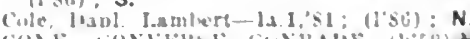

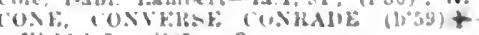

III $11, \therefore ;$; $(1,0) ; 6$.

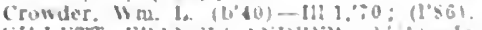

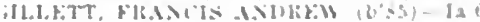

1. : $(173)$

Jisiah

(1'a): wo: In fraction

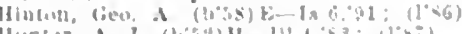

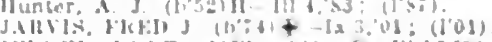

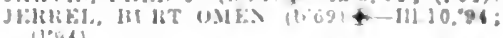
$(1,04)$

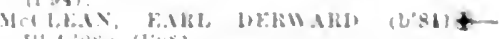

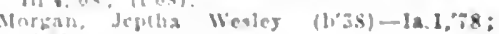
(Insi)

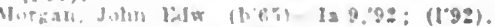

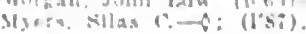


IROIBERTS, JAY (*. (b'T4) $\oplus-I 11.1,99$;

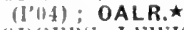

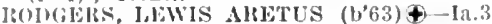
$89 ;(1 ' 89) ; G$.

Sarbagh, Wibur Jolland $\left(b^{\prime}-0\right)-0.25,97$ (1'97).

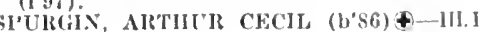
10; (I.11); Pd.

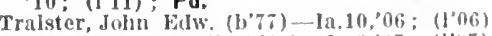
True, John 11 axwell $\left(1 y^{\prime} 45\right)-$ Ia.8,97: (1'97)

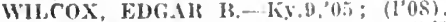

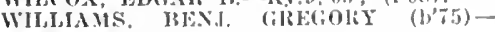
Mn. 28,02; ( (I0)

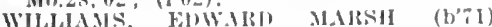
-Mo.34,10; ( ) : Mtember Mo. State Mel. Asen.

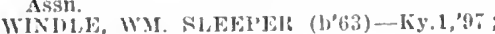
(]$\left.^{\prime}\right)$ 7) ; OALR.

OSSIAN, 749, WINNESHIEK

IIFN, IOS. ANTON (1,'55) \&-M0.7, 04 (l'04)

Lyuch, Jolu Wm $(1, \pi 1)$ - Wls. 2,$97 ;(197)$

OTHO. 47, WEBSTER

Kepler, Cornellus C. (b'88)-I11.22,"13 (1'13)

Kepler, Inther Francls-la.10,04; (1'04).

OTLEY, 300, MARION

Riwson, (Jias, Do Witt (b'52)-0.1,80; (1's6); Pd.

OTO, 268, WOODBURY

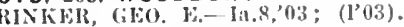

OTTOSEN, 147, HUMBOLDT

SIII'LY, Wil. II. $\left(b^{\prime}, 72\right)(4-1 a .6,98$; (1'98); 0 b.

OTTUMWA, 22,0I2, WAPELLO

ANTHONY, ENOCHI (b'59) - Ia.9,95 (1'95); $1147^{\mathrm{N}}$. Court st.; olluce, 107 (1) irket st : i-5.

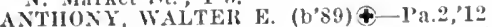
(I'12): 1213 West St.; ollice, $105 \mathrm{~N}$ Market st.; $10-12,2-5$.

BANNISTEK, ML'RDOCI (b'68)—-I'a.1 44; (1'95); 123 N. College sit.; office, Ennls ]3ldg. ; $10-12,2-4$.

BARTON, EDWIN GINN (b'7t) $\uparrow-111.10$ 00 ; $\left(\mathrm{I}^{\prime} 00\right) ; 225 \mathrm{~N}$. Sheridau Ave.; offlee, 527 ' Church st.

Bonlam. Joln C. (b'59) H--Ill.4,'83 ; (l'86) $125 \mathrm{~N}$. Jefferson St. ; offlce, $236 \mathrm{E}$. $2 \mathrm{~d}$ St. $125 \times$, Jefterson 5

Bowles, Fred W. (b'-8)-Ia.10,01; (l'01) Aralon Apts.; offlce, Leyton 13lds.; 10-12,

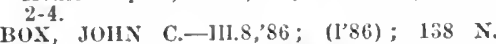
Moore st.; office, 105, N. Markét st. Boyer, Lloward C. (b'72)-Ill.15,45, I11.4, 10 ; (1"ati); Emis BIdg

BrockinN, D.JVID C.t-Ia.3,78; (l'86): $3 \mathrm{~d}$ and Court: (AT): $\mathbf{S}$

Conroy, Ilugh Ilarrison (b'65)-Ky.4,'91 (191); $34: 2$ Richmond Ave.; offlce, 312 lain st.

Denoon, J. W. (b'52)- $\rightarrow$; (1'86)

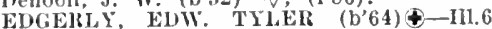
's9; (1'44); 319 F. 5th St.; oftlce, IIofmann Bldtr.; $10-12,2-5$

ELERICK, JOHN WESLEY (U’ङ1)-Ia.1,90 (I'y2) ; $401 \mathrm{X}$. Benton St. ; offlec, Hof man Bldg. ; 8-9, 1-5.

GRIIAM, DELL EWING (b'76)Ð-Ia.3, 02: (I'02) ; 315 E. 5th St.; office, Ennis

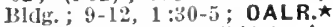

Halloway, Joln G. (b's 9$)-0 ;\left(l^{\prime} 8 \pi\right) ; \operatorname{not}$ in practice.

HANSELL WU. (b'55)- $\rightarrow(1,92) ; 505 \mathrm{~N}$ Market St.; offlee, 116 E. Main st.; 9-12, $2-5 ;$ OALR. $\star$

HAUCK, SAMLEI, L. (b'69)థ-111.1,'91 (I'93); $210 \mathrm{~W}$. 4th St. ; offlce, Burlington Railway Depot Bldg. ; 9-12.

IIRRICK, JOHN FRANCIS (b'64) \-Ia.9, Hofmann Blig.; $10-12,2-5 ; \mathrm{S}$.

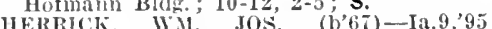
(1.45); 316 Gara st.; office, Jlofmam Bldg.

Jill, Ermma Powell (b'74)-Ia.10,00;

(l'00); not in practice.
ILOVELL. ELIA BCKTON (b'84)-1a.3, 07 : $\left(10^{\prime} 0 \pi\right)$; $325 \mathrm{~N}$. Sheridan Ave.; offlee, 'conirt l'ark' Bldg.: 2-5: S.

TIIB.ND, (HAS. EDWARD (b'i2)-Mo.2T (1'96); $00 y$ W. 2d St. ; office, $2 d$ and

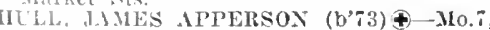
tos; (1) Bldg. ; $10-12,2-5,7: 30-8: 30$.
L.A FORCE, 1HUIREETTE D, (b'69) $\bullet$-III.I, 93: (I'03) : $420 \mathrm{~N}$. Court St. : oftlce, $105 \times$ Court St.; 10-12, 2-5; (BI); OALR.

LA FUltCl:. WM. IBROOKS (b'67) \$-III.6. (1) (lyi) ; 427 W. th St.; oflce, Ennls Blolig.: 10-12, 2-4; S

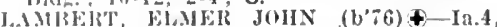
"4.'; (l'ts) ; 328 W. 5th St.; ottlee, IIofmann IHIJg.; : -12, I :30-5; OALR. *

Malon, Nolw, (1, t5)-Mass.1,02; not in practlee: 140 bs. Court st

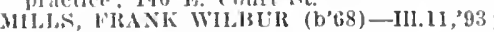
$(1,13) ; 113$ Altrany st.; offlce, 107 N. court st.

MHIs, Margaret BHllingshy (b'62)-Ill.9,'93; (1'3); 11: Albany st.; offlce, $107 \mathrm{~N}$. Court st.; $10-12,2-5$

Morgan, Wim. D. (b'33)-Ia.1,64; (1'8i): (H) church st.

NFWHI. FLOYD WILAUTH $\left(b^{\prime}, 6\right) \$$

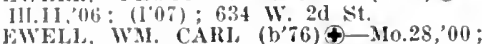
NFWEL, WM. CARI, (b'76) $4-M 0.2$
(1'00); 1303 F. Maln st.; 1-4, 6-8.

Ifolierts, Hurace W. (1,49)-I11.4,74; (1'86) 326 N. Market St.; offlce, Market and $2 d$ sits. ; $8-10,2-4$.

Sellers, Harry W. (b'80)-Ky.4,07; (㫧) ; Jalli and fireen $\mathrm{Sts}$

SIIFAFE, HIVW. AUGUSTUS (b'61)థ-Ia.3. 94: (1'94) ; 301 N. Benton St.; oftlce, 120 s. Court St. ; $8-10,2-4$.

Slauglit, Arthur Wayland (b'55) H-Ill.10 '87; (1'96); 502 E. JIamilton St.; oftlee, $2 d$ and Market Sts.; $10-12,2-4,7-8 ;$ G. Spilman. II.ırold Augustus (b's 8$)-111.6 .13$; (l'13) ; 214 N. Jetrerson St.; offlce, Jlopmann 13!dg. ; $10-12,1: 30-4,7-8$.

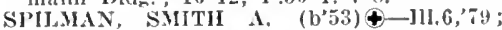
(I'86); $125 \mathrm{E}$. Maple Ave.; Once, Market (I'86); 125 E. Maple $A$

Sprague, Manley H. (b'53)-0.14,80; (l'86); 102 s. Schuyler St. ; $8-12,1-6, \tau-9$.

toker, Wm. Bay (b'69)-Ia.1,'96; (1'97) : .02 Church sit.

Strickler, Benj, F. (b'52)-Ill.1,75; (1'86) $126 \mathrm{~W}$. 4th St.; offlee, $105 \mathrm{~S}$. Market St. $8-11: 30 ; 1-5,7-8$

Tait, Thomas Eliot (b'5y)-Ia.6,'88; (l'96) 110 Market St. ; $9-5: 30$.

THYoR, HAIDE-Ia.3,06; (1'06); $111 \mathrm{E}$. Woolland Ave, ; offle, Conrt and 3d Sts.; $10-12,2-5$.

VINSOX, IIARRY W. (b'76)†-111.1,02 (I'02); 131 N. Ward St.; offlce, Court and 3 d sts.; $11-12,2-5 ; 0$ b.

Wilkinson, John E (b'37)- $-;(1 ' 86) ; 420$ s. Madison St.; office, Jain and Green Sts.

WILIIAMS, ALFRED OSCAR (b'50) Ia.3.75; $\left(1^{\circ} 86\right) ; 216 \quad$ N. Jefferson $S t$. offlee, $120 \mathrm{~S}$. Court St. ; 11-12:30, i-9; S

WILSON, JOHN BUCHANAN (b, 72$) 4$ Ont.3,97; (1?:18); 702 E. 2d St. ; $1-3,7-8$

OXFORD, 614, JOHNSON

Burbank, Frank Elbert (b'70) - Ia.3,'92;

DO'TY, ELMER A. (b'50) \&-1a.3,'85; (l'86) I'HTERS, JAMES A. (b'76)屯-Ill.11,'99; (l’99)

OXFORD JUNCTION, 822, JONES

BLEEN, WH. (b'82)\&-la.3,"08; (l'08)

cook, JESSE LEE $\left(b^{\prime}, 6\right) \oplus-1 a .10,00$ (l'il)

DAYIE, JAMIS EUGENE (b'73)屯-Mo.t, (9s; ; $(198)$.

PACIFIC JUNCTION, 501, MILLS

B.I('), LYMAN BON-0.6,'82; (l'91)

MeElwee, 13enj. F.-Ia.1,'92; (l'07).

PACKWOOD, 264, JEFFERSON

lloorman, C. T. (b'36) E-0.2,'76; (1'86)

Forth, Frank Raymond (b'i4)-Ia.10,04; (1'09).

PALMER, 177, POCAHONTAS

SMIL\}IE, BEXJ. A. (b'69) \$-Mich.1,03 ; (I'03)

PALMYRA (R.F.D., CARLISLE), I50, WARREN

Blake, J. 1. (b'38)-0.3,'69; (l'86)

PALO, 208, LINN

HOLSER, CASS THOS. (b'79)-Ia.3, 04 ; (1.05).

PANAMA, 232, SHELBY

WALSII, JOHY GRAXEY (b'80)-Ia.3,'07: (l'07).
PANORA, 1,080, GUTHRIE

IBIROWX, SAMI JOS.4-III.I, 98 ; (I'98).

SONES, CALVIN O. (1)53) $†-1 \mathrm{I} .3,86$; (1'86)

TÍner, Amella C. Weldman (b'62)-Ia.6,86: (1'86).

PARKERSBURG, 938, BUTLER

IBIUECIIET, HFNKY NICIIOLAS (b'82)

$19.3,08 ;([\circ 08)$

OBstos, Thos. A. (b'64) † - Ia.3, 89 ; (I'89)

rout, Alfrel o. (1,49)-III.6,'75; (1'87)

PARNELL, 369, IOWA MCMANIS, JOS. I'ETER (b'82)థ-Ill.6,

SIIIFL, TIIOS. J. (b'53) $\oplus-$ Ia.3, 80 : (1'82).

PATON, 358, GREENE

MIller, Fvelyn (b'74)-Ia.6,'96; (1'98).

Hlller, James Patterson (b'64)-Ind.5,'90; (I'95)

WAIJELI, JESSE CLYDE - Ia.10,07 (l'0

PATTERSON, 147, MADISON

JITTLE, HU]TON I. $\left(\mathrm{b}^{\prime} 70\right)-\mathrm{Ja}, 6,94$ : $\left(l^{\prime} 94\right)$

PAULLINA, 796, O'BRIEN

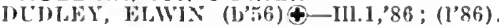

Janllton, Wm. Alexander (b'72) H-Ia.4,00 : (I'99)

OT.DAG

PELLA, 3,021, MARION

ASCIIENBIR ENNER, CARL F. $\left(b^{\prime} 63\right) \oplus-I a$ 4,'94; (l'94).

BIRON, IIENIRY S. (b'52)థ-Ind.5,78 : (l'03).

30s. COKNELIUS N. (b'76)థ-Ill.6, 04 (l'04); S. Fred F. (b'70)-Ia.6,'96; (l'97). CARIENTEl, LEWIS J. (b'38)-Mo.18,'86: (l'86).

Chllds, Alpha G. W. (b’71) - Ill.10,00 (l'00) ; not In practice.

CRFW, WM. F. (b'72)-Mo.28,04; (1'04); OALR.

KEABIJS, IIALLEI FRANCIS (b'66) III.1,90; (l'90):

Kramer, Martin (b'54)-Mo.1,80; (1'87)

PAYNE, IIARRY C. $\left\langle b^{\prime} 71\right) \oplus$ - Ia.9, 97

warren, Elbert Taylor $\left(b^{\prime} 85\right)-1 a .6,10$ (1'10).

PEORIA (R.F.D., PELLA), 100, MAHASKA Ayres, Chester A. (b'81)-11l.11,04; (I'04). PERCIVAL, I50, FREMONT

Wiese, Henry Geo. (b'60)-Neb.5,86; (1'95) PERRY, 4,630, DALLAS

Burleigl, Benj. W.-Ill.6,05; not in ppractice.

Doidgre, Renfred F. (1,62)-Ill.1,97; (1'97).

FREE, SAML.P. (b'78) \&-1a.3,02: (1,02).

Fultz, Eloise M. Grosenbaugh (b'66)E111.8,94; (1'94).

Griksby, Ulysses G. (b'68)-0.2,96; (1'96).

Haden, Eugrene B. (b'66)-Neb.5,'95; (l'95)

Johnson, Nellie May (b'78) H - Ill,4, 06 ; $\left(1^{\prime} 08\right)$.

Johnson, Theo. F. (b'48) H-o.7,76; (I'86)

McPherrin, Henry IrI (b'87)-Ia.6,'12; (1'12).

NOWER, WM. P. (b'7l)-Neb.5,97; (1'97)

I'aul, Irvin N. (b'59) H-Ill.4, 85 ; (1'86).

ROSS, Al:THUR J. (b'59)-Ir.1,80, N.Y.10 84; (l'86).

Trout, Alexander W. (b'44)-Ill.1,'67; (l'86).

Wilkinson, Harry Blaine (b'82)-Ia.s,'10 (l'10).

PERSIA, 358, HARRISON

TTAGMAN, JOHN FREDK. (b'76)-Neb.6, 03; (1'03).

PETERSON, 480, CLAY

CIITTERTON, ALLEN SMITH $\left(b^{\prime} 55\right) \oplus-$ Ia.3,'82; (1'86).

Esser, Wm. (b'57)-Ill.1,91; (l'91)

(Gage, Alan Edw. (b'86)--111.11,'12; (1'12).

sproule, E\&dert W. (b'7)-0nt.5,'05; (1'05).

PIERSON, 4I6, WOODBURY

law, Elmer Jos. (b'74)-Ill.11,'99; (l'99).

PILOT MOUND, 347, BOONE

LAIDLEY, WALIACE GILMOUR $\left(b^{\prime} ; 6\right) \oplus$ Ont.5,'06; (I'06)

Sllane, Robt. S. (b'86)-Ia.3,'1́z; (1'12).

Smith, Newton M. (b'74)-Ia.6,'96; (l'96). 
PISGAH, 212, HARRISON

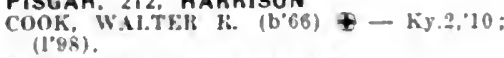

PLAINFIELD, 288, BREMER

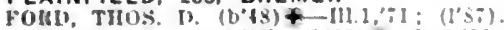

JAY, LEOS DOWXI: (b.55) - is 3,10 :

J.1.

PLANO, 150, APPANOOSE

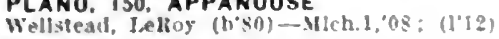

pleasanton, 200, Decatur

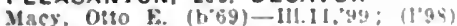

Pleasant Plain, 174. JefFerson

Halley", Casilus W'-la.9,"9:; (1'G8).

PLEASANTVILLE, 691, MARION

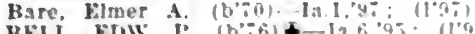

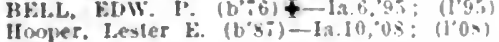

II oojer. le

Merritt. Anthur M. (b's1)-Ia 10,01; (I"0

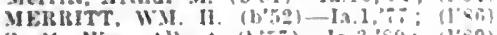

Scoll. Wm. dliert (t'5i)-Ja.3, $\$ 9$; (l's9)

PLOVER, 187. POCAHONTAS

WAI.I.AC'F, JAMES DICK $\left(b^{\prime}\right.$ b3 $-111.1 .9: 3$ (l'93).

PLYMOUTH. 358, CERRO GORDO

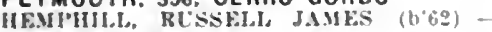

III.6."12: (1.92).

POCAHONTAS, 987. POCAHONTAS

BARTHEL, OSCAR H. (b.57) - MI.1, (l'9z).

BRIJ)(iMAx, JoIrx C. $\left(\mathrm{b}^{\prime}, 0\right)+-111.1,03$ : $(1.05)$. RIORDAX, JAMES C. (b'6s) - III.,91;

Starr, John W. (b'5s) $\rightarrow$; (1 82$)$

POLK, 310, POLK

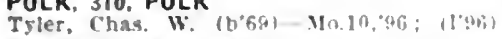

POMEROY, 815, CALHOUN

MARTIS, DAYII, THEO.(6'5t)+-HI. 1,'s: : (1'86)

Taylor, Chas. J. (b'il)-Ill.11, (a): (1002)

PORTSMOUTH, 347. SHELBY

Welr, kdw. C. (b"75)-la.3,"00): (1*00)

POSTVILLE, 952. ALLAMAKEE

Blessin, Otto James 111.4 . $\left.^{\circ} 1:(1)^{\prime} 0\right)$

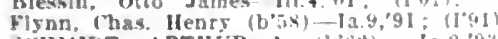

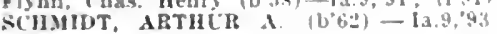
(1294)

PRAIRIEBURG, 187, LINN

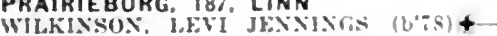
Ia.3, 07 : $(10 \%)$.

PRAIRIE CITY. 764. JASPER

CHASt, WY. If. (b's) $4-1 \mathrm{a} .3002$ : $\left.11^{\prime} 02\right)$

II

Mcconnaughey, W. D. (boj) - Pa.,

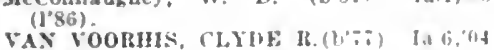
(1) 04 ).

PRESCOTT, 426, ADAMS

Clary, Wra. Henry (b's0)-Ia.3."13: (1'13).

Uufrman, John Win. $\left(t^{\prime 50}-0\right)-0,79:(1 " 60)$

PRESTON, 642, JACKSON

AILASTRONG, C'IAS. IIERMAX (b's0)Alth
III.8,0\%: (1'11).

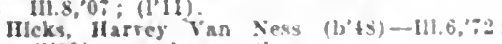
$(100)$; not In lractice.

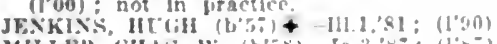

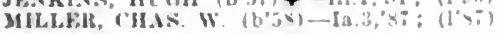

PRIMGHAR, 733, O'BRIEN

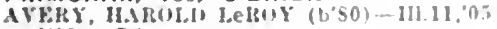

(1.09): $P d$

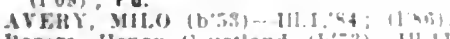

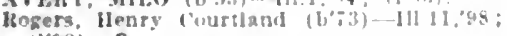
(1) 08 ) : $\mathrm{S}$.

PRINCETON, 379, SCOTT

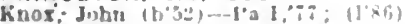

PROMISE CITY, 274. WAYNE

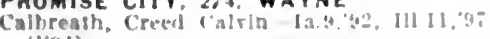

$(1 \cdot 04)$

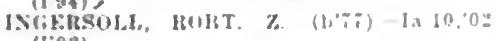
(I.0).

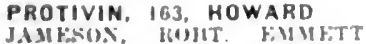

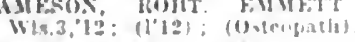

PULASKI. 382, DAVIS

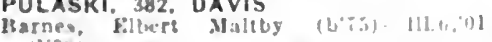
(1'0:3)

เาхен. .60: (1'sx); 0 b.

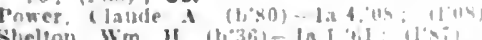

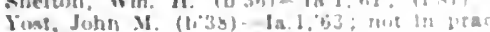

ilce.
QUASQUETON, 394. BUCHANAN

JOIINSOX, VOIBMAN WHLLIS-1A.10,04: (1'04)

QUIMBY, 268, CHEROKEE

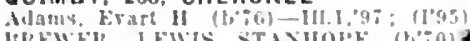

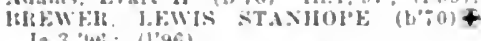

Ia. 3, "1,t: $(1,96)$.

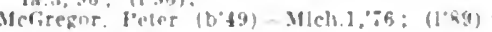

not in pract!co.

RADCLIFFE, 660, HARDIN

Mrens. l.ewis H. (b'sl)-Mo ma, I0: (l'11).

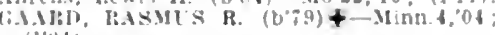
(1'(1)

RAKE, 163. WINNEBAGO

Rissq. Jesce bugene $\left(b^{2} 8.5\right)-111.11,0$;

RALSTON, 175, CARROLL

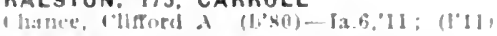

RANDALL, 200, HAMILTON

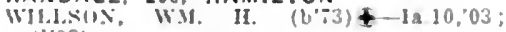
(1'03)

RANDOLPH, 304, FREMONT

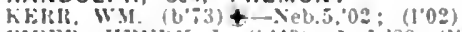

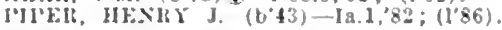

READLYN, 227, BREMER

GERXSEY. MEKITT $N$. (b'9)‡-IH.11, (05); (1'0) )

REDDING, 269, RINGGOLD

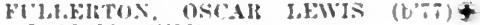

1. $10.02:(102)$

REDFIELD, 659, DALLAS

MOOMMAX" ALLEN (b'70)-1 a. 3,96; (1"96)

THOKDBLHG, MATUEW WATSUX $\left(\mathrm{b}^{\prime} 59\right)+$ -N.1.10,'91; (I'YI).

REO OAK, 4,830, MONTGOMERY

ASHIBY ATCHSON ALMOND (t,62) + 111.1.83; (1's:).

liutchart, Fugenia May (b'z)-111.4.96; unt in practice.

Butchart. Thos. R. (b'6.i) II-I11.4,"95; (1'48)

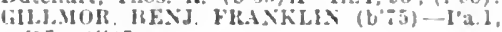

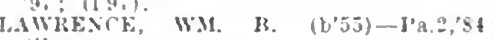

Martin, J. A. J. (b'tt)-Ind.t, 75 , Mll

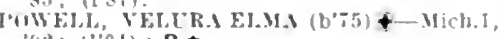
(1):- (1,01): $\mathbf{P}_{-} \star$

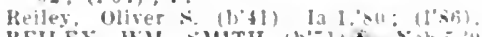

IRILEY, WM. SMITH $\left(\mathrm{b}^{\circ} \mathrm{i}\right)+$ Yeb.5.45 $(1, i) ; \mathbf{s}$.

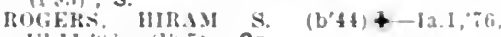
$111,11,86:(1: \div) ; 0$.

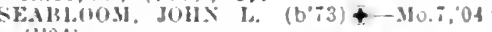
$11001)$.

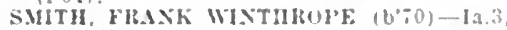
(4) $(194)$

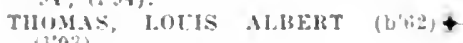
$11293 \%$.

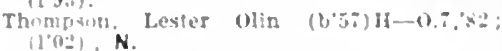

REINBECK, 1.205, GRUNDY

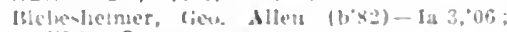

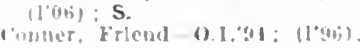

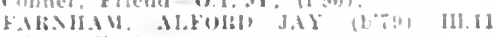

llaplanay. Lawrence kryant (bot) M.1.

$\left.\because 4 ; 1 x_{i}\right)$

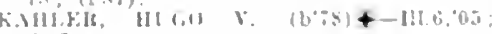

REMBRANDT, 128, BUENA VISTA

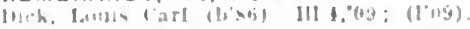

REMSEN, 1,076, PLYMOUTH

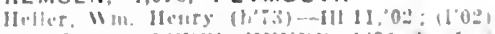

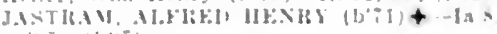

RENWICK, 3\%2, HUMBOLDT

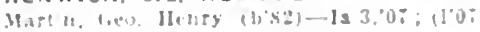

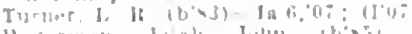

RHOUES, 300, MARSHALL

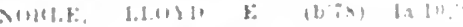

RICEVILLE, 846, MITCHELL

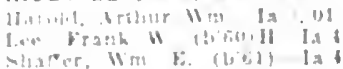

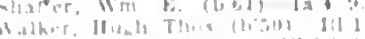

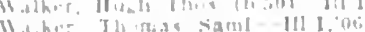

RICHLAND, 613, KEOKUK

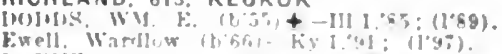

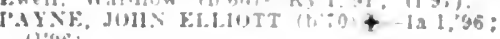

(1) $19(i)$

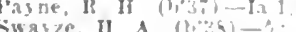

RICHMOND, I50, WASHINGTON

CHITTIU, JOSIAII MHTON

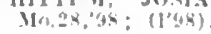

RIDGEWAY. 354, WINNESHIEK

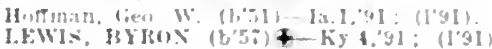

RINGSTED, 3।3, EMMET

BOSSIXIHAM OTTMEK X. $(2: 2)+$ Ja 3 , 1.02: $(1004): S$.

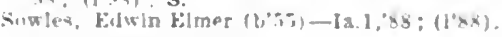

RIPPEY, 407, GREENE

MATTI, WGRILY GEN (b*6)-Ia 3,09:

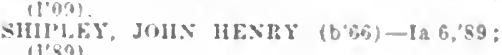
(1) 891 .

RIVERSIDE, 652, WASHINGION

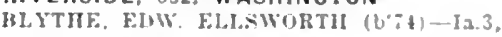
'04: (l'0) : OALR.

Maresh. (ien, (h's1)-Ia 3,02 ; (1'02)

RIVERTON, 583, FREMONT

BAIDWIS, LEIIN ALVA (bra)-IILI, Of: (1)

Hatton, S. C. (b'?)-Mo.17:s?; (1'86).

ROBINSON - DELAWARE

Dun Van, Fdw. Kithland $\left(b^{\prime} ; 4\right)$-ia $f$ : $9:$

\section{ROCKFORD, 916, FLOYD}

Hrown. lutuer (b'3s)-111.1, $b 6$; (1'sti).

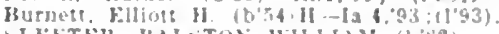

GLETBI, MAILTOY WIJLIAM (R'se) -

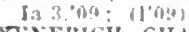

Y:NFHCH, CIARLES OTIS (b'si) $\$-1 \mathrm{a} 3$.

ROCK RAPIOS, 2,005, LYON

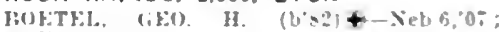
(III)

(UROMAX, LOTIS LFONARD $(6,76)+-$

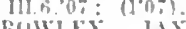

(1003).

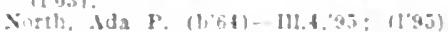

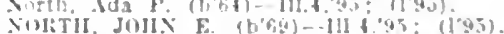

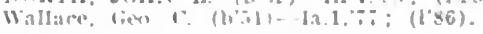

ROCK VALLEY, 1,198, SIOUX

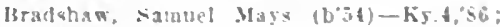
(1's?)

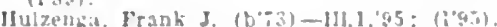

I ElMHER, likHLITT EIW. (b's:)-Jil. 11: (1) I:-1

ROCKWELL, 700, CERRO GORDO

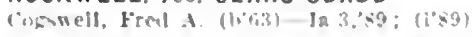

ROCKWELL CITY, 1.528, CALHOUN

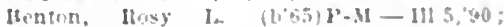

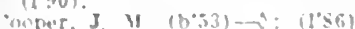

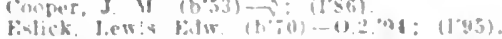

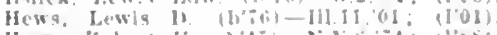

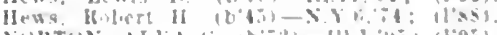

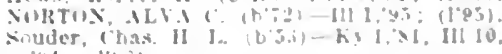

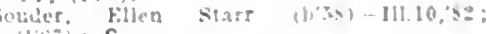

RODNEY, 163, MONONA

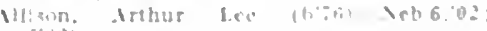

"Wan. Joabul billob

ROLAND, GHI, STORY

Here Kist (I cin) Ia

ROLFE, 954. FUCAHONTAS

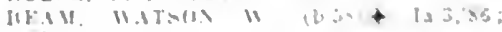

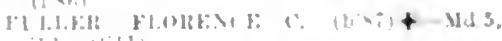

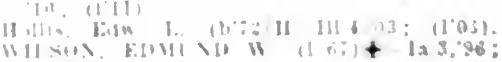

ROME, 135, HENRY

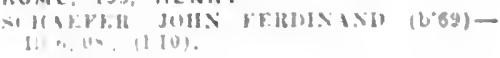


ROSE HILL, 269, MAHASKA

JARVIS, HARRY DWIGITT-Ia.3,06; (1'06). Wrlght, Walter Yelson (b'68)-Ia.3,97: (1'37).

\section{ROWAN, 256, WRIGHT}

(Gordon, Wm. Null (b'70)-Ia.3,'04: (I'04). Rhlne, Arthur Calvln (b'75)-Ill.11,'12 (l'12).

ROWLEY, 200, BUCHANAN

Rentz. Chas. Bernard (b'78)-Ill.1, 01 (1'01).

\section{ROYAL, 300, CLAY}

Jones, Danlel s. (b'65) $-0.3,95$; (1’98)

Scliwerdtecer, Frank 1). (b'88')-IIl.6,'11 (1'I2).

RUDD, 296, FLOYD

FIENCII, YAUL Y'ENNEY (b'T4)థ-IIl.1, '97; (1'9i).

IIuribut Deloss $\left(b^{\prime} 44\right)-\mathrm{Y} .5 .10,79$, Ia.3, '83; (1'8\%).

RUNNELLS, 428, POLK

BUFKIN, CALVIN W. (b'72)-Ia.6,'98; (l'98).

RUSSELL, 612, LUCAS

Buzzard, Samuel (b'45)-Pa.14,' 71 ; (ま).

IIIIIs, Robt. Asa (b'81)-Ill.11,07; (1'07)

ROBB. JAMES BRYSON (b' 6$)$ \&-J11.1, 03 ; (I'06)

RUTHVEN, 655, PALO ALTO

BALDWIN, GILBERT-Mo.1,'82; (1'86)

Bosley, Carl Estep (b'84)-1a.3,"13; (1'13)

HUSTÓ HERRERT MARC $\left(\mathrm{b}^{\prime} 70\right)-\mathrm{Ia} .3$ 92 ; (1'92).

RUTLAND, 212, HUMBOLDT

Prettyman, Oscar Robt. (b'81)-Ia.6,'10; $\left(1^{\prime} 10\right)$.

RYAN 5II, DELAWARE

Cummings, Wm. C. (b'74)-Ia.3,03; (1'03)

DONNELLY, WM. (b'57)-N.Y.10,'83; (1'86)

SABULA, 918, JACKSON

AYERS, FRANKLIN D. (b'67) --Md.6,'93 (1'98)

SWIFT, FREDK. JAMES (b'83) 4 -IIl.11, 04; (1'05)

SAC CITY, 2,201, SAC

Adams, Chas B.-H-0.7,83; (1'86).

FINDLEY, WM. JOHN K. (b'60)๑-Ill.6,

'94; (1'94) ZACHARY (b'53)๑-1a.3,'76; (]'94).

Messenger, Fred H.-Ia.3,'06; $\left(\mathrm{l}^{\prime} 06\right)$.

STALFORD, JOHN HOLLENBACH $\left(\mathrm{b}^{\prime} 69\right) \oplus$ -Ia.6,'92; (1'92); OpAL.

SWEARINGEN, GUYY IIOWARD (b'81) -

Ta.6,11; (l'11). HAROLD (b'69)-Ia.3, 97 ; $\left(1^{\circ} 97\right)$.

SALEM, 501, HENRY

Cox, Elmer Lee (b'83)-M0.28,'08; (l'12) Dilts, John J. (b'64) - Ia.1,'s8; (l's8).

PITTMAN, CARSON W. (b'53)๑-Ky.4,76 (l's6).

STEWART, EDGAR ALLEN (b'81)-Ia.3, $12 ;(1 ' 12)$.

SALIX, 390, WOODBURY

TAYLOR, JAMES FITZ (b'67)-N.Y.10,'92; (1'92).

SANBORN, 1,174, O'BRIEN

Horton, Frank W. (b'70) H-1a.4,'94; (1'94)

HUTTERER, EDW. G.-Ia.8,07; (1'08).

Kuyper, Will (b'84)-Ia.6,11; (1'11).

SCHALLER, 646, SAC

Andre, Thos. J.-IIl.I,'82; (l'86) ; S.

McCRAY, FRANK HERBERT ; (b'66)๑-

Ia. 8,'96; (1'97).

SCHLESWIG, 455, CRAWFORD

JONES, HENRY DURST (b'80) $\odot-I a .3,03$; (1'03).

Schultz, Walter Henry (b'77)-Ill.1,00; (l'0l).

SCRANTON, 845, GREENE
ARTHUR, SAMUEI HOWARD (b'63) Mich.1,93; (1'94).

MIICh.1,'93; (l'94). M. (b'74)థ-Md.3,00;

(l'01); Pd. PARTY, ROY EVERETT (b'86)-Ia.6,'12;

PRESNELL, J. WILI (b'70)-Ia.3,92; (1'93).

SEARSBORO, 226, POWESHIEK

Logue, Paul T. (b'71) H-Ill.4,97; (1'97).

llcGarry, Sami. Burton (b'74)-Ia.6,03; (I'03)
SELMA, 200, VAN BUREN

Gray, Albert Bartlett (b'70)-1a.6,'10 ;

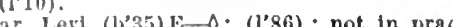

tlee.

SERGEANT BLUFF, 525, WOODBURY

CONMLY, ROY MEIRILL (b'83) -Ia.3, '05; (1'05).

SEWAL, 200, WAYNE

Ingraham, Darld Robt. (b'81)-Mo.22,'13;

McN'13).

SEYMOUR, 2,290, WAYNE

IBUICIIETT, IDWIN (b'82) (4-Ill.11, 03 ;

COVER, OLERIANNUS ALVIN (b'62)

Md.4,'93, Pa.2,'94; (1'93)

Davis, Arthur Earl (b'82)-Ill.11,09; (I'09)

Farnest, Wm. H.- 0.8,70; (1'87)

lunyon, John H.-Ia.1,'90; (1'92).

SHAMBAUGH, 245, PAGE

BFNING, JOHN FIEDK. (b'76)-Neb.5,'04; (1'09).

SHANNON CITY, 292, UNION

KYLE, WM. SIMP'SON (b'77)-Ill.6, $O 4$; (1'05).

Loomis, Francls Wm. (b'54)-Mo.28,'94; (1'98).

SHARPSBURG, 181, TAYLOR

Maulsby. Udams E.-Ia.1,87; (1'87).

SHEFFIELD, 824, FRANKLIN

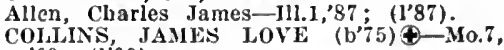

09: (1'09).

SCHV̈AB, FREDK,-Ia.6,'06; (1'06).

SHELBY, 586, SHELBY

ATCHLEY, BARNEY D. (b'79) -Ia.6,'11; (l'II).

NES, N. JASPER (b'44)@-Ia.3,'83;

Kegel, Áugust H. (b'44) H-O; (l'91).

SHELDAHL, 202, POLK

Horner, Amos Alexander (b'79)-Ia.6,04; (1'04).

SHELDON, 2,941, O'BRIEN

BRACKNEY, HERMAN JOHN (b'81)-Ia.3 05; (1'05)'; Pd.

BROCK, WALTER R. (b'70)-Ia.6,'94 (l'96).

CRAM, FREDK. WARREN (b'54)థ-Ill.1, $78 ;(1 ' 87) ; \mathrm{s}$

Longshore C. (b'42)-Pa.14,'72; not in practice.

Myers, Frank L. (b'65)-Ml.11,'88; (1'88) IYERS, W M. H. (b'58†-Ill.1,'82; (l'86) Page, Clarence Vernon (b'74) H-la.4, 02 ; (1'02) ; Pd.

SHELLROCK, 741, BUTLER

Clasen, Henry W.-Wis.2,97; $\left(1^{\prime} 97\right)$; not in practice.

ENSLEY, BRUCE (b'78)థ-Ia.3,07; (1'07)

Smith, Wm. Henry (b'51)-Ill.6,78; (1'86).

SHELLSBURG, 527, BENTON

Boles, Irwin S. (b'44)-0.6,74; (l'86).

LASHBROOK, ELAM E.-Ia.3,'06; (l'06).

SHENANDOAH, 4,976, PAGE

ALDRICH, J. FRANK (b'73) - Ill.1,'97 (1'97); Anes.

ARMITAGE, ALBERT CIEGLE (b'63)-Ia.9, '91; (1'91) ; OALR.

BARNES, BENJ. SPAFFORD $\left(b^{\prime} 84\right) \oplus-$ Ill.1, 09 ; (1'10) : Pd.

Brush, Milo Orlon (b'84)-Ia.4,'08; (l'08); $\mathrm{ObG}$

KELLOGG, CHAS. ELMER (b'63) $9-I l l .11$ $93 ;\left(l^{\prime} 94\right) ; 0 b$

TNAM, LYNN J. (b'86) - Md.1,09 (l'09)

Putnam, Tilford L. (b'59) - I11.1,'85; (1'86)

Smith, Geo. Luther (b'52)-Ia.I,'82; (I’93) not in practice.

TOTLER, WILLIS FREDERICK (b'67)థKy.4,'93; (1'93).

Sutton, Robt. H. (b'41)-0.2,63; (1'87).

Van Meter, Fletcher J.-Ia.6,'06; (I'06).

SIBLEY, I,330, OSCEOLA

Farnum, Earl P. (b'77) H-la.4,'98; (l'98), Heetland, Louis Herman (b'6s)-Mich.8,'95:

HOUGH, FRANK SHERMAN (b'64) $\oplus$ Mich.8,'90; (1'97).

Lawrence, Wm. R. (b'43)-Ill.6,78; (l'86) WINKLER, FRANK P. (b'82) $\uparrow$-Ill.11,'06
$\left(l^{\prime} 06\right)$; Member S. D. State Med. Assn.
SIDNEY, 1,019, FREMONT

Ambler, Samuel B.-Mo.22,'85; $\left(l^{\prime} 86\right)$. JOVELAIY, JAMES M. (b'54) - Mo.15. '81, Mo.1'87; (1'86).

LOVELADY, RAII'H SMITH (b'88) -Neb.6. 11: (1'11)

Morris, Willis G. (b'52)-Ia.1,'85; (l'94).

NELSON, AUDLEY EMMET (b'68) - - Pa.2, 97 ; (I'97).

Stephens, 'Thomas G. (b'32)-0.6,'56; (1'87).

SIGOURNEY, 2,032, KEOKUK

DULIN, JOIIN ALRERT\$-Ia.3,'03; (1'03) DUIN, TARANA J. GROTIIUUS $\$$-Ia.3. 03 ; (l'03).

EASTBURN, WM. W. (b'53)-Ia.3,87; (1'87).

JOHNSON, ALBERT PERCY (b'62) -Mo.1,

'91; (1'91).

Kemp, Malcolm E. (b'77) H-Ia.4,'03; (l'03). OLIVER, LEONARD BRIGGS (b'58) - -Ia.3, '87: (1'87).

PFANNEBECKER, WM. (b'64) $9-M 0.1,91$; (1'91)

Sherlock, Margaret (b'77)-nl.11,'05; (l'05).

Strawbridge, Frank A.-Ia.4,86; ( ).

SILVER CITY, 4I6, MILLS

Baker, Lewls L. (b'55)-Mo.18,'92; (1'92).

McCUE, JAMLES GETTUS (b'69)థ-Ky.4 91; (1'91).

Moore, Robt. A. (b'54)-la.1,81; (l'86).

Swarts, Mable (b'88)-Neb.6,11; (l'11).

SIOUX CENTER, 1,064, SIOUX

de I'ree, Selne Bolks (b'74)-nl.1,03: (l'03).

Jongewaard, Carl Albert (b'80)-nl.1,04; (1'05).

SIOUX CITY, 47,828, WOODBURY

NUMBER OF PHYSICIANS, 107

Amthor, John Graham (b'85)-Mo.28,'10 (1'10) ; Metropolitan Block; 11-12, 1-5.

ANDERSON, AUGUST (b'63) -Minn.4,'91; (l'98) ; 1917 Ingleside Ave.; office, Schulem Bldg.

Angle, Steuben D. (b'51)-Mo.18,'86; (l'86) ; 3015 Irene St. ; 2-4.

Barr, Guy Ernest (b'85)-Ia.8,'03; (l'06); 2216 Jackson. St.

Bartlett, Thomas W.-H-nl.10,'78; (1'86).

Bowden, Isaac-Mlch.7,'94; (1'94); Davldson Bldg.; $9-11: 30,1-5$.

Brady, James Ray (b'68)-Ia.3,'93; (l'93) : 1503 Jackson St.: office, Metropolitan Block: $9-12,1: 30-4$.

Brothers, Howard N. (b'70)-Ia.8,'03; (1'03); 1806 Mornlngside Ave.; 10-12, 3-5.

Brown, Foster Vletor '(b'78) - Ia.8, 05 ; (l'05) : 1732 Orleans St.

Brown, Harold Learned (b'86)-Mass.1,'11: (1'13) ; 904 Jennings St.; offlce, Security Bldg. ; $2-4$; ObG.

RROVVING, GEO. STILLMAN (b'75)Ill.11,'99; (1'04); 504, 10th St. ; offlee, 622 . 4 th St.; $10-12,2: 30-6 ; R$

BUSSEY, WM. JOS. (b'il) $\oplus$ - Pa.2, 01 ; (l'01) ; 2401 Nebraska St.; offec, Securlty Bldg. ; $10-12,2-5$; (B31); OALR.

CHRISTIANSEN, JAMES (b'71) - Ia.3,05 (I'05); Member Minn. State Med. Assn. ; United Bank BIdg.

CLINGAN, CHAS. EDW.(†-Ill.1,'77 ; $\left(1^{\prime} 86\right)$; 814, 6th St.; office, 5 th and Nebraska Sts. ; $9-10,2-4$

COMSTOCK, HARRIET CONNIFF (b'48)Ia.3, 80 ; $(1,86) ; 1600$ Nebraska St. ; 10-4. CONNIFF, ROBT. E. (b'58) $\oplus$ - Ia:3,'84; (1'86); 1417 Pearl St.; office, Security Bank Bldg.; $10-12,2-4$.

cOURSHON, BENJ. (b'68) - Ga.11, 01 ; (1'07) ; 1422 Douglas St.

Cremin, Wm. J. S. (b'81)-Ill.11,06; (l'06) ; 1514 W. 7 th St.; office, Davidson Block.

DAILY, MILTON' (b'70) $\odot$-Minn.5,'95; (1'96); 1717 Pearl St.; office, Securlty (1'96); 1717 Pearl St.

Bank Bldg.; 9-11, 2-4. Ill.1,90; (1'90); 1116 Court St.; office, Ill.1,90; $(1 ' 90) ; 1116$
Davidson Bldg. ; $2-4$.

DAREY, J. HERB́ER'T (b'61) (4-Que.1,'85 (1'87); 1249 Morningslde Ave. ; 8-10, 2-4, $7-8$.

DEAN, WILIIS WARREN (b'72)-Neb.5,'95 (l'98) ; 622 Nebraska St.; offlce, Farmers

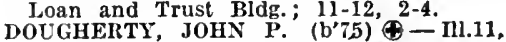
04: $\left(1^{\prime} 16\right) ; 615$ Kansas St.; oflice Farmers' Loan and Trust Bldg. 
DUNI.AVY, JOIIS C. (b'49)-Ja.1,"78, Ky.2 82; (1'85) : 1316 Nebraska sit.; unlec, ;01. 4th st.: 9-12. 2-5; OALR,

EICHELBEIRGER, AGNES $\left(\mathrm{b}^{\prime} 64\right)+-111.9$ '88: (l'90); 1502 Douglas

Security Bank Bhlg.: 9-4; Db. *

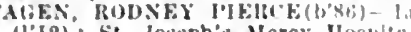

(I'I2): St. Joseph's Mercy Ilosplitat.

eenstra, Johan 13. II. (b'43)-Xeth ay 'tis (1'86),

RA.YCHHE, FREDK. F. $\left(15^{\circ} 66\right)+. M n n 4$ '90; (l'92); 2825 iebraska si. ; nflle" Farmers' Loan and Trust lHals:; 10-12 2-4; (I331); OALR.

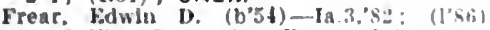
3525 VIne St. ; oflece, Farmers' Lotall and Trust IBIdg. : 9-1:1-5; D.

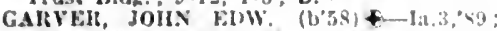
(1'89); 2606 Jacksou st.: oflce, rarmert (189) :

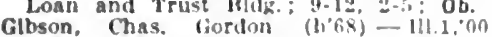

(1'00); 280\% Nebraska St.; onlce, 512, th st. : $10-12,2-5: 0 b$

Glllin, Chas. Wesley - III.1.90; (1"90) Farmers' Loan and 'Trust Mlde'

Hanchett, Wm. H.-111.10,79; (1'06)

Ilanchette, Johil Lerell (b'6́) H-III 10,89 (l'89): 2203 Plerce St.; once, Davidson Blde: $3-5$

HANSOX, CLARENCE B.-Ia.8' : (

Havens, Jamos A. H. (b'st)-Id.s, 08 $\left(l^{\prime} 08\right)$ : Cnited Bank IBIdg.

Hermann. John (b'60) H-lil.10,'89: (l's9): Metropolltan Block.

IIOI'E, FRAXK G. (b'83)-Ia.8, 06 ; (1'06) 1105 W. 3d St.; oftlce, Farmers' loan and Trust Bldg.; 10-12, 2-0.

Horner, Kate Z. (1,68)-Ja.s,'96; ( ( '96j).

llosklns, Samuel lennett (b'-1) -Ia 4,96 (1'96): 1+15 w. 19th st.; oflec Massi chusetis 13ldg.; 10-12, 2-4.

IIoyt. Wm. Ilenry (b'62)_X.Y.5's6; (1'Si) 1425 Summlt Ave. ; $11-12,2-4$.

Jeukinson, Ernest Alvert (b,72)-II1.11,03 (1'04): 831 Nebraska St. oflle, Farmers Loan and Trust Bldf.; $\mathbf{S}$.

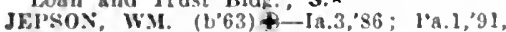
Eng.14,9:; (1.86); ith and Jomes sily.: offlce, 5th and Jackson sits.; 2.5: I'rof. Surg., IA. 3, : (A): S.

Johnson, Hidw. firant-Ill.1,87; (1'05).

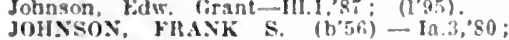
(184): javldson duto llock.

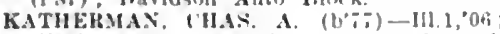
(l'09); 1210 l'earl Se; oflce, 403, th

KEEFF', PATRICK ETCHNF (1)'\$6)-PA2, 10: (1'12): $90 x$ I'lerce st.; oflec, Dablison Ildg.: $11-12,2-5 ; 5$

Kllthorne, J. M. (b't2) II - ia.

$329.41 \mathrm{~h}$. : $10-12,2-1,0$

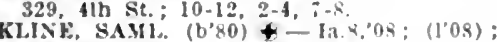

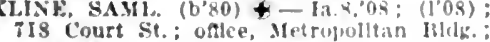
$9-12,2-5$

हXоT, JOHS M. (b't) $+-1+1,1,70$ (1'86): 914 Jackon st. ; vitlce, securlty Bank Bldg. ; 10-12. $2: 30-4: 30$

KNOTT, VAX BURFX (b'il) - D. 1, 1, (1'93): 2323 Sebraska sit.; unce, Securlty lidg.: 2-5: (Ai, F5): S.

MIdR. 2-5: (Ai, F5): S. 2015 s. St. Mary"d St.; odlce. Ilavldsun Blds.; $10-12,1-5$

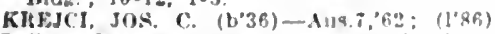

Lally. Frank Ifughes (h'Q5)-Neb,6,"11:

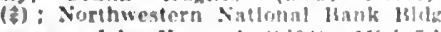

Iawrence, John Hancock (b'bi)-Mlch.5,"88 (1'90) ; 1712 l'lerce Sit: : otlce, 505, 4th St.; 10-1: OALR.

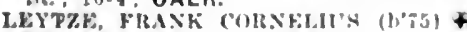
Ira.2.04: (1'05): 2100 Jarksien Sit.: onlc Metrofulitan Bliok: $1-5,30$

MacCornack, Fubence Andrew (h'sei)- 11111 13: (foplleatlon penilns,'13); 4507 Morn. Ingalde Are.

Mahowl, Wm. Hebmond $(1,+6)-0 n ! 1,0$ "

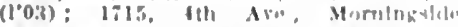
omce, Securliy Mank Hllig: 1 s

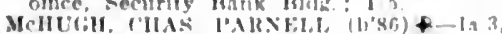

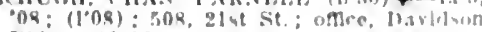
IHAk : $10.12,2-5$

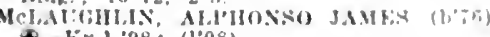
+ Ky.1, $98 ;(109)$

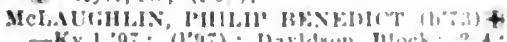

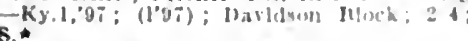

Mris, Enw. W.M. (1,75) $+-12.3,00:(100)$ Metroptllian block.

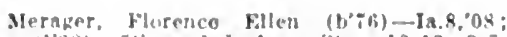
(1'0s): 5th and Jacksun Sts.: 10-12, 2-5

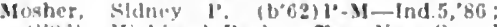
(l'AB): Hiphland Park; once, Jew lirand Thutier blelin: $10-1$. 2-4

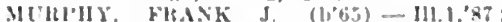
$(1 \times 2) ; 1814$ Jones st.; onthe, Luted Bank

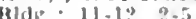

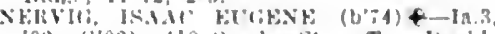
'02; (1'02) : 119 ()muha st, once, Lavldsin IMlds. : 11-12,3-?.

I'ALMUIST, LITIIEI TITIS $(1,81)+-$ Yu.2X.11: (1"12); 115 (ienrge st.; onlce. Me'supolltan Iilg.; 11-12, 3-6.

Iark, kimer 1t-la.10,07; (1007); Farmers lonn and Trust kid:

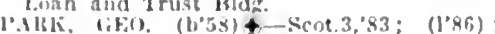
l.:0 summlt Arc.: oflce, Securlty Bank li!dg: : 9.1, 2.6; OALR.*

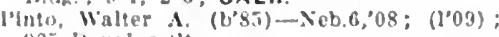
60, longlns st.

kloh. liy (yrus (b'61)-Pa.2.85: (1'89) 1100 lear! St. : oflce, [nlted Bank Bldg. $9-11,2-1$

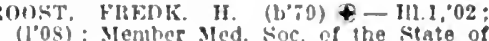

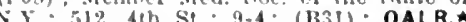

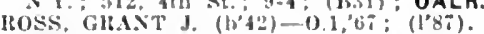

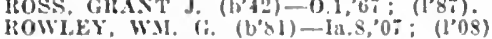

Massachuserts lildg.

I:OWSE, IROHT Q. $4-0.1,03 ; \quad(1,05)$; Northwestern Bank Blug.

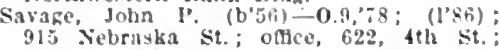

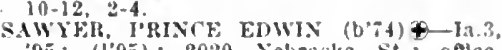
Farmers' Loan and Trust Bldg.: ' $1: 30-4$; S.*

Schott, George (b'5s)-Mo.1,'s2; (1'37); 1415 Pearl St.; omce, Davilion Blds. 2-i.

S'HOTT, IIKIY JOHNSON (b'Si)-II.1, '11; (1'12) 2 2R2I Nobraska St.; offlce, bavldson kldg.; 10-12, 2-4.

Seavey, Mark A. (b'7s)-Ja.8,08; (1'08): 2418 F. lst st.; oflce, 120 Falrmount Ire. ; $10-12,3-5,7-8$

SECOY, FHA.N I. (b'87)-In.3,11; (1'11): 1309 Douglas st.: once, bavldańn Bldg. $9-12,1: 30-5 ;$ OALR.

Seemann, Frelk. A. (l,66)H-II.4,9I, II.I, '97: (1'91): llavidson Rldg.: 9-12,

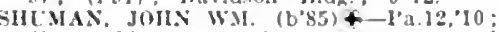
(1'11): 1719 court St. : oftce, parmers

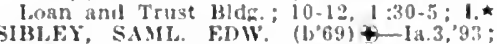
(1'94): it23 Pearl St.: oftlece, security lank Bldg. ; $1-5$

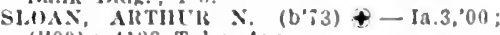
(l'00): 4133 Tyler Ave.

sureng. Theorlore F. II. (b'53) II-111.4,79;

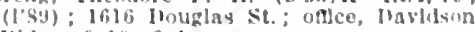
liklt. : $9-10,2-4$.

stasuly, Soeren W. (b'69) $11-111.30,92$; (1'93) ; 3002 Jackwon sit.; onlec, Mtissa. chusetts Isldis: $10.12,3-3$

stephens. Thomas (alderwood (b',6)-Kant of: (Bumloglat): $131 \%$ Newton Are: of tlee, Mornlugalde College.

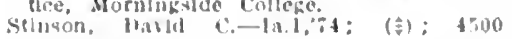

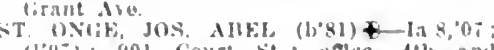
(1'0i); 901 Court st.; once, the and Lublelis sts. ; \&.12, J-B, i-8.

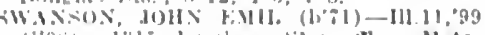

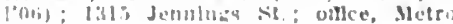

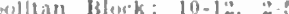

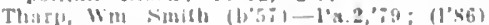
112. lentl sis onle secuslty lank Halg, ; $8-12,1-6$, i.9; U.

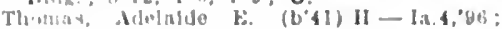
(1'yei).

Thumbsin, thas. Fredk-1) 2.895; (1'y)

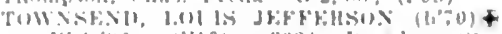

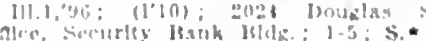

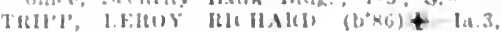

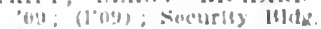

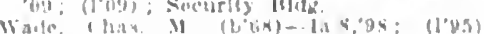

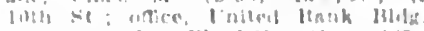

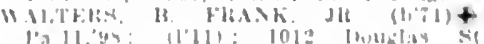

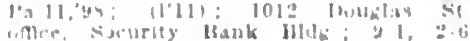
OALR.

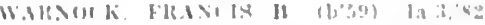

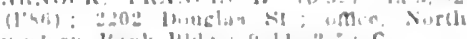

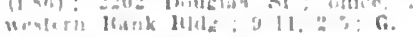

W.ARIRE, ALFXIS

$\left(b^{\circ}: 3\right)-13.8,02 ;$

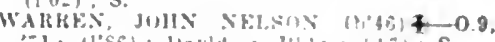

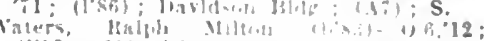

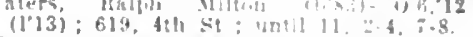

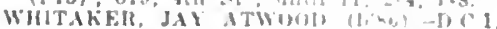

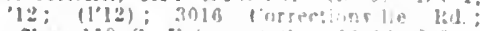
ralce, 119 s. I'alrmin!

Whlte, Mllton wykor (b"bi)-ia.3,52 XY10.88; (186); 1611 Nelraska st.

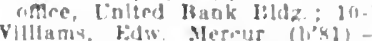

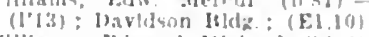

Wlllamy, Fiduard Mlohael (b'i)-Ja.3,12: (1'12): Darlaluon Jildg,

Wond, fen. Ibaker (b'il)-Ill 10,95; (1'98):

113\% Nebrauka Are.

SIOUX RAPIDS, 868, BUENA VISTA

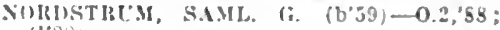

$(1 \times 8,4)$

Oberg. llscar (b'72)-Minn.5,98; (1'98).

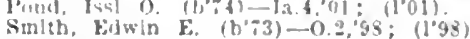

SLATER, 473, STORY

I'B.ISE, IIFIRIBERT (b'TI) -IA.3,"04; (I'04): OALR.

SEYFUSOX, GEO. JAMES (b'81) \&-IA.6, '10; (l'10).

SLOAN, 547, WOODBURY

ISIIER, OLIVEIl (b'5i) + -Ia.3,'s3: (1's6) :

Hilis. Mark B. (b'59)-111.1,'86; (1'86).

I'IlE, Mark B, (b'59)-III.1,86; (1'86) Ia.3,'03; $(1,05)$; Pd.

SMITHLAND, 334, WOOOBURY

P.MMUI'IST, NATHANIEL (b'7) \&-Mo.28, $109 ;(1 \cdot 12)$

Stoll, Louis \& (b'45) $\rightarrow$ : (I'S6).

SOLDIER, 167, MONONA

JUN(IFK, EMIL CARL (b,75) -Ia.8,02: (1'0").

SOLON. 450, JOHNSON

NETOLICKY, JUSEI'I (b'SI) -Ia.3.'09; STALCH, MALTIX OSCAI (b'ss) - la.3, "11; (l'11).

SOMERS, 169, CALHOUN

Farlow, Sanuel James (b't)-Ia.6.93: (1'y3).

SOUTH ENGLISH, 338, KEOKUK

Austin, Homer M. (b'0)-0.1,02; (1'0s): MLLOWAY, MLTON BLYTHE (b'SI) [II.1,1]: (1'12).

SPENCER, 3,005, CLAY

(OIIASTEH, VIIALLES CHAIMAN (b'SS) -1'a.2.09: (1'11): OALR.

Collewer, Jos 1: (b'601-11! 10.90: (1991).

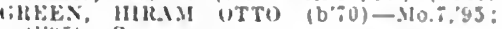

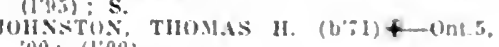

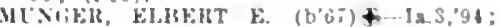
(1'm)

sokol, J0H: MURRISOx $\left(\mathrm{b}^{\prime} 6\right)+-11.2$.

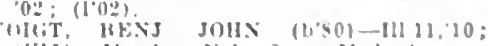

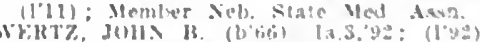

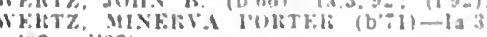
:13; (1'93).

SPERRY, 62, DES MOINES

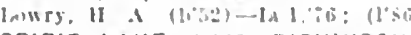

SPIRIT LAKE, I,162, DICKINSON

Battes), Frandy II. (b'65) - lians,"y3: (limeti).

Brounell. Ellas lawrence (b) 13 -bes bs:

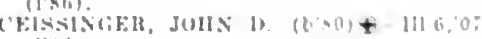

(1.04)

Jathon, James Macumber $(1,73)-121.102$

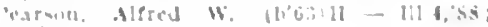

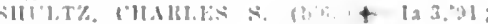

SPHINGDALE, :OH, CEDAR

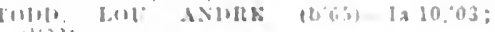

SIRINGIILLE, 588, LINN

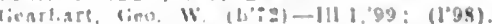

irshatu, Jacub lo. Wilt (bos)-ill.1.91: (1'9 
ST. ANSGAR, 747, MITCHELL

Howman, leonard J. (b'62)-Md.4,'93; (1'93): not In practlee.

IOTT, (iEY A. (1,'81) + - Ia.3,06: (1'06) Vestenberger, Jos. Chas. (b'zl) 11--Ia.4,97; (I'97)

ST. ANTHONY, 199, MARSHALL

Cralg, John J.' (b'49) r-Ia.6.'90; (l'90),

ST. CHARLES, 399, MADISON

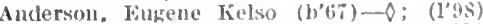

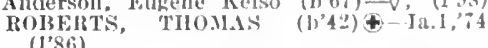

Sayre Iran K. (b's9)-Ia.6,13); (l'13)

SAYRT, SAMUKL N. $(1,5,5)+-19.6,86$ (1'S6).

ST. MARYS, 48, WARREN

Nusum, fieo fi. I3. (b'3) Mllch.1,95: (l'95) STACYVILLE, 407, MITCHELL

Brown, Warren Grallam-Ill.1,93; (1'93). Ilarrington, John Fredk. (b'71)-Ia.9, 85 (1'35).

STANHOPE, 28I, HAMILTON ICCALL, IIARRY K. (b'76)-Ill.11,01;

IcFarlaing, (I'II).

STANTON, 653, MONTGOMERY

LINQIIST, ARTILIK L. (h'82) \&-Ill.8, '06; (1'06).

Whisler, IIiram (b'49) H- 0 ; (l'87).

STANWOOD, 5II, CEDAR

IAAlER, CIIAS. W. (b'54) $4-0.3,78$ (1'S7).

TILDEN, WM. CLARK (b,7I)థ-Ia.3,02; (1'02).

STATE CENTER, 898, MARSHALL

EYGLE, THEODORE (b'57) †-Mo.1,85;

KAUFFMAX, IRA D. $\left(b^{\prime} 75\right)-I l l .10,01$; (L'OI).

Sherman, Emory (b'36)-Ill.1,85; (1'86);

not in practice.
WOODs, AItTILR D. (b'8I)-Ia.3, 00 ; (1'06).

STEAMBOAT ROCK, 378, HARDIN

CALDWELL, JANIES W. $4-0.8,76 ;(1 ' 86)$. CALDWELL, J. WILLARD, JR. $(b, 80) 4-$ Mo.7,01; (1'04).

STILES, 100, DAVIS

Giles, Grant (b'68)-Ia.9,'98; (l'98).

STOCKPORT, 265, VAN BUREN

GKABLK, FKEDK. J. (b'bS) —-Ia.9,'9I; (1'9I).

Morris, Livingston (b'58)-Ia.I,'92; (1'93).

Morris, Zenella E. N. (b'64)-Ia.1,94; (l'97).

STOCKTON, 138, MUSCATINE

Stephens, W'm. II. (b'58)-Ill.8,'\$3 ; (1'87).

STORM LAKE, 2,428 , BUENA VISTA

Graves, Rex Vale (b'78)-Ia.4,'03; (1'03).

NUSBAUM, LEE M. (b'64)-Ill.6,'93:

(l'0I); Member Ill. State Med. Soc.

o'DONóGHUE, JAMES H. (b'68)-III.I7, O'JONOGHUE

SMITII, EDGAR FRANCIS $\left(b^{\prime} 73\right) \oplus-1 a .3$, $08 ;\left(10^{\prime} 08\right) ; \mathrm{S}$.

Swallum, James Alra $\left(b^{\prime} 74\right)$ - Hll.4,01; (l'01).

Woodruff, Alva C. (b'50)-Ia.I,'82; (1'86) not in practlce.

STORY CITY, I,387, STORY

GILBERSON, PETER ('HRISTIAN (b'64) 4 -Wis.3,95; (1'12); Member State Med. Soc. of wis.

HAEREM. HAXS TH, K. (b';2)థ-Nor.1, 98; (l'04); OALR.

Molison, Robert Crichton (b'68)-Ia.3,97; (L'97).

STOUT, I45, GRUNDY

Roe, Cúllen Bryant (b'88)-Ia.6,'I2; (1'I2).

STRATFORD, 554, HAMILTON

BEACH, MELVILLE A. (b'68)屯-Ia.3,'01; (l'0I)

Kail, Carl (b'85)-Ia.6,'08; (l'08)

STRAWBERRY POINT, 1,052, CLAYTON

Anthony, Ernest Joseph (b'83)-Ia.3,'09; (1.09); OALR.

Howard, Fred Henry (b'59)H-Ill.4,'85;

(1'87), Irving Proctor-H-Ill.4,97; (1'97).

kawson, Edw. Clark (b'66)-Ihl.6,'91;

STRUBLE, 327, PLYMOUTH

Kincbel, Walter Jos. (b'87)-Ia.3,'11; (1'11).
STUART, I,826, GUTHRIE

I3AII JOS. A. (b'72) 4 -Neb.6,'98; (1'98) CLAIK, IIOWARD I. (b'81)む-I'a.12,05; (1'07).

TROSBY, ISAAC F. (b'65)†-III.II,'89; (l'8y).

Wosh, datcob 1t. (h'43)-Ill.1,70; (1'86).

Jinox John A. (1) 40$)$ II-Mo.5,71; (1'86)

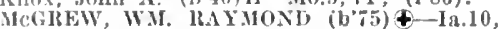
,03: (l'03).

Treat. Joseph A. (b'41)-Mlich.1,'67; (l'86) WIXNETT, JUS. IKODEITICK (b'8 i)-Ia.6, '12; (1'12).

SULLY, 282, JASPER

CARI'WNTEIR, OSCAI 0. (b'67) ४-Ia.6,99: (l'y 4 )

Snith, Juhn C. (b'58)-Ia.9,98; (1'98).

SUMMITVILLE, 200, LEE

COULTER, JOHN IILNIY (b'56)-Ia.1,90; $\left(l^{\prime}, 0\right)$

SUMNER, 1,404, BREMER

IUNKELAERG, BELT CLAY (b'63)-Ia.3, '89; (l'89).

STAFFORD, RICHARD H. (b'59)థ-111.1, $90 ;(1,90)$$$
\text { (1'90) }
$$

WLTTKE, EDWIN E. (b'79) -Mo.20,'06; (I'12)

\section{SUNBURY, 100, CEDAR}

Frank, fieo. W. (b'i6)-Ia,3,98; (l'98)

SUPERIOR, I54, DICKINSON

ATIINS, GEORGE LESLIE (b'76)-Ia.3, $05 ;\left(\mathrm{l}^{\prime} 05\right)$.

SUTHERLAND, 664, 0'BRIEN

KAS, THOMAS D. (b'83)†-Wis.2,'09;

LOUTHAN, BRUCE S. (b'47)-Ia.3,'73; (l'86); Óp. Nichols, Frank Lane (b'65) H-Ia.4,'95;
(1'95); Pd.

PARKER, EDWARD W. $\left(b^{\prime} 45\right) \oplus-I a .1,76$; (L'8ti).

SWALEDALE, 235, CERRO GORDO

Harrington, Wm. B. (b'66)-Mo.7,96; (l'96) kennedy, Edw. Philip (b'82) - Ia.3,'I2: (1'12).

SWEA CITY, 402, KOSSUTH

LUNDQUIST, CARL WM. (b'77)๑-Ia.10, $0 T ;(100 T)$.

MATTISON, CHAS. WESLEY (b'74)屯Ill.II, 04; (1'04).

TABOR, 909, FREMONT

DIETZ, CHAS. FREDK. (b'65) $\oplus-N \mathrm{eb} .5,97$; (l'97); OALR.

HARRIS, THEODORE C. (b'52) $\rightarrow$; (l'86). McKitrick, Salathiel C. (b'47)-0.2,'88; (1'95).

MILLER, BROWNLOW BARTLEY (b'85) -Neb.5,'08; (l'08).

Tweedy, Joh Taylor (b’55) - Ky.4,'90; (1'90).

TAMA, 2,290, TAMA

AILEN, MANNING L.๑-HI.11,93; (l'86) ; Pd.

AIPLETON, VIVIA BELLE $\left(b^{\prime} 79\right) \oplus-M d .7$,

, Pd.^

Carpenter, Wm. Edwin-Ill.1,95; (1'95).

Corms, Win. (b'34)-Ia.1,63; (1'86)

THOMPSON, BENJ. (b'44) †-Pa.I7,70; $(1 ' 86) ;\left(A^{\prime} 7\right) ; S$.

WHALEN, RICHARD H. (b'73)-Ill.17,04,

Ill.4, 05 ; (l'05).

Woods, Herbert C. (b'69) H-Ill.4,94; (1'94) ; $0 p$.

TEMPLETON, 278, CARROLL

DE GARZON, HARKY G. (b'TI)-Ill.14,'04; (1'04). LYNCH, MARCUS HENRY (b'82)థ-Ia.6,

TERRIL, 253, DICKINSON

SCHOOLEY, ALFRED H. (b'71) 6 -Ia.3, 02 ; (1'02).

THAYER, 198, UNION

WRIGIIT, W. A.\&-Ill.12,88.

THOMPSON, 500, WINNEBAGO

IIage, Nartin Nilton (b'85)-Ill.4,'12 ; (1'12). Gisle Martin (b'68)-Ill.1,'93; (1'94).

THOR, 27I, HUMBOLDT

Dabl, Daniel Irerson (b'66)-Ind.10,'98; (l'98).
THORNBURG, 233, KEOKUK

HAMILTON, CIHAS. M. $\left(b^{\prime} 56\right) \oplus-I a .1,81$; (l'87).

THORNTON, 27I, CERRO GORDO

Young, Iloward osbon (b'85)-Jll.8,'12 ; (I'12).

THURMAN, 336, FREMONT

COIE, HAIOLI) I'AUL (b'88)-Ill.6,'11; ( I'I $\left.I^{2}\right)$.

Colds, THEOJNOIF CIIFTON (b'54) Ia.I,'78, $110.20,36 ;\left(l^{\prime} 86\right)$.

TINGLEY, 380, RINGGOLD

Asbury, T, I'. $\left(b^{\prime} 57\right) \rightarrow$; $\left(1^{\prime} 87\right)$.

De Iong, Saml. IV. '(b'63)-Mo.22,'07; (l'07).

TIPTON, 2,048, CEDAR

GRIFFIS, AIRTIUR AIANSON (b'61) $0.26,98 ;(198) ; 0 p$.

HOFF'IAN, PAUL M. (b'76)†-Ia.3, 05 ; (1'05).

MCKINLEY, ETHEL MAE (b'87)-Neb.6, II ; (1'I1) ; G.

PETEILS, liICIIALD A. (b'63) ()-Ill.1,'84;

VAN METRE, EDW. J, (b'58)†-Ill.1,'86 ; (L'86).

TITONKA, 278, KOSSUTH

WATLACE, ROBERT' I. (b’Tб)-Ill.8,06; (l'06).

TOLEDO, 1,626, TAMA

Boynton, Henry W. (b'37)-N.Y.3,66; (1'90); not in practice.

Fee, Kuight Elias (b'81)-Ia.4,'12; (1'12). MAPLETHORPE, CHARLES WM. ('b'86)Ia.3,'10; (1'10).

llorford, Cómelius M. (b'65)-Ia.4,90; (l'90).

PACF, ARTHLR A. (b'70)-Mich.7,96; (1'96); (Indian Servlce).

Russell, Robt. Lee (b't0) - D.C.I,0I: (Indian Service).

SMITH, EUGENE RILEY (b'5I) †-Ill.I 76; $(1 ' 86) ; \mathrm{S}$.

TRACY, 200, MARION

PARK, LEWIS E. (b'55)-Ia.1,'80; (1'86).

TRAER, 1,283, TAMA

Ashton, C. W: (b'51) H-D: (1'86)

CRABBE, ALBERT ANDREW (b'70) Ia. $10.00 ;\left(l^{\prime} 00\right)$.

Nauerth, John Heury-Ill.1,'9I; (l'91).

Parsons, I'ercy Leigh (b' 6 ' $\mathrm{H}$-1a.4, 01 Ill. 10,$02 ;(1,01)$.

PINTERTON, JAIIES A. (b'60)๑-Ia.3,

WAGNER, WM. C. (b'72)-Ill.11, 03 ; (l'03). TRENTON, 75, HENRY

Day, Archie Loraine (b'78)-Ia.3,'04;

(l'04).

TREYNOR, I22, POTTAWATTAMIE

Stephens, Robt. Henry (b'80)-Neb.6,'04; (I'04).

TRIPOLI, 755, BREMER

ENNIS, HARRY H. (b'80)Ф-Ky.2,'09; (1'11); Member Ark. Med. Soc. N.Y.10,9I; (1'91); S.

TROY, 175, DAVIS

Garrett, Elmer E. (b'60)-Ill.6,'89; (1'86);

SIVINXET, ROY GOLDSONФ-Ia.10, (l'06).

TROY MILLS, 174, LINN

Yost, Bartley B. (b'72)-Mo.7,'98; (l'98).

TRURO, 3I0, MADISON

HUTCHISON, JAMES A. (b'53)-Ia.6,'89; (1'89).

UDELL, 186, APPANOOSE

REPLOGLE, JERRY A. (b'59)-Ia.3,'98; (1'98).

UNDERWOOD, 27I, POTTAWATTAMIE

WYLAND, ASA 0. (b'66)-Ia.3,'89; (1'90).

UNION, 540, HARDIN

Hammitt, Walter Frank (b'85)-Neb.5,'13; (1'I3).

KAUFEMAN, EDW. CHAS. (b'72)甲-Ia.4, 01 ; (1'0I).

UNIONVILLE, 300, APPANOOSE

CASE, THOS. J. (b'62) \-Ill.1,'89; (l'98).

Patterson, Leonidas S. $\left(b^{\prime} 60\right)-0.1,84$; (1'87). 
URBANA, 306, BENTON

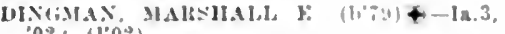

Moore, ludley A. (1*79)-Ias:06: (1'06).

UTE, 490, MONONA

Sherlock, John Ilodges $\left(b^{\prime} ; 9\right)-$ Ind 18, $00^{\circ}$ $(1,09): 0 b$.

SIATTriky. Jos. T. (17i) - Neh.b,09 (1009).

STEWAIRT, BFNJAMIN $($, (bos) + Ia

03: (I.03): S.

VAIL, 631, CRAWFORD

barllng. Fidw. (b'3S) -0 : (I'SB

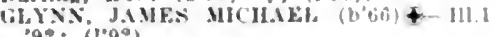

(0):

VALLEY JUNCTION. 2.573, POLK

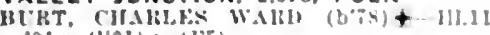
$01:(1,01):(1,3)$

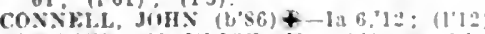

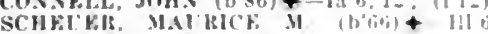
3\%: (1'8S): (F5): Ob.

VANDALIA (R.F.D., PRAIRIE CITY), 100. JASPER

Norts, Anson Jonroe- $Q$; (I'B?)

VAN HORN, 44, BENTON

Douplas, Clalr locksley (b'si)- Onth.l"? (1'12)

THOMSOE, THOMAS IFWIS $\left(b^{\prime}\right.$ a + Ont $6,{ }^{\circ} 05:$ : $11^{\circ}(0.5)$.

WAGNER, GEO, A. $(6 * 7)+-H 1.11,13$ : (I.93).

VAN METER, 386, DALLAS

SHIDFLER, ALIIERT H. (1', 1) - Ia.1, 81 $(9,8)$.

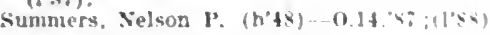

VAN WERT, 46I, DECATUR

Belding, Clifton Lelioy (b'si) III,b.'II

Pbelps, Myron (b'6t)-1a.t.'91: (l',

Tallman, Geo. barldion $(1,0 \%)-$ Jlo:6, 98 (1.98).

VARINA, 183, POCAHONTAS

PORATH, WM, CH.IS. $\left(b^{\circ}+3\right)+11140.2$ Colo., 03 ; (1.02).

\section{VICTOR, 640, IOWA}

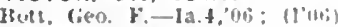

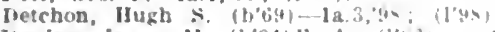

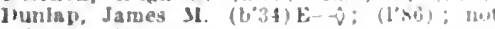
in practice.

McMAHON, THOMAS (b.75) + IA.3, $\left(1^{\circ} 06\right)$.

J'hlllps, nasld W. (b'58)-0.14.2.: (1'ali).

VILLISCA, 2,039, MONTGOMERY

COIIYKR, JAY CLAllK (b':)

$(1) 0$ क

Hough, Eegar Clayton (b.50) ll 111.,

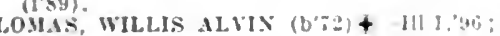
$(1,96)$

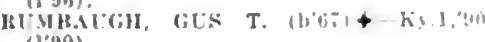
(1'90)

WILIMS, FHAK SPALMNG ( III.1.01; (1'01).

VINCENNES, 100, LEE

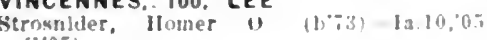
(1) 05 )

VINCENT, 213, WEBSTER

Jardine Goo, Indrew (b'ss) 1114.12 (1'13).

VINTON 3,336, BENTON

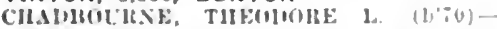
Ilct $t$, ty

Mleht.

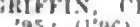

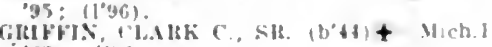
68: $(1800)$

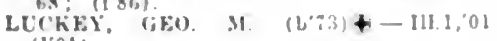

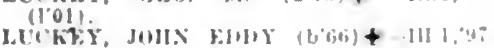
(l'mi)

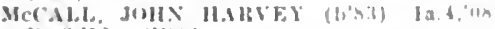
'

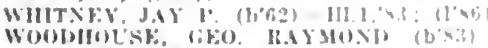

Ia.3,0s: (1'04).

VOLGA, 416. CLAYTON

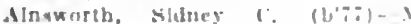

$(1,08)$

Cahlil, Jobn dloymlum-la b:"0: : (100")

WADENA, 233, FAYETTE

WADEN
WALCOTT, 4I6, SCOTT

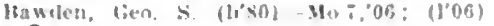
S.

Schuniacher, Henry-13.3.82: (I'S6).

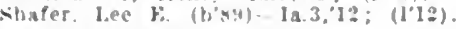

WALKER, 317. LINN

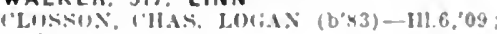

Wilk, Frealk liarld $\left(b^{\circ} \times(0)-1\right.$ is 10,04 (1)

WALLINGFORD, 300, EMMET

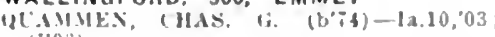
( l'03)

WALL LAKE, 561, SAC

Habden, Arthur S. (bog)11-1at,96:

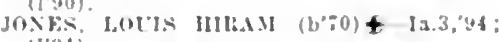
(1:D)

WALNUT, 950, POTTAWATTAMIE

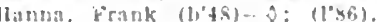

Latchern, Baymod Lee (b'85)-III.1I

10010

loss inso It (b's0)-1a.3,0i: (1.0i). OALR.

WAPELLO, I,326, LOUISA

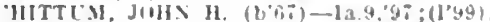

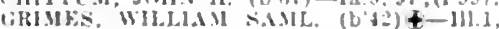
$\because 1 ;(1 * 06)$

Rokers, kaluin C.-Ia.9, 98 : (198)

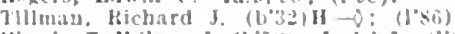

Wimulruf, II Hson J. (b'sy)-la.1,s; (l'vi) Ob.

WASHINGTON, 4,380, WASHINGTON

indersou, "Wm. Filmer (1,'bt)11--I11.10,'94 (1) $4+\{)$.

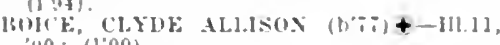

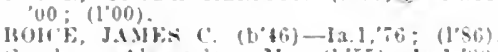

cowden, dlexander M. (his)-ia.1, so $(1 \cdot 06)$.

DHAX, HAY HYRISERT (b'60)-Ia.3,02

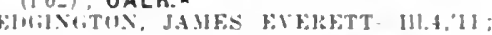

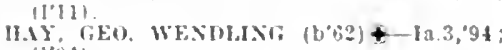

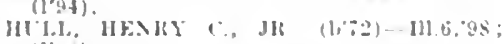

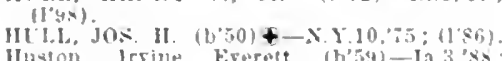

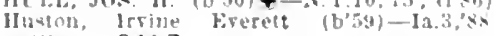
(I) OA): OAL. *

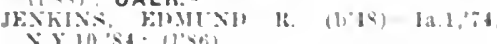

Vasmo, llerrey fulton (b's) Jas,os (I) 0 s)

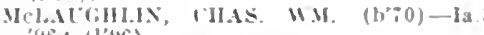

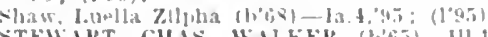

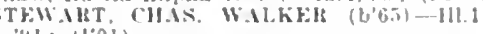
, $1: 11^{\circ} 011$

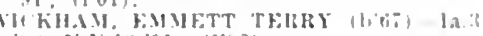

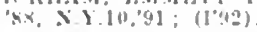

\section{WASHTA, 10 , CHEROKEE}

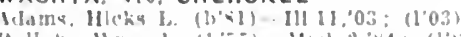

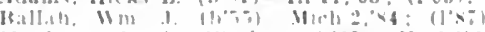

llotain, Lewis Wesloy llibi) ky 1,91 $11^{1} \div 11$.

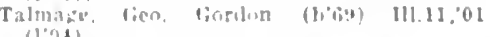

WATERLO0, 26,693, BLACKHAWK

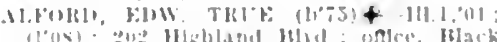

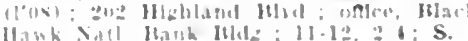

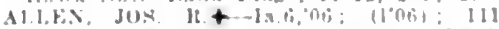

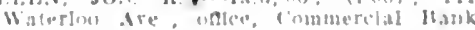
lildis

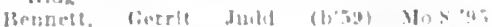

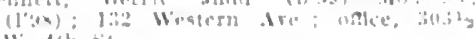
II. It 13 it

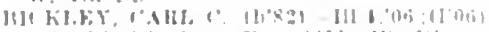
1:25 w th (11) $1: B+0$. 0 .

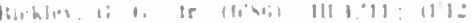

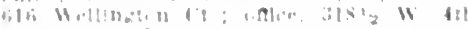

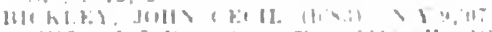

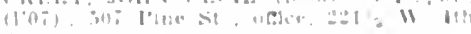

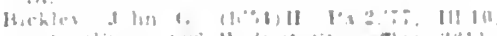

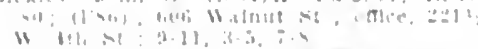

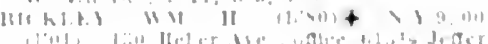

Blowers. Walter M twa1,-l116,05: (1'05):

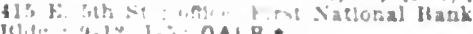
IIII: : 1.1\%, 1-: OALA.

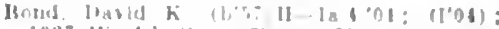

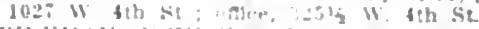

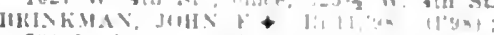

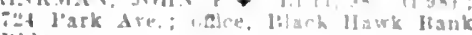
lld

Jrown. Harey W. (1)

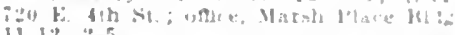
$11-12,25$

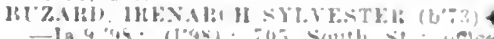

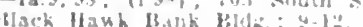
OALR *

CASE, LAFAYHTT: W - II1.790; (1.97)

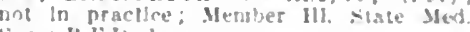

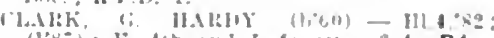

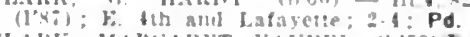

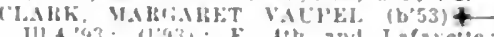
Ill. $4,(4,3 ;(193)$ : E. Hith and Lafayelte $2-1 ; G$.

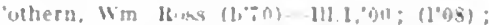
$11: 2$ if at Ave : inire, Russell-damson Hlikis: $9-12,2+5, ; .2$

hakin, limers tir!an (190)-111.11.03; (⿳); III linworm Are, oalce, $206 \mathrm{La}$ fayele 1 lod

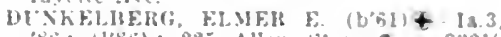

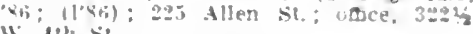

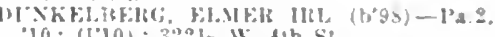

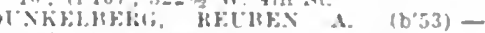

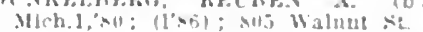

Everall. Menj. chester (b'41)-la.6,0: 11"0i) ; 10 Walnut st: once, Marsh

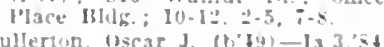

$x:(195)$ nus in practice: Fullerton Fl.: 9-4.

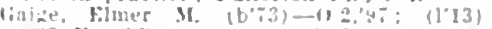

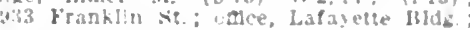
$10-12,2-1,-\infty$

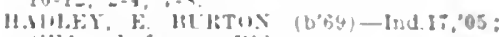
(1']1); Lafayelte Blid

Ilinna, Huward Harry (b'63)-III.1, 85 $(1: 48)$ : not ln practice; $1200 \mathrm{~W}$. औ si

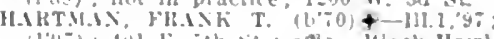

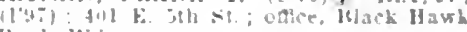
liank ling.

Ilufmann, Alfrul A. (b'yg)-Nicb.'1=: (l'13); st. Francls II sptal.

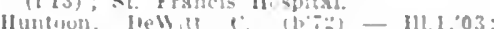

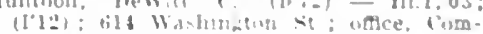
mercial Hunk litwo : 10-12, $0-4$.

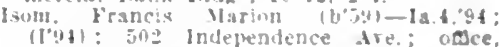
l.apalette $16 ! 4 !$ :

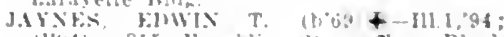
(l'yt): 315 l'ranhlin st. : Alce, Black

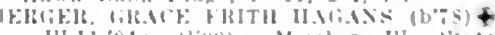
III 16.04: 1/063): Menluer Ill. Siate

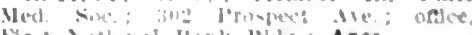

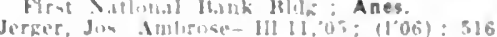

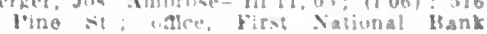
Hhls:

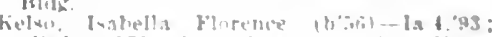

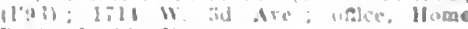

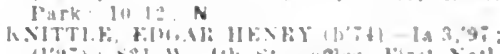

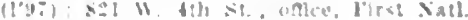
Hank lik!:

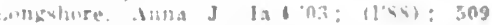

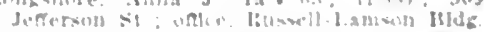

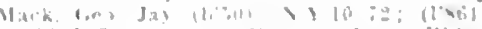

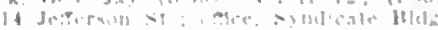
OALP

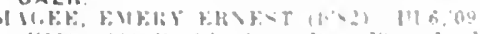

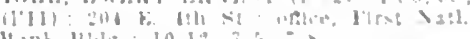
H,Inh Hide: 10 l:

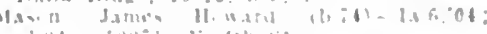
(1)

1.1. $3.0 \%$

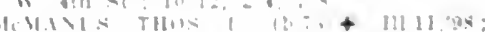

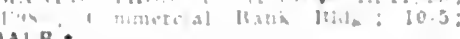
OALR.

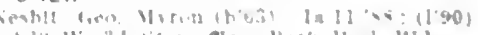

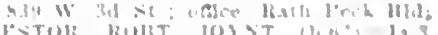

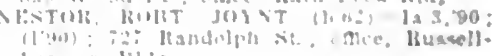

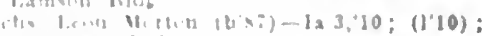
sind rate lllue 
O'KKEFE, JOIN ELBERT (b'71)థ-Ia.3, 96 : (1'96); 1'rospect and Hlghland Sts. otuce, Commerclal I3!dg.

Parsons, Emma Arlinda Dawson (b'59)III.90: (l'90): not in practlce: Walnut 'St.

I'ORTLRFIFLD, FRANK W. (b'5i) III.0, 79: (I'86): 2II Irrlng St. ; oflce, Commerclal Bank IBldg. ; $2+6,7=8 ; \mathrm{S}$.

POWERS, FRED w. (b'68)-Ia.3,'89; (I'89) not ln practlce: $742 \mathrm{~W}$. 34 st.; omce, Black Hawk Bank I3ldg.

RIDENOUR, JOS. EI.MFiR (b'73) †-III.II 01; (1'01); 400 Commercial St.; $2-4$

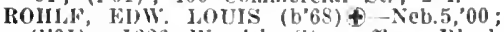
(l'0I); 1226 W. 4th st. ; Once, Black Hawk Pank Bldg. ; 2-5, 7-9

SAGE, FIRLI). CARLTON (b't4)†-Ia.4,93 (I'93); 930 Walnut St. ; offlce. First Natl. I3ank 13ldg.; $9-12,2-5$; OALR.

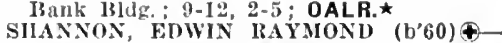
11I.10,'96; (l'96); 215 Franklln St.; oflece Black Ilawk Bank Bldg. ; 11-12, 2-4, 7-8; S.

Slgworth, IIarry W.(h'77)-IIl.1,99;(1'98); 720 W. Park Are. ; offlce, Russell-Lamson Bldg.

Small, Laurence M. (b'67) - M0.27,97; (l'97); 222 Maple St.; oftlce, Lafayette

SMALL, WM. B. (b'62) क-Ill.6.'90; (l'90) ; 206 Iowa St.; oflce, James Black Blds. 206 Iowa St. ; oflce, Jame
$9-12,2-4 ;(B 8) ; 0 A L R . \star$

Sinith, Sidney Danl. (b'84)-N.Y.20,10 ; (I'12) ; 78 Iafayette St.

Spelcher, John G.-Ia.4,'83; (l'86) ; not in practlce: $620 \mathrm{w}$. I1th St.

STEVENSON, EBER FORTNER $\left(b^{\prime} 74\right) \oplus$ Pa.2,04; (l'04); 515 Pine St. ; offlce, Marsh P'Iace BIdg. ; II-I2, 2-4. 7-8.

TAYLER, THOMAS GEO. (b'63)-Pa.2,'86 ; (l'00); 624 W. 4th St.; offlce, Syndlcate Block: 1-4, 7-8:30.

TIIOMPSON, JAMES REED (b'83)-Ia.3 05; (l'05); Black Hawk Bank BId

Thompson, Oscar P. (b'54)-1a.3,76; (I'95).

Thornton, Thomas Fruncls (b'85)-Neb.6, '13: (I'I3); Commercial National Bank Bldg. : $10-12,2-5,7-8 ; \mathrm{S}$.

WADDEY, ERNEST J. (b'67)-Md.1,91 (1'96); Ells Hotel; offlce, Flrst Natlonal Bank BIdg.

WATERBURY, CHAS. ARTHUR (b'74) Ill.4,'99; (l'9s) ; 713 W. Park Ave. : offlce, James Black Bldg.; $11: 30-12: 30,2: 30-5$; Pd.

WATERVILLE, 125, ALLAMAKEE

DILLON, BERT JOHN (b'80)-Ml.11,04; (l'05).

WAUCOMA, 433, FAYETTE

FOX, WALTER H. (b'82) (-Ia.3,'05; (1'05).

Kaufman, Ernest Leslie (b'79)-Ia.4,05: (l'05).

Smittle, Jacob M. (b'75)-Ia.3,'97 ; (1'98).

WAUKEE, 340, DALLAS

Jones, Thomas SamI. (b'75)-Ia.6,'13;(1'13).
McMahon, Geo. Thos. (b'61) - Ia.6,95; (I'95).

WAUKON, 2,025, ALLAMAKEE

BOWEN, DANL. HAMPTON (b'50) $\oplus$-Ill.1, 76 ; $(1,86)$.

CAIN, JOHN W. (b'56)-Ill.1,'83; (1'87).

CRAWFORD, JOHN CLIFFORD (b'54)-IIl.6, '82: (I'86).

Earl, willard C.-Pa.2,'67; (1'86)

Gilchrlst, Wm. Thos.-III.I,'84; (I's6).

HUECKER, JOHN (b'70)థ-Colo.1,'98; (I'98); Pr.

LETOURNEAU, PHILIPP HENRY-Ill.6, '81; (I'97).

LEWIS, JOHN C. (b'58)-Ia.3,'89; (I'89).

McCULLOUGH, JoS.-Ia.8, 05 ; (1'05).

Mosby, Geo. (b'8I) -Ia.4,07; (I'07). ROM1NGER, CLARK W1LSON (b'80)-Ill.22,

Strock, David (b'40)-Mo.3,'75; (l'84).

SVEBAKKEN, OTTO O. (b'75) $₫$-Ill.22,'06 ; (l'07).

WAVERLY, 3,205, BREMER

AUNER, JAY FRANK (b'72) - III.11,'97; $\left(l^{\prime} y 7\right)$.

CHAFFEE, ORLYN LEE (b'76)-Ill.10,02 ; (I'02)

Adele Kimball (b'61)H-Ia.4,94; $\left(1^{\prime} 94\right)$; not in practice.

GRAENING, CHAS. HEINRICH (b'71-Ia.4,
IFRN, LESTER CORNELIUS (b'71)థIa.3.95; (I'35); S.

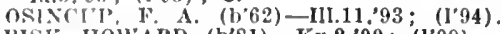
KISK. HOW $A R D\left(b^{\prime} 81\right)-K y .2,09 ;\left(l^{\prime} 09\right)$.

ROIBISON, ROIT. E. (b'69)-Ia.3,'94;

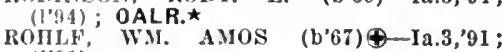

Rubel, Harry Francls (b'79)-Ill.11,04; (I'04).

WAYLAND, 550, HENRY

ALLEN, FDW. C.-Mfo.7,'98; (1'98).

Jones, Gieo. M. (b'61)-Ia.3,'86; (l'86)

MCCONNAUGIEY, D. S. (b'37)-Ia.1,67;

STONE; JACOB CLAY (b'77)థ-Ky.9,03; (I'I2).

WEBB, I50, CLAY

Rust, Emory A. (b'81)-Pa.2,'04; (I'04)

WEBSTER, 127, KEOKUK

GAIRINER, EDGAR WINFIELD (b'84) Ia.10,'06; (I'06).

WEBSTER CITY, 5,208, HAMILTON

Andrews, Syrena-E-Ill.8,82; (1'87).

Buxton, O. C. (b'57) E-Ia.7,'88; (1'86)

CONRA I), BELLE H. (b'72)-Ia.3,94; (1'94).

DESMOND, THOS. FRANCIS $\left(b^{\prime} 65\right) \oplus-$ Ill.1,'95; (1'95).

HAIJ. FOREST FRANK (b'86)థ-Pa.2,09;

HALL, ORLANDO A. $\left(\mathrm{b}^{\prime} 48\right)-0.2,76$;

HANNAH, WARD (b'79)థ-Ill.6,'I1; (l'12).

Hatchklss, Mary M. NeIsen (b'74) H-Ill.4, '04; (1'04).

Homan, Ralph Waldo (b'69)H-Ia.4,'94;

McCAULIFF, GUY T. $\left(b^{\prime} 74\right) \oplus-111.6,02$; $(1,04) ; 8$.

Richardson, Everett E. (b'69)H-Ia.4,95 . (I'95).

WHITLE, FRANK E. (b'57)@-Ill.1,'81;

WYATT, WM. WALTER $\left(b^{\prime} 71\right) \oplus-N . Y .10$, 95 ; (1'08) $\mathrm{S}$.

\section{WELDON, 308, DECATUR}

Jamison, Oliver Perry (b'79)-Ia.10,'05; (1'05).

MITCHELL, ENOS (b'53)-Ia.1,78; (1'87).

\section{WELLMAN, 724, WASHINGTON}

BRADEN, AUSTIN IYNN (b'70)-Ia.3,'03; (I'03).

DOWNING, LEROY MORGAN (b'79)-Ia.3,

Gardner, Wm. P. (b'60)-Ia.3,'86 ; (l'86) ; Mot in practlce. (I'I0)

Wells, Jos. Edw. (b'55)-Ia.1,'92; (1'92).

WELLSBURG, 283, GRUNDY

Chlnn, Wm. Thos. (b'52)-Ia.1,'90; (1'90).

Heddens, Claus Hesing (b'68)-Ill.1,98; (I'98); not in practice.

URAN, JOS. ALFRED (b'77)థ-Ill.11,'03;

WELTON, 69, CLINTON

WATSON, JOHN D.-Ont.6,07; (1'07).

WESLEY, 457, KOSSUTH

Adair, Wm. S.-Ia.3,'91; (l'9I).

Adams, Fred L. (b'68)-Ia.3,98; (1'98)

CARMOOY, THOS. J.4-Mo.34,'07; (1'07) ;

WEST BEND, 679, PALO ALTO

BISIIOP, ALBERT HENRY (b'73)-Ill.10, ,00; $\left(I^{\prime} 00\right)$.

HILGER, CARL H. (b'69) $€-W l s .3,04$;

WEST BRANCH, 643, CEDAR

LEECH, LOUIS JOSEPH (b'46) @-Ia.3,'8I ; (I'86).

MCGREGOR, JAMES CHAS. - Ia.3,06 ; (l'06).

MOORE, WALTER N.(-Ia.3,06; (I'06).

WEST BURLINGTON 1,206 , DES MOINES

KELLY, JOS. IGNATIUS (b'73)-Ia.I0,'0I ; (I'01).

KIRKENDALL, EDW. E. (b'59)-Ia.3,'85; (1'86)

WEST CHESTER, 222, WASHINGTON

Caldwell, Edw. James (b'72)-Ia.10,02;

HENDERSON, JOS. G. (b'54)-0.3,79 (I'87).
WESTFIELD, 143, PLYMOUTH

BRINNER, WALTER JACOB (b'82)-Ill.6, '09; (l'10).

WESTGATE, 232, FAYETTE

SPAlRS, FIRANCIS RUFUS (b'82) $\theta$-Ill.6, 01; (I'04).

WEST GROVE, 24I, DAVIS

STONE, JAMES G11.MIIR (b'83) (-)-Ill.4, '08; (1'09).

WEST LIBERTY, I,666, MUSCATINE

Ady, Emmett (b'55)-Ia.3,'82; (l'86).

llll, James Win. (b'82)-Mo.22,07; (l'07).

KImball, channing 13 . (b'5i)-Ia.3,74; (l'86)

KINBALL, JOHN EGBERT (b'85) - Ia.3, 08; (I'08).

Royal. Lester Ambrose (b'84)H-Ia.4, 00 ; (I'06).

Welh, Eimer 1. (b'89)-Ia.3,'12; (1'12).

WEST POINT, 570, LEE

Dierker, Frank Henry (b'78)-Ia.10,06; (I'06).

MEENTS, DIEDRICH JANSSEN (b'78)

Ia.3,07; (1'07).

WESTSIDE, 367, CRAWFORD

Palterson, Chas. Luther (b'69)-Ill.1,'99;

Patterson, James Carroll (b'81)-Neb.6,'I0;
(l'11).

WEST UNION, 1,652, FAYETTE

Ainsworth, Elbert Augustus (b'49)-N.X.15, $74 ;\left(I^{\prime} 86\right)$.

DARNALL, GEO. D. (b'43)๑-0.1,'72; (1'80)

KING, THOMAS'A. (b'77)-Ia.3,'05; (l'05). illlamson, Charles Hodge (b'78)-Mlch.1, 03; (1'03).

WEVER, 100, LEE

McKaig, Richard Frank (b'66)-Ia.1,94; $\left(1^{\prime} 97\right)$.

WHAT CHEER, 1,720, KEOKUK

IcDonough, Arthur WIIlls (b'78)H-IIl.4,

Rayner, Herbert W. (b'73)-Ill.1,01; (1'01) ; ayner.

TAYLOR, CHAS. B. (b'67) @-Ind.9,'99; (l'99); S.

WILLIAMS, JOHN CALVIN (b'45)@-Ia.3,

Wlison, Lanson C. (b'60) E-0.2,'87; (l'87).

WHEATLAND, 539, CLINTON

Bittner, Edw. Wm. (b'84)-Ia.3,07; (1'07). COOK, ACHILLES WALTER (b'66)-1a.9, '91; (1'91).

DEAN, JOHN SEDGWICK (b'64)-Mlch.1,

WHITING, 576, MONONA

HOI'T, JEFFERSON NEWTON (b'75)IA.10,04; (I'04). Que.1,'96; (1'98).

WHITTEMORE, 518 , KOSSUTH

ICCREERY, JOHN WM. $\left(\mathrm{b}^{\prime} 77\right) \oplus-1 \mathrm{~T} .6,98$; (I'98).

\section{WHITTEN, 219, HARDIN}

BUTLER, FRANK POST (b'61)๑-Ia.3,'87; ( (1'87)

Duncan, Wm. Cass (b'65) H-Ill.4,'85; (l'98).

WHITTIER, I50, LINN

Ross, Alice Idella (b'70) H-Ia.4,'94; (l'94)

WILLIAMS, 457, HAMILTON

O'Connor, Maurice J. (b'77)-111.6,'03; (1'03).

Tedrow, Jaines B. (b'56)-Mich.1,'86; (1'87).

WILLIAMSBURG, I,060, I0WA

LONG, ENOCH CLOUD (b'54)-Ky.2,'90; $\left(l^{\prime} 90\right)$.

IOON, ARNOLD C. (b'60) $O-I a .3,84$; $(1 ' 86)$.

MOON, ARNOLD ROBERT (b'86)@-Ia.3, '10; (1'10).

SCHÚG, GEO. F.-Pa.2,'04; (1'07).

WILTON JUNCTION, I,157, MUSCATINE

COOLING, WM. ANTHONY (b'72)థ-Ill.1, '99; (l'98).

LEITH, ALEX. R. (b'57)-Ia.3,'82; (l'87).

LEITH, GEO. GUYFORD (b'84)-Ia.3,'08; (l'08).

Mason, Harry Philson (b'74)-Ill.11,00; $\left(I^{\prime} 00\right)$.

Mlller, Wm. Jacob (b'68)-Ia.9,'94; (1'94);

not in practlee.

wluter, L. C. (b'72) H-Ia.4, $0 \mathrm{I}$; (l'0I). 
WINDHAM (R.F.D, OXFORD), 35, JOHNSON

Blgelow, Saml. Edw. (b'80)-Md.4.04 (1007).

WINFIELD. 934, HENRY

Gardner, Charles Wallce (b'59)-Ia.2.94: (I'94).

Hanna, John w. (b'4i)-1a.3:73; $\left(1^{\circ} 8\right.$ ( $)$

HAIRRISOX, KDW. W. $\left(\mathrm{b}^{\circ} 6 \mathrm{6}\right) \downarrow-1 \mathrm{a} 9.94$ : (1'94): 0 o

McCAW; WM. II. (b't1)†-la.1,78: (l'RB)

MeConnaughey, J. Terry (b'i6)-la 10,03: (1'03).

WINTERSET. 2.818, MADISON

DAVENPORT, FKANK D. (b'39) -0.2 187: $(1,87)$.

DAVISSON, RORT. RUTLKDGE (b'66) III. $1.90:(1 \circ 90)$.

EMBRFE, EDWARD (b'64)†-IA 3,39 ; (1'89)

HCKENLOOPRR, CARL B, (b'84)-310.22, $10:(1 \cdot 10)$

Muholland, John $\left(b^{\prime}+4\right) \rightarrow 0.8,: 4:\left(l^{\circ} s z\right)$

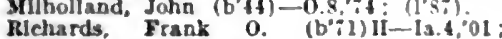
(1'01).

RJppes. M. P. (b'29) $\rightarrow$ : $\left(1^{\prime} 86\right)$

SKINYER, GEO. N. (b'53) $\$-1 \mathrm{a} .6 .59$; (1'86).

SMITII, JESSIE VALERIA (b'66)-1a.1.9:; (1'92).

8lerman, wubur Flske (b'61)-111.1\%,96: (1'98).

THOMPSON, WM. H. (b'57)-Pa.2, 84 ; (1’86).
WINTHROP, 529, BUCHANAN

IIOCSEIIOLDHR, HAROLI) A ('B'81)

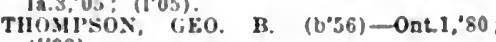
(1'93).

WIOTA, 239, CASS

Polluck, John 1. (b'69)-Tenn.8,'11: (1'12) STULTS, MIILARD F. $\left(b^{\circ} 5 i\right)+i a .10^{\circ}$ (I'si).

WODEN, 162, HANCOCK

RAI, NEWTON D. (b'54)-1a.3.'99; (1'89) WOODBINE, 1.538. HARRISON

ANDERSON, IIARRY NATHANIEL (b'80) -12.3,02: (1'02): OALR.

COL.F. El.MEJ J. (b'65) -111.1.'89: (1'89),

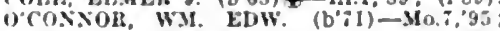
(1'96).

PAYNE, WALTER S. (b'i8)-Neb.6,03: (1.07).

WOODBURN, 420, CLARKE

Bowen, Fredk. S (b'i9)-Ill.1,01: (1'01).

Martln. Marion T. $\left(b^{\prime}+0\right)-0^{\prime}:\left(1^{\prime} 86\right)$.

Wulles, Wade R. (b'62)-la.6,98; (I'98).

WOODWARD, 712 , DALLAS

BROOKINGS, DAVIII JENNESS $\left(b^{\prime}+2\right)$ 111.1, 69 : (1'86).

Cartmell, wm. H. (b'76)-111.1,92; (I'94).

Smlth. Howard Wilford (b'8i) - Ia.6,0s; (1'0s)

WIEELWRIGHT, DANL. WIXFIELD (b'6l) F-III, 1,86: (1's6); OpA.

WOOLSTOCK, 264, WRIGHT

Reed. Chas. Jerome $\left(b^{\prime} 81\right)$-Ill.10,'01; (1'10).
WORTHINGTON, 314, DUBUQUE

3) artindale, Hoscoe Beldea $\left(6^{\circ} 6{ }^{\circ}\right)-$ Mich.1. $95:$ : (1.98).

WYOMING, 733, JONES

CHAMISLILAIS, BE.S H - ia 3.03: (1'03). CORBIT AILFF: BETTEY (N7)Milch lon. (1.03)

Guthrle, John I. (b'66)-Ky.J,'8: : (1'8i).

suence. Haymond Haym $(6,6)-090^{\circ} 01$ : (1'02).

YALE, 273. GUTHRIE

I.AKIX, ALVIN MIARION (b'57) \$-111.1.'\$4: $(1,86)$.

THORNBURG, w.M. $v .\left(b^{\circ} 79\right)-I 23,05$ : (1'05).

YARMOUTH. 100 , DES MOINES

Hammer, LeRoy Aanon (6'84)-Ia.3,'11: (1'11).

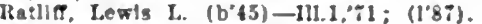

YETTER, 107, CALHOUN

IIopklns, David Howell (b'85)-IA.6,'11: (1'11).

YORKTOWN, 228, PAGE

SCALES. HAKVEY W*. (b'55)-0.1,79: (1'06)

SIgatoos, James Frank (b'8i)-Xieb.6,10: (1'13).

ZEARING. 46I, STORY

Hertz. Henry John (b'55)-1a.3.'09: (1'03). POWELL, CHAS. WISBERN (b'-2)-IA10 04: $(1,04)$.

ZWINGLE, 69, JACKSON

Wheeler, Edwin Ruel (b'si) -Ia.s, 02: (1'02).

FOR KEY TO SPECIALTIES, ABBREVIATIONS, SYMBOLS, ETC., SEE PAGE 516

An educated man is known not only by his store of horredge. but also by the fact that he knows where to look for the things he wants to know. If you do not readily find what you want to knou in this directory, turn to the contents, page 51 , and index. page se. 


\section{KANSAS}

NOTE:-The generil liformation of thls state Includes: Merleal Iaw, State IBoard of IIealth, Members of the Advisory Board. Llcenslng Ioard, State Society, State Journal, County omcers, County and City Ifealth Oftcers, State Institutions, IIospitals, Sanatoliums and Charitable instlutions.

\section{KANSAS}

Population (1910 eensus).

$1,690,949$

Number of Counties.

105

Number of Physieians.

Members State Society, Dec. 31,

1913.

Area of State in Square Miles....

1,213

82,158

MEDICAL PRACTICE LAW OF KANSAS

\section{An Act}

To Create a State IBoard of Medical Regisration and Examination and to kequ late the Practice of Medicine, Surgery and Osteopathy in the State of Kansas, Preseribing Pewaities for the Violation Thereof and Repealing chapter 68 of the Session

laws of 1870 .

Be It enacted by the Legislature of the State of liansas:

Section 1. APIOINTIEXT OF STATE BOAk1): Within sixty days after the passage of thls Act the governor, hy and with the consent of the senate, shall appoint a the consent of the senate, shall appoint a amination, consisting of seven members, one to serve for one year, two for two years, two for three years, and two for four years, and the successors of each shall be appointed in the same manuer for the term of four years, who shilll be physicians in good stauding in their profession, and who shall hare received the degree of doctor of medicine from some reputable medical coliege or university not less than six years prior to their appointment, representation to be given to the difsible in proportion to their numerical strength in this state, but no one school to have a majority of the whole board. Each member of tile board shall take and subscribe the oatin prescribed by law for state offleers, which oath shall be filed with the secretilry of state.

The board shall orcanize by the selection of a president and secretary from among thelr orn number, each to serve for sucl term as the board may designate, not exceeding four years. It shall have a common seal and shali formulate rules to gorern its actions. Its president and secretary shall have power to administer oaths pertaining to ali matters related to the business of the board. The secretary shall furnish to said board a satisfactory bond, conditioned for the faitiful performance of his official dutles. Sald board shall lold regular meetings on the second Tuesday in February, June and October of each year, and one other meeting at such time and plice as the board may desigsuch time and place as the board may desig-
nate, in such of the chief citics of the state nate, in such of the chief eities of the state
as the board may designate. Fire members shall constitute a quorum for the transaction of all business, but no license to practice medicine and surgery shall be issued by the board on less than fire affirmative votes when the full board is present, or on less than a majority affrmative rotes when less than fuil board is vresent. The board shall heep a record of all of its proceedings, and also a register of all applicants for license to practice medicine in all of its branches within the state, together with a record showing the age of the applicant, time spent in the study of medicine and the name and location of the institution or institutions from which the applicant nay hare receired degrees or certificates of medical instruction; a]so, whether the candidate was licensed or
rejected; saicl books and register shall be prina facie eridence of all matters recorded thereln.

sec. 2. LICENSING: All nersons engaged In the practice of medleine on the date of the passate of thls set shall, witiln four months from the date of such pilssage, apply to the Board of Registration and Examinatlon for a lleense to practice. To ali such as present the following quallfications the hoard shall issue a license on paynient of fee liereinafter specified. If a graduate in medicine or surgery, he shall elther personally or by letter or proxy present his diploma to the State Board of Nedleal leglstration and Examination for verifleation. Accompanylng such diploma the applleant shall file his affldarit, duly attested, stating that the applicant is the person named in the dlploma and is the lawful possessor of the same, and giving his age and time spent
in the study of medicine. If the board shall find the diploma to be genuine, and from legally chartered medical institution in good standing as determined by the board, and the person named therein, be the person holding and presenting the same, the board shai] issue its certifleate to that effect, when left for record with the county clerk when left for record with the county clerk tices, as hereinafter required, shall be conclusire evldence that its owner is entitled to practice medicine and surgery in this state. If a practitioner of medicine, in liansas, at the time of the passage of this Act, but not a graduate of medicine or surgery as above defined, lie shall either personally or by letter or proxy, furnish the board affidavits duly attested, stating the period during which, and the places at which he has Ing which, and the places at which he has
been engaged in the practice of medicine and been engaged in the practice of medicine and surgery. If the board is satisfled from the affidavit and other information received that tinuously in the practice of medicine in the state of Kansas, for seven years prier to th passage of this Act, it shali issue its certifieate to that effect, which when left for record witis the county clerk of the county in which he resides shall be conciusive evidence that its owner is entitled to practice medicine and surgery in this state. If engares in the practice of medicine in this state at the time of the passage of this Act for a less perlod than seven years, prior to the nassage of this Act, and not a graduate in medicine or surgery as above defined, the applicant shall present himself before the board and submit to such examination as to bis qualifications for the practice of medicine and surgery as the board may require. If the applicant passes the examination satisfactory to the board, the board shall issue its certificate to that effect, shail issue its certificate to that effect,
which, when left for record with the county clerk of the county in which he resides shall entitie its holder to practice medicine or surgery in this state. The board may refuse to grant a certificate to any person guilty of felony or gross immorality or addicted to the liquor or drug habit to such a degree as to render him unfit to practice and hearing, revoke the certificate for llke cause.

Sec. 3. SPECIAL APPLICATIONS. Ail persons intending to practice medicine, sur gery or osteopathy after the passage of this Act, and all persons who shall not hare apply to rith section 2 of this Act shall or ally regular meeting designated by the board for a license. plication shall be made in writing, and shall plication shall be made in writing, and shall fied, together with the age and residence of the applicant, proof that he or she is of good moral character and satlsfactory eridence that he or she has deroted not less than three periods of slx months each, no two within the same twelve noonths, or If than six inonths each, periods of not less tweive months, to the study of niedieine and surgery. Ail sucl candidates, except as hereinafter provided, shall submit to an exhereinafter provided, shall submit to an examination of a character to test their qual-
iffeatlons as practitioners of medicine or ificatlons as practitioners of medicine or topies and subjects a knowledge of which is generally required by reputable medical colleges of the United States for the degrce of doctor of medicine; provlded, that the examInation in materia medica and therapeutles and the theory and practice of medlcine stall be conducted by those members only practice as the appllcant clalms to follow; practice as the appllcant clalms to follow;
prorided, further, that graduates of legally prorided, further, that graduates of legally States or foreign countries in good standing, as determined by the board may be, at the discretion of the board, granted a license without examinatlon; provided, further, that any graduate of a legally chartered school of osteopathy wherein the requirements for the giving of a diploma shall Include a course of instruction of not less than four terms of fire months each, in two or more separate to practice osteopathy upon the presentation of such diploma; provided, further, that the of such diploma; provided, further, that the board may, in its discretion, accept, in lieu
of examination or diploma, the certificate of the Board of Registration and Examination of any other state or territory of the United States or any foreign country whose standards of qualification for practice are equivalent to those of this state; provided, that a temporary certificate may be issued to any student of medicine, or practitioner of medicine, who is not qualified under the law upon the written request of a majority of the practitioners of medicine under this Act in the county in which he or she desires to practice, or if there be no practitioners registered under this Act in any county in this state, the board shall issue a temporary permit to persons as above described upon missioners of said the board

Sec. 4. CERTIFICATES: Upon the completion of the examination or the acceptance of the diploma or certificate as herein proapplicane said board shall, If it finds the cate to said applicant to practice niedicine and surgery or osteopathy within this state, and which shall be signed by the president and secretary and attested by the seal of the board. ivithin thirty days of the date the board. Within thirty days of the date of any certificate or license having been thereof shall have it recorded, as hereinafter provided, in the office of the clerk of the county in which he resides, or, if a nonresident of this state, then of the county in which he has an office or intends to practice, and the date of recording shall be Indorsed thereon, and until such certificate or license is recorded he shall not exercise any of the rights or privileges therein conferred. The county clerk shall keep in a book for the purpose a complete list of the certiflcates recorded by him, which book shall be open to public inspection during business hours. Between the first and twentieth days of December in each year, the county clerk shall furnish the secretary of the board a list of all certificates recorded, and in force, and also a list of all certificates which have been reroked, or the owners of which have re- 
movel from the county or tlled durlug the year. The fee for the recurdlog and repors. dollar.

Sec. J. FER: COMl'E.NSATIUN OF Hosks: The fee for llye lusuatre of a certincate to all these found yualifled to practlce medlclue, surgery or imbertithy wlthous examination as proviled under ses. without examination as provided under sec tlon 2 shall be two deillary The pere por

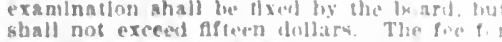
examination of diplomil. or certifleats from all examinlng [miari] of annther state. shull also he fixed by the buaril. lut whill tat

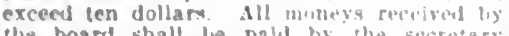
the board shall le pald by the secrotary thereof Into the state treastary minthly. The expensation and actual traveling and wher exjenses of the buard shall he patd from the treasury of the state; previlded, that the cotal amount paid from the state trasury under the provfwions of thls . Ict shall buit exceed the amount paid into tho treanury as hereln prorlded. The comprestation of the members of the imard shall he wly dollars $P$. erery day actually spent in the dlschargo of thelr dutles. In audition to his actual trar. elling expenses. the secretary shail recelre a salary to be nxed by the moril, but it shalt not exceed elght hundred dollary per annum. All of such compensation and trareling pspenses shall be approved by the president penses shall be mpproved by" the prestdent and aecretary of the boald board to make a repurt of their pruccedings to the governor anmually on or before the 15 th day of November, whoth remort shall Include an a.ermut of all moneys receired and dlshurved hy them.

Sec. 6. PR.IOTICINi MEIICINE HE-

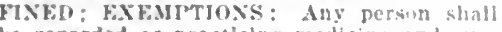
he regarded as practleling medicine and surwery withln the meaulng of this let whw sliall prescribe, or who shall recommend for a fee for llke use, any drug, or medicine, or berform any surgleal operatlon of whatsiner nature for the cure or relief of any woutid. nature for the cure or relief of ang wouthds,
iractire or bodlly Injurs, Infirmity or disease Iracture or bodlly Injury, Infirmity or disease
of another person, or who shall use the wurds of another person, or who shall use the wurds other wte in connection with his name whlch In any way represents hlm as enkaged In the practice of mediclne or itrgery. or any person attemptlng to treat the rick or others atuleted with bodily or montal inArmlies, or any person regresentur, ur auvertsing himself by any meass or through rertsing himseif bo any meds or through any medlum whatsoerer or in ally manmer Whatsoever so as to indicate he is suthor-
ixed to or does practice medleine or silfiery in this state, of that he Is authurized to or does treat the slck or uthers atllicterl with bodily inflimitles, but nothleg lis thls act shall to construed as Interfering with any religlous bellefs In the treatment if diseases: provkled, that quarantine regulatlons relatine to contaplous diseases are nut infringed upon. Ill persens whis [iractice fiste. opsthy shall be reglstered and licenumblas dnctors of osteryathy ns hereinlefure pros dnctors of osterpathy as beretnlefure joo-
rided, but thes shall not administer ilrugiv or

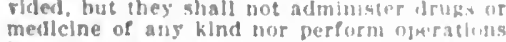
In sursery. This Act shall neit Hujly (1) athy commlsaloned medscal nnleer of the rinted siates Arny, Jinty or lublle llealsh surrle in the diacharze of hls undelal duties, not bo any leqally qualitiod dentlst, when dinaticed In the legltimate practlce of his birifusicin: nor to any physlclan or furboun whe la called from amulier atate or errtiory in mon-

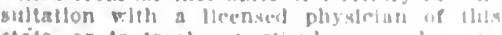
atalo, or to treat a particular came in cosp function with a licepret practitloner of this alate, and who does not mberwa practice in

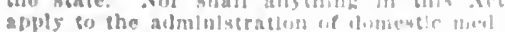
apply so the admlalstration of nomientir moth

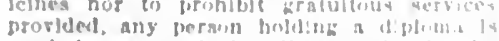
aned by an vylleal collexe and uhin hat atudled the anatingy of the eye and contisuoud [narts. humant bly slology and nat:11,

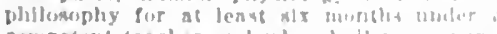

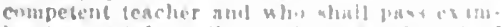

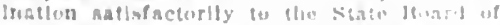

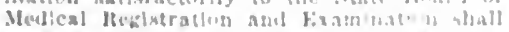

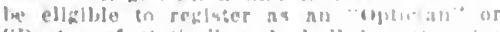

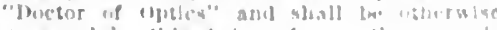

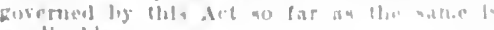
avplicatile.
Siec. F I'E.NAl.TIES: Frnin and afier the drat tlav uf septemter, I!nI, any person who shall Jracesen mellewa aud surgery o

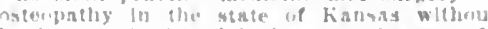
havlsz reoplverl nonl had recurted a certin.

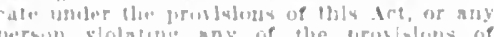
person vlolntang any of the firmblotens of

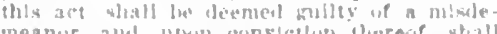
meanor. numl. upoin ronv!ctlug llereof stall pay n the of nut less than Af(v dollars mor more than two humbed dollar por exach

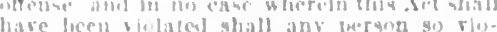
lating realve cumpansition for serrime romered It whall he the duty of thw serre-

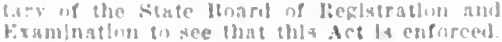

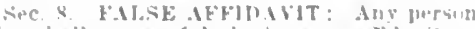
who slaall swear faluely in any andiarle or oral teat!mony mathe or telren by rirtue of

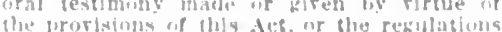

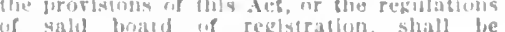
deened sullty if berjury.

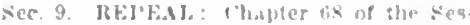

slon Laws of isio la horetiy repealed!

Sec. 10. IN FFFEc'T: Thls dit shall take effret and be In force from ind after its ublication to the oflelal state papter.

Auprovel March I, Istol.

\section{STATE BOARD OF HEALTH}

Irr. O. D. Wniker. I'restuent. Sallnat: Dr 3. Aummings, Vlec-I'resident, Hronson ('). Welch, Ithorney, ruthezwlle: Jir. H. J

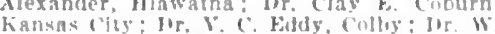
il. Thompon. [Ondze clev: Jr. Jessle $\mathrm{T}$. urr. 11. Thompson. Wodfe cle : Hr. Jessle T. Ur 11athe: Jr. W. l', Junt, Fmpuria : Dr. C. II tary, Tupeka.

\section{Members of the Advisory Board}

F. II. Junes, C.F. Consulting Enzinger tawrence : C. A. Inaklas, Enginear, Law rence Fred Cl Jlenser, Asststant Fogine't

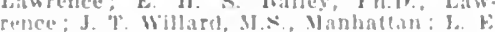
sayre, jh y lawrence: Jur. It s yace Payre, Ph. H. Lawrence: Wr. W. S. Magee Bacterjologist, Topeka; F. W. Blackmar, bacterjologist, Topeka; f. W. Bltekmar,

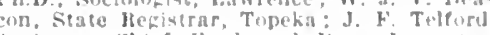
Assistant Chief food and lirug inspecur, Tupeka.

\section{STATE BOARD OF MEDICAL REGISTRA} TION AND EXAMINATION

L. A. Ifyder, I'resldent, Tupeka: A 3 snderson, lawrence ; L. H" (iallardet. For

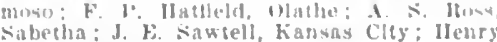
A. lykes, Sceretary, Lebanon.

\section{KANSAS MEDICAL SOCIETY}

uncer 1913-14

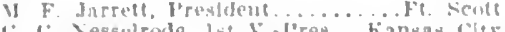
C. Nessulrode lst V.. Trea... Kansan Clty

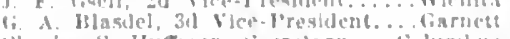

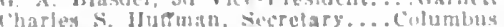
L. II. Murn, Treisurer........... Topeka

\section{State Journal}

Jumenal of hansas Vedical siclety, Kan

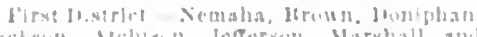

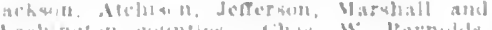

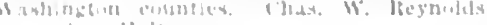

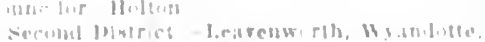

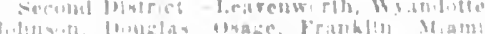

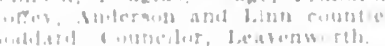

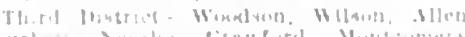

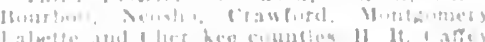

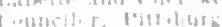

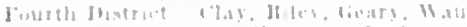

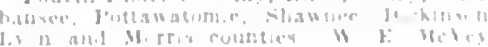

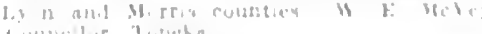

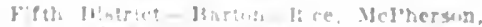

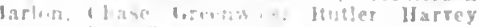

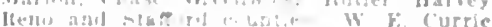

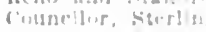

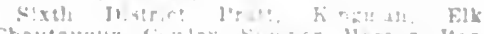
Chatauguas kley. Coumelter, Wichlta.

Seventh llimtrict - lio pribl

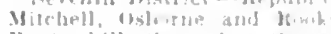

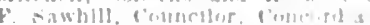

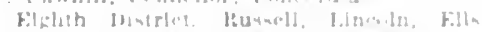

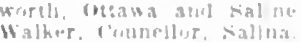

Ninth bistrlot I'buyesue. Itaulats, Jeeca 12r. Nurton. Ph!lligu and smleh countes

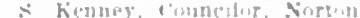

Tenth listrict Flerman. Thumas shert. dau, Ciraharn. Trewe liove le wan and il at.

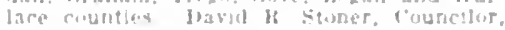

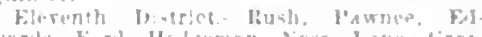

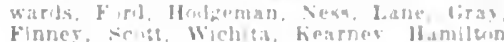
and lireteley croumles. J. A. Ihildon. roun

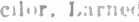

Twelfth bistrict -... hicha, comancle, rlark, Mrade, Siward, Ilsohell, sieveris lirant stantin anel II reng counties. W. $F$ Fie, Councilor, Meale.

\section{Component Counly Societies of the Kansas Medical Sociely A,J.E. CULNTY}

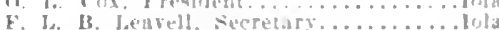
ANUEKSON AUI NTY

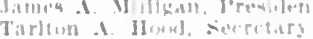
ATUHAHA (1)L NT

11. T. Jingesis, Jrudifent.........Atehlson

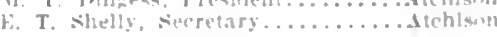
H.hHEK COLNT

Jardin lillners. I'residene. . . Medlclne Ladge 1. K. Waite. Sererelary............ Klow an

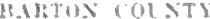
it If connell, Jrestident........ direat Itemd hothinde cutext

IV. Dirith, l'renident............ st. sot

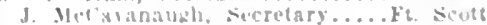
Hแm coțT:

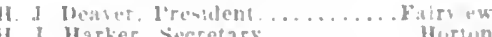
II TI. EIR COLNT

F A Ciarvin. l'resfden:.............

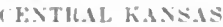

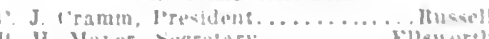
ii. II. Mitjer, secretary........... Ellswurt] (H.ANE; (O) NT

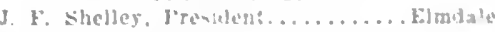

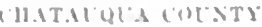

"' kirby Jrusilen?

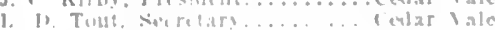

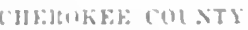

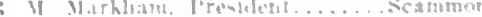

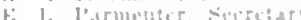

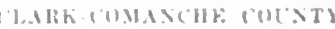

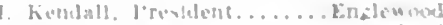

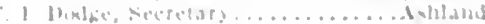
(1.1) ( 1215$)$

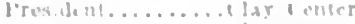
$11.41118,111 \times 58$

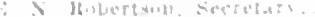
intis (4)

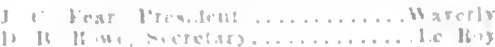

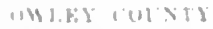

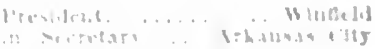
It Holin (11 \T)

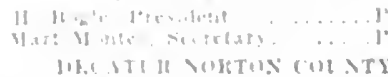

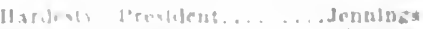

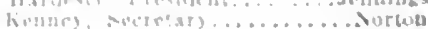




\section{AMERICAN MEDICAL DIRECTORY}

DONIPIIAN COUNTY

IV. 13. Campbell, P'resident............Troy

IV. M. Boone, Secretary........... Highiand DOUGLAS COUNTY

II. I. Chambers, President........Lawrence E. J. Blutr, Secretary................ Luwrence ELK COUNTI

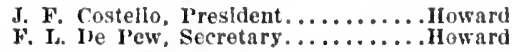
FRANKIIN COUNTY W. I. Tacobus, I'resident............ Ottawa
James Parker Blunk, secretary..... Ottawa GEARY COUNTY

W. A. Carr, President........Junction City w. A. Smbley, Secretary........Junction city GOVE COUNTY

(Included In Tri-County Medical Society) GRAHAM COUNTY

(Included in Tri-County Medical Society) GREENWOOD COUNTY

Jeptha Dillon, I'resident............Eureka Smith F. McDonald, Secretary......... Screry HARPER COUNTY

G. S. Wilcox, President.............Freeport H. '. Galloway, Secretary............. Anthony IARVEY COUNTY

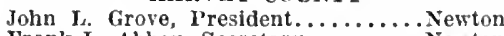
Frank L. Abbey, Secretary............... Newton JACKSON COUNTY

V. V. Adamson, President............ Holton Chas. MI. Sierer, Secretary.............IIolton JEFFERSON COUNTY

Albert D. Lowry, President..... Valley Falls Fredk. P. Mann, Secretary..... Valley Falls JEWELL COUNTY

J. W. Johnson, President...........Formosa

Dorothy D. Allen, Secretary..............Mankato JOHNSON COUNTY

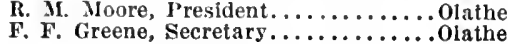
IINGMAN COUNTY

A. C. Johnson, President.......... Kingman J. M. Mckamey, Secretary............. Kingman KIOWA COUNTY

J. A. Gardner, President......... Greensburg H. J. Willey, Secrctary .............. Greensburg LABETTE COUNTY

J. H. Ilenson, President.......Mound Valley

o. S. Hubbard, Secretary............ Parsons IEAVENWORTH COUNTY

C. D. Lloyd, President........... Lea venworth J. L. Everhardy, Secretary.........eavenworth LINCOLN COUNTY

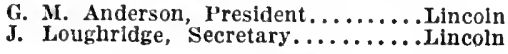
LINN COUNTY

D. E. Green, President.......... Pleasanton
H. L. Clark, Secretary.......... Cy Cygne LYON COUNTY

B. E. Garrison, President..........Emporla

A. W. Corbett, Secretary............. Emporia MARION COUNTX

H. Brunig. President............. Hills

C. I. Appleby, Secretary..............Peabody MARSHALI COUNTY

W. E. Hain, President................ Beattie MICPHERSON COUNTY

E. o. Smith, President............... Marquette MIIAII COUNTY

J. D. Walthall, President............Paola MITCHELI COUNTY

F. B. Home, President.............. Beloit W. H. Cook, Secretary................. Beloit MONTGOMERY COUNTY

Harry L. Aldrich, Presldent....... Coffeyville

James A. Pinkston, Secretary....... Coffependencence NEMAHA COUNTY

C. R. Townsend, President......... Centralla

J. R. Nathews, Secretary.............. Sabetha NEOSHO COUNTY

W. E. Barker, President......... Chanute

A. M. Garton, Secretary............... Chanute
OSAGE COUNTY

F. M. Smith, President............. Lyndon OSBORNE COUNTY

I. W. Lindley, President.............. Natoma W. W. Miller, Secretary.............. OTTAWA COUNTY

C. B. Aplin, President.............. Deiphos 3. F. Brewer, secretary............ Minneapolls PAWNEE COUNTY

Virgil Standish, Presldent........... Tarned

A. E. Reed, secretary.................... . . POTTAWATOMIE COUNTY

J. W. Wilhoit, I'resident.........St. George PRATT COUNTY

Athol Cochran, I'resident............. Iuka Frank Peak, Secretary................ Pratt IRAWLINS-CHEYENNE COUNTY

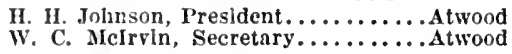
RENO COUNTY Chas. I, Mfekittrick, President.... Hutchinson
W. F. Schoor, Secretary......... Hutchinson REPUBLIC COUNTY

c. M. Arbuthnot, President........ Bellevilie lienry D. Thomas, Secretary.........Belleville RICE COUNTY

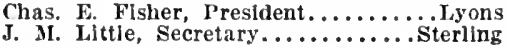
RILEY COUNTY

Robert Leith, President..........Manhattan T. R. Cave, Secretary............. Manhattan SALINE COUNTY A. G. Anderson, President.......... Salina
H. N. Moses, Secretary.......... Salina SEDGWICK COUNTY

L. P. Warren, President............Wichita SHAWNEE COUNTY

J. A. Crabb, President............Topeka SHERIDAN County

(Included in Tri-County Medical Soclety) SMITH COUNTY

Victor E. Watts, President..........Bellaire C. Corwin Funk, Secretary.............. Belth Center SOUTHWEST JOINT COUNTY

Arthur L. Knisely, President........ Liberal

Thomas L. Higginbotham, Secretary..Liberal STAFFORD COUNTY

Chas. S. Adams, President.......... St. Iohn
Cyrus Wesley, Secretary......... Stafford SUNINER COUNTY

R. A. McIlhenny, President.. Conway Springs H. F. Hyndman, Secretary...... Wellington TRI-COUNTY MEDICAL SOCIETY-GOVEGRAHAM-SHERIDAN COUNTIES

w. II. Pope, President............... Selden D. I. Stoner, Secretary.............. Quinter WABAUNSEE COUNTY

Geo. W. B. Beverley, President........Alma WASHINGTON COUNTY

11. II. Horn, President...........Morrowville Wm. M. Earnest, Secretary........ Washington WESTERN KANSAS

H. A. Stroup, President...........Winona

E. J. Beckner, secretary................. Hoxie WILSON COUNTY C. A. Thomas, President............Fredonia WOODSON COUNTY E. K. Kellenberger, President.. Yates Center
H. W. West, Secretary ........ Yates Center WYANDOTTE COUNTY John F. Hassig, President....... Kansas City
C. C. Nesselrode, Secretary.....Kansas City

\section{COUNTY HEALTH OFFICERS}

County Address

Allen.-J. Sutcliff..................Iola Anderson.-C. B. Harris.............. Garnett Atchison.-C. W. Robinson........... Atchison Barber.-Hardin Gilbert................ Barton.-John 0. Skinner....... Great Bend
Bourhon.-J. C. Lardner..........Ft. Scott Prown.-w. w. Nye............. Hilawatha Chase-Clias, Mckiniey........ Strong City Chautaugua - Milton T ............... Chautaqua.- Mrton T. Evans........ Sedan Cheyenne.1B. F Jeffers........... St. Francis Clarke. $W$. F. Taylor................. Ashiand Clay.-Samuel Reynolds................ Ashian Center

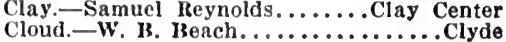

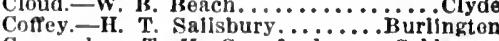
Comanche, - T. H. Crawford....... Coldwater Cowley. - F. A. Keliey............. Winfeld Decatur.-Eber C. Reeves............ oberlin Dickinson. $-T$. $R$. Conklin................ Abiliene Doniphan.二J. W. Graham............. Highiand Douglass.-S. T. Gillispie........... Hawrence Douglass._-S. T. Gillispie................. Elk. J. A. Archer................. Grenola Ellis. $-K$. C. Haas................. Hays Ellsworth.-Alfred O'Donnell.......Ellsworth Finney. W. J. Stllson.......... Garden Clty Ford. $-\mathbf{X}, \mathbf{F}$. Alexander.......... Dodge City Franklin.-F. C. Herr................ Ottawa Geary. - w. S. Yates..................... Gove-J. II. McNaughton............... Gove Graham. - G. E. Webber............... Morland Grant.-Mr. J. E. Tarbet............ Uly Ulyses Gray.-G. W. Hollembeak............ Clmarron Greeley.-S. S. MIcGinnis............ Tribune Greenwood.-John M. Reid............ Eureka Hamilton. $-G$. W. Irvin ...........

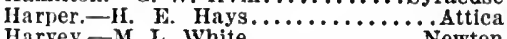
Harvey.-M. I. White.............. Newton Ilodgenan. -I. F. McDonneli.......... Jetmore Jackson.-Chas. M. Siever........... Holton Jefferson.-J. M. Marks................ Holiey Falls Jeweil -Dorothy D Allen............ Mankato

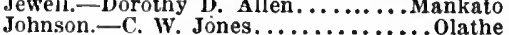
Johnson.-C. W. Jones............... Olathe Kearney.--Sanford Bailey.................kakin Klowa.-J. A. Gardner............. Greensburg Labette. - P. S. Townsend............ Oswego Lane.-J. R. Newton .............. Dighton Leavenworth. -J. L. Everhardy, Leavenworth Iincoln.-L. A. Kerr................ Lincoln Linn.-Geo. A. Paige.................. Pieasanton Logan.-C. M. Miller................ Oakley Logan. -C. M. Marvey $\ldots \ldots \ldots \ldots \ldots \ldots \ldots \ldots$. Oakley Lyon.-C. C. Harvey $\ldots \ldots \ldots \ldots \ldots \ldots \ldots$. Emporla

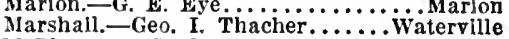
McPherson.-L. F. Quantlus........... WcPherson Meade. -Wm. F. Fee..................Meade Míami.-Joseph Fowler................ Paola Mitchell.-E. E. Brewer.................. Beloit Montgomery. $-F$. B. Taggart.... independence Morris.-W. E. Crawford....... Councll Grove Morten.-A. T. Coffman..............Richfield Nemaha.-S. M. Hibbard.............. Sabetha Neosho.-A. M1. Daris................ Ness.-Thns. $\mathbf{S}$. Venard........... Ness City Norton. - Wm. . C. Latbrop........... Ness City

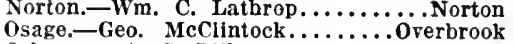
Osborne.-A. C. Dillon.............. Osborne Ottawa.-Fred E. Harvey.............. Pawnee.-A. E. Reed.................. Larned Phillips. - H. D. Brotners.................. Agra Pottawatomie.-J. W. Lauck, ......... o. olsburg Pratt.-Herbert Atkins.................Pratt Rawlins.-L. G. Graves................ Atwood Reno.-F. A. Forney........... Hutchinson Republic.-C. M. Fitzpatrick........ Republlc Rice.-L. L. Vermlllion............... Lyons Riley.-J. C. Montgomery.................. Rooks.-W. B. Callender........... Stockton Rush.-A. D. Gray.................. Crosse Russell._Carl J. Cramm........... Russell Saline.-J. A. Simpson.................. Salina Scott. -W. E. Mowery ............ Scott City Sedgwick.-0. G. Hutchinson.......... Wichita Seward.-George S. Smith.............. Wiberal Shawnee.-C. M. Hensley........... Topeka Sheridan.-E. D. Beckner.............Hoxie Sherman.-F. H. Smith................ Smith.-C. Corwin Funk............... Stafford.-Millard M. Hart.........Macksville Sterens.-W. E. Bundy.............. Hugoton Sumner. $-T$. H. Jamieson. .......... Welllngton Thomas. $W$. M. Beaver................. Colby Trego.-W. Y. Herrick..........W Wakeeney wallace.-W. J. Scott............ sharon Springs Washington.-W. C. Burnaman. Washington Waubansee.-W. F. Richardson.......Paxico Wichita. -0. E. Smith...................eot1 Wilson.-E. C. Duncan................... Fredonia Woodson.-Geo. W. Lee......... Yates Center Wyandotte.-James A. Fuiton...Kansas Ctiy 
HEALTH OFFICERS IN CITIES OF 3.000 POPULATION AND OVER

Arkansas Clty.............. C. Geeslln

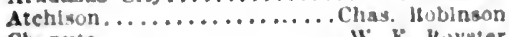
Chanute................W. K. Hoyster Corteyville.................W. II. Wells Emporla...................W. 11. Ilun Ft secti................. L. Hopher Galena..................... 13. Nchinney Hutchinson.................W. Fichoor Independence............... W. Kelly lola.................... s, sutelirm Junction Cliy.................W. A. Carr

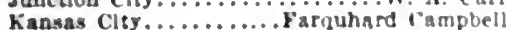

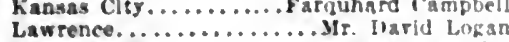
Leavenworth................ Stewart Mchee Manbattan..............J. C. Montgoner Newton.................... W. Whit Otrawa...................... C. Herr Parsons..................... C. Cornel Plttsburg................... F. Monte Rosedale..................... J. O'Connel Salina..................... S. Simpson Topeka..................... C. Medil Wellngton.............Guy l. M!llington Wlchlta................... T. Dohert Winfeld.................... Forest $A$. Kelley

\section{Atchison}

\section{STATE INSTITUTIONS}

State Orphans' Iome, Atchison, Kan. Fistablished I\$55; publlc; for dependen chlldren: 225 beds: Virgil Morrlson, phy sleian in charge; Mrs. E. K. Burnes, superintendent.

Beloit

Kansas State Industrial School for Girls, Belolt. Kan. Establlshed 1599: 10 bods in hospital; F. B. Home, medlcal superlntendent.

\section{Ellsworth}

Blekerdyle Home and Hospltal, Flls worth, Kan. Fastabllshed 1992; for wldows and children of old soldlers: 20 heds In bospltal: J. S. Chase, Dhys!clan and silverlntendent: branch of Kansas state Soldlers' Home, Ft. Dodge, han.

\section{Ft. Dodge}

Kansas State Soldlers' Home, Ft. Dodze, Kan. Fistabllshed 1893: general: 60 beds physlclan in charge: branch at Eulustort

\section{Hutchinson}

Kansas State Industrla! Reformatory. Ilutchingon, Kan. Histabllshed 159: : gen eral: 425 bedy: Fred A. Forney. physiclan: J. X. Herr, superintendent.

Kansas City

Kansas School for the Bllnd. Kansas Clty, Kan. Established 1567: 125 beds: C. W. Mcloagblla, physlelan: Grace Nur ton Ioveberry, superlntendent.

\section{Lansing}

Kansas State I'rison Howpltal, Iatasinz. Kan. Fatalulshed 181;4: Eeteral; 5. hed J. T. Faulkner, medical superlntegdent.

\section{Norton}

State Tuberculosls Sanltartum, Nortun, Kan. 1'ublle: C. S. Kenny, blissletau tn charge.

\section{Olathe}

Scheol for the Deat, Olathe, Kan bis labllshed 1864: 275 beds: ('yrus 1: White, sujerintendent.

\section{Osawatomie}

Osawaronle state Hoapltal. Ovam atomfo

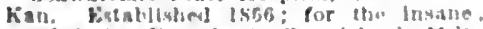
1.3ic beds: Francla A. Carinl(bael, It I. ouperintendest.

\section{Parsons}

Partons siate Hospltal for biblleptlog Parsons, Kan. batabllsher! 190:3: 600 beds: II I. Ferry, medleal supuerinteul ent.

\section{Topeka}

Iloys' Industrlal School, Topres. Kian Extabllshed 18:9; reformatory: 250 heds C. 1h. Van Horn, phystelan: II W hurios superinteulent.

Toucka state Howplend for tlın Insane. Topeka kat fistabluher] 18:5: 1.40\% beds: T. C. Idddle. superlubendeni

\section{Winfold}

State Home for Feeble sinded. Winflell, kan. Histullated 188I: for feeble. nilnded: 500 beds; $H$. C. Cave, modical superlutendeut.

\section{HOSPITALS, SANATORIUMS ANO CHARI. TABLE INSTITUTIONS}

\section{Anthony}

Anthony Howpltal, Anthony, Kan. Fs, tablished 19!: 10 berls: (i. M. Wooden abl II. L. Cialloway, physiclans in charge. Arkansas City

Arkansas Clty Hosplta!. Arkansas ("Ity Kan. kisallished $1605 ; 45$ beds: Claude loung, physlclan in charie.

Mercy llospltal, Arkansas Clty, Kan. bistabllshed 1906: gelleral: 32 bels: Wm. T. Mckay and kimest r. Lay, pliysiclass In charge.

\section{Atchison}

Atchison County IIospltal, Atchlsor, han. (R.F.J. 2) Established 1903; public 34 beds: S. J. CInnan, superlutendent. l'rospect l'ark Hospltal, H'rospect I'ark. Atchlsua, Kan. Kistabllshed 1890 vrliate for feeble-ninded; 50 beds; G. W. Wells. superlntendent.

St. Francis Ilospltal, 420 $\mathrm{x}$. $3 \mathrm{~d}$ st. Athison, Kan. Bostabllshed 1909; then eral; I 6 beds; Irs. Belle fillmore, super intendent.

Beloit

O'Brien Ilospltal. Belolt, Kan. EstabItshed 1912 ; feneral; 10 beds: D. S O'Brlen, physlclan

\section{Bonner Spring}

Honner Springs lodge Sanltarlum, Bonner Snriugs kan. Fistablished is 90 : nerrous and niental, narcotlc and alcohollc 35 beds; Henry' C. Hass, nhysletan in charge.

\section{Caney}

Caney Hospltal, Caney, Kan. Estallished 1909 ; zeneral: 6 beds: W. $F$, Cuon thysiclan in charte.

\section{Carbondale}

Merrill Sprlng Sanltarlum, Carbondale.

Kan. Established 1793: private; 1: veds

II. I1. Siwallow, medical superlutendent.

Chanute

Harrison Hospltal, Chanute, Kan. Foytabllshed 1906; General; 20 teds; L. D.
Juhnson, chlef surgeon; Mlss L. Lillen llarrlson, R.Y., superintendent.

\section{Chelopa}

led Star Sanltarlum, Chetopa, Kan.

\section{Clay Center}

Clay center Hospltal, Clay Center, han. fistabilshed 1900; private: 18 beds: Mis. Martha M. Buchanuan, superlntendent.

Sipeer llospltal, Clay Center, Kan. Fis cublished 1900: erneral: 6 beds: W. I. speer. M.W., superintendene.

Coffeyrille livod Samaritan Hospltal. Cotfeyvllie kan. patabllshed 185,1 pritate: 20 beds T. Frazler, Hystran in charge; Mr. s. lisle simith, sujerlutendent.

Krugk Husbltal Ixarlation, Cutpeyblie.

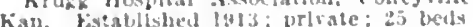

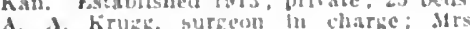
Mary l'utter, stiverintembent.

Concordia

lir. \& I). Mekiaden's Sanatorlum, fon cordis, lian. tistablshed 1901: Jitrite 12 bedy: 1. I. Mctuden, phigsictan in charce.

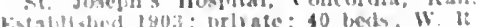
l'rient, chlet surzeon.

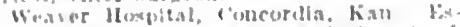

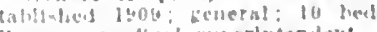

lleaver, modled ruperlutendelit.

Cunncil Grove

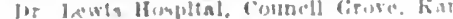
tolatilsteel 1012: "eneral: 10 peuts. drenur J. Lewis, surbeon.

oouge cily

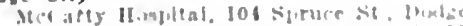

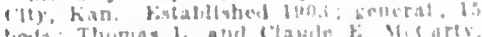

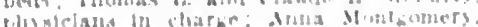
sujwrintendent.

Thomyron aud pirna llemilat. $1403 \mathrm{Cen}$ tral Ale. Irotge rity, hinn. Extatullsbed

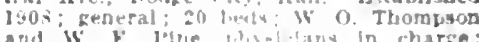

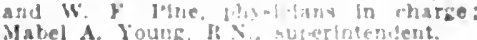
Easton

kaston Hospital, Kimsto, Kian, kostabUshed 1511: 10 beds; W. A Adaras, why. slclan in chisine

Ellsworth

kilsworth Hospltal, Fllsworth, Kan. Fiv. tabllshed Isi:; general: 13 beds; Misy inna Nhehols, sugerintendest.

Emporia

St. Mary's llogpltal, Emoria, han. Es. tablished Ignt: General: 40 beds; Sisters of sit. f'rancls, in clarze.

\section{Ft. Leavenworth}

J'rison Ilospital, Inited States Army. Ft lison llosplat, Cnited states Arms: Major Kent Nelison, Medlcal Corps. U. S. Army, surgeon In charze.

inited states Army Ilosplial, Fr Leavenworth, Kan. Histabllshed 1827: 160 beds: "apt. Il. M. Sny der, in charge.

\section{Ft. Scott}

Goodlander Sanltarlum, Ft. Scott, Kan. Fistablished 189s; publle: 23 beds; Lira Gardner, superintendent.

Holluess Industrial Chlldren's Home. Sycamore and rinklln sts. rt. scott, han. Mrs. Madrle shull, matron.

Nercy llospltal, Ft. Sicott, han. Kotabllshed 1890; Leneral; 50 beds: Sisters of Mercy, in charge.

old leuple's llume, lit. Scolt, Kan.

Mrs. I". Johnson, superintendent.

\section{Garden City}

Garden Cliy ILosplial and Sanlinrlum. Garden Clity, Kan. kistabllshed 1902: prlrate: 16 beds: Chas. Rewerts, Dbyslcian In charge.

Goessel

Mennonite liethesda Hospltal, Goessel. kan. kistabllshed 1599 ; fenera!: 15 beds: C. i1. Kalser, surgeon in cblef.

Great Bend

it liosa's llospltal, Great Bend, Kan. Fostabllshed 1903 : pubilc: 40 beds: Sisters of st. Dorulnle, in charge.

\section{Halstead}

Ilalstead Ilos:Ital, Halstead. Kan. Eslablished 1904: Feneral: :0 beds: Arthur Hertlueham, physlclans in charge.

Hays

st. Anthony's Hosplsal, Hays, Kan. Es tabllshed 1909; vublic: 30 beds.

Hiawatha

Hawatha Hospltal, Hawatha, Kan. Fstabllshed 190\%: Fcneral: 10 beds: W. C. Palmer, M.I., supertntendent.

\section{Holsington}

Holstngton Hospital, Holslngtnn, Kan Fstablistied 191?; Eeneral: 23 beds llelen 31. Irnold, R.A., superintendent

\section{Horton}

llorton Hospltal, IInton, Kan. Fistab. olued lgoti: Feneral: T: heds

Hutchinson

Stewart Association Husplal. Huichla. son, han. Finatished 1s9:- private: 30 hedis: 11. A. Stewart, uresfuent; Sharloble Irine llazon, suberblendent

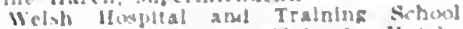

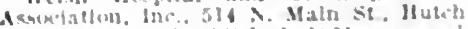

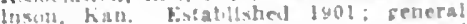

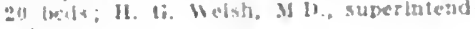

Independence

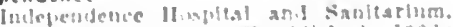

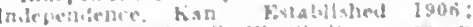

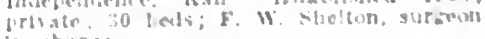

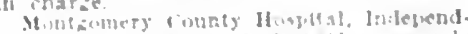

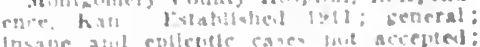

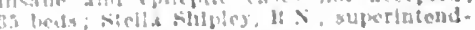
Iola 
Iula Sanltarium and Mincral Wells, Iola, Fiu. Fistilished $1910^{\circ}$ reueral 40 beds: Jall. Fostallished 1910; general; 40 beds: G. Sutcliffe, IR.N., supcrintendent. st. John's IIospltal, Iola, Kan. Establisicd 1905; public; 35 beds : Slsters of st. Joseph, in charge.

Kansas City

Bethany Methodist Ilospital. Tenuey and Orchard Sts., Kansas City, líau Established 1892; general; 52 heds; billa betl J. bascn, superintendent.

Children's Orpllan IIome, $g h \mathrm{~h}$ st, and Washington 13lvd., Kansas (Ity, Kan. Fs tablshed 1:01; publle; 2I beds; C. II Browne, physlclan in chatge; Mrs. Ifenrletta Johnson, mafron.

Douglass Hospltal, 312 Washlneton Blvd., Kansas Clty, Kan. Fstabllshed 1898; ceneral; 20 heals; Miss Frances Melilliams, superintendent.

(irand Vlew Sanltarhum, Kansas city Kan. Lstalbllshed 1904; for mental and Kan. Estallished 1904 ; for mental ani nerrous and alcohol and drug adlletion City, Mo.), physlcian in charge.

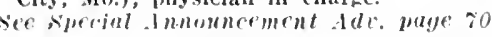
Ilealth and lerguson Sanitarium, 192: N. Ith St, Kansas City, Kan. kstabIIshed 1894: private; 12 bods: W. Ferguson, physlelan in charce.

st. Margaret's Hospltal, Vermont and Harrison Sts., Kansas City, Kan. EstabHarrison Sts., Kansas City, Kan. Establlshed 1887; general; 400 beds; (H. M. Francls, Jil cliarge.

Kingman

Kílngman Ilospltal, Kingman, Kan. Establislied 1908; gencral; 6 beds; W. I'. Callahan and II. F. Ilaskins, physlcians In charge: Miss Margarette scliacklett. R.N., superintendent.

Lansing

Ilospltal for Crlminal Insane, Lansing, han. Established 19II; public; nervous and mental; 48 beds;'J. T. Faulkmer. medical superintendent.

Larned

Larned IIospltal, Larned, Kan. EstabItshed 1905; private; 20 beds; Ellzabeth Schmucker, superintendent.

Larned Saultarium and IIospltal, Iarned, Kan. Established 1911; 40 beds.

\section{Lawrence}

Lawrence Hospital and Tralning School for Nurses, Lawrence, Kan. kstablished 1904 ; private; surgery ; 20 beds ; George W. Jowes, physiclan in charke.

Simmons Hospltal, Lawrence, Kan. EsJ. Simmons, physician in charge.

J. University Inflrmary, Lawrence, Kan. Established 1908; private; for students Established 1908 ; private; for students mittee, in charge.

\section{Leavenworth}

Cusbing Hospital, Leavenworth, Kan. Establlshed 1890 ; public; 75 beds; Miss Estrid Bergman, superintendent.

EImwood Hospital, Learenworth, Kan. Established 1889; nervous, mental and narcotic ; 20 beds; Felix C. Brown, superintendent

Evergleen Place Sanitarium, Leavenworth, Kan. Establlshed 1875; for ner vous, mental, drug and alcoholic; 50 beds Sherman L. Axford (Lansing), medical superintendent.

Guardian Angels' IIome, Leavenworth Kan. Established 1888; eolored orphans 90 beds.

Mitehell IIospital, Leavenworth, Kan Established 1900; private; for colored patients; 13 beds; Charles M. Moates, physician in chargé.

physician in charge. Jeavenworth, Kan. St, John's llospital, Leavenworth, Kan.
Established i 865 ; public; contaglous cases not accented ; 75 beds.

st. Vincent's Home, Learenworth, Kan. Established 1866 ; private; for orphans: I20 beds; $\mathrm{k}$. I'hillips, physician.

tuited States Penltentiary Hospital, Leavenworth, Kan. Established 1893 ; penal; general; 100 beds; A. F. Yohe. plysician in charge.

Lebanon

Lebanon Hospital, Lebanon, Kan. Estahlished Ig0s; general; I0 beds: H.
and J. B. Dykes, physicians in charge.

\section{Lincoln Center}

J). ('ole's Sanitarlum, IJncoln Center. Kan. (Lincoln l'o.). Establlshed 1005 ; brlvate; 10 beds; Sarah A. Cole, physiclan In charge.

Manhattan

Corporation II ospital, Manhattan, Kan. 26 beds; II. It. Daris, manager; II. wlllard, president.

park Vlew Hospltal, Mauhattan, Kan. rtilllshed 1903 . private: 22 beds; II. S villard, plysiclan [u charge.

Marion

Marlon Hospltal, Marlon, Kan. Established 150s: prlvate; 12 beds: C. S. Smith and G. J. Goodsheller, physlclans in eharge.

Ilarier and Coffman IIospital, Marion. lian. Establlslied 1910; private; 5 beds

(i.j. Yarner and J. Ii Corman, physicians in cliarge.

Mccune 1)r. E. W. Ioan Hospital, McCune, Kan.
Fstablished 1900; private; 12 beds; E. W. boan, physlclan in charge.

MoPherson

IcI'herson IIospital Assoclation, McPlierson, Kan. Established I909; Leneral 25 beds; Mlss Marle lfansen, R.N., superintendent.

\section{Mulvane}

Atchlson, Topeka and Sante Fe Rallway

Hospital, Mulvane, Kan. Established I9I3; prlate; general; 42 beds; II. W Goelitz, physlcian in charge.

\section{National Military Home}

Natlonal Mtlitary Home for Disabled Volunteer Soldiers, National Military Houne, Kan Western Branch; 396 beds in hospital; Maj. J. L. Fryer, physiclan in cliarge.

\section{Newton}

Axtell Hospltal, Newton, Kan. EstalyAxtell, surgeon in chief: Edna M. Goethe, superintendent.

Bethel Heaconess Hospital, Newton.

$\mathrm{K}$ an. Established 1908; general; 40 beds

\section{Olathe}

Johnson County Infirmary, Olathe, Kan.

Established 1900 ; general ; 40 beds

ottawa

Atchlson, Topeka \& Santa Fe Railway Hospltal, Ottawa, Kan. Established 1885 private; for railway cmployees; 40 beds Edward B. Gossett, physlclan in charge. Franklin County Kansas Infirmary, Ot tawa, Kan. Established 1882; publl

Paola

Van Pelt Hospltal and Sanitarium Paola, Kan. Established 1908; general 15 beds; L. A. Yan Pelt, physiclan in charge; Mrs. Louise Van Pelt, superintelident.

Parsons Julius Rotter Prirate Hospital, Parsons.
Kan. Established I91I ; surgery and kynecology; 15 beds; Julius Rotter, physyllecology; 15 bed

Nercy Hospital, Parsons, Kan. Established $1911 ; 70$ beds; Sisters of St Joseph, in charge.

Parsons Home and Hospltal, Parsons, Kan. Established 1900; publlc; 25 beds:

Irs. Frances Dinsmore, superintendent.

\section{Pittsburg}

IIt. Carmel Hospital, Pittsburg, Kan. Established 1903; general ; 40 beds; Sisters of St. Josepli, in charge.

samaritan Sanitarium, Pittsburg, Kan. Established 1894; private; general; 40 beds; George W. Williams, M.D., superintendent.

Pratt

Iottridge Sanitarlum, Pratt, Kan. Established 1906 ; private ; 10 beds; M. II. Iottridge, medical superintendent.

Rosedale

University of Kansas, Bell Memorial Hospital, Rosedale, Kan. Established 1906; general; 70 beds; Claude A. Doty, superintendent.

Sabetha

Sabetha Hospital, Sabetha, Kan, Established 1904; private; 50 beds; Samuel

Murdock, Jr., physlelan in charge; Pearl wilson, superlutendent.

\section{Salina}

St. Barnabas Hospital, 0 tis and $N$. Santa Fe Sts., Sallna, Kan. Establlshed 1910; general; 31 beds.

St. John's IIospital, Sallna, Kan. Established 1913; public; 80 beds; Sisters of St. Joseph, in charge.

\section{Stafiord}

lykes Hospltal, Stafford, Kan. Fstahlished 1902; private: general; it beds; W. Lucas Butler, superintendent and physlclan in charge.

liuggles Sanltarium, Stafford, Kan. Established 1896; general ; 50 berls; Charles A. Ruggles, pliyslcian in charge.

\section{Sterling}

Sterling IIospital Assoclation, Sterling, Kan. Established 1902; general; 25 beds; Marlon Trnelieart, physiclan in charge.

\section{Topeka}

Atchlson, Topeka \& Santa Fe Rallway Hospital, Topeka, Kan. Established 1896 ; general; 75 beas; J. D. Freeman, surgeon n charge.

Christ's IIospital, Topeka, Kan. Establlshed 1882; general; 100 beds; J. C. IcCllntoek, medical superintendent.

Detention IIospltal, Topeka, Kan. Es-
tablished I90I; for eontagious cases: 40 beds; clty pliy'slelan in charge.

Jane C. Stormont Hospital, 332 Greenwood Ave., Topeka, Kan. Establlshed 1895; general; 70 beds; Miss Theresa Smith, superintendent.

Kansas Florence Crittenton Mission, 26th and Union Ave., Quinton Helghts, for maternity cases; 20 beds; I. B. Bushfor maternity cases; 20 beds

ong, physician In charge. tablished 1909; general; 100 beds; ir. C. Porter, superintenden

Topeka Orphans' IIome, $3 \mathrm{~d}$ and Fll1more Sts., Topeka, Kan. Establlshed 1888; 75 beds; Mrs. Carrie Hanley, superintendent.

\section{Waconda Springs}

Waconda Sanitarium, Waconda Springs, Kan. (Cawker City P.o.). Established 1906; public; 30 beds; G. F. Abrahams, superintendent.

\section{Wellington}

St. Luke's Hospltal, Wellington, Kan. Established 1911 ; public ; 30 beds; Frances Jones, R.N., superintendent.

\section{Wichita}

Kansas Masonic Home, IVIchita, Kan. Established I\$96; James Snedden, superintendent.

Kansas Sanltarlum, Wichita, Kan. Established 1904; general and bealth resort; 50 beds; L. L. Jones, medical superintendent.

Modern Hospital, 716 N. Lawrence Ave., Whita, Kan. Established 1910; general: 20 beds; H. Philipp, pbyslclan in charge. Sedgwick County Home, Wichita, Kan. Establlshed 1890; 40 beds; O. G. Hutchlson, physiclan in charge.

Sedgwick Ilouse, 223 w. 3d St., Wlchita, Kan. Established 1908; general; 10 beds; O. G. Hutchison, physiclan in charge; $\mathbf{i}$. W. Woods, superintendent.

St. Francis Hospital, Wichlta, Kan. Established 1887 ; public ; 180 beds: $A$. Fabrique and Charles E. Bowers, attending physicians; Sisters of the Sorrowful Mother, in charge.

Wesley Hospital, Wichita, Kan, Established 1912; public; general; 35 beds: E. D. Ebright, chief of medical staff ; Rev. A. B. Hestwood, superintendent.

Wichlta Hospital and Training School for Nurses, Wlehlta, Kan. Establlshed perintendent, Pro. Tem.

Winfleld 


\section{PHYSICIANS OH KANSAS}

Ninmes in caplails slgnify taemlershlp In

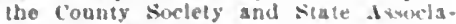
thon (1)Or, Joll.:).

- Inulleates reljowshly in the tmerlatu Med. disn. (Irot, JOHX $t$ ).

(b'is) Year of blrth.

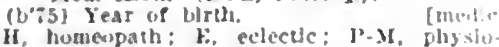

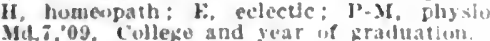

- Informatlon recelied does not slum brat cation.

S.-Surgeow.

Ob.-ubstetrlclan.

ObG.-Obstetrlcian. Gineculaglse.

G.-Gynecolosist.

Or.-Orthopedlst

Pr.-Proctologist.

Op. - Ophthalmologlst.

A.-Aurist.

LR. - Laryngologist, Rhinologist.

KEY TO ABBREVIATIONS, SYMBOLS, ETC.

\section{(l'su) livar of llcenae.}

(2) In furactio.e lefure tossage of present law and llcensed be tiling dluluma or lis jeats us practice.

(1) J,fichived lut year not known.

(t) Infurmation receited does not show Hoenve.

I. S.... Inlted siates Irmy.

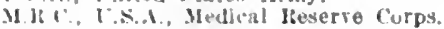

SPECIALTIES ARE INDICATED AS FOLLOWS:

ALR.- - Hurlat, Jarynologlst, Ithinologlke.

OALR. Ophthalmologist, durlst, Jarsmguloglat, Ihinologlst.

U.-I'rolnglst.

D. Dermatologtst.

Pd.- Pedlatrlite

N.- Veurologist.

P. - isychlatrlst.
I.N.X., Inlted Silal' Navy.

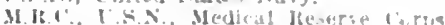

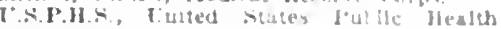
vertlce.

Colleno gusitions hels are indicated is

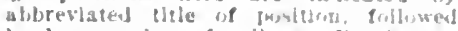
ly key unalier of collewe. For hey tis rolleges sae Inslde fromt cover pare.

(A1.3, 15, 1t) Mentierstaly in sperelal sincletles. (see key Table, uages $12: 2$,

NP.-Neurulogint, Pychiatrist.

I.- Internist

T. - Tulerculotheraplst

Anes.-Anesthetlst.

LD. - Ialnratory IVianostlcian.

R.- tetinutealst loadiolonte

Path.-J'a:Lologist.

Bact. Hacterlologist.

WHEN THE ABBREVIATION REPRESENTING A SPECIALTY IS FOLLOWED BY AN ASTERISK (*) IT INDICATES THAT THE PHYSICIAN CLAIMS HIS PRACTICE IS LIMITED TO THAT PARTICULAR BRANCH OF MEDICINE: WITHOUT THE ASTERISK. THAT HE IS ESPECIALLY INTERESTED IN. BUT DOES NOT LIMIT HIS PRACTICE TO. THAT BRANCH. THIS INFORMATION CONCERNING SPECIALTY IS BASED ON PERSONAL DATA FURNISHED BY THE PHYSICIAN AND IS NOT VERIFIABLE.

\section{KANSAS}

ABBYVILLE, 300, RENO

Erans. Chas. W. (b'-1)-J!o.8,'99; (l'0I).

ABILENE, 4,118, DICKINSON

Attwood, Chas. F. (1,'82)-Kats.3,06; (1'06)

Conklin, Tracy R.-Mo.i, $98 ;(1 ' 01) ; S$.

Dleter, Johann X.-. Jo.20,"04; (1'04)

Felly, Jlarry Bowman (b'69)-Ya.z,'y2; (l'01).

Gish, Abraham S. (b'+3) E-Pa.17.69: (1'01).

Hayes, Nelson W.-0.1, :-; $(101)$.

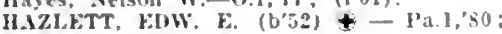
(I'0l): OALR.

Klrsch. Martin-H-M0.5,80; (l'01); not In vractloe.

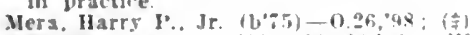

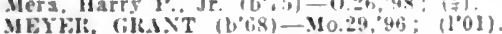

MElkik, CikiNT (b'68)-Mo.29, 96 ; (l'01)

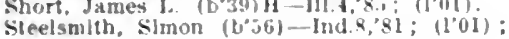
S.

Witiner, Peter H. (b'69)-l'a.2, 96 ; (l'0l).

ADA, I60, OTTAWA

Lee, Wm. H. (b'56)-Mo.8, $8 \%$, III.I,94: (1'01).

Mchener, Wm. Ernest (U'sl)-Kan.2,'10: $\left(I^{\prime} 10\right)$.

ADMIRE, 205, LYON

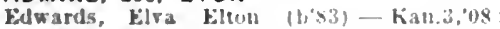
$\left(l^{\prime} 09\right): 0$.

IIATCHER, CIIAS. D.-Kan

AGENDA, 100, REPUBLIC

SMITI, ARTHCI FIRNEST (b'\%3)-Kan.2. 0\%; $\left.11^{\prime \prime} 0 \%\right)$.

AGRA, 347. PHILLIPS

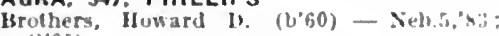
(1'01).

ALBERT, 250. BARTON

Meckfessel, rrank G. II.-Mo.33,03; (['0.3)

ALDEN, 255, RICE

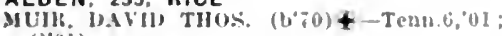
( ('Oi). $^{\prime}$

ALEXANDER, 120, RUSH

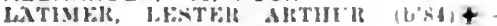
So.20, 0 ! ; $(100)$.

ALLEN, 286, LYON

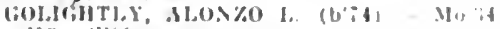
03: (l'08).

ALMA, I,010, WABAUNSEE

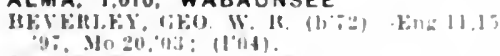

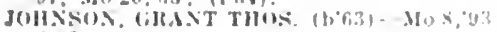
(10i).

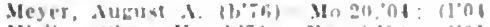

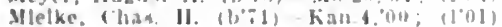

ALMENA, 702. NORTON

Bennle, Andrew $\left(6^{\circ} 38\right)$-Neb. I.'4: : (1'01).

Heeses, Irthur (b's.3)- Mu:
Rumsey, Fred B. (b'te)-la.t. 33 : (1001). Sullban, stcplsen W.-Mo.27,99; (l'0I).

ALTAMONT. 606, LABETTE

MOIBIOW, NELSON C. (b',9) D-Ill.11,0J; $\left(10^{\circ}\right)$.

I'RTY CHAS SIJULEON (b'69) 4 IL.S, $96 ;(1 \circ 01)$.

ALTA VISTA, 499, WABAUNSEE

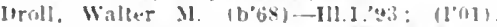

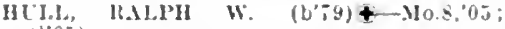
(1)0i,

lidsle, Wm. H. Mo.s, 00 ; (1.0I)

ALTON, 4I4, OSBORNE

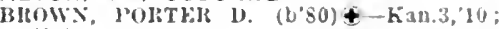
(1'10).

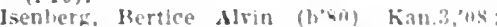
(l'0.s).

ALTOONA, 1,462, WILSON

AIUISETUE, WHAISTON H. $\left(b^{\prime} 54\right)+$ I. $1.6,7 y:(106):$ LR.

BJIINGLEA, MALTIS TAYIOR (h'72) III.23, $20 \%$ 111.11, $05: 11091$.

GIAY, NIHEHT NEWTUN $\left(10^{\circ} 0\right) \downarrow-K a n$. $00^{-}:(1,0)$

SOMEIS. MAITIS I.†-Ky.5.S4; (1"0t)

AMERICUS, 451. LYON

HIII Kil.J. JUIIX 1R. $(663)+$ Tenn. 6.93 : (1)(1) .

AMES, 120, CLOUD

Mcrallen. John Juke-O; (1'01).

ANDALE, 237, SEDGWICK

Sierrets, Wllmer M.-.

ANDOVER, 83, BUTLER

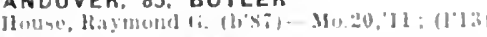

ANSON, 50, SUMNER

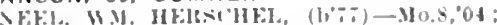
(1, 0 i).

ANTHONY, 2,659, HARPER

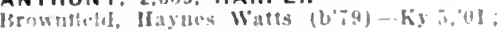
(1) (0) 1 .

lallepliter, chas Jason- XY.5, 90 ; (l'0I)

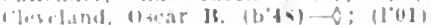

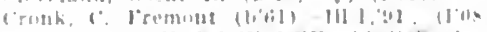

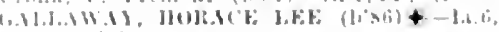

III. $11,11 \%$

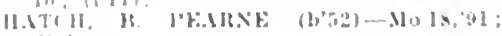

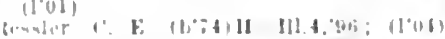

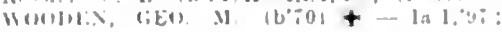

ARCADIA, 691. CRAWFORD

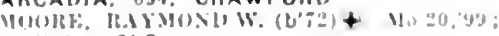

(1०11): ObG

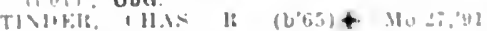
(1) 1) : G.

ARGENTINE (IND. STA., KANSAS CITY),

- WYANDOTTE

Iirinita. Frolle 11

(sice Karsas (liy. Yo)
ARGONIA, 466, SUMNER

MCIINUN, JOIIN (I.INTUN (b'T5) I0.10,10: (1,10)

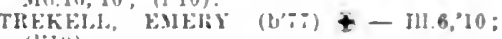
(1" III).

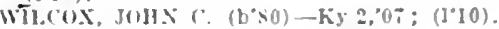
ARKANSAS CITY, 7,508. COWLEY

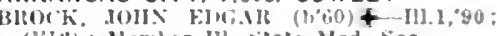
(l'I:): Mlentuer IIl. State Med. Soc.

Clark, Harriet A. Spaulding $\left(6^{\circ} 60\right)-K a n .3$, $97 ;(1+01)$.

(I.MTIOS, H.MSTEL, H.SHRY (b'St) 1!1.11.0\%: (1'09).

Clastun, lone shultz $\left(\mathrm{b}^{\prime} \mathrm{s}\right.$ ) $)$ - III.II,08: (l'(4)!: not in practice.

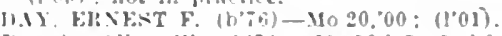

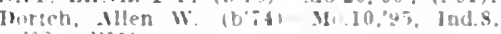
or: 1101$)$.

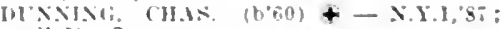
$(1 \circ i): \mathbf{s}$.

G.LFE. JUHN GRIY (h's:)-Mch 1.0s:

(1"1:) : Mentrer Wheh. sisto Med. sioc.

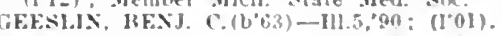

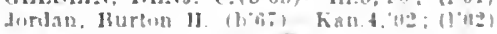

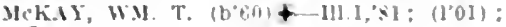
S.

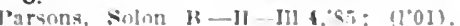

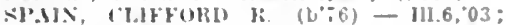

("O3) ; OALR.

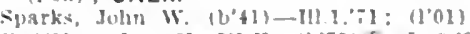

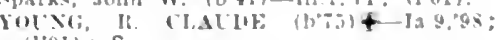
(1.01): $\mathrm{S}$.

ARLINGTON 450, RENO

Jallory, Juenj $F^{\circ}$ II! $1,95:$ (1.0I)

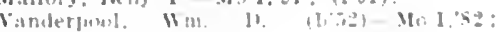
(1) I)

ARMA. 327. CRAWFORD

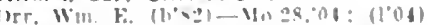

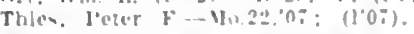

ARRINGTON, 200, ATCHISON

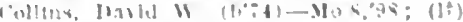

ASHLAND.910, CLARK

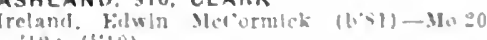
(11): (1010)

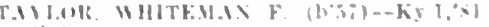
(10)!1

ASHTON, 125. SUMNER

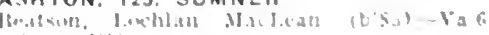
il (1)11).

ASSARIA, 246, SALINE

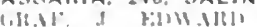

U० OALR

ATCHISON. 16, 29 , ATCHISON

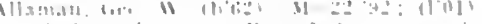

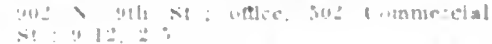

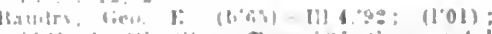

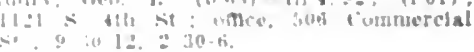


Boglo, Wm. II. (b'5 7$)-$ Pa.2,85; (1'01); 719 N. 5th St.

BHIHACH, EUGENE JOHN (b'83)థ-Mo.2 05: (l'11): 301 T St. : once, Slmpson Islde, : $9-12,2-5$.

Calclwell, Waiter w. (b'78) - Kan.3,06: $\left(1^{\prime} 06\right) ; 624$ U. St. : $10-12,3-5$

Campbeli, Donald w. (b'ti2)-Mich.1,'80 (l'01); $703 \mathrm{~N}$. 5th St. ; offlee, $701 \frac{1 / 2}{\mathrm{C}}$ Comnierclal St. ; $9-12,2-5$.

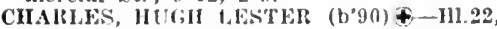
12; (1'12); :19 N. 5th St.; oftice, Simpson Bldit; $2-4 ; \mathrm{S}$.

Cole Judson (' (1, 59$)$-ont. 1,86; (1'01): 7 Ih and ('ommerclal Sts. 9-12, 2-5: Pd. Dlckey, Roht. (b'37)-Pa.1, 62; (1'01); 1515 N. 15 th sit.

DINEFS: MATTIEW T. (b'67) \&-Ky.1 "90; (l'01); $1030 \mathrm{~N}$. $51 \mathrm{~h} \mathrm{St.;} \mathrm{oftlee,} 5271 / 2$ Commerclal St.: 2.5 .

Ferguson, Chas. S. (b'69)-l'a.2,'89; (l'04); 417 N. 3d st, ; offlee, cor, 5th and commercinl Sts, $10-12,2-5,7-8$

Fluney, Chas, C.-Mo.24,'94; (1'01); $510 \mathrm{~N}$. $2 \mathrm{~d}$ St. ; oftlce, $5001 / 2$ Commcrcial St. ; 3-5. Gress, Peter C. (b'49) F-Pa.16,'85; (1'01); 802 N. 9th St.; offlee, $3261 / 2$ Conmerclal St. $; 9-12,2-4,7-8$.

HOIRER, TIIOS. EDW. $(h, 75) \uparrow-K y .1,97$; 702 N. 3d St.; offlce, $5221 /$ Commerclal St. $10-12,2-4,7-8 ; 0 b$.

IIowe, (has. F. (b'60)-Mo.18,94; (1'01); 119 N. Fth St.

llowe, Fannle H. (b'65)-Mlo.22,91; (1'01); 119 N. Tth $\mathrm{St}$.

IIUDSON, HM. II. (col.) (b'62) - Tenn.7. 87; (l'01) ; 609 Dlvlsion St.; office, 614 Commerclal St. ; $8: 30-10: 30,2-4$.

Johnson, Chas. 'H. (b'69) - N.Y.1,95: (l'01); 320 N. 2d St.; oflce, 108 N. 7th St. $10-12,5-6$.

Johnson, Fieo. H. T. (b'42)-Mo.5, 09 ; (1'01) ; 325 N. $2 d$ st.; offlce, 108 N. 7 th St. ; 8-10, $2-4,6-9$

LIIIY, CORAT, ADEIBERT (b'77) †-III.1, 01; (1'01) ; 501 Dlrlsion St.; offlce, 510 Commerclal St.; 11-12, 3-5.

Llnley, Chas. II.-0.9,77; (I'01) ; 814 S. 4 th St.; offce, 501 Commerclal St. ; 8-12,

MlcLintock. Mlnda A. (b'56)--Ia.1,'88; (1'09); $521 \frac{1}{2}$ Commerclal St.; $10-12,2-5$, 7-9; ÓbG.

Morrison, Virgll (b'82)-Mo.22,05; (l'11); 714 N. 3d St. ; $2-6$.

Murphy, walter A. S. (b'51) $\longrightarrow ; \quad\left(l^{\prime} 01\right)$; 514 Santa Fe St.; office, 116 S. 6th St.;

PITTS, EDW. F. (h'80)-Mo.22,02: (I'02); 50 T Kearner St.: OMce, Simpson Bldg.; 9-12, 2-5; OALR.

Preston, Otls R. (b's5)-Kan.3,'11; (1'12) ; 7th and Commerclat Sts.

ROBINSON, CHAS. WII, (b'90)-Kan.3,'13; (1'13): 50 s Commercial St

SIIELLY. EDWIN TAYLOR (b'59) †-Pa.1, 81; (l'01) : 701 Park St.: offlee, Slmpson Bldg. ; $10: 30-12,1: 30-3 ; 0$ b.

SMITH. WM. F. (b'84) †-M0.22,09; (l'09) 811 S. 3d St.; offee, 6 th and Commerclal Sts. ; $2-5 ;$ Pr.

Stockwell, bydia-No.22,'97; (1'04); $817 \mathrm{~S}$ 6 th St.

Ward, Jos, o. (b'63)-Kan.4,'99; (I'01) ; 318 Laramie st.

ATHOL, 180, SMITH

Scott, Walter W. (b'80)-Mo.20,'06; (l'06).

ATLANTA, 330, COWLEY

Barr, Lewis-Tenn.10,'93; (1'01).

Houser, Franklin A. (b'56) $-0 ;\left(l^{\prime} 01\right)$.

Smith, Ira Irving (b'76)-Mo.22,'13; (1'13)

WEDDELL, JAMES D. (b'49)-MId.2,72; (l'04).

ATTICA, 737, HARPER

IIAYS, HENRY EVERETT (b'76) \$-Mo.20,

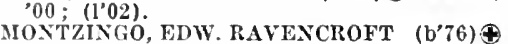
III.13,'03; (1'06).

ATWOOD, 680, RAWLINS

Graves, louis fireen $\left(b^{\prime} i 0\right) \rightarrow$; $\left(l^{\prime} 01\right)$ OIINSON, HARRISON HINDŚ (b'79) lian. 2,06 ; (1'06)

MILVIN, WILL CANTWELL (b'59)-Ia.1,

Melugin, Jolin N--Ia.1,'si; (l’01).
AUBURN, 100, SHAWNEE

IlacDomald, Orville Austin (b'85)-Kan.3,

$10 ;\left(I^{\prime} 10\right) ; 0 b$.

AUGUSTA, 1,235, BUTLER

GAKVIX, FRE1) AIKEN-Ky.1,'93; (1'01).

Ilall, Lewls Smith-N.Y.10, 78 ; (l'10)

III1 Г, IIARVEY A.-Ill.1,'98; (1'01).

Marshall, Rlcliard A.-Tenn.6.'84; (l'0I)

MCCLUGGAGE, JOHN RANDOLYH $\left(b^{\prime} 44\right) \oplus$

- 111.1,77; (1'01)

Smlth, I'eter I3. (L'44)-Mo.10,'82; (1'04).

AURORA, 269, CLOUD

KINNAION, FRANK (b'80)-Kans.3,'12;

(1'12).

Tourligny

\section{(l'05).}

(l'08).

'lper, Porus H.-Kan.3,07; (l'07).

BAILEYVILLE, 125, NEMAHA

CAI'l'ER, FRANKIIN F. (b'i4)-Mo.22, 00 ; (1'07).

IIouston, Raymond B.-Mo.29,'05; (1'07).

BALDWIN CITY, I,386, DOUGLAS

Bell, Fred H. (b'81)-Mo.20,05; (1'05).

Hankins, Tlmothy $\left(b^{\prime} 44\right)-0.8,74 ;(\neq)$.

LISTON, GEO. MCCLELLAN (b'64)-Ind.8,

'92, Ky.5,'96; (l'0\%).

Steplien, Chas. E. (b'62)-MLo.20,92; ('t'01) UIIL, FARL IAAWRENCE (b'85) (-111.1, 11 ; (1'12).

UII, WILBERT A. (b'59)-Ind.10,'82; (l'01).

\section{BARNARD, 425, LINCOLN}

llinkley, llarry L. $\rightarrow$; (I'01)

Rees, Ioln $\left(\mathrm{b}^{\prime} 39\right) \longrightarrow$; $\left(\mathrm{l}^{\prime} 0 \mathrm{I}\right)$.

TOWNSDIN, ASA M. (b'80)-Mo.8,'03; $\left(l^{\prime} 05\right)$.

BARNES, 454, WASHINGTON

Groody, Hazley Thos. (b'83)-Ill.22,'13; (l'13).

Taylor, Harvey L. $\rightarrow$; (l'01).

Weiss, Albert John (b'80)-Kan.2,'06; (I'06)

BARTLETT, 249, LOBETTE

Bendure, Chas. S. (b'60)-Kan.4,'97 ; (l'04).

BASEHOR, 200, LEAVENWORTH

Brown. Chas. McHroy (b'88)-Mo.20,'13: (I'13).

BAXTER SPRINGS, 1,598, CHEROKEE

Boswell, James Henry (b'78)-Ill.6, 05; (1'05).

Engllsh, Robt. B. (b'50)-Mo.2,74; (l'01)

Wear, Robt. C. (b'59)-Mo.20,'85; (1'0I).

BAZINE, 125, NESS

Bennett, Chas. C. (b'90)-Mo.20,'13; (1'13) ; Pd.

\section{BEATTIE, 497, MARSHALL}

HAM, WM. ENIETT (b'58)-III.1,'82;

Mattliews, James T. (b'58) - Mo.18,'91; (l, 01$)$.

MecOY, JOIIN HAMILTON (b'7z)๑-III.1,

'02; (I'03); Member Mo. State Med. Assn.

Yoder, Earl H.-Ill.4,'13; (l'13).

BEAUMONT, 165, BUTLER

I'hlllips, Wm. James (b'56)-Ia.3,'85; (1'01).

BELLAIRE, I35, SMITH

WATTS, VICTOR EVERITT (b'78)-Kan.3, 07 ; (l’07).

BELLE PLAINE, 849, SUMNER

BAKRR, RINALDO EVERETT (b'75)110.35,'12; (l'12).

BARTLETT, WALTER E.(b'70)(-Mo.7,'93 ( 1 01)

Clark, Thos. J. (b'68)II-Mo.26,'01; (I'01). Hutfman, Hichael V. $\left(1^{\prime} 39\right)-0.2,70 ;\left(l^{\prime} 01\right)$ RUUOLPH, JOHN FRANCIS (b'72) -0.6 03; (1'13).

BELLEVILLE, 2.224, REPUBLIC

ARBUTHNO', CHAS, II. (b'52) -Pa.2,'81 (1'01).

BILLINGSLEY, JAMES S. (b’57)-Ill.1,'83; (l'01).

DECKER, JAY C. (b'81) $\uparrow-N e b .5,04$; (I'05) : OALR. G. (b'59)-IIo.22,83, Ill.1 Haning, Wm.

KAMP, WI. (b'56)๑-N.Y.3,'s2; (l'01)

ICFARLAND, WM. I. (b'7)-Neb.6,05; (1'05).
Radabaugh, Justln G. (b'70) E-III.10,04; ('04).

TIONAS, HENRY DAVID (b'82) -Ia.3, 10; (1'10); OALR.

BELMONT, I30, KINGMAN

Wallace, Eugene (b'79)-I11.11,'05; (1'05). BELOIT, 3,082, MITCHELL

BHEWER, EZIRA EIJMUND (b'59)-Mo.20, '92; (1'01)

COOK, WM. II. (b'68)థ-II1.1,'94; (1'07). DANIELS, EDMUNU N. (b'70)屯-Mo.20, $00 ;(1,01)$.

IIOME, FRANKLIN B. $\left(b^{\prime} 44\right)-111,4,73$; (l'01).

JOBDELI, MARY J. (b'47) $\oplus$ - Ill.9,'84; (l'01).

O'BRIEN, DANIEI، S. (b'58) \&-H1.1,'80 ; (l'03)

Seager, Arthur Z. (b'64)-Jll.10.'94: (1'01) SMITH, RICHARD C. $\left(\mathrm{b}^{\prime} 86\right)$
( ) ; Member Oregon State Med Assn. ; (B19) ; OALR. $\star$

SIESSARD, MICIIAEL ROIBT. (b'69)कII 0.27,93; (l'0.1); Assoc. Prof. Surg. OkIa.G1; G.

BELPRE, 485, EDWARDS

BOYD, CIIAS. ARTIUUR (b'81) -Colo.2, 'I1; (l'12).

Clark, Thos. F. $\rightarrow$ : (1'01).

Belvue, 164, POTTAWATOMIE

Searl, Oscar R. (b'72)-Mo.20,98; (1'01).

BENDENA, 125, DONIPHAN

Clutz, Ralph R. (b'87)-IIo.8,'00; (1'01).

BENEDICT, 215, WILSON

RHLEY, BRETTE R. (b'71) $-M 0.29,96$; (1'01); S.

BENNINGTON, 386, OTTAWA

Hinshaw, Llewellyn M. (b'75)-Kan.3,05; (l'05).

Oood, Orlln P.Mo.20,00; (1'01).

BENTLEY, 200, SEDGWICK

Anderson, Arthur (b'81)-Ky.2,'11; (\$).

BENTON, 240, BUTLER

Hurd, Marcus Chas. (b'81) E-Neb.4,06 ; (1'06); G.

BERN, 300, NEMAHA

Thomas, Wm. M.-No.20,97 ; (1'01).

BERRYTON, 56, SHAWNEE

Burr, Wayne B. (b'85)-Kan.3,'13; (1'13).

TAYLOR, NORTON J. (b'42)-Pa.8,'65 ('’01).

BEVERLY, 335, LINCOLN

Ulils, Russell Todd (b'88) - Mo.20,'11;

(l'11).

(I'10); Pd.

BIRD CITY, 190, CHEYENNE

l'egg, Geo. R. $\rightarrow$; (1'01).

BISON, 350, RUSH

ROBISON, NORVAL W. (b'82)-Mo.20, '10; (1'10).

BLAINE, 245, POTTAWATOMIE

Miller, Ransley Jacob (b'89) - Kan.3,'13 (I'13).

BLUE MOUND, 596, LINN

B'ARNES, HUGH M. (b'77) - Mo.20,'99;

Giles, Alexander Porter (b'58)-I11.1,'83 ; (l'01).

KENNEDY, JOHN T.๑-Mo.20,'04; (1'04).

BLUE RAPIDS, I,756, MARSHALL.

FILLMOKE, ROLLIN S. (b'54) †-MO.1,'83 ; (1'01) ; $\mathbf{0 b}$.

Hunter, W'm.-Mo.14,79; (1'01).

McFarland, Carl R. (b'81) - Mo.22,'05; (l'06).

Reed, W. W. (b'80)-Kan.3,05; (1'06); S.

Smlth, Helen Seymour $\left(b^{\prime} 87\right)-K a n .3,13$; (1'13).

Thomas, Francis Marion (b'41)-N.Y.10,'69; ().

BLUFF CITY, 307, HARPER

BARBER, ANDREV H. (b'64) - ; (l'04).

BURNETT, JAMES R. (b'81) †-Kans.3,'12; (1'12).

BONNER SPRINGS, 1,462, WYANDOTTE

CANDLER, FRED D. (b'74) $4-M 0.32,02$; $\left(\mathrm{I}^{\prime} 04\right) ; \mathbf{R}$.

CASE, CLAUD HOUSTON (b'74)-Kan.2,

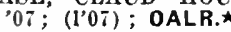


Downs, F. M. - Ia.1.75; $(101)$; rot in practice.

llays, Henry Ilornwell.

(See Kansas Cly, Mo.

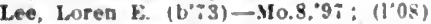

Lneback, Chas. B. (b'59)-lad.8,"ys: 1 1'01)

BREWSTER, 500, THOMAS

IIawklns, Leroy $\left(b^{\circ}, 1\right)-0$ : $\left(l^{\prime} 01\right)$.

BRONSON. 395. BOURBON

CUMMINGS, JAMES SCOTT (b'51) $0.8,30$ : (1'01)

Howell. Dust!n D.-E-Mo.33,03: (1001)

BROOKVILLE, 280, SALINE

FOWLEI, WHIBER FMMETT (b०55)111.11,'84: (1'01).

BROUGHTON, 118, CLAY

FOOTE, ALSTIN ALFRED (b'85)-III.11, 09: (1.09).

BROWNELL, 100. NESS

Pagan. Frank D. (b"is)-Kan.3,06; (1'06).

BUCKLIN, 696, FORD

Fannon, Hubert (b'-4)-Colo.3,01: (1,01) Prltehard, Wm. W. $\left(b^{\circ}+0\right)-T e n u .1,6 s$; (1'01).

Scolt, Alexander B. (b'il)-Mo.20.94; (1'01).

BUCYRUS, 100, MIAMI

Knoop. James Arthur (b'34) - Mo.20,03: (1'09).

BUFFALO, 807, WILSON

BHLL, GEO. P. Y-N.Y.10,'s6; (l'01)

Preston. James C. (b'63) - Temm. 85 : (l'01).

Sutherland. Chas. I. (b'5s)-I11.6,83; not In practlce.

BUHLER. 400. RENO

Bredemott, Jullus C. (b'7i)-110.32,00 (1'01).

Schellenberz, Katherlne Lorenz-H-Mo.35. 04: (1'04).

BUNKERHILL. 2\$2, RUSSELL

MLIER, ERXYST ANI)REW (b'84)III.22,'10; (I'12); Member III. State Mled. Soc.

BURDEN, 424, COWLEY

BROOKS, EDGAL FIRNEST (b'S3) Mo.20 '08: $(1.08)$.

MANSER, WM. H. (b'59) -0-1,81, Mo.8, 89: (1'01).

BURDETT, 130, PAWNEE

ELTING, WM. V.-Kan.4,02: (1'0\&)

BURLINGAME, 1.422, OSAGE

Goluman, Davilla $\mathrm{X}$. (b'62) If-Mo.2e,"9s: (1'01).

Scluenck, Franklln k. (b'5f)-la 1,82 ; (I'01)

Seabrook. Clarence Cullen (b'5t)-I'a.l, 78; (1'01): $\mathbf{N}$.

Stahl, clare w. (b'78)-Kan.3,04: (1'04): ObG.

BURLINGTON, 2,180, COFFEY

Berry, Alex. K. (b'52)-la.3,84: (1'02).

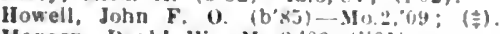

Manson, Davld-W-Mo.8, 02 (1'01).

MCMULLF, VEHBE.SIA $\left(\mathrm{U}^{\circ}, 9\right)+-M 0.32$, 02: (1'02).

Norris, Ciranille R. (b6i) E - Mo.10,92: (l'0i).

Sallsbury, llarry T. (b.65)-M0.20,90:

BURNS, 489, MARION

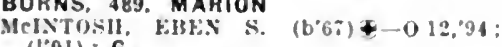
$(1 * 01): \mathrm{G}$

Shoukwller. Jos. A. (2,09)-Inu.8.05;

(I'Y): Pd.

BURR OAK, 1,132, JEWELL

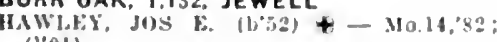
(1.01),

HKRSHXFIR, CHAS. S. (b'a) - M+3:04: $\left(1^{\prime} 04\right)$.

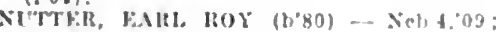
(l'03).

BURRTON, 689, HARVEY

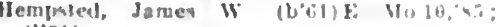
(1'01).

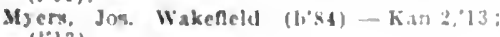
(!"13).

BUSHONG, I50, LYON

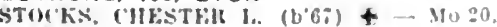
'96: (l'01)
BUSHTON, 222, RICE

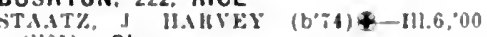
(l'01): Ob.

CALDWELL, 2,205, SUMNER

Carver, llarry fiverelt (b'-75) - Ia.4,39: (l'0;).

Eirlckwin. Enull T. (b'83)-Kan 2,08; (l'08) Calbert, Ira T (1, 12$)-\mathrm{Pa} 2.83 ;(101)$.

KISF, KEIt, IAVII) E. (b'-1) - IIII, 01 11021 .

Noble, Wm. I. (10'48)-Mo.1.7R: (\$)

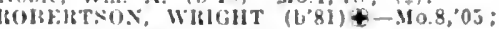
(I.0.)

Thrallkill, Mllton R. (b'63)-Mo.18,85; (1'01).

CAMBRIDGE, 225, COWLEY

Il lland. Danlel Alcut (b'83) - ky.2.09 (I'09)

Rude, Thos. J. (b'56)-D: (1'03)

CANEY, 3.397, MONTGOMERY

H.IUIRIII, HAIRISS I. (b'69) - III.15, 02: $(1 \circ 0: 3) ; 6$

Mlirleh, llattle Bassett (b'69) Il-Kan.3,04 (1.04).

Blgelow; Gardner J. (b'7)-Mllch., 96 ; lewett, Wm. F. (b'f1)-Kan.4,99; (1'02):

crob. wM. F. (b'75) +.Inn 4,03; (1'09)

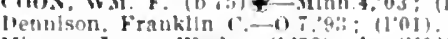

Mtnner, James Wesley $\left(1 y^{\prime}, 8\right)-8$ (1'04).

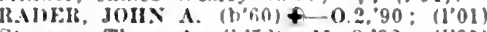

Stevens, Thos. A (b'56)-Mo.8,92: (1'01)

Taylor. Andrew M. $\rightarrow$ : (l'01).

CANTON, 684, MCPHERSON

Edlerton, ILarry W. (b's0)-Mo.s, $04 ;\left(l^{\prime} 04\right)$

Filgerton. Wm. M. (b'69)-Mo.7,99; (1.01)

Ifedlnger, Chas. (b'22) II-Ger., 42; (l'01)

CARBONDALE, 461, OSAGE

Heckart, Elllott Tate (b'82)-Kan.3,08; Suallow, Ir. Ileaton $\left(b^{\circ} 56\right)-0.3,84 ;\left(1{ }^{\prime} 01\right)$. CARLTON, I60, DICKINSON

Foward, Il. W.-D: (l'01).

Johnom, Walter Wendell-Kan.3,05: (1'05).

CARONA, 400 , CHEROKEE

RFII, CHAS. T. (b':4) †-Mo.34,06; (1'06).

CASSODAY, I00, BUTLER

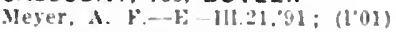

CASTLETON, 200, RENO

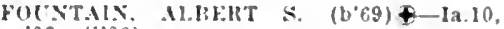
$06 ;(1 ' 06)$.

CAWKER CITY, 870. MITCHELL

Battey, Gialen $\therefore$ (b'55)-ll1.4,'s0; not in practlee.

Brown. Carl Logan (b'S5)-Kan.3."13: (1'13)

MAS(1), kINIS (i. $\left(b^{\prime} 54\right)+0.2,85$

(1'0]).

M. 1.50 (S)

KIRK P. (b'is)—-Kan.3,0:

CEDAR. 125, SMITH

BOSTWIOK, WATEH IIEXIY (1\%:8) .10.2.4. $05:(1,05)$

IIall, Ihas. W.-Mo.22.07: $\left(10^{\prime} 07\right)$.

CEDAR POINT, 200, CHASE

Irwin, Walter it. (b'3)-MU.35,"10, Kan. '09:; (I'10),

CEDAR VALE, 948. CHAUTAUQUA

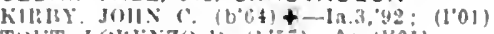

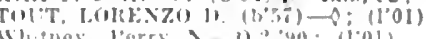

Wh:?ney, lerry A $0: 200$

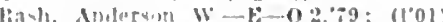

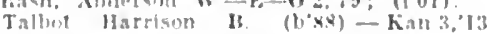
(1) 131.

CENTRALIA, 665, NEMAHA

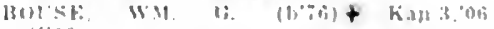

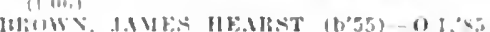
II.011:

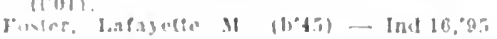

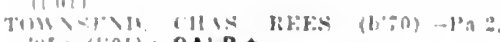

:15; (1'nI): OALR. *

CENTRUPOLIS. 90, FRANKLIN

CHANUTE, 3.272, NEOSHO

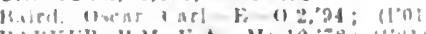

MAMKEl: II U

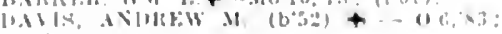

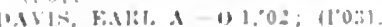

Duncan, Marlon A. (b'55)-Ind.8.81;

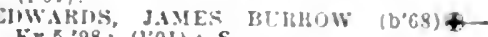
Kу. 5, 38 ; (1'01): $\mathrm{S}$.

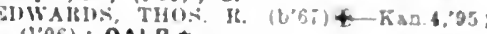
(l'06): OALR.*

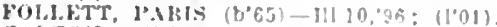
G.AlTON, AVEIt M. (b-4) - Kan:0, (1CKE: S.$$
\text { (1)0? }
$$

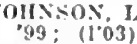

: (1'03). lankfort, Win. J. (b'52)-Mo.18.,92: (1.01) LIIIIT, JOS. H. (b.45)-0 13, (1'01): LD.

MATils, wil. KLRTZ $\left(b^{\circ}, 50\right)+-1020,03$; (1'04).

Mcfioun, Caslus M. II. $\left(b^{\prime}+7\right)-0$; ("'01)

lakestraw, Henry E. $\left(b^{\circ} 50\right)-$ Mo.5, 54 (1'01)

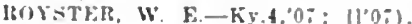

Sumers, Ira C - Tenn $11.01:(100)$

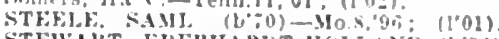
STEWAKT, EIEIRHARLT HOLIAND $(1,04)$ -Mo.Is,92: (1.01).

CHAPMAN, 781, DICKINSON

Greenlee, Ciullerd G. (b's0)-Mo.20, 05 : $(105)$

O'Brien, John J. (b'66)-Ky.2,'90; (1'01),

CHASE, 263, RICE

WHAACF, FLOYD ELDRIDGE $(b \div 8)+$ Mo.s, $04 ;(104)$.

CHAUTAUQUA, 348, CHAUTAUQUA

Jack. Wm. lien. (b'-4)-Mo.8,00; (1'01).

CHENEY, 734, SEDGWICK

Artman, Byroul $k \rightarrow 0.288 ;(1201)$

MIIDLNE, AITHTR ROYAL (b.7) Kan.2,06: (1'06): Pd.

Mahin, Francls M. (b'69)-Ky.9,04; (l'05): Ob.

Shanion, Thos. H.-la.1.79: (1"02).

CHEROKEE, 1.\$52, CRAWFORD

(owden. Mlva l. (b":5)-Mo.20.00: (l'09) UAYS. ALMONTA I. $\left(b^{\circ}: 2\right)+$-Md 3,01 (I'0i)

IILIFF, DANIEL A. (b'55)-Kan.4; $01 ;\left(1^{\prime} 01\right)$, CHERRYVALE, 4.304, MONTGOMERY

Casetwer, Iluward il. (b'3t)-Mich.1, 76 : $(1,04)$.

FINIFY, MAYARD A. (b'69)-Mo.:97;

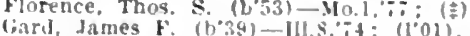

Hale, Buron I. (b'66)-Kan.,00) (1'01): s

Kellam, saml. II. (b'ss)-Kant,00: (1'01)

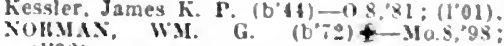
(1.0ㄹ.

SEMC IT, GEO, MCKESIILE $(1, \% t) \mp$ Ky.1.'55: (1,0i).

Watkins, Fred Morgan (b'6s)-Mo.99.9\%: IOIXGs, WM. E. (b'42)-Mo.29,99:(101):

CHETOPA, 1.5:8. LABETTE

Anclersul, Julu R. (b'49)-0.1,:02: (1'01)

laubli, Clara $\$$ - la.1,:00: (1'01).

Carter, Rube (; - (1'0il).

Karkley, John d Ilo l, :0: (1001),

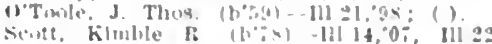

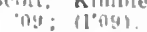

VON TRFHKA, FITESTIXE \&.-Ja 10,08:

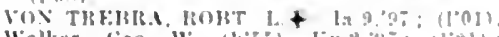
Walker, (ien. IV $(6 \cdot 3)-k y=3 ; ; 1101)$

CIMARRON, 587, GRAY

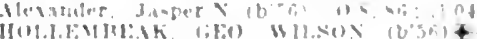
III Ii]

CIRCLEVILLE. 265, JACKSON

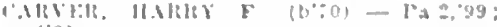

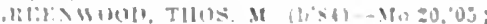

CLAFLIN, 53., BARTON

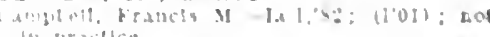

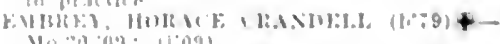

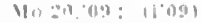

J11t). Iltillmit W+Mu3t,03: (I'03). 
CLAY CENTER, 3,438, CLAY

13.SL, GEO. WIXFIRED (b'83) †-Kan.3, $10 ;(1,10)$.

COOK, DANi. PECK-Mll $.5,81$ : (1'01) lurant, Ira F.-In.20,98; (1'01).

Griuam, Rolt. H. (b'S2)-Tenn.15,'11 (1.13)

(l'13). JOIN ARTIIUR (b'83)£-111.11,

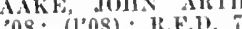

MRNER, MARSIIII WM. (U'75) Ill.11,05; (1,05).

Lawson, fico. Il. (b'63)-Kan.3, 06 : (l’06) R.F.J. 6 .

Martin fimmanuel X. (b'7t) - Mo.20, 00 (l, lin

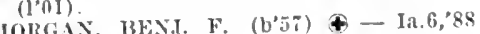
(I"0I).

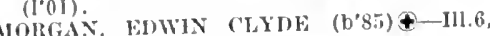
$10:(1,10)$

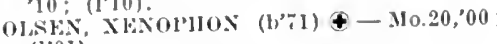

(1"01). SAMIL. F. (b'45) - 0.1,73 (l,oul)

SIIYUIRD, IIARRY R. $\left(b^{\prime} 73\right)-0.8,02$ (l'08).

Speer, Win. Louls (h79)-Ta.2,12; (1'12)

CLAYTON, 191, NORTON

Glyer, IIllary S.-Ky.2,79; (l'05)

CLEARWATER, 569, SEDGWICK

Beal, B. Clyde-Mfo.20,02; (l'04)

Ataglil, Clycle (b'87)-Kan.2,12; (1'12)

Whinery, Solon C. (b'i2)-Kan.4,01; (1'01).

CLEBURNE, 170, RILEY

Schumann, Fnoch-Mo.22,'07; (l'07).

CLEMENTS, 200, CHASE

Billunglea, S. Wm. (b'69)-Mo.33,'04; (l'11).

CLIFTON, 614, WASHINGTON

POTTER, IIORACE I. (b'58)థ-Mo.5,'85; (1'01); 0 p.

SCO'T JAIES STANLEY (b'66)-Mo.20, $96 ;$; (1'01).

TYLER, DE WITT C. $\left(b^{\prime} 50\right) £-I 11.1,81$;

Van Scoyoc, Wnı. M. (b'86)-Mo.20,'03; (1’04); G.

CLINTON, 250, DOUGLAS

13EACH, IIARK (b'T3)థ-Kan.3,'03; (l'03). CLYDE, 1.057, CLOUD

Warren 13.-Kan 3,00: (l'01).

1ELO' MONTE I. (b'85) -Kan.3,10 (1'10).

Girard, Arthur J.-Que.3,'94; (l'01).

laughlin, Darld F. ; ( (l’02)

IOFFATT, FRANCIS J. (b'79)-Mo.20,04; (l'12).

Sexton, Albert G.-111.1,78; (1'01)

COATS, 269, PRATT

PADFIELD, ]ROBT. ELMER (b'84)-Kan.2, '11; (1'11).

CODELL, 175, ROOIKS

Llttlejoln, Wm. (b'65)-Kan.3,'99; (l'11)

COFFEYVILLE, 12,687, MONTGOMERY

Baird, Jay (b'70) E-0.2,'00; (1'04); $105 \mathrm{~W}$. lst St.; offce, $116 \frac{1 / 2}{W} \mathrm{~W}$. $9 t_{1}$ St.; $10-12$ 2-5; Pd.

Baskette, J. M. T. (b'80) - Tenn.7,'06 $\left(l^{\prime} 06\right) ; 107 \mathrm{E}$. Neu St.; office, $1023 \frac{1}{2}$ Walnut St. $9-11,2-4,7-8$.

Brown. Geo. W. (b'78)-Mo.29,'98; (1'01) Sth and Walnut sts.; $9-12,2-5$.

CAMPBELL, CHAS. SAMI. (b'78)థ-Ill.1. (1'04) 611 Beech St.; oftlce, $118 \mathrm{~W}$ '02; St. ; 10-12, 2-4:30; S.

COYLE, EMORY GOLDEN (b'S9)-Mo.34, 11; (1'12); 112 W. 8th St.

DUNCAN, FRED WALLACE (b'84) $\oplus-$ Mo.2,06; (1'07) ; 606 W. 6th

FISHER, WHLELM RUDOLPH (b'84)\$III.10,10: (l'11); 706 Willow St.; office, Ill.10,10; (l'11); 706 Willow St.
Columbia BIdg. ; 10-12, 2-4; ObG.

FLACK, FRANK LeROY (b'88) -Kan.2,'12 (l'12)

FORTNER, CIIAS. HUGHES (b'72)-Mo.20, 04; (l'04) ; 616 Lincoln St.; offlee, 127 W. 9 th st.; $10-12,2-5$.

Frazier, Thaddeus C. (b'41)-0; (1'01): not in practice; 1411 Maple $\mathrm{St}$.

Gricsby, Clement E. (b'69) - Mo.22,'93; (1'02) : 613 Lincoln St.; offlce, 120 W. 9 th St. ; $10-12, \quad 2-4$.
HAI.I, W.M. C. (b'60)†-MI.3,"85; (l'01); $402 \mathrm{~W}$. ath st.; oftce, 818 Majle St. $9: 30-11,1: 30-5,7=8: \mathbf{S}$.

Iforne, John G. (b'56) $\longrightarrow$; (l'01); $9241 / 2$ IVilnut sit.

JuHINOX, ClIFFOR1) I'. (b'83)-Kan.2,

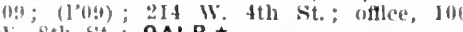
II. Sth sit.: OALR. *

JOIIXSOY, JOIIN II. (b'59) $\uparrow-M 0.8,30$ (I01); 216 W. 4th St.; offlec, $106 \mathrm{~W}$ 8th st.; (131); OALR.»

KRIGG(i, AlBERT A. (b'64)-Mo.32,98; (l'01); 405 F. 8th St.; ottlee, 813 Maple

Fiviler, Fmll $\left(b^{*}, 51\right)-0$; (l'01)

ICDonale. Saml. Gilbert (b;2)-111.5,05 III.*2.0s: $(1 \circ 06) ; 12816$ w. 9th st.

lowers, (rhas. $\mathrm{l}_{4}$ (b'44)-H-Ill.4, 78 ; (l'0t); 5II W. sth St.; offlee, IIall Bldg. Myan, fames W. (b'66)-0.1,'88; (1'01); $211 \mathrm{~W}$. Fth st.; offlce, $112 \mathrm{~W}$. $8 \mathrm{~h}$ St. $8-11,1-5, \bar{i}-8$.

Stansbury, lleury M. (b'46) $\rightarrow$; (l'02);

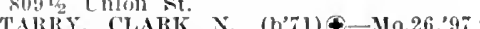
(l’03): 617 w sth st; offece, Flrst National 'Bank Hidg.; 2-4. an Gorder, Frank L. (b'67)-Mo.20,'07 ; $\left(l^{\prime} 07\right) ; 200$ W. 9 th st.; offlce, Kellogg Bldg. ; Pr.

Washington. ("has. 1'. (col.) (b'64)-111.15; (1'04); 502 sycamore st.

Wellman, I'. F. -0 ; (l'01)

WELIAS, WALTER II. (b'47)-D.C.2,68; (l'04); 202 W. Tth St.; ofllce, The Plaza; $8-11,1-4$.

Whittaker, Rlchard Sallnthus (b'81)-Ky. 08 ; $\left(1{ }^{\prime} 08\right)$; 808 E. 9 th St.; offlee, $1021 \%$ F. Sth St.; $10-12,2-5,7-9$

COLBY, 1,130. THOMAS

lieaver, Wm. II. $\left(b^{\prime} 45\right) \rightarrow$; $\left(l^{t} 01\right)$

Eddy, Victor \&. (b'62)-M11.4,84; (l'01).

I. owis, Wm. I. (b'-5)-J13.6,04; (1'05)

COLDWATER, 684, COMANCHE

Crawford, Thos. H. (b'59)-N.Y.5,'81; (l'01). 1101COM1, FRED, LOUIS (b'7t)-Ta.10. 01: (l'01); S.

Tavior, Walter Earl (b'84)-Mo.28,06; (l'06).

\section{COLONY, 530, ANDERSON}

BUCHANAN, CASSIUS C. $\left(b^{\prime} 60\right)-0.1,85$; not in practlce; Memiber Ill. State 'Med. Soc.

Martin, Clcero S.-Mo.1,'82; (l'01)

Metcalf, Edwin F. (b'43)-0; (1'01)

SMITH, THOS. E. $\left(\mathrm{b}^{\prime} 77\right) \oplus-M 0.8,04 ;\left(\mathrm{l}^{\prime} 04\right)$; OALR.

COLUMBUS, 3,064, CHEROKEE

B.XXTER, LEIROY W. (b'S0)Ð-Ill.1,'06 ; $\left(1^{\prime} 06\right)$.

BROOKHART, HARRY H. (b'72) -Mo.27, 95; (l'01)

GRISWOLU, J. LOUIS $\left(b^{\prime} 60\right)-$ Mo.7,'99; (]'01).

Hendrickson, Paris J. (b’57)-Ill.4,'82; $\left(l^{\prime} 02\right)$.

HEFFMAN, CHAS. S. (b'65)Ð-Mo.1,90; (l'01); Sec. Kan. Med. Soc.; S.

Janes, James $w$ - Tenn.6,87; (l'01).

JOHNSON, WM. N. (b'53) $\oplus$ - Ky.1,94; (I'01)

MCKINYEY, ROBT. F. (b'85)-Mo.20,'11; (1'11).

Scammon, Ezra Albert (b'43)-Mich.1,67 (1'01); D

SCOT'T, WALTER R. (b'i4)-0.2,'99; (l'01).

COLWICH, 258, SEDGWICK

Walker, Wm. F. '(b'58)-Mo.1,84; (1'01).

CONCORDIA, 4.415, CLOUD

Caton, Chas. W. (b'66)-Ky.5,'98; (1'01) OALR. $\star$

Cotfey, Geo. W. (b'66)-Mo.8,93; (1'01); Op.

Daries, John D. (b'82)-Kan.2,'06; (1'06)

DOTY, HERBER'T E. (b'T $\tilde{i}) \Phi-M 0.22,06$ (1'06); G.

Grigsby, Anna Colby (b'48) H-0.7,'83; (1'02)

LACER'TE, G. A.-Ont.4,'79; (1'06).

Laing, Robt. (b'79)-Mo.34,06; (1'06).

ICDONAJD, FRANK A. $\left(\mathrm{b}^{\prime} 60\right) €-N . Y .10$ 87 ; (1'01)

IPIGMAN, SAML. C. (b'57) $\oplus-$ Pa.2,'79;

(l'01).
PRIEST, WILSOX (1'01).
Ralnes, Taylor F. (b'52) II-111.4,"91; (1'01) ; G.

ROREIRTSON, FWWIN NOHRIS $\left(b^{\prime} 78\right)$ Neb.5.'06; (1'07); OALR. *

SAllIII, WM. F. (b'55) \$-Pa.2,82; (l'01).

Starr, R. I'. Fllis (b'83)-Ky.2,'12: (l'13);

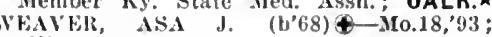
(l'01).

CONWAY SPRINGS, 1,292, SUMNER

HITRIIS, 'TREMAN G. (b'70)-Mo.18,'03; (1.01).

FVAXs, EluIS A. (b'76) $\oplus-$ Mo.24,01; (l'0I).

(itAASON, WILSON I. (b'59)-II1.8,'88:

(1'07); Member Ore. State Med. Assn.

Jeffrles, James E. (b'35) - Ind.4,76; (1'01) ; not in practlee.

IIILHENNY, ROI'T. A. (b'66)థ-III.1,'91 ; (1t).

CORBIN, 174, SUMNER

G(IT,OFF, GEO. EUGENE $\left(\mathrm{b}^{\prime} 80\right) \oplus-I 11.6,05$; (l'13).

CORNING, 4II, NEMAHA

lleuschele, W'm. Menry (b'84)-Mo.22,'10: Magili, Isaac H. (b'61)-Mo.20,'84, Mo.7,'94 ;

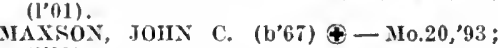
(1'01).

Thompson, Preston (b'51)-Mo.22,'92; (1'01).

COTTONWOOD FALLS, 899, CHASE

Johnson, Franklin T. $\left(\mathrm{b}^{\prime} 40\right)-0$; (l'01)

Owen, Clay M. -Mo.41,01; (1'04).

Titus, Albert Iornest (b'85) - Kan.3,'12; (1'12).

Woodlunl, Maurice W. (b'78)-Ill.11,06; (1'07).

COUNCIL GROVE, 2.545, MORRIS

Crawford, W. E.-Mo.8,'88; (1'01).

II arvey, Leland H. (b'82)-ILo.20,'11; (1'11).

IIARVEY, LEWIS S.-Mo.20, 01 ; (l'01).

Harvey, Will T.—la.1,97; (击).

Lewis, Artluur J. (b'69)-Minn.5,'95; (1'11); S.

IILLER, BERT LI.BY (b'80)థ-Mo.20,'05; $\left(l^{\prime} 05\right) ; S$.

Snow, Míadison Howard-Mo.27,97; (1'01).

COURTLAND, 454, REPUBLIC

IIAUGIEY, LEO EUGENE (b'86) †-Kan.3, 08: (1’08).

SNIIER, SIION J. (b’72) $\oplus-\mathrm{Pa} .11,97$; (l'01).

Stewart, Robert A. (b'67)-Mo.27,'93; (1'01) ; G.

COYVILLE, 227, WILSON

Henderson, Leonard E.-Mo.20,98; (1'04).

CRESTLINE, 287, CHEROKEE

ron Cannon, Roy Francis (b'88) - Mro.20,09; not in practice.

CROWEBURG, 1,000, CRAWFORD

IrKay, Bert Jewell (b'80) - Mo.20,08; (l'08).

CUBA, 466, REPUBLIC

DITTEMORE, JAMES HENRY (b'i4)-Ill.1, 99 ; (1'01).

Kiohout, Jos. A. (b'80)-Neb.5,'05; (1'0 î).

CULLISON, 256, PRATT

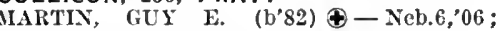
$\left(l^{\prime} 0 T\right)$.

CULVER, 326, OTTAWA

Loyd, Perry Armstrong (b'82)-Kan.3,09; (l'09).

CUMMINGS, 175, ATCHISON

Rhodes, James J. (b'78)-MI0.20,00; (1'01).

CUNNINGHAM, 395, KINGMAN

FA1N. CHAS. HOWARD (b'80)-Tex.4,'12; (l'12).

Maxsol1, Ira L. (b'70) H-MFo.31,01; (1'01) ; Ob.

Nossaman, Silas W. $\left(b^{\prime} 73\right)-M 0.20,02$; (l'01).

DEARING, 250, MONTGOMERY

Barker, Jos. L. (b'63)-Mo.8,'87; (l'01).

Pearn, Geo. (b'69)-N.Y.9,'94; (1'09).

DEERFIELD, 152, KEARNY

WATSON, JOHN B. (b'66)థ-Mo.28,'98; (1'10); also Member III. State Med. Soc. ; S. 
DELAVAN, 95, MORRIS

Mecullough, Wm. A. (b'ti) - Mo 20, 02 : (l'02).

DELIA, 100, JACKSON

VRISHEY. W.H. H. (1"*3)-Kan.3, $0: 2 ;(1003)$ O'Malley. Kdir, $b$ (b'tii)-Mo.20,04; (l'0s) DELPHOS, 767, OTTAWA

AJLIS, CILIS. B. $\left(\right.$ b'69) $^{\prime}$ - 0 11,92; (1'01) ObG.

TH1'KL,OOD, R. CAULTON $\left(\mathrm{b}^{\prime}, 5\right) \div-30.20$ "09; (1"09)

DENISON. 295, JACKSON

1).III.ISGTON, JOIIS W. (b*54)-\$I1.3,8: (1'01).

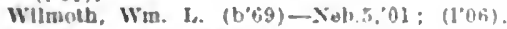

DENNIS, 250, LABETTE

BALL OKRIE H. (b'il) + - Mo.20.00 (1'0I).

DENTON, 337, DONIPHAN

Grose. Saml. S. $\left(b^{\prime \prime}+1\right)-K y, 1,44$, Mo $22, n g$ (I'01).

Stepp. Juhn E.-.Io.8,99; (1'01)

DERBY, 350, SEDGWICK

Dron. Wm. Ellsworth $\left(b^{\circ} 60\right)-N e b .5,92$ (1'0l).

DE SOTO, 337, JOHNSON

Fortney, Alran M. (b's2)-Kan.2,08: (l"0s)

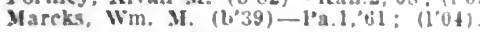

DEVON, 150, BOURBON

Adarason. Adam llandeock (b'82)-Mo.20 13: (1'13).

Sheeler, Dani. Webster (b".,9)-3n.20:s5 (1'01).

DEXTER, 5I2, COWLEY

Cooper, Harrison D. $\left(b^{\prime} 38\right)-\mathrm{V}:\left(l^{\prime} 01\right)$

llawklis, (ieorge M. (b3z)-j: (1'01)

Willians, R. II.-IIt.6.00; (1.0J)

DIGHTON, 370, LANE

Mullins, Hobt. B. $\left(b^{\prime} 60\right)-K y, 1,82 ;\left(I^{\prime}\right)$ I)

Newton, John R. (b'70) $\mathbf{M}-M 0.35,04:$ (1'vs)

lownd, Franklin Lafasette $\left(b^{\circ}\right.$ il) - Hil.

it: (1'01): not in practlee.

DOBY. - GRANT

Hremer, Geo. H. (b'bo)-O: (立).

DODGE CITY, 3,214, FORD

Alexander, X́no F. (b's1)-Mu 22, 0 ;

BIODERICK, EIGENE JAMES (b'73)IIlch.10, $0^{-}:$: (1'11): G.

Hawkins, James (b'3\$) $\rightarrow$ : (l'0l).

McCARTY, CLA UIVE E. $\left(b^{\prime}, 3\right)+-111.1,97$ : (1, 01$): S$

McCAITY, THOS. L. $\left(\mathrm{D}^{\prime}(\mathrm{s})+\right.$ l'a.2,:0 : (1"01).

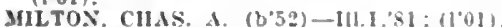

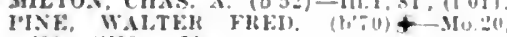

Thompinon, windeld otls (b'78)-ra.2,03; (1'05).

DONIPHAN, 134, DONIPHAN

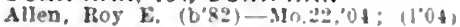

DORRANCE, 281, RUSSELL

FLETNITZ, WH. TIIEOIORE (b'i) III.14,01; (1'01).

DOUGLASS, 657. BUTLER

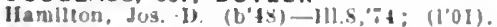

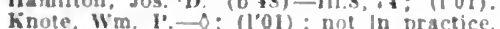

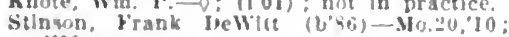
$\left.(1)^{\prime} 10\right)$

WILSOX, X. F- M०.20,"0z; $(1007)$

DOVER, 175, SHAWNEE

kradley, Chas. Chitlenden-Ia.3, 00 ; (1'6i)

DOWNS, 1,427, OSBORNE Allaman. John Mack (b'8i) - Mu.20,'1:"

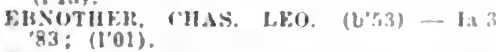

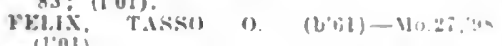

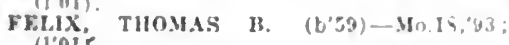

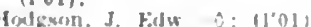

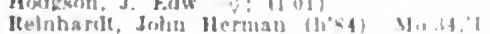
(1'13).

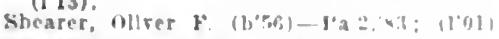

DRESDEN, 200, DECATUR

Funk, lired liangond $11, \cdots, 4)$

DUNLAP, 333, MORRIS

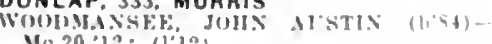
Mo.20,12; $11^{*} 121$.

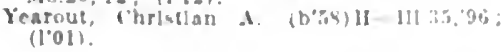

DUQUOIN, 25, HARPER

Asher, U(to I. (b':1)-Ia.10,08; (1'09).

DURHAM, 268, MARION

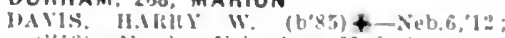

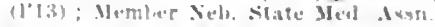

DWIGHT, 298, MORRIS

Ibrellum, fieo, Elum (bos)-Kans,og;

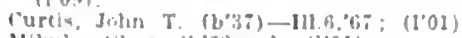

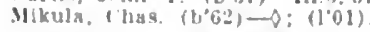

EARLETON, 225, NEOSHO

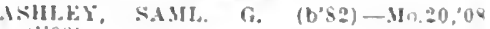
(l'0s)

EASTON, 310, LEAVENWORTH

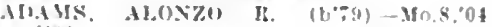

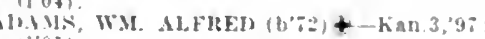
110i1.

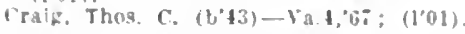

EDGERTON, 443, JOHNSON

LiREER, TITOS. S. $\left(b^{\circ} 61\right)+-1 J 0.20,267$ (1'01)

$\left(b^{2} 31\right) \longrightarrow:(100)$

EDMOND, IOO, NORTON

J.IOI'ISS, GEO M. (b.6) - W0.33,05 (1'06).

EDNA, 489, LABETTE

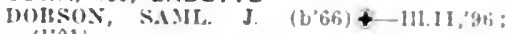
THOMAS, CILS. ALFRED (b"7) + -1a.10 OL: (1"04): Op.

EDWARDSVILLE, 250, WYANDOTTE

IH.ITII. T. RESTIN (b'76)-Mo.32,07,

EFFINGHAM, 674, ATCHISON

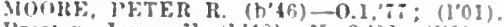

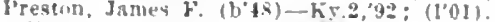

WHTF. (iEo. F. (b'bi) + - Mo.20, 0.5

ELBING, 100, BUTLER

boldlng, Folmund lt. (b'al) - Kan t, "ts (I'13)'

\section{ELDORADO, 3,129, BUTLER}

ISennelt, Wm. Mbo (b'c0) Ind.s, ? ?: (I"0)

Caplile, Jonatlian $11 . \quad(t+4)$ - Iol, st: (1.01)

IHLF.XISE, FREDK. E. (b 67$)-M 0.20$, 'yti: (1'01)

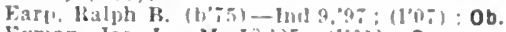
Eyman, Jos. L.-Mo.IS.'2; 1101$)$ : S.

fullenwiler, Marcus L. (b'19) "111.15: (1"01).

Ilunt, Crrus E. (b'10)-Wloh. 2.70 (1.01)

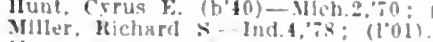

Mutz, Agnes llawell Tucker (bis) -0 :

Mulz, (lias. II $\left(b^{\prime}, 53\right)-K y 1 ; \% ;(101) ; G$

I'EILIXS, IXNA +-Kan,

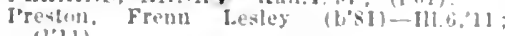
(1'11).

ELGIN, 400, CHAUTAUQUA

Jetrers, fien, X-Ill.6.03; (1'03)

ELK CITY, 659, MONTGOMERY

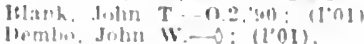

lombon Jolin Wr- $\rightarrow:(1,01)$

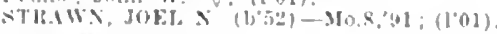

ELK FALLS, 271. ELK

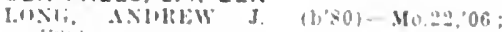

ELKHART. - MORTON

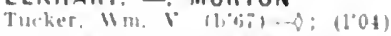

ELLINWOOD, 976, BARTON

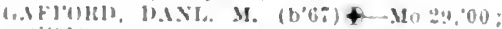

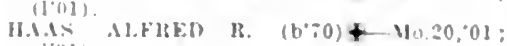

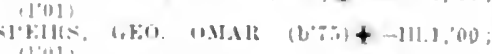

(I'i) 1).

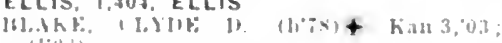

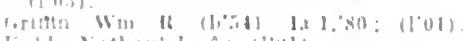

kiold. Vathenlal $6: 11011$

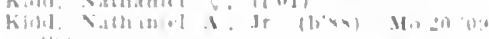

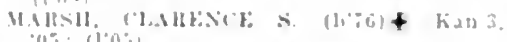

ELLSWORTH, 2.04I, ELLSWORTH

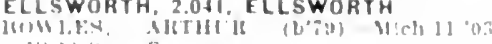

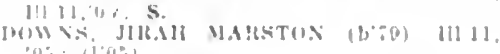

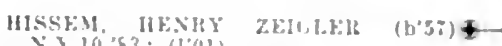

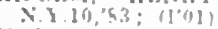

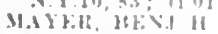

Mille

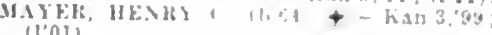

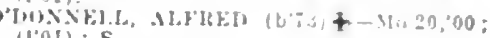
(1'01): $\mathrm{S}$.

ELMDALE, 253, CHASE

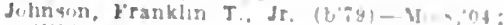
(1'0t)

SIIHLLEY, JACU1? FOSTER (b'S) + MII

ELMO 125. DICKINSON

KIINTHEIGG, WI. A. (b'75)+-111.1,0I (1'01).

ELSMORE, 216, ALLEN

liraden, Siam! it Ia I.:6: (l'0)

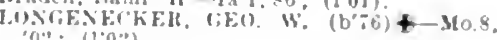
(1): ; 1100:)

EMMETT, 200, POTTAWATOMIE

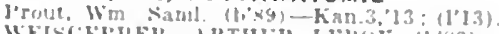

SEISGFAIIEL, IITHLI LEIGOY (L'S3)han.3.09; (1'09).

EMPIRE CITY (GALENA P.O.), 982,

Jchintus, Flecher R.-E-A: (l'Ol).

EMPORIA, 9.058, LYON

lcheson, Fredk, Ira $\left(b^{\circ} 66\right)-$ Kan.2,06: (1'06)

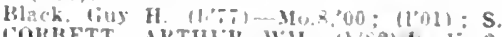

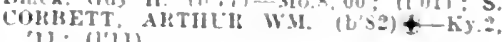
'II: (1']l). OLIVER J (b" $51-5 y+03$ (1'nt).

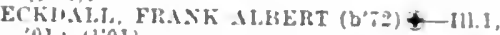

Ellswortb, inna rillabetu-11-Mo.20, $40^{\circ}$;

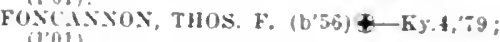

G.IFEURL, (FORDON M. (t'63)-Mo.25.95; (1*11): $\mathrm{S}$.

G.1MMISOS ISENJ. E. $(6 \% 4)-M 0.20,04$ : UIKL:- OALR.

hit)

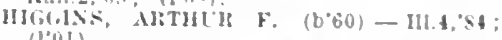

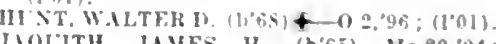
JIQTITH, JAMES H. (b'65)-Mo.20,91; (1'01).

King, Robe, (b'3a) H-X. Y.9,63; (1'01).

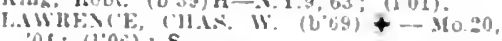
II: $\left(l^{\circ} 0\right.$ ii) : $\mathbf{S}$

I.eth (hrislopher Eugene (1'60)-Kan 3 .

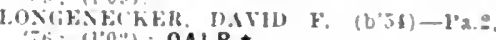
Mefrert (19m) : OALR.

Merfert. Wm. M-K).

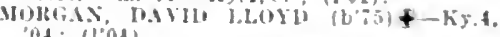
it: 1104).

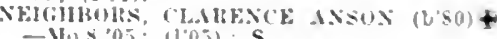
-Mos.05: 1105$): \mathrm{S}$.

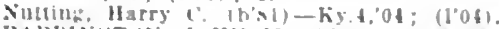

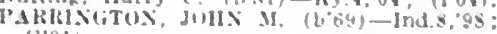
(1'01).

WELCH, TH(1. E. $\left.\left(\mathrm{b}^{+}+6\right)\right)+-0.2 \mathrm{~s}$. Mo, 0,$93 ;([\mathrm{d})]\}$.

Mas, ,07: 11!2); Wut in pipacles: Men-

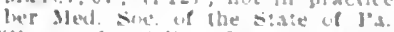

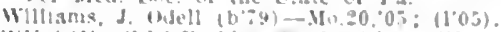

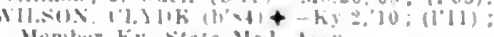
Mentwe ky state Met dwin

WUM.F. J.MES FUACIS (B.\$2) \&-1'a.1. ov: $(1009)$.

lituling, Wm. A. (2)51)11- $110.86 .90:$ 1101).

ENGLEVALE, 376, CRAWFORO

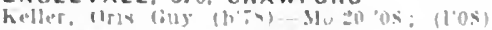

ENCLEWOOD, 518, CLARK

Inugats. Archic la (big) IIo

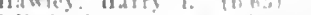

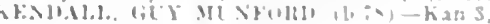

ENTERPRISE, FOE, DICKINSON

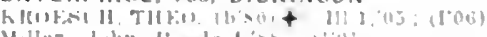

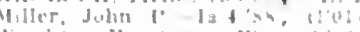

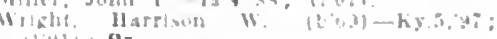

011: Pr.

ERIE, 1.300, NEOSHO

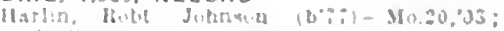

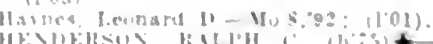

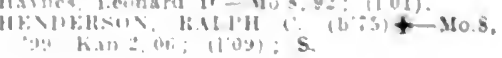


LAKli, MLTON E. (b'58)థ-Ind.8, 85 ; (l'0i) : Op.

Palmer, Jcremiah Allen (b'65)-0nt.1,87, Ont.4, 87 ; (1'01).

ESBON, 347, JEWELL

DYKES, SPENCER B. (b'70)-Tenn.8,02; (1'01).

Staley, Willbert A. (b'71)-Ill.11,07; (l'10),

ESKRIDGE, 797, WABAUNSEE

Bennett, James C. $\left(b^{\prime} 79\right)-K^{2} a n .3,04$; $\left(l^{\prime} 04\right)$.

Jewett, Geo. N. (b'0 0$)-0.25,02$; (1'03).

Stewart, Frank C.-II-Ill.22,'05; (l'05).

Walker, (has. Wn. (b'76)-Kan.3,04; (1'04).

EUDORA, 640, DOUGLAS

LEE, JAMES (i) (b'68)-No.8,92; (l'01).

Hollinson, Wm. Henry (b'4S)-Mo.8,72; (1'01).

Schellack, Alvin (b'39)-Mo.8,77; (1'04).

EUREKA, 2,333, GREENWOOD

DILLON, JEI'THA $\left(b^{\prime} 44\right) \oplus-0.1,73 ;\left(l^{\prime} 01\right)$.

GROVE, WM. T. (b'67) $₫$ Mo.27;92; (1'01); OALR.

Huss. John R. (b'54)-0.13,'79: (1'01).

MANNING. HARRIS W. (b'68)-11.1,97; (1'01): D.

Moonljght, Walter Scott (b'75)-Mo.34,05 ; $\left(1^{\prime} 05\right)$.

NORMAN, EDWARD J. (b'73)-Mo.20,'97; (l'01).

Reld, John M. (b'4i) H-Mo.26,97; (l'01).

Younkln, Geo. Wesley-Ia.3,76; (1'01).

EVEREST, 436, BROWN

HERRICK, SAML. J. (b'62)-Mo.22,92 ; (1'01).

Howard, Chrlstopher C. (b'59)-NI0.32,'05; ().

FAIRVIEW, 386, BROWN

ATTWOOD, WlLLIAM G. (b'78)-Mo.20,06 ; (l'06); ObG.

DEAYFR, JIENRY J. $\quad\left(b^{\prime} 66\right) \oplus-0.3,92$; (l'01).

FALL RIVER, 383, GREENWOOD DODGE, ROBT. KANTZ (b'64)-MIO.I, 87 ;
(1'01).

McCOMAS, MARMADUKE D. (b'85) $\oplus-$ Kan.3,11; (1'11).

FALUN, 94, SALINE

THOMPSON, GLEN-Ill.4,06; (1'03).

Watt, James S. (b'50)H-Pa.2,'81, 11l.15,'00; (I'01).

FARLINGTON, 140, CRAWFORD

Keeler, Francis L. (b'58) $\rightarrow$; (1'01).

FARLINVILLE, 100 , LINN

Paddock, Ira D.-E-D; (1'01).

FLORAL, 103, COWLEY

Ravencroft, Lelghton P. (b'60) $\rightarrow$; (l'01).

FLORENCE, 1,I68, MARION

Brakebill, Martln Luther (b'80)-Kan.2,'12; (1'12).

Haas, Edwln S. (b'T4)-Mo.20,00; (1'01).

WAGAR, LEONARD S. (b'71)-Kan.4,'01; (l'01).

FONTANA, 246, MIAMI

Flsher, Chas. A.-Mo.32,01; (1'04).

FORD, 205, FORD

Coffman, Francis Marion (b'i 7 ) -Mo.20,'I0 ; $\left(l^{\prime} 10\right)$.

FORMOSO, 453, JEWELL

Gallardet, L. Philippe (b'5 $\tilde{)}$-0nt.4,78; $\left(l^{\prime \prime} 09\right) ; S$.

Stewart, Richard (b'57)-Ky.1,'83; (1'01).

FOSTORIA, 100, POTTAWATOMIE

King, Geo. Albert (b'82)-M10.22, 05 ; (1'05).

Monk, Geo. W. $\longrightarrow$; $\left(1^{\prime} 01\right)$.

FOWLER, 473, MEADE

BURNETT, FERD. (b'79)Ð-Ia.10,06; $(1,06)$.

ROBB, JANES CAREY-Ia.10,01; (1'05).

FRANKFORT, 1.426, MARSHALL

Brady John Jos.-No.26,'96; (1'01); OALR.

BRAWLEY, MARK A. (b'49)Ð-0.8,73; (l'01).

Brawley, Mark A., Jr. (b'87)-Kan.2,'09; (1'09).

FRANIKLIN, 500, CRAWFORD

GIBSON, CHAS. II. (b79)Ð-Kan.2,07;

FREDERICK, 151, RICE

M.TRTL, MELVIN C. (b'87) - Kan.3,'13;
FREDONIA, 3,040, WILSON

DI:NCAN, EUGAR CECIL (b'75) -Mo.24, '0I; (l'01).

Erray, Fred L. (b'80)-1a.10,'08; (1'09).

FLAC'K, ALEXANDER C. $\left(b^{\prime} 58\right) \oplus-0.1,85$; (l'0I).

THOMAS, CLIFTON ALLEN (b'80)-Mo.8, $05 ;(1,05) ; P d$

WILEY, FRANK is (1,55)๑-0.3,77; (1'01). Wilson, Carl W. (b'(9)-Kan.3,'99; (1'01); A.

FREEPORT IOI, HARPER

IIAZLE, JAMES A. $\left(b^{\prime} 54\right)-0$; (1'01).

WILCOX, GEO. SAML. (b'73)†-KY.9,04; (1'09).

FRONTENAC, 3,396, CRAWFORD

Patton, James S. 0 ; (1'01).

Scott, Mcrle K. (b'78)-Mo.20,01; (1'01).

Sturm, Walter C. (b'79)-Mo.20,'07; (l'08)

FT. DODGE, 450, FORD

LEFTWICH, ODA T. (b'76)↔-M0.22,06 ; (1†).

FT. LEAVENWORTH, 2,500, LEAVEN. WORTH

BISPHAM, WILLIAM N. $\left(b^{\prime} 75\right) \oplus-M d .1$, 97 ; Maj., M.C., U.S.A.

CRAIG, CIIAS. F. $\left(b^{\prime} 72\right) \oplus-$ Conn.1,94; Capt., II.C. U.S.A. Nember Conn. Staté Nied.' Soc.

DUNBAR, LEE ROY (b'81)๑-N.Y.3,06; Capt., M.C., U.S.A.

HAINES, EDGAR FREMONT $\varphi-M a s s .5,06$;

1st Lleut., M.R.C., U.S.A.

KEAN, JEFFERSON R. (b'60)-Va.1,'83; Lleut. Col., M.C., U.S.A.

MAGEE, JAMES CARRE甲-Pa.2,05 ; Capt., M.C., U.S.A.

NELSON, KENT (b'76)†-MInn.4,00; Maj., I.C., U.S.A.

WOODSON, THOS. DUPUY (b'82)థ-Mo.2, '07; Capt., M.C., U.S.A.

FT. RILEY, I,000, GEARY

COFFIN, JACOB M. (b'78) $\oplus-P a .1,00$; Capt., M.C., U.S.A.

DAVIS, ADDISON DIMMTT (b'83)Ð-Pa.2, '06; Capt., M.C., U.S.A.

MCCULLOCH, ERNEST CHESTER $\left(b^{\prime} 86\right) \oplus$ -0.41,10; 1 st Lieut., M.C., U.S.A.

RAYMOND, HENRY I. (b'57) $\oplus-$ N.Y.10, ' 80 ; Lleut. Col., M.C., U.S.A.

FT. SCOTT, 10,463, BOURBON

AIKMAN, ROB'T. (b'43)-Mlch.I,'68, N.Y.10, 80 ; $\left(1^{\prime} 01\right)$.

Ball, Saml. E. (b'70)-1I0.7,'92; (1'03); 124 N. Crawford St.; offlee, Natlonal Ave. and Oak St. $9-5$.

Blatchley, Warren D. (b'50)-0.10,'77; not in practice.

CAYANAUGH, JOHN J. (b'68)థ-Neb.6,'98; (1'01).

Currier, A. E. $\rightarrow$; (l'01)

Dunlavy, Saml. W. (b'73)-Ia.10,02; $\left(\mathrm{l}^{\prime} 06\right)$; Main and Wall Sts

GRIFFIN UINCOLN WADE (b'59)-Mo.5,

'84; (1'01); 318 S. National Ave.; office, $201 / 2$ S. Maln St.; 8-10, 1-3

HARRAR, CIIAS. F. (b'67) - Ill.10,'03; (1'03); 323 S. Main St.; offec, Masonic Temple.

Harrow, AIrls L. (b’56)-D; (1'01); $713 \mathrm{~S}$. Ransom St.

Hawkins, Anthony L. (col.) (b'80)-Tenn.7, '13: (l'13); 12 Hendricks St.; offlce, 205 E. Wall St.: $9-11,3-5,7-9$.

HOPPER, WILBUR L. (b'79)-Mo.20,05; $(1,05) ; 211$ S. MIain St.; offce, Hopper

HUNTER, JOHN DAVIS (b'73)థ-No.20, 05; (l'07)

JAPRETT, MHLLARD F. (b’5T) $€$-N.Y.10 '92; (1'01); I'res. Kan. Med. Soc.; 710 Crawford St. ; office, 9 E. Wall st.; 10-12, $2-4 ; O A L R . \star$

LARDNER, JOHN C. (b'67)-Kan.3,'02; (1'04); 1001 S. Crawford St.; offece, 209 $\mathrm{S}$. Main $\mathrm{St}$.

MCDONALD, WM. STEPHEN (b'53)థPa.2,88; (1'01); 102 S. National Ave. $9-11,2-4$

McLemore, Benj. A. (col.) (b'59)-Tenn.7, '87; (l'01); 223 Ewald St.

NEWMAN, JOHN R. (b'81) §-M10.29,05 ; (l'05); 2099 Main St.; office, Hopper Bldg.; $1-5 ;$ S.ネ
PAYNE, EDWARD BELL $\left(\mathrm{b}^{\prime}(0) \oplus-\mathrm{Mo} .20\right.$, 89, N.Y.10,90; (l'01): 124 S. Crawford St. ; omle, $112 \mathrm{E}$. 1 st St. : 8-10, 2-4, 7-8. Roberts, Alonzo J. (b'52)-Que.2,84; (1'01). VAN VELZER, CHAS A. (b'59) @-III.4, 86 ; (1'01);224 S. Maln st.; office, I4 E 1st $\mathrm{St} \cdot 8 \cdot 30-10,1-3,7-8$.

WHTFIELD, RO1T JOHN (b'62)-Md.1,03; (1'01); 323 W. Wall St.; oflce, Masonlc Temple; OALR.*

FULTON, 4I6, BOURBON

Roe, Benj. Franklin (b'72) - Mo.20,08 (1'08).

HOOT, JOHN W.(-1ll.1,91; (1’01); Pr.

GALATIA, 44, BARTON

BRYAN, HARRY RAYMOND (b'85)ФMo.20,09: (1'09).

GALENA, 6.096, CHEROKEE

Browne, Herbert A. (b't8) - Mo.26,'98; (1'01).

Gavln, Robt. M. C. (b'37)-Pa.14,78; (l'01)

Green, John H. (b'44)-Ind.4,78; (1'01): Op.

Hart, Wlllard $\mathrm{R} \rightarrow$; (1'01).

Higglnbotham, Edw. L. $\rightarrow$; (l'01).

JONES, CLEI H. $\left(b^{\prime} 65\right) \oplus \rightarrow ;\left(i^{\prime} 01\right)$

LOWDERMILK, $R$. CLAUDE (b'72) -

Mo.20,98; (l'01).

MAItTIN, JEFFREY (b'51)-Ia.3,76; (1'01). MCKINNEY, FRANK LECORTIS (b'78)Mo. 20, 08 ; ( $\left.\mathbf{l}^{\prime} 08\right)$.

Savage, Ilarrison Burgess (b'63)-N.Y.10, '86; (1'01); LR.

SHELLEY, ALBERT A. (b'67)థ-Kan.3,

Walker, Wm.

GALESBURG； 300, NEOSHO

Roller, Raymond FoX (b'84)-Kan.3,'13; (1'13).

Strahan, Chas. Saml. $\rightarrow$; (l'08).

GALVA, 322, McPHERSON

Gore, Lewls M. (b'81)-Mo.22,09; (l'09).

GARDEN CITY, 3,17I, FINNEY

Ardery, Mary Dugan (b'42)-Ia.9,91; (走).

Blanke, Theo. F. (b'61)H-Mo.5,'89; (1'07)

Brown, Albert Leroy (b'74) E-Mo.8,98; (l'03).

Gilllan, Virgil Eugene (b'76)-Mo.32,01;

Gray, Bobt. E. (b'61)-Ill.1,96; (l'00).

Knapp, Albert R. (b'51)-Ind.12,'86; (1'01).

Neal, Geo. L. (b'35)-N.X.5,58; (1'01).

Rewerts, Chas. (b'81)-Mo.20,11; (l'11).

Sablne, Andrew (b'31)-Pa.2,'56; (I'01).

STILSON, WM. J. (b'70) - Kan.3,04 ; (1'04).

Troup, Ronald M. (b'86)-Mo.35,'09; (l'09).

GARDEN PLAIN, 296, SEDGWICK

Bobo, Calvin W.-0.2,89; (1'01).

MATTESON, GEO. WWI. (b'81) $\oplus-M 0.22$, 08 ; (1'08).

GARDNER, 514, JOHNSON

ARISTRONG, JOHN B.-Ia.1,'68; (l'01).

Crawford, John R. (b'69) - Mo.27,93; (1'01).

Fear, Rawlings Clarence (b'67)-Mo.27,97; (1'01).

GARFIELD, 333, PAWNEE

Orrow, Augustus M. (b'72)-Ia.9,'98; $\left(1^{\prime} 10\right)$.

GARLAND, 345, BOURBON

ANDERSON, ELMER ELLSWORTH $\left(b^{\prime} 59\right) \oplus$ $-111.1,84 ;(1,01)$

HOLEMAN, JOHN 'T.๑-Ky.2,'92; (l'01).

GARNETT, 2,334, ANDERSON

BLASDEL, GILES A. (b'72)(-Mo.8,'98 ; (l'01): $\mathrm{S}$.

Cralg, Danl. M. (b'53)-Ia.1,'76; (1'01).

Curningham, Nartha E. (b'54)-I11.9;86; (1'11).

Harris, Claib Bosworth (b'76)-Mo.20,06;

HOOD, TARLTON AMBROSE (b'72)Kan. 3,'97; (l'01)

Jones, James B. (b'45)- $\rightarrow$; (l'01).

KIRKPATRICK, THOS. (b'58)-Ill.11,'83 ; (1'01); $\mathbf{S}$.

MILLIGÁN, JANES A.๑-Ind.9,'83; (l'0I). Pilkington, Geo. W.-0.2,'i6, 0.9,'81; (1'01). GAYLORD, 308, SMITH

Holmes, Chas. J. (b'43)-N.Y.5,68; (1'01) TALLMAN, E. WALTER-Mo.34, 05 ; (1'05). 


\section{GENESEO, 566, RICE}

Bush, Geo, E. (b'65)-MId.3,'98; (1'01).

GEUDA SPRINGS, 254, COWLEY

Fall, Norman Iryce (b'91)-Ky 2,'13: (1'13)

HOLT, TIOMAS TALLMAN $\left(b^{\prime}, 6\right)+$ $310.80,00:(1 \% 01)$.

Part. Geo. W. $\left(b^{\prime} 11\right)-0.6,68$, X.Y.10,76; (l'01).

GIRARD, 2,446, CRAWFORD

Adamson, Lawrence Pbllllp (b'59)-\$o.20. "94: (1.01).

Alexander, James T. (b'48)-Mo.2,\%2: (1'01).

Boez, Folney T. (b'61)-Mld.,'95; (1'01).

Cole, Geo. H. (b't5)-0.11;99: (1'01).

Cushenberry, John H. (b'33)-\$0.2.72 (It).

Grimn, Ulrich M.-H-Mo.5, 80 ; (1'01)

Ilewets, Sbeldon 11. (b'is) - Mo.20,04 (1'04).

Ingels, Mary A. (b'57)-Ia.9,' 1; (l'01)

Jones, Fredk. W. (b'il)-Mo.28,"98; (1'01) 0 p. McXaught, James Frank (b'\$2) - Mo.20
$.06 ;\left(l^{\prime 00}\right)$.

Strode, Llndley E. (b'72)H-I11.4,00 (l'01)

Swart, Wm. S.-Mo.2S,99; (l'01).

GLADE, 200, PHILLIPS

Le Rew, Wm. G. (b'63)-Mo.18,'92: (I'01)

GLASCO, 720, CLOUD

Tarris, Rlchard W. (b'34) $\rightarrow$; $\left(I^{\prime} 0 I\right)$.

NEWTON, WM. BROWN (b'7s) $t$-Tenn.1, 01: (l"01): G.

Palmer, Whiliam Robt. (b'76)-Kan.2,'10 (1'10).

STEIX; CHAS. (b'76) - Neb.5.07; (l'08)

GLEN ELDER, 565, MITCHELL

NELSON, RALPII G. (b'80)-Mo.34,08:

(l'08). HORISH, HENRY W. (b'70)-Mo.22.'24 Mo.1, 95 ; (1'02).

Postlethwalte, Frank M. (b'83)-Mo.20,13 (1'13).

Relnharde, Robt August (b'86)-Mo.34,'13; (1'13).

\section{GODDARD, 225, SEDGWICK}

Magee, Chas. BenJ. (b'83)-Mo.35,'08; (i'08).

McMllea, Chas. F. (b'72)-Ky.5,'98; (1'03)

GOESSEL, BO, MARION

Kalser, Chas. II. (b'73)-Kan.3, 00 ; (l'0I)

GOFF, 422, NEMAHA

Corwla, Luther A. (b'60)-M0.20,90; (l'01)

Smlth, Dwlght C. (b'78)-Mo.20,04; (1.04)

Tolle, Cecll kibert (b'85) - kan.2,07: ( $\left.{ }^{\prime} 0 \%\right)$.

GOODLAND, 1,993, SHERMAN

GULICK, ARTIIUR C. (b'68) \&-Pa.2,00 (1'01).

MeCulloch, Jennle (b'73) - Mo.28,03; (1'05)

SMITI, FRANCIS H. (b'56) -la.3,'s2: (l'01).

GOVE, 196, GOVE

MCNACGIITOX, JAMES II. ((',0)-Kan.3, 02: (l'02).

GRAINFIELD, 309, GOVE

Beekner, Kirnest J. (b'i'9) - Tenn.1,05 (l'05).

GRANTVILLE, 200, JEFFERSON

Smith, stephen E.-Kan.3,93; (1'01)

GREAT BEND, 4,622, BARTON

BUTTOX, EDWIN CH.ABENCE (b'79) + Kan. 2,0e: (1'06): OALR.

CONNETT, AAHON HENDIICK (b'49)Ia.1,"78; (1'01).

FocIIT ADIM F-II!.4.85: (1'01).

Kendali, Addlson-111.13,01: (1"01)

MORIBISOX, KLMER E. (b'68) $\$-30.28$ OQb : (1'01): $\mathrm{S}$.

NIXON, WM, A. (b०\% $-M 0.20,0 \% ;(1.00)$

l'aze, John llardy $\left(\mathrm{b}^{\circ} 36\right)$ - Mass "2.65: (l'01): not in practlce.

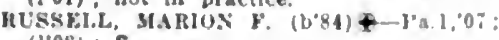
$\left(1^{\prime} 0.5\right): S$.

STINSON, BERT. LANIDON $\left(b^{\circ} ; 0\right)-111$. 01: (1\%02).

WESTWOOD, ETHFL I'AGE (b'is) -111.0. 99: (1'01); OD.
GREELEY, 492, ANDERSON

[hesmond, lyenls Myron (b'bi)-Md4."92 (I.03)

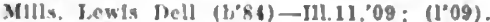
MUXFOHD. RAYMOSD IIUNTER-Kan.S. OT: (1'0\%).

GREEN, 289, CLAY

MOKTOS, HOHT. J. (b'58) \&-111.11,'s3: (I'01)

GREENLEAF, 781, WASHINGTON

ARMSTIRONG, ELWOOD $\left(b^{\prime} 54\right) \$-\$ 10.20$ $95:(1.01)$

GAIONRR, MELYIN NEWTON (b'5i) Mlch. $1.33 ;(1 \circ 01)$

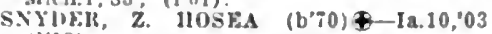
(I'03)

\section{GREENSBURG，1,199, KIOWA}

liennett, Almon L.-E-0.2,89; (l'01): not in practico.

Hentelt. Mary M. (b'J2) II-0.7, 84; (1'01) not In practlce. CIRTYR, FI.ZA MORRIS (b'75) -Kan.3.

GAlLDER, JAMES A. (b'55)-0.6,78: (1'01)

MCLAUCHLIN, JAMES AITHUR (b'69) Yo.28;99; $\left(1^{\circ} 01\right) ; S$.

WILLI, H.IRKY J. (b'82)-\$10.20,04: (I'04).

GRENOLA, 532. ELK

Archer. J. Alec (b'6i) E-0.2.01: (1'01)

MASON, BURGFSS B. (b'85)-M0.20,'0s: (l'08).

Mason, Wm. B.-Ky.5,7\%: (1'01).

GRIOLEY, 870, COFFEY

Monroe, Ilenry I. (b'54)-Ia.1,83; (l'01);

stockton, Marcellus L. (b"62)-0.14,"87; (I'0I).

GRINNELL, 200, GOVE

Barclas, John Judson, Jr.-Pa. 2,"24: (1'01).

GYPSUM, 623. SALINE

CHYNEL, ENOS RAIPH (b'TI)-M0.8,'91: ( 1 '01).

Cerfoh. F. Kan.4,03; (l'05).

IIWTHORNE, E. W. (b'54)-\$0.20,94; (1'01).

\section{HADDAM, 408. WASHINGTON}

IIOOVEK, JOIIX 11. (b'57) \&-310.22,'86: OCHILTREE, IIENRY M. (b'49)-Ia.1,72; (l'01)

Sbearborn, Edwln W. (b.62)-III.10,02; (1'0I).

HALLOWELL, 250. CHEROKEE

Ball Frank L. (b'tis) - Io.20:00: (1'01)

Ilenderson, Edw. Emmett (b'6i)-Kan.2, (1"0\%).

HALLS SUMMIT, I50, COFFEY

Kesner. Gllbert C. (b'81)-Mo.20,03: (I'03)

HALSTEAD, 1,004, HARVEY

WILIINGIIM, WM. MOY (b'S3) \&-Mo.20, OR: $(1,08)$.

IIFRTZLFR, ARTHUR EMANLEL

(See Kansas Clty. Mo.)

Iloover, Ell Marlon (b'50) F-Mo.10,85:

Howalin, ROBT, OS(iOOD (b'80)-III.4. 09: (1'09).

HAMILTON, 325, GREENWOOD

Lewis. Albert H. (b'5\%)-Ind.8,82: (1.01)

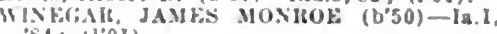
$81:(1,01)$.

HAMLIN, 206, BROWN

STRINIIISER, WM. (b\%2)-0.2.05:

Taylor. Wranon $\left(b^{\prime}+j\right)-0.14,80$ : $(1,01)$

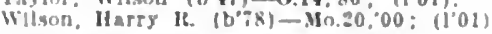

HANOVER, 1.039, WASHINGTON

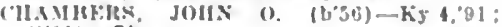

(I) 01$) ; 0$,

MFIS, HUW, MARTIN (b'\$5)\&-Mo.20,

Poper. (iec). Franklln (2.3i) - Mo.20.10; (1'il)

HARDTNER, 230, BARBER

Coffey. Hichard Nightingalo (b'68)-Mo:00. COQ: 11'0!)

HARPER, 1,638, HARPER

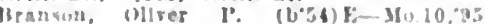

(1.01)

praner, Archlbald Henry (1,53) - \$cot.\$.\$8 (I)

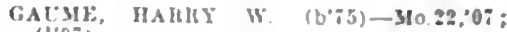

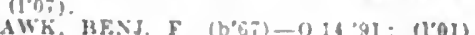

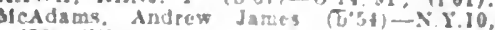
:6: (101).

Muir, Wm. F. Mleh I.81: (1.01).

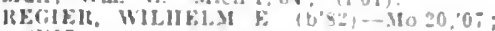
(l'07).

WALKFR, ARTIUR E. (beo) $(1.01)$.

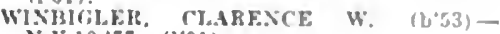
N.1.10,77; (1\%02).

HARRIS, 175, ANDERSON

COI.FMAN, WILLIAM DIRANGE (b':z)Mo.35,03: (1.12); Meraber Mo. Siale Med. Assn.

HARTFORD, 589, LYON

Dary, Gllbers $\left(b^{\circ} 54\right) \Rightarrow$ : (1.01)

fuller, Henry I. (b'50j-310.1.85; (l'01)

llurtls. Henry G. $\left(b^{\circ} \times t\right)-$ Neb. 6,12 ; Intern. St. Anthony's IIosplial.

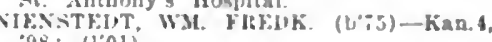
$98:(1.01)$

RESER, SAML, P. (b'51)-IA.1.80; (1.02). HARVEYVILLE, 331, WABAUNSEE

Canfletd, Henrs lvale $\left(b^{\prime} ; 4\right)-0.19 .95$ : (Dentigt).

Tomilnson, Louis Slonroe (b's.)-Kinn.3. 13: (1'13).

Walker, Luther $A .\left(b^{\prime} 65\right)-K a n .3,93:\left(1{ }^{\prime} 01\right)$. Wyatt, Cbas. Arthur (b'90)-Kan.',13: (1'13).

Youngman, Charles I. (b-76)-Mo.31,01: (1'01).

HAVANA, 227, MONTGOMERY

IIOWELL, DAVID WSL (b'6t) -M0.\$2,0?: (I'02).

HAVEN, 528, RENO

Klrkpatrlek, Walker H. (b'8I)-M0.20,08; (08)

MCNAIR, CHAS. F. -Kan.3,05; (1'05)

Sans, Clement E. V. (b'69)-Mo.10,'94: (I'01).

HAVENSVILLE, 412, POTTAWATOMIE

MC.11ANIS, JAMES EDWIX $\left(b^{\prime} 6 i\right)+-310.32$. 02 ; (1.02).

HAVILAND, 368, KIOWA

HENXETT NATHAN G. $\left(b^{\prime}: 3\right)+-M 0.28$, 02: (1'02): 0bG.

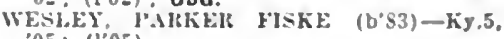
05; (1'05).

HAYS, 1,961, ELLIS

llaas, Karl $C$. (b'sti) E-Kan.:.10: (J'10).

llemm, lieo, P. (b'82)-Mo.34, $0:(1 \cdot 10): S$.

HENSERICH, OTTO ANIREW LEWIS (b' $\$ 1)+$ Mo.34.09; (1'13); Member Mo. slate Med. Axin.; S.

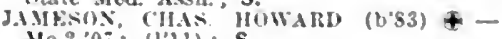
Mo.2,07: (1'11); S.

Meadle, Frank $k .\left(b^{\circ}, 5\right)-1111,02:\left(l^{*} 02\right)$.

Mlddlekaut, Jos. H. $\left(b^{\circ} 5 i\right)-M(d .1,79 ;$ (l'01).

Snyder, Geo. Bowers $\left(b^{\circ} 53\right)-1 \cdot a .1,76$ : (I.04).

HAZELTON, 315, BARBER

STAJJAL1), FHANK L. (0,\%) K-Ky.9,06; (1.0it)

Welsh, Wm. I. (b*7:)-Kan.3.9z; (10\%).

HEPLER, 2\%6, CRAWFORD

Movloy, Chas. Lou!s, Jr. (b'\$6)-Mo.2s, 08: (1.03).

Puckett, Chas. F. (b'az)-Mo.35,04: (1'0i).

HERINGTON, 3.273, DICKINSON

Ilartlson. Ilbert Eurene $\left(b^{\circ} 90\right)-M 0.20,12$ : $11121 ; 20$.

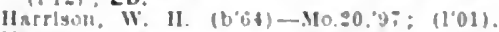

llayes, claude $\%$ (b\%3) II-III $1,9 \%$

$\left(10^{\circ} 05\right.$

Marshall, llarles (b):32)-110.2.09; (1'10). Mouey, Jarmes W-Ky at: $(1001)$

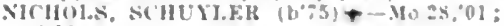
(1) 011 .

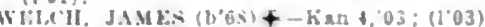
HERKIMER, 200, MARSHALL

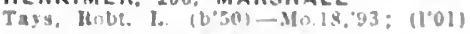

HERNDON, 273, RAWLINS

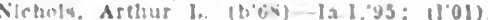
HESSTON, 130, HARVEY

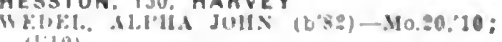
$(1,10)$.

HEWINS, 225, CHAUTAUQUA

.ambelis, (i. (1). Sluore (b's)-Mo.\$, 05: (1) (1) 
HIAWATHA, 2,974, BROWN

ALEXANDER, 1BEXJ. J. (b'55)-1a.6,'82; (l'01).

Beckett O. F (b'68)-0; (l'06)

E.MERY, WM. GollDoN (b'73)-N.Y.9,99; (log).

Heatley, John Evans (b'87)-M0.20,'11; (l'11). Thomas Clark (b'76)-Kan.3,04; (l'04); $\mathbf{N}$.

Houts, Orlando-E-III.8,'81; (l'01)

Lelgh, Ebberly J. (b'to)-H́l.1,84; (l'01) Liftreal, Wm, 18, (b50) Ki,:36; (l'01)

ICKXIGIIT GEO, CAMPIBLL (b' $(66)+$ III. 1, :1: (1'01).

NE, wiLt

(l'01).

PALMKR, WALTER C. (b'78)-Mo.41,99; (l'09)

SHANXON, LEON WM, (b"70)+-HII,'99; (l'01) ; 0p.

HIGHLAND, 763, DONIPHAN

BOONE, WM. M. (b'60) \&-M(l.3,91; (l'01) Fraham, Janes W. (b'i 7$)-M 0.22,09 ;\left(I^{\prime} 09\right)$

LIKENS, HARRY W. (b'70-liy, $0 \%$ (I'07).

HILL CITY, 983, GRAHAM

Bundy, J. A. (b;78)-Mo.20,06; (1'06)

Findley, Lottle 1\%. (b'79)-Mo.30, $0^{2} ;\left(1^{\circ} 02\right)$

OALR.
Parker. Ivan B. (b'71)-Mo.20,94; (I'02)

OALR.

Vanpuyn, Arnold H. (b’71)-1ll.11,93 (l'04).

HILLSBORO. I,134, MARION

BHUNIG, HENKY R. (b'72)థ-Mo.8, 98 ; (l'0s).

Entz, Jacob J. (b'64) E-Ill.8,'86; (l'01)

Riegle, IR. If $\rightarrow$ : (l'0I)

Schelper, Chas. H. (b'41)- 0 ; (l'01)

HILLSDALE, 260, MIAMI

King. Joln W. - E-0.2,'83; (l'01)

Morrison, Peter J.-Mich.1,69; (I'01)

Morrlson, Ralph Waldo-MLo.20,07; (I'07)

HODGEMAN (R.F.D., HANSTON), 50,

HODGEMAN

Bowle, Thomas C. (b'47)-0.2,'71; ( (l'01)

WYCOFF, CHAS. B. (b's2)-Kan.3,'11 (l'11).

HOISINGTON, I,975, BARTON

Atkin, Fuw. II., Jr. (b'85) - Ky.11, 08

Burton, Thomas C. (b'67) E-0.2,'97; (l'04)

KOCII, GEO. LOUIS (b'67)థ-Mo.1,'91

(l'01); $\mathrm{S}$.

ICCAULEY, FRANK L. (b'77) ๑-I11.17,'05; (I'05).

HOLCOMB, 75, FINNEY

Williams, Morton 1'. (b'43)-Ky.1,76; (*).

R.F.D. 1.

HOLLENBERG, 200, WASHINGTON

EPIAER, JOIIN W. (1)'55)-Pa.2, 83

Member Mo. State Med. Assu.

HOLLIS, 50, CLOUD

Belot, Amy C. (b'80)-Kan.3,'11; (l'11)

McLaughlin. Robt. J.-Pa.:,'85; (l'01).

HOLTON, 2,842, JACKSON

ADAMSON. TALENTINE V. (b'34)-Ia.1,

Brookins, James S. (b'43) H-N.J.1,'72: (I'02).

LOCKE, GEO. EUGENE (b'49)-N.Y.13,'s0 ;

Mcrrew, Milton S. (b'67) H-Ill.4,'91 ; (l'01). REED, ELIAS W. (b'70)屯-Mich.1,04 I'04)

REYYOLDS, CHAS. W. $\left(b^{\prime} 70\right) \oplus-1 a .9,97$ (I'04).

SHAW, JOSEPH COOK (b'69)-Kan.3,00 (L’01); $\mathrm{S}$.

SIEVER, CHAS. MOSES (b'74) $\$$-Tex.10 '03, Kian.2,07'; (1'09); OALR.

Smythe, Jay B.' (b'78) H-Mo.31,01; (l'01)

Smythe, Milton B. (b'44)H-0.7,69; (I'01) Spencer, Enily F. (b'46) H-Ill.4,'86; (I'01).

HOLYROOD, 36!, ELLSWORTH

ZEliZAN, GEO. FRANK (b'78)-111.1, 00 (l'05).

HOME, 200, MARSHALL

Shumway, John R. (b'78) - Mo.20,'01 $\left(1^{\prime} 04\right)$.

HOMEWOOD, 60, FRANKLIN

TANQL.ARY, EARL D. (b'72)-Kan.4, 01
HOPE, 567, DICKINSON

Ent\%, Johann C. (b'72) $\mathbf{E}-0.2,96$; (1'01)

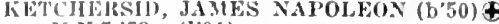
.5.5.73: (l'01)

HORTON, 3,600, BROWN

I1'NI.AY, FRANK (b'T1)-Mo.26,'94; (1'01)

FINK, RALI'II F. (b'T9)-Kan.4,01

(l'01): (Indlan Service)

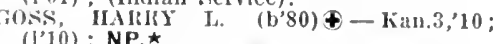

HAIKEIR, IHARRY JAMES (b'82)థ-Mo.20 on: (l,03)

Poutre. Fred Gerald (1,88)-Kan.2,'10 (

[EYNOLD, LAWRENCE (b'60)థ-Ia.3,'84 (l'01); $\mathrm{S}$.

HOWARO, I,I63, ELK

COSTELLO, JOHN F,-0.14,'80; (l'01)

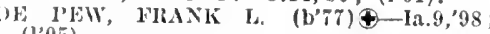

ARNER, ROMEO C. (b'67)థ-111.11,05

IIYS, JOIIN L. (b'37)-III.1,71; (1'01)

OALR.

Youngs, Benj. F.-O; (l'01).

HOXIE, 532, SHERIDAN

Beckner, Eilbert D. (b'\%8) -- Temn.1,06 (I'06).

HOYT, 350, JACKSON

Culp, Chas. W. (b'69)-Mo.24,'93; (l'01)

MURRAY, JOHN W.-Ky.2,'86; (I'01).

PTTIJOIIN, JOIINSON W. (b'33)-D.C.2, 64 ; (l'01)

HUDSON, 253, STAFFORD

'Lilier, Lewls Adisan (b'57)-Ind.8,'81

'10; (1'10); ObG.

HUGOTON, 105, STEVENS

Bundy, Wm, E. $\rightarrow$; (1'01)

HUMBOLDT, 2,548, ALLEN

Cope, lsenj. (b'49)-Mo.18,'83; (l'02)

IINIMIIN, JOS. II. (b'72)-Kan.3,95; (1'01).

Lee, Wm. S. $\left(b^{\prime} 50\right)$-Ia.1,'75; (l'05).

PAYNE, OSCAR C. (b'68) - Neb.4,'03;

VERB, iIERBEHT M. (b'77)-Neb.4,06 (I'06)

Wilson, John-Hll.1,'82; (I'01).

HUNNEWELL, 203, SUMMER

MAY, FLOYD B. (b'7i)-Mo.28,98; (l'01)

Richardson. John F. (b'49)-0.9,'82; (1'01).

HURON, 200, ATCHISON

Jones, W'iley S. B. (b'54)-Mo.3,78; (l’01).

HUTCHINSON, 16,364 , RENO

Allison, Guy W. (col) (b'86)-Tenn.7,'08; (ま).

ARNoLn, CHAS. 0. (b'57)-Ill.5,'87 ; (1'01) $709 \mathrm{E}$. Fth St.; office, $106 \mathrm{~N}$. Main St. $9-11,2-5$.

Bacon, Charles H. (b'5 Brashear, Wm. Clifford (b'79)-M0.35,08; $\left(I^{\prime} 08\right) ; 304$ W. 12th St.

Brownlee, John J. (b'83)-Kan.2,'11; (I'11) : 113 F. 11th St.; office, Rorabaugh-Wile BIdg. : 9-12, 2-5.

Cady, Frances A.-Mo.35,03; (I'01); 202 N. Main $\mathrm{St}$.

CARHART, FARL C. (b'79) (-Pa.2,05; (l'06); Menber la. State Med. Soc.; Rorabaugli-Wiley Bldg.

Casto, Okey J. (b'66)-Ky.2,'91 ; (I'04) ; 608 E. Sherman St.; offlee, Times Bldg.

CLARY, LLOYD: ANDREWS (b'83)€Mo.20,'06; (1'06); 321 Ave. A, East; Affice, Horabaugh-Wiley Bldg.; $\mathbf{1 0 - 1 2}$ $2-4 ; \mathrm{G}$.

Colladay, Steplen M. (b'42)-Mich.1,73 (I"01); 305 Ave. A, East; offlee, $16 \mathrm{~N}$. Main St.; $10-12,2-5$.

Cone, Armanellie S. (b'68)-Ill.9,97 (l'01) ; not in practice; 212 Are. A, East. Core, Chas. B. (b'54)-ril.1,'85; (I'01) ; 104 E. 12th $\mathrm{St}$

UVALL, HUNTER J. (b'67)-Mo.8,94; (1'01); 531 Sherman St., E. ; office, First National Bank Bldg.; 10-12, 2-5; S. EVANS, CHAS. S. (b'71) 4 -Ky.9,02; Wiley Bldg. ; $10-12,3-5 ;$ U.

FOLTZ, J. ELIOT (b'78) \&-III.11, 04 (l’04); $926 \mathrm{~N}$. Main St.; office, $202 \mathrm{~N}$ Main St. ; 2-5.
Forney, Fred. A. (b'81)-Mo.20,06; (1'06);

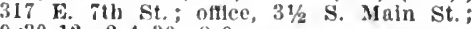
$9: 30-12, \quad 2-4: 30,8-0$.

Forney, Lee 0. (b'71) - Ia.10,05; (l'05): $14 \frac{1}{2}$ N. Maln St.

(l'(1) (b'72) †-Mo.20,97 (T), Are. $A$, East; offlee, Roralough-Wlley Bldg.; 10-12, 2-4; ObG.

Grage, fredk. Joachlm ந. (b'72)-Mo.34, 04: (I'09)

HEYLMUN, HARRY H. (b'69)-Mo.8,97 (I'01) ; 123, 1st Ave, ; offlce, RorabaughWlley lBldg.; $0-12,1-5$.

Holloway, Abraham L.-E-Hll.8,78; (I'01) 313, 1st St.; offlce, $5 \mathrm{~N}$. Maln St.; 9-11, $3-5 ; 0$ b.

ONES, ROBT. YOUNF (b'82) क-111.1,07 (108); First National Jank 13ldg.

MONROF-Neb.6,05; (1'05) 1210 N. Main st. ; offee, Koraloaugh-Wiley B]dg.; 10-12, 2-4:30; (B8) ; OALR. $\star$

JUSTICE, IOW' KhIPPEL, CLEMEN'S (b'52) 4-111.1,'85 (l'01); 402 F. lst Ave.; oftice, Rorabaugh-Whley IBIdg. ; 10-12, 2-5.

Maguire, John Wm. (b'53)-N.Y.10,78;

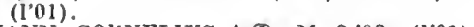

MANN, COIINELIUS A.†-M0.2,93; (l'01) $26 \mathrm{~N}$. Main St.

MAYFIELD, CIAUDE†-Ind. 8,02 ; (1'04) 506 Are. A, East; offlee, First Natlonal Bank Bldg.

McAlilly, Marquls J.-Mo.1,80 ; (I'01) ; 510 E. B St. : offlce, $14 \mathrm{~N}$. Main St.

McKITTKICK, CILAS. L. (b'78)-Mo.8,'04;

(I'06); 134 Sherman St., East; office, Rorabaugh-Wiley Bldg. ; 10-12, 2-5.

l'otter, Albert C. (b'46) II-M0.5,'80 ; (I'01) $171 \frac{2}{2}$ S. Maln St.; $9-12,2-6$.

ROBERTS, M. CLAUDE (b'78) $\odot$ - Ill.6, 06 ; (1'07); Chalmers Hotel; office, Flrst National Bank Bldg.; 11-12, 2-4; S.

SCALES, JERBERT L. $\left(\mathrm{b}^{\prime} 70\right) \oplus-K y .4,92$; (l'01); 506 Ave. A, East; offlce, Rorabaugh-Wiley Bldg.; 9-12, 1 $30-5$; OALR. SCHOOR, WHLIAIf F. (b'77)-Mo.20,04 (I'04); 119 W. 10th St.; offlce, $126 \mathrm{~N}$. Main St. ; $10-12,3-5$

SCHRANT, JOHN H. $\quad\left(b^{\prime} 76\right)-110.20,04$ (I'04); 25 E. 12th St.; offlce, First cott, Taylor W. (b'59)-Ky.2,'81; (l'01): 126 . Main st.; OALR.

SEEHORN, NEWTON ALFRED (b'81) Mo.20, 06 ; (['06); 9 N. Main St. ; $9-12$,

Sidlinger, Saml. H. (b'45) - Mlch.1,74; (1'01); not in practice; 203, 1st Ave. East; offce, 17 N. Maln St.

STERRETT, IIERBERT D. - Mo.22,'99, Kan.2,06; (I'01).

Stewart, Henry M.-Ill.1,98; (1'01) ; not In

Stewart, Rlchard A. (b'69) - Ky.5,90. (1'01); 801 N. Main St.; offlce, First Natlonal Bank Bldg.

Tucker, Claude C.-I0.35, 09; ( ) ; $1214 \mathrm{~N}$. Ifonroe St.

von Leonard, Geo. (b'69)-Ger.10,'92; (l'01); Main St. ; office, 417 N. Maln St. $8-11,2-6,7-9$

Webb, 0wen E. (b'66)-Mo.24,96; (l'01) ; not in practice.

WELSH HORICE G, (b'55) (l'01): $520 \mathrm{~N}$. Main St.; office, $514 \mathrm{~N}$

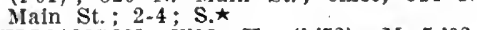

WILLIAMSON, WM. H. (b'72)-Mo.5,02 ; (l'02) ; 130 E. 12 th

tional Bank Bldg. '; 79$)$-Ill.1,02; (l'06) $709 \mathrm{~N}$. Main St.; office, Rorabaugh-Wiley Bldg. ; 9-12, 1-5; S.

IDANA, 225, CLAY

Moore, David J.-Mo.20,'92; (l'01).

INDEPENDENGE, 10,480, MONTGOMERY

ALFORD, JOS, SAVAGE (b'83)-Pa.1,08 (l'12); Demott Apts.; office, Kress Bidg. $10-1$.

Chaney, Geo. C.-E-0.2,77; $\left(1^{\prime} 01\right) ; 218$

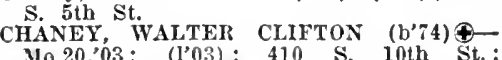

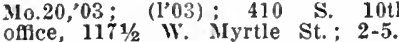

DAVIS, DOWDAL H. (b'83) $\oplus-\mathrm{D}$.C. 3,06 : (1'07): $301 \mathrm{~N}$. $3 d$ St.; office, $215 \frac{11 / 2}{\mathrm{~N}}$ 1'ennsylvania Ave.; 10-12, 2-5. 
DAvis, J0Hx, T. (b'53)+-Mct.1:99: (1'04): 300 w. Maple st. oalco $102 \mathrm{y}$ v. Main St : $10-12,2-4$

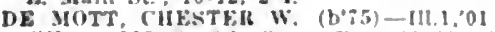
(1'01): $307 \mathrm{~s}$. sih st.: once, $10 \mathrm{~s} / \mathrm{s}$ rennsiranla ire. EVANS, ARTHLIt W.

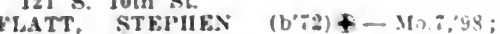
(l'12): $103 \frac{1}{1 / 2}$ W. Matn St: $1-5 ; \mathrm{G}$. IUDIICRE, WALTER S. $\left(b^{\prime}+8\right)+-M 0 Q$ 03; (1'05): $212 \mathrm{~S}$. sth st. : once, $105^{2}$ N. Pennsylranla iro, ; $10.12,:-5$

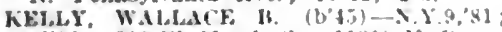
(loi): 313 W. Myrtlo st : 11:3 he N lesin: ylrania Are: $11-12=5$

Lans. Nellle Lyster (b'63)-Ark.1,07; not in practlce: $\mathrm{S}$. 10th St.

LosG. THos. C.st-Mo.28, 01; (1'02): LoxG, Tllos, C.t-Mo.Ms,

MINER, EIMUER A. $\left(0^{\circ} 70\right) \mp-111.6,04$ (1'07): $311 \mathrm{X}$. Pennsylvanla Ave; $2-5$

otwell. L. S. Barton (b'33)--1).1,65; nol In viscilce: 912 W. Laurel st.; $N$,

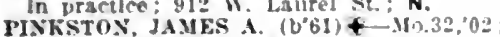
(102): $115 \mathrm{x}$ 9th st.: nfloe, $115 \mathrm{~s}$. Pennsylranla Are.; $10-12,2-6$

Shelton, Frank W. (b', 6$)-M O, R, 0$ : (1'04) $321 \times 10$ h $\mathrm{St}$ : once, Kress Imlin.

SMTH, CHAHLES L. (b'b6) \&-1a.3,0t (I09): I15\% W. Msrtle St.; 9-12, 2-5 OALR. *

SURBER, CASILS C. Mo.8, St; (l'0I)

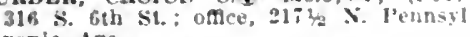
vanla Are.

TAGGART, FRANK R. (b'si) Mn,, 04 (1'04): 406 N. 2d St.: oftce, $110 \%$ W. Myrtlé St. : $2-5 ;$ Anes.

TAXQUARY. MAME I. '(b'70)-Kan.t 01: (I01): 210 X. 11th St. : oflce, Booth B)dz.: $11-12,2-5$

WICKERSHAM, ENOCH C. (b',56) †-Kan.4 "OI: (1.01): $605 \mathrm{~W}$. Myrtle St. " uftlce. $2194 \times$ Pennsylranla Are.; 9-12, $1-5$ Wllllams, Medrin J. (b'5t)-Ind.8.51 (1.01); not in practlce.

INDUSTRY (R.F.D., WAKEFIELD), 250 DICKINSON

Lexis. Clemens C-Mo.20,04: $\left(b^{\prime} 04\right)$

Schenberger, Saml. W. (b'55)-Kan.3,'4y: (l'01)

\section{INMAN, 484, MCPHERSON}

Enns, Jacob IIarlow (b'S2)-III.1,"11; (I'12)

Graves, John S.-1a.1, Xs: (1'01).

Sprouse, Oscar-Mo.28, 03 ; (l'0t).

IOLA, 9.032, ALLEN

HASS, J1IX SILAS (col.) (b'50)-Tenn. $\because 8 ;(1104)$

Bass, Lew is $\mathbf{x}$. (col.) (b'89)-Tenn.7, 13 (1'13).

BOLTO:, Joll w. (b'62) - Mo.22.94; (1'02).

BROWX. HEXRY A. (b'61) $\rightarrow$; $\left.(1)^{\circ} 04\right)$

CIIRISTIAN, IROBT. ORD. (b; $; 5)-$ II 0.20 03: (1/03).

COX, OMAR I. (b'6i) +Neb.t,94: (1'0i)

OALR.

Curtls, Mlldred (b'83)-Kan.2,06; (I'06)

ObG.
FULTON, ARCHUBALD J. (b'4i)-l'a.2,it (l.01)

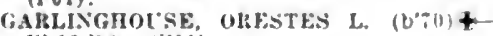
[11. 15,"99: (1.01).

Gisnn. Gullfonl Cresse (b'7i) - Mo. 20 , $9 p^{\circ}$ (1'0i).

Hendricks, Herschel Ledzer (b'65)-Mts.20, '97: (1'01).

llendricks, Wm. S. (b'98)-(9.1,60: not in practice.

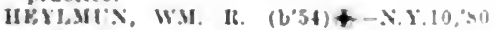
(1'03),

Johnson, Telle K. (b'5n)-1 a.9."9l: (1"01).

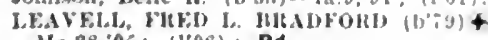
Mo.28,05: (1006); Pd.

Manley, Julius It $\left(10^{\circ}, 6\right)-0.2,89$ : (I01)

Mellowell. Wm. It. (1,it) - 2, 1101

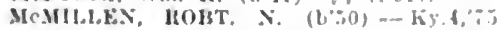
(1'01).

MITCIEIL, PAUT, STAFrull! $(1, i j)+$ 111.15,99, 111.11,00; (1"02)

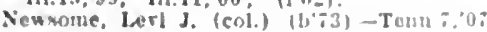
$\left(I^{*} 0 i\right)$.

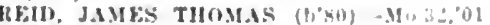
(1'01).
Reynulds, Fiduard Cecll $\left(b^{\prime} ; 6\right)-111.8,0 \%$; (1'0?)

Shalwlck, fieo. W. (b'o $)-M 0.5,00 ;\left(1^{\prime} 01\right)$

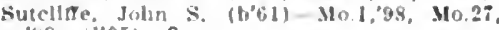
99: $1 l^{\circ}(0.5) ; \mathbf{S}$

Toza'r, l.uke $(1,83)-0 ;(101)$

WI.KLIS, Jos. G. $\left(\mathrm{U}^{\circ} 5\right)+-$ Neb.5.03: (I'0).

IONIA, 200, JEWELL

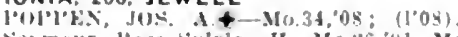

cezmour, liose sylsla-II-Mo.\$6, U1, Mo.33,

0.2; (1.0l); not In practlce.

IRVING, 409, MARSHALL

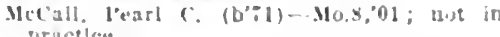
pructlee.

osualt, Jos, $\left(b^{\prime} 3 i\right) I I \rightarrow 0 ;\left(l^{\prime} 01\right)$

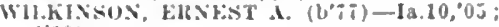
1000

ISABEL, 222, BARBER

Cinlegrat, Chester D. (b'S1)-Kan.t, 03 111.11,"01; (1'04)6

IUKA, 228, PRATT

Boren, Arihur Justlce (b'80) - Kan 2,90

(b) i) IIR.A $\left\{I^{\prime} 0: 2\right)$

JAMESTOWN, \$62. CLOUO

llartwell, (ieo, N- - lltch.1,7s; (1001)

McG.1UGHEl, HCGII 1).-Kan.2, 06 ; $\left(1^{\circ} 06\right)$

Nelwn, Chas. Robt. (bo5)-.110.35,04 (1"04).

JARBALO, 200, LEAVENWORTH

WO(1), KIWIIX SYDSEY (b.72) \&-111.1 Q6: (I,01)

JENNINGS, 259, DECATUR

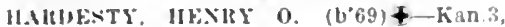
$00 ;(1001)$

Jerties, Albert-Mo.20,07: $16^{\circ} 07$

JETMORE, 317, HODGEMAN

Fwing, Ilarry ("hester (b'St)-Colo.2.'1] (1'ii).

JEWELL, 839. JEWELL

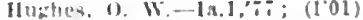

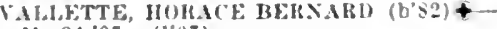
Ylo.34.07: $(1,6 i)$

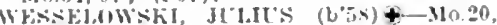
$\mathrm{S} 5$; (1"01)

JOHNSON, 40, STANTON

(WU, F, $(0,-3) \rightarrow$ han.3,0.

JUNCTION CITY, 5.598, GEARY

(AIIR, WII.TEIS A LETIN $\left(b^{\prime} 6 \%\right) \mp-11.6$, 05 ; (1'05).

Ilannah, Herbert C. (b'5) - M0.5, 97 (1'04); (Osteryath).

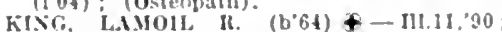
(1,01)

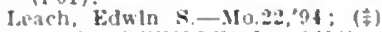

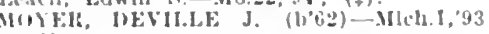
$(1001)$.

Nirthruj, John F'. (b'5)-Mo.31.99; (1 04 )

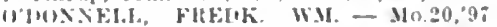
(l'ul).

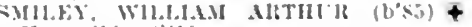

Kan.3.'10: (1.10).

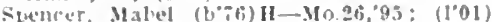
steadman, thas, Folw. $(2+4)-111,1,66$ (1,011

STFIIMIN, I.EONAIR \&. (b*1)-110.20, ?o6i: $(1,01)$

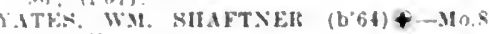

KACKLEY, 230, REPUBLIC

Ifowland, Jue Whor (b's:) - Mo.2,10 (I'1B)

KANOPOLIS, 577, ELLSWORTH

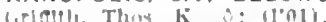

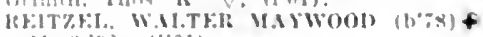

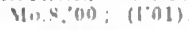

KANORADO, 75, SHERMAN

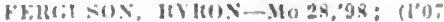

KANSAS CITY, 82,331, WYANDOTTE

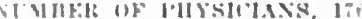

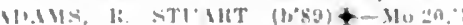

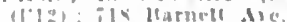

Mrluger, Allat $X$ (b.01) - Mo 20,1 lutern, se Marzarel's Hospltal

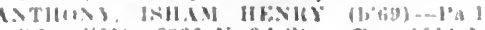

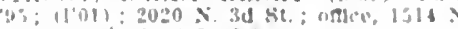

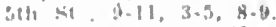

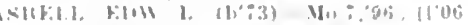
(fuindari, libus]. : $1-3,:-4$
Ranks, Sylrester M. (rol) (1, ; 5$)$-Tenn.:

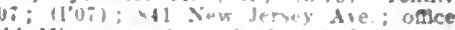
514. Mnnewita be : $411,-6,7-9$.

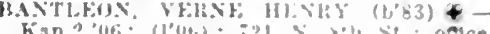
Kan. 2, $06:\left(1^{\prime}(0 *,) ;: 22\right.$

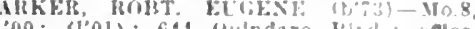
on; (lol); 64t Qulndaro Lisl.; once Q qutudaro Mird. 1 -

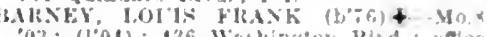

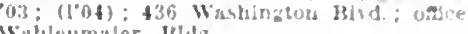
Wallenmaler Itha.

Baughnan, reo, i. $\left(b^{\prime}, 3\right)-k a n .3 .97$

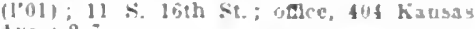
Razan, Ju4. T. (b"5)-Mo 29,96; (1'12): izi rentral Are.

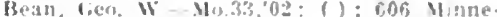
sita Ire, oflce, Sis Ridre Ilouse Ridz. $8: 30-12 ; 0,1-i$

lleman, Thrinas rlarkan (b's5) - Mo.20 41: $(1,0 !) ; 42 Q$ stewart Are. ; oflce, 650 Mnnewata ire.; 2 .

Hetwan, Wm. T. (1,an) - Kan.4,02; (1002) Iand Qulardars lavd.

IHatchly, Hicar I'. (b'50)-I!1.10,82: (1'10) liblos. Valley sit.

Boughnou, llarvey Peter (b'sR) - IIo.3\$,'13; st. Margaret'y ilomplat.

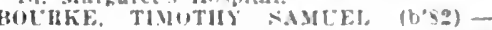
Mo.2,'10: (1'11): Vermont and Hartson Sts.; oftec, 1002 Centra! Ire. : 2-3, 7-8.

Iboyce, xelson V. (toz)-(3.1,89: (1"01): 610 sandusky ire, $5-10.2-3 ; 0$.

Brockett, Warren 1 , (b'i1) - Kan.3,"9s; (1'01): 1600 $x$. ith si.

Brown, Christlan 11. - Mo.32,01; 1101); 21.5. James $\mathrm{si}$. (1'01): 1015 freman Ave.

B1 ChLEs, Jos. II. (boj) + Mo. 22,05: (1'05); 1734 s. 23d st.; otlce, 1001 s. 22d st. : $10-12,2-3,7-9 ; \mathrm{s}$

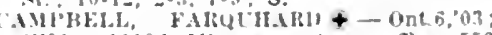
(1"01): 1110.1 M!nnesota Are.; oflce, 552 Mlumenota die.

Carey, Francls \&. (b91)-Neb.6.'13; (1'la) it. Margaret's llowpltat.

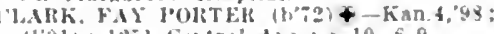

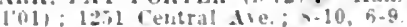

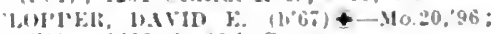
(1001) ; 1402 s. 26,th St.

Coburn, Clay F: (b\%") If-Mo.31,99: (1'01) gox Grrille Are, nalee, Portsnouth Bld:$2-5 ;$ l'rot. I'hys. llak, IIu.3.

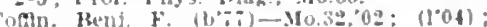
$140 \mathrm{l}$ llallurk st.; offce, $1 \times 20 \mathrm{X}$. $5 \mathrm{ht} \mathrm{st}$ $-7,5: \mathbf{S}$.

MIS. JEFFERSON A. (b'63)-Mo.39,09 (1.02); 304 $\leq$ 10th st.; ollce, 10th st and Central ore.

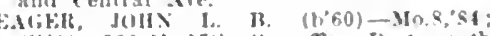

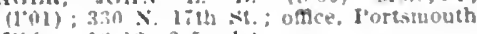
1tlliz, ; 10-12, 2-5; 1.

Ermest, John lival (bst)-Ma. $=0$. 10 (I’11): lon s lith st, once, 911 Central Ale: $2-j$. (1'0)

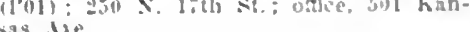

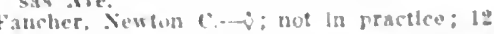
s. Sth sit

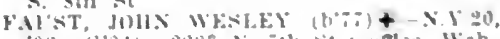

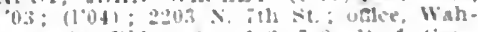
lenmaler lihg : $5 \cdot 4,1 \cdot 3,7-s ; 1$ rot, liyn.

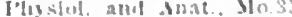

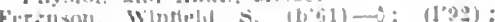
18.0. 14 h $>1$

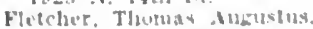

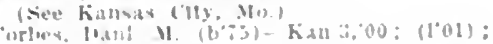
onelow. loand II.

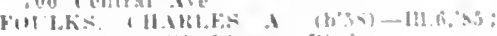

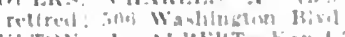

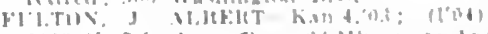

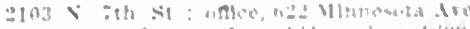

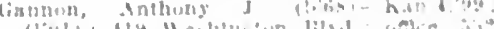

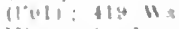

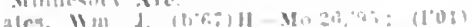

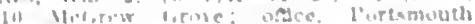
illis:

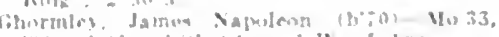

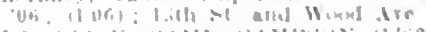

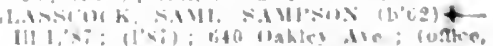
Ithalto ibhle, hassan (Jiy, Mo., l'sil: loruif l'asch, Kan:; NP. 
fordon, E. I1. (b'79)-111.17,10; (1'11): 2121 Metropolitan Ave.

GKAY, GEORGE MORRIS $\left(\mathrm{b}^{\prime} 56\right)+-M 0.8$, 79, N.Y.10,80; (l'01); 40 s. 18th st. ofice, 1'ortsmouth Bldg.; 2-5; Clln. Prof. surg., Kan.2; (AT); $\mathrm{S}$ *

CIRENE, MAMLL A.

(See Kansas Clty, Mo.)

Greenlee, Edward W. (b'63)-Kan.4,'99; (I'0 I) ; 1117 W. Ruby st. : $7-10,1-4$.

Grimn, Theodore (b'42)-0.6, ${ }^{\prime} 9$; (l'01) 42 s. $15 t)$ st.; (oflice, $10 \mathrm{~W}$. $8 \mathrm{th}$ st. Kansas rity, Mo.)

GItOWNLY, JON J. $\left(b^{\prime} 67\right)-\mathbf{M} 0.29,97$; (l'06) 74l Central Ave. Haigh, Jos. (b'51)-.110.18,'81; (1'01); 604

IIAINS, J011N W. (b'66)-M0.20,03; (l'07) 936 illnnesota Are; oflice, 652 illnunesota Ave. ; 9-12, 2-5

HAMHLTON, GEO. I. ALEXIS (b'68)-MId.4, (1) : $(1.0 .5)$

H.ARMS, ALBERT (b'78)-Mo.26,'02; (1'11) ; $63 \mathrm{~S}$ Mnnesota $\mathrm{A}$ re.

IIASSIG, JOIIN FRANK (b'75)-Kan.4, 99 (l'01); 339 N. 17th St.; offlee, 1000 Central Ave. ; 2-4.

Hayden, Roscoe Conklln (col.) (b'81)Tenn. 7,$07 ;\left(l^{\prime} 07\right) ; 1403$ N. 10th st.

Hee, 400 Minnesola Are, ; 9-12, 7-9.

1720 N. $22 \mathrm{~d}$ St.; oflee, 552 Minnesotá Ave.

HAYWAIRD, JEFFERSON WM. (b'85)Mo.20,09; (l'09); 1313 Qulndaro Blvd. offlec, 1848 Qundaro Blrd.; 10-12, 2-5.

Ieath, Edwin Ruthven.

(See Kansas City, Mo.)

Iledgecock, Zella B.-1:-Mo.33,'06; (I'06) 240 N. Talley St. ; offlce, 626 Minnesota

IIOBSON, GEO. IIENRY (b'82)-Mo.20,08 (l'08); 13 th St. and Quindaro Blvd.

Horsey, Gee. Edw. (col.) (b'69)-Tenn. i,'01 (1'01); 828 Nebraska Are.; 9-10:30, 3-5, $6-8$

IIOWE, EDW. (b'58)-0; (1'01) ; 1119 Osage Are.

IIUBER, AIBBERT M. (b'80) - Mo.20,04: (I'04); 738 Quindaro Blvd.; office, 640 Minnesota Ave.; $10-12,2-4$.

HUGHES, KATIERINE S. (b'62)-Kan.4, '96; (1'01); 720 Ann Are.

Jenkins, Noah S. (b'65)-Neb.4,07; (l'10); 1505 S. 22d St. ; 8-12, 1-9.

Johnson, Thomas II. (b'44)-Cal.4,'87 ; (ま) ; 318 Minnesota Are.; 10-12, 2-5, 7-9.

JONES, JAY ARTIIUR-Kan.4,'04; (1'03); 1001 Central Ave.

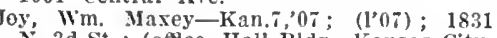
N. 3d St. ; (oftlee, Hall Bldg., Kansas City, Mo.).

KAULBACH, CHART,OTTE L. (b'82)-Kan.2, 10; (l'10); 632 Minnesota Ave.; 11-12,

Keefer, Matthew II. (b'84) - Mo.20,07

(l'07) ; $201 \mathrm{~S}$ N. 3d St. ; 10-12, 1-3.

King, Marry Walter (b'90) - Mo.20,'13 (l'13); 2112 N. 13th St.

Klnley, Clarence E.-H-Iro.35,'01; (l'03)

1963 Parallel Are.; Prof. I'ed., Mo.35.

KLINE, JOHN S. (b'53) 4-Tenn.6,'86; (1'01); 625 Oakland Ave.; offlce, Husted Bldg.; $9-12,2-5$.

Krall, iaul Morton (b'84)-Mro.34,12; St. Margaret's Hospital.

Layton, Roy Wilfred (b'88) - Kan.2,'13; (1'13) ; Grossman Bldg.

Leighton, Orrin L. (b'77)-Kan.7, 09 ; (1'09); 621 Lafayette Ave; office, 504 Mínnesota Are.

LEMMON, HENSON B. (b'82)-Kan.2,'07 (l'07); 501 Kansas Are.; $S$.

LEVERICH, LESLIE (b'65) $\oplus-\mathrm{M} 0.20,{ }^{\prime} 9 \tau$ (I'01); 30 N. 7 th st. ; 12-3.

LEYSER, JEREMHAH C.

(See Kansas City, Mo.)

LIDIKAY, CHAS. J. (b'69) $\oplus-\mathrm{Ky} .2$,'94; (l'04) ; 244 N. 17th St.; offlce, Portsmouth Bldg.; 10-4; Prof. Clín. Ophth., Kan.2; OALR. $\star$

LIND, ARTIIER J. (b'77)-Kan.4,'01; (1†) 552 Minnesota Are.; $2-5$.

Little, Alonzo Woodford, Jr. (b'79)-Mo.20, ,00 (l'01) ; Armourdale Bank Bldg.

LODGE, ATHENS VAILETTE (b; $)$
Mo.20,00; (1'01); 638 Minnesota Are.
I.WMAN. IRIC11ARD C. (b'07) -Mo.8,'90; (I")I); $816^{\circ}$ iv 9th St.; onlee, 6th st. and Minnesota A ve.; $2-4 ; \mathbf{s}$.

1.T'T'\% FARNW'T' J.' (b'65) (I'0i); $1247 \times$. Tth st.; offlce, 624 Minnesota Ave. $9-10,2-4$.

MABIE, IO'T 1). (b'66)—-Kan.4,97; (1'02) ool Cleveland Ave.; offlce, 600 Minnesota Ave.: $2-4 ; \mathrm{S}$.

MARCII, SAMULI, FIRANKLIN $\left(\mathrm{b}^{\prime} 82\right)-$ Mo.3,09; ( ) Menber 11!. State Med. Soc.: 1221 Garfleld St.; (ofllce, 1320 Maln St., Kansas (Ity, Nio.; l'09)

Markley, Wm. Franklin (b'80)-Kan.2,06; (l'06); 534 Minnesota Are.

Marsh, John L. 13.-Mo.35,07; (1'07) ; 1423 Independence Ave.; $U$.

MAY, JAMES W. (b'79) $\oplus$ - Kan.4,00; (1'01); 330 N. 17th St.; once, Portsmouth llldg.; 10-12, 2-5; Clin. Prof. Ophth., Kan. 2 ; OpA.ネ

McCarthy, lIarvey Fdward (b'89)-Mo.34 '13; Intern, St. Margaret's Hospltal

McDoUGALl, WM. T.-Kan.4,02; (l'02) 07 l'arallel Are,; offlce, Grossmán Blelg. LD. $\star$

McGontgle, Gerald Louls (b'90)-Mo.20,'13 (l'13) : St. Margaret's Hospltal.

IcCIBEGOR, JOIIN A. (b'64) - ont.3, 90 $\left(I^{\prime} 04\right) ; 2217$ N. 5th St.; oflle, Husted Blde.

MCKENZIF, HFNRY S. (b'84)-Mo.35,09 Mo.33,'11; (1'00); 1971 N. 27th St. office, 25th St. and Wood Are. 11-12, office, 2jth St. and Wood A

vclaughlin. Chitton W. (b;'-2)-Kan.4 '00; (l'01); 815 N. 9th St.; (offlce, Alt nan Bldg., Kansas Clty, Mo.; 10-11 $2-5)$; Prof. Gen.-Urin. and Ven. Dis. Mo.G1.

MeI.eod. Wm. H. (b'67)-Kan.4,01; (l'01 534 Minnesota Ave.; 9-12, 1-4.

IcNaughton, J. F. - Kan.3,'99. (Dentist); 765 osage Ave.

MEDEARIS, CHAS, MARCELLUS (b'61)Mo.18,'92; (['01); 1968 N. 3d St. ; 8-10, 2-4. 7-9; 0 b.

Mercer, Jámes B.-Mo.32,05; (ly 05) ; 337 Lafayctte Are.; office, 552 Main St.

Miller, John Welch (b'56)-Mo.8,96; (1'01) 1117 Euclid Ave.; offlce, 6 N. James St. ;

Miller, Walter P. (b'87)-Mo.20,'13; (1'13): St. Mrargaret's Hospltal.

Miller, Wm. Adam (b'52)-Pa.2,'88; (l'01) : 1229 State Are

Millis, Farl R. (b'82)-Mo.35,09; (†); Ave. ; $2-5$.

MIINER, JOHN ORR (b'61)థ-Mo.20,'87 $\left(I^{\prime} 01\right) ; 18 \mathrm{~N}$. Thorpe St.; offlce, 968 Central Are.; $10-12,2-4$

IItchell. Géo. B.

(See Kansas City, Mo.)

Mitchell, John A. (b'51)-Pa.2,77; (1'02) 1803 Central Are.; $12-4$

Montgomery, Wm. W. (b'84) - D.C.3,'07 (l'09); 400 Minnesota Are.

MORLEY, FRED HENRY (b'89) ๑-Kan.2 '12; (1'12) ; 2209 N. 12th St.; office, 1005 Campell St.

Iroses, Jabez H. (b'35)-ח1.1,'64; ( ) ; 200 N. Valley st.

NASON, ZACHARIAH (b'54) †-MI.3,'88; (I'02); 13th St. and Central Ave. ; offlce, Packard and Osage Sts. : 8-9,

NAVE, HENIY A. (b'82) $\oplus-M 0.20,04$; (1'05) ; 1616 S: 21st St.; office, 2100 Ruby St. : 1-3, $7-9$.

NESSELRODE, CLIFFORD C. (b'80) Kan.2, $0 f_{1} ;($ ' 04$)$; 939 Cleveland Are. offle, Portsmouth Bldg. ; 2-5; S.

NEWTIRK, JESSIE S. (b'73)-IIo.30,'98; $\left(1^{\circ} 01\right) ; 26 \mathrm{~N}$. Tth St.; 1-4; ObG

OWENS, PATRICK IIENRY (b'84)-Kan.2 '12: (I'13) ; St. Margaret's Hospital. PALMER, WM. RAILARD (b'77)థ-Mo.8, 98 ; $\left(1^{\prime} 10\right)$; 951 Minnesota Ave.

Paul, John 'Birsdall (b'71) - Mo.8,'97; (I'01); 2112 N. 5th St.; 11-3

PAVLISH, ANDREW S. (b'67) $\oplus$ - Kan.4 01; (1'01); 22d St. and Parallel Ave.

PEARSON, WALTER J. (b'64) \$-Kan.2,'07 ;
(l'07); 934 Armstrong St.; offlee, 640 Minnesota Are.; $10-12,2-4,7-9$.

Petty, Lee Roy (b'79)-Tenn.7,09; (1'10) 516 Minnesota Are.
Philllps, Myrtle I1. (h'78)-Kan.7,'08; (l'08); 610 Minnesota Ave.; (offee, IIall Bldg., Kansas ('lty, Mo.)

'OOLE, JOHN GUY (b'49) $4-\mathrm{Il} .1,{ }^{\prime} 92$ (I'04); 1125 Central Are.; oflce, 964 Central Ave. ; $10-12,2-5$.

PIROUSE, THEODOIt ALIEN (b'74) Kian.2,06; (l'06); $411 \mathrm{~N}$. 6th st.

Quiring, Walter otto (b'87)-Kan.2,'13; (1'13); St. Margaret's Ilospital.

kautert, Jullus 11. (b'73)-Mo.33,'11; 1510 state Ave.: 1'rof. Obst., Mo.33.

IREEVES, ELAM A. (b'i1) $\$-\mathrm{M} 0.20$,'03; (1'03); 950 Ohio Ave.; $2-5 ; 0$ b.

REGIER, HENIY 1.-Kan.2,'07; (['07); (l'01) Hinnesota Are.

RHODES, WM. IEMUEL, (b'83)-Mo.20, 09 ; (1'09); 3414 Metropolltan Ave.; offlce, 1410 S. 26 th St.; 2-6; S.

Iilchards, Fnanuel (b'33)-0; (1'01); 330 N. 18th St.

RICHAIRLS, (iEO. W. (b'68)థ-Mo.20,92 ; (l'01); $16 \mathrm{~h} \mathrm{~h}$ St. and Central Ave.; offlce 7 th st, and Central Are.: 9-10, 1-3, 7-8. RIHMOND, 'THOMAS (b'72)€-Mo.20,'97; (l'01); 814 Minnesota Ave.; 2-5.

ROBER'S, ANNA MASTERSON (b'71)Kan.4,98; (1’01); 712 Ann Ave.; office, 632 Minnesota Are.; 1-3.

ROBERTS, RUSSELL A. (b'57) - Ind.8, 87: (l'01): 12 Ann Are.; offlee, Portsnouth Bldg. ; $10-12,1-4,7-8 ;$ Asst. Prof. nouth Bldg.;

Rochelle, Mae A. (b'72)-Kan.7,'08; Assistant Physlcian; 710 Riverview Aré.

ROMEO, PASQUALE (b'84) $\odot-$; $\left(l^{\prime} 07\right)$; 346 N. 5th St.; office, 6th and Ellzabeth Sts. ; $10-12,7-8$; ObG.`

ROSE, JOHN 1H. ( (b'77)-Kan.2,06; (l'06) ; 763 osage Ave.

Russell, Ezra R. (b'42)-Pa.2,'66; (\$); 602 Quindaro Blvd.

RUSSELL, GUY JAMES (b'75)-Kan.2,06 ; $\left(l^{*} 06\right)$; 1102 Osage Ave.; 8-12, 3-9.

SAWTELL, JOS. EPHRAM.

(See Kansas City, Mo.)

Scott, Jesse E. (b'74)-Kan.7,'07; (l'07) ; 628 Minnesota Are.

Scott, Mollie E. (b'85)-Kan.7,09; (l'09); 628 Minnesota Ave.

Seright, James H. (b'68)-Mo.20,'97 ; (l'03) 419 State Are.; office, Portsmouth Bldg. SHEPARD, CHESTER ORVILLE (b'87) $\oplus$ 111.11,'12; (I'13); Member 11l. State Med. Soc.; 1918 N. 13th St.; 2-4, 7-9.

Shively, Delbert Melvin ( $\left.b^{\prime} 71\right)$-Mo.20,'01; (l'01); 700 St. Paul St. ; 8-10, 1-3, $7-9$.

Shively, Saml. S. (b'39) E-0.2,'81; (l'01); 700 St. Paul St. Sitterman, Edw. F. (b'82) H-Mo.35,'10;
(1'10); 911 Ann Are.

SMITII, DANL. M. (b'59)๑-0; (l'01) ; 1409 SMITH, DEROSTUS E. $\left(b^{\prime} 77\right) \oplus-$ Kan.4, 00 IIo.26, 01; (l'01); 715 Sandusky Ave. office, 552 Minnesóta Ave. ; 2-5.

office, 552 Minnesota

(See Kansas City, Mo.)

Smlth, Geo. Hewett (b'67) E-Mo.33,'06 (l'06) ; 742 Nebraska St.; office, 650 Minnesota St. : $2: 30-5 ; 0 \mathbf{~ b .}$

SNIITH, GUY A. (b'83)-Ind.10,'05; (1'09); 2500 N. 11 th St.

Smith, Harry L. (b'84)-M[0.35, '09, Kan.7, 10; (l'09); 528 Minnesota Ave.

MITH, HOUSTON E. (b'53)-Ky.1,94; (l'01); 1026 Central Ave.; offlee, 724 Central Are.

Smith, Jay LaVinne (b'90)-Mo.20,13 ; (l'13) ; 1520 N. 5th St.; 10-12, 2-5.

Smlth, John W.-Ky.2,89; (1'01); 333 N. Valley St.

Smith, Wm. H. (b'62) E-Ill.21,'98, Mo.26, '01; (l'01); 1520 N. 5th St.; (offlce, Shukert Bldg., Kansas Clty, Mo.; 10-12, 2-5) ; Prof. Anat., Mo.35; OALR.ћ

SOANES, JABEZ GEO. N. (b'74)-D.C.3, '01; (l'01); 941 Splitlog Ave.; offlce, 500
IInnesota Ave.; $9-11,3-5,7-8: 30$.

Spake, LaVerne B. (b'90) - Mo.20,'13; (1'13) ; 21 S. 17 th St. ; 3-5, 7-8.

Sparks, James W. (b'53)-Mo.35,'07; (l'07) 1720 Central Ave.; Adj. Prof. Minor. Surg., $\mathbf{M 0 . 3 5 .}$ 
STEMEN, CHAS. M. $(6,68) \rightarrow$ Ind 10.87 ; (I01): $1900 \therefore$ ith st. ; once, 5\%? Mnsesota Are.

STERR FTT: WM PHFSTO ( once. 500 Kansas Are. 9.2

Stuiwagon. Win. A. (i, - Kant, 02; (I'02): Di23 Qulndato Blvd.

SUTTON, WA.TER S.

(STO Kansas Clty, So.)

TEXXEY, EDWIS hol (b.7t)-110.20,97

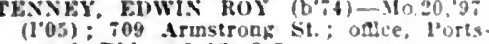
nsouth Bldg.; 9-12, 2-5

Thornoson, Jasper IR. (cul) $\left(b^{\prime}-i\right)-T e n n .7$. 06: (1.06): 1520 is. 10th St.: unce. 1512 s. 5 th St: $2-11,3-5$.

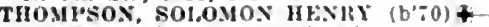
D.C.3,92: (1'01); 1321 N. sth st.; oflce. 1512 X. 3th St. ; $10-12,3-5:$ S.

WALKER, WM. II. (b'नt) $4-k y, 9^{\prime}$ (100): 2721 i $130 \mathrm{~h}$ (1)

Whlmster, Wm. Caven (b'74) - Ky.5.'95

Whimster, Wm. Caven

Whitaker, Grafton D. $\mathrm{D}$-0.8, 70 : not in nrac Uce: 849 Qulndaro Bivd.; onfe. 710 Minnesola Are.

While, Thomas

(See Kansas Cl1y, 310. )

Wilding, Fredk. K. (b'32) - Kan.7, 09

(1'09): 2067 . 13th 5

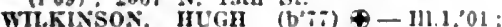
(104) : $2010 \mathrm{~N}$. 5th St.; once, 640 Mlanesota Are. : $10-11,2-4$ : 's.

WILLIAS, ERNEST D. (b\%0) -Mo.20, 99 : (1'01) : 616 s. 10th sit.

Wllson, John Frankllin (col.) (b's9)-Tenn. 12; (1): 945 Everelt St. ; $-10,4-3 ; G$. Yereiman, O. II. (b'79)-H11.401. Mo.2n.

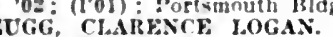

(See Kansas Clts, Mo.)

KECHI, 67, SEDGWICK

Madden, Alvin C.-H-Mo.35,06; ('/10)

KELLY, 200. NEMAHA

Filzrerald, Darld II. (D'54) $\rightarrow$; (1'01)

KENSINGTON, 497, SMITH

Bllby, Francis, M.-Ind.8:83: (l'01).

GOLDEX, LEVI A. (b'58)-111.1,80; (1'01)

pearson, wi. H. (b'il) $\rightarrow$-Neb.6.0s (l.08)

SCHOONHOVEN, R. GROTER (b'85) - M0.20,'12: (1'12).

KIMBAL, 10O, NEOSHO

Morgan, Geo. W. (b'69)-Mo.22,'96: (l'01).

KINCAID, 426. ANDERSON

Splakn Robt. C-O (l丷01)

Sprinkel. Chas. G. (6'6 $\left.{ }^{\prime}\right)-0.3,94 ;\left(l^{\prime} 01\right) ; S$.

KINGMAN. 2570, KINGMAN

CALLAIIAX, WYI. PAUL (b'si) 8-Mo.20,

10: $(1 \cdot 10): \mathrm{s}$.

DAVIS, NEWTON C. $\left(b^{\prime} 56\right)-0.728$ : (l'09)

HASINS, HENIT E. (b"i8)\&-MO.24,01: (1'01); $\mathbf{s}$

JOIINSOX, AI.BERT CHHISTOPIER (b'65) \& 1a.9,96: (1'01)

LIGIT, JACOB WILBERT (b':9) - 0.13 . 84: (1'01).

LONGESECKRR, CHAS. WILAKD (b't2) -Mo.8.99: (1.01): OALR.

MCKASEY. JOSEYH MCUOWELL (b.82) I10.20:10: $(1,10)$.

KINGSDOWN, 150, FORD

HANUY, ChALIDCS ESTYLI (b.T) Ky.5.05: (1'11).

KINSLEY, 1.547, EDWAROS

DE TAR, MONROE $\left(6^{\prime} 61\right)-.10 .32,01$ (l'01).

Donnell, James B. (1, 45$)-111.22 .0^{13} ;\left(1^{\prime} 13\right)$

Mosher, Clasence $x-0.2,90:$ (1'01)

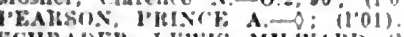

SCHlDSER, LEWIS MHLWAR (b'79) KY. 2,05: (1)05): OALR.

STOLTEXIER(, WAITHI. PETER (b'S2) + -la 3,05; (1'05).

KIOWA, I.520, BARBER

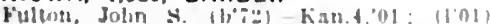

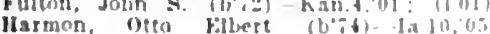
$(105): 00$.

II arrle, Wm. II - Mn $10.81:(1 \% 01)$

WAITE, GFo. 16. (6'76)-IIl.17,01: (1.01): s.

KIRWIN, 626, PHILLIPS

Brown, Beonldas T. (6'69) - 11 22.99!

(1.01).

Johnson, Harry H. (b'66)-Ky. 2.85: (1'0j) ObG.
LABETTE, 350. LABETTE

Connos, Win. J.-0..'82; (1'01).

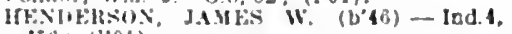

OVYLE EAll $\left(b^{*} 2_{2}\right)+-$ Kan.2,11: (1'11)

LA CROSSE, 806. RUSH

Altwool, Lewls (1)'99-kan.3,04: (1.01).

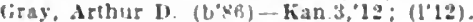

LA CYGNE, 957, LINN

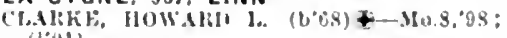
(1)01).

MAY, ANIRES J. (b59)-1a.1,85: (1'01)

MGisisox, scotT D. (b'bt)-Mo.20,13 (1'13).

rerdler, Wasblngton T. -Mo.18.8\%: (101).

LAFONTAINE, 160, WILSON

MeroNixil.t., WESTON II. (b'60)-Ind.s, 'Q2: (1'01).

LA HARPE, 2,080, ALLEN

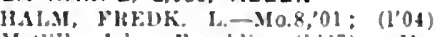

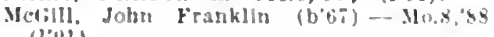
(1'in)

STAPIETON, FIELDING P. (b'68)

27,$92 ;(1002)$

LAKE CITY, 150, BARBER

Connor, James Arthur (b'ii)-Kan.4,03: (1'04).

Bogers. Cornellus B. $\left(\mathrm{b}^{\circ} 66^{6}\right)-\mathrm{ky} 9.1,02$

LAKIN, 337, KEARNY

Balley. Sanford (b'71)-K5.1.93: (l'10).

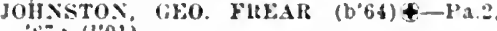
si: (l'01).

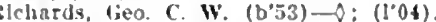

LANCASTER, 220. ATCHISON

Charle3. Augustus L. (b'55) - Mo, , '7S; (1'02).

LANE, 272. FRANKLIN

COWAX, MeCl,LRE W. (b'56)-X.Y.0,'80 : (1.01)

FILI.ER, JOIIS A. $\$$ : (1'01)

Heath. J. Frank (b'69)-MU.20,05; (I'05).

LANGDON, 200, RENO

Grieve, George Harry (b'85) - Ill.4,09 (1609).

LANSING 800. LEAVENWORTH

FATLKNER, JAMES THOS. (b'a) - MO. $0.8 ;(1.13)$

FORO, CHAS, WESLYY (b'67)-1a.8,00: () Mct.AiMAN, [RA J. (b'67)-111.1,92; (1'01)

Tealley, Geo. $r$. (b'4?)-111.6,70; (1'01).

SWIXX, LKO JOHX (b's2) - Mo.20,08 (1'0s).

\section{LARNED, 2,911, PAWNEE}

Arnold. Wm. M.-la.1,tii; (1.0z); nol In Iractice.

DILLON, JOHX A + Kan 3.93; (1'06i)

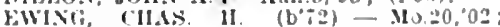

(1'04); $s$.

KogNs: C. CLAYTUN (b'a)--MU.A.01;

RE:H, AIBERT EALL (6'81)-I11.1.05:

$(105): \mathbf{S}$.

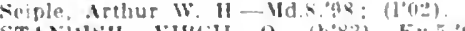

STINIHSH, VImil, o, (b.83)-ky.5,

(1) TO).

LATHAM, 364, BUTLER

Allor, Bnlin (1.45)-11010,'s9: (1.01)

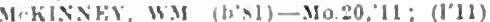

LAWRENCE, 12.37\%, DOUGLAS

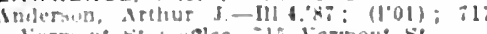

bermont $\mathrm{ki}$ : unlce, ils bernont st.

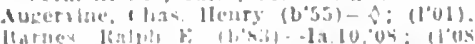

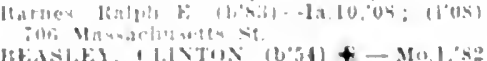

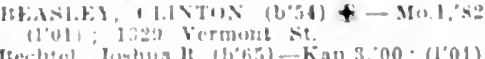

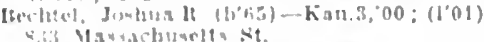

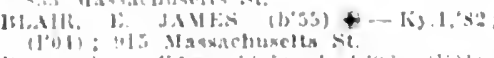

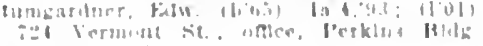

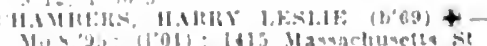

Mi.

I'rof' $11 b^{\circ}$, kant? 20 b.

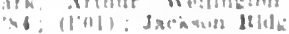

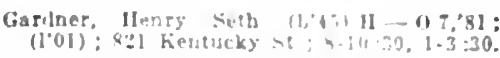

ilfort, Ilered

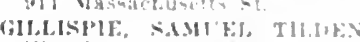

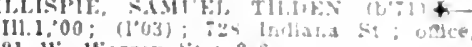
al W. Warters st, o-

(1"01): 1240 Ohle st.

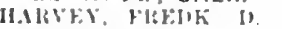

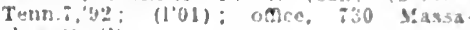

Ianac, llenry W: (2.53)-; (101): Kress H11:2

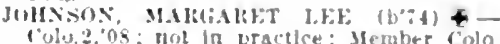
Colu.2.08 not in practlce: Member colo. onke, state Cnlrersity of Kunad; 9-12, $3-4$

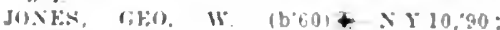

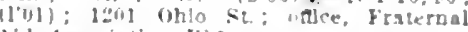

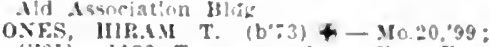
(1'01): 1130 Tennessee St: ofice. Fra. ternal Ald Assoclatton Blig.; 10-12, 2-4 Pr.

Lielth, Filmond R. (b'64)-M0.10.91: (1.01): lilck Bldg.

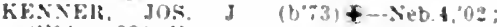
(1'04): 830 Vermont sit: $4-11$ :-4 i-y

Laslett. Ellzabeth (b'il)-Kan 1,$00 ;$ (i.01) 13. I. 11.

Matthews, Saml. Alexander $\left(b^{\prime} 66^{6}\right)$ - Mlch 1 , $95: 1004$ Nlsslsslgpl st.; omce, Cnlversity of Kansas: I'rof. Physlol. and Exper. Phar., Kan.2

Mllburn, Frank W: (b'8i)-D C.1,12: i): Hiskell Instlite.

MOHSE, FREDERIC D. (b'33) - II1.1, 67 (1.01): 1011 Tennessee St: oflce, 801 Massachuselts St.; $9-10,1-3$.

calamith. James foln.3, 4 : (1'nei: not In practlce; Prof. I'hss. Educatlon, Kan. 2 Owen, Elljah II. (b'63)-110.20,00; $\left(1^{\circ} 04\right)$ : ito vermont st. : $\mathbf{N}$.

PIILLIIS, CARL (6.69) + Mo.5:01; (1'01): Assoclation Bide. : 10.12, 2.4.

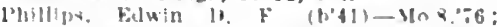
(1'01): Fraternal Ald Assoclation Blde.

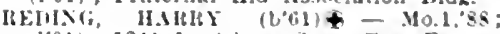

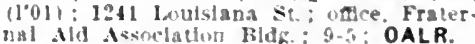

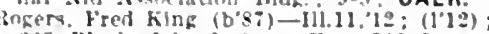
265 Hhmle laland st.: oftce, 2.2 Locust St.; $8-11,2-5,7-9 ;$ Pd.

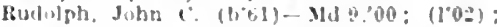
SIMMOS. CHAS. JEFFERSON (b'5s) \& X.Y.10,'s5: (1'03): it4 New llampsblro

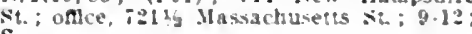

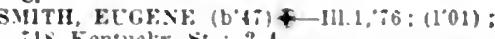
ils Kentucky st. : :

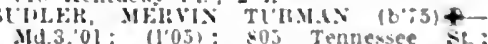

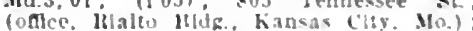

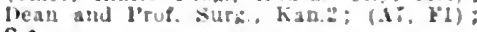

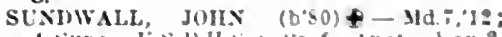

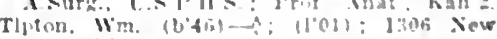

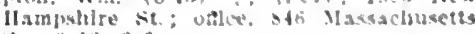
Sit. : $9-12, \pm-6$.

Whihelm Lerl th- Fo-Mo33,01, Mo 31,0:

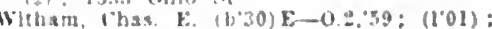
16 - 4 Tennessito sit.

LEAVENWORTH, 19,363, LEAVENWORTH

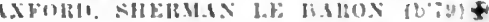
- Kan 6.0:- 11.0:1

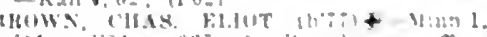

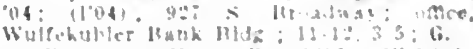

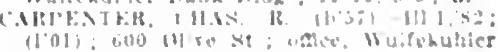

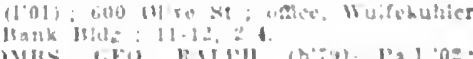

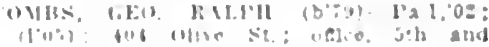

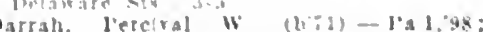

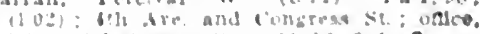

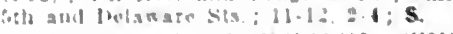

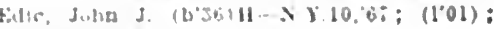
(ils seneca sit 


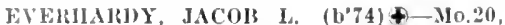
97 (I'01): 510 osage St, olllce, Axa IB]dig.; $11-12,3-5$.

FITER, J()]IN LAYGIEY (b'66)-No.8,90 (1'01): 4th and pelaware sits. ; 9-12,3-5.

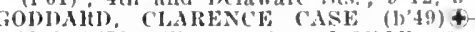
N.Y.10,73; (I'01); 5th and Mudle Sts. oflce, 406 1) blaware st. : $2-5$; I'rof. Neur. lian. 2 ; NP.*

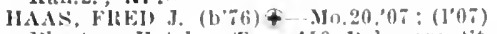
planters llotel: otlde, 410 llelaware st. $10-12,3-5 ;$ OALR. $\star$

10-12, 3-5; OALR.
Iamilton, Joln lilewellyn $\left(\mathrm{b}^{\prime} 55\right)-0.14,81$; (1'01).

JAClisis, s. XATIINHLL - Tenn.7, 94 (1"01); 220 Plaware st.

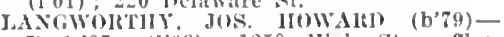
I'a.1,07; (l'08); 1250 1Ijgh St. ; oftlee, Axil Bldir. : $10: 30-12: 30,2: 30-5$

LANGWOHTIY, SIMON B RTRON (b'5s)t - Mlo.8'87; (1'03) ; 1250 lligli St.; oftlce, Axa 13idg. $11-12: 30,3: 30-6:$ G.

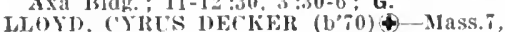
'98; (1'05) ; 310, 5th Ave.; oftlee, Cherokee and 5 tl sts: $11-12,2-4$.

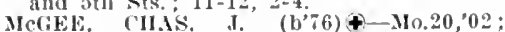

(1'01); 934 s. Broadway; oflec, 5 th and (1)01) , 9.

lolaware sis.: 2-5; S.
McliEL, STEWAIt (1'01); ith and ('hestuut Sts.; offlce, 400 Shawnee St.: 2-4.

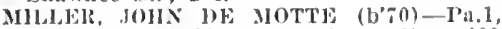
98; (I'01) ; 122 Spruce St.; oftice, 409 Delaware Si : $2-4$

MOATES, cIIAS. II. (col.) (b'62)-Tenn. 8s: (l'01) : 509, 5th Ire.; office, 5 th and Cheroke sits. ; 11-12, 3-5.

MORIOW, FRiNk M. (b'79)†-Kan,3,05; (1'05): $2: 3,5,5$ th Ave.

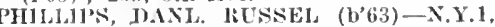
'87; (1'04); 228, 5th Ave.; offlee, 5th and Delaware Sts. ; 11-1, 5-6.

RISUOS, JADES WALDO - Mo.20,05: (I’05); 229, 5th Are.; offlce, 412 Dela-

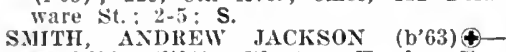
Mo.8.'94; (1'01); I'lanters Hotel; oftlce, 600 N. 5th St. ; $2-5$.

Smltl, Bu(I (b'60)-11o.8,86; (I'01); 600 N. 5 th St.

ST,ACEY, HARLEY JAMES $\left(\mathrm{b}^{\prime} 70\right) \oplus-\mathrm{Pa} .1$, 96 ; (l'01); Maple Are.; offlce, Wulfekubler IBank Bldr. 11-19' 4-5.

SUWALSKY, ADELBERT L. (b'79)-Mo.32. 01; (1'01)'; 406 Delaware st.

TAY1.OR, FJETCHER B. (b'82)-Kan, 2,08; (I'08); 319 Spruce St. ; offee, 515 Delaware St. ; $11-12,2-6$.

VAUGII, CIARENCE K. (b'75)-Tenn.8 '98; (1'01); 212 Vine St.; office, 5th and Delaware Sts. ; 11-12, 3-5.

YOHE, ALFRED FRANKIIN (b'65)-IIl.1, '88, N.1.10,' $9{ }^{*} ;$ (I'01); 6 th and Seneca Sts.

LEBANON, 731, SMITH

DYKES, HENRY A.-Ky.2,'88; (I'01) ; Sec. State Board of Med. Reg. and Exam.

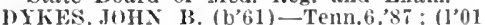

Mays, Wm. Tillman-Tenn.10,'94; (1'01)

LEBO, 560, COFFEY

Lusk, Chas. F.-Ill.1:'84; (l'01)

Mills, Claude J. (b'82)-Ill.11,09; (I'09)

LECOMPTON, 386, DOUGLAS

Holloway, S. S.-HI-IIl.10,96; (I'01).

KERR, CAREY C. $\left(b^{\prime}, 7\right) \oplus-M 10.20,05$; (l'05).

Lewis, Philip M.-Mo.8,84; (1’01); not In practice.

LEEDS, - J JACKSON

Lane, Harry Saml.

(See liansas City, Mo.)

LEHIGH, 385, MARION

Brunig, Conrad P.-Mo.8,'03; (l'0T).

LE HUNT (SYCAMORE P.O.), MONTGRISON, JOHN IIOLLENBACK (b'82)甲 IORRISON, JOHN IIOI

LE LOUP, 82, FRANKLIN

Reid, James D. (b'81)-Mo.20,'12; (1'12).

LENEXA, 383, JOHNSON

Burnett, John A. (b'76)-1a.10,03; (\$).

HARKEY, WM. CATHEY (b; 72$) \&-M 0.20$

00; (1'01).

Jones, Perce Leroy (b'7) E-0.2,05; (1'05).
LENORA, 454, NORTON

(AITIIEl?, FAY F. (b'81) - Neb.6,06; (l'07) liart. Carter Wm. (b'85)-Kan,2,10 (I'10).

LEON, 494, BUTLER

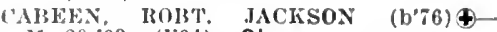
Mlo. 20,$03 ;$ (I'04); 0 b.

WEliER, WM. W'EIT (b'87)-Mo.35,'12 (1'12); U.

LEONARDVILLE, 376, RILEY

IIENI)EIRON ARCIIBALD G. (b'64) No.1,99: (I'01)

Lovene, Arthur W. (b'82)-Ill.17,08; (1'08)

LEOTI, 288, WICHITA

Doyle, Adolphis M. (b'42) E-Mo.10,'82

S.MTII, ORMAN E. (b'76)\$-110.10,01; (l'05)

White, John F.-Mo.1,'98; (1'01)

LE ROY, 918, COFFEY

CULIER, CART, CALVIN (b'87) - -Kan.2, 11; (1'11); ALR.

kesner, Christopher C. (b'57)-Ky.4,'84; $(101)$

ROWE, MITRY B. (b'65)-Mo.8,92, Mo.24, 9.5; (1'01)

\section{LEWIS, 557, EDWARDS}

HAYYES, ELMEI ELLSWORTI (b'70)-Kan.4.'00: (l'01).

RAIRDOS. CIAREXCE W. (b'62)-Mo.20, $89 ;\left(l^{\prime} 01\right)$.

LIBERAL, I,716, SEWARD

(iregolre. Jos. A. (b'78)-Mo.41,'00; (I'13) HIGGINBOTILA, THOMAS I. (b', 9$)$ Ill.11,06; (1'07) ; OALR *

INISELY, ARTHUR L. (b'73)థ-Mo.28, 01 ; (1,01).

YltIIOJS, ROSCOE TOWNLEY (b'81)€Ill. 6,$02 ;\left(1^{\prime} 02\right)$

S.IITH, GFORGE S. (b'55)థ-Mo.8,'91 : (1'01).

LIBERTY, 385, MONTGOMERY

ICIRIDE, FLOYD B. (b'81)థ-Ind.18,'06 ; (l'09).

LILLIS, I2, MARSHALL

Holliday, Saml. N. (b'53)-IIo.18,'82 ; (1'01)

LINCOLN, 1,508, LINCOLN

ANDElRSON, GEO. M. (b'73)-Kan.4,01 (1'01)

Cole, Sarah A. (b’55)-Ia.4,'89, Ill.4,'98 (I’01)

IIall, IIenry M.-Ia.1,'58; (I'01)

IIULTNER, ALFRED (b'67)థ- $110.20,96$;

KERR, LA.MBERT A. (b'85) $\odot-K y .2,09$; (1'09)

Newlon, MaIcolm (b'86)—Ino.20,10; (l'10). SLTTON. JOHX MAGRUDER (b", 6$) \oplus$ Mo.20,08; (1'11).

LINCOLNVILLE, 475, MARION

Smith, Darid W. (b'62)-Ky.4,'84; (1'05).

LINDSBORG, 1,939, MePHERSON

BECKMAN, PETER W. $\left(\mathrm{b}^{7} 6\right) \oplus-\mathrm{I}$ - 28, $00 ;\left(\mathrm{I}^{\prime} 0 \mathrm{O}\right)$

Berquist, Gustarus E.-Ky.2,77; (1'01).

Mammel, Frances (b'53)-Mo.10,'01; (l’01)

LINN, 400, WASHINGTON

AIRIE, ROB'T. (b'74)థ-Mo.28,'99; (I'01)

MA1NTZ, R. W. (b'63)-Mo.1.'89; (I'01).

LINWOOD, 323, LEAVENWORTH

Little, W.' T. (b'74)-110.22,'95; (l'01).

VANNOY, HARVEY E.-MO.22,07; (I'07)

WARRING, JAMES W.-110.8,"73; (1'01).

LITTLE RIVER, 66!, RICE

BEYEIR, LOUIE JOHN (b'84) £-Kan.2,'10 $\left(1^{\prime} 10\right)$

Chesshir, J. MeIsworth S. (b'71)H-III.15; 04; (1'04).

LOGAN, 7I4, PHILLIPS

'Iuranc, Vietor Boone (b'S0)-Mo.34,09; (1'09).

Davis, Alexander G. (b'69)-Mo.18,'91; (I'01).

Richmond, F. E.-Mo.8,'02 ; (1'01)

LONE ELM, 125, ANDERSON

Forsyth, Manley-Ia.10,08; (I'08)

LONGFORD, I00, CLAY

Jackson, Dana O'. (b'81)-Ǩan.3,'04; (I'04)

LONG ISLAND, 29I, PHILLIPS

CASSEL, OLIVER MARCO (b'83)-Mo.28, 09; (1'09).
LONGTON, 6II, ELK

1)AY, FREN. K. (b'66)-Mo.20,97; (I'01) Flack, Wul. F. (b,57) li-0.2,86; (I'01). Jones, W'm. 13, (b'72)-Wis.4,96; (I'01); R.F.1).

LORRAINE, I80, ELLSWORTH

lartill, Frauk 11. (b'33)-Kiın.3,'96: (1'01) $\mathrm{S}$.

LOST SPRINGS, 276, MARION

LOONIS, SYUNEY I'. (b'82)๑-Tex.3,'11; (l'11).

LOUISBURG, 603, MIAMI

lerrell, Jesse $V$. (1,71)-Ind.5, 97 ; (1'06) Gatley, P. Frank (b'75)-Mo.20,02; (1'01) KLILLY, JOIIN W.-IIO.2!,98; (l'02)。

LOUISVILLE, 246, POTTAWATOMIE

Cutrlght, Albert-0.25,98; (1'01).

LOVEWELL, I00, JEWELL

Batchelder, stephen I.-O; (1'01).

Kan.3,'08; (I'08)

LUGAS, 573, RUSSELL

Allgood, Solomon E.-Tenn.8,'87, Ky.2,'9I: (1'01)

Donne, Ray G. (b'81)-Kan.3,'10; (1'10).

Smith, Francls I. (b'T4)-Mo.22, 00 ; (I'0I).

LUDELL, 200, RAWLINS

WImer, Henry (b'64)-0.2,'94; (1'05)

LURAY, 341, RUSSELL

MAYS, CHÁRLES 0. (b'81)-Tenn.1,'07; Mays, Roscoe B.-Tenn.1,05; (I'05).

LYNDON, 763, OSAGE

lieasley, Chas. W. (b'70)-Mo.1,94; (I'01).

Niles, Rolt. H. (b'58)-Ill.11,'85; (l'01).

MITH, FRENCH MILES (b'79)-Mo.20, 09 ; 109).

LYONS, 2,07I, RICE

Rradbury, Lewls A.-Mo.20,07 ; (1'07).

HISHER, CHAS. E. (b'78) (4-111.6,'03: (1'04); OALR.

FISIIER, EDW. COMBIE (b'44)-MIch.1, 72 ; (l'01).

rank, Carl Schurz (b'75)-Ia.3,01; (1'06). ICBIIIIE, JOS. S. (b'67)-Mo.8:98: (1'01) ERIIILION, LOUIS E. (b'50)-Ia.9,'91: (1'01); G.

MACKSVILLE, 626, STAFFORD

HART, MILLARD M. (b'58)-Ind.5,'82, Ind.9,'96; (1'01).

IIaynes, Jacob M. (h'74)-Kan.4,02; (1'02) Haynes, Linnie C. (b'76)-Kan.4,02; (1'02). Powell, Fred C. (b'77)-Kan.2,11; (1'11). MADISON, 721, GREENWOOD

('ranston, Chas. O. (b'69)-Mo.8,'94; (1'01)

Cunkle, Israel W. (b'47)-Ill.1,69; (l’01).

LOSE, FKED D. (b'84)-Kan.2,06; (1'06)

IOOKE, JAMES M. $\left(\mathrm{b}^{\prime} 70\right) \oplus-K a n .4,00$; (101).

MAHASKA, 246, WASHINGTON

Wall, Victor J. (b'87)-Mo.22,'11; (l'13)

MAIZE, 200, SEDGWICK

l'arker, Clarence A.-Tenn.1,'03; (1'03).

MANCHESTER, 250, DICKINSON

Beitzel, Chas. W.-Pa.2,'90; (1'01).

MANHATTAN, 5,722, RILEY

BENTLEY, WM. E. (b'65)-Mich.8,'94 (1'12); ÓALR. *

BRESSLER, ALEXANDER H.๑-Ky.2,'94; (l'01) ; G.

CAVE, THOS. R. (b'52)థ-0.1,74; (1'01) CLARKSON, WM. H. (b'76)థ-Kan.3,00, Kan.4,04; (1'04).

COLT, JAMIES D. (b'67)-Mo.20,'00; (1'01) : OALR.

Jenkins, Mike Clemont (b'86)-Mo.35,'11 :

LEITH, ROBERT (b'65) $\oplus-$ N.Y.5, 94 ;

(I'10).

ITTLE, BESSIE BELLE (b'7I)-Pa., 06 ;

UT'TLE, CHAS. F. (b'36)థ-Ill.1,'63; (l'0I). lyman, Lewis J. (b'38)-N.Y.10,'62; (l'01) MOFFITT, EDWIN JAY (b; 71$) \oplus-I a .6,96$;

MONTGOMERT, J. CARROLI (b'74)Kan.4,01; (1'01).

Murdock, F. L.-Kan.3,06; (1'06).

Stiers, A. L.TKan.4,97; ( ). (1'07) ; S

(1'01). 
MANKATO, 1,155, JEWELL

ALLE: WOROTHY W. (b'G) Mo.30,"00 (1'01)

pefers, Mex. M.-Mo $20,23:(1, n)$

Kaynolds, Elmer lo (b'6s)-Mo $3 . s^{\circ} 01$ : (1'01).

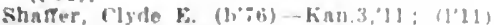

MAPLE CITY, 100, COWLEY

NHPSOS. His D. (b'is)t-Ia.10.04 (l'04).

MAPLEHILL, 277, WABAUNSEE

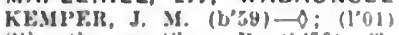

sllverthorne, Chas. K. (10\%0) 'l'omul1, sh (1.01)

MAPLETON, 230, BOURBON

GOOCH. WH. S. (b,i5) + M0.26, $00:(1,0)$ Katz, Plement J. (b) 63$)-0: 11011: G$

Rees, John 13. (b'+8)-1a.1,9l; (101).

MARION, 1,841 , MARION

COFYMAX, JOHX F., JU. (1,83)-MO.2. "08: (l'08)

EYE. CHO. E. (b'68)+-Mo.22,"95: (101):

COODSHELLER, GEO. J. (b'a6)-IH.4,04: AIBNE: GIDEON P. (b'56) + -1a.3, 83 : (1'01): $0 \mathrm{~b}$.

smilh, Reuben chrlstoplier (1):-3) - Mns 03 : (l'04): LR.

MARQUETTE, 7!5. MOPHERSON

Balrd, Olln W. ( $\left.W^{\prime} 51\right) \rightarrow$ : (I'Rl)

Blake, Frank H.-Mo.8,04: (1.04)

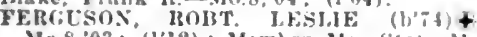
Ylo.8,03; (1'12); Member Yo. Silate Med Asen.

MARYSVILLE, 2.260, MARSHALL

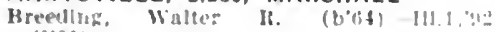
(1ose. J. liurt (b'-9)-Mo.22,08; (1'0s)

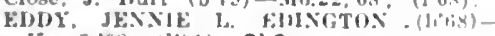
Kan. 3,98 ; $\left.11^{\circ} 01\right)$; 0 bG.

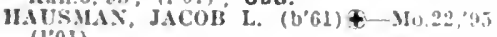
(l'0i)

II awklns, Robert (b'59)-111.2, 85 ; (1'01)

IlcAllster, Kobt. I.-Wo.t.?

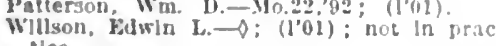

WHIson, F. I... Jr. (h'is)-Mo.20,"02; (1"nh)

MATFIELD GREEN, 225, CHASE

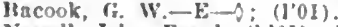

Newell, John Frank (b'bI) - Ia.3.'s9; (los)

MAYETTA, 337, JACKSON

Iusein, ()rrin Wm. Nash (b'83)-Mo.2., 08 (I'09).

H.ISS, CILAS. JAY (b'8L)+ kan.3.12

HOHSON, IHOIST,-MO.22,'89; (l'01)

MAYFIELD, 200, SUMMER

CAAKK, FARI, FILLI $\left(b^{\prime} 80\right)+-k a n .2$ $10 ;(1,10) ; P d$.

veel, Wrus. HI., sir. (b'st)- Tennl it

MCCRACKEN, 371, RUSH

Ifutten, Sherroul W. $\left.(1)^{\prime} 4: 3\right) \rightarrow:\left(I^{\prime} \cup 1\right.$

lireene, cieo. A. (bia) $\rightarrow$ : (liof)

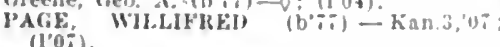

MCCUNE, 736, CRAWFORD

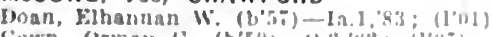

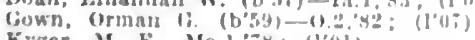

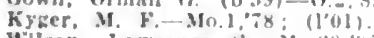

Wlison, Lawrence \$.-Min.20,96: (1'01)

MCOONALD, I00, RAWLINS

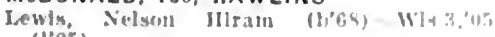
$(1 " 0)$ ).

MCFARLAND, 388. WABAUNSEE

Pharles, Jarrey Jhillp $(1, x)$ Kan.3, 13 (I.13).

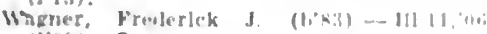
(1')!n): S.

MCLOUTH, 571, JEFFERSON

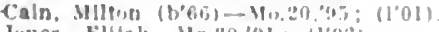

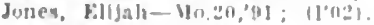

MCPHERSON, 3,346, MCPHERSON

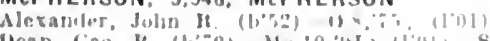

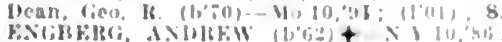
(I'0L): OALR.

Jall, jobn (rawford (b"ai) Vis y. cavtury. G.

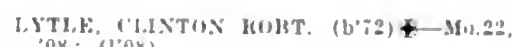
ox: (1,0s)

Matchette, fieds. H.-Mo.10,7s; (1'01)

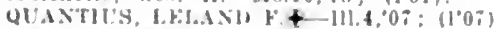

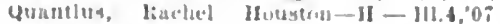

(1'0 : )

Salthouse, Ilenry I. - O. 3,8:8; (1001).

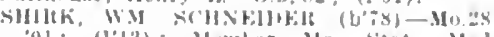
$01:$ (1'12): Momber Mo. Stato Med.

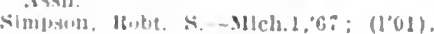

MEADE。 66 \$ MEADE

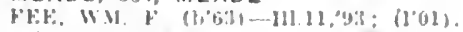

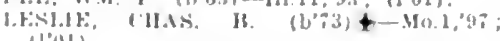
(1")1).

MEDICINE LODGE, I,229, BARBER

(U)FHAN, THUMAS $A+$ Kan.4, 02

(1) $\left.10^{\circ}\right)$.

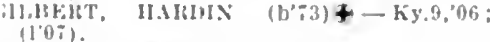

Koclell, sylrester (b'45) $15--1 a .4,81 ;\left(I^{\prime} 01\right)$.

MELVERN, 505, OSAGE

forwln, Lewls K: (b'50)-13.1.84: (1'01)

Farly, Judlah follzalueth Ball $(1,+2)-0: 1)$

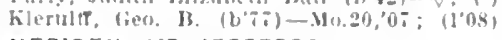

MERIDEN, 467, JEFFERSON

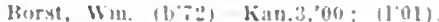

Taylor, Jobt. A. (U'SI)-Kan.3, (Ob; (1'0n).

MERRIAM, 127. JOHNSON

Marroun. Wim. Arthur.

(Nee Kansay ('lly, Mo.)

MICHIGAN VALLEY, I00, OSAGE

MeNalley, Michael (bir) - Mldh.2, (I, 01$)$.

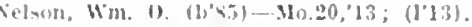

MILAN. 350, SUMNER

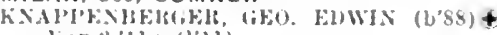
-hisn.2,11: (1'11)

MILDRED, 419, ALLEN

Korsyth, Chas, A. (b'iT)-Ja.10,'1)8: (1'00)

NEVITT MOLLIX $100 \%\left(b^{\circ}=0\right)+-M 0.06$, ST; (1'0y).

MILFORD, 200, GEARY

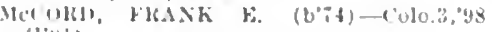
(1)i1)

MILTONVALE, 829, CLOUD

FAllt, W.M. I. (b'11)-Mo.20,ys: (1001)

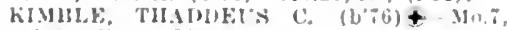

:48; $11^{\circ}(11) ; \mathbf{O b}$

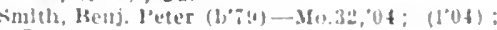
S.

MINERAL, 1.770, CHEROKEE

Cuss, Claude 13.-Kan.j,0:; (1'01).

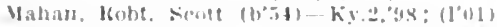

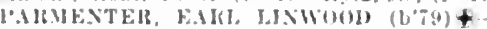
Iก. 20,07 ; (1'0i); G.

luksell, Chas. I. (b'-8)-Mo. 20,05; (105)

MINNEAPOLIS, 1,895, OTTAWA

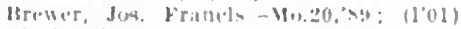

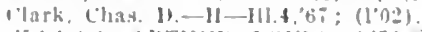

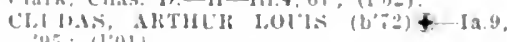
in: 11,01$)$

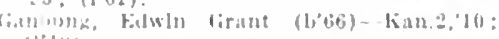

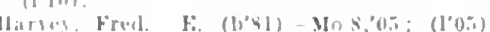

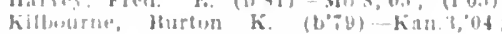
(I'o:3)

Miller, Juhn-lll 4, hti: (1'01).

Viers, Wifrel (b'y0)-Kan,3,12; (l'12),

MINNEOLA, 348, CLARK

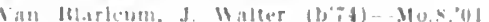
औli?

MOLINE, 808, ELK

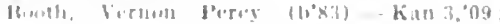

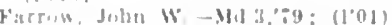

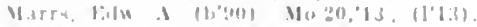

MONMOUTH, 179, CRAWFORD

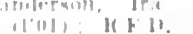

MONT IDA. IO0. ANDERSON

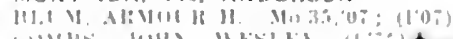

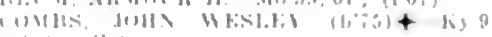

MOIIAN, 539, ALLEN

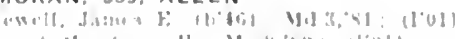

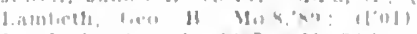

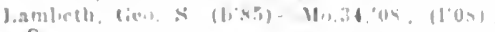
S.
MOREHEAD, I30, NEOSHO

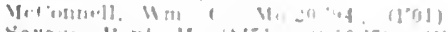

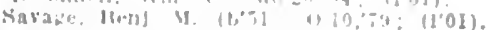

MORGANVILLE, 285, CLAY

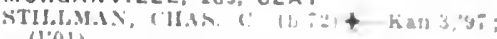
(1'01).

MORLAND, 237, GRAHAM

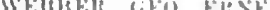

"11: : 1100\%

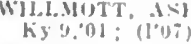

MORRILL, 398, BROWN

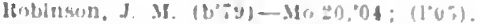

MORROWVILLE, 200, WASHINGTON

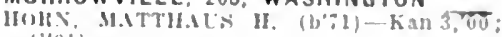
(1,0i).

MOUND CITY, 698, LINN

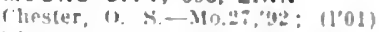

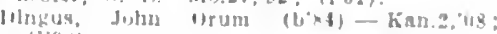
(I'() $x)$

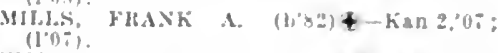

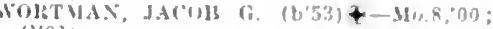
(l'0l).

MOUNDRIDGE, 626. MCPHERSON

Baer, D. ( (l'01)

Isaac, Fillzaturth L.- H-Mo.26,00) (1001)

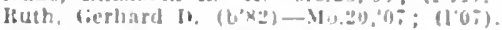

MOUND VALLEY, 956, LABETTE

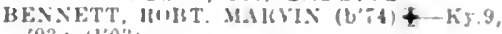

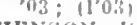

IIFAsios, JuHA II +- : $\left(1^{\circ} 01\right)$.

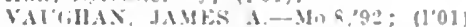

Foluer, Jolu (b"\%)-Ark.2.23; (1.13).

MT. HOPE, 5I9, SEDGWICK

Junsherger, Ifoward 1:. (b'i4)-Mo.20,01 ; (1'01).

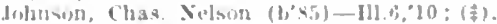

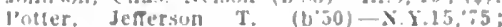

(1'13); ODA.

MULBERRY, 997, CRAWFORD

Nimple, Frel. K. $\left(b^{\prime} 65\right)-\$ 10.200^{\prime} 06^{\circ} ;\left(1^{\circ} 0 b^{\circ}\right)$.

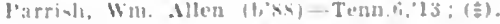

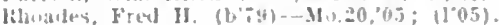

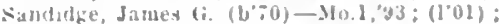
S.

MULLINVILLE, 289, KIOWA

Ihurney" lholu. Illekma:1 (U'ús)-\$o 20,01: $(1 \circ 04): G$.

MULVANE, 1,08\%, SUMNER

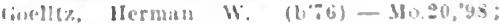
$(1,01)$.

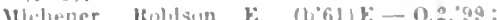
(1) 011 .

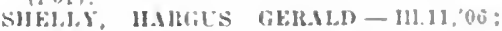

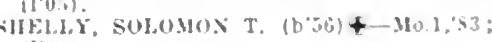
(l'O1).

MUNCIE, 40. WYANDOTTE

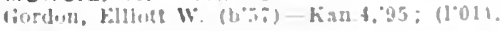

MUNDEN, 275. REPUBLIC

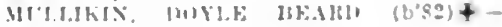

MURDOCK. 150, KINGMAN

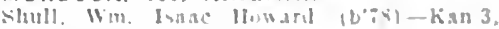

MUSCOTAH, 491, ATCHISON

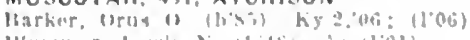

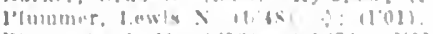

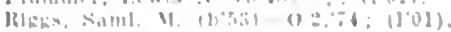

NARKA. 278, REPUULIC

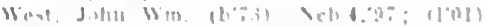

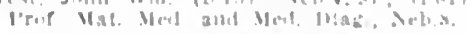

NASHVILLE, 200, KINIIMAN

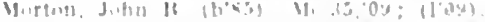

NATIONAL MILITARY HOME, 2,500, LEAVENWORTH

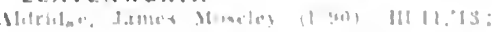

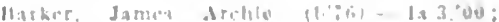

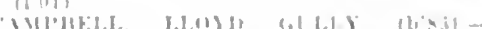

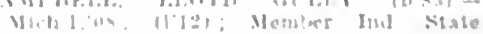
Med Dow

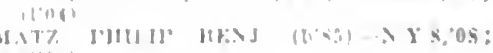

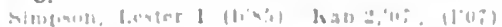


NATOMA, 407, OSBORNE

Irake, Fmory A. (b'82)-Kan.3,'10; (I'10) Isenberger, Forest Jacob (b'74) -Kan.3,'08; (1'09)

LINDLEY, JOSEPH WILLIAM (b'80)Mo.20,10; (1'10).

NAVARRE, 135, DICKINSON

Karnes. John-Mlo.10.87; (1'01)

LEIIMANN, EMIL, II. (b'63)-Mo.28,'01

(I’13) : Member Mo. State Med. Assi.

Maust, Calvin 11. (b'76) - M $0.29,{ }^{\prime} 05$; (1'06)

NEODESHA, 2.872, WILSON

ALLEN, FRANK TIIMIER (b'51)-III.6, $73 ;(1,01)$.

Blakeslee, Thos. (b'43)-Ill.1, '60; (I'01)

Flynu, E. A. Q; (l'07)

Tones, saml. (1,25) E-0.30,55 : (101)

MeGliRE, JOIIF W. (b'80)-Mo.20,05; (l'05).

MOORHEAD, JOHN LOUIS $\left(b^{\prime} 70\right) \oplus-K a n .3$, $96 ;\left(l^{\prime} 01\right)$

RANIOALI, CLINTON I $-111.6,00$; (1'01)

SIIARPE, ORIAN DAYTON (b'68)-Mo.8,

$95 ;(1,05)$.

WILLIMIS, AIEX. P. (b'74)-Mo.8, 01 (1'01).

NEOLA, 15, STAFFORD

Smith, Bartley (b'34) $\rightarrow$.

NEOSHO FALLS, 571, WOODSON

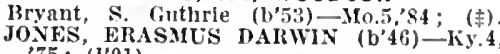

IIEURANCF, A. J.-0; (1'01).

McCool, Stanton A. (b'82) - Mo.22,'08 (1'08)

Morgan, John-Ia.1,67; (I'01).

Slavens, Iforace G. $\rightarrow$ : (l'0I).

NEOSHO RAPIDS, 256, LYON

Simpson. Geo. W. (b'58) $\longrightarrow$; (1'01).

NESS CITY, 7I2, NESS

Burns, James S. (b'38) E-S; (l'0I)

Egerton, Cecll Granville- $\rightarrow$ (I'01)

FLEWING, WM. S. (b' 73$) \oplus-$ Neb.6, 03 ; (1'03)

VENARD, JOHN N. (b'4s) $\rightarrow$; $\left(l^{\prime} 01\right)$

VENARD, T110S. S. $\left(b^{\prime}, 6\right)-11.11,02 ;\left(1{ }^{\prime} 02\right)$

NETAWAKA, 250, JACKSON

McCreery, Guy R.-Kan.4,02; (l'02)

MYERS, EDWIN T. (b'54)-0.6,"76; (1'01).

NEW ALBANY, 213, WILSON

MeCray, Moses E.-E-Mo.10,'80; (1'01).

NEW CAMBRIA, 200, SALINE

GRAHAM, HENRY GEREON (b'63)థ-111.6, 93 ; (1'08)

NEW LANCASTER (R.F.D., FONTANA), I23, MIAMI

Potts, Geo. W. (b'62)-Pa.2,'84; (1'01).

NEWTON, 7,862, HARVEY

ABBEY, FRANK L. (b'61)-Kan.4,'97: (1'01)' AXTELL, JOHN THOMAS (b'56) (1)-N.Y.10,

AX'TELL: LÚCENA C. (b'65)-Kan.4,'97; (1'01)

BENNETT, GE0. D. (b'55) - Pa.1,79; (1'01) BOUDREAU, CLARENCE E. (b' 6 '

Boyd, Gaston (b'44)-0.1,'74; (l'03).

GRAYBILL, JACOB W. (b'71) -Kan.4,'98 ; (1'01).

GROVE; . IOHN LEON (b'S0) - Ill.11,06;

(I'06); $\mathrm{S}$. HA IRY,
(1'04);

HERTZLER, RALPH HAROLD (b'86) Ill. 6,208 ; $(1,10)$.

MacELREE, GEo. A. (b'57)-Pa.1,'80;

(1'01); Op.*

MILLER, MAX (b'58)థ-Ia.3,'84; (l'01);
ROFF, OCRAN w. (b'66)-III.11,93; (I'01)

Royer, Simon W. (b'53)-Mo.26,94; (1'01)

SCOTT, IDA MOXON (b'64)-Kán.3,04 (I'04); OALR.ネ

SCOTT, JOHN RUTHERFORD $\left(\mathrm{b}^{\prime} 62\right) \oplus-$

Mo.i,'92; (1'01); OALR.*

Seaton, James H. (b'40)-Ky.1,'66; (1'02)

SMITH, LA URENCE T. (b'67) - -IIl.6,'98; (1'01).

SHOLT, $\triangle$ LFRED E. (b'72) - Ill.1,'97;

WHITE, MYRON L. (b'r2)@-Ill.18,01 ;

NEW ULYSSES, 100, GRANT

Buckmaster, Reuben E. (b'68)-Kan,3,'94; (1'01).
NICKERSON, 1,195, RENO

CORNELI, FRED. IBURTON (b'76)-Md.3 (02) (1'03).

IIull, June II. (b'72)-Kan.3,04; (1'04).

k00NS, FRANKLIN w (b'72)-Mo.8,98; (l'01).

osborme, Worthlngton H. (b'40)-Mo.8,76; (l'01).

NICODEMUS, 50, GRAHAM

Stewart, Donald L. (b'79) - Mass.6,'04 (1'06)'

NILES, I60, OTTAWA

dams, Saml. (b'7̃)—Kan.3,08; (l'09).

NORCATUR, 482, DECATUR

KNOX, WALTER LUGENE (b'84)థ-La.1, $09 ;$; ( I'09).

NORTON, 1,787, NORTON

COLF, CIIAS, WILLARD (b'77)๑-No.29, '03; (1'03); OALR.

IIaworth, AmI S. (b'63)-Mo.18,'94; (1'01)

FENNEY, CHAUNCEY S. (b'7T) 4 -Mich.7, 02 ; (1'02).

LATHROP, WM. CUMBACK $\left(\mathrm{b}^{\prime}, 6\right) \oplus-I 11.11$, 09 ; (1'05) : $\mathbf{S}$

Strickler, J. F. (b'39)-0; (l'01).

Tinney, Grace G. (b'7 6 - Mo.30, 02 ; (l'04) ; (inney,

TINNEY, RAY M. (b'75) - -Mo.8,'03; (l'04).

NORTONVILLE, 636, JEFFERSON

GROFF, WM. D. (b'65)థ-Kan.3,98; (I'01). Stevens, Delos M. (b'90)-Kan.3,'12; (I'12) WILSON, DAVID D. (b'61) 4-Ill.1, 90 ; (l'01); Or.

NORWAY, 46, REPUBLIC

SIIERRARD, JOHN C. (b'79)-Kan.4,05; (1'05).

NORWICH, 392, KINGMAN

FLOWERS, MARSHALL B. (b'83)-Ky.5 '07; (l'11); Member Ky. State Med. Assn. Koger, Robt. Gordon $\left(b^{\prime} 80\right)-K y .5,05$; (l'08).

OAKHILL, I00, CLAY

1)leter, Chas. A. (b'84)-Mo.20,'13; (I'13) Need, Omar U. (b'77)-Mo.20,'01; (1'01).

OAKLAND, 1,465, SHAWNEE

Ensign, Geo. H. (b'51)-0.11,79; (1'01)

Millard, Morris A. (b'4i) -N.Y.6,73; (1'04).

OAKLEY, 68I, LOGAN

MILLER, CHAS. M. (b'78)-Mo.8,'05; (l'05).

WINSLOWV, CHAS. W. (b'54) $4-M 0.22,{ }^{\prime} 86$; (l'01).

OBERLIN, I,I57, DECATUR

Miner, Selden ( $\left.b^{\prime} 35\right)-M i c h .1,67 ;\left(1^{\prime} 01\right)$.
Reeves, Eber (b'79)-Mo.29, 05 ; (1'05).

TILDEN, LESLIE CHAPMAN (b'66)-N.Y.5, 89: (1'03): Op.

OCHELTREE, 80, JOHNSON

Beaver, Harvey M. (b'60)-Ky.4,'88; (l'01). Molesworth, James (b'44)-1a.1,76; (1'01).

OKETO, 253, MARSHALL

Chambers, John Wm. (b'50)-Mlch.1,74; (1'01).

Noble, Floyd W.-Mo.20,'05; (1'05).

OLATHE, 3,272, JOHNSON

Bronson, Dellett E. (b'75) E-0.2,06 ; (1'06)

Ewing, Chas. w. (b'61)-Pa.2, 88 ; (1'01).

Francke, J. Marian-Mo.20,04; (1).

GREENE, FRANK F. (b'52)థ-N.Y.6,79;

Hatfleld, Franklin P. (b'61) E-0.2,'86; (l'01); OALR.

Hudson, Joln F. (b'45) H-0.13,'85; (1'01).

JONES, CHAS. - W. (b'75)థ-Ia.9,'96; (I'01) ; $\mathbf{S}$.

Lenion, Wm. E. H. (b'46)H-Mo.5,'74; (l'01).

Moberly, Robt. L. (b'68)-Mo.32,00; (1'01).

HOORE, ROBERT II. (b'67) $€$-IIo.2,92;

ORR, JESSIE THOMAS (b'64)-Ill.9,86; (l'01).

Wilson, Saml. B. S. (b'43) E-0.2,'81; (l'01).

Woodard, Jos. J. (b'58) E-Mo.20,'99; (l'01);

R.F.D. 2.

OLIVET, I50, OSAGE

DeMarr, Lewis H. (b'48) E-Ia.6,'93; (l'01).

OLMITZ, 200, BARTON

Atkin, Edward N.-Ire.6,'72; (1'01).

OLPE, 215, LYON

PATTON, CHESTER L. (b'73) -Mo.22,'04; (l'06); 0 b.

OLSBURG, 220, POTTAWATOMIE

Lauck, John Wilson-Kan.3,'98; (l'01).
ONAGA, 759, POTTAWATOMIE

KOENTZ, CHIRISTIAN 11. (b'77)-Mo.8, $01 ;(1,01)$.

(b'72)-Mo.8,97: (I'01)

ONEIDA, 2II, NEMAHA

SIIELTON, GEO. W. (b'49) - Mo.7,'83; (1'01).

OPOLIS, 250, CRAWFORD

MCKILVEY, WM. ALLEN (b'64)-Mo.7,'01 ; (l'07).

OSAGE CITY, 2,432, OSAGE

Brown, Albert C. (b'33)-Pa.1,70; (1'01).

CURI'II $X$, JOIIN J. ( (b'64)-Mo.20,07; (I'08)

Heller, Jos. Mosher (b'53)-Ill.1,77; (l'01); U.

MOORE, DAVID B. (b'41)-Mo.14,'80; (l'01).

Packer, Edwin B. (b'54) E-0.2,'84; (1'01). STEPIIENSON, WILFRFD $\mathrm{V}$. $\left(\mathrm{b}^{\prime} 79\right) \biguplus$ Mo.20,'05 ; (I'05).

WALKER, WM. JAMES $\left(b^{\prime}, 6\right)-M 0.20,07$; ( ) : Member Mo. State Med. Assn.

OSAWATOMIE; 4,046, MIAMI

BROOKING, SILAS L. (b'48) -Pa.2,'68; (1'02).

CAIRIIIIAEL, FRANCIS A. (b'71)-Ill.6, 04; (1'04); NP.

Hays, D. W.-Ky.2,'82 ; (l'01); not in prac-

HEPLER, CLARENCE R. (b'74) $-M 0.20$, 02; (l'05).

Jacobs, Llewellyn W, (b'44)-Pa.1,68; not in practice.

Munger, C. Herbert H. (b'81)-Mo.10,06 ; (I'12); Pd.

Pace, Eúlsha C. (b'61) E-Mo.10,'88; (1'02)

Redmond, Franklin H. (b'71)-Kan.3,05; (1'05).

ROBINSON, PLATO W. (b'76)-Mo.22,'97; (l'01).

SELLERS, LUCULLUS R. (b'48)-Ind.4, SPEER, NEWTON C. (b'76)(-Mo-8,'00; (l'01)

VAN NUYS, JOHN D. P-Pa.2,70; (l'01).

Walker, Andrew J.-Mo.18,'93; (l'04); not In practice.

OSBORNE, 1,566, OSBORNE

CHILCOTT, BENJ. F. (b'60) - Pa.2,'86 ; (1'01).

Dillon, Albert $\mathrm{C}$. $\left(\mathrm{b}^{\prime} 50\right) \rightarrow$; $\left(\mathrm{l}^{\prime} 01\right)$.

HENSHALL, EDGAR OWENS (b'58) IlI.1,85; (1'01); OpA.

MILLER, WALTER W. (b'70)๑-Mo.20,08 ; $\left(l^{\prime} 08\right)$.

NYE, HARRY WOLFE (b'73)@-Ia.1,'95, SCIIVAUP SAIIL.

(l'06).

Stevens, Calvln G.-N.Y.15,'84; (1'01); Op. *

OSKALOOSA, 85I, JEFFERSON

MCCREIGHT, MARLIN S. (b'70)Ð-Ill.1, 94 ; (1'01).

SIITH, ALBERT GODFREY $\oplus-M 0.20,86$; (1'02).

OSWEGO, 2,317, LABETTE

BARBE, PORTER W. (b'46)-0.6,'80; (1'01).

Draper, John B. (b'42)-Ill.1,68; ('́01).

HILL, EMMA LINTON (b'59)@-Kan.3,'95, $111.11,02$; $\left(1{ }^{\prime} 02\right) ; \mathbf{G}$.

LIGGETT, ELMER; E

ownsend, Pinkney' S. (b'88)-Kan.2,'10;

OTIS, I50, RUSH

Nothdurft, Danl. H. (b'77)-Mo.5, 02 ; (l'02).

OTTAWA, 7,650, FRANKLIN

Attwood, John Edw. (b'75)-Kan.4,'01 ; (1'01).

BALL, JAMIES (b'66) †-Mo.26,93; (1'0I). BLUNK, JAMES PARKEI (b'74) -Mo.22, '00; (1'02) ; OALR. *

Buckley, Chás. Eugene (b'76)-Ill.23,07 ;

Davls, Geo. W. (b'69)-Mo.20,96; (1'01)

Davis, Jephtha (b'34) H-0.7,'53; (l'01).

Davis, John B. (b'68)-0.1, 94 ; (1'01).

Davis, Josaphyne R. Eshom (b'81) -Kan.3,

05; (1'05).

Gilley, Henry W. (b'50) H-Mich.3,'72; (1'01).

Gossett, Edw. B. (b'65)-Mo. 20,94; (l'01).

Guimn, J. C. (b'68)-II0.22,97; (1'iI).

HAGGART, ALEXANDEI $\left(b^{\prime} 76\right)-K a n .3$ 98 ; (1'01) ; S. 
Hardy, Cbas. Webster (b'32)-M0.1,81; (1'01). wullon Bens. (b'il) - M0.5:01. Iaworth

Terr, Francls c. $\left.\left(\mathrm{b}^{*} 52\right)-\mathrm{Pa} .2 \cdot 79 ;(1)^{\prime} 01\right)$.

Hugbes, Jos. C. (b'13)-0.3,69: (1'01)

JACORUS, willis i. (b"68)-Mo."o, "00 (1.01)

Kennedy, Harrey Leander (b'6y)-Kan.3. 03; (1.04).

Lawrence, vilas F. (b'55)-Mlch 1, 33 : (1'01).

Lozan, John Pressly (b'42)-0.1,67: (1'01)

Mahaty, Geo. C. (b'67)-Mo.:0,96; ( ( $\left.^{\prime} 01\right)$.

Markbam. Homer E. (b'6i)-I11.1,92: (1'01)

MeWbarf, John Morton (b't2)-XY.6,6s (1'01).

Pennington, Wm. R. (b'5i)-11l.11,98; (l'0:)

\section{OVERBROOK, 571, OSAGE}

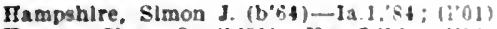

Hoorer, Chas, O. (b'81)-Kan. :.20: (1'10)

Meclintoek. Geo. (b'72)-Kan.4,99; (1'01)

Valentlue. Herbert Spencer $\left(\mathrm{b}^{\prime} 90\right)-\mathrm{Kan} 3$. "13: (1'13).

OVERLAND PARK, 200, JOHNSON

Stough. J. Mowensteln (b'3S)-Kan.t,98: (1'01).

CHLS, LYMAN 1.4-III.1,84; (I.01); b'o? Psych., Kan.2; (EI3).

OXFORD, 624, SUMNER

COLLINS, MELVIX (b'60) $\$$ - III.1, $: 1$ $\left(1{ }^{\prime} 01\right)$.

Kelly, Geo F. (b'6i)-Mo.32,01: (1'02).

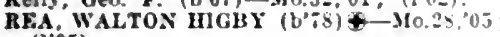
(1'05).

Russell, Chas. I. (b'43)-MIch.?66; (安),

OZAWKIE, 283, JEFFERSON

Puderbaugh, Aaron-Mo.8, 82: ( 1 0I)

Puderbaugh, Ira (b'-8)-Mo.8,01; (l'01)

Shaetrer, Frank-Kan.2,0 : (1'07).

PALCO, 279, ROOKS

Teal, Raymond EdwIn (o'st)-Kan.2,10; (l'10).

PAOLA, 3.207. MIAMI

Fowler. Jos. (b'82)-Mo.20,07; (1'07).

MALDEMAX, JACOB IIENKY' (b'62)-Pa.2. 83: (1'01).

Hooper, cllnord I. (b'82)-Kan. $:^{\prime} 07 ;\left(l^{\prime} 07\right)$

KOOGI.KK, JOH. FLOYD (b'il) \&-Pa.11 10: (1101).

Petlit, Percy A.-Mo.35,08: (It).

Potter, Jos. L. (b'54)-I11.1, 81 ; (1'01)

VAX PELT, CLIFFORD I.EVI (b's5)Mo.20.10: $\left(l^{\prime} 10\right)$.

VAX PELT, LEVI A. (b'64)-Mo.32,00: (1'01).

WALTHALL, JOIN DANL. (b'59)-Milh. 83; (1'01).

PARALlel (R.F.D., BARNes), 20, WASH. INGTON

Ewing. Henry Z. (b'70)-Mo.8,0t: (1'0t).

PARKER, 398, LINN

Turner. Andrew Jackson (b'T4)-Mo.8,02: (1.02): $\mathrm{S}$.

Vall, Geo. Telson (b'40)-Mlch.1, 69 ; (l'01).

Warner. Terry W. (b'63)-Mo.18,98, Mo.20 "95: (1’01).

\section{PARSONS, 12,463, LABETTE}

Allison. Thos. Is. (bos)- $\left.(1)^{\circ} 01\right): 151 \mathrm{~s}$ Broadway: oflce, 1731 Main St: 10.12 2-5, $7-8: u$.

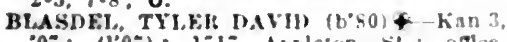

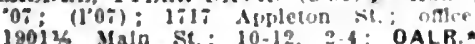

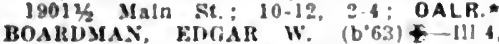
84: (1.01); lill Relruont s! : once. IRL K MaIn St: $2-4$.

BuAr cins

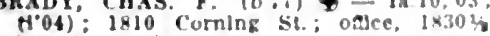
Broadway: $8-11,2-5$

Brady. Win. Klley (b'st)-('ollo.2,12; (1'12) 151 Waslington Are.; office, $1524 / 2$ Irosdwas: 9-11, 2-5.

CHIISTMAX. PAI'L, $\left(\mathrm{b}^{\circ} \mathrm{K} 0\right)+-111.199^{\circ} 03$ (1'04): 1613 Morian lve; onte iz:30

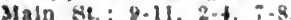

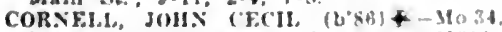
"09: (1'11): 2504 Maln st: ontec, $2130 \mathrm{x}$ Main st: $9.10,3.7$

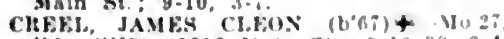
99: (1.03): 1812 Jaln st: $9.10: 30 .=-4$

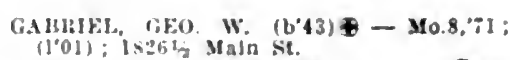

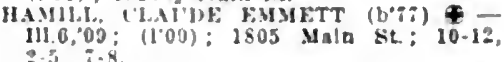
narrey. Ciusparus french $\left(b^{\prime}+7\right)-111.1,76:$

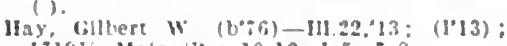
17194 Jain st: $10.12,1.5, i-8$

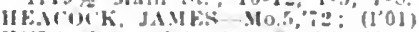

H1:13.1111. "16TOS st-111.0,01: (1'05): Slate llosulfal; NP

KAKLE: l.ok!) HYros (b'52)-Mo 20 , (4): (1.01): 17:0j Belmont Nie.; odtce, iklo2 Maln st. $8-10,2-5,7-9$.

I.ANIUE, CHO AIHERT (U.81)-I11.1,04

(1.12): Ma!n S!.; 10-12, 4 -4: OALR."

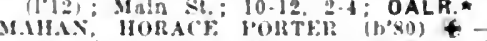
Kan.2,06; (l"06): Parsons State IIospltal. M.AKKIAM, HOW ofip $(l, 0 j) ; 1826 ! 2$ Maln St: 9-12, 2.4:

MISALIIINE, JOHX GLIRLEY (b's4)Wet1,11; (1'12): 16th and Washlngton sts.; oflce, sicele I3!dg : 10.12, 2-4; LO.

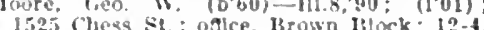
Iorton, Edward Clarence (b+12)-Colot. '9s; ( ): 2311 Maln st.

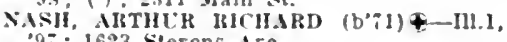
$97 ; 1623$ Slevens Are.

Osturn, Wm. Fowler $\left(b^{\circ} 66\right)-$ Kan.4.02: (100) : 1423 Rroadway; ofice, 1713y Maln St. : 9-12, 2-5, 7-8.

PERRY, MLDIETON LEE (b'68) Tenn.6, 9: : (1'04): State Hosnltal: (El:). RoTTER, II.1L' (b'81)+-Mo.34,0s: $(1 \cdot 10) ; 1: 122 \%$ Maln St.: S.*

SHITII, AIIREKT (b'70) $\$$ - N1.10,95; (1'01): 1610 Maln St.; oflce, 1512 Main St : $2-4 ; S$.

smlth. Robt. F. (col.) (b'85)-Tenn.7'13: (1'13).

Tluder, Jnel T. (b'45)-Ind.9,83: (1'01): 1526 Main St.; offee, 1903\% Maln St. : $30-12,2-5$

PARTRIDGE, 246, RENO

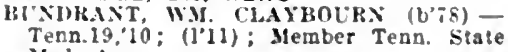
Med. Assn.

PAWNEE ROCK, 458, BARTON

lasrence, Edw. $k$. (b's1)-Yeb.4,03; (1'02).

MUIl, (ito. E. (b'ti)-Ky.2,94; (1'03)

PAXICO, 238. WABAUNSEE

MEN.IRD, CHAS. E. (b'66) \&-Kan.3,98: (l.0).

Rlchardson, Wm. F. D; (1'01).

PEABODY, 1,416, MARION

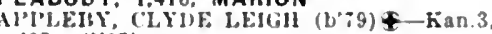
$0 \%$ : $\left(10^{\circ}\right)^{\circ}$.

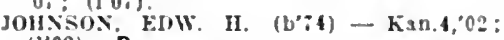
(1'02):D.

MAYK, HARVEY M. (b',4)-Mo.32,05; (I'05); OALR.

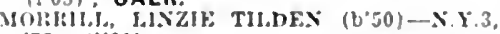

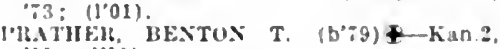

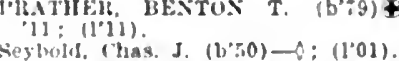

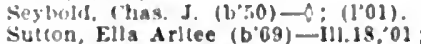

PECK. 130, SEDGWICK

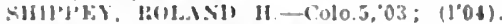

PENALOSA, 200, KINGMAN

Adkills, Erulyn L. (b'63)-la. 10,08; (1'03),

PERRY, \$00, JEFFERSON

Jurns, l'alrick-CTenn.1,6i; (1'01)

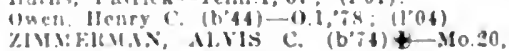

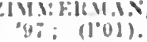

PERTH, 200, SUMNER

VING.NT, IIF, (l.0l)

PERU. 575. CHAUTAUQUA

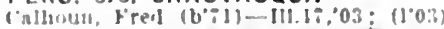

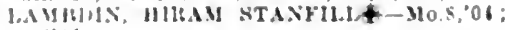

PHILLIPSBURG, 1.302, PHILLIPS

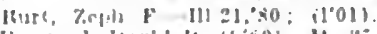

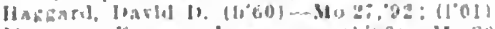

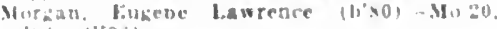

(Thi)

Seluan Hom 1.- Mo 20,02: $\left(1^{\prime} 01\right)$

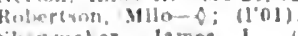

(1'0\%).
PIEDMONT, 200, GREENWOOD

Yandell, Wm. Ileary (b":0)-Ky,4,01:

PIPER, 75, WYANDOTTE

Isley, Jos. I'alestlue (titi) - Mo.s?,0s: (l'oi).

PIQUA, 200, WOODSON

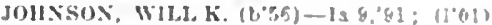

PITTSBURG, 14.753, CRAWFORD

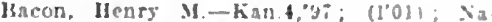
tlonal Hank Hids.

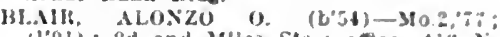
11"01): 20 and Jilles Sts.; odce, 11: $\mathrm{s}$ liroaduay.

IUILK, IIERMAN IIOLMES (b'6i) III 11.93 ; $(101) ;$ tos $x$. Walnut

Irafe, kilfeleda s. (6.70) II - Mo.j,00: (1'01): $201 \mathrm{~W}$. Fuclld Are.

(AFFF), IICGII B. $(0,09)+-$ La.1.01: (I'v1): 5lv W. th st. aflec, Globe Holg: :9-12, 2-5: (111); OALR.*

Cantleld, curtesta" T. (b'33) H - 0.:\%:

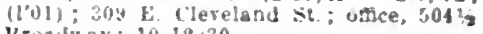
13ros!kay ; 10-12:30.

Coltman, syliester 1. (b'.5is)-Mo.21,85: (1'01): 3114 X. Ihroadway.

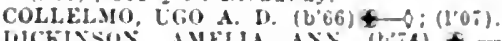

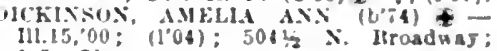
$1=5 ; 0$.

Irodds, Andrew J.--0.1,85; (1'01); 50615 X. Brosdwar.

Dudley, Chas. A. (b'50)-310.20,06; (1'06) : $\$ 02$ IV. Euclla Are.; oflce, Commerce Blds. : 2-1.

isher, Chas. A. (b'56)-Ind.5, 81 ; $\left.11^{\circ} 01\right)$ :

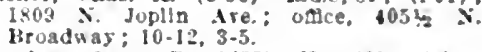

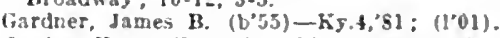
Gcelter, llarry T. (col) (b'a)-Tenn., 04 ; (1+); 103 W, 4th St: 8-10, 11-18, 1-3, GIIBS, ROHT. B. (b*is)-Ky.5,00; (1.01)

605 W. Euclld st.; oflce, Klrkwood Bldz: $9.10,2.5$.

Graves, Astury c. (b'36) - Tenn.1,82: (1.01) ; 509 W. Euclld Are. ; otce, 606 N. Hroadway.

GMIVES, WILIULR H. (b's3) \&-Mo.20, 0:: $\left(10^{\prime}\right)$; W. Euclld Are. : otice, Commerce IMde: 10-12, I-5: OALR.

HARIEI, FIANCEA $A\left(b^{\prime} B 9\right) \neq-K a n .3$. 0t: (1'04); Kirkwool Blds.: oalce, Com. merce HIdF: $9-12,1-5: G$.

IIartman, Wm. Vernon (b'82)-I.1.1.' (1'12): 401 iv. th st: oatie, 412y : Broadway: 1.5.

Ilowe, Phtlip 1. (b\%s)-K5.9.04: (1"04): 205 E. Adams s?. : odlce, 301 is $\$$. Broad: way.

Hunter, Chas (b53)-Mo.98,96; (1'01): 123 E. 3d st. : OD.

Johnson, Monroe pilltoll (b'33)-0.9,80:

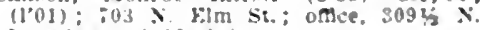
liruadras ; $8.12 .2-8$

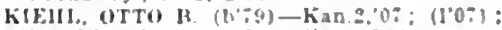

511 W. pith si ; onlce, Glote Hid,

Kitler, Alphonsio T.Mo.33,00; (1'01): $3132=$ Ilroal $x$

Moberw. Arthur $(6 \% 01-M 027.9:$ : (1001): $30 \%$ W. Fiscllil Ave : ofice, th and lirondway: $9-10,1-3, i-9$

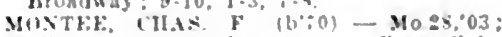
(1'10): 1106 s. Hnadway: once, cilote

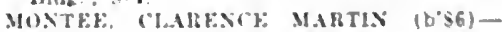
Mo.ay,jo: 11,101; (ilobe HId

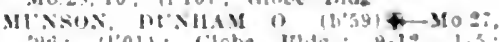

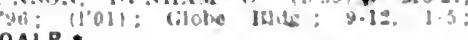
oALR.

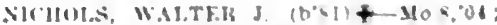
Iloti: ith and lelne stes

Oxtwrne. IIm

0lWtivill

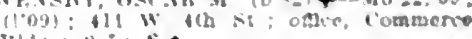

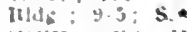

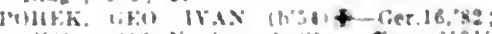

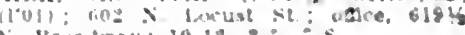

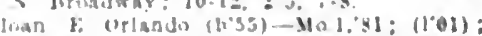
ino if al it: ofle. Commerce Huds. $10.18=4: 06$. 
SMITH, CLAUDE A.†-IIo.28,99; (l'01): $207 \mathrm{~W}$. Fuclld Are, oltce, Natlonal Bauk I3Idg. ; 1-5; S.

suyler, Byron S. $\left(b^{\prime} 50\right)-1 a .4,22:$ ( ) .

STILLE, IIALUY IAWIS (b, 72$)+-M 0.24$ 96: (1'04); $60 \mathrm{I} \mathrm{W.} \mathrm{3d} \mathrm{st.;} \mathrm{uftlce,} 50216$ $\therefore$ is rualus $1-5$

uphegrove. Wm. II. (b'九) - Mo.35,09: (1.09); $5211, \mathrm{~N}$. Broadway ; $9-5$

Whllams, fieo, w; (b'50)-ky.2,78; (l'01) $311 \mathrm{~N}$. Walnut st.; oftce, 412 N. Broad way.

WIJIIAMS, WM.(1'61)—-Mo.1, s6: (1'01) (ios W. Enclil Are.; ollhee, $4121 / 2 x$ Broadway: $9-12,2-5: G$

PLAINS, 350, MEADE

Newton, W. J. (1, 633$)$ E $-0.16,80 ;(1901)$

NUKRLSON, (1E0. A. $(1,64)+-111.11,02$; (I'0:T).

PLAINVILLE, 1.090, ROOKS

Barber, ('has. Ldward (b'78) - Mo.8, 01 ; (l'01); Op.

Caludal, Jos. U. (b'60)-Ont.4,'85; (1'01).

Isenberg, Higar E.-Mo.28,99; (l'01).

Iecormilck, Thos. Edward (b'78)-Mo.34 06 ; (1'06).

Mlller. Mohler Jacob (b'7s) - Kan.2,06; (l'06).

PLEASANTON, 1,373 , LINN

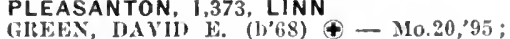
(1'01).

Lee, Cornellus $I^{\prime} \rightarrow$; (l'0I)

XAYLOR, JESSF, A. (b'81)-Mo.20,06 (1'06).

PAICE, GEO. A. (b'66)-Mo.20,07; (1'07)

Plumbl, Henry (b'36)-Conn.1,'61; (l'01): not in pracilee.

REES, WM. 1I. (b'43)-111.1,'83; (l'01).

PLEVNA, 300. RENO

llorton, Jos. Davls (b'66)-Ky.5,'93; (l'01).

POMONA, 523, FRANKLIN

Johnson, Ilenry 3. (b'il)-11l.1,02; (l'02).

Siarkweather, John (b'69) - Mo.24, 00 (l'04).

Vigor, James F. (b’49)-0.14;79; (1'01).

PORTIS, 400, OSBORNE

B1'RTCH, CLAUDE E. (b'74)Ð-Mo.20,04; (l'04).

POTTER, I50, ATCHISON Myers, Saml. Montieth (b'75)-Mo.29,'96 ;
(l'01).

Kedmond, Geo. W. (b'48)-O; (l'01).

POTWIN. 249, BUTLER

S'TAIILMAN, DAVII) C-Mo.8,00; (l'01)

PRAIRIE VIEW, 191, PHILLIPS

ISURINK, JOHN (b'66)-110.28,99; (1'01)

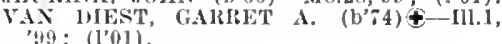

PRATT, 3,302, PRATT

ATKINS, IIERBRLT (b'81) - Mo.20,'10; (1'10)

Douthart, xames I. (b'43) $\rightarrow$; (l'01).

Fleteher, Michael A. - Ark, 1,12;

R.F.1). 2.

GASTON, P.LL K. $\left(b^{\prime} / 2\right) \oplus-$ Ill.19,03; (l'07).

Lottridge, Ixdla J. (b'-1) $\rightarrow$; $\left(l^{\prime} 01\right)$.

Lottridge, Melvin 11. (b'64)-Mo.8,93; ottridse,

Patterson, Benj. J. (b'73) E - Mo.33, 03; $(1 \dagger)$.

PEAK, FIKANK (b'66)†-Mo.20,'98; (l'01).

Youmans. James-11l.8,78; (1'01).

WALKER, IIOMER MOSS (b'81)£-Mo.8, ,05; (1.05).

PRESCOTT. 255, LINN

O'NEIL, FR.ANK E. (b'69)-Mo.20,95; (1’01).

PRESTON, 278, PRATT

MELTON゙, D. WALTER (b'73)-Mo.22,'06; $\left(l^{\prime} 06\right)$.

PRETTY PRAIRIE, 327, RENO

Buhler, David B.-.110.8,'04; (1'04).

TAYLOR, EDGAR C. (b'\%) 4-iIo.20,09; (l'09); Pd.

PRINCETON, 250, FRANKLIN

Thornbury, James R. (b'43) - Ia.1, 78 ; (1'01).

Woods, Saml. D. E. $\left(b^{\prime}, \tau\right)-$ Mo.31,02; (1'02); G.

PROTECTION, 390, COMANCHE

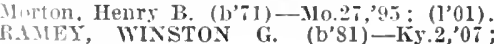
(1'0s)
QUENEMO, 556, OSAGE

liutler, Filmer-0.1,89: (1'01)

l'oston, Wim. Osee (1'80)-Ind.20,08; (1'09).

QUINCY, 200, GREENWOOD

l'l'EY, JOHN H. (b'T9) - KY.4,01; (l'01).

QUINTER, 450, GOVE

lilienblse, Josluma M. (b'6i) - Mo.20,00: (I'04).

STONEI (1'06)

RAMONA, 265, MARION

SAYLOIR, JOIIN HATVEY $\left(\mathrm{b}^{\prime} 66\right) \oplus-M o .8$, 0.4; (l'0.5).

RANDALL, 325, JEWELL RANIIS, JOS. B. (b'76)
(I'05).

RANDOLPH, 455, RILEY

Hroady, Geo. A. (b'64)-Ind.5,91; (1'09). Filgerlon, Owen E. (b'59)-Mo.t,'84; (1'01). RANSOM, 204, NESS

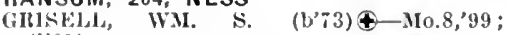
(l'01).

RANTOUL, 200, FRANKLIN

Birney, Wm. Leonard-Mo.1,79; (1'01)

l'ettel, Jos. D. (b'75)-Mo.7, 00 ; (l'01).

RAYMOND, 150, RICE

FISHER, LEWIS S. (b'83) - Kan.2,07; $\left(l^{\prime} 0 \tau\right)$.

READING, 289, LYON

BROWN, THOS. O. (b'69)†-Mo.20,97; (l'01).

Flsilili, DAVIn S-Md.3,'84; (l'01)

SETTIE, JAMES ALBEIT' (b'69) $\uparrow-\mathrm{M} 0.20$, '93: (1'06); OALR.

REAMSVILLE, 60, SMITH

ICCAMMON, JAMES A. (b'47)థ-Ont.5,'79; (1'01).

REDFIELD, 232, BOURBON

I.EASE, IRICHARD WV.-la.1,78; (l'01).

Ulery, Menry Clayton (b'75)-Mo.20,11; (l'11).

REPUBLIC, 450, REPUBLIC

Foristall, Danl. E. (b'53) H-Ill.10,'78; (l'01) ; OpA.

FITZ1'ATIICK, CHAS. M. - Mo.20,03; (l'04).

RESERVE, 300, BROWN

Gillisple, James Chas. (b'86)-Ill,11,'10 ; (1'12).

RICHFIELD, 53, MORTON

Collman, Allen Thomas (b'76)-Mo.32,'05; (1'05).

Showers, James B. (b'53) -0; (专)

RICHLAND, 250, SHAWNEE

CAliSON, ALBERT W. (b'50)£-0.1,75;

Smith, Clarence M. (b'53)-0.2,85; (l'01) Tibbitts, Weden M. (b'66)-0; (l'01).

RICHMOND, 400, FRANIKLIN

LYTLE, JAMES IEFED (b'50)థ-IIl.1,84; (1.03)

Smith, Delmar H. (b'71)-Mo.8,'96; (l'01).

RILEY, 343, RILEY

Goodwin, Fredk. P. (b'76) H-0.26, 05 ; (1'05).

ITSINGLR, GEO. H. (b'70) $\oplus-M 0.20,{ }^{\prime} 00$; (1'01).

ROBINSON, 492, BROWN

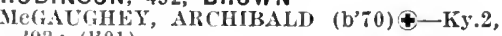
'93; (1'01).

YAN YOORIIS, VAN C. (b'66)-Mo.29,'98; (1'01).

ROSEDALE, 5,960, WYANDOTTE

B.IINELT, BLNJ. II. (b'54)屯-Pa.2,'82; (1'01)

BOUGHTON, THOS. HARRIS (b'81)€l'1, Bof. Bact. and Path., Kan.2; (F4).

Fowler, Lilian Edith (b's1) - Ill.1,13; (1'13) ; T'niversity of Kansas.

If ammond, Ioretta M. (b'42) - Pa.7, 71 (䒠)

Jackson, Blyford B. (col.) (b'78)-Tenn. $\bar{t}$, $09 ;\left(l^{\prime} 09\right)$.

LONGEXECKER, OSCAR M. (b'66)థMo.8,'99; (1'01) ; OpA.

MILNE, LINDSAY STEPIEN (b'S3)థScot.3,04; (l'12); University of Kansas:

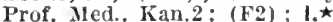

Myerly, Clark L. (b'86)-Mo.20,'13; (l'13) University of Kansas.
O'CONNELA, I'AUL JAMES (b'87)-Mo.20, $10 ;(1 ' 10)$

SANDEIRS, CIARFNCE ERMER (b'85)kan.2,07: (l'07)

Smlth, Delbert O. (b'\%)-Kan.2,13; (1'13); Path.

Staggs, Wm. F, -Kan.4,02; (l'02)

Zellinger, Finlle H. (1)'80)-Mo.35,'08; ().

ROSE HILL, 90, BUTLER

Barkalow, James A.-In.1,'81; (1'01).

ROSSVILLE, 672, SHAWNEE

Illler, Henry Ilackburn (b'81)-Pa.1,08; (l'09).

Mlller, IIenry H. (b'51)-Pa.1,72; (l'01).

I'ratt, II. Fuller (b'61)-0.1,84; (1'01).

ROXBURY, 75, MCPHERSON

Cornellus, Lanea (b'85)-Mo.35,'10; (l'13).

ROZEL, 160, PAWNEE Tapscott, John Halley (b'82)-Mo.20,'09;
$\left(1^{\prime} 09\right)$.

RUSHCENTER，250，RUSH

Colglazier, lilward Ellsworth (b'66)-Mo.33, 02: (l'04).

RUSSELL, 1,692, RUSSELL

CHAMM, CARL J. (b'75)-Ky.2,'97; (l'09).

HAWES, FREDK. SEARS - Colo.3,02;

(l'11).

Koerber, Gustav Adolf R. (b; 74$)-N e b .5$, ' 97 ; (1'04).

MAISSII, HOWARD (b'71) - Mo.27,01; (l'09); OALR.

Mckeen, Dean W. (b'53)-Ia.1,78, Mo.7,

STEWAR

\section{SABETHA, 1,768, NEMAHA}

Carlyle, Wm. L, (b'66) - Ill.1,'83; (1'04); Anes.

HIWIN, FRANK II. (b'60)-Ky.5, 82 ;

AYNES, WILIARD A. (b'52) \$-N.Y.5, 81 ; $\left(1^{\prime} 01\right)$

Ilibbard, Sainl. M-Mo.22,07; (1'07).

MATIIEWS, JOHN R. (b'72)థ-Kan.3,'97; (l'01); OALR.ћ

MURDOCK, SAML.-Ia.1,76; (l'01); S. MUIRDOCK, SAML, JR. (b'72) \&-Mo.8,'93; (l'01).

ROSS, ALBEIiT S. (b'61) - Neb.4,'96; (l'01).

RUCKER, CIFNENS (b'83) - Mo.22,05; (I'05); OALR. $\star$

Slosson, Emily Brooke (b'51) - Pa.7,'75; (l'09).

SAFFORDVILLE, 250, CHASE

HOOVER, CLARE F. (b'74)\&-Kan.3,'99 (l'01).

SALINA, 9,688, SALINE

Allerson, Miles H. (b'41)-Ky.2,'6 $\vec{\imath}$; (l'01) ; not in practice.

ANDERSON, ANDREW G. (b'70)-Mo.7,'98 :

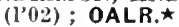

Armstrong, Carroll D. (b'81)-I1l.10,03; (l'03).

BRITTAIN, OMAN R. (b'78)-Neb.6,03; (l'04) ; R.

Brown, Manuel Jay (b'58)-Ill.4,'82; (l’01) : OALR.*

Cockey, Melcher Gist (b'59) - Md.1,79; (l'01) CHAWFORD, JAMES R. (b'58)-Pa.1,'86;

HARVEY, JOHN KING (b'81)-Kan.2,08; (I'08).

HARVEY

Jenney, Chas. Maxwell (b'79) H-Ill.10,04 ; (1'04) : Pd.

Jenney, James W. $-\mathbf{H}-0.7,6 s ;\left(l^{\prime} 01\right)$.

LUTZ, EDGAR J. (b'61)-Md.6,'86; (l'01).

Maylleld, Amanuel B.-Mo.7,'86; (1'01).

Miller, Jos. E.-Pa.2, 86 ; (l'01).

MOSES, HOWARD N. (b'73)థ-Ill.1,'99; (l'01)

MOWERY, WILLIAN EUGENE (b'84) Mo.20,09; (1'09); S.

NEPTCXE, JOHN' W. (b'68) - Mo.8,'94; (l'01); D.

FORDSTROM, LOLIS O. (b'76)థ-Kan.4, 02 ; (l'02) ; $\mathrm{S}$.

1'adfield, Earl Geo. (b's7)-Kan.2,10; (l'10)

RIDDELL, JOHN D. (b'68) $\oplus-$ Mo.8,'96; (l'01); $\mathrm{S}$. 
SEITZ, GEO - \$1 . 20.00: (1.01),

Sbaffer, Fratklln Win. (b:0) $\rightarrow$ : (ln

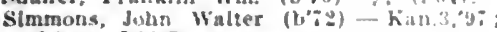
(1'01): OALR.

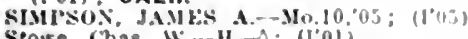

stowe, (has. II. $-\mathrm{H} \rightarrow$ : (I'01).

Switzer, Egerton R. (b"37)-que.l, bi (l'0l)

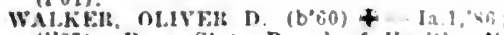
(l'0.5): Pres. Slate Board uf IJealth: N.

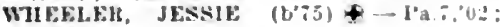
$\left(l^{\prime} 06\right)$.

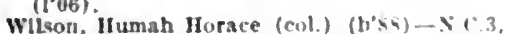
พ180: (1'11)

'10: (1'11). JUSATIA HAREY (b'73) $\rightarrow$ - I11.1,96: (1'01).

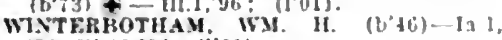
i2, III.11, 81: (1'01).

SAVONBURG, 257. ALLEN

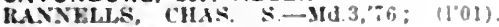

SAWYER. 250, PRATT

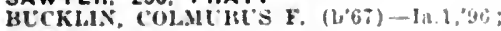
(1'01)

SAXMAN, 60, RICE

Anderson, Fred Meado $\left(b^{*} 80\right)-M o .36,0 t$ (1.0\%).

SCAMMON, 2.233. CHEROKEE

MAIRKHA. ITOBT. M. (b62) $\&-M 020$, 92: (l'01).

Rereli, Arthur T. (b'is)-Mo.8.00; (l'0I).

\section{SCANDIA, 579. REPUBLIC}

HALGMAS. CIIAS. V. $\left(b^{\circ}: 6\right)+-110, "(1)$

Mo.8,04: $(1,04)$.

IIVKY, JUHN H. (b;8)-II0.20,03; $\left(\mathrm{I}^{\prime} 04\right.$

SCOTT CITY, 918, SCOTT

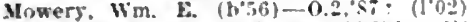

Myers. Saml. S. $(1,72)-M o .20,95 ;\left(I^{\prime}\right) !$

SCOTTSVILLE, 248, MITCHELL

BLAIIES, SAlIL. T. (b"6) 16 - $10.20,03$; (1'04).

SCRANTON, 770, OSAGE

Meddlar, (Iyde A.-111.6,"05: (音).

Stewart, llavld Lloyd (b'83)-111.2., 0 , (1'10).

SEDAN, 1.211, CHAUTAUQUA

courwright, Wm. Thos. (b'ti) - 0.1, tit $(101)$.

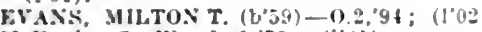

Illukh, C. W.-Ia.1,"75; (1'01).

McNALGHTE. WM. L. (bol)-0: (l'0l)

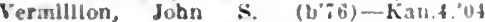
(1'04).

\section{SEDGWICK, 626. HARVEY}

Huley, belmond $G$. (b'i)-Ky.5, 03 ; (1'0:? IIymer. Edw. Staton (b"83)-111.6.0.19; (1'vi) Kanarel, badwin J. (b'by) - N.Y.l U.'. (1.01).

Smlth. Win. Nlwert (b"il)-0.1,

SELDEN, 297. SHERIDAN

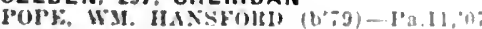
(1'11).

SENECA, 1.806, NEMAHA

Hrewer, Albers Mathas $(1,70)-h y$, ,

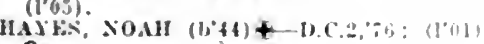
Op.

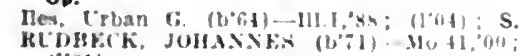
(1'01).

Sayder, Alrin (11'ti)-110.1:33: (1'm1\}.

Snjler, Henry lialen $(1,86)$ - III 1,03 (10.3).

SEVERANCE, 383, DONIPHAN

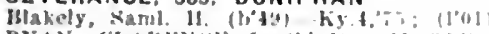

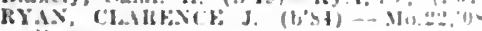
(l'0s).

\section{SEVERY, 608, GREENWOOD}

Hutcher. Howht the

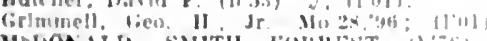

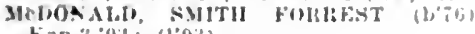

Kar.3,"0:1: (1'0.h).

SEWARD, 102, STAFFORD

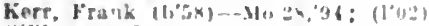

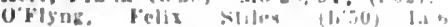
(1'1)1).

SHARON, 350, BARBER

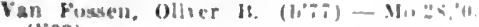
(1'03).

SHARON SPRINGS, \$0, WALLACE

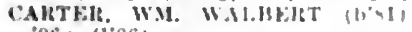

oti: (1'06i).

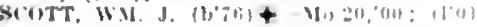

SHAWNEE, 450, JOHNSON

IIIHABI, EIW "y4: $(100) ; \mathrm{S}$

SHERWIN JUNCTION, 100. CHEROKEE

Foung, Drios I. (h'53)-Kian.3.98: |l'il]

SILVEROALE, 100, COWLEY

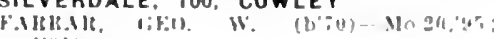
11 'U)!

SILVER LAKE, 260, SHAWNEE

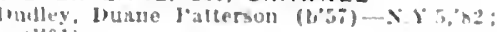
$1801)$.

SIMPSON, 2II, MITCHELL

Ulater, Jus, $1 b^{\prime}$ s(l)-Xeb.i, 0 i

SMITH CENTER, 1.292, SMITH

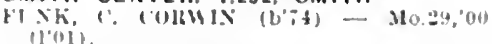

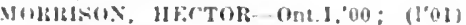

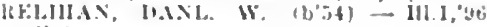
(1)(1)

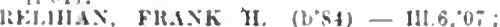
(I,0is.

SOLDIER, 358, JACKSON

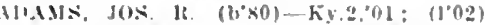

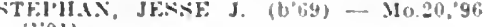
$01)$

SOLOMON. 949. DICKINSON

Imliats, Isaae B.-Mungl: (l’0!): G

layton, Igratlus 5: $\left(b^{*}+0\right)-I a . J, " i s ;\left(l^{\circ} 02\right)$ o.

Itoberts, Claude X. $\left(13^{\prime 2}-2\right)-310.7,00 ;(101)$

loung, I'ear! liymond (b'ic)-\$10.20,ns (1"0.i).

SOUTH HAVEN, 483. SUMMER

("ivallagh, Frank $A$. $\left(b^{\circ} 60\right)-0.2,94$ (1'0).

HOL.HNGSHORTH. THOS. J. $\left(\mathrm{b}^{\prime} J 4\right)+-6$ (l'ol)

SOUTH MOUND, 57. NEOSHO

'rafidon, klchard l'.-hy.5,"7: (l'02).

SPARKS, 125, DONIPHAN

IIFIIIISG, AMLON $(6.53)$ - Mo.22.30 (1'01).

Herring, Hubert finthrle (hs3)-Mo.22,06 1)(Hi)

SPEARVILLE, 576, FORD

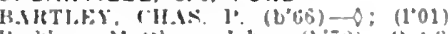

"erkins, Mathew Juhn $\left(0^{\circ}: 2\right)-0 n 13,03$

(1.09): S.

SPEED, 82, PHILLIPS

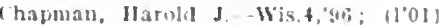

SPIVEY, 252, KINGMAN

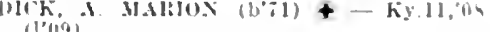

SPRING HILL, 605, JOHNSON

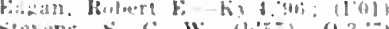

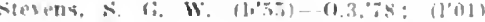

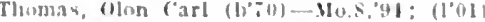

ST, FRANCIS, 492, CHEYENNE

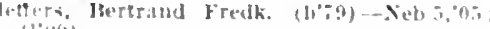

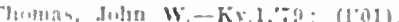

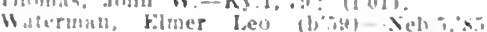

ST, GEORGE, 225. POTTAWATOMIE

WIIIUIT. JUIS W $(1,1,3)-11014,3$

ST, JOHN, 1.785, STAFFORD

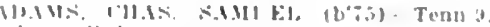
a). 11011$)$

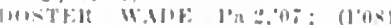

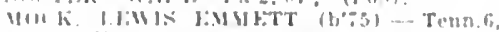

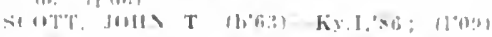

ST, MARYS, 1.397. POTTAWATOMIE

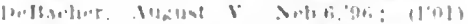

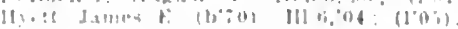

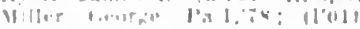

ST, PAUL. 927, NEOSHO

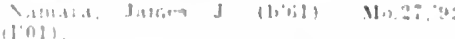

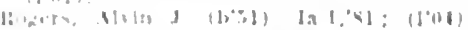

STAFFOAD, 1.927, STAFFORD

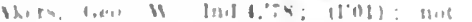

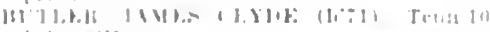

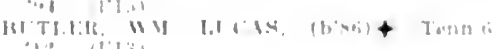

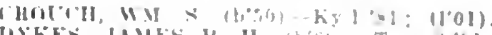

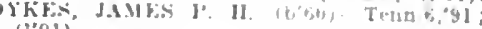

Kendlo, Jesne $11-K y$

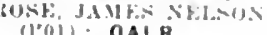

(1"0) : OALR.

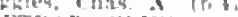

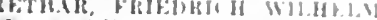

+ Mo 9,$05 ;(1004) ; 0 A L R$.

(1)01): $\mathrm{G}$

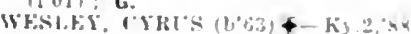

STANLEY, 200, JOHNSON

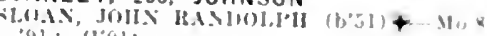

(1): (1001).

STARK, 19I, NEOSHO

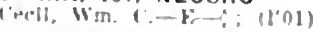

STERLING, 2.133, RICE

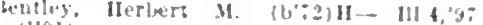

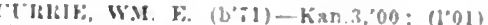

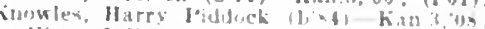

(1) (1) : It है in

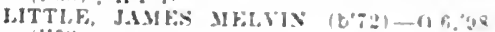

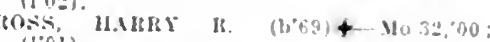
(I'0I)

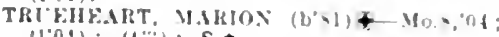

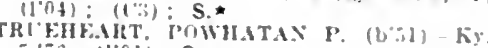
Y.66; $11011 ; \mathrm{S}$

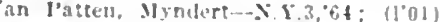

STILWELL, 300, JOHNSON

logers, Marlon Wm. (b"*6)-Mo.20,0,

toan,

STOCKTON, 1.317. ROOKS

brok, Vinli L. - 111.1.01; (l"01).

callender. Wru. II-Iande: (lou)

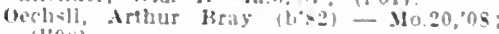
(1'0s).

White. Eirnest Filward (b'71)-13.6.96;

(1.13): Pd.

STRAWN. 125, COFFEY

barmer. Serry-11,'6s,-110.20,09; (1'09).

STRONG, 762, CHASE

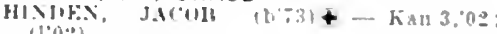

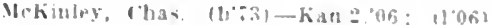

SUBLETTE, - HASKELL

IIITer, Lorlng $V$. (b'RO)-D: (I'UL).

SUMMERFIELD, 554, MARSHALL

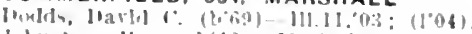

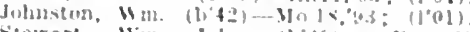

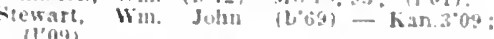

(I'n:?

SUN CITY. 150, BARKER

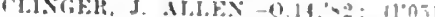
SUTPHEN (R.F.D. CHAPMAN). 20, DICK.

lbarls, l. Finer-han 4,9 : $(101)$.

SYCAMORE, IHO, MONTGOMERY

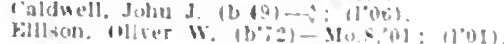

SYLVAN GROVE, 454. LINCOLN

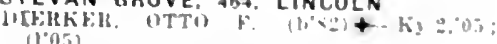

SYLVIA, 634, RENO

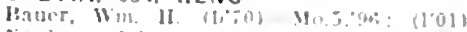

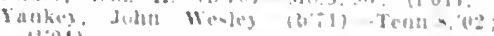

$1100 \mathrm{j}$

SYRACUSE, 1,126, HAMILTON

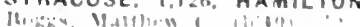

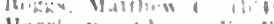

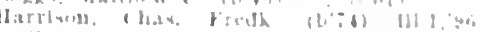

TALMAGE, 150, DICKINSON

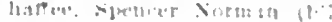

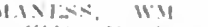

IAMPA. 256. MARION

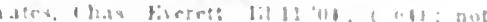

TECUMAEH, 300, SHAWNEE

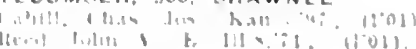

TESCOTT, AOI. OTRAWA

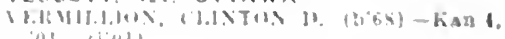


THAYER, 542, NEOSHO

Cottman, Gllbert Lee (b'69)-Mo.27,'96 ;

(l'01). (1.05)

De.lloss, James A. (b'59) -Mo.27,'82; (1'01)

RFF('), IIAL E. (h'76) Mo.20,00; (1'09)

Member Okla. State Med. Assn.

TIPTON, 210, MITCHELL

BIEIER, KARL, ALGUST (b'84) \&-Kan.3, 09: (1'0y); LR.

TONGANOXIE, 1,018, LEAVENWORTH

CON, WAl'TER B. (b'68) 4 -Ill. I, 96 ;

GLAIIIA WM. R. $\rightarrow$; $\left(l^{\prime} 01\right) ; 0$ b.

Slaukhter, Robt. F. (b'58)-Mo.8,'82; (1'01).

TOPEKA, 43,684, SHAWNEE

NUMBER OF IIIYSICIANS, 137

Alams, Earl V. (b'75)-Kan. 3,'00; (l'01)

ADAMS. IIARRIET E.\$-Kan. $3,{ }^{\prime} 94 ;$ (1'01); 1501 Mulvane st.; offlce, New England Blalg.; $11-12,3-5 ; G$.

ALKIRE, HERBFRT LEE (b'62)†-Pa.2, '87; (1'01); 424 IIonroe St.; otilice, $6 \mathrm{I}$ Kansas Are. ; 9-12, 2-4; (IB1); OALR. Morrls Are.

Allen, George Henry (b'79)-Ia.3,'08; (l'13) ; 813 Tyler St.; oflico, Mllls Bidg. (1213); 813 ; Tyler

Allen, Geo. Viven (b'i2)-Kan.3,'98; (l'13) 1501 Mulrane St.

ARMSTEAD, JOHN B. (b'78)థ-Kan.3, 00: (1.01); 819 liansas Ave.

ARMSTRONG, JOHN B. (b'sI) \-Mo.20, 04; (1'04); 1298 College St.; office, 321 Kansas Are.; $9-11,3-5$.

Baker, Estella' Frances (b'65)-Kan.3,'98;

(l'0I); 624 Kansas Ave.
BEASLEY, JOHN NEWTON (b'74)\&Mo.7,97; (1'0I); 1517 Western Are.; of fice, 822 Kansas Are.; 10-11, 1-4.

BIDDIE, THOMAS C. (b'57)-II1.1,'81; (1'01); Topeka State Hospltal for the Insane; (EI3).

BHLINGS, ATVA EDGAR $\left(b^{\prime} 80\right) \oplus-$
Mo.20,09: $\left(l^{\prime} 09\right) ; 1257$ College Ave.; of fice, 703 Kansas Ave, : 9-12, 2-5.

Boam, Silas A - Eng. I 0 ; (l’0I) : 1407 W. 10th St.; offlee, 629 Kansas Are.

Bowks, Wir. F. (b'72) $4-K a n .3,9 s$; (1'0I); $80 \mathrm{I}$ Western Are.; office, 330

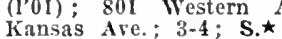

BOWER, WILLIAM; CLINTON (b'61)ФIll.1,'86; (1'01); 615 Quincy St.; office, Mills Bidg.

Broady, Mary Brown (b'73)-Ind.5,00; (l'09) ; 2040 Bolles Are.; offle, 106 W. 8th St. ; $2-4 ;$ G.

Ill.22, 07 ; (l'09) Soc. ; 610 Kansas Ave. ; 9-12, 2-6.

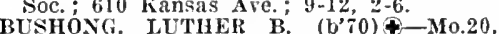
97; (l'01); 804 Lindenwood St.; office, '97; (1'01); 804

Chase, James S. (b'48)-0.6,71; (1'06);

1526 Harrison St. ; offce, 716 Kansas Are.

Cliurch, Mary Violet (b'68) - Kan.3,94; (1’0I); 1301 Mulvane St.

CLARK, HERBERT LEE (b'83)-Kan.3, 09; (1'09); 510 Buchanan St.; office, Copper Bldg.

Clark, wlllard olin (b'85)-Kan.3,'12; (1'12) ; Chrlst's Hospital: S.

CONNER, HARRY MILTON (b'81)థKan.3,09; (1'09); 1516 Mulvane St.; offlce, 834 Kansas Ave.

Cookingham, Dorwin A. (b'50) $\mathrm{H}-\mathrm{M} 0.26$, '89; (1'01); 922 King St.; offlce, 634 Kansas Ave.

COOPER, JOHN H. (b'78) †-Mo.20,01; (l'0I); Topeka State Hospital for the In-

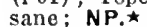

CRABB, JOHv A (b'69) A-Kan.12,06 ; (1'06); 124i Lane St.; offlce, Orpheum Bldg.

CRUDBINE, SAMT. JAT (b'62)(-0.8, ' 89 ; (l'01) ; Sec. State Board of Health; 12, 2-5; Dean and Prof. Prev. Med. Kan. 2.

Darls, Amos C.-Ia.1,67; (1'01) ; 507 Park

St.; offlce, $\$ 39 \mathrm{~N}$. Kansas Aré.

DAVIS, 0. PORTIS (b'69) (-)Mo.20,'96, Y.Y.10,97; (1'01) ; 1027 Central Ave.; office, 839 X. Kansas Are; Pd. Dawson, Alvert (1)'47)-Mo.13,77; $\left(1^{\prime} 01\right) ;$
I019 X. Kiansas Ave.; oflee, 830 N. Kansas A זе. ; 9-12, 2-5.

DAWSON. AIBEITT MARCELLUS (b'80)lian.3,07; (1'07); I019 W. 10th Avo. offlee. S3o N. Kansas Are.; $9-11, I-5$.

DeIAND, MALD SAYERS (b'69)-Pa.t I0; (l'12); Topeka State IIospltal.

Dick, Geo.-1I-N10.5,'61 (1'01); 503 Monroe st..

Durant, Saml. W.-Ill.I,70; not in practlce: 1407 W. 15th St.

Eidson, Ansel M. (b'45)-0.2,60; (1'01) 934 Kansas Are.

Erlekson, Osear 1.conard (b'88)-Kan.3,'12 (l'12); 315 Elmwood Are.; oftlce, 627 Kansas Are. ; $9-12,2-5$.

Ermest Elvenor A.-Kan.3,'04; (1'04) ; 826

Katisas Ave.
EIiNiST, FOY J. 4 -Kan.3,04; (1’03) ; 826 Kansas Ave, ; 1-5.

ESTERLY, DANIEL EDW. (b'66)†-Pa.1, 93; (1'01); 807 Western Ave. ; oftlce, 813 Kansas Ave. ; $9-12,2-5$; (B1); OALR.ネ

Farley, John Aloysius (b'84)-1a.3,'12; Atchíson, 'Topeka \& Santa Fe Rallway Hospltal.

Fay, Jos. Ranson (b'55)-Mo.8, 87 ; (l'01) ; 1214 Harrison St. : 10-12, 3-5.

FITZGELALD, JAMES JOS. (b'88)-Mo.34 12; Member Mo. State Med. Assn. Atchlson, Topeka \& Santa Fe Rallway

Ilospltal.
FLOERSCI, MICIIAEL A. (b'76)-Neb.6, 00; (l'05) ; 1305 Hlarrison St.; offlce, 623 Kansas Are. ; 9-12, 2-5.

Ford, Thos. J.-Ky.2,74; ( ) ; 135 Madison St.

FRLEMAN, JOHN DWIGHT $\oplus-$ Ill.1,97; (l'01) ; 623 IIadison St. ; office, Atchison, Topeka \& Santa Fe Railway IIospital. GREENFIELD, SARA E. (b'74) - II.11, 00; (1'01); $1105 \mathrm{~W}$. 10th St.; LD. Greldér, Wm.' H. (b'65) -Kan.3,'11; not in practlce; 615 W. Euclld St. (I'06); 81I Kansas Ave.; Path.

Hammond, Chas.-Kan.3,'97; (1'04) ; 713 Kansas Ave.

Harding, Eva (b'57)-111.4,'82; (1'04); 710 Kansas Ave. ; $10-12,2-4$.

HARRISON, ALVIN F. $\left(b^{\prime} 66\right) \oplus-M 0.20$, 95; (l'01) ; 1318 Mulvane St.; office, 718 Kansas Ave. ; 9-12, $1: 30-5 ; \mathbf{O b}$.

Havlland, Agnes-110.22,'93; ( ); $710 \mathrm{Kan}$ sas Are.

HAZLETT, HAL H.-Mo.28,97; (1'01) Heller, John L. (b'55)-D; (1'01); 250 Oak-

HENSLEY, CHARLES M. (b'77)-Mlch.1, 04; (1'04); 704 W. 8th St.; offlce, 735

Kansas Ave. ; $9-10,2-5$.
Hesner, George Earl (b'85)-IIl.22,'11; (l'12); Topeka State Hospital; NP.

Hogeboon, Henry B. (b'73)-Ill.1,'96; (1'02); 801 W. 6th St.; offee, 515 Kansas Are. : $1: 30-5$.

Hunter, Wm. Seward (b'79)H-IIl.15, 04 ; (1'05); 1209 E. 6th St. (b'57)-Kan.3, 05 ; (1'05); 1200 Harrison St.; 10-12, 2-4.

Iserman; J. C. -0 ; (1'01); 209 E. 7th St. JACKSON, WM. E. (b'66)-D.C.3,97
(1'0I); 404 Kansas Ave. ; 9-12, 2-5:30.

Jamlson, James M. (col.)-Tenn. 7,$7 ;$; (l'0I); 327 Madison St.

JEFFREY, ALEXANDER BALFOUR (b'79) (†-Ill.6,06; (l'06); 821 Lane St.; office, 706 Kansas Ave.

JOHNSON, SAML. A. (b'59) $)-K a n .3,97$; (1'01) ; 421 liansas Are.

JOSS, CHESTER EARLE (b'84) @-Pa.9,
,08, Pa.2,10; (1'10); 1907 Inncoln St. office, 735 Kansas Are.; 10-12, 2-5.

KASTER, JOHN P. (b'57)థ-Ill.1,'S1; (1'01); 616 Madlson St.; offce, Atchison, Topeka \& Santa Fe Raliway Hospital.

KIENE, O'TTO (b*79)-Kan.3,04; (1'04) ; 526 Lincoln St. ; office, 330 Kansas Are.

Klemp, Herman F. (b'37)-H1.4,'67; (1'01); 334 Kansas Are.

Lerrigo, Charles H. (b'i2) H - Mo.5, 00 ; (l'01); 1317 College Are.; offlce, Mills Bldg. ; $11-12$ :30, 2-5; Pd.

LINDSAY, MERRILL KIRK (b'84)-N.Y.1, '10 (l'10); 1256 Western Are: office 823 Kansas Are.; (Fs).
LINDSAY, WM. SIIARP (b'52) -Ia.1,74; (l’01); 1256 Western Ave.; offlee, 823 Kansas Ave.; NP.

Longshole, Deborah K.-Pa.7,72; (1'01): 1261 clay sit.

LOVELAND, FOLREST L. (b'85) 9 -Neb.6, 11; (1'12); 500 Topeka Are.; office, Central Nati. Bank Bidg.

LULL, CIAUIDE C. (b'91) - Kan.3,'13: (l'13); 301 E. 6th St. ; offle, 612 Kansas MAGEE, HOBT. S. (b'6I) $4-M 0.8,90$. (1'0I) : Asbury Apts.; offlce, Mllls Bldg. 9-12, 2-4; (B1) OpA.

Marcotte, Oscar F. (b'75)-Kan.4,01: (1'01); 625 Kansas Ave.
artin, Thaddeus P. (b'78) - N.C.3, 02 ; (1'08); 721 kansas Ave.

Martln, Wm. Glles (b'55)-Ill.I,'88; (l'03); 725 Kansas Ave.

(1'04); 818 E. 4th St.

Iassey, Robert E-E-Kan.3,98: (l'0I): 818 E. 4 th St.

McCIINTOCK, JOHN CALIHOUN (b'55) Ill.1,79; (1'01); 1313 Flllmore St. ; offlce, 330 Kansas Aré; S.

MCDOXOUGiL, Wa. C. (b'67)-I11.1,02 (1'04) ; 702 Fllimore st. ; offlee, 603 Kansas Are.

Mc(iill, James Culmer (b'76)-Kan.3,09; (l’09); not in practlce; 731 Kansas Ave.

MCGUIRE, CLARENCE ALONZO (b'62)థIll.1,'84: (1'01); 1008 Topeka Ave.; office, 622 Kansas $A$ ve. ; $1-4 ; 1$.

McVEY, WM. E. (b'64)థ-Mo.8,'88; (1'01) ; 626 Buchanan St.; office, 612 Kansas Ave. : " -5 ; LR.*

MENNINGER, CHAS. FRED. -IIl.4,'89; (1'0I)； 1251 Topeka Are.; offlce, 727 Kansas Ave.; 11-12, 2-5; 1.

Messick, Chas.-Ky.1,'88; (1'01); 1016 Fillmore St. ; offce, 421 Kansas Áre.

MILLARD, SAML. THOMAS $\left(b^{\prime}, 6\right) \oplus-$ Kan.3,06; (1'06); 724 Kansas Ave.: 1-5;

Miller, Chrlstopher B.-Kan.3,00; (1'01) 1307 Mulvane St.; offce, 1602 Seward A re.

Miller, Mary M.-Kan.3,00; (1'01).

Mlller, Mllt on Bradford (b'88)-0.41,'12: (l'12) ; 1710 W. 10 th St. ; offlee, 700 Kansas Ave. ; 3-5.

MILIS, WILLIAM MERRILL $\left(b^{8} 83\right) \oplus-$ offce, Mills Bldg.; 12-1, 3-5; S.

MTCHELL, MATTHEW R. (b'35)-0.1,68: (I’01) ; 931 N. Van Buren St. ; offlee, 426 Kansas Ave. ; ObG.

MOORE, ORVILLE O. (b'80)-Kan.3,'06 ; (1'06); 733 Kansas Ave.

MULVANE, GUY I. (b'50) $\odot-$-Ia.1,'78; (I'0I) ; 617 Taylor St.; office, 714 Kansas Ave. : $10-12,2-4: 30$.

Muma, Lydla A. -E-Mo.10,94; (1'01); 1105 E. 6 th $\mathrm{St}$

MUNN, I.EWIS HOLLAND (b'58) ๑-Ia.3, '80, N.Y.10,'82; (1'01) ; 315 Topeka Ave. office, 513 Kansas Ave.; 12-3; S.

Nicoll, Darid T. (b'64)-Ill.15, 03; (1'04) 1435 Topeka Are.; office, 909 Kansas Are. ; 2-5.

Nicoll, 'Dorothy B.-Ill.15,'04; (1'04); 1435 Topeka Ave.; office, 909 Kansas Ave. $1-5$.

Niles, Julia-Kan.3,'97; not in practlce; 716 W. 6th Ave.

0'Connell, John Hanly (b'84)-Mro.34,'09 : Intern, Atchison, Topeka \& Santa Fe Railway Hospltal.

PETTYJOHN, ELMORE SLOAN (b'55)(111.1,'82; (1'09); 723, 6th Are., W. ; offlce, 703 Kansas Ave. ; $2-5 ; \mathbf{N}$.

PLUMMER, RODNIA S. (b'49)-Ky.4,'83 (l'01) ; 914 N. Quincy St

PORTER, MELANCHTHON C. (b'62) (Ill.11,'90; (1'01); 1409 Topeka Ave.; of flce, New England Bldg.; 11-12, 2-5; S.

POWELL, LEWIS MORGAN (b'58)-Pa.1, 91; (1'01); 701 Taylor St.; offlee, 700 Kansas Are.; 3-6.

Pratt, Saml. M.-Mo.5,'61; (1'01); 1523 Mulvane St.

RIGHTER, WMr. H. (b'53)@-Pa.2,79 (l'01); 1220 Fillmore St.; offlee, 807 Kansas Ave.; 2-5; U. 
Minehart, Jolun II $\left(b^{\circ}, 3\right)-110,33,03:(100)$ $911 \mathrm{~S}$ Kansas lre. once til? sas Are, : $2-3, i-8$.

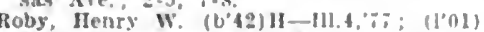
olol Kansas Ave, offet, $7: 0$ Kansas Ave.

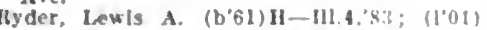
l'res. Stale Bosard of Med. Iteg. and kix m. : 8.4 Gulney SL; once, sl: Kansas

SAMS, I, V-Mo.90,03; (1†)；110! . Ir b

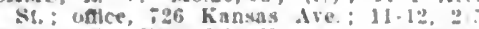

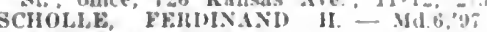
(1'01): 1436 Topeka Are, once, Now kingland Rids.

SCIIWARTZ, CHARLES W. $\left(b^{\circ} 0\right)+-110$ "9:; (1'01); $2115 \mathrm{~W}$. 10th Ave.; unce. s: Kansas Are. : 11-12, 2-5.

SCOTT. THOMPSON" $P$ (b" $\mathrm{s})+-0.9 \cdot 05$ (1'0) ; State Hospltal; NP.

sharp, Alexander A.-I'a. 1, Sti: (1'01): 1251 Western Are.

Shlelds, Isate A. -0 : (l’01)

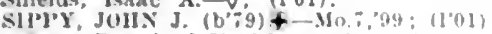
siate Board of Healih: s-12, $1: 30-7$.

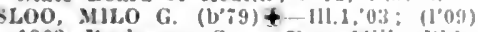
1308 Juchanan St; onlee, MHls Mldk. $10: 30-12,2-5$

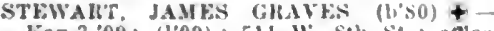

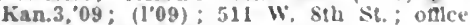
621 Kansas Ave; : $1: 30-5$

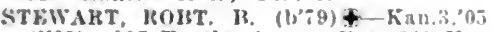
(I'05); 905 Topeka Are.; once, 621 Kan

STEWAKT, SAML. G. $(1,4,1)+-(1,3,7.3$

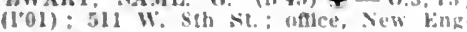
land Bldz.

STORKS WILIS DASA (home; - hism, 95 ; (101): 1318 killmore St.; onte, 70 : hansas Ave. $2-5:$ S.

suess, Henry c. (b'4)-Pa.9,78; (1'01) 1016 Western Aro.

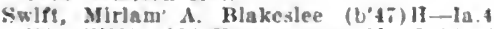
91: (1'01) ; 824 Kansas Ave., X. ; : :30-1'. $2: 30-5,6: 30-7: 30$.

TAYLOK, OLIVKH A. (col.) \&-Tent.7'94 (1.01): 1535 Van Hureu Si. ; oftce, 334 Kansas Are.

True, Maßelle (b'i2)-Kan.3.97; not in practlce: 1300 Mulvane St

VAX HOHS, CIIAS. Is. (b'72)-Kan.3.'04 (1004); 1215 Mulrane si.: oftce, sop Kansas Are.: 11-12, 3-5:30.

Vest, Fredk. Eugenc (b'5)-Ia.3,85, J'a.D. 'xt: (1'09); Mllls Rldg.

WAKKINKK WM. L.CIAN (1,62)-111.6,88; (1'0I): 1120 W. 13th st.; unce, 913 killsas dre.

Weeks. Jos. $\left(b^{\prime 29}\right)-\vartheta$; (1'01); not th prac

the.

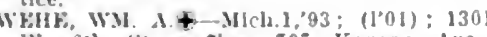
W. 6lh st. onlce, $70^{\circ}$ Kansas Ave. $11-12,3-5: 30$

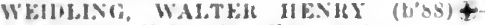

III.1,13: (1'13); i0t Kansas dre.

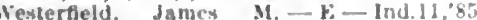
(1'0) 815 gulney

NuIT) (1'01): 835 lone

W'01) : 835 labe St. $\left(b^{\prime} 69\right)+-111.6,00$ (101); 1605 Topeka Aic.; uflce, Mlls llddL. : OALR

WOHK, JOLS I. (b'it)-Kan.3,97: (1'0I) 1112 Topeka Are, offlce, 614 Kansas Ave YATYS, WAl.TEH W, (b'68) +-111.1, '02

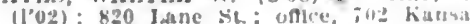
Are. : $11-12,3-5$.

\section{TORONTO, 627. WOODSON}

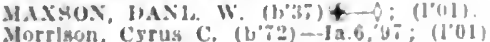
$\mathrm{Op}$

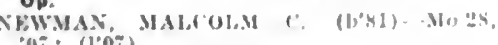
Q0i; $(1.07)$.

Spadding, oliver s,-H-b: (l'01).

TOWANDA, 295, BUTLER

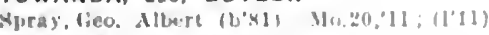

TRIBUNE, I58, GREELEY

Medinnla, Kebree Sumuel (b'84)-Mo.29, 09: $\left.(1)^{\prime} 04\right)$.

TROY. 940. DONIPHAN

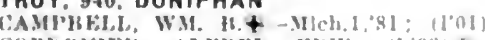

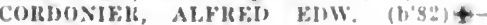
Mo.3, 05; $(1,06)$.

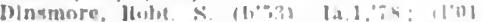

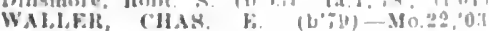
(1'1:).
TURON 572, RENO

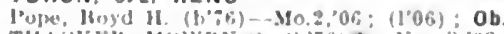

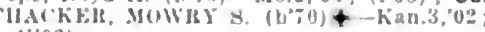
( $(1002)$.

TYRO, 603, MONTGOMERY

CHAHWICK, HRA HKAlYHIII (bo8) Mo.3:,02; (1102)

UDALL, 330, COWLEY

Simnns, bevello r',-1a.1.'88; (I'06).

UNIONTOWN, 256, BOURBON.

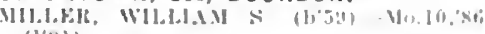
(I'UI)

URBANA, 100, NEOSHO

Iles, Wm. A. (b"\$3)-M(1).20,"40; (10)

ficely, Mex. H.-l'a 2,:0; (I’0i)

UTICA, 300, NESS

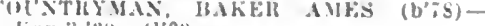

KAB.3.0!?: (1'0!1).

VALLEY CENTER, 381, SEDGWICK

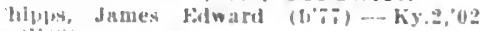
(l'us)

VALLEY FALLS, I,129, JEFFERSON

(iephart, Jesse T. B.-111.1,70: (1.01)

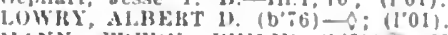

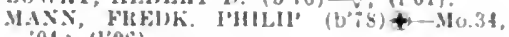
04: $\left(1^{\prime} 0 t^{3}\right)$

larks, Jos. Mllard (b'81)-M0.20,06 (1"06)

Marks, Mlllard f*,-Mo.s,'8s; (1'01).

VAS MEkR, WM. H. $(b, 54)+-M o, 26,90$ (1'01)

VERA (R.F.D., PAXICO), 300, WABAUNSEE ('lothler, saml. H.-II-Mo.26,'y!; (1"01) not In practice.

VERMILLION，366, MARSHALL

I'lifton, John-D; (l'01)

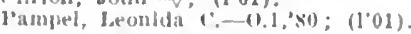

VICTOR, 35, MITCHELL

H(I'E, H[Cill AlLEN (b'85)-Kan.3,09

VINLAND, 50, DOUGLAS

ander Wys?, J'etros Gerardus Hendrtcus (b"7) I11.15,"12; (寺)。

VIOLA, 156, SEOGWICK Hilworlli. belsur
(1 07$)$.

VIRGIL, I50, GREENWOOD

13lack, Jolan Simulisun $\left.\left.(1)^{\circ}+3\right) \rightarrow(1)^{\circ} 01\right)$

WAKEENEY, 883, TREGO

Herrick. Wu. Y. (1,"I)-1a.10,01; (l'neb)

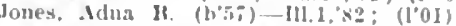

WAKEFIELD, 5I4, CLAY

Hewle, Chas.-Md.1.'68: (l'01).

Hewlt, John k. (b'70)-110.20,99; (1.01)

Nyers, Eilner dllen (b'85) - Kan.z, 1 (1'11).

Pearson, Andrew $\left(10^{\circ} 0\right)-111.1,83 ;\left(10^{\prime} 01\right)$

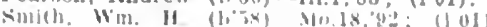

WALDO, 300, RUSSELL

Mitchell, John (: (b'it) Mo.22,98; (1'01)

WALDRON, 262, HARPER

SHELAEY, IHOHT. A. J. $\left(\mathrm{b}^{\prime} / 5\right)+$-TenU. 00:1; (1009): Pr.

WALNUT, 639, CRAWFORD

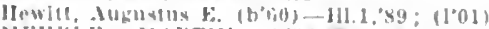
MEllil. MAKTIN (b.85) - Mo.28,08

Sitaford. Itulla H. (1,\%s)-Mo.20,01: (1'01)

WALTON, 357, HARVEY

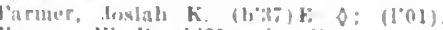

farmer. W II (b'a) $9:(100)$

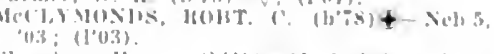

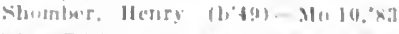

WAMEGO, 1,7I4, POTTAWATOMIE

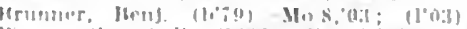

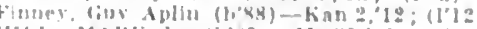

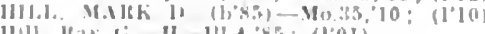

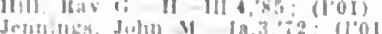

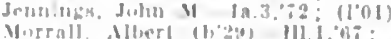

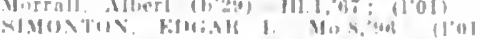

WASMINGTON, I,5.1\%, WASHINGTON

Iturnaman. Wm. ( $(b, 84)$ Neb) ${ }^{\prime}(0)$

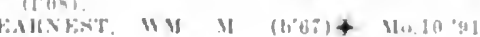
(1) 011

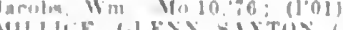

11, 11'11

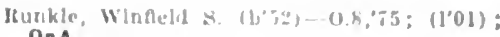

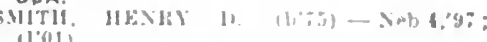
(]"()』)

WATERVILLE, B04, MARSHALL

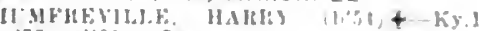

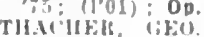
OALR.

WATHENA, 777, DONIPHAN

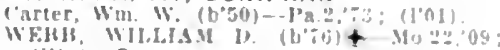
(1'U1): $\mathrm{S}$.

WAUNETA, I50, CHAUTAUQUA

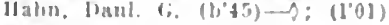

WAVERLY, 751, COFFEY

lhoggs, Frank C. (b's6)-Kan.3,'10; (1'10).

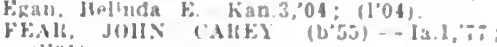
(I)(ii)

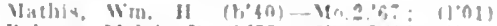

Hoberls, Melvin B. (tom)-Kan.2,"06: (1'06).

WAYNE, 200, REPUBLIC

'TYliEk, Fred Chas. -Kan.2,06; (1'06)

WEBBER, 300. JEWELL

Maxey, Fred liasco-Mo.29,05; (1'05).

WEBSTER, 200, ROOKS

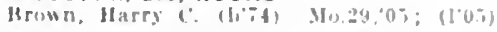

WEIR, 2.289, CHEROKEE

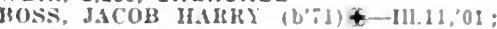
(l'02)。

Ifoag, ("lark W. (h'ti) F- Q (l'01).

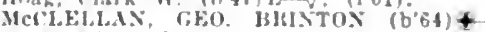
MO.18,94: (1'01).

WELDA, 250, ANDERSON

Heldrick, Ibinl. I.awrence (b'84)-Kan. 2,06: (1'06).

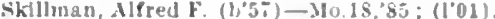

WELLINGTON, 7,034, SUMNER

('aldwell, John ('-Mo.1,"yy ; (1'12)

COBEA, MARR L. (b\%)-Mo.2,03; $\left(1^{\prime} 0 z\right)$.

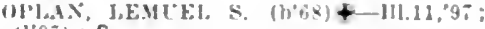
$\left(1^{\prime} 00^{*}\right): \mathrm{S}$.

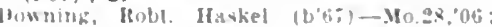
$(108)$

FMBISOS, FHANK G. (b*61)-1as, 85 ; II.1.11). JoHx 1. (6:6)-Que.1,02: (1'0:1).

Ifarmon, Lafayette F. (b'j4)-Ky.2,89; (I'01)

HATCIER, ALBERT K. (b'83)-MO.2,0?; Hois

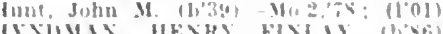
Kan:2:10; (1'10).

MMIESUX, THUS, II. (b65)+-111.1,91; (1'01): (B1): OALR. *

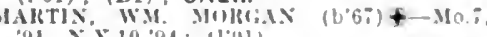
$91, \times 1.10,94 ; 11.01)$.

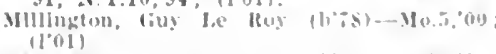

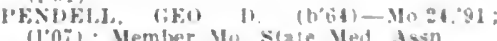
(107) Member Mo slate Med Asn.

, ne

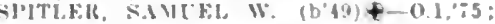
(I) (1) ].

WELLSVILLE, 648, FRANKLIN

bennelt, Huwarl Malcom (bii)-Mich.1. is; (1'01): OpA.

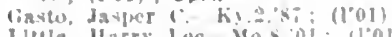

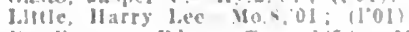

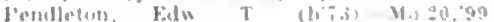
(l’o)

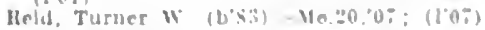

WEST MINERAL. - CHEROKEE (Sine Minetil)

WESTMORELAND, 484, POTTAWATOMIE

Touthaker, sibreatit il (b'i:) is $\$ .03$ (I'U)!

WESTIPHALIA. 500. ANDERSON

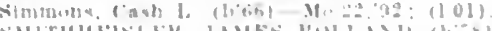

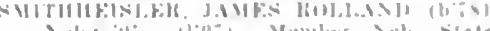

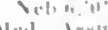

WETMORE, 4B3. NEMAHA

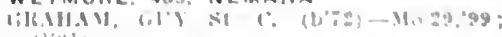
(I) $n$ !),

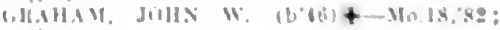

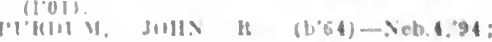
(101). 
WHEATON, 225, POTTAWATOMIE

Lelnbach, Itoscue Conklln (h'84)-IIo.20,07

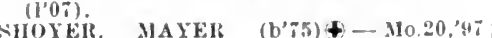
(1'01): $\mathrm{G}$

summers, Laurel A.-Mo.27,93; (1'04)

WHITE CHURCH (R.F.D., BETHEL), 100 , WYANDOTTE

WOOI, WATSON F'laLEL (b'60)-Mo.20, 91; (1'01).

WHITE CITY, 506, MORRIS

RANDLES, HERIEIT (b'69) £-Kan.4, 00 , Pa.2, 07 : (l'01)

Chls, C. (C-Mo.1,8\%; (1'02)

Webster, chas. S.-L-Pa.1,80; (l'0I).

WHITE CLOUD, 1,119, DONIPHAN

llohsom, stcphen Franklln-Ito.j, 10; (1)

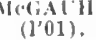

WHITE WATER, 518, BUTLER

Holner, John (b's3)-0.2,'80 ; (

Vorris, llarrlson II-b-0.2; $55^{\circ}(1,02)$

Sossaman, Arthur II. (b'75)-Mo.20,04: (1'04).

\section{WHITING, 426, JACKSON}

(1) V', JOHX E. (b'59) \&-111.1, 82: (1'01)

MAIS, JAMES ROY (b"7) $\rightarrow \longrightarrow$; (1"04)

Woodu1. James 11. (b'34) E-Mo.s,'31; (1'01)

WICHITA, 52.450, SEDGWICK

TIMBEL OF PIIYSICIANS, 129

ANDERSON, SAML. MLIAGANT-HIII, '03: (l'04); 10:9 W' Doughas Are

twell, Frank s. (b'60)-X.'.8,'83; (1'04); $435 \mathrm{~N}$. sencea St.

Baker, E. 0.-110.26, 99 ; (1'04)

Barnett, Geo, C - 110.7,92; (1,01)

Harr, rlysses s. (h'(i8)-111.15,94; (109) s.t s. Market st.; oftlce, 119 s. law

BASHAM, 1)ÁVII WALKER (b'54)—-Mo.8, st, N.X.5,92; (1'01); 824 N. Emporia Ave. : otyce, Schwelter Bldg. ; $2-6 ;$ (A7)

Hass, Selvy A.-H-111.4,81; (1'01); $111 \%$ Vniverslty Ave.; 10-12, 2-5.

Bobo, Wm. H. (b'5i)-Mo.22,98; (1'04) 331 Dourlas Ave, ; 8-5.

HODENHAJER, ELMER ALLEN $\left(\mathrm{b}^{*} 70\right) \uparrow$ la. 10,'01; (1'04); 1901 W. Douglas Ave. office, 201 E. Douglas Ave.; $\mathbf{2 - 4}$.

ROWERS, CHAS. EDWH (b'55) $4-111.1$ 83; (1.01); 1004 N. Na

Beacon Bldg.; (At); S.

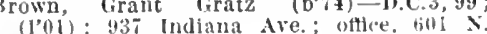
Itain st.

BROWN, 30HN CLARKథ-D.C.4, '00; (1'02) schwelter bldg.

Burton, Archie 0. (b'56)-Ky.2, 79 ; (1'01); 926 E. Douglas Are.; $1-5$

Carpenter, Saml. J.- $\diamond ;\left(1{ }^{\prime} 01\right) ; 520$ E. Donglas Ave.

(urter. Wm. 1I. (b'as)-.Mos, 14 ; (1'04) $139 \mathrm{x}$. Main St.

casburn, Frank Estil (b'-y)-Kan.2,'0ti (l'06): 115 s. Volutsla Ave. : offlee.

N. Narket St.; 9-12, I:30-5, $\mathbf{i}-8 ;$ U,

CASWELL, CHAS. E. $\left(b^{\prime} ; 0\right) \$-$ Kan.3, 02
(l'04); 1324 E. Kellogg St. ; offlee, $258 \mathrm{~N}$ Main St. : $10-12,2-5$.

AVE, IAHES WM. $4-\mathrm{Ky} .1,92$; (1'01) 111 E. Douglas Are.

Cave, Matthew W.-Ky.1,'86; (1'01); Maln st. and Douglas Are.

CHEXEY, JAMES YV. (b'74)-MIO.8,9s; (I'01) : 1113 N. Topeka Ave

schweiter Bldg., 9-12, 1;30-5. (1,01)

CLARK, JOHN D. (b'74)-Ill.6,'01; (1'01); 1027 N. Empor

cobt, Ellzabeth Emma-b;

bouglas Ave.; $2-5$

Curts John -

$135 \times$. Mlain St.

pamon, Lena Leota Holland (b'îl)- Ill.19, 06; Asslstant Plysician: 711 S. Seneca St, offlce, kansas Sanitarium.

1)argatz, Fredk. Fdward (b'86)-Mo.20,'13 (): Wichita IIospital.

Deltand, John Wesley (b'86) - Kan.2,12; (1'12); St. Franels' Hospital.

Gemand, Jilton IIenry (b'83)-Kan.2,'12, (l'12): St. Francis' Hospltal.

De Ross, Darid E.-E-0.2,75; (1'01)

DIXON, CHAS. HALL (b'8: + Mo.2.'07; 13l(k, $9-12,-2-5$.

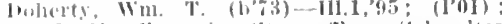
2X. Emporlat St.; attice, schwelter 13lak: : $11-1: 2,2-5$

WORSEY, JACOB GRAY (b'60)—-Ia.1,'83 (1'01): $1315 \mathrm{~N}$. Topeka Are.; offce, 105 W. Douglas Ave.; 9-12, $2.5 ;$ (IB1) OALR.

borsey, James Kiron-N.Y.5, '02; (1'01) ; 147 Johuson A ve.

Ehrlght, Edwin D. (b'73)-MIo.8,96; (1'01) Beacon BIdr.; $10-12,2-5 ; \mathrm{S} . \star$

FI)GEITON, ERASTUS SAITII $\left(b^{\prime} 84\right) 4$ 11l.1,10; (I'12); 928 Faulkner Are.; ottlee, Schwelter I3ldg. : 2-5; S.

EVANA, JOHK L. (1)'78) $-110.2,04$ (105); $1054 \mathrm{~N}$. Lawrence st.; offlce, 130acorit Bldg. : 11-12. $2-5$

PABRIQUE, ANDREW II. (b'35)-Ill.6,05: (1'03) : 503 X. Law rence Ire. ; uftece, Beacon 13]dg. ; 2-4.

Farmer, James Emerson (b'80) - Tenn. T,02; (1’04); 727 Wlchlta St.; ofllce, $703 \mathrm{~N}$ diain st. : $8-9,2-4,8-9$.

Flsher, ltoy C. (b'72)H-Ill.4,06; (1'06) yarket st, office. Schweiter Bldo. $2-5,9-12$

FORNEY, CHAS. DAVHD $\left(b^{\prime} 7 \tau\right) \oplus-M O .7$ 02 ; (1"02) ; $1725 \mathrm{~N}$. Lawrence Are. ; oftice, Winne Blig. : 11-12, 2-5.

Fuller, John if (b'59)-Ky.1,81; (l'01) 901 N. Waco St. ; 9-11, 2-5.

(BARDNER, ALFRED E. (b'69) †-Ky.2,'95: $(1$ '10) ; 1408 N. Lawrence Ave.; offlce, 10 N. Nain St. $; 0-12,2-5 ; \mathrm{S}$

Goodrlch, C. W.-0.29,74; (1†)

GRA V'ES, WALTER H. (b'53)-111.6,'83 (1'01) ; 113 N. Lawrence Are.

GIREENING, WM. P. (b'̃5)థ-Ky.5,0I (t'it); schwelter Bldg.

(ASELL, JACOB FRANKLIN (b'T3)†-IHI. $95 ;\left(1{ }^{\prime} 01\right) ; 3708$ E. Douglas Are.; offlee Beacom Bldig.; 10-12, 2-5: OALR. *

IlAGAN, JOHN (b'75)\$-11l.6, $04 ;\left(l^{\prime} 10\right)$; $1+11$ N. St. Francis St.; offce, Beacon lildg.

HAGAN, MARTIN $\left(\mathrm{b}^{\prime} 75\right) \oplus-111.6,04$ (l'04); 1224 N. Market St. ; offlce, Beacon lildg. ; $10-12,2-5 ; \mathbf{R}$

llale, Arthur Ernest (b'86) - Kan.2,13: (1'13) : St. Francis' Hospltal

HAMLTON, ERNEST F. $\left(\mathrm{b}^{\prime} 55\right) \oplus-M i \mathrm{ch} .1$, 79 ; (l'01); 1227 N. Topeka Ave. office,

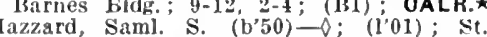
Francis sit. and Douglas Are.

Francls st. and Douglas Are. Neb.5,45: (l'04); Schweiter Bldg.

HISSEM, RALPH WALDO (b'86)-Kan.2 11; (1'11); Whichita Club; offce, schweiter Bldg. ; $11-12: 30,2-5: 30$.

Hobson, Mark F. (b'53) P-M - O.4,7y (l'01) ; 137 Clereland st.; offlee, $406 \mathrm{~F}$ Douglas Are. ; $8-11,1-5$; Ǵ.

HOFEMAN, JACOB ZIEGLER-I'a.1,86;

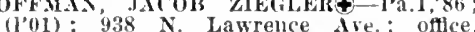
Scliweiter Bldg. : L-5.

1100 VER, EMELSON F. (h's3) - -.IIo.28, 05; (1'05); $150 \mathrm{~N}$. Erie St.; office, Sichweiter Bldg: 9-12, 2-5; G.

110RN, IIARRY W, (b'i4)థ-111.1,98; $(108) ; 938 \quad \mathrm{~N}$. Topeka

HORNOR, LEVI (b'56) S. Mo.8,'86: (1'01) 1043 S. Emporia St. ; office, 420 E. Norris st. ; $10-12,3-5$.

110 skins, John M.-Ky.2,'86; (I’0I); 524 E. Donglas Ave.

Howe, Abdallah M. (b'45)-0.9,73: (l'01); 1034 N. Market St. ; oflice, $113 \mathrm{~N}$. Law rence Are. : 10-4.

11T'T(IINSON, OWEX GHORMILY (b'79)Ill.11,04; (l'06); 1223 Riverside Ave. offlce, 108 E. Douglas Ave.; 10-12, 2-5.

HUTCHISON, THOMAS L. (b'71)-Mo.8, 02 ; (1’01) ; 330 \&. Market St. ; offlce, Schwelte Bldz. ; 10-12, 2-5; OALR.

Iutton, John Wr.-Mo.2,83; (l'01)

Ingles, llavid F. (b'56)-0.1,81; (l'0I) $925 \times$. Main $5 t$; office, Central and Main Sts.

JAGER, T1101t J. (b'82)-111.6,07; (1'08) 1350 N. Emporia St. ; offlce, Beacon Bldg. 2-5: $1 . \star$

JONES, ARCIHBALD DOERR $\left(b^{\prime}, 6\right) \notin$ Mo.28,98; (1'01) ; 923 S. Topek
office, Schweiter Bldg.; $2-5$; Pd.
JONES, LLEWELYN I. (b'70)-Tenn.I,90; (I'01); 1901 W. Douglas Ave.; oftice, Kansas Sanltarlun ; $9-11,2-5$.

Keester, Chas. Clarence (b;0)-1a.1,97; (l'07) ; 1015 Ellls Are ; offlce, $500 \mathrm{E}$. Douglas Are, 8-12, 2-5.

Kilbomrn, bilward 1). (b'81)-111.6.04: (l'08) ; 140 X. Estelle Are.; office, schwelter Bldg. ; 2-5; 0 b.

lilrkwood, James iv (b'51)-Ky.2,73: (1'01); 325 N. I,awrence Ave.; office, Schwe!ter Bldg. : 10-12, 2-5.

LA'TA, JOIIN MthlTON (b'53) \&-Mllich.1, '83; (l'01); 1542 Fairrlew Are.; office, liutts Bldg.: 10-12, 2-4.

Lawrence, Arthur K. (b'75) -0.25, 07 ; $\left(1^{\prime} 07\right) ; 517 \mathrm{~N}$. Main St. ; 8-11, 1-4, 6:30-8. Leatherman, John R.-Ky.2,84; (I'05); 119 S. Lawrence Aye.

LITTLE, GEO. R. (b'80)-111.6,07; (l'07) ; 523 N. Lawrence Are.; oftice, Schwelter Blde. ; $10-12,2-5$.

IOGSDON, RONALD OWEN (b'87)-Ky.2, 09; (1'09); 831 W. Central Ave. ; offlce, 116 F. Douglas Ave. ; $8: 30-12: 30,2-5: 30$; ObG.

LOGSDON, WH. T. (b'58)-Ky.2,89, 111.10 , 02 : (l'04); $908 \mathrm{~N}$, Maln St. ; offlce, 116 E. Douglas Ave. : $9-11,3-5$.

LOONIS, WESTERN CASS (b'81)-Ill.11, 10 ; (l'I1); $902 \mathrm{~s}$. Fern St.; offlce, 206 E. Douglas Ave. : 8-12, 2-6.

LYON, FIRED B. (b'80)థ-111.6,03; (1'04) ; .17'. Topeka Ave, offlee, Beacon Bldg. : $11-1,2-5$.

MAGGARD, DELANO I. (b'77) $\oplus-111.6,03$; (104): 1127 Emporia Are: offce, Beacon Bldg.; 10-12, 2-5; OALR. *

Maggard Irrin' J: (b'41)-Mfo.2,77; (l'01) 114 I N. Market St. ; offce, Barnés Bldg. ; $9-12,2-5$.

MATASSARIN, LEON (b'78)€-Rou.1,'0I (l'09); 1214 I'attie Are.; offlce, Schwelter Hllg. : $4-11: 30,2-\frac{1}{2}: 30 ;$ S.

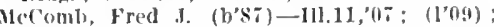
943 s. Water St.; offlee, Schweiter Bldg.; 11-12, 2-5.

ICCORMICK, GILBERT COPSON $\left(\mathrm{b}^{\prime} 74\right) \oplus$ 111.17,09; (1'11); 337 S. Seneca St. offlee, 311 E. Bouglas Are. ; 8-8; $\mathrm{s}$

McCoy, Addison W.-11l.1,74; (l'01),

IcVicker, Wm. D! (b'7I)-Mo.8, 00 ; (1'11) ; 1336 N. Market St.; S.

II (11 ENER, H. (b'63)-0.2,90; (l'01) 205 N. Washington St.; offlce, Schweiter Bldg. ; 2-5.

Mllford, Ethan S. (b'71) H-Ill.15, $\mathbf{H}$; (l'01); $641 \mathrm{~N}$. Market St. ; offlce, Sedrwick Block.

liller, Frank O'Hara (b'75)-Ky.7,'06 (1'09) ; $513 \mathrm{~N}$. Main St. ; 9-10, $2: 30-5$.

IILLER, LOREN B.-III.18,01; (1'04) $1344 \mathrm{~N}$. Waco Ave; office, $103 \mathrm{~W}$. Douglas

Ave. $10-12,2-5: 30 ;$ G.
Mills, Harry Lee (b'80)-Mo.29, $04 ;\left(l^{\prime} 04\right)$; 355 Clifton St. ; office, 505 Douglas Ave. 9-12, 1-5; $\mathrm{Pr}$

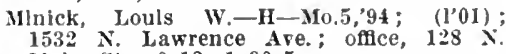

Maln St. ; $9-12,1: 30-5$.
Minick, Win. W.-H-Mo.5,91; (l'01).

MTCHELL, WALTON I. (b'77) †-Pa.9, 03 ; (1'05): 1819 N. Lawrence Ave. : offlce, Beacoń Bldg. ; 10-11:30, 2-5; ObG.

Montgomery, Fredk. W, (b'56) E-Me.3,'82 ; (1'01) ; 1106 k. Douglas Ave.; 2-5.

MYERS, THOMAS W. (b'80)థ-Mo.20,'04; (1'05); 2403 E. Douglas Are. ; offl

CORTON, HOWARD GEO. (b'86)-Kan.2 11; (1'13); 1119 Riverside Ave; offlce Beácon Bldg. II-12, 2-5; Pd.Æ

OLDHAM, JAMES E, (b'47) $₫-0.1,7 \tau$ (l'01); $1030 \mathrm{~N}$. Lawrence Ave.; offlce. Beacon Bldg.; $1: 30-5$.

PALMER, EDWARD II. (b'74)屯-IIo.20, 04; (1'02); 1111 Bitting Ave.; offlce, Beacon Bldg. ; 9-12, 2-5; OALR.*

Parr, William P. (b'32)-Pa.2,59; (l'01) : $\nabla 23$ Ida Ave.; $N$, $\star$

PHARES, WLLARD ALAN (b'80)-0.9 05; (1'07); 3428 E. Douglas Ave.; office, Schweiter Bldg.

PHIllPP, HERIIAN (b'62)థ-Ger.1,'s6 ; (l'09) : Barnes Blig. ; S.

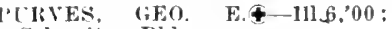

(l'(ii) Schweiter Bldg. 


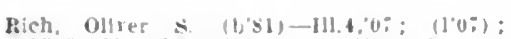
$174 \% x$ biminarla $x t$; unlce, lbeacon lilock : $9-1: 2,5$.

Hoss cuAs. E. (b'69)-110.5.95: (1.01)

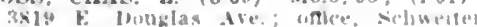
Blig: : 105

s'OTT, CHARLES E. ( (1'01): 621 X. Market St, omce, liarte: Hldk.: $9-12,:-5 ;$ Pd.

SRYUELL, BRSEST MORHA (b'2) H11.6,09: (l'11); 133 \&. Estelle Ire otllce, $105 \mathrm{~W}$. Louglas Are. : $9.12,25$.

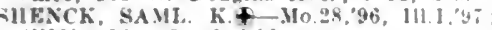
(l'01): Live stock lilds.

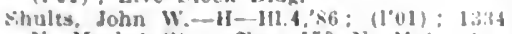
\$. Warket st. once, iso $\mathbf{x}$.Maln st. $4-6$

Slectl, lieo. Henry (b'68)-Kan.3.,00; (1'01) $134 \mathrm{~S}$. Water st; onlce, 120 b. Duglas Are.: $3-5$.

Simon, Vm. Fhert $\left(b^{\prime} 8 i\right)-k a n .2,13$ $\left(1^{\prime} 13\right)$ : St. Francls' Hospltal.

SI.ATOX, FRED II. $\left.(1)^{\prime}-5\right)+-111.1,01$ (1007); $1216 \mathrm{~N}$. Lawrence Are.: offle (l'07) 1216 N. Lawrence Are: offlee
:chwelter Bldg. : $2-5$.

Snilth, Orril L-Web.4,0t; $\left(l^{\circ} 0 t\right)$; $1110 \mathrm{X}$ Emporla st.

SI. John, J. Ada (b'4)-Mich. 1,81; (I"01) 600 N. Topeka Are.

Sutter, Loe Albright (b's3)-Colo.2, 12: (1)

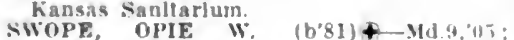
(1'10): Schwelter Blds.

TAGGART, HFNRY HLTCHISON (b', $190.8,00$; (1'01); 221 Indlana Ave. : Offle" Schwelter Bldg.; $0.12,2-5$

Taylor, Ollrer J.-Ill.t, 90 ; (l'01); 114 f: Douglas Are.

Trice, chas. W. (b,54) 11-Mo.10,'82, 0.2. '8s; (1.01): not in practice.

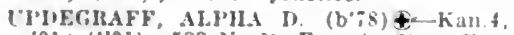
$01 ; 1101)$ \&33 X. st. Francts st. ; onfee, Schwelter Bldg. ; $-5 ;$ S.

vickers, John L.-Ky, 4,95; (1001) ; $32: \mathrm{s}$ Topeka Are.: 9-12, $2-4$.

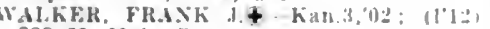
$333 \mathrm{x}$. Ialn St.

WaIsh. Fidward Jos.-111.1,91; ( ) : Muind Blily.

Walsworth, Frank [1. (6;9) - $110 . \mathrm{n}, 1+1$ : (1.06) : $120.5 \mathrm{~W}$. Douglas IVe.

Ward. Criah Irvin (b'38)-0.11, "4j; (I'01) Jisonic Home.

WAHAKX, LLOID P. $\left(b^{\prime} ; 0\right) \pm-M w, 24,00$ (1'01): $927 \mathrm{X}$ Liwrence Ire. oflice sichweiter Hldg.: 9-1\%, 2-5: OALR. *

Wayson. Jewton Edw. (L'83)-111.t, 10 (1): st. Francls' Josital.

WEA VER, THE()HORE WALKEK (6.85) + Mo.2.12; (J'12); $127 \mathrm{~N}$. liutan die natce, $105 \mathrm{~W}$. Dumglas Ave; $9-12,2-5:$ Op.

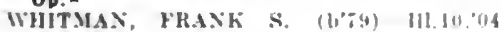
111.6,05; 11'121: 1201 Hirerside die. once, 14 X. Maln : $110.12,2,5 ; 0 b$.

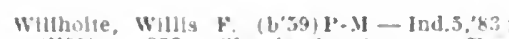
(l'01): 333 ('loveland Are.; nnce Schueltor Midz: : 10-12, 2-5; Pr.

WILLIAIS FHED \&. (b'1)-111.10.04

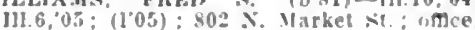

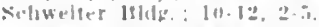

WILLARD, 200, SHAWNEE

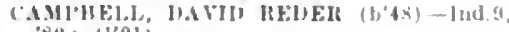
$80: 11.01)$

smith, (1yde S. (b'81)-Ia.10,05; (1'0.5)

WILLIAMSBURG, 399, FRANKLIN

Mrown. Wurwlek Thos, (b'gu)-Kan,3,13: (1.13)

Janes, (ieo. K-Mo.184; (1.01).

lieed, Geo. I). (6'70)-Kan.3,99: (1'01).

WILLIS, 188, BROWN

(') MF.ll, JoHN J. (b.66) $4-111.1 .93$; (103)

WILMORE, 120, COMANCHE

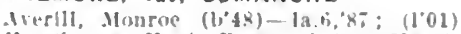

llawllornte, Huzh Hogkx (b.R)-Kan.3,"1", (1'13).

WILSEY, 400, MORRIS

Heam, Alverl (b'71)—Mo.20,0s; (l'0s)

(iarey, J. H. (b'51)-Pa.2, 85 ; i1.01)

swann, Alfred Thomas (b'63)-Mu.20, 03 ; (1,05).

WILSON, 981, ELLSWORTH

(AJTEK, JOHNATHAN BASII, (b'Ti)

Kan.2,10; (1'10).

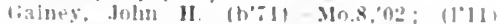

(1) 0 NELL, ARTHUI E. (b'ii) \$-Mo.2n 00 ; (1'01)

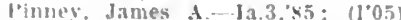

WINCHESTER, 456, JEFFERSON

Boyd, Abner II. (b'59)-Ky.4.'34; (l'01) : S 'et?la, Artbur Lekoy (b'86)-Kan.3,13. (1'13).

STEIETT, DAVID ROBL $\left(b^{\prime} \& 0\right)+-K i n .3$ OT; $(1,07)$

WINDOM, 176, MCPHERSON

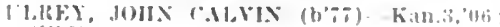
$\left(I^{\circ}(16)\right.$

WINFIELD, 6.700, COWLEY

lsurroughs, (has, Lelloy-111.1, it, X.Y.10, 66: not in practlee.

(atre, Freal 1'- - M10.28,03: (1.04)

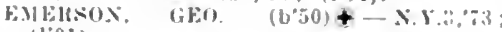
$1101)$

Emery, Frank W.-Mo.20.95; (I'01).

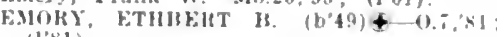
(1'*1):

Evans, John liaust-0.1, $81:(101)$

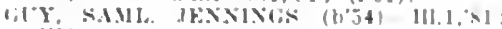
(1)01)

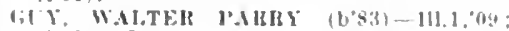
1'101: $\mathbf{S}$.

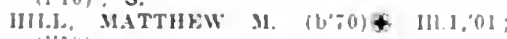
(1'10).

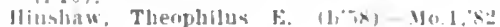
(l'o)

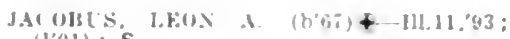
$(101): 8$.

JAMES, RALHH WARU $(6,00,+-111.6,03$. (1.0\%): S.

KFILEY, YORRFAT A. (b':5)-Vieb.6.06: (l'06).

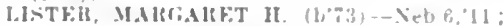
(1.11): not In practlce

Marsh, IIram W. (b'34)-Mich.1,66; (1)01).

I'OWEHS, JOHN HAROLT $\left(b^{\prime} 6\right)+-M 0.8$. 04: (1'02); S.

l'ugh, ('bas k $\left(b^{\prime} n t\right)-01,84 ; 1 l^{\prime} 01$

RALIAS, CLAYTON THOSHS $\left(b^{\prime} 81\right)+$ .ld.3,04: (I'05); OALR.*

Heynolds, Oscar Hugh W. (b'54) H-Mo.35

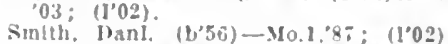

SМITH, EDWAKD 0. (b.69) +-1a.9.95: (1)01). FLAVIL'S II. (1)"63) †-Ia 1,89 (line; : S.

SNYDKR, HOWAIR I. $\left(6^{\circ}, 8\right)+-1 \cdot 2,04$ (I'04): S.

TORMSICE, FRED E.IERSON (b'82)-I11.1 '12: (I'13): Member 111. State Med. Soc. WILMER, FRINCIS M-III.11.96; (1'01) Wrighe, Wm. T.-1a.1,68; (1'01); not fo

Wractice. (1'06); S.

WINONA, I30, LOGAN

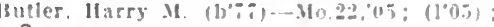
S.

WONSEVU (R.F.D., CEDAR POINT), 25, CHASE

Mason, Walter S. (b'50)-IIl.1,50; (\$),

WOODBINE, 230, DICKINSON

Foster, Wm. B. $\rightarrow$ : (1'01).

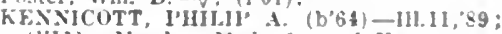

(l'i1); Némber Med, soc. of Ya.

WOODRUFF, 200, PHILLIPS

hueffer, Fredk. Mllion-1lo.5,05; (1\%).

WOODSTON, 299, ROOKS

("nlby, kimery E. (b"i3)-Mo, -,01; (101). l'arker, James (". (b)43)- : (I'01).

YATES CENTER, 2,024, WOODSON

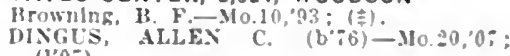
$\left(1^{\prime} 07\right)$

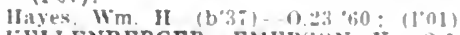

KELLENBERGER, FMERSUN k.-0.1," 1 ; (l'01).

I.Ek, GEO. W-MO.:2:92; (1.01)。

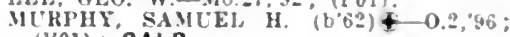
(1'01): OALR.

Reynolds, Mortinure $\therefore$ (b) bis)-1a.1.90: (1'05).

Robinson, Ole F.-Ia 111, n1; (1.04)

WST, HEXHY II $\left(\mathrm{b}^{\prime}, \mathrm{J6}\right)+\mathrm{Ky}, 1,80$ (1'01).

ZENDA,200, KINGMAN

Ihlllips, Chas. Elston (b': $)$-Kan 3,05; $(105)$.

FOR KEY TO SPECIALTIES, ABBREVIATIONS, SYMBOLS, ETC., SEE PAGE 55I

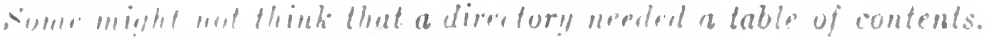

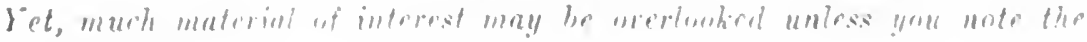
iontents, puge il. 


\section{KENTUCKY}

NoTE:--The general information of thls state inclueles: Medical Law, State Board of Health, State Association, State Journal, County Offlers, County mul Cly Health Ottleers, State Institutions, Ilospltals, Sanatoriuns and Charitable Institutions.

\section{KENTUCKY}

Population (1910 census)

$2,289,905$

Number of Counties...

120

Members State Association, Dec. 31, 1913.

Area of State in Square Miles.....

3.621

2,100 40,598

\section{MEDICAL PRACTICE LAW OF KENTUCKY}

Section 1. STATE BOARD OF HEALTH : $A$ board to be known as the State Board of Health is hereby established. It shall consist of eight members, all of whom shall he legally qualifed reglstered practitioners under this Act, seven of whom slatl be apunder this Act, seven of whom sliall be ap-
pointed by the governor, by and with the pointed by the governor, by and with the adrlce and consent of the schate, and the
elglitl member, who shall be the secretary and executire offlcer, shall be elected by the board, and by virtue of his offlce of secretary shall be a member of the board. One member of the board shall be a homeonatlic, one an eclectic, and one an ostcopathic physician, and the other appolnted members shall be regular, or altopathic physicians, all to be appointed by the governor from lists of three names for each vacancy, furnished respectively by the state society or assoeiarespectively by the state society or associa-
tion of such schools or systems of practice tion of such schools or systems of practice cessors of such members sliall be appointed in the sane mamer. If the board shall elect one of its members secretary, as it may do, the governor shall appoint another member to complete the full number of the board. The president and secretary shall have anthority to admintster oaths for the purpose of this Act, and the memibers of the board shall. hefore entering upon the discharge of their luties, take the oath pre-
scribed by the constitution for state offleers. Sec. 2. MEDICAI IHGISTEIt KEPT BY Shall be CLERK: DUTIEs; FEES: It county to purchase a book of suitable slze, to be known as the "Medleal Itegister" of to he known as the "Medical Itegister" of the county, and to set apart one full page
for the registration of each physiclan : and for the registration of each physiclan; and
when any physician shall die or remove from when any physleisu shall die or remove from same at the bottom of the page: and said elerk shalt. ou the first lay of January in each year, transmlt to the offlee of the State Board of IIealth a duly certlfled list of the physleians of said county reglstered under this law. together with sueh other informatlon as is hereinafter required, and perform such other duties as are reduired by thls such other duties as are reduired by this taw; and such clerk shall receive the sum of fifty eents from each physlcian so recisfor all the duties required under this law.

Sec. 3. REGISTRATION BEFORE PRAC-

TICING: It shall be unlawful for any person to practice medieine, in any of its branches, within the limits of this state, who has not exhlbited and registered in the county elerk's offlee of the county in which he resides, lits authority for so practicing medicine as herein prescribed. together with his age, address, place of birth, and the sehool or system of nedielne to which he mopuses to belong; and the person so registered shat subscribe and verify by oath before such elerk, an afflavit containing such facts, which, if wilfully false, shall ishument for perjury.

CERTIFICATES; QUALIFICATIONS: FEEs: Authority to practice medicine under this Act shall be a certifleate from the state board of Health, registered
In the county in which the holder resiles und said boari shall issue a cartlfleate to uny reputable physiclan who deslres to practice mediene in this state. who has passed a satlsfaetory examination before it, in the iranches of mediclne as taught in reputable medleal colleges; and sald board shall, upon application. alnit to examination any person of good moral character, who may po

se any of the foltowing qualifications:

1. A diploma from a reputable medieal cotlege. legally chartered under the laws of this state.

2. I diploma from a reputable and legally chartered medical

state in this union.

3. Satlsfactory evidence from the persun claiming the same thint sueh person was reputably and homorably engaged in the practles of mediclue in thls state prior to cub. 23, 1884

Applicants may present their credentials by mail or proxy and shall receive due notice of the mite and date of examination. Certifleates shall be signed by the president and secretary, and attested by the seal of the board, and the fee for each examination. including the certlflcate, slatl not exeed the sinm of ten dollars. The members of the bourd shall be entitled to receive ten dollars per day and thelr necessary traveling exper day and thelr necessary traveling exlenses for each day devoted to such exam-
Inittions, to be pald from the fees provlded lerein, and the board shall have authority to provide for such assistants as it liay leem necessary any pay for the same from the fund arlsing from such fees.

Sec. 5. ExAMINATIONS : Examinations shall be held at least semi-annually at Frankfort, louisville, Lexington, or other centraliy located places, and on such dates as the bourd may deen will best sult the convenience of the applicants. The questions for all examinations in the branches common to all schools or systems of practlee shull be prepared by a committee of llio board, to conslst of five members, one if whlch shall be a homeopath, one an eclectic, and one an ostcopath, and sald committee shall conduct alt examinations and grade that conduct ali examinations and grade the sume, and when any applieant has made rraded the board of Health shall admit such applicant to the practice of his or her profestion in this state. All examinations shall be condncted in writing, and in such manner that the result shall be entirely falr and lmpartial, the applteants being known by numbers so that no member of the board shalt be able to identify the papers of any applicant until tisey have been graded and applicant until they have been hraded and the case passed upon; and all questions and
answers, with the grade attached shall be answers, With the grade attached, shall be
preserved for one year. All applicants exbreserved for one year. All applicants exquestions asked them in auatomy, phystology, obstetries and the other branehes common to all systems of practice, and shall be reguired to make an average grade of $\mathbf{7 0}$, with a minimum of 60 in any one branch; but all examinations, involving methods or principles of treatment, shall be made and graded by that member of the board whe represents, or most nearly represents, the represents, or most nearly represents, the appllcant befongs, or the board may, in its applleant belongs, or the board may, in its
discretion, omit the examination in sueh discretion, omit the examination in sueh
loranches. No member of the board shall bo a stockholder or memher of the fneulty or board of trustees of any medical college.

See. 6. PItACTITIONERS OF OSTEOPATIIY; QUALIFICATIONS ; CERTIFItice of osteopathy in this state prior to Feb. $1,190^{\circ}$ who holds a diptoma from a reputable osteopathic college, laving a course of not less than four terms of fire ntonths each, legally chartered under the laws of any state in this union, as deter. inined by the osteopathic member of the board, und who makes applleation to the state Bonrd of Health within ninety days after the passage of this Act, aceompanted by the fee hereinbefore provlded, shall receive a certiflcate from the board withont an examination, which, when registered in the office of the county clerk of the county of his residence, as required of other certif. of his residence, as required of other certifi. cates issued by the board, shall authorize this commonwealth, but it shall not permit him to administer drugs, nor to perform surgical operations with the knife The words "practlce of mediclne" in this Act shall be held to include the practice of osteopathy But no person shall be permitted to practice osteopathy in this comand certifleate as provided in this seclion.

Sec. 7 SPFCIAL APPLICANTS ; FXAMINATIOSS: Any other person applying for authority to treat the sick or injured, or in any way discharge the duties nsually performed by physlelans, whether by medical, surgical or mechanical means, shall apply to the State Board of Health, who shall examine them as to thelr competency in guch manner as they nay deem fair and best. but manner as they niay deem fair and best. but
such examination shall always include such examination shall always inelude terms "practice of medlcine" as used in thls Act, shall be construed to be the treatment of any human allment or infirmity by any method; but this shall not include trained or other nurses, or persons selling proprletary or patent medicines, when not trareling as a troupe or troupes composed of two or more persons.

Sec. 8. LICENSE FOR TRAVELING MEDICAL COMPANIES; FEES; FINES : That any itinerant medical company of two or more persons traveling as a troupe or conpany as vendors of any drug, nostr'm or instrument of any kind, intendel for $11, \mathrm{e}$ treatment of any disease or injury, or who shall, by any writing or printlng, profess to the pubile to treat disease or deformity by the use of any drug, nostrum or instrument shall pay to the board a lleense of $\$ 100$ per month, which shall at once be conveyed into
the state treasury. The board shall issue a license to reputable and worthy applicants under this section on payment of the fte each month, but may for sufficient cause refuse such lieense. Any such itinerant rendor traveling as a company or troupe, whth two or more persons as members or in its cmploy. who shall treat or profess to treat or cure disease or injuries by the use of any drug. nostrum or instrument without license to do so, or shall sell the same for such purpose, in violation of this section, shall, upou conviction, each and every person so engaged, be fined fffty dollars for the first offense, and upon each subsequent con
viction shall be fined one hundred dollars.

Sec. 9. ITINERANT DOCTORS: Nothing in this Act shall be so construed as to authorize any linerant doctor to register or to practice medleine in any county in this state.

Sec. 10. EXEMPTIONS FROM THIS LAW: Nothing in this law shall be so construed as to discriminate against any pecullar sehool or system of medicine, or to prohlbit women from practicing midwifery or to prohibit gratuitous services in cases of emergenes; nor shall this law apply to com missioned surgeons of the United States Army, Navy or Public Health Service, or to legally qualified physicians of another state, called to see a particular case or famlly, 
but who does not open an omie us ajuolust any place in thls state whern the or the may meet patients or revelse calls.

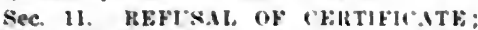
REVOCATION: The state lond of Healti may refuse to lasue the certilleate prowlded causes:

1. The presentation to the buand of any license, certiffcate or diploma whic's tras illegally or fraudulently obtalned. if the practlce of fraud or deception In pasing the exacuination.

\&. The commlssion of a criminal absetlon or conviction of a felony luvolvina moral turpltude.

3. Chronlc or perststent Inebrlets, or .ut diction to a drug hablt, to an exte'it wi $\mathrm{ch}$ disqualites the appllcant to pracifre with alety to tho peojle.

4. Or other grossly unprofesslon al ur dis honorable conduct of a character likely to decelve or defraud the publtc.

The board may suspend or reroke a cur lifcate for any of the causes for which may refuse to grant a license under the pro. rislons of thls Act. In all proceediuks for suspenslon of revocation under this fot the holder of the certiflcate shall be furnivibel with a copy of the complaint, and shall le giren at least thirty dass thereafter is prepare for a hearing: and he shall be leara in person or by counsel, or both, as he liay elect, and ln such hearlng and in wll matters arlsing in the course of thelr dutles the president and secretary shall hare suthorliy president and secretary shall bare suthorliy the board may take oral or writen primf for the board may take oral or wristen ptimf for will best present the facts. In all cases of refusal, suspension or revocation the appllcant or holder may appeal to the gorernor. who may amrm or operrule the declsion of the board. Upon the suspension or rerocation of any certfleate It shall be the ciuty of the board to glve ofticial notice of $: i \cdot 1 \mathrm{ch}$ action, under seal, to the county cleri of the cointy in which the holder is reslstered. and such name shall be market as suspended for the period indicated, or sirlcken pended for the perlod indicated, or sirlcken
from the rezlster. In accontance with such notice, and if such holder shall contlnue to practlce he shall thereupon be subject to tho penalties provided in the law to which this is an amendment.

Sec 12. REPEAL: Tils Act shall take effect and be in force in accoriance wlth the provlslons of the constitutlon, but it is expressly provided that all certiflcates issued by the board under the proslsions of the law to wlich this is an amendment are hereb condrued and continued in force, ant all students who are matriculated in any medlcal or osteopathic college in this commonwealth on is before Feb. 1.1904, and shall hare graduated prlor to Sept. 1, 190:, and make applicatlun to the boand prlor to Jan l. 190s. shall recelse certificates without examination. NIl acts and parts of acts In examination. All acts and parts of acts in conflet with the

Sec. 13. VIOIdTIOxs: it shall the the duty of the state and Ineal boards of healu to bring to the attention of the courts any rlolations of the prurlsions of this law wlehin thelr resyective jurludictlons.

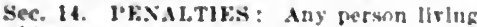
In this state, or any person coming into this inte, who shall practice mediclus, or atstate, who shall practice mediclise, or aturanches, or who shall treat or attempt to treat any sick or afflicted person by an treat any sick or affleted person by any compensatlon withous first complylng with the provistons of this law shall, on cunvio ton therecif, the fined s5o, and on each and every subsequent conriction shall the ineal $\$ 100$ and Imprisoned thirty days. of elthe" or both, In the discretion of the cuurt is jury trging the case: and in no case where any prorlsion of this law has been vlolatou hall the person so violating be entielel in shall the person su violating be entitlel to recelre ally compensation for the services
rendered. To open an offlce for such pur pase or to annunce to the public in an way a readines to treat the slck or anlicte shall be deemerl to engage In the vracllore of mealieine wlthin the meaning of this $A(\mathrm{ct}$

Act as amesuled Felb. 1, 1901.

\section{STATE BOARD OF HEALTH}

Juhn 1:. Snuth, l'resldent. Frankfort:

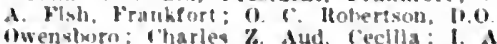
Owenstmorn: 'harles Z. Aud. Ceclla: I. A

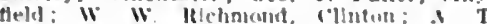
MeCormack, Secretary, Bnwllog Gieen.

\section{KENTUCKY STATE MEDICAL ASSOCIA. TION}

(Inlcers 1913-14 Wm. O. Hoberts, Presldent....... Inulswile J. I. Neel Ist Vlce-I'resldent. J. B. Kinualrd, 2l VIce-Presldent. . Jancaster

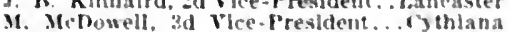
i. T. Mccormack. Secretary. . Bowling fireen

\section{State Journal}

Kentucky Medleal Journal, Kowllng tireen. A. T. Mecormack, M.D., editor.

\section{Councilor Districts and Omcers}

Fonest Iau, Chalrman, Bowling Green.

First District-Ballard, Caldwell. iallo way, Carllsle, Fulton, Graves. Hickman, Jir Ingston, Marshall, Iyon, IcCracken an Trige counties.
cilor. clinton.

Second Itstrict. - Crittenden, Dariess, Hancock, Henderson, Hopkins, Muhlenber, Inlon, Ohlo, McLean, Breckenrldge and Wiebster countles. Cyrus (iraham, Councilor. Itenderson.

Third Distrlct. - Allen, Harren, Butler, Chrlstian, Cumberland. Fdmondsnt, Logan Metcale, Monree, Simpson. Todd and Warre countles, Ernest Rau, Councilor, Bowling ireen.

Fourth District.-Bullti, Grayson, Har dlin, Henrs, Larue, Meade, Hart, Velson. Oldham and Shelby counties. C. $z$. Aud Councilor, Cecllian.

vif:h bistrlct.-Inderson, Boone, Carroll Franklln, Gallatin, Jefferson, Owen, spencer and Trimble countles. D. s. Witson, Coun-llor, Valley station.

Slxth Distrlet. - Adalr, Boyle, Freen. Yarion. Mercer, Tayler and Washington countles. R. C. Mcchord. Counctlor. Lébilhon.

Serenth Distrlet-Cases, Clinton Gar rand, Lincoln, Pulaski, Hockeastle, Kussel and Wayne countles. Councllor, Dunnsllle.

Elghth Distrlct-Wourbon, Bracken Flem ing. Graut, Varrisnn, Jessamlne, Kemton, Campbell, Mason. Nicholas, Pendleton, Rob ertson. Scott and Woodford countles. J. Wolls, Counellor, Cyuthlana.

Ninth Distrlet. - Boyd, Carter, Ellloute, Greenup, Johnson, Lan rence, I,ewis. II gotnn and Plke countles. J. W. Kincalt Councllor. Catlettsbure.

Tenth DIstrlct.-Hath, IBrothitt, Clark

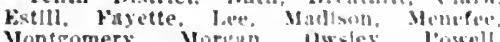
IIonigomery. Morkan. Jwsley. Lowell. Howan, hinot, Letcher. berry and Wulf chuntes.

Elerenth Dlstrlet-Bell, ('lay, Harlan. Jackion, Knox. Leslle, lanirel and Whttle counties. J. s. Loek, conncilur, barlume
ville.

Component County Socleties of the Ken. tucky State Medical Association Alinit rol.NT

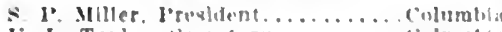
I. Taslor, secretary......... Columbia

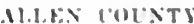

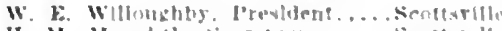

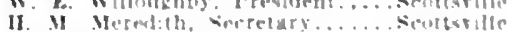

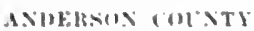

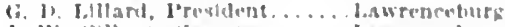

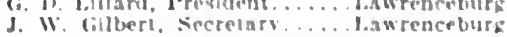

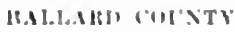

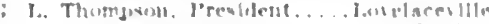

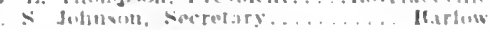

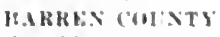

(T Ilints. Irtudalant.
H.1TH OH NT

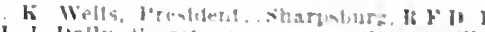
H. J. Dally, Secretary........ (jublasille IIELI, IOENTY

Fdward Wilsest, l'rewlent

i. P. Nuckols, seretary.

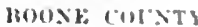

I'Inesille l.ine ille

13. K. Mendfee, I'resilethe BOLIBHON con:Th

Wm. Kenny, Jr., presilen:

C. G. latughery, sectetary. III) (OT)

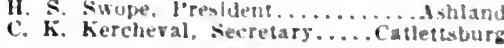
BOYTE COLNTI

O. L. May I'resldent............ Nanrllle W. II Smith, secretury.............. IIanvillo

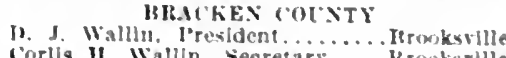
Corlls II. Walln, secretary..... Hronkstlle MIE.LTHTT COINT

Myrrin F. Hoge, l'resident....... Qulcksand Asa M. Irnoli. Secretary............ Jackson BIRCKF, HIDGE COUNT

John W. Meador, resident........ Custer

John E. Kincheloe, secretary....ilardiasbur. HULITT COLNTI

W. W. Hill, l'resident........... Reechmunt

S. H. Kidgway, secretary....... Shephendsrlle BLTIRK COUNTI

F. 1. Cherry, Eresident..........Morzantown C.UDWELL COLNTY

․ J. Pollard, President.......... P'rlaceson R. W. Ogilrle, Secretary........... Prince:on CALLOWAY COLNTI

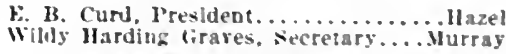
CAMRELL-KFNTUN COLNT:

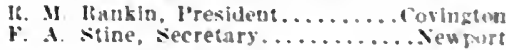
CAILISLE COIXT

J. F. Dunn, l'restdent............ Arling?un

T. J. Marahall. Necretary............ Barducell CAKROLL COLNTY

E. H. Driskell, l'resldent........Worthrille

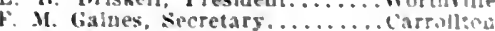
CARTER COLNTI

T. T. Bays, President............fraywn

11. B. Wileox, secretary.............tirarum CASEL COLNTI

1. S. Wesley, l'resddent............ Literty

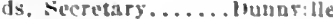
CHRISTIST COLNT

II. IN. Watts, Jreallent.......... Hetulirohe t'Math COLNT

W. A Busli. I'resilent.

Winchester Sceretary..... (0)

sant. simblh, l'restelent.

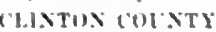

F. W. IItublestum, prestelent ....... Aloany S. F. sterbenson, serretary..........lbany CHTTENLE: COIDTY

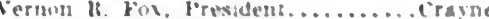
J. kirnest box serretary........... Marion

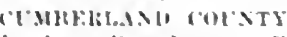

R. L. Hebardson, I'rewilent.... Kurkessille

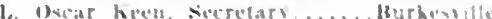

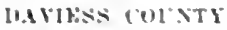

3. II simart, I'ruvilent

oremalnato

J. J. lindasan, siceretary R.1.1.70Tt COl:Nty

J. II Harmer, lereshlent........

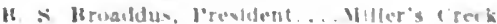

(i. I Fintiry. secretary............. trone FAYTt: col一ts

art l. Whecler, Frealdent.

tevenou, smorelary. H.HUIN COIT: 
FIANKLIN COUNTY

i. A. Budk, I'resident............ Frankfort FULTON COUNTY Horace Iuten, I'resident........... Fulton
P. B. Curlín, Secretary.......... Hifkman GALLATIN COUNTY James Brown, l'resident............... GALIIRALD COLNTY

Wm. L. Curmen, l'resident........'Paint Lick J. B. Kinmalru, Secretary.......... Lancaster GiRANT colote

A. V. Mencfer. Iresident.... Wiflianstown dimaves covinty

J. L. Dismukes, l'resídent............tayfiet Herbert 11. Ilunt, Secretary.............hayfleld GRAYSON COUNTI W. S. Clark, President............ Leitchtleld GREEN COUNTY

0. 1. Shively, President.........Greensbur

13. .1 Taylor, Secretary.............Greenstur GREENUE COUNTY

II. T. Morris, l'resident............Greenup

J. I. Rathburn, secretary.............1kussel HANCOCK COUNTY

A. Griftn, I'resident............ Hawesville

J. T. Milner, secretary..............Patesvilile HARDIN COUNTY

F. I. Susz, President............... Cecilia HAILAN COUNTY G. P. Bailey, President........... Harlan HARRISON COUNTY H. T. Smiser, President........... Cynthiana
William B. Moore, Secretary.....Cynthiana HAIT COUNTY I1. P. Honaker, President....... Horse Cave
c. H. Moore, Secretary ........... Canmer HENDERSON COUNTY

W. A. Poole, President..........Henderson

B. J. Neary, Secretary.............. Henderson HENRY COUNTY

A. M. Zaring, President.......... Smithfield owen Carroll, Secretary................ Neweastle HICKMAN COUNTY

R. L. Bushart, President.....R.F.D., Fulton HOPKINS COUNTY

F. P. Strother, President.......... Iradisouritle

A 0 . Sisk, Secretary...............Earlington JACKSON COUNTY

G. C. Goodman, President........Welchburg

w. B. Hornsby; Secretary.............teKee JEFFERSON COUNTY

C. H. Harris, President.............. Louisville
E. L. Henderson, Secretary...... Louisville JESSAMINE COLNTY

T. R. Welch, President......... Nicholasvilte
J. A. Van Arsdall, Secretary... Nicholastille JOHNSON COUNTY

F. M. Williams, President........Palntsville

J. H. Holbrook, Secretary........... Paintsvitlo KENTON COUNTY

(Included in Campbell-Kenton Counties.) KNOTT COUNTY

M. F. Kelly, President............Hindman

Owen Pigman, secretary.................... KNOX COUNTY

S. C. Jones, President.......... Barbourvllle
Chas. L. Heath, Secretary......... Lindsey LARUE COUNTY

C. O. Moore, President............Gleanings IAAUREL COUNTY

J. W. Crook, President................ Bush LAWRENCE COUNTY

W. A. Hayes, President.............Adams

F. D. Marcuin, Secretary............ Torchlight LEE COUNTY

C. E. Baker, President........... Heidelberg
A. B. Hoskins, Secretary....... Beattyrille
HSLIE corvTy

P. I. lieith, I'resident............1sig Creek

is. 1. Collins. Seeretary............... . Hyilen HETCHER COUNTY T. A. Cook, President............ Democrat L.WIS COUNTY

(. E. Stout, President.............. Hartin IINCOLN COUNTY

1. r. Iones, fresident............... Orangard IIVNGSTON COUNTY

J. V. Hayden, l'resident............ Salem Edward Darenport, secretary................mpton LOCIAN COUNTY

.1. K. W. I'iper, I'resident.......Russellville Walter Byrne, Jr., Secretary.....Russellvllle LYON COUNTY

'T. I. I'hillips, I'resident........... Kuttawa II. Hussey, Secretary............... Eddyrille MAIISON COUNTY

Mturison Dunn, I'resident.......... thelmond James $w$. scudder, secretary...... Riflumond MAGOFFIN COUNTY

R. C. Adams, President.......... Salyersville I. C. Kash, Secretary............. Salyersville MARION COUNTY J. K. Cissell, President............. Loretto MARSHALI COUNTY

Alonzo J. kean, Presldent...........llardin Lawrence $\mathrm{L}_{\text {. Washburn, Secretary..... Benton }}$ MASON COUNTY A. O. Taylor, President...........Maysville MCCRACKEN COUNTY

O. R. Kldd, President.............. Padueah Delia Caldwell, Secretary.............Paducah ICLEAN COUNTY J. S. Fitzhugh, President............ Island MEADE COUNTY

T. H. Hardesty, President.......Paynesville E. C. Hartman, Secretary....... Brandenburg MENEFEE COUNTY

Stephen Swango, President...........Means J. M. Kash, Secretary................... Feanchburg MERCER COUNTY

A. G. Freeman, President............ Burgin

$\therefore$ B. Van Arsdall, Secretary.............Burging METCALF COUNTY

1. W. Bushong, President......... Edmonton

H. R. Van Zant, Secretary.........Edmonton MONROE COUNTY

Jesse T. Smith, President...........Gamallel

Richard F. Duncan, Secretary. Tompkinstille MONTGOMERY COUNTY

Banford M. Manning, President. .Mt. Sterling

J. F. Jones, Secretary.............it. Sterlíng MORGAN COUNTY

B. F. Carter, President........W West Liberty MUHLENBURG COUNTY H. D. Newman, President....... Drakeshoro NELSON COUNTY H. E. NeKay, President.......... Bardstown
I. D. Rodman, Secretary...... Bardstown NICHOLAS COUNTY

J. C. Martin, President............ Carlisle oHIO COUNTY

J. W. Taylor, President...........Hartford

Oscar Allen, Seeretary. ............. Crom well OLDHAM COLNTY

J. E. L. Harbold, President...... La Grange

E. D. Burnett, Secretary...........Anchorage OWEN COUNTY

J. C. B. Foster, President.......... Owenton John H. Chrisman, Secretary.......... Owenton OWSLEY COUNTY

C. M. Anderson, President........ Boonerille A. i. Glass, Secretary..............Booneville
PENDLETOX COUTTY

J. Ed. Wilson, Iresidelt........... Falmouth PEIRY COUNTY

S. Marcellus Ritchle, President......Hazard Marshall E. Combs, Secretary....... Hazard PIKE COUNTY

J. W. Viears, President...........Plkeville POWELL COUNTY

W. ('. Martin, President.......... Clay Clty

1. W. Jolnson, Secretary........... Stantoin IULASKI COUNTY

Leonlidis IIughes, President.......Faubush

Carl Norflect, Secretary............. Somerset ROBERTSON COUNTY

J. B. Wood, President............... Ollver W. S. Chandler, Secretary............. Olivet ROCKCASTLE COUNTY II. H. Joyner, President.......... Iivingston ROWAN COUNTY

F. II. Thomas, President..........Morehead RUSSELL COUNTY

L. D. Hanmond, President.......Irvins Store

1. B. Scholf, Secretary..............Jabez SCOTT COUNTY

L. F. Heath, Presldent................ Newton SIIELBY COUNTY

s. 1. Beard, President.......... Shelbyville W. E. Allen, Secretary...R.F.p., Shelbyrllle SIMPSON COUNTY E. K. Lamb, President.............Franklin SPENCER COUNTY

J. F. Furnish, President.........Waterford Secretary............. Wakefleld TAYLOR COUNTY

o. M. Kelsey, President........... Eik Horn J. L. Atkinson, Secretary...... Campbellsville TODD COUNTY

C. I. Gower, President...........Trenton TRIGG COUNTY

Homer Blalle, President.............Cadi\% J. L. Hopson, Secretary...................... TRIMBLE COUNTY

C. C. Fix. Presldent.............., Bedford ck, Secretary............Bedford UNION COUNTY

c. P. Cottingham, President......Uniontown

S. 1. Henry, Secretary........... Unorganfleld WARREN COUNTY

T. W. Stone, Presldent......Bowling Green B. S. Rutherford, Seeretary..Bowling Green WASHINGTON COUNTY

W. T. Barnette, President....... Springfleld J. H. Hopper, Secretary........... Springfield WAYNE COUNTY

J. A. Jones, President.............Monticello J. F. Young, Secretary...............Monticello WEBSTER COUNTY

D. H. Cosby, President........ Vandersburg Roy Orsburn, Secretary............... Sebree WHITLEY COUNTY C. G. Ellison, Presldent.......Williamsburg
Clive Arthur Aloss, Secretary. . Williamsburg WOLFE COUNTY

W. T. Center, President.........Hazel Green B. D. Cox, Secretary................... WOODFORD COUNTY

S. A. Blackburn, Presldent....... Versailles J. w. Crenshaw, Secretars.......... versailles

\section{COUNTY HEALTH OFFICERS}

County 1 Address Allen.-J. E. Pace.............. Columbia Anderson. - C. W. Ka rana........... L cottsville Ballard.-N. L. Rogers............ Wickliffe Barren.-S. J. Smock................. Glasgow Bath.-A. W. Walden.......... Bell.-J. G. Foley ............... Pineville Boone.-F. L. Peddicord............. Burlington Bourbon.-Silas Evans................Paris 
Boyd-J W. kincald.......... Callettuburz

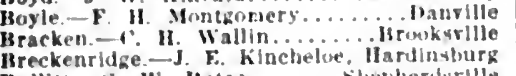
Bultlt. $\rightarrow$. W. Isates........ siliegherdsrllle Butler.-J. II. Austin............ Morkantuwn Caldwell. - R. W. Gallele......... l'rinceton

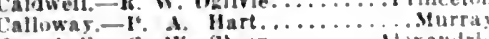

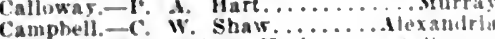

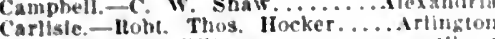

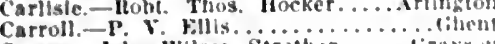
Carter-John wilson Strother....... liray we,

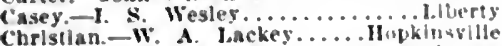
clay.-Isaac s. Manning............ Mubeheste clinton. John A. sloan............ Allany Crittenden. - T. Atchlson Frazer.....Martm Cumberland.-L. Osear Keen.... Murkestll

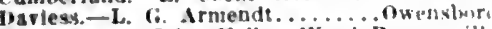
barless. - L. - John Kelley irood. Brownsville Ellott. - A. II logon...........sandy llook Estlll. - Gildeon A. Embry........... Irrin Fayette. - E. It. Mradley........ I.exington Fleming - J. C. S. Brice...... rlemingshurg
Floyd-HIon. A. J. May..... Prestonsturg Franklln.-Fugene Carl icemele. Frankfort Fultou. - John Marshall Alexamler...Pulton Gallat!n. -s. B. Robinson.......... Warsaw

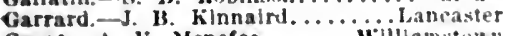
Grans.-A. Menefee......... Whithation Graves.-Jolin 1.. Dlsnukes. Jr........Ma fifeli Grayson.-Wm. S. Clark......... i.eltelifleld Green. -B. M. Taylor........... lireenshurg

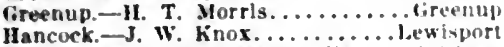
Hardln.-Martin Sylvester Ailen..... stltizson Harlan. -W. I. Cawood............ Harlan Harrlson. - Marshall McDowell.... Cynthlana Hart_Sarah Felt Richardson. . Munfordville IIenderson-Peyion Ligon....... II Ienderson Menderson.-Peyton ILIon....... Henderson
Henry, Owen Carroll........... Castle Henry.-Owen Carroll................ Clinton Hopkins. -J. D. Sory........... iladisentille Jackson. - Wm, Boyd IIornsby

....................Burning springe Jefterson.-B. iw. Smock......... Loulssille Jessamine. - Theodore B. Pearson...Wilmure Johnson.-F. v. Danlel........... Palntsrllle Kenton. - R. L. Blrd...............utonta Knott.-Montford Fulton Kelly....IIndman Knox.-William Burnslde ........Barlyurrllle Larue. - W. E. Rodman ........... Kodgenrille Laurel.-George $\mathbf{8}$. Irock.............tondan

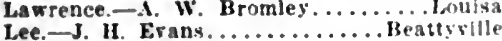
Lesise. - w. E. Ray................. letcher. $\rightarrow$ M. Bentley......... Whitesturs Lewis - Willam Bowman ....... Vasuehur Lincoln. -J. G. Carpenter............... Llvingsion.-F. G. La Rue........... Kustellville Lyon.-Cyrus U. Lynn............... Kuttawa Mecracken. - C. r. Kldd.......... l'aducah Mclean.-II. W. tiates............ ('alkoun

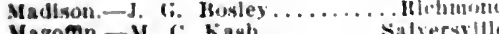
Magomn.-M. C. Kash................ Kebanon

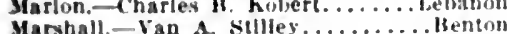

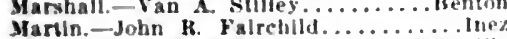
Mason.-samuel It. Harover........ Maysrille Sleade. - John n. Dink........ Hratudenlur Mlercer.-3. 1. Forsythe....... Ilarrodshusin

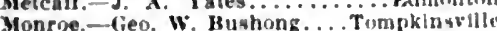
Montgomery. - William It. Thompson.

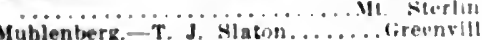

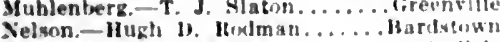
Sicholas. J. M. Wells........... Utarliste Oblo._. J. Wertsing...

Oldham. - R. If I'avsally.

Owen-Darid $E$ L Lusto.

Owiles.-John A. Mahatres.

Perry. - II. Michle.....

Plke.-J. W vears....

Pulaki-1. iv caln.

Mrekenstle, - A. is. Lovell

Rowan, ...J. Willson . . B.i.

Russell.-Joel II. Scholl.

Shellig, - T. Hearil.

simpson. - Notley conn wits.

8pencer. - k. T. Me Mathat.

Taylor.-J. 1. "sikinsoln .

Trigg-Domer Hlane

Trimble.-W. A. Wright. folon - T J slueruaker ...... Vortantely

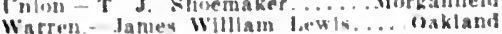

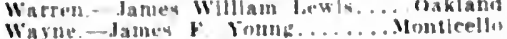

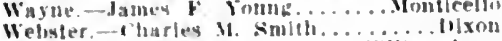
Whitley. - -. s. Moss......... Wilitamabure Wolfe.- General Marlon ienter...stillwater

\section{CITY HEALTH OFFICERS}

Nhland.................W. " Eatun Mellerue............... G. Keney

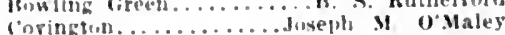

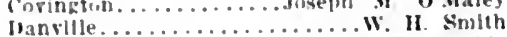

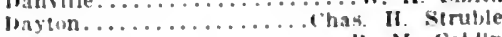
Frankfurt................... M. Cohstn Geurgetown........... llarry V. Jubnson

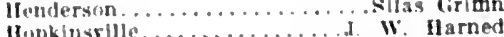
Honkinsrille.............. it. sinmoned l.exington............... It. Simmons

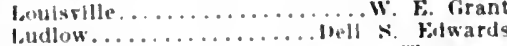
Madisonvllle............. T. Thompson Ilasfleld. Masfleld. Hiddegboro....... W. ...... C. Howard Morgantleht...................... H. When sewport..................... John Tndd Bwensboro............... W. Barnhll Paducah.................Marry I'. I.lun laris..................... II. Keller Richmond. .............. Bales

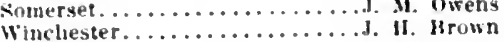

\section{Danville}

\section{STATE INSTITUTIONS}

Kentucky schuol for the Deaf, Danrllle. Ky. Ristablished $1823 ; 10$ beds; J. R. Rogers. supertmtendent.

\section{Eddyville}

Kentucky renttentlary Penal Hospltal, Eddyrllle, Ky. Established 1886; publie: Trasls, M.J., supkerintenuent.

\section{Frankfort}

Instlute for reeble-Minded Children, rrankfort, hy. Fistallished 1860 ; pulsIlc: educational: 400 beds; II. C. Kehue, M.D., superlutendent.

Kentucky State Reformatory IIospltal. Frankfort. Ky. Fistabllshed 1836 ; public: peneral: 55 beds: W. C. Caywood, physiclan in charke.

\section{Greendale}

Kentucky state IJouse of Reform, lireen dale, Ky. Fistablished $1909 ; 18$ beds.

\section{Hopkinsville}

Western state Hospltal, Hopklusrille, Ky. kistablistied iss; public: mental. medleal superintendent.

\section{Lakeland}

fentral state Hosprital, Lakeland, Ky. Eivabliahed 1873 ; publle: Insane: 1.400 terulent.

\section{Lexington}

Eavtern state Hluppltal, Jexington, $K y$ Established 19:4: nervons and mental nareotle and alesholle: 1 .64. berd4; Joseph I Gomban, modical superiutendent.

\section{Loulsville}

kintucky lfomu suclety for inlored

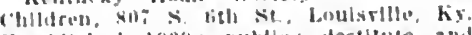
katablished 19009; publle: destlute atsi

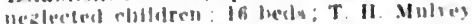

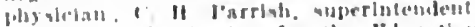
Kentucky Inetturlons for tha bolusention

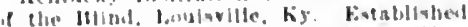

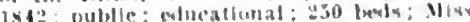

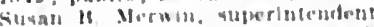

fienturky tusblfutlon for the koluestion o the dilnd. Department of ciblerent

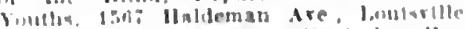

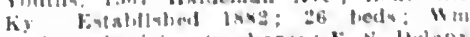

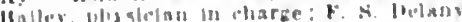
(orluctiol.

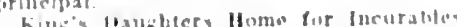

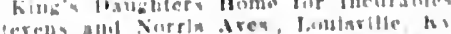

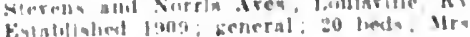

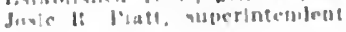

Pewee Valley

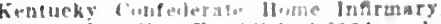
pewee Vallu, hy folahllatied 1904; pub.

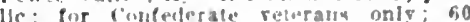

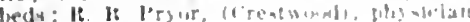
in charge.

HOSPITALS, SANATORIUMS AND CHAR ITABLE INSTITUTIONS

Ashland

King's Daughters Iforpital, Anhand Ky. Festablisted 1898 ; private and put lie; 10 beds: controlled iy Kingos losugh

Berea

Herea college Hosplsal, Berea, hy. Ey. tablistied 1200 : seml-pulllc: zeneral: 38 bedl: K II. Cowles, physlelant in charge.

\section{Bowling Green}

st. Josepth's IImpleal, 633, 12th st Bowling lireen, Ko kestablished 1908 ; medleal superintendent.

Burgin

Twin Oak Sinllarlum, burgin, Ky Futabllshed 190:s; prisate: lis betw: bilwin G. Ginttery, physlcian in charke.

\section{Corydon}

Henderson County sanlarium, Corydon, hy. Fostablished 1834 ; vullle: 65 beds: II. B. Poweit. Jhysictan

\section{Covington}

Corinkton General Itospital, 1901 Marlison Are., Corington, hy hed kckman, medical superintendent.

Covlngton P'rotestant children's Home, $140 \%$ Madlson Are., Covingron, Ky. kistat. Hshed tsa2; general : 46 beds; : Mrs, Bessie it. Wait, superintendent. Kenton County Inftrmary cirington.
Ky. Established 1907: 100 beds: $F_{\text {. T }}$. Adamy. physician In

St. Elizabeth's Iloupltal, lth st. Cor. Inton Ky Estallished 1850: publle: general: "00 hets: sisters of the poor. in charce.

\section{Cynthiana}

Harrlson IIospltal, Cynthlana, Ky. Es abllshed 1907; pubile; ceneral : 20 beds Danville

Danvlle and Boyle County Hospltal. Danrllle, Ky. Fistablished 1912; Reneral 19. beds: Mrs. Parsions, superintendene.

\section{Dawsonsprings}

Russell sanaturium. Darsonsprinas, Ky Established $1900^{-}$: private: nerrous: is beds:

Dayton

speer's Memorlal Iluspital. l'ayson. Ky kistablishey 189.3: prirate ; sil beds: Mia sophia $\mathbf{F}$. Steintaluer, sugerintemtent.

\section{Earlington}

st. Hernaril Hespltal. Farligizton. Ky Fistablisthed 1901: jirloato: (1,r mine eul. physiclan in charge.

\section{Elizabethtown}

Jathan sandarlum, robalketheorn, ky Restahlishent 1sas: prirate: chronte dis

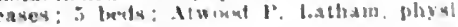
clan in charge.

Elkhorn City

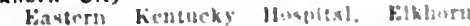

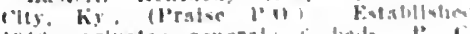

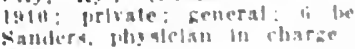

Farmdale Stonart llome, farmulate. hi lidul

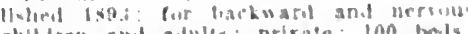

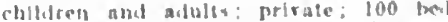

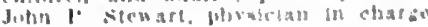

\section{Frankfor!}

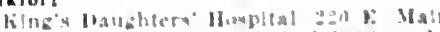

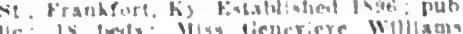
vilinorinteritert.

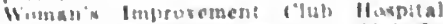

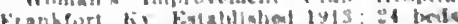

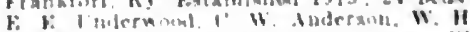
Gimplofil ent nimeral stan: vies II

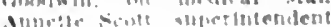




\section{Frankiin}

Southern Kentucky Sanitarium, Frank lin, Ky. Established 1908; 50 beds; W. A Guthrie, chlef surgeou.

\section{Hardinsburg}

Kincheloe's Inflrmary, Ilardinsburg, liy. Fstablished 1901; private; surgteal; beds; John E. Klncheloe, surgeon in chargo.

\section{Harrodsburg}

Mereer County Poor Farm, IIarrodsburf. Ky. Fstablished 1875 ; pntilic: 25 beds: w. Horace Witherspoon, medical superintendent.

\section{Henderson}

('ity Hospital, Henderson, Ky. Established 1896 ; publle; 30 beds; Miss Minnlo Blalr, superintendent.

Eruptire IIospital, Zlon Jlke, Ilenderson. liy. Established 1898; small-pox onis ; 40 beds; Peyton ligon, physician in charge $\mathrm{F}$. II. I'rounds, superintendent.

\section{Hopkinsville}

llopkinsville Inflrmary, 5th and Clay Sts., IIopkinsrille, Ky. Established 1912 prirate; medical and surgical; 15 beds Jrs. Winda Willains, superintendent.

\section{Lebanon}

Fllzabeth's Jospital, Jebanon, Ky. Extablished 1895 ; private : surical; 14 beds Robert C. McChord, surgeon ln charge.

\section{Leitchfieid}

Leltchfleld Sanltarlum, Leitchfield, $\mathbf{K y}$. Establisleed 1903; pricate 18 beds: Mar cus lhelps, surgeon lin charge; s. Givan, (springlick), physictan.

\section{Lexington}

Dr. Dale's Sanitarium, 453 w. 3d st., Jexington, $\mathbf{K} y$. Establlshed 1910; private; 8 beds; Chas. F. Dale, medical superintendent.

Elnwood Sanitarium, Leestown Rd., Jexlngton, Ky. Establlshed 1912 ; nervous diseases; 14 beds; C. A. Nevitt, physician in charge.

Good Samaritan Hospital, 320 S. Ihimestone St., Lexington, Ky. Established 1889 ; public; general; 135 beds; Josephine F. Royan, R.N., superintendent.

HIgh Oaks Sanatorium, Lexington, $\mathrm{Ky}$ Fstablished 1887; private; nervous and mental, narcotic and alcoholic: 35 beds: George P. Sprague, physician in charge.

House of Nercy, 519 W. 4th St., Lex ington, Ky. Established 1895; private rescue lome; 12 beds; Josephine D. Ifunt physiclan in charge; Mrs. Kniendorf, matron.

St. Joseph's Hospital, 644. 2d St., Lexington, $K y$. Established $187 \%$; private and public; general; 200 beds.

\section{Loneoak}

McCracken County Sanitarim, Loneoak, Ky. (Paducah P.O.). Established 1906 ; public; 48 beds; II. P. Carter, superin tendent.

\section{Louisville}

All-Prayer Foundlings' Home, 1622 Story Ave., Louisfille, Ky. Established
1905 ; prlvate; bables; 24 beds; R. E. Willoyte, physician; G. C. Cromer, super intendent.

Association Sanatorium, Ilazelwood, Louisville, Ky, Establlshed 1907 ; private: tuberculosis ; 45 beds; Dunuing S. Wilson, physician in charge.

Beechhurst Sanitarium, Louisville, $\mathbf{K y}$. Established 1896 ; private; for nerrous and mental diseases, aleohol and drug addiction: 30 beds; Harrey B. Scott, medlcal director.

Sce Spccial Announcement $A d x$. page $\gamma \gamma$ Dr. Board's Sanatorium, $1412 \mathrm{~S}$. 6th St., Louisville, Ky. Established 1908; private: for mental and nervous diseases, alcohol and drug addiction cases: 20 beds; Mlilton Board, physician in charge.

Sce Special Announcement $A d v$. page 78 . Cessna Sanitarium, 4521 Park Blrd., Louisville, Ky. Grnecology; 40 beds; Frank L. Cessia, (Highland Park), nedical director.

Children's Free Hospital, 226 E. Chestnut St., Louisville, Ky. Established 1892; private: 56 heds; Mlss M. C. Dunn, superintendient.

'hrlstlan Clunrch Orphans' Jome, 225 F: 'olfero st., Loulswille, Ky. Established $1889 ;$ private; 45 bedis; ilss Mary J. (hambers, superintendent.

Church lifome and Inflrmary, 1508 Nor ton Ave. Louisville, Ky. Established 1885 private; 75 beds; W. B. Cossett, physleian ill charge; Julia $T$. Maury, superintendent. Citizens' National IIospltal, I06 W. Citizens' National IIospltal, Lof W. Cireen St. Loulsvlle, Ky. Established lichard W. Oliver, physician in charte; ltiehard W. Oliver, physician in charge Clay Lodge knights of lythlas Home 528 s. 6 th St., Louisville, Ky. J. C. Nicholas, In charge.

Colored Orphans' Home, 1224 S. 18th St., Joulsvile, Ky. Mary II. Davis, matron.

Convent of the food Shenherd. 2214 Bank st., Ioulsville, Ky. Establlshed 1865 ; private; reformatory ; 400 beds Willam B. Doherty, physlcian in charge. Cook Benevolent Institution, 622 IV Kentucky St., Loulsville, Ky. Establlshed 1837 ; private lome for old ladies; Fivir T. Williams, matron.

German Baptist Orphans' Home, 923 Cherokec IR., Loulsville, Ky. Irs, A Gelau, matron.

German Methodist Deaconess Flome and Hospital, 529 S. 8th St., Louisville, Ky. Fstablished 1895; private and pubtic; 33 beds; Miss Lydia Scheirick, superlnten dent.

German Protestant Orphan Asylum, 1240 Bardstown Rd. Louisville, Ky Fitablished 1852 ; private; 90 beds; C. H Toelle, superintendent.

Good Shepherd Home for Colored Girls, 800 W. Wainut St., Louisville, Ky. Established 1900 ; prlvate: 50 beds: Sisters of the Good Shepherd, in charge.

Home and Reformatory for colored Girls, 518, 8th St., Loulsville, Ky. Established 1911; private; 39 beds; Sister of the Good Shepherd, in charge.

Home for Aged and Infirm, Salt River Rd., Louisvllle, Ky. Established 1870; public; 350 beds; J. K. Westfall, superintendent

Home for Friendless Women, $512 \mathrm{~W}$. Kentucky St., Louisville, Ky. Established 1874; private; maternity ; 30 beds; Ewlng Marshall, chief of medical staff.

Home of the Innocents, $108 \mathrm{~W}$. Broadway, Loulsville, Ky, Established 1877 ; private; care of children under 6 years; 45 beds: Phillp Barbour, plyyslclan; Lillie Louise Zjegler, R.N., superintendent.

Hope Rescue Mission, 808 W. Jefferson St., Louisvilte, Ky. Established 1900; 50 beds; Wm. M. Bruce, superintendent.

H. B. Montfort Home, Louisville, Kv Fstablished 1871 ; public; 40 beds ; Mrs. $\mathbf{E}$ B. Long, superintendent.

Jewish IIospital, Louisville, Ky. Established 1905: private : reneral. 75 beds Jewish Hospital Association, in charge Miss Jane N. Barry, R.N., superintendent. John $N$. Norton Memorial Inflrmary 1147, 3d Ave., Louisville, Ky. Established I881; private; 100 beds; Miss Anna Iuriel Gagas, R.X., superintendent.

Little Children's Home, 2630 Portland Ave., Jouisrille, Ky. Rosa Smith, matron. Louisrille Baptist orphans' Home, 102. S. 1st St., Louisville, Ky. Established 1869 ; private; 104 beds; 10 beds in hos-
pital; Mrs. M. H. Rhodes, superintendent. Loulsville City Hospital, Preston and Chestnut Sts., Louisville, Ky. Established nedical superintendent.

Louisfille Industrial School, $3 \mathrm{~d}$ and Shipp Sts., Louisrille, Ky. Established 1865 ; public; educational ; 480 beds : Wm. A. Jenkins, physician in charge: iv. Brown, superintendent.

Louisvilte Presbyterian Orphans' Home, 1118 S. Preston St., Loulsville, Ky Es tablished 1867; general; 36 beds; Miss S. R. Barkley, superintendent.

Louisville Protestant Altenheim, 936 Barrett Are., Louisville, ky. Established 1906; private; general; home for the

aged; 50 beds; Miss Mary Rothenburger, matron.

Louisville Wesley House, 809 E. Maln St., Ioulsville, ky.

Masonic Widows' and Orplrans' Itome, 2d and Avery sts., Loulsville, Ky. Kstablisher 1870; private: destitute widows and orphans of deceased Master Masons: 375 beds: An Morgan Vance, president of medical staff; 'T. I. Adams, superintendent.

Metlodist Episcopal Church Widows and Orphans' Home, 812 s. 5th St., Louisville, IIss Laura Y. Nadal, superintendent.

O'leary Ilome, 926 Barret Are., Louis ville, Ky. Established 1898; private; for the aged; 10 beds; Sisters of Charity, in charge.

Orphanage of the Good Shepherd, 1418 Iorton Ave., Louisville, Ky. Established 1869 ; private; church home for boys; 30 beds; Mrs. Garrett, inatron.

Pope Sanatorlum, $115 \mathrm{~W}$. Chestnut St. Louisville, Ky. Establlshed 1890; private ; for nervous and chronle cases, narcotic and alcoholie; 25 beds; Curran Pope, pliysiclan in charge.

Red Cross Sanatorlum, 1436 S. Shelby St. Joulsville, Ky. Established 1903; pubic; for colored patients ; general; 19 charge; Mary $\mathbf{E}$. Merritt, superintendent. Sacred Heart Home, 218 E. College St., Loulsville, Ky.

Sacred Heart Juvenlle Peformatory, 2214 Bank St., Loulsville, Ky. For wayward girls over 12 years.

Sisters of the Good Shepherd, $528 \mathrm{~S}$. 8th St., Loulsville, Ky.

St. Anthony's Hospital, Barrett Ave. and Wlckliffe St., Loulswille, Ky. Established 1902 ; general; 150 beds; Slsters of St. Francis, in chárge.

St. Johu's Eruptive IIospitaI, Manslick Rit., Loulsville, Ky. Fstablished 1886 public ; contagious cases; 200 beds; J. I. Whittenberg, medical superintendent.

St. Joseph's . German Cathollc Orphan Asylum, Crescent Hill, Louisville, Ky. Established 1849 ; prlvate; 172 beds; W. A Bindewald, nedlcal superintendent.

St. Joseph's Infirmary, 637 S. 4th St., Jouisville, Ky. Established 1838; public and private; 150 beds; Sisters of Charity, in charge.

St Joseph's Reformatory for Women, 2214 Bank St., Loulsville, Ky.

St. 'Thomas' Orphanage, Preston Park. Louisville, Ky. Established 1841; private; 86 beds.

St. Vincent Orphanage, 2120 Payne St. Louisville, Ky. Private; Sisters of Charity, In charge.

SS. Mary and Elizabeth Hospltal, 12th and Marnolia Sts., Loulsville, Ky. Established 1874 ; private; 100 beds.

United States Marine Hospital, 2214 High St., Louisrille, Ky. Established 1846 . 50 beds; A.A.Surg. J. F. Crane, in comniand.

West End Hospital, 34th St. and Grand Ave., Louisvllle, Ky. Publlc ; 26 beds

O. Raymond Minor, physician in charge.

\section{Maysville}

Hayswood Hospital, 4th and Market Sts.

Maysvllle, Ky. Established 1908; general :

20 beds; Mrs. M. Gage, superintendent.

\section{Middlesboro}

Evans Hospital, Middlesboro, Ky. Establlshed 1912; general; 25 beds; W. K. Erans, physician in charge; Miss Myrtle B. Edwards, R.N., superintendent.

\section{Murray}

Murray Surgical Hospital, Murray, Ky. Established 1910; general; 26 beds; W'm. Mason, Jr., physician in charge; J. R. Kennedy, manager.

\section{0 wensboro}

Mary Kendall Home, Owensboro, Ky. 
general. 100 pouls: Mrs. Ella Given Uarls, sumerintement.

Paducah

llome of the Frentless, Fadueah, Ki Establlshed 1893; prtrate: for ifoperdent eblidren. 60 beds: Jis. Louk liske. chalruan managlng brard: Mls. Hllce chalrman mans

Illnols Central bIospltal, l'aducab, hv

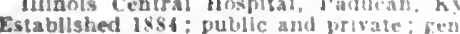

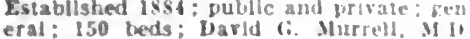
eral: 150 beds:

Jackson IIII sanatoriun, l"aduresh, $\mathrm{k}$, Erablished 1911: prlvale: inciptert and moderate tuberculosls: Mrs. 1. W. IIol. comb, superintenden.

Klverside Hospltal, th and t'lay sts l'aducab, ky. Kistablished 1903: rublic and polrate: is bels: Mlss sarali k. llock superintendent.

Paris

W. W. Massle Menorlal Hospltal, Mrls, Ky. Establlshed 1913; General and emersency: 32 lrods: Miss Itwehnte, Mr. superintentent.

\section{Richmond}

(illiwen Inflemary, Hehmond, Ky, Fo

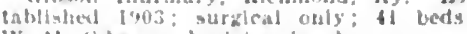

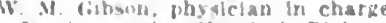

Jutrie A rlay II uspltal. Richnond, Ky

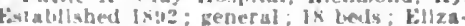
treth scutt, B.s., superlatendent.

Ruddels Mills

Hurlem l'ounty Ingranary. Hudelels

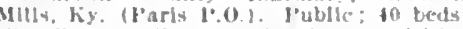

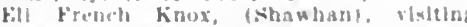
physteian; kilwarl speaks, superlntendent Salt Liek

L Rubhis llosplial, salt Lick, $\mathrm{Ky}$ Established 1:02; private; Reveral: Is bedr: 1. k. Robulns, physician in charge. Scottsville

Meredith Indrmary, Scohtspille, Ky. Ksablistoel $190^{-1}$ private: surtical: 25 beds I1. M. Meredlth, M.1)., superinterideub. Shelbyville

Kith's lbaghters' llosjifal, Shelbyrille, hy. Evealulished 1900: public; 12 beds: Mrs. Timmons, matrom.
Somerset

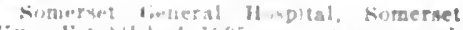

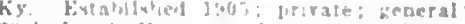

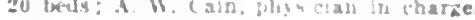
Se. Helens

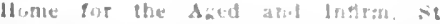

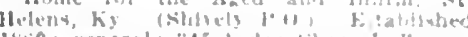

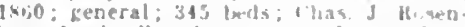
lam, lonularille, whysician in charpe. \& h Wustrall, superintendens.

Versailles

Wixalfurd Memirial Hisgizal Venulle.

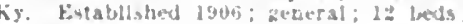
Mrs. B. lireene, superistenders.

Waverly Hill

Hoard of Tutrerculusf \$̇an tarium and Ifospltal. Warerly Mll, Ki. (Walley sta.

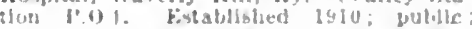

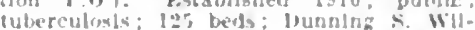
sor, (loularlle), medies! suberintendent Williamsbure

Moss Intruary. Whlliamiburg, Ky. Es. tablished Isto; : privale: general: 1 to beds; f. S. Mruss, plivstesan in charge.

\section{PHYSICIANS OF KEN'LUCKY}

\section{KEY TO ABBREVIATIONS, SYMBOLS, ETC.}

Names in capltals slgnify membership in the County Soclets and state Associatlon. (DOE, JOHN).

Indlcates Fellowshlp in the Amerlcan Med. Assn. (DOE, JOHST).

(b'75) Year of blrth. [medic. II. bomeopsth; E, eclectic; P-M, physloId. 6.02 . College and rear of graduation.

- Informacion recelred does not show grad. uation.

S.-Surgeon.

Ob.-Obstetrician.

ObG.-Obstetriclan, Gynecologlst.

G.-Ginecologis:

Or-Orthopedist.

Pr. - Proctologist.

Op.-Ophthaimologist.

A.-Aurist.

LR.-Laryngologlst, thinologlst. (l's9) Year of llcense.

(d) In practice before passage of present law and llcensed by

(It) Licensed but sear not known.

(t) Information recelved does not show llcense.

V.S.... Conlled States Army.

M. i.C., I'S.A., Medlcal Reserre Corps.

SPECIALTIES ARE INDICATED AS FOLLOWS:

ALR.-Aurlst, Jaryngologlst, Rhinologlst.

OALR.-Opbthalmologlst, Aurlst, Laryngologist, Rhtnologist.

U.- C'rologist.

D.-Dermatologist

Pd.-Pedlatrlst.

N.-Neurologist.
I.A.X., Lnited Stales Xary.

M.M.C., M.X., Medical Heserve Corps.

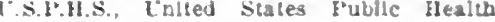
service.

College positlons held are indlcated by abtrevlated tille of posllon. followed by key number of college. For key to collezes see Inslde front cores pase.

(A1,3, B6, C4) Slembirahtp in suectal Socletles. (See Key Trule, page 122.)

NP.-Neurologlst, I'schlatrlst

I.-Internis:

T.- Tuberculotheraplst.

Anes.-Anesthetist.

LD.-Iaboratory Diannustlclan. [mlst.

A.-Actnoloclst, liadlologlst, Hoentzenolo.

Path. - r'sihologist

Bact.-1Bactertologist.

WHEN THE ABBREVIATION REPRESENTING A SPECIALTY IS FOLLOWED BY AN ASTERISK (\$) IT INDICATES THAT THE PHYSICIAN CLAIMS HIS PRACTICE IS LIMITED TO THAT PARTICULAR BRANCH OF MEDICINE: WITHOUT THE ASTERISK. THAT HE IS ESPECIALLY INTERESTED IN, BUT DOES NOT LIMIT HIS PRACTICE TO. THAT BRANCH. THIS INFORMATION CONCERNING SPECIALTY IS BASED ON PERSONAL DATA FURNISHED BY THE PHYSICIAN AND IS NOT VERIFIABLE.

\section{KENTUCKY}

AARON, 10. CLINTON

Aaron, Addison Ragen (b'56)-D; (l'9.)

ADAIRVILLE, 683, LOGAN

Cosset. Walter Iee (b'80)-Tenn.19.'11 (I'11).

asslter, Andrew J. $(6 \cdot 58)$ - Tem. (

Meflendon. John I'. (b'a) -0 : (1'94): not In practice.

ITSSELL, JF:SSE I.F:E (1,'\$5)-KY 2,11: (i'i1).

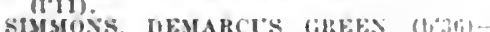
Tenn $0^{\circ}(8):(1.94)$.

Tenn-4. 81 : ([94).

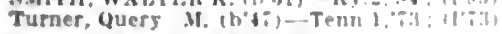

ADAMS, I50, LAWRENCE

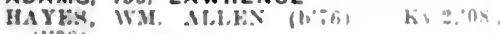
(1'08).

ADOLPHUS, 100, ALLEN

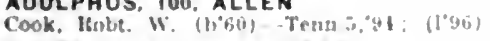

AKERSVILLE, 100, MONROE

Crabtrec laule Jichard (bis). Tenu. ls.

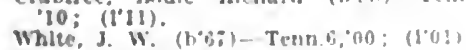

ALBANY, 579, CLINTON

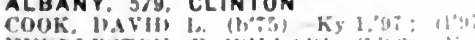

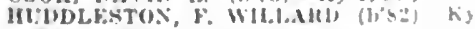

ON": (1'บB).

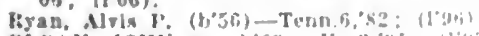

siof

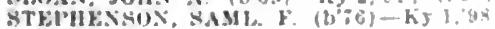

(1'98).
ALEXANDRIA, 353, CAMPBELL

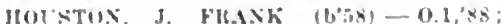

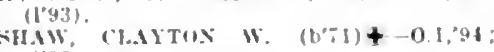

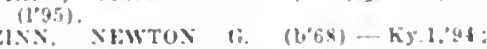
(1':4)

ALICETON, 30, BOYLE

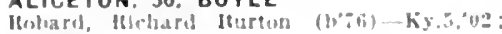
$11^{\circ} 02 \%$.

ALLEN, 75. FLOYD

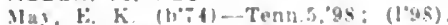

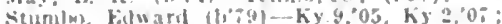
(IPO)

ALLEN SPRINGS, 100. ALLEN

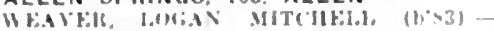
KY, $310:$ : (1010).

ALLENSVILLE, 436, TODD

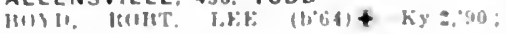
(1")iो)

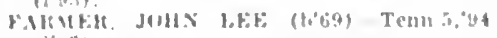
I 1001 .

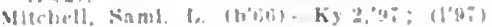

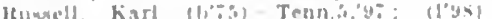

tuit In peravelios

ALMD. 125. CALLOWAY

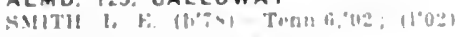

ALPHORETTA, IIO, FLOYD

ALPHOREYTA H (1) $(0 ;)$

ALTON (A.F.D. LAWRENCEOURG), 150, ANDERSON

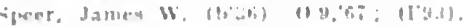

ALTONA (R.F.D. CALVERT CITY). 16. MARSHALL

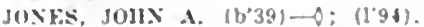

AMANDAVILLE, 35. CUMBERLAND

Haker. Thus. T. (b'39)-Tenn.6,":?: (t'93).

ANCHORAGE. 384. JEFFERSON

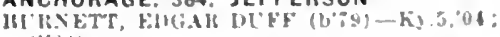
(1201).

Winstun, 3os. l'endletun (bo9)-Va.1.92: (1.99)

ANTON (R.F.D., MADISONVILLE)。 30. HOPKINS

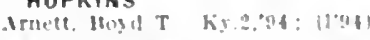

ARJAY. - BELL

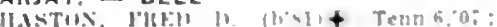
(I) (1)

ARLINGTON. 335. CARLISLE

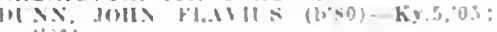
(l'us).

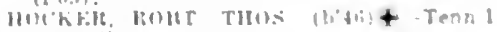

15. (1)

ASHBHOOK (SINAI P.O.), 30 ANDERSON

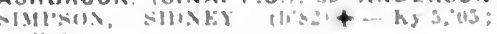
$(100 ;$.

ASHEYBURG, 130, HOPKINS

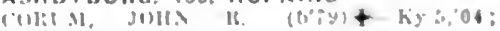
(1) ind.

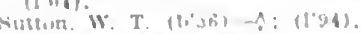

ASHLAND, 8.688, BOYD

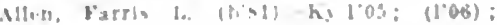
ob. 


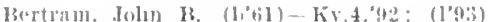
N. IBERITY, WM. A (b'til) … Ky

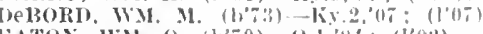

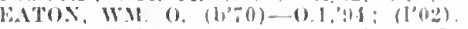

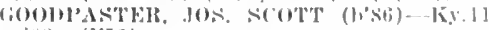
'118: (1'11).

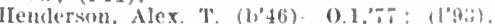

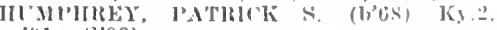
91: (1'93)

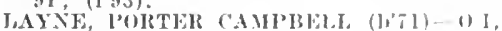
94 ; (l'02).

Martin. Joln W. (1,2s)- $\Delta ;(1,33)$

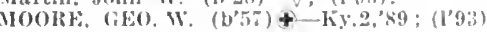

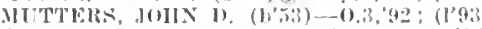
Ogden, Karan Fredk. (h'si)-0.9,04 (l'04): not. In practle.e.

PRICHARI), JOHX MHAON (J't8)\&Ky.1, (12; (1'96); OALR。 *

klcharisoll, James $\mathrm{L},(1,74)-0.2,99$ : (l’99)

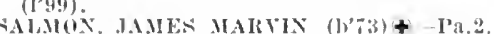
$96:\left(1^{\prime} 96\right)$.

Saulsherry, Wm. II. (b'bif)-1'a.2,91; (1'01).

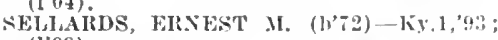
(l'93).

SPARKS, JAMES A. (b'87) $\mathbb{f}-\mathrm{K} y_{.1}$, , $^{\prime}$ (l'00)

WOPF, HARRY s. (b'6) \&-Ky.4, $(1,08)$

WADE, JOHN IIENTY (b49)-Ky,4,72; (l'mis).

Wolfe, Joshua Geo. (b'67)-Ky.5,'06; (1'06)

ATLANTA, 40, LAUREL

ATIJLINGS, JOHN I. (b'69)-IIY.2,93; (l'95)。

ATTILLA, 12, LARUE

Willians, Chas. I. (b'61)-Ky.1,'89; (1'02). AUBURN, 631, LOGAN

Belcher, Alvin Marion (b'73)-Tenn.6, 00 liy.5, 01 ; (1'01).

BTIR, Wí. R. (b'63)-Ky,2,87; (l'94),

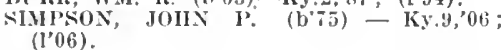

TIRNFi, TIIOS. H. (b'67)-Tenn,6,93; (l'93).

AUGUSTA, 1.787, BRACKEN

Bradford, Thos. (b'49)-Ta.2,7 1 ; (1'93). IONEYHON, THOS. JEFFERSON (b'50)$0.1,82 ;(1,06)$.

Norris, James C. (b'61) - 0.7,'84; (1'94)

RICE, ('HAS. R. (l'SI)†-KY.2, 07 ; (l'08).

IELTON, JAHES LEN (b'69)€-Ky.5,'97; (1'97); Pd.

AUSTIN, 50, BARREN

FERGCSON, AElIC EDW. (b'75)€-Ky.2, '05; (1'05)

AUXIER, 25, FLOYD

ARCHER, ERX゙EST ELAIO (b'8s)\&-Ky. 'I0; (l'10)

Hatcher, Wm. L. (b'68)-Ho.7.'03; (l'03).

AVON, 20, FAYETTE

Jrown, Oliver F.-N.Y.10,'84; $\left(1^{\prime} 96\right)$.

BAGDAD, 184, SHELBY

ADAHS, JOHN F. (b'58)-Ky.4,'84; (I'93). AUSTIN, ( CRTIS (b'60)-KY.4, 83 ; ( $\mathrm{l}^{\circ} 93$ ). Ilutf, John F. H.-Ky.2,78; $(100) ; 0$.

BALKAN (WASIOTO P.O.), 21, BELL

(LAYTON, CHAS. F. (b'86) - KY.2,'I0: (1'10).

BANDANA, 337, BALLARD

DORLIS. STEIHEX M. (b'61)-Mld.6,' 86 ,

Ky.2, $95 ;\left(1^{\prime} 93\right)$

AYNE, JANES B. (b'4s)-MIo.24,'88; (194); $\mathrm{Pd}$.

TITSWORTH, GEO. EZIA, JR. (b'86)Ky.2,'10; (l'10),

BARBOURVILLE, 1,633, KNOX

AlBRIGHT, GRANVILl,E H. (b'כ6)-Ky, 2 ,

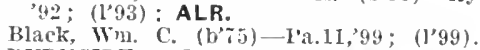

BTRNSIDE, WILLIAH (b'45)†-Ho.7,89; (1'93).

Herndon, Benj. F. (b'53)-Ky 2,'s4; (1'43)

IONES, SOLONON CRITTENDEN' (b'69) Ky,2,98; (1'98).

loNES, TIPTON W. (1,67)-Tenn.10,'95; (l'95).

l.0('K, JAMES S. (b'74)-Io.7,99; (1'01).

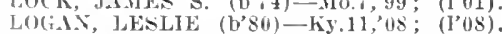

I'L, JOHN GLASSCOC $\left(b^{\prime} 81\right)-\mathrm{K} y, 2,09$ : 1109)
BARDSTOWN, 2.126, NELSON

("berry, Robt. l. (col.) (b'tio)-kiy.i, '02 (1'02)

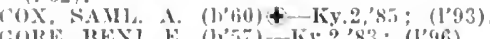

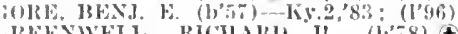

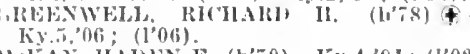

McKA), IAINEN F. (h'70)-Ky.4,91; (I'02)

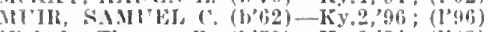
Thebols, Thomas 13. (b'59) - Ky.2,'84; (l'03)

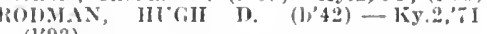
(1'93).

BARDSTOWN JUNCTION, 300, BULLITT

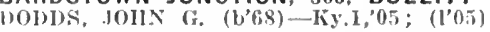
BARDWELL, 1,087, CARLISLE

CROI CII HITIII T (b)'56)

Elsey, John Henry (1,40)-Ky.2,75; (1'93)

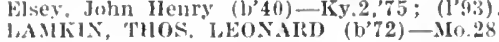
$, 99:(1,99)$.

MARSIIILI, TIIOS. I. (1)83)£-Ky.5, 06 $\left(l^{\prime} 06\right)$

Moshy. Hazel P. (b'89)-Ky.2,'I0; (l'I0)

MOSiY, WH. L. (b'61) \&-110.1,83; (l,93)

BAREFOOT, 40, NICHOLAS

CINVILLE, SOLOMON IILTON (b'80)Ky.9,05; (1'05); (Centervllle).

BARLOW, 532, BALLARD

JOHNSON, JAMES SIDNLY (b'84)-Tenn.5, "08; (l'08).

IESIIEW, JOSHUA w: (b'i3)†-Ky.2,'89; $\left(1^{\prime} 93\right)$.

PA(HE, war A. (b'76)థ-Mo.7,03; (l'03)

shemwell, I. N. (h'32)-Ky.I, $89 ;\left(l^{\prime} 02\right)$

BARRENFORK. 500, MCCREARY

WHIDLE, HFRRERT C. (h'8T)-KY.2,'11. (l'11).

BASIKETT, 270, HENDERSON

HODYGES. JOHN R. (b'SI)-Ky.5,'04; (l'04)

BEATTYVILLE, I,360, LEE

CANX, CHARIES BRECKENRIDGE (b'S8) Ky.2,'11; (1'11).

FVANS. 10HX H. (b'73)-Ky.1,95; (1'95) HOSKINS, AlRERT B. (1) 73$)-\mathrm{Ky} .5,05$; $(105)$. Pryse, Wayne (b'82)-Ky.5, $05, \quad$ Ky.9,06;
(l'06).

SCTTON, JOS. P. (b'86)†-Ky.2,'10; (1'11)

BEAVER DAM, 762, OHIO

MCKENNEY, JOHN OSCAK (b'79)ৎ-Ky.2, '05; (l'05); R.F.D. 2.

Hitehell, Geo. F. (b'43)-Ky.2,7 7 ; (1'93)

TAYJOR, SIMEON DOSSON" (b'62) Tenn.5,'87; (1’93).

WILLIS, PALESTINE T. (b'73)-Ky.4,04; (l'04).

BECKNERVILLE (R.F.D., WINCHESTER) 25. CLARK

STEPHENSOX. CIIAS. G. (b'69)-Ky.5,'98 (1'98).

BEDFORD, 269. TRIMBLE

HANCOCK, FLOYD WILRLR (b'75)-Ky.5. 98; (l'98). JOIN w. (b'65) - Ky.2,'93; (1'93).

BEECH CREEK, 60, MUHLENBERG

WHITED, 11ERMAN F. $\left(b^{\prime} 79\right)$-Tenn.6, 01 ; (l'02).

BEECH GROVE, 208, MCLEAN

Froitzheim, Wm. J. (b'86)-Mld.3,'10; (l'12).

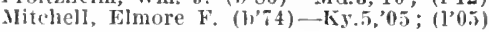

BEELERTON (R.F.D., FULTON), 27, HICKMAN

13L'SHART, RÖBT. IEE $\left(b^{\prime} ; 5\right) \oplus-T e n n .6$, 01; (1'01) ; R.F.D. 4.

BELLEVUE (NEWPORT P.0.), 6.683,

Bach. Julius E. (b'76)-0.2,08: (l'08)

BAIK LK, JOHN H. (1)"52)—-0.1, '7; (1'06).

GARIISON, SIIERTOOD P. (b'81) $\mathbf{+}-0.9$, '05; (l'06).

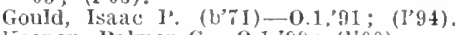

Keeney, Palmer G.-O.1,99; (l'00).

Northeut, Edgar Wm. (b'si) - Ky.2,'12; (1'I2).

NORTIICTT, JOS. IONAIHIX (h'82) Ky.2,08; (1'09).

SENOCR, WHFORD E. (b'67) - Ky.2,91 ; (1'97).

Spitzlberger, Lawrence M. $(1,80)-0.1,05$; pitzlber

WOLFRLM, ANXA E. (b'59)-0.20,95; (1'95).
BELLJELLICO, 50, BELL

UAIRTIN, l'IERCE (h'-2)-Ky.9,04; (1'0,5). BELMONT, 75, BULLITT

('OOK, CIIAS. J. (1, 42 ) -Ind.4,76: (l'(0)'

BENGAL, 20, TAYLOR

IIaselwood, Rlehard W, $\left(1 b^{\prime} 37\right)-k y .1,60$; (l'93)

BENGE, 73, CLAY

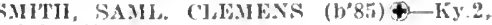
'12; (l'12).

BENHAM, - HARLAN

NASII, IAMES CARROL], (1,82)-Tenn.10

'Il; (l'12); Nember Tenn. State Med.

ASS. MIRERT BENTON (b'il)-Tenn.5, '99; (1'11).

BENTON, 624, MARSHALL

COILMAN, TILMAN C. (h'54)-Temn.5,'88; (l'93) : R.F.D. 6.

IIall, Benj. T. (b'52)-0.2,76; (l'93)

Ilelm, Thos. 13. (h'70)-Ky, 1,93; (1'93):

R.F.D. I

llenson, Ellas Alexander - Tenn.5,'90; (l'93); R.F.D. 8.
OWARD, CIIAS. F. (b'65) $\odot-$ Ky.2,92; (1'93)

SKIXNEK, JAMES MIUARD $\left(b^{\prime} / 3\right)-K y . I$, "48; (1'48) ; R.F.D. 5 .

starks, Ibufus II. (b'52)-Ky.4,'-8; (1'93).

STIJLEY, VAN A. (b'66) $\oplus$ - Ky.2, 90 : $(193)$.

Stlnson, Leonard E. - Ky.1,04; (l'04):

R.F.D. 6.

STONE, WM. S. (b'62)૯-Ky.2,'88; (l'93) : (also Birmingham).

THOMAS, EDMUND G. (b'52)Ð-Ky.2,73; (I"93); R.F.D. 1.

WASIIULR, ILWRENCE LEF $\left(b^{\prime} 81\right) \oplus$ Ky. 2,07; (1'08).

(1'(3) ; l.F.D. 1 .

BEREA, 1,510, MADISON

13OTKIN, DINL. ROBT. (b'82)-Ky.2,'II; (l'1i).

Cornelius, Preston (b'6I)-Ky.2,'92; (l'95) DAVIS, LEWIS $\Lambda$. (b'i4)-Mo.T,99; (l'01). MOSSMAN, PALL DARWIN (b'87)-0.40, 12 ; ( ) ; Pd.

Robinson. Chas. H. (b'49)-Ky,2,'90: (l'93).

BERLIN (R.F.D., BRADFORD), 100 , BRACKEN

Rees, Wm. S. (b'65)-0.8,'92; (l'93) ; R.F.D.

BERRY, 339, HARRISON EARLE; HFRSHELL M. (b'62)-Ky.1,'98;
(1'98).

Gillespie, Benj. G. (b'70)-Ky.2,94; (1'94);

IIEIGES, LUTHER ANDERSON $\left(b^{\prime} 74\right) \notin-$ H1.22,09; (1'11); R.F.D. 2.

MCVAY, ELLRIRIGIT T. (b'62)-0.3,'88: (1'01).

Hoss, Grover Hendrick (b'84) - Ky.2,09 (1'09).

BERRYS LICK, 58, BUTLER

TLRNER, VIRGI, ALONZO (b'74)-ky.2, ,09; (l.09).

BERTHA, 75, KNOX

'FNSING'TON, IIONROE $\left(\mathrm{b}^{\prime} 72\right) \oplus-\mathrm{Ky} .4$, '98; (1'98).

BETHANY, 30, OWEN

Taylor, John W'm. (b'80)-Ky.5,"03; (l'03)

BETHEL, 175, BATH

letton, James 'John (b'67) - Tenn.5,'95; (l'y5).

Roberts, Osear H. (b'72)-Ky.1,98; (1'98).

BETHLEHEM, 68, HENRY

Howard, Ererett Edmunds (b'87)-Ky.2,'13 (l'13).

BEWLEYVILLE (R.F.D., IRVINGTON), I40, BRECKINRIDGE

Walker, James M. (b'50)-Ky.2,74; (1'93).

BIGBONE, 75, BOONE

hyle, Robt. E.-O.3,96; (1'96).

BIG CLIFTY, 260, GRAYSON

Brandon, James Wilbur (b'81) - Ky.2,'06 (l'06).

NIMMO, THOMAS M.-Ky.2,95; (1'95)

STUTEVILE, OLIVEK R. (b'62)-Ky.5,'89; (l'93).

BIG SPRING, 300, MEADE

WTT, CAKL B. (b'80)-Ky.5,'04; (1'04). 
BIMBLE. - KNOX

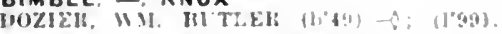

BIRUSVILLE, I00, LIVINGSTON

MAHKLY. JAMHO HAISIE (liSY

09: (1'09).

BIRMINGHAM. 349. MARSHALL

STONL, W11.1.1.1. S

liee henson)

BLACKFORD, 449, WEBSTER

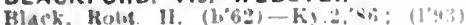

Hack, Rolut II. (1,62)-hl. [1.98).

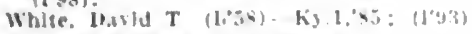

BLACKS FERRY. 65, MONROE

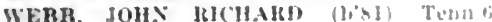
12: (1'12)

\section{BLAINE. 136. LAWRENCE}

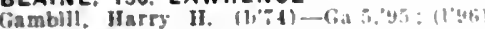

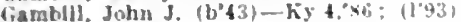

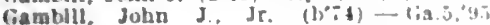
(1'96).

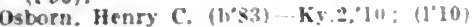

BLANCHE, - BELL

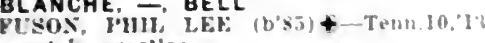

on In practlce.

BLANDVILLE, 229, BALLARD

Seay. John $S .\left(b^{2} 43\right)-K y .2,65:\left(1^{\circ} 43\right)$

BLOOD. 22. CALLOWAY

Uenslee, Thomas $\}$. (b'bI)-Ky.2.90; $\left(1^{\circ} 9.3\right)$

BLOOMFIELD, 352. NELSON

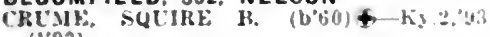
(1'93).

WAKFFIELD, JOHX J. (b'נ2)-Ky (l'93)

BLYTHE, - MONROE

BEHFOH, THOMAS H. (litis) - ky i, is (1"93).

BOAT, 30. PERRY

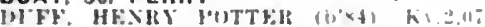
(110:)

BOAZ. 100, GRAVES

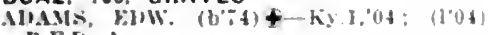
R.F.I. 1.

WRIGiT, LONIIF, 1. $(1, \times 1)-K y, " 11$

(1'0\%); $\mathbf{G}$.

BOHON, 100, MERCER

AWEENEY, CHAS. W. (1, \%3) Ky, 1, (0) (l'00).

BOLTSFORK, 52, BOYD

l'rlchard, Lon 3.

(Sice Rugh.)

BONANZA, 200, FLOYO

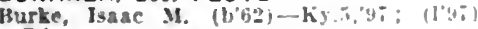

Pd.

BONNIEVILLE, 257, HART

(TARK, JOII. H. (1:51) $\rightarrow:(1: 44)$.

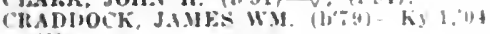
(l'04).

BOONEVILLE, 236, OWSLEY

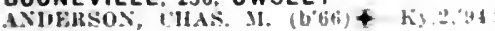
(1'94).

H.ASs, AKCIIH.ALI) II. $(1,63)+-k y 2$ 'S5; (1'y's).

BOONS CAMP, 30, JOHNSON

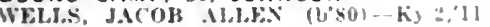
(I'II).

BORDLEY (R.F.D. CLAY), I50. UNION

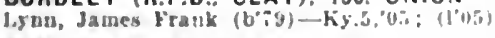

BOSTON, 93, NELSON

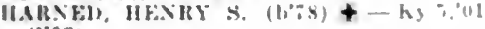
(I'02).

BOSWORTH, 400, BELL

HTTIATHIK, JUS. W

(1'(M)).

BOWEN, 80, POWELL

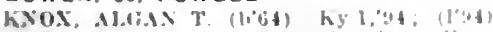

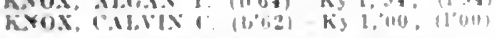

BOWLING GREEN. 9.173. WARREN

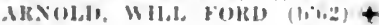

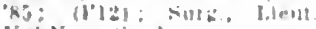

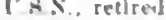

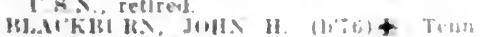

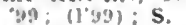

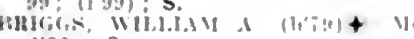

(l'02): S.

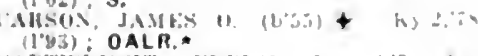

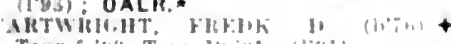

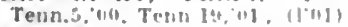

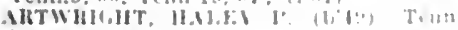

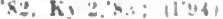

Coxmb. saun. W. $(862)-$ Tenn 5.5.

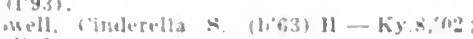

$(1+113)$

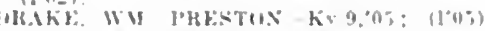

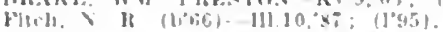

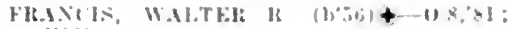
(1.93).

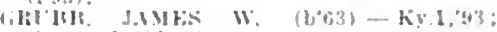

(1):31; $13.511,2$

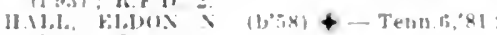

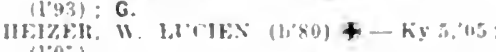
(1) $0: i)$

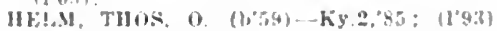

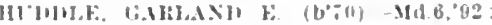

lones, Gacharis K. (coll.) (1,s3)-Tenn.; oy: (1'11).

MAHK, H: H. $(1, .2)+K y 1.02:(111)$

Martls, ihas Weierly $(465)-h 32,90$

(1'(1); 1R.F.1). 2.

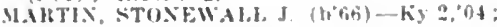

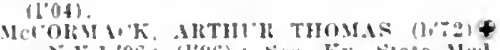

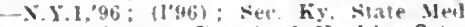

Asin and state foard of ifealth: $S^{*}$

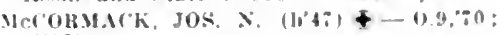

Moss, MOKTON M. (1,bii) - Tenu.5.94 (1'94).

Porter obho Il. (col.) (bint) - Tens. :"4t

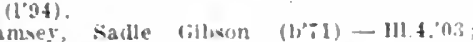

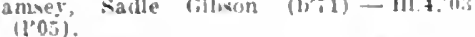

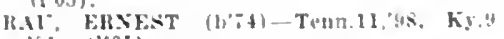
(1): (l'01)

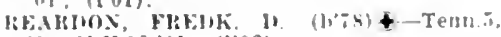
(nii. X., 10 , 01 : (1;02)

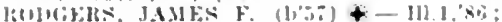
$(1+9,1)$.

Ruwe inderson Maveltil $\left(b^{\prime} b t\right)-k y .39 x$ (1'0i1): $\mathbf{G}$.

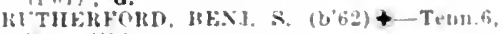

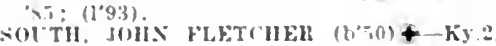
11: (1'11)

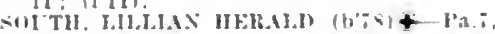

(1): 100t): 3d vile I'res. Imerlean Med. Ixvibelation.

ATEELF, MIHTIN W. (b'b) - Ky., 05 : (1) 05 :

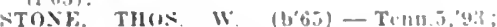
$\left(I^{2} 93\right) ; \mathbf{P d}$

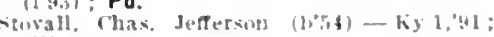
(1'93)

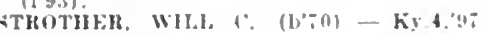
(I'A) II F.D. 4.

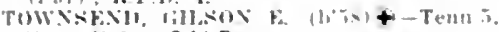
$\because 4:(190 \%)$; OALR

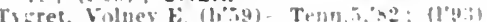

Warfleld silvanum ll (xol) (h's) -Tenn. (if: $(104)$.

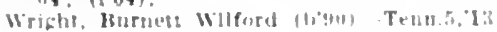

BOXVILLE, II5. UNION

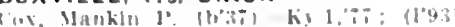

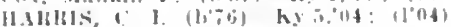

BOYDSVILLE, 100, GRAVES

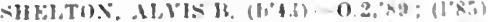

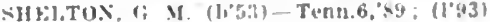

BRADFORD. 15. BRACKEN

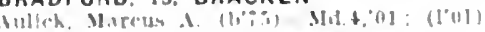

BRADFORDSVILLE, 330, MARION

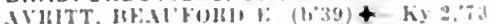

1] 640,5

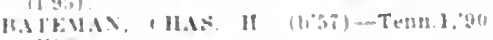
(1) $(4,5)$

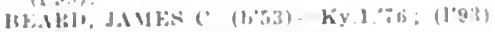

BRANDENBERG, 482, MEADE

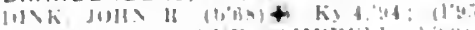

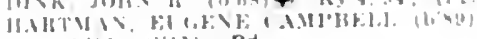

(i):2.11. (1'11): Pd.

IJRATTON W5. HOBERTSON

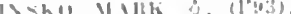

BRECKINRIDGE IR.F.D. CYNTHIANA 7B. HARRISON

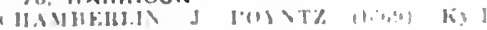

BREEDING, I31, ADAIA

(I)

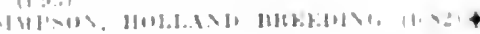
h. Bui tinit
BREMEN 254, MUHLENBERG

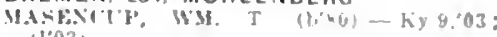
(1.03)

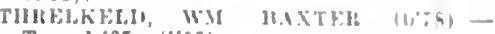
Tenu. 3,05: (1,05)

BRIGHTSHADE. 20, CLAY

H1'KE,TTS CIAHBDE T $+-h ! 1.0 B$; (1'01i): ObG.

BRODHEAD, 477, ROCKCASTLE

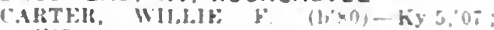
$\left(10^{\circ}\right)$ ).

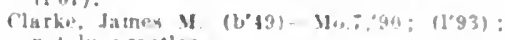
nuil In uracelce

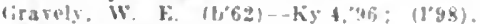

BROOKS, I00, BULLITT

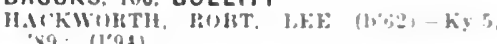
" $\mathrm{x} 9 ;$

BROOKSVILLE, 492, BRACKEN

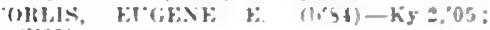
(lioj)

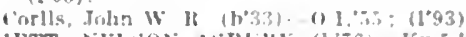

JETT. NEI.SON ASIHA (lovi); Pr.

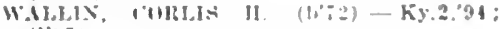
$(1,0,1)$.

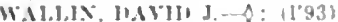

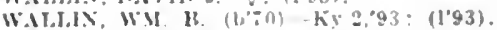

Workman, Renj. Frankllu (10, (1'10): It.F.I. 2.

BROWNSVILLE, 3I3, EDMONDSON

Morrow, Joln W. (b'bs)-Ky ?.'94: (1'94).

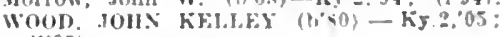
(1.05)

BRYANTSVILLE. 85. GARRARD

MOXTHOMKHY HKIILEY IHXXETT (i. (i) - hy.2, i1 ; 11'11.

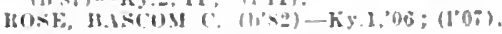

BUCKEYE, 125, GARRARD

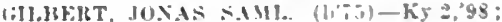
$(1+99)$.

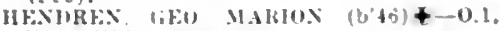
$\div 5 ;(1.94)$

BUCKHORN, 100. PERRY

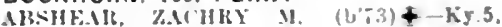
(0): $\left(l^{\circ} 02\right): \mathrm{G}$.

BUECHEL, 50, JEFFERSON

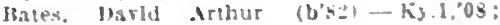
(l'0s).

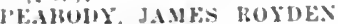

(see Loulsille.)

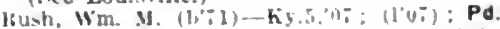

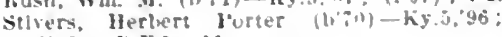
(1'06); IT.K.11. 11

\section{BUFFALO 298, LARUE}

JUXE. J. C. (2.33)+-KY.4, 39 ; (1'94)

Ifrely, Wn. T. (lit:3-Ky. 2, :5; (1'43).

MUs: RICHAR, H. $(1,49)-K y, 2,74$ (1'93).

(I01).

BULLITTSVILLE, 33. BOONE

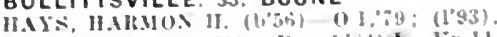

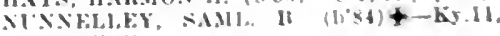
(AS: (1.0S).

BURDINE, 20, LETCHEA

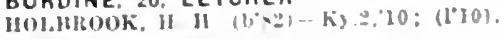

BURGIN. 679. MERCER

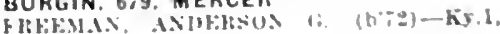
$\because 60 ;(1+2,6)$

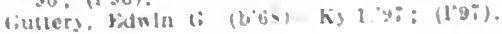

BURKE, 35, ELLIOTT

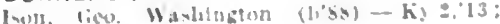

BURKESVILLE, 817, CUMBERLAND

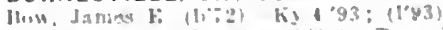

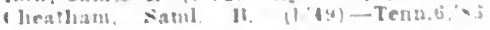

प1, 31.

hrit. LSTTI.t.TuX

Tenn. bi, $01:(1,04)$

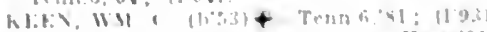

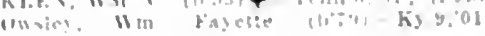
(1) 0 - i)

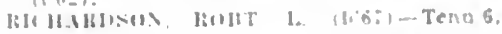
I)

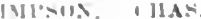

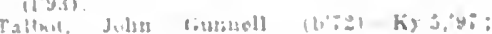
(10\%)

BURKLEY, IBS, CARLISLE

Jinde il in 1 (10,8) Tela3 9,02: (1.03). 
BURLINGTON, I72, BOONE

buncan, Lidwln W. (b'61)-0.1,85; (I'95).

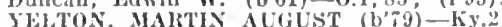
$05 ;(1,05)$

BURNING SPRINGS, I00, CLAY

IIORNDIS, HENRY CI.AY' (1)'59)-ky.4,'98; (1’98)

WEBB, (3. 1'. (b'70)-Ky,4,05; (1'07).

BURNSIDE, 1,117, PULASK1

GAMBLIX, THEO, J.-Ky,1,'96; ( )

HART, JOHA LAFAVETE (b-iT)-Ky.5, $05 ;(1,05)$.

Stlgall, John II. (b'61)-Ky.2,'89; (l'95).

STI(iAlL, NICHOLAS D. (b'63)-Ky.2,'91; $\left(l^{\prime} 94\right)$.

BURTONVILLE, 74, LEWIS

Furitt, Walter W. (b'b3)-Ky.1,92; (l'94); Pd.

BUSH, 200, LAUREL

CROOK, JAMES W. (b'76) - Ky.5,'07: $\left(l^{\prime} 07\right)$.

BUTLER, 426, PENDLETON

BECKET', AUSTIN l. (b'81)-Ky.5,'07 $(1,07)$.

BIADES, JOHN M. (b'80)-Ǩy.5,04; (l'04) I'oe, Lafayette J. (b'47) E- $0.2,76 ;\left(l^{\prime} 43\right)$. WILSON, JOHN ELMER (b'65) - $0.8,97$ : $\left(l^{\prime} 96\right)$.

YELTOX, WM. II. (b'44)-0.8,'66; (l'93)

CABELL, 20, WAYNE

13ryan, William (b'43)-Mo.28,'94; (l'95).

CADIZ, I,005, TRIGG

BLANE, HOMER (b'74)-Tenn.5,'94; (l'94). CREXSHAW, JOHN WAIDEN (b'49) 4 P’a.2,70; (1'93).

Frazer, P'attcrson T., Jr. (col.) (b'89) Teun.t, $13 ;$; (1'13)

IOPSON, JOS. LACY (b'84)-Ky.2,07 $\left(l^{\prime} 0 \pi\right)$.

Icfterson, Wade HI.-Tenn.6,'94; (l'94).

Horrls, John Henry, Jr, (b'8 8$)-\mathrm{Ky}_{2},{ }^{\prime} 09^{\circ}$ (l'11).

CAIN'S STORE, 65, PÚLASKI

WEDDLE, BRENT (b'84)-Ky.2,'08; (l'08).

CALHOUN, 742, MeLEAN

GATES, HUGII W. (b'60)-Tenn.5,'82;

IAYNES, WM. I. (b'63)-Tenn.8,'88; (1'93).

Miller, Wm. P. (b'45)-Ky.4,94; (l'94).

Moore, Paul D. (b'81)-Ky.11,08; (l’08)

SIICER, WOODSON WASIIITGON (b'so) - KY.11,08: (1'08)

CALLA, I00, BREATHITT

Hurst, C. Hardin-Ky.1,07; (\$).

CALVERT CITY, I24, MARSHALL

JONES, R. M. (b'57)-Ky.1,'89; (1'93).

LTTLE, WM. THOAHS (b'84)€-Ky.2,07; $\left(l^{\prime} 07\right)$.

CAMPBELLSBURG, 269, HENRY

Coblin, Louls (b'52) $-0.9,76$; (l'93).

HUMSTOS, O. M. (b'51) -Ky.4,'74; (1'03)

SUTER, WEBB-Ky.5,05; (l'05)

Vorles, Wm. L. (b'63)-Ky.2,'89; (l'93).

CAMPBELLSVILLE, 1,206 , TAYLOR

ATKINSON, JEFFERSON L. (b'63)థ-Ky.2, 87 ; (1'93)

BLACK, BENJ. T. (b'64)-Ky.2,'85; (l'93).

BUCHANAN, JAMES BRAXTON $\left(b^{\prime} 50\right) \&$ Ky, 4, $\% 6, \mathrm{Ky}, 5,7 \%$. (1,03)

Chandler, Woodruff 'T. (b'52)-Ky.4,'74; (1'93).

GOWDY, EDWIN L. (b'84)ङ-Ky.5,07; (l'0 $\pi$ )

REESOR, OTTER R. (b'79)†-Ky.4,01; (1'01).

SANDERS, HARRY G. (b'68)-Ky.2,93; (1'93).

White, James Sanders (b'63)-Tenn.6,'87.

(l'93) ; R.F.D. 2.

CAMP KNOX, 75, GREEN

Booker, James J.-Ky.2,'86; (l'91).

CAMPTON, 326, WOLFE

CARROLL, JONATHAX R. (b'68)-Ky.1,'94; COX, BRAXTON D. (b'34)-Ky.1,'89; (1'93). CON. JOHN L. (b'S4)-KY.5,'
CANE VALLEY, I63, ADAIR

ATKINGON, EDW. BROADUS (b'69)-Ky.1, H.NOO(K. NATHAN H. (b'5i)£-Ky.2,
CANEY, 480, MORGAN

Whereler, Jasper ('lintoll (b'82)-Ky.5,06; (10)

CANEYVILLE, 430, GRAYSON

B.IINFT, NESTOK (b'56) - Ky.1,89; (1'93).

DEWEL, EUCHEF B. (b'79)-Ky.5,05; (l'05).

(HASCOCK, ROI3T. I. (b'69)-Ky.2, 02 ; (l'02)

Ralus, Van 13. (b'56)-Tenu. 5,'84; (1'93).

Stone, Jared S.-O; (1'y3).

CANMER, I3I, HART

13OWIIN(; W.M. W. (b'39)-Ky.2,'71; (I's)

MOORE, CIIAS. IIUUSON (b'81)థ-Ky.5, $05 ;$; (1'05).

Sutphin, P’. C. (1)'25)-Pa.4,'50; (1'93); not in practlce.

CANNEL CITY, 200, MORGAN WIITTAKEK, JAMES D. (b'72)-Ky.1,94;
(1'94).

CANTON, 60, TRIGG

TAYH(OR, JOHN C. (b'68)-Tenn.6,'89; (1'93).

CARL, I0, CHRISTIAN

BARNES, OSCAR LAFAYETTE (b'82)Ky.2, 09 ; (l'09); R.F.D. 6.

CARLISLE, I,293, NICHOLAS

BRADI.EY, ALFIRED (b'75)๑-Ky.2,09; (1'12) ; R.F.D. 3.

BUNTIN, HANSFORD II. $\oplus-\mathrm{Ky} .1,91$; (1'94).

CAMPBELL, EDWARD A. (b'74)-Ky.8,'97; $(1997) ; \mathbf{O b}$.

DHLIS, MALCOLM (b'49)-0.1,'TI; (l'93)

FISHFR, SAHL. ROGERS (b'52)-0.1, 76 ; (1'93); R.F.D. 5

Howe, Wm. D. (b'66)-Ky,2,85; (1'93)

KASH, CLARENCE W. (b'84)-Ky.1, 06 ; (l'06).

KASII, OLIVER S. (b'56)-Ky.1,'82; (1'94); R.F.D. 2.

Martln, Ermine W. I). (h’81)-Ky.2, 03 ; (l'03).

MAR'TIN, JOHN CRAI (b'T5)-Ky.2,97; $\left(l^{\prime} 9 \pi\right) ; \mathrm{s}$.

MARTIN, WM. H. (b'65)-Ky.2,'89; (l'89). McNew, W. H. (b'36) $\longrightarrow$; (l'93).

MOORE, ROBT. LOVE.

(See Marion.)

Prewitt, Albert Blackburn (b'68)-Ky. 96; $\left(1^{\prime} 96\right)$

REYNOLDS, BENJAMIIN F. $\left(b^{\prime} 80\right) \notin-K y .2$ 03 ; $(1$ '03) ; R.F.D. 1

SPENCER, GEORGE B. (b'68)-Ky.8,'96 ; (1'97).

CARPENTER, 30, WHITLEY

BRYANT, WM. H. (b'T6)-Ky.5,04; (1'04).

CARROLLTON, I,906, CARROLL

Adcock. John H. Ky.2,01; (l'02)

CALVERT, WM. L. (b'84)-Ky.4,06; (l'07).

DONALDSON, ALLEN (b'77) ๑-Ky.2,'98 (I'98).

GAINES, FRANK M. (b'70)(-Ky.1,93; (l'93).

HARWOOD, CHAS. P. (b'72) -Ky.2,'94 (1'94).

HOLMES, BENJ. L. (b'66)థ-Ky.2,'89; (l'93); S.

WHEELER, JOHN P. (b'71)-Ky.4,93; (l'93).

CARRSVILLE, 298, LIVINGSTON

CASPER, ASA A. (b'68)-Ky.5,03; (l'03)

Fowler, Milliard M. (b'70)-Tenn.6,'97; (1'99)

Gardner, Wm. Franklin (b’7 $)$-Ky.9,03; (I'03).

CARTER, 259, CARTER

Ferguson, H. C. (b'41)-0.8,76; (l'93).

FULTS, HARVEI HLTON (b'il)-Ky.9, '01; (l'01).

CARY, 30, BELL

HENDRON, JAMES HARRY (b'i3)-Ky.5, 02 ; (l'02).

CASEY CREEK, 75, ADAIR

Gabbert, Zach, T. (b'49)-Ky.2,'81; (l'93).

CASKY, 50, CHRISTIAN

SANDBACH, WM. SPURRIER (b'i8)-Ky.5 07 ; $(1,07)$
CATLETTSBURG, 3,520, BOYD

Banfleld, Allen I', (b'50)-0.2,76; (l'93). Iteputy", Sol. R. (b'70)-Ky.5,91; (l'00); Pd.

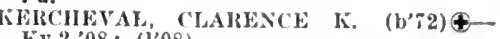
Ky.2,08; (1'08).

KINCAID, JAMFS W. (b'59) $4-0.1,80$; (1'93).

Oblluger, Frank V. (b'80)-Ky.2,'05; (l'05). Patton. Silas W. $\left(\mathrm{b}^{\prime} 46\right)-0 ;\left(l^{\prime} 94\right)$.

Rice, Berryman s. (1'39)-0.1,72; (l'93). Smlley, Martln L. (b'42)-0.2,77; (l'93). Wlllams, Joln D. (b'i2)-0.9,'95; (1'09); OALR.

CAVE CITY, 645, BARREN

CAIROLI, FIELDING G. (b'81)-Ky.2,'10; (1'J0) ; Pd.

Coombs, Horace W. (b'46) -0.2,70; (1'94).

EWING, WM. MHTCJELL (b'82)\&-Ky.2, 04; (1'04).

Godbey, John Taylor (b'5I) - Ky.1,96; (1'96); IR.F.D. 4

MHLLER, THOMAS FINIHE (b'85)-Ky.2, 09; (I'09); K.F.D. 3.

Parker. Geo. T. (b’54)-Tenn.5,82; (1’94);

R.F.J). 4.

WIITE, JOHN њ. (b'49)-Ky.2,'88; (1'93) ; R.F.I. 2.

CAYCE, 250, FULTON

NAYLOR, JOHN W. (b'66)-Ky.2,'87 ; (l'94).

WRIGHT, CHESTER A. (b'82)-Ky.5,'07 ; (l'07).

CECILIA, 275, HARDIN AUD, CHIAS. Z, (b'46) (-)-Ky.2,68, N.Y.10,

LAYMAN, REASON T. (b'73)-Ky.2,'I0; (1'10).

NUSz, HERBERT R. $\left(b^{\prime}, 6\right) \oplus-\mathrm{Ky} .1,98$; (l'98)

CENTER, 100, METCALFE

YORK, SAIIL. RODFORD (b'68)థ-Tenn.I, '99; (1'99).

CENTERTOWN, 299, OHIO

CROWE, SAML. WESLEY (b'76)-Ky.9,05; (l'05); Pd.

Smith, J. L. (b'77)-Ky.4,01; (1'01).

Warden, Wm. M. (b'60)-Ky.2,88; (\$).

CENTERVILLE (R.F.D., PARIS), 200 , BOURBON

JINVILLE, SOLOMON MHTON. (Sce Barefoot.)

CENTRAL CITY, 2,545, MUHLENBERG

FHRGUSON, JOS. M. (b'76)-Ky.9, 02 ;

(l'02).

FOLEY, FLOYD K. (b'85) - Ky.2,'11;

Hendrick, John G. (b'4i)-Ky.1,'66, Kу.2, 68; (1'99).

MCDOWWLL, JAMES I. (b'60)-ky.4,'90; (1'93).

McDowell, Wm. R. (b'53)-Ky.4,'83; (l'93). TAYLOR, SEPTIMUS THEODORE (b'79) -Ky.4,'02; (1'02)

TYLDESLEY, HARRY (b'74)-Ky.4,03; (l'03). WALTON, JOHN PORTER (b'82)-Ky.5,

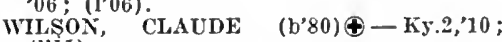
(l'II).

WOODBURN, CIARENCE (b'63)-Ky.4,'84;

(l'94); Pd.
WOODBURN, JAMES TAYLOR (b'49)Ky.4; 6 ; ( 1 '93).

CERALVO, 90, $0 \mathrm{H} 10$

Everly, G. I. (b'62) E-0.2,'95 ; (l'95).

CERULEAN, 272, TRIGG

Fellx, Benj. F. (b'44)-0.2,'86; (l'93)

WHITE, JOHN G. (b'71) - Tenn.5,'94; ('’94).

CHAPLIN, I70, NELSON

NICHOLS, WM. P.-Ky.5,03; (1'03).

POPE, FREDK. W. (b'59)-Ky.2,83: (l'93).

CHARLESTON (R.F.D.,

SPRINGS), 46, HOPKINS

EARLE, BENJ. PRINCE (b'46)@-Ky.5,'89; (1',93).

CHARLEY, 100, LAWRENCE

Hayes, L. Scott (b'82)-Ky.1,08; (I'08).

CHENOA, 75, BELL

PETRIE, HAZEL GRAHAM $\rightarrow\left(\mathrm{b}^{\prime} 72\right)-\mathrm{Ky} .1$, 94 ; (1'94). 
CHESNUTBURG, 20, CLAY

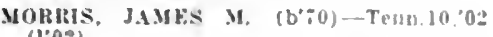
(I,0) 0 .

CHESTNUT GROVE (R.F.D. SHELBY VILLE). SI, SHELBY

AI.LEN. WM. E.MMHTT (b'SO) - Ky.5,03: (1)03): K.k.11. 3.

KA. WALTEIR K, (b'60)-Ky,4, 85: (1'93).

CHILESBURG, 90, FAYETTE

Conns, Thos. C. (b'+8)-K): :?5; (1'93).

CHILTON, 25, CASEY

COX. WISEIR-KY,9,04; (1"01)

CHRISTIANBURG, 150, SHELBY

Alexander.
(I'93).

CISNEY, 80, MUHLENBERG

SMITH, JAMES H. (6"33)-0: (1"yi)

CLARENCE, 75, PULASKI MCWILLIAMS, WILEY EVEIIETT (b'SI
KY.:11! (1'13).

\section{CLARKSON, 376, GRAYSON}

HIGDON, IOAWR E.SCE. S.-Ky.9.'05: (l'0,

Ward, Kalph s. (1)321-Ky.1,91; (1'03).

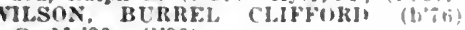

Ga.11,'99: (1'99).

CLAY, 1.098. WEBSTER

Aluridge.

(1) 93 ) y

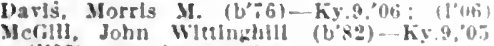
$\left(l^{\prime} 05\right)$; not in pracilce.

stgler, Latorn J. (1)"5s)-Ky.2.93; (1"931) G.

WHite. GEo. W. (b'58)-Ky.l.'s5: (l'93) (1'0;)

\section{CLAY CITY, 581. POWELL}

IRVT, RORT. A. (b'-2)-Ky.5,96; (1'3(j)

MARTIX, WM, C-Ky.1,07: (1'07) WILIIAMS, JOHN W. (b'53)=K5.2, 87 ;
(1'9i).

CLAYPOOL, 25, WARREN

ADAIR, JOS. MILTON (b'62)-KY, T.'92; (1'93)

CLAY VILLAGE (R.F.D., SHELBYVILLE) 101. SHELBY

JONES VERSOS R. (b.92)-Ky.1,0: (l'0i); Anes.

CLEATON, 10, MUHLENBERG

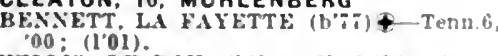

WTLLIS, LE ROY, (b'\$1)-Ky.9,05; (1'05).

CLINTON, 1.497, HICKMAN

BLELE.IS, GEO. F. (b'66)-KY.2,9I; (1'03)

JEFLFR, JOHX M. (bo5)-Ky.2,4s; (1'98) Farabough, Jegerson A. (b' 16$)-110.13,76$, $0.2,94:\left(d^{\prime} 95\right)$.

HUNT, CHAS. (b'it) E-Tenn.1,00; (l.01) I.F.D. 1.

MeMORRIES, ERWTA BOWDEN (b'SI)Mo. $, 04:$ : (1.04).

Moss, will.s h. (h6i)-Ky.2.93; (1'93) PEEBLES. WM. FEIR(iLSON (b ii)-Ky.

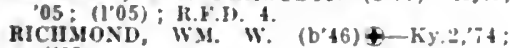
(l'93)

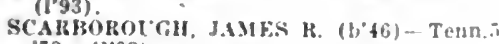
$\because 8:$ (1’93).

CLINTONVILLE, 100, BOURBON

Worthington, Wm. C. (b's3) - Tenn.1,08: (I'08).

CLOVERPORT, 1,656, BRECKINRIDGE

Lightfoot, Chas. Koss (b'75)-Mi.7,02 (1'02).

Whhtfoot, Forrest d. (b'76)-Mo.i,gs

MCDONAID, KANEST CKOCII $\left(\mathrm{U}^{\prime} \mathrm{B} 3\right)+$ Ky.2,10: (1'101.

Owen, Jaines Thomas $\left(b^{\prime} 39\right)-K y, 2, p_{i}$

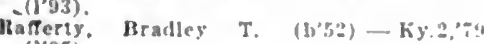
(l' 12,3$)$.

SIMONS, ARMl A. $\left(b^{\prime} 58\right)+k y .40$ $(1.93): 5$.

CLOYDS LANDING, 40, CUMBERLAND

HOWMAX, JOHN W $\left(b^{\circ}-0\right)$ Tenn B, 00 (l'01)

COBB, 15. CALDWELL

Amoss, Larld A.-(1.), 80 ; (1'33)

Young, JotIs O. (b':2)-Ky,s,yi; (1"y:)

COLD SPRING, 600, CAMPBELL

HAGAN, GEO. W. (b'Gi)-KY.2,"91; (1.93)

\section{COLESBURG, 200, HARDIN}

Cralg, Thumas bidwin (b'8s) - Ky 2,10 (1'io)

H[BISS, S.MI. T. (b'43) - KY.5,:3; (1'93) COLLEGE HILL, 200, MADISON

Herryman, Thomas J. (b'4)-Ky.1, 85 (1"93)

Combs, rolie. Is (b'51)-Ky,J, 59 ; (1.95).

COLMAR, - BELL

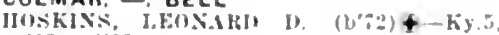
$03 ;(1 ' 03)$

COLUMBIA, 1,022, ADAIR

('AHTW RIGIT, WAI.KEL F. (b'5l)-Ky.?, is: (1'43)

Ciflssom. Giarland John-ky.2,09: (t).

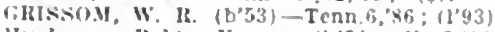
Hindman, lobt loung (b'it)-ky.2, 0 ? $(102)$. MHLFIG, SAMLEL, P. (b'61)-Ky.2.'83;
(1.93).

RISSEIJ. CHAS M. (b\%0)-Ky.l,90, ky. "(1): (l'95)

TAYl.0K, LRIAI, I. (U'33) - Ky.2:5: $\left(l^{2}(0 ;)\right.$

\section{COLUMBUS. 970. HICKMAN}

L.F.E, J.1.11:S R. (b'0)—-K5. 2,02; (1.93)

WHAYNE, THOMAs s. (b'6y) - MO.24, I'0(1)

CONCORD, 213, LEWIS

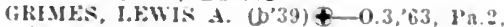
bit: (1,g).

CONCORDIA, 100, MEADE

MILE. JUS. LEWIS (b'76)-Ky, I, 0?: (1'03):

CONSTANCE, 80, BOONE

Marret, Albert i. (b'4)-Ky.2, it; (l'b3)

CONSTANTINE, 40, BRECKINRIDGE

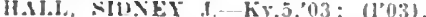

silose, Ilenry C. (b'4t)-Ky.t,'92; (1'93).

CORBIN, 2,589, WHITLEY

13.4LLARD. THOM.SS J. (b'/8)-Ky.5, 05 $(1.05)$.

BIIANT, JASPER F. (b'63)-Ky.,85 (1'98).

lirgant. Wm, C.-Ky,s,s: (l)

(OOX, WM. MOSS (b's

ELWARDS. HERH J. (b'56)-ky,5,05 $(1,05)$

EDWARDS, EIM. K. (1, 33$)-K y, 5,07:$

ELIWAIRDS, GEO. liRANT (b'79)-Ky.5,05: (1,0)

HARKR, JOHX HENRY (b'60)-Ky.2.90 (1'93)

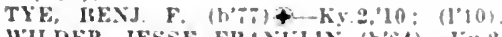

WILPER, JESSE FRANKLIN (b't)-Ky, i4: (1'94).

CORINTH, 252, GRANT

Gentge, James Dudley (1,68) II - (13,192; (l"13).

lancaster, Buford K. $\left(b^{\prime} 33\right)-0.8,76$;

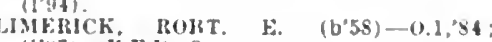

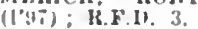

bobluson. Wm. labler (b'ti)-o.s.;iti (l'yk)

SIMMUNS. HAJIRY H. (b'66) - hy.1,93;

CORN CREEK (R.F.D.. BEDFORD), 50 . TRIMBLE

FIX, CARIIULL 1', (b's2)-Ky.5,00: (1'06) WKIGHT, WM. M.KXANUER (b'50)-Ky. $\triangle D^{\circ} ;(103)$

CORNISHVILLE, 300, MERCER

Nime. Frank Jewell (b'05)-Ky.5,05: (1005).

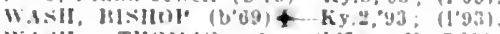

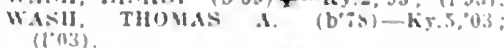

CORYDON, 942, HENDERSON

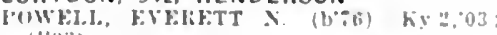
(1'u:\})

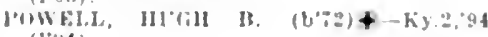
(10:4)

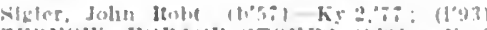

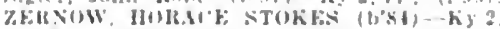
D.s: (1'08), L.R.

CoTTAGEVILLE, 30, LEWIS

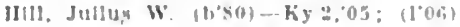

COTTONBURG, 25, MADISON

J'dUI:, WM K. (b'B)
COVINGTON, 53.270, KENTON

IIIMS, FE:NTIN T. UN"11-K5.9,06

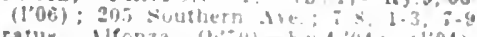
Aratur, difonza (b'ou hy tot: Hot) IlERJCh, JAJk

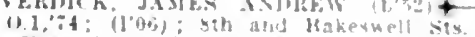
OAlce, :11 W. $8: \mathrm{h}$ s: :

(ser" "incinuatl. ")

BECKETT, J.MES

$(1+23)$; 1041 Matlison

MEIIGMAN, MICHAL (b'sl)+-0) I,03;

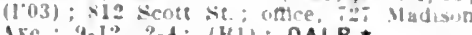

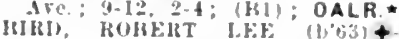

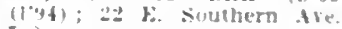

Mau, Jihn M. (4:39)-0.1, $81:(1244): 1050$ ltukell sit. $8-4,-3,-4$

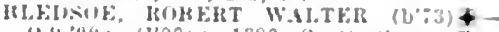

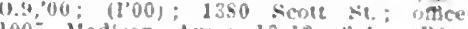
lo0, Madison Are: $10.12,2-1 ;($ B 1$)$ : OALElie, Jo.

102 E. ith sit

Bryant, Win. Henry (crl.) (b's)-NC.3

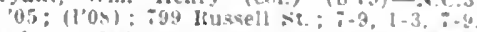
Carlion, Inamer Lee $\left(b^{\prime}-9\right)$ - kyt:01; (101): (ivldringer and becoursey Ave fince, hain and snutlum, (1'90): 1017 Madison se: $7-9-k 5.1 .98$ Danks, Fellie Jones (b'70)-0.s, 00 ; (1'00): i26 Madimon Ave.

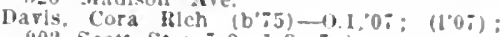
902 Seote St; $i-3,1-3,7-8$

D.IVIS, JAMES ALHERT $\left(b^{\circ} 66\right)-11.13,43$ (19:i) : 902 sect $5 \%,:-3,1-3, ; .8$ corinton Eckman, Wm. G, (b'3)-0.1.95; (l'95) 33 11: till Si

ELLIS, GFOR(iE: J. $\left(b^{\prime}, 5\right)+-0.1$, 96 (1.9i); 23: W. 11th st: otce, 503 Pike St. $80^{-9}$ l $-3,0-8$

Firtel. Robe Jos, $\left(b^{\prime} \times 6\right)-0.1,199$; (1"09) : 16:3 k. I7th st : untll $10,1-3,6-10$; Afce,

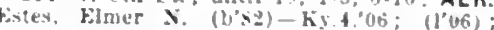
1s. Fo. Robbins Se.

Flscher, Frank W, (b'74)-10.13,97: (197); 1135 Madison Are

FUIRISH, JOSIAH GRAVRA (b'52)-0.1.

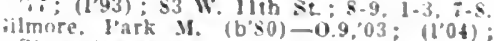
Sterrett itre.

GIEXX, THOMAS J.MMES $(284) \leftarrow-0.1$,

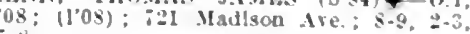

Gross, Jol:n II. (b'53)-Pa.1,79: (104): 1340 seoli st.

Hanks, Kathertne (b'36)-0.21,96: (l"9s): $11^{21}$ siones st

H.RIRS CIHFORD JAMES $\left(b^{\circ} ; t\right)-0.9$.

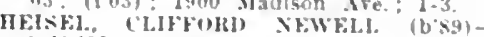
(1.t1, I2: (1'12): 1+49 Madison Ave.

thle. Clarence $I$

(siee cinolunati, 0

heurns, Charless (b'36) 0.1,63; (193)

kearny, chrenup sts, $:-9,1-3,7-9$

3d and (ircenup siv

kelley, I I) (col.) (b'61)-Tenn.:.96;

kelly, wi11 H. (b's)-0.1.51; (1'93): 1000 IIalison ore: 3 :

Kerkow, l'aul fo, (b'st)-o 13,0i: (1'as):

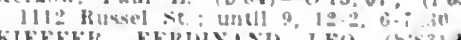

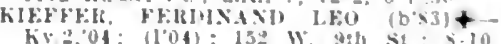

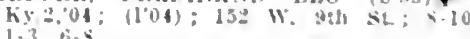
1.

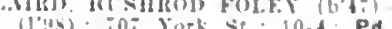

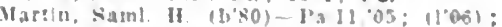
106: Mallienl Ire

MatTIl:Ws. I. I. (bón) Ky 1,93: (19:5): ivis liadisnt Are.

Мk:к. JUIV KISK

and Incinali, (1)

hivet. Pripet

Meier Juhn

[xes I'Ine!ninas!, (1)

Molloy, John J (b't0) - N Y.10, 56 : (1993): Ind: Madison Are: : $8.9 .:-3,7.8$. 
Morgan, 'Thoinas J. (b'64) -0.1,'0I; (1'01) ; 1007 Madison Ave.

lotl, Irvine Ketcheson.

(see I'Inclnnat1, 0.)

HIRN.1N, J011X" It, (b'61) $+-0.1,83$ (1*93); 1007 Madison Ave.; $8-9$, I :30-3, $7=8$.

NELSON, TIIOS. 11. (b'67)-ky.I,94; (1'94): 1555 (;reenup St

0'MALEY, JOS. M. (b'72)-0.9, $09 ;\left(1^{\prime} 09\right)$ 957 Maln St.; oftlce, Ylke and Maln sts. 957 Maln St.; oftlce, Plke and Maln sts.

owens, cleon C. (b'63)-1'a.2,'87; (1'95); 9II Madison Aro.

Peun, Nathan F. (b'63)-Ky.4, 84 ; not in practlce: 52 w. 5th St.

Pleck, Chas. (:. (b'61)-0.1,'89; (1'94);

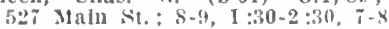

J'IRlit:

(See Ciuchnati, o.)

l'rewitt, John Itcrarvey (b'83)-Ky, 0 ; ; (l’07); $45 \mathrm{~W}, 4$ tl $\mathrm{St}$.

HANKIX, ROBT. II. (b'61)-0.I,'90; (l'94) : 1014 Iiadison Ave. ; 8-9, 1-3,6-8

Itanslaw, W. II. Tébbs (b'84)-0.9, 07 (I'08); 1030 Madlson Are. $7-9,2-4,7-8$.

REYNOII)S, CIIAS WAUGH (b'71)-0.1, 94; (1'95): 48

ITEYNOLDS, ORRIN LYLE (b' 74$)-0.1,99$ (l'99); 82 W. 4th St. ; offlce, 48 W. 4 th St. ; 8-9, I-3, $\mathbf{6}+7: 30 ; \mathbf{R}$

RYAN, JAMES A. (b'87)-0.9,09; (1'09) ;

1525 Scott St.
SALLEE, THEODOLE (b'68) - Ky.9, 06 ; (1'06); 30 W. 4th St

Simcox, Joln S. (b'52)II-0.13,89; (1'93); 58 W. 4 th St. $8-9$, I-3, 6-8.

SIMLSOX, CAITEIt S. (b'52) - $0.8,83$; (1'02); 1364 Greenup St. ; $7-9,2-3$

SLEET, WM. FVERETT (b'59) $\$-0.1,89$; (1'93); 1113 Decoursey Ave.

SMITH, LUCIEN LYNE (b'76)-Ky.5, 03 ; (1'03); 1414 Madison Ave.

Southgate, Loulse.

(see Cincinnati, 0 .)

staughton, James Martin (b'74)-0.2,03

(1'03); 833 Scott St. ; 8-10, I-3, 7-8:G.

Stephens, Darid W. (b'81)-0.1,04; (1'04) ; R.F.D.; $8-9,1-2$.

Strouse, Lee (b'63) E-0.2,87; (1'93) ; E. 4 th St. ; $8-9,1-2,7-8$.

sluard, Edw. L. (b'43)-Pa.8,'65; (l'y3) ; 520 Russell Ave.

Tanner, Klrby L. (b,73)-0.1,00:

2511 Madison Ave. : $7-9,1-3, i-8$

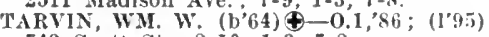

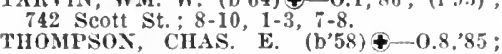
THOMPSON, CHAS. E. (b'58) †-0.8.'85;

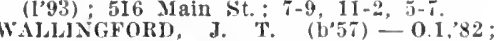
(1'93): 1446 Madison Are.

WAITERS, GEO. W. $\left(b^{\prime} 50\right)-0.10,70$; $\left(1^{\prime} 97\right) ; 1521$ Scott st.

Watkins, Simon J. (col.) (b'64)-Tenn. i,91 : (1'93); $63 \mathrm{E}$. 9th St

Wels, Francis W. (1,52)-Ky.2, 'ty; (1'93);

Wh!te, Chas. W. (b'72)-Ky.5,94; (1'97);

hlte, Chas. W. (b'72)-Ky.5,9.

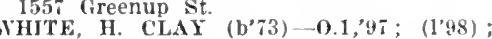

1125 1)ecoursey Are. $6-8$.
1LSOX, HERBERT F, (b'76)-Ky,5,01;

WLSON, HERBERT F.

WINTEINEIER, ADOLPHUS C. (b'68)$0.1,93 ;(1993)$; 1001 lladison Ave.; 8-9; $\mathrm{I}: 30-3,6: 30-8$.

Yates, S. Annie.

(See Cincinnati, O.)

COX'S CREEK, 30, NELSON

MeCLLIBE, CHAS. (b'T3) \& - KY.2.46:

OVERALL, JOHN R. (b'69)†-Ky.4,92; (l'9.t).

Wright, Alonzo D. (b'5s)-Ky.1,'s6: (I'93).

CRAB ORCHARD, 467, LINCOLN

Doores, Wm. M. (b'30) $\triangle$; $\left(\mathrm{l}^{\prime} 93\right)$

Edmiston, Willie J. (b'72) - Ky.2,95; (l'y6)

HARMON, JOHN A. (b'7i)-K4.5, $06:\left(1^{\prime} 06\right)$

IS.AACS, HLBERT H. (b's.) - liy.II, 08 ,

$0.2,10 ;\left(l^{\prime} 11\right)$

ONES, LORANZA FRANK (b'8I)-Ky.II, '08; (1'08).

CRAFTSVILLE, 45, LETCHER

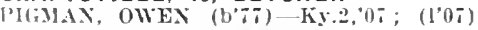

CRANSTON, 10, ROWAN

Davis, Andy .I. (b'b6)-310.28,99; (I'99).
CRAWFORD, 20, LAUREL

Tuller, Yalcom I3acon (b' 52 ) -l'a.4, 73 ; (1'03).

CRAYNE, 125, CRITTENDEN

F()X, VEIRNON It. (b'S4)-Ky.11, 08 ; (1'08)

CREELSBORO，75, RUSSELL

J3uster, Jolin F. (b'53)-Ky.2,78; (I’93).

Giricler, Thos. (C. (b'49) -liy.2,'i6; (l'93).

CRESTWOOD, I50, OLDHAM

FIt LEMAN, JOIIN A. (b'5I) \&-Ky.4, il $(10 \% 3)$.

JRYOK, ILOWAX゙ BARCLAY (1,74)-Ky.5, 97 ; $(1,03)$.

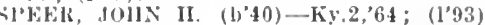
Fecks, Edw, F. (b'60)-Ky.4,'86; ([',4): R.F.D.

CRIDER, 100, CALDWELL

Moore, Wm. Bain (b'7 7 - Tenn.1.'99; (l'by) MO'T'T, JOIN 1). (b'41) -0 ; (1'03).

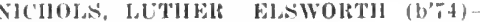
liy, 5,$03 ;$; (1'03).

CRITTENDEN, I89, GRANT

BIt)WN, JAMES IIENITY (b'48)-0.1,73: (1'88).

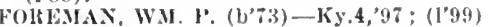

R.F.O. 2.

MAISIIALL, JOHN JAIES (b'55)-Ky,2 $07 ;(1,07)$.

\section{CROFTON, 402, CHRISTIAN}

Croft, Chas. Covington (b'77) $-K y \cdot 1,00$ $\left(l^{\prime} 00\right)$.

CROFT, MARIOS ELGENE (b'75)-Teun.I 00 , Ky.5, 02 ; (l'02)

DURHAM, WALIIS WYATT (b'81)-Ky.5. 05; (1'05); R.F.J. 1 .

JOHYSON, JOIIN EVAN (b'82)--Ky.5,05; (1'05) ; H.F.D. 2.

JOVAN, GEO. WILSON (b'67)-Ky.I, 92 ; (l'93)'

Tutt, Chas. A. (col.) (1)'69) - ky.7,'y! ;

WIILIAIS, SAML, HANSON $\left(b^{\prime} \check{\imath} 0\right)-$

Tenn.6,'94; (1'94).

CROMWELL, I63, OHIO

ILIEN, OSCAR (b'82)-Ky.9,'05; (1'05)

WATKINS, LEE BENJ. (b'83)-Ky.2,'1?;

(1'12).

CROOKS (PRESTON P.O.), 100, BATH

Williams, Henderson A. (b'45)-0.8,'40; (l'93).

CROPPER, 159, SHELBY

(IARYEY, JOHN FREDK. (b'8I)-Ky.2, '1) (l'08).

Underwood, Wm. I. (h'49)-Ill.I,'69; (l'44).

CROSSLAND, 175, CALLOWAY

PASCHALL, ADOLPHUS F. (b'67)-Ky.2 $90 ;$ (practicing ln Tennessee; l'94);

Menber Tenn. State Assn.

CRUTCHFIELD, 100, FULTON

Henry, Wim. D. (b'70)-Ky,2,98; (l'98).

Turney, Alton J. (b'67)-Tenn.5,'91 ; (l'93)

CUB RUN, 75, HART

HALI, CHASTEEN (b'55)-Ky.1,03; (l'03)

CUMBERLAND FALLS, - WHITLEY

IICCLELLAN, MAKY CARSWELL (1'T3) 4

-Pa.̋̃,07; (1'08); Member IIl. state Med. Soc.

\section{CUNNINGHAM, 250, CARLISLE}

Burrow, Reuben ( $.\left(b^{\prime} 68\right)-$ Teun.5.'91, 0.2, 94; (1'00); It.F.I). 1

SHELBURN, SILAS C. D. (b'it)-Ky.5,06; (l'06).

CURDSVILLE, 235, DAVIESS

PAINE, J. E. (b'67) $€-K y .2,91$; (1'91).

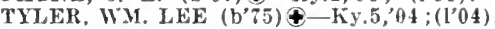

CUSTER, 50, BRECKINRIDGE

MEADOR, JOHX W. (b'53) - K.?.', (1,43). MEADOR, RAYMOND W. (b's0)†-Ky.
'03; (l'12).

CUTSHIN, 70, LESLIE

Baker, Boyd Yan Buren (b'si)-Tenn.10, '12; (1'I3).

Baker, John J. (b'7.j)-Tenn. I0, I3 ; ()

CYNTHIANA, 3,603, HARRISON

BATSON, JAMES R. (' 560$)-0.1,79$; (I'93)

BOYD, MARIE CLARE (b'6̈) $\Phi-0.1,03$ (1'10).

CARR, WILLIS H. (b'63)£-0.1,'87; (1'93)
R.F.D. ?.
GIFXS, LAMNE \$. (b'66)†-0.1,'87; (1'93); (13I); OALR.*

$\triangle A N G$, R. I1. (b'61)-J'a.2,'85; (1'03) ; R.F.D. 5.

MARTIX, JOSELIICS (b'6I) - 0.1,85: (1'87).

JCDOWELI, MARSHAJL (b'72) $\bigoplus-0.1,94$; (1'95).

McIanurin, Archie F. (col.) (b'72)-Tenn.7. $02:(102)$

IOORH, NIMllion

.1.81; (1.93)

MOORE, 'WM. H. (b'68)-Ky.2,94; (1'97)

'ETTY, BAIIEY H. (b,59) $\$-0.1,84$ (1’93); R.F.D. 6 . REES, JOHN MIITON (b'72)థ-0.1,95 ;
(1'95).

Rlghter, Geo. W. (b'44)-0.7,72; (l'y3).

Itlghter, T, $11,-0.13,03 ;\left(1{ }^{\prime} 03\right)$.

SMISER, H, TOD $\left(\mathrm{b}^{\prime} 77\right)-N . Y .9,0 I$; (l'0I) Stewart, Wallace $T$ - Ky.2,90; (1'93) R.F.D. 3.

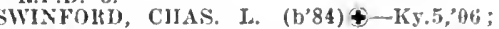

VAN DEREN, JOHN HARLAN (b"il)

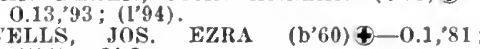
(1'93); ObG.

wOON, R. WICKLIFEE (b'73)-Ky.2,'03 (l'03) ; G.

WYLES, JOHN PETER (b'71)-Ky.2,'10;

(I'I0); R.F.D. 8.

DABNEY, 20, PULASKI

PRICE, WM. M. (b'67) $₫-0.2,95$; (1'95)

DAISY, 15, PERRY

COMBS, SPENCER P. (b'81)-Ky.2,09: (1'09).

DALTON, 121, HOPKINS

Brown, Benj. Green (b'51)-Tenn.6,'82: (l'93).

Brown, Michael (b'63)-Ky.2,'90; (1'93).

DANIEL BOONE, I50, HOPKINS

Veal, Ifarrln S. (b’'̈8)-Ky.5,06; (l'06i).

DANVILLE, 5,420 , BOYLE

COWAY, GEO. (b'33) - Pa.2,55; (1'93).

COWAN, JOHN RICE (b'72) $\uparrow$-JIass. I, 94 ;

OUNLAP

EAUS, SAML. O. (b'69)-Ky.5,90; (1'95) ; Memher Ill. State Med. Soc.

Frye, John IIenry (col.) (b'75)-Ky. 6,05 ;

GRIFFIN, THOS. R. (b'80)థ-0.I, 00 ;

(l’00); S. JOH D. $(\mathrm{b}, 76) \oplus-\mathrm{Cal.7}, 02$ $\left(l^{\prime} 02\right)$.

Jones, Benj. Franklln (col.) (b'58)-D.C.3 '90; (1'94)

Kincaid, Douglas Howard (b'63)-D.C.2,'91 ; (1'03): not in practlce.

Marsh, Henry M. (b'61)-0.7,'84; (l'93).

MAY, OSCAR L. (b'63)-Ky.2,07; (l'07)

MONTGOMERY, FAYETTE H. $\left(\mathrm{b}^{\prime}, 0\right) \Phi$

D.C. 1,$92 ;(1,96) ; \mathrm{S}$.

Moore, J. Harrison (b'65)-X.Y.10,'88 (1'45)

Rawson, Vance (b;6) H-Ill.4,02; (l'09)

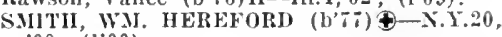
$00 ;(1>00)$.

Wood, Buford Thos. (b'49)-Ky.2,;3;(1'93) ; not in practice.

DAWSONSPRINGS, 1,350 , HOPKINS

Boitnott, H. Kufus (b'76)-Ky.5,'06 ; (l'06) Brown, Geo. W. (b'42)-0.8,80; (l'94)

Darby, Andrew G; (b'39)-Ky.4,94; (1'94).

Hardy, llobt. Lee (b'69)-Ky.2,'04; (1'04)

JACKSON, FRANCIS YONROE '(b'70) Ky.II,08; (1'08)

Lutz, Cora E. Brown (b'69) -0.8, 90 ; (1'94).

Niles, ('has. A. (b'72)-Ky.5,98; (1'98).

Waters, Allen I'reston (b'72)-Ky.I,9s ; (l'12).

DAYTON (NEWPORT P.O.), 6.979, CAMP BELL

Bray, Gen. Richard (1,6.3)-0.1,'05; (1'12) GRIGGS, SAML. 0. (b'75)-0.1,'96; (1’0I).

RICHARDS, WM. DALLAS (b'50)-0.9,'89; (1'94).

Snitzlberger, Lawrence M.

(See Bellevue.)

STRUBLE, CHAS. H. (b'72)-0.13,95; (l'95).

(See Yewport.) 
DEANEFIELD, 75, OHIO

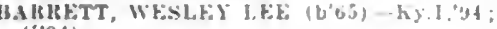
(1.94)

DEERING, 30, WHITLEY

HAIBMON, F. LAEAVETTE: (b'so) Ky, $0 B^{\circ}\left(1^{\circ} 06^{\circ}\right)$.

DEFOE, 90, HENRY

Murdock, John (b'50)-Mllch 4.73; 1100)

DEKOVEN, 600 UNION

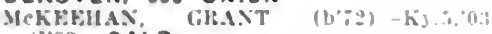

II'03: OALR.

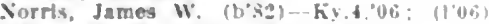

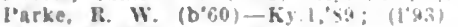

DEM OCRAT, 100, LETCH

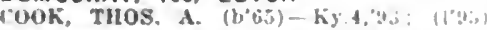

DE MOSSVILLE, 150, PENDLETON

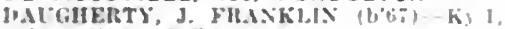

$91 ;(1 \cdot 94) ;$ K. F.I, 2

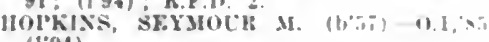
(1.94).

OENNIS, - LAWRENCE

Wheeier, Casablanca $0^{\circ}(10,0,-k y, 0,04$; (I'04).

DENVER. 100, JOHNSON

lianlel, David Ilarmon ( to's)-Ky.2un: (I"OS).

DEPOY, SO, MUHLENBERG

IRGABRITE, BENJ. G-K) $2,0 \%$; (I'0i)

DEXTER, 260 CALLOWAY

'HATON, CHAS. LDW, (1)60)-MI.3,'S4: (1'93).

\section{DIXON, 741, WEBSTER}

(amplell, J. P. (b'34)-Ky.1,"76: (1'93)

KEVI" WM. (HESLEL (b'st)-Ky.J.0 : $(106) ;$ R.F.D.

SMTH, CILA. II. (b'63)-Mo.1.85; (1'94); OALR.

WINSTEAI, FRANK Y.-K3.2.92:, (193),

DOGCREEK, 23, HART

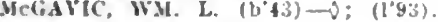

DOTSON, 20, FLOYO

DOTSOE MALCOLM T. $(b \times 0)-k y .11$.

os: $(109)$.

\section{DOVER 386. MASON}

IIutching, James Henry (b':4)H-0 13,"03: (f'03).

Smlth, Fletcher $\left(b^{\circ} 23\right) \rightarrow ;\left(1^{\prime} 93\right) ;$ wol in practlce.

Smith. F. M. (b'+s)-O; $\left(I^{\prime} 00\right)$

ORAKE, 42, WARREN

NELI. JAMES LC'11.11' $\left(\right.$ b' $\left.^{\prime} 9\right)+$-Tenn,1, "73: (1'94).

DRAKESBORO, I,I26, MUHLENBERG

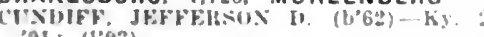
$91 ;(193)$.

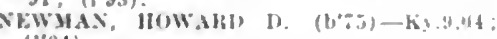
( 104$)$.

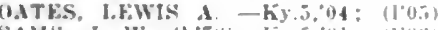

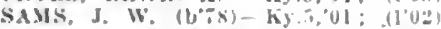

DREYFUS, 50. MADISON

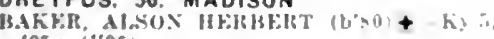

05: (1'05).

DRY RIDGE, 500, GRANT

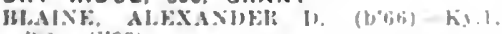
(y0): (I'93)

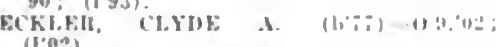
(I'02).

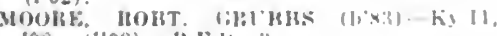
(08: $(1,08)$; if l1.

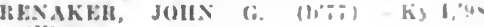
(I"9k).

DUBLIN, 123. GRAVES

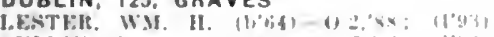

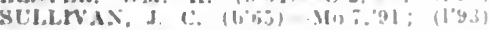

DUCKERS、200, WOODFORD

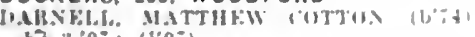

h) $2,0 \% ;(110 i)$.

OUGANVILLE (R,F,D. BONDVILLE), 65. MERCER

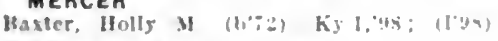

DUNDEE, 200, OHIO

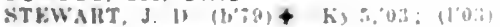

DUNMOR, 138, MUHLENBERG

llaterer, (harlea II (b'bis) - h) : 943 (I.94)

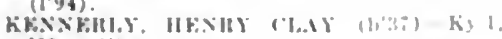
$\left.69: 11^{\circ} 93\right)$

THixi:H,
DUNNVILLE, I44, CASEY

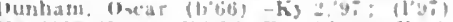

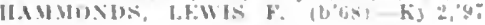

$(1,0 ;)$

DYCUSBURG, 176, CRITTENDEN

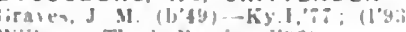

WIIlurs, Thad $F$ : (I'Y3)

EAGLE STATION, 100, CARROLL

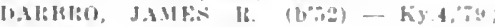
$1193)$

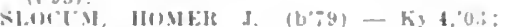
(1.1):31; IT.F.I) 1 .

EARLINGTON, 3.931, HOPKINS

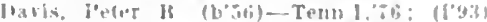

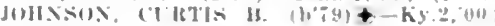
(100).

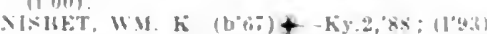

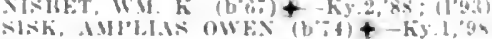
(I"us): S.

EAST BERNSTADT, 698. LAUREL

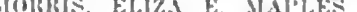

$(1,94$

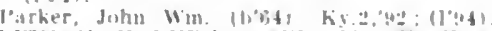

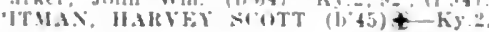
ii: $\{123: 3\}$

Truulnan, columbus I. (b'tia) - Ky 2,94 (1, 34$)$

EAST FORK, I00, METCALFE

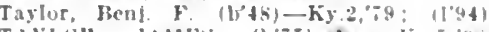

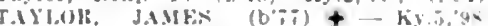
(1.0.3).

EAST POINT, 250, JOHNSON

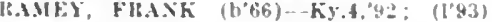

EDDYVILLE, 1.442, LYON

HIstri, J(1) il. (1,60)-Tem.6, 83 (1'9.3)

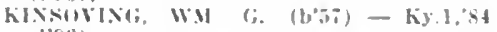
(l' 933$)$

Th.tVIs, H.N. J. $(6,73)+-k y 2,01:$ (I) 011

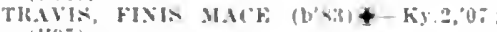
(I) (0)

EDGINGTON, 20, GREENUP

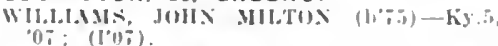

EDMONTON 250, METCALFE

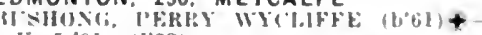
Ky $.5,91 ;\left(\left[l^{\circ} 93\right)\right.$

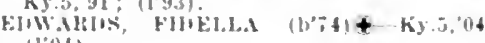
$11^{\circ} 0+1$

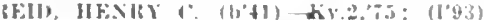

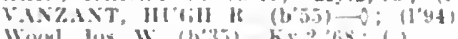

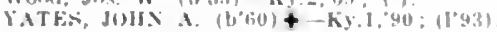

EKRON, I68, MEADE

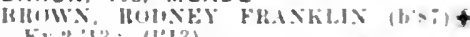

Ky:2, 13: (I'13).

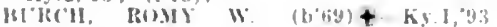

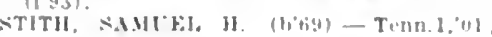
(l'0I).

ELI. 20, RUSSELL

(BI.AII6. IAIIF: MUIIII):- D: (L'I0)

ELIZABETHTOWN, 1,970, HARDIN

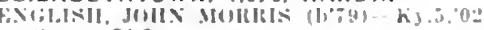
$11^{\circ}(0) 1 ; 0 \mathrm{ObG}$

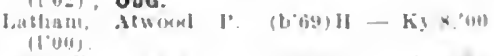

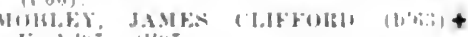

k) $1,0 \%$ ( 1,$4 ;$

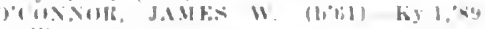
(19, is

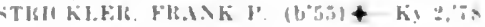
(1):0:31,

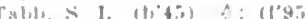

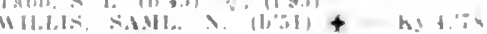

11.93

ELIZAVILLE。 135, FLEMING

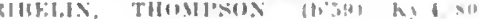

ELK CREEK. 36, SPENCER

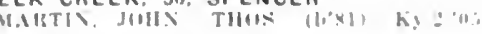
II'11:1

ELKFORK, 50。 MORGAN

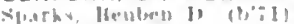

ELK HORN. 94. TAYLOR

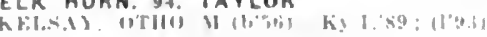

ELKTON. 1.228, TODD

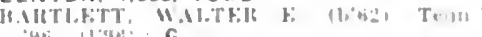

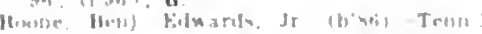

(1) $31,1,6$

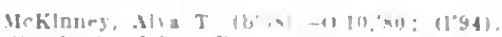

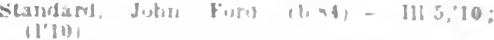

TRABI L: IEE;

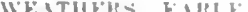
(1.0:3).

ELLIOTTVILLE, 115, ROWAN

suetram, Juhn Willlas (b"ä)

EMINENCE, 1,274, HENRY

IIIWIIF, AIBEIIT I".

$1100)$

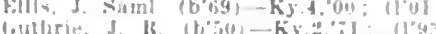

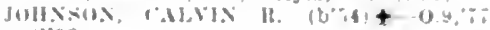

$(1+93)$

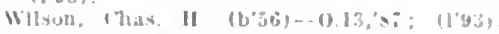

ENGLISH. 100. CARROLL

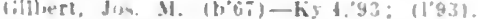

ENSOR (R.F.D., PHILPOT), 25, DAVIESS

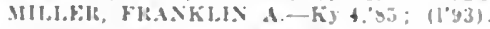

ENTERPRISE, 25, CARTER

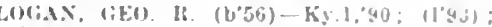
U.

ERLANGER, 200, KENTON

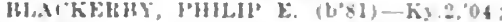

(rorey, Win. M. (b'65)-0.2,86: (1'93)

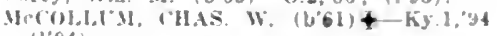

(Itre, James I". (b'az)-1) I, 94: (195)

SL.TTEK, (HAS. H. $\left(\mathrm{b}^{\circ} 60\right)+-0.1,31$ : (1'43).

ESTEP, 25, LAWRENCE

llall, John relsus (b\%,

ETOILE, 25, BARREN

Cooksey, II. E. (b'39)-Ky.5, $\$ 0$; (1'93).

EUBANK, 182, PULASKI

M'TUN, JOHS HASTON (b's0)-Ky.d1, OS: (1"0x)。

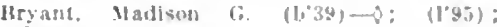
is $\boldsymbol{r}^{2}$,

(illson. (has. Valentine $(b * a)-k 5 z ; 0$

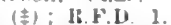

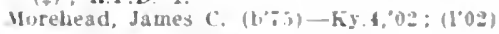

EWING, 300, FLEMING

Morfurd, Archlbahl 1. (b'

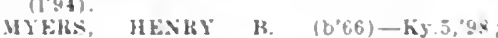
(1ㄴ)

Thumpson, James (b'34-K! fas: $(193)$ It..1.1). i.

EZEL, 128, MORGAN

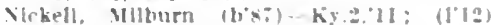

Waluleck, James M (b'43) - 4 : (1'94)

FAIRFIELO, 292, NELSON

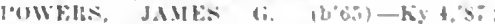

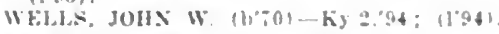

FAIRVIEW, 108, CHRISTIAN

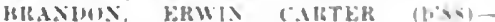
Tenn

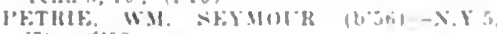
iy: $(1093)$.

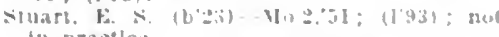
in practlce.

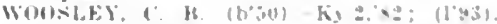

FALCON, 200, MAGOFFIN

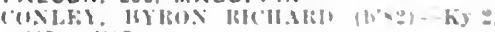
$0 \%$; $110 \%$.

FALLSBUHG, I3\&, LAWRENCE

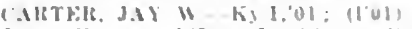

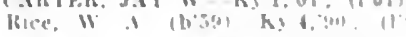

FALMOUTH, 1,180, PENDLETON

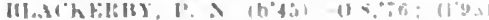

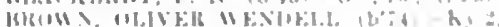

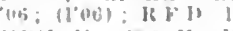

HIIIIN Matil It

$(1,: 4,1)$

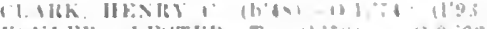

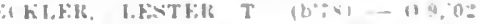

$(1+1):$ it $10=$

lithisitil. WM. (1) $4: 31$

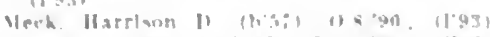

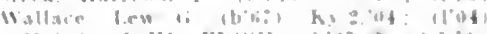

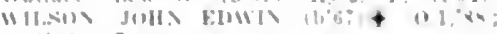
(1) 0 की 0

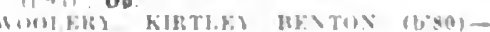
h, 1,01101104 
FANCY FARM, 200, GRAVES

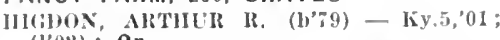
(1'02); $0 p$.

MERRITT, B. Ross (1)69) - Mo.27,91; (1 193$)$.

MERTHTT, WM. ERYEST (b'78)-Mo.34 '02; (1'02).

FARMDALE, 25, FRANKLIN

STEWAIR, JOIIN I'. (b'70)-Ky.2,93: (IPO4).

FARMERS, 427, ROWAN

Carter, Franel's .l. (1,:i1) - D: (1'93)

EVIXS. TIOS, ASA E. (1) 44$)-0.16,95$,

Ky. 2,$07 ;\left(\mathrm{l}^{\prime} 0 \pi\right)$.

ICCIALS, NLILX W. (b'73) +-Ky.1,94; (1'94).

FARMINGTON, 136, GRAVES

ALFXANDER, WM, I'. (b'61) - Tenn.5,84: (1'93)

Colley, L. G. (1,74)-Ky.2,97; (1'9i)

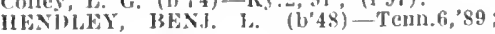
(1'93)

STOKFS, WM. B. (b'62)-Ky.2,90; (I'93),

FAUBUSH, 100, PULASKI

IIUGIIES, LWONIHAS (1,\%(i) - Mo.28,99: (1'00).

FERGUSON, 200, LOGAN

CRITTENHEX, ALBIUS M. $\left(b^{\prime}(5)+-\right.$ Tenis.5,'94; (1'94).

FILLMORE, I0, LEE

Ollver, Herman K. (b'65) - Ky.1,'92; (1'93)

FINCASTLE, 50, LEE

Roherts, IIoses (b'37) $\rightarrow$; (1'99).

FINCHVILLE, 75, SHELBY HANKINS, EWART (b'68) - Ky.1,97;

NASH, WM. IIAßMON (b"88) - Ky.2,'12 (1'I2).

FISHERVILLE, 50, JEFFERSON

REID, S'TEI'HEX L. (b'66)-Ky.2,94 $\left(1^{\prime} 96\right)$.

SELIFES, EARL DENXIS (b'78)-Ky.5,06; $\left(1^{\prime} \theta 6\right)$.

FISHTRAP, 70, PIKE

Dlskins, J. Tllden (b'82)-Ky.9,05; (1'05)

FISKBURG (R.F.D., DE MOSSVILLE), 250 , KENTON

Wolfe, Edward Foster (b'72) - Ky.4,'98; (l'98).

FLAHERTY (R.F.D., VINE GROVE), 35, MEADE

Cosby, II. D. (b'46)-Ky.1,'i6; (1'93).

FLATGAP, 68, JOHNSON

Meade, Parls P.-Ky.1,98; (1'99).

FLAT LICK, 250, KNOX

BURTON, FRANK RILEY (b'82)-Tenn.10, '11; (I'11).

Clark, Wllliam G. (b's0)-Tenn.6,'03: (l'03)

LATTIMORE, ROBT, LEE (b'6i) - Tenn.9 '95; (1'97).

FLEMINGSBURG, 1,219, FLEMING

AITKIN, CHAS. WM. (b'59) - - 0.1,'80; (1'93); G.

BRICE, JOHN C. S. (b'59)—KY.5,'82; (l'93)

BUNTEN, ELMER T. (b'83)-Ky.1,07; (l'07).

GARR, CHAS. R. (b'58)Ð-Ky.5,'80; (1'93)

GARR, CLYDE LOUIS (b's ) - Ky, 2,'10 (1'10).

Morgan. James Frank (b'92) - Ill.15,'13 (1'13). ROBERTSON, ADDISON S. (b'67)-Ky.5,
$990 ;\left(l^{\prime} 03\right)$.

Skinner, Richard M. (b'63)-0.7,'s6 ; (l'93) VICE, THOS. BYRAM (b'68) - $0.1,90$ (1'94).

WALIINGFORD, ALEX. M. (b'68)-Ky.2, : $90:(1,93)$

WALLINGFORD, ALVIN M. (b'41)-Pa.2, '65; (1'93)

Yantis, Robt. H. (b'38)-Pa.2,'60; (l'93).

FLETCHER, 20, LAUREL

IIOLT, SETH M.-Tenn.6,'S4; (1'03).

FLIPPIN, 175, MONROE

WILLIAMS, JAMES BART (b'90)\&Tenn.5,12; (1'13); also Nember Tenn. State Med. Assn.

FLORENCE, 250, BOONE

Dulamey, Benj. A. (b'45)-0.8,'i5; (l'96).

FLORENCE STATION, 60, MCCRACKEN

CRAIG, I. E. (b'6i)-Tenn.8,'89; (l'93).
FOLSOMDALE (R.F.D., HICKORY GROVE), 250, GRAVES

Thomas, M. 1\% (b'74)-Tenn.8,98; (1'98). FORD, 702, CLARK

PENXINGTON, MAMES FRANKLIN (b'84) -Ky.11,08, 1'a.2,'1's; (1'08).

FORDSVILLE, 649, OHIO

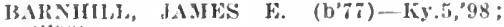

ENTOX, IRYTNG LEE (b'S1)-No.28, 04 ; (1'04).

DE WEESE, ('ARRECE (b'80)-Ky.5, 06 ; (l'06)

Ifale, Danl. s. (1,35) - o; (1'93).

Matthews, D. Mi. (l),50)-Ky.4,89; (I'93) kogers, Early 1', (b'75)-Ky.1,02; (1'02).

FOSTER, I58, BRACKEN

Vullen, ('has. Hope (b'38) - Tenn.1,'58; (1'98).

FOUNTAIN RUN, 188, MONROE

DUNN, THIOS. C. (b'60)—Tenn.6,'89; (l'93).

IInghes, J. T. (b'-4)-Tenn.6,98; (1'98).

FRANKFORT, 10,465, FRANKLIN

Anderson, Chas. Wn. (col.) (b'70)-Ky.7, (02: (1'02); 609 IIIgh st.; offlce, 321 cinton St.; $8-10,3-4 ; 6-8$.

I3arr, Jos. 1. (b'81) - Ky.4,'04; (1'04).

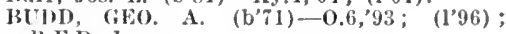
R.F.D. 1 .

Chinn, (4. W. (b'41)-0.1,64: (1'93).

Coblin, Reuben M. (b'75)-0.9,97; (l'97)

Coleman, Clarence T. (b'82) - Ky.2, ${ }^{\prime} 07$ : $\left(I^{\prime} 07\right) ; 418$ Logan St.; office, 219 Nlain St.; $9-12,2-5$.

COLEMAN. IACOR S. (b'55)-Ky.5, 76 ; (1'06); 203 Maln St. : 9-12, 2-4.

DORSEY, JAMES TAYLOR (b; 76$)-\mathrm{Ky}, 9$, 0.5; (1'0.5) ; R.F.D. 3.

FISH, CARLOS A. (b'74)-Ky.8,01; (l'0I) ; United Amerlean Bldg.; 10-12, 3-5, 7-8

FRYMURE, EWETT WATERLY (b'80) Ky.2,05; (1'05); R.F.D. 2 ,

GARRETT, NEVIL, if. (b'70)-Ky.4,97; (1'97) ; 519, 2d St.; office, United American Bldg. ; $9-11,2-4$; 0 b.

Goodwln, W. H. (col.) (b'خ2) -Tenn.7, ${ }^{2} 01$; (l'03).

HEILMAN, GEO. HARLAN (b'T9)-Ky.2, 09 ; (I'09).

HIhl, JAMES W., JR. (b'68) $€-\mathrm{Ky}^{\prime}, 2,89$ $\left(1^{\prime} 91\right)$; 215, 3d St.; office, Capltal IIotel; 11-2.

KELIER, HERVEY S. (b'T1) - 0.13,92; (l'93) : Anne St.; office, St. Clair St. $11-1,7-8$.

MAÁTIN, FLORA W. (b'65)-Mlh.I, 86 . (1'03); 112 Todd St.; office, Farmers' Bank Bldg.: 10-12, 3-5; G.

MINISH, LAWRENCE T. (b'76)థ-Ky.1,98 (1'99); 121 W. 4 th St. ; Offlce, $210 \mathrm{~W}$. Maln St.: $9-12,2-5,7-8$.

MONTFORT, WARREN (b'64)థ-Ky.2,'87; (l'93); Wapping St.; office, 308 W. Jaain St. ; $2-4 ; \mathrm{S}$

Montgomery, W. I. (b'53)-Ky.5,'83; (1'93) Moore, Thos. R. (b'76)-Tenn.6, $00 ;\left(1^{\prime} 03\right)$.

PATTERSON, JOHN (b'78)€-Ky.5, 00 : $\left(y^{\prime} 00\right)$; Capital Hotel : office, Anne St, : $\mathbf{S}$.

Price, J. Lampton (b'55)-N.Y.10,'77;(1'06); 238 Steele St.; offlee, Capital Hotel; $10-$ 238 Steele

Reynolds, 0. H. (b'51) -Ky.1,'88; ( $\left.\mathbf{l}^{\prime} 06\right)$.

ROEMELE, EUGENE CARL (b'75)-Ky.5. 97 ; (1'9S); 218 Conway St.; office, ilcClure Bldir.; 2-4; Pd.

Sanders, Louls Angustus (b'53)-Ind.8,'88; (l'10)

SOUTH, JOILN G. (b'73)€--Ky.2,'97; (1'06) Pres. State Board of Health; Wapping St.; offlce, Mcclure Bldg.: 10-12, 2-4 TEWART, ALBEKT $\left(\mathrm{b}^{\prime} \mathrm{i} 0\right)-\mathrm{Ky}, 4,93$; (l'93).

Underwood, Edward E. (col.) (b'64)-0.6, '91; (1'93); 234 Mero St.; ofllee, 236 Mero St. ; 8-9, 1-3, $7-8$.

WALLACE, CHRISTOPIIER K. (b'49)N.Y.10,70; $\left(l^{\prime} 06\right) ; 333$ Sun St.; office, Anne St. and Broadway; $11-12,2-3, \bar{i}-9$ WILLIAMS, URBANE V.' ((b'33)-T Pa.2,58 (1'93); 220 Steele St.; office, Bank St. and Elk PI. ; $10-12,3-\overline{3}$.

WILSON, JAMIES W. (b'57)-N.Y.10,'80 : (I'02);40i Wapping St.; office, N1ain St.; $9-12,1-5 ;$ OALR.
FRANKLIN, 3,063, SIMPSON

Rurrus, Benj. (col.) (b'i4)-Tenn.7,'97; (198).

DOUGLASS, JAMES C. (b'47) \-Tenn.1, 73: (1'94).

GOSSETT, WM. LEE (b’0)-Tenn.5,'92; (l'08).

GRAY, Jos. G. (b'ĩ) - Tenn.6,'99; (l'99); OALR.

Guthrle, Saml. Rlchurd (b'si)-Tenn.5,'13: (l'13).

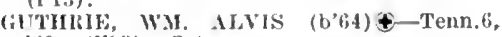
'89; (I'93); S.*

Head, Elkanah B. (b'48)-Tenn.1,'70; (1'95) ; R.F.D. 1

Key, Albert M. (b'48)-Tenn.1,'76; (1'97). 1AAMB, ELZOIRY KIN (;-Tenn.5,'93; (1'12). LONDON, WHLLIS (b'64) - Tenn.5, 88 ; (l'93),

I'EI'I'Ek, YOUNG (1)73)-Ky.5,04; (1'04): R.F.I.

I'rocter, Wm. Adolphus (b'66)-Tenn.5,88; (I'94); R.F.W. 3

VENABLE, CIIARLES LEE (b'67)-Tenn.8, '87; (1'93).

WILLIAMS, WM. IIARRISON (b'4l) Temn.5,'84; (l'93).

WITT, NOTLEY CONN $\left(b^{\prime} 80\right) \notin-T e n n .5$. '11; (1'11).

FRANIKLINTON, 60, HENRY

Humston, 0. B. (b'56)-Ky.4,'80; (l'03).

FRAZER, 20, WAYNE

Kelley, wilton J.-Ky.2,'92; (1'94).

FREDERICKTON (R.F.D., SPRINGFIELD), 75. WASHINGTON

CRUNE, WA. ERNEST (b'S1)-Ky.9,05; (1'05).

HAMILTON, SAML. FRANK (b'82)-Ky.4, '05; (1'05).

FREDONIA, 42I, CALDWELI.

BAILEY, IACOB N. (b'83) $\$-K y .5,07$; $\left(l^{\prime} 07\right) ; S$.

Buckner, Jos. S. (b'32) - 0 ; (1'93).

Bunton, John F' (b'63)-Ky.2,89; (l'93).

Leeper, Saml. M. $\left(b^{\prime} 48\right)-0.9,73$; (l'93).

Orr, 5. Allen $\left(b^{\prime} 63\right) \longrightarrow$; (l'93); R.F.D. 1 .

SPICKARD, LUTIIER J. (b'82)-Ky.11, 08; (l'08).

TODD, JOHN N. $\left(\mathrm{b}^{\circ} 59\right) \notin-T e n n .6,79$; (1'93).

FREEDOM, 25, BARREN

BULLOCK, THOS. JEFFERSON (b'43)-0; (i'95).

FRENCHBURG, 172, MENIFEE

KASII, JOHN MASON (b'81) - Ky.1, 05; $\left(1^{\prime} 06\right)$.

Kash, Reese B. (b'7I)-Ky.5.'98; (1'06).

FRYMIRE, 35, BRECIKINRIDGE

Frymtre, Junlus B. (b'43)-Ky.2,'67; (l'93),

FT. MITCHELL (ERLANGER P.0.), 80 , KENTON

Rellly, Wm. F.

(See Cincinnati, 0. )

FT. THOMAS (NEWPORT P.O.), 500, CAMPBELL

DAVIS, JEPTHA DICKEY.

(See Cincinnat1, 0 .)

DOERR, CHAS. E. (b'83)£-0.1,06 ; Capt., M.C., U.S.A.

HOHNSTEDT, JOHN HENRY (b'73) $\oplus-$ Ky. 2, 08 ; (1'08).

PEED, GEO. P. (b'74)€-Va.1,95; Capt., M.C., U.S.A. ROBERTSON, JAMES ALBERT (b'6 6 ) - 0.8,

SOU'IUGATE, FRANK H.Ð-0.1,'92; $\left(l^{\prime} 94\right)$.

FUGET, 45, JOHNSON

ESTEP, WU. WESLEY (b'73) - Tenn.10, 07; (1'09).

FULLERTON, 50, GREENUP

Bennett, B. F.-E-0.2,'91; (l'93).

BRYSON, ANDREIV J. (b'80)-Ky.1,06 ; $\left(l^{\prime} 06\right)$.

Hunt, Alexander Pope (b'84)-Ky.2,'11; (l'11).

MEADOWS, МATTHEW W. (b? 68$)-0.2,04$; (1'04).

NICHOLS, WM. ELLIS $\left(b^{\prime} 76\right)-0.2,06$; $\left(I^{\prime} 06\right)$. 
FULTON, 2.575, FULTON

Alexander, Henry T. (b'90)-0.2'11: (8.11).

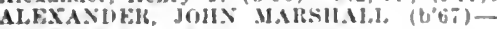
N.Y.10,91: $(1 \cdot 93)$

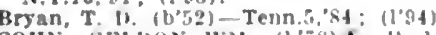

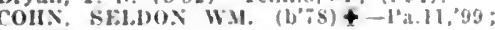
(1.99).

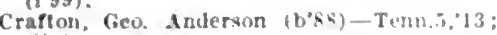
(1'13)

ITEN, HOR.ME (b"\%

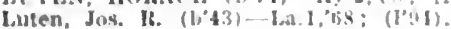

Mafor, Geo, 1. (L'5ti)-Tenn.3.'sti; (1'35)

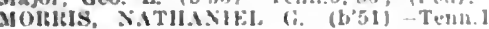
73: (1'9:)

PAlls, sAML. W. (b'72)-Ky.5,9s; (1'95); not in practlee.

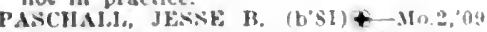
(l'il) : Vember Tern. State Med. Ivil

Ifudd, Robt. Thos, $\left(6^{\circ} 62^{2}\right)-0.2, " 4 t^{\circ}$ : (1"96i)

Slsron. S. J. (col.) (b't4) $\rightarrow$; (l'at)

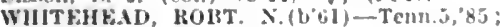
(1'93).

FURNACE, 40, ESTILL

Seay, Joln 1. (b'6s)-Ky.4,89; (1'93)

GAGE (R.F.D., LA CENTER), I5, BAL. LARD

ASHRHOOK, W.M. A. (6:9)-Ky:?04: (1.04).

GAINESVILLE (R.F.D., SCOTTSVILLE), 75. ALLEN 'so; (1'93).

GAMALIEL, 125, MONROE

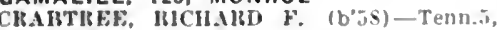
'82: (1'93).

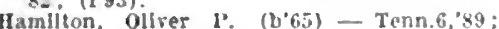
(1.03).

IHges, Caswell C. (b'4l)-Ky.2.75; (1'93). SMITH, JESSE T. (b.67) - ThIn.10,95: (1'03).

GAME, 120, BARREN

SIII)E.NS, JOIIX \&. (b'-3) - MO.28, 02 : (1'02).

GAPCREEK, 65, WAYNE

DYER, JOS, I', (b'Xt)-K'y.2.09; (l'09).

GARFIELD, 75, BRECKINRIDGE

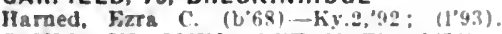

SANDRACH, JOHN NLEXANIIE (b'it)

KY.5.04: (1'04).

GARLIN (COLUMBIA P.0.), 35, ADAIR

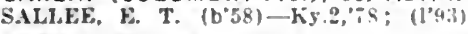

GARNETTSVILLE (R.F.D., STITHTON),

200. MEADE

WALKEIK, BFN], R. (b'si)-Ky.1,S2: (1'93).

GARRISON, 200, LEWIS

HEXTIJOHX, AITELL' CAITER (USS) Ky. 2,10: (1'10).

GATLIFF, 50, WHITLEY

HOWALD, GAIRFIELD (b'8) - Ky.., 0 \% (1’0i).

GENEVA, 42, HENDERSON

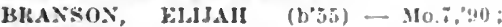
(L'93).

GEORGETOWN. 4,533, SCOTT

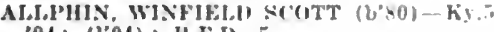
04: (1'04) : IC.F.I). 5.

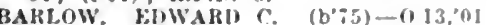
(1'01).

Rrown, Greenberry 13. (b'43)-hy.2,7!: (1'94); not in practlce.

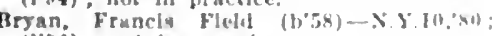
$\left(l^{\prime} 96\right)$; not In practice.

Bryan, Fraurls $k$., Jr.-Ky.g,on); not In uractlce.

COrFMAX, W.M. H. $\left(b^{\circ}, 2\right)+-k y .5,74 ;$

$(1,03)$.

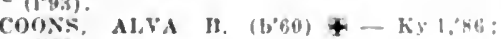
(1'93)

DOWXs, I.AWRFACr HTILA (b'A3) — KY:,12: (1'12); OALR.

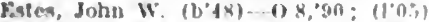

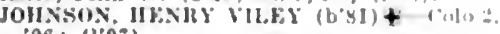
06: (l'0í).

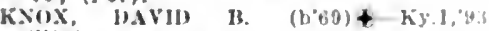
(1'93).

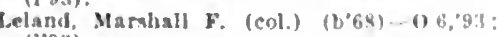
(l'9:t).

Iewls, John A. (b' 41$)$ Va 4,68: (1.83);

nos In practlee.

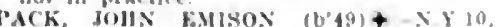
"93: (1'93).

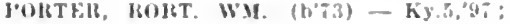

Thomasson, John (c. (b'5i) - 0.13,"69: (l'93)

Tinsley, llenry (c) (col.) (b'ts) - Tem. :, 00 11.031.

GERMANTOWN, 287, BRACKEN

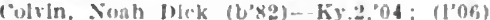

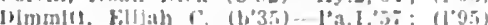
lelton, Finery day (b's2)-Ky.2,07; (1'09) GHENT, 421, CARROLL

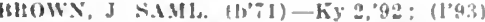

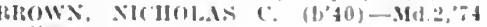
(1) $(13)$

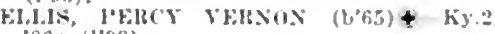
\$6; (1'93).

GILBERTSVILLE, 458, MARSHALL

(XKTK:H, HERMAX T. (b'7) -Tenn.s, 03 (1'0:0).

GIMLET, 100, ELLIOTT

HAKPER, JAMES H. (b'b4) - Mo.28,'y9 $\left(l^{\prime} 00\right)$.

GIRKIN (BRISTOW P.0.), 30. WARREN

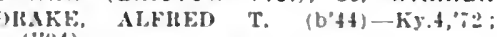
(1":14)

GLASGOW, 2.316. BARREN

ICTOX, JOIIS WESLEL (b'Tl)-KY.1,9\%: (1.98)

Alexander, Frnest Raspberry (col.) (b'sti) -Ky.; $; 2:$ ( ).

ROTTS. ANDREW T. (b'69) - Ky.5,91 (I'93).

IITT, WM. T. $\left(b^{\circ} 64\right) \neq-T e n n .6,9$ (1'01): (Temple IIII).

burette, J. S. (col.) (b'6i)-Tenn.t, 97; (l'98)

kllson, Eugene T, $\left(b^{\prime} 5 t\right)-T e n n .6,,^{\prime}$ : ROFI)(iE, C. W. (b'66)-Ky.2,93: (1'93): R.F.D. 4.
RISTEAD, cHuIs T. (b'42)-Ky.2,68 (1'94): $\mathrm{S}$.

HOWAJD, CARI, CLIFFORD (b'8B) - KY'.2, 11: (I'11).

IORIDAX JOHA CRITTENTEE (b'60)Tenn.6,94; (1'94) : R.F.D.

LFECII, JOS. S. (b'is)-Ky.2, \&I : (1'93)

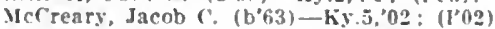

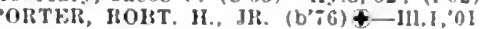
(]'01).

Rlehards, Wm. Clfton (b'88)-111.15,'12; (1'12).

SMOCK, STONFWARL JACKN(O. $\$-K y .2$ 93: (I'93) : OALR.

TAYLOK. JAMES MOHGAN (b'48)-Ky.2. $\because 8:(199)$.

GLASGOW JUNCTION, 303. BARREN

Brown, Chas. C. $\left(b^{\circ 5} 5\right)$-Tenn.5.86: (1'94)。

IInlmes, A. G. (b'+1)-1; (l'93).

SYMISON, W. A. (b'66)-Tenn.6,'92; (1'93).

GLEANINGS, 40, LARUE

MOORE, C. OTHELLO (b'6i)-Ky.2.8R: (l'0.3)

GLENCOE, 237, GALLATIN

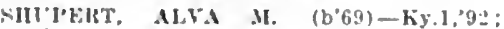
(1'93) JOS. MI.T.E. (b'\$0)-Ky.1.0?

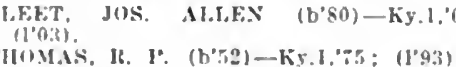

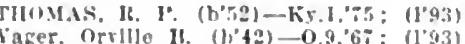

GLENDALE, I50, HARDIN

Wlulnek. Janies H. $\left(b^{n} 56\right)-K y .2,75 ;(1931$

IIUglues, ()rJan T. (b'81) - Ky'z,09: (l'09)

GLEN DEAN, 200, BRECKINRIDGE

lumpser, l'aul $k$ : $\left(b^{\prime} \times 1\right)-K y+4,02:(1,02)$

lienusicr, Bolst. T. (b'50)-Ky, 'T6; (1'03)

GLENSBORO (LAWRENCEBURG P.O.)

250. ANDERSON

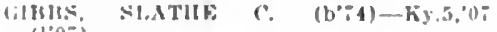
(100;).

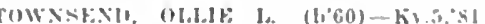
(I, $(\mathrm{n}, \mathrm{s})$

GLENS FORK, BS, ADAIR

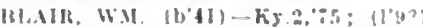

Italin, Itemj. Jackson (it) lis 2,10 (I) 10$\}$

GOFORTH (R.F.D. FALMOUTH), 26 PENDLETON

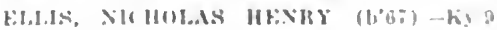
1: 1104
GOLD CITY (R.F.D., FRANKLIN), 10 SIMPSON

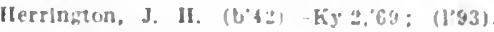
GOLDEN POND, 50, TRIGG

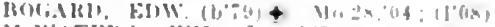
I.WTERS, WM. J. (b"G) Tesing, 01 (1"01)

GORDONSVILLE, \$3, LOGAN

(HTTENIUE, JOHS K. (b'b) + Tenn.l. 4t: $\left(1^{+} y+1\right)$.

GOSHEN, 40, OLDHAM

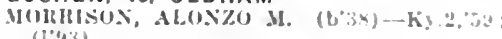
(1"y3).

GRACEY, 157, CHRISTIAN

B.TKCS, JAMES JACKSON (b'J0)-III.10, (n6; $(1.93) ; P d$.

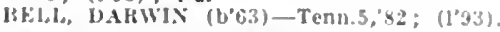

GRADYVILLE, I50, ADAIR

Nell, bawrence C. (b'bis)-Ky.l,'gl: (l'at).

IMMONS, SIMISON JOH (b'st)-Ky.2, 10 (1'10).

GRAHAM, 50, MUHLENBERG

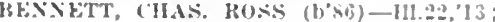
(l'13).

Bourland, Charles A. (b'45)-Tenn.5,68:

11'94).

W(ik, THOMAS J. (b'\&I)-Ky.11,0S

HITAKER, LEVE DEFUR (b'5)\$-Ky,2, OT: $(107)$.

GRAHN, 210, CARTER

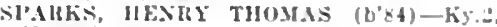
$09 ;(1 ' 09)$.

GRAND RIVERS, 300, LIVINGSTON

IUIBINSON, JOHS WILLAHU (b'bi)-Ky.I. 9:: (1'05).

GRANT, 125. BOONE

HICHMONH, JUS. A. (b'82)-Tenn.l, "OS (1'12).

GRASSY CREEK, 35, MORGAN

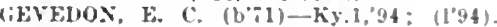

(ievedon, IV. Is. (b'39)-D; (1'94).

GRATZ, 213, OWEN

Alexander, Chas. Forrest (b'6s)-Ky.1,"93: (193)

USISII, JOHN A. (b\%6)-Ky.1, 00 ; $\left(1^{\prime} 00\right)$

GRAVEL SWITCH. 50, MARION

CAMPUELI. THUMAS IKYINE (b'S\&) + Ky.2, $07 ;\left(1^{\prime} 0 \%\right)$.

GRAY, 400, KNOX

JONKS, WM. H.SKIISON (b'S2)-Ky.20? (1'09).

PAlktil, JAMks W. (b'6i) Ky.2.94 (l'94).

licars, Thomas Garrard (b': (1 $\left.1^{\circ} 0 j\right)$

GRAY HAWK, 70, JACKSON

TIELW.M. EWW. FYEHHT (b':9) Colo.3,08; (1'13).

GRAYSON. 735, CARTER

IBAYS, TIIOS. T. (b'5)-Ky,0,03; (l'09) HoHT(1), WM. A. (b'66)-0.1.91: (1'43).

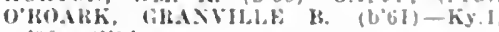
$90 ;(1.94)$.

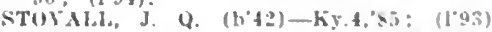

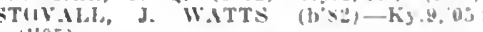
(l'0.i).

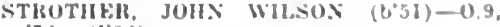
"iti: (1'9:h)

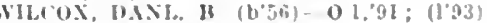
GREENDALE, 50, FAYETTE

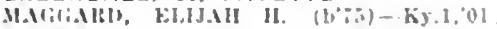
(l'0) .

fiolverts, Wr. I'.-(0.13,ss: $(100)$.

GREEN HILL (BOWLING GREEN P.O.) 102, WARREN

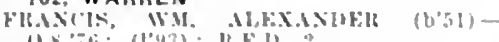

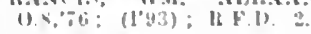

GREENSBURG, 450, GREEN

Sinfealy, Aloxanter (2,3i)-KY:

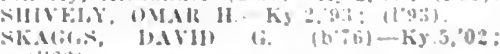

$(102)$.

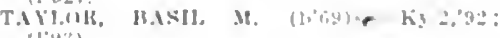

GREENUP, 680, GREENUP

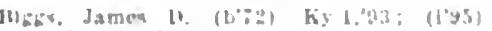
not in praciliee.

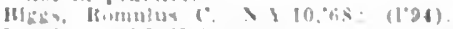

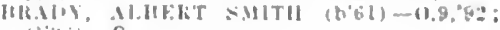




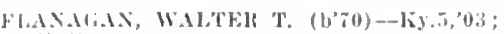
(['113).

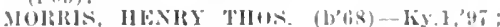
$(1,4)$.

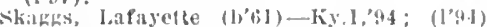

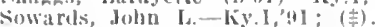

GREENVILLE，1,604,MUHLENBERG

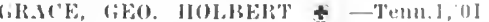
(I'0I)

Ko(IXT\%, JAMES WM. (b'-0)+-Ky.1,94 (l'00)

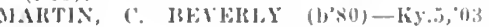
(I'03)

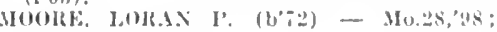
(l'ms)

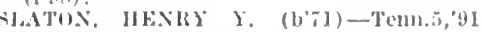
(1'4); OALR

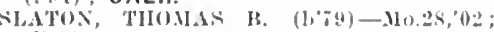
$\left(l^{\prime}(i \cdot 0)\right.$

SIATON, THOMAS ILFFERSON (b'44) 310.2, $13: 94)$

Yost, Folmond IR. (b'ab)-lis.5, 00 ; (l'00) GROVE CENTER, I00, UNION

SLOAN, 1).111) M. (1)'TI)-Ky.4'9s: (1'98) GUAGE, 46, BREATHITT

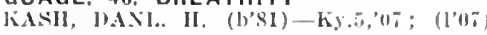
GUERRANT, - BREATHITT

Moore, Jos. II. (b'5ti) E-Mo.10,'79; retireul. GUSTON, I50, MEADE

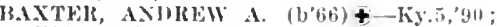
(1'93); Pd.

GUTHRIE, I,096, TODD

FRIY, EMMETT M.-Tenn,

lefferson, W. H. $\rightarrow ;(1.94)$; not in practice;

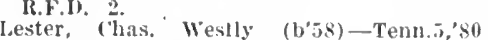
(l'94).

HOHBNSON, JAMES y. (b'55) \&-liy.2,82; $\left(1^{\prime}, 4\right)$.

TYLER, BLRNLEY DIKE (b'b3)-Tenn.1, 94: (I'94) ; R.F.D. 2.

Yolsci, WI. T. (b'64)-Tenn. 3,$87 ;(197)$ R.F.D, 4.

HABIT (R.F.D., PHILPOT), I0, DAVIESS KIRK, A. (b'\%2)-Ky.5,92; (I'93).

HALEYS MILL, 35, CHRISTIAN

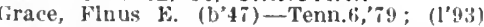

HALIFAX (R.F.D., SCOTTSVILLE), 60 , ALLEN

HOLhAXD, CHAS. W. (b'73)-Tenn.6,96; (l'98).

HAMPTON, I50, LIVINGSTON

DAYENI'ORT, EIW.-KY.2,01; (l'0I).

HANCES, 30, BELL

Mlracle, Ewing W. (b'73)-Ky..5,'98: (l'98)

HANSON, 509, HOPKINS

Hayes, .1. K.-Ky.2,'80; (1'9:3)

HEWl_ET, LON L. (b'86)-Ky,2, 12 ; ( $\mathrm{I}^{\prime} 12$ )

TIMHOS, JAIES D-Ky, 96 : (1'9ti)

WALIER, JOHN S.-Ky.2, :5; (I 93$)$.

HARDIN, 366, MARSHALL

BEAN, A.ONZO J. (b;\%)

COFFIELD, FRANK C. $\left(b^{\prime}, 5\right) \uparrow-\mathrm{Ky}, 5,04$; (1'04); R.F.I. 2.

COVINGTON, ELCLID D. (h'sa)\&-Ky, 03 ; (l'03).

HTGHES, HARDHN I.\&-Tenn.5, 01 ; (l'0I)

Russell, Thomas E.-Ky.2,'86; (1'!3).

HARDINSBURG, 737, BRECKINRIDGE

KINCHEHOE, ALLEX M. (b'\&S) \& Ky.! \% 0 ; (1'93)

KINCHELOE, JOHX E. (b'78) £-Ky.1,99 (1'99); S.

Sutton, James C. (b'3i) - Ky.2,70; (1'93)

HARDIN SPRINGS, 40, HARDIN

IIAI.E, JOS. GRAN'T (b'SU) $4-K y .2,0 i$

HARDYVILLE, 166, HART

MLDD, JOHY' JAMES-Ky.2,"6, Hit.?,90

YORK, JAMES WIRT (b'84)-Tenn.1, (1'09).

HARLAN, 500, HARLAN

B.1LEY, (FANVILLE l'E.ARI, (b'b. $)$ \& Ky 4,$94 ;\left(I^{5} 94\right)$.

(11001), WII. P. (1,83)-Ky,2,0\% (107) How

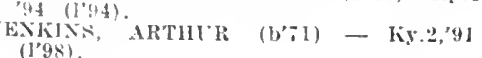

MAl:TIN, W. M. (b80)- Ky,

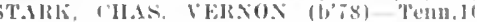
'(1): (1'0)1).

HAROLD, 50, FLOYD

l'richari, ('arl 1. (1,71) - Ky.2,'94; (l')9) HARRELDSVILLE, 30, BUTLER

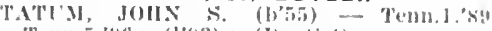

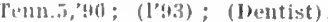

HARRODSBURG, 3,147, MERCER

llawis, W. 'I',-Ky, I, 53 ; (1'y9).

(ORSYTIIS, M. IFANIIER $\left(b^{\prime} 40\right)$-I'a.2, (i4); (13)

MESATGiII. THOMAS b. (b'6I)-Ky.4, s's (l'9.3) : K.F.1). 2.

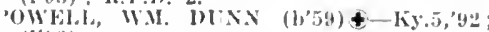

I'IR'F, ('AIROLL FOHTEOL'S (b'80) \& $0.1,03 ;\left(I^{\prime}(13)\right.$

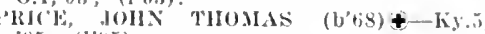
(1); $(1,95)$.

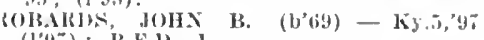
$(1,3 i) ;$ R.F.1). 1

TILAIIR, LRXEA'T HIOHTFOOTE (b'76)

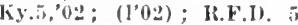

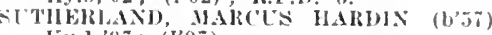
Ky.1.97; (I’9i).

TRII", FR.ANK SIISIK (b'5s) \&-0.1,'83 (l')

AN ARSIALL, CONUIT BREWEL (b'75) $+-11 d .0^{\prime} 02 ;\left(l^{\prime} 02\right)$

HTILESIOON, WM. HOKACE (b'79) \& $0.1,04$; (1'04).

HARRODS CREEK, 50, JEFFERSON

IIobson, Willis W. (b'50)-Ky.5,'85; (I'b4).

HART, 25, LAUREL

JOHNSON, WM. (L'69)-Tenn.10,'96; (I'96)

HARTFORD, 976, OHIO

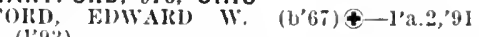
(1'93)

'ENI) FTON, EEGFNE B.-Ky.2,'89; (1'93)

Ríley, Ingustus Baxter $\left(b^{\prime}, 6\right)-k y .4,06$; (1'0ti); Pd.

TAlioR, Jos. W. (1,40)-Ky.2,'75; (I'95).

I'IT'IIENOR, B. F.-Ky.1,'91; (1'95)

HATCHER, 35, TAYLOR

KEILAY, NHEIBY IHARRISON (b'T9) Ky:4,04; (I'04).

HAWESVILLE, I,002, HANCOCK

Baker. los. T. (b'43)-Ky.2,'76; (1'93)

cosis. IR. b. (b'80)-Ky.9, 03 : (1'03)

GRIFFI, TR. DLER' $(1993) ;$ K.F.D. I.

Grifla, Forrest Marion $\left(b^{\prime} ; 7\right)-\mathbf{K} y .1,98$ (l'us); R.F.L. 2

HARRISON, JOSEHH H. (b'22)-110.28, $48 ; \quad(1,99)$

Mlason, 3. M. -0 ; $(196)$; not in practice.

HAZARD, 537, PERRY

OMBS, MARSIIALL E. $\left(b^{\prime} ; 6\right)-K y .9,06$ (l'08).

ETERSOLE, ('IESTER ARTHLIR (b'81)Ky.5, $46 ;(1,08)$

HROAS, AMERIDA M. (b's0)-Ky.j,05 (1'06).

HCIST, TAYLOR (b'79) †-Ky.2,09; (l'09) KELLEY, EIHIT (b'67)-Ky.5,'96; (I'97)

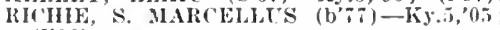
(I'06)

SCMINER, J. C. (b'67)-Ky.4,93; (1'93)

HAZEL, 300, CALLOWAY

('R.IIFORD, ROBT. P. (b'82)-Ky.2,'04: (l'05)

1RD, EDMOND B.-Ky.2.70; (1'93)

;RTBBS, WILLIAM F. (b'65)-Tenn.1,98

(I.98) : R.F.D.

HOLSTOX, EIWARD BRENT (b'81) Ky.4, $07 ;\left(l^{\prime} 0 \pi\right)$

Mason, Wim. II.-Ky.2,'T5; (1'93)

HAZEL GREEN, 257, WOLFE

('EN'TER, WI. TAYLOR (b'81)-Ky.5,"07 (l'ot)

Nickell, Indrew ('. (1)'62)-Ky, 1,94; (1'94)

HEATH (R.F.D., PADUCAH), 50, MECRACKEN

IORRIS, CHAS. CHINTOX (b's $\theta)-K y .2$, 10: $\left(\mathrm{l}^{\prime} 10\right)$.

TOLNG, LOCls E. (b'82)-Ky.5,03; (1'03) R.F.D. 3.

HEBBARDSVILLE, 350, HENDERSON JONES, IEANDER 0.-KY,2,80; (I'93)

TRAVIS, WALTER T.-Ky.5, $0 \%$; $\left(\mathrm{I}^{\circ} 0 \mathrm{~T}\right)$.

HEBRON, I00, BOONE

SAYRE, FRAXK LEE (b'66)-0.9, (l'93).
HEDGES, 100, CLARK

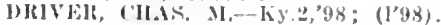

HEIDELBERG, I5, LEE

BAKElR, ('HAS. LUWARI)-Ky.2,05; (1'05).

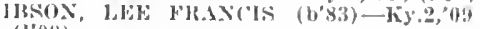
( $\left.{ }^{2} 04\right)$.

MeboNAll, (iko. s. (b'68) - Ky.4,"90 (1'Ji)

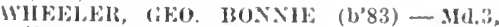
I:- (I'12)

HELENA, 75, MASON

l'hlllips, Wm. Ciraves (b's:) - Fa.2, 09 ; (l'09).

HELLIER, 525, PIKE

ibson, Irlas Palmer (b'82) - Ky.9,05 (l'05)

HENDERSON, II,452, HENDERSON

IRNET, Ël.IJAH DAVIS-Ky.2,94; (I'94) K.F.l. 3.

('LAY, Hexilis F, (b'-2)-Ky.2,'98; (1'99); k.F.?.

DIXN, AR(JIBAL) (b'44)\&-Ky,4,7\% (1'93); $330 ~ N$. Green st. ; offce, Barrett Blig.; $11-12,2-4 ; \mathrm{Pd}$.

Maln st.; $9-12,2-4 ;$ OALR.

Fhơ'l, W.H. M. (b'67) †-Ky.2,'91 : (1'93) 422 N. Main St.; oftlce, Ohlo Valley Bank BIIg. ; $9-11,2-5 ;$ OALR.

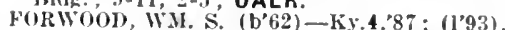

(iAlloWAY, WAlTER S. - Mo.28,97: $(197) ; 1302$ Jlelm st

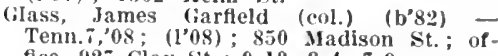
fice, 927 Clay St. ; 9-10,3-4, 7-9.

GRAILAM, CYRUS '(b'63) $\oplus$-Tenn.1,92: (1'93); 307 S. Green St.; office, 228 2d St. ; 1-4; S.

FRIFFIX, SILAS (b'75)థ-Ky.9, 00 ; (1'00) 231 X. Maln st. : $8-I 0,2-4,7-8$

HANCOCK, DAVII) O. (b'61) \&-Ky.1.'9I (I'93); l'res. Ky. State Med. Assn.; 430 , $2 d$ St.; offlce, 432,2 (l st. ; $8-9,1-3,7-8$; Pr.

Johnson, Adam Rankin (b'69)-Pa.11,00;

ETCILR, JAMES HUGHEST-Ky.2, 73 ;

IGON, l'EXTON\&-Ky.1,'86; (1'93); $50 \mathrm{~s}$ Alrasla sit.

Mlller, J. Lonlse-H-Ky.8,'98; (l'98) Johnson Bldg.

IOSELEY, JOHN CABELL (b'T4)-Ky.1 '96: (l'96) ; Powell St.; offlee, 2d St. $11-12,2-4, \mathrm{~S}$

XEAIY, BERNARD JOS.-Ky.2,'11; (1'11). NEEI, W.1. V.-Ky.8, $02 ;\left(1^{\prime} 02\right) ; 2 d$ nnd Main Sts.; offlee, Ohio Valley Bank Bldg.; 9-11, 2-4; Pd.

vollau, Chas. Lee (b'80)-Ky.2,01; (l'0I) : 1302 IleIm St. ; $8-9,12-2,7-8$.

NORMENT, HENRY T. (b'53) (-Ky.2,"94 (1'94); K.F.D. 3 .

O'Neal, Saml. Andrew (b'62) (col.) Tenn. $i, 38$; (l'96); 828 Powell St.; offlce. 231, 2d St. ; 9-12, 2-6.

POOLE. WI. ALBREY (b'80) - Mo.34 :06: (1'06): 1306 Helm st. : 8-9, I-2, 7-8. QFIN, WM. A.૯-Ky.4,83; (1'93); 526 $2 d$ st.; office, $2 d$ and Elm St.; 2-4; S. STONE, IAMES W.-Ky.2,80; (1'93); 321 Center st.

TAYLOR, THOS. W.-Ky,2,'45; (1'93)

WATSON, JOHN WM. (b'63)-Ky,1,94; (1'94) ; 503 Center St.

Weston Wm. J. (col.)-D.C.3,03; (1'03) : 134 .Julia $\mathrm{St}$.

YHLSOX, WH. W. W. (b'78)-Ky.1,0z (I'03) ; 121 Powell st.; offlce, ohio Valley Bank Bldg. 8-10, 2-4.

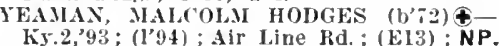

HENSHAW, 300, UNION

Snow, John ('urtls (b'S3) -Ky.2,'09; (l'09).

HERNDON, I50, CHRISTIAN

CHAMPION, LEONARD (b'84)-Ky.2,09; (l'09); R.F.D. l.

GATES, ERNEST LESTER (b'7)-Ky.5, 03; (1'03). Roach, Durward B. (b'82)-Ky,1,06; (1'12) ;
R.F.D.

HICKMAN, 2,736, FULTON

Bright, Wil. M. (b'4;)-Tenn.1,69; (I'99).

(TRIIX, CHAS. W. (b'-8)-Tenn.5, 99 ; (l'99). 


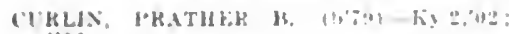
(1.02).

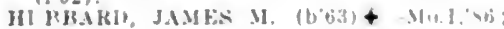
$\left(1^{\circ} 93\right)$.

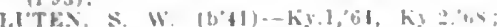
$(1+93)$

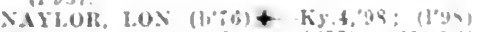

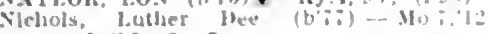
$1)=115.3: 5$.

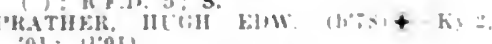
01: 11.011.

HICKORY FLAT, 15, SIMPSON

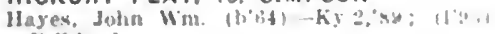
K.V.I. 1.

HICKORY GROVE, I48, GRAVES

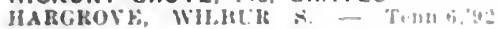
(1'93).

SHEITOS. W. J.- - hy.1,"12: (1 0\%),

HIGHLAND PARK (LOUISVILLE P.O.). 1.977. JEFFERSON

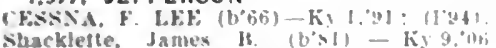
(1'06).

HILLSBORO. 182, FLEMING

CONWAY. WM. H. (b'5ti) $\rightarrow$ : H'b(i).

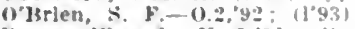

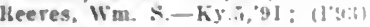

HINDMAN, 370, KNOTT

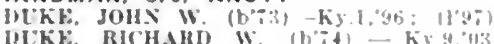
IKk: RICHARD W. (b'i) - ky.

KELLFI; NOXTFORI FIITW (b": K5.3,06: (1.06).

HINESDALE, 50, HART

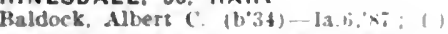

HINKLEVILLE (R.F.D., LA CENTER), 100 BALLARD

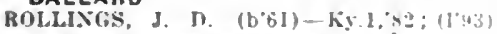

HISEVILLE, 179. BARREN

WEIP. CANIVOR (I.ALITON $\left(\mathrm{b}^{\circ} \cdot \mathrm{b}\right)+-\mathrm{K}$.

PALMOKE, EWINI; L.AMB-Ky,

HITCHINS. 28, CARTER

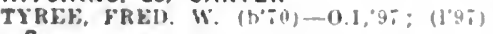
S.

HITESVILLE (R.F.D. UNIONTOWN). 75 UNION GUY DAVII) (bS- KY 2,10

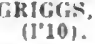

HODGENVILLE, 744, LARUE

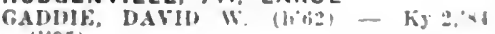
$(1.95)$

GRAHAM, FIJAH J. (b'39) - Ky.z, riti (1'93).

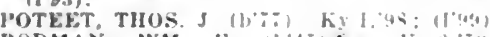

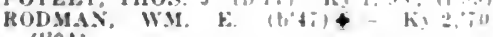
(1'9t).

Saunder, Ava M. Whllew (J) bill-h! : SMITH, RDWAKL STOKELY (b), h. $\left.\because 9 . \times 1.10, x 3 ; 1 l^{\prime}: 3\right)$

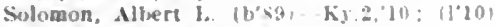

HOLBROOK (R.F.D. OWENTON) 35 GRANT

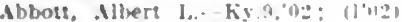

Agee, dirles $(b \circ 6)$ i)

HOLLAND, I50, ALLEN

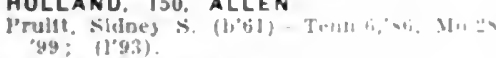

HOODS. 50, GREENUP

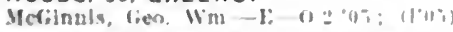

HOPKINSVILLE, 9.119, CHRISTIAN

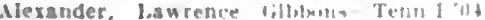
(l'0),

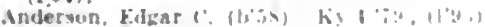
not In jracilice.

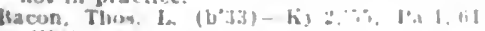
$-(1.93)$.

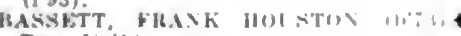
Tenn.19,"10

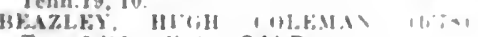

Tenf.s.01; (1'02); OALR.

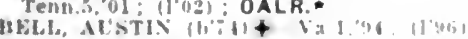

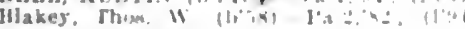

not lo practlce.

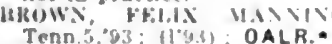

(Menn.s.83: 11"91): OALR。*

IMI Hithi;

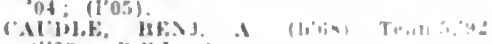

$(1.93): 12.511$ i

[ouvis, itre 1; (h'sul) Weatern stale linspled

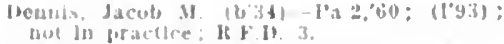

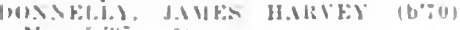

Iruncan. Janies is $(\mathrm{col})(1, ; 1)-$ Tenn.; ot $(1,0+1)$

Flomlater, Juhu $T$ (col) (6*3)-Tens): 00 : (1':3s).

(i.ATHF, Jis. 1.16.NT (10:4)-Tenn.II. (1): H'us,

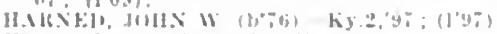

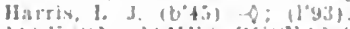

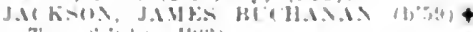

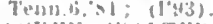

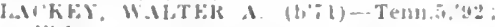

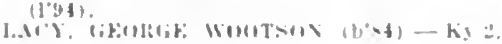

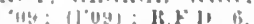

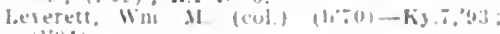
$\left.1 l^{2} \theta 4\right)$.

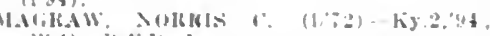
$\left(l^{\prime}, 9 t\right): 3 k$ r.w. 1

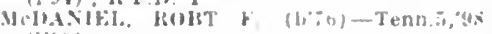
(1'9!)

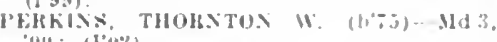
(U11: (100)

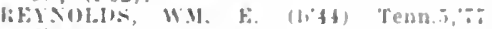
$\left(10^{\circ}+4\right)$.

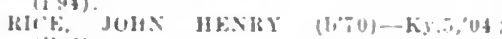

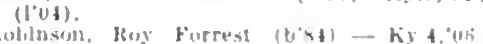

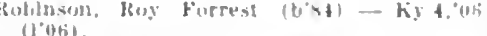

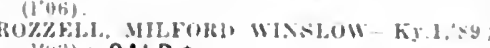
(1'y3); OALR.

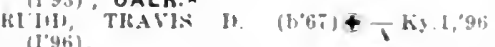

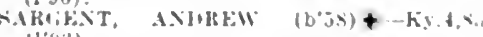
$(1,43)$.

SICITS, HFNKI l'IKSTUN (het)t hy?, (4) (1):4); (K:L3); NP.

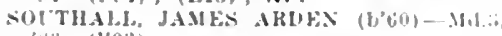
Sis: (1,03)

STEIHKAS, JASES WALTEK (h'63)Tenn $\rightarrow, ? ;$;

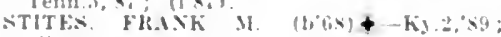
(1's)

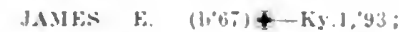

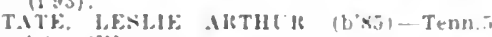
(1): (I'0y)

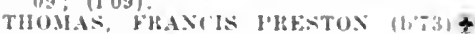
Ky.t.yi: 11.94

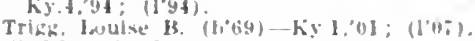

Whlolle, HuWr, H.-ky.2.23; (1.93) not in sractice.

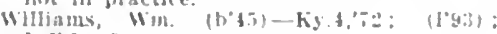
II K. II, 3.

HORSE CAVE, 881, HART

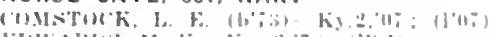

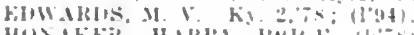

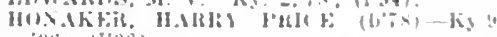
060 : 1106$)$.

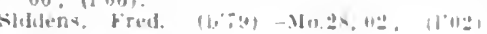
It $\mathrm{F}$ li.

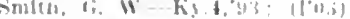

HOWEL. \$0, CHRISTIAN

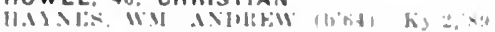
$11: 2, a^{3}$

HOWE VALLEY (R.F.D. CECILIAN), 20 HARDIN

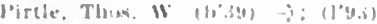

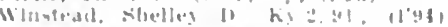

HUMPHREY. 26. CASEY

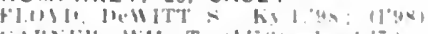

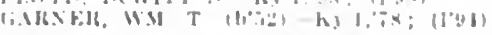

HUSTONVILLE, 38\%. LINCOLN

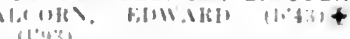

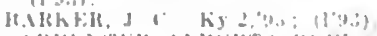

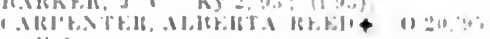
(1) ini

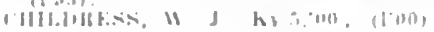

HUTCHISON. 7I, BOURBON

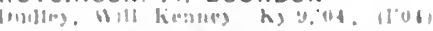

HYDEN, 3I6, LESLIE

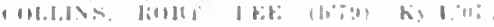

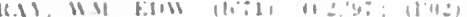

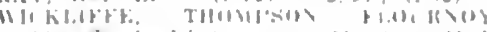
II:

ILSLEY. GS. HOPKINS

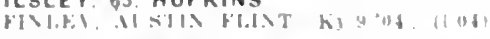

INDEPENDENCE, 153. KENTON

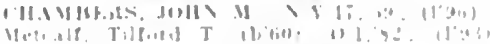

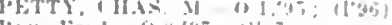

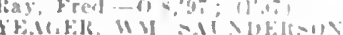

[sce IIrelmiand, 1)

INEZ, 370. MARTIN

FAIRTHILL, JUHI

(1.93).

Ward. Joseph $R$. (b't)

IRVINE, 272, ESTILL

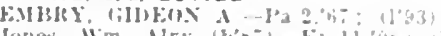

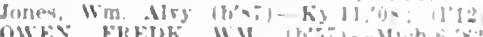

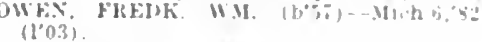

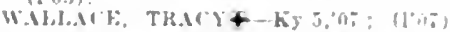

IRVINGTON, 665, BRECKINRIDGE

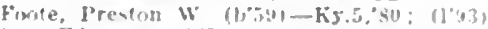

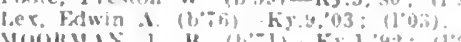

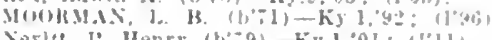

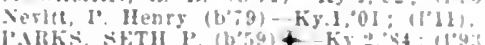

IRVINS STORE, 25, RUSSELL

HAMMOND, LEWIS DANI. (bPS)-KY?. $45 ;(10,5)$.

ISLAND, 647, MOLEAN

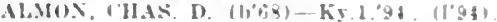

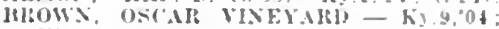

(1'04).

FITZH

IVYTON, 73. MAGOFFIN

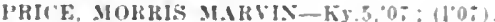

JABEZ. 10, RUSSELL

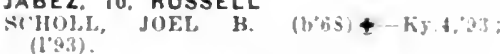

JACKSON, I,346. BREATHITT

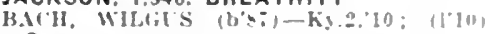
S.

Cardner. Iimdulphus B. $-\mathrm{C}:(1 \cdot 93)$

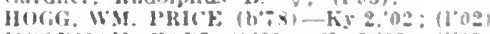

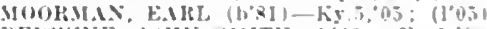

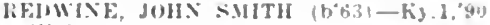
(1'43).

Alli:ili(1)

JAMESTOWN. 177, RUSSELL

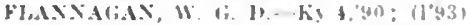

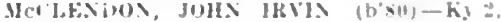

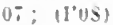

JASON (DUNMOR P.O.), 30. TODD

l"lark. Tyler Ky: ":": $(1 \cdot 94)$.

JEFFERSONTOWN. 3\$3, JEFFERSON

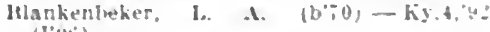
(l'voi).

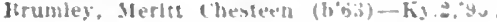
$(1.93)$

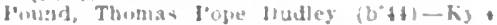

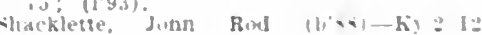

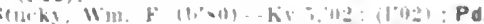

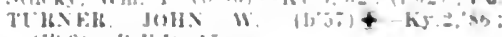
(11!3): $16 \mathrm{~F} 11.1 \%$

JEFFERSONVILLE, 86, MONTGOMERY

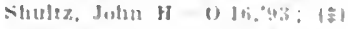

JENKINS. - LETCHER

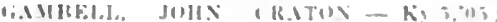

(1)

JEWEL. 50, PIKE

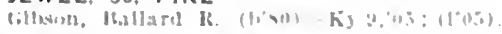

JONESVILLE, 648, OWEN

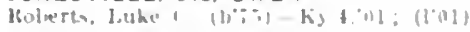

JOROAN. 100, FULTON

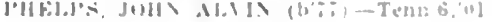

JOSEPHINE (SADIEVILLE P.O.). I00 SCOTT

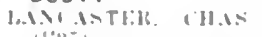

(I)

JUNCTION CITY, IH: BOYLE

If

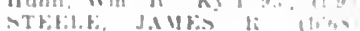

11:ii)

KB.ENE, SO0, JESSAMINE

JH:IV JUII) WII.I.H.I!

KELAT IRF.D. BERRY?. 60 HARRISON

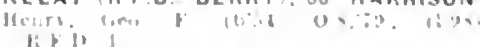

KELLY. 200. CHRISTIAN

III. IH. (1) 
KENNEDY (OAKGROVE P.O.), 25, CHRISTIAN

kollow, stonewall J. (b'65) - Tenn.5,'87; (l'94).

KENSEE, 200, WHITLEY

Hrowne, Mary Irene (col.) (1)'84)-Tenn. 7 . '10; (1'11).

Smlth, Wm. J. (b'83)-Ky.5,07; (1006).

KENTONTOWN, 50, ROBERTSON

THOMI'SON, 'THOS. E. (b'66) -0.8,'94; $\left(l^{\prime} 94\right)$.

KERZ, 25, JOHNSON

Jones, littleton 16. $\rightarrow$; (l'94).

KETTLE, 65, CUMBERLAND

SHARI, ALBBLIT W, (1,50)-Ky.2,'88; (l'93)

KETTLE ISLAND, - BELL

GLNNINI, F'liLL, F. (b'86)-Tenn.19,'10; (1'10).

KEVIL, 200, BALLARD

HU1ROW 1). E, - 0.2,'98; (1'98)

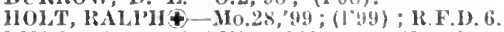
IBUDOLP'II, L.LSIIL (b'78) - KJ.2,03; (1'03).

KIDDS STORE, 47, CASEY

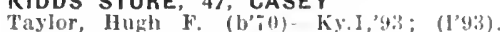

KIDDVILLE (R.F.D., MT. STERLING), 150, CLARK

YOUN'(i, JOIIN G. (b'it)-Ky.5,'06; (1'06): 13.F.D. 5.

KINGS MOUNTAIN, 350 , LINCOLN

SMITH, MAMES BRITTON (b'6')-D.C.3, '06:" $\left(1{ }^{\prime} 13\right) ; 0$ :

Thompson, Columbur II.-E-0.2,'91; (l'93).

KINGSTON, 125, MADISON

Eakins, Fred.' J.' (b'86)-Ky,2,'10 ; (1'10).

KINGSWOOD, 50, BRECKINRIDGE

Galloway, Chas. A.-Ky.4,'83; (1'93); not in practlce.

KIRBYTON (R.F.D., BARDWELL), 55,

CARLISLE

GHOLSON, WM. E. (b'60)-Ky.2,94; (1'94).

KIRKMANSVILLE, 200, TODD

lioll, kobt. L.-Ky,2,93; (1'93).

KIRKSEY, 200, CALLOWAY

Gingles, John T.-Ky.2,'70; $\left(l^{\prime} 93\right)$; not in praetice.

PHILLIP'S, JAMES R. (b’58)-Ky.2,'92; ('93).

STAKKE,. J. Y*. (b'8I)-Ky.2,'06; (1'06)

KIRKSVILLE, 175, MADISON

BOXLEY, HART M. (b'70)-Ky.4, 01 ; $\left(l^{\prime} 01\right)$.

CONBS, WALLER G. (b'83)-Ky.2, 06 ;

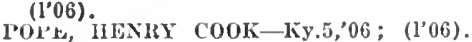

KITTS (R.F.D., CUXTON), 一, HARLAN

BOONE, LON HENDRISOX (k'86) -

Tenn.10,'11; (1'12).

KNIFLEY, 100, ADAIR

Gose, John C. (b'6i)-Ky.2,'94; (1'94).

KNOB LICK, 145, METCALFE

HAIRVEY, PHILIP D.-Ky.1,06; (l'06).

KNOTTSVILLE (R.F.D., PHILPOT), $2 / 2$ DAVIESS

EDGE, ORA W.-Ky.5,07; (l'07).

Popham, Austin E. (b'79)-Ky.1,04; (1'04) KNOXVILLE (R.F.D., DRY RIDGE), 50, PENDLETON

Bethel, Robt. L. (b'33)-La.2,'60; (1'95).

Cllfford, Alvin H. (b'48)-0.8,'89; (l'89).

Webb, Jos. L. (b'51)-0.8,'i9; (1'93).

KODAK, 10, PERRY

Roark, F. C. ( (b'53)-Ky.4,91; (1'93)

KOSMOSDALE, 50, JEFFERSON

Applegate, Abel B. (b'50)-Ky.2,'74; (1'93). Blanton, Loomis C. (b'83)-Ky.5, $06 ;\left(1^{\prime} 06\right)$. KUTTAWA, 889, LYON

LINN, CYRUS H. (b'62)Ð-N.Y.10,'91 ; (l'93).

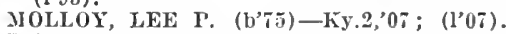
PHILLIPS, THOS. LOWERY (b'68)-Ky.1. '98; (1'98).

PURDY, ARCHIBALD DIXON (b'54)Tenn.6,'82; (1'93); G.

\section{LA CENTER, 426, BALLARD}

Mlanor, Jesse B. (b'44)—IIo. 1,'82; (1'94).

HARTIN, JESSE EDW, (b'69)-MO. 6,96 ;

ovisBi, BOB C. (b'67)๘-Ky.5, 03 ; (I'03).
LACKEY, 100, FLOYD

('handler, Thomas Jetferson (b' $\mathbf{0} 0)-\mathbf{k} y, 5$, (16); $\left(l^{\prime} 06\right)$.

(OLINS, MAHSIIAL M. (b'71)-Ky.I, Wickor, $(197) ; 0$ p. LAFAYETTE, 266, CHRISTIAN

Brandon, liobt. Wesley (b'82)-Tenn.5,08; (1'08).

Ezell, Jas. J. (b'54)-M10.28,'99; (l'00).

STONE, JOS. F. (b'54)-ky.2,75; (1'93).

LA GRANGE, 1,152, OLDHAM

13LAY'DES, IIAKRY 13.-Ky.9,03; (1'03).

CASSAHY, RICIIAKD 13. (b'44)屯-Ky.4。 CONNEL, THOMAS GAYLE (b'T9)-Ky.5,

Gollislokovgir, CHAS. N. (b'62)-Ky.5, IL

HAR1BOLl, JOIIN E. L. (b'53)-Ky:2,74;

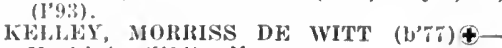
KY.4, '04; $\left(1^{\prime} 04\right) ; U$.

LAKELAND, 55, JEFFERSON

DAVIDSON, ANDREW JACKSON (b'83)KY. 2,09; (1'09); P.

GARDNER, WN. FNMET (b'7) 1 -Ky.2,

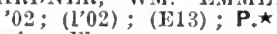

Neder, Florence

(See Loulsville.)

PEDDICORI, l'HANK LESLIE $\left(b^{\prime} i 1\right) \oplus-$ Ky.9,'06 ; (l’06) ; P.

Wagner, Geo. Byron-0.8,92; (l'93); not in practice.

LAMASCO, 134, LYON

WALLACE, HARRY LEE (b'85)-KY.2,'11; (l'11).

\section{LANCASTER, 1,507, GARRARD}

ACTON, JOHN MHLTON (b'66)-Ky.1,'98 $\left(1^{\prime} 98\right)$

AMION, JESSE A. (b'65)థ-Pa.2,91; (1'93). 13alley, kobt. Thomas (eol.) (b'78)-Ky.

'I0; (阷). WM.-Ky.5,'92; (1'94).

ELIIOTT, WH. MACK (b'74)屯-Ky.1,96 $\left(1^{\prime} 96\right)$

Evans, Elljah-0; (l'93); not In practlce. Johnson, Wm. (col.) (b'74)-Ky.7,02;

KINNAIRD, IANES BROWN $\left(b^{\prime} 56\right) \oplus$ N.Y.10,'82; (I'93).

LANGLEY, 70, FLOYD

Allen, Jos. Hawley (b'88)-Ky.2,'10; (1'10).

Hagans, Allen C. $\left(b^{\prime} 43\right)-0 ;\left(1^{\prime} 93\right)$

LATONIA (COVINGTON P.O.),

KENTON

Armstrong, Wm. N. L. (b'28)-0; (l'98); R.F.D.

CARLTON, ROBERT ELLISTON (b'56)-

KE.I'T7; (l'93); T. ATWOOD (b'68)૯Ky.1,'98; (1'98).

SINPSON, EDW. N.\&-0.1,93; (1'94).

Wadsworth, Lee C. (b'65)-0.1,'93; (1'94).

LAWRENCEBURG, 1,723, ANDERSON

Campbell, John R. (col.) (b'80)-Ky.7,'07 ;

GILBEIRT, JOHN W. (b'80)-Ky.2,04; $\left(l^{\prime} 06\right)$.

KAYANALGH, CHAS. WM. (b'58)↔-Ky.2, '85: (1'93).

Leathers, Chas, A. $\left(b^{\prime} 60\right)-\mathrm{Ky}, 2,82 ;\left(l^{\prime} 93\right)$.

LILLARD, GUSTAVUS D. (b'64)€-Ky.2,

'93; (1'93).

I.yen, John B. (b'

MeQuiddy, Robt. Irvin (b30)-Pa.2,'54; $\left(l^{\prime} 06\right)$ OVERALL, A. CAPERTON (b'81)-Ky.4,

Shewmaker, Oscar Francis (b'83)-ky.2, , 0 ; ; (I'08).

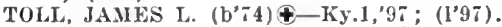

Witherspoon, Ambrose Henry (b'70)-Pa.2, '94; $(1,97)$.

LAYNESVILLE, 100, FLOYD

Webb, Tobe Turner (b'79) - Ky.2,'09; (l'09).

LEBANON, 3,077, MARION

BOLDRICK, JOHN T. (b'85)€-Ky.11, 08 ; (1'08).

CLEAVER, THOS. F. (b'65)-Ky.2,'8i;

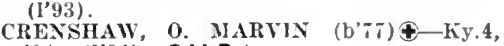
'04; (I'04); OALR.*
Hodgen, Itobt. T. (b'38)-Ky.2,'59: (1'93); IIOSKINS, MIJIAIRD D. (b'79)-Ky.5, 05; (l'05).

KHILY, EIWAl\{1) (b'60)‡-Tenn.1,'81; (l'93); 0 p.

KNOT', ILOY') 1). (b'45) - K5.2,66 ; (l'93); not in practlce.

FOHEIRT, CHAS. HISMARCK $\left(\mathrm{b}^{3} 78\right)+$ $0.1,01 ;\left(l^{\prime} 01\right)$.

Me(IIORI), CIHAS. IIARIRISON (b'84)Ky.2,10; $\left(l^{\prime} 10\right) ; \mathrm{S}$. Me('IIOR1), HOL'T. C. (L'51) †-Ky,4,75; (1,93); $\mathbf{S}_{0} \star$

TIIORNTOX, GLO. G. (b'62) $4-K y^{\prime} 2,87$;

LEBANON JUNCTION, 807, BULLITT

Johnson, Otto Earle (b'82)-Ky,2,04; (l'04); S.

Napper, Wm. S.-Ky.2,'91; (l'02).

THOMAS, CHAHLES 'T.-Ind.2,'81; (1'95); Pd.

LEDOC10, 50, LAWRENCE

MOOI\$L, JAMES O. (b'73)-Mo.20,'01; (1'01)

LEE CITY, 269, WOLFE

DLNN, JAMES HENRY $\left(b^{\prime} 77\right)-K y .1,07$;

LEESBURG, 100, HARRISON

Blount, Henry Clay (b'80) - Ky.9,06; (l'06).

LEITCHFIELD, I,053, GRAYSON

ARMES, J. A. (b'70)-Ky.4,96; (l'97).

ARMES, SAML. H. (b'68)-Ky. 2, 92 ; (1'93).

Berry, J. M1-Tenn. 5,82 ; (1'93).

CI.ARKE, WM. S.-Ky.2,'86; (1'93).

Conklln, John W.' (b'58)-Ky.5,'82; (1'93); OALR. $\star$

CONKILIN, WILL A. (b'54)-Ky.5,'83; (l'93).

PHELPS, MARCUS $\left(b^{\prime} 81\right)-K y .2,07 ;(1+)$.

LEROSE, 10, OWSLEY

GIBSON, WM. HENRY (b'82)†-Ky.5, 06 ; (l'06).

LEVEE, 100, MONTGOMERY

SEE, SHERIIAN-Ky.1,'00; (l'00).

LEVEL GREEN, 98, ROCKCASTLE

Lawrence, Geo, B. (b'65)-Ky.2,'91; (l'99).

LEWISBURG, 253, LOGAN

FELTS, LOGAN (b'82)-Ky.9,'05; (I'05) ;

R.F.D. 2 .

LASLEY, WM. W. (b'52)-Ky.2,'85; (l'94),

RICHIARDSON, WI. F. $\left(b^{\prime} 70\right)-K y .4,{ }^{\prime}(04$; (l'04).

Sneed, Wm. J.-Tenn.1,'84; (l'94).

SUTTON, KARON P. (b'61) $4-0.3,84$; (1'94): R.

LEWISPORT, 596, HANCOCK

Berkshire, Park Laurlmore (b'75)-Mo.28,

'01: (l'01). Havis, Thomas (b'46)-Ky.2,'81; (l'00).

Grlffin, James W'. (b'69)-Ky.1,'93; (l'93).

KNOX, J. W. (b'56)-Ky.4,76; (1'93).

SHERMAN, FRANCIS MARION (b'83)Ky.9,'06; (1'06).

\section{LEXINGTON, 35,099, FAYETTE}

NUMBER OF PHYSICIANS, 113.

Allen, James M. (col.) (b'60)-Tenn.7,'93; (l'93).

Anderson, Chas. F. (b'73) - Ky.9,'06; $\left(l^{\prime} 06\right)$; 317 S. Broadway; offlce, Lexing-

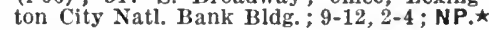

ANDREWS, ALFRED J. (b'62)↔-N.Y.1, '94: (1'97) : $160 \mathrm{~N}$. Upper St. : 8-1, 6:30-8.

BANNISTER WU TINER (b'70)

92 (1'95): 605 F. Maln St.; offlee, Short '92; (l'95); 605 F. Maln St.; oft
and Limestone Sts. ; 8-10, 2-4.

BARKLEY, ARCHIBÁLD HENRY $(b ; 72) \oplus$ -N.Y.1, 96 ; (l'96); 248 N. Broadway;

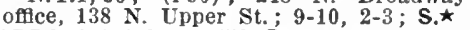

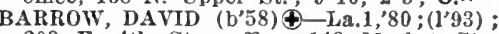
203 F. 4th St.; offlce, 148 Market St. ; $2-3 ;(\mathbf{A} 5,6) ; \mathrm{S} . \star$

Barrow, David Woolfolk (b'82)-Mich.1,08 ; (1'09) ; 203 F. 4th St. ; offlee, 148 Market St. : $9-10,2-3$

BEARD, EUGENE FERRIS $\left(b^{\prime} 52\right) \oplus-K y .2$, '76; (l'93); 626 Euclid Ave. Belote, Garrett B. (b'88)-Ky.2,'13; (1'13); 544 W. $2 d$ St. Bewlay, Henry (b'53)-0.2,79; $\left(1^{\prime} 04\right) ; 146$.
N. Mill St. 


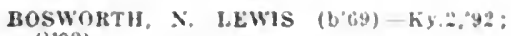
(1'93)

HRAIIEI, ERNKST HIESNAY (b'a)Mlch.1,06: (1'0i): Hamprom

I46 Market st. $9-10,2-3$.

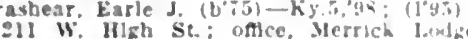
Hids.: $9-10 \div 30,1-3: \mathbf{N}$.

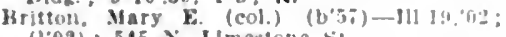
(102): $345 \times$. Limestone $\mathrm{x}$.

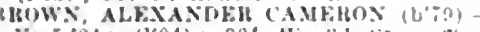
Ky.5,04: (1.04); 304 W. 311 :

Truvt (omany ludg : $9.10,24,-5$

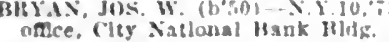

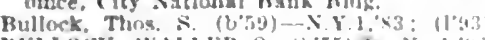

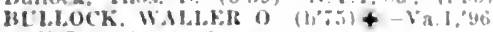
1199): ift Market si.

Burrls, Ellas II. (b'40)-0.20.'81; (1.94) ArRICK Jerits

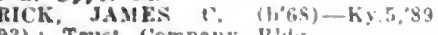
$\left(t^{\prime} 93\right)$ : Trust Company Mlels.

CARRICK, HOHT, L. (l, 15$)-0.13 \therefore$ S (1'94)

Cavins, John H. $\left(b^{\prime}(6) 6\right)-5 y .9,03:\left(1^{\prime} 0: 3\right)$ 115 woodland Are.

CLARKE, FIKAXK H. (b'53)-Ind 2,:5 Ky.2,'s9: (1'93): oftice, 150 Market si COLE.IAX, BEXJ. I. (1,4T)-XY.10, II (1.93) 150 N. Market St.

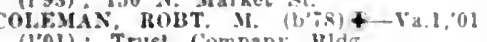
(1'01): Trust Company Bldg.

Cuoley, obed (col.)-Mlch..5,03; (1'03); S Bmadway.

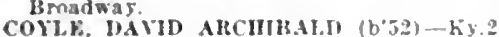

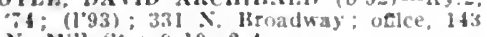
x. MIII st. : $9-10,2-4$

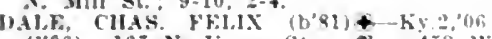

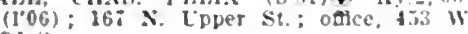
id st:

DAVIS. MALRICE S. (b'So)-KY 2, 03 : (1'03): $553 \mathrm{~W}$, 2d st: oflle, Mcclelland Blelg: : $9-1: 2-4: U$ :

DAY, Gro. IICFF" (b'90)-Ky.2.13: (1'13)

Good Samarltan IJospltal.
Dunlap. Mlanle C. (b'58)-K5.8.99: (l'09) kiastern Kentucky Asylum for Insane.

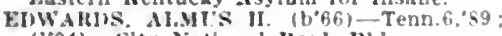
(1'04): Clty Nallonal llank HIdg.

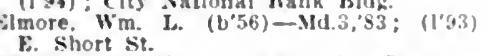

EsTILL ROBT. JULAAX (b'i) $+-\mathrm{X}$ Y.1 02: (1"02): 140 X. Toper st.; $9-10,4-0$ Trust Company Ildg.

roushee, Henry lilluert $\left(b^{\circ} 82\right)-\mathrm{hy} . \mathrm{I} .0 \mathrm{~b}$ $\left(I^{\circ} 0 b^{\circ}\right): 250 \mathrm{~s}$. Lime st. ; oflce, IIcClel. land Bldg. $9-11,2-4: U$.

GARR, CHAs. CHAIN (b'81) - Ky.5.07 $(10 \%): 153$ church si. oflce, rayetie Xational Jank Bldg.: $9-10,2-3: \mathbf{S}$.

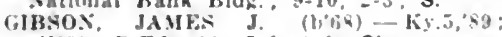

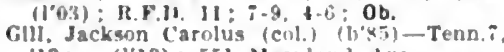
13: (1'13): 551 Marylami Ave.

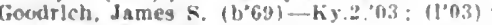
428 b. Marwell st. oftee, rity Yatletual Jasik Hldz. : 9-12, $1: 30,+;: 30$

coolsox jos. A (b-5)-Tenn 5,40 (1.99): Kinstern State IIospltal

Gordon, lelgh It. $(1,70)-k y 4$. 162 Harr SL: offlec. City Sational laak itid2: : $9-11,2-5$

crakg. logan (b'68)-0 1,'91: (1'93) R.P.D. 3 .

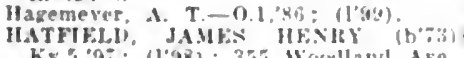

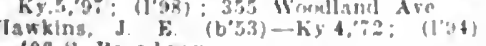
102 Hroadway.

IHoLY, lini. J-quel, $96:(100): 530$ ment silation.

btrals, lowlse Hergmann-l'a :,3: : (1'03) 530 Sayre ive.

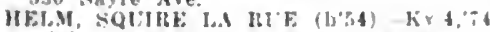

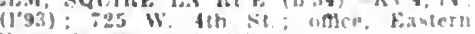
Kentucks llospltal: NP.

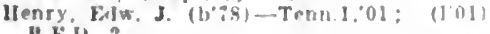

RRR HARRY (iAl.J.OWAS (h', +

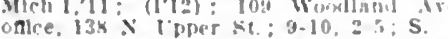

Holloway, Walter W. (b3i)-ky,an

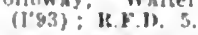

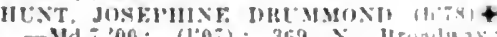

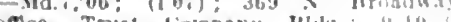
$2: 30-3: 30$

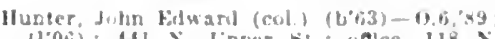

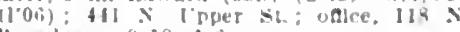
Broadway: $9-10,1-6$.

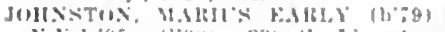

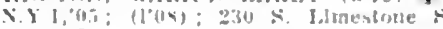
$1: 1: \mathbf{S}$

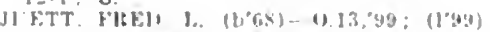
[til) N. Brualdway: $8=10,=-4$

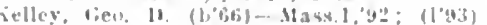
Truist Inmpany HId

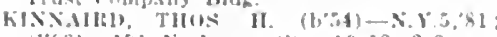
$(10(4) ; 101 \times 1$ lper sit: $10-12,2-3$

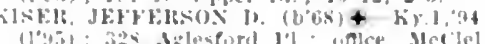

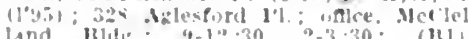

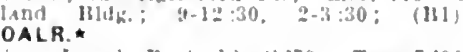

laine, Joseph F. (cril.) (1,\%9)-Tenn.

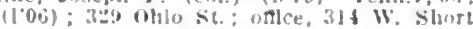
$\therefore 1.8-10,2-4,6-3 ; u$.

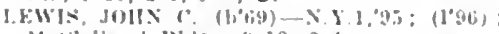
Met'lellatul Hliz; $9-12,2-4$.

MACIIH: JOHS WRIMMONI) (b\%6) 15: vill S?: $\mathbf{G}$

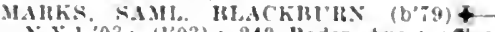
V.Y.1,03: (l'03): 243 Rodes Ave; oftlce. ilt Market st. $9.10,2-3 ; \mathbf{S}$.

MotiUHE, WILLIAM B. (b'58) - K5., 83 (1'93); Ilarrulsburs, Ikel. : on

Mct.MONis, Jilis T. (b'70)

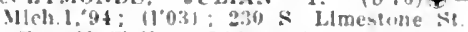
ontee. Mcclelland bldg.: 10-12, 2z-4

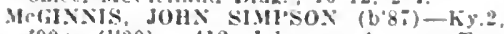
09: (l'n9); +12 Johnson Are.; inter, Faselte National liank Jdg.; $i l-1,5-6$. $\because .8: U$

MCKEE. EMIIJUS MORANCY (b'ic) (1.4,00: (l'01) : +17 W. High st.; ottite Mctlelland Blig.: 10-11.

lliller, German B. (b'52) - Mld.3,'82; (1'93) H.F.D. 1.

slllion, Jackson Epbert-111.4,'11; (l'13): ijlt Central Ire

llolloy, Patrick Henry (b'51)-0.1:N0

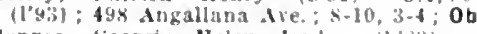
Monroe, (ieorgia Helen Jurdan (b) s.t\})
Mlch.5, 03 ; not In practice: logan Hall.

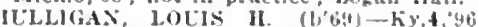
(l'ybi); tij: Hose sit. ; unce, securlty Trust Company Blds: : 9-12, 2-4; D.*

NEELEY, JAMES E. (b'36)-X.Y.5, 63 (1.9b); Mcrlelland Hiclp.

NHITT, CHAS. A. $(1,73)-k y .4,04$ : (1"04) Filmwood Stallartum; (k]3): NP. ORIS, CHA: W. (b.61) $+-111 ., 83$ Ky.4,05; (l'93); 152 Market st.: nnlce Trusp Company Hids.: 10-12, 2-3.

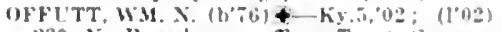
230 ×. Hroadway; nflice, Truvt iompany Bldg.: 10-1, $2-4:$ : (H) : OALR.

l'eck, Ferdinand Edward (b'mi)-Ky.s, 's kilmwood sinltarlum.

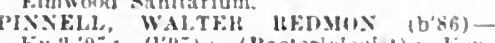

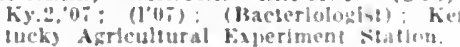

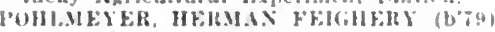

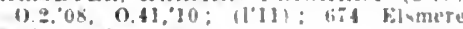
lark; intee, securliy Trust company lidg.: $9.10,2-3$.

lolk, John kinox (bos) J1.C.3.13: (1'13)

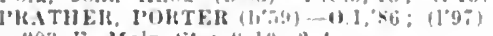
zor: F. Maln st.: s-111, 2-4

rlisols. Jos. W. (boti)-Mo.3:76: (1.93) not in practlce: (FI).

IEHMMN, LYK COLLIXS $\left.\left(\mathrm{b}^{\circ} 85\right)+\mathrm{K}\right) .2$

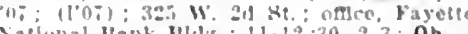

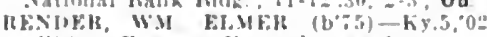
(1"02): Hastern Kentueky Asylum.

Rluley, Nathanlel J. (cul.) Tenu :00

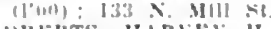

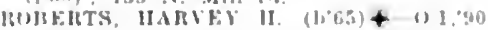

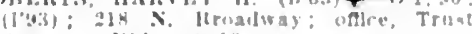

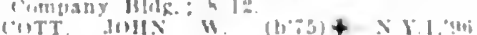

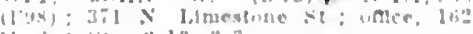
Whand : a $10 \%-3$.

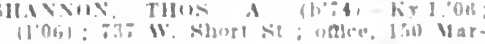
hes se : $80-11$. 3.

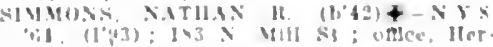
(1) $(1,03): 1+3:$

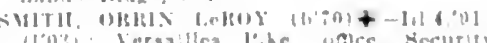

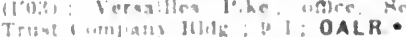

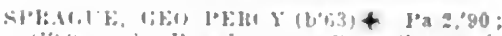

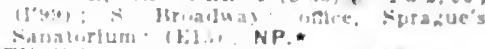

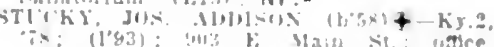

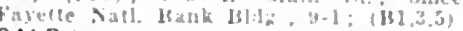
OALR.

STl'kl, WM. SWEFYY (b) + 11 , 1

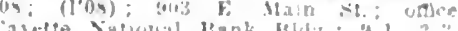
OALR.

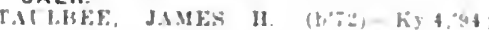

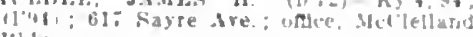
Iilis.

Tilylor, Isa l'. $(1,56)-0.1,73 ; \quad(194)$ Merrick l,amba Hliln

Talor, A. I"artare (b)'s])-K5.5,03; (1"03) Verrick londze llldir

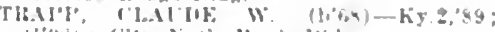
Il'(bi); rlly Nail. Hank Bda.

(1'03)

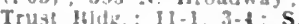

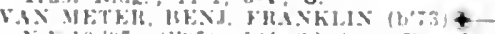

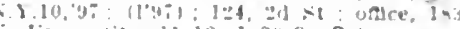

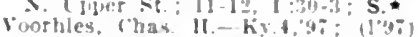

Wadfly, 16. lsurns (b'ut)-Ky 1, 91 : (l'y3) 203 E. Maln vit.

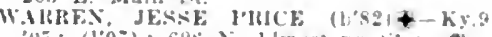

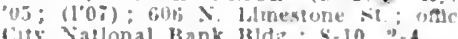

Washburn, Julla (t'62)-0 23,91; $(1.93)$ 179 Market Si.: 11-12, 2-1: G.

Werdell. Thos. T. (coll Tenn:-00: (100)

WHFELEI, RAHI ILWTS $\left.\left(\mathrm{b}^{2} \mathrm{3}\right)+-\mathrm{k}\right)$

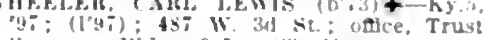
(inmpany lide : 9.5 ; $(1 \%)$ U.

WILEY, ENWAHD M $\left(b^{*} 50\right)+$ Ind $4: 35$ 1!'9:1); It Wondlanel Ave: ofllce, Fasette Pational lank Bldg: $9-10,2-5:$ NP.

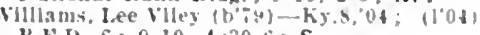

H.F.I. $6: 9+10 ; t: 30-6 ; S$

whllis, Jobn $C\left(b^{\circ}\left(b^{\circ}\right)-h^{\prime}\right) .9,06:\left(1^{\prime} 06\right):$ 4\%5 Walnut st. onlce, Securiby Trust Hldg. : $9-12,2-4 ; N$.

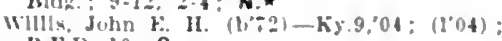
W.In. 10; S.

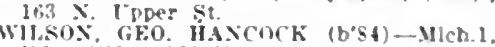
10 : $(1,13):$ is 3 . Cpper st.

WITT, WAITH SIMAAI, (1) 33$)+$ Trust company Hidis: 9-12, 2-4:30:1.

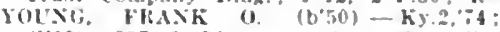
(l'93); 957 s. LImestone st: once. Clty Natlonal mank Hlds: $8-4: 30,1: 30-3$ : Pd. LIBERTY, 330, CASEY

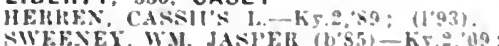
(1.09)

WESLFY, ISAIAII S-KY.2*\$9; (1"93)

LICKING RIVER, - MORGAN

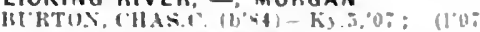

LILETOWN, 20, GREEN

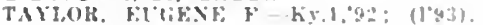

LILY. I6I, LAUREL

WSi.k. JUHX (i. (b'6) - Ky 3,04: (1'05): 0 b.

LINDSAY, 25, KNOX

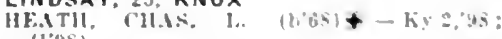

LINTON, 29, TRIGG

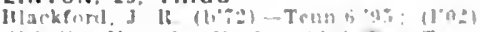

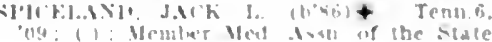

if ilitis

LISMAN. I54. WEBSTER

llare lio

LITTLE CYPRESS. 100, MARSHALL

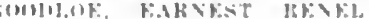

ITTLE MOUNT R.F.D. TAYLORSVILLE) 75. SPENCER

Whitugloll, Hibere I (1) (1) 103$)$

LIVERMORE, 1.220. MCLEAN

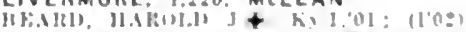

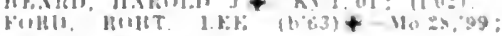

LIVIA. 23. DAVIESS

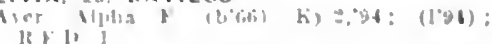

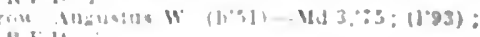


Complis. ALVAII J. (b'80) - liy.5, 05; (1'uis)

H.ARWICK, Gis A. (b'io)-Ky.4,74 (1) 433$)$.

J)hnson, Frank 1. (1)'66)-0.2.05; (1'05), LIVINGSTON, 685, ROCKCASTLE

AIYX. WM. THOS. (b'6i) liy.4,94; (l'94)

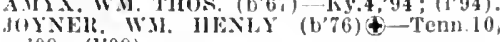
$09 ;(1,09)$

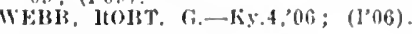

LOCKPORT, 153, HENRY

LESLIE, WH. W. (h'67)-Kiy.5,04; (1.04).

LOCUST BRANCH, 70, ESTILL

NOWBEX, IHICHAHE RAYAOND (b'8i) KYY.2,12: (1'12)

LOGLICK, 35, CLARK

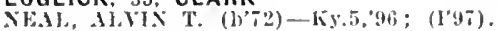

LOGMONT, 75, BELL

SCIICLT\%. JACOH (b'79)-Ky.5, 06 ; (l'06).

LOLA, 100. LIVINGSTON

llavis, Will. (b"7I)-Ky.5,02; (1'02)

Nasencup, Chas.-Ky.1,98; (1'98).

LOMBARD, 45, POWELL

LINOX, M. 1..-KYYl.01; (I'01)

LONDON, 1.638, LAUREL

Block, GEO. S. (b'i4)-Tenn.10,'94, Ky.2 '96: $\left(11^{\prime} 94\right)$.

BHOCK, OSCAR DANL. (b'83)-Ky.2,11 (1'II).

BHYANT, PASCHAL E. (b’o)-Ky.2,94;

COLDWELL, THOS. P. (b'42)-Ky,2,71; (1'93).

Foster, James D.- 0 ; (l'93)

(iIVES, JACRSON (b'67)-Mid.3,'82: (1'93)

MASON, JAMES BOYD (b'it)థ-Ky.2, 94 $\left(1^{\prime} 94\right)$.

PENAICTON, HENRY VINCENT (b'60) Teml10,91, ky,s,99, Pa.2,00; (1'93)

LONE OAK (R.F.D., PADUCAH), 50, MC CRACKEN

DAVIS, IOHN SENTER (b'67)-Tenn.5,92 (1'93): R.F.D. 1

GORE, RANDOLPII C. (b'T5)-Mo.28,'98 (1'98).

SHEITON, QUINTUS L. (b'67)-Tenn.6,99 (1'99).

LONG RIDGE, 100, OWEN

GRAY, EDW.' (b'52)-0.1,'80; (l'93).

LOOKOUT, 200, PIKE

ENTON, MATTHEW A. $\left(\mathrm{b}^{\prime} 60\right) \oplus-K y .1$, '04; $\left(l^{\prime} 04\right)$.

LORETTO, 140, MARION

CISSEL.L, JOS. K. (b'62)-Ky.4, $90 ;\left(1^{\prime} 93\right)$.

LOT, 250, WHITLEY

siler, John E.-Ky.5,03; (1'03)

LOUISA, 1,356, LAWRENCE BROML,
O.2,98; (1.98).

BlRGESS, THOS. DICKINSON (b'69)๕Nid.1,92; (1'06).

The $0.1,89 ;\left(1^{\prime} 93\right)$

PESEN W.-Ky.1,07; (1'07)

Porter, B. B $\longrightarrow$; (1'93)

hesnolds, James $H .(b ; 0)-Q$; not in prac tice.

Wellman, Ira (b'i4)-Ky.2,10; (\$)

Wroten, Geo. W. (b'38)-Pa.3,61; (l'94)

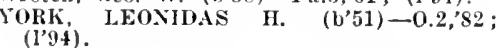

LOUISVILLE, 223,928, JEFFERSON NUMBER OF PHYSICIANS, 611

ABELL, IRVIN (b'76) A--Ky.4,'97; (1'98) : 1136 S. $2 d$ st.; offtce, Atherton Bldg.; 12:30-2; I'rof. Prin. and prac. Surg. and Clin. Surg., Ky.2; $(\mathbf{A 6}, \mathbf{C} 3) ; \mathbf{S}$

Abell, Nathan Douglas (b'i4) $-\mathrm{ky} .2,{ }^{\prime} 09$; (l'09); 524 N. 1st st.; offee, Starks

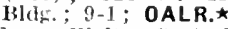

Adams, Walter S. (col.) (b'Ts)-Tenn. 7,03 ; (l'03); 2818 W. Madison St.; office, 612 Center $\mathrm{St}$.

Allan, Benj. A. (b’58)-Ky.5.78; (1'93); 1344 s. 2Sth St.; office, $415 \mathrm{~W}$. Chestnut St.; $\quad 12-1,5-6$.

dllan, Henry (1. (b'31)-Ky.1, 53 ; (l'93) 2214 W. Jefferson St.; until $10,3-5$.

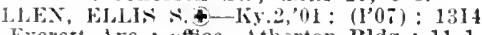
Everett Are.; uffice, Atherton Bldg. ; 11-1,

ALLEX, IOHN D. (b'84)-KY.2,12 ; (1'I2);
Allen, Moverell Kinx (b'46)-Ky.2,67;

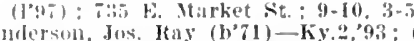
Mrderson, Jos. Itay (b'71)-Ky.2,93; (1'93) : $10(0)$ Fierett Are.; oflce, 671 s. 5th st. OALR. $\star$

Inderson, Itichard Taylor (b'8I)-Ky.2, 02 $\left(l^{0} 02\right) ; 621 \mathrm{~W}$. I3roaldway ; $I-2$.

ANokItsor, SIMRAL, (b'79)-Kr 2,01 (i'v1) ; 1511 s. th sit.; oflee, Atherton BIdg: ; $12-1,3-4,5-7$.

Anderson, Wm llenry (b'43)-Ky.2, 72 ; (1993);25:6 Montgomery St.; 9-10, 2-3.

ARNOLI, CALVIN GARNETT (b'85) - Ky.2, 10 ; $\left(l^{\prime} 10\right) ; 909$ S. th St.; ofllce, Atlierton mills.

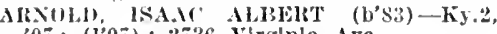
$07 ;\left(l^{\circ} 07\right) ; 2736$ VIrglnla Ave.

A.HIY, WM. HAMMONI (b'78) - Ky.5, 04: (I'04); Ned. liept. of loulsville chiversity:

ANKEXSTEDT, FRIT\% C. $(1,65) \oplus-0.13$, $89 ;(1 ' 93) ; 1210$ S. 4 th St.; $11-1,6-\tau$

Askenstedt, Lilllan Bryan (b'6i) II-Ky.8, 04: (1'04); 1210 S. 4th Ale.; 4-6; NP. ASMAN, BERNARD (b'72) $4-K y .1,97$ (1'97); 1450 Bardstown Rd.; offlee, Atherton Bldix.; 11-1; I'rof. Dis. of the Hectum, Ky.2; Pr.ネ

Badertscher, Gottfried (b'61)H-Ky.8, 01 . (I’01); 940 S. 18 th St. ; $9-11,6-7$.

BAILEY, EVERETT R. (b'86)-Tenn.7,10; (1'11).

BAILEY, WM. O. (b'62)-Ky.2,'88; $\left(l^{\prime} 94\right)$; 130 Weissinger-Gaulbert innex; office, Atherton Bldg; $10-2$.

Baker, Thos. II. (b'59)-Ky.5,'89; (I'93) 1613 Story Ave.; 8-9, 2-3, 7-8.

Baldauf, Leon Kahn (b'Ti) - Md. T,'05. (l'10); not in practice; 9 Eastover ' ('t. Prof, Path. and Bact., Ky.2; (F2).

Baldwin, Lloyd Byron (b'53)-Pa.1,74 Surg., Lieut., Commander, U.S.N., retired 820 S. 4 th st.

BABBOLR, PHILIP F. (b'67)૯-Ky.5,90;

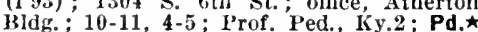
Barnes, Chas. W. (b'78) H-Ky.9,06; (1'06); 42. W. Chestnut St

Barnes, Willis W. (b'52) $\rightarrow$; $\left(1^{\prime} 03\right) ; 525 \mathrm{~W}$. Oak'st.; office, Atherton Bldg.

BARNETT, ARTHUR MORRELL ( $\left.\mathrm{b}^{\prime} \mathrm{i} 1\right) \oplus$ Ky.2,96; (l'96) ; 839 Barret Ave.; office, 638 k. Market St. ; $9-10,7-8 ; \mathrm{S}$.

Bate, R. Alexander (b'71)-Ky.5,'92; (l'92) $1443 \mathrm{~S}$. $2 \mathrm{~d}$ St.; office, $316 \mathrm{~W}$. Broadway 9-10, 5-6.

Battiste, Simeon I. I. (col.) (b'60)-Ky. 7 $2-3,7-9$.

BAXTER, WM. EIWARDS (b'63) - Ky.5, 93: (I'94): Western Parkway: ALR.

BAYLESS, BENJ. W. (b'81)థ-Va.1, 02 $\left(1^{\prime} 02\right) ; 130$ Weissinger-Gaulbert Annex oftice, Atherton Bldg.; $\mathbf{R}$.

Beck, (hals. Kirtley (b'84) - Ky.2,08 (1'08) ; 1329 s. 2 d St.; office, 3343 W Market St.; 10-12, 4-6.

Brek, Ilenry 13. (col.) (b'T2)-Tenn. 7,01 (I'0I) ; 828 W. Walnut St.; 9-10, 2-4, $7-9$. lheck, John II.-Ky.5,05; (1'05); 115 E Gray st.; office, Atherton Bldg. ; 8-9, 5-7. leckham, Richard P. (col.)-Ky.t,12; (application pending,'13); $80 \mathrm{I}$ S, Floyd St.; offlee, soI $S$. Hancock $\mathrm{St}$.

BEDiN(iER, JOHN VAN DOREN (b'sa)-

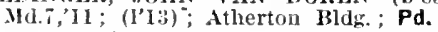

liennett. Aifred T.-Ky.1,6I ; (1'97); $929 \mathrm{~s}$ 28 th St. ; $7-8,2-4$.

Iennett, J. Steward (b'58)-Ky.5,'y1 ; (1'93) ; 912 s. 6 th st.

Ben\%, Jesse (b'87)-liy.2,13; (1'13) ; Louisville City IIospital.

Yerresheim, Anthony J. (b'81)-liy.1,06 $\left(l^{\prime} 0 \pi\right)$; 104.j Caldwell st, office, $702 \mathrm{~s}$. Shelby st.

BESS, WM. EDIIE (b'83) \& - Ky.9,10 (I'12) ; 626 S. $2 \mathrm{~d} \mathrm{St}$.

Beutel, Geo. Philip-Ky.2, so; (1'93); 1230 Bardstown 1d.; office, 434, 4th Ave.; 8-11, $i-8: 30$.

Beutel, Geo. Philip, 3r. (ט'78)-Ky.2,98; (1'03) ; 1230 Bardstown 1id.; offee, $412 \mathrm{~s}$ 4 th Are.; $12-2,5-7$

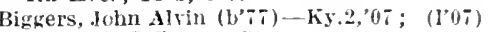
2225 W. Jefferson St.
Inindewald. Win. Andrew (b'40)-liy. 2, r1: eirclielt. iVm. G. $\left(\mathrm{b}^{2} 78\right)-0.1,02 ;\left(\mathrm{I}^{\prime} 02\right)$; 513 s. $2 d$ St. ; offee, Atherton Bldg.

rizor, ALPIONS R. (h'74)-Ky.2,01; (1'01) : 3409 W', Broadway'; offlee, Atherton Blidg; $1-3 ; \mathbf{S}$.

BLACKFORD, COPE H, (b'77)-Ky.5,07; $\left(\mathrm{Y}^{\prime} 0 \mathrm{O}^{\circ}\right)$; 129 ' E. Grey St.

HLACKFOR1, WILTON F. (b'73)థ-Ky.1, 01; (1'01); 129 E. Gray st.; onlee, AHh: (erton Blikg.; $1 \mathrm{I}-12,5-6$.

lHand, Joy. E. (b'58)-liy.2,79; (1'93) ; Taylor I3lvd. and Blue (irass Ave.; 7-9, $12-3$

HLOC'H, LEO (b'75) - Ky.2,99; (1'99) .22 11. Ormsby st.; 2.3 ; $\mathrm{G}$

BLOCII, OSCAR EDGEWOR'TI (b'îl) Ky.2,'93; (1'93); 976 Cherokee Rd.; office, 314 W. Broadway; $11-1,5-6$; S.

BLOOMI, ISADORE N. (b'58)థ-Mass.I,'8I ; (1)93) A Alexander Apt.; office, Athertol fien.-Urln. Dis., Ky.2; (C3); D. $\star$

BOARI), MILTON (b'70)\&-Ky.2,93; (1'93) ; 1412 S. 6th St.; 9-11, 3-5.

BODINE, JAMES MORRISON (b'31) $\uparrow$ Ky. 1,$54 ;\left(1^{\prime} 93\right) ; 4$ th and Chestnut; $9-10$, I: $30-1: 30 ;$ Emer. Prof. Anat., Ky. 2

BOGGESS, WALTER FISK (b'63) $€-K y .4$, ' $86 ;(1 ' 93) ; 1204,2 d$ St. ; offlce, 3d St. and Broadway; $9-10,2-4, i-8$.

Bohannon, Geo. H. (l's1)-Ky.1,04; (l'04); 112 W. Burnett Are.; offlce, Securlty 13llg. : 11-1, 7-8.

Bohannon, James F. (b'T2)-Ky.5,'97; (l'98); 910 W. Jefferson St.; $9-10,2-3,7-8$.

POLIANG, WM. A. (b'68)-Ky.2,91; (文); $185 \mathrm{x}$. Vernon $\cdot$ St. ; $7-9,6-8$.

Bome, 'assius A.,' Jr. (b'8i) - Ky.2,'13 (l'13) ; Louisville City Hospital.

Borgman, Deddo II. W. (b'72)-Ky.2,94; (I'06) ; 1832 W. Main St. ; 8-10, 2-3, $7-8$.

Boss, Edw. (b'66)-Ky.2,97; (1'97); 520 s. $3 d$ St. ; 9-11, 2-4. 7-8

BRANDEIS, FLORENCE (b'60)Ð-Pa.7,94 ; (1'95); 1209 S. 4th St. ; $2-4,7-8$

BIRACN, SAIIL. ALVIN (b'8I)-Ky.2,'13; () 13: E. Gray'st.

REIDENTHAL, GEO. B. (b'79) (-Ky.5 BRENNAN, IAMES E. (b'76) - Ky.4,90 (1'93); $726 \mathrm{~s}$. $23 \mathrm{~d}$ St.

BRENNAN, J. ARVID O. (b'80)@-Kv.2, 01; (1'01);63I S. 5th St. ; 8-9, 2-3, 7-8. BRONNER, HERBER'T (b'79)థ-Ky.2,02; (l'02) ; Navarre Apt.: office, Atherton
Bldg. ; $11-1,3-4,7-8 ;$ Adj. Prof. Ven., Cutan. and Gen.-Crin. Dis., Ky.2, : U. ${ }^{\star}$

Brown, Ester A. (col.) (b'80)-Ky.7,05; (los); 410

Brown, Wm. A. (col.) (b'65)-Tenn. $t, 92$; (1'93) ; 1738 Frankford Ave.; office, 221 S. Jackson St.; 10-11, 3-4, 7-9.

Brownsteln, Saml. Jos. (b'86)-Ky.2,08 : (1'08); 1919 W. Chestnut St.

BRUCE, EDWIN T. (b'80)థ-Ky.5,05 (l'05); 1 i 12 S. 4 th St.; office, Gaulbert lildg. ; $10-12,2-4,7-8$.

BRUN,ER, BEN L. (b'72) $\uparrow-\mathrm{K} y .5,97$; (1'99); 218 Birchwood Ct.

BliCNER, HENRY CIAY (b'78)-Ky.5,02; (1'02); 2110 Kenilworth Ave.

Bruner, Wm. T. (b'71)-Ky.5,96; (1'00) ; $8 \approx 0$ S. Brook St.; office, Atherton Bldg.

Bryan, Jos. 'T. (b'99)-0.13,'83; (1'93); 824 S. 2d St.; office, Atherton Bldg.; 11-1. $5: 30-6: 30$.

Brzozowski, Grover S. (b'86)-Ky.4, 07 (1'07); 1648 Beechwood Are.; office, $20 \%$ S. Jackson St.; $8-9,1-3,7-8$.

Brzozowski, Stanislaus (b'43) - Ky.4, 66 (1'95); 1648 Beechwood $A$ ve. ; office, 207 S. Jackson St. ; 1-3, 7-8.

Buckle, Bernard (b'67)-Ky.2,78; (1'93); $8 I 1$ E. Jetferson St.; 8-10, I-3, $;-8 ;$ ObG. uckner, Frank Ingram (b'87)-liy.2,'13; (1'13) ; Louisville City Hospital.

Buechel, Valentine, Jr.-Ky.1,'94; (l'94):

Bullington, Traris Alexander ( $\left.b^{\prime} 61\right)$ - Tenn.5, '89; (l'93); not in practice; 1932 S. 3d St. 1831 Deer Park Ave

Burch, Will. E. $\left(\mathrm{b}^{\prime} 40\right)-0.1,69 ; \quad\left(\mathrm{l}^{\prime} 97\right)$ Park Are. and Grand Blvd. 


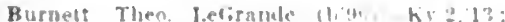

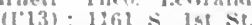

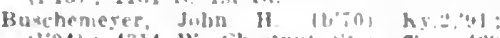

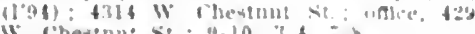
W' Chesenu: si: $4-10,3$ \&

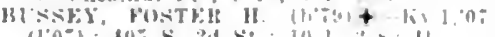

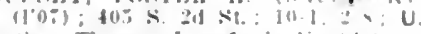

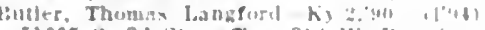

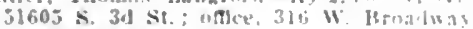

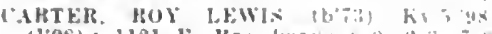

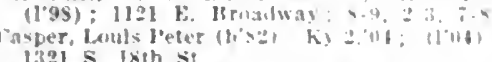
1321 S. Ixih st.

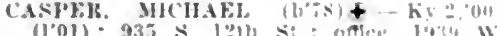

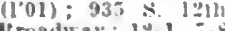

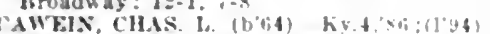

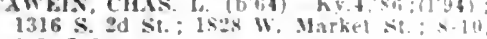
$1+3, i-8$

(heatham, Luther T. (b69) Ky, B.

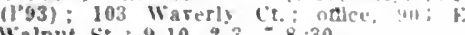

Walnut st. : 9-10, $2-3,7-8: 30$.

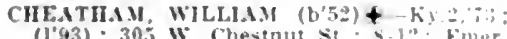
prot. Ins. Five, Ear. Jose ash Tlisual hy.2: (11, 3,4): OALR.

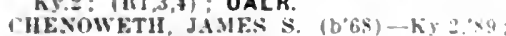

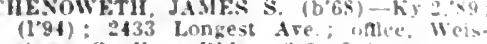
slnger-Gaulbert IBIda.: $8-9.2 .4$

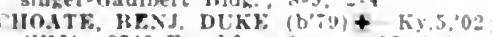
(I'II): $: 40$ Frankfort Ire. : *-10, (i-s

1LAKR, DOXALI KEYES (b's)--Ky. 11; $(1,12): 513$ E. Mroadwas: ntice Alberton lildtr.

Clark. Edfar Kaymond (b's?) ky (1)1i): 2408 W Market St ; $7-9$, ti-s.

('LAKR. FRANCIS S.-Ky.2,32; (d'yt); not Ir practlre: 514 E. Broadway

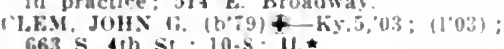
663 s. th st, : 10.s: U.

obh, Walt

bhest.

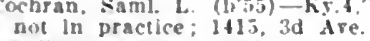

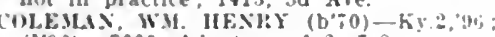
$(1 \% 26) ; 3000$, th ire.; $1=2$,

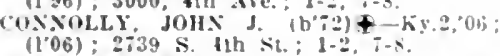

couk, Jos HHAKkls (b'-6)-ky.11, in (10.09); 2316 W. Jefferwn st: onter. 150 i

W. Walnut st. $9-10: 30,2+4,0-8$, whi

"wok, Macbonald $\left(b^{\circ} 80\right)-k y+204 ;$ (I'tioi

Hroadway; $11-1.5-6 ; \mathbf{G}$.

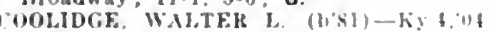
(104): Sew Welstinger-liauluert bidg. $11-1,5-6$.

COOMkS, MARTIS b. (b'ti)-Ky 1,73 (1.93) : 526 , tit Ale : $4-12.2-4: 34$,

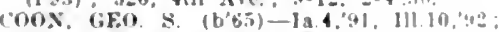
(1'94): 558 s. tih St: 12-1.5:- :

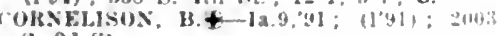
S. Id St.

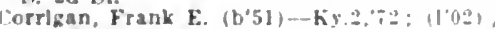
501 F. Jinadway ; 1-3.; 8 .

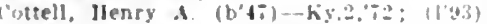

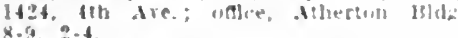

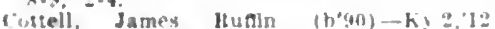
(1'12): $1424 \mathrm{~s}$. 1th Are, oftce, lihertio HId $: ; y-10,3$.

crandeli. Lafta Arthur (b'8:0)-Ky.2.11 (1'11): 1064 symamore Are, I1-1. b.s.

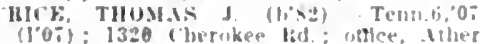
tun Hils

(RA)

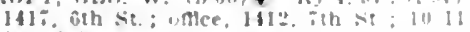

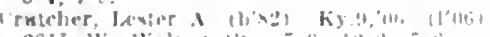

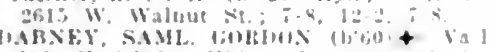
\&2, Кi

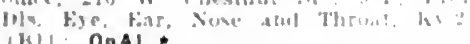

17II ODAL.

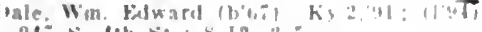

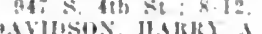

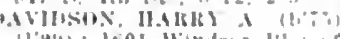

11 s!+1: 100I Windwor

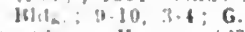

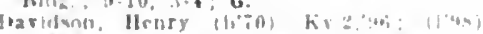
sis t. Narkre si : s.u $1: 2$.

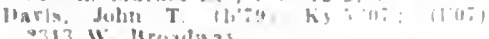
Ears 11 Mrominas

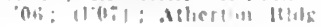

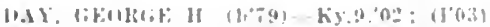

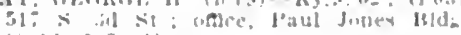

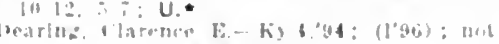

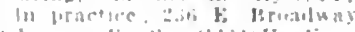

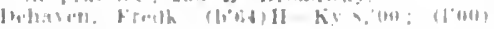
91:- is 51 .

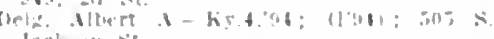

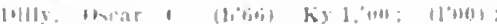

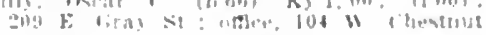
Si. : $\{-1\}$

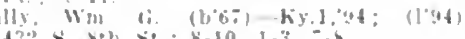
43: s. ven st: $4-10,1-3 .=-4$

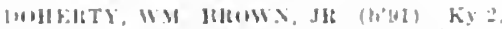
13: (1.13): Jonisolle folsy Hespltal.

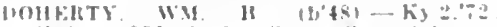

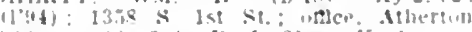

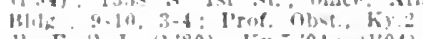

Bull. Emll J. (b.80)-Ky 00 : (1'0t): 130 ¿ letersin Ire; oflee. 121: F. Kentuch? Nit. : $9-10: 30,2-3,7-8$

(14)utrick. Harry (6.54)-ky 4.90; (1'01) 601 inud Are

[MII.F OS('A W. (b'79)-Ky, 2,0]; (1'01) 204 is (hestnut st.; $11-1$.

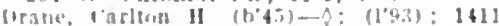
$\therefore$ bromk si : $b-12,3-6$.

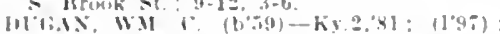
lefi ll rouk st: 12-1; Prof surg and Clln Surt. Ky: S.

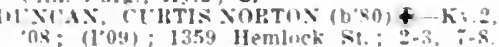

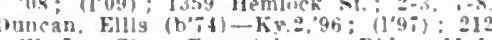
w. I.ee St : riftce, Allierton Blds. : 11-1. :-s; Alj Jrof Patholokical Anat. Ky. 1111: $54 t \therefore$. 12th st.: oflec, $40 \mathrm{~F}$ lefterson st.

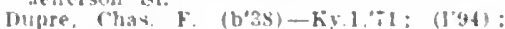
tont in practlce: 659 S. 45 th st.: 7.4

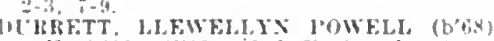
Ky. $12 \div,-2$

Husch, Irse I. (b'2)-Ky,5,03: (1.03) - +16 w Market st. $8-9,-3,-$

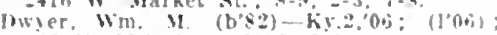
tow $x$ zeth st. $10+12,3-h$

neer, fiariand lanibuth $(h, 3,5)-5 y .2,13$; (1'i3): st. Inthony's Hospltal.

rockels, lowis W. (h'56)-Ky,t'si: (1'43): te1 $x, 26$ th $\leqslant$ i. : $12-2,7=4$

tekels. Inuls if.. jr. (b'si)-ky a

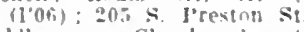

Folleman, rlaud : (b's5)-Ky.2. lntero. loulwille cliy IIniltal.

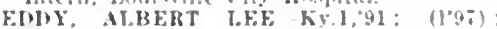
1238 Preston st. : oflce, $1254 \mathrm{~s}$. Preston Si. : $1-3,7-8$

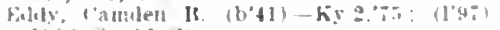
1004 $\therefore 21$ si

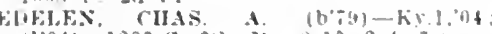
$\left(1^{\circ} 04\right) ; 1200 \mathrm{~s} .6 \mathrm{th}$ st, $x-10,2-t, ;-6$ kdlewn, Louls R. (1, $53 j-k y .0 \%:(100)$

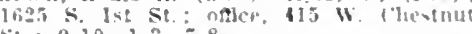
Si. : $9-10,1-3,7-8$

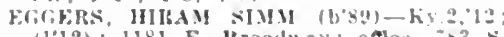

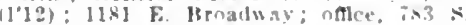
Sllelby st. : s.9. $=-3, i-<$.

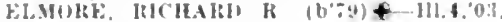

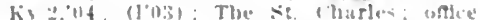

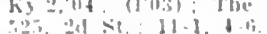

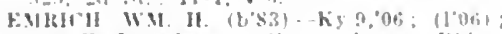

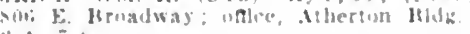
- 1. $;$ in

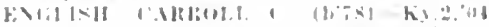

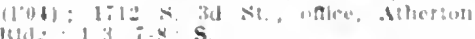

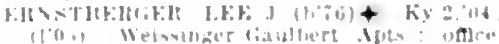

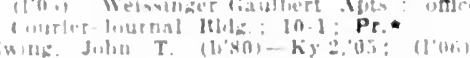

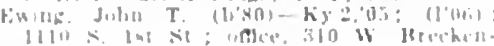

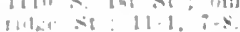

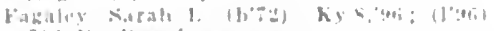
il 11 lit allom

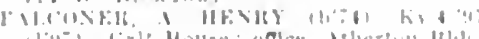

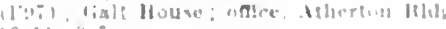

Fall lime l, (t)

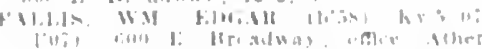

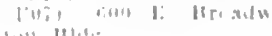

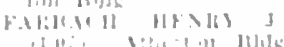

U. U.

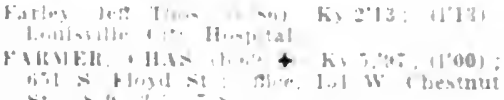

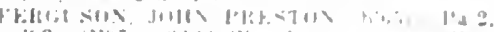

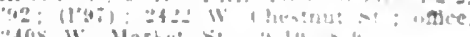

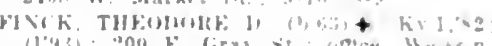

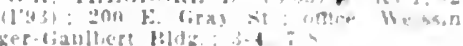
per-lianllegt lldic

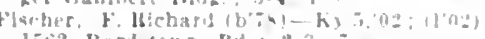
listio Bariniroun tod

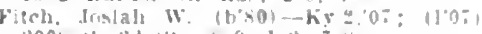

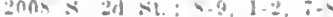

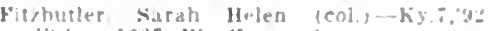
$(1,4): 10: 7$ W Vireen $x$

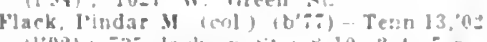

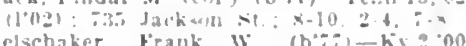

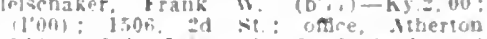

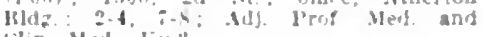

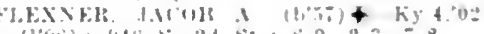

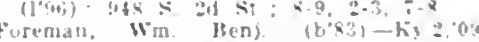
(1"0!4) $310 t$ kank si : calce. 3134 lort lawd ire : $:-10,-3, \div-8$

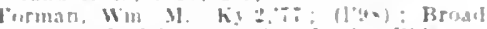

way and tith is conlros. Kioliy Mlad

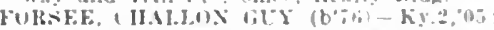

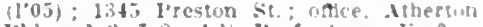
l3lug : $1-2, i-8 ;$ Alj. Prot surg, Ky.

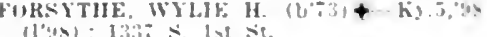

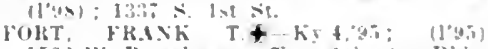
150: W. Mrnaduas; unce, liherton Blds $2-3 ; \mathbf{S}$.

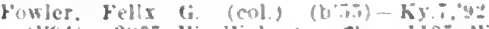
(1'94): 2407 W Walnut; othere, $110 ; \mathrm{W}$ thestrut st: $3-7: 30$

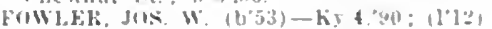
not in practice: eyty II ompual

Frank, John II. (chl) (b'59)-Ky., (1'0i) ; $530 \mathrm{~s}$. ish $\leqslant$.

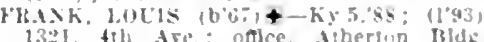
-t: l'ore. Ilud surg. and Gin. ky. (1.11.6. (3): S.

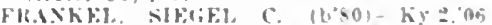

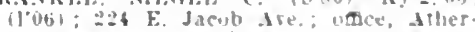
We klug: $3.4-30$ - -8

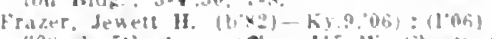
zos s. 5th we : once, th w, Chesint St. $10-2,1 .+2$

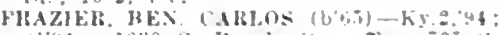
(1.44); 1030 s. Browk st. nalee, $70 j \mathrm{j}$ औ) $51: 11-12,4-3$

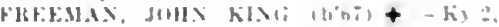
-4t: (1.94): 1:26 W. Sertersin si ; utice,

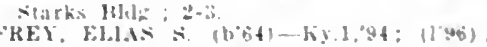

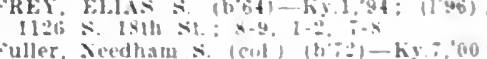

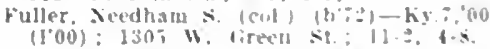

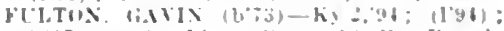

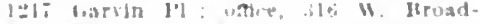
way : $9-10,2 \cdot 3$.

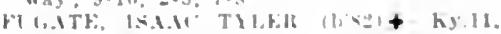

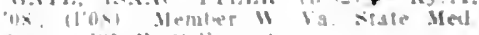

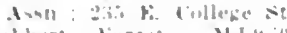

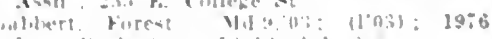

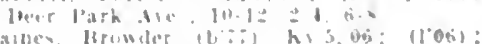
:-1 il. defreturn st. liallut Julu II hy =

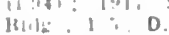

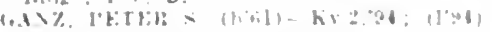
16:- wit $=2$

-1.1 II Hr. 11 .

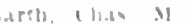

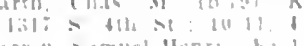

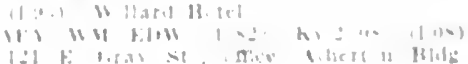

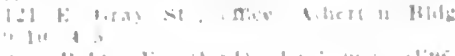

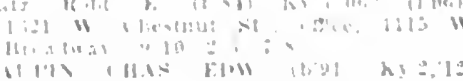

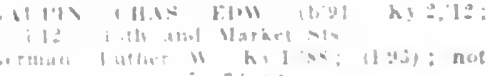




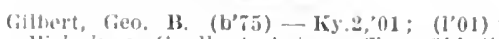

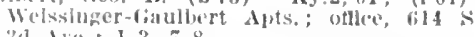
3) A $1 \mathrm{c}$, ; $1-3,7-8$.

GILHRT, IUCIIARI) R. (b'42) + Ky.2, 68 (l'03); 308 W. Broadwily $1-3,7-5, \mathrm{G}$

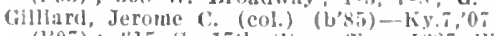

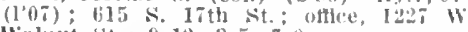
Wnlnut st. : 9-12, 3-5, i

Coodman, clifford $\$$ (1) (1) - Ky $\left(1^{\prime 2} 12\right): 1441$ s. Ist st.; ofllece, 1126 s. I'restou st.; $8-9,2-4,7=8$.

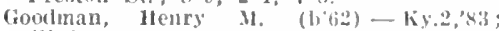
(1'04); 111; Garvin 1'l, ollece, 721, sd St. $8-9$, $5=6$

Gosnell. Whos, lo (b'59)-hy.2,86; (1'43) $22 \mathrm{ls}$ W. (hestunt st.; offlce, isog M\% Broadway ; $9-10,2-3,7-8 ; 0$ b.

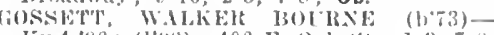
liy,4,96; $\left(1^{\circ} 96\right) ; 400 \mathrm{E}, 0$ il st. ; $1-3,7-8$ Graham, IIugh W', (b'61)-Ky.I, 'se; (1'93); not In fractlee; 1036 Brook st.

GRANT, HENRY IIORACE (b'53) \&-1'a.2 is: (193); 1146 , 3d st.; office, Atluerton lilgg.; 2-4; l'rof. Surg. and (lin. Surg. Thag. 2-4; Prof. Surg. and clin. Surg.

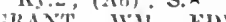

(I'I3); Welsslnger-(iaulbert 13ldy.; onlou, Masoníc Temule; lean, hy,

Grasser, Emil T. (b'73)-Ky.I, '00; (1'01): 1938 Frankfort Ave, offlce, 2029 Frankfort Ave.; $\$-9,2-3, \approx-8$.

Green, Frank Kerrick (b'70)-Ky.2,99; (lofi); not in practice: Station is.e,

GREFA, WALLK O. (b'67) (- Ky.2,89;

(1'93) : Welssinger-ciaulbert Bldg.; oftice, 712 s. 3 d st.; 11-1, $4-5$; Pr.

Green, Winnlfred (b'69)-Ky.1,03; (1'03) 210 W. Chestnut St.: $9-1,5-6$.

Gribble, Bert (f. (b'-9)-Ky.1,06; (l’06); 1326 Bardstown Ro. : $8: 30-9: 30,2-4,7-8$ GRIGSBY, GUY PARHAM (b'84) \&-Ky, '06; $\left(1^{\prime} 06\right) ; 130$ Chestnut St.; 11 -1, 5:30-

GRISWOLD, ATEXANDER VIETS (b'63)థ Ky.2,'86; (I'93); 1531 s. 4 th St.; offlce, Atherton Bldg. ; $10-12,7-8$. Groves, Charles I. (b'65)-Ky.2,'89; $\left(l^{\prime} 94\right)$;
Hampton and Speed Aves.; $10-11,5-6$.

Grunwald, Fredk. (b'74)-Ky.1,98; (1'96) ; 2654 liank St.

GULST, JAMES WELCH (b'6s)-N.Y.10,'88; (1'93); Atherton Bldg.

Guthrle, Herbert S. ( (b'79)-Ky.5,02; (1'02) ; 1253 (herokee lid.; oftice, 1308 s. 1'reston St.; $7-8,2-4$

Guyon, Fred M.-Tenu.1, $76 ; 211$ E. Oak St.

llaack, Oscar B. (b'7)-Ky.2,07; (l'07);

HAlL, GAYLORD CRAWFORD (b'79) कKy.5, 02; (1'02); 1113 Brook st.; ofllec, 526,4 th' St. ; 9-1; (B1) ; OALR.

IIAL,, SAMl. JOHNSON (b'65)-Ky.4,'94; (1'94); 522 E. Kenutcky St.; office, 640 E. Márket St.; $9-10,1-3,7-8 ; \mathrm{S}$.

Halpern, Marcus Benj. (b; 74$)-\mathrm{ky} .5,06$; (I'06); 714 s. Brook St.; $9-10,2-4,7-8$. Hambrick, Walter Saml. (col.) (b'40)Teun.7,;98; (\$); 448 West St.; 8-10, 2-4, 8-9.

HAMILTON, JOHN D. (b'58)-Ky.5,'85: (I'93) ; 3720 W. Broadway; office, 1931 Walmut st.; $9-10,1-3,7-8$.

IIancock, Jethra (b'75)-liy.5, 05 ; (l'05) ; 533 S. 2d St. ; office, 131 W. Chestnut St. ? $9-10,2-4$.

HANES, GRANTILLE S. (b'65) —-Ky.5,00 ; (1'01); The Masonic; 11-1, 5-7; l'rof Dis. of the Rectum, Ky.2; $(\mathbf{A 4}, 6) ; \mathbf{P r}$.

HARRIS, CLARENCE H. (b'i1)-Ky.4, 91 ; (1'94); 3201 Portland Ave.; $7-8$.

Hart, Fred 11. (b'79)-Ky.2,97; (1'97) ; 205 W. Jefferson st.; $2-3,7-8$.

HARTMAN, HENRY G. (b's2)-Ky.4, 07 $\left(I^{\prime} 07\right)$; 237 Pope St.; offlce, 1822 Frank fort Ive. ; $9-10,2-3,7-8$.

IIarrey, Chas, Win.(b'44)-Ky.2,'66; (1'93); 117 E. Chestnut St. ; $8-9,12-2,7-8$.

Itathaway, Jos. H.-IId.7, 0I; (赤); 9 Maple Ct. ; (FI).

HAYES, WM. T. (b'59) $₫-K y .4,92 ;\left(1^{\prime} 94\right)$; 306,1 st St. ; $8-9,1-3,6-8$.

liaymond, Raymond G. Earl $\left(b^{\prime} \pi 8\right)-K y .2$, ${ }^{2} 03$; (I'09); IIJ W. Chestnut St. ; 8-1.

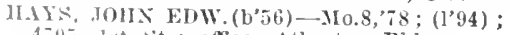
470,1 st st.; offlce, Atlerton Bldg.
IIas, dohn Edwin (1)58)-Ky.5,80; (1'94) (316) W. Broadway; offlee, Welssinger liaulbert bldz.; $9-10,2-4$

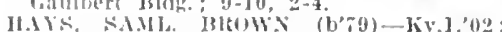
(I'w); $971, \vdots d$ st.: oftce, Atherton Hidg. (1) - , 2 (131); OALR. *

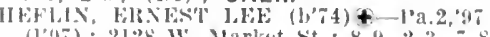
$\left(1^{\prime} ! 7\right) ; 21 \geq 8$ W. Market st. ; $8-4,2-3,7-8$

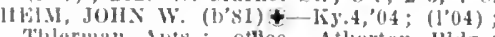
'lilleruan Apts.; ofllce, Ntherton Mldg. : $12-2 ;(121)$.

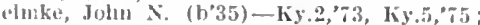
$(1+94)$; $20: 3$ Frankfort A'e.

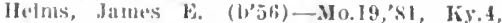
1.5; $\left(1^{\circ} 97\right) ; 2015$ W. Broadway; $8-9,12-2$,

llemlir. John Irenry (b'8z) - Ky.2,10; (l'I2): $8.7,5$ th sit.; $S$.

11ENUERSON, ERALR 1.EE $\left(\mathrm{b}^{\circ} 85\right)+-\mathrm{Ky}$

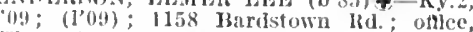
'lle Atherton; $3-4,7-8 ; \mathrm{S}$.

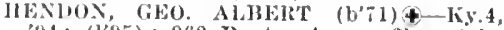
4); (195); 962 Baxter Ave.; Oftce, Athcrtón Bldg.; 11-12; l'rof. I'rin. and Irac, Surg. and (lln. Surg., Ky.2,; $(\Lambda(i)$; S. Herget, Louls J. (1'72)-Ky.4,94; (1'94); 1492 shelby st. ; $8-10,2-4,7-9$.

Ilerl, Melnral J. (b'83)-Ky.4,07; (l'07) 719 W. Jefferson St.; $9-11,2-3,7-8 ; U$.

IIERTZSCH, DELLA (b'60) \$-Mich.1,91; (1’91): 110 F. College St.; offlce, Masonic Temple: : $2-4$

Herzer, Elw. (b'63)-0.7,85; (l'94); 311 E. Iroadway: 8-10, $7-8$.

Ieuser, Henry W. (b'i3)-Ky,5,00; (1'00) 1240 L. Broadway; office, 54 I E. lBroadway: $8-9,2-3, \tau-8 ; \mathbf{G}$

HEUSER, JOHN HENIT (b'66)-Ky.2,'91; (I'y4) ; Weissinger-(*aulbert Annex; offle, 935,12 th St. ; $9-10,2-3$.

IIBBITT, CHAS. W. (b'70)↔-Ky.4, ${ }^{\prime} 97$; (1'97); $1215 \mathrm{~S}$. Brook St.; offlee, Atherton Bldg.; 11-1, 4-5:30; Prof. Gyn., Ky.2; G.

HIGBEE, BEELER DAVID (b'82)-Ky.2, 08; ( $(108)$; Atherton Bldg.; 9-1.

IIILI, WALTER WAILACE ( $\left.b^{\prime} 73\right)-K y .4$, $00 ;\left(l^{\prime} 00\right) ; 470 \tau, 3 d \mathrm{St}$.

Hitt, NIbert E. (b'64)-Ky.1,'93; (1'94); 1804 Fraukfort Ave, office, 1333 Story Are. ; $9-10,2-3,7-8$

IIOFWMAN, "LAUDE GRAHAM (b'79)Ky.2,01; (1'01) ; 331 E. St. Catherine St.; office, Atherton Bidg.; 10-1, 5-6; U.* Hollinshead, Theo. H. (b'60) H-l'a.9,98; (1'98); 320 W. Lee St. ; office, Masonic Bldg. ; 10-1, $7-8$.

Holloway, Saml. Warren (b'68)-Ky.4,'91; $\left(l^{\prime} 94\right) ; 215$ k. Madison St.

Hood, John C. (b'58)-Ky.2,'87; (I'06); 1022 S. 6 th St.; offlce, 673 , 7th St.; $9=10$, $2-3$

IIopkins, Mary Flla (b'81)H - Ky.8,'04;

(I'04); 609 E. Chestnut St.; $5-\tau ; \mathbf{G}$.

Iopson, Jos. (b'46)-Pa.2,',0; (l'94)

Peterson Ave., Crescent Hill; 1-3.

HORINE, EMMET F, (b'85) $\oplus-$ Ky.1,07 (1'07); 1036 Bardstown Rd.; I-2, $5-\tau$

(A21); Anes.
IIoskins, John S. (b'58)-Ky.2,'81;
not in practice; 953 s. Brook St.

not in practice; 953 S. Brook St.
Houck. Isaac Thos. (b'63)-Tenn.6,'89 (1'93); 1344 S. 6th St.; office, Jasonic Temple.

Houser, (larkson W. (col.) (b'53)-Ky. 00 : (l'02); not in practice; 2523 Hagazine St.

HULSKAMI, IOHY THEODORE (b'81)† Ky.2,09; (1'09); 546 W. St. Catherine st.;

Hume, Walter Irvin (b'85)-Ky.2,'13;
(I'I3) ; St. Anthony's Hospital. Ifummel, John L.Ky.4,93; (\$); 508 W Jefferson $\mathrm{St}$.

Humphrey, Heman (b'80)-Ky.2,04; (l'04); 1300 Hepburn Ave. : $2-3,7-8$

HUMPHREY, WILLIA.M OTHO (b'-4) $₫$ -
Ky.5,'98, Ky.9,99; (l'98); 1039 Cherokee Ky.5,98, Ky.9,99; (l'98); 1039 Cherokee
lid.; office, Starks Bldg.; 11-12:30, 4-5. $\mathrm{S}$.

Hunt, Chas. H. (b'69)-Ky.5,97; (I'97) 1723 Rosewood Ave.; offle, $939^{\prime} \mathrm{E}$. Main St. ; 8-10, 2-3.

Hutchinson, James G. $\left(b^{\prime}-8\right)-$ liy.5,04; (1'04); 2004 Bank St.

Ingram, Julia A.-Pa.',82; (1'93) ; Bards

town Rd.; offce, 824 S. 4 th St.; '2-4.

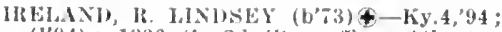
(I'94) ; 1326 - $\therefore$. 2d St.; olflce, Atherton Bldis. ; 2.4; $S$.

Irwll, Edward Lampton (b'87) - Ky.2,09;

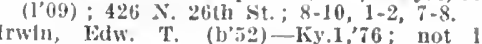
uractle' $414 \mathrm{~N}$. $26 \mathrm{th}$ St.

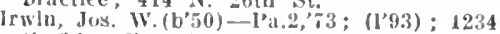
$\therefore 2 d$; oflce, 419 w. Chestrut St.; 11-1. Jackson, W'm. H. (b'85)-Tenn.7'11 (1'12) 1517 W. Madison St.; oftlce, I014 W. Walnut St.; $y-11,2-3$.

JA('OB, IONAil) li.-Ky.2,98; (1'98); 105 Callwell St.; ofluce, Atherton Bldg.; $2-3$,

FFFLISON, CILS. WM., IR. (b'88)-Ky.2, '10; (1'10); Holmhurst ipts.; offec, 4th and llill Sts.; $1-3,7-8 ; \mathbf{O b}$.

fenkins, reo. 13. (1'74)-Ky.5,'98; (1'02) ; lulverslty of Loulsville; Prof. Anat., Hist. and kmbry, ky.2.

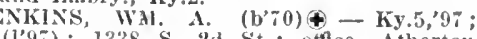
(1997); $133 \mathrm{~s}$ S. 2d St.; offlce, Atherton Bldg.; 11-1; 1rop. Med. and Clin Med., $k y, 2$

Jennlngs, Theo. S. $\left(b^{\prime} 50\right)-K y .4,87 ;\left(l^{\prime} 93\right)$; 1169 E. Broadway; offlee, 1001 E. Jefferson St. ; 8-10, 2-4; G.

Johanboeke, Fred. H. (b'61) - Ky.2,'96: (l'03) : 2129 W. Walnut St.; office, 1912 W. Walnut st. ; $9-10,2-3,7-8$.

Jobuson, Chas. A. (b'60)-Ky.5,04; (1'04); 1501 W. Jefferson St.; $8-9,12-2,7-8$.

IOHNSON, HURENE YATES (b'61)-Ky.9, 00 ; $(100)$; 942 S. 4th St.; office, Equitable Bldg. ; $2-3,7-8$.

Jones, Aubrey V. (b'80)-Ky.9,06; (1'08); 2604 W. Nialn St.; offlce, $125 \mathrm{~S} .26 \mathrm{th}$ St. ; I1-12, 6-8.

Jones, Richard M. (b'69)-Ky.2,'93; (I'94);

532 Broadway, $9-10,2-3,7-8$; LR.

Kaelin, Louis (b'57)-Ky.1,'94; (1'94); 1110 Logan St. : 8-9, 2-3, 7-8.

KAHN, LEE (b'78)థ-Ky.4,03; (l'03) IIermitage Hotel; offlce, Athertón Bldg. 3-5; Adj. Prof. Surg., Ky.2; S.ネ

Kannapel, Amzl Peter (b'80)-Ky.2,13 : (I'13); Louisville City Hospltal.

Karazlozlan, John (6'60)-Ky.4,07; (1'07): 122 W. Cinestnut St.

KARRAKkR, CIIAS. WM. (b'81)థ-Ky.11, 08; (i'10); $3 d$ and Broadway; office, 712 S. $3 d$ St.

KATZMANN, EDW. F. (b'80) - Ky.4,02; EANEY JOHY: 18th St.; 12-2, 6-8.

(1'96) ; 1226 s. Shelby (b'75)-Ky.2,95;

Kefghtley, Abraham J. $\left(b^{\prime} 4 \overline{7}\right)$ - Ky.2, 67 . (I'03); 2003 W. Market St.

KEITH, DAVYD YANDELL (b'81)-Ky.2, 09: (1'09); 326 W. Broadway; , offlce, Masonic Temple; 11-i, 5-6; R.

KELLER, WM. A. (b'67)-Ky.2,93, Ky.4, Kelly, Alfred Harris ( $\left.\mathrm{b}^{3}, 3\right)$; $10-12,7-8$. $(195) ; 818,3 d$ Are.; offlce, Atherton Bldg. ; $9-1 ;$; OALR.

KELLY; CLINTON WAYNE (b'44)-Que.1, ' 67 ; (1'93); 818, $3 \mathrm{~d}$ St, ; offlce, $531 \mathrm{~S}$ 2d St.; 9-10, 3-4; Prof.' Anat., Ky.2.

Kelly, Grlffin C. (b'87)-Ky.4,'04; (I'04) 407 S. $2 d$ St. ; $9-11,6-9$.

KELSALl, OLIVER H. (b'78)-Ky.2,'99 : (l'00); 1138 s. 28th St.; offlce, Atherton Bldg. ; 2-3, ;-8.

Kennedy, Linn L. (b'72)-Ky.4,'97; (1997) not in practice; 1825 Eastern Parkway kenner, Robt. Coleman (b'59)-Ky.2,79; (l'94); 2505 1'ortland Ave.; 7-9, 11-12, $7-9$.

KERN, AARON (b'78)-III.6,98; (l'12); 1465 S. $2 d$ St. ; $7: 30-9,12-2,6-7: 30$.

KERNS, IRA N. (b'80)-Ky.9, 05; (1'05) $2 \pi 03$ Portland Ave; offlce, IIasonlc Temple; $12-2$

Kerr, Lemuel Harris (b'82) - Ky.1,'04; (l'04); 3423 w. Broadway; office, Secur. 4.53 Louisrille Are.; office, 676 E. F St. $7-8,12-1,6-8$.

Kessler, P. Louls, Jr. (b'79) - Ky.4, 00 ; (1'00); 984 Goss Ave.; $8-9,12-2,5-\%$.

KIEFER, FRANK JOHN (b'63)-Ky.5,'98; Frankfort Are.; 8-10, 2-4, 7-8; G. 


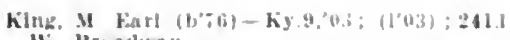
W. Bruarlway.

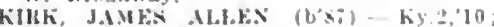
(1'10): I529 Irosewiond lie: anlen, stherton Blds: $11-1,4-6$.

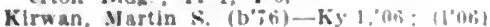

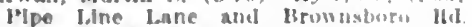
otmee, $502 \mathrm{k}$ Wainut st. : I:- I.

Kleln, Warwlck W, $\left(b^{\circ} 83\right)-K y, 2,05 ;(10$ in z23s Portland Are.: unlice, Kentuck Title 13lug.: 10-3.

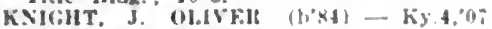
$\left(10^{\circ}\right) ; 628$ F. (lhesimi si.: oflice, 73 b. Market st. : $9-10,1-3,6-8$

Koch. Finst If. Jr. $\left(\mathrm{b}^{\prime} 7 \mathrm{~s}\right)-\mathrm{Ky} 99^{\prime} 90$

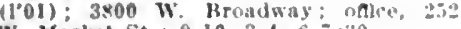
w. Market St. ; 9-10,3-4, 6-: $: 30$.

Koehler. Fedor W. (b'5i)-ky, s, 81 ; (1'03) 918, ith St.: 12-1, 5-6.

KOEILER, HFXIt II. (b"(ig) + -Ky, l, 4 " $(1 * 94): 918$, th St.: $11 \cdot 1,5-t i: U$.

coontz, fred 1. (b'is)-Ky.l,00; (1'00) Hesten Apts. : offce, (iatulbert Iblde.: -f $\because-8$

KHEMER, JOHX W. $\left(b^{\prime} 69\right)-k y .5,9 \%$ $\left(l^{\prime} 9 \% ; 1830 \mathrm{~W}\right.$. Jefferson st. : 8-8, :-3, $\overrightarrow{0}-8 ;$

lammers, Rernard J. $\left(b^{\prime} 61\right)-K y+y^{40}$ (I'93): 1833 Windior Pl.: oflce, $03 \mathrm{r}$ Broadway; untll $9,2-3,7-8$.

lampton. J. I1, $\left(b^{3} 54\right)-K y .2,75$

3202 Vircinla dre.

Lanahan, Chas. Hice (b'\$9)-Ky.2, $1: 3$ (l'13): Loulsrille Cliy Ilospital.

INGOLF FKHIK. A. $\left(b^{\circ} 79\right)-K y+t^{\circ}$ (t'g2): 643 E. Oak st. ; 12-2, 6-t.

Lattimore, J. A. C. (col) ( 01: (1'01): 1502 W. Walnut st.: $8-10$ 。 3.4. $:-9$

Laverty, Edw. C. (b'69)-Ky.2,'05; (1'05) 406 E. Ormsby Ave.

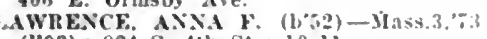
(l'93): 824 s. ith st. : $10-11$

LEACIMAX, GFo. c. (b'T) - Ky.l, $\left(1^{\circ} 06\right): 1127$ s. th St: $9-10,2-3$.

Leatherman, C. E. (b'b3)-Ky.1,"95; (1'98) 514 W. Walnut St. : $9-10,2-3$

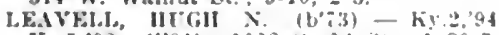
Ky.5, 98 ; $(1.94) ; 1028$ \$. 24 $\leqslant 6.1: 30-7$ I'rof. Mat. Med. and Ther., hy.

1.EDEIRMAN, ISANC (b'-3) - Ky.2.96 (I'9i): Siratford Apts.; once, ctherton BIdg.: 9-1: Prot. Dls. Eit, Nose and Throst and Clla. Dls. of Koye, Ky.: (BI) : OALR.

LEVI, WAITEIR DEAN (b'83)-Ky"2,09: (I'12) ; 1259 Jassett Are.; oftce, Starks HIds: : 9-1; OALR.

Lewls, Harry 11. (b'68)-Ky.2.90: (1'93) I630, th Are.; $9-1,5-8 ; G$.

lewls, James Hi. (b'bl)-Ky, 01 ; (l'01) not in practice: $170 \mathrm{x}$. Peterson Aie. Arett, Ilarry Thompson $\left(b^{\prime}, i+\right)-k y, l, 0 ;$ (l'05): Atherton Blde.

HMBACII, HAHIK MARTIN (limu) liy. '12; (li2): 623 \&. 4th st.; oflee, wher

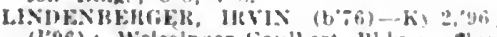
(l'96): Welssinger-liaulbert HIL': onces Atherton Hdz: $11-1 . ;-9$.

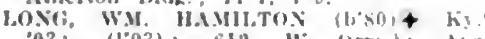

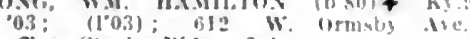
oalce, starks Hlde.; 2.4

Idord, irthur K.-Ky,4,05; $(105)$; not in practice : $1036 \mathrm{~s}, 31 \mathrm{~s}$ st

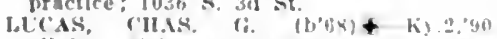
(1"93i) Welsslinger-Caulbert Abs. incer

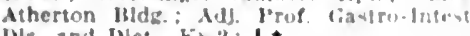
Dls. and Dlet. $k$. 2 ; 1 .

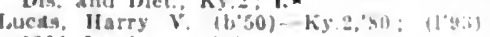
ljil liardatown lid.

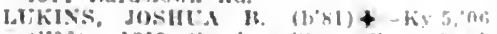
$\left.-11^{\circ} 06\right)$ : 1318 latalna si : onlon, starky

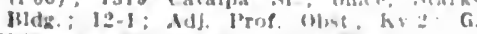

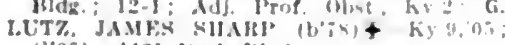
(los) : 1121 l'ark Blrts.

Malor, iluso $(\mathrm{L} 63)-k, 2.9 k$

Manly, samuel $\left(b^{\circ}+t\right)-K_{3} .2, p i s$

ipis: $\left(11^{*}+6\right)$ :

2305 11. Walmut st. $4-10$ i-

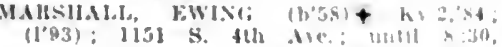
$1-2: 30^{\circ}: \mathrm{S}$.

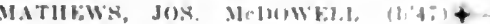

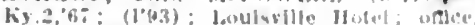
Masnive Itld : 11-1: (.14)

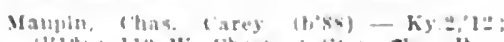
11!1:; $110 \mathrm{~W}$. Chestnut st.; anlec, bove Ninaloflum.

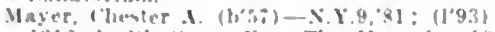
$1: 316$ is bith st.: onler. The Masulfo; 10 . $1: 2,2-4$

Mastlelil. Wn. llenry (b+91-k) t,7:

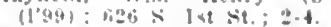

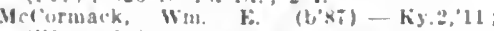
(1'1!): 1:01: \& 1 wth sit.: 12

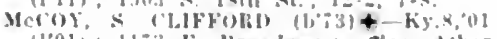
$1101)$ 1183 Fo Mruaduas: unce, Ither (on) Bhls.: :-4: S.

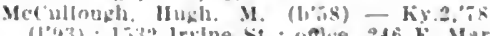

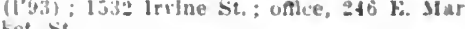

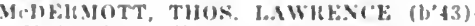
X. 10), 60 : $\left(l^{\circ} 94\right): 547$ w. St. Catherlne Sit : chle, Athertur lildg.; $2-3,7-4$

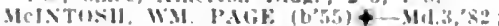
(loy): Surg, I.S.I.II.s.; l'nlted States Marlue Ilospltal: $9-4 ; 5$

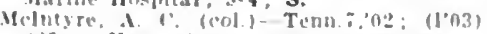

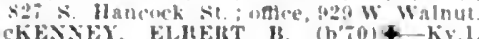

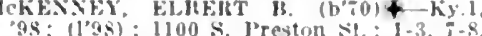

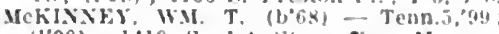
$\left(1^{\prime a 9)} ; 1419\right.$ S. 1st St.: oflce, Masonic Blde: $11-1=0$

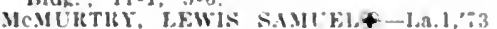
(1"93): 621 Ormshy 1'l.; offlea, Mtherton 13!dg.: 11-1: l'rof. Mr.' Surg. and tisn. Ky: : $(A 1,5,6): 5$.

MeXiliL, NLIAX (b'72)-Ky.4,94: (l'9s) 119 Itoberta st.; odlce, Atherton Mldg. $10-1,6-8:$ U.

MCPHFRSON, HCGII DIXCAN (b's.i) KY.?.J2: (1'12); It.F.J. 3.

Mechling, Harry E. (b'69)-Ky.5, $00 ;\left(l^{\prime} 03\right.$ ) not [i] practice; 109 Kennelly Ave.

Metler. Florence-Ky.s,'9s: $\left(l^{\prime} 00\right)$; (Jake land); oftce, Central State Ilos]utal: NP.*

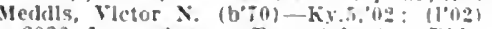
2936 long ire.; offce, Atherton Blds.

Mehler, Louls A. (b'a2)-Ky.2, os; $(100)$ 110 Boberta Are. once. 245 s.

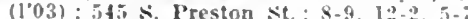
Merchane, Wumison T. (col.) (b'61) Ib.c.is. 68: (1'97) : 819 \&. Jackson st.; untec, 71 iv. Walnut $\mathrm{s}$.

lleredith, Fdward F. $\left(b^{\prime} ; 3\right)-k y \cdot 8,01:$ (liil): 2509 Portland Nie.

Metcalfe, Mary I. (col.) - Ky.6.02: (1'03) 1722 w. Walnet St.

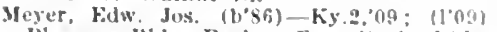
Pleasure Hilge Park; ottce, starks bida. $11-1,5-7$

MEYFR, SIMUEI-Ky.2,91；(1"99); 92: s.

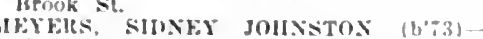

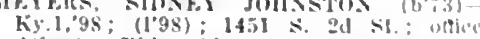

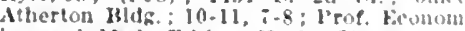
Ies and Med. Ethies, Ky ; Ob.

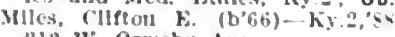
21: W. Ormsby Are.

llles. Wint T, (bols)-ky, a $2323 \mathrm{~W}$. Jetrersoll st.

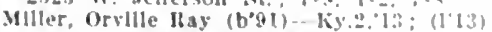
st. Mary"s and blizabeth's llospital.

Minor, oller Raymond Ky. 1,03; (l'0:s)

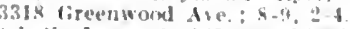

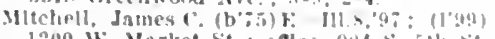
1200 W. Market st, onlos, and s. bht st. $10-12,3-5,7-9$

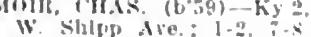

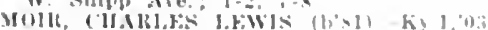

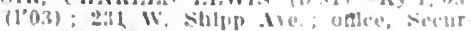
Ity lilig: R

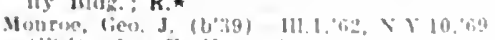

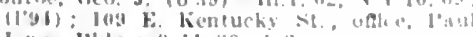
Joner lilita: : $11: 20$,

Montgomery, is is (1, i

Is: W. Jeffermisn kit

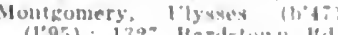

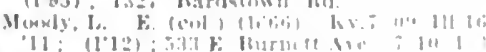

molit, late 11 (1)

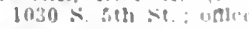

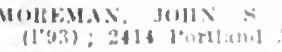

Mont:s, Jolld a $110 ; 1$

$145 ; 11^{\circ}, 41$

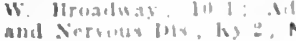

Murris, ('has, ll. Ki g,"ul: (1001): 2214

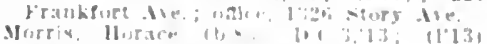

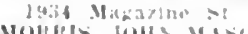

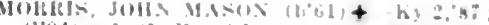

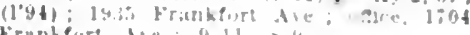
Mratisox, J. mins

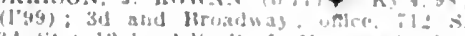

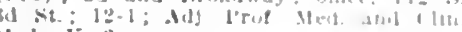
Mul Ky:-

MEleTOX, lidVIH

(1'0:3): $8: 39$, th wi

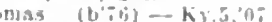
If(t): $2 t$ th and Walnut Sis.

Jounsey, fien. T. (b"63)-Ky \&,"94, Ky"

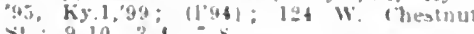

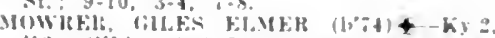
"12: (1']2): stis Jaxter Ale.: $4,7-5$

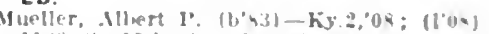
11:? 5 15th st.; $1-2,6-8$

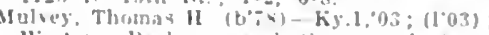

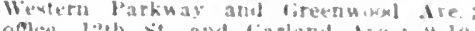
oftre, lath it. and fiartand Aik, ; $4-1 ;$ : $\mathbf{S}$.

Murphy. Moses I. (eol) (b'it)-Ky. Z, ve:

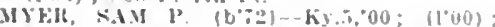
21: Kennedy ile.; ofice. 216 W. Chestmit st. : $1 \pm-1,+1: 30-5: 30: P d$

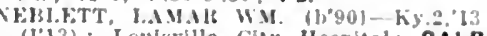
(I'13): Louisville City Hospital; OALR.

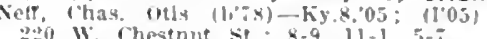

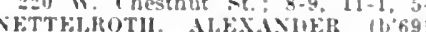

Ky 4,"ys; (1.99); Jonglas J1rd.; oflce. tion Barter tre, $y=10,1-2,8$

NICHOLs, CIAI L. (b's)-Ky, 1,$03 ;(103)$ $1342 \therefore 1$ \& 5 st : \& $11-1$.

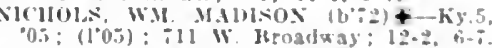

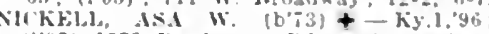

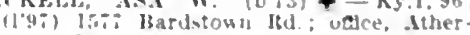
toll 13luk.; $1-3,7-8$

Corman. I.ee (b'65) $11-\mathbf{K}_{3} Q_{0} 05 ; 1105$ ) W droadway : $\$-10$

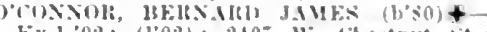
Ky. $1,02:(102) ; 210 \%$ W. Iliestnut st. oftice.

Oguen, F. Parks (b'is)-Ky.2,00: (1002) 3001 s th st: $12-2,6 \cdot 7: 30$

oliver, Hehard w. (col, (1),5)-ky, :03

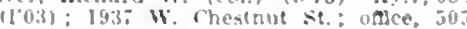
s sth st: 9.12, 6-2: OALR.

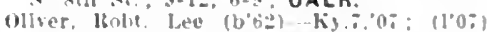
2.216 Zimlluth Ave.; uttice, $905 \mathrm{~s}$. Sth si

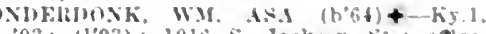
"03; 11'03) 1016 Sackwn St: once

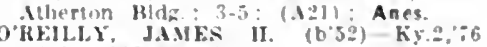
$(1,38) ; 802$ s. th st

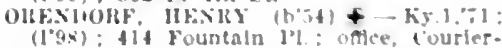
Journal 13lde

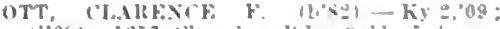
(1'05) : 125: Cherokee ltd. : \& 11, :-

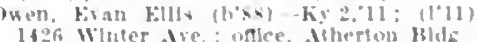

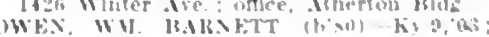

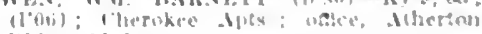
lihl:; $11-1$

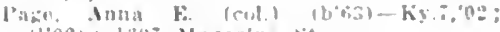

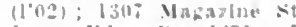

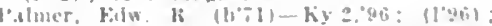

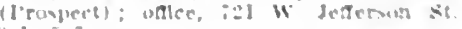

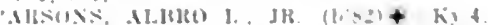

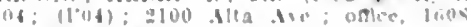

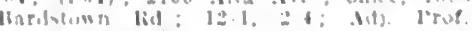
Sils. hy a : $\mathbf{s}$.

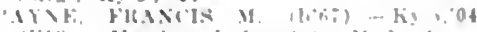
(1'13): Methlaer Inil stale Mel. last

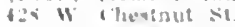

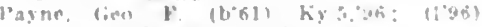

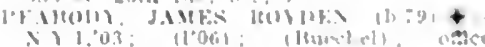

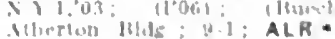

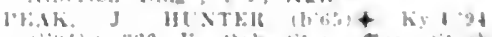

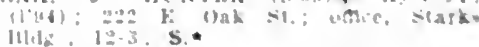

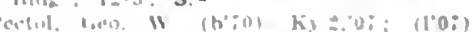
it is anke. Tagler lini: il 1.20

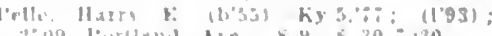


lenle, llarry 1. (b'86)-Ky.11, 08 : (1'0s): $52 t$, Itl A Ave, ofthe, Atlierton Bldg.

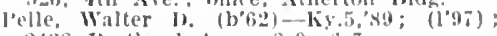
2438 P'ortland Are.; $\$-9$,

l'ennington, l'atton A. (b'67)-Ky.5,'95 $(139 \pi) ; 2110$ Cherokee Parkway; office, Courier-,Inurnal Bldg. ; 9-4.

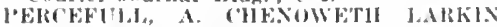
(b'it) $\left.4-\mathrm{Ky} .5,04 ;(]^{\prime} 06\right)$; Tyler IIotel. oflce, vell Woissinger-fianlinert lbldg. office, - Xell

Peter, 1'reston (1'36)-X.5.5,'61; (1'06) not In practlce; 152 Bellatire A Ae.

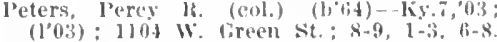
retrle, Charles 13. (b'63)-Ky'l,'s9; (1'04) not in practice; lose cheroke kit.

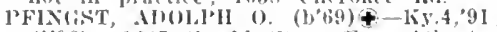
$(196) ; 1207$ S. 2 d St. ; onthe Ntherton kllg. : 9-1; l'rof. llis. Eye, kar, Nose and Tliroat, Kr.2

IIIIL119, HAliR J. (b'72)-Ky.2,93: (193); $2126^{\circ}$ W. Brotdwily; othee, 1813 iv. Hrondway ; $9-10,2-3,7-8$.

PICKETT, ALICE $\times$. (1) T9) +-1'a.7, 09 (1'13); Member lled. Soe. of Vu.; 1145 4th sit. : 11-1.

Plickett, Wm. H. (col.)-Ky.7,'as; (l'00) 528 Fin\%er St. ; offlee, $315 \mathrm{~s}$. preston st. $10-11,2-3,8-9 ; \mathrm{G}$

Plnkert, Wm. (1),65) H-Ky.8,96; (l’97) 1151 F. Hroadway; $8-10,2-4$.

PIRKY, EVEIFT" I.AYTUY (1,8, 4 Ky.2,11: (1'11); R.F.I. 2.

PIRTI. ROBT. T. (b'79)-Ky.2,'02; (1'02) $1410 \mathrm{s.} \mathrm{lst} \mathrm{St.;} \mathrm{offlce,} \mathrm{Atherton} 13 \mathrm{hg}$. $11-12,4-5,7-8$

I'OPE, CIRPAX (b'66)€-Ky.2,89; (1'93); $225 \mathbf{E}$. Walnut St.; oftlee, 115 W. Chestnut St.; $10-2$; NP. *

Pope, Cieo. Laughton (b'56) - Ky.2,83; (1'99); 1111 Cherokee $1: d . ;$ office, Atherton Bldg.; 12-3.

l'orter, Ellis s. (col.) (b'49)-N.Y.8,78. $\left(1^{\prime} 93\right) ; 1212 \mathrm{~W}$. Madison St.; offlce, 503 s. 10 th st

lotter, Mary Etta Green (eol.) (b82)Ky., $02 ;\left(10^{\circ}\right) ; 543 \mathrm{S.} 13 \mathrm{th}$ St; 8-10. Pottinger, Saml. L. (b'69)-Ky.2,94; (1'94); 627 E. Broadway ; $1-2,7-8$

P'RATIER, S. SCOTT (b'73) - Ky.4, 97 $\left(1^{\prime} 97\right) ; 537$ s. 2d St. ; offlee, 525 s. $2 d$

PRICE, JO11N WM., JR. (b's2)-1'a.1,05; (1.06) ; 317 w. Hill St.; offce, Atherton Bldg.: $2-4 ;$ S. $\star$

PliTCHETT, JAIES HENRY (b'38)-Ky.2, '11; (l'11); 4553 3d St.; offlce, Atherton Bldg. ; 9-10, 5-6; Pd.

IAPP, HENRY LOLIS $\left(\mathrm{b}^{\prime} \mathrm{r}^{2}\right)-\mathrm{Ky}, 2,{ }^{\prime} \mathrm{z}$ (1'9-) ; 620 E. Broadway; $8-9,2-3,7-8$.

RAV1TCH, MCHAEI LEO (b'65) \&-Rus.6, '89. No.29,'95; (1'95); 1508 , 1st st. ; oftce,

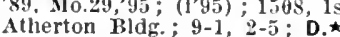

RAY, JAMES MORRISON (b'61) - -Ky.2, '82; (1'93) ; Atherton Bllg.; 9-1; C'tin. Prof. Dis. Eye, Ear, Nose and Throat, Ky. 2 ; $(\mathrm{B} 1,3,4,5)$.

READ, HARRY LYON (b'80)\$-Ky.2, 07 ; (107) 1005 S. 28th St. ; 12-2, 6-8.

mon, Edw. C. (b'83)-Ky.2, 06 ; (l'06) Bldg.: 2-3, 5-7.

Reld, : 2-3, 51828 Chestnut st.; oftce, 1201 W. Chestnut St.; $8: 30-11,2-4,6-9$

REYNOLDS, DUDLEY SHARPE (b'42) Ky.2,'68; (1'93); West Meath Farm, Lin (B1) ; OALR.

Reynolds, Oliver M. (b'83) - Tenn.t,'09 (1.11); $653 \mathrm{~S}$. Jackson St.; offlee, $340 \mathrm{E}$. (ireen st.

Richards, John S.-Ky.5,'03; (l'03) ; 322 E. Ormsby Ave.

Richardson, Joln Breckinridge (b'42)-1'a.2, RICHARDSON. JOHN BRECKINRIDGE, JR (b' 6$)-\mathrm{Ky} .4,02 ;\left(10^{\prime} 02\right) ; 112$ E. Jacob
Ave.; offee, Masonic Bldg. ; 12-1, 5-6. Richardson, Wm. R. (col.) (b'ii) - Ky.; , 08 ; (4) ; 2215 Standard Ave.

liICIEY, EIWALD BERT (b'79)-Ky.11,

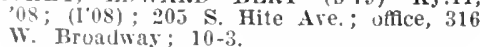
RITTEk, FRANK H. (b'87) - Ky.2,'11 (111); St. Charles Pl.; 12:30-1:30;'s.
litTTEL, 11AIRY N. (b'85)-Ky.2,10;

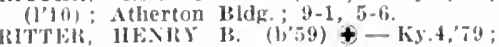
(l’!3): Besten Apts.; ottce, st. Charles 1.: $11-1: 2,2-3$

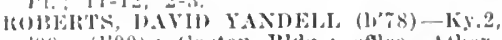

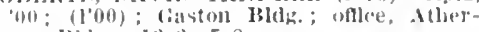
lim liklk. $12-2,7-8$.

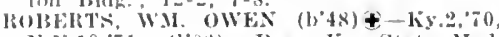
X.1.10,71; (1,0:); I'res. Ky. State Med. Assu, ; 1370, 3d St.; otflce, Atherton Rldg, ; $8-1.2-4$; Emer.

Itohertson, fieo. A. (1, 72$)$ - Ky.2, $96 ;\left(1^{\circ} 96\right)$;

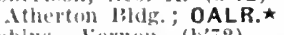

lioblns, Vermun (b'72) - Ky.2,94; (1966)

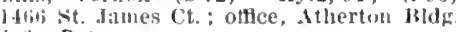
4-6: D.

liobinson, Montague F. (eol.) (b’iz)-Ky.7 "42; (1'94); 1303 W. Fireen st.

likgers, Iohn $\left.\mathrm{C}\left(\mathrm{b}^{\prime} \mathrm{7}\right)-\mathrm{K}\right)-\mathrm{K} .9,93$;

$1: 31$ Galt Ave.; 10-2.

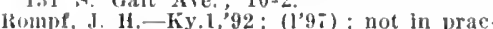
tien; 1238 s. 18th st.

hose, Elward Arthur (h'85) - Ky.2,08; (1'0.1) ; 2716 s. 5 th St.; oftlce, $3100 \mathrm{~s}$. 4th st. ; $8-9,2-4,7-8$.

Rosentleld, Walter 1 . (b'79) - кy.2, 0 \% $\left(l^{\circ} 0^{-}\right) ; 213 \mathrm{~s}$. Hite Ave.; ottlce, $609 \mathrm{~W}$. ('hestnut st.

MOSFNHA.M, ('11AS. J. (b'55)-Ky.11, 08 ; (1'08); 1427 s. 2d st.; offlce, i2s w. Jefferson st.; $11-5$

liUHEL, HENRY M. (b'85) $4-\mathrm{Ky} 4,0^{\prime} 0^{-}$; (l'07); 1443 s. $3 \mathrm{~d}$ st.; oftlce, Athert on Bldg. ; 10-12, 2-3; 0 b.

Rudelf, Jouls 'C. (b'86)-Ky.2,07; (1'07) : 1318 Bellewood Are; offlee, 941 F. Jef ferson st.

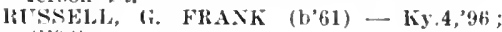
$(1+3(i)$.

ltussman, ('harles G. (b'68) - Ky.2,'97 $\left(1^{\prime} 97\right) ; 1041$ Goss Ave. ; 8-9, 2-3, 7-8; Pd tyans, Lewis $\left(b^{\prime}+1\right)-K y .2,04 ;\left(10^{\prime} 04\right) ; 1206$ iv. Jefterson st. : $12-1,5-6$.

sage, Edward orville $\left(\mathrm{b}^{\circ} 5\right)-\mathrm{5y}$ - 9,00 (I'00); 925 Baxter Are.; until 8, 1-3,

samuel, Fouche W. (b'68)-Ky.1,'86; (l'43) ; The Seelbach; office, Atherton Bldg.; 11-1. sanders, llugh B.-Ky.2,'84; (1'94); 2115 Hortland Are.; $8-10,4-8$.

SANDELS, WMi. (b'71) $\oplus^{\prime}-\mathrm{Ky} .1,04 ;\left(1^{\prime} 04\right)$; 831 s. Preston St.; office, Atherton Bldg. $1-3,7-8$.

satterwhite, Thos. P. (b'35) - Kv,2,57 (I'93); 234 E. Gray St.; $8-10,6-\bar{T}$.

a aunders, (ieo. B. (b'78)-Ky.7,'07; (l'08); $819 \mathrm{~N}$. Walnut $\mathrm{St}$ : : offlee, $547 \mathrm{~s}$. $13 \mathrm{th} \mathrm{st}$ AUTEK, CHARLES (b'47) $4-\mathrm{Ky} .4,70$ (1’93); 719 E. Broadway; offlee, 814 E. Walnut St.; $9: 30-10,2-3,7-8$.

Schachwer, August $\left(b^{\prime} 65\right)-\mathrm{K} y .4,8 \mathrm{~s}$
844 S. 4th Ave. : $2-4 ;(\mathrm{A} 6) ; \mathrm{S}$ `

CHMIEDEKNECHT, EDWARD, JR. (b'82) †-Ky.2,09; (1'09) ; 1824 W. Jefferson st.; offlee, '723 W.'Jefferson St.; $9-11$,

S(HOTT, CHWISTOPHER G. (b'T) ?04; (1.04); 2103 w. Walnut St.; 1-3, $\overline{7}-9$. tice: 450 s. $\mathrm{C}$ -

Schwankhaus, l'aul H. (b'-8) - Ky.2,98; (1'99); '2821 Greenwood Are. ; 2-3, $7-8$.

S(IIWARTZ, WM. P. (b'62) $\oplus-$ Ky.2,'95; $\left(1^{\prime} 95\right)$; 721 E. Oak St.; offle, 723 E. Oak St. ; $8-9,2-3,7-8$

Scott, Argle MacClarren (b'61)-Ky.4,'84 not in practice; 2011 Kenilworth P1. offlee, 439,4 th sit.

SCOTT, HERVEY BARBOUR (b'-8) Ky.5,06: (1'06); Beechhurst Sanitarium: Scott. Robt.
$\quad$ B. (col.) (b'60)-Tenn.7;02; Walmit St.

Scrlbner, Chas. Abner (b'58) - Ky.9,'06: (1'06): Realty Bldg.

Seay, B. S.-Ky.4,'91; (1'94); 2074 Preston St.

Sebastian, John N.-Ky.2,'99; (l'99); 1202 II. Broadway.

Sedgwick, Wm. H. (b'75)-Tenn.6,01; not in practice; $639 \mathrm{~W}$. Magnolia $\mathrm{St}$.

210 E. Jacob St.
.
Selhert, Alyin Henry (1)'83)-Ky.4, 05 , Ky.s, 06: (1'05) : 2017 kenllworth Pl.; offlee, Starks Hldg: $12-2,5-6$.

seltz, Louis A. (b'b0)-Ky.4,'91; (l'94) : 2021 Honnyeastle Ave, offlee, 1529 1righland Are. $7-8,1-2$.

Sliacklette, Jacol, P. (b'72)-K5.9,'04; (l'04) ; $1.331 \mathrm{~W}$. Walnut st.

SHIAFEIt, JOS. J. (b'72) \&-Ga.10,97; (1'02) ;

1477 S. 21 st. : offlee, 4 th and 'Walnut Sts. : 10-1; OAĹR.

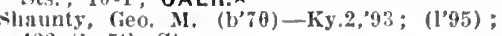
422 s., 5 th St.

SHIRHILL, J. GAMLAND (b'68) - -Ky.4, ' 88 ; (I'93) ; 1307 S. Ist St, offlee, Atherton Bldg. : 11-1; Prof. Surg. and Clin. Surg., Ky.2; $(\mathrm{A1}, 6) ; \mathrm{S} . \star$

sllver, Robt. I. (col.) (b'72) - Ky.7, 05 ; (l'05) : 1436 Levering St.; office, $1225 \mathrm{~W}$.

Thank $,-11,5-7$

slmpson, Frauk C. (b'57)-Ky.2,80; (l'93) ; 208 W. Oak St.; offlee, Welssinger-Gaulbert Bld ${ }^{\infty} ; 11-12,4-5$

Slmpson, (ieo. F. (b'59)-Ky.2,81; (1'93); 2100 W. ('hestnut st.; $2-3,7-8$.

S1.II'SON, JESSE HALL (b'82)-Ky.2,07 ; (l'09) : 1229 Hassett Are.; offlce, Atherton Bldg. ; $10-1,5-6$; OAĹR.

SIMPSON, VIRGIL E. (b'73) -Ky.5,00; (l'01); 1310 Cherokee Rd. ; offlce, AtherTher, ky, $2 ; 1 . \star$

sklnner, Cornelius (b'60)-Va.1,'82; (l'93) ; 1156 s. 1st St. ; 9-10, 5-6; WelssingerGaubert Bldg.

SMITI, GILBERT C. (b'69) - Ky.2,92; (l'93) ; 916 S. Brook St.; office, 625 W. Jefferson St. ; $9-10,2-3,6-7$.

Smlth, Luclan S. (col.) (b'76)-Tenn.7, 08 ; (t'09); Kirby Ave. and 37th St.; 8-9, $2-3,7-8$

Smith, Wm. H. (col.) (b' 72$)-\mathrm{Ky} .7,06$; $\left(l^{\prime} 06\right) ; 1225$ W. Walnut St. ; $9-10,2-3$, $7-9$

Smith, Wm. W. (b'68)-0.1,'91; (1'93)

SMOCK, BENIAMIN W. (b'60) $\oplus-\mathrm{Ky} .5,{ }^{\prime} 89$;

(1'93); 1756 Frankfort Ave. ; 8-9, 1-3, 7-8.

SNEED, CIIAS, FRANKLIN (b'65)-111.39, 09; (l'11); IIember Ill. State Med. Soc.; 1521 Bismarck Are.

SOLOMON, LEON L. (b'71) $\oplus-\mathrm{Ky}^{\prime} .2,94$; (1'94); 976 S. $2 d$ St. ; $2-4,7-8 ; 1 . \star$

SPALDING, CLEMENT B. (b'80)-Ky.4,'04 ; (l'04); 518 W. Broadway; offlce, 531 s. 2d St.; 2-4, $7-8$; Adj. Prof. Surg., Ky.2; S.

Spangler, Chas. I. (b'49)-0.2,72; (l'94); SPEARS, LLEWELIYN P. (b'7T) - Ky.9, '99; (1'01); 2200 Longest Are. : 6-8; office, Itherton Bldg. ; 11-1.

SPEIDEL, EDWARD $\left(\mathrm{b}^{\prime} 59\right) \oplus-\mathrm{Ky} .2,95$; (1'95); 1292 Cherokee Rd.; ofllce, Atherton Bldg. ; 8-9, 1-2, 6-7; Prof. Oust., Ky.2; Ob.

217 Haldeman A. (b'

217 Haldeman Are.

123 Caldwell St.; offlce, 208 W. Chest -
W. (l' nut $\mathrm{st}$.

Stanley, Saml. F. (b'66)-Ky.8, $00 ;\left(l^{\prime} 00\right)$;

Security Bldg. ; $10-1,7-8 ; U$.

Steedman, James B. (b'63) - Ky.4,'84; (1’93) ; 1325 Hardstown Rd.

Steinberg, Sol A. (b'88)-Ky.2,'11; (1'11); $1619,2 \mathrm{~d}$ St.

Stevenson, Jos. (b'61) H-Ky.8,'01; (l'01); 2330 W. Jefferson St. ; $9-16,2-3,6-7$
STOKES, EDGAR WM. (b'67) $€-\mathrm{Ky} .1,94$; (1'94); 539 E. Chestnut St.; 8-2; NP. * Stoll, Albert A. (b'86)-Ky.2,10; $\left(1^{\prime} 10\right)$; 1760 Frankfort Are.; 2-3, 7-8.

STOLTZ, MICHAEL P. (b'56)-Ky.4,'96; (l'96) ; 829 E. Broadway; offee, $814 \mathrm{E}$. Walnut St. ; 1-3, 6-7.

Stone, Solomon (col.) (b'54)-Ky.7,'97; (1'97) ; 544 E. Jacob Ave.; office, 525 W. Green St.

Straus, Ernest Chas. (b'81)-Ky.2, 05 ; (1'05); 1141 S. $2 \mathrm{~d}$ St. ; office, Atherton Bldg. ; $10-12,4-5$.

Stroud, John B. (b'67) - Ky.4,'03; (l'03); 410 E. Lee St.; office, 676 E. F St. ; $1-2$, $7-8$

STYCKY, THOMAS H. (b'60)-Ky.5, 80 ; ithertion Bldg. 
SULLWSAX, HOHT FBINT (b":?) hi. 06: (I'06): $21: 4$ W. Walnut st.; utteo

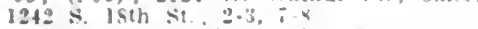

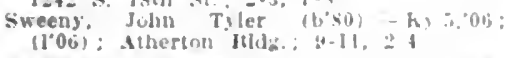

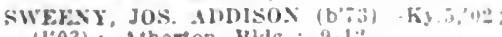
(I'03): Atherton Mldg.: $9-1 \%$

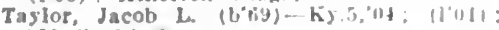
519 \& 34 it.

Taylor, Jetrerson D. (bes) - Ki.1,

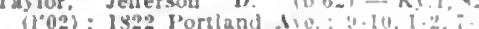

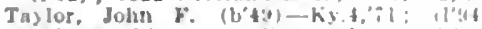
$1906 \mathrm{~S}$. 3d Aie.: untee, Whertur Milda $9-12,3-6$.

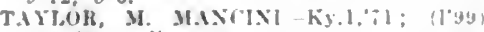
$1: 2 w$. college $\leqslant$.

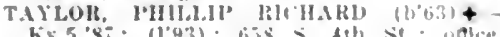
ky.5.5:;

Thomas, Ansel le boy (b'st)-Ky.2, ils: (1'(1); 2334 Alta ive.; ontee, liner

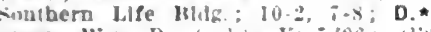

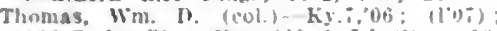
\$6S S. 1st St.; oftice, 109 S. ith St.; $4-10$, 2-3. $\div-9$.

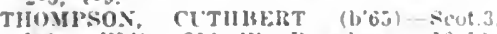
27: $(194)$ : 316 W. Lroadiray

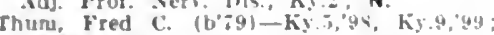

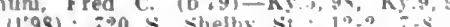

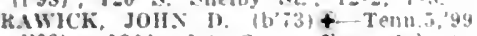
(1'03); 1366, Ist st.; ndice, Athertor Blug.: 11-1, Pd.

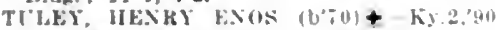
ky.1.94: (["93) : 100 k. Magnolla lie. once, $705 \mathrm{~s} .3 \mathrm{~d} \mathrm{sis} ;$ : 2-1; Pr.

TWOMEY, (EF, WATSOX (b'80)-KY, 03; (1'12); Menalver Ind. State Med Assn.; 1028 S. 2sth st.; 10-11,2-4, 7-8;U Trdings, Jos. A1, $\rightarrow:(1,94)$; not in praeliee: 1300 s. 34 si

Tyler, Saml. II. $\left(b^{\circ}, 15\right)-K y, 40 ;(194)$ 1914 W. Walnut st.

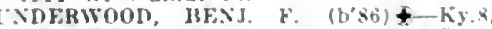
$10 ;(110): 2829 \leq 3 \mathrm{~d}$ st. $; 11-1,5-7$

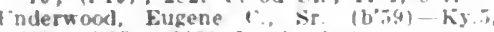
88: (1.9i); 232i Fortland tie

Inderwood, Figene $(\therefore$ Jr. $(1, s ?)-k y$ 04: (1004): 2803 .Inigumery st.; onter. 2325 Portland Are

VANCE, Al MORGAX $\left(b^{\circ} 34\right)+K y 2,88$

VAN ZASDT, THOMAS KELAT (b"ö5)

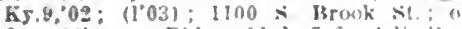
fice, stherton Bidg.; 11-1,5-6; Adj. Irrit Obst., Ky.z; $\mathbf{O b}$.

Vaughan, Henj. (b'at - Ky t,06; (I'(60)

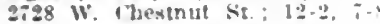

reech, lee R. $\left.\left(b^{0} 6.3\right)--k\right) .2,93$ 3013 s. $3 d$ st.

vertes dlex-110.7,02; (1'02) ; Weirsinger Gaubert Apts.: offce, 310 W. Mroalway. MIJECK, HESIT $\left(1^{\prime} 05\right)$; Stark Bldy

Walden, Rearll MHilard (b'89) - Ky.z.'1:3 1): Loulspllle Clty Hospital.

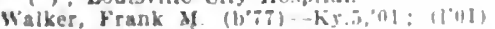

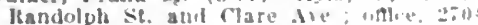
Frankfurt Are.

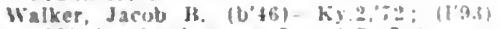
3099 Portland He: a

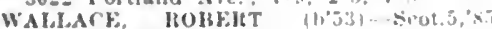

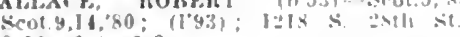
S-10, 2.4, 6-8.

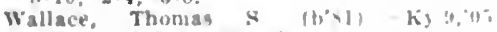
$\left(1^{\circ} 06\right)^{\circ}: 1216$ s. $28 \mathrm{sh}$ st

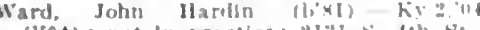
(1004): not In prartice: "ylt \& th st

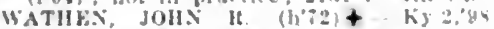

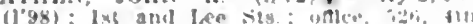

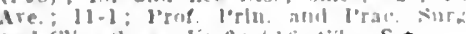

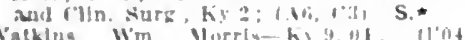

Watklus, W'm

WFISEK, IISISIS

(1'ys): 501 st castureting (193): U.

WEHER, JACOH (1, b.i) hi?

1514 is. Mrosdwas; \&.11,

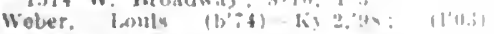
2225 wate st.

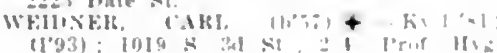
ad l'rey Vel Ki:

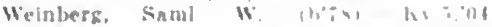

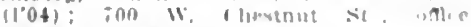
therion mas: o.

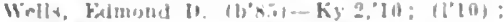

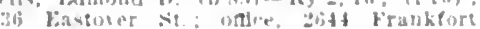
ise.

Wheat, Boral 11,61)- Ky.4,0!) (1"09): 11:Whe at it: It - I

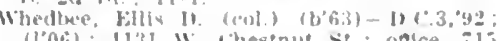

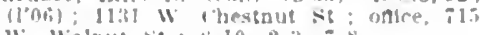

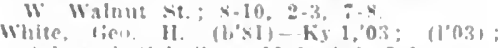
llak and "with stis: 1I-I, f-ti, i.

whlt: Wy $(1,70)+-(1311,07:$

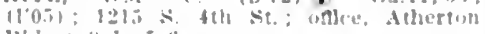

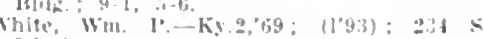
ith"s?

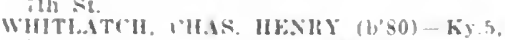

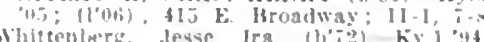

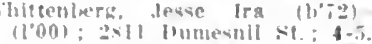

WHHOIT rRE:I L. throlt-kyan 11021: 1142 : 20 ?

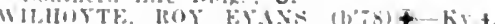

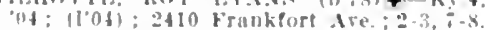

WILLIS, THOS X. (bos) - Ky. 9:2.8 Cherokee Hid: $:-\$: 30,2-3$

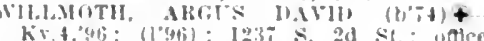

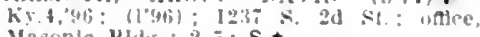

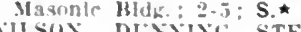

WILAN, DTNXING STEELF $\left(b^{\prime} ; 6\right)+$ Ky.2.99: (1'99): (Valley statlon): unloe. 121 11. Chesinut St: 1.*

Wilson, Frank Carutlers (totl)-Vabst: $\left(10^{\circ}\right)$ : $218 \mathrm{~S}$. Bayly sie.; oftce, wher ton lidg. : $9-10,3-4$

WIndell, Alex. M-Ky.2, 10 ; $\left(1{ }^{\circ} 00\right): 132$. Singy Are. nfflce, itj W. Jefferson st.

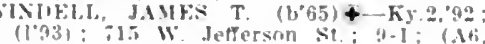
(3): U.

WITHEHSPOOS, FZRA O. (h'大s) - Ky. 01: (1'01); 100 W: Burnets tre.; oflice,

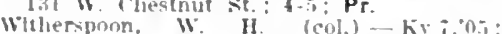

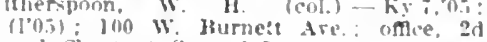
and Chestnut sts. ; t-5.

WOLFE, RLATISF, T. (b'\$2) - Ky $1,0^{\prime}$ (I'II): 2nt5 Barlnger die ; oftce, ltherton Bld

WULF, IIF WITT HEXItY II (bSO)-Ky, 2,03; (1"03): $1+15$ s. th Are.; oftce. therton Bide: 11-1, 5-6:30.

WOODAIID, HORT LFE (b's - Ky, 2,0

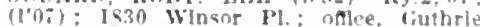
coke Bldg.; 11-12:30; (also st. Matthewr: $\{-6: 30): \mathbf{S}$.

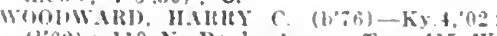
$(102)$; 119 x. Bayly Are, nffice, $415 \mathrm{~W}$ (hestnul st.: 10-12, 2-4.

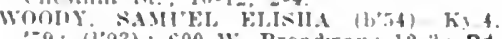
:9: (193) : cino W Broadiray : 12-3) Pd. Worden. The D (b'sn)-ky,nf: $(1+3$ : 2603 S fih St. 8-9 It-2 -

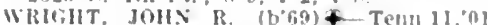
IInt): 2103 W. Markes Se. wetlee, sher

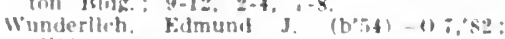

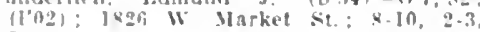

Winn Jus Jackann (b'8i) - Pagens: (1) 11

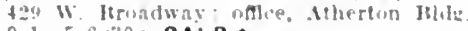

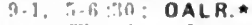

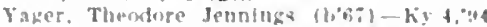
(1)94): 1100 s shelly si.: 12.2 di-s

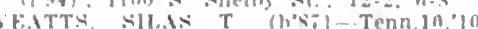
11'11: Member Tenn. Stafe Med Musl

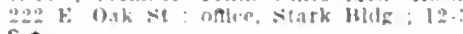

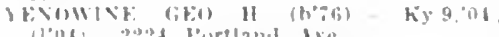

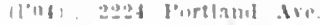

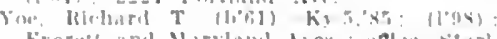

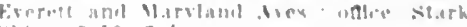
Mit: : 9 10, ?

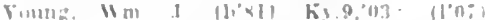

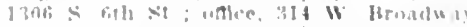

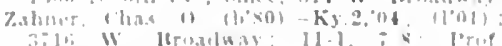

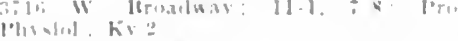

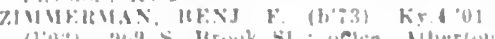

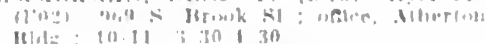

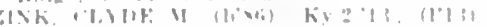
ifo hougllat

LOVELACEVILLE, H00, BALLARD

Vertive liend Pranklin (b'at) hy I wo

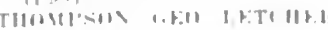

LOWER GREASY, 100, JOHNSON

11003

LOWES, 200, GRAVES

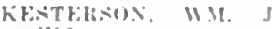

ता 101

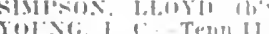

LOWMANSVILLE, 80, JOHNSON

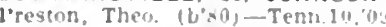

LUCAS, 50, BARREN

TI ITNER, TASWLI,

(lin)

LUDLOW, 4,163, KENTON

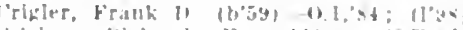

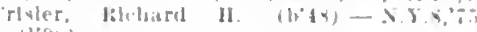
$(109 n)$

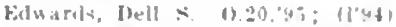

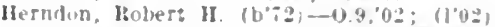

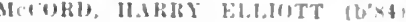

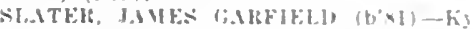
of: (1'04).

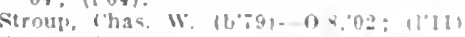

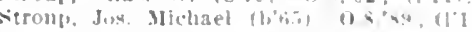

LYNDON, 50, JEFFERSON

BAIRD, JOIIN W: (h'59)-Ky ?.'4: (1'98

LYNN. 10, GREENUP

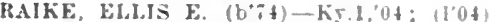

LYNN GROVE, 25, CALLOWAY

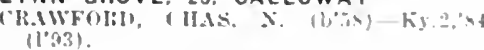

SHOLES, CHAS, E-Tenn 6, 90; $119 \%$

LYNNVILLE, 118, GRAVES

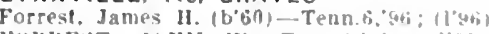
FOHBEST, JOIIS W- Tenn.b,'100; 1101) 0 .

\section{LYONS, 44, LARUE}

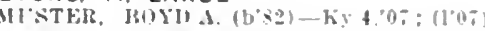

MABEL (HICKMAN P.0.). 15. FULTON

MABlace, I. A.-KY.5,04; (1"0\$1.

MACEO, 100, DAVIESS

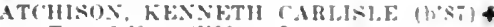
-Tenus.09: (1091: G

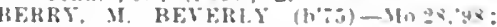

\section{MACKVILLE, 190. WASHINGTON}

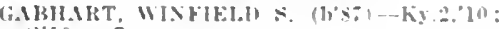
(1'10): $\mathrm{s}$

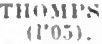

\section{MADISONYILLE, 4966, HOPKINS}

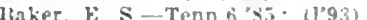

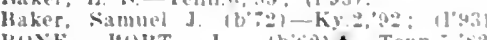

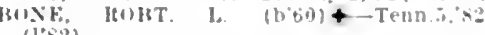
(1's:2).

Brishear,

Gardiner Thomia II

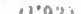

H.MMAr. WM. MU1RE + - k. 9,05: (1) 0.5 .

kell, w. $r-0: 12): \mathbb{R}$ F

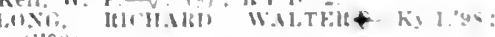

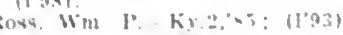

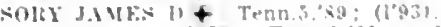

sory, labte (bis)-Tern.1,00; (100): OALR.

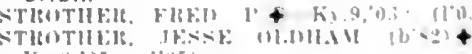
K) $: 00 \%: 110.1$

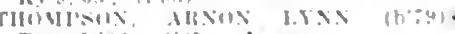

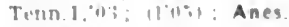

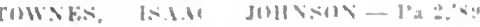
(103i)

MAGGIE (R.F.D.. CADIZ), 35. TRIGG

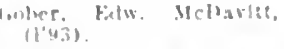

MAGNOLIA, 100, LARUE

$11.1111 .1 .1 \% 11,11 \quad 11 \%:$

MAJESTIC. - PIKE

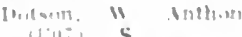

MANCHESTER, 6:6, CLAY

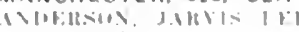

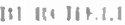


KEITII, JOIN PAUL (b'is)-Ky.5,04; MANNiNg, ISAAC S. (b'46)†-0.9,72; (1'93).

MANITOU, 75, HOPIINS

Crow, Thos. A. (b'69)-Ky,5,96; (1'96).

MANNSVILLE, I09, TAYLOR

ELLOD, W'II. R. ('b'S2)-Ky,11,'08; (I'08). MARION, 1,627, CRITTENDEN

CLhMLNT, ISAAC H.-Tem.6,'85; (1'93);

CoOk, OLIVER C. (b'70)-Tenn.6, 99 ; (1'99). Andrew J. (b'61)-Tenn.5, 89 ;

Drisklll, Andrew J. (b'61)-Tenn.5,'89;

FoX, JAMHS ERNEST (b'67)†-Ky.5, 04;

FRAYLi, THOS, ATCIISON (b'69)屯'Tenn.5,'94; (1'94).

MOORE, ROBT. LOYE (b'58)-Ky.2,'82; (t'93); (Carlisle).

MORFLAND, CLAREXCE G. (b'56)-Ky.2, 994; (1'94).

PERKY, JoHN R. (b'84)-Ky.5,07: (l'07) THRELKELI), JOHN DUNCAN (b'51)Ky.2,'74; (l'93).

MARROWBONE, 100, CUMBERLAND

DAVIS, HERBEIR' G. (b'74)-Ky.5, 03

TAYLOR, WM. S. (b'58)-Ky.I,'89; (l'93).

MARTHA, 100, LAWRENCE

Rlee, Conrad B. (b'7I)-Ky.5,'98; (1'99).

Hice, Nelson T. (解7) - Ky.4,'s6; (1'93).

MARTIN, 20, LEWIS

STOUT, CLAYON EVAN (b;3)Ð-Ky. , 06 ; $(1,07)$.

MARTINSBURG, 20, MONROE

DAVIS, WI. LARKIN (b'T6)-Tenn.6, 08 ; (1'10).

MASON, 125, GRANT

ABERNATHY, JOHN W.-0.9,03; (1'03).

MAUD, 50, WASHINGTON

SIEHAN, JOHN N. (b'64)€-Ky.2,'87; (1'93).

MAVITY (R.F.D., CATLETTSBURG), 35, BOYD

Prlchard, I. Allen (b'67)-Ky.1,92; (1'93).

MAXON MILL, 300, MCCRACKEN

Kimbrough, Frank V. (b'TI)-Tenn.5,93; (1'94).

MAYFIELD, 5,9I6, GRAVES

DISMILEES, JOHN I.-Ky.I,94; (l'94).

ERKILETIN, DICKRAN II. (b'80)-

Tenn.6,'03; (1'03)
FULLLR, GEO. THOS. (b'55)-0.2,'89 ;

GREFA,; BENJ. F. - Mo.7,'s9; (1'93); R.F.D. 5 .

HENDLEY, AZARIAH PATTERSON (b'59) -Tenn.1,'86; (1'93).

HUNT, HERBERT HOBSON (b’i2)—Tenn, '95; (1'02).

HURT, A. A.-Ky.5,'76; (l'93) ; R.F.D. 3

HURT, HOZA WEST-Ky.2,'11; (i'li) ; R.F.D. 3 .

Mecrory, '. H. H.-Tenn.6,'7t; (l'93).

Neal, Richard J.-Tenn.6,'85; (1'93)

Newton, Grant (b'68)-Ill.10,94; (1'12).

PURYEAR, JOHN G.-Ky. $1,{ }^{\prime} 03$; (1'03).

Ray, T. I.-Tenn.6,'98; (1'98); R.F.D 5.

Riley, Eddie (b'82) - Ky.2,'i2; (l'12); R.F.D. 10.

SHELBY, HENRY ALEXANDER (b' 65 )Ky K.2, $06 ;\left(I^{\prime} 06\right)$; G.

Ky. HLLON, JOHN ;H.-Ky.2,92; (1'96).

coln YENS, EDWIN A. (b'63)థ-Ky.2,'85:

(BI) ; i); S.

(1'11); Augustus Geo. (col.) (b'75)Green $S t .97 ;(1,9 \pi)$.

Richards. Judson L. (b'54)-0.2,'89; (1'93): E. Orusby Lieut., U.S.N., retired; R.F.D. 6. Richardson, JHN CALVIN (b'66)-Ky.2,92; $65 ;(1 ' 93)$

RICHARDSON, 308, MASON

(b'76)-Ky.4, udweil Y.-Pa.1,66; (1'94).

Are.: office, rd H. (b'59)-Ky.2,81; (1'93)

Itichardson, Wim. M. (b'62)-0.1,96; (l'97).

(\$) ; 2215 Stan 6,141, MASON

CIIEY, ENWALIE (b'73)-NId.4,0I; (1'0I) '08; (1'08); 20 'oos G. (b'34)-D.C.2,60; DITT: Broadway;

(1'11); FRANKY R.ฯ-Ky.I, 03 ; (1'03); R.
HAROYER, SAMYLI。 R. (b'67) †-Pa.2,'93; ( $\left.l^{\prime} 03\right)$.

Hord, Winn Fistlle (1,8⿰氵) -0.4I,12; (l'12), MeriliRe, CockTNEY S. (b'77) - Ky.1 '06; (l'06). I'atton, W'm. Cornellus (col.) (b'70)-Ky.7,

QIIGLEX, AUSTIN R. (b'84)-Ky.5,07;

SAMUELS, JOHN H. (b'55)-0.1,77; (l'94). SMOOT, I'ETER GORDON (b'63) - N.Y.9, $86 ;\left(l^{\prime} 93\right)$.

Strode, John Thos, (b'38)_Pa.2,62, 0.19, ?9; (l'93); not in practice.

TAITLBEE, WOODSON II. $\$$ - KY.4,04; $\left(l^{\prime} 04\right)$; S.ネ

TAYIOR, AIRVID OUCHTERLONY (b'83)థ $-\mathbf{k} y, 2,06 ;(106) ; \mathbf{S}$

YAZELL, WN. S. (b'66)-0.8,9I ; (l'94). MAYWOOD, 100, LINCOLN

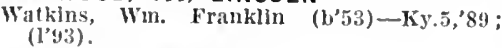

\section{MOAFEE, 75, MERCER}

IAAPSLEY, JANLS P.4-KY.5,'90; (1'93).

Lapsley, John B. (b'4I)-1'a.2,'64; (l'93).

McCOMBS, 10, PIKE

Jaekson, Joln M. (b'69)-0.2, 05 ; (l'12).

Jackson. R. L. (b'38) $\longrightarrow$; (1'93).

MODANIELS, 100, BRECKENRIDGE

Hart, John H.-Ky.2,'it; (I'93).

LAMP'TON, JESSE B. (b'79)-Ky.5,0 (l'0T) TLCKER, JOHN CLINTON (b'74)-KIY.l,

MCHENRY, 530, OHIO

CROWDER, CHAS. G. (b'80)-Ky,5,06 ; $\left(l^{\prime} 06\right)$

SMITH, JOHN S.-Ky.2,'90; (l'93).

MOKEE, 146, JACKSON

Anderson, Ieremlah E. (b'83)-Ky.5,'07; $\left(1^{\prime} \theta \tau\right)$.

HOKNSBY, WILLIAM BOYD (b'85)—Ky.2, '11; (l'I1).

MEKINNEY, 400, LINCOLN

Grider, Frank-Tenn.6,92; (1'93)

SINGLETON, TILDEN H. (b'76)\&-Ky.s, '04; (1'04); Pd.

MCQUADY, 70, BRECKINRIDGE

KINCHELOE, ALLEN LINDSEY (b'88)థKy.2,'11; (1'12).

MCROBERTS, - LETCHER

CORNELIUS, AIMBERT FRANKLIN (b'86) -Ky.5,06; (1'07).

MCVEIGH, 一, PIKE

NEEDHAM, WM. SPENCER (b'88)-Ky.2, 12 ; (1'12).

MoWHORTER, 50, LAUREL

PHILLIPS, GEO WENDELI (b'79)-

WHITIS, HACK $\left(b^{\prime} 83\right) €-K y .11,08$; (1'08).

MEADOW CREEK, 25, WHITLEY

TERRELL, LELAND L. (b'89)-Ky.2,'10 ; (l'i 10$)$.

WEST, EDW. HERBERT (b'82)-Ky.5,07;

MEEK (LOWER GREASY P.0.), 25, JOHN.

CASTLE, WII. ROGERS (b'82)-KIy.5,07; $\left(l^{\prime} 07\right)$.

MELBER, 150, MCCRACKEN

Davis, Elmer E. (b'76)-Mo.T',98; (1'98).

OTEY, IRA G. (b'60)-Tenn.6,03; (1'03).

MELBOURNE, 90, CAMPBELL

PINGUELY, JULIUS E.-0.1,'S8; (1'98).

MERRIMAC, 50, TAYLOR

HIESTAND. CLEMENT V. (b'i1)-KY.4 $96 ;(1,96)$.

META, 50, PIKE

Bond, Oscar K. (b'81)-Ky.5.'06; (l'06).

Craft, Nicodemus W. B. (b'81)-Kíy.5,07; $\left(1^{\prime} 0 \tau\right)$.

MIDDLEBURG, 98, CASEY

CREECII. CHESTER B. (b'82) —-Ky, 2,07 $\left(1^{\prime} 0 \pi\right)$.

HANEY, JAMES M. (b'54)-0.3,87; (1'94).

MIDDLESBORO, 7,305, BELL

Bell, Thomas (col.) (b'84)-Mich.5,'10; (1'11).

BROSHEER, CHAS. H. (b'73) 4 -Tenn.I, 00 ; (I'01); S.
HIRUMETT, U. GRANT (b'79)-Ky,2,07 ; (1'07).

CURD, THOS. H. -Ky.2,79; (l'93).

EDMONDS, JAMES PARK (b'74) - Ky.5, "98; (I'II) ; OALR.*

EVANS, J." TIIOMAS (b'77)-Ky.5,03; (1'02).

EVANS, WM. K. (b'79)-Ky.5,02; (1'02); GIISON, TMIOTIY TILMAS (b'84)Ky.2,09; (1'09).

Howard, Joln C. (b'78)-Ky.9,02; (l'03). JONES, LEWIS J.-Ky.5,02; (1'03) ; Pd.

ROBFRTSON, LESLIE L. (b'67) $4-\mathrm{Ky} .2$, 89 ; (1'93).

TINSLEY, JOIIN R. $\left(\mathrm{b}^{\prime} 84\right)-\mathrm{K} y .5,{ }^{\prime} 0 \overline{7}$ : (l'07).

MIODLETOWN, 302, JEFFERSON

MASON, LLCY DUDLEY (b'7i)-Ky.2,02 ; $\left(l^{\prime} 02\right)$.

WETHERBY, SAMLLL DAVIS $\left(b^{\prime} 69\right)-\mathrm{Ky} .1$, '94; (1'94)

Wltherbee, Silas 0.-N.Y.1,67; (1'93).

MIDLAND, 35, MUHLENBURG

NORRIS, ROBT. B. (b'73)£-Tenn.1,96; (1'00).

MIDWAY, 937, WOODFORD

ANDERSON, SIDNEY J.-Ky.2,91; (1'93).

IIolt, J. W.-Ky.4,9i; (1'97); not in practice.

LEMINAN, JOS. S.-0.23,96; (l'96).

Means, Itay Morrlson (b'82) - Ky.2,'04; (1'04).

PARRISH, BENJ; F. (b'66)-N.Y.10,90; (1'96).

HISQUE, WM. E:-Ky.2,93; (1'0I).

Thomas, James J. (col.)-Ky.7,'94; (1'94).

MILBURN, 207, CARLISLE

GILLIAII, HOMER ALFONSO (b'84)-Ky.2, 09; (l'09).

SIMPSON, FRANK NUSOM-0.2,89; (1'94).

Sutton, J. T. -No.I, 63 ; (1'93); not in practíce.

MILFORD, 175, BRACKEN

KEFFER, SMITUFIELD (b'6 $)$-Ǩy.1,'91 (1'93).

MILLARD, 25, PIKE

Adkins, IIoses (b'70)-Ky.4,95; (l'96).

MILLERSBURG, 799, BOURBON

CALHOUN, JOHN DANIEL (b'86) - Ky.2, '10; (1'12); Member Tenn. State Med. Assn.

DAILEY, WILSON G. (b'60)-Ky.2,88;

Huffman, Wm. V. (b'58)-Pa.2,87; (1'93).

Ailler, Wm. M.-0.1,'89; (l'93); not in practice.

Peterson, Henry D.-0.2,'92; (1'93); G.

SNITH, CHAS. BRUCE (b'64) A-Ḱy.2,'86;

MILLER'S CREEK, 35, ESTILL

BROADDUS, BEVERLY S. (b'78)-KKy.5, 05 ; (1'05).

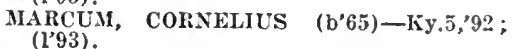

MILLERSTOWN, I30, GRAYSON

BOTTS, JOHN H. (b'82)-Ky.2,'07; (1'07).

MILL SPRINGS, 59, WAYNE

JONES, THEO. LANIER $\left(\mathrm{b}^{\prime} 76\right)-K y .5,0 \mathrm{I}$; (1'01).

MILLWOOD, 80, GRAYSON SHERMAN, CHAS. LOUIS (b'80)-Ky.9,04 ;
(l'04).

MILTON, 233, TRIMBLE

CALVERT, JOHN H. (b'61)-Ky.2,'81 ; FISFER, SIMEON KING (b'54)-Kiy.2,'84; $\left(l^{\prime} 93\right)$.

HAMPTON, S. E.-0.9, 66 ; (1'93) ; R.F.D. 1.

RAND, B. O. (b'70)-Ind.9,03; (1'03);

MINERVA, I54, MASON

MENRY, ONIER CLINTON (b'81) - Ky.5,'05;

POLLITT, SAML. E. (b'60)-0.1,'89; (l'93).

MINTONVILLE, 75, CASEY

Dye, Henry Clay (b'67)-Mo.28,'04; (l'04).

MONROE, 120, HART

ADDINGTON, ELBERT L. (b'77)(4-K5.9, '06; $\left(\mathrm{l}^{\prime} 0 \mathrm{0}\right)$.

Pace, Wm. T. (b'47)-Ky.2,'74; (1’94). 
MONTEREY, 260, OWEN

BELL, MAUTICE, JR. (b'T1)-Ky.1,93; (1'93)

Long, Saml. C. (b'69)-Ky.2,91; (1'93).

Taylor, Wm. K. (b's1)-Ky.2,'I3; (l'I3): R.F.D. 4.

\section{MONTICELLO, 1338, WAYNE}

CARTER. (UI)I MARLIN $\left(b^{\circ}, 9\right)+$ Tena.I, 05: (l'06): Member Kan. Med. Soc.

CoOK, A. S. ( (b' +1$)-k y .2,{ }^{\prime} 67 ;\left(1^{\prime} 94\right)$. GAMILIN, THEOYHLL's H. (b'6i)-Ky.4,

JONES, JOSIAH A. (U59)-X. Y.10,67; (1'06).

RANKIX, CLALDE BERXAIRD (b'71)Ky.5.98; (1'9x).

WOODROW, W.II. E. (b'6i) - ky.5,98;

YOU'NG, JAYES F. (b'59)-Ky:2,'90; (1'94).

MONTPELIER, 45, ADAIR

TAYLOR, SAML. A. (b'5i) -KY,, 90 \% (1'93).

MOOLEYVILLE, 95, BRECKINRIDGE

SPHIRE, DOMIT S. (b'75) -Ky.9,03; (1'03).

MOOREFIELD, 200, NICHOLAS

Holmes. Luther bayne (b'St)-Ky.I1, 08; (1'08).

SWATí, L. K. (b'6i)-Ky.4,9I; (1'94).

MOREHEAD, 1,105, ROWAN

BLAIR, AARON L. (b'63) -Tenn.6,"99; (1'99)

NICKELL, GROVER C. (b'84)-Ky.9,06; (1'06).

SCAGGS, ALFX. (b'OI)-N0.28,06; (1'06): 0 o.

THOMAS, F. M.-KY.I:"5: (1'05)

WILSON, JEREMIAH (b'5:) -KY.I,'89; (1'93).

MORELAND, 250, LINCOLN

PIPES, M. LEE (b':2)-Ky.5,'94; (1'02).

MORGAN, 30, PENDLETON

Denny, Geo. W. $\left(b^{\circ} 56\right)-0.8,76$ R.P.D. I. (I'98).

NICHOLS, THOS C $\left(b^{\prime}+9\right)-\mathrm{Ky} 2,-3$ (1'93).

MORGANFIELO, 2.725, UNION

ALLEN, HENRY B. (b'-9) - Ky.5, 03; (1'03)

CONWAY, JOII, WY, (6, 2)-Ky, (1'93)

DONAN, DAVTI CLMMHS, JR. (b'82) K'9.2,07; (1'08); S.

GRAYE'S, CASEY B. (b'ï)-Ky.5,05 (1'05).

HENRY, SAML. L. (b'53)-Ky.4, 6 ; ; (1'93)

NUNX. WM. H. (b'54) $\rfloor-$ Tenn.6,'81 (1'93) : Pr.

Ransom, M. G. (col.) (b'it)-Tenn.i,ol (1'01).

HHEA, HOLAND H. C. (b'58)-Tenn.5 91; (1'93).

Rlchards, Wm. A. (b'5.3)-X.Y.10,79; (1'93) : not in practlce.

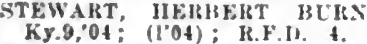

MORGANTOWN, 569, BUTLER

A USTIN, JOSHL:A H. (D'TI)-Ky.I,"98:

(I'98); FIIJAII A. (b'62)-Kร.2,"90; (1'93)

KMBRY, GE(), FATIL (b's6)-Ky.2,'10 : (I'II).

JAMES, JRESTON FMNETTE (b'6S)Tenn.5,"93; (1'93); Ob.

MORNINGGLORY, 50, NICHOLAS

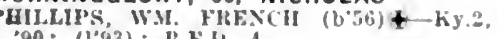
30 : $(1.93)$; I.1.11. 4.

MORTEN'S GAP, 1,266, HOPKINS

AIMON, FV EIRETT T. (b'50)-Tenn. 5, , 80 ;

(I'93); G.

O'Bryan, Chas, F. (1'60)-Tesun.6,99: (1'99)

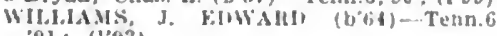
i1; (1.93)

MORTONSVILLE, 200, WOOOFORO

Ilackley, John M. (b'66) - Ky.2.91; (1'95)

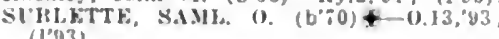
(1'p3)

MOSCOW, 500, HICKMAN

MAHAS. JUHN I3.-Ky.2.89; (103)
MOUNTAIN ASH, 100, WHITLEY

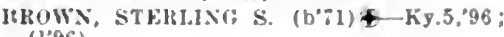
(1"96).

MOUTHCARD, 250, PIKE

Lewls, Arery Ionlal (b'-5)-Tenn.10,0s (l"11)

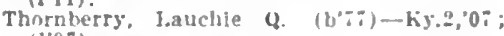
(1007).

MT. AERIAL, 60, ALLEN

Alexanler, John Fulton (b'55) - Tenn.5.80 (I.93).

MT. CARMEL, 8I, FLEMING

Groohs, Thomas B. (b'70)-Ky, 9,$03 ;\left(l^{\prime} 03\right)$ (1.93).

MT. EDEN, I57, SHELBY

COLIINS, LISTER (b'it) + - Ky.5, 02 ; $(1,02)$

Mtlion, K. II. (1'66)-Ky.5,'92; (1*93).

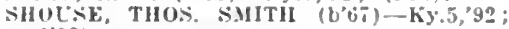
(1'93)

Snlder, James W.-Ky.2,'80; (1"93),

MT. OLIVET, 321, ROBERTSON

CIAYPOOLE, HARIAN GROVER (b'85)Ky,5,0\%; (1,0\%).

(HANULK, WALTKR \&. (b'63) + (9.1,89 (1.43)

LINILLF, EMMETT EAIIE (b'S $0 \%:\left(I^{\prime} 07\right)$

I.Invllle, P. Dlck (b'62)-0.1,83; $\left(l^{\prime} 00\right)$

WELIS, ALTON L. (b', 4$)-K y, 5,07$

(1'0i); Pd.

WOOD, JOHX BELI_- $0.1,83$; (1'93)

MT. STERLING, 3.932, MONTGOMERY

Bonner, Dalsy Brown (col.) - Pa.j, '07.

Bunner, James T, (col.) - Ky. 6 , $05 ;\left(1^{\prime 05}\right)$

BLSH, DAYID H. (b'72) - Ky.2,'98; (1'98).

COX. GEO. X. Ky 2, 85 ; (1'45).

I)EMAREE. OWE. B. (b'6)-Ky.2,9I (l'9s) : R.F.1. 3.

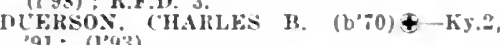
91 ; $(193)$.

HARNESS, ANDREW J. (b'83)-Ky:9,04; (1'0t).

JOHSSON, J. KELLER (b'6t)-Ky.2,'ss; JoNEs, JoSIAI " FERGLSOX (b'52)\&Kу. 5,79 ; (1'03).

LOCKHART, JOII FLOYD (b'55)-Ky.I ×9: (1'94).

MAXING, BAXF(nI) M. (b'-s)-Ky.1,04 (1'05); $\mathbf{G}$.

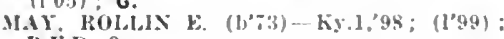
IR. F. D. 3 .

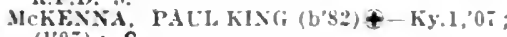
$(100) ; G$.

REINGLDS, J. F.-Ky.5.90; (I'93) ; (BI) Ricketts, John T, Jr-Ky, T: (1'93)

IROBBIX, ARTH'l? H. (b'61)-Ky.2, 89 (1'9.3) B.F.1) 1 .

SHILLEL, JAMES A. (b't6)-Ky.2,"2:

SIMIKALL, WM. T. (b'tz)-Ky,t;3; (l'u3)

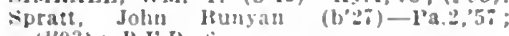

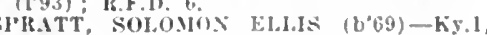
00 : $(1,00)$

stoops, Alexander It.-I'a. 1, $69 ;\left(l^{\prime} 83\right)$

THOMI'SON, WM. 16. (b'il) \-Ky.d, (1'93).

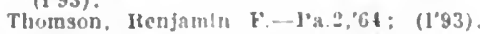

WIILIS, M.M. T.-Ky.5," $46^{\circ} ;$ (1'9i)

MT. VERNON, 930, ROCKCASTLE

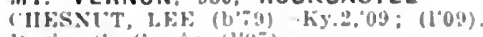

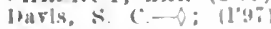

I.ASWEI.L. WM. I, Ky,5,04: (1"04)

I,1)Yil.1, i. A - liy 4, $\times 3:(1,93)$.

(WF.S. WHLKKK-KY,ol; (1'04)

MT. ZION (R.F.D., ELLISTON), 50, GRANT

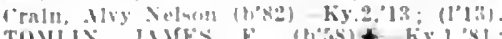

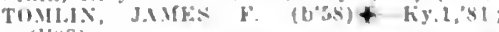

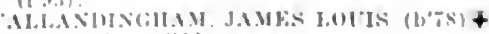
hi) 1 , "0: ; 1102

MUDLICK, 40, MONROE

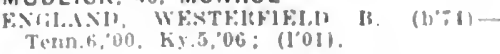

MUNFOROVILLE, \$75, HART

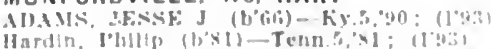

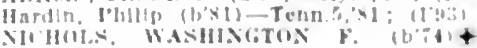

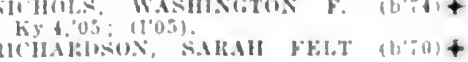
in (1,01).
MURRAY, 2,089, CALLOWAY

EVANS, NHWTUN G, MUOS

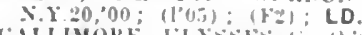

GALIMOHE, TLYSES i, (bib)-Tenn.s. $9.5:(1 ' 960) ;$ It. $\mathbf{F}^{2} .1 \%$

GINGLES, CIHAS. O.-Ky 2, ; (1'ga).

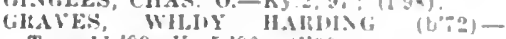
Tenn.11,"99. Ky:5, $00 ; 11^{\prime} 001$

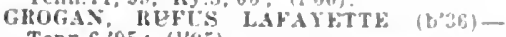
Tenn.6,"95: (1'95)

llarrls. Wyly lIumphrey-Ky.205; (1'0, )

IIART, PRINCE ALBEIRT (b'83)+ iy. '06; (1'06); OALR.

OHXSOY, WALTKK G. (b'5i) + Tenn.6, '00: (1'01).

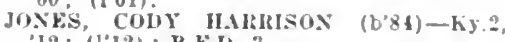
'I2: (1'12); R.F.I). 3

KFYS, BENJ. BUTLER (b'S0) \pm -Tenn.5, '08: (1'08).

Mason, Roh. M. (b'ss)-Tenn.5,"12; (1'12).

MISOX, WM. HFRBERT, JR. (b; Tenn.w. $99 ;(1999) ; \mathbf{S}$.

MCKEK, AMBROSE V (b'62)-111.1\%,00。 (I'OI); OALR.

MYERS, 200, NICHOLAS

ITRILI, AQL'ILLA II. (b'58) \&-0.9,90. (3)

artin. Geo. Earl (b;,

NANCY, 100 , PULASKI JASPEI, ROBT. FLLLTON (b'35)-Ky.I,'05;
(I'08).

NAPOLEON sllupert, John W. (b'S5)-Ky.2,10; (1"10). NARROWS, 70, OHIO

Lawless, Willam Lngan (b'56) $\longrightarrow$; (1'95) NEBO, 298. HOPKINS

Ferkuson, ("larence $x_{\text {. }}\left(b^{\prime 6} 68\right)-T e n n .6,91$; (1'93) not in practlee.

$98:\left(1^{\prime}(48): \mathbf{N}\right.$

MORTON, CUARLES IR (bon) - K (1'06).

SETZEK. ABRAM K. (b'59)-Ky.9, $06^{\circ}$

Tllford, F, I.-Tenn.6,"9s; (l'9s).

NELSON, 50, MUHLENBERG

11'FF, JAMKA A. (b'O5)†-Ky,J,'04; (1'04), NEPTON, 235, FLEMING

II worl, John S.-Illch.1,67; (1'93).

NEVINS (MCBRAYER P.0.),50, ANDERSON Sevlus, Nus:I1-Ky,8,01: (1'01).

NEWBY, 20, MAOISON

COX, FIRLIIK. C. (b'N0)-KY.2,04: (1'05).

NEW CASTLE. 468, HENRY

CAHROLI. OWEN M. $\left(\mathrm{b}^{\circ}: 1\right)-\mathrm{Ky}, 1,90$;

EIANTON, ARTHIR (iLI-0.1,94: (乡)

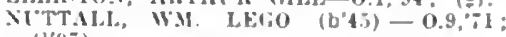

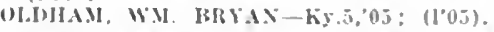

NEW COLUMBUS (R.F.D., CORINTH), 118. OWEN

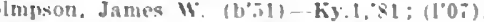

NEW CONCORD, 80, CALLOWAY

W'llson. Marıuls I". Tenn I, '1:

NEWFOUNDLAND, 72. ELLIOTT

Iohnson, Wllls W: (b+ti)-ky.490; (1'93),

NEW HAVEN, 405. NELSON

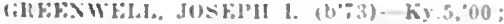
IIEIZ:

(1)

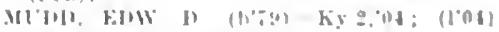

NEW HOPE, 240. NELSON

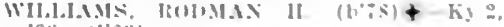
; $(103)$

NEW LIBERTY. 214, OWEN

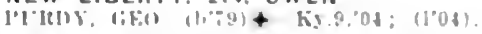

NEWMARKET (R.F.D., LEBANON)。79, MARION

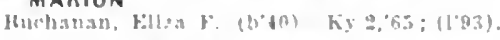

NEWPORT, 30.309, CAMPBELL

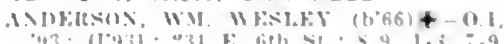

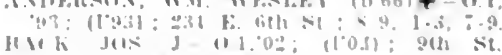
and Wadblugton IVe

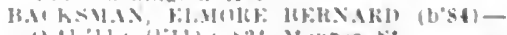

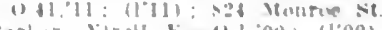

hather. Virgll F (1),00: (1000): 311 E. i, th 3 il 
BEHIY, SHALER (b'7 7 ) $-0.1,00$; $\left(l^{\prime} 01\right)$; I2 E.' 3d st.; offle, Jork st. and lourt I.

RILINEISS, MAHTIN H. (b'T0) \-Ky.8, 01: (1'01); 130 E. 35th St. : $7-9,1-3$ Roehme, ltaymond Gustare $(1,88)-0.41,11$ (1'11); 821 Washington Are.; $7-9$, 12-3

BONAIt, DO'(iLAS s. (b'59)-Ky.l,86 (1994); 132 b. 5th st.; offlce, 3il and Monmouth sts.; $8-9,1-3, \quad ;-8$.

BHow, (Bko. W. (b'69)-0.2, 90 ; (l'93) : 610 Washlngton Are.; $1-2, ;-9$.

Bl'TFN, ElWW. J. (b'82)-0.2,07; $\left(1^{\circ} 07\right)$; \$3ti York st.; OALR. *

(AIIWELL, IIMES ASHEIt (b'71) \pm-0.1 , "ol: (lo1) : Electrle and shaler dies. CALINELL. JOHI HADLEY.

(see (Inclnnatio 0 .)

CHOWLYY, JAMH W. (b,52) $+0.8,96$ (1'96) : \& F. 30 st. ; 8-10, 1-4, i-8.

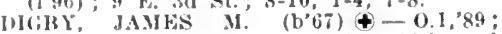
(1'94) : $319 \mathrm{k}$. 10 th st.; offlce, 10 th and

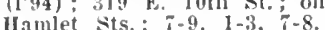

Flschbach, Frederiek Win. (b'61) II-0.13,

'89; (1'93); 4 tl St. and Waslungton A.e.; $8-9,1-3,7-8$

FISTIIBACII. HOWARD l'HILLIP (b'84)$0.13,09$; $\left(1^{\prime} 09\right)$; th St. and Washington Ale, : $8-9,1-3,7-8$.

FHK'KMAX, OSCAIt A. (b'68) - 0.1,96 $(196) ; i 24$ York st.; $8-9,1-3,7-8$.

(iERINIS, WM. J. (b'74)-0.1,97; (1'9i) 1026 Central Are, ; $8-9,1-3,7-9$.

Iefiln, Wm. K. (b'70)-0.1,94; (l'94) ; 235 E. 5th st. ; $1-3,6-8$.

IIHLMBOLI), AUGU'ST (b'63)-0.2,'si (193); 718 Columbla st.; 8-9, 1-3, 6-8.

HERMANX, EDW. (b'79)-0.9.03; (1'03)

If E. 6th St.; $7-9,1-3,6: 30-8$.

HERMANN, GEO. J. (b’33) $4-0.1,94$ (197); 937 Monroe $\mathrm{st}$.

Irorner. ('harles Edw. (b's2) - 0.2, 0 T (I'10); 406 W. 4th St.; 8-9, 1-3, 6-8.

IENKIAS, ,IALES OLIVEK (b'51)-0.1,82 (1'93) ; 839 Washlngton Are.; office, 29 W. sth St. $=1-3, \mathrm{i}-9$.

Keenes, Eben W-0.1,70; (1'94); 206 E

30 st. ; 8-9, 1-3, 6-9.

КЕHM, CHAS. I. (b'69)-0.2,96; (1'96); 942 Columbla st. ; $i-9,1-3,6-8$.

kelum, Cora E. (b'6 7$)-0.2,97$; (1'97); 942 Columbia St.; ; $i-9,1-3,6-8$

KING, CLATENCE JOS.

(see ("Inclnnatl, 0 .)

Krlezer, W'm. Arnold (b'86) - Ky.2,09 (1'09); 39 E. 10th St.; office, 47 E. 10th st. : $8-9,1-3,7-8$.

Locke, Frank E.-0.2,82; (1'94); i24 MIon mouth St.

NORTH, EDW. AtsTIN (b'81) $-0.2,06$ : $\left(10^{\circ} 06\right): 40.5$ W. 11 th St.

OKIENT, SAMI. (b'88) £-0.41,'12; (1'13) 24 w 5 t : $8-10,2-4, i-9$.

I'HYTHAN, JOHX L. (b'0) (1'98); 225 E. 6th St.; office, 227 E. 6th

St.
Qulnn, Janet D.-0.2,'94; $\left(l^{\prime} 9 \tau\right)$; 10 th and Isabella Sts.

ltaines, Loulse G. $-0.21,02 ;\left(l^{\prime} 02\right) ; 11 \mathrm{E}$ bith St.

IOEBC CK, KATHERINE S. (b'61)-0.24 94; (1'95); 707 York St.; offlce, 10 W. 5th st. $: 9-10,2-4, \tau-9 ; \mathrm{G}$.

Sandoe, Jacob $\mathrm{L}$.

(See Clucinnati, 0.)

sauter, (ico. F. (b'69)-0.2,08; (1'08); 908 Ann St.

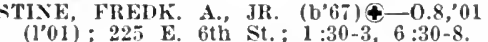

THOMASSOY, WM. JAMES $\left(b^{\prime} 69\right) \notin-0.1$ '93; (1'94); 942 York St.; $1-3,7-8 ;$ (B1) OALR

Thornton, Robt. H. (b'4 7$)-0.1,68$, N.Y.10, $72 ;(1,93) ; 17$ W. 5th st.; $8-9,2-3,7-8$ TOND, JOHN-0.1,00; $\left(1{ }^{\prime} 00\right)$; 118 E. 5th st.

Truesdell, Wm. E.-0.1,95; (195); 15 E 6 th St.

WAMSLEY, CAREY E (b'80) - 0.9,06 (1'08); 3d St. and Washington Are.; 8-9,

Weher, Fred. Carl-0.13,04; (l'04); 632 Washington St.

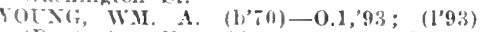
(Dayton); office, 3d st and Wilshington Are.

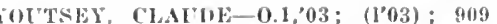
Waslalngt on Ave: oftce, 721 Washlngton Aie.: 1-3, 6-8,

YOT'TEY JOLX J. (b'55) - Ky,4, ה (1'at: ; 721 Washlngton Ave.; 1-3, 6-8.

ZIMMEILMAN, (AROLYN W. (b'59) +-0.8 "40; (1'97); 821 Washlugton Are, 7-9, (i-8.

NEW PROVIDENCE (R.F.D., HAZEL), 40 CALLOWAY

Mlller, kunlce W'ilson (b'82) - Ky.2,'10 ; (1.10).

NEWTOWN, I60, SCOTT

HEATIT, HLEWLLAYN F. (b'T1)-Ky.5,04 $\left(1^{\prime} 04\right)$.

NIAGARA (R.F.D., ROBARD), 30, HEN DERSON

Howarl, Tryon Y., (b'38)-Ky.2,'67; (1'93) not in practlce.

NICHOLASVILLE, 2,935, JESSAMINE

leverly, Wm. F. (b'59)-0.1,'88; (1'93) IR.F.I). 3.

('omls, Carlow B. (col.) (b'i 8)-Ky.7,0 ; (1,07)

COOK, THOMAS Gitile (b'73)-Va.4,03 (1'l0)

MATHEWS, WILI H.-Ky.5,'83; (1'93).

P'ENICK, DANL. A.\& N.Y.10,'98; (1'97).

PENT', MARYIN CHESTER (b'82) - Mo.i, $05 ;(1,05)$

AN ARSDALL, JOS. ATWOOD (b'68)Ky.2,91; (1'94)

Welch, H. A-Ky.1,83; (1'93)

WHLCH, THOS. R-111.4,'85; (1'93).

NIPPA, 20, JOHNSON

Balley, Thurman B. (b'81)-Ky.5, ${ }^{\prime} 0 \mathrm{i}$; (1 $\left.1^{\circ} 07\right)$.

NOLIN, 150, HARDIN

SHACKLETTE, WARNEI J. (b’il)-Ky.5, '98; (1,98); $0 p$

NORTH FORK, 200, MASON

LONG, LEWIS H. (b'i2)-Ky,5,94: (1'94)

ROBB, TILMAN J. $\left(\mathrm{b}^{\prime} 81\right) \oplus-\mathrm{Ky} .2,08$ (1'09)

NORTH MIDDLETOWN, 390, BOURBON

Cook, Gilber1 A.-Ky.2,05; (1'05).

HENIT, LOT RICHARD (b'i4)-Ky.9, 02 $\left(l^{\prime} 02\right)$.

Wearer, Robt. D-Ky.4,'71; (1'93).

NORTH PLEASUREVILLE, 235, HENRY

Dudley, C. F. (b'46)-Ky.1,70; (l'93)

HOWER, THOS. J. (b'62)-Ky.4,85; (1'93)

RENFRO, C. J. (b'42)€-Pa.2,6i; ; (1'06).

NORTONVILLE, 254, HOPKINS

IIOWELL, THOS. K. $\left(\mathrm{b}^{\prime} 72\right)-\mathrm{K} y .5,04$ MOOHE, WM. I.EE (b'66) - Mo.28,'96; $\left(1^{\prime} 96\right)$.

OAK GROVE, 10, CHRISTIAN

Lowry, Squire M. (b'38)-Pa.2,'61; (l'00)

Word, John Andrew B.-N.Y.5,'91; (1'94).

OAKLAND, 257, WARREN

HACKNEY, J. W. (b'33) $\rightarrow$; (1'93).

LEWIS, JAMES WI. (b'72)€-Tenn.5, 03 ( (1,03).

WHITE, GEO. W. (b'42)-Ky.1,'70: (1'93); R.F.D. 1.

OAKTON, 200, HICKMAN

BERKY, W. T.-NO. T; 01 ; (1'01).

HOWELL, ELSEY W. (b'78)\&-Ky.5, 0 $(100)$

OAKVILLE, 50, LOGAN

BEALCHAMP', PAUL (b'ĩ 0 -Tenu.9,'96; $\left(1^{\prime} 96^{\circ}\right)$

Brodie, Martin L.-Tenn.6,'89; (1'94) ; R.F.D. BUTT, ALBERT L. (b'58) - Tenn, 82 $\left(1^{\prime} 93\right) ;$ R.F.D

MORGAX, EDWIN CLAREACE (b'i Tenn.6.05; (1'05) ; H.F.D. 1 .

ODESSA (R.F.D., OWINGSVILLE), 30 , BATH

GILMORE, HENRY S. (b'82) - Ky.9,'05: (1'05); R.F.D. 1 ; Pd.

OIL SPRINGS, 78, JOHNSON

Kice, Grant (b'i2)-Kr.4, (04; (1'04).

WITTEN, FRANCIS M. (b'66)-M0.28,95; OKOLONA (R.F.D., LOUISVILLE), 75 ,

CARIMER, WM. A. (b'55) - 0 ; (1'93); It.F.P. 8.

Cooper, Chas. L. L. (b'64)-Ky.4,8z; (1'94). OLATON, 30, OHIO

Byers, A. 11. $\rightarrow$; $\left(1^{\prime} 93\right)$

Fellx, Chas. W.-Ky.2,90; (1'93);

OLDTOWN, 50, GREENUP

Iorrls, Wm. S. (b'i0)-Ky,1,06; (1'0i).

OLIVE HILL, I,I32, CARTER

ARMSTIONG, H. WYLIE (b'70)-Ǩy.1,94; $(1997)$

Autenreld, Feliela-NHeh.1,99; (末)

Hillman, Andrew Jackson (b'î)-Ky.5,97, (l'9i)

HLDGINS, CECIL L. (b'57)£-Mo.7,'89 $\left(1^{\prime} 93\right)$

MrCleese, Chas. (b'76)-Mo.28,99; (1'99), HOSE, JAMES MADISON (b'84)-Ky.2, 09 (1'09); $\mathrm{S}$.

OLMSTEAD, 50, LOGAN

KRMP', Al'THUR R. (b'83) - Tenn.6,05; (l'05); It.F.D. 1.

LEE, FRED iVILSON (b'76) - Ky.5, 00 ; $\left(l^{\prime} 00\right)$; R.F.D. 1.

OLYMPIA, 200, BATH

CLAIK, NIMHOD T.-Ky.2,'92; (1'93).

ONEIDA, 400, CLAY

JONES, PRESTON JENNINGS (b'80) Ky.2,0 0 ; (1'11).

ONO, 75, RUSSELL

TARTER, JAMIES BALLINGER (b'81) - Ky.2, 10 ; $\left(1_{1} 10\right)$

ONTON, 50, WEBSTER

JWNKINS, J. EMERY (b'8i) - Ky.2,'12; (1'12).

ORANGEBURG (R.F.D., MAYSVILLE), 125,

HOKD, Wa1. H. (b'63)--Ky.2,86; (1'94), LE KITES, DELBERT L. P. (b'80)-Ky.2, 09; (1'09) ; R.F.D. 3

ORDINARY, 35, ELLLIOTT

Brown, Wales S. (b'69)-Ky.1, 00 ; $\left(1^{\prime} 00\right)$.

OSCAR, 50, BALLARD

CSHER, HARLAND VFRNON (b'80)-Ky.2, $05 ;(1,05)$

OTTENHEIM (R.F.D., WAYNESBURG), 100 LINCOLN, HANS JAMES $\left(\mathrm{b}^{\prime} 48\right) \notin-I \mathrm{I} .3$, '87; (1'12).

OTTUSVILLE (POLSGROVE P.0.), 20, FRANKLIN
IIN, ROB'T. BENJ. (b'71)-Ky.1,93; (1'93)

OWENSBORO, 16,011, DAVIESS

ARMENDT, LOUIS G. (b'51) - Ky.2,'76; $\left(1^{\prime} 93\right) ; 801$ Loeust St. ; office, 110 W. $3 \mathrm{~d}$; AKNHIII

$4151 / 2$ Frederlca St.

BARR, GEO. L. (b'î)-Ky.5,98; (1'98): 505 Griffith Are, office, 209 w, 4 th St

Bell, Robt. B. (col.) (b'72)-Tenn.7,"03; (l'03); 1208 W. 5 th St.; offce, $210 \frac{1 / 2}{\mathrm{Al}}$ len St.; 9-10, 12-1, 4-5.

Carpenter, A. W-Ky.5, 6 ; (1'93) ; 1010 Walnut St.

CotPman, John Marvin (b'78)-Ga.9,'12 ; (1'12); 315 Allen St. ; 8-12, 1-5.

(unningham, Isaac Summersvllle (col) $\left(b^{\prime} 77\right)$-Tenn.,,$^{\prime} 08$; (1'10); 524 Vine St.; $8-10,2-4$

Danlel, Chas. T. Ky.2,92; (l'93) ; R.F.D.

DAVIS, ANIOS (b'48)-Ky.2,74; (1'98); 609 Allen St.; office $1061 / 2,2 \mathrm{~d}$ St.; 8-12, 2-5. IXON, JAMES THOMAS $\left(\mathrm{b}^{\prime} 69\right) \oplus-$ Mo.1 '94; (1'94); 600 Frederica St.; office, $3 \mathrm{~d}$ and St. Ann Sts.

EARIY, JAMES LOCIS $\left(b^{\prime} 67\right) \oplus-K y .1,94$ (l'94) ; 902 W. 1st St.; office, Allen and 2d Sts.; $9-12,2-5,7-9 ; 0 \mathrm{bG}$

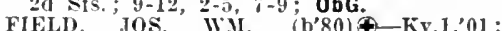
(1'01); 3d and St. Ann Sts.; office, Smith Bldg. : 9-11, 2-4, $7-8$; U.

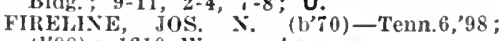
(1'98); 1210 Werner Are.

FOSTER, ALEX. C (b'62) - Ky.2,97. $(197) ; 330$.llen st. : $9-11,2-4, i-8 ; G$ FONTER, RI(HALI) I. (b'70) (l'u(1); Nember Okla. State Med. Assn. 


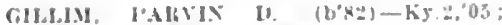
$\left(10^{\prime}(0): 113\right.$ st. Ann st.

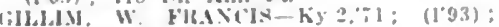
319 Fredlerlea sit.

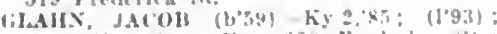
600 Allen st. once. 280 Frederlea st. 9-11, $2-4$.

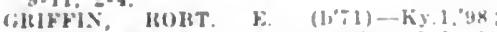

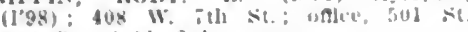
Inn St. : $9-11$. $2-4$

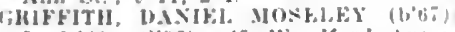
La. 1,88: (1'93): 4.5 llimlford Al' flee, 207 W, th st.: $9-12:$ OALR.

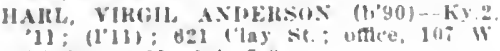
3d St. : $9-11,2-4, i=8$.

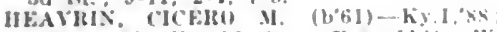
(1.93): 801 11, ad si. : oftece, $116^{\circ}$ \% 11 2d st.: $8.10,2.4$.

IIESTR, JAMr: IIARVE (b*s) lis

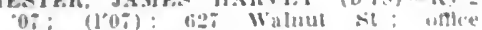
Masonlc Mldy.: $y-1$ : OALR.

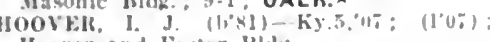
IJover and Fositer Mlgh.

noovklk, JU1: (') $(1,61)+111,11,23:$ (1.93); $103 \mathrm{~W}$, th st. $9.11,-2$,

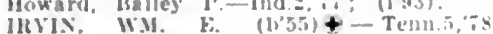
(1.93); 5i: st. AnI si. ofles (entril) Trust HIds: : $9-11,2-1$ : R

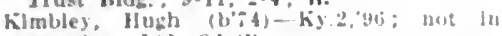
practice: 102. 31 51

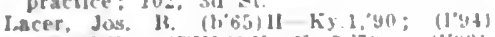
I.AMHKT, STIXSOX-Ky.5.7y; (1'?3) 714 Whg Ave.: (intce, smlth bidg.

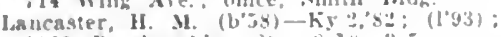
1125 Breckenridge st. : 8.10. 3-:

LOCKHAIT, CIIAS. J.-h), ;

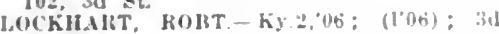
St.

Maddox, John loayton (b"5s)-l'a $2 . x !$ (I'93): not In practlce; 700 Polloar $x$ t.

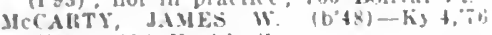
(L'y3): 914 k. th st.

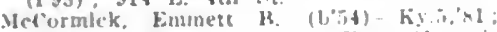

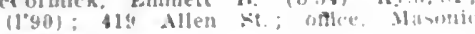
Teinule.

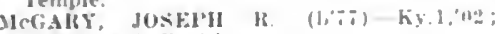
(1'v2): 522 k. 4 th Are

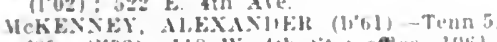

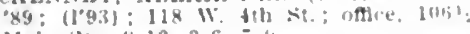
Valn st. : $x-10,3-6, ;-4$.

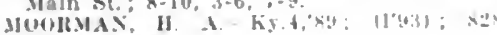
Triplet ite.

yoreland Klobard (cul) (lifio)-Tenn. $94:(1,34):-31$ ienter $\mathrm{xi}$

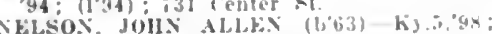
(1'98); 1619 s. Frederlci st. omet smith BIdL: $8+11,1-1$

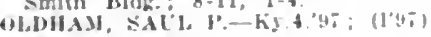

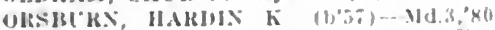

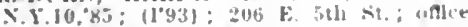
106 is W. ad se. : $2-4$

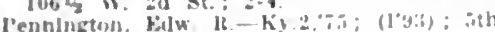
and Mullerty sts.

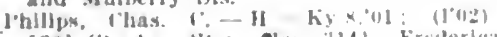

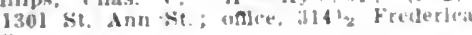
St.

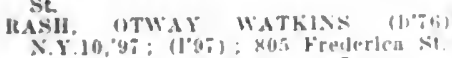
fle, 213 W. th sit. ; 2.-4: S.

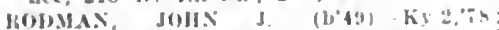

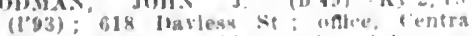

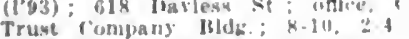

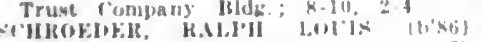

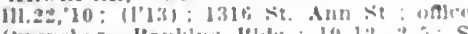

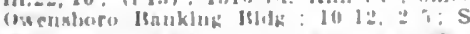

MIIILT\%, MIIEKT ANIIIFW $(1,40)+$

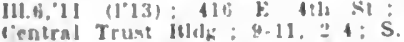

'entral Trust Itlek :

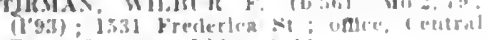
Truvt Company JHale: $9 \cdot 11$

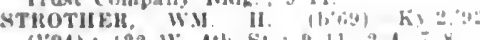
(1.94): $: 22$ 11. ith si : 9-11, 2-1.;

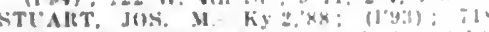

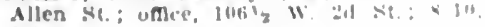
$2-3$

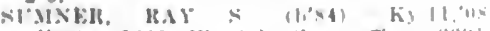

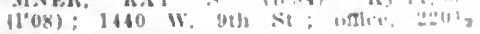
Prederlca st, $9.11,21$

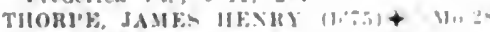

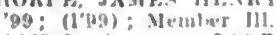

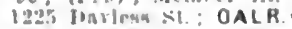

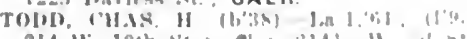

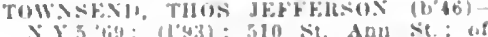

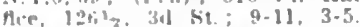

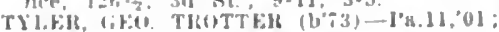

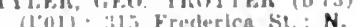

Walker. l'elry li. (col)-li) f'al,"gl; $(1.94)$; t11 pophin is.

Wawhing(on, Kansom l. (col.) (b;3)-

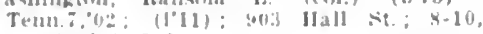
$11-12,2-1,5-6$

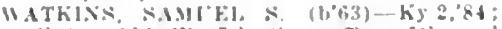

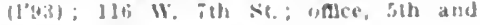
lis.

OWENTON, 1,024, OWEN

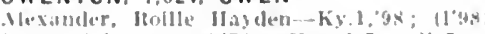

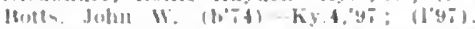

(IIHSMAX. JHIX II. (1,t6)-Ky.1.92: (l'9:3)

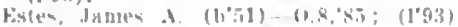

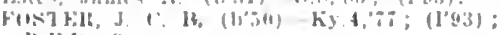

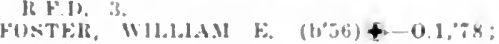
(l'9.3)

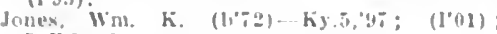
H F.I. 1.

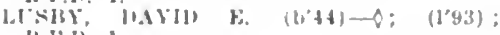

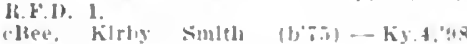
(1,is).

\section{OWINGSVILLE, 9\$2, BATH}

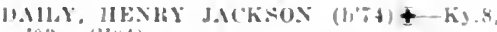
$03:(1204)$

illuikilo, FlBasis b'HESTOS (b60) ky $2,2^{2} ;\left(1^{\prime} 43\right)$

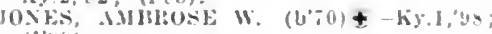
(1) 140 ).

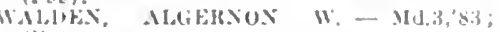
(10.0.

OXFORD (R.F.D. GEORGETOWN), 85 SCOTT

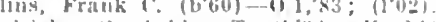

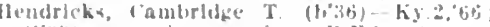

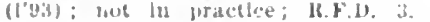

PACKARD, 75, WHITLEY

I'ETLEY, I'ASTHAL (i. (b'tib) hy t, $(1.93)$

PADUCAH, 22.760, MCCRACKEN

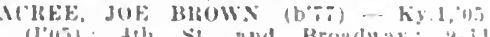
(1'45): thl st. and Broadmat; it. il. viifik $30, a^{+}+8$

hy, llospltal.

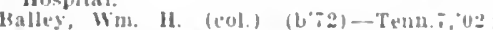

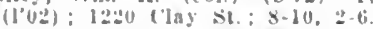

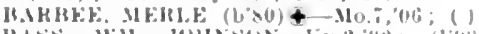

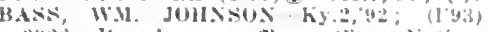
az:2 Hroadway: unce, Cliy clatona Bank Mld.: 8-4, 1-3.

BLYTHE, FFKXVIN $\left(\mathrm{b}^{\prime} 76\right)+$ Y $1.1 \% 00$

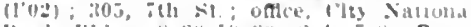

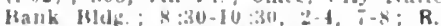

mill Fllar (1)

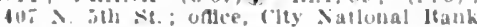
M1.13.

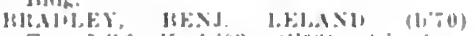

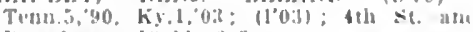
Iroaluas; $110-11,2-3$.

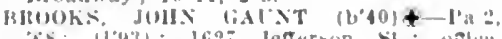

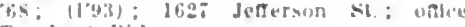
Truehart Hels.

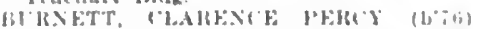

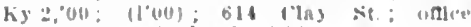

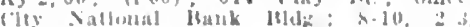
$7-10: 5$.

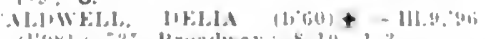

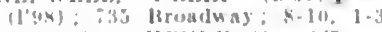

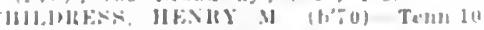

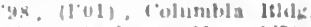

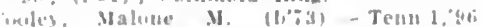
(1'vii) $4: 1 \leqslant$ \& ans

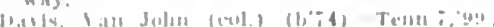
$11,4: 9$

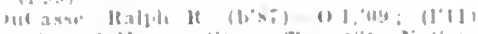

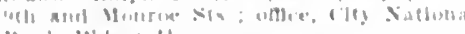
lionh 1 ill. : :

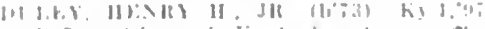

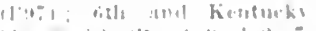

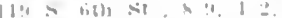

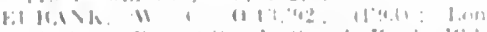

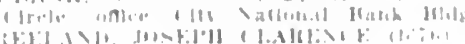

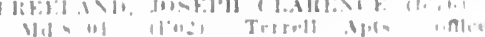

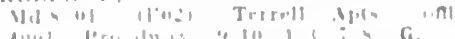

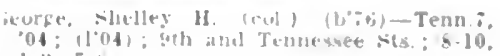

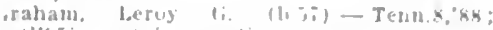
$11.45) ; 130$ in juacilo

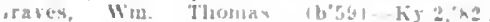

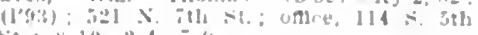

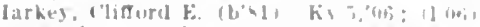

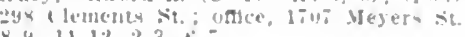
$x-4,11-1: 2,2,4,2$

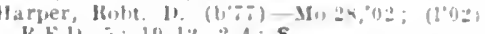
k f, l, i: $10-1: 2,-4 ; s$.

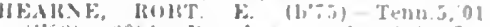

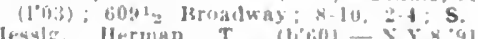

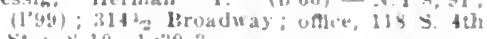
Si. : $x-10,1: 30-3$.

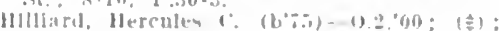
$\mathrm{K} \mathrm{F}^{\circ}$.l.

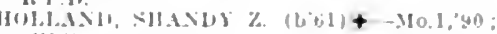
$\left(l^{\prime} 93\right)$.

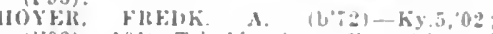
$11^{\prime} 021$ : 1015 Trimble st: unlee, eith and Kruadway: 9-11, 1-3, ;-4: G.

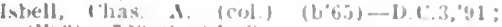

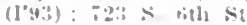

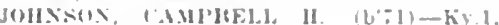

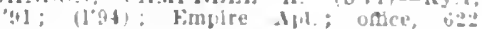
lirualway, $1-1,1-4$.

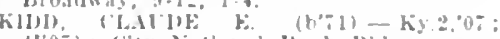
(I.0-): (Jly Natlonal Jank Bldg.

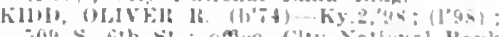
ilitis

1V H oy: (1'10); 1619 Jefferson si: otlce,

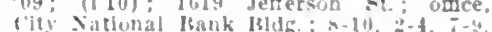

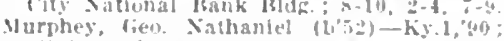
$(1.43)$ tih si. and Itroadway.

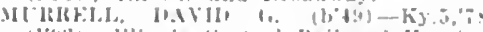

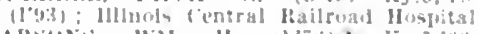

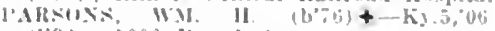
(l'(1)is) : ifion Itrual st.

lendley, Juhn W. (bothl) Tenn. \&.93; (1943): 1711 Madison sit, : onjce, 20abo IBroadway.

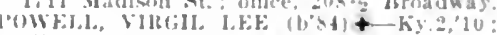
(lio): it23 kroudway: athe, lilinuls

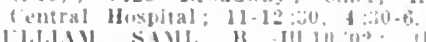

1.1.1.1.11, F.1.11, 13 -111.11, 02,11021

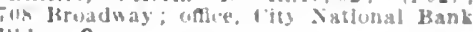
Is!d L : G.

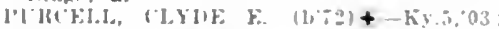
$(1+1,3): 321$ x sils si : onlee, Fraternlty lide: $9-1 ;$ OALR.

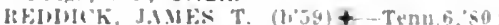

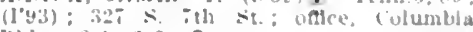
IBdg: $: 8-9,2-3 ; G$.

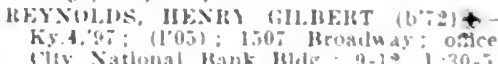
(1il) Nationa

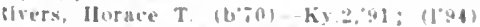
flig Natlomal bank Bldih.

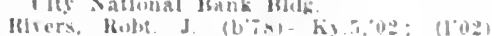
Fraternlty आlda

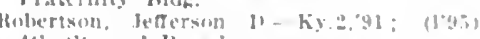
tih sit. and Broaduay.

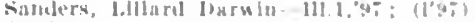

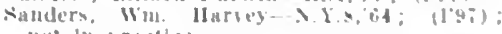
eus In prillethere

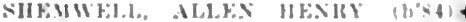
Mo.34,10: (1"10); flty Datonal Bank III

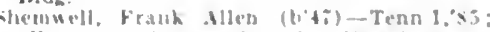

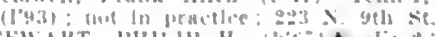

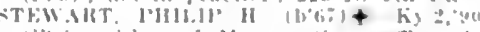

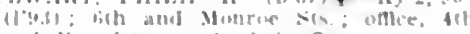

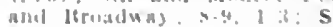

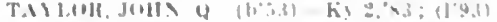

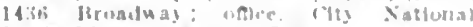

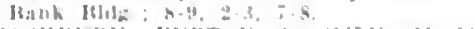

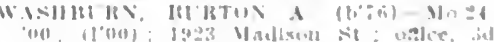

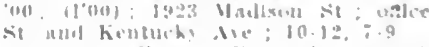

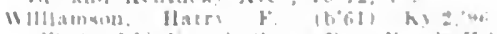

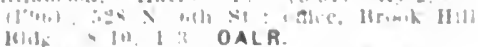

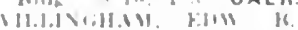

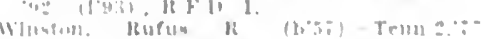

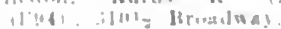

PAINT LICK. 223. GARRARD

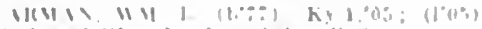

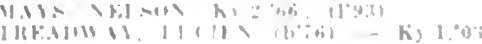


PAINTSVILLE, 942, JOHNSON

A'TKINSON, WM. 'T. (b'48) - Mo.8,'̈2;

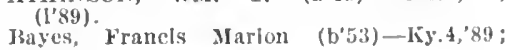
(1'?3).

DANIFi. GItEEX Y.-Tenn.10,01; (1"01).

HOLBROOK, JAMkS H.-Ky.I, 00 ; (I'00).

SPALKS, JAMES C'ECHL (b'75)-Ky.5,06; (I'06).

Turner, J. K. $\rightarrow$; (1'43)

WHLIAMs, FlE.HI: Mc.-Tenn.10,93; (1'93).

PANOLA, I00, MADISON

Jolunston, silas $\mathrm{N}$. (1,'ib)-Ky, 2, 88 ; (I'93),

PANTHER (R.F.D., UTICA), 75. DAVIESS

WALKEIt, M[RRY IIAMIII

KY.2,'I2; (I'I2); R.F.I).

PARADISE. 91, MUHLENBERG

simlth, Firbert s. (b'54)-Ky.2,'s9; (1'93).

PARIS, 5.859, BOURBON

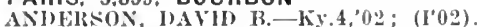

ASOWN, JOIN TIOMAS (b't5)-Ill.1,89 (1.93).

COX, WALTER (b's8)-KY.2,'12; (1'12).

DALGHEHTY, CHAS. G. (b'T1) $\oplus$ - N.Y.19, '99; (1'99).

EVAXS, S'llAS-KY.J,'82; (1'93).

FAKIES, FIKANk M. (b'61)-0.13,'85; (I'I0)

FI'THAN, FRANKÐ-I'a.1,'84; (1'93)

GILKEY, JOIIN A.-Pa.I,'93; (1'93).

KELLEI, ARTII'R H. (b'60)-Ky.4,'8I ; (l'10).

KENNEY, WM., JR-Ky.1,98; (1'98).

LAPSLEY, FRANK I. (b'66)-Ky.5,94 (I'95).

Mcclure, B. F. (b'bI)- $\rightarrow$; $\left(l^{\prime} 94\right) ;$ R.F.D. 3

Melone, John W. (col.) (b'66) - Tenn. 6,94 ; (l'94).

oberdorfer, Nathan (b'b0)-Ky.2,'82; (1'02) not in practlce.

POAGE, LYDIA LLOYD-0.21, 02; (I'04).

RANKIN, GEOHGE L. (b; 77$) \notin-K y .1,04$; (1'04).

Sebree, James H.-Ky.7,'92; (1'93).

Stern, Mllton J. (b'89)-N.Y.19,'11; (1'13) OALR. *

Stivers, Margaret C. Wood-0.8,'89; (l’93) not in practlce.

TSSERY, WM. C. (b'61)£-0.1,'90; (l'96)

van-Sant, John T. (b'53)-N.Y.9,79; (1'93)

Wallingford, J. Stnart $\left(\mathrm{b}^{\prime} 68\right)-0.1,95$ $\left(1^{\prime} 96\right)$.

Wlikerson, Wn. C. (b'54)-Ky.2,'81; (1'93); 262 IIouston Are.

Wllliams, John M. (b'70)-Ky.4,93; (l'93).

PARKERS LAKE, 200 MOCREARY

Cain, Cornelius E. (b'72)-Mo.28,'01; (1'01).

PARKSVILLE, 200, BOYLE

SPARROW, WM. D.-КУ.5,'05; (I'06)

PATESVILLE, 300, HANCOCK

Frymire, It. W. (b'5I)- 0 ; (1'94).

IIJNER, J. T. (b'72)-Ky.4,97; (1'97).

PAYNEVILLE, 75, MEADE

HARDESTY, THADDEL'S H. (b'62)€Ky.I,'94; $\left(I^{\prime} 94\right)$; 0b.

YOUTSLER, DAYID E. (b'63)+-Ky.9,'06; (I'07).

PEACH GROVE (R.F.D., BUTLER), 35, PENDLETON

CRAM, FIVA A. (b'it)-Ky.1,03; (1'04).

PELLYTON, 85, ADAIR

GABBERT, FORDYCE G. (b'83)-Ky.2,'09; (l'09).

PEMBROKE, 731, CHRISTIAN

ALIEN, THOS. POTTS (b'59)-Ky.2,'84

(1'93); R.F.D. 1 . LOUIS (b'76)-Ky.2,'98; (1'98)

Ferguson, Robt. Vaughn-Pa.2,'85; (l'93)

Lackey, Geo. W. (b'41)-Ky.5,'76; (I'93).

Morrison, R. P. (b'59)-Tenn.5,'80; (I'94).

PAINE, JAMES R. (b'46)-Tenn.1, 72 ; (I'93).

WATTS, HENRY W.-KY.4,'94;

(1'94); R.F.D.

PENICI, 25, MARION

HOURIGAN, ROB'. R. (b'64)-Ky.2,'89 ; (l'93)

PUTXAX, JOHN L. (b'82)-Ky.1,06; (l'07). PENROD, 68, MUHLENBERG

Bewley, Eugene M. (b'66)-Ky.4,'89; (1'93). PEOPLES, 100 , JACKSON

KISG, ROBT. W. (b'72)-Tenn.9, 02 ; (1'04).
PERRYVILLE, 407, BOYLE

('AlIWElla, J. KIIIIN (b'61)-Ky.2,'88;

GODBEY, DUKE M. (b'79)థ-Ky.5, 05 ;

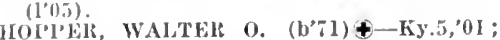
(1'01).

I'ITTMAN, IIENItY M. $\left(b^{\prime} 6 \sigma\right) \notin-K y .5,94$; (1'b4).

PETERSBURG, 393, BOONE

BHACKBURY, JAMES THOS. (b'65)-Fy.1, 'si ; (l’93); Ob.

(IRINT, JAMES iI. (b'52)\$-0.1,73, Pa.2,

'75; ; (1'93). Kalph c.-Ky.1,'89; (l'93)

Walton, Ilubert-Ky.5, 05; (1'05).

PETERSVILLE, 80, LEWIS

Bellony, John W'm. (b'84)-Ky.2,'12; (l'12).

PETROLEUM, 75, ALLEN

NII.IER, AltCY OSCO (b'85)-Ky.2,11; (1'11).

PHIL, 40, CASEY

IcIBeath, Welby A.-No.28,01; (l'01).

PHILPOT, 50, DAVIESS

Ford, Otwell Howird (b'76)-Ky.2,0I ; $\left(1^{\prime} 01\right)$; not in practice.

IIARRIS, SAML. JUSTUS $\left(b^{\prime} 42\right) \oplus-K y .2$, $72 ;(1,93)$.

KILK, JAMES A. (b'81)-Ky.5,04; (1'04) ; R.F.D. 1.

PIERCE, 20, GREEN

THOMI'SON, EDWAIRD L. (b'66)-Ky.1,'92; (1'93).

PIKEVILLE, 1,280, PIKE

CASEBOLT, SOLOMON B. (b'85)€-Ky.2, 'I1; (1'11).

Gray, 1. E.-0.9, 73 ; (1'93).

l'inson, Marlon-Ga.9, 92 ; (1'97).

S'TALLARD, HAZELTON' H. (b'64)-0.14, $90 ;(1,93)$.

THOMPSON, ZACH. A. $\left(\mathrm{b}^{*} 58\right) €-\mathrm{Id} .6,05$;

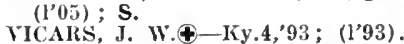

WALTEIS, WM. J. (b'67) $\$$-Tenn.10,'98, Ky.1,00; (1'00).

PILOT OAK (R.F.D., FULTON), 90, GRAVES

Cavender, Jos. Oscar (b'84)-Ky.2,11 ; (1'11); R.F.D. 3.

PINCKARD, 90, WOODFORD

Smith, Reuben Henifee (b'75)-Ky.9,05: (\%) ; R.F.D. 7 .

PINE KNOT, 200, MCCREARY

HARMON, J. EDW.-KY.5,'05; (1'05)

SIEVEIL', ROBT. C. (b'83) - Ky.11,'08; (l'08).

Stephens, Wm. C.-Tenn.9,'94; (1'97).

PINEVILLE, 2,16I, BELL

IIN(HHAM, JAMES S. (b'62) - Ky.2,'85; (l'06).

COCKRELL, BENJ. ALISON (b'86)-Ky.2, COMBS, MASON (b'83)€-Ky.5,05; (l'05) UIRHAM, CIIRISTOPHER C. (b'66) Ky.1,'94; (1'94).

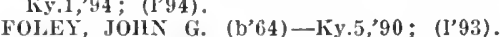
NUCKOLS, O. P. (b'61)-Tenn.6,'91; (l'91) RAISEY, TILAAN (b'75) - Tenn.6,'99 (l'02).

WIIs0N, EDWF. (b'79)-Ky.5,'03; (l'03); $\mathrm{S}$.

\section{PIQUA, 70, ROBERTSON}

Mullikin, Josiah Wm. (b'82) - Ky.2,'10; (1'10).

PISGAH, I5, WOODFORD

HART, ROBT. S. (b'43)-Mf.3,'69; (1'93)

PITTSBURG, 934, LAUREL

ACTON, JAIIES A.-Ky.2,'93; (1'95).

PLANO, 25, WARREN

FREEMAN, GALEN II. (b'76)-Tenn.6.'00 (l'\$8).

PLEASANT RIDGE (R.F.D., LIVIA), 30 , DAVIESS

SHULTZ, ZEBULON HAHILTON (b'67)KY:5, $01 ;\left(l^{\prime} 01\right)$

PLEASANT VIEW, 325, WHITLEY

CROUCH. EDWARD S. (b'84)-Ky,11,08; (1'09).

PLEASURE RIDGE PARK (VALLEY STA P. D.) I50, JEFFERSON

SHACKLETTE WADE G. (b'76)-Ky.9,'06 (1'06).
PLEASUREVILLE, 522, HENRY

Goodwin, O. P. (b',6)-Ky.4,'02; (I'03)

Innes, II. 13. (1'66)-Ky.5,'92; (1'97).

PLUM LICK (R.F.D., NORTH MIDDLE.

TOWN), 30, BOURBON

Ilcclure, P. L.-K.'.4,91; (l'93).

PLUMMERS LANDING, 104, FLEMING

IITFF, JOIIN I'RESTON (b'47)-0.2,85; $(1,93)$

Jessee, W. F.-0.8,02; (1'03)

POMEROYTON, 30, MENIFEE

Kendrick, James W. (b'50) $\rightarrow$; (l'94).

POOLE, 179, WEBSTER

Duncan, Itoscoe C. (b'75) - Ky.9,'06 : (l'06).

Thornberry, Wlll M.-Ky.2,'74; (1'93).

POOR FORK, I50, HARLAN

Flelds, David Ilaggard (b'82)-Ky.2,07 ; (1'09).

POPE, 18, ALLEN

DIXON, ANDItFW J. (b'51) - Tenn.6,"92; (1'93).

POPLAR PLAINS, 190, FLEMING

Swetnain, Elmer (b'7z)-Ky.1,03; (l'03).

PORTSMOUTH, 50, BREATHITT

Boon, Eugene Herbert (b'83) - Tenn.19, 10; ( ).

POTTERTOWN (R.F.D., ALMO), I00, CAL. LOWAY

BLALOCK, ELIJAH POB'T. (b'79)-Ky.2, 05 ; (1'06)

OUTLAND, JAMES ALFRED (b'84)-Ky.2, '12; (1'12) ; R.F.D. I.

POWDER MILLS, 50, HART

FORD, GEO. W. (b'57)-Ky.5,'89; (I'94).

POWERS (ELLISBURG P.0.), II6, CASEY

MURPHY, WM. 'T.—Ky.2,'92; (l'98).

POWERSBURG, 15, WAYNE

l'owers, Millard F. (b'59)-Ky.2,95; (1'95).

PRAISE, 300, PIKE

JOHNSON, IKEED SPENCER (b'82)-Ky.2, '12; (1'12).

PINSON, YAN BUREN (b'77)-Ky.9,'06; SANDERS, PERRY CLINE (b'81) - Ky.2, 10 ; (1'10).

PRENTISS, 66, OHIO

Smith, Henry (b'79)-Ky.5,'03; (1'03).

PRESTONSBURG, I,120, FLOYD

CaIlihan, G. Darwin (b'80)-0.2,04; (1'04).

Callihan, Wm. R.-0.2,'03; (l'03).

IIOWARD, GROVER LA'THAM (b'84)MId.1,11; (1'13); Nember W.Ya. State Med. Assn.

Richmond, W. W. (b'73)-Ky.4,'97; (1'97).

Sizemore, John-0.1,96; (1'96).

PRESTONVILLE, I62, CARROLL

Webster, Albert T. (b'58) -0.13,'99; (I'98) ; not in practice.

PRINCESS (R.F.D. I, ASHLAND), 300 , BOYD

Sturgell, John D. (b'72)-Ky.1,'94; (l'94).

PRINCETON, 3,015, CALDWELL

Baker, W'. T. (b'69)-Ky.5,92; (l'02).

BARBER, IRA ZELNA $\left(b^{\prime} 76\right)-K y .2,05$; (1'05).

CASH $_{*}$ WM. LOUARD (b'80)-Ky.5,07; (1'07).

Cunningham, Zachary Taylor (b'49) Tenn.5,'80; (1'94)

Jones, John R. (b'82)-Ky.5,'02; (l'02)

MILLER, JOS. A. H. (b'59)屯-Ky.2,'89; (l'93).

HOORE, JESSE M.-Ky.5, 01 ; (l'01).

Norse, Wm. Livingston $\left(b^{\prime} 7 t\right)-K y .2,13$; (1'13)

MORSE, WI. PATRICK (b'74)-Ky.5,0T: $\left(1^{\prime} 07\right)$ : R.F.D. 1.

OGILIF, RICHARD WOODS (b'76)-Ky.5 $00 ;(1,00)$.

POLLAIRD, CHAS. JACKSON (b'73)-Ky.8,

'97; (I'98). (1'93).

Sloss, Imit Herman (col.) (b'80)-Tenn.7,

(l'93).

TAYLOR, GEO. CARR (b'S0)-Ill.22,'I0; (1'11) : OALR.

Vadlington, John B. (b'76) - Ky.8,99: (l'98).

WALKER, FRANK (b'69)-Ky.2,'94; (1'94); R.F.J. 1. 
PROSPECT, SO, JEFFERSON

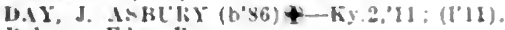

l'almer. Edw. It.

(See Loulstille.)

PROVIDENCE, 2,084, WEBSTER

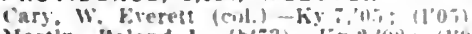

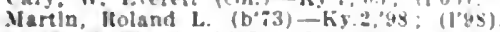

RICE, KIIN. X. (6'6i)-Ky.2, $43 ;\left(1^{\prime} 93\right)$.

stone, James chas. (col.) (b'bis)-Ky.7,05: (1'95).

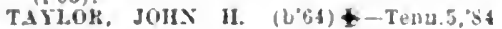
(1.93).

WALLACE, JAMES BEXJ. (U66) -KY, 05 ; (1'05).

whllians, Alrlas O.-Ky.2,'9i; (1'9i).

PRYORSBURG, 242, GRAVES

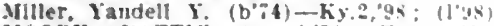

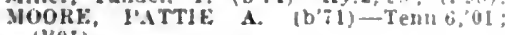
$\left(l^{\prime} 01\right)$

Slaughter, Saml. II -liy.2."99; (1'03)

PT. ROYAL. 152, HENRY

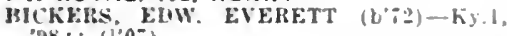
$95::(1,07)$.

CHAPMLA, OSCAR I', (b'it)-ky,j,00; (l'03).

PUEBLO, 35, WAYNE

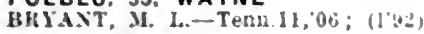

PUROY, 25, ADAIR

I'ERRYMAX, IR. H. (b'11)-Ky, I,'J5; (1'43)

QUALITY, 60, BUTLER

IIARIEK, RICHAKD W. (b'i)-Ky,2, 33 : (1'33)

QUICKSAND, -, BREATHITT

HOGE, IYKVIX ELGENE (L? (1'06).

RABBITT HASH (R.F.D., GRANT), 75 BOONE

CARLILE. WAN EARLE (b'8H)-Ky.? OS: (1'09).

RAGLAND (R.F.D., KEVIL), 25, MC. CRACKEN

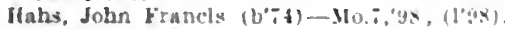

RALSTON, - BELL

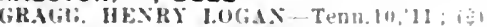
Member Tean. Siate Med. Assi.

RANDOLPH, 78, METCALFE

OWEX, JAMES H. (b"50)-Ky 4,75; 11.93$\}$

RAYWICK, 182, MARION

MTCHELI. ULDKOX A. (b.3) - KY:L, 05 (l'03).

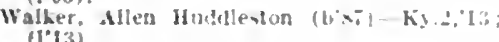

REDASH, 500, WHITLEY

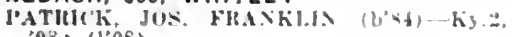
03: (1'05)

REDRUSH, 100 , JOHNSON

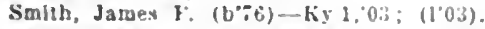

REDHOUSE, I30, MADISON

WILLIAMS, DAVID JUHS $\left(\mathrm{b}^{*} \mathrm{i}\right) t-$

REED, 75, HENDERSON

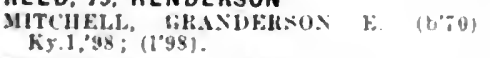

REPTON, 35, CRITTENDEN

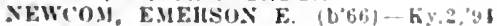
(1'94).

REPUBLCAN (KITE P.0.), 50, KNOTT

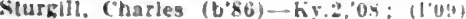

RICHAROSON, 150, LAWRENCE

WRAL. WM. W. (b'i0)-MU.4,

RICHARDSVILLE, 30, WARREN

I'RANCIS, CHAS, B. (b's1) - KY, 4,04:

RICHLIEU, 10, LOGAN

QOTSU:, JAMBS CABI,ISI.

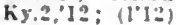

RICHMOND, 3,340, MADISON

Halen, C. J.-MII., 28 : $11^{\circ} 031$

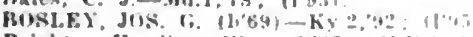

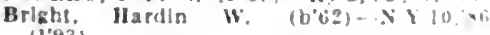
(1'93)

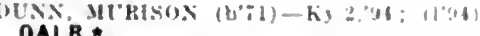

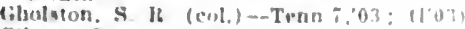

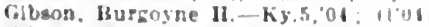

Cibson, Iluah $K$ - Tenn $5,2 x:$ i

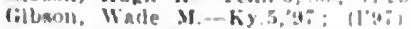

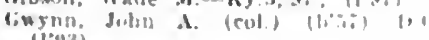

II:y3)

Heach, Moses C.-N Y.10:-7: (19y:
Hollon, thas, Sincot (b'61)II- I11.4,85;

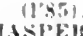

JASPRA, HFNIt C. (b'63) - Ky.1.89:

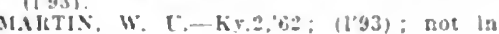

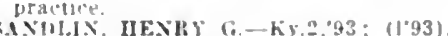

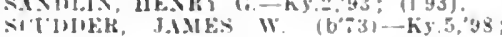
a Tlilk

suren (has F-III.10,499: (l'49)

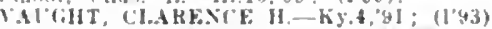

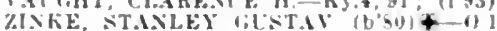

(11.): $11,131: \mathrm{s}$

RICH POND, I5, WARREN

HEAX, HESII FRAXKI.IX (1,53)-KY.2 $76 ;(1+13) ; \mathbf{G}$.

RIGHTANGLE, 20, CLARK

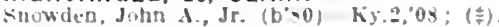
RIM, 100, BELL

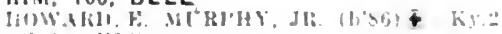
'IR: ITOS).

RINEYVILLE, I00, HARDIN

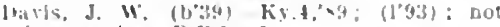
in practice; R.F.I' I. W. (bens) Ky. U1: (1.93).

RIVERSIDE, 25. WARREN

HIIIIS, JOHN ANIERSON (b\%:)-Ky:" Q0:; $(1007)$.

ROARING SPRINGS (WEAVERS STORE, TENN.. P. O.). 75 . TRHGG

Hille, Henry J. J. (b'50)- (1.94)

ROBARD, 334, HENDERSON

B(W)K, H.MU'TUX' D.KY.2.84; (1'93)

HENTON, AlHERT \&-Ky.1,

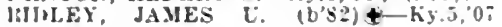

(loi).

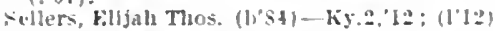

ROCHESTER, 437, BUTLER

III'NT, W.I. C. (b'58)-Ky.2.'59: (1'93).

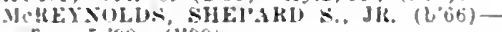
renn. 5.'99: (1'99).

WKSTEIFILLL, WM. I. (b'35)-Tenn.s,'y3; $\left(l^{\prime} y 3\right)$.

ROCKCASTLE, 73, TRIGG

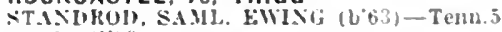
X6: (1.43).

ROCKFIELD, 181, WARREN

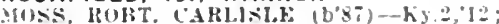
(1'12)

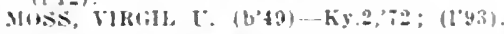

ROCKHOLDS, 300, WHITLEY

SMITH, rkSTES STEKLY (b'79)-lis.5,05;

ROCKPORT, 638, OHIO

Jark, Indersen 1). (2:5.5)-Ky,5,01: (l'01)

ROCKYHILL STATION, 138 , EDMONSON

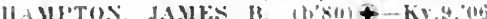
$(10 i): \mathbf{G}$.

II udige, Francls Marton $\left(b^{\prime 2}-s\right) \rightarrow A$ : (1'03).

ROGERS, 30, WOLFE

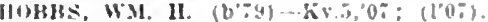

ROME, 50, DAVIESS

It.IIIR, FIII.-Ky.4,03; (l'03)

Medley, ('has. L.-hy, 1, 6 ; (1'ys).

ROSEDALE, 30, CARTER

T.IBII, HIIRIII II. (b'67) + Ky l, 99 $(1)(2), P) ; P d$.

ROSINE, 166, OHIO

Iains, $\times$ J. $\left(b^{\prime}+5\right)-K+175:\left(1^{\circ} 07\right)$

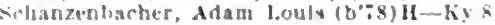
03: 1 1'031)

ROTHWELL, I00, MENIFEE

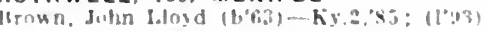
Het in practice.

ROUNDHILL. 50, BUTLER

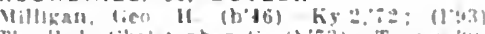

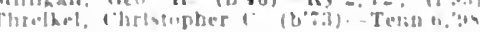
(1:?צY)

ROWENA, 25, RUSSELL

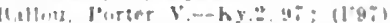

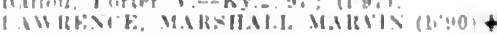
KY: $13 ;$; (1'13); OALR

ROWLETTS, 233, HART

(UIII) MUISUIN I.

RUSH. 300, BOYD

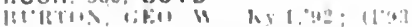

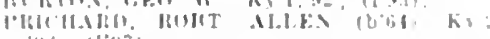

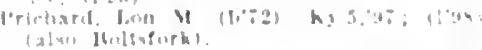

RUSSELL. 1,038 , GREENUP

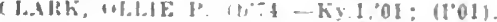

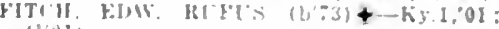

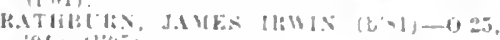

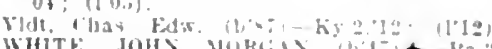
WItTh JOHS MURHA

RUSSELL SPRINGS, 104. RUSSELL

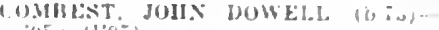
(05); 110.5$)$.

RUSSELLVILLE, 3,111, LOGAN

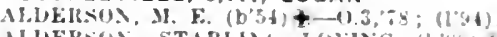

IIUERSOI, STIRIIN, LUVING (b'ss) III.il, ob: (1'09)

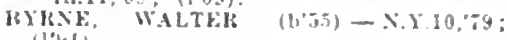
(l'y)

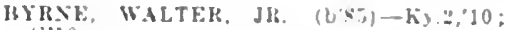
$(l, 10)$

Thambers, W. H (col.) Ky.t,

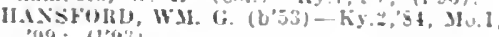
jot: 11293$)$

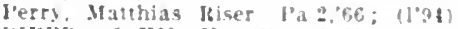

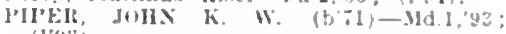
(1'93)

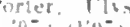

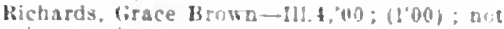
In practice.

WLKERSON, LEONART L. $\left(\mathrm{b}^{\prime}, t\right) \notin-k y 9$, $02:(1,0:-)$

RYLAND (VISALIA P.D.). - KENTON

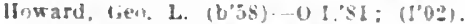

SACRAMENTO, 438 , MCLEAN

l'larke, J. Wu. (b'5s)-Ky.7.49; (1"43)

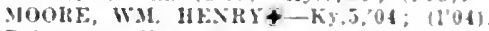

Robertan, Chas. li.-Ky,a'st; (I"y).

SADIEVILLE, 467, SCOTT

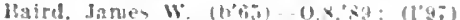

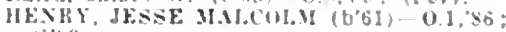

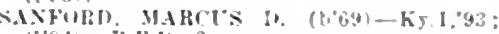
(1'24); L. H.I). 2

SALEM, 320, LIVINGSTON

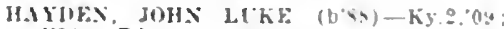

HAlDEX: JOHS Y+o.4 is: (1"93)

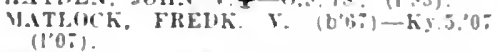

Waddell, loy (b'si)-Ky.2,09: (l'09).

SALOMA, 45, TAYLOR

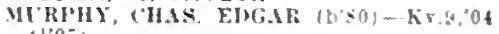
(l,0i)

SALT LICK. 332, BATH

ILF.XINIIEL, SI'FATE.K $90:(1,93)$.

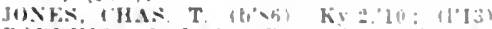

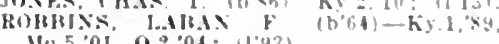

Me.5,01, $02001 ;(1.93)$

SALVISA, 300, MERCER

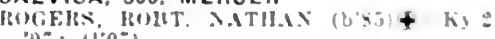
(i) $:(100 \div)$

SE.AY, F. V-Ky 2:93; 1193

SALYERSVILLE, 310, MAGOFFIN

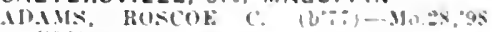
(1098)

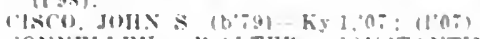

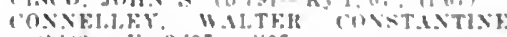

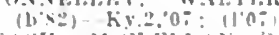

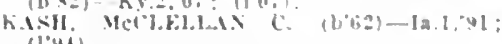
$\left(l^{2} y+\right)$

SANDERS, 250 , CARROLL

WII.I.IMX, RKNU D

11 loma

SANDGAP, 20, JACKSON

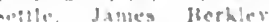

SANDY HOOK. 148, ELLIOTT

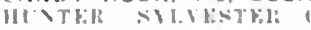

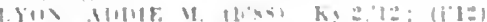

SARDIS. 261. MASON

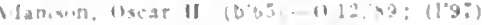

SCHOCHOH IRT.D., ADAIRUILLEI, 33 LOLIAN

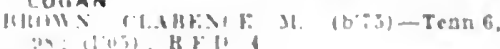


SCHOOLFIELD (R.F.D., CALIFORNIA), 75, CAMPBELL

SPILIAN, WU. IIENKY-0.9,69; (1'93). SCIENCE HILL, 257, PULASKI

KELLY, JOHN C. R. (b'61)-Ky.2,87 $\left(l^{\prime} 94\right)$.

Plimell, Geo, W, (b'39) E- - $2,27:$ : (1'43)

WARKEX, NARIOX (b) - Ky.

(l'06)

Weddle, Achllles (b'79)-Ky.11,08; (I'X2).

SCOTTSVILLE, 1,327, ALLEN

(ALLS, WI. ALLEX (b'73)-Ky.9, 03 (I'03).

CALVERT, CALEB A. (b'76)†-Mo.28,98;

HARIIS, WM. H. (b'66)↔-Tenn.6,'88; (1':3); R.t.1).

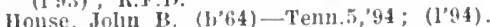

KEEN, GEO. MHAY (b' 53$) \uparrow-$ Ténn.6, 00 ;

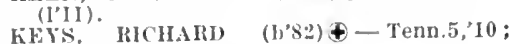

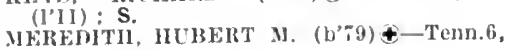

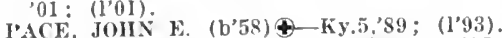
WHITI,OW, ELONZO A. $\left(\mathrm{b}^{\prime} 79\right) \oplus-\mathrm{K}$ y.2, 07

WHLOCGHBY, WM. F. (1, 66$)-\mathrm{Ky} .4,93$; (l'94).

SEBREE, 1,500, WEBSTER

DL'YALI, WM. NELSON (b'i6)-Ga.9, 00 ; (1'01).

EIWALOS, CHAS. L. (b'63)-Mo.I, 86 ; (I'94).

HARDI ; wy y. (b'64)-Ky.2,93; (1'93)

HARDIN, WM. M. (b'64)-KY, '10; (1'10).

SEDALIA, 250, GRAVES

KIRLSEY, JOHN F, (b'i5) - Ky.2,97; $\left(1^{\prime} y\right)$.

Bhodes, Arnolphus W.-Tenn.5,83; (1'93).

SEVENTY-SIX, 150, CLINTON

Frogge, Wm. Arthur (b'85) - Ky.2,'09; (声).

SEXTONS CREEK, 80, CLAY

Sparks, IIenry C. (b'65)-Ky.4,'92; (I'93). SEYMOUR (R.F.D., HORSE CAVE), 75,

\section{HART}

Edwards, W. T. -Ky.1,5z; (1'93); not in practlce.

SHADY GROVE, 200, CRITTENDEN

Collins, Geo, C-KY, 5,07; (1'07).

McConnell, Jeff. D.-Ky.2,90; (1'93).

SHARONGROVE, 300, TODD

ESCUE, BAKER E.-Tenn.6,'03; (1'93) ; Pd.

SHARP (R.F.D., BENTON), IO, MARSHALL EDDLEMAN, OWEN A. (b'i6)-Tenn.9,02; (1'02).

SHARPSBURG, 4I0, BATH

CONWAY, SETH-KY.9,05; (l'05).

Donaldson, Espey R. (b'82) - Ky.4, 06 $\left(1^{\prime} 06\right)$.

FFLAND, JOHX M.-Ky.5,'85; (I'94).

Renfro, Jos. W. - Ky.2, $78 ;(1,98)$.

WELLS, JAMES K. (b'6\%)-Ky,1,94; (I'94) R.F.D. 1.

SHARPSVILLE (R.F.D., MACKVILLE), 50. WASHINGTON

Adams, Robt. F. (b'37)-Ky.2,75; (1'93).

SHAWHAN, 300, BOURBON

KNOX, EI, FRENCH (b'6i) - Ky.5,'05 (l'05).

Smith, Frank Harman (b'83)-Ky.2,'13; (l'13).

SHELBYVILLE, 3,412, SHELBY

BEARD, FRANK MAJOR (b'69)Ð-Ky.2,'93 (1'94).

BEARD, SAML. JOWRY (b'76)†-Ky.2,'00; BLAND, T. EUGENE (b'66)-Ky.2,'92; BLA,9D,

BRANAMAN, ERNEST I. (b'i2)-Ky.2,94; Bt'CKXER, WH. THOS. (b'68)-Ky,2,'83;

EG(9EN, JOHN L. (b'45)-Ky.4,'71; (l'93) ;

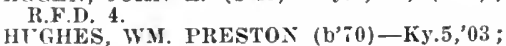

LAWPFiNCE, GRAHAM (b'70)-Ky.2,'92;

Lncke, Willis D. (col.) (b'i4)-Tenn.i,'01; IfcClasky, Benj. (b'59)-Ky.2,'80; (1'94); not in practice; R.F.D.
MELTON, JESSE L.—KY.5,'02; (1'05) :

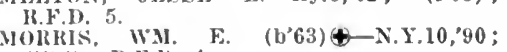
(1'94); R.F.I). 4.

Norris, Rolit. I. (col.) (b'65)-D.C.3,89; (I'sis)

S.MITH, k. 13.-111.10,'95; (1'95).

Turner, Lconard A. (b'83)-Ky.9,06; $\left(\mathrm{I}^{\prime} 06\right)$; not in practlce.

SHEPHERDSVILLE, 318, BULLITT

BATES, SA.MI. W. (b'74)థ-KY.2,"96; (1'45). (l'y4) ; K.F.1. 2.

KIRK, GEO. W' (b'61)-Ky.5, 83 ; (1'05) ; H.F.D. 2 .

Purdom, Drue McBride (b'86)-Ky.2,'10; RINGWAY, SAML, HOWARD (b'72)‡-

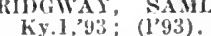

shafer, John H. (b'53) $\rightarrow$; (

SHERBURNE, 253，FLEMING

ICCLURE, WM. BOONE (b'74)-Tenn.1, '99; (1'99). (1'02).

SHERMAN, 350, GRANT

PRICE, JOS. L. (b'60)£-Ky.1,'84; (1'93).

Zinn, Wm. J.-0.1,'57; (1'03).

SHIVELY, I90, JEFFERSON

('ooper, Jos. B. K.-Ky,2,'94; (1'94).

SHORT CREEK, 125, GRAYSON

MC:MLLLIN, ROBT. H. (b'60)-Ky.1,91; (1,93).

OZMFNT, W.. LEE (b'i6)-Ky.2,'13 (I'13); Member Tenn. State Med. Asśn.

SHREVE (R.F.D., FORDSVILLE), 35, OHIO (iodsey. D. II.-Ky.5,0I; (Y'OI); R.F.D. 2. SHREWSBURY, 100, GRAYSON

DUYALI, GEO. WILBUR $\left(\mathrm{b}^{\prime} 80\right) €-$ Ky.5, '06; ( $\left.1^{\prime} 06\right)$.

SILVER GROVE, - CAMPBELL

FRANZ, JESSE ALBEHT (b'85)థ-K'Y.2, 10 : (l'10).

SIMMONS, 20, OHIO

LAKE, WILLARD $\left(\mathrm{b}^{\prime} 83\right) \oplus-\mathrm{Ky}, 2,{ }^{\prime} 10$; $\left(\mathrm{I}^{\prime} 10\right)$; S.

\section{SIMPSONVILLE, I85, SHELBY}

ICMCRRY, TINSLY J. (b.66)-Ky.2, 89 ; (1'93)

PERRL; JOS. (b'43)-Ky.4,'83; (l'94).

SKYLIGHT, 75, OLDHAM

SMISER, W. J. M.-KY.1,'84; (1'93).

SLATER (R.F.D., WICKLIFFE), 25, BALLARD

DAVIS. THOS. J. (b'78) - Tenn.5,'94; (I'94).

SLAUGHTERVILLE, 443, WEBSTER

COSBY, W. C.-Tenn.6,'93; (1'93).

TANNER, CHAS. R.-Tenn.6,01; (l'02).

Whitson, Harmon H.-Tenn.1,57; (1'93) : not in practice.

Whltson, James H. (b'84)-Ky.1,05; (1'05). SMITHFIELD, 350, HENRY

(ilasscock, H. W.-Ky.2,75; $\left(1^{\prime} 9 T\right)$; R.F.D. 1. HAXCOCK, CURTIS LEWIS (b'83)-Ky.5, 04 ; (1'04).

ZARIXG, ABKAHAN MASON (b'T0)-Ky.5. $98 ;\left(1^{\prime} 99\right)$.

SMITHLAND, 557, LIVINGSTON

Adams, Lynn D. (b'80)-Ky.5,04; (1'04).

Duley, Henry H.-0.8,'81; (1'93).

LA RUE, FREU. G. (b'66)-Ky.2,94; (1'94).

SMITH MILLS, 300, HENDERSON

COOPER, JAMES $W$ - Ky.1,68; (1'03).

GABHART, JOHN HENRY (b'i 78 - Ky.2, 08 :

(1'09).

JONES, GEO. FIELDING (b'90)-Ky.2,12;

JONES, OWEN G. $\quad\left(b^{\prime} 67\right) \oplus-K y .1,98$; (1'98).

ROYSTER, GEO. MARTIN (b'8i)-Ky.2,11; (I'13).

SMITHS GROVE, 726, WARREN

COOKE. JOHN F. (b'64)-KY.2,'88; (1'93). EWING, GEO. T. (b'50)-KY.2, 71 ; (1'93). GRIDER, JAMES A. (b'i1) - Ky.2,94; $\left(1^{\prime} 01\right) ; P d$.

Ruble, Wm. R. (b'56) E-0.2,87; (l'93).

SIMMONS, WAITER CLARENCE (b'68) -Tenn.1, 90 ; (1'93).
STONE, DANL. BOONE (b'60)-Tenn.6, 88 ; (1'93); K.F.D.

Thomas, Jullus B. (b'4l) - Ky.2,70; (l'93).

Wooten, Junlus (i'45) - Ky.2,68; (1'94).

SMYRNA (R.F.D., LOUISVILLE), 26, JEF. FERSON

Cooper, M. L. (b'36)-Ky.1,59; (1'93).

SNIDER, 60, SPENCER

SNIDER, TIOMAS J. (b'8I)-Ky.11,08; (l'08).

SOLDIER, I50, CARTER

Goodman, T. Dellitt (1,87)-Kiy.2,'12; (1'12).

SOMERSET, 4.49I, PULASKI

Baute, Jos. A. (b'68)-III.15,96; (l'96)

BOLIN, J. A. (b'72)-Mo.28,98; (1'99).

CAIN, ACIILLLES WADE (b'6 6$) €-\mathrm{Ky} .2$. $\left.90 ;(1)^{\prime} 93\right) ; \mathbf{S}$. JASP'ER, GÁLEN E. (b'64)↔-Ky.1, 02 ;

NORFLEET, CARL $\quad\left(b^{\prime} 81\right) \oplus-K 5.5,05$; (1'05); OALR.

Owens, Jos. M. (b'65) - Tenn.6,'86; (1'98). PARKER, SAMIL. F. (b'82) - Ky.5,05; $\left(1^{\prime}(05)\right.$.

Richardson, Robt. Gibson (b'88)-Ill.15,'13; (1'13).

Taylor, Frank A. (b'46)-Ky.2,90; (l'00).

TRIMBLE, VOLANTUS G. (b'75) - Ky.2,09; (l'09).

Waddle, Chas. L. (b'80)-Ky.5, 03 ; (l'03).

WAHLE, AUGUST JOHN (b'81) \&-Ky.2,

WARKEN, IS $A A C$ S. (b'55) - Ky,1, il; (1'95).

SONORA, 250, HAROIN

GLASSCOCK, JOHN F. (b'79)-Ky., 01 ; $\left(l^{\prime} 02\right)$.

LIGON, WM. A. (b'39)-Ky,2,74; (l'93). $\left(l^{\prime} 06\right)$.

SORGHO, 100, DAVIESS

TURNER, EDHOND DANL. (b' 74$) €-K y . \bar{y}$, 06 ; $\left(1^{\prime} 06\right)$.

SOUTH, 20, GRAYSON

Tilford, J. K. P. - 0 ; (l'93).

SOUTH CARROLLTON, 365, MUHLENBERG BARNES, JOHN ROBERT (b'60)-KY.2,'92; (1'93).

Moorman, John Newton-Tenn.1,60; (l'93).

SOUTH ELKHORN (R.F.D., LEXINGTON), 100, FAYETTE

Crosby, Davld A. (b'64)-No.27,'97; (1'97).

SOUTH PARK, I00, JEFFERSON

COOGLE, CHAS. PERRY (b'8i)-Ky.2,'11; (l'I1).

Díck, Edgar G. (b'51)H-Ill.4,'88; (l'06).

SPARTA, 107, GALLATIN

GRANT, JOHN B. (b'45)-Ky.4,'78; (1'94). STALLARD, JAMES M. (b'i1)-KY.I,'98; (1'98).

SPEARS, 30, JESSAMINE

EADS, JOHN B. (b'70)-Ky.2,97; (l'98)

SPEEDWELL, 75, MADISON

COOMER, ROBT. C. (b'i4)-K'́y.1,02; (1'02).

SPENCER (MT. STERLING P.0.), 50, MONTGOMERY

FAULKNER, MORTON-Ky.1,04; (I'04).

Hickman, Benj. J. (col.) (b'64)-0.2,'91; (1'01).

SPOTTSVILLE, 448, HENDERSON

DIXON, ROBT. W. (b'70)-Ky.1,96; $\left(1^{\prime} 96\right)$. IfcCarty, Thomas Clayton (b'39) $\longrightarrow ;\left(1^{\prime} 94\right)$.

SPOUTSPRING, 40, ESTILL

W'inburn, Henry M. (b'68)-Ky.4,'94; (l'94).

SPRINGDALE, 90, MASON

W'Inder, Thos. J.-Ky.1,'81; (1'93).

SPRINGFIELD, I,329, WASHINGTON

BARNETTE, W. T. (b'75)-Ky.1,00 ; (l'01).

Beam, Augustus G. (col.) (b'80)-Ky.7,06; $\left(l^{\prime} 06\right)$.

Debo, John (b'39)-Ky.2,68; (I'93).

HOPPER, JOS. HOWERTON (b'i6)-Ky.5, 98 ; (l'98); R.F.D. 3.

HYATT, M. W. (b'67)-Ky.1,94; (1'95)

ICINTYKE, EDW. L. (b'64) - Ky.1,89 ; (1'93).

MUDD, JAMES C.-Ky.1,97; ( ( 96$)$.

RAY, WM. W. (b'52)-N.Y.10,77; (1'93).

WRIGHT, J. S. (b'i 1 )-Ky.5, 02 ; (1'02). 
SPRING LICK. 144. GRAYSON

GIVAX, SADFOLD LAMMIEA-KJ.2,"93; (l'93).

5T. CHARLES, 660, HOPKINS

CUKRY, DALFERE.S P. (b'79)-Ky.0,03 (1'03): T.

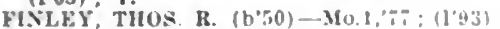

ST, MARY, 154, MARION

FLA.NAGAS, THOS. ER.NEST (b's0)-Ky.1. 03: (1'03)

SMOCK, HARVEY r. (b'11)-Ky,1,96; (1'98).

ST, MATTHEWS, 125, JEFFERSON

Brady, John A. (b'\%0)-Ky.2,93; (1.97).

WOODARD. ROBT. LEF

(See Loulsville.)

STAMPING GROUND, 381, SCOTT

CRUTCIIFIEL, PlNK 11. (b'69)-Ky.1,'93; (1*93): R.F.D. \&.

MasoN, WM. (b;8)-Ky.1, $06 ;\left(l^{\prime} 00^{\circ}\right)$

SALIN, WILI, B. (b'67)-Ky.4,88: (1'93).

WILIIOIT, DFNXIS (b'69) - ky.5,00; (1 05).

STANFORD, I.532, LINCOLN

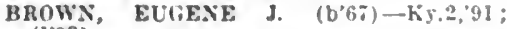
(1'93).

CARPESTER, JAMFS GIVESS (b.54) N.1.5, $\div 5:(193)$

Cralg. W. X. (b'7l)-Ky.4,95; (l'95).

Cralg. W. N. $\left(b^{\prime} 71\right)-K y 4,95 ;\left(l^{\prime} 9.\right)$

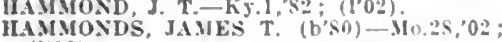

MORRIS, JAMES T. (b' 61$)+\mathrm{Ky} .2,89$; (l'93).

O'BAXXON, Wม. B. (b'55)-0.2,'s3; (1'93) : Op.

PERKY, GEO, G. M-M.3,93: (1'93)

PEYTON, JAMES FHANKLI (b'33) \&

-1.1.67:(1.93): s.

I'HILLI'S. MILTON IILLEIR (b'\$1)-Ky.5

Philits.

Reld. II

SOUTHLAD, DANL. H. (b'it) $\$-K y, 5,2 x$ (l'98).

Tardlf, Win. D., Jr. (col.) - К‥7,94; (1’94)

STANLEY, 200, DAVIESS

FILIATIREAU, RAYMONI N゙. (b'63) 110.27,99, kj.2,00; (1'99)

HOBERTS, JABES I). (b'TI)-Ky.t, 0 i: (1'07).

STANTON, 278, POWELL

JOHXSON, ISHMAEL, W., (b"i4)-Ky,, 01 ; ( 1 in I)

JEMMISG, JOIN E.-O.1.84; (I'95)

MANSFIELT, CASSIU lV DI.E (b'68)-

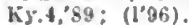

STATION CAMP, 30, ESTILL

Serirner. James $k$. (b',0)-ky.2,92; (1'93)

STEARNS, 100, MCCREARY

GODBEY, LESLEE, JONES (b\%0)-KY. . "98: (1'98).

STEPHENSPORT, 205, BRECKINRIDGE

SIIVELY, GEO. EVEKET $\left(\vartheta^{*}: 8\right)-M \cap .28$ '99: (L'99).

STILLWATER, 75, WOLFE

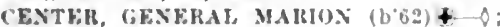
(1’94).

STINNETT (SINAI P.O.), 52, ANDERSON Adams, Wm. E. (b'66)-Ky.2,'\$9; (1'84).

STITHTON, 300, HARDIN

ALILN, MAITTIN SYLVYSTER (b60)Ку. 1,'85: (l'93).

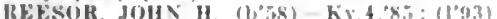

Tarpley, John C. (b'43)-Ky.2,68; (1'93)

STONE, -, PIKE

Clarkwon, James Wrlght (b'89)-Va.4,12: (l'13) : LD.

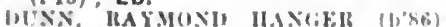

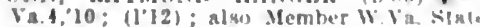
Med. Asisn.; 8 .

STOWERS (R.F.D., FRANKLIN), 120. SIMPSON

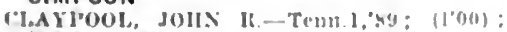
H. F. I. I: Pr.

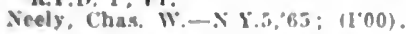

STRAIGHT CREEK, 15, BELL

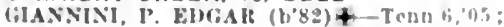
(1'03).

STRODE, 45. MONROE

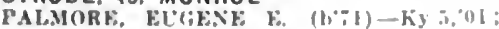
(1'01): Anes.
STURGEON, 50, OWSLEY

MAIIAFY'Y, JOIIX A. (b'66)—-K).5:93: (l'93): 0 p.

STURGIS, I,467, UNION

HIMIIIR: L (1'01).

LINIILF,

(1.03).

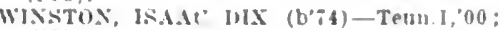
$(1,00)$.

WYXNS, J011. F. (b’7i)-Ky.5,03; (1'03)

SUBLETT, 75, MAGOFFIN

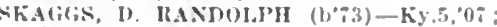
$\left(10^{\circ} 0 \%\right)$.

SUGAR GROVE, 25, BUTLER

(OFFMAN, SAMI. I". (b'56) - Ky.1,86: (I"34).

SULLIVAN, 100, UNION

AMEIRSON, SIMEON SMITH (b'b9) + Tenn. I.9: (I’96).

SULPHUR, 255, HENRY

HANOOIK, FOILIEST INI'KIAP (b'\%)Kу $, 5,98:(1,98)$.

Martin, ( $\because$ Robt. (b't2)-0.9,66; (1'93)

MOIRIS, EVERETT (b'78) † Ky.206: (I'06); T. IORIRIS

SULPHUR WELL, 50, METCALFE

ICPHEHSON, UBFRTO W. $\$-k y .5,97$; (I'98).

SUMMER SHADE, 2I0, METCALFE

BOWMAX, S.MI. MEDFOKD) (1,82)-Ky.2. $00 ;(1,09)$

Denew, rieu. Menbourn (b'61) $\mathbf{E}_{4}$-Tens.5, 93 (l'93).

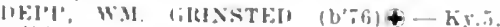
$03 ;(1.03)$

WATSON, MARCLS JINEEY (b'50) Ky.5,'s9: (l'93).

SUMMERSVILLE, 320, GREEN

IF FNIDELSON, ARVIN (b'88) †-KY.2,1! (I'11).

WILIAMS, JOHN M.-KY,4,8s; (1'93).

SUNNYBROOK, 75, WAYNE

BH:RTRAM, OTTO DIBRELI, (b'st) -

Tenn.19,'10: (l'10)

SUNRISE, 65. HARRISON

Beckett, Grover Athey (b'8t) - Ky.1,07: (1'0\%).

TOHD, LAWIEN(F, NEWTON (b'90)-Ky.2 "I2: (1'12).

SUTHERLAND, I0, DAVIESS

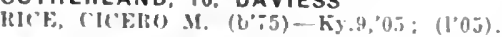

SWITZER, 300, FRANKLIN

DAWTON, WM. H. (b.53)-O.I, 80 ; (1.06).

SYMSONIA (R.F.D. FRISTOE) 75 , GRAVES

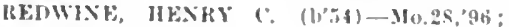
(1'96).

TALEGA, 10, LEE

I1IINSOS, IHCHARI R. (1,*8)-Ky.1.0\%; (l'0i).

TAYLORSVILLE, 622, SPENCER

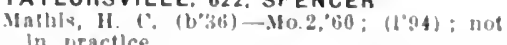

In practlce.

McMalan, k. T. (b'3)-Ky.5.98; (l'9s).

Ohllum, lien, I'. (6'sk)-Ky.2'82: (['93).

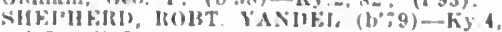

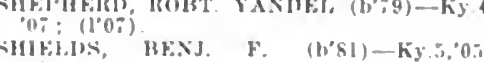
(1'0(i).

TEMPLE HILL, 47. BARREN

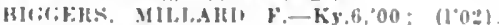

[B]ITT. WM. T

isev lilasgon

TEXAS, 125, WASHINGTON

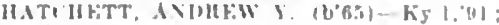

THOMAS, 30, FLOYD

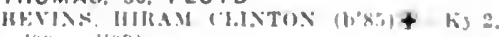
(1)! ; 11.09$)$

THREEFORKS (R.F.D., OAKLAND), 25, WARREN

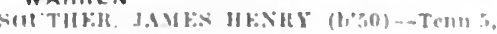

$\because$ :

THREE SPRINGS. I 5. HART

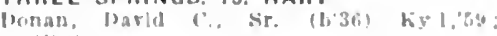
$11 \div 931$
THURSTON (R.F.D. OWENSBORO), 16. DAVIESS

WOOLFOLK, IINLLE A-KY 2";: (I"93)

TILDEN (R.F.D., DIXON), 40, WEBSTER Newman, Vau Buren-0,4, :2; (1.93); not in practlce.

WHITE, qFO. WASHIN⿴囗十OS, JR, (t'ge)Kу.11,08; (1"08).

TILINE, I00, LIVINGSTON

RAIUCI.IF'F, THOII.E'S M. (b':5)-Ky.2,04 (l'04).

TINSLEY, 15. BELL

('OHIM, JUHX L.WWS (b'5)-K, 5,04: (l'04). TODDSPOINT (R.F.D., SHELBYVILLE),
20, SHELBY

BFIUYMAX, HENRY DITTO (b'il)-Ky.2, 08: (l'08).

TOLESBORO, 400, LEWIS

kurellek, Wm. Thos. (b'19) - X.1.15,75: (1'93)

IRIINE, JUIN F. (b'53)--Ky.1.80; $(1.93)$.

TOLU, 182, CRITTENDEN

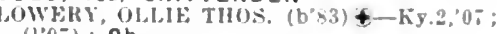
(1'0\%); $0 \mathrm{~b}$.

TOMPKINSVILLE, 639, MONROE

BL'SHONC, (iEO. W.-KY.5,9i; (l'9i)

DLNCAN, RICHARI) F. (b'63)-Ky 2,86; (1.93)

MARRS, J. FRANK (b'80) - Ky.5,05:

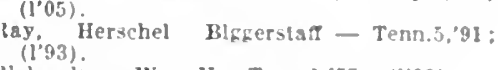

Klchardsun, Wm, k-Tenn. J,

TORCHLIGHT, - LAWRENCE

MAICLM, FRED II.-Ky.4,

TRENCH, 50, ELLIOTT

Sl'AlKKs, WI. E. (U"i1)-K5.1,07; (l'07).

TRENTON, 653, TODD

"olib, llubt. L. (b'8:2)-Tenn. FIRYY, RORT. WESLEY (b'60) + -Tenn. 'Ri : (1'93); R.

GOWER, CH.IS. M.—Tenn. 6,$95 ;(100)$.

IRIIRI, FUGAR T. (b'T1)-Ky.2, 96 ; (1'96).

TRIBUNE, 20, CRITTENDEN

P'ERKINS, THOS.-Pa.4,'52: (1'93).

TRINITY, 75, LEWIS

Graham, John C. (b'68)-Ky,1,'9:; (1'97).

TRISLER (R.F.D. FORDSVILLE), 30 。

Hedden, Wn. C. (b't2)-C; (l'94).

TROSPER, 10, KNOX

JONES, HEVEIRLY 1. (h\%s) - KY.9,06; ( $\left.I^{\prime} 06\right)$.

TROY (R.F.D., PINCKARO), 100, WOOD.

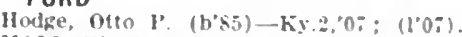

HOLLOWAY, C. C., (b'5)-Ky,:;9; (193).

TURNERS STATION, II5, HENRY

ASHYIL, WM. FRANIIS (b'-3)-Ky 2,0s; (l.08).

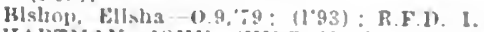

H.IRTMAN, JOHA (HH.TUN (b's3)-K5.2. os: (1,0S).

TYRONE, 544, ANDERSON IPIndar, Leonidas orley $(b ; 0)-01.91$ :
(l'03).

ULYSSES, 20, LAWRENCE

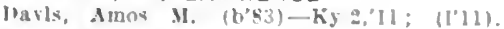

UNION, 275, BOONE

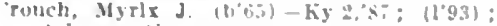
not in practlec.

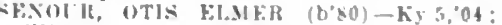
(1.04).

UNION CITY, 40. MADISON

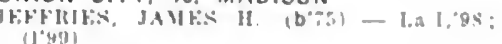

UNION STAR, 80, BRECKINRIDGE

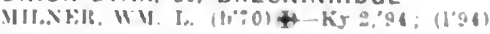

UNIONTOWN, 1.356, UNION

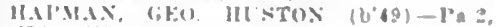

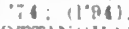

compivilla 1 Als rabis (bse) h! :04: 1104

lingu, Jith II (1,:3)- $:(1,93)$.

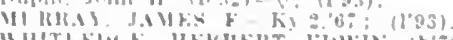

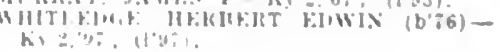


UPTON, IHI, HARDIN

Gadhlie, Wm. I. (b'it2) - Ky.s, 's!?; (I'93) R.F.I. 2

RHGis, CHAS. THOS. (b'5) \&-ky.1,04 (1'04); S.

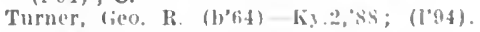

UTICA, 300, DAVIESS

DE WITT, WR.1.Ni B l'enn 6.,99; (1'99)

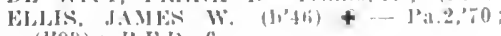
(1?93): R.F.I. 6.

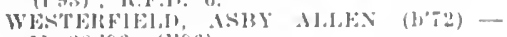
.II0.28.96; (1'96).

VALE, 12, ROWAN

Iorter, silml. J. $\triangle$; (1"00)

VALERIA, 40, WOLFE

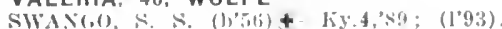

VALLEY, 62, LEWIS

Araham, (lias. J. (b'71)-Ky. I,06; (l’06).

VALLEYOAK. 25, PULASKI

GARNER, THOS. MONROL (b's3)-KY.2, $12 ;(1,22)$.

VALLEY STATION, 200, JEFFERSON

BURXS, WM. ARTIL'R (h'00)-KIy.2,'13;

(1'13); T. *

CHMMAN, O'T"T

'12; (l'l2): T.*

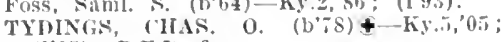
(l'05): R.F.I. 6

WHSOX, DUNNING STEELF:

(Sce I.oulsille.)

VALLEY VIEW, 500, MADISON

Balley, Nẹtson Alouzo (b'80) - Ky,5,05; (l"05).

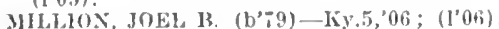

VANBUREN, 15, ANDERSON

Addls, Chas, F. (b'79)-Ky,9,06: (l'06).

VANCEBURG, I,145, LEWIS

BOWMAN, WM. (b'43)-0.1, T5: (l'93).

FULT\%, CHAS. II. (b'76)-Ky.9, 01 , Md.3, ot: (l'01).

I.ILS. JAM ES INALLAS (b'82) \&-Ky.2,'05; (1'05).

WELLS, JASPER MOSS (b'46)-0.2,7\%; (l'94).

VANDERBURG (R.F.D., SLAUGHTERVILLE), III, WEBSTER

COSBY, D. H. $\rightarrow$; (1'93).

Gllbert, Lossie Edmond (b'82) - Ky.2,08; (l'09).

VERONA, 200, BOONE

Finnell, Robt. L.-0.1,' 2 ; (l'94)

MeCormack, James F.-0.1,'95; (1'95).

VERSAILLES, 2,268, WOODFORD

ARNOLD, JOHN IlARRISON (b'69) \-Ra.2, 92; (I'94)

BLAĆKBLRN, S. ALFORD (b'75)-D.C.1 $99:\left(l^{\prime} 99\right)$.

CRENSHAW, JOHN WERXER (b'4s) - Va.1, 75 ; (1'93).

Holt, Jos. P. (b'83)-Ky.4, $04 ;\left(l^{\prime} 04\right)$

Holt, Jos. P. (b'83)-Ky $4,^{\prime} 04 ;\left(\mathbf{l}^{\prime} 04\right)$
Markwell, Chas. (b'68)-Ky.5,'92; (l'94); R.F.I. 5 .

ICCAULEY, WM. CHARIECE (b'69)\&Ky.1,93, N.Y.10,94; (1'94).

Neet, Iohn D. (b'53)-X.Y.5,; 6 ; (l'93),

PARKER, WALTER C. (b'59)-0.1,86; (1'95).

Smith, Richard Saml. (col.) (b'it)-Ky.7, $02 ;(1,02)$

STEDMAN, SAML. M. (b'6s) A-KY.2,91;

Taylor, Harry I'. (col.) (b'ä)-Tenn. Z, 03; (l'03).

VINE GROVE, 570, HARDIN

Cowherd, Joln R.-Ky.5,'03; (1'0:?).

Gray, Oscar A. (b'80)-Ky.4,07; (l'0z).

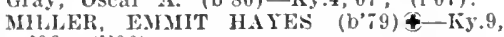
06 ; (1'06)

Viller, Otis Filmore (b'b5) H - Ky.8, 02 ;

(1'02) ; OALR.
MOXTCOMHRY, EDWI WALLACE (b'76) + -Ky.2, $00 ;\left(l^{\prime} 00\right)$

VIPER, 67, FERRY

('AMPIBELI, GREEN W. (b'テT)-Ky.2,1I: (l'12)

VIRGIE, 125, PIKE

Bund, Alwert Curtis (b'84)-Ky.2,'11; (l'11) hond, Clras. F. (b'75)-Tenn.10,01; (1'01). Walter, Edgar Poe (b'so)-Ky.5,07; (I'09).
VISALIA, 250, KENTON

Foreman, limest Mason (b'75)-Ky.4,97; $\left(1, u_{i}\right)$

(iranf. Juck 11.-0.1,95; (1'95)

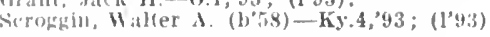
VORTEX, 75, WOLFE

I'rollte, Iria (i. (b'3!) - Ky.1,'92; (1'33).

WACO, $2 I 0$, MADISON

T.AYJalk, V.JRII (b'Tl)-Ky.5,06; (l'96).

WADDY, 254, SHELBY

JESSEL' JOLN F. (b'58)-Ky.4,'s8; (l'03).

WADESBORO (R,F.D, HARDIN), 45, CALLOWAY

Covlngton, Gius 11.--0; (1'93).

WAKEFIELD, 100 , SPENCER

WO0], ERNEST C. (b'78)-Ky.9,06; (1'07).

WALLINS CREEK, 75, HARLAN

IIUWARD, W.I. K. (b'84) $†-K y^{\prime}, ' 12$; (1'12).

WALLONIA, I0I, TRIGG

H.AYWOE, WM. CLINTON, (b'80)-Ky.8, 05 ; $(105)$.

WALNUTHILL (R.F.D., LEXINGTON), 60, FAYETTE

lavin, Wm. J. K. (1'70)-Ky.2,93; (l'04). WALTON, 650, BOONE

Hagby, Daml. M.-0.1,66; (I'93); not in practice.

Jones, Asa N. (b'55)-0.1,'8I; (1'95).

MENLFEE, B. KNIFFIN (b'64)-Ky.4,93; (I’94); OALR.

Metcalfe, Columbus c. $\left(b^{\prime} 76\right)-0.1,01$; (l'0]).

liNkIN, GROVER C. (b'84)-Ky.11,0s; (l'08)

WARFIELD, I00, MARTIN

Ilaws, Hezekiah (b'T3)-Ky.1,03; (1'04).

WARREN, 50, KNOX

SNEAD, WM. WINSTOY (b'80)-Va.1,06; (l'09).

WARSAW, 900, GALLATIN

BROWN, JAMES S. (b'44) - Tenn.1,'66 (I’93)

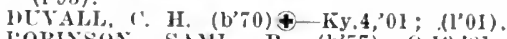

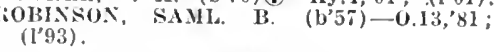

WASHINGTON, 433, MASON

Berry, Irvin (b'78)-Ky.1,04; (1'04).

Hunter, Alexander (b'43)-1'a.1,'69; (l'94)

WATERFORD, 206, SPENCER

Fl'NISH, JAMES FLOYD (b'82) - KY.l,

'08; (l'11).

not in practice.

WATER VALLEY, 228, GRAVES

Hamlet, Wm. Stephen-Ky.1,98; (1'98).

Iramlett, Gardie A. (b's3)-Ky.5, $06 ;\left(l^{\prime} 06\right)$

IR.F.D. 3

Johnson. Oliver 11.-0.2,'85; (l'93).

RiN(io, IROB'T, E, LEE (b'i3)-Ky.2,"98; (1'98).

Teaks, Geo. Finis (b'54)-Tenn.1,75; (*)

WAVERLY, 311 , UNION

GRAI. 'TIOS. B. (b'72)-Ky.2,01; (l'01)

HARDESTY, WM. II. (b'68)-Ky.1,'92; (l'93).

JOHNSON, JOS. EDWIX (b46)-Ky.2,'万1, X.Y.10,'78; (l'y3)

Yewman, Thos. E. (b'65) $\rightarrow$; (l'93).

Watkins, J. A. (b'-4)-Ky.9, 03 ; ( 103 )

WAYNESBURG, 62, LINCOLN

АCTO:, THOS. J. (b'64)-0.2,'91; (I'95).

(ALDWELI, ARAD IEEITH (b'6s)-Ky.2, '97; (l'9s).

WEBBS, I0, GREEN

(iRAHAI1, JMMES C. (b'T)Ð-Ky.2,'11; (l'1I).

WEBBVILLE, 200, LAWRENCE

Nickell, Leander G. (b’s3) - Ky.2, '99; (I'09).

Thompson, David J. (b'74)-Ky.1,'04; (I'04).

WEBSTER, 85, BRECKINRIDGE

Hendrick, Thos. J. (b'60)-Ky.1,'83; (l'93).

Kurtz, H. B.-Ky.2,'76; (l'01)。

WEDONIA, 50, MASON

King, Geo. Ethelbert (b'-4) - Ky.1,'95 (1'98).

WELCHBURG, 50, JACKSON

GOODMAN, GEO. C. (b'66) - Ky.2,90; (l'93).
WEST COVINGTON (COVINGTON P.O)

1.75I, KENTON

Way, Edw. (b'55)-0.8,'88; (l'97).

WEST LIBERTY, 442, MORGAN

CAR'TElk, 13EXJ. F. (b'52) Ky.5, 75 ; (1'94) ('ARTEH, L. L. (l'55)-Ky, I,'82; (l'94).

NICKLLL, If. VOL.VLY (b'6)-Ky.1,98; (1'98).

WIEELKK, WHLEY II. (b'78)-Tenn.10,01; (10I).

WEST LOUISVILLE, 192, DAVIESS

'IAIYTOX, JOIIN II. (b'65) \$-Ky.2,'88: (1'93).

WEST POINT, 782, HARDIN

ClRTCHLR, WM. E. (b'69)-Ky.2,'91 (I'93).

Ilorrison, I.indsay (b'70)-Ky,5,00: (l'00) I'REWIT', JAMES V. (b'62)-Уo.7,'89; (1'93)

HOBELTS, DANL. STHLWELL (b'TI)Ky.1,05; (l'05)

WESTPORT, 300, OLDHAM

OCLESISY, JOS. W:-Ky,4,86; (1'93).

WEST VAN LEAR, - JOHNSON

DAVIS, EUGENE A. (b'69)-Va.1, 99 ;

(1'13); Member W.Va. State Med. Ássn.

WESTVIEW, 25, BRECKINRIDGE

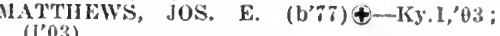

WHEATCROFT, 490, WEBSTER

(RAWFORJ), J. FRANK-Ky.2,01

Dodds, David M. - Ky.5,98; (l'98).

WHEATLEY, 75; OWEN

THRELKELl), AR'THUR E. (b'62)£-IH.10, '86; (1'01). Tinsley, WV P. -Ky.I,'66; (l'93); not in
practice.

WHETSTONE, 20, CUMBERLAND

MYERS, JAMES H.-'Tenn.6,01; (l'01).

WHITE HALL, I5, MADISON

KL'TLFDGE, JOIIN HUNT (b'83)-Ky.2,05:

WHITEHOUSE, I50, JOHNSON

Osborn, Narid (b'66)-Ky.1,'94; (l'94).

WHITE MILLS, 100, HARDIN

cARROLL, CLYUE C. (b'78)-Ky.5, 04 ; (I'04).

OWSLEY, JOSEPH H. (b'41)-KY.2,70; (l'93).

WHITE PLAINS, 281, HOPKINS

BAlLEY, THOS. LIGGETT (b'8i)-Ky.2, '11; (1'11).

BAILEY, WES'T B. (b'61)-Ky.1,'91; (l'93).

BALEY, WM. N. $\left(b^{\prime} 58\right)$ - .Tenn.6,'84; (1'93).

WHITEPOST, I00, PIKE

stepp, Colbert Cecil (b'72)-Ky.9,06;(1'06).

WHITESBURG, 321, LETCHER

13ACH, BLRT C. (b'82) -Ky.2,'10; (1'11); S.

Bently, James Monroe (b'j6) - Ky.9, '06; ( $10 \%$ ).

Fitzpatrick, John D. (b’79) - Ky.9,'04; (l'04).

lson, Gideon Douglas (b'81)-Ky.2,08; (l'08).

I'URSIFULL, PASCHAL Y. (b'79)-Ky.5, '04; (l'06)',

S.HTH, DEMSEY FRANKLIN - Ky.,${ }^{\prime} 0 \%$; (I'07).

WHITESVILLE, 452, DAVIESS

('ARTER, JAMES L. (b'70) - Tenn.8,'98; $\left(I^{\prime} 98\right)$.

MCDONALD, MOSES ALFRED (b'56)£-

TUDIV(;

Ky.2,'84; (1'93).

WICKLIFFE, 989, BALLARD

Juett, David Polk (b'36)-Pa.2,'5\% ; $\left(\mathrm{l}^{3} 93\right)$; G.

MELTON, HARRY R. (b'82) - Ky.5, 05 ; (l'05).

ROGERS, NATHANIEL L. (b'63)\$-Ky,5, '90; (l'93).

SHELTON, EDWIN BRYANT L. (b'65) \&l'a.2,'89; (1'93).

WILDIE, I00, ROCKCASTLE

I.EWIS, ROBT. HENDERSON (b'65) $\oplus-$ Teun.10,'95; (1'98).

WILKERSON (PEARL P.O.), 18, WHITLEY KISHBALGH, GEO. W.-HIJch.5,'87; (1'00). 
WILLARD, 177, CARTER

F'RAIE:Y, HIVII IB. (b'65)-Ky 4,95; $(1.95)$.

WILLIAMSBURG, 2,004, WHITLEY

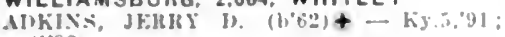
$\left(10^{\circ} 93\right)$

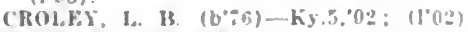

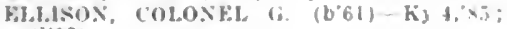
(1.03).

bluley, Frank Wimlford $(6,63)-K y+29:$ $(193)$ : (Montreat, $5\left(c^{\circ}\right)$

Catlin, Ancll-ky,.., $6 b^{\circ}:\left(l^{\circ} 9 s\right)$

MOSS. CHIVE ARTILL (1,8i) (I"00): OALR.

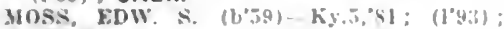
OALR.

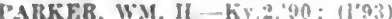

RICIIARDSUN, ANCII, i (b's0)-liy.j, 04 (1"06).

SMITH, LORESZO Osr.A (b'is)-Ky.5, 03: (1'93).

WILLIAMS MINES (MCHENRY P.O.), OHIO

PFNDLETON, HORACE; H. (b;6)-KY: 10: (1'10).

WILLIAMSTOWN, 800, GRANT

ECKILRR, CIIAS. II. (b'RO) \& - Ky.l,os: (1'05).

IIogan, Overton P.-XY.5,'T2; (1'72)

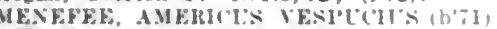
+-KY.4.92; (1"93); OALR.

O'UARA, CLIS. I).-0.1,"95: (l’99)

Scott, Jos. T.-0.8,69; $\left(1^{\prime} 93\right)$; not in practice.

Vloletie, John W.-0.1'T: (1'98\}.

Webb, Albert D.-0.1, 86 ; (1'9;)

ZIXX, WM. J., JR.-0.8,93; (1'94); (Den tist).

WILLISBURG, I50, WASHINGTON

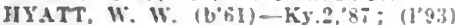

YATES, JOHS BRINTOL (b"6, -K5.9, 05 ; (1'12).

WILMORE, 1.000, JESSAMINE

GIlltsple, Virnll Clay (b'85)-Ky.2,10: (I'II).

McLFi: HLGH L. (b'65) +-Ky.2.'94: (1'94).

Morgan, Alonzo C. -Ky.2,'8g; (1.94).

PFARSON, THEODOKE H. $\left(\mathrm{b}^{\prime}: 9\right)-K y 2$, 03: (1'03).

Phlllps, wim, F-Ky.9.95: (1'93)

SMITHERS, ALREIT L.LKY.2, '8R; (1'93). WILSON (R.F.D., CORYDON), 35, HEN.
DERSON

Ciritin, Fugene M.-Ky.9:97: $\left(\mathrm{l}^{\prime} 00\right)$

WILTON, 200, KNOX

COBLM, GFO. TYE (b'82) - KУ 2,09; (1'09).

WINCHESTER, 7,156, CLARK

Allen, Klchard-Ky.2:90: (1"931: K.F. D. 6

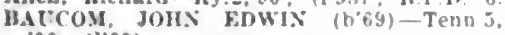
00 ; (l'09)

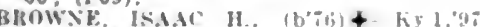
$\left.(1)^{\circ} i\right) ; \mathrm{S}$.
Browne, Moreau s. (b)tt)-- Y. I.10,:4

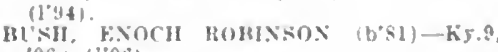
of: (1"0hi).

BI:SII, IIII ALLEN $\left(b^{\prime}, 0\right)-K y .9,05$ :

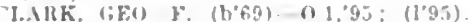

(1)I, Fill

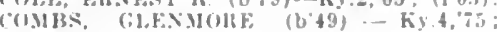
(1.23).

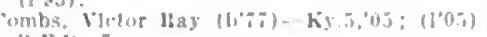
li 5 iा :

beany, Aloraham 83. (col.) - Tenu, ,03 $\left(1^{\prime}(0) \hat{i}\right)$.

FI.OWER. WOUIITFF J (b83)- ky.2 10: (1'11)

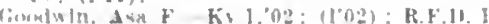

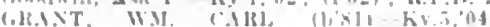

(1) int

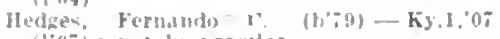

1]"0i) : not in practice.

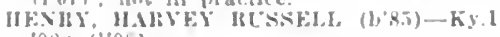
$08 ;$ (1.0s).

Ilutmes, John H. (coll)-Il. (.3.'90: (1"93) lluner, Iilchard Bush $\left(b^{*}+4\right)-0.1,97$ (1'93): not In lractlce; K.F.D. 2

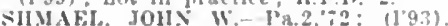

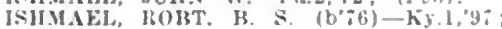
$(1,9 ;)$

JOIISAO, BEXJ. FRANK (b'66)-Ky,j, (I'93).

LJON, HOWARD (b'80)-Ky.4.04: (1'04)

MCKISLFY, NAVID HOWARD (b'84) + Kу.11,08; (l'03).

Nunnelley, Henry c. (t'6i)-Ky.5.90 (1'93)

SHIRLEY, ISAAC A (b's)-Ky.275.

XY.10,79: (l'93).

S.NOWE:, "JOHN A. (b'52) - Ky.4,"79 (1'04).

Tyler, John H. (col.)-Tenn.7,98; (1'98).

Vautht, John C.-H-0.13,90; (193); not in practlce.

F.N.IBLE, Ol.IVER R.MICh.1,85: (19.3) OALR.

Wetrb, Jetgerson-K5.5,"98: (1"98); K.F. I. *

WINGO, 404, GRAVES

Bowllng, W. T. $\rightarrow$ : (1'93).

Davls, Thos, Fdgar - Teun.6,"94; (1"94) R.F.D.

Fllnt, Reauregard F. (1'62)-0.2, 86 : (1"93).

McVeley, Mon-Tenn.6.97: (1"97): OALR

Mulling, stanley (b'82)-Ky.2,06: (1"06).

PAGE, MARION WESIEY (b's1)-Ky.2,09; PAG, M

Wesson. Isaac A (b'48)-Tenn 5,"8I: (I"93).

WISDOM, 50, METCALFE

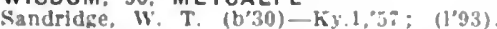

WOFFORD, I20, WHITLEY

AISIIP, AIIUSON W.-Tenn.10;94; (1'y4)

WOLF CREEK, 150, MEADE

Chlism, Fillsha $\left(b^{\circ} 34\right) \rightarrow:\left(l^{\circ} 94\right)$

THENT, JOHX F. (b+5)-KY.2,00: (1993).

WOODBINE, 100, WHITLEY

SILLR, I. STFELI (b'TS)-K5.5.'03: (1"03)

sulliran, Seberry $\left(b^{\circ}+2\right)-0 ;(195)$.
WOODBURN. 217, WARREN

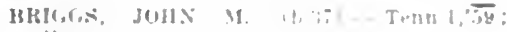

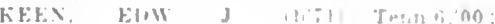

(1'al)

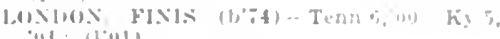
(i1) (1'11).

WOODBURY, 173, BUTLER

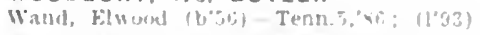

WOODLAKE (R.F.D., STAMPING GROUND), 25. FRANKLIN

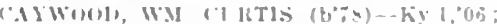
(1)opi)

kihne, II (2. (h'59)-0.13,'s5: (1294)

WOODSTOCK, 50, PULASK1

IS.A.S, (.R:) W (b'59)-0.2.'9I: (1'93)

WOODVILLE (R.F.D., KEVIL), 250, MC CRACKEN

Antlt, WM. Dls/e Ky 2,03: (["03).

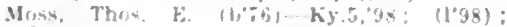
B.F (1).

WORLEY, I50, MCCREARY

("INUFF, W.A.THK BOSCOE (U'b9)-KУ.J, $0 \% ;\left(100^{\circ}\right)$.

WORTHINGTON (R.F.D., ST. MATHEWS) 65. JEFFERSON

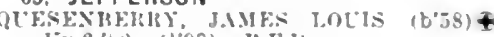
-Ky.2,2:2: (1.93); IS F.II.

WORTHVILLE. 326, CARROLL

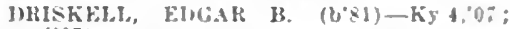
$\left(1^{\prime} 0^{-}\right)$.

GOLIEX, WM. \&-Ky.2,'\$2: (1'93).

MESSISK, W. B, (b'69)-K',4,92; (l'93)

WRIGLEY, 50, MORGAN

Gullett, Jerome $\left(b^{\circ} 80\right)-K y, l, 0 ;$; $(100)$.

WYOMING (R.F.D. OWINGSVILLE), 97. BATH

Anderson, llezkiah Huteher (b"so)-Ky 2 , 10 : $(1,12) ; 0$ b.

YALE, 200, MENIFEE

Nickell, Homer hee $\left(b^{*} S 6\right)-K y .2,10 ;\left(l^{\prime} 10\right)$.

YEAGER, 55. PIKE

DEMPSEL, JIAKK (b"75)-K).J,07: (1"0\%).

YEAMAN, 45, GRAYSON

Reyers, R. A. $\left(b^{*}, 2\right)-K y, 4,03 ;\left(l^{\prime} 03\right)$.

YELVINGTON (R.F.D., MACEO), 400 DAVIESS

MOOKMAX. AIBAN-KY.,90; (1'93).

YERKES, 260, PERRY

Morgan. Geo. Wa-hington (b'su) - Ky a,ll (I'II).

ZION (HENDERSON P.O.), 224, HENDERSON

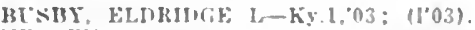

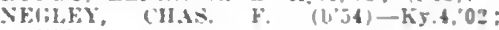
(1'02).

ZULA, 25, WAYNE

HHIT(IW, S.IM). W (1):3) Ters b:06: (l'06).

FOR KEY TO SPECIALTIES. ABBREVIATIONS, SYMBOLS, ETC., SEE PAGE 577 


\section{OU IS I A N A}

Notw.-The general inforration of tinis state includes: Medical Jaw, State Board of Ifealith, I.Icensing Boards, State Soclety, Parish Societies, Parisl and City Health Omcers, State Institutions, IIospitals, Sanatoriums and Charitable Institutlons,

\section{LOUISIANA}

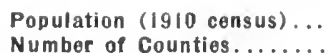

$1,656,388$

Number of Physicians.

64

Members State Society, Dec. 31 ,

$1913 . . . \ldots \ldots$ Area of State in Square Miles.

960

48,506

MEDICAL PRACTICE ACT OF LOUISIANA

Act 49 of 1894 as Amended by Act 244 of (No. 49 .)

908 as Amended by Act 16 of 1912

\section{An Act}

To regulate the practice of medicine, surgery and midwifery; to create State Boards of Medical Examiners, and to regulate the fees and emoluments thereof; to prevent the practice of medicine, surgery and midwifery by unauthorized persons; and to provide for the trial and punishment of violators of the provisions of tilis Act by fine or imprisonment, or both; and to repeai all laws or parts of laws in conflict or inconsistent with this act.

Section I. WHO MAY PRACTICE: Be it enacted by the General Assembly of the state of Louisiana, That from and after the promulgation of this act, no person excepting those already engaged under existing laws in the practice of medicine, surgery, midwifery and cine in any of its departments within the clne in any of its departments within the possess all the quafiflcations required by this Act.

As Amended by Act 244 of 1908 Sec. 2. APPLICANT'S DIPLOMA: Be it enacted by the General Assembly of the state of Louisiana, That Section 2 of an Act entitled "An Act to regulate the practice of medicine, surgery and midwifery, to create State Boards of Medical Examiners, and to regulate the fees and emoluments and to regulate the fees and emoluments thereof, to prevent the practice of medicine, surgery and midwifery by unauthorized persons; and to provide for the trial and punishment of violators of the provisions of this Act by fine and imprisonment, or both; conflict or inconsistent with this Act," being Act No. 49 of the General Assembly of the state of Louisiana, for the year 1894, approved July 4, 1894, be amended and reenacted so as to read as follows: That after the promulgation of this lct, any person before entering on the practice of medicine in any of its branches, dentists and osteo paths excepted, shall present to the Board of Medical Examiners, as hereinafter constituted, a diplona from a college in good standing, of any sect teaching medicine or the healing art, and shall stand a satisfactory examination before the board on the following branches, to-wit: Anatomy, physiology, chemistry, obstetrics, gynecology, physical diagnosis, surgery, pathology, therapeutics and hygiene, provided that any person not using internal medication in his or her practice shall be exempt from examination in therapeutics. The person shall also years of age of possesses at least a fair primary education. factory to the board, they shall issue to such person a certiflcate in shall issue to such facts. Said board, however, is authorized, at its discretion, to waive said examination in favor of any applicant who shall present to the board a satisfactory certificate of examination from a Board of Medicai Ex- aminers of another state; provided, however, that said board created under this Act slials have found that sald Board of Medical Examiners of another state has a hoard created under this Act; the sald board created under this Act to be tie sole judge as to the sufficiency of the
standard required and of the certifleate issued by said board of another state.

Sec. 3. TWO BOARDS OF MEDICAL EXAMINERS ; QUORUM ; APPOINTMENT: Be it further enacted, otc., That the medical examiners herein provided for shall consist of two boards-one of physicians and surgeons recommended by the Louisiana State Medical Society, and one of physiclans and surceons recommended by the Hahnemann State Ifedical Society. There shall be flve members of each board, any three of whom shall constitute a quorum for the purpose of holding an examination and granting a certiflcate. All the members of both boards shall be graduated physicians and practitioners. The board composed of physicians and surgeons recommended by the Louisiana State Medical Soclety shall examine all applicants who propose to practice any other than the homeopathic system of medicine, than the homeopathic system of medicine, and the board composed of physicians recommended by the Hahnemann State Medi-
cal Society shall examine all applicants who propose to practice the homeopathic system of medicine. The certiflcate of either board shall be conclusive proof of the effleiency of the applicant examined by, said board. All examinations held by the boards and the answers of the applicants shall be in writing, and shall be kept as records. All members of both boards shall be apAll members of both boards shall be apa list of names presented by the Louisiana State Medical Society and the Hahnemann State Medical Society, and the governor shall have the right to remove any or all of the members thereof for inefflciency or neglect of duty, and to fill all vacancles occurring in these boards from names recommended by their respective societies.

Sec. 4. ORGANIZATION; TERM OF OFFICE: Be it further enacted, etc., That the first boards of medical examiners appointed under this Act shail meet and organize within thirty days from the date of their appointment, and shall name one nember to serve for the term of two years, one member for the term of three years, one member for the term of four years, one nember for the term of fire years, and one member for the term of six years; deciding member for the term of six years; deciding their respective terms. At the expiration of the above terms each member shall be appointed by the governor for the term of six years, from names recommended by their respective State Medical Societles.

\section{As Amended by Act 16 of 1912}

Sec. 5. MIDWIVES; REGISTRATION FEES; CERTIFICATES; EXAMINATION; TO WHON NOT APPLIED: Be it further enacted, etc., That every person practicing midwifery in this state on the passage of this Act, shall, within ninety days thereafter, register with the secretary of the Board of Health, in the parish of Orteans, and with the clerk of the district court in the other parishes of the state, in the manner provided for the physicians, giving her age and length of time, and the place or places during and at which, she has been engaged in said practice, and make affdavit thereto, and shall pay to the secretary of
the Board of Health in the parish of
orleans, or to the clerk of the district court in the other parishes of the state, as the case may be, a fee of \$1. Said secretary of the Board of Health of the parish of Orleans, or clerk of tile district court, shall issue a certifleate to the one so registering In according with the facts herein set fortin on a biank to be furnished by thie State holder to practice midwifery in the parish in which certiflcate is issued. The clerks of the district courts of the several parishes the district courts of the several parishes on the first Monday in January make returns to the secretary of the State Board of
Health in the parish of Orleans of all such Health in the parish of Orleans of

Ail persons beginning the practice of midwifery in this state after passage of this Act sinsil appear before one of the State Boards of Examiners and submit to such examination in midwifery as the board shail require, and shall pay to the board for such examination the sum of $\$ 10$. If suchl examination is satisfactory, the said board
shall issue a certiflcate the same as provided for midwives in. practice at the time of the passage of this Act, which certiflcate shali be registered as in the manner provided for midwives in practice at the time of the passage of this act, but for such registration with the secretary of the State Board of
Health, or with the clerk of the district Health, or with the clerk of the district court, the holder of said certiflcate shall be required to pay a fee of fifty cents only. midwife of rural districts and plantation practice, who, in the sense of this Act, are not considered as practicing midwifery as a prof ession.

\section{As Amended by Act 244 of 1908}

Sec. 6. ADMINISTRATION: Be it further enacted, etc., That Section 6 of sald Act No. 49 of the session of 1894 be amended sc as to read as follows: That the Boards of Medical Examiners are authorized to elect such officers and frame and adopt such by-laws as may be necessary for the efflcient operation of the boards

They may provide that the examinations required in section 5 of said Act, as a prerequisite to the practice of midwifery may be conducted by one member of said Boards of Examiners, and the certificate of satisfactory examination issued by such nember shall entitie the holder to be
authorized by the president and secretary of said boards to practice midwifery in thi state; and may also provide that any member of said board may make any afflarit necessary to the issuance of any injuction or other legai process authorized under thi Act. Each board shall have its seal and the president and secretary of the respectire boards shall be empowered to administer oaths in the taking of testimony on any matter appertaining to the duties of said boards.

Sec. 7. MEETINGS OF BOARD: Be it further enacted, etc., That the regular meetings of the boards shall be held at least twice in each year in the city of New Orieans, but the president of the board may call special meeting elsewhere in the state whenever the boards may deem it necessary or expedient; the call to be issued by the secretary and signed by the president.

Sec. 8. TEMPORARY PERMITS: Be it further enacted, etc., That to prevent delay and inconvenience, one member of a board of medical examiners may grant a permit after a satisfactory examination to any applicant, and shall report thereon to the boards at the next regular meeting; such temporary permit shall not continue in force longer than until the next regular meeting shail in no case be granted within six 
months after the appllcant las been refused a permit by the boards.

Sec. CEITHFITES: HOW KEcoklitil: le it further enaesed, elc. That the certificates issued in accurdance with Sectinn : of this det shail be recorded in of the parish in which he or she resldes. who shill make thls recordation in a hook to be kept for that purpose otlly, and also certifs to stich recordation by an endurstecertify to stlch recordation by an enderse holder thereof shall transmit or deliver io the state Board of Ilealin: and the clerh recording the same shall be entitied to a fee of one dollar. Such certificate iratnsmisted or dellvered to the state Board of IIealih shall entlue the hollter to be plared on the list of reglstered physiclans and surgenns. the publications of which is heruinafter provlded for. Sald Boand of lloalth shali preserve such certificates, and a cony preserve such certificates, and a copy therent. slgned by its secretary, shall be
recelred as erldence in the courts of thls recelred as erldence in the courts of this
state. and for such copy a fee of fifty cents shall be paid. Iutil such recordation is made. the holder of such certiflcate shall not exerclse any of the rights or privileges therein conferred to practice mediclne.

Sec. 10. AXNLAL JURIACATIOA OF BEGISTKRED NAMks: Be It further en-
acted. etc. That it shall be the duty of the acted. etc. That It shall be the duty of the
State Board of Health to publish annually State Board of Health to publish annually
in the offlclal journal of the state (and if there is no such journal. In one of the daily newspapers published in the city of New Orleansl a list of the registered physicians and surgenns in the state and their rest. dences, and such pullished list shall be recelred in erldence by the courts of this state as proof that the physiclans and surgeons thereln named are duly reyistered as required by law, and the said state Board of Health is bereby required to strike fromi sald list the name of any person whose cerlificate may have licen revoked as herein provided for.

As Amended by Act 16 of 1912 Sec. 11. COMPENSATMX; FAAMIXI TION AND CEHTIFICATF FEE. lie is sald Boards of Jedical Examiners shall recelve, as a compensation for their serrices, ten $(\$ 10)$ dollars per day during thelr ses. sion and, in addition therefo, thej hotel and travellag expenses by the most dirict route travellng expenses by the most dirict route
to and from their respectire blices of to and from their respectire Jlaces uf the treasury of the boards on the certiticate of the president and secretary. The baris are empowered to demand a fer of une (है।) dollar for the insuing of each certitluate five $(\$ 25)$ dollars. If the appifeant pa-ces a satisfactory examination no otlue reey ance of the certifleate provided for in ance of the certifleate provided for in

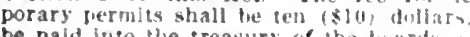
be paid into the treasury of the lwards, salil fee to be credited to the asplicant wholl ho applies on the boards of a pormstrent $\mathrm{fer}$ tifleate.

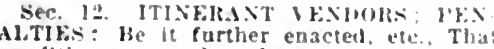
Al.TIk.s: be it further enacted, ete., Tha: any itinerant bendor of any drug. nustrum. tenderl for the treatment of 11 sions. infury, or who may by writing, print other methols. profess in cure "r treat ali manipulatun or other expedlens lin this

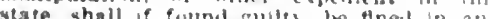
sum not less than tหenty (s:0) dollass and not exceellng one humbed (stail) dollars for each offense, to le recurrert in ant petent jurludiction. "ir whall be imprisuluet for a rerm of not lows than ten (I0) dayk or flned and liujrisuned

sec. 13. HHACTICE Of MEDH INF UE FINED; To WHOM NOT Alllitil ite it further enacted, etc. That Tertion 13 of mald and re-enacted so as to read as follows:
That ang jerson shall be regarfed as yrac. tieing nedicine within the neaning of this Act who shall abuend the letters M.H. in bis or her name. or shall examine. prescribe, direct, or apply, or shail profest or publiciy alverise that he prescribes, directs of abllies for the alleged purpose of treating. curlug or relieving any indily of mental dicease, inflrmity, deformity, defect, ailment or injury in any person other than himself. any dirug. Instrument or force whether physical or psychlc, of of whatever nsture, or any other ageney or means. whether such druge, instrument, force or ctlier aceney or means is to be applied of used by the patient or by any other person: and whether such preseribing, directing, or applying, be for compensation of any kind or enployee or mentber of ang corporation. assuciation or partnership which does or professes or publicly adrertises that it does examine for. cure. irtat or rellere such dis. examine for. cure, treat or rellere such dis ur jnfirmities, in any of the modes mentioned in this section shali be regarded as practlcing

This provision shall not apply to farmers or planters when treating without compensation their famllies. employees or tenants exclusively, or to attendarts and plantation midwives; or to optlcians fltting glasses, or resting eres in their own establishments, or to water-cure establishments. Nothing in this Act. howerer, shall be construed to pro-
hibit the practlce of the rellgious tenets of any church whatsoever.

\section{As amended by Act 16 of 1912}

Sec. 14. PENAITIES; INJUNCTION SUIT: SLMMARI TRIAL: Be It further
enacted, etc.. That section it of sald Act 49 of the session of 1894 be amended and re. enacted so as to read as follows:

That any persons practiclag medicine or midwifers in any of Its departments in this state without flrst haring obtalned the cer. tiflcate herein provided for or contrary to the provisions of this Act, shall be deemed gullty of a misdemeanor. and upon conrictinn therene shall he punished by a fine of no less than $\$ 50$, or more than $\$ 100$, or by imprisonment in the parish fail for a period of not less than ten days or more than ninety days, or by buth fine and inprisoment for each nffense. It shall be to prosecute vinlatcrs of the prurlsions of this let, before any court of competent juristiction. The sald the shail be divided the parish in which sald offense may hare loeen prosecuted, and the state Board of Hedical Examiner.

said buard of Medieal ks:miner through slyeir proper oftcers maly canse to kscue in furblding ans enfoinita sala person from furtler practiclng mediclne in any of its departments in this state until sucil persen whall liase Prst uhtained the certiticate herein prorlued for and umer the prorisions if this Act: and salel Injunction shall not -ubject to being releasiod nown bond.

In the same suit in whlch sald infunctions may be applionl for, the sald hostels through their respectlie prestlent aforrald, ma Denalte not to exceed one Jundred doflars.

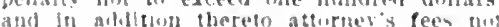

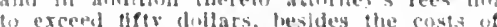
julgment for which penilisy affur. mos" fow ami costs mal be rendered in the mase nluminte

The trat of silis procerdlug whall twe trled by the durlge withotit

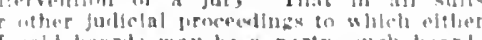

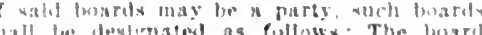
whall for dewenoted as followis: The luaril

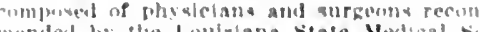

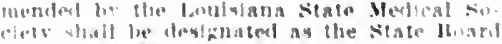
of Vollcal Firaminers. and the boral com fuscel "it phyvelans recommended by the

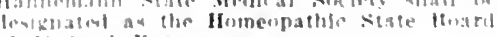

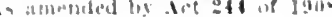

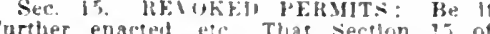
Ict is of the sewsinil of Inist he arnended cled so as in read as follows:

That if any berson licensed under thi Act shall be comvicted of a crimp or of $z$ ros unprofessional conduct, "he sald buafds shall fore any competent court fur the purgase haring the permit or licenve franted by th (6) such person revoket: and if it shall (b) such person revoket: and if it shall licensed has been ernsicted of a crime or

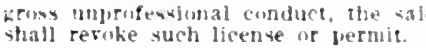

see li. J'ERSOXS NOT COMPLYIN; HAVE NU HIIHTS OH PHIVILEGES: B It further enacted, ece. That any practiments, falling to comply sa of th deparsments, failing to crmply with the requirejury or milltary duty, nor ve permitted to collect any fue or charges for services rend. ered, nor be allowed to testify as a medical or surpical expert in any court in this state. or surgeon, nor to hold any medical ofice. nor to be recognized by the siate or parlat or municipal corporation as a jhy jician or surgeon: nor shall be be entitied to enjoy any of the priclleces. rights or exemption granted to physicians or surgeuns by the laws of this state.

Sec. 1\%. TO WHOH ACT DOEs NOT this Act shall not apply to any commis. sloned surpeon of the Inted states Arms. vary, or public Health serrice: to phrsicians or surgeons from other states or territories in actual consultation with a reglstered physician of this state, nor in any physician actually practicing in this state cordance with then existing laws.

Sec. 1s. RFPORTS OF BOARDS: Be it further enacted, etc. That the said tmards shall report to the prosecuting offcer of the
state of Loulsiana all persons rinlating the provisions if this ict. They shall report. annually, to the gorernor of thls state upon the condition of the practice of medicine in provement of the practice, as well as a record of the proceeding of the lmarl dur. ing the year, towether with the names of all thysicians of surebuns to whom the sate board shall have jesuet certificates during the lear. in accopdance wit! the provision: section - of this ICt.

As amenuled by det itt of $190 \mathrm{~s}$

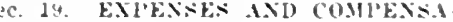

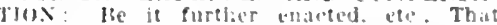

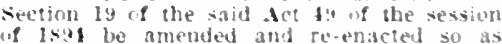
lsol be amended
read as fullows

That it shall niag lee lawel for the soul Joards of Molical kisammers or an menatiy purpuse, t, chatge ur whilgate the state uf bousiana for the folbment of any molley cxept as provited for $m$ det it of the

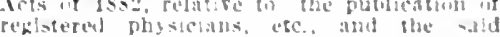
lowaris shoil lowk illowe to the revenus derised from the "reeration of the Act for the compensation desated in section II -ualcient fil pay each memter in full, as ber

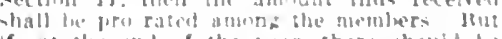

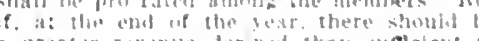

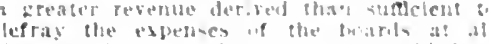

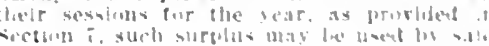

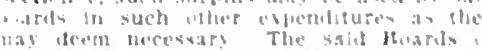

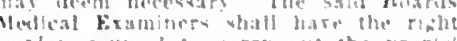

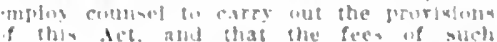

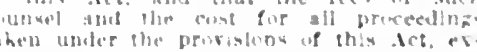
ont the cotminal prondecutions. shall be pal

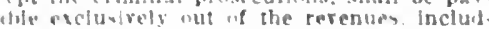
no genslites under the provistions of this

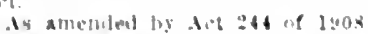

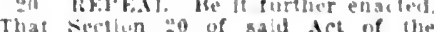


session of If94 be re-enacted so as to read as folfows: That all laws and parts of laws contrary to and in conflict with any of the prorisions of this Act be and the same are hereby repealed.

STATE BOARD OF HEALTH Oscar Dowing, I'resldent. Shreveport A. H. Fiadden, Vee-resident, Monroe; T

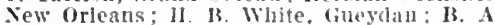
ledbetter. New orjeans: Thomas i. Bov, Mansura; Wm. M. l'erkins, SeeretaryTreasurer, New orleans.

STATE BOARD OF MEDICAL EXAMINERS J. C. Marth, Prosluent, Lake Charles; S. L. White, Viee-I'resident, Ruston; Espy M. WHllams, Patterson; L. T. Florance, Esq., Counsel, New Orleans; Ifomer Dupuy. vew Orleans; F. I. Leckert, secretaryTreasurer, New Oricans.

\section{HOMEOPATHIC BOARD OF MEDICAL EXAMINERS}

C. R. Maver, President, New Orieans: J. w. Belden, New orleans; R. A. Bayley, New Orleans; $\mathbf{F}$. II. Hardensteln, New orleans Edward IIarper, Secretary' and Treasurer New orieans.

\section{LOUISIANA STATE MEDICAL SOCIETY Offlcers 1913-I4}

Fred .t. Mayer, Prestdent........ Opelousas A. J. Perkins,' Ist V.-Pres..... Lake Charles A. H. Fiadden, 2d Vice-President...Monroe W. S. Rutiedge, 3d Vice-President... Ruston 1. D. De Buys, Secretary L. R. De Iuys, Secretary...... New Orleans

\section{Councilor Districts and officers}

H. B. Gessner, Ciairman, New orleans; w. H. Seemann, Secretary, New orleans. First Congressionai District.-W. H. Seemann, New orleans.

Second Congressionai District-Hermann B. Gessner, New Orieans.

Third Congresslonai District.-L. J. Menville, Houma.

Fourth Congressionai District.-D. J.

IlcAnn, Atkins.

Fifth Congresslonal District.-R. W. Fauik, Sonroe.

Sixth Congressional District,-J. W. Lea, Jackson

Serenth Congressionai District.-I. N. Adams, Eunice.

Eighth Congressional District.-E. Lee Henry, Lecompte.

\section{Component Parish Societies of the Louisiana} State Medical Society ASCENSION PARISH

Wm. M. MeGailiard, President.Donaldsonvilie Paui $x$. Thibodaux, Secretary.Donaidsonville AYOYELLES PARISH

S. J. Couvillon, President........ Woreauville P. E. Brahic, secretary.......... Horeauvilie BEAUREGARD PARISH

J. D. Toy, President........... Do Ridde

S. H. Mchahon, secretary......... Re Ridder BIENYILLE PARISH

o. o. Hamner, President.........Blenville

E. Otis Edgerton, Secretary............ Arcadia BI-PARISH

C. E. Edgerton, President......... Coushatta BOSSIER PARISH

D. .1. McAnn, President...........Atkins C. ii. Tucker, secretary........... Haughton CALCASIEU PARISH

S. George hreeger, President..Lake Charles Joseph D. Tuten, Secretary.....Lake Charles CLAIBORNE PARISH

P. Gibson, President..............Homer

J. F. Gladney, Secretary...................... DE SOTO PARISH

H. J. Parsons, President...........Mansfleid H. W. Jarrell, Secretary............. Mansfieid
E.AST BATON ROUGE I'ARISH

d. I. Robert. I'restdent........ Baton Ronge EAST FELICIANA I'ARISI

T. S. Norwood. I'resldent......... Norwood F. ir. Toler, secrctary................. FIRANKIIX PARISII

D. D. Gill, Preslient.............. Giblbert s. Wllsm, secretary............Winnsboro GRANT I'ARISH I'hilip Goode, I'resident............. Colfax IBFHTHLE: PAIISH

A. A. Landry, Presldent........ Plaquemine 1. D. Marthez, Secretary...... Wivilite Castle JACKSON PARISII

.. H. Landrum, President...........Eros

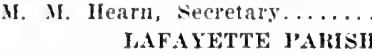

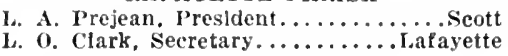
LAFOURCHE PARISH

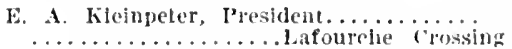
c. J. Barker, secretary........ Thibodaux LA SALLE PARISH

W. F. Wade, President..........Good Pine

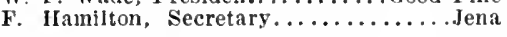
LINCOIN PARISH

J. L. Smith, President........... I) ubach LIVINGSTON PARISH

H. II. Faust, Presldent................. Jontgomery Williams, Sec..Denham Springs MOREHOCSE PARISH

Rae B. Learei, President............Jones

Otis M. Patterson, Secretary..............3astrop NATCHITOCHES PARISH

C. E. Edgerton, President....... Coushatta E. W. Breazeale, Secretary.......... Campti ORLEANS PARISH

Chas. N. Chavimny, President..New Orleans F. 1. King, Secretary,........ New Orleans OUACHITA PARISH

Robert $w$. Fauik. President.........Monroe I. B. Fauik, Secretary................. PLAQUEMINES PARISH

C. Y. Seagie, President........... Beialr H. I. Ballowe, Secretary............... Buras RAPIDES PARISH

R. L. Randolph, President........Alexandria James A. White, Secretary.........Alexandria RED RIVER PARISH (See Bi-Parish.) RICHLAND PARISH

G. C. Pardue, President .........Mangham J. s. York, Secretary..................... SABINE PARISH

T. B. Younger, President............Fisher

J. M. Middleton, Secretary ................... SIIREVEPORT-CADDO PARISH

Louis Abramson, President........ Shrereport S. H. Betts, Secretary.......... Shreveport ST. CHARIES PARISH

(See St. John and St. Charles Parish.) ST. HELEYA PARISH

C. M. Sitman, President........ Greensburg

I. A. Lea, Secretary............... Greensburg ST. JAMES PARISH

N. Himel, President...........Welcome W. F. Bolton, Secretary............. Patrick ST. JOHN AND ST. CHARLES PARISH R. II. Johnson, President......... Hahnville L. Cheres Tebo, Secretary..........Reserve ST. LANDRY PARISH I. N. Adams, President.................. Eunice ST. TAMMANY PARISH

K. W. Ney, President..........Madisonville W. E. Vanzandt, Secretary........... TANGIPAHOA PAPISH

W. T. Newman, President..... Independence James M. Adams, Secretary............ Amite TENSAS PARISH

J. G. Liliy, President............... Joseph H. S. Trice, Secretary............... Jt. Joseph
VERMIJION PARISII

C. . Edwards, President..........Abberllie c. A. Schilling, Secretary.......... bbevllie VERNON T'ARISH

II. O. Whilis, Presldent...........Leesvilie ii. IR. McAipin, Secretary........... Leesville WEBSTER PARISII H. II. Smith, Jr., President.... Cotton Vailey WEST BATON ROLGE PAIISH

II. Guy Riche, President........ Chamberlin Eugene Bourgeols, Secretary........... Brusly WEST CARROLL PARISH

J. J. Flake, Secretary.............Pioneer

\section{PARISH HEALTH OFFICERS}

I'arlsh

Acadla.-H. C. Webb............. Address

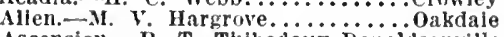
Ascension. - P. T. Thibodaux. Donaldsonville Assmmption.-Chas. S. Roger.. Napoleonvilie Avoyelles. - A. L. Bordeion....... Cottonport Beauregard. - S. o. Turner......... Cottonport Ridder Bienvilie - E. o. Edgerton............ Readia Bossier.-T. N. Keoun............... Areadia Dealing Bossier.-T. N. Keoun........ Plain Dealing Calcasleu.-J. s. scott........... West Lake Caldwell.-Ieby B. May............ Columbla

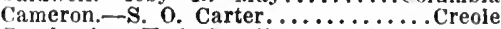
Catabouia.-H. S. Rawlings..... Harrisonburg Claiborne. W. L. Stone............. Homer Concordia. $-M$. C. Reeves........... Vidalia De Soto.-J. L. Leopold......... Grand Cane East Baton Rouge.-A. L. East.....Zachary

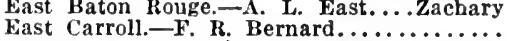
East Feliciana...... East Feliciana.-E: i. Toler........ Clinton Evangeline.-Theo. H. Littell... Vilie Piatte
Frankiln.-L. F. Robinson..... Winnsboro Grant. - F. o. IIaxweli.............Poliock Iberia. $-\mathbf{F}$. O. Darby ................. Iberville.-Guy A. Darcantel... White Castle Jackson. -J. A. Gaar............Jonesboro Jefferson. -Geo. Rossner........................ Jefferson Davis. - R. R. Arceneaux...... Welsh JefPerson Davis.-R. R. Arceneaux.... Welsh Lafayette.-L. O. Ciark........... Lafayette
Lafourche.-P. J. Dansereau.... Thibodaux Lafourche.-P. J. Dansereau..... Thibodaux

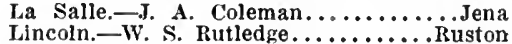
Livingston. Geo. W. Mixon............. Walker Madison.-G. W. Gaines........... Tallulah

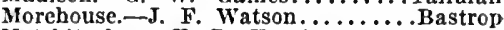

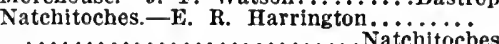

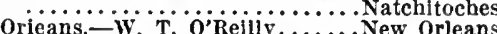
Ouachita - Thos F Wright..............

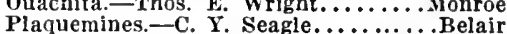
Plaquemines.-C. Y. Seagle.............. Belair Pointe Coupee.-M. O. Becnei.... New Roads
Rapides. - R. O. Simmons.......Alexandria Rapides.-R. O. Simmons........ Alexandria
Red River.-W. T. Wilkinson..... Coushatta Richiand $-\bar{J}$. C. Sartor........... Rayville

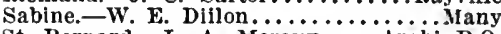
St. Bernard.-L. A. Meraux...... Arabi P.o. St. Charles.-L. T. Donaldson, Jr. Hahnville St. Helena.-W. B. Travís........ Llverpool

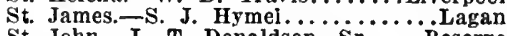

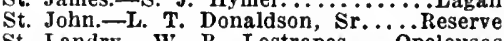
St. Landry.-W. R. Lostrapes.... Opelousas St. Landry.-W. R. Lostrapes.... Opelousas St. Martin.-C. W. Boring....Breaux Bridge St. Mary.-W. J. MeClellan.....Morgan City Tanglpahoa. - G. o. Sanders............ Slidell Tensas.-L. A. Murdock............. Jt. Joseph Terrebonne. - L. J. Menville........... Houma Union.-R. L. Lore...................... Vermilion.-C. J. Edwards............. Abbevilie Vermon.-D. o. Willis..................... Washington.-J. E. Pierce............. Bogaiusa Webster. $\rightarrow$ S. Richardson............... Minden West Baton Rouge.-E. Bourgeois.....Brusly West Carroll.-J. J. Flake...........Pioneer West Feliciana.-J. M. Daniel......... Star Hill viun. -J. J. Peters............. Winnfield

HEALTH OFFICERS IN CITIES OF $\mathbf{3 , 0 0 0}$ POPULATION AND OVER

Aiexandria................. A White Baton Rouge.......................... Duchein

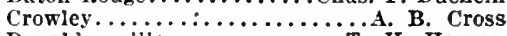
Donaldsonvilie.......... Hanson Dubach .............. I. Smith Franklin.............. W. Smith

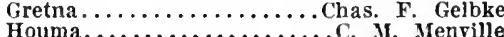
Jennings.................. 
loake in that

Varrue.

Murgan i il

New llwria

Now urleas.

upelousas.

Playuemine.

Ruvisu.

Shreveyurt

Thiludaux.

\section{STATE INSTITUTIONS}

\section{Baton Rouge}

loulsiana state school for the Itrint

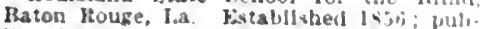
lie; $\$$ beda; fi. C. Iluckahy, superintent ent.

\section{Jackson}

East Loulslana Ilosultal for the Insand, Jackson, La. Established 1846; publte: insane: 1,450 beds: Clarence plerson. physlclan in charge.

\section{New Orieans}

Charity Hospltal, Tulane Are. betwpen Howard and S. Kobertsun Sis. Sew beds: C D wilkins y I : The Delgado and Richard Mlliken Menorial Itoxultals are adjuncts.

loelgado Memorial Hosplta

leaus. (See Charits llospltal)

Memorial Hospital, Uospltal.)

Soldlers' Home of Ioulsiana, ('amp Nicholls, No. I Bayou St. John Yeu Orleans. Establlshed 1884: 149 heris: James i. Rlchard, physlcian in charge: Chas. Smith, superintendent. State Boys' schoot, New orleans.

\section{Pineville}

Loulslana Ilospital for Insane, I'neville. La. Establlshed 1906; 675 beds; John $\mathrm{N}$ Thomas, medlcal superlatendent.

\section{Shreveport}

State Charits Hospital, Shrereport, 1. Establlshed 18:2; public; general: 2: leds: S. L. Wlllams, house surgeon and superintendent: A. 1'. Craln, surgent Ir charge.

\section{Whitecastle}

Leper Home of the state of Loulsiana. Indian Camp J'autation, Whltecast]e, I.a Fistabllshed Is94; is beds: Sisters in charge.

\section{HOSPITALS, SANATORIUMS AND CHARI \\ Abbeville TABLE INSTITUTIONS}

Abberllle Sanitarium. Abberille, Ia K iablishel 1898: mental and nerrous dis eases, alcohol and drug addiction: $y$ beds: H. 1;. F. Edwards, physletan in chlee.

\section{Alexandrla}

Alexandria Santarium, Alexandrla, Ia Fatabllshed 1903: pirlsate: genera!: :" beds: Mlis Jane Mi. Jeach, sugerinteidert.

\section{Baton Rouge}

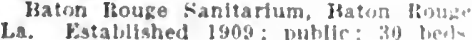
T. 1. Singletary, physiclan in cliarge.

\section{Bogalusa}

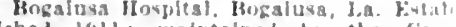
Itshed 1911: mantalned by the riput sinuthern Lumber rompany; Miss . Thls clagett, snperinlendeus

\section{Covington}

Gzonla Ibent cure, lorlugtom, ba Fis

Tablished 1900: pritate: 12 pedv: 1.0015:

it. Tolson, physlelsn in iharge.

Stevenson Siaftarium, forlugton. Let Ristablished lant: private: tubrombuls 30 beds: W. Lawrence steimpinn, mollnal superintendent.

Crowley

Crowles Sinttarlun, liruwley, fia $t$.

tabllsher 1912: publle: coneral: 20

Frankilin

St. Mary Sanltarlum, Frankltu, l.a Fis

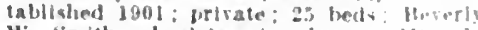
w. Snith, phisklan on charge. VIus I. A. Mullaril, superintesulent.
Hammond

the batalo

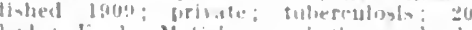

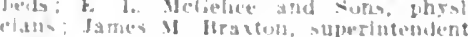

Moncoe

Sil brancls Sumlarlum, Mourne, La bistafilshed 1413: firlsate; seneral: 120 freds: 1). He fusby, Mblstun surgeon in charge.

\section{New Orleans}

lethlehem Frangelleal butheran Orjhan Asylum. New Orlens. Fistablislied last prlvate: 90 treds: II. I. Hutumann, superintenilent.

Hr. Mrusnau's Hosfftal, 1201 Prytanla

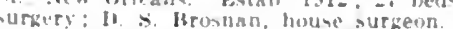

llurguleres II onne for incurables, Xew irlesns. Nisters of Charity, in charge.

convalescent llome, New orleans. by. tablished 18,9: Jublio: 22 beds: Robert 'arker, superintesulent.

Deviliute Orphan Boys" Asylum, 5220 st. Charles die. New urleans. Listab lished I8:5: prlvate: 65 beds: J. L. Sut un. superinteudent

Eye, Lar, Nose and Throat Ilospltal. Eatabllshed Thane ire.. New orlean. lie Roaldes, surieon-in-chlef.

ralth Home for the Aged and bestitute, 4934 Pitu St. New Orleans.

balthise Infant llome, Jlenry Clsy dve. and Patton St., New Orleans.

Fenner's Sanitarium, New Orleans. Es sabllshed 1905; private: for chlldten; 30 heds: F. D. Fenner, physicisn in charge. French Benevolent Assoclation Asylum st. Ina and $X$. Koman Sts. New Orleans. Cierman Irotestant Kethany Home, 1643 - Platmorne Are. New orleans. Estab lished $190 \mathrm{f}$ : nrivate: 30 beds: John Marrus koelle, physlelan in charze: w. T. Richards, surgeon.

German Protestant Home for dzed 919 Magazine St., New Orleans. Futab. lished 1890: Jrirate; 60 beds; $A$. Goed dert $z$, superintendent. German I'rotestant Orphan Asylum, 920
state Si, New Orleans. Establisbed isfí: prtrate; 83 beds: J. i. Mohr, superintendent.

IJome for Ilomeless Women, I 4 \& Polsn ula st. New orleans.

lome for Incurables. 612 Henry clay We New Grlesns. Established 1590 oublic : if beds: Mrs. L. lehman. matrun Hotel Iheu, New Orleans. Established 1859 ; general; 125 beds: Jarton souchon, if Sisters of Chartis.

llinols Central Hospleal, Magnolia and Lafsyette sts. Sew orleans Eatablisbor 1413 ; private; 7.5 leeis: J. D. David hinlie surkeot.

mmaculate conception Female Orphan

livlum, 3:03 $x$. Ramprart st. Yew reans.

Infant Jesus Creclie Orphan Asylum, 20. Marals St, New Mrleans.

Iqudation Irosifta]. New Urleans. Cien.

l. heard. Justcian in charge

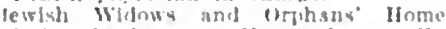
42 st charleg We. Xew orleans tos

allibhed 1s5s: jrivate: 200 beds: is

H)man, superintendent.

fultur Wols Hume for Iged anil Inflrm. findint and collseum sits. New Orleans

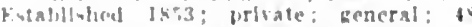

inds: I II Thpolus sugeriutendent.

little sluters of the Four, 3618 t'rs mias. Sew orleans.

Lonlelana Materujty Ifowpleal, Vew Os

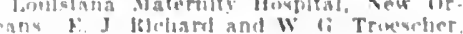
1) (1) sjoinn

Joulelarsa lictreat. Now Mrlears, Futh.

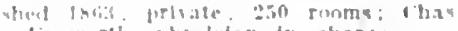
fiswerth. phuletan in rharbo

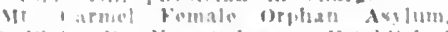

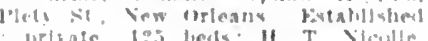
hinvician

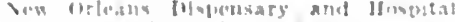

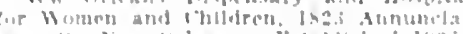

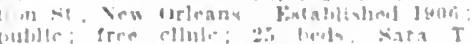

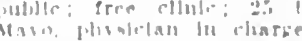

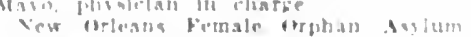
Maple st, Nuw Mrleant

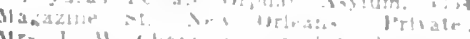

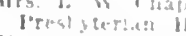

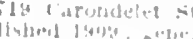

is liativitin

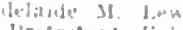

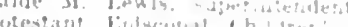

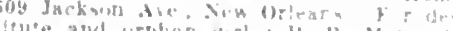
eon, whysctan tn charze.

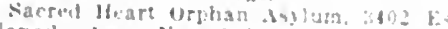

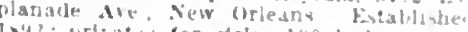

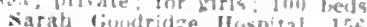

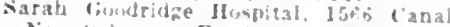
St. New urteans. Eutablished 1 agis: put. lic fur colrored patients: general: beris; II T. Fuller, nuedral superlitionit. ent.

Ionnenth street P'ostestant orshan leans. Fotabllobel is53: public: 13. berts: 1. $r$. Oechomp, attending phys clan: hoard of managers in charge

Small-lox Jumital. :00 s. Jezerson. lavls lonkway, New Urleans. Kotab

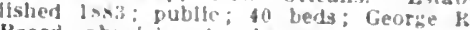
Beard, physlctan li charge.

st. Nphunsus Oruhanage. 2703 Sara tora st. New Urleans. tastablished 14; jublle: :ont tieds.

st. Anne Asyluns Itrounla and st Mary Sis. New orleans. Establlshed jo0 ireds; II. A. Veazle physlclan is 100 bed

st. Joxejh's Maternity Hospltal, 150: Magazine st., Хew Orleans. Establlshed 1858: Urivate: maternity only: $\mathrm{st}$. Yin-

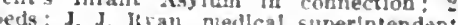
sisters of Charly, in charge. sit of charly. In chatge.

sit. Joseph's Orghan Asylum, 835 Jose phine st. New Orleans. Kstablished 1854

St. Mary" Carrollton Mrphan Asylum, 32: Maple St. New Orleans.

st Mary" F Cathollc Orghan Astum. chartres and Mazant sts., New Orleans. Established 1835: public: boys' orphan. age; 300 beds; IV. T. O'Rellly, physiclan in charge.

st. Mary's Orpban Boys Asylum, 111 hartes St. New orlean.

St. Vincent's infant orphan Atylum, l.00 Magazlne St. Dew Orleans. Fo. talilished 1858 ; public; St. Juseph's MIa ternity llospital in connection: 200 beds J. J. Ityan, medical suberinterdent sister of Charity in charge.

Thony Lafon Oid Fulka Home (colures) S. Jobertonn atud [delachalke sts., New orleans.

Touro Inflemary Vew Orleane Estah.

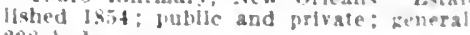

Touris-Shakespeare IIome, $\therefore$ ksmpart and llameel sta., New vrieans. bistab. Helied 1sue: vublle: old folks" bome: 15 bets: Ifarlon suthon. visitlng physiclan: "I I lhourk, superintendent.

Inltul states Marine Hosgltal. New orlean. Fistillshed 1,2t: vublle: Ren-

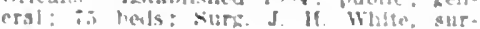

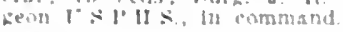

\section{Patterson}

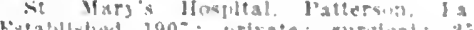

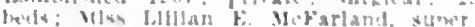
intuident.

\section{Shreveport}

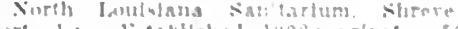

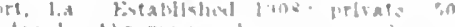

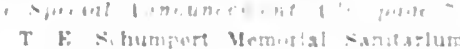

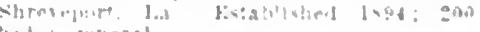
t3uts: meveral.

sidell

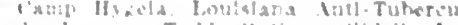

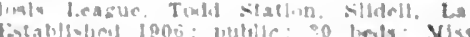
clato firmbers. mumpthiendont.

St. Francisville

si Frallowotile sanleasium st Francls.

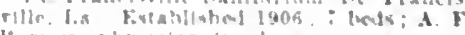
Harruir, bhisician in charge. 


\section{PHYSICIANS OF LOUISIANA}

\section{KEY TO ABBREVIATIONS, SYMBOLS, ETC.}

Xames in capltals slgnify membersilip in the County soclety and State Associatlon. (10E, JOHN).

- Indicates Fellowshin in the American Med. Assin. (DOE, Jo11 N+).

(b) T5) Yeit of birti.

II. homeoratla; $\mathbf{E}$, ectectle; 1 - $\mathbf{M}$, physioId. '09, college and year of graduation 0 Information reeelved does nort show grad uation.

S.-Surgeon,

ob.-Olistetrlelan.

ObG.-Olstetrician, (j,uecologlst.

G.-Gynecologlst.

or.-Orthopedist.

Pr.-Proctologist.

Op. - Ophilhalmologist.

A.-Aurist.

LR.-Laryngologlst, Rhinologist.
(I's(1) Vear of llcense.

In practlec before passage of present law and lleensed by flling diploma or by Vears of l'ractlee.

(1†) lisensed but year not known.

\#) Information recelved does not show license.

I.S.A., Vnlted States Army.

M.R.C., U.S.A., Medleal Reserve Corps.

SPECIALTIES ARE INDICATED AS FOLLOWS:

ALR.-Aurist, Laryngologist, Rbinologist.

OALR.-Ophthalmologist, Aurlst, Iaryngologlst, Rhinologist.

U.-Urologist.

D.-Dermatologist.

Pd.-Pediatrist.

N.-Neurologist.

P.-P'sycliatrist.
I: N.N., Lulted States Navy.

M.K.C. U.S.X., Medical Reserve Corps.

U.S.H.s. Unlted States I'ublic Health Service.

College positlons held are indicated by aburevlated title of position, followed by key number of college. For key to eolleges see Inside front cover page.

(AI,3, B6, C4) Membership in speclal socleties. (see Key Table, page 122.)

NP.-Neurologist, P'sychiatríst.

I.-internist.

T. - Tubereulotheraplst.

Anes.-Anesthetist.

LD.-Laboratory Diagnosticlan.

Path.-I'athologlst.

Bact.-Bacterlologist.

WHEN THE ABBREVIATION REPRESENTING A SPECIALTY IS FOLLOWED BY AN ASTERISK ( ) IT INDICATES THAT THE PHYSICIAN CLAIMS HIS PRACTICE IS LIMITED TO THAT PARTICULAR BRANCH OF MEDICINE; WITHOUT THE ASTERISK, THAT HE IS ESPECIALLY INTERESTED IN, BUT DOES NOT LIMIT HIS PRACTICE TO, THAT BRANCH. THIS INFORMATION CONCERNING SPECIALTY IS BASED ON PERSONAL DATA FURNISHED BY THE PHYSICIAN AND IS NOT VERIFIABLE.

\section{LOUISIANA}

ABBEVILLE, 2,907, VERMILION

Boudreaux, Luke Martial (b'86) - La.1, I3; (l'13).

Carter. Nelsoli S.-Tenn.1,59; (1\%); not in practlce.

EDWARDS, Cl.ARENCE J. - Ky.2,'83; (1'83).

Edwards, Harold Gnegnon Fabien (b'88) La.1,'11; (1'11).

Eldredge, II artweil A. (b'81)-Tex.3,03; $(1 ' 03) ; 0$.

Johnson, J. L.-Tenn. 7,06 ; (1'07).

Kibbe, Chas. W. (b'T5)-Ténn.11, 01 ; (l'09).

Langlinais, Jos. Rousseau-Ky.2,09; (l'12)

Miller, Weston Peter (b'85) - La.1,09; (1'09)

SCHILIING, CHAS. ARTHUR (b'67)-Ky.4, 93 ; (P'95).

(l'69).

Young, Marion A.-Tenn.11,95; (l'96).

ABITA SPRINGS, 350 , ST. TAMMANY

Heintz, Ludwig Cochran-La.I,06; (1'06).

ALBANY, 10, LIVINGSTON

FAUST, WM. W. $\longrightarrow$; $(1 \dagger)$.

ALBERTA, 500, BIENVILLE

NEILL, JAMES ABNER (b'69)థ-Tenn.11, "00; (1'0I).

\section{ALEXANDRIA, 11,213 , RAPIDES}

Biscoe, Alex II. (b'78)-Mo.24,01; (l'01)

Bonnette, J. Valarus (b'65)-Ky.1,93; (1'95): $\mathrm{S}$.

BRIAN, FRANCIS N. $(1,60)$ - La.1,'84 (1'84); Johnston and 6th Sts.; offlee, 30 and Murray Sts.; $9-11,3-5 ; 0$ b.

Brown, II. C. (col.) (b'56)-Tenn. 7,94 ; (l'94); 824 Beauregard St. ; 8-10, 3-5.

CAPPEL, MARYIX (b'89)-Ky.2,11; (1'11) $3 d$ St. $10-12,6-8$

GREMILLION, CYRIAQUE J. $\left(b^{\prime} 72\right) \oplus$ La.1,97; (1'97) ; 517, 3d St. ; offlce, 120 Murray 'St.; $9-11,2-4$.

GREMLION, FIELD VERNON-La.1,06 ; (1'06) ; 529, 3d St. ; offlee, 120 Murray St. : $9-11,2-5$.

IIARRELL, RICHARD FULLER (b'54)థLa.1,79; (1'79); 708 Jackson St. ; offlce, Medical Bldg. ; 9-12, 2-4; OALR. *

Ifolloman, Lucius Waiter (b'89)-Tenn.6, '13; (†).

Jones, James P. (col.)-Tenn.7,93; (l'93).

Kyes, Edwin Stuart (b';1)-La.1,99; (1'99) ; 1923 White St.

LITTELL, ISAAC FLAVIt'S (b'86)-La.1, 'A9: (1'09); 921, 2d St.; 9-12, 2-5;

O(LESBY, JOHX MALCOLA (b'i6)-La.1, (0); (1099)
PETERS, JAMES INGRAM (b'85) †-LA.I 12: (112); 928,4 th St. offlee, Ifedical Bldy. : $9-10,1: 30-4 ; \mathrm{s}$.

Prosser, Wm. Baldwin (b'82)-La.1,11;

RANDOLPH, ROBT. IEE (b'62)\&-La.1 '84; (1'84); 1330, 3d St. ; office, Rapides Bank Bldg.; 10-12, 2-4:30; Ob.

Siess, Isaac E. (b'71)-La.1,94; (1'93); 3d and Johnston sts.

SIMMONS, R. O.๑-Ky.4,92; (1'92); 4th and Johnston Sts.

Smith, Geo. Washington (b'-3)-La.1,'10.

STAFFORD, G. M. G. (b, 6 - 4 -La.1,01; (1'01); White St.; offlce, $1006,3 \mathrm{~d}$ St.

Waddell, Preston E.' (b'61)-La.1,'95; (1'95)

WHITE, IAMES A. (b'68)థ-N'M.3,92 $\left(I^{\prime} 92\right)$; I016, 4th St. ; offlce, 932, 3d St. ; $10-12,3-4 ; \mathbf{S}$.

WILSON, JOHN LUTHER (b'69)£-Tenn.5, '89; (1'89); 4th and Jackson Sts.; 10-12, $3-4$; 5 .

roung. Isaac w. (col) (b'74)-La.4, 00 (1'00); 1032, 10th St.; office, 604 Lee St. $\left(l^{\prime} 00\right) ; 103$
$9-11,3-5$.

ALGIERS (NEW ORLEANS P.O.), ORLEANS

Pollock, James Ernest.

(See New Orleans.)

Wailes, Prince Oliver (col.) (b'66)-Tenn.7 09; (1'11).

ALLEMANDS, 500, LAFOURCHE

HT־BERT, JOS. M. (b'74)-La.1, 95 ; (1'95).

ALTO, I50, RICHLAND

PARDUE, CARL G. (b'83)-Tenn.8,09; (1'09).

SARTOR, DANL. R. $\left(b^{\prime} 4 \bar{i}\right)$ - Ia.1, 72 (1'72).

Washington, Wm. I'. (b'58) - Ala.2,'91: (1'93).

AMA, 800 , ST. CHARLES

Plauche, Jos. Winfleld-La.1,05; (1'05).

AMELIA, 400, ST: MARY

Prosser, Jos. Talbott (b'83)-La.1,09; (l'09).

AMITE, 1,677, TANGIPAHOA

MDMMS, JAMES MOORE (b'83)(6-La.1, 09 : (I'09).

Carter, John W.-Ky.4,'92; (1+); not in practice.

Craig, Jos. M. (b'3I)-La.2,'61; (l'61); not in practice.

JOHNSON, JESSE RALPH (b'65) £-Tenn.8, 94 ; (1'94).

LE FOIR, JAMES I. (b'69)-La.I,'94; (l'00).

ICCLENDON, JESSE HARRELI (b'86)La.1,'10 ; (1'10); U.

Sanders, Geo. Olin (b'82)-La.1,'05; (l'05).

SMITH, GLENN-110.10,06; (1'06).

STEWART, CHAS. S. (b'60)థ-La.1,'84; (1'84).
ANACOCO, 300, VERNON

FRANKLIN, WM. T. (b'66)-Tenn.8,99; (i’04).

ANDREPONT, 30, ST. LANDRY

FIDRINE, FREDK. (b'71) $\$$ - La.L.98; $\left(l^{\prime} 98\right) ; \mathbf{G}$

ANGIE, 346, WASHINGTON

McNeese, Wru. T. (b'76)-La.1,'08; (l'08).

Warner, Wilbur II.-Ky.1,94; (1'94)

ANGOLA, 10, WEST FELICIANA

Ehlert, Emile (b'78)-ILa.1,'04; (1'04)

ANSLEY, 600, JACKSON

MCBRIDE, JOIIN S. (b'60)థ-KY.4,'86 ; $\left(1^{\prime} 86\right)$.

ANTIOCH, 65, CLAIBORNE

Schley, Jinkens L. (b'84) - Teun.6,09; (1'09).

ARABI, 800, ST. BERNARD

ESTOPINAI, JOS. A. (b'76) - La.1,'99; (I'99).

ARCADIA, I,079, BIENVILLE

ATKINSON, JOS.-Ala.2,72; $(1 ; 72)$.

Baker, Wm. M.-La.1,74; (1'74). EDGERTON, EDWIN ÓTIS (b'75) $\oplus-T$-Tenn.s,

MADDEN, TILDEN H. (b'76)@-Tenh.s, 03 ; (l'03) ; R.F.D. 1.

MOSELY, JOHN M. (b'79)-Tenn.8,03 (1'05).

TEER, WM. W. (b'89)-Tenn.8,'03; (l'03). THORNHILL, FRANCIS MARION $\left(\mathrm{b}^{\prime} 49\right) \oplus$ La.1,72; (l'72).

Welch, Warren N. (b'74)-Ark.2,'11; (1'11): R.F.D. 2.

ARNAUDVILLE, 279, ST. LANDRY

Durio, Abbe C.-La.1,'89; (1'89).

MARTIN, GEO. W.-La.1,79; (1'79).

Simpson, A. H.-Ky.5,'89; (l'89).

ASHLAND, 200, NATCHITOCHES

Joyner, S. I.-Tenn.8,03; (1’03).

ASHWOOD, 50, TENSAS

WHITAKER, JOS. (b'82) $\oplus-$ Tenn. 11, 08 ; (1'11).

ATHENS, 5I4, CLAIBORNE

BAILEY, CURTIS A.-Ky.4,'90; $\left(\mathbf{l}^{\prime} 90\right)$.

CRAIGHEAD, C. C.-Ky.9,06; (1'07).

SIMPSON, JAMES F. (b'76)-Temn.1,04; ( $\left.1^{\prime} 04\right)$.

ATKINS, 300, BOSSIER

ICANN, DAVID J. (b'76)-Tenn.8,99: (1'99).

ATLANTA, 311, WINN

Pugh, John J. (b'70)-Tenn.8,'05; (l'05)

Wilkinson, Leo. A.-Tenn.1,07; $\left(l^{\prime} 07\right)$.

BAKER, 30, EAST BATON ROUGE

Lee, Henry Watkins Allen (b'85)-La.1,'13.

YOUNG, EDW. B.-La.1,96; (1*96). 
BALDWIN, $O 00$, ST, MARY

Lafarkue, Aran H. (b's3)-Tenns,10 (1) 10 )

Sewell, Juln Banks-Tenn.5,'so; (1'ab)

BALL, 50, RAPIDES

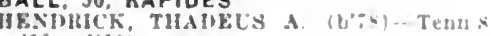
'0S: (l'0s).

BARHAM, 250, VERNON

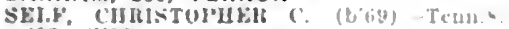
$02 ;(1,0 \geq)$

BASILE, 40, EVANGELINE

Chachere, Hussell Bertman-La 1, $04:$ (l'0t)

MeCaln. Clareuce M-La.1,'90; (I'9t).

BASKIN, ISO, FRANKLIN

Campbell, Firrln M. (b':5) - Trentas, $0 e^{\circ}$ (1'06).

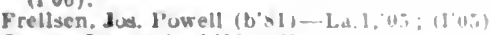
Green, Leonard (b'S6)-Tenu.19,11; $11^{\circ} 11$ )

BASTROP, 854, MOREHOUSE

laker, John Heuben (b's') - $k$ )

laker. Thus. M. (b'41)- (1) 10 . vir

liRAVEs, S. DCFAX (b'3)-hy 404 (1'06).

PatTERsox, otis M. (b'bl) + Tenas '87; (1'si).

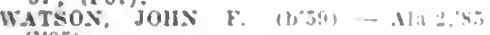
(1.95)

BATCHELOR, 200, POINTE COUPEE

lacour, August Hass (b'S1)-Tenn $\because$.0y (1'05).

BATON ROUGE, 14,897, EAST BATON ROUGE

Baranco, Haymond M. (col.) (b'00) Tenn.;

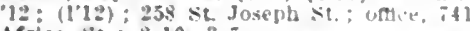
Africa st: $8-10,3-5$

CARUTHERS, JOHX ALLEX (b'if) + Tex.2,99; (M'1): 327 Conrentlo offee, Masonic Temple: $9-12,3-5$.

Cumming, Claude Wigglos (b'so)--Tenu. 12: (1'12): Ob.

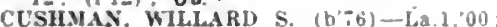
(100): Goverument and Ferdinand Sis. (100): Goverument an

DUCHEI, CHAS. FRAcis (b:-5) + Tenn. 1,99; (J'00): 415 Torth Blrd.

YOREMAX, THOS. C.-La.1.89; (1'89) R.F.1.2.

Frldge, John Russell (b'6z) - Ky.t'xy $\left(1{ }^{2} 9\right)$ : 310 Conrentlon St.: 11-3; OALR. HYDE, ALBERT SIDNEY JOHNSTO (b'84) - La.1, Tromple: 9-12, $2-4$

JoNes, PHILIP H $\left(b^{\prime} 55\right)-L a, 1,8 ;(1,95)$ 736 Contentlon SL; otlo, Masunic Temple: 3.6 .

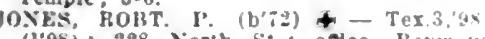
(1'95): 228 North St; oalce, Reymunt Bldg. : 10-12, 3-5: Pd.

JONES, THOMAS SI'EC (b'\$I)-La., 0 , (1'06): 1202 fonventlon St.; odice, ihey mond Bldg.: 5-8: U.

KEM!, BOBT. CHRISTIE (b'i3)+-I.A.I 00 : (l'00): 956 Florlda St: unice, Rey mond Hdg: $10-12,3-5 ; \mathrm{S}$.

MeVHA CHAll,Es (b'69) - I. 1,93 (1'93): 802 Conrention st.; once, Houmain Blds.; 11-1; S.

Morean, Loftus E-Ont.3,'90: (l'90)

siureay, Wm. (col.)-i.a.,"9i; (1'9i); 1301 North B|rd.: $7-9,1-3$.

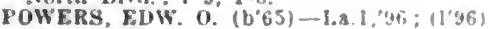
Masople Temple.

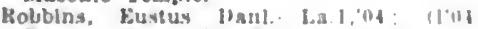
Romain Hlde. OALR.

ROBERT, JAMES JEHU (b'85) + V V J. O

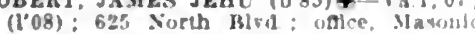
Temple: $8: 30.11,2-4: 30$

SINGI.TARI, THOMAS I'. (b'G0)-hyt '8: (1'8\%) : 308 korlda st: $12-2$.

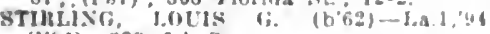
(1.94): 338 , 5th 8 .

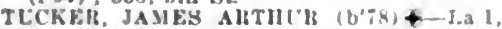
or: 11.04): 1030 North st.: omce, Hey

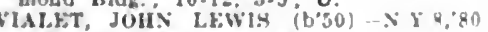
(1'83); 74 Collego Are.

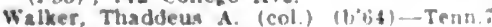
"R5: (1'85): 838 Siorth BIrd: 11-2, 1-. :301

wethers, whllam it. (col.) (b'83)-Tem? 10: (1'10): 1019 Main sit. ; ince. Ma.t and lofel,re sis. : in.12, 3-5; U.

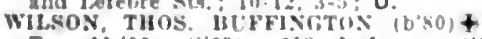
Tean.d1,00: (1"09): 218 lafajelle st.

omce, Houmain Hlds.; 10-12, 5-z: U

BAYOU CHICOT. I50, EVANGELINE

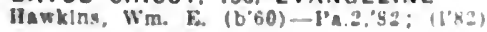

BAYOU GOULA, 1,000, IBERVILLE

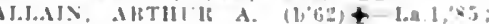
(1'85)

BAYWOOD. I50, EAST BATON ROUGE

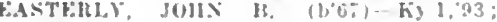
(1.93)

BEEKMAN, 50, MOREHOUSE

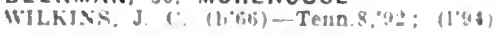

BELAIR. 600. PLAQUEMINES

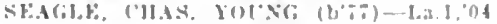
(I)

BELCHER, 200, CADDO

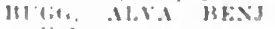

lenderann, J. Folw.--Tenu.1.'05; (1'05)

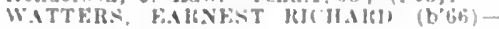
hy, 5, $\left.91:\left(10^{\circ} 0\right]\right)$.

BELGROVE (ALEXTON P.O.), IO, LIN COLN

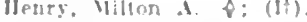

BELLEVUE, 25, BOSSIER

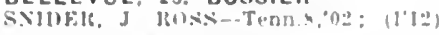

BENTON, 318, BOSSIER

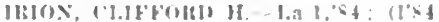

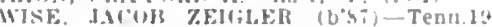
$\left.11 ;\left(1^{\prime} \llbracket\right]\right)$

BERMUDA, 200, NATCHITOCHES

linchleld. Le lior A. (b'4j-lad 1,08: (l'us).

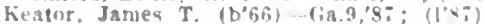

l.arvton, F. 1:- Kу.4.9n; $(1.90)$

BERNICE, 78I, UNION

Culvin, Clyde C. - La.1, 0 ; ; (1'07).

Tarland, D. B.-l.A. 1, (15: (1295)

Glover, Oscar F. (h'-2)-Ky.l.96; (1'04),

Smlth, 1. 1'.. Tenn. 8,$90 ;(1,30)$.

Tanner. Jesse $f$. (b'8t)-Tenn.6,"09: (1 0:4) R.t. I). 3.

BERWICK, 2,183, ST, MARY

BRAWIC, IAMES CIABEXCE (b"

1.a.l.00; (l'00): (also \orzan rity).

BIENVILLE, 606, BIENVILLE

CRAWFORD, CHARIL $\left(\therefore \quad\left(b^{\prime}, 9\right)\right.$-Tenn 8 01: (l’09).

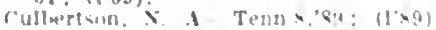

MAYXER. OHWFH $0 .\left(b^{\prime}, 0\right)+-T e n n .5 . " 43$ (1).93).

BILLES (ALOHA P.O.), 50, GRANT

MORAT, AXTOINE J. (b's5)-Tenn.15,'0; (I"0).

BLACKBURN. 75, CLAIBORNE

Vorman, Beriram Allen (b'SG) -Tenn. "0y. (1'09).

BLANCHARD, 200, CADDO

"utts, stere \&. (1)'90) Teun

BLEWETT, 15, BEAUREGARD

"ARLTOS, ARTHUW LESLIE — Mo.8,"03 (l'09)

BOGALUSA, 1,800, WASHINGTON

Alord, Doc. Wendell-La.1,"04: (I'04).

H.11., J. X-Ky.4.93; (1'95)

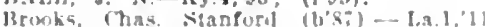
(I'11)

Cole. Nerbert clalborne-i.a.1.05; (1'09).

Kontfer, Jos starus $\left(b^{\circ} 90\right)$ - Tenn.s,i2 (l'13)

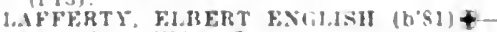
1.a.1.n9; $(109)$ : S

THEHCF, JAMFS FUR (b'0i) + TEU: (11:): $(1,0)+1)$

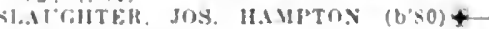
1.A $7,01:(1,0)$

BOLINGER, 300, BOSSIER

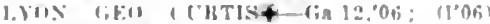

BONAMI. 300, BEAUREGARD

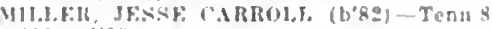

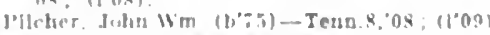
BONITA, 273, MOREHOUSE

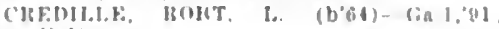
$(1,9)$

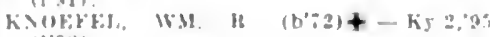

BOROELONVILLE, ISO, AVOYELLES

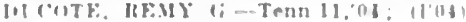

BOSCO, 40, OUACHITA

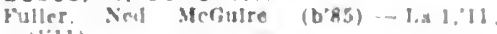

BOURG, 400, TERREBON NE

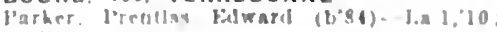

BOWIE, 1.000. LAFOURCHE

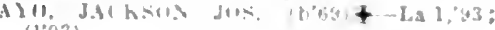

BOYCE, 865. RAPIDES

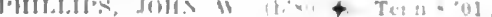
(1'0)

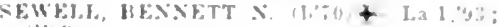

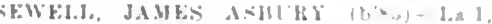

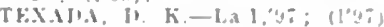

BRANCH, 25, ACADIA

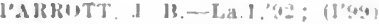

BREAUX BRIDGE, 1,339, ST. MARTIN

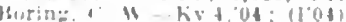

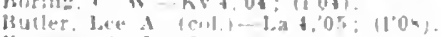

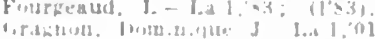

litantens. $[1.3$-f : 1101].

iniltiedu, Arelsur (1, wh)-1.a1.79; (105)

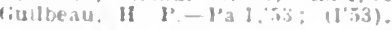

BROUSSARD, 499, LAFAYETTE

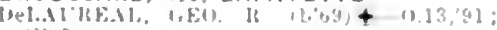

sitromer.

BRUSLY, 390, WEST BATON ROUGE

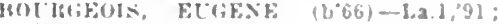

LEVERT, MAKK W. (b\%t)-TEnR 11, 9: (1'Sर).

BRYCELAND, 250, BIENVILLE

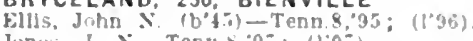

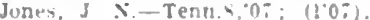

BUCKEYE. 100, RAPIDES

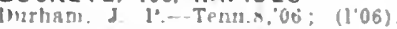

BUCKNER, 5, RICHLAND

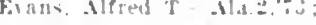

BUNKIE, 1.765, AVOYELLES

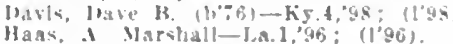

Haas, I Marthall-Ja.1,96; (1"96). Iiractlce.

MATHEWs, EM(AK STANLEI (b"3)-

Las 1,00; 11'00).

Sewell, E. G. Ky :,95: (102)

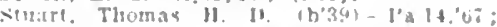

BuRAS. 300, PLAquemines BALLOWE. HEWITT L. $\left.\left(\mathrm{b}^{\prime}: 6\right)+1 . \mathrm{B}\right), 00$;
$\left(\mathrm{d}^{\prime} 00\right)$.

BURNSIDE, SO, ASCENSION

BHINIILI?, JILIEN TRIST (b'Ga)-LA.I XV: $(1,38)$.

BURRWOOD. 25. PLAQUEMINES

Trepagnler, Dalion H. (b'79)-La.1,03: (1'03).

BURTON, 400, ST. JAMES

Allson, Jacob S. (b'i:) - Md.3,'90; (1'96).

BURTVILLE. 125, EAST BATON ROUGE

SITMAN, CH:O. WUMU(Ch $\left(b^{*}: 0\right)-L a 1,92$ : $\left(10^{\circ}\right)$

BUSH, 75, ST. TAMMANY

Foung, Fornest $\longrightarrow$ : $(1+1)$

CADES, 150, ST. MARTIN

Hatrisun, J. I', Jr- I.5 \& $94 ;$ (1 G4

Thomas, Koland Flsher-La.1, 0t: (1.0t).

CALHOUN, 260, OUACHITA

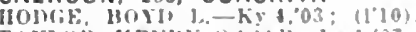

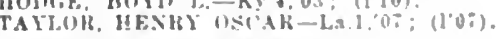

CAMERON, 200, CAMERON

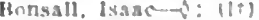

CAMPTI, 664, NATCHITOCHES

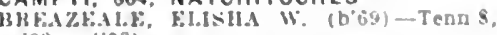
$0: 1:(1,03)$

lichluwar, Tbnmas $1^{2}-K v 1,85:(100:)$

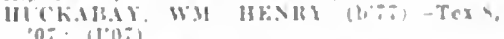

Perot, Clatence liabrlel 1.3 1:00; $\left(10^{\circ} 00^{\circ}\right)$.

CARENCRO, 609. LAFAYETTE

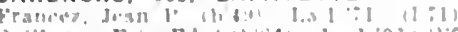

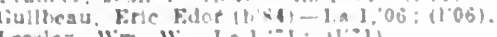

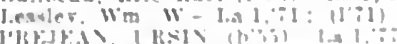

CARSON, S00, BEAUREGARD

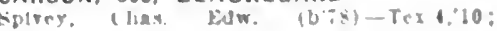
(I'II)

CASPIANA, 250, CADDO

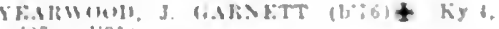

CASTILLE, 50, ACADIA

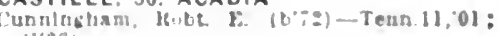
$(1,02)$. 
CASTOR, 200, BIEN VILLE

Mlume, J. N.-Tenn.s.'ns: (l'03).

Bond, E. O. (b'71)-Tenn.s, 0 ?; (1'09).

CECILIA (R.F.D., BREAUX BRIDGE), 125, ST. MARTIN

Boudrean, Martial-La.1,07; (l'07)

CENTER POINT, 10, AVOYELLES

Anderson, Jolun (:- 0.2, fil); (f'tio)

Baldrldge, James Washlngton (1,:39) - 0 ; (1†).

DanleI, James A. $\rightarrow$; (1\%).

CENTERVILLE, 500, ST. MARY

Bowman, Ira Tenn.5," 86 ; (1'S6).

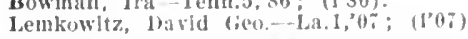

CENTRAL, 150, ST. JAMES

DE ROLEN, 1BOI'T. FIRANCIS (b'69)-La.1, 08: (1'09).

CHAMBERLIN, 60, WEST BATON ROUGE RICHE, II. GUY (b'75) $₫$-La.1,'99; (1'99). CHAPMAN (LOUISA P.O.), 25, QUACHITA Larche, Luclan Eldred (b'84)-Tenn.8,'09; (1'09).

CHARENTON, 400, ST. MARY

Pecot, Louls F'. (b'60)-La.1,89; (l'89).

WInn, Robt. Blanks (b'78)-La.1,08; (1'08).

CHATAIGNIER, 75, EVANGELINE

ARDOIN, YVUS (b'Y0)-La.1,08; (l'08): Ob.

Stagg, Wade H. (b'7て)-Ja.1,'99; (l'99).

CHATHAM, 181, JACKSON

BROWN, DAVID E. (b'S4)-Tenn, 8,07; (1'07).

DOÜGLASS, ALVIN E. (b'85)-Tenn.8,09; (1'09).

GILL, JOIIN J. (b'66)-Tenn.8,91; (l'07)

Wllder, Saml o. (b'56)-Ky.4,84; (l'86).

CHENAL, 50, POINTE COUPEE

MATTHEWS, WILLIE W. (b'59)-Ky.4,87; (1'87).

CHENEYVILLE, 498, RAPIDES

FOO'TE, CHAS. A. (b'67)-Ia.1,'90; (1'90)

KILPATRICK, RALPH-La.1,'85; (1'85).

CHERRY RIDGE, 30, UNION

Tatum. Perry A.-Tenn.5,91; (l'91).

CHESTNUT, 20, NATCHITOCHES

Joyner, I. M.-Tenn.8,'06; (1'06).

CHOUDRANT, 375, LINCOLN

COOK WV. H. $-0.8,89 ;\left(I^{\prime} 88\right)$

FISIER, AURELIU'S EARLE (b'84) Tenn.8,'06 (1'06).

CHURCH POINT, 481, ACADIA

ARCENEAUX, LOUIS B. (b'69)Ð-La.1,91 ; (I'91).

Chachere, T. C.-Ky.4,'36; (l's6) ; R.F.D. 1.

Childs, Wn.-La.1, $79 ;(1,79)$

Jenkins, Harry (b'84)-La.1,08; (1'08).

Jenkins, Walter A-Ky.4,'87; (1'87 ).

CLARENCE, I22, NATCHITOCHES

Brlan, N. M.-Tenn.8,'11; (l'11).

CLARKS, 750, CALDWELL

GARDNER, ELMER D. (b'62) \&-Mich.1, '88; (1'04); OALR.

Mecom, F. H.-Tenn.8, 07 ; $\left(1^{\prime} 07\right)$.

CLAYTON, -, CONCORDIA

Ferguson, Earl C. (b'84) - Tenn.1,06 : (1'06).

CLINTON, 918, EAST FELICIANA

MCKNEELY, JOHNSON FRANKLIN (b'90) -Ky.2,'12; (1'13)

TOLER, ENÓCH MCL. (b'74)£-Tenn.5, 00 ; (1'00).

YOUNG, TACITUS W., JR. $\oplus-$ La.1, ${ }^{\circ} 0 \mathrm{~T}$; $\left(1^{\prime} 07\right)$.

CLOUTIERVILLE, 300, NATCHITOCHES

County, A. V. $\rightarrow$; (1

Samplti, J. Alphonse-La.1,'02; (\$).

Scruggs, S. H.-Ky.2,'88; (1'88).

CLYDE (ZWOLLE P.0.), 25, SABINE Armstrong, Jos. Clifton (b'i1)-La.1,'92 ;
(I'92).

COE, 50, ACADIA

McCuller, D. C.-Tenn.8,'12; (贲).

COLFAX, 1,049, GRANT

Blackwood, Eddie H. (b'80)-Tenn.1,03: (1'03).

Chapman, J. C. $\rightarrow$; (l'04). Creed, Abner B. (b'78)-Tenn.S,'11; (1'12);
13.F.D. 1.

(,OODE, PHILIP-Ala.2, $7 \%$; $(1 ; 7)$

GRAY, EDWIN BOOTH \&-Tenn. (I'98).
Jones, Win. A. (b'5i)-Tenn.8,'88; (1'88). Wlillamson, Phlllip Goode (b'88)-Ark.1. wonlall, John Lewls (b'71)-Tenn.1,01; (1'01).

COLLINSTON, 333, MOREHOUSE

I) relsbach, Lee (b'62)-Ky.1,'85; (l'84).

Freeman, Edwin Scott $\left(b^{\prime} 8{ }^{\prime}\right)$ - Ky.2,12 (I'12).

RE(TOL, JAMES MA1)ISON (b'6z)-Tenn.8, 97 ; (1'00).

VAT'CIIN, JAMES 13. (b'7i)-La,1,01 (1'01).

COLOMB, I50, ST. JAMES

('olomb, Brooks A. (b'62)-I La.1,'85; (l'85).

COLQUITT, 75, CLAIBORNE

Palmer, Fleater (b'85)-Tenn.6,'12; (1'13).

COLUMBIA, 500, CALDWELL

Brown, S. H. -Ky.4,'97; (I'99)

May, I. 13.-Tenn.11,06; (1'07)

Shcrman, Dollie 0. (b'86)-La.1,'11; (I'11).

CONVENT, 300, ST. JAMES

Gaudin, Louls A. (b'70)-La.1,'94; (l'94).

CONVERSE, 200, SABINE

ALLEN, IWM. GREEN (b'84)-T-Tenn.8,'10 ; (1'10).

HARRIS, EDW. K. (b'87)-Tenn.8,11; (1'11)

Ifeard, J. D. $\longrightarrow$; (1†).

CONWAY, 50, UNION

Tugwell, Egbert-Tenn.1,'08; (l'09).

CORBIN, 50, LIVINGSTON

FAUST, HENRY M.-Tenn.8,02 ; (l'02)

COSSINADE, I5, VERMILION

Latour, E. Alexis-Ky.4,98; (I†).

COTTONPORT, 866, AVOYELLES

BORDELON, ALBERT L. - Tenn.11,'99; (l'00).

LEMOINE, BLUMES J. (b'71)-La.1,'95; (l'96).

Lemolne, Jules D. (b'82)-Tenn.5,04; (l'04).

COTTON VALLEY, 700, WEBSTER

COYLE, CHARLEY GRAVES (b'75)-Mo.27, 01; (1'01)

SMITH, HARDY HORACE, JR. (b'80)-La.1, '03; (1'03).

COUSHATTA, 564, RED RIVER

Boylston, Wm. A. (b'42)-Md.1, 71 ; (1'71). DAVIS, WM. LACY (b'76) - Tenn.8, 09 ; (1'09)

EDGERTON, CLARENCE EUGENE (b'58) -Tenn.8,'89, La.1,'00; $\left(\mathrm{I}^{\prime} 89\right)$.

GAJAGAN', WILEY W.' (b'81)-Tenn.8,'11; (I'11).

Wilklnson, Emmet-Md.9,10; (\$).

Wilk!nson, Waddy T. (b'66)-Tenn.1,'96; (1'05).

COVINGTON, 2,601, ST. TAMMANY

BUQUOI, JOHN F. (b'77)-Md.3,'98; (l'98).

GAUTREAUX, HENRY E. (b'82)-La.1,04; (1'04)

Hebert, Numar M.-La.2,69; (1'69).

Marrero, F. G.-La.1,'84; (1'84)

I'lgott, James Franklin (b'64) - La.1,'92 ; (1'92).

STEVENSON, W. LAURENCE (b'70)-I.a.1 . 32 ; (1'92).

Tolson, Geo. R.-Ky.1,'88; (l'88).

WARREN, BASCOM B. (b'60)-La.1,'82; (1'82).

Young, F. F', Jr.-Tex.3,'11; (I'13)

Young, Francls Fenwlek (b'63)-Ia.1,'84; (1'84).

CRAVENS, 75, VERNON

Miller, Edw. TayJor (b'79) - La.1,'09; (l'09).

CREOLE, 125, CAMERON

Carter, Stephen Orland-Tenn.5,'93; (1'93).

CROWLEY, 5,099, ACADIA

Azar, James A. (b'82)-La.1,'11; (1'11).

Breaux, Louis J. (b'84)-Tenn.6,07; (1'07)

Cross, Alblon B. (b'82)-La.1,06; (1'06).

ELIIS, E. M. 4 -Tenn. 8,'95; (1'89).

Ennis, Walter H. (b'78)-La.4,08; (1'08).

HOFFPAUER, MAXASSEH L. \$-La.1,"94; (I'94).

Lyons, Raphael R.-La.1,62; (1'62)

Martin, Francis Rene (b'59) - La.1,'85; ( I'85).

MIMS, DAVID D.--La.1,'96 ; (1'94),

Raney, Ralph B. (b'69) H-Mo.5,94; (1'94).

Webb, Hines C.-Ky.4, 89 ; (1'89).
CROWVILLE, 40, FRANKLIN

ritiledge, Joel G. -0 ; (1t).

JARRELL, COLCMBTS MARION\&-La.1, 07 ; (1'07).

CUT OFF, 200, LAFOURCHE

Sigur, (:. Adolph-La.1,'94; (l'94) ; R.F.D.

DANVILLE, - BIENVILLE

Talt, Fled W.-Tenn.8,'12; (朱),

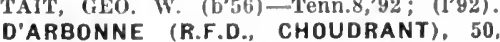
UNION

Grlfiln. Wm. Perry-Mo.27,'98; (l'98).

Wade, James L. (b'86)-La. 1,09; (l'09).

DARROW, 100, ASCENSION

Brunifleld, J). Clyde (b'T0)-La.1,'00 ; (l'00)

laymond, Ernest- $\rightarrow$; (1†).

DELCAMBRE, 308, IBERIA

Landry, Adolphe (b'77)-La.1,03; (1'03).

DELHI, 685, RICHLAND

BARRIER, JOHN M.-Ky.4,'83; (1'83).

COLIJNS, NASHథ-Ky.1,'91; '(1'91).

May, Robt. I. (b'74) - Tenn.6,00; (1'02).

Powell, Cinclnnatus Dickson (b'83)

Teun.8,'08; (1'08).

DENHAM SPRINGS, 574, LIVINGSTON

MINTON, JOS. A.(b'63)-Tenn.8,93: (1'06) WILLIAMS, MONTGOMERY (b'75) €-La.1. 05 ; (1'05).

DENNIS MILLS, 50, ST. HELENA

Odom, Stanley Glbson (b'88)-Mla.4,'13; (1'13).

DE QUINCY, 7I5, CALCASIEU

Lyons, Geo. S.-Tenn.8, 00; (l'00).

Price, Cecll R. (b'82)-Tenn.8,'12; (l'12).

DE RIDDER, 2,100, BEAUREGARD

CANNON, JOHN HENRY (b'66)-Tenn.11, 00 ; (1'02).

FRAZAR, JOHN D. (b'83) - Tenn.8,'11; (l'11).

HORTON, WADE H. (b'Ti) -T-Tenn.8,'99; (l'07); Member Miss. State Med. Assn. ; LD.

MCMAHON, SAML. HOUSTON - Ky.1,'98; (1'07).

ROBERTS, SAML. T. (b'80) -Jelln.11, TOY JAIES (1'09) ; $\mathbf{S}$.

(1'09); S. '09, Tenn.8,'10; (1'10); U.

DESHOTELS, 50, ST. LANDRY

GUILLORY, J. B.-Ky.4, 07 ; (1'08).

DIDO, 200, VERNON

STROTHERS, RODOLPH - Tenn.8, 03; (1'03).

DiXIE, 75, CADDO

Baker, Linus Terrell (b'85)-Tenn.1,08; $\left(\mathrm{I}^{\prime} 08\right)$.

DODSON, 845, WINN

Faith, James Franklin (b'82)-Tenn.6,'13; (l'13).

Pankey, Jos. H. (b'79)-Ga.11,02, Tenn.1, 09; (1'02).

TALBOT, BENJ. H.-Ja.1,'93; (1'93).

DONALDSONVILLE, 4,090, ASCENSION

HANSON, JOHN D. (b'49)థ-La.1,'80; (l'80).

HANSON, TUITE IJ. (b'68)థ- La.1,95; (1'95).

Lowery, John H. (b'76)-La.4,'94; (l'94)

Martin, Allen Walker (b'82) - Ky.2,'0i; (l'07); OALR.ネ

MCGALLIARD, WM. MILLEN (b'38)-La.2, 66; (1'66); not in practice.

SIMS, E. KITTREDGE (b'72)థ-La.1,'94; (l'95) ; Pd.

Thlbaut, John S.-La.1,"83; (l'83); not in practlee.

THIBODAIX, PAUL T. (b'74)-La.1,95: (1'95).

DONNER, 400, TERREBONNE

Garrison, J. E.-Tenn.8,'04; (l'05).

DOSS, 75, MOREHOUSE

PUGH, WM. E. (b'55)-Ky.2,'81 ; (1'83).

DOWNSVILLE, 100, UNION

Hamilton, J. M.-Ala.2,'80; (I'80).

DOYLINE, 200, WEBSTER

Fuller, Jesse I. (b'76)-Tenn.8, 07 ; (1'07).

DRY PRONG, 100, GRANT

DONALDSON, DANiL. V. (b'82)-Tenn.8, 09; (1'09).

Sanford, Ira W. (b’74)-Tenn.19,'10; (1’10). 
DUBACH, IIT, LINCOLN

FE.ATHF:HSTOX, BICHIB!

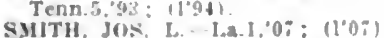

SMlth, lo. I'. (b.52)-Tenn \&,

DUBBERLY, 150, WEBSTER

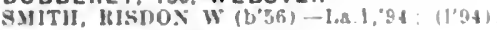

DUSON, 120, LAFAYETTE

Arreltets. I7ysses J. (b.00)-Ja 1,11: (1'11)

DUTCH TOWN, 75, ASCENSION

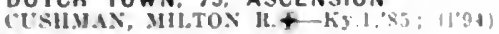

DYKESVILLE (R.F.D. HAYNESVILLE)

100. CLAIBORNE

Worles. A. G.-Ky,4,06: (1"0ii)

EAST POINT, I00, RED RIVER

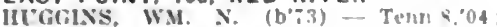
(lo 04$)$.

ECHO, 238. RAPIDES

marls, Calrin-Ga.s, 81 : (I'sI)

de Nux, Fmerle (b'it)-Tenn.11.95; 119;i)

Rleble, Noab saml (b'sI)-Tenn.9,0": i

EDGARD, 250, ST. JOHN THE BAPTIST

COOHER. HIHAM D.—Ala.2,'S3; (I'33).

KLMORE, JAMES L, (b'3)- La 1,75 (1?:\%).

EDNA, 200, JEFFERSON DAVIS

liftrman, J, W- Tex.t,05: (I'05)

EFFIE, 10, AVOYELLES

Uanlel, Alpheus A. (b'it)-Tenn.s, 03 ; (1'0i).

Lafargue, Leo Douglas (b'si)--Tenns.'II (III).

ELIZABETH, 1,500, ALLEN ELIZABETH, J,500, ALLEN
HRANCH, JOHX SIUNEY + KI:2,"81:
(1'81); S.

Jucket. Frank Burkley (1):-9)-lat.l, $(1,10)$.

ELMER, 25, RAPIDES

Cilass, iv. if.-lnd. 4. il: (I'SB)

ELMGROVE。 75, BOSSIER

Crow. Harper Leonlatas (b'S6) $-\mathrm{k} y, 2,13$ (l'13).

ELTON, 100, JEFFERSON DAVIS

Fletcher, Warren A. (b's0) - Tenn.1, 0 , (1'05) l'H.NiNGTON, SIMHON A. - Teun 6,00

Smith, Theodore Shay-Ky.1,93; (I'94).

ENTERPRISE, 15. CATAHOULA

Brlan, Elljah M. -0 ; (1†).

ERATH, 575, VERMILION

Huperler, Douglas (6.64)-La.1,92: (1.95).

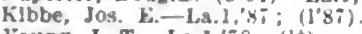

Young. I. T. - I A.1, $18 ;(1 \dagger)$.

loung, Isaac Townsend, Je, (l, 'x: L La 1 . 'T2: (1'12).

EROS, 898, JACKSON

Viw InR. J. Juther-Tenn.8, 11: (I']2).

HEAK., MARSHALL II, $(1,80)$ - Ga.11, $0: 2$; (1.02),

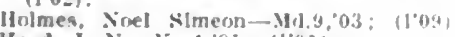

llood, J. X-ky,t.8I; (I"9I)

I.NDULiM. JACOB HANSFOH (b's0)-

KY, 4, 0.): (l'09).

ESTHER, 50, VERMILION

llarrington, Augustus $W .0 ;(1)$

EUNICE, 1,684, ST, LANDRY

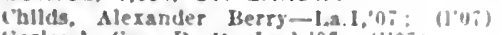

liarlane, Geo, I'rall-Ia.1, $07 ;\left(10^{-}\right)$

1.EWIs, M. D.-I.a.1, 86 ; (I' 86$)$

Itay. Wm. H.-La.1, 8.8 : (1'88).

Stakg. Jublus J.-la.1,88: (1中)

EVA, 50, CONCORDIA

Balrnshather, 11. M-1.a.1,:9: (1)

EVANGELINE, 400, ACADIA

Trezerant, Retrhert Tenn.2, $014:(1,4,0)$

EVERGREEN, 299. AVOYELLES

Kuck, Ciurdon $\left(b^{\circ} \wedge\right.$ (b) Ky.2.11:

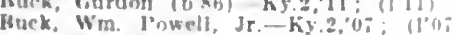

Hack, Wm. I',-Ia.I, is; (10iz)

llollinwheal, John A. (b.4s) - (ia) 1.70 $(1 \div 0)$

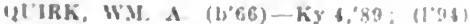

FAIRMOUNT, IS3, GRANT

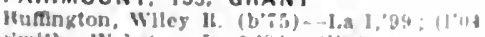

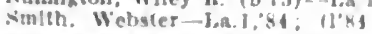

FARMERVILLE, 398, UNION

Eirana, Jamea (i.-Tenn...0\%; (1.01)

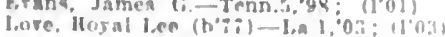

Thylor, J. 1;. (to
FAY, - WINN

POITER, ST.UKL (b"a) \-Ala 4,08 ( $\left.T^{\prime} 0.5\right)$.

FERRIDAY, 577, CONCORDIA

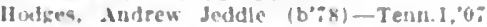

James Truman - Mt

FIELDS, 20, BEAUREGARD

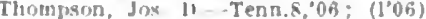

FISHER, I,200, SABINE

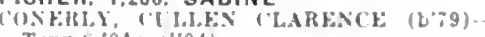
Tenn.s, 0 t: $\left.11^{\circ} 04\right)$.

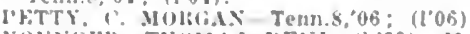

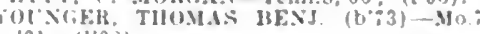
01 ; $\left(I^{\prime} 0 H_{i}\right)$

FLORA, 100, NATCHITOCHES

F'rautum, Jos. (b'82)-Tex.8,08; (108).

FLOYO, 200, WEST CARROLL

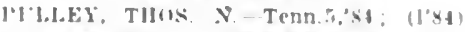

FOLSOM, 100, ST. TAMMANY

BIJLOCh, HEY\%IK I). (b'S2) + -Tenu.II,

0.3; (1'11)

FORBING, SO, CADDO

Phlllys, Alrin Forrest $\left(b^{\prime}-3\right)-$. Cia 5, 95 ; (1'46).

FOREST, 64, WEST CARROLL

lisharan. James Alesander (b'is) - Ark.: 09; (l'09).

FOREST HILL, 200, RAPIDES

llean, W. II.-KY.4, 8i; (I'8;).

FRANKLIN, 3.857 , ST, MARY

Dauterlte, Henry Joseph (h'si) -1.a.1,10 : (l'10).

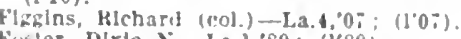

'uster, Dirle X.-La.1, 89 ; (i'89),

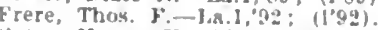

Cates, Homer H. (b'66)-Ia.1.99: (1'99)

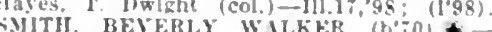

La.1"03: (1,93)

FRANKLINTON, 814, WASHINGTON

BHOIK. JEPTIII I.IT.MNORE-I.A."O3. (1.03).

lones, Wullam Johnson (b'6s)-La.1.00:

RENCH SETTLEMENT, 75, LIVINGSTON

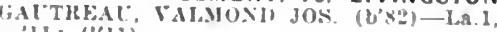
'11; (l'11).

FRIERSON, 300, DE SOTO

Stewart, Itollaud A. $\left(b^{*} \cdot 3\right)-M 0^{2} 0,08$ (1.08)

FROGMORE (WILDSVILLE P.O.). 30. CONCORDIA

Simlth. Temule J.-Mo.2,03; (1'08)

FT. JESUP, I00, SABINE

Smith, EHloth (b's3) - Tenn.1,08; (1'us)

FT. NECESSITY, 75, FRANKLIN

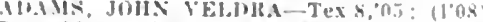
Reynolds, Albert J. (b's3) - Tenn.8, 09 (II09)

FT, ST, PHILIP, SI, PLAQUEMINES

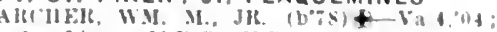

ING LeUt. MIIC.. IT.S.A

FULLERTON, 1.238, VERNON

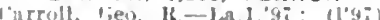

Monk, Murrul-Tenn., 1, : (l'Q8).

CAHAGAN. 25, RED RIVER

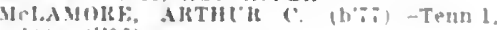
(1).); (l'06).

GALLION, 40, MOREHOUSE

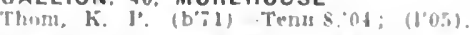

CARYYILLE, 1,000 , ST. JOHN THE BAP.

TIST

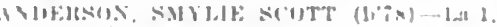

"Ub: (1.08)

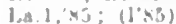

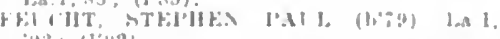
(11: $(1,02)$.

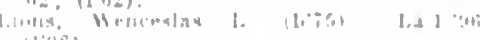

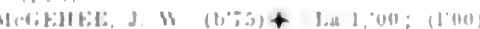

GAYLE, I8. CADDO

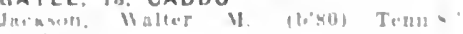

GENESEE, fOO TANGIPAHOA

WUht) JUES I' (b'i)

GE ORGE TOWN, SO, GRANT

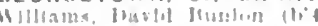

GIBSLAND 1.065. BIENVILLE

Sinlti, II. I. - B: \{:"HO

GIBSON, ACO, TERREBONNE

SImmon, Wm. I, (l, ', li

GILBERT, 250, FRANKLIN

1:11. L., IN

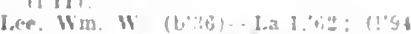

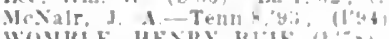

तथा पो

ISLIAM. ISO, CADDO

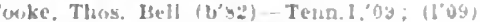

Wrorley. I". C.-Tenn1.8,"19; (1"39)

GIRARD, 100, RICHLAND

"MAMHELS, HOT'STUN CMILISLE (L'8, $-11 \mathrm{a} .2,1) ;(1) 11$ )

Thouan, vocar-1la.3.91: (l'yl)

Hollinawerth, s l. (b'bj)-b (1'05).

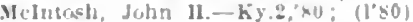

GLADE, 20. CATAHOULA

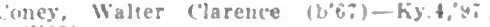
(1'03).

GLENCOE, 50. ST, MARY

Tlly, Wllton I'al Dugean $\left(b^{\prime} s b^{\circ}\right)$-Tenn 19 '11: (1'Ii)

GLENMORA, I00 RAPIDES

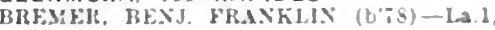

03 : (l,03)

Broadway, lien. B-Tenn.,01; (1'0s).

Craupurd, Jefterson A. (b's3)-Tenn.8,12

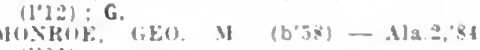

(1's4)

I'hHllps, James T (b'00)-Ala.2'sio; (l'si). GLOSTER, 250, DE SOTO

Hrinkley, Floyd O. (b'72)-110.20,"11!: (1002)

GOLD DUST, 80, AVOYELLES

loung, J. 1-Kis.J,05; (1'06).

GONZALES, 300 . ASCENSION

Le Sueur, Geo. Huckner-I.a.1,04; (I'0) I

suith, Hulit. Maclay (b's3)-1a.1,"09; (1"0y)

it. Anant, tuj stanhope (b'ot)-Ia 1,11 (I'II) : Pd.

G00D PINE, 500, LA SALLE

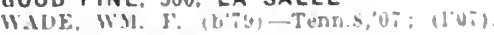

GRACE, 250. WINN

Reed, Carsur 16-dia.11,06: (l'06).

GRAMERCY, 100. ST. JAMES

Ezldure, F. X. (col) (b'st)-Tenn. Z."U: : (l'US).

GRAND CANE, 485, DE SOTO

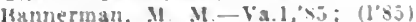

Leopold, Joseph L.-La.1.91; (1'9l)

GRAND CHENIER, 67, CAMERON

IIllet. Laurene ubld (b'sl)-Lal," (l'vs).

(10.0)

GRAND COTEAU, 392, ST. LANDRY

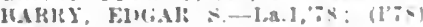

TAKLTOX, THEOHUILLS TULLOHS (b'i)

$+-114: \because 1:(101)$.

GRAND ISLE, 252, JEFFERSON

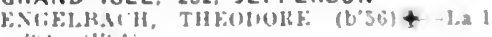
:44: $\left(11^{\circ} 44\right)$

GRANGEVILLE。 60, ST, HELENA

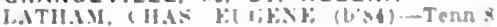
$1: 2 ;(1.12)$

Tylas, Humbert \&. (b)so) - Tens s.os $(1)^{\circ}(0,3)$

GRAYSON, 250, CALDWELL

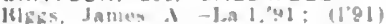

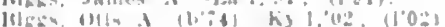

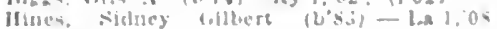

GREENSBURG, 268, ST. HELENA

willue linman? II lh li) La l, :A

in

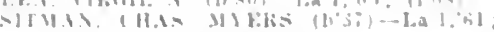

CREENWODD, 230. CADDO

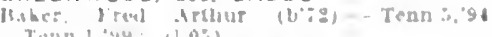
Tonn $1.24 ; 4105$

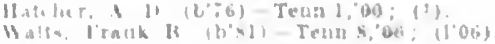

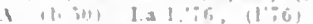

GRETNA. H,S00, JEFFERSON

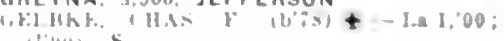

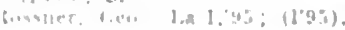


GROVE, 25, WEBSTER

Killgore, John 1). (b'8t)-Tenn.8,'10; (1'10). GUEYDAN, 1,081 , VERMILION

Heard, James 1', - Tenn.8, 01 ; (l'01)

Kibbe, l'ressley Aloyslus (b'91)-La.1,'12; (l'12).

White, Ilenry Bascomb (b'75)-Tenu.5,'99: (l'00).

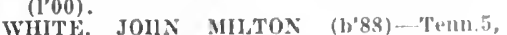

'11; ( ); Member Ark. Med. SOE

HACKLEY, 100, WASHINGTON

Murpley", Thomas Walter (b'78)-Ia.1,'10; (['10).

HAHNVILLE, 300 , ST. CHARLES

Donaldson, 1.. 'T'. Jr.-La.J, 07 ; $\left(1^{\prime} 00^{\prime}\right)$.

JOHNSOX, ROR'T. HAIRISOX-TenI.8, 04; (1'04).

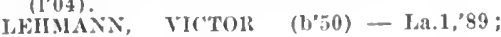
(l'89).

HAILE, I20, UNION

Medlln, Miless (b'82)-Ga.12,08; (1'08).

HAMBURG, 25, AVOYELLES

Keller, Clas. w. (b'39)-I'a.3,'(61; (l'01);

not in practlce.

HAMMOND, 2,942, TANGIPAHOA

Bruning, John L. (l'60)-.I0.8,'83; (\$).

Carter, A. R.-Tenn.8,05; (l'05).

Gates, Augustus F. (l, 72)-La.1,98; (1'98).

Ilenkel, Wm. F. (b'til)-Ky.4, 85 ; (1'85).

Hollister, kalph O. (b'63)-Mich.1,91; (l'91).

MCGEHEE, EDW. I.

(See New Orleans.)

MeGFHEE, EDW. I., JR. (b'79)-T, T.1,02: (l'02).

AtCGEIIFE, LICCIIS IEYAMPERT (b8J)La.1, 04; '( I’04).

Roblnson, John 1\%. (b'.51)-111.10,'85; (1'85).

HAPPY JACK, 75, PLAQUEMINES

HAYS, GEO. A. B. ( IAa.1,74; ( 174$)$

story", Benj. S.-Ky.2, 80 ; (l'80).

HARRISONBURG, 36I, CATAHOULA

Holloman, H. S.-Tenn.8,00; (l'00).

Prichard, H. W. A.-La.1,'99: (l'94)

Rawllngs, Hardy-La.1,'87; (l'87).

HARVEY, 175, JEFFERSON

IEV1N, ABRAHAM I.OUIS (b'79) †-La.1 $0 T^{\prime} ;(1,0 \pi)$.

Odom, Guy Leary (b'80)-La.1,'08; (1’08)

HATCHER, 50, SABINE

Armstrong, Geo. D.-Ky.2,'80 ; (l'80)

HAUGHTON, 249, BOSSIER

Lawrence, Paul-La.1,67; (l'67).
Rooks, JoHN E. (b'74) $4-$ Md.1,05;

TUCKER, CLARENCE M. (b'72)-Tenn.8, 03; (1'04).

HAYNESVILLE, 663, CLAIBORNE

Baucum, Henry C. (b'77)-Ky.4,04; (1'04) BAUCUI, JAMES DANIEL (b'89)-Ky.2 10 ; (l'10).

Baucum, Wm. H. (b'56)-Ky 4,'94; (1'03)

Day, Mtontrose (b'55)-Mo.1.'81; (1'81).

Sherman, John Clayton (b' 6 ) -Tenn.5, 01 (1'01).

Waller, Lee T. (b'66)-Tenu.8,'92; (I'92).

Waller, Leroy T-Ky.4,06; (1

WALLWR, S. C. (b'62)-Ténn.8;88; (1'88).

HEFLIN, 75, WEBSTER

Middleton, Eugene Bernard - Tenn...'I:; (1'13).

HENRY, 25, VERMILION

CUNNINGHAM, JAMES IARVIN-Tenn.11, 04; (l'05).

HESSMER, 300, AVOYELLES

CHATELAIN, LEONARD (b'84) - Tenn.8 '10; (l'11).

JEANSONNE, PHILIP (b'80) - Tenn.6,03;

PORET, EDW. ALFRED (b'is)-Tenn.11, '04; (l'04); ObG.

HICO, 65, LINCOLN

Cook, Elmer B.-Teun.8,'10; (l'10).

Johnson, John Monroe (b'86) - Ky.2,'11 ; (1'11) : R.F.D. 1.

Wise, Olen L. (b'83)-Tenn.8,'10; (l'10).

HIGHLAND, 15, TENSAS

Gibson, Wilmer Claude (b'84)-Tenn.1,'08; (1'08).

HODGE, 300, JACKSON

MOSELY, CHARLEY HODGE (b'82) $\oplus-$ Tenn.8,'11; (1'11).
HOLDEN, I00, LIVINGSTON

CAITTER, N. W.-Tenn.8,'10; (1'11).

HOLLOWAY, 55, RAPIDES

Jurham, ('ornelus Burnebass-Tenn.8,'12; ( ).

HOMEPLACE, 175, PLAQUEMINES

lavlgne, basllide-La.1,94; (l'94).

HOMER, I,855, CLAIBORNE

AI)AMS, WM. MATTIIEW-La.1,03; (l'03)

Featherston, John W. (b'75)-Tenn.8,02 ;

(1'02): PIIIIIP (b'62) $\oplus$-Tenn.8, 90 ; $(101)$

GlADNEX, JAMES FRANK (b'84) - Lat.l '0s: (1'08)

Ileath, Arthur G. (b'87)-Tenn.19,'10; (l'10)

Stone, Wm. L. (b'69)-Ky.4,93; (1'95).

HORNBECK, 459, VERNON

Self, Robt. Lansferd (b'59) - Tenn.8,'06 (l'06).

HOSSTON, 200, CADDO

Collins, Mathlas Mills (b'81)-Ia.1,07: $(1,07)$.

HOUMA, 5,024, TERREBONNE

Collins, Chas. S. (col.) (b'69)-La.4,'10 (亦).

Collins, Robt. Walter-La.1,03; (1'03).

BELCOIJT, ADOLPIIE JOS. (b'47) 4

Belg. 3,$73 ;(1,73) ; \mathbf{G}$.

Delcourt, Adolphe Jos., Jr. (b’79)-La.1, 01 (l'01)

Duval, Joseph Berwlek-La.1,03; (1'03).

Ford, H. II. (col.)-La.4,'99; (l'99).

Jastremski, I.eon H.-La.1,'88; (l'88).

Jastremski, Vlncent-La.1,07; (1'07)

Lovejoy, Chas. A.-La.1,'89; (1'89).

MENVILLE, CHAS. M. (b'58)-Ky.4,8.;

(l'85).

MENVILLE, LEON J.†-Md.9,04; (1'04) ALR.

St. Martln, II ugh l'aul (b'84)-La.1,09; (1'09). St, Martin, Thaddeus Ignatius (b'84)-La.1,

Thomas, John W. (col.)-Mass.1,00; (I'04). HURRICANE (R.F.D., ATHENS), 25, CLAIBORNE

MASK, THOS. W.-D; (1'89)

IDA, 500, CADDO

Additson, Wllllam P. (b' (1'99).

Herring. Wm. Edwin (b'62)-Md.3,'91; (ま)

INDEPENDENCE, I,004, TANGIPAHOA

Bamber, James Ionroe (b’ $\mathfrak{t} t)$-Tenn.8, 08 (1'08).

Kemp, John J. (b'40) $\rightarrow$; (1\%); not In NEWMAN, WM. THOMAS $\left(b^{\prime} 73\right) \oplus-$ Tenn.8,03; (l'04).

Stafford, Fielden $\left(b^{\prime} 50\right) \longrightarrow$ : (1'82).

Strange, Anthony J. (b'79)-La.1, 01 (1'01).

INNIS, 50, POINTE COUPEE

Pratt, James W.-0.1,'51; (1'51).

IOTA, 769, ACADIA

Brooks, Geo. E.-Ky.4,'85; (l'92)

Clark, Jeon A.-La.1,'93; (1'93).

Hayes, F. N. (b'76)-Mich.7,'99; (1'99).

\section{ISABEL, 75, WASHINGTON}

HICKMAN, WM. PRESTON (b'84)థ-IA.1, 08; (l'08).

JACKSON, 2,I46, EAST FELICIANA

Cooper, Albert Syoney (b'84)-La.1,09: (l'09)

Daly, Oliver l'erry, Jr. (b'86)-Ia.1,'10 ; $\left(l^{\prime} 10\right) ; P . \star$

Holcombe, Armelead R. (b'53)-Ala.2, $7 \%$; $\left(1^{\prime} ; 8\right)$

I.EA, JESSE W. $₫$-La. 1,'91; (l'91)

1'IERSON, CLARENCE (b'68) ¿-La.1,'94 (1'94); (E13)

Thetford, Sami. Lewis (b'79)-La.1,06; (1'06).

JACKSON BARRACKS (NEW ORLEANS P.O.), - - ORLEANS JONES, HAROLD WELINXGTOX (b'T) —Mass.1,01; Capt., M.C., U.S.A.

JEANERETTE, 2,206, IBERIA

Bouvier, Joseph G. (b'69)-Ga.5,'95: (l'95) Boykln, Phares Allen (b'it)-Ala.2,'96: (1'98)
MNEVILLE, GFO. I.-I.a.1,77; (1'78). Morvant, Mlchel Faustln (b'87)-La.1,09: (l'09).

TARIGTON, MARCLS HRECKINIRIDGE (b'58)-La.1;86; (1'86).

JEFFRIS, - , CONCORDIA

smith, Weden T. (b'64)-Tenn.8,'86; (1'87).

JENA, 689, LA SALLE

ADAMS, I. N.t-Tent. 8,$01 ;(1 ' 01)$

Coleman, James A.-Tenn, 1, 07 ; (1'07).

IrAMILTON, H.-La.1,05; (l'05).

Thompson, Baxter I.-Iá.1,84; (l'84).

JENNINGS, 3,925, JEFFERSON DAVIS

CRAIG, NORMAN S. (b'48) $\$$ - Ill, 1,71 , N.X.10,75; (l'02)

Flint, Helen Callsta-Ill.4,99; (l'09) ; G.

FIR, BERNA C. $\left(b^{\prime}, 7\right)+-K y .2,00 ;\left(1^{\prime} 01\right)$,

Ilall, Edw. I.-Ill.1,'81; (l'95).

IIunter, Clinton Elmer (b'65)H-Ill.10,'01 : ('12).

Lee, Ldw. A. (b'67)-N.Y.10,'?2; (1'01).

Melancon, M. C.-La.1,85; (1'85).

Morrow, John J. (col.) (b'75)-La.4, 08 ; (l'08)'

Perrault, Fdw. J.-I,a.1,97; (1'97).

REMAGE, GEO. W. (b'37)-Mich.1,'63; (l'6)

Snitb, Morgan-Tenn.5,06; (l'06).

Wood, Julia Stoddard (b'60) H-Ga.9,'98 ;

Wood, Willls Sumner (b'56)H-Ga.9,'98 : (1'02).

JESUIT BEND, 243, PLAQUEMINES

Aubry, Albert J. (col.) (b'73)-La.4,'99; (1'99).

JONES, 105, MOREHOUSE

Uurlam, Silas. Luclus (b'84)-La.1,13; (1'13).

KNOEFEL, ARTIIUR ECGENE $\left(b^{\prime} 72\right) \oplus$ Ky.2,93; (l'01). (1'08).

JONESBORO, I,I34, JACKSON

GAAlR, J. ALBERT (b'80)-Tenn.8,'04; (l'04).

JEFFRESS, ROBT. P.-Ky.2,'88; (1'88)

Jomes, W. S.-Ky.4,88; (1'88).
SIMONTON, AUGUST E. (b'60)-IId.3 SIMONTON,

JONESVILLE, 287, CATAHOULA

Bennett, H. S.-Tenn. 8,07; (1'07)

Newman, Jewell Arthur (b'86)-La.1,11; (1'11).

Yancey, D. Edward Rhinehart (b'87)La. 1, 10 ; $(1 ' 10)$.

JUANITA, 300, BEAUREGARD

Culpepper, Henry Wilkins $\left(b^{\prime} 50\right)-$ Tex.1, '81, La.1,'88; (l'10).

KAPLAN, 3I5, VERMILION

Poche, Walter Andrew (b'75)-La.1,02 ; (1'02).

Saparito, Leo (b'82)-La.1,08; (1'08).

KEATCHIE, 500, DE SOTO

MORGAN, WIILIAM H. (b'72)-Ta.1,'95; ([’95).

Mosley, Wm. X.-N.Y.5,'60; (1'60).

KEITHVILLE, 100 , CADDO

Woolworth, Jos. D. (b'i8)-Tenn.8,'9y ; (1'99).

KELLY, I50, CALDWELL

CRACROFT, THOMAS BYRON (b'79)๑La. 1,07 ; $\left(l^{\prime} 07\right)$.

Murphey, Jos. White-Tenn.1,08; (1'09).

KEN NER, I,253, JEFFERSON

Genella. Alphonse J. Kennedy (b'72)La.1,'95 ; (1'95).

KENTWOOD, 3,609. TANGIPAHOA

Fllls, John Hamllton (b'65)-La.1,'88 : (1'88).

Kennon, Chas. E.-La.1,95; (1'03).

Iazar, Henry Iussan-La.1,'05; (1'05).

MORRIS, HARRISON GALMIOREE (b'65) -La.1,00; $\left(l^{\prime} 00\right)$.

Thames, Joln Allen (b'82)-La.1, 08 ; (l'08).

Travis, Wm. Barrette-La.1,'02; (1'08).

KINDER, 635, ALLEN

Buck, Henry (b'is)-Ky.4,00; $\left(l^{\prime} 00\right)$.

HEFIIN, ANDREW JACKSON (b' 76$)-$ Tenn.1,06; (1'07). 
HOWELL, CHAS, F. (b'il) +-1.a 1,01 (l'01)

Mayes, James W, (b'i2)-Mo.1,9n (105)

Oden, R. E. K'y.4,91; 1191)

KINGSTON, 500, DE SOTO

"arlisle, F. A - Tenn.8,"06; (1"0e)

Scots, Lockwood A. $\left(b^{\circ} 55\right)-1.3 .1$.

KLOTZVILLE, 500, ASSUMPTION

HASCHACD, VIPTOR (b" 73$)+-$ Que.3, 0 : $\left(10^{\circ}\right)$.

LABADIEVILLE, 500, ASSUMPTION

Choppln, At...ur 16-La.1.'34; (1'D4)

DANSEIFAL, IHFYH THAS.

LACOMBE, 600, ST. TAMMANY

FARMER, (HRISTOIIIE FHATKLIX (b'73)-Tenמ. 8, 08; (1'08).

LAFAYETTE。 6.394. LAFAYETTE

Boyd. Franklla Virginlus - J.A.l, "0? (1.02).

(hapman, Isaac C. (col.) (b'61)-1.4.4, 94 : (1'94).

CLARK, LAMBERT ORAN (b'79)+-LaL,

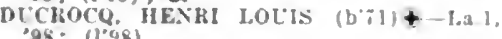

Whon, John $0 .\left(\mathrm{b}^{\circ} 82\right)-$ Tex.10,03,

Tenn.11,04; (1'05)

Girard, Fellx E. (b'69)-J.a.1,"43; (1'9.5).

Girard, I'. M.-La,1,'s2: (1'94)

Guldrs. llomer D-La 1,$70 ;(1 ; 1)$

Hopkins, Thos. B.-Pa.? $(1.54)$

Martln, Geo. A. (bobi) la.i, 87 ; (1:2)

Moss, Nathanlel 1'-1.a.1, $\mathrm{N} ;$; (1\%); nut in practice.

Mouton, John F. (b'68)-M(1.3,899; (I's9)

Mouton, Mare Monroe $\left(b^{\prime} 90\right)-1$ - La.1.13 (l'13)

SAUCILR, MERRICK FDMOXI) (b's2) -

TOLSON, FREVK. R. (b'49)+-Ial,'ss;

TOLAOX, JOHN (b'82)-Tenn.11,04; (1'05).

TRAHAX, ANATOLE RAOLI $\left(\mathrm{b}^{\circ} 0\right)+$ La. 1,92 ; (1'92).

Trahan, Jobn D. (b'4k)-I.a.I, 67: 116ii).

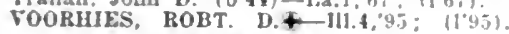

LAFOURCHE CROSSING, 300.
LAFOURCHE

KLFINPETEB, EWELI A.-I.I,03 (1.03).

LAGAN, 50. ST. JAMES

HYMEL, SIDNEI J. (b'T9)-Tear.11,0l (1'02).

LAKE ARTHUR, 1,093, JEFFERSON DAVIS

Abney. Walter R.-Ky.1.92; (1'92).

MHLER, VAIFHION ALBEHT (b'-3) Tenn.5.'95: (1'9i).

LAKE CHARLES, II.449, CALCASIEU

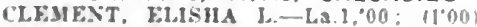

Coleman. Louls M. (col.) $\rightarrow$ : (l'teil.

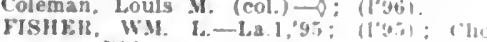
ronue Islif.

Hases, Wm. $\quad(.,-111.1 \%, 03 ; \quad(103) ; 11 \%$ Bmilerard: offlce, 331 Hólevard; $9-1:$ 3-5, $i-0 ; 0$.

HOLCOMBE, RICHARI) FORDON (b'S1) -

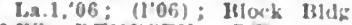

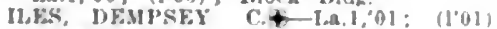
urjestle Holel: oalce, chovonne thli: $0.12,1-5:$ OALR.*

Jomhua, Merrlll M. (col.)-1.a 4.92; (l'u2

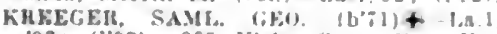
92: (1'92): 905 kirby Si. ollee Vot I'hul and fordon Bldz: :9:30-11,3-1:30

I. OOMIS, CHARI,ES W. - Kan.3, $\left(l^{\circ} 95\right): 915$ Jroad SL: OAlce, X/6 H3 at St. : $8.1 \mathrm{I}, 1=\$ ;$ OALR.*

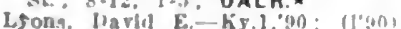

Lfons, Mavhl E.-KF.l, [d, : $x-10$, \&.6.

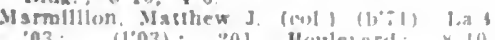
03: (1003): zol Moulebard: 8 10 4. $n ; G$.

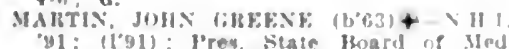

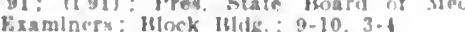

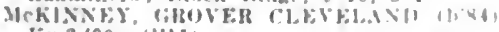
Kу 2,$00 ;(1911)$

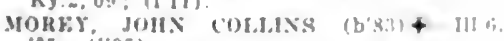
05 ; $(1.05)$.

Mons, Leland IJugh -Tenn 1.'3!?; (1, : : nut In prartire.

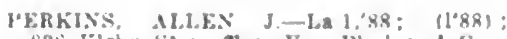
82A Kirby Sit. omce, Fon l'hul and for. don Itldin; $10.12,2-4 ; G$.

blerce, Almon $\mathrm{x}-11-$ () $13, ' 84$; (1'84).

I'ryce, dien s. (col.)-Tenn.7.88: (1"B.s):

1516, Mlll st. once, 331 Boulerard: 8.10, 1-3; U. micliarisoni

Nililph yeyer Ridg.

Llewirt. Nlerander P.-1.8.1,89: (1'89); 606 Kirloy sis.

TI'TF. Jus N.-Tenn.3,00; $(100)$; Von l'hul aud Gordon llde.

WAThINS, THOMAS HFNRY +-1.2.,9: (1'y5): (ol. Xatl. Bank HUlg.

LAKE END, 150, RED RIVER

Hrown, Andrew ('. (1)'5)-Ky,4,9s: (1'09)

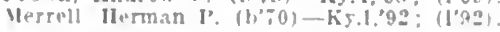

LAKELAND, 100, POINTE COUPEE

Delambre, Jules John $\left(\mathrm{b}^{a}\right.$ is) - La.1.02 (1.02).

\section{LAKE PROVIDENCE, 1.568, EAST} CARROLL

Rernard. Fredk R. (b'51)-Ian.1,76; (1.2.

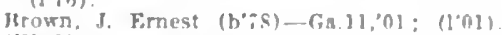

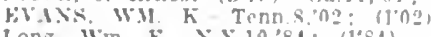

t.nnz. Wm r.- N Y.10.84: (1'84),

LAMOURIE, I00, RAPIDES

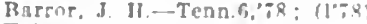

Holsteln. Tames H.-Ia.1, $99:$ : I"9n!

LANDERNEAU, 25, CALDWELL

IPchlhald. Edw. Frerette (b'S6)-Tenn.19, "10: (l'10).

LAPLACE. 375, ST, JOHN THE BAPTIST MONTFEITT, SIINES (h'69)-Pa.11? (1'? 4 ).

LAROSE

F.D. LOCKPORT),

185.

LAFOURCHE
TETREII

TFTRF.IT T'AT"

LAUREL HILL, 25. WEST FELICIANA

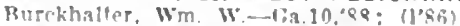

ITnuell, (Thas. F La.1,82: I'ni)

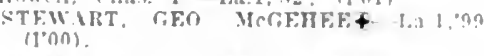

LAVACCA, 10, CATAHOULA

Calhoun. Wm. S. X. (bosl)--3.1.74 (1'8.3)

LAWHON, I00, BIENVILLE

FERRTESON. HORERT C. (h'70) - TeUn Q:04; (104).

LECOMPTE, 1,058, RAPIDES

Frerett, Jnhm D. (b'53)-Ky.2,81: (1'83)

IIARTY, J"I.IAN CARR (b'88) क-ia 1,00:

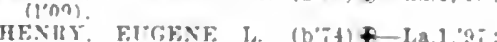

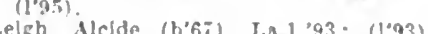

Lelt. Frank Montague (b.8n)-l.a l,0?:

whitehead, Chas I (b'f $)$ - N 10.69: (†)

LEESVILLE, 2.043, VERNON

JONF.S, FINAS P- (IA.9.') : (1)95)

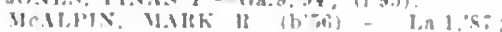

$(1.8 \pi)$

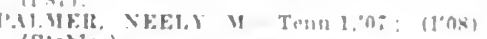
(sishles)

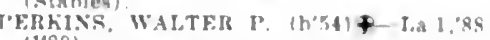
$(1 \cdot 8,8)$.

Simlih. Jameq frank I.s I.04: (1"04)

Wllyams, S 5 -Tenn.s'll: (

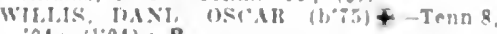
(1): $(1004): R$

: $(1,3)$

LENA STATION. 200, RAPIDES

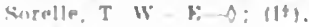

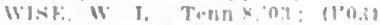

LEONVILLE, 300 ST LANORY

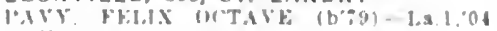

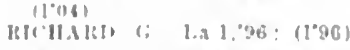

LEROY, IO, VERMILION

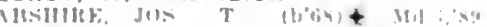
(I'sy)

LEWIS. 25. CADDO

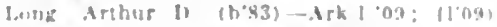

LIBERTY HILL. IS0, BIENVILLE

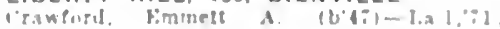
(I) $x+1)$

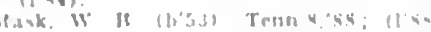

LIDDIEVILLE (P.F.D., WINNSBORO). 5.
FRANKLIN lunlap, Mokking $\boldsymbol{H} \rightarrow$; $(1 \uparrow)$.

LILLIE, 100, UNION

Melionald, Charles S. (b)is)-Ark 1,05; 11 0y).

LISBON, 75, CLAIBORNE

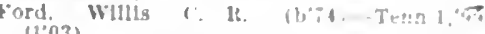

Falup, Tboman F.-La.1; 1 ; $11 \times 1)$

LOBDELL, S00, WEST BATON ROUGE

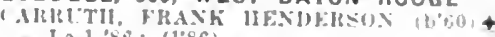

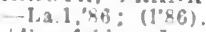

lleldingsfelier, Jos. E. Las. 1,00; (I'00).

LOCK LOMOND, 50, UNION

nimline, llukis Tienn \&."Ot;: Il'obil.

LOCKPORT, 669, LAFOURCHE

GOUAl"X. WH.NK THEOI'HILE (b'b3)

Pa.11,06; $\left.11^{\circ} 0 \%\right)$

Knolilach, i j-1.a 1.43: 1104

Price, J. Alluer! (b"if)-I.a 1, $04 ;\left(l^{\prime} 04\right)$

LOGANSPORT, \$20, DE SOTO

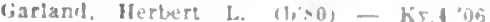

(1"07)

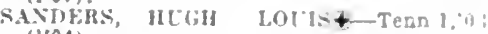

$(1.04)$

Scales. J. 11. $\rightarrow ;(1 \uparrow) ;$ not in practlee

SMART, SAMUEL J.LA.1:;3: (1'T3).

LOGTOWN, 200, OUACHITA

Horing. W'. IR.-Tenn.8.'11; (1'11).

IIII, Organ A. (b'S1)-Ky,5,07; (110:).

LONGLEAF. 750, RAPIDES

JONBS, HIXTHW CMBH (b'83) - -Tenu 1

LONGSTREET, I00, DE SOTO

I.arson. Thomas-Tenn.8,"sQ; (1'94)

Reeves, Norbume lowel (b'26)-Ala.1, 55 ;

(ns); not in practlce.

LONGVILLE,

Alams. Coma E. (b'85)-Tenn.8,"10; (1'11): G.

Maxler. Mlllard Fllmore (b'il)-111.15,03: (1'10).

LOREAUVILLE, 291, IBERIA

DARRY, FHANi'S OLIVER (b'OS) \&-Md 9 , $05:\left(l^{\prime} 05\right)$

Shaw, Guy i. (b'69)-Md.3,'20: (1'90).

LOTTIE, 50, POINTE COUPEE

Lorlo, Llonel Francls (b"90)-1.a.1,"12: (1'12)

Maddux, Thos. II -N. Y.j, $54 ;(1 \%$ :

LOUTER, 50, UNION

(ircen, Herj. Franklis (b"is)-lrk l, as:

Junes, H. $\mathrm{x}-\mathrm{O}:\left(1^{4}\right)$.

LOYD, 25. RAPIDES

L'CKETT, FIIW: F"

LUCKNOW, 75, RICHLANO

thurk. Thos (b'sl)-Tern.'

LUDINGTON, 150, BEAUREGARD

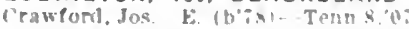

LUDIVINE (R.F.O.. LOCKPORT).

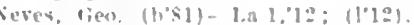

LULA, 27, OE SOTO

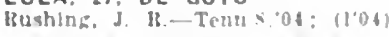

LUTCHER, 1,000, ST. JAMES

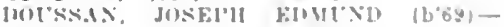
1.4. 1,91; (1.91).

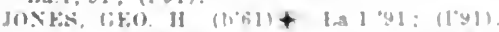

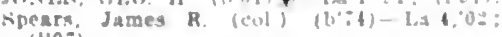
(l'0i).

LYDIA, 20, IBERIA

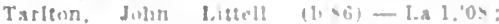
$\left(l^{\circ} 0,4\right)$

MADISONVILLE, 1.028, ST. TAMMANY

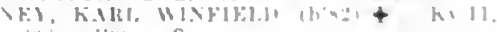

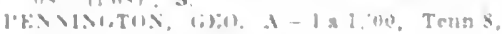
(1):- 11,0:1

MAGOA. 73, RAPIOES

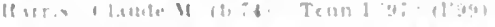

MAHON IR.F.D.. HOMER). 35. CLAIBORNE

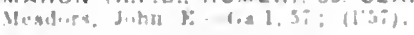

MAMOU, 150, EVANGELINE

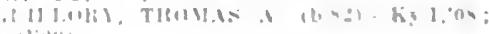


MANDEVILLE, I,166, ST. TAMMANY (IVINS, ALONZO-La.1,57; (1'5\%).

MAY'IS, ALEX G.-La.1,8; ; (1'87).

Viltchell, Carlion.

(sce New Orleans.)

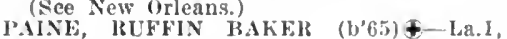
'88; (1'88); Ob.

Van Zant, Wm. Emory (b'ï)-La.1,01; (1'01).

MANGHAM, 470, RICHLAND

MCCONNELI, CLALIIL'S FMMETT (b'84)

Ala.2,'10: (1'10).

PARDE'

(b's1) - Tenn. 8,03;

Polndexter, Thos. 13. (1't1)-La.1,69; (1'69).

SHEPPAR, F. C.-Penn.1,07; $\left(1^{\prime} 07\right)$.

Wheless, Wm. D. (bit:)-Ja.l, '00; (5).

MANIFEST, 45, CATAHOULA

michardson. Orvilie Jay (b'85) - La.1,07;

(1'05); Pd.

WERl'; AI.BERT A. (b'68)-Ky.2.94; (1'94)

MANSFIELD, 1,799, DE SOTO

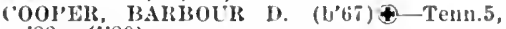

DAVIES, El)II: (b'38)-Pa.4,'56; (l'94).

HEWITT, WM. BEALI, JR. (b's')-La.1,

'1I; (1'11).

JAIREILL, IIFNRY W. (b'69)†-Tenn.1,98; (l’03). Whifred A. (b'05)-Tenn.5,92; (1'92)

PARSONS, HENRY JACKSON (b'T3) I.a.1,94; (l'94); S.

Persinger, Ellas I. (b'49)-Ia.1,93; (l'93). Shallowhorne, Wimington E. (col.) (b'so) La.4,'06; (l'06).

MANSURA, 695, AVOYELLES

DROI1X, GEORGE 1. (b'70)-la.1,'99; (1'99).

RF(GARi), FMII ( $\left.b^{\prime} T 1\right)$-La.1.94; (l'94).

ROY, THOS. A. (b'6z)-Ky,4,90; (1'90).

MANY, 683, SABINE

Cade, Sanul. C. (1's2)-Tenn.8,'02; (l'02)

not ln practice.

Dlllon, D. Harrey-Tenn.8,'99; (1'99).

Dillon, Win. Edw. (u't5)-Teni. 8,00; $\left(1^{\prime} 07\right)$.

Lester, Wills D.-Tenn.8,06; ( $\left.\mathrm{r}^{\prime} 06\right)$.

MIDDLETON, JAMES MONROE $\left(b^{\prime}(6) \oplus-\right.$ Tenn. $5.90 ;\left(11^{\prime} 90\right)$

MARINGOUIN, 447, IBERVILLE

WAGLEY, WI. HA.MLTON (b'74)-La.1, 01; (1'01).

MARION, 226 UNION

I'OWELL, JAIES I'. (b'68)૯-Ark.1,96; (i’9i); G.

Thompson, Oliver H.-Tenn.1,84; (1'83).

Wheelis, Allen B. (b'83)-Tenn.1,05; (1'08).

MARKSVILLE, 1,076, AVOYELLES

BALBIN, ARISTHES THLOU (b'77) -

Tenn.1,01; (1'01).

COYVILLION, WALTER F. (b'69)-La.1,90 (1'90).

De Nux, Sylvaln (b'79)-Tenn.11,00; (1'01).

TARLETON, LEO. C.-La.I,'80; (1'80).

MARTHAVILLE, 285, NATCHITOCHES

Glass, John B.-Tenn.2,'03; (l'03).

l.ee, J. N. $\rightarrow$; (l'61).

I'attlson, Chas. G. -Tenn.8,03; (1'03); not in practice.

MAURICE, 75, VERMILION

VILLIEN, JOS. A. (b'70)-La.1,90; (l'90).

MAXIE, 100, ACADIA

IcGuffey, John IIardee (b'71)-La.1,09; (1'09).

MEDONOGHVILLE, - JEFFERSON

Odom. Marvin Milton (b'83) - Ga.11,'13; (l'13).

MEELROY. - ASCENSION

Lamon, John W. (b'79)-Pa.11,'08; (1'08).

MENARY, 23, RAPIDES

RREWSTER, CAREL LAFAYETTE (b'82)Tenn. 8, 09; $\left(1{ }^{\prime} 09\right)$.

MELDER, 50, RAPIDES

Reid, Wm. E. (b'91)-Tenn.8,'12; (1'12).

MELROSE, 25, NATCHITOCHES

KELLI', JOHN LLTHER (b'S2)-Tenn.15, ${ }^{\prime} 0 \tau$; $\left(\mathrm{l}^{\prime} 0 \mathrm{t}\right)$.

MELVILLE, 1,093, ST. LANDRY

Coudehaux, Chas. 1-Tenn.11.97; (I'9S), JOSEIH, HORATIO SEYMOLE (b'68) †ky.1.93; (l'93).

Williams, Lester J. (b'80)-La.1,04; (l'04).
MERMENTON, 323, ACADIA

lones, Thumas N-Tenn.8,'94; (I'94).

Wright, Chas. II,-Ind.5,'91; (1'91).

MER ROUGE, 536, MOREHOUSE

('LALK, ERLF MAYO (b'85)-Tenn.I9,'10; (1'10).

larby, J. W, (b'î)-Tenu,11,06; (1'07).

IoKoin, Bunnle MeEwln (b'86)-La.1, 12 ; (1'1:2); G.

MERRYVILLE, 600, BEAUREGARD

Flemlng, Ir. II. (b'73)-Mo.28,03; (l'04)

Kinglit, Joln A.-Tenn.8,'04; (1'04).

MILFORD, 25, RAPIDES

Sorelle, J. II. $\rightarrow$; (1†)

MILLIKEN, 50, EAST CARROLL

IIllikin, Marle (l,89)-P'a.7,'13; ( ); ObG.

MINDEN, 3,002, WEBSTER

Blume, Claud (b'78)-Tenn.8,'03; (1'03) : R.F.D.

Cason, lin. F, (l'60)-Ky.4,'86; (1'86).

Gladney. Jos. G.- IId. $3,{ }^{\prime} 66^{\prime} ;\left(1^{\prime} 86\right)$.

1.NGINo, LUTHER (b'48)- Io.1,'82;

$\left(l^{\prime} 86\right)$.
Martin, Shelly F. $\left(b^{\prime} 76\right)-T e n n .1,01$;

(l'0l)

Morkan, John W.-S.C.1,'57; (1'57).

IICHARDSON, SAML. M. (b'78)-Ky.4,06;

SMITH, RISDON ERNEST (b'84)-La.1, 0 ; ; (1'07).

Tompklns, Rutledge C,-Tenn.1,01; (1'02).

Vance, Thos. J.- I'a.2,'58; (1'58).

Webl, Kobt. D.-1.a.1,92; (1'42).

MIRA, 200, CADDO

AWTON, WINBOISN BENJ (b'68)

Tenn.8,94; (1'94).

MITCHINER, 35, RICHLAND

B.ISKIN, JAMES $\left(\therefore\left(b^{\prime} 82\right)\right.$ - Ala.4, 09; (l'10).

MONROE, 10,209, OUACHITA

ADAMS, JESSE LC̈CAS (b' 3 )

(1'06); 215 De siard st. ; $2-5$.

BENNET', FRANCIS CLAYTON (b'70)Mo.20,00; (1'01); 204 Louise Ann Are.; 110 S. Grand St. ; $9-12,2-5 ;$ OALR.

BLACKMAN, ROBT. HODGES $\left(b^{\prime} 71\right)-$ Ky.2,'94; (l'95); Ouachita National Bank Bidg.

Cier, Irenee (b'7 )-La.1,'98; (l'98); 207 Louise Ann Ave.; office, 513 Ouachlta Are.; U

COSBY, OSWALD W. (b'75)\&-Mo.27,"96; (1'03); 216 Ouachita Ave.; offlce, 211 Grammont St. ; $3-6$; $\mathrm{S}$.

FALLK, LEONIDAS BARKDLLL (b'89)La.1,'12; (l'12) ; 315 Pine St. ; offlce, 202 De slard st.; 11-12, 4-6.

FALLK, ROB'T. W. (b'59)-Ky.1,'S7 ; (1'87) ; 315 1'ine St.; offce, 202 De slard st. ; 1-12, 3-5; Ob.

Forsythe, A. A.-La.1,87; (1'87); not in practice; 114 Jackson St.

iLADDEN, ADDLEY H.\$-La.I,'88 ; (1'88) ;

816 St. John St.; offlee, 110 S. Grand St.

GRAVES, JAMES Q.-La.1, 06 ; $\left(l^{\prime} 06\right) ; 312$ Grammont st.; office, 211 De Siard St. ; $11-12,2-5$

GRAY, COLRTLAND P. (b'82)-Md.9,04; (l'04) ; $110 \mathrm{~s}$. Grand St. ; $2: 30-4 ; \mathrm{S}$.

IIIRSCH, DAVII) ISAAC (b'86)-Ia.1,08; $\left(l^{\prime} 08\right) ; 123$ Catalpa St.

Johnson, A. H. (col.)-Tenn.7,06; (l'06).

McCaleb, Jonathan Howard (b’55)-Md.3,

8I: (1'83): 1609 Jackson St.

Miller, John T. (eoI.) (b'80)-La.4,'08; (1'08).

NEWTON, ISAAC JAMES (b'56)\&-Ky.2, '79; (1'83) ; 305 Louisville Are.; office, 211 Grammont st. ; $3-6 ; \mathrm{S}$.

O'DOXNELL, ROBT. WM. (b'71)\&-La,1, South Drug $\left(l^{\prime} 00\right) ; 117$ Store.

SCHTLZE, WILLIAI (b'75) \&-1).C.1,0.4; (1'04); 114 Jackson St.; offlee, 212 De Slard 'St. ; $10-12,3-5$.

SNELLINGS, GEO. M. (b'79) \-1.a.1,04; (1'04); 1357 Front St.; office, 200 Dé Siard 'St.; $10-12: 30,3-5$

SLLLIVAN. WH. EDW. (b'84)-Mich. I,12 (1'13); 320 Wood St.; offlee, 212 1)e siar St. : $10-12,3-5$

SURGHNOR, GRAHAM (b'61)-La.1,'89 (l'90); 320 Pine st.; offle, 202 De siar st. ; 9-12, 2-4; OALR.
Woodwarl, Katherine B.-Mo.5,97; (4).

W1:ICIT, THOMAS E. (b'76)-La.1,00; (l'09) ; 1112 .fackson St. ; offce, $2291 / 2$ Dé

Slard St.; 2-5; Baot.

MONTEREY, 40, CONCORDIA

BIRLEY, (IIAS. HESIRY (b'78) \$-La.1, 04; (1'04).

MONTGOMERY, 174, GRANT

HAKKISON, THOS.'J.-La.I,79; (1'79).

Woods, Clias. Eugene (b'81)-Tenn.8,07 ; (1'07).

MONTPELIER, 600, ST. HELENA

CEWMAN, ALBHET JOINSSON (b'80) \&-

Tenn. 8, 05; (l'05)

MONTZ, 90, ST. CHARLES

Bonnemer, Charles L. (b'73)-Ia.1,97; (l'97).

MOORINGSPORT, 350, CADDO

GULLEDGE, IROBT. IIENIR (b'69) La.1,'99; (l’99). SIMS, CHAS. CRAWSON (b'74)£-Tex.3,

Tillinghast, H. I.-La.1,'6I ; (1'61)

MOREAUVILLE, 728, AVOYELLES

IBRAHIC, I'ALi, EMLE (b'84)(4-Mo.34,

OUVILLON, SAMBOLA JONES (b\%9)La.1,04; (l'04). FOX, GEORGE RANDOLPH (b'63)-La.1,

PARROTT, JAMES CRITTINGTON (b'74)-

La.1,'03; (1'03).

MORGAN CITY, 5.477, ST, MARY

Alurons, Perey-La.1,'93; (1'96)

BIWICK, IAMES CLARENCE.

(See Berwick.)

de Gravelles, Charles Camille (b'83)-I.a.1, '10; (l'10).

Dreher, Thos. E. (b'72)-1,a.1,97; (1'97).

Mcclelan, Wm. J.-Tenn.8,89; (1'89).

Nelson, Jeff D. (col.)-Ia.4, 06 ; (l'06).

MORGANZA, 296, POINTE COUPEE

Singletary, Emerson W. -Ga.11,00; (l'00)

MORLEY, 75, WEST BATON ROUGE

LANDIRY, PAUL BERIARD-La.1,04; (l'04).

MORROW, I50, ST, LANDRY

Teagle, Ollver C.--Tenn.8,'02; (1'02).

MORSE, 237, ACADIA

Fontenot, Gllbert Gabriel (b'82)-I.a.1,09: (1'09).

MOUND, 200, MADISON

Yerger, Win. P. (b'77)-Tenn.8,01; (1'03).

MT. HERMON, 200, WASHINGTON

Brock, James Ionroe (b'55) - ; (1+).

Brock, Lucious William (b'88)-La.1,1I;

(l'II).

Illler, Wallace Eugene (b'85)-La.1,10; (1'10).

MT. LEBANON, 205, BIENVILLE

IIIlkiNsox, JoEl A. (b'89) -Tenu.8,'11 (l'11).

MT. PLEASANT, 10, CALDWELL

Dial, Joe N.-Tenn.1,'52; (l'52).

MYRTLEGROVE, - PLAQUEMINES PIPES, WILLIAM HENRY (b'78)\$-La.I,
'06; (l'06).

NAIRN, 300, PLAQUEMINES

Gilmore, Victor Lee (b'62)-Ia.1,'89;(1'89).

NAPLES. - AVOYELLES

WHARTON, W. L.-Ky.4,'89; (1'89)

NAPOLEONVILLE, 1,201, ASSUMPTION

Duffel, L. E. H.-La.1,'00; (l'00).

Kittrldge, Willoughby E.-La.1,99; (1'99).

Nelson, Geo. H. (b'70)-La.4,93; (1'93).

Nelson, Geo. H. (b'70)-La.4,9

Pugh, Wm. Whitmell, Jr.-La.1,06; (1'06)

Roger, Chas, Stephen (b'S3)-La.1,08 (1'08).

NATALBANY, 150, TANGIPAHOA

BRENT, WALTER HUGII (b'S0)‡-La.l,

Bath, Jos. (b'79)-La.1,'06; (l'06).

GALLION, ZACHARY TAYLOR (b'49) \&-

La.1,75; (I'65).

Halrington, Eager R.-La.1.'06; (1'06).

PheIps, Meade Hubbard (b'8 1 -La.1,'12 ;

(1'12).

Pratt, J. Bennett (b’ĩ)-Ark.1,05; (l'05). 


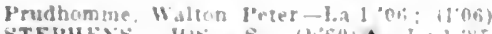

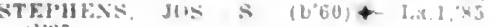

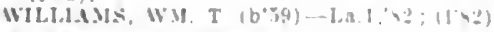

NEAME, 500, VERNON

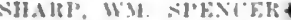

NEGREET, 30, SABINE

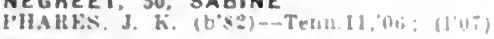

NEWELLTON. 42\$. TENSAS

lurrans. Andrew J., Jr. (col.) ibtit) Tenn. oi: (1'0i)

Hosers, Jasper I1. (b's0) - Tenns, (0); (l'ua).

NEW IBERIA, 7.499, IBERIA

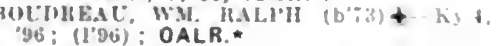

(10): (106): OALR.

Saster, is

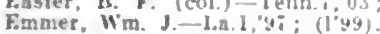

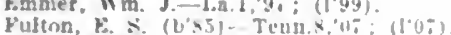

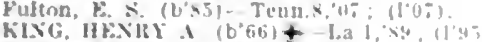

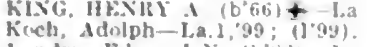

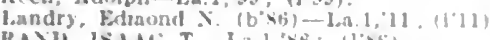

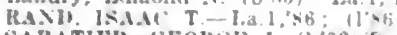

SABATILR, (IEORIF J. $\left(b^{6} 62\right)+-$ La 1.59 (1'x9).

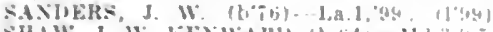

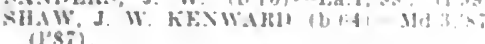

(ivlol.

NEW ORLEANS, 339,073, ORLEANS

NIMBER UF I'HYSITIISS

AHBOTT, LOLIS LEF (b'63)-1.a1,95

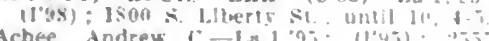

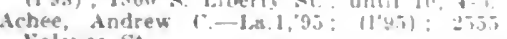
Valence $\mathrm{St}$.

Adams, John K.-La l,ss; (1'si): 31:

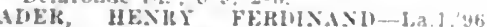

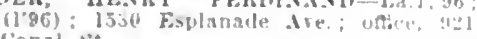
canat st.

Adlger, lavld (b'ss) - La.1,13: (113) ; 11 Valetle st.

Arnstlne. 1. I'.
isee New Iork IIty

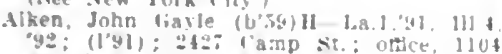

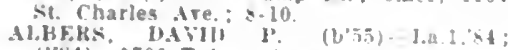
(I'si): 1:0I Tulane Ar

lerander. II. "

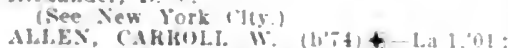
I'01); 1312 Ieftuklana Ir

Caual st.: $3.5 ;(.45) ;$ S.

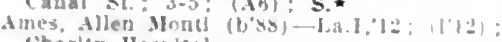
Charlty Hospltal.

Arizell, Wichard H.-La.1,"90: (1.44): 2300 Baroune si. : 10-11. 1-5:30

Ansley. Chas. II. (l, -3)-II) io, y: : (l'ou); Montelenne llotel; rate, g:1 Canal st

Arlra, Juan It

(Sice liew York Cliy

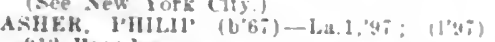

91:- Ifroadwas

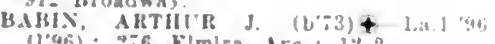

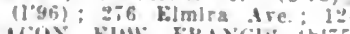

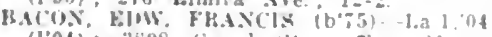
(l'04); 3308 Canal it. (iflce. Matsin Hanclie HIds. : $12-12$

BAIN, CHAS. I-Ter.20\%: (1'0:) 1524

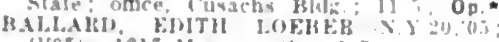
(1'05): i2l: Marengo $51 . ; 1.3$.

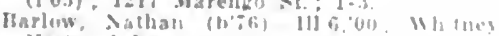
Pabloinal Katsk Hlde

Barnes, Juhn A. (cos) (h') (b)-Lid.(1);

(l'03) : 617 rentulun st. : s-10.:

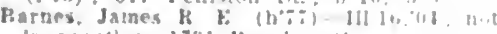
In practlce: 1731 unurion st

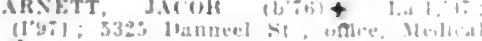

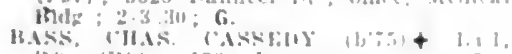

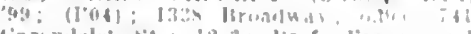

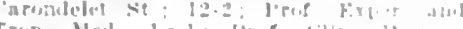
Trup

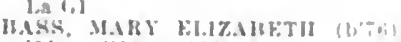

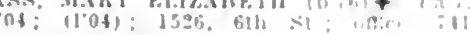
Caronitclet st ; $3: 3$

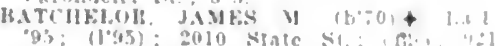
Cinal si?: $1: 30-3 ;($ (li

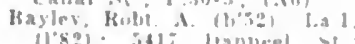
ranal st.; 10 11, 12-1

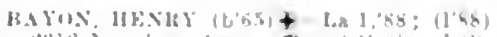

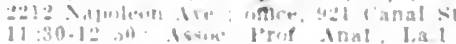

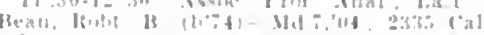

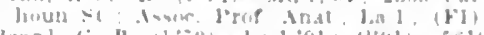

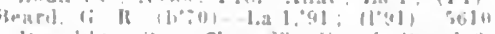

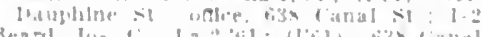

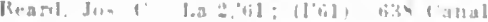

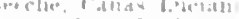

HE. like sill. $(2 \% 2)+-1.21 .93$

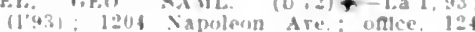

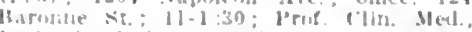
l.al 1. I'ruef. Inter. Med. I.a 1.!

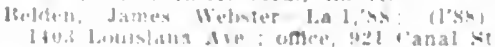
H.II. Thaddeus l'arker (b'-5) -Telan.11,00 (1'10): 93 i liermuda si.; aflee, cudubon Julp; 11-2\%, 1:30-1:30.

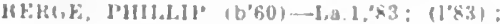

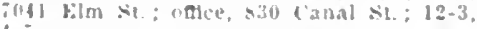

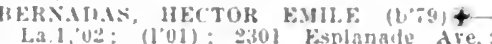

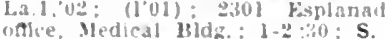

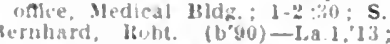

iharity Hosplisl.

kerry, Chas. lichard (b\$3)-ba,1,12. (1'12) : Charly llospltal.

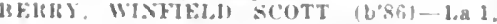
'12: (I'12): l'resbsterian Hispltal.

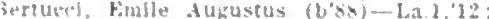
(l'12): Charlty llospital.

lather. James Albertus (b's:)-1.41.'13; (113) : Touro Infrmary.

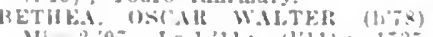

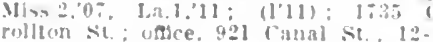

Hezou, Henry La 1,$71 ;(1 \% 1): X$ lampars and lsirrack sis.; not in practice.

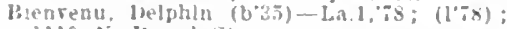
$1119>$ broad st

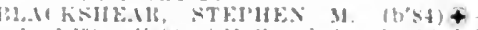

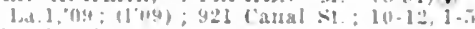
Hately, kupert Mbelum (boj)-baj,il (1'11): Touro Intrmary

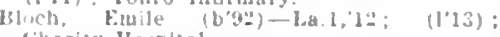
Tharlty llosplial

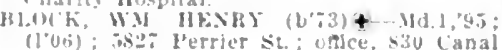

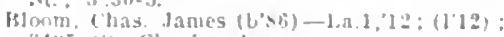
$340:$ ti charles Ire

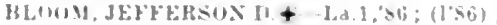

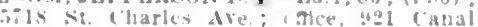
Si.; $1.3 ;(.16) ; \mathrm{S}$.

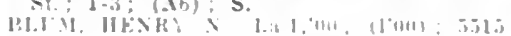
kampart st. withe. sio 1 itnal st.

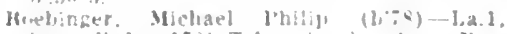

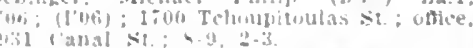

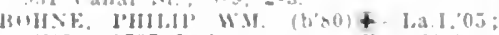

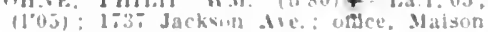
Hathehe lllds: ; 12-2.

Burdenave Clatude Jurth (b'vi) La.1,12; (1'12): Charty llowltas

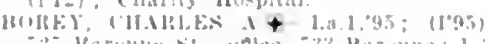

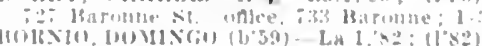

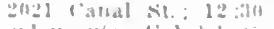

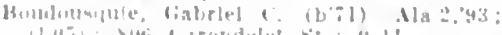

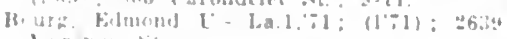

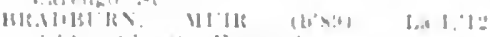

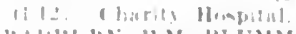

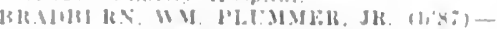
1. 1:12: (1'12): Charity If Inolist.

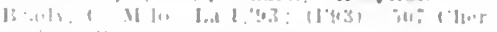

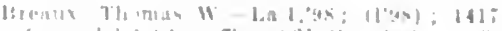

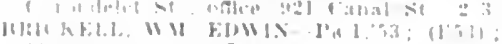

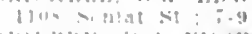

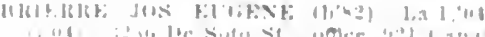

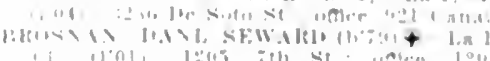

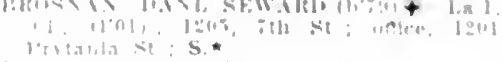

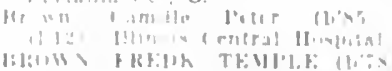

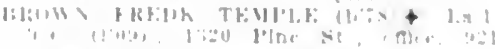

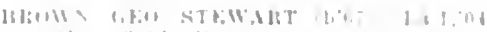

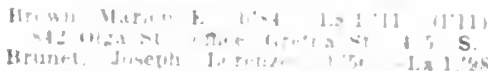

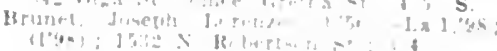

Brunlug thisto,

[1], 3 in

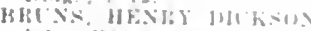

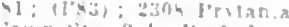

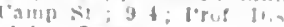

(B) : $\mathrm{OD}$.

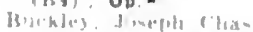

I.tee Xi.n Y.rk i

Buer. A. I

(aves Dew Jiurk rits

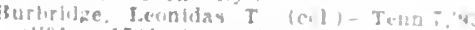

Hurns irank st. Andreus si

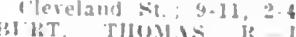

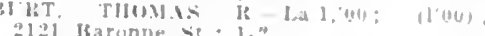

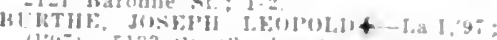

$1150), 5133$ si. Charles . We, udee, 821

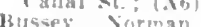

busiey, Drman Albers (bisy)-La.1, 12 (1'12): Tharigy Humplral.

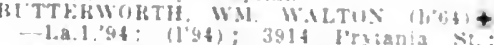
once, Malson Manche Hol byania s?

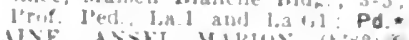

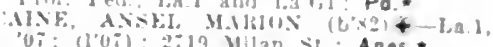

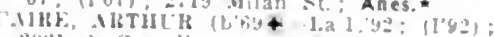

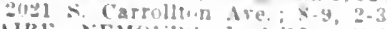

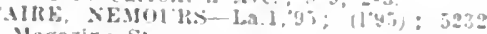
Marazine S!

(aldwell. John williamson (b+2)-bat of nut in pracilce: 1:1s I'almer ire.

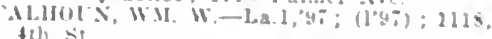
till $>$ it.

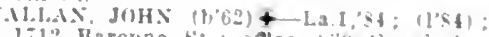

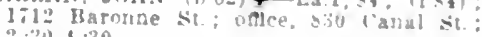
$2: 31)-4: 30$.

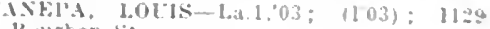
linurbon st.

arter ic is

Nove lew lork lir

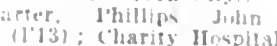

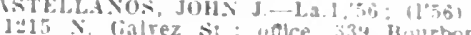
it, : $2-2$.

1 aldin, Madses

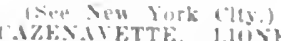

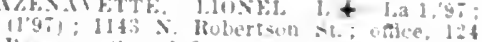
Haronue si : 1-3.

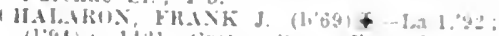

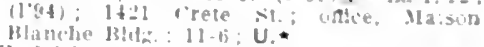

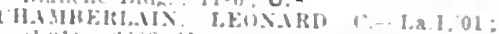

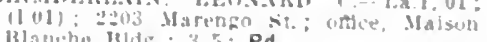
llathe Hage: $3-5$ Pd.

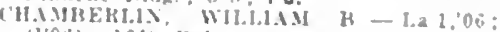

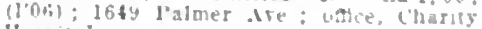
llospilal.

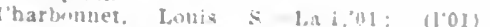

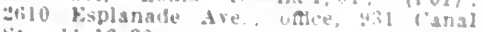
Si ; 11-12:30

isce vin lisk 1011

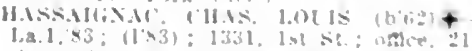

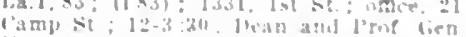

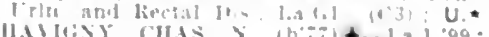
1'40): figl si. Chartes ire, umce, gef canal st.

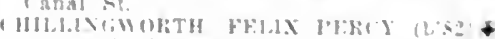

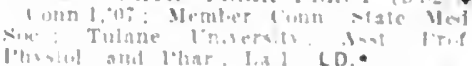

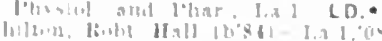

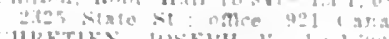

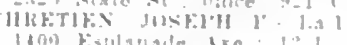

$13610.10 \% 11+1.4$

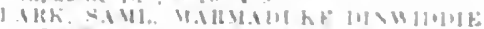

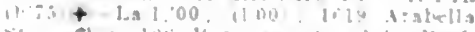

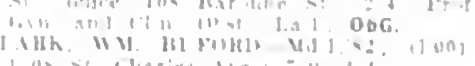

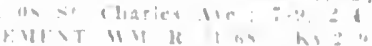

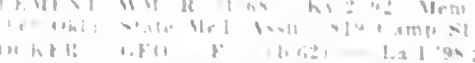

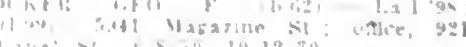


COCRAM, IIFNRY S. $\quad\left(b^{\prime} 67\right)+$ - La.1,, 91 ; (1'91) 14 Rosa I'ark: office, Cusachs BIdg: 1-3; I'rof Críu. Gin., lail.(il; (A6).

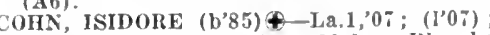
3435 l'rytanla st.; office, Malson I3lanehe Bldg. ; $\mathbf{1}-3: 30 ; \mathbf{S}$.

Coker, Iraleigh Jos. (b'83) - Iaa.4,09; (l'10) 1414 Dimaine $\mathrm{St}$.

COLF. CIIRISTIAN GRFNES (b'82) La.1,08; (1'08); Matson Blanche 1BIdg.; 12.2. '09." (1.10): 2206 ('anal st.; ontlee, 108 Baroume st.; 11-12:30.

Comeanx, Amable Albert (b'86)-La.1,13; (1'13); ('Harlty Ilospital.

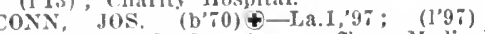
3339 St. Charles Ave.; office, Medical BIdis. : $3-5$

CORPUT, GUSTAVE M. $\oplus-G a .10,97$; Surg. U.S.P.II. ; Quarantine Sta.

COUBET, 2HURICE JOHN-La I,96 $\left(1^{\prime} 96\right): 3803$ Camp St. : Asst. Prof. P'ath.

and Hact., La.1; (F2); LD,
Craddock, French Hood (b'S9)-La.1,12 ; (I'12); ' Touro Infirmary.

CRAWFORD. IEWIS B, (b'82) †-La.1,05 (1'05) ; 612 Itoyal St.; offce, Charity Ilos pital; 1 -3

Crebbin, Alex. Ramsay (b'87)-Mich.5,'12 (1'12); 8331 I'anola St.; office, Mlaison BIanche Bldg.: 11-1: 0p.

CREIBIN, JOHN T. (b'73)屯-III. 4, 00 (I'00): 38 Neron PI.: oftlee, Jaison

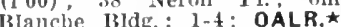

Cupp. Chas. Danl. (b'81)-La.1,'12; (I'12) 224 Walnnt St.

DABNEY, TIIONAS SMITH $\left(b^{\prime} 50\right) \oplus$-La.I, 79; (1'79); 1719 Jackson Ave; 8-9,3-5. Naison BIanche Blig.; $12-2 ;(\mathbf{A 6})$

d'AOUIN, JOHN J. (b'i2)-La.1,92; (1’92) 1800 .Iarengo St.; office, Whitney Bldg.; $1: 30-3$.

DASPIT, HENRY (b'84)-La.1,07; (I'0it) 5829 IIurst St. office, 921 Cañal St. $11-1$; NP.

D’Aunoy, Jos. Rigney (b'90)-La.1,13; (l'13); Touro Inflrmary.

DAVID, JOS. DUNCAN (b'83)€-La.1,12 (1'12) ; Medical BIdg.; $10: 30-11: 30$.

DAVIE, NECKOLS THORNTON (b'87)La.1,09: (1'09); Sensus Hospltal.

DAVIS, ROBT. A. (b’78) - Tenn.6,04 (I'03) ; 1121 Foucher St.; offlce, 30 liedical Bldg.; $12-4$.

Day, Edw. (L'84)-La.1,'11 ; (1'12) ; Presbyterian Hospital.

DeBergue, Edw. Jos. (b'7ll) - La.1,'08 $\left(1^{\prime} 08\right) ; 1910$ Felicity St.: $9-10,4-5$.

DeBUYS, LAURENCE RICHARD (1, 78 ) I.a.1,04; (I'04); Sec. Ja. State Ned. Soc.; 1776 State St.; offlce, Maison Blanche Bldg.: 3-4; Asst. Prof. I'ed.

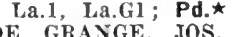

DE GRANGE, JOS. T.-La.1,'88; (I'88) 1636 Berlin St.; offlee, Macheca Bldg.

Dejole. Faul H. V. (col.) (b'72)-La.4,95 (I'95) ; 1131 Dufossat St.; office, 1832 Dryades St. : 9-10, 3-4; G.

DELAUP, SIDNEY PHİLIP (b'63)†-I,a.1, '90; (I'90); 1120 Esplanade St.; offlce, 124 Baronne St.; 12-3; Prof. Surg. La.G1; U. de Mahy, Marcel Joseph (b'86)-La.1,'10
(1'10); 3100 Grande Route St. John offlee, $\$ 30$ Canal $\mathrm{St}$.

DEIIPSEY, J. GE0.-La.1,99; (l'99); 942 Jackson Ave. ; offlice, 830 Canal St. ; 12-1. De l'oincy, Edgar S- $\rightarrow$; (l'81); not in ampart St. 525 Lower Line; office, 124 Baronne St.

DERBOFEN, JOHN C. (b'-1)-La.1,99 (1'99); 1526 Melomene st.; $7-9,12-2$

DE ROALDES, ARTHUR WASHINGTON† La.1,' 0 ; (1'71); 1328 Jackson Ave.; Office, Dis. Ear, Nose and Throat, La.G1; (B2,5).

DeToledo, Bernardo $\longrightarrow$; (1'01) ; 615 Flood

St.
I) VERGES PHIIIP CAJETAN (b'80)-
La.l,03: (1'03): 4318 Canal St, offee, La.1,03: (I'03); 4318 Canal St. ; offece

Devron, John A.' (b'74)-La.1,96; (I'96);
Dlaz, Paul-Cubal,'84; (1'84); 1110 N. Clal-

isks, John Fleming (b'83)-La.1,12 ; (1'12); Touro Juflemary; $S$.

IDMITIY, THEOINOLE J. (b'79)థ-Ja.I, 01 : (I'01); 6831 West Fnd 13lvd.; offce,

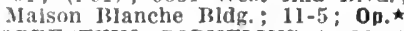

DORILASTEIN, CORNELIUS A, M. (b'T4) -La.1,97; (1'97); 7624 St. ('harles Ave.; office, Audubon Bidg.; $3-5 ;$ S.

HOWLING, OSCAR.

(See shreveport.)

j) relfus, Emanuel (b'50)-La.1,76; (I'76)

1409 Carondelet St. ; office, 921 Canal St. $12-2$

Dufner, Carl Travis (b'92)-La.1,13; () Charity Hospital.

Duggan, M. Linus-La.1,'99; (l'99) ; 4031 Canal St.; office, 931 Canal St.; 2-4.

Inuggan, Thmotlyy A.-La.1,92; (1'99); 4153 Canal St.; offce, 921 Canal st.

DINN, JAMES FREDK. (b'82)-La.1,08 ; $\left(1^{\prime} 08\right)$; 5332 Magazlne St.; office, 921 Canal St. ; 1 -3.

l'umn, John Sylvester (b'78)-La.1,08; (1'08); 2023 Dante St.; office, 165 S. 13asin St.

DUPAQUIER, EDOUARD MICHEL $\left(b^{\prime} 58\right) \oplus$ -Fra.6,'85; (1'85); 819 orlean

LUL'UY, HONER J., JR. (b'71) †-La.1,97 ; (1'96); 1658 Valmont St.; office, 124 Baronne St.; 1-5.

DUREL, WALLACE J. (b'7?)@—La.1,97; (1'97); 2003 Peters Ave.; office, 124 Baronne St. ; $12-3 ; 1 . \star$

DUYAL, CILAS. WAIREN (b'76)Ð-Pa.1, '03; 2024 Richmond Pl.; Prof. Path. and Bact., Ja.1 : (F2) ; LD.

DYER, ISADÓRE (b'65) ()-La.1,89; (1'89); 2222 Prytanla St.; office, 124 Baronne st.; Dean and I'rof. Dis. of Skin, La.1; (C, $;$; .

EGBERT, JAY HOBART.

(See New York City.)

Elfer, Henry 13. (b'45) $\rightarrow$; $\left(1^{\prime} 86\right) ; 1408$ Magnolia St. ; 7 -9.

Elllot, James Nelson Frazee.

(See New York City.)

ELLIOT, JOS. MANUEL (b'60)†-La.1,'89 (I'89); 1625 Hospital St.; offlce, Medical Bläg. ; $12-2$

ELLIOT'T, JOHN BARNWELL, JR. $(\mathrm{b}$ ”־ 0$) \oplus$ - la. 1,94; (1'94); 1423 Louisiana Ave.; offce, Maison Blanche Bldg.; 1-4; Prof. La.1; $1 . \star$

ERNST, OLIVER F. (b'76)€-La.1,97; (197); 911 State St.; office, Maison Blanche Bldy. $8-9,2-3$

ERWIN, ISAAC (b'77)-Ia.1,04; (l'04); Maison Blanche Bldg.

Escanaverino, Gines Pineiro.

(See New York City.)

ESHLEMAN, CIIAS. JEVERICH (b'S0)@ La.1,04; (l'04); 1138, 3d St. ; office, 921 Canal St. ; 1-3; Asst. Prof. Clin. Med. La.1.

EI'STIS ALLAN CHOTARD (b'76) -LAa.1, 03 ; (1'03) ; 1326 St. Andrews St. ; office, 08 Barome St. ; 2-5; Asst Prof. Diet. La.G1.

Faget, Frank Marle (b'88) - La.1,11; (I'l1); 2103 Ursulines St.

AIVRE, GE0. WILLIAM (b'85) †-La.1, FEINGOLD, MARCUS $\oplus$-Aus. 7 , 96 ; $(1,98)$; 4206 St. Charles Are, nfflce, 124 Baronne St.; Prof. Ophth., La.1; (BI).

EENNER, ERASMIU'S DARWIN (b'68)†La.1,'92; (1'92); 850 Carondelet St. 2-4:30; Prof. Ortho. Surg. and Ped., La.1. FICKLEN, EDW. PORTER ALEXANDER (b'87) (-La.1,11; (1'11); 813 Baronne St.; offce, 921 Canal St. : $11 ; 30-12: 30$.

Flinn, James A. (b'80)-Aía.2,01; (1'03) 802 Broadway; offlice, 1013 Canal St.

FORTIER, LUCIEN AMIEDEE (b'88) -La.l, '12; (1'12); Charlty Hospital; $\mathbf{S}$.

FOSSIER, ÁLBERT E. (b'81)-La.1,02 (1'02); 8134 Cohn St.; office, 921 Canal

FOSTER, ALBERT D. $\$$-Nich.1,'99;

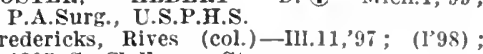
Fredericks, Rives (col.)
$4305 \mathrm{~S}$. Claiborne St.

FRIEDRICHS, ANDREW G. $\oplus-$ La. 3,75 ;
FRIEDRICHS, EI'IRAIM D. ( $\left.\mathrm{b}^{\prime} T \mathrm{~T}\right) \oplus$-La.1, "00; (l'00); 474 l'Ine St. ; offlce, Medlcal Bldg. : 1-3; ObG.

FRIERSON, SAMI. EVANDER (b'79)La.1,07; (1'07) ; Member Miss. State Med. Assn.; Touro infirmary.

ULLER, RAY T. (b'75) \$-Mich.9,03; (I'10); Member Mich. State Med. Soc, ; 1566 Canal St.; G.

Gabert, Hugo A.-La.1,79; $\left(1^{\prime} 79\right) ; 1023 \mathrm{~N}$. Rampart St. ; 8-9, 2-4.

Gandy, Edw. R.-Tenn.8,96; (1'97); Ear, Gaster, Louls D. S. $\left(b^{\prime} 77\right)-$ La.1, $00 ;\left(l^{\prime} 00\right)$. 3330 Magazine St.; office, 619 Canal St.; $8-10,5-7$.

GAUDET, AMBROSE BFNJAMIN (b'73)La.1,96; (1'96); 496 Walnut St. ; offce. Medical Bldg. ; 1-5; ALR. $\star$

Gaulden, Chas. I.ewis (b'87)-La.1,'12;

(I'12); Charlty HospitaI.

Gaulden, Frederick W.-Ky.2,'91; (l'91) :

709 St. Charles Ave.

Gelsmar, Simon (b'87)

1539 Loulstana Ave.

GELPI, MAURICE JOS. (b'83)@-La.1,11 ;

(I'11): 3720 Canal St.; office, Audubon BIdg.; $12: 30-2$; $G$.

GELPI, PAUL J., JIR. (b'74)†-I,a.1,96 ; (1'96) ; 1700 Esplanade Are.; offlce, Audubon Bldg. ; $2-3: 30$.

GENELLA, LOUIS J.(-La.1,'98; (I'98); 922 S. Carrollton Ave.; office, Nacheca Bldg. : 12-2 ; LD. $\star$

GESSNER, HERMANN B. (b'72)థ-La.1 95: (1'95): 1528 LouIsiana Ave. ; offlce, Malson Blánche BIdg.; $12: 30-2$; Prof.

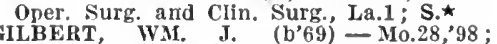
GILRERT, WM. J. (b'69)-

Gill, Howard L. (b'71)-N.Y.1,94; (1'02); 3319 Magazine St.; $9: 30-10,4-5$; Pd.

Gill, Simon G. (b'45)-La, 1,78; (I'78); retired; 1034 Baronne St.; 8-9.

GILLASPIE, WM. AUGUSTUS (b'72)Mo.3,'96, La.1,00; (1'00); 2131 Banks St.; offlee. 830 Canal St. ; 1-3.

Ginty, w. $J$.

(See New York City.)

Glenk, Clara T.-Pa.T,'96; (1'05); 4514 Prytania St.

Godchaux, Paul M. (b'81)-Ky.5,'06; (1'07) ;

GOMILA, FRANK RAYMOND (b'87)-La.1, '08; (l'08); 911 St. Ferdinand St. ; office, 2132 N. Rampart St.

Gouaux, Theophlle (b'50)-La.1,'85; (1'85) ; 708 Orleans St. ; $9-10,12: 30-2$.

Gondolf, Harold Jos.' (b'91) - La.1,'13; (l'13); 5359 Magazine St.; office, U.S. Marine Hospital.

GRAFFAGNINO, PETER (b'86)-La.1,'12 (1'12) ; Charity Hospital.

GRANER, EDWIN JACKSON (b'62)-La.1, '87; (1'87); 1633, 1st St.; office, Whitney Bldg. ; 8-9, 12-1:30, 4-5.

GRANGER, AMEDEE (b'79)థ-La.1,01 ; (l'01): 833 St. Claude St.; offlce, 921 CanaI St. ; $1-4$; (G1) ; R.*

Graves, Wm. Earl (b'82)-La.1,12; (1'12) ; 1440 Magazine St.; office, Capo Bldg.; $10-11 ; 0 \mathrm{~b}$.

Gray, Denver Francis (b'86) - La.1,'12 ; (1'12); 1132 St. Charles Ave.

Graybill, Jacob D.-H-0.13;78; $\left(1{ }^{\prime} 78\right)$; 1317 Napoleon Ave.

Green, Samuel C. (col.)-La.4,'03; (1'04); GROETSCH, CHAS. WM. (b'76)†-L8.1,03 : (I'03) ; 1922 Prytania St.; office, Audubon

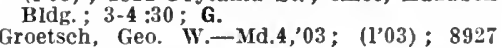
Jeannette St.

GUTHRIE, JAMES BIRNEY (b'76)థ-La.1, '00; (1'00); 921 CanaI St.; $1: 30-3$; Prof. Clin. Med., La.1.

Hackett, Robt. Kells (b'70)-La.1,'99; (1'99) ; 1122 S. Carrollton Ave.

Hale, Saml. Echols.-Ky.2,72; (1'72); 4838

Hall, Harry D.-La.1,97; (l'98); 2507 HALSEY, JOHN TAYLOR (b'70)Ð-N.Y.1, 93; (1'05); Malson Blanche Bldg.; $1: 30$ $3: 30$; Prop. of Phar., Ther. and Clin. Ned., La.1; Prof. Clin. Ther., La.G1; I.‡ Hamilton, Wm. Stewart, Jr. (b's8)-La.1, '12; (I'12); Charity Hospital. 
Hamllton, Wm. T. (b'\$S) - Nla.2, 80 : (l's0) not In practlce; $1520 \mathrm{st}$. Andrew st.

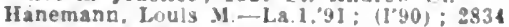
Grande Route St John: 8-9, 3-4

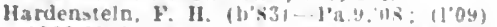

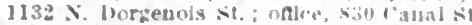
Hard!n, Jos.A. (col.) (b;5)-I.a 4.04 (lot): 1912 Itlenrllle Art: 11-12.

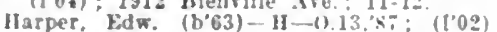
sec. Homeo. Board of Med. Finminers 2004 St. Charles Are; oftre, Macheca Bluk. : 10-11, I-1

II.AIBISIs, WM. II- - 1,at.1,

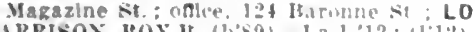

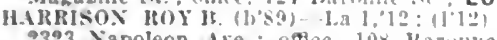
2323 Xapolenn wre : oftece lox lharumine

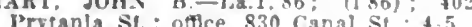

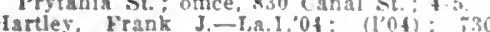
Hartley, Frank J.-la.1:0
Clouet st. $8-10,1-3$, at 5

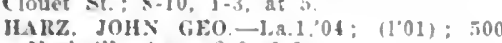
Nastrille Are; $\$=9,6=3$

IASPEL, M. IIIVII)+ 1.R.1.0.5: (1.05) 170 Perrler st. offlce, lizt Ibarunne St

HATCI, EDWARD S. (b'75)†-Mass.1.'09 (l'06) : 2035 Octarla St.; oflce, 1120 Malson-Blanche BIdg.; $3-5$; (GI)

Ilauer, Geo, Jos, (b's9)-La.1,12; (1"1?) Cbarlty Jospltal.

ILA. AIRIE.N-La.1,'st; (I'st) : 1459 Annunclation St.; oftice. Macheca luidg. 8-4, 5-6.

IIajes, Wm. Mcleod (b'\$4)-Ia 1,10;

HEREIT, JOS. S. \&-1,a, 1,01: (I'01) : 170; llobert'St.; oflce, 921 ('anal st. : 1-3 Obc.

IENDERSON, JIME: 1.-La.1,03: (103) 2533 Crsuline Are: oftlee. 921 Canal st.

-3.

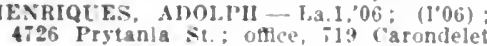
426 Prytanla
St.; $2-1 ;$ R.

High, Dani. Lee (b;i)-N.(C.1,0i; (1'12) -23 Camp St. $9.11 ; U$.

Ilme!. Augustlue J. (b',59)-La. I, \$1 ; (1'81) 816 Fine St

Rlneks. M. Fdtuond (b'51) H-0.13,'s: (l'82); \$29 Jumaine st. : \$-9. Alneks, Wm.-14a.1,'88: (1'38):

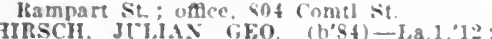

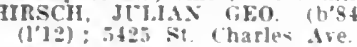

HOEFELD, A. O-IA.1.01; (I'01); 926 City Park Ave.; offe, 330 Canal st.; $1-3$ HOGAX, EARL A. (b;5)-111.6,01: (1'13): 1534 Hens Clay Ave; oflea, Hibernia Bank ItId

llolbrook, Chas. Shute $(1,36)$ - Iar.1,12: (I'12): Charlty Hosplta!

TOLDERITH, CIIS. I' +-I.a.1.'06; (1'06) 2903 Annunclatlon st.; oflce, 8.30 Canal St. : $1: 30-2: 30$.

IOLT, JoS. JoHNSON-La.2.'61; (1'61) 2120 Pryanla onlce, $30 \%$ Rironne: $1:-2$

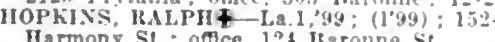

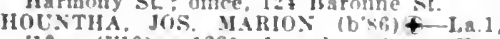
10 (I'10): 1239 Iirgades st.; office. Macheca Itldg. : $12: 30 \cdot 2$

Huhner, Edw, J.-1.3.1.93: (I.84): 3649 Magazine St. ; rmce. 830 (:and st

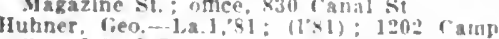
St. : $: 3,3-5$.

ILME, JOSt $501,01:(1004): 16,23,:(1)$ St. offee, i2t Haronne st: $12.5 ;$ Anst. IUMMEL, EJW. II (b-6)+-1, J,02 (I'02): 5020 Hurmt St, once, $9 \geq 1$ Canal Sit. $(\mathrm{E} 1)$

NTEK, JOSIAII I. (b'65) ₹-1.a 1, 0.

mivelter, 11.

(kee New lork lity.

Irwin. Wm.

(See New Jork ris.

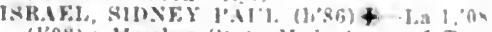
$\left(I^{\prime}(0)\right.$ ): Member siate Ved. A 1819 valence st.

Jacobs, Niolph (b'it) las 1, lo:; (1'1:) Charley llosplat

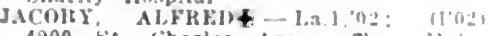
4900 st. ('harles tre. unlice. Walson

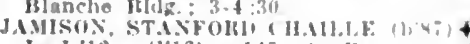

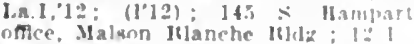

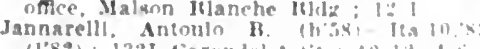

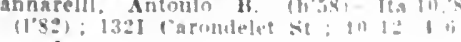

Jase, Wllson f. (col.) (b'a)-1.a.t, 02)

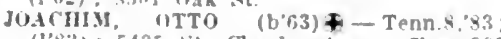
(l's:b) ; $5435 \mathrm{si}$. Charles Are.; nflce, 501 Machera Mide, 11-4; (B3); ALR* JOHAs, FOSTEI MATTHFil (b'yo

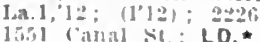

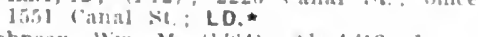
Johnson. Wh. M. (b'st)-Ma.4,12: Jntern,

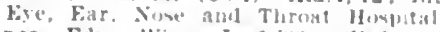

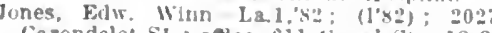
Carondelet St.; once, bil ('anal st. 19-2

Jones, Ford Jelson-Mich.5. (0): (1'ux) 2016 Gen. Tuylor st, omle, Hil Canal st JONES, IIAHILTON IOLK†-LA.1.44 (1'94): cilo saratnga st. once, yat Canal St. ; $1: 30-2: 30$. Jones, John $T-1 . a .1,40 ;(1 ' \$ 0)-2023$ st.
Charles Are, oflce, 21:it Magazlne st.

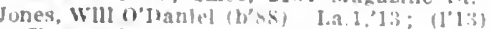
Charlty Hospltal.

Jumel, Allen, Jr. $(b 74)-1.31 .97 ;(1947)$ 1215 s. carrollton the : unter, Carroll ton Are. and Oak St: 1 1-12.

JURGELWICZ, EDW. A.-L,a.l,03; (['03) 5420 Prytanla St.; oflce, 12t Haronne St.; $3-5 ;$ G.

KAILE, TIERRE JORIA+ - La.1,0: (l'05) ; 1432 Esplanade Are.; chlce, Berrin 13ldf.; : : $: 4-4: 30,4-8$

Kane. Isaac J.-1.a.4:05; (1'06); 1635 Iew Orleans sit.

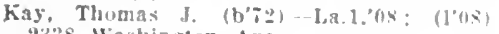

233. 16 aslington Are.

2351 Nagazlne St.

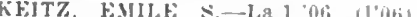

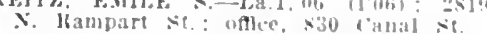

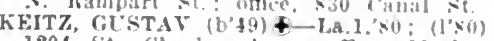
1204 St. Charles Are.; oflle, Machees BIdg.: : 12-2. KELLER, ALFItED ANTHONY (b'ss)
La.1,10; $(1,10) ; 4120$ Magazine st.; iftce. 40.1 ('anal st.

Port St.

Kennedy, Allan A.- La.1.06; (100s): 14 Berlin St.; oftce, tal Canal st.

Kennedy, Thos. Scilles-l.a tig.

124 Háronne St. ; 3-5.

Kirbs, James $w$.

live lew lork tigy

HINRERGER, FRANCIS JAMEs (b's)oflice, 830 Canal :

KIXG, ALFREI Vallette st.

KING, EDWAID IACY (b.84)

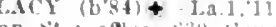
St: $1: 30-2:$ ObG.

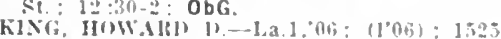

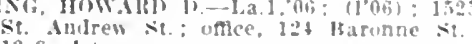
$12-3 ; 1$.

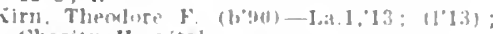
Chariey Hospital.

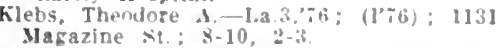

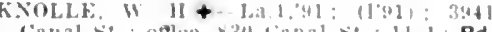
KOELLE. JOHS MARCIS $\left(\mathrm{b}^{\prime},-1\right)+1$ I 1 .

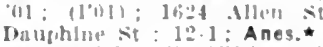

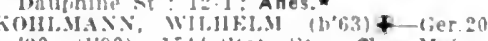
"yo: (190)": 154t siale si, once, Malson Blanelie Hido 11.1: IAti) ObG.

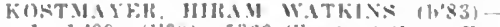

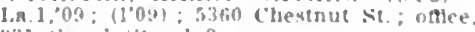

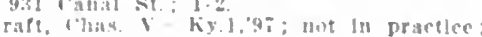

Krap, ?has ! ky.1.9a; not ln practlec

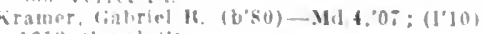
16, I atla! $\leqslant$.

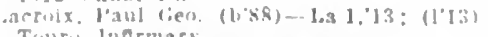
Tumbi lufrmar

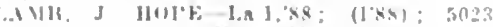

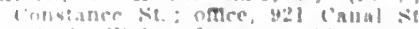

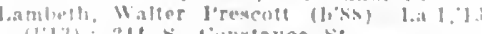

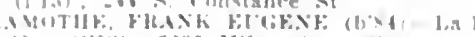

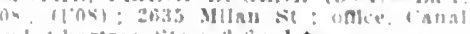

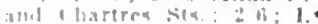

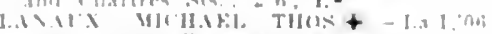

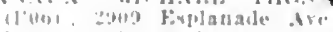

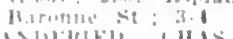

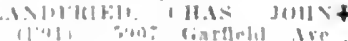

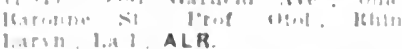

LANUIR, JEROME FMANCEI, (b'8I)

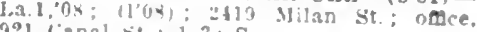

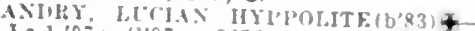
ba.1, 0 ; $(100) ; 2.55$ Si Charleq Are. "iffee, 3503 I'rstanla Si: : $2-5:$ S.

Esplauade Ave. : $2-3$.

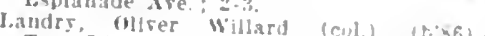

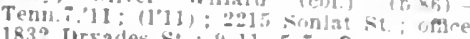
1832 Iryades st,

charity Hospltal.

LA Charity Hospltal.

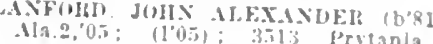

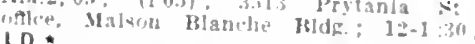
L.D. *

Langworthy James S. (b'55)-La.1, i.j (1'ss): 201: Lisuline Are.

lanng Oscar Rosenon-llen.l,\%o; $11 \% 01$ 1Po: Crsuline St. : 10-1

MPOSE, JAMES IHROWXE (b's6) \& LA.1,

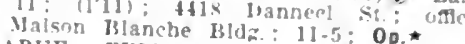

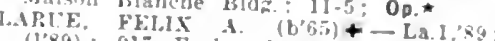
(189); 917 Esplanade Are.; oflce. 11 ramb s?: 12-1, \&:; I'rof. Oper. and LACRANS. IOH:

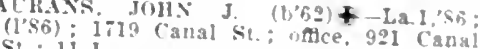

b.awsor. lisace Harty

LEAKE. WM. WA ('lty)

(1.09) 1.06 W.TER (b'S4) †-La.1.03 bon Bidg. : 2 -4.

I.e Blane, I. IIoa-La.1,94; (1'94): 144 LECKERT, EDYIT

(100\%); Sec. State L. (b'82) F-Ia.1.07 iners: 12z: Magazine st. Med. FramCanal Si: $3: 30-5 ; \mathrm{S}$.

FIHETTER, HENJ. ALF. $†$ LI.1.92

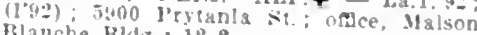
Planche Rldz: 1:-2.

I.EDOLX, AIEXAXEER Hanche Bidge Are; ottce. I215 Malson

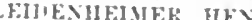
(1'11): 5014 Camp st. Oflce, Malson Blanche B!dg.: $11: 30-10: 30 ; \mathbf{S}$.

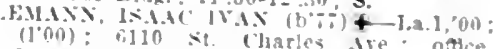

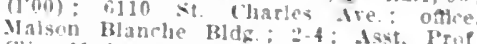
Clin. Mei., M.a.?.; I.*

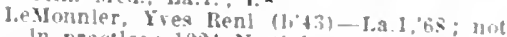
In practlce : 12at N lialvez

L.1611, OTTO-La.1,94; (1'94); 1698 [1. per Lime: oflee, Malson Hlancbe Bldg. $1: 30-3$; Jof. Med. lliag. La.til.
lescale, Jos. Fermand-I.

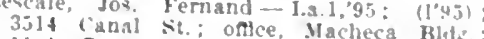
3j14; Prana

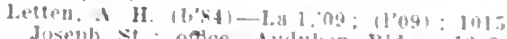

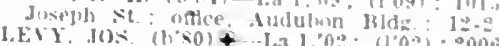

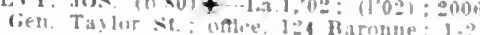
tey, bewis llartis (b'ss)-La.1,13; (1'13): Tuuro Intlrmary

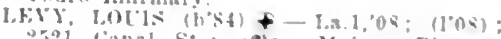
2521 Canal St; nalce, Maluon Blanche

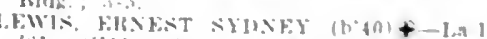

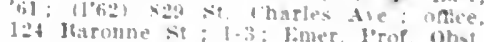
and liyn la 1 : ( $(15)$

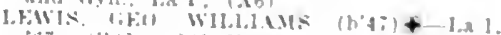

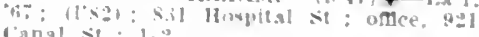

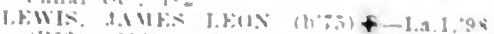

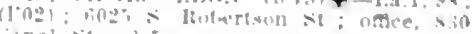

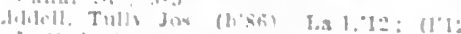

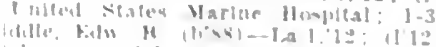

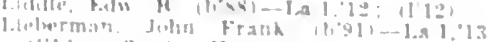
11! i inarly llowplial

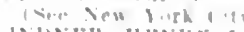

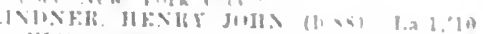

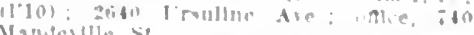

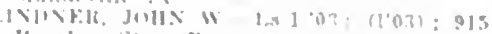

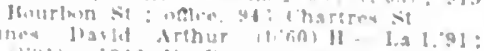

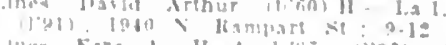

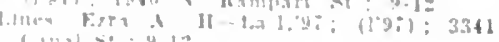


Lobenhotfer, Joln phillp (b'v9)-Tenn.10, '04; (1.03) ; 3703 Saratoga st.; oftlee, Touro lnfilrmary.

I.UEHEI, MAU1) (b'83)--N.Y.20,'10; (1'10) ; 1729 Marengo st. : $1-3$.

I.0G.A. (iEO. K1NG (h'73) \&-Ja.1,99; (1'99); 1539 1'nhllp St.; ottlee, Millson Blanclie 13lek.; $11: 30-1$

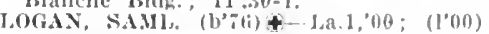
1435 i'leasant St.; offlce, 724 ibarome st. $12-5$; U.

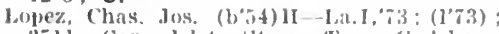
3711 ('arondelet st.: oflue, Godehaux 131dg., $10-11,2-3,4-5$

Lope\%, Jose 1

(Nen Nest York Clty.)

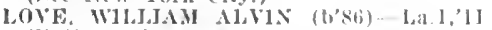
(l'11); 1423 valence st.; offlee, Ios Baromise st.; $11: 30-1$.

Lowe, Edniund 1'. (b'150)-1.a.1,'85; (1'85) 5301 Canı st.: $8-9,2-4,5-6: 30$

lowe, Vincent $F$. (b'72)-La.1,93; (1'93) 428 Opelousas Are, : 1-3.

Jureas, (i. WF. (col.) (b,76)-I,a.4,07; (l'07): $212 \%$. 1st St.; offle, $624 \mathrm{~S}$. Rampart St.

LY YCH, 180IBT. ('IYDF (b'80)£-Ia, 1, 03 (I'03); 1527 Caronilelet St. ; office, 624 Gravler St.; 1-4; 1'rof. 1)Is. Ear, Nose and Thront, La.G1.: (133)

Jynch, Whllam ii. (h'55) -La.1,96; (1'96) 1527 Carondelet st.; $8-8$

Lymn, Wm. J.

(Nee New York Clty.)
4yoNs, RANI)OL'H (b'81) - La.1, 0 ; (l'07): 1428 lst st. ottlce, Malson Blanche 13ldg.; 12-1:30; I.

MAES, TRJAN (b'-8)£-Ja.1,00; (l'00) ; 1661 Octavia St, ; oftlee. Malson Blancho Bldg. ; $1-2$

MAESTR1, ANGELO $\nrightarrow-$ Ia.1,'95; (1'95); 2232 Fisplanade Are. offlce, $2132 \mathrm{~V}$ Rampart St.; 1 -2.

MAGIEDER, MARCUS J. $\left(b^{\prime} 66\right) \oplus-$ La.1 89; (1'89) ; 1230 Loulsfana Are.; office, 1103 Malson Blanche Bldg.; $1: 30-3$.

IHAHLER, EVERARD W,-La.1,05; (1'05) 2626 Mllan St.; offlce, 124 Baronne St.;
$3: 30-4: 30$.

MAINEGRA, ROBERT J.-La.2,69; (l'69) 802 Washington $\Lambda v e$; offlee, 800 Washington Ave. ; 8-9, 3-5.

IIAIEGRA, ROBEIT J., JR. - La.1,06 ; $\left(1^{\prime} 06\right) ; 4730$ St. Charles Ave.; offlce, Ialson Blanche Bldg.; 1-3.

Malkin, Gen. M. (b'83)-Ky.4,'05; A A surg. 1.S.X.; Navy Hecruiting Station.

Maloney, Louls J. (b'74)-La.1,'99; (l'00); 2101 S. Carrollton Are.; $11: 30-1$.

Malter Jacob M.-La.1,'82; (1'82); 2001 Perdido St.

Manderlle, Wm. R. (b’51)-La.1, $71:\left(l^{\prime} ; 1\right)$; 522 Short St.; office, Medical Bldg.

MANN, GLSTAV†-Scot.3,'92; Tulane Lniversity; Prof. I'hyslol., La.1, ; (F1).

MARTJN, EDMUND DENEGRE (b'63) La.1,91 ; (l'91); 741 Carondelet St. . 1-3. Prof. Gen. Surg., La.G1; (A6); S.

MARTIN, JONEPJ D. (b'79)థ-La.1,03; (l'03) ; 1226 Josephine St. ; offlce, Audubon Bidg.

Martinet, Jouis Andre (col.) - La.4, ${ }^{x} 92$; (1'92); 1222 Orleans Park.

MATAS, RUDOLPH $\left(b^{\prime} 60\right) \oplus-$ La.1,'80 ; (l'84); 2255 St. Charles Ave.; offee, 3523 Prytania St.; $3-5$; Prof. Gen. and Clin. Surg., La.1; (A5,6, F1); S.

Mattingly, Arthur R. - La.1,'8;; (l'89) ; 5401 Laurel St.; 2-4.

Maxwell, Thomas Andrew (b'91)-La.1,'13; (1'13): Cliarity Hospital.

Nay, Clarence Prentice (b'85) - La.1, 08; (l'08) ; 2425 Collseum St.; offce, Cusachs Bldg. ; 11-12:30.

Mayer, Chas. It. (b'60) H--Ill.4,'85; (l'85) Pres. Homeo. Board of Med. Examiners: 919 st. Charles Are, ; 9-10,3-4.

M.IYO, SARA T. (b'69)\&-Pa.ĩ,98; (l'98); 2005 Octaria St.; office, Macheca Bldg. $3: 30-5: 30 ; \mathbf{G}$.

MCCORMICK, ETTA PEARL (b'84)-Ky.1, 08: (1'11) : 1823 Annunciation St. ; office, Nalheca Bldg. : 1-2; Pd.

Ir Cutchon. Percifal B.-La.1,79; (I'79); 4020 Frytania St.; offlce, Macheca Bldg. ;
McliLkMII), (ifo. A. (b'63)-Ont.4,'86 : (l'si) 1422 Jackson Are.; offlce, 931 ('anill St. : I-3.

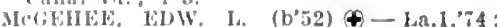
(I'\$4) ; (Hammon(I); offlee, 921 Canal 'st.

McGrane, ('las. J. (b'66)-La.1,98; (l'98) ; 233 Canal St.; $7-8: 30,5: 30-7$.

MCGUIIE, IIARION IIEHBERT (b'73) 4 La.1,'98; (1'98); 1628 State St. ; offlce, tid I Mcheca Hldg, 12-1:30.

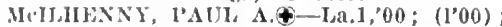
1125,4 th St.; offlce, 741 Carondelet St. Mcklssack, lames 'T, (b'4l)-0; $\left(l^{\prime} 70\right) ; 833$ Gilrod st.; oftice, Girod and Barome Sts.; $9=10,3-4$

Mchowen, John (b'89)-La.1,'12; (1'12) ; Charlty IIospltal.

Mchenn, I. W.

(see New York ('ity)

MCMAION, JOSEPHÚ'S B. (b'61)థ-Ala.2, 86; (l'86); 1626 Carrollton Ave.; oftlce, 108 Baromine St.; $11-1$.

Mcl'hall, Nell Percy.

(See New York (Ity.)

Icshane, Aug.-La.1,'82; (l'82); 1911 N. Clalborne St. ; offlce, 830 Canal St. : 12-4. ITENAGF, 11ENRY KDW. (b'71) $4-$ la.1, 92 ; Haronne St.; 1-4; Prof. Derm., La.GI; D.

Meraux, Louls A. - La.1,04; (l'04); St. Bernard l'arlsh; offlce, $2132 \mathrm{~N}$. Lampart. Mercler, Chas. S.-La.1; $\left.78 ;(1)^{\prime} 78\right) ; 932$ S. Carrollton ive.; $7-9,11-12$.

Merendino, bonienico (b'72) - Ita.12, 00 ; (I'08); 714 Frenchmen St.; office, 607 Toulouse st.

METZ, ABRAIIM LOUIS (b'64)†-La.1 '93; (l'94) ; 9 lkosa I'ark; offlee, Richardson Chemistry 13idg.; Prof. Chem. and Med. Juris, La.1. METZ, WALDEMAR JICE (b'91)-La.1,'13;
(1'13); Touro Inflrmary.

Meylor, John J.-La.1,'61; (1'61) ; 3052 N. liampart st.

MICHINARD, PAUL (b'58) - La.1,'83; (l'83) ; 3420 St. Charles Ave.; offlce, 931 Canal St.; 2-4; Prof. Obst. and Gyn., La.G1; (Á6).

Milholland, Wm. Henry (b'65) - 0.2,'89; (1'91); 135 Jaronne st. ; 9-12, 2-5, 7-8. MILLER, CHAS. JEFF. (b'74) 4 -Tenn.6, 93; (1'95); 1638 Joseph St.; offlce, 12 Baronne st. ; 1-3:30 ; Prof. Obst. and Clin. (iyn., ha.1; (A6); ObG.

MINIS, CAIOULINE (b'73)-Pa.7,'12; (l'12); 51 i Lowerline st.; offle, 921 Canal St. ; 1-2.

Mlms, Thomas H.-La.4, 06 ; (l'06) ; 2624 Tulane Are.

Mioton, Eugene Jos.-E-La.1,7 ; $\left(1^{\prime} 7 \tilde{\imath}\right)$; 852 St. Cliarles St.; office, Maison Blanché Bldg. ; $12-2$.

MOTON, SIDNEY FITZHUGH(b'74)-La.1, 9.5: (i'95); 2523 Esplanade Are.; offlee, Medical Bldg. ; 12-4:30

MITCHELL, CARLTON - La.1,'98; (1'98); (Mandeville); office, Macheca Bídg.; 9-2. Monette, Geo. N. (b'46)-La.1,71; (1'71) ; 4322 saratoga St.; offlce, 1021 Baronne St.; until $9,2-3: 30$.

IOXT\%, INTHONY JOSEPH (b'80)-La.1, 00 (l'00); 2726 Ersuline St.; offle, Macheca lídg.; 11-12:30.

MOOLF, PIERRE ALBERT - Pa.2,95; (l'95); 1424 1'lllip St.; offle, 103 Chartres St.

(See New York (ity.)

MOSS, EDMUND-La.1,97 ; (1'98) ; 4817 St.

Charles Ave.; office, 921 Canal 'St. 12-1.

Mouledous, Andrew Dominle (b'84)-La.1, 08; (l'08); 3622 Laurel St.; offlce, 830 Canal St.

(See New York City.)

IIULLER, J. SAUTER-La.1,05; (1'05) 1402 S. Carrollton Are.; office, 124

tullon, 1. E. (col.)-Tenn. 7,'83; (1'93) ; 931

Valence St.; offle, 1131 Gravier St.

MURPHY, PE'TER FRANCIS (b'86) \&-La.1, 10; (l'10); 1203 Josephine St.; offlce, 321 St. Charles St

Murphy, Rene A.-La.1,'89; (1'89); 1718
NELKEN, ABE (b"6) $\$-1$-a.1,99; (l’99) ; 5529 liurst st.; offce, 305 Barome St. $12: 30-5 ;$ (C3); $U$.

Nelson. Francls M. (col.) (b'78)-La.4,04; (l'04); 8525 J'oplar Ave.

SFILSON, llARIt EVELETT (b'85)-La.1, 12; (1'12); 2004 Tulane Ave.; offlee, Iacheca Bldg.; $2-3: 30 ; 5$

NEWIIACSEI, MAYEL A. (b'83)-La.1,'10 ; (l'10); Loulslana State Brard of lealth. NHWMAN, JACOB WARlR Charles Ave, oflce, 3523 prytunla st. $11-12: 30$.

Newman, James Turner (col.) (b'47)-La.4, 93: (1.93); $2600 \mathrm{~s}$. lamparte St.

ilcolle, Ilenry Tecle (b'82)-L,a.1, 08 ; $\left(1^{\prime} 08\right)$; $1461 \mathrm{~N}$. l'rieur st.

NIx, James Thomas, Jr. (b'87)-La.1,'10: (l'10) ; 7930 Jeannette st.; oflice, Audubon Bldg. : $3: 30-5$.

NOIIA, ADOLP1I (b'62)- La.1,'90; (l'90); 726 Mandevllle st. ; $8-9$.

NOL'TE, ART1IUL \&-Va.1,'80, N.T.1,'81. (1'81); 1505 state st.; office, Maison Blanche Hidg.

OTILACKER, WM. (b'60) $₫$ - La.1, 89 (l'89); 930 Louisa St. ; $8-9,6: 30-7: 30$.

OECISNEK, HERMAN' (b'62)థ-Ja.1,99 ;

$\left(l^{\prime} 99\right) ; 1445$ Lafayette Ave.

OECIISNER, TOIIN FREDK, $\left(b^{\prime} 68\right) \uparrow-\mathrm{La} 1$. 94; (l'94) ; 5330 Danneel St.; offlce, 830 Canal St.: 2-4; Prof. Ortho. and Surg. 1 ; $(\mathbf{A 6 )} ; \mathbf{S}$.

O'Ferrall, Iohn T., Jr. (b'85) -La.1,08; 2341 Camp; offlce, MaIson Blanche Bldg.; Or. 'IIARA, JOS. A. $\$$-La.L,00; (l'00); 2241 Baronne St. ; 8-9, 4-5.

O'KELIEY, J. PHÁRES (b'70)థ-La.1,'93 ; (1'93); 1701 Marengo St.: offlce, 830 Canal St. : 11-4; (B3); ALR. *

OLIVIER, ('HAS. KOSSUTY (b'81)-Ia.1, '10; (I'10) ; 901 Bordeaux St.; offlce, 2715 Baronne St. ; 9-10.

O'REILLY, Wy. T. (b'61) $\oplus-$ La.1,84; (l'84); 2610 Royal St.; offlce, 2513 Royal

Orlol, Raymon Adrlan, Jr. (b'89)-La.1,'13 ; (l'13); 1806 Ursullne Are. ; offlce, Audubon Bldg.; $12-1,1: 30-2: 30$.

Ornelas, P.-Pa.1, 7; (†); Audubon Bldg. Otís, Susanna - Mass.7, $01 ; \quad$ (l'03); 1803 Peters Ave.

OTTO, HENRY JOIN (b'79) - La.1,00; $\left(l^{\prime} \theta \theta\right)$; 1107 Gravler St. ; 9-10, 5-6; U.

PAGE, JOS. HERBERT (b'86) - La.1, 09 ; (1'10); 921 Canal St.

Page, J. T. (b'50) $\longrightarrow$; (\$) ; 2808, 2 d St.

Palmisano, Dominlck Andrew (b'88)-La.1. '13; Intern, Charlty' Hospltal.

PAIRHAII, FREDK. WMI. (b'56) †-La.1,'79; (I'90); 1429, Tth St.; office, 741 Carondelet St. ; $1-3$; $(\mathbf{A} 5,6)$; S. $\star$

Parmele, Lydia Estelle K. (b'65) - Ill.19,00 ; (1'12); 810 Jackson Ave.; $9-12,2-5 ;$ ObG. $\left(1^{\prime} 12\right) ; 810$ Jackson Ave. ; $9-12,2-5 ; 0$ bG.
PATTON, GEO. FARRAR (b'53)-Ger.2,76;

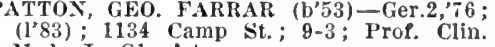
Med., La.G1; I.*

PATTON, THOMAS HERBERT (b'84)La.1,12; (l'12)

PAT'ON, WM. THOMAS (b'85)-La.1,'08; (1'08); Maison Blanche Bldg.; ALR.

Payne, Walter Clifton (b'89) - La.1,'12; (l'12); Charity Hospital.

PERKINS, RUFFIN TROUSDALEథ-La.1, 06; (l'06); 1135. Fern St.; offlce, 921 Canal St.

PERKIYS, WM. MARTIN (b'73) $\oplus$-La.1, 297 ; (l'97); Sec. State Board of Health; Bldg.; 1-2; Prof. Clin. Surg., La.G1; (A6) ; S.

Jouis C. (b'75) - La.1,99; (l'99); 2111 Dauphine St.; offle, 2132 N. Rampart st.

Petersen, Fredk. Carl (b'62) - La.1,94 (1'94); 1106 Elysian Fleld Ave.; office 1432 St. Roch Ave.; 8-9, 4-5.

PETTIT, WM. F.-La.1,98; (1'98); 1758 Jackson Ave.

PHILLIPS; WMI. DAVID (b'83) †-La.1,'09; (l'09); 1629, 4th St.; offlce, Medical (l'09); 1629, 4th St. ;

PICARD, MICHAEL' SHELLY (b'79) $\oplus-$ La.1,'03; (l'03); 1539 Loulsiana Are.: office, Maison Blanclue Bldg. ; 1-2:30; Pd.` I'ITMAY, MASON W. HENRY.

(See New York Clty.) 


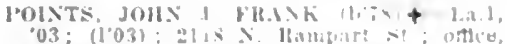

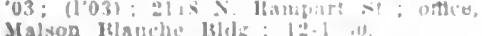

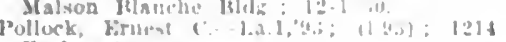
Easplanatle .tre

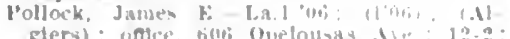

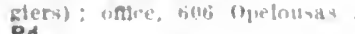

Pd.

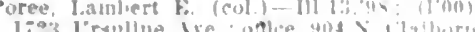
Irip: $8.93-8$

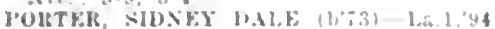

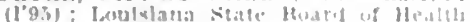
12t lbarld sit: 9.4 .

Posmalusky, Isaac-Las.1,04: $\left(1^{\prime} 04\right)$; Mesilcal Bldg. : $12-1: 30$

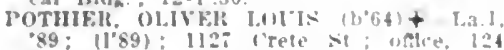
Baronne st.; $3: 30.4: 30 ;$

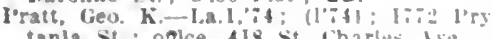
tanla st.: oasce, als st. Thateles Are.

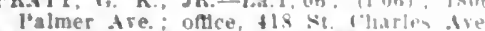

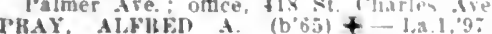
(1'0I): Ilotel De soto: oftce, II acheca Hids.: $11-12: 30$

rrels, clotllde C. Jauguel-1'a.7, 04: (1'05) 909 Julla St.; :-5: OALR. *

PREIS, EDW. BURKET-LA.l,"94; (1'98) 909 Julla St. oflce, Medical Bldg

PROVOSTY, IXCIEN MALRICE (b'6S) 931 Canal St.; 2-4.

Purser, John L. (1'79)-Tenn. 1,00; (1'05) luot Bordeaux st.; offce, Malson lalanche HIde. $10-11,2-4 ; U$.

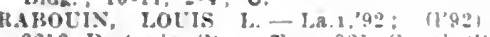
2216 Prytanla st. : odtce, 92l Canal st. RAMSFY, THOS LFROY

(see New York r'lty.)

Hand, Paul King (U'38)-La.1,'13; (1'13): 1468 Calhoun st.

Rappanler, Erriest A-I - 1.1,94; (l'94); Jist N. Clalborne st.

Reed. Wm. Arthur (b's8)-1.a.1.12: (1'12) Touro Infrmary.

Relllez, Walter if-La.1;02; (1'03); 2662 Canal St.: oftce, 921 Canal st.

KEISS, PACL L.-La.1,90: (1)(9u): 1.31 Pelers Are. : office. Macheca Buld: l:llesnaud, Brunner Burke (b'i9)-1,a 1, 09 (1'05): 1238 Josephine st.; office, Aurlation Bldg. : $12-5 ; U$.

IBENALI, I.OT'TS F.IVROT - LA.2.'biti: (1'66) i 1238 Jasephlne st. : Enuer. I'rof BICE, CLARK HUTON, JR (b-0)

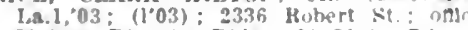
Malson Blanche Bldg.: 11:30.1: Pd. Malson Rlanche Rldg.: $11: 30.1:$ Pd.
BICHARD, E.LCLID J. - 1,a.1,97: 1197 $3500^{\circ}$ Canal st. ottlee, $\$ 30$ lathal st $1-2: 30$.

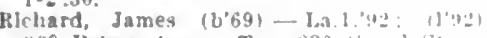
yng Pelers Ase. : offce. 430 cinal st.

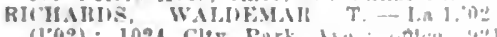
(1'02): 1024

mles. Rolvert I. (b'63) 1.a 1.'4 11'0!e): 23: Rermurla st.; $11-1$

In)lialnas. $\mathrm{B}$

isee New York rlty,

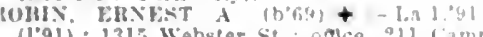
(1091): 1315 Wehster st ance, 211 camp

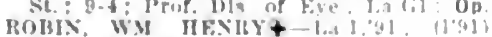
2200 Explanade Afe.; nalce. Sudulum Bids: : 1 -3

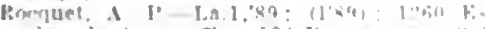
llanade sre: viflee 124 Harm ne

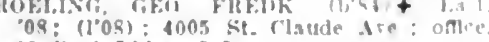
Menical Budg.: I-3.

Bowllng. Henry Wm. Jr. lland -1,a 1, I" Il'101: i2s Mazant :

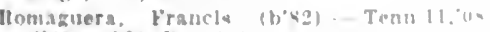
(1.09): 403 Hoys) st

nosfextHA, SIMON JON,

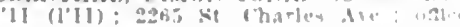
Tourn Infirmars

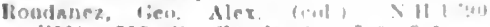

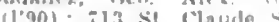

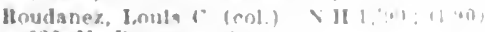
fi22 $\times$. Hampart st

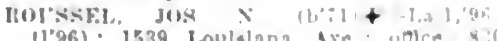
l'anal st: ; 11.12, 1

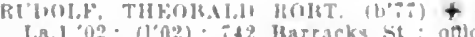

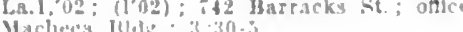

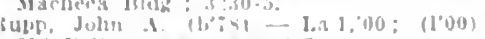
339 l'elican $110 ; x-40,4-5$

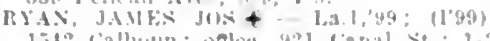

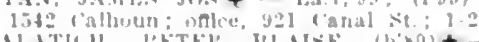

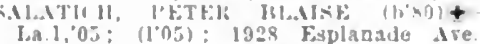
ofice, Audubon bldg.; 2.4: $G$

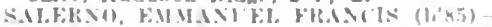
la.1.10: $(110) ; 3031$ Tulane we : iflce $601 \leq 1$ ampare st: $8.4,2-3,5,-6$.

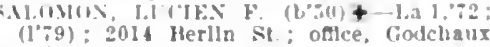
Hid $2:+1$

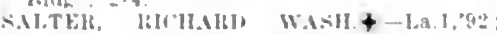

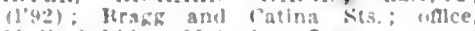
Metleal Whig; $10-1,2-4 ; 0$ p.

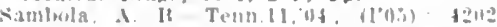

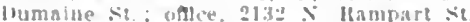

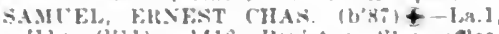
11: (1'11): 1416 I'enjaton st.; oflce, 3529 l'rertanta St. ; $1: 30-5 ;$ R.*

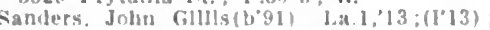
Charly llospital.

sartin. I. Rennest (b'90)-La. \}'1': (1'13). ('harlty licespltal.

SAITER, IIIAS. F. - La.],94; (1'94) 3153 chlppewa si

Schart, Edwin stanley (b'is) - La.l,06

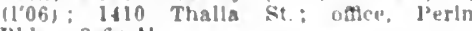
Blldg: : $3-6 ; 0$.

SCIIEI'P'EGREIL, WM. $\left.\left(b^{\prime} 60\right)+-S_{1}\right)^{\prime}, 1,89$ (1'90): 497 Walnut St.; oftce, Audubon IHdE.: $11=1,3-5 ;$ (B1); ALR.

SCOTT, JOS. TILFORD, JR. - La.1,94 (l'94); 164 I State St.; offce, 921 Canal St. : $10.2,3.5$

Scote, Warren Flelding (b'8s)-1.a.1,12: (1'12): Charlty Hostltal.

Seay, Roberdeau Wheat (b'5i) - Ky.1.'79; (1'79); +927 Collseum st.

SEFBOLD, HERMIAN B. (b'T5) - -La. l, '02. (l'02): 232: C'anal st.: office, Medlcal BIdg. : $1: 30-3: 30$

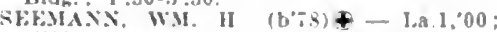

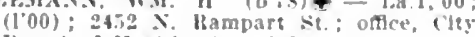
Foard of llealth: 8-9, 6-

Sellers, Thos. Henton (b's9) - La.1, I 3 ; (1'13): Touro Inflrmary.

SHXTOX, I.ETHER (b'59) + - I.A.1, 81 ; (1'\$2) : 162:1, 4th St. : oftce, 124 Baronne st. ; $11-2,4-5$ s.

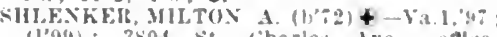
199): 3xit st tharles we ontce

slekmann, J wan F, - La.1.92: (1'9i); 370 ; Camp st. : 3-4.

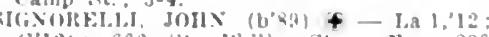
(1'12): 6int st 1'hl11p st.; nftice, 830 ranal st

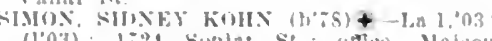

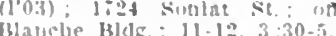

imonton. Folwin (aldwell (b'sib) - I.a l.'13

(l'1:31: Cliarlty IIospltal.

suleh, fames biluarl.

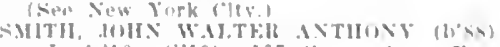

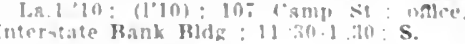

Intertate Bank Budg
smith. luitan comway

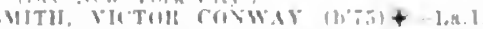

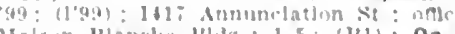

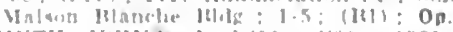

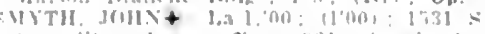

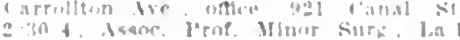

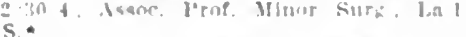

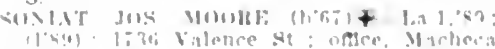

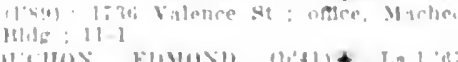

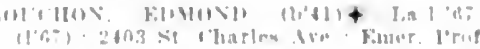

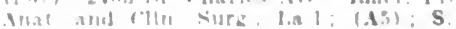

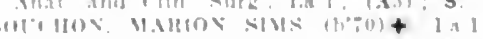

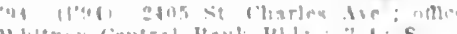

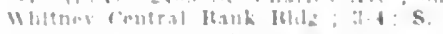

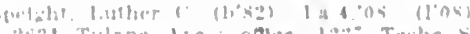

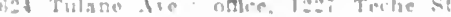

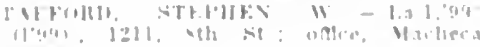
$13 \cdot 16$

lam, Hewhriek ban Menhle

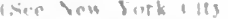

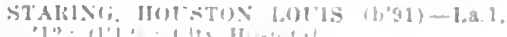
inlum, II

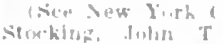

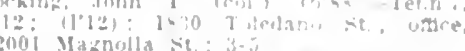

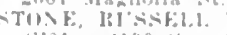

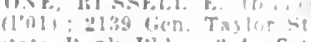

stale lank Mllle : :

STH

Lit 1 .

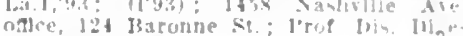
the syot, La fil; i.*

Stowe, let Ro

the Sew York $111 \mathrm{y}$.

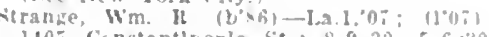
14 . Conctantsuople st ; 8.9.3n, 5-6:30 ATHONG, BORT MLEANLER.

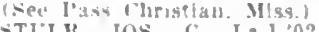

Loculsiana Are.; 8.9 .

TI YUI GE Imryades st.: 8-9. $2-5$.

WORls, MERRIC K WAIB - LA.1,07 (l'0i); 153\% stort st; oftce, Malson Blanche Bldg.

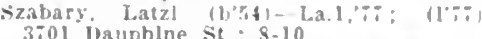

TALBOT, PALI TILNAN (b'82) — La 08: (1'08): 3508 Magazine st.; otbce

Malson Blanche BIdg: : $3-5$.
Taqulno, Geo, James (b'st)-La.l, l1 : (1'11)

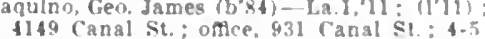
Tehault, Chrlstopher H.-La.1,62; (1'62)

TEZ3 Xorth St. 12-2 95; (1'95); 1:22 Batonne st.; 8-11.

Tedesco, Imatlus (1.89)-1.a.1.13; (1'17): Charity Inspltal

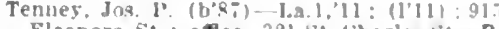

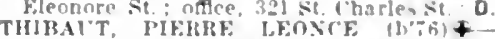

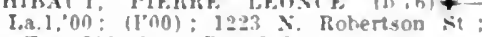

nffice, 211 camp si. $1-2$. 9.9: (1'99): 2021 I'rsullne st.; office. Nacheca $\mathrm{Bl}$ de. : $2-4$.

Thomas, Innle T. I.-1ll4,86; (1/86); 1411 Washington Are. : 8-10, 3-5.

Thomas. Feo. A (b'-6)-La.1.07: (1'0i): 435 s. Rampart st : 9-2. 5-8: U.

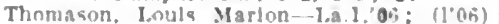
1715 $x$ Clalborne Are.: oflce, 124 Ra. ponne s.. : 1:-1:30.

Thompson, if - O 1.60: (1+) : 2603 ranal st Thornhlll, Fugere Chas (col.) (n'sl)-J.a 4 ng: (1'09): 8216, 24 st: oflce, 2331 linward st: $9-11,6-7$

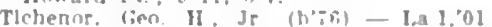

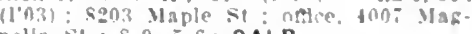
nolla st, $\$-8,5-6 ;$ OALR.

Tinney, J. I

INin lew York rlly.

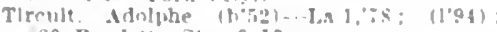
Tirent

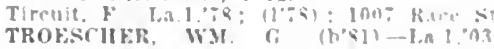
(1'n3): 11112 Rerltn st ; nflve, Mathecs $\mathrm{HICl}_{2}: 19: 30-8$.

Tudury. Ralyh A. (b':1) -I.a 1.93: (1'03) :

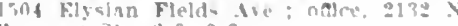
lampart sq : 59.9 .93

Turnee, Jolin IIm

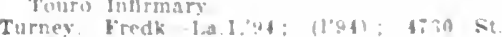
Pieter sis.

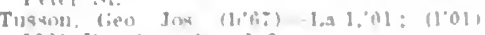

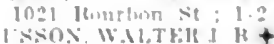

gon kinguade atre

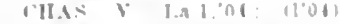

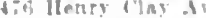

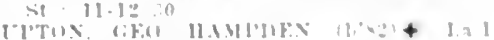

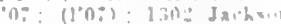

1 rueter, Hoduard.

alen vew Vork

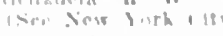

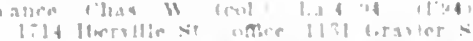

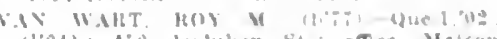

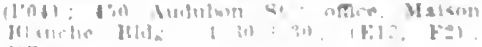
NP.

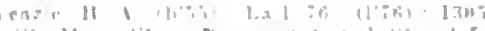


VERTIER, ('HAS. FDWIN (b'82)-l'a.9, 04; (l'09) ; 3018 Fisplanade Ave, olltee, Malson Hánche H]h.; 11-6; U.

rlniug. Ituby (col.)-lad.4,07; (I'07); 3004 s. Rampart St.

WADE, IIFIRELT WINDSOR (b'86) + La.1,'I2; not In practlce; 5256 .Magazine St. ; oftlec. Tutane l'nlversity ; LD.

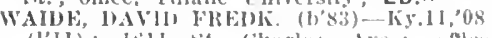

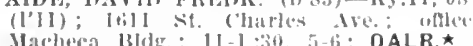
Macheca BIdg.; $11-1: 30.5-4 ;$ OALR.
Walles, deonard II:s berliu st. : not in gractice.

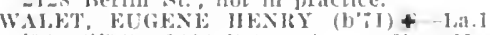

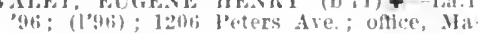

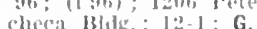

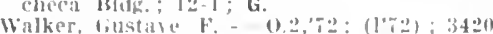

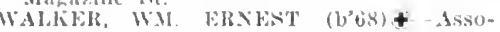
clate Follow. Fat, 00 : (Dentist); 1020 Burdette sir.; olthe, Malson Biancleo Bld d. : : $y-1: 2,2-5$

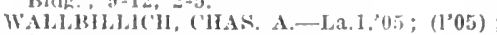
913 Elyslan Flelds Ave, $8-10$; offee, Macheen Mldg. ; 12-1.

Walshe, Thos. John-la.1,97; (1'y i) ; 3534 Tulane Are, offlce, 830 Canal St. WALTIFIR, IIEXRY WLLLMAN E.MIIE

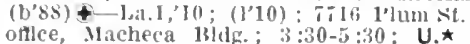
oftlce, Macheca 13ldg.; $3: 30-5: 30 ;$ U.* ( ) ; 2031 Fiysian Fields tre.

WATSON, DAVIJ 1. (b'68) + -1la.2,9l (J'y1); 2424 ('amp st.; oftice, Cusacl Bldg.; 1-3; ObG.

Weaver, Wm. Henry (b'כi) - Ill.11,'83; (l'06); 339 Belleville st.

WELEK, AL'THLR (b'ti) \pm - La.I, 90 $\left(l^{* 90}\right)$; 2725 Hsulanade Ave.; ottice, Au dubon bldg. ; 12-1.

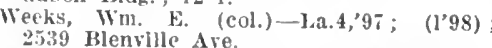

WÉlL, ARTHUR IRVING (b'-5) \&-Mass.I, "9s; (l'07); 16 Rosa Park; offlce, Perrin Blog.; I-4; A L.R.*

WEILBAECHEK, JOS. OSWALD-IA. I, 06 ; $\left(l^{\prime} 06\right) ; 2100 \mathrm{~N}$. Clalborue St.; offlice, Macheca Bldg.; 12-1.

WEIS, JOSEI'II 'D. (b'72) $€$ - Mass.1,'98; (l'03); 1448 Jackson Ave.; offlce, $108 \mathrm{Ba}$ ronne st.; 2-4:30; Asst. I'rof. Med., La.1; $(1,2) ; 1 . \star$

WEISS, CARL A.-La.1, 00; (1'00) ; 4139 St. Charles Are; offlce, Macheca 'Bldg.; 2-5; ALR. *

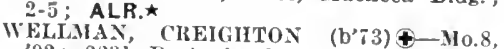
'92; 2231 Prytanla St.; Prof. $\mathrm{Hyg}$. and Trop. Med., La.I.

West, Dandridge J'ayne (b'86)-La.1,'10 (l'13); 1534 Henry Clay Ave.; offlee, Mal son Blanche Bldg. ; $2-3.30$. Pd

WIITE, JOS. H. $\oplus$ - Md.3,'s3; Surg., U.S.P.H.S.

WHITEMIRE, ARTHUR L. (b'8i)-Ky.4, 0 i ; (l'09); G3I Canal St.; office, Walson Blanche Bldg; 12-1, 2-5.

Wilbert, Beneijah' G. (b'84)-La 1, '06 : (l'06)

$1219 \mathrm{~N}$. Rendon St.; offlee, 931 Canal St.

WILCOX, GERTRUDE LOUISE (b'79) Illeh.9,02; (1'08); 2208 Sonlat $\mathrm{St}$.

WILKINS, CHAS. D.-Mass. I,'99; Superintendent Charlty Hospital.

wilkinson, Clement P.-La.1,74; (L) ; not in practice; 1402 Peters Are.

Wllllams, Richard Pericles (col.) (b'85)Tenn.7',12; (I'12); 2736 Belmont Pl; G.

Wilson, M. F.-La.1,03; not in practlce;

Wilson, Peter F.-LaI, 02 ; (1'04) ; $700 \mathrm{Web-}$ ster $\mathbf{S t}$; ; 1 -2

WILSON, SOLON G. (b'7i) - La.1, 01 ; (1'09); 5414 St. Charles Are.; offlce, IIaison Blanche Bldg.; 2-4; Pd.

WOGAN, GALLY-La.1,'03; (1'03); 1709 Burgundy St.; offlce, IIacheca Bldg.; $12-3 ; 0$ p. $\star$

Wolf, Monroe (b'89)-La.1,'12 Charity Hospltal.

WOLFE, JAMES TOWNSEND - La.1,01; (l'01); I719 N. Clalborne Are.; offlce, Macheca Bldg.; $12: 30-1: 30 ;$ Pd.

Woods, Wm. H.' (b'70)-La.1,93; (1'95); 2224 Berlin St.; offle, Maison Blanche Bldg. ; 1-5; OALR.

WRIFHT, HERBERT L. (b'70)-I11.14,06; ( ) ; Member Okla. State Med. Assn.; 1904 Canal St.

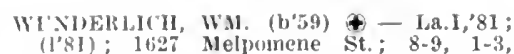
ifter 6 .

WYHR, 10S. J.†-La.1,06; (1'06); 3429 ('allal st.: oftlee, Maison Banche' Bldg.

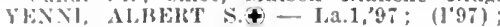
jol canal st. offlce, Malson Hancho Blily ; I2-1:30.

\section{NEWPORT, 15, WINN}

Ciwsome, J. M.-Tenn.s,"09; (l'09).

NEW ROADS, 1,352, POINTE COUPEE

13.'onel, Marle 0. (b'73)-La.1,'96; (l'96). ('a rruth, 1bolut. MeC. (b'55)-Md.3,80; (1'82) (azayoux, Jos. Fernand (b'82)-La.1,07; Rolverts, Jim

(1'12)

loist, llenry Jacob (col.) (b'73)-Ill.11,'97 ; (l'99).

NEW VERDA, 182, GRANT

l'ay'le, Davld Iley (b'79)-Tenn.8, 10 (l'10).

NINOCK, -, BOSSIER

lliddleton, Eugene Bernard-Tenn.5.'1" (1'13).

NOBLE, 453, SABINE

I'RINCE, SIIHA EDWARD (b'69)-MId.3,'96

TRIBHLE, THOMAS JEFFERSON-Tenn.8, $07 ;\left(1^{\prime} 0 \overline{6}\right)$

NORWOOD, 52, EAST FELICIANA

Gayden, Agrippa (b'53)-Ia.1,'7\%; (l'77).

La.1.06; (1'06)

OAKDALE, 500, ALLEN

Abington, Thomas l. (b'69)-Tenn.8, 03 (l’03).

('ather, Ernest J. (b'78)-Mo.20,03; (l'03) IIARGROVE, MATTIEW VERNON, JR (1)'80) †-Tenn.8, 09; (1'09); Pd.

OAK GROVE, 398, WEST CARROLL.

Bllss, Arthur S. (b'74)-0.13,'98; (l'09).

Fowler, lvy liobert $\left(b^{\prime} 85\right)-K y .2,10 ;\left(1^{\prime} 10\right)$

Lewis, Olirer Brooks (b'71)-Colo.3, 95 ; (l'95); OALR.

S.ITH, CHAS. W.-Tenn.8,'06; (l'06).

OAKLAND, 40, UNION

Culley, Chas. Ilenry-Tenn.6,05; (l'09).

OAK RIDGE, 332, MOREHOUSE

Barham, Ben Edw'. (b'85)-La.1,'12; (l'12)

IlOPE, CIIARLES l. (b'62)-Tenn.8,'94; (l'94).

Jordon, Francls Y. (b'78)-Tenn.11,04; (l'05).

Russell, W. A.-La.I,'9I; (l'9I).

OBERLIN, 232, ALLEN

Balley, Buford Lee (b'T2)-Tenn.8,'98; (1'98)

Sartor, Thos. Ryan (b'80)-La.1,'05; (1'05).

OIL CITY, I,000, CADDO

Alexander, Paul T. (b'i6)-Tenn.8,03; (l'10).

MeGLATHERY, ROZELL (b'82)థ-La.1,'08 (1'08).

OLIVE BRANCH, I0, EAST FELICIANA

Roberts, Albert James (b'45)-La.1,'68;

OLLA, 260, LA SALLE

Benton, John B. (b'86)-Ark.2,'10; (1'10) Taylor, W'm. Vannah (b'50)-Tenn.2,72: (1'72).

OPELOUSAS, 4,623, ST. LANDRY

Boagnl, Chas. F. (b'72)-La.1,'96; (I'96). Chacliere, Theogene-La.2,'61; (1'61) DLY, JAWRENCE (b'63) - Ky.4,'85; (l'85).

Donata, Raphael Emile (col.) (b'iI)-La.4, 95: (1'95)

FOSTER, PALL-Ky.2,79; (I'79).

Haas, John 1.-Pa.2,'82; (l'92)

LAFLEUR, ERTEMON, JR. (b'86)†-La.I,

Lastrapes, Wm. R.-Ia.1,90; (1'96). LTTELL, BENJ. AUGL'S'TU'S (b'66) - La.1, '88; (l'88).

MAYER, FRED J. (b'59)-La.1,'83; (1'83)

Pres. La. State Med. Soc.

practice.

McClelland, Benj, Abner (b'S5̃) - La l'08;

(l'08). JOS. P. (b'66)-La.I,90; (l'90).
SHUTE, FRANK C. (b'78) †-La.I,04;

$\left(l^{\prime} 04\right)$.

La.1,'II; (l'II) : U.

OSCAR, 30, POINTE COUPEE

IBEKGERON, LOUIS F. (b'n5)-La.I, 04 ; (I'04).

lougon, Francols Fredk. (b'85)-Ga.12,'II; (I'I3).

OUBRE, 23, ST. JAMES

WA(ALESACK, I.IONEL O. (b'九8)-La.1, 00 ; (l'00).

PACKTON, - WINN

Vilton, John iI. (b'50)-Ga.1,7\%; (1'95).

PAINCOURTVILLE, 550, ASSUMPTION

Le Blanc, IIenry' A. (b'i4)-La. I,'98; (1'98).

PALMETTO, 100, ST. LANDRY

HAWKINS, IOBT. GARNETT (1)'62)-l.a.1, " 90 ; (l'90)

PARADIS, -, ST. CHARLES

Youngs, Luther Archlbald (b'78)-La.1,'08; (l'08).

PATOUTVILLE (R.F.D., JEANERETTE), 175. IBERIA

Perret, Ursin S. (b'75)-Ja.1,'98; (l'98).

PATTERSON, 2,998, ST. MARY

Aycock, Guy A.-Tenn.8,'12; (\$)

Murray, Jaines H.-Ia.4,07; (1'07).

IOUSSEL, WII. D. (b'67) $€$-La.I,'89; (1'08).

Simms, Jacob E. (col.) (b'79)-La.4,09; (l'09)

Tarleton, T. W. $-\mathrm{Ky} y, 4,74 ;$ (1†); not in wractice. 04; (l'04); (A6); S.

PAULINA. 75, ST, JAMES

DESI ATTES, J. LOUIS (b'49)-I.a.1,' 66 ; $\left(l^{\prime} 76\right)$.

Gaudet, Gaston I. (b'79)-La.1,04; (1'04).

PELICAN, 300, DE SOTO

Burdett, W. W. (b'86)-Tex.8,08; (l'06).

Cheek, Wm. Augustus (b'74)-La.1,04; (l'04).

KEARNEY, SAML. D.-Tenn.II,05; (1'09).

Mason, W. II.-Ky.4,'89; (1'89).

Shoemaker, Rollin C.-E-0.2,98; (\$).

PICKERING, 750, VERNON

Stephenson, James II. (b'84)-Tenn.5,'07; (l'08).

PINE GROVE, 70, ST. HELENA

Gibson, John Sims (b'84)-La.1,09; (l'12).

PINE PRAIRIE, 50. EVANGELINE

Butchee, Geo. Edgar (b'66)-Ky.I,'94; (l'94).

Walters, James B. (b'48)-Ky.2,74;, (1'74).

PINEVILLE, I,2I2, RAPIDES

ADANS, GEORGE BUNCH (b'83) - La.1,'10;

FOUGEROUSSE, HENRY LOUIS ( $\left.b^{\prime} 8 I\right)-$ La. 1,'08; (l'08)

Holladay, J. L.-Tenn.8,07; (l'07)

QCINN, FRANK W. (b'78)-La.1,'11;

THOMAS, JOHN NEWTON (b'60)-La.I, 86; (1'86); NP.

PINEWOOD, - VERNON

Cole, Benjamin Jefferson (b'84)-La.I,'I0; (l'10).

Tallot, Milton Wm. (b'82)-Tenn.19,'10 ; (1'10).

PIONEER, 150, WEST CARROLL

Dollerhide, Wm. McG. (b'76)-Ky.9,04; (1'04); not in practlce.

FLAKE, JOHX J. (b'il)-Tenn.6,'0I; (l'0I).

PITKIN, I50, VERNON

Stalsby, James Darid (b'71)-Tenn.8,'98; (1'98)

PLAIN DEALING, 474, BOSSIER

BELL, W. F.-Tenn. 8,01; (l'03).

Doles, Honvard Patrick (b'87)-La.1,'12;

(l'12). Thomas x. (b'68)-Tenn.8,'90; (I'90).

PLAQUEMINE, 4,955, IBERVILLE

BARKER, WLLLIAII E. (b'60)-La.1,'85; (1'85)

Danos, Joseph L. (b'80)-La.1,03; not in

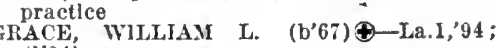
$\left(1^{\prime} 94\right)$. 
Grant, Rob? R.-N 1.3.91: (1.91)

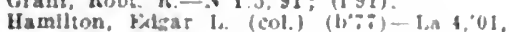
Tenn. ${ }^{\circ}, 13:\left(1^{\circ} 01\right)$

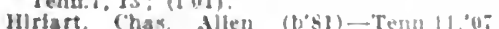
(l'0s) : $U$.

HOLLOWAY, HEGENE (b"7)-lat,"9: (l'ai)

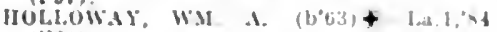
(l'st).

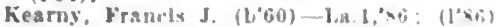

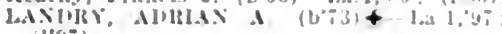
(1109)

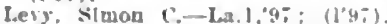

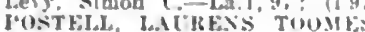

Lo. 1, 82 : (1.82).

La.1.82; (1'82). Achiving.
tice.

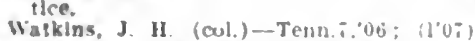

PLATTENVILLE, 400, ASSUMPTION

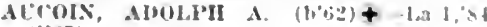

Chaslet, Alcle M-La 1,91; It's]

PLAUChEVILLE, 380. AVOYELLES

Haydel, John J.-Ia.1,01: (J'01)

KIRLINGEIt, ADA IHISTIXE SIIWINI $\left(b^{2} ; 6\right)+-111,17,0 ;:\left(1^{2}(1 i): S\right.$

KIBLINGF, FLLIOTT $(6 ; 3)$-Tenn.8.97 (1'98); G.

PLEASANT HILL, 442, SABINE

Armstrong, Kezln I., Jr.-Ky.2,"

sumford, J. E. $\rightarrow$ Ky.t, J (1):5)

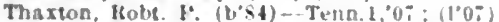

POINT A LA HACHE, 500. PLAQUEMINES

SINGLKTOS, YOOTE UIFISS $(b+i)+$ Tenn.5.0\%; (1'07).

POLLOCK, 675. GRANT

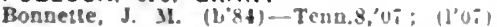

Maswell, Frank $U$. (b'sl)-Tenus, ut: (l'06).

willett, Leander (b'59)-Tenn.s.95; (1'06).

Wlison, James W. (b'bj)-Mo.', 89 ? (I'06).

PONCHATOULA, 1.055, TANGIPAHOA

Abbolt. ("has. 31.-Tenn. : $^{\prime} 02$; $\left(1^{\prime} 02\right)$.

Estabrook. W, kugene (b'si)-0.

Kevin, Edw. James-La.1,04; (I'uis).

Iccorkle. John A.- ; $(1,95)$.

POWHATAN, 230, NATCHITOCHES

Truly, Fleteher W. E.-Ky t, $\$ 9$; $(129)$.

POYDRAS, 30, ST. BERNARD

Dunshle, John Francis $\left(b^{\prime}(6)-1, a 1\right.$, , $4 b^{\circ}$ (l'9i).

PRAIRIEVILLE, 200, ASCENSION

ODOM, THOS. B. (h'64)-I.A.1.94: (1'94).

PROVENCAL, 262, NATCHITOCHES

Addison, Wille F. Tenn.8.97: (1'9i)

Wagley. Beaj. Franklln-Tenn. 8,12 ; (\$)

PT. ALLEN, 750, WEST BATON ROUGE

HHAEK, GEO. H.-IId.6,'86; (l'Sb).

PT. BARRE, 600, ST. LANORY

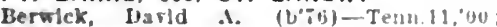
(l'01).

Plerce, Kilmer A.-H-IIl \&,91; (I"99).

PT, EADS, ISO, PLAquemines

Suarez, Jak, M.-Tenn.11,01; (1'0\%)

PUCKETT (R.F.D. BATON ROUGE). 50 , EAST BATON ROUGE

Storkwell, John $b^{\prime}$ (b'89)-Trun, R, 12: (1'12).

QUITMAN, 215, JACKSON

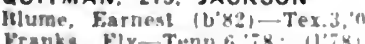

(l'0 0 a)

RACELAND, 500. LAFOURCHE

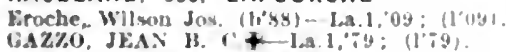

RAMSAY, 425. ST. TAMMANY

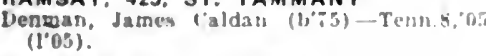

RAVENSWOOD, 7. POINTE COUPEE

MCXieal. Hinrry (10'56)-Mllll.1.'110: (1'0y)

RAYNE, 2.247, ACADIA

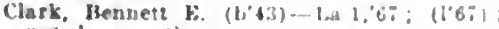

nos in practlce.

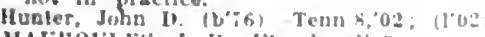

MAIHOILF, J IP., JIR $0: 11^{\prime}: 0,1$

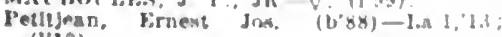
(l'13).

Webl, Ilufus $C$ - Tenn $3.83 ;\left(1^{8}: 83\right)$

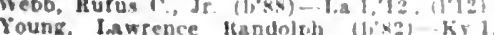
$06:$ : (1'06).
RAYVILLE, 1.079, RICHLAND

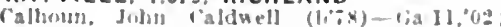
$(100:): G$.

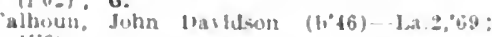
(I"6:1)

WNEx, HOLT. J.5: (269)-Ky4:97:

Jcurdan, IIarriann-Tenn. II,0): (109)

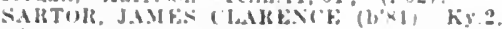

'oy: (1'10).

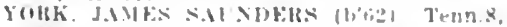
- (10xiv)

RECKNOR (R.F.D., MANY), 20, SABINE

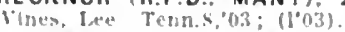

REDLANO (R.F.D., PLAIN DEALING), 30. BOSSIER

Itutler, Jujert - Tenn.s,os; (lonit).

REEVES. 50, ALLEN

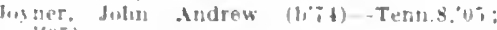

REIDS, - ALLEN

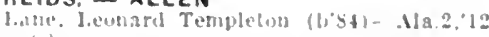

RESERVE, 400, ST, JOHN THE BAPTIST

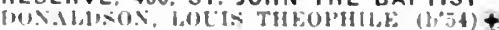

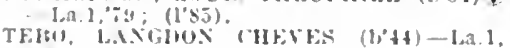
"is: (J'SZ).

RICHARDSON, 319, WASHINGTON

Hateman, Haurlce (b'S6)-loa.l, lo; (1'10).

RIDGE, 50. LAFAYETTE

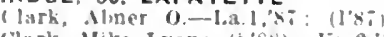

(lirk, Mike layns (b'sk)-ky 2,1?; (1'13).

RINGGOLD, 400, BIENVILLE

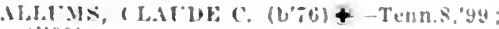

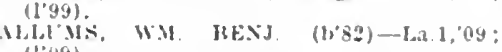

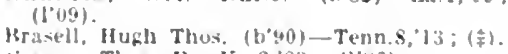

liraves, Thos. 1'-Ky 2, 83 ; (1'86).

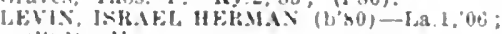
(l'(Ji) : U.

Vanghan, A. I). (b's6)- Tenn.s,10: (1'10).

Mangham. James A.-Ky,, $0^{\prime} 8$; (1'\$6).

WIMREKI, FUANCIS "OS: (I'U.S); R.F.D.

ROBELINE, 438. NATCHITOCHES

Givdner. Jas. Sidury (b'\$9) - La.1, 11 (l'ill.

llendrick, Wh. Columbus (b) $08 ;(108)$.

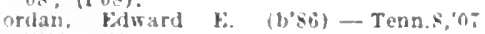
(1.11): U.

tephens, Mltebell $\therefore$ (b's)-Tenn.19,10; (1'10).

Thomas, dantes F.--Ky.2, 83 : (1's3).

ROCHELLE, 600。 GRANT

Sccull, John W: $\left(b^{\prime} \times 6\right)$-Tenn.s, 0s; (1'09).

ROCKY MOUNT, 75, BOSSIER

II.LI., JOIIN H., JR.-Tenn.s.11: (1'11)

RODESSA, 104. CADDO

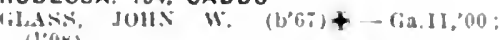
(l'0s).

ROOSEVELT. 100. EAST CARROLL

Honus, Balph l'rosser $(1,85)$-Tenn.s.'11 [1])

ROSEDALE, 400. IBERVILLE

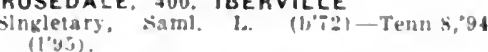

RUSTON, 3,377 LINCOLN

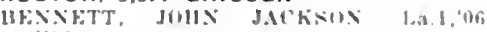
(I) 96,

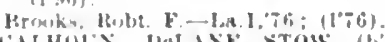
Al.101

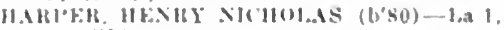
of: $(100)$

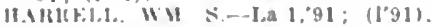

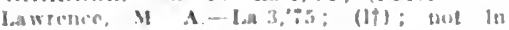

Jiracthen

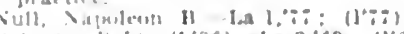

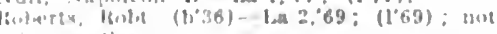
in gractice

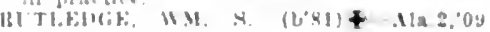

timition

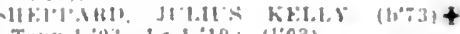

Toun 1,"01, 1.A 1."10: (1.03)

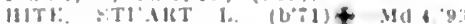
$(1,4,3)$

SALINE, 345. BIENVILLE

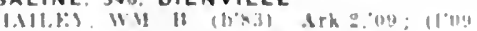

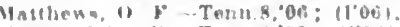

Vivore, Jula 16 -. Tenn 8.05 ; (1"96)
SAREPTA, 350, WEBSTER

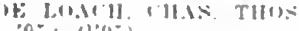

Ilouston, J. T - Tenn.\&, $1: 1101)$

SCANLON, 100. TANGIPAHOA

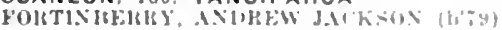

-Tenn. :04: $\left(10^{\prime} 04\right)$.

SCOTT, 239. LAFAYETTE

('blacson Jighn
$\left(l^{\circ} 10\right): P d$.

Intilli.l.

SELMA, 300, GRANT

P.WKHI

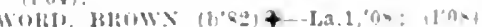

SHAMROCK. 150. NATCHITOCHES

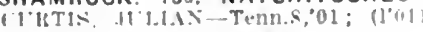

SHAW, 15, CONCORDIA

SHONGALOO, 100, WEBSTER

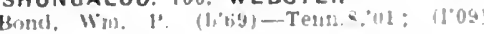

Pd.

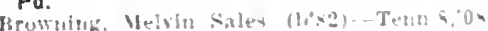

(30)

SHREVEPORT, 28,015, CADDO

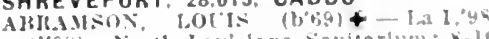
(los): Virth Ioldisiana Santarlum: s-ln $1-3$.

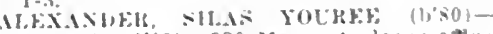
1.a.1.03; (1'03) ; 930 Marquet ulace ; othice Majestic Blde.

Nllen. Fthan (i. (1,56) $11 \rightarrow 0$ 13, 9 ?

-os cotton si. : ollice, Lery blds.

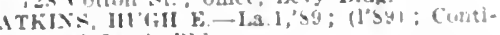

nental Bank Blds.

lies, helano hichard $\left(1, s_{i}\right)-$ Tex $z, 13$

interi. T. E. Schumpert Memortal Sanı.

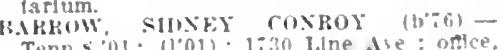

Tenns,o1; (1.01); 1:30 I.lne Abe : ortce

Iluthimon lildg 10-12, 3-5: R.

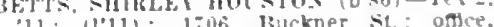

Contiuental Rank RId : 10-12. $3-5$

Blulnzaley, Wiley Hugh (b'ss)-lad 1, 12 : (1"12) 1734 orford St.

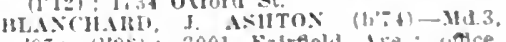
Gommerchal Bank Bldg.: 9-1 :-: Oo." Hommerclal Bank Rldg. :

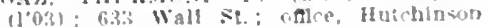
Blde : $10-12,3-5$

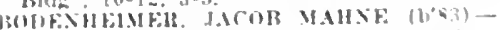

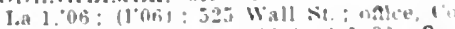
inental kank Bhl: $11-1,4: 30 . \mathbf{S}$.

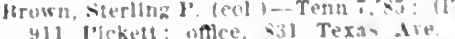

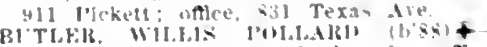

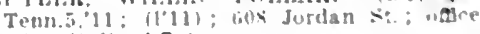
lliy Hall: LD."

Caln, ireen . . (cul) (hil)-Tenn as:

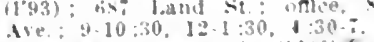

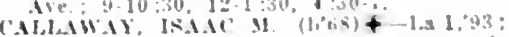
(1)!4) Thordali] and whikinsons st.: of

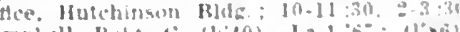

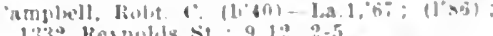
13:3: kegnohls st. 9 12. $2-5$

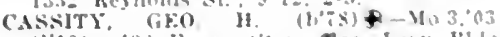

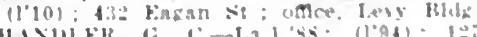

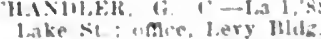

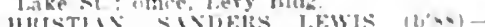

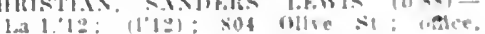

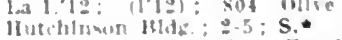

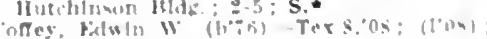
simon What : 9. U.

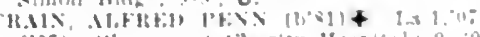

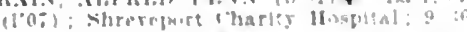

$11: 20,2.30+30: \mathbf{s}$.

Depung. Hram sinth

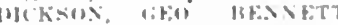

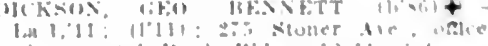

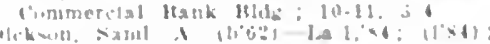
mot la practlce.

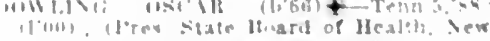

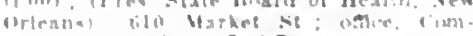
m.rolal il H1, OALR,

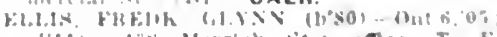

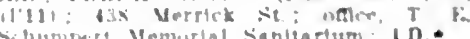


Findng, Thos, I. (b'86)-Lat, I, 13; (1'I3); 'harity llospital.

FITER, HRED J. (b'70)-La.1,97 : (1'99)

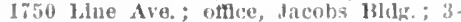
FRATER, JOS. J. (b'61) - Temm.5, 06 ; (1'06) 1750 Line Are, offlee, First National Baink Hldk.: 10-5; R.

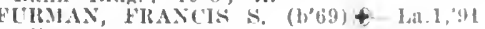
(i'yI).

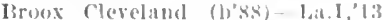
T. k. sehumpert Memorial llospital.

Gozey, W'm. (col.) - La.4, '166; (l'06) :

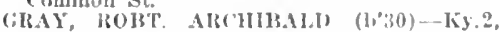
'53; (1'53): y0I Lake St.; oftle, 6I. Mar Gray. Robt Hollingsworth (b't0)-N.Y.IO 95 ; (1'96) : 201 Lake St.; oltice, 612 Mar ket st. ; 11t-1, 3-5.

HANDS, GEGAR BEAr'H (b'T3)-La.1, 03 (1.03); 250 stoner Ave.; oftece, $6141 / 2$ Nilam st.; 12-1, 4-5.

Hawklns, Watter H. (b'59) —Ala.2,'83; (1'83) 1441 lrvin st. ; offlce, levy Bldg, ; 10-11,3-5. llenderson, Joln Thos. (col.) (b'81)-11l.6, 09; (1'11); 204 Plerre st. ; oflce, 522 Common st: : $10-12,2: 30-5,6-8$.

HENDRICK, IOIN A. (b'is)-Tenn.1,03 (l'03); 630 Jordan st. ; offlee, Commerelal rank Bldg.: 11-1,3-5.

HEROLD, ARTHUR' A. (b'82)†-La.1,'07; $\left(1^{\prime} 07\right) ; 628$ Stoner Ave.; offlce, First Na tlonal Bauk Bldg.; 11-1, 4-5.

HICKS, OLIVER B.-Ga.11, 07 ; (1'08) ; 714 McNell St.; offlce, IIajestlc 1kldg.

HUCKABAY, GEO. NIANLY (b'74)థTenn.8,00; (l'00); 453 Jordan St.

IIUNT, RANDELL ('b'65)-La.1,89; (l'89) 822 Hope St. offlce, Contlnental Bank Bldg.; $11: 30-1: 30,4: 30-5: 30 ; \mathrm{S}$

IUNTER, WALTER B. (b'82)థ-Tenn.8, 09 ; (1'09) ; $211 \mathrm{E}$. Wail St.; oftlce, Levy Bldg.; $10-1,3-5$.

Iones, F. T. (col.)-Tenn.ĩ,05; (1'06); 8.52 Texas Are.

Kappel, Archlbald Chas. (B'89)-La.1,13: (1'13); State Charlty IIospital.

KIMBELL, JOHN LAMAR (b'62)Ð-Ky.5 '84; (1'86); 1920 White St. ; office, Contsnental Bank Bldg. : 11-1, 3.5: Anes.

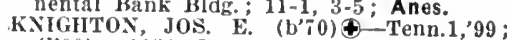
(i'99); 1154 Park Place; offtce, Cont1nentai Bank Bldg.; $9-1,3-5 ; 1 . \star$

LAWHASON, GEO. B. (b'54)థLa.1, '83; (1'83); 752 Hope St. ; offlce, First National Bank Bldg. ; 11-1, 4-5:30.

Ledbetter, J. M. (b'54)-La.3, $76 ;\left(1^{\prime} 76\right)$; not in practice.

LEDBETTER, WILTZ M. (b'78)-Tenמ.8, 01: (1'02) ; 1011 Gary St, ; office, Majestlc Bldg.

LLOYD, THOS. P. (b'î)£-MI.4, 96 . (l'04); 925 Jordan St.; offlce, Jacobs Bldg. ; $10-12 ; 3-5$.

Iaclin, J. B. (col.)-Tenn. T'87; (1'87); 1109 Ilunter St.; office, 862\% Té2 Tas Ave IcAbee, Daul. IIays, Jr. (b'75) - 111.10, 02 : (1'11); Kendall Bldg.; 8-12, 1-5, 7-8.

McLeod, (Faylord Floyd (b'86)-La.1,'13 ; (l'13) ; State Charity Hospltal

IIiddleton, Walter C. (b'78)-Tenn.1,05; (1'06) ; 2917 W. College St.; office, 1872 Texas tre.

Millican, W. Y.-Ky.1.94; (1'94) ; 688 Jordan

MOHLER, D. A. ('十'5)-Tenn.8,'96; (1'06) Levy Bldg.

MOISE, ALLYN B.£-La.1,03; (l'03); 525 Edwards St. office, Commercial Bank Bldg. ; 9-5; ALR.*

MINDAY, C, PEARI (b'75) †-La.1,96; (1'96); 1923 white St.; offlce, Commercial Bank Bldg. ; 10-12, 1-3. D*

NELSON, ARCHIBALD B. (b'75) †-Tenn.8 02; (1'02); 423 Stoner Ave.; office, Continental Bank Bidg.: $3-5 ;$;.

ODEN, 1'OI'E WEBB (b'86) $\uparrow-$ Tenn. 19,10 ; (1'10); 893 Jordan st.; offlce, Continental Bank Bldg.

O'LEARY, JANIES F. (b'47)-N.Y.10,73; (113) ; Christian St.; offee, Lery Bldg. ;

PENICK, R.IWLEY (b'i1)-Ya.1,93; (l'93)

842 Irving $\mathrm{Pl}$; offlce, Hutchinson Bldg.

PIHKLE, LEWIS IIENRY (b'73)-La.1,04; (1'04); 556 Dalzell St. ; office, $614 \frac{1}{2} / 2$ Milam

PTRNELL, MILLARD R. (b'69)-Tenn.8, nental Bank Bldg.; 10-12, 2-3.

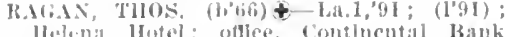
llewenat Ifoted ollice, Conthentil lbank

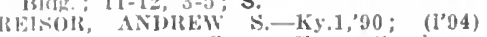
ill caperton st. aflce, Contluental IBank Mldy.

BEISOK, ANDIEW S., JR-La.1,07 ; (1'07)

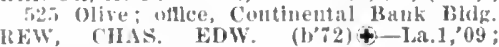
(1'09): 1337 Onkland $s t$. ; oflce, Ilutculn-

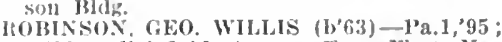
(1'00); Falrfleld Are.; offlce, Flrst Natlonal Bauk kldg.; 9-1, 3-5.

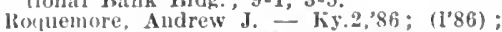
1623 southerl $\mathrm{St}$; offlce, 1501 Texas Ave HOUCON, ISIDORE BARTIIOLOMFIV (b'87) La.1, 09 ; (1'09) ; 513 Jordan St.; office, Levy Bhlg.; $10-12,2-6$; U. $\star$

RUTLEUGE, '(LIFFORD PHILIP (b'85)Ala.2,'12; (1'12); 610 Market St. : office,

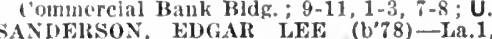
'08; (1'08); 230 Wall St.; offlce, Hutchinson Blde.; $2-5$; S.

SCALES, JOHN I,TLE (b'i1)†-Tenn.1, 97; $(198) ; 1713$ Buckner St.; offee, Commerclal Bank Bldg.; OALR.ћ

scofleld, Harry Walker (b'86)-IAa.1,08; (1'08); 830 Cotton St.; office, Majestlc Bldg. ; 10-12, 2-4; U.

Scott, John Pluckney (b'60)-N.Y.10,'81; not in practice; 1608 Falrfield Ave.

Selby, J. Algood ( $\left.b^{\prime} 60\right)$ - Tenn.5,'90; $\left(l^{\prime} 09\right)$; 1624 Dirlsion Are.; offlce, 1872 Texas Ave. : $10-12,3-5$.

SIMNONS, VALENTINE (b't1)-La.1,97; (1'13) ; 1740 Falrfteld St. ; office, Flrst Natl. Bank Bldg. : 10-12, $2: 30-3: 30 ;$ ObG.
ilcer. Jos. Edwin (b'79)-La.1,01; (1'01): Contlnental Bank Bldg.

Smith, Dlckenson A. (col.)-111.1,'92; (1'92) ; P'lerce and Hotchklss Sts.; office, 856 Texas Ave.

SMITII, MILTON FINNEY (b'73) $\oplus-$-Va.1, '95; (1'02) ; 840 Jordan St.; office, Flrst National Bank Bldg.; $11-1,5-6$.

MITH, WILFORD w. (b'82)-Va.1,05 (1'07); 840 Jordan St. ; offlee, Clty Hall; $10-12,3-5$.

UTHERLIN, WM. KEENER $\left(\mathrm{b}^{\prime} 59\right) \oplus-$ N.Y.5,81, 'Ger.1,'97; (1'81); 422 Common St. ; $3-5 ; \mathrm{S}$.

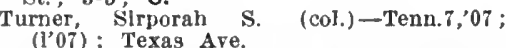

WALKE, FRANK HICKS (b'87)-Md.4,12; (temporary permlt,'13); Nember Med. and Chlr. Faculty of IId.; 419 Travis St.; offce, First Natl. Bank Bldg.; 10-12, 3-5.

Wallace, Wm. (col.) (b'T4)-Tenn.7, 05 ; $\left(1{ }^{\prime} 06\right) ; 8621 / 2$ Texas Ave.

WELSH, EMMET A. (b'64)†-Md.1,87 ; (1'9i); 1752 Falrfleld A 5 re.; offce, Hutchinson Bldg. ; $10-12,3-5$; G.

WHEELIS, JOHN MATTHEN (b'79) Tenn.1,05; (1'05) : 1919 White st. ; offlce, Commercial Bank Bldg.; $11-1,3-5 ;$

WILLIAMS, SIDNEY L. (b'77)-La.1,99 (1'99); Charlty Hospital; offee, Hutchlnsol1 Bldg. ; 10-11, 4-5; Pr.

Willians, Thos. E. (b'73) H-Ill.10, 01 ; Pa.2, 05: (1'13); 617 Wyandotte St.; office, First National Bank Bldg.; 8-10, 2-4.

WILLIS, JAMES C. (b'65) †-Tenn.5; 87 (1'94); 1200 Park Place; office, Cont1-

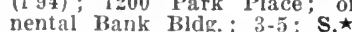

WILSON, ROBT, RUDOLPH (b'86) Tenn.8,'12; (1'12); Majestic Bldg.; 9-1, 3-6.

Wilson, W. D. (col.) $\longrightarrow$; $\left(l^{\prime} 06\right)$.

SHUTESTON, 25, ST. LANDRY

Daly, Otiver P.-La.1,'81; (1'81).

SIBLEY, 450, WEBSTER

MCDADE, W'ILKINA (b'85) - Tenn.8,09 (1'09)

SICILY ISLAND, 200, CATAHOULA

Gordon, Chas. J.' (b'73)-Ky.1,'98; (1'99).

Necom, Virgil H. (b'71)-La.1,'93; (1'94).

SIKES, 25, WINN.

Parker, J. B.-Tenn. 8,'03; (l'03)

Stovall, Geo. Edgar (b'83)-Tenn.8,09; (i'09).

SIMMESPORT, 103, AVOYELLES

PERKINS, THOS. J. (b'68) \-La.1,'92 (1'92).

SIMPSON, 22, VERNON

SANDERS, L. J. (b'66)-Tenn.15,'11; (l'11).
SIMSBORO, 282, LINCOLN

l)llard, Saxon $\left(b^{\prime}, 54\right)-k y .5,76 ;(1 \% 6)$.

Givens, kdw. A. (b'47) -Tenn.8,'82; (l'92).

Ioole, Saml. A. (b'58)-Tenn.8,"82; (1'82).

IIOMAS, ACGT'ST'S J. (b'78)£-La.1, 00 ; $\left(1^{\prime}, 00\right)$

SINGER, 100, BEAUREGARD

Lupton, (ico. 11.-0.6,'T3; (1'T3)

SLAUGHTER, 287, EAST FELICIANA

THOMISON, FRANK II. (b'て1)‡-La.1. (19); $(197)$

ALL, W.I. 1.t-Va.4;65; (1'65).

SLIDELL, 2,188, ST. TAMMANY

Brazter, Aaron W. (col.)-l_a.4,05; (l'05)

GRIFFITI, JOIIN KELLER-La.1,06; $\left(\mathrm{l}^{\prime} 0 \mathrm{C}^{\circ}\right)$.

UTLAW, PHAU RIVERS (b'69)-N.Y 10,$93 ;\left(l^{\prime} 95\right)$

POS, HASTON-Tenn. 8, 00 ; $\left(1^{\prime} 00\right)$. SLIGO, 25, BOSSIER

CARTLR, ROSCOE OWEN (b'86)-IAa.1, $09 ;\left(1^{\prime} 09\right)$.

SONDHEIMER, 500, EAST CARROLL

Abernathy, Iferry Chapman (b'80)-Tenn.5.

SPEARSVILLE

UNION

Dudiey, Varner Edw.-La.1,06; (l'06).

SPRINGFIELD, 250, LIVINGSTON

EHLERT, JOHN MATTHEWS (b'i2) 4

I,a.1,05; (1'05).

SPRINGHILL, 750, WEBSTER

Brownlng, Jos, R. (b'67) - Tenn. 8, 00 ; (1'11).

ST. AMANT, 150. ASCENSION

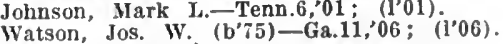

ST. BERNARD, 500, ST. BERNARD

Ducros, Louls A:--La.1,98; (1'98).

T. FRANCISVILLE, 966, WEST FELI. CIANA

BARROW, ABRAM FELTUS (b'68)-La.1,

'90; (1'90).

Butler, Thomas (b'78)-La.1,02,
Kllbourne, James-La.1,81; (1'81).

Levert, Elol II-La.1,'98; (1'98).

aylor, Wm. H.-Ky.4,80; (l'80).

ST. GABRIEL, 750, IBERVILLE

LE BLANC, BOOTE OCTAVE-La.1,03 ; (1'03).

ST. JAMES, I50, ST. JAMES

Gaudet, Luclen S. (b'78)-La.1,01; (1'01). HIMEL, CLIFFORD A.-TEN,

IILI, JOHN GILI, (b'73)屯-La.1,'99 ; (1'99)

Montgomery, Wm. E.-Ky.4,78; (1'78).

IrURDOCK, LOUIS૯-Ia.1; 83 ; (1'94).

TRICE, HOX'TE SALE (b'85)-La.1, 10 ; (1'10).

ST. MARTINVILLE, 2,318, ST. MARTIN Beyt, John Lamar (b'86)-La.1,09; (l'09). De Mahy, Henry (b'67)-La.1,83; (1'83). Fieming,

Martln, Jos. S.-I.a.1,95; (1'95).

Martln, Jos. S.-1.a.1,95; (l'95); 94 ; (1'94). Stockton, Fredk. E. (b'83)-La.1,'11; (1'11). ST. MAURICE, 75, WINN

Brian, S. M.-Tenn.8,0i; (1'0i).

ST. PATRICIS, 200, ST. JAMES

BOLTON WI. FRANKLIN $\left(b^{\prime}(4) \oplus-I\right.$, L.1, 204; (1'04); $0 \mathrm{~b}$.

STABLES, 600, VERNON

PALMER, N. M.

(See Leesville.)

STANDARD, 800, LA SALLE

FERGUSON, BENJ. TALBOT

Tenn 8'04: (l'04): Ob.

Harper, (b'51) -Tenn 8.92. (1'94).

STARHILL, 45, WEST FELICIANA

DANIEL JANIES MADISON (b'75)€-La.1, '00; (1'00).

STERLINGTON, 400, OUACHITA

WILIIAYS, JOHN BURT (b'83)-Tenn.6, 09 ; (1'09).

STEVENSON, 100, MOREHOUSE

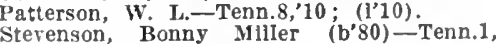
'08; (l'09).

STONEWALL, 100, DE SOTO

Johns, John B. - Ky. 2,'90; (1'90) 
SUGARTOWN, 50, BEAUREGARD

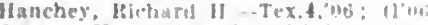

omcer, Henry \& Tenn.l,0:; (l"0s).

SULPHUR, 500, CALCASIEU

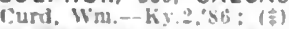

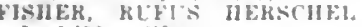

La.1,09: (1'0y)

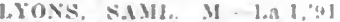

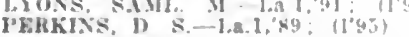

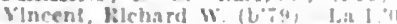

SUMMERFIELD, 100, CLAIBORNE

Allgoud. Joseph C. (b"il)-Ki, "Yt; (1'94)

SUN, 250, ST. TAMMANY

Thompson, Jos. II.-Tenn.11,05: 11 u.,

SUNSET, 377. ST. LANDRY

GABDISRK, (HAS. IKTIICI $(1, \%)$

1.3.1.'96: (1'96).

Gullbear, Benj. II.-- La.1.'85: (1'85)

Gullbeau, Yellx (Has.-Ion l, 04: (f'nt)

fiuldry, Louls A. (b'8:)-1.3.1.03; (1'03)

SWARTZ, (MONROE P.O.), I67, OUACHITA

(asper, Win Y.-Md:;0; (1'Mt).

TALISHEEK。 - ST. TAMMANY

Hohmer, $\%$ J.-Tenn.S, 03; (1'0:3)

TALLULAH, 847, MADISON

GAINES, (iEO. WOOIJPO (beie)

Tenn.5,"85, N.1.10,90: (1).88)

lireet. Thos Young (bsi)-La.1, 07 : (1'07)

Oghourne, r. II. $\left(b^{\circ} 5 s\right)-k y^{\circ}, 1,58$; 1135$)$.

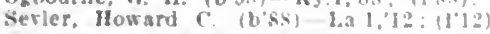

TANGIPAHOA, 394. TANGIPAHOA

LAMBERT, JOIIN WAL.THK (b'BL)

L.I, 87 : (1'8i).

Travls, Hipley W. (b'-6)-Tennec,01:(102)

TAYLOR, 100, BIENVILLE

Pasbe, Ererell H. (IV.Jt)-Tenn.R, $8:$ : (1'si)

TAYLORTOWN, 75, BOSSIER

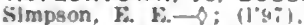

THIBODAUX, 3.824. LAFOURCHE

HARKFR, CHARLES JACOH (b'Xti) la

10 ; $(1,10)$

Bryanl, Geo. r. (b'6I)-1,at, yo: (l'gen)

Dansereau, Hercule-.Y. $3,{ }^{\prime} 53$; (1'5:t); not

in pristice.

DANSEHEAU PHIII JOS-Yy 1 .9I (1'91).

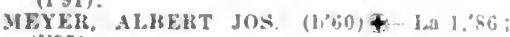
(1.95).

MFYFK, IOL'IS L. $(1,62)+-1.1,1,4$

$(1 / 95)$.

I'rlce, Abel J.-I.a.1."44: (1'95)

SMITH, HUHFRT S-IAI, $98:$ (I'96)

STAKК, THOMAS $\left(\mathrm{b}^{\circ} 65\right)+$ - L. $1,9 !$ : (1.91)

Trosclalr, Gaston E. Tenn.11.03:

TIMBERTON, 500, ST. JAMES

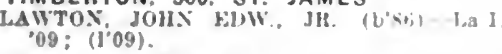

TIOGA, 633, RAPIDES LITTOS, LLEWELLYX k. (b'a) TEI

TORO, 50, SABINE

Killzey, Kobt. L. (b'8I) - Tenu.8, 13; (1'13)

TORRAS. 500, POINTE COUPEE

BOX, THOMAS JEFFEISON $\left(\mathrm{H}^{\prime \prime}, \mathrm{Ni}\right)+$

J.a.I.'91: (1'91): T.

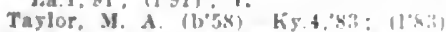

TRICHELL, 25, NATCHITOCHES

Dunckelman, b. J.-Ky...0": II0

TROUT, 800, LA SALLE

Itutler, Thonas M...Trna 8, $8 b^{\circ}$; (1'Mi

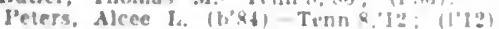

TULLOS, 35, LA SALLE

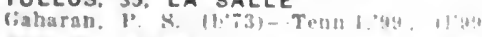

TUNICA (WINNFIELD P.O.), 27, WINN

Sinllh, S. McIl, - : (1t).

TURKEY CREEK, 150. EVANGELINE

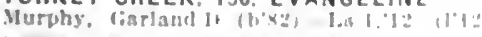

UNEEDUS, - TANGIPAHOA

Kennedy', 'bas, I TenR. $X$ 'L

URANIA, 300, LA SALLE

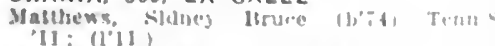

VACHERIE, 250, ST, JAMES

(iLII.J,TTH. WM FKEIU

$10 ; 11101$.

Mary, Ametlee $\left(h^{\circ} \times 4\right)$ Tann $\rightarrow, 10$

VARNADO, 75, WASHINGTON

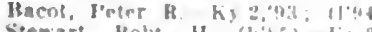

VERNON, BO, JACKSON

VERNON, 30 , JACKSON

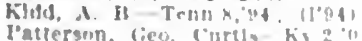

VICTORIA, 350, NATCHITOCHES

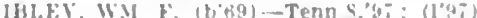

VIDALIA, 1.345, CONCORDIA

Magoun. I'ele Eirnest-Ky.2.00i (1'UG)

MFEVES MARCI'S (LIFYORI) - Md

(1) : (1.96): aloo Member Mlsa. Sisare Ment

VIENNA, 500, LINCOLN

Silnks. LeW $N$-Tenn.8.93: 11991

VILLE PLATTE, 603. EVANGELINE

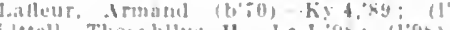

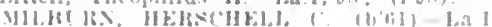
$3: 11.53)$

VINTON, 1,000, CALCASIEU

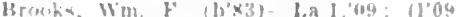

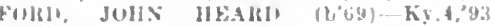

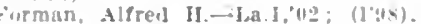

VIVIAN, 826, CADDO

banrence, I'aul Andrew (2'il) Tenn. (10): $(1 ' 00)$.

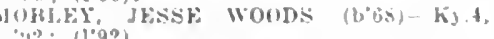

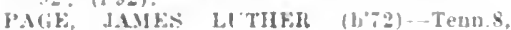
00: $(1.00)$.

Iorslue, C. i1. (b'84)-Ky.11."08; (1'08).

WALKER, 592, LIVINGSTON

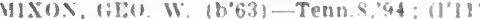

WALLACE, 300, ST, JOHN THE BAPTIST

GHOLIIE, 1.OL'IS A. (b\%s)-Tenn.11,0

(l'0i)

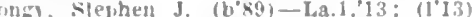

WALLS, I00, WEST BATON ROUGE

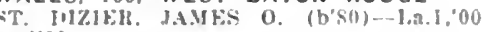
(I,00)

WALNUT LANE, 75, UNION

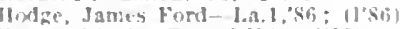

lodze, W. J.-Tenn.8,0s; (1.08).

WARD。- ALLEN

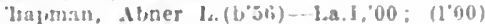

WARNERTON, I30, WASHINGTON

larker, Luclus J.-Ia.4;0: : (1'0:1.

Brock, llellit T. (bo"to) lia.ll,"13

WASHINGTON, 1.528, ST, LANDRY

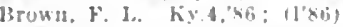

BHOWX, JOS. NIIHOH. (b' (l'()i)

HOLAOMAS, \&. CICERO - TERn.\$.00 $\left(l^{\prime} 00\right)$.

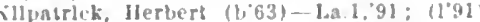

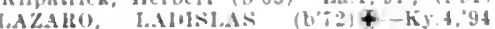
(1"94).

llogers, Gabrlel li-lia.1,"st: (1'84)

WATER PROOF, $\$ 45$. TENSAS

Gorton, Joseph Marton (bivi)-Tenll.

cosicas

WEIL

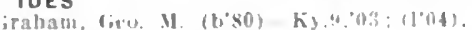

WEISS, 300. LIVINGSTON

HILUIKS, W. II-O: (1†).

WELCOME, I00, ST. JAMES

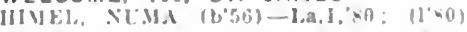

WELSH, 1.250, JEFFERSON DAVIS

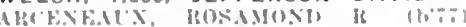

hy 2, oul: (j)00).

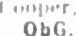

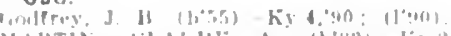

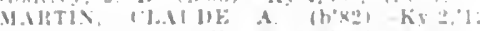

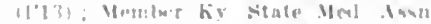

stinart. Win

WESTLAKE, I.300, CALCASIEU

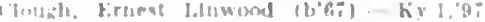

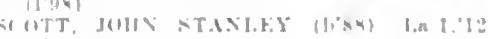

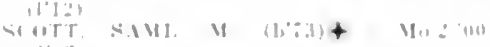

WEST MONROE, 1.127, OUACHITA

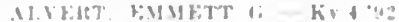

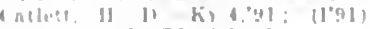

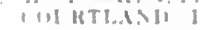

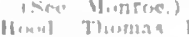

WESTON

R.F D.

JONESBORO

50.

JACKSON

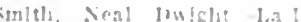

WHAM (DOSS P.D), 30, OUACHITA

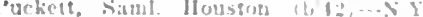

(1'63)

WHITE CASTLE, 2.289, IBERVILLE

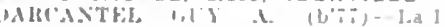

(1'0ri).

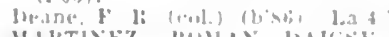

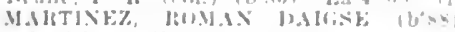
I.a. 1, $0 \%$ : $\left(10^{\circ} 04\right)$.

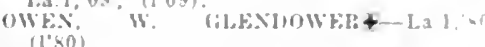

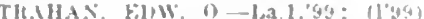

WHITEVILLE, 500, ST, LANDRY

Jones, rred. $K$ Ind : R?; (1'02)

WILDA. 40, RAPIDES

WILDSVILLE, 30, CONCORDIA

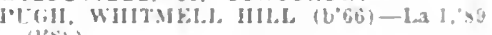
(l'sis)

WILHELM, 25, WEST FELICIANA

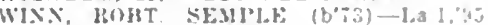
(1) 453$)$

WILLHITE, 25, UNION

Ferkuson, John Ralyh (b':3)-Tenn.1, "9s: $(1 \circ 08)$

WILSON, 762, EAST FELICIANA

("arruth. Anal A. (b"3a)-La.2,"Js; $(1$ 'b)

JOHXSTON, HARRY-1.a.1,00: (1'00)

Slmeletary, S. L. - l, 2,$58 ; 11050)$

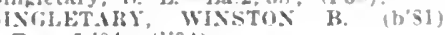

Tenn."i, $\left.04 ;(1)^{\circ} 04\right)$

WINNFIELD, 2.925, WINN

FITTZ, SAML !+-IA.1,07: (1'0I)

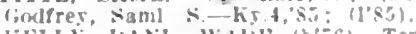

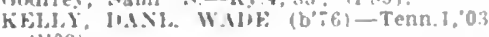
(l'03).

Peters. Jonatluan Jus. (b"ä) - Tenn R, y? (]'con).

W'lllams. W. II.-Tenn.8,92; (1'9:3).

WINNSBORO, 821, FRANKLIN

DFNSON, J0: I. $\rightarrow$ : (1'93).

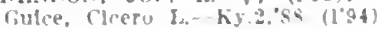

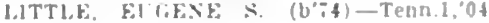

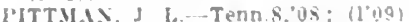

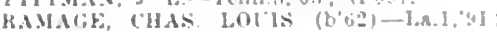
(1,91).

RUL1:N NIISUN, (TLYIE SCHWERIN (b'si) + Tive: OALR

WISNER, 75, FRANKLIN

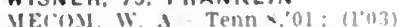

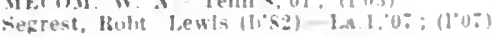

WOODSIDE, 20, AVOYELLES

HolfGal, filku(N) (b'bi)+-hy tis

WOODWORTH, 125, RAPIDES

Klid. Drum i. (b'81). -Tenn \&, 0 : (1'09)

WYATT, 350, JACKSON

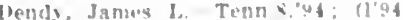

YOUNGSVILLE, 328, LAFAYETTE

rumeaur. Irlatlde d. (b)"(i)-Tens s, $0=$ $(1, n: 2)$.

Comeaux, Rindulph Kosith - Tenn.11.03: $(1,0 ; 1)$

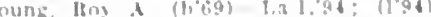

ZACHARY. \$19. EAST BATON ROUGE

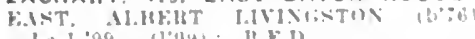

I. 1,09 (1?!1!) : It F.I

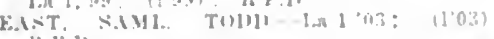

is $\mathrm{k} \|$

M11.. THOM.S $1.11 .1 \%$

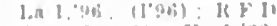

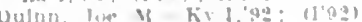

Thom Jamem Nerander llivi $1 . a 1,1:$

$(11) 101$

ZINIMERMAN, 500. RAPIDES

ZONA. 30, WASHINGTON

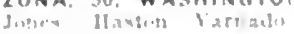

ZWOLLE. 973. SABINE.

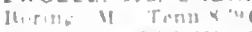

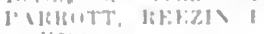

Tramil Thumas if (b'si) Tomn 990

cinen, Hebari \& Tern* 09: (1"0) 


\section{MAINE}

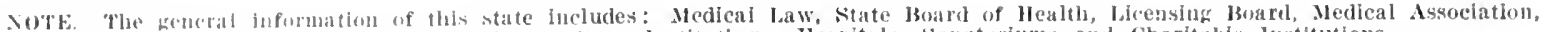

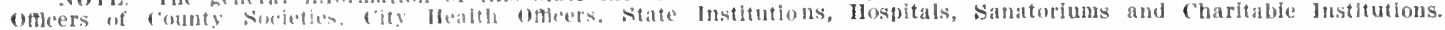

\section{MAINE}

Population ( 1910 census). Number of Counties...
Number of Physicians Members State Association, Dec. 31 , 1913

Area of State in Square Miles.

\section{1,200} 625
33,040

\section{MEDICAL PRACTICE LAW OF MAINE}

Registration of I'hysicians and Surgeons Chapter 17, Revlsed Sta.

section 9. BOARD OF IREGISTRATION; APPOINTMENT; TERM: The gorernor, with the advice and consent of the councll, with the advice and consent of the councl, vedicine consistlng of six persons, resldents in the state, who shall be graduates of legaliy chartered medical college or unlversity having the power to confer degrees in medlelne, and who shall have been actively employed in the practice of their persons qualified as aforesaid, shall be appointed nembers of said board on or before tie first day of July of every alternate year the first day of July of every alternate year after July 1, 1895, to hold office for six
vears from the first day of July following sald appolntment. No member of said board shall belong to the faculty of any medical college or unlversity. Any vacancy in sald board shall be fllled by the appointment of "l persols qualitied as aforesaid, to hold oftice during the unexplred term of the member whose place he fills. Any member of said board may be remored from office for cause by the governor, with the advice and consent of the council.

Sec. I0. HEETINCS; RECORIS: The members of said board shall meet on the second Tuesday of July of eacl alternate year after the year 1895 , at such time and nlace as ther may determine, and sliall elect a chairman and secretary who shall loct a chane hold thetr respectie onces for the term of treasurs. The sectetary shall give to the treasurer of state a bnnd in the penal sim of one thousand dollars, with suffelent sureties to be approred by the goveruor and council, for the fathful discharge of the duties of his office. The said board shall loold regular meetings, one in March, one in such additional meetings at such times and places as it may determine. Said board shall cause a seal to be engraved and shall keep correct records of all its proceedings, and may make such minor rules and reguand may make such minor rules and regulations as it shall deem necessary for the
successful enforcement of its authority and the performance of its duties.

Sec. 11. EXAMINATIONS; CERTIFI('ATES; FEES: Any person shall, upon the payment of a fee of flfteen dollars, be entitled to examination, and if found qualifled by a majority of the nembers of the board present shail be registered as a pliysician or surgeon, and shall receive a certificate thereof under the seal of the board, and signed by the chairman and secretary, which shall state the facts and must be publicly displayed at the person's principal place of business as long as sald person contimues such practice for gain or hire. Any person refused registration may be reexamined at the regular neeting of said loard, witlin two years of the time of such refusal. without additional fee and thereafter nay be examined as often as he may desire upon rayment of the fee of fifteen
dollars for each examination. All fees receired by the board hereunder shall be paid by the secretary thereof into the treasury tile state once in each month.

see. 12. APPLICATIONS : QTALIFICATIONS; RECIPROCITY : The board shall ane all applicants for registration as then pach ap plicant shatl, at least seven lays before the retary of the board an applleation under oath of affiniation, contalning satisfactory oath of affirmation, containing satisfactory of age, of good noral character and a graduate of some reputable nedjeal scliool or college in good stancling, having power to confer degrces ln medicine, and malntaining a standard of prellminary education and of medical instruction approved by the board, which sald standard shall at least require that the applicant for admission to said medical school or college slıall present to
said school or college, before beginning the study of medlcine therein, the diploma of a hlgh school or equivalent school having a course of study requiring an attendance through four school years, or a certificate of having passed a satisfactory examination before the state superintendent of schools, in the curriculum of such high school or other equivalent school. He shall also present such other facts as the board in Its blank application may require, and must pay the fees provided in the preceding section. Examinations shall be in whole or in part in writing and shall be of a thorough and practical character. They shall embrace the pathology, bacteriology, sanitation, chemis try, materia medica and therapeutics, surgery, the principles and practice of medicine, obstetrics, and such branches of niedcine, obstetrics, and such branches of nredical science as the board may deem neces sary for the applicant to be versed in. The
board may make such rules and regulations as may be necessary for reciprocity of licensure with the boards of other states which maintain a standard of education a least equal to their own; but no such rules shall become onerative until they have been apploved by a justice of the supreme judicial court.

Sec. 13. RECORIS; ANYUAI, REPORT The board shall keep a record of the name and residence of all persons registered here under and a record of all moneys received and disbursed by said board, and said records or duplicates thereof shall always he open to inspection in the offlce of the secretary of state during regular office hours. said board shall annually on or before the first day of January in each year, make a report to the covernor containing a full and complete account of all its official acts dur ing the preceding year, also a statement o its receipts and disbursements and such
comments or suggestions as lt may deem essential.

Sec. 14. IXIESTIGATION OF COMPLAINTS: REVOCATION OF CERTIFI CATES : DISPOSITION OF FEES: The board, its members or arents shall investigate all complaints and all cases of non compliance with or violation of the provi sions of this chapter relating to the registration of physicians and surgeons, and shall bring all such cases to the notlce of the proper prosecuting officers. Said board, after a convlction before a proper court, for crime in the course of professional business, of any person to whom a certiflcate has been issued by them, and after hearlng, may by rote of two-thirds of the entire board revoke the certiflcate and cancel the registration of the person to whom the same was issued. Said board may also suspend or revoke any certificate by a two-thirds vote of the entire board, in any case where such certificate has been wrongfully obtained or for any fraud connected with the sald registration. Sec. 15. PFNALTY FOR VIOLATION: linless duly registered by sald board, no person shail practice medicine or surgery, out to practice medicine or surgery or any branch thereof for gain or hlre within the statc, by diagnosing, relleving in any degree. state, by diagnosing, relleving in any degree, or curing, or professing or attempting to diagnose, relleve or cure, any human disease, ailinent, defect or complalnt, whether
physical or mental, or of physical or mental orlgln, by attendance, or by advice, or by prescriblng or furnlshing any clrug, medlche, appliance, manlpulation, method or any therapeutle agent whatsoever or in any other manner unless otherwise provlded by statute of thls state. Unless duly reglstered by said board no
person shall preflx the title "Doctor" or the person shall prefix the title "Doctor" or the
letters "Dr.," or append the letters "M.U." letters "Dr.," or append the letters "M.U."
to his name, or use the title of doctor or physician in any way, exceptlng that any member of the Iraine osteopathle Assoclatlon may preflx the title "Doctor" or the letters "Dr." to his name when accompanled by the word "Osteopath." Whoerer not being duly registered by said board practices medicine or surgery, or any branch thereof, medicine or surgery, or any branch thereof, surgery, or any branch thereof in any of the ways aforesaid, or who uses the tltle "Doctor" or the letters "Dr." or the letters "M.D." in connection wlth hls name, contrary to the provisions of thls section, shall be punished by a fine of not less than one hundred, nor inore than five hundred dollar for each offense, or by imprisonment for three months, or by both fine and imprisonthe letters "Dr." or the appending of the letters "MI.D." by any person to his name, or the use of the title of doctor or physician in auy way by any person not duly reglstered as hereinbefore described, shall be prima facie evidence that sald person is holding contrary to the provisions of thls section provided that nothing herein contained shall prevent any person who has received the Doctor's degree from any reputable college or university other than the degree of "Doctor of Medicine" from preflxing the
letters "Dr." to his name, if he is not engaged, and does not engage, in the practice of medicine or surgery, or the treatment of any disease or human ailment.

Sec. I6. TO WHOM ACT DOES NOT AP PLX: The seven preceding sections shall not apply to commissioned officers of the Enited States Army, Navy or Public Health Service, or to a physiclan or surgeon who is called from another state to treat a parpractice in this state, nor to prohiblt gratuitous service or the rendering of assist ance in emergency cases; nor to clairroyants or persons practicing hypnotlsm, mas netic healing, mind cure, massage, Christian Sclence, osteopathy, or any other method of healing if no poisonous or dangerous drugs are employed nor surgical operations performed; provided such clajrvoyants and other persons do not violate any of the provisions of the preceding section in relation to the use of "M.D." cian.",

Sec. 17. EXPENSES AND COMPENSATION OF BOARD: The compensation, incidental and traveling expenses of the board shall be paid from the treasury of the state. The compensation of members of the board shall be one hundred dollars per annum for each member of the board, except the secre- 
eary who shall pecelve three lumbed dollars per annum, and in addition each neuber shall revelve flre cents a mlle each way for necessary irareling expensey in attending the meetinas of the bord. but in ni) case shall any more be palil for trateling expenses than aro The secretary shall he allowed extra comThe secretary shall he allnwel extra com pensatlon for books, stationery, postage and and extra compensatlun, fir each day nctu. ally spent in the investigation or brosecul. thon of complaints and caves under seuglun 14 of this chapter, shall let allowed (1) each member of the board artually engajer! member of fhe hoart artually madiced therein. such compensation and the firr. dentals ard travelng expelloth shath the approred by the board and auditet by the
corernor and councll. and pal, from the state treasury: provlded. that the amount so pald shall not exceed the anount re. celved by the treasurer of the state from the board in fees as hereln specifled, and so much of sald receipis as may the necessars is liereby apuropriated fir the com-

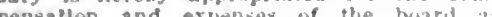
pensallon

Act approved 1911.

STATE BOARO OF HEALTH

Dr. C. D. Smlth, Presldent, Portland; Dr. G. M. Woodcock, Bangor; Dr. R. H. Stuhbs, Augusta; Dr. W. I. Haskell, Lewiston; Marshall P. Cran, I'h.D., Brunarlck; Fukene W. Coss. Lewiston; Dr. A. ti. Yontig, Seeresary, dususta.

BOARO OF REGISTRATION OF MEDICINE

George H. Emerson, Chatman. Bucksport; Wm. S. Thompson, Augusta ; J. L. M. WHIIs, Ellot: Austin 1. Harves, Bangor: Luther A. Bunker, Watervllle; Frank W. Searle. Sice relary, Portland.

\section{MAINE MEDICAL ASSOCIATION} Offerr 1913-14

IV. C. Feters, I'resldent,.......... Minnor Eben Marsen lst 1 - President.... llath c. J. Emery, of V-I'revldent..... Bldifeford J. B. Thompon, Secretary........... Inangor F. W. Gehrigg, Treasurer............ Portland

\section{State Journal}

Journal of the Malne Medical Aranciutulu, l'ortland. Frank Y. Gilbert, M.l, ell: ir

Councilor Districts and Dfficers

Firat Ilstrict. - Cinzlierland and link countles. Jasper II. Iochrane. I'Huneflur. Saco.

Second bistriet.- Indrowenggin, Franklir and oxford countley. F. S. ramminis. and oxsoris enuntie

Third Ibatrlet. - Sagadahuc, Koox and Lill roln counties. Geo. H. Cormobs, (muni:bl. Vialioboro.

Fourth Jivirlct-Kennelvec. Somnerupi dist Waldo counties. Vieu. Li. risingledl.

clinr, Augusta.

Fleth Jiatrles.- Waslingtin and llanowek

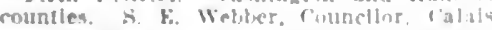

Slxth Mlstrich - Ironvionk lenwbical am

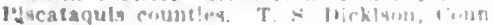
clor. Iloulton.

Component County Societies of the Maine Medical Assoclation ANDRoseoritis Cor'st

John A. Ionoran, Jerestedent... lewiatun

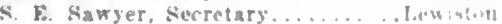
AROOSTOOK IMI'N

Thon s. Dicklann, J'revlilent...... liwultion IV. di, Chamierlain, Secretary... be kalrplin CUMHKI.AND COT:NT

It. F. Dunn, l'resldent......... l'urtannt Alam 1'. Lelghtou. Jr. Siecrebiary . Purtlatud FHNKI.I. ['OT NT

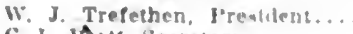

HANcoCK COLNTY

k. J. Morrlson, President........Bar Harlk,r

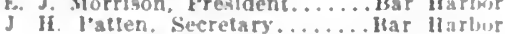
KЕXXEBHC COUNTY

Wellingion Johnson, I'realdeat....... iugust:

II. II. HIller Secrelary........... Augusta K.NOX COUNT:

F. I Adans, l'restdent........... Rocklaml iI. W frohock, secretary. oxfoitn cotsty

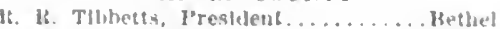

i. M. Stewart. Secretary.......... Suuth Parls l'ENOHSCOTT colNT

lien. K. Landry, I'resldent......... Oldtown
J. $K$. Thompson, secretary......... Hangor I'ISCATAQLIS COLNTY

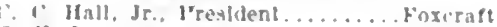
i. t. Jure, secrelary ............ Gullfurel SAGADAIOOC COL'XTY

I. I". Irlsh, l'resident,..... Bowdoinhan

R. IIannigen, Secretary.................. SOMERSET COUNTY

r. I. Tuzier, I'resldent........... Farffleld if. II. Smith, Secretary............. Surrldgewock WALDO COINTY

Fimer Simall, Presldent............Belfast Idelbert Mulett, Secretary..............Belfast WASHIFTON COUNTY

IV. Melnstadt. Presldent...St. Stephen, N. B.

if. I. Mason, Secretary................ Calals YORK COUNTY

Iosegh Warren Gordon, Presldent. Ogunqult
A. Reon Jones, Secretary....... Old Orchard

\section{HEALTH OFFICERS IN CITIES OF 2,500} POPULATION ANO OVER

Auburn............. Danlel A. Barrell Augusta............... George A. Coombs Hangor................ Chas. H. Culltaan [Bath.

belfast.

IB]ddeford.

itrewer.

Brunswick.

('alals.

Parllou

Fiastport

billsworth

Gardiner.

Houlton. .

Lewivion.

l'ortland.

lockland.

Itumford.

Saco.

sanfurd.

skowlegan.

Simpth lortland.

Waterwille.
Weatlarmik.

Mir. B. I. MeFadden ........ A. Whlson . Jr. James Nellon ..A. II. Nchriver Frnst H. Cranston J. WV U lustor janies I". Mellere II. I. 11. Wimdruf T. F. Strout ii s. sleeper Frank f. II varmey If. I'. Judkin i. if. Rishee f: If Rishee (1.) Frlahan W. St. Stuchflel 1. . I.nmbard E. 1\%. rish

\section{Augusta STATE INSTITUTIONS}

Augunta siatr Husplal, Muguve, Mr

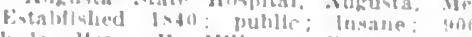

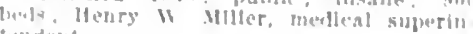
tringint

Bangor

llangur state llowpltal, liangur M.

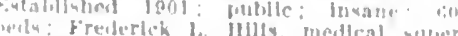
iturentent

fautera Malne tieneral ll wplal, Mn

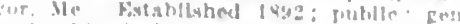

"ral. Iall peds: Ha Waviburne. vupuer. intenilont

Hallowell

Valne Induatrial sichemel for colrls

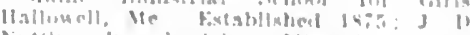

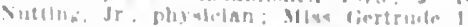

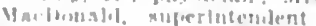

Hebron

Malue state sianaturlum, lirenweral Jeuntain. Helering. Me. Kovtablialied

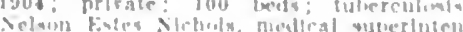

ilent
Lexiston

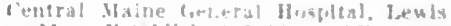

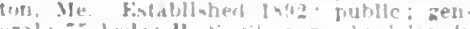

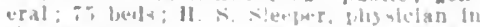

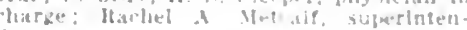
cherit.

\section{Portiand}

Malne liereral Hoqultal, vortanu. M

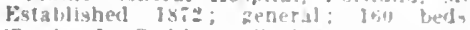
Tharles I) Smlth, nedleal isperlutendont Walue Schosel fur the lowaf, lourtarial.

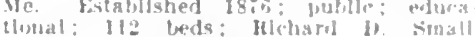
medical superintendent.

Pownal

Walne School for Feeble-Mlnded. I'on. nal, We (Went lounal Jo.) Evtals. herls: (arl J lledln, it D. superintendent South Portland

situte sibmol for Boys. South Fortland. Ye. Eisabllohel lein: publle: educa tlonal and reformation: $150^{\circ}$ beds: tharles Jumu, Jr., surerdntendent.

\section{Thomaston}

Maine siate Prison Hospltal, Turmaston. Me.: establlshed 18:5: general: beds: J. E. Walker, II., suprerintendent

HOSPITALS. SANATORIUMS AND CHARI. TABLE INSTITUTIONS

\section{Andover}

Glenells, Andorer, Me. Fatabllsherl In0J: prtrate: santiarlum for nerwi: and mental cases: 20 beds; $\boldsymbol{F}$. E. Leslio. phystian in charge.

Auburn

Autirn lfone for Aged Women, du murn, Me. Fitabllshed Iosti: publle clara 1. True, matron; k. L. Siulth, secretars

Aupusta

Augusta kieneral Ilospital, Augu-sh Me. Fstablished Is9s; publle: Reneral: ro hedls; Mrs. Sarah Hayden, superlntendent and matron.

Bangor

Hangor Children's Hone. Banzor. Ne.

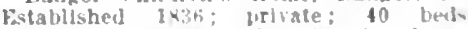
Rertram I. Mrvant. phsslclan in charze Establl-hed 1905: publle: Il beak: Mir. Eatef 1 . Mcleod, matron.

Home for lgell Women, $27 \%$ siate st Janor, Me Eotalllshel 1 sig: pullio ox leds: Katherime lurnap, matrum

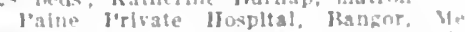

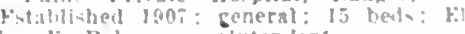
len $t$ Palne. suimerintendent.

Bar Harbor

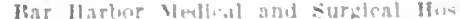
nital liar llarlar. Me Gotabl the

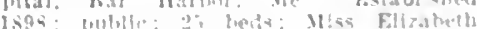
Murray, superintoment

Bath

Hath Gle Mundtal. Jith. Me Estal

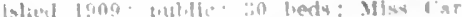

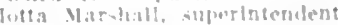

Beilast

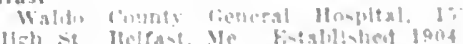

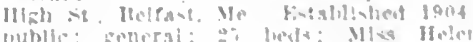
Lumn. viluer!nferiblers?

Biddeford

Trull II.spltal. Midofinl Ve Fivab-

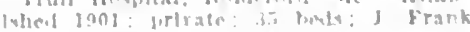
Trull. shs-litan in rlaseres

Wible: llumpltal, Mthlofort. Me ris

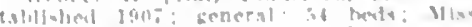

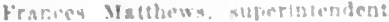

Boothbay Harbor

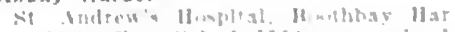
bur Mo Folalllabel lone ernersl. If

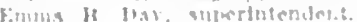

Brewer

Itukell lerivate llosplest. Holyohe si

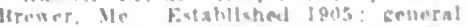
1. Medv: Mrudlla buecll, vupertntendent Cano Cottago

I. int Hueplta: I' WHHams, l'ape fot. lace lic bostablished Isgs: seneral: 30 mals. James lintl, lhurch, II ID. (F) Williams?. Qupertintentent 
East Parsonsfield

Naple Crest Sanatorlum, East Harsonsfield, Me. Kistahlished 1912: private: tuberculosis: 30 beds: Franels J. Weich (l'ortland), medieal director.

\section{Fairfield}

Fairtleld sanatorlum, filltheld, Mr. Fistublished 1910: tubereulosis; 32 beds: 1. I. Jus ditrlens (Waterville), medlest ilirector.

\section{Frenchville}

st. Aruthat Iospital, Frenclubile, Me Establisled $190 \%$. Iuntho 10 beds: lst dore (ote, physlowan in cinare.

\section{Gardiner}

llonse of the food shepherd, Gardiner, Ife. Establlshed 1862 : prirate ; for orphans and neglected ahlitren: lirules tant Eplscopal Church, in chare: R. II. simous, house plysician; Mrs. Wm. I Simons, house
Foye, inatron.

\section{Houlton}

Aroostook Hospital, Houiton, Me. Established 1906; public and prirate; 22 beds; T. S. Jlcklson, physielan in charge; Niss Myrtle Bolstridge, superimtendent.

\section{Lewiston}

Girls' Orphanage, Lewiston, Me. Hstabilished 1878; publle; general; 118 beds.

st. Mary's General Hospital, Lewlston, IIe. Establlshed 1888; public; general; 140 beds.

\section{Mars Hill}

Mars Hill Hospital, Mars Hiil, Me. Established 1912; surgleat: i beds; Robert J. Kineald, physleian; I. lanet Jrown, superintendent.

\section{National Soldiers' Home}

National soldiers' llome, Fastern Branch, National Soldiers' Home, II Estabilished 1866; national home for disEstablished 1866; national home for dishospital: 1,203 in barraeks; Naj. B. D. llidlon, surgeon.

\section{Norridgewack}

Nirridgework sinaturlum Sorridgewoek. Ve. listablished I9io: prirate; fonceral: 35 beds; Florence 8 . Merrow Wigner, physiclan in pharge. Oldtown

Varney llospltal, Olatown, Me Es-

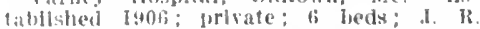
Varmey, phystelan in charge.

Paris Hill

Beeches, J'aris Hili, He. (I'aris r'O.). Establisied 1896; general: 30 beds: charlotte F. Hammond, plosichan in charge.

Porlland.

flitilren's Hospltal, llanforth and Higl Sts. Portland, Me. Fstablished 1908; publte; orthopedic; 45 beds; Edville i, Abbott, surgeon in chlef; Fdith I. Souie, superiutendent.

City Hospital, Portiand, Me. Pubilc: 70 beils; F. F. Mactane, physicialu in charge.

Ft. Mckiniey Post Ifospital, Portland, Me. Established 1404; 24 beds; Major James L, Bevans (Ft. McKiniey), Med. Coris, U. S. Army, in comnand.

Jsolation Ilospital, I'ortiand, Ile. Established $1892 ; 40$ beds ; $\boldsymbol{k}$. F. ('arnilehael, physlelan in charge.

Ur. l.elginton's Naternity Hospital, 109 Fuery St., Portland, He. Establislied 1912: private; 20 beds: Adam P. Lelghton. Ir., physlcian; IIss Flora Jack, ton, ir., phy

Maine Fye and Ear Inflrmary, PortMaine Fye and Ear Inflrmary, Port-
land, Me. Estahlished 1886 ; general; 70 beds; E. F. Holt, exeeutive surceon.

st. Barnabas Hospltat, 231 Woodford st., Portland, Me. Established 1905; generai; 50 beds; iV. J. Cousins, physician in charge.

Temporary Home for Women and Children, Portiand, Me. Estabilished 1885 . 48 beds: Lueinda Hateh physian in charge: Irs. Whitman Sawyer, president charge; Irs. Whitnan Sawyer,

Inited States IIarlne Ilospital, Port. land. Me. Established 1859; public; general; 50 beds; Chas. F. Banks, surfreon in clarge.
Presque Isle

Presque Isie General Hospltal, Presune Isle, Me. Fistablished 1912; general ; 17 beds; Minnie F. Ilemphlli, superlntendent.

\section{Rockland}

Itanscom Hosyital, Rocklaud, Me. Fs. tablished 1904; private; general; 12 beds. IV. V. llanscom, superintendent and surgeon.

linox County General Ifuspital, 2 Maple St., Rockland, Ne. Fstabilished 1902 : kenerai: 27 heds: W. M. Spear and $\mathrm{I} . \mathrm{H}$. Silisty, surgeons; Katherlne $\boldsymbol{A}$. Donovan, superintendent.

\section{Rumford}

Oxford County Emerzeney Itospital, Strathitass Pk., Rumford, Me. Established 1903; general; 15 beds: Iatura Fellows Noyes, medical superintendent.

\section{Skowhegan}

Somerset Hospital, Skowhegan, Me. Establlslied 1902; prlvate; general; 15 beds; John F. Wadsworth, phjsiclan in eharge.

Union

Seuropathic Sanatorium, Lnlon, Me. Established 1910 private merve cases: H. H. Plumer, II.D., superintendent.

\section{Waterville}

Waterilie Hospital, Waterville, Me. b. B. Cragin, physlelan in charge.

\section{Westbrook}

Barrett Hospltal, Westbrook, Me. Established 1909; general: 12 beds: $F$. Barrett, physician in charge; IIss Ethel iv. Jackson, matron.

\section{Woodfords}

Dr. Klng's Hospital, Woodfords, Me. Established 1904; private; 28 beds; Alfred King (Portland), surgeon In charge.

\section{York Village}

York Hospital, York Village, Me. Established 1905; general; 20 beds; Minnette B. Butler, matron.

Ilave you reatized the amount of raried informution to be found in this divertory? The intromluetory juges (.53-5. 4 ) will tell you about it. 


\section{PHYSICIANS OR MAINE}

KEY TO ABBREVIATIONS, SYMBOLS, ETC.

Names la capltals slanlfy uembership in the County Soclety and siate Assocla. ilot. (I)EE, JOHN).

- Indlates Fellowship in the Anerican Med. Assn. (100k, JoII.

$(\mathrm{b}, 5)$ lear of birch

traedle. II, Lomeopath: L, eclectle: I'-M, physlo-

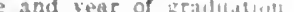
- Informallon recelred dives not abou grad. uatlon.

S.-Surgeon.

Ob. - Otstetrlelan.

ObG.-Obstetriclan, fiyneonloght.

G.-Gynecologtst.

or,-Orthovedlst.

Pr.-I'roctolorlst.

Op. -Ophithalmologist

A. - Aurist.

LR. - Laryngologlst, Rhlouloglit.
(I's9) lear uf llicense.

(3) In practlco befure passago of present law and IIcensed by fulng diploma or by years of practice.

(it) Lilcensed but year not known.

(5) Information recelved does not show license.

IS.A. Finfled States Army.

It $\mathrm{k} \mathrm{C..} \mathrm{l.A.l.} \mathrm{Medical} \mathrm{heserve} \mathrm{Corps.}$

\section{SPECIALTIES ARE INDICATED AS FOLLOWS:}

ALR.--Jurlst, laryngologlst, Rhinologlst. OALR.-OphehaJinologlut. Nurlst, Laryngologist. Uhinolomist.

U.- C'rolocist.

D.-Dermatologlst.

Pd. - I'ediatrist.

N.- Neurologlst.

P.-I'sychiatrlst.
I.s., lnited states Nis

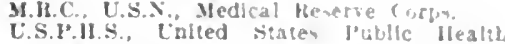
service.

College pusletiona held are Indicated by abureviated tille of pusliton. fullower ly key number of college. Fur bey w culleves see Inside front corer pare

A1,3. J36. (1) It mbership in special sincielies. 1.ee hey Table. page l:2,

NP. Neurologist, Psychlatrlst.

1.-Interulst.

T. - Tuberculotheraplst

Anes. - Inewthetlst.

LD.- Laboratory Diagnostietan.

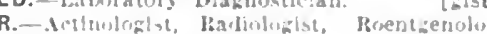

Fath.-l'atholomis?

Bact.-Bacterlologlst

WHEN THE ABBREVIATION REPRESENTING A SPECIALTY IS FOLLOWEO BY AN ASTERISK (*) IT INDICATES THAT THE PHYSICIAN CLAIMS HIS PRACTICE IS LIMITED TO THAT PARTICULAR BRANCH OF MEDICINE; WITHOUT THE ASTERISK, THAT HE IS ESPECIALLY INTERESTED IN. BUT DOES NOT LIMIT HIS PRACTICE TO. THAT BRANCH. THIS INFORMATION CONCERNING SPECIALTY IS BASED ON PERSONAL DATA FURHISHED BY THE PHYSICIAN AND IS NOT VERIFIABLE.

\section{MAINE}

\section{ADDISON, 420. WASHINGTON}

Cbandler, Fredk. Mlpheu,-Masi. 1."

ALBION, 645. KENNEBEC

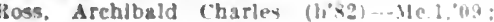
$(1$ '10).

Wilson, Geo, HL-Me.1, $3 f_{1} ;(2)$

ALFRED, 625, YORK

LANIBI:, CHAS. F, (U'61) Me I ai:

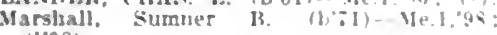
(1'98).

AMHERST, 364. HANCOCK

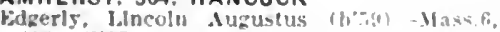
"05; ( $\left.110{ }^{\circ}\right)$.

ANDOVER, 520, OXFORD

LESLIE, PHA.K E. $(89,3)+-1164,111$ : (J'OJ); $N$

ANSON, 520, SOMERSET

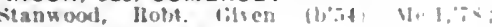
not in pracllce.

APPLETON. 1,080, KNOX

KEI.I.K. HFIJ. HENIEY (b) $\left(I^{\prime} 00^{-1}\right)$

ASHDALE, 100, SAGADAHOC

Bongartz, Walter kingeste (libidll Mani '33: not in practlce.

ASHLAND, 1,200, AROOSTOOK

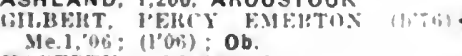

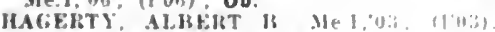

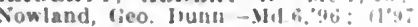

ATHENS, 896, SOMERSET

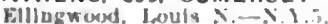

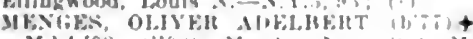

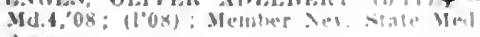
Assn.

ATLANTIC, 432, HANCOCK

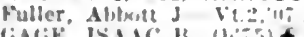

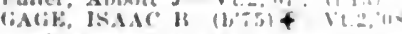

AUBURN, 15.064, ANDROSCOGGIN

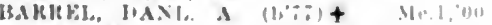

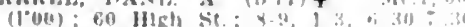

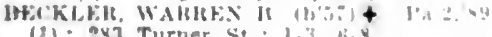

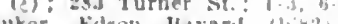

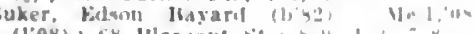

cokr A הit.

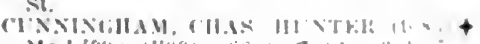

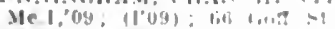

(I)

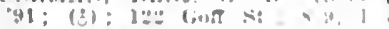

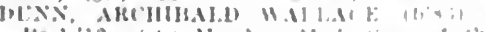

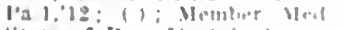

Ninte of l'a.; : io, ibls st

mirltis, Jox vil.tili 06: $110101:$ fis, 301 si: :

IIltheork. Ilarry Fiantma $(1+98) ; 10 \%$ iout

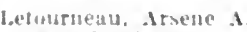

(see lewistum.)

corcross, Winfleld si-II-Ia.4,"sti (z); 8 Olliver sit.

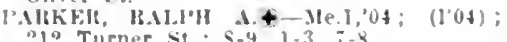

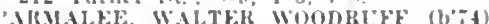
\pm Vt.2,09; (1.03); 347 Turner St. ; 2-4.

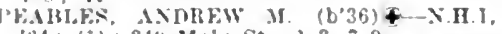

(f); (2): 2fl) Maln St. : 1-3, i-9

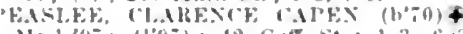

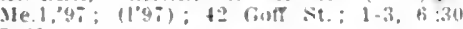
$7: 30$

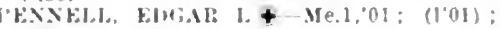
anx Maln st.

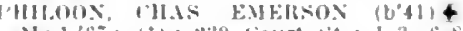

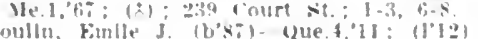
loill Bromd St.

lienwick, Ward J.-H-0.7, 07 ; $(197) ; 102$ tiof sit.

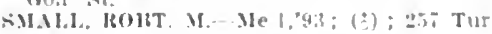
ner st.

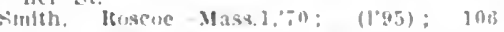
spring st.

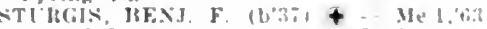
121: 138 court st. 12-2. bi-;:30

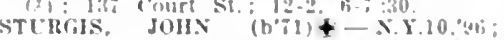

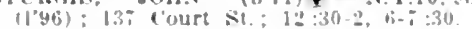

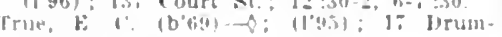
momd sit.

Webler, Ilenry Jolin-X.11.,95; (5): 83 plpasant it.

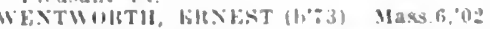

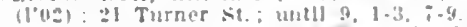

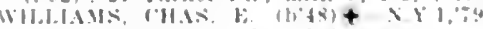

MT1.10

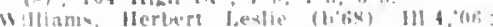
11 I31

AUGUSTA, 13.211, KENNEBEC

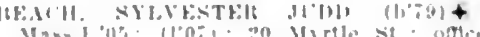

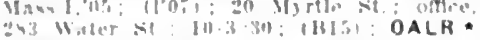

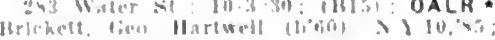

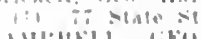

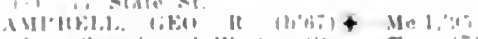

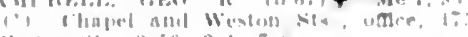

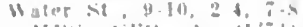

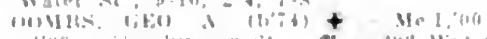

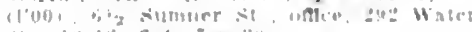

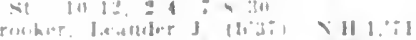

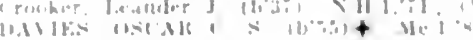

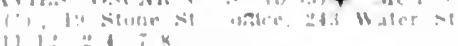
I Holl. Hurne t:

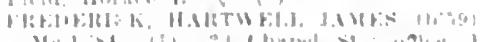

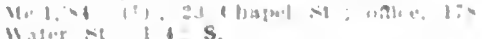

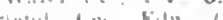

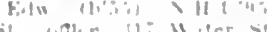

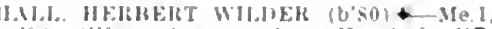
"0s: (lons): Augusta state Hospltal; NP H.IIKIS, WI. H. (b'ti)-Y6.2.88: (2): 335 Water st.

Hill, Winfleld Scote (b\%39)-XY.10,67: (c) lit state st. $\quad$ i-8:30, 1-4, $;-8$

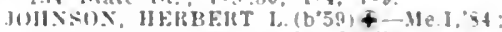
(2): 17l state st.: I lalso Hadley. Mass. 1'201: $\mathbf{s}$

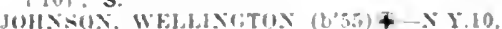
"x; (3): ft thapel st.; oflce, 335 water

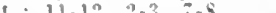
hugan. Sami Henry (tov9) Mass. $\because 10$

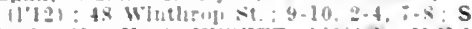

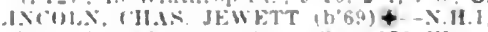

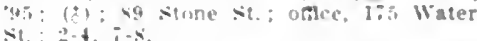
I.I.N, 1.t:11:5

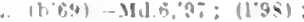

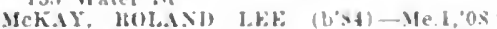
(los): alt Hosplal si. : otice, gaz Water St. : $:-1,7-5$

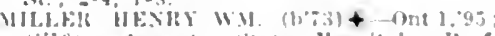
(1\%10) Allgus?a siate llovital: Inof

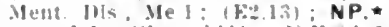

Momre, Jula Wint ibot) NY Y (a) Wevtern Are: $y-10,2-3,6-8$

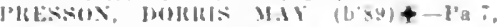
-11 : (1"11) :

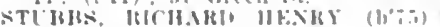

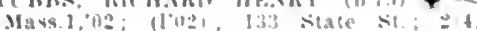
-s: (113) (l'b): Auguata state Herspital.

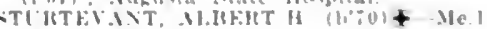

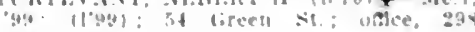
Water st: : t: S.

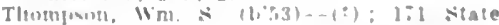

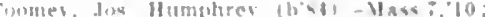
11'13): Suzusta state Howptal: NP.

Turuer pliter it

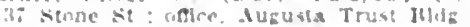
4 \& (1) : OALR *

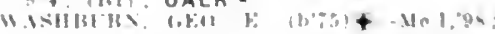

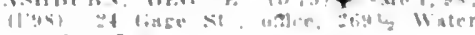
ii 1 i, :

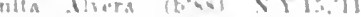
11 13!: Nusuola sian Husplal $3+$ Me 1 hiti

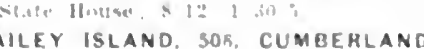

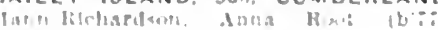

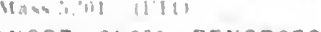

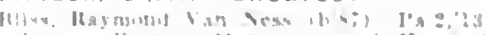

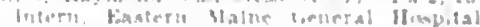

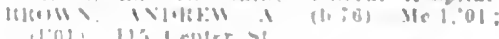

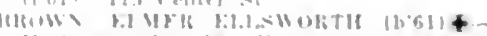

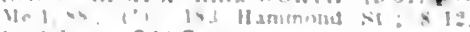
OALR. 
BIRYNT, BERTRAM LEWIS $\left(b^{\prime} \overline{2}\right)+-$ Me.1,'98; (I'98); 265 Hammond St.; $2-4$, 13UNKLR, DAVID WELLINGTON - N.Y.T,

'82; (\$). CIIAS. 11.Me.1,98; (1'98) ; 239 llamnond $\mathrm{St}$.

CAULFIELD, GEO. B.-Mass. $\overrightarrow{6}, 98$; (1'99) 189 State St.

CHAPMAN, HENRY M. (b?1)\$-N.Y.5, 95; (1'95) ; 80 Jroadway; oftlec, 22 State

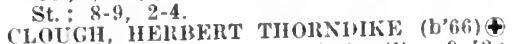
-N.H.1,95; (む); 209 state St. ; 9-I2: (B15): OALR.

(IB15): OALR. (l†); not in practlce; I36 ('ourt st. ; oflece, 11 ti llammond sit.

Cox, James Francls (b'so)-Me.1,09;(l'09) ; 156 Maln St.; $1-4,6-8$.

CRANE, IAROLD HAYES (b'78)-Pa.2,03; (1'04); 19 13roadway; $1-3,6-8 ; \mathbf{S}$ oolun, ilugh F. (b'70)-Yt.2,02; (l'02)

17,1 st st.; $9-12,2-5,7-8$. (1,95); if5 Hammond st. ; offlee, 181 II Ianmond st. ; $2-4,7-8: 30$.

mond St.; $2-4,7-8: 30.96$;

Harvey, Austln I. (b’53) H-1'a.9, ‘s; (ठ); 64 Centre st. : I-3, $7-9$.

HENNESSEY, DANL.-N.Y.4, 66 ; (b) ; 5 HIgll st.

HILIS, FREDK. IYMAX $\left(b^{\prime} T 0\right) \oplus-N . Y .1$, 92; (1'10); Bangor state Ilospital; (E2 13)'. 14t Essex St. 9-12, 1-4; OALR.

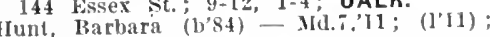
Bact.

HINT, WALTER LOWRIF (b'48)థY.Y.1,75; (1'95); 150 State St.; offlce, 5 Grove St.; 1 -4.

Inkrote, Warren Webster (b'8s)-Pa.2,'13 Inter, Fastern Maine General Hospltal. Intern, Eastern Ma.1, $8 s ;(t) ; 47$ Main St KING, IENR A.- Me.1, 58 '(b'84)-Md.1, 09 ; (l'11); 6, 5th St.

MANSFIEL, BLANCHE M. (b'76)-ra.7, "00; (I'00); 191 State st.

MASON, 1UTHER SIITH (b'r3)-Pa.1,00 (1'01); 109 State St.; 1-3.

MASON, WM. CASTEIN' (b'52)-Mass.1,'78 (b) ; 70 Jaln St. ; 12-1, 4-5.

MCCANY, DANL. (b'66)థ-N.Y.5,89; (む) 135 Cedar St. ; 2-4, $\overline{-}-8$.

MeCurdy, Chas. L.-IId. 3,88 ; (ઠ) ; 47 Main.

IeNALI WM. 1'. (b'65) ধ-Que.1,97; $\left(1^{\circ} 97\right) ; 131$ State St. ; $1-3,6: 30-7: 30$.

MILLIKEN, HARRIS J.-Ne.1,04; (l'05) Kenduskeag Are.

MURP1IY, THOS. JoS.-IId.3,'99; (む) ; 89

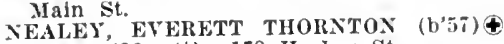
-Ne 1,83; (t) : 178 Harlow St.

Norrls, Lester Francls (b'84) - Md.3,'12

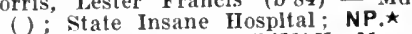

( ) : State Insane Hospital ; NP. osgood, Harry Weldon $\left(b^{\prime}, 1\right) \mathrm{H}-$
(1'98) ; 12 Grove St. ; $1-3,7-8$.

Pastor, Louls It.-N1.1,06; (l'0T) ; i6 Essex St.; until 9, 1-3.

PETERS, WM. CHUTE (b'68)-Mass. 7, 02 (I04); Yres. Me. Med. Assn.; 15 State St. ; 9 - 12 ; Or. $\star$

PHILBR1CK, CHAS. S. (b*55)-Pa.9,'81 (t) ; 253 Hammond St. ; 2-4:30.

Preble, Melvin-Me.1,'66; (l'95).

QUINN, HUGH FRANCiS (b'79) - Me.1 '09; (l'09); 203 Naln St. ; 2-4, $\bar{i}-8$.

ROBINSON, DANL. ARTHUR $\left(b^{\prime} 50\right) \oplus-$ Me.1,'81; (t); 142 Hammond St. ; offlce, 140 ilammond St.; $2-4,7-7: 30$.

SANGEP, EUGENE BOUTELLE (b'71) 4 S.1.1,94; (ち); 42 Broad

simtoxs, WM. H. (b'48)€-Ger.20,72 (t) ; 30 High st.

SIALL, AMOS ELWYN (b'69)-Me.1,'95; (1'95); 32 Congress St.; offlce, 44 Central St. 8-12, 1-5; OALR.

STARRETT, JOS. F. (b'九0)૯-Me.1,98; (1’98) ; 83 Essex St. ; 2-4, $7-8$.

Thomas, Evander W.- 0 ; $\left(1^{\prime} 95\right) ; 461 / 2 \mathrm{MaIn}$ THOMPSON, HERBERT ELLERY $\left(\mathrm{b}^{\prime} 78\right) \oplus$ Me.I,09; (l'09); Bangor State Hos-

THOMPSOX, JOH: B. (b'74)థ-Me.1,99; (1'99): Nec. Ife. Mted. Assn.; 109 State
Trlekes, Winfleld Benj. (b'80)-Me.1,'13; Intern, Eastern Malne General Hospltal. TYSON, FORREST C. (b'81) $€$-Mass.7, 05 :

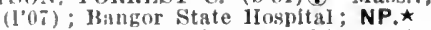

Waltnn, Alfred (b'32)-Ate.1,67; (む); larkrlew Are.

WARIREN, I'ERCY (b'55)-Me.1,79; (ঠ); 171 State St.

WIITNEY, WALTER E. (b'65)-Pa.2,93; (ट) 95 Essex St.; offlec, 89 Essex St. OALR. *

WOOIOOCK, GALEN M.-N.Y.5,'73; (†); 17 Alams St.; 1-2, 6-7.

WO(YIS, JARYIS BELCHER (b'67) $\oplus-$

BAR HARBOR, I,I8I, HANCOCK

F'REMION'T-SMITH, FRANK.

(see Washlngton, D.C.)

HAGERTII, (iEO. R. (b'65) - N.Y.10,92: Hitifixs, royal (:. (b'67)-Pa.9,92; (1'03).

MORRISON, CHAS. CARR (b'56)-r'a.9, $83 ;(\delta)$.

IORRISON， ELMER J. (b'62)-Nd.3,98 (I'98).

Musgrave, l'orey (b'72)-Mass.1,'98; ( )

I'ATTHN, J. IIERBERT (b'62)-N. '.5,'86,

'HIILII'S, GEO. A. (b'52)૯-N.Y.5,'82;

WAKEFLLD, RALIII WALDO (b'T)†1'a.2,02; (1'03); S.

BAR MILLS, I40, YORK

Owen. Herbert A. (b'71) -11l.1,'98; (1'99) (l'03).

BATH, 9,396, SAGADAHOC

BARKEK, BYRON FULLER (b'72) \&-Pa.2, 96; (l'96).

Briry, Hdw. E-H-Hass.5,'84; (む).

FOX, IIORACE (b'67)\&-Pa.1,90; (l'96). FULLER, EDWIN MOTLEY, JR. $\left(\mathrm{b}^{\prime} 80\right)-$ Me.1,04; (l'04).

HANNIGEN, ROBT. C. (b'T5)-Me.1,01: (1'01).

Kersliner, Warren E. - Md.9,'03; (1'03) OALR. *

LINCO1.N, JAMES OTIS (b'63)-Me.I,92; (l'09).

MARSTON, EBEN JORDON $\left(b^{\prime} 70\right) \oplus-M e .1$, '93; (む).

Morin, Harry Franklin (b'80) H-Mass.5,04. (l'04)

PEASLEF, ClARENCE A. (b'55)థ-Me.1, '83; (

SNIP', LANGDON T. (b'67)૯-N.Y.1,93; (t).

Wescott, James Buzzell (b'41)-Me.1,'81; (む).

BELFAST, 4,618, WALDO

Flanders, Davld P. (b'35) H-Mass.1,'57 ; (1'95).

IIammons, Luther W. $\rightarrow$; (ठ).

JOHNSON, SAML. WORTH (b'42)-Me.1, 64; (l’95)

KILGORE, GUSTAVUS C.-Vt.2,80; (l'96). MILLETT, ADELBERT $\left(\mathrm{b}^{\prime} 58\right) \oplus-$ N.H.1,'88; (む) .

Sidellnger. Tom Horatio (b’i4)-Wis.3,'96; (l'95).

SMALL ELMER-Me.1,70; (1'95)

Small, Foster ('has. (b'85)-Vt.2,'12; (1'12). Stevens, Carl Hervey (b'85)-Me.1,11;

(I'11). (1'95).

Tapley, Eugene Dole-N.Y.8,'99; (1'99).

VICKERY, ORRIS STORER (b'78)-N.Y.15, 04; (l'04).

WILSON, EVERARD A.-Vt.2,'97; (1'98).

BELGRADE, 450, KENNEBEC

Reynolds, Leon F. (b'64)-Pa.1,'86; (ठ).

BERWICK, 2,280, YORK

ELLIOTT, WM. T. (b'70)-N.H.1,00; $\left(1^{\prime} 00\right)$

Goodwin, Geo. Erring-N.H.1,91; not in practice.

Lord, Jos. E.-E-Q; (む).

BETHEL, 834, OXFORD

GEHRING, JOHN GEO. (b'57) \&-0.6,'85;

( $f)$; NP. -I Ie.1,01; (1'01)
Twaddle, John A.-Mle.I,'z7; (t).

WIGHT, I. HENRY (b'i5) $\$-1 \mathrm{t} .2,01$; (I'01).

BIDDEFORD, 17,079, YORK

Chapron, l'hileas E. (b'78) - Que.3,04:

'(l'06); 287 Maln St. ; 1-4, 7-8, 32 Alfred St.; $7-9,1-4,6-8$.

DAVIS, FIRENk. I.-Me.1,88; (f); 293 Mfaln St.; $1-4,7-9$.

DOL.LOFF, DAVID ERNEST (b'78) -Me.I $07 ;(1,06) ; 20$ Jefferson St.; 1-4, 7-9; S.

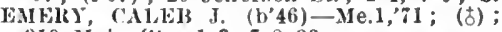

319 Nain St.; $1-3,7-8: 30$.
FERGUSON, M. IIUBBARD (b'55) - - N.H.I,

'79; $(\delta) ; 38$ Jefferson St. $1-4,7-9$; $\mathrm{s}$. FOGG, JOHN SMITH (b'65)-Me.1,'91; (†);

Fortin, Emile A. (b'65) $\rightarrow$; (l'95); 9 Ambush St. : offlec, 46 Alfred St.

GIRARD, LEOPOLD A. (b'71)-WIs.2,'95; (l'04); 42 Bacon st.; offec, Maln st. ;

Hayward, John Albert (b'78) H-Mass.5,'06 ; (1'10); 155 South st.

HILL, PAU1, STANLEY (b'81)-D.C.1,06; (l'06); 73 South St.; offlce, Masonic

Bldg. ; $2-4, \tilde{-}-9$. WTLLIS (b'72)-Me.1,99;
HURD, HENRY (I'99) ; 344 Maln St.; offlce, Masonle Bldg.

KENDALL, CLARENCE FAIRBANKS (b' 66 ) -Me.1,01; (l'01); 60 South St. ; $7-8,1-4$, $0.30-8,5$.

'07; (1'07); 32 Foss St. ; 1-3, 7-9.

MAYNARD, ALBERT C. $\left(b^{\prime} 77\right)$-Q Que.3,'01: (l’01) ; 24 Center St. ; 1-3, 6-8; $\mathrm{S}$.

Moran, Thos F.-Tenn.5,03; (1'03); 283 Moran, Thos. F.-Tenn.5;03; $\left(l^{\prime} 03\right) ; 283$

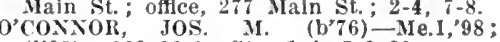
(l'98); 260 Nlain st. $1-4,7-8: 30$.

O'NEIL, EUGENE D. (b'65)-MI.3,'93; (む) ; 338 Main St.; 1-4, 7-9; LR.

PRECOURT, GEO. CHAS. (b'83)-Me.1,08: (l'08); 86 Bacon St. ; 8-9, 1-4, $7-9$.

Raclcot, Donat F. $\rightarrow$; ( $\left({ }^{\circ}\right) ; 249$ iraln st.

Reny, Henry (b’56) E-Me.2,'85; (屯); 61

Bacon St. 2-4, i-8; 0pA.

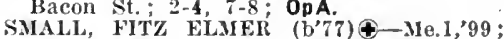
(1'99); Masonic Bldg.; offle, Main St. ;

$1: 30-3: 30, \overline{-}-8: 30$.
TRAYNOK, CHAS. FRANCIS $\left(b^{\prime} 74\right) \oplus-\overline{-}$
Me.1, $10 ;\left(l^{\prime} 10\right) ; 34$ Union St. ; offlce, 201 Me.1,10; (l'10); 34 Union St. ; office, 201 Main St. ; $8-9,1-3,7-8 ; \mathbf{S}$.

Trull, Joel Frank (b'68)H-Mass.5,'94; $\left(I^{\prime} 95\right)$; South St.; office, Masonlc Bldg. Warren, Frank Sumner (b'51)-Me.I,72; (l'95); 28 South St.

BINGHAM, 800, SOMERSET

Brown, Ray C. (b'80)-Pa.2,05; (l'05).

HOPKINS, PERCIVAL 0. (b'74)€-Me.1, 01: (l'01).

Williams, Fredk. G.-Me.1,71; (†).

BLAINE, 976, AROOSTOOK

FULTON, AARON J. (b'51) - Vt.2,'90 ; (l'95).

McCrea, Robt. (b'50)-N.Y.10,'75; (す).

BLUE HILL, I,828, HANCOCK

LITTLEFIELD, OT1S A. (b'61)-Me.1,'85; (t).

BOLSTER MILLS, 460, CUMBERLAND

WIght, Edw. Archer (b'64)-Me.1,89; (む).

BOOTHBAY HARBOR, 2,000, LINCOLN

BARROWS, HARRIS CLARK (b'8I)-Me.1,

06; (1.06)

GREGORY, GEO. A. (b'65) $\oplus-$ Me.1,91; (む).

Stevens, Thos. H. (b'61)-Md.4,'93; (†).

BOWDOINHAM, I,302, SAGADAHOC

IRISH, ISAAC C. (b'54)-Me.1,78; (t).

BRADFORD, 495, PENOBSCOT

Blckford, Frank A. (b'53)-Me.1,74; (l'95).

RICHARDSON, HORACE KINIBALI' (b'80) (-Mass.7,05; (l'06); Nember Mass.

BREWER, 5,667, PENOBSCOT

LETHIECQ, JOS. ALBERT (b'65)€-Pa.2,

Newton, Carrie E. (b’75) H - Mass.5,'98; (1'01).

Schriver, Alfred Herman-Me.1,06; (1'06).

THOMAS, CALVIN MERRILL $\left(b^{\prime}, 9\right) 4^{-}-$

Pa.1,02; (1'03)

THOMAS, CALVIX P.-N.H.1,76; ( 
BRIDGETON, 1,474, CUMBERLAND

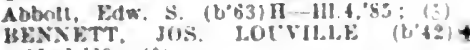

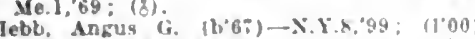
LOMBARD. U६HBERT A. (b'tis)-Mel. 'St: (b).

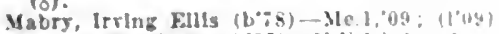

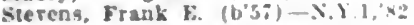

BRIDGEWATER (BRIDGEWATER CENTER P.O). 1.238, AROOSTOOK

JACKSON ELMEK HERUVITT (1) Sh) Me.1,11: (1'11).

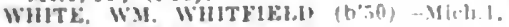
\%4. Pa. 2,78: (8)

BRISTOL, 706, LINCOLN

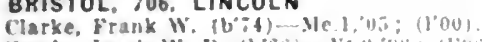

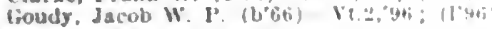

BROOKLIN. 506. HANCOCK

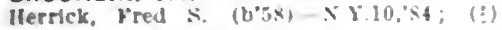

BROOKS, 669, WALDO

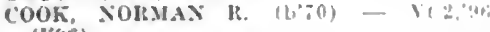

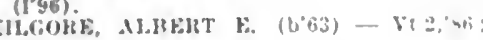

hill.cion.
(z).

Luce, prince Edwlu $\left(b^{\prime} i s\right)-0 ;(b)$

Ranusay, Albert II. - J11.4.84, (1'y, R.F.I. 2.

BROWNFIELD, 1,025, OXFORD

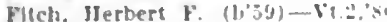

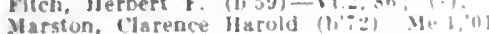
(1) 01 ).

BROWNVILLE, 1.570. PISCATAQUIS

Jenle, llarry Hallock (b'si) Wellid (1'12)

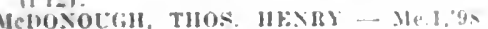
(1"98).

BROWNVILLE JUNCTION, 380, PISCATA QUIS

HAKDEN, DON I. (b"is) + Me.l. M.

Weacherbee, Cieo Bradfort (bixi) - Mass i 12: (1'12).

BRUNSWICK, 6,621, CUMBERLAND

Adams, liva Argene $(b \%+)$ Ilass.i, $0:$

(1'06)

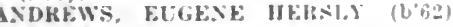

Me. 1,94: (2)

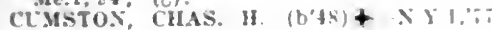
(3).

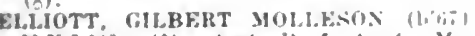
X.Y.1,89; (8); Asst. J'TuR Anat. Me.1 (II).

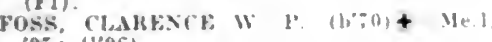
$95:(1.96)$.

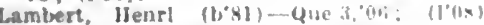

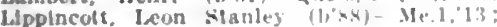
(I'I3)

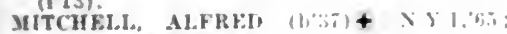

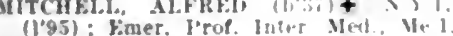

PALMER, CIIAS i (bot) + Ve $1,0=$ (8).

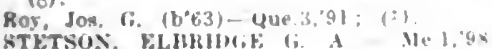
(1)98)

WHITIFR, FHANK NATIANHE, (lipl) +

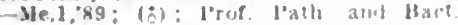
Me. I: $\left(\mathbf{H}^{\circ} \mathrm{z}\right)$ : LO.

BRYANT POND. 250, OXFORD

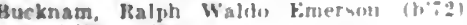
Me.1.93: (1'07).

BUCKFIELD, 357, OXFORD

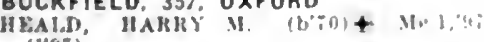
$\left.(1,9)^{\circ}\right)$

Marnton, Eduln John (b's0) -Tenag, 11:

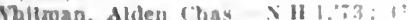

BUCKSPORT, 2.399, HANCOCK

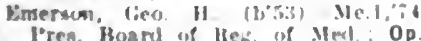

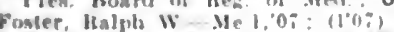

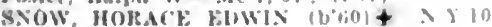

"86: (8).

CALAI8, 6,II6, WASHINGTON

Wrehaut, lamuel (b't2) -N I : .090 (log)

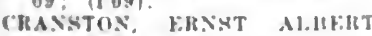

Mam. 6,$05 ; 1100 \%$

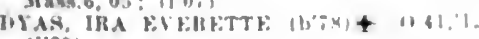
(I'09).

Gilkrit, W.M.THE J. $(10 \%$ int $([09)$
HOH.1.NI, HUIST. A. $(6 \% 0)+M c .9,95:$ $(1,95) ; 5$.

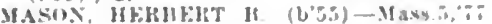
(i): Anes.

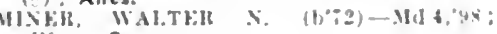
(1'9x): S.

SMTH, 3.1.ME It.

isee Milluwn

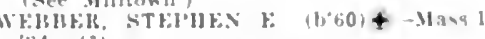
: $1: 12 ;$

CAMBRIDGE, 421, SOMERSET

WIINUN, JUHN II - Md \$, 90 ; (2)

CAMDEN, 3.015. KNOX

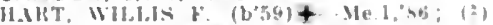

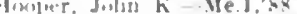

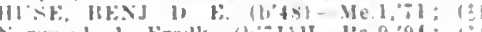

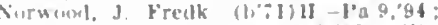

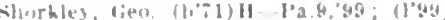

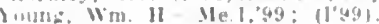

CANAAN, 1,130, SOMERSET

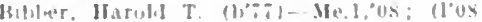

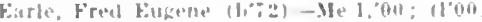

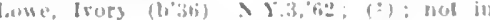
ritctice.

CANTON, 1,953, OXFORD

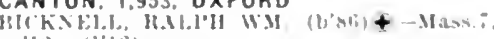

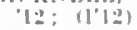

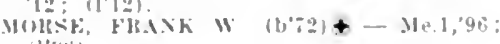
(1)?(1)

CARIBOU, 5.377, AROOSTOOK

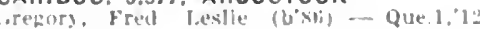

(1"12).

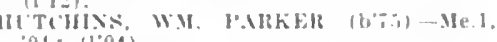
ofot: (1.04).

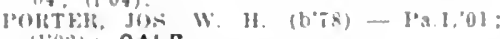
$(1+()=1):$ OALR.

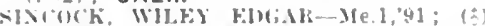

THUMAs. CHAS. b' M.

THUMAs, (HAS, FHAX(A, JH, (b'85)

Mans.1,12: (1'12).

llham, Vieo, C Y Y 10,82; $131: 0$

CARMEL, 1,066, PENOBSCOT

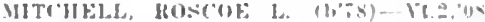

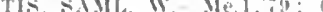

CASCO, 810, CUMBERLAND

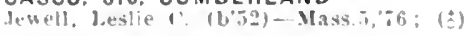

CASTINE, 947, HANCOCK

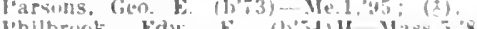

l'hllbrok, kdw b. (b'st)ll Mass.j,

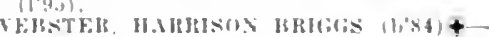
Mas4. 1,04; (1'12): S.

CHARLESTON, 796, PENOBSCOT

WHMUITH. FU.ISK [D. (1):3\}

CHEBEAGUE ISLAND, 500, CUMBERLAND

CHEBEAGUE ISLAND, 500, CUMBERLAND

CHERRYFIELD, 1.800, WASHINGTON

Morelen, Alonzo Win. (b'i1)-Me.1,02;

VanWart, Wm. A. (11Bi)-X.Y.10,"93; (ด).

CHINA, 550, KENNEBEC

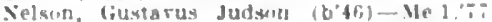

CHISHOLM, 800, FRANKLIN

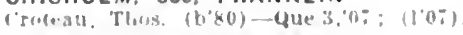

CLINTON, I,398, KENNEBEC

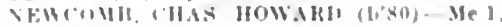

$0 \%: 110 \%$

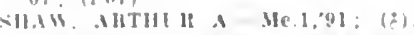

COLUMBIA FALLS, 698. WASHINGTON

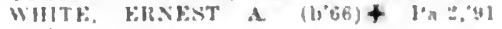

COOPERS MILLS, 450. LINCOLN

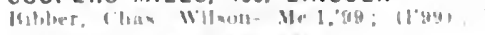

CORINNA. I, 100, PENOBSCOT

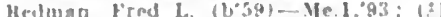

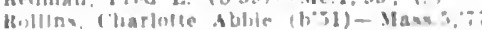
1112

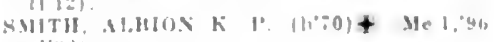

CORNISH, 1,II8. YORK

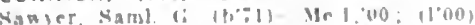

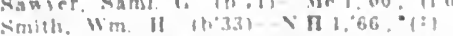

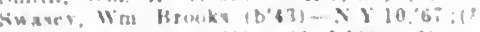

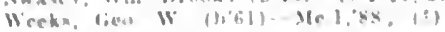

CUMBERLAND CENTER, 6T2, CUMBER

LAND

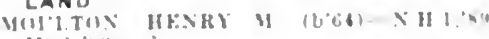

CUMBERLAND MILLS, 2,400, CUMBER. LAND

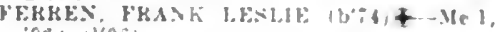

DAMARISCOTTA, 350, LINCOLN

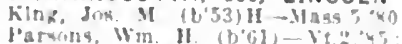

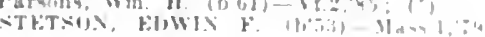

DAMARISCOTTA MILLS, 227, LINCOLN

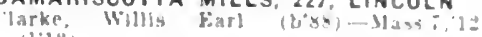

1114

DANFORTH, 1,300, WASHINGTON

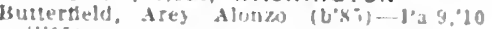

(1'1I)

Cा ITI

(i)

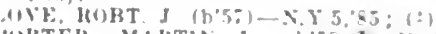

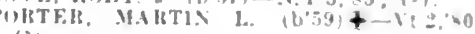

(ڤ)

DEER ISLE, 897, HANCOCK

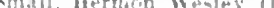

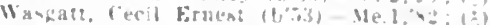

DENNYSVILLE, 452. WASHINGTON

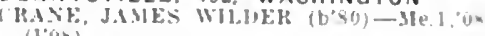

(IPou)

Aneoln, Irshur Talpeq Mau

DEXTER, 3,530 , PENOBSCOT

liasum, Mary Hertek II-Man-

(1)

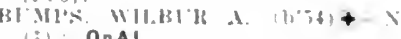

1:1: ODAL.

Hurgess, Frank E. $\left(b^{*} 55\right)-\because(\vdots)$.

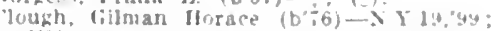
$(1,90)$

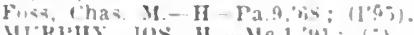

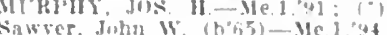

Thatcher, llenry $\mathrm{k}-1$ 'a2,s!: (").

OIXFIELD, 563, OXFORD

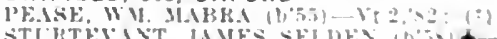

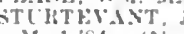

Me. $, 84:$ (:).

DIXMONT, 757, PENOBSCOT

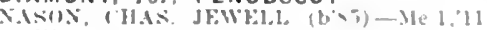
(I'1i).

DOVER, 1.900, PISCATAQUIS

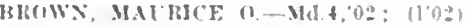

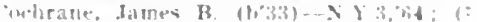

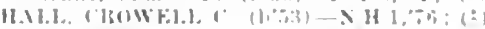

STANHUIVE. NINIX H. VI:,

DRESDEN MILLS, 225, LINCOLN

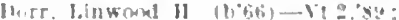

DURHAM (R.F.D., AUBURN), 587, ANDROSCOGGIN

Wright. Jusiah Lester-y) $(193 i)$.

EAGLE LAKE, 700, AROOSTOOK

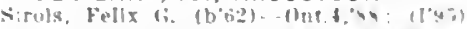

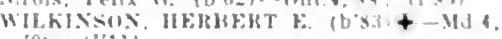
"0.; : (I'11).

EAST BALDWIN, 380, CUMBERLAND

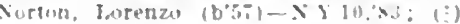

EAST BOOTHBAY, S00, LINCOLN

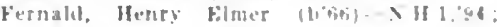

EAST CORINTH, 589, PENOBSCOT

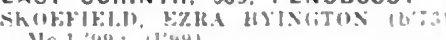

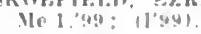

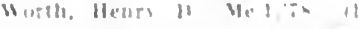

EAST DIXFIELD, 250, OXFORD

WHTE., V'FHE]l. (HHRUX Mavs. 1,

EAST EDDINGTON, 620. PENOBSCOT

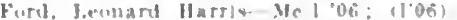

Jacksull, Heward 1. (b'is)-Mase 6,03 :

EAST MACHIAS, 1.637, WASHINGTON

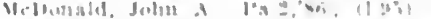

EAST MILLINOCKET, 2,000, PENOBSCOT

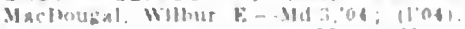

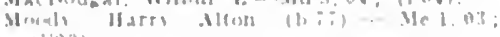

i: 11:1:

EAST PARSONFIELD, 300. YORK

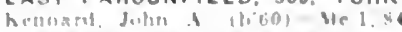

EASTPORT, 4.961. WASHINGTON

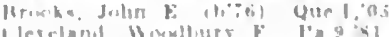

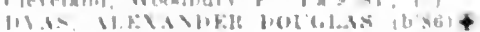

(i) 1 i 11 . 


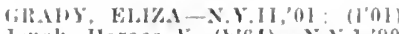

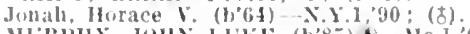

IL'BPII, JOHN LLKE (b'85) +-ilc. I, 09 (1"09):

TUSTIX, ITUTII-X. Y.20,:99; (1'02).

EAST RAYMOND (R.F.D., RAYMOND),

\section{CUMBERLAND}

Jordan, Lester Howard $\left(10^{2} 50\right)$-Me.I, $13 ;(3)$

EATON, 100, WASHINGTON

Mclachlin, Ilubert-Ie. I, ib; (*)

EDES FALLS (R.F.D.. NAPLES), 125.

CUMBERLAND

llall, I,eo, Horalo-N.Y.s, 8 ; ; (logi).

ELIOT, 650, YORK

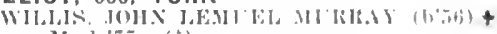

-Me.1, i: (1)

ELLSWORTH, 3,549, HANCOCK

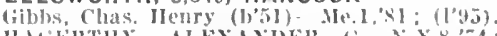

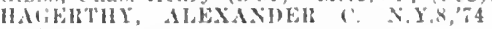

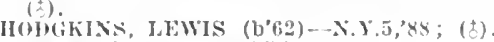

King, Nathan (.-N.Y.5,'86; (ठ)

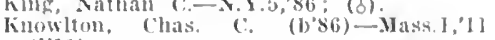
(l'11).

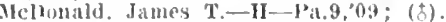

WOODRLFF, HARLOW L. D.-X.Y.5,70 (I'99)

ENFIELD, 970, PENOBSCOT

B.ITES, WHLIARD ASA (h'77)-N.II.1,01 (l'0) ; S.

llammond, Waller Jan (b'sl)-Me.l, ly (I'Iㄴ)

EXETER, 887, PENOBSCOT

BDMA.' S.IM. J. (D'68) - Me.1,'99; (1'99).

FAIRFIELD, 2,80I, SOMERSET

(iousse, Wim. Louts (b'7s)-IId.4,11; (l'11). Ilooper, Edw. Curtis (b'73) - Me.1,99; $\left(l^{\prime}(\theta)\right.$

Prlest Maurice Albert--Me 1,07: (l'07).

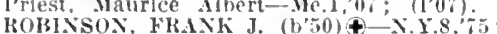

(引)

TASII, WORY I',-N.Y.5, 79; (0)

TOZIER, FIRAK INCOLN (b'69)-Yt.2, $01 ;$ (1'01).

Walters, Ethel Wilson llobbs (b 66 ) II -0.26 '09: $\left(1^{\circ} 01\right): \mathrm{G}$.

Walters, Wilson II. (b'73)-0.26,98; (l'00)

FALMOUTH (R.F.D., PORTLAND), 245 , CUMBERLAND

ROBINSON, EDW. F. (b'60)-N.H.1,93 (1'95).

\section{FARMINGTON, I,240, FRANKLIN}

'roswell, Mary Sibylla (b'73)—Jass.7,'03, (l'05).

Cushman. Mary Floyd-Mass.5,92; (t).

IOWARD, ALBERT G. (b46)-Yt.2, 81 (j)

Linscott, Jolin J. (b'46)-Mlass. 2,67; (0)

lyford. Franklin o.-1'a.9, ; t; (

IAKEPEACE, BEXJ. F. (b'60)-N.Y.5

' $8 \% ;(t) ; A L R$.

NICHOLS, JOHY w. (b'59)‡-Me.1,8 8 ; (t).

PRATT, GEO. I. (b’7

Pratt, Harold Sewall (b'87)-Me.1.'12; (1'I2).

Reynolds, Austin- 0 ; (む).

ANBORY, WARREX BIGELOW (b'is)

IId.8,09; (l'09).

FOXCROFT, 1,726, PISCATAQUIS

('hamberlain, Allen Howard (b'61)-Mass.1,

'88: (о); Op.*

F'LINT, EDGAR T. (b'7z)-IId.4,01; (b); S

HAIL, CKOWELL CIARINTON, JR. (b'84) f-IId.7,10:(1'10); OpLR

IERRHL, ELMER DELMONT (b'OT) Pa.9,'S6; (है).

FRANKFORT, I,099, WALDO

WALTON, HESSELL D. (b’ $7 \bar{\tau}) \oplus-I I d .3,02$; (1'02).

FRANKLIN, I,I6I, HANCOCK

leBeck, syoney S. (b'63)-Yt.2,'8: : 18

FREEDOM，300, WALDO

simall, dllen MeDonald-Ile.1,94; (1'95)

FREEPORT，965, CUMBERLAND

Drummond, Augustus Bidwell - IId.9,'99; $\left(I^{\prime} 00\right)$

Gould, Irthur L. (b'83)-Me.1,05; (l'05)

Hyde. Fathan I). (b'51)-l'a.2, $79 ;(195)$

I.EWIS, WM. JERHIS-Me.1, $07 ;\left(10^{\prime} 07\right)$

FRENCHVILLE, 1,600, AROOSTOOK

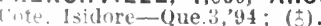

FRIENDSHIP, I,000, KNOX

Ilillm, Wm.'II M(I.4.04; (1'04)

FRYEBURG，540, OXFORO

I, (H) (ELE, AlBTHI'L JEWWTT

(ा०); ; Op.

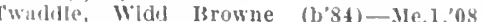
(1'0)

FT. FAIRFIELD, 1,620, AROOSTOOK

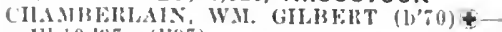

111. $10,29 \pi ;(1,9 \pi)$.

Gariliner, Wim. Fo $\rightarrow$ : (o).

Kalloch, Herbert F. (b'6s)-..1.10,9s; (I'Ms)

S.IWYKR, AINRED D. (b'55) \-N.Y.5,'S0; (0)

SAWSEL, M.HED LOMISt - Me.1,07;

Whley, Inln $\mathbf{E} . \diamond$; (ち)

FT. KENT, 2.528, AROOSTOOK

Archambault, Jos. T.-que, 1,93 : (ह).

lage, liosario J.-Que.s,"0:; (1'04)

L'HA.M, I:OSCOE CHAS, (b'85) —-Md.4, "08; (l'08) ; OALR.

FT. MCKINLEY (PORTLAND P.0.), CUMBERLAND

1SEYANS, JAMES I. (b'69)£-111.6,'93; Maj., M.C., U.S.A.

KIKAMER, FLOYD (b'84)\&-0.40, '08; Capt., I.C. U.S.A.

FT. WILLIAMS (CAPE COTTAGE P.o.), -, CUMBERLAND

('IIURCII, JAMES ROBH (b'66) \&-D.C.1 93: Maj., M.C., U.S.A.

WARRINER, BENJ. B.\&-Va.6,96; Member Med. Soc. of Va.; Ist lleut., M.C., U.S.A.

GARDINER, 5,3II, KENNEBEC

IIEX NNDER, GEO. WILFRED $(1,76) \oplus$ D.C.2, 08 ; (1'09); LR.

('lason, Silas Oliver (b'79)-Ne.1,04; (I'04)

Colb, Wm. O.-N.H.1,97; (1'99).

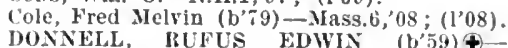
N.II.1,'89; (t)

HEATI, GEITRLIOE E. (b'59) \$-III.4, 83: (1) ; OpA.

Lamb, Bert Everelt-X.If.1,91; (t).

Putnam, Frank IIason-N.H.1, 78 ; (

SAWYER, AlTON (b'48)\&-Pa, 2,$78 ;($ (む).

SIMONS, RALPI DUMPHRY (b'- 2 ; ( 99; (1'99); Pd.

Small, Reuben Dunn (b'37)-Me.1,69; (む)

not In practlee; R.F.D. 14

sirout. Arthur W. (b'79)-ile.1,03; (1'03)

STROUT, FIED E.-ME.1,'90; (

GARLAND, 7I3, PENOBSCOT

Strout, Arthur Chester (b'81)-Mass.6,04; $\left(1^{\prime} 06\right)$

GORHAM, 2,650, CUMBERLAND

Haynes, Chas. Fredk.-Me.1,62; (1'88)

LEWIS, PHILIP P. (b'70)\$-IIe.1,98 (l'98)

Lincoln, Albert w. (b'33)-Me.1,65; (b).

RIDLON, CHAS. H. (b'59)-Me.1,86; (f).

GRAND ISLE, 430, AROOSTOOK

Dussault, Etienne A. (b'84)-Que.3,'08 : (l'0T).

Lupien, Lucien-Que.3,93; (む),

GRAY, 1,300, CUMBERLAND

ANDREWS, ANSON MORRILL $\left(b^{\prime} \%\right.$ Me.1,01; (1'01)

INDREWS, FGBER'T TILTON (b'4t) N. Y.1,73; ( 10 )

Ellinwood, Geo. Albert (b'71)--Vt.2,'91; (l'95).

GREENE, 675, ANDROSCOGGIN

HA.SCOM, OSCAR F. (b'72)--Me.1,99; (l'99)

GREENVILLE, I,400, PISCATAQUIS

HINT, IIRAM (b'60) $९$-Ne.1,84; (5)

GREENVILLE JUNCTION，330, PISCATA QUIS

I'RITHAM, F'RED JOHN (b'80)屯-Me.1,05; (l'05)

GUILFORD, I,500, PISCATAQUIS

Butterfleld, John C.-E-X.Y. 60 ; (t).

DORE, GUY EVERLYN, (b'8)-Vt,2,11; ('11)

MARSH, RALPH H. (b'63)£-Me.1,'9:; (ड)

POTTER, JOHX LYMAX (b'-8)-Vt.2,04; (I'09); D.
HALLOWELL, 2,864, KENNEBEC

HE.ANE, ('IAS. E. II. (b'78)-Me.1, 05 ; (I'0.5); U.

MILIAKE, 110WAlRH ALGUSTLS (b'74)t

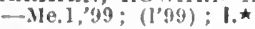

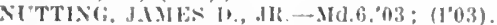
Nut1lng, James I),-..Ye. J,65; (3).

HAMPDEN, 500, PENOBSCOT

Cowill, C. Fremont (h'56) -0 ; (d)

HAMPDEN HIGHLANDS, 500, PENOBSCOT

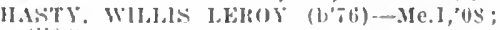
$(108)$

NISOX. W.ILTEL I1-N.Y.10,84;

(む) ;

HARMONY, EOO, SOMERSET

Dyer, John Small (h'76)-Me.1,04; (1'04)

MeLaughlin, Wm. (1)"32)-Me.1, (16); (1'y6)

HARRINGTON, 865, WASHINGTON

BURITTT, GLY L.-Ill.6,'01; (1'06).

HARRISON, 65I, CUMBERLAND

BHIKE, JAMES P. (1'65)-Me.1,92; (\$).

SYVFNTER, (IIAS. BHADFOIID (h'6.) t

-IIe. 1,8: ; (1).

HARTLAND, 974, SOMERSET

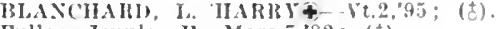

Fuller, Jennle-Il-Mass.5,"82; (む).

MOLLTON, CHAS. A.-Me.1,84; (b).

HEADTIDE, I82, LINCOLN

CARD, ALBEIRT MAITIN (b'48)£-Me.1, $75 ;(\delta)$.

HEBRON, 400, OXFORD

Evans, Leslie Howard (b"79)-Vt.2,'12; Assistant I'lyyslelan and I'athologist.

Garrison, Wm. Miles $\left(b^{\prime} ; 8\right)-M d .3,02$;

Resident Physlelan, State Sanatorium.

NICHOLS, NELSON ESTES.

(See Portland.)

HERMON, 802, PENOBSCOT

Whitaker, Frank 1;.-Me.1,83; (す).

WRIGIIT, LAFOTEST JULIA $(\mathrm{b} ; 81) \uparrow$

Vt.2,'05; (1'95); R.F.0.8.

HINCKLEY, 102, SOMERSET

Santee, Ellis Monroe (b'62)-Mo.5,90; not in practlee.

HODGDON, I,500, AROOSTOOK

EBBETT, IIENKY L. B. P. (b'81)-Que.1, 03; (1'03).

HOULTON, 5.845, AROOSTOOK

BATES, EDWIN CASSIUS (b'83) $₫-$-N.Y.1, 08; (l'08).

DICKISON, THOS. S.-N.Y.10,93; (ち)

GIBSON, WM. B.-Pa.11.'04; (l'04)

JACKSON, FRANK II. (b'76)€-N.Y.1,01; (1'05); $\mathbf{S}$

IANN, FREDK. W.๑-Md.3,92, Que.5,"00 ;

MITCHELL, FREDK. W. (b'73)-Md.4,98; (1'98); OALR. $\star$

POTTER, JOHN GARFELD (b'79) $\uparrow-M e .1$ 08; (1'08).

PT'TAM, HARRY IYMAY (b'63) N.Y.10,90; (t)

WALKER, ALBA G. (b'75)-Mass.6,'02: (1'02); G

WARD, PARKER MYLES (b'73)థ-Mass.1, '98; (l'00); OALR.

WhLLIMS, ClLAS. E. (b'5̃) †-N.Y.1,'83; (5) ; Pd.

ISLAND FALLS, I,550, AROOSTOOK

BIGELOW, FHEDK. F. (b'58) $4-$-Pa.2,'83; (ठ)

SCHYEIDER, GEO. A.-MId.4, ${ }^{\prime} 06$; (1'07).

ISLE AU HAUT, I 60 , KNOX

SNELL, FRANK W. E. (b'63) †-Ga.9,02; (1'95).

ISLESBORO, 276, WALDO

Larrabee, E. Burton $\left(b^{\prime} 72\right)-M d .4,03$; (l'03).

JACKMAN, 357, SOMERSET

Boothoy, John Maloney-Me.2,82; (む).

Humplreys, Ernest Davis (b'83)-Me.1,'10; (1'10).

JAY, 275, FRANKLIN

Merritt, Frank W.-Vt.2,'89; (1'95).

JEFFERSON, I,I55, LINCOLN

JACKSON, FREDK. WI.-N.Y.8,85; Tetired; Member Med. Soc. of State of N.Y XASH, ALBERT WII.SON (b'71)-Me.1,95; $\left(l^{\prime} 95\right)$. 
JONESPORT, 2,124, WASHINGTON

IInll, Ira lluller (l,x3)-Mast.l, lz; (1'l:;

KEENS MILLS, 100, ANDROSCOGGIN

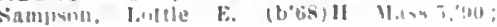
(1.00).

KENDUSKEAG, 423, PENOBSCOT

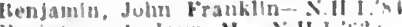

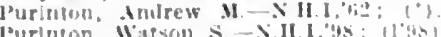

KENNEBUNK, 3.099, YORK

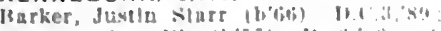

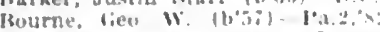

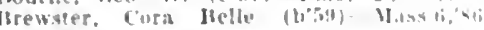
(1'03)。

llawkes, bilgar sampon (lifii)ll Mavs.?

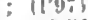

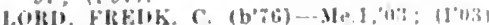

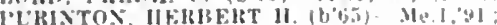
$(1,4 \%)$

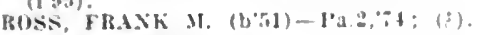

KENNEBUNK PORT, 2,I23, YORK

HISSH.LLE, MIL'Y

isee llot Springs. Va.)

Merrill lieo Frank (b'49) Me.1,7it: (1:1)

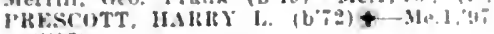
$\left(0^{\circ} 97\right)$.

KEZAR FALLS, 600 , YORK

Chelllu, fidwlu ll $\rightarrow 0:(3)$

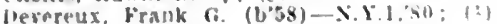

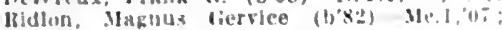
(1.0:).

KINGFIELD, 693, FRANKLIN

11'0ะI.

KINGMAN, 1,075, PENOBSCOT

Sumerville, Beverly h. (b"5t)-Ja.2, id (1'06): G.

KITTERY, 3,533, YORK

SIIIILEIGIl, EIIIS. H. (b'68)-Me.I,:40 (3).

KITTERYPOINT, 1.000, YORK

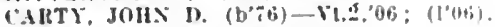

LA GRANGE, 574, PENOBSCOT

HAIIKETT, JAMFE NIOYSII'S (J6:)

IId.4,10: $\left(I^{\prime} \mid l\right)$; NP.

Ilunter, W. Bruce (b'79)-Que.I, 0s: (l'0s)

LEEDS, 1,000, ANDROSCOGGIN

Russell, Danl. r. I). (b'7y)-Me.I, $05 ;\left(l^{\prime} 05\right)$

LEWISTON, 26,247, ANDROSCOGGIN

BCLSTER, WM. WHELLEIS, JH. $\left(h^{\circ}-3\right)$ Me.1,0s; (los); It: College si, 1-3 $7.8 ; \mathbf{s}$.

Ifourgoln, Jos, kruest (b'i6)-Que.3,0: $(1,10): 99$ thestnut st. ; $9-11,2-5,7-5$

CALL, FIRSFAT VICTOR (b'it) - MeI ot: (1'(1): 118 l'lne st: : I-3.

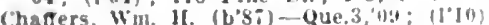

25is Jislinn st.

Chopuetle, Jos. Alfred (b'75)-cluef, int: (l'07); 326 bates.

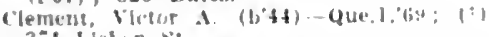
3it Listoun sit.

Cominls, Wyverti Almon (b90) Me.1,li3;

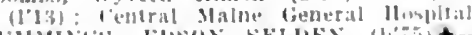

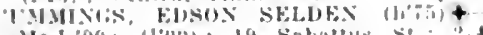
ye.1.00; (10uv); 19 Sabattus st.: "2-4.

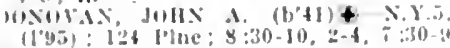

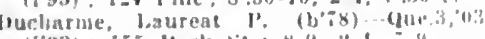

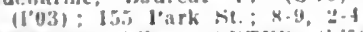

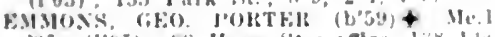

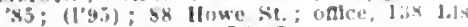
luñ st.:- $-4, i-9 ;$ OALR.

Fabey, Willam Jos. (b) $8(j)$ Me 1, I0:(1'10)

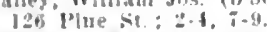

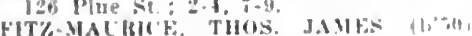

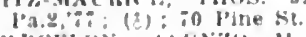

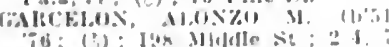

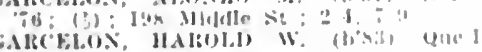
os: llosi: If

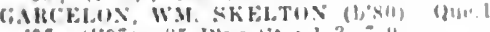

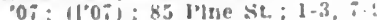

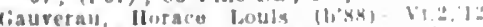
(I'13): Se. Maty's Veneral Huspllal

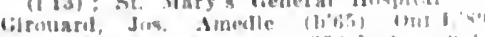

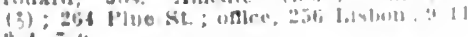
at- $7-6$.

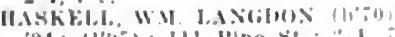

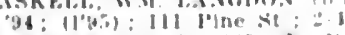

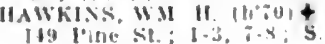

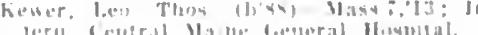

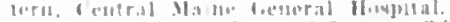

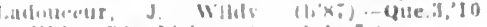

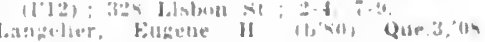

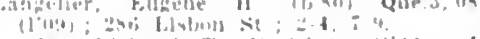

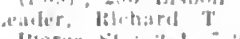

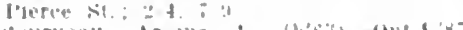

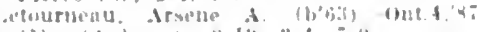
(1): (.)uhurn]: $y-[1,: 4,:$

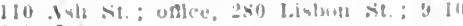
$2+1,-9$

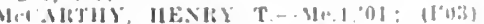

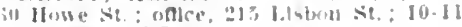
is, OALR.

IF⿱

(iin) lolie ke

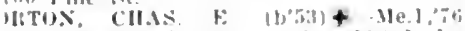

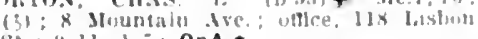
St. : 4-11, 1-, : OpA.

"1)

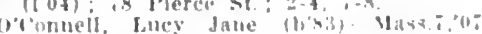
(107): is pine si

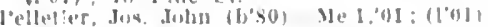
1:14 Liston st.; ontee. 11 liridge st: :-1.

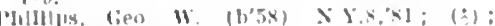
160 P.mo sit. : $:-4,7-4$

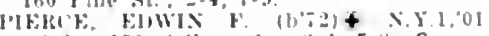

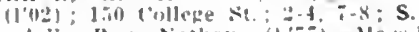

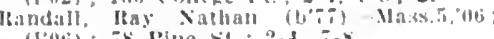
(106); is Plne st. : $2-4,7-x$

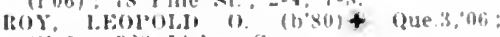
I'(10i) : 328 I.Istwin Sit.

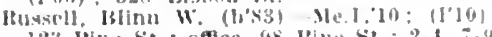

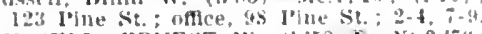

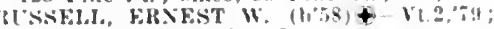
(अ): 48 pine st. ; $2-4$; $7-6$.

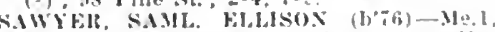
'(IS: (1'08); 326; Maln St.;2-4, 16-8; (A2J).

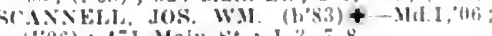
(106): tij Yain st.; $1-3,7-8$.

Alupleigh, Ilarty l.ee (biv) Mass.b,'11: (1'I?): (oak st.

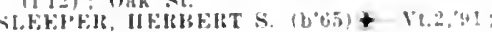
(b): 700 Mala sic

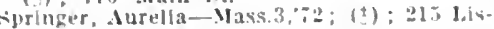
luit $81.7-7=0$

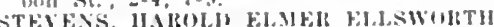
$(1,78)+$ Mass.1, (1); (106); 374 Мain si: $: 7$ : Path.

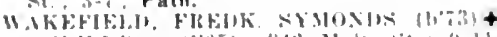

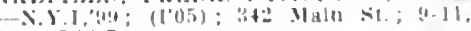
: OALR. *

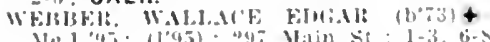
Ye.1,45; (10.4.8);

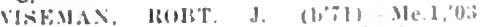

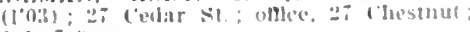

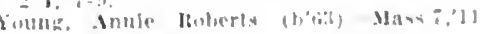

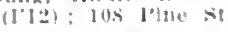

LIEERTY, 737. WALDO

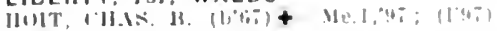

LIMERICK. 800, YORK

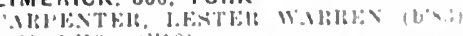
Me. I.10; $(1010)$

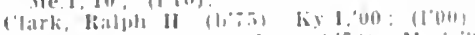

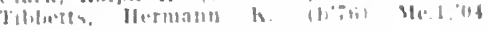
(1'01).

LIMESTONE, 1,400, AROOSTOOK

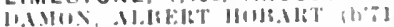
(i) : (1) (1) (1)

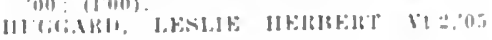
(I) 11,1$)$

LIMINGTON, 1,001, YORK

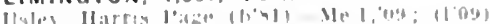

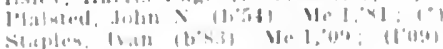

LINCOLN, I,IfT, PENOBSCOT

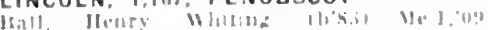

11 (1):

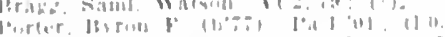

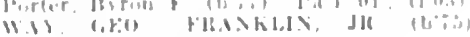

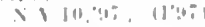

LISHON. H,IIt, ANDHOSCOGGIN

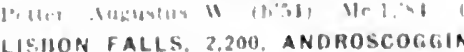

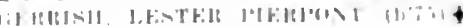

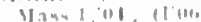

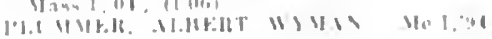

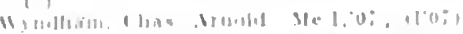

LITCHFIELD, 306. KENNEBEC

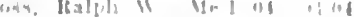

LITCHFIELD CORNERS. 580. KENNEBEC

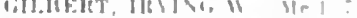

LIVERMORE, 8\$6. ANOROSCOGGIN

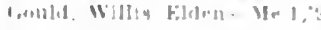

LIVERMORE FALLS. 2.200, ANDROS. COGGIN

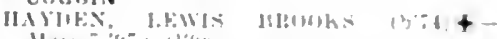

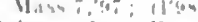

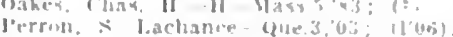

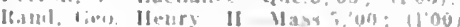

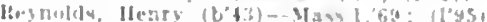

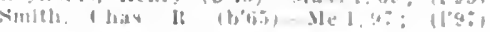

LOVELL, 691, OXFORD

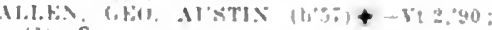
$1=1 ; \mathrm{s}$

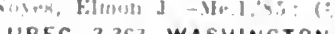

LUBEC. 3.363. WASHINGTON

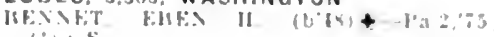

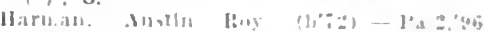

$\left(1^{2}(10 i)\right.$

Tahlman, It

LYMAN (R.F.D., KENNEBUNK), YORK

IIBBITT I'KIBCI HIIBIS (b'a) - Me.1

'10: ("10).

MACHIAS, 2,082, WASHINGTON

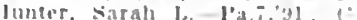

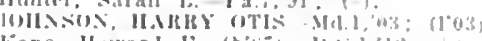

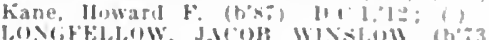

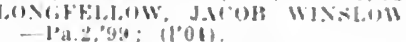

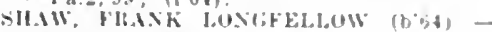

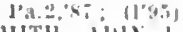

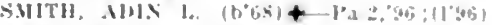

MADISON, 3.379, SOMERSET

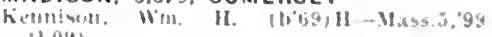
(1) $0 ! 1)$

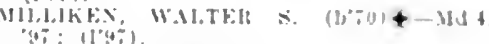

lemer, John 1. Me l, at: (:)

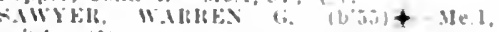
4: (:)

MAPLETON, 925, AROOSTOOK

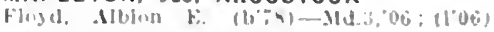

MAPLEWOOD, 90, YORK

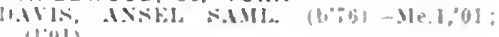

MARS HILL, 1.500, AROOSTOOK

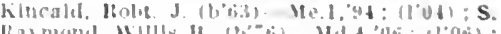

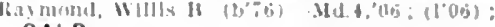
OALR.

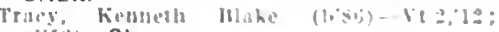
(I"III); Ob.

MAYFIELD, 90, SOMERSET

lirown. II. S- - 0.13, I1: 1?

MECHANIC FALLS, 1,68\%, ANOROSCOG.

LiIN

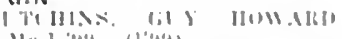

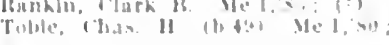

MEXICO. 325, OXFORO

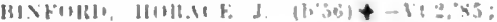

MILLBRIDGE, I,9म33. WASHINGTON

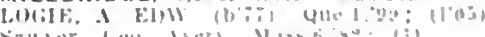

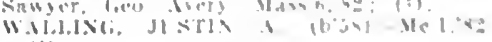
(3).

MILLINOCKET, 3,368, PENOBSCOT

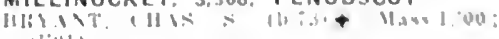

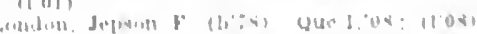

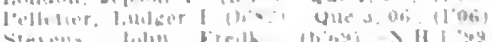

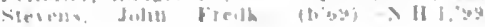

MILLTONN, I,200, WASHINGTON

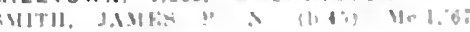

MILO. 2.536, PISCATAOUIS

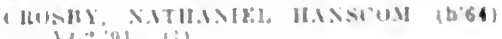

(1)11, I.,IIS I- $1101, \because: ;$ : (j).

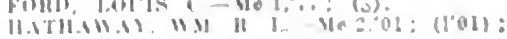

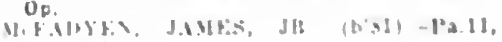
H.113ris 


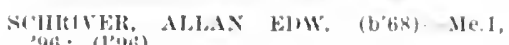
$396 ;\left(1966^{\circ}\right)$.

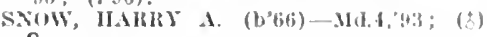
G.

MONHEGAN, 120, LINCOLN

("aliol, Jolum.

(See Weelawken, X. 1.)

MONMOUTH, 1,236, KENNEBEC

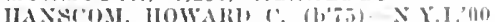
(l'ii): Slember lled sione of the state of $\mathrm{N}$.

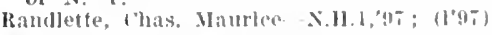
MONROE, 829, WALDO

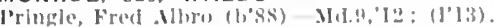

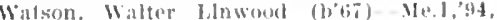

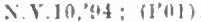

MONEON, I,237, PISCATAQUIS

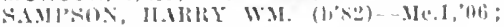
(l' (l(i) : S.

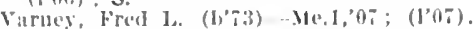

MONTICELLO, 1.332, AROOSTOOK

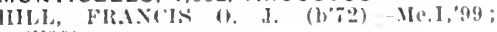
(l'9)

MORRILL, 453, WALDO

learsom, "1. N.-1"t.2, 193 ; (1'95).

MT. DESERT, 400, HANGOCK

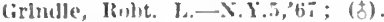

MT. VERNON, 900, KENNEBEC

Shaw, Herhert F,-Mass.ti,s3; (\$)

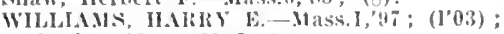
Nemther Miss. Medi. Assn.

NAPLES, 746, CUMBERLAND

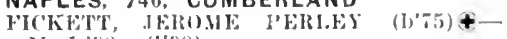
Me. I, 98 ; $\left(l^{\circ} 98\right)$.

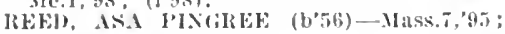
(1'95).

NATIONAL SOLDIERS HOME, - KENNEBEC

Carthans, Alfred Herman C. (b's9)-Wis.2, '11: (1'11).

Farrell, ("halmers firegg (b's6)-0.40,11; restclent physician.

Ovldlu, Malemed (b'79)-I'a.13,'09: ( $\mathrm{f}^{\prime} 09$ ) RIIION, BERTRANH \%, (b'68)-ile.1,'94 (ठ) .

Sawyer, Chas. Milton (b'49)-Pa.2,'72; (t). STINSON, IIENIR
Me.1,00; (I'00).

NEWBURG (R.F.D., HAMPDEN HIGH. LANDS), I50, PENOBSCOT

Hill, Francis o. J. Smitl - Mass.1,'67; (1'95).

Newcomil, Eugar C.-Me.1,93; (む).

NEWFIELD, 456, YORK

Jenigor, Fmile ( $\because-$ Que.2, 79 ; (

I'reston, Walter Evereft Scott (b'58) N.11.1,"88; (1'03).

NEW GLOUCESTER, 1,125, CUMBERLAND TTUBCiL, JOUS I $\left(b^{\prime} 44\right)$ - Me.1, 68 . (ち)

NEW HARBOR, 310, LINCOLN

Whiltman, Luther $0 . \quad\left(b^{\prime}-6\right)-$ - Yenn.11,05; (l'09).

NEWPORT, 1,000, PENOBSCOT

Benson, Ifomer Fremont-N.Y.5,'S1; (む),

EMERSON, OACAR RONAY - IIe.1,'g4; (t)

Hawthorne, Jefferson Warren (b'33)-Tit.2, $96 ;\left(l^{\prime} 98\right)$.

MeVefy, Jos. James (b'se) - Mass.6,12: Sewall, John Jasper (b'5i) - N.Y.5,84;

Walker, Wm. E.-H-Pa.9,91; (古).

White, Louls H.-Vt.2,'84; (ठ)

NEW PORTLAND, 400, SOMERSET

Spear, Irerman S. (b'69)-N.H.1,'97; (I'98)

NEW SHARON, I,064, FRANKLIN

HEAD, OWEN BERRY (b'ï) - Me.1,00; (1'00).

NEW SWEDEN (R.F.D., NEW SWEDEN STATION), 507, AROOSTOOK

IIARMON, CHAS. H. (b'it) \& - Pa.2, 05; (I'05).

NEW SWEDEN STATION, 50, AROOSTOOK latgerson, Victor E. (b'i3) - Ga.10,'89: $(198)$

NORRIDGEWOCK, 1,700, SOMERSET

AMES, JUTIX D.-NIC.1,92; (\$).

Brown, Llewellyn (b'35)-11ass.1,62; (d).
S.MPTH, H.ALR W. $(1,70)-$ N.H.1, 00 ; (l'(ii).

Nagner, Forence s. Merrow (b’73)—o.13

NORTH ANSON, 1.200, SOMERSET

Anirews, Ellril i:-.-.Me.1, \&4: (b).

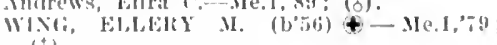

NORTH BERWICK, 1,800, YORK

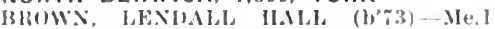

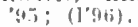

l.ghth, Wm. F. (bis) M(I.4.94; (I'9x).

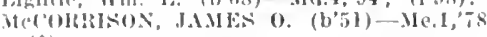

NORTHEAST HARBOR, 600, HANCOCK

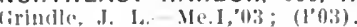

NORTH FRYEBURG, 210 , OXFORD

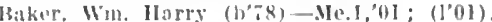

Mabry, Irving V.- Me.I, $\mathrm{NO}$; (t).

NORTH HAVEN. 655, KNOX

liammons, Jesse Louis $\left(b^{\prime} 79\right)-V^{2} .2,(1) 4$ (l'i) 4 ).

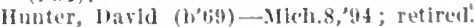

NORTH LEBANON, I36, YORK

lluray, Davbl Litingstone - que.5,"01 (10)

NORTH NEW PORTLAND, 550, SOMERSET I'ritt, bawin Francis $(1,74)-M e, 1,00$ ( 100$)$.

NORTH PALERMO (R.F.D., PALERMO) 125. WALDO

belaney, Mlchiel-Me.1, '1: (l'9.5).

NORTH VASSALBORO, 700, KENNEBEG

M.ABIK, ('ILA.-ME.1,'79; (む).

Nalker, Francis bavid (b'86) - Me.1,1:; (l'I3)

NORTH WATERFORD, 300 , OXFORD

Coolidge, (has. Mariner-N.H.1,'88; (す)

NORTH WHITEFIELD, 400, LINCOLN

Brimlgloll Thurlow W. (b'69) $-0 ;$ (

ODORYE, JOS. ERNEST $\left(b^{\prime} ; 6\right)$ - - Je. 1,01 (1'01).

NORTH WINDHAM, 350, CUMBERLAND

I'ARKER, CIIARLFS F'. (b'69) - v't.2,'98 (1'99).

NORWAY, 2,215, OXFORD

BARLEK, FRANK $\mathrm{N}$. (b'5t) $\oplus-\mathrm{Vt} .2,85$ (t).

BARTLRT', IIERHAN I. (b'67) $₫-\mathrm{Vt} .2$ 9. : ( ( ) : Pd.

Bedari, l'rudent $\rightarrow$; ( $\left({ }^{\dagger}\right)$.

BRADBURY, BLAL'F. (b'61)†-('a.10,'82 (む)

TRIFANT, LESTER H.LL, (b'82)†-Que.1 $07 ;(10 \%)$.

OAKFIELD (R.F.D., BURLEIGH), 928, AROOSTOOK
Rowland, Edw. Gould (1,78) - MI.4, 03 ; (I'12)

OAKLAND, 2,400, KENNEBEC

Holmes, Manuel S.-Mass.5,79; (t)

TOTMAN, YIRGIL rONNOR (b'T2)-Me.I 00: (]$\left.^{\prime} 00\right)$.

MTIIERELL, CARL H. (b'78)-Mass.1,06; (I'(1:i).

OGUNQUIT, 500, YORK

GORDON, HOS, W. (b'.51)-X.1I.1,'79; (t)

GMITH, WII. WIRREN (b'67)-N.H.1,94 (t).

OLD ORCHARD, 757, YORK

JONLS, ARTHIT LEON (b'75)†-Me.1,'08 (l'08).

RANDALL, IESSE A. (b'63) $\uparrow-M \mathrm{e} .1,88$; (b)

OLDTOWN, 6,317, PENOBSCOT

Bradbury, Arthur I. (b'67)-Yt.2,92; (ot). EIKINS, PKIRY H. (b'59) - Me.I,'80; (ち)

IAXIPI, (iEo. EnW. (b'69)£-Que.3,'93;

MADDAN, MARTIN CROWELL $\left(b^{\prime} 69\right) \oplus-$ Me.I, 01 ; (I01)

MARQEIS, EDOLARD M. \&-Que.3, 06 ; $(107) ; \mathrm{S}$

Porter, Chas. B.-N.Y.5,'80; (t)

Rowe, Arthur W.-Me.1,'87; (c)

TWTCHEJL, ASA HOWARD (b'52)-Me.1 $82 ;(195)$.

YARNEY, JOHN ROSCOE (b'63)-Mrd.4,'96; (l'03).

WELD, GARVIN GILMORE-N.H.1,89; (古).
ORLAND, 1,390, HANCOCK

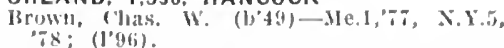

ORONO, 3.555, PENOBSCOT

IBAYARI), ('L.AYTON H. (b'66) - Id.3,'92;

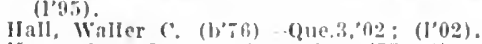

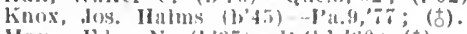

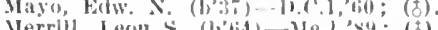

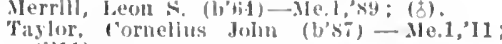
(ग'I1).

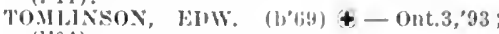
(l'nt)

ORRINGTON, 636, PENOBSCOT

TIBHE'T'S, (iEO). B. $\left.(1)^{\prime} 54\right)$ - Me.1,78; (8).

OXFORD, 473, OXFORD

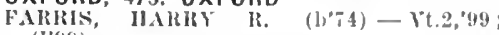
(I'(19),

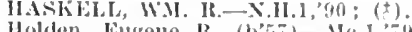

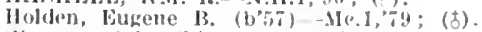

slevens, orin (l,is) H-Je.l,'69; (c).

PARIS, 3,436 , OXFORD

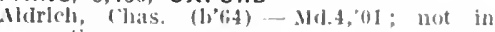
practice.

Hougliton, Merlndis M. (1,'36) F--Me.1,86; (す).

PARIS HILL (PARIS P.O.), 262, OXFORD

IIammond, ("latrlotte $\mathrm{F}$. (b',5i) 11 - Mass.5. 87 ; $\left(\begin{array}{l}0 \\ 0\end{array}\right)$.

PATTEN, I,200, PENOBSCOT

FAKNIIAM, ELMLIt JOIIN (b'74)-Pa.2,99;

FELI, EVERETT IIOWALD (b'ส2)\&-Vt.2, 08; (1'10).

Woodlury, (ieo. H.-Mass.5,"99; (1'00).

PEMBROKE, 824, WASHINGTON

BEST, HEKBERT H. (b'-1) - N.1.5,'96 (1)

PENOBSCOT, 938, HANCOCK

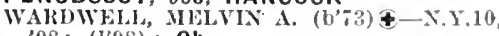
'98; (I'98); ; Ob.

PHILLIPS, 823, FRANIKLIN

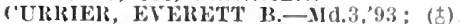

IIggins, Everett C. (b'80)-Jle.1,'11; (J'11)

PHIPPSBURG, 1,254, SAGADAHOC

IILIIA.IS, ADELBEI'T F. $\left(b^{\prime}, 0\right)-N . I I .1$. ${ }^{9} \bar{i}^{\circ} ;\left(\mathrm{l}^{\prime} 97^{-}\right)$.

PITTSFIELD, 2,23I, SOMERSET

brake, Thos. X.-T'a.9,84; (ह),

Lathbury, Vincent T. (b'-9) II-.Iass.5, 04

Marston, Henry k. (b'76) -..Me.1,08; (1.09).

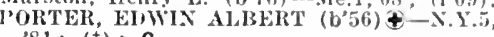
'81; (t) ; G.

PLYMOUTH, 689, PENOBSCOT

Higglns, Geo. Trery (b'84)-Mle.1,09; (l'09).

PORTLAND, 58,57I, CUMBERLAND

NUMBER OF PHYSIC'IANS, 162.

ABBOTT, ElNILLE GERHARTT (b'72) \&156 Free St. 1:30-3:30: 'Prof.' Ortho.

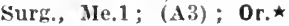

ILLEN, JOHN HOWÁRI (b'66)£-Pa.1,02 ; (1'02); 717 Congress St.; $9-11,1-3$; (B3,15); ALR. *

IIWARD, MARK (b'53)-N.Y.6,85; (†) 160 ocean Ave.; offce, $12 \%$ Congress St.; $8-9,2-4, \vec{\imath}-8$.

Baker, Clarence Atwood (b'52)-Me.1,82; (す) 300 Congress St.

BALDWIX, ALBERT KILBLRN (b'78) Me.1,'II; (1'11); 929 A Congress St. ; 2-4, $\overline{7}-8 ; \mathrm{S}$.

BANKS, (HARILS ENWARDE-X.II.1,'78: Senlor surg., U.S.P.H.S. ; Marine Hospltal Barker, Edgar E.-Ky.1,"03; (1'03); 38 Verinda st.

BASSFORI, SAM1. J. (b'48) $₫-M e .1,21$; (t); 42 IIellen St.; office, Young MIen's Christian Association Bldg.; 9-12, 1-5. Black, Richard Percival (b'66)_Mass.6, (1'11); Peaks lsland; $1-3,6-9 ;$ ObG. Bodge, Jos. I'. (b'73)-Me.1,'99; (l'99); 61 Roberts St.; offlce, 946 Congress St. BOWERS, JOHN W. (b'61) \&-IId.3,82 ; (t) ; 732 Congress St. : $9-3 ; 0$ op.

BRATFORD, WM. HERBERT $\left(\mathrm{b}^{\prime} 66\right)-\mathrm{Me} .1$ 91 ; (ठ); 208 State St.; until 9, 2-4, $7-8$; Prof. Clin. Surg.; Me.1; $\mathbf{S}$.

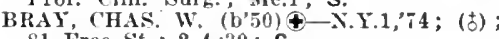
81 Free St.; $2-4: 30: \mathbf{G}$.

BROCK, HENRY HEIBERT (b'64)-Me.1 90; (t) ; 687 Congress st.; 9-10, 2-4; Prof. Clin. Surg., Me.1; S. 


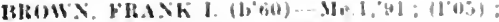

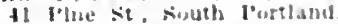
Brown, Luther Alnsley (l)" s) (1"1)1) : bisu fongress st. : 1.1

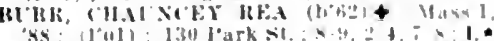

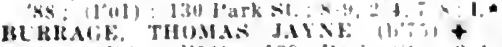
Mass. 1.03: (104): 139 l'ark of: 4 Asat, Irof clin. Méd., Me I : I."

Cammert. Wn. (b"3i)-XY.1;79; (2); 2ur

Congress sit

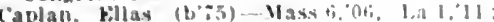

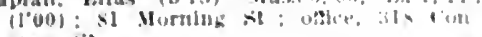

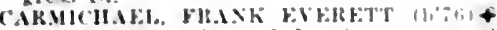

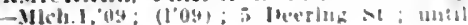
9. $1-3,-8$

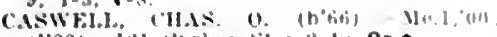
(1000): i:2 siring si : :-t; or.*

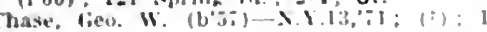
loine sit.

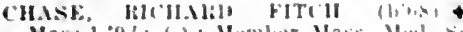

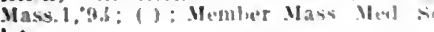

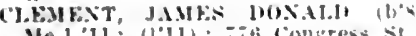

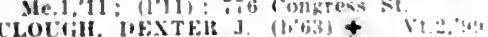

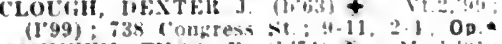

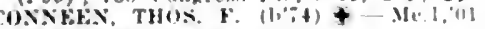
(l'01): 650 congress si.

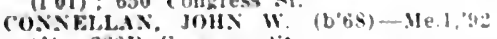
(3) ; $286 \pi$ ( ongress st.

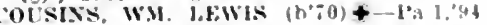
(8): 231 Womdford st.: ofline, 151 siate st. $: 2.4 ; 5$.

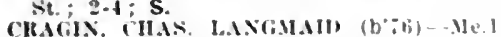
04: (1004): s27 fongress st

DAVIs, GILMAN (boy) -Me.1.93; (1'ul)

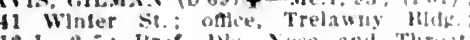
12-1, $2-5$; Irof. Jls. Nuse and Throlt Me.I; ALR.

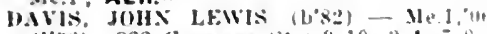
(1'0h) : 333 Congress st. : $9-10,2-4,7-8$

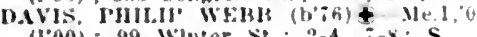
(1'00): 99 Winter st.: $2-4 . ;-x:$ S.

lelxel, Wm. C. (b'st)-Ma.s. 994 Congress st ; $8.10,1-3, d: 30-x: 30 ; G$

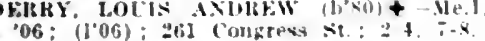

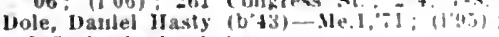
it5 Cumberland tre

DHISCOJ.L, DANi. (b60)-Me.1, 6 Deerlng st. ; $2-4,7-8 ; 0 b$

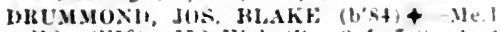

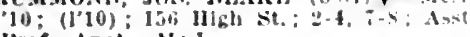
l'rot. Anat., Ne.I.

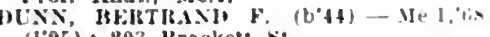
(195); 203 krackett *t.

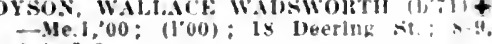
2-4, $\div-8$.

batoo, Idalleta shaw $(b x$,$) - Mast. "1s$

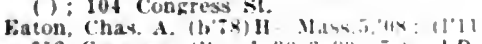
612 Congress sit : $1: 3(1-3: 34), 7, n$ L L

Elllote. Geo. W. Man. I."4!: ( )

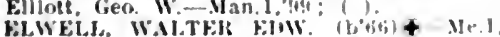
si: (s): not ln practlce; sy wenti. office, 13 franklln st.

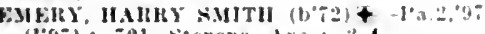
(1.9i): 721 sterens die.: $:-4$.

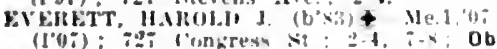
(I0) 1. Hill st.

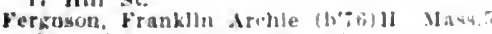
02: (1002): 705 Congress st.

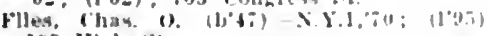
195 IIIgh st.

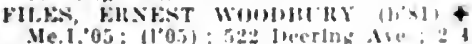

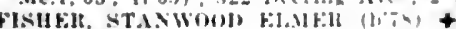
Ve lor (1)i5): ALR.

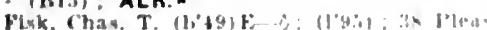
ant die.

bugt. dila o

P1)

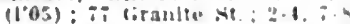

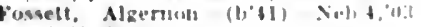
110 : 41 .

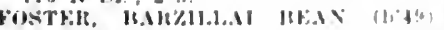

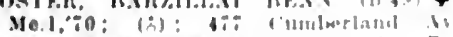
office. 653.1 cingrewa:

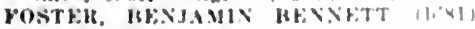

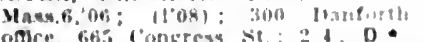

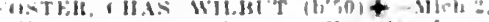

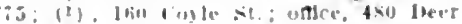

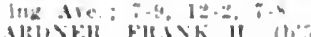

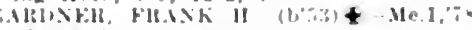

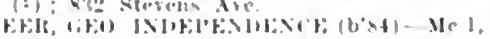

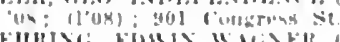

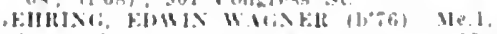

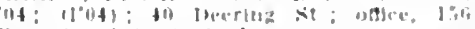
Fre st: 1 :31-: $: 10: 1$.

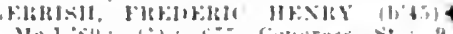

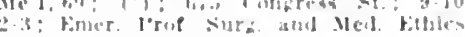

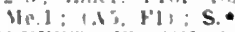

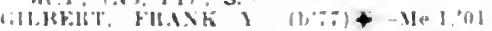

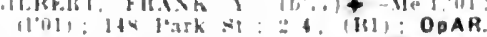

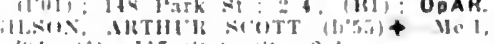
(14: (2): 11 : state sit: : 21

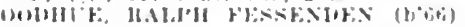

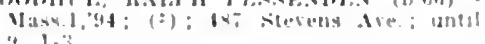

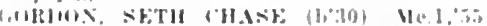

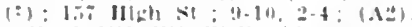

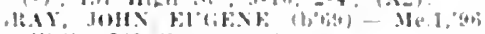

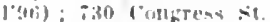

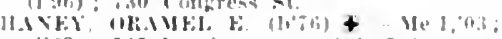

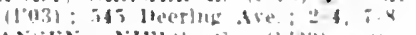

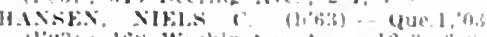

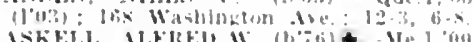

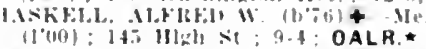

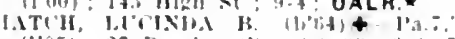
$(1005)$ : 27 Deering st. : $x-3: 311 ; 2-4.7-5$ ObG.

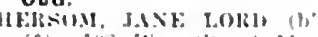

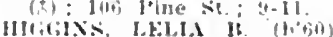

(1097) C

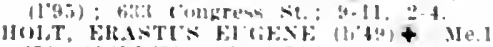
it. Xl.1, (II,4,5.14,1;); OpA.

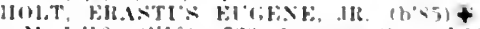

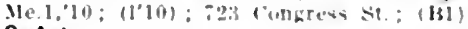
ODA $\star$

IInkins, James II

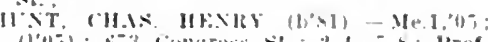

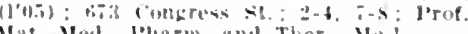
Vat Iod. Iharm. and Ther. Me.l.

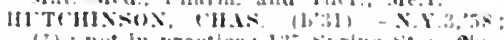

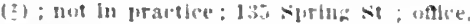
liark st.

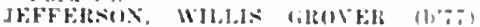

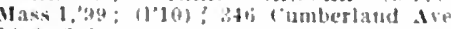

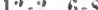

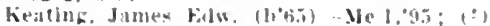

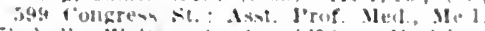

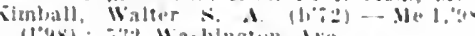

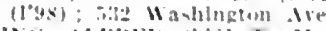

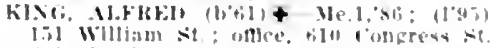

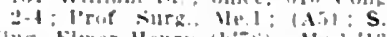

kling. Hmer Henry (16-5)-Me, 1,1:1: (1'13) Malne lieneral Iropltal

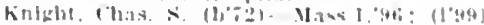

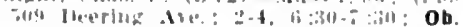

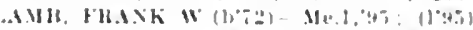

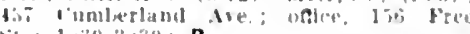
$\therefore$ : $1=0,00.30: \mathbf{R}$.

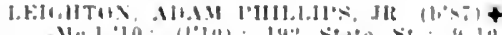

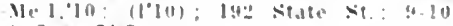
2. $1, \quad \therefore$ : ObG.

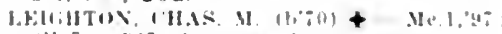
11:40): 3rit comereus st.

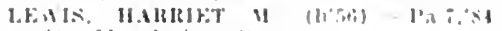

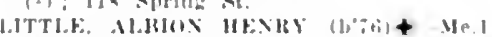

onto (1)

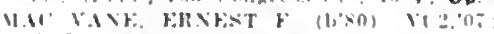

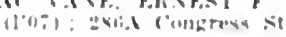

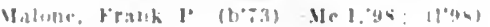

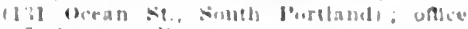

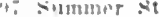

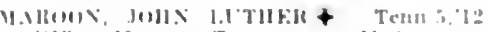

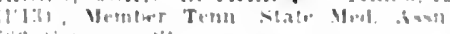

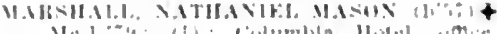

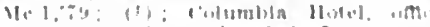

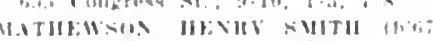

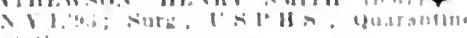
- intion

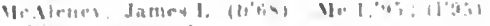

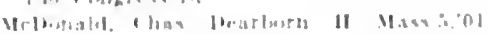

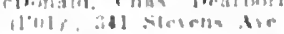

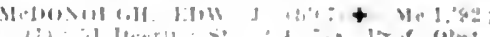
$M=1 ; 1,1,10$

Merril:, Hesis

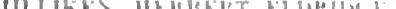

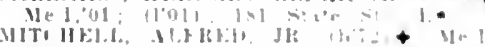

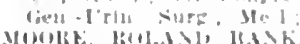

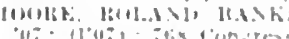

mois Wy Ta mo

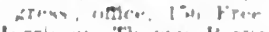

管

(1)

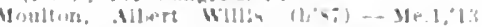

(1'13: Malno finoral Homples

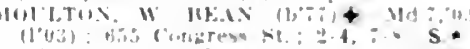

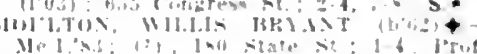

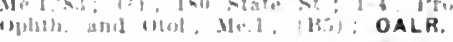

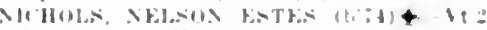

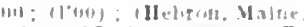

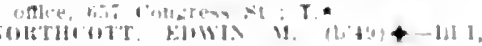

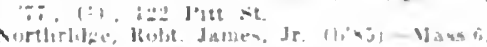

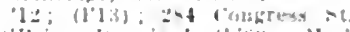

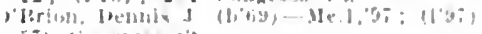

Bin lignarens st

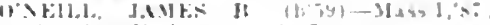

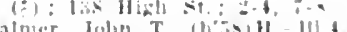

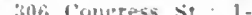

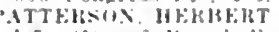

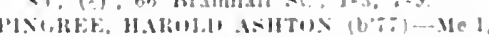

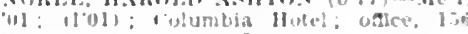

Froast $1: 30-3 \div 30 ;$ Or.

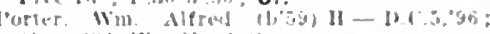

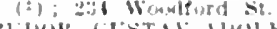

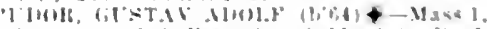

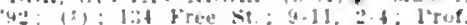

Derm. Mo. 1; D.

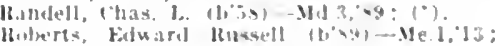

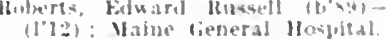

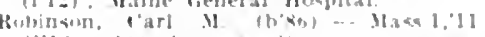

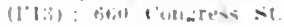

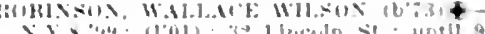

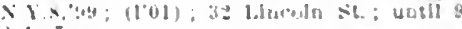

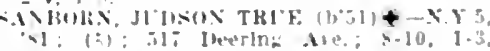
$1: \quad 1 ; 1:$

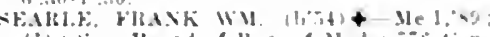
(?): igresi st.

ligh 5 is

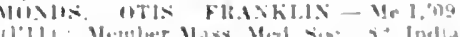

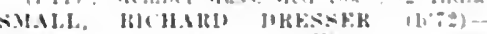

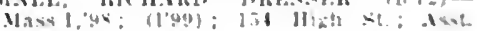

iorof ilivi. Vle 1

stmith, Irthar .1-1: $2.93: 19): 0.4$ con-

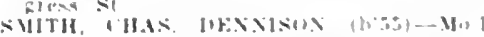

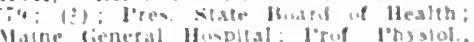
Me.1: (FI)

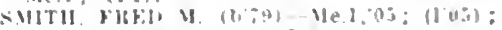

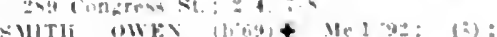

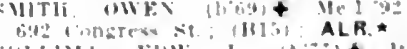

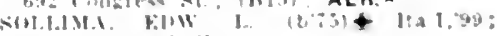
(1) 11 ;) : wit hell. bis

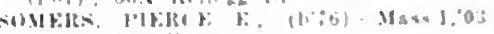

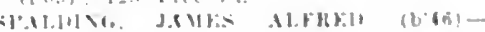

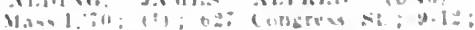
ItI I: OpA.

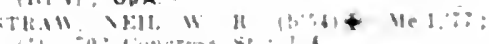

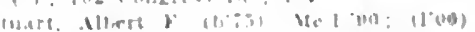

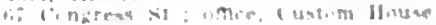

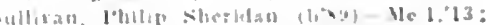

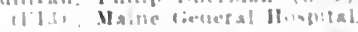

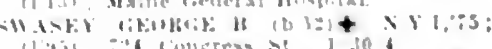

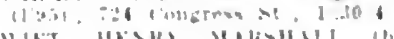

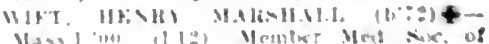

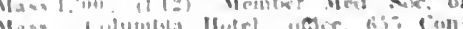

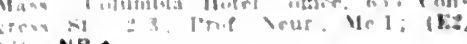
NP. 
Sylvester, sllas F. (b'35)-Me I, 60 ; (1'95): ate cumberland tre

THAYKIt, ADDISON SANFORD (b'58) \& Me.1,'S6. Mass.1,'88; ( $\star$; ; 10 leering st. 2-33: Doan and I'rof. Med. Me.1; I.

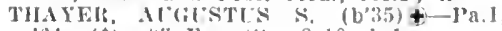
$64:(t) ; 44$ Freo st. ; $8-10,1-1$ THOMIBs. \$AMI. Is. (b'53) \&-Me.1,80; (ट) $; 121$ spring st.

TIIOMIPON, JOHX FRAXKLIX $\left(\mathrm{b}^{2} 5 y\right)+$ Me.1.86; (ठ) ; 211 state sit.; $5-4,2-4$ I'rof. Iis. of Women, Me.1; (A2)

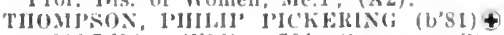

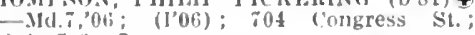
$2-4,7-8: 5$

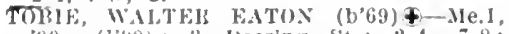

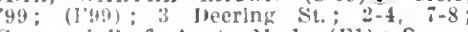

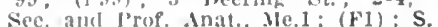

Tozer, Frell. W. (b, 147 Pleasant ire.

TUISFlk, (iHo. H., Jlk, (b'78)-Me.1,03; (I'03): 1:3 Compress st. : $9-10,2=4,7-8$.

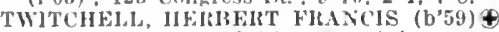
-.Ie. 1,$83 ;(3) ; 10$ l'Ine st, ; $2-4$.

Vaumee, Taleot Ostrom-N.Y.1,01; ( ) ; 181 situte st.

WAILES, STANLFY J'ElRKAS $(1,46)+$ Conn. $1 ; 74 ;(8) ; 159$ Hligh st. ; $2-4 ; 0$ b. WEBBER, MERLON AIDEEN (D'83)+ Me. 1,$10 ;(1 ' 10) ; 359$ Congress St. ; 2-4,
i-8:30.

WHBBER, MILLAIRD CAITROL (b'82)Me.1,10; (1'10); 849 Congress st. ; 2-4, $6: 30-8: 30 ;$ OALR.

WEBSTER. FHED l'. (b’i8)-Mass.1.01: (I'04); is I'ine St.; office, Y. II. C. A. (I’01); 12 I'ine St.; offlee, M. M. C.

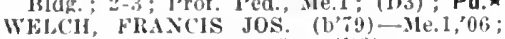
$\left(l^{\circ} 06\right) ; 698$ Congress sit. ; (1)3)

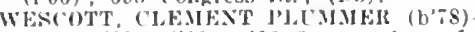
Mlass.7.09; (J'12); 493 sterens Are. ; $1-3$ $\mathrm{T}-\mathrm{S} ; \mathrm{N}$.

White, Arfhur Winford-Vt.2,06: $\left(l^{\prime} 06\right)$ : 273 Congress sit.

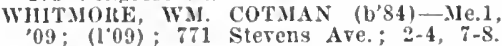
WIJMAMsoN, WALTER D. (b'63) \&-Vt.2, '83: (l'01); 7 Deerlng st.; 8-9, 2-4, 7-8. Witlam, Walter H. (b'73)-T'a.11,06; (J'06); is Pleasant Ave.; offlee, Masonic Temple; 2-4, 6-7:30.

WTHERLE, CHAS. BRYANT (b'55)Mass.1, s1; (103): 21 neering st. N. (Y09); T81 Congress st.; 2-4, $7-8$.

Wrigt, Chas. Sias- Mass. 1,$45 ;$ not in practice; 24 Monument $S$ t.

POWNAL (R.F.D., WEST POWNAL), 592, CUMBERLAND

Vosmus, Solomon Addison (b'57)-Me.1,84; (ठ).

PRESQUE ISLE, 2.938, AROOSTOOK

BENNETT, FREEIIN ELISHA†-Me.1,

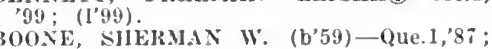

$\mathrm{BOONE}$
(ま).

DOBLE, E, H._Mich.4, 00 ; ( ('00).

Dudley, lionel Elwood (b'-8)-X.Y.1,08; (l'08).

Gould, L E-Md.4, $0^{-7} ;\left(l^{\prime} 0 T\right)$

Graves, Riehard Alexander (b'so)-l'a.1,12 ; (I'1:)

KILBURX, PRANK\$-Pa.2,79; (ठ).

MCNAMARA, WM. F.-Mass.6,'93; (b)

PRINCETON, [,027, WASHINGTON

I) P PEE, 11ALOLI) IROSS (b'8I)-VL.2,1] (I'I 13 )

JoHssox, CHAS. E. (b'65)-Me.1,97 (I'95).

PROSPECT HARBOR, 240, HANCOCK

LARRABEE, CHAS. COLBY (b'46)-I.H.1, '83; (

PT. CLYDE, 300. KNOX

HALL, WAITER IMITS (b'it)-Mass. 7 , B. 8 ; (

RANGELEY, 695, FRANKLIN

COLBY, FRED BENNETT (b'69) - - X.H.1, " $96 ;$; (1'07); Nember lled. Soc. of the

ROSS, ATHERTON M. (b'80)—-Me.1,06; (1.06); $\mathbf{S}$.

RAYMOND, 552, CUMBERLAND

Plummer, Summer J. $\rightarrow$; (⿱士口)
READFIELD, 994, KENNEBEC

Ilanmafurd, Fil sinow--Me. 1, 60 : (z)

MILIKKL, JoHN s. (b'75)-Me.1,00; (1?00); 0 b.

Wright, Warren N(lums (b'3i)-Mass.1,62

RICHMOND, 2,049, SAGADAHOC

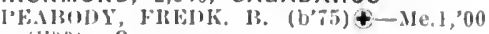
(1'00); $\mathrm{G}$.

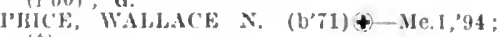
(b).

RIDLONVILLE, $1,000,0 X F$ ORD

IIamlon, Orville Leon-Me.1,01; (1.01).

If a rmill, (has. day -0 ; (d).

RIPLEY, 450, SOMERSET

l'alluer, Folw: (b:39) - 0 ; (c)

ROBBINSTON, 850, WASHINGTON

MALONEY, DANI. ARTHUIS-Pa.11,98; (1")8).

ROCKLAND, 8,174, KNOX

AJAMS, FIREK, JARNARD (b'64)థ

X. $5,5,90$ ( (3).

ALIVEN, FHEN+ N.Y.8;78; (t).

Armstrong, Win. 11.-II-Pa.9,96; (1'96)

Bachelder, Lucien $1 \% \rightarrow$ ( $\rightarrow$;

B.IRTIETT, FILED (0.-Vt.2,87; (t).

Bradford, Jester B. (b'82) - Mld.9, 05 ; (l'09).

FoSs. ALV1N W. (b'71) --Mass.1,04; (1'04)

Fould, Edwin W.-Me.I.87: (t); U

(iHBBIN, JAARRY EVERET'T (b'75)๑Me.1,'00; (I'00); OALR.*

llanscon, Walter V.-P'a.9, 90 ; (1'95).

IIII, Jesse Cluambers (b'58)-D.C.2,'91; (引)

J'DKINS, MARTIN I. (b'53)-Me.1,84; (む)

Moftlt, ('arl Walner-Pa.9,'94; (\$).

O'CONNol, MCHAEL J. (b'82) -Md.4, 06 ; (I'08).

SIIBY, EDW. B. (b'53) †-Me.I,'82; (1'95).

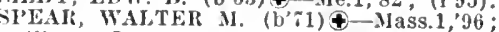

$\left(I^{\prime}, 96\right) ; S_{0} \star$

Wasgatt, Rowland J. (b'73)JI-Pa.9,96; ( I'96); 0 p.

ROCKPORT, 2,314, KNOX

STEWARD, CARLETON WHITE (b'81)-

Mass. T, 11: (l'11); G.

Weidman, Clara B. T. - N.Y.6,'90; (t).

WEIDMAN, STEPHEN Y.†-N.Y.5,'86; (t).

RUMFORD, 6,777, OXFORD

Andrews, Sullivan L.-Me.1,01; (l'01).

BISBEE, CHAS. M.MUe.1, 71 ; (ठ).

Gagnon, Jos. Leon Que.3, 02 ; (1'02) ; Pd.

IRENE, JOHN ADOLPH (b'si)-Me.1,08; (l'08).

Lesieur, Louis Osear $\left(b^{\prime} 69\right)-$ X.X.3,95; (l'05)

MCCARTY, EUGENE MILLER (b'74)థ lle.1,00; (l'00).

SILE, JOS. ABBO'T'T (b'63)-N.Y.8,'99; (l’99)

Noyes, Harrlett douella (1,'88)-Mass.6,11;

voYis, JALRA FELloW's - Mass.6,00; $\left(\mathrm{l}^{\prime} 02 \mathrm{z}\right)$.

Noyes, Sarah Fvelyn (b'S5)-Mass,6,10; (l'10).

Kowe, Wm. Thos -Me.1,07; (l'07)

ATANWOOD, M.BEIT IINSCOTT-Me.1

$\because 6 ;($ ( ) .

stanwood, Jarold Wm. (b'84)-Me.1,12. (1'13)

WHEET, HIKD. E. (b'65)-N.Y.5,92. (1'98).

RUMFORD POINT, 300, OXFORD

AJuott, Hiram F. (b'35)--Je.1,'6t; (ち).

SABATTUS, 800, ANDROSCOGGIN

Newton, Mark T. (b'55)-Me.1,84; (t)

Sleeper, Frank E. (b'46)-lle.1,70; (ち)

Wyman, Arthur E.-Md.4, 06 ; (1'00).

SACO, 6,583, YORK

COCHRANE, JASPER DUNCAN (b'51)థ

GOY.1,86; (む) WATER TEMPLE (b'51)-

Mass. 1,'87; (t)

Graves, Roscoe S.-II.-0.7,83; (ई).

Graves, Stockbridge P. - . X.9, $61 ;$ (f).

Haley, Jesse Durrell (b'61)-Me.1, 86 ; (t)

laybury, Robt. Lincoln (b'87)-Mass.6,'11; (1'11).

Maybury, IVm. Jordan (b'58)-Me.1,'86 (5); Prop. Otol., Ruln., and Laryn.

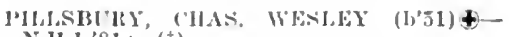
N.11.1,'81; (ठ).

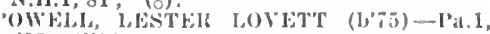
$0 . \overline{0} ;\left(l^{\prime} 06\right)$.

SHAXNox, JaMks 1l.—I'a.2,"'s4; (t)

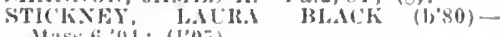

HOMISON, CHALENCE E. (b; 65$) 4-$ virion

HAItiY A. (1,'58)-Me.1,82: (古)

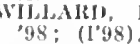

SANFORD, 9.049, YORK

Bermier, Ferdlnand 1 . (l'y,5).

BH, $\mathrm{AGIDE}$

(l'95).

CITNIAM, EITNEST LINIVOOI) (b'65)Me.1,'95; (1'96)

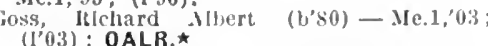
(T03); OALR. *

GOVE, HOJANIi s. (1)70)-Me.1,92; (s).

IILl, SUMNEH C. $\left(b^{\prime} 83\right)-K y .1,{ }^{\prime} 06 ;\left(l^{\prime} 0{ }^{7}\right)$ Pd.

KFILY, WM. JIEXKY (b'68) \&-Md.4, 05 (l’10)

amoureux, Arthur (b'82) ; Que.3,08; (I'I0).

L'HEUREAUX, JEAN A. (1,79)-Que.t, 1 l ; $\left(l^{\prime} 0.5\right)$.

WENTWOLTI, DANL. WEBSTER (b'60)Me.1.99; (1'01); $\mathbf{S}$

SANGERVILLE, 1,300, PISCATAQUIS

PURINGTON, W.I. ABIRA - III.11,98; (L'98).

RAY, CHAS. WILLAIRD (b'60)-N.H.1,82; (む).

SCARBORO, 350, CUMBERLAND

VENTWORTH, BENJ. F. (b'71)-Me.1,97; (L'97).

SEARSMONT, 949, WALDO

Slmmons, Clarence liaymond (b'78)-Me.1. '09; (l'09).

SEARSPORT, 1,500, WALDO Fairebild, Solomon Lincoln (b'83)-MId.9

Pattee, Sumner C. (b'76)-Pa.1,03; (l'03).

SEDGWICK, 950, HANCOCK

Hagerthy, Rufus Edwin-N.Y.8,'85; (†).

SHERMAN, 79, AROOSTOOK

UPTON, GEO. WASHINGTON (b*65)N.H.1,'88; (").

SHERMAN MILLS, I,I00, AROOSTOOK

Harris, Freeman Cram (b'50)-Me.1,'il (ठ).

SIDNEY (R.F.D., AUGUSTA), 927, KEN NEBEC

Wllliams, Fdmund l'erey (b'76)-Me.1,08; (1'08).

SKINNER, 75, FRANKLIN

Warren, Arthur Bradley (b'85)-Vt.2,'12; (1'12).

SKOWHEGAN, 5,341, SOMERSET

Bigelow, Frank $\$$. (b'53)-0; (I'95).

Brilge, Ezra Ralph (b'sti)-X.Y.1,13; (l'13)

BTHON, JOHN 12. C-X.Y.5, 93 ; (3).

CAZA, OLIVER (b'81)-Que.3, $0 \%$; (1'07).

DASCOMBE, LEANDEP A. (b'53) N.Y.10,7T; (t).

Joh'ison. Cóna May (1)'61) H-Mass.5,'83. ( l'95).

Pulsifer, Wm. Woor (b'63) H-Mass.1,'86. P'a.9,'87 ; (I'95).

STINCHFIKLD, WALTER S. $\left(b^{\prime} 73\right) \Phi-$
N.Y.10,96; (1,98).

TAGGART, HOWARD C. (b'54)-X.Y.5,'87; (ち).

WADSWORTH, JOHХ E. (b'70)£-Ne.1,96; (1’96); S.

SMYRNA MILLS, I75, AROOSTOOK

LABBY, ALGCSTINE B. (b'3i)-.IId,6,94; ARBELL, FRANK WASHIXGTON $\left(b^{3} 79\right)$ X.Y.1,08; (1'08).

SOLON, 1,000, SOMERSET

GREENE, SELDEN F. (b'5 $)$-Me.1,79, Piper, Jobn obed (b'81)-Que.1,10; (l'10).

SOUTH BERWICK, 2,935, YORK

Cook, Chas. E., Jr. (b'83)-Va.2, 08 ; (1'08). Jaques, Edwin D. (b'41)-Me.T,68; (5).

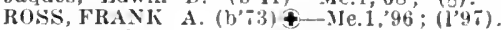

sleeper, Chas. il (b'56)-Je.1, 83 ; (t):

OpA. 
SOUTH BREWER, 980, PENOBSCOT

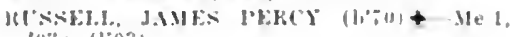
"0:5; (1.03).

SOUTH CHINA, 223, KENNEBEC

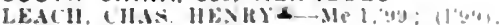

SOUTH ELIOT, 950, YORK

lul If(II) HF.NISI I. (bit)t

OUTH GARDINER 490. KENNEBEC

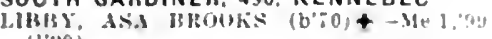
(1'28)

SOUTH PARIS, I,542, OXFORD

JITTLEFIELI), JAML: G. (b:33)

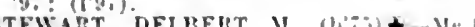
01: (1'04).

SOUTH PORTLAND, 7,471, CUMBERLAND

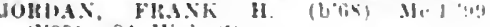
(1.99) : st lllgh sit.

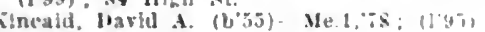
109 sawer st?

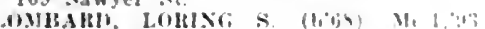
(j): suo suminer st.

Jalone, Frank $l^{2}$

Isee lortland

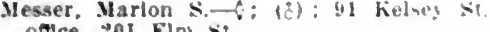
(1)

J (2) : 112 (1cean si

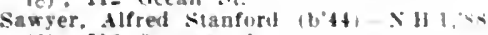
(8): 316 summer sit.

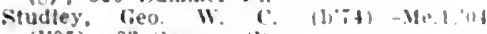
(105); 62 sawyer st.

Sisphers, James H. (b":1i) - Me.1."

sphers, Lekol S. (b'it)-Me.1.04; (1'06)

SOUTH THOMASTON, 50N, KNOX

b'ROHOCK. HOHATIO W. (U'S?)-Mais bi "0\% ; $\left(1^{\circ} 0 \%\right)$.

SOUTHWEST HARBOR, 850, HANCOCK

NEAL, GEO, A. (b'-2)-Md.4,05; $(105)$

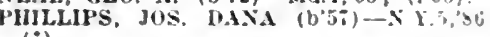
(8).

SOUTH WINDHAM, 1,200, CUMBERLAND

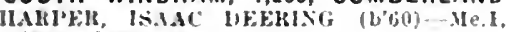

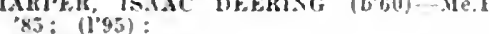

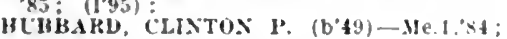

MOULTON, OLIS CATES (b'ts)-M11.1\%, (l'05).

SPRAGUES MILL (EASTON P.0.), 550 , AROOSTOOK

Willing. John T. (b'56)-Me.1,90; (1'04)

SPRINGFIELD, 500, PENOBSCOT

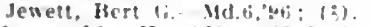

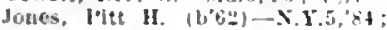

SPRINGVALE, 2,500, YORK

Bragdon, Fred dugustus $\left(b^{\circ} 59\right)-. M e, 1,83$ (\%)

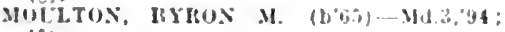

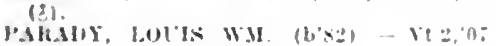
(1'i(i).

Saster. lla ciule Nillopit

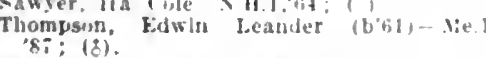

STANDISH; 1,500 , CUMBERLAND

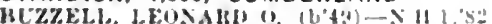

тH(1). (3)

\section{STETSON, 6I8, PENOBSCOT}

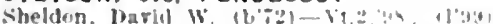

Tibuetts, Inlal Witiee- $111 . ;$

STEUBEN, 890, WASHINGTON

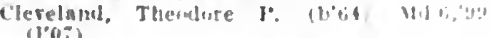

STOCKTON SPRINGS, 774, WALDO

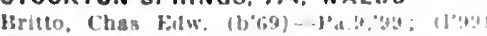

Fleree. James 1-11,74: (1,5).

STONINGTON, 1,648, HANCOCK

HLTCHISS, JAILS A.II,ISEIG

ทc. 1.01: (1'0).

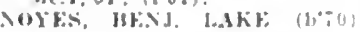

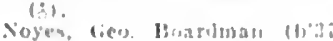

Noye's

STRATTON, 300, FRANKLIN

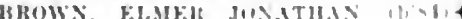

IIC. 10 : 11"101.
STRONG, 627 FRANKLIN

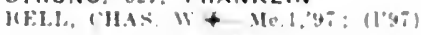

SULLIVAN, 325, HANCOCK

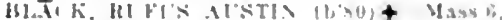

(0)i: (1'05): ALR.

SURHY, 900, HANCOCK

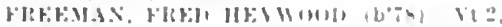

out; (1.11)

SWANS ISLAND, 800, HANCOCK

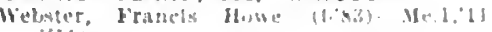
IIII!

TENANTS HARBOR, 2,000, KNOX

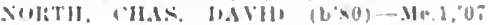

$(120 \%$

Thumpen vlater veranus (beti) vars 11: (1"ii).

THOMASTON. 2,688, KNOX

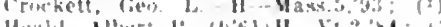

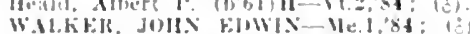

THORNDIKE, 589. WALDO

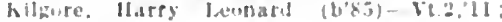

(l)

Porne. Frank Wilmens (b's0)-Temol11.03;

TOPSHAM, 1.000. SAGADAHOC

('urtls, Hartis 0). (b)(il)-Me.1, S1; (j)

TREMONT, I, I16, HANCOCK

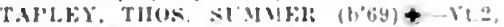
:99: (l'39).

TURNER, 1.000, ANDROSCOGGIN

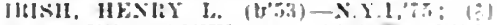

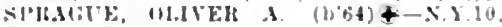

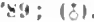

UNION, 1,260, KNOX

II.UILEY J.IIREXZO W.SI.TEIS (b6\%) 1) 1,$\left.98 ; 11^{\prime 98}\right)$.

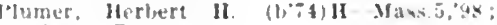

$(10,0, i): P$.

UNITY, 922, WALDO

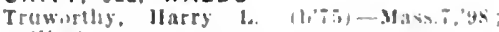
$(1, y x)$

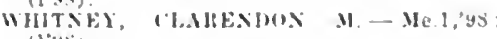

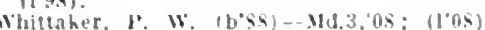

UPTON, 232, OXFORD

Hibntt. Claude t"pton (b'66)-Minn 4,04 (辛).

VANBUREN, 3.065, AROOSTOOK

Albert. Louit X-Que.3."is: $\left(1^{\circ} 05\right)$

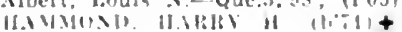
$00 ; 11 \% 0$ i

Pellelier. This II - 0 : (f): not In uractice

VANCEBORO, 870, WASHINGTON

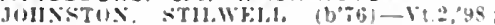
$(1,3 S)$.

VINAL HAVEN, 2.338, KNOX

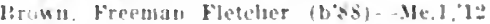
$11,1=1$

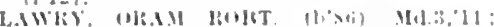

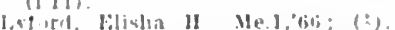

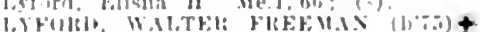

I1: 1,$193 ;(1+104)$

WALDOBORO, 2,656, LINCOLN

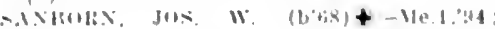

WARREN. 1.3\$2, KNOX

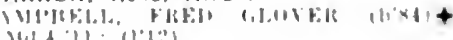

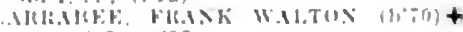

$1111.0 \% ; 107$

WASHBURN, 1.223, AROOSTOOK

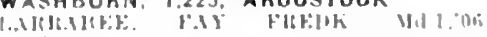

(1) $10 ; 1$

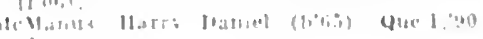

WASHINGTON. 1,000, KNOX

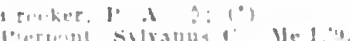

WATERBORO, I\$2, YORK

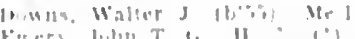

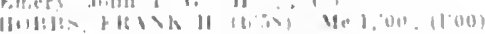

WATERFORD. 201, (IXFORO

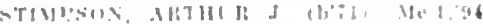

WATERVILLE, 11,458 , KENNEBEC

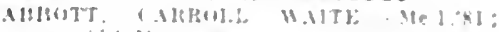

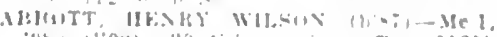

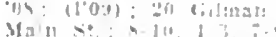

Aus? (4) 1-1: IBi): OALR.

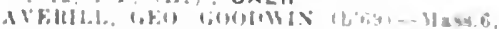

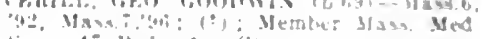

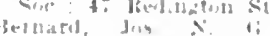

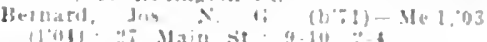

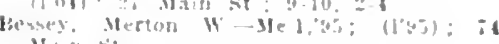

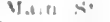

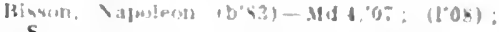

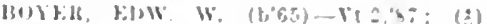

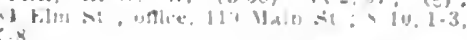

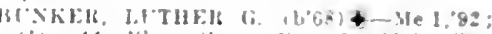

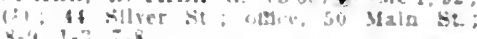
(liskis, WoNAll KRETT $\left.10^{\circ}-3\right) 4-$

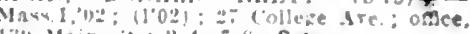
$13:$ Uain st: $2-4,-5 ; 5 *$

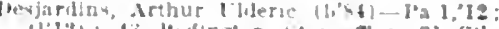

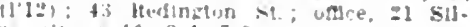

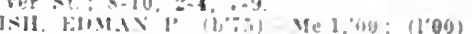

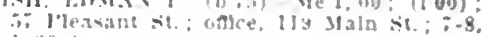
1 , :

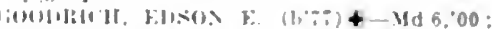
(1'00): :20 Matn st.; once, 60 Maln St: - + - s : S.

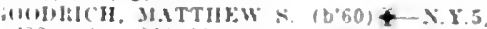

82; 121: 224 Main st.; once. 53 Maln S1: 4. $x-4: 5$.

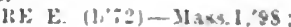
$(1993): 139$ Malu SL

[II.]. J. FHEIJK. $\left(\mathrm{b}^{\circ} 54\right)+-\mathrm{Mle} 1,95$ :

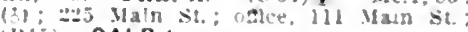
(1613): OALR.

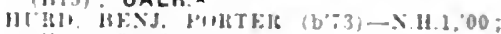
(l'0u): 5 silver st.

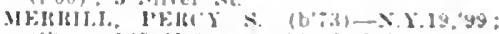

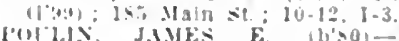

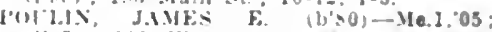
(1) 191 Water sis: unce, 131 Jiain phister. Halph lloward (b'65)-ra.9,90,

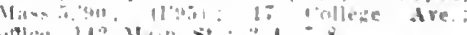

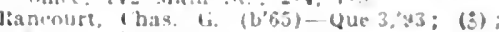

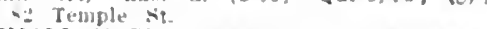

SMALL, MULT(IN MAXWELL (b\%3)-Me.I

THAYEl, FHELR. ('HAS. $(b+4)+$ Me. "rit: (1); 2lt Main st: orce, 139 Malo St: $:-5$.

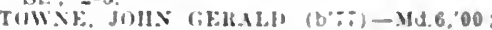

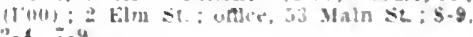
WAYNE, 709. KENNEBEC

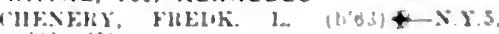
$\therefore 5: 13 \%$

WEBBS MILLS, 200, CUMBERLAND

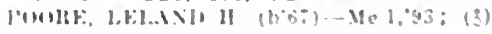

WEEKS MILLS. 330 , KENNEBEC

sendewick, atis Whlto $\left(b^{\circ} ; 6\right)-12: 004$ : (1"0)

WELD, Z\$0, FRANKLIN

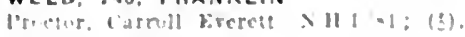

WELLS, 1,200, YORK

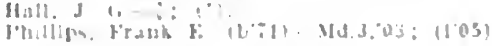
WELLS DEPOT, 130 , YORK

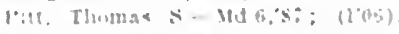

WESTHROOK, 8.281, CUMBERLAND

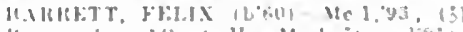

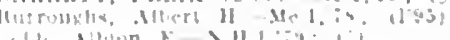

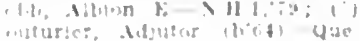
ips.

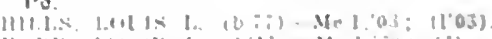

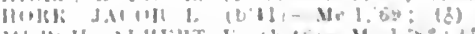

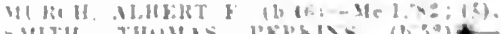

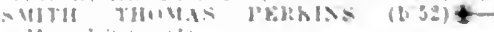

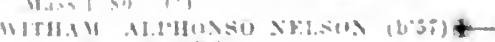

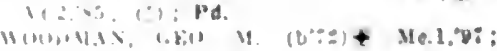

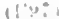


WEST BROOKSVILLE, 250, HANCOCK Farrow, Franklin-Mld, '9?; (

WEST BUXTON, 861, YORK

Meclure, (c. B. (b'56)-l'il.12,88: (1'05)

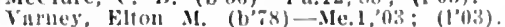

WEST ENFIELD, 380, PENOBSCOT

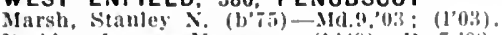

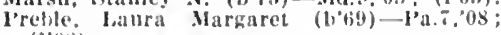
(l'is).

WESTFIELD, 689, AROOSTOOK

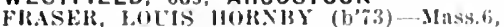
10; (III).

WEST FRANKLIN, 500, HANCOCK

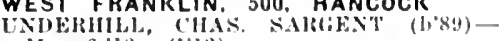

Mass.6,'12; (1'I2).

WEST GARDINER (R.F.D., GARDINER), 629, KENNEBEC

Merrill, H. F, $\oslash:(195) ;$ h.F.1. I5.

WEST HARPSWELL (R.F.D., BRUNS.

WICK), 120, CUMBERLAND

lillefleld, (ieo. S. (b)'5)-Me.1,?6; (l'96). WEST JONESPORT, 617, WASHINGTON

HAMBLETON, MARCLS HIILIN (1)80)Me.1,03; (1'03).

WEST PARIS, 700, OXFORD

Palciarl, Franels Henry $(1,+8)$ - Mie.1.7x;

WHELLR, FRE EVBRGT (b'72)-Me.I, 01; (1'01).

Yales, Oelavius King (1,33)-Me.1,70; (f).

WEST POWNAL, 250, CUMBERLAND

HEDIN, CARL, J. (b',2)Ð-N.H.1,04;

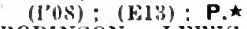

ROBINSON, LEWis $\left(\mathrm{b}^{\circ} 60\right)-\mathrm{N}$ Y.10,'80; (す).

WEST SULLIVAN, 600, HANĆOCK

HOL'T, HHKA ALLEN (b'68)-1'a 2,96; ( I'96).
WEST WOOLWICH (R.F.D., WOOLWICH), 67. SAGADAHOC

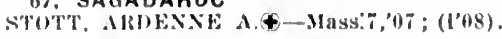
WILTON, 1,800, FRANKLIN

lerklus, belle bora Curtis (b'5i)-Md.5 (4.5: Asslstant loyslelan.

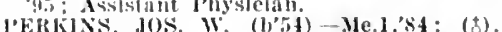

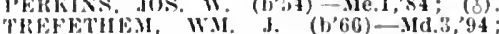
(1'95).

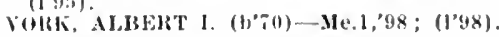

WINDSORVILLE, III, KENNEBEC

Ritley, Davis Augustus $\left(b^{251)}-\mathbf{N} .11 .1,7 ;\right.$; (1.3i5).

WINN, 700, PENOBSCOT

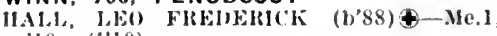
10: $(1,10)$.

Merrili, Ferdinand Wilsey (b'4:) - Me 1,72. (引).

Sherrard, Fredk. D.-.Vt.2,97; (1'98).

WINSLOW, 2,709, KENNEBEC

l'alie, Edwald Warrea (b'82) X.Y.1,13; ( )

WINTER HARBOR, 600, HANCOCK

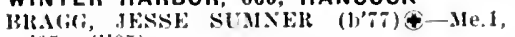
(0); (l'05).

WINTERPORT, 1,566, WALDO

Bovington, Elward H. (b'53)-0; (む).

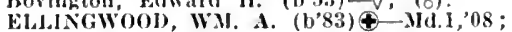
(l'08).

Fellows, Albert R. (b'51)-O; (1'95)

Feodrich, Edw. P. (b'74)-Mid.4,96; $(1996)$.

Mansfleld, Wdw. R.-X.Y.20, $07 ;\left(l^{\prime} 0 \tau\right)$.

WINTHROP, 2,088, KENNEBEC

Badger, Forrest Harlley (b'70)-Me.1,94: (ह).

l'AKKER, GEO. C.-N.H.1,'81; (お).

Taggart, Chas. W.-Me.1,73; $(0)$.
Towle, Geo. Nash-H-Mass.5, 90 ;

$(\vdots)$
WISCASSET, 1,273, LINCOLN

balley, Bernard Andrew (b'69) -N.H.1,90;

Dav be forest smith (b'78)-Me.1,05; (l'05).

leathers, Enoch (b'68)-N.II.1,02; (l'02),

WOODFORDS (IND. STA., PORTLAND), -, CUMBERLAND (See Fortland.)

WOODLAND, 1.500 , WASHINGTON

BAKKER, NAT. 13. T. (b'78) \$-Me.1,05: (l,05).

WYTOPITLOCK, 109, AROOSTOOK

Jolmson, Harry W. (b'79)-Md.3,'08; (l'08).

YARMOUTH, 950, CUMBERLAND

Bates, (ieo. Franels $\left(b^{\prime} 60\right)-X . Y .8,85$; (l'05).

STURHIVANT, (AARDINER L. (b'63)Me. 1,99 ; (I'99).

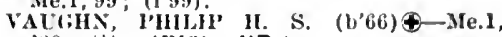
'89; (す); (E13); NP.ネ

YARMOUTHVILLE, 1,100, CUMBERLAND

Corliss, Walter (b'57)-N.H.1,'85; (t).

Russell, Frank Wayland-Me.1,97; (1'97). WOODMAN, DANL. NASII (b'61)-Md.3, :93; (ठ) ; Pd.

YORK HARBOR, 300, YORK

COOK, EDW, CHASE $\left(b^{\prime} 69\right) \oplus-M e .1,94$;

(†) SITR, HLHAH HOHLINGWORTII

(See Philadelphla.)

Varrell, Wm. Walton (b'82)-.Mass. i,'13 ; (1'13).

YORK VILLAGE, 1,200 , YORK

Hazen, Jasper J. (b'42)-Vt.2,'67; (t).

SMITH, FRANK W. (b'59)-N.H.1,83; (t)

Stewart, John Collant (b'50)-N.II.1,77; (ठ).

FOR KEY TO SPECIALTIES, ABBREVIATIONS, SYMBOLS, ETC., SEE PAGE 629

The P'hysicians' Purchasing Index, beginning on page 12, will be found a great concenience in those instances in which one wants to purchase something and is not sure where to get $i t$. 


\section{MARYLAND}

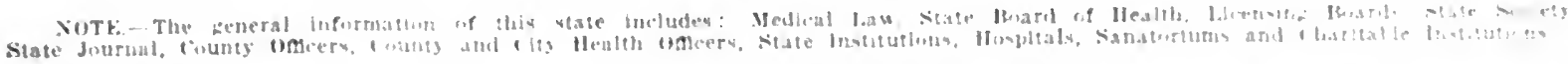

\section{MARYLAND}

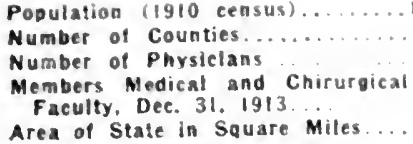

$1,295,346$

1.066

12.327
MEDICAL PRACTICE LAW OF MARYLAND

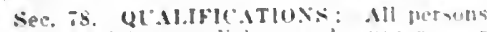
now practicint medicine and surpors or icine and surgers in any of their depart. ments, except dentistry, In lile state of Varsiand shall possess the gualiflcation required by this sub-tille.

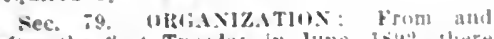
after the thrst Tuesilay In June, 15:32. Alere boards of Medical Examlners for the stilte of Marsland one representing the Mcdieal ant Chirurgleal paculty of the state of Marylande and one rupreseneing the Matsland Sante Homeopathle Medleal soctety if the state of Maryland. The memliess of saul State of Marsland. The metrliess of sam

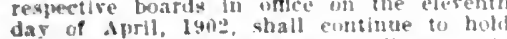
and exerelse their respective nnices isp to the first Tuesiay in June, 1902. On the frst Tuesday of June, 190$)^{2}$, said two buard. of Medleal kxaminers shall he reorzanized and thereafter said hoards shall les constituted as follows: Hach wh shall be ste lected by the Medical and thirurgleal far

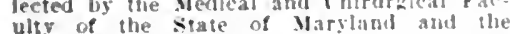
ulty of the state of Marylith amd the Maryland state llomeopathle Medical suclets, respectirely, at the annual mentings of sald respective sucletiex. and each appolntee is, immediately after his clection, to te furnished with a certifleate thermof by the soclety electing him. Fach sweh mem elected in the yos 1902. shall sirve for four

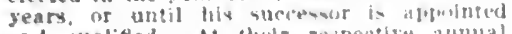
and tyualifler. It ihelr respective amual meetings held In the year lowiz. each of sald meetings held a the year shil elect the full number of elghe examiners fur its rendinetive board, of whom two shall le elected fur fors seats. iwo for three yearn. ind fur twis seaps, aud two for one sear, send thereafter

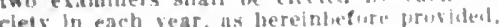
to serve enp a term if fous years or unt!l

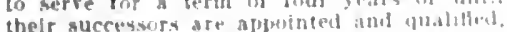

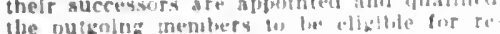

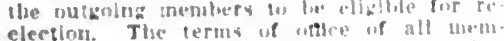
bers so electerl whall ingin of the flrot

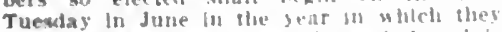
shall be respectively elected! wath twarel is to hare the excluvive riglit to esmithe gas upon the qualinestums of and licellag it

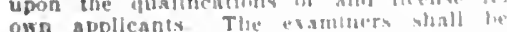

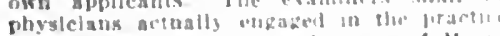
of merlicine or aurgers in the stale of Vars

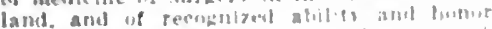

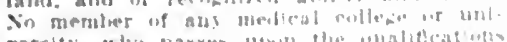

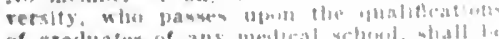
of Eraduater of any mintint

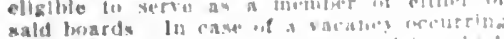

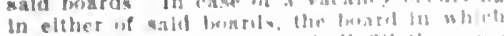

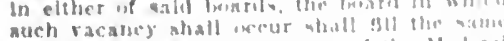
untll the nest antuat menting of the Warticit

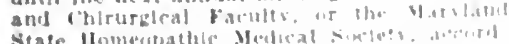

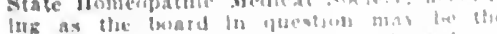
reprewentafle of olle or uthorg of va:l of

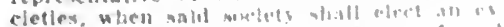
amber to serve for the retwa nut unexpireil tim.

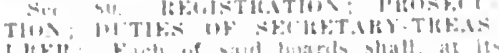

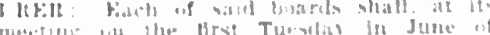

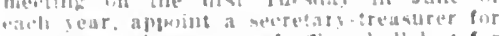
"lige lward, whome term of ande shall lant for the bear. and who slisll be cligilile for re appolinguent, and whose dutues shall the ay

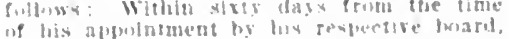

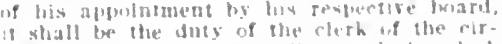
"ust cotert of Ballimore l'irs, and the clerk of the circuit easurt fur each counts in the state. to furnish the secretary-treasurer ut

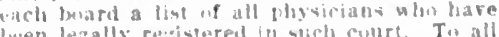
been lezally rewistered in slich const. Th ath

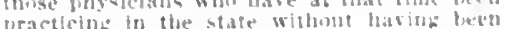

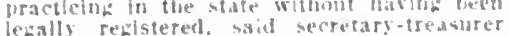

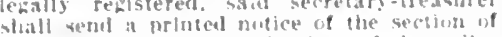
shatl rend a nrinted notice of the sectuon inf

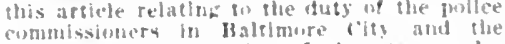
-heriffs of the counties of the state under thls law. Whthin four monthe of the time

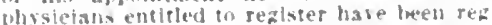
isferesl, and that the names of all thome who are nut intitled (1) he reglstered under thla ath-itle hare been presentud for mrosecu. ilon to the state's attorney of the city of litilimure, and of each county in the state in which the acouved, rospollvely, reslde Those phy dians, uho, being enetted to regetmuly at the explation of ahis time-four monthe from the election of the secretary treasurer of the hosil- shall also he prose culed, and no one after the elesenth das of

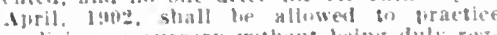
medicine or surgery without leeing duly res sub-tille. The secretary-treasures shall keep sub-title. The secretary-treasures shatl ketep the onteial recurds of the mari for whint he is seereqary. as provicled for th section st applicants for at leavt three rears. Mfter they hase been pased upon liy the lward. after which thes are to he destonged. and: complete list of all regletered phrstcians in the antire veate. He shall call to the atten Ilon of the state ats arneys of Baltimure che and if the liferent conntien theronghom

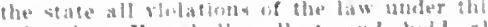
subs-atle Ilo whall pollece and hold all

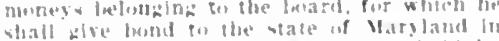

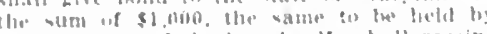
the preshleng of the loward. the whall receire fom llie fnchum of the mard ulach vilarg at

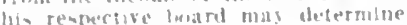

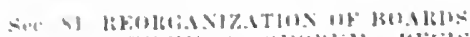

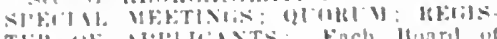

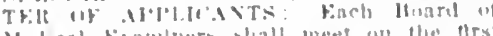

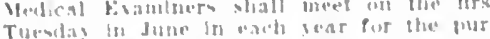
Tuevlay in Jute in wath lear for the mat

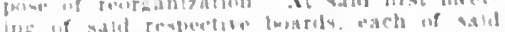

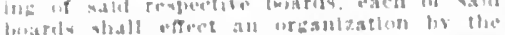

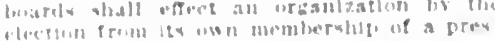

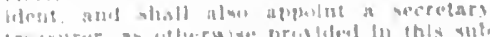

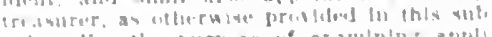

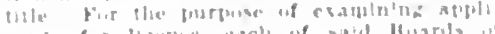

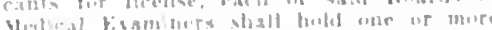

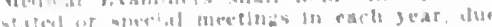

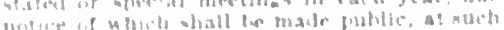

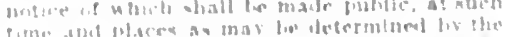

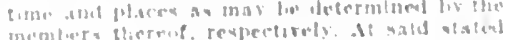

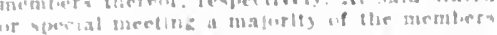

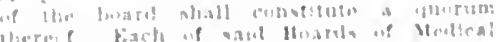

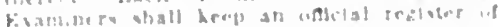

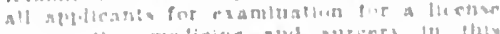

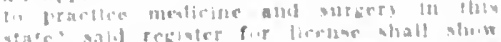

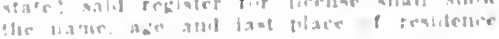

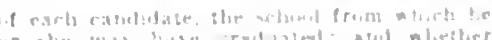

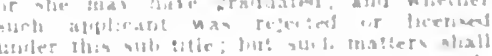

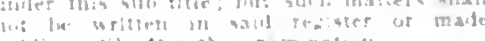
fublic unetl water the erimination

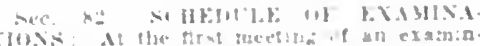

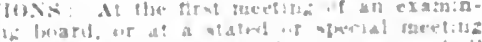

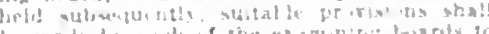

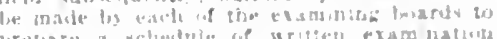

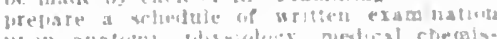

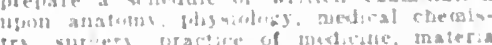

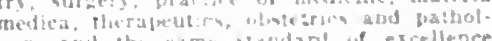

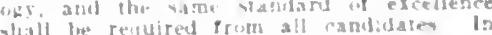

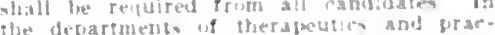

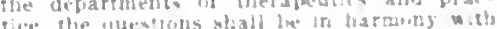

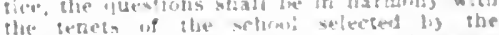

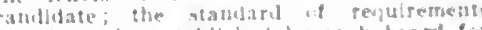

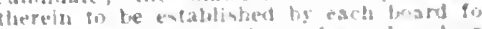
itinif. Wheneres uacmbers of amy lusard are the exalnation of applicanis for licenom. snltable remporars proriston shall be rusde for florough examination in each and all of the aforesald subjeots hy ruembers present. The examination whall the fundamental in character. The roten of all the eraminers present ihall he "ses" of "an," woltten with their signature unon the lackis of the the respective branches.

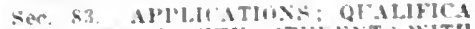

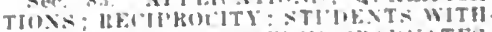

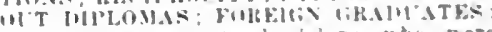

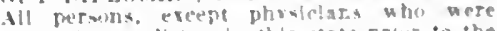
practicing medicine in thls siate prow to the Arst lay of Jamuary, Is a who are bow practicing milicine of surgery and can sald date sald robrician hall treated ta his fornessinnal capacisy at leath twelre permellolne or surgery in ans of the ro hanches atter the elerenth day of I liril. 1 wots. hall

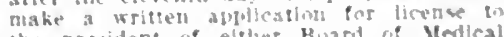
the prening which salu appliesint may elert. Examinat which sald aptricest mat that the

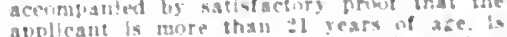
applicant is more than 1 years nf ace. is

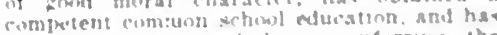
either recelral a dinna molerring the

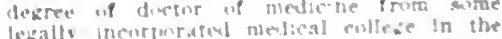
linted siates ur a digloma or bicense enn-

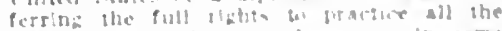

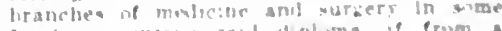

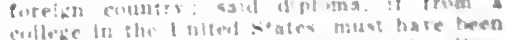

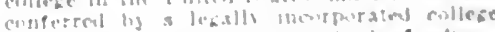

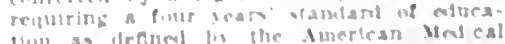

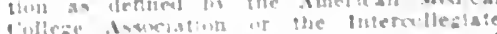
anzabice of the imerican Inst tuie of

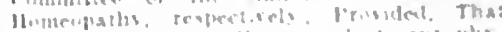

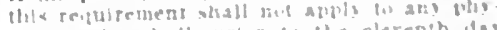

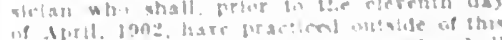

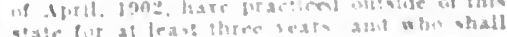

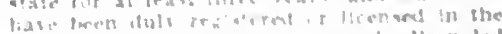

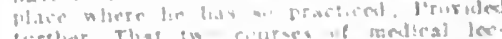

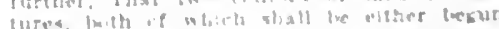

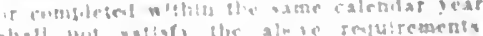

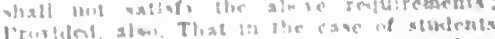

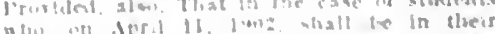

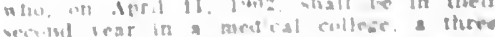

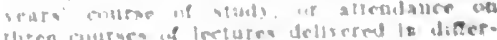

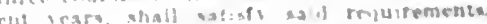

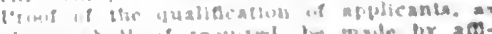


clarits at the time of the making of said

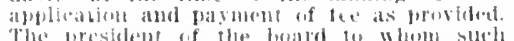

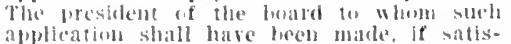
tied with the satme. shatif diriet the sceretary-treasure there of to issue to silal apsald applicallt shanl have passed an examination ats to proticicency satisfictery to sald bard, the presiclut thereof shall frimt w such asplicatic a license to practse medicine and surgery fin the state of Marylatud. if the

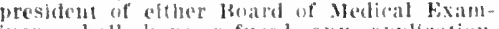

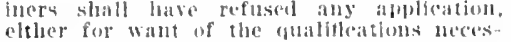
sary' to entitle such applie:ant to an exanination, is hereinbefore provided, of for want of profledency of such applictint upoun being subjected to an examination, then the entertain or palss ugen a subsefuent applícation from salis applicant untit ifter the expiratlon of six monthe from the rejectlon of sald previous ayplteation. The respective boards are authorized to licesise, without cxardination, atpplicants who present proper rertiflates of proftelency and profossional standing at the time of upplleation, issued by boards of medical examtners of the Ilstrlet of Colmubia and of other states, the requlrements of which are of as high a Medical Examlners of this state: provided such boards of such states or distriet grant the same privileges to licentiates of the examing boards of Marylnnd, such apslleants, same proof of anditications regulred of other applieants by this section. Medical students at the end of their seend year of
study who have, as rerified by the eertiflcate study who have, as rerified by the eertiflcate
of the dean of the college which they have attended, completed the studies of anatoms, physlology, medicat chemistry and materia medica in said college, shall on application, the examined in such studics by the state Lleensing lboard, the result of said examination to be considered as part of the final tion to be considered as part of the final examination. the full regular fee to be paid
at this time. no part thereof to be returned, hut placed to their credit for the remainder of the exanination yet to be taken. Iledieal students who have, as verificd by the certiffcate of the dean of the college which they, have attended, conpleted a full four years, course of studies and lectures, but who have application be examined in all the branches enumerated in Section 82 hy the state Licensing Bonrd. the final certificate and license of the said board heing withheld license of the satd hoard heing withheld
until the diplowa of the proper medical college, with the candidate's name inseribed, be lege, with the candidate's name inseribed, be
produced to the seeretary of the board. Diplonas presented by graduates of foreign colleges shall be accepted if a course of four years' study has heen required by said for

Sec. 84. INTERSTATE REGULATIONS: Any phrsician who may change his residence
from the District of columbia to the state of Maryland, or who while living in the listrict of Columbia, shall desire to practice medicine or surgery in the state of Maryland shall, upon application to the examining to a license, without fee and without examination, provided, that the application be properly endorsed at the time it is presented ly the examining board of the District of Colmmbia, ecrtifying to the proflciency and prosided, further. that the examining board of the District of Columbia shall, under the laws thereof, grant like and equal privileges may remove to said Distriet of Columbia, or while continuing to reside in this state may desirc also to practice in said district.

sec. 85. ExAMHATloxs: All examinatims shall le combeted in such manner that the name. schow of graduation and preparamade known to the Board of Examiners until Inis examination papers have been graded. applicant receiving a majority of the f the board before whom the applicant

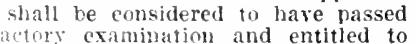
it satiofactory cxamination
the license of said board.
Sece. 86. FEEs: I fee of $\$ 15$ shall be paid to the weretary-treasurer of the board
hafore whom the ajulleant appears before hefore whom the abslicant appears before
such examination is had, wheh pasment chall contitle saluf applteant to a second exannination, In case of fallure, at the expirathereatter: satid foe to he applled by said luatrit.

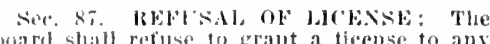
board shatl refuse to grant a licelse to any
applieant who maly he rattieally defleient in applieant who maly he ratically defleient in
his exambitions in any e'ssential branch movidiel. that in any ease of faiture at any surh examination, the candidate slanll not he permitted to take another examination before wher board until after the expiration of six munths from the sate of his rejection; provided however that any applleant who has the eleventh day of Anril 1902, or who shall the elefter so fail, shall be credited as havhe passed in such hranches us he has or shatl have been found proticient in, and be shiall not he agilin examined in sald subjeets.

See. 88. Fol M OF IJCENSE: Every $11-$ rense to practice medicine and surgery, Issued pursuant to the provisions of this sub-title, shall be subscribed by the president and secretary of the board before whom the applicant has bassed. It shall also have affixed
to it by the person authorized to affix the same the seal of the snicl Medical and chirurgical Faculty of Maryland or of the Martand State Homeopathic Nedieal Soeiety, as the license may require, every such the following effeet.

To all whom it may concern, greeting:

Be it known that - on the - D., - having of
day of fered to us satisfactory proof that of was more than twenty-one years of age, education, we, therefore, give a written order for the cxamination of said before one of the Boards of N saidical $\overline{\mathrm{Ex}}$ aminers of the state of Maryland; tbat the said was fulty examined before our said board and found proficient and
qualified to practice medicine and surgery : we, therefore, hase granted to said - . - this our license to practice medicine and surgery in the state of Maryland as a physician and surgeon, and have caused the names of the pressubseribed and the seal of nur society subscribed and the

witness our hands and seal of our Witness our hands and seal of our
said society, this day of S. D. D.

(Seal of Society.)

Sec. 89, REGISTRATION OF LICENSE Any person receiving a license from either of said boards shall file the same at once with the clerk of the circuit court of the county in which he or she may reside, or with the clerk of the circuit court of Baltimore City, if said person sliall resicle therein, and it
shall be the duty of said clerk to register the name of said person and of the president of the board signing said license in a book kept for the purpose, as a part of the records of his office; and the number of the book and the page therein containing said recorded copy shall be noted by sald clerk upon the copy shall be noted by said clerk upon the
face of silid license. In case said person face of silid license. In case said person
should, after the recording of such license, permanently remove his or her residence to some other part of the state or to Baltimore City, he or she shall thereupon at once file said license, or certified copy thereof, for
record as aforesaid, with the clerk of the circuit court of the county or eity to which he or she shall have so remored; said records shall be open to public inspection under proper restrictions as to their safe keeping, and in all legal proceedings shall hare the same weight as evidence that is given to the
records of conrerance of land. The fee for such registration shall be 50 cents, to be paid by the person whose license is registered. The elerk of the superior court of Baltimore City is authorized and direeted to
turn orer to the clerk of the circult court turn orer to the clerk of the circult court
of Babtimore City the register or registers of licensed physicians which he has been re- guired to keep mole and by virtue of the

See, 90. I'ENAlTiks: Any person to whon the provisions of this sub-titie applies. practichn or antempting to practlee medicine "r surgery int thise state, withont first huards of dedical kxamhers, shall be gutlty of at mistemeinor, and slatil pay a fine of of it less than $\$ 50$ nor mire that $\$ 200$ for eacle corronse, or th tefoult of payment shall be conthed in the eity or eoninty jall until the fines and costs are pafd, and shall be
debarred from recovering compensation for serviees rendered als sach physietan or surgeom.

Th ANAL REPUITS : sald boards shall make at report to the Medieal and $\mathrm{Ch}$ rurgieal Ficulty of Maryland and the Maryland state Houmeopathe Ifedleal Society, respectively, at each anuual meeting of said respective societies.

Sec. 92. CERTIFICATES OF PROFES liwn request issue certificates of professimal standing to bhysicians moring out of the state.

Sec. 93. Nox-REgisterED sIILL NoT IRACTICE : From and after the first day of July, 1894, no person shall practice medicine or surgery in the state of Miryland unless siclan or surgenn in accorlance with the provisions of the sub-title of this article.

See. 94. APPLICATION FOR REGISTRATION: kvery person who was practicing before the first day of June, 1892, slatl he entitled to be registered as a physician or surgeon, or hoth, upon making application to sure president of either board of State Medthe president of either board of State Yledieal Examiners, which application shall be applicant taken before any officer entitled to administer oaths under the law of this statc and shall state that the applicant was iclne in good standing, actually engared in the practice of such profession in sald state, on or before said first day of June, 1892 . And upon receiring said aptlication, and ment therein contained, said president of ment therein contained, said president of said board shall issue or endorse his per-
mit for such applieant to be registered, upon a copy of such application, which permit shall also be countersigned by the secretary of said board; and any president of such board, to whom such applieation is addressed, may in his discretion make inquiry and examine witnesses under oath, or restatements contained in such application, for a permit to be registered; and if the president of either of such loards of Nedical president of either of such Boards of Metipeal and shall refuse the same, then 10 president of the other of said boards shill entertain or act upon any application of such applicant for such permit. And upon the pre-
sentation of a permit to be registered, signed by the president and countersigned by the secretary of either of said Boards of Nedical Examiners, to the elerk of the count $y$ where silch applicant may reside, of to the clerk of applicant shall reside in Baltimore City, it shall be the duty of the said elerk to regisshall be the duty of the said elerk to regisname of such applicant as physician or surgeon, or both, in a book to be kept for such purpose, and a certified copy of sueh entry of registration, under the seal of the court, sliall be legal cridence of such registration in all the courts of the state; provided, howerer, that the prorisions of this sub-title in the state of Maryland prior to June, 1892, and who registered as pra

Sec. 95. All persons who hare commenced to practice medicine or surgery in the state of Naryland since the first iay of June, 1892, or who shall hereafter commence to shall not be entitlerl to be registered in the registry of physicians and surgeons, as required by law, except upon flling with the clerk of the cireuit cuurt of the county or city 
In whilh he our she shsll resibe a beense from whe if the lluly collotifuled la arth it ance with the ternis of sectlots on and $\mathrm{sa}$.

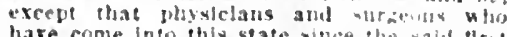
hare come into this state vince the wald flrat

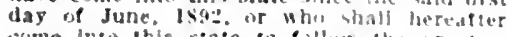
of medictne state the follus the practure

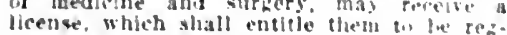

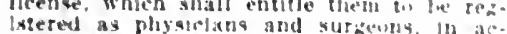

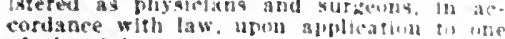
of the duly contiluted hatrls in Vedfed bixaminers In accordance with the peolistons of section $90^{\circ}$ of this sub-title

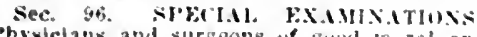
protestans and surens protesslonal slanding who shall herrafter come moto this state with futent lo folluw this state, being graduates of a meellual eol. leze or untrersty of com standing at harlng a certiflcate or license from a lward of medical examiners of any state wluep the regulrements for practice are are al to those regulred by the board namial in this sub. of either Boand of Medica! Fiamlners of this state, whlch applleation shail toe made the oath and shall state when and bus ling such applicant has lieen engaged in the neas. thee of medicine and surgery and frut what medical college. untverity or othe" institutlon of learning he or she has graduated. And, thereupon, the ltoard of Medical Exam. lners shall hare the authrity and discretion io regulre applleants to underto an slons of Secions 81 to 85 , inclusire, 18 may regulre sald applleant to cubmit to a special examination. the terms and methuls of which shall be prescrlbed by the Board of Mediral Examiners, and npon pasing the fee for the examination and determination of sald the examination and determination of sald Ifled to practice medleine and surgery, and that he is entitled to a license, a ficense shall be losued to him to the sasne efreet as the form of license set out in seetim ss. Fhich license shall be fled and reeordes is prorided by Section 89 , anis it shall then be the name of the person so licensed as physlclan or surgeon, or binth, in accorlance with the prorlsions of this sub-titis.

Sec 4i, FEE FOR REGISTR.ITHN: AUI persons whose licensey hare been herpingre tlled and recorded in accordance with secthon sa shall be held to the duly reglitered siona of section 94 , and alt persins who shall hereafter receire and fle licenses to tie recorded in aceordance with sald socthon 8.0 shall be reglstered as physicians and surgeons under sald section, and the ferd in lise pald for such reglstrasion and for the regit tration of the apslleation to the elerk. or the lleense therewith
quire, shall the $\$ 1$.

Sec. 98. PENALTY FOL FAlSE STITV MBNT: If any person shall lnglawfully i, tain and procure himself to be regluterion an physiclan or surgeon. either by false of untrue statements entialned in his arplles.

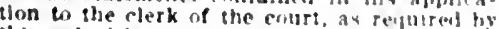
this sub-title, or by presenting in sald clerk a false or untrue licenser, or ente fratudu. lently obtalned by falve and foaldulent statements made in one if said biarise nf Medleal Eraminers, he of stie shall he deemed gulle of a mlstemeanits and shall he flned net less than $\$ .50$ nor more than s.no, and shall forfelt all rlalits and Im.

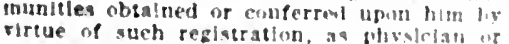
virtue of
surgeon.

Sec. 99. PRACTIN, MTHu't LA

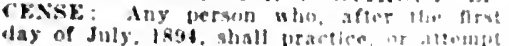

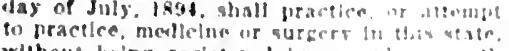

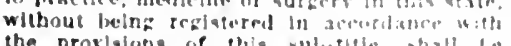

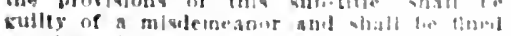

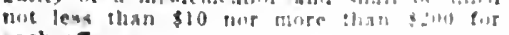
"ach ofense.

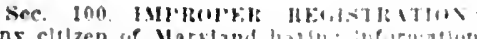

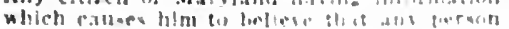

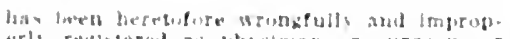

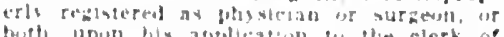

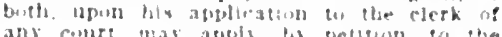
any conth, mas apple. Bu pelitum, to the

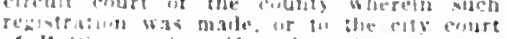

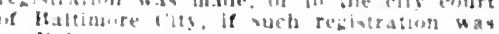

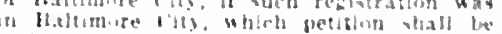
under wathe and thail efate that the gret

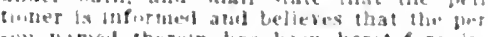

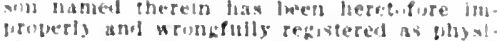
cian 05 surgent or beth. upm his on appliextwh and andasit upin the realster uf

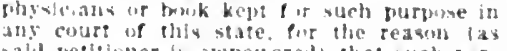
salid getitinger is enmonered) that such per-

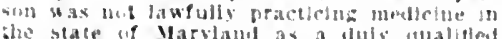
the state cif Yarylam as a duls jualited

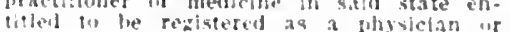

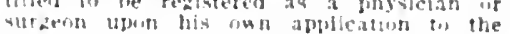

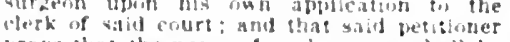
irass that the name of weth grersen shall be siruck from the registry if phssleisnt afore. solid. Ipon the thling of such petition the bass an urder requlring the berwn iherein slleged to be wronafully or imbregerly rea latered to answer the sance. nniler nath, on or before a date to be named whin thirs hiow eause, if any there be. why the prayer if such petillon shoulat no be the which order shall she served umon said lian. named peronn: and if said petition shall nin be answeres within the time named. ay aforesald. ur If the answer thereto shall the adjudired insuntelent by the conrs. thren the name of such peratin alleget in be wrongfully ur imoroperly regixterend sliall toe stricken from the reglistry of phosicians of surgenns where the same shall have been reglstered: bue if side petition shall be answered by the defendant. Leing the person atialnst whom li is exhltbited ty an anauer under oath, fairly and fully denying the rassed slatl be heard and determined by the court. and elther party may be entitled to a jury trlal hefore a jury of the regular In said court: and the defentlunt stail be competent and compellable to restify at such he:tring. and unon such heariut the such shall gender judzment with costs azainst the shall render judgment with costs azainst the mine that said defendant was not practeing mine that sald defendant was not practicing before the date of Jume 1. 1s:t? not theing a lawful practitionet of medle ine in said state, on or hefore said date, it shall bast ant to be strleken from the realstry of

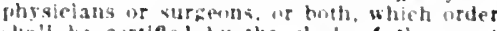
shall twe certlfed by the clerh of the cont we shall thereupin vithe his name from said

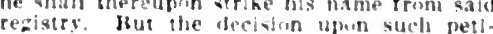
registry, hut the decisin upon such pets.

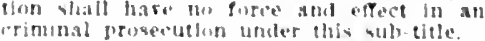

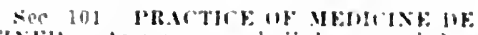

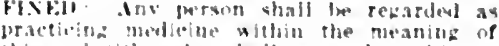

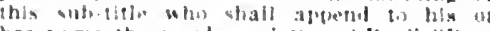

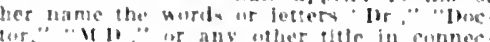

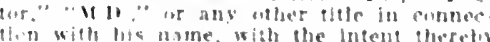
for with lite mane, with the Intem thorely

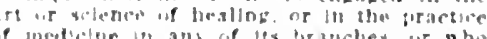
if medtetser its ans of les branclied, io whe

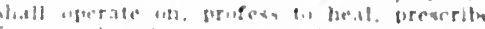

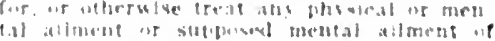

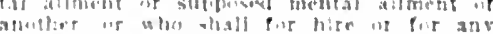

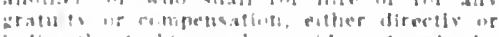

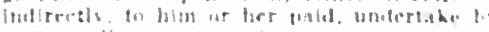

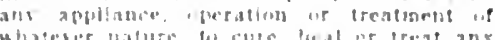

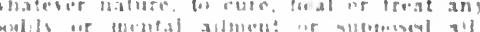

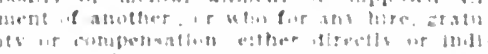

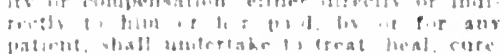

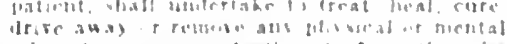

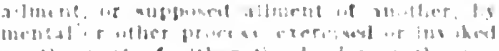

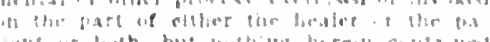

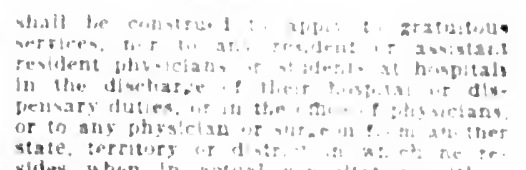

lezal noctiefonim

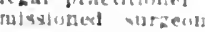

Army, ot Nury,

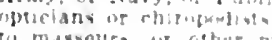

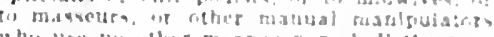

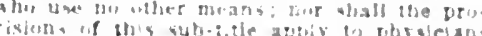

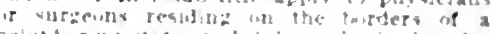
nelotureng state, and dulv auphorian under

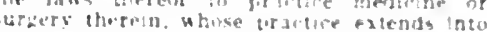

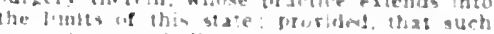

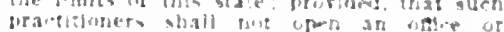

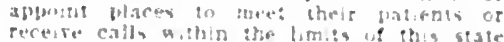

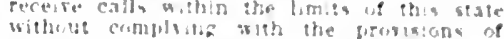

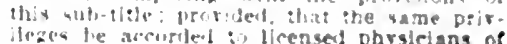

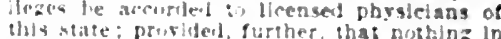
this suld the chall annul any of the proptshall apply to any tille "leeritiatry"." not dental suraery now borticing in ibe sald itate of Marbland with the siats vule

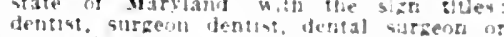

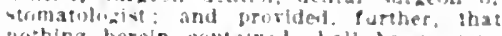

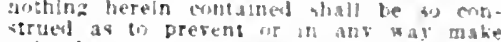
umlatul or inferfere with the ale by manu. factiring, whulessle wr getail drugalas or ans perouns dealing in drue no mesticines of ant nempletars or patent medwine
amclal or standard dru: "ir medicine

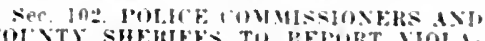

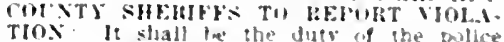
TION It shall the the duty if the blifice sherit of each collats in llip state, in the

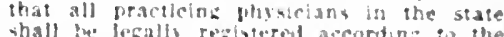
thall be legallo reglotered accorting in the

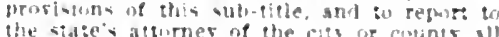
case's of the riolation of the provistons of

sice 10\%. DITIES OF SBA RETARY It shall the the duty of the secrmary of pither fixaminers th inciulte intu all roulations of law thnder thls artcle, and th institute alt primeeding or prosecution therend. and all either of whe toards herennder shail be altorist and naid wut of the funds scousted

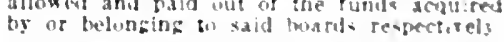

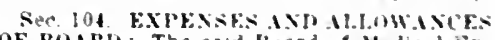

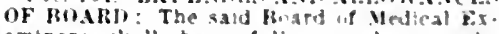
aminers shall hare full cons.,l crer the callected from the fers anil charieg auther|zed to be inalde under the term. at this

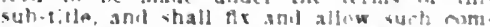
grenathon as they mas deen proper for serp.

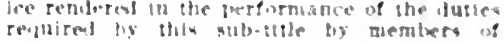
and luostl or "thers with the full puwer

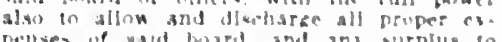

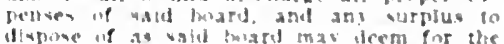

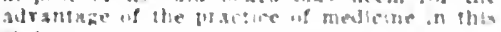
itste

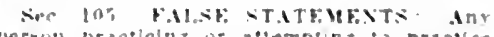

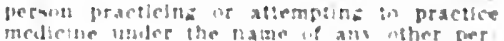

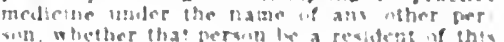

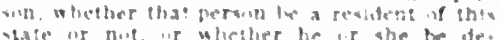
thate or nut. "s whether he er the be de.

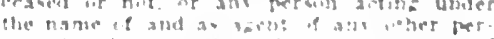

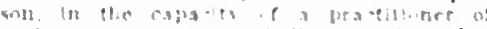

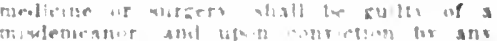

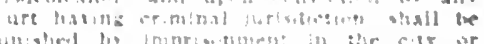

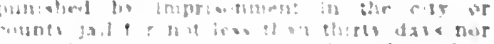

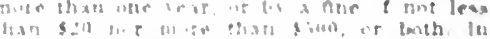

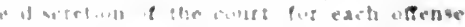

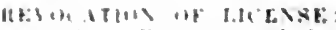

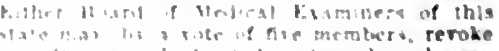

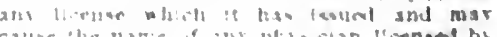


sald buard to be remowed from the register of the licentiates of the city or county where of the licentiates of the city or collnty where It may he recorted, for any of the pollowing
eanses, to-wit: The use of pratul or cleception in passing the examination provterl in this sub-title, labbltual drmukenness. crminat abortlon, convidetion of erime Involving moral turpitude or umprofessional or dtshomorable eonduct. Isefore proceeding to revele any such license, the ferson afatinst whom eomplaint is made shitl be furnisherf with cony of the complatint and chlarkes made

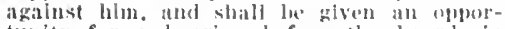
tunity for a dearing before the lonatri, in persion or by attormes, and at such heirlng testmony nily the sterered forr and atritinst the

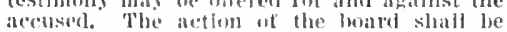
reduced to writills, stating also the reilsons

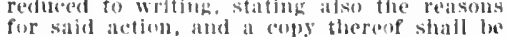
delivered or mailed to the person against whom compla fint fs made; within sixty diays after sald notice of reveration of license shall have lreen delisered or maled to ingy persoll, sald party shall have the right of comte wherein he maty reside. the judive or judies of which said court slinll fully liear and determine all matters connected with the action of said board from which appeal is

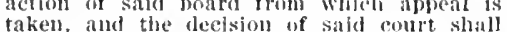
be thral; should no such ajpeal be taken le thinal ; should $10 \%$ such ajpeal he taken
witnin sixty days. or should said appeal result Ju the aftirmation of the action of said loward, the elerk of the eireuit ecourt or eourts where said lleense so revoked shall lase been reeorded shall, upon due notice from the secretary-treasurer of satd board. strike off the name of said party from the list of licunsed practifloners recorded upon sald register. At any time within two years from the revocatlen of any license, the board revoking the sime mas, lis a vote of five members. issue without exanination, a new license to the person whose lleense was so license to the person whose lleense was so
revoked; but after the revocation of two revoked; but after the revocition of two
years sucls person can obtain a new license only by compliance with the same requirements which are imposed on of her applleants for licenses under this sub-title.

\section{STATE BOARD OF HEALTH}

W'm. II. Weleh, President, Baltimote: Edgar A. Jones, Cambridge; W. W. Ford, Baltlmore; Nathan R. Gorter, Baltimore; John E. Greiner, Baltimore: Hon. Edgar Allan Baltimore.

STATE BOARD OF MEDICAL EXAMINERS Herbert Harlan, Tresident, lBaltimore; B. W. Goldsborough, Cambridge James A: Stevens, Easton; Lewis A. Criffith, Upper Harry L. Homer, Baltimore: A. L. Wilkinson, Raspeburg: .I. MeP. Scott, Secretary and Treasurer, Ilagerstown.

\section{STATE HOMEOPATHIC BOARD OF MEDI- CAL EXAMINERS}

Wm. Dulany Thomas, I'resident, Baltimore; H. II. Stansbury, Baltimore; G. I. Ewalt, Baltimore; M. E. Shamer, Baltimore; G. H. Wright, Forest Glen; c. F. Gondell, Frederick, I, Stautfer. IIagerstown; O. N. Durall, Secretary, Baltinore.

\section{MEDICAL AND CHIRURGICAL FACULTY OF MARYLAND \\ Officers 1913-14}

Randolph Winslow, President.....Baltimore A. L. Franklin, Ist V.-President.Cumberland C. R. Winterson, 2d $\mathrm{v}$.-President...Elkridge Gorlon Wiłson, 3d V.-President...Baltimore John Ruhräh, Secretiry..........Bałtimore Wn. S. Gardner, Treasurer........Baltimore

\section{State Journal}

Bulletin of the Ifedieal and Chirurgical Faculty of Marylind, Baltimore. A. P. Herring, il. M., editor.

\section{Ceuncilers}

1. l', Barker, Batimore; David streett

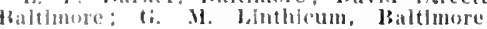

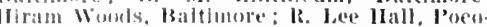
moke city; Cilly siterle, Cambridge: Js ('arrico, Bryantown; ('has. O'bonovan, Baltimore; t. E. beets, Clarkshurg; leregrlue IIroth, ir.. IItgerstown; J. S. Bowen, Ilt. Waslibugtuin.

Component County and Other Societies of the Medical and Chirurgical Faculty of Maryland

HLERANY rOENTY

1. 1. foltusm, l'resident........ Cumberiand 11. 1. Simmons, setretary....... Cumberland ANNE ARI NUEL COLNT

Thus. 11. Bratslaw, President...tilenburnie L. If. Henkel, Ir., Secretitry........mmapolis 13.ALTIMORE CITY

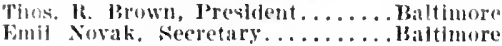
B.ATTIOHE (OOENTY

(' Mecormick, l'resldent. . Sparrows l'olut

.1. Slommonier, Seeretary...... Catonsville CALVERT COENTY

tomuton Wilson, I'resident......Frlendslin

I. I.eitch, Secratary........ ifuntingtown CAROLATE COUNTI

l'. R. Fisher, bresident...........Jenton CARROLL COENTY

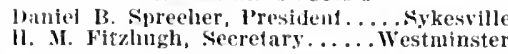
CECH COLNTY

Ernest Ruwland, I'resident.... Liberty firove Howard Bratton, Secretary........... Elkton CHARLES COUNTY

I. W. Mitehell, President...... Indian Head

Thomas s. Owen, Secretary......... Pa Plata DORCHESTER COUNTY

Guy Steele, President........... Cambridge FREDERICK COUNT

Raljh Jrowning, l'resirlent....... Myersville 3. 0 . Thomas, Secretary............. Frederick ILARFORD COUNTY F. Lee Hopkins, President...IIavre de Grace
('his. Bagley, Seeretary........... Bagley HOWARD COUNTY

W. R. White, President......... Ellicott City Wm. B. Gambrill, Secretary..... Ellicott City KENT COUNTY

H. G. Simpers, President....... Chestertown F. B. Jines, Secretary ......... Chestertown MONTGOMERY COUNTY

('has. H. Nourse. President..... Iarnestown rlaborne H. Maunar, Secretary... Rockville PRINCE GEORGES COUNTY

II. B. MeDonnel], President.... College Park s. M. Mesillan, Seeretary......... Riverdale QUEEN ANNE COUNTY Ii. Perey Kenty, President........ Sterensville SOMERSET COUNTY

Gordon 'T. Simonson, President.....Crisfield Henry M. Lankforl, Secretary.......... Princess Anne TALBOT COLNTY

Samuel C. Tripje, President.....Royal oak

A. IicC. Stevens, Secretary...........Easton WASHIXTTÒN COUNTY

1). A. Watkins, l'resident........ Hagerstown I. II. Wertz, secretary...........Hagerstown WICONICO COUNTY

John M. Elderlice, I'resident..... Salisbury Henry s. Wailes, Secretary........... Salisbury WORCESTER COUNTY J. R. Bishof, President............ Showell
E. E. Wisehart, Seeretary....... Snow Hill

\section{COUNTY HEALTH OFFICERS}

County Allegany,-J. C. Holdsworth........ Adidiand Allegany.-J. C. Holdsworth.......... Midand 5th District, Ist Precinct.-Chas. H. Brooke ................ Brooklyn

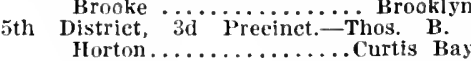

Ibaltimore City.-Nathan R. Gorter.

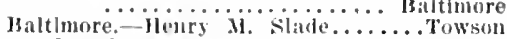
listriets

Ist.-11. 11. West........... Catonswlle 2d. - II. k. Shlpley........... (iranite 4th. -llenrs it. Siatle...... Relsterstown

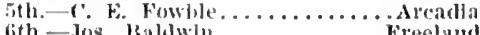

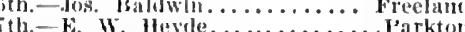
8th.-Wenj. 1benson.......... Cockeysville

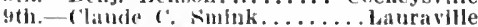

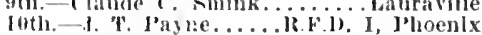

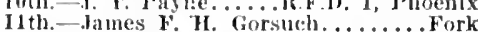
12tl. - W. k. irctaushat. . irighlandown I3th.-Frank if. Ruhi......... Lansdowne 14th. - Wnt. F. Clayton........... overlea 15th.-John W. IIarrison......tiddie River

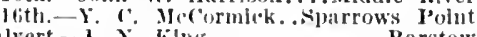
Calvert.-1. N. Klug............ Barstow Carrull - R. Downes............ Preston Ist.-Franklin it. Seiss........ Taneytown 2l.-- Luther Kemp.......... Jnlontown 3d.-G. Lewis Wetzel........ Union Mills

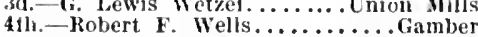

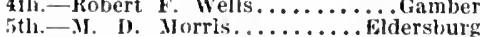
6th. John F. B. Weaver........ Wanchester 7tll.-Chas. It. Foutz........ Westminster 8th._l. C. Wells.............. Hampstead 9th.-Edwin li. (ronk............ Winfleld 10th. Clas. II. Diller............ 11th.-Geo. H. Brown........... Wew Windsor 12th. - das. Watt.......... Union Bridge

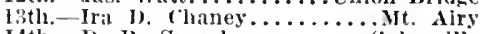
I4th.-D. B. Sprecher........... Sykesville

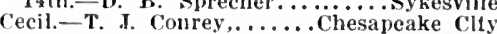
(harles.-1. 13. Spencer........... Relalt on borchester. Victor C. Carroli.... Camhridge Frederick.-James M. Goolman..... Frederlek Garreti.-X. I. Broadwater................ Itarford.-Frank Le nugles........ Bel Alr Howard County.-

1st.-W. K. Eareckson..........Elkrldge 2d.-W. C. Stone................. Ellicott City

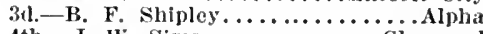
4th.-J. W. Sims................ Glenwood 5th.-s. A. Nichols............. Dayton

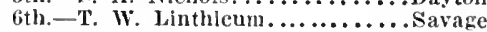

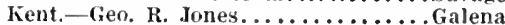
Montgomery.-C. II. Mannar....... Roekville

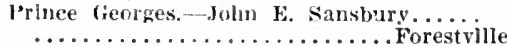

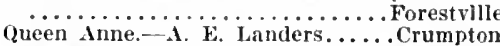
S1. Marys.-F. F. Greenwell...Leonardtown Somerset.-T. Jacob Smith...Princess Anne Talbot._E. R. Trippe............. Easton Washington.-W. 1. Campbejl...Hagerstown Wicomico.-Chas. R. Truitt........sallsbury Worcester.-I'aul Jones............. Snow Hill

HEALTH OFFICERS IN CITIES OF 2,000 POPULATION AND OVER

Annapolis............Wm. S. Welch Baltimore................... Gothan $\mathrm{k}$. Gorter

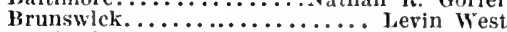
Cambridge...................... Jos. Walliek Chestertown............ Har. W. Simpson Chestertown........... Harry W. Simpson Cumberland.............. E. E. Collins

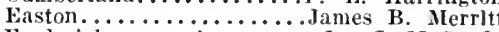

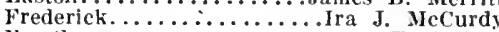
Frostburg.............. T. Griffth Hagerstown..........Wm. D. Campbell Harre de Grace.............James H. Bay Laurel.................. F. Taylor Pocomoke City................... wedk. Wilson Salisbury.................. Truitt Salisbury $\ldots \ldots \ldots \ldots \ldots \ldots \ldots \ldots \ldots \ldots \ldots \ldots$
Westminster......

\section{Baltimore}

\section{STATE INSTITUTIONS}

Maryland Penitentiary Hospital, Forrest and Eager Sts., Battimore. Established 1811 ; general; 25 beds; Wm. F. Schwartz physictan in charge; John F. Leonard, arden.

State Industrial School for Girls, Baltimore. Established I867; Mary Holland Keene, superintendent.

\section{Cambridge}

Eastern Shore State Hospital for Insane, Cambridge, Md. Established 1913; public; nervous and mental; 300 beds; Chas. J. Cares, physician in charge. 
Catonsville

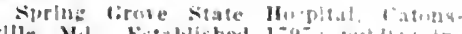

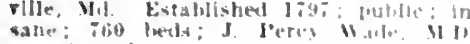
saber interident.

\section{Cheltenham}

Houve of Befurmallum. Melienfann. Mat Establlshed 18:

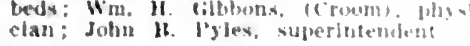

\section{Crownsullle}

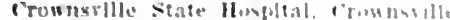

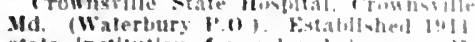
state Inatlution fur colloted invane: : is beds: Robert I. Whinferchle, medical sujer Intendent.

\section{Frederiek}

Maryland school for the lledf and liumb. Fredertek. Md. Fitalill-finl this

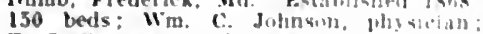
T. C. Forrester. princlial.

\section{Jessups} Iid.

\section{Loch Raven}

Maryland school for boys, lowh karen.

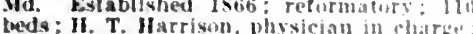

A. E. Lipham, superintentent.

\section{Melvale}

Industrial Ifome for colored Minla. Mel.

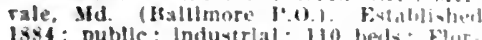
ence $\mathbf{S}$. Penninglon, sulverintendent.

\section{Overlea} Maryland school for the Mltud, Merlea
Md. Established I853; private: jou heds Johu F. Bledsoe, superinterdent

\section{Owings Mills}

Rosewool stale Tralning. Shlukel for

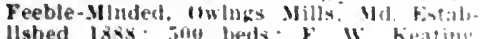
medical superlutendeut.

\section{State Sanatorium}

Maryland Tuberculosis sanutur!um, state

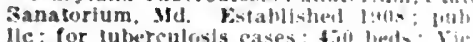
tor $F$. Cullen, medical superintemient

\section{Sykesville}

Sprlngfleld state Ilompltal fin the Inume, sykesrlle. Mil. Fitablisherl Is:at: 1.Iini beds: J. Clement clark, physiching charge.

\section{HOSPITALS. SANATORIUMS AND CHARI. TABLE INSTITUTIONS}

\section{Annapolis}

Amnapolis bmergency Hosultal. AnnapuIls. MJ. Fistablished I!ll:; Hetreral; in beda: James J. Murplyz, chice if medical stat: A. Hell, H.X. supromendent.

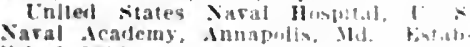

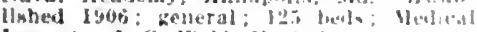

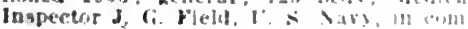
mand.

\section{Baltimere}

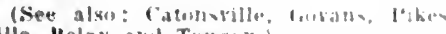
vlle. llelay aml Tousory

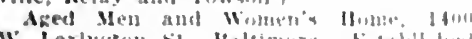

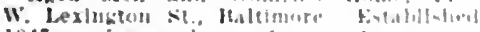

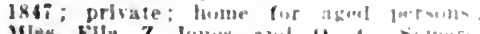

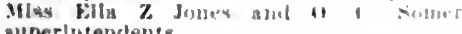

All salne Home for lhbllen. Warwith are and Northwest ot Malemols"

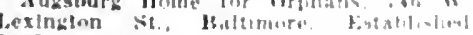

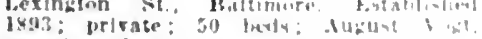
1403: prisate

Balesmure cily Jall Junpleal, Italmmope

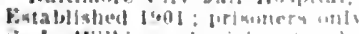

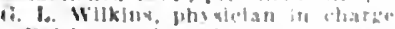

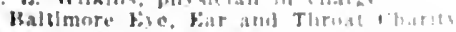
Ifosultal, doy W. Franklin st, Maltimense

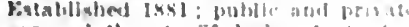

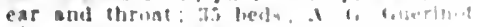
phisician in charge.

Hallmore Human Imbarbin

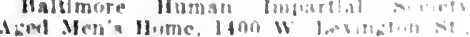

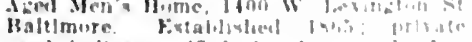
aged Indlgent: 1: lurls bermal I 1.. worms bhy

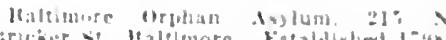

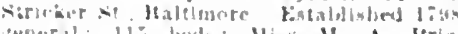
streral: 1i: leats: Wios \$1. A I'rice upartatemilatis.

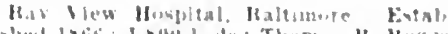

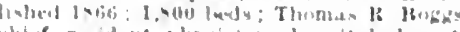

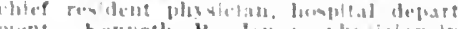
ment hemeth $R$ Jomes, whiclan-la-

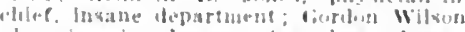

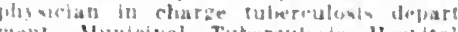

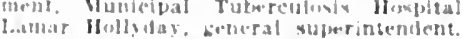
Hedlet - Sullman Humplbal. 20:4 y

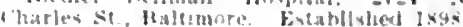

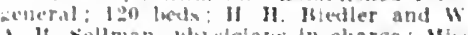
ift sellman. Jhy welasi in charge: Misw Julla 11 liagenluch superintemient.

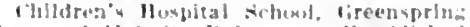

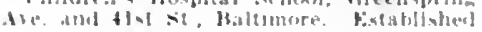

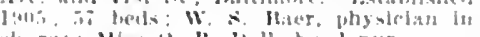

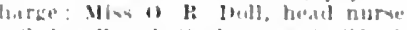

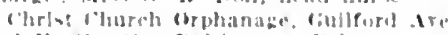

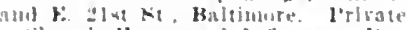

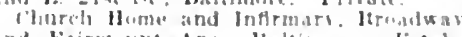
and fairmeme Are. Haltimure. Fosalo.

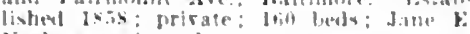
Vash. suberintendene.

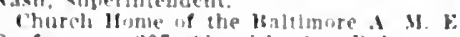

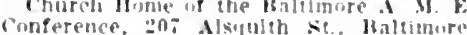
Foxtalliwhed 190: : mblle: lor the agud: 20 heals: J. Hidwird pisher. phystctan in charge: Hev. Ib. C. MIll, superintendent. colored Ized Men"a and Women's Ilome 2]t W. lee si. Maltinire.

biden sireet Home for Frlendless 1"hll tren, Chase and Fiten sis.. Maltimure

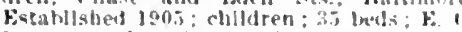
leperson, physirian In charge.

Figentein Female Orphan Isylum, Roland and Werryman dres. Maltinore

ploteryman Ires.. Maltimore St.. Haltimore. Established Jash: private

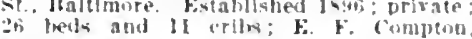
-uperimenderis.

Franklin sifuare Hospltal, Palhoun and

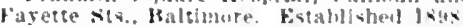
uutblle: general: braukh, Weat kinel Mater

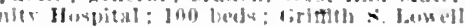
II.I., superlntendent

Friendly Inn Iswelation, 300 \& Sbary Sit.. Baltinore. Kostaldished Igol private gon beds: t: 1 . Wise. Ir. superintendeme Veneral Cerman Drphan Isylum, 1 a gulth and Brleans sts. Baltimirt. Kintah llshed 18ti3: zeneral: 125 bedti: Clas. selimied. sibjerintenterit

fierman Afed Men ard Wunen's Home. baltimose and Payson sis. Baltlmore.

lierman Erangelical Immistam Hous

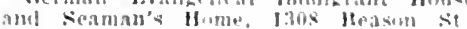

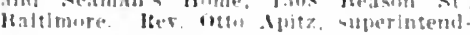

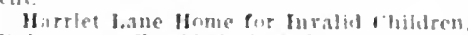

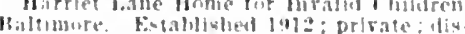

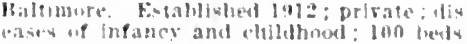

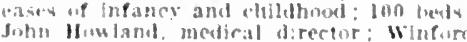

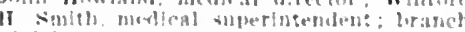

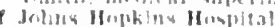

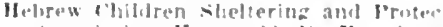

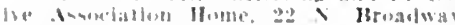

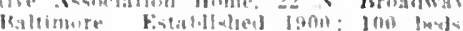

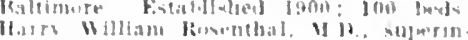
sentlans

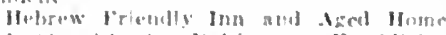

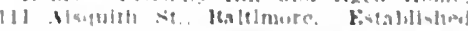

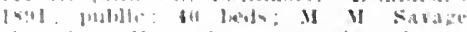

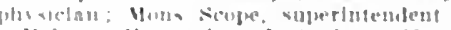

Hebrew Huaptal and Andum. Vons

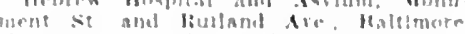
ment st and listand Are Malemore

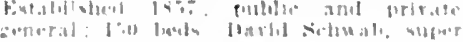
intomilane

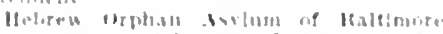

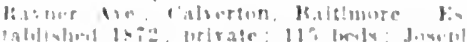

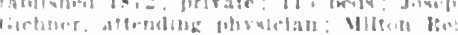

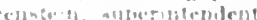

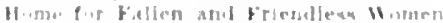

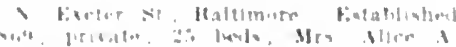

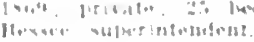

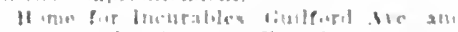

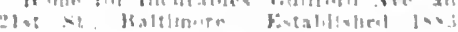

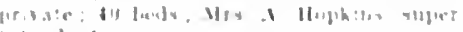

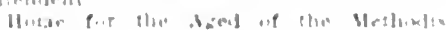

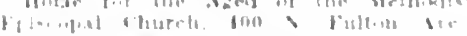

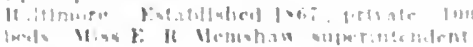

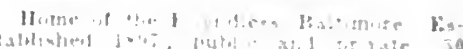

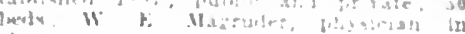
clarise.

ing pier it

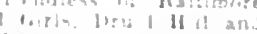

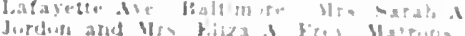

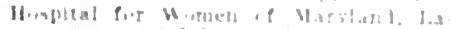

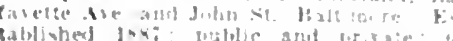

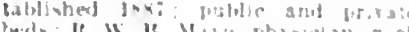
[wdv: It W b Wabe, phometan in charse

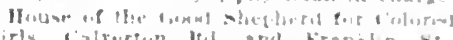

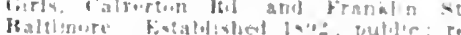

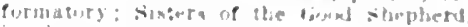
a char:

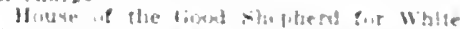

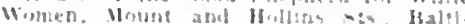

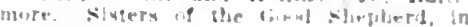
Hatre.

formen losurence Kerman H iagles] ank

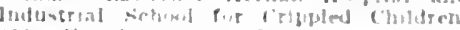

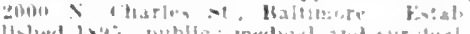

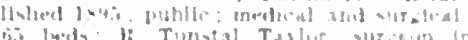

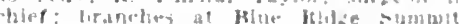

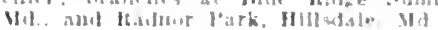

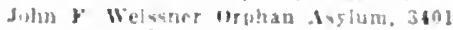
kantirn lre.. Haltinure.

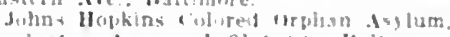

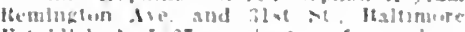

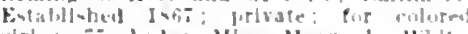
chrla: $:$ beds; Mlas Vary \& White

Iohn ITuthlus Homftal, Itroalua, Ital

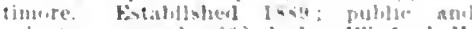

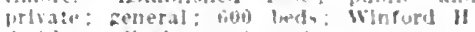
snith, nuedical superintenderset

Ir. Kelly's sanitarlum, I1] Eutaw IM

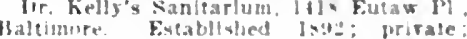
ilurical: 40 leds: H. A. Kelly, phyalcian "I charze.

kelvo Home pur wrohand. Forent park Baltmore. Finthishet I 4 prirate: for

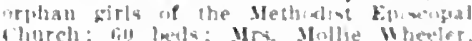
une rintervedent.

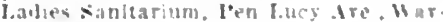
rly. Haltlmore.

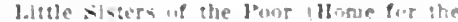

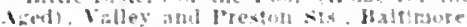
Finfablished intig: public: powr. all ses 7 Leals: Dr. Wanter, physlolan.

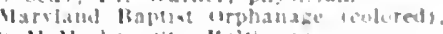
McVlechen st., Malimure

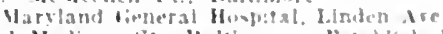
and Maliton St. Haltimure kivaldivien

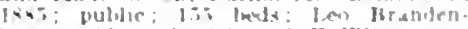

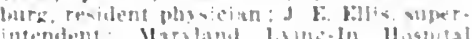

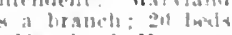

Marylat Hombelmathic Itropital, II

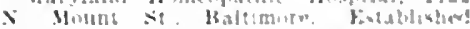

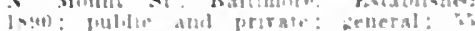

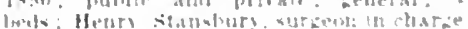

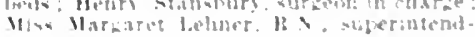

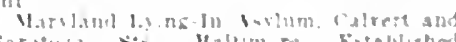

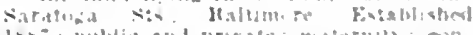

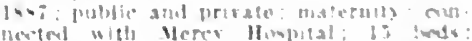

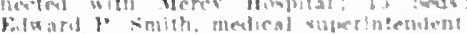

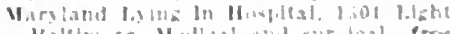

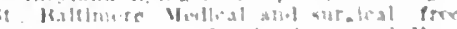

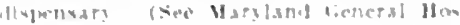
$\operatorname{lins} 311$

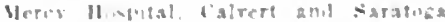

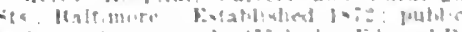

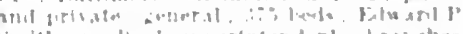

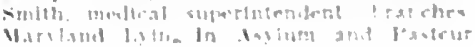
We partment

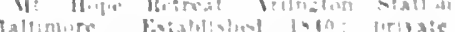

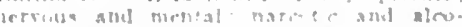

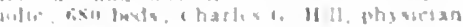

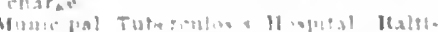

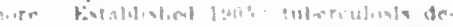

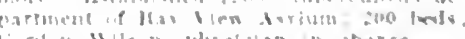

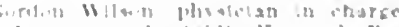

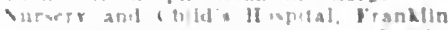
bul wolirenter siv lialatmole kivab.

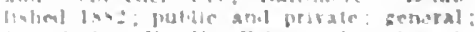

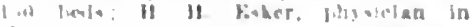
lialisent

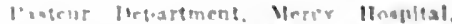

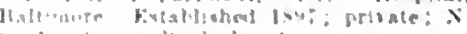

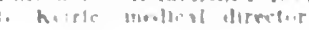


Pearson Hone, Hllisdale, Baltimore. Fstablished 1011. prirate . narcotk: 40 beds C. B. l'earson, inedical superintendent.

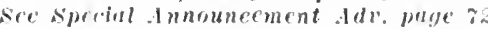
l'resbyterlan Eye, Ear and Throat Char ity Hospltal, 1017 k. Baltimore St., Baltl more. Established 1877; public aul private: 60 beds: Herbert IIarlan, allef surgeoll; Mrs. J. T. Wade, superintendent. geon; Mrs. $\mathrm{T}$. Wade, superintendent. Baltimore. Established 1844; public ; to

Baltimore. Established 18
colored patients; 24 beds.

Quarantiue liospital, Patapseo liver. 13altimore. Estiblished 1853; 30 beds Thomas L, lichardson, physlclan in charge.

lohert (iarrett liospital for Children. 27 N. Carey st. Baltimore. Fistablished 1888 : private: 33 beds: W. B. I'latt med eal superintendent. (See summer branch. vit. Airy, Ml.)

Shelter for Ared and Influm Colored Persons, if w. Biddle St., Baltimore. Miss L. ( Wluarton, matron

Skln and lancer llospital. 1132 Mount St.. Baltinore. Established 191\% publie; 52 beds; G. II Everhart, fliysi clan ln cluarge.

South Baltinore Fye, Far, Nose and Throat Hospital, I211 Light st., Baltimore. Establlslied 1901; eye, ear, nose and throat: 15 beds; II. E. Péterman and Janes Bordley, Jr., surgeons ; James V. Clarken, medical superlutendent.

Clarken, medlcal superlutendent. more. Established Is63; public and private; general; 200 beds; A. Dural Atklnson, president of medical staf?

St. Anthony's Orphan Asylum, 925 s. Central Ave., Baltimore. Established 1858 ; 120 beds; Francls A. Warner, physiclan in charge:

St. Elizabeth's Home of Baltimore City 317 St. Paul St., Baltimore. Established 1881; publlc; for destitute colored children; 200 beds ; Alexius McGlannan and Eren; 200 beds; Alexius McGlan

St. Francis' Academy and Asylum, Chase St. and Forest Pl., Baltimore. Established 1829 ; publlc; orphanage for colored girls The Oblate Sisters of Provldence, in charge; Mary Voeglein, medical superintendent.

St. John's Protestant Episcopal Orphan Asylum, Falr Oak Ave., Baltimore.

St. Joseph's German Hospital, Caroline and Hoffman Sts., Baltimore. Eslablished IS64; public; 400 beds.

St. Joseph's IIouse of Industry, Charles St. Joseph's IIouse of Industry, Charles
and 28th Sts., Baltinore. Sisters of Cbarand 28 th Sts.,

St. luke's Hospltal, 114 W. North Ave. Baltimore. Established 1905; public and private; general; 50 beds; Miss I. F. Cornlsh, superintendent; John A. Evans, chlef physician.

St. Mary's Female Orphan Asylum, Roland Park, Baltimore. Established 1816; public; 250 beds; Sisters of Charity, in charge,

St. Mary's Home for Colored Boys, Presstman and Vincent Sts., Baltimore. Presstman and Vincent Sts., Baltimo St. Patrick's Orphan Asylum, 1707 Gough St., Baltinore. Rev. J. F. Donahue, super intendent.

St. Paul's Industrial School for Girls 2411 N. Charles St., Baltimore.

St. Paul's Orplaan Asylum, \& E. FrankIin St.. Baltimore.

St. Peter's Asylum and School for Female Children. 1221 Iyrtle Ave., Baltimale Children, 1221 Myrtle Ave., Balti-

St. Raphael's Institute of Proridence, 509 Hanover St., Baltimore.

St. Vincent de Paul Male Orphan $\mathbf{A s y}$ lum, Schwarz Are. and Fork Rd., Baltimore.

St. Vincent's Infant Asylum and Maternity IIospital. Division and Lafayette Aves. Baltimore. Established 1857 ; private; 25 beds; Sisters of Charity, in charge.

Star of llone Rescue Home, $333 \mathrm{~N}$. Fulton tre.. Baltimore. Rev. Harry J. Olsen, superintendent.

Sydenham Hospital, Eastern Ave. and 26 th St.. Baltimore. Established 1909 ; public and prirate; for infectious cases 220 beds; $s$. T. Nicholson, Jr., medica superintendent.
Inion d'rotestant inflruary, IjIt bivlflon Sit. Baltmore. Established 1854 mublle and private: general: 112 beds Mliss Roberta L. Hall, superintendent.

Lnlted states Marine lospltal, Reming ton Ave, alu 3 Ist st.. Baltimore. Establisheel issi; general; 100 beds; Senlor surgeon Il. li. Carter. in command.

inlverslty of Maryland Ilospltal, Ionlharel and tireene sty., Baltlmore. Estallished I\$23; public: general; 300 beds; IT. I. Coleman, medical superintendent. lulversity of Maryland Lying-In IIos vital. Lombard and Green sts.. Baltimore. Established 1885; public ind private: maternity ; 55 beds; L. F. Neale, medlcal director.

West End Maternity Hospital, $112 \mathrm{x}$. Calhoun St., Baltlmore, Establlshed 1901 publle; materulty ; 20 beds; 13. Purcell luse, physlcian in charge.

\section{Boonsboro}

Falirney Menorlal liome, Boonsboro, Ma. Established 1004: private: home for the aged; 24 beds; United Rrethren Church in charge; George A. 1'errott, superintenclent. Brunswick

Baltimore \& Ohlo Rallway Emergency Iospital, Brunswick, Md. Private; beds; H. S. Hedges and Levin West, physiclans.

\section{Cambridg} Id.

bupont 1ying-In Hospital, Cambridge,

Emergener Hospital Cambridge Ma Established 1895; public : 50 beds: $B$. W Goldsborouch, chief of medical staff; Mis. Ella Nabb, superintendent.

\section{Catonsville}

(See Baltimore.)

(iundry Sanitarium, Athol-Catonsville. II. Established 1900; nervous and mental; women only; 50 beds; Alfred T. Gundry, physlcian and superintendent in charge.

See special Announcement Adr. page 80 Hollywood Children's Summer Home, old Frederick and Rolling Road, Catonsville, IId. Estab. 1892 ; private ; fresh-alr home 32 beds; Mrs. W. Thomas Shaw, president. Richard Gundry Home, Harlem Lodge, Catonsvllle, Md. Established 1891; private; nervous and mental; narcotic prialeoholle; 55 beds; Richard F. Gundry alcohollc; 55 beds; $\mathrm{R}$

sce spccial Announcement Adv page 62

siellngs Sanatorium, Pine Crest, Norwood Ave., Catonsville, Md. Establlshed 1910 ; private; mental and nervous; alcoholic and drug addlction cases; 35 beds H. R. Kolb (Baltimore) medical director iiss a Sleling, R. superintendent St. Lukelands College for Couvalescent Women, Rolling Rd., Catonsville, Md. EsWomen, Rolling Rd., Catonsville, Md. Es-
tablished 1886; maintalned by the Hospital tablished 1886 ; maintalned by the Hospital MacGill and West, physicians in charge

Mrs. T. O. Tongue, superintendent.

Centerville

Queen Anne's County Hospital.

Cherry Hill

Cherry Hill Asylum, Cherry Hill, IId. Insane.

General and Marine Hospital, Crisfield, Ird. Fstablished 1909 ; public and private 30 beds; Mrs. Florence Smith, superlntendent.

\section{Cumberland}

Allegany County Tuberculosis Sanatorium, Cumberland, Md. Established torium, Cumberland, Md. Established

Allegany Hospital of the Sisters of Charity, Cumberland, IId. Established 1905 ; public : general; 100 beds.

Baltimore and Ohlo Rallroad Y. M. C. A Hospital, Cumberland, Id. Established 1906 ; private; 2 beds; Wm. Foard and $C$. L. Owens, surgeons; Wm. C. Montignani, superintendent.

Sylvan Retreat, Cumberland, Md. Estab. 188S; public; Allegany County insane asylum; 96 beds; J. H. Wilson, physiclan in charge; J. T. ilinnlcks, superintendent. ivestern j J. T. Mlinnlcks, superintendent. Western Maryland Hospital, Cumber-
land, Md. Established 1891; public ; 60 beds; Mary F. Hale, superintendent.

\section{Easton}

Easton Emergency IIospltal, Easton, Ifd. Established 1906; general; 25 beds; Jane G. Garner, 13. $)^{\circ}$, superlntendent.

Elkton

Union IIospital of Cecil County, Elkton. Ud. Fistablished 1908: it beds: Howard Bration, II.W., secretary board of directors.

Ellicott City

Maryland Home for Friendless Colored Chlliren, Ellieott, Md. Establlshed 1899: pulslic: peneral; 23 beds: llarry S. MeCard. (13iltimore), pliysleian in clarge.

I'atapsco Manor Sanitarlum, Ellicolt City, Mll. Establlshed 1907; private; 30 beds; W. Rushmer White, nedical superintendent.

Forest Glen

Carroll Springs Sanltarium, Forest Glen, Mill. Establshed 1886 ; private; nerrous and health resort; 32 beds; Geouge II. Wright, physician in charge.

\section{Frederick}

Frederick Cily IIospital, Frederick, Md. Fstablished 1899:; public; general; 60 beds; Mary 1. Nies, superintendent.

Home for the Aged, 115 Recurd St. Frederick, Ad. Established 1892; private; 18 leds; Wm. C. Johnson, nedlcal superintendent; Mrs. G. E. Glfford, matron.

Lost's Orphan Asylum, Frederick, II. Established 188\%; private; for girls; 20 beds; Nrs. W. H. Hillary, matron; Geo. H. Zimmerman, superintendent.

Montevue Hospital, Frederlck, IId. Estallished 1870; for the Insane; 300 beds

Chas. F. Goddell, physician in charge; $S$. U. Gregg, superintendent.

Orphan IIouse and Eplscopal Free School, Frederick, Md. Established 1808; private; 20 beds; W'm. C. Johnson, attending physician; Niss Mabel Hatton, superintendent.

\section{Frostburg}

Miners Hospital, Frostburg, Md. Established 1913; public; 60 beds; Helen $A$ Binule, medlcal superintendent.

Govans

(See Baltimore.)

\section{Hagerstown}

Bellevue Washington County Home, Hagerstown, Id Established 1879, general; 120 beds; Geo. S. Everhart, physician in charge; Oswold Crist, superintendent.

Washington County Home for Orphan and Friendless Children, Hagerstown, IId. Established 1884 ; private; 34 beds; D. A. Ziezler, superintendent.

Washington County Hospital, Hagerstown, Md. Established 1905; general; 52 beds; Emma II. Glorer, superintendent.

\section{Havre de Grace}

Havre de Grace Hospital, Union Ave. and Revolution, Havre de Grace, Md. Established 1911; publlc; 25 beds; Miss E. s. Featherstone, R.N., superintendent.

\section{Hilısdale}

James L. Kernan Hospital and Industrlal School for Crippled Children. (See Baltimore.)

\section{ljamsville}

Riggs Cottage, Jjamsville, Md. EstabIished 1896; private; nervous and mental 20 beds; George H. Riggs, physlcian in charge.

Laurel

Laurel Sanitarium. Between Baltimore and Washington, Laurel, Md. Established 1905; nervous and mental; 100 beds: Jesse C. Coggins and Cornelius De Weese, medical directors. 
Mt. Airy

llobert ciarrett sanltarlum for chlldren, (Summer Mrancb). Mt. Alrs, Mis Kistab.

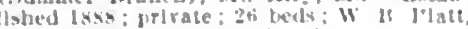
(balthnopt, physlclab in charge

\section{Mt. Wilson}

Thomas Wllson Sunitarlum, Mt. Wllont If. (Itoslyn I'.(i.). Histablished Isis 105 beds: publlic: infanes: hastro-lestes Inal dlseases: J. II II. Knux, Jr., (Italt! morej, pliystclan lis charge.

\section{Oakland}

Home Sanatorlum, Oakland, Md. Fos tablished 1905; private; M. C. Mineliaugl. physleian in charge.

\section{Orange Grove}

Grange Cirove Country Home for Chall. dren, ceange dirove, Md. 10atonsmlle

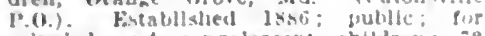
cripuled and conralescem childreli : bevis; Marshall 1 . West, phrslclan in charge.

Pikesville

(see Halthoure.)

Ihee Lark, l'ikesvllle, Md. Estabhislted 1910; private; for Invallds; 12 leeds; W

I. F. Wyse, physiclan lin charge.

Maryland Line cunfederate soldiers

Marsland Line cunfererate soldiers Home, Plkestlle, Md. Fatabllshed loss; R. 3. silnson, superintendenl.
P?. Deposit

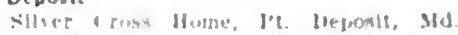
ristalilisheel isto4, Por eplleptics; 25 teeds;

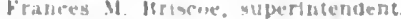

Reisterstown

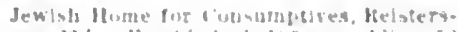

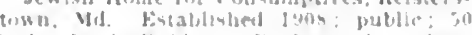

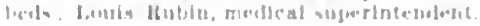
Relay

Sire [ois]timese

Relay crutarlutu, Relay, Md kistab-

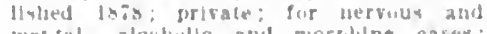
mestial, alcuhollc and norfulne cases: lio treds: lew is 11 liundry, mellical superintrinclent.

Rockrille

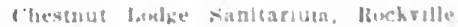

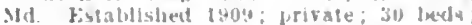
Pir nerous and merita! cases: Ernest I. Isullard, plyystelan in charge.

Salisbury

fenlnsula fieneral Ilospleat, Sallabury. Nd. Fistablsherl IN!n: nublic and pri.

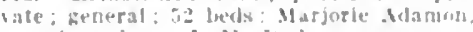
superlntendent; J. M. Wick, sugkenti.

Pine blut sunatorlum, Sallsturs. Mis Established 191:; nuthlic; adrancel tuber culosis croes; 25 lends: tier. W. Tolds. inedlcal superinteudeut.
Takoma Park

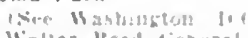

Whater lieed lieberal II isintal. Taknera Yark. Md bisiabliabued 1000,10 of Army

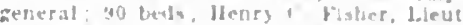

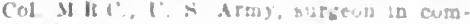
unand

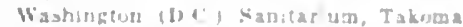

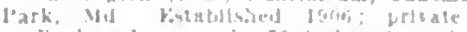

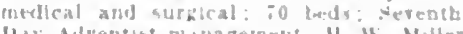

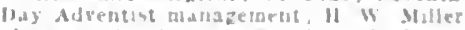

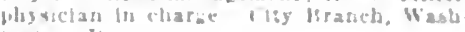
infen, I) 1

Towson

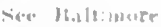

Ilospleal for fousuruptives of Mapyland. (Fondermelt sonliarlums). Tuwson, Md

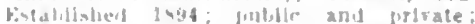

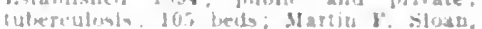
V11. minerintendens.

shespard and rinech l'asti llubltal. Tunsoll, Ml risiblislied 1841; prlvate: nervous ald coental; 150 teds: boward $\mathrm{X}$. bruah, whystan-in-clief and superlatendent

Wasingeton Grove

Starmunt samalisium. Wasbiagton Grove. Id Eviablished 1905; priraie; tuber-

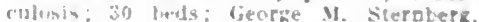

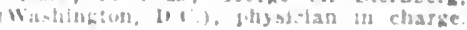

\section{PHYSICIANS OF MARYLAND}

KEY TO ABBREVIATIONS, SYMBOLS, ETC.

Vames in capltals signify memulerifip in the County soclety and State Issucith Hon. (JOF. JOHI).

* Indlcales Fellowshlp in the Americar Med. Assn. (DOE, JOHIt)

(11):5) Year of plrth. H. homeopath: $\mathbf{k}$, eclectlc; I-M, jhysiu Mid.i,02, Cullege and year of graduation. o Information recelred does not slanw grad uation.

S.-Surgeon.

Ob. Otetetriclan.

ObG. -Obstetriclan, Gynecolnglat

G.-Gynecologist.

Or,-Urthopedlst.

Pr.-Proctuloglsi.

Op.-Ophthalmologlst

A.-Aurist.

- Holublogist.

\section{(1'89) lear of llicense.}

(i) In practlce lefore passage of present

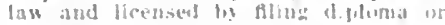
las verars of loriactloe

(1) Licencel but beir nut known.

(a) Information recelbed does not show llcense.

l's.l. Inlted siates Army

MII. I. M. Medical Meserve Corys

SPECIALTIES ARE INDICATED AS FOLLOWS

ALR. - Murlst, largtiguloglst, lthlnologist.

OALR. Hpdatialmologist, Aurist, Laryngoluklst. Iblubologist.

U. I'rologlst.

D. He rmituloglst

Pd. I'ediatrlsi.

P.. Neurologlst.

P. lisychlatrist.
I.s... lunted staten vary.

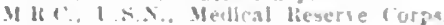

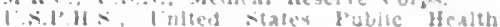
sintlce.

follere moltions beld are andicased by abbresiated title of publina, pullumed by key number uf chilece. For bey to collegess see inslife pront corer pane.

(1, Ibi, (t) Memter bly in specla]

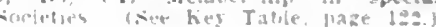

NP. Nemolotise, loychlatrive

I. Internist.

T. Tulerevilutherapist.

Anes. Alutwethets.

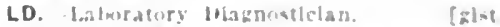

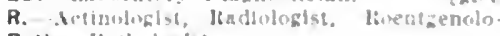
Path. l'athilonglst.

Bact.-- Iacterlologise.

WHEN THE ABBREVIATION REPRESENTING A SPECIALTY IS FOLLOWED BY AN ASTERISK (*) IT INDICATES THAT THE PHYSICIAN CLAIMS HIS PRACTICE IS LIMITED TO THAT PARTICULAR BRANCH OF MEDICINE: WITHOUT THE ASTERISK. THAT HE IS ESPECIALLY INTERESTED IN. BUT DOES NOT LIMIT HIS PRACTICE TO. THAT BRANCH. THIS INFORMATION CONCERNING SPECIALTY IS BASED ON PERSONAL DATA FURNISHED BY THE PHYSICIAN AND IS NOT VERIFIABLE.

\section{MARYLAND}

\section{ABERDEEN, 6I6, HARFORD}

Kentudy, Jatne 11. $(1,+5)-M d .3,: 4 ;(3)$

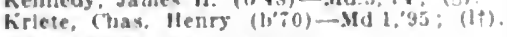

ABINGDON, 200, HARFORD

d)

ACCIDENT, 200, GARRETT

Hirlscoe. Beverly Wumb Ma 1,03: (1'03).

ACCOKEEK, I50, PRINCE GEORGES

Murphy, Frankllu liashlell (b's:) - II] la'13 $(1,13)$.

\section{ADAMSTOWN. 200. FREDERICK}

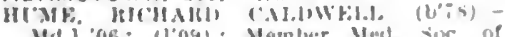
Md.1,06: 11091; Member Met stor. of

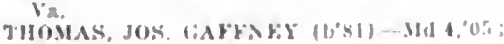
(l'06).

ANNAPOLIS. 8.609, ANNE ARUNDEL

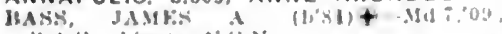

I'A.S., Lleut, P.s.

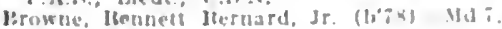
0.:- (1.0.3)

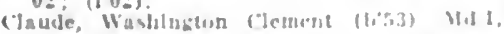
$\because 5 ;(2)$.

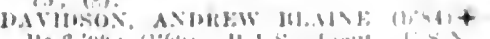

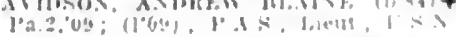

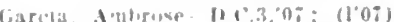

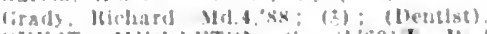

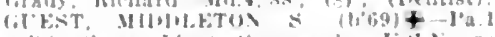

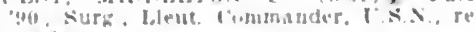
ured

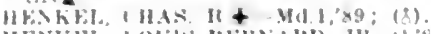

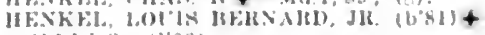

प111 1.018: 11 '0.3)

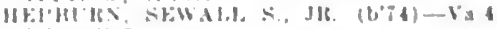

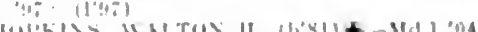

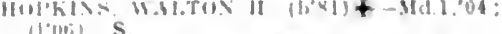

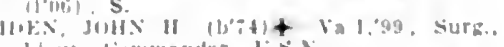
J.hut lingumander, it:

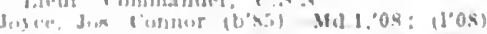

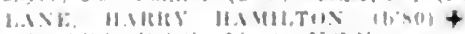

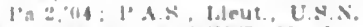

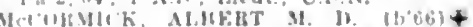

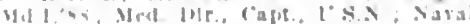
leadrmy

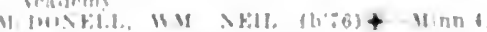

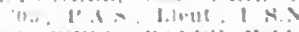

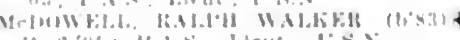

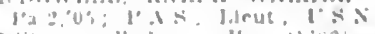

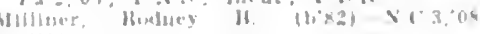
11.18

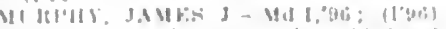

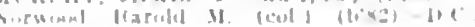

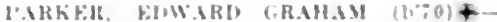
llass 1.96: surb. laleu?. ("orugander,

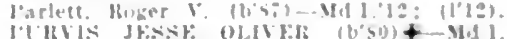
Thist. Jis

int: $(1004)$

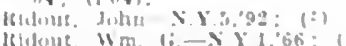

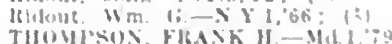

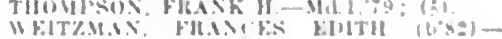

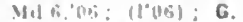

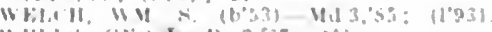

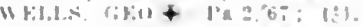

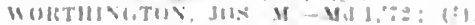

AQUASCO, 330, PRINCE GEORGES

(6) Un

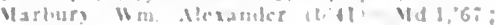
ievired.

ARABY, :O FREOERICK

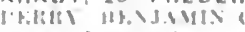

ARCADIA UPPERCO P.O.), 3'TS BALTI. MORE

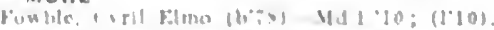

ARLINGTON, 1,000, BALTIMORE

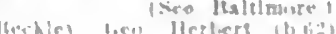
(1) in! 


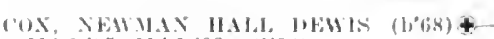

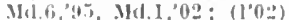

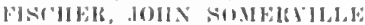

(xice Jblilmore.)

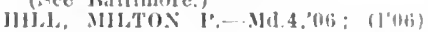

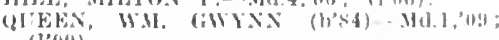
(1'0!)

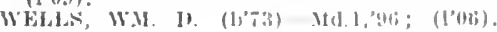

ARMIGER (R.F.D., ELVATON), 50, ANNE ARUNDEL

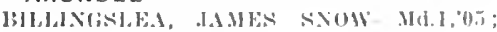
(l'05)。

BAGLEY, 40, HARFORD

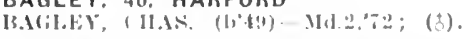

BALTIMORE, 558.485, BALTIMORE CITY

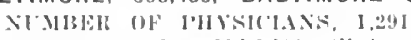

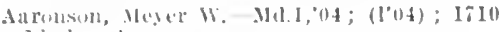
].lnden dre.

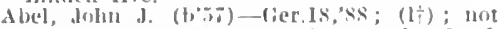
in practice; Julaud l'ark brimeh; Prof. thar. Mllit; (loti)

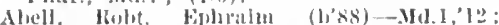
isst. l'hysician, Cniversity of Maryland Hospltal; S.

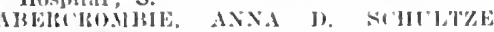

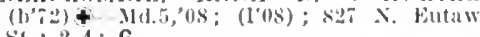
St. : $2-4 ; \mathrm{G}$

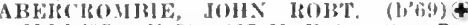

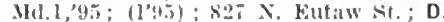

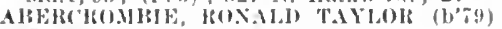
4-Nd.7,05; (l'0.5); ('harles and 31st Sts.; onice, Homewood Apartments; 9-10 Sts.; oflice, HI

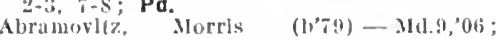
$\left(l^{3} 06^{*}\right): 1707 \mathrm{k}$. Jilltmure st. ; $9-10,1-2$, $6-8 ; \mathrm{U}$.

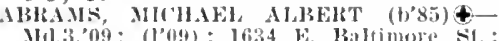
IH.3,"09; (l'04); 1634 F. Baltimore st. ; $8-10,6-5$

Aloromaltis, Jos.-Rus.6,'93; (l'07)； $601 \mathrm{~S}$. l'aca St.; $9-11,6: 30-8: 30$.

Alams, Frank 13-1ld.3, (t): $2124 \mathrm{st}$ I'alul St.

ADAMS, JAIES FItEMK, (1,69)-Md.1,94; $\left(l^{*} 94\right) ; 1314 \mathrm{~N}$. Charles st.; $11-12$.

Adams, Lester (b's5)-Mt.t,'il ; (I'11) ; Bay Vlew IIospltal.

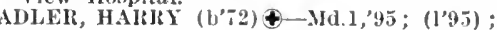
1 Is Eutaw I'lace, I'rof. Clin. Med., Mid. 1.

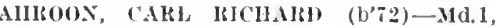
01; (1'01): 820 N. Eutaw St.

Akelurst, James s. $\left(b^{\prime} 73\right)-1 h d .1,00 ;\left(10^{\prime} 00\right)$; 4012 l'ark Helghts Ave ; 6-8, 8-10.

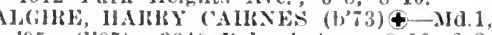

'95; (1'95) ; 3640 kolaml Are.; 8-10,6-8.

Aronsohn, Abram T.-O.I1,76; (It); livi

linden Ave

ARTHUT, HARRY HALIAN (b'6 Mal.1,94; (l'94); 1426 W. Lanvale St. $8-9,2-3,7-8 ; \mathbf{0} \mathbf{b}$.

ASHHCIC, JOWARD ELMER (b'so)-Md.1, ,03; (1'0:3); 1017 calledral st.; $2-5$; ((i) ; R. $\star$

ASIIIY, THOS. A. $\left(b^{\prime} 48\right) \oplus-M d .1,73$; (1'73); 11:5 Madison Ave.; $8-10,1-3$; Hrof. Gym., Md.1; (A2); S.

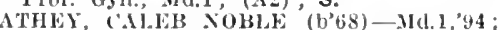
(l'94); 100 s. Jatterson Park tre.

Athey, Jenry benedict (b'80)-Md.1,11; (l'12) ; 200 N. 1'atlerson Park Ave.; $9-10$, $2-3,6-8$.

ATKINSOX, A. IUVAL (b'71)Ð-Mld.I,94; (l'y4) ; $92 \mathrm{I} \mathrm{N}$. ('harles st. ; 2-4

II'GIL, IRALI'H H (b'82)-IId 4,09: (l'0s); $2: 16$ E. North st. ; oftice, The Winona ; $8-10$, ड-s.

Al'STIIAN, CHAS. KOBT. (b.85)థ-Md.7, '09; (l'09) ; Johns Hopkins Hospital; ( $\left.\mathbf{H}^{*} \mathbf{2}\right)$. Avery, John Thomas-Ild.6,'01; (1†); 1603 N. Broadway.

Ayd, John-Md.3,'86; (t) ; 1937 E. Monument $S t . ; y-10,2-4,7-8$.

BACON, RROBT. B.

(See Washington.)

Bacoll, Walter Compton (b's6)-Md.1,11; (1'11); 100 E. 20th St.; 8-9; 7-8; Pd.

BAEI, WI. STEVEXSON (b'-2)-MId. $98 ;(I 9 S)$; 4 k. Madison St. ; Assoc. I'rof. Ortho. Surg., MId.7; (A3,26).

BAETJER, FlKEDK. HENKY (b'T4)-Md. (1): (104): (Catonville); office, $4 \mathbf{E}$. Mladison st.; $(\mathrm{GL}, 2)$.

Batjer, Walter A. (b’83)-IId.7,09; (1'09); Iti W. Iitdison St.

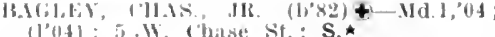
(1) lsou Ave.

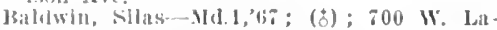
firvette dre, antil 10,2-4, $7-8$.

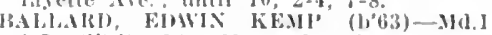
"87; (l’94); Itoz Hount hoyal Ave.; 8-10. Barenlmrg, fa(col) W. (b'85)-.lld.9,'12; (\$) : 835 Holllns st.

Barker, Chas. W--Md.1,'85; (8); I403 W Lamialo si.

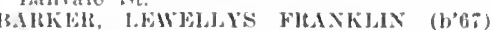

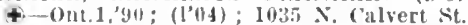
ollice, Johus Hopkins Jospltal; I'rof. Ned. II l. T; $(1106,1,1,10)$

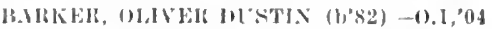
(); Member IV.Via. State Med. Assu. I0:s $\mathrm{x}$. Jrondway.

litrkman, lieorge W. (b'5I)-Md.3, 81 (l'09); 1117 Madison Are.; office, 2106 H. Fayelle $\mathrm{st}$

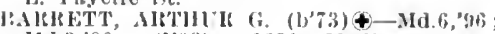
M(I.3,00; (1.98); 1631 Madtson Are. $9-10,6-3 ; \mathrm{S}$

Barrett, Framels oliver (b.85)-..Mld.9,'11; (1'II) ; 19 No Cares 8 .

l3arlle, Harvey (b'74)-l'a.1,0z; (l'05) 2402 quilford Ave; omce, Union station.

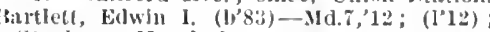
st. Agnes Hospital.

barwick, Geo Irvin (b'69)-Md.1,94 (1'94); 1103 Poplar Grove; 8-9:30, 6-8.

BALEX, HFNISY MINIFIE-MU.4, 92 ; (5) 1126 W. North Are.

BAY, ROBT. PAIKE (b'84)థ-Md.1,0J

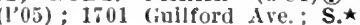

Baylin, Mlorils .I. (b'84)-IId.9,09; (l'09) $21:$ Aisquith St.; $9-11,6-3$.

Beach, Jueonaral Edw.-Md.9,'99; (l'99) 857 W. Fayette St.

Bean, Philip Jenifer (b'91)-Md.1,'13; (l'13) ; Bay View Hospital.

BEASLEY, FDWARD BALEY (b'82)11. $T$, 06 ; (l'06); Homewood Apariments. BECK, IIAKVEY G. (b'70) \&-IId.3,'96 $(196) ; 20$ F. Preston st.; 2-4; Clin

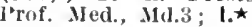

liecker, Wu. $\diamond:\left(J^{\prime} 9.5\right)$; 708 E. Ballimore Becker, Wm., Jr.-Md.6,"95; (I'06); 708 E. Baltimore St.

Beetham, Allen (: (b'87)-Md.9, '09; (l'09) 3016 E. Baltimore $S t, 8-10,6-8$.

BHLT, SAML. JONES' (b'44)屯-IId, '76; (1'83); 1516 E. l'reston st. ; 8-10, 2-3 $i-8$

Bennett, George E. (b'8z)-IId.1, 09; (l'11) 1127 Jadison Ave; office, 4 k. Madison. enson, Clas. Edgar (b'80)-IId.9,04; (1'04) ; 2412 Maryland Ave.

BERGLAND, JOHX MCFARLAND (b'79) IId.7,04; (l'07) ; 4 W. Biddle St. ; 3-4.

BEHKLEY, HENIY J-Md.1, 81 ; (1广) 1305 l'ark Are.; Clin. P'rof. P'sych., Md. $(\mathrm{E} 6,10,13)$.

Bermgart, Bermard Mark (b's3)-Mhd.1,12 (1'12) ; 913 E. Fayette st. ; (office, Tow son) ; $N$.

BEKXIEII, BEHTHAM MOSES (b'0) IId., $05 ;\left(l^{\prime} 07\right)$; 2319 Linden Are.; S.* BEVAN, (HAS. FREDK.4-Md,1, б; (o) ; sot ('athedral st.; (C1)

BHEII,EK, HAMH'SON HUBEIK $\left(b^{\prime} 54\right) \oplus$ Ild.1,76; (1'83); $119 \mathrm{~W}$. Saratoga st. $10,2-4$

Billstein, Aaron M.-P'a.1,'92; (1'92) ; The Plymoutl Hall

13ILLUPS, GAIUS -WILLAMS-Md.1,06; (l'06); $2224 \mathrm{~W}$. North Are.

Bilstein, Emma L.-1'a.7,'93; Mt. hoyal Apts.

Biser, Franeis H. D. (b'67)-Md.1,90; (す) $20 t^{\circ}$ E. lafayette Ave, (offlee, Martinsburg, W.Va., l'02).

BINHOP, JOHN SAIIUEL-Pa.1,95; (l市) 8:2 $N$ Carroliton Ave.

Blackfan, Kemmeth Daniel (b’83) - N.Y.3,'05; l'ediatrician, Johus Hopkins Hospital.

Blades, Geo. Clinton (b'72)-MId.9, 00 (l’01); 143 x. Broadway; 8-10, $7-9 ;$ Pd

BLAKE, 'HAS. FRENCH' (b'66) - -Md.3, 93; (1'93) ; 20 E. Preston St. ; 9-11 Prof. Proet., MId.3; S. $\star$

BLAKE, HERBERT C. $\$-M d .4,05 ;\left(l^{\prime} 05\right)$ $1014 \mathrm{~W}$. Lafayette Are.

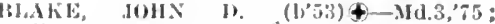
(l'92); 1014 W. labilyetle Ave, $8-10$, 6:30-7:30; Prop. Clln. Surg., Md.1; lii) ; $\mathrm{S}$.

IBLAKE, IRORT. LEF-MU.4,05; (l'05); $85 \pi$ Colmulula Are.

Blaney, feo. W. -0 ; $(1+) ; 3$ x. Calhoun Nt.: offtce, 1537 F. I'ratt St.

Blaney, Win. James Francls (1,73)-Md.1. 96: (1'u9) ; 110 s. Gillmor st.; 8-9, 6-8.

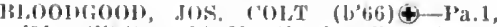
91: (1'4.1); 404 $\mathrm{N}$. Charles St.; Assoe l'rof. S'urg., M(1.7; $(\$ 5,6$ FI, $) ; S . \star$

Bloomfleld, Arthur lo (1,88)-Md.7,'11; (l'11) : Johns Ilojekins Ilospital.

Bode, Win. C:-11-Mld.8.04; (l’04) ; 1000 Nitryand Ave

loorisis, $7110 \mathrm{~s}$ Ih $(1,75)+-3 \mathrm{~d} .7,0 \mathrm{I}$ (I'11); 21 W. ('hase St.; Assoe. Prof Med., Md.7; (1)6); I.

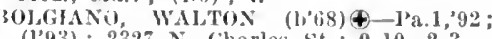
(1’93); $2327 \mathrm{~N}$. ('harles st. ; 9-10, 2-3.

13OLTON, JOHN IIENIRY (b'40)-Md.1,62 (l'94); $1201 \mathrm{~N}$. Broadway; 8-10, 4-6,

OND, ALLEN JEERJ' $(1,59)-M(1.1,82$ (ঠ) ; 3104 Walbrook Are, ontee, 849 Park Are.; $12-2$ Bond, Cieo. Saml. (l,84)-Mich.1,08; not
in practloe; 171\% Madison Are.; offee, Johns IIopkins Ilospltal.

Bond, Janes L. (b'41)-Md.2,'69; not in practlee; $716 \mathrm{~N}$. Fulton Ave.

HOOKEIt, WH. D. (b'44)@-Va.1,67 (1'94); 208 iv. Monmment St, $8-9,2-3$ ? Emer. C'lln. J'rof. P'ed., Md.7.

Boo\%e, Wu. S.-Md.3,'79; (ठ); Hotel Rennert.

BOJWENSKY, NATHAN B. - Md.3,07: (l'0T); 2114 Wilkens Ave.; 8-10, 6-8;

BOlRILEY, JAMES, JR. (b'74)૯-Md.1,'96 ; (L'96) ; 330 N. ('harles St. ; 9-1 ; (B4).

Boring, IIugh M.-Md.3,'94; (l'08); 2712 iv. North st.

Bonchelle, Elizabeth Taylor (b'84)-Md.9, 'I2; (l'12); 2006 st. I'aul St.; 8-10, 6-8;

Boulanger, Theophlle $\mathrm{D}$. (See Montreal, Que.)

Bore, Chas. F. W. (b'88)-Md.4,'13; (1'13) ; st. Joseph's Hospital.

Boyd, Wm. Alexander (b'T4)-D.C.1,07 (); 1414 Mulberry st.; offlce, $114 \mathrm{~W}$ Franklin st.; 10-12, 3-5; NP.*

BKACK, CHAS EMIL, JI. $\left(b^{\prime} 66\right) \oplus-M d .3$ '95; (1'95); 500 F, 20th St.; Clin. Prof. Obst., MId.3,; Ob.ћ

13raeekleln, Affred H.-Md.6, 03; (1'04): 1328 S Charles St

Brandenburg, Leopold W. A. (b'86)-Md.4, 12; (1'12): 2501 W. Sorth Ave.; 8-10, after $12,6-8$.

Branhan, Henry Gwynn-Nd.9,05; (l’06) ; 926 W. North Are, office, 2200 Eutaw Il. ; S.

BRANHAM, JOS. HFXIR (b'57)థ-JId.3 '79; (\$); 2200 Eutaw Pl.; 8-10, 5-7.

(A1); S. CHAS. N. (b'76)థ-Md.4,97; (l'98); 400 Hanover st.; 8-10, 2-3, 6-8.

BJENT, HUGll WARlikN - Id.1,03 ; (1'03) ; $906 \mathrm{~N}$. Calvert $\mathrm{St}$.

BRJASLER, FFANK C. $\left(b^{\prime} 59\right) \$-11 \mathrm{~d} .3,{ }^{\prime} 85$; (†) ; 125 S. Broadway ; 9-10, $7-9$.

Bridgman, Eveleth Wilson (b'88)-Mid. (I'12); .Johns Hopklus Hospital.

Brlllhart, Harry S. (b'84)-Md.3,'12; (1'12); Merey Hospital.

BRINTON, WILIER (b'54)क-Md.1, 76 ; (l'91) ; $1232 \mathrm{~N}$. CaIvert St. ; 8-10.

Brition, Edgar B.-0.13,78; (ई); 1711 E. Baltimore St. ; $9-10,1-2,7-8$.

Brown, Alfred Whittemore (b'86)-Mass. $\bar{t}$, 13; (1'13); 221 E. North Ave.; office, Garretl Bldg.

BROWN, FRANCIS EDW. (b'67)-MId, 93; (1'93); 917 St. l'aul St.; 8-9, 2-3.

Brown, Harry Francis (b'84)-D.C.3,06 (l'06); 1501 Presstman St. ; 8-10, 2-3, $7-9 ;$ Pd.

Brown, Henry James (eol.)-MIlch.6,85; (ङ) ; 426 N. Gilmor st. Brown, Paul (b’84)-Md.1,'09; (1'10); 1841 l'ennsylvalia Ave. ; 8-10, 2-3, 7-8. 


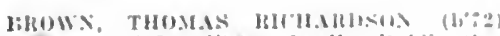
+ Mu.7.47: (109s): 19 11. Huldle se. $-3-8: 30: 1 . *$

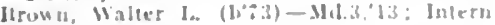
Merey llosplat.

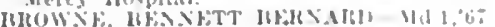
1:): :10 lark We: ObG

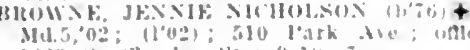

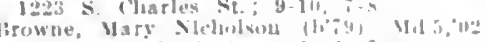

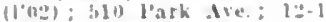

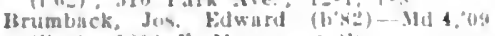

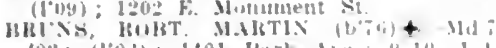
"0os; (1'03); 1 101 l'ark dre.

(kiti): N.

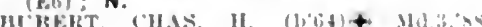

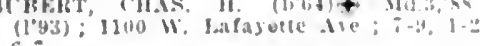

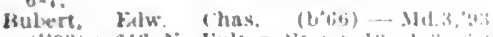

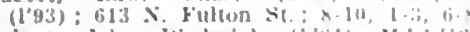

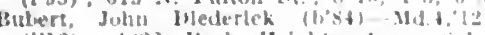

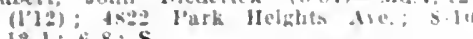
$12.1 ; 6-8 ; 5$

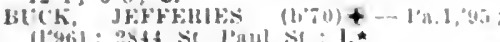

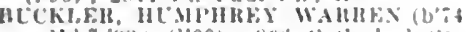

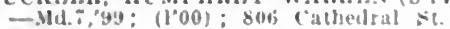

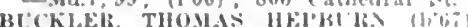

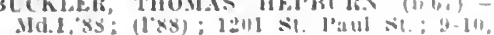
IId.I.

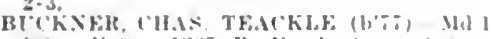
"49: $\left(1^{\circ}, 39\right)$ : 1337 b. Sorth tie.; ti-s

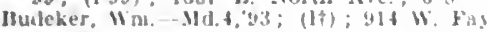
elte st.

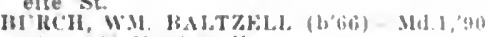
(3): 8.2s X. Carrollion ive.

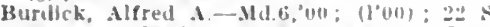

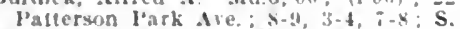

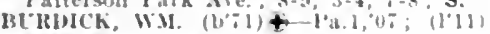

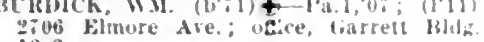
$12-2$.

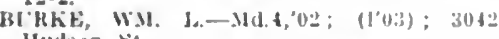
IIudson si.

BLRKHALTEI, JOHXN THOS +-M11.999 P.A.Surg, I'S. I IH.

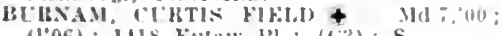
$\left(l^{\circ} 06\right) ; 1+18$ butaw Jl.; $(13) ; S$.

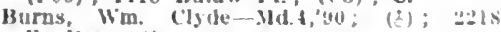
t. Iratt st

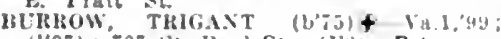
$\left(l^{\prime} 0 \bar{c}\right): 707$ St. I'aul St. : (t,b): P.*

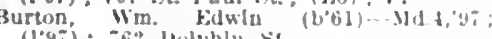
$(1.97): 762$ llolwhln si

ltush, Maurlce summervlle (col.) (b'ail) Tenn.:13; (\$); 1617 Jivislon sit.

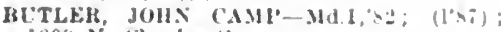
$1809 x$. Charles st.

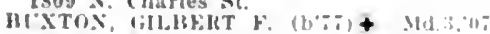

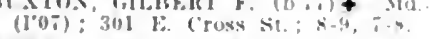

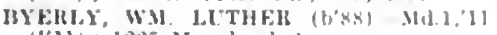
(1'11); 12.2. Maryland die.

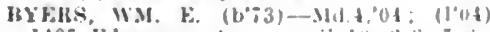

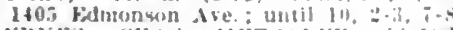

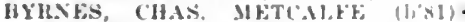

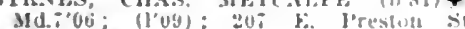
(ki10); N

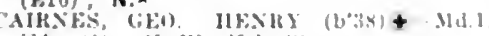

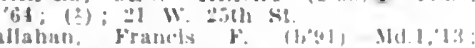
allahan, Francls b. 1)
(I'ls): Hay lleu Hospital

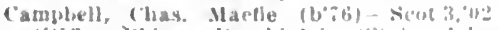

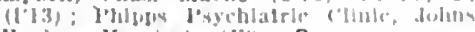
Honkirir Hownlal: (rix): P.

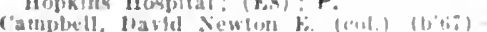

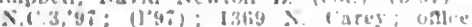
t:y $x$ ientral die.

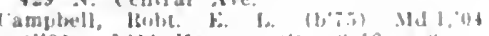
11.01): lew llanever 56 : \& $10,1,-8$

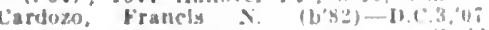

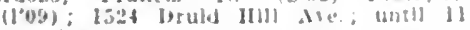
3-4. $\because-8$

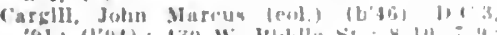

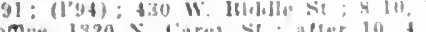

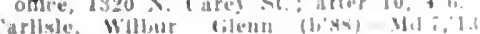

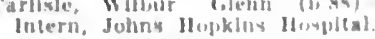

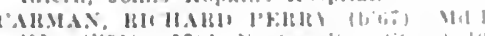

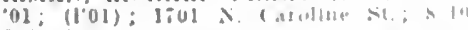
3-4, i-s.

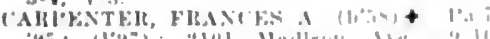

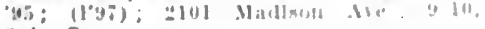
$\because-1 ; G$.

lär, Wrm. T je lout

art: Mosiner st?

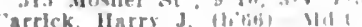

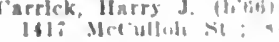

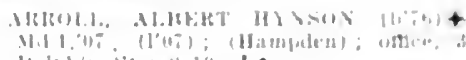
Jublublo st. : \& 10, I.*

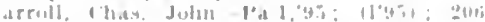

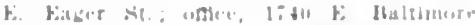
St: 50.10

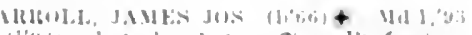

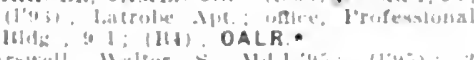

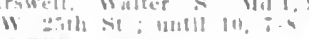

$+141.12$

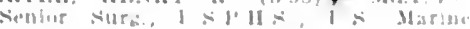
Ilies!

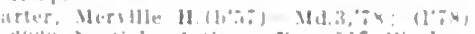

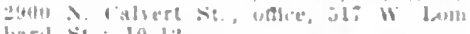
lard sit: : 10.1:

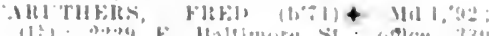

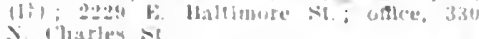

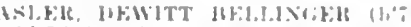

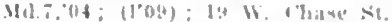

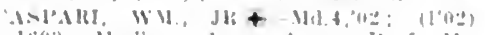

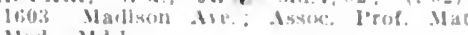
Med. Mi.l.

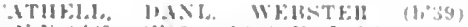

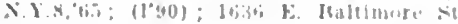

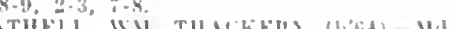

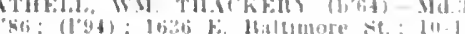

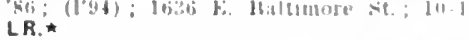

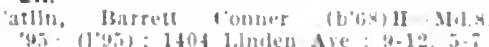

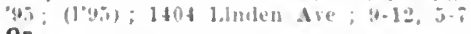
Op.

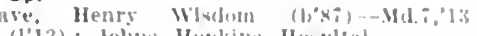
(l'i3); Jolus Ihopkins Jaspleall

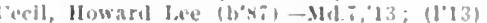
Jolun Hopklas Hospllal; $\mathbf{S}$.

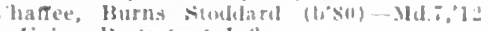
Indon lerolestant Intrmars.

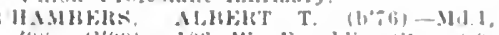

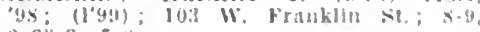

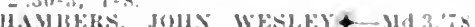
(1t); 18 W. ranklla st.; louf. sing Ilis.

HAMBRS, THOS, H(MNES (HST)

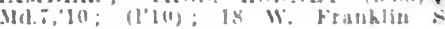
$9-10,3-1, i-k$.

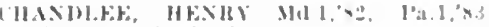
flt); F" W. North are.

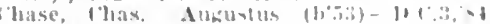

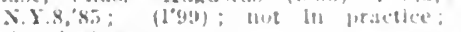
Mread Are.

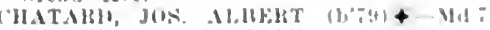

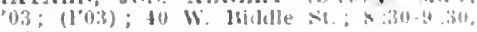
$\pm-3$

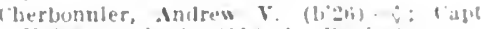

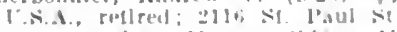

Jesmey, dlan II

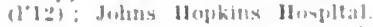

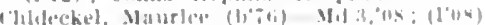
glti $x$ IItgh st. : x 10, 2-3, x-9.

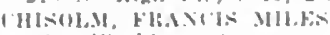
(Sit't Washlugton).

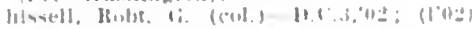
t24 5. 23415

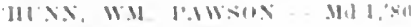

lines Sudimon in

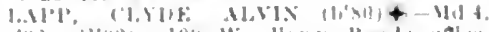

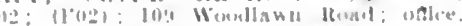

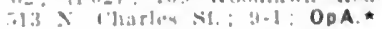

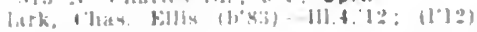

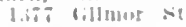

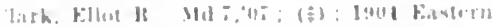
Alie., (F])

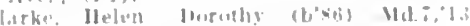

(l'lib) Jolanx Hopklnd Iloupleal

1.

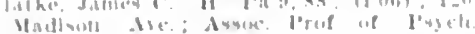
|II I

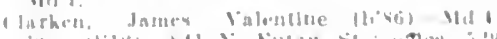

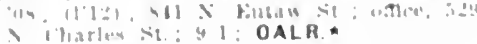

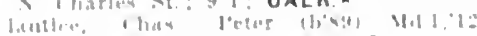

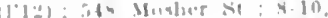

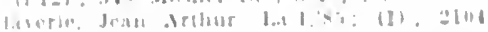

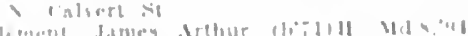

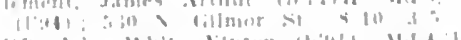

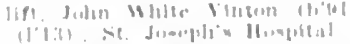

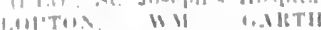

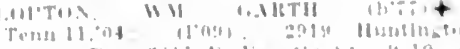

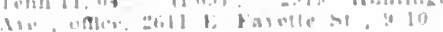

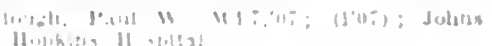

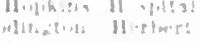

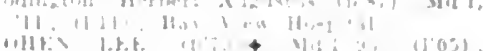

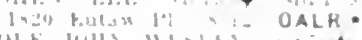

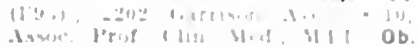

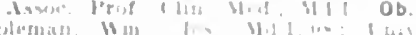
of Marstand Hininten!

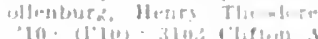

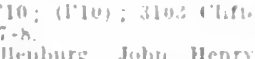

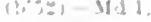

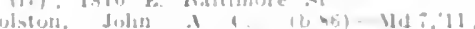

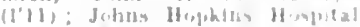

comber, bila blo (2)

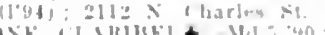

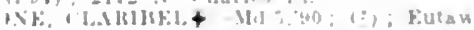
l'l and Wilens

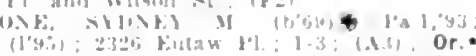

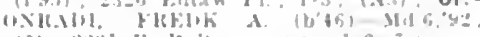

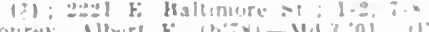

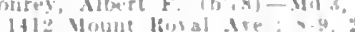

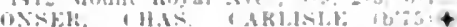

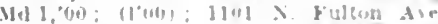

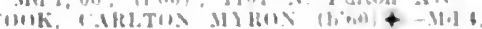

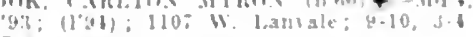

owh, thas re (1)64)-Mul,0); (1001): 1:39 leruld HIII Are: : $\$$ - 19

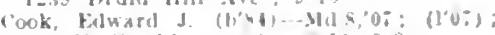

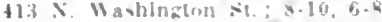

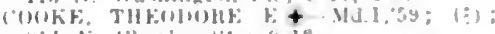

ouk t

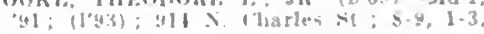

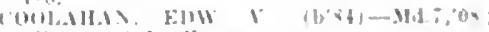

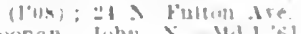

"orman. Jober $x-1 \mid 11, \infty 1 ; 10)$; 331 ह and sit.

onver. Harrion F. (b's0)-VId.1.0? (lon):

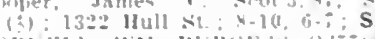

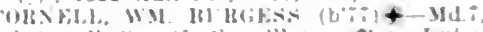

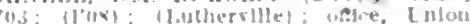

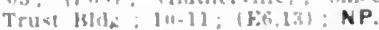

cornte (o, Washingtur, ill (b,s9)-

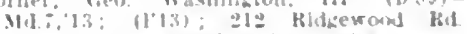
onlee, Johns Hophlas Indveraliy

ostello. Wm. John $\left(b^{\prime}: 1\right)$ - Md $\Omega^{\prime} 11$

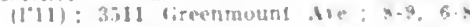

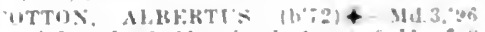
$\left.11^{\prime} 0_{0}\right)$ : 1303 ylarnland tre 5 -11, :

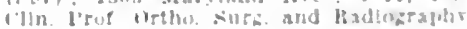
III.3; (1il); Or.

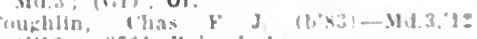
(11.12): 3:01 lioland tue

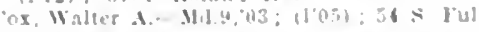
iut die

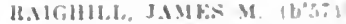

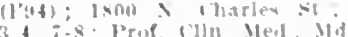

II $1.2:$

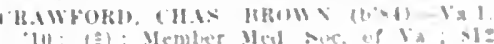

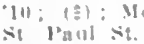

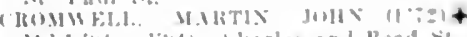

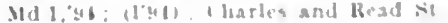

Hus

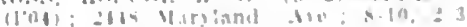

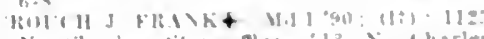

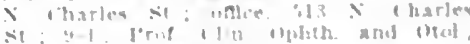

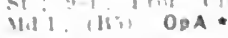

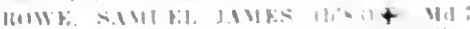

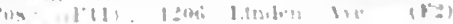

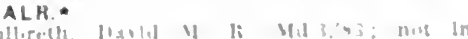

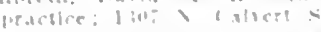

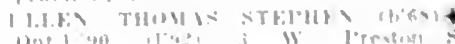

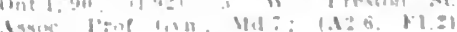
C..

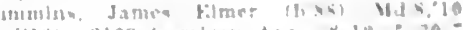

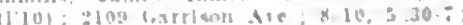
S.

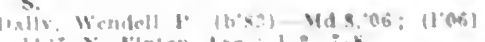

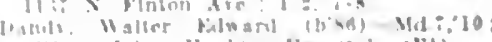

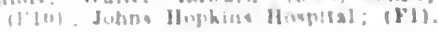


llaniets, Win. H. (b'84)-IId.1,07; (l'09); I03. II. Laubale st.; oftlee, $2000 \mathrm{~N}$ ('hatles st. ; $y-1$; or.

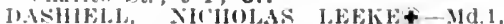
's: : (8); $242 \%$ st. l'aul st. $; 9-10,5-7$

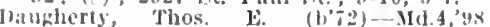
(1'99); 1621 P'ennsylvmia Ne.; 9.11 (i-8.

Davles, Arthur J. (b'86) E-Mdd.s,'10 $\left(\mathrm{r}^{\prime} 10\right)$; 711 W. $33 \mathrm{~d}$ st., $\mathrm{x}$.

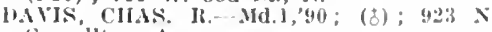
Carrollton Are.

Davls, Daul. (b'86)-Mf.7,'13; ( ) ; 626 N. Broadwuy.

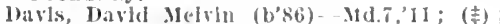

Davis, Ft. l'aul it.; (F1). (i’1) 1514 live

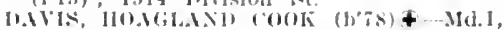
(12; (l'02); 114 W. Franklin St.; $9-1$ OÁLR. *

Davis, Isaac Howard (b'59)-M(I.I.'R5 (1'09); (20 Overhlll lid., lioland Park) oftce, 33I N. ('hurtes s.

lhavls, Joln-Md.1,'86: (1广); 2102 Orleans

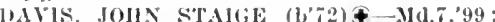
(l'03) : 1200 Cathedral st. : $3-4 ;(\Delta 6)$.

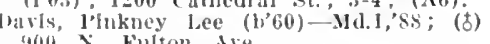

liavis. linht. (ialen (b'59)-IId.3, 82 ; (1) ; $1507 \mathrm{~N}$. (arollue st.; 8-10, 1-3, $(i-8$.

11.WI, SAMI. GRIFFITH, JR. + Md.1,'93 (1.93); 1230 l.Ight St.; 6-S; (A21); Anes.

Iintis, Wm A.-Nd.4,9S; (1'98); $424 \mathrm{~N}$. gireene sit.

WAVIs, WILLIAM B. (b'4S)\&-Ya.l,70: lol., T.A., retired ; Iniversity club. Wum Mary Meidl-1I-Md.8,01; (1'01)

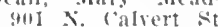

Docklet. John Frank (b'4t)- $0 ;(194) ; 327$ Aun St.; oflece, 171s Thames st.; $8: 30$ 12. $2-9$

DEETJEN, ('THRATIAN (b'6:3)-Ger.20, 40: (1'97) ; 1702 Sutaw i'l.; 11-1, 5-i ((i)

Dehoff, Geo W.-II.S,05; (1'05)； $2110 \mathrm{~N}$. charies st.

UEIBEL, IIARIRY (b'90)-M11.1,'12; (1'L2) ;

I21: IIanover st.; $10-11,8-9$

Hetcher, Elw. W., Jr. (b'63)-ky.1,'91; (1'91) : $2250 \mathrm{E}$. Iloffman St.

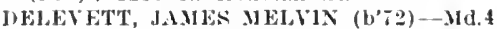
03; $\left(\mathrm{l}^{\prime} 03\right)$; 62: Columbia Ave.; 8.10, 6-8.

Demarco, Salvatore-IId.1,00; (l'00); 1604 Linden Are, ; until 9, 6-7.

Dennis, Chas. Edw. (b'53) II-Pa.9,'92 (l’92); 1021 IIadison Are.

ICKEY, FZRA A.-Id.9,04; (1'04); It N. Monroe st.

bickson, Isaac Cockey-IId.1,97; (1’97) (keyport, N.J.); oftice, 3053 w. North Are.

lidenhover, Chas, Webster-Ild.1,y4: (1'94); 3611 Pimlico Are.; offlce, $829 \mathrm{~W}$. (1'94) ;

pigres Franels Harry (b'7) - Md.1,04. (1'11) ; $534 \mathbf{~}$. Carrollton Are. ; office $\mathbf{A r}$ lington Ave. and Pratt St.; 9-12, 1-4; S. bill. Philip Gustar (b'62)-MId.1,85; (ठ) 1433 W. Lombard St. ; 8-10.

DOBBIN, GEO. W: (b'70)\&-Md.1,'94 (1'04); 56 w. Biddle St.; Prof. Obst. and Gyn., Md.3; ObG.

wodds, Solon Árthur (b'77)-M1d.7,05 (1'10); 3101 Clifton Ave. ; 9-10, 7-8.

1)orlson, C. Marion - Md.4,83; (ơ); 1408 Madison Are.

DOIIME, GLSTAYUS CHAS. (b'76)థ Ma.7,02; $\quad(1,02) ;$
$8-10,12-1,6-7: 30$.

l)onovan, John Jos. (b'80)-IId.4,04; (丰); 1302 Linden Are.

DOtGLASS, EUGENE (b'60)-IId.1, 89 (1'04); $830 \mathrm{~W}$. North Ave.; 9-10, 2-3,

Douglass, Louis Harriman (b'89)-IId.1,11; (1'11); 40.25 Greenmount Ave.; 3-4, i-8 ob.

Douglass, Malcolm Eugene (b'4i) H-Pa.9 80; $(197) ; 1915$ st. Paul St.; 8-10, 3-5.

Downes, Clarence Eugene-Pa.2,'88; (t) : on ingulhurst Are.; offlee, 1122 Madi
Jownes, Julla V.-H-Md.8, '95; (I'95); lit: Madisom Nro.

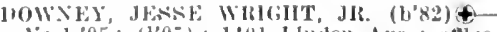
Ya. 1,05; (1'05); 1401 liluden Are. ; onlce,

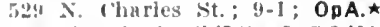

loyle, Frank J. (b'78) [1.C.2.0 I; (1'06); 349 Warren Ave. ; 10-12, 7-9.

Irain, whepherd $\left(b^{\prime} 76\right)-.11 .9,06$, IId.8. '07; (l'07); 1043 W. Janvale st.; 8-10,

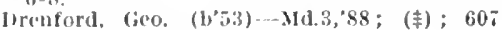
l'um Ave, ; 10-4

Driscoll, Albert I1. (b'79)-.11.1,02; (1'02) ; 312 N. Carrollton Ave.

lunane, Cien. I.eo.-Md.4,96; $(1,96) ; 721 \mathrm{~N}$. Fintaw; oftlce, 1

Dugatu, dames Archle (b'8s)-IId.1,12 ; (l'12); Confrersity llospital; G.

1) I'kE, O'TTO 11. (b'67)-Na.3,04;(1'04); (i2) E. North Ave; $8-10,6-8$.

Mimm, Mm. Milton (b'86)-Md.7,'12; (l'13); Joluns Hopkins Ilospltal.

DUNOTT, WANL. ZACII.-Pa.J,91; (む) ; 3 Eplani Rol.

Duvall, Oliver Newall-11-NI.8,01; (1'01); siec. State Ilomeo, Board of Mled. ExamIners, $1817 \mathrm{X}$. Fulton Ale.; 8-10, 2-3, $7-8$.

Durall. Wirt Alams IId.1,38; (t) : 2435 Wi. Nortl Are

bwyer, Frank (b'81)-MId.3,13; I4 E. Center St.; offle, Mercy Hosphtal Hispensary. Eareckson, Edith-Md.5,93; (1'94); 953 Madison Are.; offece, 924 Madison Ave.; $9-1,2-5$.

FARLE, SAML. T., JlR. (b'49)†-IId.1,70; (1'92); 1431 Linden Are.; S-11; (A4);

Sastman, lewis M., Jr.-Md.1,93; (1'02); 1505 Edmondson Ave.

lexbaugh, 1rvhl (b'62)-Md.1,'89; (5) ; 700 w. North Ave.; $8-10,2-3,6-8$.

Filkelton, Milton Thomas, Jr. (b'87)-Md. 12; (1'12); Clty Iospltal, Bay View.

W1MUNDS, 1'AGE (b'2) - Md.1, ys ; (1'98); 311 Cathedral St.; 8-10, 6-8; Clin. Prof. Gen.-Urin. Dis., JId.1.

Edwards, Chas. Reid (b'88)-MId.I,'13; (l'13) : Iniversity of Maryland IIospital.

Eggers, Henry B. (b'60)- 0 ; ( North $A$ ve.

Eichelberger, Wu. Wirt-IId.1,04; (1'06) ; Bay View Hospitul.

EILAU, EMANUEL. WM. (b'54)€-Md.1, 79 ; (l'06); 1908 Madlson Are.; until $10,3-4,6-7$

Eisenberg, Adolph C.-IId.6.'94; (1†) ; 2213 Orleans; $8-10,1-2,7-9$; ObG.

ELL1S, A. LEE (b'69)@-Md.3,04; (1'04) 924 Madison Are.; $8-9: 30,2-3,6: 30-9$. Ellis, Edw. Dorsey (b'68)-ild.4,'90; (1'92) ; 2024 Mt. Royal Terraee; offlce, 915 Jjght St.; until 9, 1-2, 6-7:30.

EMMART, HATTIE M. FRIST-Md.5, 90 ; (1+) ; 817 N. Fremont Are.

Enfield, Saml. E. (b'88)-IId.3,'13; (1'13); Merey ILospital.

ENSOR, CHAS. B. (b'78) -11d.4,03 ; (1'03); Park Heights and Singer Ave.; 8-10, 6-8; (E6) ; Path.

Ephratin, Louls H.-IId.9,02; (l'04); 218 s. Exeter St.

Erb, Frankin H. (b'ro) H-Md.8, 02 ; (1'02) ; 729 N. Fulton Ave.

Erlch, Lourse-NId.5,95; (l'95) ; 615 Park Ave.

Erkenbrack, Clarenee Philip-Md.9,'01; (l'02) ; 1412 Light St.

ESKER, HARRY HOOD (b'84)-IId.3, 06 . (l'07): Franklin and Sehroeder: office, 2505 p'ennsylrania Ave.

Essick, Chas. R. (b'83)-Md. 7,$09 ; 180 \pi \mathrm{N}$. Caroline St.; offlce, Johns Hopkins University; (Fi)

Evans, Nlexander Mason-Md.3,'12; (I'12): Mercy Hospital.

Erans, Florence L. A. (b'72) H--Md.8, 02 ; $\left(l^{\prime} 02\right) ; 301$ E. 21 st St., $\mathbf{X}$.

Erans, Gilman Pitt (b'57)-Md.4,95; (1'96) ; 833 N. Fulton Are.; until 10, $6: 30-8$.

Erans, Herbert II. (b'82)-IId.7,08; 2036 F. $31 \mathrm{st}$ St.; Assoc. Prof. Anat.; $\mathbf{I d .}$. (F1).
EVANS, JOIIN (b'78)-MId.4,03; (1'03) 501 Franklln Terrace: $8-10,6-8$; $\mathbf{R}$.

kvans, John A. (1)'66)II-I'a.9,'95; ( $\left.\mathrm{Y}^{\prime} 95\right)$;

101 X. Carey st, ; 8-10, 2-4, 7-8.

Fvans, 1.orenzo B3. (b'76) - Md.3,'04: $\left(1^{\prime} 04\right) ; 1013$ Madison Ave, $9-10,12-2$, ti.9.

Fverhart, Geo. Hauer (b'61)-IId.1,90 ; (\$) ; 100 W. 25th st.

Ewalt, Geo, Latrolve (b'75)-Md.1,00. $\left(1^{\circ} 00\right)$; $905 \mathrm{~N}$. (Hllmor St.; untll $9,1=2$.

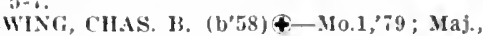
U.S.A., retlied; 400 F. Fayette St.

Falr, IIorace l.: H.-Mi.8,94; (1'94); I: E. 25 th St., X.

Falr, Mliton Alvah (b'73) II - Md.8,95; (195); 12 F. 25th St., N.; 8-10, 7-8.

Garber, Dawson L. (b'92)-.11d.4,13; ( ): Maryland (ieneral Hospltal.

Fargo, Bunnel! (b'60) — Ild.9,'13; (l'13) 746 Dolphin st.

Fawcett, Robt. (b'67)-Md.1,92; (1! ) 4215 ' 'enhurst St.

FAYLIRWETHER, HOADES (b'7) $\mathbf{t}-$ 529 . Charles St. ; 2-5; (A26) : Or.

Fechtig, James Amos-H-Pa.9,71; (b) ; 1303 N. Cinarles Sit.

FEISSFAFEL, ARTHUR LOLIS (b'8\%) + -Id.1,09; (l'09); Falrview and Gal rlsoll Aves. ; $7-9,6-8$

FENBY, ENWIN BOLLDIN (b'52) $\$-$ Ma.1, 68; (1'94); $1223 \mathrm{x}$. Carollne st.; $8-9$, I :30-2:30, $7-8$

Fenton, James M.-Ya.1,94; (1'96); 700 I chase St.

Ferguson, Frank C.-Md.1,01; (l'04); 1006 S. Sharp St.

Fetterholy, Chas. Alfred, (b'8⿰)-Pa.9, 10 ; (1'10) $1130 \mathrm{~W}$ Lafayette Ave ; office. 1908 W. Worth Ave.; $9-10: 30,3-4,7-8$.

Id.1,85, I'n.9,'s6; (1'14); Lafayette and Carrollon Aves, until $10,3-4,-8 \cdot G$.

Field, Philip s.-Id.1,52; (む); 1324 iV. Lanvale st.

FINNEY, JOIIN MILLER TURPIN (b'63) \& -Mass. 1,89; (1†); 1300 Eutaw H.; Prof. Clin. Surg., IId.7; (A5,6); S.

FISCHER, JOIIN SOMER VIILE-IId.7, 03 ; (1'03); (190 Belvidere Ave, Arlington) offiee, 9 E. Biddle St.; Pd.

Fishbaugh, Ernest Ciyde (b'84)-IId. 7,13 ; (1'I3); Jolns Hopkins Iospital.

Fisher, Geo. W.-Wis.4,'94; (l†); 1509 Lin. den Ave.

Flsher, Jacob (b'82)-MI.3,'08; (I'08) 1926 E. Lafayette Ave.: $8-10,2-3,7-8$.

Fisher, J. Edward (eol.) (b'79)-N.C.3. 07; (1'07) ; 1612 E. Honument St.; unt!l $10,3-4,7-9$.

FISHER, WM. ALEXANDER, Jr, $\left(\mathrm{b}^{\prime} / 4\right) \notin$ Md. 7,00 ; (1'01) ; 715 Park Ave.; S. $\star$

FISKE, JOHN DWINELLE (b'53)£-II 1 , 75 ; (1'04); 611 St. Paul St.; offee, 5 S. Gay St. ; $\mathbf{1 - 5}$.

Flannery, Frank J.-Id.1,'80; (5) ; Mt. Hope Ave. and Reistertown Rd. ; (E6)

Flautt, Campbell Fair-IId.4,01; (\$) ; 1504 Mosher $\mathrm{St}$.

FLECKENSTEIN, HARVEY K. $\left(b^{\prime} 74\right) \Phi-$ Md.3,'04; (l'04); 1312 Linden Ave. oflee, $700 \mathrm{~N}$. Iloward St. ; $9-12 ; 0$ OpA.

FLEMING, GEO. ALEXANDER $\left(b^{\prime} 62\right)(-$ Md.1,84; (1'90); 1018 Madison Are.; 8-1; OpAL

Flood, Henry H.-Md.6,96; (1'06); The Colonlal; offiee, 106 Lobe Bldg.

'lora, Ernest F. (b'85)-1Id.3,'13; Interu. Mercy Hopltal.

Foard, Andrew Jackon (b'32) $\rightarrow$; $(1 \div) ; 511$ N. Chester St. ; 8-10, 2-3, 7-9.

FOLLIS, RICHARD HOLDEN $\left(b^{\prime} \% 6\right) \oplus$ Md.7,99; (1'05); 3 E. Read St.; $2-3: 30$ S. $\star$

Fooks, Fredk. F. (b'49) ;-MId.2,'73; (l'92) 2305 Madison Are. offle, 403 w. Sara toga St. ; $10-2,7-9$

FORD, WM. WEBBER (b'71)-IId.7,'98; (1t); 11124 Cathedral st.: Assoc. Prof Bact. and Iyg., IId. ; (D6, F2).

FORSYTHE, HCGH (b'66)†-IId.4, 89 ; (1'94): 424 E. North Are.: $8-10,3-4$ $7-8: \mathbf{P d}$. 
FOKT, SAMI. JAIDE (b'sy)-I'a I, :- :

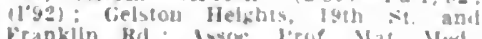

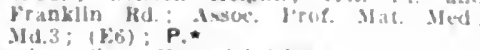

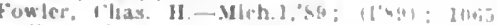

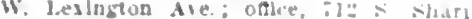
Sil.

rames, Win. Wayland $\left.(1)^{2} b^{2}\right)$-Mas 3.

$(1933)$ : 610 ithedral sit. : 1 : ALR.

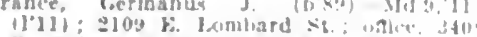
E. Hallunote st. : $-1 n$, bos: ALR

HANCE, JOHX WM 1' Md.,

$140:-x$, fiay

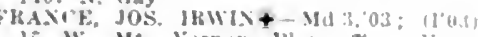

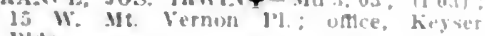
Bldit.

Frankin, llavld-Mdl,"0s: (100): 120 W I.ee St.

FHAKS, HOHATE I.FF: $(667)+$ Md.

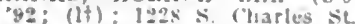

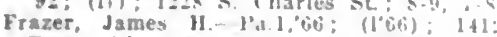
Eutaw I"l. : oflce, kquitable Bld: ; $111-1$ reedom, Adolsh (i. (b'\%2)-Md 3 , (11) $\left(l^{\prime} 00\right)$ : Filmondson tre and lith si unce, 915 k. bayetre st. $9-10,2-4,6-1$ FRFEMAN HIMK MKRT (bos) - MUt 00: (1"00): t1: lathedral Si: $2-4$.

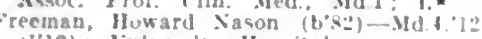

(I'12): Culversley Iuspital.

Frellnzer, Matthew C, (b'3)-Md.1, "mi

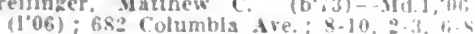

French, Kernard simon $(1,80)-$ id 9 ,

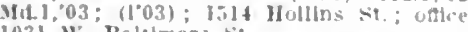
1031 W. Baltmore st.

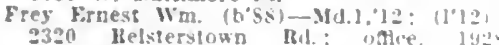
Pennsylvanla Are.: $9-10,-3, \div-3$

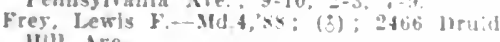
IIIII Are.

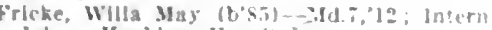
Jolins IIojkins boxpltal.

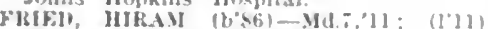
25i1 Madson ave.; oftice. Church 11:me and Infirmary: Path.

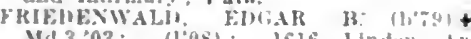

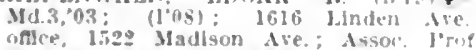

ils. of Chil., IId.3: Pd.*

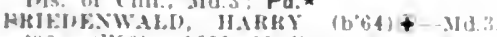
\&6: (1.90): ing9 Madison Me.; \$-12 Irof. Ophth. and Otol., IId.3: (ML,3.4 3): 0 pA.

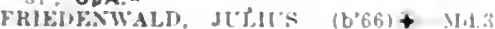
90 : (1'90) : 1013 $\mathrm{N}$. Tharles St.: $10-1$

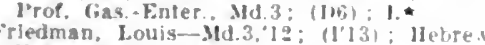
Hodman, Louis-Mld.3.

Frontz, Wm. A. (b'85)-Md.,11: (1'11) 29 iv. Monument sit.

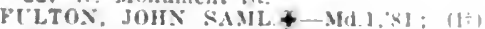
sec. State Buard of Health: woll st. l'aul st, : oflce, $16 \mathrm{~W}$. Saratoga sit, I'pu? siate Med. Mil.

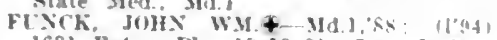
1631 Futaw Pl.; 10-12:30:-:; OpA.

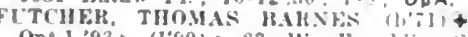
Ont.1,"9.3: (1'99): 23 W: Franklin :

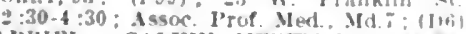

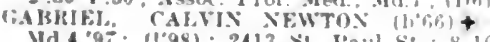
Md.4."9:; (1.98); $2413 \times 1$. J'aul st

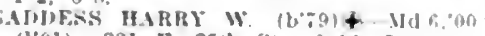
(l01): 321 K. $23 \mathrm{th}$ St. ; 9-11, $;-8$

cake, Alexander s. $\left(b^{\prime} 65\right)$.Id.3,

i09 $>$. Broadway: $8-10,6-8$

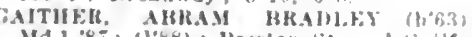
Md.1,85: (1'88); 1'peston st. and tiullepeil ire onlee, fialther kst. Mda.

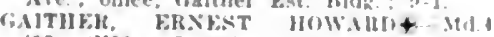
05: (l'06): Latrube IBIdE: :

ine. Henry E. (b'6t)-Md l, $x^{\prime}$

W Horman st : $9-11,3-4,6: 3$

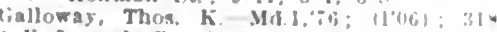
5. Ianvale St ; 8-10,5-:30:U.

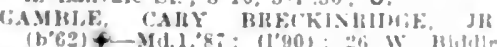

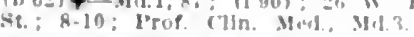

inrb. Nathanlel (b.43)- Vd.1.10: 1111

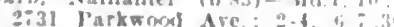

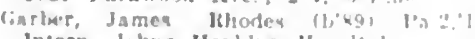

Intern. Johms HoJking limpltal

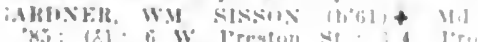

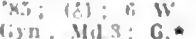

itrig, Jus bill + Mis ling

111 S. Mrosideat. aullue. I tas. b:

$16 !$

(1) : : 1011 (1in) ) orn

Lline. James

(1) : Hal rioh Ris and lombarturs tw

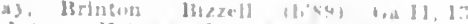
lutern, IIrbren Ilomplal athis lovlum

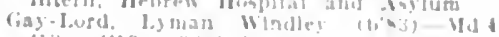

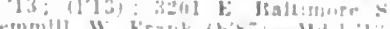
linferslte llaspltat.

linterslty llampltats

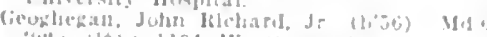

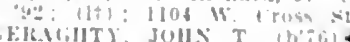

Tuti):

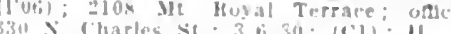

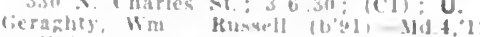

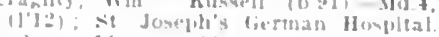

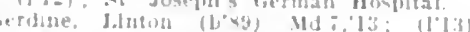
hay ila.s llospltal.

Gormoth, Frank if Md:"

lifcene $\$ 1,-10,2-4 ; 0$

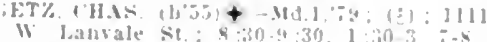

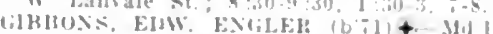

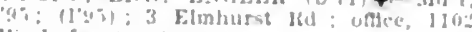
II Iorfayetie tre: $4-1$

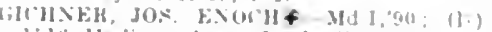
$1 \% 16^{\circ}$. Madisun Ale: I'rue I'lin. Med and lhys. Tlier., Md. 1

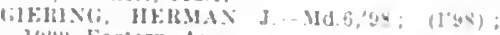
laisis bastern Ave.

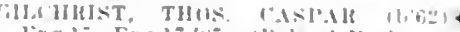

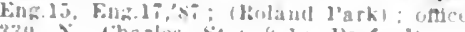

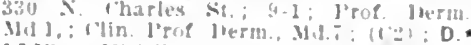

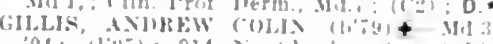
04: (1'15); 914 > tharles sit: $9-1$ :

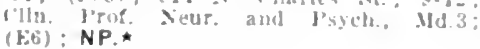
(Kib) : NP.*

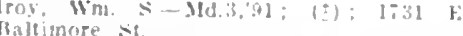

Giklowo(1) Jull $\left(b^{2}=1\right)+$ Md 1.44

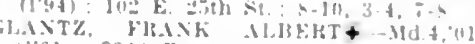
1101); 324 Bilern ive.

ilasman, Marry (b'as) - Tenndl, (b (l'l(1): :bis Wilkens $\leqslant 1$

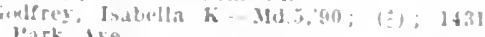
bark live

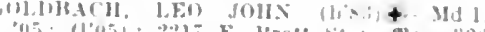

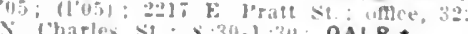

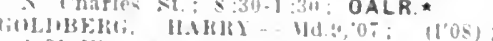
2031 W. Jrate st

(iolduan, IJarric (1,4ki Md 3.10: 11'10)

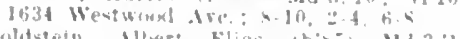

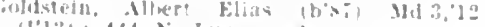

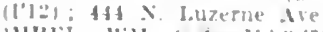

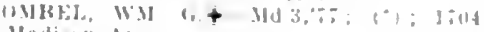

Malisold dre

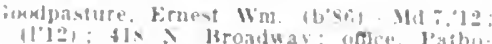

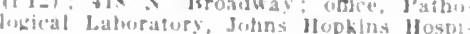
is!

horgas, Ferdinand d. $\therefore$ If 1,$63 ;(1+) ; 30$ s

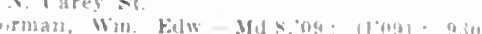
Jarlom Alo

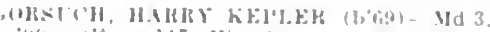
$\$ 6:(1+) ; 11:$ W saratrga st: $\$ 11$.

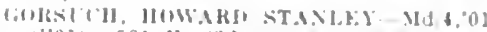

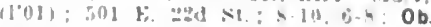

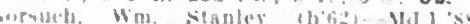

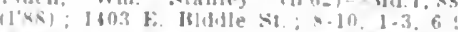

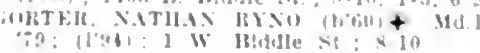

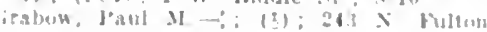
Are

Cirant, Wm ky 6.82: (1+1: 1495 X pultul

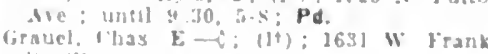

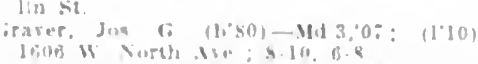

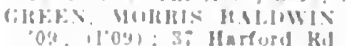

recell. Hestej a

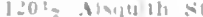

- Is

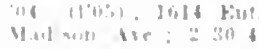

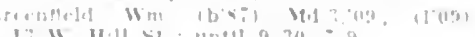

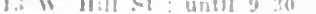

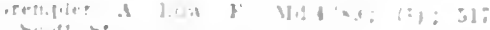

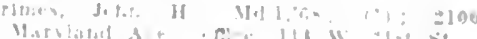

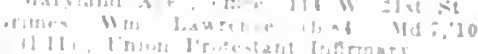

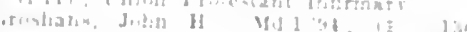

loght is?

those. H.1k:16

I harlen

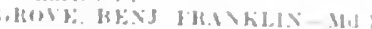

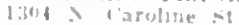

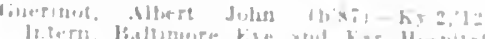

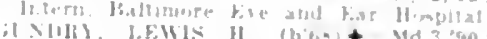

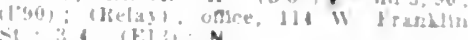
(li g r

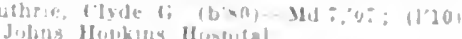

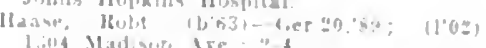

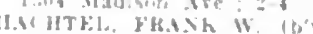

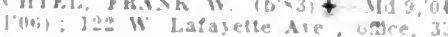
$x$ pharley sl

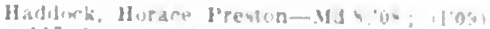

II. I 1 arroblecr athe

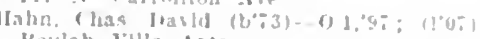
Hewlah villa Apts.

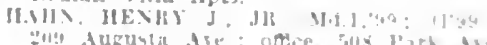

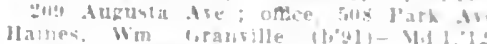

111:1: 16:9 IV. Lauble st: 8.9. 1 .

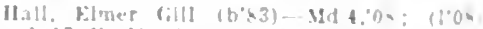

10il: bi Nurth ire : i is

Hall. Reverdy M tool.) - II.

tivi limber st

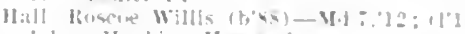

Whith, Ilugkins Jlowpial.

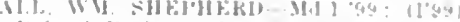

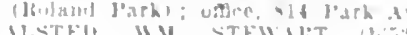

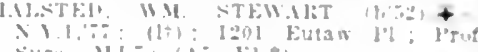

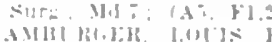

Yu: (E) 1.

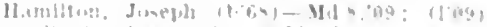

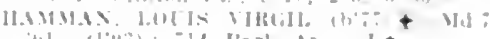

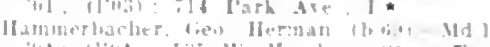

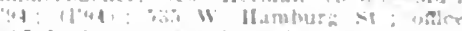

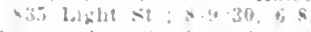

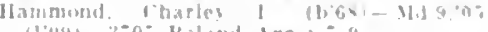

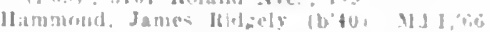

Hamptch. Jatuis F Mdt.01; Ifomit; lion

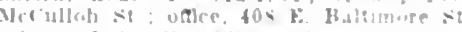

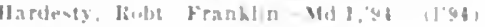

Jala it and llaguard ive.

H.1rily. Hocharl Thum-1/\$3.94: 11"931:

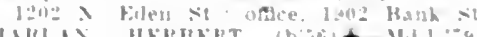

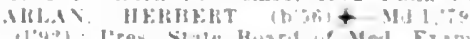

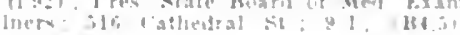
OALR.*

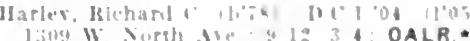

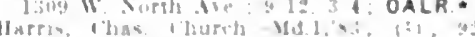

I athultal of

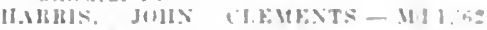

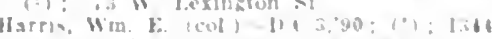

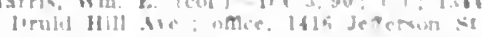

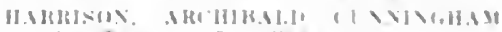

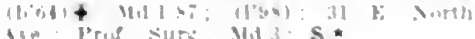

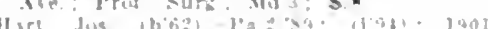
" Fayelle se: $\$-10=1$

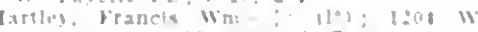
Fabrle :5: $10,1: 5$. ALR.

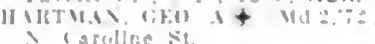

$11=1$

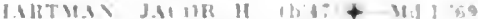
Al $1,011:$

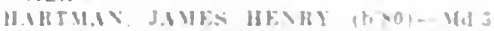

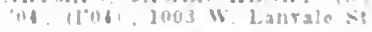

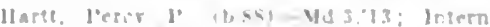

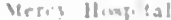

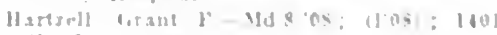


Hawhins, John frederlck (b'82) 一 Md.1, 06 : (l'(14i): J6]s lught st.; 8-J0, $7-8 ; \mathbf{N}$.

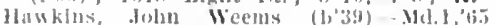
(l'(i.5); Dentlst; Maln st. and Belvldere

Hawkins, Thomas southall (cot.)-ly. (0); (1'00); 1202 Jrull H111 Ale.; s-lit, $2-4, i-9$.

Hnylen, Benj. S.-.Ma.6,97; (1.98); 121t;

HAYHE, HOLAHAS 11 . (1) 699$)+$ MH.3. 92; (1) ; 14:5 J.Jint st. ; !-10, 3-4,

Assoc l'rof. Ipulled Aual Mal.

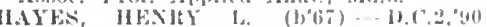
(); Member Hawalian Territurlal Ved soc.; Walbrouk; oblen, tiabler Fistate Blilg.

Hays, Leonard (b's9)-.Mal, 13 ; (1'13) infrersity lospltal.

IISWARI, FIIENE I1. (17\%7)+MI.4

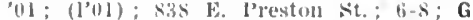
Hayward, Thomas $13 .-\vartheta ;(1+) ; 1230 \times$ ×. Caroline st.

Hazell, Benj. Woolwarl (b'72)-Md.9,0.5

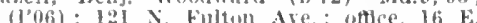
Ihaltlmore st.; 10-4; OpLR.*

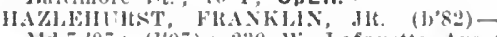
Md.7,07; (lo7); 230 W. Lafayente Are ;

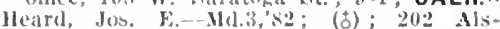
quith sit.

Hearn, Arthur C. (b'7t)-Md.1,97; (l’99) ; 2600 E. Baltimore $\leqslant t$; $9.10,1-2,7-8$.

lleatwole, Thmothy $0 . \quad\left(b^{\prime} 65\right)-j(1.1,97$; not in practice; $2003 \times$. Charles $\mathrm{St}$.

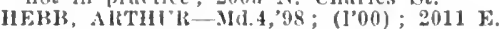
Pratt st.; oftlee, Professlonal Bldg. ; (A4); Pr.

HW(K, JOHX JOSELII (1,79)-MI.3, 03 ; (l’03) ; 936 E. Monumenț st.; 8-10, 2-3,

IIEISF, FIEEDK. IHFNIT CASJFR (h'83) -Ma.1,07, 1'a.9,08; (l’07) : Member Med. soc. of the state of X. Y. T2I W. Lanvale st. (offle, Trudeau,

Helskell, Doralyn B.-MI.6,"01; (末); 1708 Iladlson Are.

Helfgott, Max Aaron (b'83) - Md.9,'12 ; (1'12); 1133 E. Baltimore St.; offlee, 229 s. Hond St. ; $8-9,2-3,6-8$.

Heller, (Yeo. (b’74)-Md.4,97; (1'97); 1937 Gough sit. ; 8-10, 6-8.

Hellweg, Elizabetli Singley (b'75)-Md.7, '07; (\$); 710 W. North Ave; ( F9) 1 (12): Ielm, F. L. C. (b'ss)

HEMMETER, (iEO. W. H. $\left(b^{\prime}, 6\right) \uparrow-3 I .1$, 01; (1'01); 800 Harlem Are. : 8-9:30, $7-8$. HFMMETEH, JOHN COHN (b'63) §-MIl.1. '84; (1\%); 739 University Parkway; of flce, Read and Charles Sts.; Prof, Physlol.

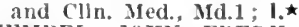

IIENHEI, JOHN FHEDK. (b'64)†-MId.4, 94; (1'94); 1103 Valley St.; 8-10, $6-7: 30: 0$ ALR.

Henderson, David Kennedy-Scot. $3,{ }^{\prime} 07$; In teru, Johns Ilopkins Hospital.

llendry, Ernest singleton (b'si)-Md.7,'11; (l'ii); Unlon l'rolestant Hospital.

HENXING, ENIL HELLER (b'80)-Md.1, '08; (1'08); 2000 Hollins st.; 8-10, 7-8; Pd.

Hering, Jos. Trumbo-Md.1,85; (1'06) ; 1712 st. Paul st. and Mt. Royal Are.

HERRING, ARTHF $\mathrm{P}$. (h'T5) $\uparrow-M I d .4,96$ $\left(1^{\prime} 96^{\circ}\right) ; 2609 \mathrm{~N}$. Charles St.; offlce, $330 \mathrm{~N}$.

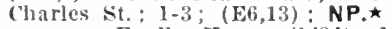

lferrmann, Fredk. Henry (b'84)-Md.1, 0 $(107) ; 3115$ F. Baltiniore St.; 8-10, 2-3, $6-8$.

Jerzog, Bernard Phlllp (b'79)-Md.4.'06: (l'06) ; 1305 N. Patterson Park Ave. ; 8-10, 6-s; Ob.

IIesser, Fredk, Ëlw,-H-IId.8,04; (I'04); I301 $\mathrm{N}$ Patterson Park Ave.

Hener, Geo. I. (b'82)-Md.7,07; Intern. Jolins IIopkins Hospital.

Hichew, Arthur Lee (1)91) - Md.9,'13; (l'13): Franklin Square Hospital.

HILL, CHAS. G. (b'49) †-IId.2,70; (l'06) Park Heights and Wrlle Are, offee, 82 Hamilton Terrace : ${ }^{3-6}$; Pror. Psych. Md.1; (E6.13) : NP;

son Are. offee, 1001 Edmondson Mre Hillis, Frink Norman (b'83)-MI.3,'12 (1'12); 2817 Ednondson Are.; 8-10
IIIMAN, FKANK $\left(b^{\prime} 80\right)+-$ MI. t.06 Mcmber Wash stute Med. Issn.: Asslst

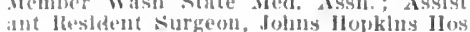
int that: $U$ औ

Ilinton, Clias. ('rawford (1,88)-Ma.;,13 not in practice: Hay Vlew Ifospltal.

lirschman, Moses-Md.6,98; $\left(1^{\circ} 99\right) ; 900 \mathrm{~F}$ Baltiniore sit.

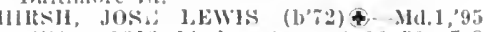
(I*9); 1819 linden Ave.; $9-10: 30,7-8$ l'rop. inth. and litet., Mal.

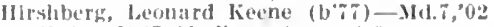
(1'(1)2); 1937 Madlson Ave.; (i-8

HOAC, J. MOItLEI + Md.3, $02 ;\left(10^{\prime} 06\right) ; 729$ (olumbla Ave. : 8-10, 1-2, 6-8.

(3) BLMANX, FIEIJK. WM. (b'76) Md.4.01: (1'01); 1908 W. Maltmore st. oflle, Gunther Blllg.; 4-6:30; $U_{*} \star$

Hoener, l'redk. (i. $\left(b^{\prime} 52\right) l^{2}-11-0$

112 S. Broadway; $9-1,4-10$

Hotrman, ' has. W'ilbur (b'76)-1'a.2,03 (1'03); 2000 W. Norlh Ave, 8-10, (;-8.

Ilotfuan, John Homer (b'57) Md.1,81 (ठ) ; 1627 Eutaw 1'l.; offlee, 702 W. Fay ette $\mathrm{St}$.

IIOFFMANX, ROJ3T. (b'59)-Ger.20,84; (5) ; 1325 Park Are.; 9-11

(OCAN, JOHN F.4 Md.3,11; (I'11) ; sydenham llospltal; $\mathbf{S}$.

Ilolbrook, Edw. H. (b"45) II-MId.1, 68; (古) 730 Newlngton Ave. ; 8-10, 4-7.

HOLLANI, JOS. W.M. (b'69) \&-Md.1,96 ; (1'98) ; 1624 LInien St.; $8-9: 30,2-3: 30$; $7-8$; ssoc. I'rof. Anat. Hd.1; $S$.

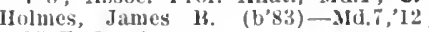
15 E. Read St.

Ilolmes, Walter Hilhard, Jr. (b'88)-Md.7 '13; (1'I3); Johns Hojklns Hospltal.

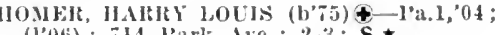

llood, Joln- II- Nich.1, 68 ;

Gilmor st. ; $8-10,2-3,6-8$. Iood, M. Bowman $\left(b^{\prime 7} 7\right)-$ Ild.4, 00 ;

Hooper, James Le 'Compte (b'69) II-Md.8, '94; (1'94); 1016 Wr. Fayette st.

Hooper, John R.-MI.1,'86; not In practlce; 1425 Linden St.

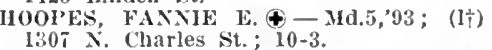

HOPKINSON, BENJ. MERRILL $\left(b^{\prime} 60\right)$ Md.1,'85 ; (1'94); (Holand Park); offlce, J'rofessional B!dg.

Horka, Leon S. (b'86)-IId.9,'13; (1'13) Frauklin Square llospital.

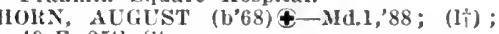
40 E. 25 th st.

IIornsteln, Abraham Louls (b'87) - Md.1'11

(1'11) ; 733 Alsqulth St. ; 8-10, 6-8; Anes.

Houck, Geo. L.-H-Pa.9,'98; (1'98); 212 W. Madison St.; $9-12, ;=8$

llouck, Henry Christopher ( $\left.b^{\prime}, \bar{i}\right)$ - IId.1,05: $\left(1^{\prime} 06\right) ; 1929$ W. Worth Ave.; 8-10, 3-4, $6-8$

HOUFF, JOHN (b'75)-Md.1, $00 ;\left(l^{\prime} 00\right)$; $15 \mathrm{~N}$. Monroe St.

Houlton, Saml. Searley (b’73)H-Md.8,'95,

Md.4,97; (1'05); 2801 W. North Are.

IIoward, James MeHenry (b'39)-Md.1,69; (5) ; 939 St. Paul St. ; office, 202 E. 25th St. ; $10-4$.

HOWELL, WM. HENRY (b'60)-Mich.1,90; (1) ; not in praetice; Johns Hopkins Medical School; P'rof. 1'hysiol., Md. 7 .

IOWLAND, JOHN $\left(\mathrm{b}^{\prime}, \mathbf{i} 3\right) \oplus-\mathrm{X} . \mathrm{Y} .5,97$ (1'13) ; 20 E. Eager St. ; oftce, Johns Hopkins Hospital; I'rof. I'ed., Md. 7 ; (D1,6, F8) : Pd.

HTGIES, SINGLETON BEITARD - D.C.3, 05 ; (I'05); 1413 I)ruid Hill Ave.

Hughes, Wm. James-Md.1,'93; (㘹); 1341 x. l'atterson l'ark Ave.

Hults, Robt. M.-Md.1,71; (1t) ; $626 \mathrm{~W}$.

Barre St.
llume, Edgar Erskine, Jr. (b'89)-Md.7,'13 (l'13) ; Johns Hojnkins Hospltal; $\mathbf{N}$.

HUNDLEY, JOHN MASON (b'58) $€$-Md.1, 82; (I'83) ; 1009 Cathedral St. ; 3-4; Prof.

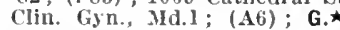

HUNNER, GLY LEHOY (b'68)૯-Md. 7,97 (1'02) ; $230 \%$ St. Paul St.; (A6, C3); G. HURD, HENRY HLLS (b'43)€-Mich.1, '66; (I'92) ; 1023 St. I'aul St.; offlee, Cal'66; (l'92) ; 1023 St. I'aul st.; offlce, CalEmer. Prof. Psych., MId.7; (E6,13); P.

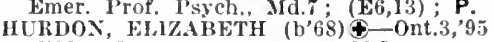
(I98); 31 W. I'reston St. ; ObG. *
HITCHNS, EILIOTT H, (1) 80$)+-$ Md. IYuk: (106);

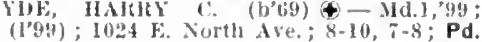
ICISHAIT, JAMES DAVIJSON (bo50) I'a.1,75; $\left(1^{\prime} 80\right) ; 211 \mathrm{~W}$. Ianvale st. $8-9,2-3,7-8$.

I(GLHHAIT, JAY HOWAHI) + - Md.l,03; $\left(l^{\circ} 03\right) ; 01 \mathrm{~N}$. Carrolltoll Are.; until 9 $7-7 ; \quad$ ObG

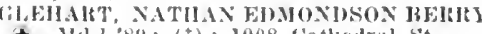
+ Mcl.1,89: (8); 1008 r'athedral st.

Imhofe, Henry 11.-M $1.6,93$; (\$); $535 \mathrm{~N}$. carey sit.

ng, Wm. Mldael-Md.6,'99; ( ); 1802 E. Baltimore st.

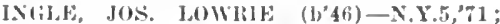
$\left(I^{\prime} 02\right) ; 1007$ W. Lanvale St. ; 8-10, 3-4, $-8$

Ingram, Marle L.-IId.8, 07 ; (1'07) ; 2439 N. Charles sit.

XNILYY, JAMES KXOX (b'86)-M(1.1,08 (1'08); 2938 b. Balt!more St.; 8-9, 12-3.

ACOHS, HENIT B.ALTON (b'58) $\oplus$ Mass.i,'si; (1'89) - 11 Mt. Vernon Il.

Jacolss, Sllas Baldwlu - Md.8,'05; (l'06); 634 Mosher st.

lanney, Edw. W.-MI.1,'63; (む) ; 3502 Вапк Sit. ; offlce, 1435 E. Fort Ave.

JANNEX, FltANCIS W. (b'82) $\oplus-M d .1,05$; (1'05) ; Wentworth Apts.; oftice, 327 \% Charles st.; 9-1; OALR.

JANXEY, O. EINW. (b'5ti) \-Md.1,'81, 1'a.9, 82; (t); 825 Newington Ave.; offlce, 141 E. 'North Ave. : $8-10,3-4,6: 30-7: 30$.

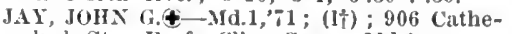
dral St.; Prof. Clin. Surg., Md.1.

Jefrers, John Geo. (b’71)-Md.4,95; (I'95);

413 S. Carrollton Are.; 8-10, 1-3, 6-8.

Jeldell, IIelmlna (b'78) - Md.7,'12; Johns Hopklns Hosputal.

Jelks, Fdward (b'88)-31d.7,'13; Intern, Johns Ifopklns Ilosilital.

Jenklns, Fellx S.-IId.1,87

(专); 3011

Hosher st.

JNNINGS, FRANK LESLIE (b'88)-Md.3, '11; (1'11); Mercy Hospital.

Jewett, Fredérlc Clarke (b'69) - Md.6,93; (1'94); 2635 l'emnsylvania Ave.; untli 10 , $3-4,6-8$.

Johnson, Edw. Sooy-Md.1,'12; (1'12) ; St. Joseph's German Hospltal.

Johnson, Richard Henry (col.)-D.C.3,'94; (I'02); $413 \mathrm{~W}$. I3iddle st. ; office, $655 \mathrm{~N}$. race St.

JOHNSON, ROBT. W. (b'54) - Pa.1; ;9; (A5) ; $\mathbf{S}$.

Johnson, W'm. H.-IId.8,92; (1 ) ; 2017 E. Baltimore St. ; 9-10, 2-3, $7-8$.

Johnston, Chrlstopher (b,56) - Md.1,80 (\#); 21 W. 20th St.

JOHNSTON, RICHALD HALL (b'71)-Md.1, '94; (1'94) ; 807 . Charles St.; $9-1,6-7$; Clin. l'rof.' Dis. Nose and Throat, Md.1; $(\mathbf{B} 1,3)$.

JOHNSTON, SAML. (b'4i) $\oplus-\mathrm{Pa} 2,70$ : $\left(I^{\prime} 94\right) ; 204$ W. Monument St. ; $9-1 ;$ (B2);

JONES, ALFIEED POWER (b'85)-Va.1,'10; ( ) ; 111 Jackson P1.

Jones, Caspar Frank (b'63)-M1.4,'95; (1'95); $1714 \mathrm{~W}$. North Ave.; 9-10, 6-8.

JONES, C. HAMPSON\&-Scot.3, 83 ; (1\%)

2529 st. I'aul St. ; $7: 30-8: 30,6: 30-7: 30$

Prof. Hyg. and Publlc Health, Md.3.

ONES, DAVID W.-Md.6,'86; (む); 3116 o'Donnell st.

Jones, Harry G. (b'81) H-Md.8,05; (1'05) : 1235 W. Lafayette Ave, 8-10, 3-4, 7-8. (1'03) ; 222 Augusta Ave.; offlee, 931 Frederick Ave.; 9-10:30, $7-8$.

Jones, Kenneth B. (b'85)-MId.1,11; (1'11) ;

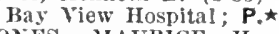

JONFS, MAURICE H. (b'84)-Md.9, 09 : (1'09) ; 423 E. Fort Are. ; $10-11,7-8$; Pd. Joslin, Chas. Loring (b'88)-Md.1,12; ( ) ; 839 Hamliton Terrace.

JOYCE, JAMES BURCH (b'T1)-Md.1,94: (l'95) ; $1800 \mathrm{~W}$. North Ave.; offlee, 2510

Judd, Chas. Chauncey Wlnsor (b'83)-Md.7, '11: (l'13): 3702 Forest Park Ave; office,
College of 'I'hys. and Surg. : 9-5; LD. 


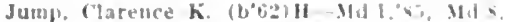

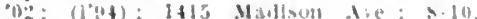
(i)

Kailer. Henjambu (LA1)-311 1,10: (1'11):

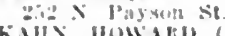

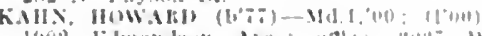

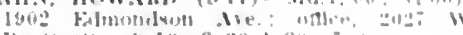
Irais si: 10.10, 3:50-4:30, "

h.HIX, Mixt- Mal, 35

columbla die.

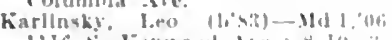

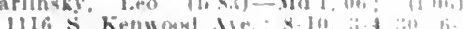

Kaslen, Win. Jullau (lifie) Md L .

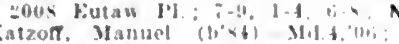

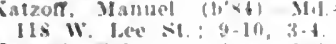

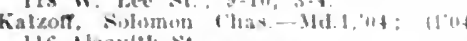

116 ilsquulth st

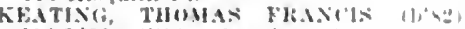

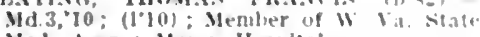
Med. Axsn.: Meres IInspltal

KEL, ALKEKT I. (b"to

311 Calhedral si.

heech Henry Hubare II Mul v'

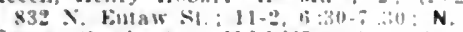

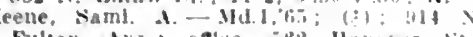

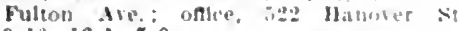
$9-10,12-1, \div-9$

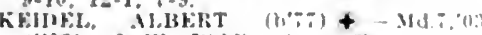
(1003): 2 W. Hudle st.: ince, 330 Charles st.: 4-6: U.

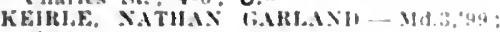
(1"99): 1419 W. lexington st. : Hof. Med Jurls. \$d.3.

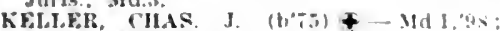
(195): 222 W. Monument st. $8-9,3-4$. $\div-7.45$

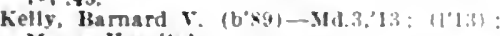
Hercy Hospltal

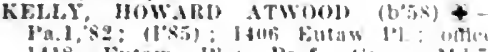
1418 kutaw l\%: Prof. li!n. Bd : (A2,6, (3, Fl) : G

Kelly, Katherine besales-Md.., 49 ; ( 1904$)$

916 . T. Trey st.

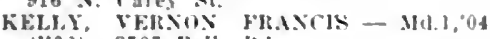
(1'06); 3705 Falls lid.

Kemler, Joseph Isac (b'\$3) - Md.1, 0 : (1'09); 519 X. Charles St.: 10-1;OALR.

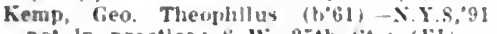

Kempe, Folward Joln (b's5)-0.6.'10: 1 . slstaut Ithysiclan, Jubns Ifophin, Hexpital:

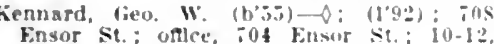
Ensor St.; onlee, 70t Fuser st.; $10-12$
$i=0$.

KESTARD, HEXRY WATEIS (b'it)-

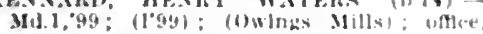
lolf Cathedral st. : $11-1$

Kenney. Frank J. (b'2)-Md.4, 11 ; (1'12): 1202 McCulloh Si.

Kenyon, Roth. Hrowning $\left(b^{\circ} 6 f_{6}\right)$ - Md t,

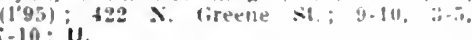

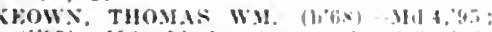
(1'95): 193x Iinlen lie, : $x-10,2-3, b_{0}-x$

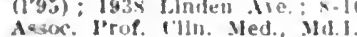

Kernes, Jos bowards (bol) (unn 1,0 ,

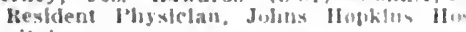
pila!.

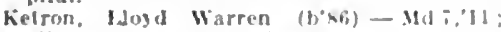
(1)11): 1119 N. Iarolla it

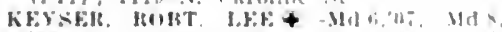

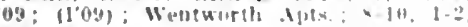
Gi:3: $\mathbf{S}$

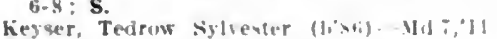
intern, Jobns ifopklov llexpiltal.

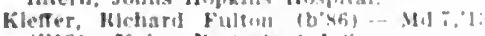
(1"13): Cnlon Irofestant Intlemary.

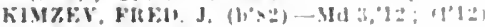
i46 lolphln st.

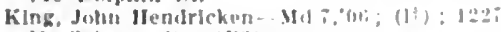
C rallert sit.: $\left(r^{* a}\right)$

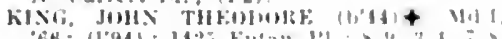

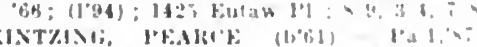

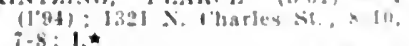

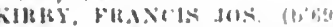

(1î): 110 tore lie :

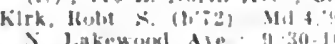

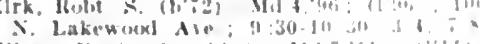

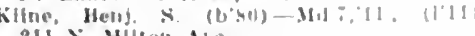

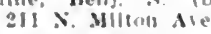

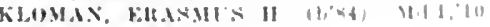

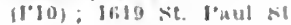

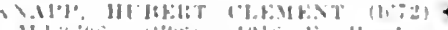

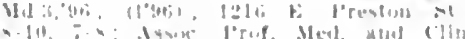
lialli., Mil.3: (k,t)

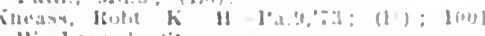
W. lam ale ki

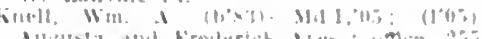

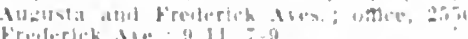
Tulctirath

(1) $02: 11010$ R.

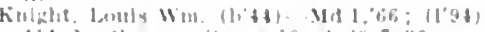

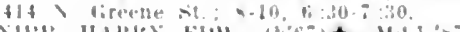

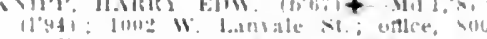

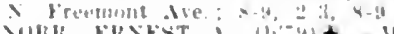

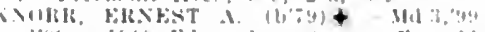

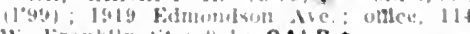
II Frantiln st : 1; OALR.

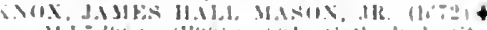

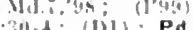

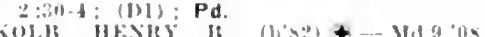

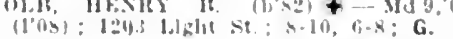

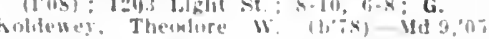

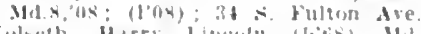

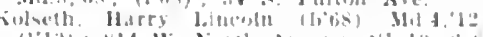

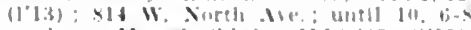

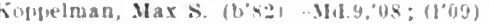

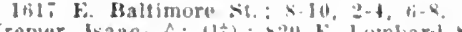

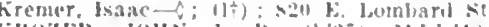

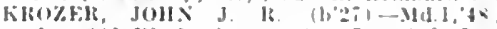

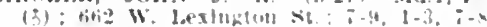

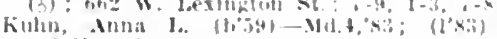
I. futrert st.

Kuhn, Juhn I.-M(I.6,04, Mats, 07 ; (107) t.s fiorsisch die.

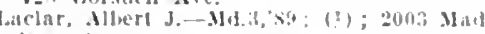
Jan Are.

Jamdin, Edu, s. $(1,60)-M 4.1,80$ : (104)

I.IXI, JOII FHEI

W. Fayelte st.

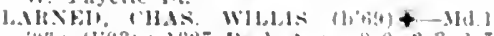

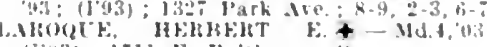

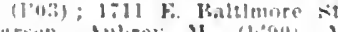

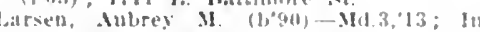
tern, Merey Hospltal.

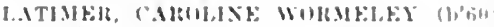

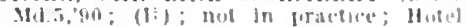
sllerwiond.

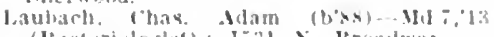

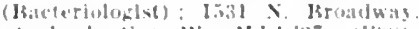

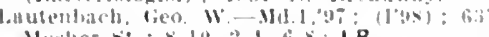

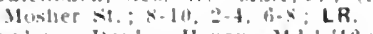

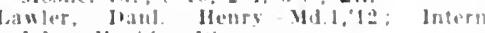
Jehns llogklns Hispensary.

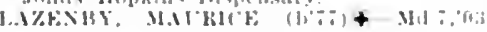

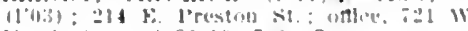

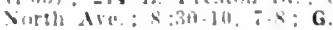

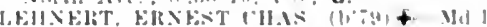

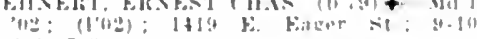

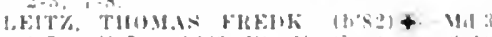

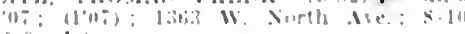
hi-s; $1 . \star$

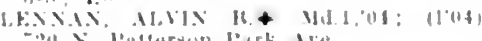

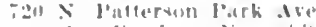

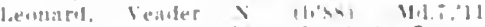
(1'11): Jolne Hophilla Ilowpltal: G. * 1. Fol?

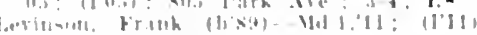
$\because 1>$ istratum

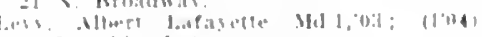

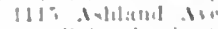

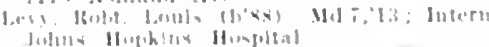

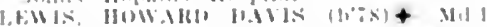

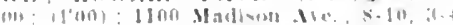
: S. S.

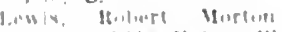

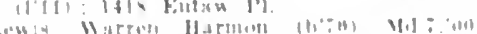

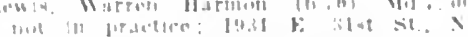

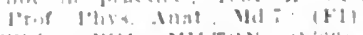

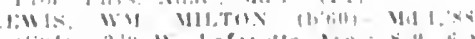

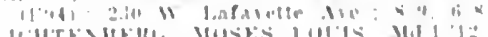

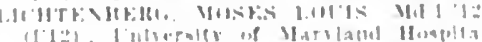

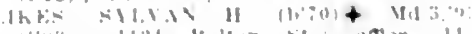

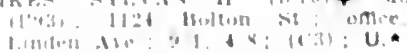

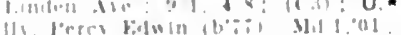

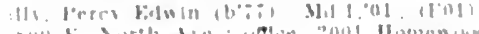

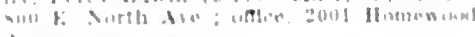

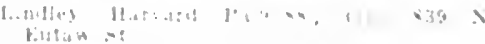

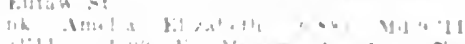

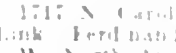

II Durth int

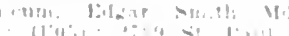

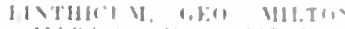

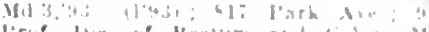

Pr.:

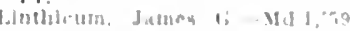

il risuter sit

l.tuthienm, Jihn W Mill, is

W Panetio si

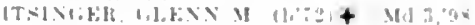

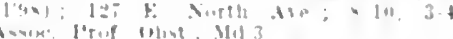

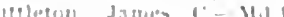

II. Jamale + is

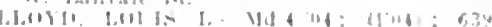

W' Fearklls :

(1"10) : 13:4 11 Xurth ile

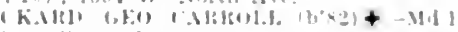

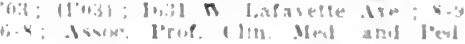
$111.1: P d$.

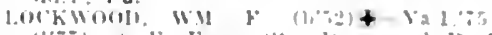
(1") : E. Eager st: l lean and lurut

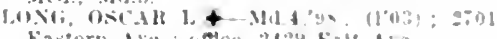

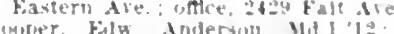

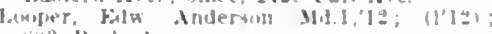
Sil:3 l'ark twe.

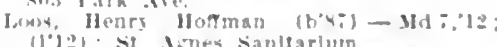
(1"1.2): si. Dones Sanltarlum.

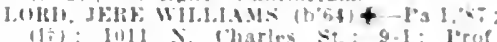
Gin lierm. Ma: : D.

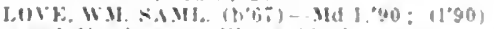

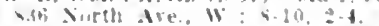

Lubchansky. Jacol woir-Rus 898 : (1t): 1 t: Exwer st

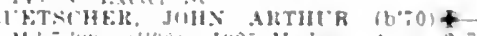

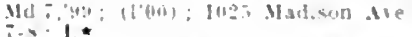

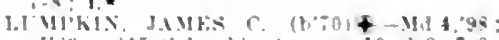
(Iํ) : bis columbla otre: $-10,2-3, i-8$ S.

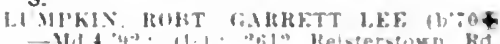

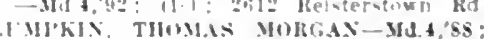

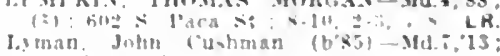

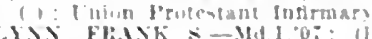

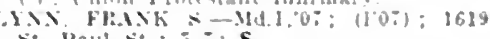
Si. Paul st. : $5-8: \mathbf{S}$.

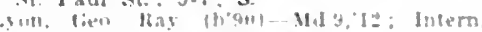
rianklin siguare Hospital.

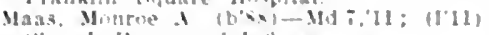
"laterh Home and Intrmary.

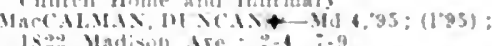

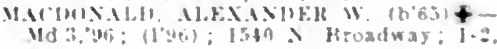

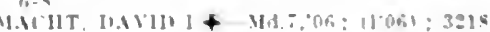
- buclantoroly Terrace: unt:i :30, 5-6.

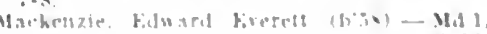

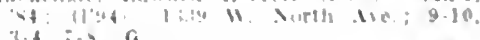

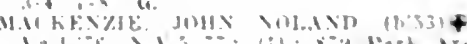

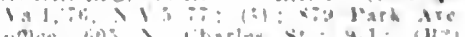
ALR.

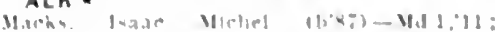

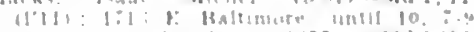

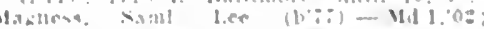

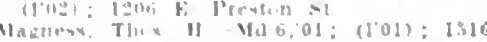

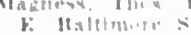

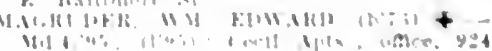

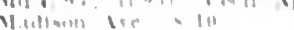

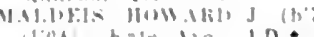

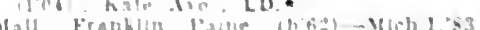

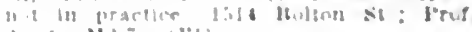
Ahat. Jul i (bl)

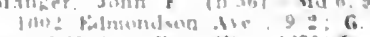

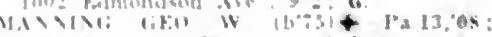

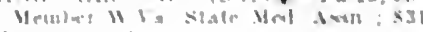
II Intming 
Mansfleld, Arthur Dumning (b'68)-Md.1,

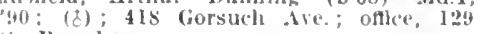
Broadway

Marchunt, Annle W.-I-Md.8,'99; (l'99) 1 i.1 Mondawin Ave.

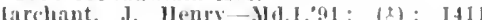
Mount Royal Are.; onlee, $11 \mathrm{I}$. Charies

Warden, Tllghman Brice $\left(b^{\circ}, 0\right)-M d .1 .92$;

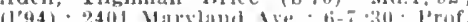
IItst. and Embry. Md.1.

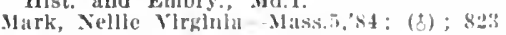

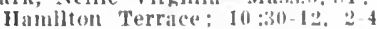

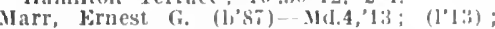
llaryland (ieneral llosultal.

Marriote, Yeanans smltl-X.Y.lo, at: ( ) :

Martin, Chas. Isurrell-II $1.9,10$; (萗) ; 310 E. Mandall st.

MARTLN, FIANK (h'63) + Ma.1.86; (h'94) 1000 Cathedral st. : loof (Tin. and Oper. surg. Mal 1 (Abi) : S.

Martin, Patrlck f.-Wtl. ${ }^{\prime}\left(00 ;\left(l^{\prime} 00\right) ; 1002\right.$ Wi. Lafayette Ave.

Mathews, James biwin (b'32)-Md.1,60; (ま); 1516 l'ark Are.

MAYER, ALFIEII IENRI \& Ger.20,8\% (c) : 1618 Madison Ave.

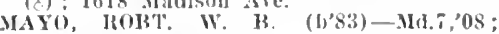
(l'08); sot Cathedral St.; ontice, $819 \mathrm{~N}$. Charles st.

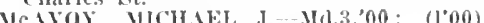
3006 Elliot st.; offlee, $839 \mathrm{~S}$, Fllwood Are. IIccard, Ilirry stanton (eol.)-Ill.1,00; (l’01); 2005 Inruid Ifill Ave.

Mecarrier, Francis bavidsun- II-Ma.s.00, Ild.4.04; (l'00); 2624 X. Charles St.; oftice, 416 E. North Ave

McCarthy, Clias. C.-IId.8;08; (1†); $901 \mathrm{~N}$ Ntrieker st.; oftlce. 524 $\mathbf{N}$. Mount st. Mc'arthy, Jolin '1,-Md.4,93; $(1 ' 94) ; 656$ w. Franklin st.

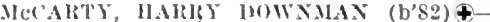
Md.1,05; (1'06); 37 W. Preston št.; $8-10,4-6$.

Meclanahan, Wm. E.-Md.1,02 ; (1'02) ; 619 $\therefore$ Clinton St.

Me('Icary, Benj. O.-Md.3,'10; (l'11) ; 404 x. Payson st.

MeCIFARY, STANDISI $\left(b^{\prime}, 0\right) \uparrow-M d .3,90$; (1'90); 1609 linden Are. : 2-3, 6-8; Prof IIist. and Spccial Path., IId.3; LD.

Mcclure, lioy Donaldson (b'st)-Md.;,'08; (l’08); Johus IIopkins Ilospital; S. $\star$

MeClure, Win. 13radbury (b'84)-Md.7,'12

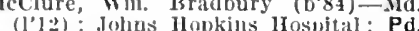

(l'l ly Johns IIopkins llospital ; Pd. (b'64)€-.11d.1,'90; (190);805 $\mathrm{x}$. Charles St. : $9-1 ;$ OALR.*

NeCornick, John Harry (b'70)-.1ld.6,'93 (l"as) 1016 N. Fulton Ave.

lccormick, Tilos PUGil (b'52) \&-lld.1 '77; (1'34); 1421 Eutaw Pl.

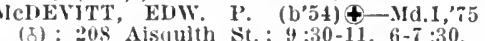
MeDONALD, WM. BARLOW (b'73)\&-Md.4, MCELFRESII, CHAS. WESLET + - Id. 1,89 : (It); 1415 Linden Ave.; Clin. Prof. Mel.,

Md.1.
MeGiNXAN, ALEXICS (b'72) \&- Md.3, $95 ;(1 ' 95) ; 114$ W. Franklin St. ; 2-3,
Assoc. Prof. Surg. aud Surg. Path., Md.3 S. $\star$

Mc(ilannan, Sally lorter Law - Md.7,07 (l'07); not in practice; $114 \mathrm{~W}$. Franklin

CIVLLEN, JOHN-U1, 1,95

U.S.lus, Jurg., Steward Bidg.

Mesherry, Jichard (b'55)-Md.1,'80 :

Alqunquin Apts.; offlce, $11 \mathrm{E}$. Chase st.

MEDDERS, CHAS. HAMILTON-MId.1,94; (l'94); Cathedral and Franklin sts. office, $330 \mathrm{~N}$. Charles st.

Nelvin, James A. $\left(b^{\prime} 63\right)-M d .1,{ }^{2}-$; 1303 W. North Are.; 8-9, 2-4, 6-8.

IERKICK, SAML. K.4-Md.1,72; (1†) 824 Park Ave.; Prof. Dis, Nose and Throat, Md.1

Messick, Wul. Irvin (b'69)-.Md.1,95; (1'05) 1700 Linden Ave.; 8-10, 6-8.

IETZEL, ROSCOE' C. (b'79) क-Md.1.'05 (I'05); $1903 \mathrm{~W}$. North AFe.; 8-10,6:30-8 MEYEK, ADOLF (b'66) - Switz. 7,92 11.11); (I01 Edgevale Rd., Roland Park) Tolns Hopkins llospital: Prof
Meyer, ('arl H., Jr. (b's6)-Md.4,08; (l'08); $401 \times$, Lalkewoud Are ; $9-10,2-4 ; 7-8$. Mroer. ('hiss. HI.

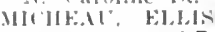

IIt... $110.3,75 ; \quad(1 \dagger) ; 50$ Hituoler st.; LR.

Baltimore st. : $x-10$, $6 ;-8 ; 0$ b

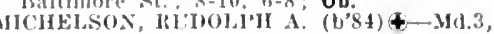
09: (1"04); I420 F. Laltimore St. ; 8-10, $6-8$.

Mlillin, Itolst. W. - II $13,9,76$;

Mllbourne, leander isurkess (i)

(98. (199): li s (jilmor st, Mliles, Jos. A. (b'72) - Mal.3, 07 ; (1'0s) ; 1620 E. Fort Ave. : untl] 10,2-4,7-9.

Mllholland, Edward F.-Md.1,58; (c) ; 115 II. Framklin st.

Milholland, Edw. V.-Md.1,'95; (1'95) ; 2620 Guilford Are.; offlec, B. \& $O$. Bldg.

Willea, Win. Lawrence (b'86)-Ma.,${ }^{\prime} 12$ (1'log); Johus Hopkins Hospital; Ob. MIJIEK, IIVING (b'58) - MId.1,7\%;

1211 N. Calvert st. ; $1-3,6-7: 30$.

Miller, John Albert (b'87)-Md.9, 09 ; (1'11); 272:3 Eastern Ave.

MILLEK, SYDNEY ROBOTHAM (b'83) IId.7,10; $\left(1{ }^{\prime} 10\right) ;$ Elgln Ave. and 12th st.: L.

Milliman, Thomas A. (b'60)-Md.6,'90 (I’00); 2445 (ireenmount Ave. ; $\bar{i}-9,1-3$, $6-7$

MIIAS. JAMIAS A. - Nid.4,89: (১); (ireen Spring Valley; offlce. 853 Park Are. MISOT, GLO. HiCHAKDS (b's6) \& Mass.1 12: (l'12) ; Johns II pkins Hospital.

linsk, Louis Ihavid (b'89) - Md.7,'13: Intern, Johns lJopkins Jospital.

MTOIIELL, CHAS. WELLMAN (b'59) \& II.1,81; (1'92); \& E. Chase St.; 2:30

MTCHELl, GEO. WASIINGTON (b'75)\& Md.1,'96; (l'96); 2607 N. Calvert St.; $8-10,7-8 ; A$ Assor.
Thront, Ni.3; ALR.

MITCHELI, ROB'T, I, (b'81)-Md.1,05 (1'05) ; 2112 Maryland Are. ; 8-10, 6-8.

MTNICK, JACOB H. (b'57)-Md.4, 90 ; (I'94); 424 N. Greene St. ; 8-10, 6-8.

Mohr Dwight Harold (b'86) - Mfd.9, 09 (l'i1); 1631 Madison Are.; office, 2935 Fastern Are.

Morfitt, Clias. M.-Md.1,61 ; (ơ) ; 208 McMechen $\mathrm{St}$.

IORGAN. WILBUR PHELPS $\left(\mathrm{b}^{\prime} 41\right) \boldsymbol{\theta}$ Md.1,62; (1'88); 315 W. Monument St. $2-4,7-8$

Iorgan. Wm. I. (b'32) II-0.13,76; (1'94) 202 W. Franklin St.; $10-1,7-8$.

Morriss, Wm. Haviland (b'86)-MId., , 12 (I'12): Hospital for the Women of Maryland.

Morrissey, John Jos., Jr. ; (b'\$4)-Md.9,'10 ; (1'12); 3632 Roland Are.

MORTIMER, EGBERT LAIRD (b’て2)-Md.9 '03; (1'05); 530 N. Fulton Are.; 8-10, $\mathrm{i}-8 ; \mathrm{S}$

MOSS, WILLIAM LORENZO (b'76)@-Ma.7, 05: (1'09); Johns Hopkins Hospltal; (F2).

Moyer, Frank G. - Md.3,'81; (む); 1500 Eutaw Pl.

Munoz, Edmund A.-Md.3,92; (1\%); 1801 Guilford Ave.

MURGATROYD, GEORGE W. (b'85)-Md.4 '10; (1'10); 607 E. 27 th St. ; office, 2643 Greenmount Ave.; 8-10, 7-8; LR

Murray, Edw, Oliver (b'81) H-Md.8,'03: (I'03); 1221 W. Lafayette Are.; 8-10, $2-4,7-8$.

Nurray, Robt. J. (b'71)-IId.3,'95; (l'95) : 510 ₹. Fremont Ave.; 8-10,3-4; $;-8$

IUSE, ALEXANDER EUSTACE (b'64) IId.9,04; (l'06); $1000 \mathrm{~W}$. Cross St. oftice, $316 \mathrm{~N}$. Gílmor St.

MUSE, BERNARD PURCELL (b'68) IId. 3,$88 ;$
$9-10,2-4,6-8$

MUSE, JOS. ENNALLS (b'6i)-Md.4,'98: (l'98); 1520 Hollins St. ; 8-9,6-8.

Vaiman, Benjamin L. '(b'84)-Md.3,'10 (l'10); 1523 E. Baltimore St. ; 9-10, 3-5

NEALE, LEONARD ERNEST (b'58) Md.1,81; (l'93); 822 Park

Veel, James Craig (b'82)-MId. I, 10; (l'10): Johns Hopkins Hospital.
Neer, Chas. Sauford $(1,70)-M d .3,93$; (1'94) ; 408 S. Hatterson l'ark Are.; 8.10 $2-3,6-8$.

Wr., J'88)-Md.7,'12; (1'12) : Church llowe and lnfirmary.

istatt, Clono: ('las. (b'91) - Md.1,'13.

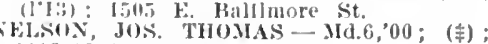

$103 x$. Fulton tre.

Sewcomer, Elmer (b'89)-Ma.1,13; (1'13) ; Iniversity Hospltal.

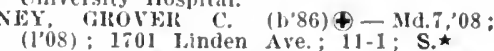

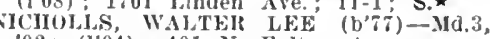
$02:(1 ' 04) ; 401 \mathrm{~N}$. Fulton $A$ ve.

NCHYIS, FIRMADGE KING (b'84) \&

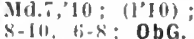

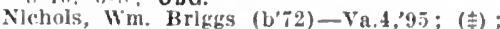

3435 1'jedmont Ave.; oflce, American

Bldig.; 8-6, 12-1, 5-6.

NICHOLSON, IIORACE W. (b'80)-Md.? 06 ; $\left(1^{\prime} 06\right)$; $225 \mathrm{~W}$. Madison St.; office, Ifoward and Madlson Sts.

NICIOISON, SAML. TINOTII, JH

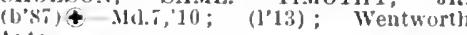
Allts.

VOLEN, CHAS, FHEUK. (b'68)†-MI.1, 90; (d) ; I0 E. lladison St.; olflee, 114 11. Frinklin st

MITENT, IRICHARD BAXTER, JR.IJ.1,'s0; (t): 3543 Chestmut Are.; 8-4,

Norris, Amancla Taylor (b'49)-Pa.7,'80; (t) : 1404 Matison Ave. ; $10-12,5-6$.

NOITON, RUPERT (b'67) $€$-Mass. 1,93 (1'10); $111 \%$ N. Calvert $\mathrm{St}$.

Sorwool), VERNoN JEE (b'62)-MId. ' 8.7 ; (l'y4); 939 W. Fayette St.; $9-10$.

NOVAK, E.IIL (b'83)\&-Md.4,04; (1'04) 823 ․ Patterson Fark Ave.; office, 330 N. Charles St.; 12-1; Assoc. Prof. Gyn., IId.3; G.

Nuckols, (c. Lunsford (b'71)-Md.4,93 (I'94): 311 s. (iilmor st. $8-10,2-3,6-8$

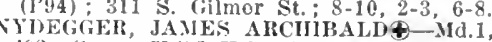
o2 ; Surg, U.S.P.H.S.; U.S. Marlne Hospital : Prof. Trop. Med., Md.1.

O'Douncll, James A. (b'86) - Md.7,11 (I'II) : St. Josepli's German IIospital.

O'Donnell, Thomas Jos. (b'79) -IId.1,03 : (1'03); 405 Warren Are.; office, $1340 \mathrm{~S}$. Charles St. ; $9-10,7-8$.

O'DONOVAX, 'IIAS. (b'60)૯-Md.1,'81. (1'90); 5 E. Read St. ; 8-10, 3-4; Prof. Clin. Med. and Ped., Mld.1; Pd.

OHLE, IIENRY ('HAS.' (b'60) $€-M d .1,86$ (1'86); 1203 W. Fayette St.; 9-10, 3-4,

Oler, Vernon Llewellyn (b'86)-Md.1,11; (1'11) L Liberty Heights and Woodbine Ave. : intil 10,6-7:30; S.

olmsleád, Wm. De Forest (b'82)-Md.4,'03;

(l'03); 1832 W. North Ave.; 8-10,6-8; U.

0'MARA， JOHN T. (b'81) $\oplus-\mathrm{Md} .1,03$ (1'06) ; 1042 Edmondson Are. ; 8-10, 6-8 O'NEILL, JOHN E. (b'74) (-Md.1, 10 (I'10); 2508 N. Charles St, ; T. 00; $\left(I^{\prime} 00\right) ; 108$ N. Fulton Ave.

Onnen, John' G. (b'87)-Md.3,'08; (l'0s) Fairmount Ave and Potomac St. ; 8-10, 2-3, T-8:30.

OREM, FREDK. STRATTNER申-Md.1,00 ; (l'00); $2827 \mathrm{~N}$. Calvert St.

(b'90)-Md.1. '13; (1'13); St. Agnes Hospital.

overman, Chas. Augustus (b'79) - IId.1,03 not in practice: 2019 W. I'ratt St.

Md.1,04; (1'05); 1815 N. Charles St: 11-1; (E6); NP. *

owINGS, EDW. R. $₫-M d .1,89$; (t) ; 1738 Linden Are.

PAGE, ISHAM RANDOLPH- $\rightarrow(1+) ; 1327$ Bolton St.

Page, Kollin B. (b'75)-Ma.9, 05; (l'11); 2805 Woodbrook Are.; until 10, 2-4, 7-8

Palmisano, Augustine (b'7 7 ) Md.3,04 (1'04); 316 S. Exeter St. ; 9-10, 6-8

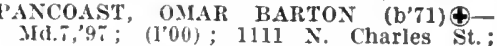
2-3: S. $\star$

Pannebaker, Wm. M. (b'64) H-MId.8,94; (1'94); 1209 Madison Ave.; 8-10, 3-5,6-8; G.

Park, Edwards A. (b"7)-X.l.1,05; Johns Hopkins Hospital. 


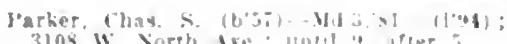

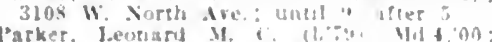

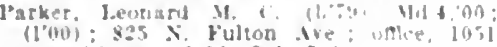

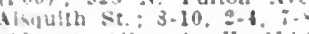

Parklatest NIIn

(i): Jio Jark lle.; $10-1$ (1'02): 1313 Juhn st.

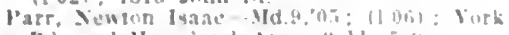

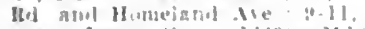

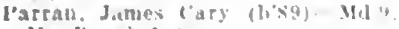

Mt. Kroyal Ints

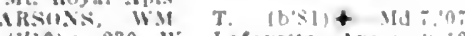
(1'10): 230 W. Iafaserte Ave: $y-12$ OALR.*

Patrick, Robt Bruce (b'si) - Md.?.1? Intern. Hay Vlew Hosnital

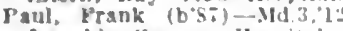
Joseph's German Hospltal.

PEARCK, WILBLK MAKTIN (b*i) +-Fal

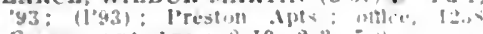
Greenmoun ire. $8-10,-3,-2$

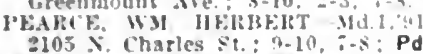

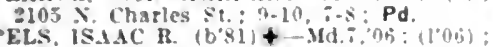
PELS. ISAAC R. $\left(b^{\prime} 81\right)+-M d .700$ :

IELTEKIAN, HUVIASTES KEVURK (b:71)-3id.t.93; (102); 3it w. I'reston St.

Penniman. W. B. D.-Md. 1.99; not in prac. tice 1120 Cathedral St.

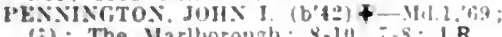

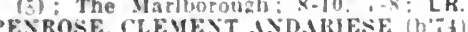
PENROSE, CLEMENT IXPAIRIESE (b' -Ma.7,9: (1'98): Wantucket, Mass:

IRKKINS, EDGAR SHIRLEI + -Md.1,07: (1'06): The Rrucbambeau

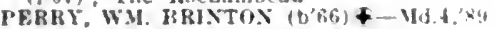
(1's5): Charles and Franklin Sis.; $2-1$ : l'rot. Clin. Fisn. Md.l.

lessagno, Euzene J. (b'80)-MII:"0i (107): 2311 K. Ballimore s: : $8.10,6.8$ PHTEMAX, HARIEY ELMEM $\left(b^{\prime}, 1\right)+$

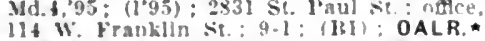

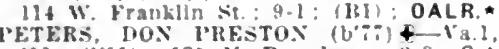
02: (I'11); 131 ×. Broadway: $-3 ;$ S.

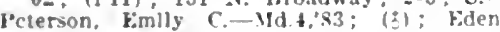
and Chase Sis.

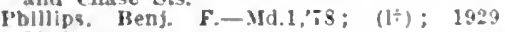
Madison Mre.

Phillips, Thomas II. (b'6) - IId 1,0 $;$; (1'0s); 170l Hollins st.

PICKF, JOHS U. (bo4)-MI.3.55; (1994): 1312 Ashland Ive: $8-10,7-8$.

PEKSON, JOHI WM. (b'83) +-IId 1.05;

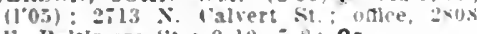
to. Haletmore si. : 9-10, :-8; or.

Pllisbury, Wm. James (b.68)-Md I.89; (1'94): 2801 York lill. : \$.9 :30, :-4: T. Vlew itospltal.

Plpltone. Pletro Jos. (b'8.i) - Tenn.11,09; (苂) 110 L. Lombard st.

Pirosh. Sigmar (b'81)-III.11,05: (l'0s) 1510 F. Fore Are: $9-19,5-s ;$ Pd.

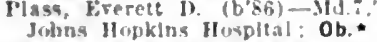

PLATT, WAITEIR HREWSTFE (b'53) Mass. $1,79:(1.81): 502$ ("atherleal 9.10. 3.4: (A6): S.

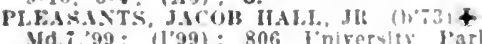

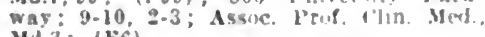
अ.3: $(1,6)$.

Plumb, Anes E.-MA.8,93:

Madiann Are.
PLIMU.

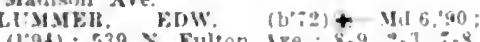

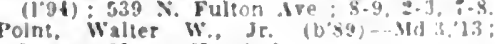
Intern, Mercy Hóspital.

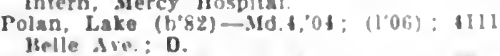

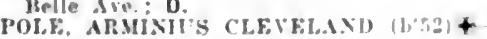

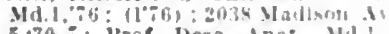

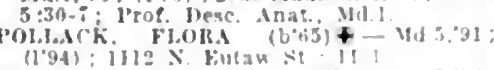

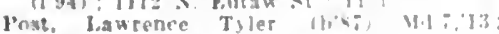
Intern. Johus Hojkln.s Hosplial

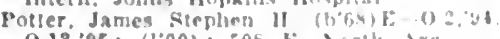

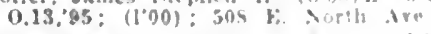

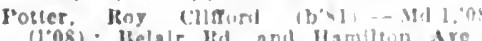

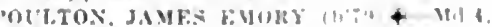

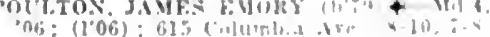

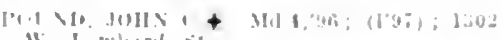

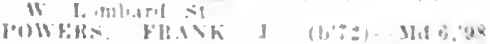

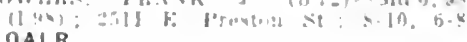
OALR

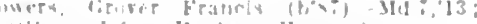

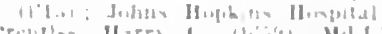

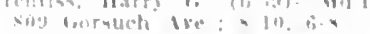

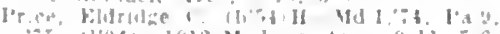

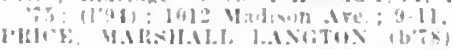

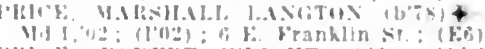

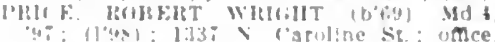

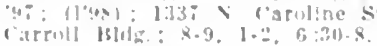

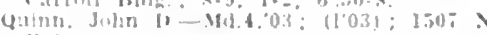

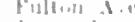

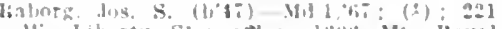
II Leberty St; ontere 1:0: Mi koyal

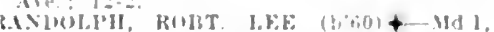

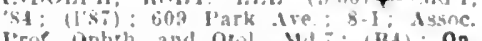

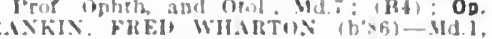

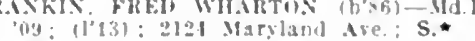
'oy: (l'13): 2lof Maryland Are: S. I'nluevtly of Maryland Inopltal

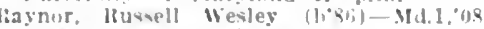
$(1008)$; 101: r. Ballimare st

liagsor, Harry ${ }^{\circ}$ (b'8S)-Md.1, 13: Hay View Hospital.

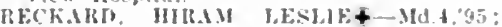
$(1925): 3100$ thell Ire

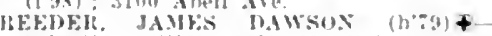
IId.1.01; (1.01); ti39 N pulton Are ntice, 330 S. Charles St. : \$1 :30, 3-5

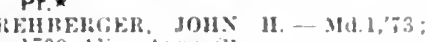
1709 Alice Anua $\leq 1$.

IIFID, EJ.IIII MILIER (h't (1) : yod $x$. Fremont Are.

Reid, Mon: IRogers (b'xy)-Mld.,'12: (1.12)

Juhne Hopilins Hospltal: $\mathbf{S}$.

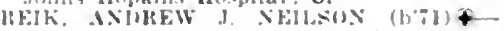

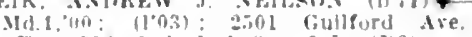

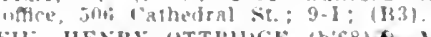

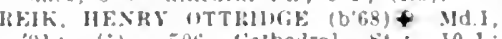

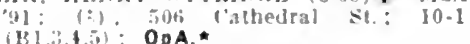

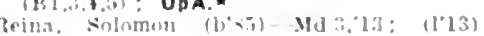

I:i Aisiuilh s!

Reinharde. tien. 11. (bo9)-MA.3.04: (1'09) atio3 5 . Calvert st. : $8-10,2-3$, fi-s.

Relnharit, Otho M-MU.6.93; (1.94); 1017 \& charles $S t: 8-10$ o 1 ri-s

leinhart, Irarid Jerume $\left(b^{\circ}+5\right)$ Ill. $\because 1$

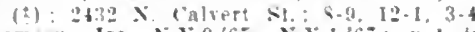

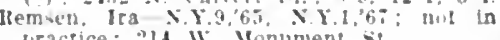
uractice: 211 W Wonument st. Sit. J'an1 st

RFQRIRTT WM WHTMLA Md I. 26

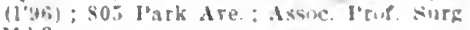
Ifd.?

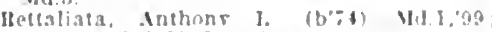

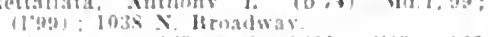

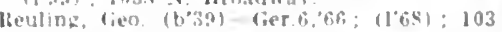
W Virument sit. : \&.

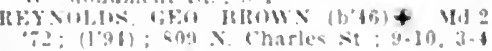

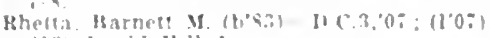
al:" lirula II:1] Ire

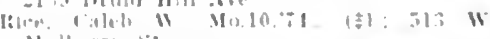

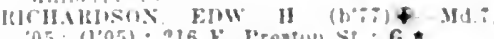

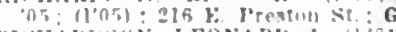

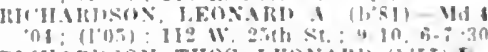

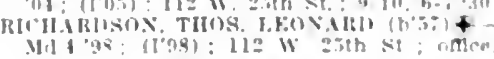
Quaranune statlon.

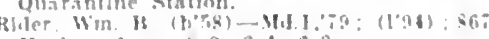
Ilarlom in: -9. a.t. 5 .

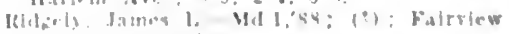

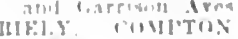

(1, the anos Or.

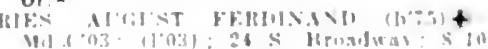

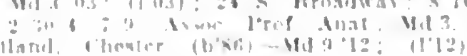
3:1:- Felmonement Iro

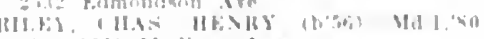
111: Vanllansi lie

VIa) wert lie

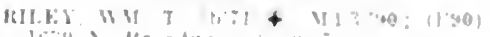
ISW II, Ju, H.

ive. gehn A

liwsly it Are

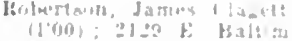

ALR.

Ii. binken $140, F$ II MI

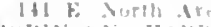

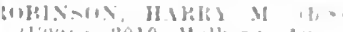

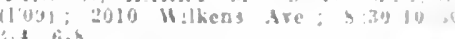

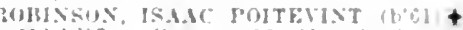

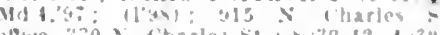

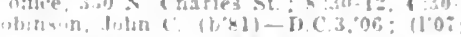

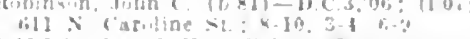

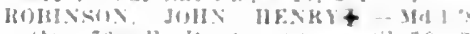

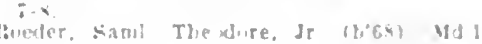

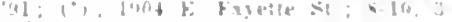

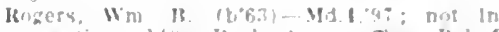

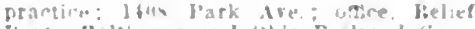

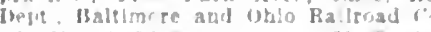

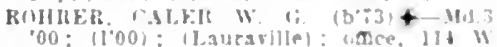
Frankin si. A.senc. Irof I'ath., Mta U

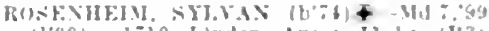
(l'flon): 1710 Linded Are: 11.1: (IB3)

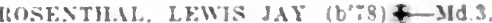

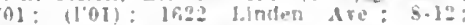
Arsice Prot. Merl. Mis.

KOSENTHA. MEITX S.M. (b.69) Md 3,9I; (19i); 1996 Linden Are. nfice

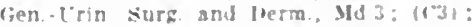

U.* W. Fagette st. ROSF:TT, Jusll

Ihwe, birnes! Hirriann-Mal 1.0\%: (1"0s)

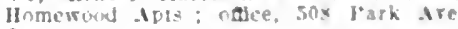
Op.*

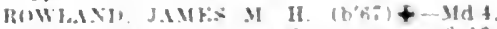

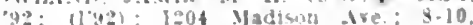

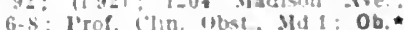

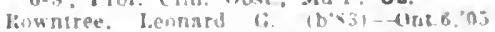

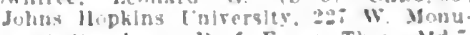
ment st. : Aswe l'rof. Exper. Ther. Wd:

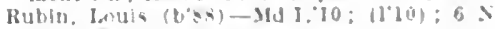
Front st

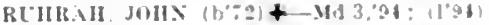
Sec. Mel and rhit Faculy of Md: : It F. Chase sit: 0.10: Pros. led. Md 3 (Iil) : Pd.*

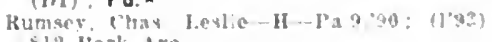
S1: l'ark . Ire

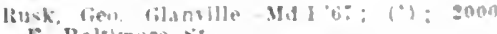

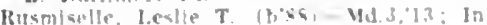
tern. Veres Hospital. Ruviell. Alpert T 1 hatil Tent 11.09

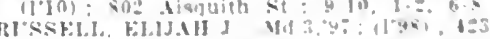
$x$ Itronatas

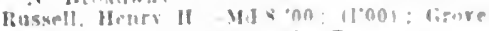
land tie: $\$ 10$ ti- $30: T$.

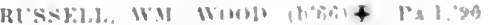

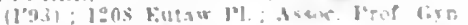
Id: : (AB) : G.

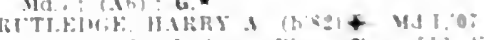
(1000) 100 Jarkios? In

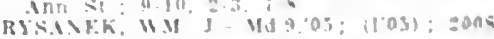
Avilamil ire

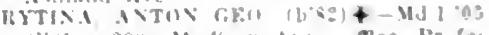

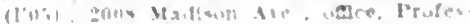

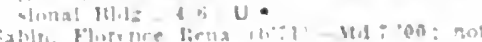

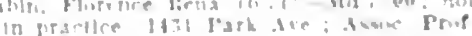
lina: Hat: (HI)

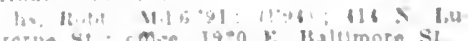

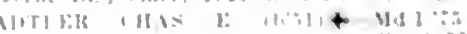

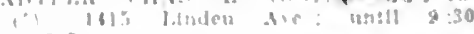

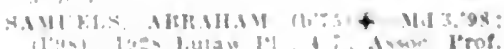

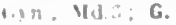




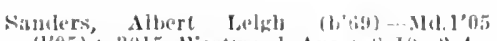
$\left(l^{\prime} 05\right)$; 3015 Westwoul Ave. : s-16, 2-4.

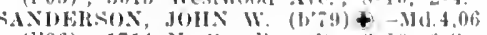
(1'06) ; $1714 \mathrm{X}$. ('aloline st. : S- $10,6-8$.

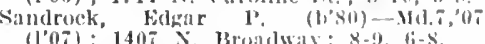

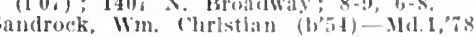
(丈) : 12042 ×. Broadway

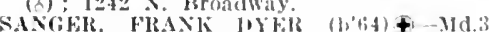
S8: (1t): (Ruvtun):

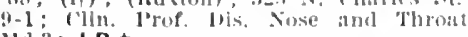
IId.3; LR.*

Sarason, Jeter bonj. (b'ss)-Mat, In: (1'12); Johns Hopkins IIospital; ObG. sauer, Francls 1. (b'1i) M113,74; (1'y4) 1400 Jetferson $\leqslant \mathrm{t}, ; 9-10,6-8$

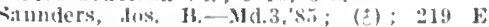
l'reston sit.

SAYMF, MOSES M. (1'

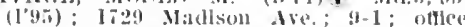
1121 F. Ballimore Si.; 5-8: OALR

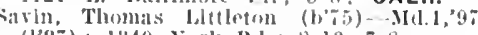
(1?97) ; 1349 York IRI.; $\$-10,7-8$.

saxtun, Mlexander 11. (b't1)-ild.1, 63 (1*63); $4: 32$ X. ('avey st. ; $9-10,2-4$

S('HAFFER, C. I'. OTTO $(1,68)+-\mathrm{I}$ (1. 94; $(104) ; 1105$ Madison Ave.; $\$-12$

Schaefer, theodore A. (b, 73$)-i d, 1,0 i$ $\left(l^{\prime} 07\right) ; 2505 \mathrm{~W}$. Laltimore st. ; 8-10, 1-2 6-8.

Schapiro, Wm. 13. (b'9I)--Md.3.'13

term, llebrew Jospltal and Asylum.

scheldt, Bobl. 1. C.-Mll.6,93; (1,93) ; 131 s. Charles st.; $8-10,2-3,6-8$

Sclimmel, Maurlee s._-Ma.6,95; (1'95) Garrlson and Belvlew dies.; R-10, 6-8. Sellleder, Iulius W-.IId.4, 05 ; (l'06) ; 3307 $\mathrm{F}_{\text {. Biltimore } \mathrm{St}}$

Schmelsser, 11 itry (hrlstian (b'8.5)-Mld. '12; (1'I2) ; Homewood Apts. ; Path.

Schmidt, Chias. Jouis (b'sy)-Mld.1,'il (l'11) : 1617 W, Chase St.

schmldt, saml, (b'63)-Md.3,'0I ; (立) ; 2211 Futaw il.

SCHMITZ, wM. JOS. (h's2) †-M1.3, 07 $\left(l^{\prime} 07\right) ; 2620$ F. Monument St.; $8-10,6-8$ Sciloeler, Wm. L. (b'75)-1ld.1, $00 ;\left(\mathrm{I}^{\prime} 00\right)$ not in practice; $1507 \mathrm{~N}$. Bradford $\mathrm{St}$

SCHOENRICI, HFRHEPT (b'83)-IId.1, 07 (1*0T) : I134 finden Are.: 9-1, 4-8; U.* Schofleld, John (alvin-Jid.6,91; (1'92) 148 Highland Are.

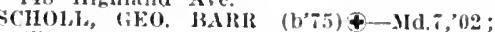
(I'02); 1605 w. Lanvale st

Schutz, Elw. A. (b'64)-Ild.4,'88; (1'88); $110 \% \mathrm{X}$. Caroline st.; offee, Bond and ollver sts. $9-10$, i-8.

SCHWART\%, WM. F. (b's6) $₫-M d, 1,0 z$ : (1'07); I200 X. Caroline st.; $1-3,6-8$; (E6)

SCHWATKA, J01IN B.-MI.1,82, Md.4,86; $(1+) ; 822$ W. North Are.; $8-10,1-2,7-8$;

(hweinslerg, John Geo, (b'ss)-Mld, ,09; (I'11); 1120 W. Cross St.; 8-9, (j-8.

Scott. ilouglas firant (col.)-W.c.3, 95 ; (l'00); \$5i ll. Biddle st.

Scott, Wilbur Noate (b'90)-Md.1,12; In tern, Enlversity of Marylani Hospitil.

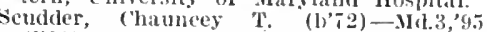
(l'00); 2 s. J'atterson Park Ave.; 2-3, i-8.

Seabury, Wm. T. (b'82)-Mld.8,0s; (1'08) 621 F. Fort Are.; 8-10, 6-8.

Sears, Thos. Edw. (b'54) H-Md.1,74; (b) 6.5. W. Franklin st.; $8-10,2: 30-4,6-8$

Sebalı, Frauk Jos,-Cier.10,'90; $(190) ; 100 \mathrm{I}$ Als ipuith st.

SEFGAR, JOIIN KING B. F. $(1 \% 69) \&$

Seen, Ralph Berger-IId.T, $0 b^{\prime}$; (1'13); Johns Hopkins llospital.

Selhy, John (iibert (b'72)-Mcl, '99; (l'99); 12 W. 24 th St

Seloner, saml. Wm. (b’31)-IId.1,72; (b); $150 \mathrm{I}$ E. Faurer St.

SEIAMAN, JOS. ALBERT (b'66)-IId.1, '92: (t); 1920 Linden Are ; 6-8.

Sellards, Andrew Watson (b'84)-IId. 7,09 ; liesident l'hysician, Johns llopkins Hospital.

sellman, Reginalal oliver (b'st)-Ml.í,12; $\left(1^{\circ}+2\right)$; It. Rogal Apts.; oflce, BeilderNe]lman simatoriun.

SELLMAX, WM. AJFRED BELT (b,30) \&5 E. Bidlle St.;8-10, 4-5; (A1); G.

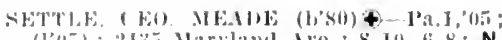

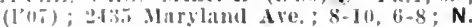
exton, Willer (i. (b'st)-Ma.i, 11; Helirew IIospltal.

filfertl, lurt (b'52)-Md.1,85; (o) ; 23 s. T'alboun st.; N.

Sliamer, Maurloe F. (b'70)-Md.8,04, Md.4 '10; (104); 1848 $x$. Fulton Ale.; 8-10, $1=2,0,6: 30$

SIINNON, GRORG; IONKLE (b'64)

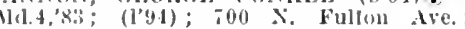
$8-11,3-4,7-8$.

Shaw, Ilenry Newton (b'st)-Md.7,'13; (l'13); Iohns llopklns llosjltal.

Shearer, Thos.-1I-1'ac6, 58; (ot); $905 \mathrm{~N}$ rluarles Sit.; 9-1 $: 30$.

shearev, 'Thomas 1. (b'59) ]I-Scot.9,'82 (d): $905 \mathrm{X}$. (harles $s \mathrm{i} ; 10-1: 30 ; \mathrm{AL}$.

IILLLEY, AIBERT-I'a.2,'95; (I'06) ; 3840 linind Aro.

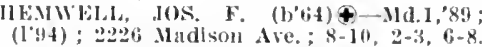
heppari, Thos. A. (b'84)-Md.a,'13; (1'13)

Franklin sifuare Ilospital

heppe, Jos. buther (b'56) - Md.9, (I'13); 6:2 $\mathrm{x}$. Arllngton Are.

hertmer, Nbrim Trego (b'44)-Md.1,69: (I'ST); $25 \mathrm{~W}$, l'reston St.; $7-9,2-4,6-8$ Al ERWOOl, MARY-Nwlt\%.,91: (1'95) 13 W. Mt. lRoyal Are.: office, The Armulel.

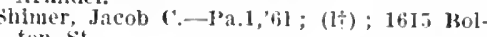
tom sit.

III'LEY, ARTH1K MARRIOTT (b;8)\& l'rof. Mat. Med. and Surgleal Path. IId. 1 ; S. .

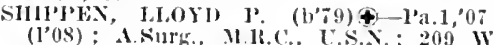
(l'0S) : A.Nirg., M.ll

shoemaker, chas. 1R.-Mr.3.9I; (む) ; 1204 E. North Ave.; $10-12 ;$ OALR.ネ Shorh, Marlin W'-IId.s,'06; (1'06); $806 \mathrm{~N}$ Fulton Ave.

Short, Folward-Mass.6, 05 ; $\quad$ (1†)； 1812 Druld 11 ill dre

Shorts, Wm. Francis (b'83)-Md.9,'11; (l'13) ; 1011 Mec'ulloh st.

Shower. Fdmund (i.-Pa.9,78; (む); 1224 IV. North die.

hlower, lieo. 'T' (b'+1) II-Pa.9,82; (l'94) 3721 Roland ive.; until 10,3-4, 6-8

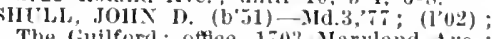
The Guilford; office, 170.3 Maryland Ave. $y-11,3-4$

Sillerman, David-IId.1,12; Intern, Hebrew Hospital and Asylum.

sllliman, firover Asa (b'90)-Md.4,'13;

Intern, Maryland General Hospltal.

Silljacks. Geo. S. (b'59)-IId.1,'86;

2818 b. Baltimore st.; $8-10,7-8$.

Silver, Iloward C.-Md.1,'s8; (১); 1914 Bolton St. ; offle, 1439 F. Fasette St.

SIMIONS, HORACE MHWVLLE $\left(\mathrm{b}^{\prime} 54\right)+$ Mll.1,81; (b) : 170\%; Park Ave, ; oltice, 'rofessional Bldg.; (also 597i' chula Vista Way, Los Angeles, Cal.).

Simms, Thos. J.-Id.3,'80 ; (ち) ; $1025 \mathrm{~N}$. olfe st.

SIMON, CHAS EDIIINI) (b'66)†-Md.1 90 ; (1'90); 1734 linden Are.; Prof. Clin. l'ath. and Exper. Med., Md.3.

S1NGEWA], ALBER'T G. (b'75)థ-MI.1, 02; (l'02); 1503 E. North Ive.; oftlce 1202 X. Patterson Park Ale.; $9-10,7-9$.

SINGEWALD, EDW. M. (b'68)థ-Md.1,'88; (b) ; 5 N. Washington st. ; $8-9,2-4,6-8$. sinskey, Henry Lyon-Ild.1,0s; (l'08) 1610 E. Baltimore St.

SISCO, HENRY NATHANIEL $\left(b^{\prime}, 6\right)+$

-Mich.1,02; (l'06); 215 E. North Ave. ISCO, 1'ATHENCE S. BOL'RDEAU (b'60) -Mich.1,02; $\left(1^{\prime} 06\right) ; 215$ F. North Are. $10-1 ;$ ObG.

SKILIING, WM. K. (b'84) - Md.T,'l1 (1'11); 4107 liberty Heights Are.

Skillman, Wilbur Francis (b'-8)-MId.1,00 $\left(l^{\prime} 00\right) ; 1504 \mathrm{~W}$. Lafayette Are. ; 8-9, $7-9$ Skladowsky, John Andrew (b'90)-MLd.1,'12 (1'12) ; 629 Columbia Are.

slack, Harry Richmond, Jr. (b'88)-Jl. '12; (l'12); Jolnns Hopkins Hospital; AL

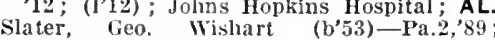
(l'80); 2300 Chelsea Ave.; offlee, $1703 \mathrm{~W}$ Fayette St. $9-10,7-8$.

SMINK, A CLAIENCE-Md.1,'96; (l'96)
Simlth, K. Holly-Ma.3, 83 ; (\$) ; 1007 Mad-

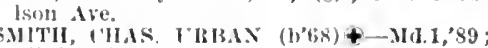
(l'92); 817 Fark Afe.; 11-1, 5-6.

Smlth, Manl. Webster (1,54)-Md.1,84; (2) : 206 W. $36 t h$ St. ; N.

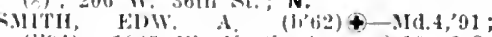
(I'14); $1605 \mathrm{~W}$. Nortl Ave, 8-10,6-8; Ob.

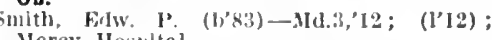
Mercy IIospltal.

sinlth, F. Edw. (1)'81)-114.9,02; (1'05) ; 910 l.lght st.; s : :30-10, $6: 30-8$.

SMIT1, F'RANK ROBT. (b56(t)-Jd.1,91; (194) He ( athedrat se, lon; Iadison Ave.; offlee, Johns Hopkins Hosplial.

S.IITH, HEXRY JNE (b,68)†-Md.1,94; (1\%4); 2\%01 N. C'alvert St.

SMITH, JOHN 1101,M ks, JK. (1,57)-Pa.1, 80 ; $(1 \dagger) ; 37$ W. I'reston St.; Prof. Anat. Ml.I; (FI).

S.IITII, Jos. TAIT $\left(b^{\prime} 50\right)-M d .1,72$ $(1+) ; 1117 \mathrm{x}$. Eutaw st.; $8-10,3-4,7-8$; l'rof. Med. Jurls. and Hý., Md.1.

Smlt1, J. Tyler-IId.1,77; (ơ); Eutaw and bolphin st

SIITI, MAISSHAII, G. (b'64)-IId.1,87 (1'94); 118 N. Calhoun St. ; 9-10, 7-8.

SMITI, NATILN RYNo (b'63)-N1.1,'86; (ठ); Green Spring Valley; offee, $211 \mathrm{~W}$. Madlson St.

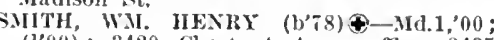
(l'00); 3429 Chestnut Are.; offle, 3435 Chestnut Ave.; 8-10, 6-8.

S.MITH, W.I. S. $\left(b^{\prime} 60\right) \oplus$-IId.1, $83 ;(194)$; Rochambeau Apts.; offlce, 528 Hanover St. ; $9-10,7-8 ;(A 1) ; \mathbf{G}$

YI 7,03 ( l'13)

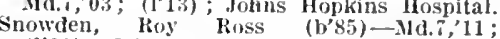
(l'11); Jolns Hopklus Hospital.
(lins

Snyder, 'Chas. Fredk. Wm. (b'85)-MI.1,'12 ; (1'12); Maryland (ieneral Hospital.

OWERS, WALTKR FRANKLIN-Md.1,06 (1'06) ; 2311 Edmondson Ave.; 8-10, $7-8$.

Sparck, Jos. (b's7)-MI.1,'13; (l'13); 1442 E. Baltimore St.

SPEAIR, HRV1NG J. (b'75) $4-3 I d .1,00$ (l'00); 1810 Madison Ale.; Prof. Neur. Md.1; (E6); NP.

Spearman, John F. (b'89)-Md.3,'12; (1'12); Mercy IIospital.

Spencer, Ilugh Raymond (b'88)-Md.4,'10 ; (1'10); not in practice; 1103 Linden A ${ }^{\prime}$. ; Assoc. Prof. l'ath. and Bact., Md.1.

(1'11). Lewis Cass (1,87) - Md.7,'11 (111); Johns Hopkins Hospltal; Or.`
Spencer, Roscoe Roy (b'88)-Ild. ', 13; Bay
Vlew IIospital.

spleknall, John T.-Ky.4,76; (c); 2112 E. Baltimore St.

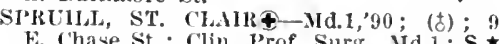
sprunt, Thos, P. (I's4)-II(I.T, 99 ; (Pathologist); Johns Hopklns Hospital; (F2). Stanshury, Henry H. (b'71) H-.Md.8,'96; (1'96); 'Eutaw 1'l, and W'ilson st.: $3-4$ : S. *

Stanshury, John Cllnton-IId.1,12; (1'13) ; $103 \pi$ Edmondson Ave.

Stark, Henry (1,'4t)-Ger.10,66; (1'82): 2461 Druid Hill Are. ; $8-10,6-8$.

Starks, Bennet M. (b'7 7 - D.C.3,08; (l'09) ; 1506 Presstman St.

Starr, Trammell (1,'88)-MI.T,'12; (1'12); Church llome Infirmary.

Steele, Jos. W. - Ml.1,56; (\$) ; $504 \mathrm{~W}$. Ilulberry St.

teenken, Chas. Danl. (b'71)-X.Y.1,96: $(19 i) ; 4015$ York R(l. ; 8-10,4-5, $i-8$.

STEIYILER, JEO FLEISCHEK (b'85)IId.1,08; (1.08); 1203 W. North Ale. Steplienson, Henry Augustus (b'8 i)-Md. 7 , '10; (1'13); Johns Hopkins IIospital. STFIRING, FINACE BLANCHE (b'73) Id.5, 05 ; (l'05); $2017 \mathbf{N}$. Chartes St.

Steuart, Cecilius Calvert (b'60)-.Md.1,' 82 ; (1'94); 122 W. $23 d$ St.; 8-10, 2-3, 6-8.

Stevenson, IIarry IICK. $-\mathrm{H}-\mathbf{M d} 8,01$. (1'01); $1022 \mathrm{~W}$. Lafayette Ave.

Stevenson, Holland Newton (b'86)-Md.7, 12; (Pathologist); The Severn Apts.

Stevenson, 1I, Kurton (b'69) - Md.1,92 ; $\left(1^{\prime} 92\right) ; 6$ S. Front st. 


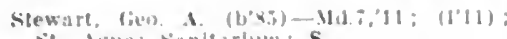
it. Aines santharlum: $\mathbf{S}$

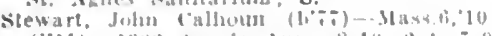

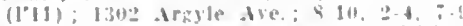

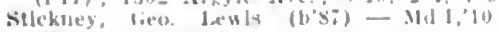
(1'lu): 1tily l'ark Ire.

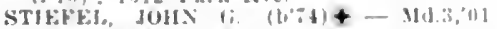
(1.01): $200^{\circ}$ X. Fulum Ale. : uflce. :ill Myrale Nie: $9-10,:-3, ;=$

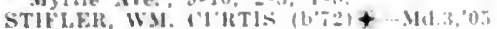

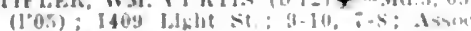
l'rof. Inat. Md.3: LR.

storkef. Inat. Md.3: LR. Maryland Are

stukts, WJ. HOV.11, (b'70) \&-Mal, 91 $(196) ; 1639$ N. Calsert st.: 1'rue. Itath and Itact., Mil.3,

stonclpher, Minde A (b'xu) - Matot (1004): 1655 S. Fulbull die.: $8-10,1=2$.

STOSE. HAKVEY MUSTOX (1)

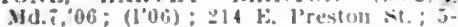
S.

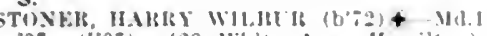

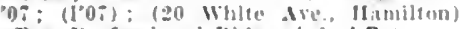

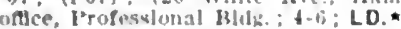

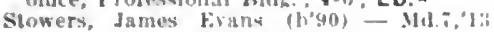
(1'13): St. Alues Hospritisl.

Straus, Henry Wn. (10.91)-M1.3,13 Fathologlst, Hebrew Ihosplit.

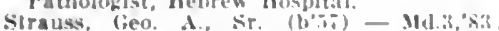
(1'83): 13 b: Juntunery st.

STIALSS, CEO, MANI, JR. $\left(b^{\prime} 86\right)+-$ MId.3, os: (l'0s) : $723 \mathrm{~W}$. Xorth He. : $x-10$. $6.8: G$.

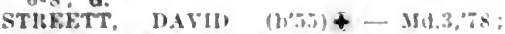

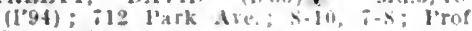
I'rac of Med., Md.1.

Street, IVavld foring (b'sis) - M11.7, 12; (I"12): 7l2 lark tre.

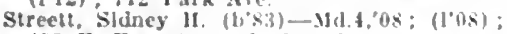
$435 \mathrm{E}$ Fort Are. $8-10,6-8$. Strlckler, Iferschel J., Jr.-IId 1,00; (l'00) : Sil Gorsuch Are.

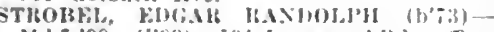

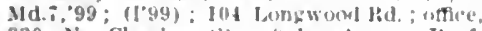
330 N. Charles s!: $!-1$; Assoc. I'rof Itern.. Md.1; D.

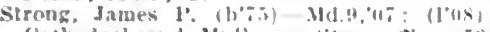

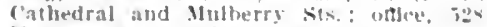
Hanorer si.; until li, 3-4, :-8: G.

STEAIT, DANIEL IELHANTI FIAIEN,

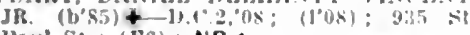
Haul St, (E.6): NP.

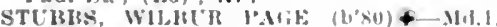

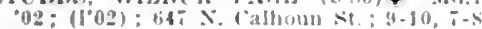

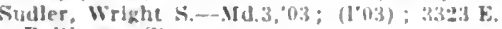
Baltimore st.

Sulfran. Wn. Jos.-114.9,01; (1.03): 1;01 v. Fullon ire.

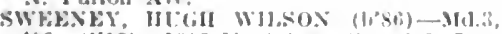
08: $\left(1^{\circ} 08\right) ; 1813 \mathrm{X}$. Calvert st.; 8.9.7-x: Pd.

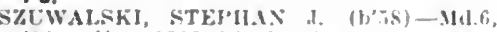

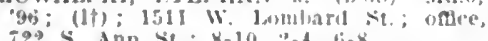

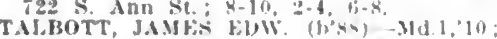
(1'10): 1353 w. Nurth Ave

TAL

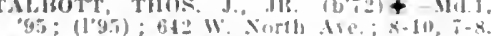

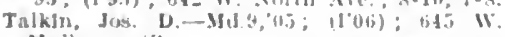
Mullierry st.

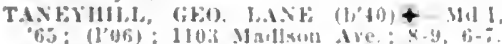

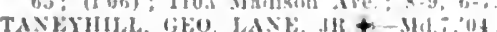

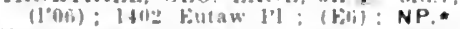

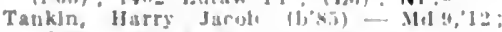
(1.12): 1632 k. Ballumere -2 .

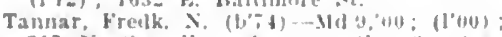

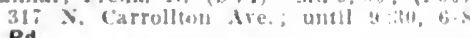
Po.

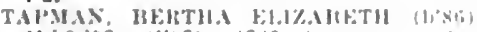

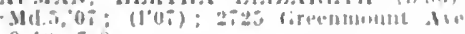
$9 \cdot 10, i-8$

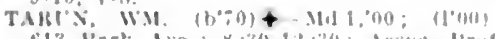

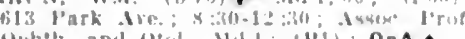

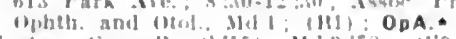

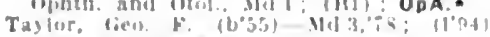

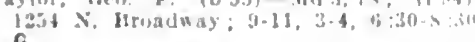

Taylor, Jefferwn Zarlary (1, W l'a:-

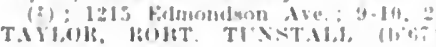

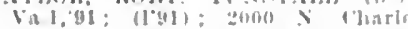
10-1: I'rose ortho. Nists. Ma.1;

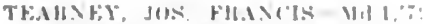
gelly Maryland due.

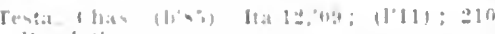
leeart sit

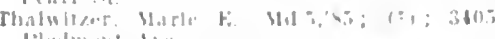

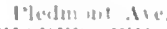

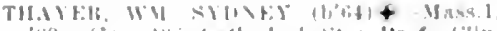

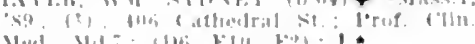

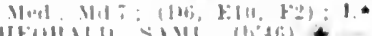

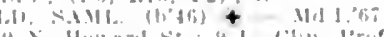

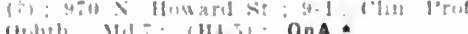

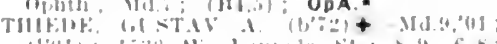

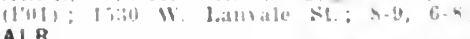
$A L R$.

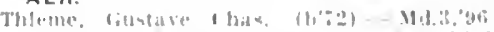

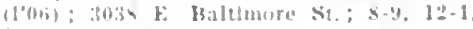

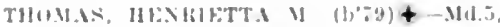
ont: (1'0t): lis Juhu st

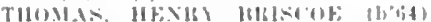

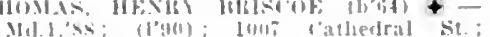
$3-1: 3 n ;$ LR.

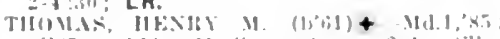

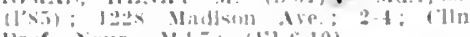

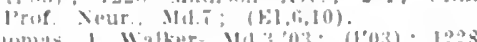
Thomns, I Watker No.3, $03 ;(1003)$; 1228 I. forulge st.

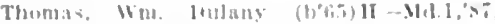

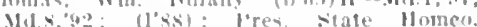
lhard w Med. Foumbers; bisis X. Car-

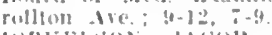

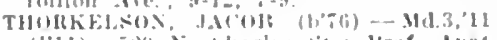

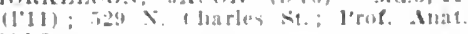
Ma.3.

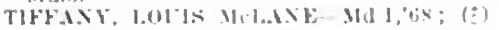

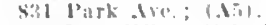

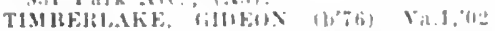
(1.08): 837 [ntversity barkwas: ofter

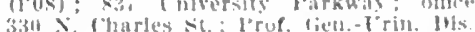
Ma1: $\mathrm{U}: \mathrm{m}$

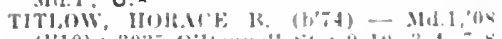
(1'10); 3035 (1)]buntell st.; 9-10,3-4, i-s Pd.

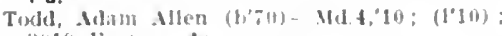
Buls bilstern Ave

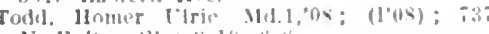
N. rulturs 51 ; s-10, ti-k

Todd, Martillus H. (b!tu) - Md:,1:; (I'13) Johus Jlogklos Haspital.

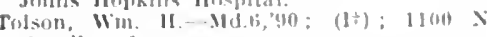
Cat rollne si.

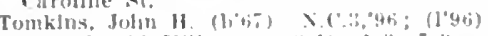
lols brukl thll die. : $8-11,1-3,7-9$.

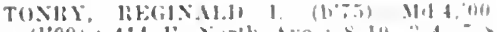

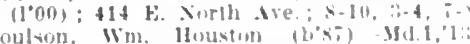

Toulon, Wm. Houstom llik

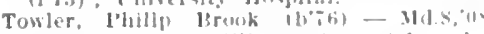
(t’os): 1432 Whllian st.; s-11, 1$t_{i-S ;} ;$ G.

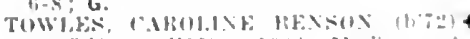

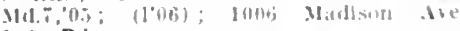
$1-\therefore:$ Pd.

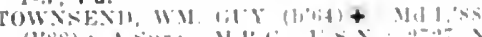

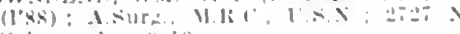

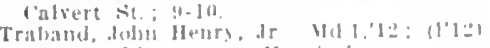

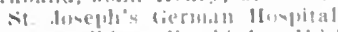

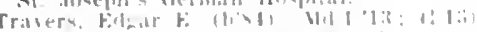

Iniversio of Marsland Ju-pital

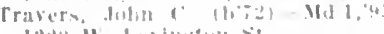

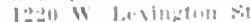

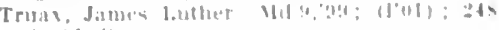

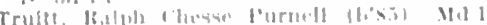

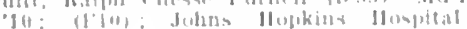
(ri, $1, i\}$.

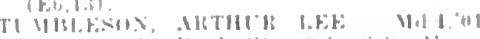

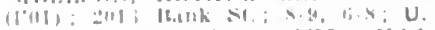

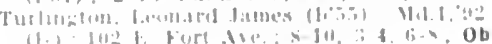

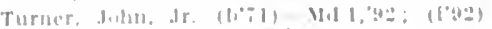

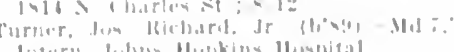

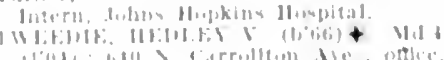

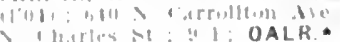

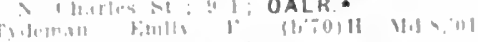

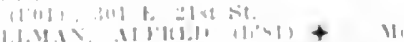

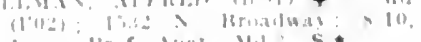

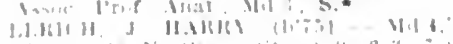

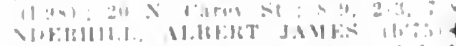

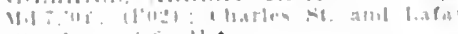

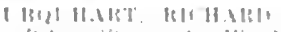

Pd. *

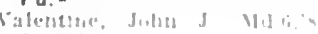

Broaluay

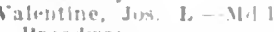

Hroaduay

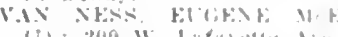

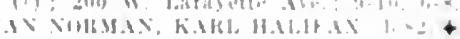

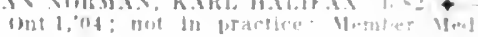

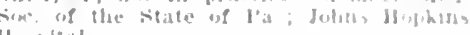
llompliall

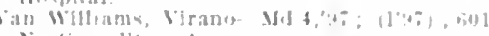
$X$ Carrollion die

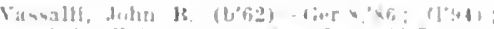

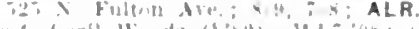

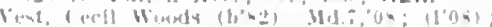

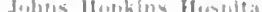

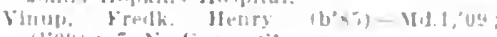

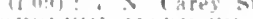

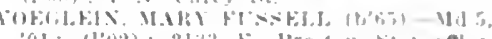

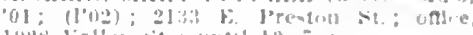
1110x lat!us st : until 10, ; -

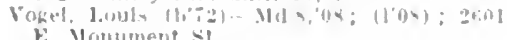

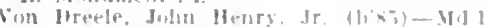

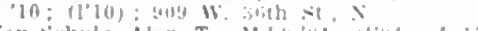

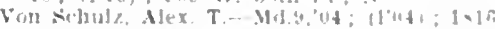
bidmondion die.

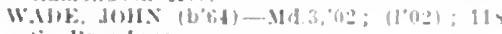
$\therefore$ Jroadian.

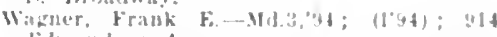
Eilmumbion Are.

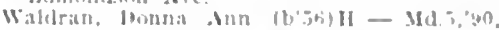

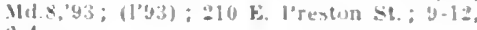
$-3-1$.

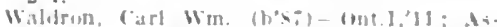

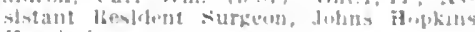
llospital.

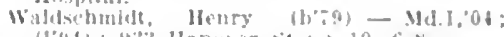
(l'ut) : \$:3 Hanower st.; $\$ 10$, di.x.

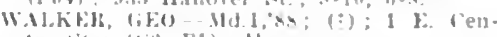
ire $=1, ; 1,6, F i) ; U$.

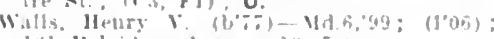

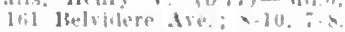

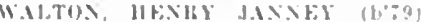

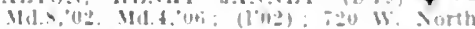
Wre: $x-10, ;-; \quad$ a Ward, Thos. 1- Md1.7\%; 1. ; 20; E. ha faryette ire

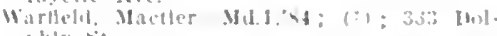
lohln st.

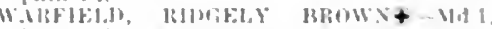

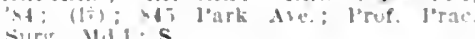

等 Highland tice.

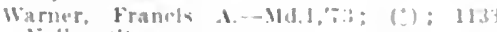
Villey sit

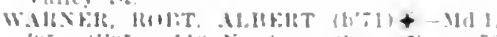

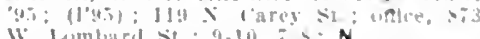

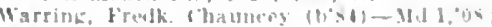

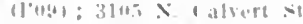

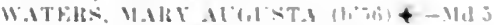
"9y: (1)

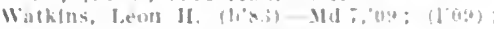
loluas Hopklns Huspla il.

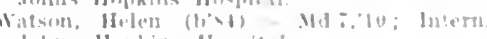
Jubns bepkins Homplat.

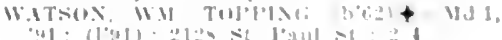

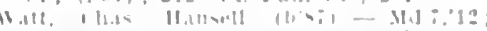

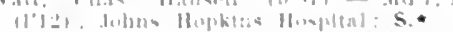

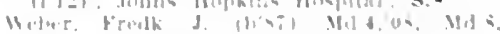

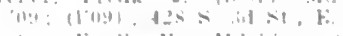

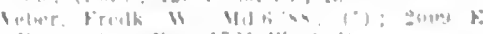

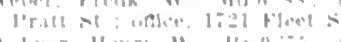

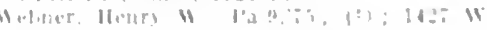

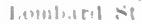

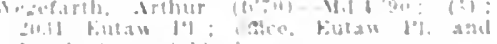

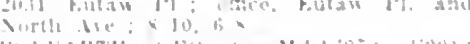
11 tiol

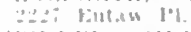

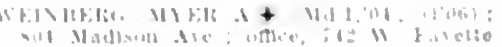

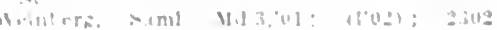

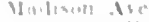

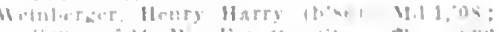

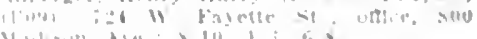

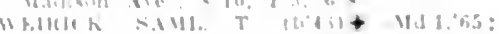

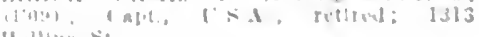
II. intun st. 


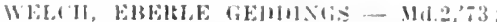
(ג) : $600^{-} \times$. Charles St.

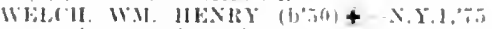

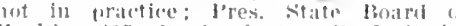
lleallh; sor st. l'aul st.; I'rop. I'ath. .11.7; $(110,52,10)$

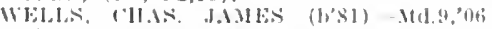

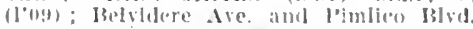

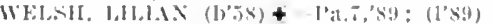
"lise irmulel: $2-4$.

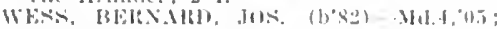

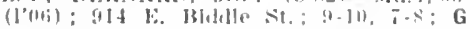

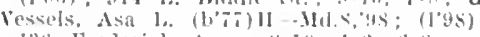

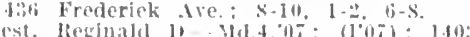

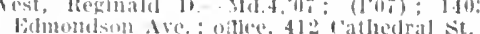
li.1:-; OALR. *

Westlirouk, 11. Youmg-. VIlb,90; (Ii) ; 237 fiorsucli are.

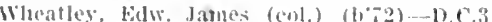
98: (I"99); 1230 Irrild IIIII Ave.; $8-10$ Wheeler. bulwin Miles-Mld.t,9ti; (1'98); 212911 . North sie.

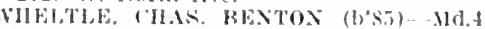
10; (l'I1) : 1260 Wolliams st. : 8 - 10, 6-8 WHIPLE, diEO HOXTt-Associate Fellow -Mll. .05 ; mot in practlee; Johns Hopkins Ilospital; Assuc. Prof. P"atl., MI.(F⿻).

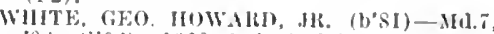
Ob:; (l'nti): 1029 Cathedral st, ; $9-10,2-3$ Assoc. l'rof. l'hys. Chem. and Clin. P'ath. IId.3.

WIITH, W.ALTEM W.MLTOX, .IR.-Md.1,96; (l'9b); 1101 X. Broadway

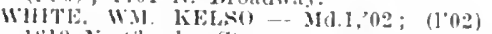
$1819 \mathrm{~N}$. Warles St

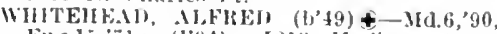
Eng.15, $71 ;$ (1'?t); I21: Hadison Ave.

Whitehurst, Jesse IIerhert-Ma.1,00: (1†) not in practlee; 1732 Bolton sit.

Whitelutrst. Milton Morris-II.1,99; (1’99); 17::2 l3olton st.

WHITHAH, L,OYD BAXKSON (b'87) l'a.1.'10; (1'12); $1007 \mathrm{~N}$. Calvert St.

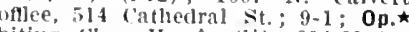

Whiting, (has. II. 0 ; $(1+1) 314$ x. Paea St

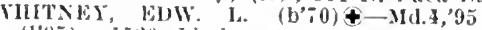
(I"is) ; Iz:0 Linden Ave. Assoe. Prof. I'lys. r'lrem. and I'har., IId.I. Whitridge, lioland B.-Mass. 1, 83 ; not in
pratctice; Stafford Hotel.

I'ltittle, II arry L.-IId.1,03; (1'03); 806 Homestead Se

Widdowson, Ordway K. (b'sl)-Md.9,07; $(1 ' 123) ; 509$ N. Entaw St.; 10-2; G.

WIELAXD, WM: EDW. (b'53) \&-Md.1,76; (3); 1011 Madison Are.; $8-10,3-5,7-8$.

viley, Zephanlah K.-Mid.3, $75 ;$ (引); 724 $x$. Carey st

Wilkens, Fredk. I.-JId.1,03; (1'03) ; Munieinal Hospital, Bay riew.

WhKlNs, GEO. LAWSOX - Md ' (1'94); 6 x. Broadway; $8-9,2-3,6-8$; (Ev).

WILLEY. WAITMAN T. (b'75) \$-Md.8.'98; Md.4, 07 ; (1'98); 2129 St. Paul St.; $9-10$, $4-6 ; \mathrm{S}$.

Wllliums, Francis Thos. (b'87)-Ifd.7,'12; (1'12) : $227 \mathrm{~W}$. Monument St. $\mathrm{S}$.

Williams, Fredk-Md.8, 08 ; $\left(l^{\prime} 08\right) ; 203 \mathrm{~N}$. Fremont Ave

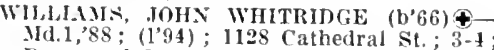
Dean and I'rof. Obst., If(.7; $(\mathbf{\Lambda 2}, 6, \mathbf{E} 6)$ ObG.

Willing. lames Flerick (b'68)-IId.1,90; $(190) ; 8$ i I Harlem Are ; $9-10,2-4,8-9$

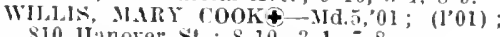
810 IItmorer Nt.; 8-10, 3-4, ;-8.

willse, R. Geraril (h's)-Md.1,09; (1'11) 132 Park Ave.; G.

Willson. J. Ward (b'41)-YI.6, $89 ;\left(1^{\prime} 90\right)$; $2100 \mathrm{x}$. Edrew

MHAOx, GORDON (b'6, \& - Va.1,99 (l'01) : $1: 31 \mathrm{~s} \times$. Charles St. ; $2: 30-4 ;$ Prof. lled. IId.1.

WIISOX, HENRY MERRYMAX (b'29) $\$$ IId.1,50; (5); 1008 Madison Are.

Wilson, Karl M. (b'86)-Que.1,08; (1'13);

HILAON. T.OT FIDGELT (b'59) \-Md.1, 'so: (今); 1735 Hollin st.; $9-10,2-4,7-8$;

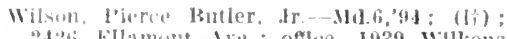

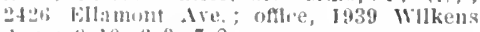
llilthire. James fierard-Mfl 1,69; sl:b liamlltom Terrace.

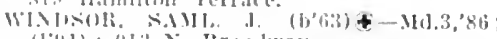
(1? 11 : if: N Broblway

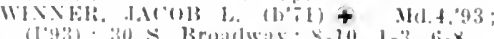

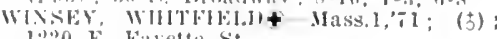
$12-2$ Fo ranette st

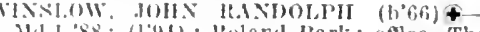

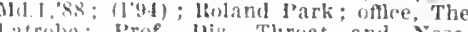
introbe: Frof. His. Throat and Nose, N11.1; (.16. 132,3); ALR. *

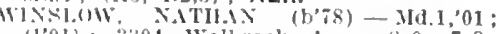
(1'01) ; 3304 Walbrook tre.; $8-9,7-8$

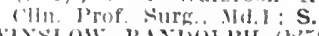

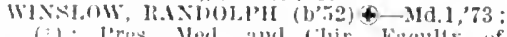

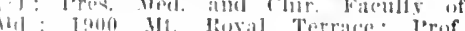

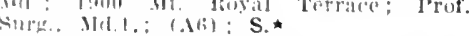

cinternitz Louis o

luternilz,

WINTENIT\%, MITON CHAS. (b'85)कMe.7,07: (1'08); Joluns Hopkins Ifospltal:

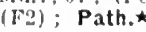

WISE, EDW. MARTI-MA.1, ; ; (b); 706

WISE, WAITER DFNT (b'85) —-MId.3,06 (l'n6); Charles St. and La Favette Ave, $0-10,2-3,7-8 ;$ Assoe. Prof. Surg. l. $3 \cdot \mathrm{S}$.

Wismark, Arvid Theophllus (b'67)--Ill.4,09; (1'10); 1820 E. North Ave.: $7-9,6-8$.

Wisner, lacoln Ward (b; 1 ) II - Md.8, 95 (1'95): I4 W. Worth Ave.;8-10, 5-7:30; G. Wolf, Eleanor Bittlnger (b'86)-Md. '12; (1'12): Iolns Hopkins Hospital.

Wolf, Wn. (b'63)-Md.s,'si; (1\%) : (Dentist) : 2039 Merullol st.; offle, 1 1519 E Baltinnre St. ; 2-9.

WOLF, WM. B. (h'69) †-Md.3.'96; $(196)$ : 113 W. Franklin St. $9-1,2-4:$ Assne.

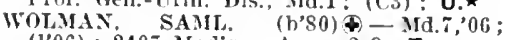
(l’06): 2407 Madison Are. $2-3: \mathrm{T}$.

WOLTERECK, GTSTAV H. (b'83) M M. 09: (l'09); 1210 Guilford Ave.; 9-10.6-8. Wooden, Howard E. (1, 78$)-$ Nd.4, 01 ; $\left(1^{\prime} 02\right)$ : 736 E. Preston St.; $8-10,6-8$.

Woodruff. Caldwell (b'82)-IId.3.'11; (1'11) : 3410 Garrison Are.: 8-10, 6-8.

WOODRTFF, CHAS. S.—Md.1,'91; (b) ; 211 E. IIt. Roval Ave.

WOODS, HIRAM (h'57)क-Vld.1,82: (l'92): 842 Park Are.: \& :30-1: Prof. Ophth. and Otol., Md.1; $(\mathbf{B} 1,4, \overline{5}) ;$ OpA.ネ

Woods. Thomson Butler (15:8!) - Mrt.1,13. Intern. [niversity of Marvland Hosnital. Wondward. Chesier Pearee - M(1.9,1I (I'll) : $2 s 00$ Edmondson $\lambda$ re.

Woolford, Chas. Irving-MId.6,'98; (1'06) ;

WORTHINGTON, THOS. CHEW (b'54) Md.1, $76 ;(む) ; 1022$ Madlson Ave.; 9-12:
$(\overline{\mathbf{B}} 3):$ LR.

Worlman, Albert Monroe (b’52)-Mo.2,73; (1'00); 1520 Madison Are.

Wright, Eugene Baseom-Ifd.1,09; (1'13); lol: Cathedral St.: S.

Wright, Nathaniel Van W.-U-Md.6,01, Md.8,02; (l'02) ; 3048 O'Donnell St.

Wright. Wm. Houston (col.)-Conn.1,00; (1'00); 1209 Presstman St.; 8-10, 3-4, 7-9.

Wyatt. Zachariah W. (b'84) - Va.4,'13;

(1'13) ; 15 E. Montromery St.

Wylie, Hamilton Boyd (b'8 $)$-Mdd.4,'12; (1'12) : 303 Robert S?

Wylie, IIamilton Boyd (b'55)-Md.3,'76, N.Y.10,78: (t); 751 W. North Ave. Fynne. Roland Fdw. (b'86)_Id.3,'13; Intern, Merey Hospital.

Fomng. (has. 16.-MId.7,03; (\$) : Baltlmore St. and Ilighland Are.

Yolng, Gen. Ira-H-Md.8,01: (1'01) : 1531 F. Forth Are. : $8-10.7-8 ;$ op.

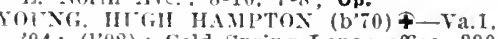
94: (1, 48$)$ : Cold Spring Lane; office. 330 x. Charles St.: $9-1$; Assoe. Prnf. Gen. Irin. Sul., Id. $7 ;(16, \mathrm{Cl}, 3, \mathrm{E} 6): \mathrm{U}$

Fourex, Edmunt Sambert $\left(b^{\prime} 63\right) \mathbf{H}-\mathrm{Pa} .9$, $92 ;(1,02)$ : 2106 Allendale St.

ZEPP, IIERBERT ELMO (b'79) †-Md.1,04; (1'05); 3050 W. North Are.; 8-9:30, $5-6: 30$
Zlegler, Clus Benj. (1) 55$)-M I .2,76 ;(\$) ;$ 830 X. IBroadway, $8-10,3=4,6-8$.

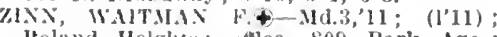
Itoland Helghts; oftlce, 809 Park Are.; 10-1; ALR. *

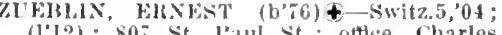
and lieed sts.; 3-5; Irof. Ired., IId.1; 1. BARNESVILLE, I25, MONTGOMERY

liot(iII, THOS. RELUEK $\left(b^{\prime}, 7 t\right) \pm-D, C . I$. '01: (1'05).

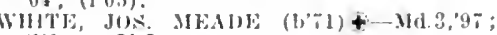
(1'09); ObG.

BARSTOW, 25, CALVERT

KINI, ISAAC NEII'TON (b"74)†-Md.4,"97, Md.3,01; (1'02).

BARTON, 1,200, ALLEGANY

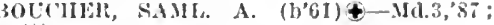

NeGiNx, JOHN IL. (b'58)-II.6,91;

BEL AIR, I,005, HARFORD

MIRTILK, WM. S.-M(l.1,80; (3).

IOILIXGSWORTH, CHAS. A. - Md.1, 81 ;

H1:CIES, FllANK LFE (b'74)-Md.1,99; (l'99).

PAlit, liOR'T. STEVENS (b'7t)-Md.1,9s; $\left(l^{\prime} 98\right) ; \mathrm{G}$.

QUARLES, ENW. (b'77)-.Md.1,99; (l'39). MIUARDSON, CHAS. R.-Md.l,03; (l'04). SAI'INUTUN, I'LINELL F. (b'68)-Md.I, 8!; $(104)$.

(1'02)-IId, ARMFIEL

BEL ALTON, 100, CHARLES

SI'WCEIt, LITNLST-Md.1,92; (1'92).

BELTSVILLE, 87, PRINCE GEORGES

FOX, CIIAS. A.-Ya.t, 68 ; (む).

BENEVOLA (R.F.D., BOONSBORO), 103, WASHINGTON

Lovell, Albert G.-Pa.2,'65; (ち).

BERLIN, I.317, WORCESTER

Bell, Emory b. (b'it)-IId.3,04; (1'05).

Henry, Zadok 1'.-Ild.3,'02; (1'02),

HOLLAND, EBE (b'6l)-Pa.2,90; (l'02). G.

TYNDALJ, IItA C. (b'i4)-Md.6,96; (l'02). BERWYN, I,000, PRINCE GEORGES

ETLENNE, ARTHUR O. (b'70)-IId.4,'96; $\left(1^{*} y 6\right)$.

GRIFFITH, WM. ALLEX (b'80)Ð-MI.3, 09 ; (l'09).

BETHESDA, 250, MONTGOMERY

LEWIS, JOIL LATANE (b'65) \&-Md:1,'88 ; (

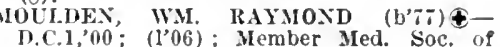
I.C.; $\mathrm{S}$.

Porter, Henry Clark (b'40)-D.C.2,'69; not in practice; R.F.D. 1

BETTERTON, 308, KENT

Nurkin, Jos. J. (b'85)-Md.9,'11; (1'11).

BISHOPS HEAD, 250, DORCHESTER

Tawes, Patrick Henry (b’79) - Md.I, 04; (1'04).

BISHOPVILLE, 262, WORCESTER

COLIINS, ROLLINS P. (b'64) $\uparrow$-Md.1,'90; (t)

BIVALVE, 107, WICOMICO

Caldwell, Robt. E. (b'69)-Va.4,'98; (l'09)

BLOOMINGTON, 372, GARRETT

KEMP, HOWARD M. $\Psi-M d .1,81$; (ち).

BOONSBORO, 759, WASHINGTON

D.AYIS, S. SEIBERT-Va.1,75; (ठ).

Smith, Edgar Thos.-N.Y.l0,'s6; (†)

WADE, JOHK II.MId,4,95; (1'95).

Wheeler, W. B.-Id.1,'62; (ठ).

BOWIE, 496, PRINCE GEORGES

Rvon, Nelson A.-D.C.3,83: (t).

TRUTTT, JAIIES H.-Tenn.9.04; $\left(l^{\prime} 0 \pi\right)$

BRANDYWINE, I50, PRINCE GEORGES

COE, JOHN A. (b'64) E-Md.3,'8i; (1'92).

BRENTWOOD, I00, PRINCE GEORGES

Keenan, John F.

(See Washington.)

BRIGHTON, 50, MONTGOMERY

STABLER, ALGUSTUS (b'58)-D.C.3,'83; (3); not in practice. 
BROOKEVILLE, 835. MONTGOMERY

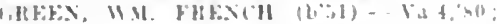

BROOKLYN, 1,200, ANNE ARUNDEL iset Haltimore?

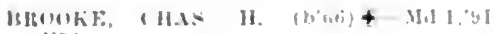

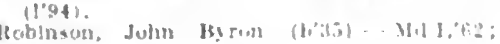
(в).

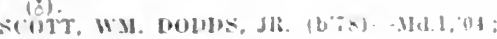$$
\text { (l'ojbi). }
$$

BROOKVIEW, 78, DORCKESTER

schmilt. Johri William (liss)

BROWNSVILLE, 80, WASHINGTON

Blesilug, Arllut I. - IId.1.91: tל. .

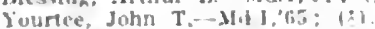

BRUNSWICK. 3,721. FREDERICK

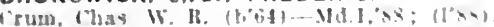

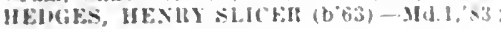
(i).

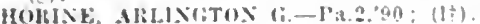

Schame!, Henry Franklln-M(I.1."4; ( 190$)$

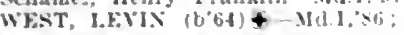

BRYANTOWN, 50, CHARLES

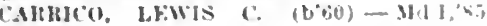
(1'92).

BUCKEYSTOWN. \$15. FREDERICK

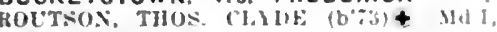
"99: (1?99).

BURKITTSVILLE, 228, FREDERICK

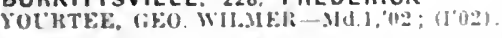

BURTONSVILLE (LAUREL P.O.), 125. MONTGOMERY

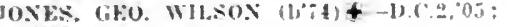
1)'0.il.

BUTLER, 150, BALTIMORE

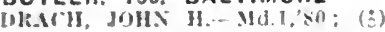

CALIFORNIA. 50. ST. MARYS

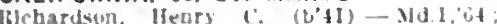
(c).

CAMBRIDGE, 6,407, DORCHESTER

AHEY, (1IAS, JAMES $(0,7)-M(1.3 .67$;

(1) $\left.q_{i}\right)$ : (Eti): NP.

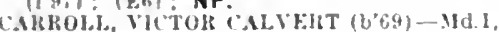
(1): $(1 \circ 06)$

coll. Thomas bynch (b's5)-MH.t.09; (1) 10$)$

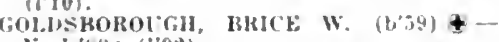
Va.1, $90:(1992)$.

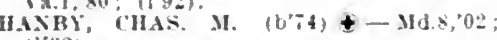
(1'02).

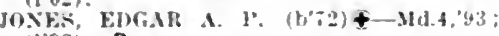
(I'93): R.

VACE, JOHI $\left(b^{\circ} 60\right)-11.1,87 ;(1,93)$

Maloney, saml. b. (col.) (b'bs) $\rightarrow:\left(l^{\circ} 05\right)$

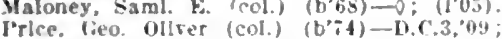
(1'0s).

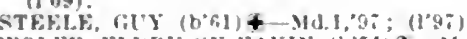

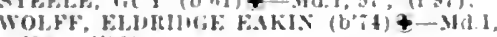
99:- (J'49).

CAPITOL HEIGHTS, 150, PRINCE GEORGES

Mackenzle, Wex hoss $\left.\left(\mathrm{b}^{\circ} 64\right)-1\right)^{2} 3.9,65:$ $(105)$.

CAROIFF, 500 . HARFORD

Arthur. Wh. K. (b"*i)-Md 1..92; 1:)

CATONSVILLE, 4,000. BALTIMORE (sice Hallmore.)

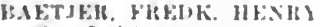

(Sice liallinute.)

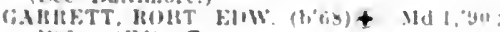
$(1 * 40) ;(5: 6) ; P$.

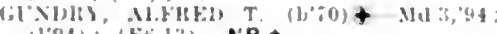

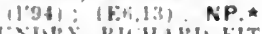

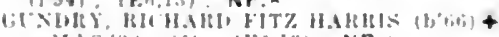

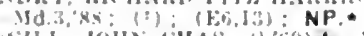

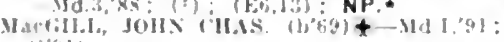
(1) 11$\}$

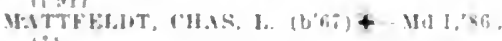

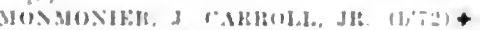
(id) $1.47: 11.431$

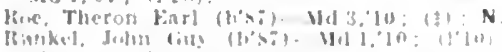

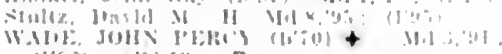

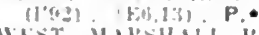

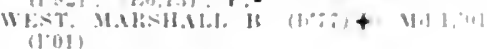

CEEILTON, 518, CECIL

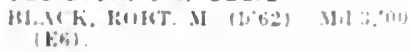

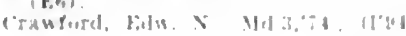

CENTERVILLE, 1.135, OUEEN ANNES

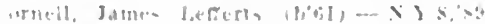

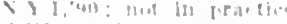

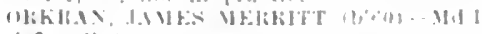

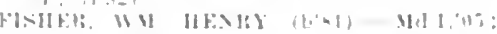

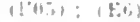

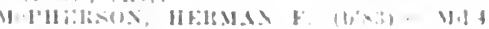

in: 110101,

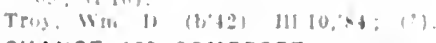

CHANCE. 1.50, SOMERSET

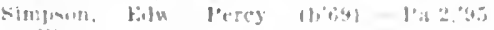

CHAPTICO, 100 ST. MARYS

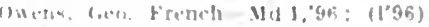

CHARLOTTE HALL, 81 , ST, MARYS

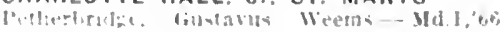

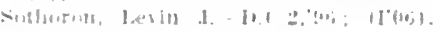

CHEFRY HILL. 350. CECIL

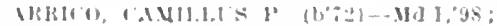
(I)I)

CHESAPEAKE BEACH, 100, CALVERT

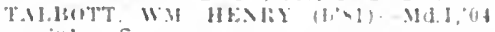

CHESAPEAKE CITY, 1,016. CECIL

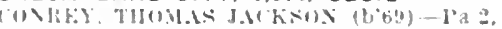

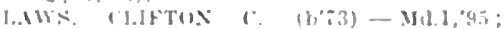

11'(1):).

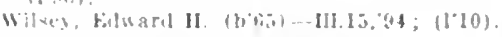

CHESTERTOWN, 2.735, KENT

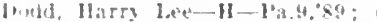

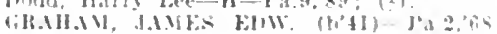

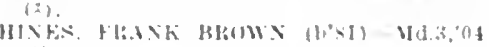

1 1 10.11

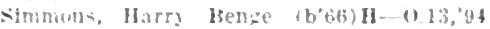

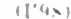

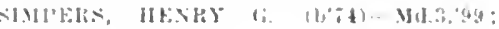
(1)

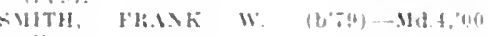
(1) (1)

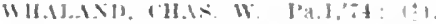

CHEVY CHASE, 250, MONTGOMERY

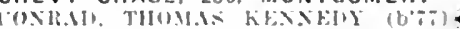

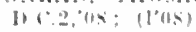

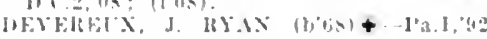
Illo): not in practice: Prof Mal Med

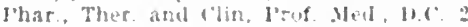

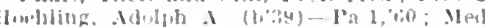

bir. har Admiral, 1 s.: refired I.F.11. $:$

Mollote, sommul W

(see Wa thington.)

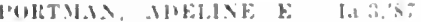

Memiver Verd. SIM of 111

CHEWSVILLE, 152, WASHINGTON

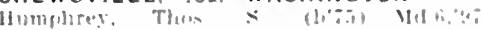

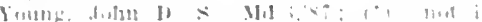

irisititr

CHURCH CREEK, 396. DORCHESTER

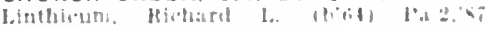

$(1,4)+$

CHURCH HILL, 306, QUEEN ANNES

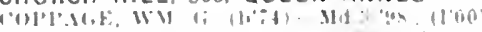

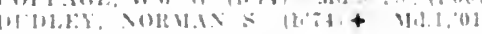
(1)

CHURCHTON, 150, ANNE ARUNDEL

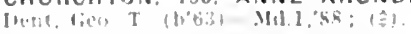

CHURCHVILLE, 200. HARFORD

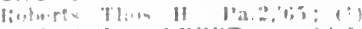

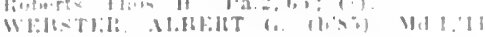
11"11।

CLARKSBURG. I6\%, MONTGDMERY

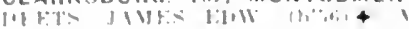

CLFAR SPRING. 321, WASHINGION

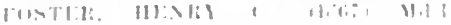

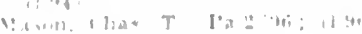

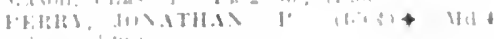

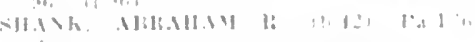

CLINTON 100 PRINCE GIEORGES
COCHEYEVILLE. I SOO. BALTIMORE

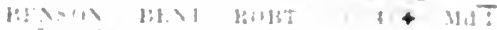

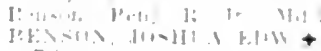

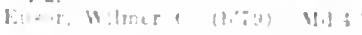

COLLEGE PARK SOO PRINCE GEORGES

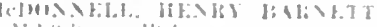

Mation. $11^{2}+41$.

CONGWINGO, 300, CECIL

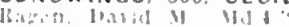

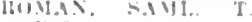

CORBETT. 25. BALTIMORE

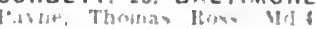

CORDOVA, 103. TALBOT

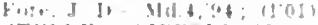

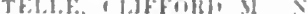

CORNERSVILLE, 100, DORCHESTER

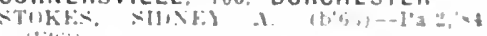
(1):3i)

CREAGERSTOWN (R.F.D., ROCKY RIDGE) 140. FREDERICK

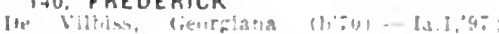
II (int)

CRESAPTOWN. 61. ALLEGANY

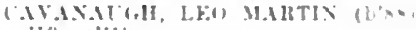

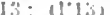

CRESWELL (R.F.D. BELCAMP), \%亏. HAR FORD

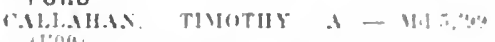
(I) 00,

CRISFIELD, 3.468. SOMERSET

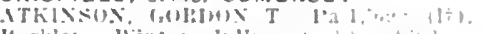

Wingter Jullus (an) (b)is -

1) 1 I : 11 111

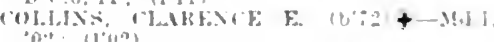
$02,11,1121$.

coulburn, Wm. Henry (b'si)-Md.1,01 (1) 01$)$.

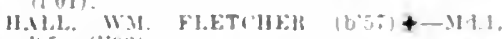
$1 ; 043)$

Mritis, li.tst :

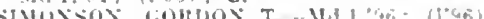

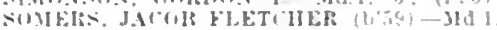

Nit: $\{* 1$

MIII) (IHISTOHHER C - MA A OA: 1:1

CROOM. 180. PRINCE GEORGES

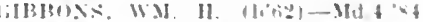

CROWNSVILLE (R.F.D. WATERBURY) 20. ANNE ARUNDEL

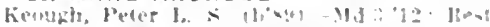
dent ldy-iclan. I'rommulle state liw jilal: NP.

WIXTEIOUE, IRUERT IRRETUX゙+ II\}

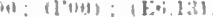

CRUMPTON, 228, QUEEN ANNES

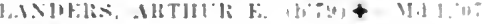
(I"):

CUMBERLAND. 21,839. ALLEGANY

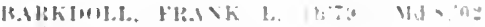

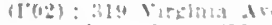

135.100 ibas bi if

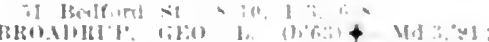

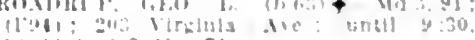

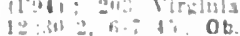

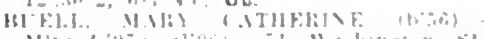

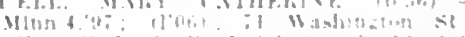

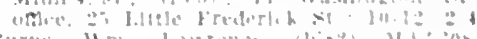

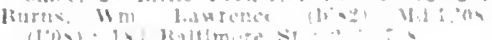
aralor a cese ly to

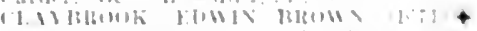

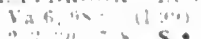

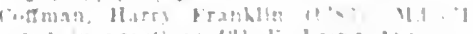

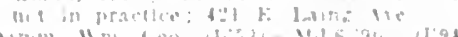

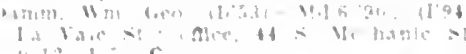

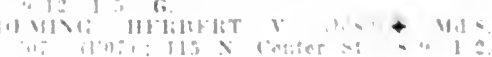

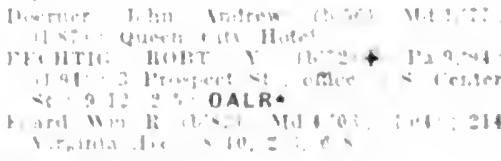




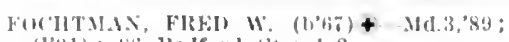
(l'al); sé Bedford st, ; $1-2$

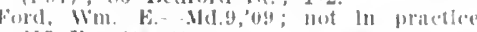
21. Filvetre st.

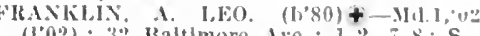

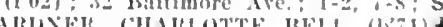

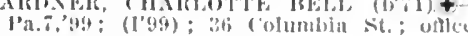
Pa.t. Liberty 20 : $: 3-4$

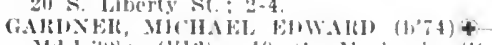

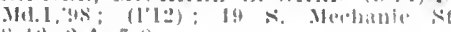
$8-1,2-4, i-4$

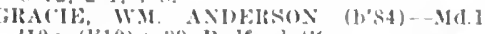
'I0: (1'10): 39) buedford it

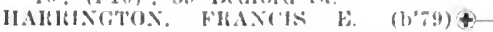

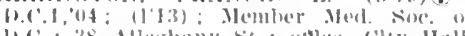

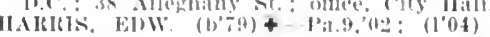
IIAlits, EllW (1)

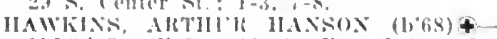

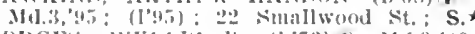

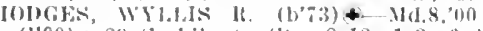
(1'00): 29 s. Biberty st. ; 8-12, 1-3, fi-s HOHGSON, HFNII W. $(1,46)+-M d, 2,7$

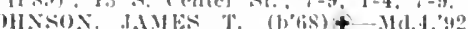

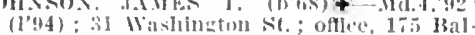

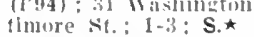

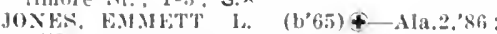

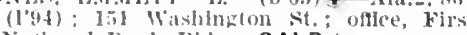
Na(lonal Balnk Bhlin.; OALR. *

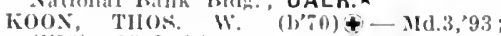
(1.99); 15 Ballimore Ave, ; 8-9, 1-3, 6-8: Ob.

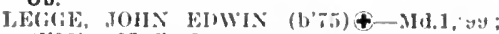
(I'99): 27 S. Cencer st.

LITTLEFIEL], WIIN IRAMSEL (b'79) AI.C.1, $08 ; \quad\left(I^{\prime} 09\right) ; 42 \mathrm{~S}$. Mechanie st. $1-2: 30,6-8 ; \mathbf{S}$.

Mchonald, Thos. B. (b'71)-1).C.2,95 (1'?4); 33 S. Center St. ; $8-9,1-3,6-8$

Nelpling. Clarence E. $(1,8 x)$ - I'a.11, il

(l'11) : 33 Iecntur st.

Norris, Lester Dimmitt-Ma.I,'0s; (1'0s); (jueen (Ity jotel.

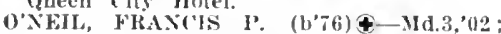
(1'02); 197 Washington St.; office, 115 Baltimore St. ; 10-12, 2-4, 7-8; OALR. ${ }^{*}$

OWFS, CHAS. ILEWELLY (b'T) 4 Id.1,04; (l'04); 126 VIrglnia Are.; until $9,1-3,6: 30-8$.

Palmer, James A., Ir. (b'79)-Tenn.8, 06 ; (); Annex lildg., Central station.

Panlman, Geo. P. (b'7t)-IId.4,06; (l'09) ; 64 Columbla si.

SHARRETT, GEO. OLIVER (b'si) †-MIL, $08 ;\left(1^{\prime} 08\right) ; 45$ Bedford Ave.; 9-12, 1-5; OALR. *

SHMIOXS, MAYXAKI) J. (b'-3)-D.C.1,03 (I'09); 82 Redford St.; 1-3, 6-7; Pd

SIMONTON, IALREN('E I. (b'so)-D.C.1 sparks, spurgeon-11.C.3, 03 ; (l'04); $104 \mathrm{X}$ Mechanic st.

SPFAK, JAMES MITON (b'50)-0.9,69; (I'87); 26 s. Mechanle st.: $8-9,3-4,7-8$ SPICER, JOSEF'H H. (b's6)-JId, 10 (1'11); $101 \frac{1}{2}$ Virplnia Are. $1-3,7-8$.

TREVASKIS, RI(HARI) WHTTE (b'82) + Mld.4,'11; (1'11); 20 S. Mechanic st.

TWIG(i, Wנ. FRANKLJN (b'58)-IId.1, 83; (1'87) ; 22 S. Center St. : 8-10, 1-3, 6-8.

WILSOX, IAMES HOMEIK (b'83) -Md.7 os; ( Liberty st. : $10-12,2-4,7-8$.

WHITE, ЕDW. H. (h';0)£-Md.4, 99 (199); 19 Baltmore A re.; $1-3,6-8$.

WILSON, JACOB JONES (b'48)£-Md.3 '71; (1'8s); 28 L'ulon St.; 8-10, 4-6.

CUMBERSTONE, I0, ANNE ARUNDEL

Elzes, Mason (i.-1a.4,61; (\$). CURTIS BAY (BALTIMORE P.O.). 10,
ANNE ARUNDEL

Daris, ('eo. R. (b'81)-ud.3,'0s; (l'09).

HORTOX, THOMAS B. (b'66)-MId.6,'91; (1'91).

DAMASCUS (R.F.D., GERMANTOWN), 170 , MONTGOMERY

BOYER, GEO. MIITON (b'72)థ-D.C.1 $02 ;(1,02)$

DARLINGTON, 200, HARFORD

fillion. Wu. Edwin, Jr. (b'86)-Md.1,'12;

Kirk, WaIter B.-M(1.1,93; (1'93)
DARNESTOWN (R.F.D., GERMANTOWN), 75, MONTGOMERY

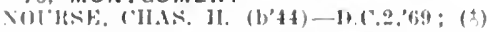
DAVIDSONVILLE, 30, ANNE ARUNDEL lites, fum Mortimer- Md, I, 01 ; (1'01) DAWSONVILLE, 80, MONTGONERY

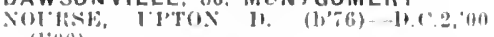
(100).

DAYTON, 25, HOWARD

VIIIOA., S.IML. A. (b'70)-M(1.4,!" (l’98).

DEAL ISLAND, 1,600, SOMERSET

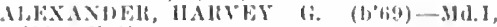
11: (I)

DEER PARK, 988, GARRETT

Sillars, Folw: Hil (b'84)-Mila, In; (l'10). DENTON, 1.481, CAROLINE

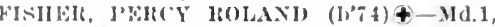
औ\%: (197)

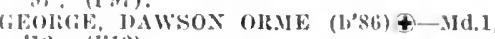
1:: (1'12)

SICHOLS, FHEHK. x. (1)79)-Md.1,02; $(102)$.

Slmmols, (i. W'-H-O.13,'88; (I'98)

DETOUR, I00. CARROLL

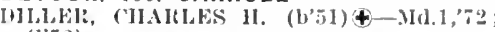
$(1,-2)$.

mildili, RolaNi) h. (b'83)-Md.1,10: (1'10)

DIGKERSON. 125, MONTGOMERY

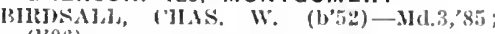
(l'06).

DUNKIRK, 36, CALVERT

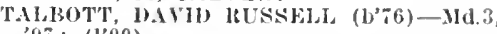
$97 ;(1,00)$

EAST NEW MARKET, 280, DORCHESTER IONES, EIIll. I. (b'\% HCHOLS, Hilki F. (b'61)-1id.4,92; $\left(l^{\prime} 03\right)$

EASTON, 3,083, TALBOT

DAIIDSON, CHAS. FITZSIMMONS (b'65) + IId.1,'88; (1'88); S

llaig, Wn. Ifenry (eol.) (b'T0)-D.C.3, 08 ; (l'11)

IAMMOND, WM. THONAS (b'86)థ-Pa.9, 09; (l'10).

llard Castle, Hughlett (b'61)-Md.1,95 ;

I.0WXUES, CHAS. (b'66) †-Md.1,88; not in prictice; Iled. Insp., Commander. I.S.S.; Surteon General's offlee.

Jackintosl1, James Atwood-Ill.1, 05 ; not In practice; R.F.D. 3

MERRITT, JAMES BLACK, IR. $\left(\mathrm{b}^{\prime} 83\right)+$ IId.4, 0 ' ; (I'09) ; OALR.

Merritt, James Hack (b'58)-Vt.2,79; (t). I'AL.MER, WM. NEAVITT $\left(b^{\prime} 83\right) \oplus-M d .3$, $0.5 ;\left(l^{\prime} 05\right)$

STEVENS, ALEXAXDER MeC. (b'86)Ild.T,'11; (l'11)

STEVENS, JAMES A. (b'54)€-Pa.2,'82; ( $( \pm)$.

TIRAERS, PHILI' J.EE (b'テ8)-Md.1, 02 ; (l'02).

THIPPF, EDW. RICHARD (b'40)-MI.1,'62 ; (1'62)

EASTPORT, I,500, ANNE ARUNDEL

IICSEELL, JOHN T. $\$$-IId.1,'09; (I'09)

ECKHART MINES, 1,600, ALLEGANY

('romwell, Benf. II. (b'3\%) - '.5.5.5.

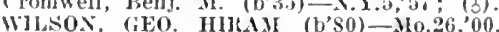
I'a.9, 03 ; (1\%).

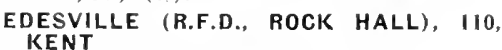

Wilson, Thomas B.-MId.,'61; (t).

EDGEWOOD, 100, HARFORD

hOTH, ('HAS. EDW. (b'73)-Pa.9,98; (1'98).

ELDERSBURG (R.F.D., SYIKESVILLE), 76,

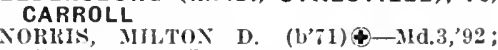
(I'94); (E6); P.

\section{ELIKRIDGE, I,000, HOWARD}

\section{See Baltimore.}

BENSOS, THOMAS P.-Md.1,'98; (1'98).

EARECKSON, WM. R. (b'67)థ-Md.1, 90 ; (l'94); Ob.

Jarris, Hamlet-Md.3,'80; (d).

Tongue, Harrison (b' 4 )-Md.1, 71 ; (t)

WILIAMS, Al'THLR (b'53)-Pa.1, ‘4 (ち).
ELKTON, 2,487, CECIL

JIRATTON, IION'AHI) (b'59)€-Pa.1,85; (\$)

(AWIFY, WM. D. (b'72)-Md.1,02; (l’02).

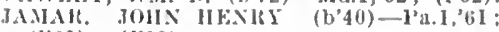
(1'b1) : (1'10).

MITCHELL, IIEXIR AIRHUR (b'75) Fil.1,00; $\left.\left(1{ }^{\prime} 01\right)\right)$ : S. Morriso

ELLERSLIE, 600, ALLEGANY

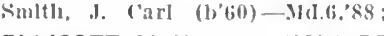

ELLICOTT CITY, 1,15I, HOWARD

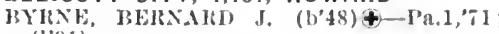
([’9!).

(t).

(iNMBHIL, WM. BARTLE'T'T (b'49)-Md.1, '7s; (I'34).

Gassaway, Wm. X. (b'81)-Md.1,04; (1'06).

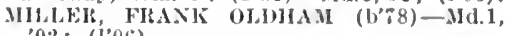
$02 ;\left(l^{\prime} 06\right)$

Owings, 'Tlios. H. (b'30)-Md.1, 22 ; (ठ)

STONF, WM. CAJtTEK (b'79)-IId.4,03; (l'04).

WHITE, W. HISHAER (b'72)\&-Ont.1, (00); (1'01): (E6,13).

ELLIOTT, 400, DORCHESTER

Britton. Itoland $I_{4} .\left(b^{\prime} 86\right)-M d .3,,^{\prime} 07$; (1'07).

EMMITSBURG, 1,054, FREDERICK

JIEAWNEI, .JOII B.-IId.1,72; (す)

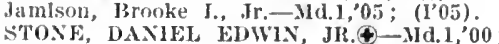
(1'00).

EWELL, 725, SOMERSET

icliwatka, C'has. Taylor (b'82)-Md.6,'04; (l'05)

FAIR PLAY, I00, WASHINGTON

l'EI(TIAII), Y. MIITON (b'58)†-Pa.2,'82; (己).

FALLSTON, I50, HARFORD

YELLOTT, IHJC'IIARI) E. (b'75)-S.C.1,06; (1'12); Nember S.C. Ired. Assn.

FAULKNER, 35, CHARLES

l'osey, Cataldus H.-Md.1,86; (ठ).

FEDERALSBURG, 1,050. CAROLINE

Breeding, EarIe, Griffth (b's\$)-Md.1,13; (l'13).

Rrooks, Fred Talbott (b'78)-Md.1,00;

GAJI,OWAY, GEO. FIETCHER (b' 64$)-$ Md.3.'94; (I'95); Ob.
(Ienterson, Robt. Kemp (b'68) - Md.1,90; (b)

FISHING CREEK， 650, DORCHESTER

HOISTON, WM. HUWES $\left(b^{\prime} 75\right) 4-M d .1$,

IFAD́E, "MUES WM., JR. (b'86)-Md.1, '09; (l'09).

FLINT STONE, 315, ALLEGANY

TWIGG, ALVIN I'TMAN (b'60)- $\diamond ;$; $\left(\mathrm{l}^{\prime} 89\right)$,

FOREST GLEN, 125, MONTGOMERY

W]IGHT, GEO. H. (b'58)-D.C.1,84, Ill.4, $86 ;\left(\mathrm{I}^{\prime} 8 \mathrm{i}\right) ; \mathbf{N}$

FOREST HILL, 350, HARFORD

Smithson, Frank P.-Md.1,'80; (‡)

FORESTVILLE, 200, PRINCE GEORGES

Sansbury, John E. (h'69)-Ild.3,'95; (1'95).

FORK, 300, BALTIMORE

GORSICH, JAMES F. H.-JI.1, 6 ; (む) ; (E6).

FOWBLESBURG, 80, BALTIMORE

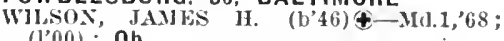
(l'00); Ob.

FOWLING CREEK (R.F.D., PRESTON), 50. CAROLINE

Iu Hadway, John (b'59) -Md,1,87; (5).

FREDERICK, 10,411 , FREDERICK

Bauersfeld, Emil G. (b'89)-Md.4,'11 ; (1'11).

Bourne, Wm. G. (eol)-N.C.3,02; (1†); 30 W. All Saint St.

Brooks, Chas. S. (col) (b'75)-D.C.3,10; (l'10); 102 F. 5th St.; $10-12,2-4,7-9 ; U$.

Brown, Louis Lmmitt (b'81)-Md.4,'03 (l'09) ; $102 \mathrm{~W}$. 3d St. ; offlee, Market and Church sts. ; $10-12,3-5,7-8: 30$.

Burek, Lewis A.-If-Md.8,'95; (1’95); 23 E. Church St.

CONLEY, CHAS. HENRY (b'76)-Md.4,'99; (l'99). 


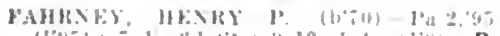

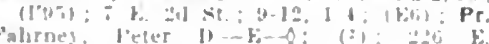
Falurnes l'te

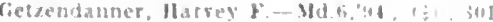
(1) Warticel sil

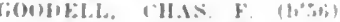

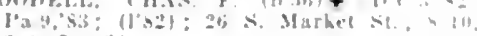

$3+i-2.30$

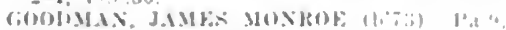

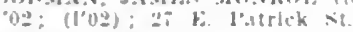

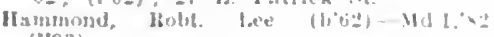
$\left(1^{\circ} 93\right)$.

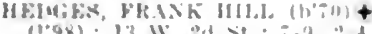
- II1. 1,30

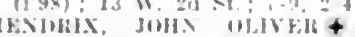

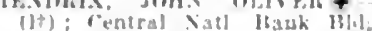

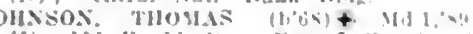

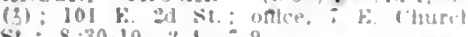
st. : $8: 30-10,=-1, i=9$

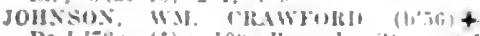

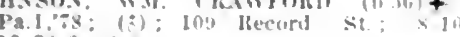
$18: 30)=0.8$

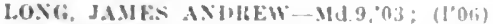
$109 x$ ylarke $s$

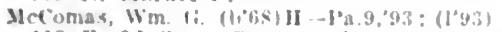

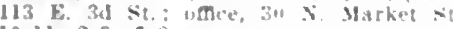
$10.11,2-3,3-8$

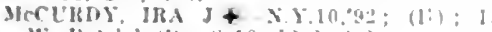
W. "latrick st :

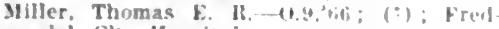
erlck City llosjutial.

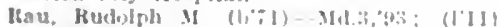

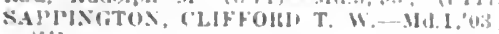
(It).

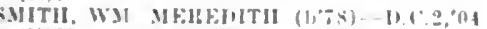

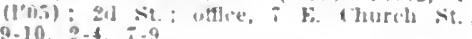

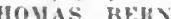

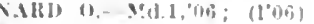
- Market sit.

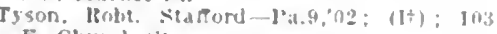
E Church s:

FREELAND, 75, BALTIMORE

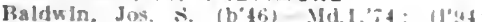
R. ह. [1, I.

Norrls, Jolin R.-Md.I.fiti (S): H.F.l.

FRIENDSHIP, 100, ANNE ARUNDEL

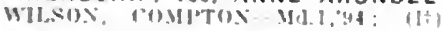

FRIENDSVILLE, 466, GARRETT

Jason. Allen J.- l'a 'St. (i)

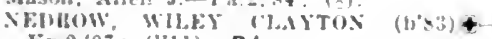
K5.2,07; (1'11); Pd.

FROSTBURG, 6.028. ALLEGANY

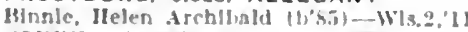

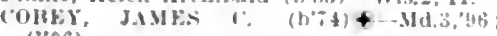
(1'06).

CONROY, TIMOTHY 1. (1, G.5) + Md.3.92: (14).

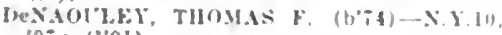

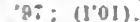

GRHFITH, TIMOTII (lifi)-XY.AR: (1.93).

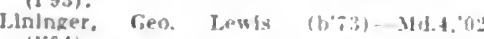
(I.01).

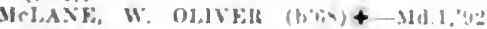
(1.93).

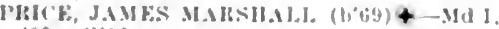
20 ; $\left(10^{\circ} 0 \%\right)$

WAIKFI: AIHOTT HEVEIL: $(1, \div 0)-$ (1.).3, $02:(1.02)$.

FRUITLAND, 350, WICOMICO

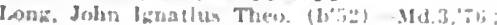

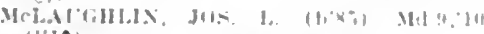
(I'IO).

FT. HOWARD, - BALTIMORE (AHSWB:LL. RU)IST. I. (b'a)

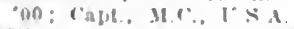

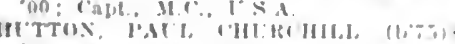

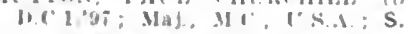

FULLERTON, 375. BALTIMORE

Whlteford. Ilimpard I... (I)

FUNKSTOWN, 568. WASHINGTON

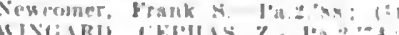

GAITHERSBURG, 625. MONTGOMERY

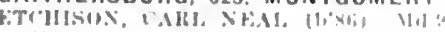
(I'I1).

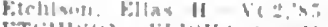

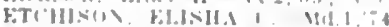

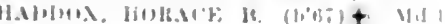
$(1 * 0 ; 1)$.

\section{GALENA. "Fi2, KENT}

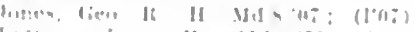

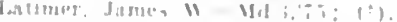

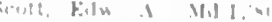

GALESTOWN (R.F.D.. SEAFORD, DEL.) 225. DORCHESTER

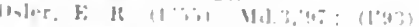

GALLOWAYS, 230, ANNE ARUNDEL

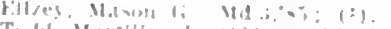

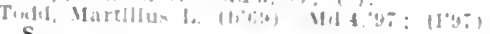

(RMBER., WESTMINSTER), 225

GAMBRILLS, 65, ANNE ARUNDEL

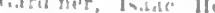

GARDENVILLE, 600, BALTIMORE

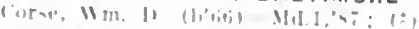

GERMANTOWN, 300, MONTGOMERY

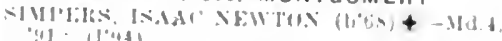

(:) 1: (10:4)

GITTINGS, 50, BALTIMORE

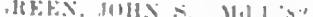

GLENBUANIE, 100. ANNE ARUNDEL Stede Ihltinusre.

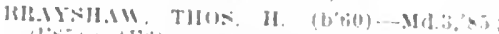
(l’si): (

GLENCOE, 200, BALTIMORE

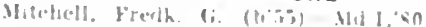
retired

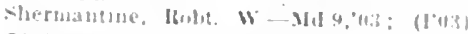

GLENN DALE, 100, PRINCE GEORGES

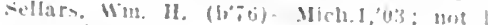
Dractice.

\section{GLYNDON, 3I1, BALTIMORE}

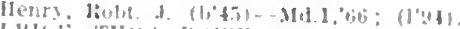

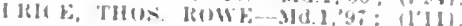

GOLOSBORO. 20I. CAROLINE

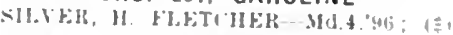

GOVANS, I,500, BALTIMORE

\section{(Sice Hammore.)}

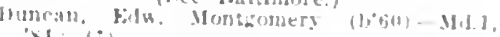

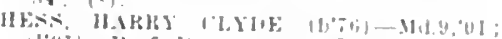

(l*aI): Irof. Iherm., Ildy; D.

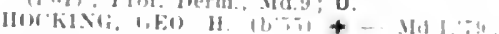

(1"?(1)) ; (E)tis.

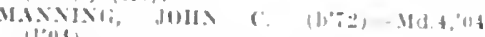
(I"04).

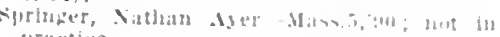
practicen.

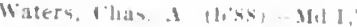

GRANITE, 6\%8, BALTIMORE

Barluer. Thus K. Mili, tit:

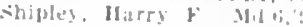

GRANTSVILLE, 248, GARRETT

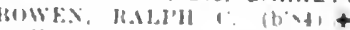

(1) $11 \%$.

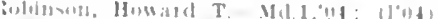

GRAYTON, 20, CHARLES

SI.EIKL, SIMI. H. $(1,110)+M(14.3$

GREENSBORO, 609, CAROLINE

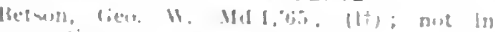
liraritine

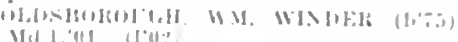

(1) II) Flik

GUILFORD. 500. HOWARO

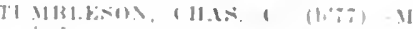

HAGEHSTOWN. 16.507, WASHINGTON

1.11 11.11 SIIRI.

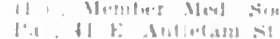

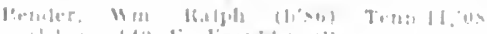

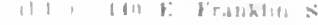

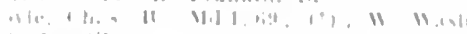

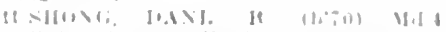

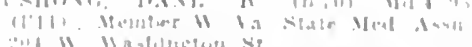

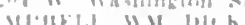

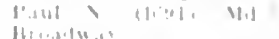

1..1 $211:$ indit: 11

lili.uk:1: Hr: $1 ! 3$

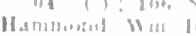

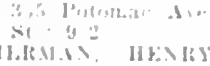

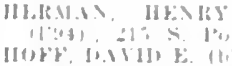

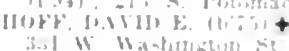

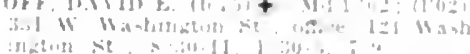

IIrinmoler, Frank

i) $30-8$

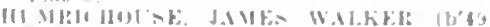

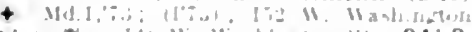

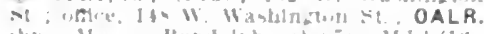

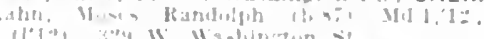

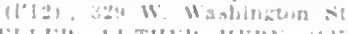

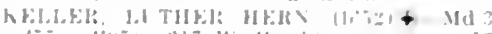
$\because 0^{\prime}$ ALR.

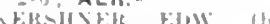

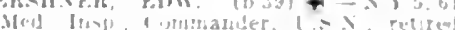

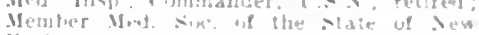

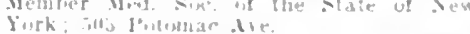

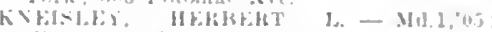
Illan: Washlnatarl the

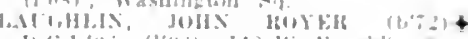

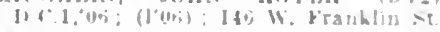

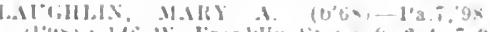

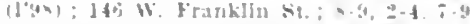

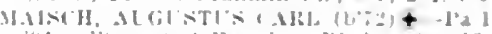

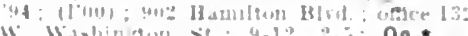

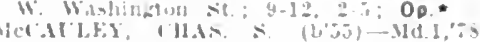

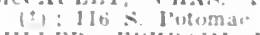

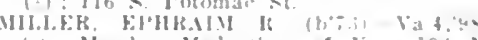

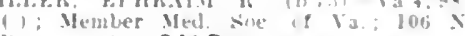
I'otomac st. : OALR.

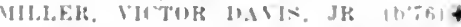
Ita.100: (1'00): 135 W. Washizaton sis

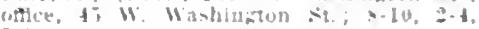

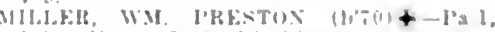

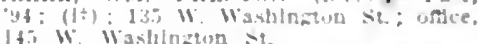
Iti W Waslington st

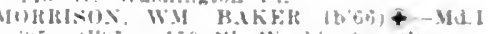
16: 1104is: 179 3\%. Wishlegton s.

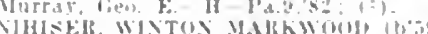

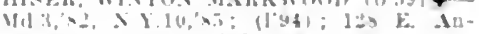
lietan st: $-10,10.9-6-8$

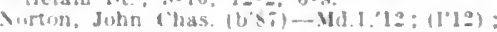

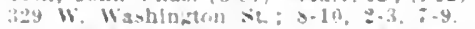
IITEOILF, JEITHA FLLWOHTH

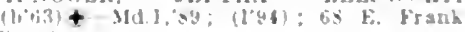
$\operatorname{lin} x+$

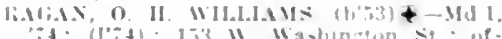

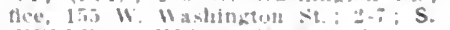

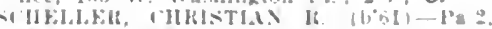
Q.?: $1: 1$, Ins $x$ l'osumac st. ustit y,

Nillille, Fo MYlEY VII,

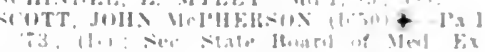

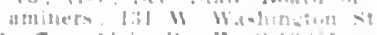

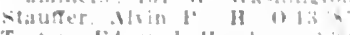

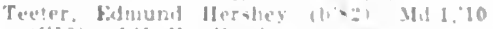

([']0): I:Z1 W. Washetun ot.

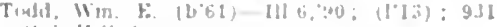
llah IIII Ars

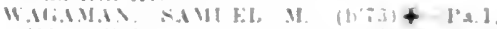

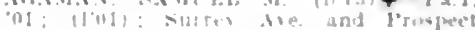

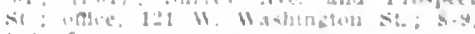

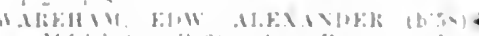

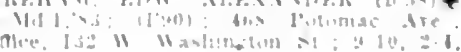

W

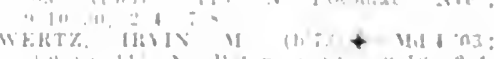

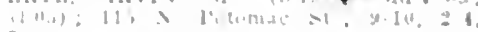

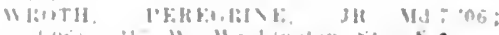

MALETHORP, 300, BALTIMORE

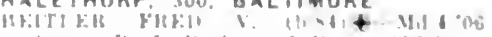

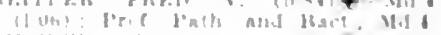

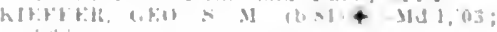

HALLS, 30. PRINCE GEOHGES

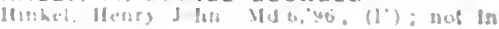


HAMILTON, 1,500, BALTIMORE (sice Baltmore.)

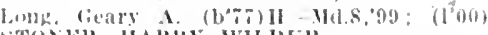
STOAER, HARKY WILIBER.

(sice baltmore.)

Pogker, Geo. C. E. (b'6.5)-Md.4, 91 : (1',5)

HAMPDEN (BALTIMORE P.O.), - BAL. TIMORE

'ARROPL, ALRIER'T HYSON.

(See Baillimore.)

HAMPSTEAD, 555, CARROLL

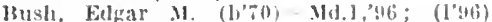

['reston. Ilarry clevelamel (b'so); Temm.]

'0s: (l'09).

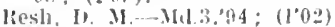

Wells, laichard (c) (b) 41$)$-.Md. $1,{ }^{\prime 2}$; (d)

HANCOCK, 893, WASHINGTON

(iray. Win. S. (b'33) - Va.1, U4; not ln prac

Ilce.

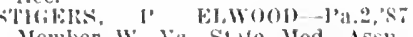

TAll,ER, IOJER E. (b'80)-ild.9,04 $\left(1^{*} 04\right) ; P d$.

TOLIIS, I. IILIBHEART-0.25, $03 ;(107)$

HANOVER, 100 , HOWARD

WIXTERSON, CIIAS. R.-II.1,7I; (14).

HARRISONVILLE (R.F.D., OWINGS

MILLS), 194, BALTIMORE

M.MITIX. WM. K. (b'S1) - Md.1,09: (1'09)

smili, Nerrick $A$. V. (b'86)-Iid.4,08 (1"08).

HARWOOD, I0, ANNE ARUNDEL

Cheston, Ionlel Ifurray (b'43)-Pa.l, 64 (b)

HAVRE DE GRACE, 4,2।2, HARFORD

Bay. James Hugh (b'82)-MId.1,0S; (1'09)

Burns, Iris.

(see Wilnington, Hel)

Crothers, Angustus C.-Md.1,'s8; (o).

llepkins, Danl. W.-Md.1, $77 ;$ (t)

IOHKINS, JAMES LEE (b; 73$)-$ IId.1,97; $(1,1,1)$.

Smlth, Richard II. (b'49)-Md.1,75; (1'84)

S'TEINER, lREDK. W. (b'79)-Md.3.07; $\left(l^{\prime} 0 \pi\right)$.

Woodwdurl, Israel J.-MA.6.93; (1\%).

HAYDEN, 72, QUEEN ANNES

REAIING, IAURA EWING (b'5I)-Md.5,

'8.5: (1'S5).

HEBRON, - WICOMICO

Connaway, Henry C. (b'79)-Md.4, 02 ; (1'03).

HIGHFIELD, 225, WASHINGTON

BE(K, JOIIN ('HAS. (b'78)-MU.4, 98 ; $\left(1^{\dagger}\right)$

HILLSBORO, 209, CAROLINE

llopkins, IIoward R. (b'52)-Pa.2,'82 ; (1'82).

ROWE, HUMPHREY WILAER BARIBOUR (b's0) - Mld.3, 01 ; (l'01)

HILLSDALE, -, BALTIMORE

Frerhart, (Feo. Y. (b'62)-Md.1, 85 ; (1'85)

Hubbard. James Elw.-Mld,'12: (l']2).

NIBLETT, WALTER AATLABIIYY (b'84)

idd.1i: (I,il)

PEAIRSON, CHAS. B. (b'63)-Mieh.1,86; (1'11); N. *

HOLLANDS ISLAND, I00, DORCHESTER Ruby, John T. (b'68) -Md.4,93; (1'93).

HUGHESVILLE, 300 , CHARLES

Chappelear. Fredk. De Sales (b'sI)-MId.1,

CHAPPELIER, HARRT C. (b'73)-Md.I $97 ;(1,98)$.

HUNTINGTOWN, 25, CALVERT

LEITCH, JOHN W. (b'70)屯-Md.3,'96;

HURLOCK, 5|6, DORCHESTER

FLE.UING, ELIAS C. (b'54)-AHd.3,78; $(1,0 \%)$.

FRIZIER, LOUIS G. (b'67)--Md.6,'95; $(1 \cdot 95)$.

IIERS, GEO. ROGER (b'74)-Md.I,02;

HYATTSVILLE, I,917, PRINCE GEORGES I.ATHER, GLY WALTERF-Md.1,01; (l'01).

1.ATHER, THOMAS EDHIN (b'74)\&Md.1,07; (1,0 $\left.0^{-}\right) ; \mathrm{G}$.

Judd, Jos. A.-IId.1,64; (l'9t); not in practice.

Wells, Chas. 1.-MId, 62 ; (む).

WILL], II. T. (b'-4)\&-Va.6,98; (1'05)
IJAMSVILLE, 7I, FREDERICK

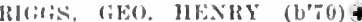
$(1 \cdot 4) ;(E+1,13)$ : NP

INDIANHEAD, 20, CHARLES

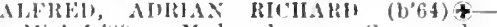

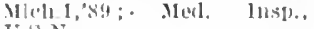

MIT('IILL1, JOIIX W.-Md.3,94; (1'91)

INGLESIDE, 200, QUEEN ANNES

BOWEN, WILALII W. (b'82) \&-Md.4, 07 ; $\left(\mathrm{I}^{+} 0 \mathrm{~T}\right)$

JARRETTSVILLE, I50, HARFORD

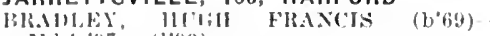
IId 1,97; (l'09).

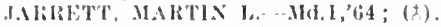

Riprlon, Franklin E. (b'71)-MJl.9, 0 i $\left(l^{\prime}(0)\right.$

JEFFERSON, 350, FREDERICK

Bates, Carleton (b'84)-Md.8, 08; (l'08)

(iross, Jlenry Boteler (b'49)-.Id.1, 71 ;

JERUSALEM, 75, HARFORD

WALSH, RAIJII (b'41) \&-D.C.2,'63;

(1t); Member Med. Soc. of 1.C.

JESSUPS, 150, HOWARD

llammond, d. Alex-Md.1,'92; (1+).

JOHNSVILLE (R.F.D., UNION BRIDGE), I7I. FREDERICK

Messler, Jolm Henry (b'86)-Md.4,'10 (l']0).

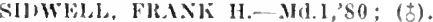

JOPPA, 50, HARFORD

FEYSER, NEWTERRY A. S. (b'60)-Md.1 '83; ( $\left.{ }^{\circ}\right)$.

KEEDYSVILLE, 367, WASHINGTON

SIMMERMAS, HENRY HARMON (b'86)Va. 4,$10 ;(1,12)$

KEMPTOWN (R.F.D., MONROVIA), 72, MONTGOMERY

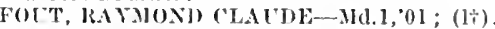

KENNEDYVILLE, 200, KENT

Urie. James Wm. (b'63) H-Pa.9,'86; (l'06).

KENSINGTON, 689, MONTGOMERY

JONES, EUGFNE (b'73)-Md.4,96; (1'96)

LEWIS, WM. IATANE (b'60)6-Mid.1, 92 (1'92).

KITZMILLER, 865, GARRETT

Copeland, Garvey l.-Ya.ti,01; ( ).

Copeland, Herman l'- Va.6,'0I; (1'01).

Miller, E.lw. Judson (b'72)-Mid.9,03; (1'03) ; G.

LADIESBURG, 60, FREDERICK

LIGGFT, JOHN J. (b' $\$ 6) \uparrow-M d .1,69$; (1'94).

LANHAM, 73, PRINCE GEORGES

IONTGOMFKY, HERBERT B. (b'76)-

1).C. 1,$06 ;(1,06)$.

LANSDOWNE, 600, BALTIMORE

ITIIL, FR.INK H. (b'62) + Mit.6,'92 (1'94).

LA PLATA, 269, CHARLES

Edelen, James Jos. (b'88)-Md.1,11 ; (l'1l) WLN, THOMAS SOMERSET $\left(\mathrm{b}^{\prime}, 0\right)$ Ild.1,92; (1'92).

LAURAVILLE, I,000, BALTIMORE

lolIRE (See also Baltimore.)

(see Baltimore.)

Snink, Claud C. (b's 7 )-MId.1,09; (l'09)

Wright. Jos. Le Roy (b'86)-Md.4,'08; (los); not in practice; Assoe. Prof Anat., Nid.4.

LAUREL, 2,415, PRINCE GEORGES

Byerly, Thos. Watts-H-Pa.9,'93; (1'93). COFGINS, JESSE CARROLL (b"74)థIII.3, $96 ;(193) ;(\mathrm{E} 6.13) ; \mathbf{N}$.

('ronmfller, Joln D. (b'32)-MId.1,57; (t). DEWEESE, CORNELILS.

(See Washington.)

Iuntt, Jos. R. (b'65)-Md.3,'88; (l's8)

Sehaefer, Chas, A.-IId.8,09; (1'09).

TAYLOR, WM. FRANKLIN (b'56)@-Md.I $84 ;$ (1'92)

LAYTONSVILLE (R.F.D., GAITHERS BURG), 133, MONTGOMERY

DE VILBISS, CLIETON NORWOOD (b'85) -IId.1,10; (1'10).

DISON, YERNON H. (b'66)థ-Md.1,94; (1'94).
LEITCHS, 10, ANNE ARUNDEL

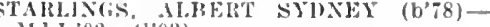
Id. I, 0 : ; (1'03)

LEITERSBURG (R.F.D., HAGERSTOWN), 350, WASHINGTON

Wlshard, .1. Henry-1'a.2,83; (t).

LEONARDTOWN, 526, ST. MARYS

"A.HALK, FR.INKLIN ALIXANDEI

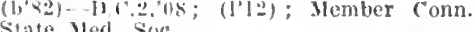

Greenwell, Franeis F. (1)'68)-Md.1,92; (I":?2).

I,ynch, Thomas (b'5y)-Md.3,81; (I'94).

LEWISTOWN, 225, FREDERICK

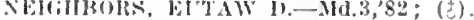

LIBERTY GROVE, 125, CECIL

JACK, W.I. C (b'81)\&-Md.4,06; (l'06) loWidAl), ERNEST (b'74)-Mid.4,'95; (1'9.3).

LIBEPTYTOWN, 600, FREDERICK

Beall, Ira W.-M(l.3,'93; (I'93).

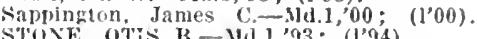

LIME KILN, I.000, FREDERICK

MCKINXEY, 11.1VII) F.-Pa.3,59; (1\%).

LINDEN, I00, MONTGOMERY

Fox, fieo. L.

(see Washlngton, D.C.)

LISSON, 145, HOWARD

LACY, HOHN W.11. (b'67) 4-Ml.3,'96:

Warfield, R. O. D. (b',9)-Md.2,70; (l'06)

LOCH RAVEN, 50, BALTIMORE

beatty, Jos. Edw: (b'39)-MId.1,61; (ठ); IARRISON, HENRY TUCKEIR (b'44)-

Ild. 1,74; (1:94)

LONACONING, 1,553, ALLEGANY

HOJGSOX, HENLY MARVIN (b'78)屯Ild. l,03; (l'03).

BETLOCK, JAMES O. (b'42)-X.Y.5,72; (l'y4).

Skllling, John I). (b'27)-0.6,'65; (l'65); SKIILING, WM. QUAIL (b'57) -Md.1, $83 ;\left(1^{\prime} 94\right)$.

LOWER MARLBORO, I80, CALVERT

HINHAX, ELLSWORTI II. - Md.3,'90; (茎).

LUSBYS, 25, CALVERT

CIIAMBERS, ('EO, F.-MI.I,'96; (1'96).

LUTHERVILLE, 663, BALTIMORE

(URAFLL, WILLAII BURGESS.

(See Baltimore.)

I'eebles, T. Chalmers (b'43) - Ire.9,63, l'e.6.64; (1'97)

SMART, L. GIBBONS (b'62)థ-Md.3,85 (192) : (E6) : NP.t

MADISON, 350, DORCHESTER

SMIITH. BEN.J. l. (b'38)-Md.1,'59; , (1'93).

MANCHESTER, 523, CARROLL

Demner, Win. R. S. (b'83)-Md. $t$, 08 ; (I'09)

Preston, James H. (b'55)-MId.2,80; (I'06)

Sherman, Jacob H. (b'61) -Pa.9,90; (1'94).

WEAVER, JOHX F. B. (b'41)-MId.I, 64; (1'06).

MANOKIN, 50, SOMERSET

(iill, Grewor Wrmond-Mass.5,78; (c).

MARDELA SPRINGS, 300, WICOMICO

Betson, Geo. W., Jr.-Md.4,05; (1'06)

Wilson, Louis $X$. (b’52)-Md.3,76; (1'94).

MARION STATION, 275, SOMERSET

AJJEE, IKA A. B. (b'79) \&-IId. 9,05 : $(1,06)$

COLLBOURN, GEORGE COOKMAN (b'86)๑ -IId.1,'10; (1']0)

MARYDEL, 200, CAROLINE

Chalres, Wesley W. (b'56) $\rightarrow$; (l'91).

McKENDREE, 75, ANNE ARUNDEL.

PERRIE, ALFRED HALL $\left(\mathrm{b}^{\prime} 71\right) \oplus M d .4$, '95; (1'95).

MECHANICSVILLE, 500, ST. MARYS

llorgan, Zachary H. (b'45)-D.C.2, 80 : $\left(1^{\prime} 80\right)$.

MIODLERIVER, I00, BALTIMORE

Harrison, John Winfield (b'69)-Md.3,'90; (む).

MIDDLETOWN, 692, FREDERICK

BECKLEY, EDTVIN L. (b'58) 4-Pa.2,'79; (1'94). 


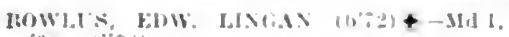

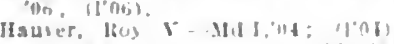

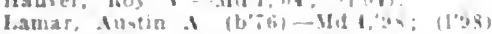

MIDLAND, 1,173. ALLEGANY

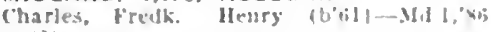

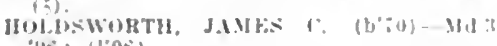

" 26, (1)0ti)

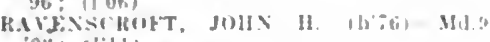

$02:$ ill1,

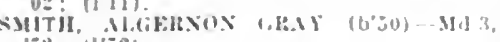
$\because: ; 1, \div 21$.

MIOLOTHIAN, 100, ALLEGANY

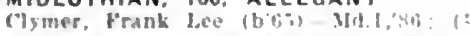

MILLERSVILLE, 100. ANNE ARUNDEL

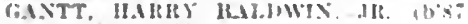

Id.1,09: (1.09).

MILLINGTON, 399, KENT

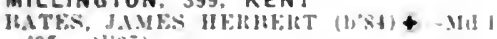

$07: 110 \%$

BRIC

Comegys, Nathandel W-Md.1, tif; ;:)

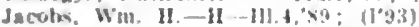

MITCHELLVILLE, 150. PRINCE GEORGES

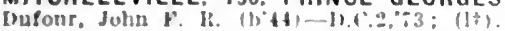

l'each, John $(6 \cdot 35)=$ Md1., :3: (z) ; nol in

prastlice.

Walklns, Wm. lane-Mass.j, :b; (1:).

MONKTON, 300. BALTIMORE

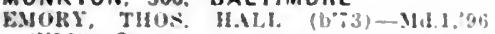
(I'96): S.

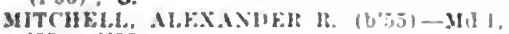

"i:: (1":\%).

MORGANZA, 30, SAINT MARYS

Johnson, Leonard B.-Md 1, "92; $\left.(1)^{\prime} 02\right)$.

MT. AIRY, 622, CARROLL

BROMWELL, JOHI E. $\left(b^{\prime}+0\right) \notin-M d .1$,

CHASEY, IRVISG DREIT-MAI, OH; $\left(I^{\prime} 06\right)$.

Gowman, C. 1.-.M!ch.:093; $(1 \div 9$

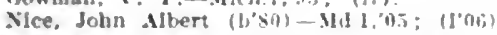

MT. PLEASANT (R.F.D. FREDERICK) 185. FREDERICK

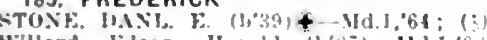

Willard, Edzar Harold (b'4)-Md.1, $0 x$ (I'OS)

MT. RAINIER, I,2+2, PRINCE GEORGES

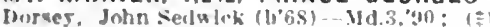

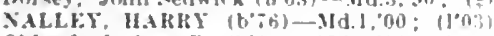

Oblendorf, Jos. C. (b"t2)-MH.t,9s; (l'ys

MT. SAVAGE, 3.500, ALLEGANY

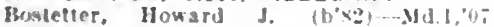
$\left(I^{\prime} 0:\right)$.

Murray, F. Man (;. (b\%G) - Md I.t? (1"9i).

MT. WASHINGTON, 1.500, BALTIMORE

(A.ee Balimore.)

bectem, Chas. II (b'69)-Vd.9."(1); (1'00)

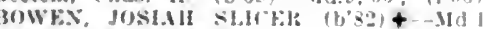
OS: (1004); OALR.

HOOKER. DONALI) IST"SEELI, $\left(b^{*}: 6\right)+$ Mel.:0\%; (14): not in practlre: Iswo Hrot J'hyslol. IId.

TAHLX, WHALMM

(see Haltinore.)

TOLD. WM. J. $\left(b^{2} 57\right)+-M d .3 .84 ; \quad(1292)$ (k, 6 )

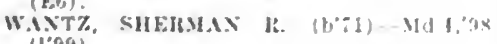
(1'99).

MT. WINANS, 1,500, BALTIMORE

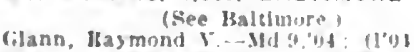

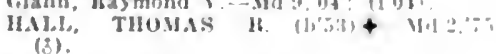

MUTUAL, SO, CALVERT

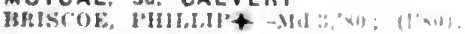

MYERSVILLE, 280, FREDERICK

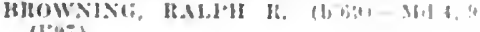

Cieczeminuer, John W.-Md I, :0

NEWARK, 200, WORCESTER

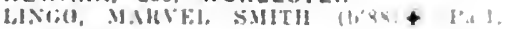
10: (1"10).

NEWMARKET, 320, FREDERICK

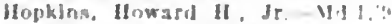

NEWPORT, SO, CHARLES

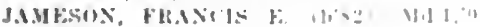

(I00.4).
NEW WINDSOR, 46, CARROLL

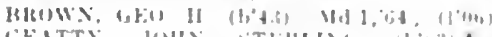

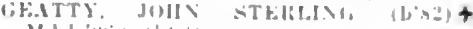

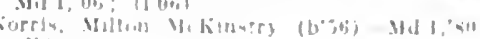

(l'sil: :ut th tor

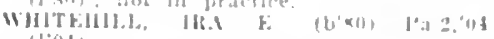

(In)|

NORTH EAST, 9it, CECIL

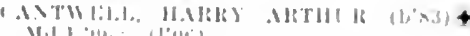
VIl, Ho.; (l'olid.

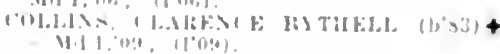

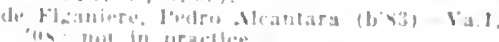

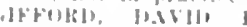

R. $\boldsymbol{y}^{\prime \prime}$

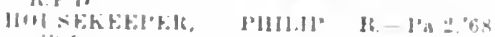

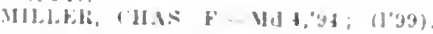

OAKLAND, 1.366, GARRETT

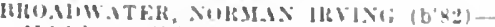

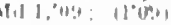

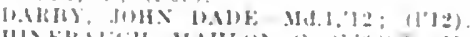

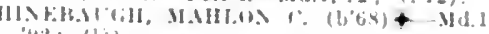
"2, : (19)

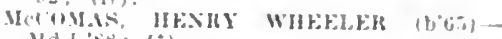

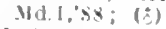

I. Iumas, Jusiah l.ce $\left(b^{*} 35\right)$ Mal, jo $(1,58)$

OAKLEY, 25, ST, MARYS

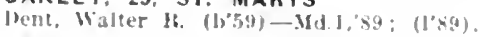

OAKVILLE, 25, ST, MARYS

King, Jos. O). (1,73)-MU.6, 95 ; (1'93).

OCEAN CITY, \$76. WORCESTER

Tulnend, Francis J. $(6,75)-V a .6,(0)$;

ODENTON, 20, ANNE ARUNDEL

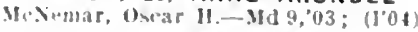

OLOTOWN, 150, ALLEGANY

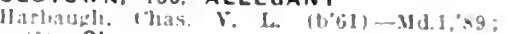

OLNEY, 75, MONTGOMERY

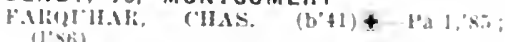

OVERLEA, IOO, BALTIMORE

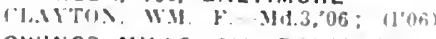

OWINGS MILLS, 2I2, BALTIMORE

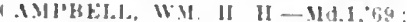

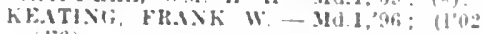
(if)

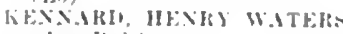

(see Ballimore )

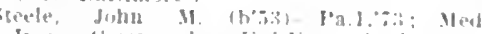

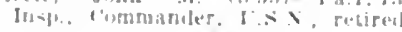

OXFORD, 1.191, TALBOT

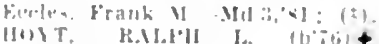

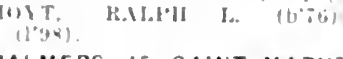

PALMERS, 15, SAINT MARYS

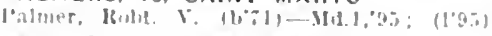

PARKTON, 300, BALTIMORE

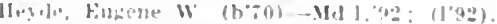

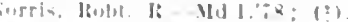

PARRAN, 25, CALVERT

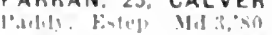

PEARSON, I0, ST, MARYS

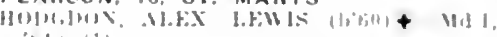

PERRYMAN, 271. HARFORD

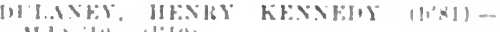

$$
\text { [I] } 411,1] \text {. [0, }
$$

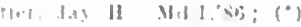

PERRYVILLE, 635, CECIL

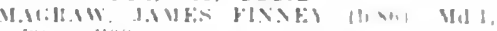

s.

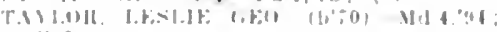

PETERSVILLE (R.F D., KNOXVILLE). 200 , FREDERICK

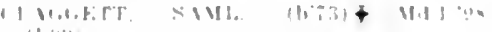

PIKESVILLE, 1,200. HALTIMORE

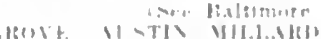

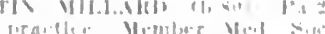

if 11, - wate uf $1 \%$ : S

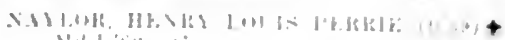

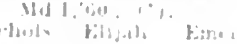

$11 \%$

311,11

WI: H. HW

PISCATAWAY, i3. PRINCE GEORGES

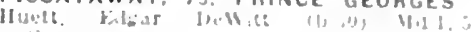
(1)

PISGAH, 225. CHARLES

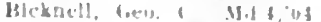

PITTSVILLE, 300, WICOMICO

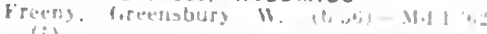

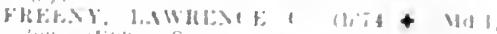

(I11), 110:i). S

POCOMOKE CITY. 2.369, WORCESTER

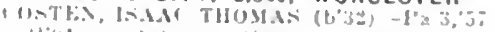

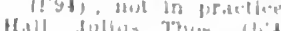

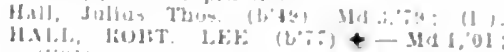

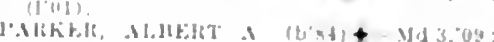
(1) $\left.00^{\circ}\right)$.

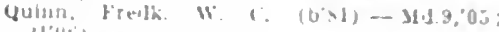
(I)

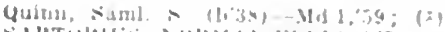

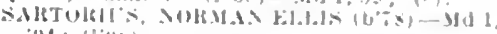
Truit; (1103)

(2).

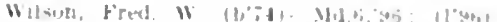

POINT OF ROCKS. 476 , FREOERICK

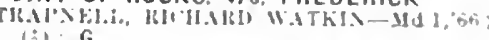
$(\because) ; \mathrm{G}$

POOLESVILLE, 175, MONTGOMERY

Mann, Arelur H, Jr. IJ 1," 11$)$; 13).

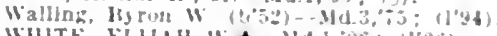

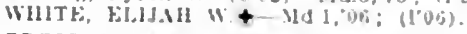

PRESTON, 288, CAROLINE

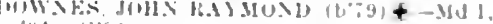
"Ut: $(1004)$.

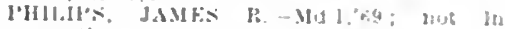
Jractice

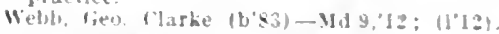

PRINCESS ANNE, I.006, SOMERSET

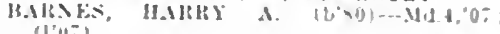

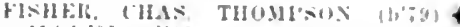
IIt 1,0I : (10)1

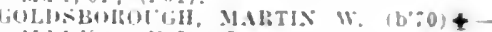
I! 1,$80 ;\left(1 y^{\circ}\right) ; R$.

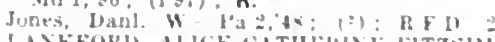

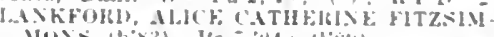
III)

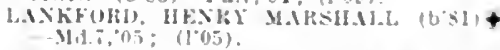

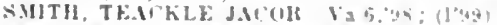
WMAWHIHT, MAS Wt-VU3,

PT. DEPOSIT. 1.394, CECIL

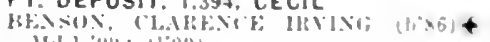
III $1,0 ! 9 ; 11^{\circ} 0 ! 01$

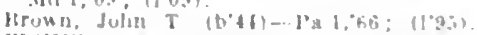

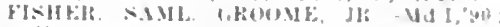

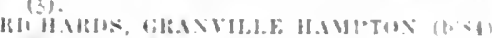

+ MI1 1,00: 1100

PT. TOBACCO, 100, CHARLES

blignes, Juhn T. $: ;$ (1)

QUANTICO, 325, WICOMICO

ParImantir Janin'

QUEEN ANNE, 200, QUEEN ANNES

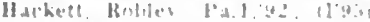

QUEENSTOWN 279. QUEEN ANNES

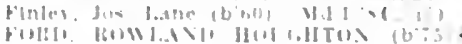

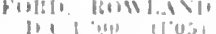

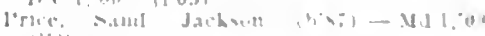

BASPEBUFG - BALTIMORE

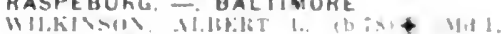

RED GATE. - ST. MARYS

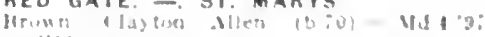

REISTERSTOWN, I.000, OALTHMORE

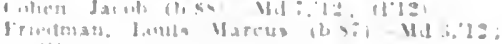

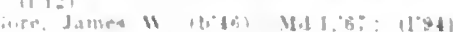

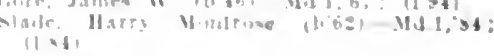


RELAY, 2,000, BALTIMORE (Siee Jalt mort.)

Imbrman, E. Kay-MId.8,'97; (I'4i).

(iLDIRY, LEWTS II

(Noe Baltlmore.)

TRAVERS, CHAS. F. $\left(b^{\circ} 82\right)+-.11 .4,10$ (l'11).

RHODESDALE, 40, DORCHESTER

MAGUHE, C. FRANK (b'bI) - Md.l, 's: (ठ).

RIDERWOOD, - BALTIMORE

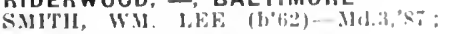

RIDGE, 175, ST. MARYS

l.loyd, [ratrlek II.--1).('.l,04; (1'04).

RIDGELY, 9\$3, CAROLINE

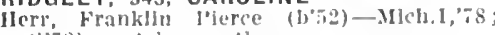
$\left(l^{\circ} 8\right)$ : not ln pracelece.

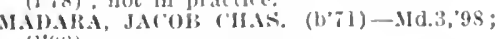
(l’ys).

Rlekards, Harry X... Md.1,'ss; (ठ).

s.MTI, IRNENT FRANKLIN" (b'7T)-IId.3

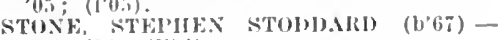
IICl.],94; (['!4)

RIDGEVILLE (R.F.D., MT. AIRY), 60 , FREDERICK

Todil. Benj. II. (b',54)-M(I.1,74; (す).

RISING SUN, $\$ 6, C E C I L$

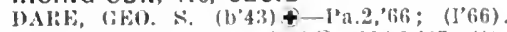

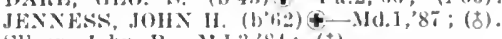

sllcer, Juhn 13.-Mil.3,'s4; (ठ).

RIVERDALE, 1,000, PRINCE GEORGES

Haggerty, James E. (1'72)-D.C.1, 06 ; (1'09)

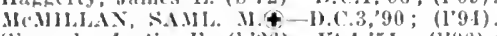

simonds, Justin F. (b'26)-Vt.1,'51; (1'96);

not in practice.

Slmonds, .Hartla R. (b'49)-Mass.6,'91; not in practlce.

RIVER SPRINGS, I42, ST. MARYS

Blackistone, IR. I'inkney-IId.I,'49; (b).

ROCK HALL, 781, KENT

Beall, Wis. W.-D.('3, 88 ; (む).

sehwatka, wm. H.-ild.4, 89 ; (

selly, Witer 0.-Md.4,'9I; (b).

ROCKVILLE, I,181, MONTGOMERY

ANHGRSOS, EDW. (b'4I) $4-$ Md.1, 75 : (

BUILARU, ERNEST T. (b'59)€-111.1,'83: (I'08); ( Fto, I3); NP.`

llarward. Joln Joshua (b'\%4) - Md.1,99; (1†) : ALR.

HENUEliso:, FREDK. N. (b's0)Ð-Pa.1, 03 ; (I'03).

King, Geo. W. (b'86)-Conn, 1, 09; ( ).

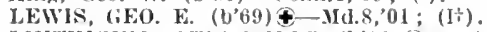

LINTHICUM, OTIS MILAS (b'66) \&-Md.I, '90; ( (b) .

MANNAR, CLAIBORNE II. (b'62)-N.Y.10, 98; ( I'04)

IRATT, WM. T. (b'68) - Md.3,'90; (b) ; IR.F.D.

ROHRERSVILLE, 150, WASHINGTON

BAKER, CHAS. D.૯-Md.I,'BI; (ठ).

ROLAND PARK, -, BALTIMORE

$$
\text { (See Baltmore.) }
$$

CASSIDY, IIENRY F. (b'69) †-MI.I,'90; (I’90); S.

Chew, samI. claggett (b'37)-Md.I,58; $\left(\mathrm{I}^{+}\right)$; not in practlee; Emer. Prof. Med. II. 1 .

CLARKE, SYDENHAM RUSH (b'7) HIl. 1,05 ; (1'05).

Davis, Isaae Howard.

(See Baltimore.)

FAYERWEATHER, ROADES.

(see Baltimore.)

GIJCHRIST, THOS. CASPER.

(see Raltimore.)

Grimes, SamI. Butler-Ma.1,97; (l'97).

HAlh, WM. SHEPHEIR.

(See BaItimore.)

Hanna, Benj. S. (b'75)-Md,3,12; (I'12); U.

HOI'KINSOX, BENJ. MERRILL.

(Gee Baltimore.)

MEYER, ADOLF.

(See Baltimore.)

PORTER, MHOR GIBSON (b'65)\&-MI.I, $86 ;(1,94)$.

WILLOCK, JOHN SCOTT (b'7) †-Md.7. 04 ; not in practice; Member Med. Soc. of the state of $\mathrm{Pa}$.

WOODWARD, JAIES SAVAGE-D.C.I,'S0: (1',0).
ROSSVILLE, 600, BALTIMORE

Male, carville V, MU.1,"97: (I'02).

ROWLANDSVILLE, 117, CECIL

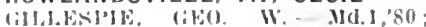

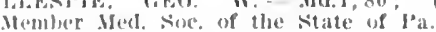

ROYAL OAK, I50, TALBOT

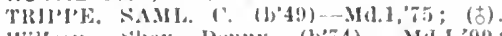

Willson, slacy Denny (b'ï) - Ma.I,00: (l'0(1).

RUXTON, 350, BALTIMORE

$$
\text { (See Baltimore.) }
$$

13.1BXEY, WM. MINOR $\left(b^{\prime} 73\right) \oplus-\mathrm{Ta} 1,96$;

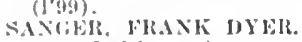

(Sice lialtimure.)

SABILLASVILLE, 200, FREDERICK

WA'IITHK, (HAS. 1.-IId.3,84; (3).

SALISBURY, 6,690, WICOMICO

MUOTHMARKI.F, ("JINTON (b'60) \&-Md.3, 'S1; (\$); OALR. *

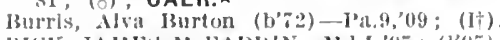

IIK, JA.MFA M(FADWN-Ml.I, $45 ;(1,95)$.

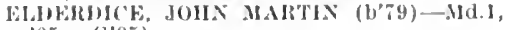

$05 ; \quad(105)$

Pilchard, Sewell Norris (b'86)-r'a.2,'I0; ( $\mathrm{l}^{\prime} \mathrm{I0}$ ).

I'O'T'TER, DE MITON JURR (b'79)-M(1.1 04; (1'04); Anes.

Roberts, Jos. W. (col.)-J.C.3,07; (l'08).

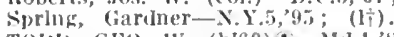

TOIII, GE0. W. (b'60) \&-Md.1, 85 ; (1'04)

I'rultt, thas. IR.-MI.1, 91 ; (ơ).

TLLL, HARR C C-IId. 1, (00; (1'00)

WAILE, IIFNRY STEVESSOX (b'73) + Va.6, 01 ; (l'01).

SANDY SPRING, 75, MONTGOMERY

BIRD, JACOI3 WIIELILEK (b'85) \& - Md.I, ot; (1'07).

Iddings, Charles M. (b'60)-Md.1,'88; (l'09) MAGRUDER, W.I. F. (b'34) - Md.1,54; (I'94); not In practlee.

SAVAGE, I,000, HOWARD

I.NTHICUM, TIIOMAS W. (b'54) - Md.I, $79 ;\left(\begin{array}{l}0 \\ 7\end{array}\right)$

SEAT PLEASANT, 80, PRINCE GEORGES

Apgar, Raymond (b'S0)-Ya.6,'12; (l'12);

not in practice.

SHADY SIDE, 125, ANNE ARUNDEL

Howard, Foster Cannon (b'88)-Md.9,'12; (l'12); S.

SHARPSBURG, 960, WASHINGTON

GARDNER, SAMUEL IIOWELL (b'64) Va.I, 89; (I'90)

Garrott, Frasmus Mortimer-IId.I,'91; (d).

SHARPTOWN, 722, WICOMICO

JAMES, CHARLES FMERA (b'85)-P'a.2, '11; (I'11); G.

SHOWELL, 125, WORCESTER

BISHOI', JAMES IOBINSON (b'82)-MId, 04; (I'05); G.

SILVER SPRING, 50, MONTGOMERY JBOW. W. W. T. (b'64)-NId.3,92; (I†) ;
I.F.D.

HOWLETT, HOWARI HENRY (b'83) $\oplus-$ Va.; Ob.

waller, CIifford Ellison (b'86)-H.C.1,10 ; (I'I1).

SMITHSBURG, 48I, WASHINGTON

IBISHOI', E. 'TRACI-IId.1,47; (ま)

KEFAUVER, MAURICE D.-Md.4, 04 ; (I'04).

Kuhler, Geo. A., Jr. (b'87)-IId.3,'12; (I'12)

Massie, J. Llewelly-0.8,75; (8).

I'ROTZMAN, JOS.-Md.4,'9I; (†).

SNOW HILL, 1,844, WORCESTER

AYIELOT'TE, JOHY S. $\left(b^{\prime} 42\right) \notin-V a .4,68$; (1'94).

Jones, Paul (b'52)-Pa.2,72 ; (さ).

RHLEY, JOHN L. (b'75)\&-Md.1,05; (I’05); OALR.

WISEHART, ERIC E. (b'8T)-Pa.2,'11; (l'11).

SOLOMONS, 318, CALVERT

CASTER, EARLE SOMERVILLE (b'84)IId.1,06; (1'06)

MARSH, WM. H. (b’51)Ð-Md.1, ' 6 ; $\left(\mathrm{I}^{\prime} 94\right)$.

SOMERSET (GLEN ECHO P.0.), 173, MONTGOMERY

Grffin, Thomas $\boldsymbol{A}$.

(See Washington.)
SPARROWS POINT, 4,000, BALTIMORE (siee Baltinore.)

CMMMNE, WMITER MHALS (b'81)-Ma.1, $07:(1007) ; \mathrm{S}$

ELI)]ED, FRA.TK (ORAL-M(l.1,91; (8).

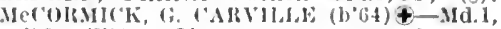
90; (I'90); Ob. Iocum,

\section{(I'I2).}

VILLE, 84, MONTGOMERY

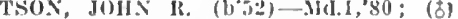
SPRINGFIELD, 75, PRINCE GEORGES IIVIIA, JOHN .I.4-UG.6,"94; (1\%).

ST. MARGARETS (R.F.D., ANNAPOLIS), 150, ANNE ARUNDEL

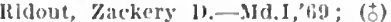

ST. MICHAELS, 1,517, TALBOT

Jodson, Itoht. A. (b'36)-Ma.1,59; (o).

Cilascoek, Arthur B. (b'59) - Md.1,88; (J'94).

IIOH'E, JAMISA H. (h'82)—-Md. I, 06 ; (1'06). Seth, Jos. Brul' (b'it)-Mi.1,99; (1'00)

STATE SANATORIUM, 250, FREDERICK

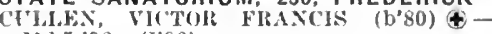
II., 060 ; (I'06).

Denchtield, Arlhur Lelghton (b's0)-X.Y.19, 05; (l'12).

firschman, Istlore Isaac (b'89)-Mf.1,'11; (I'12); T.

IIussey, Raymond Garrlson (b'83)-MI.1,

'I1; (l'12); T.
latane, IIenry Augustlne ( $\left.{ }^{\prime} 85\right)-V a .1,12$; Maykew, Walter H.-Nd.1,01; $\left(l^{\prime} 01\right) ; \mathrm{T}$. OWENS, ROIBERT HAMILTON (b'65) IId.3,02; (1,02).

Scruggs, W'm. Henry, Jr. (b'88)-MId.1,13 ;

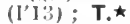

Yeager, W. Howard-IId.1,'12; (I'I2).

\section{STEVENSVILLE, 350 , QUEEN ANNES}

Benton, Johm R.-Mi.1,83; (ठ).

IIFNRY, W.I. T. (b'68)-Md.3,96; (l'96).

KEMI', CHAS. PERCY (b'68)-Md.3,95;

Snyder, Chas. E.-Md.1,02; (1'02).

STILL POND, 400, KENT

Atwell, Lewls Price (b'89) H-Md.8,'04; (]'04).

Kelley, J. Hornton (b'50)-1'a.1,'81; (o). MAXWELL, WM. STEELE (b'51) 4 -Ifd.1,
73 ; (o).

STOCKTON, 252, WORCESTER

IIC'KLISON, JOHN D. (b'6i) \&-Md.4,'92;

(l'94).

Parker, John T. (b'39)-N.Y.19,'61; (1†).

STREET, 25, HARFORD

Famous, (has. W. (b'76)-Md.1, 01 ; (I'01).

SUDLERSVILLE, 247, QUEEN ANNES

Sudler, Arthur $16 .-1^{\prime} a .2,59$; $\left(1_{\dagger}^{\dagger}\right)$; not in practice.

sudler, Foster (b'70)-Pa.1,96; (I’02).

SUNNY BROOK (R.F.D., PHOENIX), I50, BALTIMORE

Payne, Joslah T.-Md. 1,'68; (I †).

SYJESVILLE, 565, CARROLL

CLARK, JOS. CLEAIENT (b'58) †-Md.I,'80; (I'94); Assoc. I'rof. I'syeh., Md.4; (E6,13); NP.

Disbrow, Geo. Ward (b'90)-Md.1,13; (I'13); P.`

Hamilton, Claude Dewls (b'8̈)_Md.3,'13; (I'I3).

HEFFENGER, CIARENCE W. (b'60)-MFd, '81; (l'96).

Irwin, Henderson-II.1,'12; (\$).

IUCAS, WM. FRANK (b; 73$)-M d .1,93$;

MORIIS, JOHN N. (b'72)-Md.I,93; (1'93); (E6); NP.*

PURDUU, HARRY DORSEY $\left(b^{\prime} ; 6\right) €-M d .1$, $02:\left(\right.$ l'06) $^{\prime}$ (E6); P.

SMITH J. G. FOWBLE (b'82)-Md.1,06;

PRECHER.

IId.3,'8I; (I'8I).

TAKOMA PARK (WASHINGTON P.O.), 1,242, MONTGOMERY

CLARK, JOH. (See Washington.) Capt., M.C., U.S.A.; Walter Reed General Hospital.

FISHER, HENRY C. (b'67) $\oplus-$ D.C.2,'91; Lleut. Col., M.C., U.S.A. 


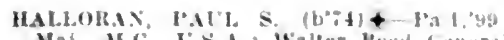

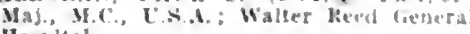
II asplital.

lleald, lieo. 11.-1'al.1,93; not lit pracslon

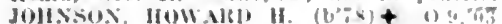
Caps. M.C., C.s.s.: Walter llevel lieweral II osultal.

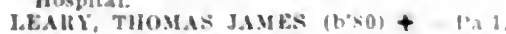
0i: Ist lleus, II $C^{\circ}$. C.S.A: Walle: Reed General Hosjlial

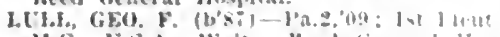

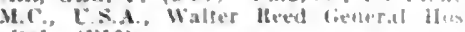
plal: (

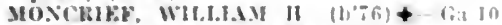
"9:; Capt. M.C., L.S.A.: Walser lited General Hosplial.

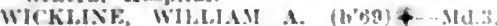
"93: Capt. M.C. 1\%.S.

TANEYTOWN, 824, CARROLL

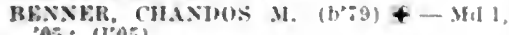
$05:$ (1205)

HKxIE, ClotwoRTHY $(1,+3)+-1$ a. 1,70 $\left(1^{\circ} ; 0\right)$.

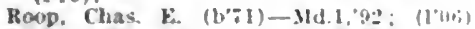

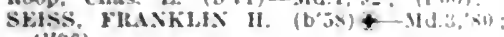
(1'06).

Selss, Itaymond S. (b.25)-Md.1, "5a: not in practlee.

TANNERY, 50, CARROLL

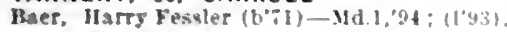

TAYLORS ISLAND, 60. DORCHESTER

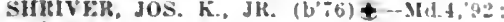
(1.97)

TAYLORSVILLE (R.F.D., WESTMINSTER), 204. CARROLL

CRONK, AHKAHAM T, (b'62) - IId.1,90: (1'06).

TEMPLEVILLE, I50, QUEEN: ANNES

Smlth, Jos. Roop $\left(b^{\prime} 66\right)-1$ 'a.1, $8:$; (5)

TEXAS, I,000, BALTIMORE

BUSSEY, BENNETT F-Md.1, 84 ; (1's.j)

Bussey, Thomas (C-Md.3,'93; $1\left(1 \frac{1}{1}\right)$

THURMONT, 903, FREDERICK

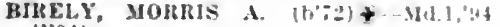
(I'94).

KEPAUVHR, ELMER C. (bPR) 4-.MU.1. 91: (1"91)

Walers, James K.-IId. 1,51 ; (ह).

TILGHMAN, 1,200 , TALBOT

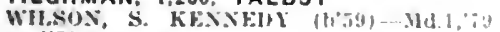
$(1 \div 8)$.

TOWSON, 3.500, BALTIMORE (See lBaltimore.)

Asper, Burt Jacob (b'SS) - Ild 1, 11: (1'11) (E6).

Berngart: Iternard Mark.

(See Balthore.)

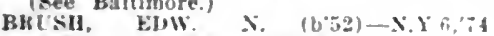
(192); Irof, Hsych. Md.3; ( $1,1,6,10,13)$

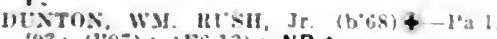
'93: (1997): $(k: 6,13)$ : NP.*

GRFF: JOSIII K KOYSTON $\left(b^{\prime}+t\right)+$ Md. I.:93: (1'99).

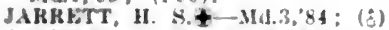

JARRYTT, J. H. MA.,

Jenlfer, lanj. St. Thomas (b'x3)-M11, (14

Jenlfer,
(1'06)

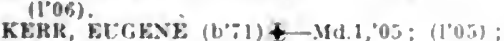
R.F.D. 8 .

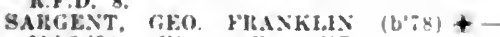

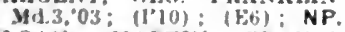

SLOAX MARTIX FRisels (bsi) Tex.4.0: : $\{1 \mid 0\}:\left(E_{0}^{\prime}(3)\right.$

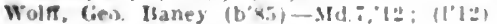
(V.6): P.

TRAPPE, 273, TALBOT

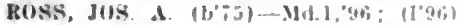

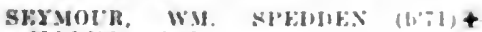
Md.1.93: (1,85)
UNION BRIDCE, BO4, CARROLL

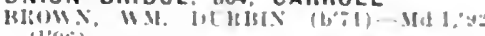
$(1,40 i)$

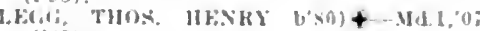
$(101, \div)$

Lewls, Elwlu lialols (b'ai)-Mat,0y

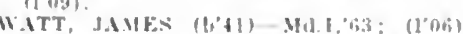

UNION MILLS (R.F.D., WESTMINSTER), 250, CARROLL

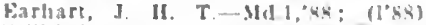

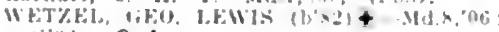
(l'llii): ODA.

UNIONTOWN (R.F.D., WESTMINSTER,

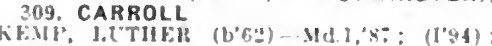
$0 \mathrm{p}$

UNIONVILLE, 250, FREDERICK

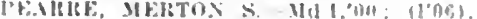

Whitelli, Marlmus $\left(b^{\circ}-3\right)$ - Md.1,76: $(1.9+1)$

UNITY (R.F.D. GAITHERSBURG), I00, MONTGOMERY

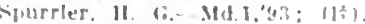

UPPER CROSS ROADS (R.F.D., FALLS. TON , 50, HARFORD

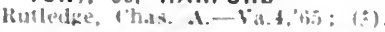

UPPER FAIRMOUNT, 500. SOMERSET

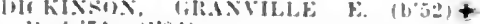

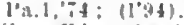

Miles, Fdw. \& Moll, it; (1̂).

UPPER MARLBORO. 361. PRINCE GEORGES

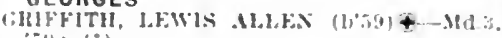
$2: 1:(2)$

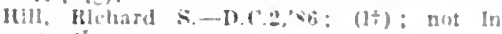
princilce

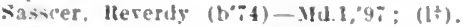

URBANA (R.F.D., IJAMSVILLE), 30C, FREDERICK

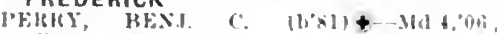
(I0ni); (Aralin).

VALLEY LEE, 10, ST. MARYS

lyuch. Thirs. Hower-Md.3.9n; (2)

VIENNA, 332, DORCHESTER

liunt, Elwool bauthan (b'i3)-Md.9.'la. (1'12).

lankin, Edw k. Vd.198: (1'98).

WALDORF, 50, CHARLES

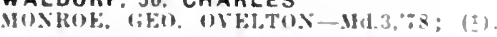

WALKERSVILLE, 582, FREDERICK

l.ong, Jos. W.-I'a.9."0?; (I'(13).

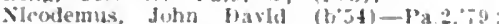
$(1-9)$.

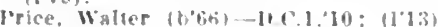

HFISHTR1, dOHA JA( (01: [1'0is]

Zimmerman, Mchael 1. $\left(b^{\prime}+9\right)-M d 2,7=$ (:)

WALLVILLE, 25, CALVERT

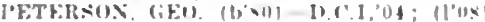

WASHINGTON GROVE, 75. MONTGOM

ERY

Fidili, WM. F. (b'til)-Md, s, not h

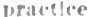

WATERSVILLE, 50, CARROLL

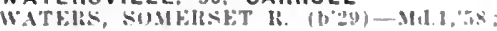
$(\because)$

WAYSIDE, 25. CHARLES

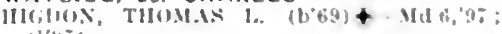
(lisi)

WESTERN PORT, 2,702, ALLEGANY

AHISUTT. J. Rill.HBRT

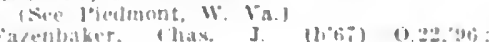
(lyi).

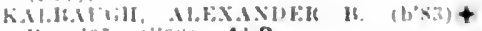

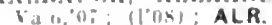

WEST FRIENDSHIP, 50, HOWARD

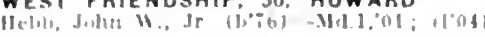

WESTMINSTER, 3.293, CARROLL

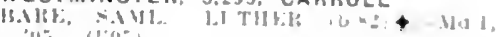

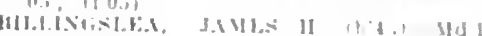
pit: (list)

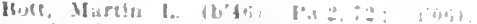

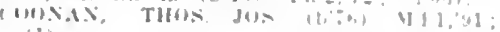

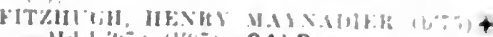

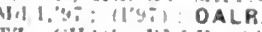

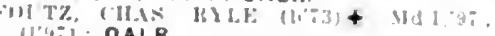
$\left(I^{\prime}(4):\right.$ : OALR.

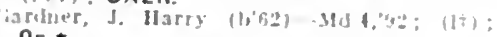
Op.

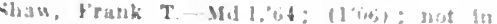
firactire

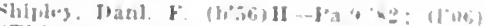

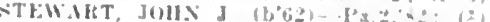

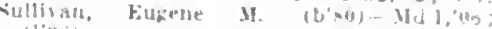

W1) (4): 11995)

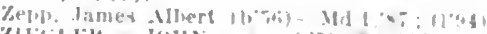

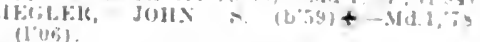

WESTPORT, 1,000, BALTIMORE (ried balmmure)

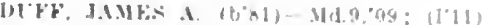

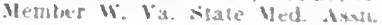

WEST RIVER, 40, ANNE ARUNDEL

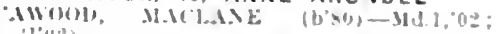
(1'112).

WHALEYSVILLE, 325, WORCESTER

HOIAANI), ('HAS. A. (b\%:)-Md.S,01

WHITE HALL. 300, BALTIMORE

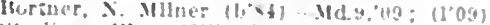
sierling. Wm. Millard-Mit.

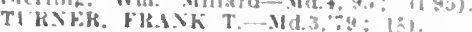

Yust, $11 \mathrm{~m}$. Melean $(0,0)-M d, 1,01$

WHITON WICOMICO (R.F.D. PITTSVILLE). 40.

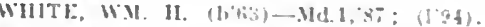

WILLIAMSPORT, 1,571. WASHINGTON

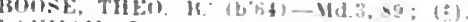

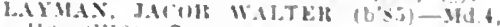
(1): $\left(1^{\circ} 10\right): \mathbf{S}$

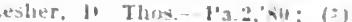

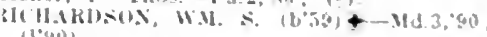
(19.9i)).

WINFIELD (R.F.D.. WESTMINSTER), -

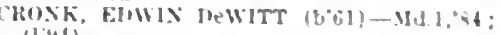

WITTMAN, 150, TALBOT

SETII, I.UIIS HAMILTON (b'S3)+-Ud1, os; $1 \mathbb{l}^{\circ}(0 x)$.

WOLFSVILLE (R.F.D., SMITHSBURG), 100, FREDERICK

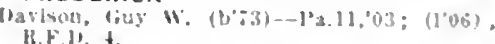

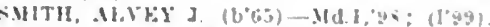

WOODBINE. 125. CARROLL

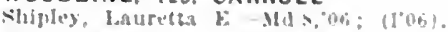

WOODLAWN. - BALTIMORE

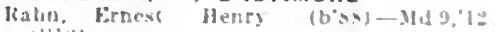

WOODSBORO, 362. FREDERICK

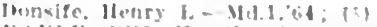

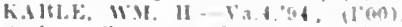

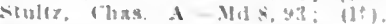

WOODSIDE (SILVER SFRING P.O.), MONTGOMERY

Calduell, I Has. T

(siee Wiablonglon)

WYE MILLS, 160, TALBOT

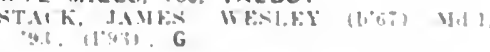




\section{MASSACHUSE'T'TS}

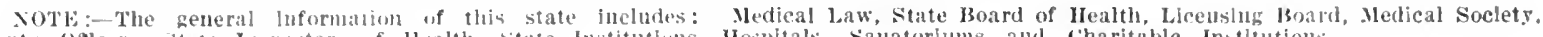
Comity oficers, state Inopectors of llealth, state Intituthons, Hospltals, samatoriums ant charitable Instlutions.

\section{MASSACHUSETTS}

Population (1910 eensus) ..........3,366,416

Number of Counties.............

Number of Physicians.

Members State Society, Dee. 31.

$1913 \ldots \ldots \ldots \ldots \ldots \ldots \ldots \ldots \ldots \ldots \ldots \ldots \ldots . \ldots \ldots$

Area of State in Square Miles.... 8,266

\section{REGISTRATION LAW OF MASSACHUSETTS}

(Rerised Laws, Chapter 76 , Sectlons 1-9, as Amended 1913, Anendment Approved Jareh 26, 1913.)

section 1. ADMINISTRATIVE: There shall be a board of registration in medicine consisting of seven persons, residents of this commonwealth, who shall be graduates of a lekally chartered medical college or unlversity having the power to confer degrees in mediclue. and who shall have been for tell sears actively employed in the practice of thelr profession. No member of said board shall belong to the faculty of any medical college or unlversity, and no more than three college or university, and no more than three hers of any one chartered state medical hers of any one chartered state medical
society. One member thereof shall annually in June be appointed by the Governor, with the advice and consent of the comseil, for a term of seven years from the flrst day of July following.

Sec. 2. OIRGANIZATION OF BOARD; TEIRM : said board shall hold regular neetings on the second Tuesday of March, July and Norember in each year. and additional meetings at such times and places as it may cletermine. At the regular meeting in July it shall organize by the choice of a chairman and secretary who shall hold their offlces for the term of one year. The secretary shall give a bond to the treasurer and receiver general in the penal sum of five thousind dollars, with suffeient sureties to thousand dollars, with suffeient sureties to be approsed by the Governor and council, eor the
duties.

see. 3. AlPliCATIOS FOR REGISTRATION; UT ALIFICATIONS; IRE-LXAMIAATION; lREOCATlON: Applications for registration shall be made upon blanks to be istration shall be made upon blanks to he
furnished by the board, and shall be signed furnished by the board, and shall be signed
and sworn to by the applicants. Each appliand sworn to by the applicants. Each applicant for rejistration shall furnish satisfac-
tory proot that he is twenty-one years of age or over and of good moral character and upon payment of a fee of twenty dollars, shall be examined by said board. If he is found by four or more members thereof to be twenty-one sears of age or orer, of good moral character and qualified, he shall be registered as it qualified physician and shall receive a certificate thereof signed by the receive a certifcate thereof signed by the fails to pass an examination satisfactory fails to pass an examination satisfactory
to the board, and is therefore refused regis tration, shall be entitled within one year after such refusal to a re-examination at a meeting of the board called for the examination of applicants, without the payment of an additional fee; but two such re-examinations shall exhaust his privilege under his original application. Said board, after hearing. may by unanimous vote reroke any certifcate issued by it and cancel the regis tration of any physician who has been convicted of a felony or of any crime in the rartice of his profession. The board may subsequently by a unaninous vote, reissue any certificate formerly issued by it or issue a new certificate, and register anew any plysician whose certlficate was revoked and Whose reglstration was eanceled by tho
boarl. All fees recelred by the board shall, once in each month, be pald by its secretary into the treasury of the Conmonwealth. See, 4. COMPENSATION OF BOAltD: The secretary of the Board of legistration ill Medicine shall recelve a salary of twentyfive hundred dollars a year, and other members of the saill board shall each receive a saliry of three humdred dollars a year.

Sec. 5. RECOIRD ; ANNUAL REPOR'S : The board shall keep a reeord of the names of all persons reglstered hereunder, and of all money recelved and disbursed $1, y, 1 t$, and a duplleate thereof shall be open to linspection in the oftice of the Secretary of the Commonwealth. Said board shall annually, on or before the first day of January, make a report to the Governor of the condition a report to the governor of the condition of medicine and surgers in this commonwealth, of all lts ofticial acts during the
preceding year and of its receipts and dispreceding 5
bursements.

bursements.

sec. 6. INVESTIGATION OF COMIJAINTS: The board shall Investigate all eompaints of the violation of the provisions of Seetion 8, and report

see. - ExAMINATIONS; sUBJECTS : Examinations shall be wholly or in part in writing in the English language, and shall be of a scientific and practical character. 'Tley shall include the subjects of anatomy, surwery, physiology, pathology, obstetrics. grnecology, practice of medicine and hyglene, and shall be suffciently thorough hyglene, and shall be sufficiently thorough to test the

Sec. 8. PRACTITIONERS NOT REGISTERE1); PROSECLTHON: Whoever, not being lawfully atuthorized to practice medicine within this commonwealth and registered as aforesaid, holds hiniself out as a practitioner of nedicine, or practlces or attempts to of medicine, or practlces or attempts to practice medicine in any of its branches, or whoever practices medicine or surgery under a false or assumed name, or under a name
other than that by which he is registered, or other than that by which he is registered, or whoever personates another practitioner of a like or different name, shal, for each offense, be punished by a fine of not less than one lundred nor more than flve hunced dorlar or by ment. In a case in which a provision of this ment. or the jreceding section has been violated. the person who committed the violation shall
not recover compensation for services not recover
rendered.

sec. 9. To WHOM Not APPLIED: The provisions of the eight preceding seetions shall not be held to discriminate against any particular school or system of medicine, to prohibit medical or surgical service in a case prohibit medical or surgeal service in a case of emergency, or to prohibit the domestic administration of family remedies. They shal not apply to a commisstoned medical officer
of the United States Army, Navy or Public of the United States Army, Navy or Public offleial duty; to a physician or surgeon from another state who is a legal practitioner in the state in which he resides, when in actual consultation with a legal practitioner of this Commonwealth; to a physician or surgeon residing in another state and legally qualifted residing in another state and legally qualifed 10 practice therein, whose general practlce
extends into the border towns of this Comextends into the border towns of this Com-
monwealth, if such physician does not open

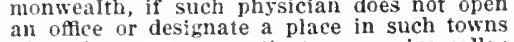
an office or designate a place in such towns
where he may meet patients or receive calls; to a physician authorized to practice medicine in another state, when he is called as the family physician to attend a person temporarily abiding in this Commonwealth; nor
to registered pharmacists in preseribing gratuitously, pharmacists, elairvoyants, or persons practicing hypnotism, magnetlc heal ing. mind cure, massage, Christian Selence (lo not violate auy of the provisions of sectlon 8 .

In force June, 1894.

\section{STATE BOARD OF HEALTH}

Dr. Ilenry 1'. Walcott, Chairman, Cambridge; Ir. Milton J. Iosenau, Boston IIram F Mills, C.W., Lowell ; Dr. Robt. W' Lovett, Bosion; C. E. Mcrillícudds, LL.B., Worcester; Clement $\mathbf{F}$ Coogan, I'ttsfleld; Jos. A. I'louff, Ware; Dr. Mark W. Richardson, Secretary, Boston; Dr. Wm. C. Manson, Asslstant to the Secretary, Boston.

\section{BOARD OF REGISTRATION IN MEDICINE}

Samuel II. Calderwood, Chalrman, Bostoli; Geo. L. Rhehards, Fall Rlver; Augustus L. Chase, Randolph; Nathanlel R. Perkins, Boston; Chas. II. Cook, Natick; Matthew T.
Mayes. Springfield; Walter I'. Bowers, Secretary, clinton.

\section{MASSACHUSETTS MEDICAL SOCIETY} Officers 1913-14

Walter $P$. Bowers, I'resident.........Clinton Lyman A. Jones, Vice-I'resldent... Yorth Adams Walter L. Burrage, Secretary........Boston Edward M. Buckingham, Treasurer...Boston Edwin 11. Brigham. Librarian.....Brooktine

\section{District Societies of the Massachusetts Medical Society} BARNSTABLE DISTRIC'T

W. D. Kinney, President.......... Osterville 1. F. Miller, Secretary.............. Harwich BERKSHIRE DISTRICT

J. B. Thomes, President.......... Pittsfleld

o. L. Bartlett, Seeretary.............. Pittsfield BRISTOL NORTH DISTRICT

R. D. Dean, President........... Taunton

i. R. Crandell, Secretary............ Taunton BRISTOL SOUTH DISTRICT

A. B. Cushman, President... South Dartmouth

R. W. Jackson, Seeretary........Fall River ESSEX NORTH DISTRlCT

F. W. Anthony, President....... Haverhill ESSEX SOLTH DISTRICT

P. 1', Moore, I'resident........Gloucester

H. Bennet, Seeretary.................. Bym FRANKLIX DISTRIC'

C. F. Canedy, President............ Greenfleld IIAMIDES DISTPIC'I

A. I. Weston, l'resident......... Springfield

H. L. Smith, Secretars............ springfleld HAMPSHIRE DISTRICT

VV. P. Stutson, President.......Cummington

J. D. Collins, Secretary.......... Northampton MIDHESEX EAST DISTRICT

W. H. Keleher, President.........Woburn

A. E. Snall, Secretary,.................

MUDDLESEX NORTH DISTRICT

C. F. Simpson, l'resident........... Lowell MIDDLESEX SOLTH DISTRICT

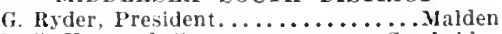

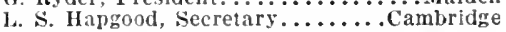
NORFOLK DISTRICT

.. S. H. Leard, President..........Boston Bradford lient, secretary............. Boston 


\section{VOHFOLK SOLTH DISTRICT}

Chas x Adams Presldent.......W Willaston

D. F Reardon, Secretary.............. Quincy HLYMOLTH DISTRICT

Chas b. Lovell, Fresident.........Whitman

Alfred $i$ Smlth. Secretary.......... krockion SUFFOLK DISTHCT

II. 1. Arnold, I'resident............. Boston

iv. C. Howe, Secretary..................... WORCESTER DISTICT

J. T. Dugkan, J'restdent......... Wiorcester

k. I. Hunt, Secretary............Worcester WORCFSTE NORTH DISTRICT

W. F. Sawyer, Prestdent.......... Fltchburg

C. 11. Jennings, secretary.......... Fitchulur

\section{STATE INSPECTORS OF HEALTH}

The Southern Hay and Cape Ilealth Dis

trict-Idam S. Mackinght, Fall Itlres.

The soush VIdland Health District.-

Elllos: Washbusn. Taunton.

The Mldand Heath Dlstrlet.-Wni. W valcott. Natlek.

The Massachusetts Bay Health IIstrict... Harry Linenthal. Boston.

The North Metropolitan Health Wisirict.-

Frank L. Morse, somerville.

The Northeastern Ilealth District-Wm.

Hall Coon, Harerhill.

The Sorth Midland Health District.Chas. E. Slmpson. Wowell.

The North Central Health Dlstrict.-Jewis Fish, Fitchburg.

The South Central Health Dlstrlet.-Melrin G. Orerlock. Worcester.

The Southern Connectleut Vally Health Mstrict.James $v$. W. Boyd, Springfeld.

The Norshern Connectlcut Valley Health The Northern Connectlcut Valley Health

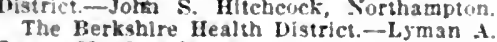
Jones, North Adams.

\section{STATE INSTITUTIONS}

Boston

Boston State llospltal, Dorchester. Center, Boston. Establlshed 1839; pul. Ile; for mental and Iusane cases: 1,364 beds: Henry 1. Frost, physlclan in charge.

Massachusetts State J'rison Hospital. Charlestown, Boston. Estab!lshed Is0. Joseph I. MoJaughlin, physlclan it charge: B. F. Bridges, warden.

Psychopathic Department of the Boyton State Hospltal, 4 Fenwood Road. Boston. 110 beds: nubllc: nerrous alj mental: E. F. Southard (Cambrige) physletan in charge.

\section{Bridgewater}

Bridgewater State Hospital, State Farm I'.O.. Bridgewater, Mass. Fistablished 1886 ; male insane : 1,000 beds; Ernest B. Emerson. medleal director.

state Farm, Bridzewater. Mass. (State Furm ['.O.). Establisbed is54: general 150 heds: Ernest B. Emerson, medical director; I. M. Hackitone, superintend ent.

Canton

Massachusetts IIospltal school for the Care and Fiducation of Crippled and lieformed Chlldren, Ramulph St., Canton. Mass. Fistalllshed $190 \% ; 275$ beds; John i. vish. physlelan in charze.

\section{Chelsea}

Soldiers' Home In Massachusctt, the! sea, Mass. Futablished 1862: for dlsabled rolunteer soldiers: 6.50 beds in barracks. 225 beds in boupical: fies. H. Mantiold. surgeon-In-chief; Htchagd li. Fuster, com zavdant.

\section{Coneord Junction}

Wassachusets ltefirmatury Hosittal. (concord Junctlou, Mass. Listablinlied 1884: publle: zencral: 00 heds: liuy li rernald, phyalcian in charzo.

\section{Danvers}

lonren State Howplal, Hanvers, Mas

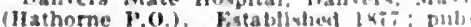
lic: Inane: i,500 hects: tieco. II Kilse II.. superintendent.
Foxboro

Foxivoto State Ilospltal, forboro, Stass. listabllatued lis.3. publle. for lneliciate. and Imsane: 408 bets: Irwin H. Ner. medical superintendent.

\section{Gardner}

liarduer state Colony, Gardner, Mans. Fistabllsherl 1902: public: qulet chroule Insane: 700 heda: chas. T. Ia Joure M II, supertntenderit.

Lakevitle

Ioakeblle State Sinatorium, Lakerllle. Mas. (Mddlebro I.O.). Fastabusbed

1510: mible: tuberculos!s: 200 bets:

1.10: mublic: tuberculosls: 200 beds: Lancaster

Industrla! school tor Cirls, baneaster. Mass. Exialilshed 1856: general: 30 beds in liospltal devartment: (C. (C) Berk. ley, ghrslelan In cliarge: irs. Amy Everall, superintendent.

\section{Medfieid}

Medfleld siate Asylum, Metfleid, Mass. (11) rung F.O F). Ftablished 1896: for the jusane; 1.800 beds; ridward French. physiclan in charge.

\section{Norfolk}

Vorfolk State Hospltal, Norfolb, Mass. Establlshed 1912: alcoholle and dru: habitues: brinch of loxtornugh state Hospltal: Irwin H. Nef, physician in charge.

\section{Northampton}

Nortbampton State Houpital, Northamptoli, Miss, Establlshed 1856 : for the in sane: 912 bells: John A. Houston, med. tcol suberintendent.

\section{North Reading}

Fin Readiog State sanatorlum Sorn Reiding. Mtass. (North Wilmington $\mathbf{1}$.0.) Establlshed 1909; public: tuberculosis: Is3 beds; rarl C. Maccortson, M.1. superintendent.

Palmer

Minson state Hospltal, Yalmer, Mass. Eitabllshed 1898; public; for elllevtlo: - 50 beds; Everett Flond, mellical superintendent.

\section{Penikese Island}

l'enikese Hospltal, Penthese lsland, IIass. Kistabllshed 1905 ; leprosy; pubIlc: 20 beds; rrank II. Yarker, medical superiniendent.

Rutland

liutland State Sanatorium, Rutland. Vass. Establlshed Is95; tuberculosin: 350 beds; Eillott Wanliburn, medlcal su. perintendeut.

Sherborn

leformatury for Women, Shepborn. Mass. (Franingham P.O.). Establlshed IQ: : reformatory: 17 heds li hospltal Folli R. Spaulding, reshlent physiclan: tesile It. Hodder, auperintindent.

Shirley

Industrial sillool for Boys, shirley. Mass Fotallithed 1909: Eeneral: lo trets: Thomas k. Lilly, physlclan in 1hace ; tieo. I. (ampbell. superintend. ('ilt.

Taunton

Taunton state llospltal, Taunton, Ma. lintabllated 1sit: Inublic: fur Insane 90. treds: Arthur ve liass, II II., super. Internlents.

Tewkobury

siatc Infirmary. Tewkmbury. Mass Eutabltulued 1832: for the Invane: speelal dopartment for tuloerculosis cases: 2.500 trools: Jelan if Nirbols, medleal suberintenilent.

Waitham

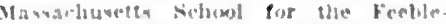

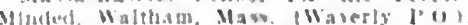

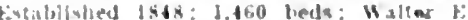
lernalif. phystcian in charzo.

Westboro

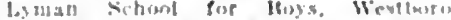

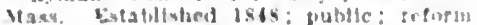

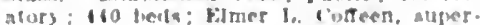
inteblient.
Wraturars Insane llosplisl, Westhopos, Man. Yivablished Ixeb; publle agd bri vate: Derrous and mental: 1,260 inds: It i) spalding. M.I., superloterdent.

\section{Westfield}

Wentrelu state sanatorim, Weancld Masy. Kistablisted 1910: public: tuberel

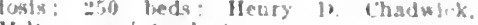
U. 11. superintendent.

\section{West Rutjand}

l'rison Camp and Iospital, West Rut land. Il as rotablistied 1g0t: public ruberculusis: grelsoners only: ino bed lipo. A krskige, superintenden?.

Worcester

Wirculer state Asylum, Sumner SL, Wincester, Mass. Vatabllobed Is:-; wubIle: for the Insane: 1.300 beds: II. Louls Sitrk, mediersl suberintement.

Worcester state Hoipltal, Wo-pester. Mass. Latablished 1933: for the inwane: 1,350 beds; kinest $v$. Scrlbner, Medlcal sugrertiterdent.

Wrentham

Wrentham state sichool, Wrentham. Mass. Fistahished igor: nervous and mental diseases: 41s hels: Gentye $L$ Waltace, medical superintendent.

HOSPITALS, SANATORIUMS AND CHAR. ITABLE INSTITUTIONS

Acushnet

Pine Lawn Sanitarlum. Acusbnet, Yas

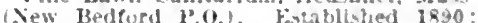
pitrate: 25 beds: $j$. F. Wecks, house hystelan; Mrs. L. F. Asbley, superiaiendent.

Adams

Sdums Anti-Tuberculos!s Assoclatlon. Adams, Mass. Fstablished 1910: I: ineds: Mlss klyzabeth Collins, stiverta. terdent.

ireylock licst, Idam4. Mass. potali. livhed 1900: nerrous: 45 beds: sisters of F'rovidence, In charge.

\section{Allerton}

lir. C. P. Sylresier's brivate llosplal. Alletton, Mass. histablisted 1908; zen. eral: :0 beds: C. P. silrester, myst cian in charge.

Amesbury

Amechury and sallabury Home : Aled Woneu, Amesbury Wase kivitr$\therefore$ Wells, superintendent.

Aniherst

l'zatt Ilealth totage, Amberst. Mass. Fistabllobed 159n: gencral: for student. it Anherst inlleze: lit beds: ["aul lfillips. phrstclan in charge.

Terrave, Anherst, Mass, Eitablishew? 1882: private; a houre soluod for hach ward chlluren and routhis: 1: heds: $14 \mathrm{R}$ Frances J. Herrich prmoinal.

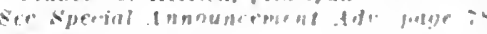
Andover Madorer HIl Sanliarlum. Aldover. lieds: Henry l. ilarke, pligsiclan in chargis.

Whan inmenary, Inderer. Mas, B-

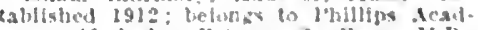
emy; to beds: l'etronn s. I'age. MI.W. lhysical direosus.

sanburn's Horne for Imiactic Hos

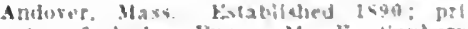

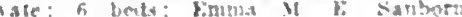
physletan in charber

\section{Artington}

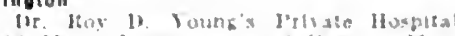

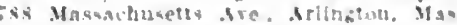

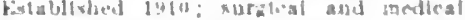

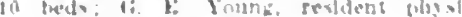
clan and sufwertatendent

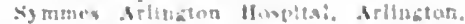

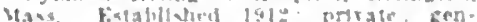

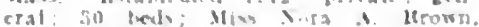
sugerintenglent.

Arlington Height:

Irlinaton llealth liesurt and Itue sin.

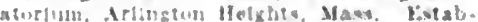

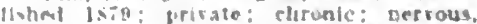
nensita: so leds: Arthur II. Rine and liartiof $T$. Inin, medteal superintendents. 
Atticboro

Alleboro Jome Sanitarium, 15: I'leas aut st. Attleboro, Mass, Estabilished 1880 irivate: branch at Oak IBfults; nervous and chronle eases; I2 beds; dutura ciustln-liackle, physictan in charge; b. f. Fustin, sujerintendent.

Allebro Sanitarium, Attleboro, Mass. Fatiblished 140s: private; 150 beds: It. E. und Mary 13. Nleola, fluysiclans in charge.

Sturdy Memorlal llospltal, 211 l'ark

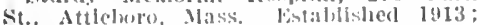
generni; 20 heds; Miss fi. h. klee, superintendent.

Baldwinsville

Ilospltal cottages for children, Ihaldwhsvilte, Itass, Establjolled 1882; for diseased, matmed, feeble-nlnded and destllute chlluren: 140 hols: llartstein wen dell l'age, mendical sujerintendeut.

Dr. Mulln's Ifospital. Baldwissille, Mass. lipiste; rarcinoma cases exclusively oly sleian in sliejy

loine Terrace, Baldwinsrille, Mass. Established $190 \%$; private; mental sud nerrous, narcotic and ulcoholic: 10 beds tralter $F$. liobie, plifsiclan in charge.

Barre

Ifim IIII, Harre, Mass. Fstablished 1845 . private school and nome for feebleminded routlis; 75 heds; Geurge $A$. lirown, physiclail in charge.

\section{Beimont}

(Sice alsc: Boston.)

Comatescent IIosuital, Belmont, Iass.

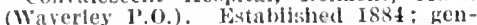

eril: 36 beds; Frederie $A$. Washburn, Hoston, physician in charge.

Beverly

Beverly City Itome, 18 Cedar St., Hererly. Mass. Histallished 1903; general; 12 beds; N. M. MacLeod, eity physician

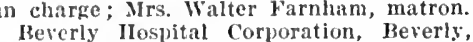
Mass. Listablished 1893; private; 55 beds; general; Alice C. S. Cushman, R.N., superintendent.

New Fngland Industrial School for 1s76: private; 40 beds; Miss Joulse Upham, principal.

Old ladies' Home, 12 lovett St., Beverly, Nass. Fstablished 1900 ; private; 7 beds; IIiss Emma J. Fraser, matron.

\section{Boston}

(See also: Arlington Ileights, Belmont, Brookine Cambridge, Chelsea, East Vilton. Frerett, IIalden, Medford, Melrose, Melrose Hlphlands, Newton, Newton Highlands, Newton Irper Falls, Newtonrille, Quines, Somerville, Watertown, Waverley, West Winthrep and wollaston.)

Adans Nervine Asylum, 990 Centre St. Ianaica Ilain, Boston. Fistablished Tamaica Plain, 50 beds; Edward B. 187 ; nervous; 51 bed.

Berke!ey Infirmary, $44 \mathrm{Dwight}$ St., Boston. Established 1905; public; general $M$ iss Annle I. Hollings, superintendent board of directors in charge.

Bessey Hospital, 845 Beacon St., Bos 20 berls; Earle E. Bessey, physician in charce.

Boothby Surgical Hospital, 1 Worcester, S1., Boston. Established 1889 private; surgical; 50 beds; Franklin $\mathbf{B}$. Ifuntress, superintendent.

Boston City Hospital, 818 IHarrison Ave., Boston. Established 1864; public ; general: 655 beds; John H. MeCollom, inedlcal superintendent. Branches: East Boston Relief Station, Conraleseent IIonie, IIayniarket Square Relief Station, Ionle, Haynarket Square Relief Station, and South

13oston Consumptires' Hlospital, 13 Burroughs Fl., Boston. Fstablished 1908 ; muricipal day eamp in connection: publie: 260 beds; Simon Cox, medical superintendent.

Boston Dispensary and Hospital for hildren, 25 Bennet St., Boston. Established 1909; private; 30 beds; Arthur A.
Howard, [Hystian in charge of hespita] Mlehatel M. Witis, Ir., superintendent.

looston Floating Hospltal, offlee 54 levolshire si. Haton. listablisher 1s:t; private; medlenl; children under Hears; l25 day batlents; 120 permas pliysictin.

Foston llome for Incurables, 2049 Dor hester Are. lioston. Established 1882 . private: 50 heds; I. Ir. Merrimn, superintendent.

Hoston I,ying-in llospital, 24 Mefean it Isoston Established 1832: private: olstefrical; 52 beds; Mrs. E. J. A. Hig (-ins, suj) rintendent.

Postom North lind Masion, 313 Ford Hidg, Hoston. Established is67; children's department, Florence and Bourne Sts. to beds: lier. C. I. D. Younkin. superintendent.

Boston Nursery for Hilnd l3ables, 147 S. IIuntington Ale. Boston. Establisherl 1901: private; 25 beds; Jane A. liussell, ujerintendent.

Cirney ILospital, South Boston, Bosto" Established 1863; prlvate; general; 200 heds; Wm. II. Derine, president of medical stati?.

Channing flome, Francis and I'llgrim Rd. Fenway, Boston. Establlshed 185:; tuberculosis. for women only. 23 beds: Frederick $T$. Lord, attending physlcian; Mrs. I. L. l'. Fenuell, superintendent.

Chardon street Ifome, Chardon and Bowker Sts., Boston.

Children's llospltal, Ifuntingdon Are., IBoston. Wstablished 1869; private; general: branch convaleseent Ilome, at Wellesley; 100 berls; Episcopal Sisters, 11. rharye.

Codman Hospital, 15 Pickney St., Boston. Fstablished 1911; private; surgical ; 12 beds; E. A. Codman, physician in charge.

Collis $I^{2}$. Iluntington Memorial Ifospital, Harvard Medieal School Boston. Fstabllshed 1912 ; private : tumor investigation: Iniversity Cancer Hospital for Research; 20 beds; Thomas Ordway, physieian in elarge.

Convalescent IIome, City ILospltal, 2150 Dorchester Ave., Boston. Yublic; branch of Boston City IIospital; 36 beds; lits: Elizabeth C. Fairbank, matron.

Cruft IIospital and Dispensary of The Franklin Square Ilouse, 11 b. Newton St., Bostou. I'rivate; I0 beds; Bernard W. P'ond and IIilbert F. Day, physiclans in charge.

Cullis Consunptives' Ilome, Grore Hall, Boston. Established 1864 ; private, tuberculosis; 40 beds; Rev. Edward I) Mallory, superintendeut.

Cusling Hospital, 61 Parker Hill Ave., Boston. Established 1893: private: 3\% beds: (irace $\mathrm{I}$. Rochford, medieal superintendent.

Iarid H. Judd Hospital, Brunswick. Boston.

Deer Island IIospital, Suffolk County IIouse of Correctlon, Deer Island, Boston. Established 1861; 126 beds in hospital department; B. F. McGaffigan, resident physician; James II. Cronin, superintendent.

les Brisay Hospital, 36 Newbury St. Boston. Established 1904: pricate; surgery; 23 beds; Lucy I. Des Brisay, superintendent.

Dorcliester Cottage Hospital, 32 Moultrie St., Boston. Established 1899; private; 12 beds; Flora F. Welch, R.N. vate; 12 beds
superintendent.

Douglas' Sanatorium, 321 Centre St. Dorchester, Boston. Established 1903; private; narcotic and alcoholic; 20 beds; C. J. Douglas and C. G. Stearns, medical staff.

East Bostion Rellef Station of the Boston (ity Hospital, 14 Porter St., East Boston. Establíshed 1906; public; general; 10 beds; Joseph Gordon Hegarty, resident physiclan.

Eliot Private Hospital, 107 Auduhon Rd., Boston. Established 1886; surgery ; 25 beds; Miss N. J. West, R.N.. superintendent.
Eillen M. Glitord Sheltering Home, Irrighton, Ioston.

Einı IHill I'rlvate Hospital, 75 Cheney St., Hoston.

Emerson Ifospital, 118 Forest IIIIs St. Iamalca l'Jail, lhoston. Fstablished 1904: private; general; 50 beds: Nathanjel W Emerson, physteinn in charge; Mrs. G. T Shadmun, suyerinteudent.

laulkner llospltal, Janaica I'Jatu, Bos ton. listablished 1900 ; pritute; general 38 beds; Miss Edith I. Cox, superintend-

Fenway IJospital, 298 Newbury St., Boston. l'rivate; 15 beds; Mlss Rogers, in charge.

Fiorence Crittenton IIome of Compassion, 701 Massachusetts Are, Boston. Listablished 1898 ; maternity; 33 beds: Irs. C. M. lillinwood, matron.

Free Home for Consumptives in the City of Baston, 428 quincy St., Boston. Hstablished IS92; private; 110 beds: Elizabeth $\Lambda$. Powers, superintendent.

Germanja kye Inflrmary, 168 Massachusetts Ave., Hoston.

(;) Boston. Establlshed 1909: urlrate; nervous and mental; 7 beds; Itabel D. Ordway, physiclan in eharge.

Gordon Home for Ared l'eople and Incurables, 3 Aspinwall Rd., Boston; 25 heds: Mrs. M. M. Mackenzie, superintendent.

Gordon Maternity Hospltal, 532 Tremont St. Boston. Private; George Cutler, thysiclan in charge.

Grilce Uospital, 144 Kingston St Bos ton. Estahished 1891 ; private; 60 beds II. II. Gernain, surgeon-in-chief.

Hart I'rivate IIospital, Inc., 95 Moreland 40 beds. Berthit C. Hart, R. N superintendent.

Uaymarket Souare Relief Station, IIaymarket Si Boston Established 1901. publie; general; 26 beds: Wm. J. Briek ley and Franeis T, Jantzen (I.owell) surgeons in charge.

Hebrew Iadies' IIome for Aged, Dorhester, Boston.

Hillside Hospltal, 51 Sawyer Are., private: general; 11 beds; Lena Boutilier, private; general

IIome for Aged Colored Women, 22 Haneock St., Poston.

Home for Aged Couples, Walnut and Columbus Aves.. Boston. Established 1884; private; 100 beds; Flizabeth Abbott Carleton, physician in charge.

Home for Aged Men, 133 W. Springfleld St., Boston. Established 1860 ; prirate; 48 beds; Helen L. Mallory, superintendent.

Home for Destitute Roman Catholic children, 788 Harrison Ave., Boston.

IIome for Friendless and Unfortunate Women, 4 II awthorm St., Boston. Established 1878 ; private

llome for the Aged Poor, 424 Dudley St. Boston. Estathlished 1870: genera!: St., Boston. Estatilished 1870 ; Genera!: intendent; Litte Sisters of the Poor, in charge.

House of the Good Samaritan, Boston (Fenway P.o.). Established 1861; medical and tuberculosis cases, indigent women and children; public; 43 beds; Mis

IIouse of the Good Shepherd, 841 Ilouse of the Good Shepherd, 841
Huntington Ave., Boston. Established 1867: private; reformatory ; 250 beds; Francis C. Murphy in charge.

Industrial Home, 132 IIampden St., Boston.

Infarts' Hospital, 37 Blossom St., Bostoll. Established 1881; private; infants under 2 years; 24 beds; Thomas Morgan Roteh, medical director.

John Howard Industrial Home, $\mathbf{5 6 0}$ Massachusetts Ave., Boston. Established 1890: public; discharged prisoners; 45 beds ; Albert Arnold, superintendent.

Leopold Morse Home for Infirm Hebrews and Orphanage, Mattapan, Boston. Established 1888 ; public: 70 beds : Henry Woolf, superintendent. 


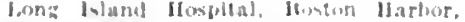

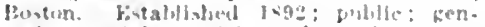

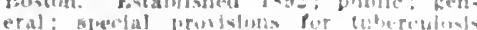

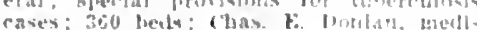
cal thiterlntemdeit.

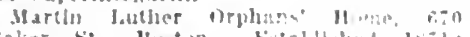

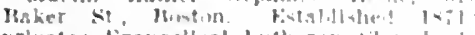
pelvate: Ecancolleal loubleran thireh, in cliario: Mrs. Varte schwoles, maston

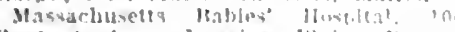

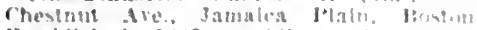

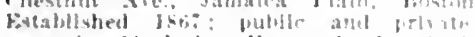

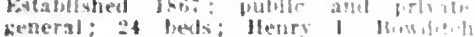

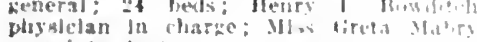
sujerfntemdent.

Masachusetts Charltatie be and pa

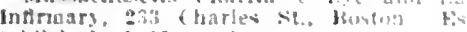

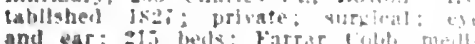
cal su[verinteudent.

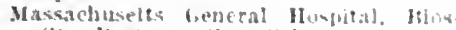

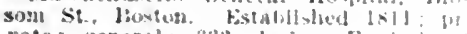

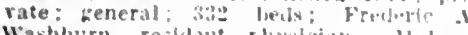
Washburn, restdent physloian. Melout

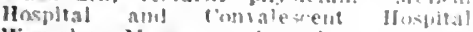
Waverleg, Mase, are branclies.

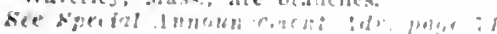

Massaclusets Home and Jufnwind Hospital, lathituonl, Husin.

Masachusetls Heme for Interngerate Wongen, 2 Hinuey st. Bustum Fotal. thshed 1879: prlvate: 4.5 benls: Willam f. Temple, philelan in harze: liv Ida Mcculludi, superintendent.

Massachusets Huneopathle.

82 F. Coneord st., lisston. kictitulthel 1855: prirate: whitable: general df part merat, 250 beds: contazious disease jo partment. 125 beis: Win. O. Matm. mell cal superimtendent.

Massachuselts Women's Hospltal, Parker Iill We, lioxtury. Puston. I:s

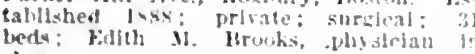
charge.

Iccreight sanitarium it lowbils Aie. Boston. Established 1902: Por in.

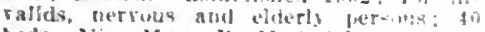
beds: Miss Mary H. Mctrelitht, superits tendent.

Jrbowell Hosplial. 172 Newhury sit beds: Innle Mcllowell, sulerinterdent

vi. Pleasant Iont. 59 Elın llill IV.

Grove llall stallon. iloston. Fitallislle, 1901: publir: for the aged: 4 th herls

J. J. J. Wingate, nanaker

Me. Sinal Hospltal, It stanifurd st

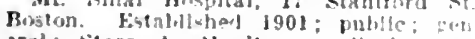
eral: Nert $A$. Noulton, medieal

intendent.

Mrs. N. S. Janl's Santarium, 32 1'ip+4 land Sit. Isuston.

New England Haptlat Hospltal, Pitrt,

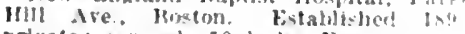
prliate: Ceneral: in leds; Emma A. A derson, subertriendent.

Cew kingland lreaconess noupital, 17.

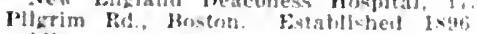
publle: general: 50 beds: Nieliza I Betse. R.N. superintendent.

Sew Frigland kye and Eat Hosjulal,

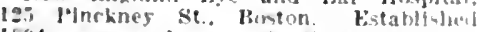
1894; eye and ear: $r$. F. and $W$. It. stacey. plasslotans in charge.

sew England IIospltal for Women alsul rhlldren, liniork si. jouton bistill. Wahed 1863; privale: general for womm and chlldres: 150 peds: stella u ras. for, resletend fhystrian and sugerlutinl lor.

ent. tnn. tomce. it livylaton st.): no insat or contaglous cases admlttel: Herlert | defrersull, physirlan in charke.

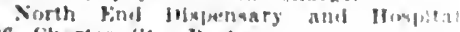

26 fluarter sit. Jumton.

leter flent Hrlaham Inopleal, Ifurdabe

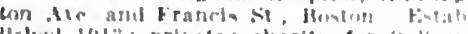

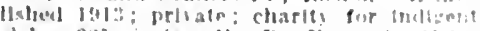

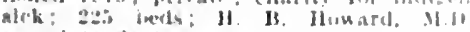
superintendent.

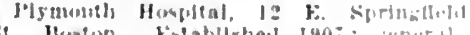

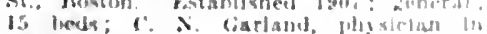
iharie.

I'retulergast famp, Harrarel and (tak

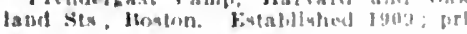

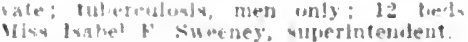

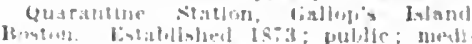

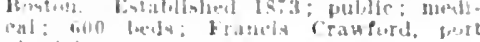
lon: $10,1,1$ is

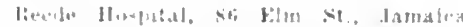

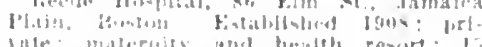

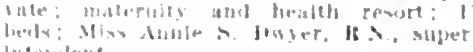
lateringerst

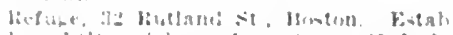

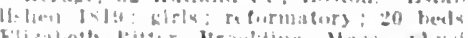

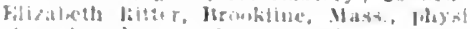

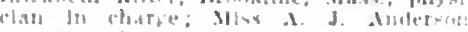
uperintentibeist.

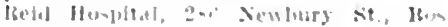
m. l'rivate.

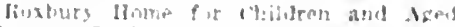

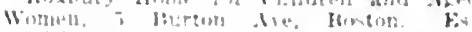

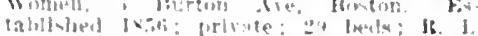

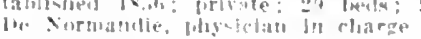

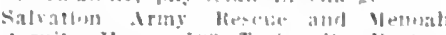

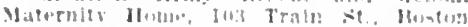

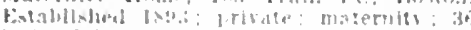

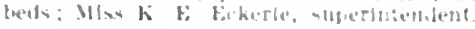
sonfinavan sallors and Jmularall. Humn, Fil-t Bastons. Heston.

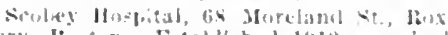

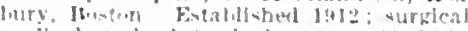

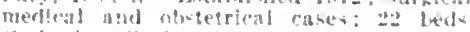
callerine scolvey, sugerlnewdent.

small-pox fiospltal. Southanton si Mostun.

Solth Tepartment if Boston ciev Hes

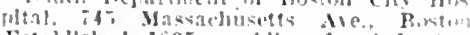
Fatalllshed 1595: public: for Infeetiou dicenves: 340 bess: Fodirin H. Place fhy-lelati-in-chied

Sonth lind fol-pensary amd llospltal. 2.

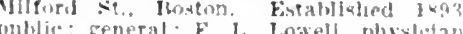
In-reharge.

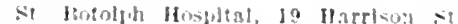

Briston.

st. Filizabeth's IIospital of Boston, 61

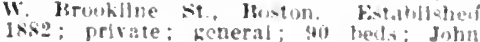
issog private foneral; sio bed.

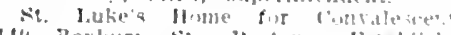

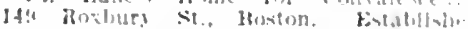

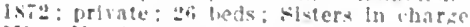

Hes if 0. Coombs, matron.

st. Marwaret's Vaternlty Hospitasl.

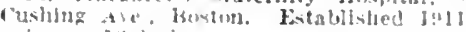
moluate; ats licios

st. Mh19"s Infant Asylum and I, vin in Hospitil. Fiveret? Are and lerume it

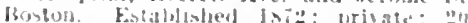
ineds, francis J. Giblun, previdelt? mell "al statt.

st. Monlea Home for sick returb

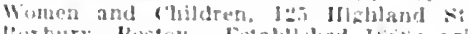

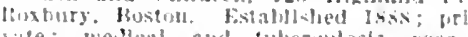
inte; medleal and tuber"ulosis rase zll leds: Nathanted K. Wood, phrslesta 18 charge.

se. Jaula'y llospltal, 29 Wr. Cedar St. Boston. Eatablabel leps: grlvate: 1 . prole; Mlaps of.

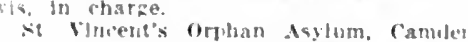

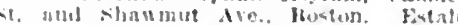

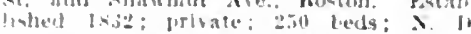
lorummey. Why alclan la tharge.

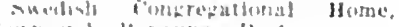

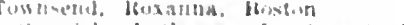

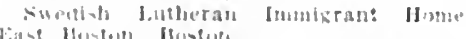

Talltia fuml Malernity Home. New

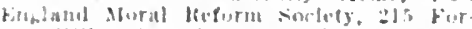
et Hille st. Jumalca liain. Mneton

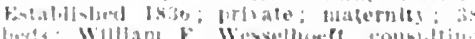

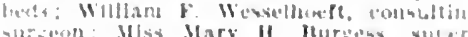
sisonent:

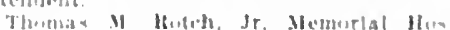

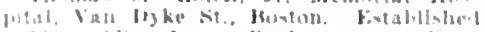

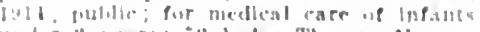

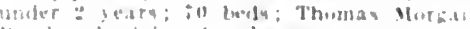

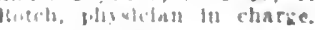

1 mban lieneral lluqultal. 158 w sprtu.

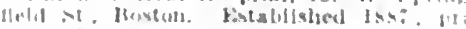
a

Iincent Mamorlas Hospltal, la: s

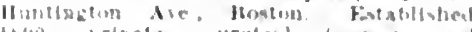

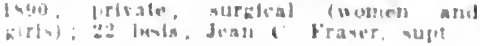

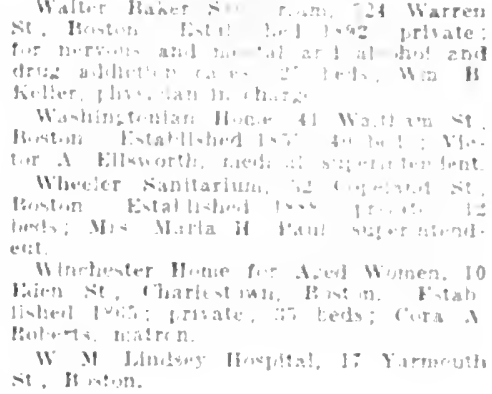

Brurkton

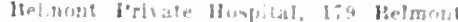

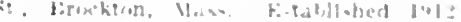
If ir.J. Heles or Maye, ISX, super.

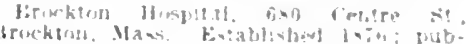

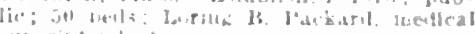
superintenctatit

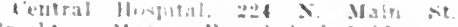

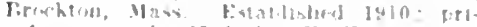

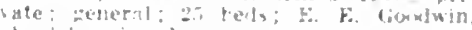

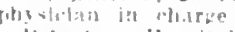

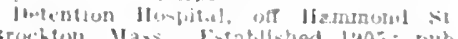

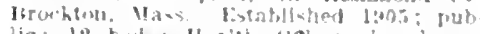
lic: 1: heds: Weaith waver, in thar:e

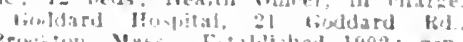

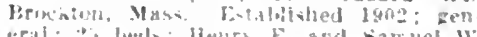
eral: \& leeth: Jinsty $E$ asd samuel $W$

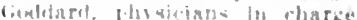

Saturd Maternaty fJ sulal, je Pleavan

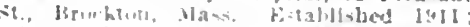
firivate: : Loedo; W. I". Satford, re-lotent

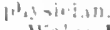

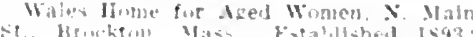

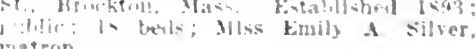

Srookline

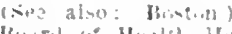

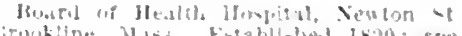

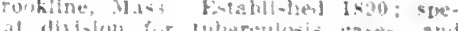

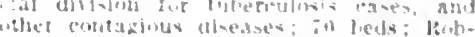

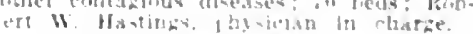

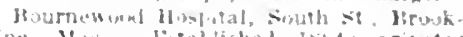

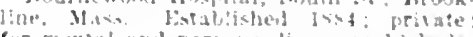

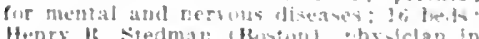

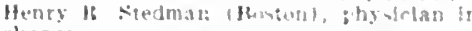
- Uharize.

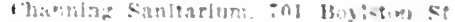

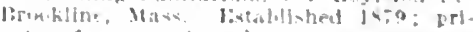
bute: fur methal and nervour cases: linels.

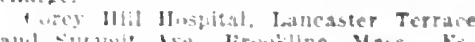

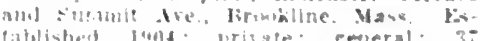

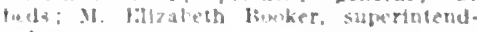

Flok Ifombtill. The. Int sewall tre

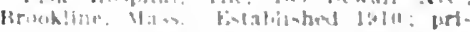

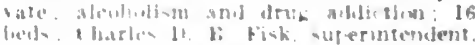

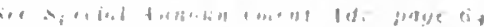

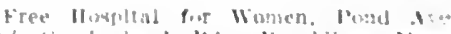

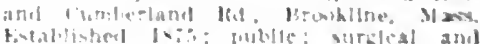

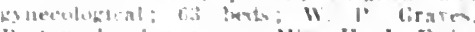
Huslan, beal surgeon: Ilas II J. Faln.

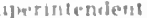

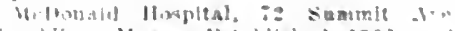

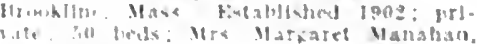
ugertutemilent

Bumbin Istano

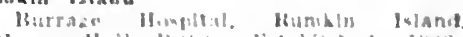

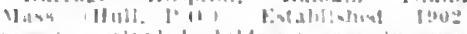
provair crlpplen! chuldrerz: upens in sura.

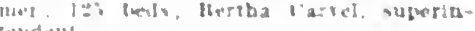

\section{Cambrioge}

ISce alou: floution t

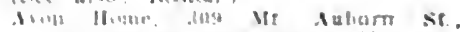

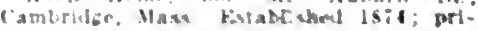
labe: Por destitule elliblen: 0 berts: Mlar Fimma staunafid. matron. 
('antbrldge 10lphtherla Hospltal, Cambrldice, Mass. Estublished 1899; dlphitheria only; 24 beds; l'atrick Joseph Fleming, M.D., sueprintendent.

Cambridge Ilome for A tred People, 360 Mit. Auburn St., Cambrldge, Mass. Chrlstine Nichoison, superintendent.

Cambrldge Ilospital, IIt. Auburu st. Cambrldge, Mass. listabllshed 1871; general; 100 beds; Alma $\mathrm{E}$. Grant, superintendent.

Cambridge Rellep Hospital, 199 Prospect St. Cambridive, Mass. Establlshed 1905:25 beds: (ieorse $\mathrm{V}$. Buehler, pliyslclan in charge.

Cambrldge Tuberculusis Hospltal, iag Concord Are, Cambridge, Mass. Cistabllshed 1908; 75 beds; Felix McGirr, phlysiclan in charge.

Cirarlespate Ilospital, Charles Rlver Bd. Cambridge, Mass, Establlshed 1906: peneral: Nurses' Home at 84 Magazlne St cambridie: 50 beds: viss Amo b. kadford, R.x., supermtendent.

Chester Hospltal, 10 Chester St.. ('aulbrldge, Mass. Established 1904; 25 bed: Miss Mae Copp, superintendent.

Holy (ihnst llospltal for Incurables, Cambildre Mass. Establlshed 189:3; incurable tuberculosis aud chronic diseise; 150 beds.

Middlesex Ifospitai, Cambridue, Mass. Established 1894; private; 12 beds

IIarrlet N. G. Bellamy, superintendent.

Stllman Inflrmary, Cambridge, Mass.

Establisled 1902; general; for Harvard stisdents; 62 beds; Marshall II Balley, physician in charge.

Sumprside Surgical IIospital, Cambridge, Hass. Established 1880; 20 beds: F. N. and F. F. Yaudell, phystcians in cinarge.

Chelsea

(See also: Boston.)

lafayette Private IIospital, 11 Lafayette Are., Chelsea, Mass. Established 1906; 12 beds; Marion Cummings, G.N. superintendent.

Rufus S. Frost IIospital, Bellingham and Highland Sts., Chelsea Mrass. Establlshed 1890 ; private; 50 beds; Miss Emily Pine, superintendent.

United States Marine Hospital, Chelsea, Nass. Established 1858; private; general 150 beds: Surg. Senior Fairfax Irwin (Boston), in command.

United State Naral Hospital, Broadway, (heisea, Mlass. Estabilished 1842; general; 144 beds; George B.

Clinten

Clinton Hospltal, Clinton, Mass. Established 1889; public; general; 55 beds tendent.

St. Mary's Hospital, Clinton, Mass. Es tabilished 1902; private; for women; 16 beds; Philip T. O'Brien, physician in charge.

Concord

Concord Hospital, Concord, Mass. Es tablished 1908; private; 11 beds; Mrs. K. G. Johanson, G.N., superintendent.

Danvers

Danvers Home for the Aged, Danvers, llass. Established 1907; public; Mrs. Enma Fatirfield, matron.

Eims, Danvers, Mass. Established $190 \overline{7}$ hospital and Sanitarium; 5 beds; John $F$. vaientine, physician in charge.

\section{Dracut}

Dr. Flint's Sanatorium, Dracut, Mass Established 1902: general; 10 beds; Omar A. Flint, physician in charge.

\section{East Braintree}

Abbie Crafts Wade Hone for Invalids and Aged People, East Braintree, Mass. (Quincy P.O.). Established 1887; prirate; 14 beds: Abbie Crafts Wade, superintendent.

\section{East Bridgewater}

Millett Sanatorium, East Bridgewater. Mrass. Established 1900 ; private; 40 beds;

Charles $S$. Millet, physiclan in charge.

\section{East Milton}

(See aisn: Boston.)

Militon Couralescent Home and Hospltai, East Milton, Mass, Estabilshed 1885; prlvate; general; 31 beds; Ellen J. o'lirlen, siperlutendent.

East Walpole

I)r. Coon's Sanitarium, kast Waipoie, Mass. Fstablished 1902; private; Insane; 15. beds; Cieo. B. Coon, physichn In charge.

Everett

Everett Smallpox Ilospital, Fuller St., Everett, Mass. Established 1902; 9 beds; virs. Maher in charge.

New linglasid llone for Deaf Mutes, Wverett, IItass. Established 1901; prisate; for aged, bilnd or infirm; 15 beds; Frances 1. kyan, matron.

WhIdden Iemorial Hospital, Fremont Ave and lamelne St., Everett, Mass. Fstablished 1897 ; generai ; 20 beds; 11 annah F. Seavey, matron.

\section{Fall River}

Bay View Ilospital, Woodman and Bay Sts. Fall River, Mass. Established $190{ }^{\circ}$; public; tuberculosis; 60 beds ; maintained by the Board of Heaith; David H. Fuller, physician in charge.

Children's Ilome of Fall Hiver, Robeson and Wainut Sts., Fall River, Mass. Establislied 1873; private; for needy children; 64 beds; F. M. l'adelford, pliyslcian in charge; Niss Eliz. Colburn, matron. Fall Niver City IIospltal, Staniey St., Nall River Mass. Established 1894 ; public: general; 100 beds; Wm. A. Dolan, physiclan in charge.

Highland IIospital, Fall River, Mass. Established 1905; private; for surgical cases only; 30 beds; 1. E. Truesdale, surgeon in eharge; Miss Mary K. Nelson, superintendent.

Home for Aged People, 1168 Highiand Are., Fall River, Mass. Established 1892; private; 25 rooms; Mrs. L. G. Francls, superintendent.

Ilethodist Episcopal Deaconess Home 5.25 .d St. Fall kiver, Mass. Established 1893 ; prirate; charitable; 2 beds; Mary E. Williamson, acting superintendent.

Seaslde Home, 17 Riverview St., Fall River, IIass. Establishled 1903; private : general ; 35 beds; open in summer; infants onty; E. I. Eddy, superintendent. St. Joseph's Orphanage, 56 Bassett St., all beds; J. A. Barre, plysician in

Sev. 'Vincent Orphans' Hone, North Mlain St., Fall River, Mass. Established 1885 public; 175 beds; Sister of Miercy, Mary Benedict, superintendent.

Ste. Anne's Hospital, 795 Middle St., Fall River, Mass. Establislied 1906 ; publie; general; 150 beds.

Union Hospital, 538 Prospect St. Fall Kiver, Mass. Established 1900; public:- general: 80 beds : Mrs. Anna E. E. Rothrock, R.N. superintendent.

Woman's Union Home, 101 Rock St. Fall River, Mass. Established 1909; public ; Mrs. Wm. H. Jennings, president.

\section{itchburg}

Burbank Hospital, Fitchburg, Mass. Estabilslied 1894; public; general; 70 beds Freeman A. Tower, medical superintendent.

Fitchburg Home for old Ladies, 14 Cedar St., Fitchburg, Mass. Established 1883; public and private; 15 beds; Wm. $H$ Bennett, physician in charge.

ritchburg Union Aid Home for Children, 27 Holt St., Fitchburg, Mass. Establislied 1896 ; 18 beds; M. Cook, house physician; Nirs. Abbie E. Demmon, matron.

\section{Framingham}

Framingham Hospital, Framingham, VIass Established 1890; public; general; 80 beds : lliss Lucy J. King, superintendent. Framingham Nervine Sanatorium, Framingham, Mfass. Established 1896; private; 18 beds; Ellen $L$. Keith, physician in charge.

Woodside Cottages, Framingham, Mass. W. lateh

\section{Ft. Strong}

Enited States Army Post Ilospital, Ft. Stroug, Mass. (Boston P.O.). General ; 28 beds: Janes F. Ilali, Capt. Med. Corps, L.S.A., in command.

\section{Gardner}

Gardner Ilome for Eiderly People, 162 Pearl St., Gardner, Mass, Fstablished 1599; 6 beds; C. 1I. Iballey, house physician.

Henry Ileywood Memorlal Hospital, 342 Green st., Gardner, Mass. Established 1907; prifrate; teneral; 35 beds; Miss Marlettil D. Barnaly, superintendent.

\section{Georgetown}

Carleton Home, Georgetown, Mass. Established 1902; private; for aged people: 4 beds; Clara J. Terry, matron.

\section{Gloucester}

Addison Gillbert Hospital, Gloucester, Vass, Listablished $1897^{-}$prlvate: renerai: 35 beds; Miss Juila May Leach, R.N., superintendent.

Gillbert llome for Aged and Indlgent Persols, (Hloueester, Mass. Established 1889; publle; 6 beds; Mary Willans, ination.

(iluucester IIospltal, Gioucester, Mass. Established 1903; general; 15 beds; Horace II. Choate, physlelan in charge.

IInntress Home, 110 l'rospect St. Gloneester, Mass. Establisined 1889; private: for aged women; 13 beds; Mrs. Abble s. Morse, physician; Mrs. Isydia A Mlarston, matron.

\section{Greenfield}

Franklin County Publle Hospital, Greenfleld, Mass. Established 1895; publie; general ; 56 beds ; Anna M. Sweeney, R.N., superintendent.

\section{Haverhill}

Hilizabeth Home, Haverhill, Mass. Established 1866; private; for children; 55 beds: Children's Aid Society, in charge. Hale Hospital, Haverhill, Mass. Established 1888; private; general; 50 berls; Emma A. Mortimer, R.N., superintendent. Haverhill City Hospital, Ha rerhill, Mass. Established 1903; public; 40 beds; Louis A. Savage, superintendent.

Haverhill Contagious Hospital, Buttonwood Ave., Haverhill, Mass. Contaglous diseases only ; 34 beds; Emma A. Mortimer, R.N., superintendent.

Haverhill Day Nursery, Haverhill, Mass. Private; 14 beds: Young Women's Building Association, in charge.

Haverhill Tuberculosis Hospital, Boardman St., Haverhill, Mass. Established 1913 ; tuberculosis; 32 beds; I. J. Clark. physiclan in charge; Alice C. Marshall, superintendent.

Old Ladies' Home, Haverhlll, Mass. Established 1876 ; private; 25 beds; Miss H. II. Smith, matron.

\section{Holyoke}

Holyoke City Hospital, Holyoke, Mlass Established 1891; general; 125 beds; Geo. Dallas Henderson, medical superintendent.

Holyoke Sanatorium, Cherry St., Holyoke, Mass. Established 1911 ; public ; tuherculosis; 38 beds; Miss Margaret Ilealy. R.N., matron.

House of Providence Hospital, 679 Dwight St., Holyoke Mass. Established 1876 ; general; 70 beds.

\section{Hyannis}

Cottage Hospital, Hyannis, Mass. Establisiled 1911; private; 4 beds; Dr. Harwood, owner.

Hyannis Hospital, Hyannis, Mass. Established 1911; private; 6 beds; Miss 11 J. Rimner, R.N., owner and superintendent.

\section{Hyde Park}

MIrs. Chapman's Home for Invalids, Hyde Park, Mass. Established 1910; invalids and maternity; Mrs. Chapman, superintendent. 
Ten Fingland leatody Home for cripbled Children. Ilale st. Mbde l'urh. Mav fistablistsed 1894: privati: surkfeal and ancational: 30 ieds: liobert II. Loret (Boston), surgeon in charge; ("lara II Thurston, superlutenden.

\section{Lawrence}

Arlington lay Nursery aud chllusen's Temporary llone, lawrence, Mass. kista', llohed 1009: prirate: t1 heds: Mrs. Mlas 1. Hack. matron

Cultage llospita1, 121 Marston St, I.tW

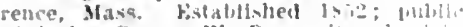

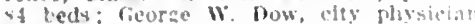
in charge: condurted by elty lowal uncreers of por.

ferman linth sochety Ilone. it llowat st., Lawrence, Mass. Jistahlished 10tiz yrivate: for meti und women; 12 beds Mrs. Mary Welduer, matron.

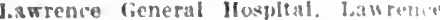
Viass. Extablfshed 1855: private: cenerat: 110 beds: tharles $(i$. Tarleton, presidout of niedical stat: Mliss Mary L. Bart. superlntendent.

Lakrence llomic for Aged leanle, I.aw rence. Mass. Fstabltshcel 1895: frivale 25 beds; Mirs. Filizaheth A. Furbush niatron.

Lawrence Isolation Hospital, dowrellce II ass. Estallisbed 1902: publle: if liedt: (ity Board of llealth, in charge.

Lawrence Tuberenlosis Hosplial. Thick ering and Cutler sts. lawrence, Mis ristahllshed 1910: public and prlvate: : 11 herculosis; $8 \mathrm{~s}$ beds: lieorge W. Wow, vlatt ing phrsielan; Miss Anua M. Allan, K.S. superintendent

Irotectory of Mary Immaculate. Iaw rence Ias4 Establinhed 1865 ; private: for chlldren and aged women: 28 beds. Lee

Mountaln Vlew Farm for Conralescent. Lee, Mass. Establlshed 1903 ; general; 1 beds: Mlss E. F. Folsom, superintendent. Lincoln

Sherwood, Lineoln, Mass. Fistablished 1902; Derrous and mental diseases; beds: J. Frank Edgerly, phystelan in charge.

Chelmsford street Ifospital Lowell, Mass. Publle; 450 beds; Michael Tighe, physlclan in cliarge; $\mathbf{x}$. J. lowd superintendent.

Falth Home for Chlldren, 249 Westfor st. I.0well. Mass Establlshed 1883; 1 beds; James R. Fleld, plustcian in charge; Mrs Foss, matron.

Lowell Corporation Ilospital, Merrimack and Pautucket Sts. Lowell, Mass. bs tablislied 1840; private; general; sti bets E. J. Clark, superintendent and physi clan In charge.

Lowell Cenera] IIospital, Lowell. Mass. Established 1893; prirate: rharitable Leneral: i0 beds: Mtiss Sara $d$. Howen R.X.. silper

old Iadles' llome, 520 fletcher St. Jowell, Mass. kistabliahed ISGT: private old ladies over 65 years; 42 beds; Martha b. Mills, superintendent.

St. John's IIospltal, Lowell. Mass. Fs tablisbed 1867; general; 62 ivenls: Slster of Charlts. In charce.

\section{Ludlow}

Ludlow Ilospltal Soclety, Ludfow, Maq4 Fistabllshed 1908; 25 beds: Iouise if

kolt, K. . superintendent.

\section{Lunenbure}

Itilleroft, louenburg, Mass. Fatab lished 1909: Drlvate: tutercutusts: " heds: Mrs. (ieo. Justlce kirlng, superin. tendent.

\section{Lynn}

J)"nn Home fur Aged Men, Lynn, Mand Established 1907: urlvate: 8 tieds: Mrs I. I. I'ullbrook, matron.

Jynn llome for Aged Women. 197 5 Colnmon sit., loyns. Mass. Katablished IBit: privale; aged: 20 beds: lione l. Iralnerd, natron; thas. S, lirover, super Intenitent

l.ynn llospltal, J.ynn, Mas. Eurah llwhed 1880 : prliate; ceneral; an trets: Chaucey $C$, sheldon, medical superln. tendent: Aifred T. Haues, physleian in cliarge.

Hnn Ilospltal for Contarluts Iniseases. Wun, Mass. Bistablished I 895 : muntefpal ¿1) beds: Janes T. Beastas, superintend.

lynn Tuberculosts Sanitarlum, 131 lfolyoke st., Jymn, Mavs. listabliphed 1912 : publis: medlcal and tuberculosis: 912 publit: medical atsd tulercmlosis: veriutedifent. Sier summer branch alos at 1., nu. Mass., 21) bede

hyun White lyagte liellet fund Asan anleriun, Ionn, Mas4. Gitablisted 1:+12: vulle: 20 bedi: I'eter llesiln, M. II. atemdant in chllden. Sumuer Branch of Lynn Totrereulos!s sintarium.

lum Working Mton's llome, Lynn, Mass Hivlitshed 1901: prirate: for homeloss men. women and chlldren: $: 0$ beds; Vol. untecrs of interta, in charge.

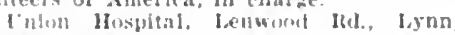
Miss. Fitahtsheol 1901: general; mater

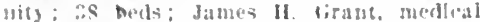
vincrintendent.

Malden

Contagtous Iospltal, Malien, Mass. Kir

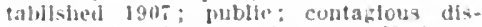
thes: 30 beds: Clarence Hathorne staples, attending pliysiclan: Miss Annte i. Monrue, sujerintendent and matron.

Malden Home for lged l'ersons. 578 Main si., Malden, Miss. Established 159:; mublic: aged (1'rotestant) ; 24 beds: (ivelfrer Kyder, attending ghysleian; lla R. Rriglian, nedical superintendent.

Malien llospital, llospltal lid.. Malden. Mass. risublished 1.90; general; 85 heds; Charlonte M. perry, It..... supertntendent.

Marblehead

Chlhiren's Itland suniturium, Cat is. lami. Nalem Harbor, Mass. (Marbtelaced 1.0.). lostablished 1853 ; general; tuler heated term; 85 beds; Arthur M. Grceswood, risiting nhyslcian; Jiss Lucy Davis, superintendent.

Devereux Mansion, Marblehead, Mass. Fistablished 1912; prlvate; lervous dis-

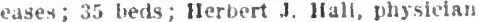
in charge.

\section{Mariboro}

Marlburungh Ilospital, Unlon kit, Mari horo Mass. Fstabilsted 1890; public general: no cuntarious cases; 40 beds IInnte (1. Itoblus, superintendent: ( $T$. Warner, M.W., president.

\section{Medford}

(Sce also: Hoston.)

learborn llospltal, 2 Central Are., Med Purd, Mass. Hstablished 1903; private: chronic and nerrous: 25 heds; Ifrs. II Abbie Iearborn, superintendent.

Medford llospllat, 67 Magoun tue biedford, Mass Fotahllshed 1913; prliate; comeral; 20 beds: Mrs. I1. Abbte learborn. superintendent.

l'eckliain llospltal, IIs Wobnes st. Medfort, Mass. Establistied 1012; sure (rit, nedleal and maternity cases:

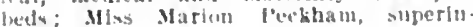
endent.

\section{Melrose}

tree also: Bomton.

Melrose lluspteat, it. Mrele st Mel

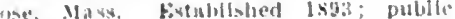
seneral: t2 beck: Mls M. J. Conk, su uerlustendesst.

Melrose Maternfig Mowpital, 42 W. Fimer on st. Melruse, Mass, Hotabllabed 1906 fulbato; t leds; Myrton It. Itaynes, ptos Grian la charge.

Nen Fingland sanitarlum, Molrose. Nays tiuslilshed ixyy: wrlvate: cencral 100 tieds: W. H. llliws, medileal sugerln ecrdent.

Sunnyalde Hospital. Murose. Mass

\section{Melrese Hiahland}

\section{(vice alsul lloston.)}

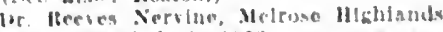
Mass: biablishey is0a: nervus and netatol, matcotic and ateoholles 15 beds

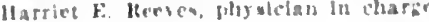

\section{Methuen}

Henry C. Newing Bugse for ilse dzed

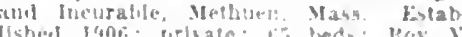

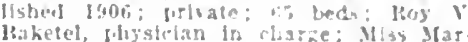
lithetel, bily striat ira

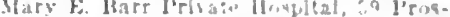

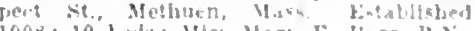
superfutendent.

Milterd

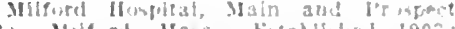

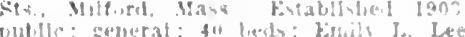

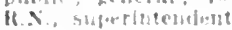

Montague City raren Memoriat Hosplal, Mishague

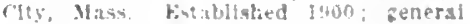
45 tierls.

Natick

leonard Uorse Homplial, Nathk, Mass.

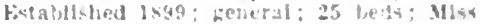

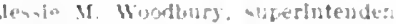

Needham

itlover llone and Huspital. Needhar: Yasy Kstablishell 19:2; public; pezeral

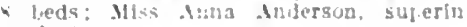
tendent.

\section{New Bedford}

doubnet Sanftartum, Sew Pedford.

Mass. Establwhed lyots prisate; pelleral

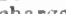

ir Derbr's Prirate Hospltal, Campleil und liteasant sis. New Eedford. Mass. Fiablished 1901: prirate: 23 bedi; C. 1. Lerby, metlical superintendent.

Few liedford Tuherculoi is sanatorium. Sew Perlford. Masa. Firablisbed 1908 prlvate and publle: tuterculosls: 0 beds: Sumar II. Remich. M l... superintendent. it. Luke' Lluspital, New Bedfond. Masa.

leds: Sisan L. Emmut, R Y. superinlieds: :

\section{New buryport}

Inna Jacues IIospltal, Vewburyport. Yass. Fiahlished iss3: ceneral: 10 heds: Mlss Jessle $b$. lirspr, superlutend-

I'hlldren's llome. 9 Court St. Newburyport. Mass. Establlshed 185i; 36 beds; Frerti. Tha, M.D, superintendent.

llome for Aged Men. Newburyport Mass. Establlshed 190J : prirate: In beds: Clarles ll. Lltole, superintenden:

Seuburyors Homeupatic Homplial. Cenburyort Mass Eitabltheal 1400. jublic; ceneral; 30 bedi; Theodosis Man. well. K Y.. superiutendent.

Old Ladles" llome. Newburyport. Mass. Eiablished 1s:2: brivate; 10 beds: Mis. l.tuy J. Little, unatron.

Newton

Harkendon Sanitarlum. 331 Waitham St. West Newton, Mass. Established 190: frivate: nerrous and chronte:

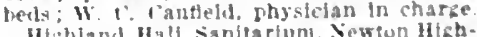

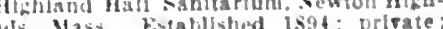

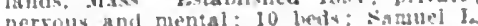
Gervons phsician in charce.

bafum, physlctan in charke. Lower Falls, Mass. Finablished inso: publle and priale: ceneral; 165 heds; Miss Masy M liallie. superintenderst.

Newion Nerrine, 1 beto Wabbington st. West Vewton. Mass. Fistatilshed 1592: fipliate; for netrous and mental diseases. I olubl and drug audefletlon cases: 23 leeds: Courd Mellus, plostician in charge

Vengon sanatorimen, 1650 Wavbington Weut "Venton. Mass listablished 190 pirtrate, fur nerrous and mental

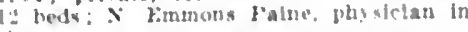
tharge.

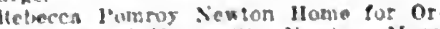
ghan filrls, Horey sit. Newton, Mass. Fintabltshed 18:2: nutlle: :0 beds: Je. tmrat bawcett. physiclall: Mliss Clara M. llas es, superintendent.

shone Instrfute and Viewton llome for Jori Jeoule vewion i pper balis. Mass. Fitabliahed isgs: pritace: lo tects: Ana . Hale, matron: Thas. A. Thompson and areiline $r$. Wentworth, phsslctans. 
Woudlaw Sanltarlum, 500 Crafts st., Vest Vewton, Mass. Fstablished 1907: brivate; 9 leds; for the trentment of ejlevtles; II. W. Hammond, medleal suverintendent.

\section{North Adams}

lBerkshlre Illls Sanatorlum, North Adains, Mass, Estabilshed 1807; privato: cancorr 150 beds; Wallace b. Bromm. physician in ellarte.

North Adums llospltal, North Adams, Mass. Establlshed lsst; puhlle; general; 75 beds.

\section{Northampten}

('larke school for the Deaf. Northamp ton, Mass. Established tstit; prisate l5ol heds: Miss faroline a rale, princlpal.

(o)lege Inflrmary, Forthampton, Mas. l'rivate: 8 hats: Florence (Himan, physl clan in charge.

Cooley llicklnson Hospital, Jocust St. Northany!ton, Mass. Fistublished 1855: general: 84 bedis: 40 beds lin contaglous: Mary It. laser, li.N., superiutendent.

lsolatlon lfospital, Northampton, Mass. Bratuch of Hitekluson Hosplens; 4 mration

lathrop Jome for Ared Women, 236 Soutli sit., Northamptom, vlass. 10 beds: Irs. Asres, matron.

\section{North Breokfieid}

West l'lnes sanitarium. North Brookfelel. Mass. Fstablished 1903: urivate: beds: Idelle 1. Edmance physiclan in charge.

\section{North Woburn}

Home for Aged Women in Woburn, Porth Wolurn Mass. (Woburn I'.O.) istablishel 1887; irlvate.

\section{Peabody}

Chas. B. Haren Home for Aged $M \in n$, l'eabody, Mass. Fstablished 1903: prilate: Leds; Mrs, Maria $\mathbf{P}$. Willams. matron.

Josiah 13. Thomas, King st., I'eaboriy, Mass. Established 1907; publlc : general i2 hecis: Florence IlcLemman, It.X., su perintendent.

Sutton IIome for Aged Women, l'eabody,

Mass. Establlshed 1899 ; rlarity ; 9 beds Mrs. Lydia $A$. Poole, matron.

\section{Pittsfieid}

Antl-Tuberculosis Association Sanatorium, Lelanon Ave., I'jtisfield, Mass. Es tablishea 1913; public; tuberculosis; 20 beds; J. F. A. Adams, M.J., wresident Irs. Henry Colt pliysluan.

IIIllcrest IIospital, 708 North St., Pitts fleld, Mass. Established 1908; pulyle surpical ard gynecological: 3 z beds; Chas. II. Iklchardson, plysician in charge; Niss Marion lieffer, superintendent.

House of Mercy Ilospital, Pittsfiel, Mass. Established 1874; publie: 130 beds Ienry Colt, chairman medical and sur giral board; Mary M. Marcy, L...., superintendent.

\section{Plymouth}

lordan Hospital, Sandwich st., Plym outh, Mass. Established 1901; ceneral 20 beds; Elizabeth R. Allen, superintendent.

\section{Provineetewn}

Oeean View Sanitarim, Provincetown, Mass. Established 1900 ; private; 10 beds Willam s. birge, medical superintendent.

Quincy

$$
\text { (See aiso: Boston.) }
$$

(amp Mount l'leasant, Faxon Park Rd. Quincy, Mass. Established 1910; tuber culosis: 9 beds; Wn. Campbell, superintendent.

City Hospital of Quincy, Quincy, Mass. Established 1890: public; general; 52 bets: Caroline Hill, It.N., superin-

Fore River Hospital, Quincy, Mass. Es† lliklfed 1902; jrivate; surgical; 6 beds W. H. Blanchard, medical superin-

\section{Reading}

Irr. Wdes Private IIospital, Reading, mental, narcotic and atcoholle: 6 beds lioliert $T$. Biles, physician in eliarge.

Rockport

leancler M. lIaskins Hospital, Summit We leockurt Mass. latabllshed 1906: puble: general: 14 becls: Augustus it 'lupper and fharles 13. IIall, medical board; Katherine I. Fanning, superininnolint

Rutland

fentral lim llome, Itutland, Mass. Fs tablished 1900; prlvate; tulerculosis; 20 heals: F. E. Somers, sumerintendent.

Crane sinatorium, ltutiand, Jass, lis talltshed 1910; prlvate; tuhereulosis; I4 lueds; Bayard T. Crame, physician in harine.

Haple lodge sanatorim, lutiand, Mass. Fstablished 1906 ; tuberoulosls; 12 heals: (ieo. X. Japham, physictan in tharine.

Itutland Cotlages, liutland, Mass. Established 190\%. private: tuberculosis: is heds: feo. Lapham, pliysictan in clarge.

Wischusett Cottage, Rutland, Mass. Es aillshed 1903; tuberculosis: 15 beds; Buyard T. Crane, attending physlcian.

\section{Salem}

Bertram Home for Afed Men, 114 Derby st., salem, llass. Estalilsied $187 \%$; pilate; 17 beds; Mrs. Martha 1. Whittlesey, inntrou.

Juard of Health Hosjltal, Salem, Mass. Fstablished 1913; 25 heds; Wm. V. Mc Dermott and Walter (i. P'hippen, jinysiclans.

(ity Orphan Asylum, Salem, Mass. Fstablished 1860 ; private; 290 beds.

Itome for Aged and Destitute Women, Salem, lass. Establlshed 1860; private: 25 beds; Miss Emma C. West. matron.

Hospital for ('ontagious biseases, Salem Iass. Fstablished 1907; 8 beds; Wm. H vorce, in charge.

North shore Hables' Hospital, Salem, Mass. Fstablished 1905; medical and tuberculosis; 25 beds; Miss Marinll Ilolmes, it. N., superintendent.

Salem Ainisiouse, Salem, Mass. E\&tablished 1816; inblic: 90 beds; stephen F. Tracey, superintendent.

Salem Chillren's Home, Satem, Mass. Established 1899; 60 beds; A. N. Sarrent. attending physician; Miss Julia E. Pratt matron.

Salem Day Canp, Salem Wlllows, Salem, Mass. Established 1908; private; Leneral; 60 beds; Walter G. Ihippen, phy sician in charge: E. Janet Sherry, superintendent. Dispensary, 10 Washington Sq., W.

Salem Hospitat, Sillem, Mass. Wstablished 1873; privite: reneral: ing beds: Wibur B. Bigelow, superintendent.

Snlem seanen's orphan and Children's Friend Society, 7 rarpenter St., Salem, Mass. Fstabllshed 1841; private; 50 beds Ara $Y$. Sargent, physleian in charge; Miss Iulla F. Pratt, sujerintendent.

Smallpox Hospital, Salem, Mass. Established 1908; public; Wm. V. McDermott, physician in charge.

\section{Sandwieh}

Locust Grove Asylum, Sandwich, Mass. Established 1886; nerrous and mental; 6 beds; George E. White, physlcian in charge; Alice R. Cooke, superintendent

\section{Sharon}

Sharon Sanatorium, Sharon, Mass. Established 1891; private; for tuberculosis cases, women only; 23 beds; Vincent $\mathrm{r}$. Bowditch (Boston) medical director: Walter A. Ciriffin, II.D, superintendent. Semerville

(See also: Boston.)

Somerville ('ottage Hospital, 12 Pleasant Are., Somerville, Mass. Established 1908; private; maternity; 17 beds; Mrs. E. A. southall, superintendent.

Somerville Home for the Aged, 7 Grand View Are. Somerville, Mass, Established 1900; 18 beds; L. M. Phillips, physician; Miss 1. 1.. Hubbard, matron.

Somerrille Iospital, Somerville, Mass. Establlshed 1891; private; general; 40 beds; Miss Elizabeth C. Hogle, superintendent.

\section{South Hansen}

Hanson Almshouse, South Hanson, Mlass. Public: 10 leds; Flavel $s$. Thomas, Hanson, Mass., physiclan; Geo. 3. Italfe, sujerintendent.

Iacuna Sanatorfum, R.F.D. South Hanson, Yass. Fstablshed I894; private; 10 beds; Flavel s. Thomas (Hanson), physiclan in charge.

\section{Springfield}

Buscall's Nursing IIome, 235 Pine F. Springtield, IIass. Fstablished 1890; for aged and feeble; 19 beds; Isaac and Fisie Buscinil, minagers.

City Almshouse, 1400 State St. Springfield, Mnss. 50 beds in hospltal departunen ; 1. W. Sextou, superintendent.

Collins" Emergeney Hospital, 379 Worthington st., Springfleld, Mass. Establlshed 1900 ; general ; 8 beds; Fdgar C. Colstus,
jhysiclan in charge; Agnes C. Turnbuli, suj, erintendent.

Hampden 1'ospital, Sprhgfleld, Mass. Wstablished 1912; public; general; 57 beds; Waiter It. Weiser, surgeon and medleal dlrector; Hiss Alice F. H'lerson, superintendent.

Home of the (iood Shepherd, Spring fleld, Mass. Established 1895; reformatory ; 190 beds.

Mercy Hospital, 233 Carew st., Springfield, Mass. Established I896; general; 150 beds; Sisters of Providence, in charge. Naulein Sanitarium, 46 Forest Park Are., Springfleld, Mass. Established 1904; Lenelal; 16 heds; Mary Sanderson, pbysician in charge.

see spccinl funouncement Aav. paye 79 Springlield Association for the Prevelltion of Tuberculosis, 6131/2. Main St. Springfield, Mass. Established 1908; tubereulosis; George I. Schadt, medical director.

Springfleld Home for Aged Men, 74 Wainut St.. Springfield, Mass. Established $1903 ; 5$ beds.

Springfield IIome for Friendless Women and Children, 136 Willam St., Springfleld, Mass. Establlshed 1865; 20 beds; Miss Elizabeth B, Epstein, superintendent Springfleld IIospital, springfield, Mass. Established 1869 ; general : 100 beds; Miss Jessie E. Catton, superintendent.

Wesson Maternity Iospital, 120 High St., Springfleld, Mass. Established 1308 maternity ; 45 beds; Miss Winifred $\boldsymbol{H}$.
Brooks, superintendent.

Wesson Memorial Hospital, 140 Hlem St., Springfield, Mass. Established 1900; formerly Hampden Homeopathic: 60 beds; IIilda I. Boyd, R.N., superintendent.

\section{Swampcolt}

Florence Crittenton Home, Swampicott, Mass. \& beds; R. E. Bicknell, medical superintendent.

\section{Taunton}

Morton Hospital, 88 Washington St. Taunton, Mass. Established 1888; private; general; 75 beds; Frances $P$. West, R.X., superintendent.

\section{Vineyard Haven}

Inited States Marine Hospltal, Vineyard Haven, Mass. Established 1869; public; general; 26 beds: D: A. Car. michael, senior surgeon U.S.P.H.S

Vineyard Haven Sanitarium, Vineyard Haven, Mass. Fstablished 1908 private 14 beds; S. T. Daris, physician. in charge. Waban

Knollwood Sanitarium, Waban, Mass. Established 1911; private; nervous and mental; 12 beds; Earle E. Bessey, phystcian in charge. 


\section{MASSACHUSETTS}

\section{Watertown}

(Sie A!so: Bostun.)

lerkins institullon and Mavrahugets Scherl for the Hlind. Watertown. Masy. Establlthed 1829: publle and prlvate: blind: hindergarten department: 245 beds: Oucar s. Creeley, attending jayst. clan: Fulw. F. Allen, directur.

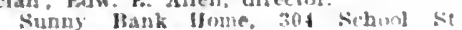

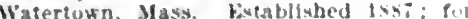

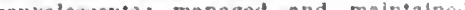
contalewerits; manapet and malnante

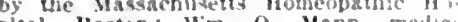
superlntendent.

\section{Waveriey}

(see also: Boston.)

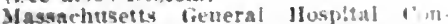

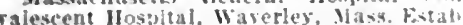
lished 1882; urluate: 3t beds: Hrelleric A. Washburn, medleal superlntendent.

A. Washourn, medlat superintindent. Mblished lsis: prlvate: nervous and tabllshed 18ls; prlvate: nerrous and leal superintendent: branch of Massaclum setis fieneral II cistital, Bonton.

\section{Wellesley}

Cedar lodoe Wellesley. Mais Evin. llshed 1912: private; \& leds; Huyal Hatch, medical dlrector.

Convalescent Home of the children's Uospltal of Hoston. Wejlesley Intls, Wellesly, Mlass. Establlshed 1890; public: general: department of the childrets Ilospltal of Boston: i2 becls: Mliss is barldson, resident director.

Wellesley Collew Huspltal Coltowes Wellesley, Mass Estabivined 1907: private General; it leds: kath-

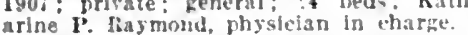

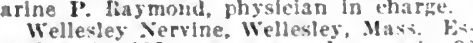
Wellesley Nervine, Wellesley, Mast; H-
tabl'shed 1597 ; nerrous and mental; 30 beds; kumard H. Wiswall, physiclan in charge.

\section{West Bridgewater}

Greystone Towers Sanlfarlum, West Bridzewater. Mas3.

\section{Westheld}

Noble Hospltal, Westfleld, Mass. Fitabusbed 1593: Eeneral; 55 betls: Miss Dona $G$. Burgar, superintendent.

\section{West Mediord}

(Stee also: Boston.)

Sarah Fuller Ilome. West Medford.

Mass Eutabllshed 1848: uricate; for little deaf chlluren: 10 Imis: James kenuedy, medleal superintenden:

\section{West Somerville}

\section{(see aliso: ltoston.)}

soniervile Hoard of llealth contaghems Ilimease Ifuspltal, 1323 Hroaduay, West ciomervllle. Ilass. Fistabllshed ltob; pul. lle: narcotic, alcoholle and contaglons: so leds: l'rank 1.. Morse (Sumervllle). ghosiclan ln charge.

\section{Williamstown}

Sand sirlngs sanltarlum. Whllams toun, Mass.

Willams college Infrmary. W'll]amstoun blass bistabllshel 19i]: general 44 beds. Misx sarah burton, matron.

\section{Winchendon}

Millers River Hospital Winchendon. I ass butablished $1900^{\circ}$, private: gen

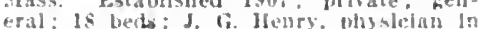
charge: Miss balsy inanger, superintend rhat.

\section{Winchester}

Home for Afed Venple. Winchester. Mass. Establlsied 1904: 12 heds: II. I. 'umbulnes, physlclan in charde; Mrs. Fances whltord. matron.

Winchester Hospltal, Winchester. Mass. Established 1911; pullio: genteral: 20 beds: Mlss Cushlng, matron.

\section{ivinthrop}

(See also: Boston.)

Beacou villa sanltarim, Wlethrop Mass. Established 14nt: prisate: 12 beds

A. B. Dorman, physlclan in charge.

Melcalf Ilosphal, Itt Winthrop st. Winthrou, Mass, Establisheal 1905; private: surgleal: 15 treds: B. II. Metealf, physlcian ln charge; $\therefore$. I. Intidaw, R.N., assistant.

\section{Woburn}

Charles Choate Memorlal IIospltal, Womurn. Jasq. Fstablished 1909: general. 20 beds; ldih I. Murgan, H.X., superin. iendent.

\section{Wollaston}

(See also: Boston.)

Sationa! Eislors" Home. Wullaxton, Mass. Estafllished 1865: private; 40 beds if. .. Whitelaw, superintendent.
Worcester

lierbert Hall Highltai, Juc. ges Salk lury st. Woreeter, Maus. kintabilstied

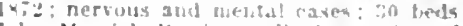

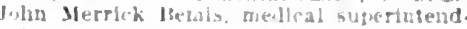
ent.

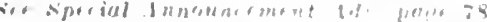
Home tor Mirl Men Worcher May.

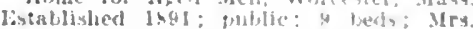

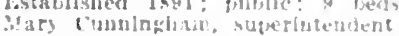

Maple Hall sagulartum, 19 King s: Wurcexter, Mass. kiviablisherd 1904: urtvate: 1s, beds: Mrs. B. L. I.srued, G.X.. stiperintendent.

Memorial Jlome for the Hillnd, I Eir Ni Wircester, llass tivtalollabed 190. prlvaie: for aluits: 14 beds: Johs $C$ Lerry, II J.. medical superintesuent: A 3!. Inderson, matrun.

Memorlal llospltal, staton $A$ Wrar cester. Mass. Establlinhed 1kes: putlie: for women and chlluren: 1:20 leeds: Lueda

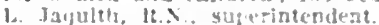

st. Vlneent Hosplat. Worcester, Masa. Fistallished lass; pubIlr: general: 110 heds.

Trusteres of the Home for Ased Women in the l'lty of Worrester, IJ 3 'Maln st. Worcester, Mass. Watablished latg; geaeral: 30 berls: (has. D. Wheeler and $\mathrm{F}$ R. Lelb, house physiclans; IIrs. $x$. livermore, matron.

Westland IIosilial, 3 Westland st Worcester, Mass. Fitabllsherl 1912: private: Arthur C. boten, fuysiclan In harge.

Wutcester rity Ilosiltal, Jacques Ave. hing and uleen sts. Worcester. Mars. Fstabllshed 1sil; puble: general: 300 liculs: Chus. A. lirew, medlcal superin. tendent.

Worcester Fmergeney Hospltal, 50 Or. anze st., Worcester, Mass. Establlshed 1399; pritiate; surglcal: 30 beds: Alston 11. Lancaster and L. A. Cuttle, whyslclans.

Worcester Hahnemann Hospital, 2s H.Incolu si., Worcester. Mass. Establtshed 1.45; publle; general; 24 beds; ceorge A shomb, ursiclan.

Wurcester Jsolation Hosplial. Worcester Mass, Fintalislied Isye; : so heds: st beds for tuberculosis: Board of Health. In charke: Ilay saluna Holmes, medical superintendent.

The location of rariens medical libraries and information concorning theme is given on ponges /1?-1/is. This is something you will ment is knou'. 


\section{PHISICIANS OF MASSACHUSE'T'TS}

\section{KEY TO ABBREVIATIONS, SYMBOLS, ETC.}

Names in capitals stgnify membership in the County Soclety and State Assocla tion. (DOE, JOHN)

- Indicates Fellowshly in the Anterican Med. Assn. (DOE, JOHN\$)

(b'i5) lear of birth. Md. 09 , college ind yectle; l'-M, physio

Q Information received dues not show erad uation.

S.- - siurgeou.

ob.--Ubstetrician.

ObG.-Obstetrician, iynecologist.

G.-Gynecologlst.

Or.-Orthopedist.

Pr.-Proctologist.

op.-Ophthalmologist.

A.-Aurlst.

LR.-LaryugologIst, Rhinologist. (l's9) Year of llcense.

(d) In practlce before passage of present law and licensed by fllng dipluma or by years of practice.

(1†) licensed but year not known.

(京) Informatlon recelved does not show license.

I.s.A. Vinjted States Army.

II.R.C., L.S.A., Medleal IReserve Corps.

SPECIALTIES ARE INDICATED AS FOLLOWS:

ALR.-Aurist, Iaryngologist, Rhlnologist.

OALR.-Ouhthalmologist, Aurist, Iuaryngologist, Rhinologlst.

U.-Urologist.

D.-Dermatologlst.

Pd.- Pediatrlst.

N.-Neurolog!st.

P.-Psychlatrist.
I.S.X., Inlted States Navy.

II.M.C., U.S.N., Atedical Reserve Corps.

U.S.I.H.S., United States Publle Health Serrice.

College positions held are Indicated by abhrevlated title of position, followed by key number of college. For key to colleges see inside front cover page.

(A1,3, 136, C4) Membership in special societies. (Siee liey Table, page 122.)

NP.-Neurologist, Psychiatrist.

1.--interntst.

T.-Tuberculotherapist.

Anes.-Anesthetist.

LD.-Laboratory Diagnostician.

R.-Actinolorist, Radiologist, Roentrento

Path.-Pathologist.

Bact.-Bacterlologist.

WHEN THE ABBREVIATION REPRESENTING A SPECIALTY IS FOLLOWED BY AN ASTERISK ( $\star$ ) IT INDICATES THAT THE PHYSICIAN CLAIMS HIS PRACTICE IS LIMITED TO THAT PARTICULAR BRANCH OF MEDICINE; WITHOUT THE ASTERISK, THAT HE IS ESPECIALLY INTERESTED IN, BUT DOES NOT LIMIT HIS PRACTICE TO, THAT BRANCH. THIS INFORMATION CONCERNING SPECIALTY IS BASED ON PERSONAL DATA FURNISHED BY THE PHYSICIAN AND IS NOT VERIFIABLE.

\section{MASSACHUSETTS}

ABINGTON, 5,455, PLYMOUTH

Greeley. Wn. Ilenry--Mass.6,'84; (t).

HLTCIINSON. WALTER PERKINS (b'66)

- Itass 1.0I: (1'01)

Sterens, Wm. Russell-Mass. 7,$06 ;\left(1^{\prime} 06\right)$.

ACTON, 2,120, MIDDLESEX

Allen, Louis Fdmund (b'52)-Mass. I,'83 : (1.94).

Sllitw, Fredk. Li. (b'î)-Mass.1,"02; (l'0I).

ACUSHNET (STA. NEW BEDFORD), 1,392, BRISTOL

(See New Bedford.)

Brightman, 11. (b'66)-Mass.7,96; (1'96); D. falmothe, Alesander (b'0.5)-Oue.3,?6: (1). ACCORD, 50, PLYMOUTH

LYOX, FREDK. DOW (b'69) - Mass.1,'96; (1'96).

ADAMS, 13,026, BERKSHIRE

f3ond, Aaron John (b'57) H-N.Y.9,'83; (f) ; 34 Summer St.; offlce, 25 l'ark St. ;

BOOM, AUGUSTUS KEEEER (b'66)†0.12,'s8; (†) ; 14 Summer St. ; offlee, 51 lark St. ; $9-10,1-3,7: 30-9$.

('liopuette, Henri-oue 4,"9g; (l') ; Park. (ROWLEY JEREMIII FRANCIS (b'72) -Md.4,94: (o); 15 J'ark St. ; 1-2, i-8. Desroehers, Alfred-X.Y.3,95; (1’).

HOLMES, HARRY BIGELOW (b'63)N.Y.1,92; (お); 6 Ifiberty St. ; offlee, 39 I'ark St. ; 8-9. 2-4, $7-9$.

Hurd, Wm. Weymouth (b'59)-N.H.1,88; (古); 54 Center St.; oftlee. 20 Center St. Mahady, Jos. John (b'67)-Mid.4, 93 ; (l'97): 3 School St.; ofllce, 25 Park St.; 8-10, 1-3, 7.9.

I'ASCOE, WM. W'HELAN (b'69) -Md.4, ?4; (古); 67 Summer St.; 9-10, 1-3,

ALLERTON, 300, PLYMOUTH

STLRGIS. WALTER HORATIO (b'73)-

Mfd.4,'95: (1"95); (Hull).
SYLVESTER, CIIAS. PORTER.

(Seo Boston.)

AMESBURY, 9.894, ESSEX

ADAMS, JOHN QUINCY (b'50)-X.Y.10, ' 72 ; ( ( ).

iron, Jos. Fredk. Rodolphe (b'66)-Ont.4, DOLGLASS, JOHX ABBOTT (b'3I) - N.Y.I,

FITZHUGH, JOHN ALEXANDER (b'54)0.6,'80, Pa.9,'81; (む); D.

Hines, Clarence Reynolds (b'81)-Mass.5 $07 ;\left(l^{\prime} 07\right)$.

LESIIE, HERBERT GRANYLLE (b'i1) -Mass. 1,99; (1'9;); ALR.

MTDGE, OTIS POPE (b'79)-MIass. 1,07: $(1,07)$.
MULLEN, JETER JAMES (b'75)-Y't.2,02; (1'02).

MURPHY, DANL. DAVID (b'63)-N.H.1, $9 \mathrm{I} ;($ ( ).

RAND, IOIIN WM. (1)55)-Miel1.1,85; (t). ROBINSON, HARIY PRINGLE (b'75) Mass. 1, 02; (1'02).

ROCHE, THOMAS NEIL (b'84)-Mass. 7 , $08:(1,08)$.

SAVIGNAC, ARTHUR YOËI (b'61)-Ont.4, $30 ;$ ( ( )

Foung, Benj. Herbert (b'56)-Mass.5,'80; (む); Pd.

AMHERST, 5.112, HAMPSHIRE

BARROWS, STERLING-N.Y.1, 06 ; (1'10);

BOWEN, JAMES FRANCIS $\left(b^{\prime} 78\right) \uparrow-V t .2$, 1I: (1'12); S.

IASKELL, NELSON CARY (b'66)\&-Me.1; 90; (ठ); (D3)

Parkhurst, Danl. Burleigh - H-I'a.9,'00 (1'01).

Phillips, Paul C. (b'65)-N.Y.1,'95; (\$).

RAWSON, GEO. W.LLACE - N.H.1, 88

ROCKWELI, IIERBERT GEORGE-VI.2. $96 ;\left(l^{\prime} 96\right)$

Rockwell, Marion Balfour Marshall (b'i3) -Scot.3, 99 : (1'03)

Tuckerman, Fredk. (b'5 i) - Mass.I,'S2; not In practice: (FI).

ANDOVER, 7,301, ESSEX

ABBOTT, CHAS. EDW. (b'56)£-Mass. 1 81; (む).

CLARK, JOHN DONOVAN (b'ï)-Mass.1, 04; (1'04).

Clarke, Henry Little (b'59)H-Mass.5,'84 (ङ).

CONROY, EDW. CORNELIUS.

(See Lawrence.)

DALY, JEREMIII JAMES $\left(b^{\prime}, 75\right) €-$ Mass. 7,03 ; (1'03); (also North Andorer). FULLER, JAIIES ROBT. (b'48)-X.Y.10 75 ; (む); not in practlee.

uane, Elwin Dexter (b'76)-Mass.5,'12 (l'i2) ; ObG.

Page, Peirson Sterling-N.Y.19,'99; (1'99). Sanborn, Emma Mary Eastman (b'4I) HMass. 5,$76 ;$; ( )

Scott, Cyrus Wallace (b'56) H-N.Y.8,'82 (t)

TORREY, JOHN PAINE (b'70)థ-Mass.I $96 ;(1,96) ;(D 3)$.

WALKER, WM. DACRE (b'78)థ-Mass. '05; (l'04).

ARLINGTON, II,187, MIDDLESEX

\section{(See Boston.)}

ATWOOD, CHAS. FENNER $\left(b^{\prime} 74\right) \oplus$ Mass.1,00; $\left(1^{9} 99\right)$; 821 Massachusetts Aте. ; $1-3,7-8$.

Buckley, Danl. Joseph-Mass. T,04; (1'04) Broadwas.
CHAMPION, MERRILL EDWIN (b'80) $\$$ Mass.1,06: (1'05); $82 \pi$ Massachusetts Are. : (US) : Bact.

DENNETT, CHAS. ALGUSTUS $\left(b^{\prime} 63\right) \oplus$ Ile.1,'88; (1'95); 754 Jiassachusetts I ve. $2-3 ;$ LR.

Derby, Fredk. Wm. - Mass.t,06; (l'07) Post Offlee Bldg.

HANSON, WM. THOMAS.

(See Boston.)

KEEGAN, CIIAS. ANDREIV (b'65) ₹-Y't.2, '89; (ठ); 734 Massachusetts Are.

Libby, Chas, Adelbert (b'51)-X.Y.3, '73; $($ b) $; 2$ Pleasant St. $2-4$

Percy, Davld Thos. (b'68) II-Mass.1,'91; (1'91); I1 Water St.; 2-4, $7-8$; (D3).

SANGER, GUY EDW. \&-Mass. 1,03; (1'03) ; 607 Massachusetts Ave.

STICKNEY, EDWIN PANGMAN (b'6:) Mass.1,92; (t); 58 Pleasant St.; $2-3$. (D3).

TOLMAN, JULIAФ-Mich.1,'84; (c) ; 695 Massacliusetts Ave.; 1-3.

WEBB, HAROLD RANDALL (b'79) $\$$ IId.7,06; (1'07): (D3).

YOUNG, ROY DEMAS (b'71) - Y Y I,98; $(1,98) ; 788$ Massachusetts Ave.; $2-3,7-8$;

ARLINGTON HEIGHTS, 1,900 , MIDDLESEX (See Boston.)

CHEEVER, JOHN HOWARD (b'T0)Mass. $\tilde{f}, 01$; (l'0I); Member R.I. Med. Soc.

Grady, Joseph Wm.

(See Boston.)

KNOWLTON, WALLACE MILES $\$-V t .2$, '80; (す); NP.

Ileikle, Robt. Howard (b'i1)-Que.5,97.

RING, ARTHUR HALLAM (b'i4)કMass. 5,97; (1'97); NP.

Ring, Barbára Taýlor (b*72)-MIass.5,'99;

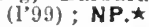

Sanford, Margaret McPhee-Mass.5,98; (1'98).

ASHBURNHAM, 904, WORCESTER Bates, Charles Atwood (b'i0)-Vt.2,'00;
(l'03).

FOSGATE, ELILER GILAAN (b'59)-X.H.I, '89; (1'95).

WARREN, HOBART ENDICOTTS-Mass.1, 94 ; (ち).

ASHBY, 885 , MIDDLESEX

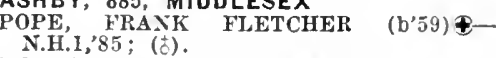

Schenek, Ellen Eastman-Mass.5, 80 ; ( $\left.{ }^{+}\right)$.

ASHFIELD, 593, FRANKLIN

Fessenden, Geo. Russell (b'49)-Mass.1, '79; (5)

URQUHART, JOHN EDWTN (b'59)\&_If.I 83 ; ( $)$. 
ASHLAND, 1.682, MIDDLESEX

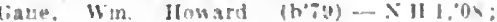

(lion): (also Southrlle).

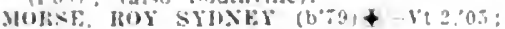
(1)

Whitcomb. tharlos stunner frement (boin) -Me. 1, "45; (1'10).

ATHOL, 8.536, WORCESTER

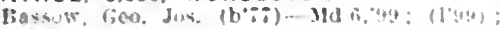
$\mathrm{S}$.

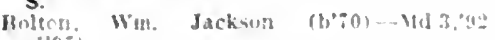
(I) 3.0$)$

Bowlier. Aluhonso Varlon 17.2,"is: (195): Op.

Howber. Marlon Esther (h+s)-Mass. : n:

comerfont, Ethel rances (bos)-Matsi,

"11: (l,i2).

"11: (l'12). Conlhige. Davld Coldthwalt (b"ti") Michl.

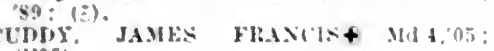
(1.05).

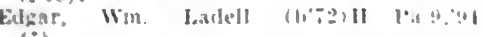

Forbes. Chas. Holt (btiv) H-XY.9.8: (क)

Holmes, Loulse Dorlson-0.20:95; (1.04)

Ollrer, James-Mass. 1,62; (1'95).

PERRI, GEO, LEWIS $\left(b^{+}+9\right)->$ I 1,79 : (i).

simith. Jos. Arthur (b\%5)-Mase i, 98 : (1'gs).

\section{ATLANTIC, - NORFOLK}

BntCF, DANI. ANCLS (b'63)-Que.1,92; (i)

Smelizer. James Flulay.

(S.e Boston.)

ATTLEBORO, 16,215, BRISTOL

BATTERSHAIB JOS. WARI-X $1.1,74$ (b): 18 x. Main St. : $7-9.1-3 ; R$.

BATTERAIIAL, MARY IIANXII WOH.FEXDEN (b'5t)-Pa.:"79: (b); $18 \times$ Main St.

CIARE, JOSHCA WIJLAMS $(4: 0)+$ Tenn.11,01. I'a.11,19; (1,02): to Hank St: : 1-3, ;-8.

CoNRi, InTHLR CIFTONF-Tenn. 01 : (J)(01); 155 pleasant St.; uflce, 13rouson [3]d: : 2-5, $-3 ;$ OALR.

Depew, Win. Robertson-f; $(100) ; 9$ rounly Glbbs, lloward Augustine $(1,78)$-Mass.5.

HEWITT, WM. OAKES (6":)-Mass. 2,00

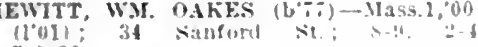
$\because-8: 30$.

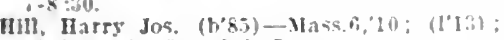
20 s. Maln st: 2.4. :-s.

HOLIEE: CIIAS SLMIMEIR (

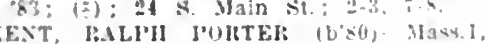

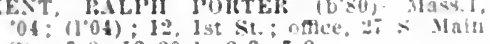
Si: : :-8, 12:30-1, 2-3, $;-3$.

lake, John, Jr.-X.1.10, st.

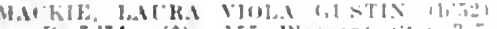

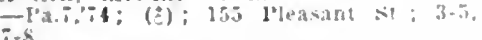
MILOT, WILFRII FRANGIJS (1):00)-

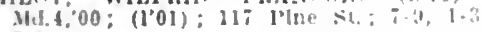

MUNTY, ADFIIIERT IHWALI) XY. $\left(\mathrm{t}^{\circ} 06\right): 26$ I'ine st.

Mmets. Chas. Alber-X.19:7t; 1:1; not In practice: i2 County sit

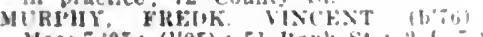

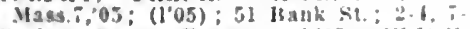

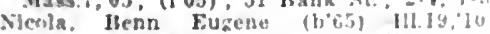
(l'11): Atleboro Sianitarlum: $\mathbf{N}$.

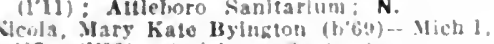
19:; (199): Attleboro sanienrium. IREFAS, JOIN ARNoJ, (b's5) Mass 08: $(108)$ :

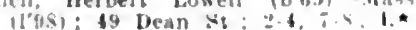

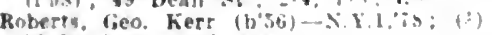
s. Bank St. : 2-t. $i-k$

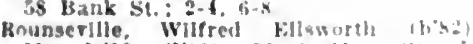
Mass.1,09: (1'11): 30 s. Man st. : 1.3. $\because-8$.

AUBURNDALE. 3.685. MIDDLESEX Hee Newton anil Honton bastman, luther fiould. isee Siewton.)

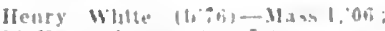

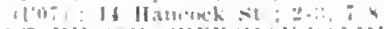

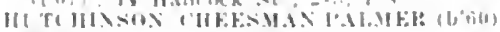

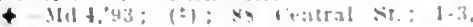

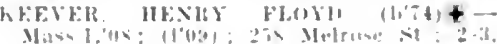

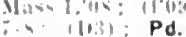

1.1) See Hostun.

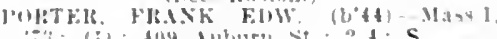

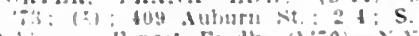

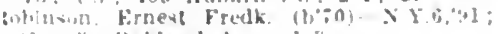
lahland I'?

AVON, 2.013. NORFOLK

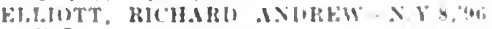
$110 \%$

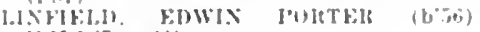

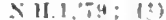

Uay. Chas. Fourson-1: (l"ys).

AYER, 2,797, MIDDLESEX

ISLKEI.Y. F'IANK STFIUAS $\left(\mathrm{U}^{\circ} 30\right)+$ Ilast. 1,02: (1002)

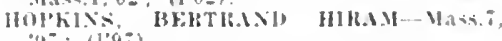

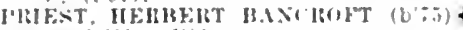

Itavi, 0 ) : (1.01)

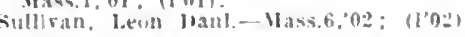

AYERS VILLAGE (STA. HAVERHILL

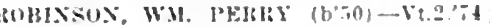

$(1,08)$

BALOWINSVILLE, 2.077, WORCESTER

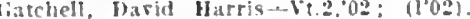

LHKY, MHUREI, ALGCSTA-Pa.i, 98 ; $(1 \cdot 10,+): \mathbb{N}$.

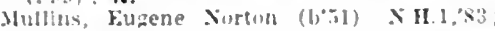

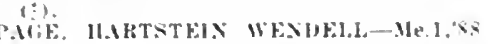

1

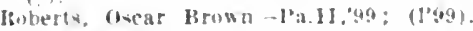

HORIE. WIJTEK FHANKLIN (b'bis)-

บ II.1.93; (†)

WALRES, H.YZE MAIH-Mass. :05 $(100)$ : Pd.

BALLARD VALE, 532. ESSEX

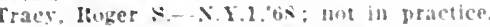

BARNSTABLE, 4.676, BARNSTABLE

IIIUIKEX (IIA WARIEN $(8 \% 3)+$

X. $1.5,95:(1.95)$

BARRE, 2,957. WORCESTER

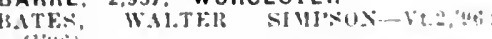
(1"4i)

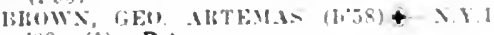
४.3: (\%): P.*

laull, Merle llastings (h8:)-Mast."." (1'1:).

BEACHMONT (BOSTON P.O.), -, SUF. FOLK

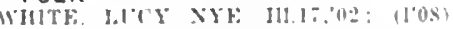

BECKET, 790, BERKSHIRE

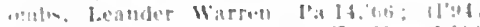

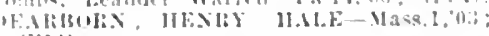
(I'04).

BEDFORD, 1,131. MIODLESEX

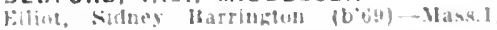
w: $(1+45)$

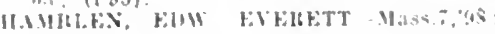

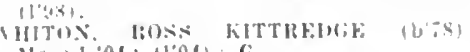

IISW, 1,01; (1'0): G

BELCHERTOWN, 2.068, HAMPSHIRE

1.ullarl Janies Lounslatry (b'sll Mal. (1): 11004$)$

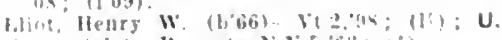

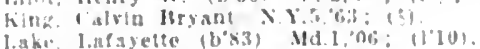

BELMONT, 5,542, MIDDLESEX

\section{(sien Hostorti.)}

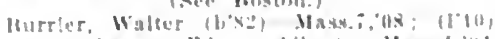

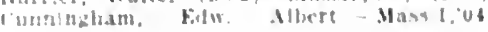

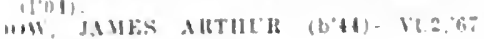

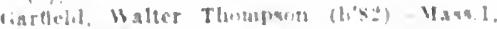
oy: $\{109\}$

silver, Frank Rusolph.

isen cambrldié ?

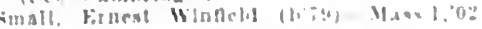
$110 \%$

BERLIN. 636, WORCESTER

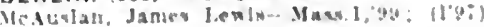

BERNARDSTON, I\$1, FRANKLIN

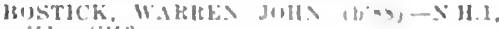
il: (l, (1:-1)

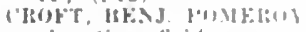

(see vircentlobl

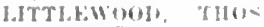

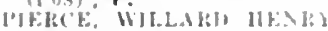

ISee ireenfleh

BEVERLY, 18,650, ESSEX

Miss, Marla Washburn 1"a.:"04: 1!061:

ilus sit

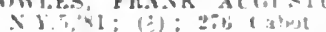

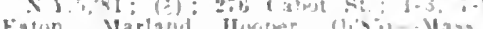

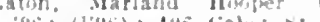

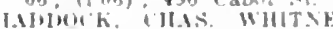

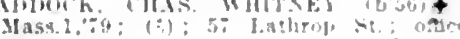

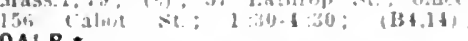

OALR. *

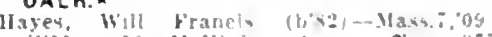

(1'1i): 10 Mckinley Ire, oalce. 37: rabut st.

111.1, like. Juksul (b?9) - Mass.1.

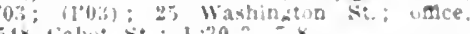
"lo

Itinman, Heverly Hospltal.

Jollsox, Pkik PRFscotT $(b: 3)+-$ Y.2,00; (1,03); I5 Washungton st.

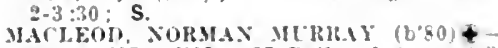
Mass.1,05: (1'07); $3 ;$ Mallruad Ave : $: 3$.

rbllips, Chas. Jenry (b*al)-Me.1,00 (100): 376 Cabot st: : $=3$

SEAKs, IIAKKY F. $\left(6^{\circ} ; 0\right)+-1 / a 5 \% 1.60$ (1'p(i); 25 Broadway : 1-3, $:-3 ; \mathrm{S}$.

SEAKS, HFNRY FRAS(IS.

(See Boston.)

SIIATSWELL, JAMFA ARTHUR (6.63)Id.3:40; (105); is Thorndike si: 1-3. $6 \cdot 3$.

SHEA, JOIIS Jos $\left(0^{\circ} 6 \%\right)+$ Mas 1,97

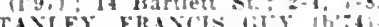

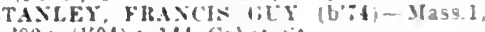
$03 ;\left(l^{* 04)} ;\right.$ 1tt Calmot s?

STICKNEY, fibll. AlYit'ST'S $\left(b^{\circ} 56\right)-$

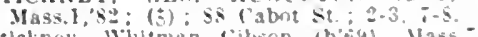
stlckney, Wibluan likson (b'es)-Mast. ol: (1+03): 1: Thurndike st.

TONE RILIII ElNARTIS (b":)

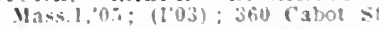

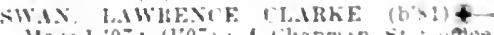
Mass. 1.07; (100); I ('baprean st.; "aftce $\because 3$ Mot 2 .

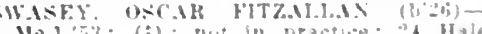
: thut in practice: it Hale it.

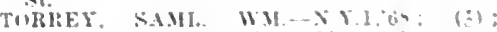
10ti labot st.: calce, $10 x$ inet st $-3: 30,7-8$

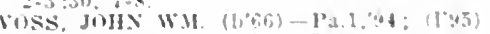
ie, rabut st. : untll

Webster, Fredk. Alobza (19,1) H Mass 5 ,

03: (1'03): :3 1lale s

BEVERLY FARMS, 1,000 . ESSEX

bouzherty Wm. J.Q MU 10 :

Hat : : : 1.1, 6...

MKSUN, IAME MARSI

(sice lionton.)

BILLERICA, 2,789, MIDOLESEX

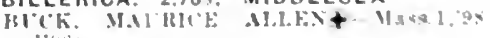
(1) 18 )

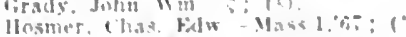

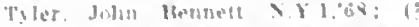

BLACKINTON, 8\%2, BERKSHIRE

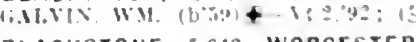

ALACKSTONE, 5,648, WORCESTER

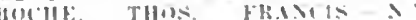

I I 10, $\$ 3: 1 " 1$.

BLANDFORD, 549. HAMPDEN

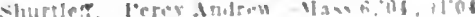

BOLTON. 764. WORCESTER

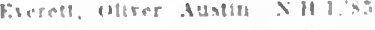

RONDSVILLE, I.BIS. HAMPOEN

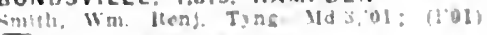

BOSTON 670.585. SUFFOLK

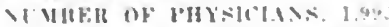

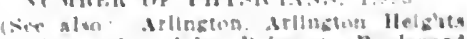

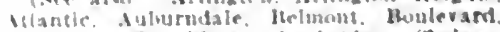

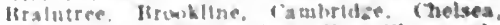

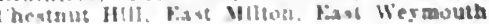


liverctt, Iswer Falls, Malden, Medford, Melrose, Melrose Llghlands, Mllton, Iount Allburn, Newtou, Newton center, Newton

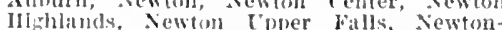
fille, Vortl wewton Cpuer Falls, Sewtonsille, Nortl Weymonth, Qulncy, Revere,

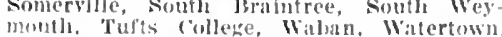

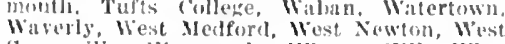
Somervilie, Weymonth, Winter HIII, Whnthrop. Wellaston and Siqnantum.)

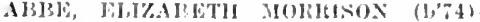

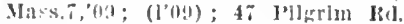

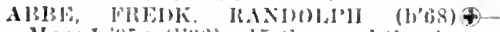

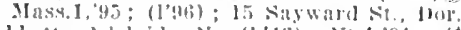

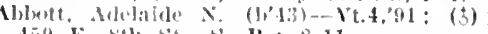
459 F. sth st., s. 1 . ; 8-11.

Ahote, Allert Foneds (h'33)1I-Mass.5.

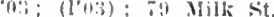

Alhott, Frealk. Lfmeoln Mass.6,'s8; (t) ; 2.52 Newhing st.

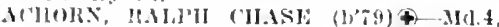
'fls; (l'0s); (Norfolk lowns); otllee, 6.3 Boylstom st

Arone, Modestino (b'(34)-Ita.10,90; (l'09); 419 i IIanover St.

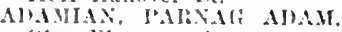

fice Woreserter)

ADAMS, HERBBRT WM. (1) '84; (む) ; it4 Dudley St., Dor.

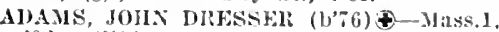
$02 ;(100) ; 261$ Beacon st.; $1: 30-3 ;$ (A9) ; Or

ADAMS, IOHN P.\$-V.2,9s; (1'97); 1637 Tremont sit., Rox

Adams, Wm. (Gray-Mass.1,07; (l’98); 236 Commonwealth Ave.

ADAMS, ZABIIEL BOYLSTON (b't5) Mass.1.'0\%: (1:03) ; (4:3 fottage Firm Rd., Brookline): offlee, 166 Newbury St. ; 2-3; (13,9, 1):3)

ADIDELSOX. NATHAX (l'81)-Mass. (l'09) ; 548 Warren St., lox.; 1-3, 7-9.

AILFIR, IJERMAN MOIRIS (b'76) †-N.Y.1, '0I ; (1'07); it Fenwood Rd.; Asst. Irof. l'sych.. Mass.1 and Mass.(11; (12, F2).

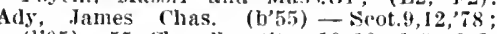
(1'05); 55 (handler st.; 10-12, 1-3, 6-8. Aiken, Thos. Franels, Jr. (b'70)-l'a.1,94; (1'97) ; 784 Bencon St.; office, 431 Shawnut Are.; 11-12:30, 2-4, 7-8; $\mathbf{S}$.

Alcuzar, Izak (b75)-Mass.1,I3; Intern, Massichusetts (haritable lye and car IIospital.

Alden, Flora Sweet- $-(5) ; 140$ Boylston St. Alden, Silns Augustus-IIass.6,06; (年) ; 43 Massachusetts Aro.

AlIARD, CAILTON ELGENE (b'84) Mass.', I2; (1'12); 8 Belfort St., Dor. office, 419 Boylston st. ; $1-3$.

Allard, Frank E.lsworth (b'61) II-Mass.5, '92; (b) ; I 33 Massachusetts Ave.; offlce, 419 Boylston st. ; $4-6$.

ATLEN, NRNOLI NOBLE (b'90)-Mass. 13; (1'13): 22 ('onway st., Ros.

Allen, drihur Wilburn (b's)-Ma.t,'13; Intern, Massachusetts General Hospital.

Allen, Edw. Everett (b'68) 11-Jass,5, 96 (1'y6) ; 32 Monment Sq., Charlestown; Secy. and Prof. Anat., Mass. 5 .

Allen, Elwin lloward-Mass.1,'89; (o) ; 3 i IJancock St. : office, 120 Frankiin $S_{\mathrm{t}}$.

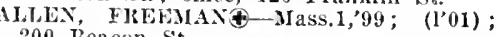
200 Jiencon St.

ALIEX, GAIDNER WELD (b'56) 9 Mass.1, S:; ( $\left(\begin{array}{c}7 \\ 0\end{array}\right) ; 419$ Boylston St.; 1-4: All.EN, GEO. EDGAR (b'ss)-N.II.1,'13; (l'13); Boston Clty Hospitil.

Allen, Nathan Jeverett $\left(b^{\prime} 54\right) \mathrm{F}-\mathrm{Vt} .4,88$; (8); (13 Forest St., Cambridge); office, 17i) Tremont St.

ALLES, SENBCRY WELLS $\left(b^{5} 70\right)($ Mass.1,97; $\left(\mathrm{l}^{\prime} 97\right) ; 20$ Charles liver Sq.; once, 5t9 Reacon Sq. ; 2-3.

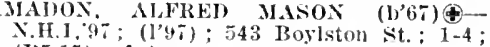
(135, 15); A. $\star$

AMADON, AlETHCR FRANK (b'58)-N.H.1, 93; (0) ; 543 Boylston St. : I I -3.

Ameer, Llafiza (b'86)-Mass.5,'12; (l'12) ; 62 Tyler St. ; $9-10,2-4 ; \mathrm{G}$.

AMES, JOHN JINCOLN\$-Mass.1,92; (\$) ; 8i (hestnut St.; Prof. Theo. and Prac. Med., Mass. 7 .

MES, MATTIEW H. (b'81)€-Pa.1,05; I.A.S., Lieut., U.S.N.; Nary Yard.
Imes, WinJleld Ifoward (b'68)-X.X.15,93; $\left(l^{3}, \pi\right) ; 92$ romytem St.

Imoulume Irom ('uthlert Italelgh-Mass.5 , 10 ; (i); 871 Dorchester Ave., I)or.

ANIIEWS, ANNA IIDKIN - Mass.7,"ys;

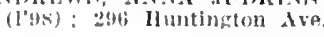

ANDIEWS, HAlLOI, VILGH, (1),73)

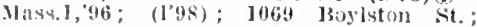
$1-3,7-8.8$

Anrell, Worester Mandolph $(1, \pi s)-\theta$; (l'I1): 74 Boylston St.

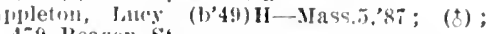
$4 i s$ lieacon $\mathrm{st}$.

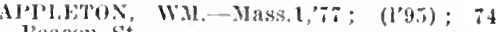

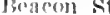

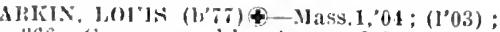
:G6 commonwealth dre.; 2-3; (I)3);

AliNS, BTIRIETT JOOMIS (b'69)\&-Vt.2, '0.; (1'05) ; Mass. Instifute of Technology; (1): $\mathrm{F} 2$ )

AHNOLD. IJOIBACE DAVID (b'62) Misis. 1,89; (†); 427 Beacon Si.; offlec, 520 Commonwealth Ave, ; $2: 30-3: 30$; Detn

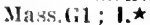

Armold, Seth Fonelon (b\%s)-Mass. i, os; (1'08) ; 94 Worcester St.

ASCIILI, JOSEPII--Mass, 1, 04; (1'03) ; 163 Ilarold st., IRox.; offlee, 344 Jlanover st. llanover.

ASII, JAIEN WARLE (b'84)-P-l'a.1,05 lejt. of l'ath., llarvard Medical Sichool (F2); Path.

AINTIX, ARTHUR FVERETT (b'61)\&-

Mass.1,87; (5); 110 Marlhoro st. $2-4$

Austin, Clura C.-Mass.5,'82; (\#); 165

liunfington $A v e$.

Averill, Edna B. (b'70)-Mass. 5, I0 : (l'I0) 693 Massachusetts Ave.; until 9, 1-2:30 AYtR, JAILS BOE'RNE, JR. (-Mass, I, 07 $\left(l^{\prime} 07\right)$; 25 llme St.; ofllce, 518 Beacon st. ; $2-3 ;($ E2) ; N.

AYEL, SILAS IIJBBARD (b'bi) -Mass.1, 84; (f); 318 Shawmut Ave.; 2-3, $30-7: 30$

zadlian, David Gen. (1,85)-Mass.7,09; (l'10); 451 Shawnut Ave.

Babcock, llaroll Iester (b'86)-Mass.5,'10 (l'10) ; 535 Reacon St.

P.IDGTIR, (HO, SHERWIX (JAIKE (b'̈0) 1:30-3.

Bailey, Florence-Mass.6,03; (I'03) ; 424 Main St.

BAILIY, FREDK. JAMES (b'7)-Mass.1, '03; (l’03) ; 344 lBowdoin St., Dor.; 2-5,

Bailey, Karl Roland (b'86)-Mass.6,10 Mass.7,13; (l'10); 31 Paul Gore St.

BAILEY, WALTER CIIANNING (b'T0) 8 Jass. 1,98; (1'9S); (Edgartown); office, 269 Beacon St. ; $2-3$

Bailey, Wm. II.-N.Y.10,85; (屯); 11 Bowdoin st.

Pailey, Win. T. (h'34)-Mass.7,09; (l'13) IJomeopathic Hospital.

Bailey, Wm. Thomas (b'69) - Mass.1, 00 (l'0I) ; 24 Binford st.

Baker, Domald Vinton (b'88)-Mass.1,'12; (1'13) ; 44 Gloucester St.

Baker, IIarold Woods-Mlass.1,'06; (l'08) 44 Houcester $\mathrm{St}$

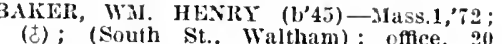
IIt. Vermon $\mathrm{St}$.

BALBONI, GERARDO MONAIRI $(1 ; \%)$ Mass. 1,$04 ;\left(l^{\prime} 04\right) ; 142$ Willow St. ; office, 9 l'rinee St.; $10-12,2-4$

BALCii, FRANKILN GREENE (b'64) Iass.1,92; (さ); 279 Clarendon St. 2-3; $(\mathrm{C}, 3,5) ; \mathrm{S} . \star$

BAIJWIN, HFNRY CUTLER (b'59) Mass. 1, $84 ;(๖)$; 126 Commonwealth Ave. ; $2-3 ;(E I, 2, I 3)$ : NP. *

BÄL,OT, AMBROSE ROCHE-Md.4,05; (1'06) ; 327 Neponset Ave.

BANCROFT, WINFRED BAXTER (b'50)-

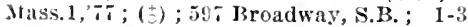
BANGS, CHIS HOWIRD (b'61) -Me.1, 92; (c) ; (130 Green St., Lynn; 11-2) also 149 Tremont St.; 3-5; D.

Bannon, Bernard James-Jass.1,94; (ち) 206 Massachusetts Ave.
BAIWWELL, FRJDK. ALBERT (b'64)N. Y.4,'93, Mass. I, $01 ;\left(l^{\prime} 17\right) ; 140$ Warrell, IRox. : $8-0,23-4,7-8$

l'AILEK, WILISTOX WRIGHT (1,82)कMass.1,06; (1'06); 4 lyndluurst St., Dor. ; $2-3,7-8 ; \mathrm{Pd}$.

Barnard, Belle Strlckland-Mass.5,'97; (1.97); 820 IBeacon St.; 9-12; G.

Barues, Francls llenry (b'ct)-Mass.1,'93; (t) ; 6.j(i Tremont St. : $2: 30-4,7-8$.

IARNES, IIARIE ALDRICII (b'72)Mass. 1, 96 ; (1'149); (Jrookllite); office, 205 Beacon St.; 2-4; (B3,15); LR. *

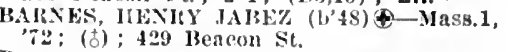

4:2 Columbla lilsworth-Mass.5,'93

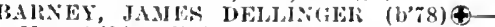
Mass.1,04; (1'04); 80 Marlboro St. ; ofHe'e, 344 Marluoro 'St.; $3-5 ;(C 1,3,5) ; U . \star$ Barney, Wills ollver, Ir. (b'88)-Mlass. '12: (1'13); I3oston ('ity IIospltal.

BARONE, JOS. (1'85)-Mass.7,'11; (l'11); 282 llanover St.

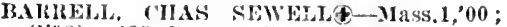
(l'98) ; 425 Beacon St.

BARIVON, EIMEL WALTER.

(Sec Malden.)

BARLY, IAMIA HENIR (b'70)-M-Mass.7, 96 ; (1'96); 2990 Washington St., Rox.: $2-3,6-7$

Barry, Johin Aloyslus-D. (.2,'91; (l'96); 70 IIigh St., Chsn.

BARSTOW, ANDREW THADDEUS (b'72) (-Nass.7,06; (l'06); 52 Westland Ave.;

B.IRTLETT, PIJIJP CllALIIS (b'75)@ IIts4. 7,$00 ;\left(1{ }^{\prime} 01\right) ;(1$
office, 583 Iseacon 'St.

B.ARTIFT'T, WALTER OSCARP-Mass.1, 02; (l'02) ; 18 \& Warren St., Rox.

BARTOI, JOHN WASHBURNA-Mass.1,91 : (t) ; 1 Chestnut 'St.; oftice, 3 Chestnut

Bartols, lillle Anastasia Aberle-Md.5,'01; (l'01) ; 94 Milton Ave., Dor

Barton, Isyman (iny, Jr. (b'8 $)$ - Jass.1,'12 Intern, Massachusetts General Hosjital.

Bassett, Nlice Haley (b'68) H-Mass.5,'98; $\left(1^{\prime} 98\right) ; 56$ W. Cedar St. ; office, 520 Beacon St. ; 3-5.

Batchelder, Fredk. Prescott (b'61)-Mass.5 91; (t); 4 I1 Massachusetts Ave.; 3-4 Prof. P'lysiol., Mass.5.

BATCHELIER, IIOYLIS GOODELL. (see Dedham.)

BATCIIEIJEER, WM. BURDETT $\left(b^{\prime} 70\right)-$ Mass. 1,94 ; (ठ) ; 163 Washington St., Dor. untll $9,2-4,7-9$

FACER, LOCIS HOPEWELL (b'\&8) $\odot$ Miss.1,'12; (1'12); 20 Burrough St., J.P Baxter, Wim. Elihu (b'63)-N.Y.10,87 (l'96) ; 384 Commonwealth Ave.

EAN, CHAS. I'IERCE-N.Y.10,91; (†) ; 426 I assachusetts Ave. ; $2-4,7-8$.

Reaton, Archibald E.-Md.4,96; (1'96) ; 12 Sarin Ilill Are., Dor.; until 9, 2-4, $7-8$.

Beatty, Franklin 'Thomason (b'si)-Pa.2, '85; (5); 139 Beacon St.

BEEISE, THEODORE CHAPIN (b'74)థMass. 1,00
$1: 30-3: 30$

BEEDE, iI. JOSEPHINE - $\mathrm{Y}$ Y.14, 98 (1'99); 10 Conway St., Ros.

Beering, Fredk. Willian, Ir.- $;$ (1'99) ; 61 South St., Jamaica Plain.

Begg, Alexander Swanson-Ia.6, ${ }^{\circ} 07$; (1'07); Harvard Medical School; (F1).

Behlow. Wm. Wallace (b'86)-Mass.1,'12 Intern, Boston City Hospltal.

Belding, David Lawrence (b'84)-Mass.5, '13; (1'13) ; 80 E. Concord St.

Belin, Harry' (b'79)-Mass.7,11; (1'11); 7 Chambers St.; $9-10,2-3,6-8$.

Bell, James Bachelder (b'38) H-Pa.6,'59; (5) ; 178 Conmonwealth Ave.

Bell, (nrlstina E. C. $\rightarrow$; (ङ); 179 Tremont. Bellany, Wm. Woolsey (b'i - -Mass.1,02; (1'02); not in practice ; 17 Bowdoln Ave. Bellows, Howard Perry (b'52) H-Mass.5,'7 : (b); (West Jewton); office, 220 Clarendon St.; 10-12; J'rof. Otol., Miass.5; A.ネ Peter Bent Brigham - Mass.1,

Peter Bent Brigham Hospital.
Bennett, Fredk. Sherwin-NJass.1,94; (t); 456 Centre st., Jamaica Plain. 


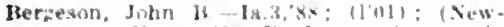
(oun): oftre, 419 lboytston st.: 2-t OALR.

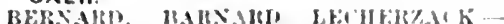

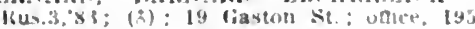
lorchemer si.. S. B.

lernard, Frank F, (b, bis) - Masm, bi $(190)$; 291 Shawmut Aie.

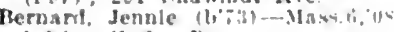
4 lifruell si. Ror.

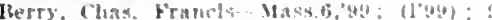
Ilassacbusets Iro: f'rof. Theo, an:l l'race Med. Vhas

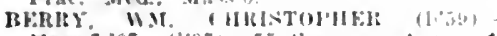

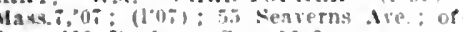
Ace. 419 ihylison st. : $10-2$.

HESEY rollt. Fom

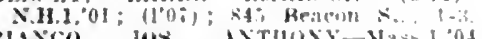

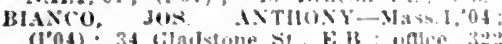
Hanover st.

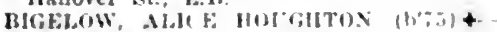

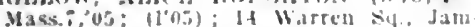
alea I'lain: 1.3.

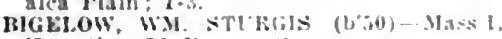
:1: (8): 56 lescosn si.

BIXNE), HORA'

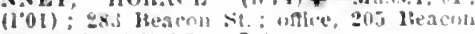
St.: $2.3:(1,1,3,5): \mathrm{S}$

St. : 2.3: ( $(1,3,5)$ S. S

(3): 114 II untlngtor Ave.

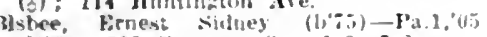
(100.i) : 7iz Tremont Sc. : $1-3,7-8$.

Blohop, Frankun lew-l'al, $01 ;\left(10^{\circ}\right)$; lis l'rinceton st.. E. B.

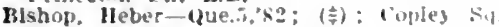
llotel; oftice, 4 fllherty sil

Blshop, tane r.- $D$; (2): 325 lantworm Are. Fen.

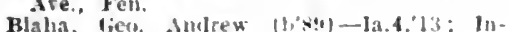
tern, Ifonienpathic lluspltal.

BLAISIIEI.I. JOHX H.MII'ER. (siev Lynn.)

HLAKE, CLARENCI: J011: (

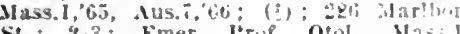

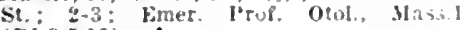
$(\mathbf{B}, 3,3,15): \mathbf{A}$.

Blake, Francls tillman (b'si)-Mass.1.'13 Intern. Peter Ient Mrlgham Huspltal.

BLAKk, HAIRIRINON lilid (b'6t)-Mass. I 'As: $(3)$ : (51: Maln st., Woburn); witlee. 33 Iroad sit. ; $9-5$.

BIAKE, JOHN IbII'ST (b'6) ₹-Mass?

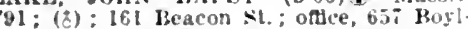
ston st. : 2-3: Asst. I'rue. Surg. Jass. I and Ilass. Uil; (AS,S, (3,5); S.

BLAhE, Joll: liko. (b'37)-Mass.1, 61 : (3): 212 Heacon st. : 1-3: (AS).

Blake, SIary Jane $0 ;(3) ; 633$ Tremont st

BLAKELY, DAII1) NEWTOX (b'ti + Bronkline) ; once, 535 Beacun St.; $3-4$. (Dronk

Blanchard. Stanley Wayne (b'iz)--Masu. 04: (1.03): 10.8 Boylston st.; 2-4; LR.

RLSS, GEO. D.NEORTI (b'5)-Mass.J. "81; (z): 508 Washlingtun 2t., Nor.; until $9,-3-4,6-i$.

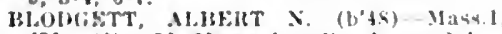
\%1: (8): 51 Massachuselts Ave $2-4$.

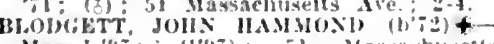

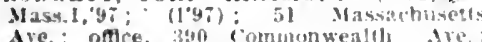

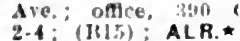

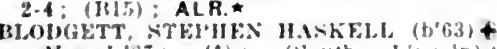

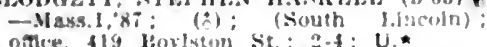

Ploom, lavtel Nathan-Md.6, 04: (104); 33 Saratora St., k: Is.

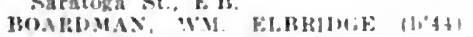
Mass, "68; 1:): 3ss Marlloro st.; 24 ObG.

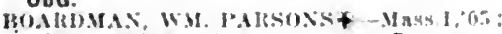

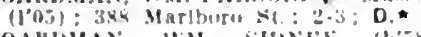

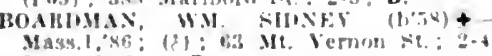
7-9: (i) i i : $R$.

Borltah. Gertruile Trevete-Tenn. 1,00: (1t) Ifotel Oxpord.

Hoemer, Frank f. b; 38 l'aul liors st

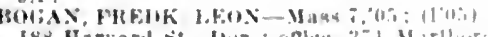

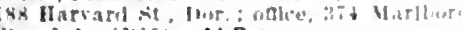
St. : 1.4; $(115): A L R$.

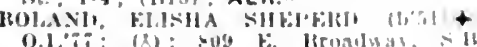

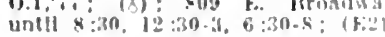

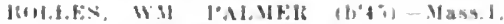

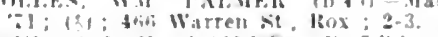

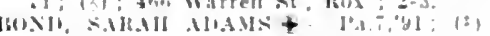

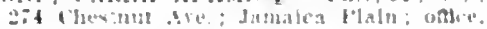

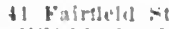

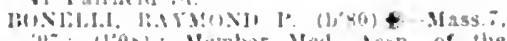

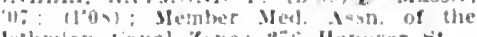

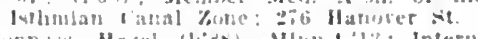

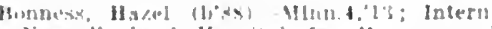

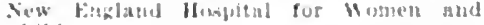
indiltem

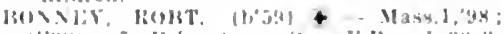

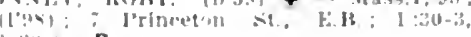
(i) : $(1)-\infty ; R$.

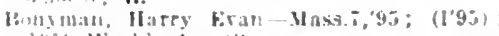
lose Washlnktun sit

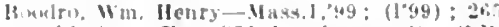

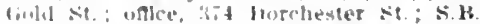

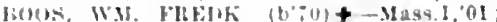

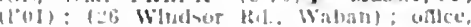

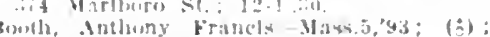
$\therefore$ Castlegate lad., lour

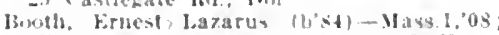

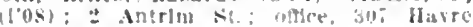
st., r.l.

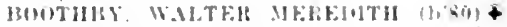

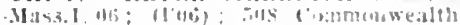
Are. $(121) ; S^{-\star}$

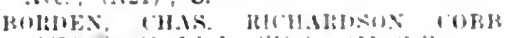
(1)'i4)-Me.1,"96: (1'9y) : (II colburre

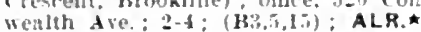

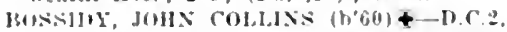

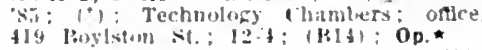

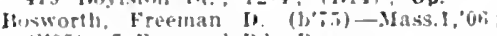
(10.5); ; Fenwood Red. Rox

Joiwerth, John Wllllams-Mass.5,"7t; ( ibis wouth St. Mos.

MOTTUMLFY, JOHS T.IYLOR (h'69)

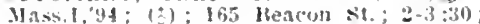
(.1.i) : S.

Bouin, Chas.-D: (I'ne); 1690 Washlngton st. : nthle, ros: Trement si

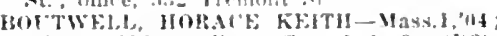

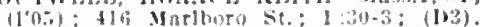
Bowlolath. HI.SROI.I;

ow

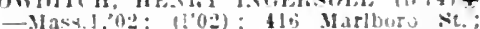
$2-3:(1,1,3):$ Pd.

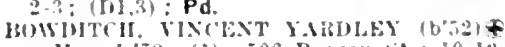
- Mass. 1, i9: (:); jog Beacon st. : in-10

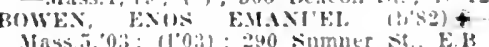

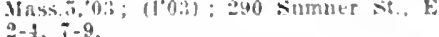

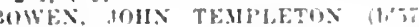

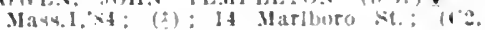
4. Fil.

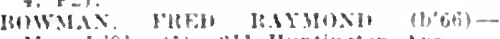

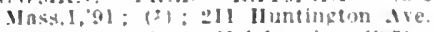

Ibowmin. Winthrop Helght- $0 ;(1 \times 4) ; 228$ Newlours st

Boyd, Herhert lirummonel--Mas4 $5,72:(\vdots) ;$ 4 Revere si. J.1\%; oflce, 6s: Hoylktun Si: : 3-t;: S.

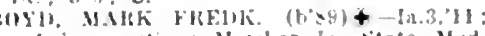
not in practice: Mcanler la sitate Med.

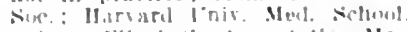

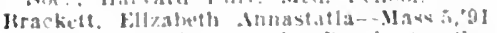
("); "̈til Washington st., Detrobester cen 10.8

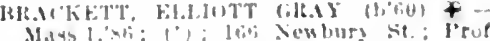

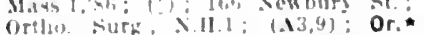

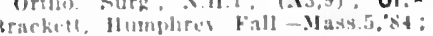

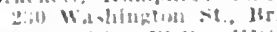

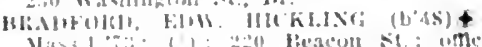

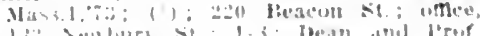

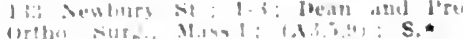

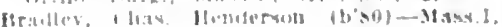

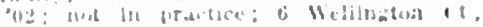

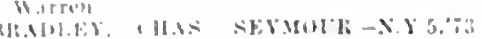

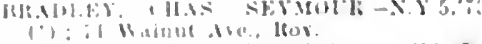

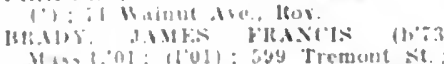

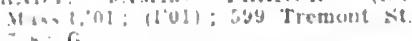

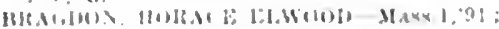

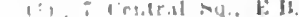

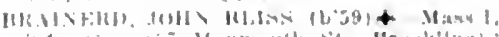

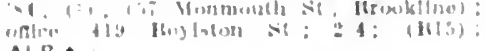
ALR.

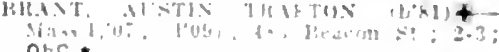

atc *

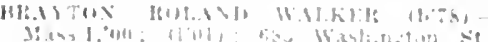

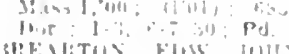

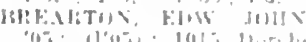

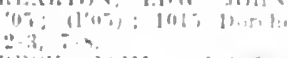

Hetik S.MT.

lit iffigrta lid. Fer

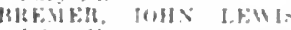

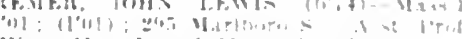

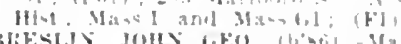

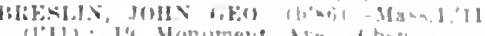
(1011): I! Monsment Ale of $h-n$

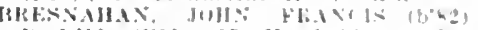

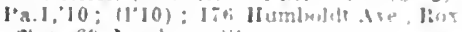
uthe fid bew bury to

HREW.TFR, GEO W.SHHNGTUN W.ULKS

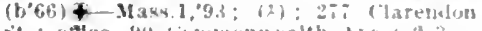

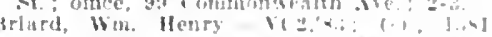

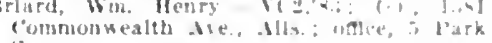

Hilis

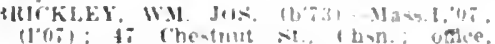
Ifasmarket rellef Hovilal: S.

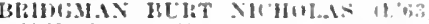

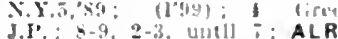

J.I. : $8-9,2-3$, Uutll : : ALR.

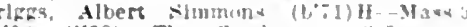

"02: (1"02); The Chariestale:

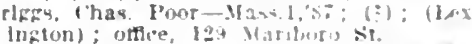

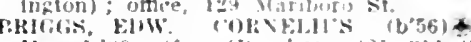

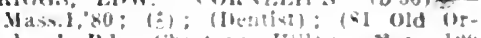

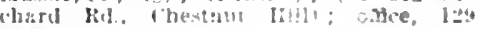
Marlbore st. : 4- i.

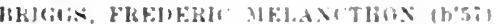

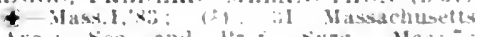

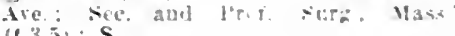
$(13.5): \mathrm{S}$

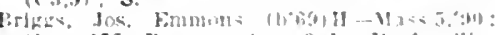
(2); fi: Pearon si.: 3.1; I'tor. ilin. Surio., Masy.t: :

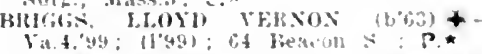

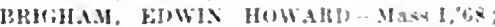

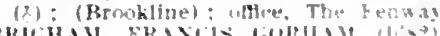

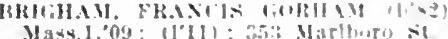

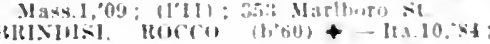

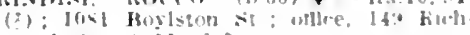
mond si. : $9-11,6-9$.

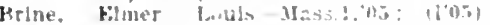
Is:e l'umbonveath A

Hanurer is

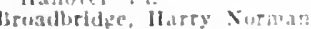

Brlahton Are. All.

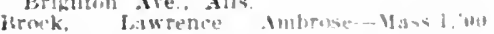

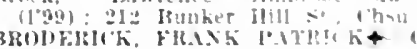

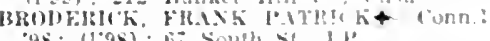

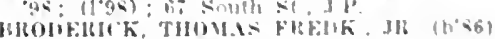

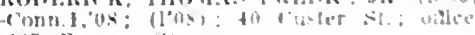
10. Retacen si

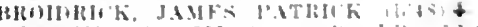
1...... 69

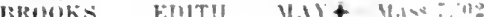

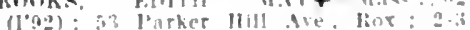
G.

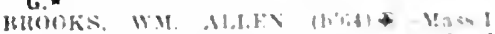

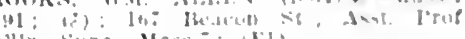

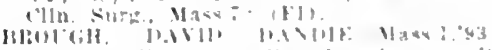
(") : 11 :1!

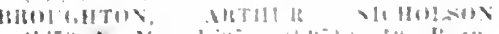

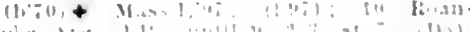

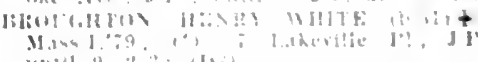

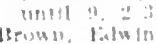

$M .2 \times 6,3$

Brwan, linkens

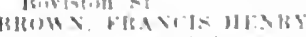

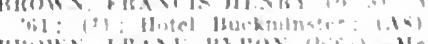

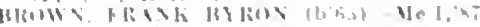

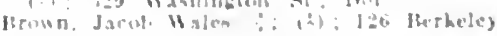

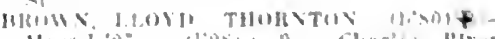

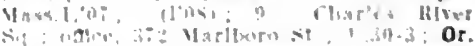


HLOWX, MALSHALL LABANOX (h⿻3 :.11.1,67

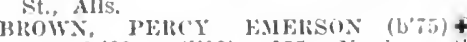

Ilass, 1,00; (1'00); 155 Newbury

( $(3,5,113,(91,2)$.

Irown, Wh. Francls- $0 ;(1) ; 3$ Vhne sit. Rox.

HROWX, W.1. JAMFs (b'so)-Mass.7,06 (1006); 1080 boylston st.: 2-4

Browne, l'erey (jilbert (b'69)II Mass,5,92

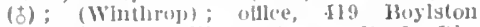

St. : also

Brownell, Gadys Howard (b'ss)-Mass. 12: (l'12); so li. Cuncord st.

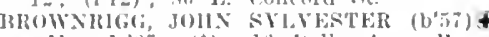
Mass.1,8:; (8); 16 lelle Ave., Lox.;

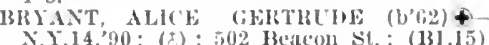
BRYANT, JOHX (b'80)-Mass 1, 07 ; $\left(1^{\prime} 10\right)$ ('ohisset); oflee, 338 Marlboro'st.

HUCHOL\%, CAHL IIEISMANX (b', Ger.14,01: (1'09); (27 Gurney st., Cam. brlige); oftice, 139 lieacon st.: 1-3 $(A 9,26) ;$ Or. $\star$

Buck, ('has, Edward-Mass, ĩ,03; (l'03)

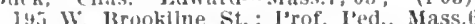
IBC(K, 110 WARI MENDFNIIALI_Mass.] '82; (1995); 85; 13eacon St.

BLCKINGHAM, EDW. MARSHAII (b'48) -llass. 1; 74 ; (5) ; 34* Marlboro st.; 2-3; (D3)

BC'CKI.FY, PlHIJIP TOWXSEND - Mass.1, 84; (t); 339A W. Jroadway, S.B.

BUCKl.EY, WM. STEYHENt-Mass. , 02: (1*02); 253 Market St., Br

BIFHLER, GEO. VAN BLSKIRK - Ia.1, 93: (193) : (199 Prospect St., Cambridge); office, 1075 Boylston $\mathrm{St}$.

BIFFOIRD, JOHN IIENRY (b'76) Iass.1,02; (1'01); 1079 Boylston st. : 2-3:30.

Buffum, Wm. Jotter, Jr. (b'88) - Mass.1, 13; Intern, Massachusetts General Hospltal.

BLLLARD, WIF. NOHTON (b'53) Mass.1,80; (む); 89 Marlboro St.; (1)3, El, 2$): N$

Burack, Abralıam (b'\$9) — Mass.i,12; (l'12) ; 39 Stanwood St., Rox.; office, 344 Harrlson AYe.; $9-10,2-3,6-8$.

jurbank, Ifly Owen Baker $\left(b^{\prime}-0\right)-$ Mass. 7 , 03; (l'02); (Elmwood) ; oftce, 212 Huntlngton Ave: $2-4 \cdot \mathbf{N} \star$

Burchmore, ('has. Francis Preston (b'58). Ilass.6,'y3; (1.95); (105 Grover Are. Winthrop); ofthe, 100 Boylston St.; 10-5; R.

BURLINGHAM, LOUIS HERBERT (b'80) -.II l.7,06; (l'08); Peter Bent Brigham Hosjital.

BLKNETT, FRANCIS LOWELL (b'78) £ Mlas. log; (1'07) ; sz Beacon st.; Path. BLRNHAM, IIMOND ARTILIR (b'65) 4 Mass.1,94; (ठ) ; 134 II 13 tington Ave.; $2-4$.

BLRXS, FREDK. STANFORD $\left(\mathrm{b}^{\circ} \% 5\right) \oplus$ Mass.l,'98; (1'98); 237 Marlboro St.; $1: 30-3: 30 ;(C 2,4)$.

BTRXS, NEWELL BLY, (b'82) †-Mass.1, 09; (1'10); (North Wilmington); offlee, 48: Beacon st.

BURRAGF, WALTER IANCOLN $\left(\mathrm{b}^{\prime} 60\right) \uparrow$ Mass.l'ss; (t); Sec. Mass. Med Soc. 282 Newbury St.; 11-1; (A2).

Burroughs, Amelia E.-0.7,'81; (1.95); 31 Massacliusetts Ave.

BL'RT, FRANK LESLIE (b'5̃) †-Mass.1 8.5; (t) ; 528 Massachusetts Are.; 1-3. Prof. Surg., Mass. 6.

Busl, Chas. Wm.-Mass.5,'99; (1'99); 196 Huntington Ave.; $2-4$; LR

BLSH, JOHN STANDISII FOSTER +IIass.1,74; Retired; 651 Boylston St.

Buswell, Arthur True- $\rightarrow$; (ठ) ; 552 Massa. clusetts Ave.

BUTLER, CHAS. SHOREY-Mass.1,'98 (1'Gi) ; 25i Newbury St.; 2-3:30; S.

RITI.ER, JOHN EDIY. (b'63)-..Mass.1,'91 (1); t4 Monadnock St.; 2-3; Anes.

Butler. John Henry (b'i6)-Mass.jo,'09; it kuggles kt., Rox.

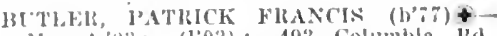

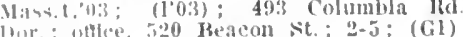
R.

ABOT, 111 (ill (1)72) +-Nass. 1,98; (1'98) 87 Mariliaro St.; 2-5: Asst. J'ruf. (ien.

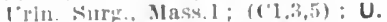

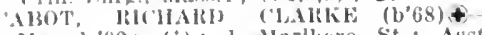
Mass, 1,92: (1) ; ] Marlloro st. ; Asst.

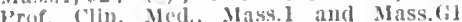
(1) (i) : 1 .

'adigan, John los.-Wass.1,99; (1'99); 93 Mllton Ave., Dor.

Cahil, Wliza Buckman-Mass.5,'86;
'The Westninster.

Cahlli, Harry Pllllip (b'84)-Mass.1,1l (l'12); Massachusets (haritable Eye and Ear Inllrmary.

'all, Thomas Wm. (b'85)-Mass.6,'10 (li1): 7 laley st., Hox, ; oflce, 1150 Columbus Ave.; 2-4, $7-9$.

Calderwood, Edw. Swazey (b'7s) H-Mass.5, "14; (1'04); 2.23 Warren st., lkox.; 8-9, $4-6$; Assoc. P'rof. Anat., Mass.5.

Calderwood, Sami. Herbert $\left(b^{\prime} 53\right)$-Mass. '75: (0) : l'res. Boitrd

(1) 91; (f) ; 2 Uakview Terrace, l.P.; 1-3, $6-8$

Ali, FMMA LOUISE $\left(b^{\prime} 4 i\right)+$-Mich.1, 73; (5): 502 Beacon st.; $2-4 ; \mathbf{G}$.

ALIAIIAN, IIFNRY AlPHONSES Mass. 1, 06

MLIMNAN, SAIPSON ALOISIUS (b'63) -Mass.1, 86 ; (ठ); 109 Warren St., Hox. - $3,6-8 ;$ OpLR

Camplell, 1Benj. Franklin-Miass.1,57 24 White St.; office, 163 Meridian. anavan, Myrtelle Moore (b'79)-I'a.t, 05 not In practice (l'athologlst); Boston Stilte Irospital, 425 Harvard st., Dor.

ANNON, WALTEK BRADFORD (b'71)థ Irass. 1,00; (1t); (2 Dlvinlty Ave., Cambrldge); office, Harvard Medical
School; Prof. Physiol., Mass.1 and

Mass.Gi.

('arbone, Luigl (b'83)-Ita.10,'09; (1'11); 288 Hanorer $\mathrm{St}$.

Card, Horatio Smitl (b'66)-Ne.1,99; $(1,99): 491$ itassachusetts Ave, $1-3,6-8$ Carl, Isaire Danl-Ifass b, 96 ; $\left(1^{\prime} 95\right) ; 1081$ Boylston st. ; Prof. Gyn., Mass.6.

Carleton, Elizabeth Abbott-Mass.3,' 22 ; (t); 30 Union Park.

CARLFY, MARGARET ELIZABETHEMass.7,04; (l’05) ; 48.5 Beacon st.

itrpenter, sylvester sililes $-0 ;(t)$;

(NRROLL, CHAS. ClRTIS (b'78)-Md.4, "07; (l'05); 10 Fsmond st., Wor.; 1-3, $7-9 ; \mathbf{S}$.

C'arroll, Wizabeth Minnette-0; (5); 675 Boylston st.

('arroll, Francls Elw-Mass.1,'90; (t); 217 Iuntington Ave. ; $2-5$

(ARRUTH, SIDNEY STETSON (b'71) -

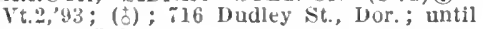

Carter, James ('has. (b'85)-Mass.1,13 ; Intern, Boston Clty IIospital.

(ARVILL, LIZZIE MAUD.

(See Somerville.)

Cary, Jennie Sophia Dunn (b'62)-MLass.j. 'si' (†) ; 43 Moultrie St., Dor.

ASEY, JOIIN FRANCIS (b'85) $€-$ N.Y.1, '09; (l'11); 84 Franklin, Alls.; 3-4, í-s. CASSELBERKY, CIARENCE MARMA-
DUKE (b'75) \&-Pa.1,97; (1'98); (1891 Beacon St., Brookline); offlce, 1075 Boylston St.; 1-3; D.

CASTLEMAN, P'HILIP (b'82)-D.C.1,'11; (Bacteriologist); Boston Board of Health. Caranagl, Walter James-N.Y.10,'94; (ち); 153 W. Broadway, S.B.

CAVANAUGH, CHAS. RUSSELL-Mass.1, '92; (1'95); 19 Riclimond St., Dor.

CECONI, JOHN ALOYSIUS-Mass. 7,04 ; (1'04); 14 Arcadia St, Dor.

CHADBOURNE, ARTHUR PATTERSON (b'62)-Mass.1,'89; (ठ); 193 Beacon St. Chadwell, Orville Rogers (b'75) H-Mass.5, 03; (1'03) ; 793 Centre St., J.P. ; $1: 30-3$. CHA.MBFRLAIN, MYRON LEVI (b'44)థ
Chamberlin, James prescott (b'31) $\rightarrow$ : (t) ; 12s lierkeley st. ; 10-3.

Chandier, Chis. Ilenerson (b'86)-Mass.7 ,11: (4) : II Bowdoly st.

Chandler, Ilarold Beckles (b'86)-Mass.1, 11; (1'12); (West Newton); offlce, $341 / 2$ Bencon St. ; $11: 30-3: 30 ;(134,14) ; 0$. *

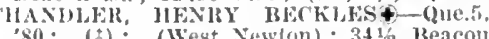
80; (c): (West Newlon); 341/2 Jeacon $(134,14) ; 0 p$.

(HANDJER, TIIOS, ENANS (b'71) + Iass.5,00; (1,00); (51 Yerndale St.

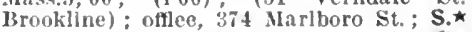

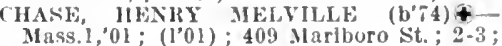
Mass.1,01;

CHASE, HORACT - Ger.1,65; (む) ; Morse, Dor.

CHASE, WALTEI GREENOUGII (b'59) Mass.1,01; (1'01) ; 279 Marlboro St. CHFEVEK, CIARENCE ALONZO (b'58) Mass. 1, 83 ; (t) : 1531 Bine Hill Ave.

CIHEVHR, DAVIU $\left(b^{\prime}, 6\right) \oplus$ - Mass.I, 01 (l'01);20 IIereford st.; offlee, 355 Marlboro St.; $1: 20-3$; Asst. Prof. Sury. Anat., Mass.l and Mass.G1; (A8, C $3, \dot{3}$ HEEFik, DAVIl) WM. (b'31)-Mass.1,58; (3) ; Boylston St.; $2-3 ;$ (A5) ; S.

CHFXEIY, WM. ELISHA $\left(b^{*} 64\right) థ$-Mass. 1 , 90; (ठ); 222 Huntlngton Are.; $2-4$; Prot. Laryn., hlass. 7 ; (B3,15); ALR.ネ

CHENEL, FREDK. EDW. (b'62) 4 -Mass.1, (85: (t): (Concord) ; offlce, 126 Communweillth Ave. ; 1-4; (B1,4,14) Op.

Cheng, Ensang Wanlella (b'83) $-0 ;\left(l^{\prime} 09\right)$; 7 Tyler St.; 2-4, $7-8$.

Chlek, Wm. Härison- 0 ; (f) ; 978 Harrison Ave., Rox.

Childs, Edna Marguerlte-Mass:5,'06;(1'06) 98 Hemenway St.

Childs, Helen Simonds-Mass.5, 90 ; (む) ; 98 llemenway St.

Chlrurg, Michael ( $\left.v^{\prime} 67\right)$-Ind.8,88; (ङ) (Newton Center) ; offlce, 419 Boylston St. :

Clirlstlan, Andrew Forest- $\rightarrow$;
Marlboro St. $; 9-11,2-5,7-9 ; \mathbf{N}$.

CHRINTIAN, IIENKY ASBURY (b'76) Id.7,00; (1'05) ; Franels St. and Hunt ington Ave.; I'rof. Theo. and Prac. ington Ave.; Prof. Theo. and Prac. CIILTE, ARTIIUR JAMBERT (D'69)థMass.1,95; (l'96) ; 350 Mirlboro st. ; $2-3$. $((1,3,5) ; \mathrm{S}$

Cianl, Lulgl G. - ; (l'05); 391 Hanover St. cilley, Orran Geo. (b'40)-N.H.1,68; (t) ; (Ifamllton); office, 57 Cambridge St.; 2-4, $7-9$

ChAP, EHMUND WRIGHT - Mass.1,'98 (1'98); (Waban); offlee, Hotel Puritan (134,14); $12: 30-3$.

('lapp, Herbert Codman (b'46) $\Pi$-Mass. I, 70; (1) ; (67 Wroolilluester St. Jass.5. Clapp, James Wilkinson (b'47)-Mass.5, ĩ (3) ; (Drugglst); (Brookline); 439 Boyl ston St.; Emer. Prof. Pharmaceuties, Mass. $\tilde{j}$.

Clapp, Susan Ida Dudley (b'50)H-Mass.5. $7 T$; (d) ; 52 IIart ford St., Dor.

CLARK, GEO. OLIVER (b'78)-Mass.1, '03; (1'04) ; 142 Beacon st. ; $2-3$; $(\mathrm{C} 3,5)$

' 'LARK. HARRY AINSWORTH (b'85)Mass.7,10; (l'10);9 Brent St.; Dor. CIARK, JOS. PAY'SON (b'60)థ-Mass.1 '87; (B); 11 M Marlboro St.; $2-3: 30$;

Clarke, Wm. Crocker (b'45)-Me.1,73; (t) 4 Charter St.; offlce, Suffolk Dispensary. Cleary, Robt. Fmmett (b'88)-Mass. i,'12 ; (1'12) ; Carney Hospital.

CIEAVES, FREDK. HENRY (b'64)€D.C.1,'s7; (1'95); (10 Wellington Rd. Brookllne); office, 287 Atlantle Are.; 9-4. CLEMENT, GEO. WILMOTథ-Mass. 1,73 ; (b) ; 275 Warren St., Rox.

CLEVELAND, HEBER HOWE (b'72) Mass.1,'99; (1'98); (Wellesley Hills); offle, 205 Beacon St.

Cliff, Alfred Addington-Mass. 1,'99; (1'99) : 70 Stephen St.; offlce, 226 Huntington Ave. 


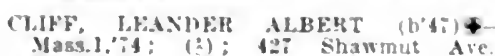

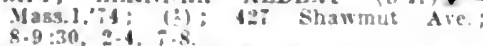
CIYMER, CiEo. (1)

386 Commonkealth Ne. : $=-3$.

COBB

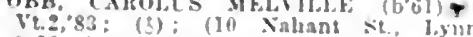

8-10, 1-5): once, 119 Boylston st.; 1-3: (III): OALR.

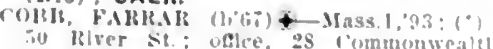
io miver st

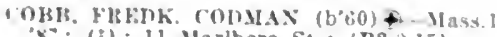
's: (8) ; 11 Marlboro 5 ? : (B2,3,15)

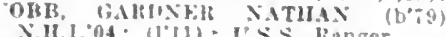
X.11.1,04; (1'18); t's. kange

Cochrane. Ihll!g
IIunungton Are.

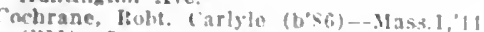

(1'11): Boston lylug-in llosultal.

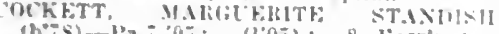

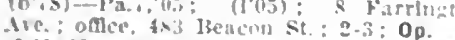

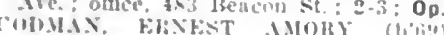

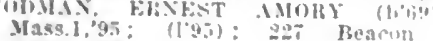

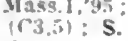

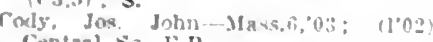
Central Si. F. B.

COFFIN, ARTULR BAYLIHS $(1,60)+$

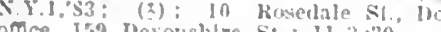
omce, I59 Devorishtre st. : $11-3: 30$

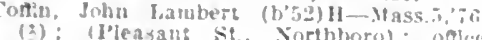
(2): (I'leasans st. Northbora); Mrtce LR.

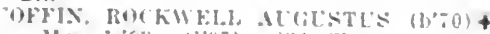

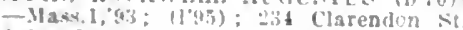
$2-1:(112.15)$.

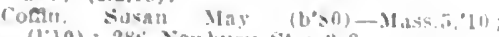
$(100)=38 t i$ xewhury $\$$ t. : : $2-3$.

(1"12, Whluman Klug (b'66)-Mass 1, 12 (1'12): Boston r"ity HIospital.

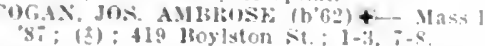

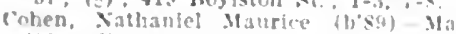

11: (l'11): 43 llolborn st.; ottice. Warren st.:-4, 5-8; Ob.

Colburn, Fredk Wilkinson (b'70) II-Mass.T 9: : 1197): (1123 Ifyde Park Are., Hyd Park) : oftce, aso vewhury st.; $2: 01$ -

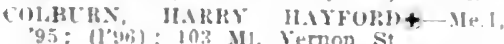
95: (1)!wi): in: N1. Vemon $\mathrm{St}$

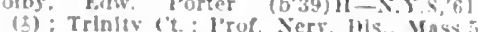

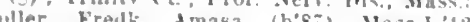
Intern, Massachusetts General Ilospltal.

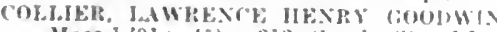

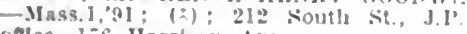

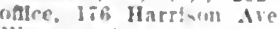

Colllna, Aubrey Joln (1, $: 5)$ - Mass.7,02 colrllle-henundy, Nichael $\rightarrow$ :

The

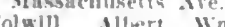

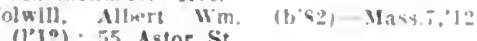
(1'12): 55 Astor St.

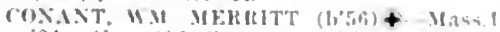

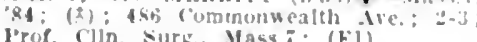
Pror. Cin surk. Macs. : (Fi) as.1,04: $(104) ; 2$

Connor, Jolun llenry Francts - Mass.b. 0 :

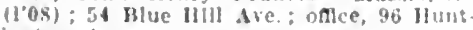
Ington Ave.

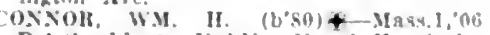
P.A.S., loleut, U.S.X. Naral Hospltal.

Connors, W'llets surgenn (bos) - 11 9]: (1) : 34.5 Shanmut Ire.; 9-10, 1 ti.k.

conkay, franels periard - Mass.; 0 :

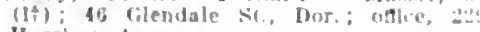
Harrison dre.

Conwell, Wallar ldulngstone, Jr. (h'it)

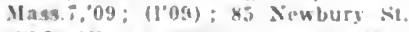

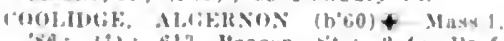

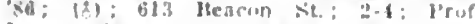
laaryn., Matse1 and Masa 6:1: (162,3,15): LR.

coomlas, Jolun T, - 111.10,93\%; (9); 1024 Washington Sit.

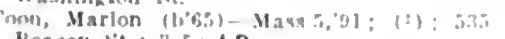
Bracon st : $3-5 ;$ : Lo

voner, filady: Adelphla (b's3) Micla 1 . ns: (1'11): 541 lloyluton st

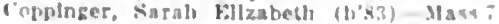
II: (li1i: (Needham Helghts): unte. Tufes Medlcal college.

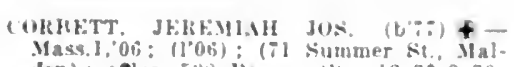

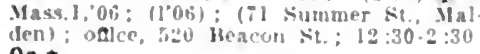
Op.

COKAT, ISADOR HENRY (b'5) M Mana,

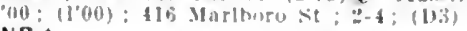
NP:

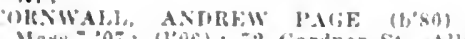

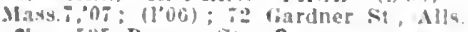

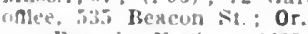

(o)rr, Francis Xavter (1) (1') So Magn

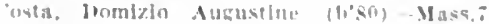

'0s: (1.09): 330 Hantuer st. : 2. :-s: ObG.

costri.jo, Jolls HFiks Ih Mass

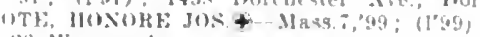
$2 ?$ Wurren Are.

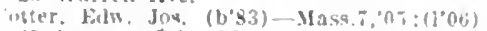
2.: inmerer Rd. J.P.: 301 shawrut . Ave

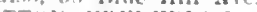

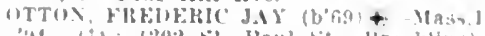

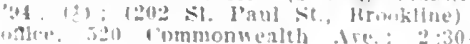
3 : $(121,(3): \mathbf{s}$,

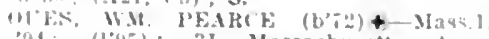
94 (195); 31 Massachusetts Ave (i) viluty s.

Mel,'is: (t): Ilarvard Medleal sicheol l'riff. I'ath. and that., Mass.i and

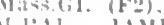

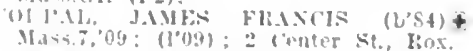

"ursey, frank liudolsh $(6,80)$-Dass.

12: ir12); sod Tremont st.

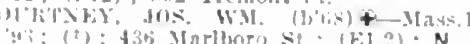

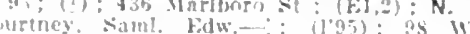
suringteld si

over, tillen (harlofte (b'ss)-Tex.2.'13 Intern, New England llowpltal for Women and (lilldren.

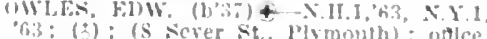

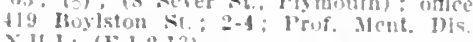
X111: (F,1.2.13)

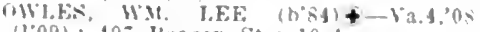
(1.09): 437 Heacon St.; $10-4$.

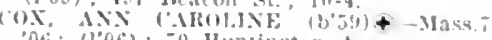
ox: (log) :0 Huntington Ave.

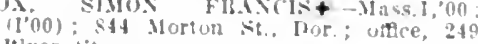

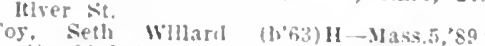
(2); 22 1'rincetun st. ki.B.; $1-3, i-8$

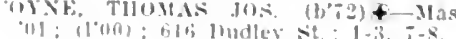

rubtree, Harsard llerseg (b's2)-Mass. 11: Intern, Mysachusetts licneral Ilos: pitilil.

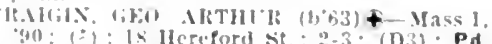

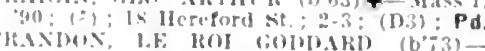

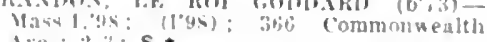
Are. : : s: $s$.

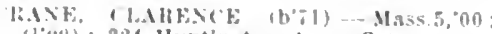
(1'011) : 2.24 Huntinkton Are.: $s * *$

"ralle K(ella lloward (b)'t) li - Masa 5,00 . (100ii): :2et Huntington . Iro.

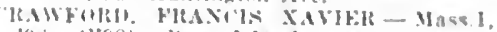
"as: (1"gs); heer laland; once, diallupies islani

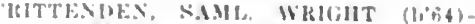
III.1,9s, lie 1,'98: (1'00): Boston State Iloxptal; NP.

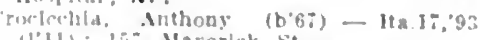
(1'11): 15 W Warerick st.

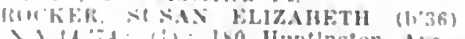

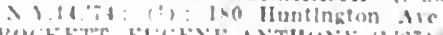

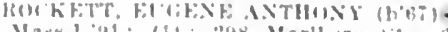
Maw 1,of: (3): age Marlbere st:

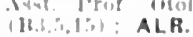

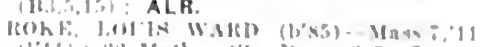

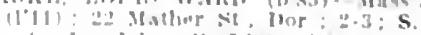

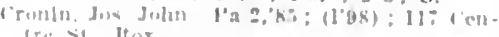
trat, itiox

Howix Mll Hare JoHx $(1,70)+$

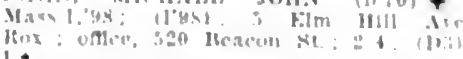
I.

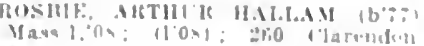

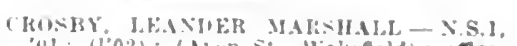
"I!: (10n2); (Alun st. Wakefeld); oace, t19 lboylston st.

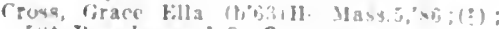
sxt Hroaluas : 1-3; G.

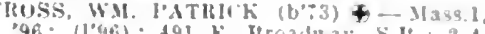
$98:\left(1^{\circ} 96\right) ; 491$ k. Froadsay, st It : 24

CHOSSMAN, FRANK ALLFRT (b53)-

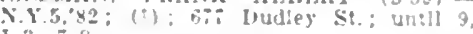
I- $3,7-8$

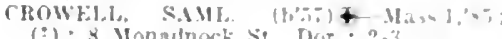

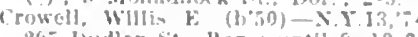

aci budley si Rox untll 9 10.2

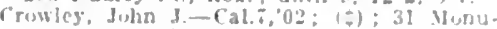
ment Ale.. Ithon.

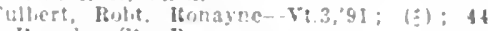
dopuntey st., doux

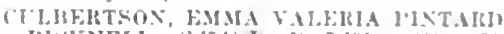

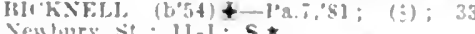

Jo

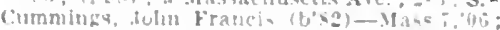

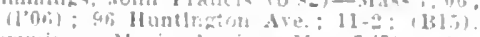
umminich, Naria lonica Masia

$2 \% 1$ Inilley $\div$, Rox.

(TMMIS, LORLTTA JOY UREIES +

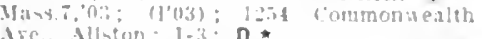

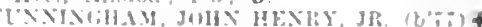

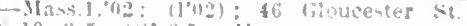

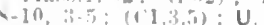

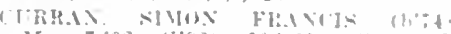

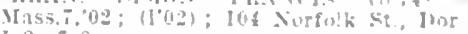
$1-3, z-8$ urrler, Mhelhard noe st, $3-1 ; 0$ o.

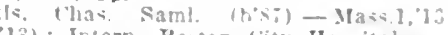

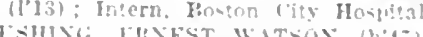

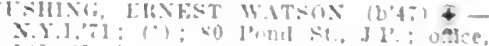

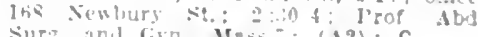

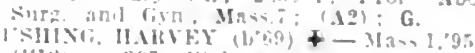

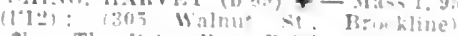

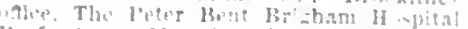

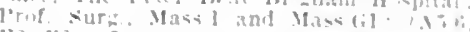

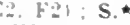

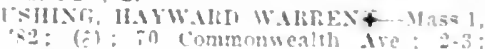
(1): 5

cu-mbng. Gilver fernald-Me 1,83; Chandler si: : 2-4, i-s.

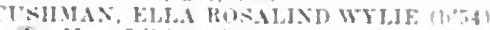

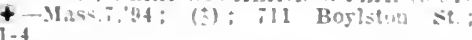

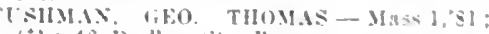
(2): 4h mudley st. lint.

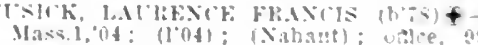
vewburs st -3.

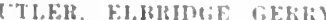

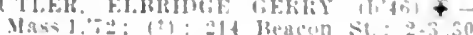

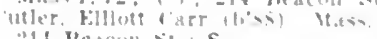

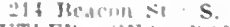

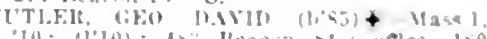

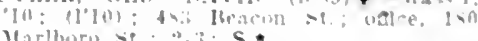

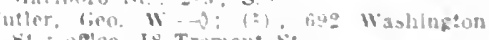
Al. after, IS Tromont si

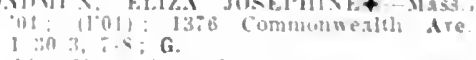

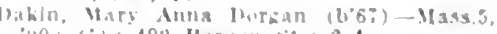

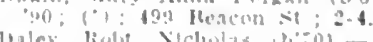

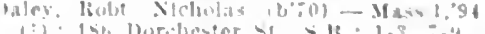

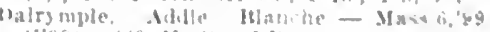
ता

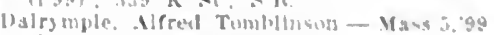

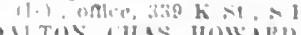

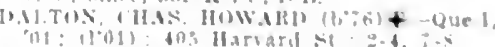

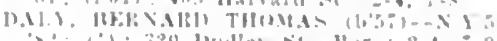

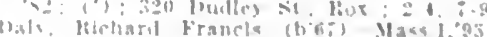

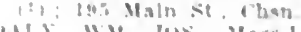

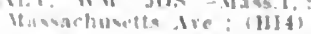

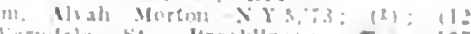
Vormlalu st, Itronkllnel: once, 100

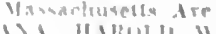

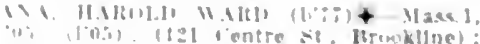

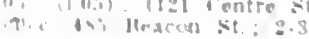


DAXE, IOHI M:Iss. I,92; (t); Woodland

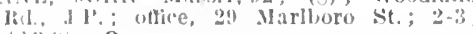

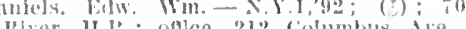

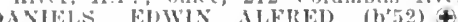

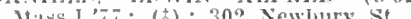

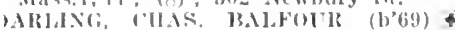

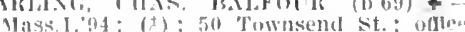
llas loist (

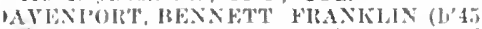
+. X.Y.1,'71, Mass.1, 7]; (ठ); (67 Cool ilges Hill st. Watertown); nlllee, I 6 il l'remonl sit. ; $10-4$

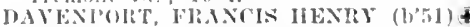

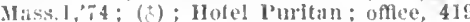
Bollou

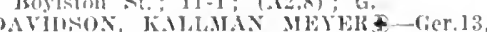
si: (1): I93 llumbolat Are, oflec, 31 Mclean sit

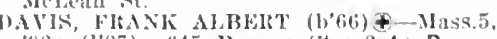
"98: (1"97); $(245$ 1Beacon st. ; $2-4 ;$ R.

liarls, Frelk. Nuguslus-l'a.9, $84 ;$ (d); 896 liricion sit.

WAVIS, I.IX('OLN (b'72) \& - Mass, 198 (l'09) ; 217 learon st.; ollee, 205 Heacon sit. : $2-3: 30 ;((3,5): \mathbf{S}$.

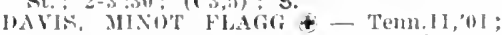

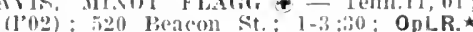

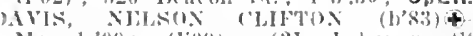

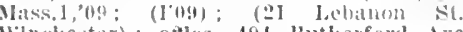
Wlnchester); oftce, 481 lintherford tve

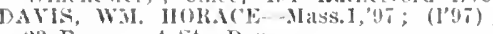
2:- Beaununt st., Dor.

MAYISON, ALTICH HOWAKL (b't). Iass. 1,02; (l'00); 564 Washlngton St.

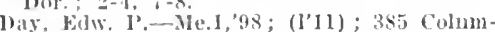
bla licl., Dor

DAY. IIIHERT FRANCIS (b"79) + Mass.I '05; (l'04) ; 657 Joylston St.; 2-3; S DHACON, THOS. HHYNG (b'79)-Mass. 06 ; $(107)$; (35 Lee St. Cambrikge): of fice, is Iluntington Ave.: 10-5: GALR.

DeAnezaga, Gualtiero-t: (す): 104 Gilinsborough st.; oflce, 342 Ilauover st.

DEAIBBORN, GEO. VAN NESA $\left(b^{x} 69\right)+$ N.Y.1,93; not in practice: $(6$ Mason st. ambriage) : Prof. Plysiol. Mass.

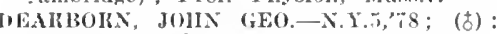
2 liond st., r'lisn.

DeBI,OS, THOS. AMORY (b'48)-N.11.1,78, N.Y.5,78; (0) ; 52:3 Newbury st.; (B2); LR.

Deelian, Peter Eugene-Mass.6,94; ( Waldeck St., Dor.; office, 238 Iluntington Are. : 10-12, 2-4

De Feo, Jasiuale- 0 ; $(105)$; 4i. IIanover St.

DELAxo, SAMIL.-Mass.1,'s3; (d) ; $89 \mathrm{New}$ bury St.

DE IUL, FIEDK. SPATLDING (b'69) Mass.1,94: (5); (Needlam); offlee, 419 Boylston St. : $1: 30-4$.

DENIG, BLANCHE ALPINE $\left(b^{\prime} 62\right)+-$ IIl.9, 91 ; ( $)$; 11 otel Bristol ; 2-4.

Denkinger, Jos. Anton (b'62) E-Vt.4,'s9 (b) ; 14 IIarris Are., J.J.; 8-9, 2-4, 7-9.

DENNING, EDW. IOHN (b79) 4 -IIAss. 05; (1'04); 57 E. Broadway, S.B.; 1-3, $6-8$.

DENTING, FIRED JOS. (b'85) $€$-Mass. 08; (1'08); 216 W. Broadway, s.P. until $9,2-3,7-9$.

Denay, feo. I'arkham (b'87)-Mass.1,'13. Intern, Jeter Bent Brigham Hospital

IE NORMANDIE ROBERT L. (b'Th) Mass. I, 02

DERBY, GEO. STRONG (b'75) F-Mass.1, '00: (I'00); i Hereford St.; $(\mathbf{B} 4,14)$ $0 \mathrm{p} \star \star$

DERBY, HASKET (b'35) \&-Mass. 1,58; (む) ; Blue Hill Are., Nattapan; (B4,14).

De liobertis, Antonio-Ita.10,92; $\left(\mathrm{I}^{\prime} 02\right): 32$ (iaston st., Rox.; office, 046 Washington. Derrin, peter Jolin-N.Y.3, $92 ; \quad(0) ; 157$ Harvard st., Dor.

(1)VENNY. IOS. HEXRY - N.Y.8.95 (1'96); 34 Florida st., Dorchester ('enter. DEVINE, WI. HEXRY (b'60)\&-Mass.1, (83: (t): 787 Broadway : offlce, 59.

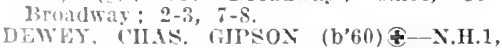
(f.: (5); 44 Alban st., Dor.; $2-3,6-7$; DEWIAG, IOTIS AJEXANTERS-TR.11 ol: (lot): 21 Huntington Ave.

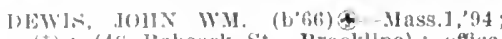
(1) : (4s Balleork St, Brookllne); offlec, (ii) Jewhury st. $8-9,2-5 ; 1 . *$

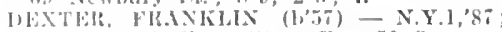
( $)$; 27 . Marlboro st.; oflece, 50 Congress ilition:

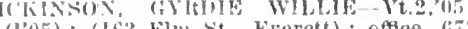
(16i3 $\mathrm{HIm}$ st.. Fiverct) ; offlee, 673 13ton st. ; $\$$ :30-12:30.

l) lemar, Jena lless Mass.5,98; (1'98); 1,2 IVelles Are., lbor.

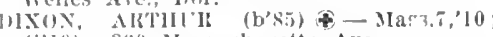
(I'lo); 360 Massachusetts Ave.

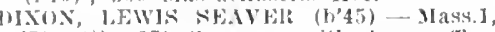

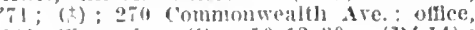
Op.

WAON, ROR'T. BREWEK (h', 6) M-Mass.1,

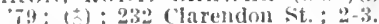

DIXWFil, JOHN (D'48)-Mass. 1,73 ; (t) ; $\Rightarrow$ W. Cedlar st. ; $12-3,5-\bar{t}$

boane, (lias. Britlley (b'71)-N.11.1,95 $\left(l^{\prime}(0)\right.$, ; Jarrarel Are., Alls.; mtil $9: 30$ $3-4,7-9 ; \mathrm{S}$

loble, Finest Fdgar-Mass.1,82; (5) : (150 1'ross st., (Ouney); oftle, l22 Huntlugt(i) Are.: (13:5).

DOBSON, 11ATHOOK HNDHEY (1): Member Me. Iied. Assn, ; Tob II intom $A \mathrm{re}$

bOBNON. WM. MAKLIIALI (b'83)-Mass. 07 ; (1'09): Boston state Ilospital; NP. Dorld, Walter lames (b'70) Yt.2,'0s; (1'I2) ; (Somerville); offtce, 205 lseacon St., Back Baly ; (GI)

OOM(iE, MLTIITI MALCOLM (b'62)

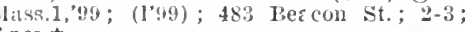

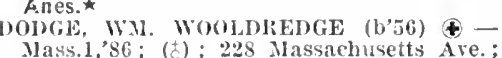
Mass. 1,86
$2-4, ;-8$.

OGGETT, YKEOK. FOBES - Mass.1,80 (む) ; 805 1. Rroadway, S.B.

Doherty, Francis Jos. (b'79)-Mass.1,'12; (1'12) ; 433 Shawmut Ave.

Dolan, Wm, Francis (b'y - Mass.1, 13 ; Isoston City Hospital.

OONLAN, CHAS. ENWIN (b'73)-Mass.1, 98; (1'98); Long Island Hospital.

DONOGHLE, FRANCIS DENNIS (b'71)£Ifass. 1,94 ; (b) ; S64 Beacon St.

onoran, Benedict - Mlass.1,8:; (১) ; 212 Columbus ire, ; 12-5.

Donovan, Jos. Átorslus (b'83)-Mass.1,'12 ; (1'I3); Carney liosital.

DORCEY, JAMES IBDMUND-Mass.1, is; (t) ; 172 Ilarrison Ave.

Douglits, Chas. Jos. (b'b0)-Ill.4,91;

321 rentre St., Dor.

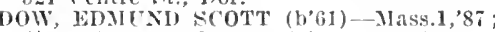
(t): 18 Harvard Are., Als.; until 9, 1-3;

Dowling, Joln Jos,-Mass. 1, 14 ; $(1 ' 96)$ : 652 Massachusetts Are.

DOWXING, ANDIEW FRIXCIS\&-Mass.1, 04; (1’06); (501 Huron Ave., Cambridge) ; offlee. State House.

Downing, Dana Fletcher (b'75) H-Mass.5, 04; $\left(1^{\prime} 04\right)$ : 53A Dale St., Rox, ; offlce 419 Boylston St., 12-1, 2-4; NP.

Doy, Wilberforce Clarkson (b'51)-0.7, (l'94) : 74 Boslston sit. ; 3-5

noyle, Danl. Patrick (b'65) - N.Y.5,90; (5) : 19 Mt. Bowdoin Terrace, Dor.; office, 33 Hollis St. ; $9-8$.

Drake, Arathena Bianca-Mass.6,'94; (t); 35 G St., S.B.

Drake, olin Milton-Pa.9,70; (1'95); 1767 Commonwealth Are., $\mathrm{Br}$

DRAPER, ALEXIS ICIIB (b',2) -Pa.1, 96 : (1'97): 1107 Washington St., Dor. until $9,1-6$.

Draper, Frank Eugene (b'64)-Mass.1,86; (5); (Winchester); offlce, 101 Tremont St. ; 9 -4.

Drew, Frank Haynes-Mass.1,82: (ह); (Iowell) ; offce, 705 Tremont Temple; 10 . 3):30

Drew, Fred-Mass.1,94; (ち) ; 409 Marlboro St.

ORUMMEY, NICHOLAS DANI. (b'65)థMass. $1,8 \pi ;(0)$; 533 Washington St., Dor-
chester Center; office, 546 Shawmut Ave.; $3-4$

DRURY, DANA WARREN (b'80) -Mass.1, 04: (I'04); 407 Marlboro St.; 1-3; (B15) AL'R.
HCKEIING, FIOItENCH WEST (1) ; (1'01); 4 \&3 Beal"on st.; 2-3; $\mathbf{S}$.

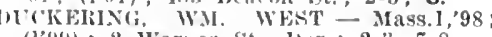
(1’yy); 2 Warner st., lor.; $2-3,7-8$.

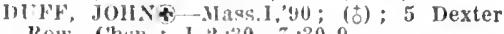
kow. ('hsn, ; $1-2: 30, \quad 6: 30-9$.

WTNBAR, FRANK (OLLINS (b'0)-Md.4, 93: (t) : 9 Bechlingen St., liox.: 2-3, $7=8$ $111 \mathrm{~N}$, (IIAS, IIINTEL $(\mathrm{l},-5) \notin$-Mass.1, 00 : $(1 * 00) ; 178$ Marlboro St.; 2-3; (1)], 3) $\mathbf{P d}$. $^{\star}$

IXN, WM. AloYslls-Mass.1,75; (1†) $1 . i 4$ lichnond st.

UNX, WM. AMBROSE-N.Y.5,93

154 Rlehmond St.

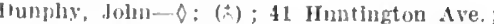
oflice, 114 Court sit

loutra. Emmanuel Chrlatian (b'61)-Md.3, 91: $\left(1^{*} 94\right) ; 33$ Nontello st.

uValley, danes Francls (b'-5)-Mass.7, 11 ; (i'l I) ; 57 ('imbridge St.; $10-2,5-7$.

"WHIIT, HUWIN WELLES 4 -Mas4.1,91; (c) : (Pramingham) ; offlce, 19 Pearl st.

1)WI(11T, JAML-Nass.1,79; (1†); not in Jritclle: ; 225 Beacon St.

Dyer, Frank l'lerce- $\rightarrow$; (t); 356 IIanover St.; otflee, 3.44 llanover st.

tyer, W'lllard Knowlton-o; (d) ; 210 l'leasant st.

PAMEs, (iEO. FRANKLIN (b'54)-Ta.2,82; (4); (1)entist) ; 249 Newbury St.

JWILL, GEO. IIENRY-Mass.5, 84; (t) ; 160 Longwood Are.; Prof. Obst., Miss.5. (D3) ; Or.

litrle, Geo. Wm. (b'86)-Mass. T'10; (1\%) ; 4 Farrington Ave., Alls.

Earle, Wm. Alva (b'58)- 111.8, 79; (t) Isoylston St.; $9: 30-2: 30 ; 0$ o. $\star$

Eastman, Eugene Saml. (b'71) - Mass.5, $04 ;\left(I^{\prime} 0(3) ; 2\right.$ Westiand Ave.; $3-4,6: 30$ -

ASTTIAN, THEOIORE JETETT (b'79)థ Mass. 1,05; (1'05); il Marlboro St. $2-3 ; 1 . \star$ EAsToX. ELWOOD ThACY (b'76)-Mass.1,
son: (1,99): 209 Newbury St.; $12: 30-3$; (B14) ; Op.`

Khann. 'has. Deletang-Mass.7,'94; (む) ; 25 Marthoro St.

delstein, Saml. (b'89) - Mass. 7'11; (1'11) 31 Caston, Rox.; ofnce, 26 Davis St. ; $9-10,2-3,6-8$

EDLs, liol't". TIIXXTEk (b*38)-Mass.1 61 : (c) ; (Reading); office, 419 Boylston St. ; I1-I; (E1) ; NP.

DISALL, WAVID IINN (b'69)D-1'a.1,'93; $\left(Y^{\prime}(2) ; 80\right.$ Marlboro St.; Prof. Clin. Med. Mass.1 and Mass.G1; (D1,6, F10); $1 \star \star$

E1SON, I'TOLEMY O'MEARE - Vt.2,'60; (ठ) ; 36 Elm 11 ill Are., Rox.

EDWARDS, WM. LOTIIROP (b'64)-Mass.1, "14; (ठ) ; 33 Filoncester St.; 9-10, 2-4.

EHIENFRIHI), AlBERT (b'SO)\&-Mass. "15: (1'04) ; 362 Commonwealth 4 ve.; 2-3; MIiLICH, 1IANRY (h'65) @- Mass.1,'86; ( $\ddagger$ ) 172 Conmonwealth Ave, ; 1-3.

DLIHIDGI, DAYID GOHHA.I (b'56) क Mass.1,'86; (ठ) ; 15 Monadnock St., Dor.; $2-3: 30 ; 0$ ob. (b) ; 124 Beacon St.; (A5)

irist: (A5) LIIOTT, IUSSEIL. DUNSON-Mass.1,73;
(む); 9 Dwight St. ; offlce, 154 Richmond St.

LLLIS, HDW. KEITH (b'79)\&-Mass.7,02 (1'02); (38 Beacon St., Hyde Park); offlee, 232 Clarendon St.; $12: 30-3 ;(B 14)$; Op. $\star$

ELLIS, WM. IRAYMOND (l'98) . 26 Ashford St,'98;

Ellsworth, Vlctor Albert-N.Y.6,76; (む) ; 41 Waltham St.

EIY, THEODORE W' (b'84)-0.6, 09 ; (1'13) ; Member S.C. Med. Assn.; 374 Marlboro st. ; (D3).

EMERSON, FRANCIS PATTEN (b'62)@N.Y.1,'86; (t): (124 Longwood Are., Brookline); office, 520 Commonwealth Are.; $(\mathrm{B3}, 15)$; ALP. $\star$

Emerson, Fredk. LincoIn (b'61)-Mass.5,'92; (t); 50 IIancock St., Dor. ; 4-6; Ob.

EMERSON, GEO. EDW. $\oplus$ - Mass.1,03; Boylston St. 
EMrisox, NATIISIFI, WAIIm) (b54) - Mass 5i: (2) 295 commemuealth

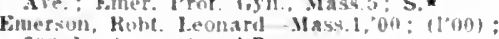
i.39 Moylsten si : LD.

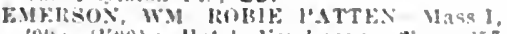

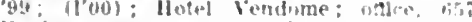
Beylstom st.; Asit. I'rof. l'ed, Mass.; (1).3); Pd.

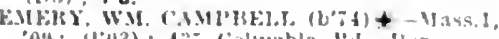

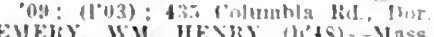

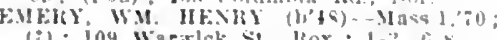
lo 109 Warork st. liox. D-3. li-s. 02: (1'05): (1wiver): onlce, st Bay stu Hd.: :-3: (D3): 0 b.

Emmons, lienry Sanning (b':6) H-Vacs.

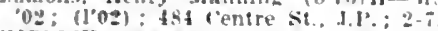

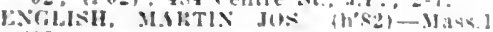

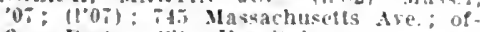
the. Hovton Clty Hospltal.

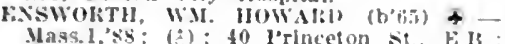
Mass.1.

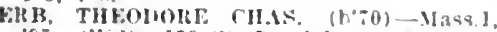
$605:(196): 159$ st Botolpl st.

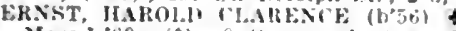
Mass.1, s0; (c) : \& (ireenough Ale., J.J. ondee, 240 longwoud Are.; P'rue. Hact. Massi 1 anil Mastifil (r)

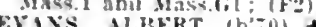

E) Al, Mass.1,"12: (1'n1): 402 Marlboro st.: 2-3: S

EVAXS, MINER HALLOW AMOS $\left(\mathrm{b}^{\prime} \mathrm{Q}(1)+\right.$ -Mass.1.02: $(1002)$ : sR Alban st. Dor. offce, 138 Nerrbury St.; :-11; NP.Æ

EVHHFT, EN"(IENE ELLSWORTI-Mass I, 99: (l'98): 427 VIrhoro st.: 1-3: G

FABYA, MaRSHAI (b'9) - Massi, 04: (1'05); 379 Commcarealth Ave.

Fallace, Gatano- $:\left(l^{\prime} 0.5\right): 81 \mathrm{~s}$. Hunting

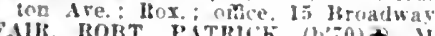

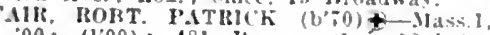
$00 ;(100) ; 481$ leacon $5(0,12-4,31)$ ODG. *

FAIRBASKS. ARTHI'R WJLLARL (b'49, -Mass.1,94: (2) : (Brooktine) : office. 591 Beacon st.; $2-3$; (1) 3, E:2); $\dot{N}$.

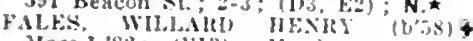

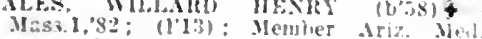
Asan.: 200 llarold ist. t:ox.

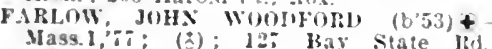
oflee. 234 Clarendon St.; id-i; (BZ, 1., LR.

FAlR, EDWIX IAWSON $\left(b^{\prime}+5\right)+-x_{-3}$. "7: (?): 3 Highland st. Wox. : 1-3.

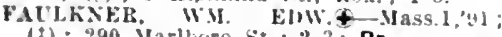
(3) : 290 . Marlbriro St. ; $2-3 ; \mathrm{Pr}$

FAINE, CALIT MAISTOW, JR. Id tot (1'04): 42 Sirtug Park Ale (B15) : ALR.*

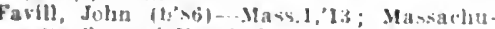
setts rienteral Hunpital.

Fancett, Debrarah (b'a)-Nas4.5,03; (1'04): 1400 (entre St. Sewion: 2-4): whlet, llotel Puritan.

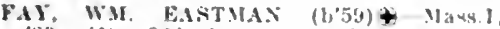

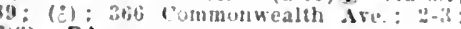

Peeley, Wditer clarence (b's5)-isass.l. 11: (1'11): Lying-in Hospital.

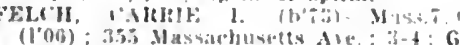

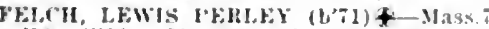

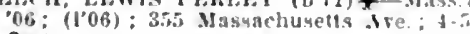

Or. $\star$

enelon, Katherlne dones (b-73) - Masas" 01: (1'02); yo charles st. liack liuly 2-4, 7-8: l'rot. Mlin. Med., Mass.ti.

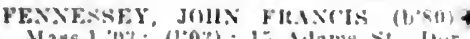

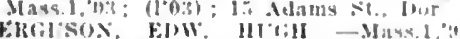

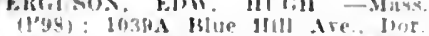

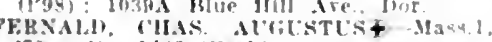
"72: (3): 1483 washington st.

Fewell, Samu. dackson fl.c.3, 94 racnden si

Flek, Hermann Andtew

(e); lug Warren Are.

Pleld, Harvey Adams-Mass l, gs: (I':0) 4.9 Mret st. Mat.

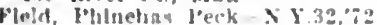

lfuntington Alp. box.

rield. Susan Hammend-Vasq.5. i6s Ilunthentsen Are. Hox

Fillebrown, Chas Dalton (brif) - Masu $\mathrm{KT} ;(3)$; 119 froylston si.; 2.1
FiRkLSTEIX, HAIEY (b'81) + Mass I, "04: (1.04): 3t: Hanorer st.: : $2.3,7.8$; obc

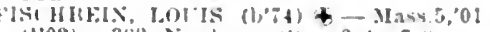

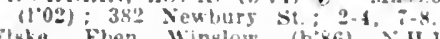

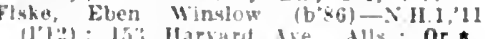

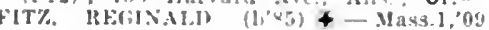
(1'11): (Manchester); ontice, is Arilngion si.: (De)

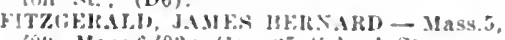

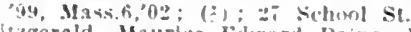

Piozerald. Maurlee filwari l'aine-Mass.1,

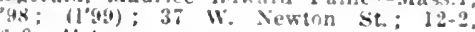
is-s; U.*

pirgerald, Thomas Parrick (b'il)-Mass.l. 9 : (100); 34 strarlawk st.; $2-4,7-9$. tritrglblon, Edward James - Mass lot. (l'0t): 82 Waldeck St., Vor.; - -3, - - 8 : l'rof. I'ed., Mass.ti; Pd.

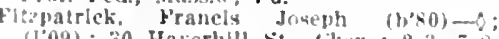

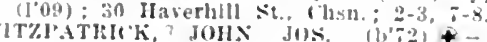

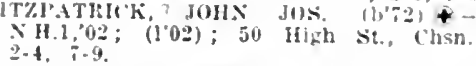

ITZSIMMONS, HENGY JOS (b'\&1) Matss.1.08; (l'08); Chltdren's Ilospltal. mice, 2iz Sewbury st.; Or.*

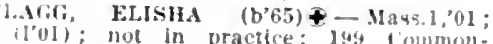
wealih ire.

Elatili, haRRY HOWARI) (b's1)-Mass. os; $\left(1 l^{\circ} 08\right) ; 30$ Elm St., Chsn.; 1-3, ;-s; $G$

Finders, Alton Le Roy (b) $(1.95) ; 19466^{2}$ Columbus Are., Rox.; after

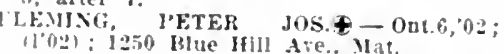
E. ETEIIER, [BORT WUITXEY 4t:

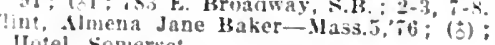

tiwer, Alfred Hollis-E-O.34,94

101 St. Botolph St. : 9-1.

L. IID, CLEAYELAXII (b's0) \& Mass.1, van, (1403); 1348 Iseacon St.; (1)3, F.2). (1"14) : 19 IIarforel it., Dor. Mass.1,07, linn jolin Edre be por

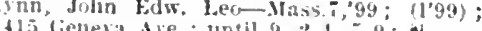

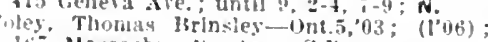
Itit Massachusetts Ave.. S.I

Folger, lieo. Irthur (b'sfi) - Mass.5,'1l; (1'li) ; 1293 ronmonwealds Are., stis.

Foot, Nathan Cbandler-N.Y.1,07; (Brook-

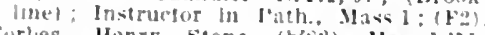

wrive, Henry stone (b's)-Massidil (l'13): l'eter Bent Jolghan Hospital.

Furd, vanl. Frank-0; (5); 265 Stawnut

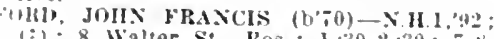
1:) ; 8 Walter st, Ros. : $1: 30-2: 30 ; ;-x$. vount sirnal Hospital.

Foster, Arthur $x$ (b's3)-Que.1.12: (1'12) lilld llurehuster st

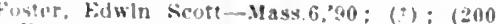
Fairmont Are., Hyde rark); once, 1:0 Premint st.

Findly, saml. (b'51)-1'a.17,75; (\$); 4

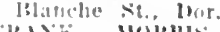

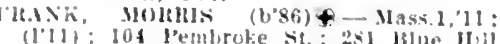
We" $160 x: 2-3+30,7-5$

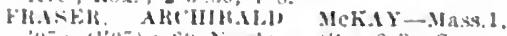

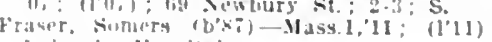
L, lain-in llospltal.

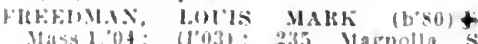

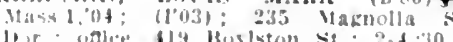

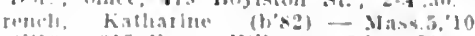

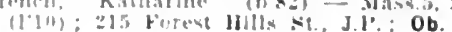

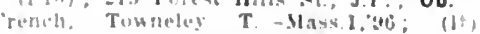
unice, tis to fill st. s.tt.

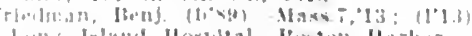

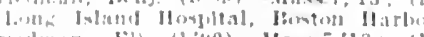

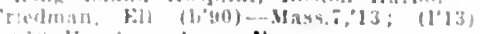
B] Marrisull die.; $\mathbf{N}$

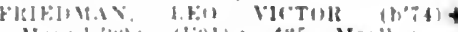

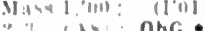

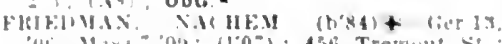

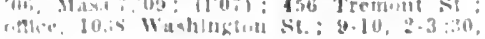

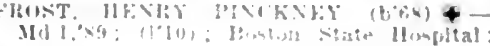

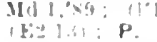

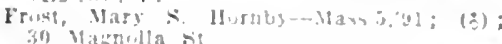

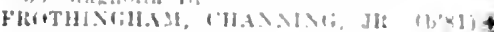

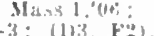

Frminingham, James kilsr.

11 . Nlutun st: 12-2, aiter

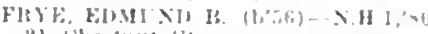
21 ibertinut st.

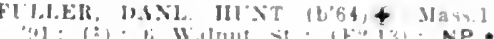

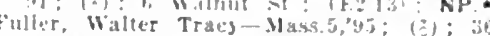
llarrard st., Inor.

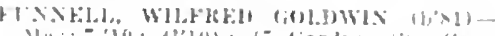

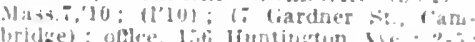

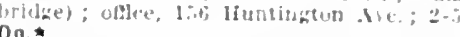

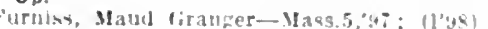

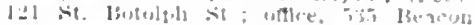
Caterner, Nlexander (b) 19.3 L'1lgriu Bil., fen.

ialpgloll, Girolamo-lta.1,79; (E); 2t5 Tlantree st.

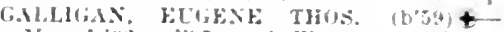

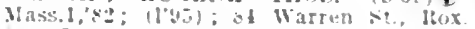

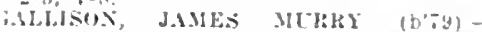
Massi, 0 : (108); Ioby Boylaton st.

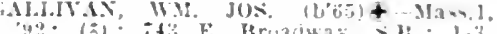
"92; (3); itz E. Bruadwag, \$.L.; 1-3,

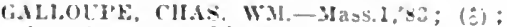
lis. crommonwealth dre

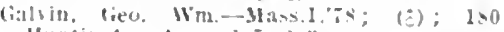

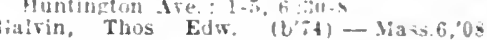
11'111; 1.21 Veruun st., Kux.; 1-3, 6-s. Ganthe, Janes Larider (list) -Mlass.1,10: (1'10); 279 larenden st.

Gitmmons, llertert frarcis (b'85)-Mass.5.

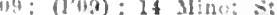

G.SXX:TT, WM, WHTHOHTH - Nass.

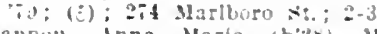
Gancun, inna Marla (b'en)-Mass.s,'ss: (2): 34 Isabella st.; I t - y.

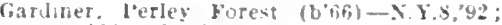

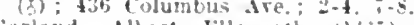
iarland, Albert Fallsworth (Lij)-N.Y.3. 'y5): Medical birectur. Yuunz Meu's Chrlo tian Asan.; 66 Westiand Are

Garlani, curnefius Xathantel-N.C.3,01: (103): 20.511 . Cantun st.

(iarland. Fredk. Tugene (b'a)-Mass l.0\%;

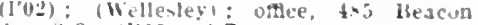
St, : - -3: (1315); LR.

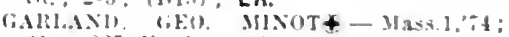
(i) : 227 vewburs st

Garllek, Fredk. Jos. (b's - N r.3,11; (1'13); 13uston ('ity Hospitil.

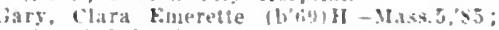
(2): 116 Marfloero st: $11-1$

Gart, $11 \mathrm{~m}$. 11. II. (b'25)-Mass.int: (1'04): (4) Lowell Rd., Winthrop): attec, 1140

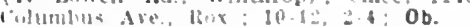

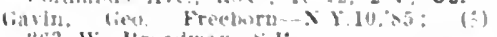
"63 W. Hreadway, $\leq 16$

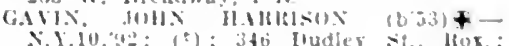
$1 \cdot 3,-9$.

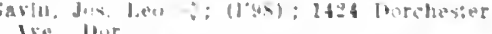

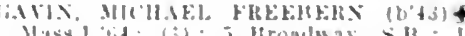

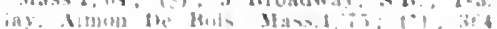
IInlnut the lisu

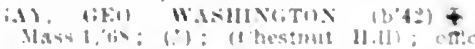

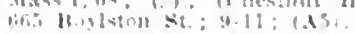

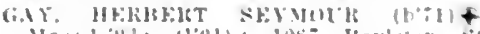
$1,5 \times 0$
1006

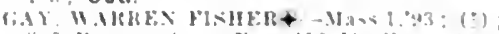

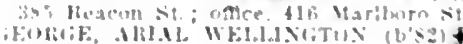

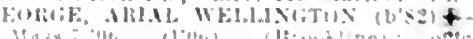

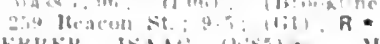

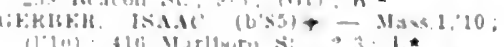

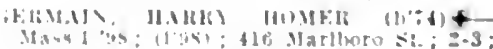

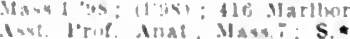


(;ERSTEIN, MATRICE-N.Y.5,96; (I'96) 493 Warren st., lox.: 1-3; 1'rof. Mat Med. and Ther., Mass, 6 ; Ob.

Gervais, Harriet Marlon (b'89)-Mass.7,12; (1'13); I'sychopathic Ilosplital

Gettings, James Henry-Mass.7,07; $\left(1^{\prime} 06\right)$ 415 Columbus Are.

GHOREYEB, ALBERT AILIIONSO WOOH (b'86)_Mass 1,09; (l'09); 483 Ibacon st. GIBLIN, FIANCIS JOS.-Nass 1,93; $\overline{(8)}$ 33 Adams st., Ior.

Gibson, Arthur, Stanley (b'a6)-N.Y.10,97 (1'0r) ; $2: 3$ Warren Ave.: onter, it Boyl ston st: $10-5$

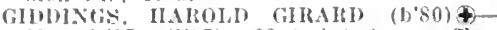

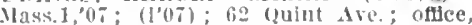
28 Commonweilth Are.: $2-4: S$

(itclurlst, chas. 1t.- 0 ; (1†); Ifil Ifuntington

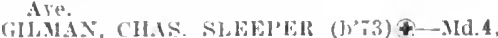

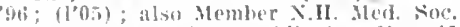

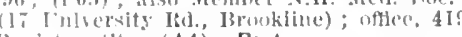
Brigkton St, : (14); Pr.*

GLMAX. EUGENF A B B BRT-Mass.1,72 (苂 : 6i: Dudley st. Dor.

(iHLPTIICK, ROY IIIWKES (b'77) VIass 1,05; (1.05); 1069 Boylston st. $1: 30-3: 30: \mathbf{S}, \star$

Gleason, Edw, Francis - Yt.2,99:

$(1,93)$;

Gleason. Geo. Ilathaway (b'7s) Mass.1,02; (1'01); not in practice; 13fi rosscler st. Dor

GLTNT, D.1YIV (1,83) + Mass.7,12 (1'12); 39.7 Charles st.; ottlee, Carney Hospital.

Gobron, Ioufs constart (b'5.)-N.Y.10,'ss (t) : 2550 Washington St. Irox.

CODDT, IOT'IS AJILORE OLIVER $(1,79)$ \& -Mass.7.05; (105); 407 Marlboro St.; $=3 ; 0 r . \star$

Goetsch Emll (b'83) - Md.7,09: Peter Bent Brlgham Jospital; (FI,2) ; S. $\star$ *

GOLDEN, LAZARUS (b'66)†-Mass.1.00 (1'99); 69 Chambers St.: 9-10, $2-3,7-8$. GOLITHWAIT, JOEL ERNEST $\left(b^{\prime} 66^{\circ}\right)$ t Mass. 1,90 ; (b) ; (Milton);

Marboro $\$$ t.
GOLDTHWATE, SETI VALE Mass.5,'80; (t) ; 25 Rill St., Dor.

GOOI, FREDK. 'LEO. (b'8') -MISss.1,04 (1'04); (1928 Beacon St. Brookline) office, 95 Newbury St.; $1: 30-3: 30 ; 0 b G$. GOODALE, JOS. LINCOLN $\left(\mathrm{b}^{\prime} 68\right) \oplus-$ MIass.1,93; (t) ; $25 \mathrm{~s}$ Bcacon St.; 2-3; $(B 2,15) ;$ L R

GOODALL, IIARRY WINFRED $\left(\mathrm{b}^{\prime} 76\right) \oplus-$ Vass 1, (1): ([’02) 207 Beacon st.

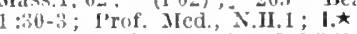

Goodman. Nathan Mlark-N.Y.5,'91; (†) ; 52 Chambers $\mathrm{St}$. ; offlce, 419 Boylston 'St.

GOODMAN, SAMIL.૯-N.Y.5,'89; (ち) ; 148 Towns nnd St., Rox. ; $2-3$.

Goodwin, Haroli Nerle (b'86) - Mass.1,'13; Boston City Hospital.

Goodwin, Wilford Watson (b'60)-Que.1,'88; (b) ; 39 Princeton St., E.B.; 1-3, 7-9.

COOKIN, EDW. RICHARD - IId.4, 06 (1'06) ; 801 Columbia Rd., Uphams Corner

GORHAM, GEO, HARTLEY (b'74)Ð IIass.7,03; (l'03) ; 14 Hastings St., W'est Rox. FPIXCIS WEBSTER $\left(b^{\prime} 42\right)$ IIass.1,69; (f); The Warren, Rox.; 2 :30$3: 30$

Goulding, Timothy Francis $\left(b^{\prime} 72\right)-M a s s .1$, '96; (1'96); Commonwealth Hotel.

Grady, Jos. Wm.-X.Y.5, 90 ; (f) ; (Arlington Heights): office, it Boylston St. $10-12,2-5,7-8$.

GRALAM, DOLGLAS $\left(\mathrm{b}^{\prime} 48\right) \oplus-\mathrm{Pa} .2,73$; (ᄒ); (177 Aspinwall Ave., Brookline) office, 74 Boylston St. ; 9-10, 12-1,3-4.

GRA1NGER, EDW. JOHN (b'78)-Mass.1 03; (1'03); (Bartlett Park Rd., Winthrop); office, 66 Paris St., E.B.; 3-4, 8-9.

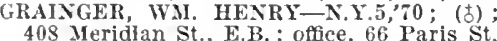

GRANDISON, WILRED GEO. (b'76) Mass., 01 ; (1'01); 65 High St., Chsn. GRANGER, FRANK BUTLER (b'75)€Mass.1,'02; (1'02); 591 Beacon St.; (G1);

GRANT, WH. HERBERT (b'72)(-Mass.I, '96; (む) ; 293 Newbury St. ; $1: 30-3$; G.
GRATES, BEN.I. AUGUSTUS†-N.H.1, 97 ; (196): I78 Bowdoln St.: Dor.

Graves, $\mathrm{F}$ stuart $\left(\mathrm{b}^{\prime} 79\right)-\mathbf{X} . \mathbf{Y} .15,11$; Asst. I'athologist, loston City IIospltal.

Gruves, Walter John (b'63) - Nass.5, 99

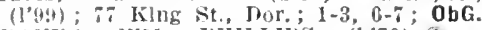

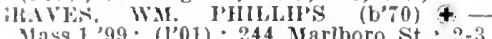
Mass. 1,99: (P01); 244 Marboro St. (AR); G. $\star$

GRAY, AIICE MAUN-Mass. 7,00 ; (1'00) liotel Warren. Ibox.

GHAY, ELIZABETII TAYLOH (b'65) N.Y.14,95; (1'95); 149 Warren St., Rox.; $2-4 ;$ G.

Greco. Pranceseo Sarerio-Ita.10,02; (1'04) 9: Prince st.; office, 327 Ilanover St.

Green, Abraham-Mlass.1,03; (1'03); 1 Allen GIREE, (IIAS. MONTRAVILLE $\left(b^{\prime} 50\right)+$ Mass. I, 77; (屯) ; 78 Marlboro St. ; 1-3; l'rop Obst and Grn., Nass.1 and Mass. (i) ; $(\mathbf{\lambda} 2,8) ;$ ObG. $\star$

(inkex, JoHN OLNE (b'41)-Mass.1, tio;

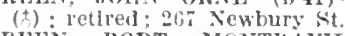

GREEN. ROBT MONTHAILLE-Mass.1, 06; (1'06); is Marlboro St.

GREFN, SAMI. ABIBCTT (b'30)-Mass.I, 54: (1) ; 1164 Boylston st.

GREFE, DANL (HOSBY (1)'? + (IB2.3,15) ; LR.

GIREENE, EDW. MHLER (b'61)£-Mass.1, 88; (5); 45 Chesinut St.; 8:30-9:30 $2: 30-3: 30,7-7: 30$.

Grecne, Jared Alon\%o (b'45) E-C.2,67);(0); (Long Island, X.II., l'97); office, 597 Albany St.

GREENE, THOS. FILANCIS (b'62) Mass. $\pi, 94 ;(\delta)$; 322 Warren St., Rox;

GIEENE, WM. HENRY (b'55)-Nass. 7,96 ; (1'96); 322 warren St., Rox.

GRENNOUGI, ROBT. BATTEY (b'71) † Irass.1,96; (1'97); 377 Beacon St.; $2-3$ (A5) $: \mathrm{S}$.

GREENWOOD, ALLFN $\left(b^{\prime} 66\right) \oplus$ - Mass. 1 , '89: (†); (Wellesley Hills); office, 101 $\begin{aligned} \text { Newbury St.; } 10-1: 30 ;(\mathrm{B1}, 4,14) ; & 0 \mathrm{p} . \star \\ \text { Grey, Ernest Geo. (b’84)-Md.7,11; } & \left(\mathrm{l}^{\prime} 12\right)\end{aligned}$ l'eter Bent Brigham Hospital; S. $\star *$

Grimes, James Henry-MIass.1,'98; (1'97); 1085 Boylston St., Fen.

Grinnell, Francis Browne (b'87)-Mass.1, '13; (1'13); 240 Longwood Are.

Grogan, Margaret Víctorlne (b'83)-Mass. 7 , 13: (I'13); New England Hospital for Women and Children.

Groppner, Max Carl $\longrightarrow ;\left(l^{\prime} 00\right) ; 187$ Lamartine St., J.P.

Grover, Jos. Isaac (b'85)-Mass.1,'11;(1'11) 1329 Blue IIill Are. Mat.; office, 272 Newbury St.: $3-4 ; \mathrm{Pd}$.

Guibord, Alberta Sylvia Boomhower (b'73) H -Mass.5,'99; (1'01); 409 Huntington Are. ; GUILD, P. (I'96) ; 1550 Blue Hill Are., Mat.; 12.192 $6-8$.

Guptill, Lucien Hayden-N.Y.5,78; (ち) ; 179 Blue Hill Are., Rox.

GUTHRIE, ANIREW DOHERTY (b'91)-

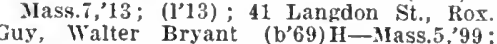
(1'99) ; 277 Warren St., Rox. ; 2-4; 6-7:30. Gwin, Robt. Campbell (b'70)-yld.4;95; (l'98) ; is Brighton Ave., Alls.; 4-5.

Gwinnell, Alfred Weston (b'78)-Mass.7,11; (1'12); 558 Washington St.,Br.; untll 9 $2-4,7-8$

HAINES, IGNATIUS (b'71)-Mass.1,97; (l'98); 580 Commonwealth Are.; offlce, 120 Franklin St. ; $9-4$.

Haines, Thos. Harvey (b'71)-0.40,12; In tern, State Psychopathic Hospital; NP.

HALF, WM. WORTH $\left(b^{\prime} 76\right) \oplus-M i c h, 1,04$; Mlember Ifed. Soe. of D.C.; 90 Cypress St., Brookline) ; office, Harvard Mfedical
School ; 9-4 ; Asst. Prof. Phar., Mass.1 and Mass.G1.

Haley, W'm. Thomas (b'82)-Mass.7,'13; (257 Washlngton St., Marblehead); Intern, Boston City Hospital.

HALL, GARDNER WELLSథ-MI. 7 ; 01 $\left(1^{\prime} 02\right) ; 475$ Beacon St.
HALL, IOIIN BAYTISTE (b'76)世-I'A.I, 01 ; (1'02); 60 Windsor Sto, Rox.; 3-5.

Ifall, Wm. (b'57)-Seot.9,'85; (l'95); 199 Neponset Are., Dor

IALL, WM. WUDLEY (b'56)€-Mass. 1, 83 : (t); 416 Marlboro st. : 10-4; (B4.14)

Haller, Davld Alexander (b'88)-N.Y.1,'13; Peter Bent Brigham Ilospital.

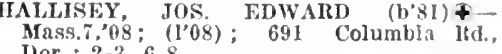

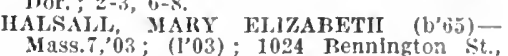
E.R.; $2-4,6-7$

Ialsey, Fre(lk. Wadsworth (b'49) II-I).C.1 '71; (5) ; 272 Newbury St.; 1-3.

(1'03) - 1799 Dorehester Are Mass.5, 0 ? :

HAMILTON, ALBERT JOIN ADAMS (l, + Pa.1,06; (I'06); 69 Newbury si.

GAMILTON, ANNIE LEF (b'64) "98; (1'98); 164 Longwood Ave, i : HAMILTON, BURTON EVERETT $\left(b^{\prime} 8\right.$ h) \& Moss.1,10; (1'10); 152 Park St., West Box.

Hamilton, Frank Andrew - Mass.1, 06 ; (1'04); 50 Chambers St

Hammond, John W., Jr. (b'85) - Jass 1,'12: Intern, Massachusetts General Hospital.

IIAMMOND, PIHIIPA-Mass.1,24: (11 Haneock st., Winchester); office, 483 Beatcon SI. ; 2-4; (B5,15) ; A. *

HAMMOND. WM. JOHN (b'69)£-Mass. 99 (1'99); 495 Washington St.; Dor.

HAMIOND, WMr. PENN-Mass. 1, 73 ;

47 Jonument Sq., Clisn.

IANSON. WM. CIINTON (b'74)-Mass. 05; (1'05). (1619 Massachusetts Ave., Ilealth $9-5$

HANSON, WI. TIIOMAS (b'80)-N.H.I '04; (1'07); (Arlington); offlce, State

Harding, Edw.

74 Boylston St. Mass. 1,$89 ;(5) ; 419$ Boylston
St. ; 11-1;

HARDWICK, EVERETT VINTON $\left(b^{\prime} \pi 7\right) \oplus$ Mass.1,00; (1'00); 43 Algonquin St., Dor.; I-3, $7-8 ;$ G.

Hardwick, Fredk. Veazie- 0 ; (1'04); 212 Ashmont St., Dor.

HARE, CHAS, HENRY (b'63) - Vass.I, $89{ }^{\prime}(5) ; 483$ Beacon St.; 2-3; (18)

HARMER, TORR WAGNER (b'S1) $\oplus-$ Inass. 1,$07 ;\left(1^{\prime} 07\right)$; 192 Marlboro St. ; -3 ; S.*

Harnett, Edw. Henry Lewls (b'83)-Mass. 7 , '10; (1'12); 327 Genera Ave., Dor.; 2-3, $7-8$.

HARRINGTON, DANL. JAMES LEO (b*86) (-Nass.7,10; $\left(l^{\prime} 10\right) ; 975$ Dorchester ARPINGTOX

-MIass.1;81; (t); 201 Beacon St.; 2-3; (A5) ; S. $\star$

HARRINGTON, HARRIET LOUISEFIIIch.1,"83; (f); 20 Monadnock St., Uphams corner.

HARRINGTON, THOMAS FRANCIS $\left(b^{\prime} 66\right)$ †-Mass.1,'88; (\$)); 310 Commonwealth Are.; $1 . \star$

Harris, Saml. Jacob $\left(b^{\prime} 75\right) \longrightarrow$; $\left(I^{\prime} 96\right) ; 114$ Huntington Ale.: 2-5.

HARRISON, COLUMBUS WM. $\mp$-MaSS 7 , '06; (1'06) ; 35 Comnon St.; $12: 30-2: 30$,

HARRISON, HENRY - Mass. 7,$04 ;$ (1'05) 153 Iluntington Ave

Hart, Chas. Oliver $\left(b^{\prime} 59\right) \rightarrow$; ( $(5)$; 2 Kearsarge Terrace, Rox.; office, 55 Tremont St.; $10-5: 30$.

Hart, Michael Jos.-Mass.1,'96; (1'96); 1635 Dorchester Ave., Dor.

HARTNETT, EDW. DANL. - Mass.1,98; (l'98); 128 London St.

Hartshorn, Edw. (b'70)-N.H.1,96;(1'95) : (Brooklíne); offlee, 419 Boylston St.; $10: 30-12,1-4$

HARTUNG, HARRY HALI (b'75)—Conn.1,96; (1'98); 224 Huntington $\mathbf{A}>0$. ; $2-3,7-8 ;$ D. 
Hariwell, balw. Mussey $\left.\left(b^{\circ}, 0\right)\right)-(0,9,5:$ (1t); not lo practle? : Burroughs St. uflce, Clty Hall.

HARTWEI.I, HAHKY FAIRBAXKA (b:3) -Mass. 1,98: (1'89); 343 Jleatun St:

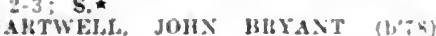
Mass.1.04; (1'05); 960 (1arembon sto $2-3: 5$.

HAKVEY, JOHX FIANKLIN-X.Y.5.90

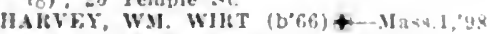
(I'9s): 516 Warren st. Itox: 1-3; G.

llaskell, ('usa rell (1,8;)-Miss.5.'13; In tem. Massachusetts IIomeopithte "Itos pltal.

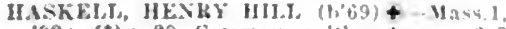
93: (3) : 29 Commonweall Ave.; : $(B 4.14) ; 00$.

Hastlas, Frank Fugene (b":t)-Mass, : "n? (l'03): 204 II untiugton dre. ; $1-3,7-k$ Asst. Frot. Mat. Med, and Ther. Mass.

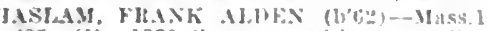
85; (ह) ; 1379 commonwenlo Ale. Alls. $1+3 .-8$

Iasman, nald Jorris (bowi) - Mass. .13 Intern, Roston rlsy Husyltal.

Ilastlngs, Carollne Fllaa (b'tI)II-Mass, 68 : (ह) : (Sharon); nfles, 210 Newlury

H.STIX(:S, JOHX MASUX - MAS 1,95 (1'96): I1 stoughton si., lor.

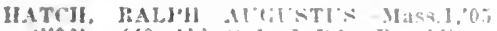
(J'03); (40 Abbotintori Ild. Broukline) oftice 3ns Commonvealsh lie.

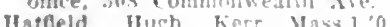

360 Jarlboro St.

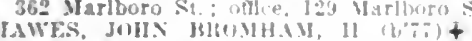

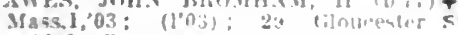
$1: 30-3 ; \mathbf{T}$.

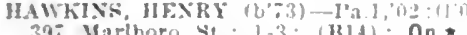
397 Marboro st. 1-3; (H1H): OD.*

layes, Darld Patrick-II

Hayes, Edward James (1,-6) -. Mass.5.0. $\left(l^{\circ} 08\right)$ : 1840 Columbus ave, hox.

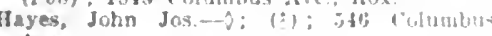
Ave.

Leard, Yary Ann $\rightarrow:$ (1'01): 24, Wurten St. Rox.: oflice, 30 II unthzton Ire

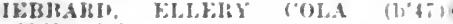
S.Y.10,-0; (t); Iga lluntlontor die 10-4.

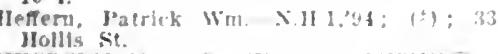

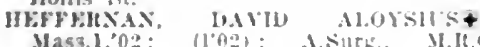

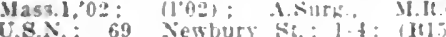
OpR. *

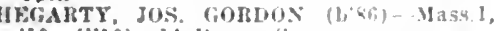
10: $\left(1{ }^{\prime} 10\right) ; 1+$ lorker sit

HEMEON, FHEILK rHIJMA (l,69) 1'a.2,97: (1'9i); standish st., llor. t16 $9: 30,1-3, i-8$.

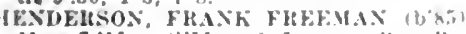
Mass. T.11: (1'11); 6 locinan it, Hux otfice, 39 Nenbury $\$$.

Ilenderion, lawrence Jns. - Mass. 1,02 (1'02): (52 Concurd Ne. ('ambridge) oflce. 240 Jongword Aif.; Iste Prof Blul. Chem., Mass. I and Mans i il.

Blol. Chem., Jass. I and Mandid.

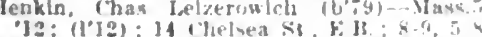

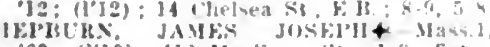

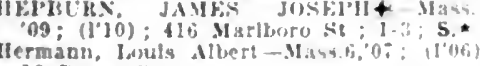
16 Wover sit.

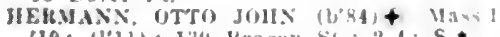
10: 11'11): 1:19 Meacon Si. :2-4; S.

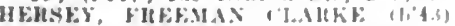

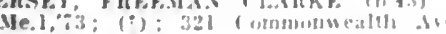

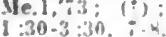

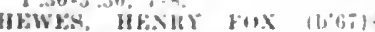

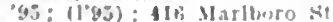
แFW

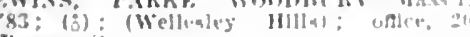
licaron sit.

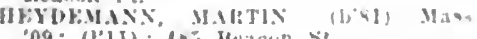
Ilickey, John Alus slum Mas. I."

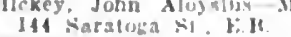

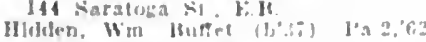

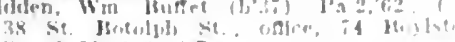
St : $11,1.1$ LR.

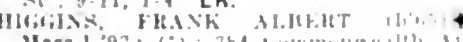

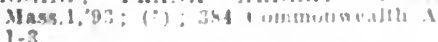

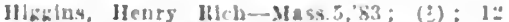
Harrard Are. All ; : 8-9, 4.0

HILL, GFo SUMNEK $(6,6,1)-M a s .1,99$ (1'99); 295 Beacun si. : :

IIII, Johrison Washlnkton $(b * 5)$ ) - Mass of os: (1'11); 304 Columbuy st. : uneil 9 . $12-2,5-8 ; \mathbf{G}$.

11111, Jewls Webl, (b'93)-Mass.1,13: (1'13): 23 Sil. Jubn st.

Hubie Hind-Mass.5,"92; ("); Is9

fumbington dre.

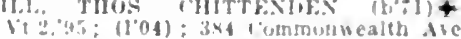
$1: 30 ;(A 1)$; Pr.

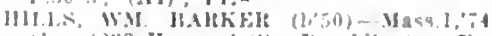

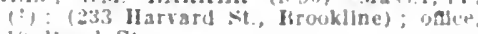
1.t loarl St.

HII. KI.Fy, JAMl: WV. h'J7)-Mass. a: (1'95): Ifroukllue); oflce, 419 bust

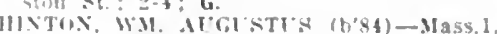
12; (l’lz): IIarvard Medlcat Schuol.

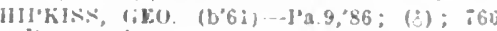
Buiteris sit.

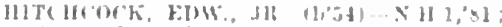

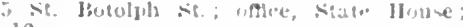
10 .

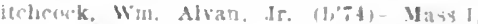

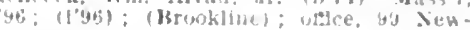
Hurs st:

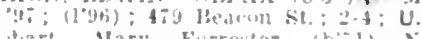

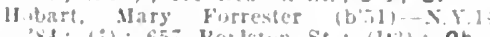

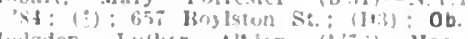
llodidon, Luther Nlwon (b'ij)- Mase

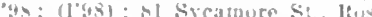

HOLGES, ALAONIU INAFUHTH (b,T) + Mass.1,93; (*); The Wasten, lios,

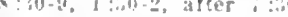

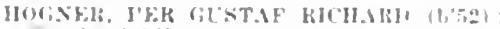

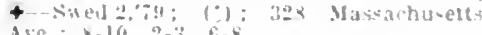
lotuingon, Walter le Ville

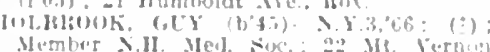
Ulembrt $>11$.

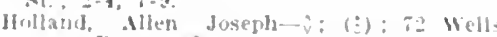
Ne nor. onke, $10 \%$ Washiniston 5

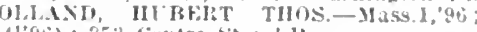

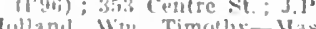

Inibi centre st. West hox.

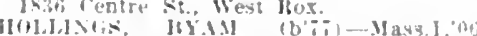
("06); Massachuetsi fieneral Joupltal.

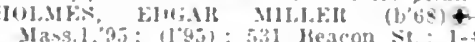
MIas.1.35: (I.05)

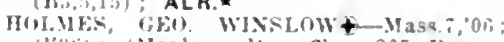
(1'0b): (Maplewond); uflce. 205 Heacun

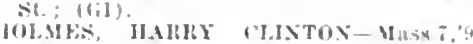

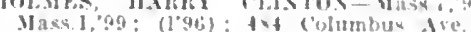

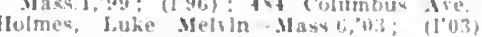
jio Nurthamptur sit.

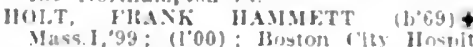

Mass J.99: (100): Buston rigy Hnafital is lirnal st.

Ilolman, Joseph-111.11,92; (1"15): I Falm

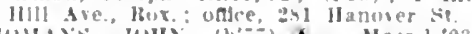

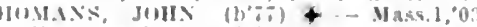

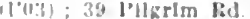

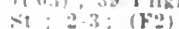

llimer, Sunford Jurton (h'sh) - Mass.5

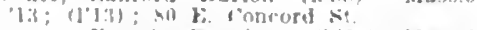

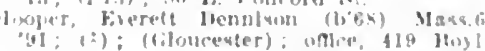

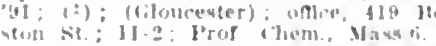

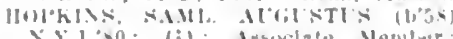

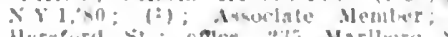

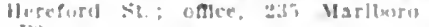
$\left(\mathrm{B}^{\mathrm{n}}: 0\right)$

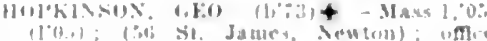

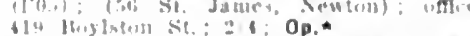

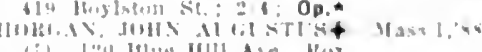

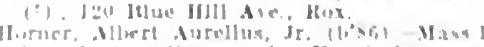

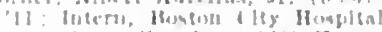

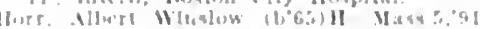

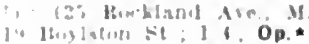

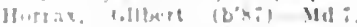

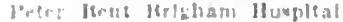

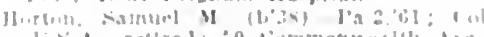

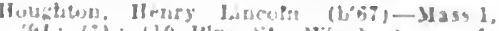

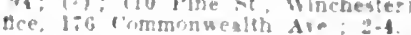

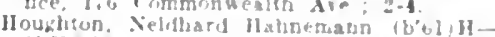

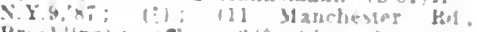

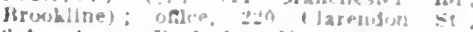

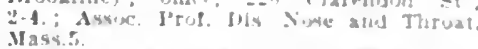

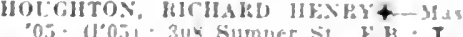

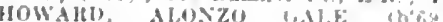

Mas9.5,95: (1'95): 101 Arsuan ire

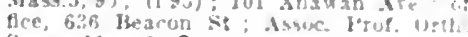
Surin., Masu.j. Or."

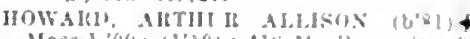
Mass. 106; (1'10): 114 Marlkoro si (II.) : Pd.

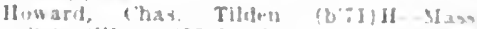

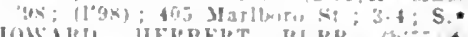

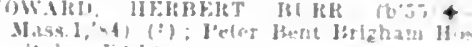

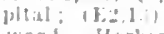

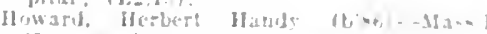

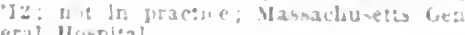
era! Irosplial.

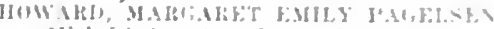
$-11 ! \cdot 1$. 1, :-2:

Homilat.

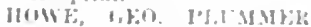

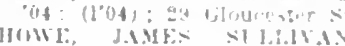

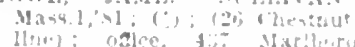

$112+1)$

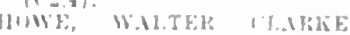

S.*

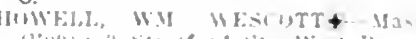

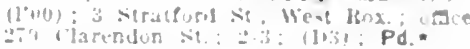

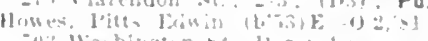

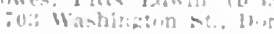

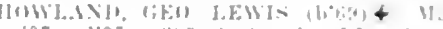

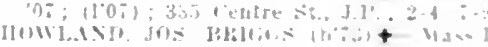

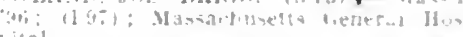

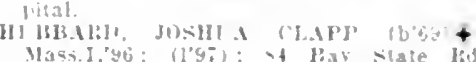

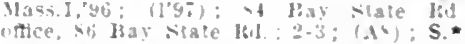

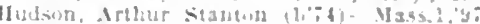

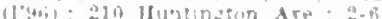

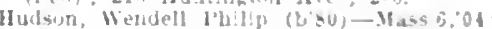

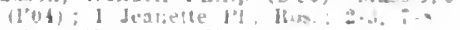

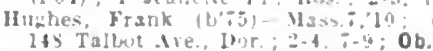

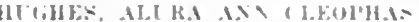

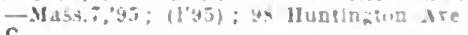

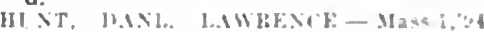
(\$); 243 fommonwealth ire

Ilunt, lemuel Judsis:-1.13,:3;

"Nondbluc :

isee Itronkline)

IIunt, Hrot. Bates (b'56)-.Mass 1,'1:; Intern, Hoston fliy Ilospltal.

IIINTINGTOX, JAMF IANOAN (bsD \&

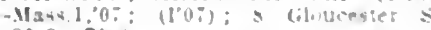
1:30-3; Ob.

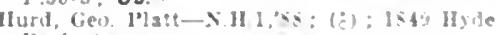
Park Ire.

llurley, Cornelus Thos Mast b, $0.5 ;(100: 1)$

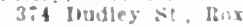

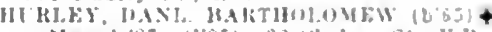

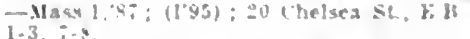

llurley, Daniel Jos, (L)1) Vasal. 0 :

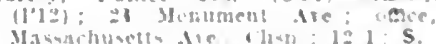

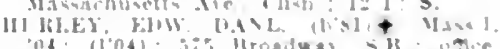

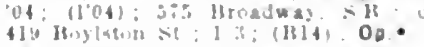

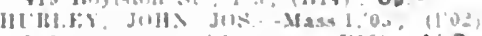

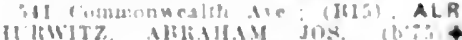

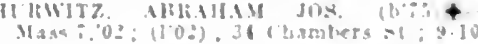

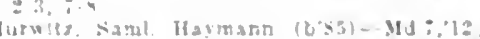

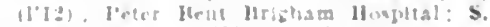

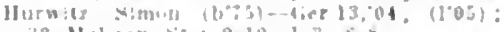

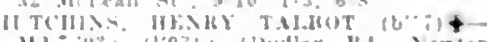

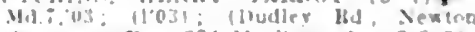

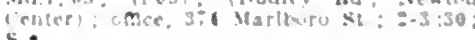


IX゚G1.15. IIARRY JAMESt-Mas4.1,04

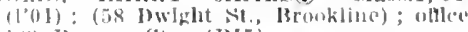
4x:3 Beatron St. ; (BIS)

Ingoldsby, fos. Emmanuel - Mass.1, '98 $\left(I^{\prime} 94 i\right): 47$ ('olumbla kel., bor.

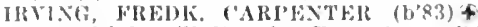
Yass.lo: (1'11); 9ti Hay state lis. $3-3 ; \mathbf{O b G}$ *

Irvelng Ilenry Washlngton (1,7y)-_llass, 01:: (1'titi): 138 (o)lumbus Ive: 2-4, $7-8$

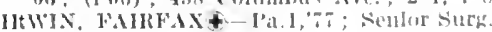
I.S.IP.JI:

Israeli, ('latra (b'68)-1'at. T.,0l; (Patholo gist); Now England IIospital for Women and chiliren.

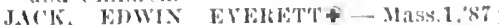
(t) : 215 laneon st. : $(134.34)$

JACK, FRFUK. I.AFAYRTE (b'61) क-

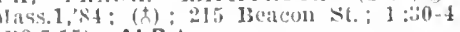
(I3. 3.5 .15$)$; ALR.*

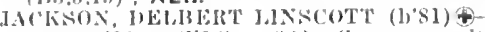

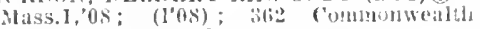
Ale: $1: 30-3: \mathbf{O b G}$.

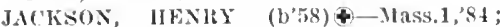
(5); 3 so Marllouro st. ; $2-3 ;$ (D6)

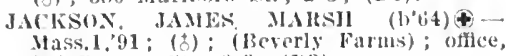
$2: 30$ Beaeon sit. ; $2-3 ;$ (1)3).

Jackson, Rufus (L's:3) - Ky.2.08; Juterm alassideluselts charltable Fye and Far Infirmary.

Jacobson, conrad (b'-8)-Mal.7,il Peter Bent firigham Hospital: (F*)

JAKMAIH, IUIL JOHA (b'si)-Mass. '13; (\$); 1007 k. 8th St.; office, 5us Broidway ; $2-3$,

James, II cward' (b'66)-D.C. 293 ; (1'96); 27 Upton st.; 9-12,2-5, i-10.

JANES, ARTHIR PERCY (b'73) \&-Mass.7, '05. (I’04); 49 Hilneock st.

JEFFERSON, HERJBERT PEIRT (b'56) Mass. 1,80; (ठ); (Winthrop); offlee, egt Washington st.:' $10-t$.

JEFFIRIES, BENJ. JOY (b'33)-Mias.1, (t) ; 15 (hestmint st.: (BI4); Op.

JELLY, ARTIUR CARLTON (b'56) 8 Mass.1,91; (t); 10 Arllngton St. ; $2: 30-4$ ( $\left.\mathrm{F}_{2}, 13\right) ; \mathrm{NP}$.

Jenkins, ('tus. I). - : (t) ; 92 Bird st.. Ior. Jenkins, Geo, 0-IIass. I, 4 ; (t) ; 508 E Broadway; offle, $6 s^{7}$ Boylston st.; also 508 E. J J roadway, s.P.

Jernegan, Jlolmes H. (b'47) - N.Y.9,'69; (t) 375 Commonwealth Ave; 2-4, i-8; $\mathrm{s}$

JILJSON, FRANKLIN C. (b'64)£-Mass.1, '\&6; (t); 11 Jastings St.; West IRox. $8-9,1-3,6-7$; LR.

JOINSON, ALPRED EMILE, JR. (b'87)Mass.7, I1; (1'13); Boston City Hospital.

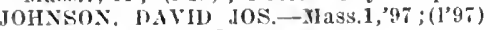
I sehuyler St., Rox.

JOHXSON, FRANK MACKJE (b'56) Vhass.1.83: $(1.95)$; The Tudor: offlee, 43 Mnss.1.'83; (1.9:); The Tudor; office,
Tremont st.: $10: 30-4: 30$; (c3.5).

JOHXSON, FREHK. WM. (b'53) $₫$-Mass.I '81; (5); 167 Newbury st. ; 12-4; G. * Johnson, Inhn Herbert (b'í) Mass. 1, 01 (1'03); 405 Marlboro St. ; $1: 30-2: 30$.

JOHNSON, JOLN WALPO (b'56)-Mass.1, (t) 20 Woreester St.; until 9 $12: 30-2,6-7: 30 ;$ ob.

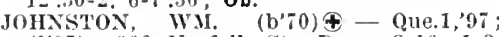
$(197)$; 206 Norfolk St., Dor.; 8-10, 1-3, $6-8$.

Johnstone, Wm. Jos.-Nass.6,'94; (†) ; 8 Cumberland St.

JONES, CIIAS. DAVID (b'64)-Mass.1, 89 ; (む); (Malden); offlce, 137 Newbury St. 11-12; (Is I t)

JONES, DANI. FISKE (b'68) - Mass.1 $96 ;(1.47) ; 195$ Beacon st.; $2-3 ;$ S.

Jones, Ellis Preston-Vt.2,'s9; (古); 519 Columbus Ave.

JONES, EVERETT (b'68) \$-Mass.5,'98; (1'98); (1658 Beacon St., Brookline) office, 419 Boylston St.; 12-I ; LR.

JONES, FREDK. ELMER (b'69)\&-Md.6, 97; (1'97); (4s Corey Rd., Brookline) offlee, 50 i Warren St., Rox.; 1-3, $i-8$.

Jones, John Thos. I'aul (b' 74$)$ H-Mass.5,0I ; (1'(1) ; 391 W. Broadway, S.B.; 2-4, 7-9; R.

Janes A. (J'74)-Mass.5,01; (1'0I) MARY ELIZABETHP-N. Y.14, 90 James Sit.

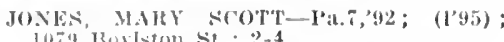
1 190 130y Istom st.: $2-4$.

JOR!AX, likNFst MAJOR - Mass.5,'99 (1) ; 93 Newlury St.

fordan, (irace E. Atkins (b'72) H Mass.5.

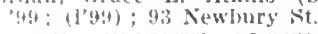

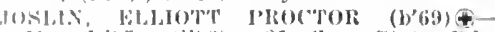
Huss.1,45: (1'96); 81 lBay slate lid. lsst. I'rof. Med., Mitss. 1 and Mass.til (1)is) : $1 . \star$

Journeay. Warren Wm. (b'66)-Mass.7,on (1'00); 16-1 Iluntlugton Ave.; $2-4: 30,7-8$ Iudd, lavid lilram-(2110.5, $00 ;$ (ó); 624 Vivaren sit., Itox.

Judfe. Albert Aumustlne-.Itass.1,"97; (1'95) II Woutwarel Jark St., J)or.

KANN, GEO. WARTON†-.Hass 1,90; (b) (162 Aspinwall Ave, Brookline); olflee, 414 Boylston St.; $2-3$; J'rof. Clin. (iyn., Mass. 6 ; G.*

kane, Peter (b'89)_.lld.9,'I0; (1'1J); 158 Chambers SI.; $10-12,6-8 ; \mathbf{G}$

KARSiEIt, IIOWARI THOS. (b'69) PAve, Itox. ; Asst. J'rof. P'ath., Mass.I and Mass. (il : $(F \geq 2, I 0)$.

KATSAINOS, GEO. MICHEL-Greece 1, 01 (I'03); 106 Juntlngton Are., Hack Bay.

KEANY, FKANCIS IOS. (h'(68)-Mass.1,'92 (1'96); 73 Marlboro st.

Keegan, Vineent Flljal-Mass.1,65 not in practice; $9 \mathrm{~W}$. Celar St.

KEELER, WM. ISASIL \$-Nass.7,03; (1'03) 470 Warren st., Grove IItall.

Keenan, Geo. Francis-Mass. T, $06 ;\left(l^{\prime} 0.5\right)$ 11 Menlo St., 13r.: offee, 85 Newbury st KEENAN, HERBERT ,IOHN (b'al)-Mass.1 94; (ち); 254 W. Broadway, S.B.; 2-4,

Keller, E. Victor (b'7f)-Gat.I2,1I; Massachusetts General Hospital.

kellert, Ellis (b'86)-N.Y.3,09; Huntington llospital : $\mathbf{R}$.

KEILEY, JOS. HENRY HART (b'7) Mass. i,98; (l'00) ; l'eabody Square, Dor. : $1-3,7-8$

Felley, Itobt. Edward Stock (b'86)-Ma.3, '11: (1'12): Boston Consumptives Hospital. Kelley, Walter Henry (b'71)-Mass.1,02; (I'0I) ; 1281 Rorchester Ave., Dor

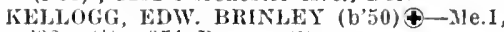
82; (t) ; 854 Beacon St.

KELJOGG, FOSTER STANDISH (b'83)థllass.1,'10; (1'I0); 96 Bay state Rd.

KFLLOGG, FHEDK. LELOY†-N.Y.I0,89 (t) ; 366 commonwealth Are., Fen.

KEIIY, JOHX MCHAEL - MaSS. $\mathbf{f}, 05$; (l'05); 182 Bowdoin St., Dor.

KELIY, WM. JUGAN (b'S0)-Mass. 1,03 (l'03); 57 Hancock St. ; $3-5,7-9$; (1)3).

KENDIRICKEN, Jos. THOS. - Mass. 7,05 (1'05); IIT Bowdoin st.; offee, 938 i)orchester Ave., Dor

KENXEAIY, JOHN HEXRY - Mass.1, 76 ; (む): (117 Harvard St., Brookline); offlee, 1570 Tremont Si., Rox.

KENNEDY, AIEY. CILAOSTONE€-Md.3, 97; (1'97) ; 1075 Boylston Ave.

Kennedy, Harris-Mass.1,98; (1'98); (Milton); office, 286 Warren St.

KENNEDY, JOHN T. (b'73) †-N.Y.5, 94 ; Surg., Lieut. Commander, U.S.N.; Naval IIospital.

KENNISON, FIEDK. MAISSHMAN (b'63) - Mass. 7,05 : $\left(1^{\prime} 05\right) ; \quad 107$ Warren St.

KENT, RRADFOKD (b; 6 - Mass.1,02 (1’02) ; 798 Blue Hill Ave., Dor.; $2-3,7-8$

lient, Dánl. Jarley-0; (f); I4 Boylston PI

KLPILR, CHAS. ORER (b'68) $\$$-Mass.i, !9 ; (1'99); 362 Commonwealth Ave.; $1-3 ; \mathrm{s}$.

Kernan. Wm. Everett-Mass.1,'96; (1'96); 402 Neponset Ave., Dor.

KERR, ISABELLE DICKIESON@-MaSS.7, '03: (1'03); 821 Beacon St. ; 2-4; (1315);

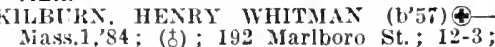
Mass.1, 84 ; (t) ; 192 Marlboro St. ; 12-3
(Bt,14); op. Fillory, Geo. Leo- 0 ;

office, 91. C Court St. $7: ;$ (t) ; 15 Elm Hill Ave., Rox. ; 8-9, 2-4, $6: 30-7: 30$.

Kimball, Saml. Ayer (b'5ĩ)H-Mass.1,'82, Mass.5,'83; (t) : 229 Newbury St.; $\mathbf{2 - 5}$.

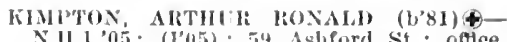
N.ll.1,05; (I'05); $5 ! 4$ Asliford St. $;$ oftlee,

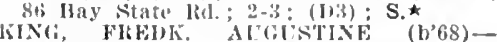
Mass.5,95; (195); 857 Massachusetts Ave. ; $1-\pi: 30$.

IING, NICIHOLAS JAMJES (2UAN (b'84)Mrl.3,08; (1'08); 4!) Florence st., Ros.;

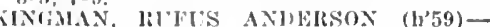
Mass. I,'se: (8): (45 windsor Rd. J3rookline); office, 366 Commouwealth Ave. : line); office

kingsley, Fredk.-Ont.5, $05 ; \quad\left(I^{\prime} 06\right) ; 416$

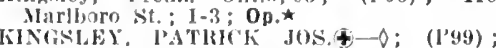
5 Adams st.. Dor.

Kinney. John Edlrar-Ilass.5.'80; (\&); (Buzzards I3ay) ; offlee. 24 Mlllk st.

lilrk, luey Anne (b'59)--Mass.5,93; (b) : 67-7 Dudley St., Jor. ; $9-10,2-4,6: 30-7: 30$. Klrshmer, Melaikle Ikosalind - Mass.7,00 (1广); 821 Beacon St.; N.

KINAO'K, WOB'T. JAMES (b'82)-Mass. 1 , '06; (1'08); 48 ; Jeacon St.: 2-4; ALR. Klein, Ditust Andreas $\left(b^{\prime} 47\right)$ iI $\rightarrow$ Mlass. 5,82 ; (ह) ; 123 Ilue Hill Ave., Rox.; office, I85 Silmmer St.; 10-4; Op. *

KLEIN, ISAAC-Mass. 6,$06 ; \quad(106) ; 1043$ Washington St.

KNA1P, PHHIT COOMBS (b'58)థ-Mass.I, NP: (t); 535 Beacon St. ; 2-4; $($ E1,2,8);

KNIGIIT, CHAS. IEWIS (b'74)థ-Mass. I 01: (1'00); 6t Stratford St., West Rox; offle, 544 Columbus Ave. ; $2-4,7-8 ; \mathrm{S}$.

KNOWLES, WM. FLETCHER (b'61)कMass.1,85; (ち); 220 Clarendon St. ; $2-3 ;$ $(133,15) ; A L R . \star$

KNOWLTON, (HAS, JAVISONF-Mass.7, 94: (t) : 574 Warren st., Rox. Asst. Prof. Theo. and Prac. Med., Mass.7; (B15).

KNUDSON, NETTE MARJE (b'75)-MaSS.7 09: (l’10): T8 l'ark st., West Rox.

Koch, Iames Iafayette (b'73)-Pa.1, 95 ; (1'98); Hotel Westminster; offlce, 419 Boylston St. ; 10-12, 2-4; LR.

Kohan, Nlexander (b'63)-Jus.6,85; (お) ; 54 Hoxbury St., Rox. : 8-9, 12-4, 6-9.

KOXIKOW, MOSES JOS. (b'67) $₫-$ Switz.2, 93; (古) ; 486 Warren St.; 2-3, 6-7; ObG. Konrad, Frank Chas. Wm. (b'85)-Mass.1

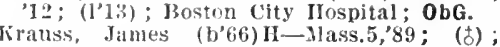
419 Boylston St.; 12-4; U.*

Lacaillade, James oliver- - ; $\left(l^{\prime} 00\right) ; 415$ Columbis Ave.

L.AHD, MAYXIARD (b'73)థ-Mass.1.98; (1'00) ; 270 Clarendon St.; 2-3; (BI) ; Pd *

IAIBD, WM. EDW.†-Mass. 1,$06 ;\left(1^{\prime} 06\right) ; 42$ (iloncester st.; $\mathrm{S}$.

LAIIEY, FIRAK H.(-Mass. 1,04; (1'04); 638 Beacon St.; 1-3; Asst. Prof. Surg. Iass. 7 : S. $\star$

Lambert. Jolun Franeis-IId.4,03; (1'04) : 55 Cambridge St

Lamson, Paul Dulley (b'84)-Mass.1,'11. (1'11); Peter Jent Brigham Hospital.

JANCASTER, W.LTER B. (b'63) - Mass.1 89; ( 5$)$; 101 Newbury St.; 12-1; (B1,4, 14); Op.

JANE, EDWARD BINNEY (b'60) $\mathrm{C}$-Mass.I, '85; (†) ; 1020 Centre St., J.P.; office, 419 Boylston St.; $2: 30-4$; Prof. Ment. Dls.

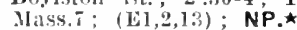

Lane, Iolin Goodwin (b'54)-Ire.3,76; (t) ;

538 E. Broadway, S.B.

ANE, JOIIN WII. (b'77) †-Mass.1,03 ; (l'05); $5 y$ Rtclifield st.; offlce, $5 \underset{0}{0}$ Beacon st. ; 1-3.

IANGNECKER, HARRY LESLIE\$-Md.7, '06; (Y'08); (Bromley Ct., Cambridge) ;

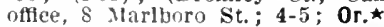

Lapham, (ieo. Yelson (b'72)H-Mass.5, 00 ; (l'00); (Rutland); offlee, 419 Boylston

Larkin, Edmund Peter (b'87)-Pa.2,'12; Intern, Carney Hospital.

LARRABEE, RALPH ('IINTON (b'70)థMass.1,97; (I’97); 912 Beacon St. ; offlee, 520 Commontrealth Ave.; $2: 30-3: 30$; (D3)

Larsson, Johan Gustave (b'78)-N.Y.8,07; $\left(1^{\prime} 07\right) ; 366$ Massachusetts Ave.; 2-4,6-8; OpLR. 
Iattinine. Andrew IB. $\left(b^{\prime} 8 z\right) \rightarrow \vartheta:\left(l^{\prime} 13\right): 19$ Corenwicls sit.. lox.

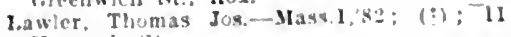
Hatucrek Sit.

I.A WILACE, CHAS HENIt), AIR $\left(b^{2} \times 2\right)+$ - Massolos: (1'11): (2x Weluter st. I. $\star$

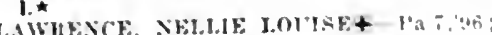

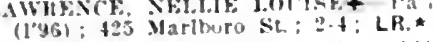

I.AWREXCE, ROBT, ME.ANS (b'ti) Mass.1, $3 ;(1 \div 3)$; not lil practice: 1: lia) sitate lid.

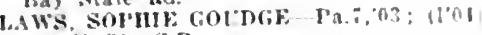
11 i1 $\mathrm{St}$., S. B

Lazarus. Benl.- Mass. I,99; (1'93): 94 War ren St. Rox. : $2-3, i-8$

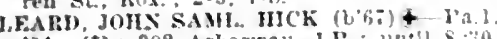
94: (ह) : 392 Arborway, J.I. : untll s:30, 2.3, 6- $6: 30$.

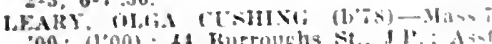
00: (1000): 4t Juproughs st.

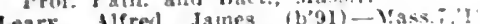

(l'13): Carney Hosplial.

LEARY. TIMOTHY (b'-0) - Massl.

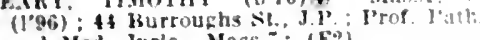
and Jied. Jurls, Mass. $;$; (Fo).

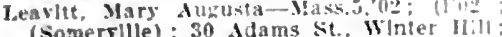
(Somerrille) : 30 Adams

olle, Fernand J. (1,'1) -0.21., 13: Inem. Massachusetts Homerpathle IIospital.

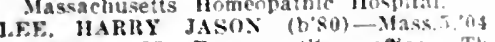
11041: 535 Bencon

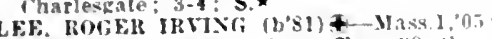
(1'05); 295 Beacon st.; ofice, 49 iritu

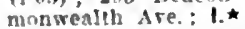

LEFA, THOMAS FRAX(Is $\left(b^{2} 75\right)$ t-Masul. 01; $\left(\mathrm{I}^{*} 01\right): 19$ Ibay state Mal. : 2-3:30;1.

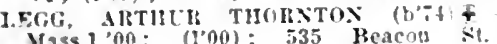
Mass.1,00: $(1,00)$;

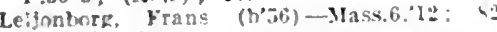
rhandler si.

LELAXI, GEO. ADAMS (b's0) F-Mn:0I

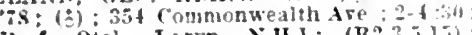
l'rof. Otol., Iaryn, X.II.I ; (B2,3,5,1.1) ALR.

I. HAND, GEO AIAMS 316 (b'e) Mass.11: (1'11): Massachusetis leneral IIosplial

Leonard, Fdward Dewite (b's.5) - Ma-s, I, 1 Intern. Ilassachusett. General IInsiltal.

Leonard. Ilenry jatrick-Mass, 5 ,

157 Huntington Are, $1-\overline{5} ; \mathbf{G}$.

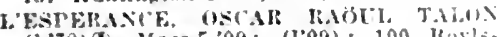
(b'8) I!ass.5,09; (1.09): 100 Juyls ton st.: $1-5 ;$ : U.

Iererone, Lou!se May (b'st)-.Mansb,on:

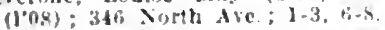

LFVINS, NATHAN NOAH $\left(b^{n}, t\right)+$ Mase '04: $(104)$; 30 fhambers sit. : :-

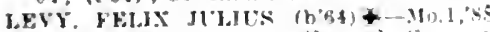
(1'02): (Brookilne): oftice, I Comuknwealin Are.: 10-:

Lewandowskl. Joseph (h'bl) -. Aus.' 94 ;

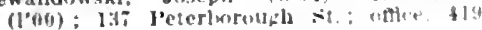
(lofi) : liti leterlwriston st.: II-1.

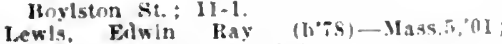
(1'0i) : 82 k. Cuncoral sit.

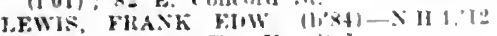
(1'12): Bnston Clsy HospitaI.

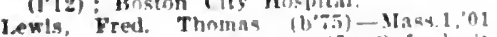

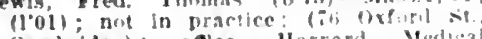
Cambridge): rifice, IIarrard Ifeedusal Schom! isst. Proe. Embry.. Mass.1 and

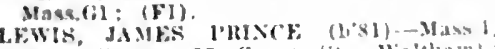
of: (1'04); (is firant st. Walthamb

\section{ALR.*}

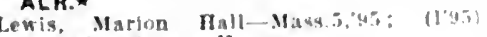
rranhlin sipuare House.

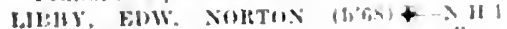

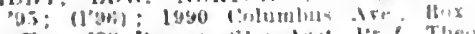

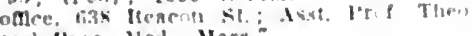
ant Irac Ilel., Mass?

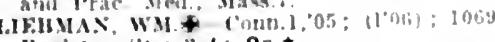
Itis) laton si: :-4:00,

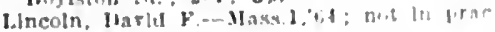
tice; I31 ifytte st.

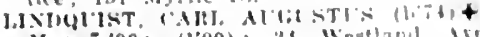
$M a \notin, ; 00$ $=3,6,7: N$

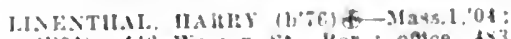

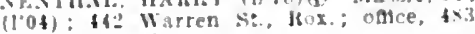
He $: 3$. 3 .

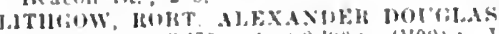

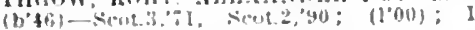
Jount?urt sis.; $\$-10,2=4$

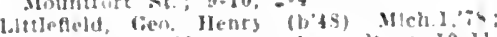

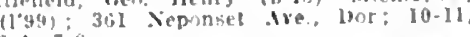
i3. -1.8 .

ITTI.FHFLI, SAMIE, HOHAC: -

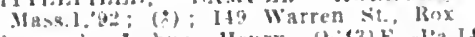
werponi, Jushun Ienry $(1,13)$ E - Ina It , 584 Tremmest. st. $10.4,7-6$

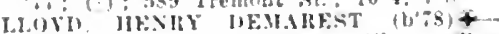

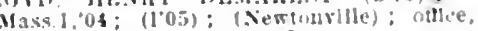
67 Is ylsen si: : $=-3 ; \mathbf{S}$

Lork, Irtuur linculn (285)-lat, 13;

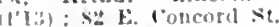

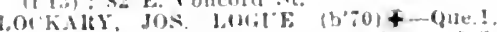
4:; (19iz); 10s Warreu st., Itux.; 1.3. OCKF, EDWIX MLLF (bot) Mass I

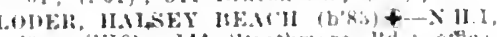

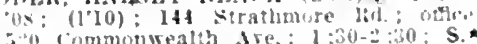
5.) Commonwealth Are : $1: 30-2: 30 ;$ S." luteru Huston rie llospltal.

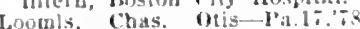

Churles be Hack bay $8-4,2-3,-4$

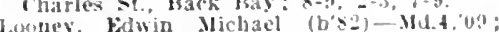
(1'10) : [eer Island.

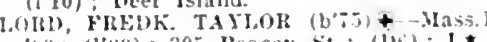

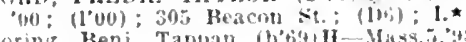

loring, Benj. Tappan (b'tofli Mass. (1:1s); (11atertown); onte, 2:0 Claren don sit.

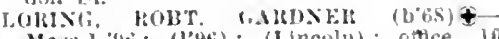
Mass. 1, "ys; (1'4t) ; (Jincolu): oftice,

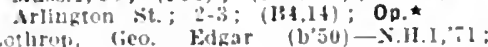
I.othrep lieo kidga

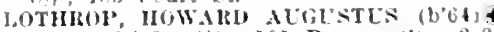

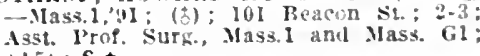
(A.t) : S.

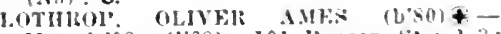
Ilass. os: (1'03); 101 Beacon st.; 1-3: (B15): ALR.

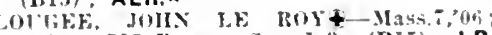
(100); 535 Beacon St.: I-3; (II5) : LR.

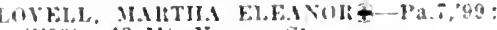
$(1.94) ; 43.11$, Jarnon st.

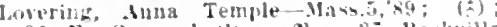
Sil foncurd st; oflce, az lockille latk, Itux: $11 \cdot 3: 30$.

1.0YETT, HOHT MTHLAMEON (1,58) Mass 1, 85; (8) ; ; Falrfleld st : offlce, Yarboro si. 1-3: Asst l'ruf orth.

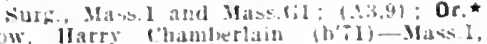
wi: (100) (1) (arlon st., Itrooklne! unice 31? Hencein sit.

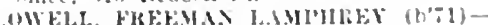
Mas. I.00; (1001); 2.8 Mlliford s?

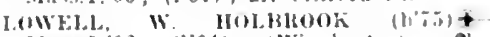
Mass.102: (1'04); (Whehester): ince,

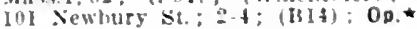

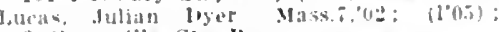

lirenrille St. IRos.

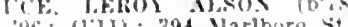

De: (111); 394 Marboto Ifrexaclusente Are.

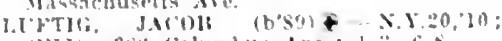

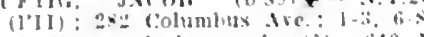
lull, Jenry lialsman $\theta$; lit; tito II

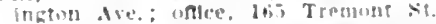

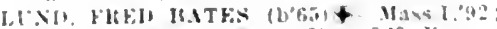

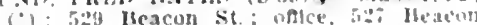
S1.:-3; (A5, 13,5$):$ S.*

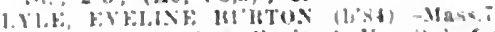

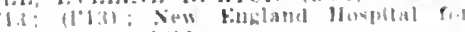
Wumph agd 1 haldren.

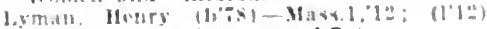
3ij commonseraleh Are.; LD.*

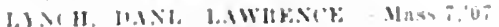

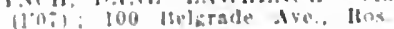

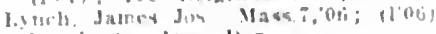

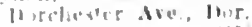

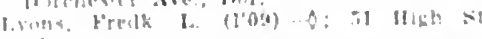

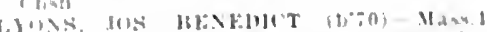

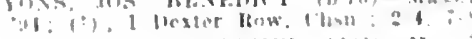

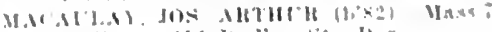

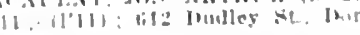

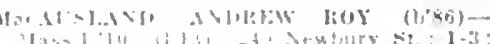

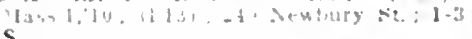

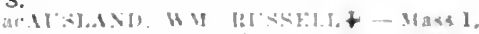
Or.

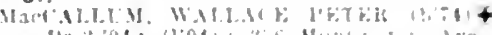

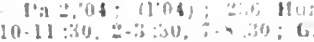

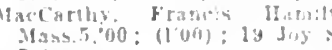

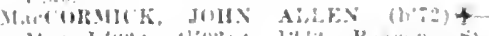

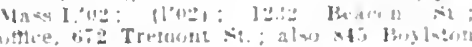
it: : 4.:- : G.

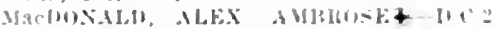

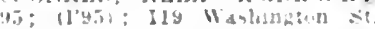

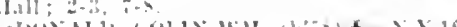

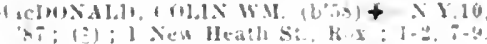

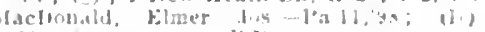
11: safateg $=1$, K. 18

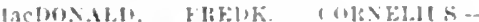

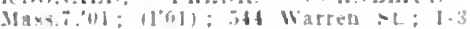
ti- $\rightarrow$; $P$ d.

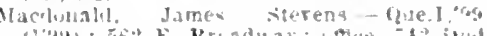

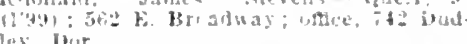

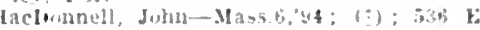
Broadus.

Mace, llerbert Eugena NIII, Intel Voscinghitur.

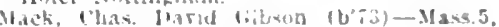

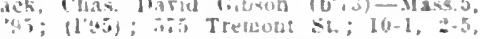
Sack, Ilelen foentiana blagler

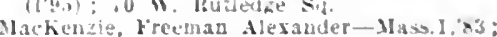
f:, it llablecth st., I Hur.

M.MJE, WM. IHAS-Mass 1,

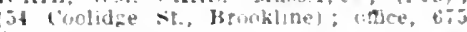
iectmitut $\leq 1$

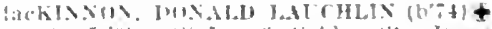

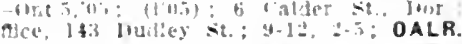

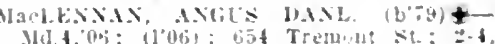

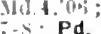

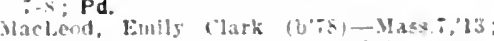

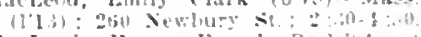

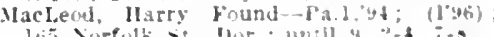
lot Norfolk -t., lor.; unill $4,2-4, i-5$.

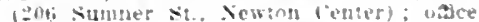
lobinion and Tremont sis.

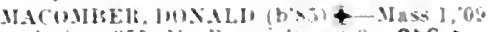

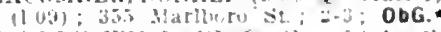

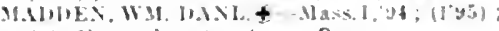

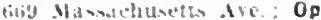

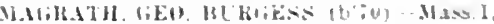

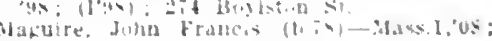
(I)

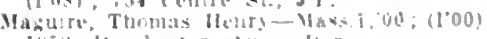

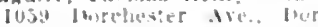

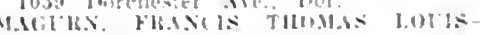

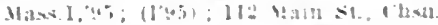

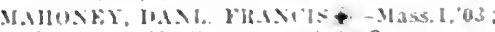

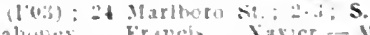

daluticy, Franciv Xavict-Masa. 1,05

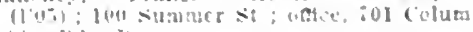
his Itd. Jor.

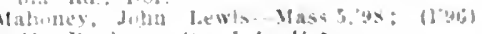

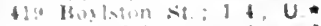

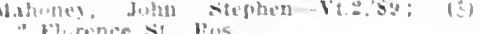

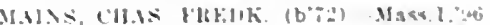

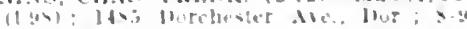

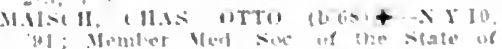

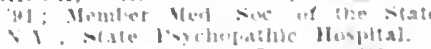

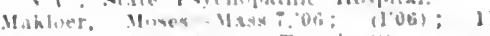

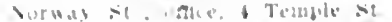

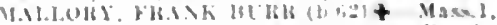

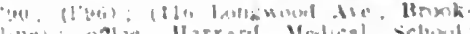
doser l'rue l'ath. Mase I aghl Mass, 1 l bi. bl

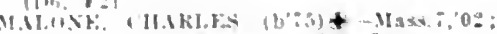

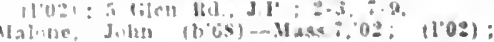
land columbur ire., Kox.

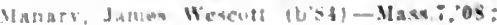

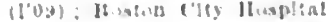


Mann, Iouis (b'SI)-MId.9,'11; (l'I2); 127 Chambers St.

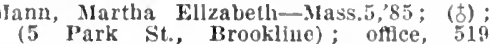
Boylston.

MANY, WM. ORRIS (b'69)-Mass.5,'92 (す) ; Massachusetts Ilomeopatille IIospltal.

MAXSFIEID, JAMES ALHERT $\left(16^{9} 65\right) £$ l'a.2,96; (1'96); 342 Indley st., Rox

Mansfeld, Walter Raluh $(1, ; 2)$ Mass. I, 07 ; (1'01);8 Cumberland Are.; 2-4, $7-5$.

Mara, Frank Timothy-llass.1." 1069 MoyIston Si.

MARILL, MENLY ('MASE (1,85) †-Mass.1 10: (1'10) : 210 Newhury S1, ; $2-3 ; \mathrm{S}$

Mareus, Jacoh (b'84)-Mass.7,12; (1'19) ; II Parmenter St, : $8: 30-10,2-4,7-9$

MARCY, IIENRY ORLANDO (b'37) $\uparrow$ Mass.1.64; (১); Is0 Commonwealth Are. unill 10; (oflece, 860 Massachusetts Ave. ('ambridge; 2-4): (A6): S.

Mareth Wm, Clinton (b'S6)-MU.I,'1I kevident l'hysician, bostom ('onsumption Ilospitit, Mit.

Margot, Fredk. E. (b'65)-Mass.6,08; 680 Centre St. J.P.

MAIR, MVRON TAWRENCE - Me.1,79; (l'9;) ; 11 Ifopestill St., Dor.

MAR, MYRON WIITMORE (b's0) \&Mass.7,07; (l’07) ; 1 I Hopest (also Plnehurst, X.c.; l'09)

Ifars Anthony Wayue (1,85)-Yt.2,'1I (I’12); 145 Felgrade Are. Ros.

MAISIIAL, IIERMAN WESTOX (b'75)

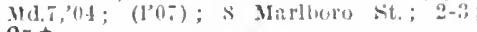
Or. *

MARTEL, STANISLAS \$-Que.4,93; (1'96); $36 \%$ commonwealth Are. ; 1-4; OALR. $\star$

Mirtin, harid Lorenzo (b'74)-Mass.5, 09 . (l'ot) : 4 Rosedale st. Dor, : 2-4, 6-8; Op.

M.IRTIN, EDW. (b'84)-Mass.7'11; (1'1I); ¿6 Gilenarm St., Dor.

MARTIX, FRANCIS COFFIX (b'58) - Mass.1. 's3; (t); 27 Dudley St., Rox.; 8-9, 1-2,

6-7. 1 Mountfort St. ; 2-4, $i-9$.

MARTIN, JOIN MACLFOD (b'59) que.1,'s9; (1'95) ; 238 Warren St., lox.; $\stackrel{2}{2}-4, \quad \overline{-}-8$

MART1N, MULES-Que.1,91;

Westminster; until $9,2-4,6-8$.

Marvin. Grace-Mass.5,90; (ち); 84 Maple sit., Rox.

MASON, AMOS LAWREXCE (b'42) -Mass.1, ‘2; (む) : 265 Clarendon St.

IISON, GILBERT MCCLELLAN $€$-Mass. $\%$, "0s: (1'98) ; 354 Adams St., Dor.; 1-3.

MASON, NÁTHANIEL ROBERT (1, 6 Jass.1,01; (1'01); 485 Beacon St.; $2-3$; (D.) ; ObG.

Masse, Mathilde Marie-Mass. i,02; (l'02) ; Hotel Oxford.

Mastrangelo, Marco - Ita.10,'93; (l'02); North Sc. ; $7-12$, 3-8;

Mastromarino, Cosma Alfonso (b'84)-

Ita.10,'10; (1'12) ; 429 Hanover St.

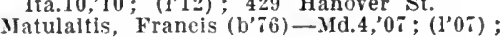

495 E. Broadway, S.B.; 8-10, $7-9$

MAY, JOHX SHEPARD-Pa.2,97; (197); 495 Warren St., Rox.; 2-3, 7-8.

Mayers, John Edw.-Vt.2,99; (1'00); 749 E. Broadway, S.B.

MCADAMS, PETEK STEVENSד-Mass.I, 99; (l'99); (1039 Massachusetts Are., Cambridge

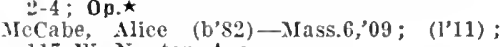
$117 \mathrm{~W}$. Jewt on Are.

MCCARTHY, FRANCIS PATRICK (b'83) \$llass. 7, 05; (1'05); 1420 Blue Hill Are.; 7-8; Path.

MeCartin, John Fdw. (b’ïs)-Mass. ̈,08; (1'09) : 467 Columbia Rd., Dor.

MACAILAT, JOS. ARTHUR (b'82)-Mass. 7 11: (1'11) : 612 Dudley St., Dor.

IeCauley, Albert Anthony (b'69)-Mass.1, "97; (1'96) ; 3 Mapleton St., Br.; $2-3, \boldsymbol{i}-8$.

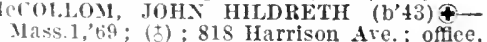
Boston ("ity Hospital; (F2)

MeCormack, Tohn Sears-N.X.3,07; (1'0s); $1: 6^{\circ}$ Chestnut Ave. office, 351 centre
McCok.ICK, 'HOS. JOS. HFNRY-Mass.I, '00; $\left(l^{\prime} 00\right)$; 33 Highland St., Rox. MCCREAPY, LEO TIIOS. (b'80)-Mass.7, 06; (1'06); 2 l'eter I'arley Rd., J.P.; 2-4, $7-8$.

Mecrudden, Francis IIenry (b'79)-Mass.I, '08: (1+); Rohert Brigham IOospital. IIC CRN, 'THEODORE EDV. A. (b'7) X.C.3, $04 ;\left(l^{\prime} 05\right)$; 798 'Tremont St.; untl1 MeWFRIJOT', JOS. EDW. - Mass.1,99; (1’99); 296 Bunker Illl St., Chisn.

Melerit, James Joln- N.Y.5,'S6; (む) ; 42 chelsea st., F.l?

Mchonald, Louls Round $\rightarrow$; $\left(l^{\prime} 07\right) ; 55$ Iligh St., Chsn.

McIOONMII, SAMI. JAMES (h'T4)థMass. 1,01; (I’0I); $65 \%$ Boylston St. ; I -4;

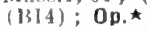

M(WOX.11, WM. JOS. (b'58) \$-Mass.1, ')9 ; (199) ; 209 Bunker IIIll St. ; offlee, 55 Iligh St., Clusil.

VCFVOY, GEO. ALRERT (b.73)-Mass.1, 99 ; (1'98); ¿ sumner St., Dor.; otllce, 153 Vewhury St: I-:3.

Mceiafflpan, Rermard Frameis - Mass.7,04; (l'04); Weer Island Hospital.

llecann, I'ierce Powers (b's1)-Mass.i,'12; (i'I2); ( 15 I'utuam St., Somervllie); Ioston City Ilospital; S.

ICGURN, WM. J. (b'72)-MIass.7,04; (1'03); 216 Iiuggles St.; office, 1165 Tremont St., liox. ; $2-3,7-8 ; U$.

MCINTOSII, HEILBERT (b'5\%)థ-X.X.I0, 466; (l'96); (Sharon); office, 419 Boylston St.; $9-4: 30 ; \mathbf{N} . \star$

MeINTYR, DAYII) (b'58) \&-N.Y.5,'s6; (5) ; 240 I3oston st. ; 1-3, i-s.

Mekane, Alice Woodly (b'63) - Pa.t,92;

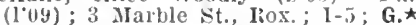

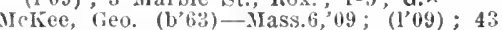
Waverley st., Br.

MCKREN, SYLTESTER FOUSHAY (b'72) Iass.1,'95; (1'97); 556 Cambridge St., Alls. ; $2-3,7-8$

MCIENXA, FRANCIS PATRICK-MaSS.1, 32; (5) ; 382 Centre St., J.P.

MeLaren, Alex. Iorne-IIass.i,99; (1'99) ; 265 Princeton St., E.B.

MCLAUGHIN, IIENRY VALENTINE (b'56) \&-Scot.9,'84, Ire.9,'84; (t); (40 Kent St., Brookline); office, 394 Marlboro $\mathrm{At.}$; $2-4 ;$ ALR.

MeLACGHEIS, JOS. IGNATUUS (b'6I)Mass. 1,90; (む); 92 Walnut Ave., Rox. after 2, after $i$; office, State J'rison.

MeLEOD, JOIN SCOTT (b'75) \&-Mass.7, 00; (l'00); 151 Warren st., Rox.; until I0, after 6.

MCNANN, WN. IIENRY-Mass. 1,$00 ;\left(l^{\prime} 00\right)$;

$32 S$ Centre St., J.I'.

MeNALLY, WM. JOS. (b'63)-Mass.1,'S7 (d) ; 31 Monument Sq., Chsn.; 8-9, 5-7. Ie Jeil, Edmund J. (b'i1)-Mass. ̃,'03; (l'03) ; (30 Ash St., Cambridge); offlee, 24 Warren St., Rox.

I'Coy, George Madison, Jr. (b'76)-Mass.1, '03: (l'02); (West Newton); offlce, 153 Milk St.

McI'eake, John Richard-Mass.6,'07; $\left(\mathrm{l}^{\prime} 0 \mathrm{~T}\right)$ 1585 Blue Hill Ave., Mat.; 2-4. MeQUADE, LEWIS STELLE (b'82) †-
Yiass.7,07; (I'07); 10S1 Blue Hill Ave.,

Dor. ; $1-3,7-8$.
IcSweeney, Danl. Justin-Mass. 1,$03 ;\left(1^{\prime} 03\right)$; 26 Auckland St., Dor.; office, 43 Tremont St. ; 11-2.

MeYey, Fredk. Jos.-Mass.6,'04; (1'05) ; 200 IJancock St., Dor.

McWeeny, Bernadette Marie (b'89)-Mass.7, 12; (1'12); New England Hospltal for Women and Children.

MEAD, LOUIS GUY (b'73)థ-Mass.1, 00 ; $\left(1^{\prime} 00\right) ; 259$ Beacon st.; $2-3$

MEANS, JAMES HOWARD (b'85)甲Mass.1,11; (1'11) ; 196 Beacon St.

MEDALIA, LEON SAIIL. (b'81) Ð-Mass. $T$, 0 ; (1'05); 483 Beacon St.; 1 :30-3; LD. MFN1DELSOIN, LOUIS (b' 79$) \oplus$-Mass.1, 04; (l'04); $47^{\prime}$ Washington St., Dor. $2-4,7-8 ; 0$ b.

MENDENHAIL, WALTER LESLIE†-Ia.6, 06: not in practice; Nember Ia.

UERRICK, ROBT. MICHAEL $\oplus-$-IIass.1,'93

(c); 18 IIt. Ida Rd., Dor.; (D3).
Merrill, Wm. Truman (b'61)-Me.1,90 : (l'13); 740 Adauns St., Dor

Ietcalf, Rlehard (b'88)-Mass. ', 13; (1'13) ; Boston Clty Hospltal.

Metcalf, Stephen IIliael Ryres- $\downarrow$; (む) ; 485 Shawmut Ave.

Meyers, Alfred Edw. (b'83)-Mass.1,12;

Millard, Jean Sears (b';6) - Mass.1,'12; (I'I 2$) ; 440$ Newbury st.

MILLER, CII.IS. HERMAN (b'63)૯-N.Y.5. 91 ; (†); Ilotel l'enbody; 1-3, 6-8. Mller, Frances Jine- 0 ; $\left(\begin{array}{l}\dagger \\ )\end{array} ; 18\right.$ Huntlngton Ave.

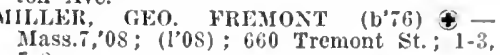
$7-8$.

Miller, Jes. Kernochan (b'80)-Mass.5,'12 ; (I'13); 86 Chestnut St.

Miller, Malcolm vean (b'79)-MLs3.1,05; (l'05); (Wollaston); offlce, 419 Boylston Sit. ; 1-2, $;-8$

IILLER, IICHARD MENRY (b'84) \$Mass.1,10; (l'10); 279 Clarendon St. :

Mlliken, Wm. Hardy (b'57) - Me.I,'80 (t) ; 149 Warren St., Hox.

Viner, Leroy Matthew Simpson (b'82) Mass.5,07; (1'07); (Dentist); 153 Newbury st. : 2-4.

MIOT, JAMES JACKSON (b'52) \&-Mass.1, ,

Iintz, Fishel Tonchel Zelmarowich $\rightarrow$; (t) : 115 Salem st.

Mint $z$, Saml. ('has. (b'S4)-Mass.,,$^{\prime} 07$; (1'07) ; 38 WeLellan St., Dor.; offce, 119 Boylston St. ; ]-3, 6-7:30; U.

ifiteliell, John' Jos,-Mass.1,'02; (1'03) ; 35 I'rinceton St., E.B.

Mitchell, Wm. Iliram (b'69) - Me.1,99; (1.02); 658 Tremont St.; 2-4, 7-8.

Mitsakos, Demetrios A. (b'73)-Gireece 1,'98; (i'10); 422 Trenont Are.

Mitt, Geo. I'mest (b'8i) - Mass.7,13; 5 Spring St.; offlce, Boston City Hospital. IIATER, CHAS. GALLOUPE $\left(b^{\prime} 82\right) \pm-$
IIass.1,06; (1'08); 247 Beacon St.; office,

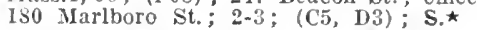
MATER, SAML. JASON (b'55) $\$$-MLass.1, 79 (d); 180 Marlboro St.; $2-3$; (A5, 6 , FI) ; S.

MIXTER, WM. JASON (b'80) \&-Mass.1,06 ; $\left(l^{\prime} 07\right) ; 42$ Fairfleld St.; oftice, 180 MarlSt. ; $2-3 ;$ S. $\star$

HONKS, GEO. HOWARD (b’53)૯-Mass.1, 80 ; (ठ) ; 67 Marlboro St. ; 2-3 ; Prof. Oral Surg., Mass.1. and Mass.G1; (A5).

Moore, Fontaine Bruce (b'86) -Pa.1,'11; Intern, Mass. Charitable Ear and Eye Infirmary.

Moore, Francis Vincent (b’83)-Mass. i,'09; (l'09); 644 Columbia Rd,, Dor.

Moore, Geo. Colton (b'76) - Mass.1,02; (1'02); 16 Union Park; $2-3 ; 0 r$.

IOORE, HOWARD (b'81) - Mass.5,'05; (l'05); (190 Church St., Newton); office, IOORE, JOHY HEXRY-IISs. ${ }^{2}, 9$ 18 thitney St., Ikox. afflee, 419 Boys) St. ; Pd.

Moore, Mary Teresa Veronica (b'90) IIass.7,'13; (1'13); 126 Fisher Are.

Moran, Edmund F.-Xlass.7,07; $\left(l^{\prime} 07\right) ; 64$ Bennington St., E.B.

MORAN, JOIIN BRENNAN (b'3s) $\oplus-$ Rox. ; $1-3$.

Moran, Martin Wm.-X.Y.10,87; (ち); 9 Hariland Ave, offlee, 419 Boylston St.

Morelli, Costantino Luigi-Ita.10,05; (l'05); 294 Hanover St.

Morey, Mary-Pa.7,'89; (1'95) ; 43 Charter. IORGAN, CHAS. RÉSSELL' $\left(b^{\prime}, 7\right) \subseteq-$ Mass.7, 07 ; (l'0S) ; $335 . \mathrm{A}$ Columbus Ave.: office, 115 Hemenway St. ; 2-4, 7-9.

MORGAN, JOHN (b'45)థ-Conn.1,'69; (t) ; 39 Huntington Are. ; 8-6; Op.

Morgan, Wm. Edw.-Mass.1,96; $(1 ' 96) ; 297$

Fuller St.; offee, 143 Summer St. 'Dor.

Moriarty, Julia Mary Lombard-Mass.5,'95; (1'95); 334 Massachusetts Ave.

MORONG, ARTHUR BENNETT-Mass.1, 76 (†) ; 12 Blackwood St.; Prof. Clin. Ired., Mass.6.

Morris, Frances Morris (b'51)-Mass.5,'85 ; (t); (Waban); office, 520 Beacon - St. 10-2; G. 
MOIRRI, GiEO PATRICh - Mass 1,91;

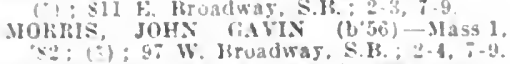

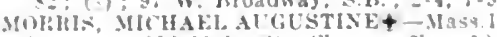

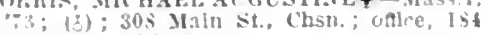
(i) fumonweslth die.

MokRLSOS, ARCHIHAl, HEXI (b'bl)-

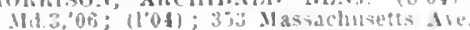
$4.7,-8:$ OALR

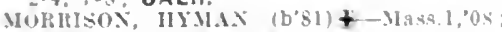
(100s) ; 103 Glenwals st, Nor, : $2-4,-8$, Morrlion, James-X, Y.3.60; (2) ; 35 Ke WIn St, Dor : offle, 52 Chatuers

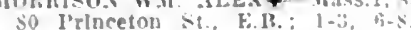

MORRISOX, WM. KELI (1) (1313): so Princeton st., k.M.

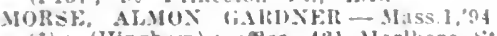
(ह); (Hingban): offce, tol Marlboro si MOKSE, FREDK. HARISIS $(6,5 \overline{5})+-\mathrm{X} Y .5$ sil: (3); (92 Shore brlve. Winthrop) oflice, 462 Hoylston st.; $9-12$.

MORSF, GEO. W., JR. (bisi) - Miss., OS ; (1"0s): (Clinton): oftec, 13 rinckney st. $2-3:$ S.

MORAE, HEXRY LEE (b'52) +-Mass. l, is (l'95); 112 Marlboro st. ; 11.1; (B5,15) ALR.

MOISE JOHX LOFETT $\left(b^{\prime} 65\right)$ +-Mass. 1

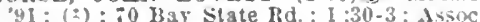
I'rof. Ped., Mass.l and Mass.til (Ai. $[$ ) $1,3.6) ; P \mathbf{d}_{+} \star$

Mlore, Xathanlel Xiles (b'76)-Mass 1, 04 (l'lii); 69 Newbury St.

Morton. Helen-Mass.3, 62; (t) ; 17 Cbestnut

Morton, Juhn Janleson. Jr. (b'86) - Idd.",'13: Intern, Peter Rent Bricham Hospltal. MUSHEL, HAKIS PFITON (b'6i) Mass.1,96: (1'96): s.s Beacon st. (B:, $3,3,15)^{\circ}$.

Mosher, Mary Elua-E-Masi.J, \$: ;

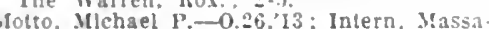
chusetts Homeopathic Hoipital.

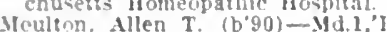

Mculton, Nlen T.

Moulton, starr Abner (b'is) - Mass.;.01; $\left(l^{\prime} 01\right): 17$ stanlforel st.: $1-3,7-2$

Mulr, Robert Jos. (b'sj) - Viass. i, 10; (l'1n) Toplif st. yor.

Mulliner, Mary Rees-H-IIass.5,'96; (1'9h) 5:20 Beacon St. ; $1: 30-3$.

Mulranlty, John joseph (b'8z)-Mass, ,'l3: (1'13); St. Elizabeth Hosplial.

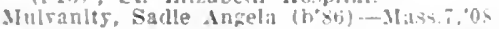
I'ln): 677 Dudley : 5 . . I or.

MLMFORI, ELGE.E HISHOF (!'

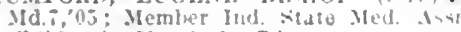
(')lldren's Hosvitisl: pd.

Jurphy, Chas, Aurustis Mass. $-04:$ 1014 140 Iloward Ire., Hor

MurJly, Edw. Frelk. - Uue.1,99; 11 '00

1451 Tremont si. Iins

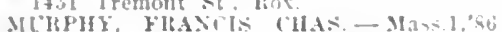
(ह): :15 Marlboro st.; offee, Ibog Tre-

mone si. Box. $\left.11^{\circ} 09\right) ; 15$ Oakwond it., liur.

Murpluy, John Ilenrs Mass. 1,

Colnmbla Itd., jor.

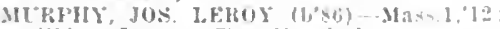
(1'12); Ilosinn rity Hosultal

Muruly, Jos. I'atrick- Mass.1,'8t: (1'95) (3i Harrard it., Mrookline); comice, lojo; Tremont st., Hox.

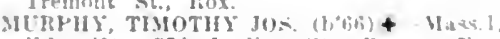

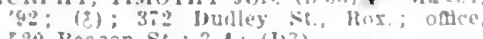
sou beacon St. ; 3.4: (1)3)

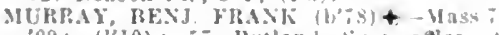
09: (l'10); "5 Itullani sil ; oflce, reacon st.

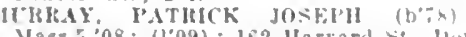
Mas4,5,08; 1100); 162 llarvarl si, llot: 2-4. $\vec{i}-8 ; P d$

Sultart, fice Mnrley-l'a.1,90; ("): 118 Princeton st. F. F.

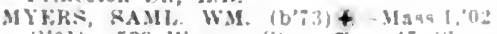
$(1201)$ : 534 Warren kif; once, 47 (ham hers xt.; $9.10,2.3, i-8$ IYFRs, SUl.0MON + - Masa 1.00: $\left(1^{\prime} 00\right)$

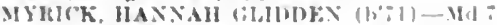

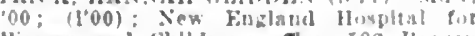
Women and chllaten: oflec, 502 Beacon St: $: 30-4: 0$ b

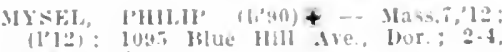
7-4:30: S.

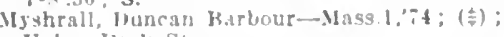
'nlon I'ark St.

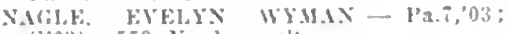
(100*); 50 Newbury sit

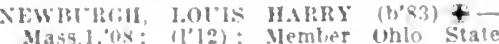

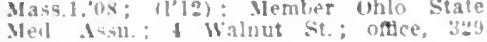
liencort st.; : 2 -3: 1.*

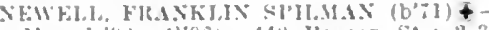

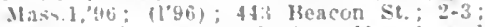
Asst. Prof. llbst. and fiyn. Mass. 1 and

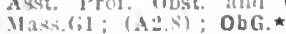

Vewman, Len (b'a)-Mass.6.04; (1'03); 9 Harbara st. : 1 $2,6-\$ ; 0$ ob.

verron, Fillw. lioswell Massi, '92: (1'98) (50) Benton Ha. Simerville); oflee, 113 Boylston st. ; (B15); ALR.

Newton, Frank Lownls (1)':5) -Mass.5, \& (d) : (3t Illebland Are. Somerille; 1-2); oflee, :-it Newbury st.; 3-j

NICHOA, ARTHLli HOW.AKI (b*4) Nass.1,66; (ह); 5.5 .It. Vernon st. ; untl? 9. $2-3$

Nichols, rhas, $k d w,-\Delta:(t)$ : 19 contes st.

Yichols, ('has. Fessenden (b'th) H-Mass. L, 70 ; (x): Cburch and Centre sits., West Rox.; otlee, it Boylston st.: 10-t.

Nillors, EUW: HALL $\left(b^{\prime} 6 t\right)+$-Mass.I, 92; (す); 294 Marlboro St. : 1:30-2:30; Assoc, Irof. Surf., Mass. I and Mass.fil (1*2); $\mathbf{S}$.

NIFLAEx, EUWIX IJORNE (b'76) + Mass, 1,99; (l'99): (35 lleuster st. New ton); offlee. 543 boylston st. : $2-3$.

Noblle, Angelo--I1a.10,'s6; (さ); 24 Prince sit.

Soble, Firmy corser (b\%3)-Que.1,07; $\left(10^{\circ}\right)$ : Bositon state Mospltal; $P_{*} \star$

Noble, Lenuel Franklin-Mass, 6,'13:

ili llorcester st.

NOHLE. MAlli E:YA Gil.l. (b'72)-MLass.", 0.2: (l'03); Boston siate Hospltal.

Nolan, James l'atrick lugustus (b'78)Mass. "05: (1005): F:? Heath st.; oflce, 415 Centre St., J.J.; 2-3, 7-s.

Solat, Wn. Francis-f: (l丷as) ; 49 rhestnue Ire. onlee, 14 iive si. J.I'

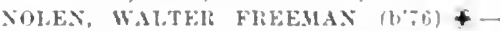
Mass.1,01: (1'01): 505 IBeacon $5: ; 2-3$

vircross, Frnest Freeman--11ass.5,9:; ; in: Washington st.. Wor.

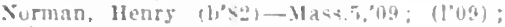
ol Lawrence Ave. lkos.; :-4

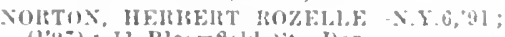
(1"yi); Il Blnemflil st. Bor.

comcll, How arel Wllbere (1,72) Mass.5,"ll; (l'11); sis Heacmis si.

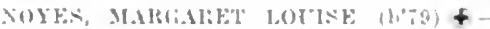
In.103; (1'03); 10:; si. Jimes Ave. -1: (1Bi,15): ALR.*

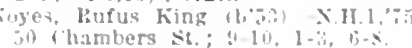

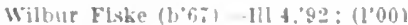

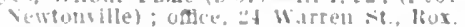
2. OALR.

(ii) lis, WII. (20i) - Mass 1.

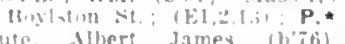

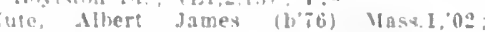

(1.01) : 131 st. Butulbls st.; station Fond Lenth Whare.

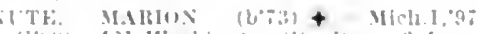

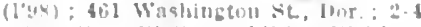

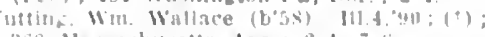

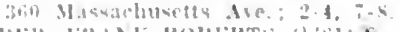

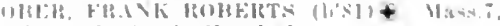

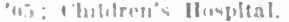

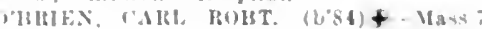

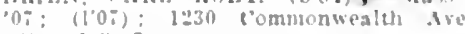
Al14: $1-3,7 \cdot 5$

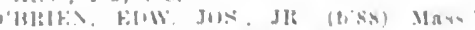
12: (1'12): 713 Iteylston st.

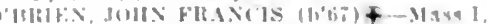
on: 1:1: fill Munher Itill siz: : $3 \cdot 30$, 1)

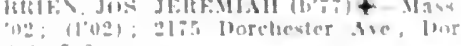

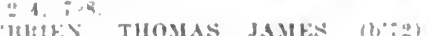

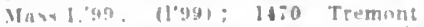

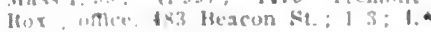

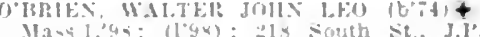

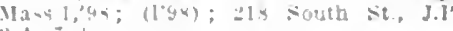

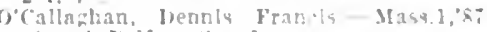
$1: 1 ;$ \& belfort sit., lyot

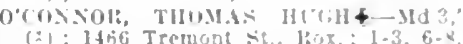

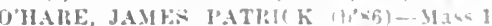

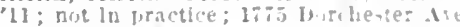

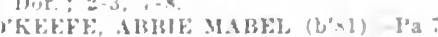

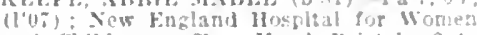
and children; once, Hutel Bristul; a t Anes.

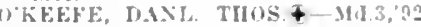

as Cilen lid., J.P.

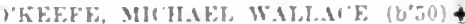

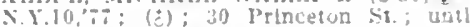

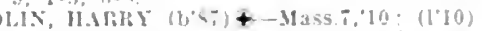
tif Warten si., Rox. 2.4. i.9; S.

OH.WER, EVERARI LAWREXI E $\left(b^{*} \cdot 5\right)$ Mass. 1,04; (1'0ti); 36\% Commonwealth Ave : $2-3 ;(r+) ; D . \star$

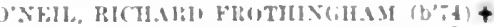

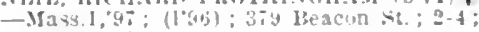
$((1,3,5) ; U$.

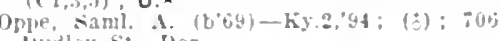
loudley St., fior

ORHWAY, MABEI, DIER + Mas3. 5,05 ; (I'05); 6 Parley Vale, J.1.; NP.*

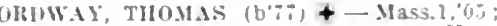
(lo.i) : 69: Huntington Ale. : oflce, Har rard hed. School: 1r:1; 1. *

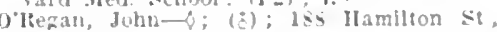
Dor.

O'lieiley, Wm. Jus.-X.1.10,33; (z); $12 \%$ Wasbington st., Ros.

orR. SAML. NAXFORD (b'os) +-Mase. $11-i$

Gigood, Garlner Holway (b'is) -Mass.5, (1.10) 43 Manthorne Rd West Rox ofice, Masi. IIomernatuic Ifospltal.

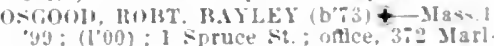

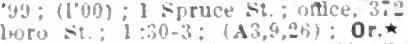

Thea, lranl. Jus-; (199); - 45 Saratoga sit., F. IB.

0'Slea, Folir Flain-3ass.1,90; $\left(1^{\circ} 95\right)$ : Chelsea st., Fil:

thea, Win. Vichiel (b'37) - Mass.1,12; intern, Joston (ity llospltal.

Jsman, Chartes Frank (h'56)-Mass, l, s0:

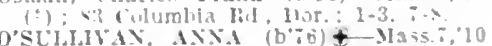
(1'10): Trinle it: $2-4$.

(2) $(6+4)+-313 \times 5,15$ (3) : 381 beacon sit: $:-1$

ofls. Mlnnle Krumbolz Fink (b\%9)-Mass.6,

'10; (travellng).

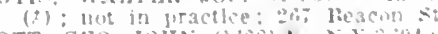

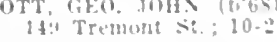

OFHLLATEK, I HAS I.FONAli

II

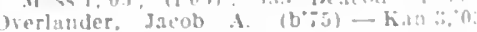

10.t.

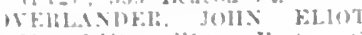

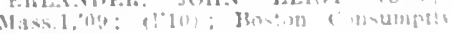
linspltil: i.

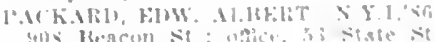

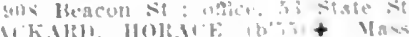

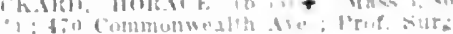
Maxn: S*

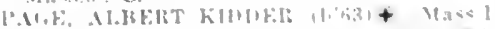

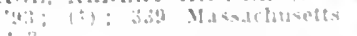

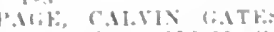

(14: $(195): 195$

(AY. H. Bact.

(II)

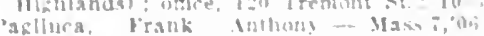

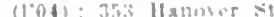

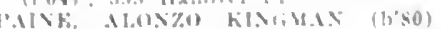

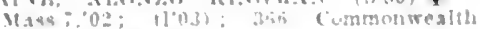

Aie: $24: 0 b G$

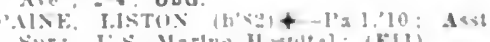

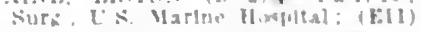

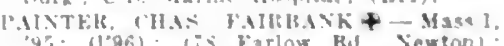

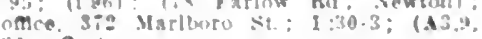
of ; Or. 
PALFTEY, FIANCIS WISSLOW (b'5)

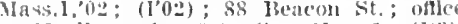
50) Marlboro st. ; 2-3; See. Ilass.1; (113)

PAi,MER, EZIt It-0; (*): Trinlly ('t

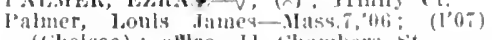
(1heisea): ollece, II ihaminers st

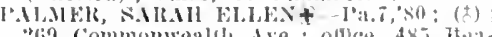

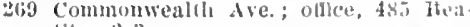
(con sit.;

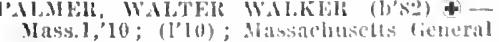

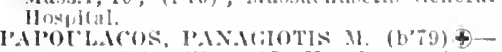

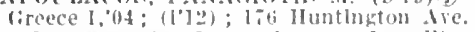

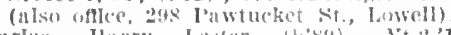

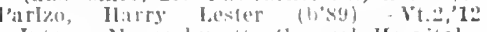
Intern, Massaclusette demeral Hospital. larker, Haruld Franele (b-s) Mass. $\tilde{t}, 09$

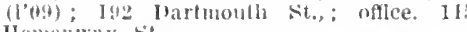
Hemenway st.

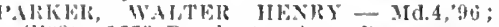
(1'98) ; 1733 Dorehester Ave., Dor.

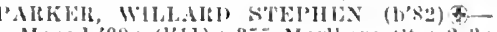

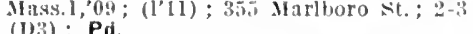
(1)3) : Pd.

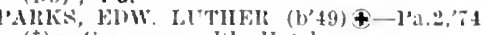
(t): commonwealth Hotel.

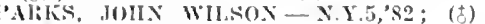
132 London st., E. 13.

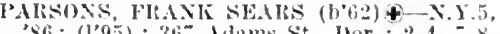
Miver, It (1009); (i2 (ilemway st., Dor.; $3-4,7-8$. PATCH, W. THY TSTOX (D'tI) + - N.Y.5.

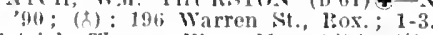

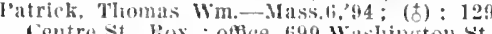

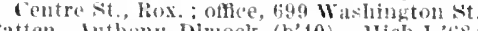
l'atten, Anthong: Dlmock (b'40)-Mich.I, (tis (t) : i2 Hale st., lox

PATTEN. STEIILN KERI (b'50)-Mass 1 97: (1'95); : Waumbeck st., lox. ; until

MTTELSOS, WM. FRAXCIS (b'66)Mass. 7,$95 ;\left(l^{\prime} 95\right)$; O Oak St., Clisn. office, 385 , Main St.; untit $9,1-3,7-8$.

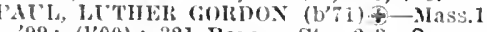

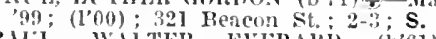

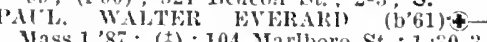
(E1,2); $\mathrm{N}$

P’anI. Willard Augustus (b'55) H-Mll.4, 81 (196); ts Charlotte St., Dor.; until $2-3,6 ;: 30-7: 30$.

Payme, Jolun Howard-Mass.5, '79; (8); 352 Commonwealth Are.: $2-3: 30$; Emer. 'Prof. Ophth.. Ylass.5; Op.

PEABOTY, Frixcis WELD (b's1) Yass, I,, $0 \pi$; $\left(I^{\prime} 0 \pi\right)$; I'ter Bent Brigham Hospitall.

PEARE'E, ARTHER IISHING-Mass.1,03: (l'0:3): (Brookline); office, 543 Boylston St.: : :-5; U.

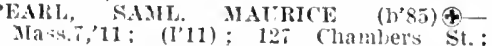

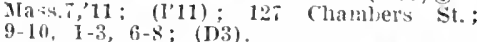
$9-10,1-3,6-8 ;$ (D3).

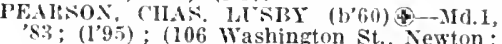
mitil $9: 30,7-8)$; offe, 127 .iariboro st: $12-3$.

Pearson. Mary Morey-irass.5,'s5;

Pense $\mathrm{klla} \mathrm{G}$.

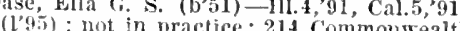
Are.

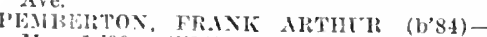
Mass. 1,09; (1'l1); 165 Darlmouth St. ifflee, $3 i t$ MIarlloro st.; $1-2$.

PFNHALLOW, DENLAI' PRABCE (b'80) $2-1 ; \mathrm{s}$.

Percy. Kiarlton foodsell (b'86)-Mass.1,'11, (1'l2); (191 Aspinwall tre. Brookline) office, 8 Gloucester st. ; $2-3:$ (I) 3 ; : Pd.

Perkins, ilamilton ('hesley (b'is)-Mass.6, '11; (1'11): 224 East St.

Ierkins. Nathanicl Royal (b'17)II-Mass.5

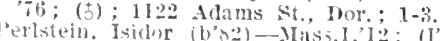

Assictant I'hysician, Roston state Hos pital, Nat.

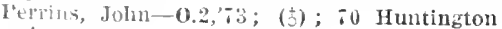

I'erit: Wm. Arthur-0.2,31; (む); 118

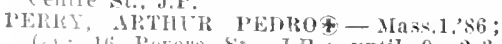
(1) 16 Rerele st. J.E.; until 9, 2-3,
Perry, Ehten lireeley-1't2,85; (b); 6t Ilimenway st.; onlee, 362 Massachusetts Ire

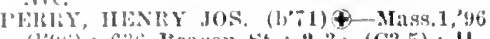

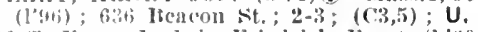
l'pal', Franz ludwig Friedrich lemst (b'tio) led. school; (116). 17,94; (o); Harrard

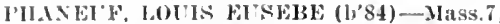
1:3: Intern, ('arney Hospital.

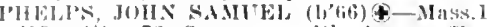
93; (t): it Commonwentll Ave.; ofllce, Frinklin st.

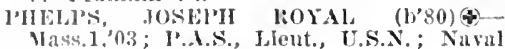
IInspitial.

Phillinore, Fredk. Geo.- $\diamond$; (む); 146 Whodrow Ave, Dor, ; office, 329 Hanover st.

PIIlLLIIS, WHSON FRANK (b'T2) Mass.5,98; (1'98); 3 Whitman st.; onlee, 138 Xorfolk St., Dor. ; $8-9,2-3,7-8$.

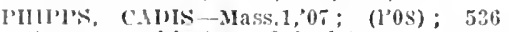
comunonwealtll Ave.; 2-3; 1.

I'liEOS, JAMLS COGSWBLA Di

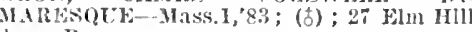
Are., Rox

l'liE, WWFLED CARLE $\oplus$-Mass. 0,00 ; (1'00); 415 Columbus Are.; ofllce, 82 Huntington Are.; 1-3, 7-8.

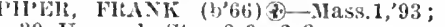

39 Iraneock st. ; 8-9, 2-3.

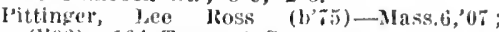
(l'06) ; If 4 Tremont St.

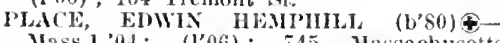
Mlass.1, 04 ; $\left(1^{\prime} 06\right) ; \quad 745$ Massachusetts Are.; offlee, South Dept., Boston City Hospital.

I'LUMMLR, FDW. MARWICK $(1,56)$ ( X.1I.1.'s2; (c); 5 Adams St., ("hsn. ; offlee, 583 Beacon St. : 1-4; Prof. Otol. Mass. 7 : $(\mathbf{B} \bar{n}, 1 \overline{1})$; ALR.

Plummer, Henry Llucoln - Mass.1,'90; (1'95); 728 Saratoga St., E.B.

Plunkett, John Jawrene-11d.6,94; 25 Cortes St.; office, 18 Boytston St.

Polsey, Frnma Aurienne (b'83)-Mass.5. '08; (1'10); 71 Howland St., Rox.

POMEROY, HIRAX STELLNG (b'48) Ger.14,'85; (d) ; (59 Grove St., Auhurn
dale); office, 65 - Boylston St.; $\mathrm{I}-3: \mathrm{N}$. OND, BERNARD WLSLEY (b'T3) 4

Mass. 1,01; (1'01) ; 4 concord Sq. ; until $9.1: 30-3,6: 30-7: 30$

I'oole, Alva Emory (b'75) - - ; (1'01) ; (Foxboro); offlee, 43 Tremont St.; 10-4.

Pope, Caroline Angusta-Mass. 3,70

not in practice; 163 Newbury st.

POPE, EMILY FRANCES-Mass,3,'70; not in practice; 163 Newbury $S t$

OR'TER, CHAS. ALLEX (b'66) Mlass.1, '92; (む) ; 254 Beacon Nt.; $2-3: 30 ;$ Assoc. Prof. Surg. Mass.1 and Mass.Gi; (A5, Porter, G1

Porter, Chas. Terrell (b'89)-Va.1,12; Intern, Massachusetts (haritable kye and Ear Infirmary.

Porter, Nonald Wallace (b's6)-Mass.1,'12; Boston City Hospital.

PORTER, WM. TOWNSEND (b'62)-Mo.2, 85; (1ث); (Dorer); office, Harvard Medical School; Prof. Comparative Physiol. Mass.l and Mass.fi.

POST, ARNEIT-Mass. 1 , T 0 ; (b) ; 16 Newbury st.; $1: 20-3: 30$ : Prof. Strph., Mass. 1 ; $(C 1,2,4)$.

POTTER, ALEXANDER CARLETON (b'T3) (4-Nass. 1,98; (1'01); (1 Potter Park, camlridge; $1: 30-2: 30, \quad 7-8) ;$ office, 186 Commonwealth Are, ; $3-4: 30 ;$ s

Poulin, Damase Mark-Mass.6,'87 ;

15.3 W. Prorkline St.

Powell, Jonathan Rider, Jr. (b'tu) - Vt.2,'88; (I'95); (old ('batham, N. Y.) ; office, 92 Huntington Ave, ; 9-11, 1:30-3:30, 6-8.

Power, Robt. Wm. (1'71) - Mass.6,09, (1'12) ; 73s E. 6th St., S.B.; offlce, $221 /$ liroadway.

Powers, Abner Howard (b'55) H-Mass.5, 85, ; (t) ; 8 Cumberland St.; until $9,1-3$,

POWERS, EDW. PARNELI (b'81) $\oplus-$

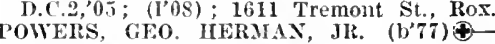
Cal.2,02; (1'05); 295 Mlárlboro St.; 2-3 (B15, D3) ; ALR.
PliAINO, GAETANO (b'83) - Mass.7, 07 $\left(10^{\prime}\right) ; 159$ llarrison Ave.; office, 39 Broadway Extenslon; ; 2-3; (1)3) ; Pd.

PllAT', bZEKILL (b'85) - Mass.1,12; (1'12); Boston City Hospital.

l'liATT, JOS. HEISEY (b'72) क-MId.7,98;

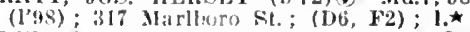

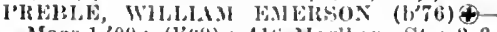
Mass. 1,09; (1'09) ; 416 Mariboro St. ; 2-3

HEXN, Jos. (1,82)-Mass.ä, b8; (1'08); 407 Marlboro st.; 2-4; ALR.

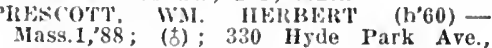
J.1.; offlee, 2\& Court Sq.; $10: 30-12$ (I)3) $P$.

Irevett, Jos. $\rightarrow$; $\left(l^{\prime} 04\right)$; (Hevere); office, 38 Hanover St

IHINe, MOLTON (l, 54$) \oplus$ - Mass. 1,79 (1); 458 Beacot St.; Winer. l'rof. Dis.

I'rior, James IId.6,'96'; (1'97) ; 36 Hancock St.; $1-3, i-8$.

PRor"POR, F'TRNCIS IXCEBSOLL (b'64)Viarlborn (f) (Wellesley)

I'ROC'TOR, IOS. WHIPPLI (b'75)-Mass.1, "9s; (\$); (2:35 (Clifton St., Nalden); offlee, state IIouse.

PIT'NAM, C'HAS. PICKEIING $\left(b^{\prime} 44\right) \&-$ Mass.1,69; (d); 6.3 Marlloro St. ; (D) 1,3) ; Pd.

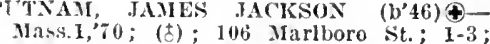
(B14, D6, K1,2); $\mathbf{N}^{\circ} \star$

PUTNAM, JOS. NORKILL (b'48)థ-N.Y.10 70 ; (t); (West Medford); offlce, Ola South Bldg: $11-4$

QTAC'KLNBOSS, ALEX. (b'66) (8-Mass.1 92; (†); 175 bartmouth st.; office, 14 ! Newlury St.; 12-3; Prol. Ophth., N.H.1; $(\mathrm{B4}, 14)$.

QHEST, JMES FHANCIS (b'a) (-V-Vt.2 '06; (1'0 ) ; 191 Huntington Ave.; 1-3, $6-8 ; U$.

Quigley, Wm. Sullivan (b'86)-N.H.1,08 (l'08); 14 I'rospect St., Chsn.; office, 40 Monument sid. ; 2-4, 7-9.

QVINIY, WM. CAITER (b'T) 2 -Mass.I, 02; (1'01); 520 Commonwealth Ave.; $(\mathrm{C} 3,5)$.

RABE, EDITII MITH ELIZA MEEK Mass. 7,998 ; (1'98) ; 481 Beacon St.; 2-4;

RACKEMAN, FLANCIS NINOT (b'87) Mass.1,12; (1'12); Massachusetts General Hospital.

Ramsey, Wayne Stevenson (b'86)-Mass.1, '12; Intern, Boston City Hospital.

Rand, Carl Wheeler (b's6) - vid.7'12; (1'12): Peter Bent Brigham Hospital.

Ransom, Eliza Taylor (b'6 6 ) H-IIass. J, '00 $\left(1^{\prime} \theta 0\right)$; Hotel Puritan; office, 390 Commontrealth Are.; 1-4; NP. *

1SEAGH, ARTHUR LINCOLN-Nass. 1,98; (1'98); 39 Mlaple St., West Rox.

REARDON, THMOTHY JOSEPHA-Mass.1, 94; (196); i6 Commonwealth Are. (B15)

REDDY, JOS. WARIEN-liass.1,95; (1'96) ; $211 \mathrm{~K}$ St., S.B.

REDMOND, JAS. WM. (b'6T)Ð-Mass.I,'92 ; (1'94); 512 E. Broadwas, S.B.; 1-3, $7-8: 30$.

Reed, Bentrice Alma (b'90)-Mass.7,'i3; (I'13); 521 E. 8th St.

Ieed, Carlisle (b's0)-Mass.1,05; (1'05): 153 Nassachusetts Ave.; 1-2.

Reed. Floyd Orton (b's3) - Mass.1,'11; Intern, IBoston City Hospital.

Reeves, Marcellus (b'63) H-Mass.1, 90 ; (l’04) ; 1059 Boylston St. ; 2-4, 7-8.

REGAN, JAMES JOS. (b'88)-Mass.7, 13 ; (1'13); 21 Thomas Park.

Regan, Wm. Henry $\left(b^{\prime} 76\right)$ - Mass. $\boldsymbol{\prime}^{\prime} 06$; (l'06); (863 Massachusetts Ave., Cambridge); offlce, 15 Beacon St.; 10-5; 0p. $\star$

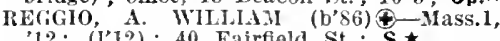
'12; (I'12); 40 Fairfield St.; S.

Reid, Eustace Palmer-Nlass.,${ }^{\prime} 98$; (1*98) 722 Commonwealth Are.; office, 100 Boylston St.; $9-6 ; 0$.

Reid, Francis Walsh-Ire.1,'80, Ind.8,'88; (1'96) ; 205 Huntington A re. ; $11-1,6-8$. 


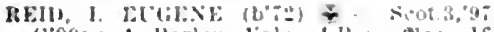

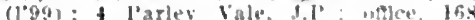

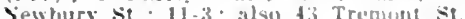
Sewbury

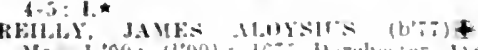

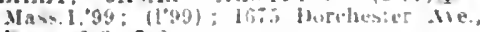
line, $2-3,7-8$

Relly, Thumas l, 16. Masachusetes die.

Rels, Fredk-Mass.7.03: (1'03): 17: Xitpolk se, Dur.

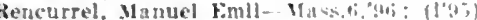

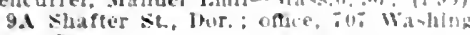
tois St.

RFINOLDS, Fill, $(660)+M a 41,5$

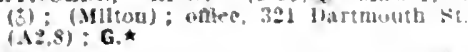

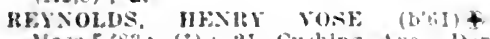

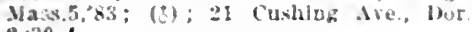
$2: 10-4$.

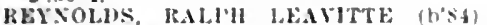

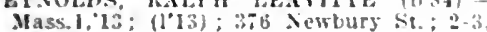

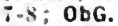

thames, Kudulph Frnest Trenholm--Mass.6.

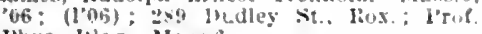
rhys Wlaz., Mass.6.

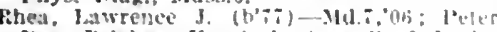
Jent Brlgham liogital: Asst. !'rof. la's, Jass. G1: (1)3, $5 * 2)$

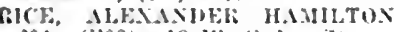

04: (l'03) : 13 W l'edar st.

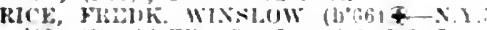
93; (c); 16 Elko st., Irr. ; 3-9, 2-3, - -

Rice, Geo, Brackett (b59) II-Mass 5, sti: 20 Clarendon $S:$ : $1: 30-3: 30$; Prot. luhin. and Larsn.. Mass.5: ALR.

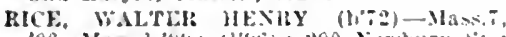

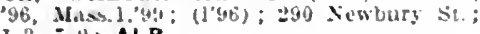
I.3, $-9:$ : ALR.

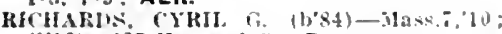
(1'L2); 425 Harrard st., Dor.

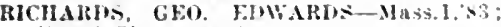
(t) : 11 Giluucester St.

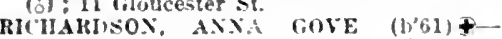
Pa.:91; (b): 4\$3 lieucon st: G.*

RICHAIIDSON, FII, PEIRSON (h⿻一𠃋] Mass.1,06: (I'0i) : 2at Hearon S!: I:30-

Richardson. Frank (hase (1,5s) II-Masit

79 ; (5): 29.5 Commonwealih . Ive. : l'rot. Neur. an Elec. Ther.. Mass.j: NP.*

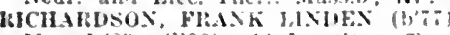
Mass. I, th: $\left(l^{\prime} 06\right) ;$ t: Iry st. ; uftice, it Boylston st.: 2-3: $\mathbf{S}$.

RICHARISUX, MARK WYMAX (b't) Mass. 1, "It (5): Sec. State Boalrel al State Hous: $4-5 ;$ (I)6, F:); NP.

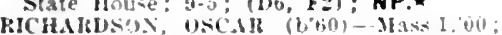

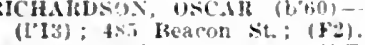

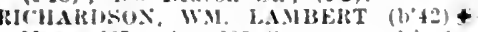
Mass 1, 60; (ठ); 225 Commonuenlih the $1-2 ; 30$.

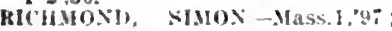

2il llumboldt Ale., Ris.

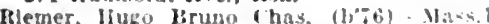

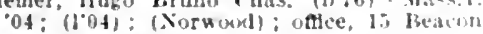
St: $2-5 ;$ Op.

HHE: MCETIE $(1,-8)+-M a s i, " 11$

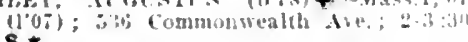
S.*

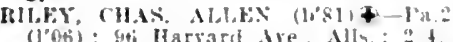

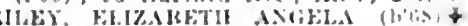

Mass.

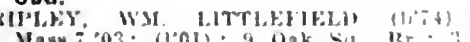
Ilass. i,03; (1"01): 9 1)ak sil. 16r.; : 1 , $\because \cdot 3$.

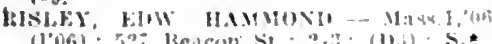

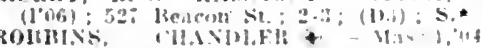

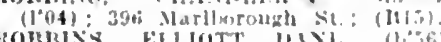

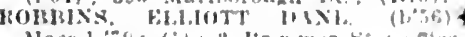

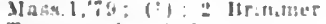

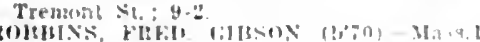

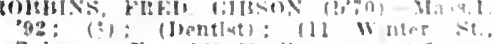

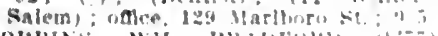

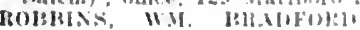

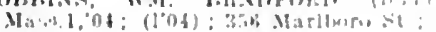
(1)3).

Folverts, Frank liurne- 11.16

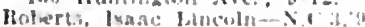

lievero st.

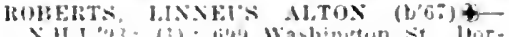
.ll 1,26 ; "he

Holertam, James llamplas - Maszob,94: (a) 00 liaj viate liel.

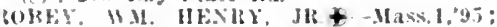

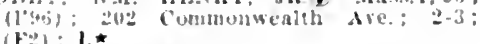

(1)

loti liartmonch st.

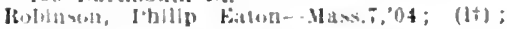
I0] Tremont st.

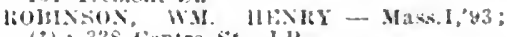

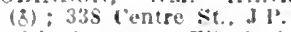

Bocheurd, dirace Elizalueth (b'se)-Mass. 0.: (1'0i): 61 l'arker Hill Ale., Kox.

rono, victor l.mman (b:5)-ial.5,13; luteru, (arney Hospltal.

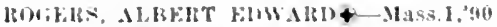
(3): 424 Washington st., lor.; otfle, 261 beacon st.

lingers, dolus conway (b;7)-Mass. I, 04; (lof): $35:$ Ihorchester st.; unell 9, 2-4.

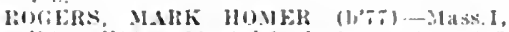
et; (l'04): 11 Asliford st.; offlec, ts. Beicon st.: (A9); Or.

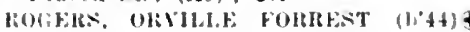
N.1.163: (6); th5 Washingten st. lourchester Center; :-3:30; $1 . \star$

Iovers, Orville Forrest. Jr. (b'sfi) - Mass. L, 11:; (1'1:); Massachusetts (ienceral llos pltal.

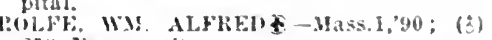
giv juscon sit.

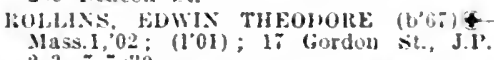
$2-3,7-7: 30$.

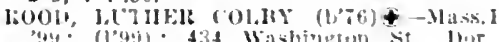
until 10 ; oftice, 4ls Buyliton st.; $2-5$ OALR, *

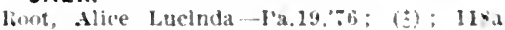
llarvard st., Dor.

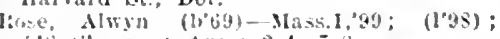

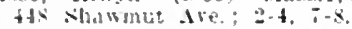

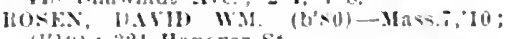
(I'](1) : :2L Ilanores St.

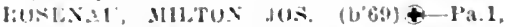

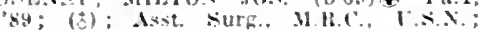
(to) Naples bil. Mramklines) atroe, Ilarvard Medical sehuml: l'ruf. I'rerent. Med.

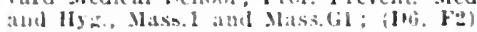

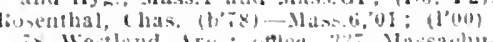

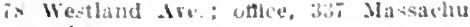
setts Ale

ROTEII, THOMAS MORLIS $(\mathrm{bit})+$

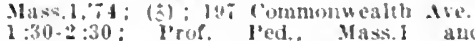
I:30-2:30; I'rof, l'ed. Mass.l and

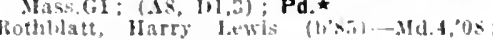
(l'0:4): 39 W. Cedar st. : (II:3)

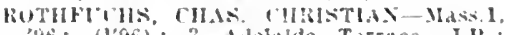
96 ; (1'96): 3 Nilelalde Terrace, J.l. utllee, it Itoglstom st.

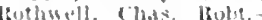

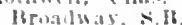

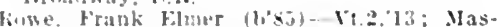
saldukette llowe pathic Hospltal.

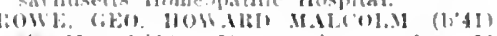
tiv st.

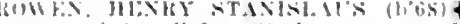

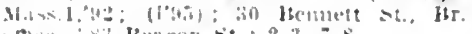

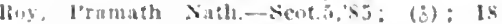
rerdts sir. (list.

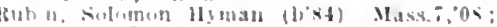

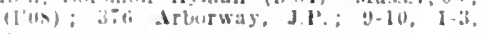

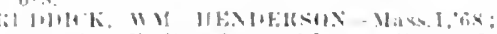

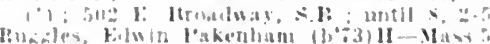

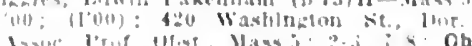

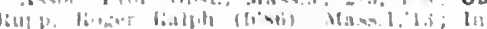

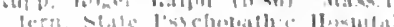

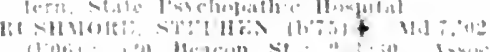

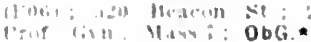

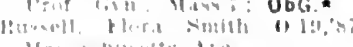

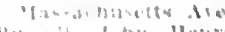

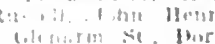

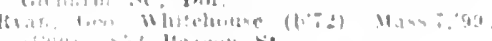

$144^{2}, 6+111$ sit

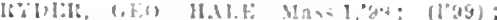

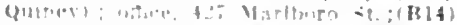

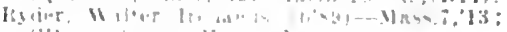

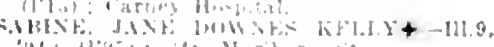

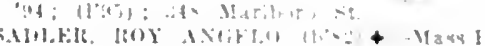

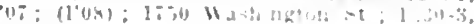
:-v; $(10, i)$

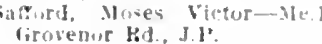

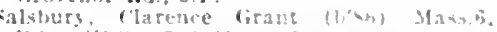

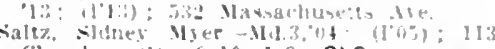
rhambers st.: $9-10,1-3 ; 0$ OG.

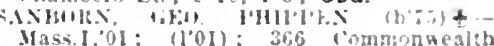
Are: $:-3 ; 1 . \star$

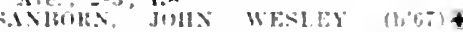

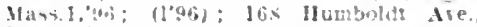

liot: Op.

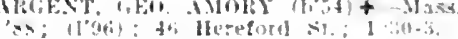

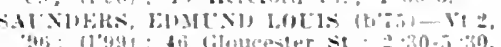

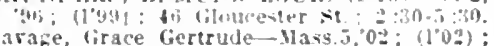

The Charlesgate.

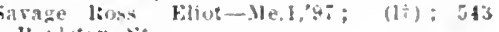

busiston sis

AVHAL, SLMXER (AIKITH $\left(b^{\circ} b^{\circ}\right)+$ Mass.1.44: (1"at): 1.7 shepard st.

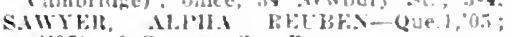
(1005): 6 Conwas st., Ros.

SAIV YR, ElW. KEY LS - Masa. I,99: (1'is): 419 lhorlston st.

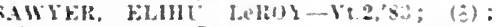
i) Conway st., Pnw

Sawyer, Herbert Houston $(6,0)-M a s, 5$

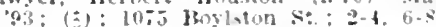

sawyer, Wrn dffed inst-ra.1.13:

Peler Rent Brigham Inspicil.

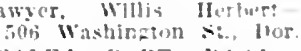

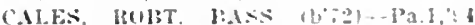
11'95); 546 Washington st, fher, : 2-4,7-8 Sealzlll, Erieo Irmaido-j) (I'0:); (West

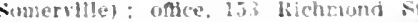

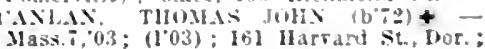

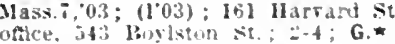

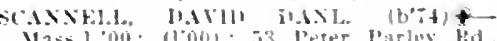
Ilass.100: 11000, is l'eter Farloy

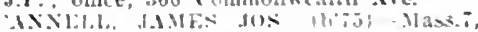

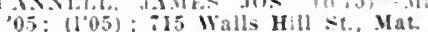

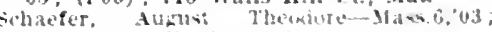

(los): 30t Newhes sit.

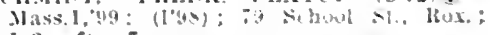

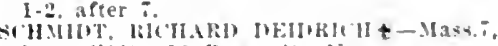

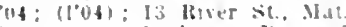

Schuartz, Alralasm liermard $\left(b^{\prime} 9(0)-\right.$ lial.11,11: Musalchusetts liptaral llospltal: Pd.

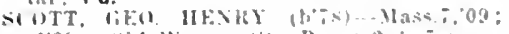

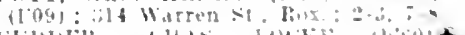

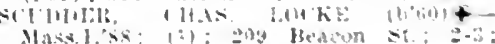
(A J, ( $3, \pi, 1,3)$

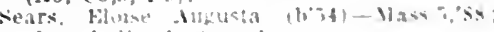

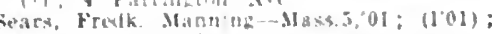

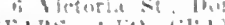

ง

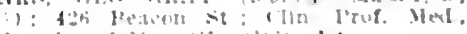

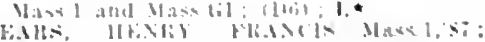

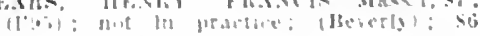

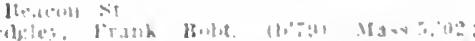

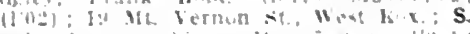

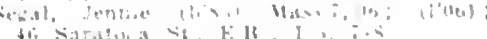

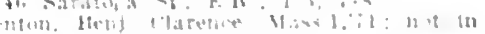

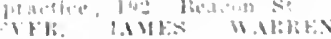

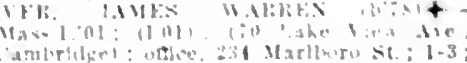

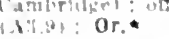

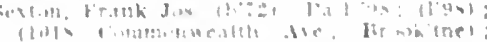

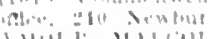

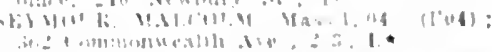

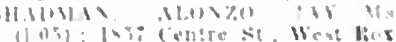


SHANAHAN, THMOTH Jos, Mass.

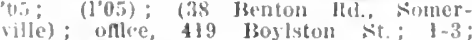
(Blle); oflle,

Shapira, Allert Abrallam (b'si)-Mass. 13: (1'13) : 32 (hambers sit. ; olluce, Ibistun City Hospltal.

Shaplril. Israel Jarlus tillhaf (b'63) Ma.t;

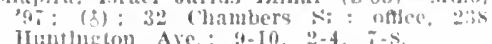

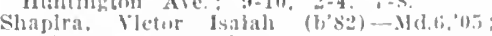
(10.5): 61 liradihaw St., Dor.

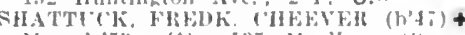

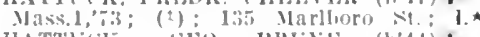

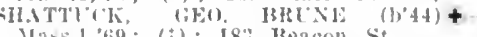
.1as. 1.69: ("): 18:" Beacon st

SILATTIK, CHO ("HEEYEI (b'79) Mast, 10.5; (1'06); 135 Marlburo

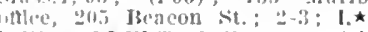

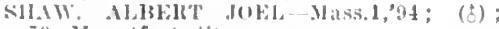
ia Mountert sit.

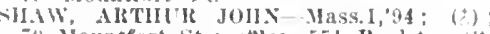
If Mountfort st. ; onke, 5.5 JBoylston st IfA, IISil A. (b't

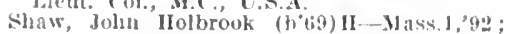
¿); (14 IBrewster st., I'lymouth); oflice. 220 Clarendon sit.

HAY, CHAs. Howly (b'80)-Mass. б, os (1'04): 62 trawford St.: oftece, I36 War ren st., Rox.; $2-4$, i-s:30; LR.

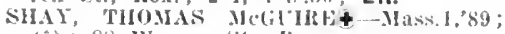
(j): 88 Warren sit. hox.

Shen, John Francls--X.1.5,98; (1'98) ; $5: 3$ south, II. I'.

SHEA, THOMAS BERNARD (b'63) Mass.1,87; (c); it Marlboro st. heehan, Edward Bernard (b'8 1$)$-Mass.1, 13: Intern, Boston City 1Iospital.

SHEEHAN, WM: JOSE,H $\left(b^{\prime} 75\right)$-Mass. 7 ,

$03 ;$ (1'03); 197 W. Broatdway, S.B.; 2-4,

SIIFLINON, RUSEELL, FIRTH (b'85) Mass.I,'I1; (1'I1); 207 Bcacon St.; 4-3; S.

slepard, Juther Dimmlek, Jr, (6;2) Inss. I, 00 ; (l'00); (Dentist); 390 Dartnouth st.

SIIEPPAIL, PIILI" ALBERT EDW

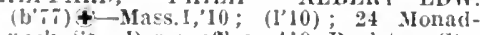
nock st., Dor, oftlce, 419 Boylston St.; $2-4$

SIILKBLRNE, ANDIEW HDW. †-Mass.I, (1)3: (1'01) : 4ti Brent sit. Dor.

SIIERIDAN. PHILI HIW. ANTIUNY

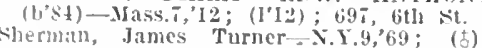
24 Virginia St., Hor.

shermall. John Howard (b'30)H-Vt.I,'ji (L); 534 E. Broadway, S.IB.

Sherwin, Aurelius Calvin (b'40)-Vt.2,7a; sherrood, Walter-Nass.1,96; $(1995) ; 193$ IIuntington Are.

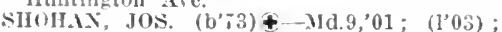
I56 II

shurtleff, Eugene (b'61)_Mass.6,'s6; (ह) Jones Are. ; oftce, 517 Shawmut Are (Portsmouth, N.H.): oftice, 485 Beacon IIN1, FRAX゙C1S PIHRCE-Mass.1,93; (*); 206 Main St. Chsn.; $2-4,7-9$

NIMONS, CHANNING CHAMBERLAIN $\left(b^{\prime}, 7\right) \pm$ Mass. 1, $94 ;(1001) ; 245$ Commonwealih Are.; office, $31 \mathrm{i}$ Marlboro St. $2-3 ;$ S.

Clara Cogdon-Ill.4,'85.

(inellesley) ; office, The Canterbur

, 7 , lienry Anderson (b't3)-W.C.3, II, $2-4,6-8 ;$ U.

simmons. Wm. Elmund (b'52)-IId.3,'86; (5): 27 Hollis st.; $11-1,7-9$

simpson, John Thos. Llonel-

Cliambers St., North Postal.

inelair Hin $A,\left(b^{\prime}-2\right)$ 25 Temple Pl. sissa, Silwlo-f; (1'04); 1008 Bennington
st.. E.B.

Issox. MTCHELL (b'87) - Mass.1,'13 (13) : 26 Frinceton St.; office, 281 Hanover st.; in-12, i-s.

Warren Richards (b'85)-Md. Intern, Peter Bent Brigham Hospital;

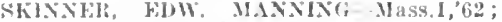
(8) 56 Massachusetts Ar

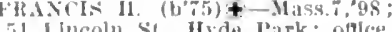

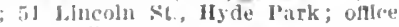
Jo0 Nummer st.

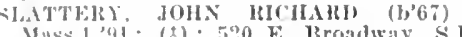
Mass. I, 1; (3); 520 E. 13roadway, S.B.; calce, 520 dieacon st. ; $2-3: 30$.

lattery, Jos. - Mass.6.07; (1.07); 8 Worcester st.

stattery. Maly Hllabeth (b'68)-Mass.f "0\%: $\left(l^{\prime} 0 \overline{0}\right)$; sl Worcester St.

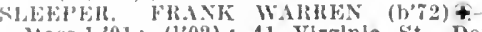
Mass.1,01; (1'02); 41 VIrglnla St., Dor. smallwood, ieo. Washington $\left(b^{\prime}(12)-N\right.$ Y. Y.j.

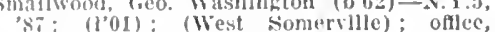
'si: (toI): (West Somerv

Smeltzer, James Flinlay-Mass.7,02; $\left(1^{\prime} 01\right)$; (Allantic); offlce, 100 l3oylston sit.

smbllie. Wlison fieorge (l'86i)-Mass.1,12 Intern, l'eter Bent Brlpham Ilospital.

S.MITH, C. MORTOX (b'67) + - Mass.1, 94: (t): 437 Marlboro st. ; I :30-3:30

19.

14:3 Newlury st. ; $2-4$; LR.

S.ITH, EDWIN WIILACE (b'S0)-Mass.5, 01; (1'01): (Newton); offlce, 374 Marlboro st.; $\mathbf{0 b}$.

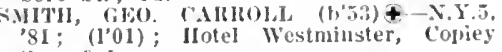

SMITH, GEo. (iILBEIT (b's3)\$-Mass.1, $08 ; \quad\left(l^{\prime} 09\right)$

(C.5) ; U

mith, Harry Allerton-Me.1,90

corey st. West

HITH, IIOWAIRD HARRY $(b ; 2)+$

Mass. 1, 00 ; (1'01); 845 Boylston šl.

SMITH, JOHN HALLE-Ky.4,'96; (1'98) Boylston st: $2-3 ; \mathrm{S}$

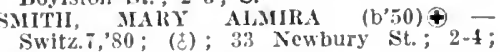
Switz. 7,80; (d); 33 Newbury St. ; 2-4; SMITH, PETER MATTHEW

(l'96); 758 Tremont st.; Pd.

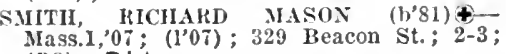
(D.3); Pd. *

SMITII, THEOBALD (b'59)\$-N.Y.3,83; not in practice; 397 south St., J.P. not in practice, Śchool; I'rof. Comparative Path., Mass.1 and Mass.Gi; (D6. F2)

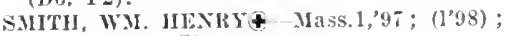

375 Beacon St.

Smith, Wm. Morgan-Mass.7,04; (l'04) 255 Park St., Dor.; offee, 101 Tremont

Sulth, Winfield Scott-Mass.5,83; (む) (Brookline); office, 638 Beacon St.; Prof. Oper. Surg., Mass.5

SMITHWICK, MARSENA PARKER (b'6i) - Iass. 1,95 ; (5); (Lexington) ; office, 483 Beacon St. ; $2-3,6: 30-7: 30 ; \mathbf{S}$.

SMYTH, DUNCAN CAMPBELX (b'85) Mass.1,09; (l'0

MITH PATRICK SOMERS $\left(b^{\prime} ; 6\right) \uparrow$ Hass.1,04: (1'04): (75 Wincliester. Rrookline); offle, 69 Newbury St.; 2-4; (BI4); Op. $\star$

NOW, FREDK. STEDMAN†-MaSs.1,'99;

(1'99); 166 Townsend St. ; $8-9,2-3,7-8$,

yder, Jacob Daniel (b't6)-Pa.1,03 (I'06); 543 Boylston St.; 2-4, 6-8; $\mathrm{S}$. SOBOTKY, IRVING (b'80) \&-Mass. 1, 07: (1,0\%); 366 Commonwealth Are.; 2-3;

ALR. $\star$

Solomon, Saral Augusta- - ; (屯); (Mansfleld); office, 181 Tremont St.

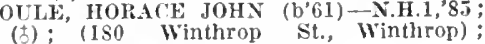
(†); (IS0 Winthrop

SOUTHARD, ELMER ERNEST.

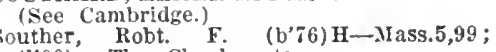
$\left(l^{\prime} 00\right)$; 'The Charlesgate.

Uintick, Geo Rinaldo - Mass.5,81, Mass.1,'98; (t) ; 433 MarIboro St.; 8-9, $1: 30-3$; Prof. Gyn., Mass.5; G.

SOUTTER, ROBT. (b'70)థ-Mass.1,'99. (l'99); 53 Hereford St.; office, 133 Newbury St.; $1-3 ;(\mathbf{A} 3,9,26) ; \mathbf{O r}$.

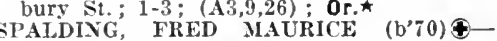
MALDING, 1,97; (1'97); (Brookline); office, 390 Commonwealth' Ave.; $(\mathbf{B 4}, 14) ; 0$.`. sparlug, John Henry-Man.I,91; (l'o!!); 17 Harvard Are., bor.; ottlee, 144 lluntlngton Are.

palding, Ebenezer Furrlnglon (b'35)Mass. 1, 66 ; ( Rox.: $3: 30-\frac{1}{4}: 30$, $: 8$.

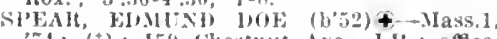
74: (t): 159 chestnut Are. J.I'. : offlee, 100 13oylston St.; $1: 30-4 ;$ (135) ; A.

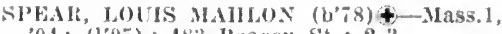
04; $(1.05)$; 453 Beacon st.; 2-3.

sisunney, Frederic Ira (b'78)-Mass.7,12: (1'13); (24 Bradley St., comervile): oftice, 4 (Columbus Sil.

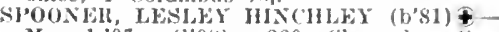
Mass.1,07; (1'08); 260 Clarendon sit. $2-3 ; 1 . \star$

I'ILAGIE, FRANCIS PELEC; - Mass.1,57; (1) ; 229 (ommonwealth Ave,

I'RAGLE, IRLSSEII, B. (h'87) †-Mass. ĩ 11): (1'I2) ; 374 Marlboro St.

Sproules, Jos. Aloyslus-0; $\left(\mathrm{I}^{\prime} 00\right) ; 1615$ Tremont sit., Hox.

Angelo, Joseph A. (b'8I)-Mass.6, 12 (1'12); 130 Salem St.

ST, CLAIR, AUSTIN EMERY (b'64) 1.2,93; (ठ); (63 Concord st., Framlng II-2; OpA.

St. George, Norman-X.H.I, 89; (t): (150 shore Drive, Winthrop); oftice, 74 Boyls. ton St.

STACFI, CHAS. FRANKLIN $\left(b^{\prime} 66\right)+$ Mass.1,92; (t); 456 Audubon Hd.; 2-3; Op. .

Stacey, Winthrop Downlng (b'81)-Mass.7, "06: (l'06); 33 Hlgh St., Chsn.; 2-3:30; STACK, JOHN JOSEPIX (b’ $07 ;(1,0 \%) ; 415$ Geneva Ave., Dor.

STAMI", Floy H: (b'81)-Mass.7,'12. (l'12); 400 Marlboro St.; $\mathbf{N}$.

STANDISH, MYLAS (b'51)—-Mass.1,79 (5) ; 256 Newbury St. ; offlce, $72 \mathrm{St}$. and Mass.G.1; (B1,4,14); Op.*

STANTON, JOSEPH (b'78) - Mass.1,03 (1'02); 520 Beacon st. ; $1: 30 \sim 3 ; \mathrm{S}$. Stanton, Thos. Leo (b'70)-Mass. I,'94; (I'95); 367 Massachusetts Ave.; 1-2.

STAHIIHD ENW PERLEY (b'72) until $9,2-3,7-7: 30 ; 0$ bG.

Statsny, Olga Frances (b'78) - Neb, 5,13 ; Intern, New kngland Hospital for Women and children.

S'TEAIINS, ALBEIRT WARREN (b'85) Mass.7, 10 ; (1'10); 330 Hyde Park Ave. Rox.; office, $520^{\prime}$ Commonwealth Ave.; N. $\star$

tearns, Chas. Goddard-Mass.1,'81;

32 I Centre St., Dor.; N.

STEAINS, ROBERT THOMAS (b'75)'t Mass. 1, $02 ; \quad\left(l^{\prime} 01\right) ; 2 t$ Hazleton St. Mat. ; $3-4,7-8$.

Stearns, Thornton (b'86)-Md.7,'12; Massachuselts General Hospital; Or.ઐ

STEDMAN, GEO.૯-Mass.1,"75; (ठ) ; 380 Newbury St.

STEDMAN, HENRY RUST (b'49) §Mass. 1, 75 ; (t) ; $(27$ Irving St., Brookline); office, 48 Beacon St.; 10:30-12; $(\mathrm{E} 1,2,8,13) ; \mathbf{N} . \star$

STEDMAN, JOS. CYIUS $\left(\mathrm{b}^{\prime} 67\right) \oplus-\mathrm{Y} . \mathrm{T} .5$, '90; (t) ; 23 Lakevllle Pl., J.P.; 8:30-9.

STELLE, ALBERT EDW. (b'7)†-Mass:I 00; (1'01); 79 Robert St., llos.; 2-3; Path.

Steenberg, Donald Benjamin (b'90)-Pa.1, 13; Massachusetts General Hospital.

Stelmen, Jacob Erhard-Mass.6,07; (107) 3 Jongwood Ave., Rox.

Stephenson, Milton kimer-O; (t); (Newton); Irvington St.

Sternberg, Jos. Edward (b'74)-Mass.5,'09 ; (1'09); 244 Warren St., Rox.; offlce, 100 Boylston St. ; $1-4 ; 0 p . \star$

STETSON, FREDK. WINSLOW (b'71) Mass.1,97; (1'97); 504 Warren St., Rox. 2-3, after 7 .

STEVENS, GEO. BECKWHTH (b'45) STEVENS, HENRY BURT (b'70) Mass.1,'94; ( 5$)$; 79 Park St., West Rox. office, 419 Boylston St. ; 1-3; (B14);:Op. 
Sievens, James Herlert-X.1.9,93; (?): copley-lliaza II ulel.

Sterens, Ruey Itartleth-Mass. :9s: (1'9s) 94: suth st. Itos.

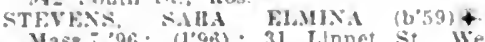
Yass. $196:\left(1^{\prime} 90^{2}\right)$ : 31 I.Innet St. West

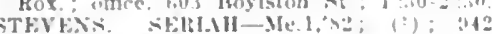

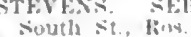

sterens. Wm. stanford $\left(b^{\prime 59)}+\right.$ Mass.l. S.e: not in practlce: 295 lleacon si

Slewart, Janes Hogne Vassf., 1

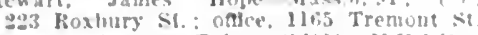

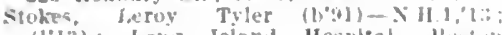

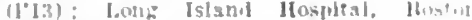
Itarbor.

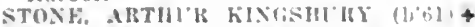
Uass. 1, SQ; (:); if Falrfleld sit.

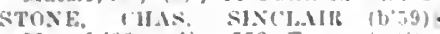
Mass, 1, s6: (i): 752 Tremont $\rightarrow$ t. 6-8.

STONF, GEO. IIFXKY (b'S2)-.MP.L."0 (1"09): 13oston (Ity Ifospltal; OALR. Stone, Henry Folw (b's9)-Mass. "1 TONE, JAMES S.IFAGE (b'GS) +-MSS. p4: $(9):$ ('raningham): once, 234 M.tr "34: (\$) : (Framinghim)

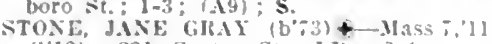
(1'12): S21 Centre SL, J.1.; 2-4.

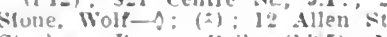

Stoukey, Hyron lolk (b's:)-Mass, 1, 13: Intern, Moston City IIosultal.

STOLFH, MAI,COLM $(b 02)+$ Mass l, (द) : 302 Beacon st: oflec, fib Huyl sion St: $:-3 ;(A S) ; G$

story, Hielen Lonlse Mass., "Q; : (laz)

is Fallson Giren. Ilut.

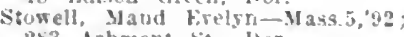

2s.3 Ashmont st. Iror.

Streeter, Edward I lark (1)'it)-111.40, (1) $\left(10^{\circ}\right) ; 413$ Beacon st.; 1:-3

atrong, Seth Lake (b'84) - Mass, 1, 1" (l'13): Carney Hospltal.

STRONG, IBICHAKI I. (b'z2) F Md::yz Member I'.l. Med. Soc, Harsarl ini verslty, I'top. Trop. Med., Mass.l and Mass.G1; (F2)

Sirong. Seth Lake (b'\&4)-Mass, 1, I: $\left(l^{\prime} 13\right)$; Carney Hospital.

strong. Thomas Moris (b'48)-N. I.9.': I? ; 176 IImulugton Are.: 2-4; ALR.* STIAIR FBEIK. WM (b'o 0$)$ Mass. I

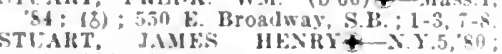
(b) : 236 Clarendon St.

STLHXICK, MAX+Mass.1, 04

12 Columbla IRd., Dor.

Sura, Geo. Alson (b'5')-1'a.9,39, 1a.t, 'gs: (c): Iy Nottraham, Dor.; oflce, 'gs: (i): I' Notthgham,

suffrin, Joseph (b'S6)-W1s,6,13: (1'13) s. Russell St.

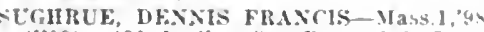
(1"99): $\$ 30$ [vadley st. Rox. $2-3, i-4$

sukeris, Comas Jordan (b'so)-Md.t, 0.

SLLLWAX, CHALLFS BRENT (b', 2$)+$ Mass.1,04; (1'04); 134 Warren st. Hus

Sulliran, I)anl. H.-Mlch.9,01: (l'01): 936

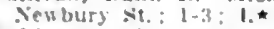

sulliran, Jolin Frincls-M Mas 1, "95,

1460 Tremont sit. Hor

SITLWAX JOHX JOSKIH $\left(\mathrm{b}^{\prime} \mathrm{b} 4\right)+$ Mrss. 1,00; (100); 93 Bowdoln st. Dor. $2-1,-8.8$

sulliran. John Thomas (b) (is) $\times 111,8$

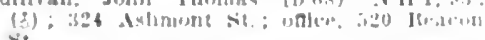
Sit

STLLISAX, JOHN THOMAs, JK-Maqs,

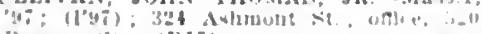
Heacon $x$ i.: (1315).

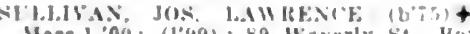
Mass.1,00; (1'99) ; 89 Waverly St., Ihox

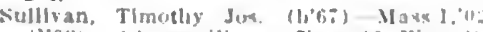
(los): (somervllte); ontce, te Fim sit i.t.

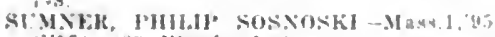
(1.95): 83 Wextlaud Ave

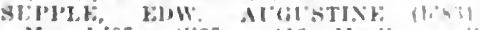

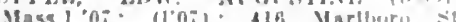
1: $: 30=3: 30$,

Sutherland, John I'reseon $(1,54)-11$ ian

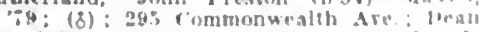
and frot. Theo. and 'rac Med. Maso
SWMX, HOWARD TOWXYFID (b'a)

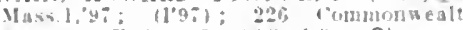

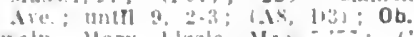
swaln, Mary lalpote Was

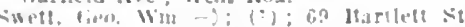

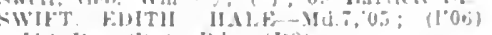
111) Hay Sinte M(1.: (113).

SWIT, JOHX H.IKER, JR. (b'\$t)

Masel.ns: $(1410): 421$ Marlbero s:

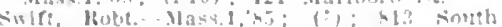
si. IRos.

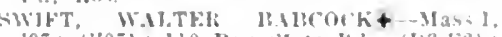
(07: (100); $110 \mathrm{Bay}$ slate Ild.; (113.6.2) N.

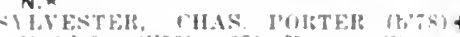

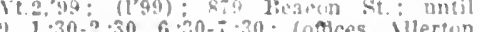
and Huli) : (D3).

TAIBOT, FHT\% IBRIMIFY (1)"-

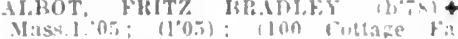

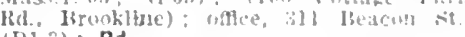
(III.3); Pd.

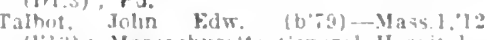
(1'13); Massarhuselti temeral Huspitid

TIHAMAX, AITISTIS I,ITTIAFIFIU

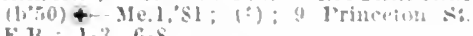

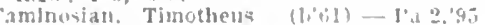

(1'95): 594 Tremont sit: $:-11:$ s.

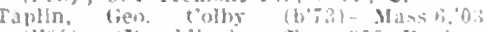

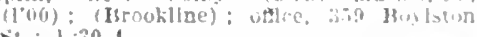
Ne. : $1: 30-1$.

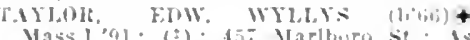

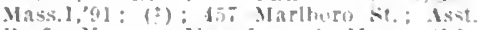
l'rof. Nemr. Mass.1 and Mass. li.1;

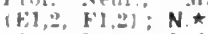

Faylor, Jamo" Kalph-Mass, 5,03 :

ils ionm

in rommonthesth Ate. $10-4 ;$ NP.

il jolnceton St., F.B.

Taylor. Stella Mars-I'a.i,'8s; Ont.3,89; $(19,5)$ : New Enyland IIosplial.

Taylor, Walter Oglethorpe (b':-) -Mass.o 09: (1'09): 217 W. Jewton se

Tearnsn, Clyde Hadrlan (b'ss)-Mass.1, 1:: Intert, Boston ('ly Hospltal.

TEMILE, WM. FRAXKLIX+-Mass. 1, $R 1$ (*): 240 Huntlngton Are

THYH'L, WM. FHANKLIN, JR. (b'si)Mass.1,11: (1'13): 240 Huntington ire Ten Itroeck, iarl (b.5)-Mass.1,13; ( ) :Hinckney
School.

TEXNFY HENJ (b'63) \$ MaSs.1,02: (3) 30s Marlboro sit: $: 2-3 ;(C 3,5) ; U$.

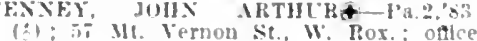
(19) Hoylston st.; (IBL): Op.»

TEXXEY WM XORTHENI) (b'09) Mass. 1, 45 : $(196)$ : (ranton); ontice, tig Boylston st.: i:-2; ALR.

TFNNIS, MATTHEW NICHOLAS (b'st) Mass., 13 ; (1'13) ; s9 IIamllton st.. Hor. foffle, I'nlon Ilospltal, Fall Rtrer)

Terrall, Jolun day (h'si) Mass 1,13

is leverell sie. lor.

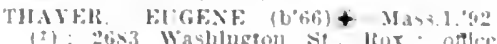

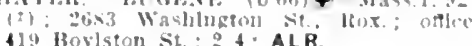

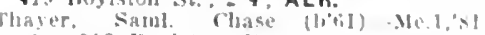
(1) 913 Boylstun sit.

Therrles, Juhn-A; (1'90); 397 Massachu-

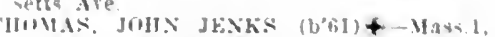

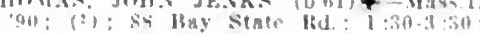

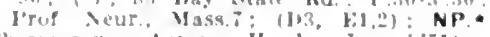
Thomasoll faron IIond. J5. (b)

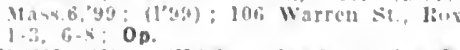

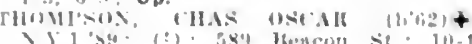

it.

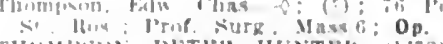

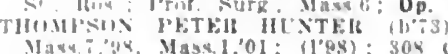
Masy 7'ts, Mass 1,01: (1098): 304

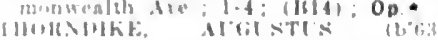
Vase 1 , ES:

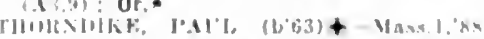
(1): : Marlboro si: once, at Marlimar

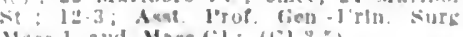
llaien 1 and Masa $\left(: 1\right.$; $\left(t^{*} 1,8,4\right)$

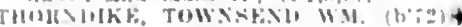

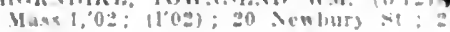

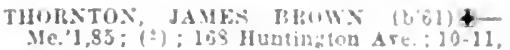

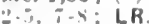

Thorpe. Hidw. Fleghade: Manz:

ill Broyluton -i. : 1.4

Thumen, saml-

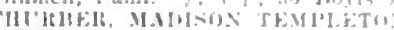

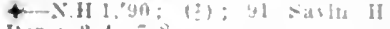

Thurlow, bidar Thendere- : i

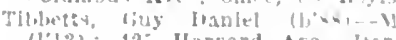

(102): 125 Ilarvard Are., [ho:

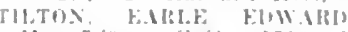

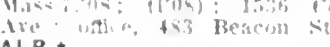

ALR *

IITWN, HHANK HIIHSFIT H

riltor, I, thitia larte-Maw

liwel nximrit.

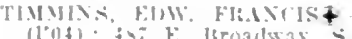

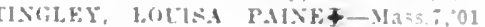

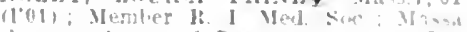

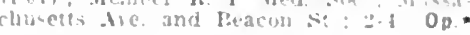

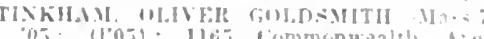

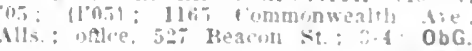
ITIS MUMONI STINTON (H., 4

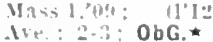

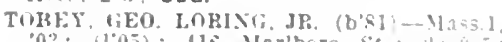
$03 ;(1005) ; 415$ Marboro si;

Tolmas, Henry, Ir.-Mass.1,06

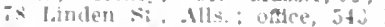

t. : (B15): $A L \mathbf{R}$.

TUMKIFA, JAMES SCOTT (b.82)-MaE

UR: (1'i]); Iong lsland Hoapital,

THOHFY, TIIOS. VILTOR-M.

(l'(it): 10: ralumet

Toomey, Juhn jeter-Mass.1,'93:

Warren si.. Ror.

TOHBERT, JAMES ROCKWEL,

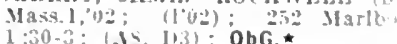

Tower, Fredk. liussell-Mass 1

$11:$ bogloton si.: $2-t i$

Towle, 113. Edw.-N.

Blue Hill tie. Kox.

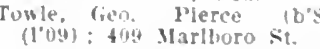

TOWHE, H.IRIF P.IHKF.R

IIass.1, "2:; (2); 433 Marlboro

TOWIE, IHEXY CHAS

14:3 Ihrobester die.

Towne, rolu. Bancrofs (tist)-ya

Intern. Peter Hent lirtgham Hovitate

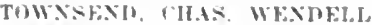

Mass.1, $:$ : (f) : it Marlloro

(III,3); Pd.

TUZHK, HAILES HKHMIX

Mass. I.01; (101); (Winchester)

(i)l buslston st

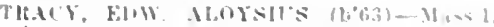

1: $(:)$; to b. Rruadway, $\$ 1$

Traftun. Dlonzos liarilluer Me

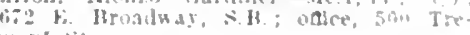

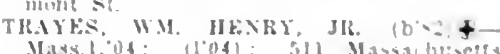
Mars. $104:(10041$ :

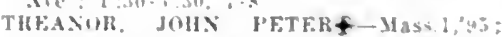

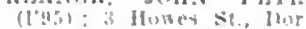

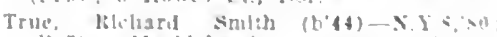

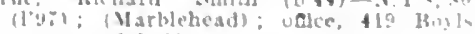
tom st. : $:: 30$

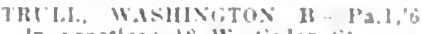

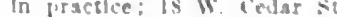

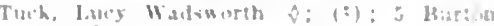
Ale. liner

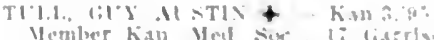

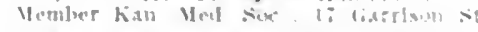

Turetahy Wn Jeen (1.20)- - Wase: 18

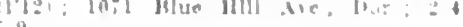

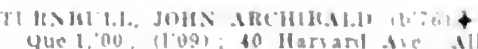

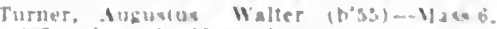

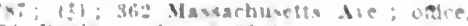
it hujluton si. " so 4 . 
Turner Folw. 1. D. (b'ti7) - Mass.6.04 ([01): (18] Plasant st J'rovllence, K.I.); offler, sot Waslulugton st.; $2-4$; I'rof. I'ath. Mass.6; Op.

TUTTLE, ALBELT HENIS (b'bl) +

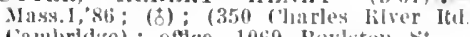
(ambrlde) : offle, 1069 Boyluton sit.

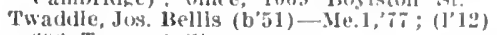
libi: Tremont st

TWITCHELL, EIIW. TIIVIL + Mass. 1 86: (t); 25 Alban Sit., lool.

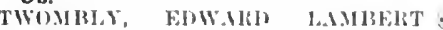
Mass.I, 8ti: (t) : 416 Marlboro: 2-3: G.

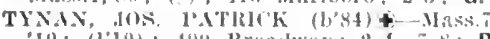

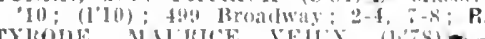

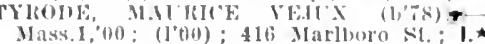

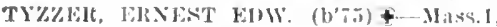
'0): (l'0(i) : (4l Fairmount We Wakefleld): oftce, Harvard Medical sidoul -5; Assl. I'rof Path Mass. I ani Mastil: (15); Path.

Underhlll, ('has. 1)udley-Mass. 1,'s8; I60 Newbury St.

Cuderhill, Geo. IIerbert-Mass.1,98; (1†) 86 Galmsborough St.

Urich, Joln Henry-Mass.5,92 : (t) ; (34, 2d St., Cambrldye); oftee, 434 Columbus ive.

Vamsas, sipyros bemetrlus (b'sis)-Mass,ti, '13; (t): it Iludson st.; oflet, Greel cross loinfuensary.

Van Allen, kemmeth D. (b's4)-(ia.9, I:; (1) : 483 Beacon st. ; $2-4$

an Alsllue, Seymour M.-.- ; (む) (Meirose

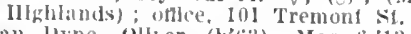

Fan lyne, olther (b'63) - II ass.6, 13 (4.) Waverley Are, Newton); offlo', 739 Buglston st. ; 9-I:

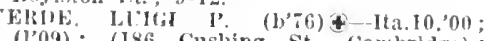
(1'09); (I86 Cushing St., Cambrldge); oftice, $37 \div$ 1Innover sit.; $10-12,6-5$

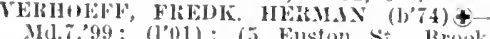

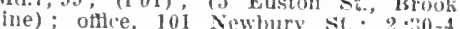
(P4,14, Fo).

V16LEKS, HFRMAN FRANK (b'Jti)\& Iass.1,82; (む); 263 Beacon St.; 2-3;

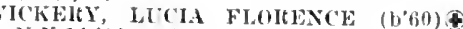
N.Y.14,92; (b); '4 Lakevlle Pl., J.P $2-3: 30$

IETOI6, AGNES (.\$-N.Y.14,'92; (ま) Trinity ('ourt; $\mathbf{S}$.

Hinal, ('hals. Itenough (b'81)-Mass I, 0 (1'04); 682 Tremont st.; 10-12, 1-5.

linal, llarry G. (b'75)- $-0 ;\left(1^{\prime} 96\right) ; 5 \mathrm{t}$ II ssachusetts Are.; until 9, 1-3, ;-8; G. VINCENT, BECHE-IIASS. 1,02; (I'03) 29 ; Beacon St.; 2-3; (I)3); S. forel, fico. Louls (b'74)-Mass.1, 00 (I'00) ; 90 Exeter st.; (B15); ALR.

Von Groll, Maximillian Chas.-Mass.i, 98 ; (l'03); 6 Humboldt Are, Rox.

Yon Jankel, I\{ulolph (b'59) H-Kus.2,'87 (l'12); $5 \pi 6$ Blue Hill Ave.; 10-11, 2-3.

Von Sonneberg, Archie siegfried $\left(b^{\prime} ; 4\right) \rightarrow 0$; $\left(l^{\prime} 02\right)$; 36 Boylston St. ; 3-5; P.

'OSIBIIGGH, STEI'HEN E.IRIE (b'\$1)
I'a.2, $05 ;($ I'10); 425 Harrard St., bor. Pa.2,05; (I'10); 425 Harrard St., bor.
P.`. ROBT. IIENRY (b'70)-Mass, 1,96

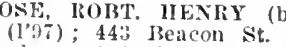

rahuos, Antonios Nieholas-0; (1'03); 543 Boylston st.

WAINWORTH. RICHARD GOODWIX (b'74) \&-Jass. 1,00; (1.01); 3it llarlboro st.; $2-3 ;(\mathrm{As}):$ ObG.

WALCO'T, IIINIIY PICKERING $\left(b^{\prime} 38\right) \notin$ Me.1, 61 ; (f); Pres. State Board of IIealth; (II Waterhouse St., Cambridge) oftice, state Mond of IIealih.

WALKEL, CLIFYRD BLACK (b'84)\& Md.7.11; House surgeon, Iassachusett Charitable Eye and Ear infirmary.

WALKRR, WAVIl HAROLD (b'-3)Mass. I,' 98 ; (1'01); (1.I Jommouth Ct., Brookline); offce, 390 Commonwealth Ave. : 2-4; (15.15)

Walker, Edmund Eugene w. (b'88)-Que.1, 10; ( ) : 25 ('hester si., Mlls.; offle, Missachusets fieneral Hospilal.

17.51 Commonwealth Are., Br.; office, 434

WALkEl, IHYNG JAMES (b'79) $\$$ Mass.1,07; (lo9); (Malden); office, 527
WATKRIT, ISAA' 'HLANIILR (b'83) 1cl.7,09. Vember la. State Med. soc. Bosflint phislcian, leater Bent Jrlgham IIuspltal; LD.

Walkur. Waldo Webster (b'85)-Ia.4,'13; ) : 82 E. Colleord St.; offlee, Massa. chinselis liomeopathle IIospital.

WA1.KEI, WM. M. (b'(5i)-Mass.7,'94; (t): (Revere); offle, 8 Battery st.; 1-3. WALLACE. HAIROJW LOWE $\left(\mathrm{b}^{\circ} 81\right)+$ lass.7,0s; (l'10); 264 Brlihton Ave. A]ls.

willace, John $\left(b^{\prime} 70\right)-s \cot .9,12,14,93$; (lon); 219 Warren st.. Rox.; 1-3; S.

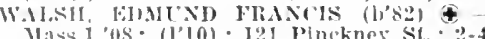
Mass.1, (1s; (1'10) : 121 Plncknes st. 2-4 illsh, Thos, Emmet-

WALTON, liEO IIXCOLN (b'54) llass.,80: (b); IIotel Lullow; ofthe, 199 Marlioro st.; $(\mathrm{El}, 2)$; $\mathbf{N}$. WAlTON, WM, JOA-Mass. 1,97; (1'97) ; 110 lsowdoln St., Dor.

warden, labpll Nexander-0; (l'9s); 1 is liarmouth St.

WAIWWEL, IAMES KNTGHT (b'81)Mass.1,05; (1'06); 278:3 Waslilngton St. lox.; $2-3,7-8$. Intern, Massachusetts General Hospltal

WAIBITS, JOIIX-Mass. I, 00; (む) ; Beacon st.: Asst. Prof. Ánat., IIass.1 and Mass.(iI : (FI). WAIREN, JOHN COLLINS (b'42) 4 -
Mass. 66 : (d); 58 Beacon st.; ottlee, llarvart Med. Sichool; (A5); S.

Wasliburn, (hester Angus (b'81)-Ill.4,08 $\left(1^{\circ} 09\right)$; (Everett) ; office, 15 ('ourt $\mathrm{S}(\mathrm{q}$.

WASHBIIN, FHEWELIC A. (b'69) -Mass.1,96; (1'96); 190 Bay State Rd. office, II assachusetts lieneral Hospital.

WASHBUIR, GEO IIAMLIN (b'60)Mass., $86 ;$ ( $3: 30$; Emer. Prof obst., Mass. 7 (As) ; S Washlington, Jos. Pent

WITERMAN, GEO. ARTIUUR $\left(b^{\prime} ; 2\right) \boldsymbol{f}$ IIass.1,99; (1'00); 410 Beacon St. ; $(\mathbf{H} 1,2) ; N . \star$

Watkeys, Fredk. Wm. (b'65)-Mass.I,'96; (1'cib); (53 Park Ave., Winthrop) : office, 43 IIawkins St.

Watson, Ernest Mllton (b'84)-MId.7,'13, Massachusetts General IIospital; $\mathrm{S}$.

WATSON, FRANCIS SEDGWIK (b'53) t Ilass.I, $79 ; \quad(195) ; 263$ Clarendon st. offle, 92 Marlboro St.; 10-12, 1:30-3:30 (A.), $(1,3,5) ; \mathrm{S}$.

WATSON, IR.AK GIJIANक-Mass.1,98; (1'98); 219 13oxbury St., Rox.

WATTERS, WM. HENRY (b'76)-Mass.5, 00; (1'00); 109 MIt. Vernon St., West lkox. offlce, so E. Concord st : 9-4; alsu 419 Boylston St.; 4-5; Prof. Path. IIass.5: Lo.

WATTS, HENRY FOWLER IRAXSFORD (b*6) \&-Mass.1,94; (む) ; 6 Monadnock St., Dor. ; $2-3,7-8$.

Webb, Albert Edw. (b'74)-Mass.7,'10; (l'10); (Salem) ; office, 543 Boylston St. ; $11-3 ; 0$ p. $\star$

Velbb, Mary Wlizabeth-Mass.5,'90 4 Longwood Terrace, Fen.

Webler, Wolfert (ierson (b'89)-Mass.1,'13 Intern, Boston City Hospital.

WEASTER, GEO. ARTIIUR (b'65)థMiss. I,'89; (f) ; 28 Greenwich Park; A.

Weed, Lewis Hill (b'86)-Md.7,'12;640 Huntington Ave.; offlee, Research Laboratory, Harvard iedical School.

Wegefarth, Paul (b's7)-Md.7,

Peter Bent Brigham Hospital.

Weinert, Ernesto (b'62)-1ta.8,87; (1'10) 385 Hammond St.; 9-11, 1-3.

Welles, Franklin (b'6T)-Mass.6,07; (l'07): 739 Boylston St.; NP.ネ

Vellington, Anna Colburn (b'82) - Mass. $i$ 12; (I'13); 903 Beacon St.

WELLS, DAVID WASHBURN (b'62) Mass.5,'97; (I'97) ; (50 Putnam St., West Newton); office, Hotel Westminster; Prof Ophlh., Mass.5; (Bl) ; Op.*

WELIS. FRANK (b'42) (-Mass. 1,'68; (f) ; St. : $9-4$.
WLLLA, JAME心 L. (b'69)-III.13,'02; (ठ) ; 150 Warren Ave., liox.

WE.TWWOItTH, AI'THUI HOWARI $\left(\mathrm{b}^{\prime} 64\right) \oplus$ $\rightarrow$ Mass.1,91 ;

Wentworth, Jowell Frankiln (b'59)-N.H.1, '84; (1'99); (I9 Bartlett St., Melrose); offle, 36 sitate Ilouse: 9-5.

WENTWOKTH, MAKK IIUNKING (b'79)థ -Mass. I, 05; (1'06); 86 Bay state Md.; 2-3; (D.) ; Pd.

WWRNICK, BENZION G. (b'67)क-Mass.7. 03; (l'03): 162 jIumboldt Ave., Rox.' offlce, 259 1ianover St. ; 1-3, 6-8

Wesselhoeft, Conrad (b'85) - Mass.1,11 ; (1'I1); (39 Garden St., Cambrldge); oftlee, 5.35 Beaeon Nt.; 4-5.

Wesselhoeft, WVm. Fessenden-Mass.1,87 ; (l’95) : 398 Marboro st.; Assoe. I'rof. Surg., Mnss.5.

WEST, EIVW ('RAFFF (b'55) \&-Mass.1. '80; (t): 630 Warren st., lRox.; untll 9. WEsTCOTT, WM. IIENKY (b'40)-Mass.1. \%4; (1'96); not ln practlee; 66 Cllfton st., Rox.

Weysse, Arthur W'lsswald (b'67)-Svitz.I, 07 : $\left(l^{\prime} 05\right)$; $42 \mathrm{I}$ Narlboro St.; I2-1, $6-\vec{i}$ l'rof, Exper. I'hyslol., Mass.5; (FI); U.

Wheeler, dilman Ivery-0; (1'99); 416 Marlboro St.

Whelpley, George Fredk.-Md.I,03; (1\%); 420 Massachusetts Ave.; until 10, 2-4, WIII'PLE, FARRINGTON HASIAM (b'65) -Mass.1,92; (t) ; 1079 Boylston St. ; $2-3: 30$

WHITCOMBE, CHAS. REED - N.Y.8,'83: (f) ; 829 South st. ; office, 758 South St. WHITE, ARTHLR JOSEIH - Mass. I, 04 ;
(1'04): 5 Houghtor St.; office, Boston ('ity IÍospital.

WIHTE, ('HAS. JAMES (b'68)\&-Mass.1. '93; (1'93) ; 259 Marlboro St.; I 2-2; Asst. Prof. Derm., Mass.1 and Mass.G1:

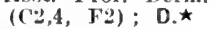

WHITE, FIRAKLLIN WAREFA (b'69)\&-

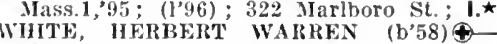
Mass.1,80; (b) ; 151 Humboldt Ave., liox. ; 4-6.

White, Herndon-MIass.6,'07; (\$) ; 106 lartsmouth.

WHITE, JAIES CLARKE (b'33)-Mass.1, '56; (†) ; 259 Marlboro St.; 12-3; (C2). WHIT, LEON EDW. (b'67) \$-N.II.1,93; (t) ; (Wellesley); office, 396 Marlboro St. ; $1-3 ;$; (B1,15); ÁLR. *

WHITE, IALL DUDLEY (b'86) †-Mass.1, 11: (1'11) : 151 IIumboldt Are.

YHITE, RORT. MARSHALL (b'80) Mass., 10 ; (I'10); 276 Bowdoin St., Dor. WIITE, WM. ALLEX-Mass.7,'94; (t) ; 249 Warren St., lkox. ; office, 150 Friend St. Whitehead, Baldy Lott (b'75)-Mass.6, 08 , Mass.й,'I3; (1'08); 355 Columbus Ave.

Whitehouse, Eugene Dizer (b'is)-Mass.1, 05 ; $\left(1^{\circ} 05\right)$; (Wollaston) ; office, 81 Stanlford st. : $2-4$.

WHITNE, CHAS. MEIVILLE (b'62) \&Mass.1,87; (ठ); 591 Tremont st.; office, 386 Commonwealth; 2-4; Prof. Gen.- Crin. lis., Mass. 7 ; (C3,5); U.*

WHITNEY, WH. FISKE (b'50)-\$Lass. 1, '75; (c) ; 228 Marlboro St.; (A8).

WHITEMORE, WYMAN (b'79) $\Phi$-Mass.1, 05: (l'05) ; 99 Commonwealth Ave. ; of flec, 259 Beacon St.; ; $2-3$

WHITTIEIt, FRANCIS FREMONT (b'52)N.1I.1,'84; (ठ); $(94$ Ifarvard Ave., BrookIne); office, 149 Tremont St.

Whlttler, Helen A. -0 : (t); 6 oxford Terrace.

WHCKES, HENRY W. (b'69) -IId.1,92; Sure. U.S.P.H.S.

Wlekham, Thos. Wm. (b'86)-Mass.1,'13; (l'13); Carney Hospital.

WIEBER, FILANCIS W. F. (b'61) \&-N.Y.8, 8I : Med. I)ir., Capt. C.S. T. ; Nary Yard. WILCOX, DeWITT GILBERT (b'58) \$-0.7, '80: (I'08); (184 Aspinwall Are. Brookline); office, 419 Boylston St.; 1-3; Assoe. Prof. Gyn., Mass.5.

Wlldes, Adeline W'ilkins-Mass.5,81; (も) ; 6 Greenville st., Rox.

WILINSKY, CHAS. FRANCIS (b'82)-Md.6. 04; (I'04) ; 80 Green St.; 1-3, 6-8. 


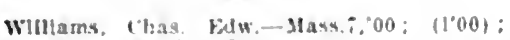
303 warren st., Inx

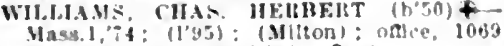

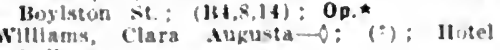
lelhan.

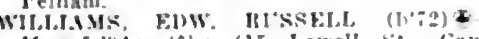
Jass.1,94: (8): (15 lowell st. in in

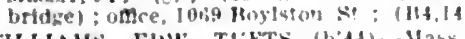

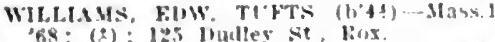
68 : (2): 125 loudley

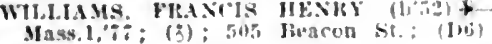
R.

WIILIAMS. FRANK PFIRISAL (b'0) + Mass.1,95: (1'96): (51 Nuhuru st, 13riek

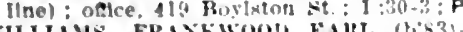

WLLIAMS. FRANKWOO!! Follt, (b's

Mich.1.'12; Member Mlch. State Med Sine: Asst. Pliyslelan. Slate J'sychopathic Hospltal.

Willams. Frederle Nllen-N.Y.3.92; (196i); 295 Newbury St.

Williams. Fredk. Iforace $(b \div a)-T w 1111$.

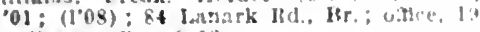

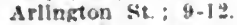

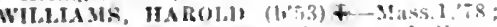

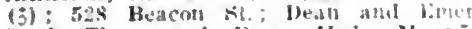
Hrof. Theo. and [rac, Mey], Misp. (DI).

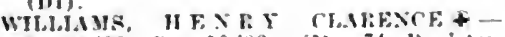
Scot.9,80, Seot.10,82; (8): it bulstom St.

Wil!lams, IIubert Jus-Mass.:,01: (1'01) 25 Aherdeen St. : odsce, if Boylston st. WHLIAMS, IITCill (b'72) Mass I, Ms (1.99): 301 Bescon $5 t: 1: 30-3: 30$.

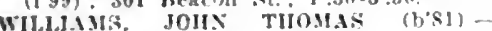

Mass.1;04; (I'04); 483 Beacon st: $2-3$; ObG. $*$

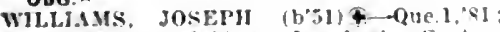
(8); 12 Bloomfleld st., Inrchester Center;

Wills, Dwlght Fletcher-0; (104); 25; II

Newton St.

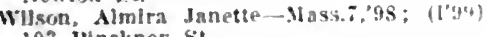
103 linckney sit.

WILsos, EIMI:X9) WIXFRED (b's. oflice, Boston ("Ity" Jiospltal.

WTLSOS, GEORGE 18. (h'B3) †-X H.l's?

Med blr Capt l.s... : Saral IJuspital.

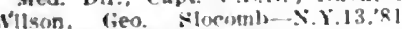

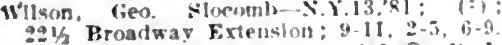

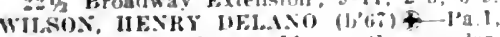
89: (1'10); surg., laleus. Commander.

Wlison. Phlllp Duncan (1,80i)-Mass.?

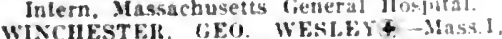

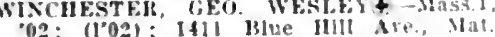

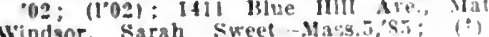
Windsor, Sarah
391 leacon st.

wingersky, Alraham saml. (b"ifi) (I'98): (60 sayamore He. Winhegl) once, 42 Vederal St.

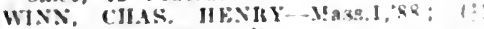
If if Tremont st. Mox

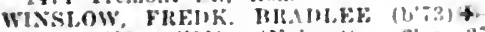

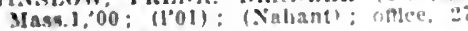
clatendon st.: $2-3$.

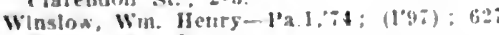
Warren St. Itox.

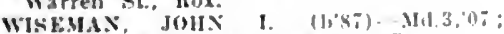
(1)ii): liogton state Houpltal: P.*

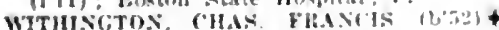

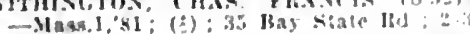
(IIi)

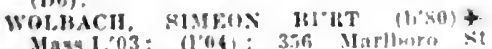
Mass. Jo3: (jofi: 356 Marllwern st Iract. Mass. I and llassil: (Fu) : Bart.

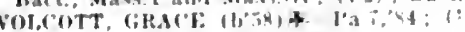
302 Marlioro si. : $2-4$ : 6 .

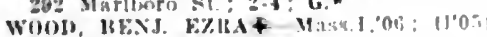
1231 rommonnealth Ire. Mls

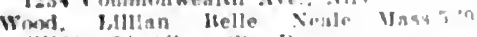
(108); 34 Allon st., Jur.

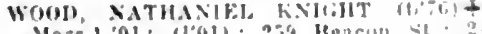

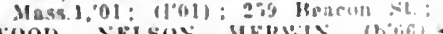
won, xisson YHBVI Mase.5,93: (:1::2 IIlsh : : : $1: 30): 0$

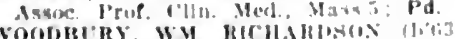

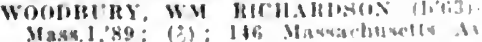

Wrollenan, Alle stuart-Mas4.5,03; (1'(13): \$16 Hue Ilill sio.

Woodworth. Helen Jda-Mld, 1,8:; (1096); llotel fluns.

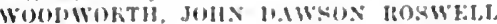

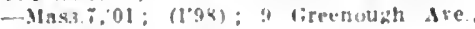
J.J'.

Windy, Mcliet (1806)-Mass, 1,12; Intern, illy Hospltal.

Wisilley, Emma M.-Mass 5,94; ()；84f Beacon st.

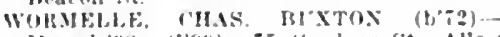

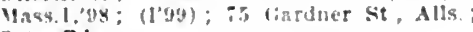
3-1: Pd.

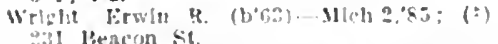

WhIIIT, IAUES HOMEIS + MII,92

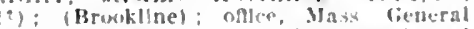
Ifrepltal: Asvt. Irof. I'ath. Maus.l and Mass (:1

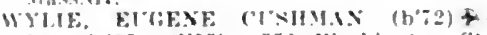
Mass.1.95; (1'95); $5.50^{\circ}$ Washtogtun St.

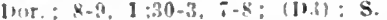

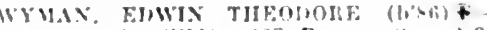
Mass.;11; (111); 4.3 Bcacon st.: :-3 Pd. *

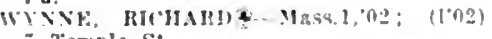
Temple st.

Carume, Manoug tiarabet - Mass.1,00 (1)99): 55\& Tremont st.

York. Herbert Jeroy-Mass 1, 9?: (1'99) I: Melrllle Nie.; office. 784 mudiey st Yorti. Roger sherman (b's)-XY.10.92 (引) 108 Henenway St.; oflle, 419 Bnyl-

(thet Danl-Vt.2.91: (:): 40? Centre St., J.J"

loullg, Edmunt sanford-X.Y.s.a1: (र): 112 Miton Are., Hor.; oflce, i29 Bnylsten st. : $1: 30-3: 30$.

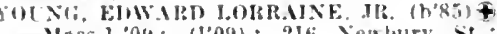
Mass.1,04: (to9); 216 Newhury st. uffice, ti Burroughs st., J.I.: 2-4.

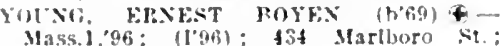

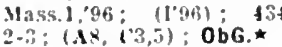

YWTXG, EVANGELISE WILSON (b'7t)Yass:-0t: (106); ltis Newbury st: $3-1$

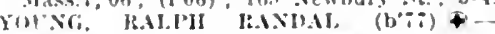
Mass. 1,03; (1'02) ; 5 Hlphland St. Rox. $1-3,6 ;-8$.

YOT'XG, WAJTER HARDING

(nee Jedliam.)

loung, Wm. Walter $(1,90) \rightarrow .11 .7,13 ;$ In tern. Peter Bent Brlcham Hospital.

Ziveluan, Max-III.4,94, I11.1,38; (:) : latmenter st.

\section{BRADFORO, 520, ESSEX}

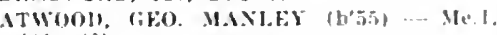
ixt: (i).

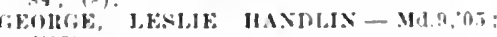
(1'05).

\section{BRAINTREE, 8.066. NORFOLK} isee Humlun.

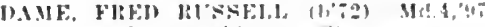

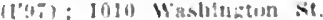

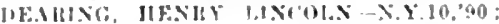

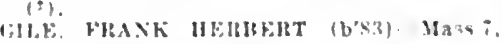
$0 \div ;(10 ;)$.

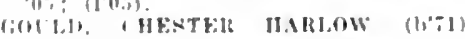

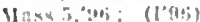

BRANT ROCK, 250, PLYMOUTH

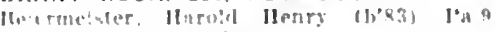
BREWSTER, 300, BARNSTAQLE

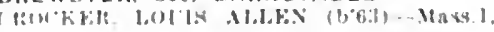
0:- 11041

BRIDGEWATER, 7,688, PLYMOUTH

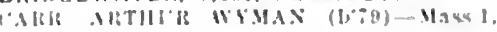

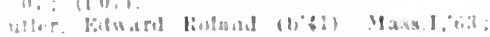

$$
\text { gistio in prantlen }
$$

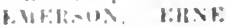

$11 x \times 1$ 1 2 : 11 gy

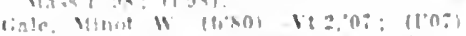

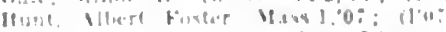

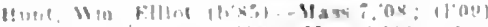

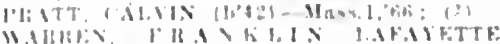

$(1,00)+101,10: 11: 91:$ ALR.
WHELAX, EHMUNI" IISTENT $\left(b^{\circ} 56\right)-$ Mask: $02: 11$ : $0: 0$

Whitnarah, Willard francls (b'bi)-Masa 1. 91: (1'ati)

BRIMFIELO, 722, HAMPDEN

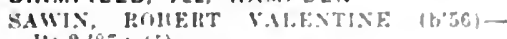
I'a.2,8:T: (:).

BROCKTON, 56,878, PLYMOUTH

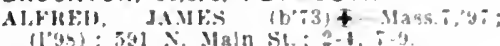

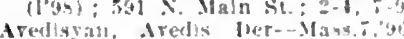

foz: $x$. Mall st. $10-12,3-5 ;:-y ; U$.

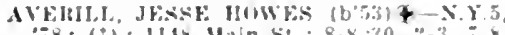

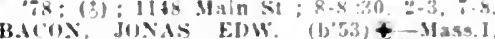
ts; (a) : wayman st. oflce, 101 Mala

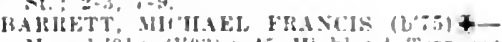

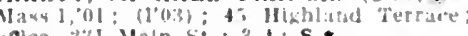

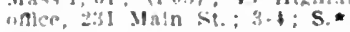

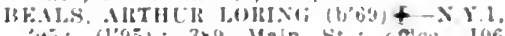
Main St: : $2-1,7-9$.

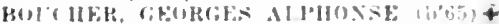

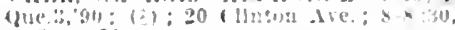

Moyd, Francis Jeter (b's)-Mass.; , 11:

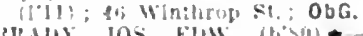

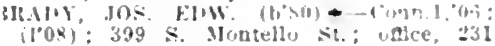
leain ; ; 2 - :-9.

kranlt, Norbert Romuius $\left(b^{\circ} y 1\right)-4$ ue 13 : HISI) 10; (1'11): 101 Main St.; ince. git W. Fim it?

hoyd, James Francis (b'xul--Mass.i.'ll.

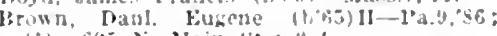
10.

Hastila (1)

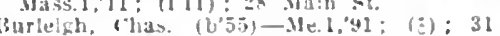
lenter st.

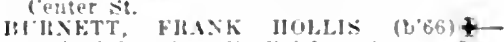

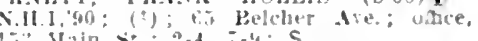
$1 \%$ Min $s: ;-4,-4: S$.

Burnebe, John Ererelt (boil)-Mcb.1,99; (1'y!); 371 x. Man st : $2-4,-5$

Callahan. John Francis (bo - a - Mass. o6: (1'0.7) : t27 Main

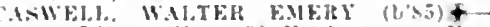
Mass,:03; (1*0:1); is Kelih Are, oulce.

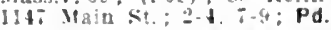

(HISE, JALISUN AYER $(0 \% 5)+-M a s 31$.

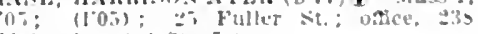
Binin St.:

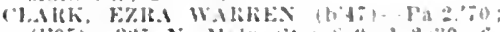
$(196): 3: 5 x$. Maln st. : $8.4,1-2: 30,6$

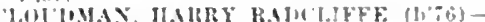

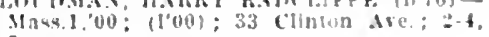

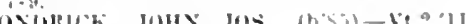

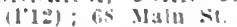

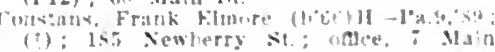
s. : :-4, :-s.

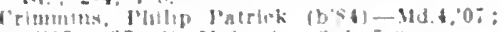

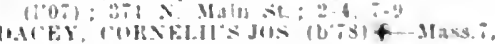

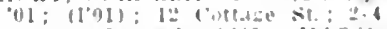

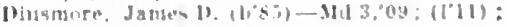

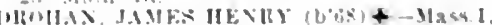

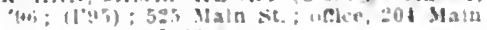

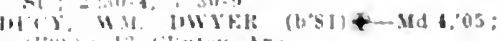
(liwe) : 1:2 clinton Are

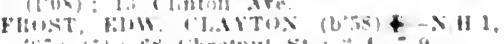

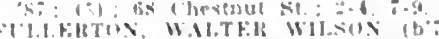

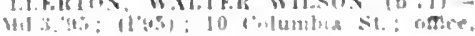

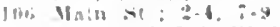

(1)

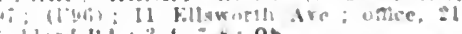

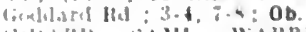

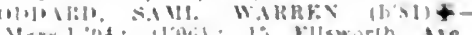

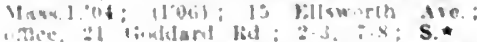

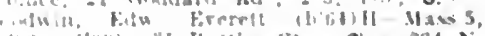

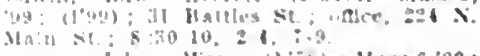

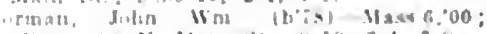

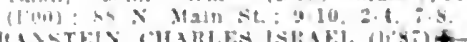
IIass: :10: $(110): 31$ II Fila sit. 


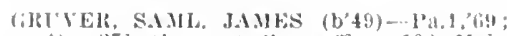
(स) : 21 Ireseent Sit.; whee, 106 IIaln St. ; $10-11,2-4,7-9$.

Halleft, Wabler Lewis (1)60)-Mass. I, 86 (t): 5 Wurren Ave, ; $2-4,7-9$.

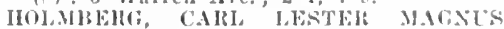

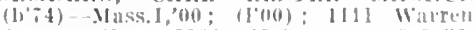

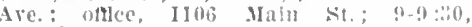
Are. ofllce

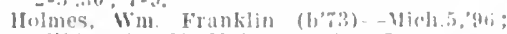

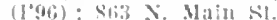

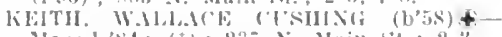

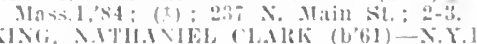
it: $\left.i^{+}\right)$; 11:n; Warren Are, offuce, II 4

Ladd. Frod linkene (1, il) - Mass b, 02 ;

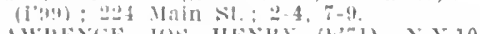

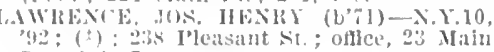

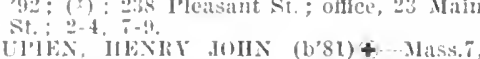

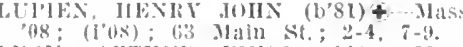

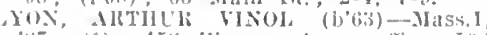

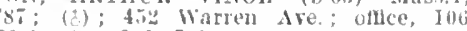
Main st. ; 2-4, i-8.

Mallfiall, Hosannal (b'an) H - Mass,a, lI

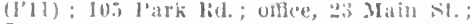
G. JOSTH IWI Mass. 6,06 ; (100,i); 616 s. Matl st.; $2-4$, IetiNx, CHI.MII.ES DANL, (b'86)-Mass.I, '1 : (1'11) : 29 lioddard lid.

MALTHJ" TIIOMAS HORATIO (b'il) + Mast. 1,90; (5): 27 IIarrard st.; oftice, 183 Milm St. ; $2-4,7-9 ; \mathrm{S}$.

MCNAMARA, JOHN JAMES (b'rl)tllass.7, 00 ; (l'00); Meimont I'l.; offlce, 231 Main St. ; 2-4, $7-9$.

Mosweeney, Edmund feo, (b'63)-I.K.C.P. scot.12.14,91; (j'99); 481 Main st, ; 2-4,

Melulek, Jilcol) (b'84)-Mass.6,'I3; Brocklom IIospital.

Ierrill, Trustum IIurd (b'41)-N.Y.10,72; $\left(1^{\prime} 99\right)$ : 288 Belmont $S t$; office, 107 Main St. ; $9-12,2-4,7-8$.

MILES, CIIAS. GARDNER (b'83)-Md.3,'08; (I'08); 138 Newbury St.; office, 23 Maln sit.; $8: 30-10,2-4, \div-9: N P$.

MILLYT, CILAS. SUMNER (b'5S) \&-Mass.1, S0; (5); 281 Spring St.; office, 23 Main st. $; 8-4,4-6,8-9 ;$ (D3); T

MOORE, GEO. ALBERT (b'78)-Mass.1, 'II; (I'II) ; 47 Green St.; 2-4, $7-8 ; \mathrm{S} . \star$ MLRDOCK, FREDK. WM. (b'7s) †-Mass.I, 99; (1.99); ist W. " Elm st.; $2-5: 30$;

OALR.
Murphy, Jolin Michael (b'80)-Mass., 06 ; (1'06); $544 x$. Main St.; 2-4, 7-9.

NOYFS, IOHX RUSSELL (b'75)-Mass.5, 04; (1'04); 262 Spring St.; oflice, 63 Main St.; $2-5$; OALR.*

O'MHIE. FlEEDK. WM. (b'81) - Mass.7, 'II: (l'II) ; I2 Cottage St. ; 2-4, i-9; R. I'.'KAKI, LORING BRADFoRD †-Mass.I, '03: (1'03); Brockton Hospital.

P.INE, AMASA EILIOT (b'43) - -D.C.2, P.IINE, AMASA ELLIOT (b'43) \&-D.C.2, PETTEY, IOHN ANDERSON (b'86) - Hass. 7 , '0S: (1'08); 63 JIain St.; 2-4, 7-9.

I'luneuf, Josephat Stanislas Policarp (b'88) -Mass.6,13; (1'13); 79 $\mathrm{N}$. Main St.;

RIILEY, FREDK. JEROME (b'58)(Mass.I,'S3; (屯) ; 956 Belmont St. ; offlee,

The Checkerton; $2-4$.
ROBINSON, LUCY MORTON-Pa.z'8s; (0); 28 Glenwood st.; oftice, 7 Main St.; $2-4,7-9 ; \mathrm{G}$

Roy, Aurile (b'79)-Que.3,05; (l'09) ; 232 Court St.; uffice, 7 Main St.; $2-4,7-9$; ALR.

SAFFORD, WILBER PRAY (b'55)-N.H.I '92; (1'95) ; 52 Pleasant St.; 2-4, 7-9.

SHAW, JOHN PORT (b'58) - Ont.3,'s6; (1'96); I Fuller St. ; ofllee, 6 N. Main St. ; Sluurtlefi, Henry Austin (b'44)-MId.4,93; (5) ; 1245 S. Main St.; $7: 30-9,1-3$, ;SIMIONS, FRED ALBERT $\left(b^{\prime} ; \pi\right) \oplus$ S.Y.I, 03; (104); $406 \mathrm{~W}$. Elm St.; ofllee, (63) Main st.; 2-4, 7-8.

S.MTH, ALFRED CHAS. (b'69)-IIass. 6,98 ; (1'ys); 25 Florence St. ; oflec, 7 Main St.

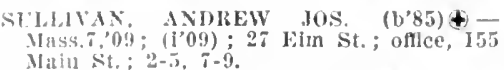

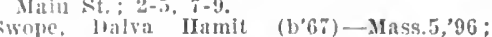
(1'bib) : $3: 3$ lerkins Are., Campello.

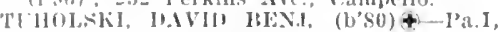
(0); $(109) ; 105$ Main st.

Wullin, linstaf Frit\% Robt. (b'T3)-Me.I, II; (1'12) ; kim9 Vaju St.; 8-I0, 23-4, ti-s.

BROOKFIELD, 1.558 , WORCESTER

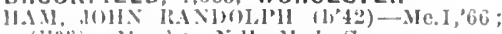
(i"0): Member Nill. Ned. Soc.

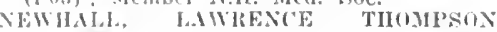
$(1,25)+11.2,25 ;(3)$

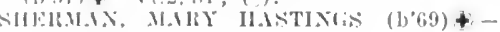

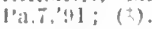

BROOKLINE, 27,792, NORFOLK

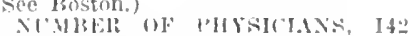

$1111 \mathrm{~N}$, \%.IIDIEI, HOYLSTOS.

(Nice buston.)

AXIMERSON, MAMES II.-X.Y. 60 ; not in practice: Member Med. Sisce of the state of X.Y.; I08.5 IBeacon St

Austin, Ricliard Sisson (b'85) - Mass.I,'ll ; (1'athologlat) ; 6: Wwight St

IB.II, JOINN W.ARREN (b'T5)--Mass.I, 03 ; $\left(I^{\prime} 02\right) ; 167 \%$ Bcacon St. : $8-9,22-3$

Balch, Alfred Wm. (b, 73)-Mast.1,98; (l'as) ; Prof. Med. Chen. and Tux., Mass.ĩ,

B.IINLS, HIIRT MIIRICII

(See Boston.)

Blshop, Leslie Carr (b'82) - Que.1,03; (10); : South St.

I 236 Beacon St.

BLAKLIY, DAVID NEWTON.

(See Boston.)

BHANCILIRI, BENJ. SEAVER (b'56) \&-
Mass.I,'82; (o); 432 Washington St. I $: 30-3$.

BORDFN, CHAS. RICHARDSON COBB.

(See Boston.)

BOWDITCH, HAROLD (b'83)థ-Mass. I, 09 ; (1'09); 60 II Iarvard Ase.; (ofllce, 520

BowkER, EVERETT M. (b'66)-Mass. ', 91 ;

$(1,96) ; 322$ Ilarvard st. ; until $9,3-4,7-8$. BRAINERD, JOHN BLISS.

(See Boston.)

BRIGHAM, EDWIN HOWARD.

(See Isoston.)

BRINDISI, ROCCO

(See Boston.)

BULFINCH, GEO. GREENLEAF-MaSS.I, '\%; (む) ; 526 Harvard St.

Burden, Frmest Druecilla- 0 ; (1'95); I684 Beacon St.

CALL, NORMAN (b'44)-N.Y.I,72; not in practice; $6 \mathrm{I}$ Sewell Ave.

Carleton, Francis Boyd (b'65) - Mass.5,'94;

(む) ; 1896 Beacon St.

Carpenter, Win. IIenry (b'37)-N.II.1,'76;

(む) ; 112 Thorndike St. ; 8-11; OALR.

Carroll, Jolm Aloysius-liass. I,'86; (ठ) ; 56

Harvard St.

('ASSELBERRY, CLARENCE MARMADUKE.

(See Boston.)

HANDLER, THOS. EVANS

(See Boston.)

CIIANNING, WALTER (b'49)-Mass.1,'72;

(ठ) ; 27 Chestnut Hill Ave.; offlec, Boyls(EI,2,13)

Clapp, IIerbert Codman.

(see Boston.)

Clapp, James Wilkinson.

(See Boston.)

CLEAVES, FREDK. HENRY.

(See Boston.)

CONNELLY, JOHN EDWARD-Mass.1, $0 \pi$;

(1'07); 156 Cypress St. : 2-3, $7-8$.

Cook, James Henry (b'83)-Mass. 7,10 ;

(l'10) ; 3 Goodwin Pl. ; 2-4, 7-8.

COOPER, ALMAN (b'63)థ-Vt.2, 88 ; ( 67 Jarion St.; 3-4, 7-8.

CORNWALI, ANDREW PAGE.

(See Boston.)

CORNWALL, ANNA MARLIN-Mass.7,06; (1'06); 76 ' Winchester St.

Crowley, Ambrose-Mass.5,'98; (1'97) ; 156 Harrard St.

CLSHING, ARTHUR ALDEN (b'81) $\$$ Mass.1,04; (1'04);

(See Boston.)

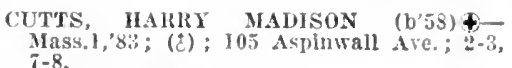

7-8.
Dam, Alvah Morton.

(See Boston.)

OANA, HAROLD WARD.

(See Moston.)

1) FAI, EDW. EDWIN (b'C5)-MISS.I,90; (5) ; Iti Winthrop Pd.

Def riez, Wm. Jeabody-Mass.5,"81; (5) ; 537 Washington SI.

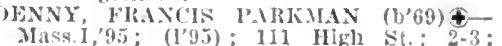
(1)3)

IEWIS, JOIN WM.

(See IBuston.)

IREYFLA, EINA HELEN WEIL $\$$-MILSS. 00: $\left(1^{\prime} 00\right): 30$ Armory $\mathrm{st}$

FMERSOX, FRANCIS PATTEN.

(See Boston.)

AIIBANIS, ARTHLR WILLARD.

(see Isoston.)

FMLLON, JOS. FRANCIS (b'82)-Ta.2,08; (l'0s); I lichdall st.

FAY, WM. EASTMAN.

(see Boston.)

FISK, SAML. IUGUSTUS (b'56)£-Mass.I, '80; (1'01); not In practice; Nembe

Foot, Nathan Chandler. (seo I3oston.)

FRANCIS, ('ARLETON SHLRTLEFF (b' $\left.6 b^{\circ}\right)$ +-Mass. I, 9" ; (t) ; 26 Daris Are.

WRANCIS, REO. HILLS (b'60)-Mass.1, si; $(\ddagger) ; 295$ Wainut st.; 2-3.

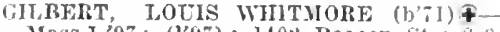
Mass.I,97; $\left(l^{\prime} 97\right)$; 1402 Beacon st.; s'-3. $2-3 ;$ (D)

GILMAN, CHAS. SLEEPER.

(See Boston.)

GOD, FREDK. LEO.

(See Boston.)

(RAHAII, DOUGLAS.

(See Boston.)

GIREGG, DONALD (b'80) $\oplus$ - Mass. I, 07 (l'07); 27 Chestnut Hill Are.; office, FOI Boylston sit. NP. HAGEN, BURGER, G. LEONHARD + -
Ont.5,04; (1'03); IF 6 winthrop Rd.; $2-4$;

IIALE, WM. WORTH.

(See Boston.)

Hall, Newbert Jackson-Mass.1,'85; (む) ; 124 Harvard St, ; $2-3,6-7$.

Hartshorn, Edw.

See Boston.)

HASTINGS, ROBT. WORTHINGTON $\left(b^{\prime} 66\right)$ f

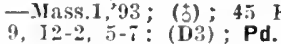

HATCH, RALPH AUGUSTUS.

(See Boston.)

AYES, FREDK, LERGO (b'70) ₹-Pa.2 ERSEY ; 12 Verndale St.; 2-3.

HAROLD WATERS (b'82)-
Mass. I, 08 ; (I'I0); II Cloflin Rd.; 1.? $7-8$.

HILLS, WM. BARKER.

(See Boston.)

HINCKLEY, JAMES IVM.

(See Boston.)

Hlrshberg, Alice Illienthal-Mass.6,02; (l'02).

Hitchcock, Wm. Alvan, Jr,

(See Boston.)

Holland, Wm. Tlmothy.

(See Boston.)

Horton, Marlon Robbins-Mass.5,'05; (1'06) 49 Thorndike St.; $\mathbf{0 b}$.

Houghton, Neldhard Hahnemann. (See Boston.)

HOUGHTON, SILAS ARNOLD (b'64) 4 Mass.1,91; $\left(\begin{array}{c}b \\ )\end{array}\right.$; 14 Pleasant St. ; 8-9, 2-3. (A8, D3).

HOWE, JAIIES SULLIVAX.

(See Boston.)

HUNT, REID (b;0)\&-.IId.3,96; Member Med. and Chir. Facuity of Md.; I28 Iongwood Ave.; (office, Harrard IIedical School, Boston); Prof.'Phar., Mass.1 and Iass. G1 : (D6).

ONES, EVERETT.

(See Boston.)

JONES, FREDK. ELMER.

(See Boston.)

JONES, JOHN CLARK-N.Y,10,'82; (5) ; 56 Hawes St. 
KAAN, GEO, WABTON.

(Sec boston.)

Kelsker, Laura B. (h'68)-Ky.s, 9s, hy. 1,02 : (l†); 12: Egmont St.

KENNEALY, JOIX HENRY.

(See Boston.)

KICKHAM, CHARLES JOSEPH (b'95) + Yass. OS: (l'0S): 19 Kendall st. : unice. 3I Harrard st. I.3; ObG.

KIXGMA., RUPU: ANDERSON. (Seo Boston.)

KITTKEDGE, JOS, (b'5s)-Mass. I, 's0 : (*) : 69 Cypress St: $1.3, i \cdot 3$

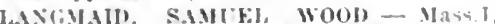
Gi: (i): 13 Garrison Rd.; (132,15).

LAWIEXCE, CHAS, RENRY, JR. (see Boston.)

LEVI, FELIX JULII'S

(See Bosion.)

Lewardowal. Jas.

(See Hoston.)

LITCHFIELI), WI. IHARVEI (b'55)Mas3.1.'82; (1.95); I37s lieacon St.; 1-3. Low. Harry Chamberlain. (siee Boston.)

MACKIE. WHL CHAS.

(See Boston.)

MacMulan, John Archtbald-I'a.9,06; (I'06) Isol Beacon St.

YALLORY, YRAXI BLIRR

(See Boston.)

MAN. Boston.)

(See Boston.)

MCLALGHLIX, HENRY VALENTISE.

(See Boston.)

MCMAHOS. FRANCIS JOS. (b'S6)-Mass : II; 11'11): 370 Wasblngton St. ; $2-3$, i-s D.

MELLLS, EDW. IINDON (b'48)-Pa 2,"is; not in practlce; (Dublin, X.H.): (EIn FI)

METCALF, JULIA TINCY (b'75) \$-Masa '08; (1.0s); 33. (iarrlson Kd.; : :30-4:30

Moore, James IIerbert (b'il) II-X.Y.9, (\&): 1339 Heacon st. : l'rof. Ped., Mass.s. (D3).

Jurnby, Jos. Patrick.

(see Boston.)

PARKFR, HELEX SCHLESISGER (b'at) X. 20,01: (1.01); Warren St.

HEAKCE, AKTHÏI CISHIX゙G.

(see Boston.)

Percy, Fredk. Hosworth (b'56)11-Masq.

so: (5): 194 Asplnwall Are.; 2.4 I'pol

Clin. Med. Mlass. 5 ; (ग3)

leres, Karlion Foodsell.

(See Boston.)

PHIPPS, CADIS.
(See Boston.)

OWERS, LERBFIT HALE $\left(\mathrm{b}^{\circ}, 05\right)+-0$

o4: (1'04): 68 Inarls Are.; 2-3, $7-8 ; N$

IURVIS, CHAS. BCHIEIMU $\left(b^{\prime}+1\right)+-0$. 65 : (1.01); I 455 Heacon st. $9-11, t-1 ;$ Emer. l'rof. Oust. and finn., W.r.3.

Itencurrel, Manuel kmll.

(See Hostun.)

Uce, Geo, Brackett.

(Siee Boston.)

Iltter, Ellzabeth Kinma khaw-Mass.う,07 (l'0 0 : 49 Thorndike st.

ROGEKS, HDMUND AL'ILSTIS (b'S1) Id.4,04; (1'06); I: IIstrart st.; 8.10. $2-4, ;-8$

HOSFENU, MHTON JOS.

(See Broston.)

SABINE, GEO. KILANS $\left(\mathrm{b}^{\prime}+i\right)+-$ MiNy I, 73: (乡); 30 Irving St

Selfew, l'aul Klbbe (b'si) - I'inn.l, I1 13121; 10n Sewall Are.; Op.

Sextull, Frank Joy.

(Siet Inaton.

SHAXAllAs, THOMAS Joskill (b'83)

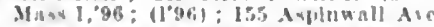

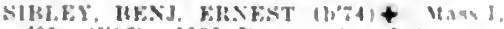

\%

silnumons. Clara congdon.

(Hee lioston.)

simlth, Whtufleld scott.

(Siee Ibomton).)

SMYTH, HTKICK SOMEHS

(sire boston.)

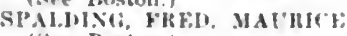

(sce Boston.)

ST'EAR, LOCIS M III

isre Hostont
Spencer, Wh. Warren Conant (b'5t)-We 2. '84: (5) ; 1888 Beacon St

STHMA.; HE.VIY R.

(See lloston.)

TAIBOT, FIRTZ HIALEEI

(See Boston.)

Tajlln, lieo. Colby.

(see Itoston.)

Taplln, Frace $k$. Matchelder (b'a)-0:

(l'0it); not In practlce; 3to Harrard st

TAYLOR, JUHAI. (FE(). (1)60) - HH.6.87

(3) : 43i Harrard st : 1-3, $7-8$.

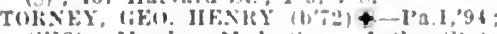
(1'13): Menine Med. Som of the state of 1 : Bournewood Ilospltal: (H:B3) NP. *

Turner, Maurlce Worcester (b'57) H-Mass.5

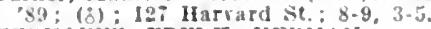

VEIIHOHF', FRELK. IEMMA.

(sice boston.)

WALKEH, IAVID HAHOL,

(See Rosten.)

WHBHEK, SAML. GILBERT (b'38)-Mas\$.

'b.5; (2) : 60 Gorham Ave.; (k,1,2) ; N

WIITTIF, FIAXCIS FILJionT.

(See Boston.)

WH.COX, DEWITT GILBERT.

(Set Roston.)

Wlider, lhurt Green (b'41)-Mass.1,66; not in practlee.

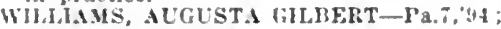
(ఏ) : $27 s$ Walnut St.

WILIAMS, FRANK JERCISAL。

(See Boston.)

Woml, filward H. (b; 4$)-0 ;(1) ; 212$ Win

throp Itd.

Wumls, Freth, Whams (b"ï)-Mass. l, "es (市)

WOODS, JONATHAS HENRY (b.50) X.Y.S,80, X.Y.1.81; (है); $16 \%$ Sallsbury Bd. : until $9,2-3,6-i$.

WRIIHT, JAMES HOMHK.

(see Boston.)

Yot:il, JOII, FItANC

BRYANTVILLE, 300, PLYMOUTH

HARS.KS, ()RILANUO WARRINGTOS (b'sti) $+M e .1 .81 ;(2)$

Chase, Janres Smalley (b'is) - Mass. , , 04 (1) 04 4)

BUCKLAND, 1.573, FRANKLIN

lireares, John Geo. (b'JS) $\longrightarrow$ : (1'95); $N$.

BUZZARDS BAY. 450, BARNSTABLE

Egan. Fdward Winfleld (b'60) $\ldots-1$ "a.2,"6! $(1 \cdot 95)$.

Einney, John Edzar.

(See Hoston.)

snow, llenry Curtis Hutler $\left(b^{\circ}, 6\right)$-Mass. "97:; $(1.97)$

BYFIELD, 880, ESSEX

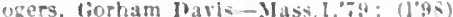

CAMBRIDGE, 104.839. MIDDLESEX Site Hoston.

NTIHER (OF PHSICIASE, 194

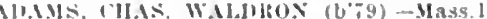
05: (105); 3:-2 Hruadway; s-9, 1-4

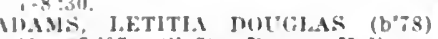
Mass.7,07: (1007); lurton Hall.

Hen. Nathan 1deveret.

(see Hostun.)

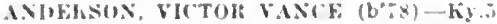
0.3: (studylng): Memler Med. Six" of via : 83 follerly st.

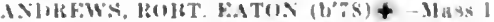
03: (1'03): 1041 Massachusetts Ire. unce, 4 Mratte st: : $2-3$.

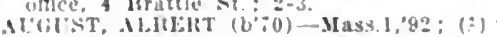
il Mrattle st.: 8.9, i.3, $i=8$

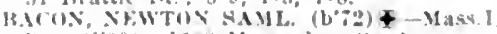
"yy; (1"99); 1654 Massachusetts Aro

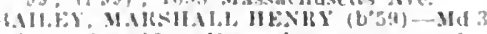
"4:3; $(0)$ : Istio Massachusetts die:?

Horker, Firneat sitanley (b'Gs) H1.11,?! leot in practlec: at shepard sit

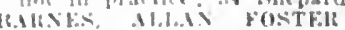

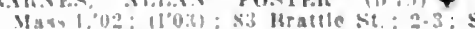

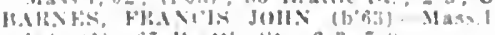

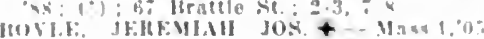
(100); 118 Antrim st.: nnce, 11:9 10am liplifee sit.

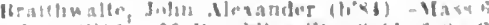

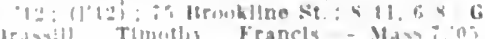
110i1: ay: Hesiluay.

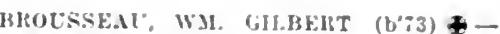
Mass.7,95; (1.96); 228: Massachusetts BHOWS, CH ESTER PEHKISS (b'84) Ilass.'12: (1') : 49 Hancock St

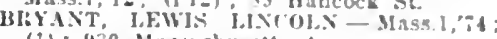
(8) 930 Massachurells Ave

BCTHOLZ, COLL IIKMAXN

(Sre Iroston.)

HLEHLEH, GFO VAN HLEKHK

HUKk, WH. HENMY, JH. - Masa 1,99 (1'95): 2 Hond sis

Burnett, J,ouls lisymond (bo81) -- Mass. :'] (1'10); 13 Waterhouse st

AlI, FHFLERTC IHEJ. MOOERS (1,"Al +-Mass.I, $0^{7} ;\left(l^{\prime} 08\right) ; 1$ Waterhouse st. $2-3,-8 ;$ NP

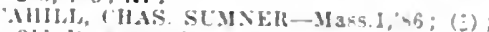
31 Irovipet sit.

Alll.1, THIMAS JisklH - Mas4.7,07; (1003); 130; Cambridse st.

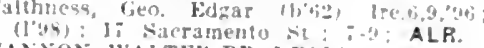

CANXOS, WALTEK BRALFOLI. (see loston.

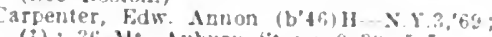

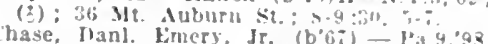

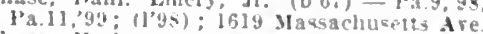
Chase, Herbert A uruetus-Mass.,, $76 ;$ ( 950 Massachusetts dve.

Chase, Hiram Luce-llass. 1, to; (c); 924 Massachusetts Are.

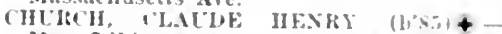

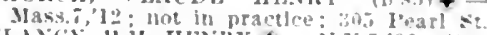

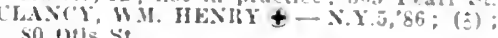
so oths sit.

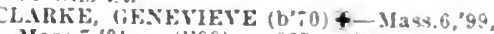
Mass :01: (1'99); 825 Massachusetis

LARKE, INFZ LOLISE-JaSQ F,04; (l'0t) 825 Ifassaclusetts tre.

CLEAIIY, JAMES-Mass.7, 97; (1'00); :70 IJssachusetty ire.

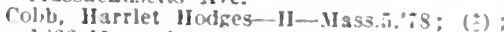
1626 Massachusetts Ale. : 8-9, 3-3.

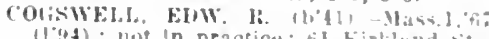
11*4): not in practice: of kirkland 5 COINWELL, likO. PROCTUR (b'bi) Mass.1.93; (5); is Garden si.; $8: 30-9$ $1: 30-3$

Colby, filman-NII.1.6: $(1 \div):$ Centre :

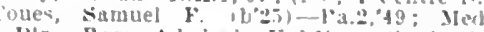
III., Rear Admiral, C's... retired; 10 Mason st.

Cl() KEI, IOHXNMIRI(K (b't) +-Mass. "pit; (2): 335 Harvard st. : s.t. 1-3.

Cronin, Herbert Jos. (b'sa) - Massi, ll (l'll): tig luncord die. $1-3, i-5$. cumnIngham, Jos. Henry (h'bi) -Mass.1.'92

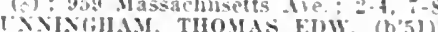

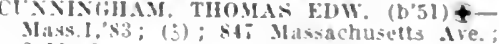
$9-10,-4$

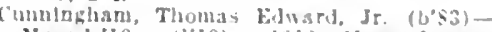
IIass.1,10; $(110): 1010$ Masidiusets. Are. : $9-10, \geq-3,=$

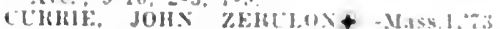

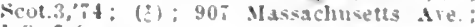
$1+3,-3.9$

D.KINA, KC'GFNE: ABIAMAM (b'6S) Mass.1.94; (2); 135 lomble st.; untll $2-3 ; \quad\left(\mathrm{F}^{2+2}\right)$

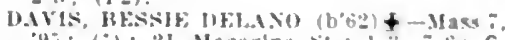

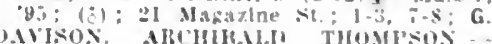
Mass. $\because 1$ : (1995); :- Francls Ire

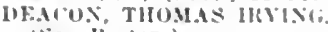

(sice Hoston.)

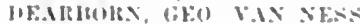

(Sice Hoston.)

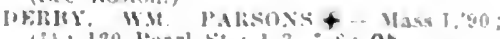
(2): iso luarl st.; $1.3, \quad ; \cdot 8: 00$.

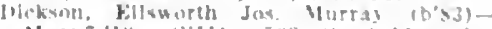

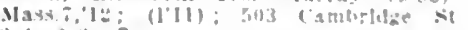
2. H.s: $\mathrm{S}$.

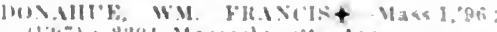

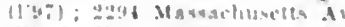

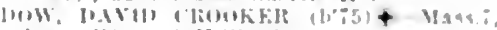

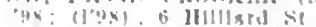

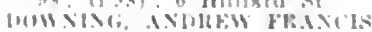
(S) Kantan)

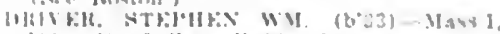

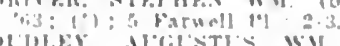

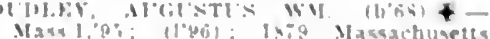
Iie: : : 3 : 
D)mbam, Adeline Frances - Mass. 7,"06 $\left(1^{\prime}(06) ; 881\right.$ Massachuselts Ave ; offlee, 101 Cione in

JWY (") : sis Massachusetts Ave; I-i, i-8.

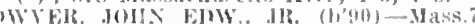
11; (111); xis Massachuselts Ave, : l-"

DWSER, WM, 10S \& Mass.7,05; (1'05) IIs l'uarl st. ; $2-3, \pi-8$.

Earle, Wm. Alva.

(sice Bostom.)

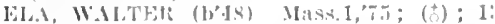
Ish st. : until ta, I

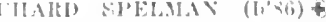

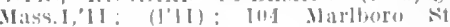

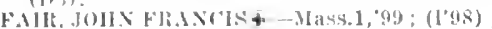
:901 ('ambrldwe sit.

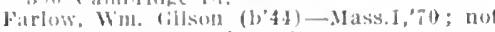
hin praction: it quincy s

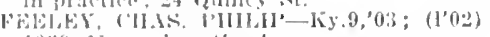
10:5? Maknolungettit Ave

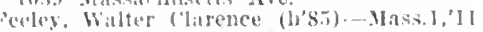
(1+i1) : 26, Western lre.

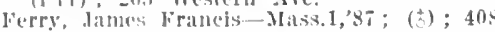
(olumbia st.

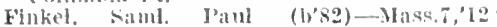
(1'J2) ; 74: Cambrldze sit. ; 8-10, 2-4, $7-9$ ObG.

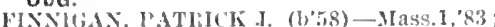

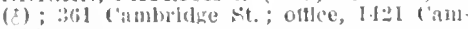
uridge st.

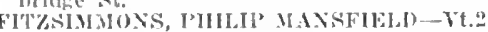

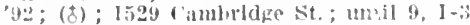
Fleet, Wm. Ernest-Mass.6,93, Mass. 7,95 (文) : columbIa st.

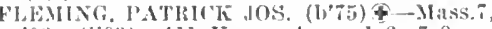
03: (l'03) : 4 ll Ifuron Ave.; 1-3, $7-8$.

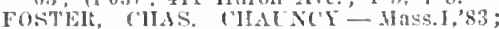
(t): s Elmbood tie.

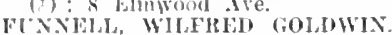
(sire Boston.)

(MALIDNER, IIARIIE MIITON $\theta-V t .2,95$ $(1905) ; 128$ Nagazlne Sit.

GEORC: AIIM, WEIIIXGTON.

(See Joston.)

Gilman, brank Madism $\rightarrow$; $(195) ; 151$ Austin st.

(GoOI) ALE, GEO. LINCOLN (b'39)-Miss.1, '63: (t): 5 Perkeley St.

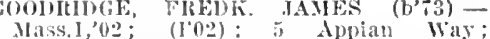

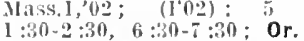

GIRESE, FR. NCLS MARX (b'63) $9-C a l .2$ 'sy: not in practice: Nember Med. Soe. of the state of cal. : $10 \mathrm{Avon}$ st.

Harckett, J.ewls Wendeli (b'84)-Mass.1,'12: not in Iractice: fio Wenclall st. ; offlee,

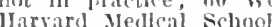

llands. Anna (arrille - Mass. 7,95:

ITsi Massachusets Are.

IIands, Iferhert Alrahan-Mass.6,'sa; (む) 1784 Massachusetts Are.

II.NSOX, W.I. CJINTOX.

(see Joston.)

III'GOOH, WYMAN SAWIN (b'at) \pmMass. 1,01 ;

Harvey, Walter Emerson (b'53)-ra.9,79: (4) 10 Hagazine. St : $8-9,2-4$.

HAYES, WEXTWORTI JARIAABEE (b'T) Milss., 00 ; (1'00); 381 IIarvard Ave. I $-3,7-8$.

IHATON, THOS. HEXRY - Mass.T, 98 ; (l'00): 315 Broadway.

Hesiderson, Iawrence Jos.

(See Ioston.)

Holt, Clifford Parker - Vt.1,'0I ; (1'01) : 1595 Masulchusetts Ave

IMNELI, JAIES ALBLRT (b'80) \&-Mass.6, os: (1'09) : 2 Aron St

IITTCHINSON. CIIAS. MARTIN (b'70) N.II.1,94; (t) ; 5 Garden st.

JOLETT, FREN FOBT. (b'4) 5 -Mass.1, 99; (1'00); 3 Garden St.; 2-3; (D3)

EILLEHFR, I'ATRICK FIAINIS (b'68) Mass.7,96; (1'96); 1636 Massachusett Ave. ; 3-5.

helley, Fdward Ios. (b's9)-Mass.7,'13; Intern. Cambridte Hospital.

FENYHIS, JTLIA GIRICE $\oplus-$ I'a.7, $00^{2}$ (1'(13); I Konnedy Rd. KIX(: Mlioy Jotis - Mass.1,'98;

iltey, ilenry urlando (b'so)-Mass. T, 08 ; (liis): 214 Massahuretts Ave, offlee, 100 Cambritge St.; $1-3, i-8$.

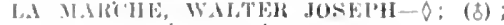

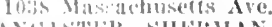

(1)

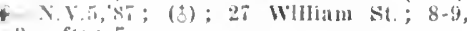

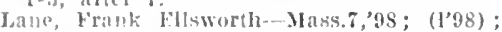
Magazino st.

Lane, Wh. Collon-0; ( ( ) ; 189 Windsor st.

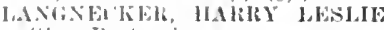

(śeo Bustum.)

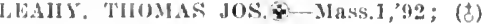
331 broadway.

lowis, Fled. Thomas.

(Sier Busterl.)

IOOKLAL', JOS. SMITII (b'5.5) - - N.L.5, 'sti; (5); 837 Nassachusets Ave, I -3

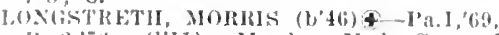
I'a.:',il; (1'11); Member Yled. Soce of the sitate of I'a.; 101 Brattle st.; (1)6, l'lo)

CIRINI, IROBT. GARDNER.

(Sice lioston.)

Harlill,OP, DANL. H-Ma.4,02; (1'02) 307 brodadway.

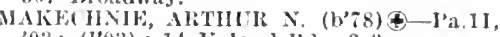
03; (I'03); 14 1"pland lid.; $2-3$.

MAIBC'Y. II ENIRY ORLANDO.

(see Boston.)

MC.MAMS, I'ETEIR STEVENS.

(See Boston.)

MeCARTII, ETCRNE ALIAN (5) ; 458 Massachusetts Ave.

EcGlik , Filut (1*a9); 1436 Cambijge St.

MCINTIRE, GEO. FIKANCIS (b'il) Mass.1,0s: (1'00); 5 Uilla st. ; $2-3 ; \mathrm{s}$ MaNTILE, IIEIIRERT MRUCE (b'ot) N.L.5,82; (o); 4 Garden St.; $2-4$, alfter i: Op.

MeKENZIL, JOIIN ROBLRT, JH.†-Mass.I, 94; (さ); 897 Massachusetts Ave.; 2-3, $7-8$.

Mexeil, Fdmund Johnson.

(Seo Boston.)

Merrick, Sara Neweomb (b'44)-Mass.5,97; (1'97); 83 Reservoir St.

ILOLL, LOUT' AR'THU1 -Ont.4,'s3; (১) ; 830 Somerville Ave

MURI'HY, JOHN JOS. (L'86) \&-Mass. L, 13 (1'12); 3 Norris St. ; $2-4,7-8 ;$ S.

NiY.ES, LEO TIIOS. (b'78) \&-Mass. 7,04 ; (1'04); 1776 Massachusetts Are.; $2-4,7-8$ NASON, OSHON CLEANUER BAKEI (b)58)-Mass.5,91; Mass.1,01; (f); 5 chester St.

NELLIGAN, JOHN PATRICK-Mass.1,02 ; (l'01) ; 2336 Massachusetts Are.

NELSON, CIRISTIAN ALGESTLS (b'74) \&-Mass.1,'11; (l'11); 1010 Massachusetts Ave. ; $2-3,7-8$.

NOONAx, WM. ANDREW (b'84)क-Mass.1 $09 ;\left(1{ }^{\prime} 10\right) ; 472$ Cambridge St. ; $2-3: 30$,

VOIRIS, ALBERT PEIRIEY $\left(b^{\prime} 74\right) \&$ Mlass.1,03; (1'03) ; 5 l'leasant St.; 1-7.

NOL'TON, GEo. EwW. ๑-Vt.2,'99; (l'99) ; 1636 Mlasachusetts Ave.

Norton, James Safford-Mass.6,'89; (b); 49 Orchard St.

Orden, ('has. ludtow (b'65)-Que.1,94; (l'9s) ; 10 Dana St. : $3: 30-4: 30$ after 8 ; O'Rourke, Edw. James (b'86)-IIass.7,09; (1'10); 2280 Massaclusetts Ave.

PAGE, GEO. TIIORNTON (b'69) -Mass.1, 96 ; (1'97) ; 113 Imman St. ; 2-5; OpA ^

PALALR, (iLo. MLNROE (b'63)-Mass.1,

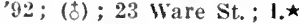

Partridge, Thomas .efferson-Mass.5,'89; (t); 11 Magazine st.

PEIRCE, BRADFORD HENDRICK (b' 79$)$ Mass.1,06; (l'06); 1717 Cambridge St. ; 2-3.

Perry, Lillian Garabrant (b'70)-N.Y.11,96; $\left(l^{\prime} 00\right) ; 59$ Magazine St.

Pillsbury, Fredk. Ainsworth-o; $\left(1^{2} 96\right) ; 17$ Farwell F1.

POTTER, ALEXANDER CARLETON.

(See Boston.)

PIEBLE, WALLACE (b'57)థ-Mass. 1,'83; (ठ); 22 Appian Way; 9-10, 2-3, 7-8; (B15); AL.

PTNAX, WIJLARD ABRAM૯-Mass.1,94; (d) ; 923 Massachusets Are.

Regan, Wm. Henry. (See Boston.)
Hae, Fhrence liances (b'55)-Mass.7,03; (1'0.3); 115 Mt. Auburm St. Itockwell, John Arnoll (b'72) H-Mass.5,99;

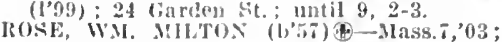
(l'03): 230 I'rosperel st.; 9-11, 2-4, 7-8. Koss, EHzabeth (1,71)-.Mass.5,'12; (1'12); 91 Trowbridtre St

Sargen1, wulley Allen $(1,49)-$ Conn.1,78; (It) ; 27 Everett st.; ofllce, 6 Everett St. stumders, Ambrose lourtis-Mass. 1,94; ( $)^{\prime} ; 25$ Orchard sit.

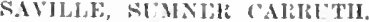

(sice Moston.)

Scorple, Hele'n Chrlstlne-Mass. $\tilde{i}, 09 ;()$ :

Seavey, IIoHlis Lester $\left(1{ }^{\prime} 76\right)-$ Mass.7, 11; (l'I2) ; 1 Frost st. ; 2-3, 7̈-8.

Semott, John lalph-IIasa.1,02; (l'02) 321 Broadway.

SIINNON, N.TIIANIEI, YACGHN (b'63) †-I'a.1,94; ( $\left.{ }^{\frac{1}{0}}\right) ; 891$ Massachusetts

Shea, Alfred Drake (b'64)-Mass.7,01 (l'0I); 943 Massachusetts Ave.; 3-4, 7-9

Sherinan, feo. Ermest (b'75)-Mass.7,05; $\left(1^{\prime} 05\right) \vdots 168$ IIarvard St.; 1-3, 7-8.

Silver, Frank ludolph (b'71)-Mass.1,03 (l'0i) ; (Belmont); ofllce, 1131 Massachusetts Are.

SMITH, IOIN MAY HAMIITON (b'87) 1).C.3,'08; (1'09); 89 Inman St. SOMERS, JOHN EDWIN $9-$ N.Y.10,75; (1) ; 1979 Massachusetts Ave.

SOLTIHARI, EIMER ERNEST (b'76)\& Inss. 1,01; (l'04); 70 Francls Ave.; (oftice, it Fenwood Rol., Boston); Prof. Neuropaflolory, Mass.1 and Mass.Gi; $\left(\mathrm{I} 1,2,13, \mathrm{~F}^{+2}\right) ; \mathrm{NP}$.

SOUTUAKI, MABEL ALSTIN FLETCHLR mid.7,00; (1'03); not in practice; 37 Trowhidge $\mathrm{St}$

SOWLRS, HARTIN JUTHER $\left(\mathrm{b}^{\prime} 92\right)$ Ya.f,'l3; ( ) ; Harvard l'ntversity.

STVENS, EDMENII HORICE (b'46) fice, 1911 irassachnsetts Ave.; 2-4; (A8); S.

TEVENS, HOR ICE PAINF (b'81)कYass. 1, 0s; (1'07); 14 Garden St. ; 2-3;

Sullivan, Franeis Augustus - Mass.7,97 (l’97) ; 376 Cambridge St.

SWAN, WM. DONNISON (b'59)థ-Mass.1,

aYiols Fri Brattle St. : $2-3$

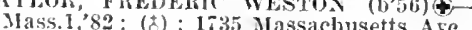
$2-3$, and $\tilde{2}$

THOMAS, ('ILAS. IIOLT (b'50)-Mass.5,'88 (お) ; I 18 Massachusetts Are.; 2-4; Assoe. Jrof. Clin. Med. Mass.5.

TIOMAS, WM. KIIPACK SIITH $(b, 8) \oplus-$ Mass.5,03; (1'03); 1718 Massachusetts Are.: 4-6.

Thompson, Iohn Stephen (b'63)-D.C.2,'95. (1.98); 1525 Cambrldge St.; 1-3. 7-8:30.

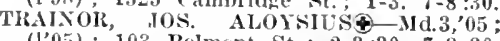
(1'05); 103 BeImont St.: 2-3:30, $7-8: 30$. THYON, FINEVA (b'73) $\oplus$ - Mass.7, 07 $\left(l^{\prime} 07\right)$; is oxford st.

TUTTLE, ALBEIRT HENRY.

(Siee Boston.)

Urich, John Henry.

(See Boston.)

FRIDE, LUIGI P.

(See Boston.)

AIC'OTT, HENRY IICKERING.

(See Boston.)

WALKER, AUGUSTCS CHAPXAN-Mass.1,

66; (b); 5 Acacla St.

WALSH, CIIAS. JOS. (b'59)-Md.3,'92; (む), 2094 Massachusetts Ave.; 2-3:30 T-8:30; Prof. Anat., Mass. 6.

WERSTER, JOS. ROWE-Mass.1,'59; (ठ) : 18 Centre St.

Feeks, Chas. Tupper-Md.6,'85; (f) ; 407 Massacliusetts Are,
Wessethoeft, Conrad.

Wesselhoeft, Con

Wesselhoeft, Walter-IIass.1,59; (t); 39 Garden St.; Emer. Prof. Clin. íred., Mass.5.

WETHEIBEE, ROSWLIJ_-2Iass. 1,'82 ; (t) ; 798 Massachusetts Ave

White, Geo. Arthur (b'86)-Mass.7,09; $(109) ; 170$ Harvard St.; 2-4, 7-9. 
WHITE, IUUERT (L'ZR) FAR 14, 13 ; (2): not in vrartlep: 1039 Mastachusetts Ave. wHT'T

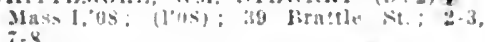

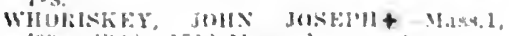

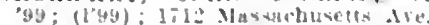

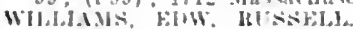

(sice lhoston.)

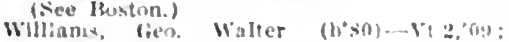

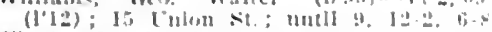

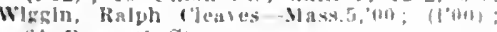
Si Prescott St.

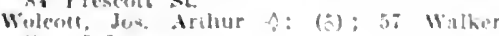
St. : 5.8 .

Worthy Wn. (coll) (b'Ts) - Massit, 04 (lovi); I1: Waslulugt on st.

Wrlght, Arthur Clarebilion (bol) - Mase: 13: (l'13): Cambrige Hospital.

CANTON, 4.797. NORFOLK

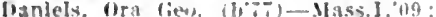

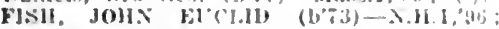

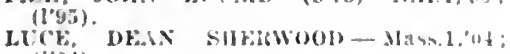
(lod). WM. Nolitirisu.

(SEe Boston.)

CATAUMET, I00, EARNSTABLE

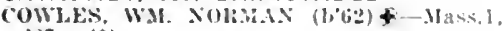
'3T: (\&).

CENTER MARSHFIE!D, 50, PLYMOUTH

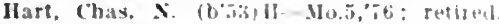

CHARLEMONT, 1,001, FRANKLIN

Carr, Kalph stantleld-Mass, 6,"04; (1"04).

CHARLTCN, 2.032 WORCESTER

Abell, laul White-N.Y.1,93; (5).

CHARLTON CITY, 600, WORCESTER

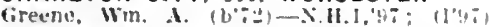

CHATHAM, 1.564, BARNSTABLE

GIYYOLD, BH.X. DOIS-N.Y.3, $66^{\circ}$; (3)

Glgber, Iugustus Geo.--1lass.5,"06; (l'0uj).

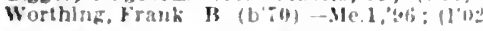

CHELMSFORD, 5,010 , MIODLESEX

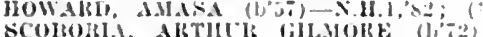

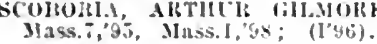

CHELSEA, 32.452, SUFFOLK

(siee loston.)

Fall. Thomas Joseply-Mass.1, $8 ;$; (c); ist

Broadwas:

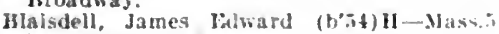

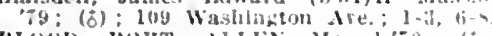

BLOUD, BOIT, AllEX-MaSs, 70 , (5)

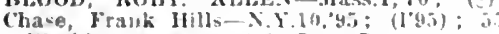
Washlngton Ive, $2-3.5 ; \mathbf{R}$.

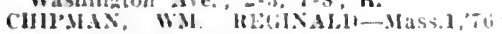
(i): It rounty Itcl.

Coates, Edw. Numustus, Jr. (h's!)--

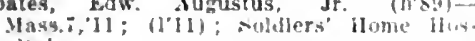
pltal.

CCTILE, CHAS NEWTON $(1, \cdots)+$ Mass. 1,98; (1'46); 30s Wa-hIngton A. $2-3$.

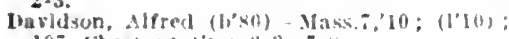
197 Chestum si.; $5+3,7-x$.

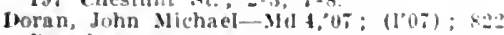

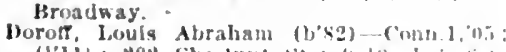

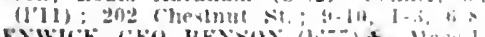

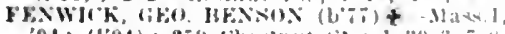
'0t: (l'0t): 259 thestnut st, : $1: 30-3,7-5$ Garrett, Fran
Broadway.

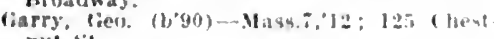
nut sit.

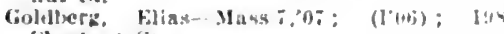
Chestnut st,

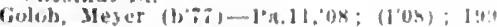
- Chestnut st.: 2-4, 6-x

Ciorwhed, Hohard-Mass.6,"yt: (:) : Walume Nit.

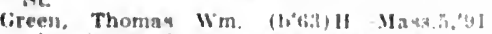
(b): 62 Wanhlugurs Ave, $:-t, 7-4$

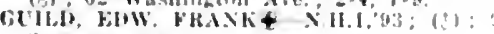
creacent ive. Cunter, Frealk. Berkeley Une. J, "4:": (t)
100 Chestmut st.

JAfKSOX, WF:1,HET I.ISACOTT.

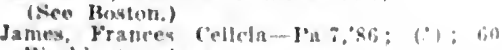
Washlnkton Ain.

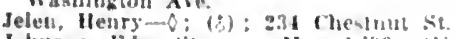

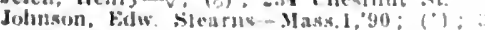
tiarilner sit.

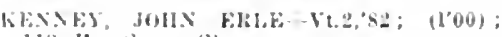
$11 \%$ Itavehorn st.

I.encer, ( ('rescentis Are. : 1-3, i-s.

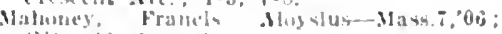
$(1+1): 43$ lary st.

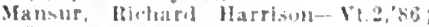

io elark lie.

Martleld, fien. Henry $(6 ; 6)$ - Mass. 1,03: $\left.11^{\circ} 03\right)$ : Sulliers' llome.

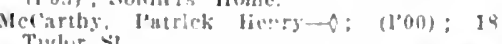
Tuelor st.

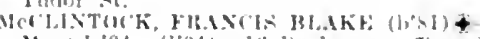

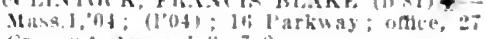
Crescent Ale, $1-3,7-8$

Mrphall, John fium - Ilass.7,05; (I'07); 35 Fileanor st.

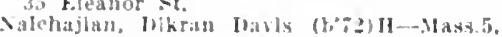

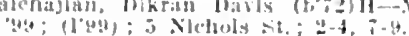

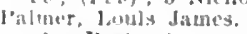
See Howtrm.)

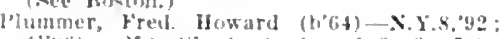

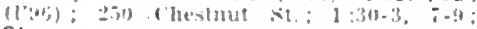
$\mathrm{Ob}$.

lolluck, Jacob Tollas (L'ss)-Mass, d, 1:3;

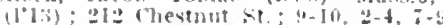

Powers, Kalw. Jos. (12br)-Ma-s. 1,92; (1t); ab Shurtlot 51

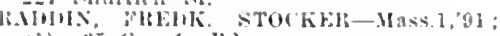
() : 25 rounty lid

lieinherz, fieo, (b'st)-Mass.7.0s: (l'0s); 17" thestnut st.; $9-10,2-4,7-9 ; 0$.

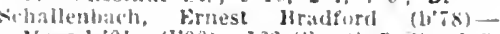

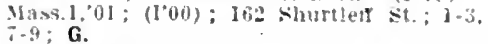

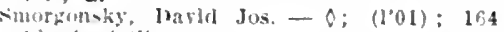
I he,tnut ist.

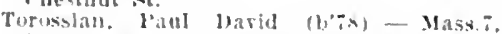

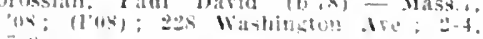

Van Marness, Benj.-Vt.2,00; (1'00) ; 591 Brosdway.

Van Ifagness, Fred-o: (l'04); 591 Hroad-

Walkley, Wm. Saml-Mass.i, 45 ;

$\left(1^{\circ} 95\right) ;$

${ }_{200}$ Washington lie.

We]ls, John Mllon-Gre.2,90, X.Y.10,93: $\left(I^{\circ}, 3\right) ; 131$ Waslington Ale.: $9-10,2-4$.

CHESHIRE, 1.508, BERKSHIRE

Irchlbalu, Jarry Nelson (b'Ts)-Vt.2,04: (I'04).

CHESTER, 1.377, HAMPDEN

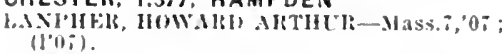

Shepardison. (1sear Jerome- $Q$ : (i).

CHESTERFIELD, 563, HAMPSHIRE

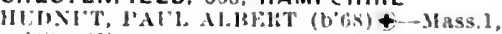
25:; (3).

CHESTNUT HILL, 310, MIDDLESEX

H.M.MWIS. HEAMAN THas

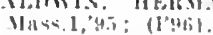

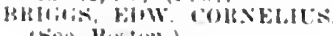

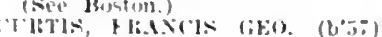

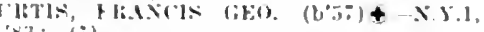

falle, Irthur firnest (b'69)-Mlla l, as; not

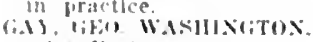

'sen limblon.?

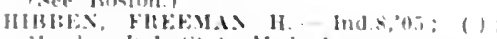
Hemline Ind state Mfed Issu.

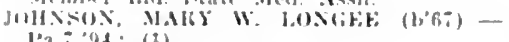
1"a $34:(2)$

H.T. HENB HIST.

CHICOPEE, 25,401, HAMPDEN

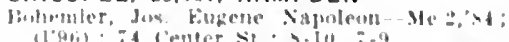

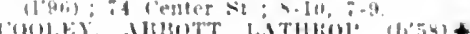

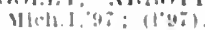

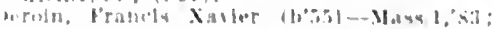

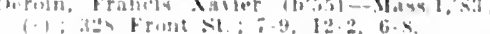

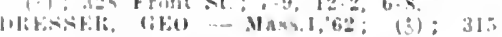
Front it

Flutelur,

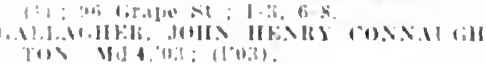

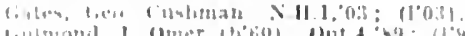

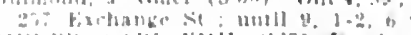

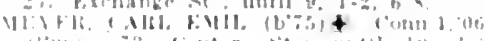

(1) Pd.

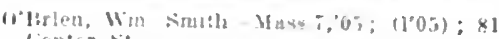
ienter $>$ it

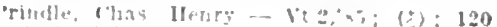
Sirlughell SL

CHICOPEE FALLS, 9,120, HAMPDEN

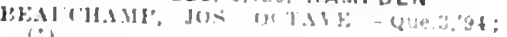

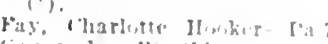

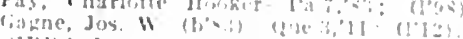

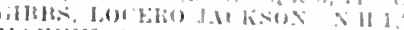

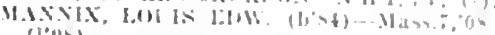

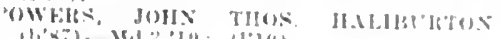

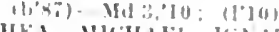

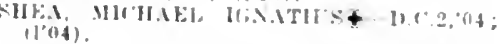

Warren. Aribur bag (1) (l'99).

CLIF TONDALE, 4.500, ESSEX

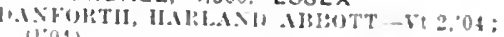
(1004).

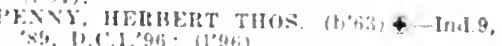

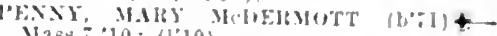

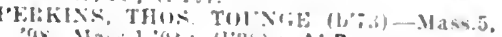

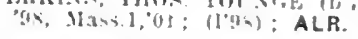

CLINTON. 13,075, WORCESTER

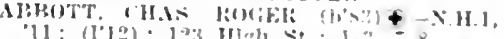

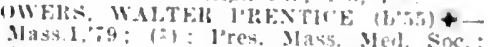

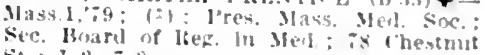
Sit. ; 1 - $20-1-5$

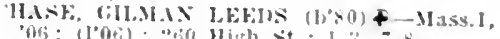

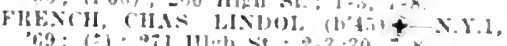

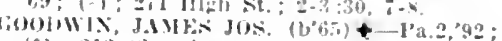

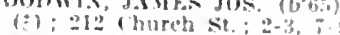

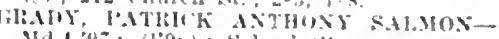

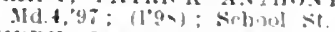

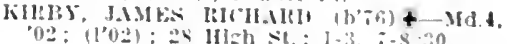

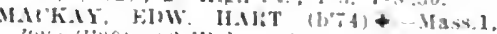

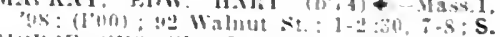
MUlase rito, W., Jn.

(áre Buston.)

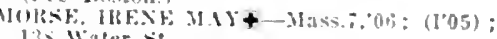
130 Water st.

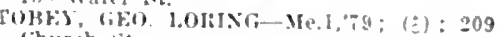
('hurch sit.

COCHITUATE, 1.303, MIDDLESEX

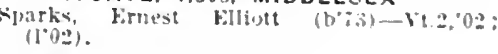

COHASSET, 2,585, NORFOLK

BHIIIT, JOIIN.

(Siee Bostion.

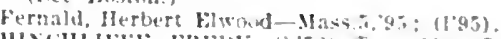

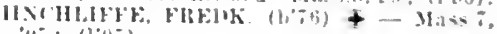
(1): (1.0.5).

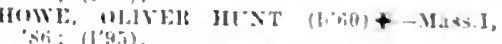

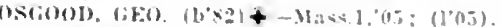

COLERAIN, I,741, FRANKLIN

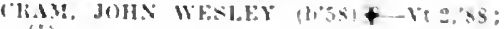

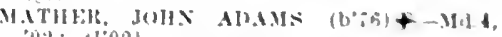
an: : 110021

CONCORO, 6.421, MIDDLESEX

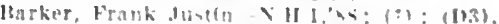

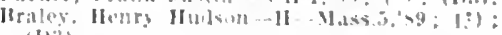

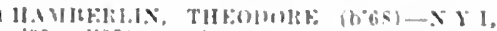

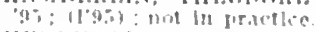

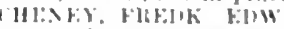

' limtnon.

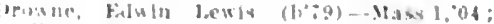
(l) ali): S.

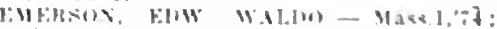

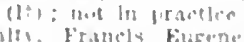

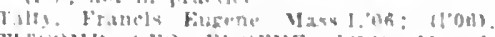

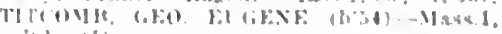

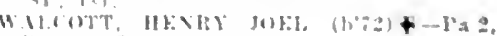

CONCORO JUNCTION. 2.109. MIODLESEX

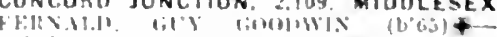

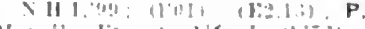

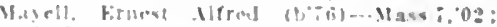

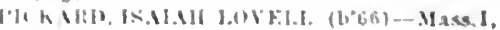

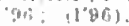


CONWAY, 1,230, FRANKLIN

Jolusoll, Clarence IIenry (b'69) II-J'a.9,97; (l, $0: 3)$

COTUIT, 650, BARNSTABLE

IIASIINS, SOLOMON FOOT (b'5S) X.11,1,'80; (⿱十口) ; 0p.

CUMMAQUID, I50, BARNSTABLE

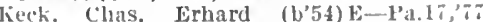
(1295).

CUMMINGTON, 5II, HAMPSHIRE

STITSON, WM. PECKHAM (b'4)-NI:I, So: (3).

CUSHMAN, 150, HAMPSHIRE

FULLEI, AXDREW HOWARD -MII, 06

(lin)

SHow, isa Vernon (b55)-X.Y.I0,79; (d). DALTON, 3.568, BERIKSHIRE

I'ortcr, Ilerbert W-D.C.1,'94: (). Y.5.90;

(1) INLA

SCOFIELI), W.HLTER W. (1,54) - N.Y.3, SLZHIYAX, I'ATRICK JOS. (b'S4) - Mass.i, 09; (1'09); T.

DANA, 736, WORCESTER

Witt, Stephen-E-0.2,'T8; (む).

DANVERS, 9,407, ESSEX

BALDWIS, FIREDEHIC WM. (b'01) -

Malss.1, so; (t)

BOL'TELLE, HARR CLIFTON (b'65)†ifass.1,'99; (1'99).

Buck. Clifton 1.eon (b'82) - Mass.i,'11; (l'13).

Deering, Charles Fuller (b's4)-Me.1,10;

rost, Woodbury Geo.-Me.1,66; (†).

Giblos, Susan Burlcy Harris (b'55) $\mathrm{I}$ -

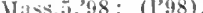

Magee, Edw. Jos.-Mlass.6, 91 ; (t).

Ialns, Herbert Llewellyn (b'it)-Vt.2,'12; (1'13).

IARSI, ANNA HOWE PEABODY-MaSS. 7 , (02); (1'03)

Moriarty, John Jos. (b'86)-Mass. i,'11; (l'11).

Nlles, Edw, Harry-N.H.1,91; (t)

Valentine, John Forrest (b'66) H-Nass.5, '99; (l'99).

DEDHAM, 9,284, NORFOLK

Babcock, Francis Lester-Mass.5,'79; (お).

BATCHELDER, HOLILIS GOOLELL $\left(b^{\prime} 85\right) \oplus$ -Mass.5,06; (l'06); (also, 520 Beacon St. Boston) S. PRESCOTT (b' 64$) €$ Micli., ,'99; (1'99)

Ebbs. Bertha Erelyn-Mass.5,01; (1'01).

FINX, EDW. WM. + -Mass.1, 90 ; (ठ).

Grady, Henry Matthew-Mass.1, 05 ; (1’01). IODGDON, AXDREW HALl, (b'5 3$) \notin-$ IIass. 1,'83; (b).

Uoffses, Granville Ernest - Mass.5,'98; $\left(r^{\circ} 98\right)$

PRATT, JOHN WASHBURN-MaSS.1,'86; (JOHTHIGTON, ARTHUR MORTON (b'T0) †-Mass.1,96; (1'97); (D3).

YOIXG, WALTER ILARDING $\left(b^{\prime} ;\right) \nsubseteq$ Soc. (also 39 Newbury St., Boston); LR. DEERFIELD, 2,209, FRANKLIN

I. VIS. PERCY GUY (b'6i) - IId.4, 96 ; (1'yi); Op.

THORN, EDWIN CYRUS, JR. (b'-4)£VId.4.'98; (l'98)

DENNIS PORT, 600, BARNSTABLE

GINN, DAVID RICHARD-Mass.1,'i2; (1'95).

DIGHTON, 2,235, BRISTOL

BALER, HARRY BEECHER.

(See Taunton)

Butler, Lester Emmons (b'is) H-Mass. r04; (1'04)

Sanborn, Jos. Lander-Ga.5,94; (む).

DOVER, 798, NORFOLK

EMMONS, ARTHUR BREWSTER.

(See Boston.)

Sanborn, IIartha Pike (b'62)-Pa.7,93; not in practice.

DRACUT, 3,461, MIDDLESEX

FHINT, ONAR ALPHA (b'43)-Vt.2,'85; (P)

DUDLEY, 4,267, WORCESTER

Merrill. Quincy Heald (b'i4)-rt.2,'98;
DUXBURY, 1,688, PLYMOUTH

DURGIN, S.MML. HOLMES - Mass. 1,64; (k) not in practlce.

E.AYITT, BYRON C. (b'58) †-Mass.1,'87,

O YES, NATIANIEL KINGSBURY' (b'65)

NII.1,90; (5); LR. (1'0I).

EAST BRIDGEWATER, 3,363, PLymouth Bannerman, Walter 13ruce-Tenn.11,03; ( $(\dagger)$

lichmond, Isus Irrin (b'69)-Mass.1,02 (ingent)

Sillrley, Allen Jincoln-Ne.1,'90; (ち).

EAST BROOKFIELD, 646, WORCESTER

IAYWAIL, WII. FRANK (b'73)-Me.1,99; (1'99).

EAST DENNIS, 250, BARNSTABLE

HART, HENKY BROWN (b'71)-Me.1,'99 (I'99).

EAST DOUGLASS, 1,550, WORCESTER

Clarke, Geo. Clarendon (b'50)-N.Y.5, 77 ; (b).

Ela, P'aul Jrancis (b'62)-IIass.I,94; (ठ)

HOLBHOOL, SILAS PINCKNEY (b'37)1'a.I,'62; (す).

EASTHAMPTON, 8,524, HAMPSHIRE

BURKE, JAMLS JOS.-N.Y.10,'85; (5).

COBB, OLTER WARREN (b'58)†-Ta.1, $97 ;(199 \pi)$.

Hanson, Chas. Joseyh (b'81)-Id.4,04;

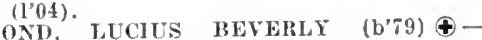

IIass. 1,$06 ;\left(1^{\prime} 06\right)$.

Sparks, Clarence Irring-Md.4,'98; (I'99).

WHLIAMS, EDW. DENISON $\left(b^{\prime} 68\right) \uparrow$

MIass. 1,94; (1'96).

MINSLOW EDW. SMITH†-N.H.1,92; (お)

EAST LONG MEADOW, 1,553, HAMPDEN CUITYS, HARLAN FULLER (b'is) -Vt.2, $03 ;$ (1'03).

Davis, Geo. Healey (b'50)-Md.3,'97; (1'96).

EAST MATTAPOISETT, 100, PLYMOUTH

Jenney, Arthur Barker-Mass.5,'88; (

EAST MILTON, 2,000, NORFOLK (See Boston.)

ROWE, CARLETON ALLEN (b'81) $\oplus-$ Iass. $7{ }^{\prime} 05 ;\left(\mathrm{I}^{\prime} 06\right)$

Schreiber, Eugene (b'83)-Mass.6,'11; (l'11).

EAST NORTHFIELD, 707, FRANKLIN

PHILBRICK, ROSCOE HUNTER $\left(b^{\prime} 81\right)-$

MIass. 1,04; (1'05).

EAST PEPPERELL, 2,000, MIDDLESEX

HEALD, CHAS. GERRY $\left(b^{\prime} 74\right) \oplus-N . Y .19$, '99; (1'99); (Pepperell).

EAST SAUGUS, 1,916, ESSEX

GALE, GEO. WASHINGTON-Mass.2,'61; (t).

EAST TAUNTON, 1,000, BRISTOL

ADAIS WM. CARLTON (b'64)€-MId.4, $96 ;(1997)$.

EAST WALPOLE, 1,023, NORFOLK

COON. GEO. BAILEY (b'68)@-N.H.1,95;

(1'95); NP. Jamieson (b'65)-Pa.7,'95; (1'01).

Fenton Alfred Archibald (b'84) -Vt.2,'08; (1'08).

HacLean, Louise (b'76)-Mass.6,'12; (1'12).

EAST WAREHAM, 350, PLYMOUTH

Hathaway, Sarah Lewis-Mass.3,'i1; (†).

EAST WEYMOUTH, 4,140, NORFOLK (See Boston.)

Chase, Jos., Jr. (b’50) H-Mlass. 5,78 ; ( $(5)$. DOUCETT, FREDK. LUKE - Mass. $i, 00$;

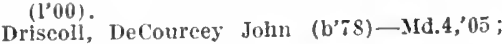
(l'05).

FRISER, JOHY CHISHOLM@-N.Y.10,76;

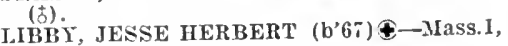
$92 ;($ ( ).

EDGARTOWN, I,191, DUKES

BAILEY, WALTER CHANNING.

(See Boston:

Terin, Clement Channing (b'82)-Conn.1, ,08: (1'08)

Walker, Thomas Jackson-Tt.2,' $\tau 2$; (t).

WORTH, EDW. PHILIP (b'72) $€$ - VIass.I, '99; (1'98).
ELMWOOD, 250, PLYMOUTH

Burbank, Llly Owen Baker.

(See Boston.)

ENFIELD, 874, HAMPSHIRE

SEGUR, WILLARD BLOSSONL-N.II.I,'92; (ठ).

ERVING, I,148, FRANKLIN

JOHASON, FRANCIS EMERSON (b'5

N.H.I, 82 ; ( ()

ESSEX, 1.621, ESSEX

Ells, W'm. Alonzo-Mass.6,'06; (l'07).

Halg, Andrew 4 .

(See Somerville.)

lmpson. Joseph.

(See South Essex.)

STEEVES, EIRNEST C.-N.II.1,05; (1'05).

EVERETT, 33,484, MIDDLESEX (see Boston.)

Brewin, John Andrew (b'76)-N.C.4,04 (I'08); 393 Broadway; 2-3, 7-8.

rown, Orestes Aorton (b'56)-Vt.2,'83 (ङ) ; 519 Broadway.

BRUCE, JOIIN ANGUS (b'58)-N.Y.5,96; (5) ; 699 Broadway; $1-3,7-8$.

Clark, Theodore Wright (b'5i)-Vt.2,'92: (t); 383 Broadway.

CONROY, PETER JOHN (b'57)@-Vt.2,

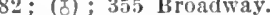

CORNISH, SOLON WASHINGTON (b'83) -Mass.1,09; (1'09) ; 64 Corey St.; offce, 79 Whintirop St. : 2-4, 7-9.

DICKINSON, GYRDIE WILLIS. (See Boston.)

DOWNING, CHAS. HARLAND (b'Tt) Mass., 03 ; (I'03); 387 Maln St.; $1-3, ;-8$; anson, Wm. Grecne $\left(b^{\prime} 57\right)-\overrightarrow{3}$

IARRINGTON, CIIFTON WARD (b'84)Mass. 7,06 ; $(1,06)$; 547 Broadway.

Howe, WInfred Lewis (b'74)-Mass.7,00; (I'99); 657 Broadway; $1-2,7-8$.

JACKSON, ALTON ATWELL (b'55)-Mass.1, '83; (1'96); 512 Broadway.

Johnson, Feo. Anson (b'65)-Mass.6,97; $\left(I^{\prime} 97\right) ; 38$ County Rd, ; I-3, 7-8.

KEANEY, HENRY JOS. (b'78) \&-II.4, 01 ; (1'03); 385 Broadway; $1-3,6-8$.

Irarshall, Foster Leroy (b'69)-Mass.5,'92; (ठ) ; 213 Vine $\mathrm{St}$

ICALLESTER, RALPH WM. (b'77)-Mass.1 '04: (1'04); 693 Broadway; 2-3, $7-8$.

ICQUAID, THOMAS BERNARD (b'60) N.1I.1,96; (1'95); 37 Norwood St.

MORRIS, RICHARD HOLT (b'7I) -Md.4,96; (1'96): 39 Corey St.

ORDWAY, CHAS. ANTHONY (b'75)屯-

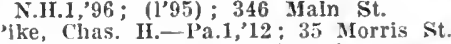

Racine, Ernest Eusebe $-;(1+) ; 104$ Main St.

Riclimond, Fred Marey (b'75)-O; (l'04); ROGERS FRAXK ALVIN (b'55)-Me 1 , T6.

(f) ; 534 Broadway; 2-4, 7-8 ; Prof. Bact., (t) ; 53.

Saunders, Jos. Henry (b'T2)-Mass.1,00: (1'01); 581 Broadway; untll 9, 2-3, $6: 30-7: 30$; Pd.

Schiey, Wm. Sullivan-Pa.9,05; (1'07); 7 il Broadway; Pd.

WARREN, ALVA HARDING (b'i6)-Mass.1, '00; (1'00); 634 Broadway.

Washburn, Chester Angus.

(See Boston.)

WHITEHILL, GEO. EDW. (b'60)-MIass.6, '93; (ठ) : 516 Broadway; 8-9, 2-3, $7-8$.

OUNG, EDGAR WM. (b'57) \&-N.Y.5;'85; (t) ; 644 Broadway; $1-3,7-8$.

FAIRHAVEN, 5,122, BRISTOL

BRUCKSHAW, ANDREW

( $\left(1^{\prime} 96\right)$.

IORNE, LESTER WALLACE (b'80)€Mass. 7,$04 ;\left(l^{\prime} 03\right)$.

OWES, FRÁNK MILLER (b'85) †-Mass.1, '10 ; (I'11).

Thompson, Charles Edward Percy (b'79) H-

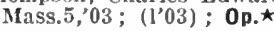

FALL RIVER, II9,295, BRISTOL NUMBER OF PHYSICIANS, 137.

ABBE, ALANSON JOS. (b'61) @-Mass.1, '85; ( Allard, Jos, (b’56) E-Ind.11.8'; ; ( ) ; 1151 Pleasant St. ; $8-10,1-4,6-9$. 
ALMY, THOMAS (6.s8) Mass. I.09: (l'10); 13x linch st.; ontee, lfol linck St: $:-3 ; \mathbf{O b G}$

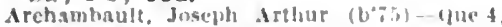
01: (1"03): 115n I'leasant si. : oflev, Fo s. Man st: $1-t, i=9$

Habeock, rianle! A riold (b'ia) Jl -X Y.9,'At; (5): 254 Hock st.

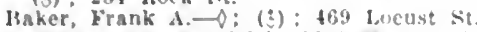

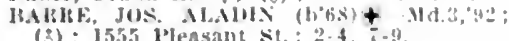

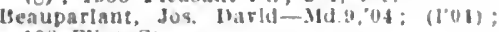
los Fllut Si.

lbergeron, Francols de burgla $(6 \% 0)-$ Jue.s. '44: (8) : 126 WHIllam st.; $8-31,12-2 ;$; Herzeron, Serayhim Enscobe Ont.t. sil (Swansea): ottice. 1301 I'leasalit sit

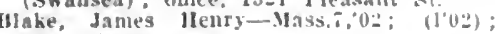
457 , th st.

MAXCHFTTE, WM. HFXli + Mal, 96: (1'96): 409 Lindsey st.

HLOOD, GLOKt: WILLAllil (1,'si) Mass. 7,$08 ;\left(l^{\circ} 08\right)$ : 723 Mlldlle $1: 30-3,7-8 ; 5$.

tholduc, Alfred Geo. (b's)-Mass.; , 10. (1'10): 1420 S. Main Sit. - $-3,3$

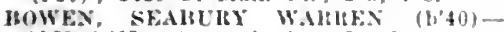

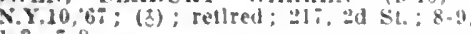
$1-3,7-8$.

Boylan, Thos. Edward-11.2, :48; $\left(1^{*} 95\right)$; 19 South St.

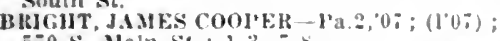
370 s. MaIn St.; 1-3, i-s

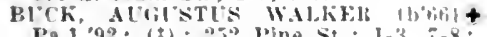
I'a.1.92; (3); 252 Pine St: 1-3, i-8; S. HUTLEK, GEO. EDW, (b'99)-D.1.10; BUTLER, HCHARD HEVXAlin (b-5) l'a.1,02; (1.02); 251 Jine st, $2-3.7-8$ $\mathrm{S}$ *

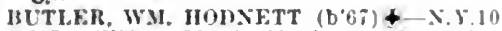
'ง7; (1'95); 234 Hedford st.; s-10, $2-1$ $i=9 ;(1) 3)$.

Capen, Thomas Allyn (b'45)II-1'a.9.72; (8); 651 Hedford 5 t. ; $12-3,7 \rightarrow$;

Caron, Amable Berthelat-Que.3,00; (1'01): 1439 Pleasant 5 .

Casgrain, ('has. Arshur-Que.3;it; (1797) TI Hassett Sit

CHACE, FH.XER ALBERT (b,

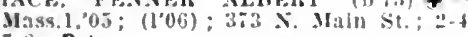
$\overline{-18 ; 0}$ D.

Clarke, Heary D. $\rightarrow$ : (

Clarke, Thos. Greene (b'88) - Mass.7,'11. (lii): 350 . 2d st.

CONE, WWTGIT ELEAZER (b'a) \&-X.l. 6 ; (8) : y38 s. Maln St; onde, (ostorn St. : $1-3,6-6: 30 ; \mathbf{G}$.

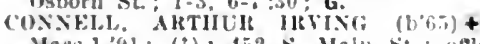
Mass. 1,91; (8); 452 s. Maln st.; oflce 46 s. Mán si.; $2-3,7-8$.

Conneli, Chas. Walter-Mass. $1,8 \%$; (5); 038 IIIghand Are, : $2-3,7-8$.

Copeland. Chas. Ward (b'5*)-Gerdi, it (t): 1 ? Jurchase st: $1-3,-3-8$

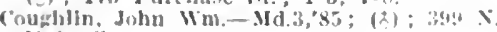
Maln sit.

Cos. Thos.-X.5.8,93; (1'99) ; 124t l'leasant sit

Creamer, Wu. Ilenry (b'st)-Mass l, ! I

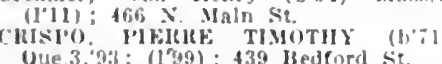
cuanings, Michael Aloysiug (b'al)-Missi

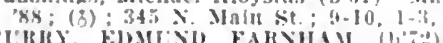

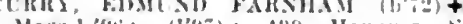
Mass., 14t: (I'3i) : $4 ! 19$

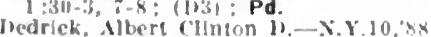

ledrick: Nibere cH

bethers. Adelard Ollvler-(zue.s, $01 ;(10)$ 36.3 F. Mali st

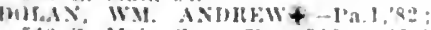

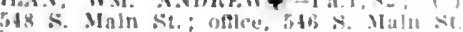
X- $-1,1-3,6 ;-S: R$

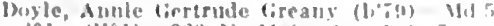

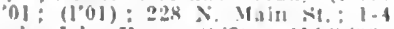

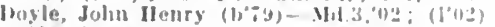

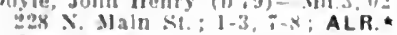

muhnime, finulfose lemaltre (h'bi) $46:\left(1+9 t^{\circ}\right): 1099$ l'leasant st?

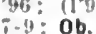

Duraliy, Frask A. (b'84)-M1.3,"10: (1'1: $330 \div$ Mall st. $1-3,7-5$.

Entln, Allas fillel-8; (8) : 605 Mldule st

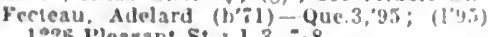
1228 ileasant $S t ; 1-3,-=8$

(1.11) 32 IInden st

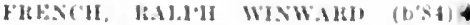
Mas 1,$10 ;\left(l^{\prime} 10\right) ; 213$ kelmont st.; fiflce

ruller, lbavil Iterman l'a.2.,04; (1005); 51: Itradfural Are.

Ciarneall, Jlphome Josenh I'lerre (b'bi)-

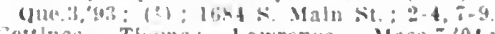
cellngs, Thumas lawrence - Mass.;.04; (1004): $10+6$ I'lymouth st.

(ilblos, Samitel Wholpley-X.1I.1,30; (2) 20.3 1'ine st. : 1-1. $-9: \mathbf{C}$

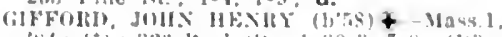

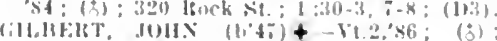

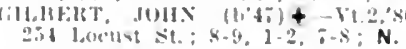

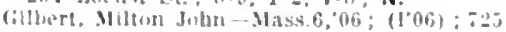
Lurust st

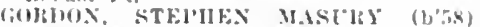

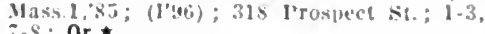

crman. Joln Jos. (6'8s) - Mal.3, 08 ; $\left(1{ }^{\prime}\left(18^{\circ}\right)\right.$; Crigln iflolite

rifln, Mlehael. Ioseph-Mel.3;07; $(100)$; 347 . Maln $\mathrm{Rt}$.

Gunning. Thumas Francls (1) 152$)-1$ - 41.101 ; (3) : $238 x$ X. Ialn st. ; 2-3. $7-4$

Iarris, Emanuel $\left(b^{\prime}: 1\right)-X .5,94 ;(1) ; 165$

Itork sit. : 1-3, 6-s

Hathanay. Mareus Morton $\left(b^{\prime}+1\right)-b$; (j) 273 Winter st. : oflee, 23 s. Vali si. !) - 12, 2-?

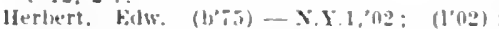

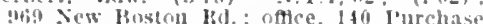

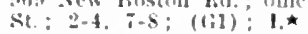

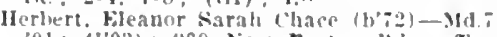
01; (1"03): 469 New Boston Wu.; coftce 1 to Jurchave it?

Hicks, Chas indrew-Ve.2,80; (195); 47 Winlus sit.

HICKE, GKO. HEXIY, JK. - X.Y., ,0, ; (1005): 1973 s. Jain st. : 1-3, 7-s.

IIil. l,ucy (haloner-H-Mass, 5,90

t. Main st.

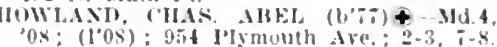

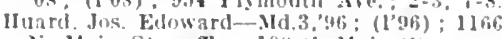
x. Main St.; offlce, $109 \mathrm{~s}$. Main st.

Hyde, James Saml.-X Y. 1,02; (1'03);

X. Man $>$.

Jackonn, dohn Patrick - II 3,$03 ;(103) ; 341$ Winslumgton st.

JAKSUY, OLIVFR HOWALH (b'\%1) Y.8."14: (1'(46): Intt Merhlian st niflec, st Main st.: $1-5,7-8: 113,151$

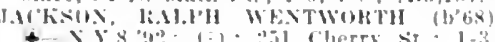
i-s: $(A+1) ;$ Pr.

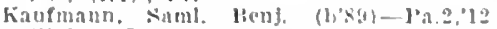
(I'12); 4 i Mulberry st.; s-4, 1-3, T-S; S

Kectey Imbrose Augustine - Id : (I0(i): $4: 3 \leqslant$ Main $\leqslant 1$

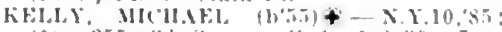

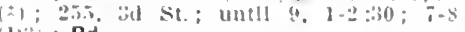
(113); Pd

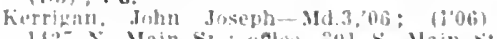

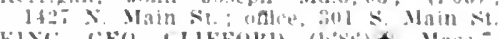

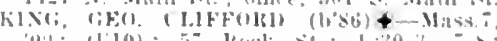

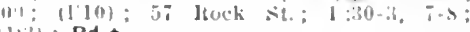

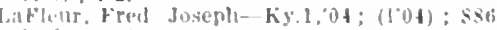

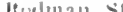

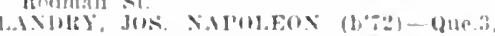

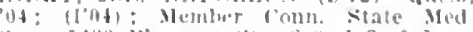

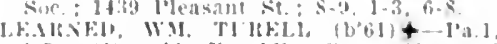
\&i: (i); dio Franklin st.; unce, f: Fraiklin $\leqslant$ - ; 2-:

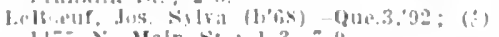
1 ti:; X. Maln st. ; $1-3, ;-1$

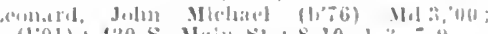

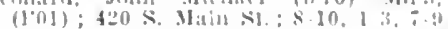

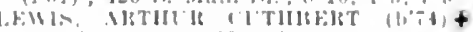

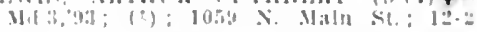

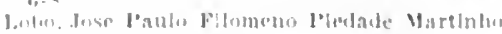

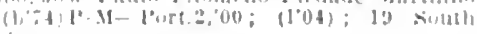

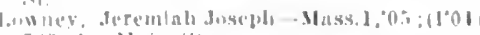
sis?

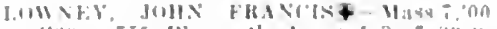

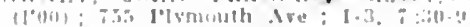

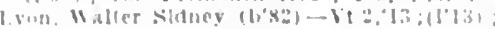

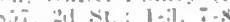

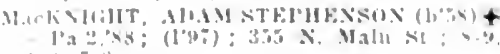

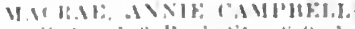

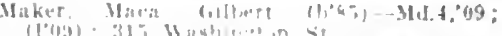

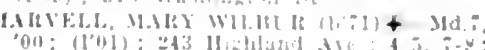
(1) (l'01): Path.

Iaverd, Arthur Fo Ma Itedturil st.: \&

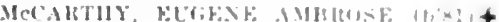

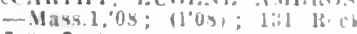

i-s; Or.

Mercher, Jos, Fuclfle $(1,2,5)$ - Ma 6,99

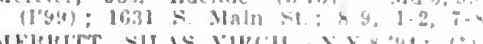

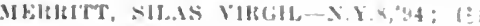

wit thlorn st.

lot, J. Ibonal (b'si)-Que.3,11: (I'1

Jun siafort ho.

Morrill, fruik trmungton (1,53). Ny

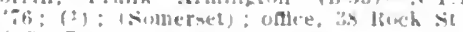

- ‥: Pr.

O'HIIF. JOHX FHANCIS (b'b

or'chimer. luilu bilu - I'a.11." a. Ilymouth Ave: $2-3,-8$

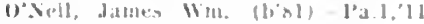

Otton, Staford Walker (h'st)-Ont.1,13; Intern, Infon liospital.

Packer. Geo. Win. (b'79)-Mass.6, 0

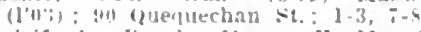

Pastelford, Frank Mason-H-Mass.5,"01: (1'01): 126 June st. ; :- \$, 1:30-3:30, - -6

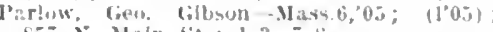

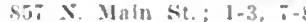

Jartington, fyrus Prown (6'89)-Mass.i. '12; (1'12): Iti2 Jenchs : th. 1050 bas st.

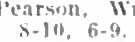

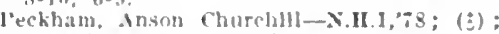
.2.3 Therry st, 1 -2, in

lerron, Albert Firnest (b'st) - Md t:07: (107): $x: 1$ s. Math st, ; $;-2,12-2,8-8$.

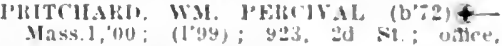

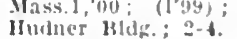

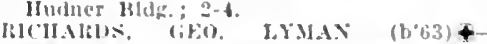
Mass. l,so; (5): Member ls. I. Med. Sirc. 3it Irvofiect st.; once, lat krankin St. : - i ; $(162,3,5,1,1):$ ALR.

lova, llenry Antullo-Mat,9y: (1.99); 158 columbla st.

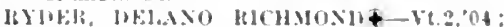
(lioi): ant Hock si.: unlee, lat Frauklin St. : 11-1. i-s; (11,15); OALR.

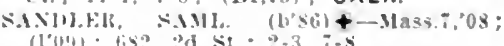

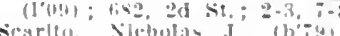

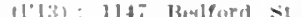

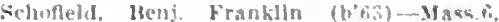

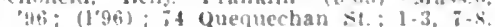

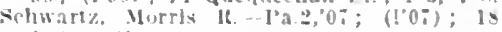
lottalge sit.

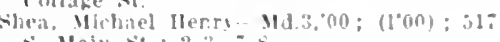
s. Main $51 ; 2-3,7-8$

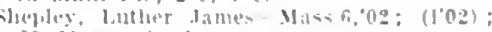
$29 \quad 11: 1 \times 5,24010$ sit

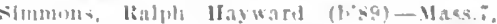
1"z; Intern, Inlem Husplal.

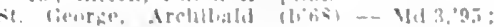

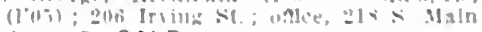
Sit. : 1.5: OALR. *

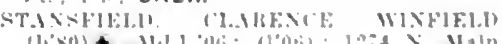

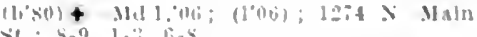

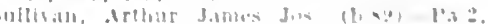
$1: 2: 11 \cdot 1 \geq 1$.

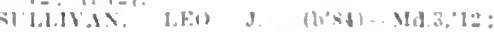

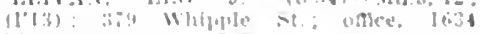

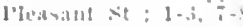

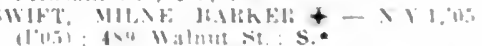

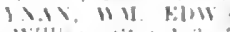

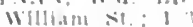

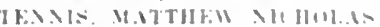
iscer isvions.

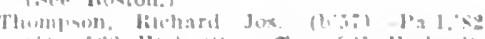

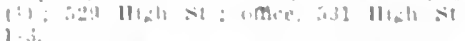
ilines

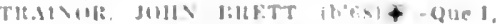

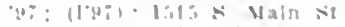

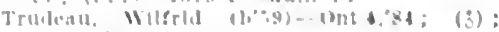
IIt I'leasant sit: $1-1$

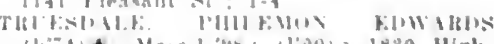

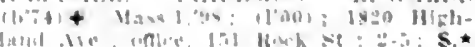


Turuer, Wm, (ieo. (b'79) - Md.4,04; (1'04); lilt June St. $12-3,6-8$.

Walsh. dames 1fenry (1,'84)-.1]1.3,'10 (1']0) ; 780 [']ymouth Are.; $-3-3,7-8$.

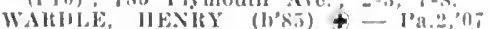
(l'07) : 863 Plymoulh Ave.

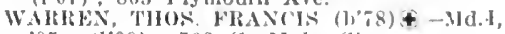
"9.5; (1'09); 502 s. Maln st.

WEST.UL WOHN (b'61) + - N.11.1.92; (196): 955 s. Mtain st. : $1-3,6-8$

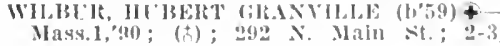
$7-8 ;(\mathrm{F} i 2): \mathrm{S}$.

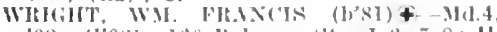

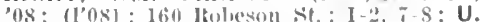

FALMOUTH, 3.144, BARNSTABLE

l'atlee, dsa Jee - o.zon: (l’aj).

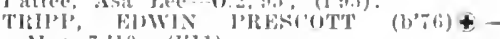

II:18.

Walker, James Titylor Yt.2,79; (む)

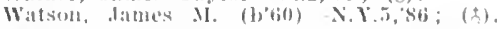

FANEUIL (BOSTON P.O.), - SUFFOLK

(JiosisY, WAl,TER IIIRAM (b's5)-Mas. os: (I.09)

FARNUMSVILLE, 710, WORCESTER

PerTy, liw. Wm.-N.II.1,77; (ङ).

FEEDING HILLS, 1,63!, HAMPDEN

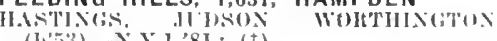

(1,53)-N.Y.1,81; (t).

Pallek, Albua Barie Norrls (b'a)Iil.15,'95; (I'98).

FISHERVILLE, I,023, WORCESTER ('ILARHOANHAU, NOE NAPOLEON (b'76)
-Y'.2,98; (1'98).

FISKDALE, I, 160 , WORCESTER

Lilwlor, Jimes Francis-Vt.2,04; (1十).

Locke, Ilorace Mam-Ilass.1,'S6; (⿱十口)

FITCHBURG, 37,826, WORCESTER

BAKEIR, LEWTA FORIESTER (b;72)-

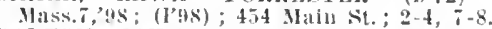

B.ATTON, hIIN ALFHEH (b'74)-Mass.1

'97; (1'97) : 43 Simmer st. ; 1-3, $7-8$. (む): 145 , Fairmount sit. : $2-4,7-9$.

Bennett, Wm. IIenry (b'63) H-N.广.9,'89; (5) ; 39 Hartwell St. ; $1-3,6-7$.

lingham, linssell (b'51)H-111.4,90; (1'95) ; 130 l)ay st.; $[-3,6-7: 39$.

BOLAND, IAWIENCE FIRANCIS (b'86)-

Ild.4,'1 ; (1'I2) ; 28 Crescent st.

Burneli, Chas. Willard (1,61)--1ld.4.96;

(1'96); 96 snow st.; 1-3, 6-8.

Burns, Mary Ellzabeth-1'a.7,10; $\left(1^{\prime} 10\right)$;

Sumner and Lunenburg Sts.

BURNS, IOBT. IIANCIS (b'83) - Md.4,

os; (1'09); i Iunenburg st.

CAREX, BERNARI) WU. (b'81) - Md.4, 05 : $(100)$; 3I Clinton St, ; office, 6 I'richard st. : $2-4,7=9$ :

CHANIULER, CLAIEXCE LUTHER (b'79) —Iass. 6,'04; (I'05); 44 Prlchard St. $2-4,7-8 ; S$

Cook, Mabell Mellssa (b'63)_-N.Y.I4,'87; (む) : Is Hardwell St. $1-3,7-8 ; \mathbf{G}$

DONOVAN, TIIOS. ROCHE (b'81)-Mass.7, '09: (1'09) ; 40 P'riellarl St. ; 8-9, 2-4, 7-8. Enroth, Emil E. (b'79)-Rus.1, of ; (1'11); 28 Simonds St.; office, 356 Main St.; $1-3,7-8 ; 0 p$.

FISH, LFWIS (h'7L)-MId4,'98; (I’99) ; 86 Day St. : $2-4 ; 6-8$

Fisher, Jabcz (b'24)-Mass.1,'51; not in practice: Fisher $\mathrm{Rd}$

FISKE, ELSTACE LINCOLN $\left(b^{\prime} 60\right) \oplus-$ Mass.1,'86; (t) ; 20 l'richard St. ; 2-4, 7-8. FRANK, MORRIS.

(Sce Boston.)

GAY, CLARENCE BERTRAM $\left(b^{\prime} 73\right) \oplus$ Pa.1,99; (l'99); 16 Cherry St. ; $1: 30-3: 30$,

Geary, Cornelius Edw. (b'80)-Mass.1,07; (1'07) ; 12 Summer St. ; $2-4,7-9$.

Grieumard, Geo. Auguste (b'68)-IId.6,'94; (屯) ; 472 Maln St.; $9-10,2-4,7-9$

Hitcheock, Alfred Owen (b'41)-Mass.1,70; (d) : 30 Prichard St.

IACQUES, J. HECTOR (b'T6)-IIass.1,'10 (1'10): 145 Water St. : $2-4,7-9 ;$ Pd.

IENNINGS, CURTIS HERNAN $\left(b^{\prime} 76\right)-$ lurbank Hospital; (G1); R.

JONES, RAYMOND CHILD (b'81) -Vt.2, (02, (1'02); 4 Ashburnham St.; 1-3, $6: 30-8 ; 5$.

KEARXEY, JOHN HENRY (b;2)-MId.3, '98; (1'98) ; 80 wallace Are.; 1-3, 6-8.
Killelea, Folw. V'lncent (b+80) - Md.4,93;

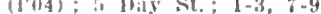

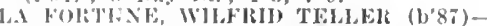
II.I, II); (1'10); I28 Falmount st.; 8-10

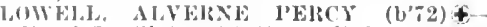
$14.2,9^{-} ;(1.98) ; 52$ llartwell St.; $2-3: 30$,

MASON, ATHERTON PEIRT Mass. 1,22; (5); $3551 / 2$ Maln St.

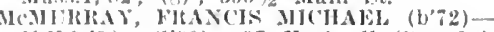
N.Y.9,93; (1'99); 3i Ihartwell st.; $2-4$, MLLEIR, ERNEST FAlRKEI (b) Tlt Iass. $177 ;$ (1) ; 408 Main st. ; 2-4, 7-8. Molllea, Zachary Amerlgo (b'8s) - S.C.1,12 (l'] $\left.{ }^{\prime 2}\right)$; 202 Water st. ; $8-10,6-8$.

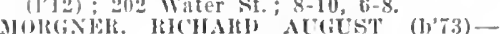

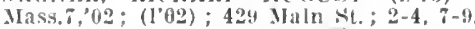
WR'PON, GEO. IAI' $\left(\mathrm{b}^{\prime}, 2\right)+-$ N.Y.10,

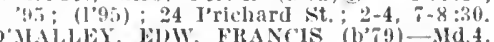
(1.MALWY, LIW. FRANCIS (b'79)-Md.

l'erkins, Arolle Emer (1)'(65) Il-HIl.4,'89;

(z) ; 99 llay st. ; 8-9, 1-3, 6-7:30.

Plerson, Ilenry Waller (b"56)-N.Y.8,84

(c) : 130 Ashburnhan st.; 12-2, 6-8.

QTESTI, ALFRED HENIT (1,76)-Md.3.

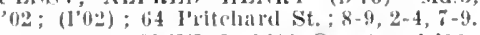

IICH, (HAS. HENRI (b'43)†-Mass. 1,66 ;

(o) ; 1'2 l'richard st. ; 8-9, 1-3:30.

RI( 1., ROIJT. ANTLEY (b'75)-Mass. l, 02 ; (l'02) ; 2 Crescent St.

RODHF'K, ALBERT FOWLEK (b'T2) -

7'0I : (1'01); 38 I'richard st. ; 10-4. SAWILK, WAITER FAIRBANKS (b'6s) † -.lass.1,"93; (t); 67 l'richird st.; 2-1,

SIDNEY, ATSTIN WILBLR - I'a.IT,'80:

N.11.1,81; ( $)$; not in practice.

STIMSON, JOHS WOMHHIRT (b'5) N.II.1,80; (む); 101 I'richard st.; 2-4, $6 \cdot 30-7 \cdot 30$

THOMPSUN, FREDK. IIENRY (b'4t) \& ilass. I, 70; (む); 3 l'leasant St.; $2-4$ i-8:30.

THOMISON, FREIK. IIENIKY, JR. (b'75) Ilass. 1,03; (l'01); io Wallace Are.;

TOWER, FlEENAS ACGTSTCS (b'-

Jass. i, 04; (1'05); Burbank Hospital; (E2).

TULLY, EDW. JOSEPH (b'70)-Mass.1,'92; (ち); 98 P'richard sit.; $2-3: 30,7-8: 30$

Wells, Delbert Arthur-D.C.1,98; (198); 67 Day st. ; 1-3, 6-8.

Whittier, Cordelia Melvina (b'72) H-Mass.5, 9.; $(1997) ; 27$ Myrtle Ave.; $1: 30-3: 30$, 100

-N.1,76; DWIGIIT SIDNEY $(1,51)$

Yron, Jean Bantiste Wilfred-Que.3,'94; (t): not in practlce; 145 Water st.

FLORENCE, (NORTHAMPTON P.0.), 2,500, HAMPSHIRE

Hickey, Garrett J.

(See Northampton.)

FOXBORO, 3,863, NORFOLK

BIATig, FHAN('IS ADELBERT (b'65)థ

Mas. 1,$94 ;(ठ)$.

CAILISIF, FRANK HENRY $₫$-Mass. 1, 04;

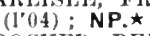

CROCKER, BENTON PULSHER (b'67)

X.1.10,91; (d).

Haigis, Peter J. (b'73)-Mass.5,'04; (l'04).

liermore, Deuny Wood (b'73)-Mass.5,

$06 ;(1.06) ; \mathrm{S}$.

Mcl'HERSON, FEO. E. (b'76) - Md.4,04; (1'04); OALR.

HOORE, FREDK. PORTER (b'82)థ

Mlass.1, 08 ; (l'0s) : State Hospltal.

EFF, IRWIN HOFFMAN (b'68) 4 -Nd.1,

89: (1'08); (E2,13); N.

Poole, Alra Emory.

(See Boston.)

PonIe, Florence Faulkner (b'78)-Mass.6, 01: (I'01)

Sawyer, Carleton (b'55)-Vt.2,'83; (l'95).

FRAMINGHAM, 19,948, MIDDLESEX

ALBRO, CHRISTOPHER DURFEE (b'42)-

X.Y.5'89; (t); Member R. I. Med. Soc. BALDWIX, SANFORD OSCAR (b'67)@Pa. 2,96; ( I'96)

BENNER, HERBERT ORRAY†-N.H.1,'96 (1'96).

BIGELOW, ENOS HOYT (b'55)(-Mass.1, '82; (む); Pleasant St.
130INELL, WM. MOL'TIMER (b'84)Joynton, $\left.{ }^{2} 10\right) ; 0$ b. Unton' Ave.; I-3, i-8; I'rof. Ilat. Med. and Ther. Mass,t.

curley, Walter James (b'74)-Pa.2,02: $\left(l^{\prime}(02)\right.$

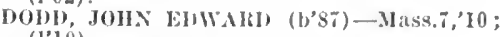
(1'10).

WIIHT, EWWI WELLES.

(Siee Boston.)

Fuller, fislomon $\quad$ :

(see Westboro.)

Glass, JAMlest Mass 1, 94 : (1'04)

IAIIIMAN, CoIA FIIZALE'II+-Mass.7 '02; (1'02); 15 111 St.; 1-3, 7-8; 0 b.

IHALY, DANL. LAIRHNCL-Mass. 1,98; (1'98).

HOHISS, EZLA MLLEX (b'45)-.He.1,69; (引).

SSAMAN, IHON WEBSTER $(1,78)+$

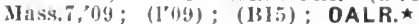

lielth, Fillen loulsu (b'5i) II-Mass, 5, 88 ; (b)

Noc'ann, .Tames Henry-(que.1,07; (l'08) Icfiam, John llenry-1tass. 1,98; (l'98). Iflls, Chas. Fisher (b'60)-Miass.1,'82
(l'12). MORROW, WM. HOLT.-X.1I.1,89; (1'99).

OWlis, AlBERT SIMPSON (b'84) Mass.711; (1'1 ); 44 lincolv St. ; 2-3,

MAMER, LEWIS MIRTITT $($ b50)

Mass. I, $81 ;(5) ; \mathrm{S}$.
Harker, Mary (b'72)-III.4, $10 ;\left(l^{\prime} 10\right) ; \mathrm{G}$.

'armenter, Kenueth Raymond (b'74) $\mathrm{H}-$ Nass.5, $96 ;\left(l^{\prime} 96\right) ; 15$
Union st. $3: 30-5: 30$

Patch, Frauk Wallace (b'62) II-Mass,5, 88 . (t); I'rospeet st.; I'rof. Mat. Med., Ilass. 5

POTTER, FHANCES WASON†-PA.7,91; (1'95); G. POTTEIE, JOIIN CLALEDE (b'79)§-II.4. Raymond, Itichard Michael-N.Y.10,91; (t)

SPACLDINY, EDITH ROGERS (b'8I)甲Mass. б,09; (l’09); (1b?); Pd,

ST. ILAIR, AF'STIN EMERY

(see Boston.)

STOXE, JAMES SAVAGE.

(Sice Boston.)

FRANKLIN, 5,641, NORFOLK

Albott, Solon-I1I.4,'82; (む)

(rowley, John Michael-N.H.1,97; (l'97).

FAXON, EIWORA IIEAIIE (b'42)-Nass.6, ' $y 2$, Niass. 7,94 ; (む) ; OALR.

GALLISOA, AMBROSE JOHN (b'56)థN.II.1,88; (b).

Hussey, chas. Bumps (b'73)-Vt.2,95: $(1,95)$

Martin, Gregory Arride (b'4')-Vt.2,79: (ठ)

Richardson, Carl Eugene (b'83)-Mass.7. OT; (l'08).

FREETOWN (ASSONET P.0.), 1,471, BRISTOL

BRIt?GS, ('ILAS. ALBERT (b'63)థ-N.Y.8, '89; (5).

\section{FT. ANDREWS, 50, PLYMOUTH}

EKWLRZEL, (;EO. M. (b'75)£-Pa.1,97;

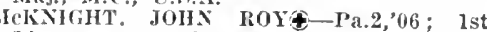
Lleut., M.C., I.S.A.

FT. BANIKS (WINTHROP P.O.),-, SUFFOLK

SHAW, HERBERT G. (b'76)థ-Cal.1,98 Maj., M.C., U.S.A.

FT. REVERE (HULL P.O.), - PLYMOUTH GAI'EN, NELSON (b'79) \$-D.C.2,00; Capt, M.C., U.S.A

FT. RODMAN (NEW BEDFORD P.O.), VALKER, THOS. CARL (b'T1)€-Va.4,95; Ist Lieut, M.R.C., U.S.A.

FT. STRONG (BOSTON P.O.), -, SUF FOLK

BLANCHARD, ROBERT M. $\left(b^{\prime} / 4\right) \oplus-0.9$, 99 ; Capt., M.C., U.S.A.

HALL, JAMES FRANK (b'T3)€-Mass.1, 99 ; Maj., M.C. U.S.A

FY. WARREN, - SUFFOLK

PASCOE, JAIIES B.4-N.Y.10,94; 1st Lleut., M.R.C., L.S.A 
GARDNER, 14.699, WORCESTER

Andrews, Orell (b't3)- II $3,29 "$

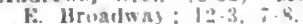

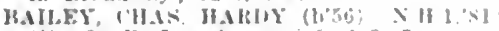

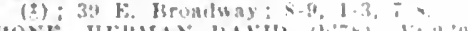

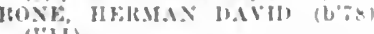
(I'II).

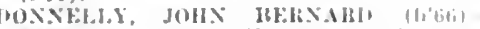
Mas. 1,93; (i); Vernon st. 1 - 7.4

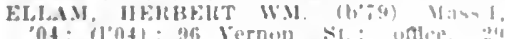
Por a

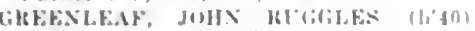

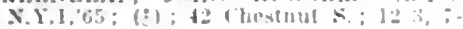
Grise, Herman $1 . \cdots$; (B)

keuworthy, Marlon kolwena (b'91) Waw 13: (l'1i) : Fiarduer stala llaspltal: $\mathbf{N}$

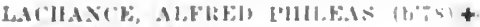

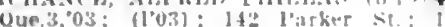
$6-8 ; s$.

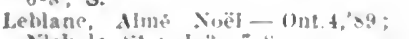
Vichuls $\mathrm{sit}$; $1-3$, ;-s

LOWELL, ALIBEHT FIV $(1,7)+11$

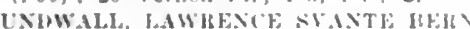

LUNIWALL,

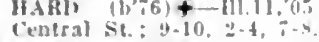

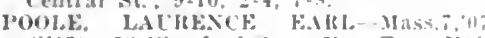
(l'07): 5s llestford st. ; oftce, Town Hall

Bact:

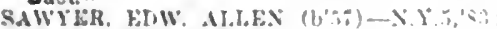

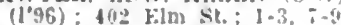

snilth. Wm. Wawle (b"iti)-Mass, 1, I] (I'II) : 117 Central $\mathrm{s}$.

Thompsin, cluas. Filw, $\{1)-9\}+-$ Maks 1 (102 (loog): Crariner state Colony

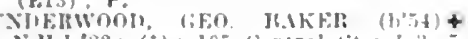

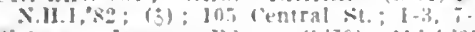

waters, James folw (b'79)-Md.4, ns

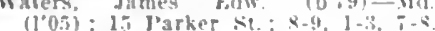

wyman, Ilarry Munroe (b, :- - (100): 22 Linwoln $\$ 1$; oflie, Maln and Heasant Sits. ; $1-3, i-8$.

GEORGETOWN, 1,958, - ESSEX

HOLBE, HOWART) FOWTER (b'1) Mass. J."01: (1'01)

Hoyt. Fiw. Maleolm (b'5s)-Mars. J, 4

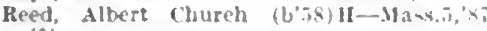
(ह).

ROOT, RICHMOND BARROER (b'4) MIass. 1, 67 ; ( (

GILBERTVILLE, 2.368, WORCESTER

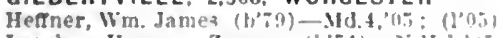

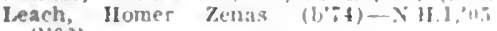
(1'06i).

GLOUCESTER, 24,398, ESSEX

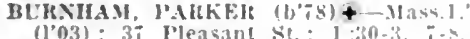

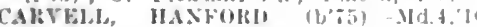
(I'II).

CHOATH, MITON IAY (1,83)-Md.9.44 (I04) : s.5 Mludle st. ; $2-3, ;-$

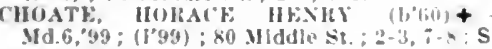

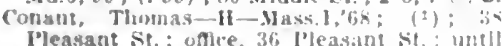
I'leasant St. ; oflee, 36 l'leasant st. ; untl
$9, \quad=3,6: 30-7: 30$.

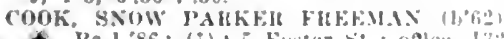
+ I'a.1,86: (3): Foster Nir: oflow.

crisiscilim,

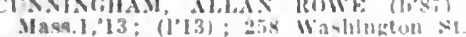

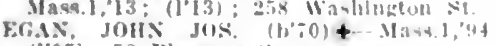
(1'95) : 52 Pleasant st

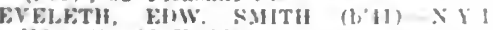
66 ; (2); 20 Hlghland st.: 2-3, 7-8

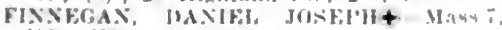
02 : (l'02); 83 Mlldle Si.

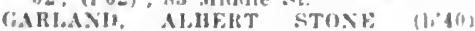

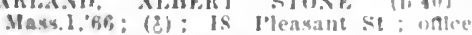
8: Mldule st. : I :30-3, i०

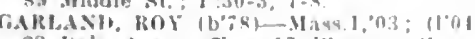

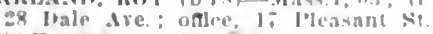

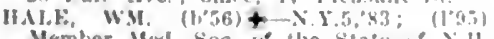
Member Med. Sinc uf the state of $X \mid 1$ 45 Mldule Si. ; 1-3, \%.8.

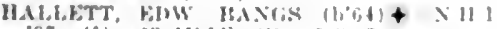
si; (8) : bis Mlithlo st.

Hroper, tiverett

ISee Hoston.)

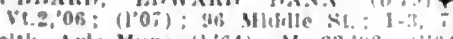

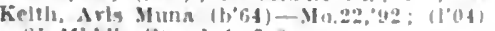
81 vidulle st. : 1-t, :-8.

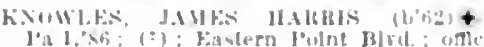

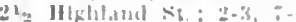

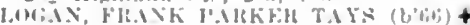

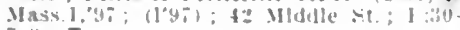
$\because-\mathrm{Q}: \mathrm{T}$.

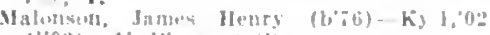

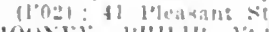

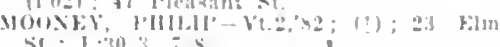

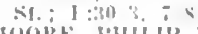

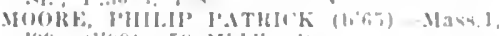

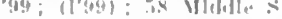

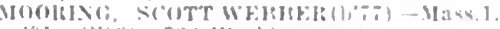

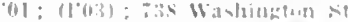

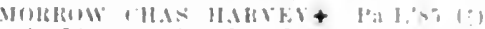

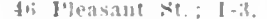

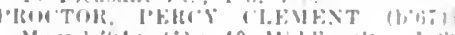
Mavs. 1,"14: (1)

(Itis): ALR.

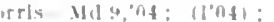

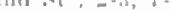

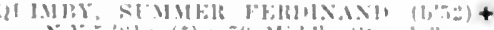

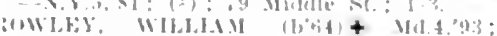

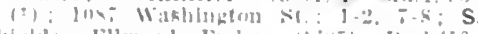

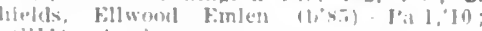
(l'li): Anulsiuam.

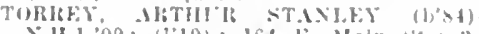

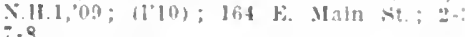

GRAFTON, 5.705, WORCESTER

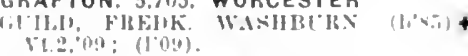

GRANBY, 76I, HAMPSHIRE

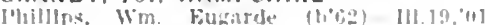
(l'DI).

GRANITEVILLE. I.290, MIODLESEX

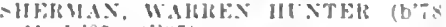

(1): $(10-1)$

GRANVILLE, 781, HAMPDEN

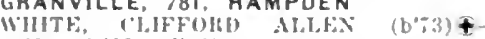

Ilass.3."00; (1'U0).

GREAT BARRINGTON, 5,926, BERKSHIRE

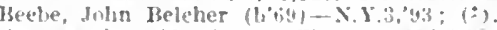

'avanath, Mortmer Thomas-MdA.94; $(1, P x)$.

HAIS, (IAFFOMD SAML $\left(\mathrm{b}^{3}: 3\right) 4$

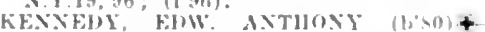

vi. 2,$05 ;(1.0 \%)$

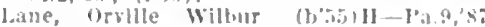
(इ): G.

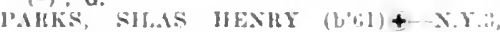
schultes. Ilugo, ar $\rightarrow$ : (l'03)

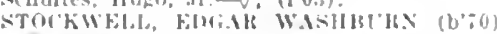

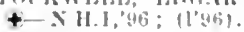

GREENFIELD, 10.42\%. FRANKLIN

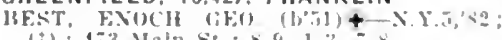
(*): 473 Maln si ; $4-4,1-3, ;=$

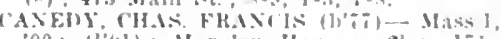
(0): (l'(1): Manslon House; onlee, 1;.

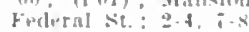

GIARK, WEMSTER KIMBIIL, (1,\%)

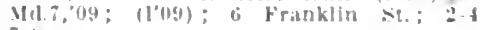

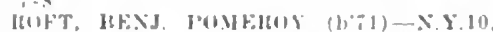

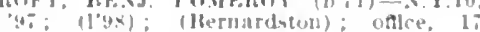
fevieral st.; $9-1$ : 0p.

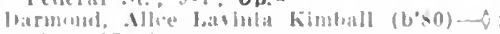

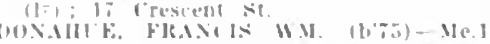

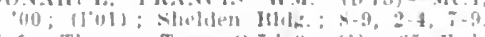

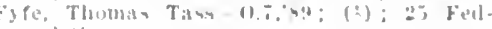
atil is:

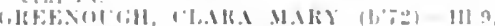

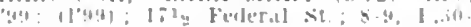

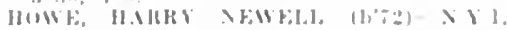

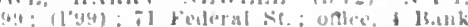

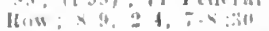

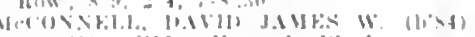

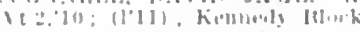

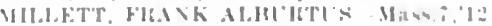

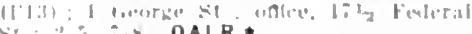
Si $A, D$, OALR.

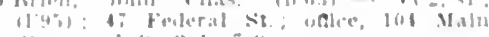

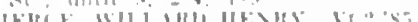

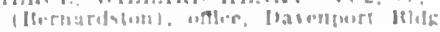

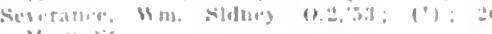
I:

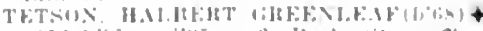

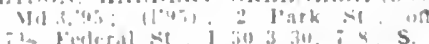

THIT II HLL.

Мasi, I,

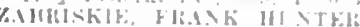

lit Millts:

GREENWICH, 357, HAMPSHIRE

(iollle, rialli Murlah DI

GREENWOOD (WAKEFIELD P.0), $\$ 00$ MIDDLESEX

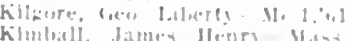

Klmbill, James llenry Mand lo"

GROTON, 2,155, MIDDLESEX

KII,HMH IS: IRTIII

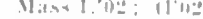

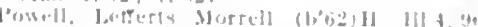
11097

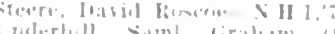

"H) : 110I): P.

GROVELAND, 2,253. ESSEX

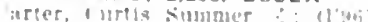

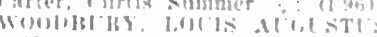

IIISis. 1,?:-

HADLEY, I,999. HAMPSHIRE

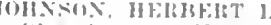

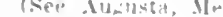

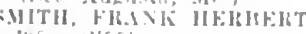

HAMILTON, I,749, ESSEX

illey, Mrran lieo.

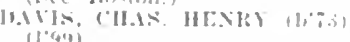

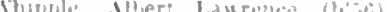

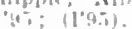

HANOVER, 2,326, PLYMOUTH

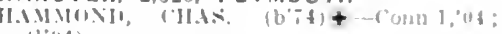
11011

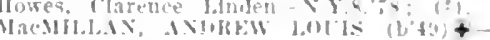

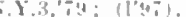

HANOVER CENTER. - PLYMOUTH

Gillsun, Wlllis sianley $(1,9,3)-1 ! 11 ;, 13$

HANSON. 1.854. PLYMOUTH

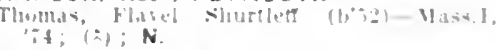

HARVARD, 1.034, WORCESTER

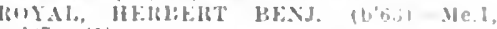

HARWICH, 2,II5, BARNSTABLE

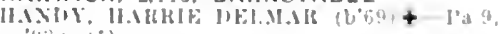

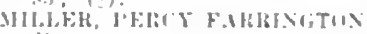
(l'ili).

HATFIELD, 1.986, HAMPSHIRE

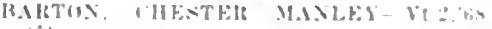

(ㅅ)

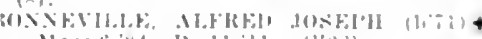

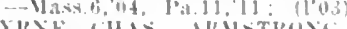

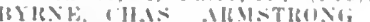

$\therefore 1: 494 ;(135)$

HATHORNE, 100, ESSEX

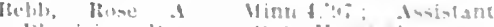

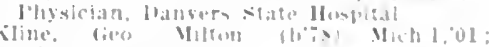

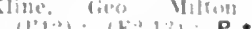

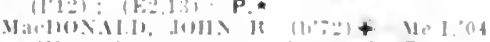

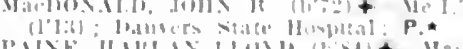

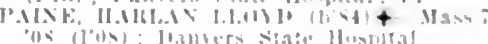

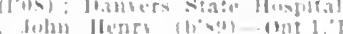

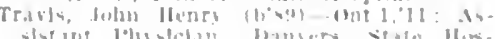
intial.

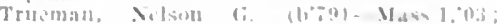

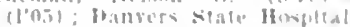

HAVERHILL, \$\$, II5. ESSEX

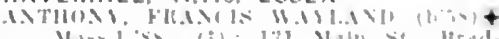

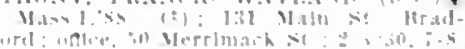

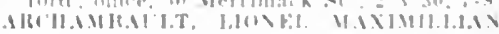

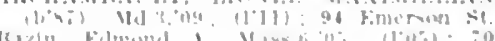
H.rntrome को

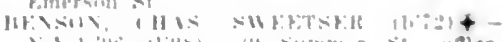

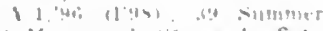

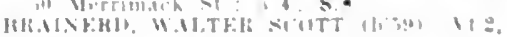

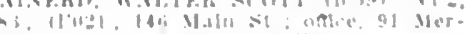

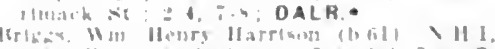

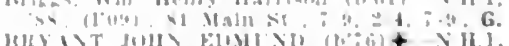

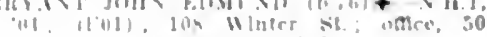
llorimark $\$ 1$. : $2-3$ 30, : 


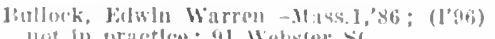
Ilot in prictl

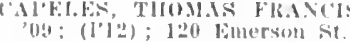

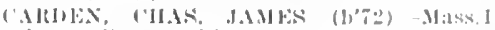

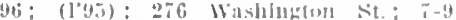
$1-3,7-4): 0 \mathrm{OB}$.

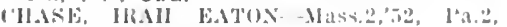

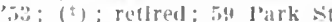

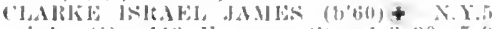

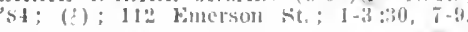

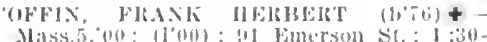

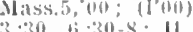

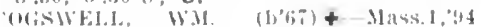

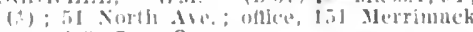

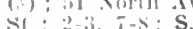

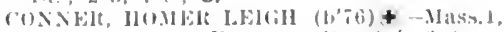
"H0; (I01); si Enerson st. : 2-4, 6-8

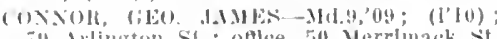
(!) Allington St.; oflle, 5 Il Merrluark st

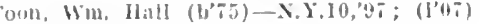

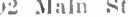

COONLE, MARGARET BLANCHE (b'90)Mass. 71 ; (I'II); 67 Wiuler st. ; $9-10$ $1-3,7-8$.

coTTElR, TJMOTHY FRANCIS-Md.4,06 ; $(198)$; 245 Walubgton St.

Crltteuden, Harrison Murray-Mass.7,9s (l'y9); 120 Winter st.; until $9,1-3$,

CROSTOX, JOHN FIRACIS $(1,55)+$ N.Y.5, , ( $)$; 8.3 Emersoll St.; $1: 30-$ $3: 30,7-8$

Delfsle, Jox. 1lanase-Ont.4,'s7; (b); 88 hocust sit.

DONAII'E, HLGII-Mass. I, 88 ; White st. oftice 19 White St.

I orion, Louis l'hillpe Allelard (b'6.) (Hnt.4,'ss; (3) ; 11 Tremont st. ; ofthe, 42 uafayetle sif.; $1-3$.

1) 1.5 , (IINS, STEN-Mass.1,83; (1'95); 133 Maln st.

DIFANT, CILAS, WDWN (b'62) \&-Mass.1. '85; (f) 5 tirand st.; offlee, 105 Emerson

FEIRIX, WM. WARREY (1,78)-Vt.2,04; (104); 7- Limerson st. ; $1-3: 30,6: 30$

FIT\%(IERAL1), JOIIN JOS. (b'76)—-Md.4, 03; (1'03); 111 buerson st. ; 2-4, $7-6$.

Flood, Thanals Wllfred-11d.6,02; $\left(\mathrm{l}^{\prime} 02\right)$ is Kenoza Ave; offlee, 3 Washington sq. $2-4,7-9$

CiEOR(iE, ARTIIT PHIlluls (b'68)v.11.1,97; (1'96); 143 Main st.; $12: 30-$ $2: 30,-8: 30$.

(ierald, Ilerbert Franklin (b'8I))-Mass.i 09; (1'04); 265 Main St.; oftice, 50 Mer rimack st.; ;-4, 7-8.

Goelsehius, 1'erey Berry (b'90)-Mlass.7,'13; (1'13); : Columbia l'ark.

Goodall, Edwin Baker-Md.9,05, II.1,09 (1 10$)$; 14 Emerson st.

110R.JROOK, (IIAS. ALBELT (b'78) Mass.1,08: (1'ts); 385 llain st.; ontece, 50 Merrlmack st. : 2-4, $7-8 ; 5$.

IIOLDEN, WX. 11AN]. (b'59) -Mass.1,82 (A); 16 lortland st.; office, it Emerson st. ; $2-4,7-8$.

HLBBELI, ADELBERT MERTON (b'63) \& -Mass.5, 89 ; (む) ; 32 Summer st. ; ofloce, 2.2 Nerrimat'k st. ; $2-4, i-8$.

Jeweli, Iloward Clifton-II-N.Y.9,88; (t); 35 Vine St.; office, 76 Merrimach st. $-10,3-4,8-9$.

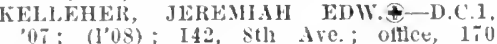
Wiuter si.

IASKEY, EIWARD l'HILIV (b'82)\&Mass. 1,09; (l'09); 17 l'ark St.; office, 94 Emerson St.; $2-3,7-8 ; U$.

LeGRo, J.ESTEK MTRNSIDE (b'65)‡IId.4,05; (1'05); 534 Salem St. ; offlee, 50 lerrimack St. ; $3-5 ;$; ALR. $\star$

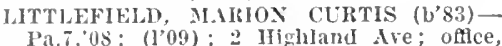
50 Merrimack St. ; 2-3:30, 7-8; $\mathbf{0 b}$.

lacdougall. Duncan (b'66) $\mathrm{H}-\mathrm{M}$ ass.5,'93 (屯) : 131 Main St.; 8-9, 2-3:30, 7-8:30.

Mciuen, ('has. Nieluolas (b'75)-Mass.6, '02: (I'03) ; 4 Columbia Park; offlee, Main St.: $10-11,1-3,7-8$.

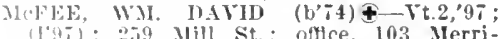
(I'T) ; 259 Mlll St.; oftc

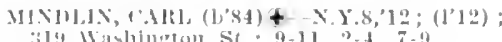

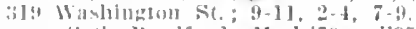

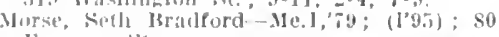
Fomerson it.

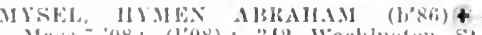

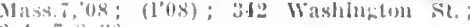

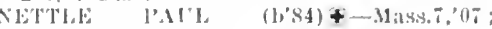
(107); 207 Grobeland st. ; unth 9, iz-2,

Nlelrolsun, Saml, Nexander (b'7t) - Mass.6.

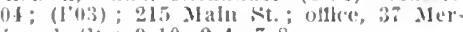
rimack sit.; $9-10,2-4,7-8$.

Nolan, Mtclanel $(b, 5,2) \ldots V t, 4,89$ :

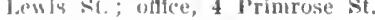

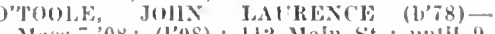
lass. T,0s; (I’0S); 11:2 Waln st. ; unlil 9,

Prlfeles, suerales Jakovos (1, 68$)$-Mass. 1:; (1'13) ; 17: Winter ste; $9-11,2-4,7-13$

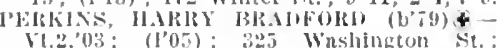
Ү1.2,03; (105);

l'ickens, Danle Ellsha (b, 69 --Masso.'l:; (1'12); 215 Main Si.; offlce, 104 Merrimack st. : $2-4,6-8$.

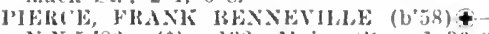
N.Y.5,'86; (t); 132 .11ain st.; $1: 30-3$, $6: 30-8 ; \mathrm{Pd}$

IPTCIIER, IIERIBEIR FRANK $\left(b^{\prime} 53\right)+-$ Yt.2, $7 ! ;$; (3); 97 Arlington

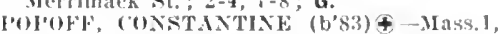
10 ; (11): 158 Mah st.; opice, 50 Merrluack st. $2-3,7-8 ; 0 b G$.

Rice, Robert (b'î)-I'a.9,08: (1'09); 2 \% Washington st. : untll 9, 2-4, $7-8: 30$.

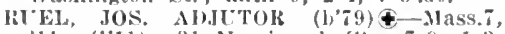
11; (1’11); 21 Merrimack st. ; $7-9,1-3$,

Sirgent, Lorenzo How-0.16,91;

$\left(\begin{array}{l} \pm \\ 5\end{array}\right) \quad 8$ Blossum St.

Sawyer, Henj. Addison (b'43)-yass.1,65; (t); T Jeademy Ave, not In practice.

SPROTLL, JOIN (b'75)\&-Mass.5, 01 (1'01) ; 36 Vine St.; office, 50 Merrlmack St. : $1-3, \quad \tilde{i}-8: 30$.

STIi, CARROLi, WIJUER $\left(b^{\prime}, 6\right)-V$ t.2, '06; (I'08) ; 156 Main St.; 2-3, 7-8.

STONE, THOMAS NEWCOMB-Mas. I, 03; (1'04); 28 White St.; $1-3,7-8: 30$.

STIJIYAN, FLORENCE ACUTSTINE $\left(b^{\prime}, 6\right) \&-M d .4,00 ;\left(l^{\prime} 00\right) ; 4 \%$ White st.; $8-8: 30,1-3,6-8$.

SMONIS, AHICE GERTRLDE (b' $(00) \pm$ Mass.7,92; (1'99); 175 Main Si.; $8: 30-$ (9) $: 30,1-3,7-9$

TOREY, GLO. LORING, JR.

Crull. Alfred (hase (b'64)-Md.1,09 (l’i0) ; 48 White St. : $2-3: 30,7-8: 30$.

Tuttie, liarl land N.II.1,'8s; (o); 3 Newell sit.; office, 91 Merrimack sit.

Warren, Wm. Jarvin- $\rightarrow$; (b); 114 . Merrimack St.

WHTTEY, GEORGF BURGES (b'8I) Me.1,08; (1'09) ; 252 Washingloul st. : 2-4, $7-9$.

WHITEX, GFO. HDWIX (b'59)-X.11.1,88; (b) : 154 IIain St.; until $y, 12: 30-3,6: 30-$

\section{HAYDENVILLE, 1,245, HAMPSHIRE}

WIFELEl?, CIINRLS HOLMES (b'79)It. 2,07 ; (1'08).

HINGHAM, 4,965, PLYMOUTH

WAY, (IINRLES ORRIX (b'80)\&-MInss.l,

ORI, CHAS. ALONZO (b'51)-N.II.1,'is; MORSE, ALMON GARDNER. (See Boston.)

PETERSON, JOIN ADNA (b'70)\&-Vt.2, 96 : $\left(1^{\prime} 00\right)$.

Spalding, saml. Hopkins (b'56) H-Mass. 5 , S4: (⿱亠䒑)

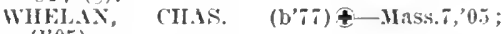
Wilde, Salmon Perry (b’si)-Mass.5,'10; (1'10).

\section{HINSDALE, I, | 16 , BERKSHIRE}

Frissell, Seraph (b'40)-Mich.1,75; (b) ; until $9,1: 30-3$

Maxwell, Chas. James (b'85)-Md.4, 09 ; (l'09).

TLCKLR, WILLIS LEROY-111.11,93; (है)
HOLBROOK, 2.816, NORFOLK

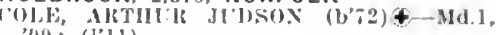
(19) (I'11).

RAWFOMI, FlRANK WILLIS (b'82) Mass.7,09); (1'0y)

MPRIAM, FIANKIAN IIENRY (b'0)-

Mass.1,99; (1'y8); (Soull Brniutree).

HOLDEN, 2,147, WORCESTER

('arr, Frank Floteher-Mass.1, $43 ;$; (o)

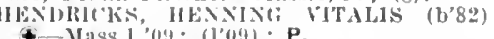

Sanborn, Nathan II, (b'sb) X.II.1,80; (ह) S'TIKX'Y, ("IFFOKI) WELSTER (b'55)-

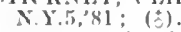

WASHB।

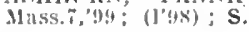

\section{HOLLISTON, 2,7II, MIDDLESEX}

Garcner, bilwin Hisher-Mass.1,75; Col., lis.d., relled

HAVILANU, NATHAXIEL 'LAKK HACON

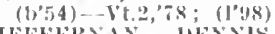

ISFFlis.ix, wisise w.M. (b'85) Massi, "10; (1'10).

Newhalt, Alden Russell-N.H.],02; (l’03).

I'ope, Irvine ('lurendon (b'55)-Pa.2,'88; (ङ)

HOLYOKE, 57,730, HAMPDEN

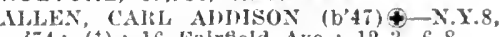
;4; $(\$) ; 16$ Falrfield Ave.; 12-3, 6-8. MLKN, FRE IIAKOLD 4 - Mass.1, 07; (l'07); Inulght st.

BAlG, E1W, I'ARSONS, JR. (b'83)llass.1,'11; (1'11) ; 243 Linden St.; ofnce, 243 Maple st. ; $9-10,2-3,7-8$.

Peaupre, Holor 1. (b'86)-Que.4,'12; (1'13); 340 .liln st. $8-9,2-4,7-9$.

BIUEL()W, JAMES B. (b'86)-Mass.7,'10; (1'13) ; 127 Chestuut st. ; 2-3, 7-8:30.

IMISE, IESEE LEONTI (b'70)\&-N.Y.i,'96; $(196)$; J06 l'leasant st.; oftce, 231 IHgh St. ; $y: 30-10,2-4$. $7-8: 30$.

Bouvier, ('lats. Wm. (1'86)-Vt.2,09; (l'11).

BRAII, WM. FRANCIS (b'85)\&-Mass. 09: (1.09); 348 Dwlght St.; offec, 290 IIligh St.

Brindamour, Jos. Edmond (b'67)-Que.3,'93; (I'98); 79 Higlı St.

CAlRoLl, IOIIN Jos. (b'78)€-Md.1,05; (1'05): 185 Chestnut St. : 2-3:30, i-8:30. CAVANAUGH, THOS. EUW, (b*75) $\mathbf{4}$ 1.C.2,'00; $(1,00) ; 239$ Maple St.; 2-3:30, $7=8: ? 0$.

CEICE, FRANK FREDK. (b'67)Ð-Pa.1, "93: (支) ; 264 Maple St.; 2-3:30, 7-8:30. CELCF, ILAX HENRIETTE (b'70)-1'a. '92:; (c); 264 Maple St.; 2-3:30, 7-8:30; G.

Chajut, Henry Ernest (b'69)-Que.3,'94; (I'99) ; 132 Beech St.; oftice, 77 Cabot St. ;

('herrette, Wilfrid Henry (b'78)-Que.3,03; (l'03); 57 Centre st.; 8-9, 2-4, $7-8$.

CLARK, \&EO, HENRY (b'68)-N.Y.8,91; (5) : 233 Elin st.

Cl,ARKE, LO1'IS HEXRY (b'63)-X.Y.1,

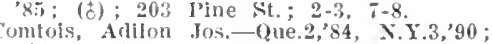
$\left(\begin{array}{c}+ \\ )\end{array} ; 25\right.$ Essex st. offle, 256 Main St.

COX, STANLEY ('TILEX (1,83)-Mich.], 10; (1'I0); 242 Maple st.; 11-12, 2-4,

OAVIS, FLLA MIXFIELD\&-l'a. T,'82; (c) ; 188 Chestnut St.; 2-4, 7-8; G.

De la Neuville, Josephine Mitivier $\rightarrow$; (1'95); i Spring st.

DIKKOX, RIIHARD ENSIGN (b'67)

I'a.2,95; (1'95) ; 105 I'leasant St.; offlce,

598 Iwight St. ; $9-10,2-3,7-8$.

Dillon, John Noysius.

(See Springfield.)

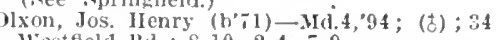
Westfield lid.; $8-10,2-4,7-9$.

Donner, John Nibert (b'56) E - Me.3,'86 ; (l'95): 498 Hirh St. : 8-10, 1-3, 7-9.

DONOCHEE, DANL. FRANCIS $\left(b^{\prime} 56\right) \leftarrow$ office, 201 Haple st. ; $9-10,2-4,7-8$.

FIRR, IRVIN HARRIS $(k, 82) \uparrow-$ N.H.1, 06 (l'06); 107 Jincoln St.; offlce, 189 Chestnut St. ; $2-3: 30,7-8$

Forster, John F. C. (b'79) - Que.1,02; $\left(1^{\prime} 05\right) ; 277$ Suffolk st.; office, Phoenlx Bldg; ; $1-3, \sigma-8 ; \mathbf{S} . \star$

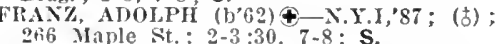

GABLER. GEO. TEWIS (b'69)

(1'02); 149 Chestnut St.; 1-3, 7-8; $\mathrm{S}$. 


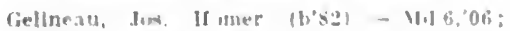

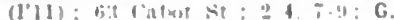

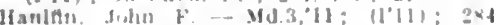

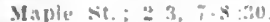

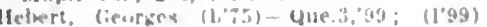
4: Eily $>1$.

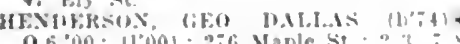
0.6.00: 11"001: :-76 Maple st. : 2 3. :

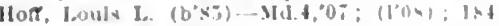
rhemturut sit.

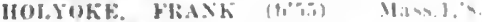

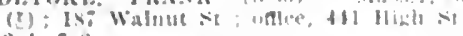

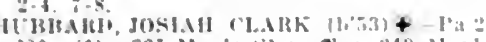
80 : (3): 321 Maple vi, oftce, "2t? Maple s. : $2-3,7-8$

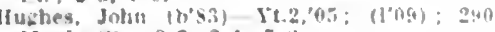
IIagle si.: 8-9, 2-4, - -

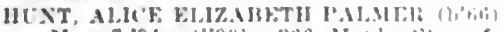
-Mass. "9f: (192) : 366 Magle st : w

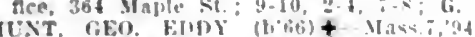
(i): 366 Maple st. unlee, 364 Malon st (2) : 366 - $:-8$

IIRLFY PATIRK FITHSE (h"6) -

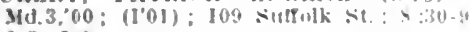
2-3, $i-9$.

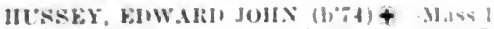

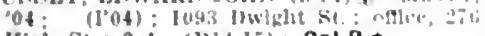
U1gh St.: 2.4; (13]4,I5): ODLR.

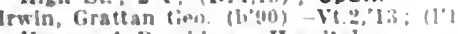

llouse of J"rovldence Ilmapltal.

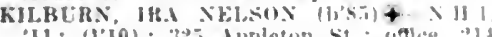

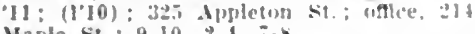
Maple st, ; $9-10.2,1$,

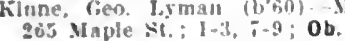

208 Maple st. ; 1-3, $7-9 ; 0$ b.

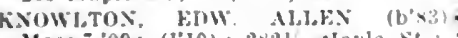

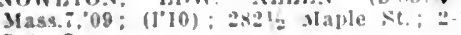
i-8; $S$.

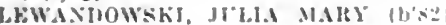
Pa.7,11; (1'11); 9 \% High St. : $2.3: 30$ i-8: $\mathrm{G}$.

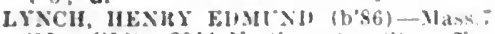
11: (1'12); 204t Northampton st.; oflece. 240 staple st.

MAHONEI, STEPIL INUHEW (b'G3) Mass. 1,$89 ; \quad(8)$ : 628 llwight st.

Marin, Jos. baul Aster (b'6i)-ont $1, x y$ (s): 339 Maln st.

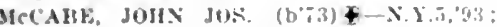
(8) : Isi (besinut st

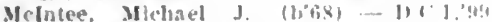
(1.01); not lis practlce: -1 finex st:

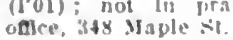

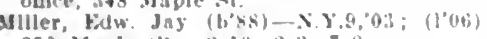
250 Maple $x t . ; x-10,2-3, ;-8$.

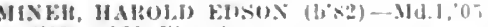
(1005) : 170 kilu st.

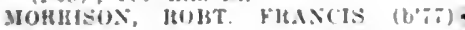
Yd.t,01: (1'01); 111 l'leasant st. ; oflece 32. Main St.

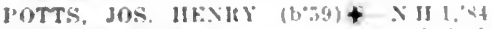

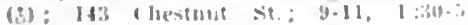
(I) : ODA.

Puers, Wn. Jin $(1,79)$ Id 4,$02 ;(110)$

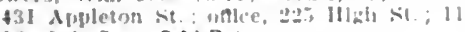
12. $2-4, ;-5:$ OALR.

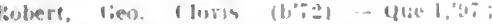
(1"thi): levelus is

Itimenblonm, (arl Webber (b'bl)-9las.:

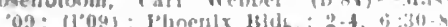

Iloubliard, Wilfrla be que" a, "vit; tout

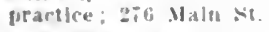

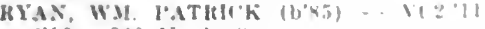
(I'12): 2lio Mapie St

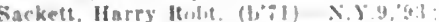
207 Waluut St. inlece ase Maple sit

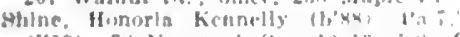

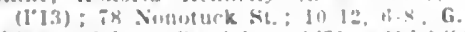

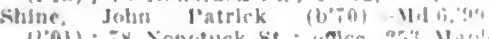

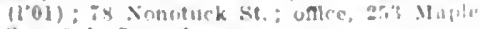
Ss. : 2-4, i-s: Anes.

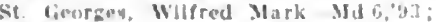
gio Maln sit

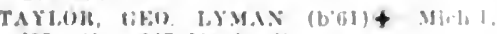
"85: (2) ; 2t7 Maple sit

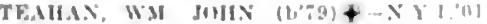

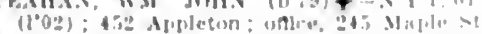

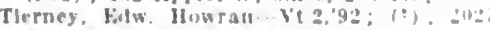
Nirthamplum onte. 219 Jileh st

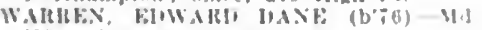
02: (1'03); Matre st.

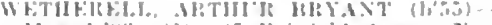

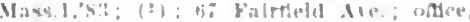

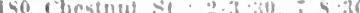

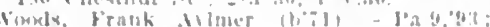

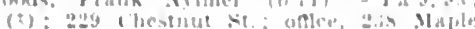

HOPEDALE, 2,188, WORCESTEH

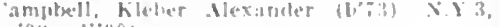

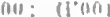

HOFKINTON, 2.452, MIODLESEX

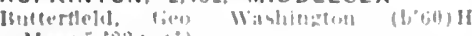

Mass, $7,83:(1)$

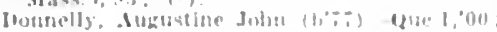
lloni.

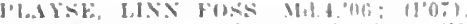

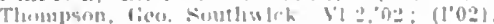

HOUSATONIC, 2,331, BERKSHIRE

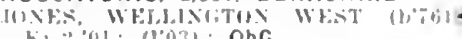

k) $\left.\ddot{0}^{\prime}(1):\left(\mathbb{1}^{\prime}\right) 3\right)$ : ObG

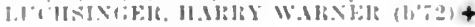

Y..., at: 1 (1).

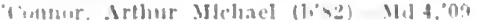
$(104)$

HUBBARDSTON. 1.073, WORCESTER

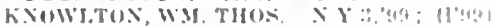

HUDSON, 6,743, MIDDLESEX

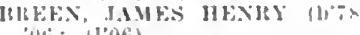

'illi: (1'06).

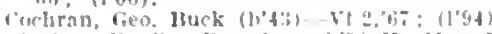

lilazler, Fredk. P'rentlss (hotoll Massin. "s.i: 121.

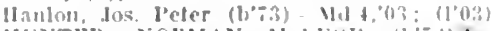

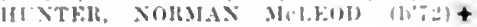

(1) 1 01 : (1'01).

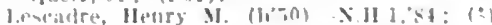

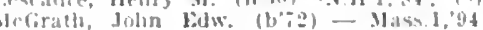
$(\because)$.

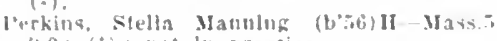
so: (s): not in practio

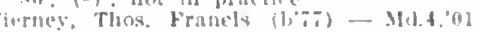
(l'vi)

HULL. 2,103, PLYMOUTH

Alurcla. Walter Horatto.

(nice Alterton.)

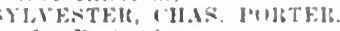

Isce Liostan)

HUNTINGTON, 1,473, HAMPSHIRE

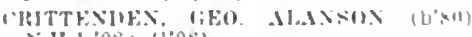

X.11.1,os; $(1,0,8)$

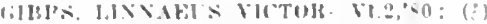

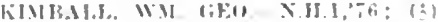

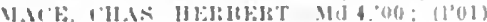

HYANNIS, I,350, BARNSTABLE

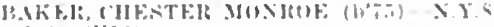

(at): $\left(l^{\prime} 9 t^{\circ}\right)$

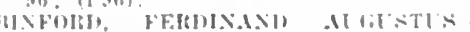

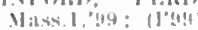

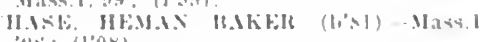
"116: (1'0x)

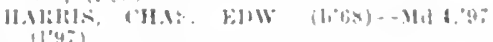

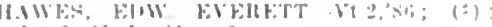

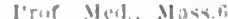

HYDE PARK. 15.507, NGRFOLK

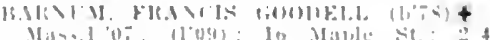
$\because$ ins.

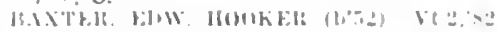

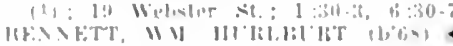

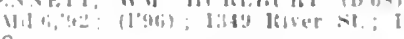
S.

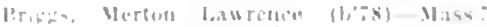

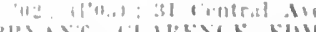

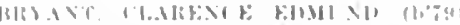

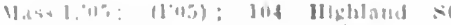

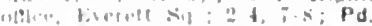

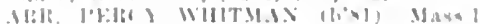

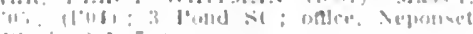

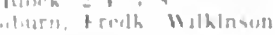

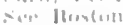

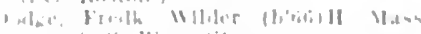

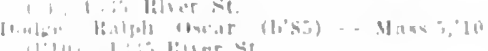

r.l.1.1s, H.III htilll

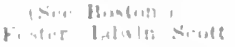

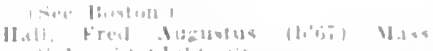

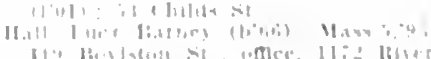

fl.t:Inon. liand bilw

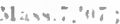

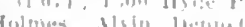

IIsule ils

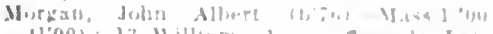

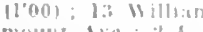
mont dre.;

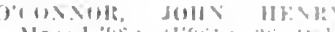

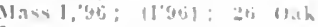

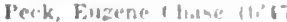

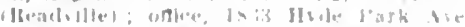

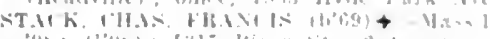

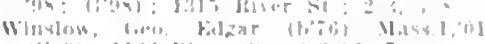

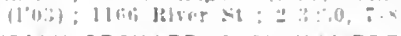

INDIAN ORCHARD, 6,153, HAMPDEN

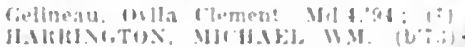

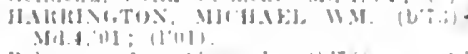

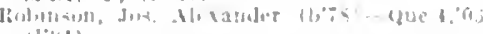
(1)

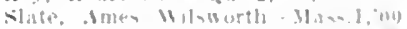

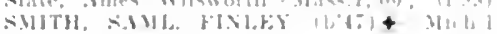

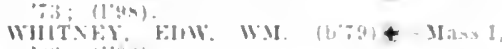

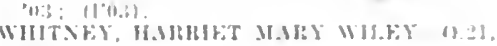
$9 \mathrm{~g}^{\circ}$; (1'01),

\section{IPSWICH, 5,777, ESSEX}

Imes, has bulw pa 9 'xi

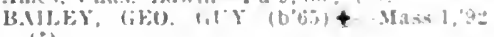
(i)

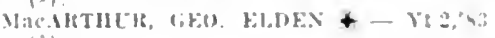

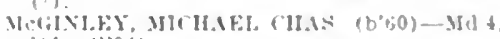
(1): 1304$)$

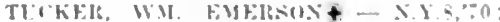
(a)

KINGSTON, 2,445, PLYMOUTH

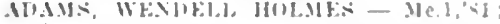

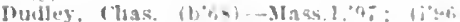

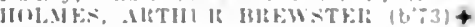

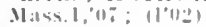

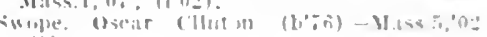
$\left(I^{\circ}(0) \stackrel{B}{-2}\right)$

LAKEVILLE, I,I\$1, PLYMOUTH

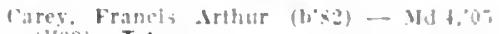
(l'(1)! : T.*

Bliden. Felson W., Jr. (bst)-Mdi, in: (lili)

Wan. llenry Sturet X.1.1, I:

LANCASTER, 2. 4 \%, WORCESTER

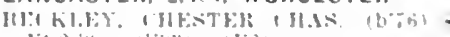

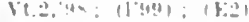

LANESBORO, 9\$7. BERKSHIRE

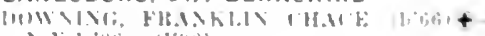

I.Y.1,

LAWRENCE, 85.892. ESSEX

WHUTT, STFIJHY WFIIUH.

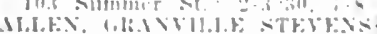

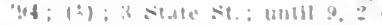

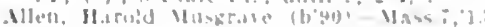

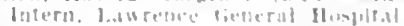

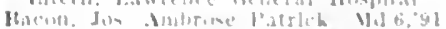

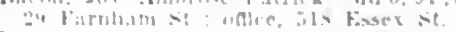

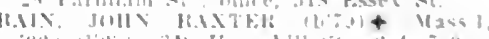

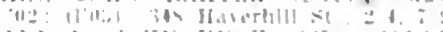

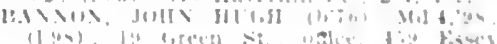

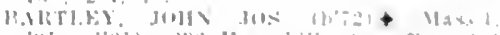

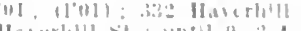

19.

HE.T.t.

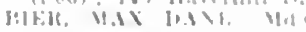

1imenred is $>10,=1$

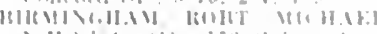

II 1, a1 1:), 1;0 ETion si

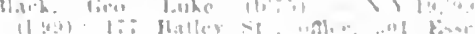

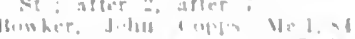

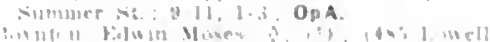

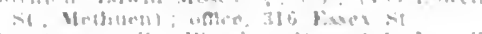

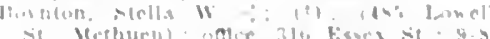

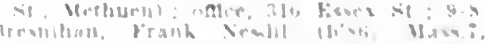

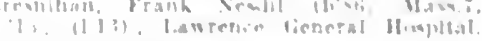


BUIR(IES, ('HAS. JAMHS (1,64) \&-Mass.7, "98: (1'ys); 37 Whitman st; ((i1): $\mathbf{R}$ Il:Ss. I,01; (l'01); L.Surk., M.K.(

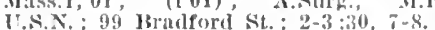

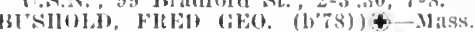
, (1’04): 204 lawrence st. $2-4,7-$

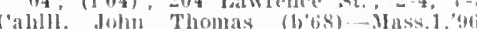
(1'95) : 341 Ilaverhlll st.; $2-4,7-9$

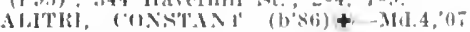

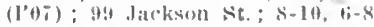

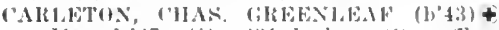

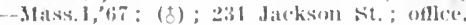

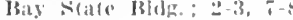

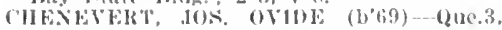

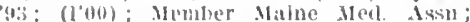
al Brillforil st.; $2-4,7-8$

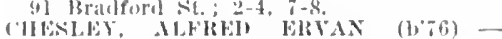
X.Y.14,04; (I014); 26 Platt si.; ollee, 181 Essex St.: $8-4,2-4,7-8 ; 0$.

coly, Telar White (b'ss)-Ia.1,82; (l'06i); 200) Antovere sit

CONLON, FRANK MOSEIL' (b'81) + Mass. 1, 04 ; $\left(l^{\prime} 06\right)$; 4 s.2 lowell st, ; olltee, 301 Exsex st. : $10-12,2-5,7-8$

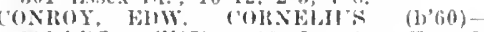
Ml.4, (17\%); (Andover); offece, 29 Fiser sit.

Crawford, ('has, IIenry-N.Y.10,82 (む) : 42 Shattuck st.: offlee, $18 \mathrm{~s}$. IBroadway; unth $9,12-3 . ;-4$

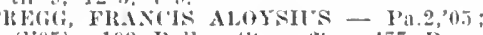
(lo5); 193 Balley At.; oftlce, 477 Essex Sit. ; $2-4,7-9$.

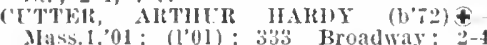
i-s.
-

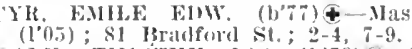

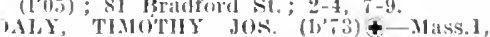
,97; (196); 62 Bralford at.; $2-3,7-8$;

beacy, fohn .los. (b's9)-Matss.7,13; (1'13); 51 Fern sit

IEARIBORN, HEN1G FOI,I.IXSIBY (b'81) 4-(que.1,07; (1.0s); 193 Garden St.;

Govitn, Tlmothy Stephen - Md.6,02; $\left(l^{\prime} 02\right) ; 78$ salen si.

DORGAN, JOA. ALOYSII'S - Mass.l, 98 ; (1'98); 12 Lenox st.; ofthe, 477 Lissex

St.; 10-12, 2-4, $\overline{-}-9$.
DOHION, KINTON (b'75) - Que.3,02; $\left(l^{\circ} 07\right) ; 129$ concord st. ; 1-4, 6-9.

ow, GEO. WM. (h'52)-Mass.1,'s1; (t); 80 L. Haverlill st. : $1-3,7-9$

Eidam, Carl Hermanm-Miss.6, 97 ; $\left(l^{\prime} 9 \pi\right)$ 334 'rospeet St. ; $1-3,7-8$.

Farley, Wm. Chas. (b'6y) H-Pa.9,94; (t) ; 9 F. Haverhlll st. ; $2-4, i-8$.

Forster, ROBT. WM. (b; 00 ; $\left(1^{\prime} 00\right) ; 279$ Broadway; 1-3, $\vec{\imath}-9$.

Fraser, Agnes-0; (1'04); 5 Albion St.; 2 - 4 .

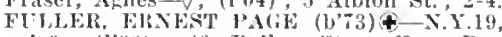
"19; (lo9); 66 Balley St.; offlce, Bay State Bldg.; 2-4.; (BI4.15);OpA.*

;RAN'T, WM. VIC'TOR+-Mass.5, 02 (l’02); 188 L. Haverhill St.: offlce 253 Essex St. ; 2-4, $7-9$.

IANCOCK, ALBERT WM. (b'7)£-Mass.1, 04; (l'06); 332 Broadway; until 9, 2-4, IIilton. John Joseph II. (b'86)-JId.4,12 : (I'13) ; 18 Jorton St

HO(AN, JOS AMIBROSE (b'72)-Mass 1 $97 ;(197) ; 54$ Bradford st.; oftce, 536 Essex St. : 2-4 $7-0$

HOWARI. IOS. FR.INCIS 4 MIass.1,99; $(1,99) ; 6$ Aron St.

HOWE, OCTAYH' THORNDIKE (b'55)Mass. 1,7:; (5); not in practice; 155 Haverhill St.

HUGHES, PATRICK JAMES $(1,79)-\mathrm{X}, \mathrm{Y} .19$ 02 ; (1'02); 21 Brookfield St.; office, 161 s. Broadway; 2-4. $;-9$.

Janson-1,aPalme, Rodolphe Gaspard-Quc.3. S2; (d); 475 IItrerhill St.: ottice, 17 Thandler st.

(5); 296 Broalway ; 2-4. 7-9

Kaplovitch, Henry (b's9)-Mass.7,'11; (1'13) 92 Bennington st.

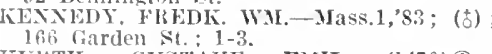

FT RTI, GLSTYE EMIL (b'70)\$-

Awiok EDW FRAVCIS (b'-

$05 ;(105) ; 04$ Bemington st. : $2-4,7-9$

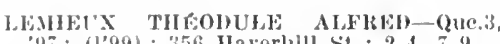
197: (1999); :356 Harerlil1 sit.; $2-4,7-9$. level, los, (b'90) - Mass.7,13; (1'13) lawrence (ieneral Ilospltal.

MINAHAN, HEHBETT WELINGTON (1)'ts) Mass.1:94; (む); 266 Andover st. oftce, $104 \times$. Broadway $; 2-: 3: 30,7-8: 30$

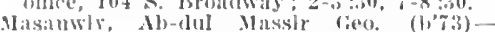
syr.1.41: (l'06); 5.3 Cross St.; $2-4$.

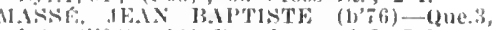
(12: : (1'02): 2tit Broadway : 1-3, $7-9$. MCMLISTER, FREDK. IMANFOHTI $\left(b^{\prime} \div 2\right)$ Mass.1,9s; (1'y9); 249 Harerhlll s't.; $8-4,7-3$

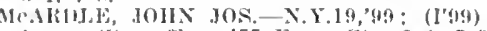
l.ofan st. ; ofllee, 47 Essex st. : 2-4, $7-9$.

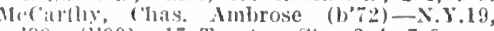
99: (j99) : 17 Trenton St.; $2-4,7-9$.

H'ianran, (ico. Daul. (b'49)-N.Y.13,75, X.Y.5, ; : (1,49); 238 llaverlill St. oflere, 362 Essex sit.

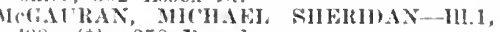

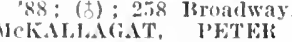

rekAIAACAT, P'WTH IEO-N.Y.1,06 (l'0s); 90 Sillem st.; ofllce, 301 lissex St. : !-10, 1-3, 6-8; (also Forth Andorer) (t)

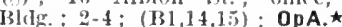

IOECKEL CARL RI('HiRD (b'82)-N. Y o7 (l'09): 143 l3roadway $9-11,2-4,4-9$ Intholland, Bertard Jos.-Md.4, 06 ; (1'06) 10 Tremont St. ; $8-10,1-3,7-9$.

MIRPIIY, THOYAS W.IS (b'70)-Hass. 04; (l’04); 246 Broadway; offlee, 248 Broadway: $2-4,7-9$.

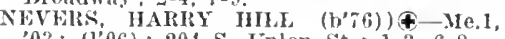

03; (1'06); 204 S. Ln!on St.; 1-3, 6-8.

Oeser, Paul Richard-II-Mass.5,'04; (1'06)

245, Jacksou St. ; $2-4,7-9$

0'Reilly, Francls Augustine (b'87)-Mass. 7

'13: ( ) ; 85 White sit.

SILLIVAN, JOHN IOS. (b'71)-Mass. 1

'96; (1'96); 340 Haverhill St. : 2-4, 6-9.

Petit, Alphonse IIubert (b'68)-M1

Tfeflerkorn, Ferdinand Carl Ludwlg- Pa.9,'S3; ( \pm$) ; 29$ Berkeley St. ; office, 27 Berkeley sit. ; 2-4, $7-8$.

REDMOND, THONAS IIENRY-Md.4, 97 $\left(l^{\prime} 97\right) ; 256$ Haverhill St.; until 9, 2-3, 6-8 REVI), VICTOR AUGUSTUS (b'69) 4 Mass 1,'97; (l'98): 23 Qulney St., office, Mass.1,97; (198); 23 Qulney St., office,

Riopelle, Alexander Jos. $-0 ;($ (b) ; 361 HaverRIORDAN, WAITER DANL. - MI.1.03; (l'03); $18 \pi^{\circ}$ Newbury St.; until 9, 2-4, $7-9$.

Robinson, Florence Nightingale-H-Mass.5, '89; (ठ) ; 265 Haverhill St. : 2-4, 7-8.

Rutter, rlara Hannal Rogers-H-Mass. 79 ; (1'98); 142 Haverhill St.; office, 228 Essex St, 2-4.

SARGENT, GEO. BANCROFT (b'70) Mass.1, 4 ; (む); 51 Jackson St.; $1: 30-3$,

SARGENT, OSCAR FRANKLYN IIBBEYMass.5,02; (1'03); not in practice; 105 Exeter' $\mathrm{St}$

SCHWARTZ, MYER-IId.1,02; (I'02) ; 265 Common st. ; until 9, 2-4, 7-9.

Sheedy, John Francis-Md.6,'98; (I’99) ; 33 Tremont St.

SIMON, ARTHUR LESLIE (b'81) \&-Mass. $千$, 05 (1,05): 24 Buswell st. ; 2-4, $;-8$.

SINCLITICO, GUISEPPE $\left(\mathrm{b}^{\prime}, 74\right) \oplus-$ Ita.10, 01: (l'04); 3 Jackson Terrace; 8-9, 1-2,

ISKIND, MELXANDER MOIIS-Máss.6, 90 (d) ; 272 Broadway ; $2-4,7-9$

towell, Fred Austin (b'67) $\mathrm{H}-\mathbf{0} .13,02$; (1005); 108 Butler St. ; 10-2.

SUHIIVAN. JOHN JOS.' (b'-7)_Mass.1, 04 ; (1’04); 343 Ames St. ; 2-4, 7-9.

SLITIVAN, MICHAEI, FRANCIS-Mass.6, 91; (す); 168 Jackson St.; offlce, 281 SIIHVAN, WM. JOS. (b'60)-N.Y.10,86; (t); 273 Haverhill St. ; office, 267 Essex St.; $9-10,2-4,7-9$.

Tobin. Joln Henry- $\diamond$; $\left(1^{\prime} 98\right) ; 557$ Haverhill st.: $2-4,7-9$.

Lniac, Thos. Vincent (b'81)-N.H.1,09; (l'10); 131 Haverliill St.; 2-4. 7-9.

WAICH, TOS. FRANCIS \&-Mass. 7,04 . (l'04); 68 E. Haterhill St. : $2-4,7-9$.

Zappala, Jos. (b'69)-Ita.17,94: (l'12) ; 42 E. Haverhill st. ; 6-9, 1-2,7-9.
LEE, 4,106, BERKSHIRE

IIASSETT, JOIN JOSEPH (b'62) Ingluam, Jưdus Thos. (b’54)-N.Y.10,'86 ; $\left(l^{\prime} 95\right)$

MARKILAM, ERIIN WALTER $\left(b^{\prime} 74\right)+$ Vt.2,"9g; (l'99)

Smlth, Henry Mareellus-Vt.2,'85; (t).

Stratton, ('has. Wm. (b'76)-X.Y,3,05

(I'05). Dorvll Miller (b'41) - Mass.2,66; (ठ) :

\section{LEICESTER, 3,237, WORCESTER}

GlfTord. Fred Hooker (b'51) - N.II.1,'75; (t)

IENEISH, ALEXANDER (b'69) 4 -Mass.

$97 ;(1 ' 96)$

\section{LENOX, 3.060, BERIKSHIRE}

arroll, Nichael I. (b'82)-D.(.2,10; (1'10)

'llit, ('has Cookeman-N.Y.3,85; (o).

JAQIES, IHENY PERCY-Mass. 1,80 ; $(t)$

not In practice.

LEOMINSTER, 17,508, WORCESTER

Abbot, Grlftitl F: (b'50)-r'a.1,79; not in practlee.

年

(ठ) ; 75 Alerriam Ave, offlee, Allen Bldg.

Blodgett, Harold Perelval (b'79)-Mass, 7 , 02: (1'0,2); 51 Pearl St. ; $1-3,7-8$.

BHIGIAY, CLARENCE SUMNER (b'67) -Tt.2,'91; (I'9J); 61 Pearl St. ; 1-2:30, $7-8$.

Chrystal, Mlchael Henry (b'68)-Md.4,01; (1'01); 83 Mlaln St. ; 1-3, 7-8:30.

CHIIER, WM. ELGENE $\left(b^{\prime}-1\right) \notin-M a s s .1$, 38 ; (1'99)

Dunham, Francis Lee (b'69)-Vt.2,'97; $\left(\mathrm{l}^{\prime} 97\right): 42$ Pearl st.

Dutra, Jos. (b'⿳9)-Irass.5,'95; (l'95); 66 Merriam Ave ; 1-8; ALR.

Frechette, ('lement (b'69)-Ont.4,90; (ô) 8 lepot St.

Grady, James Edward (b'85)-Mass.1,10. (I'io) ; 70 valn St

HALL, HARRY I'OItTER (b'53)\&-Me.1,74; $\left(1^{\prime} 98\right) ; 70$ West St. ; $1-3,7-8$.

Laserte, John Charles (b'81)-Md.4, 05; (l'05); 50 Central St. ; $1-4,7-9 ; \mathbf{S}$.

Latham, Caroline Nugusta-Mass.5,'91; (ठ) ; 25 Pearl St.

Slilsox, Wil. (h'40)-Mass.1,72; (I’96); 34 Mooreland Are.

NYE, HARRY ROYAL (b'72) - Vt.2,00 (l'00) ; 19 Lancaster St. ; $1-2: 30,6: 30-8$; S. PIERCE, APIIETON HOWE $\left(\mathrm{b}^{\prime} 70\right)$ Mass, 1,9J ; (P96); 100 West St.; $2-3,7-8$. Mass.5.'08; (l'08); 82 Main St.; 1-3, 7-8. Richardson, Dana Putnam (b'57)-Mass.1, '82; ( ${ }^{(t)} ; 43$ Lincoln St.

SHACGIINESY, Thos. Ahern $\left(h^{\prime} 74\right)^{*}-V t .2$, 05 ; (l'05) ; 62 Main St.

SHULTIS, FREDK. ('HAS. (b'T2) \$-N.H.1, $97 ;(1,97): 7$ Main St. ; $1-3,7-8$.

weoney, Bartholomew Philip (b'87)-Md.4, 11: (1'11) ; 30 Water St.

WHEELER, ALFTED AUGUSTUS $(b ; 0) \oplus$

-Mass.1.94; (む); 48 IIt. Pleasant Are.; $1: 30-3,7-8$.

LEXINGTON, 4,9|8, MIDDLESEX

BARNES. WM. LESTER (b'78) †-Mass.1, 04 ; (l'06).

Brifgs, Chas. Poor.

(See Boston.)

Kane, John Henry (b'50)-N.Y.8,85; ' l'94). PIPER, FRED SHITH (b'67) \&-Mass.5, $90 ;\left(I^{\prime} 96\right)$.

SMITHWICK, MARSENA PARKER.

TILTON, JOSIAH ODIN (b'53)-N.Y.5,'82;

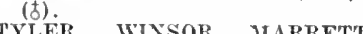

TYLER, WINSOR MARRETT (b'76)VILENTINE, HENRY CHAS.-Mich.1,92; (ठ)

Walsli, James Jos. (b'85)-Que.1,'09; (1'10).

LINCOLN, 1,175, MIDDLESEX

BROOKS, WM. ALIEN.

(See Boston.)

Wdgerly, Jonathan Frank (b'53)-N.H.1,'86; (ち); (E13) ; NP. *

Herman, Edwards Woolbridge (b'81)-

Mass. 1,$04 ;(1+)$.

LORING, FOBT. GARDNER.

(Sice Boston.) 


\section{LITTLETON, 1,229. MIDDLESEX}

Chrlstle, James liearturn (b'st)-Masi.5 OR: (I'08).

LONGMEADOW (SPRINGFIELD P.O.). 1.084. HAMPDEN

MAITIX, 11AKIL CHAS.

(siee sipringtleld.)

LOWELL, 106,294, MIDDLESEX

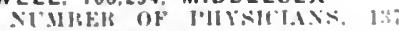

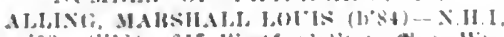
09: (1.11); 61: lipstfurl st.: oftlee, Wy man's Exchange; $2-4,7-8: 3+1$.

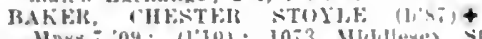

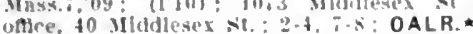

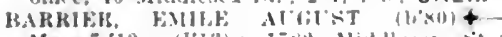

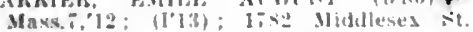
othe, Sun Hidg.

BASS, WM. (b'32)-Mass.t, 56 (

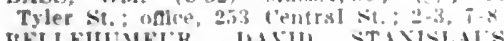

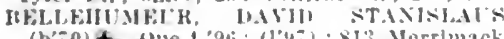

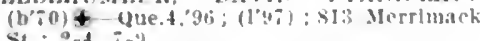

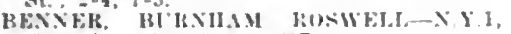

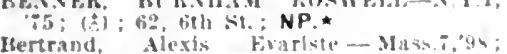

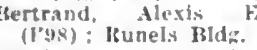

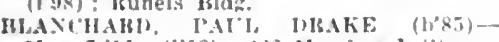
Mass.7,11; (1'13): 2:16 Merrinack st.

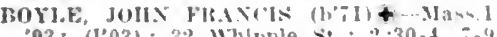
03: (1'03): 32- Whpple st.: : $230-4$. ;

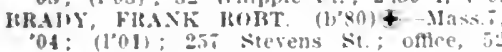

Central St. : $2-5,7-9$.

Brennan, Jos. Thos. Iamils-Mass. (") (1'99); t5 Ft. HIll Ave.

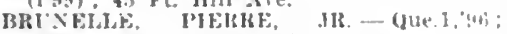
$(1 \div 46): 35$ b. Merrimack st.

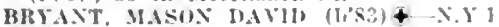
"05; (l’0.t): 31 llarvard st.; offlce. sin Bldg, ; 2.4. $\div 8$; $\mathrm{S}$.

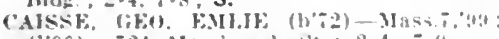
(1999): 724 Merrmack st.; 2-4, $7-4$

CAROAJ WM THIKEXCE $(1,52)+$ $3.30-4$
9.30 .1

CARROLL, TIIMAS FKIXISI-Man. 1, ", (b) : 219 Central St.

Assilv, Jalks Jos.-Mass. I, U? (1'04): sun Hldg.

Chaznon, Tancrede beodatus-0: $\left(l^{*} n\right) ; 138$ Alken St.

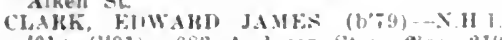

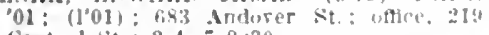
Central st: $2-4,-8: 30$.

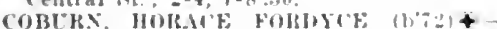

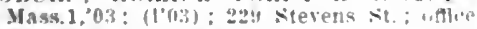

Wyman's Fixchance.

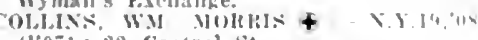

(lon): 22 ('entral st.

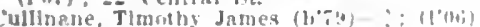

35.3 IBrluige st.

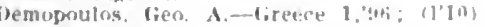

ito Merrimack st.

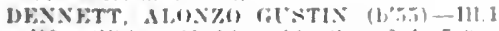

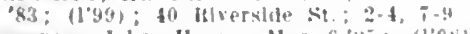

lonoran, Jolin IJenry-Masa 6, "11, (I'nk)

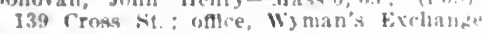
Irew, Frank Ilaynes.

(See Hoston.)

W'CINAl, ritilik.

(sice Iytin.)

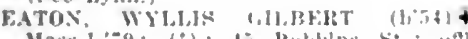

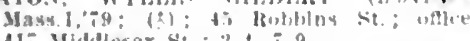
41\% Middlesex st : $:-4, i-9$

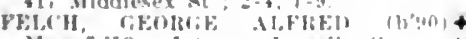
Masq liomplal.

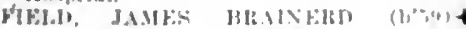

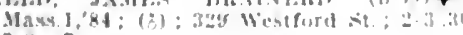
$\because \cdot 8: 5$.

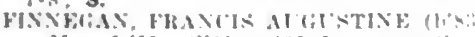

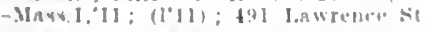

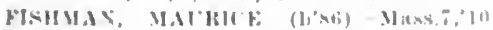

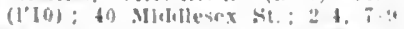

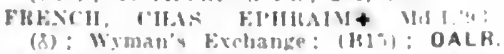

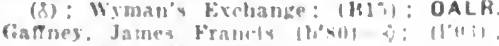
lot it st omate verrlanel si : :

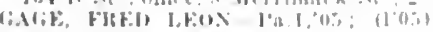

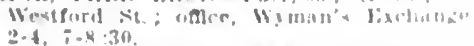

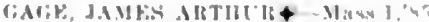

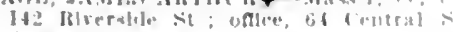

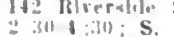

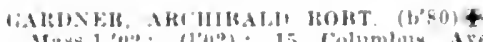

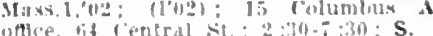

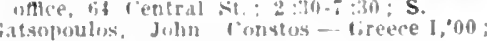
(l'0s) : Asgoclate HId:

lienerales, Demosthenes Inhn (bo9) -

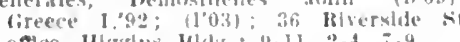

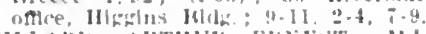

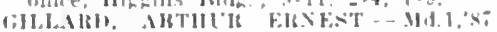

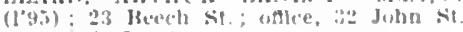
9.10, $-1 .-4.30$

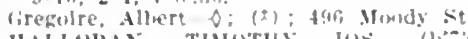

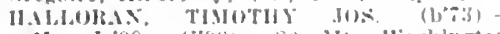
Mass.1.99; $(194)$ so Mt Washlngton

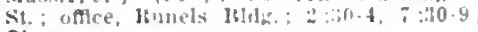
ob.

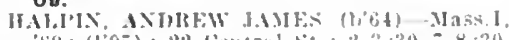

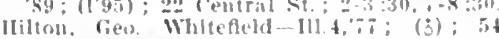
('nlumbus Ire.

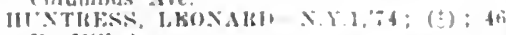
rt. IIIII die.

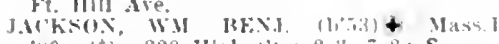

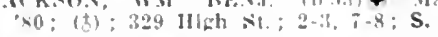

AANT\%EN, FIRAXIN TIIOS (1ist) Mant

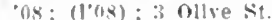

Jewelt, Howard Wakefleld (h'Th) II Pag.o:

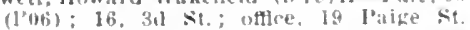
unill in, 2-4. $=-1$

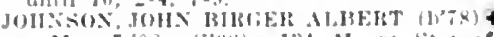

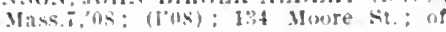
floe, is rentral si.

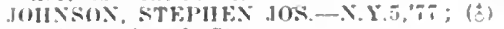
32: Merrmack Sk.

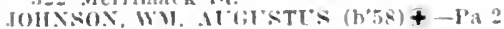
82: (2): : 44 Methuen st.; attee, 160 Mesrimack st. : $2-4,7-9$

IOXEs. HOJERT LFIROY (1,84)+-Pa

10: (1'10); 219 Central St

10NFS, WM. MAKK- $(1,6,5)+$ Mass 1,93 (a) 417 Westford st.; offlee. 145 Merrl mack st.; $2-4 . ;$

H.BWXFY WOS I'ATHICK (b'a) Miss.

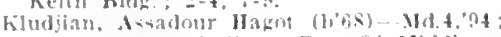

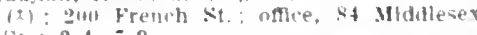
st. $: 2-4 . ;-9$.

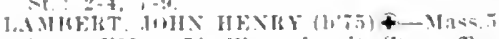

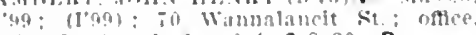

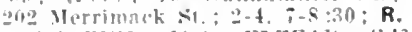

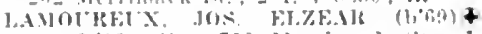
yne.3,"13: (+): in Merrimank sit.: 1

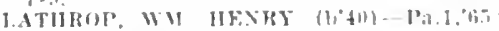
$1: 1 ; 21,1+t \leq t, ;=-3,6-8$.

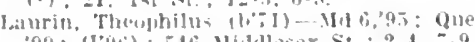

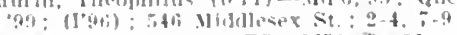

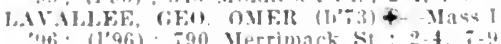

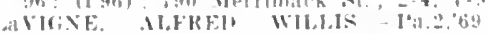
$\left(l^{*} 0,3\right): 1,3$ Merrimil $0^{\circ}$ st.

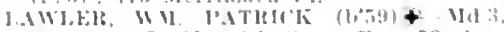

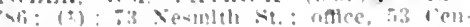
trast st. : 2-t, $7-6$

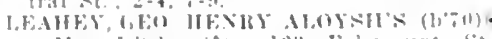

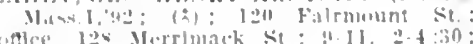
OALR*

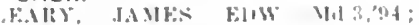
k:." Verrimack st.

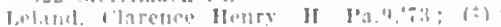

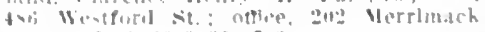
st: $1-1 n, 1 \cdot 0-3: 3 n, 7-?$

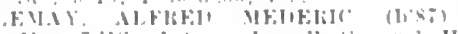

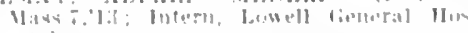
[1: 4,1$\}$

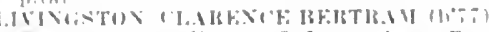

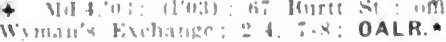

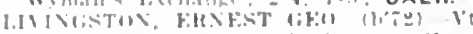

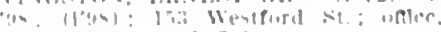

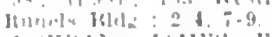

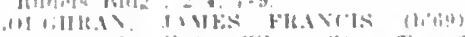

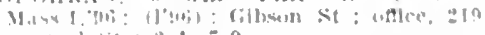
1.nाओ

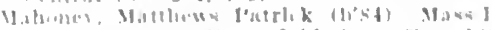

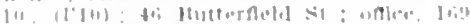
Merilume si $\mathrm{S}$

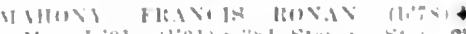

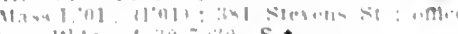

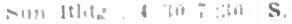

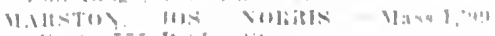

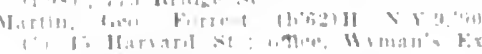

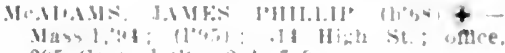

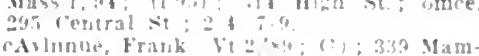
Mrdinnus,
moth Hid.

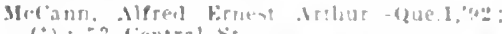
(:) : in rentral si

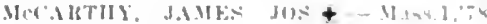
(i) iff ientral st.

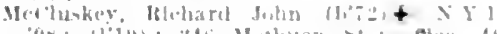

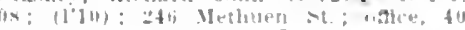

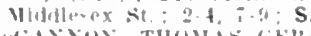

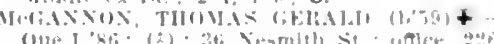
Que. I, kit: $(i) ; 30, x_{\text {enmilh }}$

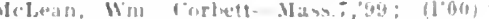
20 Tyler si. : D

Mrotagher. victiat

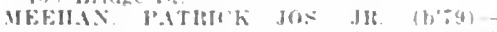

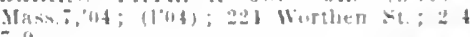
$7-9$.

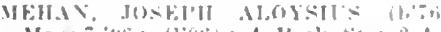

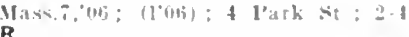

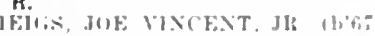

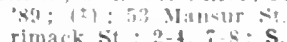

S.

MEIVA, JETIRE MINATHAX $16 \% 01+$

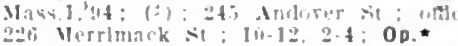

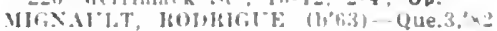

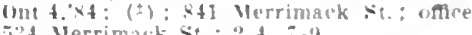

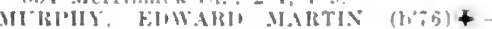

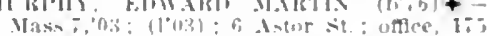

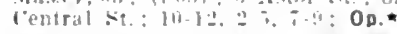

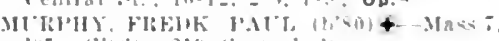
"h:5: (l'wi): 219 remeal st

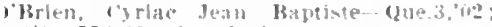
(1): 7:3 Merrimack :

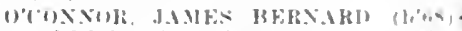

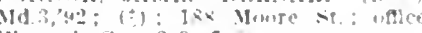

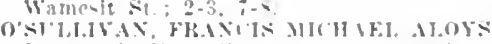

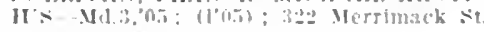

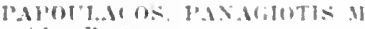

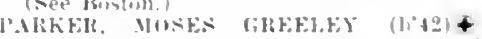

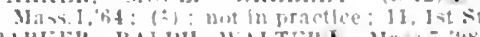

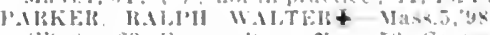

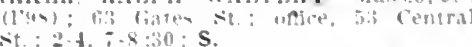
pistenialue samb vi

rimuck st. Vars. I,

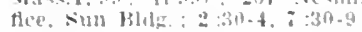

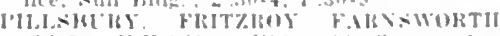

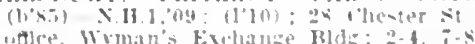

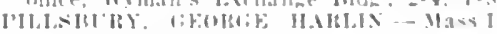

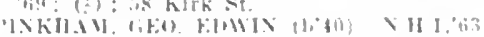

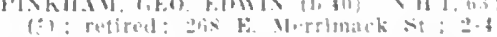

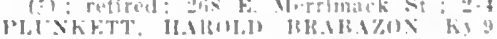

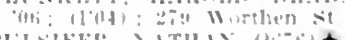

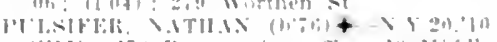

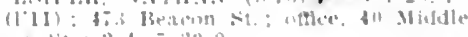

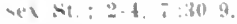

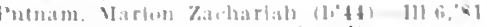

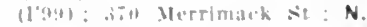

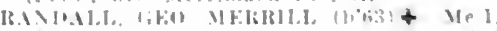

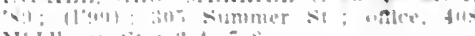

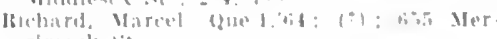
rimaits $x t$.

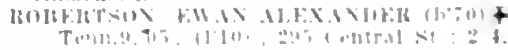

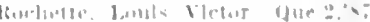

Merslmate si

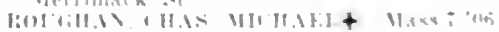

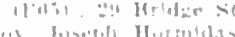

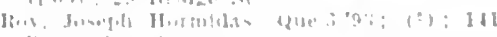
l'anfurkot si

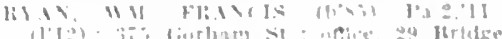
(1) :

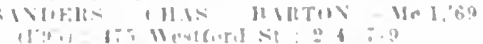

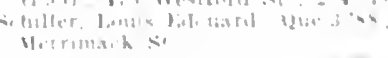

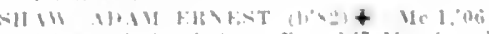

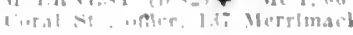


SHAW, THOMAS 1'HHLONT (1,43)Mas 1,77: (8); 110,1811 st. $; 0-10,3-5$ ss; (t); I00 llolyromi Ave, oflce, Wy s.; (8) 100 10ly romd Ave. :

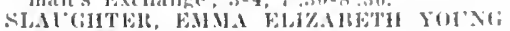

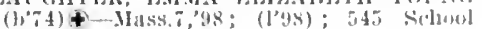
St. $; 2$

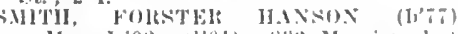

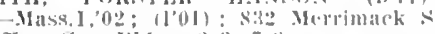
oftlee, sun like. : $2-3,7-8$.

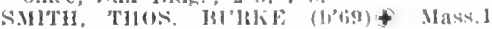

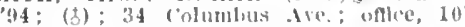

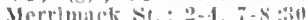

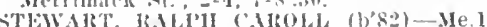

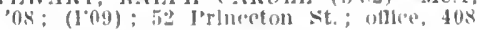

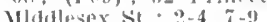

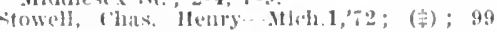
Fairmount St

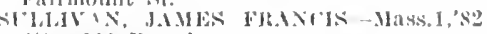

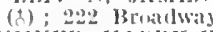

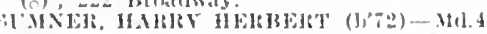

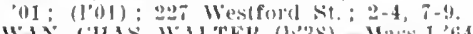

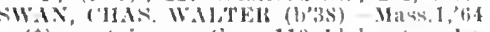

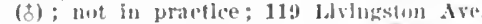

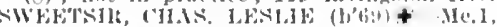
$93:$ ( $) ; 276$ Westord st. ; $7: 30-9,2-4$,

TABOR, EDW, ORIAN100 (1, 7.5$) \$-N .11,1$, , 1 ; (l'02) ; 172 Shaw St. ; offle, Is shattwo k st. ; $2-4,7-8$.

Temple, Frankl!n stuart-N.Y.3,'92; ( $) ; 97$ (entral st.

TIGHE, MICHAL AIOYSII'S (b'82)Mass. I, 0 ; : (l'0s) ; Wyman's Exehange.

Trudean, Hare Aurele-Vt.2,99; (ह); 494 Merrimick st.

Van leursen, Geo. Livesey (b'bi)H l'a.9. '96; (l'9s) ; 1039 Nllkllesex st. ; ufflee, 20 balmer st.; 2-4, $;-9 ; \mathrm{S}$

VILFs, CIALFNCE ALBETTS-Mits.1, $78 ;(3) ; 853$ Bridge St. : 2-3, 7-8.

Waller, Thos. Gilmore (b'sR)-N.H.1.86; (5); 160 Princeton st.; offlce, 40 Midllesex st. ; $10-12,2-4, \tau-9 ; G$.

WELCII, EDW. JoIr-Mass. 1,$90 ;(b)$; offla'e. 23 Rumels Bldy.

WIGGiN, WM. 1RVISG (b'79)-Qme.I, 01; (1'03); 455 Stevens st.; ofluce, Wyman's Exchange; $2-4,7-8: 30$.

WI1sON, CHAs, oscik-N.11.1,94; (\$) 624 Gorham St.

Wools, Chas. Livingston-Mass.5, 68

15 Fort llill Ire, ; $7-9,1-4,7-9$

Woolls, Winifred Morrill (b'i9)-Mass.5,08; (l'0s) : 50 John st.; offlee, 40 Middlesex St. ; $8: 30-9: 30,4-5,7: 30-8: 30$.

\section{LUDLOW, 4,948, HAMPDEN}

HOST, I'HRLEF ADELREK'T $(1,86) \oplus-V t .2$ 09 ; (1'11)

Lortle, los. Chas. Hormlsdas-Que.3,'92; (5).

Treleller, Albert Julius (b'76)-Ita.1 $;, 02$; (I'0:3); S.

LUNENBURG, 1,393, WORCESTER

Wallis, Nathanlel (b'56)-Vt.2,34; (1'01).

WOODS, CHAS. EDWIN (b'63)-N.1I.1,"90; (b).

\section{LYNN, 89,336, ESSEX}

NTMBEK OF T'11SICIANS, 14:

ABHOTT, IOWARD EDWIX - Me.I,'84; (1'95) ; 54 Park St.

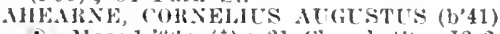

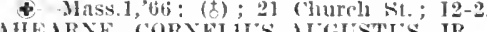
HIFARNE. CORNELIES ACGLSTLS, JR.

(siee Sialem.)

ndrews, John Henry (b'76)-Mass.1,02

1 Brond st.

Baker, Leland IIadden--II-Mass.5,'94; (ঠ) 66 Vine St.

Baker, Wm. Hewry (b'44)11-Pa.9,'80; (む) 115 hatighton st.; $11-2$

Balcom. John Alvin-H-Mass.5,95; (1'95) : 203 Lewis St.; 1-3, 7-8.

BANGS, CHAS. HOWARD.

(See Boston.)

BEIARD, JOS. ARMAND-Que.3, 90 ; (む) : 26 (ncean St. ; $2-4,7-8 ; \mathbf{G}$

BENNETT, HANLIX PERLEY-N.H.1,06 ; $\left(1{ }^{\prime} 06\right) ; 41$ lewis st. ; $1-3,7-8 ; T$.

BERG, TEKLA AMALIA JOSEFINA (b'70) - Jass. 7,$98 ;(1 ’ 98) ; 1$ Atlantic st. ; 2-3, Ihergengren, Chas. Henry- $0 ;\left(1^{\prime} 00\right) ; 150$ Timson st.

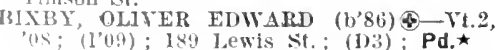

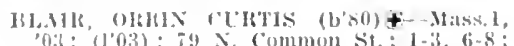
S.

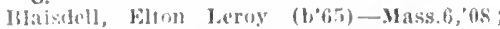

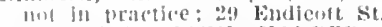

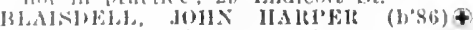

Vass.1,11; (1'11); "9. $\mathrm{x}$. Common Sit.

$4-t ; .-8 ;$ inlso 11 í Fewhing st. Iboston

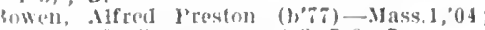

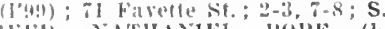

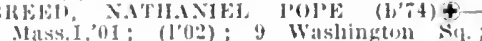
-i3, 6 - 5 : 5

Iturns, Walter l,lmu (b'-8)-Miss.1,04 (I'03) : 81 N. Common st. ; I2-3, $63-8$.

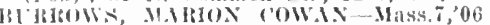

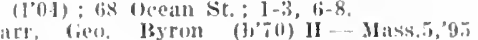

(1940) 4 l3aker st.: $3-3, \quad(j-8$

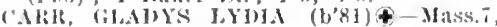

O6: (I'06i); 64 Iewis St.; Z-1; R.

('astle, lames-Mo.7, $93 ;$ (ठ); 39 silvors st.: aftice, 113 Munrue st.

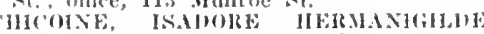
(b'64)-Ylass. I, '94; (1'95) ; 206 lewls St. ;
$1=2: 30,7-5$.

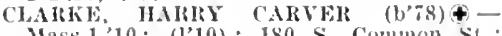
Mass. 1,$10 ;(1 ' 10) ; 180 \mathrm{~S}$.

(о)

H, CXHOL, US MELVIJUE.

(see boston.

Ogim, Thomals Franels-Mass.6,'04; (l'01) s.anrel St.

Courtemanche, Tos. Arthur (b'85) - Tenn.19 11 ; (1'12) ; 111 latighton St. ; $1-3,7-8$.

couture, Michatel IIoratius-Que.,3,93; (ठ);

95) Federal st.; 12-2, 6-8.

cushing, Eugene Bonaparte-II-1'a,9,71 (ठ) ; 8 Cliase st

aly, John Augusilne -Mass.6,05; (1.06) ; 311 Essex si

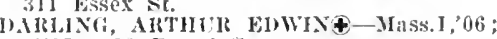
(1.07) : 12 Broad st.

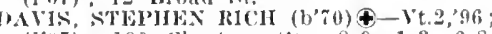
(I:9); 190 Chestnut st.; $8-9,1-3,6-8$ DFNN1SON, IRCIIIBALD SAYREO HVII - l'TER CLARKE - Yd $4^{\prime} 0^{\circ}$ (1'02); 784 Western Ive.

Dezell, Fredk. liurr-N.Y.3,96; (1'96i); 29 ? Fucild Ave. ; 1-3, 6-8.

Dolloff, Bugene Haleolm (3,67) I1-Mass.5 ollof, Eugene Haleolm (b,67) I1-Mass.5, (1) Mass.1,83; (1'95); $101 \mathrm{~S}$. Common St. $1-3,6-5$

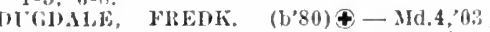

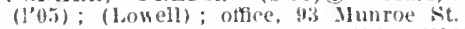
Eastman, Geo. Warren--Hass.6,05; (l'06)

Eelis, Jos. 0 . (b'76)-Mass.7, 01 ; (l'01) 445 lissex st. Eisex fic

PRASER, WM. LESLIE (b'T4)-X.Y.8,97 (1'04); 812 Summer st.

Frothingham, Chas. Benj.-X.H.1,92 ; (1'95)

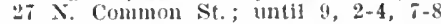

GARII'AY, ELISWORTII I'ETER (b'86)€llass. 7,Il; (1'l1); 147 Franklin St.

GOHFHEY, JOSEYH WITTER.

(See swampseot, )

RAll, THOS. FHANCIS (b'86)-Mass.1 '12; (1'12); 540 summer st.

GRANT, JAMES HENRY-N.Y.10,'83; (d) $148 \mathrm{~s}$. Common st.

GRAY, GEO. HENRY $\left(b^{\prime} 64\right) \uparrow-V t .2,88$ (t): I I Lynn Shore Drive; S.

Grow, Timothy Rose $\left(b^{\prime} 40\right) \mathrm{H}-\mathrm{Ill}, 4 ; 7$ (t); 138 Chestnut St.; $7-9,2-4,6 \cdot 7: 30$

HAGOPIAN, LEVON GEO. (b'82)†-Mass. 7 , '11; (1'11); i Lyman St.

ILARRIMAN, PERLEY (b'67) \&-Vt.2,02 (1+) : 290 summer St. ; $\mathbf{I}-3,6-8$.

IAIRIS, ARTHUR EUGENE€-Me.1,9J; (1'95) : 17 Chestnut st. ; 1-3, $7-8$.

H.APRIS, WM. DeBLOIS' (b'72)-Md.3, 99 (l'00); 96 S. Common St.; I-3, 6-8.

HARTMAN, GUSTAVE (b'Ti) \&-Pa.2,04 (104); 1 - 7 . Common St. ; $1-3,6-8$.

HASSET'T, LEONARD WATSON (b'86)Mass. 7, 10; (1'10); 586 Western Ave. HWES ALFRED TAYLOR (b'74)-rt.2,

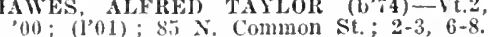

llaywood, Geo. Wm, (b'bs) I1 Mass.5.'90; (d); 11 I I arwod sil. ; I-3, $6: 30-7: 30$. Ilearn, Walter Jawrence llass. 1,$02 ;\left(10^{\prime} 02\right)$ 4) Franklim șt. ; "3.3, t-

Ileaslip, Geo. Wm. (b'83)-Mass.6,'I0 ; (1'11); 20 silhoul sit.

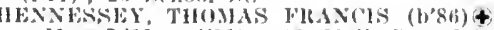
-Mass.7,11; (1’11); 2.' Mall St.; 1-3,

Hhclicock, Waller saml. 1)enne-Mass,6, 88 ; (5): 4 linad sit

OITT' CILAS. I.WWIS-N.Y.19,0;; (1'05); 114 Frankllm st. : $1-3,0-5$.

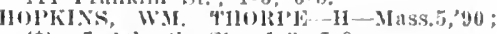
(ठ); 7 Atlatic si.; $1-3,7-9$.

Jacubsen, Nathan i. (b'82) - Ma.9,'10: (I'12); I34 summer Si.

JENKINS, CIIAS. F.-N.I1.1,81; (む); 10 lreson St.

Johnson, Fdith Charles Varney $(5,70)-$ Mass.5, 93 ; (t) ; 68 Brond sit. ; 2-4.

Johnson, Frances fiertrude Lamb (b't8) IIMass.5,93; (t); 12 Allumtle St.

OIINSON, IIAKOLL MIBHO'T'T (b'73) -

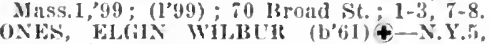
'8.; (ठ); 44 Atlantle St.; 1-5; (B14); Op

JONES, JAMES AMIBROSF-YT, ,'C6; (1'06); $173 \mathrm{~N}$. Common st.

JOSHYN, ARTHUR EVERETT (b'81)థ

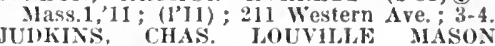
(b'83) $\oplus$-Mass.6.'09, Ky.2,10; (1'10); Mason St. ; $1-3,6-9$

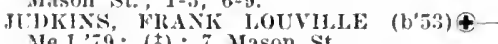
Me.1, 9 ; (t) ; 7 Mason $S t$.

KIIKI"ATIEICK, GEO. HOLLAND (b'80) $\oplus$ $6-8$

LANE, FRAXCIS AUGUSTUS (b'66) Mass.1,92; (t); 29 Jake Vlew Ave.

L.EMAIRE, WILIIAM FRANKLIN†-Vt.2, 04; (l'04); 134 Cliestinut St.

ITTI, WM. BRIMBLECOII $\left(b^{3} 59\right) \oplus$ Vt.2,84; (ち); I3 Nabant st.; $1-3: 30$ LOUGEL, FRANK TAYLOR - N.H.1, 87 (t) ; i Atlantie St.

LOIGEF, GEORGE WOODWORTH (b'59)Me.1,83; (1'10); 57 Fstes St. ; 1-3, 6-8. Mass.1,72. (1) 64 Broad St.

LOVFLL. CIIA. DIXON SMITH-N.Y.IO,

$92 ;(\delta) ; ~ 62$ Ocean St.
Lyons, Geo. Mloysius (b'85)-Mass.1,09; (1'11) ; 120 s. Common St.

Macpherson, Fredk. Wm. (b'49)-Mass.1 '71; (d); 28 Cherry' st.; 8-9, 1-3, $6: 30-7: 30$.

MANGAN, JOHN JOS. (b'5i)-Mass.6,'91, Mass. $104 ;\left(\begin{array}{l}+ \\ 0\end{array} ; 174 \mathrm{~S}\right.$. Common St.; 1-3, MANIX, EylW. T (1'99); 59 Jewis $\mathrm{St}$

Marden, Wilnot Lelghton (b'76) H-Mass.5 $98 ;\left(1{ }^{\prime} 98\right)$; 22 Iroad st. ; $1-3,7-8$.

MARSIIALJ, WM. IREGINALD' (b'83) $\uparrow-$ Md.4,08; (l'08); 26 Brond St.; 1-5 OALR. *

MARTIX, ARCHIBALD IIERRERT-Mass. 6 , 96 ; (196); 39 Cherry st.; offec, 29 Broad st. ; 1-t).

MART1X, JOHA BRAITON-Mass. ',99. (l’08) ; 25 Newliall st.

MATHES, ROY WEYTWORTH (b'83)థ N.H.1,06; (1'06); 6.5 Broad St. ; 1-3, 6-8. MCCARTY, FRANKLIN BENXETT (b'S8)Mass.1,'11; (1'11); 91 0cean St.

MeIntyre, fredk. Jos. (b'\$3) - Irass. $;, 07$; $\left(1^{\circ} 09\right) ; 63 \mathrm{~N}$. Conmon St. ; (B15)

McRobbie, Alexander (b'75)-Scot. 1,04 , b.P.F. Neot. $105 ;(109) ; 48$ Common 64 Nahant st.

Merril1, Everett Albert (b'91)-Mass.7,'13 ; Intern, Jynn Hospital.

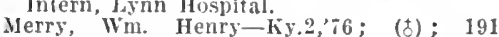
Enelid Ave.

METZGER, BITLER (b' 74$) \oplus$ Mass.1,9i; (1'95); 153 Lewis St. ; $1-3,6-8$.

MORSE, FRANK AISELBERT-Mass.1, 87 ; (む) ; II Lineoln St.

Morse, Howard Fellows-rt.2,04; (l'05): 540 Summer st.

Mullen, John Henry-Mass.1,00; $\left(1^{\prime} 00\right) ; 28$ Ireson $\mathrm{St}$.

MUNROE, HARRINGTON BENNETT (b'77) -Que.I, 03; (1'04); 875 Western Ave. 
Itusso, lienrge Ilenrs (linit) N Y i.ou; (1'99) : 104 s. Coumon st : 1.3, is.

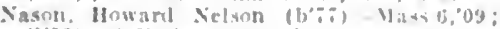

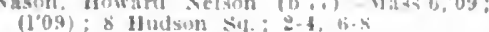
Nalluanwon, Fillas (l'sl)-Mll, (1): (l'0s); 242 Summer Sil

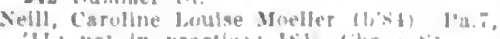

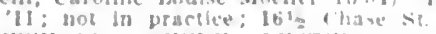

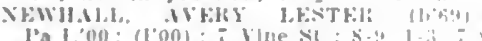

l'a.1,on; (l'00): ' Vlle Ni:

(Nevelia, Hith

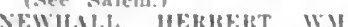

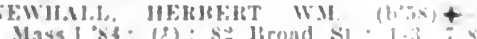

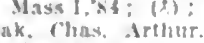

(See lievere.)

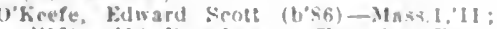

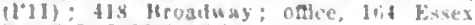
Sis. : 2-3, $7: 30-9$ : Pd.

o'keefte, James Vincent (b's3)-Mars.1, $0: 1$ (110); 231 Maple st. : $2-3,7-8$.

o'Rellly; Wm. Prancis (b)

(104): 14. Common st. (1615).

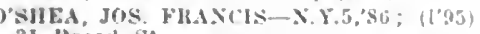
31 Hroad sit.

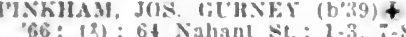

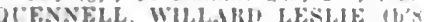

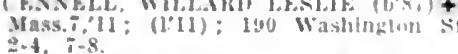

RICI, CHAS, EIIIS $\left(b^{\prime}, t\right) \mp-M a t^{\prime} 0$ ? (1'09): 36 Estes st.: 1-3, tj-s.

RICHARDSON, HFJ LUANKINA

(1) H)

Id.4:09; (1'10); 163 Chesfnut st. : 2.1. Md.

MPJEL, EMI, CARL FRASER-MASI, 92; (8) ; 23 Nahant St.: 7-9, 2-4. 6-8

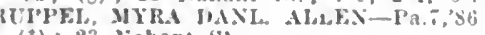
(3): 23 Nahant st

SА.NBOR., Fli[1K. R(1)XEY-X.H.1,02; $\left(I^{\circ} 03\right): 12 \mathrm{~W}$. Hallimore st.

Schron, Kiward (b'St)-Mass.6.'L2; (1'12) 152 summer st.: $1-3$. :-s; $U$.

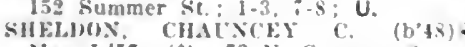

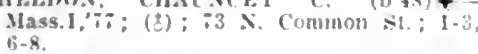

SHEIHERD, WM. FOHION $\left(\mathrm{b}^{\circ} \$\right)+$

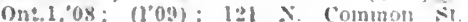
$1-4,6-8$.

Shrum, Jark (b'o9)-Ky.2.94: (I'04) (Ostenpath): $26 \pm$ Washlngton st.

SMTI, MURIOCK CAMIBEI.L $(1, \mathrm{H}$ ) + duroclate Fellow 11.8.3, ss: (3); (Jen(Ist); 10 Clty Hall sig.: office, tee IIall; 8-6.

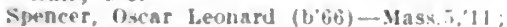
(I'11): 66 bissex st. ; until $9,1-3, i-s$.

Stitson, Clarence Augustus (li6i)-Me.1. 92: (8): 104 Joluson si. : $1-3,6-5$.

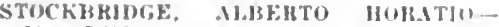
Mass. i, 05 : $(105)$ : 69 J'ark si.

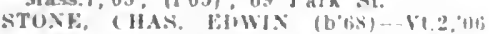

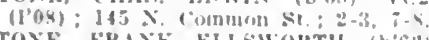

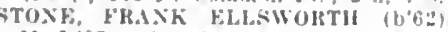
Me.1,85; (ह); : s. Common st.: 1-3,

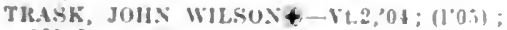
lii lewls sit.

TCCKEIR, AITHER WALIACE - Mas.: 05: (1.05): 285 Western Are

Walnshel, Verez Wm. (bos) Masw. 6,13 J.3nn Howjlal.

Waldron, liabel Inez Westwond III 15.97 (1'9:5); 6 s ranklin sit.

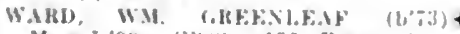

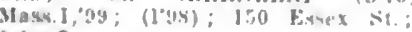
6.9; $\mathbf{S}$.

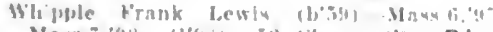

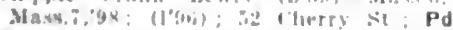

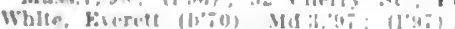
Marlanma SL: 1 -3. * :

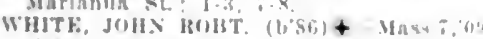

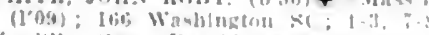

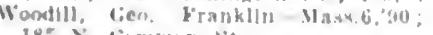

185.5 .8 .

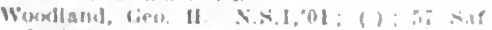
ford $\leqslant 1$

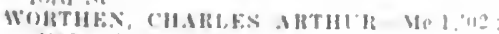
(1.02); 3: Mall सी?

LYNNFIELD, III, ESSEX

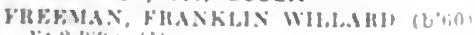
Vit:2, $89 ;(2)$
MALDEN, 44,404, MIDDLESEX

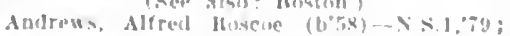
1100,0

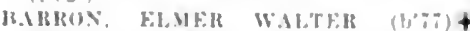

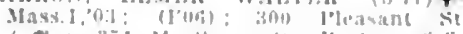

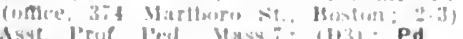

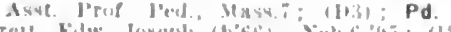

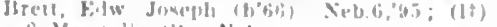
Q Magroulia si: N.*

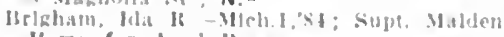

Hotne pur forel leervens.

Arown, Ralph Neally (b'sli) Mava, 1:

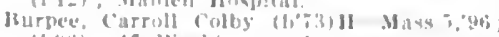

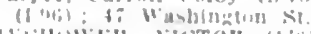

H

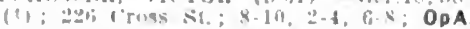

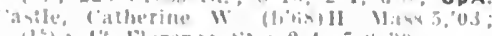
(1) : Aif Flurence st. : 2-4. :- : :30.

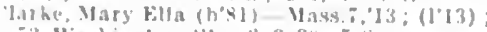

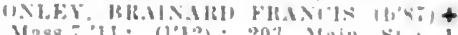
Mass.7.11; (1'12); 203 Main S1, 1.3 (1RERT, JRIREMIAH JOS

(Fee boston.)

IMINis, MURTON FiVkETT (b"76)-

Mass. 1,01; (1'02) ; 35x l'leasaut , st, : 1-3, i-s.

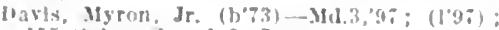
15, Silem si. ; 1-3, ;-s

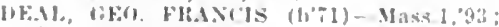
$1 \therefore$ : tig salen st.

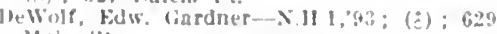
Main se.

Howris. Harry Alltum Masm. satem $51,2-4,7-5$

burrell, Henry Wm. (b'61) -Pa.2,'s9; (1'0i): (4) Plomsint st: : 2-4, i-s.

French. Kolt. Weller-Mass.5, 07 ; (100): 1 Washington st.

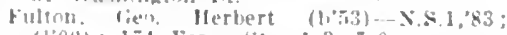

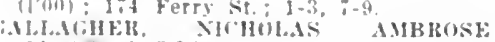

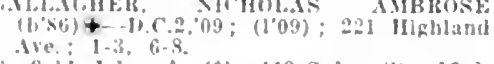

iarflelt, John $\rightarrow:(3) ; 43$ salem st. ; 12-2, $5-7$.

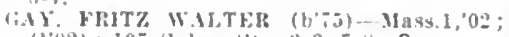
$(102): 105$ salem sit. ; $2-3,7-5 ; \mathbf{S}$.

(i)

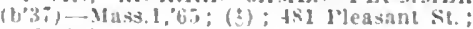
3. $13,2-4$

(irret1, Jacub livnre Hung.1,84; (3); 314 sillem si. : $8-10,2-3,7-8$.

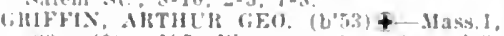

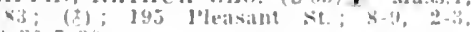
1i: :30-7:3in

H.HRTELL, WM. WISN (b'-4) -Mass.1.

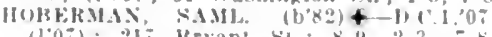
Ob.

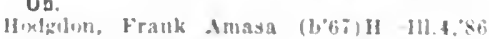
$(1+(4+i):$ s3 silem si, $2-4,7-4$.

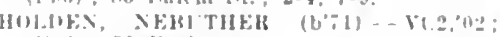
(1't2); :1 Farl xt.

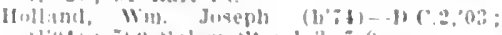
11"ut); ist sillem st : $1-3,7-\{$

Horr. Mhert Winslow.

Inee lisklon.l

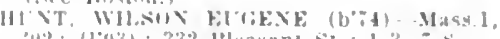

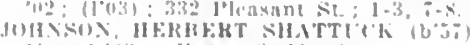

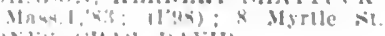

lives ins histid.

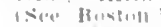

KIMTEIt lil, W.M.TEL, WAHBF,

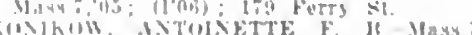

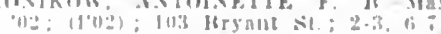

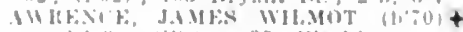

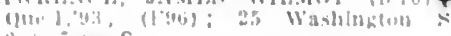

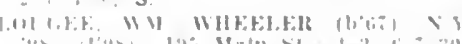

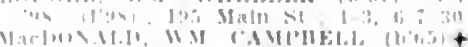

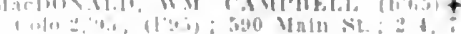

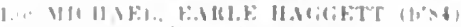

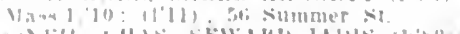

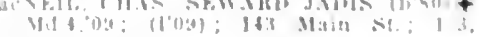
तil

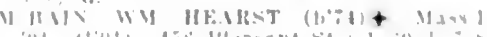

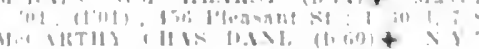

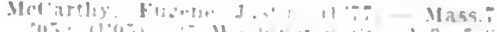

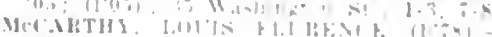

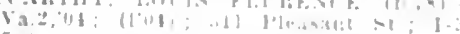

Mulearn. Ilist. W:n tos Falukner

-11 lorrant di

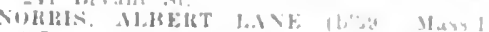

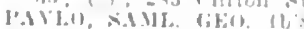

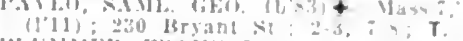

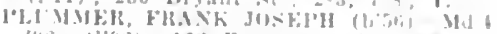

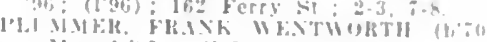

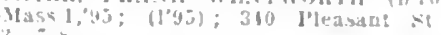

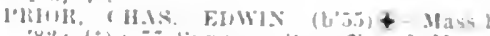

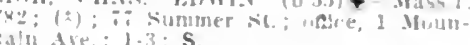
baln Are : 1-3: S

(Nee Hoston

Ratinuvitz. Jernard (b"80) - Slass. $6: 13$ : (1013): 307 ('ress sit.

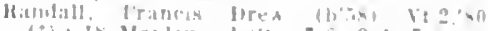

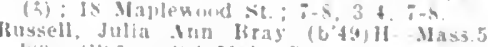

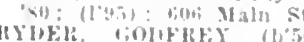

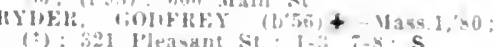

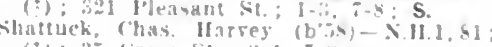

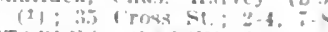

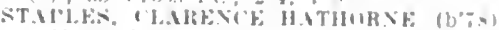
Mass 1,"04; (1'04); 339 I'leasant st. :

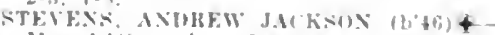

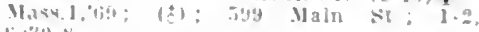

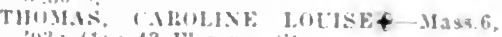

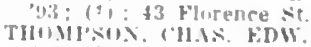

(Nee Invilion.)

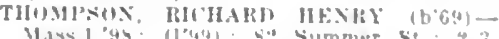

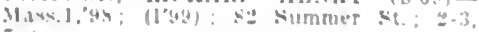
TILTON, FIRLF: E.LW.

isee Ibuston.

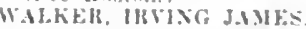

ispe Huslon!

Whithe. Walter Hooth (6+111--1'u 14.7?:

(2); -t Flotence Si.; z-4, - -S.

CHAUG, $1, \$ 65$. WOR

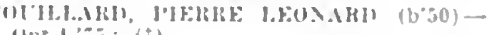
(1)t.4, $5:$; (\$).

MANCHESTER, 2.673. ESSEX

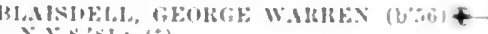

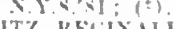

(ace Hoston.)

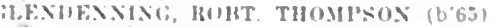
+ (8ue.1,9:8: $(\because 1$

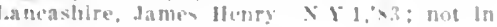
piractler.

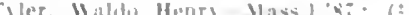

MANSFIELD, 5,183, BRISTOL

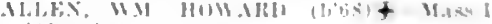

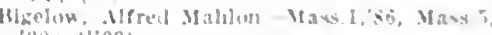
(10): (I'00)

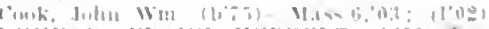

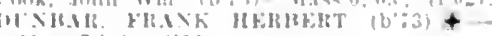

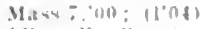

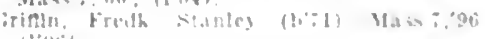
(I'mi).

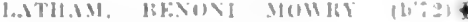

VIans, $100,(1: 040)$

sulumur sarah dimata

(seve limblas

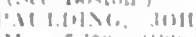

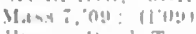

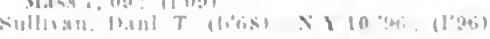

MAPLEWOOD (SOUTH DEERFIELD P.O.)

- FPANKLIN

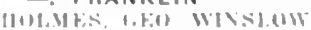

(Sive thistorn?

MARBLEHEAD. 7.338. ESSEX

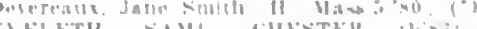

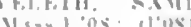

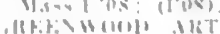

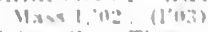

Ilain. III TIm

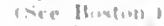

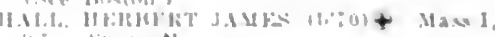




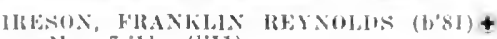
Nass.7,11; (l'11).

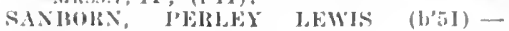
N.V.10,7\%; (5)

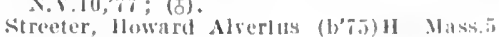
'9s: (1)

Trute, Richaril smith.

(Nice lboston,)

MARION. 1,460, PLYMOUTH

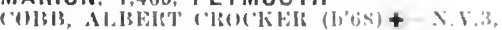

' $y=$ : ( 1 ); ALR.

Hamly, isenj. Jumes Mass. I, TI I (b).

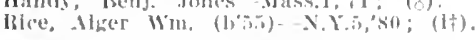

MARLBORO, 14,579, MIDDLESEX

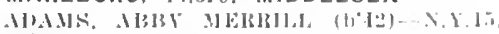
st: i $1: 25$ Nowton $\leqslant 1$.

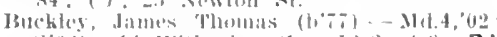

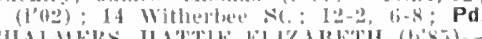

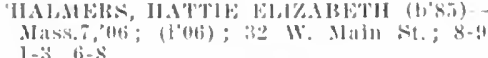

cutler ('bis. Lewls, lo r. r.10,90; (t)

julamel, olisler fitbert Qque.3, $4 ;(3) ; 0$ (ilboul st, - 1-2, 7-8; OALR.

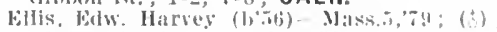
10: Neenule st. : $1-2$. $6: 30-8$

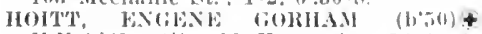
S.V.t.'sI; (5); 12 Howe st.; 1:-2. ti-s $\hat{\mathrm{S}}$.

Jacigues, Jos. Jlex, loambourges (1,76) que.3,"0I; (10.3); 179 Chestiut st. ; I: $6: 30-8$.

Kelly, lohn Josegh-Mass.7,04; (I'04)

MOCARTHY, THOMAN FIRAN('IS (1) $(0,3)$ Y.Y.10,91; (I'95); 21 Cotting Are.

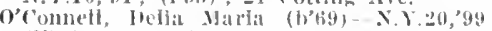
$\left(l^{\prime 49)}\right.$; bis Maple st.; office, 280 Mith st. $1-3,7-4$.

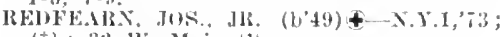
(t) : 3:2 W. Main st.

TREIII, THOMAS E. (b'S4)-X.1I.1, 10 (t'11); 6 Newton st. : 1-3, i-9.

Robiuson, llenry Ashton (b'si)-Mass. L, 11 ; (1'12); 18 Cotting Ave.

Snith, Chiron Waterrille - N.x.10,9J (l'45); 38 W. Maln s't.

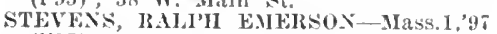
(I’97).

Therrien, Edw, Jos. (1,56)-Ont.4.'sti (t) 12 Broad st. ; $12-2,6-8$

WAINEIR, CARMILICS TLRXER +-1 t.2, '85; (5); 7511 . Main St.; 1-2, 7-8;

MARSHFIELD, 516, PLYMOUTH

Arthur, Asi Adgate-H-N.Y.10,'bi:; (b).

N.Y.1,'89; (1'95).

MARSHFIELD HILLS, 500, PLYMOUTH

King, Judson Coleman (b' ()

MARSTON'S MILLS, 175, BARNSTABLE

HIGGINS, JiUk' H.IYUN (b'71)-Mass.6 '94; (ठै) ; Pd.

Lovell, Gidieon- $\rightarrow$; (1'94).

MATTAPOISETT, 1,252, PLYMOUTH

BLAINE, WALTER EDW. †-Mass., 01 (I'01).

TIIDEx, IRVING NILES (b'70)+-Mass.I 99 ; (1'98).

MAYNARD, 6,390, MIDDLESEX

Flagg, Franklin Tarkinson (b'65)-Mass.1, '92: (1'95).

Goodenow, Diniel-N.11.1,'s9; (l'95).

Grady, Thos, IIenry-lld.4, or ; (l'01).

HAMBLEN, HOWARD (1, 63 ) - Mass. 6,00 $\left(l^{\prime}(00)\right.$.

Paine, Jlortimer llarwood $\left(b^{\prime} 76\right)$-Mass. Reed, sumi.

(1'12).

Salmon, E. I (b'70)-Mass 1,05. (17)

MEDFIELD, 3,466 , NORFOLK

Clough, Frank Herbert-Mass.1,98; (1†).

FRENCH, EDWLII) HENRY (b'57)-N.H.1 '82; (1'96); Member $\mathbf{x}$. H. Med. Soc.

MTCHELi, ARTHt'R-Mass.5,'86; (ठ). Thomson, E. Mabel (b+88)-Pa.t,'13; (1'13) Medield state Hospital; P.

TroxelI, Geo. Allen (b’ NP. $\star$

Walher, Lewis Marshall (b'67j-Mass.1,91 (1'yy).
MEDFORD, 23,150。 MIDDLESEX

$$
\text { (vieo Jioston.) }
$$

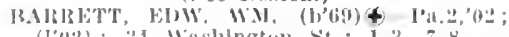
(I'01) : in II ashtn

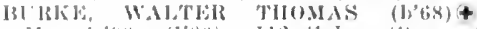

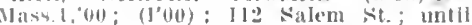
(1), I - $3,7-3: 30$

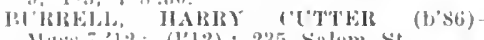
Miss.? 12 ; (1'12); 235 silem st.

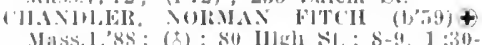
IIiss. $1,8 x$

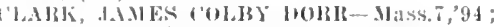
(2): \& llshlugton sit.

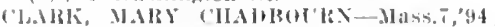
(太); I Washington st.; G.

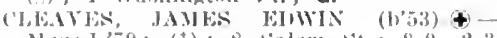

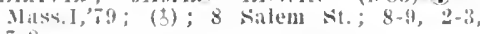
$1-8$.

HOXXELA, IHEIBLET ANTHONY (b'S2) +-Mass.7, $08 ;\left(1^{\prime} 08\right) ; 374$ Matu st. ; 2-3,

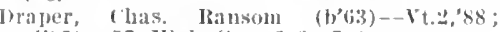
(19.7); 57 lligll st. ; 1-3), 7-8.

fleming, Elwin Rohn (b'7s)-I'a.2, 0 (I'04); 32: Boston Ave, 8-9, I-2:30, 6-8; A.

AIIAN, I'ATIRICK FRANT' (1) low

(1'10): " liorest st. 1

alwks, Alfred Joseph-Mass.5,?92; (t) ; 64 sialem st.

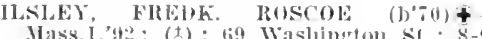

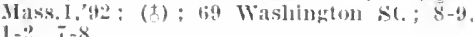

(5) : 3rooks st.

Kerr, Isabeliı Iblekieson.

(siee Boston.)

Mills, feorge Westgate (b'52)-Mass.1, 79 (5) ; 60 Salem St.; 8-9, 1-2, to:30- $7: 30$.

Nitter, Roy Birtlett (b'84) - Mass.i,'us (l'08) ; Tufts Sq.

PACKAIL, GEO, HENRY (b'65)-Md.3,'98 (1.95); 72 salem St. ; 1-3, 7-8

SISE, LAXCOLN FLEETFORD (b' 74$) \oplus$ Mass.1,01; (Y'01); 9 l'owder House lid. oftlue, 12 IItin St.; $2-3,7-8$.

MEDWAY, 2,696, NORFOLK

Burnham, Jolun I. (b'il)-Conn.1,99; not in practice.

sanborn, liate-Mass.5,'S3; (t).

Wyman, John lloward-Mass.1,06; (1'07).

YEATON, GEO. WM. (b'ts)-X.Ii.1.02; (l'02).

MELROSE, 15,7I5, MIDDLESEX (see Boston.)

Bliss, Wm. Ererett (b'72)-IH.19, 06 ; (1'08) New England Sanitarium; $9-10: 30,4-6$; S.

Bryant, Anna Mary Dorr (b'57)-Mass. 7 $95 ;($; ) ; 425 Lebanon st.

Carter, Frank Henry (b'58)-Me.1,'82; (t); not in practice; 51 Batchelder St.

CLARK, (ALFB WAKWEIELI) (h'5 4$)-V t, 2$ '89; (ち) ; 969 Main St.; 1-3, 6-8.

CLAIK, TLITS STIMPSON (b'38)-D.C.2 69 ; (屯) ; 109 Myrtle St.; 1-3, 7-9.

Dike, Joln M. (b'56) II-Mass.5,'88; (1'95); $112 \mathrm{~W}$. Emerson St.; $1-3,6-7: 30$.

FAY, JOS. IIENRY (b'S5)-Mass.7, 08 (1'10); 6 w. Emerson St. ; $1-3,7-8 ; \mathbf{S}$.

FISH, EIRNEST CLIFFORD (b'68)-Que.1, '96; (I'96); 17 Wyoming Are.; $1: 30-3$,

Handers, WaIter Hubert (b'75)H-Mass.5 99; (1'99) ; 97 Bellerue Are.; 2-4, $7-8$.

Gwynne, Sami. Carlton (b'89)-Mass.7,'12; (l'12); 32 Botolph St

HoIden, Ciarence l'arnell (b’54)-X.Y.9, 80 (1'96); 90 Essex St.; 1-3, 6-8.

HOIKINS, JOHN WILSON (b'73)૯-D.C.1 os; (1'13); also Member State Med. Soe. of Wis. : New England Sanitarium. of Wis. : New England

Houser, 11. Estella-M.C.3,07; New England Sanitirium.

TACK, HRNEST SANFORD $\left(b^{\prime} 60\right) \oplus-$ Ilass.1,'86; (屯); 56 W. Emerson St.; 1-3,

JAKSON, HOWARD BIGELOW $(b, T 4) \oplus$ Mass.1,01; (l'02); 98 W. Emerson St. office, 96 W. Emerson St. ; $1: 30-3,6: 30-8$
ILONAHI, RALIH JAVIS (b'8ti) \&Mass. I, 10; (1'10); I77 liellerue Are.; uffice, Iboston ('ity IfospltaI; R.*

hyon, Annle Isabne (1'67)-DIass.5,'89; 94 )

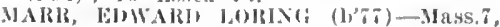
11 ; (1'I2); 3t Whittier st.; ulluce, 478 Main St. ; 1-3, 6-8

g'lomnell, lumls Patrkek (b'70)-Mass, I, 43; (t) : 476 Jatn st.

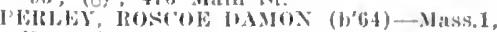
"fli; (I'b6); 63 W. Ëmersoll st. ; untli $\mathrm{I}-\mathrm{i}, \mathrm{6}, 6-8$

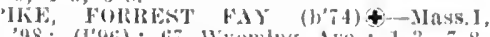

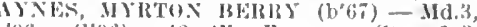
96 ; $(196) ; 42$ 11: Emerson St.; 1-3, $7.8: 30: 0 \mathrm{~b}$

Acott, Nommin . Mclean (b'84) - Jass.7,'11; (1'j2) ; 81 IIount Vernon st.

SMS, FlREIUK. IBOBEIRTSON $\left(b^{\prime} 78\right)$ \& Mass. I, 02 ; $\left(\mathrm{I}^{\prime}(02) ; 79\right.$ W. Foster St.; S.IALI, AIBIET ERNEST (b'55) \& Mass. I, $00 ;\left(I^{\prime} 00\right) ; 90 \mathrm{~W}$. Emerson St. $1-3,7-8$.

STIRATTOE, RALPH RICKEIR (J)75) \& Mass. 1, 02; (1'02); 654 Main St.; 1-3, $6: 30-8$.

Wentworth, Jowell Franklin.

(See Boston.)

MELROSE HIGHLANDS, 4,000, MIDDLESEX (See Boston.)

(FIGE, ARTHUR 'I'WNNEY (b'83)-Mass.

HARI, WW, CORYTON WEBSTER $\left(b^{\prime} 64\right) \oplus$ Me.1,88; (").

I'age, Cluas. Kdw.

(See Boston.)

"ROVANIDE, PAT'l, IIECTOR (b'76) 4 Mass.1,'98; (l'98).

Reeves, II irriet EInira (b'58)-Mass.5,92; (ई) ; NP. *

Townsend. Willis Merrick (b'70)H-Mass.5, '93; (1'95).

Tan Alstine, Seymour March.

(See 1Boston.)

MERRICK, 1,500, HAMPDEN

Dow, Harry Baker (b'76)-Md.4,'11; (1'11).

MERRIMAC, I,77I, ESSEX

J'EIICE, A.IOS HAGAR $€$ - Mass.5,'82; (5); (West Newbury).

SWEETSIR, FIREK. LLLSWORTH (b'66) (4) Ne. 1,88; (t).

METCALF, 50, MIDDLESEX

Ingraham, I,ena Vaughu-Pa.7,'83; (お).

METHUEN, 11,448 , ESSEX

BAKETEL, ROY VIN('ENT (b'77) \&-N.H.1, 99; (1'02); 302 Broadway; offlee, Odd Fellows Block; 1-3, 7-9.

Berwiek, James Roderiek-N.H.1,'99; (1'99); 150 Broadway; 1-3, 7-9.

boynton, Edwin Ioses.

(See Isawrence.)

Boynton, Stella IT.

(See Lawrence.)

('CSHMAN, HOWARD LEWTS (b'86)Mlass.5.08; (I’08); 28 Annis St.; 2-4, i-9; Pd.

LAWLOR, RICIIARD HENIR $\left(\mathrm{b}^{\prime} \mathrm{i} 1\right) \boldsymbol{\oplus}$ N.H.1,98; (I'98); 251 Broadway ; 1-3,

Maney, Iohn Jos._Id.4, $00 ; \quad\left(\mathrm{l}^{\prime} 00\right) ; 48$ Broadway ; $2-3, \bar{\tau}-8$.

Nutt, Walter Elwsn-MI.6,'99; (1'99); 36 I. owell St.; $8-9,1-3: 30,7-8$.

IARR, JOHNE-Mass.7,03; (l'03); 18 Sterens St.; until $8: 30$, affer 4 ; office, 7 Hampshire St.; 2-3:30, 7-8:30.

RELD, TICTOR AUGUSTUS

(See Lawrence.)

MIDDLEBORO, 8,2।4, PLYMOUTH

Burkhead, James Hodgen-Mld.3,07; (1'08).

COOLIDGE, SUMNER (b'59)-IIass.1, 00 (l'00).

Cummings, Chas. Stearns (b'65) H-Mass.5, '89; (む),

Drake, Henry Seudder--Mass.1,'81; not in practice.

ELIIOT'T, ALFRED (b'71)-Md.3,'00; (l'00)

ELI.IS, GEO. LIVINGSONE- Mass.1,72; (t).

Fryer, Winson Farnum-Pa.9,'86; (f).

Ham, Helen Willard-IIass. 6,06 ; $(1+$ ). 


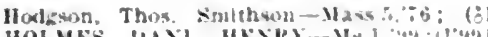

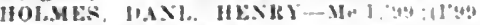
Robinson, Francls Irnold (bos). Md 4,94 (1.95).

sulth. Irtbur Vincent-Masu 1,':4: (?).

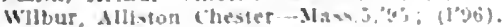

MIDDLETON. 1.129, ESSEX

EWINT, tiEO. WISHIH.

(Sce l'ealuxts.)

MILFORD. 13.055. WORCESTER

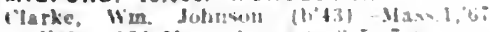

$\left(1 y^{3}\right):$ I3f Man st.; : .

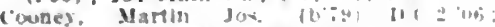

(l'0s): 173 longress st.

(urley. liev. Fredk. 11)":-1-1

10 tongress st.: $:-4,: 0$

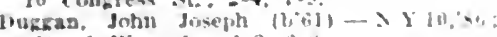
(8): 1 Weat s.: ; 1-3, b-s.

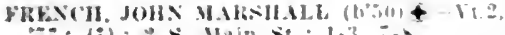

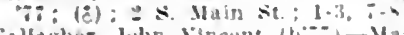

fiallagher, Juhn Vincent (6":) - Mas: :02:

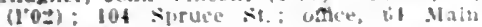
St: $1.30-3=30,-30 \cdot 3$

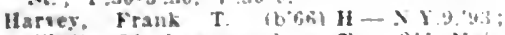
(193): ss Congrew st.; ortce, oll Malt St. :-4, :-8.

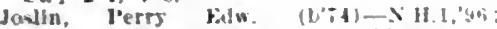
$\left(19^{\circ}\right)$; $11:$ Maln St. : 1-3, 6:30.9.

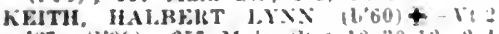

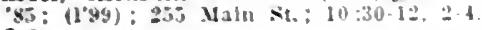

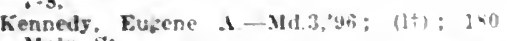
Main sit.

KXIEHT, MARCL: WHTXEY (h⿻一𠃋

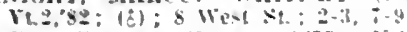

1ally, Fancli Henry (6\%)-Xill, 109 (100): - 1 Winter st: until 9. 2.4.

white, prank lunster (n)t lat

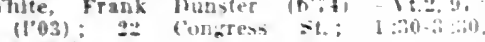
$6: 50-8$.

\section{MILLBURY, 4.631, WORCESTER}

BI60W: ARTISIl? AlUS:II's (b's) I'a.2.05: 1108). CHIIRCH, CHAS. ALBHT $(6.59)+1:=$ '34: (1'95).

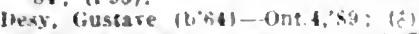

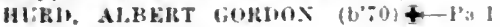
$45:(1.95)$.

1.IXOLX, J.MOH RkAll $(1,62)-M a \cdots !$ : $88:$ ( $(8):$ :

MILLERS FALLS, 499, FRANKLIN

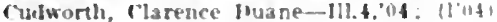

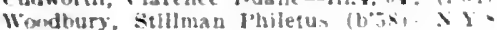
$8:$ (

MILLIS, I.100, NORFOLK

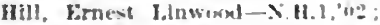

MILLVILLE, 1.897, WORCESTER

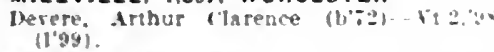

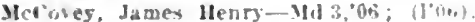

MILTON, 7.924, NORFOLK (see lioston.)

B.AKTOL, BDW HHANCIS W.AIIHIMS

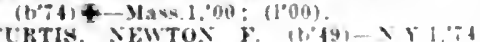
relled: Member Med. Sinc of the state of $\mathrm{x} . \mathrm{i}$.

FonHF, M.FAXINH $(1, x)+M a-1$ "10; unt in practice.

GOLITHWAT, JOEL, ERNEST. (Neve Boston.)

Kennedy: Harris

isec ismton.)

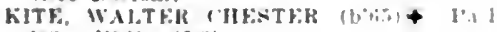

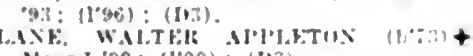
Mase.1,99: (l०AO) : (D3)

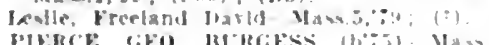

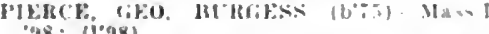

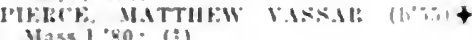

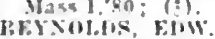

(see Ihostom.)

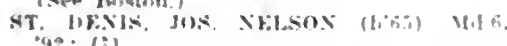
9: : (*).

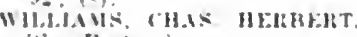

(Nien Iboaton.)

MITTINEAGUE, 3,304, HAMPDEN

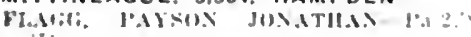
(1).

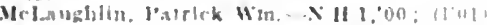

\section{MONSON 4758 HAMPDEN}

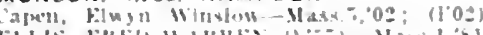

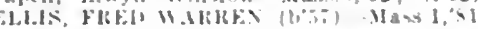
()

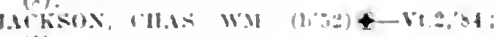

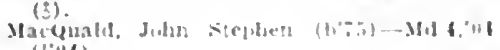
(1, 04 )

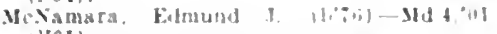
(1)01)

MONTAGUE. 6.866. FRANKLIN

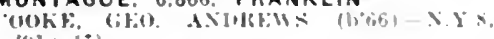
"4]: is

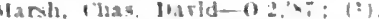

MONUMENT BEACH, 300, BARNSTABLE

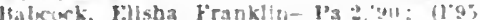

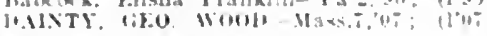

NAHANT, 1,184, ESSEX

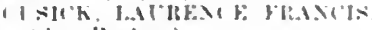

(sere Joston.)

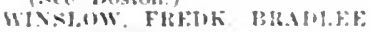

(Sipe Bintun.)

NANTUCKET, 2,962, NANTUCKET

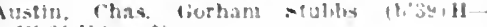

111. $21.96:$ :

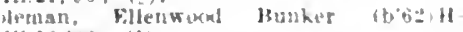

III. I0, $25 ;(\vdots)$.

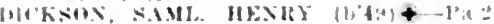

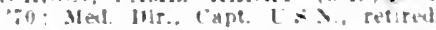

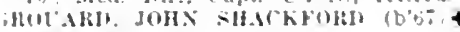

Mast. 1.89; (ः)

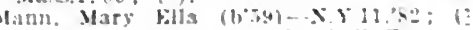

IPXIOSE. CLFMFAT ANUABIFE.

(Nie Baltimore.)

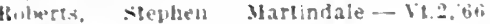

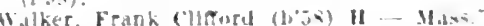

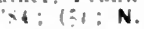

NATICK, 9,866, MIDDLESEX

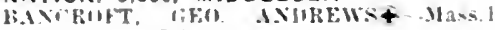

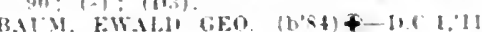
(1.11)

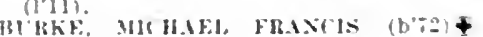

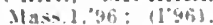

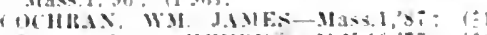

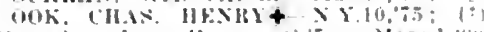

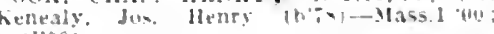
11001 .

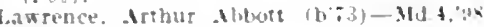
(150).

Mllet. Edw Mex (b\%) - Mass $7.4 \%$; (Jig).

PMRTER. WM TUWISExJ.

(Sice Rostun.)

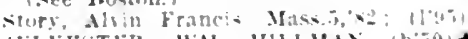

SYLESTH, WM MHLMAX $\left(\mathrm{b}^{\prime}\right.$ in)

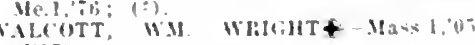

(1'05).

NEEDHAM, 5.026, NOPFOLK

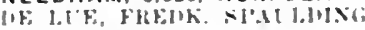

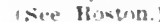

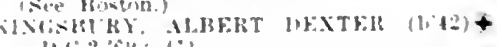
$111 \div 2,64: 1 \div 1$

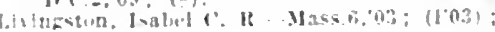

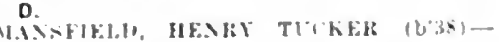

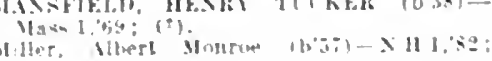

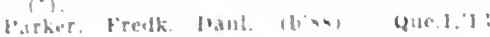

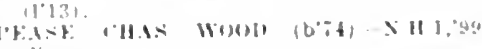

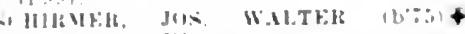

Vian

NEEDHAM HEIGHTS, 1.921, NORFOLK

uploning. Narah liliratelli.

Diti

NEW BEDFORD, 96.652. BRISTOL

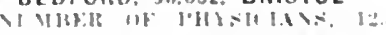

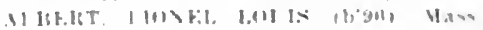

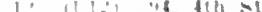

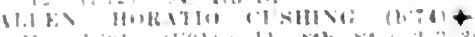

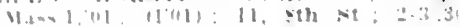

s.

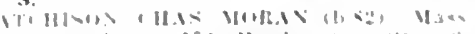

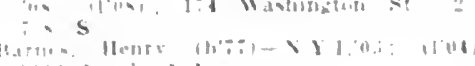

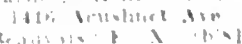

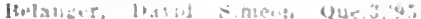

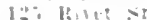

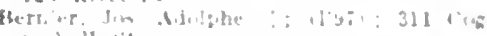

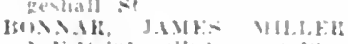

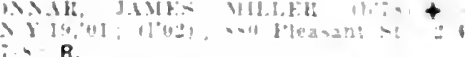

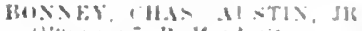

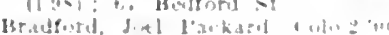

t: Ma:n it

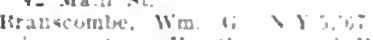

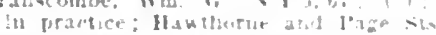

Briges, I lfion [leth Van.

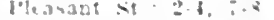

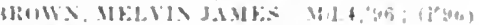

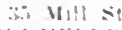

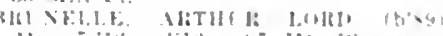

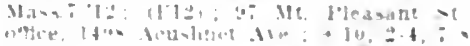

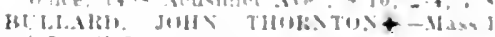

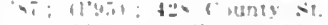

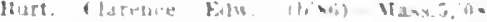

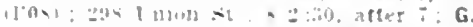

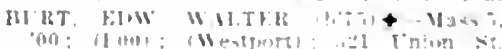

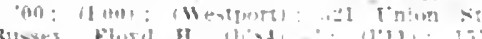

bustey, Flowel II Al,

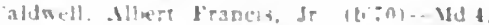

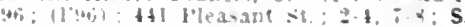

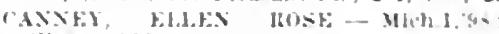
(1)

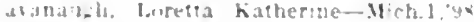
$(1+4,0)$; io bedford sit

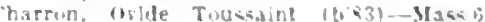

12; iflat: $w$ French Ale: 9-10,2.4.

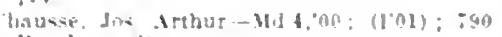
furchasis st

hompetie. Hormblas (b\%) - Md 9004

(1"ut): 1 Wld $: 1$ : $1-9 ; \mathbf{G}$

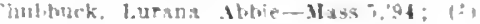

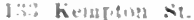

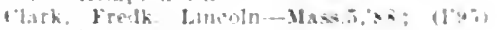

1: $x$ ith $\leqslant$

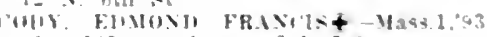

1:1) $109 \leq$ ith si.: $2-1$

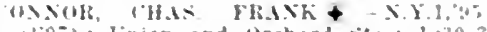
1197): Inion and Orchard sto: $1 \cdot 30-3$

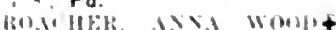

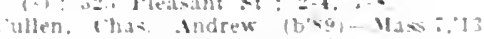

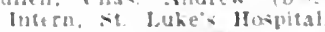

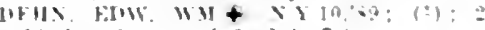

Lenden st : unet $9.9-4 ;-4$

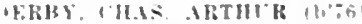

is9: 11901, Inot lourthase st

bontian, silvester Baluard

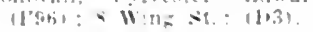

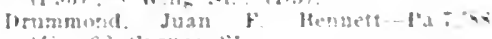

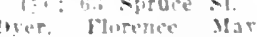

(1)

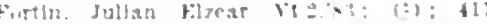

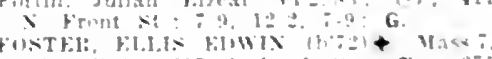

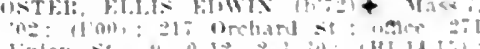

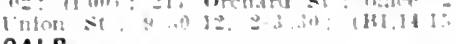
OALR.

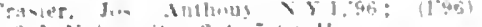

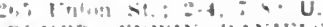

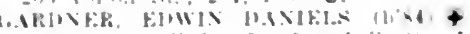

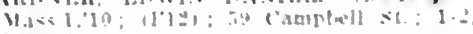
$\therefore$ s.

4.. $3: h=$

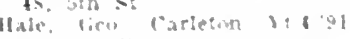

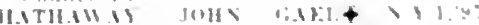

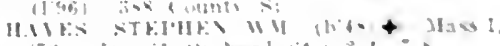

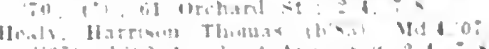

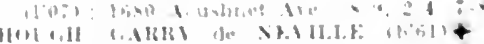

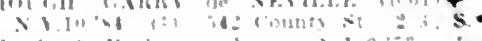

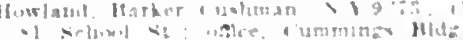

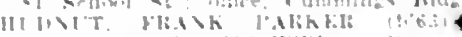

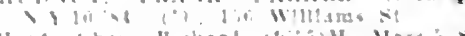

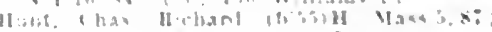
A.

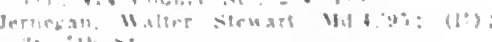




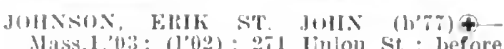

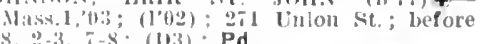
(iiker,

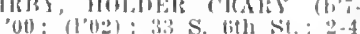

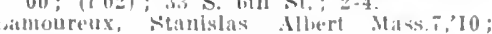
(1'10) ?11 (10)

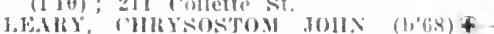

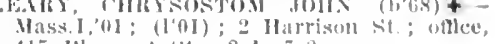

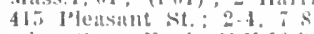

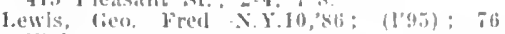
Wulnut sit.

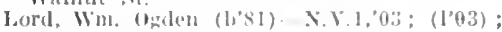
stif Purchise si

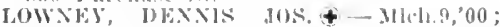

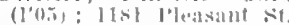

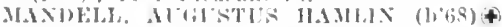
- X.1.5,97; (1'(1) ; 25 syeimore st.;

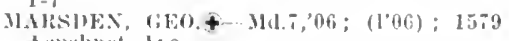
Arushnet Are.

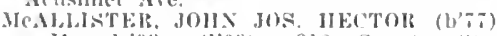
Mass l.03; (1.03); 216 County st. ; (4-10, 2-4, i-9

MONCHEFF, WM. AHMITAYE $\{1,00)$ Mass.t, 13; (1'13) ; 14: Merrimal st. ; of floce, lerby Ilospital; I-3.

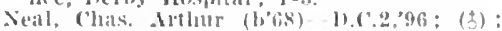
(leutist); 50 \&. Ash st.; oftles, 1.5 iulon sit.

Nelson, Wm. Wallate H.(2.3,07: (1,07) 1002 l'urelase st. : $1-3: 30,7-8$.

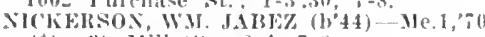
(t): 39 Mill st, : $2-4,7-8$.

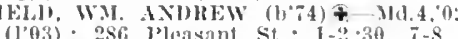

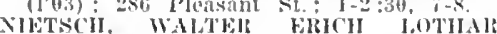
$(1,86) \mp-1.1,10 ; \quad\left(1^{\circ} 12\right) ; 294$ finon

Nixon, Alfred John (b'6.5) II-Mass.5,94; (さ) : s4 Acuslinet Ave.

Normandin, Louls Zeplírin (b'si)-ont.4, $79:(8) ; 586$ l’urcliase st.: $2-4,7-8$.

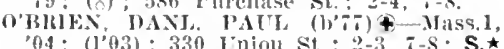

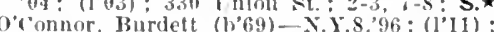
I:7 Kempton sit.: $\mathrm{S}$.

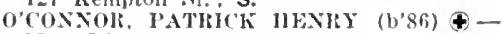
Iass. T,0.7 (l’04); 240 County St.; 2-4, $=\mathrm{i}-\mathrm{S} \cdot 30$.

Osborne, Edw. Lanl.-n.C. 3,o:; (1’08) ; $3 \pi$ S. $2 d^{\prime} \mathrm{St}$.

Owen, James Williamson- 0 ; (d); 258 Purchase St.

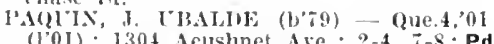

(101);

iis. 6th St.

l'earce, Geo. Girdwood (b'8z)-N.Y.1,12; (1'13); 18, ith st.; 1-3, $7-8$

Peirce, Edw-Mich.1,89; (*); 44, 5th St.

PriRAS, LOIIS ADELARD (b'87) IIl.4,11; (1'11); 129 liuth Ave.; 9-10, $2-4,7-9$

J'EHKS, HAROID EW(iAR (b'85)-Mass.1, $11 ;(1,11) ; 403$ Union St.

IETERSON. CIIAS. AI'GISTLS BLRTON -N.Y.8.86: (む) : 90 hliman st

Pierce, Aithur Vannevar (b'81)II-Mass.5, 08 ; (l'08); 99 Fim St. ; 8-9, 1-3:30, 7-8. P'TTA, JOAO CARLOS DA SILVA (b'60)థ -l'ort.2, S4; (1'35); 57 Allen St.; 2-4. POTIIER, lOS. CHAS. \&-Que.1,'8T; (ठ); 17.5 Purchase st. : $2-4,7-8$.

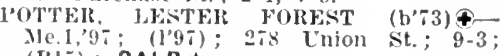
( $\mathrm{B} 15)$; OALR. *

Potter, Wm. Gage-N.Y.5,'s8; (১) ; 546 county st.

I'LATT, CIIAS. AlGFSTCS (b'62) †Mass.1,91; (ठ); 60 Orchard St.; 2-3; (Li:) ; Pd.

IRITT, NAVID DAMONE-Mass.1,06; (1'05); 405 Enion St.

PRESCOT'T, CHAS. DUDLET (b'45) X.11.1.67: (3); 108 S. Ash St.; offlce, 176 William st.

PlRESCOTT, HENRY DEDTEY (b'66) Mass.1.02; (l'04); 26 Grove St.; office, 17 William st.: 2-3; S.

Remich, Sumner Ilaven (b'86)-Mass. T,12; (1'12); Xew Bedford Tuberculosis Sanatoriun; $\mathbf{T}$.

Richard, Alfred Edourd-Ont.4,'84; (1\%) ; Prye st.

HRT, GEO. LYMAS

(xie rill River.)

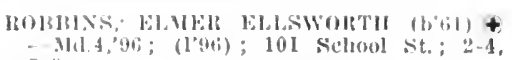

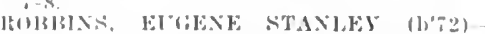

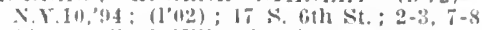
Atobinson, Fred Hllliare (b) (ix) - Mass,

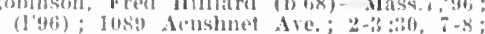
OALP.

Kuss, dos compad (1,7:3) - Mass.f," 118 (1.08): 1394 Aruslunet Aie.: 1-3, 6-8; S

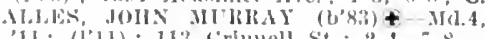
'11; (1'11) ; $11:$ (irlunell st.; $2-4,7-8$.

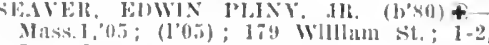

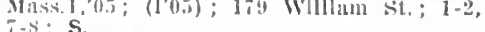
SIXEAt, ARCIIBAI, NAPOLEON (b'Tli) + (211e.3,02; (l'02); 74 lbutler St. ; offices, $1007:$ Water St.; $2-4$. 7-9.

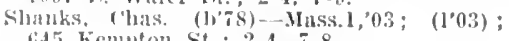
6.5 Kempton St. : 2-4. $†-8$.

Shereluy. Wm. Clinton- N.Y.5,?90; (t) ; 249 chestuut st

Silva. Savero bacheeo $(1,91)$-Mass.7,13; (1'13): 41, wing st

sisson, Jolward liateh (b'28)-Mass.2,53; I'a.9.54: (ह) : not in pluctlce: 15,841 st

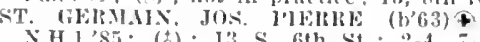

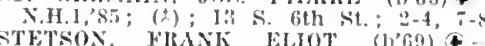
Mass.1,

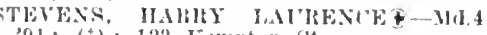

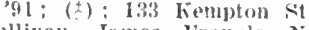

ullivan, Janes Francls-N.Y.10,86; (む) 185. Midale sit.

sylvia, Mamuel Vietorino-X.Y.5,

34 Wing st.; 2-4, $7-8$.

Taveira, Arthur Joatqulm (b'8i)-Md.9, '10:

(1'12); 238 lavis St.; 8-9, 2-4, 7-8; S.

Tessier, Jos. Napolcon' (b'86)-Que.3,'09;

(l'09); 993 s. Water st.

Thayer, Wm. Hewlns (1);5) - $;$; (1'98); 25 , Fih st, $8-9,2-3: 30$, $7-8$. Thunt, Joln Vincent (b'49) - Que.3,'90;
(t): 938 Acislinet Are.

TICKER, FNW" TOBEY (b'49)-Mass.1. 74: (5): 1050 pleasant st.; $2-3.7-8$.

Mass. $t, 09 ;(1,09)$; II08 Acushnet Ave. Mass. $\pi, 09$

Vieira. Iose Pacheco-Port.2,99; (l'03) 317 Itivel si

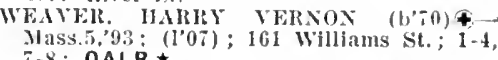
$7-8:$ OALR. $\star$

WEBBER, AMOS PATERSONZ-N.Y.1A, 83: (む) : 250 Vuion st.

WEEKS, JOSIICA FIASKLIN (b'66) \& Vt.2,90; (む) ; I Aunds Corner; 8-9, 1-2. WHEELER, EMMA HAMMOND (b'60)
Micli.1,9s; (195); 57 Morgan St.; $2-4$, 7.8

WHITEY, EDW. MELVYLE (b'55) $₹$ I’a.2,79; (ठ); 27 S. 6 th St. ; 10-12, 1-3.

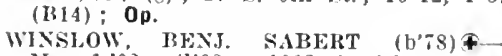
Mass.1,02; (1'02); 1063 S. Water St. $2-4,7-8$

Winslow, Geo. Fredk. (b'42)-Mass.1,64

Med. Dir., rear Adniral, J.S.N., retired.

WOOH, HENRY WAJTONA - Md.1,02 (1'04) ; 446 ("ounty St.; $(\mathbf{k}, 2,13)$.

young, Edward Wallace (b'87)-Miss.7, 13

Intern, St. Luke's Hospltal.

NEWBURYPORT, 14,949, ESSEX

DAY, CHARENCE ('LRRIEI? (b'65)

N.II.1,92; (t); 21 Titconib St.; 3-4, i-s.

Hall, Chas. Franeis Adams (b'-3) if-Mass.5 98; (1'98); 202 High St.; 8-10, 6:30$7: 30 ; \mathrm{S}$.

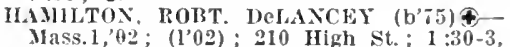
T-8; $1 . \star$

HEALY, THOMAS RAYMOND (b'79)X.II.1,99; (1'99); 12 Charter st.; 1-3, $7-8 ; R$

lewett, Arthur James (b'85)-I11.22,'12

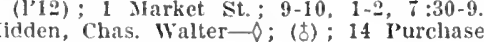
st.

HRD, RANDOLPII CAMPBFLL (b'72)\& Mass. 1,97; $\left(l^{\prime} 97\right) ; 230$ Hlgh St.; $2-3,7-8$. Jolinson, Chas. Frederic (b'60)-Mass.5, '84; (8) ; 45 Washington St. ; 8-9, 1-3, $7-8$ ITTLE, ABBY NOYES $\left(b^{\prime}+2\right) \mp-$ Pa. $7: 94$;
(1'95); 22 Essex St.; $1: 30-3,6: 30-7: 30$.
Morse, lirederlek otis $\left(b^{\circ} 60\right)$ Mass, i, 97 ; (1'01): :36 lille st.; 8-I $19,1-3,6: 30-8$.

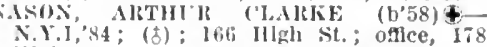
IIlgh sit. $1: 30-4,7: 30-8: 30$.

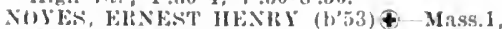
so: (c); 89 nligh st.; oflee, 12 Essex St. : $1: 30-3,7-8$.

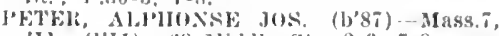
'11: (I'II); is Mllule St. ; $2-3,7-8$.

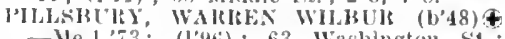
-Me.1,73; (I'9ti); 63 Washington St. $7-9,1-3,7-9 ;(113)$

SHAW, JoHX WM.t-Md.4, 06 ; (l'07); 1 Orange st. : 1-3, 7

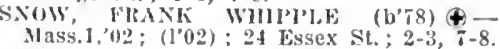

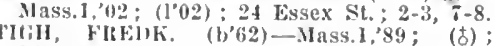
lis' High St.; until 9, 2-3, $7-8$.

TUI'AN, IROIANI) LESLEY (b'82)世Mass. 1,08; (l'08); 10 T'oppan Lame; of flce, $3 I$ lireen St. $2-3,7-8 ; \mathbf{0 b}$.

worcester, Geo. Waldron (b'60) $11-I 11,4,83$;

(5) ; 124 IIlgh st.; I-3, $6: 30-7: 30$.

NEW MARLBORO, I, 124 , BERKSHIRE

Culver, Hrerett Mallory-N.Y.I,'81; not is pructice.

Sellew, Robt. ('owan-Conn.1,'98; (l’00).

NEW SALEM, 26I, FRANKLIN

Narslail, Perry (b'49)-1'a.9,'Tl; (l'95).

NEWTON, 39,806, MIDDLESEX (Nice Boston, Newton Center, Newton
Mlighlands, fiewton hower Falls, Newton lpiper Falls, Newtonville, West Newton, Auburndale, ('hestnut Hill, Waban.)

Ibaker, John Walter (b'60) -Mass.1,'81. Surg., Jieut., U.S.S., retlred; 666 Centre St.

Bergeson, John.

(See bostom.)

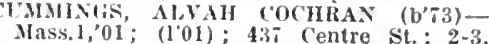
$\vec{\imath}-8$.

Davenport, ('hats. Albert (1)66)-Mass.1,94 (ङ) ; 34 Park St.; untll 9, 3-4, 7-8. DEMPSEV, JAMES EDWARD (b'83) \& Mass.1,11; (1'11); 395 Washington St. Eastman, huther Gould (b'-9)-Mass.5, 66 ; (1'09); (60 Grove st., Auburndale).

MOIY), GEO. STETSON (b'43)-Mass.1. ' $66 ;($ ( ) : 73 Sargent St.

Fawcett, Deboral.
(See Boston.)

GALLAGHER, THOMAS MORTON (b'72)llass. 1, $98 ; \quad$ ('98); 34 Channing St. $2-3: 30, \quad i-8$.

Gleason, Mlardls Edw. (b'59)-Vt.2,'84; HOPKINSON, GEO.

(See Boston.)

Jackman, Mlice May-Mass.ĩ,'02; (1'02);

Mass. $1,9 \pi ;(1,97): 140$ Sargent St.

MARSTON, WAIREN WINFIELD (b'86) Mass.7,10; (1'10); 337 Washlngton St. ; $2-3,7-8$; $S$.

Martln, Oscar (b;7)-Mass.7,'10; (l'11): 143 Charlesbank rid.

MASKEJ, J, JEONARD JOS. (b'69)-Mass.1, '96; (l'96); 2305 Washington St. ; $1: 30-3$, $7-9$.

MeIntosh, Fredk. Lemont (b'58)-I'a.9,'81; (む); 284 Waslington St. ; 4-6:30, MOORE, HOWAIRD.

(See Boston.)

NHELSEX, EDIIT BJORNE.

(See Boston.)

O'PONXYLL, FRANCrS MIIIAET, (b'63) IIass.1;87; (む) ; 619 Washington St. ; 1-3, 6-8.

PAINTER, CHAS. FAIRBANK.

(See Boston.)

PEARSON, ('IIAS. LUSBY.

(See Boston).

Reid, llobt. Alexander (b'48)-Ill.8,77; (む) ; 36 Hyde Are.; office, 234. Washington St.: $2-4$

REID, WU. I)TNCAN (b'85)-Mass.1,09; $\left(1^{\prime} 09\right) ; 36$ llyde Ave.

SUITH, WIVIN WALLACE.

(See Boston.)

Stephenson, Milton Elmer.

(See Boston.)

TONE, LINCOLN RIPLEY $\oplus$-Mass. 1,34 ;

(む); 131 Vernon St. 


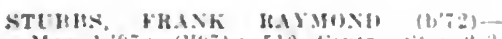
Masy, 1,97; (1'yz): 510 centre tit: : :-3. $\div-8$.

Viley, Balw. Hoswell (1,62)-Masw 1,91 (8): 97 Centre s. : 4.6.

van inne, ollver.

(Siee Hosturn.)

Walerhouse, Howere Morgan (bisi) Mawn

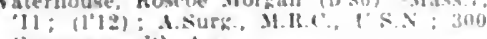
Commonwealth Are.

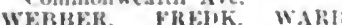

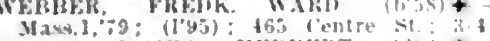

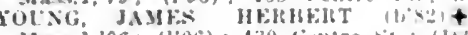

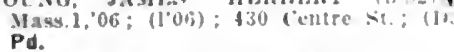

NEWTON CENTER, 3.291, MIODLESEX

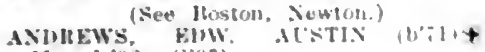
Mass.1,96: $\left.\left(1^{\circ} 9\right)^{4}\right)$.

Chlrurk, Mtihael.

(see Boston.)

Cordelro, Friderle Joaquhn Harvosa

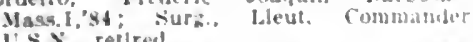
C.s.s., relired.

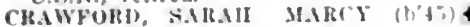
X. Y, 14, -7: (2)

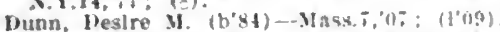

Fessenden, (has, Hill (b'63)-Maxs, (t): R.*

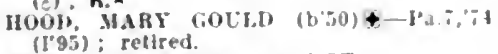

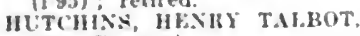

(see Boston.)

keleher, Francls Joserph (b'ij)-Mas, 1, '(it) (ह).

I.ORIXG, IROIIT, I'HAMMAIN (b'20)+

Mass 1,75 ; ().
MacMahon, John Jos.

(see Huston).

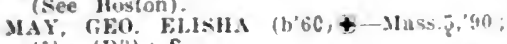
(द): (1) 3$): \mathbf{S}$

SYLVETKR, H'H11,H HASKEIL (b'sol Mass. 1,00: (1?06); (I0:3); Fd.

sylvester, Stephen Alden' (b'4s)-Masm.

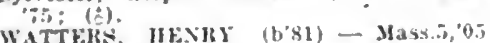

(1'06): S

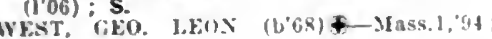
(3); Ob.

NEWTON HJGHLANDS, 3,287, MIDDLESEX (See Hos:on, Newton.)

BAITLET, IHLL' CHALLIS

(See Moston.)

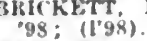

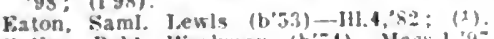

Guller, Robt. Workman (b'it)-Mass. 1, (l.98): $\mathrm{S}$.

Kelth. Fredk. Scots (1,69) Mass.1,"92: (है). MRLIES, EI,EANu

-I'a.i;03: (I'05).

Thoruyson, Chas. Arthur.
(See Jewton. Lpier Falls.)

Wentworth, Caruline Young-H-Mass.i, 9.5: (1'95): (103).

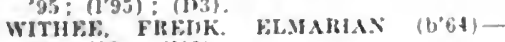
Md.3.'92: (1.97).

\section{NEWTON LOWER FALLS (NEWTON CEN -} TER P.O.). - MIDDLESEX

\section{See Isoston. Newtor.}

Fullot, Maleolm Hoberton (b'st)-Mass.1 Iz: Intern, Newtun Husultal.

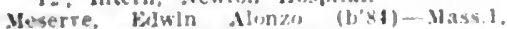

Meserve, balwin ilunzosital.

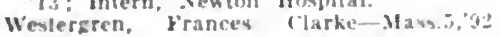
(3).

NEWTON UPPER FALLS, 2.582, MIDDLE. SEX (siee bonton, Sentom)

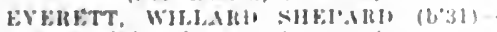
Mass. 1, it: (2): nut in practice

froey, Warren liensy (b'SI) Mass 1.'12:

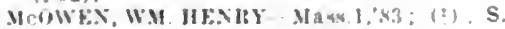

Thumpon, (thav $\left(1^{\prime}(4,3)\right.$.

\section{NEWTONVILLE, 7,261, MIDDLESEX}

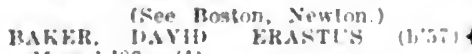

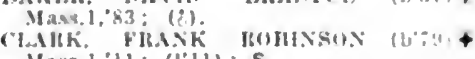
Maval, 11: (1'11): S.

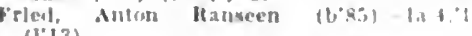

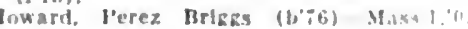
(1'113).

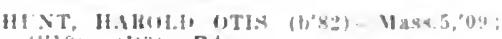
(1)10): (II:) : Pd.

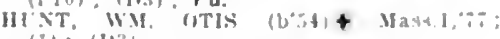

(1) : 11:3)

(sice Itimsons.)

Soges, Wllbur plake.

(E.e. (3)

Taft, Nary flisence

Tallovi, (ivo. Heqry

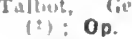

THALE, HAUTLE.

II:44. I,"99: 11"010)

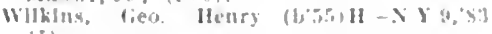

NORFOLK DOWNS (QUINCY P.O.). NORFOLK

WHOHS, RAIIH MASE

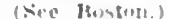

H.MTI.T:T, HRFD, A.

Asere Quilney.

(10\%).

NORTH ABINGTON, 3,047, PLYMOUTH

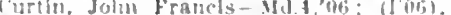

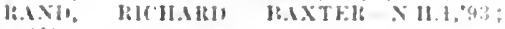

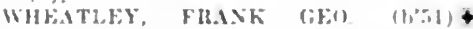
T11.1, (I): I'rot. Mat? Merl.

NORTH ADAMS, 22,019. BERKSHIRE

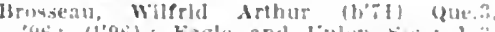
(atj; (1'96); Kagle and l"ulons sis.; 1-3.

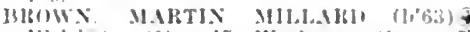

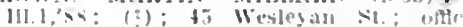
Ilil Maln st.

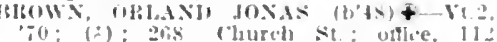
Main St: $8.4+1-3,7-9 ; \mathbf{P d}$.

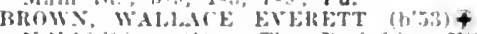
\$1.10,00; (B); The Berkihre Hills sanatorium.

Invhnell, Homer Andrew (b) (11.): $(10.3)$; ysth Main st.: $7-4,12-2$,

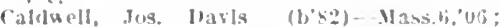
(10i) tis Hudson st.

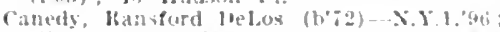

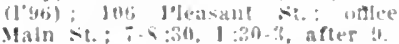

crawfurd. Jo. Warrington (b':2)-Ja:?

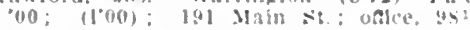

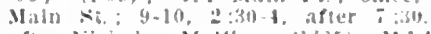

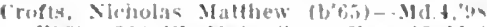

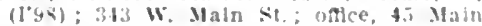
- $1,-10,2-t=-0$

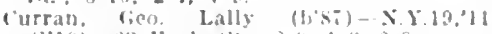
(1'lii); ti: Eagle st. ; s-3, 1-i, $6-9$.

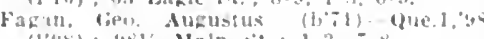

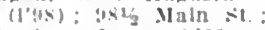

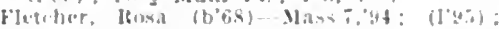

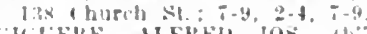

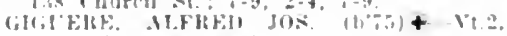

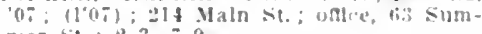
niep - $t$. : - 3 , i..?

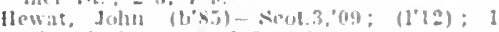

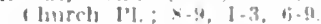

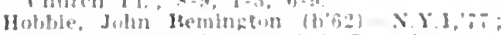

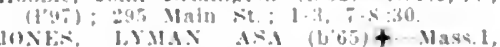
16.Nk, 1,YMAN ASt

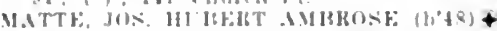

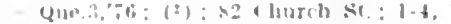

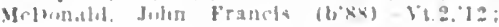

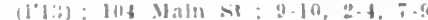

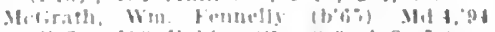

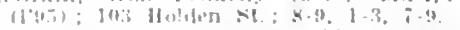

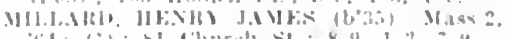

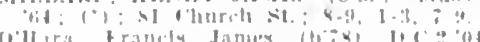

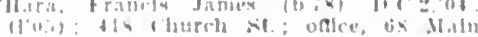

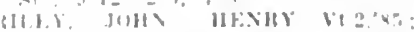

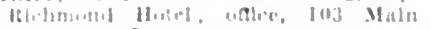

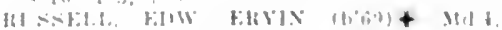

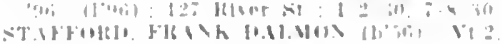

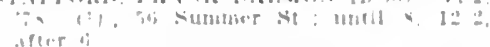

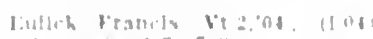

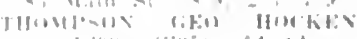

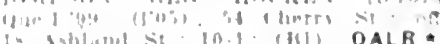

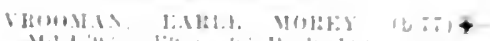

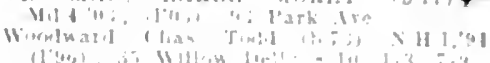
Witho,

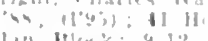

NORTH AMHERST, 1,055, HAMPSHIRE

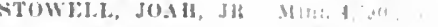

NORTHAMPTON, 19,431. HAMPSHIRE

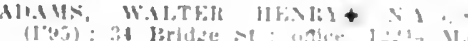

it

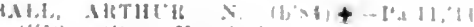

Wolner : viate Hombitil.

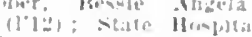

(1) killilltis

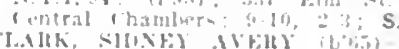

$\because 1:(?)$; In

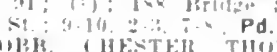

Y. i-s:s.

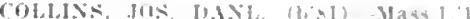

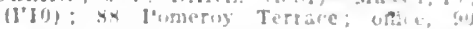

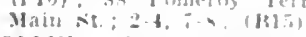

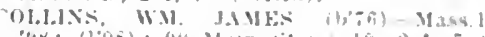

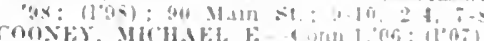

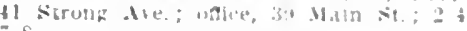

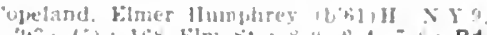

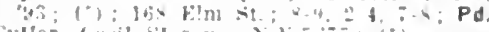

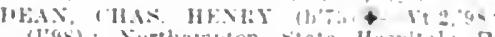
$\left(1^{+}(s)\right.$ : Jurthasamon state Itosplal: P.

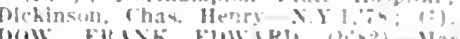

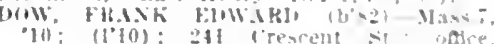
central i hambers: 0-1:- O OP.

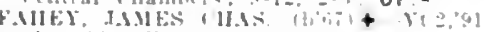

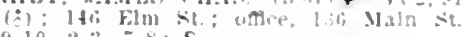

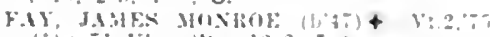

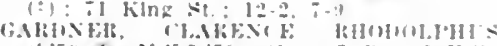

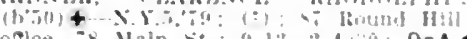

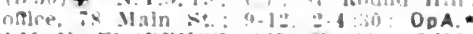

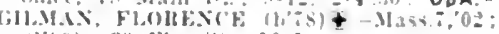
$(1019): 33 \mathrm{kin}$ st : $10-1$

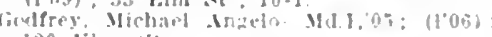
$1 \geq 0 \mathrm{k}] \mathrm{ng}: \mathrm{s}$.

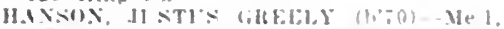

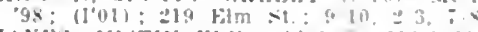

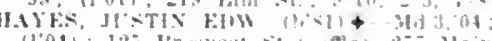

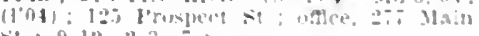
st: $9-10, \cdots+\cdots$

Hekey. liarrett dowegh Maldos

(b'lorence)

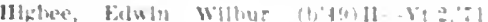
(a)

HHllard. Whllam Dostel

Hols: center rlambers

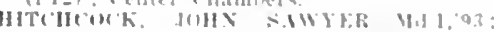

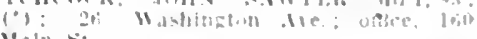
Maln $s$

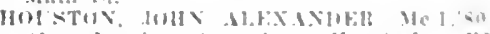

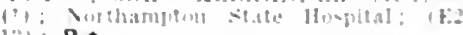
$13: P$.

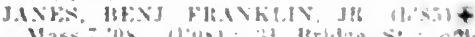

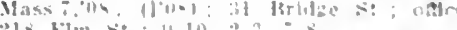

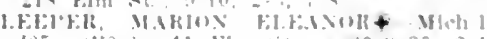

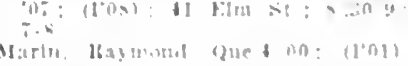

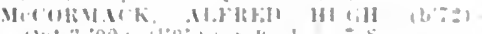

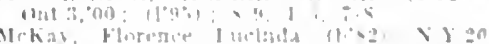

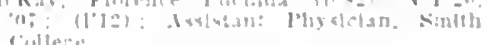

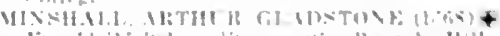

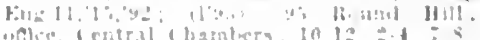
$A L R$.

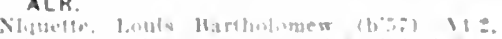

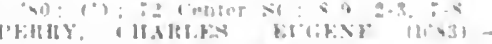

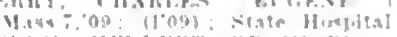

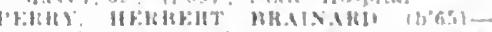
11. 1.80: 1."): Isi Main st: $1: 30.230$.

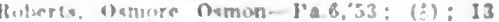
hing si: :9, : $3,: 8$ 
SHYMOIR, ("IIRISTOIHER (b'\$3)--MIM.1 '(i); (b) ; 79 KIm S6 : 9-10, 2-3. Vass, 1,94 ( liass. 1,$94 ;$

Maln st.

sterens, Gruce-H-Mass.5,0I; (I'0I); :3: IBedford Terrace.

TAYLOR, WALTER+-N.J.19,00; 7o Malle st.; $8-9,1-2,7-8$.

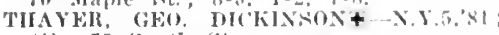
(d) : 65 Soutl st.

THOMAS, FIMER ElasWORTII (b'\$4) Mlass. 6,10 : (1'10); 1fio Main st.; 2-4,

NORTH ANDOVER, 5,529, ESSEX

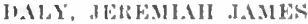

Holt. Wilw, Wells Afwoor (b'-9)-Miss.1,

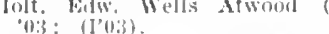

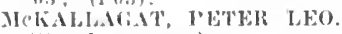

(siee law rence.)

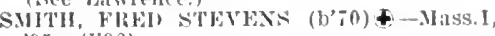
95: (I'96).

NORTH ATTLEBORO, 9.562, BRISTOL

13ryer, James Nllen-II-Mass, 品, 99 ; (l'00).

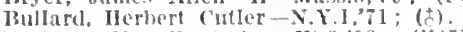

13ullard. Newoll (ntler-1t, 2,98 ; (1'0).

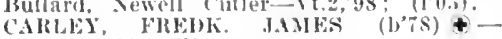

Mass.7,06; (I'06)

Foster, lames Ricliards (b'44)_Mass.1,7\%;

(bF)

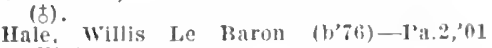
(l'01). KIIUY, HENRY SHERMAN (b'52)-Mass.1,

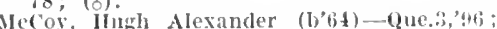
(1'96); Pd.

Pay\%ant, Clinde Louls (b'87)-Mass.5,'10; (I'10); OALR,

SIOENAKER. AMZI BEDELI (b'81) \& IId.I, 08 ; (1'0S).

Teller, Ernest-Que.3,05: (1'05)

Vance, Micliael E. (b'0 0 -N.Y.5,9; ; (1'95).

WARD, EDW. SITYACS (b'78)-Hass.1, '03:' (1'02).

NORTH BILLERICA, 625, MIDDLESEX

Forhan, Nell Kittredge (b'86)-Mass.7,'12 ; (1'13).

NORTHBORO, 1,7I3, WORCESTER

Coffin, Geo. Henry' (b'51) H - Mass.5,'03; (1'03).

Coffin, John Lanubert.

(See Boston.)

Guptill, Ira Clark (b'44)-N.H.1,75; (む).

STANIEY, JOSIAH IUURCII (b'60) $4-$

N.Y.5,84; (ठ).

NORTHBRIDGE, 8,807, WORCESTER

Des Roslers, besire Y.-Que.3,'98; (1'95)

NORTH BROOKFIELD, 3,075, WORCESTER

Edmands, Idelle Lydia (b'63) - 111.9,'97; (1'97).

Ludden, Emerson Augustus (b'61)-N.Y.3,

PIIELAX' EDW. FRANCIS (b'8 $\left.{ }^{\prime}\right)$-Vt.2,'09; (1'10).

Prouty, Albert Henry-Mass.1,'90 : (

Spooner, Geo. Robl.-Pa.9,70; (t).

Witter, Wilbur Fiske-Conn.1, 71 ; ( $($ ).

NORTH CAMBRIDGE (BOSTON P.O.)

\section{MIDDLESEX}

Hartley, Rebeeca Agnes-Mass.5.99; (1'02).

Viles, John Otis ciarfleld (b's0) 0 : (1'J); 39 Mt. Pleasant St. : 10-12, 6-7

Robertson. Jessie Wilhelnine

$\left(b^{\prime} 86\right)-$ Mass. i,'I i ; (l'12)

Wheet, Harry kay (h'si)_Mass. -'L3: (I'Is).

NORTH CARVER, 500, PLYMOUTH

Horse, Geo. F. $\rightarrow$; (む).

NORTH CHELMSFORD, 2,100, MIDDLESEX

HOBAN, JAMES JOHN-Pa.2,07; (ठ).

FARNEY, FRED ELLRIDGE (b'6i)-ITe.1, $86 ;$ ( )

NORTH DANA, 567, WORCESTER

Robertson, Chas. iv. (b'81) - N.H.1,07; $(1,0 \%)$.

NORTH DARTMOUTH, 1,500, BRISTOL

Howland, Clarence Eugene $\left(b^{\prime} 75\right)-$ N.Y.5, $97 ;(1,97)$.

NORTH EASTON, 3,000, BRISTOL

IICCABE, FRANK JOSEPH $\left(b^{\prime} 80\right) \oplus-$ Mass. 1,$08 ;$ (I'0s).

PORTER, ROBT. BRASTOW (b'76) $\oplus$ Mass. 1,'02; (1'02).
STEVENSON, WIIJIS

Mili)

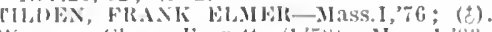
arren. Clats liverett (bos) Mass, 1,83:

NORTHFIELD, 70I, FRANIKLIN

YHWTOX, A.RON LEWIS $\left(b^{\prime} 65\right)$

9s: (l’98); 0 p.

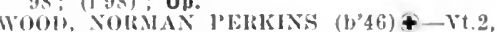
$32 ;(\$)$.

NORTH GRAFTON, I,820, WORCESTER

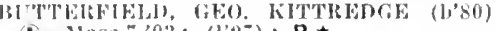

$+-M a s s .4,03 ; 100) ; P . \star$

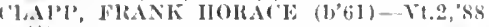

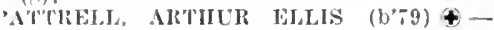
Nil1, $05 ;$; (1,05)

stevenson, Eitle Nilyne (1,71)-Mass.5,97; (1'13).

NORTH LEVERETT, I50, FRANILLIN

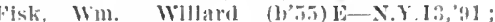
(3)

NORTH OXFORD, 1,200, WORCESTER

STONE, IBYRON-I'a.2,'t; ; (t).

NORTH READING。 I,059, MIDDLESEX

IVTELILL, (HIS, WIISON (b'65) 4

IIass i, $0: 3$; (1'03).

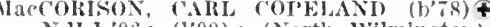
-N.11.1,06; (1'09); (North Wilmington).

NORTH SCITUATE, I,000, PLYMOUTH

Grovesteln, Wm. Pride-Mass.7,96; (l†).

NORTH WEYMOUTH, 1,000, NORFOLK

MAKE, WM. AlsRAM (I'49)\&-Me.1,'-9; (ठ) .

NORTH WILBRAHAM, 980, HAMPDEN

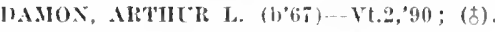

NORTH WILMINGTON, 300, MIDDLESEX BITNS, NEWELL BLY

(See Boston.)

Mac'OLISON, CARL ('OI'LLANI)

(See North Reading.)

Sewhart, IIarry Sanl. (b'83) - I'a.9,'09;

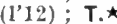

NORTON, I,826, BRISTOL

ROUND, AR'TJUR MOREY - Mass.1,'S4; (t) ; G.

NORWELL, 784, PLYMOUTH

Little, Ilarry James (b'60) II-Mass.5,'84 ; (t)

NORWOOD, 8,0I4, NORFOLK

Brennan, Edward Francis (l'84)-Mass, 7 , '08; (1'12).

Carroll, Tlomas Francis-Mass, 1,99; (1t) ; LR.

DerrIck, Geo. W'm. (b'77) - Mass.7,03; (I'03)

FIELD, HENRY MORTYN (b'75)థ-Mass.1, 04: (1'04); (D3).

FOGG, IRVING SYLYESTER (b'52) -

Mass.1,7 7 ; (t)

GOTLD, CLARKE STORER (b'66)-Mass.1, 88 ; (t)

HAGERTY, JOS. J. (b’i4) $€$ - Mass.1, 05 ; (1'05).

Hallowell, Clement Howard (b'55)-Mass.5, $79 ;$ (古).

HARTIVELL, ARTHUR SPEAR (b'73) I'a.2,'97; (1'00); S.

Hubbard, Halbert Chas-Mass.5,06; (1'06)

llurley, Danl. Madison-N.Y.10,92; (li).

SORTON, EBEN CARYER (b'56) - Yt.2, ' $85 ;$ (t) ; $(\mathbf{H} 2,13)$.

Norton, Eliza Bogart Lawrence (b'56)Pa.t,'si; ; (t).

Nutting, Fredk. Harrison (b78) - Mass.6, $97 ;(1,97)$.

0'Toole, Thomas Henry (b'74) - Pa.2,'97; (I'9T)

PLIMPTON, LEIVIS HENRY (b'50) Mass.1,79; (I'98).

Riemer, Hugo Bruno Chas.

(See Boston.)

Winslow, Richard Elliot (b'74)-MIass.5,'98; (I'98).

OAK BLUFFS, 1,084, DUKES

Dean, Hubert Tidd (b'70) H - Mass.5, 03 ; (1'03).

OAKDALE, 399, WORCESTER

Tyler, Albert Mason (b'58) - Mich.1,'86; (ठ).
ONSET, 1,660, PLYMOUTH

('rownlnshleld, l'lopeb-o: (さ)

beksteln, Carollne K.-D; (t)

ileason, Edwin l'utnim (b'66)-Mass.1,92. (ठ)

ORANGE, 5,282, FRANKLIN

BIreli, Sylvanus Jutkins-D; (ठ).

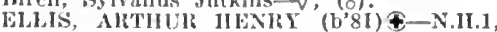
$07 ;(1,07)$

Fearl, Frod Henry- Yt.2,an: (l'96)

leach, Allert Clinton (b'71)-N.II.1, 94 (ち)

IAHAR, HAROLD ROIJT. COLLNS (b'82) -Mass.7.08; (l'09).

SMITI, IIIRÁL FRED MARKIEY (b'59)Mass. 1, 8 : : (む).

TFN BROE(K, STANTON JACOB-N.Y.J, 93; (

ORLEANS, 677, BARNSTABLE

BLSEE, FRANK AUEIIBERT - Mass.7, 06 ; (I'06).

Marrel, Reuhen Josluna (b"73)-Md.3,03: (1'04); Op.

MECIV, JAIFA INARICK-M(1.4,05; (1'05). OSTERVILLE, 500, BARNSTABLE

KINNEY, WM. DE, AKCT (b'T3)-Me.1,'99 (1'99).

OXFORD, 3,361, WORCESTER

FLETCIIEK, IROBT. SIVAN (b'72) - Pa.2,

01; ( l'01).

Lyun, Clus. Win.-N.II.1,72; (l'98).

WOOWWARD, JOHNSON RU'WLS (b'65)Vt.2, 88 ; (t).

PALMER, 8,610, HAMPDEN

Buncly, Erwin Stlllman (b'89) -Vt.2,'13: Ionson State IIospital.

Carsley, SIdney Raymond-Vt.2,02; (l'02).

Cheney, Harry Cleveland (b'7i) H-Mass.5, 01 (1'01); $\mathrm{s}$

CLEAVES, IIELEN FRANCES TAFT (b'62) †-Mich.1,'00; (l'05).

Cowen, Jelvin E. (b'82)-Vt.2, $07 ;\left(l^{\prime} 07\right)$.

Douglass, Edmund Stowe (b'86)-Vt.2,10 ;

(l'11); Monson Strate Iospital.

LOON, EVERET'T (b'55) $4-$ Me.1,81; (お) ; ( $\left.\mathrm{F}_{2}, 13\right)$.

GREENE, RANSOM ALPHONSO $\oplus$ - MId.4 $02 ;(1 \div) ; \mathbf{N P}$.

HOWSKINS, IIORGAN BREWSTER (b'75) -Vt.2,99; (I'02); (E2); NP.‡

King, Geo. Elbert (b'91)-V't.2,'12; (l'13).

Hoore, Geo. Andrew (b'72) - Mass.6,'10

CHNEIDER, JACOB PHILIP $\left(\mathrm{b}^{\prime} 67\right) \oplus-$ Yt. 2,94 ; (ठ) .

Taft, Annie Eizina-Mass.7,'07; (1'07).

'hon, Douglas Armour (b'87) - Vt.2,'12;

(l'13) ; IIonson State Hospital; Path.

PEABODY, 15,721 , ESSEX

Barnes, Ida Florence-Mass.5,'93; (t) ; 16 Chestnut St. ; 8-I, 4-6.

CARROLL, HENRY GERALD.

(See Salem.)

Currill, Francis Walter (b'91)-Mass. i,'13; (I'13) : 96 Wain St.

DOWNEY, WM. HENRY-Mass.1,'98; (1'98) 67 MaIn St. ; $2-3,6-8$

EWING, GEO. WINBURN (b'7T)థ-MI.6, 99 ; (l'00); (Middleton); offlee, 32 Main St. ; $2-5$.

FOSS, RAIPH ENERY (b'83)\&-Vt.2,08. (l’08); 178 Lowell St.; office, 39 Malin St. : $2-3, i-8$.

EOSTEI, HORACE KENDALI (b'54) $\oplus$ N.H.1,82; (t); 2 Park St. ; until 9, 2-3, Goodell, Jane Beck Sulth-N.T.20.'01; () ; I02 Tremont $S$ t.

HICKEY, JOHN JOS. (b'68)†-Mass.1,03: (I'03); 40 Main St.; 8-9, 1-3, 7-8.

JORDAN, JOHN FRANKLIN (b'67) $\oplus-$ (D)

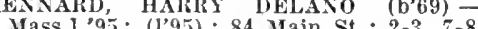
Ianoogian, Byzant, John (b'78)-Mass.5. I1; (1'11); 31 Main St.

Pomeroy, IIarris Starr-X.Y.19,"00; (1'00); 93 Nain St. ; $2-3,7-8$.

SHANМHAN, JOHN-N.Y.5,81; (お) ; 69 Main St.

TUCKER, SAML. CHASE (b'72) - -N.H.I 93: (†); 16 Chestnut St.; $2-3,7-8$

Webster, Jonathan Edwards - Mass.1,'93.

(t); 6 Tremont Pl.; office, 34 Main St. ; $2-3,7-8$. 
PENIKESE, - OUKES

Parher, Fraik H -Wass.6,9l; (?)

PEPPERELL, 2.953. MIDDLESEX

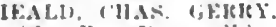

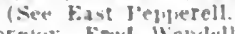

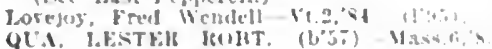

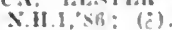

PETERSHAM 757, WORCESTER

Donaldvon, frolk: A ustis? (b'bs) - Vass "01: (I"0)').

PIGEON COVE, 955. ESSEX

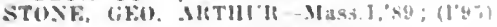

PITTSFIELO, 32,121, BERKSHIRE

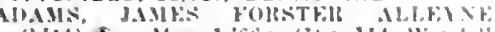

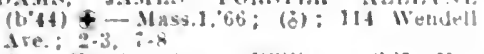

Baker, Harrict Agnes WhHams (b"-s) II

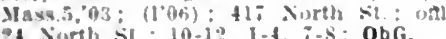

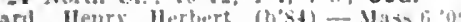

(1. I): 31 II North sh

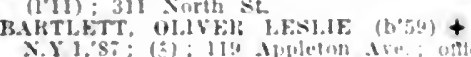

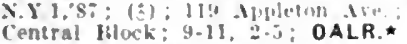

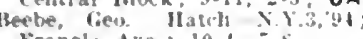

Francls ive.: 10-t, :-

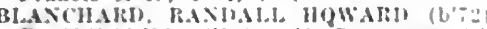

\&-N.1.10.96: $(1996) ; 40$ Commonuentih Are.: 7 North sit:-4.

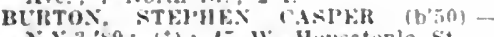

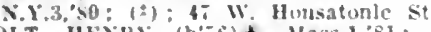

COI.T, HEXIll $\left(b^{\circ}, 5\right)+$ Mass. $1,81:$ : 193 South st. : ofice, Berkshlre life Inx. Co. 13ld: : $9-10,2-3$

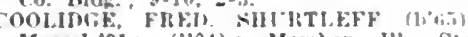

Mass.1,91: (1.04); Jember HIt. Slate

Iled. Suc.: IJwas Fleld: $9-10,2-3$; (A3)

CURAIFR, WM. HAIE-N.II.1,81: (引)

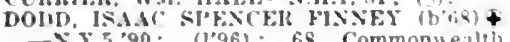

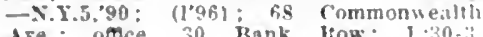

Are ofnce, 30 Bank low: I:30-:

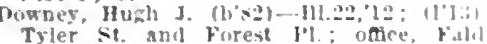
Tyler St. and Forest
man wock: $2-4,7-8$.

DTNILA, HARRY HALTIETT (b'si)O.H.1,1: (1'13); 12 North $51 . ; 9-10,2-4$.

EIsvir, Mathut: s. (1,8i)-Mds, 12 (1'121: 229 Rolwhin Iie, oflec, si; Nurth St. $8-10,1-3$.

EXILANII, AIRERT CHAS $\left(\mathrm{b}^{-7}\right)+$ Mass.1.03: (1.03): $15 \%$ I Iartlet? A offee, 124 North Si : 9-10, 2-3, i-8,

FINKELSTEIN, NiTHAN (b's6) - Mase $12:(1 ' 12) ; 8 t$ Yorth st. : 10-12, 3-5, $:-4$

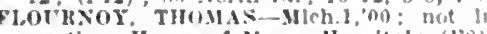
practice: IIouse of Mercy llospltal (F")

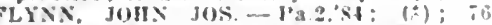
Kurbank st.: oftoe. I8. Forth st.

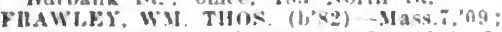
(1'09): 194 Xiorth st.; 9-10, 2-3:30. $=8 \cdot 30$

Ilendec, leslle Horallo (litif) ... Mut. it

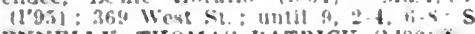

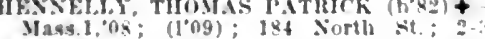
$7=8: 5$.

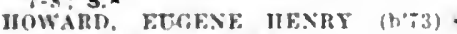
Mase I, $98 ;(198)$; 246 Sortl st.; 9 -10 $3-4, i-8$.

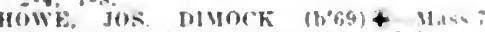
.48; (1.98): 83 tinlon st: 2.4 i.8.

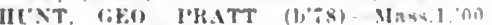

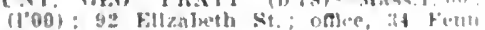
St. : $\mathbf{S}$.

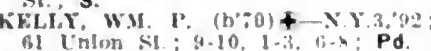

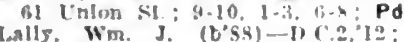

Milier Blig.

Ganclols, fhas Jos. (1'98) - Md 9:1L: (1"11): if Rradford st ; onloc, Winle" Blde.

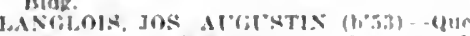
A (

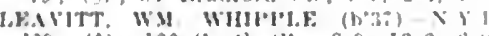

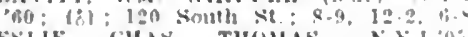

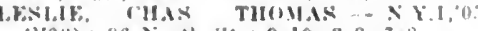
(100s): \&6 Xirth st.: $9-10,8-3, i-8$

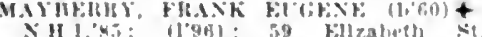

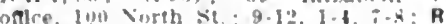
काt?

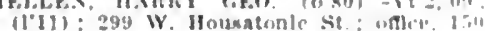
IIII: 295 W. Jousatonle St

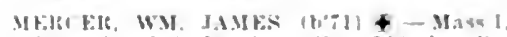

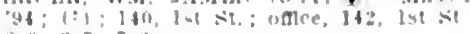
Q.4.,

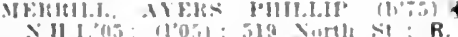

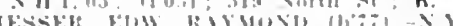

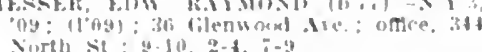

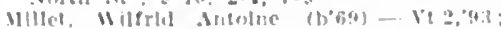

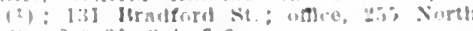
st: $;-9: 30, \because-1,7-9$

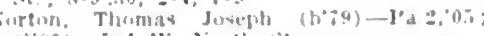

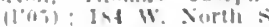

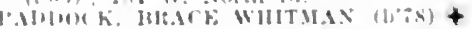

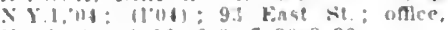
Nurll $\mathrm{si}: 4.10,-2.3=-311-8 \cdot 30$

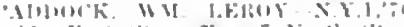

119 Filat st. ompe, North st

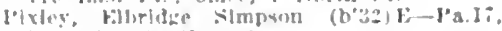
is: (2): 94 kave st

HE) (1)

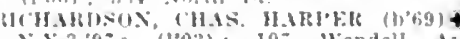
$\times 1.3,97 ;(1003): 197$ Wendell die. uflec. : Bank liow; I- is: S."

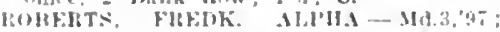

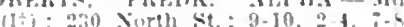

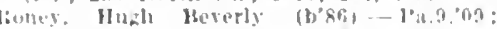

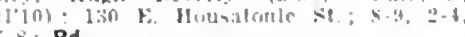
-R: Pd.

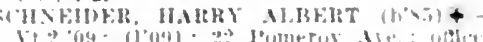

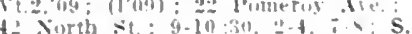

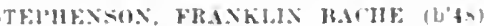
-1 1. 1,3: Med. Insp. commander. 1.A., rutled: It6 Marllet Are.

sullivan, John Slbert $(1,86)-\mathrm{Y} Y 3.10$

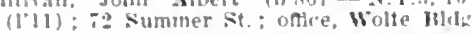

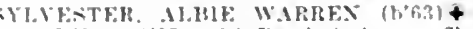
Me 1.92: (100): is Bartlett Ne.

in North Ne: M-12.

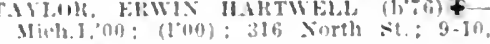
- + - :

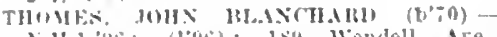

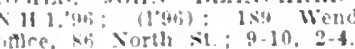

Tulu, Jumes Heury X.1.3,90; (:) : 280 West it

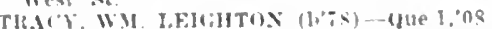
11.091: 703 Xorth st.; nalce, rark Blilg

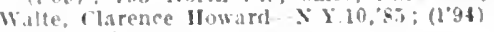
17 Vurth st.

Wheeler, James Hudiom (1, t:) 11 - Mirh.s.

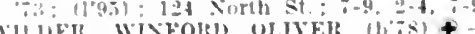

las.oi: (lob): 105 North st: $9-10$

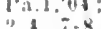

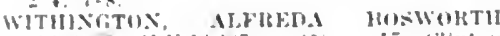

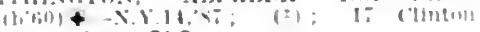
Ive: $(113)$ : ObG.

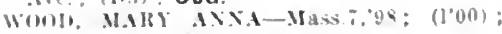
1 ti lomerny ire.

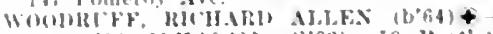

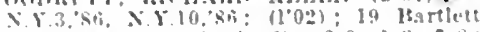

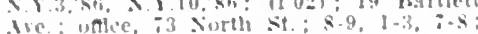
i.

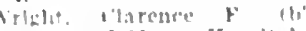

Hins if Meres Hongltal.

PLYMOUTH, 12.1\$1, PLYMOUTH

Jhes

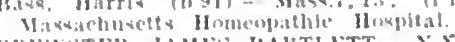

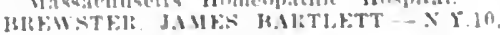
ofif: (3): nest in uractlec

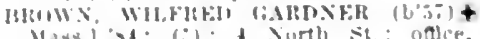

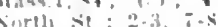

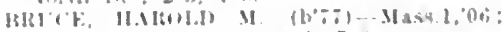
11 t for fourt sit: : 1,

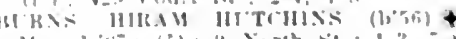

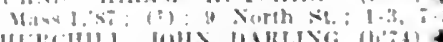

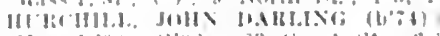

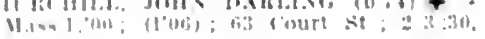
(ii) I.tis, H:l,w

(sice bueton )

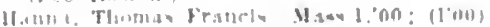

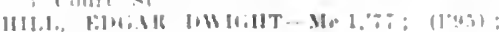

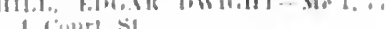

1 ( ).

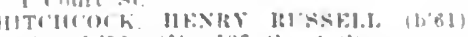

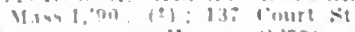

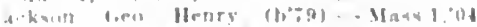

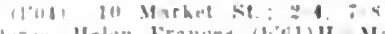

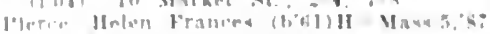

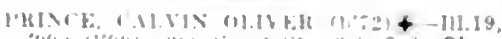

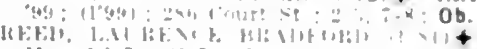

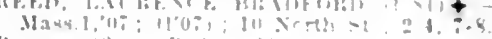
Rogers, Mass. Rugus M:as

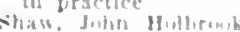

(A.e lowtin)

Shate, Juhn Jisend (1, In) II

$1: 1:$ It lirem-ler $: 1,:+4$

(1) $3:)$ : 12:- Water

Hralleirl Jinl:

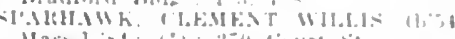

Masi 1, in

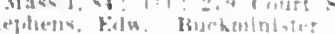

Q4.3: ("): not in prarilce.

PRESCOTT. 205. HAMPSHIRE

(]ilk, Walter Almun (b०5:) - 111.1, 8 (1'thin)

PRINCETON, 6IO. WORCESTER

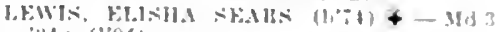

PROVINCETOWN 4,369. BARNSTABLE

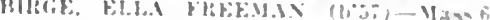

(1) (:) : Op.

(:): ALR

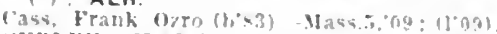

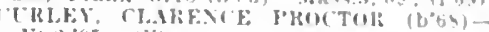
$1, \geq 0 \div \div: 11: 01$

FTTS. HFNIR BIRD (h'se) + - bas, an: (1'12): Med. Irup., Commander, I S.)

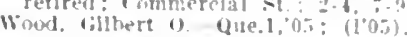

QUINCY, 32,642. NORFOLK

Thlserom, Iljalmat (b'63) - Macsi:"1!:

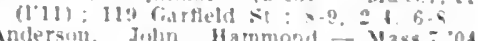

(I'04): 12 lothland St: untll $9,1-3$ Ai-s; OिA.

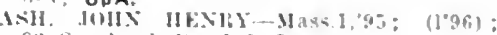

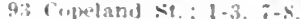

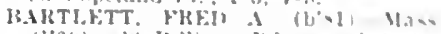

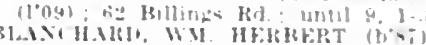

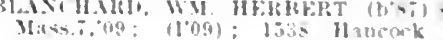
$i-S ; S$

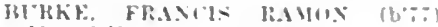

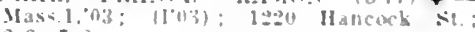

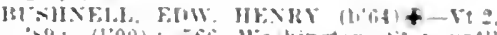

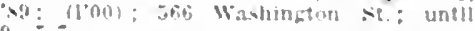
Haris, Frank stewart (b"5t) H-Mass, $\because 6$;

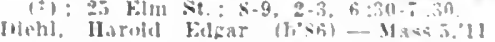

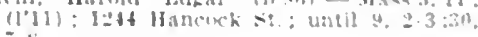

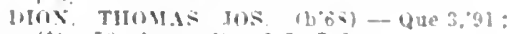

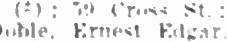

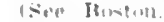

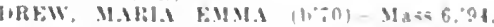

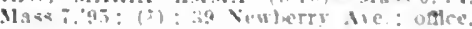

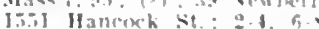

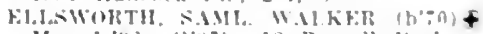
Mast 1."0io; (1"bi): is Russell 1"stk

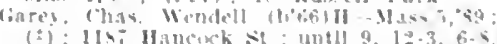

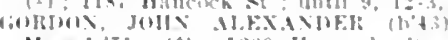

Maxq, 1,:1: (2): 1:00 Jancerk sit

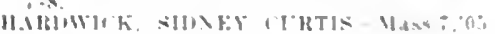
1? : 18, klm sit

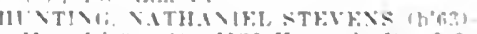

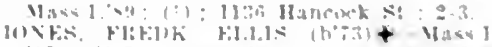

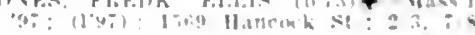

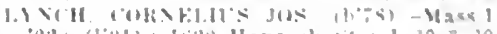

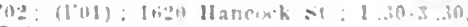

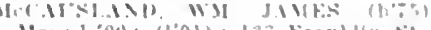

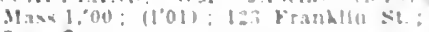

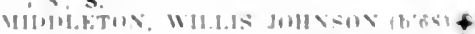

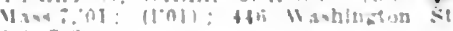

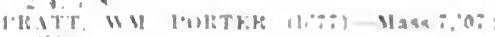
(1'01)

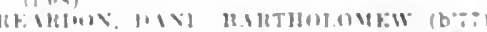

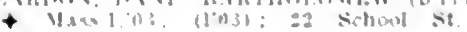

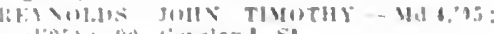

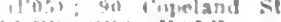

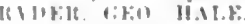


SAIUEST, WALTEI? LESLE (b'77) Hass. I, 03; (1'03); 1155 Hancerek $2=3,7-8$. SHEIIIAN, CEORGI: MAl'RICE (b's2)II ass. 1., 0

$7-8 ; 5$.

Thompson. Arthur lerclial Mass.5,97; $(1+)$ : 50 Hrook \$it.

RANDOLPH, 4,301, NORFOLK

Chase, Auguslus Luclus $(h+49)-0.2,72 ;$ (t)

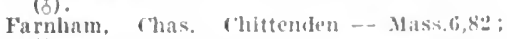
(c)

GItASAER, FIANK ('I.AKK (b'49) + Vt.2, Ti, N.II.1.8. (t)

Ifarmon, fialus Fijall (1,8i) Mass.5,09: (1) (3)!

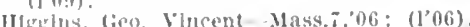

11:16

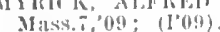

READING, 5,818, MIDDLESEX

BRONW, W'M. JOIIN (b'63) - Mass.5.'01; $\left(l^{\prime} 01\right)$.

DOW, GEO. FARWELL (b'69) +-Mass.l, '96i; $\left(l^{\prime} 96\right)$.

EDES, IOOH'T. TIIAXTEIR.

(see Boston.)

IIALIGAX. FDW. MAUIRICE (b'SO)Mlass. 1,03: (1'03)

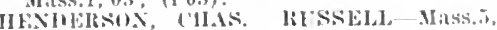
'S9; (t)

Parker, Raymund Isrewer (b'8.5)-Mass.1, '1: 2 : (1'13).

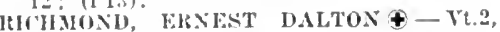
0I: (t).

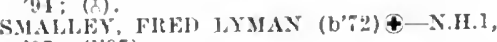
$97 ;(1,97)$.

READVILLE (IND. STA., BOSTON), 一, NORFOLK

leck, Eugene chase.

(See Hyde Hark.)

REVERE, 18,219 , SUFFOLK

(See Boston.)

Andrews, Bralnard Alge-Ilass.b,'93; (c); 687 Winthrop Ave.

ANDREWS, FREDK. FRANCIS (b'72)Mass.I,05; (I'05); 94 Beach st.; 2-3,

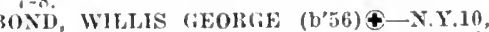
'89; (む); 74 Beach St.; offee, 76 Iseach St. $1-2,6-\pi$

Isrown, Edison Wm.-Mass.7,05; (l'05); 119 State Road.

CiMMIXAs. EDWIX FRANCIS - Mass.1, ใิ ; (ै) ; 898 Winthrop Ave.; 1-2.

Kinney, Funlce Draper (b'52)-Mass.6, 90 , "ass. 1,95; (t); 240 Beach st.; 2-4; Ob.

Knowles, Edw. Augustine (b'81) - Mass. i, '12; (1'12) : 270 Broadway.

lamb; Jos. E' (b'0)-IIass.6,08; (Chem-

lat); 935 vinthrop Are.

Melos, Jonathan Harding - Mass.7,94; (1'95); 690 Winthrop Are.

MOXAHAS, EWW. JAMES $\left(b^{\prime} 84\right) \oplus-$ Mass.7,09: (I'09); 665 Beach St.

MORIIS, JiMES STEWART (b'66) $\oplus_{2-4}$ in -8 .

NEWTON, WM. CURTIS $\left(b^{\prime}-4\right) \oplus-M a s s .5$, "96; (l'96); 370 Broadway.

oak, Chas, Arihur (b'79) - Mass.1,06:

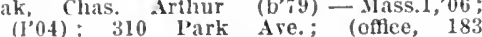
Frankin St. ; Lynn; $1-3,6-8)$; $\mathbf{S}$.

l'ark, Isaac $I^{\prime}$. (b'07)-Me.1,92; (t) ; 234 Beach St. ; $1-3,6-7$.

I'reveth, loseph.

(See Boston.)

Shaw, James Stot-Mass.j,'76; (d)

Silbermann, Naurice (b'83) - Va.4,'11; (I'11); 112 Shirley Ave. ; $9-10,2-3,6-8$.

WAKKR, WM. M.

(See Boston.)

W.IIAII, IOHN EDW. (b'73)-Md.4,"98; (l'98); 238 Beach St.; 1-2, $7-8$.

Wilkins, Geo. Arthur (b'36) - Md.4, 08 ;

(1'08); 79 Shirley Are.; 1-3, 7-8.

ROCHDALE, 487, WORCESTER

LEACH, EDWARD MORTON- N.Y.3,93;

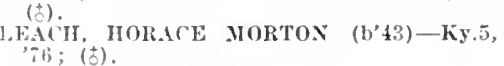

ROCK, 400, PLYMOUTH

Silurtleff, James Fredk. (b'42)-N.Y.3,67;
ROCKLAND, 6,928, PLYMOUTH

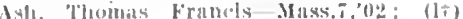

collate, Ihas, Ilenry, Jr.-Mass.5, (i)

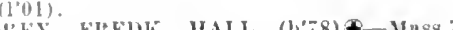

(1),ES, Fith

'04; (I'04). If.- H-I'a.9,'88; (ま)

'I'MHNis, INANA FRANK (b'84)

Mass, 1,10 ; (1'10).

Flt.Mr, Jos. (b'tic)-Mass. 1,94; (b).

Fremch, Winslow, Burrell (b'69) II-Nass.5,

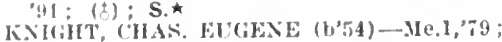
(1'95)

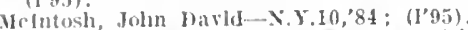

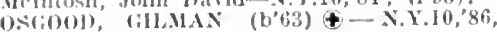

Mitss. 6,', 87 ; (ठ).

ROCKPORT, 4,211, ESSEX

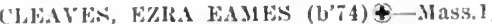
(10): (1'yy).

Emery, Robt. Loret (b'80)-Mas.5, 08 ; (l'0.8).

Hall, (has. Brackett-II-Mass.5,'78; (1'95) (")Brlen, Owen st. Clare-Me.1,66; (o). TIPIPR, AUGESTUS MACIANIILAN $(1,48)+$ - Mass. 1,70; (o)

ROWLEY, 1,265, ESSEX

I'EIIRIC, STHPHEN ACGLSTCS-Mass. 95; (1'45).

ROYALSTON, 215, WORCESTER

Adams, Franels Waylanà (1,40)-Mass.1,68; (む)

RUSSELL, 965, HAMPDEN

Wiger, (ieorge Vernon (b'80)-Mass.6,'04 (l'06)

RUTLAND, 1,225, WORCESTER

CIIMBEILAIN, WM, EUGENE-Vt.2,'83 (ठ):

RANE, BAYARD TAYLOR (b; 79$) \oplus$ Howes, Wlllard Boyden (b'81)-Mass.5,'12 ; (1'12); state Sanatorium; T.*

apham, Geo. Nelson. (sce Bosten.)

Lyon, James A. (b'82)-IId.9,'06; (l'1l)

['ettinglll, Olin Sewall (b'82)-Me.1,08; ( )

state sanatoriun.

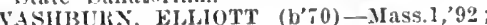
(ठ)

SAGAMORE, 378, BARNSTABLE

('IBIY, EITNEST FHANCIS (b'76)-Miss. 05 : (1'05).

SALEM, 43,697, ESSEX

AIEARNE, CORNELIUS AUGUSTUS, JR. $\left(b^{\prime}(08)+\right.$-.Mass. 1, 89; (⿱士口) ; (Lynn); ot flce. 8.3 Essex st.

ATWOOD, FRANK SUMYER-IIAss.1,'82 (む) ; 10 Monroe St.; office, 125 Federa st. : $2-3,7-8$.

BLAIR, GEO. KENNISTON (b'-5)£-Me.1 $00 ;\left(l^{\prime} 00\right) ; 311$ Essex St.; 2-3, 7-8

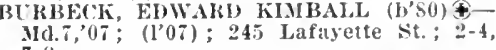
$\mathrm{i}-8$.

CARHTON, FRANK CARR $\left(\mathrm{b}^{\prime}, 9\right)$ \& Mass.1, 08; (l'08); 16 Jorth St.; 2-3, 7-8; Prof. llist., Mass.6.

CARROLL, HENRI GERAIL (b'S4)-N.H.I, 07 ; (1’07); (Peabody); offlee, 309 Essex S1. $2-5,7-8 ; 0$. $\star$

CHOÁTE, DAVIn (b’28)-Mass.1, ‘ै4; (む) not in practice; 35 Norman St.; effice, .33 Norman St.; $2-3,7-8$.

clark, DeWitt Seoville, Jr. (b'88)-Mass.1 '13; (1'13): 2 ollver St.

Cohill, David Young-IIass.5,'96; (J'96) 1741,2 Essex St.

Cote, Camille (b'59)-Ont.4,79; (o) ; 134 Lafavette st. ; $7-9,1-2,6-8$.

CLHTIS, CIIAS. LEVERFTT (b'85)\&-Me.1, 09: (I’09); 78 Federal st.; 2-3, 7-8.

E.ARBOISN, JOHN HENRY - N.H.1T8;
(§); Member N.H. Med. Soc.; 83 Bridge

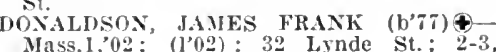
Mass.1,02; (l’02); 32 Lynde St.; 2-3, Dyer, Ernest Arey (b'75)-Mass. 1,04; (l'04) 3 Brown St. ; $1-3,6-8 ; \mathrm{S}$.

ELIJOT, HENRY LIBBEY (b'74) †-Me.1, 98; (li) ; 84 Washington Sq. ; 8-9, 4-5.

Ferguson, Arthur Bixy-Mass.5, '8 ;'; (t) 45 Federal St. ; until $9,2-3,7-8$

FIELD, MARTIY THOMAS $\left(\mathrm{b}^{\prime}, 5\right) \notin-M a s s .1$ '01; (1'04); 23 Winter St.; 2-3,7-8.
FINNEOAN, IHILI' JOS, (b'87)-Mass.1, 1I; (1'11); 921/2 Lissex st.; 2-3, 7-8. f'lynn, Johi ILenry (b'89)-Mass.7, 13 ; (1'13); 211/2 Boston St

Gardner, Frank AugustIne (b'6I) HI-Mass.5 83; (t); 23 North st. ; $1.3,7=8$. GoOHELl. (;EO. ZINA (b'5y) - Mass.

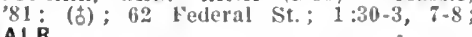
ALR

Gould, Carlisle koyal (b'90)-Mo.1,'13; Intern, Salem Irospital.

HFNXFASEY, WM. WA IREN†-Mass.7,06 ; (l'06) ; 333 Essex sit. (I31;)

Henry, Thomas Francis-Mass. 7,05 ; (1'05) 171 Federal St.

JOY('E, JAMES IIENIRY - Mass.7,03: $\left(\mathrm{l}^{\prime} 03\right) ; 17$ Federal St.

KITTRED)F, THOMAS $\left(b^{\prime}, 2\right)+-$ X.Y.8, 74 ; (o); I3 vhestnut st.; $2-3,7-8: S$.

Lakeman, Mary Iopes (b'ï0)II-Mass.5, 9. $\left(1^{\prime} 95\right) ; 9$ Summer Si. ; 2-4, $i-8$.

LE BOFI', ALFILED THOMAS (b'82)\& IIl.4,"08; (l'08); 154 Lafayette st.

LESSES, MAX (b'82) - Ont.5,05; (l'06) -0 Essex st. : $2-4,7-8$

Mackay, Andrew Jos. (b'79)-MId.3, 02 $\left(l^{\prime} 02\right) ; 25$ ('hureh sit.; $1-3,7-8$.

Machean, llector John (b'76)-ild.4, 08 (1'08): Essex St.

MEDERMUTT, WHI, VINCENT (b'i3) Mlass.1,96; (1'96); 17 Charter St. ; $2-4$, $7-8$.

Morse, ('has. Whecler-H-Mass.5,89; (む) ; 94 isridge st. ; $2-3,7-8$.

Murge, Kate liertrude-H-Mass.5,'80; ( 309 Esser St: 1-3, 7-8

NFWIALI, HARVEY FIELD - Mass.1,05 (1'05): (51 Nahant St., Lynn); offlee, 333 Essex St.

NOYES, WM. NELSON (b'T3) $\mathbf{t}$-Mass. 05 ; $\left(1{ }^{\prime} 05\right) ; 12$ P'leasant St. ; 2-3, $7-8$.

Payne, (ieo. Harkness (b'41) -Mass.5,'75; (む); (West Somerrllle); oftlee, \& Barton Sq. ; $10-12,2-4,7-8$.

PEIRSON, EDW. IAWRFNCE (h'62) Mass. 1,88; (t); 13 Barton Sq. ; $2-3,7-8$

Percy, (ieo. Emery-H-Nass. 5 ; 79 ; (o ) 359 Essex st. ; 2-4, $i-8$.

PHIPPEY, IIARDY (b'62) \&-Mass.1, 89 ; (b) \$ $\$ 4$ Washlngton Sq. : $2-3,7-8$.

PHII'PEN, WALTER GRAY $\left(\mathrm{b}^{\prime} ; 6\right) \oplus$ Mass.1,04; (l'04); 88 Washington Sq. $2-3 ; \mathrm{S}$.

POHRIER, EMILE-Que.3,'81; (t) ; 116 Lafarette Si,; offlce, $;$ Harbor St.

poirler, (ieo. Ilenri (b'86)-Mass. 7,10 ; (I'I1); T IIarbor st.

POHIER, HOR.ACE-Que.3,02; (l'03); 173 Lafayette St.; $2-3,7-8$.

ROBHIXN, FRED GHBSON.

(See Boston.)

Itoss, IIareld Danforth (b'84)-Me.1,'13 Intern, Salem Hospital.

Roulier, Jacobum Phillippe-Ont.4,'88 ; (ठ) : 195 Lafayette $\mathrm{St}$.

RUSHFORI, EDW. ALLAN (b'83)-Mass. '05; (l'05); 175 Lafayette St.; 1-3, $7-8$; Pd.

SAIRENT, ARA NATHANIEL $\left(b^{\prime} 67\right) \Phi-$

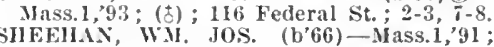
(む); 146 Federal St. ; $1-3,7-9$.

SHREVE, OCTAYIUS BARRELI-N.Y.1, 65 (b) ; 29 Chestnut St.

SIMIPSON, JAMES EDWIN (b'69) \&-Mass.1, 91; (f) ; 348 Essex St.; 2-3, 7-8.

STURGIS, BENJ. FRANKLIN, JR. (b'í5) - Ile.1,98; (1'98); 28 Pleasant st.; 2-3. TOWLE, EDWIN DUDLEY (b'63)థ-Md.9, 03 ; (1'03); 2 Mason St.; offlee, $99 \mathrm{I} / 2$ North St. ; $8-9,1-3,7-8$.

TUCKER, GEO. EYERETT (b'83)†-Me.1 08; (l’08); 86 Federal St.; 2-3, 7-8.

Webb, Albert Edw.

(See Bosion.)

Weleh, DanI. Edw. (b'85)-Mass.7,'10 (l'11) : 15 Hardy St.

WILSOS, CHARLES joORE (b'83)-Me.l

'11; (1'12); 54 Washington St.; 2-3, $7-8$.

SALISBURY, 890, ESSEX

Spalding, Jacob Franklin $\left(b^{\prime} 42\right) \rightarrow$; (

SANDWICH, 1,688 , BARNSTABLE

BEALE, SAML. MAISDEN, JR. $\left(b^{\prime} / 6\right)-$ Pa.2,'02; (1'02)

CURRIFR, CYRLS RICHARDSON (b'86) Mass. 7 , 11; (1’11); 0 bG. 


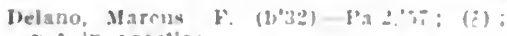

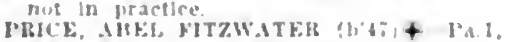

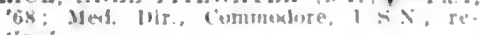
lired.

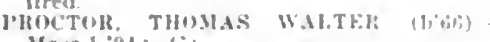
Mavs. J,OA: (:).

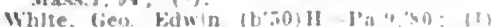

SAUGUS (LYNN P.0.). 8047. ESSEX

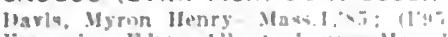

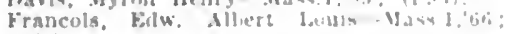

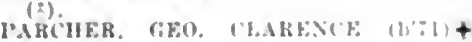

MI.3.93: (i)

SAXONVILLE, 2,000, MIDDLESEX

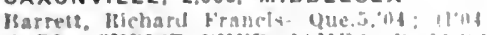

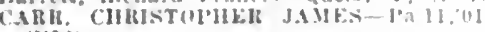
(1.0:).

Dudley, Osear abert (b's3)-Masufi, (1.0:

Weed, lico, franklin (b't5)-C: (1'4.5).

SCITUATE, 1,129, PLYMOUTH

ALFA.NIBR, THOMAS BRANCII $(1, \%+$ - Md 1, 0I: (1.01).

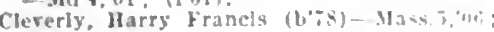
(1'0:i).

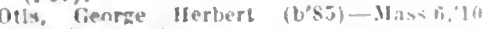
nut in practlos.

SCITUATE CENTER, 50, PLYMOUTH

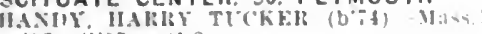
यद⿱

SHARON, 2.310, NORFOLK

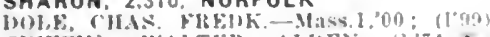

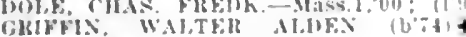

Mass. I;00: $[1,00):$ ALR.

Inastings, Iarollne Filiza.

(See Boston.)

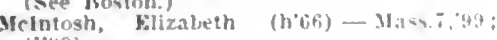
$\left(I^{*}(19)\right)$.

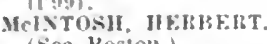

(see bostom.

Plumaer, Julla M-Mass.5,8:

SHEFFIELD, 1.645, BERKSHIRE

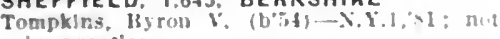

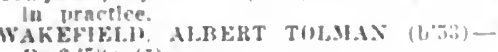
l'a.2, $\mathrm{is} ;(z)$

SHELBURNE FALLS, 1.331, FRANKLIN

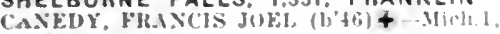
CA: (2)

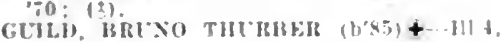
'0.5: (109). oushoure, John sianley (b)"is) - vue.1.48; (I'A8).

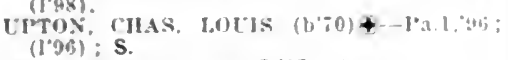

Willls. beward 1. (1.7.9:: (7.)

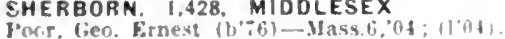

SHIRLEY, 1.892, MIDDLESEX

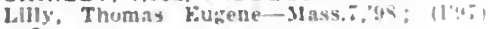
$\mathrm{Op}$.

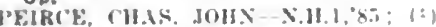

SHREWSBURY, 1.946, WORCESTER

BLISS. WILBLT HOWALI) (b'5S)-XY\&, $83: 131$

CHASE, FUWIS R.EWELLYX (L" 1 ) $\left.310,6,98:(]^{\circ} 98\right)$.

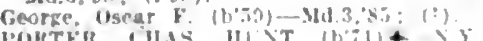

os: (l'10): $\mathrm{S}$.

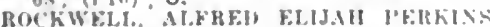
(tive Wurcemter.)

SILVER LAKE, 255, PLYMOUTH

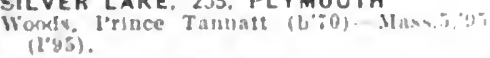

SOMERSET, 2.798, BRISTOL

Howker, Juhn Wesles. Vu $6 ., 0 \%$; $11 \%$ :

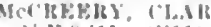

Marrill. Yrank Armingtuln.

(Wee ball Huer.)

SOMERVILLE, 77.236, MIDDLESEX

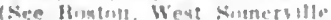

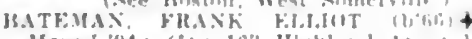

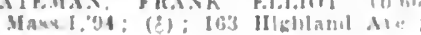

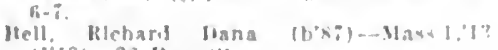

$(1 " 13): 26$ 1sow $\leqslant t$.

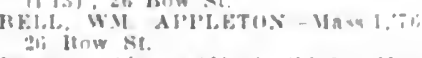

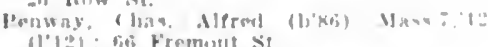

mul

Bi; rolioway si!.
16) 1:1: rellewl, 10 bsistent st.

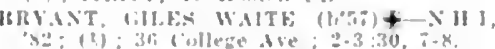

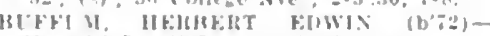

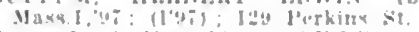

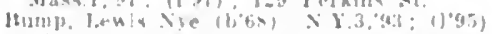

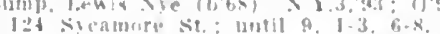

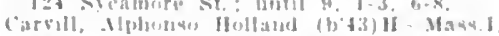

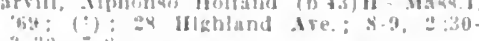

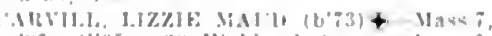

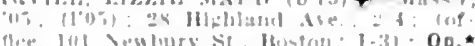

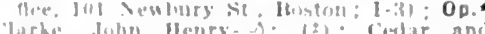
bilna sit.

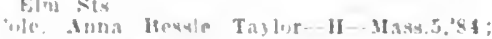

(1): if poarl se.

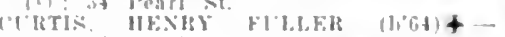

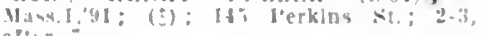
aflet

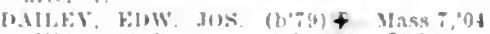

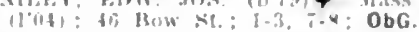

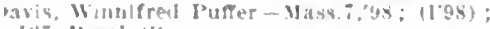
I:3 learl st.

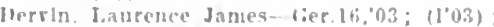
:Is higliland Are.: (1)3).

buld. Walter James.

(see Hoston.)

will Ht:ikr $1+-1$ a 2.33 ; Menter of the Med. Sirce of the sitate of Pa.; nut in fratalles: 1.it sumntr St.

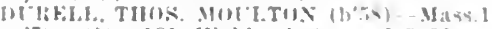
$\because !:$ (i) : 131 Hghland Ave : $2-3: 30$

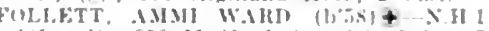

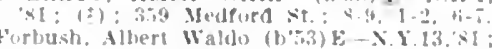

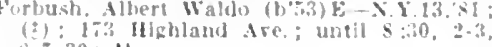
tio- : $: 20: U$

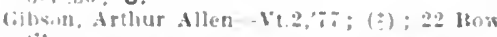
st.

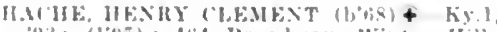
"93: (1:b5): tof Broadway, Winter bill $0-3,0-8$

II: Inirew Alchison (b57)-Md.3. $\times 3$; 1.01): 9 rarlton st.

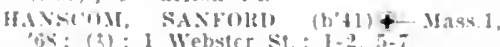

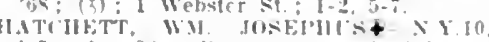
4: (2): 24 Arlington st.: $1-3,6-8$

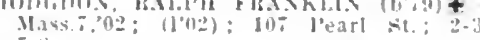

I(1) (1'a3); 35: Hhhland Are.

llughes, Geo. Fredk. Jr...Mass.7, "⿵⺆

(IIuA); 143 imax st.

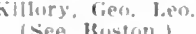

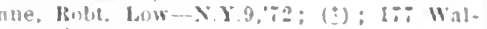
: vit st

letivlte, Mary Iurusta.

(sep lloston.)

Lee. Wesler Turrence (1,72) BI Mass.5, is

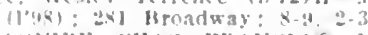

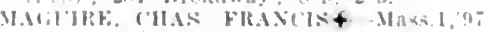
(147): 432 Mealforil se

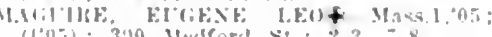

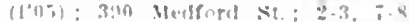

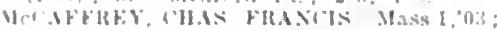
$11031:$ t :

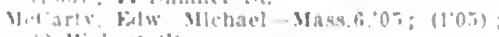
(i) Waluse st.

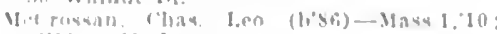
(1)11): 11 It.ow St.

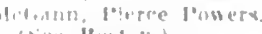

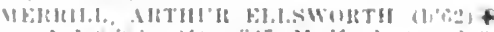
I $\because$ :

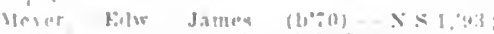

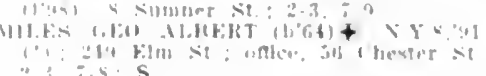

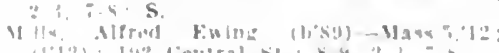

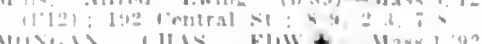

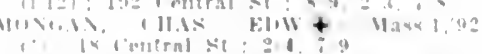

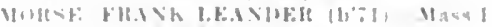

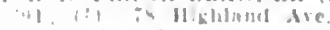

Filn Hesuril

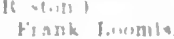

Itwe $(\cdots, 1)$

bitgictole var

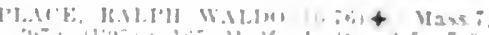
OpA.

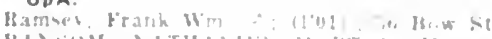

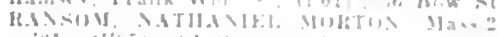

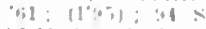

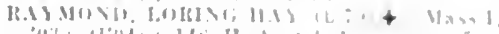

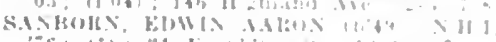

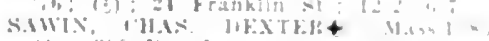
1:1; 390 Hrnalluay

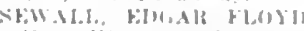

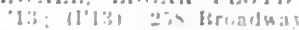

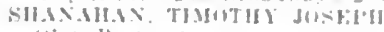

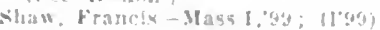

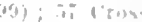

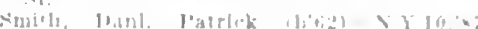

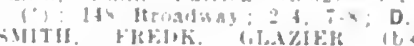

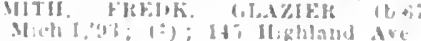

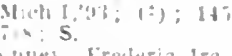

surneb Frolesic ira.

Troce Homplont

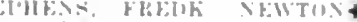
OALR

sllfer, ihas Wallare (bovolll Mas

(i) ${ }^{3}=1$ lor

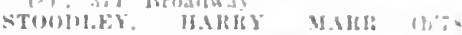

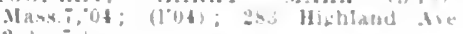

Sullian, Tlmotlyy dis.

(Siece isime(on)).

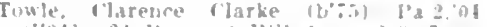
(I'nf): 21 l'rosfeet lllll Are

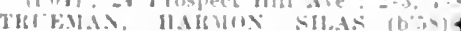

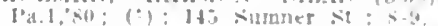

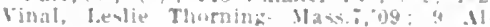
dutaty st

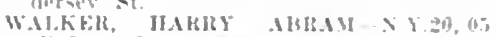

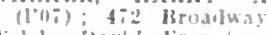

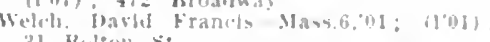
31 Hulton st.

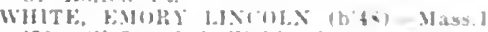

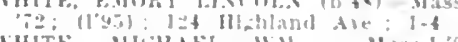

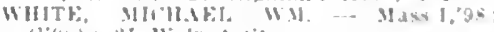
$(1+4 x):$ II Wilnut $s$

WHTIX, I,EO W.ISHINGTON WHTXY

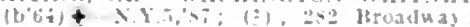
$2-3$

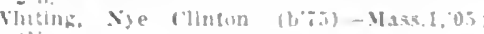
$(1+)$.

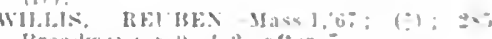
Itrouluat: 1-2, after

lWinnls. Mary Jarnard currler- If Vasi it

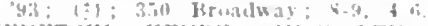

F.NFTII, HENRY ANEIIITH

SOUTH ACTON. 800. MIDDLESEX

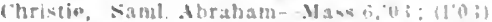

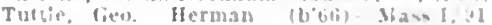
$(\because 1)$

SOUTHAMPTON, 8\%0, HAMPSHIRE

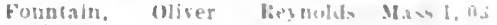
[1'11,3\}.

SOUTH ASHBURNHAM, 1,153, WORCES.

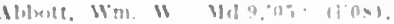

SOUTHBORO, 953. WORCESTER

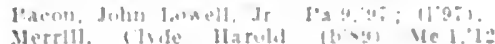
Merriti,

SOUTH BRAINTREE, 4.100, NORFOLK

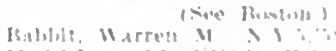

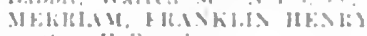

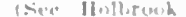

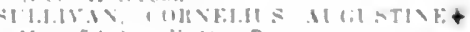

MAw

SOUTHBRIDGE, 12,592. WORCESTER

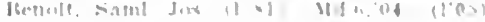

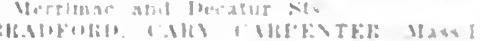

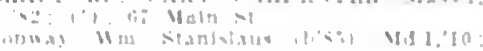
$11 \% 101$

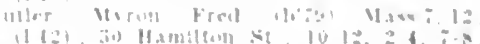
LR.

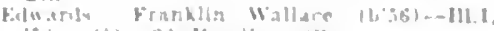
$60^{\prime}$ 
Mecrea, Allert J-E- - 0.2,?4; (t)

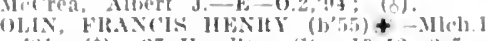

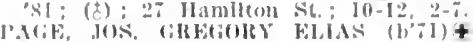

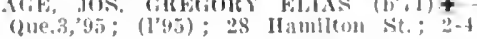

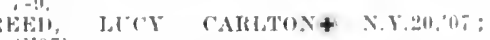
$\left(10^{0}\right)$.

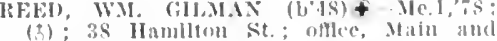
llanullwn Sts.; $2-4,7-9$

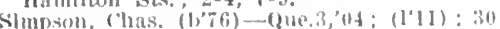
Marey st.; ofllere, st llamilton st.; $2-1$ i-9.

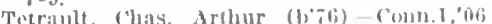

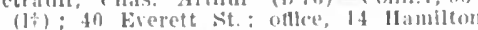
St: $24,7-8 ;$ OALR.

Tully, Cico, Wm, (b'ss)-M1ass.7,12; (1'12)

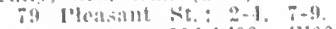

Womer, (ieo.-ill.4.00; (I'00).

SOUTH DARTMOUTH, I,218, BRISTOL

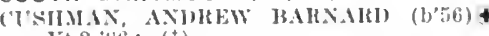
$-1+2 \times 80^{2} ;( \pm)$.

poyle, Francis wo (b'it) -.. lia.12,'lz: (1?

SOUTH DEERFIELD, I,058, FRANKLIN MOLINY, CHIILLS:

(sce sunderland).

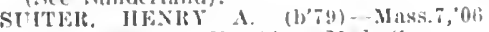

(l'0ti); Member Vt. State Med. Soc

SOUTH DENNIS, 265, BARNSTABLE

DAVIS, CHAS. MLLEX (b'48)--D.C.3, 83.

I'11.9,84: $(1,09)$.

SOUTH ESSEX, 723, ESSEX

Simpson, Jos. -Mass. 7,99 ; (l'0.').

SOUTH FITCHBURG (FITCHBURG P.O.), - WORCESTER

Landiry, Napoleon (b'60)-(2ue.3,?3; (I'94). SOUTH HADLEY, 4,894. HAMPSHIRE L.ANG, HELIBEL'?

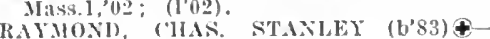
RAYHoN, ("lls: STA Mamond, Mabel ('ruttenden (b'86)-Mc.5

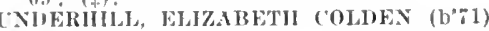
$+\mathbf{N} . Y^{2} \cdot 20,00 ;\left(I^{\prime} 01\right)$.

SOUTH HADLEY FALLS, 3,2II, HAMPSHIRE

Curran, lzcatrice Magdalene-Pa.7,04; $\left(\mathrm{l}^{3} 0 \mathrm{t}\right)$

DOONAX, HENRY EDW. (b'82)£-Md.4, 08; $(1,05) ; 0$ b.

(t)

LELAND, FORREST LEROY $\left(\mathrm{b}^{\prime} \mathrm{S0}\right)+$ Mass. 7, , $08 ;$ (l'0s).

SOUTH HAMILTON, 814, ESSEX

'ORC'ORAX, WOHA GILBERT (b'83)\&Mass., $08 ;\left(l^{\prime} 08\right)$.

SOUTH HINGHAM, 750, PLYMOUTH

Cnderwood. Jarid Cileason $\left(b^{\prime} 70\right)-M a .4$ 94: (1'94).

SOUTH LANCASTER, I,044, WORCESTER BR.ADLEY, GEO. PERLEY (b'49) \$-N.Y.1 $\because 0$; Med. Dlr., Capt., U.S.N., retired.

SOUTH LINCOLN, 564, MIDOLESEX

BLODGETT, STEIPHEN HASKELL.

(See Boston.)

HART, JOS. STORER (b'73)-MIAss.1, 00, (1'99).

SOUTH MILFORD, I50, WORCESTER

BLAKE, WELLMAN CAIMIN (b'58)N.II.I,'st; (宗); Member Vt. State Med. Soc.; G.

SOUTH NATICK, 609, MIDDLESEX

Annis. Summer Bryden (b'84)-Mass.5,'11 (1'11)

HILLS, CHAS. EV ERETT $\left.(1)^{\prime} 69\right) \mp-N . I 1.1$ $01 ;$ (1'01)

SOUTH SUDBURY, 700, MIDDLESEX

OYLATT SUDBO ALEXANDER (b'49) Y.1,

SOUTHVILLE, 140, WORCESTER

Gane, Wm. Jloward.

(See Ashland.)

SOUTH WEYMOUTH, 4,000, NORFOLK (See Boston.)

ENERSON, GEO. EDW.

(FiNGFR, KARLE HENRY (b'68)-N.II.1, $92 ;(1.95) ; \mathrm{Pd}$

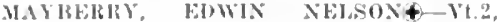

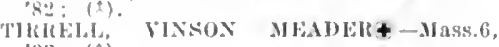
'93; (⿱艹)

SOUTHWICK, 1,020, HAMPDEN

"orler, Fred Knlglit-l'a.1l,'ys; (l"9S).

SPENCER, 6,740, WORCESTER

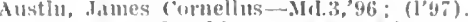

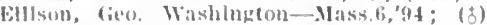

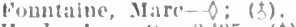

loule, Jos.- Que.3.8.5: (t)

Nurdock Edw. Aribur (bo54) H-Mass.5,

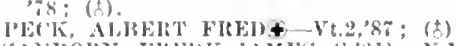

SANBOIS, FHEHK IAMES (b'BI)-XY.10, $383:(8)$.

SPRINGFIELD, 88,926, HAMPDEN

XTMERK OF IJIVSIClANS, 188.

AMAMS, (HAS. BALEIR (b'74) - N.Y.I, WH) (I'l1) ; 43 Oxford st. ; oftlee, 431 Main St.: $:-4,7-8 ; U *$.

WAMS, BUWIN BOARDMAN (b'51)N. $y^{*} 1,80:(f) ; 423$ Main St.

Bhern, John Frimels-IIass.6,"13; Irampden IIospital.

ANTHONY, JEREMLAI CHILSTOPHFR (b't6) - I't. 2.91; ( (t); 150 Chestnut st.

Atwater, Dasld F. (1,17) - Conn. 1,'39; not lit prictlce; 82 Maple sit.

BACOX, THEODOHE SPAULDING Mass.1,98; (1'98); 69 Maple s't. :

ATES, FYLIEETT ALAXSON (b'60) + Nass.1, 90 ; (3) ; $5 \%$ ('bestnut st.; $2-3$

RFAHDSLEY, WILLAAM HENRY (b'82) $)$ ('onn.1,'10; (1'12); 84 Maple St. ; 1-3

IBENNER, IHICHARD STANWOODAMass. 1, 03 ; (1'03): 25 Maple St.

Bennitt, Francis Jiarion (b'57) II-N.Y.9, '8.3; (屯): 120 Sumner Are.; offee, 2.Irarrison Are. ; 11-12, 3-5.

BIRNIE, JOIN MATHFW' $\left(b^{\prime} 78\right) \oplus$ Mass.1,06; (1'06): 34 Stern's Terrace offlee, 6 Chestnut St.; $2-4 ;$ S.*

BLAIR, ORLAND RÓSSIYY (b'T1) +

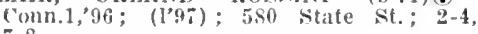
$i-8$.

Bowens, Bruce Tucker (1,68)-Mass.7,99: (I'09) ; office, 21 Hancoek St. ; $9-11,2-4$, 6-8. N.Y.1,94: (1'95): 24 Oxford St

BOYEH, JOS. NAPOLEON, JR. (b'75)థ Mass. 1,99; (1'99); 104 ' Fort Pleasant Are.; offee, 57-1/2 Main St.; $8-9,2-4$.

BRIGIIAY, FREDK. CLAYTON (b'71)Md.4.98; (1'98); 192 Walnut st.; 2-3, $6-8$; Pr.

BROGA, WM. WALIACE (b'53)-X.Y.3, 87: (1.95); 820 State St.

BROOKS, LAWTON STICKNEY $\left(b^{\prime} 47\right)+$ X.Y.1,69; (t) ; retired.

Brosnahan, John Jos. (b'86)-Y'.2,'13: House of Nerey.

BROWN, DANL. JOS. (b'61)\&-Mass.1, '86; (t) ; 317 Maln St. '98; (1'98); 421 Unlon St.; offlee, 18 State St.; $9-10,2-4,7-8 ; \mathbf{D}$.

Brown, Plumb ( $\left.\mathrm{b}^{*} 68\right)-\mathrm{Ill} .4,92$; (⿱十口) ; 503 State St. : $8-9,2-3, \tilde{i}-8$

Buckley, Cornelius Jos. (1)'76)-N.Y.3,10 (l'11); 29 yain st.; $9-10,2-4,7-9$.

BIDINGTON, HAROLD FAIR(HIH) (b'8T) †-N.Y.20,00; (I'11); 1024 State St. :

BIRKE, GEO. HERBERT (b'84)†-Que.1, 06 ; (1’09); 36 Beaumont St.; 9-10, 3-4,

BYRNES, HARRY FRANCIS $\left(b^{\prime}+6\right) \Phi$ Id.4,04; (1'04); 148 Central St.: office, 4 Chestnut St.; $10-12,2-4$; OALR.

Caldicott, Francis stephen (b'89)--Mass. $\tilde{i}$, '1s; Mercy Hospltal.

CALKINS, CHENEY HOSMER (b'60)Pa.1,'82; (t) ; 14 Maple St.; (B14).

CALKINS, IRYING ROMARO (b'ti) IId.4,'96; (l'96) ; 299 Central St. ; 1-3, $6-8 ; \mathbf{S}$.

CALKINS, MARSHALL (b'28)థ-N.H.1, CAMFILL, ROBT. EMINET-Mass.I,'95; (1'95); 148 Chestnut St.
CARLETON, DTULEY (b69)-Mass L 95 : $(196): 1371 / 4$ State St.

CAILLTON, HAIIII (b'70) \&-Mass, l, 04 ; (3) ; I21 Forest loark Ave.; oftlee, 10 Temple st.; 10-1, 2-4; (1814); 0p.‡

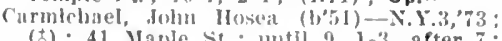
(t) ; 41 . Maple st.; until 9, 1-3, after 7 S.

HAPIN, DELIA LI'THETA (b'54)† Mrch.1,90; (3); 51 t'emple st.; 8.0, l-3. $6-8 ;$ G.

CHAPIN, LATHENG DCHLLY-Mass.1. 06 ; (1'06i) ; 20 alaple st. ; $8-10,2-4,7-8$. CIIAPIN, WALTER HLNRY (b'.59)-N.Y.I, 833; (3) ; 675 Stale st.; 12-2.

TALDIAN, (HAS. ILATCHFOHI (b’0)t Pa.2,92; (3); Long Itlll; office, 174

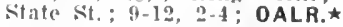

('IAFEY, IOIIN MEMAHON (b'86)-V't.2, "11: (1010); 318 $x$, Maln $\mathrm{st}$

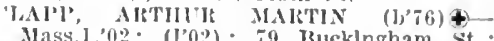
office, 10 ('hestunt st. $2.3 \cdot 30-8$

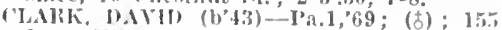
Long Hiil.

'omlns, James Brooks (b'71)H-Pa.9.99: (1'99); 287 St. James Are.; oflee, 6 Maple St.; 2-4, $7-8$.

Conrow, Matehlas Woolley $(1,78)$-N.Y.9, 05: (1'12); 73 Kenwood Park; offlee, 31 Maple St.; $9: 30-12,2-4$; (F7); OALR. 'oreoran, Luke (b'48) II-N.Y.9,'68; (屯) ; 174 state $\mathrm{St}$

COHT, PABKER MARTYX (b'T8)--Mass.1, '02; (1'02): 466 Sumner Ave.; offlce, 691 State St.; $9-10,2-4,7-8$.

CRAIG, WM. GIRSOX (b'68)£-Pa.2,92; (1 $\left.{ }^{\prime} 0.\right)$; ? Cornell St.; offee, $31 \%$ Mrain St. : 10-1; (Bt) ; OALR.*

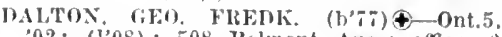
02; (I'ns); 508 Belmont Ave.; office, : Maple St.; 10-4; OpAL.ネ

DAYUSON, HEXRY JAMES DIFFQue.1, $04, \quad$ Scot.9.12,14,05; $(1,05) ; 26$ Maple st.; $9-11,2-4,7-8$.

DAVIS, ERNEST LELAND†-MISS. $\tilde{7}, 06$; (106) : $159 \mathrm{Ft}$. Pleasant Ave

Darls, Wm. Everett (b'64) E-0.32,'8i ; (t) ; $13 \pi 1 / 2$ State St.

I)EANE, WALLACE HARLOW (b'53)Conn.1, 77; (t) ; 265 l'nion St.; offce, yeems, Oren Manfred-1'a,, 04 317 Main st.

De Mareo Themas A.-Ita.10,'00; (l'03): 67 Ft. I'leasant Are, offce, $647 \frac{1 / 2}{} \mathrm{~S}$. Main st. $9-10,2-3,-8$.

EXTER, FIRD FAY (b'i9)†-Mass. 1,04; (t) ; 216 Pine $\mathrm{st}_{\text {. }}$; offlce, 2 Temple $S t$; ; $9-10,1-3,7-8$.

Dillon, John Aloysius (b'78)-Pa.1, 06 ; (I'09); (173 chestnut St., Holyoke); offlee, 310 Main St.; $2-4$; (B15); ALR*

HLLON, MICHAEL JOHN, JR. (b'83) \Mrl.4,08; (1'09) ; 182 state st. ; 8-10, 2-4.

Donovan, Walter James (b'82)-Mfass. i,'10; $\left(I^{\prime} 10\right) ; 172$ Maln St.

DOWNEY, CHLS. JOHN (b'69)§-Y'.2,'94: (†) ; 257 [nion st.; offee, 156 Mrain St.; $8-9,2-4, \pi-9$

DLBOIS, FOLINE BEATRICE CHURCII (b'78) \&-1lass.7, 03 ; (1'03); 174 Buckingham st.; offlee, 293 Bridge St.; 9-10, $2-4 ; P d$

EASTMAN, MEXANDER CRANE (b'T5)屯 Mass.1, 00 ; (I'0I); 179 st. James Ave.

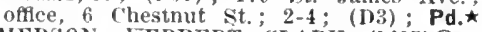

EMERSON, FERBERT' 'TAARK (b'65) † Mass.1,93; (t) ; 14: Chestnut 'st.

EVERETT, FREDK, LUTHER (b'T2)Y.Y.20,02; (I'04); 210 Pearl st.: office, 10 Chestmut St.; $9-10,2-3: 30,7-8$.

Fagnant, Benjamin (b'43)-0nt.4, 71 ; (t) ; 91 Howard st.; office, 93 Howard st.; $8-9: 30,1-3, \quad i-9$.

FINC'H, GEO. HARDY (b'68)૯-Vt.2,'98 : (1'99); 123 Main St.; office, 310 Main St.; $11: 30-1,2.4,6-8 ; U^{\star}{ }^{\star}$

Fiske, Harlo Adoniram $\left(b^{\prime} 50\right)-N . Y .1,7 \%$; $\left(I^{\prime} 95\right)$; 447 Sumner Are.; 8-9, 1-3,

FOSS, GEO. H. (b'79) † N.H.1, 06 ; (1'13).

Nember $\mathrm{X}$.H. Ned. Soc. 530 sumner Ave. FLRCol, CHAS. IAWRENCE (b'88)Conn.1.'10; (I'11); Empire II otel; offee, 591 S. Main St.: $7-9,1-3,7-8 ; \mathbf{S}$. 


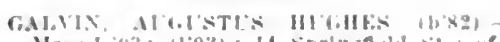
Mans I, 113: (I003): it sprlnghell st.; in

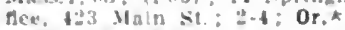

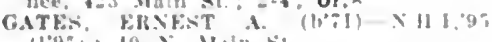
$11^{\circ 931}: 19 \times 2$. Ialn Sit.

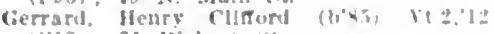
(1'13); is Walrut st.

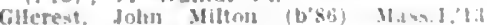
Interi, suringfiela Hosplial.

Golstur suringfeld Hosplial.

Mis?

Mul.3."48: (l'98); I0f linlon st

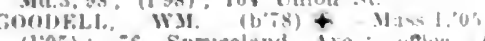

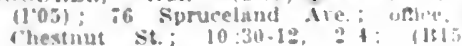

ALR.*

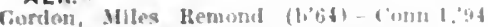

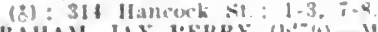

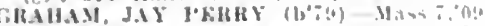
(1'09): 635 sumer Are, ; nttley. siale ist.

GLILI), FINIAR HI"XT (b'5:

(31: $13 \% 1_{2}$ silate sit

Ilamilton, Theodore Eirskine $(1,33)-\mathrm{V} / \mathrm{l}$ 61: (3): it Westumbter st

Hare, Wm, Andrew-Vt. $296 ;(190) ; 31$; Main St. : $9-10,9-4$.

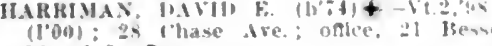
11.: $1-3 ; 0$.

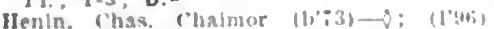
$\$ 1$ Cllnton st.; conter, 172 Main $\mathrm{xt} ; 1-3$ $\because-9$.

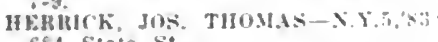
Gat State St.

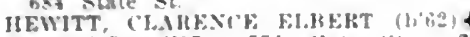

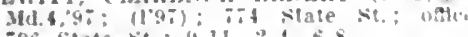
-06 Siate st: $4-11,2-4$ ti-s

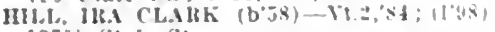

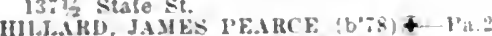
03; (103): 119 sumner Are.: until 2-4, $=8 ;$ NP.

IIKSCH, IIENK I.FON I'a.2,06: (1'Ati) 1:2 Yialn st.: 2-1. $;-5 ;$ S.

Jogan, Fremont Uincoln-3le.1:92: 10 rhestnut sit.

HOOKEIS, CHA. HAKEIS (b'aj)

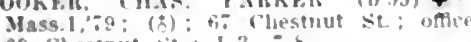

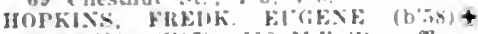

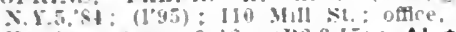
Harrlson the: :010; (132.3.15); AL.

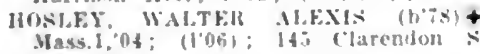
1.3 .

Hoves, Robt. Ferry (1,0,0)1 (1.99) : 5 (bak St. : untll $4,0.4$, :

ISoward. Lemonde (iarflelil (b'as) Massio

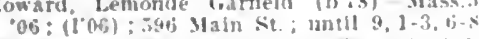

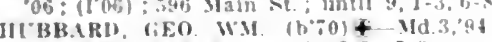
(\$): $320^{\circ}$ stale st.: $9-10,=-3,7-8$.

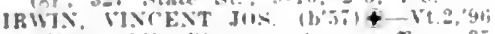
$\left(I^{\circ} 96\right) ; 330$ limnmen Are.: nftee, 35$]$ Maln :t.: $9-3$; (IBI): OALR.

acobs Chas Milchael (b'75)-Mass. : 03 (102): ? helwnol Terrace; 10-12, 2-4

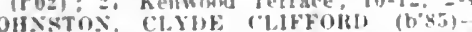

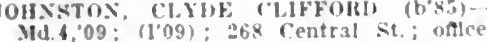
Md.4,09: $(1 \circ 09) ; 068$ Central St.

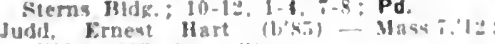
(1'13): ing state st.

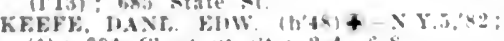
(8): 391 r'bestnut sit. : 2-1, ti-s

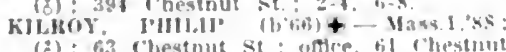
(3): $1-6: 0$.

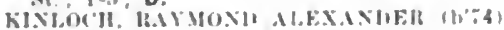

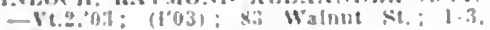
b.s: ob.

Lamarelie, fico. Tamerele $(1,63)$ Que.:.

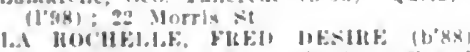

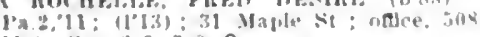

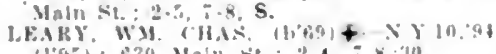

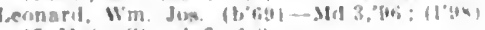
45 Maln Sit : $1-3,6-8$

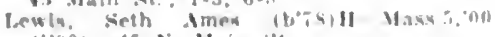
$11001:$ A $N$ Nain to

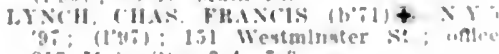
31: Maln sit: : 4 , : 8

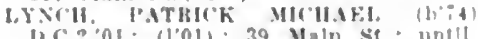

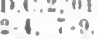

Millovil; bow Jos $(b \% 0)+111$

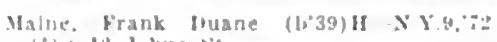
(2): 1: Johus it.

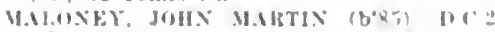

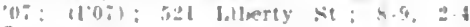

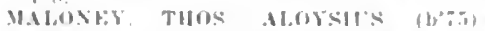

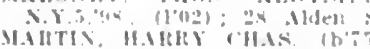

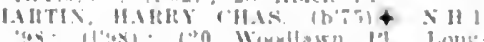

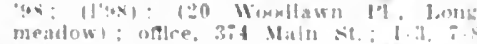

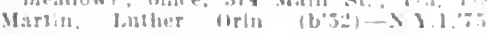
1:1: Ite Thesenul si

Maym. Mallew Tayler $11,001$. N H. $1,0 \%$

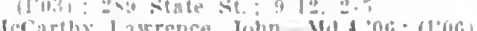

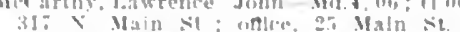

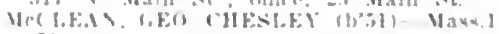

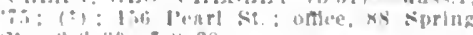
Mctivitr, ios:

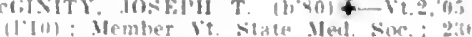
blekinson sit.

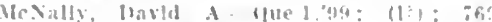

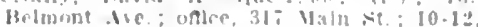
- 5 - $5: 0$

MEHITT, VITTOH SIIVIHO $(1062)+$

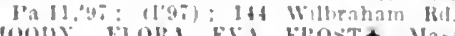

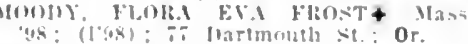

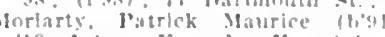
13: Intern. Hannden Homptis!

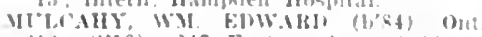
1:2: (1'13); 2ti Eastern Are, ; 11,1 .

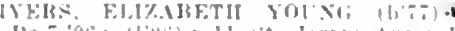

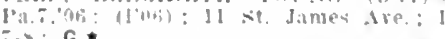

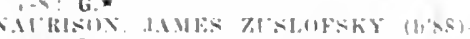

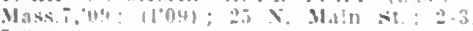

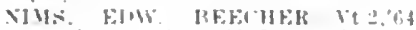

not in practice: th Harrard sit.

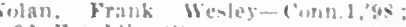

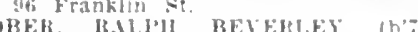

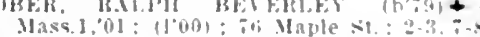

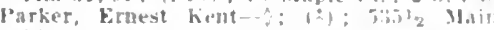

PARMEIEK, WM IOSIAH $(1, x)+V y$

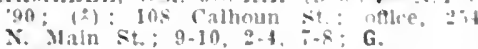

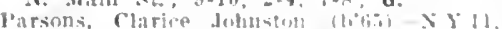

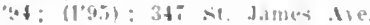

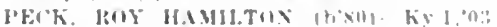

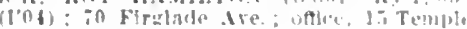
St. : $3-1:(13.5) ; U$.

leirce. Eilihu l'rometor- Mass:?

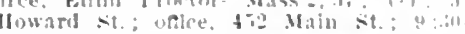
[1. $1: 3 n-4$

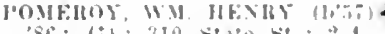

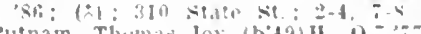

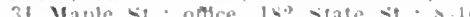

$1-3,-0$

Quina, James 11. 168a)-1102,07: 11!11 320 Holinion st

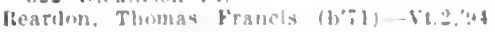
$(1+6,5):=8$. Irch :

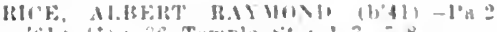

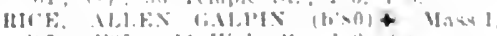

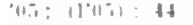

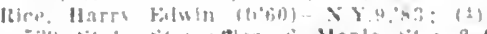

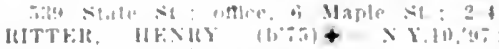

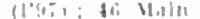

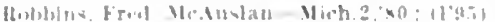

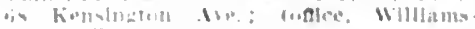
loter: T*

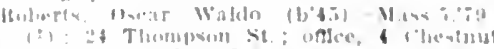

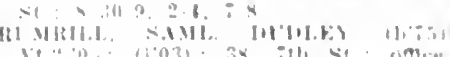

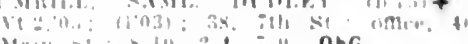
$11+11=i: 111=i, 7+4$ obG.

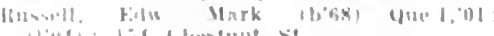

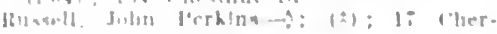

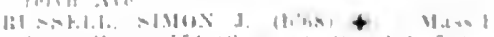

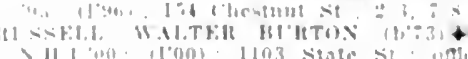

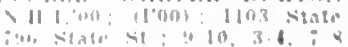

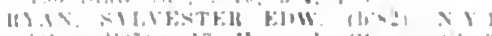

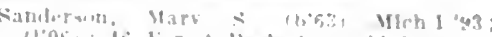
Ilobil: Hi: Hirom! larh Ave 10.1

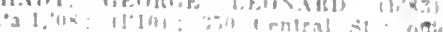
lit viate si

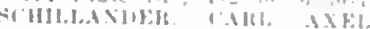

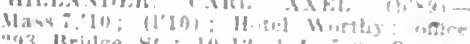

AEEL

ओаง

7.

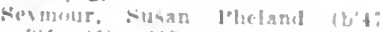

"Kt: 1 ; : H13 slate st

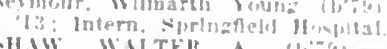

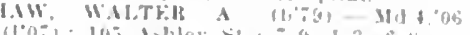

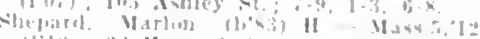

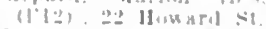

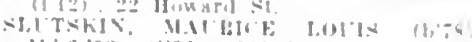

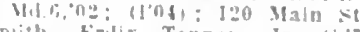

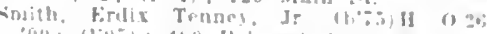

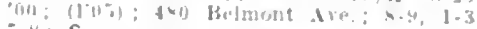

sutu S. HFHस

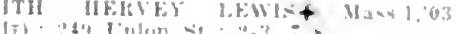

smlth, l.ewls A thiti

SMTH, WH.TH: ANEI

'80; (

now, virton $(b, i b)$ ira 1 , nai: nut in

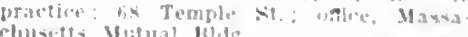
cluatti Mitual Mlde

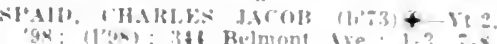

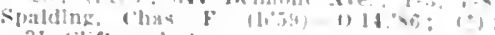
31 Cliftwond Als.

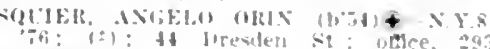
ifricline $1: 1:$ it. 3 it

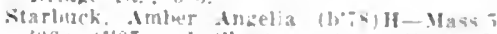
'b6: (1007): 1 'hestnut st.; once lit

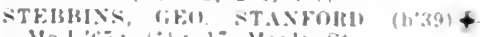

Mel.65: (") bi Maple st

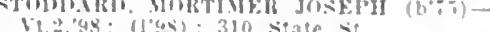

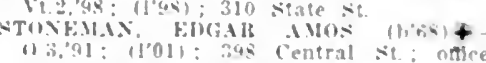
1) 3.91: 1'011: 248 Central st: nttre,

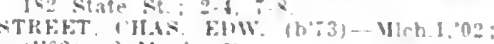
11001:- Vialest.

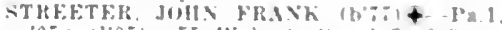

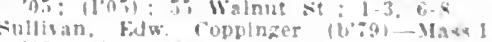

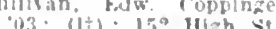

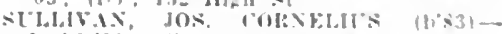
$\left.11.1^{2} 2,13 ; 11 \cdot 13\right) ;$ Merey Hus1131.

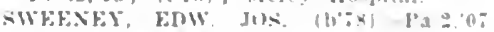

(100:): : Main st

ineet. rlara Marla

WFET, FHEMK BENONI $\{1,: 0\}$

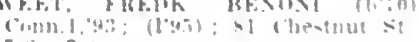

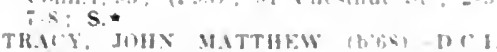

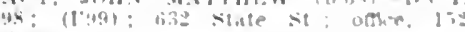
Chestnut st.

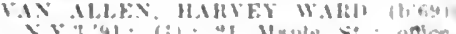

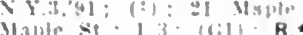

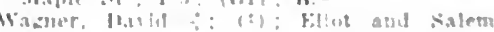

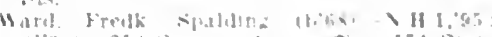

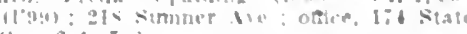
St: $:-1,5$

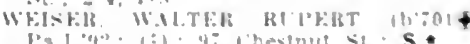

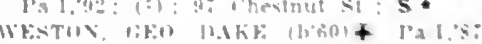

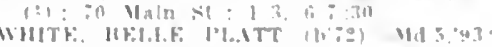
(1) 12: Simmor tro

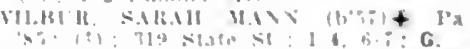

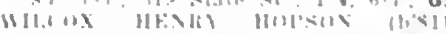

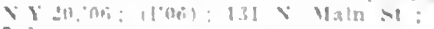

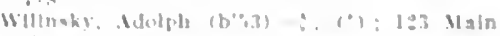

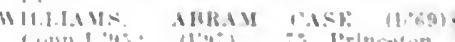

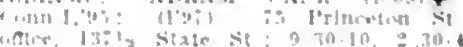

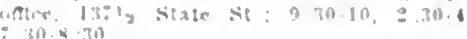

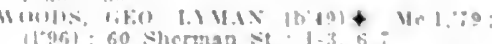

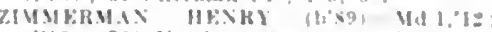

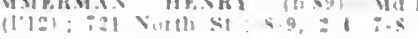


STATE FARM, 100, PLYMOUTH

BAKER, LEONALI MLLENE-Mass, 1,05 $\left(l^{\prime} 05\right)$.

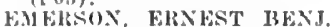

(see Mrldgewater.)

Enerson, llannals Lowell (b\%it)-Mass.7,

*00; (1'0I).

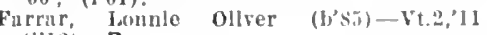

$\left(1^{\prime} 12\right) ; \mathbf{P}$.

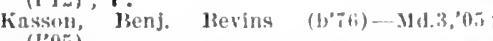

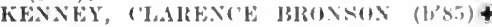

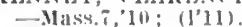

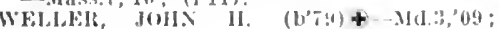
$\left(I^{*} 10\right)$.

STERLING, 860, WORCESTER

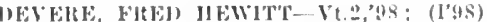

liot llarry (hester (b'4) N.11.1960 (199).

STOCKBRIDGE, 1,779, BERKSHIRE

HAVEN, IIENR CECIL_Mass, 1, T9; (\$)。

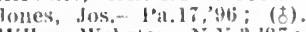

Mlller, Webster-X.Y.3,'st; (t)

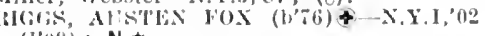

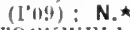

TOCLWELL, HEHBERT FMMONS \& -

Vt.2,?\%; (I,08).

STONEHAM, 7,090, MIDDLESEX

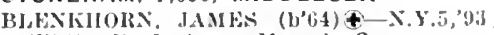

(L'93) ; J'rof. Surg., Matss, 6; S.

Ilodgson, Mlary' (olb-Mass.3,6 i ; (b) ; not

Ku practice.

$07:(1,0 s)$.

SICKlisON, GEO. WHLATON (b'52)£

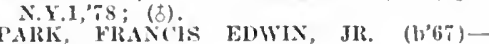

PARK, FRANC'LA
Mass. 1,90 ; (む).

SHFEHAX, MNRTIN DAVIDA-O; (I'95)

STOUGHTON, 6,3I6, NORFOLK

Ewlng, Edw, Ililts (b'-2)-Md.3,97; (1'98)

FAXUN, NATHANIEL WAIES $\left(\mathrm{b}^{\prime} 80\right) \oplus$

Mass. L,05; (1'04); S.

FAXON, WM. O'Ís (b'53)-Mass.5,76; (む).

Glennon, Michael-N.Y.10,'83; (t)

Golden, Jos. Francis (b'88)-Mass. 6 , 11 ; (l'11)

McDonald, Jos. (1'77)-1'a.11,'03; (1'03).

Rose, Danl. Campell (b'38) - Mass.1,69:

(t) : not in practlce.

SCANLAN, MATILE THOMAS (b'S4)Mass. 7,08 ; (l'08)

Swan, Chas. Jouis-Mass.1,94; (す).

Twombly, James Woodbury (b's4)-Mass.I,

11; (I'11).

SUNDERLAND, 1.047, FRANKLIN

MOIINE, CHARI.ES (b'T6) -4-Mass.1,03:

(I'03); (offlce, Soutlu Deerfield).

SUTTON (R.F.D., MILLBURY), 993, WORCESTER

Snith, Chas. Sherman-X.Y.5,'92; (ठ).

SWAMPSCOTT, 6.204, ESSEX

BICKNELL, RALPII EMERSON (b'Ts)థllass. 1,00; (1'00)

Glidclen, IIoward kenneth $\rightarrow$; (I'99).

GODFIEY, Jos. WITTEIS (b'6 6 ) - Mass. 6 90 ; (f): (office, 209 Lnion st., Lynn; $8-9,12: 30-3,6-3)$.

GRIMES, LORING' (b'81) $\uparrow$ - Mass.1,04 (1'04).

Knlght, Wm. Henry Anderson- $\bullet$; (t); not In practice.

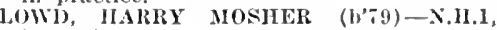

Rowley, (l'01). (I'08)

SWANSEA, 664, BRISTOL

Lergeron, Seraphine Ensebe.

(see Fall kiver.)

Jlliton, Jolan banlel (b'62)-X.Y.5,91 (1'97)

liellogr, Emery Campbell - Mass.6,03

WELLINGTON, JAMES LLOYD-MaSS. 1,42 ; $\left(I^{\prime} 97\right)$; not in practice.

TAUNTON, 34,259, BRISTOL

Nlibott, Fredk. Wallace (b'61) E-Me.2,'86; (ะ) ; i2 Broadway ; $2-3,7-8$.

Abbott, Sylvina Apphia (b'64) E-Mo.33, '1:3: (†); i2 Broadway : $2-3,7-8$.

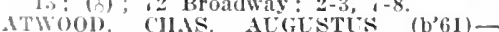
Mass.1, $83 ;(3) ; 15$ W. Britannia st.
BAKEIR, HARISY BEHECIHR (b'58)

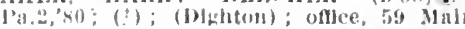
st. " 11$) ;(1)-1: 30,7-8$, (J3) : OALR. *

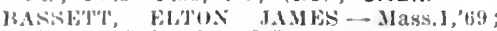
(i) ; 11 Cedar st. : 2-3

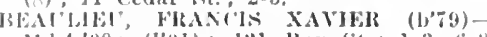
M(1.4, 00 ; (1'01): 1:21 l3ay St.; 1-3, 6-8 Bats, l'iere Gitsura Me.2.'85; (t); 151 Bay st.

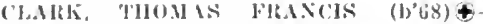
Massi.01; (1'01); 3 I Jroadway.

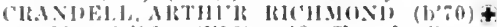
- Jass 1,46: (1.96): 48 Chureh Green: at i: (1):3)

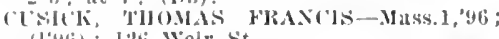
(14:1i); 1:ti Welr st.

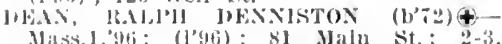
$\bar{i}-8$

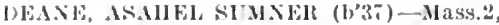

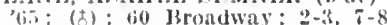

lwintl, Byron 1,ee-Mass.5,78; (t); 16 lliglı st.

(OX, WI. YALE: (J'65) \&-Mass.1,'XS ; (t) ; 26, 2d st.; 2-3.

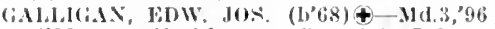

(I'06); $10 \mathrm{~N}$. J'easant St. ; $2-3,7-8$.

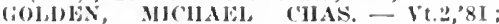

(d) : 54 brondway.

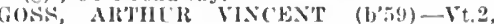

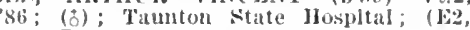
1ii) ; P.^

Grosvenor, Iemuel fonant (b'32) H-O.'tit; not lil pracilee; 223 Fremont Itd.

Inalnes, Faunle C. (b's9)-1'a.13,'11; State Jospital.

Hayward, Walter Barrows - Mass.5,97; $\left(\mathrm{I}^{\prime 97}\right) ; 148 \mathrm{High}$ St.

IIG(iNS, EUTOHA PIERCE (b'64)\& X.Y.14,94: not In practice: $17 \overline{5}$ HIgl st. llubbard, Chis. Thacher-Jass. 1, 61 ; (t) 104 Nain st.

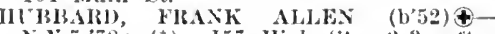
N.Y. 5,78; (\$); I5; High st. ; 2-3, atter 7 ; S.

llumt, John Abram (b'54)H-Mass.5,'93; (ち) ; 89 Weir st.; until 9, 1-3, 7-8.

FAROYL, ( ILAS. JBERRY (b'59)-N.Y.1 '8T: (t): 2 viue st.

MACJONALI), DONALD FRANCIS (b'68)Md.3,94; (ई); White and Somerset lves. ; $2-3$.

Mctiraw, Andrew James-Md.3,06; (l'06); 31 Broadway.

MEILGAX, DNNIEL, JOSEPII-Mass. I,94; (b) ; 2ti Pleasant st.

IIIO'T, ALPIIONSE FRAVCOIS-Md.4,93. (d) ; 160 Bay \$t. ; 1-3, 7-9;0b.

Mumford, John F. (b'91)-Md.3,'13; () ; Winthrop $\mathrm{S}$

MCRIIS, EMIIY FRANCES-Mass.6,92; (む) ; 23 summer St.

MURPII, FRANI ALGLSTINE-Nass. $\bar{~}$, 02; (1'02) ; 66 Broadway.

MIRIIIY, Jos. BRIC;GS (b'60)†-Mass.1, 8:3: (5): 23 summer st. $2-3: 30,7-8: 30$ MYJRSON, ARRAHAM (b'81)-Mass.7, os ; $\left(I^{\prime} 08\right)$; State Hospital; (E2). o'BRifs, JoHy FriNcis (b'86)-IId.3,

F'AlGE, Yo.ILS-N.H.1,'61; (c); 49 Broadway.

'WRIY, MARTILA - Pa.7,82; (t); 68 Broadway.

I'REABREY, SIIAS DEAN (b'38) $\oplus-$ Mass.1,'b5; (t); 103 Weir St.; 2-3.

P'rovost, Raoul (i. (b'81)-Vt.2,07; (l'11) ; State Ilospital.

RIPLEY, IIORACE GREELEY-Md.3,04; (l'04); Insane Hospital.

Robinson, James Arthur-Pa.1,'82; (1'02) ; 29 Trescott St.

HOBIXSON, THOS. JOHXS (b'65) + Mass.1,91; (f); 56 Broadway ; 2-3.

SAYLES, JOS. BORLAND - N.Y.10,'S8 N.II.1,88; (1'98); 68 Winthrop St. ; of fice, Crocker BIdg.; 1-9; D.ネ

WHITE, HENRY ÁLVERADO (b'86) †Mass. 7,11 ; (I'11); 139 Bay St.; 1-3, 7-8. Uuck, Arthur C. (b'85)-Pa.2,'12; Assist ant Physlcian; Taunton State Hospital.

TEMPLETON, 3,756, WORCESTER

GREFSWOON, SEWELL ELLIOTT (b'53) ( -Mass.1, it ; (c).

(I'96)
TEWIKSBURY, 3,750, MIDDLESEX

('nbecelrus, Jenry Jos. (b'90) - Mass. i,'13; (I'I3); Massachusetts sitate Iospltal.

Coburn, llarry Jay (b'82)-Mlass.i, 08 ;

DE WOLF, CHAS. WENTWOHTH (b'88)Mass. 7,12 ; (1'12) ; State Inflrmary.

Farmer, Wui. Hrancls (b'84)-Mass. 1,05 ; (I'05)

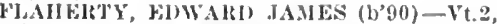
13; (I'13); Nassichusetts state Inflrm-

I.AHIABEE, IIEIBHET MANSON (b'79) + -Me. 1,01: (I'03)

landsily, John Crundall (b'93)-IIss.1,10 (1'12).

NIfHOLs, JOHX HOIYOKEt-Mass.1,92; (む) $(12,13)$.

PEIRCE, (iEO. AlPJionso (b'75) - Mass.1, $98 ;($ I'98).

l'dikx, SHERMAN (b'78)-Mass.1,07: (1'07); S.

IROACII, AIERED JOHN (b'82) - Mass.7. , 05 ; (l'06i).

Robbins, Ellmund IIenry (b'85)-N.11.1,13; (1'13); State Inlirmary.

Tuttle, Howard K. (b'80) - Mass.7,07: (l'ox); $\mathbf{S}$.

Wallle, (ieorge Jcleod (b'90)-Mass. ,', Il ; (I'J2).

Villongliby, Earle Carlisle (b'82)-Mass.7. 11; (l'11).

THORNDIKE, I,300 HAMPDEN

D[NIIIY, IIEN]Y A. (b's1)-.Id.4, 08 ; (l'09).

THREE RIVERS, 1,404, HAMPDEN

GilloLX, CHAS. II. (b'75)-Que.3,'99: (l'99).

GITHEN, BENIAMIN ALMERIN $\left(\mathrm{b}^{\prime} 79\right) \oplus$ Associate Fellow-Mass.6,10; (Dentlst). MILLEJ, SAML. OSGOOL - N.II.1,"99: (l’99).

TOPSFIELD, 1,174, ESSEX

Jenklns, Thomas Llneoln (b'66)-Mass.1, '90; (屯). BYRON (b'74)థ-X.H.1,00; (I'v1).

TOWNSEND, 825, MIDDLESEX

Atwood, Albert John- $0.7,85 ;(\vdots)$

'HANILEK, JU'HER GRAYHS (b'44) Mlass.1, 61 ; (む).

Cole, Wm. Hzra (b'42) E-Pa.17,69; (t).

TURNERS FALLS, 5,229, FRANKLIN

( harron, Jos. Itosario-Que.3,'95; (I'95)

KEII?, HOWARD MAR'TN (b's7)-M.ं.4. '11; (l'11).

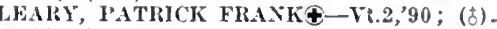

MCGILLICLDDY, RICHARD ALOY'SIL'S Md.4, 03 ; (1'03).

MESSER, CIAS. CARSON (b'53)†-N.H.I, $80 ;(3)$

TYNGSBORO, 829, MIDOLESEX

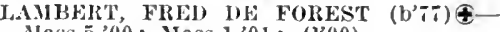
Mass.5,'00; Mass. 1,01 ; $\left(I^{\prime} 00\right)$.

UPTON, 857, WORCESTER

Capen, Saml. Hoss-H-N.Y.9,89; (t).

Traver, Edw. Clarence (b'66)-Vt.2,'88: (ठ).

UXBIDGE, 4,67I, WORCESTER

GRISWOLL, MERTON LYMAN (b'68)E-

JOHNSON, WM. LOtIS $\left(b^{\prime} 56\right)$-Mass.1, 8 ;

Ledbury, John Wm., Jr. (b'75)-Md.4,05;

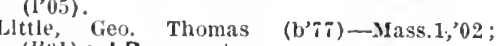
(I'01) ; LR.

VINEYARD HAVEN, 1,100, DUKKES

CARMICIAEL, DUNCAN A.\&-que.1, ;:" senlor Surg., U.S.P.H.S.

DAl'1s, SAMl. THOMAS (b'56)-X.Y.10,

'78; (⿱艹). (t) ; G.

MAYIIEW, ORLAND SMITH $\left(b^{\prime} \pi 8\right) \emptyset-$

Mass. 1,01; (l'01).

(See Boston, Newton.)

BOOS, WIILLAM FREDK.

(see Boston.)

CLAP, EDIUND WRIGHT

(See Boston.) 


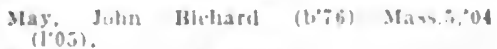

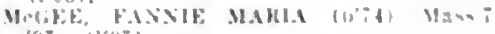
$00 ;(100 \%)$.

Morris, riances Morrls.

(Nipe H wholl

WAKEFIELD, 11.404 . MIDDLESEX

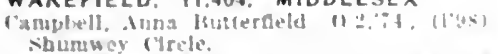

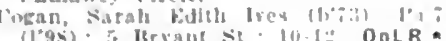
coles, fiavld smalley (lifill Mas.

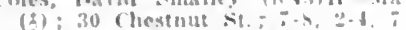

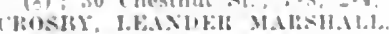

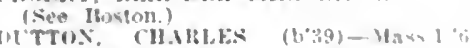
(2): 33 Hon sit: $2-4, \div-9$

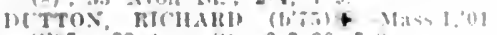

(1'9:); 33 Aron st. : $2-3: 30 ;-5$

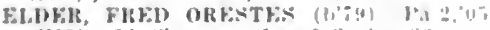

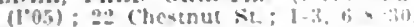

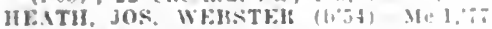
(ह): s iron st.: :-3, 6-s.

Joll[AX, (IIAS. (b, Jordin ive: $;-9.1-3.7-9$

Inughlln, Jchn Jos-Mass, 5,0 : : 1104

Montague, (has fillert (bilitill Vases

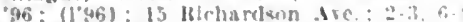

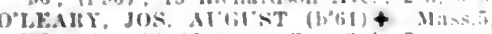

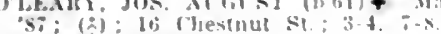

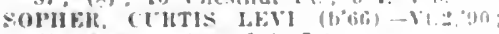
(i); 6 Aron st. : $2-4,7-4$.

TYZKE. EHSET EWW.

(siee Burlon.)

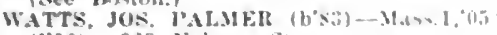
(106): 923 Nahant st

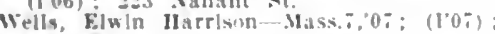
tron st.

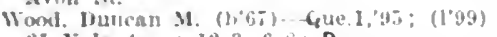
¿I Vale Ale : $1:-3,6-8 ; D$,

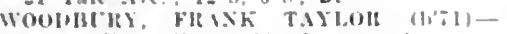

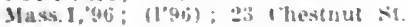

WALPOLE, 4.892, NORFOLK

fonnell, Thomas Michael (b's2) - N.H.1.,0? $(1+10)$

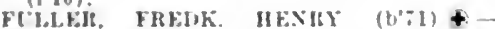

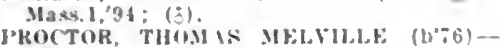

Mas. I, 0 ; ; $(1,07)$.

WALTHAM, 27.834. MIDDLESEX

Halley, Wm. Howard-Mass.;,y5; (\&): t) Hacon sit.

HАЕН, WM. НЕतH

(See Irostun.)

Fehrman, kolant Nugustux (b's!) -Mass. "11: (1'J:): 114 Vernon 5 .

Hell. Chas. Reed (b'80)-Masv.5, 00 ; (l'0i) 358 Maln St, $8-9,3-4: 30,7-x$.

Bell, Conral $(1, \div)-$ Ma s.4. 1,04

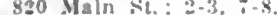

Brock, Chas. Fremone (b'62)-11.2, st (8) ; 35 Hich sit : $2-3,7-8$

collise, Mllisulu $(1), 1)+$ Mass 1,00 (1'n2): 837 Mafn st. 1-2:30, $7-4: 5$.

Courtues. Thom Jos. (b)i) Mass: 112 (1): 86 (ommon sit.

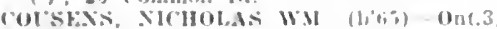
91: 18): 1: crescent si.

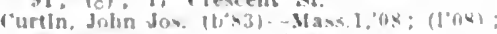
is comnun st. : $2-3,7-3$.

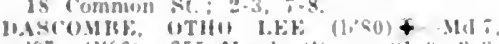

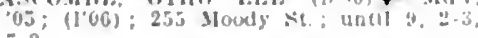

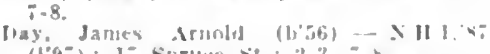

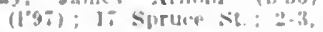

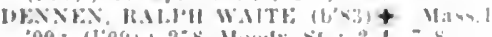

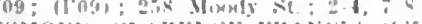

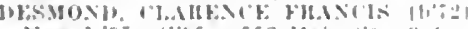

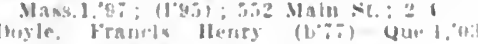

(1.03): :38 Main si: 1-3, $: 4$

Fonery, Winfed Xenell ilibitill Mas (6) (2): ans Malu sit.: B-1. i : LH

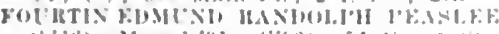

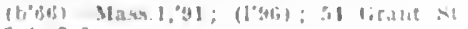
$2.1,-9$

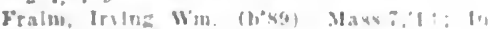
tern. Waltham IIoupltal.

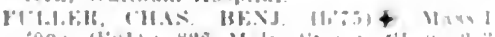

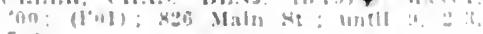

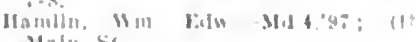

Maln si. Mare

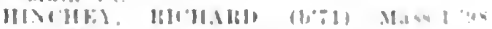

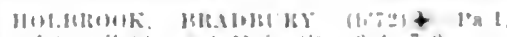

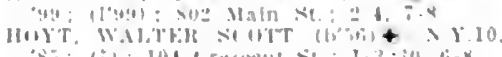

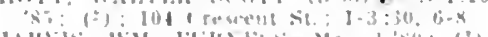

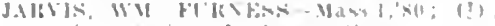

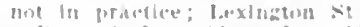

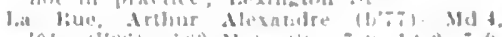

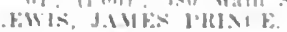

(Sine loweris)

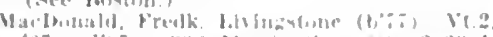

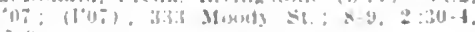

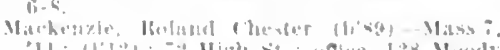

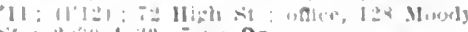

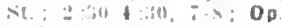

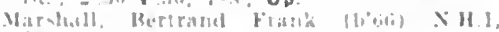

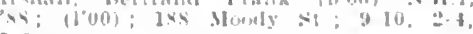

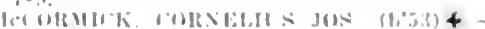

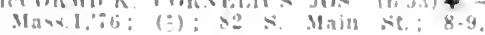
1.:311. $i-1$

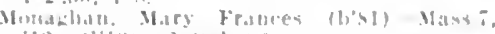

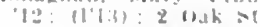

Mnsiber. Marthall James (l,60) - 1'8.2, 89

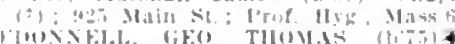

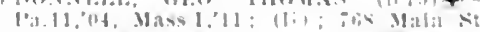

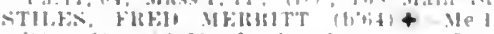

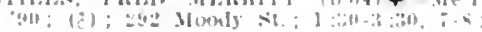
S.

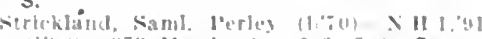
$1140 \times 1:$ :3 Mordy st: $1-2,-2: 0$.

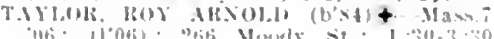

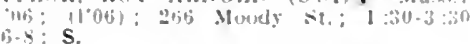

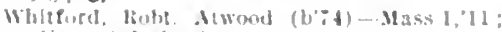
$(1+1):$ : llale st.

WIILAS IIIS IISTIX (b'70) - Mas.l,

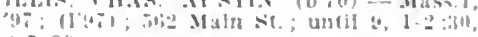

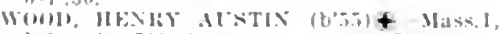

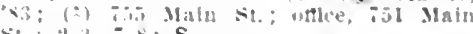
sit : $2-3,7-8 ; \mathbf{S}$.

MURเ

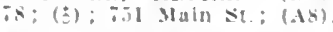

WAQUDIT, I60, BARNSTABLE

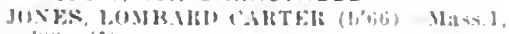
"W" ; (3).

WARE, 8.77\%, HAMPSHIRE

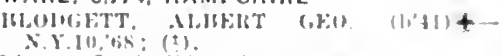

dionne, douls buward Jta.6, $8:$ : (:)

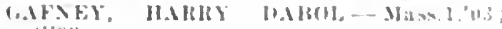

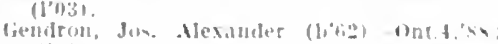
(1.4)

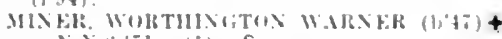

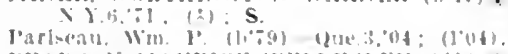

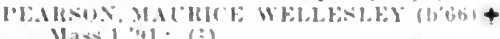

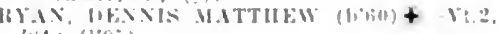
sti $([0,0)$

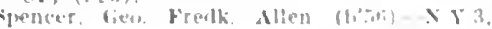
SI: IO).

WAREHAM, \$.102, PLYMOUTH

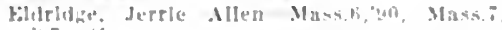

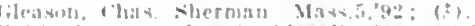

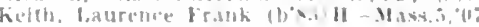
(I'i1:).

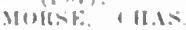

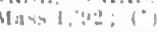

WARREN, 4.188, WORCESTER

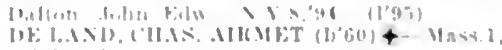

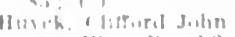

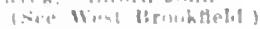

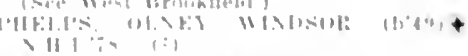

WARWICK. 17\%. FRANKLIN

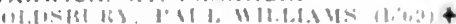

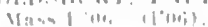

WATERTOWN, 12.875. MIDDLESEX (Sinc lousiols)

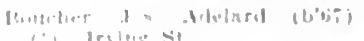

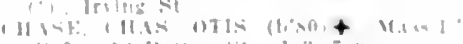

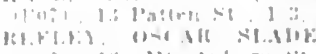
i.: 18: puburm

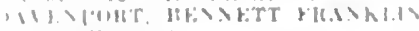

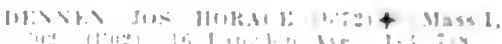

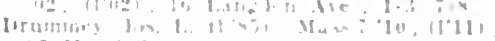
linerwent 1 thes

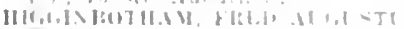

$+11, a+1,0 i$

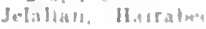

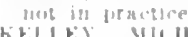

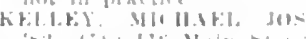

latring, IRenj. Tajpall

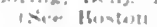

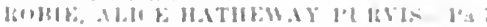

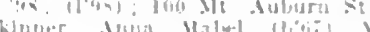

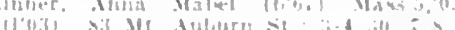

WAVERLY, 2.531, MIDDLESEX

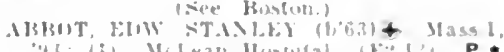

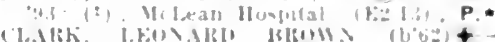
IIaw 1, "थ: : : :

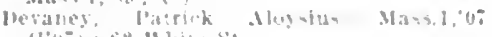

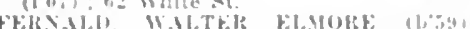

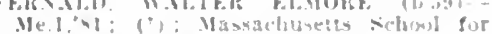

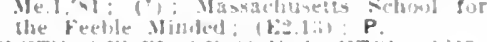

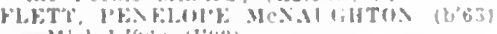
Minli.1.En: : 11'(ii)

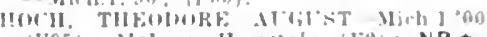

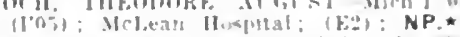

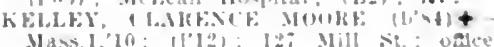

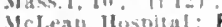

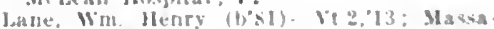

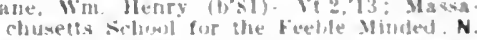

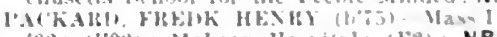

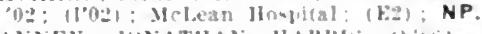

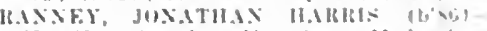

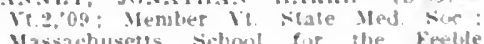
Macachusets sichool for the perble Mianted.

(u) unsefell, rlltural lion

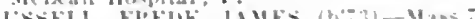

*

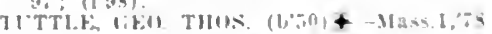

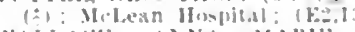

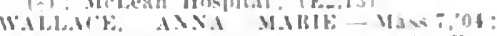

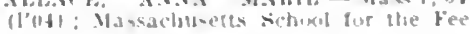
He Mraled.

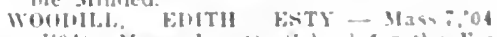

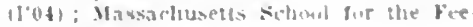
We Mineled.

WAYLAND, 820, MIDDLESEX

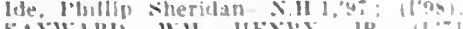

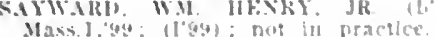

WEBSTER, I1,509, WORCESTER

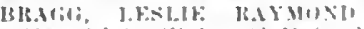

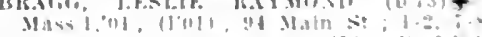

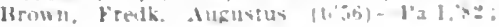

Frisiell Filw Merle th's, It

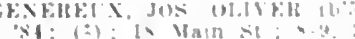

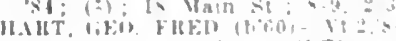

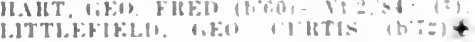

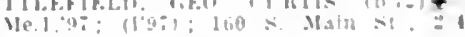

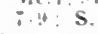

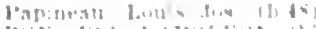

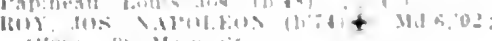

$11: 0,1 ;$ in $11 \mathrm{a}+11+2$

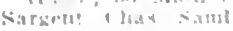

sone llorerster

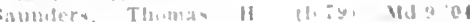

allind

THII)

WELLESLEY, 5.\&13, NORFOLK

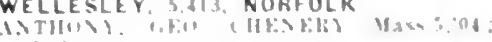

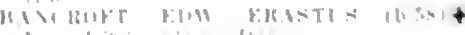

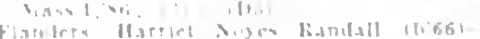

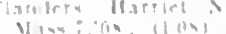

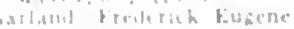

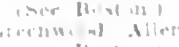

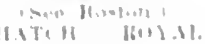

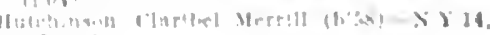




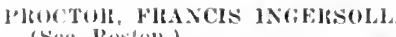

(ther Bostom.)

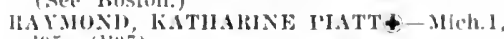
(0): (1'0i)

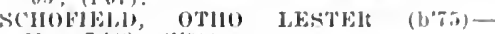
Mass. 7,$98 ;$; $\left(1^{\prime} 9 !\right)$.

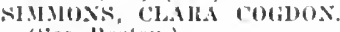

(siee Roston.)

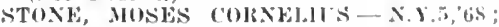
(l'95).

Weston, lsabel ciray Mass.5,s?; (b)

WHITE, HEN EIIIN.

(sce Buston.)

Jlswall, Ealw. Jibtings (b'ti) ll-Mass, 'si; (s).

WELLESLEY HILLS, 2,588 , NORFOLK

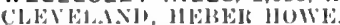

(iver Ibostoil.)

GIRERS WOOH, MHES

(viea Hostori.)

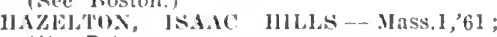
(द) ; $P_{*} \star$

IIEWIS, PALKR WUOLHURY.

(see Boston.)

JONES, IIHBELT NOHILS (b'62) \&

Mass.1,8s; (\$). (5).

l'kerson. 1'hllip Hale (b'sti)--Mass.l,'13; ().

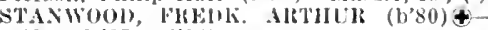
IIass. 1,07; (l’0s).

WELLFLEET，858，BARNSTABLE

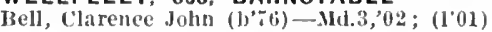
Canedy, fredk. s'now (b'bs)11-Mass.5,'91 (ठ)

WENHAM, 1,010 , ESSEX

Hhllips, Johu Chas. (b'76) - llass 1, 0.1 . (I'04); not In practlee.

WEST ACTON, 720, MIDDLESEX

STAILES, HALL (b'0)-N H.1,9'? (1'03).

Tasker, Frank Edwin-N.11.1,93; (す).

WESTBORO, 5,446, WORCESTER

AEIR, THOMAS HLIBBEIRT $\left(b^{\prime} 65\right)+$ Yle.1,93; (1'96); op.

Ballou, Harry Burcluard-Miun.6,05; state IIospiltal.

CANFILLD, WM. CHAS. (b'5̃)-I'a.1,'88 (1॰09); also Member 1.1. Med. Soe.; N.

CILLEY, DANT. 1'LUMMEI (b'54)-Vt.2, 85 : (5).

CARK, ALBEKT ULSSES FRANKLIN (b'68)-1'a.2,'96; (1'96)

Cutler, Allce surry (b'76) 11-Mass.5, 02 (l'03).

Fay, Emma Hooker (b $\left.{ }^{\circ} 63\right)$ - Hass.5, ${ }^{\prime} 09$. (l'09); not in praetice.

Fuller, solomon carter (b'-2)-Masš.5,97; (1'9s) ; (Framlngham) ; NP.*

Horner, llarriet (b'54)-Mass.5,03; (1'03)

lloward, Wm. Lee (b'61)-Vt.2,'90; ( ).

Jillson, Walter Arlhur (b's1) H-Mass. 5, 0 ;

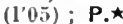

Jorlan, Michael Matthew (b’s \$) H-Minu.6, 05 ; (1'06i).

KNHIIT, CHAS. SLMNER (b'56)-Mich.1 $78 ;(5)$.

MAIIONEY, WALTER FIAACIS (b'83)Ilass. 7,06 ; $\left(l^{\prime} 06\right)$.

NEWTON, ROLAND STEPHEN (b'SO)\&Pa.11,05: (1,05)

Pierce, Reuel Alfred (b'89)-Mass.5,'12 (1'12).

spalding, IIarry Osgood (b'71) II-Mass.5 $97 ;(1+): P . \star$

Styles, Myron Franeis (b'38)-N.Y.9,'70; (1'95).

WEST BOYLSTON, 87I, WORCESTER

Trask, Harry Wallis-Vt.2,'04; (1'04)

Warren, Ernest Leighton-N.Y.8,'84; (む).

WEST BRIDGEWATER, 1,631, PLYMOUTH

Belmore, Adolor $0 .\left(b^{\prime} 77\right)-31 d .6,06 ;\left(l^{\prime} 07\right)$. leLacheur, Ellis Sweetlore (b'il)-Mass.5 '93; (b).

WEST BROOKFIELD, 1,327, WORCESTER

IBLAKE, CH.AS. ABBOTT-N.H.1,'S5; (ठ); Nember N.H. Yed. Soe.

COWLES, FREDK. WATERILAN (b'66)Y.II.1,93; (†)

Huycek, Clifford Jolın (b'T4)-0.7,96; (1’02) (also office, Warren).

WEST CUMMINGTON, 126, HAMPSHIRE

Stathenther, Chas. Robt.-N.Y.1,'82; (1'95)
WEST DENNIS, 600, BARNSTABLE

(1) Iass. $7,0^{2}$; $\left(1^{\prime} 0: 2\right)$

WEST FALMOUTH, 275, BARNSTABLE

("l"l"l"Eli, EIIllidII.

(See SiW York clity.)

WESTFIELD, 16,044, HAMPDEN

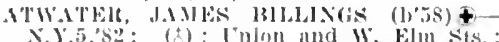

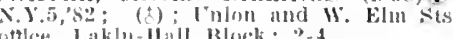

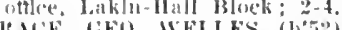

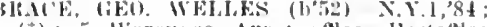
(3); Jioronemo Are.

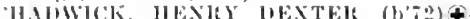
Mass, 195; (l'u(i); Westheld sotate salla tilim, $T$

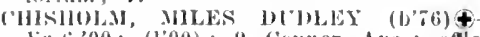
lat ti, $00 ;(100) ; 9$ commer Are.; oflee, los Jilm st.; $1: 30-4,7-8: 30 ; \mathrm{S}$.

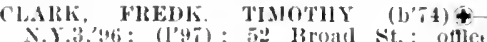
birk's block; 10-1.2 ".t: (131); OALR * ('ollius, Wallace Jason (b'61)-Me,1,86; 11'9.5) ; 35 Couturt st.; offlee, l'alk's i3lock; $(19.5) ; 35$ Collir
$4-10,2-4,7=9$.

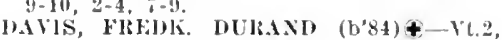
10; (1'11); ji X. Film St.; untll y, 1-is, (i. 8 .

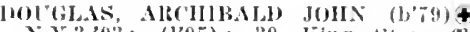
N.1.3,03; (1'05); 30 King st.; offlee, Operit llouse l3ldg.; 2-4, 7-8:30;'s.

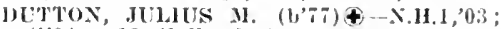
(l'04); 18 llolland Ave, ; otlice, :\$3 Film 1. ; $2-4,7-8 ; \mathbf{R}$.

llarkins, Cornelius Patrick (b'69)-Mass.1, '96; (1'95); E.Im l'ark Block; 2-4, 7-9.

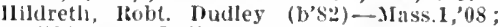
(l’08); 19 Holland Are.; oftlce, 40 Hlm St. ; 2-4, $7-8$; ObG.

JANES, GEO. HERBERT (b'62) †-XY.3 93 ; (t) ; 57 Court St. ; offlce, 5 Court St. $1 \cdot 30-3, \div 30-8 \cdot 30$.

Iowenstein, Fredk. I'lilip $\left(b^{\prime}, 74\right)-$ N. Y.5,95; (199); 136 Elm St.; 1-3, $7-9$.

MARONEY, PATRICK Jos. (b'79)-Mass. 08; (1.08); 16 Chappel st. ; $2-4,7-8$. MAlR, ROHT MCCLELLAN $(b ' 80) \oplus$ Mass.7,11; (1'11); $128 \mathrm{Klm}$ St.

Morgan, Roy (b'81)-0.6,'09; Intern, Westfleld State Sanatorium.

NOBI.E, ANNGENETTE FOWLER (b'61)థ -.11d.5,93; (1'95); 21 Noble St.

Norton, James Jos. (b'82) - Y.Y.19,'08; (1'09) ; EIn St.

Pendleton. Ernest Raymond (b'79)-Mass.6, 04; (1'04); 100 Court St.; 2-4, i-8.

Pinckney, John 1.-Yt.2,06; Westfield State Sanatorium.

Schoonmaker, Arthur Twing (b'60)H-Pa.9 94; (1'95); 13 Madison St.; office, 128 UIm St. : 2-4, $7-9$

SMITII, EDW. SIIEPARD (b'7i)€-N.Y.3, 99; (l'99); 15 Noble Ave.; offee, Court st. ; $1: 30-3: 30,7: 30-8: 30$.

Whitney. Wm. Herbert (b'58) E-N.Y.13,'81, $0.2,85$; (屯) ; 20 Pleasint st. ; offee, Elnı Park Block: until 9, $1: 30-3,7: 30-8: 30$.

WEST FITCHBURG (FITCHBURG P.O.), - WORCESTER

CORNFORTH, HERBERT HUSKISSON (b'86)-lld.4,09; (1'11); 17 Westminster St. ; $1-3,7-8: 30$

WESTFORD, 2,851, MIDDLESEX

Blaney, Cyril Arthur-Mass.5,'02; (1'04)

WELLS, ORION VASSAR (b'80)-1-Mass.1, '06; (1'05).

WEST HARWICH, 300, BARNSTABLE

NICKERSON, JOHN I'ETER (b'76) $)$ Mass.7, 01 ; (1'01).

WEST MEDFORD, 4,300, MIDDLESEX

(See Boston.)

(b's)

(b's 4 - Mass.1,12; (l'12)

BEAN, IACOB WALTER (b'55)-Vt.2,'82; (t); Nember N.11. Med. Soc.

Campbell, Franklin Eds. (b'i9)-Mass.1, DRAKE, RICIIARD ALVIN (b'79)-IIass. 02: $\left(l^{\prime} 02\right)$

IIoward, Lizbeth Niller (b'70)-Mass.5,'92; (t).

Jacoby, Rudolph, Jr. (b'90)-Mass.5,'11 ; PUTYAII, JOS. MORRILL. (See Boston.)
WIGT, D.NL. WHRSTEl (b'37)-Me.1, HILKLS, SAML. IIEXIGY, JR. (b'81)Mass. 1,08; (1'08).

WEST MEDWAY, 1,250, NORFOLK

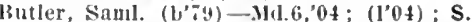

(q[1.NT, Noll.AN l'klR]NS - Mass. 1,70; (3).

sTowls, Iliveng bluble (b'68)-Mass.1, $99 ;(1 ' 99)$.

WEST NEWBURY, 1,473, ESSEX

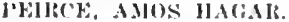

(see Merrlmac.)

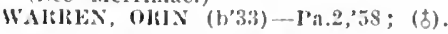

WEST NEWTON, 0.400 , MIDDLESEX

(See lsiston, Newton.)

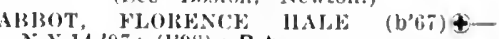

TIINSON, LIZZIE liNNl. IOOSE-Mich.1 $91 ;(8)$.

Bellows, Howard perry.

(see IBoston.)

Chandler, Harold Beckles.

(see boston.)

(HANIHLR, IIENKY 13 ECKLES.

(See 13oston.)

Coady, 1'atrick Francis-N.S.1,93; (ઠ),

Dutton, Julia Maltly-N.Y.14,'85; (1'04); 0 Otls $\mathrm{St}$.

FISHER, IIVING JEWELL $\left(\mathrm{b}^{\prime} 7 \tilde{7}\right) \oplus-$ Jass.1,00; (1'00): (D3); Pd. (b't)

llammond, Harry Weymouth (b'8:) Mass. 7,$05 ;(1,05) ; P . \star$

JACK, LEWIS HARLOW (b’ 3$\} \&$-Mass.1, '99; (1'01).

Ilecoy, Geo. Madison, Jr.

(see Boston.)

LOWE, FRED MESSENGER (b'59)-Yass,1, '85: (1'35).

MELICS, EDW: (1) 72$) \&-$ Mass.1,03: (1'99); (E13).

PAINE, NATHANIEL EIMIOXS (b'53)†N.Y.3,'75; ${ }_{(0)}^{(t)}$; Prof. Ment. Dls., Mass.5;

tram, Frank Wendell (J'it)-Mass.1,01;

Reese, Chas. Arnold-Nass.1,06; (1'05)

SIIERMAN, FRANK MORTON (b'T) \&-

Mass.1,'81; (む) ; S.

WELLS, DAYII WASHBTR.T.

(See Boston.)

WESTON, 2,311, MIDDLESEX Ellot, Alice May Ballou (b'76)-Mld. 7,05 ;
(l'06) ; not in practice.

ORR, SAHL. SANFORD. (See Boston.)

YAN NUYS, FRESENIUS (b'76)£-Mass.1, $06 ;(1,05)$.

Worthen, Clarence Field (b'82)-.Jass.1,08; (1'09).

WESTPORT, 2,928, BRISTOL

BLIRT, WDW. WALTER.

(Lee New Bedford.)

Tupper, John Darrow (1,’58) H-Mass.5,'95 ; (1'95).

\section{WEST SOMERVILLE, - MIDDLESEX}

(see Boston, Somerville.)

Ayres, Harold Winslow (b'81)-.IIass.1,04; (1"03)

BLAKE, ALLEY HANSON (b's1) \&-Mass.1, 04; (1'04); R.

BOND, WALTER LE GRAND $\left(\mathrm{b}^{\prime}-6\right)(-$

CHOLERTOA, HERBERT (b'73)-Mass.1, 01; (1'00).

Eames, Fredk. Henry-Me.1,92; (l'01).

GIBSOX, ROBT. FRANCIS (b, 73 ) $€$-Mass.1, '01; (1'00).

GILLIS, JOFN ENEN (b'-9)-Que.1,04;

Hirst, Elizabeth (b'90)-Mass.5,'13; (1'13)

Ingraham, A. Elizabeth-IIass.7,00; (1'08); 45 Hancock St.

Leavitt, Forrest-Pa.9,'90; (l'00).

LIVERPOOI, COVAL HENRY (b'80) $\oplus-$ Jass.7,08; (1'08).

IAHONEY, GEO. CLIFTON (b'65)థ-Me.1, $94 ;(194)$.

MAKECHNIE, HORACE PERKINS (b'41)N.Y.10,79; (t)

MCLEAN, JOHN ALLAN CAMERON (b'-9) -Mass.1,04; (1'05). 


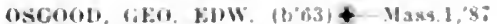
(13): (St. letersburs. Ela.): LR.

bayne, liee. Harknest.

(Seo Salem.)

Peasley, kinna Janet-Mass.

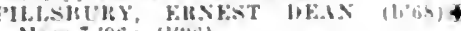
Mass. : $96 ;\left(11^{2} 406\right)$.

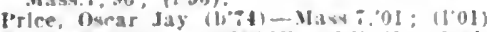

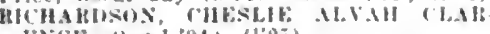

k.NCF-Que.1.04: (1'0.5)

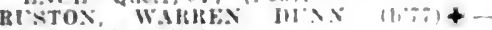

Mass. $103:(103)$.

Sawjer, Foully llarrlet-0; (b)

Sealzill, Forleo Arnaliu.

(See isoston.)

Smallwomd. lieorge Wathington.

(See Boston.)

Stephens. Finna Harrlet-Mass 5,03: 11031

Sterens, James Far. - Mass.5, 03 ; (1t).

Slurterant, Martha Loulse - Mass.j, 0.8 (1'04).

Ssirester, Sathan Howland, Jr. (b's2)Mass.5,"12: (1"12).

Wagner, Euma Julleb-Mass. 0,$\left.03 ;(1)^{\prime} 0.1\right)$

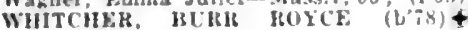

X.1.1.05: (I,05).

WEST SPRINGFIELD, 9,224, HAMPDEN

COHCORAS, GFO. BAIRTLET (b'SA) $\$ Mass.1, io: (I' I0),

DOHSEY, UENKY ARTHLH - I'a.16,98

(1'98).

Loomls, Wrn. Wellington (b'53)-Vi.2,83 (\$)

Ponerat, (C, II-Que.3,'94: (4)

WEST STOCKBRIDGE, I.27I, BERKSHIRE

Hodee, Floyd Joln (b'st)-Md.4,08; (1'04).

Leavit. Indley-N.1.1,"\$0; (z).

WEST TISBURY, 357, DUKES

Falrchlld, Courlland de Nurmandle-l'a.2, "हैं: (o). (f).

WEST TOWNSEND, 500, MIDDLESEX

Bornton, Henry Bullard-C: (l'99).

ELY RICHAKD SKINAEHE-X.11.,91: (1'99).

WEST UPTON, 1,214, WORCESTER

Brown, Adah d.oulse-(b's5) - Mass.5,0s; (100s).

WEST WARREN, 1,141, WORCESTER

Moore, Harry 11. (b'bit)-V't2.,'y9; (1'99).

WEYMOUTH, 12,895, NORFOLK

(See Ionton.)

BULLOCK, GEO. DEXTERt F'a. 2, 86 ; ( $($ ).

Hathawas, Wm. Fales-l'a.9,69; (3)

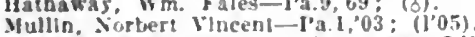

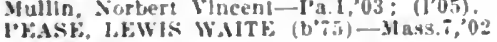
(1102)

Vlrgln, Frankiln Plerce-Mich. $2, ; \pi ;(\vdots)$.

WHATELY, 36I, FRANKLIN

L'nderwond, fordon lirosks (b's5) Mass. $\bar{t}$. 03: (1'10).

WHITINSVILLE, 5,600, WORCESTER

Halcom, Elmer Irving-N/Ch.1,'\$2; (I'95).

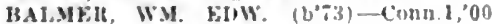
(1'00).

IARRY EMLET WM+-IId 3.97: (199i).

Bourles, Jor l'eter (b'80)-que.3,04: (1'05)

Ibrown. Harry dlhertus (b'il)-vit. (1'96): ALR.

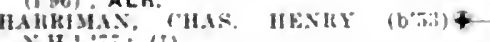
N.18.1\%: (8)

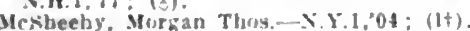

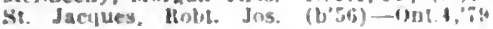
(8)

WHITMAN, 7,292, PLYMOUTH

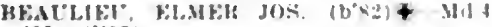
$\left.0 i:\left(10^{0}\right)^{i}\right)$.

COI'ELANI, HORATIO FRANKLIS (b) Mass. 1, '6. : (3)

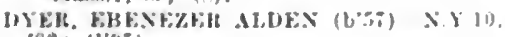
$\left.8: ; 11^{\circ} \% 5\right)$.

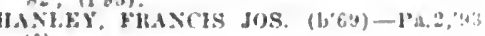
(8).

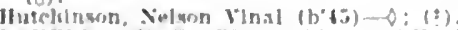

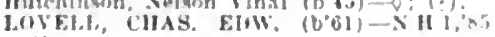
(

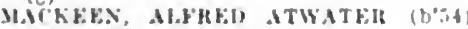

XY.10:3:

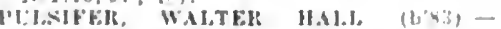

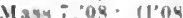

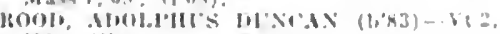
os: $\left.\left.(1)^{\circ} 0\right)_{1}\right)$

shealey, Mlchacl Jos. (b'81) N Y.9.12
WILBRAHAM, 1,352, HAMPDEN

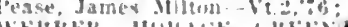

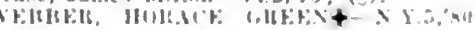

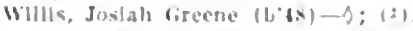

WILLIAMSBURG, 897, HAMPSHIRE

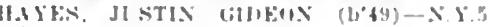

:

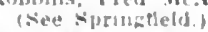

WILLIAMSTOWN, 3,708, BERKSHIRE

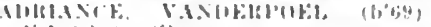

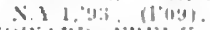

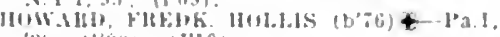
(1): (1) 001 : (1) 101

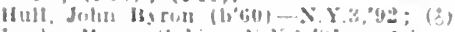

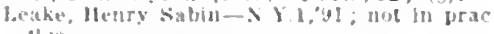
ition.

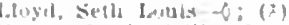

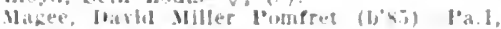
$(16$ : $(1,13): \mathbf{S}$.

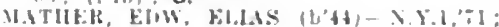

velsh. Win. Mex. (t's0) Md tat: (1'0)

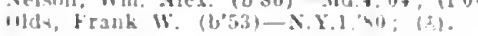

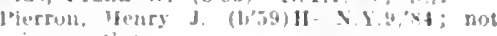
in prianlice.

WILLIMANSETT, 1.662, HAMPDEN

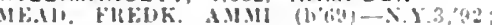
$(1+96)$

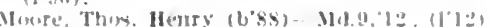

WILMINGTON, 1,470 , MIDDLESEX

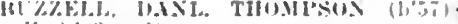

(1.2., $83 ;(2)$.

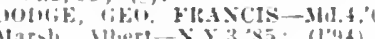

WINCHENDON, 5,678, WORCESTE

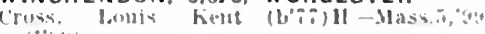

(IPUi:)

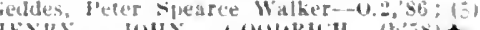

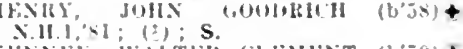

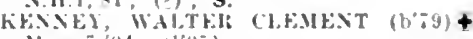

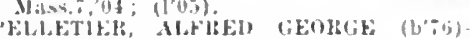
पue".3,"15; (1"00).

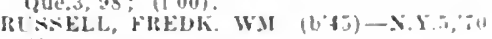
(?).

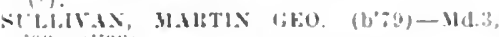
(1):3; (1, i):3).

WINCHESTER, 9.309, MIDDLESEX

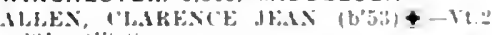

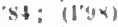

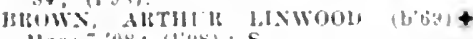

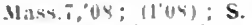

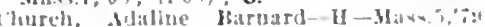
(t)

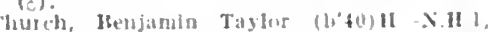
ix: (o).

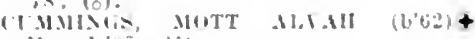

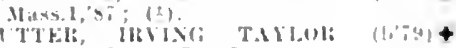

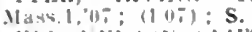

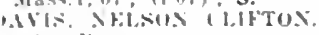

(siee $[$ [

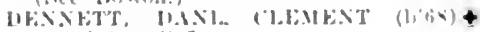

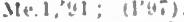

Draper, rrallk kighene,

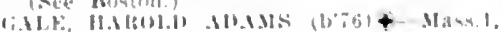
(0) 1801$) ;(11: 11$.

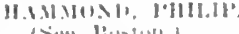

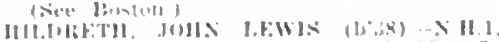

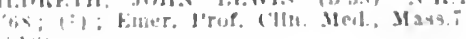
(1)

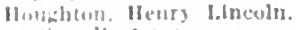

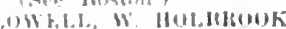

(tive lowions)

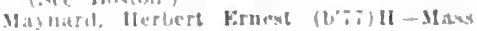
M.".

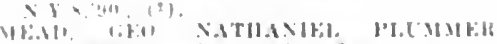

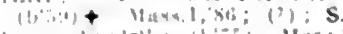

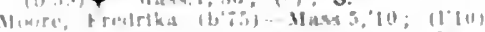

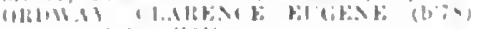

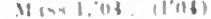

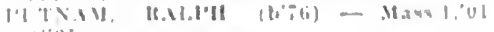

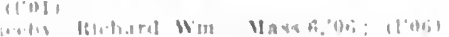

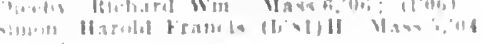

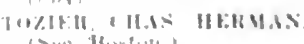

WINTEP HILL - MIDOLESEX

$$
\text { viee bision, sommerulle }
$$

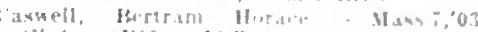

(1'0): (BI) , ALH.

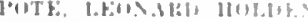

WINTHROP, 10.132, SUFFOLK

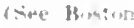

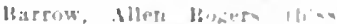

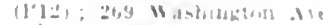

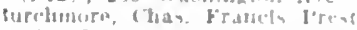

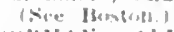

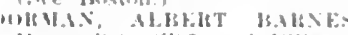

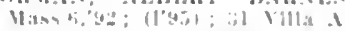

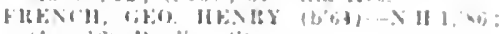

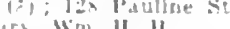

ars, Wh. II. II

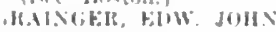

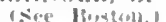

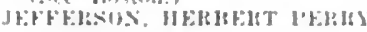

(xice Hastori.)

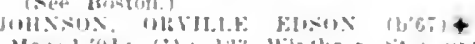

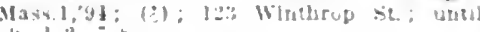

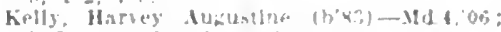
(107); 325 Winthrom st

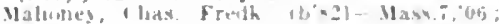

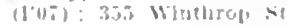

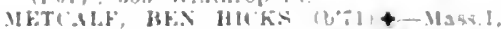

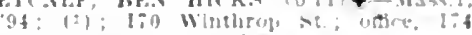
Wluthrup st. : 1.2. in

IORSE, FHFIIR. HAHKIS

isee Itosion.)

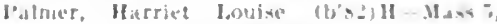
"II; (I'0s); 3n Wirmblide otre.

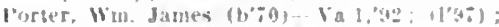

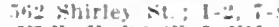

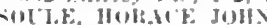

(Lee Ibustun.)

. lieorge, Jorman.

(xiee linaton.)

Watkeys, f'rederlek II

(see lisston.)

vingenty, lbralam saml

(Siee liustun.)

WOBURN, 15.308. MIODLESEX

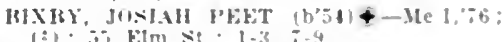

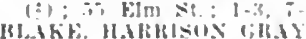

iste lonton.

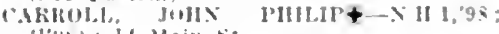

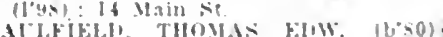

Mass.1,10!: (1001); if church Are? :-3,

illivkRs, RORT

io jleasant si

COSLIS lzolte aris Main st.

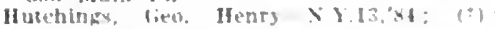
5it Maln st

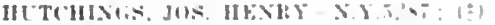

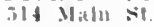

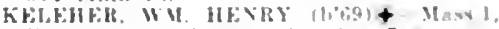

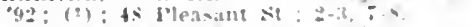

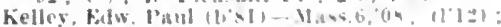

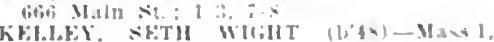
KFI.l.ki, SFTH WIIIT

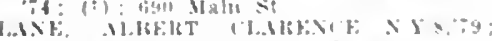

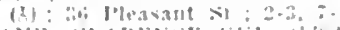

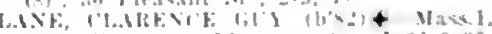

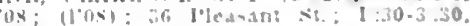

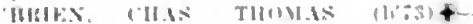

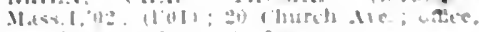

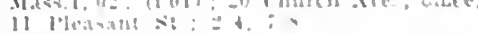

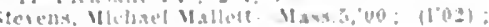

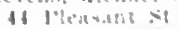

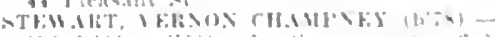

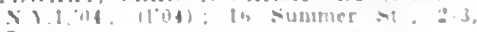

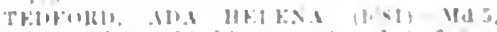

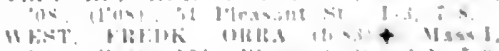
WOLLASTON. - NORFOLK

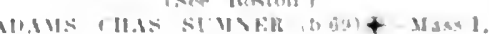

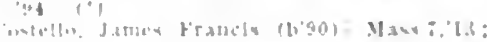

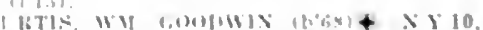

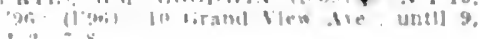



[Dun('an, Stanley Forbes (b'si) Mass. ,']2;
(['12); 25 (iInore St.

Goodlng, Fmmil Jeannette (1)31)- Mass. 17: (ह) ; not In practice.

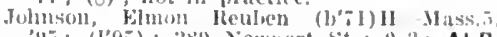

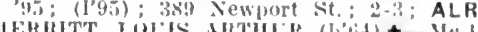

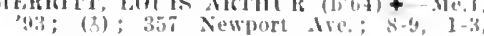
$7-8:$ LR

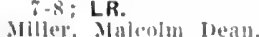

(sice Buston.)

Thompsol, Alfred Ferelsal (b'il) Milsi. $417:(1 \div 9)$

Whlthouse, lizgatie sizer.

(tive Hositin.)

WORCESTER, 145.986, WORCESTER

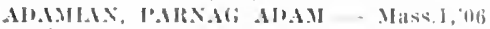
(I0.0) : So Lalurel st.: (offlee, IsI Har rjsom tre., Bostenl: 2-4, i-!) : I'rot. ('lln

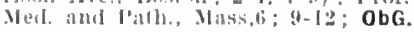

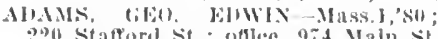
J3

1159 .1ain st.; 1-3, 7-s.

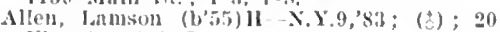
bilm st. ; $2-4,-8$

Arey, Ifirold Parleton (1980)-Me.1,13 Worcester stite llospltal.

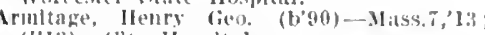
(I'IB): C"lty IIosjltal.

ATWOOI. ABEL, WILAON $\left(b^{\prime} \sigma \pi\right)+$ Mlch.1. 0:3: (I'03): is Malu st. : 3-4. $7-8$.

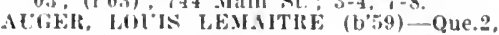
79; (3); 104 Franklin St.; 10-12, 3-6. $7-8 ; N$.

lyers, (Chas, Filton (b'89) - Mass.7,'I2 (1.3): Worcester City IIospltal.

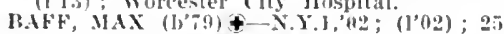
Arlington st. ; oflce, itl b. Central st. $2-4,7-8 ; P$.

BAKEL, FREILE. HEHBERT (b'67) Mass.1,93; (\$) + I Jimlen St. : $1-3: 30$.

BALCON, KENXETH IHA (b'83) \&-Mass. I '10; (1'10); 112 Lincoln sit. ; 2-4, $7-8$.

PARNES, JAMES ARTII'R-Mass.I, 00; (1'09); 126 Vernon st.; oflce, slater Bldg.

BAIRELL, MAIK FLIZABETIIt-Pa.7, $97 ;\left(\mathrm{l}^{\prime} 98\right) ; 904$ Maln st.; 2-4, 7-8; G. Barton, Jedediah Marcus-I's.9,70; (f); 796 Malı st: $2-4,6-8$.

BAYLIEs, AXOHEW-N.Y.5,79; (1'35); 30 Pledmont st.; oftlce, Siater Bidg. BEAL, HoWAIII WALTER (b'69)屯1:30-3:30; (C3,5): $\mathbf{S}$.

BEMIS, JOHS IERRICK (b'60)-Vt.2,93 (b) : 223 salisbury st.; ottlce, llerbert Hall Hospltal; $\mathbf{P}$

BHAGIX, STEPHEN ALBERT (b'73)థIlass.I, 00 ; $(1,00)$; 33 Portland St. ; $2-4$,

BF̈RR, GORDON (b's0)-Mich.l, 06 ; (I'06) ; 25 Trowlirldge Ril. ; office, slater Bldg. ; ii-is; (FLi) : ALR.

BERIR, .IOHS C'TTING (b'ti)\&-1'a.2, 71: (1'96): 28 Trowbrlage Ra.; office, if (1'96) ; 28 Trowbrldge Rd. ; oft

Lertine, Eleanor (b's)-N.Y.20,13; Intern, Memorial Ilospltal.

BIFBERBAIH, WALTER DANIEIA $\left(\mathrm{l}^{t} 81\right)$ †-Tem.11,04; (I'0.5); 31 Pleasant St. ;

PICELOW, ELW. BRINGE (b'T9) Mass.1,04; (I'04); 6I Pearl St. Boland, Manl. "

BOWERS, (GFO, FRANCIS HASKELI, (b'83) +-Wass.1,11; (1'll); T Everett st.; 2-4, Hoving. $09 ;\left(I^{100)}: 893\right.$ Main St.

Bray, Amanda Currier-1lass.5,9]; (ち) ; 2 Trowbridge Rol.

BRENNAN, WANL CLARKE (b'84)Mass.I.'12; Intern, Worcester City IIospltal.

MREXNAX, JOHX JOS. (b'B3)-Mass. 1,86; (ま): 173 Lincoln Si: office, 390 . Naill st. Ii): $30-4 ;$ OALR,

BROCKWIY, CHAS. HENRY (b'บ2)-

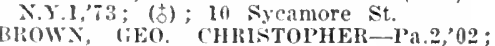
(1.02); I Trumbull Sq.

BHOWN, JOA. (b'85)-MId.4,'10: (1'10); 28 Providence St : $2-4,7-9$

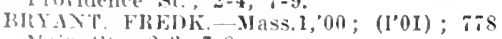

IBIILEY, BLN, THOS. (b'74) —-Mass, 1 , $01:$ (101): 25 111gh st.; $11: 30-3: 30$; ( riaj $\left._{i}\right) ; \mathbf{N}$ *

Butler, FrancIs Jom. (b'bil) - H).C.2, '08: (1'09) Io linekport lid. offlece til Lincoln st.

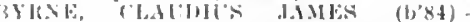
Mas, :10; (1"10); 10.3i . Mah st.; ;-t

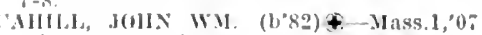
(I'08); \& Pond st.: othe, 390 Malin St.

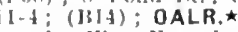

Carmoly, Wm. Francls-Mass.1,00; (1'99); live Cintudler sit.

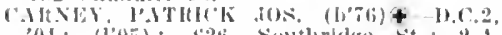
04; (1'05); tiab Soutlorldge st.; 2-4.

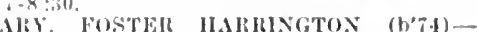
Mass. l, g.; (l'78); 82 Film st, ; offlee, II Elm st. : $2-4,7-8$

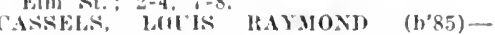
Mas.7,11; (1'11); 47 J Peasant st.

'hamberlin, IIarold Augustus (h'90)Miss.7,'I3; (1'13); Clty Hospltal.

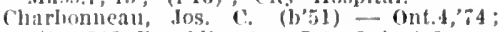
(4): 113 Franklin st. : $7-9,2-4,6-8$. ' 'harbonlleat,

CHALTERIS, IIATY ALENA (1)'65) \&-J'n.

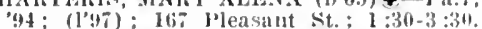

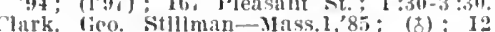
Fernain St.; offlee, 37 Higliland st.

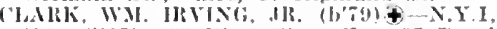
24; $\left(10^{\circ}\right) ; 53$ West St.; offlee, 37 Pearl sit. : $2-4$.

LEMFNT, MERTOX WAIAACE - Mass. 7 , $01 ;\left(10^{\circ} 1\right) ; 9$ Oberlin St.; office, 811 in $\mathrm{st}$.

COLBELA, I'E'TEIR ALBERT (b'82)-Pa.11, ,08: (l'09) it Stebhins st, $2-4,7-8 \cdot 30$ Cook, Allce 'II. (b'S6)-Pa.7, 13; Intern, Memorial Hospital.

COOK, JHILP HOWARD (b'T8)-Mass.1 03; (1'04); 761 MaIn St. : 2-4, 7-8; R.

Cooper, Edward-Pa.2,05; (1'05); 33 'Well Jngton St.

Cottle, Lotis Alberl-I'a.1,99; (1'99); 50

Orange St.

Croissant, Chas. Augustus (b'83)-X.Y.9 05: (l'08) ; 8 Blair St. : offlee, $101 / 2$ Higl St. : 10-12, I-4; OALR. $\star$

CRONIN, IIENRY WM. - II.3,93; (ठ)

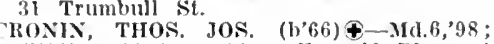
$\left(1^{\prime} 98\right): 103$ June St. : offlce, 49 Pleasant St.; $10-12,1-4 ;$ OALR. $\star$

CIROSS, AIBHRT FLMER (b'72)†-Mass.5, 00 : (l'00) : 6 Kensington Iid. : offlee, Slater HIdg. : $10-4$ : 0p.»

CUMMIXGS, IOIIN Jos. (b'T0)-N.Y.1,99 (1'99); 53 Pleasant St. ; $2-4,7-8$

Curran, John Franels (b'89)-Mass.7, 12 Intern, Worcester City IIospital.

utler, Raymond $\mathrm{Wm}$. (b*8t)-Mass.7,12; (I'12) ; 36 Alvarado Ave. : $2-4,=-8$

Darling, Casslus Harriot-N.Y.5,'83; (1'95) ; 263 Park Ave.

DAYDELIN, SIMHON ALYHONSE-QUe.3 $96 ;(198) ; 40$ Plantation St.; offee, 11 Elm St.; 2-4, $7-8$ : OALR.

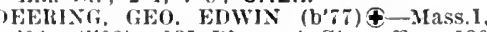
'04; (I'03) ; 13I Illeasant St.; offlce, 129 Pleasant St. ; $2-4,7-8 ; 0 r$.

DEl.AHANY, W.1. JOS.-N.H.1,83; (b) Trumbull Sq. EDW.-Vt.2,'99; (l'00); 63 Fleasant St.

Desero, Guiseppe, (b'80)_Ita.10,05; (l'10) tio suffolk st.; $8-10,5-9$.

DISBROW, EIN I'ERRY (b'80)-Md.3,'08; (l'09) : Woreester Clty Hospital.

DIX, GEO. ALFIEED (b'72)屯-Mass. 1,99 $\left(I^{\prime} 00\right) ; 105$ Pleasant St.; I-4, $7-8 ; 0 . \star$

Dolan. Wm. Elw. (b'7T)-Md.4, 02 ; (I'03) 36 Whitman Rd.; offlee, 32 Lincoln St. unt11 $9, \quad 1: 30-3: 30,7-8: 30$.

DONOHLE, JEREMIAH JOS, $\left(\mathrm{b}^{\prime} ; 6\right)-M d .3$,

07 ; $\left(\mathrm{l}^{\prime} 0 \mathrm{~T}\right)$; 48 Fernon St.

OONOGHLE, JOHN JOS. (b'5) \&-Mich. I

04; (I'04); 193 Green St.; 2-4, 7-9; Ob.

Doray, Frank Leslie (b'70) - Mass. I, 02

(1'02); 4 Normal St. ; $2-4,7-9$

oten, Arthur Chapman-N.Y.8,'99; (l'99) 3 Westland $\mathrm{St}$.

Downing, Bertha Carol (b'64)-Pa.7,96; (I'95); 4 Iowning st.

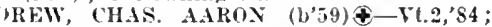
(1'96); City IIospital; (E2,13).
Jucharme, Alphonse Napoleon $\left(h^{2} 81\right)-$ Mass. $\vec{t}, 10$; $\left(1^{\prime} \mid(1) ; 77\right.$ Wall St. ; 1-3, 6-8 ObG.

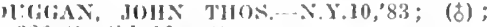
226 southbrldge st.

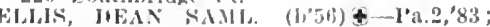
(ठ); 574 Maln sit.; I-3, 7-8.

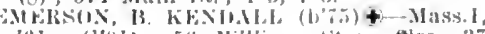

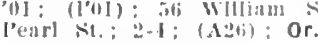

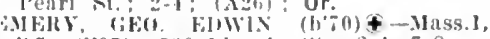

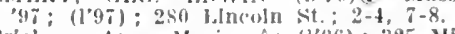

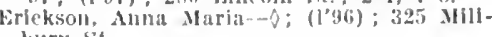
bury sit.

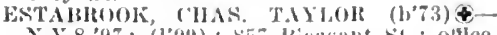

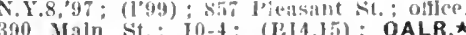

EVERETT, OIIVER? IIUIti (b,52)\&-

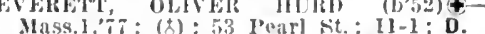

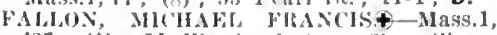
87 ; (8) ; II Westlind st.; ofthee, slater Bldy.

"arey, Humphrey Joln-Ma.4,01; (l'01) 101 summer St.

FARNHAM, IOHN MARSHALI, WLLl.ougifJy (b'68) \&-Mass. J,95: (1'96): 39 Wolliam st.; oflce, 58 ileasint st. $2-4, \pi-8$.

FAY, FHANK GLEASON-N.Y.8,84;

8. Flin St.; offlee, Slater Bldg.

Fish, Ralph Chas.-Ma,t, $94 ;(\delta) ; 2$ Hilds. (rock lid.

Fisher, Edgar Alex. (1)66)ll-Mass.5,'87; (8) ; 2 ; EIm st.; 2-4, $i-8$.

FITZGELALI), CLAIKA PALLINE - Pa.T 47 ; $(197)$; 137 l'leasant st.

Flagg, Edwin Barber-X.1.1,'65; (c); 168 listitute $]$ l] FLYNi, JoIS Jos.-N.Y.10,98; (1'98);

FOGEITY, WH. (LEMMONS (b'59)-Pa. '83; (を) : 98 Chandler st. : 2-4, $7-8$.

FOLEY, THOTHY JOHN (b'68)\&-Conn.? 92; (t) ; 28 f'ortland st.; $2-4,7-9$

FOSJETT, GEO. MASON (b'56)-Vt.2,'83; (b) ; 82 Pleasant St.; 2-4, 7-8.

FOX, MI('HAFL BERXAIt) (b'83)-Mass. I, 09; (l'09); 6 Coral St. ; 2-4, 7-9.

GAGE, HOMER (b'6I) - Mass. 1,87; (t) $\&$ chestnut st. ; offlce, i2 Pearl st.; l:30

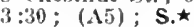

Garst, Jullus-Mich.1,'is; not in iraetice: 29 Oread $\mathrm{st}$.

Gendron, Jos. Etienne (b'43)-N.II.1, $7 \mathbf{1}$ : (む) ; 19 Trumbull St.

GEORGE, FRANK WM. (I'78) \&-Mass. 02; (1'02); 756 l'leasant st.; oftice. 6 High st. ; 2-4, $7-8: 0 r$.

GETEIELL, ALBERT ('0LB $\left(b^{\prime} 57\right) \&$ Pa.2,85; (t); 6 Linden St.; II-3; (B2, 15) ; LR. *

Giltillán, Donald R. (b; 9$)-\mathbf{M d} .4,03$; (1'03); Worcester State Asylum

GHANT, WARUEN RANDALI (b'6I)

Mass. 1,'88; (ち) ; 10 Oxford St. ; 2-4.

Greene, Jeremlah Augustine (b'85)-Mass.1

IB; $(1.13)$ : Worcester (ity Ilospital.

(iREFNE, RAY WOONVHLE $\left(\mathrm{b}^{\prime} 57\right) \oplus$ Mass.1,'86; (t); 21 West St.; 2-3:30,

ARTY, H.ARKY JOJH (b'82)-Mass. 7 , ; (10); 894 Millbury St.; $8: 30-10$

ILAKH, (iHBBRT WM. (b'84)థ-Mass.1, 10: (1'10); I89 $W$. Hoylston St.; until $9,2-4,7-8$.

HALLORAN, MICHAEL JOS. (b'53) $\oplus-$ I $3.1,30$

HARKIDS, JOHN FRANCIS - Mass.1,00; $\left(l^{\prime} 00\right) ; 11$ Salem St.

HARROWEL, JAVII) (I'AT) £ - Mass.1, '84; (8); 98 Williams st.; office, 9 Elm St.; $10-3 ;(\mathrm{B} 4,5,14,15)$.

HAITXETT, JOHN IIENRY (b'82)థ Mass.7,11; (l'11); 130 Vernon st.; office, im

HAVILANI, WALTER CHILTS (b'81)‡IIJ.4,04; (1'04); 176 Lineoln St.; 2-4, $\boldsymbol{i}-8 ; \mathbf{N}$.

Hayden, John Jos. (b'80)-Md.4, 08 ; (l'08) ; 4 Wall St.

Hayes, Ethel Millicent (b'86)-Ont.1,'12; Intern, Memorial Ilospital.

Herrick, Vanßuren - Yt.2,96; (1'97); 59 l'leasant st. $2-4,7-8$. 


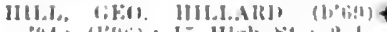

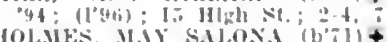

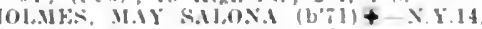

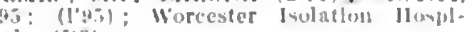
tal: (113).

Ilolyer, Wim. Francls (hoss)-N.II.1, J!I; Intern. Wurcester illy Jesintal.

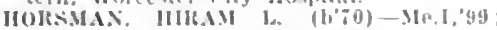
(I'13); Member .Is. Meal. Asin.; Worester state isvlum.

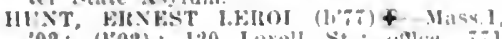

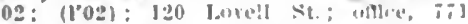

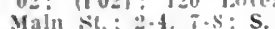

Mall st. 2-4. Hes: S. (I']1): 32 l'ortland st.: $\$ .9,1,3,6-8$.

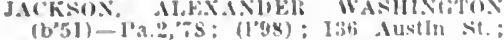
2-1, 7-8.

Jackson, Hoy C. (1)s0)-Vt:.06; Wurcester sitato Jlosplitil

Jacques, Louls lleslre Oneslpiore-que.3. 9:- (1'98) ; 48: Park Ave.

Jacques, Napoleon-que.26i: (b): it Frankin st. onle 58 jront st.

Jensen. Wm (hrlsllan (1,90)-Mass, : 13; (1'13): Tower st.

Jones, Hallert Archier (b'il) H-X.Y.9.'92 ; (d): 6 Newton Ave; ontce, is Pleasint si. : $11-12,5-6$

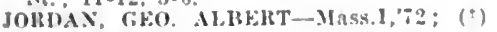
46 Myrtle $\mathrm{St}$

Jordan. Henry Jacob $\Rightarrow:(t)$ : th, MaIn st kEutis Jos HFN 3 Trumbull Sil.

HXYY, TIIUS, HISATCIS - Mass.1,05: (106): 9 Jleh st.

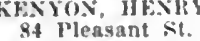

KIXNICLT, ROLiER (b'so) - Mass, 1, ot $\left(l^{\prime} 06\right)$; 2 Cedar st.; oftle, Memorlal Hospltal: (wa) ; LD.

Lancaster, Alston Howard (1)if)--M(1.3,03 (to 03$)$ : 31 Jrring St.: oflce, 50 Orange St. $: 2-4,6-8$

Lane, Jennle Theodate Miner $(1,60) 11$ Mass.5.96; (1'96); 23 Hudson st.; 2-4, $6: 30-7: 30$.

Langlll, Morton II. (b'\$4)-N.1I.1, 10 Asst. Supt. Worcester clty IIospital.

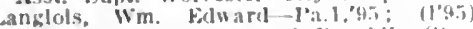
23 Oberlin st.; sttlce, 60 Franklin sit.

Lanphear, Clias, Howard (b'4i) II - o.:?80: (1'95): 46 Wellngton St. : $5.9,1: 30-2: 30$, $\because-8$.

Lazarus, louls (b'83)-Mass.1.'ll: (J'll) 97 Cirafton st. Jlen-Mas. :, $96 ; \quad$ (1'96);

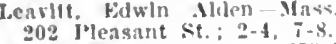

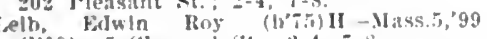
(l'00): 5 sheparel st.: 2-4. i-s

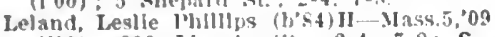
(1'09): 23R Iincolu st. : 2-4, $7-8 ; \mathrm{S}$

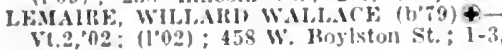
$6.9: \mathbf{P d}$.

Lemlre Jos Fiw. (b's1)-Jass.6,'11. (1'12); 141 Washlngton St.

lewls, rhas, Bernard-Mass. 0 , 09 ; f 1ondom St.: Physleal Inrector, Woreester III l sichool.

WACOLX FFO CHANDIAR (b'84) Mass.1,11: (l'11); 2 JInden St.: 2-4. i:30-8:30: Pd.

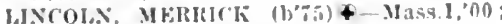

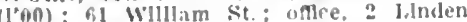
it. : untll 9, 2-4: $\mathbf{P d}$.

LINUSAl jos. Ilki (1, b3) - Vt.2.8.

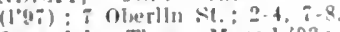

Ioftus, Jolu Thos, Mass, l, $03 ;(103)$; I1! Habover st.

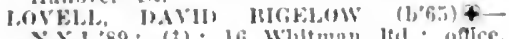
Y.Y.1,8: (ह) 16: Whit ment

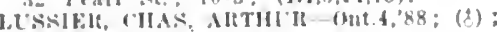
154 irand sit

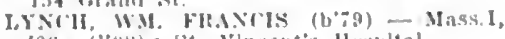
ox: (lovs); st. Vincent's llowpleal.

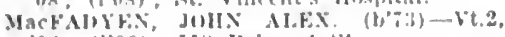

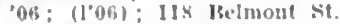

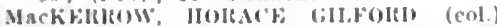

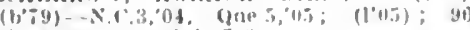
vingtern Ave, :-4,

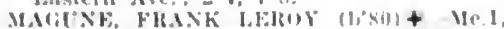

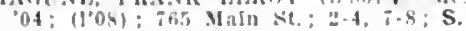

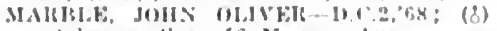
not in jravelle: 16 . Murray tie

MAISI, AlTHIIR WIITE $\left(b^{2} b(t)+\right.$ Mass. I, 957 ; $\left(1^{0} 96\right)$; 690 Maln st. : 2-1, 6 .

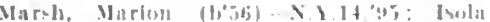
(lem Iluspltit!

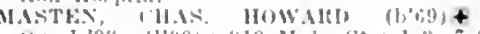

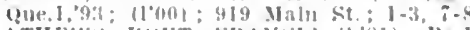

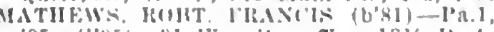

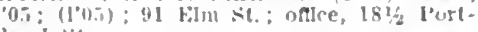
lanil st

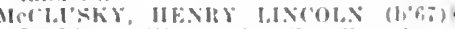

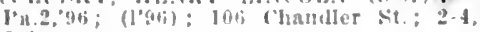

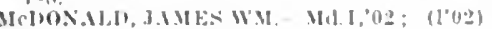
:13 Trumbull $\leqslant$

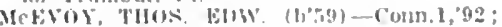
(1"95): 38 ['ortland st.; :-4, i-9.

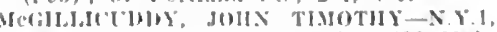
$92 ;(\$): 6$ lifent 8 t. onlce, 390 Maln St. : $10: 30-12: 30,2-1:$ OALR.

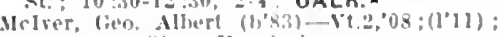
Winceater State Ilospltal.

MrkItHFs, WM. WI'ton (b)it)-Mass.1, .00: (1.01): 51 Wirluuset st.; oftlee, 390 IInin st:

Maln St. 2-4; (ID:3) Pd. P4. (1): 5 Vissuchusetts Are.; otlle, 26 lineoln St. : $2-4, i-s$.

MrLaughlin, Arthur Otls $(1,2 \times 0)-M a k s . \bar{t}$ 12 : Intern, ('lty Josultal.

MrMalon, Itchael Fraucls Edr.--Mass.i. 05 ; $\left(l^{\prime} 05\right)$ : 22 Provldence st. ; ontere. 33 Trumbull st.

MoSHFHII, THKOBALD COLFMAN (b"it)

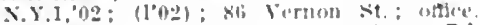

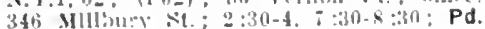

Messler, Adlor Fugene (b'si)-Mass, $i, 10$; (1'12); 151 frand st.

Metralf, Imy A. (b'84)-I'a.7,1:; (1'12) Memurlal ilosuital.

Mleczkowskl, stanislaus C. (b'ss)-MI.9. '12; (1'12) ; 25 Nillbury St.; $8-10,2-4$.

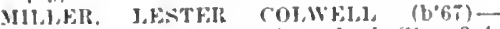
Mass. 1,$95 ;(1.95) ; 14$ Oxford st.; 2-4, 7-8: (193) : I. Franuls (b'81)-Md.4,07: $(108): 13$ waldo st. ; ofthee, 32 l.meoln it. Mary Ellzabeth - Mt.7,03; State

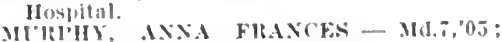
(l.03): 833 y yiln st.

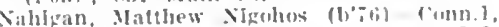
,07: (10s): 204 Miln St.; 9-J1, 2-4, :-s.

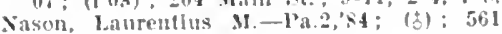
Pleasant Sit.

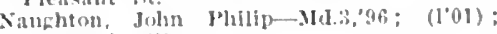
311 Maln st.

Newcomb, Marletta katon - X.Y.14,95; (1,96): 923 Muln St.

Slchots, rharles bemuel (b'51)-Miss. I, 75; (2) : 38 cedar sit.: 8-9. 2-4.

Nlon, Ihllluje IIenrl-Que, 3,00 ; (l'0l); 31 Mllibury $\leqslant$ 1.

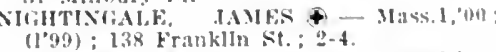

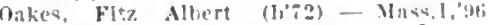

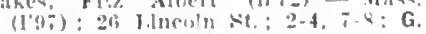

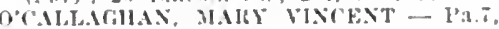
s. (¿): $13 \%$ J Jeasant St.

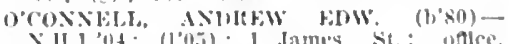
viater Blide.

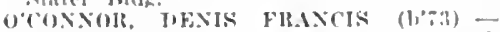
Vil. $98:$ (1.01): 13 Heechmont St: of flce, state Mutual Indlg.; 10-3:30; OpA.

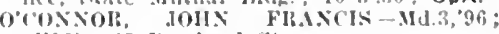
$\left(l^{\circ} 96\right) ; 0.5$ Portland st.

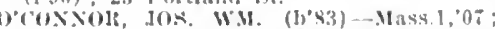

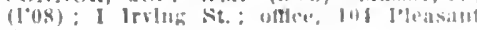

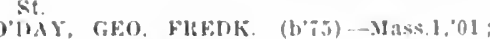
(1002): 10 Vermon st

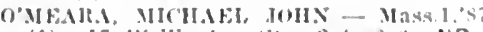
(2): 1; Nellugton st.; 2-4, li-s; NP.

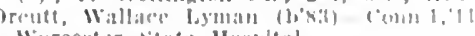

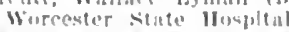

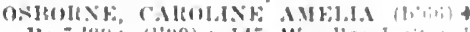

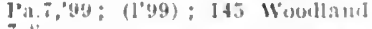

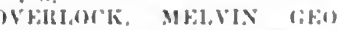
(l'gef): 100 illandle st

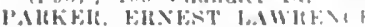
Mass] 04 : $(1.04): \quad 1: 3$ Avil: 2-t, i-k

I*artrilge, Frank Ju mberlln st. : ontion.

1: Jeimont sit.

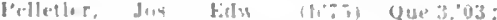

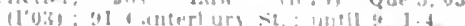

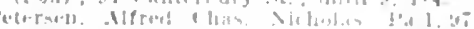

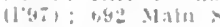

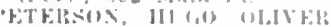

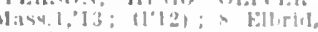

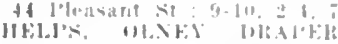
S I1 1, (1); $110 ;) ; 4$ Main

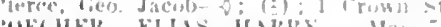

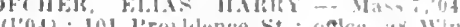
ter st. $9-10, y-t$ tis.

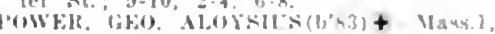

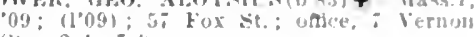
st. ; $2-4,:-4$

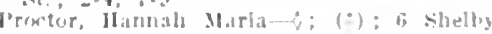
st.

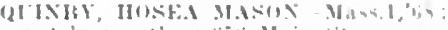
nut In practloe: biet; Main tiq

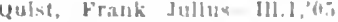

Iune st.

llaml, John l'rentice (6’ï) II - I. l.s, (2): 5 lath

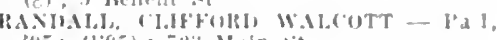

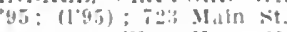

IRaynenton, Wm. H. - X.Y.1,73; not In braetlee: Jake Ire

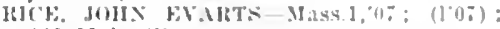
s6z Maln st.

Rolinsol, Jos. Jenry- XY.j, '64; (:) : 100 J'leasant sit.

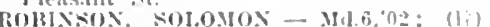
$1+1$ ireen it.

ROCHETTE. HIW. IHAS. - Mas 1.03 (l03); 1 SI Helmont st.; uflce, =0 lourt lanul st.

BOCKWEI.L, M.FIEI) FIJJAIJ JPEHKIXS

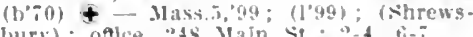

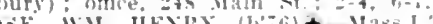

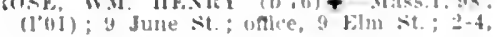

owlind, lelta Fullla (1,8,3) -111,11,12; Rowland, Melta Fulla horitil.

Intern, Menorial Hovplit.

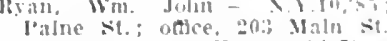

sandersen, anmes Jienry (1, liz) - I $1.1,90$ (i): 60 - lustin se.: :-4, :-

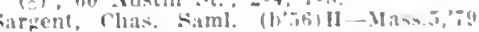
(): (Melster): oflce, if Jleavalnt st

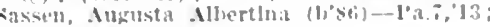
Ienumilal IIusultal.

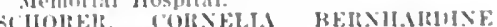

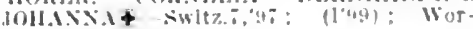

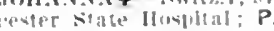

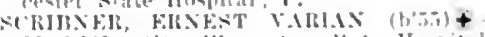
Me 1, \&1; (\$); Wurcester state I[nspitial

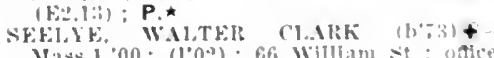
Matso 1,00 : $(1,02) ; 66_{0}$,

39m Masn sto

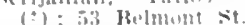

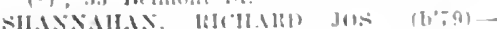

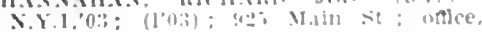
13 Walia $\leqslant 1$

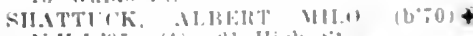

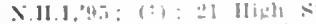

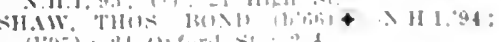

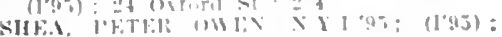
sif... i f.t

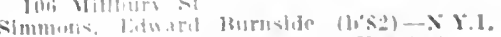

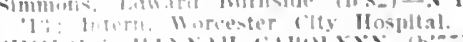

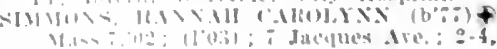

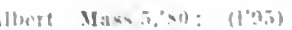

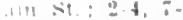

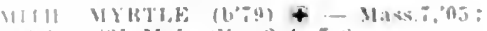
S3l Itans : : :

win. Toule Mastipis:

11,111 it

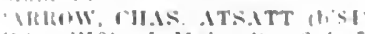

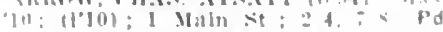

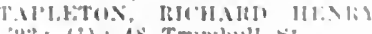

"3): (3) : As Trmmbll st

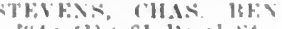

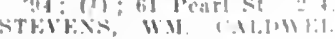

(1): If lkantion $(1$

STIR, HENLI 1.11) IS

NP.

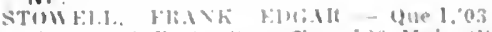

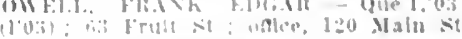


STHOM, MARIE CIIARIOTTE $(1,89)-$ Mass.7,'11: (l'12); Memorial Hospltal.

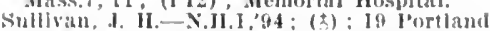
SWAN, IROS(O) WESLEY (b'60) + -Mass. 1 82; (ठ); 4 llarvarl St.; oflce, 41 l'leasant st.; $8-1), 2-4,7-8$

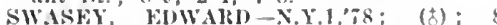
Trowbridge Rd.: office, 390 Malu st. To-

Siseet, Bllsha Wllbur- 0 ; (f); 236 Maln st. Tasse, Jos, Clirsanthe bdw. (b'64)-Que.2 's9; (ठ) : 16 Wall st.

TAYJOR, JAMES, Jik. (1)'69) + Mass. 1,00 (1'00); 49 l'earl st. : 8-1; OALR.

TRIPl, GEO. AlsTON (b'72)+-Me.1,96 (1'96) : 47 ('imbridge St, : $2-4,7-8 ; 0$ TROWLIBIDGE, HIW. HENIR (b56)\& Me.1,'s4; (d) ; 835 Maln st.; offlee, 58 pleasant st. $2-4,7=8$

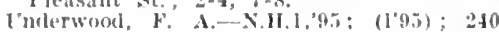
lor

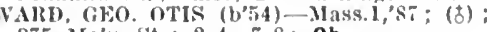
875 Maln St. ; 2-4, $7-8 ; 0$ b.

WARD, IBOV JOSLYN (b"is)+-NII.I, 00 (I'03); 397 I'lensant st. : 2-3:30, $7-8$

Warren, John Kelso (b'46) II-N.Y.9, 0 (d): 28 Chestnut St.; oftce, 78 pleasant St. ; $2-4$; S.
WATKINS, ROYAL PHILLIIS (b'67) N.Y.1,'9z; (1'95); I West St.; 1-3, 7-8; S. Werner, Andres Chrlsten-Swed.1,89; (d) : 44 ("lannlng st.; oflee, 42 Pleasunt St.

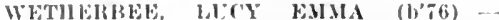
Mass.5,99; $\left(l^{\prime} 00\right)$; 2 KIng St. ; 2-4, after $7 ; 0$ b.

WHFELER, CHAS. DOUGIAS $\left(b^{\prime} 65\right) \&-$ Mass. 1,94; (ot); 18 Cliestnut St.; 2-4.

WIIFEt.kR, LEONARD A. (b'45)-Mass.I, io: (t) ; 12 Chestnut st.; G

WHITAKRL, ('LAIENCE WIJDER (b'57)Vt.2,'83; (o); 32 June St.; oflec, 44 Ileasant St. : 2-4, $7-8$.

WIITE, LEVI (b'49)\&-NY.10,72; (t): i tiates st.; 2-4.

WHTXWY, RAY LESTER $\$-M$ IISS.1,04: (l'04); Worcester State Hospital; NP.`

Willis, John Enbert (b,65) II-Mass.5,'98; (1'99); 941 Maln St.; offlee, 5 Hawthorne St.; 2-4, 7-8.

Wilson, Wm. IJenry-Mass.6,03; (1'03); Blossim St. : 10-12.

Wood, Rosto Owh-O; (

WOODWARD, LEMUET FOX (b'5i) \&-

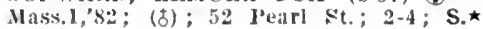

WOOHWARD, SAMI. IBAYARD $\left(b^{\prime} 53\right) \oplus$ Mass.1,78; (o); 58 learl st.; 2-4.

Work.IA, WM. H.-Mass.1, 73; not in practlce.

YoOSUF, ARRAIIAM KEVOHK (b'66) Md.4,95; (1'95); 10 Walnut St.; 8-11. $2-5, i=8$.

YoST JOIN DIXON $\left(b^{\prime} 72\right) \leftarrow$-Mass.1,98; Maj., U.S.A.; rellred; 452 Main St.

WORTHINGTON, 321, HAMPSHIRE

LYMAN, WM. IBOBINSON (b'80)\&-Mich.1, 05 ; (l'06); AL.

WRENTHAM, 1,203, NORFOLK

Burnett, Wm. Walton- $\rightarrow$; (1'96).

FAXON, HUDORA WINHREI-Mass, 04 : (1'04).

Grcene, Edw. Chace (b'65) - Mrch.1,04; (I'II).

Jenckes, Jos. Franklin (b'48)-Yt.2,'82; (ठ). l'erkins, Franklln Jasklus (b'80)-Mass. 08; (l'09).

WALLACE, GEO. IONEY (b'72)-Id.4,98; (1'98); (122).

YARMOUTH, 1,420 , BARNSTABLE

SLARS, STEI'IIEN HULI - N.Y.10,79; (1'98).

FOR KEY TO SPECIALTIES, ABBREVIATIONS, SYMBOLS, ETC., SEE PAGE 672

Wuet more information has been incorporated herein than in any prerious edition. and to save space, symbols and abbreviations have been used: it is important that the rearter thoroughly fumiliarize himself with these, as well a.s with the rarious departments of the divectory.

The information is here but much of it is available only through the use of the kieys. Uave you become familiar with them? See pages $5.5-56$. 


\section{I CH I G A N}

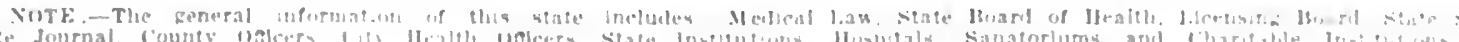

\section{MICHIGAN}

Poputation (1910 census) ........2,810.173

Number of Countles............ 83

Number of Physicians... .... $\$ .180$

Members State Society, Dec. 31.

1913.

Area of State in Square Miles a. 2,253

MEDICAL PRACTICE LAWS OF MICHIGAN

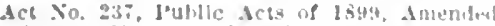
b5 Act No. 191, uf 19143. Act Nu. its, uf 1905. Act Xo. 161. of 1905. Act Xio. $20 \%$ of 120\%. ice No. irit of

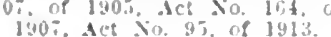

\section{An Act}

To prorlde for the kraminatlon. Begulation. l.Irensing and Reglstrallon of I'lussteials and Surgeons, and for the J'unishment of orender lealnst this Act, and (1) liepeal Acts and I'aris of Acts in Couflirt Therewith.

The people of the state of Michlgan eudit:

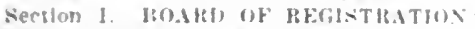

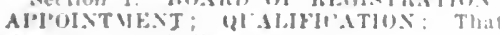
the gorerune sliall appoint, by and with the adrlee and cuskent of the renate, tell rin. dent electors of the state, who shall com-ti tule a lbaril of Legiastalion in Medicime. Xo: nure than fire of the persons so ap. poluted shall be from the school of rueditom known as resulat: not more thatl iwi letel sons so appoirted sliall te from the orlinel of medlcine kwon as homeupathic: nost nor than two of the prepsins so abpombed shatl

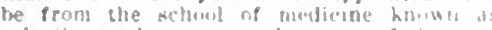
eclectic: and hos more than inte of the persons sa appofnted whall to from tle" velumi

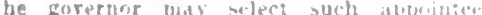
from the latest lists thed in the wathe of the secretary uf state at lanslag by each of $s / 2$ four legally incerporteal state medical

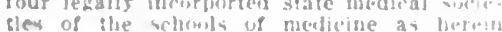

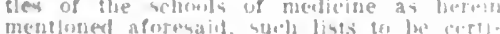
bet to under oatli of the lirestlent and

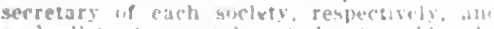
such llsts te contaln at least relit. the

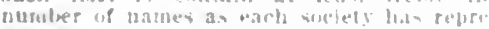
sentatise ene the troaril Hut in the velut that one or more of the suciesio nanced, through thate frevideuts

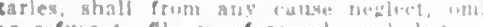
or refune hin fle as aforasaid, stacts lispo er

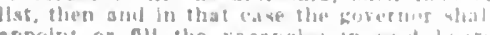
appolst of nll the vacancled in had lwarch Whout reperence to sheh llat he lists which any causo neglectol, domltiml or rofund t fle nith the secrmary of state. an licening

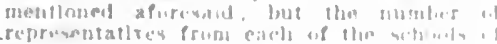

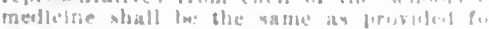

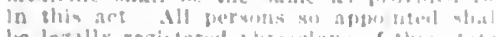

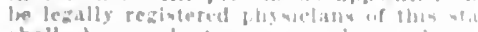

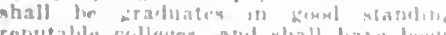

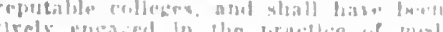

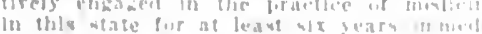

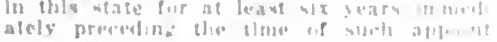

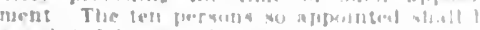

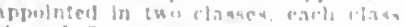

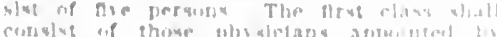
llo: governot ander Jit

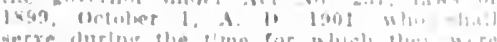
werve distong the time fior whols the

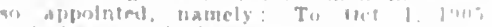

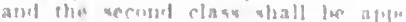

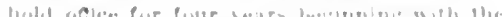

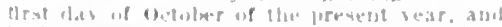

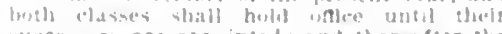
surcentor aro appointed: and thereafier the

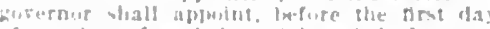

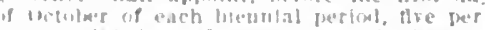

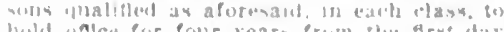

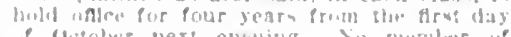

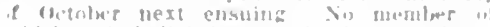

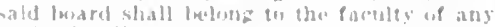
intedical collowe tap unireraifs. The dovernor

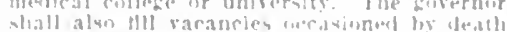

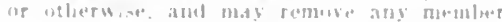
fur the continued neblect if duthe teflutred by this otot. Vateancises in salul trabel thall

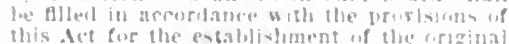

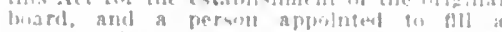
racunes shall hold ontere durtug the unes. pured lerm of the meminer whome place lie rasuacted by and recitre the concurrent rathacted of from at lease veren niemlere

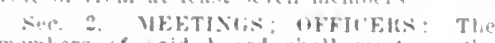
members of waid hard sinall meet on the

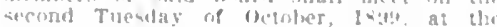
State lapitol at Jansing. ant whall then - lire a prestlene from their uwn nomber. and a secretary who need not lie of theip number. hut eacly of whom shall hold theif

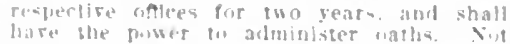
less than veren mombers allall constituse a furrum of sald lwatel fier erancaetion of tusiness. The secrotaty shall inse to the troast1res of blse state a bomil in the renal

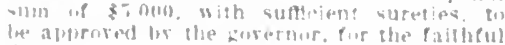
dischatap of hle dutios. The sald Jeared shall lubl two rozular meteinzo in each

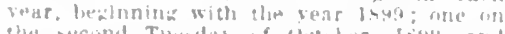

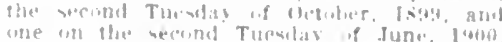
ald se wh, and suld allitional meetinge

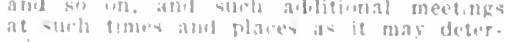
mils

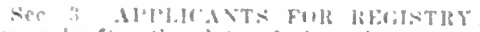
An and after the dafe of the taking effect if this Are, all metl mat "nimen who ar

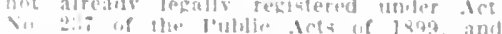

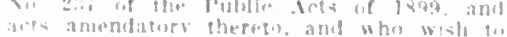

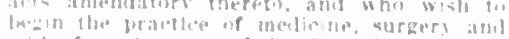

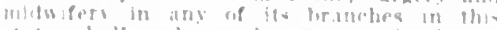

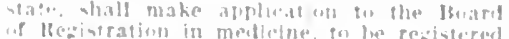

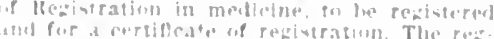

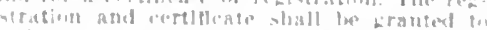

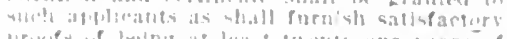

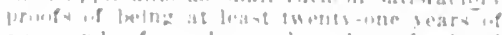

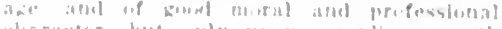

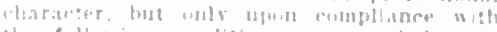

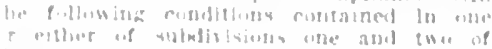

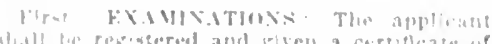

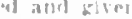

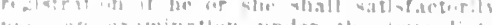

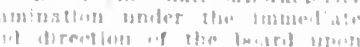

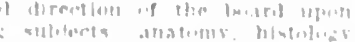

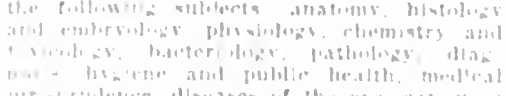

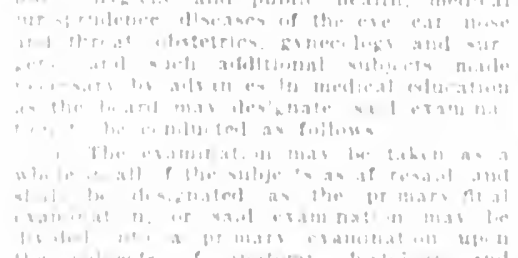

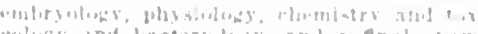

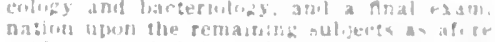

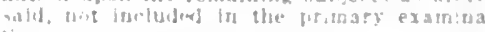
ijen.

(1.) The anul rant wall the wah the sec-

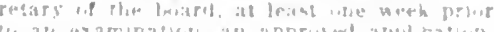

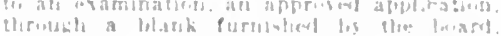

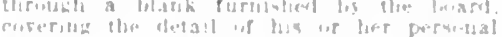

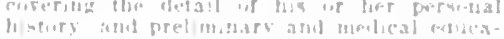

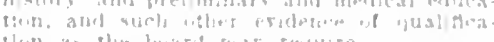

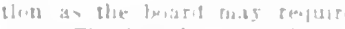

(c) Tlu imaril mas maine wuch rula anof

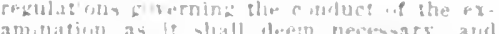

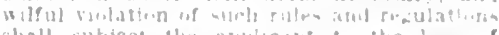

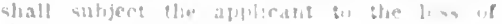
the examultilen abul for

(d) The examinatun sliall to male ax

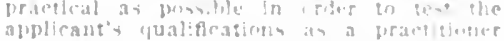
uf med rine, the niwthiml of wh ch whisl! iw $n$

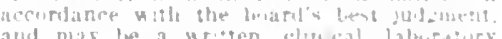

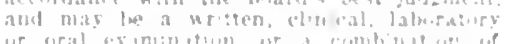
iwe of more of the abose inothely

(e) In averafe pretootrage of at least

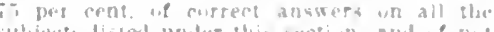

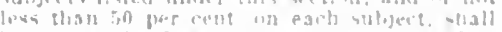

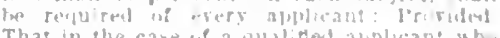
Thas in the rase of a qualifted diglwan: wh. hat heent in reputable and legal practice

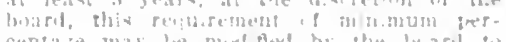

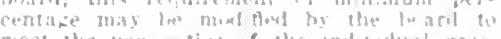

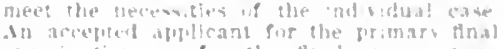

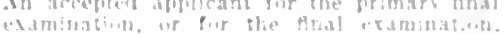

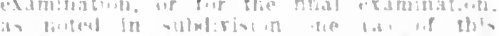

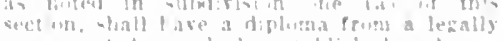

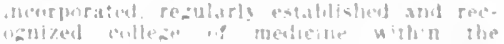

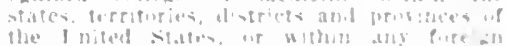
the I nitad state. or within any pige an

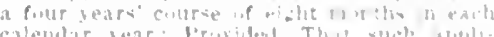

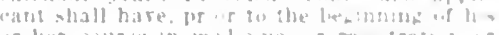

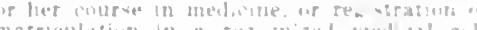

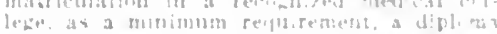

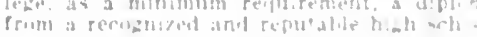

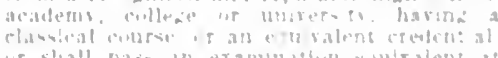

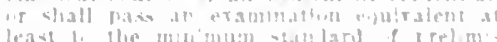
least l. the un a

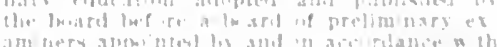

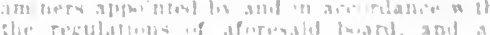

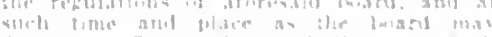

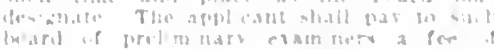

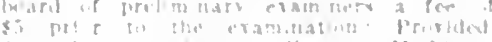

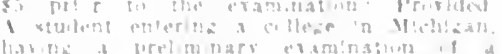

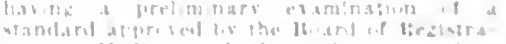

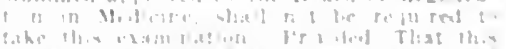

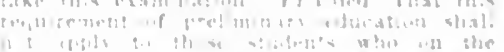

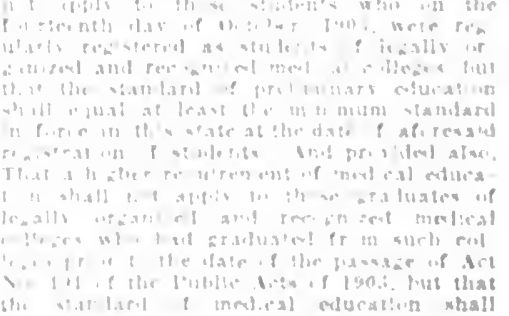


culual at least the minimum standard in "rite in this state at the date of grabluation. students of mediche in regular attendance at a lecenghlyed medical college and endorsed by sadid board at having fulfilled the legal matriculation in, recoguired medical colleges, and who have completed, in acenritance with the hoard's adopted minimum standard of medical edueatlon, in sueh reogntzed mediliation, and hot prior to tloe termination! of the second year in such institution, among

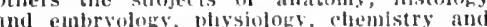
toveologs, and bacteriolory, shitl have the right to a finmary examination, as reeorded right to a blimaly examination, as reeorded tunder subdivision, Onc (a) of tisis section, to he held at such times and places as may the determined by the board, and to receivo from the boald a certiticate showing the credits receised in the several subjects upon which an examination shall have been had as aforesalid, and such credits obtained shafl, at the election of the student, be ind thed in and form a part of the examinnunder subdivisiou oue (a) of this section: provided, That subsequent to graduation from a recosnlzed medical college, in sald thin examination for a certiflcate of registration the applicant shall, if presenting salid credits to the hoard at the time of his or her application for examination, be exanined only in those remainlng subjects preand whlch have not been listed as subjects of aforesald primary examination. The applicant shall pay to the board a fee of as follows: \$10 for the primary examination, and \$15 for the final examination. If sucil examinations are taken together, or is a whole, the fee shall be $\$ 25$ for such primary-final examination. No additional fee for registration shall he charged to those who sllecessfully wass the examinations.
t'le board slinll, in the recognition of medl"al colleges, in its discretion, list such col leges in three or more classes or groups: firoup one inchuling those colleges which and whlch inaintain the board's standats of preliminary and medieal education; group wo including those colleges which have fulftled the standard of medical education demanded by thls state at the date of the diploma: and group three including those for allanced standing in recognized colleges lisied under grouy one: I'rorided, That a difloma issued by a medical college listed by the board in one or more of the groups or classes as aforesald, shall be recognlzed as a qualification under this Act, in the standards of preliminary and medical education within the provlsions of this Act. The Board of Reglstration in liediclne shall, Board of leglstration in Medicine shall, of prellminary and medical education, and no high school, academy, college, university or medical college, or other institution or its diploma or certificate be recognized by said board under subdivision one of section 3 of this Act, unless in the judgment of the board, it conforms with such standard.

second. RECIPROCITY: The applicant may, at the discretion of the board, be registered and given a certificate of registraistered and given a certificate of registraproof of the possession of a certificate of registration or license which has been issued to said applicant within the states, terrl-
tories, districts or provinces of the Lnited States, or within any foreign country, wher the refuirements for the registration of said applicant at the date of his or her license shall be deemed by said Board of Registration in Medicine to be equivalent to those
of this Act. The fee for registration from applicants of this class shall be $\$ 50$, and for the endorsement of a certificate to for the endorseme
another state $\$ 5$.

Thirl. NON-MEDICAL REGISTRATION

The hoard is authorized to issue a license riticate of registration to any person ment of human ailments or diseases, and who does not in such treatment use drugs mediciles, internally or externatly, Khin tores not prartice surgery or midwifers, inder the Jrovisions of this Act; Provided, Tlat the aptlleant for snch license or fertitcoute of registrition shall have an necredcollege or unfersity, or an equivalent ere college or unfersity, or an echulvalent cre
dential, or shall pass an examination before the Bonrel of I'reliminary Fxaminers, such examination to be equivalent to a recognized high sehon diploma, as provided in subdlviston one of this section. and shall pass an examination lefore the hoard upon the following subjects: anatoms, histology and emlryology, physolory, chemistry, bacteri-
ology, pathology, diagnosis, hyglene and puthic linith. This examination sliall be foncurrent with and equivalent to the examination provided for practitioners of medicine under section 3 , subdivision one, of this A't, and shall be in harmony with the provislons of thls section and subdivision covering such examlnation In the subjects as such examination shall be a contluuous one and not subject to a division into a primary examination shnll be \$15. A practitioner under this subdivlsion sliall not be permitted to use In any form the title of "doctor" or "professor" or any of their abbreviations, or any other slgn or apjellation to his or her name which would in any way designate him or her as a physician or surgeon qualidivisions one and two of this Act, subviolation of the provisions of this Act. All persons granted a certifleate of registration or license under the provlsions of this subdivision three, shall also conform to the provisions of Act No, 237 of the ['ublic provisions of Act No. 237 of the I'ublic
Acts of 1899 . and acts amendatory therete, Acts of 1899 , and acts amendatory therete, except as provided in this subdivislon: ProSection 3, lart 3, who have been sranted a diplona by a college incorporated for the purpose of teaching their method of of Registration in Medicine, prior to Oct. 1 , 1916. in affidarit stating that they hare period of two years prior to Sept. 1, 1913, shall be registered and authorized to pracshall be registered and authorized to practice without examination under the provi-
sions of Section 3 . Part 3 , of this Act. fee of $\$ 5$ must accompany each application or registration under this provision.

Fourth. FRAIDILENT IEGISTRY: If any person shall unlawfully obtain and prounder this section, whether by false and untrue statements contained in his application to the Board of Registration of lledicine, or by presenting to said board a false or untrue diploma, certificate or license, or one fraudulently obtained, he shall lie deemed guilty of a felony, and upon conviction thereof shall be punished by a fine by imprisonment at hard labor for not less than one year nor more than three yeirs, or than one year nor more than three years, or forfeit all rights and privileges obtained or conferred upon him by virtue of such registration.

Fifth. PERJURY: Any person who shall swear falsely in any aftidarit or oral testimony made or given by virtue of the proviBoard of Registration of Medicine, shall be deemed guilty of perjury, and upon conviction thereof, shall be subject to all the palns tion thereof, shall be subjec
and penalties of perjury.

Sixth. UNPROFESSIONAL CONDUCT : The Board of Registration of Jedicine may refuse to issue or continue a certificate of registration or license provided for in this section, to any person guilty of grossly unwords "unprofessional and dishonest conduct," as used in this Act, are hereby declarel to mean :

(a) The procuring, aiding or abetting in procuring a criminal abortion

(b) The obtaining of any fee on the assurance that an incurable disease can be permanently cured

(c) The wilfully betrasing of a professional secret: (d) All advertising of medieal buslness in whlch grossly improbable statements are made, or, where sprecitic mention is made in wich alvertisements of venereal disease

(e) Ilaring professlonal connection with, or lending one's name to an Illegal practitoner of nediclue : or hiving professional connection with any person or any flrm or corporation who advertises contrary to the provislons of this sortlon, or with any person who has heen convicted in a court of of this section:

(f) All adrertising, of any nature or kind, of any medicine, or of any means for the

(i) All advertising of any mater of an obsiene or offelsive nature derogatory to gond morals or contrary to act number ixty-two of the Public Acts of 1911 ;

(h) Employlug or being employed by any capper, solicitor or drummer for the purpose of securimg patients; or subsidizing any pose, or paying or offering to any person. money or any other thing of value with a like purtrose, or advertising to do so in any form whatsoerer; or the divlsion of fees in a consultation or a reference of a patlent service is reuclered by the pliysician referservice is l'emlered by the pliysiclan refer-
ring the case, wlthout the knowledge of the patient or the person concerned in the payment thereof ;

(i) Being guilty of offenses involving moral turpitude, habitual intemperance, or being habitually addleted to the use of morphlne, opium, cocain, or other drugs having a similar effect; or of prescribing or giving alcohol or drug for other than legal and legltimate therapeutlc purposes

Serenth. PENAITIES; REVOCATION OF Serenth. PENAITIES ; REVOCATION OF
LICENSE: It shall he a misdemeanor for any person to be gullty of "unprofessional and dishonest conduct" as deflued in thls Act. Any person who has been lssued a certificate of registration or license under
this Act, and who shall be charged with the commission of such misdemeanor, shall be tried in a court of competent criminal jurlsdiction, and upon conviction thereof shall or shall be imprisoned in the county jail not to exceed lluree months, or may be both fined and lmprisoned, In the discretion of the court. The creation of such misdemeanor by this Act shall not be construed to supersede any existing remedy or punlshment, whether civil or criminal, for any act em-
braced within the provisions of this Act, but shall be construed to be in addition thereto. The board of registration in medlcine may upon the fling with it of a duly certified copy of a final conviction obtained in acreroke or suspend for a limited period, not less than six months, the certificate or license of the person so convicted. The said Board of Itegistration in Medicine may also revoke any certifleate of registration or 11 cense of any person guilty of a criminal affense created by or embraced within the provisions of this Act or within the provisions of any state, provincial, territorial or elgn countries, when such criminal offense or such fiaud or perjury shall have been legally established in a court of competent jurisdiction. Sajd board may also revoke any certiflcate of registration or llcense heretofore or hereafter rranted umon mistake of material fact or by reason of fraudulent inisrepresentation of fact by such applicant. Any person charged with a violation of the provisions of this subdivision seven of Section 3 shall have a fair hearing before the board, apon sufficient notice of sucl hearIng: Provided, That this section shall not apply to such forms of conlract practice as Sec. 5. FEES: All moneys receired by said board shall be paid to the state treasurer monthly, and shall be credited to the
general fund of the state, and a receipt for the same shall be flled by the secretary of the said board in the office of the auditor general. The incidental and traveling exsecretary as said board such salary to the 
fald fron such tund only. The members of

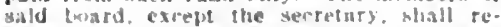

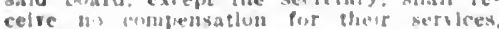

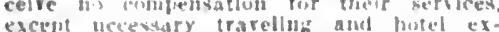

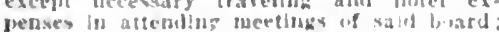

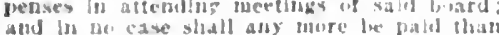

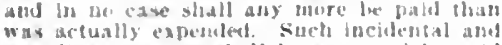
iravelisg esuenwes shall be approbed by sale board and sent (1) the audleng getheral (1) the state, who shall loww h's warrout uju, the stnte treavurer for the amounts los, ar In case of other bolls and arounge under

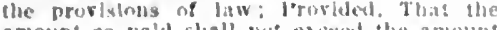
amount so pald shall not exced the amouns recelred by the treasurer of the stafe ?rim salu board in fees. as hereln specitled, ami

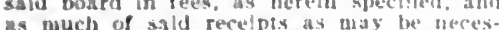

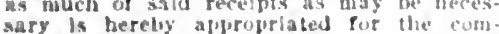
sary is herely apluppriated for the conpensatlon

Sec. 6. Itronts: sald troasid shall collect from the various county clerks of the stabe, each inonth, a report of all repistril. lons made. Salif board slatl alst beep a record of ail inoneys recelved and disbutsed record of all moneys recelved and disurtsed by it each munth, and said reerord shall always be ofven to lispectlon at the oflce annually report to the governor. on or be fore the first dny of January of each year. the condition of nediclne and surbers in bis stace, whlch repurt shall contain a full and complete record of all the oflcial acts durlug the year, and shall also contalu a wlatement of lis receints and disbursements.

sec. : LILATI: WITHOLT CFRTIF' (ATE: Any person who shall practlce med lelne or surgery in this state, or who sliall adrerise ln any form or hold himself or herself out so the public so being alle to treat. cuse or allerlate duman ailments or diseises, and who is not the Jawsul possessur of a certiticate uf reglstration or license of a cettitlcale uf reglstration of license

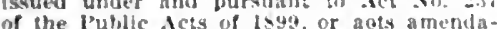
of the lublic Acts of lsyg. or aots amendathe provislons of thls Act, excejt as berecofore prorlded In section 3 of this . let ahall be deened ruilty of a mistemeanis and upon conrlctlon thereof shall tre fun jshed by a tine of not more than $\$ 200$. by Inarlsonment in the county jall for verlal of not more than $\mathrm{s} \mid \mathrm{x}$ unonths, or by iwoth such fine ard lmurlsonment, In the dis cretlor of the court for each offense. It shall cretion of the crurt or each offense. It shat the the rubs of the jrosecutlag attornes on the countles of this state to prosecut
llong of the prorlsions of this Act.

sec. 8. kxEMl'tuxs: This let shall not anply to the commissloneal surgesms rit the lniterl states Army, Nasy of lublu the Inited states Army, Naby ut luble thealth service la artual performance of their offlat duties, nor to regularly liceellsed state, in actual constultation wlih physteian and surgemen of this statc, nor to dentist In the lefitlmate practlce of thelr proftution sot to fomporary asststance in cases of emergancy, mor to the donestic aldutuistritthon if famlly remedles, not to cupenpathe practicing under the prortskons of Act $\mathbf{X}$ log of the l'ublic Acts of 1903, nur to (1) to-

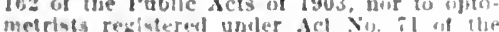

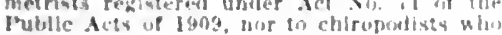
conne thelr practice til chlrofouly and whe conne thele practice to chlrofinly and win feawro or any of thelr abliteriallusis, or any other surefix or amix in a modleal kence ।

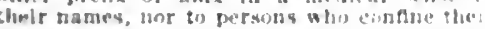
andnistratlon to the alck of anlleted to prabor and without the use of materlal remedios

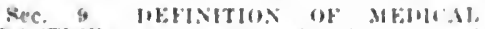

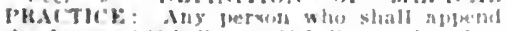

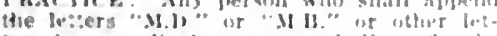
ters in a medlieal vense. or sluall prefle the

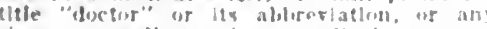

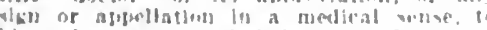
the or her nane, it sliall be bulma forle ev

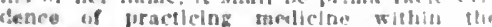
meaning of thls Act In this . Act, unlers wherwlse providesl, the terin "practice of medlelne" shall mean the u'tual diaksuring.

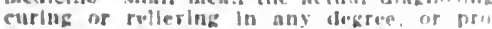
fesulng or attemutiog in llasnme.

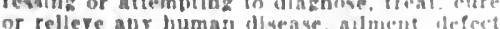
or coniplalnt. Whether of phisical it inental orlein. by atfendance or by aetrice. of li, prescribling or furmlahing any rlug, medletne. afpliance, manliulatloss is methoxl, of lis any therapeutic agent whatweret.

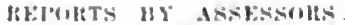
If vlatl lie the turs of the avoessing onlecer

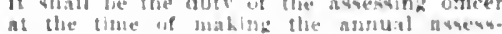

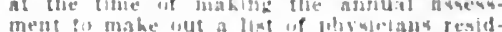

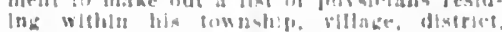

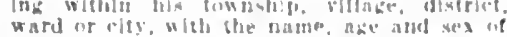
cach, ald the lemith of time earli has becell engaged ln practice sibch list shall lee reo surbed log the awesumb uftcer to the crounty clerk, anil bis the cousity clerk reourded in a lame la shleli are hept the records of the

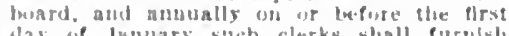
criflifol limty of the same ti) the secretary of this bonrd

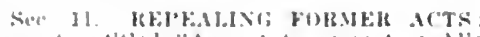

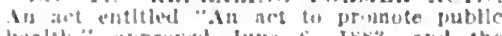

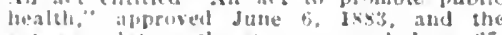

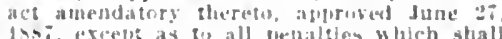
hare necrum thereunder, are hereby re.

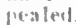

Inprosel IIay 4, 1:13.

\section{STATE BOARD OF HEALTH}

lir. Victur 6 . Vaughras, l'residens, Inn Artor: lir. Thomas $\mathbf{~ I . ~ K o r m , ~ V i c e - l ' r e s l d e n s . ~}$ Cratnd Raplds: Jir. Antrew I'. Biddle. Ibe. troit: C. M. Itinner, lsat:le Creek; Ur. E. T

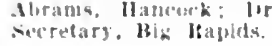

\section{MICHIGAN STATE BOARD OF REGISTRA}

George J. lop Fenfe, Iresldent, Muskezon

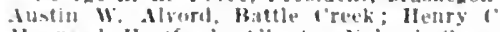
Manarl, Hartforl: Alleertus ds land, Girand

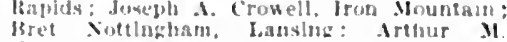
Ilume Uwose: Cellonel $\mathrm{B}$. Burr, Fllnt: Wm T. UMlge, Hig Rajlds: Cheorge W. Xafe Fromont: Heverley H. Harisom, secretary, lietrolt.

\section{MICHIGAN STATE MEDICAL SOCIETY}

giv 1. Kiefer, I'resldent........... luetroit II R. Hasudall, Ist Vhe-1'resident....thint $\therefore$ E. Taylor. "d Vlee-President... Jackon k. I1. Whbster, 3al Vice-l'resident.

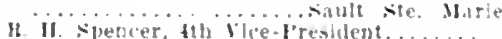

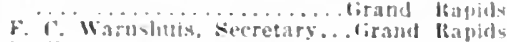

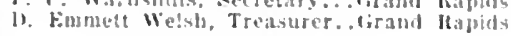

\section{State Journal}

Jnurnal of Michizan state Mediral sociens. betrolt Frederlch $C$. Warnslatsis. M.ll. edlitor

\section{Councilor Districts and Dfficers}

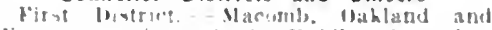

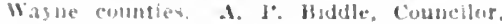
leeronit

seond Dlotrlel. Illlsiale. Inghan and

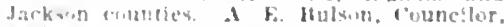
Jacking

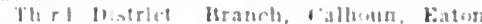

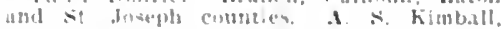
Haste riseb

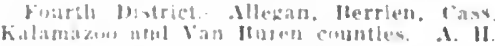

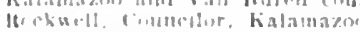

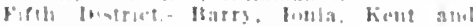

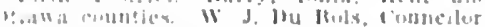
Corand diandels

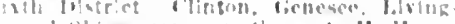

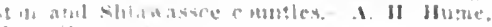

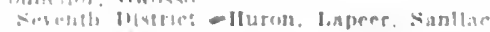

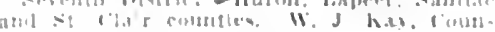
ilitenter

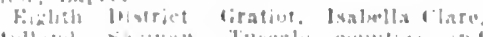

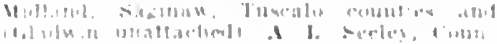

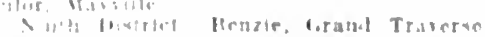

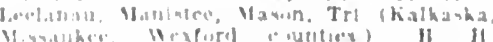

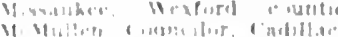

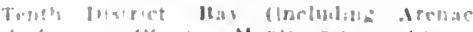

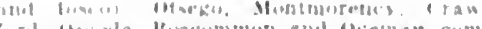

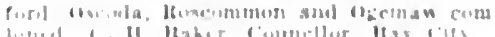

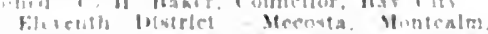

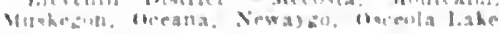

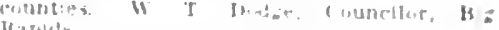

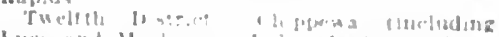

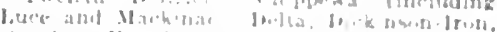

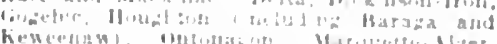

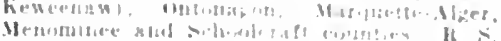

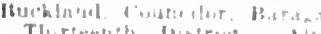

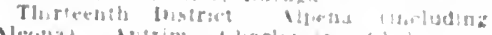

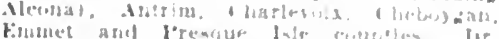

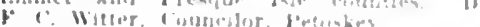

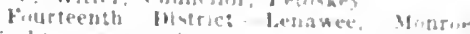

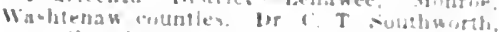

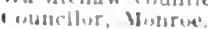

Component County Societies of the Michigan State Medical Society Mlikil rol NTI

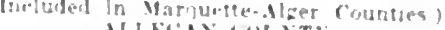

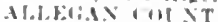

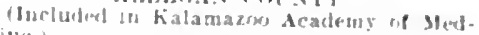

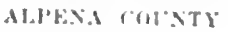

J. IN Amall, l'resthert. INTIIM (O):NT)

i. II Wilhinums, lereldeti.

ii. II. Nichols, secretary. AlE:DAC (')I, ITY

(Includel in bay-arenac-lowas (iunties)

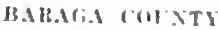

Included in IInughern-Baraga-kescenaw B.IHKY COY NTS

f. II. Lourb l'restuent........ Hastings

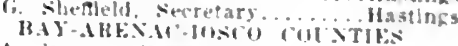

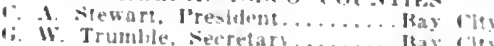

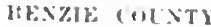

I. loyle, J'resident........... Franhfort

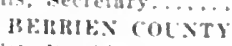

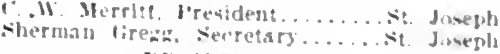
MIR.M. I 6OLNT

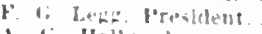

cioldwatep i.M.huly col NT

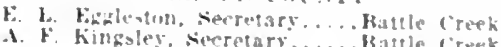
Ans ronth

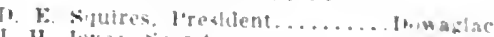

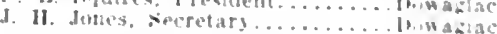
CHARHEVHX (OATT)

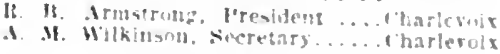

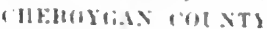

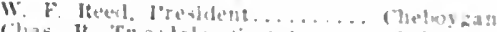

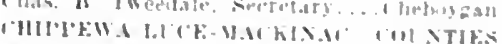

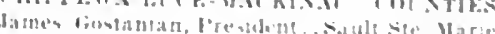

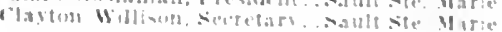

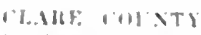

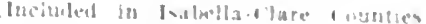
1.1XTHN III NTI

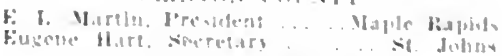

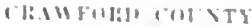

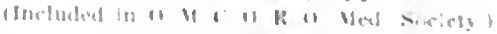
l)E.T.T in int

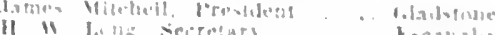
Whatill ind

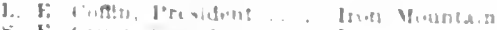

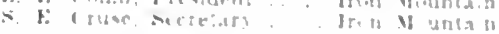
F. TUN (1) IT

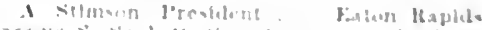

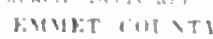

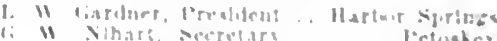
IIFVESER: I 11 NTI-

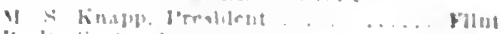

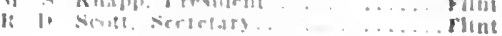

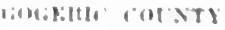

3 II bills t'revileme

Winketeld Irosicinal 
(IRANU TRAVEIRSE-LEELANAU COUN'TIES fi. II. Frallek, l'resident........... Mille city
J. A. J. Hall, Secretary...... Traverse city GRATIOT COUNTY

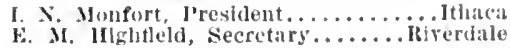
HILISIOALE COUNTY

I3. F. Green, President.......... Ilitlsulale

C. T. Bower, secretary.............. Hillsdate

HOLGHTON-JAIRAGA-KLWEENAW col:NTIES

1. 1). Mc. Naughton, I'resident....... ('alumet

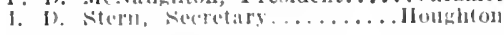
H11 1102 (OI)

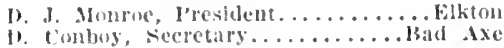
INGHAM COIXT

Samuel oshorn, President........ hansing

Fred M. Itumley, secretary......... Latusin IONIA COLNTY

F. M. Marsh. Iresident ........... Ionla fohn J. Nccann, secretary............ Ionfa IONE C COUNTY

(Included ln liay-Arenac-Iosco Counties.) 1SAIBEHALA-CIAIRE COUNTIES

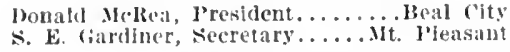
JACKNOA COINTY

W. A. Gibson, I'resldent............ Aickson (i. A. Sesbold, Secretary.............. Jackson KALAMA700 COENT

(Ineluded in kałamazoo Academy of sted.) KALAMAZOO ACAIEMY OF MEDICINFILLEGAX, KALAMAZOO, VIN BUREN COUNTIES

I. F. Maxwell, President. ......... Decatur

C. 13. Fulkerson, secretary....... Kalamazoo KALKASKA COUNTY

(Included In Tri-County Medieal Society.) KENT COLNTY

A. M. Camphell, l'resident.... Grand Rapids J. J. Fablin, Secretary.......Grand Rapids KEWEENAW COUNTY

(Included in IIoughton-Baraga-Keweenaw Counties.) l.AKE COUNTY

(lncluded In Osceola-Lake Counties.) IAPEER COUNTY

Peter Stewart, President........... I Iadley D. J. O'Brien, Secretary.......................... LEELANAU COUNTX

(Included in Grand Traverse-Leelánau ('ounties.)

\section{I.ENAWEE COUNTY}

I. L. Spaulding, Presldent..........Hudson Frank Howland, Secretary................ LIVINGSTON COUNTY

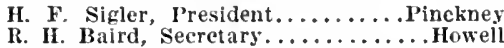
LLCE COUNTY

(Included in Chippewa-Luce-Mackinac Counties.)

MACKINAC COUNTY

(Included in Chippewa-Luce-Mackinac Counties.) MACOMB COUNTY

E. 6. Folsom, President............ Clemens
A. J. Warren, Secretary......... Clemens MANISTEE COUNTY

P. C. Jensen, President............ Janistee Lee $\Lambda$. Lewis, Secretary....................... MARQUETTE-ALGER COUNTIES Paul Vau Riper, l'resident.......... Beacon
H. J. Hornbogen, Secretary...... MASON COUNTY

F. IV. Heysett, President. ........ Ludington

T. J. Foster, Secretary................. Seottville IECOSTA COUNTY

L. S. Griswold, President........ Big Rapids MENONINEE COUNTY

Henry T. Sethney, President.......Menominee

C. R. Elwood, Secretary........... Henominee MIDLAND COUNTY

G. S. Sjolander, President..........Midland R. J. St. John, Seeretary...............
MSSAUKEE COUNTY

(Inchued "in Tri-comnty Medical soclety.) MONIROE COLNTY

1. ¿. Bont, I'resident.............Monroe T. Southworth, secretary.............. MONTCALM COUNTY

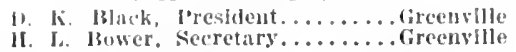
MONTMURE.NCY COLNTI

(Incluled in O. M. C. o. K. 1). Med. Soclety.) MLSERON-OCHANA COUNTIES

lacob Ousting, l'resldent.......... Muskegon J. 'T cramer, secretary.............Muskegon NHAYGo COUNT

Wm. If. Barnum, President........Fremont ti. (i. Burns, secretary.............. Fremont O.AliLAXI, COUNTY

Chas. M. Raynate, I'resident...Bhirmingliam f. J. Murphy, Secretary............ Fontinc OCEANA COUNTY

(Inchuled in Ituskegon-Oceana Counties.) OOF.MAW COUNTY

(Incluted In O. M. C. O. R. O. Mes. Society.) ONTONAGON COUNTY

F. IV. Mellugh, I'resident........ Ontonagon J. S. Nitterauer, secretary...... Ontonatgon OSCBOLA-1.AKE COUNTIES

John $x$. Thomas, I'resident.......... Je Roy Thomas F. Bray, seeretary....... lieed city OSCODA COUNTY

(Included in O. M. C. O. R. O. Med. Society.) OTSEGO COUNTY

(Included in O. M. C. O. R. O. Med. Soclety.) OTTAMA COUNTY

Artinur J. lBrower, President......... Zeeland Henry J. Poppen, Sccretary............Holland

O. M. C. O. R. O. MEDICAL, SOCIETYOTSEGO-MONT NORENCY-CRAWFORU OSCODA-ROSCOMMON-OGEMAW COUNTIES

F. E. Abbott, President............ Sterling P'RESQUE ISLE COUNTY

Bazel G. Larke, Presillent..........Rogers

W. W. Arscott, Secretary...................... ROSCOMHON COUNTY

(Included in 0. M. C. O. R. O. Med. Soclety.) SAGINAW COUNTY

kobt. Mccregor, J'resiclent........ Saginaw A. R. Nekinney, Secretary.............. Saginas SANILAC COUNTY

I. G. Robertson, I'resident........ Sandusky
J. W. Scott, Secretary.......... Sandusky SCHOOLCRAFT COUNTY

W. J. Saunders, President......... Ianistique II. W. Roos, secretary............ Ianistique SHIAWASSEE COUNTY

IV. A. Rowley, President............ Durand ST. CLAIR COUNTY

A. H. Cote, President............. Ht. Huron k. k. Wheeler, Seeretary.............. Hut. Huron ST. JOSEPH COUNTY

R. E. Dean, President........ Three Rivers s. k. Robinson, secretary............. Sturgis TRI-COUNTY MEDICAL SOCIETY-WEXFORD-KALKASKA-MISSAUKEE COUNTIES

o. 1. Richer, President....................... Cadillac TUSCOLA COUNTY

k. I. Steinbach. President......... Richrille VAX BUREN COUNTY

(Included in Kalamazoo Academy of Med.) WASHTENAW COUNTY

Ira Dean Loree, President......Ann Arbor John A. Wessinger, Secretary.....Ann Arbor WAXNE COUNTY

I. J. Hirschman, President. ......... Detroit

L. J. Hirschman, President........... Detroit
Raymond L. Clark, Seeretary...... Detroltt WEXFORD COUNTY

(Included in Tri-County Medical Soclety.)
HEALTH OFFICERS IN CITIES OF 10,000 POPULATION AND OVER

Alriall.................. Geo. M. Iochner

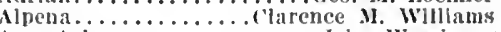
AnI Arlor................ John Wessinger battle Creck................ Fugene Miller

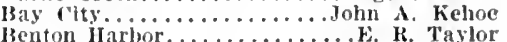
Benton I Iarbor................. Raylor

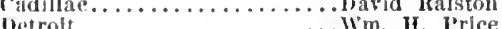

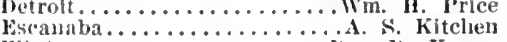
Flint.................. W. Knapp Grand Rapjds............. C. Slemons II

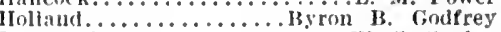
Ironwood Iron Jountain.............. Edwin Cruse Islpemfnt............... Jackson.............. Ieter D. Hyndman Kalama\%o............... II. Rockwell Lansing............... $\mathbf{c}$, Hussell Ludington. . ............... O. Switzer Manistee.............IIarlan MacMullen Marquette.............. H. Flynn

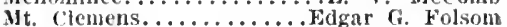
Iuskeron............... Camphell

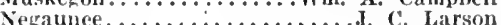
Negaunce................ L Larson Pontiac.................... Gastell ['t. IInron................. II. Cote Suginaw................. J. o'Reilly sault Ste. Marie..............J. J. Griffln

Traverse City ................. L. Thirlby

\section{STATE INSTITUTIONS}

State Industrial Home for Girls, Adrian, Mich. Established 1879; 375 beds; Emily S. Stark, physlcian ln charge; Mary Johnson, superintendent.

\section{Ann Arbor}

State Psychopathie Hospital at the University of Michigan, Ann Arbor, Mich. Fstablished 1906; mental; University Clinie of Psychiatry ; 55 beds; A. M. Barrett, medical director.

Flint

Nichigan School for the Deaf, Flint, Mlch. Established 1851; deaf; 50 beds; F. A. Roberts, attending physician; Francis D. Clarke, superintendent.

\section{Grand Rapids}

Michigan Soldiers' Home, Grand Raplds, Mich. Established 1886; general; 250 beds in hospital department; Maj. Howard A. Grube, surgeon in charge.

Howell

Michigan State Sanatorium for Tuberculosis, Howell, Mich. Established 1905 ; medical superintendent.

Ionia

Ionla State Hospital, Ionia, Mich. Established 1885 ; for the criminal and danLerous insane; 485 beds; Osear R. Long, medical superintendent.

Michiran Reformatory, Ionia, Mieh. Estahlished 1908; 20 beds; Karl B. Bucker. physician in chief.

\section{Jackson}

Michican State Prison Hospital, Jackson, Mich. Established 1839; general; 35 beds; Morley S. Vaughan, physiclan in charge.

\section{Kalamazoo}

Kalamazoo State Hospital, Kalamazoo, Mieh. Established 1859; for insane; 2,000 beds; Alfred I. Noble, medical superlntendent.

\section{Lansing}

Industrial School for Boys, I,ansing, Mflch. Established 1852; 800 beds; E. M. Lawson, superintendent.

Nichigan School for the Blind, Lansing,
Mlch. Establlshed 1880 : Clarence E. Holmes, superintendent.

Lapeer

Michlgan Home and Training School, Lapeer, Mich. Established 1895; for H. A. Haynes, medical superintendent. 


\section{Marquette}

II ospital of the Ioper I"eninumbia liranch Prlson and Ilouse of correcthm, Mar-

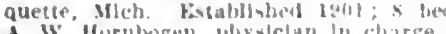

A. W.

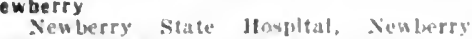

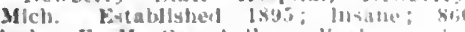
berls; Fo. 11. Campletl, medical sumertn tendent.

\section{Pontiac}

lonllac state Howpitui, l'ontlar, Mul. Establlshed isis: Insane: 1.430 leeds: Fol mund . C. Chrlatian, medical suporintend. ent.

\section{Saginaw}

Mlahgan Eabloyment Institution for the Blind, Sagtnaw, West Side. Mich. Eistal,

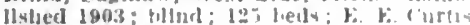

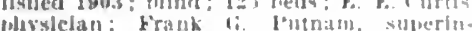
tendene.

\section{Traverse City}

Traverse City state Hospltal, Traverse Clty, Mleh. Fotabllshed txal: fur tho in-

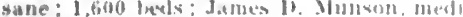
eal superintendent.

\section{HOSPITALS, SANATORIUMS AND CHARI TABLE INSTITUTIONS}

Adrlan

Einma L. Mixby Hiospltal, Nolrtan, Mich Fostabllshed 1911; general; cuntaglous cases not adnitiel; :-1 heds; Katturime Case, superintentent.

\section{Albion}

Alblon clty llospital, Alblon, Mlah Establlshes 1403; 16 beds; Mand II Stark, superintendent.

Alblon Mosnital Assoclatlon. Alblng. Mlch. Fistabllshed 100. : 10 beds; Miss Allce 3. Stuart, superintesdent.

\section{Allegan}

John Hoblnaon Ihugltal, Nleqan, Miel. Established 1909: Li beds: 1. 1. Mutin aon, physiclan In rluarge; Cora bs. Rubin son, superintendent.

Alma

liralnerd Jospital, Alma, Mich. Estalsllshed 1895: general; 15 Ineds; Ira Brainerd, physician in charge.

Mejlizan Masinle IIome, Alma, Mleh. Eistablished 1911; ukned and maimained by firand Jodge of Michigan: 140 lueds; E. T. Lamb, bhysletan; Herberi MuntaEue, sugerintendent.

\section{Alpena}

Sorthern Mlchlgan santtarium, Fidly

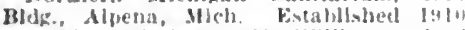
general, I: hedr; (:. M. Willans, why clan In charge; b. A. Klefer, stuperin tendent.

\section{Amasa}

Amana Hospital, Arusa, Meb. EvabJlshed 1901; 5 beds; 1". Mc.Murchle, ptyys clan In charge.

\section{Ann Arbor}

Dr. Halr's Hospital, $311 \mathrm{~S}$. Inrisim st Ans Artor, Mlch. Kistablished 1!1:; pri rate; s heds; Win. Blalr, attending plsyst. cian.

Ibr. Itreakey's Huspltal, 213 k. Hurun st. Ann Arbor, Mlleh. Fistablistied litl: privale: theds; $s$. Hreakes, attending phrate :

br. Canflell's llowital, dnn Arbur,

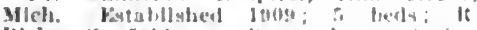

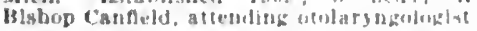

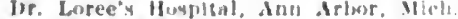

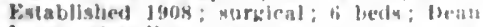
intec attending surpeos

Maplehurat, Ann Arlerr, Mleh. Everalrlished 1905; 10 lvetly; 1. ti. Marling. surgeon.

I'eterson's llewbltal, filo Furest Aro

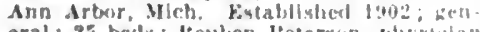
eral: 2.6 beds; Iteuben l'eterwion, physlelian in cliarge.

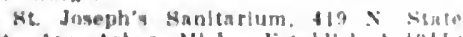

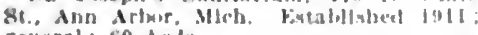
gelieral: 60 thels.

Inlversly Fice, Bar, Nuse aud Thrond Hospltal, Ann Arlur. Mich. Fotabliaberl 1910: 61 beds: K. II, cantlelu, phystedan in cliarge.
Inireralty IIospleal, Ann Arbor, Mich

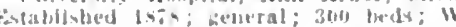

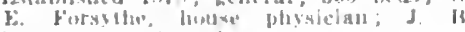
liraper, superintemilent

Inlverslty of Mlchigan Horusipathic IIospital, Ann Arbur, Nich. Eatalilishent

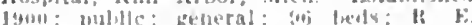
Atehisur, mollowl supertnfondent.

\section{Bad Axe}

Ilulinard Memorlal Homplial, Kat Ixe,

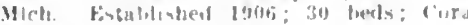
I. Itugle, sidporlutendent.

Baroda

Irr. 1. I King Hosgltat. Harmb, Mich.

Balle Creek

Itattle f'reek sambarlum, Itaftlo Crobek.

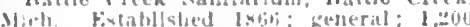

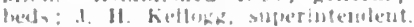

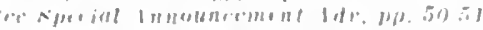
Jamey White Memortal Horme, Hatse Creek, Mlot. Extalllshed 1892: Por the ancel: 35 betls; Irs. r. A. IS. Sinth (I) atruts

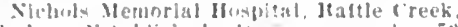

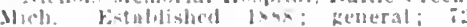
heals: rolzaneth loe, sulnerintemsent.

Bay City

Inti-.Iddrotion santtarium, 140\% Wored. side . Wre, Hay city, Mich. Kastablished I!ns: Irug and aleotolse: In beds: smith F. Eustia, phystall in charge. Kay Cley Howplal, 913 lass Ale, liay only; if heds: Mlss dmelia Landskroener. only: it heds:

influrels flome, columbus and John

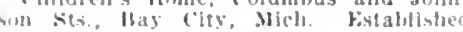

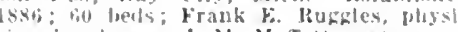
cian in tharge: J. M. Moftett, matrols. Hetention Il spital, Jay Cliy, Mieh. b.

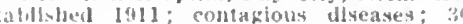
bets: Wrs. Ioseph Muhholland, matron.

Mrrey Huspital, Bay Tity, Mirh. Estalitished 1504 ; 55 beds; sisters of Merey. ia cliarge

West sicle Jospltal, 403 k. Indiana st.

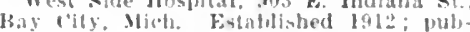

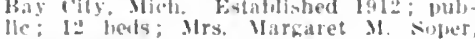
sizuerintendent.

\section{Benton Harbor}

Vercy Ulsiptal, Renton Hartur, Wieh.

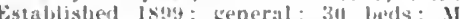

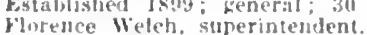

shaunan Materntty Hone. Henton MarIxor, Mlel. Estatilished l:bl:; is loeds; Mr 11. A. Shauman, Juanager.

\section{Bessemer}

lingehic llospital, Bessemer, Mich. Fs talilstued Ixs: metical and surtical: 1 : teds; r. II. Marlajesky and W. J. I’unker ton, myvichans in charge.

Paralls Hospltal, Messe'tuer, Mch. Ko talolinlied jyo:; general: 20 heds; 16 . I'aradls, physlchan In cliarge.

\section{Bie Rapids}

Merey IIospltal, We Kaphds, Mteh. E tablistion 1879: general; 100 treds.

\section{Boyne City}

Itorthe Cifs Hospital Hoyne Cits Miel

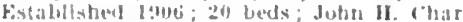
hers. Whysician in ehatro.

\section{Cadillac}

Mercy Huspital, callillat, Meb. Fos

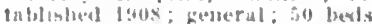

\section{Calumet}

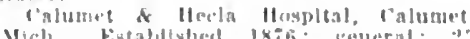

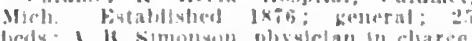

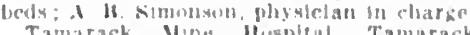
Tamarack MIn. Ilispleal. Tamarack

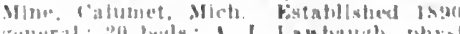

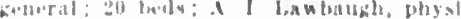
clan la riartin.

\section{Cass City}

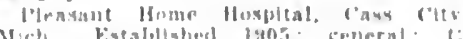

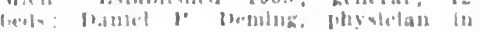
charkes.

\section{Champion}

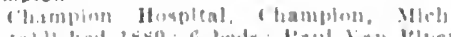

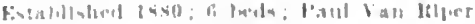

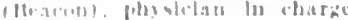

\section{Charlotte}

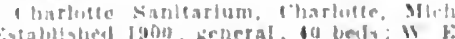
Y.w.yk, wuperiusulens.

\section{Coldwater}

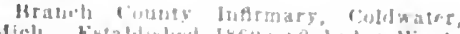

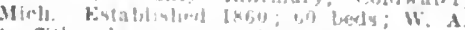

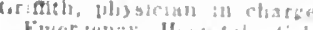

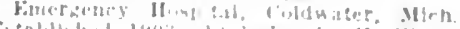

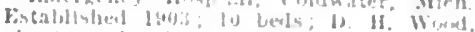
ghostclath in chargo

\section{Crystal Falls}

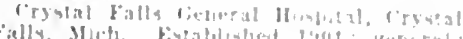

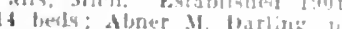
chare.

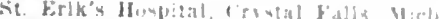
Establlstied j:07 lo bealo

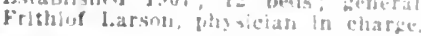

\section{Dearborn}

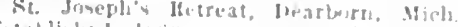

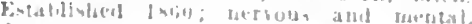

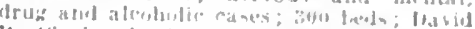

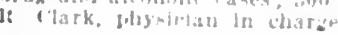

\section{Detroit}

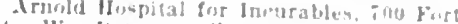

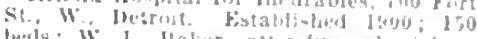

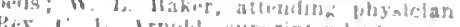
leme

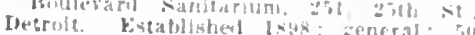

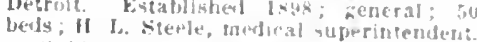

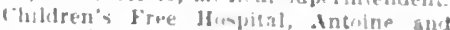

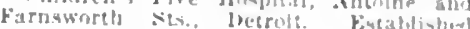

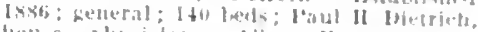

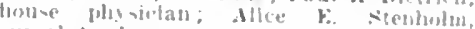
superlnterident.

Mrs. 1: H. Murrer's Maternley IIowpltal.

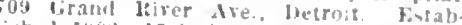
lisherl 19t2: 15 Leds; Mrs. 10. H. Murrer.

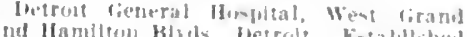

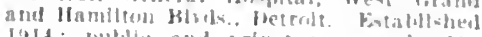
lopt; puble and private; seneral; lou

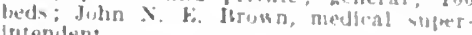
itentezt.

betrolt Sanltarinm, 250 rort st, 11 letroit Established isst; ag perds; A. I) Mcrachran, phssician in charge.

Florence Crittenton IIne, is: Follzabeth

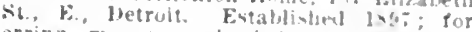
erring pomen and their chillen: It5 German irotestant Home for wethans.

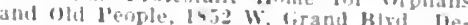
iroit. Kstablislied $18 \times 2 ; 115$ bedi ; hir. Neumann, superintenderit.

Dr. (icwan's I'hyslo.Therapeutle sunita-

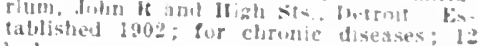
bretk

Grace Ilnspltal, Juhn R. Nt. and Willts

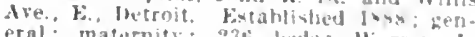
eral: maternity: 23i heds: Warren 1. Habrack, Mll. suberintendest.

Cirut kastern sunitarlum, 920 Jurerven

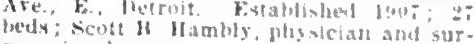

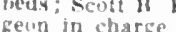

Harpur Ihuppital. Jolun R. se. and Martu

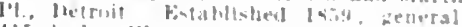

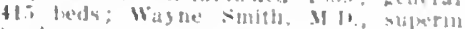
terndent.

llome of the primulless. Ait Warten ore.

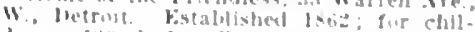
dren: lou leels: billth lirant, superin-

Hume samitarmm, D licisman lre. De.

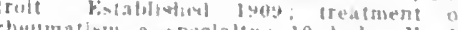
rheumatism a speclateg in beds: k: I ling. sumprintoludent.

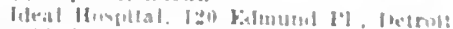

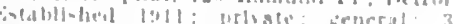

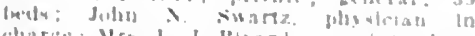

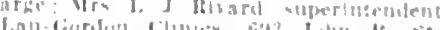

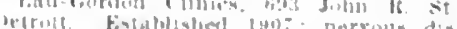

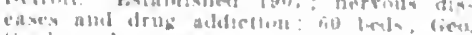

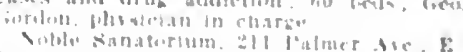
broblo sanafurlum.

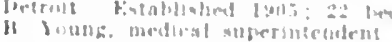

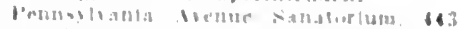

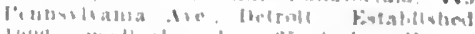


I'rotestant Orphan Asylum of Detroit 4xs Jefferson Ave. Detrolt. Estublisher 1836 ; for children from : to 12 years; 109 beds: Chas bouglas and Viu. II. Donalu, blissichans in charge.

l'rovklence Hospital, N. Grand l3lvd, and ifth Ave. Detroft. Fstablsher istig; publlc: general; for women and chllen: 350 beels.

thed Cross Hospital, 582 Fort st., W Detroit. Estublished $1900 ; 3.7$ leeds; $(:$ II courvile, physloian in charge; Mrs. Chambers, superintendent

Salvation Irmy Maternity Ifospital ant lescue llome sigf lourt st. W. betroit Established 1900; to leeds; Margaret butfy, matrom.

Simaritan lospital, $\mathbf{X}$. Gand Bird. and E. Milwatukes Ave., petrolt. Establis led 1913; general; 40 heds.

small-pox Favilion, Herman lifefer Ilospltal, Hamlfom livel. and Trog Mee. belrolt listablisled 1894; 20 beds:

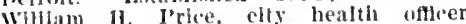
physiclan in charge; J. A. MoVelgh, at teriding physician.

Solviy (ieneral Iospital, $2035 \mathrm{~W}$. Jeffersou petrolt Estabilished 1902 ; gen eral: 50 beds; ;. R. MacClure, surgeon ill charge.

st. Agnes IIome, 3401 Woodward Ave. petrolt. Fstablished 1909; home for un cared-for girls:: 21 beds; Miss Linda Burger superintendent.

St Francis Home for Orplan Boys, 3190 Woodward Ave. petrolt. Established 1889: generai: 350 beds; Sisters of St. Joseph. In chirge.

St. Iosenh's Ilome for l3oys, 125 ('om gress st., F., betroit. Rer. Brother liegi nald, superintendent.

st. luke's Ilospital. Chureh Home and Orphamage, Fort st., W., Detroit. Established 1868. for aged people: 32 beds liss Jane E. Hentig, superiutendent.

St Mary's Hospital, St. Antoine and St. Mary's Hospital, st. Antoine and Clinton Sts., Detroit. Established 1854;
200 beds; ' $T$. A. McGraw, chlef of medieal 200 bed
staff.

St. Vincent's Orphan Asylum, 137 Mc bougall Are., Detrolt. Established 1851 250 beds; Sisters of Charity, in charge.

Star Sanitarium, I54 Iafayette Bivd.

Detroit. Established 1902: nervous and Detroit. Estases, narcotic and alcoholic addiction: Wilson Fish, medical superindiction;
tendent.

Thompson Home for Old Ladles, 888 Cass Ave. Detroit. Established 1876;34 beds: Miss Albert, superintendent.

Tuberculosis larillion. Herman Kiefer Iospital, Hamilton Blid. and l'ingree live, Jetroit. Established 1907; tuberculosis: 94 heds: V. C. Vaughan, Jr. plusician in charge.

inlted States Marine Hospital. Detroit. Estished 1855: general : U. S. Nary 60 beds: H. W. Austin, Sr., surgeon in command.

Van Leuven Browne Hospital School 31 Kenilworth Are, Betroit. Established lon:- for the care and edueation of crippled chlldren and those with chronic clippled chlidren and thosews, (Highland liseises; George R. Andrews, ard II. S. Shafor, visiting physiPark): and II. A. Shafor, visiting physi-
cians; Mlss Laura E. O'Neill, superintendent.

West side Sanitarium, 924 Fort St., W. petroit. Established 1906 ; alcohol and drug cases; 30 beds

Woman's Hospital and Infants' Home. Forest Ave and Beaubien St., Detroit. Forest Ave. and Beaubien St., Detroit. Established 1869 ; diseases of women; 200
beds: W. P. Manton, chief of medical beds; W. P. Manton, chief of medical tendent.

\section{Dowagiac}

Ackerman Iospital, Dowagiac, Mich. Established 1008: 12 beds: Hanna I. Ackerman, R.X., superintendent.

\section{Eas! Grand Rapids}

Reel's Lake Sanitarium, East Grand Rapids, Mich. (Grand Rapids P.O.). Established 1902; general, nerrous, alcohol and dru addictions; 50 beds: 'T. B. o'leefe, medical superintendent.
Eloise

Vilolse Hospltal for Mental Diseases. Eleise. Mi(ch) Established 1869; 590 beds

Joluu J. Marker, medical superintendent.

Elolse Sauatorium, Eloise, Mlic Estab-

loher 1904; 60 heds; tubereulosis; J. J. llatker, medical superinteudent.

\section{Escanaba}

Laing Hospital, Fscanaba, Mich. Fs. talllshed 1:13:20 beds; A. I. Lalng, bhyslcian; llattie Venton, li..., superintendent.

Nisters of st. Francels llospital. 1000 Fambe st., Fscanaba, Moh. Established 1852: Gelleral: 50 heds; sisters of St. lisllois in charge.

\section{Flin}

Cienesee County Influmary, Flint, Mich. Established 1913; publie; indigent advanced casez of tuberculosis; 10 beds; W II. Wiuciuester pliysiclan in charge.

Iluriey Ifospital, Fint, Nich. Established 1909: generat; 50 beds; Anna II. schlll, R.x., superintendent.

Oak Grove, Flint, Mlch. Rstablislied 1891; nervous and mental; narcotic and alcoholic; 60 beds; C. 13. Burr, medical director.

Sce sijecial dunouncement Ade. page 58

\section{Grand Rapids}

Iutterworth Hospital, Grand Rapids, Mich. Estabilshed 18\%; general; 100 beds: G. l McBride, chief of medical staff : lliss Elizabeth C. Hodgens, superintendent.

leVore llospital and Sanitarium, 21 Clancy St., Grand Rapids, Nich. Established 1903; 30 beds; J. A. DeVore, medical superintendent.

Home for the Aged of the Little Sisters f the Poor, 158 Lafayette St., Frand Rapids, Nich. Established 1984; 154 beds. Kent County Detention Hospital, Grand Rapids, Mjch. Established 1907; nervous and mental diseases, narcotle and alcobolic addiction; 18 beds; Alex Lardie, superimtendent.

Municlpal Isolation Hospital, Grand Rapids, Mich. Established 1907; speeial provisions for tuberculosis cases: 100 beds; Board of Health, in charge; Mrs. Hugo Lupinskl, superintendent.

Municipal Tuberculosis Sanatorium, Grand Rapids, Mich. Established 190\% 48 beds: Ralph Apted and Clyde C. Slemons, physicians in charge.

II. J. Clark Memorial Home, 704 Sherman St., Grand Rapids, Mich. Established 1906 ; for the aged; 45 beds; Methodist Eplscopal Chureh, in charge; Rer. Join A. DeGraff, superintendent.

Patterson Institute, 416 Michigan St. Grand Rapids, Mich. Established 1893: narcotic and alcoholie cases; 20 beds: C. F. Parterson, physician in charge. lest Cottage Reseue Home, 1041 F Fulton St.. Grand Rapids, Mich. Established 1905 ; maternity ; 20 beds ; Rev. J. E. Henry, superintendent.

Salvation Army Rescue Home, Grand Raplds, Mich. Established 1897; maternity cases; 30 beds; J. Mill Wright, physician; Adj. Dorothea Maurer, matron.

St. Mary's Hospital, 252 Cherry St.

(irand Rapids, Mich. Established 1893. feneral, maternity; $\mathbf{7 5}$ beds; Sisters of llerey, in charge.

Union Benevolent Association Hospital, Grand IRapids, Mich. Established 1847 general; 75 beds; Ida M. Barrett, R.X., superintendent.

Greenville

Belknap Memorial Hospital, Greenville, Mich. Established 1905; surgical; 10 beds; Miss J. Clark, R.N., superintendent. Gwinn

Jasper Street Hospital, Gwinn, Mich. 15 beds; D. R. MeIntyre, physician.

Hancock

Houghton County Detention Hospital, Hancock, Mich. 25 beds; $A$ lfred La Bine, county physician, in eharge.

St. Joseph's Ilospltal, Hancock, Mich. Established 1899; 40 beds; Sisters of St. Joseph, in charge.

\section{Highland Park}

Detrolt Tuberculosis Sanatorium, Jlghland Park, Mleh. Establlshed 1911; 47 heds; IR. A. Shankwiler (1)etrolt), johystclan In charge.

st. Francls' Home for Orphan Boys, llighland P'ark, Mlich. 310 beds; Mathew 13rady (metrolt), attending physlcinn; Sisters of St. Josegh, In charge.

\section{Holland}

Dr. Fred Yonkers' l'ribute Home nospltal, 13th and l'ine Sts., Holland, Mich. Medical and surgical; Fred lonkers, physlclan lu rharge.

Homer

Ilomer Clty Ilospital, Ilomer, Mich. Established 1911 ; private ; 8 beds; Louis $M$. Henderson, M.j., superiutendent.

\section{Houghton}

Jlonghton County Tubereulosls Sanatorinm, Iloughton, Mlch. Established 1912 ; tuberculosis; 30 beds; Caroline E. Ehlert, It.N., superintendent.

Ionia

Ionla City Iospital, Ionia, Mich. Establlshed 1913; general; 8 beds; H. 13. Knapp, J. J. MeCann and V. H. Kitson, physicians in charge.

\section{Iron Mountain}

l'ewabie IIospital, Iron Mountain, Mleh. Fstablished 1893; mine emergency; 6 beds; L. F. Coffin, physleian in eharge.

St. Cieorge's Hospltal, Iron Mountain, Mich. Estabilshed 1885; 25 beds; Joseph A. Croweil, pinysician in eharge; Miss ilary li. Mi. Ieer, superintendent.

\section{Iron River}

Mercy Iiosplial, Iron River, Mich. Established 1900 ; general; 30 beds; E. $\mathbf{M}$. Libbey, physician in charge; June E. Ioore, Ii.N., superintendent.

\section{I ronwood}

Newport Mining Hospital, Ironwood, Mich. Fstablished 1911; employees of Newport Mining Company; 15 beds.

Twin City Hospital, Ironwood. Mich. Estabishlied $1890 ; 20$ beds; A. H. Runstrom, superintendent.

Inion Hospltal, Ironwood, Mich. Established 1884; for employees of the Oliver Iron Mining Company; 30 beds; $J$. W. Whiteside, physician in eharge.

\section{Ishpeming}

Finnish Iospital, Ishpeming, Mich. Establisiled $1906 ; 1 i$ beds; H. H. Holm, physician in charke.

Ishpeming Hospital, Ishpeming, Meh.

Established 18.2; general; 30 beds; Geo.

6. Barnett, superintendent.

Jackson

Jackson City Hospital, Ganson and Seymour Sts., Jackson, Mich. Established 1886; Leneral, maternity ; 50 beds; Margarel M. Moore, superintendent.

Jackson Friendly llome, Jackson, Mich. Established 1908; 30 beds; Mrs. W. II. keed, in charge.

Michigan Oda Fellows Home, Jackson, Nich. Established 1904; general 6I beds; $O$. S. Hartson, resident physlelan; Frank E. Dunham, superintendent.

Wlite Cross Sanitarium, Jackson, Mieh. Kalamazoo

Horgess Hospital, Kalamazoo, Mich. Estallished 188!; 200 beds; Sisters of $\mathrm{St}$. Joseph, in charge.

Bronson Ilospital, Kalamązoo, Nich. Es-

tablished 1901 ; general; 50 beds; Edith N

Cowie, R.N., superintendent.

Willur llome and School for the FeebleMinded, Kalamazoo, Mich. Established 1884; 30 beds; E. 1'. Wilbur and Walter Den lileyker, consulting physicjans; Joseph W: Wibur, superintendent.

Sife sipceini inmouncement Alv. page 78 Lake Linden

Lake Superior General Hospital, Iake

Linden. 11 ich. Established 1895; 30 beds:

G. W. Orr, physician in charge. 


\section{Lansing}

Fderand IV sparruw Hospltat. Machinum Are., E., Lansinz, Mcb. Eatablluhed 1912; general: 75 beds; Mabel L. Morgan R.X., superintendent.

\section{Laurium} Calumes Public Hospital, laurium,
Mtch. bstablished 1908: generat: 25 lieds: Florence M. Nicholsen, R.N. superlueds: Floren
Intendent.

\section{Lewiston}

Iewlaton Hospltal. Lewiston. M/ch. Is tablished 1909: Feneral: 5 beds: Archle C. Machinnon, physlelan in charge.

\section{Ludington}

Pantina Stearng IIospltal. Ludington Mlch. Fstablished 1907; general; beds; Amanda R. Judson, superintendent.

\section{Manistee}

Mercy Hospltal and Sanltarium. 13 Vine St. Manlstee, Mich. Established 1590 general: is beds; Sisters of Mercy, fil charge.

\section{Manistique}

Manlstlque Hospltal, Manlstique, Mich Established 1892: 15 beds; Andrew Vel son, physician in charge.

Dr. Rutledge's Prirate Hospital. Man

lstlque, Mlch. Establiabed 1912; is beds.

\section{Marine City}

Marine City Sanltarium. Marine City Mlch. Establisbed 1905; for rheumatism cases; 16 beds; R. B. Balrd, phyglclan In chárge.

\section{Marquette}

Morgan Ileights Tuberculosls Sarato. rium, Marquette, Mlch. Establlshed 1911. rium, Marquette, Mlch. Establlshed 1911 tuberculosls: 20 bed
phystclan in charge.

physiclan in charge.
St. Luke's Hospital, 123 West Ridge St.

Marquette, Mich. Fistabllshed 1895; med lcal, surgery, maternlty: 30 beds Mr. Clara I. Mack, superintendent.

St. Mary's Hospltal. Marquetfe, Mlch. Establlsbed 1890: 80 beds: Frederich McD. Harkin and E. H. Flynn, phrslclans

In chirge. Quette, Mich. Estabilshed 1890; 110 beds (ward in St Mary's Ilospltal).

\section{Mass}

Mass Mine Hospltal. Mass, Mich. Extabllsbed 1902: 6 bed 5 ; W. B. Hanna,

phyalclan in charge.
Ontonagon Ilospital. Mass, Mch. Established 1912; public: 8 beds; A. I. Swinton (Ontonazon), physician in charge

\section{Meneminee}

Menomince County Hospital, Menom! nee, Mich. Establisbed 18\%0: fot the poot and aged: 30 beds: U. A. Yennema and J. F. HIcks, medlcal stati; Fred J. Tults, superintendent.

St. Joseph' Hospital. Menominee, Mich. Fastabllshed 1893; public; general; is iveds.

\section{Michigamme}

Mllehigamme Hospltal, Mtchigamme. Mlch. Eatabllshed $190 \%$ : general: II] beds: Isalah - Slontte, médlcal superintendent.

\section{Mohawk}

Mohawk Mlning Company's Ilospital, Mohawk. Mich. Fatabliahed 1905: gen. eral: 10 beds: A. R. Tucker, physician in charge.

Monroe

Blind Bables' IInme, Monroe, Mich. Ka tabllshed 1912: charltable; 20 beds; Juhn S. McMillan, superintendent.

\section{Merenel}

Hal C. Blalr Ilospltal, Mnrencl, Mleh Establlwhed 1908: surglcal: 5 beds: Chas. d. Blalt, medical superintendent.

\section{Mt. Ciemens}

lolunial. Ilt clemens, Mlch. ristab. llshed 18:6: orivate; 10; leds: I. X shotwell, phyalcian in charge

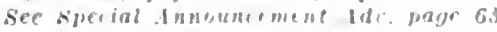
st. Jorcph's Sanltarlum. Mt. Temens. Mich. Established 18ng: So beds: slster: of Charity in char:e.

Washington Sanltarium, Mt Clemeus Mich. Eistabllshed 1911; private: 29 beds; J. U. Croman, physlclan In charge.

\section{Munising}

Munialng Jlospital, Munising. Mich. Kis tahllshed 1910: Reneral: 20 beds: T. W scholter. house physiclan; Iresse it LIndeburs. superintendent.

Munith

Sanitarium. Munitb, Mich. Fostablished 1908; Eeneral; 10 beds: It. II. Leece. physician in charge.

Muskegon

Hackley IIospital, Muskegnn, Mich, Established 1902; 65 beds: $\boldsymbol{F}$ W. Girber chtef of medical staff; Miss Ellizabeth A Greener, It.... superintendent.

Mercy Hospltal, Muskegon, Mich. Es tablished 1903: general: 42 beds.

Muskegon County Home. Muskegon. Mich. Establiabed 1906; 7 beds In hospltal department; J. T. Cooper, county pbyslclan: Mrs. Spoon, superintendent of physician: Mrs. Spoon, superintendest

Woodlawn lifospital. Muskegon, Mich. Established 1901: detention cases; J. T Cramer, physiclan in charfe.

\section{Negaunee}

Vegaunee Hospital, Vegaunee, Mich. Fis tabllahed 1902; 30 beds: Horace W. Sthel don and d. H. Andrus, physlctans.

Niles

Van Noppen Hospital, Nlles, Mll. Es tablished 1911: 10 beds: i). A. Van copren, jhyslclan.

Norway

Aragon Hospltal, Norway, Mcll. E\& tablished 1901; ceneral; If heds: Filsh: l. switt. physician in charge.

\section{Otter Lake}

otter Lake Medical and Surgleal Sanita rlum, Otter Lake, Mtch. Fstablished 1904 general; 25 beds: Phillp k. Marsh. physt clan in charge.

Owosso

Dr. Bliss sanitarlum, Owosso, Mich Established 1908; tuberculosts. nerrou and general, cancer; 20 beds: feo. F Bitss, physiclan in charge.

\section{Petoskey}

Lockrood IIospital and Iteaconesr Home. Petoskey, Mich. Fistablisher 1!40:; 20 beds: Mrs I udiey Melmald, superintendent.

Petoskey Hospital, I'etoskey, Mich. Extablished 1909 ; 28 treds: (i. W. Nihart tablished 1909 . ina March It x. superintendent.

sevelle sanitarium, l'etoskey, Mich, Esablished 1910: rheumatic defornuties; beds: kirnest Serelle, proprietor.

\section{Pinckney}

Iinckney Santarium. Pinckney, Mich. Fatablished 1901: 12 hels: H. $\mathbf{F}$. and $C$. I sigler. physletans in charge.

Pontiac

Yakland (ounty Hospital. I'ontlac. Mich. Evtabltshed 1902: seneral; 35 theds Vargaret II Melgs, superintentent.

Pi. Huron

l't. Iluron Hosultal. I't Huron. Mirl Fortabllwed 1680 : general : to Imis; Theo inge Hearcheich. phrsiclan In charge
Repubilic

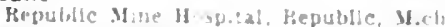

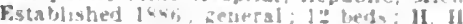
loreland. medicat muperintendor!

Saginaw Detertion II splea! Sazigaw, Mich beds; Mrs. H. Cobleigh, superingendent. Saginas Tuberculosia II spltal. Saz naw. Wich. Fstabllshed lyli: 36 incef Miss Lllliar I Yichols, superiniendent St. Mary's Hospltal, Saginaw, Mich. F.o. tablished 16it: surigical only: 100 bete sisters of Charits, in charge.

Woman's IIospital Assuciattun iti Janes St.. Sagina Mich Kistablisbew I\$89: general; for women and chlddres in Heda: Katherine Hart, superin:endent.

Saginaw West side

Saglnaw General Ilosplial, Saginaw West side, Mob Eistallshed 18v: : ceneral; ;0 treds: Mlss Jomephire F Thurlon H.., surerintendent.

sault Ste, Marie

saule ste. Marle Hospital. Saluh ste. Marte. Mieh. Establlshed 1903; gereal 3.5 beds: Fdward Jones, superintenden:

\section{Sebewain}

Seberalnz General Inspltal, Sebewaing. Ifich. Establisbed 1912; public; 6 treds Faith Allice LIpscomb, superintendent.

South Haven

South IIaren Clty Hospltal. South Ha ven. Wich. Established 190: : 15 beds Mrs. M. Porter, matron.

St. Clair

St. Clair Hospital, st. Clatr. Mich. E.s. tablished 1907; 10 beds: Mis Annie Tuckley, superiniendent.

St. Johns

Hart l'rirate Ilospltal, Sit. Johns, Mict Established 191:; 12 beds; $A$ i. an Eugene llart. physlctans in charge.

\section{St. Joseph}

Mchigan Children's Home Society. S: Joseph, Mich. Estabilshed 1902; 10 bed: A. II. Stowman, superiatendent.

St. Lovis

Andrew" Magnetic Mineral Springs an Sanitarium. Ne. Louis. Mich. Establisbed 1Ss: in bedx; D. H. and W. H. Andrew. phỵsiclans In chatge.

\section{Siambaugh}

stambaugh Ilospital, stambauzh. Mich. Established 1910: zeneral; 15 beds; Miss H. B. Melonald, superintendent.

\section{Stanton}

Danforth Hosptial. Stanton. Mch. Es tablished 1910; 10 beds; Mortimer E. Dan forth, physiclan in charge.

\section{Traverse City}

Ray Bank Hospltal. Traverse fity. Mich Establlshed 1911: it beds: Itrs. iv. Fish. superintendent.

Trlmountain

Conper Ranze Hospital, Trimountaln Mich. Fotaullahed 1906: 30 beds: W. K West (bainewdale). physiofan in charge.

\section{Twin Lake}

Shifing Sands Sanisarium, Twin loake

Mich. Verrous and cheonic dlapases.

\section{Wakefeid}

Wakefletd Ilosintal, Wakefleld. Mich

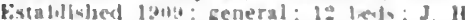
bally, medical sulerintenderst and pov. prietor.

Wyandotte

Fincrcency Hovplial Wramintte. MIch

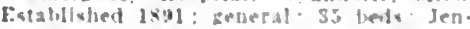

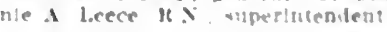




\section{PHYSICIANS OF MICHIGAN}

KEY TO ABBREVIATIONS, SYMBOLS, ETC.

Names in cupitals siguify membership in the Comnty Soclety and State Assoclation. (DOE, JOINN).

+ Inticates Fellowshlp in the American lled. Assu. (DOF, JOIINt).

(b'is) Year of birth. fmedle II. homeopith; $\mathbf{E}$, eclectic; $\mathbf{P}-\mathbf{M}$, physioid =

Informatlon recelved does not show grad. uation.

S.- surgeon.

Ob.-Olistetrician.

ObG.-Olstetrlcian, divnecologlst.

G.- Gynecologlst.

Or, - Orthouedist.

Pr.-I'roctologlst.

Op.- Ophtinalmologist.

A.-Aurist.

LR.-Iaryingologtst, Rhlnologist. (l'89) Year of llcense.

(d) In practice before passage of present law and llcensed by flitug diploma or by years of practice.

(it) licensed but year not known.

(₹) Information recelved does not slow llcense.

T.S. Inited States Army.

II.R.C., U.S.A., Medical Iteserve Corps.

SPECIALTIES ARE INDICATED AS FOLLOWS

ALR.-Iur]st, Iaryngologlst, Ithluologist.

OALR.-Opibthalmologlst, Aurlst, laryngologist, Rhinologist.

U. I'rotoglst.

D.-Dermatologlst.

Pd.-l'ediatrist.

N.-Neurologist.

P.-L'syclulatrist.
L.S.X., Cnited Stales Nary.

M.R.C., U.S.S., Medical Iteserve Corps.

C.S.P.H.S., United States Public Healti Servlce.

College posltions held are indlcated by abbreviated title of positlon, followed by key number of college. For key to colleges see inside front cover page.

(A1,3, B6, C4) Membership in specia) Socfetles. (Sec Key Table, page 122.)

NP.-Neurologist, Psychiatrist.

I.-internlst.

T.--Tuberculotherapist.

Anes.-Anesthetlst.

LD.-Laboratory Dlagnosticlan.

R.-Actlun [ [rlst.

Path.-P'athologlst.

Bact.-Bacicriologlst.

WHEN THE ABBREVIATION REPRESENTING A SPECIALTY IS FOLLOWED BY AN ASTERISK ( ) IT INDICATES THAT THE PHYSICIAN CLAIMS HIS PRACTICE IS LIMITED TO THAT PARTICULAR BRANCH OF MEDICINE; WITHOUT THE ASTERISIK, THAT HE IS ESPECIALLY INTERESTED IN, BUT DOES NOT LIMIT HIS PRACTICE TO, THAT BRANCH. THIS INFORMATION CONCERNING SPECIALTY IS BASED ON PERSONAL DATA FURNISHED BY THE PHYSICIAN AND IS NOT VERIFIABLE.

\section{MICHIGAN}

ADA, 300, KENT

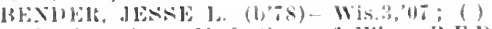
llember state Med. Soe of Wis. il.F.ll 4:.

BIEEECE, RAYMONI CLAIK (b'79) IIicll, s, 06; $(1,06)$.

Fremaln, ihas. il. (b'sl) Mich.1,8\% (i) (01)

lotey, Frank Anderson.

(Nee Grand Rapids.)

ADAIR, 200, ST. CLAIR

THOMSON, M.EXANDER $\left(b^{\prime} 68\right) \dagger$-Mich. $\bar{~}$ 94; $\left(1^{\prime} 00\right)$.

ADAMSVILLE (R.F.D., EDWARDSBURG), 100 , CASS

I.ockwoul, W. F.-Ill.4,94; (1'01).

ADDISON, 474, LENAWEE

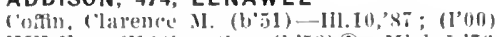

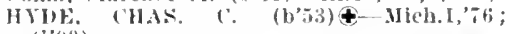
(i'(i)

MEATCER, CIIFFORD DAVID) (b's4) $111.6,08 ;\left(l^{\prime} 09\right)$.

\section{ADRIAN, 10,763, LENAWEE}

Allen, A. Marvin (b'36)-Mich.1, til; (1'06) not in prilcticas

INIUREIY, FRANK FI(GENE (b'הT) Mich.1, $78 ;(100) ; 85 \mathrm{~s}$. Main st.; office 43. s. Main st.; $1-3,6: 30-8$.

Baker, Vincent A. (b'32) E- X.Y.13, T (1'00); X.II. Broad and Toledo sits. Bland, John P. (b'75)-Ill.4,'01; (l'02); 25
W. Chureh St.; office, 12 S. Main St. ; 10-11:301 1-4, 6 ; $-8 ; 0$ b.

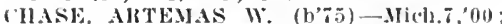
(I'v0); Broad and Maumee Sts.; $2-4,7-8$. llewes, Ara lsird $\left(b^{\prime}, 73\right) \mathrm{H}-0.26,03$; (l'03) ; $33 \mathrm{~s}$ Main St.; offlce, $37 \mathrm{E}$. II $10-11: 30,1-4,7-8$

lood, Arthur .lames.

(see Fiko Nev)

Houn c11.'S. JOHN (b'60)థ-Mich.1,8 (l'(14); Member Yev. State Med. Assn. (Filko. Nev.): $45 \mathrm{~s}$. Winter st.

HOWLAXD, FRANK A. (b'66) $£-111.8,0$; $(107) ; 81$ s. Winter St.; office, $30 \mathrm{~s}$. Iain st. : $8-9: 30,12: 30-3,6: 30-8 ;$ OALR.

JEWETT, WU, E SIR (b'42)\&-NY9, (l'u0): 2 Broad st. ; offlee, 23 F. Maumee st. $8-9$, I:30-4, $\mathrm{i}-8$

Jewett, Wm. F., Jr. $\left(b^{\prime} 72\right)-0.3,97 ;\left(l^{\prime} 00\right)$; 37 . W. Winter St.; offlee, 23 E. Maumee Ni. : $-5,7-8 ; S$.

WIRPATRIT (CLIFFORI) (b:5i) $4-$ wifice, 1 Winter st., s.; $10-11,1: 30-3: 30$, ii : (i)

(itiii) : - E. Haumee St.

in.
LOCIINER, GEO. MITCIIELL (b'86) -

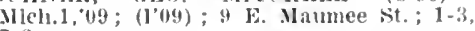

MaKkXZIE, WFILIE SMTH $(1,79)-$ IH.I

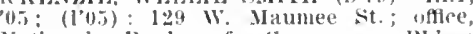
Nitional bank of conmerce Bldg.; $111-11: 30,1-4,7-8 ; \mathbf{R}$.

Marshall, Lewis Jackson (b'i1)-Vt.2,96; (i"03); i W. Chureh st. ; 10-12, $1: 30-4$, $7-8$.

MURLEX, ESLI T. (b'7)\&-Mich.8, (0) (1'(l1) ; $141^{1 / 2}$ W: llaumee st. ; office, 4" E. Nammee St. ; )-12, I-4, i-8; OALR. Morden, Marshall R. (b'44) - Mich.1,'T; (l'00) ; :44 Toledo st.; office, $42 \mathrm{I}$. Maumee st. ; $8-12,1-7,7-9$.

SFAGElR, GEO. B. MeCLELLAN (b'6i) ( dijeh.8,93; $(1,00) ; 24$ Clinton st.; oftiet. $5 \mathrm{~W}$. Maumee St.; $1-3,7-8$.

Stafford, Lee J. (b'S9) - Mich. 7,11 ; (l'11) : if $\mathrm{F}$. Maple Are.; offlce, Natl. Bank of commerce Bldg: $1-3,5-8$.

Stark, Fmily S. (b'82)-Micl..1,08; (I'08) ; 1 Broad St.; office, $45 \mathrm{~W}$. Maumee St. $2-4,7-8$.

Steplenson. Abram M.-Mich.2,76; (l'00): Main and Toledo Sts.; 1-3.

Todd. Danl. (b'2T) -N.Y.6,'51; $\left(\mathrm{l}^{\prime} 00\right) ; \operatorname{not}$ ln practice; $41 \mathrm{~s}$. Main st.; ofllee, 41 s Inin st.

TREAR, DAVII) L. (b'73) $\$-0.3,98$; (l'00); 5 W. ('hurcll St.; office, Xatl. Bank of commerce Bldg.

West rate, Julius E. (b'49)-Mich.8,90; (1'00).

Wood, Arthur $\left(\therefore\left(b^{\prime} ; 2\right)-M i c h .7,94 ;\left(1{ }^{\prime} 00\right)\right.$; 3 spring St.; offlee, $4 \mathrm{~s}$. Main st.; 1-4, (i)-8.

\section{AHMEEK, 766, KEWEENAW}

KING, WM. THOS. (b'73)థ-Mich.1, 01 ; (1'0I).

AKRON, 500, TUSCOLA

Fulton, Win. H. (b'54) E-0.2,'88; (1'00).

HAMMONL, THERON W. (b'67)-Mich.i, 96 ; (1'00).

TREAIGOLD, WM. E.-Nich.1,94; (l'00).

ALAMO, 120, KALAMAZOO

(IIFFORD, ARLOX H. (b, 0 (0)-Mich., 04 ; (l'04).

\section{ALANSON, 473, EMMET}

irillett. Francis Freeman (b'69)-Mich.9, 00; (1'00).

\section{ALBA, 600, ANTRIM}

Bruce. A. Ernest (b'T4) Mich. T,05; (1'08). lielly, Frank L.-0.14,81; (1'00).

ALBION, 5.833, CALHOUN

ABBOTT, ALFRED J. (b'61) \&-Ill.1,'8ㅁ; (1'00): OALR.

BAXGHAM, ARTHIR DAVII) (b'59) llich.1,'s:; $\left(l^{\prime}(0)\right.$.
CIIAUNCEY, EDWIN M. (b'73)-Mich.1,99; (l’00).

Foster, Irving C. (b'59)-111.11.'84; (l'00).

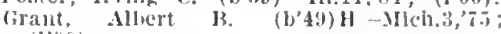
(l'of)).

GRANT, IIEMAX lMORY (b'78)£-Mich.I, $07 ;(107)$.

Hafford, Alpheus Tisdale (b'89)-Mich.1,'13; (l'13).

HAFFORD, l:EO, C. (b'62)£-Yich.1 ' (l'(0) $: \mathrm{S}$

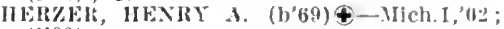
(l'02).

HOWARD, META (b'62)-Jll.9, : ; (l'00).

MARSII, WII C. (b'56) ()-Mich.1,'83: $\left(l^{\prime} 00\right)$.

PALMETER, EDW. I. (b*51) \&-111.8,76; (l'00).

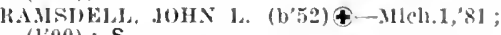
(1'00); S.

ALDEN, 600, ANTRIM

IIOAG, FRAXK J.MICh. 7,$92 ;\left(l^{\prime} 00\right)$.

ALGONAC, I,204, ST. CLAIR

lostwick, Walter F. (b'66)-Que.1,93; $\left(l^{\prime} 00\right)$.

Stringer, Thos. I. (b'65)-Ont.1,'s9; (1"0(1).

ALLEGAN, 3,419, ALLEGAN

BII,S, W.ILTEK H. (b'4i) -N.Y.6, T0: (1'00).

MAPBS, JAMES A. (b'51)\&-Ill.6,;5;

$(1,00)$.

OSMIN, FIMIER DOLGLAS-Mich.5, 92 ; $\left(l^{\prime} 00\right)$.

RORINSON, AFTHIR L. (b'73) \&-ILI.\$, $02:$ (1'02); $\mathrm{S}$.

SMITH, NALCOLM F. (b' 73$) \$-M i c h .7,07$; ( I'0T)。

ST.ARK, ltOBT. I'AGE (b' (l'I0)

Stuch, Ifoward W. (b'z̃)-Va.1,01; (l'01) Stuek, Lafayette (b'47)-Mlch.I, TT; (I'00) VAN NESS, J. IIOWARD (b'i2) $€-I i 1.23$, 05; (1'06); S

ALLEN, 550, HILLSDALE

'I.ORILIDGF, NHAS. F. $\left(\mathrm{b}^{\prime}, 0\right) £-0.7,97$; (1'00).

ALLENDALE, 200, OTTAWA

Nibbelink, Seth (b'72)-MIch.7,08; (l'0s).

ALLENTON, 150, ST. CLAIR

Davis, MIurdock Jloyd-Ont.3,7\%; $(1,00)$.

ALMA, 2,757, GRATIOT

BAGLEY, EDGAR A. (b'48)-Mich.3;'it; $\left(1^{\prime} 00\right)$.

BRAINER1), IRA N. (b'52)-0.14.81: (I'00); S.

GARDNER. CIRLS BLNTING (b's0) II ich. I,'04; (l'04)

IAMB, WIW. T.\&-Mleh.9.99; (l'mo)

SLYDAM, JOHX F. $\rightarrow$; $\left(\mathrm{I}^{\prime} 00\right)$

THORXBLRGI, FRANK COLFAX (b'is)Mo.5,04: (1'i1). 
ALMONT, 675, LAPEER

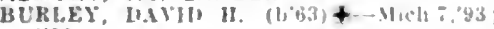

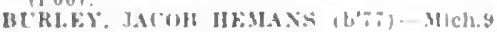
"9:4: (1"00): S.

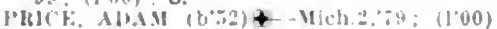

ALOHA, 50, CHEBOYGAN

"altersun, James Bentin.

ALPENA, 12,706, ALPENA

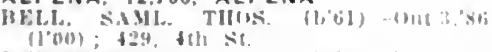

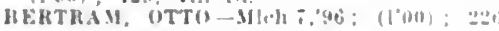
$y-12,2-j$

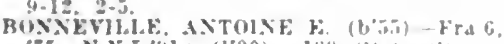

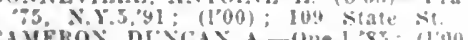

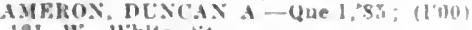
$121 \mathrm{~W}$ - Whlle st

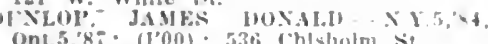
Ont.5.8\%; (1'00); 536 ('hlsbolm N.

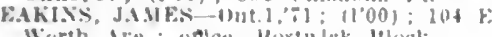
Worth tre.; intlee, Bostw lek lthock Gaurerau, Le Achille (b'55) Qun.3.".s.

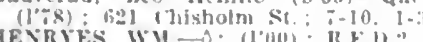

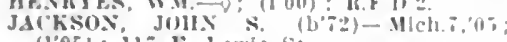
(1003) i1\% \%. lewis st.

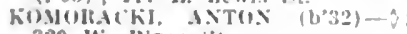

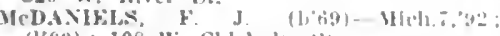

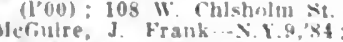

$\therefore$ al Are ; ofloe. Nipena (ounty sivinge Bank IIdy. : I:,

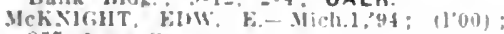

$2 \pi$ slate st.

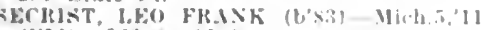
$\left(I^{\prime \prime 10}\right): 322 \mathrm{~s}$. $2 \mathrm{~d}$ St

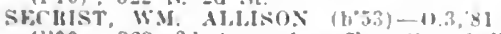
(1'00); 322, id Ave. 5 : uftce, fauphell Block: $y: 30-10: 30,2-4: 5$.

sMA1.1. WINFIE.I, J. (

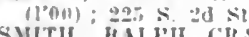

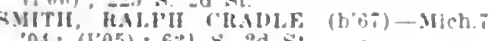

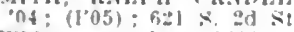

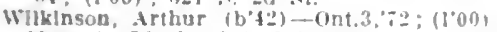
Masonlc Block: 2-4, i-9.

WILLIAMS, CLAIIENRE M. $(\mathrm{h})+$ Mlch.5.01; (l'0l); 123 Whise st.; oftce

ALTO, 350, KENT

Bnnd, Geo. Lewls-Mlleh. 1,03; (1'03)

AMASA, 900, IRON

Mc.llurchle, incter-IIlch.S,'0S: (l'05)

ANN ARBOR, 14.817, WASHTENAW

ADIMS, JAMKS F'KANKIIX (b'bi)

III.11.93: (1.00): $216 \mathrm{X}$. stale st. OOA.

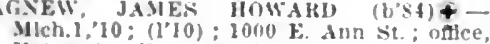
Ciniversity llospltal:

Cnlversity llospltal; 1.
Alchlson, Russell E. (b',0) H-Mich.5,00: (1'01): 109 Glen Are ; $5-12,1-6$.

BAHETT, ALHRTT MƯRE (b\%1) + Ia.3. 65: (1'06) Inlverslty IIosbital; $1: 2-2$ 6.8; I'rof. 'syeh, and ble of the

Bartholomew, Rudillu! Artlles (b8b) Mich.1.'12: (1"12): Iniversits llospital.

HELSER, MAUTIN I. (b'iy)-Mlld, al $\left(l^{\circ} 00\right) ; 600 \mathrm{k}$. Washington st: oflice. S. Maln St; 10-12, $2-5,7-8$

HI.AIR. WM $\left.(1)^{2} 64\right)+$ SIlli, $, 93:(1000)$ 221 S. 5th ire.; $8: 10-9: 30,1=2: 30-1: 30$ $6: 30-7: 30 ; \mathbf{G}$.

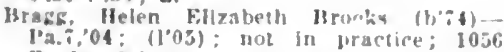
Ferilon ind.

HKEAKFY, JAMES HLEMIN; $\left(\mathrm{b}^{\circ} 0\right)+$

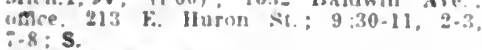

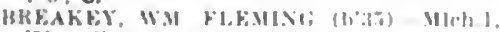

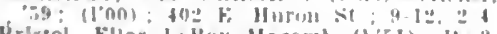

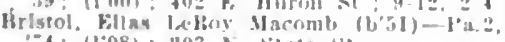
\%4: $\left(10^{\circ} 08\right)$ : 203 is viate st.

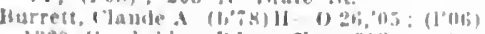

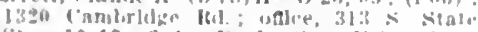

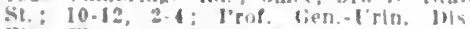
Elec.-Ther, anal Iresm., Mlch.s.

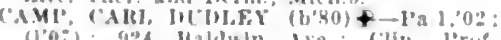

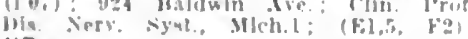
NP.*

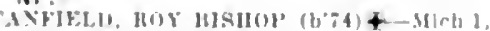
"93; $(100): 1503$ Washtenaw Are ; ratec, $3 n 0$ \&. Siate st.: l'rof (1)tol. Iearyn ilch i,: (II3,s,i1, i, i) : ALR.*
Bildar Frank (bosill

(1.00): Dlt E WHItam st:

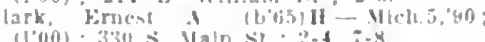

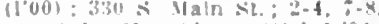

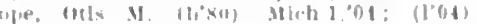
$13: 3$ Wilmost st.

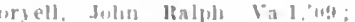

IIIII si

'owle, Amma Marien liuk (b':2)-Mlleh 1

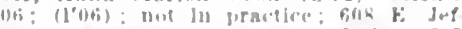
Person st a oflece laswrence Ind

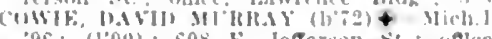

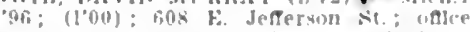

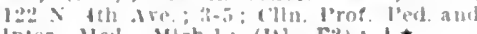
Inter. Med, Mch.l: (II), Fa) I.

Crlusey Hoy Henry (b'xis-Wich.1, 11 (1.11): lnirersity ilospltal.

'ummlng James tinrulon (h'is) Mlch, e3 (1.11): 103\% Bahutn tve, uace, lasteur instute: $0-11$

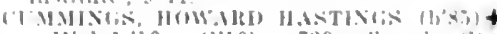
- lleh 1,10; (1'10): :23 chureh st oflee. agto ingalle s?: $8-1: 1$

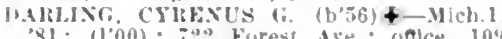
yaln st. 2-3: clin l'ros surg lich. S.

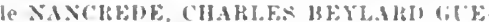

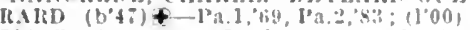
s0t S. State st.; l'pof. surg. and Clin. surf. Mch.1; and X.II.t: kimer l'ruf́ ien. and ortho. Surz. Inili: (A., Flui

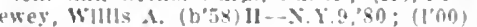
sec. and l'rof. lat. Ved. Ther and Icting Jrof. Ment. and Vers. Dis.. Mirh.

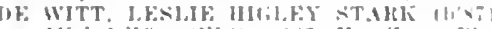

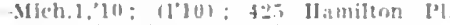
frice, Inluersity Hosilitil.

Fdmunds, Chas. Walls $\left(h^{\prime}, t\right)$-sllch.1.0I (1'03): 1619 Cambrluge Rd.; oflce, vharmacological Jaburatory. linis ne Mich. sec. and Prof. Ther. and Mat. Mled. Mlch.1: $\left(F_{*}^{2}\right)$

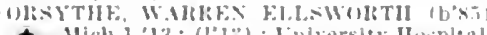

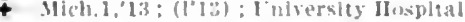

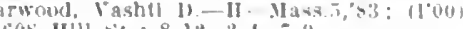

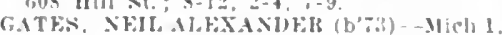

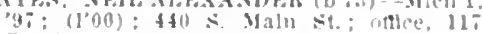

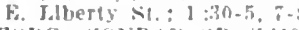

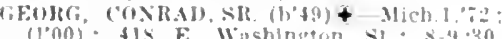
1. 2. $i-8$

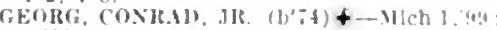

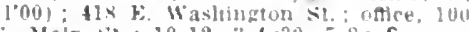
$\therefore$ Maln st: 10-12,3-4:30;-8: $\mathbf{S}$

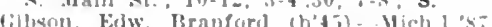

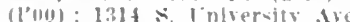

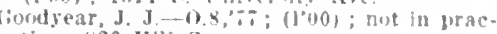
tice : 820 Hill s

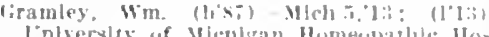
pltal.

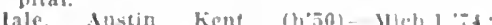
$\left(l^{\circ} 00\right)$ : not ln practice : $3: 7$ F. Liberty Sit. : oflce, $120 \times$ th tro

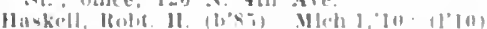

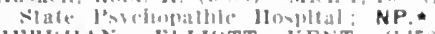
FIRIMAN, FIIIUTT KENT (b's)

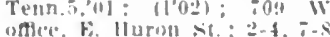

offlec, b. IIurm st: : $2-4,7-8$.

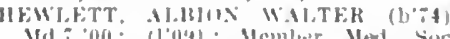

Md:.00: (1'0!n): Mromber Med. Mor the state of ral. ; la3t tambridge ted.

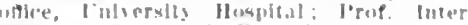

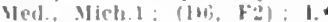

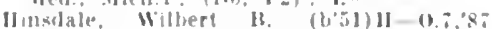

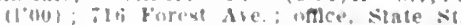
Ihan sisd I'rof Theo and Prace of Men and thlm. Meal, Hlach

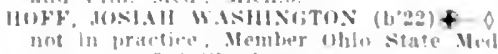
Ix+11 l:31: 11 illaril 2

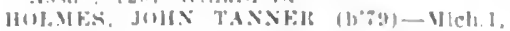

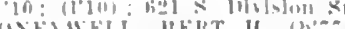

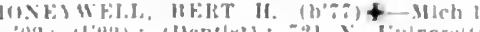

Are (1)

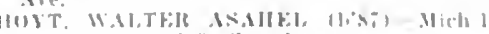
1.: : 1101: 10113 thurch st

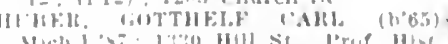
Wwh 1.4

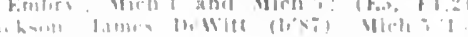
OALR.

Simplita leephena Mir.li I

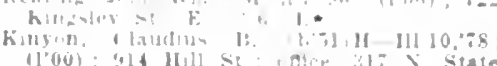

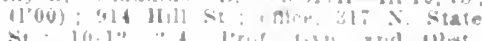
Mich

KIINIBMINY, TIIF, IIHH

4. Mirh!

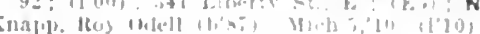

litel rhureh st?

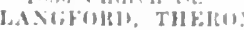

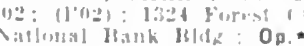

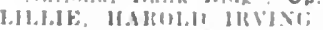
lurvity Houtenl. ALR.

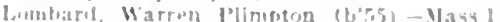

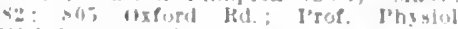
Mleh I and Mich.

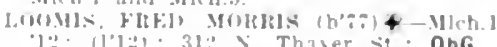

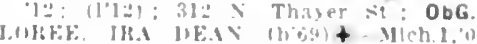

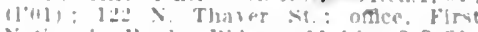

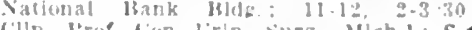

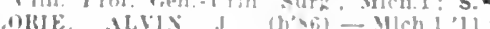
(l'1): 11s s lith st; oalce, Cnirrity llovpltal: ALR.

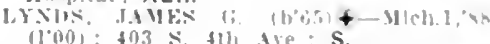

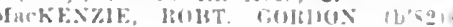

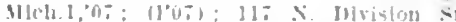
oflec, lierman-tmerlcan saslnes liank llopk 1:30-3:30, - : S.

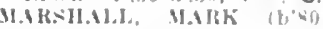

(1'0s): 1002 F. Liberty si.

MIJ GFOR(iE A $\quad 1, ; 5)$ - Conn $1, n 1$

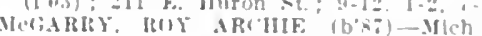
12: 11'12): 132s Washtenaw dre: uf fre. Med]cal 13/dg: $8-12,1,30-5$

Mellon, Mrda Esten (b's) H-Micb.5.'l" (l'12); 608 oskego st.

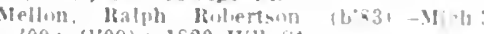
n9: (1.09); 1520 HIII st

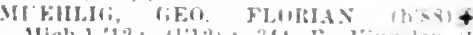

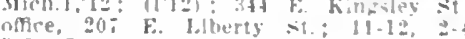
i-s: $\mathbf{s}$.

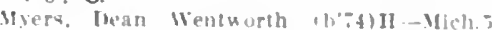

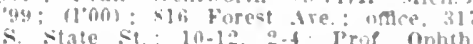

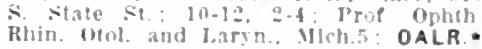

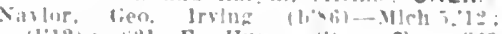

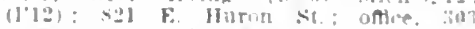
$\therefore$ Stape st : 1.3. 7- U.

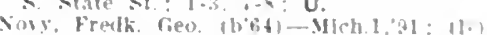
not in practice: -21 Forest lve. Prut

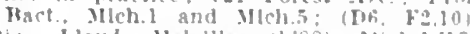

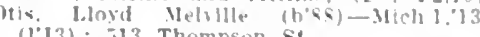
(1.13); 513 Thompaon St

Palmer. Mary simpson (b'til)-Mllehl, so

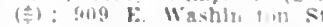

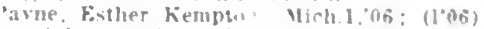
not ln pratellen 127 1 state st

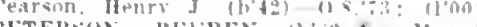

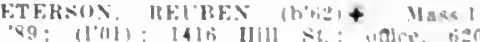

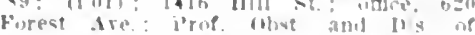

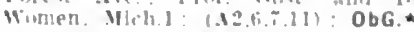

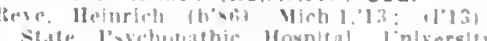
Nitle l'velt

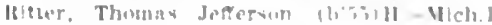

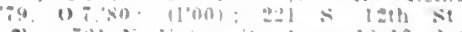

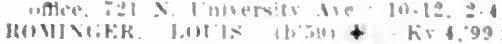

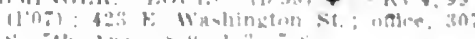

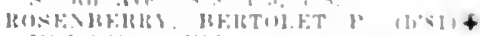

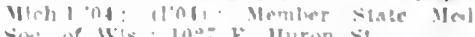
bowland. Win lontin than tichs.'ll 110111: 31? \& Siale si ; (ki)

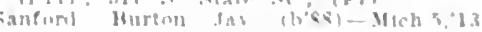

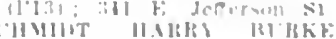

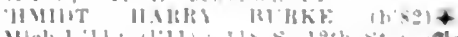
Hheh 1:11: 11.11: 110 \& 18th st : uflce

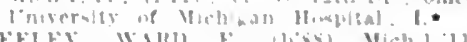

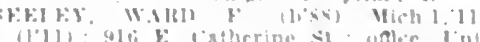

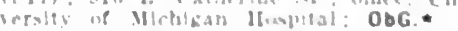

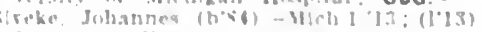

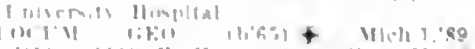

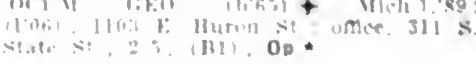


S'mith, Dean T. (b's0) II-III.10,89; $\left(l^{\prime} 00\right)$ i12 L. Washington st. ; 2-1; I'rof. Surg. and ciln. Surg Mtlch.

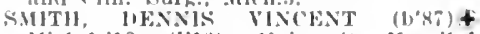
Mlch.1,12: (1'12) ; Inlverslty Ilospltal. (O),1S, JEANNE CATY (b'fi) —-Mlch.1. 92: (1'00); 403 Litherty sit. E. : 10-12 NP. $\star \star$

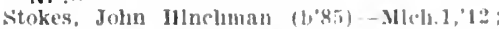
(1'12); 1608 fictles Are

Stouffer, (lyde liruce (b'7s) Mch.5.'13: (1'13); 821 E. Hurom st. ; ofller. 226 s Iugalls St. : 8-12

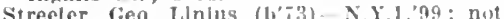
in practlce; 1025 Martin Pl. ; Prof. Anat. Mich.1 and Mich.5; (151).

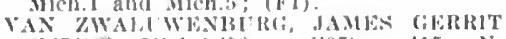

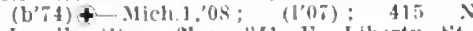
infalls st.; onlee, 3.1$]$ k. Liberty sit.

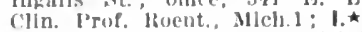

VAUGHAN, VOTOR ('IARENCE (b'51) +

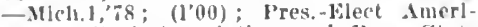
cail Nedleal Assoclatlon find 1'res. State coard of Itealtl: trean aud Prof. 11y. and Phys. '('hem. Meall : (10, F2).

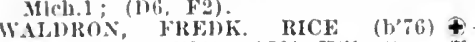

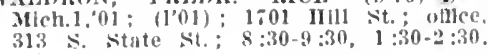
$7-8$.

Walker, Ellls 1).--Mlch.11,06; (1'06); 1030 E. Huron st.

Warthln, Aldired Scott (b'67) M1/ch.1,91 (1'00) : not in practice; 1020 Ferdon $\mathrm{Rd}$. Prof. Path. Mich.1 and Mich.5; (D6, F.)

WASHBURNE, CIIAS. LEE (b'76)-Mlch.1, '08; (1'08); 326 S. 4th Ave.; offlce, $109 \mathrm{~S}$ Main St.

Weller, Carl vernon (b'87)-Mlch.1,13; (1'13); 1116 Ferdon Rd.

Wendel, Jacob Sterling (b'84) - Mlch.1,'1: (1'13): Unlversity Hospital.

WESSIYGE JOHN A (b'60) - Mllch'?'82. $\left(1^{\prime} 00\right)$; 339 E. Washington St. ; 8-11, 2-4, 6-8.

WILE, UDO JULIUS $\left(b^{\prime} 82\right) \oplus-M d . ;, 08$ : (1'12); University Hospital ; Clin. P'rof Derm.' and Syph., Mleh.1; (C2,6); D. wilson, Frank Norman (b'90)

(1'13); Universlty Hospltal.

YUTZY, SIMON MENNO (b'56)\&-Mlch.1 State and Willams Sts. : $9-11,3-5,7-8$ : ALR.

APPLEGATE, 155, SANILAC

Partello, E. F. (b'65)-111.38,'99; (1'00)

ARCADIA, 800, MANISTEE

JAMIESON, DAVID A. (b'65) -Mlich.7'94; $\left(1^{\prime} 00\right)$.

ARGYLE, 150, SANILAC

MCNAUGHTOX, DAVID D. (b'66) - MICh.1, $87 ;\left(1^{\prime} 00\right)$.

ARMADA, 748, MACOMB

BUSH HOWARD .J. (b'84)†-NIlch. :, 08 ; (1'08).

Pelton, Roy J. (b'78)-Mlch.5,02; (1'02).

ASHLEY, 513, GRATIOT

Relchard, Orlll-N.N.Y.19,05; (1'05).

ATHENS, 63I, CALHOUN

Fox, Paul S.-Milch.1,'88; (l'00); Op.

Snyder, Balph Bernard (b'88) - Mlch.1,'12; $\left(1^{\prime} 12\right)$

Van Camp, Elljah (b'75)-Ill.6,03; (1'03). ATLANTA, 250, MONTMORENCY

CORNELL, GEO. L. (b'64) - Mich.i,',90 $\left(l^{\prime} 00\right) ; 0 b$.

Eades, Herbert Alfred (b'67)-Mich.,${ }^{\prime} 02$ (1'02); Central Hotel.

ATLANTIC MINE, 2,000, HOUGHTON

MOORE, JOHS W.-MICh. T, 95 ; $\left(1^{\prime} 00\right)$.

ATTICA, 400, LAPEER

Blakeley, Adolphus J. (b'it)-Mich.9,02 $\left(l^{\prime} 02\right)$.

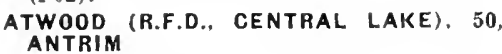

Beuker, Bernard Johan (b'T0) - Ill.23,06, Ill.11,'08; (1'08)

AUBURN, 300, BAY

BALLARD, SYLYESTER L. (b'81)-

Hich.8,05; (1'05).

nyder, John P.H-O; (1'00)

AU GRES, 252, ARENAC

Inh R.-Mich. 1,99; (1'00).
AUGUSTA, 494, KALAMAZOO

WEEKS, HO13T. E. (b'81)+-Mlch.7,04 (104)

AVOCA, 250, ST. CLAIR

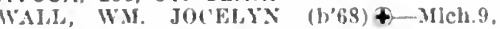
02: (1'02).

BAD AXE, I,559, HURON

CONBOY, DANIEL (b'54) \&- I11.16,97 (l'01): Op.

(1) (

Henderson, Saml. James - 11-X.Y.8,66; $(1000)$

IJERRIẌ;TON, WILLET J. (b'56) MIch, 1, 82; $\left(1^{\prime} 00\right) ; \mathrm{S}$.

I.VMAN, MAL R. (b'56)\&-0.2,83; (l'00). MCDONNELL, MATHEW C. $\left(b^{\prime} 50\right)-0$; (1'00).

MOHOEN, CHAS. B. (b'79)Ð-Mich.1,03; (1'03).

BALDWIN, 502, LAKE

STONE, JOS. M.-N.Y.3,'S3; (1'00); G.

BALTIC, 2,500, HOUGHTON

Groomes, Chas, Abram (b'87)-Mich.1,13; (1'13).

Jlodges, Roy Wm. (b'78)-Mlch.8,00; (l'00).

BANCROFT, 543, SHIAWASSEE

BENJAMIN, WM. OSCAR (b'88) - MHch.1, '11: (1'11).

Johnstone, Edwin R. (b'79)-Mch. 7,06 ; $\left(1^{\prime} 06\right)$.

BANGOR, I,I58, VAN BUREN

Giffen, John R. (b'70) - Ore.1,'94; $\left(1^{\prime} 00\right)$

Kirby, Enlly Short Flaws (b'54)-Ill.4,91; (1'09).

Low, Edwin G. $\left(b^{\prime} 60\right)-I 11.10,98$; $\left(1^{\prime} 00\right)$

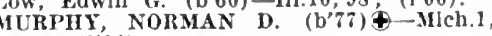
04 ; (1'04).

BARAGA, 1,071, BARAGA

BUCKLAND, ROMULUS S. (b'66) Ind.10,"92; $\left(1{ }^{\prime} 00\right) ; S$.

BARK RIVER, 750, DELTA

Cholette, Clement A.-Que.4,92; (1'00).

TREIBER, LOUIS P.-Ill.17,'04; (1'05).

BARODA, 248, BERRIEN

KING, LOUIS A. (b'69) $₫-M l$ M. 9,203 . (103) ; ObG.

BARRYTON, 4II, MECOSTA

Yeo, Gordon Hurst (b'86)-Mlch.1,12; $\left(1^{\prime} 12\right)$.

BATAVIA, 88, BRANCH

TURNER, SAML. R. $\left(b^{\prime} 58\right) \oplus-K y .2,88$; (1'04).

BATH, 300, CLINTON

BELLINGER, ERNEST G. (b'75)-Mich. 7 , 05; (1'05).

BATTLE CREEK, 25,267, CALHOUN

Allen, Herbert Rodney (b'74)-Mich.5, 01 ; (1'02); 82 Calhoun St.; offce, Tacoma Block; 9-12, 2-4, 7-8.

ALVORD, AUSTIN WHITE (b'38)-Mlch.1, '68; $(1,00)$; 29 Wendell St.; (St. Petersburg. Fla.; 1'12); 11-12, 2-5; S.

BARNHART, SAML. EDW. (b'74)-III.19, 05; (l'06) ; Daklawn; office, Battle Creek Sanitarium.

Bobo, Walter T'. (b'76)-Mo.27,99; (1'00): BROWN, JOHN CHAS. (b'53)-Ind.10,86: $\left(1^{\prime} 00\right) ; 100$ Upton Ave.; office, $23 \mathrm{E}$. Ialn St. : $9-11,2-4,7-8$.

Cameron, Marjorie Irene (b'88)-Ill.11,'13; Assistant Physiclan; Battle Creek Sanitarlum.

CARLING, WM. MONROE (b'72)-Pa.11,

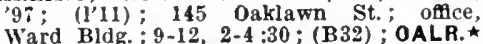
Case Helena Margaret Kellogg (b'83) III.19,'08; (1'08); 124 Manchester St.

CASE, JANES THOMAS (b'82)థ-111.19, 05: (1'05): Member III. State Med. Soc. 124 Manchester St.; offce, Battle Creek Sanitarium; 10-1, 4-6; (also office, 1431 Michigan Ave., Chicago, Ill.); (G1,4).

COLVER, BENTON NOBLE (b'80) Ill. 19,'04, Pa.1,'11; (1'05) : 315 Champlon t-6; (B1,32); ALR.

Cook, Dana G. (b'57)-Ind.10,'97; (l'00) ; 117 E. Main St.; 8-10, 2-6.

COOPER, JOHN ELBERT (b'77)థ-Ill.19, '02 ; (1'13); Battle Creek Santarium. ('orwh, Flizabeth (b'52) - N.Y.11,80; White Neniorlal Home.

'ross, James A (b'53)-WH/ch.3, 75 ; (1'00) : 9 E. Main St.; 10-11, 12-1, 2-6, 8-9.

WOCKRY, WM. E. (b'42)-0.6, $6 \bar{t} ;$ (1'01) Henry 'St., S.' ; (onlee, Urbandale).

1)reher, Jos. (.. (b'69) $\longrightarrow$; $\left(l^{\prime} 00\right) ; 40$ Jay St. WRXNEN, MARY VICTOHA WOLFt Battle Crcek Sanltarlum, 10-1, 4-6.

Dullam. Robt. E. (b'74)-Mich.7,03: (1'03)

67 Marshall st.; office, $19 \mathrm{~K}$. Wain st. $1-5,7-8$.

Dunlap, II Irley M. (b'62)-Mich.1,'86 ; $\left(11^{\prime} 00\right)$; 58 Grant st.: onlee, Ward Bblug.

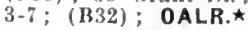

EATON, SAML. R. (b'63) —-Mich.1,00 $\left(1^{\prime} 00\right) ; 36$ w. Van Buren st.; oftice, Tacoma Block; $10-12,2-4,7-8$.

EGGLESTON, ELMER I. $\left(b^{\prime} 74\right) \mp-111.19$ ,00; (1'00); 152 Oaklawn Ave.; oflice, Battle Creek sauitarium; 9-12, 4-6; 1.* ELLIOTT, JANHS A. (b'75) - Mlch. 7,01 $\left(1^{\prime} 01\right) ; 43$ N. McCaniby St.; 11-12, 24 7.8 .

GALLAGHER, ROBT. Y. $\left(b^{\prime} 70\right) \uparrow-111.11$ '02; (1'02); 131 North Ave.; office, Tacoma Block. GETHING, JOS. W.-Lll.1,01; (1'01) ; 538
Maln St., W.

GODFREY, WILLOUGHBY IYMAN (b'52) oftice, 2 E. Main St.; $9-10,2-4,7-8 ; 0 \mathrm{bG}$. GORSLINE, CLARENCE S. (b'75) $€$ Mlch.1,01; (1’01); 134 W. Van Buren st. offee, Post Bldg. ; 10-12, 2-4, $7-8 ; R$.

freen, Chas. W. (b,73)-N.Y.1, $96 ;\left(I^{\prime} 00\right)$ 68 Wendell St.; $10-12,2-4$.

HARRIS, ELIYABETH KERR (b'7) $111.19,{ }^{\prime} 02, \quad S \cot .9,12,14,05 ;\left(1{ }^{\prime} 03\right) ; 265$ Champlon St.; office, Battle Creek' Sanitarlum.

HARRIS, ROWLANL HIL, (b'T8) +-111.14, '01, Scot.9,'12,'04, Scot.13,'09; (1'02); 265 Champion st.; office, Battle Creek Santtarium; $9-1,4-6 ; \mathrm{S} . \star$

HAUGHEY, WILFRII $\left(b^{\prime} 80\right) \&-M l c h, i, 06$ : $\left(l^{\prime} 06\right)$; 40 Poplar St.; office, $24 \mathrm{~W}$. Mali St. : 9-12, 2-5; (B1,11,32); OALR.*

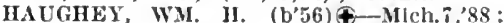
$\left(l^{\prime} 00\right)$; 24 Poplar St.; office, 24 W. Maln St. : $2-4,7-8$.

HOLES, JESSE J. $\left(b^{2} 72\right) \oplus-M$ M h. $^{-}, 04$; (l'04) ; 85 Fairfleld Ave.; office, $47^{\circ}$ W. Main St.; $11-12,2-4,7-8$.

Holton, Samuel M. (b'36)-Mich.1,'66: $\left(1^{\prime} 00\right)$; not in practice; 141 North Are.

HOYT, AURA ANDREWS (b'79)-Mlch.5. 04; (l'05); 222 Lathrop Ave.; office.

IUBLY, CHAS. CHESTER (b'78) \&-IIl.19. 04: (1'13); 219 Manchester St.; offlce, Battle Creek Sanltarium; 10-12, 4-6.

Jaime, Nicholas $\left(b^{\prime} 85\right)-I 11.11,12$; (1'12): Battle Creek Sanitarlum.

JOHNSON, GERTRUDE MILDRED (b'is) \$-111.19,04; $\left(1^{\prime} 10\right)$; Battle Creek Sanitarium; 10-1, 4-6.

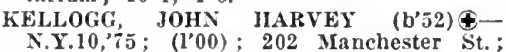
office, Battle Creek Sanltarium.

KELSEY, HARYEY S. (b'72)-Mlich.9,01, I11.19, 05; (1'01) ; R.F.D. 6; office, Battle Creek Sanitarium Dispensary; 4-6.

Kezartee, Ira $Y^{\prime}$. (b'44)-Mich.1,67; (1'67): 23 N. Union St.

KIMBALL, ARTHUR STEVENS $\left(b^{\prime} 78\right) \oplus$ Mich.1,03; (1'03); 245 Upton Ave.; office, Ward Bldg.; 4-6, $7: 30-8: 30$; Pd.

KINGSLEY, A. FLOYD (b'î, 6$)$-Nilch.1, 00 : $\left(1^{\prime} 00\right)$; 223 Calhoun St.; office, 1 w. Iain St: : $10-11,2-4,7-8$

Kneeland, Wills C. (b'60)-1ll.4, $85 ;\left(1^{\prime} 00\right)$ : 32 Chestnut St.; office, 88 W. Main St. : $9-12,2-5,7-8$

Lewls, Welcome Babcock (b'83)-Ill.11,12 ; (1'12) ; 19 Graves Ave.; office, Battle Creek Sanitarlum; 9-12, 1-5.

Long, Winona E.-Ark.1,09; Battle Creek Sanitarlum.

NaCGREGOR, ARC'H E. (b'74)-Mich 7,01 ; (1'01): Post Tavern; offce, 54 w. Ylain

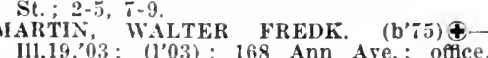

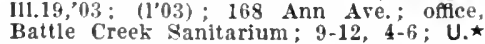




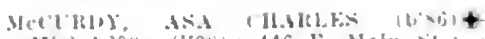

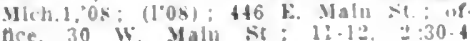

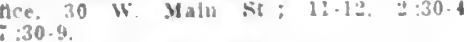

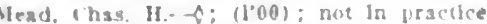
Mechan. Hanlel Lawren (b'os)-Nebutyz: 11093; 30 w. Maln St. : 10-12, 2-5.

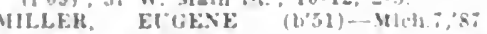
(]$\left.^{\prime} 00\right)$; 1st W, Van Huren st: o ofle, sj W" Valn st.: $9-12,1: 30-5, i-8$

Muntoe, Franklln llaker (b'49) $0.7,40$ (l'00): 34 Groreland st. oflice, l'ust Hlock: $0-11,2-5$

MURTESSEN, MARTIS I (b"1)+ Hlch. 1,99; $(100)$ : 233 Manchever mce, Battle Creek sanitarlum: 1.

MOSIIER, HEKTHA EDNA $\left(\mathrm{b}^{2}, 5\right)+-111.19$ 04: (1.04); Hatle Creek sanitarum $10-i, 4-6$.

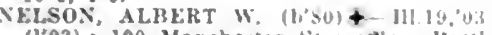
(1"03); 100 Manchester St. ; vithe, Jratele Creek Sanlfarlum: 8-1 \&-7: LD.

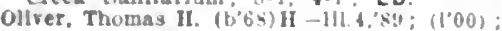
E. Maln Si.

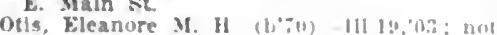
In practlce: Battle ('reek simbtarlum

DEARCE, HFNRY HEHALD-Ont 3,97 $\left(10^{* 00)}\right.$; 1 Gurucll Are., F.; offec, Tacom Bldg. : 11-19.1-4. 7.s

Pelersohn, Albert W. (b\%:)-Ark.1.0\% not in practlee: Washlngtnn

Howers, Herbert $\mathrm{A}-0.19 \times 89:\left(\mathrm{l}^{\prime}(0)\right) ; 391$ W. Maln St; offe, W. Main st.; i $0-11$. $1-3, i-8$.

("ITMAX, WILJARD NICHOL, (b'81)III. 4,06; $(100) ;: 5$ Fast Arenue, $s ;$ of

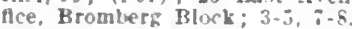

BADABATGH, CLARA v. $\left(\mathrm{b}^{\circ} \mathrm{i}\right)+-111.19$ 09: (I'09): Battle Creek Sisultartum $10-1,4-6 ; G$

liand, Sllas ihas.-H1.1,97; (春); 23+ W

Vian Buren st.

Kaหson, Fdw. (b'35)-1.2.6,59; (1"00) il River St

FFAD, IIBEKT JOSLAH (b'69) \-X.1.19 '99: (1'00): 19 Howland St.; oflce, Batte Creek sanitarlum: $9-19,4-6: R$.

lieynolds, John C. - II-0.13,82; (1'00) : 10 X. Diriston St. $i-10,2-4$

HII. (1'02); 112 Manchester St; ofice, Battle (102) " 112 Manchester st; otfce, Batti liobertson, Feo, A. (b'+1)-0.7,6i; (I'00) lit E. Main st.; ofice, ward Blds. 2-4.

kobertson, Geo. A., Jr. (1,78)-W/ch.5,01 (1.02): 174 E. Main St.: ofluce, Wart Blds. : $3-5,7-8$.

koth, Lunda M. (b'73)-I11.19,04; (l'04) not In practice: 162 Oaklain $:$ i

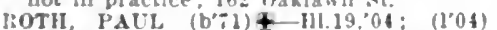
162 Oaklawn Are.; office, Hattle Creek Santlarlum: 9-12, 4-6: LO.

HYAX, CHAS. WM. (b'7i) -MIch 5,96 (1'00) : 64 Broad St; oflce, Ward Bjdg. $9-12,2-5$.

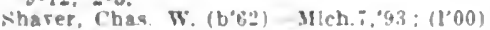
Rromberg Bldg.

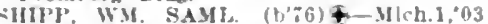
(1'03): 254 Calhoun st. oftce. Post Bidf

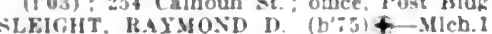

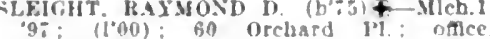

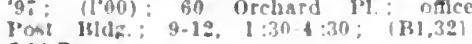
OALR*

TAINES, CARRIF。 \&. (1)6i) \$-111.19,99 (lo00): Battle (reek Santtartum: 9.1 4.7.

STECMAN, LOIIE ETHELYY VANIUEH

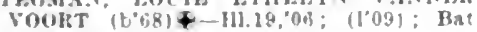
te reek sanilarlum: 9-1, i-th.

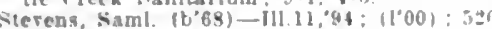

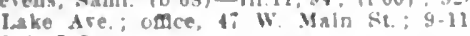
$1-4,7-8$

STRWAIT, CHAS. K. (1)'69) + Mlch. 1, 43

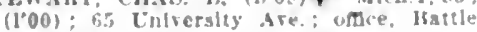
Creek sanltarlum: 10-12, \$-6

STONE lBA $\ell^{\circ}$ (1, (lot): 2: l'enn St, once, Ward Hid: $(104): 2: 20$
$2-1 ;$

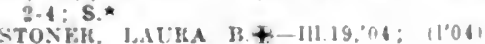
Battle creek Sanltarlum; $10-1,4-6$

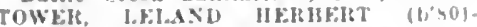
Mch.1.06: (lot): 65 (entral st.; onles. Tacoma Biack: 1-t, i-k

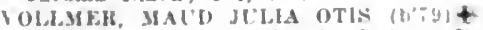

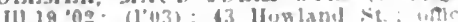
Krllere ford io. Bidg: : y $1 \pm, 3-6$

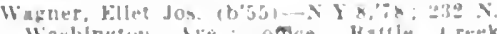
aslingter Ale; ofdec battle treek Sanltarlum

Watules, Jerils H. (t' 40$)-0.6,64 ;$; $\left(I^{\prime} 00\right)$; 116 North ire.

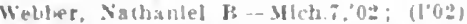

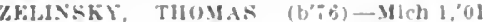
(I01); : Jenuett. St; ofice, 35 K. Maln St. : :-4

BAY CITY, 43.166, BAY

Ambrose, Joslab J.-Wl.1, '3; (1.00); 3 ray lslock.

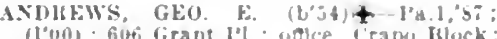
(100); 606 Grant

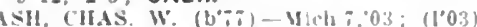

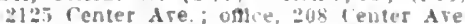
$0.11,9-4,-8: 30$

lalrd, Fredk Snilh (b's8) - Que l,'13 (1'13) ; 235 We's? Are

B.ARI, THOMAS A. I. -Que. 1, $45:([00)$ \$3j Wasblngton Are.

BAKER, CHAS. HAKI'F.H $\left(H^{\prime} 59\right)+-M$ - M. 1 . Q2: $\left(1^{\circ} 00\right): 513$ Lancoln the : once. Crapo Block: 9-12, 1:30-5; (B1,11) OALR

H.ILHAKD, WM. MOSS (b'bs) + Mich.s 94; (I'00) ; 1800 Center Are.; oftece, Ridotto Bldg.; $2-t, 7-9$.

BKAULEY, HLHBAIL NORTH (b" Mich.l.05: (1.05) : $903 \mathrm{~N}$. Jackson st $8-9,1-3, ;-8$.

Bristol, Mlles C. (b'6s)-N.Y.s.94; $\left(l^{\prime} 00\right)$ i01 w. Ohlo st. oflce, jit k. Mlaland St. ; 11-12, 1-4, -8.

HHOW, FHANK WIXNE - Mlch.5,"06 (1'06): 2161, 5th Are.; ottce, ('sapo Bldg: $9-12,1: 30-5$; OALR.

BHOWN, MLSSEL W, (b'64)-MllCh 8,59 $(1 \cdot 00):=07 \times$. Walnut si.; $8-9,1-3, i-8$

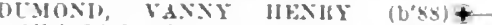
Mlch. $i, 10 ;(1,0)$; Wenonah Hotel; of Shearer Block: $9-11,2-4,7-8 ; 5$.

Ely. Nina Maynard (b'69) H - Ii. 15,00 (l'01): $\$ 18$ Washlngton st.

Everelt, Raye S. $\left(b^{\prime} 6 t\right)-0.7,95 ;\left(J^{\prime} 00\right) ; 111$ W. Thomas st. office, Gog to. Nhlland St. : 9-11, 1-4, 7:30-8:30

FLINX, EKNEST JAMES MOHFATScot.9.12,'st; Scot.13,'42: 1 1'00); Forest Cly House; oflce, Bank Block; 9-11. $1-1, \overline{-1}$

GALE, IITFII MCLAREY $\left(b^{\prime} 35\right)+$ Que.1 N2; (1'00): 517 X. Van Buren Sic; oftce 401 (enter ire.; $9: 30-11: 30,2: 30-4: 30$ $6: 30-7: 30$.

GALRAGHER, MORTUS (b'63) $\left(l^{\prime} 00\right) ;$ ith and Monroe sts.; $\$-9: 30,2-4$ $-8$.

Gillert, Harvey-X.Y.y,"̈t; (1'00); 609 Girant $P$ l.

Gillert, Nelson Is. $\left(b^{\prime}+2\right) H-0.7, \pi 1 ;\left(l^{\prime} 00\right)$ : 301 Marquette Ave, omce, tos conter Are: $9-11,2-4$.

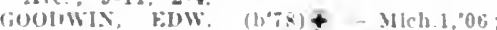
(1*06); 2015 center st. unce, Mdotto Hdin. ; $1-3, ;-8$

(HONJKAX, JOS, C. (b':3)-Ont.3,"00 (1"00); Mckinley Aic : once, Fay Block 2-4. $;-8 ; 5$

1:t"stix, JAMES WM. (b'70)-Mich.7.03 (1.03): 110 Wenona Ave: antce, isio Wenura bie.; $9.10,2.4,8.9$.

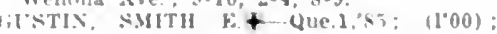

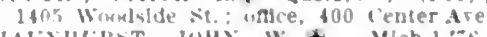
HAIXHIRT, JUHX W. $\$$ - Mch., 10

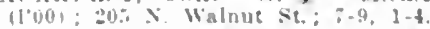

llelwadt, Fred liarenuore (bos)-Mich 2

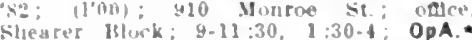

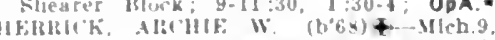
01: (l'ul); 1:1: Cencer Are ; $\$-9,1-3$

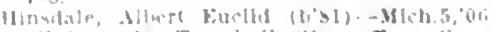
(1'vi), 4l: Trumbull st.; omee, Cram |i!l.

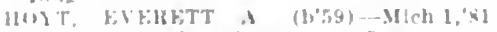

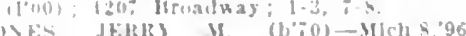

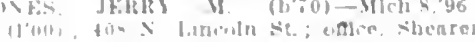

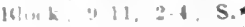

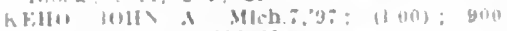
film sit. Wer. 310 Marduete sur.

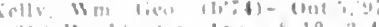

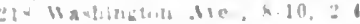

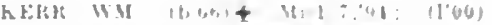
io.; $>$ karrabut

$1.4,0.5$

ANiox, HFitis

$\left(l^{\prime}(00): 413\right.$
shearer Hick

Marill, Alex

practlee.

Magll, Wm. F

Maucrel. Altred-Que

Flugerald sit

Mayber, kdx

Mayher, Edo.

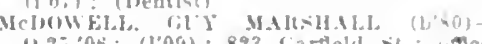
1) $25,06^{\circ} ;\left(I^{\prime} 09\right)$; 923 Gartleld it : Ince $1909 \leqslant$. Wenona Are.

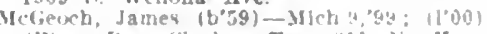

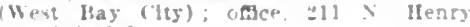
St $:=-4,6.2$.

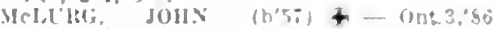
Fing.15, 8 : $\left(1^{\circ} 00\right) ;$ P.20 Madion Are

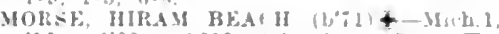

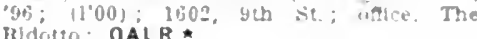
MIdrito; OALR.

Newkltk, Matland F. $(1,7,-1)-M:$ h. 1,7 ;

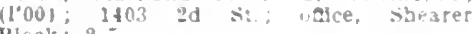
Block: $2-5$.

OVEXSHHE, BYRON H - Mich 1."30;

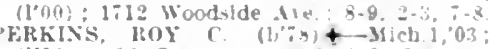
(1003); soo Cass Are. :-9, 1-3.

BANALL, FuYD II. (boj)+ Mich. 99: (1'00): 200 k. Waluut st. of oce

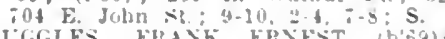

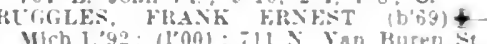
Mrb. $1.92:(100)$
$8-9,1-3, i-8 ;$

Sanders. Irring F. $\left(b^{\circ}+5\right)$ - Ind $26, " 96$ $\left(1^{\prime} 00\right)$; 610 Adams st. ; once, $\$ 03$ Center St. $10-2,2-4, i-5$

SCRHFFRL, HOY STOX EART (b-2) +

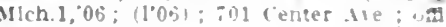
$812 \mathrm{~N}$. Grant St $9-10,1-3,7-3 ; \mathrm{S}$

Simard, Alelard ( 503 Washlngwn St. ; $\$: 30-9: 30$

SIEAKIIRD, AIOLIH O †-Ind 10,'90 II'00) $621 \times$ Van Buren St. $(100)$; $1100 \mathrm{x}$. Johnson $\mathrm{St} ; \mathrm{s}$ - 1 .

STONE, ALBFRT F. $(10: 5)-M 1 c b$ (J'10): 515 Center Are.; $9-11,2-4,-\infty$ (1'00): 240 Wasblngton Ale, 8-9.1-3.

TRALHAGEX, CLARENCE I (b\%) Mlch. 2,99; (1'00): $105 \mathrm{X}$. Walnue 2-4, $\overrightarrow{-1}-9$.

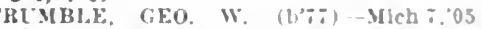
(10.5); 412 X, Llucoln Si, otace, 203 Center ine: $\$-10,2-4,-3$

TIPPER, VIRGIL L. (3'69)+-Pa: 296 (1"00): 1001 Center Are; watce, s1

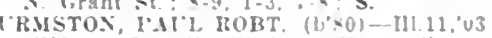
(l'09); Cartull Park nolice. Shester Hhock; 9-12, 1:30-5; OALR.*

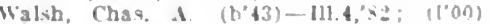
$421 \times$. Madlson dre; not in practice: $8.10,2.4,-8$

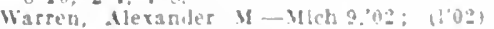
Inn and Jwh St.

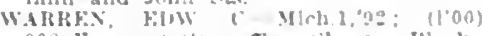
pos farraght se : welce, Shearer Hhok.

WIILIAY, MARY I W $(1,53)+-\mathrm{M}$ - 1

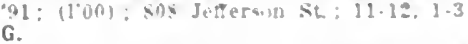

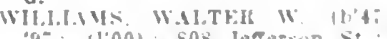

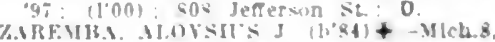

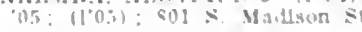

BAY PORT, 150. HURON

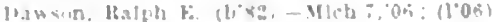
BEACON, 1.000 MARQUETTE I1.003.

BEAL CITY, (R.F.D.. ROSEBUSH), 1:0, ISABELLA

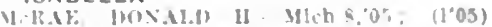

BEARLAKE, SOS. MANISTEE

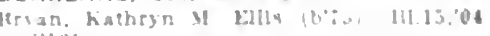
11,01

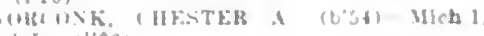
1100 
BEAVERTON, 418 , GLADWIN

Barlour, IIarry Arnold (I'ta)--Mllel.Il, 04

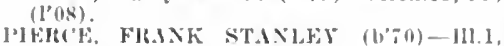
3,$3 ;(1,00)$.

Sturge, Jrthur s.-Mlcla.9,00; (l'no).

BEDFORD, 225, CALHOUN

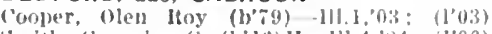

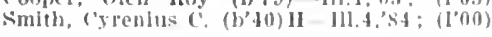
BELDING, 4.1 I9, IONIA

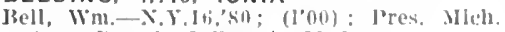
state lBoard of lieg. in Med.

Corllle, labiner- II O..,

Inut, sndrew W.-III.s,

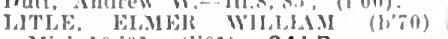

Mleli.10,'A1; (l’n1); OALR.

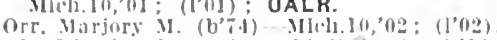

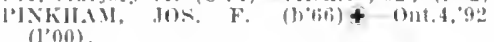

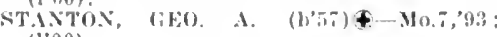
(l'00).

BELLAIRE, I.050, ANTRIM

Boolle, Arthur T., (1)"58)11-[11.]11,93, III.4.

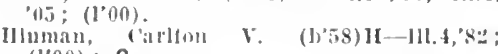
$\left(I^{\prime} 00\right) ; G$.

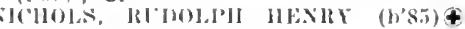

Mlh.1."lo: (l"lo): S.

BELLEVILLE, 486, WAYNE

('oh), lester li. (1,57)-Mleh.s,90; (l'00) Felloge, Edw. Rurtson (b'T6)-Mich.8, 01 ; (l'01).

Zeidler, ('arl (i.,Mllch.8,05; (l'05).

BELLEVUE. 930. EATON

AIAM, AlRERT WILFIREI

$\left(b^{\prime} 4 s\right)$

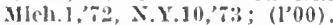

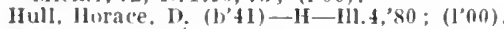

SNELI. WIXA MERIIX-III.4,05; (1'06)

WASNOS, CIARENCE H. (1)'65)-Micli.1 OI: (I,0I)

BENNINGTON, 265, SHIAWASSEE

Hec, Lewls F. (b'65)H-Mich.5, 100 ; (1'00).

BENTLEY, 100, BAY

Kiltchen, Morrls C. L. (b't1)-Mich.1,'80; (l'00).

JeCarty, John Franklln-Jd.1,96; (l’00).

BENTON HARBOR, 9.185, BERRIEN

Bastar, Wm. ('lay (b'63) H-111.4,'84; (l'00).

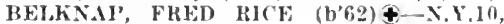
$88 ;(100)$.

Brady, Franklln E. (h'6y)-IIl.s, 01 ; (l'01).

Chapln, Claudius B. (b, 72$)-M l \cdot h .1$, , $(1,00)$.

Cur1lss, Wm. Loren (b'6 J)-Ill.22,95, Ill.1, $99,0.2,15:$ ( (1'010).

WLLIOTT, MABEI, EVElAN (b'81)—-111.1, 04: (1'06).

Freemyer, ('eo. L. (b'43)-la.4,82; (l'00).

Goodspeed, Jacol) Il (b'41)-Mich., 86 ; roodspeed, Jacod M. (b' $(1>00)$

HHRRISG, NATHANIEL A. (b'56)-Ill.8, 'so; (1'00)

HILL, HERINOS C. (b'66)\&-I11.1,'92; (l'00) ; OALR. *

KEIRIY, FRANK MIXEI: (b'59)-Mich.1, '8\%; $(100)$.

MITCHELT, CARI, APPERSOS (b' III.8, $06 ;(1907) ; \mathrm{S}$

Mlx, Homer I'-Ill.4,8n; (1'09); not tu practice.

MORRILI, WARIEX I'EARL (b'T)-Md. os ; (l'08): Member Med. and ('hir. Fac. of ju.

I'ost, Elijall 3. (b'55) H-H - H., 91 ; (l'00) Traction Bldg.

ROSENBEPRY, IJWAN AVERY (b'83)屯Micli.1, $09 ;\left(I^{\prime} 09\right)$.

kyno, Corydon liott $\left(h^{\prime}-6\right)$-Conn.1, 0 : (l'ni).

Kyno, Wakeman $\left(b^{\circ} 49\right)$ - Jlich. $, 72:(100)$ SOWER, CISS. NEWTON (b'59)屯 Mleh.1,93: (I'00).

spawr, Clarence V. (b'81)-III.22, 09 ; (1'12)

Ftevenson, Burton J. (b’33) - Mll10, ${ }^{\prime} 04$;

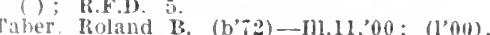
Talot, Edwin Roy (b'76)-Nich.1,05;

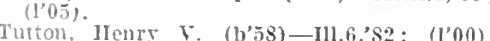
Tutton, Ilenry F. (b'58)-Ill.6,'S2; (l'00).
Watson. Berton G. (b'64)-111.8,8s; (l'00). Weir, James , T. 0 ; $\left(l^{\prime} 00\right)$.
BENZONIA, 563, BENZIE

ELIAS. ELII, J. (', (h'61) +-111.6, '8? N.II. I,, $90 ;$ (1'00)

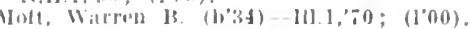

BERLIN, 400, OTTAWA

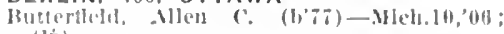
$(1 \div)$

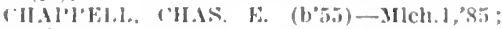
(T)(in)

BERRIEN SPRINGS, 880, BERRIEN

liullitrd, WH. F. (b'48) Ind.S,'S0; (1'00)

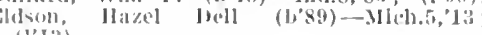
(I)I?3).

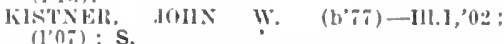
Sullh, Warren $\Lambda .\left(b^{\prime}, 6\right)-J 11.4,03 ;\left(l^{\prime} 03\right)$. BERVILLE, I50, ST. CLAIR

l.iltle, Iolm S.-0.16, '76; (1'00)

BESSEMER, 4,583, GOGEBIC

HOI (IITEN, LLSTEK ORI, (b'82)-

IIlele,ofi: (l'06i)

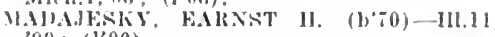
99: $\left(l^{\prime} 00\right)$

PAHADIS Ito(H ATUTSTE $\left(b^{\prime} 66\right)+$ Que.3,?] : (1'00).

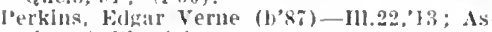
slstant l'hysiclan.

IISKERTON, WALTEIL JEWETT (h'3) III.11, 00 ; (1'06).

Tew. Wm. Fllwool (l,80)-Mleh.1, (1'03).

BIG BAY, 300. MARQUETTE

Marknight, kohert Stanley (b'83)-IH.c.1 os: (䒠)

webster, (yvmon w. (b'62)-yich.10,05; $\left(l^{\prime} 0.5\right)$.

BIG RAPIDS, 4,5I9, MECOSTA

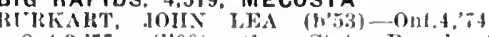

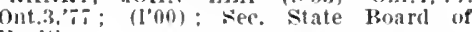
Health.

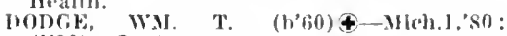
(1'00): $\mathrm{s}$.

diRISWOID. LEAVITT $79:(1,00) ; S$

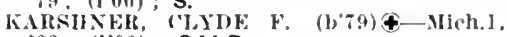
08: (1'09): OALR.

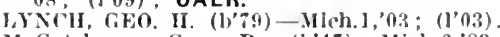
MeCutcheon, Geo. R. (b'47)-Mlleh.6,'83; $\left(l^{\prime} 00\right)$.

THRIHI, FRANKIIX C. (b*49)-Mich.1, 79 : (1'00).

WHTXEV, WHLARD ADOLPII'S $(1,44)$ 0.7.70; (1'00).

BIRCH RUN, 250, SAGINAW

HI'GIIES, E. CHAS. (b'72) - Ky.2,'94; $(1,00)$.

MeCrory; Harvey Benj. (b'85)-Mich.11,09; (I’0,

BIRMINGHAM，1,607, OAKLAND

'AMPBELL, JOHN' LCTIIER (b'55)థ-

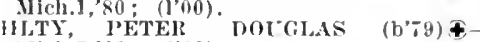

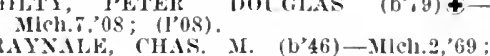

$\left(I^{\prime} 00\right)$.

IRYNALE, GEO. P. (b'80)-Mich.T,02; (1'02)

SHAW, N. T.-Mich. 7,$92 ;\left(I^{\prime} 00\right)$.

BLAINE, 125, ST. CLAIR

CAMPBELL, NEIL D.-J11.1,75; (1'00).

BLANCHARD, 219, ISABELLA

Huebner, August C.-Mich.8,'96; (l'00)

WATLEY, SAILEL H. (b'63)-Mich.8, '97; $(1,00)$.

BLANEY, 250, SCHOOLCRAFT

CAMERON, FRANK E. (b'T5)-Mich.8.'98; (I'00).

BLISSFIELD, 1,474, LEWANEE

('LENES, W.I. T. (b'68)屯-0nt.3,'95; (l'00)

ECCLES, ROSINGRAVE M. $\left(b^{\prime} 58\right) \oplus-$ Ont.3,;9; (1'00).

Krumling, Andrew (b'38) $\rightarrow 0$; (l'00).

Lanley, Arthur Edw. (b'85)-Pa.11,09; (1'1i)'

LAMLEY, GEO. H. (b\% (I’02).

BLOOMINGDALE, 501, VAN BUREN

H.IWKEY, JOHN W. (b'58) \&-Ind. 7 , 82 ; (1'00); Pd.

RANSOM, THOMAS H.ARVEY (b'T0)屯Ind. 9,?1: (l'00).

BONIFAS, I00, GOGEBIC

Weed, Harry M. (b'6:)-JH.10,'89; (1'12).
BOON, 300, WEXFORD

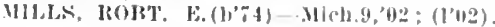

BOYNE CITY, 5.218, CHARLEVOIX

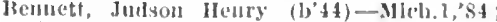
(l'tii); $\mathbf{G}$

loylan, Walter M. (b'71)-Mleh.8,00 (l'00).

Muchegor, James G. (1,62)-0nt,5,95; (l'00)

MAIRIILL, WM. IENIUEISON (b'74tOnt.", 01 ; (1'01).

SHAVEK, HARIG HRAEST†-Ont.3,47; (l'00).

Vis, Edw, W:- Mich.10,03: (l'09)

BOYNE FALLS, 325, CHARLEVOIX

Conkle, dily C.-Mich.1, $01 ;(1 ' 01) ; 0 p$.

llowe, Arden N. $\left(b^{\prime} 59\right)-\operatorname{Mich} .9,01 ;\left(l^{\prime} 01\right)$;

Ob.

BRANT, 150, SAGINAW

Benneti, Robt. B. (b'7I)-Mlch.9,'97: (l'00).

BRECKENRIDGE, 595, GRATIOT

IITAKE, WILKIF MORTIMER (b'T) $\$$ MIc].7, $02 ;(102) ;$ OALR.

HOWE, LWSLIE A. (b'66)£-Mlch.5,'90 ;

BRIDGEPORT, 50, SAGINAW

byle, Hichard Coles (b'82)-Mich.8,'05; $\left(l^{\prime} 05\right)$.

BRIDGMAN, 300, BERRIEN

littlejohn, linvld (b'76)-Mo.29,97; (l'11) Mllhan, Ollrer-Mo.2. 74 ; not in practice.

BRIGHTON, 767, LIVINGSTON

COAN, MARLIN H. (b'73)-JICh.8, 00 ;

1NGEI, JACOB DANI. (b'58)\&-Ha.li, $96 ;(1,00)$.

BRIMLEY, 500, CHIPPEWA

STOCKEI, HAIIII LNERSON $\left(b^{*} S \theta\right) \mp-$ Ilch.7,07; (1'07).

BRITTON, 370, LENAWEE

Lusty, Albert R. (b'72)-Nich.7, 97 ; (1'00).

BRONSON, 1,020, BRANCH

cornell, Seymour M.-III.8, $90 ;(1,00)$.

GTNSAULALS, PYRL, H. (b'60)-IHCh.7, '94; (1'00).

IIarley, ('laule I. (1,87)-Ill.22,'13: (1'13).

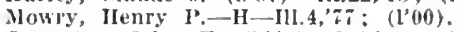

Outwater, John F. (b'45)-0.2, 82 ; (I'00).

BROOKFIELD (R.F.D,, CHARLOTTE), 60 , EATON

Banks, Harold Walker (b'כ5)-III.1,'97; (l'00).

\section{BROOKLYN, 602, JACKSON}

PALNER, EMNET NEWTON $\left(b^{2} 1 \theta\right) \$-$ llich.1,'69: (l'00)

Porter, James A. (b'45)-Mic'l, 2,69; (l'06) ;

$0 p A$

Reinbolt, Chas. A.-Mich.11,03; (1'03).

BROWN CITY, 690, SANILAC

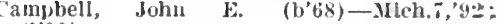
$\left(l^{\prime} 00\right)$.

Camplell, Wu. T. (b768)-MLch9,'93; $\left(l^{\prime} 00^{\circ}\right)$.

Waltz, James F. (b'85)-Mieh. 6,07 ; (l'0i).

BUCHANAN, 1,831, BERRIEN

Broderick, Henry M. (b'40)H-Mo,j,6 ;

$\left(l^{\prime} 00\right)$; not in practice.

Curtis, Orville (b'67)-N.1.3,93; (l'43).

Kinlght, Mlonroe M.-111.4, $83 ;\left(l^{\prime} 00\right)$.

Peck, Lester E. (b' $\mathbf{6} 0) \mathrm{H}$-llich.5,94; (['0t)).

slautter, fdwin R. (b'49)-0.11,79; ().

Strayer, John Curvin (b'85)-Mlich.1,'I?; (12)

Trewln, Etta May (b'68) - Mich,1'12: (1"12).

BUCKLEY, 464, WEXFORD

PLRDY, CALVIN S.-llich.9,02; (1'02).

BURLINGTON, 237, CALHOUN

Derickson, Elvia Clair (b'⿳3)-Mich.1, 01 ; (l'01); 0 p.

BURNIPS CORNERS, 200, ALLEGAN

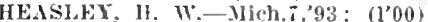

lalmer, Geo. Colden-Jich.1,'́6; (l'00).

BURR OAK, 752, ST, JOSEPH

Crofford, Rozilla-E-IIl.8,'86, 0.2,'88; (l'00).

Kelley, I. Joslyn (b'76)-Jll.4,00; (1'01).

Rolman, Carl J., Jr. (b'79)-Ĺlich. 7,06

Roltman, Jolu C. (b'36) H-0.2;60; (l'03). 
BURT, 200, SAGINAW

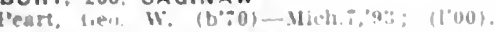

BYRON, 427, SHIAWASSEE

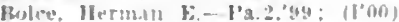

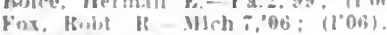

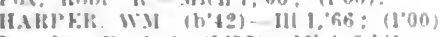

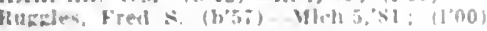

BYRON CENTER. 400, KENT

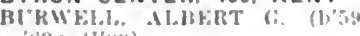

'S?: (I'vit).

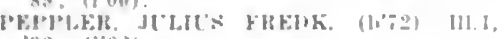
(n): (100:)

\section{CADILLAC, 8.375, WEXFORO}

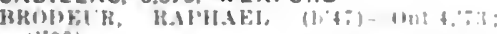
(1) 00 )

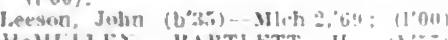

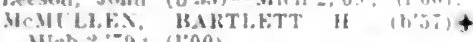

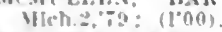

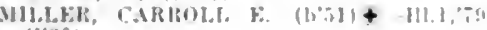
(I.00)!

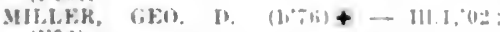
(l'0:0)

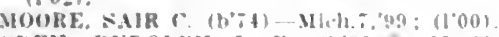

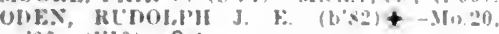
$06:(1,10):$ S.*

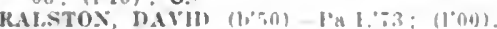

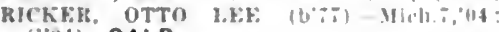
(1"0t), OALR.

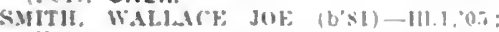
(100i)

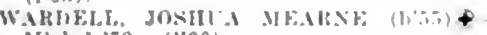
MICh. 1, $\because 3 ;(1 \% 00)$.

CALEDONIA, 422. KENT

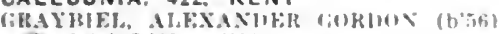

+ Mrh.:- $2: 0$ : 1100$)$.

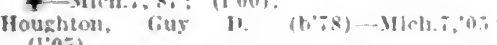
(105).

CALUMET, 25.991, HOUGHTON

ARRAMS, JAMES C. $(10,2)+-111.6, " 01$ $(1 \circ 01):$ ith $\mathrm{st}$.

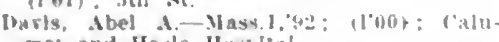
met and Herla Huspilal

BIWARDS, SLOCONB H'TkHT (b's:) WJ.1.05: (1) Palumet IIotol: oftles. Calumer and Hecla IInspltal; $9-11,2-t$ OALR.*

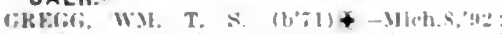
(l'nii): 1 Beech si.: intlee, (alumer snd Hecla Hospltal; $x-9,1: 30-2: 30$, Gi-z; $R$.

Ifeldeman, Almild Fulsabeth-Hus. 1, 0 n (l"03): Centemnlal Welghts.

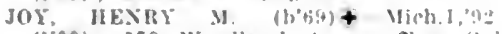
$\left(I^{\circ}(00): 159\right.$ Woodland Ire: oflce, (tilk St. : 2-4, ;-8; 5 .

Konblhase, oten il.-111.6, 03 : (1'0:3)

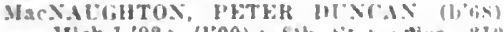

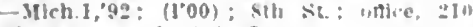
5.th \$1: $11-12,2-4 \div-$

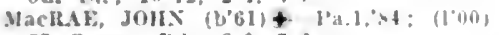
5. County kd.: $8-9,5-t^{\circ}$

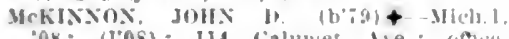
Co: (ros): Ilt calumer Ale.: othos I'alumet and lforla llompltal: si-?, 1:2, b-

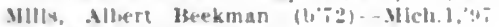
(1"00): "alumet Alo

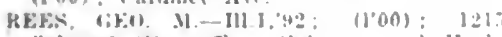

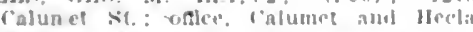
Hoxpllal: :-10, 1-2!, i-s

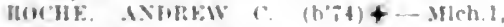

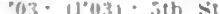

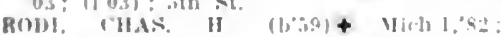

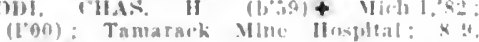
$1-2: S$.

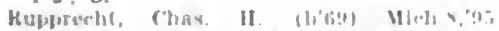

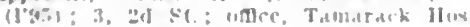
Ilal: $x-2,1-2: S$.

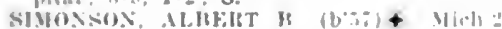

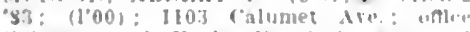
"alimer and Ilecla Howpllal: "t, "̈ 1 5.:-

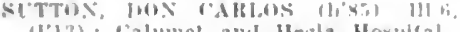
(I'IB): Palumet ani Ilecta Hoxplal.

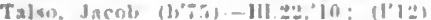

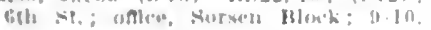

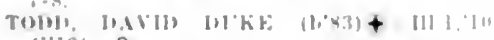
(l'12); S.

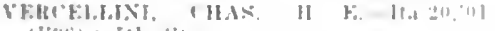
(10*)i ; sth st.

CAMBAIA (R.F.D. HILLSDALE). 350 HILLSDALE

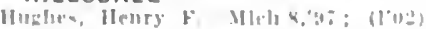

CAMDEN 392. HILLSDALE

B.ITHE I.IMIS I + IMIY, II: $11^{\circ} 001$

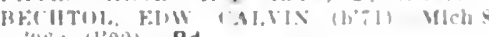
cats: 1 1'000) $\mathbf{P d}$

How

(H)e, WM. I $\rightarrow$ (I"UH)

CAMPBELL'S CORNERS (R.F.D. WEST

BRANCH), 100, OGEMAW

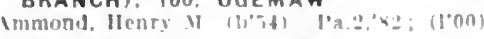

CANNONSBURG, I50, KENT

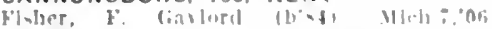

11 (16).

IIt.h $: .0 m^{3}$

viliuin,

$1100\rangle$.

CAPAC, 761, ST, CLAIR

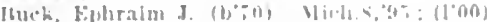

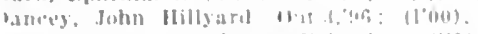

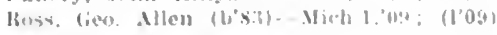

CARLETON. 500, MONROE

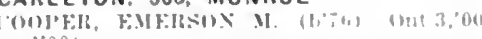
$(1,00)$.

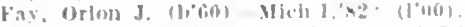

sambers, buncan l. (16it)-Mich.:,06: (1'06).

CARO, 2,272, TUSCOLA

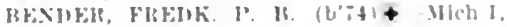

(1): : (1'02): OALR.

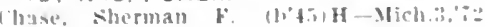
(1.014).

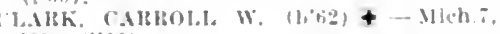
in: (1,00).

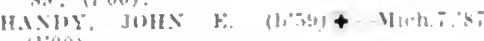
$1100)$.

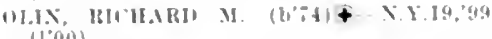

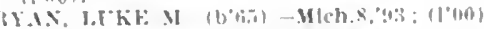

CARSON CITY, 808, MONTCALM

cilleman, silanley Hay (1,79) - \$11.11,07: (10)

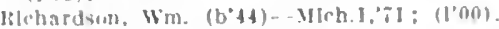

CARSONVILLE, 401, SANILAC

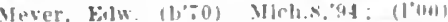

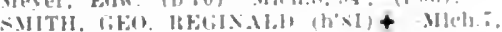
03 : (1'03)

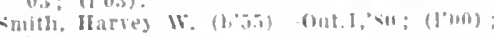
S.

CASCADE (R.F.D., ADA), I00, KENT

Clistk. JOS. I. M.- Mlch.S.'gs; (1'00)

CASEVILLE, 4+2, HURON

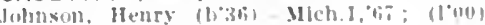

not in priactien.

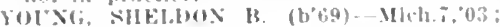
$(1 * 03)$

CASNOVIA. 308, MUSKEGON

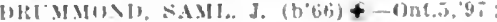

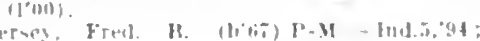
110001 .

CASS CITY, 1,126. TUSCOLA

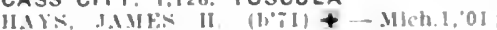
(I"॥1): OpA.

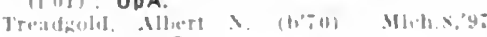

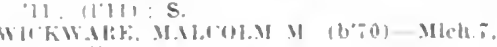

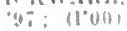

CASSOPOLIS, 1,358. CASS

Anclerselt. Thomas W. Mlelu.l, fit: (l'00) mel In bractlee.

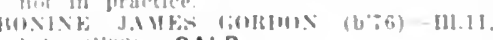
(A): (l' $11: 2):$ OALR.

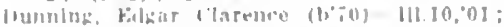
$(1011)$

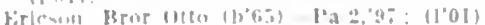

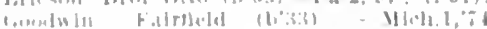
H.

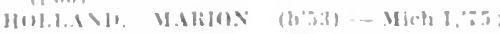
(1) $10(1)$

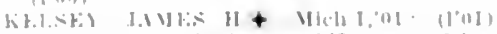

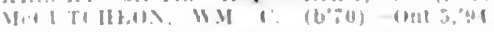

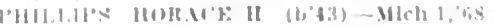

CEDAR SPRINGS, 947, KENT

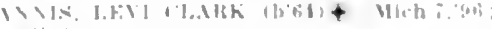

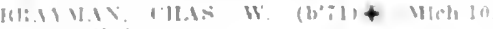

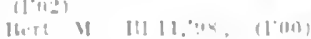

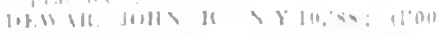

CEMENT CITY. 300. LENAWEE

CENTERVILLE. 613. ST JOSEPH

I'IAITT FIS.I K I + $\because \because+$

$(1 \mathrm{n}) \mathrm{ti}$

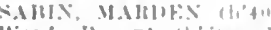

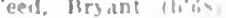

CENTRAL LAKE, 813, ANTRIM

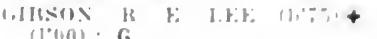

(1) That

CERESCO, 350, CALHOUN

1,I BIINS. HUITT. II (b)

(l')

CHARLEVOIX, 2.420, CHARLEVOIX

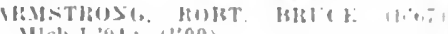

Vlch.I.'st: $\left(l^{\prime} 00\right)$.

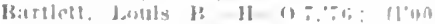

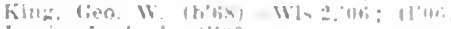

touis. l.esl \& (lou)

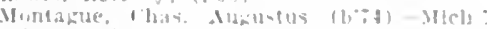

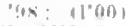

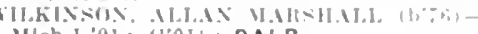

Wleh I, "01: 11'01); DALR.

CHARLOTTE, \$.886, EATON

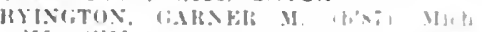

"II: II'I है।

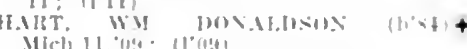

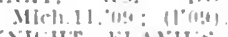

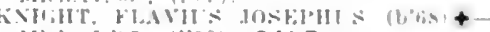

Mirh. 1,95: (I"00): OALR.

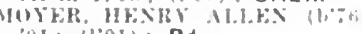

Mich.:

01: $(1,01): P d$.

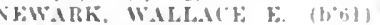

is: $(1,00)$.

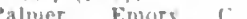

batchell, Meda lless $\left(10^{\circ} 0^{-}\right)$- 1111,00 (1'03).

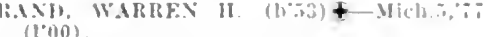

$11.0)$

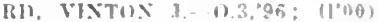

(I00) = ob.

ISTIMIN.

111.11.00: $(1001): 0 p$

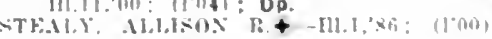

CHASE, 200, LAKE

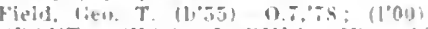

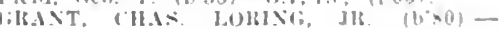

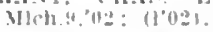

CHASSELL, 700, HOUGHTON

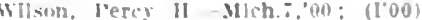

CHEBOYGAN, 6.859, CHEBOYGAN

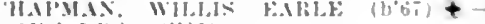

llirlu.1."yt; $(1,00)$

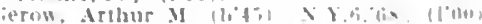

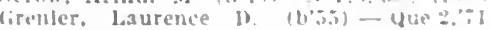
$(1,00)$.

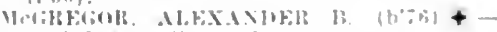

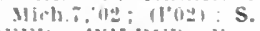

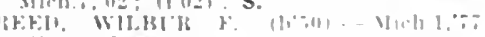

(1')(1) : OpA.

ST IIIIII T

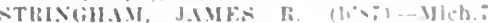

$1:$ : $11,11, \mathrm{~s}$

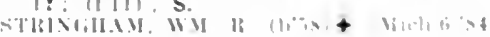
(100), S.

TWr.t.i.

(1'0)01.

CHELSEA, 1.764, WASHTENAW

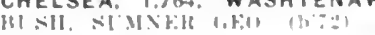

(a)

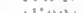

(1)

(1.03)

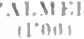

औHIHT Hस:I

ivis $11^{\circ} 00$ )

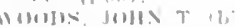

CHESANING, I,363. SAGINAW

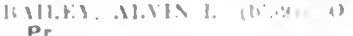

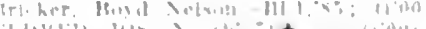

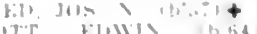

त.

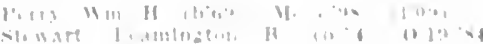


CHURCH (R.F.D., PITTSFORD), 50, HILLS. DALE

Sabhi, Erl 13,--II-0.6, 'As; $(1.00)$.

CLARE, I,350, CLARE

rlute, Wm. F. Mlleh.:,05: (1'05)

munlon. John W. (h'si) $\rightarrow$; (l'00)

Leonard, bilw \& $8-100$ : $(100)$.

Maynard, Thos. IIIII $\left(\mathrm{k}^{\prime} 41\right) \rightarrow$; (1'01).

Mussell, Arthur Robt. (b'85) - I11.8,12: (1'12).

HEEDER, MAMES A. (1)'63)+-Ml(1.7,'9s;

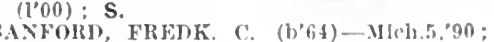

A.vol

Sober, Warren R.-0.2,'75: (1'00).

CLARIKSTON, 345, OAKLAND

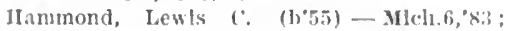
$(1,00)$

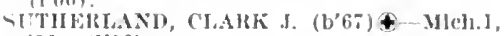
$91 ;\left(1^{\prime} 00\right)$

CLARKSVILLE, 375, IONIA

Warner, John A. (b'(5)-Illch.9, 01, Mh. 08 ; (l'01).

CLAYTON, 372, LENAWEE

Viclonald, James k. (b'40)- $0.8,69$ : (['00)

SUTTON, MAIILOX $\mathrm{R},\left(\mathrm{b}^{\prime} \mathrm{S} 0\right)+-$ MIl $\mathrm{s}$, "03; (1'03); LR

WILCOX, ALEXANDER E. (b'69)-Mllch.9, 00 ; $\left(1^{\prime} 00\right)$.

CLIFFORD, 308, LAPEER

Keillor, TItus D.-IIlch.1,'is; (1'00).

CLIMAX, 425, KALAMAZO0

Bates, oln R. (1,'09)-Mlicli.10,'03: (1'03).

CLINTON, I,011, LENAWEE

Blatchford, (ieo. (b'4i)-Mllch.5, 84 : (1'00)

Davis, Robt. Anthony (b'64) - 111.11, 06 (1'09).

T'LTTLH. JOHN L. (b'76) -Pa.2, '99; (1'00)

CLIO, 810, GENESEE

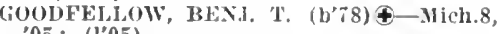

05 ; $\left(1^{\prime} 05\right)$.

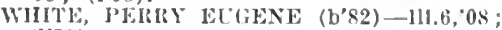
(l'II).

CLYDE, 202, OAKLAND

SNYDER, ('HAS. W. (D'SO)£-III.11,03; (l'03).

COLDWATER, 5,945, BRANCH

Baldwin, Newton R. (b'53) - Mlch.1,75; $\left(l^{\prime} 00\right)$

BALDWIN, WM. H. $\left(b^{\prime} 66\right) \notin-M 1 c h .7,95$; $\left(1^{\prime} 00\right) ; u$.

CULVER, BERT WILSON (b'S1)-Mleh.1, $07 ;\left(l^{\prime} 07\right)$.

Gamble, Ernest F. (b'67) H - Mlch.1,'92; (1'00).

GRIFFITH, WILBUR A. (b'67) $\oplus-1 \mathrm{a} .9,98$; (1'00).

Hatton, Lemuel C. (b'46)H-III.4,95; (l'07).

HEATOR, JAY J.-Ind.11,'90; 11'00).

HOLBROOK, ARTHUR GILBERT ( $\left.\mathrm{b}^{\prime} 66\right) €-$ Pa. 2,'99; (1'00).

HOWE, LLOYD WELCONE (b'84) $\oplus-$ Mlch.1,06; (1'06).

LEGG, FRANK G.-Ill.10,'79: (1'00).

MOULTON, GEO. HIAL (b'40)-N.Y.10,'92 ; (1'12).

Rldge, Ralph. Wm. (b'86) - Mlch.5, 09 ; (1'09).

SCHULTZ, SAML. (b'69)€-IIl.6,'99; $\left(\mathrm{l}^{\prime} 00\right)$. Stewart, Fredk. W. (b'61)-0.23,'91; $\left(1^{\prime} 00\right)$. WOOD, DAVID H. (b'45) - Mleh. 2,76 ; (l'00).

\section{COLEMAN, 909, MIDLAND}

HIgh, Chas. V.-0.3,'88; $\left(1^{\prime} 00\right)$.

Scoutten, Chas. L. '(b'60) - Mich.9,03; (l'03).

COLOMA, 70I, BERRIEN

Baker, Wm. Allen-Ill.I,'82; (1'00).

Barnum, Spencer Van (b'82)-Nich.1,10; $\left(l^{\prime} 10\right)$.

Bertrand, Wm. T. (b'5S)-Ky.4,94; (l'00).

COLON, 853, ST. JOSEPH

Doran, Wm. E. (b'81) - MIich.5,'04; (1'04)

Godfrey, Erwin I. (b'52)-11l.4, $7^{\prime} 6 ;\left(l^{\prime} 00\right)$.

HARTMAN, PETER LEROY $\left(\mathrm{b}^{\prime} 66\right) \uparrow-\mathrm{Pa} 2$, '90; (1'00).

COLUMBIAVILLE, 369, LAPEER

Chapin, Clarence D. (b'80) - Micl.. ,'04; (T) 04 ).

IVISNER, CALVIN A. (b'54)£—Mich.6,'81; (1'00).
COLWOOD (R.F.D., COLLING), 100, TUSCOLA

KING, IIERHERT HENRY (b'82)—Mlch.8, 05: (1'05); R.F.D. 1.

COMMERCE (R.F.D., WALLED LAKE), 250. OAKLAND

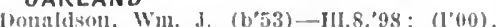

COMSTOCK, 200, KALAMAZOO

SWIFT, EAIRIE REFD (b'73) $₫$ - Mlch.1, 04; (1'04).

CONCORD, 543. JACKSON

Bacon, Marshall L.-Mich.,$; 90 ;\left(l^{\prime} 00\right)$.

IHUNGEREORD, PERRY ll. (b'T5)-Mlch.1, 02 ; (1'02).

Tuthill, Frank S.-H-MIch.5,'91; (1'00).

CONE, 90, MONROE

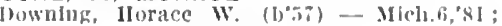
(I'00).

CONKLIN, 200, OTTAWA

Cllley, Harl 0, (b'65) - Mllch.10,00; $\left(1^{\prime} 00\right)$ Kinepper, Sylvester I. W. (b'45)-111.8,93; $\left(1^{\prime} 00\right)$.

CONSTANTINE, 1,244, ST, JOSEPH

I'artlow, Ndw. P. (b'61) -Mllch.7?94; (I'00)

Scorllle, Bela P'-11lch.1, 68 ; (1'00)

Slote, Leal Kenny (b'77) - Mich1, I, 00 ; ( I'00).

SWEETI,AND, JOIIN J.-0.8,'89; (1'00).

COOPERSVILLE, 8I4, OTTAWA

BAYER, HERMANN (b'50) - Mo.T.'si; $\left(1^{\prime} 00\right)$.

Coburn, Mllan (b'59)-MIlch.7,93; (1'00).

KASSABIAN, NUSHAN H. (b'66)-111.6,'96 $\left(l^{\prime} 00\right)$.

SMITII, FREDK. D. (b'45)£-Pa.14,'70; (l'00)

Walling, Jerry S. (b'58)-Ia.1,'90; (1'00).

COPEMISH, 490, MANISTEE

Cornell, Stephen Herbert (b'69) - Mich.i. 90 : $\left(l^{\prime}, 00\right)$.

Qulnn, IIenry M. (b'84)-Mlch.i,'07; (l'07),

CORAL, 500, MONTCALM

BOLIO, EDIIUND WM. (b'70)-Mlch.7,93; (1'93).

CORUNNA, 1,384, SHIAWASSEE

BAILEY, E. HERBERT †-MIICh. 2,84; (1'00).

Norris, Irving W. (b'64)-MIlch.8,'01; (1'01).

PARKER, WALTER T.-Mich.1, 01 ; (1'02)

COVERT, 325, VAN BUREN

VAUGHAN, ORLEY MASON (bs53)†-IIl.6, '81: $\left(l^{\prime} 00\right)$.

VATGHAN, ORLEY MASON, JR. (b'84)111.6.'11; (1'11).

CROSBY, - KENT

Geib, Oscar P. (b's7)-Mlich.7,'12; (1'12)

not in practlce.

CROSS VILLAGE, 500, EMMET

SCHNEIDER, CHRISTIAN (b'45)-D; (1'02)

CROSWELL, I,380, SANILAC

Kingston, Thos. S. (b'61) - Mich.1,'8t; (l'00); G.

EARMONT, HARRY H. (b'75)-Mlch.7

McColl, Nell James (b'76)-Ind.8,98; (1'00).

CRYSTAL, 300, MONTCALM

SMITH, RAYBURN B. (b'81)-Mich.9, 03 (1'03); Op

CRYSTAL FALLS, 3,775, IRON

DARLING, ABNER M. $\left(\mathrm{b}^{\prime} 63\right)$ - Ia.9,'92; $\left(\mathrm{l}^{\prime} 00\right)$.

HAIGHT, ARTHUR L. (b'79) - Wis.3,'12: (1'13); Member State Med. Soc. of WVls. LARSON, C. FRITHIOF (b'61) $\uparrow-I 11.1,88$ (l'00)

Metcalf, Arthur A. (b'53)-Ia.1,'82; (1'00).

CURRAN, 20, ALCONA

WEED, JOHN WEBSTER (b'62) - Mlch.8, $95 ;\left(I^{\prime} 00\right)$.

CUSTER, 277, MASON

Duguld, Lee H.—Kan.3,'98; (1'00).

DAGGETT, 228, MENOMINEE

LANDSBOROUGH, DAVID R. (b' 72 )-Ont.3 '01; (1'01).

DANSVILLE, 349, INGHAM

Lemon, James F. (b'54)-Mllch.1,'82; (l'00). Randall, Chas. L.

(See Altamont Sprlngs, Fla.)

See, Joel James-Mich.11, 06 ; (1'06).

DAVISBURG, 300, OAKLAND

Carr, Wm. Henry (b'i6) H-Ill.10,02, Ill.11, 04; (1'06).
DAVISON, 673. GENESEE

LOCY, LOHFNZO JOHN-MICh.1,'81; (1'00). WUMER, JAMLS F. $(1,58)+k$ - KY, 1, : (l'00): AL.

DEARBORN, 911, WAYNE

IBell, Wm. C. (b'86)-Miclli.II, 11 ; (1'11).

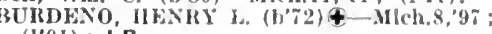

(l'0I); LR.

(See Detrolt.

Foley, Chas. (b'60)-MIch.7,'9I; (1'00).

DECATUR, 1,286, VAN BUREN

BOl'l', WM. I'. (b'71)-0.3,'97; (l'00).

Faston, J. Mandlville (b’59) H - Mo.5, 95 . (1,00) : Pd.

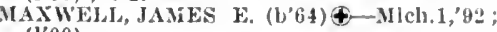
(1)00).

\section{DECKERVILLE, 628, SANILAC}

Butler, Marry J. (b'75) - MIch.7,'10; (1'10). GIFFIN, WESLEY ASBUIYY (b'67) - MIll. 91; $\left(l^{\prime} 00\right)$.

Manes, Thos. A.-Ont.3,'94; $\left(\mathrm{l}^{\prime} 00\right)$.

McLean, Juncan C. (b'70)-Ont.3,98; (l'00).

Vincent, Geo. C.-H-Mich.3,75; (1'00).

DEERFIELD, 443, LENAWEE

Bllss, Webster (b'42) E-Ill.8,'78: (l'00).

Claflin, Guy M. (b'74)-Nich. 7,$04 ;\left(1^{\prime} 04\right)$.

Yale, Nathan D. (b'42)-Mllch.1,72; $\left(1^{\prime} 00\right)$.

DELTON, 300, BARRY

Cross. Maurlce J.-MId.4,07; (1'07).

DENTON, I37, WAYNE

Arnold, Bion (b'64)-Mlch.1,'89; (1'00).

DETOUR, 721, CHIPPEWA

DUNIIAM, CLARA OSWALD (b'65)Mich.1,'89; (l'00).

Oswald, Edgar Warren (b'68)-Mlch.1,90; $\left(l^{\prime} 00\right)$.

\section{DETROIT, 465,766, WAYNE}

(See also Grosse Polnt Farms, Highland Park, and Rlver Rouge, )

NUMBER OF PHY'SICIANS, 1,034 .

Aaron, Abraham Illgham (b'90)-N.Y.6,12; (l'13); Kresge Bldg.

AARON, CHARLES D. $\left(b^{\prime} 66\right) \uparrow-N . Y .6,91$;

(1'00) ; 168 Seminole Ave.; offlce, Kresge Bldg.; 9-11 ; Prof. Gast.-Enter., Mich.7. I. $\star$

AARONS, JOS. (b'66)—Eng. 17,'96; (100)

(109 Monterey Ave., Hlghland Park) office, Smith Bldg. ; $9: 30-10: 30,1.2: 30$,

ABBOTT, ARTHUR W. (b'62) $9-$ Mlch.7, Abbott, Perclval J. (b'83)-Mlch.7,11 (1'11) ; Lothrop Ave.

Adams, Dewltt Carter (b'89)-Mlch.1,'12. (l'12) ; 153 WestmInster St.; offlce, Harper Hospital.

ADAMS, JAMES R.(-Mlch.7;96; (1'00); 649 Clinton St.

Agnelly, Edw. J. (b'7̃)-Mich.7,03; (l'03) 552 Dlx Ave.; offlce, Smlth Bldg.; 1-3, 6-8, Alexander, John Harold (b'84)-Mich.5,'11; (1'11) ; 1375 Mt. Elllott Ave.; 9-11, 7-9. ALLEN, NORMAN MCLEOD (b'83) $₫$ Mich.7,10; (1'10); 20 Pltcher
355 ivoodward Ave. $2-4 ;$ S.

ALLISON, FRANK B. (b'79)-MIlch.7, 05 . (1'05) ; 69 Canfield Ave., W. ; offlce, Smith Bldg. ; 11-12, 1-4; $\mathrm{Pr}$.

AMBERG, EMIL, (b'68) $\oplus-$ Ger.10'94: $\left(l^{\prime} 00\right) ; 756$ Cass Are. : office, 270 woodward Are. ; 10-11, 2-4; Asst. Clin. Prot. of Rhln. Laryn. and Otol., Mlch.7; (B1,5, 11, E5) ; ALR. *

AMES, JAMES W. (col.)-D.C. 3,$94 ;\left(1^{\prime} 00\right)$; 331 Frederlck Ave.; office, 155 Gratlot Ave. ; 2-4, 6-8

ANDERSON, BRUCE-M1ch.11,00; (1'01) ; $178 \mathrm{~W}$. Forest Are. ; $1: 30-3,7-8$

ANDERSON, CHAS, G. (b'69)థ-Mlch. $10: 30,2-4: 30,7-8$

ANDERSON '00; (l'00); 408 Pennsylvanla Ave.; offce, 925 Kercheval Ave, ; 2-3, 7-8; Ob.

Anderson, Wm. Edgar (b'56) - Mich.6,85; $\left(l^{\prime} 00\right) ; 474$ Wabash Are.; 2-4, 6-8. ANDRIES, JOS. H. (b'74)థ-Ger.1,97; $\left(1^{\prime} 00\right) ; 75$ Adelaide St.; $2-3,7-8 ;$ Asst. Clin. Prof. Surg., Mich.7.

ANDRIES, RAYMOND C. $\oplus$-Mlch.7,07 ; $\left(\mathrm{P}^{2} 0 \mathrm{~T}\right)$; 110 Forest Ave., E.; offce, Washington Arcade; $2-3,7-8 ; \mathrm{S}$. 
APPELIK, WM. (b'6x)-Ant 3.01: (1'0J) :9 Commonwealth Are; Wnice, Wash. Ington Arcado: --5

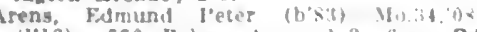

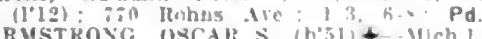

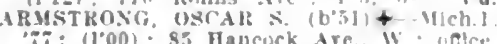
"ir: $(1000) ;$ \$3 Hanceck Are.

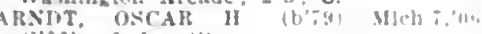
(1'06): 6 Jay st.

Aropstam, Noah E. (b'ig)-Michs.

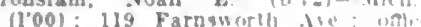
(100): 119 Farnworth . We :

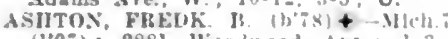
(107); 2891 Wroduard lie: 1-3,

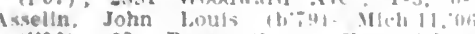

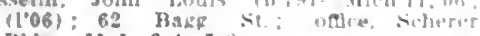
B]ds.: 11-1, 2-4, :

ALSTIX. IIRAM W $(b=0)+M i c h 1,7$ Senlor surs. C..S.I'.H.s. ; 1140 Jeftersn Are.: oflce, U. S. Marine Ilospilal

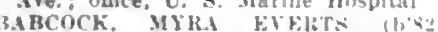
Mlch.11,10: (1'20): 163 Merrlck Ire.

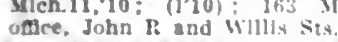

BABCOCK, WARREX 1. (b:72) Md.3.43 $\left(l^{\circ} 05\right) ; 81$ F. Wills ire.; oftce, firace Hospltal Assoc. Clln. I'rof. of Xeur. and Psych. Mlch 7: (F:5) : NP.

Babington, John-IH.4,81; $(100): 96$ owen

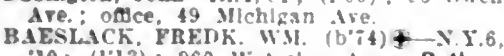
10: (1.13) : 960 Wuterlom ires: Path.

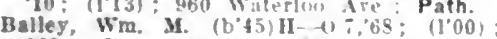
363 Cass Are. ottet. Brelinesur Bldg. : $9-4$; $G$.

Baker, Geo. John (b'73) - Mllch. .,09: (1’09) 307 Park Vlew: met. sit Kercheral Are. ; $2-4,7-8$

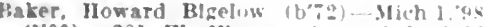
(1'00): 281 W. Warren Irr. ; $1-2$, it:30

Wm. Lindol (b'60)-Mlch.8.n?: (1'00); 1159, 3d Are : oflee, Wext slde Hosplial.

BAKER, WM. R. (bo5)-0Bt.6.9A: 1100) 1411 w. Fort St. : $1-3,-7-9$.

Balderrey, Frank Cornelius (b'8:) 111.11. 13: (1): 1142 k. Jetyerinn dre

BALIIX, MAX (b'69) + (Ger.1,92: (1'01) 91 Rowena St.: oflce, 355 Wndward Are. -4; Clln. Prof, Surg., Mlch.7: (E.5): S. Banks. Sarah Fertrude-Mich. 1;:3: (l'00)

BARIBAITT. LOLIS CLIFFORO (b't 4 ) Que 3;01; $\left(11^{\prime} 09\right) ; 548$ Congress si.; 1.3 U.

BAIRLOW, IERCX A. (b'70)-Mlch s: (1'00) : 1391 Mack Are, : 6-9, I-3, bi-s.

Barnes. Herbert Chas. (b'7\%)-Mlchs, 06 (106) : $231,2 \mathrm{~d}$ Are. $8-10,1=3, \cdots$

ORRFTT, WlMAN DOIFLAS (b'st) Ont.1.'12: (1'13); 700 Wo

BARLCH, JACOB BE.YJ., JR. (b'62)-

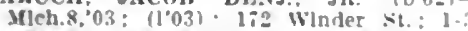
BASKERVILLE, ROBT. J. $\left(b^{\prime}, 0\right)+$ Mich. 02: (1"02): 3442 Jefterson Are 9.10 oflce, Washington Arcade: 2-4, $;-8$.

BASSETT GFO CHANIILK (L'T) Mch. $95 ;\left(l^{\prime} 00\right):$ : 6

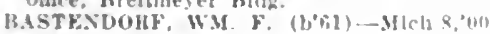

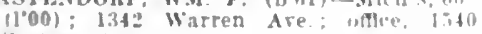
Leotien Are

Readle. Helen A-Mlch. 1,'78; $\left(1{ }^{\prime} 00\right) ;$ llancock Are. W.

BEALL. JOHS A. (b'61)-0.14,'s9: (1'00) $\because$ Taylor Are: once, Scherer IBldg.

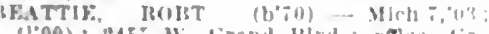

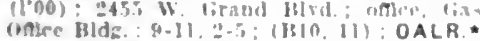
Becelaere, Joa, Van (b'65)- Ira $2,4:$ : $\left(I^{\circ} 00\right): 400$ III A

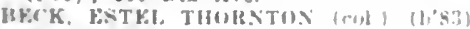

Mleli.j,10: (1'10): 10, firatlot Ave 16. $19.9-6,6-8$

BEGLE, HUWELA, L. (h"\%) +-Mich, 1,05

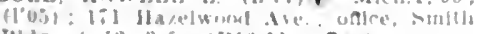
Hils ; y-12, 3.;: (1310.11) Oo** Belsman, Jos. (b'b3)-Mo." Mrunds st. : 8-6, 2-3, i-s.

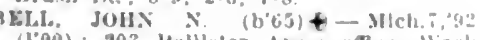

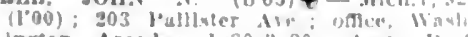
Ington Arcade: 1:30-3:30; Atsh I'r Obse. Mlch.: : $(A 1)$ : ObG.

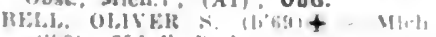

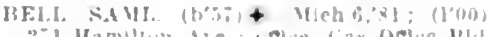

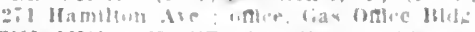

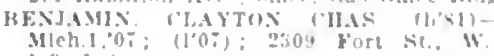

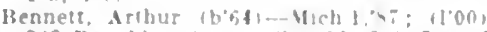

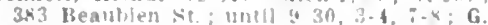

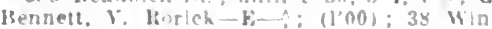
ler sit.

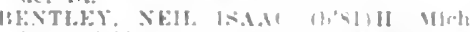

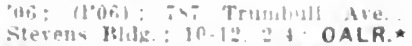

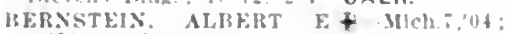
$(1.04): 433$ Intolne :

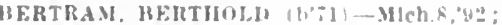
$(1001$ : is Farnsworth sit.

lherington, Harry (i. (1)'-7) 11 -... 1) 26,94

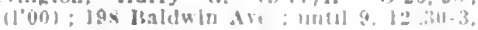
bi-s: once. Scherer 1'!d;

MODLE. ANDREW JU1RTEI (b'62) +

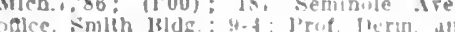
sygh. Mlcla. : : (C) : D.

Blel. Mary Kowalska- : (l'01): :94 Mel]bury Are.

HIXNIXG, DANI. F. $\left(b^{\prime}, 4\right) \mp-1114,0 !$

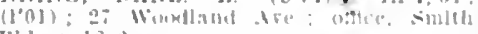
Holg : $12 \cdot 2$

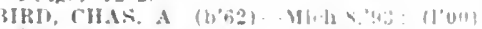

244 W. Forest Arc. : 8-10, 1-3, 7-8

BLAIX, A.EXINOER W. Meh.",06 $\left(1^{\circ} 06\right)$; 131 Elmwond Are.: offlce, j10 Jetrersin ATe., F.: :-4: $\mathrm{S}$.

BLAKF. JOHX (b'82)-MIch. i,"07; (1"07) 324 Hillger Are.; $8.9,2+3: 30,5: 30-7: 30$

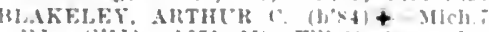
"11; (1'11); 1051 Mt. Fillsolt Are.: I 3

MINACHARD, FRED X. (b\%8) - Mich. 03. (1.03) : 361 Campell ire $1-3-7$ Asst. Prof. Hist. Inat and Embry. sich i.

Bleakley, Chas. Edwin-Mlchs, $\$ 9 ; \quad(100)$ 675 Trumbull Are.

BI,INFETT WM ERNEST (b'it)t Mass. 1, 00; (100); 40 Troquols Are.

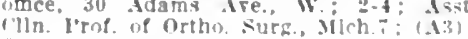
or

Bobertz. Gusta H. (b'67)-Mche:93

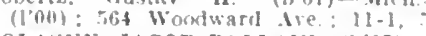
[BOLASYY, JACOR ROLIAINI (b's:) o.19 11: (1'13); 1105 Jefterson dre. ; $9-10,1-3$ $6: 30,7: 30$.

HOI.TFN, JOS. (b'89)-I'a.11,11: (1) : Mem her Mell Soc. of X.J.; C.S. Marlne Hu. pltal.

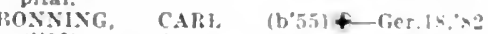
(1no): not in practlce: 3053 iv. virand H!rd.

WOOK, JAMES BLRGESS (b'4)+-1'a 63: (1'00): 181.5 Jefrerson Are: oftce. lamua Ibla : I'amina
Mich.

MOLTKR, JAMES II. (1) (1.03); 169 seward Are.; oflce. Wash ington Aresule; $2-4: \mathrm{s}$.

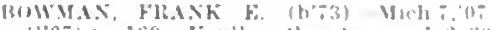
1107): lns kentlworh Ire.: 1.2311

MUAJIA, (idRARBI, K. (b96) Mich

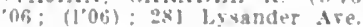

IBAIV, MATTHEW JOSHII (b'56i) + I.10:83; 11'00): Hotel Jlaza: Wavlingtun Arcale: 6 - $0.1-3$.

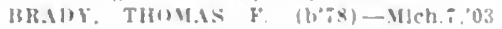

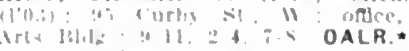

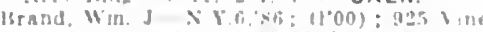

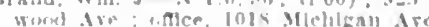

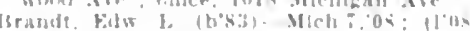

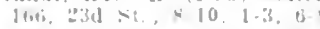

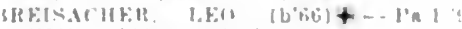

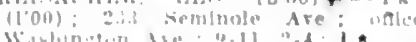

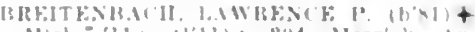
Mlet, 911 : 11'11: 294 Merrlck

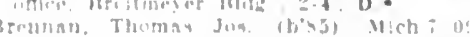

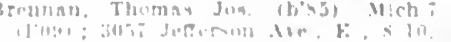

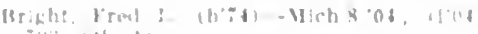

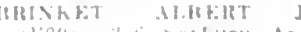

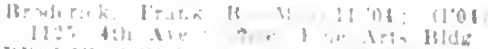

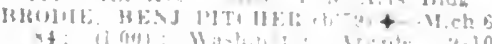
in: 4

Brumley, Allupes $1 . '$

o5: (103): 1: ह1.

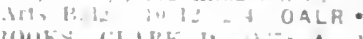

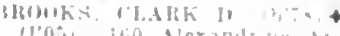

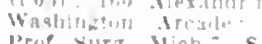

Prof vurz Wich : $\mathrm{s}$ -

BROW: (IE) VAS AMBEH

M!ch. $91:$ (1.00); 55 lilarsol

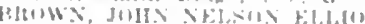

Juhn It st : surt

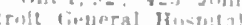

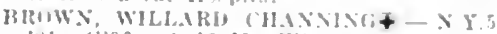
KI: (1'30); 1026 Mr. Elllolt ar

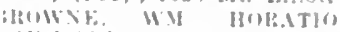

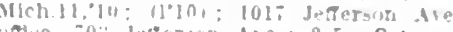

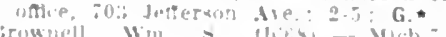

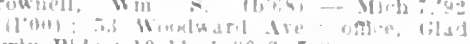

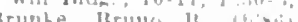

lern, st Man H shlal

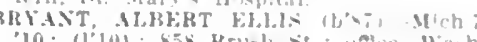

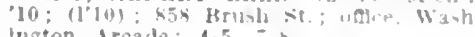

Ington Arcade: 4-5, :-6

IBRYANT, BHSJ I. (b's) + ont

(1.99): 1,002 W. Fort st. : 1.3. ri:30, -30

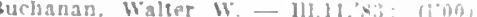
205 Irush st

Buck, John D. (b':)-Mich :Il) (I'I1)

RIESER, FHIR. (; (b's)-Mich. :05

(1.03); 2941 W. Grand Blrd.: olice, wash

Ington Arcade; $1-3$.

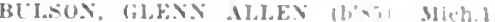
'08: (l'OS): shlrley Bld?: OALR.

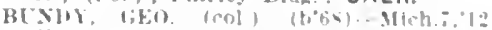

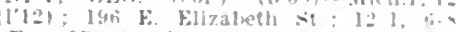

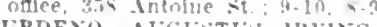

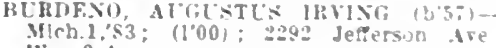
W. : $2-4$.

HIRGE, CLAYTOX W-Mich.:, $00^{\circ} ;(1)^{\circ} 03$ itl. Sh Are atlce, smlth Bldg; $9-11$

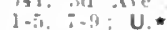

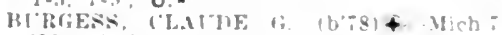
$03 ;(103): 40$ bilsun Ive; oftce, land Jos. Campar Ate ; 1- 7 -

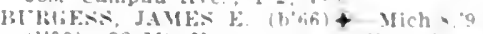
(1.00): 33 Me Vermon tre

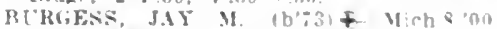
(1'00); 125 F. Bethute lie: $1: 30-3$ :

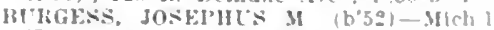

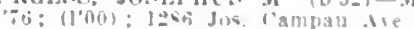

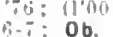

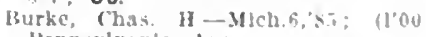

l'ennivlvanla Are

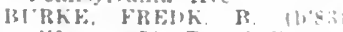

(1003): $: 3$ Trumbull tre attice

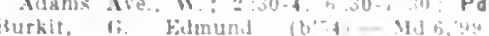

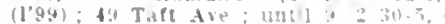

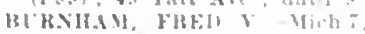
1530 Mack lie

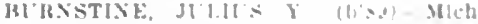

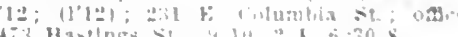
B? IRK, (')].11, Fil, [B Fil.I. (see fllnt)

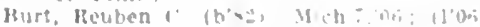

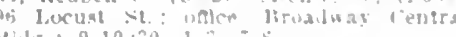
Hing: : $9-10: 30$.

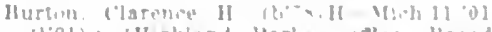

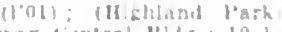

(1)il J

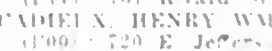

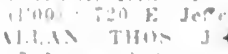

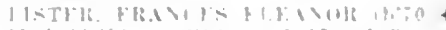
M1! 11

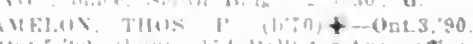

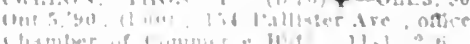

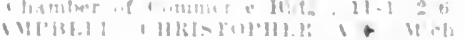




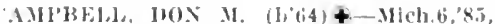
riot.1:3,8ti (l'00): lirusse lolute Fums): oftice, smlth HId : 9-1,3:30-5 l'rof. binth., Hhll., lamply. and otol.

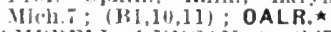

AMIBFil, IIIXAX A. $(1,76)+-M i c h .7$ 'gs: (l'9s); (Crosse l'ointe Farms); oftlce, simith IBHe.: $!-1,3-5 ;$ Asst. l'rof of Hhin., laryn. and otol., Mell. ; ; (BII)

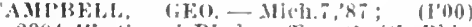

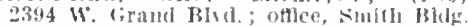
[11- 12, $2-4$.

('ampheil, Peter M. (h०(i) - Hch., ,9l (1'00); 287 llogarth st.; ottece, lias conte 13lig. : I0-1:2, 3-5.

ANFJELl, (II) U. - $0.23,94 ; \quad(100)$ 11ti Englewor] Ave, oftice, 270 Wool ward Ave.; :2:30.

farey, lecwls Marslrall $\left(b^{\prime}, 4\right)-M i c h, 8,06$; (100): 1:64 F. (irand Rlve

tarmichael, Edw K. (b'y0)-Mich.t, 12 ; (1'1:2); Ilarger llospilat.

ABON, GEO, (i.-II Mich.5,'86: (1'00) 52 Daremport st. $1-3,6: 30-7: 30:$ Pd.

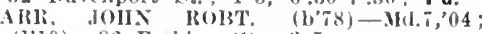
(1'10); 36 Erskine Si. ; $2-5$.

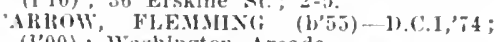
(l'00); Washington Areade

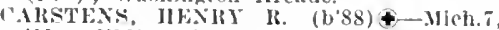
11; (l'li); $6: 0$ Woodwarl Ave.; ollece, 563 Trumbull Ale; $2-4,6: 30-7: 30$.

ARSTENS, J. HEXIRY $(b, 48)+$ Mich.2 70: (1'00); 620 Wontward Ave. $8-y$, $1-3$; Prof. Alet. and I'elvic Surm., Bích. 7 ÁEY, JAM

l'orter st.

'ASEIOT, WM. J. (b's0) \&-Mich.7,08; (I'08); 100 Webb Are, oftce Washingtou Arcade; $2-4,7-8 ; S$.

CANTER, ELISHA WIIBLR (b'79)-Mich.7, 11; (1'I1); 26 IBeresford Ave.; oltice, 3004 lWoodward Are.

Catherwood, Athert E. (b's8)--Mich.7,'I2; (l'l2); Ilarper IIospital. Caughes, Manley D. (b'76)-Mich, , 05 ;

Chalwick, Florence (b'-9) - Mich.1,'l2 (l'12); 39 Ilarmon Ave

CHAMBERS, (MIAS. LEWTS $\left(b^{\prime} 69\right) \oplus$ Micli.1,0s; (I'11); 140 W. Canfield Are. oftec, 32 Adlams Ave, w.; 9-12, 2-4; (BI0.11); OALR. *

CllANEY, WII.AKD (b'i4)-Mich.2\% (1'00); $121 \mathrm{~W}$. Hikh St.; $1-3,6-8 ;$ OALR. hamer, lulu M. Hudson-Mich.1,'92; (1'00); 1373,16 th St.; 8-10, 1-3.

CHAPOTON, EDNUND A. (b'52) Mich.2.73; (l'9y); 370 Woodward Are. oftee, 372 Woodward Ave.; 8-9, 1-2:30;

CHENE, GEORGE C. (b's2) 4-Mieh. 6 :05; (l'05); 938 Brush St.; office, Gas offlee Bloly. ; $y-12,2-5 ;$ Asst. Clin. I'rof. of Roent., Mich.7; (G:1); R.

chllds, Lewis B.-Ky.i,'7t; (I'00); 1557 seotten Are.

CHITTICK, WX. R. (b'58)£-X.Y.8, 82 ; (l'00); 22 Edmund I'I.; offlee, 270 Woodward Are. ; $9-10,2-3 ; 1$ *

CLARK, DAVID R. (b'i4)థ-Nich.I,95: I'00): (1)arborn) offlce, 347 IV Grand Blvd. : $2: 30-4$; (E5); NP.

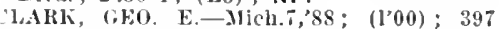
Hurburt Ave, : $8-9,1-3,6-8$

('lark. James E.' (b'79)-ifich.7,'12; (1'12); 149 Calumet $\mathrm{St}$; $9-11,2-4, \tau-9$.

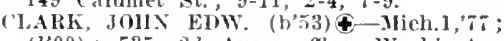
(1'00); $735,2 d$ die.; office, Wushington Arcade; 12-1, 4-6; Prof. of Med. Juris., Mich.i.

('LARK, RAYMOND LEE (b'S0)-Mich. 7 06; (1'06); \$34, 4th Are.; 1-3, $7-8$; NP. clark, Richard Allan-(que.1,70; (100); 88., IIulsom Are.: 8-10, 1-3, 7-8

('LARKE, (IRA("E if. (b' 6 ) \& Mich.1, 02 ; $\left(l^{\prime} 02\right)$; 2032 F. Grand St.; offlee, Gladwin Bldg.

(clausen. Emma (b67)-Mich.11,07; (1007) : $5-5$ f. Fort $s t ; 1-3,-8$

LEIAXN, JAMES, JR. (b'62)†-Mich.2, 84; (1.00); 104:. 2d Are.; ottlce, Waslington Areide: $2-4,6 ;: 0-7: 30 ; 1 . \star$

clevelnnd. Baldum I. (b, 45$)-0.7,70$ :

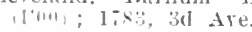

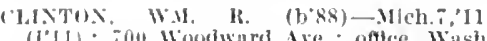
I'll); ;01 Wootward Ave. ; oftce, Wash jugton Arcude : 2-4; S.

('IIII'ERT, Fitill J. (b'66) $4-111.6,90$; (lon); it loenphorn Ave.; 8-9, 1-2, 7-8.

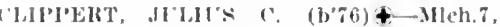
"11: (I'01): 2253 Jelferson Ave., W.:

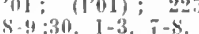

coBLELiI. EZRA J. (b'-2)-Mich.8,96; (l'00) ; $150 \%$ Mt. Ellot Ave; $9-10,1-3$.

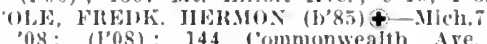
oftce, 270 woolward Ave; $:-4,7-8 ;$ U.

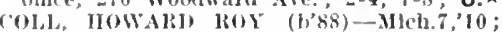
(I'li) : 440 Oakland Are.

coldixi, ALVA N. (b'6i) -Mich.1,85; (l'00); 20 Martin 1 'l. ; $1-3 ; \mathbf{G}$.

conley' Iowry curry inuncle (b'88)-0.2, 13 ; Intern, Grace Hospitai.

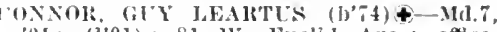
(1) (1.01); 81 W. Euclil Ave.: offlce, Washington Arcade; 1:30-3:30; Asst. 'in. I'rof. of Veur. and Psych., Meh. 7 ;

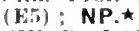

('ONNOK, IRAY (b'76)\&-M(1.7,01; (1'01); 8f lineld Ave., W; offle, Washington Areade; 10 -10. "2-4; Assoc. (:lin. Prof. Ophth., Mich.6; (131,10,II); OALR.

cook, Henry 11. (b’5)-Mieh.7,?7; (1'00) ; 120 F. I'blladelubia Ave.; ottice, Gladwil lildg.; $10-11,2-5,7-7: 30$

coley, Geo. 1'- II-Ill.10,90; (1'00); 75 Euclid tre, w.; offle, Fine Arts istdg. roOLES, TIIOS. B. (b'71)4-Mleh.1,95; (l’00): 90 W. Forest Are, oftuce, Fine Arts Mldg. ; Pd.ћ

coolidge, Maria Belfe (b'i6) $-0.13,0$; (Po9); 37 Forest Apts. ; 8-9, 1-3, 7-8; G. Coone, Francls I1. (b'81)-0nt. 1,05 , Mlch. 7 , '13; (I'13); 27 Chimmount Ave; offlee, 29 ' ('alirmount Ace.

cooper, James Momroe (b'it)-Mieh.1,03; (P03): 230 Lawrence Are.; offlce, Fine Arts BHIg.; 11-4; OALR. *

COIE, CHAS. S. $\left(b^{\prime} 50\right)-0.8,75 ;(1,00)$; 159 Merrick Ave. ; $7-9,2-4,7-4$.

Cossitt, Willete S. (b'58)-Wis.2,96; (1'02) ; 3 Gilatstone Ave.

Couch, Walter J.-E-0.2,91; (I'00); 39 lincoln Are, ; $7-9,1: 30-3,6: 30-8$.

Courtney, Wm. W. (b'65)-Mich.7,91; $\left(l^{\prime} 00\right): 617$, 3d Are.; office, 65 Washington Aive. ; $8-10,2-4,7-8$

Courville, Chas. Wm. (b'81)-Mich. 1,06 ; (l'06); 1405, 12th St.; office, Bowles Bldgr: 9-10, 3-4, $7-8$.

Covey, Afred Dale (b'69)-IIl.4,90; (1'00); 625. $3 \mathrm{~d}$ Are.

cowAx, ANGTS T. (b'65)-Mich.i,91; (1'00); 549,14 th Ave.; $1-3,6-7: 30$.

ClAGG, CHAS. J.-Mich.t, 00 ; $(1,00) ; 65$ Forest Ave.

raif, Sami. IIalleck (b'i)-Pa.2,'10; (1'13) ; 931 Trumbull Ave.

CREE, WALTER JOHNSTON (b'61) Mich.6,'83; (1'00); 710 Grand River Ave.; $8-9,1-2: 30,6-7: 30 ; 0$ b.

CRITTENDEN, CLIFFORD I.-Mich.8,'05: (1'05); 24 (ameron Ave.; offlce, 1508 Russeli st.; $8-10, \mathbf{1}-3,7-8$.

Croft, Effle McCall-II-0.23,96; $\left(\mathrm{I}^{\prime} 00\right)$; 166 Hendrie Are, ; 2-5; G.

CROW, SAMI. C. $\$$-Mich.1,98; (1'13);

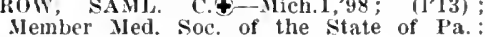
(Highland Park); offlee, 2969 Woodward Ave.; 9-11, $1: 30-3: 30,7-8$; Pd.

Crumrine Chas. (s.-H-IH.10,'89; (1'00); 100 Delaware Ave: offlee, Majestic Bldg. CLLLEN, ERNEST KEYS $\left(b^{\prime} 78\right) \oplus$ Ont.1, 03: (l'I1); Addison Apts.; offee, Washington Arcade; $2-4 ;$ S. $\star$

CEXNINGHAM, JANES W.4-MICh.7,01 (l'01); 17 Elmwood Ave.; 8-8:30, 2-4, $6: 30-7: 45$

Curran, Wm. Stuart (b'-4)-Ont.3,99 (l'00); 746 Cass Are.; 9-11, 1-3, 7-8.

CCRRIE, ERIEST M.4-Mich.8, 02 ; (1'02) ; $164 \%$ i. Fort St

C'R'T1S, J. DEMOREST (b'84)-I11.11,07; (l'0i); 5is Oakland Ave.; 2-4, 6-8.

Dalin, Geo. I.-Mlich.8, $91 ; \quad\left(l^{\prime} 00\right) ; 230$ Lawion Are.

D'ARCY, BEXI. (b'40)\&-Mich.2,\%0; (1'00); (Hayville); office, 57 Fort St., W. $9-12,1-4 ; \mathbf{N}$.
HARDAS, JAMES ALOYSII'S (b'83)-IU1.6. $09 ;(1+12) ; 2461 \mathrm{~W}$. Jetrerson Ale, ; $8-10$. $1-3,6-8$

DAVIS, CHAS. ROY (b'82)+-X.1.20,08 (I'J0); 69 II Iazlewood St, ottice, 3011 valmer st. ; 1-3.

DAVIS, JAMES ETIIEIABET (b',0) 4 lias ollue? 18ldg.; 2-4; Asst. 1'rof. Surg., Mlleh. 7 ; $S$.

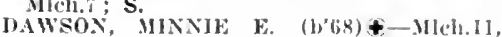

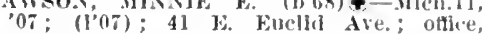
Stevens Bhit

DE BLOIS, JIIOHA FARQTHARSON (b'82) -Mleh.5,07; (l'07); 552 IIelen Ave.; beCou, Iacrob-1I- $0 ; \quad\left(1^{\circ} 00\right) ; 289$ Cadillac Are.; I-3.

I)EES, ('LIFFORD JOHN (b'̄i) —-Wich.2, 84; (1'00); 26 Bralnari st. ; 1:-2: T. vefnet, Wm. A. (b'85)-Mleh.7,'11; (1'11); 32 Aclams sie. $W$

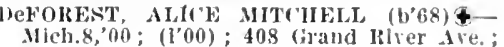
$10-12,2-4$

De ILoratius, Jos. (b'79)-Ita.I0,05, Mleh.ĩ, '09: (1'09); 461 Gratlot Are.; 10-12, $7-8$.

DELJSRIDGE, IAY J. (h'69)-Mich.7,'93: (l'00); 57 ' Yhiladelphla Ave.; office, 894 Woodward Ave. ; $1-3,6-7$.

DEMPSTER, IAMES IIERIBERT (1), Mich. I, $09 ;$ (l'09); 142 Missouri Ave.

DESROSIERS, IOS. TALUIUM (b*s7)lld.4,11; (l'12); 25 IIendrie Are.; $9-10$,

DEWAR, THOS. A. (b'i1) - Que.1, '93 (l'00); 223 Field Aie.; 1-3, 7-8.

DBRLE. HARRY F. (b'88) †-Mich.7.'11 ; (l'11); 102 Winder st.; office, 355 Woodward Ave: $10-12,2-4,7-8$

MIT, KENNETH W. (b'86)-Mlch., $0-$ (1'07); 410 Baker si.; 9-10, 2-4, i-8.

rickinson, Leslle Benton (b'82)-Mich.1. '03; (l'04) ; 54 columbla st. W.

Uiebel. Wm. H.-II-0.26,01; (l'01); 407 Burns Ave; offlce, 515 llack Are, $2-3$; Ob.

Dietrich, Paul Ilenry (b'88)-Pa.I,'13; Intern, rhildren's Free Hospltal.

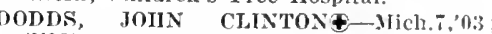
(1'03): 221 Pallister Are.; offle, Fine Arts Bldg.; 9-10, 2-4, 7-8.

DODENIIOFF, PETEK $C$, (b'7s)-Mich.s, 01; (1’01); 172 Rivard St.; offee, 174 Rivard St. ; $2-4,7-9$.

Dohany, Jolm s. (b'68)-Mich.,${ }^{\prime} 94 ;\left(l^{\prime} 00\right)$; 78 Stanton Are.; offlee, 14 th and Giand: River Aves. ; 2-4, 7-8; 0 b.

DOHERTY, VICTOR CHAS. $\left(b^{\prime}, 6\right) \oplus-$ Hich.1, $(100) ; 223$ Afedbury Blid. ; offce, Woodward and Warren Aves. $10-12,2-4, \quad 7-8 ; G$

Meh. 1,10 ; (1'11); Alberta Apts. ; offlee, 130 Henry' st.; 8-9, 1-3, i-8.

WONALD, WM. II. $\left(b^{\prime} 60\right) \notin-M i c h . ; 8 \%$; (1'00) ; Pasadena Apts.; offlee, 979 Jeffer. son Ave. ; 8-9, 1-3, 7-8; Prof. of Med., Mich.7; 1 .

DOUGLAS, CHAS. (b'43)థ-0nt.1,64; (l'00); 959 Jefferson Ave.; 8-9, $1-3,7-8$;

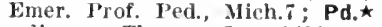

Dowling, Thos. J. (b'80)-Yrich.; '04 (l'04); Henry Clay Apts.; office, 197

Gratiot Ave. ; $9-11,2-4,7-8$.

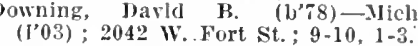

Dowswell, Clayton C. (b'68)-Mich.,${ }^{\prime} 02$; (l'02) ; $114 \mathrm{I}$ llack Are.; 8-9, I-2, ;-8.

DRAKE HARLOW B. $\left(b^{\prime} 48\right) \Phi-P_{1}, 9,73$; (l'0I) ; Pasadena Apts.; office, 32 Adams. Ave.. W.; 2 -4; Pd.

OREYER, ADOLPH E. (b'73)-MIn'h.7, 03 (1'03) ; 1609 Michigan Ave.; until $9,1-3$, $6-7$

DUBPERNELL, KARL (b'72)థ-Ind.5,'96; $\left(1^{\prime} 00\right)$; 35, 2sth St. ; 8-10, 2-4, $;-9$.

DCBPERNELI, MARTIN SAML, (b'85)Ky.2,09; (1'10); 1869 Michigan Are.; LEFITI (l'01); 248 Seminole Ave.; offlce, Washington Arcade; 2-4; Asst. Clin. Prof. Ped., Mich.i. 


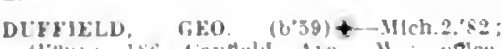

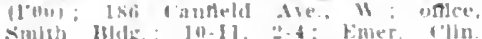

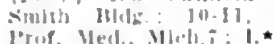

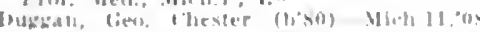

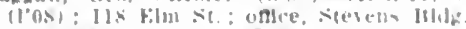

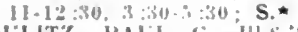

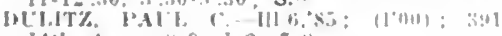
Itth Ave.: $3-9,1-0,5$

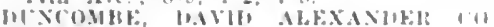

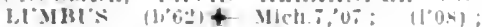
964 Mack Are, : $2-4,7.8$.

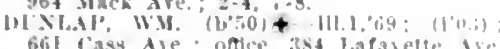

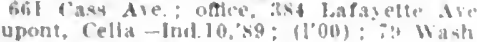
rupont, Cella - ind 10:'s9:

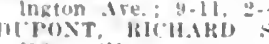

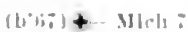

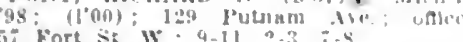

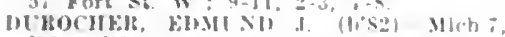

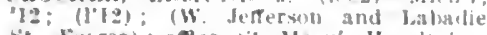
St. Forse) oflce, sl. Mary's lluspltal. DLTTOX, CHAS A $(600)+$ M Mch.?

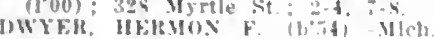
(100): 502 Putnam ate : moll lo.

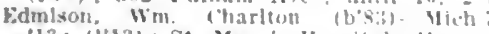
-13 f1't31: St. Mars's llowpltal: U.

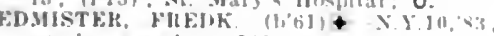
not In jractlee; 5021 lindward Ave: $8-1$.

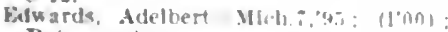
Putnam Ale

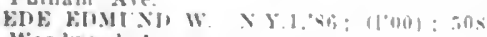
limodwarl Ase.

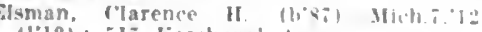
11"121: 515 Kercheval Ire.

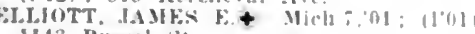
II43 Rusvel st.

325 Kercheral A

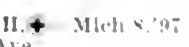

(1.011)

Ells. Ilarry ling

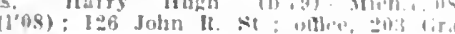
8lot Ave.; $10-11$. 1:30-5, ;-s

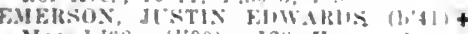
Mass l, $608:(1900)$ : 125 Henty se. $2-3: 30,7-8 ;\left(F_{5}, 13\right)$.

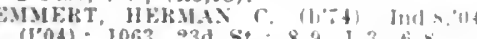
(l'04): 1063, $23 d$ St.; 8-9. $I-3,4-4$ $(100)$ : 12 Arery lia $x-4,1-3,8$

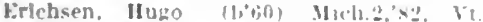

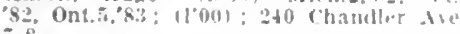

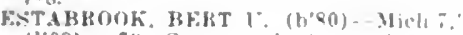
(1'03): is fireenword Ave.; 9-10, $2-4$ $7 \cdot 8$.

Estalirunk. John Iausence (bitis) Mirll 0.7: (1.05): -0.5 Parker Are.

Fotinger clayton James (b's 08: (1"ns) : 53 fratlind die.

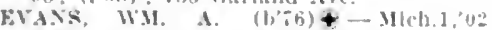

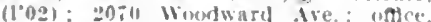
Adam Are. W.; 1I-12, 2-4: R.*

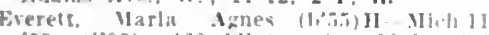
' $n$ : 1106$)$ : the rllntors st.; 10.12. $\because \cdot 8$

Farmum, Frank llayward (bob) Ill I.':

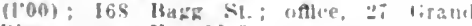
Hier Are, k.: 12-3

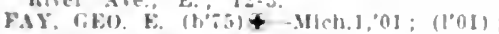

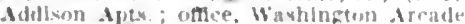
II-1, 3-5.

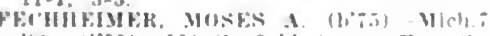

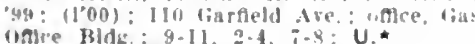

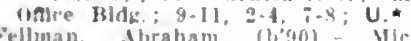

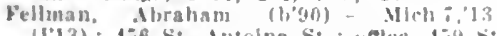

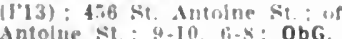

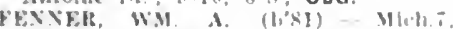

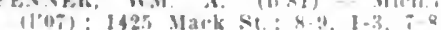

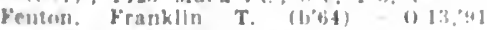
(1'00): Gref tokkland Are.

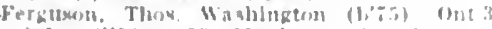

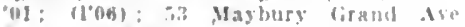
8. $10,1-3,18.8$

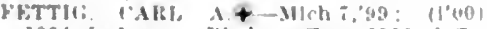

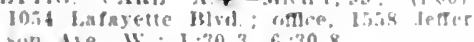

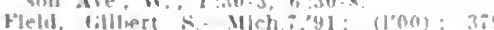

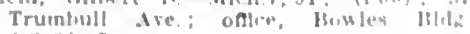
$-3: 3: 30 ;-x$

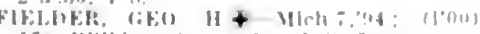
lin Wiklny st. : $x \cdot 10,2-4$;

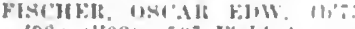

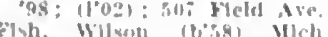

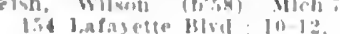

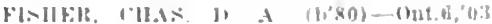
(lon): Orlential lloitel: ontec, Broarlua Market Blug: : 11.12, vluke Notar il kabaiglan (1'uin) : ofy oakiand die.

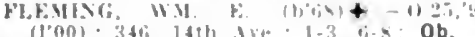

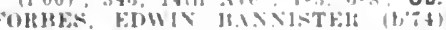

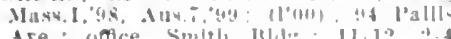

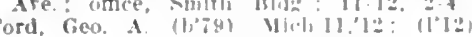

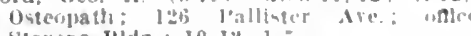
stevens Hidg : 10.1\%, 1 .

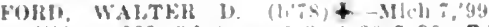
(1'0(1) : 1022, 34 Ave; $1.3,40: 30-7: 30 ; \mathbf{P d}$.

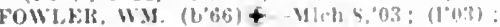
Member Ozla, Sitate Vect. Avmb.: 300 "Whltney Ave: offle, Jroadway Market HIdR. : OALR.

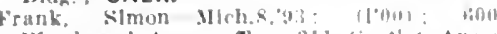

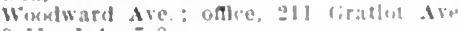
8-11, 1.4, 7.8

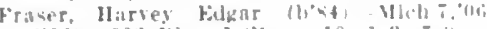

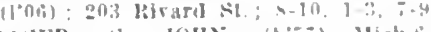

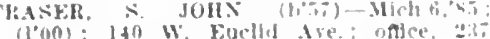
(1200): 1t0 W. Euclld Are.

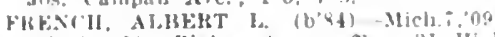
(I'09): 24's Blalne Ive; ondce, 3I Ilth] St. W.: $1.2,-3.8$.

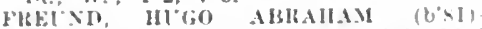

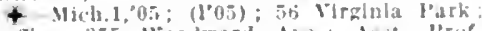
ollece, 355 lloodward Aw. Asst. l'pof Med., Mich. : $(125,12)$; 1 .

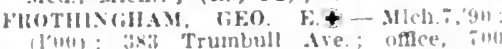

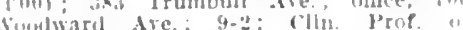
Wohth. MEh.; OALR.*

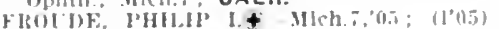

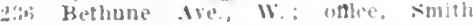
Pally: : $12-3: 30,-1-8$

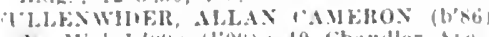

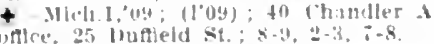

fuller, Mexamirlne Fiperolf - Mich.I, 's (l'00): Gil lincola dre

..1LEL, JOHA KNOX $\left(b^{\prime} 54\right)+\ldots 1.5,5$

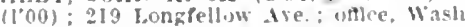
inger on Areade: $9-10.2-4$ : $S$

GARBER, TAMES X-MICh.;

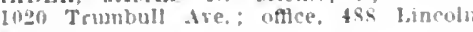
ire.

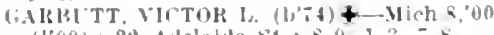

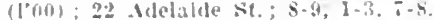

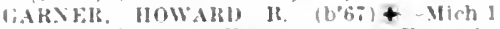

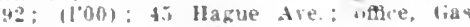
Hid; ; 10-1 i. :-4; $\mathrm{S}$.

(iastum. Robt. Bernard (b'si)-- Tenn.5,12 Intern, Cirace Ilospital.

George, Arcillald Whltelngton - Md t, 11

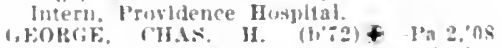
(1'11): 2209 lisatlot Ale, : $8-8,2.5,7 \cdot 8$ G.

entge, I thas. IItgh st. Wi:

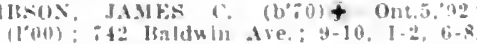

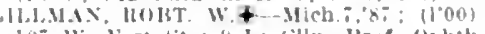

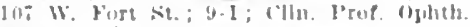
Mlch.i: (BI.H)

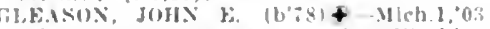

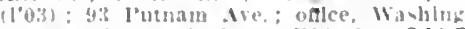
ten Mreade $9-1 \% 2+1:(H) 0.11):$ OALR

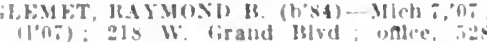
bakes sit.: $1-3$, i.8.

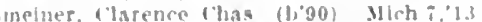
(1'13): l'rorldence llusplial.

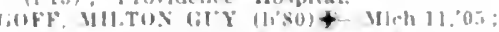

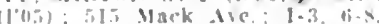

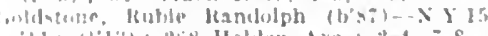

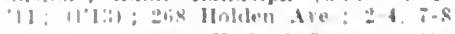

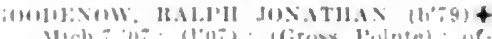

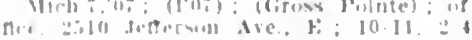

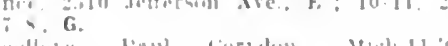

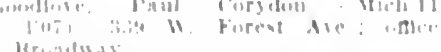
Mriantwas

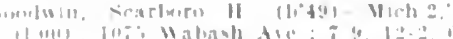

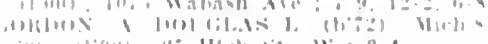

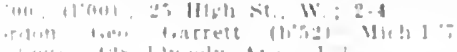

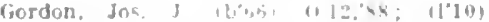

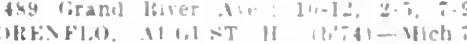

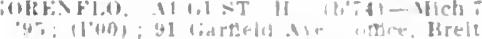

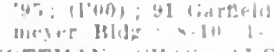

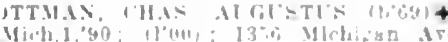
411,1 , 3 -

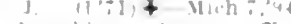

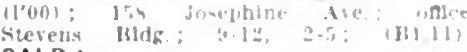
OALR. *

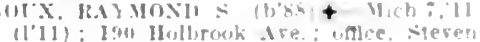
Hdi: ; 4-12, $2-5$ OALR.

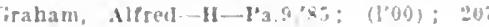
Kentlworth Are.

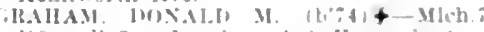

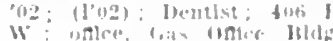

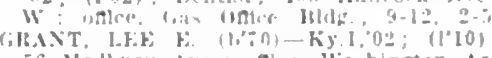

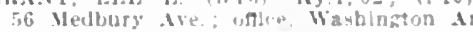

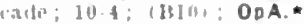

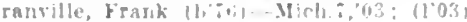
2090 liratue lre.

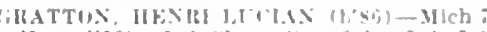

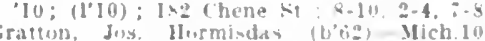
(00): (1'00): 391 seylurn itre.; oflet. 393 Seyburn Are.; s-lo.

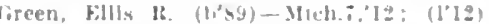

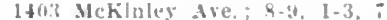

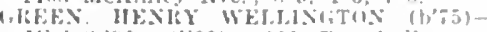

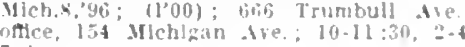

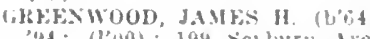

"24: (l'00); 199 sesburn dle : $2-3$ ch.

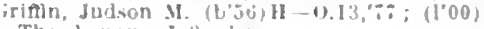

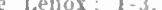

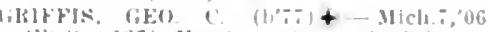

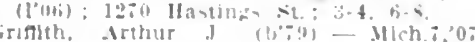

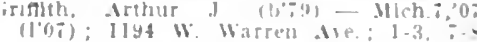
Pd.

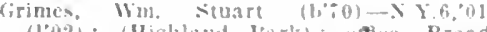

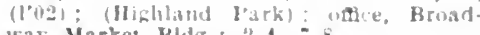

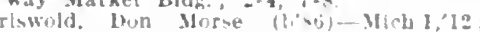
11'12) : Herman klefer IIospltal. (1) We.: :-4. 6-7:30.

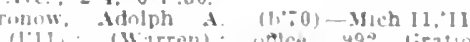
11'11: (Warren); welce. 402 liratsol

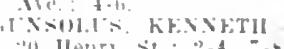

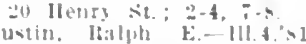

Wineduard Are

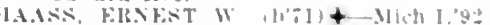

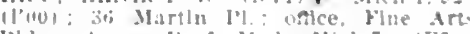

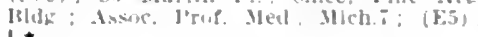
I. *

Hacken, Walter lat (bsll-ome.10 Hee. ditams dire. F:

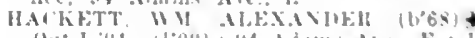

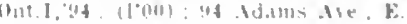

6-5.

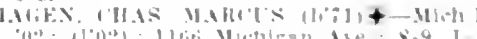

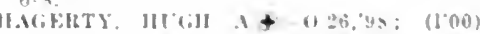

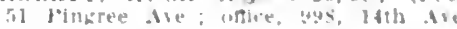
-1: G.

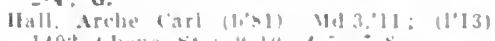

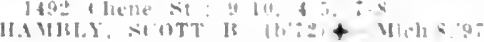

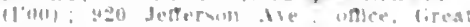

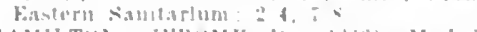

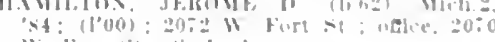
ii. Fint st.: $s, 1$,

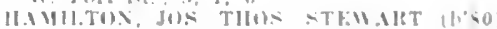

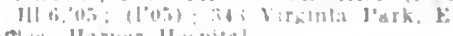
White

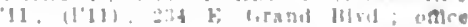
shorles 1 mis

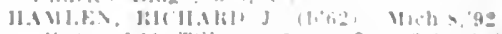

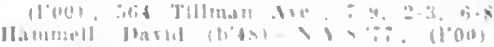
lisi rinumend Are

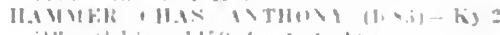

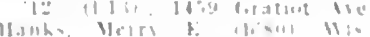

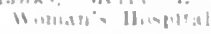




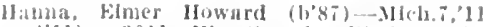

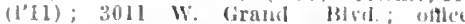
C'adillate Notor Car (o.; S.*

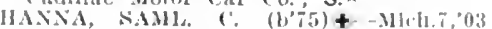
(1'02); 630 liaker St. $2-3,-8$

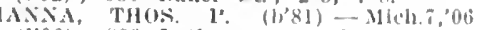
(1'06): 893 1athrop Are; $1-3,7-8$. IIASER, JOSHIA (1"74)-Mhll'06 (l'06); 887 Hack Are: 2-3, T-k: S. ANSOE JOs HENTS (b'81)

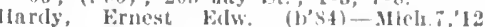
(1'13): 2035 Jetterson Ave.

HARI) (iEo (1, (1.84) (1'07); 3\$8 Artlliery Ave. ; 8-9, $1-3$

Hardy, (:Ienn II. (b'64)-X.Y.6, $03 ;$ (

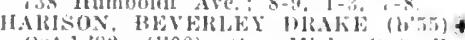
Ont.1, so: (l'00) : sec. Mich. State Honrt uf Reg. in Med.; 47 Stlmson 1'l. : oflice, Washington Arcade; 9-6.

IIAKNESA, JOIIN LINTON (b'ib) -Pa.2, 01; (I'12) : 53 Prentis Ave, oftec, Washington Arcade; $9-12,2-4 ;$ ' LR.

IIarver, Wm. A. (b'7)-Mich.8,99; (1'03) 600 Ferdinand Ave; once, 621 Disc Are. $\mathbf{1}-\mathbf{4}, 7-9 ; \mathbf{S}$,

ILarrls, Mibert Edward (b'85) Mlich.7,'13 (1'13) ; IIarper Iospltal.

Iarris, Geo, G. (b'70)-Milch.8, 06 ; (1'06) 543 Trumbull Are, : 2-4, 7-8.

Harrisou, Benj. Irring (b'91)-Teun.10,'13; Grace Hospltal.

IIRHISON, HENRY (b'73)\$-Mich.7,'06; (l'06) ; 274 Oakland Ave, $1-3,6: 30-8$

11.ARRISON, HCGH†-Nich.8,96; (l'00) 240 Moran St. ; $1-3,6: 30-8 ; \mathrm{S}$.

HARRISON, JOIIN WM.\$-Mich.7, 96

(l'00); 429 k. Grand Blvd.
llarrison, Ninian F. (b'64)-Mich.7,91 $(1,00) ; 592$ Gratlot Are.; 9-10, 2-3:30 i-8.

IIAR, THOS. MALCOLM (b'71)-Ont.3,97 $\left(l^{\prime} 00\right) ; 436$ Trumbull Ave.; offlce, $4: 8$

Trumbull Are.; 1-4, 7-8; S.
Hartman, Wm. Louls (b'64) H-Ill.4, 's (I'13); 3066 F. Grand Blvd.; offce, Smit Bldg. ; $2-4 ; \mathrm{S}$.

IHARTZ, HENRY JASPER (b'61)-Nich. $\%$ 89; (1'00); 1022 Cass Ave; office, 27 Adams Ave, E.; 10-12:30; Assoc.
Prof. Med., Mch.7; (BI,3,11); ALR.

H.ARVEY, JOHN GOOLD (b'75)-Mich.1, 02 ; (l'02); 100 W. Kirby Ave.; offlce, Sterens Bldg. : $9-10,2-4,7-8$.

HARVEY, WM. M. (b'63)థ-Mich.7,'87 ; (l'00); 303 Seminole Are; offce, 270 Woodward Ave; I :30-4; 1. *

IISKIN'S, MARY G.\&-Pa.i, $01 ;\left(l^{\prime} 02\right)$ : 410 Seminole Ave.; offce, 260 Woodward Ave. ; $2-4$; 0 bG.

Hassler, Frank-II-Ill.4,'85; (l'00); 368 Cass Are, ; offlce, Broadway Market BIdg. HASTIE, W.i. G. (b'60)-Mich.7, $88 ;\left(l^{\prime} 00\right)$; 2556 West Blvd,; office, Flne Arts Bldg.

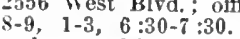

Hausherr, Wm. W. (b'71)-Mich.8,'98; (1'00); 174 Lincoln Ave.; 6-7; offlce, Gladwin Bldg.: 2-4.

H.IVERSTOCK, SAML. F. $\left(b^{\prime} 80\right) \uparrow-M i c h .7$, 09; (1'09); 1870 Scotten Ave.: offlce,

HAWKINS, HARRIET $\mathbf{L}$. (b'61)-Mich. 1,95 ; $\left(1^{\prime} 00\right) ; 768$ Cass Are., untíl $10: 30$.

HAYES, JOS. D, (b'84) 10 :30. Mich.7, 08 ; (l'08) : 944 Mack Are. ; 2-3:30, $7-8$

HAXNES, LOU WEST (b'83) $₫-M i c h .1,08$; (108); 239 Lawrence Are.; office, Washington Arcade: $11-12,3-5$

HAYWARD, EDW. H. (b'72) \&-Mich., , $^{\prime} 04$; Health: $7: 30-4$; Asst. Prof Med. Moard of Hendershott, Lizzle Amanda-H-Mlch.5,'88; $\left(l^{\prime} 00\right) ; 15 i$ Alexandrine Are., W.

MENDERSON, EDW. W. (b'63)-Mich.1,'91; (1'00) ; 846 Vermont Are.; offce, 844 Vermont Are.; 8-10, 2-4, $7-8$.

enderson. Thos. (b'54) - Mlch. i, 86 ; e. : $8-9,1-3,6-8$ IENDERSON, WM. R. (-MICh.7,'86; $\left(\mathrm{I}^{\prime} 00\right)$; 515 S. Aubin Ave. ; 1-3, 6-8; Ob.

IENKEL, JULIUS F, (b'73)-Mich.7,'96: (l'00); not in practice; 193 E. Grand Blvd.

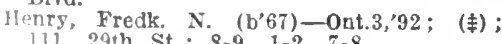

111, 29th St.; 8-9, 1-2, 7-8.

1809 Michigan ive.; 8-10, 1-3, 6-8.

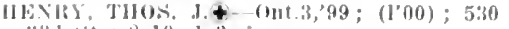

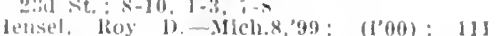
l'ark St.

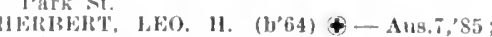
(l'06) : 56 Vanderbilt Are.; oflce, 2225 lelferson Are, W. : 8-9, 2-3, 6-8.

ILERAN, S.MI, J.-Md.9, 00 , Ma.4, 01 (1'03) : 93 King St.

ITERIRMAXN, MAX (b'85) $\oplus$ - Mich.7.10 (I'l0): lns Watson St, offlce, (ias oflled Hilg. : $3-5$

HEWI"Y, IFRBERT W. $\left(b^{\prime}-5\right)$ f-Mlch.7, 03: (1'03) ; 79 Rowena st.; offlce, WashIngton Arriale; 3-5; S $\star$

llewson, Fidmund T. (b'33)-N.Y.6.'66 $\left(1^{\circ} 00\right) ; 218 \mathrm{~W}$. Canfteld Ave; 4-10, $2-3$

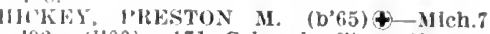
'92:; (l'00); 171 Colorado St.; offlce, 32 Adams Are, W.; 11-12, 2-4; I'rof. Roent., Mlch.7; $(131,11,(1,2.4) ; R$.

111ls, llerbert II. (b'81)-Mlch.1,03; (I'0: ) not in practice: 24 Westminster Ave.

1185 Gratiot Are.: $1-3,6: 30-8$.

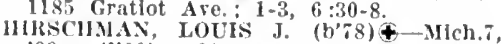
99; (I00); 64 Garfleld Ave.; office. Washington Areade: 2-4; 1'rof.' Proct. Mich. 7 ; (A4); Pr.*

HISLOI', KOBT." (b'55)-Ont.3, 83 ; (l'00) 752 Grand River Ave.

HITCHCOCK, CHAS. WELLMAN (b'58) AMlch. 2,85; (l'00); 55 Stimson Pl.; offlce 270 Woodward Ave, ; $9: 30-11,2-4 ;$ Assoc. Prof. Neur. and Psych., Mich.7; (E5,13) Prof.

HOAfi, R. R. $\Psi-M I c h .8,05 ; \quad\left(l^{\prime} 05\right) ; 213$, 24 th St.

IIodge, Iames B. (b'69) H - Mich.11,06; $\left(I^{\prime} 06\right) ; 256$ w. Hancock Ave.; until 9 , $1-3,7-8$.

OI)GES, RULTTON-Mich.8,'94

(l'00) 794 Grand Blvil., E.

Hodges, J. M. (b'86)-Mleh.7,'10; (l'10) 1345 IIarper Ave ; 8-9, 1-3, $6: 30-7: 30$ 1OFF, EDWIN C. (b'75)-0.26,01: (l'02) 101 Broadway ; untll 9, 3-5,6:30-7:30;S OFFMAN, JOHN W. (b'67) $₫$ Mich.8, 01 (1'01) ; 556 Jefferson Ave, ; 1-3, 6-8.

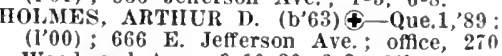
Woodward Ave. : 9-10:30, 2-3; Clln. Prof Ped., Mlch.7; Pd.

Holmes, Thos, (i. $\left(b^{\prime} 47\right)-$ V.Y.10'69; $\left(1^{\prime} 00\right) ; 251$ Hubbard Ave.; (offce, Wixom).

IOOPER. VERNON J. (b'70) †-Mlch. $\$, 98$ $(1 ' 00) ; 1993$ Jefferson Ave.; 1-3, $6: 30-$ $7: 30$

HOOPS, GEO. BARRIE $\left(b^{\prime} 77\right) \oplus$-Ont. 3,01 ; (l'01); 347 Merrick Ave.; 8-9, 1-3, 6:30-8. fopkins, Francls Allen (b' ' 2$)-0.3,98$ (1'07); 61 W. Fort St. ; $2-5$.

HORNE, GEO. E. (b'81)-Mich.8, 06 ; (1'06) 442 Joseph Campau Ave.

HOSKINS, NEAL LUTHER $\left(b^{\prime}, 6\right) \uparrow-$ Mleh. 7,$05 ;$ (l'05) ; 89 Selden Ave.; offlee, Washington Arcade; $2-4,7-8$.

HOUGHTON, E. MARK (b'67)థ-Mlch.1, 94; (1'00); 130 Longfellow St. ; offlce, McDougall and Atwater Sts.

IIouse, F Chandler (b'8I) - 0.26, 01 ; (1'03); 1717 Woodward Are.; 8-9, 1-3, $6: 30-7: 45$

IIOWARD, JOHN J. (b'66) - -Mlch.7,'93 ; (1'00); 705 Morrell Ave.; office, 671 Junction Ave. ; $8-10,1-4,6: 30-8$.

HOYT, BENJ. R.-Mich.1;72; (1'04); 935 Vinewood Ave.

Hubbert, Wm. R. (b'58)-Mlch.2,'85; (1'00); $559,2 \mathrm{~d}$ Ave.

Hubel, John T. (b'75)-Mich.7,99; (l'00) ; 1305 Trumbull Ave.; offlce, $1252 \mathrm{Mt}$. Elllott Ave.; 2-4, 7-8; OALR.

HUE(ILI, ALBERT G. (b'78) ๑-Mich.7,01; (I"01) ; 770 Joseph Campau Ave, ; 1-3, $7-8 ;$ LR.

HUGHES, ALBERTIE A. ( $\left.b^{\prime} 76\right)(-M l c h .7$, $11 ; \quad(1 / 11) ; 1704$

HULL, LEROY WETMORE (b'88) $\oplus-$ Mtich.1,11; (l'11); 863 Porter St.; 7-8; S. HULL, ROBT, CLARENCE (b'87) $\$$ Mich. 7,11 ; (1'11)
$1-3,6: 30-8 ;$ Pd.

Hunter, Wm. Gordon (b'88)-Ga.1,'13; Interu, Grace Hospital.
HURST, MJCF HASELTINE BATMANX (b'68) - $111.9,02$; (1'06); 234 Lothrop Ave. Iusloand, Chas. W. (b'88)-Mlch.7,'12: $\left(l^{\prime} 12\right) ; 320$ Manchester Are. ; 8-9, I:30-4 (i) $7: 30$.

IUSON, FLORENCE\&-Mich.1,85; (1'00) 506. Cass Ave.

IIUTCHANGS, WHLARD IILNTER (b'72) † - llich.1,99; (I'01): 473 Jelferson Ave. olflee, Fine Arts Bildg.; 11-2:30; Asst Clin. Prof. Surg., Mich. 7 : S.ネ

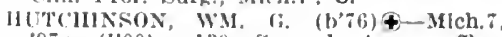
$97 ;([\circ 00) ; 139$ seward Ave.; office Washington Arcade; $2-4,7-8 ;$ Asst. CHn I'rof. Surg., Mich.7'; Pd.

MIRIE, ANDREW WM. (h'56)‡-Que.1,79 (l'00): 32 Glynn Ct. ; $9-11,2-4,7-8$.

INGLIS, DAVII (b'50)๑-MIch. 2,71 N.Y.10,72; ( $\left.{ }^{\prime} 00\right)$ : (Grosse Ile); office, 32 Alanis Ave. W. $10-12,2-4 ;$ Clin, IRINE, GEO. W. (b'66) 4 -Mich, 7,91 (1'00); 736 Cass Are.; offee, Washlngton Arcade ; $9-10,3-5 ; \mathbf{G}$.

IRWIN, JOHN LNN (b'59) \$-Mich1, 89 ; (l'00) ; $230,3 d$ Ave

IVES, AUGUSTUS W. (b'61)†-Mlch.7,91 ; (l'00): Gis office Bldg, ; $2-4$; l'rof. Neur. and I'sycth., Mlch.7; (E5); NP. *

JACOB, BERNHARDT-MICh.7,91; (l'00) 386 Alfred St.; offlce, House of Correc. tion ; $1-3,6-8$.

JACOB, JOHN C.-Mich.7,95; (1'00) ; 268 kirnrl st.; offlee, Breltmeyer Bildg. $9-10,4-5,7-8$.

lacker, Julius P. (b’74)-Micb.8,03; (l’03) : Trombly and E. (irand BIrd.; office, 1312 Joseph Campau Ave; 8-9, 12-2, 6-8.

James Henry Hall, Jr." (b'81)-Mich.11,'10 ; (l'10); 793 Seminole Ave.; office, Gas Offle Bhog.: 4-6;.

Jamleson, Raymond D. (b'91)-Wis.6,'13: ( ) ; St. Mary's Hospital.

AMIESON, ROBT. C. (b'81)థ-Mlch. 7,03 ; (l'03); 1099 Brush st.; office, Washington Arcade; $9-10,3-5$.

end, Wm. J. (b'76) H-0.26, '02; (1'03); 60 Mitchell Ave. ; 8-9, 1-3, 6-8.

JENKS, IHARRISON DARIING (b'67) Mass, 1,94; (1'00); 97 Fafayette Blvd.; 9-10, 2-4, 7-8.

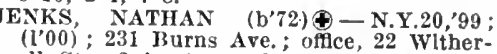
ell St. ; 2-4; Assoc. Prof. Obst., Mich.7; (Ai); Ob.

JENNIXGS, ALPHEUS FELCH (b'84) †Mass.1,'10; (I'10); 118 XCDougall Ave. office, 435 Jefferson Ave., E.; $2-4$.

JENNINGS, CHAS. GODWIN (b'57) Mlch.2,79; (l'00); 437 Jefferson Ave.; office, 435 Jefferson' Ave. ; $2-4$; Prof. Med.,

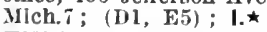

JOHNSON, ALBERT H. (b'T0) - -Mich. $T$, '93; (l'0́0) ; 209 Canfleld Ave., E.'; offlce', 717 Rlvard St.; $11-12,2-2: 30,6: 30-8$; Pd.

Johnson, Gllbert P.-MIch.7,'91; $\left(1^{\prime} 00\right) ; 621$, 16 th St

JOHNON, HENRY PEYTON $4-M$ MSs.7,97 (1'00); 758 St. Antolne St.; 3-5, 7-8.

IOHNSON, RALPH K. (b'75) †-Mlch.1, 00 (I'00); 44 Leicester Ct.; offce, Gladwlil Bidg.

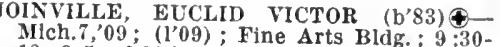
Mich.7,09; (1'09)
12, 3-5; OALR.

JONES, ARTHUR JOHN (b'81)--Mich.I, 07; (l'07); 2305 Gratiot Ave.; offlce, 2299 Gratiot Ave.; 1-2, 7-8.

JONES, JOHN KORERT (b'4i)-Mich.1 '72; (l'00); 2299 Gratiot Ave.; until 9, $12: 30-2: 30,7-8$.

JUDD, CHÁS. HOLLISTER९-Pa.1,97 (l'03); 187 Iroquols Ave.; offlce, Broad way Market Bldg.; 2-3:30; Asst. Prof. Obst., Mich.7 ; ObG.

Judson, Henry C. (b'56)-Mich.6,'82; (l'00) ; 441, 6th Ave.; $2-4,7-8$.

KADLUBOWSKI, ZYGMUNT L. (b'68) -

Mflch.8,99; (1'00); 1413 Míchigan Ave. $8-10,1-3,7-9$.

KAHL, WM. F.-Mich.7,07; (l’07); 637 MIt. Ellott Are.

KAHN, SAML, (b'69) - -Md.6,'98; (l'00) ; Mack
$\mathrm{I}-3,8$ 
Kahn, Wan. Wulf (b'6i)-Md.6,"96: $\left(l^{\prime} 00\right)$ 1048 Brush St.; omce, Flne Irta IBIdr. 9-11, 1-J; OPA.

Kalteribarh Ermat $\left(\mathrm{t}^{\prime} 56^{\circ}\right)-$ Mo.14,82: re, fired : $860,2 \mathrm{~d}$ Are.

KAMPERMAN, GRO. ABEL $\left(b^{\prime} \$ 0\right)+-$ Mleh.1,0\%: (1'0i): 193 Medbury Are. Mch. W islungton Arcale: $=5$ : G.

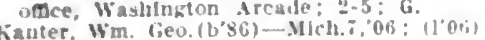

Kanter. Wm. Tieo

KIKK, HKIRHET STANLEY (b'S-

Mleh. i,08; (l'0s); Harper Il ospltal.

KEANE, WM. EDW. (b'is) \$-Mch., 02 (1.02): 362 Cadillac Mrd.; untee, 101 W Fort Si: 10-11, -4, i-3; Asst. I'rof Urolory, Mlch. $\overline{:}: \bar{u}^{-4}$

KEELER, E. BRUC :-0.13,91; $\left(1^{\circ} 00\right) ;+13$

Clar Are: $9-3,-8$

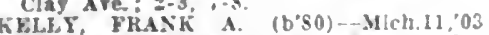
(1"03): 2359 Jefferson Ave.. E.: 8-9.;-8 (1'03): 2359 Jeffersun Ave.: E. : 8

Kelly, John Fredk.M.Mch. $i, 0 ;:\left(l^{\circ} 07\right) ; 2132$

w. Grand Blvd.; otlce. if F. Grand River Are.

Kemp?, Gustare-Mch.:'s5; (1'00)； 86 Tiliman Ave.; $8-10,3-4, ;-3$

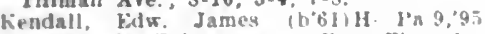
(1.00): 25 Tyler dre. $n$ the. Fine Irt

Blde. also 30 dams Ave

13: (1'13): Vigisla Hark and औl St.

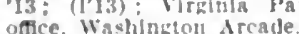

hennedy, (ieo. s. (L'6t) Mlich $7,88:\left(10^{\prime} 00\right)$ t10 Baker St.: :-4, i-s,

Kennedy", Johnson B.-Wilch.6,25; 11'00) Virglnia Park and $3 \mathrm{~d}$ St. : odice, WashIngton treade; 4-6: Fin. l'rof. Surg. Mich. $\mathrm{i}$.

Kennedy, Robt. L.

(See Royal Oak.

KFXXIXG, THOS-Micb10,81: (1'011): 218 Vinewoud Are.; $8-9.1-3,1 ;-8$

KIDNER, FREDK, CLITON $\left(\mathrm{b}^{\circ} 9\right)+$ Mass.1.04: $\left(1^{\prime \prime} 10\right)$; $701 \mathrm{E}$. Jefferson Are omce, 32 diams Are., $16: ; 2-4$. Or.

KIEFFR, GLY L. ( $\left(I^{\prime} 00\right)$ : Ires. Mllh. State Med. Soc. 655 John IR St: oftlce, $28:$ Womlwatl ire; Prof. Prev, Med., Mlch.

KILBLUS, KENSETH F:

Canton Ave.

killroy, Frank John (b'80)-Mirh.11, 11 (l'ii): 139 Larued st. E

KIMZKY, JOHX ALBFIRT $(6,79)+-M U A$ 10: (1'12); Young Men's chrlstlan Iseo. clation: onfec, 27 Adams Are., F.; $8-9: 30$

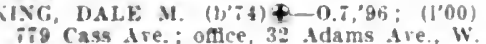
1:30-5: NP.

KNG, HAlRRY S-Que.1,92; (1'02); 131 Alexandrine Ave., $W^{\circ}$

KING, JOS. FVERHTT (\$) 82 )-Mich.7,06 $\left(1^{\prime} 06\right)$ : 736 Cass A re. : $0-10,2-4.7-x$

KIPP ARTHLR W. (b'is) - Mich : (102): 535 (hene St. : 1-3, i-8

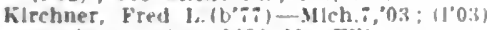
not in practlce: 108n Mt. Fillet . Ire

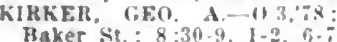

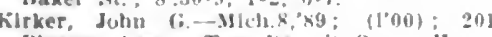
I'lngree Are.: offlce, lletrolt Opera House Hlock : 8-9, 1-3, 5-7.

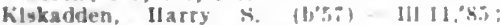
(100): Lenox Hotel; ufice, 2:1 llimalware Ave, ; 10-12, 2-4; Pr.*

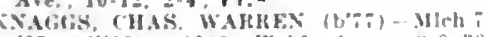
03: (1'03): 1102 flelu Ire.; \$ 9 :30. $1: 30-3: 30,6: 30-8: 30$

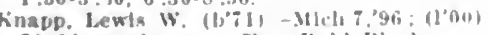
io linwond are; (nflec, Buhl block

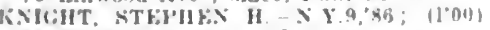

s: Wull Are., k. I :30-3. Whch 11,05 (I'03): 54: Jnmolun Are ; untll $10,1-3$ $i=4$

Kohn. Martin Folw (b'x4)-1'a I2, (48: 11'13! 32.11 W. Jefferwon St

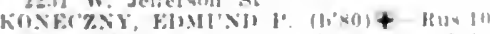
ois: (llog): 1315 sis dupln Ave: o ll 1-2. $;-9: U$.

KOHEL, Jus, o. $(1090)+-V 1 \% k:: 12$ 11'12): 203 Warren Ave.

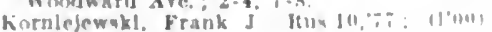
iti3 Michigan dre

hill Michlent dro

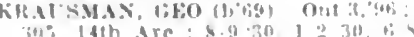

KIIIN. 1'llas. r. $\left(b^{\prime} ; 0\right)+$ Mlich s, 'UI (1'01); 999 Hastlugh st. ; 1-3, 6-7: $\mathbf{S}$.

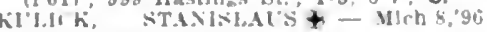
$(100): 1201$ Juaction Ave

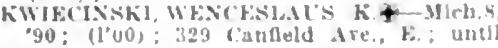
9. $12-2$, after 5

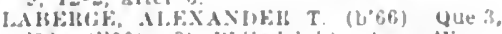

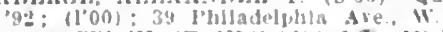

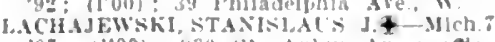

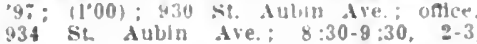
$934 \mathrm{~S}$
$:-8: 30$.

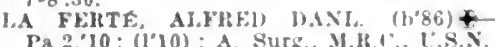

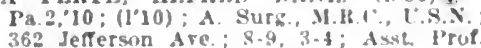
Ortho. Sur Mlch, Or.

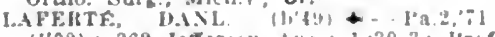
(l'00): 362 Jefterson Ale: : $1: 30-3$; I'rof (Intho. Surg. Mleh.i; (A3); Or.

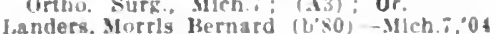

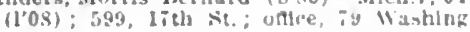

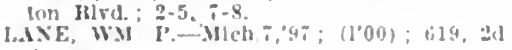
A ve.

lang. Otto $\left(b^{\prime}+9\right) 11-0.13, \times n$; (1'un): 116

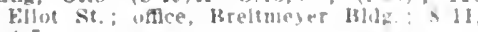

L.A.G, OTTO, J1t. (b'as) - Mich.11,05

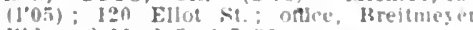
llldg, : $8-11,1-3, \quad,-=: 30$

LARSKD, EZRA BEAD (b' 68$)+-111,9 \%$ not in practlce; 11: $\mathrm{k}$. ranteld dre

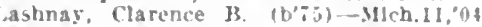
(l'04); $117 i$ Chene St. ; 1-3, i-8.

Lau, Fredk. T. (b'st)-Mich.,, $13 ;(1 / 3)$ los lelaware Are.

I.AT, OLIVEK II. (b'55)+-Mch.1, 82: (100): 693 John IR st. ontice, Dime Bank B!d : N.P.

Iarin, lieo. F. (b'70)-MIch.8,201: $\left(l^{\prime} 00\right)$ : 220 Meldrum Are ; offce, 2-0 Woodward Ale ; $10-12,2-4, i-8$.

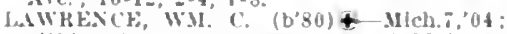
(1.01); 305 Avery Ale, ; 1-3, 6:30-:;30; ObG.

Lawson, B. Howard (b30)H-0.71: (1'00); 860 Trumbull Are.: $3-10,12-2,4-6$, lawton, Maul. (ieo. (b's)-Mlch.4,0I (1'01); 329 Jeffersin Ave.; 10-11, 2.

hatwTOX, THOS, MOKHJOX (12'56) - One.3. "it, Scot.9.81: (1'00); pitis Trumbel

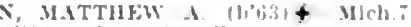
1-3: 0 b.

LFA, JCANITA INABELIAI (l'0 0 ; $4 \mathrm{l}$ k. Fuclid Are; uthe, steren. Bldg; $10-12,2-4$.

I.FF, ILTHIH C.MICh.i, M3; (l"00) thi, Helen dve, $8 \cdot 4,2-1,6-8$

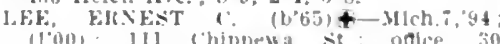
(1001; 111 rhippewa Adamin Mo. If: $:-t$.

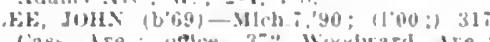
lasm Ire oftre, $37:-$ Winalward Me IIIchi.

1.efebre, Irthur (b"tis)- Que..3, 93 ; 11 (1)

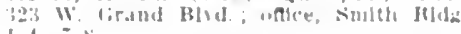

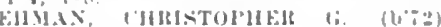

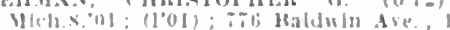

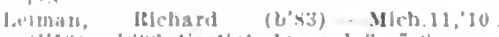

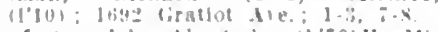

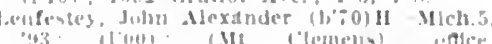

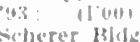

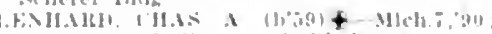

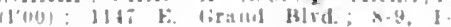
(i. $3011=30$

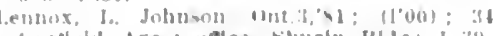

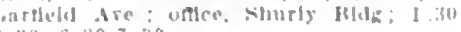
$\therefore: 30,6,30 \div: 30$

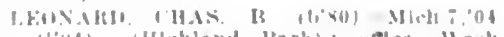

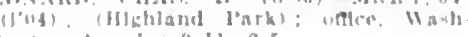

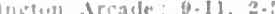

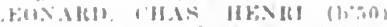

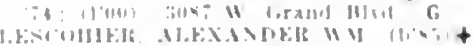

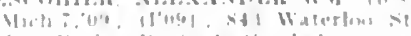

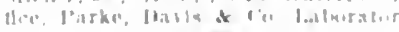

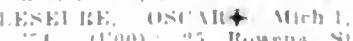

i.timn Nom
L' Esperance, Siruon

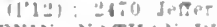

LEVIN, NITHAN IHIStAS L

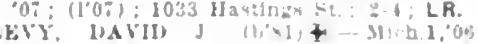
$\left(1^{\prime} \cup 0^{\circ}\right): 165$ Inntee Ave cordre, IVanbing ton Arcade ; 2-t, (1:5) ; Pd.*

LIXN, HOBT $\therefore$ (b'y) + HICh .91 (bis $10,1-3, ;-3 ; S$ LIVINGSTON, GkO. M. (b'at) + Mebl 95; $\left(11^{\prime} 00\right) ; 2594$ Woodward Are, ; $10-12$

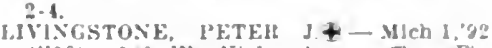
$\left(l^{\circ} 00\right)$; Iso W. KJIIs Ale.; odee, Fine Arts 'BIds.: 10-12, 2-4; (B1,10.11) OALR. *

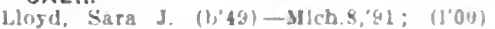
if k. Hich Si, ; $9-12,2-4$

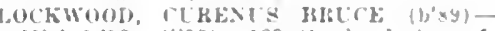
Mlek.1,12; (I'12); 129 fortland st. ; of flce, $i 1$ Washingen HIsl.; 10-1, 2-1 adge, Albert-Mllch,, 79
High St.; 8-0, 1-2, 6-7.

Lodze, kdwh H. -X.Y.9,' L; 11001 ; llirusoe Folnt Farms): uflec, 75 Bruaduas; $y-10$ 2-3.

IONGIkAh, HOWAMD MHALIAMS (252) +

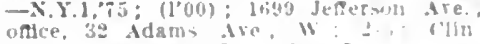
prof. Sutg. Mich,

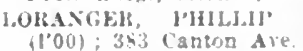

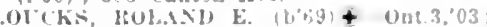

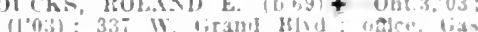

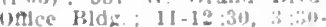

boud, Walter Eugene-lll.10,0t; not in practice: 5.3 dlexandrine die., il

lounbury, Heury A. (b'b3)-Mch., se $\left(1^{\circ} 03\right) ; 325$ Jlamllton Are. $8-y, 1-2,7-8$ (1.08): 601, 31 Ale; oftee, FIne Ar Bids. $1:-1,-4,-8$

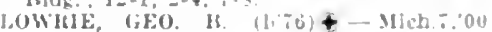
$\left(1^{\prime} 00\right) ; 903,21$ dre : nalce, 11 ashimgrum

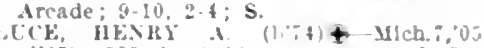
(1105); 335 se. dubla tie.; $5-4,2-3,-5$ Pd.

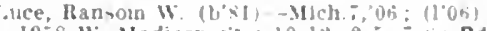
19 \& 11 . Madison $\therefore$; $10-1: 2-3 ;-9$ d JLKASZEWSKl, STANISLAW J. (b) Ill 12.06; (1'0t); 111; Chene st. : 90 $2-4, \div-5$.

lumley, Whllam Gibson (b't)-Ont, (I'00): tIy commonwealth sie: $s-9$,

- Conrad-111;30 "you:

blen st.

LCNDY, (IIAS, KJALFORD (b\%)-YIch F

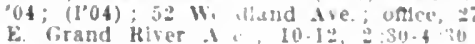
OALR. *

I.YON, LASELL W: (b'62)-[11, 1, S: ; (1'no) $\mathrm{Ob}$.

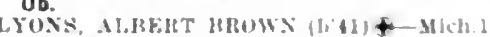
68 ; not in practlee: 102 Alaer Are.

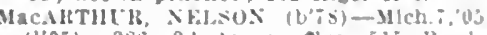
(1'05); 3sit, at die; unle, 515 kuwles Blde. : 9-1:, 1-5

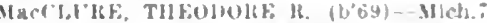
01: (1001): 1121 lafalete Blvd; once, Solray General Howplal: S.*

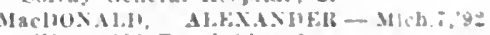
(1'00): "200 Trowbrldee sit.

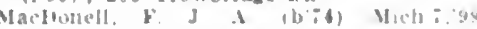

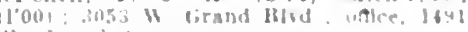
Wumluard fin

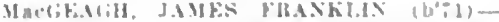

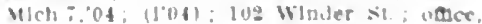
liroalwas ientral Hidg: until s, 11-1, 3-5,

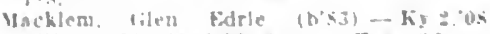

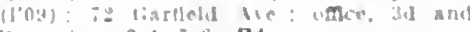
thit: $x$ is: 01 : : : Pd.

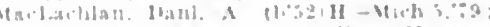
[100), II alan M10: 111 OALR

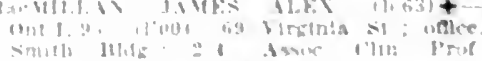
lerinel 11 rlizis 1 il

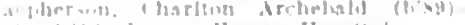

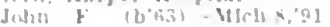
in firaction sur Blde 


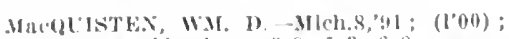
$2 x 3$ st. Aubin Are : $8-9,1-3,6-8$.

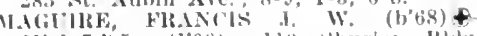

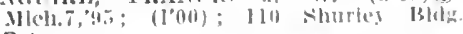
S. *

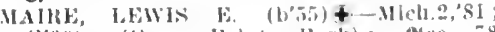
(l'0(1); (liross Polule lark); "othece

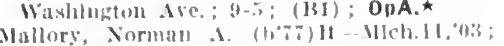
(l'03); 831, Ith Ar

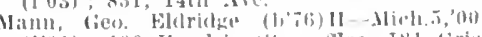

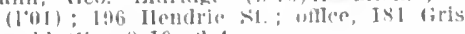
wold st. : a-10, $2-4$

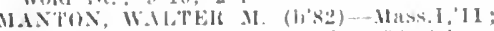

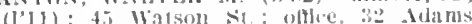
(T)

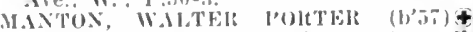

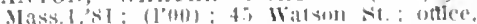

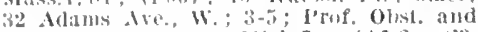

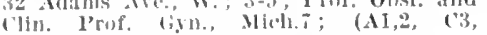
(E.i, 13); S.

Martin, Anna 1 (1) (1;2) 11 Mich.Il, 00 (100); 217 W. Girand Blud. : 12-2, ti-8

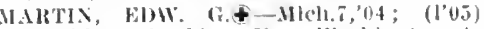
(IItglind Park); once, Washlugton Ar-

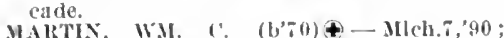
(l'(1) ; 124 Vestulnster Wre. oftlce. 57 W. Fort st. : 9-12, $2-4,7-8 ; A$ ssoc. I'rof. I'rology. Mich.i; U. *

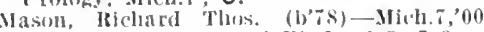
(l’0); $\$ 930$ E. Girand Blvd. $1-3,7-8$.

Wather, Fuoch (1, *8) - 0.16,84. 0.17,86, III.14,98; $\left(l^{\prime} 00\right) ; 46$ Warren Ale., E.

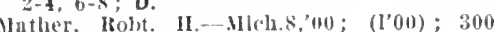
Me('lellan ire.; 1-3.

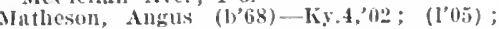
1184 Russéll st. : $9-11,2-4,1 j-8$.

MATTIEWS, JAMEN 1). (1,67)\&-Mich.7, '92: (l'00); Tuller Hotel; offlce, Fine Arts Bldg, : 2-4; S.

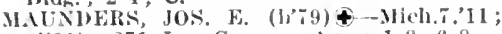
(1'11); 271 Jos. Campan Aré, 1-3, 6-8.

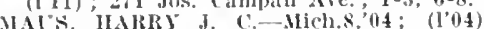
4t: irand kiver are; oftice, smith IBldg. 465 (irind
$1: 30-3: 30$.

Mayer, Ignatz (b'60)-Pa.11,94; (l'00); 29 barenport St.; oftice, Chamber of Commerce Bldg. ; I0-I2.

MCAFEE, FREDK. W. (b'78)-Mlch.', ,04; (l'04); 1840 Vinewod Ave.: 2-4.

MCALI'INE, ARCHIBALD DLNCAN (1's?) -Alich.7.05: (l05); 32 Josephine Mre.; office, 355 Voodward Ave.; $2-4$; S.

llctipine, (iordon smitl (b'90)-Ont.I, 13 ; IIarper IIospital.

McCandless, Fred (b'68) H-III.10,'y4; (l'00) 129 Owen St. ; offlce, scherer Bidg. ; 10-12, $3-5 ; \mathbf{G}$.

MeCAYN, IOS. HENRY (b'8t)-Mich.5,'10 ; (l'10); 1905 Michlgan Ave.; $7-9,2-4,7-9$.

Meclellan, Gustave Leonard - Mich.7,05; (1'05); 338, 4th Ave.; offle, 459, 14th Are.

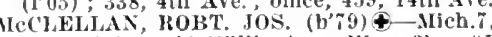
09; (1'10); 140 Willis Ave., W; oftice, 91 Grand Rlver Are., W.; $y-10,1-3,7-8$.

MeCLELLAND, CARI, ('. $\left(b^{\prime}+9\right) \notin-M i c h .1$, I0; (1'10); 130 Webl Ave.; oftice. Washington Arcade; 9-11, 2-5; (B11); OALR. YcClelland, Lela $x$. French (b'S0)-Mich. I, 01: (l'01); 130 Webb Ave.

McClure, W'm. Raymond (b'86)-Mich, 1,13 (I'13); Harper Hospital.

IcClurg, David (b'64)-ilich. 1,92; $\left(\mathrm{l}^{\prime} 00\right)$ 2795 Woodward Ave.; $8-9,1-3,7-8$.

MCCOLL, MALCOLAI (1,56)థ-Mich.7,94; (l'00); 281 Joseph Campau Ave.; until 8, $1-3,6-8$.

MCCORD, CAREY PRITT (b॰6)-Mich.1, 12; (1'12); 960 Waterlon Ite

MeCORMICK, FRANCIS TALBOT (b'80)Mich. 1, 05; (1'05); I 11 Chandler Ave.

McCORAICK, WM.' H. ( $\left.b^{\prime}, 2\right)-M i c h .8,03$; $\left(l^{\prime} 03\right)$; 704 Garland st.; office, 648 Montclair Áre. ; $1-4,7-8$.

MeCosh, Eierett A. (h'iI) - Mich.ĩ,96; (1'00); $1427 \mathrm{~W}$. Grand Blyd.; oflice, Broad ; 142 i w. Grand Bly

ycenllough, Thos. P. (b'60) - Ont.5,'88; $(100) ; 737,24$ th St.; until 9, 12-2, 6-8.

MeI) ONALT, ALLEN W. $\oplus$ - Mich. 601 ;
(1,01); I\%0 Conmonwealth Ave.; office, 6 1V. Warren Ave ; $1-3,6-8$.

MOIONALI), \&. MRANT (b'69)-Mich.7,00 (I'001); I2I Ilolbrook Are.: offlee, 1737

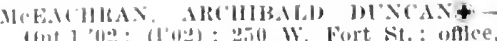

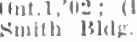

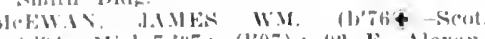

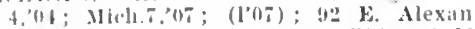

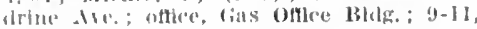

Mr.bwan, John Ifowarl (1,89)-Mleh.1,'13; (l'13); II arver Hospital.

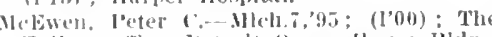
Tullin: ollice, letrolt Opera flouse Bldg. (1) $111,2-4,7-8$

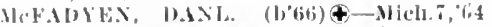
(lo4) ; 24 blalne Ave, ; $1-3,7-8$

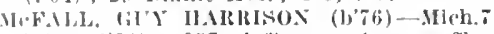

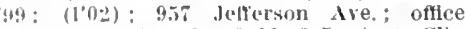
Wishington Arcade; $9-11,2-5 ;$ Asst. Cllon

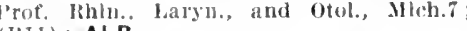
(1311); ALR.

W.Faytlen, ILugl A. (b'86) - Ont.6,'I: Intern, Tulerculosis Iospital.

Mclievch, lieginald Wm. (h'87)-Mich.1,'13 (1¹3); Harper Hospital.

Mroliongh, Albert I. (b'70) - Mleb.,$" 94$ (l"06); 502, 2d Ave.; offlce, Fine Arts Bldg. ; $9-10,2-4,7-8: 30$

IICGRW, THEODORE A. (b'39) -N.Y.1, 63; (1'00) ; 1710 Jefteston Ave, afflee, 73 rass St.;2-4; Ener. l'rof. Surg., Mich.t (A5)

MCGRAW, TIEOHORE A., JR. (b'T5) N.Y.I,02; (l'02); ITI0 Jefferson Ave. uffice, 73 Cass st.; 2-4; Assoc. ('lin. Prof. Med., Mich. $\tilde{T}$.

MCINT YRE. THOS. ( $(1, T S) \notin-M i c h .7,04$ (1'04); 1165 sheridan Ale. : $1-3,7-8$,

ICKAY, HUWIN BRUC' (h'T0)-Mich. 7,96 (I’01) ; 633,4 th Ave. ; $9-10,2-3,7-8$.

MeKEAS, liEO. E. (b'68) \$ Mich.I.'94 (l'0(1); 86 Delaware Are.; office, Wash ington Areacle: 3-5; Asst. Clin, Prof. Med., Mich, T.

Hckinley, Harry C (b'i I) - Mich 8,'96; $\left(I^{\prime}(0)\right) ; 673$ Junction Are. ; 9-10, 2-3, $7-8$ MClWAN, ANGTS $(1,62)-$ Mich. 7,86 ; (I"00); 19 Martin Pl.; office, Washington Areade; 2-4; l'rof. Surg., Mleh. $\mathbf{i} ; \mathbf{S}$,

MCLEAN, CHAS. HTGII (b'81)\&-Mich. $\bar{t}$ 04; (1'07): i46 Illinois st, office, 851 Araliot Ave. ; $2-4,7-8$

Melean, Hilliard … A. (b'75)-Mich.7,99; (1)00); sor Lercheral Ave; offlce, 242 Griswold St.; $1 \pm-7, b-\bar{t}$

MCIAION, GERALI ILASTINGS (b'84)Mlicll. .'09: (l'09); 172 Canton Ave. of flee, Washington Areade; $9-10,2-4,7-8$.

McWAHON, HENRY O. (b'7)-Mich.11,02; $\left(\mathrm{l}^{\prime} 02\right)$; 845 Jefferson Ave, $\mathrm{E}_{\text {. }}$; offlce, scliere. Bldg.

Me.Jahon, James J.-Ifich.2,'80; (l'00); 99 Baker st. ; $8-10,1-3$,

MeManus, John M. (b'69) - Mich.7,93: (1'00); 1090 Canton St.; office, I4it Gratiot Ave.; $8-10,1-3,6-8$

JeNICHAFL, ALBERT-1'a.17,78; (l'00)

157 Brainard St.; office, 10 Tuscola St.

Mesillan, Jolum B. (b'57) - Mich. $7,{ }^{\prime} 89$ (1'02) ; 872 Antoine St.; 10-12, 2-4; S.

MeNAMARA, FRANCIS W. $₫$-Mich. 6,98 (l'00); i62 Junction Are.; office, Fine Arts Bldg.; $11-12$; S.

IcNicholas, Leo Thos. (b'87) - Wis.6,'13; Intern, St. Mary's Hospital.

Mc'Taggart, John E. (b'39) - N.Y,6,'7l; $\left(l^{\prime} 00\right) ; 258$ Helen Ave.

MCVEI('H, JAMES A. (b'72) - 0.1,'96 ; (I'00); $6 \mathrm{I}$ Adelaide St.; offlee, Smith Bldg. ; 10-1 ; (A4); Pr.

MeVoy, Geo. Clinton (b'72) - Ga.5,'95; (l'00) ; 363 Cass Ave.; offlee, 96 Broad way : $2-5$.

MEAI), JAMES EDWIX (b'73)-Mich.7,99; $\left(t^{\prime} 00\right): 211$ CaIvert St.

Meade, Clinton W. (b'36)-0.1,75; (1'00) 75 Adams Ave, W; ; until $8: 30,1-4,6-8$.

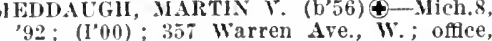
Washington Arcade; 3-5.

Melody, Wm. P.-Nich. T,02; (1’02); 647 nullet St. ; $8-10,1-3,7-8$.

MELOY, CARL R. (b'82) $\$-M d .706$ : (1'10); 219 Edison Are.; oft

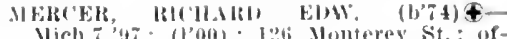

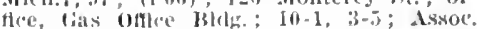

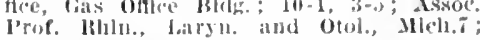
(1311) ; LR.

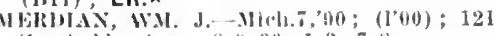
st. Aubln Are.; $8-9: 30,1-2,7-8$.

Merrili, Chas. II. (b'80)-0.12,05; not In practice: 349 chene $\mathrm{St}$.

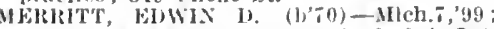
(l’00); 244 Vin Dyke st.; $10-12,2-4,7-8$.

WLTCALF, WM. FRANCIS (b'63) Mich.1,8s; $\left(l^{\prime} 00\right) ; 73$ Westminster Ave.

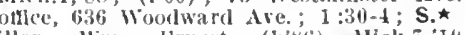
liller, Win. Eruest (1,86i)-Mich. T, It (l'10); 8st Woodward Ave, 1-3, $;-8$.

HHLIGAN, EDH. T.†-Hich.8,92; (l'00); 68. . lelferson Ave.

Mlllgan, Fredk. Louls (b'81)-Mll'h.7,'13: (l'13); Harper Hospltal.

MHLAs, ELAsWultTil l'Allo (1)'75) $\$-$ Mlch.7,'99; (l'00) : 2842 Woolward Ave. offlce, 2782 Woodward Ave; 8-11, 2-4:30, $\tau-8 ; U$.

MANR, STANLWY G. (b'6I) \$-Nllch.2,82; (1'00); $799 \mathrm{k}$. Jefferson Ave. ; offlce, 56 Cadillac Square; 2-6; (Clln. l'rof. Rhlin., Lary'l. and Otol., Mlch.7; (BI, I1); ALR.*

MINOR, EDWAR1, (iEH)W (1)88)Mich. ̈,'I2; (1'12) : 2436 W. (;rand Blv offle, 105I Mack Ave.; $9-10,2-4, i-8$.
HODESITT, JAMLS BERT (b'75) 4 -Ia.8 '09; not in practice; Member la. State Med. Soc.; 190 Englewood Ave.

Moehliz, Rolt. Conrad (b'89)-Mlch. $\mathbf{f}, 13$; (l'13); Harper Hospital.

MOOHY, HILIP EARL (b'79)థ-Mlch. 02 ; (l'02) ; 192 Gladstone Ave.; office, 1.19 Woodward Ave.; 2-4, $7=8 ;$ U.

Moon, Arthur Raymond (b'85)-Micls. $\tau, 12$; (l'12); 225 P'ingree Are.; office, 1211 Ilamilton 13lvd.; 9-10, 2-4, 6:30-7:30.

MOONEl, EDW.' W. (b'72) $4-$-Nich. 7,99 ; (l'00); 122 Trunbull Ave.; office, Fine Arts Bldg.; 2-4, $7-8$.

MOOLE, JCLUS SHEPPARI (b'82)屯Yal. ${ }^{\prime} 09$; (l'10); Irace Hospital.

MORES, CHAS. W. (b'56)\&-Ont.3,'90 ; $\left(I^{\prime}(00) ; 43\right.$ Lincoln ive.; 10-12, 2-4.

llorin, John B. (b'if)-Nich.11,08; (1'08); ¿63 W. Frand Blvd.; office, Bowles Blalg. ; I :30-4:30.

Morley, (has. Sumner-0.T,, 6 ; $\left(\mathrm{I}^{\prime} 00\right) ; 22$. Smith Ave.; office, Park Bldg.

IORLEY, WH. HORACE (b'72)థ-Mich.1, 01; (1'01): Addison Apts.; office, Fine Arts Bldg. ; 10-12; (A2); Ob.

Morris, Harold Lewis (b'89)-Mich.5,'13; (I'I3); 14th and Milwaukee Ares.

Morris, Isaiah s. (b'64) - Hich.5,'86; (1'00) ; 1988 Woodward Are.; offlee, (ias Office Bldy. ; I :30-4.

Horris, Wallen Fing (b'84)-Mlich.8,06; (l'06) ; 2413 Jefferson Nie., E

IIORSE, PLINN FREDK. (b'85) - Hich.1, 09; (l’09); 367 Vinewood Ave.; Prof. Path. and Bact., Mlch.7.

MOWRY, WM. Y'-Jll.4,04; (1'04); 236 E. Canfleld Are. ; 12-2, 7-8.

MLEXZ. CDRL F. (b'63)屯-Mich.7,'96; (l'wo) ; 421 Baldwin Ave, $2-3,6: 30-8 ; G$. ULHERON, HUGH J. (b'i3)-Mleh.l,'97;
(l'00); 102 Chope Pl.; office, Fine Arts (l'00) ; 102 Chope Pl.

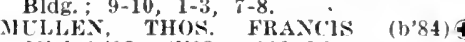
Miclu. I,08: (l'08); 112 Watson st

Munch, George A. Ky.4, $01 ;\left(l^{\prime} 00\right) ; 14$ l'ine st.; offee, 572 Grand River Ave. Ilurdie, Wm. K.-YIich. T,'86; (I'00); 50 Gratiot Ave. : 8-9, $1: 30-3,7-8$

Murray, James 1.-Mich. T, $95 ;\left(1^{* 00} ; 40\right.$ Willis Are., E:

MLRRA Y, L.'THER A. (b'84) - Mich.11,

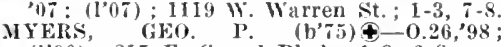
(1'00); 215 E. Grand Blvd.; $1-3,6-8$.

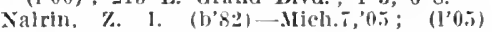
117 Idams Ire., E.: $8-10,1-3,6-8$.

Navaun, Edwardo s. (b'53) E- 0 ; $\left(l^{\prime} 00\right)$ : 327 Joseph campau tre. ; 9-11, 2-4, 6-8. NAYLOR.AR(HIB.IAll E. (b'88)-Ont. 1 , 09 Nich.t,le; (l'I2): is Willis Are.; offlee. 899 Woodward Are.: $1-3.7-8$

seal, Thos. Alvin (b; 6 b) - Mich. 1, '1) 1 : (11i); not in practice: 174 beicester' ('t. NEARS. .10HN H. $(1,76)$ - Mich.8, 60 ; (l'al) ; 6.54 lirandy Are. : I-5, 6-8. 


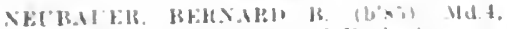

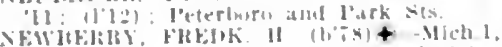

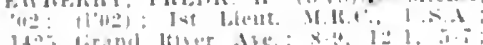

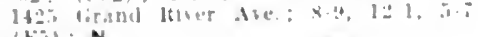
(ki) : N.

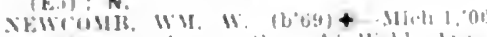

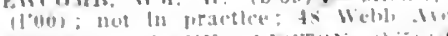

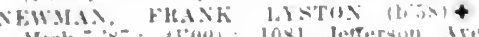
Weh. "xo: lfoul: lox! deffersint Wre

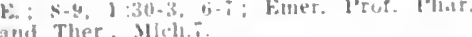
and Ther, Mleh. P(n)

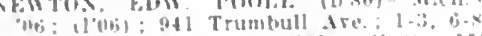

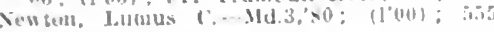
at! Are.

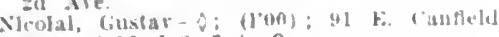
Ave : $\$-10,1-2,7-s ; G$.

vlebel, Benj, Farl (b'st) l'a.2, lz: In-

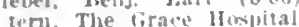

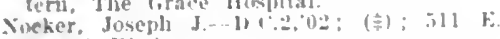
Sicker, Josephl

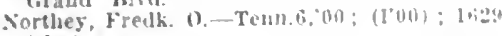

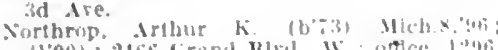

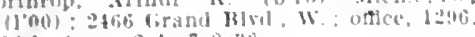
ith ire: : 2 -4. $-8: 30$.

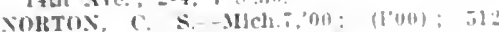
$16 t_{1}$ s: $: 8: 30-10,2-4, ;-$

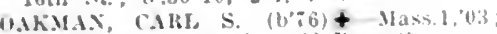
(1'05): not In practice: liz Bagk 4 .

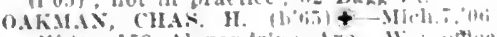

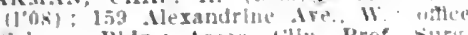
scherer Bldg.: Assor. Illin. Prof sura. Mlich.

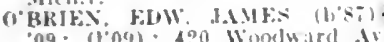

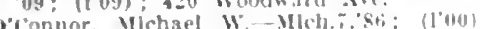
615 IIx ire.; 1-3, ; - 8:30.

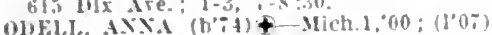

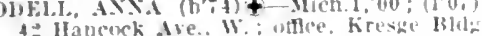

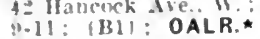

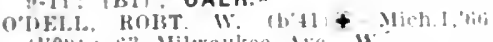
(l'0ui): to.3 Milwankee Ale. W:

(1)

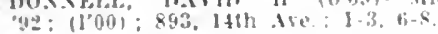

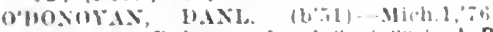
(1'00;: 11 Haker: s-11, $1-3$, ni:3ll-s, L.R. 0'Hugu, James-Mich.s, 9\%; 1100): Junction tre

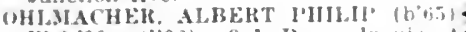

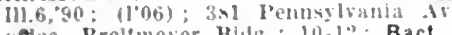
onte, Brelimeyer Hidg : 10-1:; Bact.

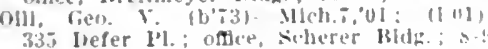

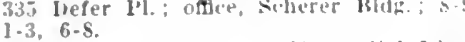
$1.3,6-5$

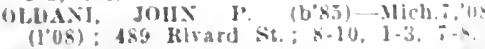

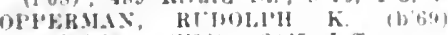
M/ch.9,"10: (100); $019 \pm 5$ Jefterson Ave E. : $: 2-3,6: 30-7: 30$.

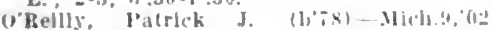
(1'02): 835, Ith Ase.: ontle'e, 930 rirand Diver dre.

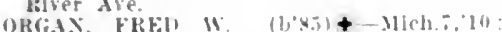
(1010): 43 Woodland Ale.; inlee, 2ist

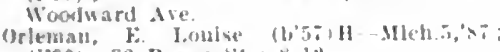
(I"00): 32 Bragh st. : $5-12$.

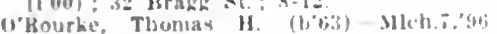
(100): 6is Alery Aie.: i- $-8,1: 30-3$, $6 ; 30-8$.

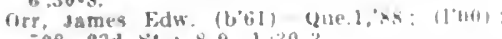

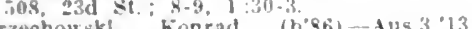

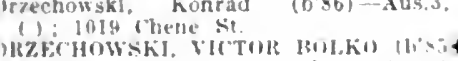

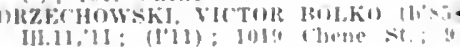
III. 11,11 :

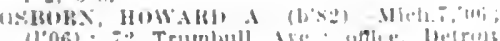

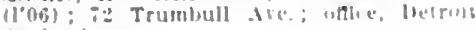

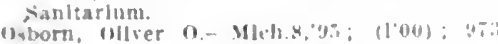

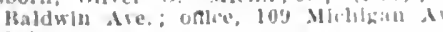
1.4.

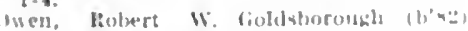

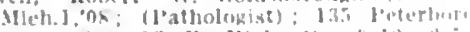
Lo. oftre, 33 k. High st.: 9 l:,

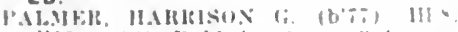

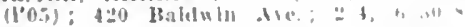
ObG.

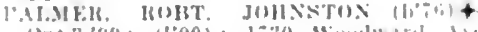

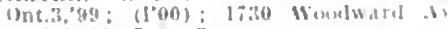

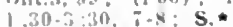

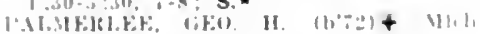

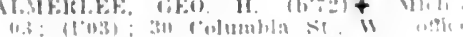
II. inhlugters incole: 1 : 5

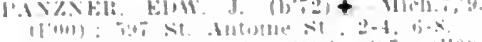

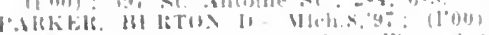

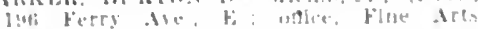

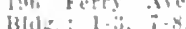

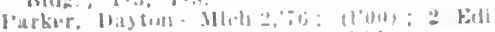

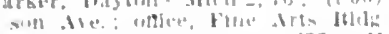

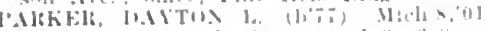

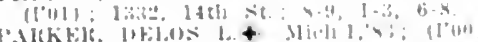

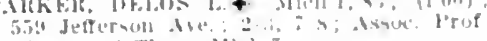
lloter, and Ther., Meh

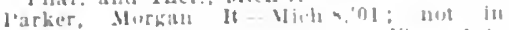

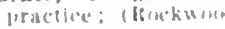
jiluth

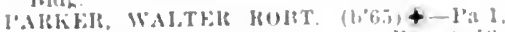
(l0)

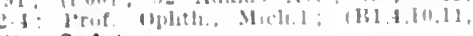
Fii : OpA. *

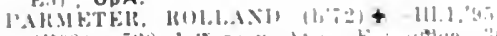

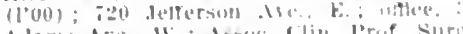
Alams Afe, W; Assoce Clin. l'rof. Sirp

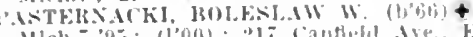

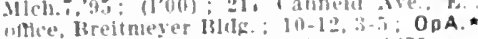

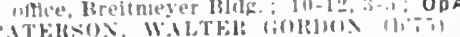

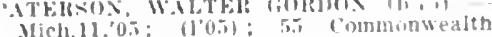

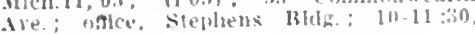
$330-3: 30$.

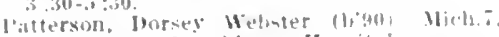
1:3; (1'13); 1'robleme Honplat

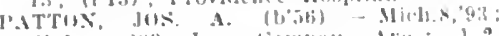

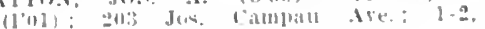
iller is.

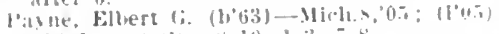

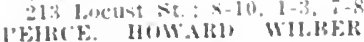

He

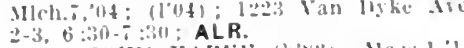

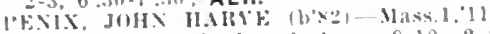
(1'I2); 1.19 lloodward lie, $9-10,2-1$ $7-8$.

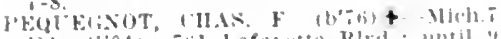

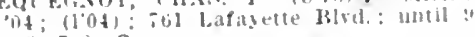

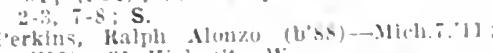
(1) : 31 Iligh xi. W.

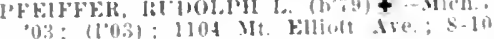
$1-3,7-8$.

Pullips, Fred. Wm. (1,:4t)-Mh't.'1: (1'1:8): Hrurdence Hosplat.

l'ike, Iawrence C. (b'3)-Mich.s. 0.3

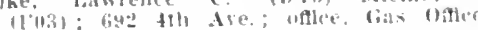

B]dg. Frank E (b'61) - Mich.7,

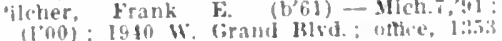

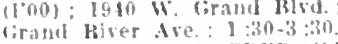

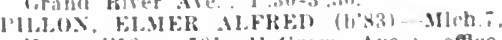

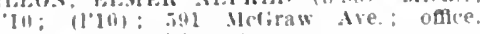
$12431 / 2$ firand Hirer Ave.

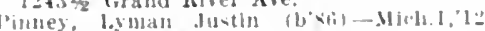

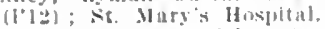

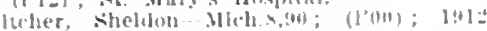
sinotean Alu

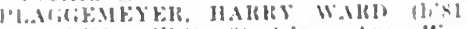
M1., $0^{\circ}:$ (1013): 30 Alams Are., W

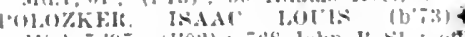

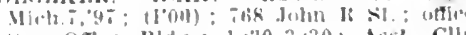
Virs ofthe liddr.; $1: 30-3: 30$ : Asst. Clln. l'rief l'erl. Mlleli. : Pd.

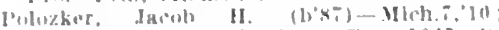

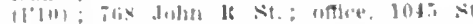
Nubh Ire: In 11, a-8.

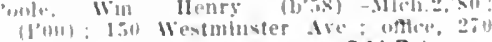
Womeluard Are: 9-12, 1-5; OALR.

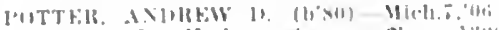

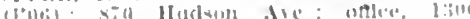
firami liner Ale

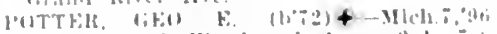

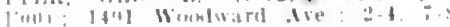
ALR

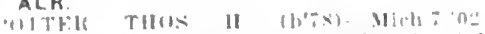

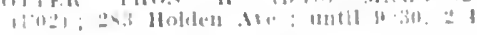

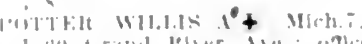

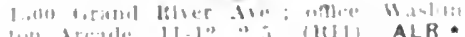

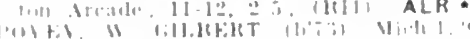

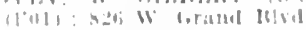

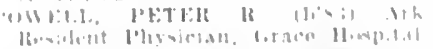

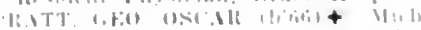

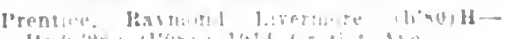

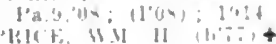

i)

I? li!n

IX\%1BYI,W:KI, FFIJ

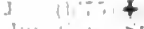
14. 13 , i \&

Thtolil, rktik w- Qut

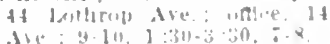

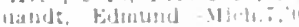

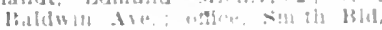

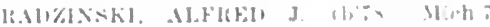

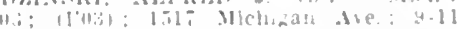
$\because 4$, i $x: 0 b$.

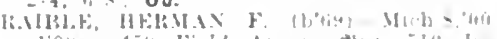

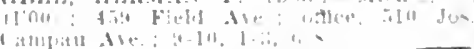
16. a

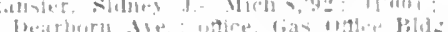

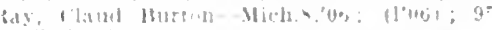
iiluter sit.

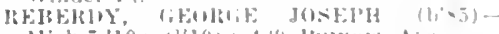

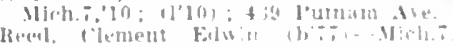

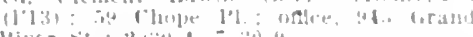

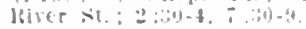

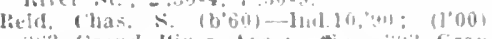

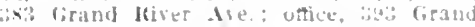
liser Are ; $1-4, b-n ; R$.

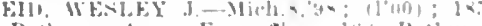

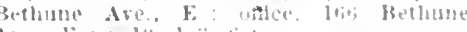

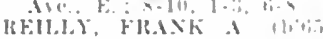

(l’16): 930 Trumbull Ale, ; $-9,2-3,6: 30$

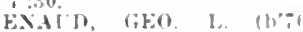
(1.00): (cirosse linitute Hlde: : $9: 30-10 ;$ ( B]

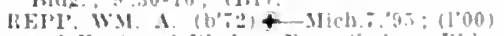

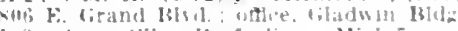

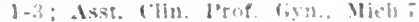

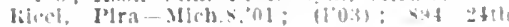
Pi. noe in lisactice RIII, HERIBERT M. (b'it) + - Mi h. 1, "11

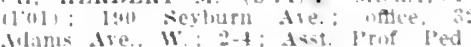

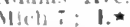

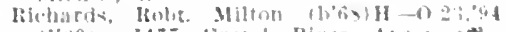
11001: 14:5 lirand River die.; othe

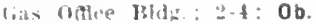

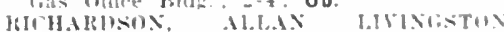

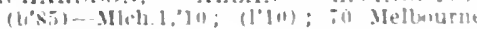

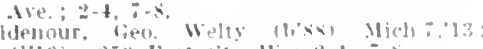

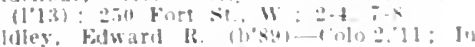
teri, llarget Jospital

BIFMAX, IIM. H. White

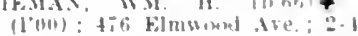

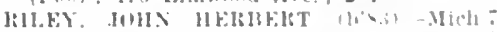

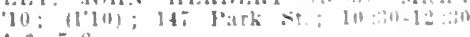
4- $6,-8$

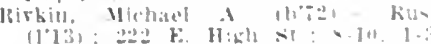

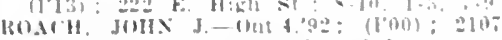

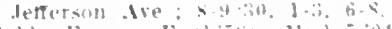

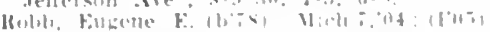

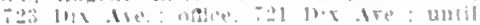

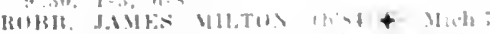

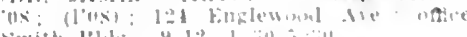
smith lilit

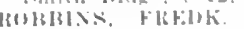
की : $(1+(10))$ : $111 \cdot 11 \div:(13): U$

kulikts rkilutikl $\mathrm{k}$

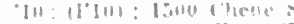

liobinusu, dimbers $\mathrm{r}$

(1")4): :31 Mrush $>1$

mensine flum

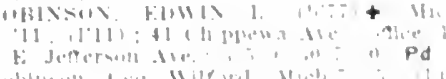

16.

$1,011,1,0,4 m+1110,1$

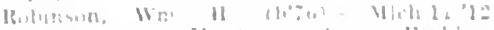

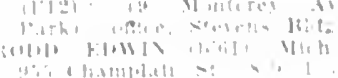


IOE, ANNA T, HINN-Mich.s, $44 ;(100)$ 281 lirby Ave. W. $8.10,2-4, \tau_{-s}$

liogers, Wm. Hiram (b'67)-1'a.9,06: (1'06) : 1541 Nack AFe : $8-9,1-3,7.8$.

liokde, I'aul chas. (b'85) - Mlch.11, '12; (1'12); 248 Slierman St.; 1-3, 6.8; offlee smith Bidg. ; 10-1; S.

Rose, Jos. L. (b'49)-Mlci.2,'85; (1'01) 955,14 th Ave, : $-9,5$.

ROSENTHAL, JACOR (b*66) $+\mathrm{I}^{\prime} \mathrm{a}, 1,90$ (1*01); 980 Brush St. ; $2-4,7=8 ; \mathrm{Pd}$.

ROSS, WORTII (b'83)-1) C.1, 10 (1'I2)

866, 2d AFe.; office, Washington Arcade: $1-3,7-5$

liothacker, Jacob W.-Mich. $797:$

ROTHSCHID, borgl is (b's "07; (1'07); 740 13rush St. : offlce, 13reit mever lildg: $10-12,3: 30-6, \tilde{i}-8 ;$ OALR. OTTENBERG JOs (b'90) — IId 1, 12 (1'12) 279 yiuder 5 t

ROWLANI), IRISSELI. STUR(ids (b'74) -Mich.1,0I; (1'03); 95 Edison Are. ; of flec, Washinglon Arcade

ROYCE, FRANK DAVID (b's2)-Ky.2,'11 (1'11); Member Ky. State Med. Assn. 12091/2 W. Warren Are.; 8-9, 1-4, 7-9.

RINO HERMAN IIJALMAR (b'79)‡

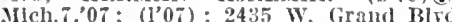
offlec, Smith Bidg.; $11-2,7-8 ;$ U.ネ

Rutledge, James C. (b'71)-Mich.7,'98 (1'00); 258 Bclviere Are.; ofllee, Gas of flce Bldg. ; 2-4, 7-8; G.

RUTIEDGE, JESSE (b'74) - Ky.9,'06 (1'13) ; 3308 . Jeficrson Are. ; 8-9, 12-1, $7-8$

kyan, Wm. Don (b'89)-Mo.34,'13; Intern, Providence Hospital.

SADOWSKI, ROMAN J. (b'79)-Mich.8. 04; (1'04); 1529 Iichigan Ave.; office, 1527 Michigan Ave.; 8-10, 2-4, 6-8.

SAFFORD, HOMER ERWIN (b'69)థ Mich.1,'96; (1'00); 22 Hancock Are. IV. $1: 30-3$.

samiter, Gabriel (b'67)-Mich.7,95; (I'00) 177 E. Ferry Are.; offlce, 114 Gratiot Ave. ; $10-12,3-5,7-8$

ANDERSON, ALVORD R. (b'88)-Mlch. 7 '10; (1'10): 3298 Jefferson Ave., E.; 1-3,

ANDERSON, IIERMON HARVEY (b'69) -Ont. 1,'93; (I'00); 110 Canfield Ave. Asst. Clin. Prof. Ophth., Mich.7 Asst. Clin. Prof

SANDERSON, JAMES H. (b'60)๑-Mich.8, $90 ;\left(1^{\prime} 00\right) ; 1038$ W. Warren st.; 8-9, $1-2,7-8$.

sanderson, Phllip G. (b'66)-I11.11,99; (l'00); Lenox Apts.; office, Gladwin

ANDERSON, S. EDWARD $\left(b^{\prime} ; 2\right) \oplus$ Mfich.7,96; (1'00); 126 Warren Are., F. $\tau: 30 ; \mathbf{s}$.

Sanderson. Suzanne Munro - Mlch.5,08; (1'09) ; Lenox Apts.; offlce, Gladwin BIdg. AYERS, CLARENCE G. - Mich.7,'03 (l'03) ; 615 Baker St. : 8-10, 1-3, 6:30-8 SIIALLER, GEO. JACOB (b'72)-Mich.8, '97; (1'00); 1656 W. Fort St. ; office, Whitney Bidg.; 12-2.

SCIIENCK, BENJ. R. (b'72)థ-MId.7,'98 (1'03); 336 Iroquois Ave. ; office, 32 Adams Are., W. : 2-3; Assoc. Prof. Gyn., Mich.7; (A2); G.*

CHERER, OTTO (b'65)థ-Mich. 5,90 ; $\left(l^{\prime} 00\right) ; 212$ Frederick Ave.; office, 106 Broadway ; $8: 30-11 ; 1-3 ; 0$.`

Schledel, Chas. Cyrus (b'62)-Mich.11,06 (1'06) ; 225 Trumbull Ave.; 2-5, 7-9

SCHMALZRIEDT, THEODORE D. C. ( $\left.\mathrm{b}^{\prime} 73\right)$

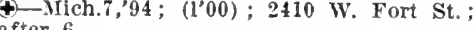
after 6

(1'05); 168 Kercheral Are.; 1-3.6:30

CHOENITH, JULIUS-Mich.8,'93; (1'00); .50 Canfield Are., E

SHORR, ERYEST (b'61)థ-0.12,'82 $\left(I^{\prime} 00\right) ; 114$ E. Elizabeth St.; 8-10, 1-3, IIORR, RORT, LEE (b'73) A-Jich-'93; $\left(l^{\prime} 00\right): 184$ Seward Ave.; office, 133 IIastings St. ; $9-11: 30,2-5: 30 ; \mathrm{S}$.

SCHLLTE, JOSEPH (b'49)-Mich. 2,75
SCIIITFMAN, IFH'TII W. (b'79) offle, 2408 Woodward Are.; $1: 30-3,6$

('IIWANZ, MAITIN J. (b'71)-MIch. 9,00 Mich.7,04; $\left(1^{\prime} 00\right) ; 1649$ Grand Ilver Ave, ofllee, Whitney Opera House Block

SCRIBER, GEO. H. (b'69)-Mich.8,9) ( ['00); 1112 Mt. Filiott A ve.; $1-3,6-\$$.

SCHIBILR, WM. F-MHch.6,83; (I'00);202 Forest Are, E. ; 8-9, 1-3, 7-8

SFABORN, RORT. A.£-Mich.7,92; (1'00) 675 MeDougall Are.

Sowell, Geo. S. (b'90)-Mich.5,'I2; (I'12) Harper Hospitai.

Sermour, A. Victor (b'84) - Mlch.11,06 (1'06); 1500 Fort St., W.

SEYMOUR, WM. J. (b' (I'03); 565 Congress St., F.; office, Fine Arts Blds. ; 2-4; Asst. Prof. Surg. Mich. $7 ;$ S. *

Shafor, II Ienry A.-E-0.2,'99; (I'00); 236 .' Woodward Are.

Shankwiler, Reed Albert (b'86)-IId.1,09 Supcrintendent, Detrolt Tuberculosis Saultarhum.

SIIAIV, MOBT. GEO. (b'66)†-MIch.7,07 (l’07); 706 Kercheval Ave.; 2-4, 7-8; LR HAWAN, HAROLD KOCH (b'84)-0.6,'09 (1'13); 30 Adams St., W. ; $2-4 ; \mathrm{S} . \star$

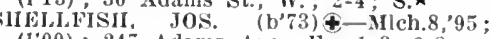
(1'00); 247 Adams Are., E.; $1-3,6-8$.

shelt on. Geo. H. (b'47)-Mich.1,72; (1'00) 6434 th Ave. $10: 30-11: 30,3-5$

sheridan, Chas. Reynolds (b'85)-Md.1,0 Grace Hospital.

SHERMAN, ANDREW T. $\left(b^{\circ} 65\right) \uparrow-M i c h .7$ 95; (I'00); 738 Trumbull Ave.; 2-4.

HEIMAN, GEO. H. (b'58) \&-111.6,'8: (l'00) ; 419 St. Aubin Are.

sherman, Relza Newton (b'87)-Tenn.6,'13 ( ) ; 41 Duffield St.

Sherrill, Edwin S. (b'54)-N.Y.1,'85; (1'00) 34 Charlotte Ave.; offlce, Broadway Market Bldg. ; 9-10, 3-4, 7-8.

SHERWOOD, DE WITT I. $\oplus$-Mich.7, 04 (I'04); 1330 Mllitary Ave.; offlce, 175 Michlgan Ave. ; $1-3,7-8$

SHOTWELI, CARLOS W. $\left(b^{\prime} 78\right) €-M 1 \mathrm{ch} .7$ '03; (1'03) ; 49 King Ave; office, Washington Arcade; $10-11,3: 30-5 ; 6: 30-7: 30$. SHUR1, BURT R. (b'71) $\oplus-M i c h .7,95 ;$ (1'00); A. Surg., M.R.C., U.S.N.; 544 Jefferson Ave.; office 32 Adams Are., IV. 3-5; Dean and Prof. Rhln., Laryn. and Otol., Mich. 7 ; (B1,2,3,5,11).

SIBLEY, CEDRIC PU'NAM (b'86)-Vt.2 '11; (1'12) ; 634 Cass Ave.; office, Fine Arts Bldg. : $1-5$; D. $\star$

SICHLER, EDW. H. (b'75)థ-Mich.7, 96 ; (l'00); 84 Forest Ave., E. ; offlce, Fin Arts Bidg. ; 2-4.

Siefert, John F. ('b'62)-Mich.1,'88; (1'00); 676 Jos. Campau Ave. ; 7-9, 1-3, $7-8$.

Sigel, Paul Ralph (b'89) - Mich.7,'13 (I'13); Breitmeyer Bldg.

SIGEL, TOBIAS (b'62) $\oplus-$ Mich. 7,89 $\left(l^{\prime} 00\right) ; 2916$ E. Grand BIvd.; offlce, Brelt meyer Bldg. : $9-10,1+2: 30,7-8$.

SILL, JOS. (b'75)屯-Mich.1,99; $\left(1^{\prime} 00\right) ; 4$ Warren Ave., E.; offlce, Harper Hospital SILVER, MAXWELL E. $\left(\mathrm{b}^{\prime} 75\right) €-M d .3,{ }^{\prime} 9 \bar{i}$ (1’06) ; 666 Brush St. ; U.

SILVER, MORRIS D. (b'80) - Mo.3,'01, Md.3,'02; (1'06); 154 Alexandrine Ave., Md.3,'02; $\left(1^{\prime} 06\right)$; 154 Alexandrine Ave.
W.: office, Gas offlce Bldg.; 2-5, 7-8; U.

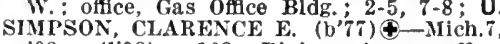
03; (1'03); 103 Blaine Are.; offlice, Broadway Market Bldg; ; $2-4 ;$ Ob'G.

SIMPSON, H. LEE (b'7)థ-Mich. 1,04 ; Grand River Ave, ; 10-12:30, 3-5; (B11);

LR.
SIPE, GEO. K. (b'69)-Mich
2167 Gratiot

2167 Gratiot Ave.; 1-3, 7-8.

Sisler, John Hoy (b'66)-Md.4,'98; (1'07); 418 Grand hiver Are.

Sisler, Lewis E.- $0.6,83$; not in practice; 32 Alexandrine Are., E.

korholt, Hilmar T.-ill.22,'13;

(1'13) ; Grace HospitaI.

SLADEX, FRANK JOS. (b'82)€-Md.7,'06 (1'13); Addison Apts. ; offlce, Fine Arts Bldg.; $1 . \star$

SLEVIN, JOHN HENRY $(b, 72) \oplus-0$ (1'01); 485, 3d Are.; office, Scherer
SLOMINSKI, LADISI.AUS H. †-I11.10,84 (l'12): 1359 ('hene St. ; $9-12,2-5,7-9$; Ob.

meck, Arthur Ralph (I'10); Grace Hospltal.

(1) 867 Porter St. ; 8-10, 2-5, 7-8. R

Smith, Alba Lee, Jr. (b'90)-Mich.7,12 (l'12) ; 867 Porter st. ; 8-10, 2-5, 7-8. (l'07) ; 249 Woodland Ave.; 8-9:30, 12-2. after 6 .

SMITII, EDGAR B. (b'62)†-Mlch.7,'87 (100); 3I 11 hgh st., W., $3-6$

SMITH, EUGENEA-N.Y.6,66; $\left(l^{\prime} 00\right) ; 5 i$ $9-11,2-4$; Clin. Prof. Ophth., Mich.7 (B10,11); OpA.‡

Smith, Eugene, Jr. (b'88)-Mich.T,'12: (1'12) ; 589 Chene st. ; 1-3, 6-8.

SMITH, FRANCHS L. (b'S0)\&-Ulch.I, 02 (1'02) ; 612 Mack Are. ; $2-4,6: 30-8$

SMITI, F. HARVEY (b'i4)-Mich.8, 01 (1'01) ; 184 Alexandrine St., $W . ; 1=3,7-5$ (1'11) IIenry Stephen (b'64) Mich. ${ }^{\prime}, 1$

Smlth, Henry V.-Nich.7, 04; (1’04); 219 4th Are. ; $9-12,7-8$

Smith, II igh L. D. (b'76)-Micl1.8, 04

(1'04); 177 Englewood Ave. ; 8-9, 1-3, $7-8$

SMITH, MARY COFFIELD - Mich.1,91 (l'00); 329 Congress St., E

smlth, Oswald Wayne (b; 6$)-M 0.2,02$ : ( ); 500 John li St. ; Superintendent, Har yer Hospital.

Smith, Theodore H. (b'74)-Mlch., 96

(l'00); 70 Blaine Ave. ; office, Fine Arts Bldg.; $10-12,2-4,7-8$

SMITH, VINE LA RUE (b'75) \$-.llich.? '98; (1'00); 109 Massachusetts Ave.; of

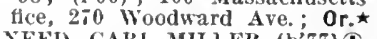

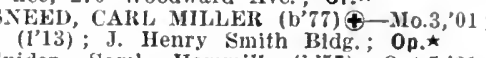
Snider, Saml. IIammill (b'57)-Ont.5,' 81 (1'00) ; 361 Vinewood Ave. : 1-3.

snure, Henry (b's ')-Ky.2,10; 33 E. Higl

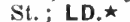

Snyder, Edw. J. (b'85)_-Tex.3,09; not in practice; 243 Porter St.

Snyder, Gardiner F. (b'64)-Md.4,'93 (l'00); 526 Mack Ave.

SOBER, FREDK. JAMES (b'76)-Mich.8. 01; (I'01) ; 408 Seyburn Are.; offle, Gas Office Bidg. ; $1-3,7-8$.

Soper, Grant D.-0.16,91; $\left(1^{\prime} 00\right) ; 352$ Ilichigan Are.

SORENSEN, JEN (b'67)-Den.1,88; (l'00) 353 Brainard St.; offlee, 347 Brainard St. : $11-12,3-4$.

SORÓCK, EMIL MAURICE (b'78)-Conn.1, 08; (1'09); 284 Frederick St.; offlce, 021 Antolne St.; $9-10,2-3,7-8$.

Southwick, Shadrach Wm. (b'67)-Mlch.i. '90; (1'00); 619 Rohns Ave. ; 9-10, 2-3:30, 6-7:30.

Spencer, Frank (b'71)-Mich.8,00; (l'00) 1449 Warren Ave., W.

PILLANE, THOMAS F. - Mich. 7,99 ; $\left(l^{\prime} 00\right) ; 517,4$ th Ave.; offlce, 598 Michigan Ave.

Spllsbury, Fredk. Chas. (b'63)-Ont.3,'91; $\left(1^{\prime} 00\right) ; 354$ Forest Ave., W. ; 8-9:30, $12-2$, $7-8$.

Spinney, Andrew B. (b'35) H - 0.7,'59 (l'00); (Smyrna); office, 502 Goethe Ave. PITZLEY, WM, ALBERT (b'73) 4 Mich.1,97; (1'00); 310 Agnes Ave. ; offlce, 32 Adams Ave., E.; 2-4; Assoc. Clin. Prof. Surg., Mlch.

Spooner, Henry M. (b'73)-ni.10,05, 111.4, 05; (1'03); 813, 4th Ave.

Spooner, Sarah Chamberlain (b'74)-Ill.4. '97; (1'03); 813, 4th Ave.

Sprangel, Michael Jos. (b'45) H-MIIch.3, 71: (1'00); 398 Jefferson Ave. ; 9-12. Spranger, Nicholas M.-Mich.7,92; (1'00) 1013 E. Grand Blrd. ; 8-9, 1-2, 6-8.

Stadden, John C. (b'88) - Neb:6,'13; Intern, Grace Hospital.

STAFFORD, CLAUDE MAURICE (b'81)థMich.7,06; (1'06); 616 Field St.; offlce, Smith Bldg. ; 2-4, 7-8; LD.

Stall, Guy Burrell (b'80)-Mich.11, 04 ; (I'04); 215 Chamberlin St.

STAPLETON, WM. J., Jr. (b'76) £ Mich.8,00; (l'00); 266 Seyburn Ave. : offee, I76 Lafayette BlTd.; 2-4, $:-8$. 


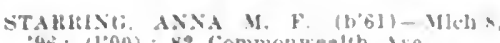
"yti: (I"00); 82 Commonwealch lue

TARRS, THOMAS IHAX (b'Sl) oflec, 250,15 th $\mathrm{si} ; 1-3,-5 ; \mathrm{S}$.

STFALMAX, WHALARD li., JR. (b'S1)

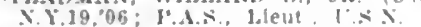

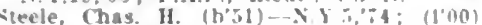
30 Joncust St. : 2-4.

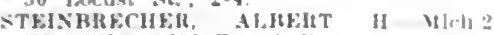
81: (1'00) ; 631 Trunbull die ; oflece, : Adams Are.: $1: 30-3: 30$

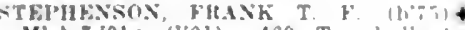

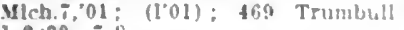

Sterllng, Chas. Fredk - $0.13 \%$ :

404 Jefferson Are.

Sterens. Fred Fo. (b'82) - Mlch. :06 : (1'06) 664 Trumbull Are.; once. Whitney Bld $9: 30-11,2-5$.

sterens, Mary Thompson (b'64) II-MICh.5 "85: (1'00) : 23 Plngree Are.: Pd.

sterens, Nellle May $\left(b^{\circ}: 2\right)-11,19,07$ (1"12): 426 Trumbull Are.

STKVEXS. ROJ.IS HOWAII (b'bs) F Mlch.5, \$9: (1'00): 23 I'lngree Are. : onlce Sterens Bldg. 2-4; Assoc. (Vlin. Prof Derm. and Syph., and Asst. Clln. Prof. Roent. Mlch. ; (G1); 0 .

STEVEXS, WM. CORNING (b'52) ₹-MIch.1 "74: $\left(1{ }^{\prime} 00\right)$; 385. 14th Are.; 12-3, 6-7; G. Stllwell, Donald Lonson (b's3)-\$Ilch. i, l' (1'12); 184 Jefterson die., E.: $\mathbf{S}$.

Stlmpsoa, Robt. A. (b'it) - Mlch.11, 0 i

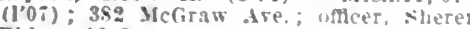
Bldg. : $12-2$.

STIRLING, ALEXAXDER M. (b'S4) MIch. 7,09 ; (I'03); i3 Ledyard St.; offee Washington Arcade; $2-4,6: 30-8$

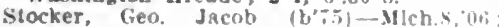
(I'06); 1142 Townsend ive.; $s-10,1-3$ $6-8$.

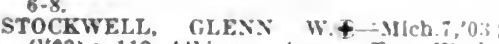
(1"03); 112 Atkinson Arc, oftce, Wash lagton Arcade; $8: 30-10: 30,1: 30-3: 30$

STUART, JHROMF DE: VFRE (1),91) Ga.9,13 : (l'13); 68s, 2d Are.

Studer, Adolph G. (boil)-Mlch.11,03; (I'03) ; 40 W. Hancoch Are. : once, Youn Men's Christlan Assoclation IB]dr.: $9-12$

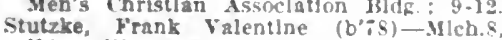

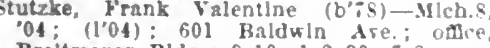
Breitmeyer BIdz.; $9-10,1-2: 30,:-8$.

suder, John F. - Ill.10,02; (1'02); :04 Camplell Are.; 1-3, 6-8.

Sudler, oden R. (b':5)-T), (.2,03: 1" Food and Drug Inspector: 142 Temmsen Are: offlce, United states Court Hunn

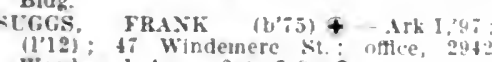
Woodwand Are.: 2-4, i-s: $s$.

Sullivan, Dennls-Mich. 8,$96 ;\left(10^{\prime} 00\right) ; 320$ lith Are.

SCMNER, BENSON K. $(b \div 2) \mp-M(h-$ 02: (I'02); 184 Ferry Are.,

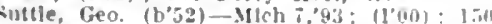
Blalne Are: oflece, letrolt opera llouse HdR. : 9-11, 3-5; OALR.

SWARTZ, JOHX $\mathrm{N}(\mathrm{b}, \mathrm{i})$ - Iflch.1.92: (l'00): 39 Hancock Ave.; omee, Palkey HIdg: : $1-3, \div-8: \mathbf{S}$

TACEY, J. PRESTON-MICh 8 , 96 ; $(100)$; 293 Hancock Are., W; $1.3,7-8$

Tamblyn, Elisha John (b'si)-Blclu 1, 10 ( ) : 2359 Jettersin Ale. F:

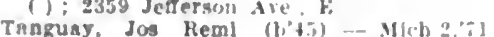
anguay, Jos Reml $(1,+5)-$ II
(]$\left.^{\prime} 00\right) ; 242$ Chene $8 t, ;-10,4-9$.

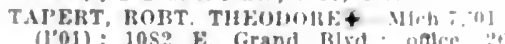
(1'01); 10S2 L. Girand Blvd.; oflece, Brodiway St. : 1-3; $\mathbf{S}$.

TAPIEY, HRNEST TAYLOH (b.5:3)-Y Y I 69: (l'00); 180 l'arker Ire : once, Ilammond Blde: $9.10,2.3$; vinur l'ruf sur. Nich. $\%$.

Tuylor, I"hllander Ji-Mlch.:04: 1104 796 Telen st. : onice, sos Mack Aw

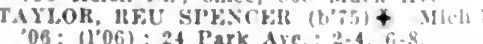

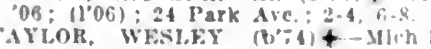

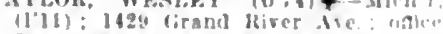
frand River Are., F.: Just. illn l'rul Neur. and I'aych., MIch i: (Ei).

Taylor. Wm. Wallace (boi) - N.Y., (l'13): 60 Watson Sit.

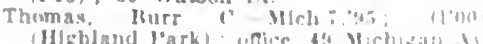

Thomas, cirlnatl a (b:\%3) - Mleh.:00:

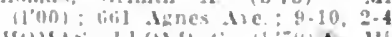

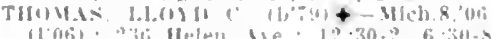

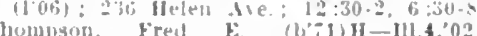

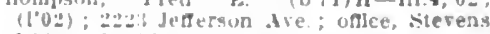

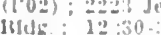

THIMISUN, JAMKS EIIJOTT (b75) Mish.4,03, 111.11.09; (1'03); 2606 E. Jef(erion Ave: $1:-3,6-5$

THIMSOS, WM. (") (b'6e) - Mlch $;, 86$ : (lno) : 13:9 Vermont Are, ottce, Broad" ay Market Hidg.; 2-4, "-8

THCNEIt, MJOIN $\left(b^{\prime} 58\right)+-$ Mlch.2,79: (1'00): 3073 firand Blyd, F. onlce, $3:$ Alams lre, W: 9 -2; ODA.*

THMAIS, FRANK IS('RR $\left(b^{\prime} 64\right)+$-MIch.1, 01: (1'0n); ige Casy dre, : once, 101 fort 4t., w; ; $9-10,2-4 ; 5$.

TICHEXOH, ELMOHE LHANE (b'83)Mlch.,'12; (I'12); 1492 (hene st.; unlce, shurly llide: $2-5$

TIFYI. W.ILTH FDWIX (b66)-Mlch. "94; (l'00); 1 : 70 llondward Ave ; $3-5: 30$,

Toepel, otto T.MUch: :93: $(100): 466$ Jos. Campau dre.: 12-2. b-k

TORREY, HARRY IORTON $(1,80)+-$ IId. "06; (106); 32 idams ire. W: : $2: 30-4$

20 ivlls a Ite. E

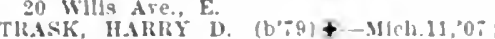
$(107) ; 146$ I'hlladelphLi Ave., 11 ; offlce, Scherer HIdg. : 12-3.

Trigger, Harry W.--11.22,13; Intern, Grace Hospital.

TRIZISKY, (iEO. A. (b':2) - MIch.79s ;

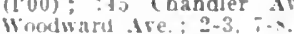

THIIB., HOY KAIL $\left(\mathrm{b}^{6} \$ 6\right)+$-MIch.h, 09 : (109); 211 Woodward Ave.; $8: 30-11: 30$, $2-5$.

TrF'FORD, J. (C. (li6i) Mich.:,94: (l'00): Q1 senard Ave.; oftce, smith Bhlg.: 1-4 $i=8$.

Turbett, claude W. (b's1)-Mllch.11,09: (l.09); 312 Cass Are.; offce, 79 Grand River Are.: $9-10,2-4,6-5$

Turbett Sami 0-H-Ill.4'S8: (1,00): 254 Meadowbrook st.; oftce, $458 \%$ Sherman st. : 8-11, 1-3, $6-9$

TCRNER, ALEX.ANIER LOLDIN (b'st) Mich.1,12: (1'13): 1042 Warren Are. W oftlee, 362 Buchanan st. : $3-4,7-9: \mathbf{G}$.

TYSON, WM. KINIA kILICOTT $(b ; 6)+$ Me. : oflce, 2609 Jeferson Are., $\mathbf{E}$.; 11-1.

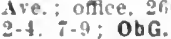

1.BUICH. HE.VRY L.. JR. (b'83) \&-Mlch. "08: (l'0s) ; 630 Mclougall Ave.: $8-9,1-3$, $6: 30-8$

ther, Lucy J. (b'45)-Mlch.6.82; (1'0n) 61\% Cass Are. ; 9.12

AN BALAX, MAIRTE R (b'83)

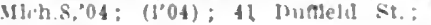
i. $;$; $\mathbf{G}$.

ANJikYF,JFN, ARTHIR (b'63) Uich 1, $85 ;\left(1^{\circ} 00\right)$; 359 Alfred St.; 8.9

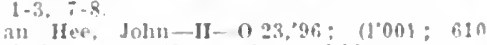
litker st.: offec, seherer isla

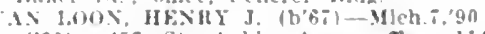

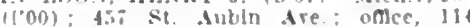
Cratlot Are.: $11-12,2-3,7-8 ;$ Pd.

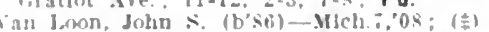
IF Brady st.: unice, "zhat Jeterson the W'

at syckle, Edgar Chas. (h'io)-Mich. Zne

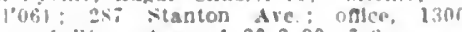
l.rand liber Are, : $1: 30.3: 30$, :-8.

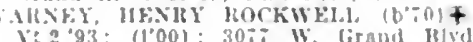
vice, Waslingion Arcade: 9-11. = issoc l'rup. lierm, and siph., Mloh? $(1+1): D *$.

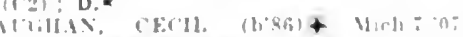
(1007): 1209 Woodwarl Ave; $8-10$, :

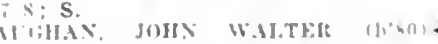

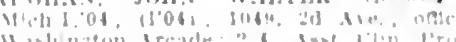

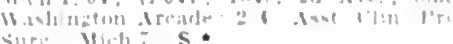

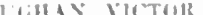

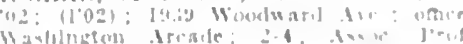

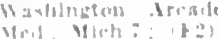

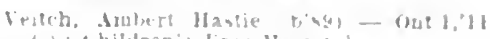

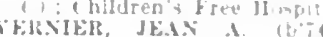
(l'00): 1 in t handler A

lertel, Fdinund

(l'00) 410 rbene $=1$.

Voelkner, (ieo. H. $-\mathrm{II}_{\mathrm{iCl}} \mathrm{i}$

Betluuse Are. 13.

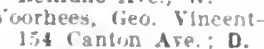

UOHHELS , WIIBLR

2380 Jetrerson Aie; oflce, pine Ars B!dg. : $10-12,2-3$

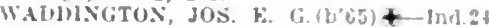
S6; (1.00); itl Trumbuls Ire; chthe smith Bldg: : $-4, ;-8: \mathrm{S}$

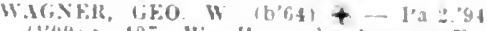

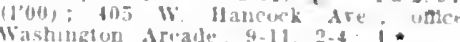

WALEEK, GEO. MATTHEW (W'A)-

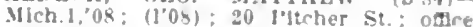
3: Adams Are, W.; $y-1], 2-4 ;(1310)$ OALR, *

Walford, kidgar S. (6'64)-111.11, \$9: (1'00) it Lothrop Are.

WAIKEF, FRANK B. (b'67)+-Micl, F,92 (l'00): 115 Watson st.: Onlce, Washlnz ton Arcade: 11-1:, :-1; Seco ard l'ro? viry. Itich : : S.

Walker, Hiran ibile (b'x)-Wrh , Mo

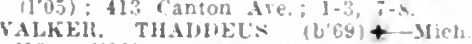
93; (100); (Walkerville, Unt.); utto 23 k. Higl ist

Walker, Walter C. $-0.16,95 ;(100) ; 112$ iladstone Are.

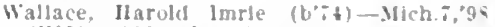
(l'00): 209 (handler ive, ofice, vine Arts Blde. $9.10,2.4,-8$

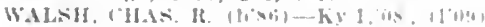
112 Alfred si.; ontce, 736 iratlut die

Ware, Frank hertram (b'si)-ont.1, '1: Intern, Harper Hospleal.

Warren, Wadiworth-Mich.1,'s9; (1'00): :1 Fan lluke 1'1: $9-1,4-3$

Waterworth, Franklly seymour-MIch.:,01 $11011: 53$ wlttell si

ATKIXS, JUHS TAYLOR (b's) Mich.1,06; (1.06); 25 Longfelluw

uflec. Washlngton Arcade: $1-3: 30$

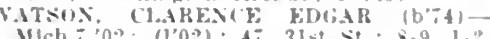
Mich.; 02; (1'02); 4i, 31st st. ; 3-9,1.2

Matson, Edward C. (b'5)-ont.5, wo (1'01): 158 Lincoll

Watson, James A.M.Mlch. I's 3

Way, Frances M. (b'60)H - Mlch 11, 11 . (102); In Idelaide st: $-11 ; 30,:-1 ;$

Welster, bav

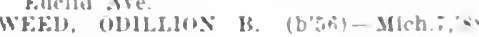

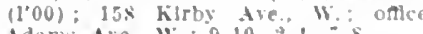

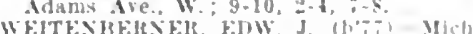

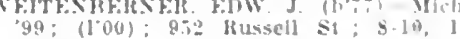
$-\div-9$

Wellinge, samb. II. Mlleb $1 ; 1 ;$; (1'00); 391 lireenwoul tis

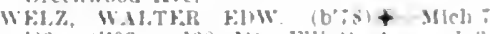
0 ,

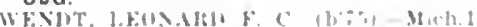
$0:$ : $100 \%$ 10 Masburs lirand b

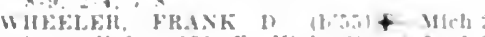

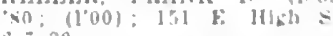

ti. : : $: 30$.

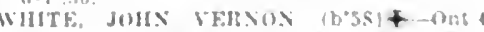

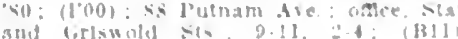
LR *

WHTF. WARK JUINTTH.

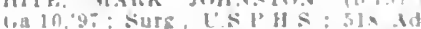

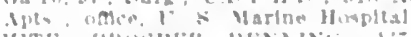

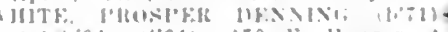
(1ut 3,94 11001): $1: 0$ \% Warren A

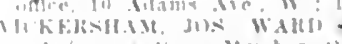
mols in pratelien. Nember

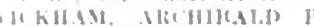

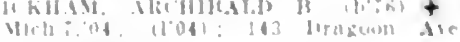




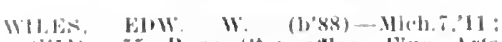

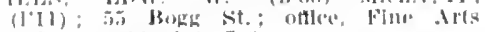

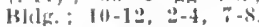

willams Freeman s (b'48) - Nich 1, 75 . (1'07): 68. Van byke Are.: $8-11,2-6$.

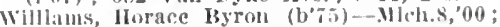
(1,00); 358 . Nitchell Ave, $1-3, \%-8$.

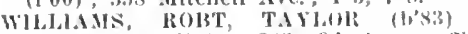

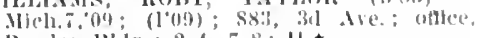
Bowles blig.: 2-4, $7-8$; U.*

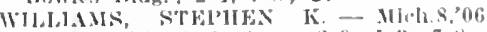
$\left(l^{\circ} 06\right) ; 39 \pi$ ("lark Ave : $8-9,1-3, i-8$

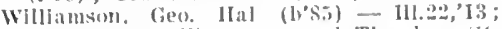
(1'13): Yt killont atr. and Theodore sit.

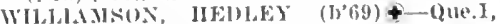
90: (I'00): $184 \mathrm{k}$. IIancock Ave.; ofllee, Gladwhll dblig. : 1 : $30-3$.

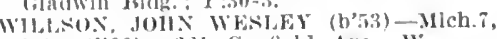
91: (l000): abl Canfleld Avo., w.

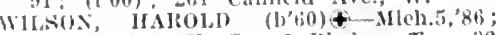
$\left(1^{\circ} 00\right) ; 3061$ W. Grand I3lYd.; offlce, 32

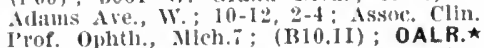

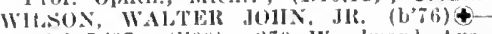
Mlch-97: (l,0t) ; 270 Woolward Ave. 12:30-2; Asst. 1'rof. I'hir. and Ther. Ilich.7; 1.

WILSON, WALTER JOHN, SR. (b'48) कMich,2,79: (1'00); 199 Ferry Ave., k. i-9, $1-3,1 ;-7$

Whsox, WM. A. (1,70)-Mich.7,95: (l’00): 498 IIancock Ave., W. : olfice. Broadway Markel Btdr.; 1-:; ObG. *

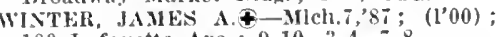
100 Lafayette Ave. ; $9-10,3-4,7-8$.

witter, Wm. Ilenry (b' 71$)$ - Mich.11,97:

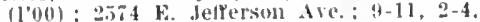
$-9$

WITTWER, WRXEST AlYIX - Mleh.9,00; (I'00): 346 Vinewood St.; offlce, 5 lRelssman st. 12.6

Wixom, Russell I'-Mirh.8,96; $(100) ; 397$

Wixom, Russell I,-Mich. 8,$96 ;\left(10^{\prime} 00\right.$
Greenwood Ave.; untll $9,1-3,6-7$.

WOLLFNBERG, ROB'T. A. C.\&-D.C.2,05; (1'05); 221 Lamrence Ave, office, smith Bldg. ; $10: 30-12$, 2: $30-4$; D.

Wondbery, Ilunter S. (b'86) - Va.I,'II;

$\left(l^{\prime} 13\right)$ : 484 Jetierson Ave., $F^{*}$

Woodrutt, Chas, Asbury (b' 76$)-$ Ind. $8,{ }^{\prime} 00$; (l'10): 409 Trumbull Ave.

WORDEX, AR'THUR LFLAND (b'54)Mich. 1,$79 ;\left(1^{\prime} 00\right)$

WRIGHT. CLINTON C. (b'76) -0.26 , 00 ; (l'00); 445 Sherldan St.; offce, Washlugton Arcade; 10-11, 1-3.

Wright, Geo.-Ont.3,90; $\left(l^{\prime} 00\right) ; 307$ Ferry ire., W.

Wrlght, John B.-Mich.2,'80; (l'00) ; 12 E. Nontcalm St.; $8-10,2-4,7-8$.

YATES, If. WELLINGTON $\left(b^{\prime} 67\right) \oplus-$ Mich. $\tau$, 94: (1'00); 1360 W. Fort St. ; offee, Gas Once, BIdg. : 3-5; Asst. l'rof. Gyn., Mleh.i: (A1); ObG.

Fork. Harry Jacol, (b'79)-X.Y.1,04 (1.ii): not in juctice: 61 Cass Ave.

5OTIG, EDW. BAWL (b'83)థ-MIlch.T, '09; (l'09); 2205 E. Grand Blvd.; 2-4, $7-8$.

Young, Herbert Geo. (b'i1)-Mlch.8,96; (1'00): 176 Chandler Ave.; office, 57 Fort St., W. ; $9-11,2-4,7-8$.

YOLXG, R. KIRK€ - Mlch.7,'94; (l'00); 603 , 14th Ave.

Ziegenfuss. Wm. E. - Miclı. I, '78: (l’00); 327 W. Ilancock Ave ; $1-3,7-9 ; \mathbf{G}$

ZIMMER, LORENZOA-Mich.7,03; (1'03) ; 885 Mébougall Are.

Z1NGER, FRANCIS X. (b'83)థ-Mich. , 07 ; $\left(\mathrm{l}^{\prime} 0 \mathrm{t}\right) ; 423$ Humboldt Ave.; 1-3, 6$7: 30 ; \mathbf{O b}$.

ZLMISTELI, FRED E. (b'66) - 0.9, 00 ; (1'01) ; 95I, 2d Are.; 8-9, 1-3, 6:30-8; Ob.

DE WITT, 450, CLINTON

Banta, Peter H.-Mlich.7,00; (l'00)

('OON, ALFRED RHINEHART (b'85)Mich.5,'12; (l'12)

Simmons, Richmond-0.13,'78; (1'00).

Wheeler, Alfred Minot (b'79)-II.22,09; (1.09).

DEXTER, 726, WASHTENAW

Aner. Fred Levi (b'83) - Mich.s.'11

we W'11). Alex. Sauders-H-Mich.5,'05; liniman. II. K.-Mich.s,97; (l'00).
IIONEY MUBT. BOSTWICK (b'68)థMich.7, $002 ;(100)$.

(1). ('has. W. (2. (1)'5is)-0.14:79: (). WY1.1F, WM. CHAS. (1) 68$)-M l e h .8,00$; (10i)

DIMONDALE, 34I, EATON

lieymul(ls, Theron S.-H-WG.5,98; (l'00)

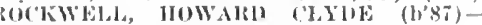
Mlch.l.'lz; (l'I') ; Op.

Delhert 1.--Wo.28,'99; (['00)

DIORITE, 400, MARQUETTE

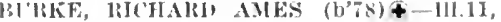
04 ; (1'0(i).

DOLLAR BAY, 1,800 , HOUGHTON

ABRAMS, EDIY, TIIOS.

Clark, fiordon Mc(all (b'88)-Mlleh.I,'13; (l'li3)

DORR, 300, ALLEGAN

B.ACHMAN, GUS'ANE A. (b'73)-Mleh.i 00 ; $\left(1^{\prime} 00\right)$

DOWAGIAC, 5.088 , CASS

BIT INT, STANIAT E. (b'72)-MIch.8, 05 * (l'0.5)

GREEN, GEO. W: (b'71) 1 - Mllch.1,05; (1'05); $\mathbf{S}$.

Ilerklmer, (ico. R. (b'66) H-Ill.4,'90; (l'00) JONES, JOHN H. (b'61) \pm - Mlich.1,'93; (l'00)

КЕ7('HUM. WM. J. (b'50) - Mlch.1,75: $\left(l^{\prime} 00\right) ;$ R.F.D. 6.

MATE1, ELMLER J. (b'67)-Ill,6,'90; (l'00) Mle.laster, Hamilton s. (b'42) E-IIl.8, 71 ; (1'00)

IIELS, CHAS. M. (b'64)-Hll.4,95; (l'00) '.AKEK, WH. E. (b'54)-III.1,79; $\left(1^{\prime} 00\right)$ Robinson, Clarence s. $-\mathbf{E}-111.8 .{ }^{\prime} \mathrm{s9} ;\left(\mathrm{l}^{\prime} 00\right)$ I.F.D.

ILARE, WALTER STOKES (

$111.6,106 ;()$

SQIIER. DAV11) E. (b*9)-Mich.1, 03 ; (I'03).

DOWLING, I35, BARRY

lieller, Guy C. (b'⿳6口)-Mllch.1,'04; (1'04) Pd.

\section{DRUMMOND, 300, CHIPPEWA}

strickland, Wm. T.-Mo.J0,'80; $\left(1^{\prime} 00\right)$

DRYDEN, 37I, LAPEER

BRAIDWOOD, CIIAS. M. (b'75)-Mich: 7,00 ; $\left(1^{\circ} 00\right)$.

PARKEL, IRA E. (b'60)-Mich.6,'85; (l'00)

DUNDEE, 1,070, MONROE

Haynes, John B. (b'48)-Mich.2, $84 ;\left(l^{\prime} 00\right)$ i8; (l'01).

UNGEK, ALBERT EATON (b'61)-0.12,9I ; (1'00).

DURAND, 2,315, SHIAWASSEE

CARNEY, EDWIRD J. $\left(b{ }^{\prime} / 4\right)-$ Ill.l,0I; (l'0).

Cowels, Ambrose (6.-E-III.8,'78: (l'00).

FAlR, ROBT. C. $\left(\mathrm{b}^{\prime} 6 \mathrm{6}\right) \oplus-$ Mich. I, 90

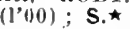

HIXSON, LEWELLYY-Mlleh. $7,9 \pi ; \quad\left(l^{\prime} 00\right)$ ROW'EY, JAMES A. (b'i5)--Mích.1, 03 (1'03).

DUTTON, 125, KENT

Hanna, John K. (b'5i) -Jich.I,'84; (l'00). EAGLE, I33, CLINTON

HOOVER, HAIROLD (b'75) - Mich.9,'03 (1'03).

EAST GILEAD (R.F.D., BRONSON), 50 , BRANCH

kupright, Francis (b'64) E - Ind.II,'88 $\left(1^{\prime} 00\right)$.

Sherman, Fred (b'54)-Ind.1I,'S9; (l'03)

EAST JORDAN 2,5|6, CHARLEVOIX

Dicken, Hugh W. (b'76)-Mich.1,'98; (l'00) Parks, Wm. H. (b'88)-Mich.', 12 ; (I'12) Ramsey, Frank P.-Ill.II,99; (I'00)

ISK, ROBT. ALEXANDER (b'81)-Mich.i, 04; (I'04).

EASTLAKE, 3,000, MANISTEE

KEOLGH, EDW. MICHAEL (b'-6)-Mich.8, 01: (1'01)

EAST LANSING, 802, INGHAM

BHLEGEL, OSCAR H. $\left(b^{\prime}, \tau\right) \Psi-M l \cdot h .1,02$;

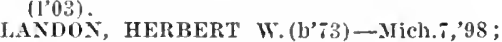
$\left(l^{\prime} 00\right)$

Patm, Milton $\left(b^{\prime} 49\right)-0.6$, , $^{2}$; not in practice.
EAST LEROY, 100, CALHOUN

IAEIANI, MOSIO GENETE

Illch.1, 09 ; (l'0!4); ObG.

EAST TAWAS, 1,452, IOSCO

Nitealy, Albert (b'62)-0.19,96: (100)

TILOM'SON, FREUK. C. (b'tib)-Mlch.I, $87 ;(1,00)$.

EATON RAPIDS, 2.094, EATON

IBRAWIEY, JAMLS BRAY $\left(\right.$ b $\left.^{\prime} 58\right) \leftarrow-I 11 . I$. ' 86 ; $\left(1^{\prime} 00\right)$.

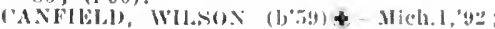
(l'00)

ELIIS, C. WARI) (b'99) \&-Wleh.1,04: (l'04); OALR.

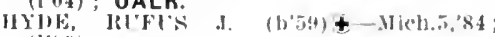
(l'(1)

Long, Davld II. (b'39)-H11.4,70; (l'00)

Long, Fredk. IIenry Moslier (b'69) II-III.10, 95, Mlel. 5,$02 ;(1,00)$.

SIIEETS, ALDEN Gor-Mich, 7,$36 ;\left(l^{\prime} 00\right)$

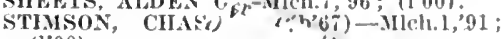
$\left(l^{\prime} 00\right)$

EAU CLAIRE, $30 ; \times a i)>0$.

Fernande\%, Leandee $]^{\circ} \quad(b, 6,71)-M d, 3,96$;

$\left(l^{\prime} 00\right)$

Ilerring, Jolin H. (h'E, , (l'00) Rinkenberker, $A . \quad$ iJ.
(['00) ; Pd.

ECORSE, I,063, WA' Higd Av'

DIROCHEH, ED.IU 1 /5FIE

(See Detroit.) iN St.

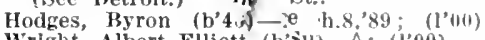

Wright, Albert Elliott (b'su)- $\rightarrow$; (lon).

EDENVILLE, 173, MIDLA ID

Heslo1), John E.-Ont.5,'87; (1'00).

EDMORE, 752, MONTCALM

I'IRDOON, JAMES (b'70)\$-1'a.2,'97

Wardell, Louls A. $\left(b^{2} 82\right)-$ Mlch.7,'11; (l'11).

EDWARDSBURG, 400, CASS

Dugdale, Thos. Alfred (b'83)-Ind.20,'08

ONKIN, ERNEST WALTER (b'70) Ilch.7,95; (I'00); 0pA.

\section{ELBERTA, - BENZIE}

Larue, Frank John (b'72) - Mich.10, 06 (l'06).

ELK RAPIDS, I,673, ANTRIM

Dustin, Herbert D. B. $\left(b^{\prime}, 0\right)-$ Ill.8, $\%$ Ill.11,93: (1'01); not In practice: R.F.D

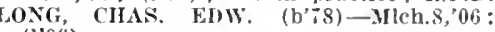
(l’o(j). Moseler, Inhn Hamilton (b'53)-Mo.5,'74,
Mo., 6 ; (l'05).

IERKES, LOUIS NORMAN (b'65)-Mich.8, $04 ;(1,04)$.

ELKTON, 553, HURON

MONROE, DENCAX J.(b'75) \&-Mich.9,'03 (I'03).

ELMER (R.F.D. SANDUSKY), II0, SANI-

LAC
Wallace, Jos. (b'53)-Mich.2, $84 ;\left(\mathrm{l}^{\prime} 00\right)$.

ELM HALL, 362, GRATIOT

SHAFFER, JOIIY R. (b'53) \&-Mich.I, 76 : $\left(l^{\prime} 00\right)$.

Wilson, Ldward-IIl.4,85; not in practice

ELOISE, 700, WAYNE

Ahlborn, Augustus $\left(\mathrm{b}^{\prime} 66\right)$ - Mich.8,'90. ( $\left.{ }^{\prime} 00\right)$.

HOWELL, ROBT. B. (b'69)-Mich.7,9: ; (l'00); NP.

MARKER, JOHY J. (b'63)\&-Mlch.1,'90 : $\left(l^{\prime} 00\right)$; Asst. Clin. Prof. Neur. and Psych., Mich.7; (E5) ; N.

\section{ELSIE, 592, CLINTON}

Beal, Geo. H. (b'70)-Mich.7,'92: (1'00).

BELL, WALTER SCOTT $\left(\mathrm{b}^{\prime}, 2\right) \vec{\oplus}-\mathrm{Ia} .3,9 \vec{\imath}$; (l'00).

PORTER, CHAS. B. (b'i2)-Mich.1,99; $\left(l^{\prime} 00\right)$.

Travis, James H. (b'48)-Mich.I,'7\%; (1'00).

ELWELL, 100, GRATIOT

MacLACHI.AN, CHIAS. (b'45) - Me.2,'82; (l'00).

EMMETT, 292, ST. CLAIR CIIESTER, JOHN ISEONARD (b'6T)-

EMPIRE, 578, LEELANAU

Shank, Laban H.-H-Wich.5,'89; (1'(12). 
ENGADINE, 150, MACKINAC

KIT.IT\%E. I.UI'IS IGUIST $11, \mathrm{~S}: 1)$ III II, 1::

4l. 1.1

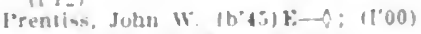

ENTRICAN, 50, MONTCALM

W(M)

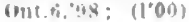

ERIE, 350, MONROE

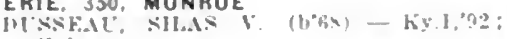
(1) (un)

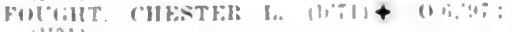

ESCANABA.13,194. DELTA

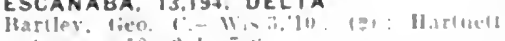
Are: $=10,-10-5$

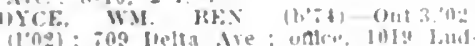

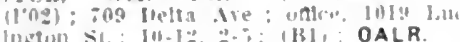

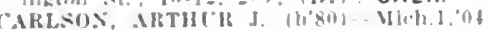

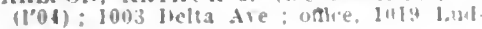
Innton st: 1-t- - .

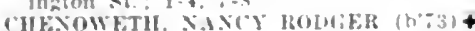

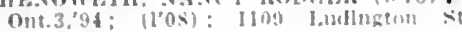
$3-1 ; 6$.

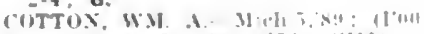

loube, ineter C.-Ont.

ELLIOTT, WM. (b'6i) + - Mnt.l, $97:$ : (190) $911 \%, 2 \mathrm{~d}$ si. oftl

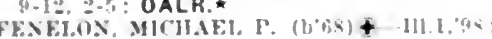
(1)00)

GIRARD, MIS I. $\left.\left(b^{3} \pi\right)+-1\right)$ met at

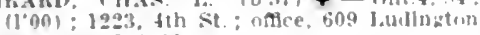
sit. : :-7, $:-8: 30$.

lirome, John olto (hora) - 111.11.02: ([0:-1) 101 Wells tre - 8-9 l-3 $=-9$

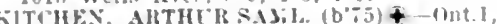

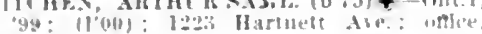

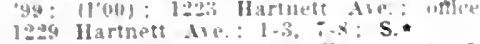

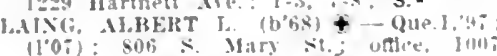
$\left.11^{\circ} 07\right):$ Sob $\&$ Mary s?.

Ludington St.; 1-i, ;-s: S.

Lambert. Oscar Bermhardi 1, st Th

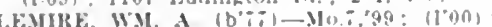
1300 Hale St : once, 1101 Jadingtom $\mathrm{st}$ 1300
$1-3,-8$

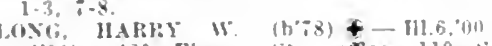
(1,00): $\$ 20$ Fimore st: oflee, 110 : Ceorela si. : $2-4$. :-

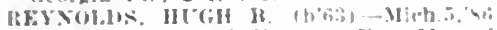
$(1006): 300$ Canuplell st : oftlce. Masonic Temple: $1-4: 5$

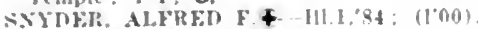

ESSEXVILLE, $1,477,8$ AY

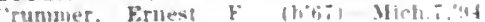
11001 .

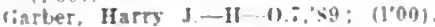

EUREKA, 208, CLINTON

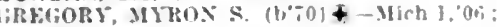
$\left(1^{\prime} 06^{\circ}\right)$.

EVART, 1.386, OSCEOLA

(onover. Wellington James (b"ii) - Wha inn: iton)

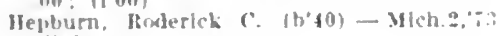
(1,00).

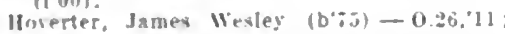
(I'11).

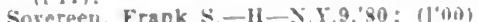

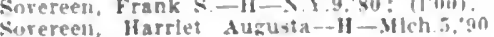
(1'00).

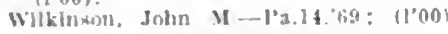

EWEN, 350, ONTONAGON

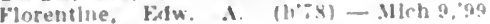
$11^{\circ} 001$.

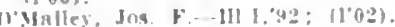

FAIRFIELO, 350. LENAWEE

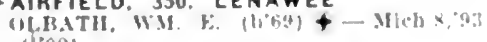
(I"nO)

FAIRGROVE, 437. TUSCOLA

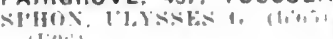

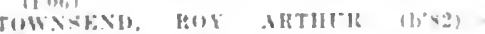

Mll.1.11: 11"111

FAIRVIEW, 20, OSCODA

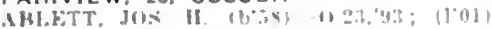

FALMOUTH, 200. MISSAUKEE

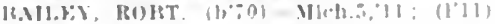

FARMINGTON, 364, OAKLAND

Hnlcomb. Fillu? $\mathrm{r}$. ( (1'00)

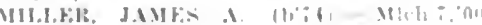

FARWELL. 522, CLARE

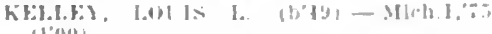

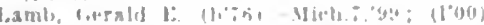

FENNVILLE, 333, ALLEGAN

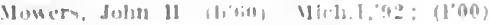

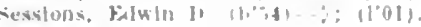

FENTON, 2.331, GENESEE

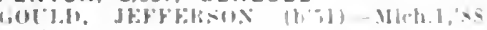
(100)\}

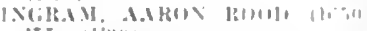

a.: (I) (I) (1)

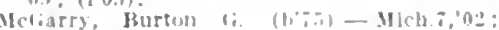
(1002).

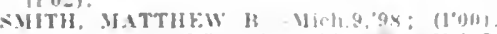

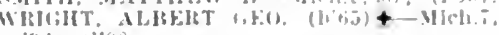
9.j: $11^{\circ} 001$.

FENWICK, 350, MONTCALM

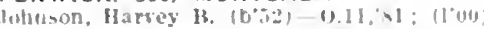

FIFE LAKE, 340, GRAND TRAVERSE

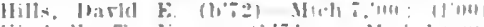
kimball.

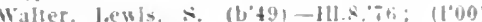

FLATROCK, 650, WAYNE

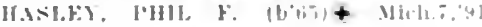

(1)

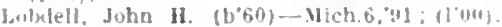

FLINT. 38.550, GENESEE

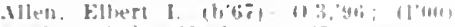

Migle, seth Marion (b)it)-Mich.i,ot; (1) : 111 b. 1 st st.

HAHLMAS, GORION HEXKY (b'si)Hich.1,13; 11.13); 321 H. 3d si.; ottice,

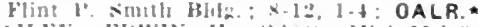

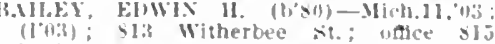
Witherbee st. : $6: 30-9,12-3,5=7$.

laker, Frank ismond-Mich.], so: (1'mo)

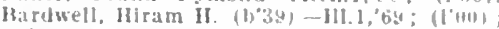

ili llatrison sio

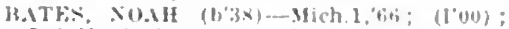

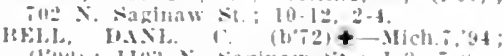

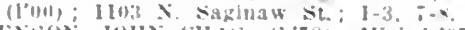

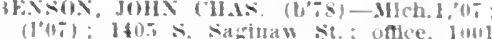
(1"4) : 140: 5 . Saglmaw st.

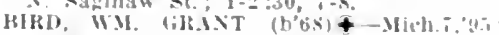

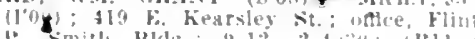

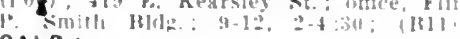
OALR.

Bradt, lien, II. II 11.23,toz: (100ut,

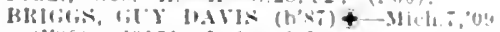

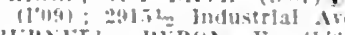

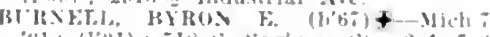

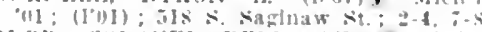

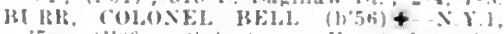

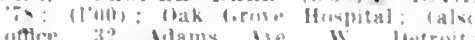

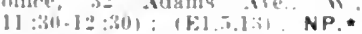

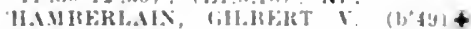

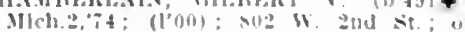
Ho

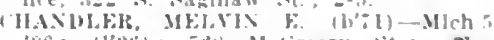

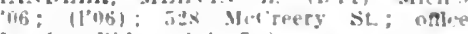

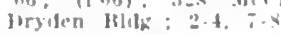

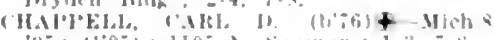

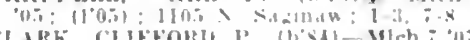

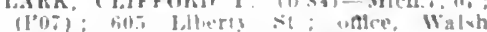

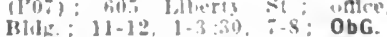

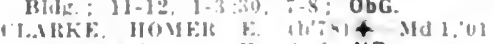
(1'uis): (Dak lirule Huppltal; NP.

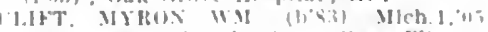

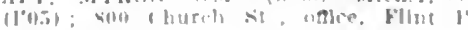

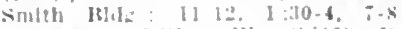

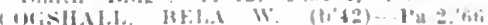

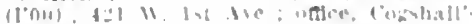
rantarlum.

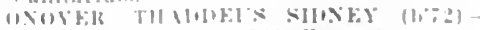

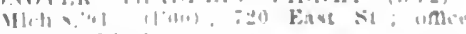
lirullun liken

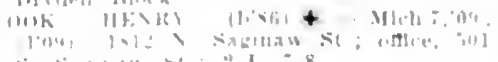

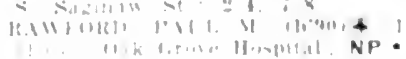

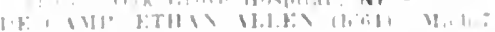

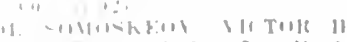

H1341) 1.101111 1.

and Hiandi, Hith

fivilis solls

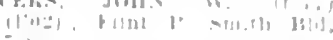

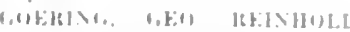

$\begin{array}{ll}1 & t\end{array}$

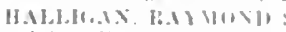

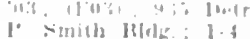

Hallw.k. Latuls Henty

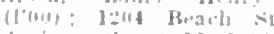

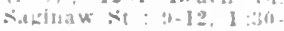

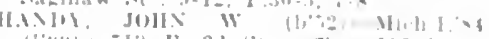

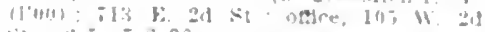

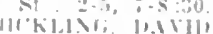

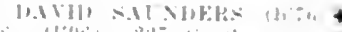

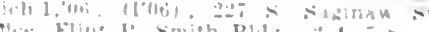

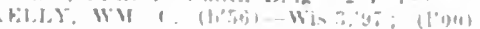
111 lbetrult st. : $=-4.7-8$

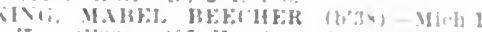

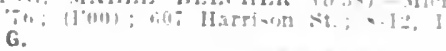

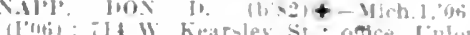

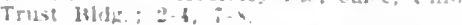

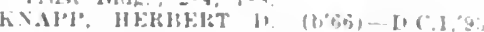

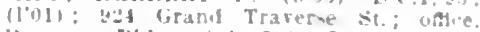

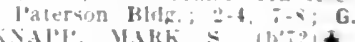

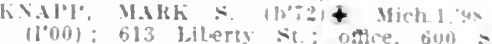
saghaw st. 2-4.

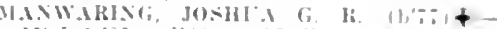

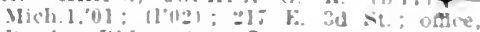
bryden Mldiz, : - i: S.*

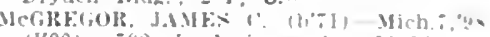

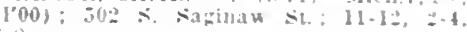
- -8.

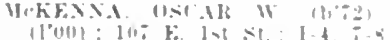

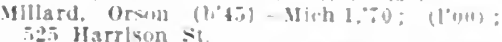

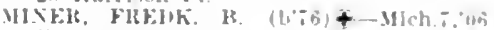

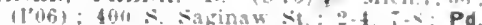

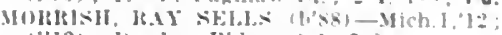
(112): Jyrgen $131 \mathrm{dg} ; 2, i, s$

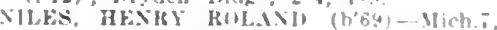
94: (1'00); 100iti lirand Traberve si. whtee, Jllchigan sihoul for beas?

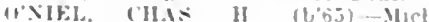
$(100)$; $314.3 \mathrm{~d}$ ive., II, ottice, sazinaw s.t.

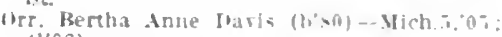
$(1,06)$

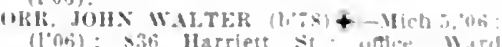

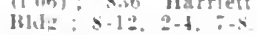

Puterwan, Architald - Mich $1,2 \times$ : (l'ph) $290:$ Industrial tre

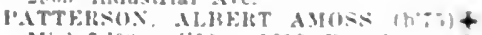
Mho:"og: (1'0!): 1933 Henadway: B

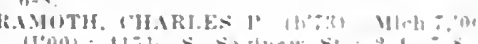

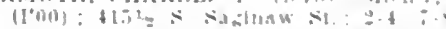

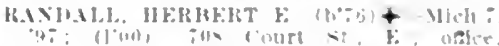

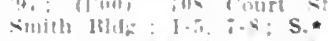

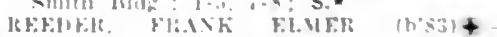

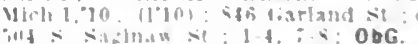

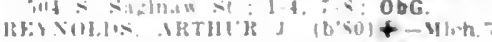

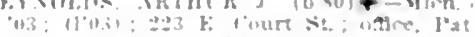

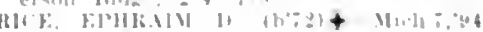

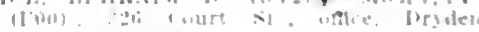
lliwh: : I. :

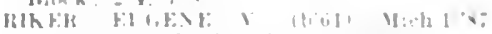

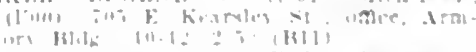

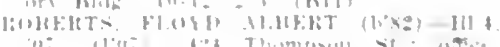

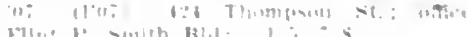

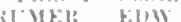

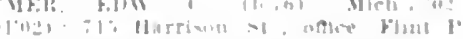

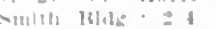

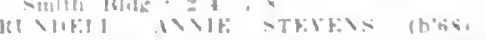

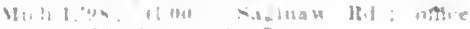

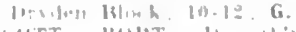

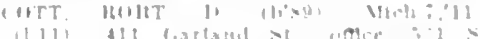

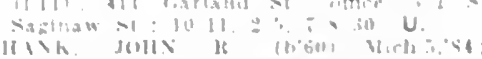


STEWAIT HLGII ALEXANIDER (b'82) + Mllch.7," $(16$ : $(106) ; 929$, tason st. : onlee, Dryden Bidg. 2-4, 7-8; $\mathrm{S}$.

CTUART, JAMES D. (b'-4) - MIA.6,99 $\left(1^{\prime} 00\right)$;. Kearsley st.; once, Flint I' smithi blelg. : 2-4, $:-8$

TAYLOR, WAIRREN 11, (b'73) - Mlch.7,'96 $\left(1^{\prime} 00\right) ; 112$ F. Court St.; once, Dryden 13lock; 2-4, 7-8.

Thomas, Hiram R. (b'4t)-0.16,'93; (100) : 275 North st.

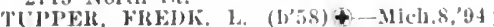
(I'00): I008 N. Saginaw St.

"HITAKEI, WM. J. (h'63)†-Mich.8,9s (l'00): 933 letrolt st.; oflle, Fllnt $I^{\prime}$ smith Bldg.; 2-4, $7-8$.

WINCHESTHR, WALTER HENRY (1,75)X.Y.I.00: (I'11): 1027 ('hureh st.; of flee, 615 S. Saglnaw St.: 2-4, 7-8: S.

FLUSHING, 938, GENESEE

HOITON, JOIIN H.-Mích.8,04; (l'04).

SCILLIDLER, 30s-MIfCh.5'01; (I'0L)

SMITH, DE YEISE (C-VICh. 1,03 ; (1'13) ; ob.

FORD (WYANDOTTE P.O.), - WAYNE

Irodersen, Harrey saml, (b'S8)-Mllch.1, '12; (1'12).

FORESTER (R.F.D., CARSONVILLE), 116,

Boy, Henry (b'57) - Ont.5,'85; (l'00).

FORESTVILLE, 234, SANILAC

tephens, Alexander (b'42) - Michll, $6 b^{\prime 2}$ $\left(\mathrm{r}^{\prime}(0)\right.$

FOSTER CITY, 300, DICKINSON

HOHL (IISTAWIS W. (b'T3)+-Mich.T $97:\left(l^{\prime} 00\right)$.

FOSTORIA, 400, TUSCOLA

JOIINSON, OHEN (¿. (b'T2)-Jllch.i, 05 (105)

FOUNTAIN, 300, MASON

'Turner, Horace J. (b'49)-Mich.I,'69; (I'00)

FOWLER, 476, CLINTON

(ook, Henry (b'7t)-Mllch.7,00; (I'00).

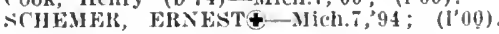

FOWLERVILLE, 905, LIVINGSTON

cooper, Aaron W. (b'tu)--llich.1, "68; (I'00)

('UNNISGHAM, JOHX E. (b'61)-Mich.; 94: (l'00).

ILEN, BERNARD II. (b'82)థ-Mich.I, '08; $(1,08)$.

lamoreaux, Chas. H. (b'55) - Pa.17,'75, III. 8,$83 ;(1,00)$

IICGARVAGII, JOS. A. (b'82)-MIich.7, 0 $(105)$

FRANKENMUTH, 693, SAGINAW

Hohn, Fred J. (b'78)-Mish.8,04; (1'04).

I'illsbury, Edward A. (b'i i)-Micis.I, 03 (I'03).

FRANIKFORT, 1,555, BENZIE

HOYLE, CHAS. I'. (b',2)€-Mich.l,'9.; $\left(1^{\prime} 00\right)$.

KINNE, HUDSOX J. (b'61)€-Md.4,92; (1'00)

Yoorheis, Isaac $\left(b^{\prime} 32\right) \mathrm{H}-\mathrm{O}:\left(l^{\prime} 00\right)$.

FRANKLIN, 150, OAKLAND

GERMAN, FRANK D. (b's0)-Mich. $t, 06$; (1'06); 0 b.

FRASER, 220, MACOMB

(iROYER, FRED (b'59)-0.12,'86; (I'00);

FREDA, 500, HOUGHTON

('ORNELL, HAKOLD DAYIS (b'84)€ Ilich.1,'10; (l'10).

FREDERIC, 400, CRAWFORD

heighton, James Allison (b'5i) - Ill.4,'85 ; (1'00).

MCDONEELI, JOHN E. (b'56)-MIich. $s, 02$; (I'02).

\section{FREELAND, 450, SAGINAW}

(line, Danl. H. (b'63)-1lo.1,91: (1'00).

IIndson, Chas. H. (b'72)-0nt. 5,96 ; (1'(0).

Ostrander, Frank W. (b'80)-Mich.9,0I (1'01).

FREEPORT, 460, BARRY

Carpenter, Jasper H.-III.10,'90; (I'00) : not in practice.

Miller, Arthur 0 . (b'73) H-0.26.01; (1'01).

IIITTERIXK, JOHA W. (b'TI)-Mich.1.'01, (1'ค1).
FREE SOIL, 250, MASON

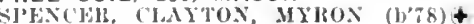
II. $1.1,07$; (1'07)

FREMONT, 2.009, NEWAYGO

B.IIÑIM, WM. II. (b'T3)-MJeh.9, 02; (ग02)

Hillsis, (l'04).

II: I.IS,

ove (1) (1) MeXabb, Joln w. (1'46)-Ky,1,94; $\left(1^{\prime} 00\right)$. Nortus, Iorenzo F,-N.Y.10,73; (l'00); not In practice.

FRONTIER, 225, HILLSDALE

Nolilis, RALIII A. (1) 85 )--Wich.11,'11; (l'11).

FULTON, 350, KALAMAZ00

LEF, I. WAINE (b'7t)-111.22,08; (1'12)

sinyder, Saml. 13. (b'5s)-Mlel..1,85; (I'00).

GAGETOWN, 358, TUSCOLA

MORHIS, WM., SR. $\rightarrow$; (I'00).

SCGNET, WM. J. (b'80)‡-Mich.1,05. $\left(I^{\prime} 05\right)$.

GAINES, 238, GENESEE

COVEIT, WLOYI ILON (b'79)-MIll. 7,06 ; (l'06) ; (Genesee)

James, ulchard falinsforth (b'83) - Mich. 04; (I'04); OALR.

GALESBURG, 656, KALAMAZOO

bOYl.k, CHAS. F. (b'62)\&-MICh.7,'9;; $(1,00)$.

IIOBBS, EDW. J. (1,68)-111.11,97; (1'00).

MOGEKS, LA VERN I. (b'82)-Mlleh.1,07; $\left(1^{\prime} 07\right)$.

GALIEN, 405, BERRIEN

Snowden, Robt. H. (b'78)-I11.6,06; (1'09).

GANGES, I00, ALLEGAN

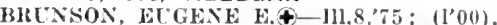

BRUNSON, ELGFNE TAYLOL $₫$-Mich.1 06 ; (1'06).

GARDEN, 497, DELTA

Irughes, Win. A. (b'63) P-.I - Ind.26,'94; (l'00).

GAY, - KEWEENAW

Ramsdell, Honer Atkinson (b'89)-Mich.1, $12 ;()$.

GAYLORD, 1.538, OTSEGO

Ford, Elmer L. (b'61)-Mlo.28,'96; (1'00).

FORD, RUEY o. (b'61) $\rightarrow$; (1'00).

HARIIS, LEVI A. (b'58)-IIich.2, 84 ;

KNAPP, IIAIRRY W. (b'ĩ)-Mich.7,03; $\left(1^{\prime} 03\right)$.

Richards, Geo. G. (b'7 T)-Mlich.1.04: (l'04).

GENESEE, 101, GENESEE

('OVERT, FLOYD EFON

(See Gaines.)

GERMFASK，750， SCHOOLCRAFT

Camplell, Norman S. $\left(b^{\prime} 7 y\right)-$ Mllch. $80^{\prime 2}$. (1'02).

GILFORD, I00, TUSCOLA

ORR, EVERET'T ALEXANDER (b'80)‡ Mich.11,'03; (l'03).

GIRARD (R.F.D., COLDWATER), 250 BRANCH

HAXCOCK, ERNEST E. (b'74)-Ky.5,'0I ; (I'01) ; Pd,

GLADSTONE, 4,211, DELTA

Bidwell, Edw. Hamilton-N.H.1,'84; (1'12). BJORKMAN, OTTO FREDRICK GEO. (b'67) (4-Neb.5,'95; (1'02).

KEE, DAVID NOBLE (b'60)థ-Que.L,'90 ;

MIILER, ALBER'T HARVEY (b'81)Iich in'04: (I'04).

MTCHELL, JAMES (b'70) - Ont.5,'99; (1'00).

GLADWIN, 988, GLADWIN

BOULTON, ARTHUR O. (b'it)-Mich.i, $00 ;(1,00)$.

Finch, Russel E.-E-D; $\left(I^{\prime} 00\right)$

LEININGER, JOHN W. (b'57)-Ont.6, 91 ( $\left.\mathrm{l}^{\prime} 00\right) ; 0$ p.

SUYUANDT, CHAS, G. (1)'53)-Mich.1,'sI; (1'00).

GOBLEVILLE. 537, VAN BUREN

BENNETT, CHAS. L. (b'75) \$-MIch.1,04: (l'04); OALR.

SMITH, HCGH EMORY (b'-3) $₹-I 11.11,01$ $\left(\mathrm{I}^{\prime} 00\right)$.
GOODELLS, I50, ST. CLAIR

Mer'TH, CHIRISTOI'IHEL (b'69)-0nt.s,"90 $\left(1^{\prime} 00\right) ; A L R$

GOODRICH, 300, GENESEE

ICIONAI,D, CHAS. FRHD (b'70)-MICh. $97 ;\left(l^{\prime} 00\right)$.

AMOS S. (h'61)屯-IIich.l

$88 ;\left(1^{3} 00\right)$.

GOWEN, 160, MONTCALM

lozar, chas. H.-II-Mich.7,'0I; (1'02).

GRAND BLANC, 300, GENESEE

PARKEK, JAMES W. (b'72)-IIJch.1,'08 (1'00)

REID, WEILS COOK (b'S6) \&-Mo.2,'12; (I'12).

Slaght, Andrew (b'32)-Mllch.1,68: (I'00)

Slaght, Wm. M.-IIJch.1,89; (I'00)

GRAND HAVEN, 5,856 , OTTAWA

WF KLEINE, W.I. (b'7) $\oplus-111.6,06$; (1'06) beWitt, Stuart Lloyd (b'89)-Mich.I, II (l'11).

HOFMA, EDW. (b'59)-Mlch.I, 84 ; (l'00).

Iofma, Ellzabeth F'ruln (b'59)-Jll.9,'91 $\left(I^{\prime} 00\right)$

Palmer, Phylander-E-O: (1'00)

PIRESLEY, W. JEANINGS - Mich,10,0I ; (I'01).

Reynolds, John M. (b'44)H-M10.5,'67; $(1,00)$.

YANDER VEEN, AREND (b'40)†-Ala.2, $86 ;(1,00)$

WALKLkY, WYLLIS S. (b'46)-Mich.1,'79; $\left(1^{\prime} 00\right)$.

GRAND LEDGE, 2,893, EATON

Conklin, Fred Lawton (b'88)-Mleh.1,'I3: (I'I3); $\mathrm{S}$.

Davis, Wm. A.-Mich.1, 58 ; $\left(l^{\prime} 00\right)$

IIIXSON, IBRAM N.-Milch.I,"83; (1'00)

HIXSON, MARTHA ESTELLE (b'67) Mich.10,0 T; (1'07).

Lown, Clyde A. (b'il)-Mich.5,'04; (1'04) IcCoy, Farl M. (b'8I)-Mich. T, 02; (I'02) SCHILZ, KDIVARD A. (b'72)-Mich.8,9i; (I'00).

Stanka, Andrew Geo. (b'79)-Micl.1.'09: (1'09).

Wilson, Walter E.-Mich.7,'9I; (1'00).

GRAND MARAIS, 2,500, ALGER

Cady, Isaac Mlller (b'i1)-Mich. 7,07 ; (1'0\%).

GRAND RAPIDS, I|2,571, KENT

NUMBEK OF PHYSICIANS, 2.2.

Adkin, Geo, R.-Mich.10,99; (1'00); 84 IIonroe St. ; $9-10,2-4,7-8$.

Albright, Jos. (b'37)-Ont.3,72, Ont.3,73; (1'00); 37 Scribner St.; offle, $342 \mathrm{~N} . \mathrm{W}$. Bridge St. : $8-10,1-3, i-8$

Allen, Wm. E. (b'58)-Ill.11, $85 ;\left(1^{\prime} 00\right) ; 809$ Sutton Ave.; office, 2001 Division Are., S. $9-10,2-4,7-8$.

APTED, RALPH C. (b'76)-Mich.I,02 (l'03); 40 Ranson Are., N.E.; 4-6, $7: 30-$

Ardiel, James-Ont.6,'99; (1'00) ; 411 Pleasant St., S.E.

Atherton, Lucy C. Harrison (b'57)-IIl.9,'90 (1'00); E. Fulton st.; 10-12, 2-5; chlropractic.

BAERT, GEO. HENRT (b'70)-Pa.I,'93; (I'00); 543 Madison Ave.; office, 16 .11onroe Ave. : 3-5, $7-8$.

Baert, Oscar (b'6T)-Mich.1,90; (1'00)

Widdicomb Bldg; $2-4,7-8$

BAKER, ABEL JAMES $\left(b^{\prime} 75\right)$ - IIich.1, 04; (1'04); 1143 Turner Ave.; office, yl Monroe Ave.; $11-12: 30,3-5$.

Bäker, Harley N. (b'64) H-Ill.15,'y4; (1'00) $35 \mathrm{~W}$. Brldge St.; $10-12,1: 30-3,7-8$.

BARTH, LOUIS (b'58)—-Ger.20,'8I; ( $\left.\mathrm{l}^{\prime} 00\right)$; Fuiton and Ransom Sts.; $12-5: 30,8-10$.

Bassett, Merritt G. (b'68)-MIlch.1,'90 (I'00); $33 \mathrm{~W}$. Burton St.; 2-4, 7-9.

Batdorf, Jacob C.-0.3,'64; (1'00); 301 lames Ave., S.E.

BEEL, IIORACE JAMES (b'87)-N.Y.6,09 (1'10); 111 Central Ave.; office, 109 State St. ; $1-3, \vec{i}-\mathrm{S}$

BEE.IAN, CORIAA E. $\left(b^{\prime} ; 4\right)-0.26,03$ (I'03) : 153 Fitzhugh Are.; office, Widdicomb Bldg. ; 9-12, 2-4:30; OALR.

BELL VANDIVER I (1, 844 S. Dirision Are.; $8-9,2: 30-4: 30,7-8$ BERGE, FRITJOF ENIL $(168) \oplus-$ IIch.1

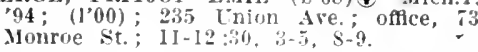




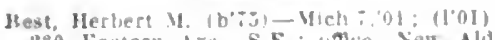
"20 Fasterus ire. SE.; othere ven Ald rich Wirk: S

HIOHA, KABL+-111.1.85: (1901): 21: Neury Are., 3.5, :-8: ObG

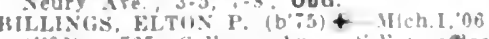
(l'0s) : 365 (college tre

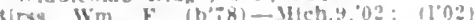

to Jelauaro

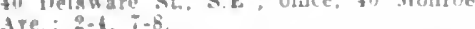

Iflackburn, IIeney Martin (b's:4)-Tinn.5. 'L3: Intern. Hutterworth Hondtai

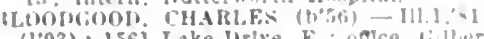
(1'03): 156i Lake Irlve, ki; oflce, libiert BIdE:; 10-12,2-5; OALR.

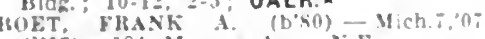

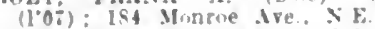

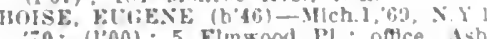
60 ; 100$): 50$,

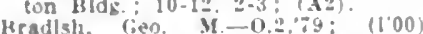

Kradlsh, Ceo. M-0.79: (T00)

IRADY, JOIIN E. (b'3i) $+->16,60$ $\left(1^{\prime} 00\right)^{\prime} ; 233$ Sheldon Are.: ualde, What comb BIdz. ; 9-12. 2-5.

Urigham. Homer C. - II-N. I.9,72; 11001 401 Terrace Are., S.W.; oflce, Widdicoml. BId 2 .

BROWN, FRANCIS W.

inlun stallon.

HROWVING, FUGENE SHEITIFY (b'SO vich $705:$ : (1.05): Powers Theaser Bld $2: 30-5,7-9$.

Bull, Chas. H. (b'66)-Ont.4.9:; $\left.(1)^{\prime} 00\right)$ $55 t$ Division Are., S, ince, 3 i Monr Are.: $11-12,2-4,:=8$.

Burleson, Gea. S. (b 65$)$ - Mlch.; ; 12 ; (1) la 929 Iake Drive, S.F.; utllce, if Monri Are ; $2-12,2-5$; Pr. *

Burleson, John F. (b'78)-Mich. 7,$06 ; 11^{\circ} 0$ a 328 Morts St.: onice, 14 Fulson sit

Burleson, Willard M. (b'68)-Mllch.9."a! (1'00): 451 Paris Are, S.E., offlce it. Fulton St., S.E. 9-12, 2-5.

BYERS, EARLE JOHY (b+85) - $111.11,0 \mathrm{a}$ (1'11): Member III. State Med. soc.; I4lit Wealthy Are: offlce, $\$ 1$ Monroe live. 11-1:,2-4, $7-8$

CAMPBELL, ALEXANDER MACKEXZI $\left(b^{\prime} 73\right)+$ Mlch.;, $06 ;\left(1^{\prime} 00\right) ; 222$ Madisin Are.. S. H.: nace. Metz Block; $3-5:$ S.

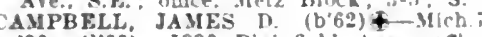
"96: (1'00) 1339 plainfleld Are.; ofticp 1418

S. (1'00): 1:01 Lafagette Ire., S.E.; office

Metz Blds: : 10-4; OALR. $\left(l^{\prime} 00\right) ; 407$ Cass Are.s.E.; oftice, Jurfir Block."

CHADWICK, HARVEY JFXXER (b'5 Mleh 6.81 : $(1,00): 420$ Franklio st 10-12, 2-4, $7-8 ; \mathrm{G}$.

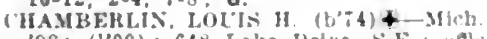

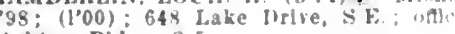

Amiton BIdg. $2-5$. 605 Stocking St. : once, nitis sitocklum si

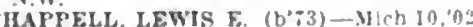
(1'02): 6ts, th St. once, 646 Stocklog

Collisi, Harrison Smlth (b'83) - Mlich.1, 1: (1'12): 645 I'arkwoort Are, N W.

CORBUS, BURTON R. (b'5) - I11.11,00 (1.02): 231 ltalon Are., S.E.: omce, Mett HIdR.: 8-10, 2-4; 1,

Cornell, Arthur Saml.-Mllch 1, as; $\{1$ '00

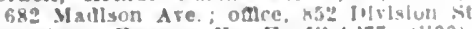
ummings, Erastus I1-11-[11.4,77; (100) ummings, Erastus il-h-IIt-

DAl.ES, ERSEST WFIKKR (b'S4)-MIch I 03: (1'08): 824 Tumer Are.: once, Monroe Ave. 11-12,3-3.

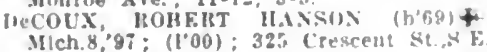
imce, porier llock.

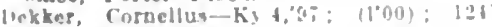
l'lalnfleld Are.

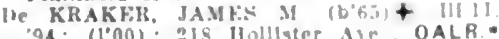
DeLano. Wm.-F-0.2,85: (1'00): not in Dractice: 322 inton Ave, lennis, Jos. De Ville ib

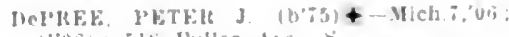

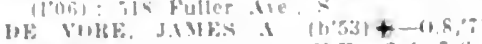

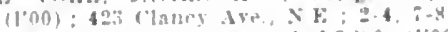

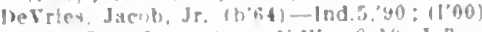

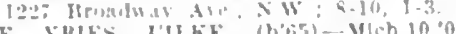

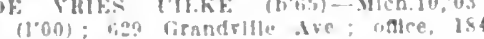

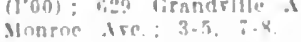

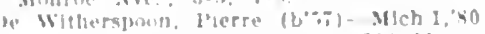
1100(1); 455 Lyon st.; nftce, 20t Mursoe

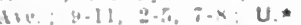

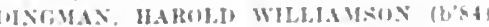
-(1nt.1,05, N/ch.10.05: (1006): 203

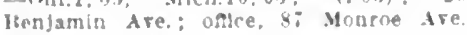
$3-5$.

Jroate, Casper M. (b'61)- I11.11,85; (1'no) 4 lexington Are. N.W. oflce, Metz Blitiz: 2-4, $i=8$

Juroste, James Casper (b'86)-111.11."13 Intern. St. Mary's Hospltal.

II: Itis, WM. J. $\left(\mathrm{b}^{\prime} \mathrm{T} 2\right)+-\mathrm{Ca} 1,09$ (100): 266 \&. College Are. (Afre.

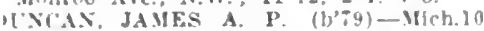
of: (1.06) : 355 Carleton Are ofice, 401 Dirislon Are, ; 10-12, 2-4, : $30-8: 30: R$. ARLE EITABETH $\mathrm{C}\left(\mathrm{b}^{\prime} 57\right)+111.94^{\circ}$ (1001) 4t6 Lyon st: ofice, Shepard Bldg. : 2-4; ObG.

HASTON, GLEN ARTIUR (b\% - Mlch 06: $(1.06)$ : $: 58$ Dlrislon ire., s. : 10.12 $2-4 ; 7-8$.

EATOX, ROY R. (b'72)-I11.11, 96: (l'00): 1345 S. Nirlslon Are.: $1-5$

Fddy, Ererett H.-Ill.6,90; (1'00); MllchiRan St.

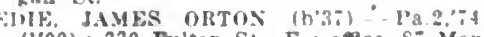
$\left(l^{\prime} 00\right): 330$ Fulton St., E. : offlce, 87 M see si, : $11-12,2-4, ;-8$.

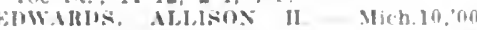
(1001): 435 W. Leonard st : $9-11,1-3,:-5$ F.TWARDS. JAMES \&\&-Que.1,80; $(100)$ 440 S. Lafayetfe St: offlce, Widdleomb Bide: $3-5$.

r H I J J COB JACOT'FS (b'\$4)-Tenn 5 o: (1010) : 572 Terrace Are: once. Met Bidg.: $2-5 ; 5$.

PARIINKS, CHAS. II-Mch.10,98: (100); 14i: Logan st. s k. ; once, Gillere Bidg.: 2-4.

F.XXIFF, FREIERI I.ENART (b"R: lleh.7,09; (lo9): 1009 Muskegnn tie. oflce Vetz Blds: $2-4$, $i-5$

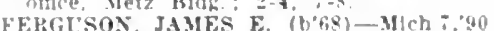
$\left(1^{\circ} 00\right)$ : Ashton Bldg.: 9-4; OALR. *

t'ermuson, Ward S. (b'86)-111.22,10; (1'12) 633 Parkwood Ave : once, Its k: Fultun Sit.: 9-12, 2.5: Pr.

Folics, Desiderius (b's0) - Hunz l."1) (I'13); 211 Jefterson Are., F. ; nfm, Me, Mt BId : : 2-5.

FIIELING, BOBT, CONBAD X $\left(b^{\prime} \times b^{\prime}\right)+$ Nich.709 (l'09); 958 wealthy Ire S E : $0-12,1-3,7-8$.

Frye Oscar Blalne (b:9) - Mlich :0: (1007): 1908 DIrlsinn A

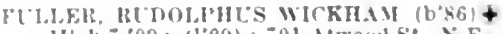

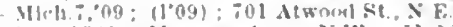
mice 13t'm Monrom Are. X.W.; I1-12.

Fifll WM + Que. $1.66 ; \quad(100) ; 103$

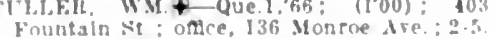
Gainey, James J. (b'78)-Mich.10,03 (I.03): II40 Jeterang Are., SE: nthe

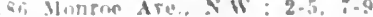

Cerrers. Juhn Ilenry kichard (b'83)-

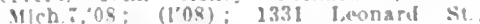
$\mathrm{N} W$; omce, 418 lewnard st, $\mathrm{N}$ w: 3.5

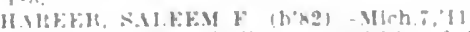
(1)l1): 309 lirandrille Aro, s.W: 21

(illbert. Hugene Alhert $(1,89)$ - Tenn 5.13 ( ); Mllchlens siate Sridliers, II ame

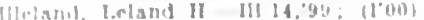

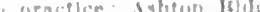

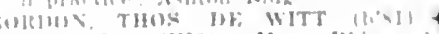
Well 009 (Inog):

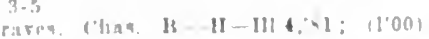
linckier sit

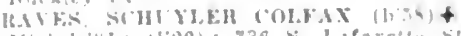

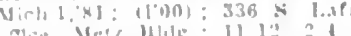

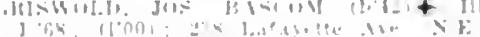

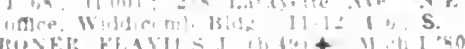

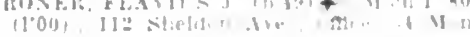
Poe Arm $11-12,-1$

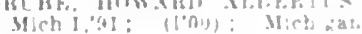

llome; $\mathrm{S}$.

ITKF: WM FRFIIK

lloo): $51:$ college Are,

Harmon, lasuan- Mirh. $\%$

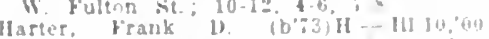

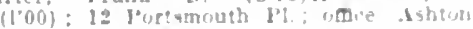
Bld: $11-1,201$

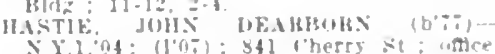

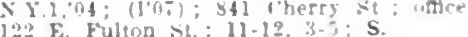

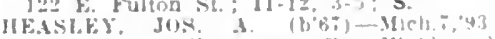
(IV(0): 360 Fuller Are; natice, Wididermt HId2: $9-11,1-4$

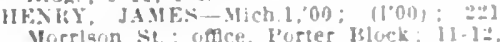
$2-4$ i- 8 .

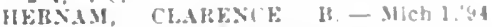
$\left(1^{\prime} 00\right) ;$ dillbert Bldg. : $2: 30-5$, i

HERHIK, ORRIS F.-N.Y.3, \%1; $(100)$ (26) LIT

HILIKFR, J(1I: IB. $(6, f 0)+-111.11 .92$ (I'(10); T14 llirtalon are.

Haman, Spencer I) (b50iH-X. I : (l’no): 131 lubrary si; oflec, Widdicomb Bldz: : 11-1:, $4-5$

HIRS IIIERG, FRIFIA (b's:) \& -11111,09 (1009): 342 Auburn Ave : otice, 14: Ful tom st., F. $12 .+30$

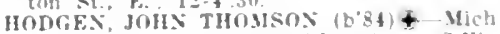
1,$10 ;(1,10) ; 14 \%$ Wealthy

oflce, Metz BIdg : 2-5: S.* I01.COMn, JOHS NEW Wlddlcomb Bldg.; 2-4, ;-5.

HOOKER, CHAS. EGGLESTON (b'72)Mich. $1.95 ;(100) ; 116$ Ititon Are., st. ofice, Mesz Hids: 10-12, 2-4:30; 0.

Hoxle, Altertus T. (b'60) H-Mich sols (l'0I): 15 Terrace Ave; oflce, 66 Monro

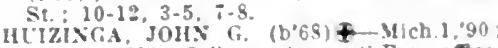
(1.01): :26 College Are., s.F.; other Wlddicomb Blde.; 10-1\%, $-5 ;$ (HI) Midlcomb Hag.; $10-12$

OALR * HENRY (b'59) - Mlch l, 'SS

(1.00); 100 Fountaln S:. F.; 2-4, ;-s $(61,2): \mathbf{R}$.

HCTCHIXSON, BOBT. J. (b'69) \$-Mch.

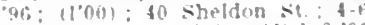

Inals, John A. (b'69) - Mllcb.8.95: (1'05) $15+2$ l'lalnteld tre.

IXNIS, JAMES HARVEY (b"JA)-III I, SG (1.00): 145 Ialayelte Are: amce, cither (100): 145 hataselte Are.

Hilock: $9-12,{ }^{2-5}:$ OALR.* ${ }^{2}+$ ont 3.91 (100); 546 Wealihy Are; ofdce, Asbron lide: $2-1: G$.

OHASTON. (OILIINS HCKEY (bog) Mch.1, 83 : (1P00); St Madiann Ire. onter. Metz kldg: $10: 30-1 \div=-4$

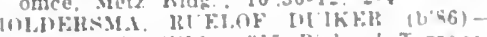

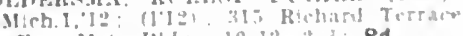

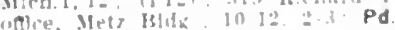

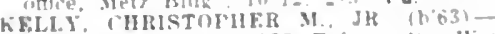
V. 1s."30; (1"00): i35 Fulsun st. W

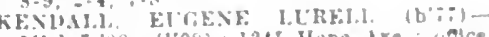

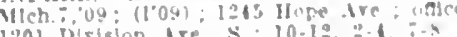

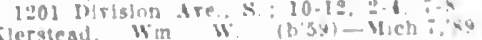
klerstead. Wm W: (b'3y)- Itich:, ka (1.00): 158 Nat!ogal Are. :

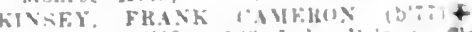
$11160,3: 11031 ; 903$ I.ake Mrlue: antee

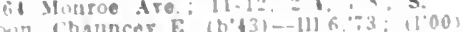

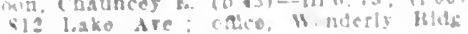
$10.15,3-3$.

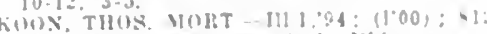

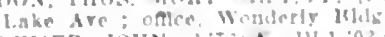

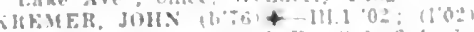
13\%1 Ilainecid Are.

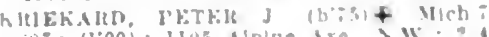

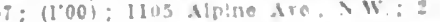

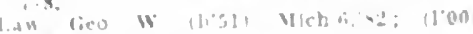

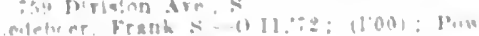




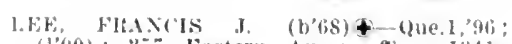

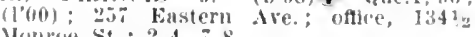

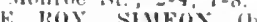

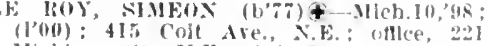

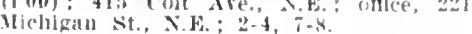
l.usqluk, Earl,I.-Mleh.10,05; (100, ; 810 Iovey st., s.11: : 1-3, 1i-s.

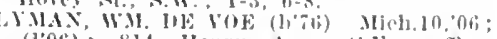
(1'0b): sit Henry tre, s.k.; oftlec, Metz Hels. ; $11-12,-4,7-s ; U$.

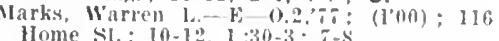

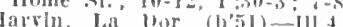

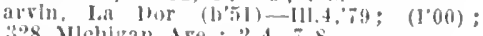
Walhews, Wallace H.-H-Ill. 0, to

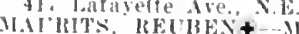

I Je(\% blitg.

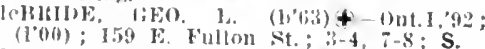

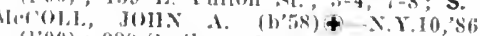

(l'0(1): 939 scribnel st. ; ottee, Widdicomb Jldg. ; $3-5$.

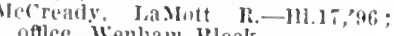

(1'01);

Iclitisery

Mich.10,02: (1,02):

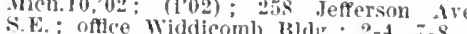

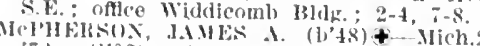

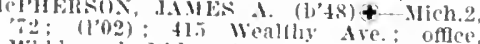
Wlddecombl 13ldg. : $11-12,3-5,8-9$.

Ieengs, Wirk li. (b'5n)-Hil. , s5;

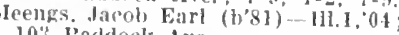

$10:$ Faddock Are.

Meyers. John Klemanz (1,72) 0 : (1'02) .17 Lexington tie.; oftlee, 1341 ig Monroe sit

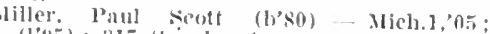
(1'0iv) : :17 simrlse Ave., W. : affle, Metz Bhile. : $3-6,7-8$.

Inffat, Watter $\left.(b)^{\prime} 4\right)-0 ;\left(1^{\prime} 00\right) ; 934$ Jefferson Ave; oftlee, 87 Iionroe Are, X.W. MONTROMELY, JAMFS R. (b'59) Meh.1,91; (l'01); 401 E. Bridge st

Mocis, colk

Ransom St A.t-11.9,00: (1'0i) ; 217 3-.5.

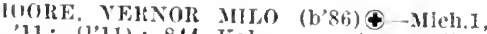
'11; (l'11); 844 Kalamazoo Ave.; office, Metz l3lidg: 12-1, 3-5.

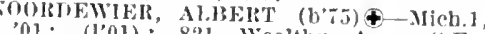
'01; (l'01); 821 Wealthy Ave.. S.E. oftlee, Porter 13lock: $3-5$; 0b.

Norris, Maria Whittelsey (b'56) II -Mass.5. '32; (1'n0): 21 Prospect Are. X.W. offles. Shemird Bldg.; $10: 20-12: 30$.

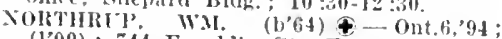
(1'00); 74t Franklin St., E.; office, Metz

Bidge : 12-1, 3-5.

(1,0 IN), ALBERTIS (b'55) - Ind.5,'86 ; $(100) ; 1566$ Wealthy Are., S.F.; offlice,
loorter Block; $9-10,1: 30-3,7-8$.

'KEEFE. THOS. B,....Iich I0,00

Reed's Lake, East firand Rapids.

I'ARKIIRST, INCOLN P. (b'65)-H1.1, $86 ;(1,00) ; 246$ Lagrave Ave.; offlce, 89

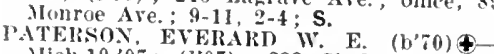
Mich.10,07; (1'07); 233 Gladstone Are.
offee. 45 Monroe Are.; $9-5 ;$ (B32);
OALR.

I'ATTERSON. ALBERT J.-MHch.2,'83; (1'00); 1306 Plalnfteld Are; ; 11-12, 3-5. Patterson, Clus, Edwin (b'56) -Mich.2, 79

leck, Louls K.-N.Y.1,92; not in prac tire : :B F. Home st.

Poposkey Jos. (b'63)-Ill.11,'91: (l'00) lowers, lssie s. (b'61) H-Mich.5,94: (1'00) 5ng ihery st.: oftice. Widdicomb Bldg.

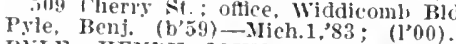

IYIF, HFNRT JOHX (b'82)-Mich.;,07 (1'(1) ; 1329 Grandville Ave.; office, Hetz B]dL. : 3-4.

Rinkin. Chas. F. (b'f3)-Vich.1,'s5; (l'00) 74,3 Terrace Are; office, Gilbert Block;

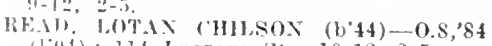

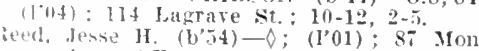

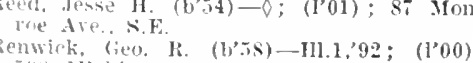
Renwick, (jeo, R. (b'ss)-Hll.92; (l'00); Thealt Bly : : $1-11,2-4$.

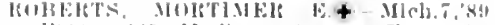

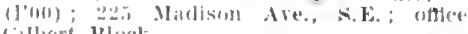
libllert block

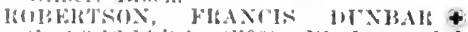

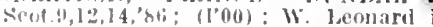

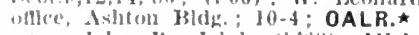

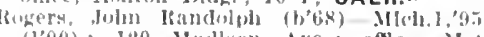
$\left(l^{\prime}(\theta)\right) ; 120$ Mallson Ave.; offlee, M.t\% HdL.: 10-12,2-4; (1B32): OALR.

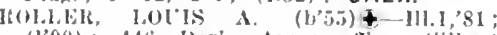
$\left(1^{2} 00\right) ; 44 b$ Jaris Are; oftce, cillbert Block; $10-3$ : (131,?3) : OALR.*

IIOOKS, JOIIN J. (b'77) \-Mleh.10,01

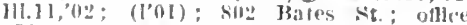
130 Mntroe lve.; $2-4,7-8$

Ross, Wm. H. (1145)-0.16, s8; (1'00); $14 !$ l, yon st. : $11-12,2-5,7-5$.

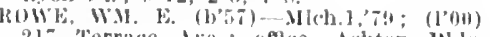
217 'lerrice Ale.; oflce, Ashton lidg. $10-12,2-4 ; \mathrm{S}$.

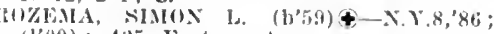
$\left(l^{\prime}(00) ; 42.5\right.$ Eastern Ale.

Rulfc, Aphonso L. (b'54) II-I11.30,87 (l'00): 145 s. Fuller St.; offece, Metź I3leg. : $3-5$.

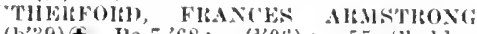
(b'39) \&-I'a."'68; (1'06); 5i slieldon Ave. s.E. : 11-12, $3-5$.

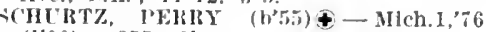
(l'00); 25 Cherry st.; offlce, Gibert Bldy; ; $5-6,7-8$.

FlkEl) L. (b'7t)-Miln. adlson Are.; $2-4,7-8$.

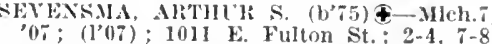

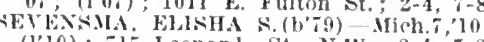
(1'10); 715 Leonard St., Y.W.; $2-4,7=8$

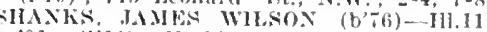
o1; (1'01): llerkimer Hotel; offle, Metz Bidg.: 10-4: ALR.

SINC'LAIR, IDANI. S. (b'5s)-Ill.10,'87 (l'00); 147 Jefferson Ave., S.E.; office, Widdliomb Bldp. ; $2-4, i-8$.

SINCLAHL, MAICOLA C. $\left(b^{\prime} 50\right)-$ Ill.4; 73 (l'00); 212 Sheilon Are.; office, Widdl romb Blalg.; $2-4,7-8$.

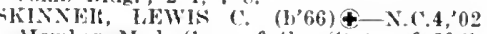
Iember Med. Soc. of the state of N.t? not in practice: 1932 s. Bivision Ave.

SI.FIONA, CHYDE C. (b'75)屯-Mich.7,05; (l'05); 1324 logan st.; offlee, fillberf I3!dy. : 3-5: Pd.

Smith. Ansel Brooks (b'84)-Mich sog. (l'n9); 216 Jafayette St.; office, Jetz lildg. : $10-12,2-4: 30$ : S.

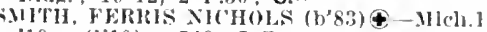
10: (1'10) ; 549 Jefferson Are., S.W.

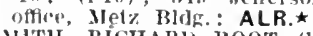

SMITH, RICHARH ROOT $(1,69) \&-M i(n .1$ 92: (1'00); 135 Madison Ave.; offlee,

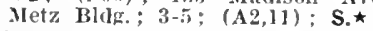

SOITHWICK, GEO. HOWARI '

Mich. $7,10:(1+10) ; 624$ Turner
flee, 100 Island Si. ; $3-5.7-8 ; 5$.

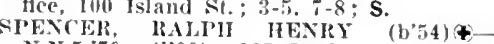
N.Y.5, T9: (I'00); $32 \%$ Parls Ave; office, 91 Innroe Ave; $10-12,2-4$.

Stephenson, J. R. $\rightarrow:(1 ; 0 n) ; 136$ Monroe Ave.

ST"IRT, IEERHARHTS 3. (b'-8) - 111.11, (1,13) : 423 Eastern Are., S.F.

(102):

THOMISOX, ARCHIBAID BI, THE (b'65) +- Scot.9,'12,14,87; (1'00); 825 Wealthy

THOMLSON, A. HOI'ISE ROSENTHAL (b':9) \$ Mich.1,'84; (1'00) ; 509 Wealtly St. ; $2-5 ; \mathbf{P C}$.

THBBITS, NEWTOX I. (b'5?)\&-Mirh. I, 84: (1,12): Member state Med. Sor. of W.5. ; 428 Ethel Are, office, Metz Bldg.

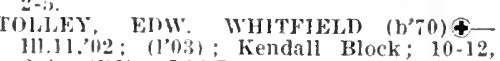
111.11.'112: (1"03): K

Towsley, (ilenn (i, (b'66) H-Mich.5,'94; (1'00): 310 Norwood Are.; offlce. Asllton Bidg. : $9-12,2-5$.

Tr'KEL, ARTHCR W. (b'-0)£-0.9,'93; ( ) : Nember Ind. State Med. Assn. ; Union Station: $9-11$.

Tuttle. Saml. Porter (b'b9)-Mich.5, 9s; (l'00); 16 Jomroe St.. X.E. ; 11-12, 3-5,

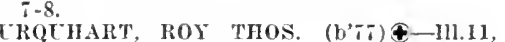
'01; $(100)$ : 438 I'leasant st.; offlce, Metz Bldg.; (B32) ; OALR.ネ

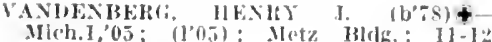

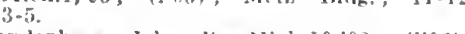
"andenherg, lohn li. Hloh 10,02

401 S. East St. ; $8-11,1-3,7-8$.

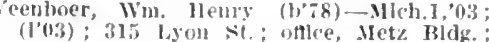
$12-1,3-10.5$.

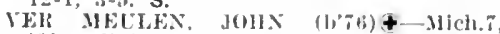

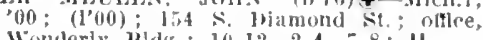
Wonderly Bidg.; 10-12, 2-4, 7-8; U.

rolk, J011x (b'fi) lli.1,02; (l'02): 936 Grandillle Are.

Votey, Frank Aulerson (b'62) - X.Y.1,'87 ; (1'00); (Ada); offlee, P'orter Block; 9-4; Pr. *

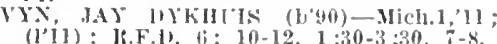
Wagner. Walier (', (b's 0$)-0.2,03$; (1'03) 21 Sheldon Are.; offlce, Kendall Bldg.

WARESHIL, FIHUK, COOK (b'80)+ Ilch.10, 02 ; (1'02); sec. Mlch. State Med soc.; 91 Monroe Nie.; $1-3,7-8 ;$ S.

Weaver, f'bas. W. (b'64)-Ind.10,'87; (1'00) 1135 Madison St.; office, Gllbert Block; $1-4$.

WEIB, ROWIAND, FOREMAN (b'5) I Ont.i, $97 ;$ (100); $208 \times$. lafarette sit.

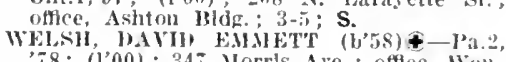

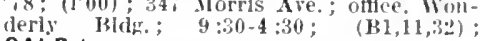
OALR. *

WEATER, AARON VERNE (b'z) Mlich.10,01; (1'01); 132 Grand Ave. N.F.; offlce, Metz Blig.; 1-3; Anes.

WEX('ER, IOHN N. (b'st)-Mich.1,12 (1'l2); Inion Benerolent Hospital.

Wesselius, Geo. W. (b'47)-.Micb.i,'si; (1'00); 108 Monroe Are.

(101)

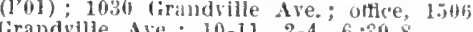

Westreer, Geo.-Ind.5,98; (l'00); IS6 Monroe Ave. ; $10-11,3-5$.

roe Ave.; $10-11,3-5$.
Wetmore, lantlue dane (b'6i) H-Mich.11, $06:(105) ; 241$ s. Wivislon Are.

WIINERY, jos. B. (b'66)\$-Nich.\}, 92 (1'00): 26 lafayette Are., S.E.; oflce, Netz Bldg.; 11-12, 3-5.

Whinery, stephen A.Mich.1,90; (1'00) 200 Nompoe Are.; 10-11.

WIIJAMS, MIDEX H. (1)'77)\&-UHch.1, "49; (1'00) : 54! Logan St.; offlce, 9I Monroe Are.; $10-12,2-4$; LB.

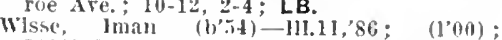
$319^{1 / 2}$ Rridge St. ; $10-12,3-5$.

Wolfe, IIarmon C. (b'77)-Mich.7,05: (I'0ii) ; 415 Ethel Ave., S.E.; offlce, tiil bert Bldg. ; 3-5.

WOLFORI, ('ERTIS T. \& - Ind.19,'96; (1'00); 410 Eastern Are.; office, Porter

W'RIGIIT, JOIN M. (b'74)-Mich.;,95: (1'00); 1936 \&. Wirision St. ; 3-4, 6-8.

Wright, Philander B. (b'41) $-0.2,68$. (1'00); 852 S. Dirision St

Folvf; Wi. G. (b'6i)£-Mich.8, 92 (l'00); 632 'Parkwood Are.: offece, Wli-

GRANDVILLE, 680 , KENT

BROOK, JACOB ], (b'76) \&-Jich.7,02 (1'02).

Fedgewood, Hewellyn fi. - Hich.z:299; (1'00)

\section{GRANT, 428, NEWAYGO}

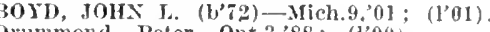
Orummond, Peter-0nt.3,'88; (1'00).

Lettinga, Dirk-Jich.10,'07; (1'78)

Pollard, Jos. W. (b'66)-llich.9,'98; (1'00)

GRASS LAKE, 760, JACKSON

LAKE, WM. HENRY (b'85) - I11.6,'10: (113).

Mcfolyan, James (b'63)-I'a.2,'89: (l'00).

GRATTAN (R.F.D., BELDING), I38, KENT Spencer, Geo. II. O; (l'00).

GRAWN, 250, GRAND TRAVERSE

Clark, Chas. A. D. (b'61)-Ky.2,94; (1'00).

GRAYLING, 1,775, CRAWFORD

INSLEY, STANLEY $\times$. $\left(b^{\prime} \% 0\right) £-0 n t .3$, $94:(1,00)$

KEYPORT, CLATUE ROY (b's.5) Mich.7,09; (l'n9).

IERRIMAN, HENRY H. (b'64)£-Ky.l, $94 ;(1.00)$ 
GREENLANO 500 ONTONAGON

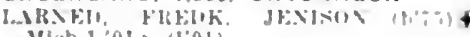
UI.h. 1,0\}: $110 \mathrm{l})$

GREENVILLE, 4.045, MONTCALM

H.AKR, MIHET STHWINT $(1,4)+$ IIIch. 1, "lly: (I'0)

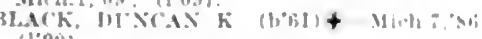
(l"0u)

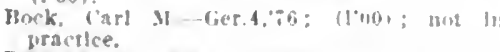

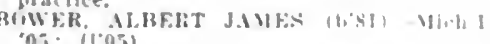

(1'00).

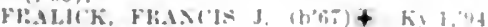
(I'00); OD.

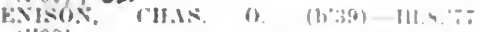

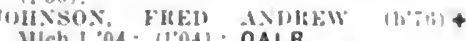

IIch.1.04: (104): OALR.

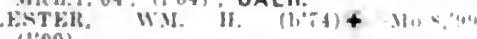
$(1,00)$.

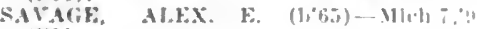
(1'00).

GREGORY, 250, LIVINGSTON

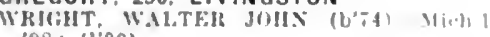
'98; $(1,00)$.

GRIND STONE CITY, 462, HURON

SHAWER, FUANK A. (b'it) + Mleh 1,"ll:

GROSSE ILE, - WAYNE

INGILIS, HIII!

(see letrolt.)

GROSSE POINTE (GROSSE POINTE FARMS P.0.), 500, WAYNE

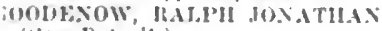

isee Detroll.)

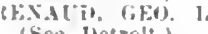

(See lletrolt.)

GROSSE POINTE FARMS, 862. WAYNE

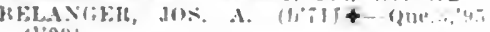
11'01)\}.

A.MHEI. MIN II

(sice lietrolt.)

Iodice, bidwin II

(see lletrolt )

GROSSE POINTE PARK (GROSSE POINTE FARMS P.0.), 290, WAYNE

WAIHE, LEWIS

(see Detrolt.)

GWINN, 1,000, MARQUETTE

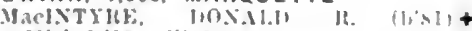
MIch.1,0: : (I'li)

Olinsted, Bertram Ienry (b'80)-Mllch. I, ll (I'I1).

HADLEY, 325. LAPEER

STEWIIT, HETER $(669)+$ MIH.1.91 (1.00)

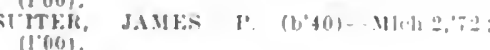

HALE, 375, 10 SCO

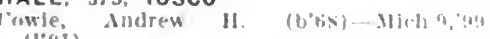
18:0I).

HALFWAY, 700, MACOMB

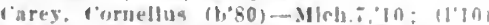

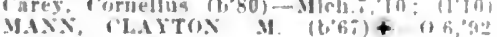
$(1,10)$.

HAMBURG, 250, LIVINGSTON

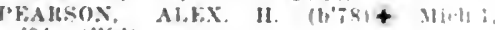
04: $\left.11^{\circ} 04\right)$

HAMILTON, 275, ALLEGAN

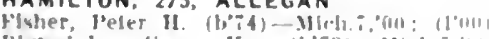

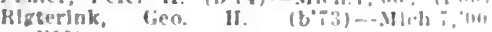
(I'00).

HAMTRAMCK, 3,559, WAYNE

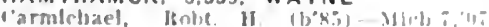

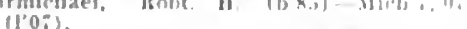

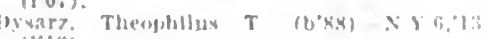
$(1,1 ; 1)$

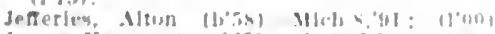

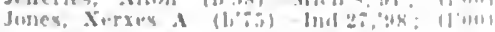

HANCOCK, 8.981, HOUGHTON

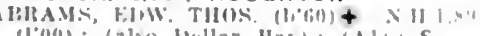
1100): (also lloillar Hay): CAli: $\mathrm{S}$.

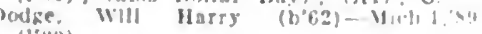
(I'(ii)

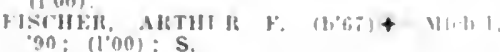

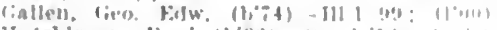

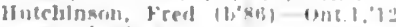

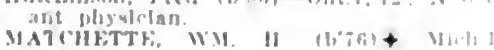

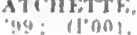

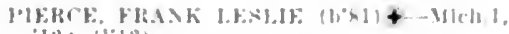
$1: 2: 11: 1: 1$

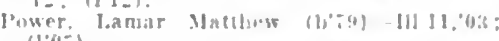
$(1,0,1)$.

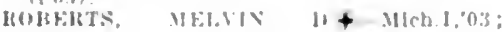
(1'0.3).

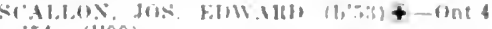
$\because 4 ;(1,00)$

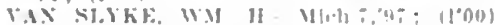

HANOVER, 364. JACKSON

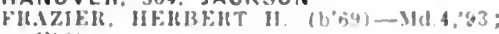
11'001.

WIIson, Frensan $r$. Iirld 1,00: 1800$)$.

HARBOR BEACH, 1.556, HURON

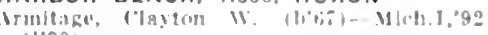
11001

louls. i has. Mlah a:? : (lono).

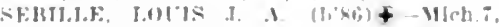
in: $11 \cdot 10)$

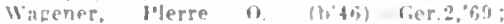
(1)(0)(1)

HARBOR SPRINGS, I.805, EMAIET

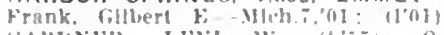

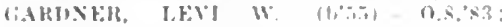
$(1,00)$

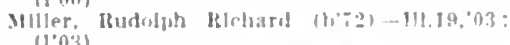
Bistin (I'OO)

HARRIETTE, 336. WEXFORD

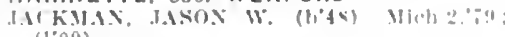
(1"nen)

HARRISON, 5\$3, CLARE

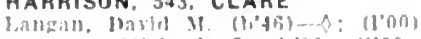

swethey, Michacl Ont.t." 1 : (1'00).

HARRISVILLE, 444, ALCONA

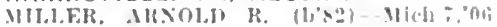
II'(0).).

HART. 1,555. OCEANA

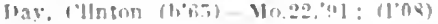

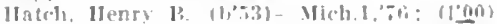

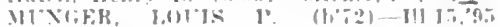
(['ni)).

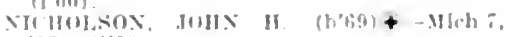

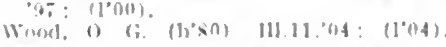

HARTFORD, 1.26\%. VAN BUREN

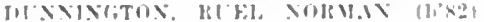

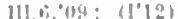

Fox, Walter if. (1, i, III.14,0:

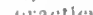

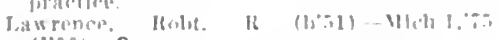
(lono): S.

Maynard.

(I'nn)

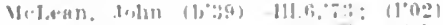

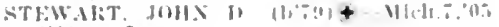
(I'05): Op.

HARTLAND. 225. LIVINGSTON

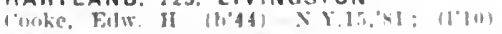

HASLETT. 200. INGHAM

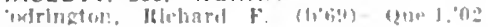
(1) 027

HASTINGS, 4.383, BARRY

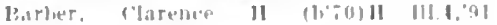

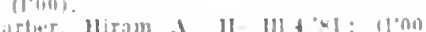

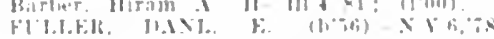
(1) (in )

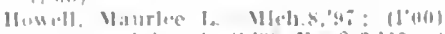

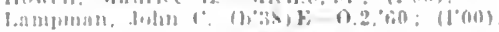

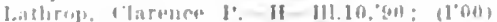

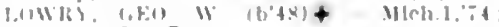

If'u(1): OALR

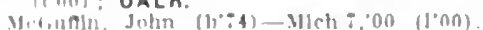

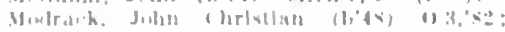
il'uil

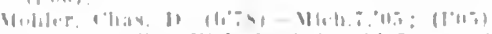

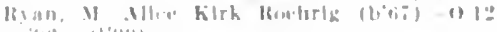

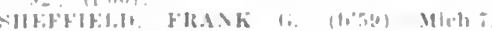

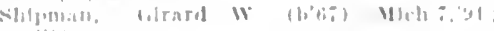

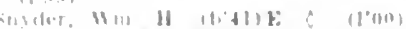

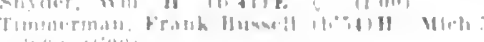

HEMLOCK, 230, SAGINAW

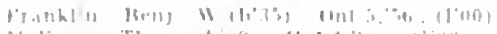

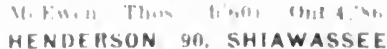

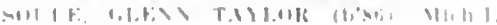

HERMANSVILLE, 1.200 . MENOMINEE

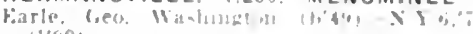
$(1, n 0)$

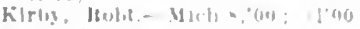

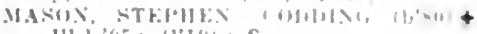

- III.1, (1?: 11?(1): S.

HERSEY, 310, OSCEOLA

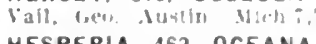

HESPERIA, 462, OCEANA

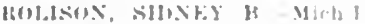

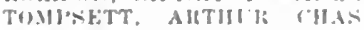

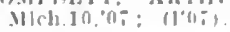

HICKORY CORNERS, I50, BARRY

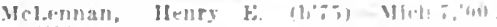
$(1 \times 0))$.

singletor

HIGHLAND, 300, OAKLANO

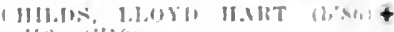

HIGHLAND PARK, 4,120, WAYNE

A.1HONS. JOS

(sine bietrolt.

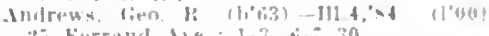

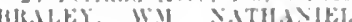

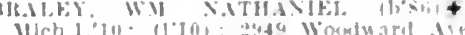
S.

IPurton, rlarence $\mathrm{H}$.

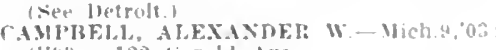
(101): 122 limald ive

('Bf)II, N1311.

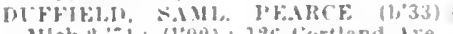

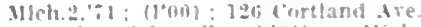

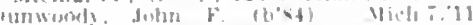
(1'11): : M Naxarhusetts st

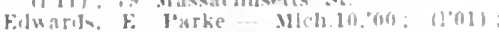
2y.-: Womlward die.

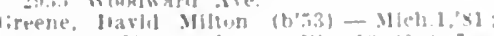

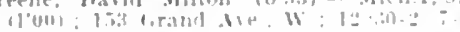

irimen, Wun. stuart.

inee [uetrolt.

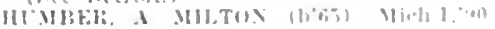
(l'(Ii)! : af lowalena die.

WES. ATHITITS W.

lave hetroit.)

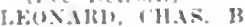

(sive letrolt.)

1.nlge, rrank T.-Mlch.8,03; uot In prace

rire : $:=$ Texedo iru

M.IITIX. Filli, G.

(sice trutrolt)

Nariln, James

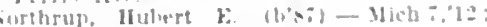

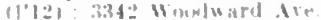

Leobinnon. Win. II.

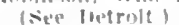

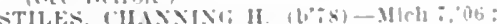
(lolti): 1:2 windemero , Nis

Thomas. Inury 1 .

(Ser. Hetrolt)

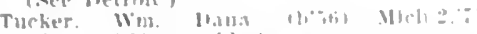
$1100)$ : l:t lipralel Are.

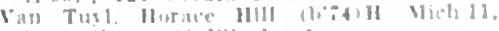

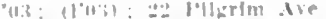

HILLMAN, HII, MONTMORENCY

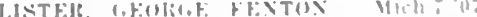

I'0i) (I"0)

HILLSDALE, 5.001. HILLSOALE

Hatue farlon I- \& II"0n)

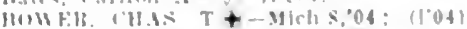

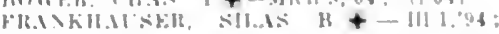
(1'00)

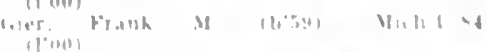

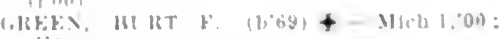
11 one!

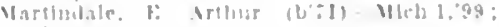

(1'n:).

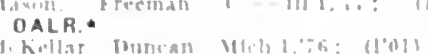

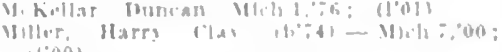

11001

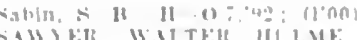

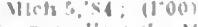

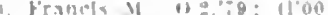

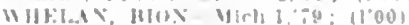


HOLLAND, 10,490, OTTAWA

Baker, llellry Brooks $\left(b^{\prime} 3 i\right)-$ X.Y.10, 'bi: $(100) ; 1$.F.W. I?

Boone, Corncllus Edw (1)86i) - III.11.11. (1'I2) : R. F I) 2

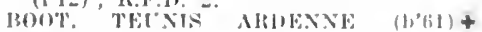
Mich.1, $86:(100) ; 62$ W. $11 \mathrm{th}, 5$

I3oss, IIenry (1) 63 - Mleh. $1.87:\left(1^{\prime} 00\right)$

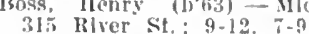

Bruinsma, Wm. I. J. (1)'62)-W1s.4, (1'03) : 63 W. 9th St. : 9-11,3-5, i-8

cook, DANI. i. (bo6) \&- vich.7.94;

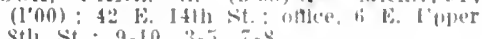
Stlo st.: $9-1$ in. $3-3$

(l'00)

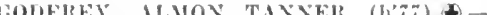
1116.04 (1004) 65 E juth st $=-9$

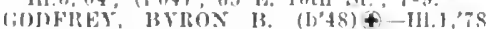
(1"0(1) fi, li. 10th St. $9-11,2-4 ; G$

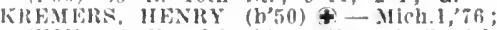
$\left(I^{\prime} 00\right) ;$ K. I2th St. ; oflec, 6 F. Sth

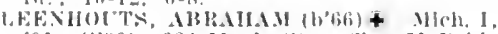

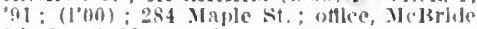
lock: $2: 30-4,7-9$.

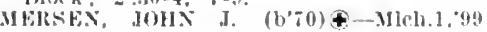
(I00): 2 E. 10th St.

Mills, David Arthur (h'78) - Mtchs, (I'12); Osteopath: 33 F. 13th St.; offere, Tower block: 10-12, 2-4.

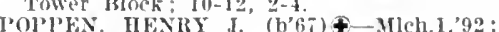
(lo0) : 40 W. 16th St.: $9-10,3-5,7-8: S$ schouten, Frodk. J. $\rightarrow$ (l'00)

TIIOMAS, ('EO) II. (b'bs) \& $111.11,04$ $\left(I^{\prime} 04\right): 21$ E. sin st. : $: 3-5,7-8$

puttle, Louis \$.-II-IIlch.5, $84 ;\left(I^{2} 00\right)$; 66 IV. Sth St

PANDER VEN, JAMES MATTIEW (b'64) -N.Y.S.91; (1'09); R.F.D. 12.

WINTHR, WI. G.\$-Mlch.1,06; (l'06); 24 F. 14 th $S t$.

Tonkers. Fred (b'.59)-Mlch.9,02: (l'02) 314 Pine Are.; offlce, $46 \mathrm{~F}$. sth St, $9-11$ $2-4,7-9 ;$ NP.

\section{HOLLOWAY, 100, LENAWEE}

NIXOX, JAMES W. (b'69)-Ont.6,'92; (1'00). HOLLY, I,537, OAKLAND

FEISHAW, CHAS. I. (b"41)-Mich.2,'7' $\left(\mathrm{l}^{*} 00\right)$

JOHNSON, FRED. TEE (b'78)-0.26,03;

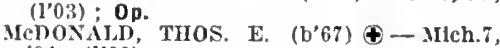

gen $(1,00)$

VAN SICKIF, I. RUSSELI. (b*80)-MIch. $\bar{t}$, 06 : $\left(\mathrm{l}^{\prime} 06\right)$.

HOLT. 350, INGHAM

AIFXANDER, RICIMLR H, (b'6 Mich.9,03:" (1'03)

North, Edw. P. (b'61)-Ill.1,82; (l'00).

HOLTON, 300, MUSKEGON

BLACK, BENJ. F. (b'63)-ont.5,'93; (l'00).

HOMER, 1,008, CALHOUN

Bien, Walter Wm. John (b'90)-Mich.5,'12 (1'12).

Haynes, Geo. A. (b'58)-Mich.1,'84; (l'00) HENDERSON, YEWIS M. - Micl.1, 00 $\left(I^{\prime} 00\right)$.

Henderson, Robert Gray (b'88)-Mllch.1,11;

THOMPSON, Jos. A. (b'63)-Mleh.8,97 ; (1'00)

HONOR, 500, BENZIE

COVEY, EZRA I. (b'73) $\odot$ - Mich.10,'99

Mlch.5,07; (1'00)

EDMUNDS, GERALD o. (b'66) $\oplus$ - Ill.II, $92 ;$ : (l,00)

HOPKINS, 400, ALLEGAN

Campbell, James Duncan (b'63)-N.Y.8,'90 (1'00)

LEIGHTON, NELSON EUGENE (b'48)\&N.Y.8,'81; (1'00); Pd.

WICKS, ALJOND H. (b'61) - Mich.1,'87; (l'00).

HORTON, 379, JACKSON

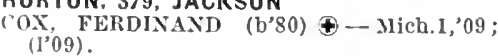

HOUGHTON, 5.113, HOUGHTON

IIDRICH. ADDISON D. (b'79)థ-Mich.9, '03, Mich.7,'10; (1'03).

BETTEYS, WM. H. (b'53) - Mich. 7 ,05; (l.05) ; Pd.

(ONRAD, GEO. A. (b'7J) †- M1ch.9,97;

Farrand, Koyal T. (b'68)-Mich.1,'92; (1'10).

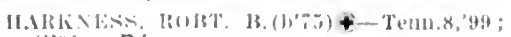
(l) (i) : $\mathrm{Pd}$.

Iones, Henry W:- Ill.1, "6f; $(100)$

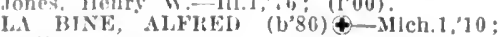

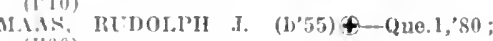

$(1000)$

I'aull, Irthur Thos. (

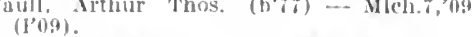

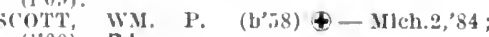

(1'00); Pd. (1'09); S.

TIRNER. JAMES G. $\left(\mathrm{b}^{5} 56\right) \oplus-\mathrm{Md} .1,78$ (1,00)

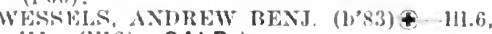

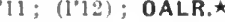

HOUGHTON LAKE, I30, ROSCOMMON

I)ay, John X., Jr. (b'65) - IIich.7,'93; (1'00).

HOWARD CITY, 1,046, MONTCALM

MILIAER, NOBLE WII. (b'82) †-Tll.1I, 06 (1'12):

NYLSON, JAY O. (b'63)-N.Y.1, 90 ; (1'01) ;

ALR.

Whelpley, E. Maud-Mlch.10,02: (1'02)

VHEIPLEY, JAY D. (b'69)-Mleh.10,01 (1'00).

HOWELL, 2,338, LIVINGSTON

BAIRN, ROBT. H. $\left(b^{\prime} 74\right) \oplus-\mathrm{Mich} .7,01$ (1'01)

BRIGHAM, WANETTE M.(b'74)£-Mich.1, 00 : $(1,00)$.

BROWNE, JAMES ERNEST (b'6r) $\rightarrow-$ Mich.1,96: (1'00)

CUIVER, CIIAS. F. $\left(h^{\prime} T l\right)-$ Pa. 2,$00 ;\left(l^{\prime} 00\right)$. IIarrey, Orlando, Emery (b'87)-0.40,'12; ( ) : T. $\star$

HUNTINGTON, HARRY GILBERT (b'84)Mich.1,12: (1'12)

HINTINGTON, WM. C. (b’50)-Mlch.1,72; ( 100$)$

PIERCE, EUGENE BENNETT $\left(b^{\prime} 75\right) \oplus-$ Mlch.1,03: (1'03).

SKINNER, CHAS. E. (b'66)†-Mìch.,,$^{\prime} 04$; (1'04).

\section{HUBBARDSTON, 450, 10NIA}

Crumnlcan, Austin J.-Wich.8,05; (1'05).

HUBBELL, I.059, HOUGHTON Manthel, Wyllys Anton (b'90)-Mich.1,'12;
(l'12).

Rowe, Chas. E.-I11.6,05; (1']1).

HUDSON, 2,178, LENAWEE

Dorge, John R. (b'48)-Mich. 1,'69: (l'00).

Eaton, Edwin (b'48)-Me.1,73; $\left(1^{\prime} 00\right)$.

Ely. Jos. D. (b'55)-Mich.2,84; (1'10)

LANE, CHAS. S. (b'67)థ-Ill.11,'02; $\left(1^{\prime} 02\right)$

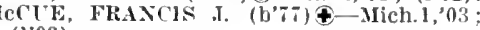
(1'03)

MeLain, Richard W.-0.26,'99; (1'01).

Nelson, Robt. H. (b'52)-Mich.2,76; $\left(l^{\prime} 00\right)$.

olmsted, Clement J. (b'59) - N.Y.8, ${ }^{\prime} 8 \pi$ : $\left(1^{\prime} 00\right)$

SPALDING, ISAAC L. (b’\%5) †-Mich. 7,97 ; $\left(I^{\prime} 00\right)$.

Veazey, Allen H. (b'77)-Ill.22,09; (1'12).

HUDSONVILLE, 300 , OTTAWA

MAXFIELD, WARREN A.-III.1,97; $\left(l^{\prime} 00\right)$.

IDA, 700, MONROE

KELLY, HERBERT ELIAS (b'73) $\oplus-$

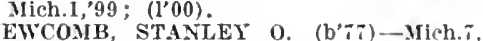
'04; (1'04).

IMLAY CITY, I,I74, LAPEER

JONES, GEO. W.-N.Y.6,'58; $\left(l^{\prime} 00\right)$

HARTIN, PIILIP E. (b'ro) - Nich. $\left(\mathrm{I}^{\prime} 00\right)$.

MCCAUSLAND, MARSHALL B. $\left(b^{\prime} 77\right) \Theta$ Mich.1,01; (1'01)

Minard, Jacob D. (b'41) E-0.2,'70; (l'00).

INDIAN RIVER, 400, CHEBOYGAN

Bell, John Wilson (b'46)-N.Y.8,'-I; $\left(\mathrm{l}^{\prime} 00\right)$

IONIA, 5,030, IONIA

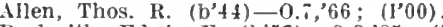

Peckwith, Edwin F. (b’5 $)-0.3,{ }^{\prime} 85 ;\left(l^{\prime} 00\right)$.

BRUCKER, KARL BARNARD (b'85)Mich.5,"09; (1'09)

DEFENDORF, JOHN JACOB - Jich.3,72

l'00); OALR.

Johns, Jos. (b'82) -Ill.19,'10 ; (l'10) ; G.

KITSON, VERNER H. (b'8i) $\oplus$-Mich. 7,10 ; (1'10); ALR.

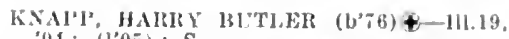
of ; (1'05) : $\mathrm{S}$.

long, Oscar k. (b'50) H-Mich.3,73; (l'00) $\left(\mathrm{E} 5,[3) ; P_{0} \star\right.$

Markham, Harold Hoyce (b'86)-MIlel.5, I2 (1'12); P.

MARSH, FAY M. (b'74)థ-Mlleh.9,00 $\left(l^{\prime} n 0\right)$.

MAYNARD, HERBEIT MASON (b'T8) Mllel.10, 07 : (l'07)

MeCANN, JOIIN I. (b'77) $\oplus-$ Mlch.1, 05 (1'05).

Robertson, Perry Clirlstian (b'86)-Mleh.5. '09, Ky,2,'I0; (1'09).

WIIJTFN, RAYMOND R. (1,84) \&-Mich. 12 : (l'12).

'04; (1'04); Ob.

IRON MOUNTAIN, 9,216, DICKINSON

ALVING, OTTO EDVIN $\left(b^{\prime} 70\right) \uparrow-S w e d .2$ 98; (1'11); s.

Bangs, James Ashley (b'55) - Vt.2,'84; (l'00)

BOYCE, GEO. IIENRY (b'80)£-0nt.3, 04 (1'06); (B1) COFFIN,' LESLIE ERIVIN (b'82)-Mass.I,

COLLINS, CHAS. D. (b'78)-W1s.2, 02 ; $\left(1^{\prime} 07\right)$.

CROWELL, JOS. ADDISON $\left(b^{\prime} 54\right) \oplus-$ N.Y.5, 81 : $\left(1^{\prime} 00\right)$.

CRUSE, SAML. EDWIN (b'71) - Ill.1,95; $\left(l^{\prime} 00\right)$.

Jue Golvan, Celestln (b'85)-Fra.6,'11; (1'11) NEWKIRK, HENRY A.-N.Y.5,'97; (1'00). IRON RIVER, 2,450, IRON

Larson, Harry James (b'78) - Mlich.9,00 ; $\left(l^{\prime} 10\right)$.

LIPBY, EDWARD M.\&-Ill.1,98; $\left(1^{\prime} 00\right)$; S.

Stevens, Willard Stlles (b'73)-Mich.1,97; (1'02),

WAJAH. JAMES LAWSON (b'iI) - III.1I, 99 ; (1'03).

IRONWOOD, 12,82I, GOGEBIC

Bellehumeur, Paul (b'57)-Ont.4,'88; (む) ;

102 W. McLeod St.

Conley, Wm. C. (b'67)-Mlch.1,90; (l'00); 626 Sutherland St. ; office, Union Hospital ; $8-9,1-2,6: 30-7: 30$.

EINDBOHM, ALBERT W. (b'70)-Mlch.9, 7-8; (1’00); 200 S. Curry St. ; 9-10, 2-8,

OORE, GEO. E. (b'60)€-Ill.1,'83; (1'01); Block: 9-11. 'Plock, 9-11.

Mich.1,08; $(1,08)$.

PIERPONT, DAVID C. (b'78)€-N.Y.1,03; (1'09).

(1) $\rightarrow:\left(1^{\prime} 05\right)$

STEBBINS, EUGENE BENSON (b'78) Mlnn.4,08; (1'09).

STEVENS, CHAS. ELMER (b'83)-Ill.11, 10; (l'12); Union Hospltal.

Thomas, Austin H. (b'55)-Ill.1,83; (l'00) URQUHART, JOHN H. (b*72)థ-H1.1,95: (l'08); Arch and Lowell Sts.; 9-12, 2-6: OALR. *

WHITESIDF, JOHN WYMAN $\uparrow-$ Ill.1,'84; (l'00): Unlon Hospltal.

ISHPEMING, 12,448, MARQUETTE

BARNETT, GEO. GILBERT $\left(b^{\prime} 52\right) \oplus-111.1$, 84; (1'00); 517 N. Pine St.; offle, Ishpeming Hotel; $8-9,1-2,7-8$.

BRADEN, ALBERT VAN DEVANTER -(b'88)-Va.1,'10; (1'13); Islupeming Hos (b'88)-Va.1,'10; (l'13); Islnpeming Hos-
pital.

03; (1'03).

FFLCH, THEO. ALPHEUS $\left(b^{\prime} 47\right) \oplus-M i c h .2$, $74 ;(1,00) ; 304$ W. Euclid St. ; offlce, 316

S. PIne St.
GOURDEAU, ATHANASE $\left(l^{\prime} 00\right)$; Sellwood Block.

HOLM, HENRY (b'82) \&-J11.4, 08 ; (1'12) Menber Ill. State Med. Soc.; Division st. Lindgren, Elis Ilmari (b'7t) - Rus.1, 03 ; (1'04); $112 \mathrm{E}$. Dirision St. ; 9-10, 1-2,7-8 PICOTTE, WILFRED S. (b'74) $\oplus$-Que. 3 , '96; $\left(1{ }^{\prime} 00\right)$; Nelson House; offece, Anderson Block: 1-3, T-8.

SMITI, HENRY SLAYMAKER $\left(b^{\prime} / 1\right) £$ Ill.1,96; (1'00); 421 Lake St.: office

Ishpenlng Hospital; 8-9, 1-2, 7-8 


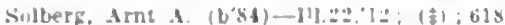
F timplre sit once Amdirsum llock s-9. $1-2,7-8: s$

VANIEVFATH, VIVIA U $(1,72)+$

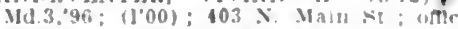

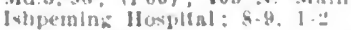

ITHACA, 1.876, GRATIOT

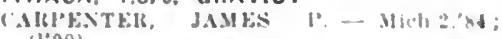
$\left(1^{\circ} 00\right)$.

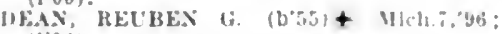
$(1,00)$.

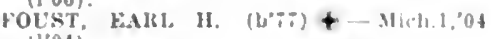

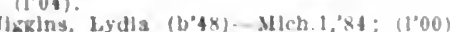
MONFURT, ISASC N. (b49); (1):3: WELLE: (1'00).

JACKSON, 31,433, JACKSON

Anderson. Mradley Weecher (b) 11$)\|-\| l l$. '80: (1'00): $230 \mathrm{~W}$. Washlngton kil.; ;

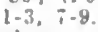

Anderson, Warren 13. (b'84)-Mlch.11,12; (l'1:): 230 w. Washlngion si: $1-3,7-9$ $99 ;(100) ;: 26$ W. Washington 5 , : unllu. lowight Bldg.; $10-12,2-4$

Brown Horalio Alford (b'sl) III l oy

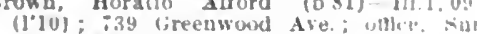
lildg: : $:-4, ;-8$.

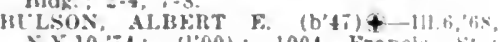
N.Y.10, is; $\left(1^{\circ} 00\right) ; 1004$ Franels
offce, Sun Bldg.; $9-12,2-5 ;$ OALR.

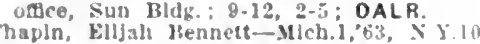

$\because 5:(100)$; 2010 F. Ganson st.

('lultock, frordon (b'ai)-III.1,"5l;

not in practlec: $103 \mathrm{H.}$ Morrell st.

-HIVEIs, ROY WM (b"is) + Mlld 1 , (0)

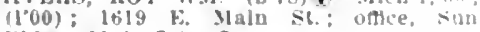

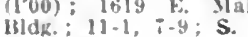

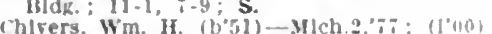

1613 E. Maln st.; ontce, Sun Bldg. :11 -5 .

("larke, Corwin stanton (b'88)-Mlch i.:u!) (I'0y); liot liockuell st.: oftice, lowighi Bldg. ; $11-12,2-4,7-8 ; 5$.

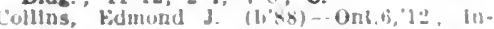
tern, Jackson Cliy Hospleal.

OOLEY, RANIYAI, MARVIS (1,86) Mlch.1,10; (1'10); 185 Chittock sit.

sun Bide: : $2-4, \div-8$

Sun Blde. : 2-4, $:-8$.

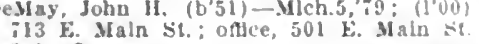

EWWARDS, IJIRESCA ISAAC (b'59) Mlch.1,'s9; (1"00); 119, 2d st.; othle, Carter Iulds. $9-10,2-4,7-8$

ENDEKS, WM. HENKY (b'78) \pm - Mll 1 , 04: (1'04); 211 Harwood St.; odle, (iv) ony' Bldg. : $9-12,1: 30-5 ; 1$.

FINTON, WATHR HLYII) (b'S5) + Mlch.1,07; (1.07): 209 W. Mason office, $410 \mathrm{~s}$. Jackson Sit. : 2-1, $;$; : S

AIBSOS, HIRNK J. (b'-4)-Mlchl, (0): $\left(l^{\circ} 02\right) ; 606$ ist $\mathrm{xt} ; 2-4$ i-s.

illsox, WM. Alkixisik $(1,43)$ Mich. 1,$66 ;(1.00) ; 733$ W. Main st: 10 , $2-4$

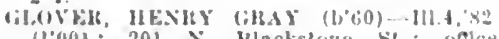
(1'00): 201 \&. Hlackstone st.; oflce Uwight Bldg: 10.1:, 4-6.

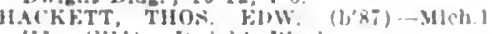
"11: (J'11); Wwigbt lHock.

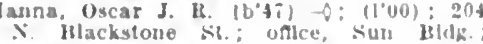
to. Hack $12,+-3$.

H.WHIs, LESTH:H 3. (bo:

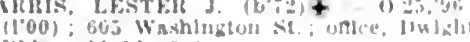
HIdk. ; 11-19, 2-4.

Hartson. Uscar \$. (tost) H- Mich.3."4 (1'001: 120, lat st, ; 10-1:.

HENURICK, HUOLA (ilk)

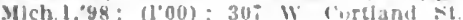

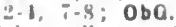

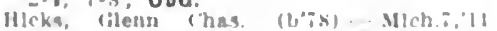

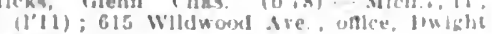
H]ds: : 2 -4. Hill, John laurence (b'sl) - III lu:

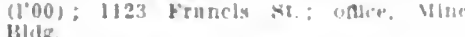
IIIIIZ.

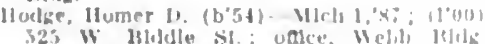
3.4. -.8

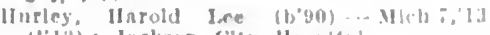

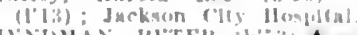

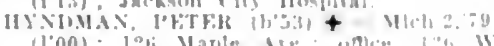

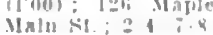

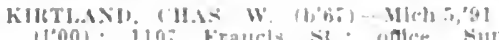

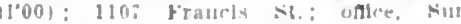

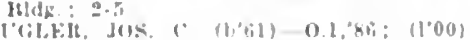

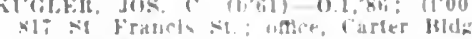
$11-12,2-4,7-8$

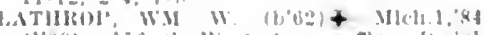

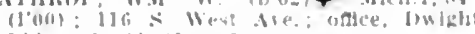
BHSt: ; $10.11: 30, "$

LEWTล, CHAS, H $(b+0)+$ Mieh 1 , pito $(1000): 301$, lst $\mathrm{xt}$.

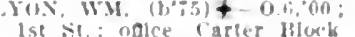

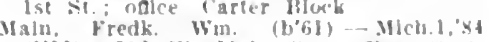
(I"00): 512 W. Maln St. once, I arter H]ock $10-12,2-4,7-x$.

Marks, Wills J. (1,6s) - Mlch.s, $96 ;(1,00)$ $\because 02$ W. Mason St.: oflce, Carter lluck $11-12,2-1$

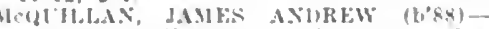
Y10.34,12; (1'12); 511, lat :-: once. White llock: 11-12, 2-4, i-s.

Whlte Block: П1-12, 2-4, i-s. Mlch 03 (1'03); 318 W. Wesley st.; onde, Colons lilds: $9-11,2-4$.

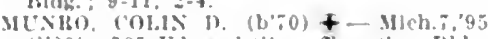
(I0) $01 ; 0.5$ Edwntd St.; ofthe, sun Hidr. $2 \cdot 4,7-8 ; 5$

Munro, James E. (b'79)-Mich.9,02; (1'02) 109 Pigeon St. ; offce, Maln St

Myers, Jus. Henry (1,69) II-0.7,93: (1'00) izg lirenwonl dve: ontce, sun l3!ds. $10-11: 4 i, 2-4 ; \mathrm{S}$

(obert, Ilarry liarwlu $\left(b^{\prime} /{ }^{i}\right)-M 11 \mathrm{ch} .11,01$ $\left(10^{\prime}(0): 120\right.$ S. West Are: ofter, Unlor Bank Jildg, ; $9-5 ;$ OALR. *

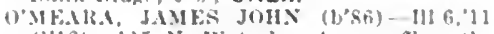
(1'12): $115 \mathrm{~N}$. Waterloo Are. ; oflce, Sur 13ldg.; $10-12,2-4,7-8$

IOARSALL, CHRISTOIHER G. $\left(\mathrm{h}^{\prime} \mathrm{SO}\right)+$ 1."lf: (1"01): 249 Wildwond Aie.

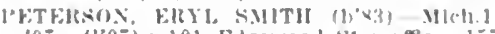
"0: : $(100)$ : 101 Folgewnot St : offlce, 15. W. Maln st. 11-12, 2-1. i-s: S.

PKAY, GEO, R.IXYIOND (b'a) + Mlch

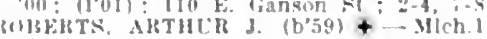

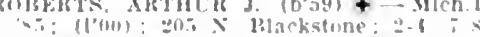

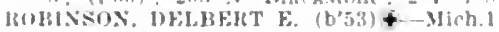
$\because 8$. X.Y.J.81; (I'v0); 410 Jackson si

norins, Flitlk. w. (b'61)-111.6, sh 11001: 214 lireenwoml we.: ance

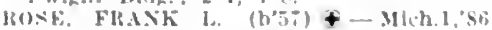
1111): Member 111. State Med. Soc : 13:20 r. Main $\mathrm{st}$; once, tos F. Maln Si: :-t. E. Maln st, once tos F. Maln Si: :-

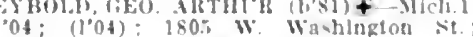
"04: (l'04) : 180 : W" Wa

SNoW. WALTEA ROZELLE (b's) - Mlch. 7

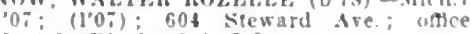
I) whlth nlock: 2-4, i-s.

SICRA, WALTER FARAST'S (has)

Mlch.1.84: (1.09): 28:3 Harn

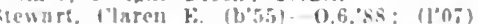
10.5 Mclirlde sit.: onlce, folony Mldi. $2-4, i-8$.

STEWAIT, MAITIAND NHWMAX (11:3)

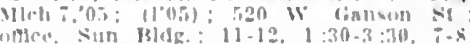

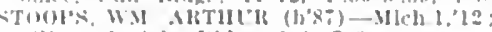
11'1:!: lowligh lllelg : $1-1, ;-8$

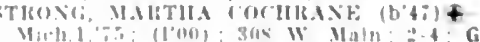

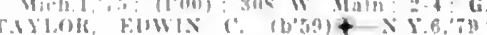

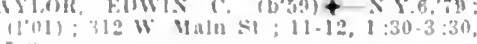

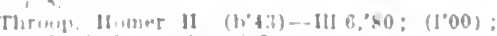
11: W $Y$ in in St; $2-3$

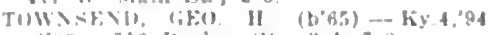
$11001: 710$ Itackus 51 : : $4, ;-8$.

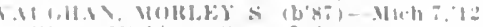

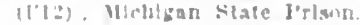

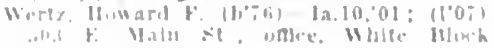

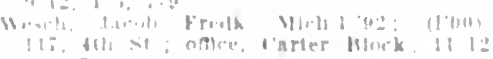

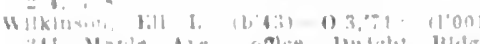

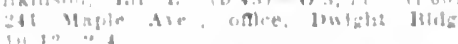

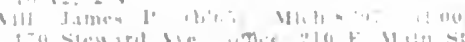

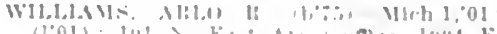

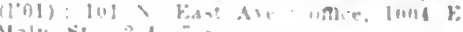

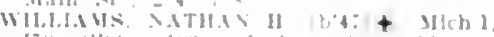

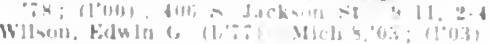
farter Mlor.k.

WISTHIt. fit:

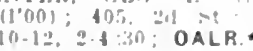

JAMESTOWN, 200, OTTAWA

I.A.TISI:, IIELK (1,01)

JASPER, 375. LENAWEE

Iar llusen, i has. Alelbert

'uti: (l'vili)

(1'0i)

JEDDO, 73, ST. CLAIR

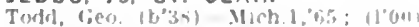

JENNINGS, 1,200, MISSAUKEE

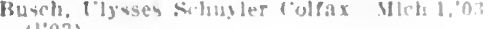
(1'03).

JEROME, I90, HILLSDALE

Sterllar. John $\therefore$ Mlah 1,03; $(1000)$

JONES, 200, CASS

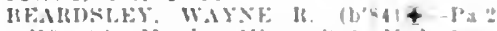

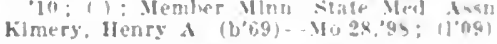

JONESVILLE, 1,396, HILLSDALE

[1TM.MS, WM. H. $\left(\mathrm{b}^{\prime-6} 3\right)+-\mathrm{MCl}$ $(100)$

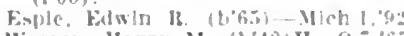

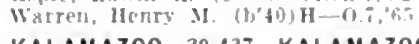

KALAMAZOO, 39,437, KALAMAZOO

Al)AMs, IIOSS U. (b's3) + Mllch ",n"

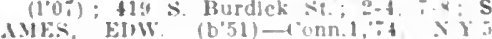
s1; $(1,00)=193 \mathrm{k}$ Lorell $=1 . ; 2-1 . ;$

luer, Edward Murray (bsi-Mici, II (1.11): Kalamazon State Hosplfal.

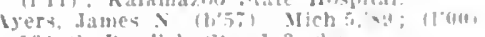

RAidi RALII E. (bo3) + III

Baldwin, Zell L. (b'6t) E-0 2 as; $11^{\circ 001}$ dullwin sanlearium.

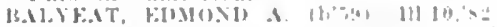

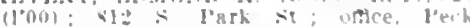

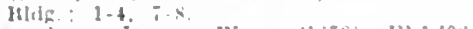

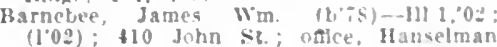

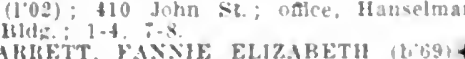
HAKIETT, FAXNIE ELIZABETH (lib9)+ - Mllch. $2: 99:$

Beehe. Ralph I'almer (b's)-Mich 2 'so: $(100) ; 713$ \&. West si.; chloe, l'ech

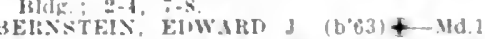
E

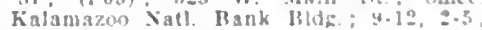
(II $1,3:$ ) ; OALR.

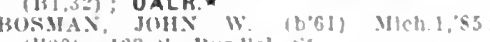

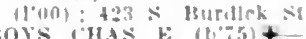

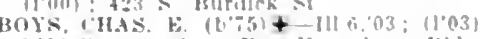
1 lof portage s! : office. Hanselman Mlde $1-1 ;-1.21) ; O b G$.

BRITTUX, Fito. T. (1)i)-Mich.,"06;

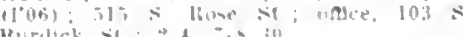

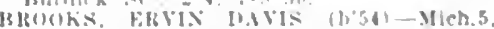

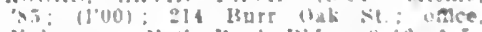

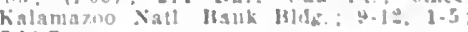

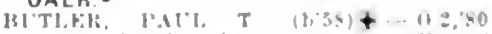

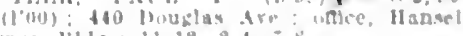
inia! Hha: $11-12,2-4$. :

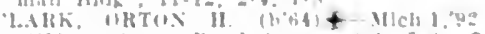

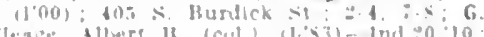

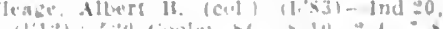

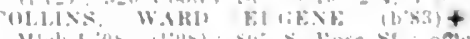

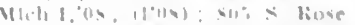

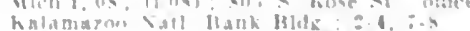

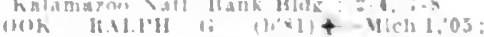

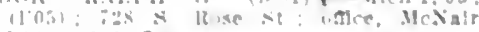

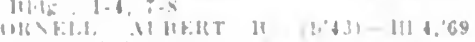

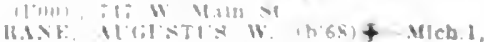

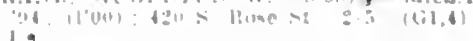

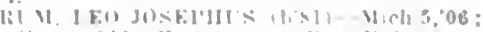

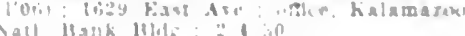


IHE IRLFWER, WATEIt (b'66)-Mich.I (1'01); 513 s. ISurdick St. ; $1: 30$ -

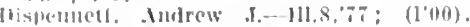

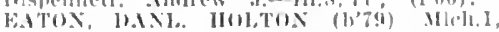

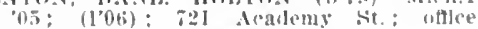

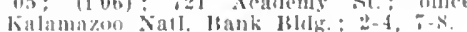

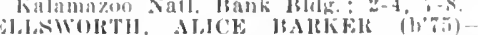
Meh.1.0.2; (1.02); 502 lohm st. ; $2-4$ $i-s, 0 b$

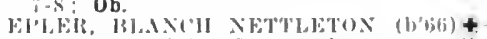

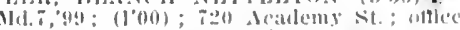
l'enk' IBlid, : $2-4,7-8 ;$ Pd.

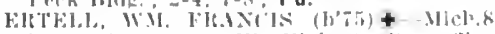

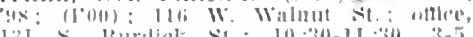
I:BI S S

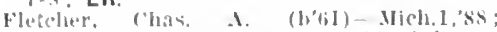

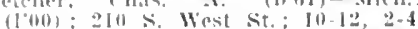

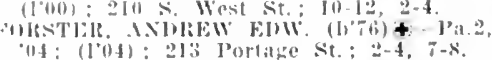

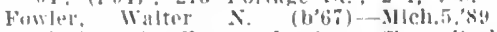

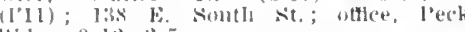
13Itgr.: ?-1:2, 2-5.

FILKEISON CIARKE REITERX $(1,75)+$ -Mich. 1,02: (102); 422 W. Vine $\mathrm{st}$. ottlee, Kilamazoo

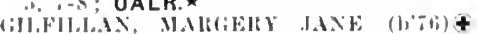
III.1,08: (I'12); Kilama\%o stale l1 pital: NP. *

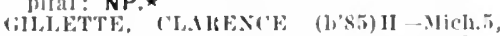

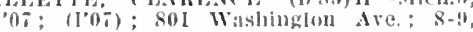
(

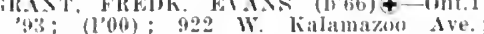
9.3: (l'00): 922 W. lialamazon Ave. offlec, Kalamazoo Natl. lkank

(1-1:2, 2-5; (131,32) ; OALR. *

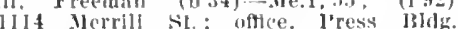
!1- I:- 1 -4.

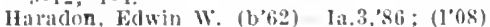
sot Van Vranken st.; offle, sluakespeare I3litu: : :- L2, 1-4.

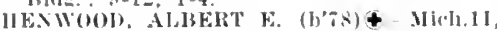
$05:(1 \cdot 05):$ Hanselman Bldg.: $1-3,7-9$.

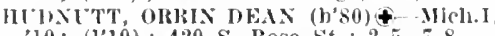
10 : (1'10); 420 s. Rose St.: 2-5, $7-8$. HUYSEk, wi. C. (b'86)-Ill.11, 11 ; (l'13) 13I Will st.; oftlee, Mexair Bldg.: 1-3, L'GENFRITZ, FREDK. II. (b'79) † Jich. 03: (l'03); 328 s. Rose St. ; offlee, 143 $\therefore$ isurdick' St.; 2-4, 7-8.

luch, Florence Nllen (b'i6)-Mich.1,99 (lon) : not in practice: State Hospital.

$(100)$ : not in practice: State Hospital.
INI, FEO. FHANKLIN (b'72) $\$$ Mich.1, '4:- (1'00); Kalamazoo State Hospital.

ACKSOS, JÓH BERT $\left(b^{\prime} 76\right) \oplus-111.1,03$ (l'03): 528 W. Iovell St.; offlee, Kalamazoo Natl. Bank Bldy. ; $2-4$.

Jones, diertrand L. (b'ti)-Ky.1,05; not iu practice; 1213 Grand Ave.

IANG, WALTER W. (b's0)థ-Jll.4, 0 ; : (l'06); $80 \%$ Washington Are.; offlce, Lalamizoo Vatl Bauk Blds

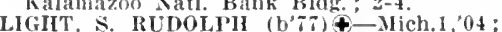
(l'04); 428 Douglas ive.; office, 223 E. Lorell' $\mathrm{St}$.

MCKIBBIN, JOIIN II. (b'48)-Ind.8,'s: ; (1'00); 420 s. Burdick St.; office, Peck Bldg.; 9-12, 1-4:30; OALR.

MeNair, Rush (b'60)-111.6,87; (1'00); Henrietta and E. Lowell sts. ; 2-4. $7-8$. (1'12); 1201 $\mathrm{x}$. Burdick St.

NOBLE, ALFRED IRA (b'60)—-Me.1,'s6 ;

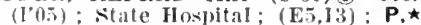

OSBORXE, DOXALIP. (b'-7s)-Mich.1,02; (1.03); 3 is $\mathrm{s}$. Rose st. ; offlce, Academy of Nusic; 2-4, 7-8,

OABORNE, HARRIS BENNETT (b'41) X.Y.10,6\%, X.Y.1, 75

OATRASIER, HERMANE- Mich.1,'s4; (I’Hi) : Kalamizoo state Hospital; (EJ, I:B) : NP.

Pease, Fdmund M. $\left(b^{\prime} 78\right)-M 0.20,07$; Kilimaroo State IIospital.

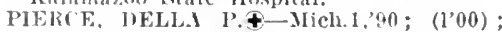
I0!4 W. lowell st.; 10-I2, 2-4.

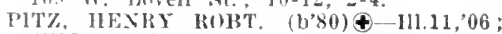
$\left(l^{0} 0^{-}\right)$; Joz EIm st. ; office, Hanselnan

PTILF, CHAS. DWIGHT (b'64)\&-Mich.5, ( I 411$)$ : Ilanselman Bldg. : OALR. Ft: iramy st,

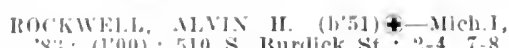

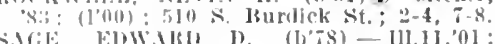

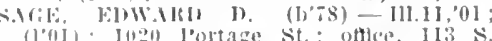
linrdiati sit.

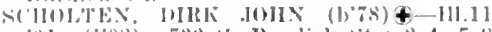

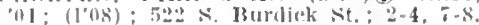

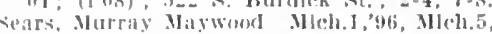
$4,-:(1,00)$

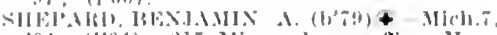

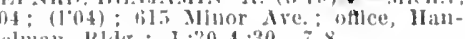
(teluam klig. : 1:30-4:30

SIIILITO, FREDK. (b*5i) - ky.l, 82, III.1.40): (100): 303 w. Vine st.; offlce, lialamazou Natl. Bank lBldg.

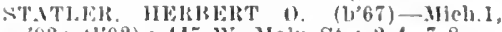
(92; 1102$): 415 \mathrm{~W}$. Maln St. : 2-4, 7-8.

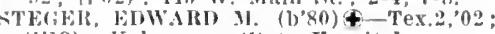
$\left(1^{\prime} 13\right)$ : Kalamazon sitate IIospltal.

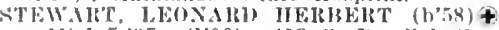
-Mieh.5.17\%: (1'00); 413 s. liurlick st. ; $1: 30-4: 30, \quad 7-8$

SONF, IIARILFTE O. MeCMIMONT+ II. Main st.

STONE, WILIJAM A. (b'63)†-MIJCh.1.'85 (l'05): $1102 W$ Naln St: (E5,13): NP.

TOMIKINSON. WM. SCOTT $\left(\mathrm{h}^{\prime} 60\right) \oplus$-I11.1] '05: (1'05); 452 W. Lovell st. ; oftec, 150

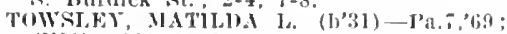
(lo0); sog s. Rose sit. : 10-19.

TYLER, FRANK HOWAIR (b'55)†Mllch.5.80; (I'00); 320 S. Park St. : offlec Kalamazon Natl. Bank Bldg.; $1: 30-4: 30$

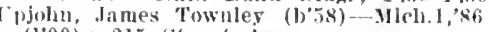
(1’00) : 21 \% stuart Are.

PPIOIIS WM. FR.ISTIS $\left(b^{\prime}, 53\right)+$ Mich. 1 $75 ;(100) ; 530 \mathrm{w}$. South St.; offec, E Lovell St. ; $8-6$.

YNT IRK, FHEDK. THOMAS (b'72)fHich.1,96; (1'03); 715 s. Burdick St.; offlce, 143 S. Burdlck St.; $1-3,7-8$

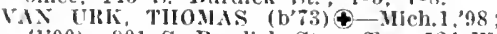
(1'00): 801 S. Burdick St.: oftice, I24 W Main St. ; 1-3, 7-8: OALR.

WAKER, RURT DEXTER (b'72)-Mich.5 91; (1'08); 1018 W. Kalamazoo Ave. office, Kalanazoo Natl. Bank Bldg.; 2-4 $7-8$

WEINRURIH, HARRY BENNETT (b'SI) -lll.11,09: (I'09); 401 W. Lovell St. ;

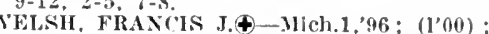

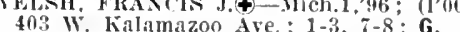

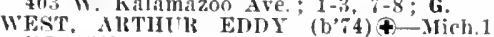
:T: (1"00); 728 S. Rose St,; office, KalaInazoo Natl. Bank Bldg.; 10-12, 2-4 $i=8 ; U . \star$

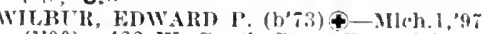
(l'00): 422 W. South St.; offlce, Kalima zoo Natl. Bank Bldg.; 9-12, 2-5.) (B1 32) : OALR. $\star$

WILLEY, GORDON FAY (b'83) \&-Mich.1, 11; (1'11); State IIospital.

Woolsey, Paul Jean (b'66)-Mich 7 96 (1.00); 502 w. North St. ; offlce, Kala mazoo Natl. Bank Bldg, St. ; offlce

loung. James L. W. '(b'49)-Jo.1, 1 (1'00) : 613 Academy St.: offlce, $126 \mathrm{~F}$ Main St. ; 10-12, 1-4, 7-8.

YOINOS. AMOS, SYLVESTER $(b ' 0)-$ Heh.8,96; $(100)$; 416 S. Burdick St. $1: 30-3: 30,7-8$.

\section{KALEVA, 200, MANISTEE}

Coates, Wm. E.-111.11,'95; (l'03).

KALKASKA, 1,415, KALKASKA

B.NBCOCK, EDGAR BARR (b'5i)-Hich.6 Pcarsall, Perly W. (b'63)-IIl.10,'89; (l'00) Ob.

Tripp, Geo. Elwin-Mich.10,'01; (1'01).

KAWKAWLIN, 250, BAY

Iayhew, Geo. Clark-Mich.10,06; (1'06)

KEARSARGE, 800, HOUGHTON

IAA DONALD, XEII, S. (b'il) \&-Mich.1,

9.5: (I’n(t).

QCICK, JAIES B. $\left(b^{\prime}, 4\right) \oplus-I 11.6,01$;

KENDALL, I50, VAN BUREN

WILKINSON, CIIESTER AMBROSE (b'62)థ -Pa.2,"88; (1'00)

KENT CITY, 467 , KENT

Mliller, Henry Lewis (b'69)-Mich.5,'81; ( I'00)

SHORTS, FRED HENRY (b', 03, HIl.1 I, 09; (1'03).
KENTON, 450, HOUGHTON

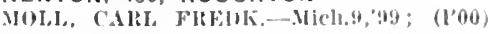
KINDE, 360 , HURON

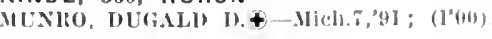
KINDERHOOK, 200, BRANCH

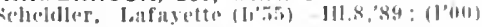
KINGSLEY, 497, GRAND TRAVERSE IHOWNSON, JAY A. (b'77) - Ill.8, 02 ;

SLATOS, GEO. I. (b'4X)-0.2.93; (l"00)

KINGSTON, 302, TUSCOLA

13.LTES, 6:HO. (b'b1)-Mich.1,'90; (l'00).

KNEELAND (MIO P.O.), 20, OSCODA

Sherlock, "Thomas J. (b'45) E-0.2,"3.3; $\left(I^{\prime} 00\right)$.

LACEY (R.F.D., ASSYRIA), 35, BARRY

losch, Theorlore Adolph (b'73)-.Illolı.1, 11 (I'Ii) ; S.

\section{LAINGSBURG, 703, SHIAWASSEE}

Alustin, David F.-Mlch.7,'94; (1'00).

scott, Arthur S.-Mleh.7,'94; (l'00).

seott Robert II (b'50)-Mich.7,94; (1'00).

WADE, G. BURTON (b'63)\$-MU.6,' (1'00).

LAKE ANN, 171, BENZIE

Shilllay, Win. J. (b'68)-Mich. б,91; (l'00).

LAKE CITY, 740, MISSAUKEE

Shbott, Nelson (b'69)-Mlich,1,91; (l'00).

Decker, Jolın W'-Mich.1,'87; (1'00).

woudna, John Fogo (b'75)-No.28,99; $(1 \times 00)$

LAKE LINDEN, 2,325, HOUGHTON Bourland, Philip Daggett (b'i3)-Mich. I,

LEVIX, SIMON (b'7)—-Mich.1,01; (L'01).

IRR, (IEO. W.A-Mich.1,7\%; (I,00).

Ilchette, J. M. P. (b'69)-Que.2,92; (l'00).

LAKE ODESSA, I,222, IONIA

Hane, Warion $\left(b^{\prime} 43\right)-\Delta ;\left(l^{\prime} 00\right)$.
Hart. Wm. S.-0.6,81; (l'00).

barques, Jois B. (b'71) $\mathbf{l}^{\prime}-\mathbf{3}-\ln 1.5,90$ (l'00).

Martiu, Andrew II.- 0 ; $\left(\right.$ l'$\left.^{\prime} 00\right)$; not in praclice.

McLaughlin. Nelson (b'82)-0.2,07; (l'09).

MORSE, FREDK. LEE (b'75) 4 -Nich.9,'98; $(1,00)$

l'abody, Chas, H. (b'76)-0.19,98; (l'00) Snyder, Edwin M. (b'66)-Mich.8,'89; (1'00).

LAKESIDE, 75, BERRIEN

larson, Geo. M.-JI-III.4,82; $\left(1^{\prime} 00\right)$.

LAKEVIEW, 954, MONTCALM

BIAACHARD, FRANCIS R. (b'63)† Mich 1,'91; (1'00).

KELSEY, LEE E. (b'80) $\oplus$-Mich.1, 04 ; (1'04): OALR.

LAMB, 125, ST. CLAIR

ILNNE. BYROX H. (b'80) - Mlleh.7,05: (1'0i)

LAMBERTVILLE, 15I, MONROE

PARMEIEE, OLIN EARL (b' 73$) \&-111.11$, $05 ;\left(l^{\prime} 06\right)$.

LANGSTON (R.F.D., GREENVILLE), 150, AYLES, CYRENIUS C. (b'39) $\rightarrow$; (1'00).

L'ANSE, 708, BARAGA

SHARPE, HOWARD ADUISON (b'81) $111.6,07$; (l'13)

ZELLEN, WALFRED ARCIIMEUES VONA - Ilich.1,00; (l'02).

\section{LANSING, 31,229, INGHAM}

HALLARU, L, ANNA $\left(\mathrm{b}^{2} 48\right)-111.9,88$ (1'00); $312 x$. Capitol Ave.; 8-9, 1-8, $7-8 ; G$.

BARBER. CHACXCEY L. (1,58)-Ill.11 '84; $(1,00) ; 415$ Washington Ave., s.; $2-4,7=8$.

BARTHOLOMEW, HENRY S. $\left(\mathrm{b}^{+} 65\right) \$-$ Mich.1,10; (1'10); 101 Main St., W.; ARTOW, IOS. GRANT (b'63)-Mich.1, 91 (I'00): 402 S. Walnut St.

BALCH, GEO. FRANKLIN $(b, 70)$ †-Pa.1

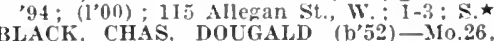
91; (1'00); 114 E. Kalamazoo St.; 8-10, 5-8.

Black, Iosiah (b'55)-Mich.6,'81; (l'00) $900 \mathrm{~W}$. Siginaw st. 


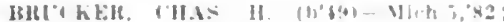

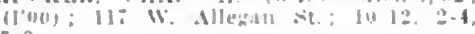

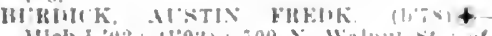

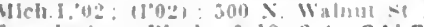
Ace, Jenisum Block; 9-12.2.4: OALR.

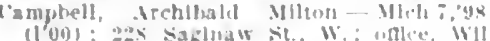
wh HIdz; ; 2-4. i-s.

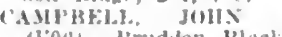

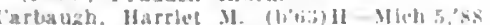
(lou): E13 shlawavice st. W. Op.

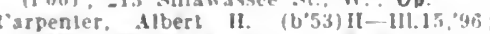

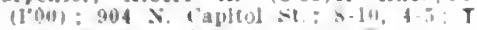

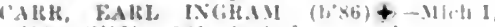
10; (1'10): 1:1 faptrol ire.

Cochrave Warno Alerander (1)'it)--llich. "0S: (l'0s\}: Tussing Hid.

cule Theulure-Mlle)! "fis: (I'unI: a.: 11 Michlgan Ave.

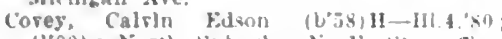
(l'00): Nurdh suburbs, $x$ r. St. ; antce 111 Washlngton Are, : 2-4

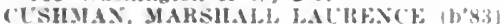
+-Mich, 1,06; $\left(1^{\prime}(t+i): 326\right.$ seythour sit. once, Tussing I Blds: 10-1: 2-4; ALR.

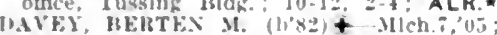

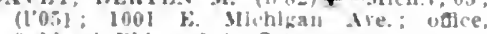
Oakland Hldg.; 2-4; S.*

DAVIS, CLARA II $\left(6^{\circ}-8\right)+-M i c h .1,04$ (1004) 332 Tuwnsend 51 ; unce. Tursing HId ; 11-12, I:30-3:30: Pd.

Trawles, Henry A (bobi) - Mlch., a, (100): 103 Wsahington Ave.

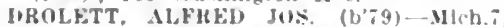
"0:; (1'0i); 111: Michlga.- die.; ontoe, 400 (bakland Bldz. $2-4,7-8$

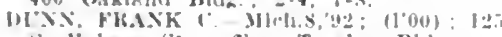
s Holmes st. : once, Tussing Rldg

foster. Walter J. (b'62)-0.12,'84; (1'mu) Prudden $\mathbf{B l d g}$

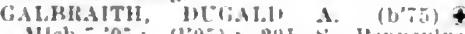

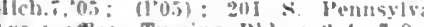

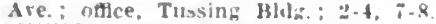

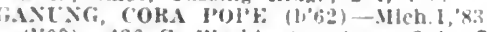
(l'00):426 S. Washlngtor dve.: $2-4:$ G

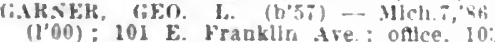
$\left(l^{\prime} 00\right)$ : $101 \mathrm{E}$. Franklin Are ; oftlce, 10 k. Franklin Ave.

forilun. Homer Farl (10,5t)-Mich.a."3x Il'0n): 11491/2 \&. Washingern Ave.; 9.19. 1-4.

Greusel, Sicholas P. (b'ib)-Wleh.8,0n $(1 " 60)$; 2006 b. Mlinhan 1 ie. II:30 $1 \geq: 30 ; 2-3,-6=8$

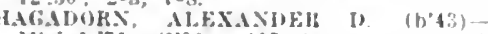

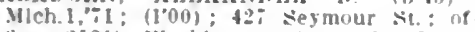
Hce, 1912 Washington die.. $5 . ; 11-1$.

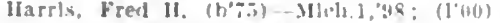
1]1/2 Washlugton Are. $\mathrm{x}$.

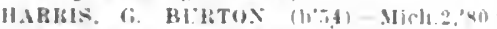
$\left(l^{\prime} 00\right) ; 602$ Capiwl Ave., s. ; onlec, 10tisy Waslington Are., $\mathrm{S}$.

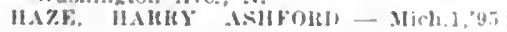

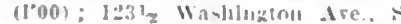

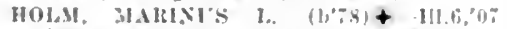
$1 l^{\circ}(18) ; 913$ W. Allegals Si: oftre. $20 \%$ Washlington st., \&.; \$-13, I-1; Bact.

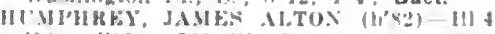

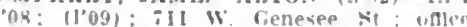

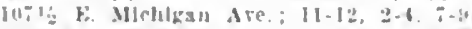

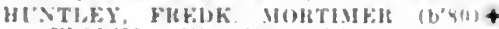
-I11.10,03: 111.11.05: 1103): IIt W

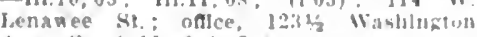
Are. S.: $10-11,2.4,7-x$

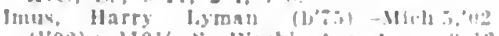

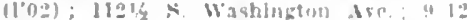
1.8

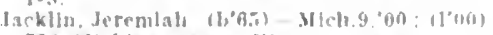
ing Mloligan Ale. 14

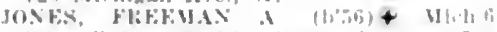

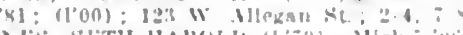

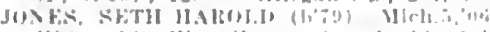

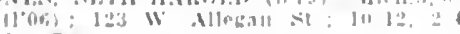
OALR.

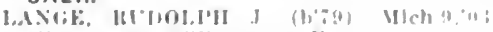

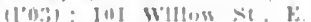

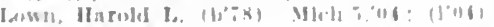
819 Valn sit.

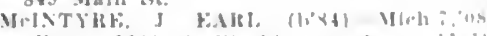

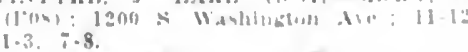

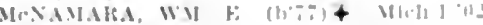
(1"u) : 61\% $>$ Butler Si

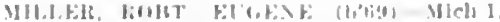

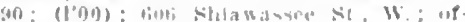

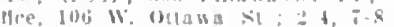

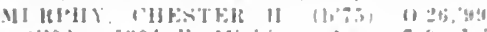

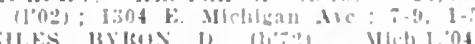

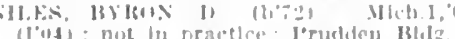

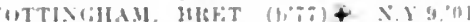

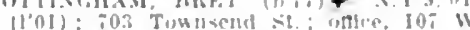

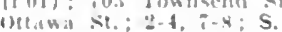

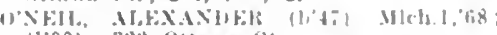
$(100) ; 320$ Ostawa si.

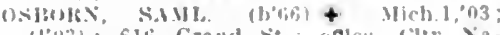

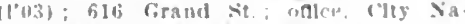
Honal Bank lildg.: :-11,,-1

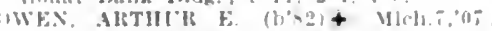

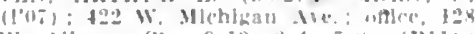

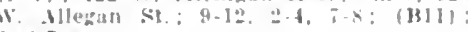
OALR.

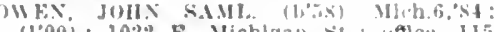

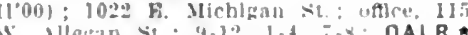

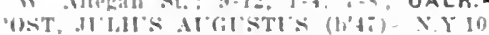
bी: (100): 210 s. Washington Ave : 1 - 3 .

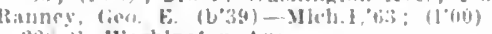
21)s Wasblngton tie.

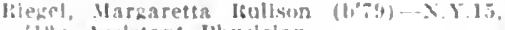
'Ie: distatant I'hystctan.

Sulverstin, Eugene 1.-0; $\left(1{ }^{\prime} 00\right) ; 218$ franklln ire.

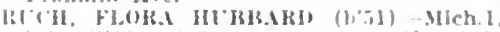

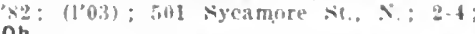
$\mathrm{Ob}$

Ibullun, John Custare (1,iti)-Mich.1.'03:

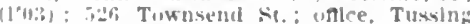
Jillz: : 2-4, i-s; 5 .

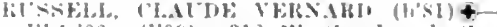
11. 1,04: (1.09); 312 W. st. Joseph st.

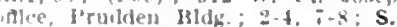

SIVFOH11. THOS. M. $\left.(1)^{\prime}+5\right)+$ Mo.28,94; (1001: Tusalng k1dg : 9-12, 1-i.

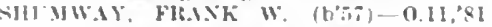
$(1000) ;+[1$ W. Miclugan Are.

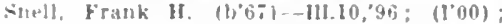
uos in practlee: 214 r. Franklin tre

teple. leancler inle $-0 ;\left(I^{\prime} 00\right): 309 \mathrm{~s}$ Wablington Are.

Tenmey. Thomas J. (b'st) Mldh.7,07; (1'(ix); 603 F. Franklln Si.

TIIUMS, FRANK M\$-Mleh.1,91; (1'00): (4)I Washlugton Are., $\mathrm{X}$ : uffice, 31616 Franklin Are., E.: I-3, $;+9$

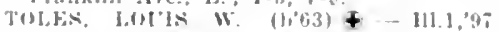
1.00): 530 i'apltol Are..s.; once, l'rud len Irlock: 2-4; S.

Toukkl, MHLixhl A. - Mich.6,94 $1 I^{\prime}(10) ; 431$ E. Mlchlipan Are.: 2-4, :-s

TOWNE, IOAWIESCE ('HATHYLLI) (b'S4)

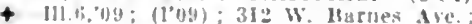
"mlce, Tusshig Rldg, ; 10-11, 2-4, ;-8.

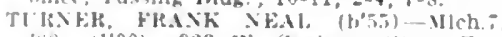
*ie; $(100) ; 323$ w. Saginaw st. : offle Jenisun Hlock; 10-12, 2-4, :-5; N.

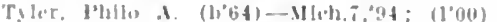

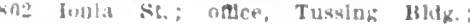

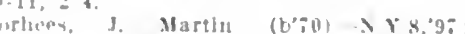
thut: 11 i Nlegan st. W.; $4-12,2-5$ Pr.

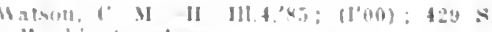
II anliliztold die

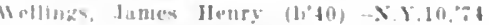

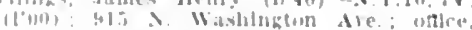

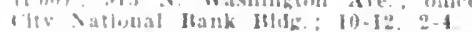

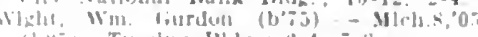

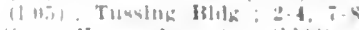

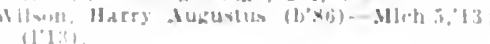

LAPEER, 3.986, LAPEER

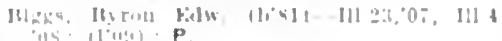

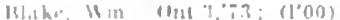

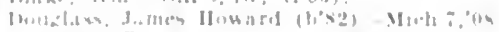

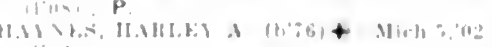

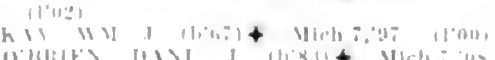

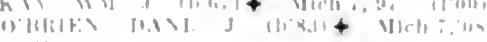

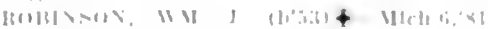

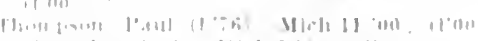

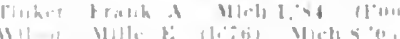

LA SALLE, 100. MONROE

II) 1111

(1'010) ).

LAURIUM, 8.537. HOUGHTON

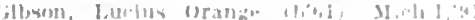
(I'0il)

hierr, Wurdion y Mi, ?

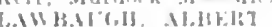

O11 $11^{\prime} 0(1):$ S.

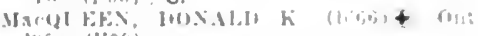

Q90); $\left(l^{\prime} 00\right)$

LAWRENCE, 663, VAN BUREN

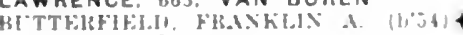

111. 1, s0: (1'0i)

crankshas, Haune Wesley itia) Michl. 13; (1'13).

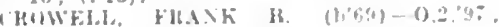
111 \&,"05: $(10100)$.

LAWTON, 1.042, VAN BUREN

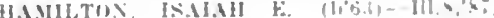
III. $1, y 4:(1,00)$.

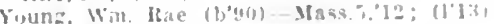

LELAND, 400, LEELANAU

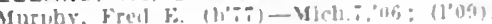

LENNON, 100, SHIAWASSEE

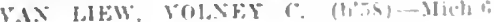
"XI; (1, (1)0).

LENOX, 350, MACOMB

Breltentiecher. Filwarl Rolit.

Vich.:11:; (1'0\%)

LEONARD, 3I3, OAKLAND

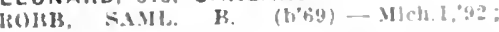
(1'00).

LEONIDAS, 300, ST. JOSEPH

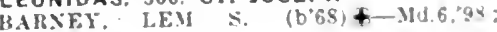
$\left(l^{\circ} 00\right)$.

LEROY, 331, OSCEOLA

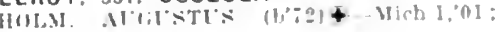
(I)

LESLIE. 1.032. INGHAM

Bronks. Wh. Won (b'a

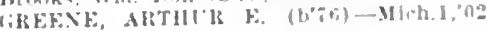

$\left(10^{2} 02\right)$.

vichols,

LEVERING. 350. EMMET

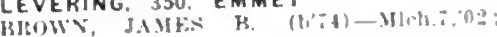
(100)

LEWISTON, 550. MONTMORENCY

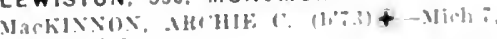
ar: 1100$)$.

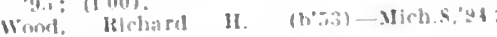
(1)(1)i): LR.

LEXINGTON, 519, SANILAC

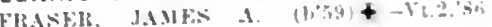
(l'01)): Pd.

o'Hrich, Dennis (1,00).

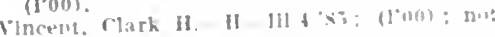
In jucactire.

LINCOLN, 122, ALCONA

stuart. Ileramler. Allen

ini: (1, i) 1$\}$

LINDEN 550, GENESEE $\rightarrow=0$. (1, 0.1

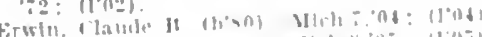

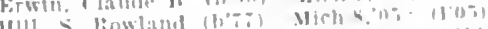

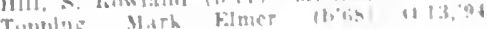
Ting

LINWOOD, 200, BAY

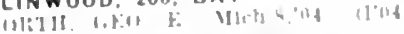

ITCHFIELD, 660. HILLSDALE

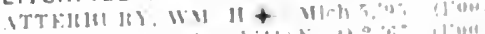

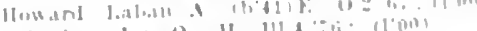

sultulus. Jay o $I 1$ lil

LONG RAPIOS. 200, ALPENA

I.I HII

LORETTO, 200, DICKINSON

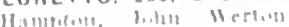

11.1?

LOWELL, 1.761 , KENT

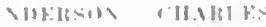

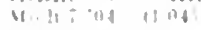




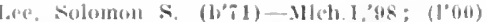

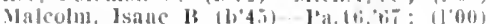

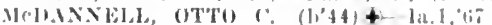
( 100 )

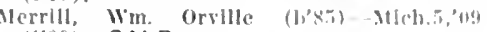
(1'09): OALR.

LUDINGTON, 9, I32, MASON

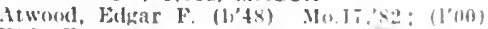

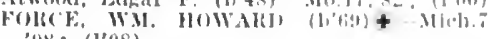
ox: (l'0.8).

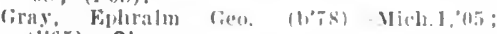
(1. (1.) : Ob.

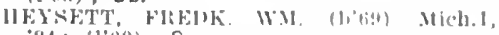
$94:\left(1^{\circ}(10)\right): S$.

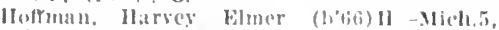
,

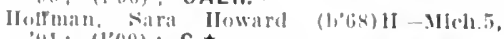

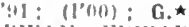

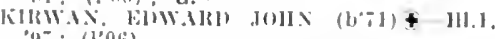

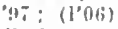

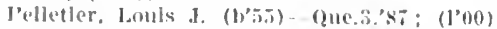

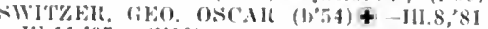
111.11,98: (l'00)

Taylor, Wm. Herbert (bos) - Wleh, ls: (l'00).

LUM. 250. LAPEER

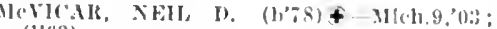
(1" (13)

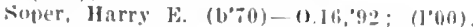

LUTHER, 626, LAKE

Fairbanks. Earl (1, 60$)-M l c h .1,88:$ (1'00).

Lewis, Wm. F. (b'73)-0.2,95; (I'00)

LYONS, 611, IONIA

GRANT. WM. A (b'-S)-M[1ch.9, 02 : (1.02).

(irunt. Wm. IR Mich.s,9l; (1'02); G.

MACKINAC ISLAND, 714, MACKINAC

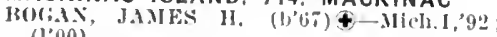
$\left(l^{\circ} 00\right)$

CIIARTER, IOHN HAMILTON (b'TO)Mich.9,03; (1'03); ObG.

MACKINAW, 697, CHEBOYGAN

Plerce, BenJ. I'. $\rightarrow$; (l'00).

MACON, 237. LENAWEE

BWARDSIEY, JOHN WALAACE (b'82)Ill.6, 06; ( ) ; Menber N.M. Med. Śóc.

MANCELONA, 1,200, ANTRIM

Beaver, (has. J. (1'61) E-0.2,'81; (1'00)

Verdier, John W. (h'73)-Pa. 2,02; (l'03).

Wessels, Richard Ifenry (b'68)-Mo.7, 00 : (l'07)

WHLOEGHBY, I.ESHIE I. - Mich.8,'05;

P.05); G.

MANCHESTER, 1,047, WASHTENAW

Conklin, Ebenezer M. (b'55) - 0.2,'81; $\left(l^{\prime} 00\right)$

Kapp, Christian (b'46)-0.8,76: (1'00) Kiopfenstein, Walter A. (b'76) $1-111.10,99$;
(1'00).

Lynch, James A. $\rightarrow$; (1'00)

SCHELIER, T'ETER ARTIILK (b'85)థ Mich. T,08; (l’08)

Tracy, Bird A. (b'66)-No.6,'91; (1'01).

MANISTEE, 12,381 , MANISTEE

FILLS, ELLSWORTH S.-N.T.1, ; $6 ;\left(1^{\prime} 00\right)$ FNSEN, PALT C. (b'55) \$-MIich.1,"82 $(1,00) ; 412$ Elm St.; offlee, 405 River St. $8-9,1-3,7-8$

KIN1;, JAMES ASABEL (b'58) †-Mich.1, General Hospltal; 1-3; $\mathbf{S}$.

KIRKLAND, IFYNOLD' J. (b'56)-Mich.1, $79 ;\left(l^{\prime} 00\right)$.

KNOWLES, GIKARD F.-111.4,'82; (1'00) ; $372.2 \mathrm{~d}$ St.; offce, 382 Hiver st.; $1-5$,

LEWIS, LEE A.-MJeh. 7,$96 ;\left(\mathbf{I}^{\prime} 00\right) ; 467$, 2l st.; office, 369 River st.; $9-11,1-4$. T-S; OALR. *

HAILEN (b'80)-.Ilich.5, ,03 (106); 397 River St.; 1-3, 7-8.

PAYNE, ALBERT S. (b'68) \&-Nich.1,92; $\left(l^{\prime} 00\right) ; 400$ Maple st.; offlce, 401 River t. : $1-3,7-8 ; 0 \mathrm{~b}$

RAMSDELL, LEWIS S. \&-111.1,00; $\left(1^{\prime} 00\right)$; S. *

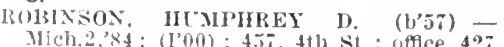
Mich.2, 'st: (I'00); 45i, th si. ; offlee, 427 River st.; 8-9, 1-3.

Szudratski, Szymon-Nich.1,99; (1'00); 356 liver st.; 8-9, 1-3, 7-8.

West, Emma Jane-1I-Jll.4, $99 ;\left(I^{\prime} 00\right) ; 408$, Ist st.; $\mathrm{S}-10,1-3,7-8 ; \mathbf{G}$.
MANISTIQUE, 4,722, SCHOOLCRAFT

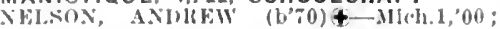
(1.00)

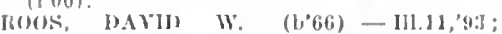

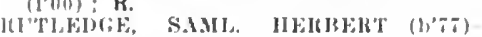
Ont.î,04; (l'12); Member 111. state Med. Soc.: $\mathrm{S}$.

SAlNUEIs, WM. J. (b;2)-Ml(h.9,03; $(1003)$.

VItIGHT, W.M. K. $(1)^{\prime 55}+$ Mo.1, 87 ; (1'I2).

MANTON, 1,069, WEXFORD

IIAI'FH, ALEXANDER W.-Mich.9,03: (l'03).

HINTLET, VICTOR F. (b'54) $-0 ;\left(l^{\prime} 00\right)$;

WAIAACE, WALTER B. (l) 67$)+-M(\cdot h .7$. '95: (1'00).

MAPLE CITY, 200, LEELANAU

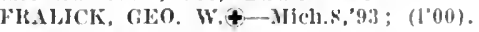

MAPLE RAPIDS, 529, CLINTON

1.UTON, FHANK I\% (b'79)\&-110.8,01;

URTIN, EIINEST 1,. (b'75) \&-MICh.1, 00

(1'00).

Sanborn. IR. H.-F- $-0 ;\left(l^{\circ} 00\right)$

MAPLERIDGE, 150, ARENAC

IBOVEF, MAKHON F. (b'SB)-Mi(ch.T,'l2 (1'12).

Green, Jarrls M.-Mllch.2,83; (l'02).

MARCELLUS, 1,047, CASS

Davis, ('harles Folward (b'4ti) - Ill.8,'8i (1'01)).

Holllson, Henry J.-111.15,'06; (I'07).

Kedney, Homer 1.-Nich.7, 06 ; OpA.

Shillito, Ernest-Ky, 1,'88; (1'00)

MARENGO, I00, CALHOUN

Case, Wm. Newton-Mich.1,75; (1'00).

MARINE CITY, 3,770 , ST. CLAIR

ARNISBURX, AALON B. (b'70)-0.23,97; $\left(I^{\prime} 00\right)$

Blagborne, Fletcher-Mich.6,'8.3; (l'00).

DE GLISE, THOS. EDW. (b'73)€-Mich.7,

'95; (1'00).

Lang, Fredk. W.-Que.1,92; (l'00).

How, Andrew-0nt.3,96; (1'02).

MARION, 767, OSCEOLA

Carrow, Jos, F.-Mich.8,'98; (l'00).

JOHNSON, DOXALD (b'62)-Ont.3,9I ; (1'00).

MARLETTE, I,062, SANILAC

Atkinson, Wm. Tisdale-Ml.h.1,87; $\left(1{ }^{\prime} 00\right)$; 0 p A.

Blair, Marion Elsworth-0.6,89; (1'00)

Merrea, Henry - Mich.1,75, N.Y.10,76; (l'00).

Sinienton, Geo.-Ont.4,85: (1'00).

WILtS, WARD W. (b'76)-Mich. 7,11 ; (1'11).

MARQUETTE, 11.503 , MARQUETTE

BOTTL11, CHAS. N. (b'T) $\$-I 11.11,03$; (l'03); 624 N. 3d St.; oftice, Savings Bank Bldg. ; 10-12, 2-4, $;-8$.

CAKRIEl, HOWAKD TURNER (b'7 $\tau)$ \&

Ill.6,02; (l'06); 602 Pine st.; office Werner Block; 11-12, 2-4, i-S; S.

CINNINGHAN, HENRY A. (b'65) \& N.Y.1,95; (1'00); 527 spruce st. ; office Frel Block; 9-12, 2-5; OALR.

CLNNIGHAM, TIIOS. H. (b'69) \&-N.Y.1 95: (1"00); Front St.; office, Flrst $\mathrm{Na}$ tional Bank Bldg.; $11-12,1: 30-3: 30,7-8$ Dawson, James Henry-Mich.1,'85; (1'03) (I'pland, ('al.).

FLYXN, EDWIRD H. (b'60)€-Mlch.1,'81; HAR 306 Front St. ; 7-9, 1-3, $7-9$; Que.1,85; (1'00); 310 E. Mlchlgan St. offee, Sarings Bank Bldg.; $\mathbf{S}$.

HORNBO(iEx, ALFRED iv. (b'66) \&

IIl.11, $89 ;\left(1^{\prime} 00\right) ; 507$ Spruce St.; office, Savings Bank Bldg.; 10-12, 1-4, 7-8; S. HORNBOGEN, HARIF J. (b'71)\&-Ili.11, 94; (l'00); 212 E. Michigan St. ; offlee, Savings Bank Bldg. ; $8: 30-12,1: 30-5$;

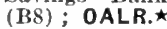

Janes, Saml. Meredith (b'61)-Cal.5,'88, Ill.17,'02; (l'03); $423 \mathrm{~N}$. Front St.; of fice, $204 \mathrm{~W}$, Rldge St. ; 2-4; S.

Jones, Arthur Curtls (b'87) - Mlch.1,'12 (I'13); Frei Block. LUNN, WM. B. (b'72)£-Mlch.1,97; (1'00); Werner Block; 8-9,2-4,7-9;S
Main, Itoscoe Conkllng (1,'82)-III.1,11 (l'13): 204 Ridge sit.: LD. Markham, Itussell f. - Ili.4,'81; $\left(1^{\prime} 00\right)$

VAINAIS, ZAIIAItIE, (b'74) 4 -Que. 3 98 ; $\left(1^{\prime} 00\right)$; 213 Wishlugton st.; 8-10, $2-4,7-8$.

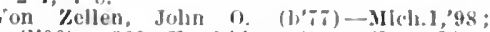
$\left(l^{\prime} 00\right) ; 329$ F. Mlage st.; offlee, First National Bank llly.; $10-12,2-4$.

TOUNGQUIST, (IAIN (GODFIEY (b'58) -111.1, $86 ;(1200) ; 204$ lildge st.; $8-10$,

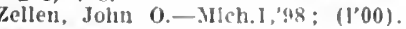

MARSHALL, 4,236, CALHOUN

('IURCH, STALR KINI: (b'6T) \&-Mich.1, 92 ; (1'00).

Foote, Frank 3. (b'61)-Mch. 1,84: (1'00) Gallup, Leonard Edwln (b'5i) H-Mich.5, $79 ;\left(11^{\prime} 00\right)$.

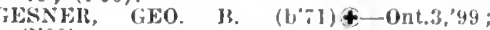
(l'00).

(HIBS, MAIHCE SNOW (1,88)-M(1).11 11; (1'11); Pd.

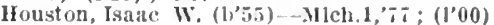

JOY, LOUIS S. (b'60)-M11ch.7,92; (1'00);

MAKSHALL, EMOLI J. (b'53)-111.4.75;

Pendell, E. I. (b'58)-Mich.1,81; $\left(1^{\prime} 00\right) ; \mathrm{S}$. SHIRTLEF', HENKY A. (b'5\%)-Min.1 $79 ; \quad(1 ' 00)$.

MARTIN, 450, ALLEGAN

BARTHOLOMEW, CAll, A. (b'76) -Mllh.i 03 : $\left\langle 1^{\prime} 03\right.$

LADJ). LEWIS FRANK-Mlch.1,'97; (l'00),

MARYSVILLE, $270, S T$. CLAIR

IERCK, W. I'ETEK (b'66) £-Mlch.7,'94 (I'00).

JMES, WM. B.

(See Port Huron.)

MASON, 1.742, INGHAM

Ballard, (has. Sherre (b'78) II-Mllch.5,'08; (1'08); OALR.

'ULVEK, SIDNEX H. (b'56)-Mlch.l,'84; (1'00).

Dutt, Geo. II. (b'62) E-Ill.8,'87; (l'00).

Evelin, Arthur C. (b'74)-Mid.6,'98; (l'00). REELAND, ORIIN IIENRY (b'69) Mlch.1,97; (1'00) ; Pd.

MeCUILOUGH, ROB'T. E. (b'64)-0.3,'98 * (1'11)

thomas, Frank E. (b'67)-Mlch.7,94; (1'00)

MASS, 1,000, ONTONAGON

IIANNA, WM. B. (b'63) $₫-$ H1.4,'89; (l'02)

MATTAWAN, 300, VAN BUREN

Coleman, Martln A.-Ill.6,75; (1†); Trar eling.

Ide, Grant (b'65)-.Mich.10,'98; (\$).

MAYBEE, 310, MONROE

Creasy, Henry (b'7)-Mllch.9, 00 ; $\left(\mathrm{l}^{\prime} 00\right)$. Lennington, Andrew B. (b'67)-Mích.7, 00 (1'00).

MAYVILLE, 687, TUSCOLA

BIADSHAW, BLRTON CLARK (b'6t)Yich 1,91: $(1300)$.

CURTIS, WARREN B. (b'38)-Ilich.1,'61 ;

WARCY. BEXJAIIN

(See Detroit.)
EELEY, ARTHUR L. (b'60)\&-Mich.2 84; (1'00).

MCBAIN, 546, MISSAUKEE

WHITE, HERBERT SPENCER (b' Vich. 11,09: (l'09)

MOBRIDES, 236, MONTCA.

HANSEN, JOHN R. (b'83)-11k..

MOCORDS, 35, KENT

Haskins, Lewis E.-H-O; $\left(l^{\prime} 00\right)$.

MECOSTA, 352, MECOSTA

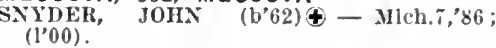

WEAVER, HEXRY BISHOP (b'81)-Mlch. $\tilde{z}$, 08: (1,08).

MELVIN, 242, SANILAC

Tomilinson, Jos. W. (b'71)-IId.6,'98; (l'00).

MEMPHIS, 557, MACOMB

Halc, Geo, P. (b'厃̃) H-III.4,'87; (I'00)

Mills, Edmond D.-Mich.8,'96; ' $\left(1^{\prime} 00\right)$.

WATERS, GEO. (b'74)-Mich.7,'03; (l'03).

MENDON, 768. ST, JOSEPH

Barninger, Chas. E. (b'65)-111.10,'94; (l'00). Saml. H. (b'36)-X.Y.6,'65; $\left(\mathrm{l}^{\prime} 00\right)$. Bennett, Saml. H. (b'36)-ŇY.6,'65; $\left(1^{\prime} 00\right)$.
RoYER, WM. A. (b'64)-Mich.1,92; $\left(1^{\prime} 00\right)$. 
MENOMINEE, 10,507, MENOMINEE

SISOOI, FAIVIN H $16 \% \mathrm{O}_{1}+$ Wheh

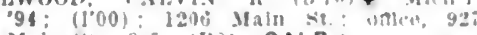
Main st. ; $9-3 ;($ HR); OALR.

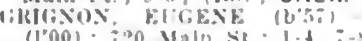
Heks, Jolin f.-Mleh. 1,$19 ;$ il'on

HIKS, WH.TEH is - X.Y, YU, '

ga? Maln sit.

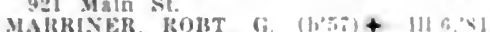

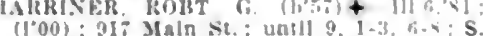

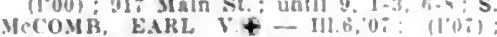

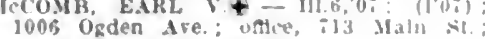
J $-3,7-8 ;$ LD

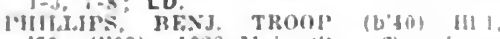

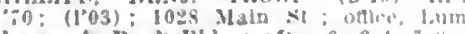
berman's Hank Hidg ; after $3.21,7$

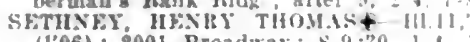
(1'06); 001 Nroadway : $5.9: 30,1.4$

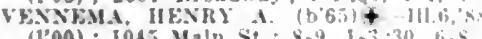

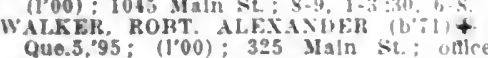
Que.s."95: (I'00) ; 325 Maln St.; ollce

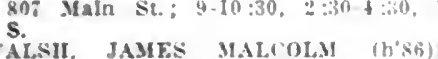

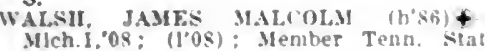
Med. issn: : G.

MERRILL, 505. SAGINAW

IIudson, James I!. (b'58) -. Mich. I. 's?

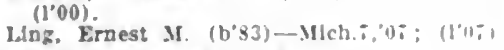

MESICK, 510, WEXFORD

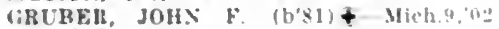
(1)09).

McMANits, EDWIX A. (b'b3)-Mlehs.'sa $\left(1^{\circ} 00\right)$

STICKLEY, ALHEUT EDN (b'A)+ Mllch. 10,$97 ; 180 ;)$.

METAMORA, 276. LAPEER

Rurnham, Arthur F, (bo9)-Mich. 6,03 (I'03).

MICHELSON, 75, ROSCOMMON

Dort, Wllland F. (b'bi) - Ml(n.11,0: (10\%).

MICHIGAMME, 962, MARQUETTE

SICOTTK. ISAIII $\left(b^{\circ}, \mathrm{g}\right)+$-Mich.1.0\% $\left.\left(1^{\prime} 0\right)^{\circ}\right)$.

MIDDLETON, 450, GRATIOT

Denney, Carlisle II. (b'Si) - Ill.22,"11 $(1,12): \mathbf{s}$.

0'Nelli. Chas. F.-Mlich.4.9:; 11'00)

MIODLEVILLE, 804, BARRY

Ilanlon, Amos (b'4) 11-J11,4, ;6, 111.10,;9 $(1,00)$;

Ifull, Francis Sidney (b'si) - IIch 1. \$o

Swlft, Blrge Carlion (b\%i)-Mllo.i, is ( 103 ).

Taylor, Ass L. (b'60)- $0 ;\left(I^{\prime} 00\right)$.

MIDLAND, 2,527, MIDLAND

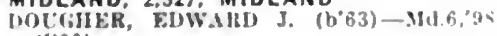
(1/,00)

JOHNSOX, J. HESRY-Mlch. :9:; (I00) SJOLANUER, Rit'ST-MIch.9.03; (1"03)

ST. LOUIS, RENE J. (b'Si) - MHlch. $; 10$

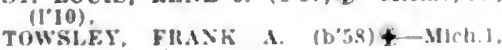
$80:\left(1^{\circ} 00\right)$.

MIKADO, 100, ALCONA

('ASE, HKRBERT W: (b*8:)-Mlch.s."Ut (1'04).

(1P0D).

MILAN, 1,335, WASHTENAW

Bell, Lachlan J $\left(b^{\prime} 75\right)$ Mllch. 8,$96 ;(1)^{\prime} 00$

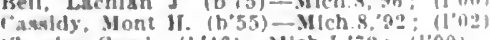

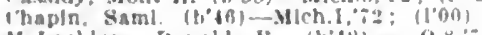

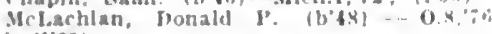
(1000)

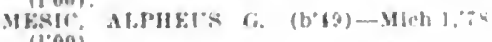

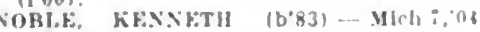
$\left(10^{\circ} 04\right) ; 0 b$.

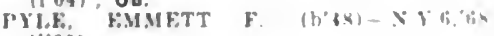
(1'00).

MILFORD, 973, OAKLAND MILFORD, 973, OAKLAND
MAKRIt, NOKMAN IHVING (19:1)
MIChI,02; (I.02): OALR.

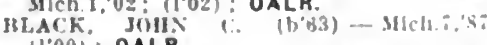
$\left(11^{\circ} 00\right):$ OALR.

Thow (1,00).

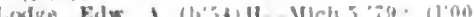

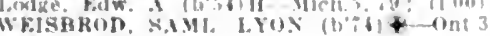
a1: 1100 ,
MILLBROOK, 400, MECOSTA

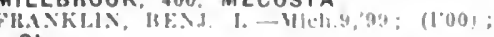
$\mathrm{Ob}$

MILLERSBURG, 519, PRESQUE ISLE

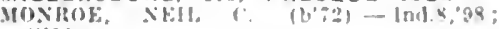
(i.00)

MILLINGTON, 623, TUSCOLA

HAIIOI, HESII) I (b\%1)+ (1)(114).

(i.)RVIN

MILLS (R.F.D., DECKERVILLE), 42, SANILAC

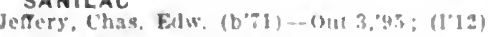

MINDEN CITY, 332, SANILAC

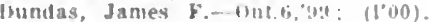

llealey, cialllard il. Mclis, : (l'iii)

MOHAWK, 1,000, KEWEENAW

IBUI.NES, JAMES, JH. $\left(b^{\prime}: 3\right)+$ Mich.8,0?: $\left(10^{\prime 2}\right)$.

TLCKER, ALIFFT R. (1)'66)+-M1ch 8,94: $\left(1^{\prime} 00\right)$.

MONROE, 6,893, MONROE

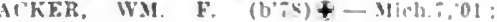

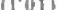

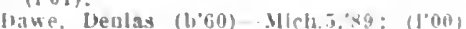

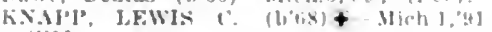
$(1,00)$.

MCCHLIU, GFO, BAR(HAL (b.55)Iich.1,80, N.Y.I, 81 : (1'00).

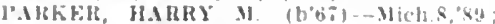
(1) 001

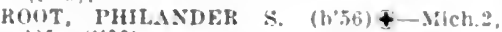
IY'FE, JULFS J (b"is)-Mlch.i。01:

sISUNG, VICTOR $\left(\mathrm{b}^{\circ} 68\right)+-$ Mch.: $(1,00)$.

SOLTHWORTH, CIIAS. TIACI (b'60) Mlich. 6,$86 ;\left(1^{\prime} 00\right)$.

MONTAGUE, 942, MUSKEGON

Julles, l.yle B.- (1).3, 55 ; (1).

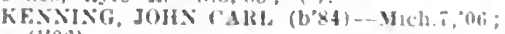
(1'06).

MONTGOMERY, 362, HILLSDALE

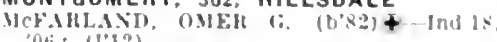
"065: (1'12).

Miner, Corncllus E.-H-D: (1'00)

MONTROSE, 443, GENESEE

C.AIBH.MTI, JOIN M. (b'69)-Mch.7.95 (l'00)

(inddard, Seth T. (6'56) $11-111 ., 81$; (1'01). lioff. Chas. W. -O: 1100$)$.

MORENCI, 1,515, LENAWEE

Hailes, Norton II (b.5) (1 13,09: (1000)

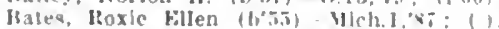

3l.Alit, CHAS. A. (b'59) - Hich.s, 92 ; (1'00) : OpA.

Hutler, Chas. M. (b'59)-Mch.s.s0: (1'00).

Hider, Henry i., (b'bs)-.jich.s.g5: (l'00).

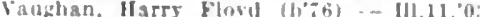

MORLEY, 337, MECOSTA

WAIR, ISAAC E. (b'53)-Ind. . 82: (1.00)

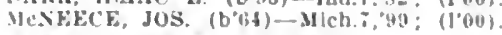
MORRICE, 470, SHIAWASSEE

Ames, Arthur Furene (b'b

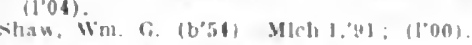

MOSCOW, 200. HILLSDALE

ronle, (15r!n II - $0.7 .59:\left(1^{\circ} 00\right)$

MOSHERVILLE, 500, HILLSDALE

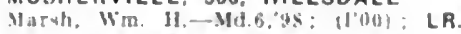

MT, CLEMENS, 7.707, MACOMB

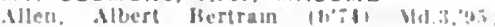

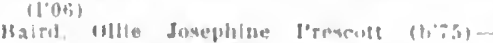

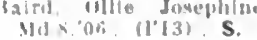

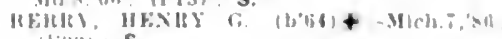
(1) (1)1): $\mathrm{S}$.

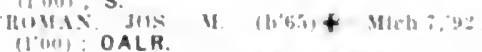

(1) Whan (

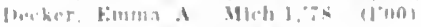

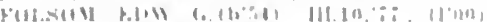

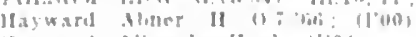

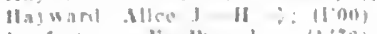

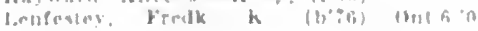
110.3

fentrotas, John Mexamer.

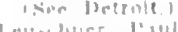

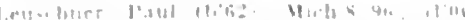

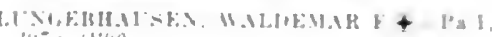

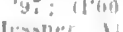

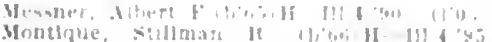
$(100)$

Morlarty, Euln. H

(Tot,

Selson, Hlece kierl.t

(1)12.

o'kicele,

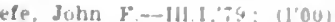

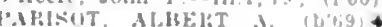

"usi: 11 (ino),

'erssion, Wustol Adidph $(3, * 5)-1111=$

(1) $011:$ LD.

SHOTWFLL. AIFREI $>\left(b^{\circ}\right)^{4}+$ Mich mith

(1'13).

Sullivan. John lfency-Md \& 98 . (1)0

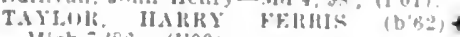

Mleh.'. $\$ 4$; $(100)$

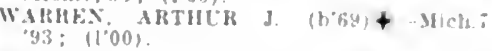

Wetherell. lites.

(xhi: (lon(i).

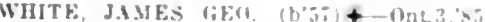
$\left(10^{\circ} 00\right) ; 0$.

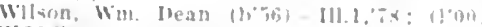

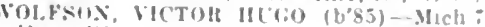

$04 ;$; $(1,04)$

MT. MORRIS, 5I3, GENESEE

CALLOW, FHANCIS H. (L'53) - MICh 1, su (1.00).

GRAHAM, HEGH WM. (bGi) + Mich I.

"anllewalker, Edw. ramillo - Mich I, gis $(1 \div)$; nut in jracilec.

MT, PLEASANT, 3,972, ISABELLA

B.ISKEHVILLE, CHAS M. (b'if)-Mich : $97:(100): \mathbf{G}$

RONISTETTEH, MCHALL FREDK $\left(b^{3} 85\right)$-Mlch. 1, I1 ; (1'11): (Indian Sert Ice); Mt. Heasant Nchnol.

Burch, Lewis J-Mich.:-96; 1100)

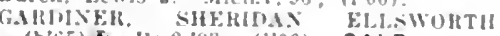
$\left(b^{\circ} 65\right) \mp-124.2,93 ;(100):$ OALR

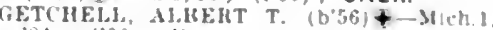
$84 ;(1,00) ; \mathbf{N}$

Holcomb. Amy Amanua lecker (b'G5) Ili.4, "45: $\left.11^{\circ} 03\right)$

Keene, Aben-Wich. g.'st; $(100)$

Kelly, Thos. J. $\rightarrow$; (1'0:)

SAIERS, WARREX A. (b'st)-Pa:sl (1'02).

MUIR, 463, IONIA

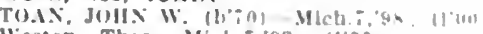
Weston, Thos, Mich, : ${ }^{293 ;}(100)$.

MULLIKEN, 312, EATON

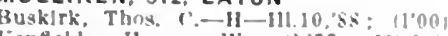

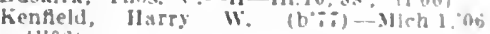
(1'06).

Samaine, L. Rernard-Mich.9.0 [: (|01)

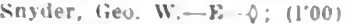

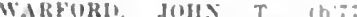

(I'13); Member Ky. Slabe Med. Inw?

MUNGER, 200, BAY

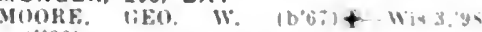
$\left(10^{\circ} 00\right)$.

MUNISING, 2,952, ALGER

"TRRIF., STEI'HEN JAMES (USO) III $0 \% ;(10 \%)$.

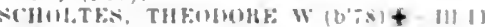
01: (1003)

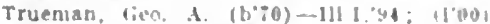

MUNITH, 200, JACKSON

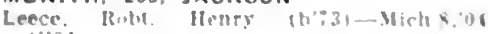
(1"0).

MUSKEGON, 24,062, MUSKEGON

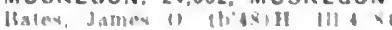

11: 5 in si

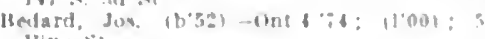

line sis

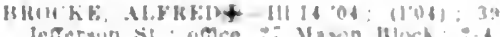

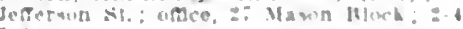

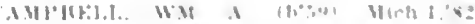
(100): 19 W Wratern An: 10.1\%, $\geq-3$

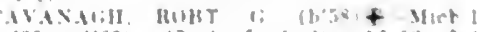

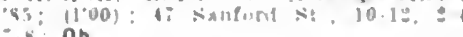
$\because-k ; O b$

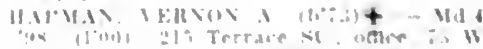

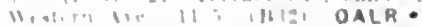


l'ooper, lohn T. (b'62)-Mich.10,02; (l'02): 5 Amity it.; ofllce, latwrence lilnek: $11-12,2-4,7-8$.

CIANER, JAOOK T. (b'81)-I11.1,04: (1'06); 76 Merrill Ave.; offlee, Iymath

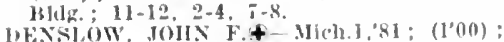
io W. Websler st.; oftece, Harkley Jank bldg.

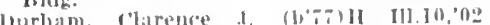

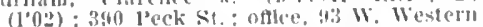
Ave: $11-12,2-4,7-8$

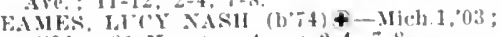
(1'04): 11 Homston Ave.: $2-4,7-8$

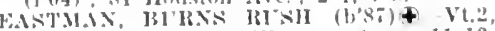
11: (1.13) ; 35 w. Western ire.; $11-12$, 3-5, '7-8.

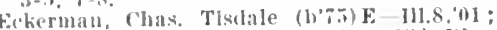
(I'0is); 35 W. Iona st.; oftlce, 1:2 I'lne $\therefore 1,3-4,7-8$.

fors, Fdw: o (h'8I) II-III.t.06i ; (1'06); 41 16. Western tre, $11-12,2-4,7-8$

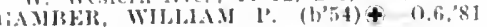

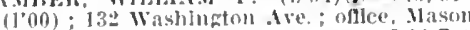

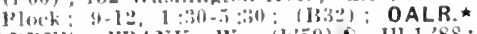

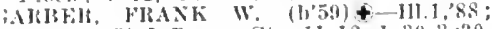
(1'00): 159 Jefferson St. ; $11-12,1: 30-3: 30$ $\div-9 ; \mathbf{S}$.

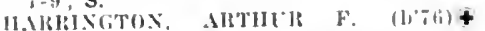

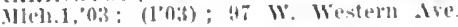
$111-4: 311 ;\left(\mathrm{B} 33^{2}\right)$ ).

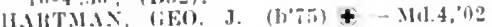
(l'04): 44 lake st. ; untl] $9,2-4$, i-s $O B G$.

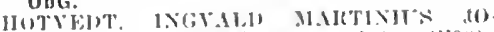

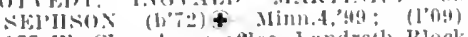
17 w. rlay Ave, oftice, Jandreth Btock $11-12,2-4,7-8 ; s$

Lmrin. Vildi siml. (1,8s) - Jl1.11,12;

(1'13i); Hackley Hospital.

LeFerre, fico. l. (1)'65) II-III.4,91; (1'00) President viloln. State Boaral of legs. in

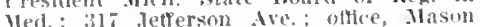
iblock: $11-12,2-4: 5$

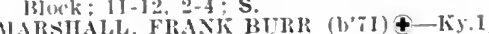

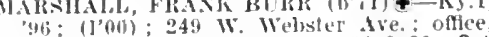

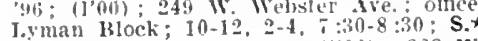
larvin, Fred I-J11.10,99; (1'00); $225 \mathrm{~W}$ ('Tay' Ave, ; office, $41,2 d$ st.; 10-12, $2-4$ i. 8 .

OOSTING, JACOB (b'67)t- Mich.7.97 $(100): 178$ l'ine st.; offlee, 35 F. Hartforl $\mathrm{it}: 2-4,7-9$

PUIPES MLERTIS B. (1)81)-II1.1.09 (1'12): 143 Terrace St.; offee, 128 l'ine it. ; 2-5, i-s.

10IERS, I.T NETTE 1. (b'兀0)-111.9.97 (1'60); S9 Clay Ave.; office, Hackley liank ]3]lg. ; $2-4,7-8 ; G$

017('K, 1'Al'A. (b'33)-N.Y.6.74; (1'00) ti. Peck St.; offlce, Landreth Bldg. ; 10-12, $0-4,7-8$

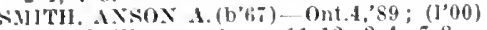
119 w. Western Ave.; 11-12, 2-4; $;-8$

199 "

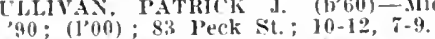

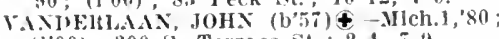
(1'00): 200 s. Terrace st. : 2-4. $7-4$.

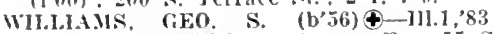
(100); $63 \mathrm{~W}$. Webster Ave; offce, $55 \mathrm{~s}$. Ist St. ; $1: 30-4,7-9$.

Wilson, Frank Worthington (b'54)Mich.1,79; $(100) ; 6$ J Jeffersou St.; 8-1I, $3-6,7: 30-9$.

\section{MUSKEGON HEIGHTS (BRANCH P.O.} MUSKEGON), 1,690, MUSKEGON (See Muskegon.)

BI'SAKD, ROBT. IRA (b'S6)-111.6,'10 ; 01:11). RAYMoxD G. (b'71)-111.16,00 ; (1'01).

NADEAU, 1,000, MENOMINEE

l'iclíf. Jos. F. (b'62)—Ont.4,'89; (1'00): ObG.

NAHMA, 700, DELTA

Alummerbell, Ferris (b'79)-Md.4.'05; (1'06).

NASHVILLE, I,346, BARRY

Baker, John J.-0.8,'万: $\left(1^{\prime} 00\right)$

Baker Minnie D.-H-Ill.4,91: (1'00)

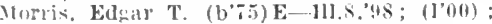

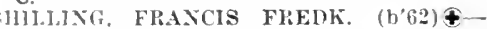
Ilich.1.01: (l'01)

NEGAUNEE. 8,460 , MARQUETTE

IVIILSON AXEL HJALMAR (b'82) -

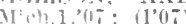

AxInles, 1011X H. (b'59)-Mich.1, 85 ; l'(0) : OpA

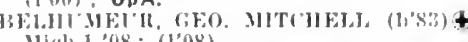
Mirlh. $1,0 \mathrm{~s} ;(1,0 \mathrm{~s})$

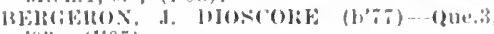
$03 ;:(1005)$

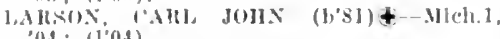
04: $\left(1^{\circ}(14)\right.$.

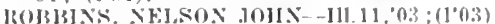

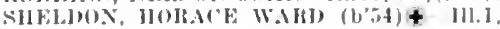
S: : (100)

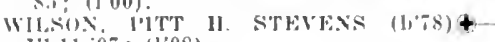
111.11, तit; (1'08).

NEWAYGO, 1,207, NEWAYGO

Meromnell, filmer lieo. (b'8:3)--.lldo., "09: (I'0:1); ObG.

Whlleheall, ('has.-Il1.8,90; (1'00).

NEW BALTIMORE, 920, MACOMB

INooker, lubn (1,65)-Mich.8,97; (1'00).

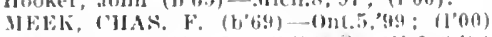

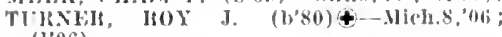
(1'06).

NEWBERRY, I,182, LUGE

BANIN, FESTIN I'F(H, (b'8!) +-Ky.2 12; (1,13): Mtomber ky, state Meal Assil. ; N.

BOII, FIRAK T. (b'66)-Jnd.8,90; (1'90)

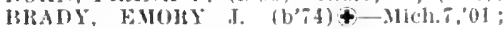
(1,01); NP

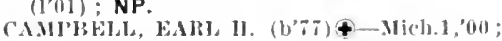
$\left(\mathbf{l}^{\circ} 00\right) ; \mathbf{N}$ *

Kemp, Minta Proctor-Mich.I, 00 ; $\left(\mathrm{H}^{\prime}(10) ; \mathrm{P}\right.$

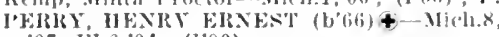
07 , III.6,04; (1'00).

NEW BOSTON, 218, WAYNE

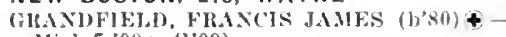
NicJ.T,09; (1'09).

NEW BUFFALO, 528, BERRIEN

Ickenzie, James C. 1. $\left(b^{\prime}, 0\right)-M i c h .7,06$ (1"0ti).

NEW ERA, 400, OCEANA

(:RAY, HARRY'T. (b'79)-Mich.7,07;(I'07)。 NEW HAVEN, 478, MACOMB

Harris, Edgar M. (b'74) E-111.8,97: (1'00). IIubbard, IIarry 6 :. (b'66) - Ind.10,"92 $(1,00) ; G$.

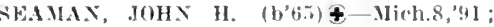
(1 $00(1)$.

NEW HOLLAND (R.F.D., HOLLAND), 100 , OTTAWA

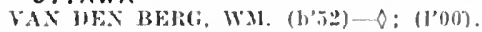

NEW LOTHROP, 305, SHIAWASSEE

Fritch, Orizabor Burnett (b'i5) - Mich.8, 04; (l'04).

SHOEMAKER, MiCOB S. - Mich.1,83; (l'00).

White, IIerbert Tock (b's0) - Mich.1,03; (1'03).

NEWPORT, 450, MONROE.

lirieger, Allhert fico. (b'76)-0.26,99; (l'11).

KOACH, FRANK T. (b'78) - Mlich.1,03; (1'03).

NEW TROY, 392, BERRIEN

IIARRISON, JEMFN L. (b'T) \&-MICh.T, , 06 ; (I⿳066).

NILES, 5,156, BERRIEN

Bonine, Fredk. N. (b'63)-Mich.I,'86; (I'00) lburns, John F. (b'72)-Ill.8,'98; (1'01).

Carr, Homer Stephen $\left(b^{\prime} 76\right)-$ Mich.5, 00 , (1.12,01; (1'01).

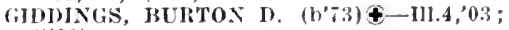
(l'03)

GIRENAMYER, JOHN D. (b'46) $\$$-IIJh.1, $71 ;\left(10^{\prime} 0\right)$

Tyler, Wn. I. (b'65) H-Mich.5,'89; (l'00) ;

G.
IJirey, Arthur 0. (b'62) H-111.4,'86; (l'00).

Waterson, Roy Snith (b'79)-Ili.22, 07 ; (I'09).

Zwigtman, baniel Adrian (b'51)-Belg.1,74, Mi('h.9.'(1)? (1'01).

NORTH ADAMS, 440, HILLSDALE

IITM.IRS, WM. K. (b'46)థ-Mich.1,'i2 ; $(1,00)$.

Fisk, Fred Bion (b'ĩ) H-Mich.11,03; (1'03).

NORTH BRANCH, 717, LAPEER

SNOW. SIPARROW A. $\left(b^{\prime} 47\right) \&$-Mich.1,'Z2; (]'00).

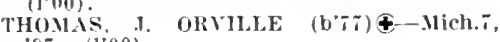
$9 \% ;(100)$.
TI:AIIAGEX, LIEX A. (b'75)-Mlch. 6,05 ;

NORTH DETROIT, 250, WAYNE

Sllepuare, Emma l. Wehster (b'ï) II Ulloll.11,08: (1'08).

NORTH MANITOU ISLAND, I00, LEELA. NAU

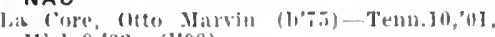
Hl(-11.9,02; (1'02).

NORTHPORT, 524, LEELANAU

Flood, R. F.- Ky.4,'9: ; retired.

NORTH STAR, 300, GRATIOT

CliANE, CHAS. A. (b'b5) - Mlch.7,91;

'AKKHIRST, CHAS. T, (b'T8)£-0.6,04: (1'1'2).

NORTHVILLE, J,665, WAYNE

Jenry, Janl. Is, (13',2)-Mlch.7,'96; (I'00).

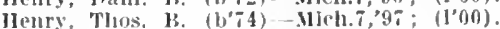
KESTEL, JOHX ROTHWEL (b'60)-

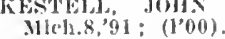

scouyler, Itandall (b'as) - Mich.1,7i; $(1,00)$.

Turner, Thos. 'H. (1,60) II-Mich.5, 82 : (1'00)

NORVELL, 150, JACKSON

Hy'ndman, buncan-0.6,'69; (I'00).

NORWAY, 4,974, DICKINSON

Brasseur, John 13. (b'62)-Belg.3,'88; (l'00).

Karch. Arthur Wm. (b'88)-111.11,12:

(l'13) : Jenn Juning Hospltal.

y(M.I. THEODORE. M. (b'69) $₫-0.13,91$; $(1,00)$

Swift, Ellsha 1'. (b'65)-Pa.1,'89; (1'00).

NOVI, 300, OAKLAND

Ifolcomb, ugustine T. $\left(b^{\prime} 6 \mathrm{I}\right)-0.6,{ }^{\prime} \mathrm{S} 4$; (1'00).

NUNICA, 400, OTTAWA

Whlle, ('liyton A. (b'87)-Mlch.7,09; (l'09).

OAK GROVE, 200, LIVINGSTON

ErWln, WM. II. (b'52)-X.Y.8,7T; (1'00).

OAKLEY, 237, SAGINAW

Itosenow, ('harles F. (b'70) - Mllch.8,'96; (1'0(0): Pd.

OKEMOS, 190, INGHAM

I'AKK, JOHX B. (b'51)-Pa.I, T3; (1'00).

loberts, David W. (h'74)H-0.7,07; (100).

OLIVET, 627, EATON

BURIES()., AKTHIR H. (b'61)-Mich.1, "ifi: (1)00).

Dewer, Clas. R. (b’58)-Mlich.1,'86; (1'00).

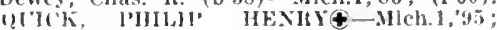
(1) $0(1)$.

SOITHWITK, CHAS. R. W.-Mlch., 05 ; (1'0.j) ; R.F.D.

OMER, 367, ARENAC

Smith, Darid T,-N]ch.7,'03; (l'03).

ONAWAY, 2,702, PRESQUE ISLE

('ARIFNTER, CLARENCE A. (b'73)-Ind.5,'98; (1'00).

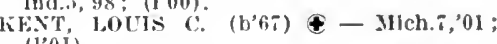
(1'0I).

SHIJLEY, VICTOK W. (b'69)-Mlch.9,02; (1'02).

ONEKAMA, 324, MANISTEE

Gotfredsen, Hans . Jeter (b'81)-IIich.5,'06; (1'06).

Ithehmoni, Albert F.-Mich.I,'81; (1'00).

ONONDAGA, 400, INGHAM

Woodwortl, Fred D. $\rightarrow:\left(l^{\prime} 00\right)$.

ONSTED, 398, LENAWEE

('ase, chas. W. (J'68)-l'a.11,99: (1'vii)

Kline, Starr Lewis (b'88) - Mich.11,11;

Ross, (GERRY WEEDOX (b'59) - Mleh.1, SO; (1'00).

ONTONAGON, 1,964, ONTONAGON

MCHLYH, FRANK W. (b'T0)-Wis.s,'0?; (l'03)

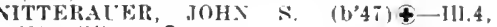

SWIXTON, ANDREW I. (b'i) \&-Mich.1, 99 ; $(\mathrm{l}$ '00).

ORION, 7I7, OAKLAND

HATHAWAY, r'AARETE l. $\left(b^{\prime}, 4\right)-$ atsere, as (l'08).

ORLEANS, I50, IONIA

WILKINSON, W.M. A.-Va.4,98; (1'00). 
ORTONVILLE, 377, OAKLAND

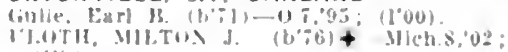
(1) $(1): 11$

OSCEOLA. - HOUGHTON

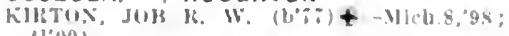
II')

OSHTEMO, 100, KALAMAZOO

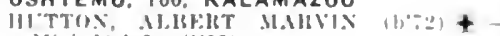
Hich.11,03: (100).

OSSE0, 385, HILLSDALE

Junes. Leenildas M. (165) - Mich.11,06:

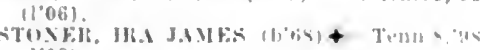
$(100)$.

OTIA, I29, NEWAGO

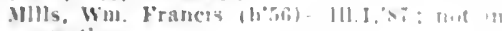
practlce.

\section{OTISVILLE, 312, GENESEE}

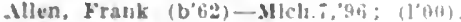

OTSEGO, 2.812. ALLEGAN

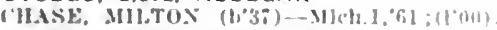

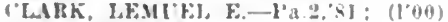

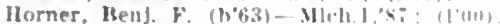

1) Rrles, laleyil Joln (livil III :-, 1.

stuck, Olln H. (1082)-I11.22,09: (1"04)

HA HOKX, AHKA.M I. (b) ifis: (l'00):

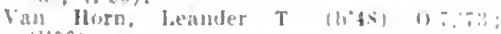
(l.00)

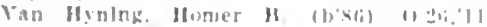

(1'13): OLR,
Whiney, Howarl t: $11,231-$ III.? (I'00).

OTTER LAKE, 273, LAPEER

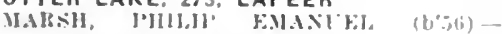

IIICh.I,'011: 1|'00\}.

OVERISEL, 200, ALLEGAN

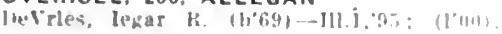

OVIO, 1,078, CLINTON

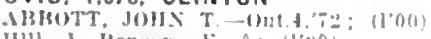

IIIII. I. Bensun $F-0 ; \quad(1 \cdot 0)$

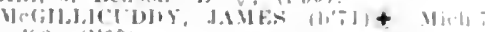
- 48 : $(100)$

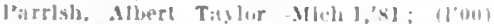

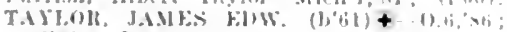
( I'UO): $\mathbf{G}$.

OWENDALE, 285, HURON

MHIHIS FIIANK I.1 Y

OWOSSO. 9.639. SHIAWASSEE

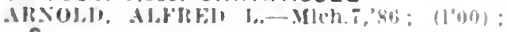
S.

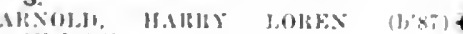
Mll.1.'11: (1'11): Lo.

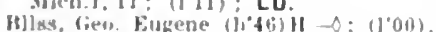

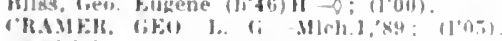

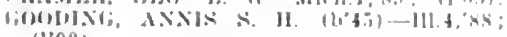
(1) 0 की

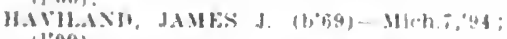
11.001.

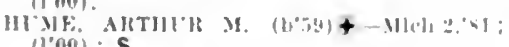

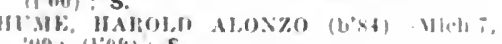
Nig: $(1209): S$.

lemplonel, fuzene-t: 11011

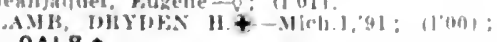
OALR,

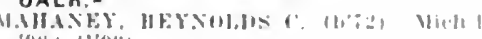

(I): llovi)

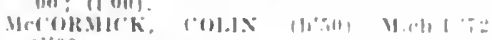
(1) 00 ).

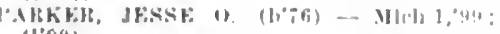
(I) 00 (i).

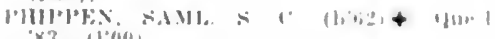

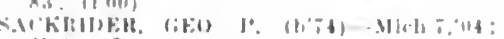
11001): 5 .

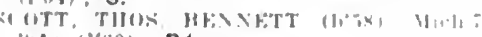
(4): (1) (110): Pd.

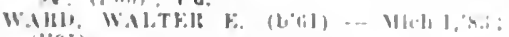
$(1,0)$.

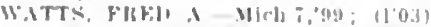

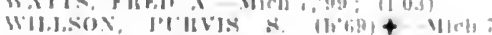

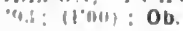

OXFORD, I.I9I, OAKLAND

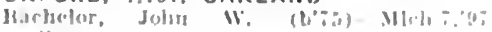
(l'v(i).

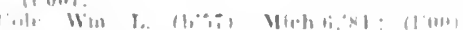

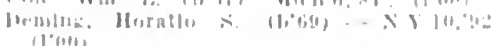

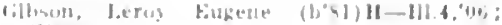
(l'(ti).

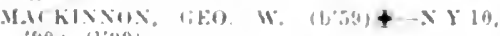

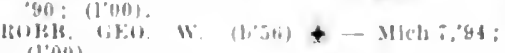
(1'00).

PAINESDALE. 1,250. HOUGHTON

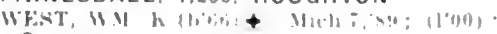
S.

PALATKA, - IRON

J.1kkart, Fdw, 1". (1,5S)-NY I, $83:(101)$.

PALMYRA, 225. LENAWEE

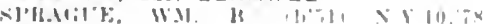
$(100 \div)$.

PALO, 327, IONIA

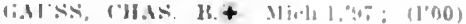

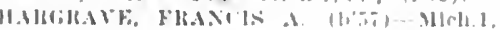
ज; (l'wio).

\section{PARMA, 509, JACKSON}

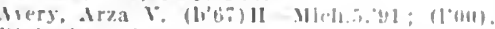

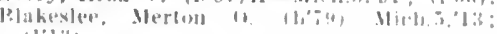

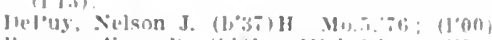

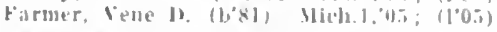

PAW PAW, 1.6\$3, VAN BUREN

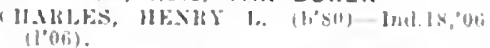

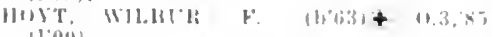

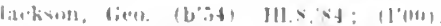

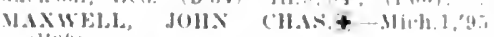
Il'0(i).

PECK, 275, SANILAC

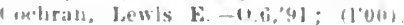

Trueselell, Ahed W.-Mich.4.02; $(1.02)$.

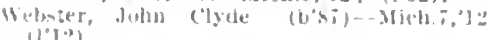
(1, IN)

PELLSTON, 1.089, EMMET

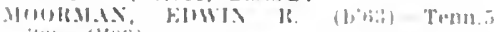

obrlen, Eidward James 16901 Mlah 11 'I11: II']:3)

PENTWATER, I,129, OCEANA

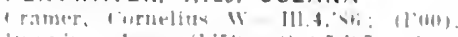

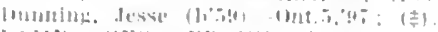

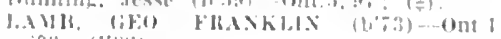
0):3: (1) (1:3).

PEQUAMING, 35, BARAGA

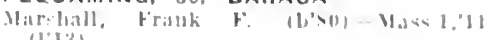
(1'Ji3).

PERRINTON, 288, GRATIOT

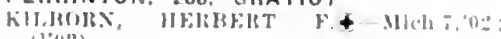
$11^{\prime \prime}(02)$.

PERRY, 720, SHIAWASSEE

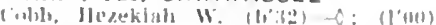

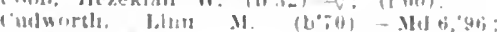

(I'(1) ; op.

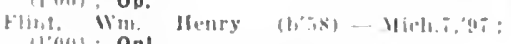
II'(1) ; ODL.

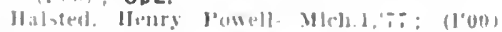

PETERSBURG。490, MONROE

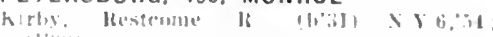
11'iii)

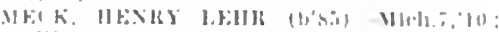

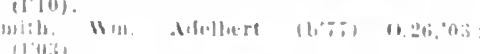

PETOSKEY, 4.778. EMMET

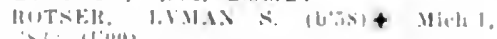

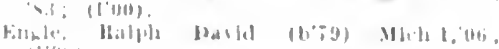
(l'(ii.).

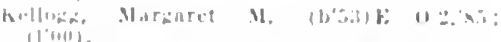

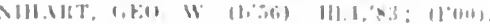

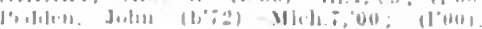

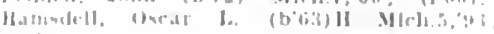
1! 1111

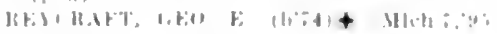
I! ini,

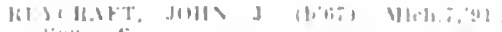

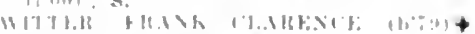

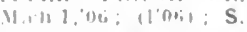

PI.WAMO 289, IONIA

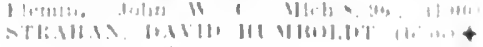

PHOENIX, T6, KEWEENAW

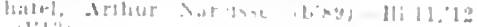

PICKFO

(1)KIIUD, 400, CHIPPEWA

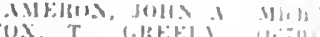

(i) (i) ;i).

PIGEON, 687, HURON

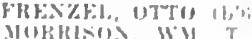

lukH(x).

Y.H.E. A.E(H)

(1). (1) (1i)): S.

PINCKNEY, 477. LIVINGSTON

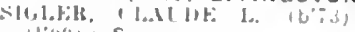

(l) 10$) ; \mathrm{S}$.

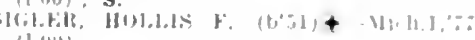

(1 (iil).

PINCONNING, 677, BAY

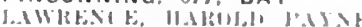

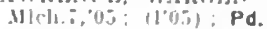

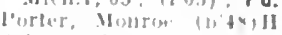

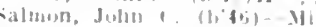

PINNEBOG, 200, HURON

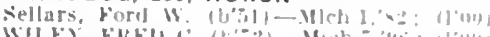

WLLE), FHEl) $C$ (

PIPESTONE (R.F.D.. EAU CLAIRE), 100 BERRIEN

'llppinter,

PITTSFORD, 450, HILLSDALE

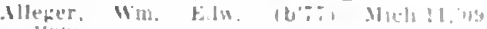
(1'09).

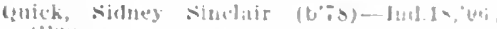
(l'li:?

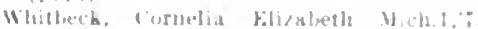
(liutit.

Whilleck, Valker J-N.Y.E, 60 ; (100).

PLAINWELL, 1.493. ALLEGAN

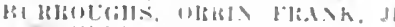

4. I11 1: $x=11011$

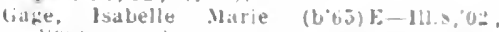

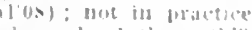

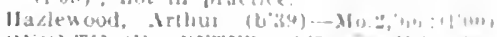

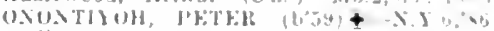
(l'010).

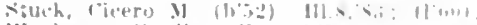

Woolsey, Fredk. E. (b'50)-Mrlal al (I.00)

PLYMOUTH, 1,671, WAYNE

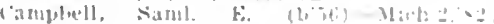
(1)

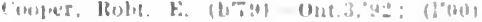

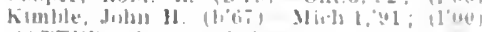

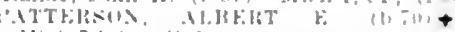

Hith.:"11: 11"11,

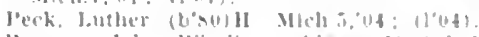

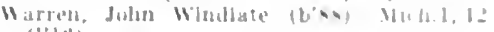

(1'12).

POMPEII, 300. GRATIOT

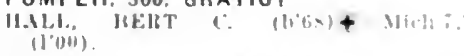

PONTIAC, 14.532. OAKLAND

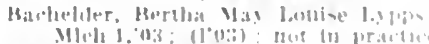

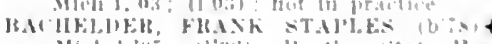

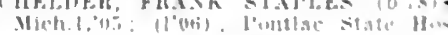
pitisl.

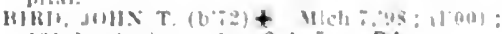

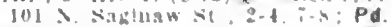

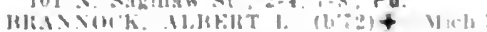
ili $1 l^{\prime} 0 \%$. Fay Mloxk

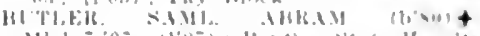

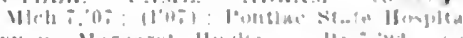

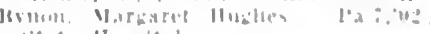
itape Inopuleal

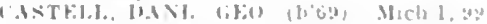

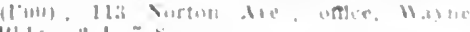
[11,

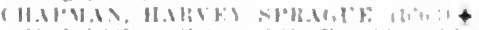

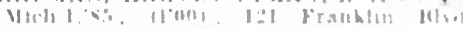

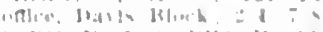

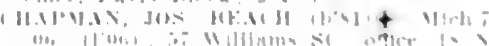

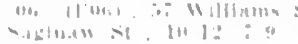

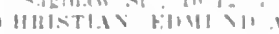

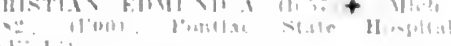

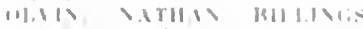

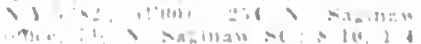

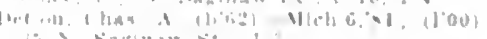


WOXNELL, LEO CHWHLES (b's! +

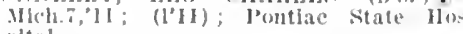
pltal.

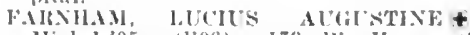

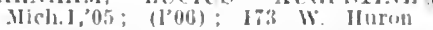
oflloe lieaudette Block:

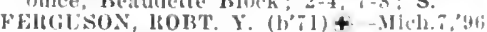

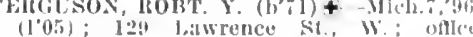
Marsh; 1tock; $2-4,7-8$.

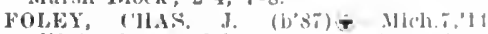

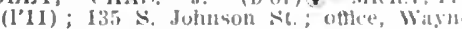
Bledg; $2-4,7-8 ; 5, *$

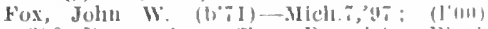

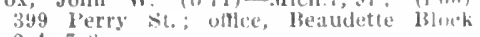

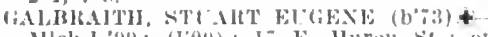

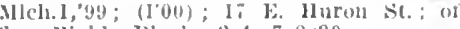
Hee, Waldo Block; 2-4, $7-8: 30$.

fierls, Frank 13rowning (b'89) - Mleh., '12 (1'12) ; 21 Mary Day dre.; ofluce, II 1/2 . Sarinaw st.; $10: 30-11 ; 30,2-4,7-8$

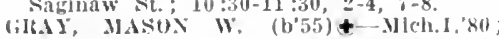
(1'no); 135 (1rchard lake IVe, ottec, 21 E. Iluron st. $; 2-4,7-9$.

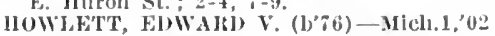
$\left(l^{2}(02) ; 345 \mathrm{~W}\right.$. IInron st. ; oftlce, Wayne lildg, $2-4,7-8 ; 5$.

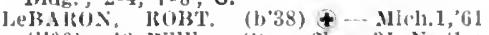

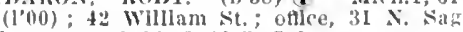
lnaw St. ; $9-12,1: 30-5,7-9$.

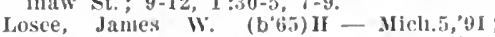
(l'00); 56 Norton Are, oftlce, $13 \mathrm{~N}$. Sag lnaw st.

lumby, Llonel IRideout (b'63)H--Mllch.5

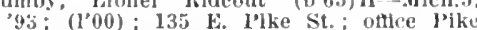
and Saginaw Sts.; $1-4,6: 30-8$

MANI, ORA (b'54)-Mich.1, ig: (l'00) $: 1 / 2$ S. Saginaw St. ; $2-4,7-8 ; G$

McCARRoLl, WM. (b'54) 4 -Mich. 1,81 (1"00): 208 larke st.; office, Waldo Block; $9-10,1-3,7-8$.

Mckenney, Ashton D. (b'7I)-Mich.11,03 (l'03) ; $247 \mathrm{~N}$. Saglnaw st. ; offlee, $3 \mathrm{~N}$. Saglnaw St.

MOIIIS, ('ARLTON D. (b'70)-Mich.1,94 $\left(1^{0} 00\right)$; I54 X. Saglnaw St. ; offlce, $K$. of P. l3lock; 9-12, 2-5; OALR, $\star$

Moss, Ransom E. (b'56)-X.Y.6, $80 ;\left(1^{\prime} 00\right)$ 297 N. Saginaw St.; offlee, 40 N. Saginaw St. ; $1: 30-4: 30,7-8$.

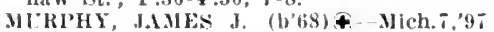
(l’00); 119 Franklin Blrd.; offce, $7 \mathrm{i}$. Saginaw St. ; 2-4, $7-8$; 1.^

reafle, Chas. A. (b'82)-Mid.1,09; (l'13) l'ontlac State Hospltal.

ORTON, ELLSWORTI (b'65) \&-Mich.7,'92 (l'00); I65 Forton st.; onlee, Wayne Bldg. ; $1-3,6: 30-8 ;$ S.

Parsons, Allan W. (b'i2)-0; not In practlce.

RIKEK, JOIIx D. (b'66) 4-iIlch.1,'90 (l'00); 27 Iluron st., W.; office. Masonlc Temple Bldg.; 10-12, 2-4; OALR.

SHARI, NILA BELLE (b'50)£-0.14, 84 (1'12); Nember state Med. Soc. of Wis. $10{ }^{7}$ Perry St.; offlce, 16 E. Jluron St. ()-1,2, $2-4 ; 0 \mathrm{bG}$.

Sharp, l'reston H. (b'48)-0.14,'84; not in practice; $16 \mathrm{E}$. II 1 uren st.

SHRLEY, HARRY AloNZO (b'82) \& fice. Knights of Phythias Bldg, $2-4,7-8$ STAIKER, CLAKENCE T. $\left(b^{*} 81\right) \notin$ Mleh. 7 , 05: (1'05): 66 Fairgrove Are.; office, Pontlac Savings Bank Bldg. ; 10-12, 2-4; Pontlac

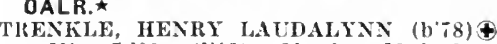
-llimn.5.09; (1'11); Member Med. Soc of the State of X.Y.; State Hospital.

\section{PORTLAND. I,832, IONIA}

Allen. Geo. Duncan (b'39) H--0.7, 66 ; (I'00).
ILON, ROBT. W. (b'54)-Mlich.1,'78;
(I'00).

Bradfield, John D. (b'i1)-Mich.10,'03; (l'03); OpL

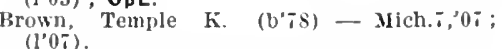

vellenbaugh, Charles C. (b'34)-X.Y.6,59; (l'00); not in practice.

MARTIN, FRANK W.-Mich.1,'86; (l'00) OALR.

POSEN, 263, PRESQUE ISLE

Vevius, Fred Porter (b'82)-Mllch.8,'06; (
POTTERVILLE, 430, EATON

IONES, FHANRLIX IITHII It (b'it)

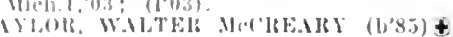
vich.1,1:3; (1'1:

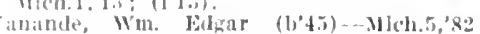
(1,i)0 0 .

POWERS, 51I, MENOMINEE

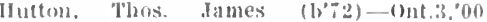
(1)'(1)0)

PRAIRIEVILLE, 250。 BARRY

llyde. lieo. 1t. N.Y.10,'85; $(1,00)$

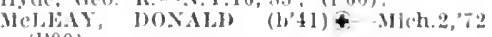
$(1,00)$.

PRATTVILLE, 300. HILLSDALE

B.IISTE, HOIIS WESLFIt-0.14,"92: (1't10)

PRESCOTT, 600, OGEMAW

urhees, (irant S.-Md.6."9s; $(100)$

PT. AUSTIN, 533, HURON

Francis, Alexander M. (b'74)-Mllch.7,96: (1'00)

\section{PT, HOPE, 344, HURON}

Katmeyer, Adolph (i.-Mlel. 8,$97 ;(100)$

Wledman. Fiallk (b'79)-Mleh.5,08; (1'()8)

PT, HURON, 18,863. ST. CLAIR

Alken, James P. (b'59)-Mlch.7,'87; (l'00); 935) Jilitary St. ; $10-12,2-4,7-8$

AT'THINGL, JAMES AITIIK $\left(b^{\prime}, 0\right)$ ( Mlch., 57 ; $\left(l^{\prime}(00) ; 1436\right.$ l'ine Grove Ave office, Stewart Block; $9-1$ : :30, 2-4, S *

BOWWR, FMMA EIIZA-Mich.5,'83; not in practlee; Harrlngton Hotel; othee, Maceabee Temple.

BRLSH, BLOCK E. (b'65) - Mleh.7, 96 : (l'00); 909 Prospect St.; office, $31 \%$ lluron Are. ; $10-11,3-5 ; \mathrm{S}$.

'ALLERY, ALBEIRT L. (b'65)-0nt.3,97 $\left(I^{\prime} 00\right) ; 1040$ Court St.; office Meisel Block; $9-11,2-4,7-8$.

'LAN('), CIIAS. C. (b'58)-0nt.5,'s3; (l'00); 929 IIuron Ave, offlee, 317 Huron Ave. ; $9-10,1: 30-3: 30,7-8$

CLEMENTS, FLOYD W. (b'76)-Mich.7, 05 (l'0i) ; 2008 Stone St.; offlee, 1028 yllitary St.

CONNER, SARAH E. (b'62) -MIfch.1, 96 ; (l'00); 1730 Nilitary St.; offlce, 1804 lilitary St. ; $9-11: 30,2-4$.

Cooper, Thomas H. (b'84)-lil. 17,08 ; (l'13); 912 Lapeer Ave.

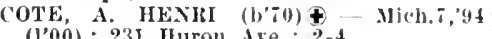
$\left(l^{\prime} 00\right) ; 231$ fluron Are.; $2-4$.

DUFF, WM. J. (b'56)-Ifich.I, $85 ;\left(l^{\prime} 00\right)$; 724 Pine St.

DUNN, ROYAL J. $\longrightarrow$; (I'04); 636 Grlswold $\mathrm{St}$

FRASER, ROBT, C. (b'84)-Mich. 7,05 $\left(l^{\prime} 06\right) ; 1216,6$ th St.; offlee, 1011 Military St. ; $9-12,2-5$.

Frazier, John Vernon (b'67)-ont.4, 88 ; $\left(l^{\prime} 00\right)$; 1231 Mllltary St. ; offlce, stewart Block.

Hansoll, Stephen S. (b'i1)-ont.6,'93; (l'00); 717 Elmwood; 8-10, 2-4, 7-8

IIEAVENRICH, THEODORE F. (b'74) 4 Mlch. :,00; (1'00); 1805 Mllltary St. ; of flee, 1011 Military St.; 2-4.

Henderson, Wilbur S. (b'66)-Mich.1,'90; $\left(I^{\prime} 00\right) ; 1015$ Lapeer Ave.; offlce, 106 Huren St.

Holdom, Isabella-Mich.8,9i ; $\left(1^{\prime} 00\right) ; 92 i$ Ontarle St.; office, Modern Maccabee Temple.

Ifooper, Elizabeth Merritt (b'60)-Pa.7,'83 not in practlce; 518 Rawllns St.; office, Maccabee Temple.

Howard, saml. A. (b'i1) - Mich.7,'93 (l'00); not in practice; 712 suffern St.

JAIIES, WM. B. (b'70)థ-Mich. T',99 (l'00); (Marysulle) ; 9-1I, 1:30-4; N.

KESL, GEO. MATTHEW (b'86)-Mo.2,'08 A.A.Surg., U.S.P.H.S., Immigratlon Serv. ice; Member Mo. State Med. Assn.; 2020 Poplar St.; offlee, $23 \mathrm{~d}$ and Rallroad Sts. $1-3,9-10$

LEWIS, ELDEX E. - X.Y.9,'84; $\left(l^{\prime} 00\right)$; 704 Huron Ave. ; 1-4.

Lohrstorfer, Fredk. (b'63) - Mich.1,'86 (l'00); 617 Military St.; office, Meise Block.

MackEXZIE, ALEXANIER J. (b'7) Mich., $04 ;\left(I^{\prime} 04\right)$; il Inlon st. : offlce. Heisel Block; 10-12, 2-4, ;-S.

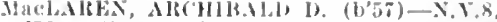
6f: $\left(l^{\prime} 00\right)$; 1308, ith st.; offlce, 20) IInron Are: $9-11,2-4$

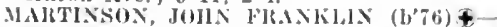
Vleh.11,05; (1'05); $91 \%$, itl st.; oftlce llartsuf Block; $8: 30-5 ;$ OALR.

Meklnnon, Abner Arnold Ont.3,'y9; (l'00); 717 Huron Ate.; ollice, opera Ilouse Block. lerrlt, sylvester W.-Mleh.1,69; (1'00); 2416 Gratlot Are.

Moffet, John Jelllson $\left(b^{2} 86\right)$ - (olo.2,12; (I'13); 1512, 10t1 St.; office, stewart (13loclis.

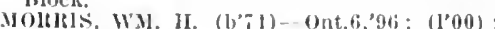
3050 Mllitary st.; offlce, 2328 Connor St. $2-4$.

EY, fiEO. S. $\left(1{ }^{\prime} 54\right)+-N . Y .10,82 ;\left(1^{\prime} 00\right)$ Lalison Reacll; offle, Melsel Block; 9-11, $2-4,7-8 ; \mathrm{S}$.

Nunn, Joslah K. $\left(b^{\prime} 48\right)$ H - Mlch.3,74; (l'00); $901, \quad j$ th St.; $8-10,2-4,6-8$.

PAT'THESON, IIYIRON ALANSON (1,36)Mlch.5,'91; (l't)0); y.28, itl st. ; oftere, Jenks Hlock; 10-12, 2-4, 7-8.

I'IATTT, JOS. \&. (b'57) \&-N.Y.5,80; $\left(1^{\prime} 00\right)$ 1225 , 6th st.; offlee, 913 Millitary St. $10-12,2-4$.

liandall, Albert F. (l)'48)H-Mich:3,'テ3; $\left(l^{\prime} 00\right) ; 824$, ith st. ; OpA.

kyerson, Frank J. (b'86) - Mlch.7,'11 (1'11); 2516 Gratlot Ave.; offlce, 2439 Gratlot Are.

RYERSON, WM. W (b'88)-Mich."̈l1 (l'11); 2516 Gratlot Ave.; offlce, 901, btli

SMTH, SAML. K. $\left(b^{\prime} 67\right)-\mathrm{X}, Y .1,{ }^{\prime} 90$ (l'00); 717 Court St.; office, 6th and Water Sts. ; $2-3: 30,7-8$.

Stephenson, Orlando M--1]l.10,82; (1'00) 1013 Ontarlo St.; offlee, Bricker-Block; $10-12,2-4$.

STOCKWLLL, CHAS. B, (b'51)†-Mass.1, 78 ; $\left(l^{\prime} 00\right)$; 617 Plne St. ; office, Sanborn Block; 8-11, 1-4; OpA

Tlbbals, Elbert P. (b'42)-N.Y.1,'64; (l'00) 1236,6 th St. ; oflee, 922 Milltary St.
TREADGOLD, GEO. H. (b'58)-Mflch. ' 86 (l'00); Bricker Block; 11-12, 2-4.

VHOMAN, MASON E. (b'73)-Mlch.7,04 $\left(l^{\prime} 04\right) ; 927$ Court St. ; offlce, Meisel Block ; 9-11:30, $1: 30-4: 30$; OALR,

WELLXIN :30-4:30; OALR, (l'05); 817 Ontario St. ; office, 229 Huron St. : 9-11, 2-5.

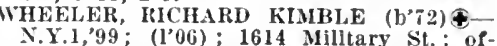
fice, 317 Huron Áre. ; 10-11, 2-4, 7-8.

WILLSON, NORTIMEil (b'47) $\oplus$ - Mich 2. '74; (l'00); 1402 Mllitary St, ; offce, 901 , 6th St.; 9-10, 1-3.

Windham, Roy A. (b'78)-Mich.7'12; (I'12) 917 Llncoln Ave, office, 201 Ifuron Ave. $10-12,2-4,7-8$.

\section{QUINCY, I,347, BRANCH}

Blackman, Edson (b'38) $\mathbf{F}-0.2,66 ;\left(l^{\prime} 00\right)$. Blackman, Jay Morehouse (b; 3$)$-Mich.10 '98, Mich.11,00; $\left(l^{\prime} 00\right)$

Dobson, Gertrude" (b'61)-H11.15,'09; (1'11). Sears, Carl C. (b'82)-Mich.11, 05 ; '(l'05).

Sears, Chas. S. ( (b'53) H-Ill.4,79; (l'00)

Whltmore, Henry W-Ill.8,'81; (l'00).

WHITMORE, RAY CLOSE (b'83)@-Mlch.1. '06; (1'06)'

RANSOM, 170, HILLSDALE Hanke, Geo. lieidt (b'82) - Mich.11, $0 \pi$;
(l'07).

RAPID CITY, 400, KALKASKA

DECKER, WM, GRANT BOND (b'69)Mlch.5,' $97 ;\left(I^{\prime} 00\right)$.

RAPID RIVER, 600, DELTA

Conover, Joln I. (b'82) - Ill.6, 06 ; (1'13).

RAVENNA, 500, MUSKEGON

Ilagen, Win. Andrew (b'76)-Mlch.10,02:

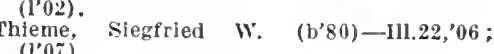

READING, 1.102, HILLSDALE

BELL, THOS. H. E. $\left(b^{\prime} 74\right) \oplus-M l c h .8,97$; (l'00); S.

ENTON, DANL. W: (b'\$3)£-Mich.2,76; (l'00); OALR.

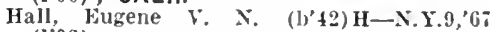

(l'02)

Niblack, Chas. F,-0.6.'80; (1"00)

Robson, Frank R.-Mich. $; 0 \%$; $\left(\mathrm{l}^{\prime} 00\right)$ 


\section{REDFORD, 328, WAYNE}

Tuprer, bewh I (boii)-Mich : : !r: $(100)$. REED CITY, 1.690, OSCEOLA

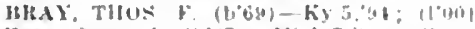

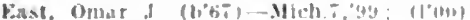

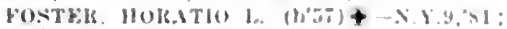
$(1,00)$

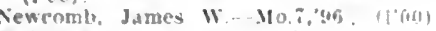

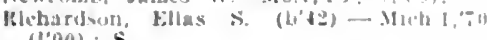
$(1,00): S$.

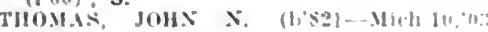

III. \&. Ot: (103).

REEMAN, 250, NEWAYGO

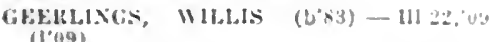
(1'09).

REESE, 465, TUSCOLA

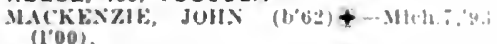

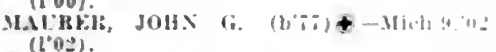

REMUS, 450, MECOSTA

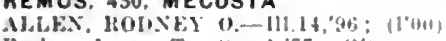

Farley, Janies T.-uue 1,:T; (l'uv).

REPUBLIC, 2.314, MARQUETTE

LOVFIASI), HORACE HALE (b'bi) Mlch.: "4i; (1'00)

stallworth, (")arke Jarkson $(1,90)-M 41$, I" (Axslstant llysiclain)

REXTON, 200, MACKINAC

Immerman, Lant. A-llt.1,

RHODES, 47, GLADWIN

Ilarris, Clarence Wilkic (h'b9)-Mieh. I, ( $\left.1^{\circ} 00\right)$.

RICHLAND, 278, KALAMAZ00

KE:XZIE. WM. NEWT(1)-111.17,00; 11'U(1)

RICHMOND, 1.277, MACOMB

Greene, Thas. F.-X.Y."

Greene, Irring Waterlos (b'49)-Mich.1, lis (1'13).

RICHVILLE, 300, TUSCOLA

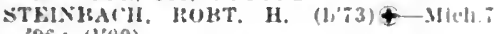
"96; (1"00).

RIVERDALE, 400, GRATIOT

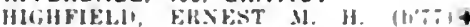

Mlch:; 0 ; ; (l'0t)

RIVER ROUGE, 4.163. WAYNE

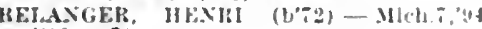

$(100) ; 00^{\circ}$

Northrup, James 1. (h'50)-X.Y.'s! (l'00).

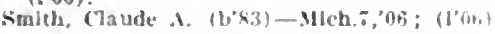

RIVES JUNCTION, 200, JACKSON

Havers, Howarl (b's9)-Illch.7,13; (1'1:1

ROCHESTER, 1.516, OAKLAND

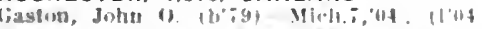

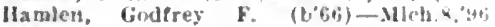
(1'00).

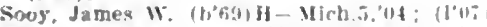

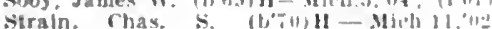
(I'02).

ROCK, 100, DELTA

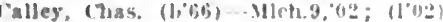

ROCKFORD, 843, KENT

viartier. Hollity 0.-U.:., $\times 1 ;(1000)$

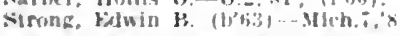

ROCKLAND, 1.000, ONTONAGON

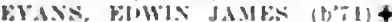

'yij: (1) (1)

ROCKWOOD, 500, WAYNE

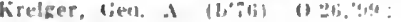

larker, Morgan,

(vee inetrolt.)

ROGERS, 705, PRESQUE ISLE

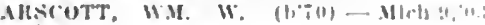
(103).

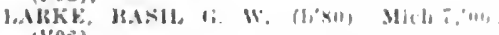

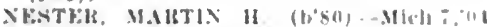
$(1 \circ 04)$

ROLLIN, 75, LENAWEE

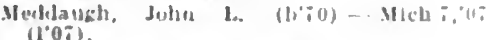

\section{ROMEO, 1.787, MACOMB}

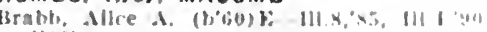
(l'00).

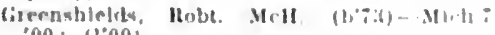
00: (100)

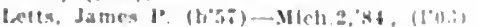

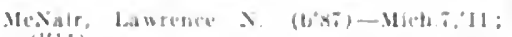
(1) [1]

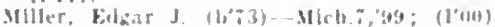

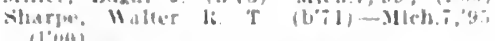

ROSCOMMON, 425, ROSCOMMON

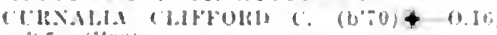

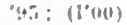

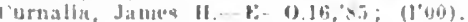

ROSEBUSH, 200, ISABELLA

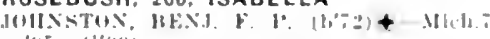

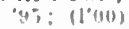

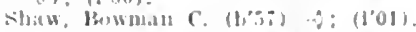

ROSE CITY, 5\$2, OGEMAW

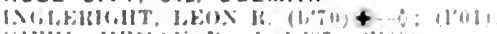

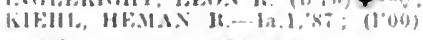

ROSEVILLE, 500, MACOMB

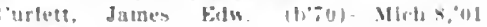

ROSS, 28, KENT

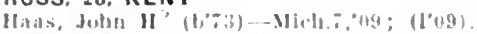

ROXANA (R.F.O. CHARLOTIE), 150, EATON

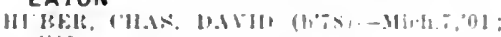
(1'0I).

ROYAL OAK, 1,07!, OAKLAND

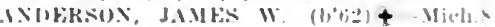
$\because 1 ;$ : (1'001: $\mathrm{S}$

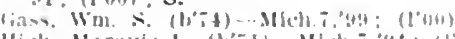

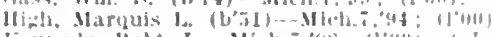

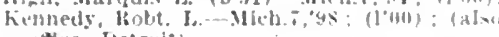
intice, Iretruit)

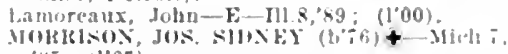
"14, ; $\left(1^{2} 03\right)$.

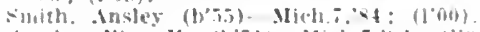

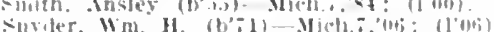

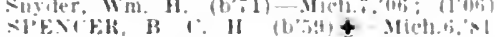
(I')iा).

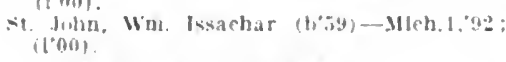

RUDYARD, 100, CHIPPEWA

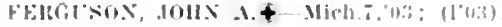

RUTH. 150. HURON

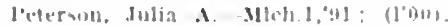

SAGINAW, 50,510, SAGINAW

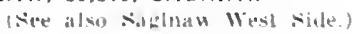

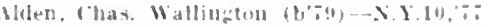

lloll1: Tower Himek.

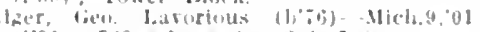

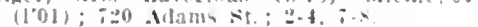

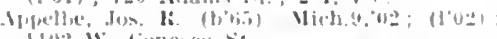

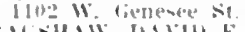

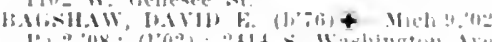

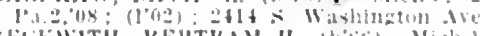

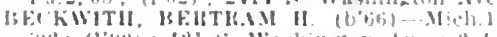
R.

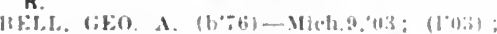

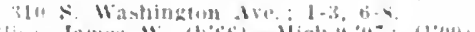

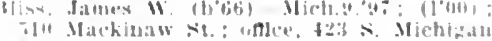
lite Malchinas

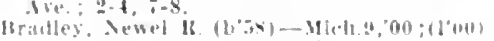

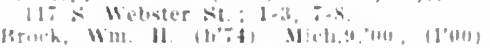

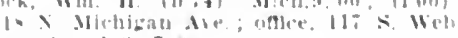

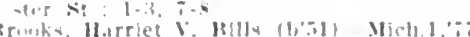

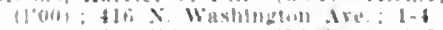

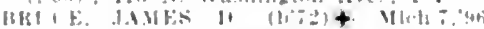
(19111): azs destermin ire

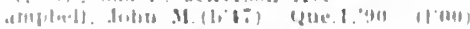

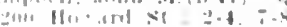

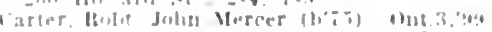

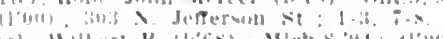

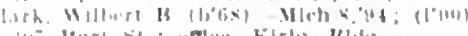

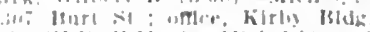

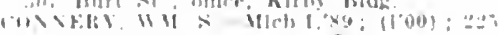

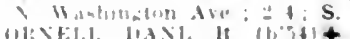

(1)

11: $11 \%$; : :0 : OALR.

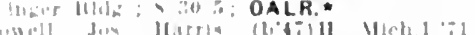

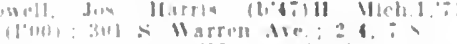

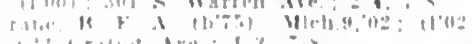

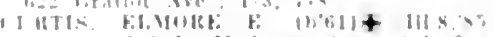

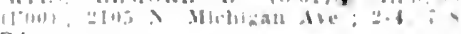
Pd.

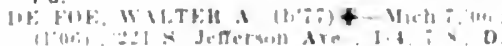

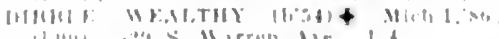

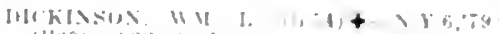

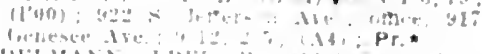

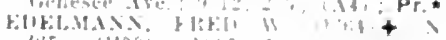
8:?: 1300

Fivit.lsil, WU

(1.00): Ifod (monase

Fortist, irthur liandothl

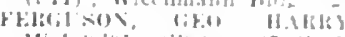

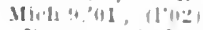

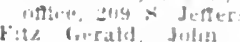

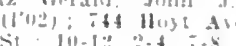

linliktive

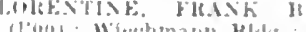

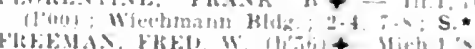

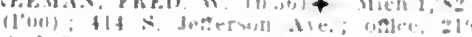

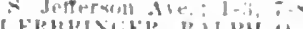

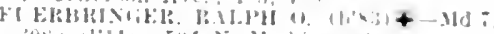

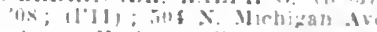

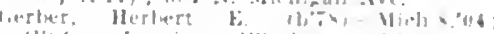

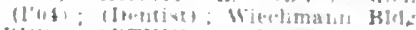

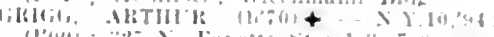

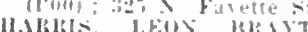

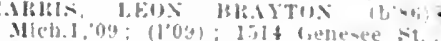

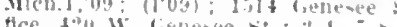

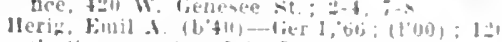

lubliard, Theron T

fn practice sli furdue

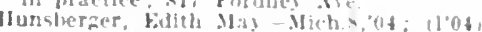

316 s. Warten dre; 1-1, t-; G

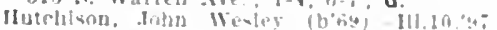

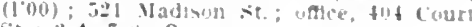
St. : $2-4,-8 ; \mathrm{S}$.

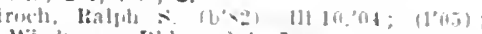

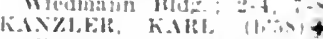

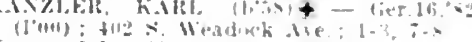

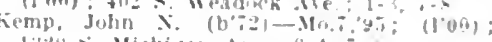

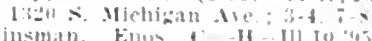

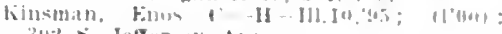

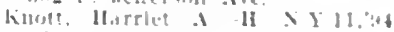

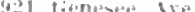

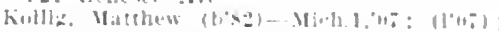

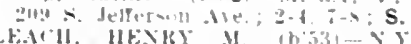

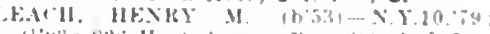

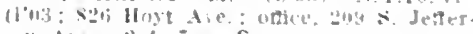

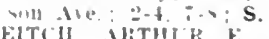

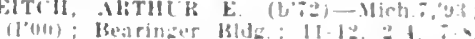

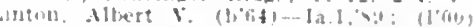

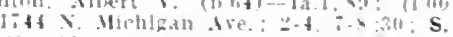

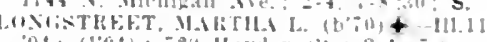

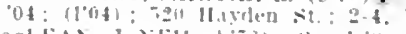

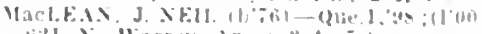

ni=1 $x$ wirren ire: :

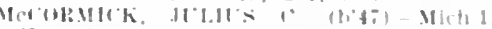

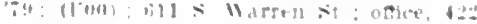

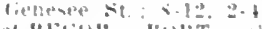

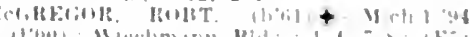
N.

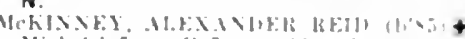

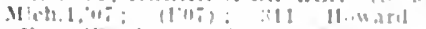

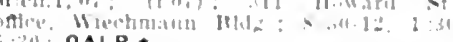
50 : OALR.

MCIkFKIX. JIUES H

1314, :

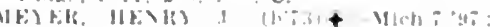

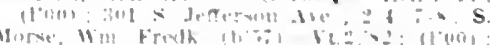

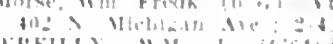

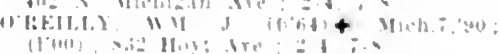

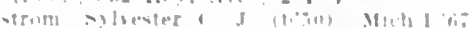

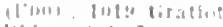

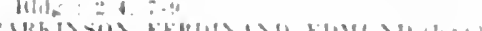

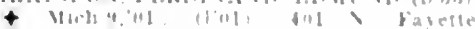

-1 i i OALR

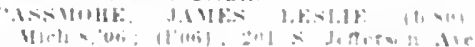

$\because 1: 3$

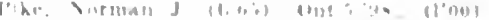

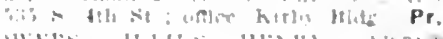

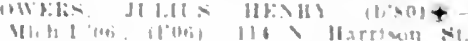

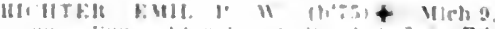


Itiopelle. Jos. Henri (b'68) Que $3294 ;\left(l^{\prime} 06\right)$; 902 s. Waslington St.: $2-4,7-9$.

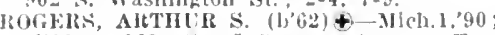
(1'00): 923 S. Jelfersou Ave.; ofllee Deisler Block: :-12, I :30-5; (IB, $;$ OALR. Itogers, Wm. II. (b'56)-Mlch.7, $45 ;$ (l'00) 416 Genesee Ave : $9-12,1: 30-5,7-8$, '88: $\left(1 \mathbf{1}^{\prime} 00\right) ; 315 \mathrm{~S}$. Jefferson Ave.; $2-4 ; \mathrm{S} . \star$

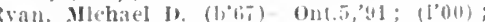
(1) 1 ashlurton twe

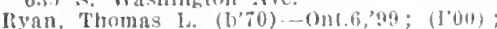
$116 \mathrm{x}$. Warrell Ave, $2-4,7-8$

SAMIJ.E, CILSTER II. $\left(\mathrm{b}^{\prime} 50\right)+\mathrm{N} 1.10$ it; (I'00); 309s. Washington Ave, ; $2-4$ $8-8 ;(17)$

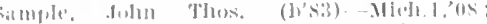

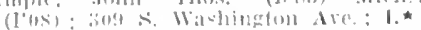
late Wilter 1. (1)6:a)-Mleh.5,'S9; (100):

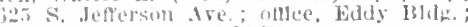
$9-12,2-5 ;$ (BII) : OALR.

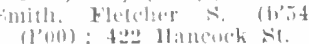
(irlo, (1) (65) - Mich.1,'92 ; 230. Jellerson Are. ; :-4, i-S.

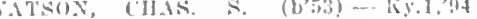
$\left(1^{\circ} 00\right) ; 826$ N. Miehigan Ave: oftce. 120 ‥ Mlobigm Are, : 9-1:, I-4: Pr.

WATSON, ROY s. (b'81)-Ill.1,04: (['04)

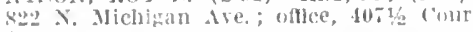

WILLIMSON, THOS, M. (b'tist) क ()nt.3 (9)2: $(1900) ; 2003$ \&. Washington dve.

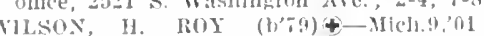

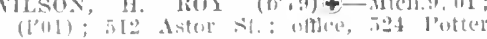

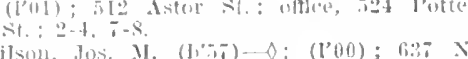

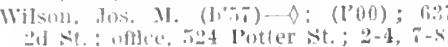

SAGINAW WEST SIDE, - SAGINAW WNINHAM, Plice Nitginaw.) (1"(1:).

SAGOLA, 360, DICKINSON

()hswaldt, Jerman F. (b’5̃)-N.Y.I6,

SALEM, 160, WASHTENAW

Waid, Fdward 1'. (1'63)-111,6,'87; (1'00).

SALINE, 816, WASHTENAW

MOItDES. WILTEl: \$. (b'55) \&-Mich.1,'80; (l'ou).

Vummery, Afred Elward A.-I-Mich.5. $06 ;(1,06)$

ENTERKIICIEH, ("IIAS. F. $\left(\mathrm{b}^{2} 58\right)-0.2$ $86^{\circ} ;\left(\mathrm{I}^{\prime}(10)\right.$.

WALLACE, JAMES BLCHANAN (b'64)+Mich.i,oI; (I'01)

WOOHIBIDGE cils o, (b'80)-Mich. $04 ;$ (I'05)

SAND BAY, - MACKINAC

Erdlitz, Frank J. (b's:)-Wlis.3,'I2; ( ).

SANDCREEK, 300, LENAWEE

IEDDACGII, WM. HENRY (b's:)-Mich. $0{ }^{\circ} ;\left(I^{\prime} 07\right)$.

SAND LAKE, 370, KENT

DELL, E. ELLSWORTH (b'71)-111.17,00 (100). MORE I. (b'03) TEEPLE,
(I'00).

SANDUSKY, 993, SANILAC

BHIBEITSON, COLIN G $\left(b^{\prime} 75\right) €-Q$ Q.1,

'U1; (1'04).
SCOTT, JAMES $11 . \quad\left(b^{\prime} 68\right) \uparrow-M i c h, 8,96$; (l'0u).

Taylor, David 0 . (b'46)-0.9,75; not in praetice.

TWEEDIE, GEO. S. (b'61)屯-MieH.7,'86; $\left(I^{\prime} 00\right)$.

SANFORD, 100, MIDLAND

Blakeley, Edwin A. (b'69)-MJch.9,'03 (I'03).

SARANAC, 845, IONIA

Rraley, Frank W. (h'ti1)-Mieh.i,'97; (l'00). Gesler, Nlbert E. (b'50) H-0.13,77; (I'00). Hay, Joln R. (b't - Mich.s,'97; ( 107$)$.

WEATER, FRANK A.-Mich.6.'8I; (I'00)

WEAVER, LELAND S. (b’43)-Mich.I, 64; (',00).

SAUGATUCK, 621, ALLEGAN

Simson, Henry H. (b'26) E-JII.8, 70 ; (I'00)

WI.KER, IOBT J (b'ta) \&-Ont.3, 95
SAULT STE, MARIE, 12,615, CHIPPEWA

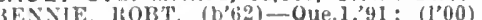

.1 illision st.; onlce, Ashmun st. ; $2-5$ - $3: 30$.

cornell, Filiphtet A. (b'63)-Mich.8,92 (l'00); Gage Block; 9-12, $1: 30-5: 30,7-8$ OALR, *

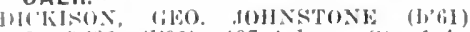
Ont.3,'s ; (1'01) ; 407 Ashmun st. ; 1-4.

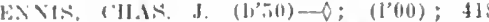
lortiare Are.; oflue, 334 Aslimum si. $12-5, i-9$.

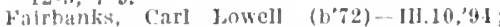
(1'13): 208 Xewton Jlock; 2-8

FolliNIEI, MAIC A.-Mlch.8,91; (1'00) 401 Minle \$t.; nflice, 141 E. Portage Are

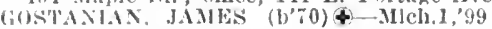
(100) : 3]2 Ashnum St.; oftlee, Haller l\}!nek; 9-12, 1-5; OALR.

GHFPIX, W(IIN J.-Y.2.'82; (I'00); 311

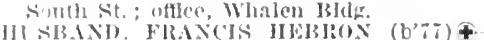

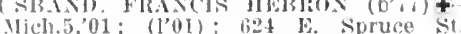
Mich.5, 01 ;

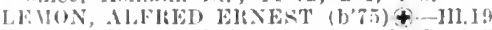
01; (1'05); Whalen Jblock; 10-12, 1-5

(emine (arrie XI. Johnson (b'75)-111.19,01 1'05); 208 l. spruce st.; offlce, Whalen [3] ick: $: 2-5$.

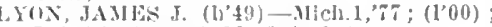

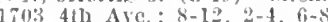

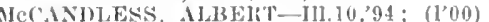
40I Jrospect. At.; ottlee, 319 Aslumun st. $2-4,7-3$.

MULONEY, FRANK J. Mich.8,99; (l'00) 404, thi st.; ofllec, (inwan Block.

o'Neil, (ien, C. D.-Ifich.1, T6; $\left(l^{\prime} 00\right) ; 305$ Japle sit.

Rogers, Thos. N. (b'60)-Ont. \&,'89; (1'00) Newton Bloek.

TOWNSEND, k'REDK.4-N.Y.5,94; (1'00) Kimball and sinuee Sts, office, Conway Block

TOWNSEND, WESLEY W. (b'73) †-Mich.8, '96; (1'00); 337 Carrie St.; ofllee, Conway Bloek.

WHPSTEI, FMHL IIENRY (b'69)-Ont.3 90; (I"00); 1st Licut., M.K.C., U.S.A." Ictyger lleights; offlee, 301 Ashmun St. $2-4 ; O A L R$.

WHILISON, CIAYTON \&-III.10,'90; (I'00) $305 \mathrm{~W}$. Sinruce St.; offlce, Adams Block.

WINSLOW, ROFIIN CIRTIS (b'73) \& Are.; offlee, Maple and Ashmun Sts.; $2-4$; $\mathrm{S}$.

YALE, IRA VICTOH-Nich.7,'02; (1'02) 919 Iohn St.; offlee, Idams Bldg. ; $9: 30$ $11: 30,2-4,7-8 ; G$.

SCHOOLCRAFT, 8I6, KALAMAZOO

('hapin. Jolun F. (b'3s) - Vt.2, 01 : (l'00)

HAITER, IHANDOLPH SAML. (L'Ti)-IH.1, 03 ; (1'04).

Sinith, Harlem S. (b't4)-D.r.2, 00 ; (I'00)

Southworth, Benj. H. (b'is)- HIl, ${ }^{\prime} 03$ (1'03).

\section{SCOTTS, 350. KALAMAZ00}

BRADEN, GEO H. 4 -Mich 1,83; $\left(1^{\prime} 00\right)$.

Ilaight, Edwatd I. (b'75) - Mieh.7, 03 (1'03).

SCOTTVILLE, 891, MASON

Foster, Itobt. F.-Ont.1,03; (l'03.)

FOATER, TIOS. JAMES (b'72) - Mieh.7, $98 ;(1,00)$.

Hunt, Ivan Lewis-Mlch.1,06: (1'07).

MARTIN, WEBSTER C. (b'68)-Mich.1,'92 ; $\left(l^{\prime} 00\right)$

Thomas, Edw.-Jll.1,'60; (1'00).

SEBEWAING, 1,347, HURON

FRIEDLAENDER, BERNHARD $\left(b^{\prime}, 0\right) \oplus$ Ml.4,'98; $\left(l^{\prime} 00\right)$

IORRIS, KEITH MAIRICE $\uparrow-M i c h .9,03$; (1'03).

SENEY, - SCHOOLCRAF

Tonts, Chas. B. (b'75)-Mich. 7,$02 ;\left(1^{\prime} 02\right)$

SHAFTSBURG, 300 , SHIAWASSEE

bunham, Wm. H.-Nich.7,06; (1'06).

SHELBY, I,260, OCEANA

BUSKIRK, JOHN D, (b'66)-Mich.T,96: $\left(l^{\prime} 00\right)$.

GRIFEIN, WILI L-Mich.1.88; $\left(l^{\prime} 00\right)$

Hayton, ArtJur R. (b'78) -Iil.11,'05; (1'05);

Reet $\%$, Fred. A. (b'83)-111.4,05; (1'05).
SHELLDRAKE (KALAMAZOO P.O.), -

Lockwood, Ambrose L. (b'88)-Que.1,'10; (寿)。

SHEPHERD, 835, ISABELLA

ABJOTT, HAIUTY V. (b'71) $-0.8,{ }^{\prime} 02$ : $(1,0,2)$

FODEN, GEORGE SAMY. (b'is)-Mieh.l, $10 ;(1,10)$.

Young, Wm. G. (b'72)-Mich.9,03; (1'03).

SHERIDAN, 436, MONTCALM

BRACEY, JEWIS E. (b'T5) †-Mlch.7,05; (I'05).

LEE, WALTEI I (b'it)-III, 10,04; (J'0;).

SHERMAN CITY (R.F.D., LAKE), 260 , ISABELLA

Rondot, Ernest Frank (b'io)-Mich.8,95; $\left(1^{\prime} 07\right)$.

Soper, Chas. J.-E-0.16,90; $\left(\mathrm{I}^{\prime} 00\right)$.

SHERWOOD, 346, BRANCH

Leonard, ("lyde A. (J'S2) - Nlch.1,'0t; (1'04).

Nelthorpe, ('hils. E.-Mich.7,88; (I'00).

SILVERWOOD, 200, TUSCOLA

AJWXINDER, (IEO,-MICl.7.'4; (1'00).

SIXLAKES, 275, MONTCALM

TOWNSEND, GFO, S. $\rightarrow$; (1'00)

SMITHS CREEK, 100 , ST. CLAIR

lirock, (;0OC. C-MIlch.7,'9i; (1'00).

SMYRNA, 236, IONIA

Ide. Henri (A, (1,50)-Mich.3,'74; (1'00)

PFin'T, ALFIEI) B. (b'68)-Wich.8, 96 ;

Siliney. Andrew 13.

(Sice lietroit.)

SNOVER, 75, SANILAC

Ingle, Jlugh II. (1,78)-Mich.7,05; (1'05);

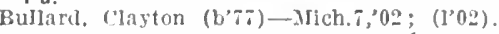

SODUS, 100, BERRIEN

IJarrison, Wm, (;. $(6,56)-\pi y, 2,79 ;(100)$. IIcCartney, John W. (b'58)-Ind.10,'96. (l'00)

SOLDIERS' HOME (BRANCH P.O., GRAND RAPIDS), - , KENT

VERMETIEN, I'E'TER (b'S6)-Mich.1,'11 (l'11)

SOMERSET CENTRE, 200, HILLSDALE

Barmaly, ('. W. (b'64)-Michi.7,94; (1'00).

SONOMA (R.F.D., BATTLE CREEK), 40, CALHOUN

Hoffman, Francis L.-Mich.5,'4?; (1'00).

SOUTH BOARDMAN, 600, KALKASKA

NEIIIAIDT, EMMETT S. (b'63)-0.12,'86: (l'00).

SOUTH HAVEN, 3,577, VAN BUREN

CARNES, (HEO. D. (b'5I) $\$-M i c h .2 ; 66$; (1'00).

Ecker, Fred J4,-Ill.22,'12; (Osteopath).

GoODRICH, NEIL L. (b'so) \-Mlch.5,'06: $\left(\mathrm{I}^{\prime} 06\right)$.

Low, Marian C. (h'63) H-Hl.4,'95; (l'00); G. PENOYAR, FRANCIS CLARK $\left(b^{\prime}, 0\right) \uparrow-$ Mich.1,03; (1'03).

RHODES, LESLIF G. (b'52)థ-Ia. 3,81 ; (1'00).

Rowley, Winfleld Scott (b'52) - Ill.1,'91; ('13).

(1'00).

SOUTH LYON, 6I5, OAKLAND

Lamoreaux, Fredk. A. (1, T9) E-0.2, 03 ; (1'03).

LO(KWOON, FIOYY WILLIS (b'St)\&Mieh. $\tilde{\sigma}, 09 ;$; ( 09$)$.

Millman, Melhourne Geo. (b'63)-0nt.3,'s8; $\left(I^{\prime} 00\right)$

Sayles, Jyman A. (b'44) $\rightarrow$; (1'01).

SPALDING, 500, MENOMINEE

WESTCOTT, EDWIN R. ('b'68) \&-Ind.8,'96; (I'00); OALR.

SPARTA, 1,203, KENT

Bolender, John Edson (b'85)-Mich.1,'12; (1'12).

Braneh, ('has. H. (1)'66)-Ky.1,05; (1'05) Pratt, Chas. G. (b'74)-111.17,00; (1'01).

SICCOTTE, RUDOLPH-QUe.5,'72: $\left(\mathrm{l}^{\prime} 00\right)$.

WALLACE, DANL. J. (b'52) \-Mich.1,76; $\left(l^{\prime} 00\right)$.

Warren, Fredk. Eugene (b'b.5)-Mich.1,'90; (1'08); G. 
SPRING ARBOR, 250, JACKSON

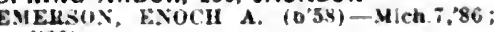
(1.00)

SPRING LAKE, 802, OTTAWA

BROWN, CIRII. P. (b.41) III.1:70:

sulder, Cornellus D. (b'7t) II-Mkh.5, 03 : $\left(l^{\circ} 03\right)$

\section{SPRINGPORT, 584, JACKSON}

Dale, Chas. II.-H-Mich,5,7\%; $(100)$

stewart, Leonard L.-Mich., 000 ; $\left(l^{\prime} 00\right)$

SPRINGWELLS, 1,500, WAYNE (See Detrolt.)

HOLMES, ALFRED WBLLWOON (b'si) Mich.7.' 10 ; $(1$ 10)

SPRUCE, 333. ALCONA

WILSON, JOHX JAMKS (b'60) Ont.3. 00 : (1'01)

ST. CHARLES, 1,45I. SAGINAW

Bradt, Chas. Mortinure (b'3B) - X.Y.5, (1:00).

Mckwen, Wm. H. (b65)-Ont.6.92: (1"00)

ICLAND́RES, JOSHUA ALEXINUFl: $\left(b^{*} 7:\right) \div$ Mich $90^{\prime} 02 ;\left(1^{\prime} 02\right) ; G$.

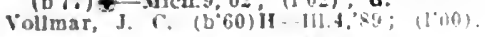

ST. CLAIR, 2.633, ST. CLAIR

HURTIESS, WM. F. (b't) \pm MIch.1,78 (1"00)

ICHES, JAMES W. (b'60)‡-M!ch. i, 96 : $(1.00)$

MCCALL, JAMES II. (b'\$A) \-MICh.','II (I'11). SCHOAIEA WM. LEWIS $\left(b^{\circ}+4\right)+M i k I$
(1)

SMITH, WY. II.-MIch.1, $78:(1,00)$

THOMPSON, ALBFRT E. (b'bI)-Mich.

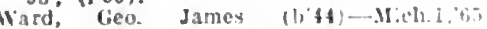
(l'00): 0 p.

ST. IGNACE, 2,118, MACKINAC

Conner, Carollne $X\left(b^{\prime} i\right)-M c h .1,76$ (1'00)

INarby, James F.-Wlch.8,'95; (I'00)

iresser, Frank F.-H-Iil.4, $82 ;\left(I^{\prime} 00\right)$

Ross, Zimmerman (b'62)-Wo.8,01: (1'01)

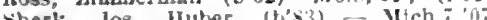
(1'0i).

ST. JAMES, 200. CHARLEVOIX

Branch, Win. Knapp $(1 ; 61)$ - Mich.1, 2 (1'00).

ST, JOHNS, 3,154, CLINTON

RICK, JUBT. ('IAT) $99 ;(1.00)$ : OALR.

nODGF, JOUi H.-Mllch.3.'80; (1'00)

boollng, Jos. V. - Mllch.i,'99; (l'00).

Fale, Wm. Hodskin (b'\%)-Pa.2, 01 ; $\left(1^{\prime} 02\right)$

HART, AITILR o. (b'71)£-Mlch.8,'94 (l'00).

ILAT, ECGENE (b־2) \& - Mlch. $S, 94$ (1'00) : $\mathbf{S}$.

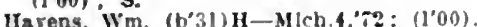

Knapp, Charles Elgar (b'42) - Mllch.1, 65 (1'00)

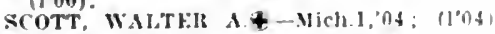

SQUAII, IIARKY D. (b'74)-Mich. 8.97 (1'00): OALR.

Tan Amburg, Lafagetle (b'61) -Mich.1, 85 $(1 * 00)$.

WEIILR, MARTIN $\left(b^{*} 54\right) \notin-M l c h .1,8 I$. (1'00).

\section{ST. JOSEPH, 5,936, BERRIEN}

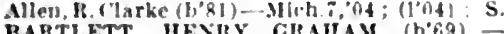

BARTI,HT, HENISY FiltAII

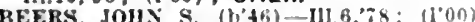

("owdy, Prank i. (b'68)-Mtlch.1,'9j; (1'00

\section{ObG.}

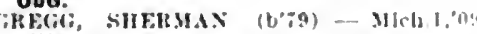

Lindenfeld. Matllda May Beers $\left(b^{*}, 5\right)$ III.9, 00 ; $\left(1^{\prime} 05\right)$.

Martin, Frink N. (b'84)-Mlch.1,06: $\left(1^{\circ} 00^{\circ}\right)$

IEHEIT, FHAS WALTHK (b'so)

III.11.0.5: (1005).

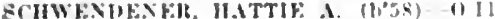
$70:\left(\mathrm{J}^{\circ} 00\right): \mathbf{G}$

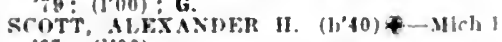
i.: $(100)$.

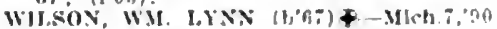
$(100)$.

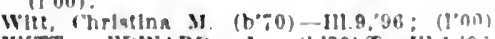
WITT, HEWARI) J. (h:0) -III. $1, \mathrm{BH}$ $\left.110^{\circ} 00\right): 5$.

VFoMASs, THEION GInOFER (h's) Ilch.j, $\left.02:(]^{\circ} \cap 9\right)$
ST, LOUIS, 1.940, GRATIOT

Andrews, bee llale - $0.8,90 ;\left(I^{\circ} 00\right)$

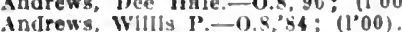

BAKSTOW, WM. k. (b'i) - Mich.1,05 (1.05).

Branch, Jillem E. $\rightarrow$ : $\left(l^{\prime} 00\right)$

Campbell, James Warter -Ont.4, $\$$ : $\left(1{ }^{\prime} 00\right)$

Pettey, Geo. IV.-0.6,"73: (1'00).

WHFELER, AAHOS ROBT. (b'J8) Mllo. $5,79:\left(1{ }^{\prime} 00\right)$.

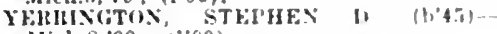

Mich.8,99: (1'00).

STAMBAUGH. 1.322, IRON

Kofmeht, Wm. Jolin (1) 67$)-111.1,12 ;()$

McBurney, Wm. W. (b'69) - Mlch.:,92; $\left(1^{\prime} 00\right)$

vilas, Fred Chaniller (2353)-Vt.2,82:

STANDISH, 829, ARENAC

Mefurk, Hobt.-Mich.1, TR; (1,00)

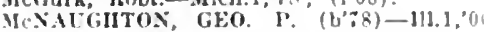
(l'03)

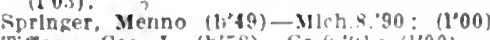

Titany, Geo. I. (b'is)-Gia. 4,401 : $(1000)$

STANTON, 1,012, MONTCALM

Iiachman, Norman E. (b'fis) - Ind.j, $(1,00)$

Bentles: Ros Lelghton-Mich - $93:(1 \% 00)$

rarle (has, A-Nili, (1,00); not in practice.

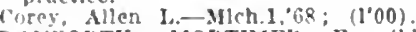

D.AFORTI, MOIRTMFI: E. $\left(\mathrm{b}^{\circ} ; 9\right) \neq$ Mlch. i0,02; $(1 \circ 02) ; S$.

IIall, Jlugh Martin (b'i2)-III.11,98; not in

Mclocin, Donald Alex. (h'15)-Mllch.1, 67 ; ('10): OpA.

STANWOOD, 185. MECOSTA

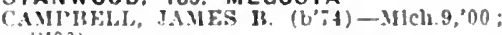

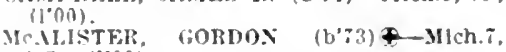
$\because 0-7:(1000)$

STEPHENSON, 527, MENOMINEE

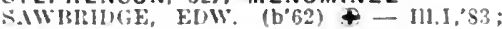
(1'00).

STERLING, IEO, ARENAC

IBB()TT, FR.I.K E. (D.58)-I11.1,'83; (I'00).

STEVENSVILLE, 243, BERRIEN

Sorby, Edgar A. (b'76)-UIch.8,97; (1'00) STOCKBRIDGE, 663, INGHAM

Ibropan, Christupher-Mlch.1,94; $\left(1^{\prime} 00\right)$

13rown. Ilerman Erastus-H-Mich.I, :0 (1'00)

Rowe, Gen. I. (b'59)-MIch.1, $\$ 9$; (1'00)

Stltt. Cora L.-H-Mich.5,94; (l'nO).

STURGIS, 3.635, ST. JOSEPH

liurileno, Frank RIchard (b'i3)-Mlch.t,0 $\left(10^{-}\right): \mathbf{S}$.

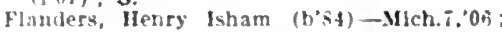
(1'06)

K.INF, DAVII M. Mlch. 1,04: (1'06).

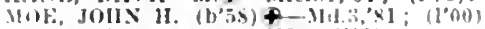

liadebaugh l'eter-0.9'87: (1'03).

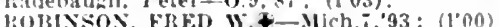

IIOIBISSON, SAML. R. (b'5)-0.14,'-28 (l'0)1.

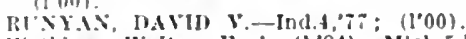

Wriktns, Walter Farl (b'84)-Mich.5, J0 (1'I0)

SUMMIT CITY, 80, GRAND TRAVERSE

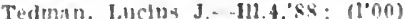

SUMNER, 300, GRATIOT

1:16.11.11, FILFU JOS, MICh.1,9I; (1'00)

SUNFIELD, 385, EATON

'rawforul, James-Ont.3,'ss: (1'00)

I'kiluck, TIIOS. I. (1);0)-Mich.s, 9 (ino).

SUTTONS BAY, 402, LEELANAU

MII.I.H. HDW ALFXANI)EIR (b'SA)Micho, 10 : $(10$ io)

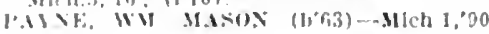
(1.001)

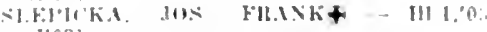

SWARTZ CREEK, 132, GENESEE

'lark, Albert Ierllton (6'06) H-Mll'h 5,20

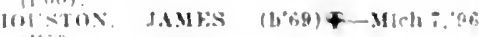

TAWAS CITY, $1.061,105 \mathrm{CO}$

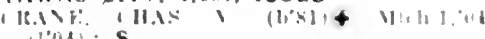

Wlit): S.
TECUMSEH，2,332, LENAWEE

Bredow, Pauline Wilson (b";6) H-Mleb.5. 00 : (1'00).

Brlegel, Wajter A. (b'8c) - Mlch 11.09: (1'09).

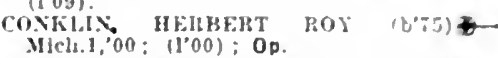

HAKDY, I'EIRAM HRROWS

S.8.8.92; $(100): S$

IIFNI EFSIIOT, EI.M
IICh.I, $86 ;(1,00)$.

IJ.h.I, $86 ;\left(10^{\prime} 00\right)$.

Jones, Ollver Q. (b'5I) H-0.:?3: (1)00)

NoltTI, LLCIAX l. (b"50) -MHch.1,7"; (1) 00$)$.

TEKONSHA, 573, CALHOUN

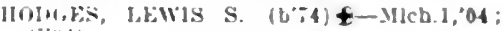
(17)

Simon, Jouhua (b'48) - Ind.12,'ss: (\$)

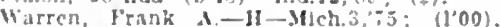

TEMPERANCE, 200 MONROE

KEI.1.广, F.LIIS W. (1.'68)-0.19,9;: $\left(10^{\prime} 00\right)$.

THOMPSONVILLE, 8I5, BENZIE

leltler. James Fodward $\left(\mathrm{H}^{\circ} 63\right)-31 \mathrm{ch} .8,9$; : (1'vio)

Stever, Millard $r .(b+4)-3 ;$

('hurchill, Owen (b'40)--3isch.1,65; (1'00)

HEl.KIE, WM. I. $\left(b^{\prime}, 0\right)-M l c h .7,95 ;(100)$.

Howard, kalph Bowen (L'83) - I!I.I,'22; (1'12).

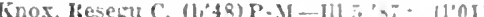

l'axson. John औ. $(t+2)-4$ (1)

practice.

Sorerelgn, Fred F. (b'46)-IIl.1, $199 ;\left(l^{\prime} 00\right)$. Williams, Nurris .l (b'j, . Vich.l.
(l'00).

THREE RIVERS, 5.072, ST. JOSEPH

indrews, Ihelta herr-(0.s.4s: $\left.11^{3} 00\right)$.

lilis , fiuy Lurerane (b'-s)-h.1,08; (1'09)

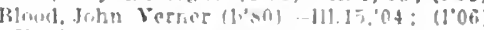

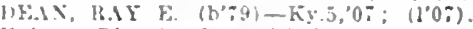

llanes, Blanche M.- $1119.86 ;(100)$.

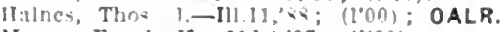

Moyer, Frank K-Md.,97; (1'00)

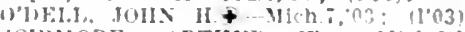

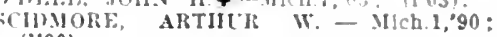
(1'00).

TIPTON, I50, LENAWEE

MICE, OSTAL NEI.SON (t.66)-Mich \&."93; (1'93).

TOMPKINS (R.F.D. RIVES "IUNCTION) 82, JACKSON

Darla. Ejber! Frank (b\%s) - Micb.i,os; (1'0S).

TOWER, 545, CHEBOYGAN

Daston, Darcy M. (b'-6)-Mich.',II; (1'II).

TOWNLEY, 545, LENAWEE

TOWN, LORESZO \&. $\left(\mathrm{b}^{\prime} 50\right\rangle-$ IIlch 2,799 ;

TRAVERS

TRAVERSE

(HISE, ONitA E. (b"iI) - Mlch.I.99: (1'00); II2 S. 1)ak sit: once, state Bank

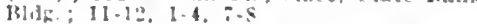

CHASE, S.MBA THOMASINA $\left(b^{\prime} 65\right)-$ Mich.1.00: (1'00): 244 W. sth st: once.

Eisperion, Alah (bial-1119,01: (1'll); Traverse fily state Hospltal.

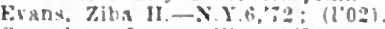

Gauntlet, Jares W. (1):0) Yo. 2801

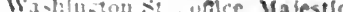
Block: OpA.

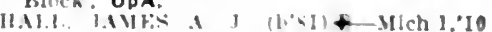
(l'lo): Trurene rits slate llospllal.

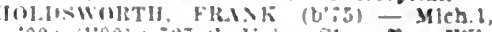

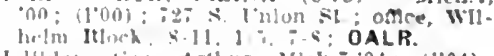

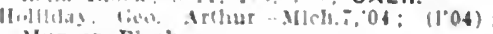
Vurion Bluck

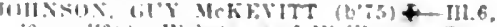
4 : (100): Welwater aud Wellungton sts.

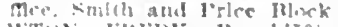

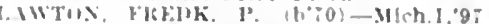
11001: Ang Wrosere st: usce, Whithelm 1.

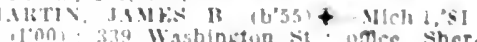

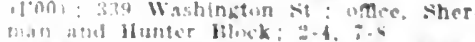

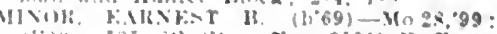

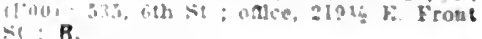




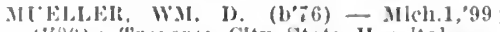
(P00): 'l'merse Clty State Ilospltal.

MTNSON, TAMES DECliER (1) 48$)+$ Ilich.I, T3: (1'00); Traverse clty Stale Hospltal ; P. $\star$

IBOWLY, ARTHIR SHOIOY (b) Mleh 1,90: (1'00); Traverse ("ily SLate Itospltal: P.*

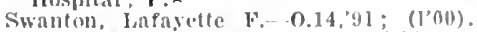

Thlrlby Edwin L-Mich.1,03; (1,03).

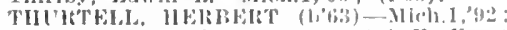

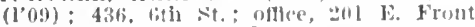
St.: $10-12,2-4,5-8: s$.

Wafer, Ramond Farnhan (1, 80 - Mleh.1.

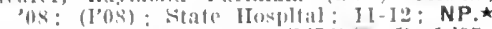

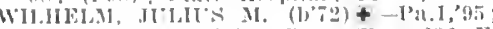

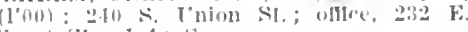
Front S.I.; 1 -4; s.

TRENARY, 100, ALGER MAYTHEN (b'S2) + -IIS'h.1,04; (1'0(i).

TRENTON, I.224, WAYNE

IIOLIDEX, IIIRAM (b'55) \& - Mich.6, 83 . X.Y.10,00; (1,00)

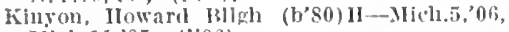
Milich,11,07: (1'06).

TRIMOUNTAIN, 2,500, HOUGHTON

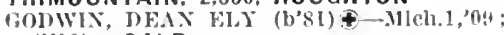
(1'09): OALR.

Witerman, Leonard (b'88) - Mich.1,13; (1'13).

TROUT CREEK, 597, ONTONAGON

POR'TER, WALD KINIRICK (1)'S3) - III.6, , 0 : : (1'11).

TROUT LAKE, 250, CHIPPEWA

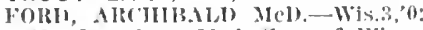

Meniber siate Med. Sore. of Wis.

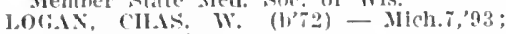
(I'00).

TRUFANT, 350, MONTCALM

BTNCE, EARI P'. (b'8ti)-Mich.i,'l1: (1'1I).

TURNER, 500, ARENAC

MeDowell, Albert Sidney (b'i2) - Mich.7, 02: (1'02).

TUSCOLA, 255, TUSCOLA

COP', ALBERT E.-WHeh.7,'96: (l'00)

HARLISON, LEE D. (b'85) - Meh.7̈, I0; (1'10).

TUSTIN, 37I, OSCEOLA

BARNAKD, JAMKS HERBERT (b'64)屯-

vilch. 10, $99:\left(l^{\prime} 00\right)$.

Bryson, Wm. A. (b'56) P-MI-Ind.5,'s9: (1'n0).

UBLY, 442, HURON

CORCORAN, IAY SYLYESTER€-MICh.1, '83 ; $(1,00)$; $\mathbf{G}$.

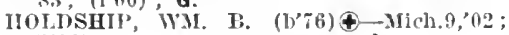
(1.02).

UNION (P.F.D., BRISTOL, IND.), I25, CASS EDGAR A. (D'b8) - 111.11,99; PLANCK,
(1,00).

UNION CITY, I,340, BRANCH

Anderson, James Henry-Mich.1,'88; (l'00).

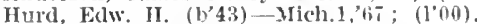

Pepper, FIarry-Nich. 6,$06 ;(1,06)$.

UNIONVILLE, 456, TUSCOLA

KAYEN, GOTTLIEB HENRY $\left(b^{\prime} 75\right) \oplus$ III. 22,08 ; $\left(l^{\prime} 08\right)$; $0 p$.

rowthian, 'Timothy (b'48) - N.Y.6, '80; (1'00)

Wegert, Wm. Rudolph (b'58) H-Mich.5,99 Nlicli.9,01; $\left(1^{\prime} 00\right)$.

URBANDALE (BATTLE CREEK P.O.), CALHOUN

WOCKIYY, WM. E.

(See Battle Creek.)

liolvoord, Theoclore (b'88)-111.11,'12; (1'12).

UTICA, 496, MACOMB

ROBERSON, GEO G. (b'55)屯-Mllch.2, 'Ti ; WI'00). HELBERT भr. (b'i3)-Mich.7,'99; (1'00).

VANDALIA, 37I, CASS

Cunningham, Ersom Mills.

(See Chicago.)

LOUPEE, SHERIIIN L. (b'T2) $\oplus-I 11.11$, ,04; (l'04)

PEXŚTERMACHER, CHARLIE C. (b'70)111.11,93; (1'00).

VANDERBILT, 523, OTSEGO

Chapin, Wm. S. (b'81)-Mich.1,06; (1'06)

Winer, David E.-Nich.9, 03 ; (l'v3).
VASSAR, 1,659 , TUSCOLA

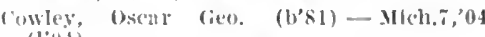
(I'ii).

("ullis, 'Thos, Allen-Mich.1,78; ()

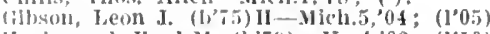
II:1\%lewod, Fred M. (b'79)-Ky.4,02; (1'10) LEVALEY, FIRANK DUANE (b'5T) .llell.1,'s:s; (l'00)

Morris, Ilarvey i. (b'if) - Mleh.9,'98, X.Y.19:99: (1,00): abroad.

1ENXINGTON, BENJ. S. (b'56)†-Ia. 0,91 ; (1'10); Ob.

sichotr, Osear F.-Mllch.1,69; (l'00).

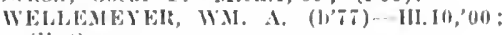
(l'o(1)

VERMONTVILLE, 650, EATON

Snell, chas. $S$ Ho.5, 75 ; (1'00).

MCEACIILAX, JOHN D. (b'T1)-Mieh.10,02; (1'02).

MCLAUGHLIN, C. L. D.-WICh.7,06; $\left(\mathrm{I}^{\prime} 0 \mathrm{~B}^{3}\right)$.

VERNON, 435, SHIAWASSEE

IIOLTZMAN, WELIINGTON HENRY (b'49) $+0.1,78 ;\left(10^{\prime} 00\right)$.

VESTABURG, 438, MONTCALM

Hulbard, Melvin C. (b'80) - Mleh.i,'06: (l'06).

Wisely, J. W.-II-III.1n,'st; (I'07).

VICKERYVILLE, 175, MONTCALM

("LBEITSON, AI"STIN I"-MIICl1, 1, \&4: ()

llangrive, Don vilrelle (b,sti) - Mich.î, (1'13); OALP.

VICKSBURG, 1,624, KALAMAZOO

('OLIFR, FRANK SMITH (b'bt)\&-Mich.1, 'Si; $(1,00)$.

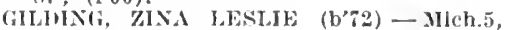
11); (1'10).

MACIIIEISON, DOXALD IIUGH (b'82)Mich.9, $03:$ (1'03)

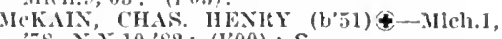
'Ts, N.Y.10,82; (I'00); S.

VICTORIA, 400, ONTONAGON

IITTES, 11.AYII) L.ENTON (b'86)-Ind.20,'11: (l'13).

VOLINIA (R.F.D., MARCELLUS), 100, CASS Irwin, I). IIarvard (b'67)-Mich,8,'04; (1'04). VULCAN, 1,500 , DICKINSON

IONEA, BERKARD W. (b'5i) - Ill.1,'81; (l'00).

WACOUSTA, 200, CLINTON

BOAS. IRET' I). (b'61) \&-D.C.I,91 (l'01).

IIinkson, Joln E. (b'70)-Mich.1,95; (1'00).

WAHJAMEGO (R.F.D., CARO), III, TUSCOLA

WIXON, ROBEI'T LIVINGSTON (b'T) Ilich.1,10; (I'10); not in practice; (F')

WAKEFIELD, 7I4, GOGEBIC

(OLF, DANL. THOMAS (b'82) \&-IIl.11, 05; (1'07): Member Ill. State Yed. Soe crosly, Theodore Saunte $\left(b^{\prime} 7 t\right)-11 d .3,05:$ (l'05) ; s.

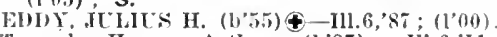

Tressel. Henry Arthur (b'si)-IIt.6,'11; (Assistant Physician).

WALDRON, 435, HILLSDALE

Barnes. James 21. (b'65)-0.19,94; (1'00).

Bates, Costello-0.14,81; $\left(1^{\prime} 00\right)$.

Yeagley, Joshua L. (b'74)-0.19,'01; (1'02).

WALES, - ST. CLAIR

Mudge, Horace H.-E- $\rightarrow$; $\left(1^{\prime} 00\right)$.

WALKERVILLE, 37I, OCEANA

BLANCHETTE, VICTOR JOS, (L'S4) III. $22,07:(1,06)$.

Robinson, Banner J, (b’53) II - Ill, 10, 01 . (1'0I).

WALLED LAKE, I3I, OAKLAND

('HAPMAN, ERWL' A. (b'55)-MHeh.2,'76, X.Y.10,'79; (1'00).

WARREN, 297, MACOMB

Addisen, Stanley M.-MIich.ï,92; (1'00),

Gronow Adolph A.

(See Detroit.)

Ladoucour, EdW. (b'62)-Nlich.8,'92; (l'00).

WASHINGTON, 208, MACOMB

Lamb, Aura R. (b'64)-Nich.i,'8s; (l'00);

$0 p$.

SCOTT, FRANCIS A. (b'66)Ð-Mich.1,99; $(1,00)$

Wlison, Saml. J. (b'50)--W's.3,98; (1’00).

Yates, Mlbert (b'42)-allch.2, 72 ; (1'00).
WATERVLIET, 728, BERRIEN

Browll, Fredk. WH. (b'i4)-NIch.9,'99; $\left(1^{\prime} 00\right) ; \mathbf{P d}$.

(iunn, John Wm. (1'60)-Ky.4,94; (1'00).

l'eer, orvllle Arnoli (b'6t)-ky.2,'i2;

(I'12) ; 0p.

WAYLAND, 725, ALLEGAN

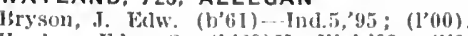

Hanion, Eslw. O. (1,69) $11-111.4,93$; (1'00).

liyno, Eber II. (b'48) II-III.4,'80; (1'00).

WAYNE, 1,263, WAYNE

Benuell, Jos. Estabrook-Mllch.1,90; (l'n0).

CUMMINGS, RICHARD BLACK (b'60)屯-

N.Y.5, $85:\left(1^{\prime} 00\right)$.

EARLE, ROMEO HORATIO (b'T) $\oplus$ .llichl. $x_{1}^{\prime} 01 ;\left(1^{\prime} 01\right)$.

Foster, Jlerbert E. (b'49) II-0.13,'81; (1'00). ZIMMERMAN, SAML. (b'57) - Mleh,1,82; $\left(l^{\prime} 00\right)$.

WEBBERVILLE, 349, INGHAM

Kunshaw, Albert IIuclson (b'S1) - Mleh.1, 09 ; (1'09).

MILIS, EU(GENE D. (b'57) - Mleh. 3,91 ; $\left(10^{2} 00\right)$

Spencer, Chas. Truman (b'86)-Mlch.7,'13; (1'13).

WEIDMAN, 500, ISABELLA

P'ayne, Loren $C \rightarrow$; $\left(1^{\prime} 00\right)$.

WEST BAY CITY (IND. STA, BAY CITY),

-, BAY

NCH, 1,276, OGEMAW

BFEPY, IROBT, J-IIl.4,05; (1'05)

(ilemn, Thos. s. (b'69)-0nt.3,91; $\left(1^{\prime} 00\right)$

IIOOI'ER, S, ELSTON (b'v3)థ-Ont.6,90; (l'(1)).

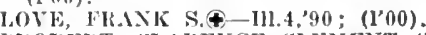

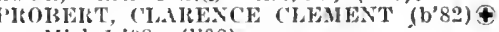

一 Mich.1,'08; (1'08).

WESTON, 254, LENAWEE

WEATCAT'E, CIAREXCE II. (b'80)-Mlch.7, "02; (1"02).

WESTPHALIA, 366, CLINTON

Altou, Itobt. A. (b'90)-MIch. 7,13 ; (1'13).

Frace, Guy H. (b'73)-Mleh.7,98; (I'00).

WESTVILLE (R.F.D., STANTON), 75,

MONTCALM

Walsh, Sophronla Cummins-o; $\left(l^{\prime} 00\right)$.

WEXFORD, 250, WEXFORD

WELIS, ROBT, FLLSWORTII (b'85) -

Mich.1,07; ( $(100)$.

WHEELER, 250, GRATIOT

STREET, FLALK I. (b'72) (-MIlch.9, 00 ; (l'0I).

WHITE CLOUD, 648, NEWAYGO

Branch, John C. (b'52)-Ky. 1,'95; (1'05).

Fowler, Wm. Edward (b'67) - Ky.9, 05 ; (l'09) ; Pd.

KUHN, WM. A.-IIl.8, 87 ; $\left(1{ }^{\prime} 00\right)$.

WHITEFORD CENTRE (R.F.D., OTTAWA

LAKE), I00, MONROE

BROWN, IROLPII (b' 73$) \oplus-$ IIich.,, 97 ; (1'00).

\section{WHITEHALL, 1,437, MUSKEGON}

Cole, Henry S. (b'79)-Ill.10,02; (l'02).

Iercik, Wm. Louis (b'86)-Ill.11,'10; (l'13).

KEYES, LESLIE W. (b'55)-0.14,82;

$\left(l^{\prime} 00\right)$.

SMITH, CHAS. F. (b'13)థ-Md.4,98;

(10)

WHITE PIGEON, 667, ST, JOSEPH

CAMERON, WM. C. (b'66)థ-Ill.1,93; $\left(l^{\prime} 00\right)$.

WHLLAXS, JOHX R. (b'49).-H1l.11,'86; (l'00).

WHITEROCIK (R.F.D., RUTH), I00, HURON

Tucker, Alfred II. $-\backslash$; $\left(l^{\prime} 00\right)$.

WHITMORE LAKE, 350, WASHTENAW

Lemen, John H. (b'57)-Mllch.6,81; (l'00).

WHITTEMORE, $218,10 S C 0$

Smith, Robt. J. (b'53)-Md.3,'84; (1'00).

WILLIAMSBURG, 300, GRAND TRAVERSE

Bunce, Chester Wm. (b'52)-Mich.10,03; (l'03).

WILLIAMSTON, I,042, INGHAM

BAILEY, GEO. WESLEY (b'68) \&-I11.19, 07 ; (1'09).

Brett, Geo. IIaylett (b'59) - Mieh.1,'85; $\left(I^{\prime} 03\right)$. 
COAb, MATHIAS $(1,+1)$ - Masa $2,65:(1900)$,

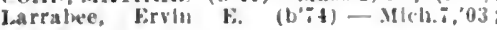
(1'03).

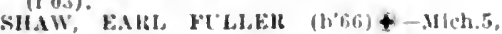

'87: $(1.00)$.

WINN, 250, ISABELLA

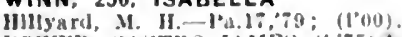

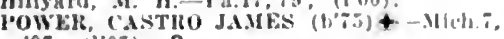
$0 \%$ : (l,0:): G.

WINONA, 120, HOUGHTON

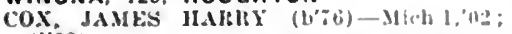
(l'02)

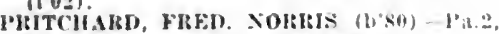
04: (l'05); Member State Mod. Sik". if Wis.

WIXOM, 200, OAKLAND

Holnes, Thomas $G$.

(see Detrolt)

WOLVERINE. 794. CHEBOYGAN

Mcklllop, Archlluald J.-U.I2,'Si: (1"u0). WOOOBURY, 75, EATON

laughlin, irthur l. (b,9)-Mlch.l, (1):; (1'03).

\section{WOODLAND. 304. BARRY}

I Benson, Luren $\mathrm{E}$. (b'51) $\mathrm{F} \rightarrow \mathrm{O}:\left(1^{\prime} 00\right)$

MCIXTYRE, CHAS. $\mathrm{s}$ (b'69)-Mlch.1, 'mi: (1'00).

WYANDOTTE, 8.287, WAYNE

BIIGHTOX, MHCHIBAL WHAON (b"T) -Mlch.8.00; $\left(1{ }^{\prime} 00\right)$.

Droulllard, Alfred ('-MIch. .,93; (I'00).

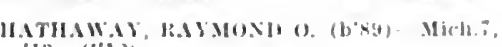
'I3; $(1,1,3)$.

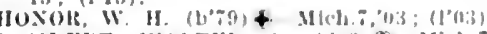

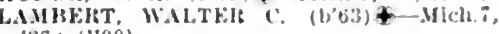
\$8; 1100$)$

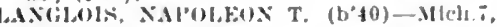
, 1 . (1'00).

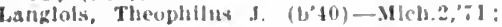
(I'00).

Martln, Albert lewls (boti)-Ia.t, s.; ; Iartlin,

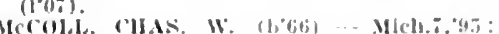

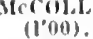

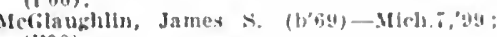
$(100)$.

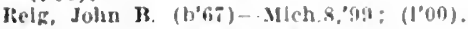

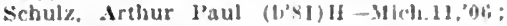
(1'06).

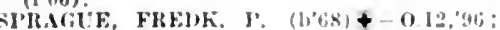
( $\left.\mathrm{l}^{\prime} 00\right) ; \mathbf{U}$.

YALE, 1.223, ST. CLAIR

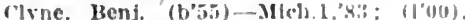

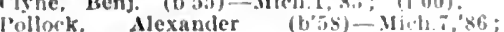
(1'00).

WIGHT. WM. G. (1)67) - Ont.3,90): (1'00).

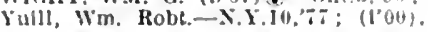

YPSILANTI, 6.230, WASHTENAW

harton. Wm. R. (b'3i)-0.5,8I; (l'00).

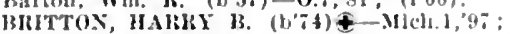
(l'00).

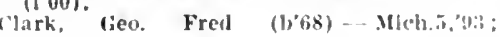
(l'0).

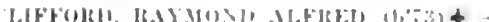

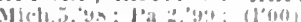

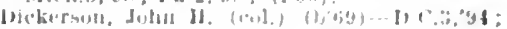

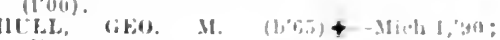
(I'00).

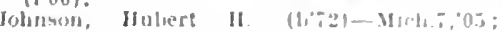
(1'05).

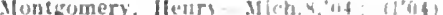

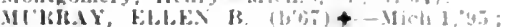
(lino).

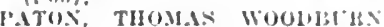
Mieh.1, 0?; (1'02)

lecet llar (Fin).

l'ose, Ilowarl I. (1)"65)-.Mlch. 7,$90 ;(1000)$

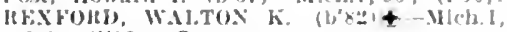
"118; $(1.08) ; \mathbf{S}$.

Shaw, Thonas $(1,45)-M / c_{1}, 1,70 ;\left(10^{\prime} 00\right)$

Westfall, Floyd bolward $\left(b^{\prime}, \omega^{*}\right)-$ Mloh. (1'(10); OALR.

YUMA, 150, WEXFORD

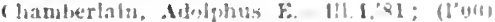
ZEELAND.1,982, OTTAWA

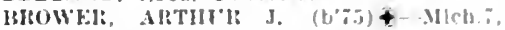
00: (l'o) : It r.ll 3

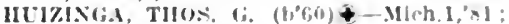
$(1,00): S$.

MASSELIXK, JOHX (b'-)-Mlld, ;04: (l'04).

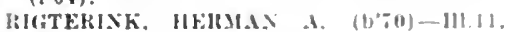
'日7:; (1'07).

FOR KEY TO SPECIALTIES, ABBREVIATIONS, SYMBOLS, ETC., SEE PAGE 730

If you are in doubt as to the towne in which a certain phlysicion lices, the alphabetiral inder will locale him for you. 


\section{MINNESOTA}

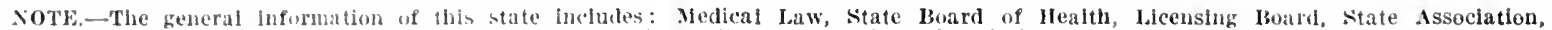

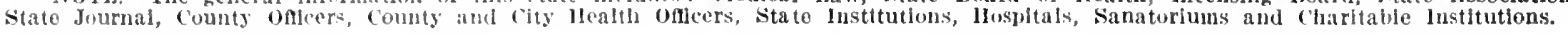

\begin{tabular}{|c|c|}
\hline \multicolumn{2}{|l|}{ MINNESOTA } \\
\hline \multicolumn{2}{|c|}{ Population (1910 census).....2,075,708 } \\
\hline 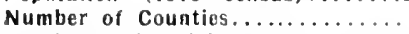 & 86 \\
\hline Number of Physicians............ & 2,381 \\
\hline $\begin{array}{l}\text { Members State Association, Dec. } 31 \text {, } \\
\qquad 1913 \ldots \ldots \ldots \ldots \ldots \ldots \ldots \ldots \ldots\end{array}$ & 1,473 \\
\hline Area of State in Square Miles.... & 84,682 \\
\hline
\end{tabular}

\section{MEDICAL PRACTICE LAWS OF} MINNESOTA

(Chapter 35, Rerised Code of 1905, in efrect

March 1, 1906). Sections 2295-2300.

Section 2295. BOARD OF MEDICAL EXAMINERS; OFFICERS; RECORDS: The State Board of Medical Examiners shail consist of nine qualifled resident physicians, appointed by the governor, each for the appointed by the governor, each for the sor qualifles. No member thereof shall serve for more than two succesive terms, nor sliail any instructor or person financially interested in a medical school be appointed thereto; and it shall at all times include three homeopathle physlcians. Vacancies shall be fllted by like appointment for the unexpired term. The board shall elect froin among their number a president, a secretary and a treasurer, and shall adopt a seal. It shall hold examinations at the seat of shan hold examinations at the seat of government on the October of each year, and at such other times as it shall deein best. The secretary shall keep a record of all its proceedings, ineluding a rerister of all applicants for license, giving their ages, description of their eciucation in medicine, and the result of their examination. Said books and register shall be prina facie evidence of all the matters therein recorded.

Sec. 2296. EXAMINATION AND LICENSE: A person not alrealy authorized to jractice medicine in the state, and desiring so to do, shall apply to the secretary of the Board of Examination, and pay a fee of $\$ I 0$ for the use of the board which in no case shalf be refunded. At a time appointed, or at the next regular examination, he shall prove that he has completed four entire sessions of twentysix weeks each at a medical school recog nized by the board, no two sessions having been held in one year, or, if such at tendance was prior to the year 1899, three sessions shall suffice. He shall be examined in antatomy, chemistry, histology, obstetrics, patholory, plysiology, preventive medicine, the diagnosis and treatment of medical and surgical diseases, and such medical and surgical diseases, and such
other branches as the board shall deem advisable. After such examination the board, if seren members thereof consent shall grant him a license to practice medicine. The examination shall be both scientiflc and practical, and shall thoroughly test the fitness of the candidate. All answers concerning the treatment peculiar to any school of medicine shall be examined and their sufficiency passed on, by the members of the board belonging to that school and their recommendations thereon shall be tinal. The board may refuse to grant a license to, or may reroke the license of, any person guilty of immoral, dishonorable or unprofessional conduct, but subject to court.

Sec. 2298. RECORD OF LICENSES; REFORT TO SECRETARY: Before engagin in practice, the holder of a license shall fle the same for record with the clerk of
the distriet eourt in the county where he re- sides. Unon removal to another county he shail there tile his license in like manner before engaging in practice therein. Such elerk shati keep, in the record book of such licenses, an index thereof, sllowing the date and page of record, and in January of each year shall purnish to the secretary of the notke to the clerk of the death or remoral of a licensee, or of the revocation of a Hcense, he sliail note the same on the record of such ficense.

See, 2299. EXEMPTIONS: This subdiviston shall not apply to commlssioned surgeons of the United States Army or Navy, to physlcians from other states in actual consultation here, or to students practicing under the direct supervision of a preceptor while they are enrolled in and regulariy atwhile they are enrolled in and regularly

sec. 2300 . PRACTICING WITHOUT HICENSE; PENALTY: Every person not heretofore authorized by law so to do who shall practice medicine in the state without having obtained the license herein provided for, and every person who shall so practice contrary to any provision of this practice contrary to any provision of this subdivision, shall be gullty of a misdemeanor, the minimum punishment whereof
shall be a flne of $\$ 50$ or imprisonment for ten days. Any person shall be regarded as practlcing within the meaning of this subdivision who shall append the letters M.D. or M.B. to his nane, or for a fee prescribe, direct or recommend for the use of any person, any drug or medicine or other agency for the treatment or relief of any igency fracture or bodily injury, infirmity wound, fracture or bodily injury, infirmity
or disease; provided the section shall not or disease; provided
apply to dentists.

\section{MEDICAL RECIPROCITY ACT}

('hapter 236. Laws 1905.

\section{An Act}

Authorizing Physicians from Other states to Practice Medicine in Minnesota.

Be it enacted by the Legislature of the State of Minnesota:

Section 1. That the State Medical Examining Board, either with or without examination, may grant a license to any physician licensed to practice by a similar board of another state, and who holds a certifieate of reglstration slowing that an examination has been made by the proper board of any state on which an average grade of holder thereof, the said applicant and holder of such certificate having been at the time of said examination the legal pos. the time of said examination the legal pos. in good standing in this state, which said in good standing in this state, which said amination as evidence of qualification. In case the scope of said examination was less than that prescribed by this state the applicant may be required to submit to an examination in such subjects as have not been covered. The fee for such examination shall be $\$ 50$.

A certificate of registration or license is sued by the proper board of any state may be accepted as evidence of qualification for registration in thls state; provided, the holder thereof was at the time of such registration the legal possessor of a diploma issued by a medical college in good standing in this state and that the ments of the examination test in this state.

Sec. 2. If by the laws of any state or the rulings or decisions of the appropriate offlcers or boards thereof, any burden, ob-
Ifgatlon, requirement, disqualiflcation or disability is put upon piysiclans registered in this state or holding diplomas from medica colleges in this state which are in good standing therein, affecting the right of said physicians to be reglstered or admltted to practice in sald state, then the same or like burdens, obligations, requirements, disqualifications or disability shall be put upon the registration in this state of physicians registered in said state or holding diplomas from medical colieges situated therein.

Sec. 3. All aets and parts of acts inconsistent with this act are hereby repealed.

Sec. 4. This act shail take effect and be in force from and after its passage.

Approved April 18, 1905.

\section{STATE BOARD OF HEALTH}

W. A. Jones, President, Minneapolis; B. J. Merrili, Vice-President, Stiliwater; H. M. Bracken, Secretary aud Executive officer, St. Paul; C. W. More, Eveleth; Christopher Graham, Rochester; W. C. Chambers, Farl, St. Paul; Frank Burton, Minneapolis ; Chas. L. Greene, St. raul.

\section{MINNESOTA STATE BOARD OF MEDICAL EXAMINERS}

F. R. Weiser, President, Windom; J. W. Andrews, Mankato; R. D, Matchan, Minneapolis; $A$. G. Noffatt, Howard Lake; Chas. Bolsta, Ortonville; Annah Hurd, Minneapolis ; John W. Campbell, So. St: Paul ; Frank B. Hicks, Grand Marais ;

\section{MINNESOTA STATE MEDICAL ASSOCIA-} TION

Officers 1913-14

A. E. Spalding, President........... Luverne (.. S. Wattan, Ist Vice-President......Warren A. W. Ide, 2d Vice-President...... Brainerd Thomas McDaritt, Secretary........ St. Paul Earl R. Hare, Treasurer............inneapolis

\section{Official Pubilication}

The Journai-Iancet, Minneapolls, W. A. Jones, M.D., editor.

Councilor Districts and Officers First District.-Clay, Becker, Wilkin, ottertail, Douglas, Grant, Polk, Marshali, Kittson, Roseau, Norman, Pope, Red late, Sterens, Traverse and Big Stone counties. C. E. Dampier, Councilor, Crookston.

Second District.-Aitkin, Beltrami, Cass, Crow Wing, Hubbard, Morrison; Todd and Wadena counties. J.'G. Millspangh, Councilor, Littie Falis.

Third District.-Ramsey, Washington, Chisago, Pine, Millelacs, Isanti, Kanabec, St. Louis, Lake, Carleton, Cook and Itasca counties. J. I. Rothrock, Councilor, St. Paul.

Fourth District.-Hennepin, Anoka, Sherburne, Meeker, Wright, Stearns, Benton, Kandiyohi and Swift counties. F. A. Knights, Councilor. Minneapolis.

Fifth District.-Renville, Chippewa, Lac Qui Parle, Yellow Medicine, Sibley, Brown, Redwood, Lyon and Lincoln counties. H. M. Workman, Councilor, Tracy.

Sixth District.-Pipestone, Rock, Nobles, Murray, Cottonwood, Jackson, Faribault, Martin and Watonwan counties. F. R. Weiser, Councilor, Windon. 
Sesenth H!ntrict,-Nleolle?, Dakuta, I.evueur ("iest half), IIcleck), scott. Carrer. Compllue lile and Wabasha countles. F $A$ Denlge rinuellor. I.esueur.

Eighth bistrict.- Blue karth, Dolge.

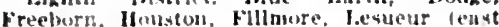
half) ilower, Oimstead, steele. Waseca

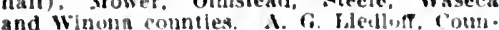
and Wincun count Mankito.

Component Distriet and County Socleties of the Minnesota Stale Medical Assuelation AITKIN CoUNTy

Cariton Graves, Pruslient........... sithin J. J. Racelltre, Secretary............... ANOKA COLNT:

(Included In Hennepln County.) BECKER COUNTY

(Included in Clay-Becker Countles.) BLLTIAMI cotNTy

Included In Lipper Mlssissippl Iedilcal Soclety.) BENTON COUNTY

(Included In Stearns-Itenton Counties.) BIG STONE COUNTY

(Inclucter In West Central Minnesota Distriet Medical Soclety.)

\section{BLEE EARTH COUNTY}

C. A. Dahl, Presldent.............. Irankato R. $\mathbf{~}$. Andrews, Secretary.............. RLUE: EARTH VALLFY-FARIBALLTIIARTI COUNTIES

. F. Ilolm, Presldent..............Wells

J. A. Broberg, Secretary......... Blue Farth

RROWX-REDWOOD COUNTIES

D. G. Glessteen, l'restdent....... Lamberton

CAY' RELFASE DISTRICT-CHIPPEWA

RENVIILE-YEILOW MEDICISESIBLEY-IAC QUI IPARLE COUNTIES

H. 3. Johnson, l'resident.......... bawson H. D. Zlmbeck, secretary............ Monterideo CAKITON COUNTY

Win. G. Iolan, Iresldent .......... Cloquet Alexander Barclay, secrelary.......... Clojuet CARVER COUNTY

(Included in Scott-Carrer Counlles.) Cass county

(Included in Lpper Nisslsslppi Medical society.)

CENTRAL MINNESOTA DISTRICT-

MILIE-IACS-ISANTI-KANABEC SIIERBLRY COUNTIES

S. H. Olson, Presldent............ Mllaca

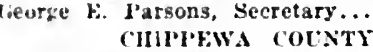

(Included in Cainp Release Distrlet Medical soclety.)

CIISAGO-PINE COLNTIES

Thomas Zelen, J'resldent ...... Vorth Branch

C. A. Anderson. secretary....... Push Clis

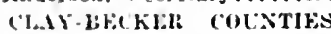

c. W. Simlson, l'resldent.......... Ilawley

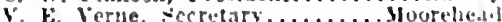
ruok cutsty

(Included in si. Louls-Iake-Itasea-cork (countles.)

\section{COTTONWO(1) (OONT}

(Included in Southwestern Soclety.) CII)W WING COUNTY

(Included In Liper sirsissippl Medical Soclety.) Doncie counTy

F. W. Darls, secretary..........hasson nOL'Gists COLNTy

(Included in l'ark lieglun Dlstrlet Med. leal Soclety.)

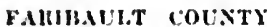

(Included In lilue Fatth Valley Medical soctety.)

HLLMOHE: COUNTY

(Included in Houston-Ftllmore Conntios.) FRERHOHX COUNTY

d. P. Fon Rerz, Prenddent.......Albert Lea liobt. (i. Sterenson, secretary...Allwert le: Goubliti: COL:NT

1. II. Cremer, Iresldent.........lled win. A. T. Conley, secretars....... iaunon Fall
GHANT COLNTY

(Incluided in lark llegton blstrlet Medical Sorlety.)

HENNEPIS COUNT

C. A. Mccullum. I'restelent.......Mnneapolls .. Irook;, Fecretary..........linneapolis HOISTON-FILLMOIR: COLNTIES

o. F. Fischer, fecretary......... Ilouston IILIHBAISD (OOCTT

(Included lis Viner Mrsalssippl Medlcal Soclety.)

\section{ISATT rOTIT}

(Included in Central Sinnesota Distriet Viedical Soclety.)

$$
\text { ITASC.I COFNTY }
$$

Included In St. Louls-Lake-Couk-Itasca Counties.)

\section{SACKSON COINT}

Antou Moe, Pres!dent ...........Heron lake her s. Benson, secretary...........Jackwon KANABEC COUNTY

Included in Central Minnesota Distrlct Medical Soclety.)

K.INDIYOLI-SWIFT COUNTIES

II. O. Oppegaard, I'resIdent.... New London Unus Johnson, secretary.........Kerkhoven KITTSON COUNTY

(Included in Red River Valley Medical soclety.)

LAC QUI PARLE COUNTY

Included in Camp Release District Medtcal Soclety.)

LAKE COUNTY

Included in St. Louis-Lake-Cook-Itasea counties.)

\section{LESUEUR COUNTY}

(Included in Nicollet-Lesueur Counties. LIXCOLX COUNTY

(Included in Lyon-Lincoln Countles.) LYON-LINCOLN COUNTIES

C. E. Pearsons, President..........Marshal

H. II. Worknan, Seeretary......... Tracy MARSHAL, COLNT

Included in lied hiver Valley Ifedical Soelety.) MARTIS couxtr

(Included in Mlue Farth Valley Medical soclety.)

Mel.Fol) ('OINTY

1. K. Clement, I'resident....... Lester Pratrle f.dmund L. Naurer, Secretary....Brownton MEKKEI CULNTS

1. W. Itobertsun, I'resident...... I.ltchfleld Karl A. Itantelson, secretary.......Itchfleld IILLELACS COUNTY

(Incluted in Central Ilinnesota District Jedleal sochety.) MOHISISON COUNTY

(Included in Ipler Mlsslssippl Medical sisedety.) MWWEll COLNT

C. Mllen, l'resldent.................... tinery i lebman secretary.........Austln IIIIIS COUNT

(linclulvd in southwestern soclety.)

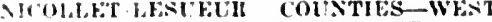

IIALF ONIX OF NICOLLET.

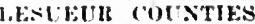

It .I. Thelpis, l'resldent............ Tet. Per

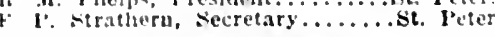
DIIIAS CUINTY

(Inchuded In sunthwestern Soclety.) Nolisax cocitry

(Included in led Itiver valley Medleal

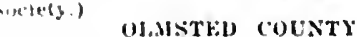

steren, lrestient. .............Jtyrots

f. Irewe, secretary.......... Hobluester OTTHITAH, COLNTY

(lincluded in lark Region Distrtet Mled (a) Serelety.)

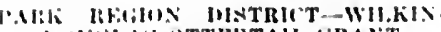

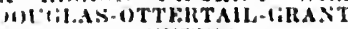
(1)i:ititis

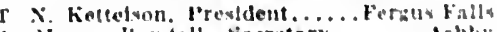

Instul Iandall, secrutary.........Ashty

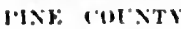

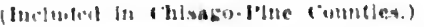

HUR

(beluded in sistlinemeth sortety.) luk int ITY

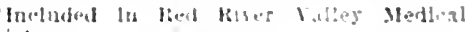
sionlots.1

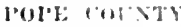

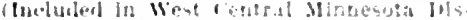

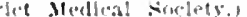

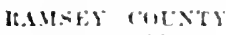

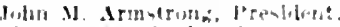

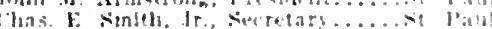

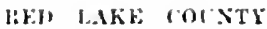

dachuded in lied ther valley Medical Siontety.)

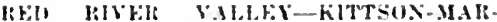

SIIAL-ROAEAT-REH LAKE-POLK. NOIGISN rocstres

1) H. Olsun, Preqident............. Friklue

F. If. Uryden, secretary......... Crookst on IЕHWOOH COIXTY

(Included in lisuwn-Redwood Countlez.) IEEvithe COLDTY

(Included in Camp Release Llsirlet yed. loat soclety.)

HIC COENTY

A. C. Hozers, J'resident.......... Faribault F. I. Davts, secretary............ Faribault bock col:NT

(Included in southwesteru Soclety.) ROSEAL COLNTY

(Fin.ludel in led river ralley Medical soctety.)

SCOTT-CARVER COLXTIES

Whn Landanberger, I'resldent...New I'rague

H. IS. Relter vectetary .......... Slizkopee SIIFRBLRNE COLNTY

(Included in Central Minnesota Dlstrlet vedleal soclets.)

SIBLEY COLNTY

(Includel in Canp Release nistrict Medical societ $y$.)

SOLTUWESTEII SOCIFTY-PIIESTONE-

ROCK-NOISHS-MLRKAY-COTTONWOOL COUNTIES

Ludwig sogge, Presldent........ Whindon

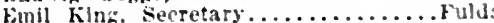

ST. LOLIS-L.JKE-COOK-ITASC. cotitits

Fred. I I'atton, Iresldent........ Inmben bood Taylor, Serret.nry............ STEMISS-UENTON "OLNTIE

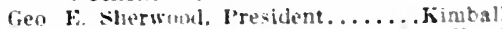
J. C. Buehm, seretirs............ Clom? STELI. 1OLXIT

F. Ertel, l'resulen. ...........Elloneth

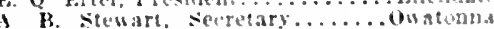
STFERS GOTST

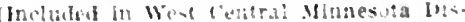
Hot Medical sigetety

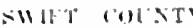

(lucluded in kandlswh-switt countes.) Toln foll

(1meluded in liner Mtsinsint Medical

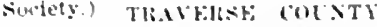

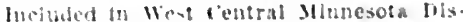

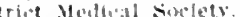

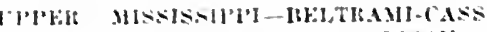

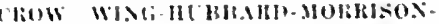

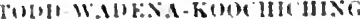
(ilititis

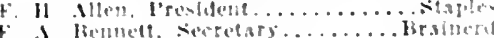
II Mi.

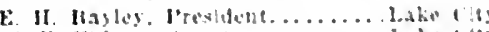

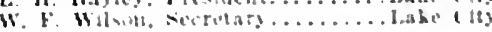

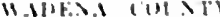

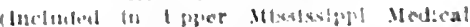
Sicless.) W.Istid cotxty

II di. Mlanohart. Ierevdent........ Waseca

II Itelliche seotetar ....... Janesrllle

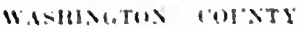

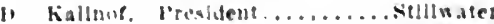

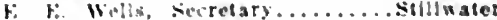

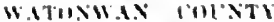

II 11 Itome. It. Irealdent...... st Jame It 11 llagnes. Sectretary.......... Jat. James 


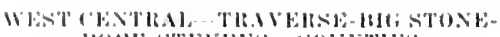

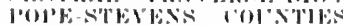

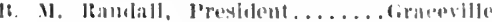

11. Hulburi, secretary...........

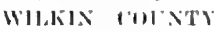

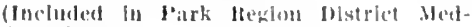
lal sil siclely.)

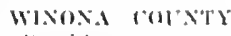

1. 1. I,ynelt, I'reslifent

Whithitil

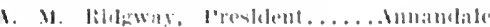

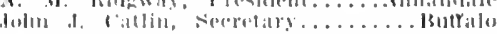

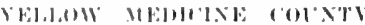

flucluded In camp Irelease bistrict Medixil sinelety.

\section{COUNTY HEALTH OFFIEERS}

risumly

Midiness

Nitkin. H. H. Lemmart. . . . . . . . Nitkis

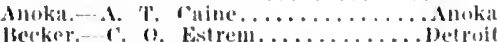

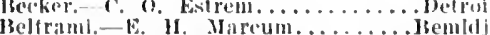

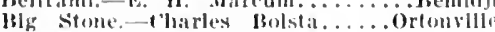

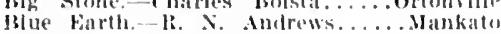

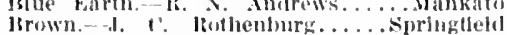

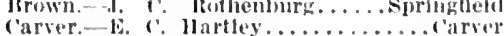

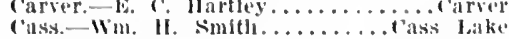

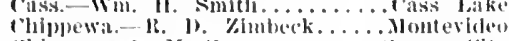

chisago, - . $\mathrm{x}$. dimi......... lenter l'ily

(lay. - i. H. lowe..............titynton

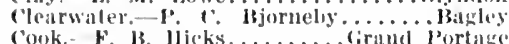

Cook. N. 13. Ilicks. ........ (irmut l'ortige

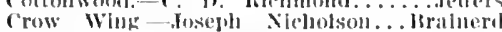

Douglas - C. Je Jecklroth

Faribunit. i. il Broberg........jume Farth

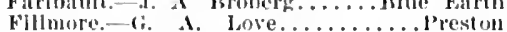

Freehoru-i. A. Nate............. Preston Goodhue, w. II. smith..........thed wing frant.-W. 18. liand.......... bibow lake

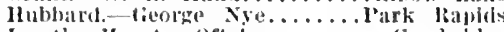
Isitull. - 11. A. Oftei............ ('ambridge

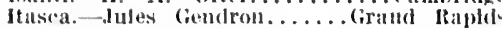
Jackson, - W. t'. l'ortmiam . . . . . . Jacksom Kanabec-C'. J. Bloom..............lloral Kandlyoht -C. Johnson............ Kitfson.-F. Engson.............. IIalloth

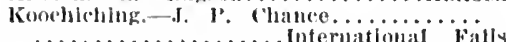

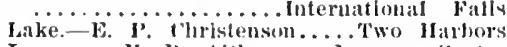
Lesueur.-11. 15. Nitkens.... Lesueur ('enter Lheoln.-Wm. Wakefleld...... Lake Benton Lyoh.-C. (i. Hateon..............Marshal viahomen.-F. M. Arohibald..... I Ihnomen Marshall._. . s. Walfam..........Warren Martin.-y. l. Firrish............sherlurmo Meiseod.E. F. Barrett............. bitencoe Meeker.-J. i. Donowan............ Litehfield

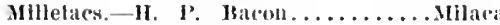
Mower.-A. F. Henslin............ Leroy Murray.-W. F. itlehardson........ slayton Nicollet -1i. $r$. Ierrilt.............. Pet. Per

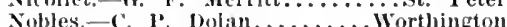
Norman,-1'. s. Vistamet.... . . Shelle Olmsted. A. S. Atams........... itochester ittertail. J. i. Iferthold.......... I'erham Penninpton. - C. Swanson............ He. Hitaire l'ine.-1). W. fowan........... Sandstont pipestone.-i. I1. Brown......... p'ipestone Polk. II. F. Nelson.............. Crookston

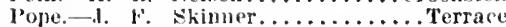
lied Lake.-I. Lemioux.... Red Lake Fults liedwood.-W. A. Jrand.... Redwood Falls Rice.-1. 11. Bollenbach......... Faribault llock-1: 0. Wright............ Lurerne ltosean.-J. I. belmore. . . . . . . . Rosean sherburne.-. f. k. Page........... Eik liver slblex - W z Flower.............. Gibbon st bouis - I J Jurphy ............. Dulut stearns - y J Kern ................... Clous

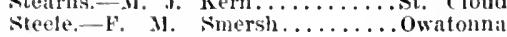
sfevens - H. L. Hulburd.............. Itorri

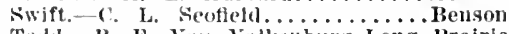
Todel.-B. F. Vatu Valkenburg.Long Prairie Traverse.-F. T. ('antur.........Wheaton

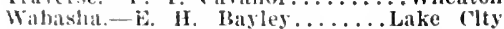
Windenil. - . A. Corse............ Verndale

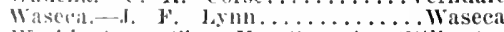
Wishington.-Chas. Van tapjeten.stillwater IVitomwatn.-B. H. If aynes.......... Jt. James Wilkin.- E. W. Iimer........Breckenridge

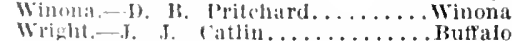

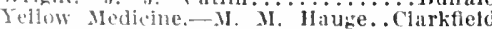

\section{CITY HEALTH OFFICERS}

Allorert lanil

Alistints.

Iustim.

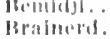

ihluhelus.

1 lompet.

(roukistorl.

louluth.

Eveloth.

Fitribiuli

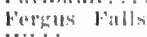

IIbhlug

lalltir Fallis

Mankato...

Illomeilpolic

Niw tim.

Dwatomana.

liacl Wing
linchenter.

sit. Iont.

st. l'anl...

silllwater.

virginia.

winowa...

\section{STATE INSTITUTIONS}

Anoka

Aloka state Asylum, Anoka, Minn, Established 1900; for the dusane; 548 beds; J. H. Frank, physiclan; John Coleman, superintentent.

Faribault

Ilinnesofa sichool for Feeble Mnded and colony for Eplepties, Fartbault, Minn. Fotablished 1879; publle; nerrous and mental; 1.500 beds; A. C. Rogers, medieal superintendent.

Minnesota Schoot for the Deaf, Faribault, Minn. Establlshed [863; jublic; 20 beds; $1 \%$. 11. Ikobllliard, medical officer J. $\mathbf{N}$. Tile, superintenctent.

Nehool for the Blind, Farlbault, Minn. Fstablished 1866; Frederick U. Davis, medtesl oflcer; J.' J. Dow, superintenctent.

\section{Fergus Falls}

Fergus Falls state IIospital, Fergus Falls, Mim. Established 1890 ; for the insane; 1,600 beds; George o. Welcli, medical superintendent.

\section{Hastings}

IIastings State Asylum, IInstings, Minn Established 1900 ; for the insane; 700 heds: A. M. Atsit, physlelan; W. J. Yan\%, sujerintendent.

\section{Minneapolis}

Miunesota Soldiery' IIome, Minnehaha Falls, Minneapolls. Establlslicd 1887 ; for disabled rolunteer soldiers: 90 bed's in hosjuital department. O. S. l'ine, (St. raul), physlcian in charge.

\section{Owatenna}

State School for Dependent and Neglected Children, Owatomna, Minn. Established 1886; public; educational; 36 beds. J. H. Adair, attending physleian; G. A. Merrill, superintendent.

\section{Red Wing}

Minnesota State Training School, Red Why, Iinn. Established 1868; 400 beds C. O. Merica, superintendent.

Rochester

Rochester State Ilospital, Rochester, Minn. Established 1879; for the Insane: 1.200 becis; Arthur F. Killbourne, physlcian in eharge.

\section{Sauk Center}

Home school for Girls, Sauk Center. Minn. Established 1910 ; general; 10 beds; nie F. Norse, superintendent.

\section{St. Cloud}

Minnesota State Reformatory, St. Cloud, Minn. Established 1889 ; public ; correctional and edueational; 22 beds; E. F. Green, jhysician; C. S. Reed, superlntendent.

\section{St. Paul}

State Sanitarium for Crippled, Indigent and Deformed Children, 1003 Jvy St., St. Paul. Established 1911 ; publie; orthoperlic; 60 beds; A. J. Gillette, surgeon in charge; Marje D. IIoppe, matron.

St. Peter

St. I'eter State Hospltul, St. Peter, Minn. Establlshed 18150; for the insane; 1.200 bets; lkwert .I. I'helps, medleal superintenclent.

\section{State Sanatorium}

Mimesola Sinnatorim for Consumptlves, State sanatorlum, Minn. Jistabtished 1907 ; pullle; luberiulosls; 110 beds; Geo. W. Beach, medical sujerintenclent.

\section{Stillwater}

Mimesola State Irrison Hospltal, Stillwat(r, Mlun. Estublished 1850; general; 30 beds; $(\mathrm{i} . \mathrm{A}$. Xewnan, superintendent and physlcian in charge.

\section{Willmar}

State Ifospital for Inebriates, Willmar, Minn Lintablislipl I\$I2; publte; narcotic and alcohollc cases: sti beds: Geo. iI. Freenal, N.J., acting superintendent.

\section{HOSPITALS, SANATORIUMS AND CHAR- ITABLE INSTITUTIONS}

\section{Albert Lea}

IIty and County Hospltal, Alhert Len, Minn. Wstablished 1905; public; 12 beds; J. F. Griffin, secretary board of truslees. City and County Hospltal Association, Albert Leat Minn. Established 1912: public: 35 beds; Ludwig Kenper, presldent board of direetors.

Naeve Ilospital, Albert Lea, Mlnn.

Alexandria

St. Luke's IIospltal, Alexandria, Mlun. Miss E. Bach, R.X., superintendent.

\section{Anoka}

Ir. Kline's Sanatorlum, Anoka, Mtnn.

Fstabllshed 1903 ; private ; 32 beds; Janies F. Kline, medieal superintendent.

\section{Aurora}

Lenont Hospltal, Aurora, Minn. Established 1906 ; 20 beds; JR. l'. I'earsall, medfeal superintendent.

Austin

St. Olof IIospital, Austln, Minn. Established 1896 ; public; 26 beds; Seymour Jolinson, superintendent.

\section{Bass Lake}

Cuenca Sanatorlum, Bass Lake, Minn. (Giatstone P.o.). Estiblished 1909; private; tubereulosls ; 20 beds : H. Longstreet Taylor, (st. ['aul), medical direetor: Mlss olive Itosenhaug, superintendent; under the management of the city and county board of control.

\section{Baudette}

Northern Minnesota Hospltal Assoclation, Haudelte, Minn. Established 1910; 10 beds; $B$. F. Osburn, physiclan in charge.

\section{Bellenlaine}

IIome for the Orphans and Aged, Belleplaine, Mlnn. Establlshed 1898; prlvate; 30 beds: C. F. Koek, superintendent.

\section{Eemidji}

Samaritan IIospital, Bemidjt, Minu. Established 1911; Keneral; 20 beds; Mrs. Smith, superintendent.

St. Authony's Hospltal, Bemidjl, Minn. Established 1898; private; 125 beds ; Sisters in charge.

\section{Benson}

Benson Hosnital, Benson, Minn. Fitablished 1912; public; general; 20 beds; S. J. Froshaug, physleian In eharge; Lille lenning, superintendent.

Biwabik

Blwabik Hospital, Biwabik, Minn. Established 1892 ; general ; 20 beds; Charles w. Bray, medieal superintendent.

\section{Braham}

Braham IIospital, Braham, Minn. Established 1906 ; private: 9 beds; Charles Swenson, physician in charge.

\section{Brainerd}


st. Jusept!'s Hoxpltal, Hraluerd, MInn.

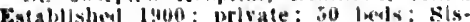
ters in charae.

\section{Breekenrldge}

st. Franils IIospltel, Ireckenrldse. Mini. Fistablisherl 1s!ss; private: sen. eral: 75 bets.

Bubl

Shaw Ilospltal, Bubl. Mlnn. Kistallished 1901: reneral: 20 beds; $A$. W. Sliaw, physiclan In charge

Caledonta

Caledonla Hospltal. Caledoula, Mimn. Fistabllshed 1:402; ceueral: 20 heds: II b. Brownlog, phistelan in chatse: Mry Cora M. Cocliralie, smperinlendent.

\section{Cloguet}

Cloquet Hospltal. CInquet. Minn. Ks tabllshed 1907 ; private : Reneral; :0 beds W. G. Dolan and James Fleming, plignt clans In charge.

\section{Coleralne}

Mining llosplial, Coleralue, MInn, bstabllahed 190s: 8 ineds; X. D. Kran, phystelan In charge.

\section{Croekston}

Bethesda Hospltal, Crookston, Mllnn. Fis tabllshed 1808 ; public: 35 beds; H. Holte attending physictan.

St. Vincent's IIosplial, Crookstou, Mlnn Fstablished 1901; publle; 38 beds; Henedietine Sisters in charge.

\section{Crosby}

Northern Mnnesota Hosplial Association Crosby Minn Estallished 1410; 50 beds: T. H. Monohan, physiclan in clurue Sewall aud McCoy Hospltal, Crosby Minn. Established 1910: prlvate: for mine employees: 15 beds; 11. J. Sewall. physlclan In charce.

\section{Duluth}

Bethel Rescue Home, Duluth, Mlun. Hstabllshed 1902; mulerilty cases; 30 beds: Jessite E. Mauck, superintendent.

Chlldren's Ifome, Duluth, Mlinn. EstabIIstied $188{ }^{-}$; 75 beds: Chlldren's Hone Soistied In char ilss Anna MacGregor. clety In cha

City Isolation Hospltal, Hice Hake Rd. Duluth, Minn. For small-pox cases only: 40 beds; I. J. Mlurphy, physlcian II charge.

Municipal Hospltal Contagious lavillon. $1331 \mathrm{~W}, 3 \mathrm{~d}$. Establisi w. 3d si.. Diluth, Minn. Establlshed 1909: to leds; Imogene harris, tendent.

Bt. Iouls County Almshonse Hospltal and Tubereulosis Sanaforluni, Hice lake Rd., Dulnth, Minn. Establlshed 1910 ; gen eral and tuberculosls: 201 beds: $C ., J$. Woolway, physlclan in charge.

St. Luke's Hospltal, Iuluth, Minn. Established 1879; ceneral: 100 heds; Frances K. Sinith, K.N., superintendent

St. Mary's Hospltal, Duluth, Minu. Fstabllshed 1888; 20t) beds; Benedictlne Kisters In charge.

\section{Eloin}

bigin Iospltal, Elgln, Minn. Fistublished $1897^{\prime}$; private; 1 beds; $W$. T. Adamts, medlEly

Shipman Hospital, Faly, Minn. Ksublished 1843; general; 30 lieds: Cinurke T. Ayery and owen II, Jarker, physiclatis in eharge.

\section{Eveleth}

Fablola Ilempltal, Fveleth, Minn, Ex tablished isag: for emplinces of the lintel states sicel Corporatlon; 25 bedk: W. F. Harwind, physlelau In charse.

More Hospltal, Fiveleth, Mlint. Fistal. lished 1845: Heoceral; for employees of 111, Fulsed states sterel forporatlon. Llepubll. iron strel to.e ind l'lekands, Mather t Co.; to beds: $C$. II. More, phystelun in charte.

\section{Faribault}

Erangrlical beaconoss llome and Ilospi. tal, Fartbault, Minn. Fintublislied 1 !nis: public: t: beds; ller. Win. Meyer, sujerintenclent.

\section{Fergus Falls}

Cicorge is. Wright Memorlal llaspltal, perkus ralls lliun Fitulifishel $140 \mathrm{~s}$ coneral: 3i: inds: ". 1. Jetkins, H.S. superintentent.

SI Luke's liexpisal, fiergus Falls. Minn

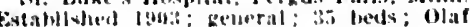
T. slierbing. surgeon.

\section{Fosston}

Fossten Iosplat, Fosion, Minn. Fis alblshed 1900: private: 10 beds: B. Turnhull, phystelan in cliario.

\section{Frazeo}

Frazee Ifospleal, Frazes, Mlano. FistubUlsher 1947: prlsate: Leneral: 12 bits: k. It. Hartoll, physlolitu lu ilaarge.

\section{Ft. Snelling}

loust Hospleal, He. Suelling, Mnn. Es talulshed 1813: generat: privite: 100 berls: Iteut. Col. Allen II. Simith, superIntendent.

Gaylord

(iaslord Hospltal, taylort, Misu, Fis tablished 1902; geveral; I: beds; $11 . X$ Jones, physlctan in clatrge.

Glencoe

Meleed County Inospital, Cleneoe, Mnn. Fitiblished Iols ; privale: It beds: F. r: karrett, physlclan in charge.

\section{Glenwood}

(jletuwood Iluspltal, Glenwool, Mlun. Established 1912: prirnte; surglcal; 10 leels; J. K. Filsey and $F$. A. Eberlin, surgeons; lura loh!, superintendent.

\section{Grand Rapids}

St. Henedict's Iospltal, Grand Raplets Minn. Fistablished 1898 ; publle; 75 beds Belledlet ne sisters, in charge.

\section{Hastings}

IIaselngs Sanltarlum, IIastlues, MInn. Established 1908; private: 15 beds ; $A$. II Alsit, physician lu charge.

\section{Heron Lake}

Southwessern Minnesotn Ifospital. IIeron lake, Mlun. Eatabllshed 1903: prlvate Ceneral: 50 beds: A. J. lloe and A. (: illullurn, phystelans in charge; Famble Iroe. IB..., superintendent.

\section{Hibbing}

Alams Ilospltal, Hlbblng, Mlnn. EstabIlsliel j!no: general; if beds; 13. s. Mlams. physiclan in charge.

llbbing Detention Hospltal. Hibbiug. Mimu. Fstabllstied 1910; for contaglous diseases; 20 beds; Hoard of Healti bi "harpe: $c$. F. Morsman, medtical superintendent.

lind Ifospltal, Mlbhing. Mlun. Fstabllslied 1896: At beds: S. S. Blacklock whysiclun In charge.

\section{international Falls}

Northern Minnesuta Josplind Associaflon, Intermatloual ralls, Mllun. BstahIlshel 19l1: 60 heds: IR. II. Momaluan. phrslofan in charge.

it Jumes llowpleal Internallomal ralls. IIIIs. Extalllsherl 1913; public: general it linds.

\section{Jackson}

sintluern Ifmuesuta llospltal, Jackson.

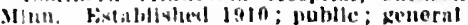

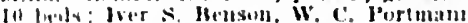
and I). i. Maltiand, physlelans In charge. Kiester

Ior Irutal Ifospifal, Klester, Minu, Kis

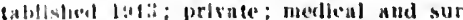

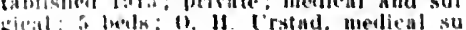
inerintelulent.

Lake Park

latk" lark (trphans' Home, Lake l'ark.

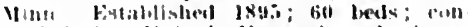
trulled ho luted voruoglan Lutheran there h: lier J. H. Jahren, superintendent

Litchneld

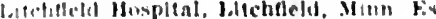

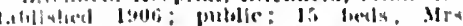

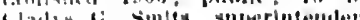

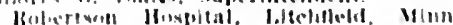

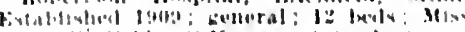
Vial t: I'rhle, li X.. superintemlent.

Little Falls

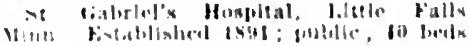

\section{Long Prairie}

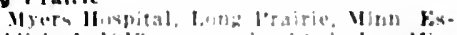

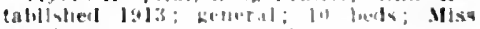

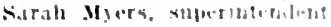

\section{Luverne}

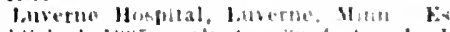

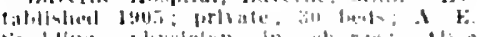

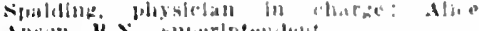

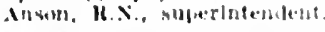

\section{Madison}

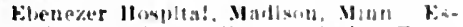

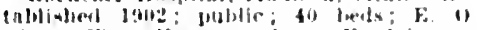

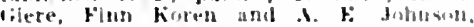

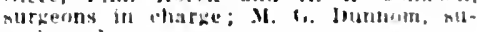
per!ntentent.

\section{Mankato}

Iumatiuel Hespltal, Mankato, Mlan. Foxtabliwhed 190is: publis: : : beds; Exantell. cal lutheran churell in charde: Amalia

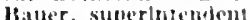

Uuarantine Hospital, Mankato, Minu.

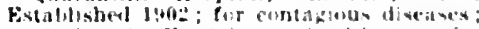

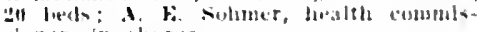
sioner. in aharge.

St Joseph's llespltal. Mankate. Mimm. Establlshed 1s:ti: publie; Joll beds: Sis. ters of the sorrowful Mnther In charge. fallished 1904; privite; 12 beds.

\section{Marshall}

Ciray's Hospital. Marshall, Minu. Fistablished 1!n!: private: :" heds; Frank

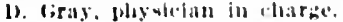

\section{Mckinley}

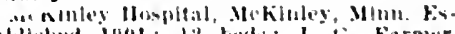

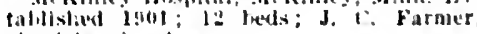
physician in charte.

\section{Minneapolis}

Ablott Hospital, 1717, Ist Mle., soutl Mlunteapolis. Established 1sy: public general: 30 leds; Dums W. Alsbent. physiclan lu cluarge; Miss s. k. Ifolnes, sujerinfondent.

Asluery Hospleal, ath st. and ath Are. Ilmmeapolls. Established 1s:92: Juble

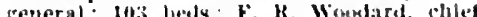
of melleal staff: Mrs. Sarah II. Kinghe. supurinfumient.

Hethany Home, 3al! Itryant Are.s. Minienpolis. Estallished 1475; publle for women and chilitren: it benls; Miss Marian lacs, superintendent.

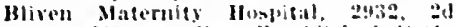

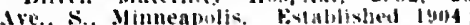
maternlty; 10 berls; dilile $k$, Jiliven. phystelall in clatre.

Cody Jispltal, eton Flliott Ire. Mluneapolls. Fistalished 18:4:; prisate: l: luds; maternity; Mrs. Cixly, superintemel-

Bltel Hospltal. Willow and $W$, 14 th sts.

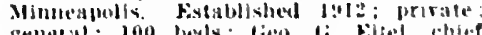
genelal: 100 herls: liew. 1:. kitel. rhief atrmeon; Mlso Mary denunette bramer. 11. Fenperimendeus.

Florenee crittempon Home 2014, stith

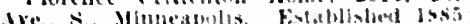
irlvite: 1: londs: Miss Jeambete A. Witox. siljerintendent.

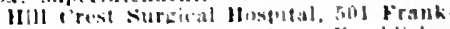

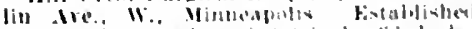

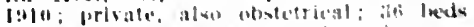
Mertla Milliek. It ... suberinsendient.

llume fur thildren and .tred Nitusu.

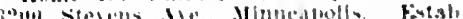
llshed losl: Helleral: 18b hels: Mrs, Mar

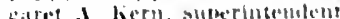

II Por en

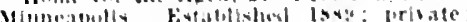

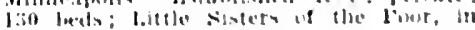
clatistion 


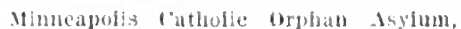
4tith st aul ('hicago dro. linmeibolis. Evtabisat isso. prite. for lus berls; sisters of st. Juseph in whise John liarber, physician.

Minneapofis Clty Hospital, ith Are. and Eth $x$ t., Minneapolis. Established issi:

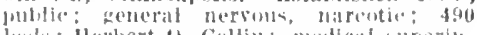
leets: llerbert 11. Collins, medlcil surerinterifent.

Minneapolls simitarium fith Ellowt

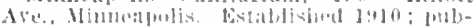
Ile; alcolulic and drur aldictions and mon-eontaglons discasts; 20 bedis; J. J.

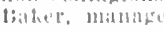

Nortlwestern liwspital atiza chleago pren Mmberic and foancto firistiansun, R.X.. suberintendchet.

Vurwerian Liblieran Deaeoness lfoms and IIospital, joth tre s and "ot s st. Minneapolis. Hotallished isss; general; 30 heds.

Quarantine IIospltal. Manhattan I'k.

Mlnmeapolis. Fstablisined $1900 ; 100$ beds:

I' M. IIall, physteian in charge.

Jer IInspital, 2527, "d Are., S., Minne-

apolis. Fotablislied Is!n; private; 25

beds 11 B. Sweotser. II. II. Jones, J.

W. Bell and W. A domes, medical stafp

llssi beja ofoumed, superintemdent.

IR. F. Ciondwin Company šnitarium, 112

Inlversity Are., Minneapolis. Estabilis?lied

1606: private; 10 beris; 16. F. Goodwin,

physician in charge.

satration Army Industrial liome, 51

Merriam st., Minneapolis. 50 beds; Major

Arthur l"iss in charge.

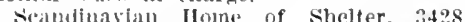

Oakland Are., Minneapolis. Established

$1907 ; A$. E. Hedback, pliysician in charge;

Mrs. Mathilda Neison, matron.

Sheltering Arm Orphan Home, kiverside,

Minneapolis. Established 1883; private:

general; 70 beds; H. M. IIall, physiclan

in charge; Miss E. K. Tings, superintendent.

South Side Sanitarium, 2429, 2\%th Are.,

S., Minneapolis Established $188 \pi$. prirate $; 20$ beds; $w$. A. Jones, physician in charge; $k$. I. Lemcke, superintendent.

st. Indrew's llospital of the German Istheran (hurch, iI2, 5th st., Minneapolis. Estalifishel 1911 ; private ; general; 35 bedis; Henry IIartwig, superintendent. St. Barnabas Hospital, 90I S. 6th St., Ilinneapolis. Established 1871; private and public; 150

superintendent. St. Mary's Hospital, 2500 S. fitl St.,
Minneapolis. Established 185i; public; generaf; 100 beds; Sisters of St. Joseph, iu charge.

Swedlish IIospital, 10 th $A$ re, and 8 th St., S., Minneapolis. Established 1898; pubiic; general; 130 beds; G. W. Olson, superintendent.

Thomas Hospital, 24th Are, and 6th St S., Minneapolis, Estabished 1908; prirate; for tuberculosis cases; 50 beds.

University IIospital (Univ, of Minn.) Essex and Union Sts., S.E., Minneapolis. Established 1909; public; general; 136 beds: 1. B. Baldwin, medical superintendent.

Washburn Memorial Orphan Asylum, Nicolfet Ire, and 49th St. MIinneapolis.

Established 1883; private: i20 beds: C.

Faulkner, superintendent.

\section{Montevideo}

Monterideo IIospital, Montevideo, Minn.

Established 1910. ceneral - 30 beds: Miss

L. I. Hebson, superintendent.

\section{Montrose}

Montrose Hospital, Montrose, Minn. Es-

tablished 1904; prirate: suroical. 15

beds; E. P. Hawkins, physician in charge. Moorhead

Northwestern Hospital, Noorhead, Ninn. Fstablished 1908; public: 60 beds; Julius :Johuson, superintendent: Nortliwestern IIospital Association in charge.

Moose Lake

Prirate Hospital, Moose Lake, Minn. Established 1909; 10 beds; Franklin Walters, physician in charge.
Mora

Mora llospltal, Mora, Minn. Establlshed (105: zraneral. 10 beds: E stansberry Velson, in cllarge.

Mountain Lake

Ibethel Ireaconess IIospltal, Mountain Iake, Minn. Established 1912; gencral: 10 beds.

Nashwauk

Nasflwauk llospilal, Nasilwauk, Minn. Estalifished 1!92; minlng hospltal; gen-

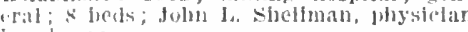
in charge.

New London

sumnyitic JIospital, New London, Minn

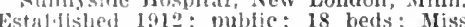
Aluat lidsile. sujerintendent.

New Uim

Loretto liospital, New IIn, Minn. Esthlishod 18\$4; private; general; 38 heds (b. C. Strickler, physician in cliarge.

Northfield

Nurtifleld Hospitai Assoclation, Northlicid, Ninn. Estabilshed 1910; public feneral; 1: beds; Warren Wilson, M.I. secretary; Miss lidna Makinson, superintenderit.

Ortonvilie

Girund View Hospital, Ortonville, Minm. Established 1906; pricate; general; 25 bets; 13. 16. Karn and Chas. Bolsta, physi chans in cirarge; Miss Josephine F. Bolsta. supcrintendent.

Owatonna Owatonna City IJuspital, Owatonua
Minn. Established 1900 ; public; 20 beds board of directors in charge; ilinnie $D$. khode, superintendent.

Park Rapids

Fark Sanitarlum, Park Raplds, Minn Established 1903; private; 24 beds; Mrs. W. T. Stone, superintendent.

\section{Paynesville}

Paynesville Hospital, Paynesville, Minn. Established 1897; private; general; 24 beds; 1 '. C. I'ilon, physician in charge.

\section{Peliean Rapids}

Dr. Boysen's Hospital, Pellcan Itapids IInn. Established 1900; general; 1 beds; Miss Amna Madsen, superintendent. l'elican Rapids Hospital, Pelican Rapids, Minn. Establlshed 1909; general: '10 beds; W. L. Burnap, medical superintendent.

\section{Perham}

St. James' Hospital, Perinam, Minu. Established $1902 \cdot 34$ beds; Frank J. Brabec physician in charge.

\section{Pokegama}

Pokegama Sanatorium, Pokegama, Mnn Established 1905; private; tuberculosis; 60 beds; W. H. Watterson, M.D., superintendent.

\section{Princeton}

Northwestern Hospital, Princeton, Minn. Established 1900; private; general, nervous and mental; 25 beds; H. C. Cooney physician in charge; Mrs. Frances S Cooney, superintendent.

\section{Red Wing}

Red Wing City Hospital, Red Wing,

Vinn. Established 1891; public: 30 beds:

Bertha S. Johnson, R.N., superintendent St. John's Hospital, Red Wing, Minn., Established 1903; public; general; 50 beds; 1. E. Claydon, M. H. Cremer and A. E. Johnson, physicians in charge.

\section{Rochester}

St. Mary's Hospital, Rochester, Minn. Established 1859; public; surglcal only 320 beds; $W . J$. Mayo, C. H. Mayo, E. S Judd, E. H. Beckman, D. C. Baifour and II. S. Henderson, surgical staff.

\section{Roseau}

Roseau Hospital, Roseau, Minn. Established 1907; private : general; 6 beds

Frank L. Norin, physician in charge.

Soudan

Soudan Hospital, Soudan, Minn. Established $1885 ; 15$ beds; R. L. Burns, phrsician in charge.

\section{South Haven}

Weum Hospital, South Haven, Minn. Established 1913; private; surgical and medical; 12 beds; T. W. Weum, physician in charge.

\section{Springfield}

St. John's Desteouess Hospital, Sprinz fleld, Minn. Establisted I901 : puthle: beds; Rev, (jco. Aplel, president of board; J. (: Itothenberg, chief jhysician.

\section{St. Cloud}

St. Iraphael's Ilospltal, St. Cloud, Minn. Establisiled 1859; general; 8f beds; Sisters of st. Benedict in charie.

St. James

St. James IIospital and Sinuitarium, st. James, llinn. Established 1910; private general, mental and nervous diseases; 40 beds; W. II. liowe, Jr., physiclan in cluarge.

St. Paul

Bethany IIome, $: 34$, 8ti St., St. Panl First Swedisil Lutheran Chureil in charre. IBethesda IIuspitah, 249 E. 9th st., St Paut. Establisiled 1850; publlc; 130 beds; Hev. C. A. Hultkrans, superintendent. Church Homo of Minnesota, 587 Fuiler Are., St. Paul. Established 1895 private; for aged women; 13 beds; Louis Renepe, physician in charge.

City and County Hospitai, Jefferson Ave. and Colburn St. St. Paul. Established 18:1; public, Keneral; 600 beds; Arthur 15. Aucker, sujerintendent, filysician and urteon in charge.

City and County Sanatorium, Lake Awasso, St. Paul. Established 1911 public; tuberculosis; 22 beds; Arthur B. Ancker, superintendent.

Cobb Ilospltal, 2056 Inglehart Are., St. Pauí. Established 1902; private; general 30 beds; Sheridan G. Cobb, chief of medical staft; Miss L. H. Kelier, R.N. superintendent

Dale Street Infirmary, St. Paul. Pubic small pox; 72 beds; Clayton $S$. Stewart, superintendent.

IIone tor Aged and Infirm Poor, 90 Wiikin St., St. Paul. Prlvate; Little Sisters of the Poor, in charge.

IIome for the Friendless, 469 Collins st. St. Paul. Established 1867; private; Mrs. II. J. Kielly, matron.

House of the Good Shepherd, Blair and Miiton Sts., St. Paul, Established 1868 . prlvate; reformatory; Sisters of the Good shepherd in charge; C. B. Teisberg. medical superlntendent.

Jewish Home for the Aged, 75 Wilkin St., St. Paul. Established 1907; private; 20 beds; B. Risach, superintendent.

Midway General Hospital, 389 Snelling Ave., St. Paul. Established 1912; private: general; 20 beds; Fredk. E. Leavitt, nsedical superintendent.

llounds Park Sanitarium, Earl and Thorn Sts. St. Paul. Established 1895: general; 85 beds; Berth Morris, superintendent.

Nugent Sanitarium, 144 Bates Are., St. Paul. Established 1900 ; private; 50 beds; J. M. Nugent, superintendent.

Protestant Orphan Asylum, 670 Marshail Ave., St. Paul. Established 1865 ; private; 50 beds; Miss Hannah M. Weinzierl. superintendent.

Salvation Army Eisinger Hospital, Langford and Pascal Sts., St. Paul. Established 1898; public; maternity: 40 beds: Jeunette M. McLaren, M.W., superintendent.

St. Joseph's German Catholic Orphan Asyium. Randolph. St., St. Paul. Estabiisined $187 \%$; public; 140 beds.

'St. Joseph's Hospital, 9th and Exchange Sts., St. Paul. Established 1853. prlvate; general; 145 beds; Sisters of St. Joseph in charge.

St. Luke's Hospital of St. Paul, Smith and Sherman Sts., St. Paul. Established 1873 ; prirate; general; 100 beds; Elizabeth Smith, R.N., superintendent

St. Paul Catholic Orphan Asylum, 933 Carroll St., St. Paul. Established 1860; 
st. Peter

Harlow Hospital, $500^{\circ} \mathrm{s}$ tith st. St. Peter. Minn. Fatabllshed $191 \%$; general 16 beds: Mlss Alma M. Mctirath, super intendent.

Starbuck

Mlunewaska Hospltal. Siartuck, Minn Evtablished 190I; prirato: 12 trels: Miss Carolyn Flaten, superintendent.

Stillwater

Srlllwater city IInsplenl, 1007 firecley St., stillwater, Mun. Fistahlihed 1880 prisate: general; 25 beds: Mrs. Marrict G. Knapj, K.X.. superintendent.

Tower

Vermllion Iake Industrlal Schnot for Chippewa Indiaus, Tower, Minn. Fistith lished 1S9s; government; 125 beds: Otis o. Henson, pbysiclan In charge.

Two Harbors

Budd Hospltal, Two Harbors, Minn. E.ytablishel 1595: private: 40 beds: tablister 1s9o: private:

Two Ilarbors Ilosplat, Two liarburs. Minn. Fistablished 1899: prlvale; Lineral: 14 beds: l'aul s. Wagner. plystclat In charge.

Vasa

Vasa Orphans' Hone, Vasa, Mlnn. Jublle: to beds: 0 . C. Herbert, superluten dent.

Virginia

Lemont IIospital, Virginia, MInn. Ks tabllshed 1901; 30 beds; Charles It

Lenont, medical superin'zndent.

MeIntyre Hospltal. VIrginla, MInn. Es. tabllshed 191:- private: general: berls: E. H. McIntyre, surgeon: Allce II Folter. superiutendent.
Virglnla Hnspital, Vlrglula, Minn. Ea tablistied 184.3: 25 beds: C. W. Miller physlelan in charge.

\section{Wabash}

Wabasha Concy Infrmary. Wabasha Mimn. loublle: I lieds In hospital department; + luels in tutuerculnals department E. H. Hayley. (1.akn 1 lis), county physt clan, In charkin.

Nt. Bllzaheth's Itwpital. Wratas Minn Established 189s; bullik::35 beds; slsters of the Snrrowful Mother in clare.

St. Joseph's Orjhanare. Walsasha, Minn Fstablished 1905: prlvale: 75 beds: Slsters of the Surrowful Mrither in charge.

Walker

Walker Hospilal sanaturia, Walker Minn. Fstabljshed 1900: Eeveral: 35 beds: Frapk I. Wilcos, phrsicsan in charge.

warren

Wrren Hospital, Warren, Minn. Eq. tablished 1906: public: 40 beds: Theodore Itratrud, physician in charge.

Watertown

Cottage Ilospital, Waterlown. Minn. Hstablished 1906; prirate: 10 beds; Ilarry A. Halgren, physlcian; Fisle Belden If almren. superintendent.

\section{West Duluth}

Duluth Iospital, West Duluth. Minn. Established 1905; General; 20 beds: I Graban, (Dulutil). physlclan: Merle Wrlght, R.N., superintendent.

Nopeming Sanatorium, West Duluth, Minn. R.F.D. Establlshed 1912 Dublic tuberculosis; 50 beds; Arthur $\dot{T}$. Laird. (Duiutb). physiclan in charge.
White Bear Lake

liva Shapie Vemolal Camp ing I'redis. prosed and Anacenle i hiliren white bear

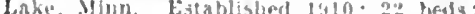

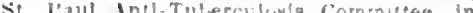
charse: li. lovino subertutentin? lake shore saniarium. White bear Iake. Minn. Hecsin Medlcased vus

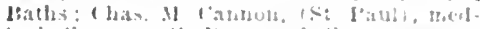

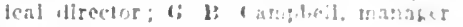

Wilmar

Rethesda llone. Wilma: Minn Lutat lished Ja05: Jeirate: to beds: Mlss Jommle rlson, superiritenders.

Wilmar Ilespital, Wlmar, Mna Lutablisherf 190\%: privale: general: 12 berls: B. J. Itranton, nhysician in charge. Windom

liuve Hosfltat, WInlom, Minn. Fistablisbed 1906; sublic: 12 heds: 1. sogge, M.ll. superintondent; MPs. A. Muso, malrun.

Winona

Winona General Hrobsial. Wincona, Minn. Fatablished 1991; public: cejeral:

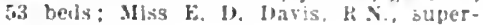
Intendent.

\section{Worthington}

City Hospital, Worthingtin, litan. Estitbllshed Isne: prirate: 15 tods; Mlss llebeca Berentsen, superintendent.

Worthington II ospltal. Worthington, MInn. Established 1906: private; genera!; 10 beds; F. M. Manson, physiclan in charge.

\section{Young America}

Carrer County llospilal, Young Amerlea. Minu. Established 1903; public; 25 beds.

\section{PHYSICIANS OF MINNESOTA}

Ihyslelans in the Indian servlce und offcers in tho gorermment medical serrices are exempl from licenie reguirements.

KEY TO ABBREVIATIONS, SYMBOLS, ETC.

Names in capitals slgnify membership In the County Soclety and State Associa tlon. (DOE, JOHI).

- Indicates Fellowshlp in the American Med. Assn. (DOE, JOHNA)

(b'5) Year of biril.

medic.

H. homeopath; E, eclectle; P-II, physioYd. 09 . College, and year of graduation

- Information recelred loes not show grad uation.

S.-Surgeon.

Ob.-Obstetriclan.

ObG.-Obstetriclan, Gynecologist.

G.-Gynecologist.

or.-Orthopedist

Pr.-Proctologlst.

Op.-Opbthalmologist.

AR.-Iaryngologist, Rhinologlst.

LR.-Isaryngologist, Rhinologlst.

(1's9) Year of llicense.

(b) In practice before passage of present law and llcensed by tiling diptoma or by lears of Practice.

(It) Ilcensed hut year not known.

(\$) Information received does not show license.

- Inited States Amng.

M.R.C.. U.S.A., Medical Keserve Corps.

\section{SPECIALTIES ARE INDICATED AS FOLLOWS:}

ALR.-Aurlst, Laryngologist, Rhlnologist.

OALR.-Ophthalmologist, Aurlst, Laryngol. ogist, Ithlnologist.

U.-C'rologlst

D.--Dermatologtst.

Pd.-Pediatrist.

N.-Neurologlst.

P. - l'syehlatrlst.
L.s.X. Inlted States Nary

I.H. I'. I.X., Medical kecerve corps.

L.s.l.H.S., Cinled States rublle Health Servlce.

College positions held are Indicated by abbrevialed titlo of position. followed by key number of college. For key to colleges see inside front corer page.

(A1,3, 36, (A) Membernip in speclal siocleties. Tee Key Table, page 122.)

NP.-Neurologist, Psychiatrist.

1.-Iniernlst.

T.-Tuberculotheranlst

Anes.-Anesthetlst.

LD.-Laboratory Niaguostician

R-Actinologlst Isdlologlst. Iloene Litst

Path.-I'atholorist.

Bact. - Bacteriologlst. THE PHYSICIAN CLAIMS HIS PRACTICE IS LIMITED TO THAT PARTICULAR BRANCH OF MEDICINE: WITHOUT THE ASTERISK. THAT HE IS ESPECIALLY INTERESTED IN, BUT DOES NOT LIMIT HIS PRACTICE TO. THAT BRANCH. THIS INFORMATION CONCERNING SPECIALTY IS BASED ON PERSONAL DATA FURNISHED BY THE PHYSICIAN AND IS NOT VERIFIABLE.

\section{MINNESOTA}

ADA, 1.432, NORMAN

Holmes, Walter It.-Minn.4:94; $(1 * 9)$

satersmoen, Theolor (b'sl)-MInnt. 10

Sholland, John T. (b'72)-Minn.5:00

$(106): S$.

ADAMS, 576, MOWER

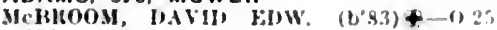
o: : (108).

ADRIAN, I,II2, NOBLES

EATUN, WM. HAMMONH (b;8)-1. $3,0 \pm$ (I13): Nember Ia. Sitate Med soe

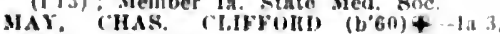
"86: (l's6).

Newril, Thomas (:. (b'58)-Mo.20."60 $(1+96)$ stock. Win. John (L'84)-M10.34.06: (1'13)

GILANAS, MICHAF, $\left(b^{\circ}, 2\right)+-1 a, 1,-8$ $(1, x+1)$

AFTON, 300, WASHINGTON

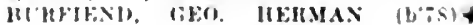

$111.6 .05:$ : (1'06i)

AITKIN, 1,638, AITKIN

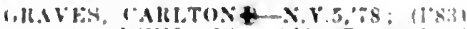

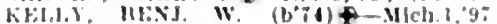

$(10), 8) ; 0 b$

(Nentan $r$ al

II.

(l'nis)

Trithri,

AKELY. 1,635. HUBBARD

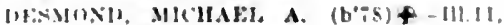
, in: (lo 03$)$.

Inrai, (ieo. M.-Mlun.s,03: (L'03)

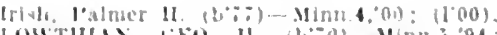
$(1.86): S$.

ALBANY, 657. STEARNS

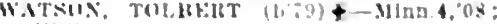

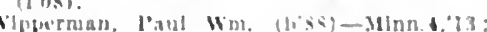
(1.13)

ALBERT LEA, 6.192, FREEBORN

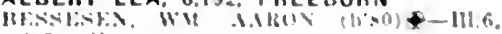

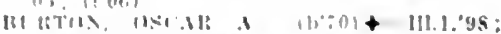
(100); not in practice: (tarasola. Ha.). M.1111:2. Fli.t.h W. (b"i)+-111.1.07:

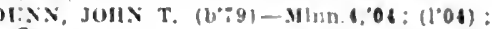
s.

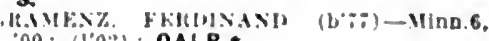
00 : $\left(l^{\circ}(0)\right):$ OALR.* 


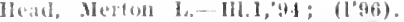

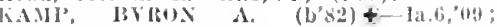
(1'I0)

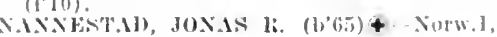

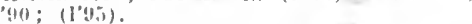

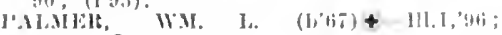

(lombi); S. (1) $(3: 4)$.

RII0I.F, s(1.0.110N F. (b'79)-111.6,05; () : Member state Medi. Sice of Wis.

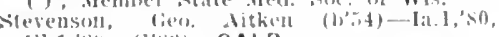
111.1, $S:$ : (I'S2) : OALR.

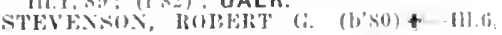
'illi; $(1)^{\prime}(1: 4)$.

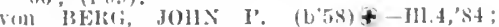
$(1 \times 5)$.

ALDEN, 544, FREEBORN

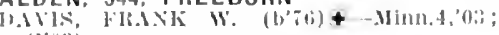
(l'(03)

ALEXANDRIA, 3,001, DOUGLAS

IBU1", JWON MOHEH.LE (L'S3) \&-MUn.4, 'OS: (1'08); OALR, *

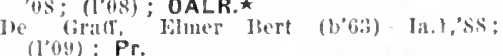
$(1$ oy) ; Pr.

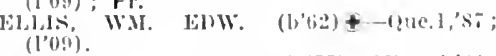

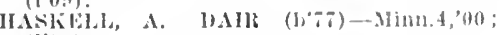
(1'(1)?

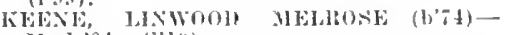
He.1,01; (1'10).

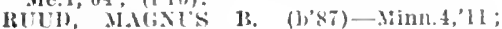
(1'1I).

Sitlerlee, Louis W. (b'5i)-Ill.4, 94 ; (l'bi).

ALTURA, 200, WINDNA.

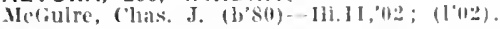

AMBDY, 435, BLUE EARTH

Mlikinl, JAMLS E. (b'6i)\&-IInn,4,

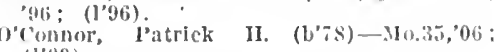
(l'0!).

ANNANDALE, 624, WRIGHT

Norrls, (;eo, H. IItch.1,9s; $\left(10^{\prime} 0\right)$

IHIGWAY, ALFIEL iI, (b'63) - Minn.4, ' 30 ; (1'90); LR.

ANOKA, 3,972, ANOKA

ALHKCH, ALANSON GEO.

(See Minneapolis.)
Addrleh, Flora L..-Minn.3,'87; (l'S5)

Calne, Arthur T. (b'75)-Minn.6,96; (l'02):

ObG.

Frank, Jas. H.-H_-Minn.3,'82, Mo.10,'83; (l'sis)

Gidelings, Aurora W. $\left(b^{\prime} 30\right)-N . Y .3,74$; (1'83); not in practlee.

Kline, lames $\mathrm{r}$. (b'62) H-Ninn.6,'93; (1'44).

Hagaman, fieo, Keteham (b'7)-Mim,4, 0.8; (l'03).

APPLETON, I,221, SWIFT

IALFMAN, WM. CARL, (b'82)\&-kंeb.6. '11; (I'11).

LALLE, BENJ. F-Ill.1, '70; (1'83)

LITTHE, DE WHLISt-Md.3,'83: (1'83).

SIIEIVIR, HENIt JLLIL' (b'84) 4 III.6, 10; (1'11).

ARGYLE, 744, MARSHALL

Belcourl, Onezime Edmond (b'52)-0nt.4,

Beleourl, Onezime Edmond (b'52)-Ont.4,

Biederman, Jacob (b'75)-Minn.4,04; (1'0) 1 ).

IIOIJ.ND, ANGELL SIGHAL'T (b'84)屯IIIm.4, I0; (1'10).

ARLINGTON, 733, SIBLEY

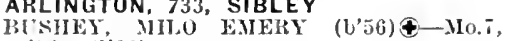

KANNE, (HLIST W.-Mieln.1,00; (l'00).

ASHBY, 334, GRANT

Normann, Olaus A. $\left(b^{\prime} 45\right)-0 ;(5)$. $03 ;(103)$

ASKOV, 100, PINE FENGER, 1'IIMIEI $x .\left(b^{\prime} 62\right) \notin-D e n .1$,'s ;
(l'I3); T.

ATWATER, 600, KANDIYOHI

Anderson, Ludwig W. (b's2)-Mimn.1,'04;

PORTER, OLIVICR M. (b'si)-Minn.4, 05 ; (1.05).

AUDUBON, 300, BECKER

lialvorson, Knute K. (b'55)-Ninn.5,99; ( ).

AURORA, 1.919. SAINT LOUIS

Marrow. Edward (b'-14)-Ill.1,01; (1'02).

I'etlosili, Roht. I'. (b'76)-H1.1,02; (1'10)
AUSTIN, 6.960, MOWER

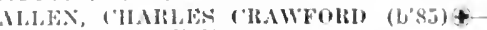
11 lin.1, $10 ;(1,11)$.

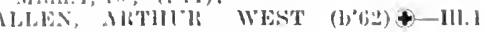
S.5; (I'S5).

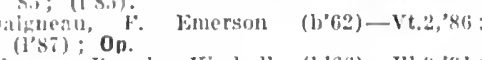

'lester, Fannle Kimball (b'66)-H1.9,'! 111.4.') $3 ;(1,43)$.

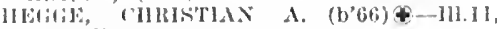
(3): $(1,14)$.

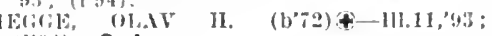
$\left(l^{\prime}: 1\right) ; 0$ D

Inollister, William I. (b'37)--N.Y.3,'(i1;

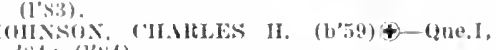
'sit: (l'sif)

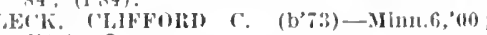
(l'(lii); $\mathrm{S}$.

GWHA, ('HAS. FRLMONT (1,68)-Tenn.5, (0): $\left(l^{\prime} 03\right) ; \mathrm{S}$.

llikenua, Jily ling (b'8s)-Ky.2,'11; (l' [2).

H.Kenna, Wm. 11.- 0 ; (t).

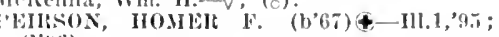
(1'?6).

HEIBMAN, GMOHY ('HESTEIt (1'8.3) B-

llun 09 (1'04) ORANK

AVOCA, 212, MURRAY

Trow, Milton A.-Ja.1, 'f?: (l'84).

BADGER, 395, ROSEAU

larls, Norman C. (b'5ti)-Ia.1,'84; (1'84).

BAGLEY, 801, CLEARWATER

bjornels, I'eter $\left(\therefore \quad\left(b^{\prime}, 0\right)-M i n n .5,97\right.$; (l'98).

BALATON, 364, LYON

GIBIIO, CHARILS (b'72)\&-Minn.4,9.; $(193)$.

WIILIMS, HIGII OWEN (b'83)\&-Wis.3.

'11; (l'I1).

BARNESVILLE, 1.353, CLAY

('yr, Alphonse (b'72)-0ue.3,'97; (l’99)

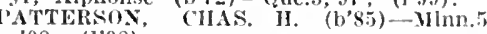
08; (1'08),

THORNBY, IMALIWART) J. (b'82) +-

Mlnn.5,'09; (1'10).

Viekers, Jos. I.-O; (t).

BARNUM, 262, CARLTON

SHANNON, SYLYESTER S. (b'81)-0nt.5, '06; (1'08).

BARRETT, 278, GRANT

IOWLRS, FUETCHET W. (b', 2$) 4$

Mlnn.5, $02 ;(1 ' 02)$

BATTLE LAKE, 567, OTTERTAIL

HALGEN, GILBERT T.4-Minn.4, 05; (1'05).

BAUDETTE, 897, BELTRAMI

Gullmette, Robt. W. H. (b' 79$)$ - Man.1, 0 ; (1'12).

Osburn, Burt F. (b'70)-Minn.5,06 (l'06).

Stuart; Frank JI.-Ky.1,8i; (l'8T).

BEARDSLEY, 481, BIGSTONE

WEIR, JAS. D. (b'64) \&-Ont.3,'96; (1'96).

BECKER, 210, SHERBURNE

Parkinson, Lindley A. (b'62)-0.14,'87;

(l'11).

Young, Eugene W.-Minn.5,'96; (l'96).

BELGRADE, 448, STEARNS

IITTCIINGS, WILIMN SIDNEY (b'S4)\&Minn.4,08; (l'08).

RHPGWAY, ALEXANDER (b'5丂)-Mimn.5, 94; (1'94).

BELLE PLAINE, I,204, SCOTT MOLONEY, GERALD R. (b'49)-N.Y.5,

MOLZAIIX, HEIMIAN EMIL (b’79)\&I. ('.1,08; (I’08)

SNYIER, GEO. WM. (b'87)-Minn.4,'12; (1'12); (F6)

ON BOHHAND, FREDK. JOHN (b'66) $\oplus$ Minn.4,91; (]'91).

BELLINGHAM, 359, LAC QUI PARLE

Swezey, Benj. F. (b'73)-Ia.10,'03; (1'06).

BELVIEW, 290, REDWOOD

Aldrich, Enma L. Scholz (b'74)H-Ill.10, '02: (1'02).

ALDRICH, FREDK. HERRICK $\left(b^{\prime} / 2\right) \oplus-$

Ill.11,'02; $\left(l^{\prime} 02\right) ; S$.
Thoresen, Thore $x . \quad$ (b'61) - Norw.1,'89; (1'97).
BEMIDJI, 5,099, BELTRAMI

Iblakestee, Frank A.-. Nlinn.5,97; (1'97).

(iAllo('K, AlTHLU VARNEY (b'84)

111.6,10: $(1,10)$

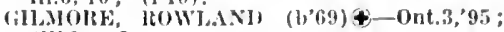
$\left(l^{\prime}(16) ; \mathrm{S}\right.$

Tenderson, A. F.-lI-Hi.4,'8:1; (l'83).

JOIISON, EINEIt WESIEY $(1,82) 4$ IInn.5, $08 ;\left(l^{\prime} 08\right)$.

MAKCUM, EALI, H. (1,78)†-I11.4,03; (l'03) ; S.

OWHLi. CIIAS. IBEITTRAM (b'71)屯-

IInn.4,9.1; (I'94) ; OALR.

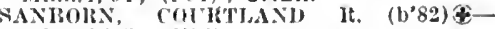

Mlnn.4,07; (l'0 0 i)

Sliannoli, Edwarl A. (b'6I)-Minn.2,'86;

(1'86); Ob.

SMI'tII, HDWIN II. (b'76)థ-Mlun.6,00 (l'00). Warcl. Lewis Amerleus (1,66)-111.4,95;
(l'02).

BENSON, 1,677, SWIFT

DAIGNAULT, OSCAIt (b'75)€-Que.3,98; (l'99)

Froshive, SAxE .T. (b'67)-Ia.9,'95;

JoHNSTON, EDMtNo B.-III.1,89, l'a.2, $9 \%$ : (1'93).

SCOFIELD, CHAS. L. (b'65) $4-\mathrm{In}^{\prime} 3,86$; (1'86).

BERTHA, 296, TODD

Jucas, IJerman L. $\rightarrow$; (

WILI, WM. W. (b'79) \pm -Minn.4,05; (1'06).

BIGELOW, 195, NOBLES

IRNOJ. EIMER WM. (b'82)\&-Neb.5 0i; (1'12).

BIG FORK, I67, ITASCA

Duncan, Thos. Nelson-Mo.34,03; ().

BIRD ISLAND, 931, RENVILLE A] AMS, RAl,II ('BAWE (b'79)-Pa.2,06;

PUFFFR, FRANK LEE (b'52)-X.Y.1,7; (1'83).

BIWABIK, 1,690, ST, LOUIS

BIAY, CHAS. W. (b'68)(-Minn.4,'95;

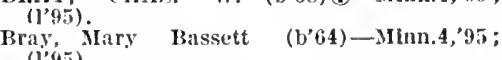

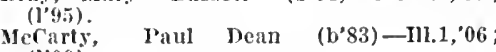
(1'09).

BLACKDUCK, 942, BELTRAMI

KOCH, JOHN C. (b'67)-MIMn.4,02; (l'02).

BLOOMING PRAIRIE, 854, STEELE

Cooley, Edwin W:-Ill.8,87; (l'8T).

DAIIEY, WH. JOHN (b'84) - Minn.5,'11;

(1'I1),

MEI,ISY

THMSEX, $x$, CIALSEN (1)' II) \&-Ia.9, '98; (I'98).

BLUE EARTH, 2,3।9, FARIBAULT

BROBERG, JOIIN A. (b'62)-MIlch.1,'92: $(1,92)$.

PLRTOX, CHAS. N. $\left(b^{\prime} 66\right) \oplus-M i c h .1,{ }^{\prime} 89$; (1'90).

HANBERS, WINSLOW C. (b'77)ellinn.4,'05; (1'05).

Chase, Barbara West (b'48)-0; (1'01).

W'ilson, Clyde Earl (b'85)-IH.11,'12; (l'13).

BOVEY, 1,377, ITASCA

Seguin, Edw. (b'75)-Que.3,'99; (1'00).

BOWLUS, 164, MORRISON

Gumper, Jos. B. (b'81)-Neb.6,09; (1'09).

BOYD, 43I, LAC QUI PARLE

MAITKX, MAITIN IIJRAI , (b'74)€III: 6,'05; (1'09).

BRAHAM, 406, ISANTI

Dedolyh, Theodore Hubert (b'89)-Minn.4 '12; (1'12).

CHARLES $\left(b^{\prime}, 6\right) €-M i n n .5$

'03; (1'03); $\mathbf{S}$.

BRAINERD, 8,526, CROW WING

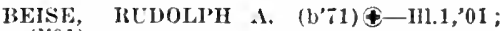
(l'01).

BENXETT, FRANCIS JOS. ADOLPH (b'88)

BERGE, PARKER LLOYD (b'88)-MInn.4, 13; (1'13).

Camp. James L. $\left(b^{\prime} 55\right)-I l 1.1,78$; (1'84).

COURTNEY, WALTER (b'56)థ-Mich.1,

$83 ;\left(l^{\prime} 83\right) ;(\Lambda \bar{i}) ; \mathrm{S} \star \star$

EVERT, JOHX AXDREWS $\left(b^{\prime} 86\right)$-Minn.4

13; (1'13) 
GKOVkS, M.HFHT F. (2.04)+-D.1.79: (1'85): OALR.

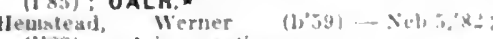
(1'33): not In litactice.

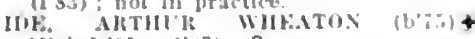

Wich. 1, $05 ; 11^{\circ}(0)$ ) : S.

Jamleson, Farl Fredk. (b'sj)-Masu.f,"ll: $\left(l^{\prime} 12\right):$ ObG.

Nicholusin. Juseph (b\%s) - Minmt. 63 ;

YORDIX, CHAS. GINTAF (b'an)-Mimm.

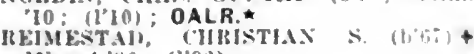

Mlun.4, $96:(196)$.

Sleeman, Hlythe Honky (b'st)-. Mleh 1,'1: Inlern. Northern Hache Hupltal.

ThOHA. FHANK JOS. $(16 \% 6)+111 \%$ 09: (l'09): $\mathrm{S}$.

THABES, JOHN A-Mlnn.t."api (1"atoi); S

Woodward. Arllur 1". (b'51) H- ; ; $\left.j^{*}\right)$.

BRANDON, 276, DOUGLAS

Hrexler, John $C$ it.p. 3.

Мвск 95: (l'95).

BRECKENRIDGE, 1,840, WILKIN

Iammund, Walier Donald $(1, \%+)-111.11$ "06: (1"01); G.

Mcl'eek, James $\left(b^{\circ}, 52\right)-$ la.1, 89 : (z)

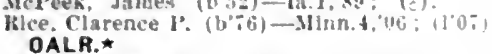

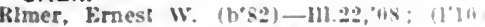

BRICELYN. 352, FARIBAULT

GELLISON, AXUItW $(157+)-111,1,0 \%$ (1'06).

Stewart, Ollver k. $\left(b^{+} i \downarrow\right)-I l l,,^{\prime} 0 \geq ;\left(1^{\circ}(t+i): S\right.$

BROOKS, 325, RED LAKE

Houcher, Frank X.-MInn i, 06 ; $\left(l^{\prime} 0 ;\right)$.

BROOTEN. 562, STEARNS

GLYEK, KICHAH, THKOLORE (b'S3)

MInn.4,02: (l'0,9).

KolskT, CAKI, D. (b'6)£-MInn.5, 0 ; $\left(l^{\prime} 05\right)$.

BROWERVILLE, 633, TODD

GAIf, EIWW. WM. (b's)-111.11,03; $11 \mathrm{t} 4$

Murphy, Martin 1. (b'5s)-Ind.26, $y^{\prime 2} ;$ (

BROWNTON, 509. MOLEOD

MACKEL, EWMLNI LAWILEXCF: (b": + - MInn.t,"0t; (1"04).

BROWN VALLEY, 1.058, TRAVERSE

FOGARTY, CHAS. $W+$-MInn.t. 03: (1'98).

Harcum, Theo.-H-IIL. A, si : (

Hayes, Fiward Win. (b's)-Ilum., l: (1'13).

Hayes, James Martin (b'so)-MHul, II (I'I1).

BRUNO, 229, PINE

13all, Francis M. (1) $3(t)-0$; (3)

Greene, Frank W. (bo53)-Minn.: $x_{0}$ (l'si).

BUCKMAN (R.F.D., ROYALTON), 137 , MORRISON

Westholler. clemens August $\left(\mathrm{b}^{\prime 32}\right)-$ (I'96).

BUFFALO, 1.227, WRIGHT

CATLIX, JOIIN" JEFFEISSON (1):SO \&

Mllnn.4.03; (103).

wOOsTH: AITHLK MONHOE (b's, MInt,

BUFFALO LAKE, 371, RENVILLE

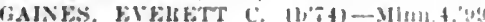
$\left.(1)^{\circ} 00\right)$.

BUHL. 1.005, ST. LOUIS

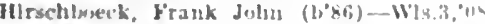
(1'10).

Johuwon, Selmer Martlu (1,8\})--M!nut, 0 : : (l'09).

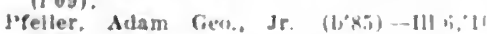
(1'12).

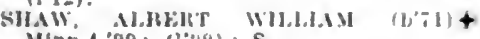
MInn.4,"99; (1"y9): $\mathrm{S}$.

BUTTERFIELO, 377, WATONWAN

Hasen, Olle billend (1,"iI)-IIl.11, $03 ; 11^{\circ} 0.3$

BYRON, 272. OLMSTED

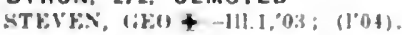

CALEDONIA, 1,372, HOUSTON

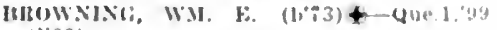

$(1,00)$

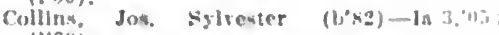

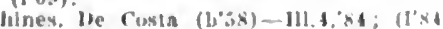

CALLAWAY, 276, BECKER

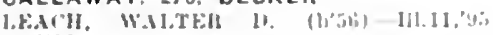
(I"0;).

CAM BRIDGE, 900, ISANTI

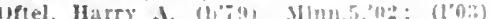

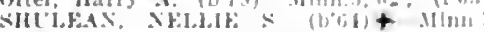

$43:(103): \mathbf{G}$

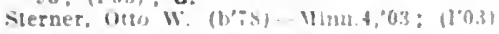

CAMPBELL, 303, WILKIN

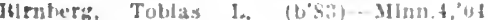
(150).

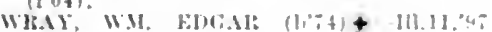

(1"1:3) Mrmber stale Med Six of Iris.

CANBY, 1.528, YELLOW MEDICINE

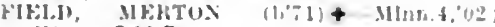
(I'OA): OALR.

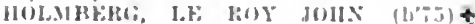
111.11.04: (1'05)

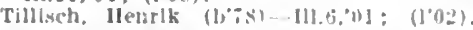

CANNON FALLS, 1.385, GOODHUE

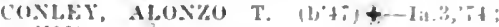
(l's3).

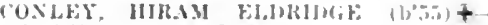
IA. 3.'st; (I'St): OpA.

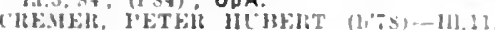
(04: $(10 \%)$

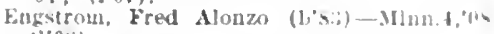
$(1 \cdot 0 x)$.

IIarson, Idolpl W. (I'60)-- $;$ (

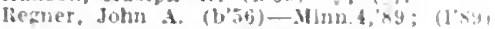

CANTON, 345, FILLMORE

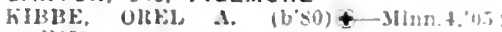
$\left(I^{\prime} 05\right)$

CARLOS, 167, DOUGLAS

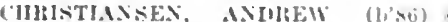

IIIIn.4, 10 ; (I'10).

CARLTON, 597, CARLTON

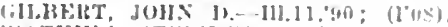

WATKLN, STEIHEN ULIX (bul)-X.' $30 ;$ (L'B3)

CARSON LAKE, - ST. LOUIS

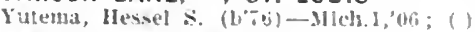

CARVER, 571, CARVER

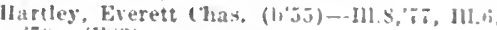
'y; (1'43).

CASS LAKE, 2,011, CASS

Christensen, liustar A. $\rightarrow$; (\$)

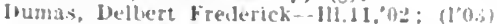

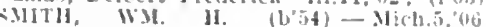
(I'0!) ; G.

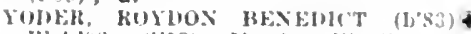
III., 05 ; (113); Nomber 111. State Merl SNOC.

CENTER CITY, 252, CHISAGO

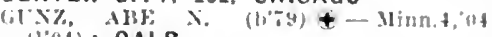
(1"04) : OALR.

CHASKA, 2,050. CARVER

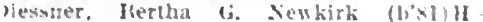
IInn, ${ }^{2} 06^{\circ} ;(106)$.

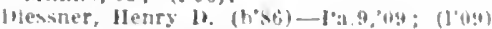
Marshall, Jelson II. (b"bo,-Mun.t,

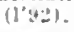

CHATFIELD, 1,228, FILLMORE

('mpler, Chas. J. (b'bi) H-Mimn.6,"yz; $(192)$. Chas

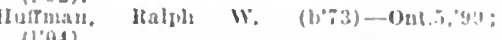

(1'ot).
N. W(o) (i): (10).

CHISAGO CITY, 276. CHISAGO

Marias, I. A.-MInn 4,04; [104).

CHISHOLM, 7,684. ST. LOUIS

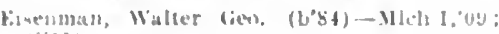
(1'11).

liatuliter, Whefred loyns

(s.er Virkin!a.)

liralum, Irolubala Wright (2iso) Vel.1.

(1) i: $1100 \%$

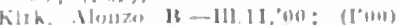

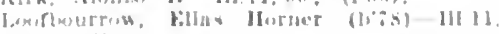

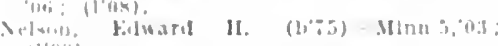

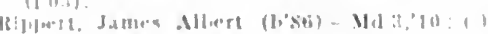

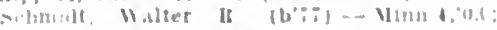

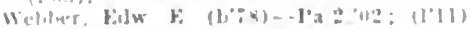

CHOKIO. 328. STEVENS

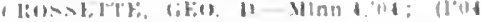

CLARA CITY, 587. CHIPPEWA

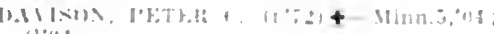
(1') औ)

CLAREMONT 275. DODGE

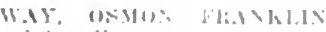

$\times 1: 11.4,1)$

CLARISSA, 364, TODD

Whander, lda Mars $H^{\prime}$ (l’0र).

Watwon, Thomas

(1'0\%)

CLARKFIELD, 603, YELLOW MEDICINE

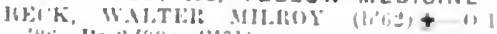

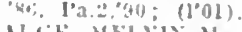

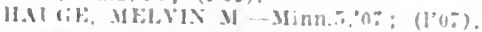

CLEARBROOK, 20, CLEARWATER

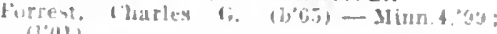

CLEAR LAKE. 263. SHERBURNE

KAKSTHIS, MI:TIfIL WM (t'Si) $\left.12 ;(1)^{*} 12\right) ; \mathrm{S}$.

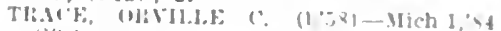
(I'S4).

CLEAR WATER, 3II, WRIGHT

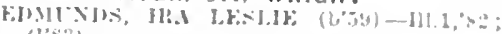
(I.S3).

CLINTON, 384, BIGSTONE

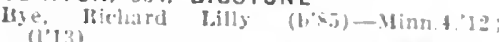

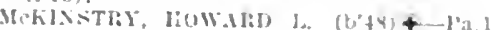
.0: (1'8:3).

CLOOUET, 7.031. CARLTON

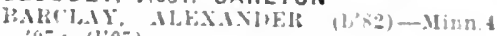
, $0 ;:(1,0 ;)$.

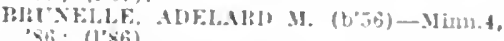

1010.010

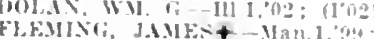

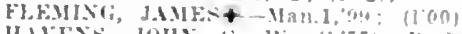

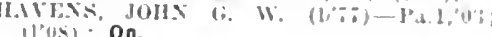
$11^{n}(u) ; 0$;

Johnsun, Indrew E. (bibi)-Mlnnt, 91 (1) 91$)$.

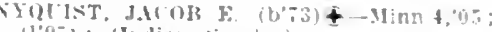
(1'0-7); (Indisu serblew).

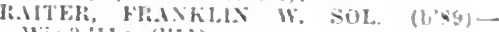
Iis. 3,"11; (1'11).

CLOVERTON, - PINE

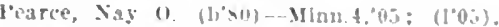

COHASSET, 521. ITASCA

Hursh, Mation M. (W\%)-Minn. ज, (Is: $\left(l^{\prime}(0)\right.$ ).

COKATO, 318 . WRIGHT

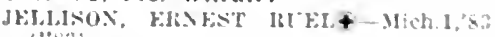
(1'xi3).

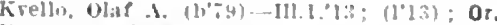

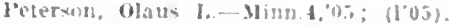

COLD SPRING. 594. STEARNS

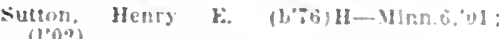

COLERAINE. 1.6\$3. ITASCA

CHIDWHIJ, I'MES I'. JR

Minn.t, 04 : (109).

AFil. NIIII, Nol)

COLOGNE, 390, CARVER

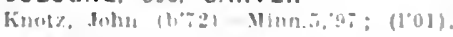

COMFREY, 23B. BROWN

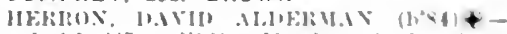

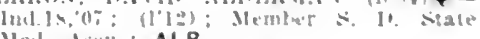
MU! lisil: ALR.

CORRELL. 102, BIGSTONE

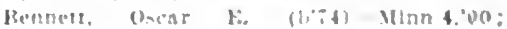
(1) 011 .

COTTAGE GROVE, I2U. WASHINGTON

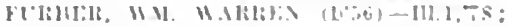
1. $=4$,

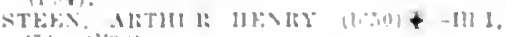
$\because$. $(1, i x)$

COTTONWOOD, 370 , LYON

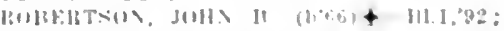

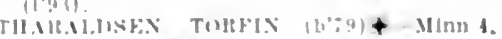

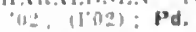

CROOKSTON. 7.559. POLK

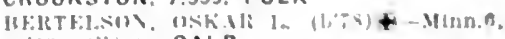
(a) (li) (nei): OALR.

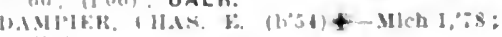
(1) $\times$. 
1)RIIFA, FRANKLIN MORTON (b'79)IH.4, 0 i; ( $\left.\mathrm{I}^{\prime} 0 \mathrm{~S}\right)$.

DCNLOI, AJEX. (L'57) $₫$ - Que.1,'92; $(\mathrm{T} 83)$.

IFOMGSON, IIELBBH?T II. $(1,60)+0$ - Ont. $98 ;(1998)$

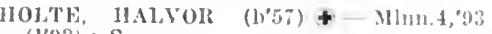
(1'93); $\mathbf{S}$.

II'ST, ADOLPH A. (b'5I) - HII.4'S1: (1'83)

KJELLAND, JACOls $\therefore$. (1)" 00$)+-311 n+1.5$ '98; (1'98).

MORI.LY 7 Y

BISON. HENTI

Iil.11, (i) : 1106$)$

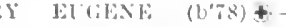

ORM.X, J. FlK $\left(I^{\prime}(0)\right.$

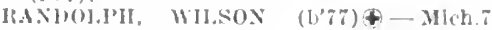

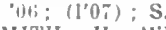

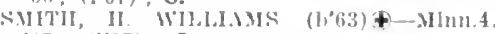
CROSBY, 400, CROW WING

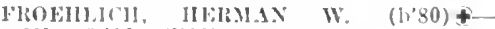
.11mu.5.00': (l'06).

MONAllAx, 'HHOMAS H. - Mlnn.5, St (l's6).

Sewall, Raph Justin (1,69)_-.Minn.4.49. (l'96)

SMITI, 1BAXTER A־-ONI.5.0.; (1'08).

GRYSTAL BAY. 100. HENNEPIN

VewlaIl, Wm. M. (b'5i)-ItI.I,'S3; (I'S3); $\mathrm{Ob}$.

GURRIE. 329. MURRAY

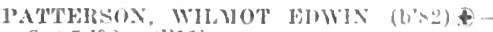
Ont.5, ${ }^{\prime} 00$ : (I'11).

CYRUS, 272, POPE

I.NDE, IIERMAN (b'T1)†-Minn.5,05 (1'0J)

DAKOTA, 250, WINONA

Gile, Orden $\mathrm{F}-\mathrm{O}$ : (t).

Wilson, Clarence E.-111.21,'96; (1'98).

DALTON, 175, OTTERTAIL

DVIS, LLTHEI A. (b'7s) \& -MInn.4, 01 ; (l'01)

DANUBE, 217, RENVILLE

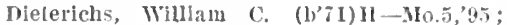
(l'99).

DASSEL, 643, MEEKER

KAUFFUAN, JOUN H-N.Y.5.84; (1'87).

PETERSON, ALFRED CARLTON (b'75) MInI1.5, 04; (1'04); 0p.

I'ETLRSON, GEO. L. (b'78)-MInn.5, 05 ; (1'05).

DAWSON, 1.318, LAC QUI PARLE

GHENT, CHAS. HARRY (b'88) \-Ill.6,'I1 (1'I3)

JOINSOY, IERMAN H. (b'7t)-MInn.4, 01 ; $(1,01)$.

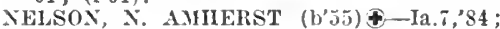
(I's6)

STEMSHLD, ARNE A. (b'72)†-Minn.4. 01; (1'01); OALR.

DAYTON, 343, HENNEPIN

Boucher. Leger Francis Xavier (b'83)Que.3,'10; (1'11).

DEER CREEK, 313, OTTERTAIL

GOSSIEE, ALBERT F. (b'5t) t-1a.1,'s1; (ち).

DEER RIVER，900, ITASCA

F'airall, Her'bert Snowden (b'äS)-1a.3,03; (I'03)

IIcGee, A. C.-E-0.2,'s1; (1'08)

DEERWOOD, 586, CROW WING

Denman. Austin Y. (b'81) - Ky.2,'09; (1'13)

lELD, W.Y. (I'65) \& Ont.3,92; (1'96).

DELANO, 1,03!, WRIGHT

Lares, Bert Y.-H-Mlinn,6,'00; (1'00)

Ifecartly, William F. (b'5i)-IIlunt4, 89 ; (I'ऽ9).

DELAVAN, 284, FARIBAULT

HETSER, TOHX R. (b'S0)-MO.7,, 07 ; (I’0S).

DENNISON, 184, GOODHUE

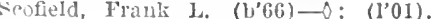

DENT, 244, OTTERTAIL

schumacher. Nicholas Wm. (b'is)-Minn.5,
DETROIT, 2,807, BECKER

(AIRMAX, WAS, BIWIN (b'75)-NHUM.4, 0I: (I'01): OALR.

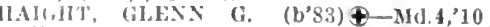

IIOIT, EIN EVERETT (b'54)-Mich.5,'78, III.1. $25 ;$; (1'83)

I.ARSLN, OSCAR O. (bُ07)+-MInn.4.07 (lintit)

(I)EX, FMMA KATHERINE (b' 40$)$ 1'a.7,75; (1'93); G.

By:tll, Wiw: 1'-111.1, 86 ; (I'93).

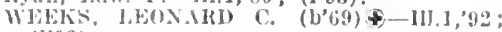
(l'92)

DEXTER, 28I, MOWER

SCHOTTIFI: GEO. JACOH (b'70) †-111.1, $960 ;\left(\mathrm{I}^{\prime} 90\right) ; \mathrm{S}$.

DILWORTH, 500, CLAY

Al:O1:X. W:I. 11. \&-Que.1,'8:; (1'87)

DODGE CENTER, 957, DODGE

BEI'T, WAllACE F. (b'5i) - Mllnn.6,'89;

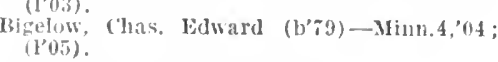

DONNELLY, 276, STEVENS

WHY'TLMOHE, J. G. $\$$-MInn.6, 03 ; (I'03). DULUTH, 78,466, ST. LOUIS

IBBOTT, WM, PI'T (b'80)†-MInn 4,06 (I'v6); 2802 E. Tth St.; office, Alwortl (10) 12,4

ANDERSEN, LOUIS NILS (b'68) †-Kan.4 "96; (1'04); 622, 8th Ave., E.; offlce, New Jersey' 13ldg.; $9: 30-11$ : $: 30,2$ :30-5 OALR. $\star$

ANDERSON, JAMES C (b'73) †-Mich. 95: (1'09) ; 1512 E. Superior St. ; office, Aworth Bíd 1512 : 10-12, $2-5 ; \mathrm{S}$.

Andres, John liénry, Jr. (b'Si)-1'a.1,'11 (I'12); 1606 Ninnesota Ave, office, New lersey Bldg.; 1-5, 7-8

ARMINEN, KARL WILIIELM (b'74)-III.1, 07; (1'12); 720 E. Ist St.; offlee, New Jersey Blig.: $9-11, I-3,7-8$.

BARNFY, LEON AMBROSE (b'84) Minn.4,09; (1'10); Granville Apts.; office, Iyceum Bldg.

Bowers, Jacob Eaton (b'41)-Mich.1,69; (1'8i); not in practice; 428 E. $2 \mathrm{~d}$ St.

Bownian, Fredk. C.-H-Pa.9,'81; (1'84) ; 119, 6h Ave., W.; offlee, Palladio Bldg.

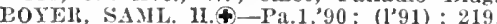
2d Ave., E.; office, Lyceum Bldg. ; 10-12 $3-5,7: 30-8$.

BRADEN, ALEX JAY $\left(b^{\prime} 60\right)(-M I i c h .1,88$; (I'94); 1814 ls. Ist St. ; offec, Fidelity Bldg. ; $11-12,2-4 ; \mathrm{S}$.

Progbamer, Frank J. (b'88)-Wis.t.'13; St. Nary's Hospltal.

Bromund, Emil Herman-Ill.16,'05； (\$) ; 1 IV. Superior St.

BROWN, HARIY (b'64) - MHinn.4,96; $\left(!^{\prime} 96\right)$ : 331,26 th are., W. $-M$ Hinn.4,96;

Burnside, Irvin Thrall (b'57)--Ill.1,83; (1'89): 701 N. 56th Ave.

CARSOX, JOHN H. (b'59) - Que.1,'81; (I'83); 2327 E. 1st St.; offce, Phoenix 13Idg.; $10-12,1-5$.

Caranaugh, lilehard E.-Ill.1,94; (l'94); $2130 \mathrm{~W} .3 \mathrm{~d}$ St.

CllAPMAN, THEO. L. (b'78)↔-Mich.7,02 ; (I'03); $15021 / 2$ E. 2 d St.; offlce, New'Jersey Blug. ; 11-12, $2: 30-4: 20$; S.

CHENEY, ERNEST LINWOOOD (b'7 Mass.1,00; (1'01) ; 12221/2 E. 2d St. office, New Jersey BIdg.; 10-12, 2-4.

CLARK, CHESTER HARLAN (b'i6) $\oplus$ office, New Jersey BIdg.; 10-12, 1-3, 7-8.

CLARK, FLOY'l) FERDINAND (b'ר T) - III '0S; $\left(\mathrm{I}^{\prime} 09\right)$; $813 \mathrm{E}$. $1 \mathrm{st}$ St. ; offlee, Fldelity BIdg.

Clark, Lenna 1\%. Jones (b'79)-111.4,05 $\left(1^{\prime} 09\right) ; 4301$ E. Superior $\Delta$ re.; office, New . Tersey, BIdr.; $10-12,2-4 ; G$.

Coddiug, Chas. Lee (b'57)—Pa.1,83; (1'88)

23 E. 3d St.; office, New Jersey Bldg. $11-12,2-4$

Cole, Emilie R. Maris $\left(b^{\prime} 72\right)-111.11,02$; (I'02) : not in practice; 2204 E. 1st St.

OLILIS, ARTHUR NELSON (b'76) $€-$ office Fidelity 08 ; 2244 Woodland Ave. COILINS, HOILR (b'59) $\uparrow$ - N.Y.1, 84;

(l'si); 2526 E. 1 st St.; offlce, New Jersey BIdg. ; 9-1, 2-4; (B1,29) ; OALR.ネ
COVENTRY, WM. AHBEHTUS (b'76) $\oplus$ Inich.1,00; $\left(1^{\prime} 00\right) ; 1427$ F. Superlor St. office, Fidellty MIdg.; 11-12, 2-4; ObG.* Curllu, Adam lee (b'8i)-WIs.3,12; (Asst. Illyslelan): (Knlfe Miver); olftec, Provl. lence IBldr.

Marls, Geo. W.-Nlch.2,79; (1'84): 1632 London Rd, amce, $17 \mathrm{~W}$ : superlor St. HAVIS, HORACE SWIF"' (b'55) \-N.H.I 84: (1'88); 1908 E. Sinperlor St.; oftlce, Sellwood Bidg.; 9-12,2-5, $7-8 ; U$.

DESLAUYHLIS, AUGUST A. (b'79) uffle. 323 w. Superior St.; $10: 30-12: 30$; $2-4,7-8$.

DRENNING, FREDK.C. $\left(b^{\prime} 67\right) \oplus-I l l, 6,92$; (l'92) ; 2011 E. 4th St.; office, Providence 13Idg. ; $10-12,2-4$; LR

EKBLAN), JOHN WM. (b'74) - Kan.3,"00 ; $\left(l^{\prime} 08\right) ; 2301 \mathrm{~W}$. 3d st.; olllce, $2030 \mathrm{~W}$. Superior St. ; $10-12,2-4,7-8$.

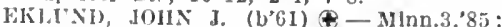
(1'85); 224, 24th Ave., E.; offlce, 7 l: Superior St.; $\mathbf{S}$.

FAllEY, EDW.' W. (b'7 693 Woodland Ave, onice, New Jersey I3Idg. ; 11-12, $2: 30-4: 30$.

GHLESPIE, NORVIMN HENRY $\left(b^{\prime} 74\right) €-$ Ilence Bldg.; $9: 30-4: 30 ;$ OALR.

GHROUX, AJCIBIADES ALEXANDER (b'85) Que.3,08; (I'08) : 3 Wxeter St.; office, $2105 \mathrm{~W}$. Superior St.; $2-4,7-8 ; 0 \mathrm{~b}$.

Goldsworthy, Will (b'65) - Minn.4,97; $\left(1^{\prime} 97\right)$; 5313 Colorado St.; offlee, Providence Bldg.; 9-10:30, 1-2:30.

liKAHAN, DAV1D (b'59) $\oplus$ - Mllch.7,93; $\left(1^{9} 93\right)$; $124 \times 56$ th Ave., IV.; offlce, 301 N. Contral Ave.: 9-10,2-4, $7-S$; $\mathbf{S}$.

GídIAN, IROBT, (b'65) $\nrightarrow-$ Mich. 7,93 ; (1'93); 1919 E. $2 d$ St. ; offlce, New Jersey IBllg; ; $11-12,3-4 ; \mathrm{S}$.

GRAWN, FRANK A. - Ill.1,96; (1'05) ; 1620 F. 3d St.; office, $7 W$. Superlor $\mathrm{St}$

GREELEY, LISTON QUINCY (b'68) $\oplus$ offlce, 932 IV. Superior St.; 10-12, 2-4, T-8; OALR.

GROVER, TRED CLAYTON (b'75)-MInn.5, ,06; (1'10); Grand and 57th Are., w.

HANEY, CLAUDE L. (b'80)Ð-Minn.4, 06 ; $\left(I^{\prime} 06\right) ; 430,23 d$ Are., W.; office, 1930 W' Superior St.: $10-12,3-4$.

HEIMAIK, KNUT ÓLAI E. (b'73) $₫-0$; (1'99); 814, 25th Ave., W.; offlce, 2032 IV. Superior St.; $10-12,2-4,7-8$.

HIRSCHFIELD, MAX S. (b'67)Ð-Minn.5, '02; (1'02) ; 830 E. 41h St.; office, New lersey l3ldg. ; 10-12, 2-5, $7-8$; ObG.

HOVDE, HAN' NICOLAS (b'61)-Norw.I, '90; (1'00); $714 \mathrm{E}$. 1st st.; office, New Jersey Bldg.; 10-12, 3-5.

Jesion, Tos. Wm. (b'89)-Wis.3,'12; (1'l4) ; 1930 W. Superior St.

Kleln, Harry ( $\left.\mathrm{b}^{\prime} 8 \tau\right)$ - Mlnn.4,'12; (1'12); 320. 9th Ave., E.; offlce New Jersey Bldg. KRAFT, PETER †-Ger.16,'93; (1'94) ; 412 , IIth Ave., E.; office, Prorldence Bldg.

Kurz, John W'esley (b's4) - Minn.4,09 (1'09); 1011': W. 4lh St.; 11-12:30, $4: 30-6$.

KUTH, JOSEPH ROBERT (b'81) $₫$-MInn.4, '04; (I'04); 422, 12th Are., E.; office, 34 W. 1 st St. ; $12-2,5-6,7-8$.

TAIRD, ARTHCR TUKNEK (b'73)--Pa.1. "00; (l'11); Member Med. Soc. of the State of N.Y.; (Nopeming); office, Fldel-

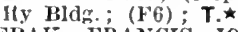

LEPAK, FRANCIS ,IOHN (b'82).థ-Ill.6 $09 ;$; $^{\prime}\left(1^{\prime} 09\right) ; 407$ E. 4 th St.; office, 405 E. 4th St.; $11-12,2-4,7-8$; ObG.

Minn.4,'02; (1'02); Sherwood BIdg.; office, Fidelity Bldg.; ( $\mathbf{F} 6)$

LUM, CLARENCE EDWARD (b'CI) $\uparrow-$ Minn.3,85; (1'85); 1103 E. 1st St.

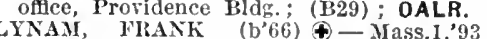
LYNAM, FRANK (b'66) †-Mass.1,93,
(I'94); 2502 E. 2d St.; offee, Alworth BIdg. ; $11-12,2-4$.

Madison, Elizabeth (b'64)-111.4,06; () ; Temple Bldg.

MAGIE, WM. HENRY (b'54)£—Mo.7,84; (I'84) ; 1401 E. Superior St. ; offlce, Sellwood Bldg.; 11-12, 3-4; (A $\bar{\gamma})$; S.

MANLEY, JAMES ROLLIN (b'85) Minn.4,08; (l'09); Fidelity Bldg. 
Martix, THOMAS ROY $\$-$ Minn. ${ }^{\circ 0}$; $\left(1^{\prime} 05\right)$ : Sherwod Apts.; ontec, New Jer sey Hidz: (FB3)

MCAULIFEE, JAMES - N.Y.6, 8 ? 2028 E. $2 d$ st. : offec, Alworth lide

MCCABE, WALTER $F^{\circ}\left(\mathrm{b}^{\circ} 64\right)-\mathrm{N}^{2}, 1.95$ (1009): 831 P. lst st.; oflce, St. Huke's (1.09) 831 F. 1st

Mccouk, CHAs, F. + - n1.1,\%9: (193)

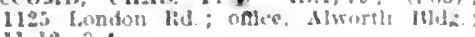
11 -12. $\hat{-1}-1$

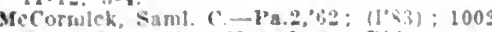

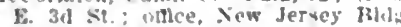

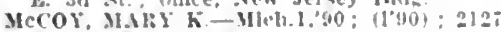
F. 5ih st.: oftce, 13 W. Superlur st. $10-12.3 \cdot 6$.

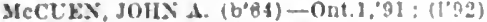
931 E. 3d. it.: once, Now Jersey Rid: $1-18,9-1,8$.

MeDONALD, ARCHIRAI, I. $\left(\mathrm{h}^{2} \mathrm{O}\right)$ + Md.7,05: (1"11): Member X.D. Sine Me Aasn.: 1930 E. Jeffersens St. : whine Fidelity Bldg: $11-12,2-4$.

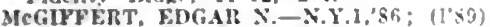
10 Chester Terrace.; offlce, Provldence Bids.

MURPHY, IGNATILS JOS. (b'sI) + Mlan.4:09; (100): Y.M.r... Rlig.: ollted $13 \mathrm{~W}$ superlor st : $19=12,3.5$, in

MURRAY NANIFL I +-NY.3.'s! (1'83) $221 \mathrm{~W}$. Sunetlor st.; ontice, 2n: ix. Bldg. : $10: 30-12,2-4$

richolson, yurdoch Alian (b'56)-Pa.1,'11 (1'13): New Jersey H1dz.

Olson, Ollver \&. (b'\$3)-111.11,12; (111:3) 2032 W. Superior st.

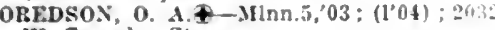
W. Sunerlor st.

PAKE, \&. GUY (b'75)—-OY.10,'35 Member State Med. Soc. of Wis. : Fildeli Bidz.

PARF. LOUIS T. (b'59) - Q (1'00): 516, 25th Are., W.; oflce, 2032 w. Superior st

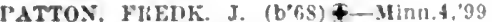

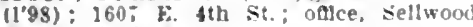
Bldz:; 10-12, 2-5.

PREDDEN, CIIDE EDW: (b's) $\_$- 11.6 09: (l'10) 326, 13th Are., F.; ollce Fldelity Rid

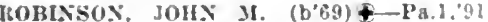

(1992): 1931 E. sth st.: oftice, Proridence Bldg. : 9-1: (B29); OALR*

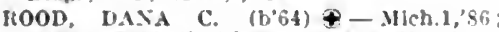
(1'89) : 2526 E. od st.: (nme, Hihling)

ROWE, OIIN WALLACE (b'81)f-MIInn.4 03: (t'0?3): 2334 Wordland Are.; office. Ildellty Bldg.; 2-4; Pd.*

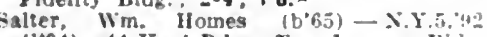
(1'94); 44 Kent Rd.; offlce, lyceum Bld: $11-12,2-4$

SCHRODFR, CHAS, II. (b'85) $+0.1,05$ (1'09): 410 F. 1st St: offce, New Jerse Blde. : 11-1, 2.5: Pd.

SCHULZE, ALJERT G. (boi) - MInn.4 04: (1'04): 532 Woodland Ave.; oflce

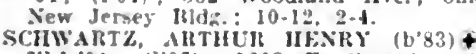
III.1,04: $\left(10^{\circ}\right)$ : 1603 E. Supersos offce, Sew Jersey Bldg.; 9-12, 2-5: D.*

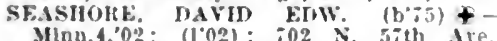
MInu. 1,02: (1.02); $02 \mathrm{~N} 5 \mathrm{Jth}^{\circ}$ Al IIAPIBO, EMASUET ZACHARY (b)

111.1.'11: $\left(1^{\prime} 12\right)$; Sellwowel 131dg.

sherwin, prank (),-l11.1, is: (1183): New Jersey lildp.

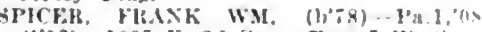
(1'12) : $100^{-}$F. 2d st.: nnce, ; W. Surm rot sit; $10.12,2-4,7 \div 8$; ObG.

STEWALT CHAS. AlDAMS $\left(b^{\prime} 48\right)+-1 a l$

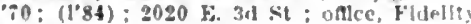
It(d; : $11-12,3-5 ; 1.17): \mathrm{S}$

slocker snmuel y (b, (118.5); 1014 k. Del s.; once, 13 w Superior st : 10-11.2-4

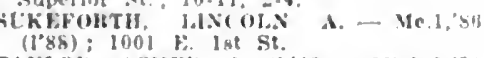

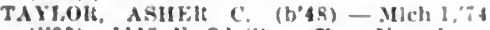
$(190)$ : 1115 k. 3d st. : onlee, New Jersons M1dG: 11.12,2-4: $\mathrm{s}$.

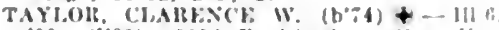
00 : (100): 2114 t. 4 th st: onlor. New Jersey Jiliz: : $12-4$

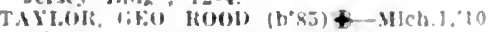

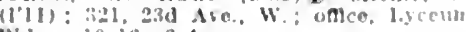
Hals: $10-12,2-4$.
TII.DFRQUTST, DAVID L. (b'72)-MIInn.4. 03: (1'03): 219. 15th A re., E.; omce. b. Superlor St. OALR.

TURTY, JONAS B. O (b) (1886) : 125 F. 21 st. ; once, $2015 \mathrm{~W}$ superlor $\mathrm{st}$

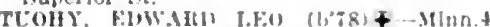

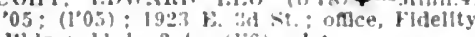
MHe $11-1,24:(16): 1 . *$

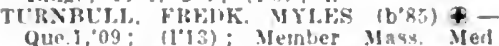

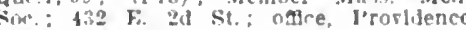
IBId : OALR.*

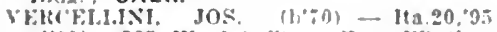
(1'11): 325 W. lst st.; omce, Winthrol lilock: io.12. i-8

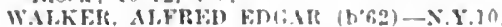

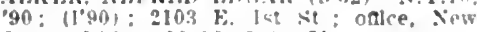
Jersey Bldg.; 11-12, 2-4: 0b.

Wallace, clas. J. (b'73) IInn 4 , "04: (1'04) 2014 b. lst st.; offce, Fldellty Blid $10-12.2-4$

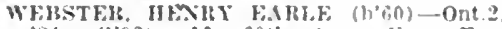
S4: (1'92): 19, foth Are, k.: oftre Isceum Blig.: j0-12, 2-5.

WILKISSOS. STEJ,A I. (b"it)-MInnt 03: (1'03): 312, 3d Ate. fo. ; uthee. Now Jersey 1sldg.; $10-12,2-3 ; \mathrm{G}$.

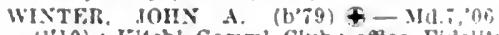
$\left(l^{\prime} 10\right)$ : Kitrhl Gamml Club; offce, Fillelity MAg.: 9-12, 2-5; OALR. *

IVolwa), Chrlstopher J. (b'54)-Que.1, (1'S5): County Hospltal; offce, Court holse : $2-4$

WVXNE, HFARY E.-MIInn.4,92: (1'92) 1613 Jefferson St.; offce, Proridence Bldg.: $9-4$.

\section{DUNNELL, 170, MARTIN}

Nerrlck Geo. Elllott $\left(h^{\circ}-3\right)-3 / 3.03$ (1'12).

EAGLE BEND, 551, TODD

riecres. Chas. E. (b'75)-1a.6,00: (')

Tyler. Joslah S. (b'40) $\rightarrow$; (s); G

EAST GRAND FORKS, 2.533. POLK

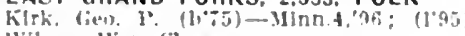

Wilson, Wm. Chas

(Sce Grand Forks, N.D.

EASTON. 262, FARIBAULT

VCFHOARTY, JOHN J. $£-M I m$ L, 0 : (1'n)

ECHO. 430. YELLOW MEDICINE

lilll, John T.-II-X.Y.9.'S6; (1'94).

EDEN VALLEY, 740, MEEKER

IIambirner, Wm. F.-F-1II.S.'83; (1'90)

O'CONOR. D.NL CHAS. (b'83) \-Neb. 6 . $10 ;(1.11)$

EDGERTON. 38I, PIPESTONE

IVE BOEI, HEIHASE' (b'il)-I1].14,03 (l'oti) : $\mathbf{T}$

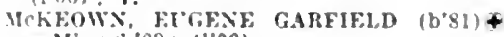
Ninn.6,"09: (1'09)

EITZEN, 200, HOUSTON

leters, Wm. August (b'it)-1a.3,00; (1'00)

ELBA LOCATION (MCKINLEY P.0.). ST. LOUIS

WOTNER, OSCAR HEITERT $\left(\mathrm{b}^{\circ}, 6\right)+$

VIIñ.4.02: (1'02): S.

ELBOW LAKE, 776, GRANT

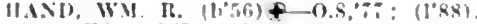

liepre, Foward T. (b':2) - MInn 5,"47: (1'99)

ELGIN. 324, WABASHA

Un,MS, WM. THOMAS $\left(b^{\prime} 49\right)+-111,1$, it (1's:)

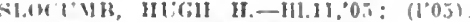

ELK RIVER, 859, SHERBURNE

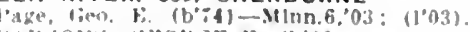

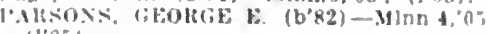
$11, n: 1$

ELLENDALE, 261. STEELE

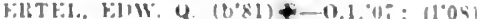

ELLSWORTH. 336, NOBLES

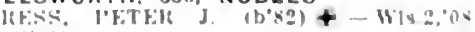
(I'is)

ELMORE, 793. FARIBAULT

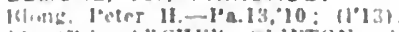

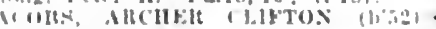
MHen $3,80:\left(1^{*} 8(5)\right.$

ELY. 3.572. ST, LOUIS

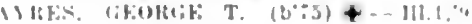

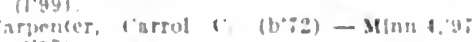
(1i?:)
I'AIRER, OWES WILIAAM (b':3) MInn 4,00: (I'0n); S.

Clatr, Gordun Girlesth (U'82)-Mleh.1. 0 : : 11008

mherland. Harty Nicholas (1,Sh)-M1.1,12: ["13): Pd.

ELYSIAN, 345, LESUEUR

ALLAN, FRANK A. (b'id) - D C $1,0 \%$ $\left(I^{\circ} 06\right)$

Long, Wm. II. (b's) - Min

EMILY, 25 , CROW WING

Maltory, John $X$. (b)51)-s

EMMONS, 223, FREEBORN

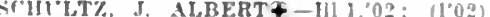

ERSKINE, 324. POLK

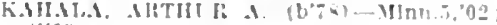
$(1.03)$

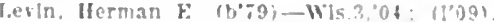

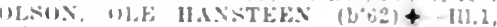
$\left(1 \times x_{0}\right)$

EUCLID, 128, POLK

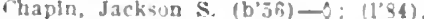

EVANSVILLE, 389, DOUGLAS

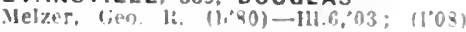

EVELETH, 3,036。 ST. LOUIS

Isulkley, Nathan C. (b'81) - MInn.4,0o $\left(1^{\prime} 0 f\right)$.

HAKWOOD, WM. E. $\left(b^{\prime} 53\right) \mp-111.1,80$ : (1'90).

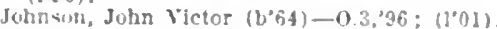

HeIntle, Jomer Marlatt (by)-lill, 13

More hounptal.

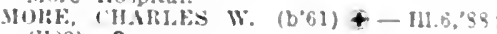
(l'ss); s.

laluter, Jesse ("arl (b'85)-ll1.1,12: (1'12)

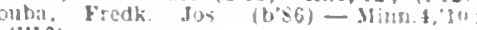
(1'jo).

EXCELSIOR, 1.015. HENNEPIN

IREL, IIUGH CLSTER (D*3) - MIMA A 02; (1"02).

Atwater, Mira Merrick $\left(b^{\circ} 65\right)-0.26{ }^{\circ}, 106$ $\left(1^{\prime} 0 x\right): S$.

La Paul. George $F$. (ince illngeapolis.)

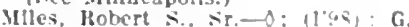

Skenip, froul scofleld $\left(b^{+}+4\right)$ - Mlinn.j,og (l'09).

EYOTA, 423. OLMSTED

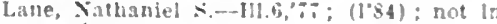

practlce.

MITH, FRFDK. LE ROY (b"79) +-Minn 4 Oti: (10010).

FAIRFAX, 815, RENVILLE

C'randall, Arthur M. (b'70)-J11.10, $+4,111.11$,

MIKEK, likO HAMUTON (b') + NInn.t, 0 : : (l'0S).

FAIRMONT, 2,958, MARTIN

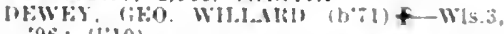
OH1 $\left(I^{\circ} 83\right): \mathrm{s}$

Jowe. Hoy ihester $\left.\left(b^{\prime} s a\right) H-111.4,06^{\circ} ; 11^{\prime} 10\right)$.

LFEDTKF, GPSAY II (b'io) + Minat 99 ; (1.99).

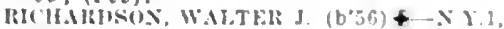

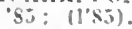

FARIBAULT, 9.001, RICE

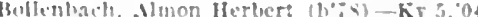

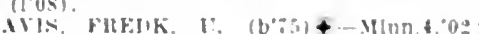

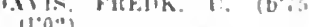

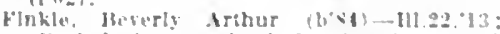
l'athologlati: Scherol gor leeble Minum nul Piolleptic colong

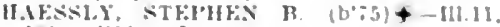
"il: 1104$): S$.

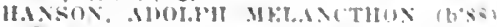
$+-111+111:(1 \cdot 11): \mathbf{S}$

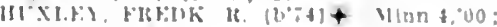
(1) $\cap \cap 3:$ ALR.

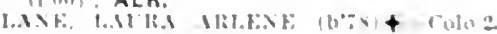

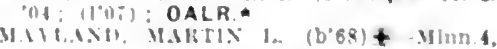

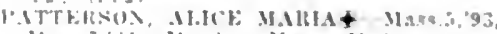

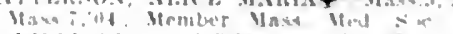

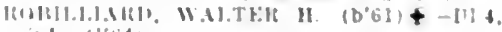

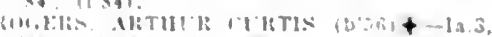

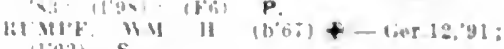
(1102) 5 . 


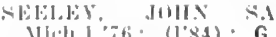

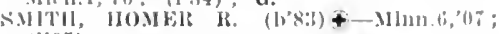
(l'0)

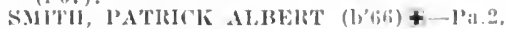
m:3: (1'93)

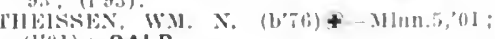
(I'i) I) : OALR.

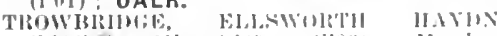

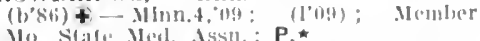

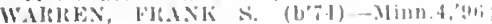
(I'(16): ALR.

FARMINGTON, I.024, DAKOTA

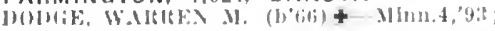
(I, ():3).

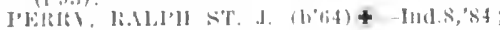

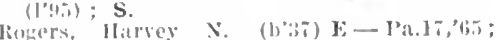

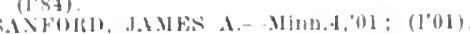
FERGUS FALLS, 6,887, OTTERTAIL

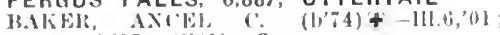
Minn.4.97; (1'01); S.

Bsurlingame, ("larence ('lats. (1,85)--111.4 08: Furgus Falls Insane Hospital.

role, Alvlnza 13. (b'4s)Il N. X.9), 's;

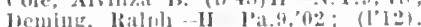

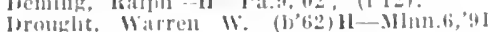
(1':11)

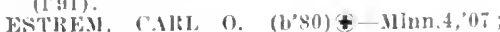
(108).

EREFBuIt, J011X A. $\left(10^{*} 64\right)+-111.1,29$ N.Y.10,?

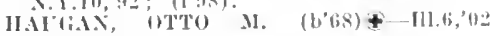
(1'0?2).

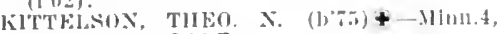
'(1); (1'1): OALR.

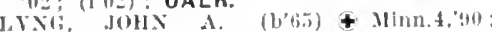

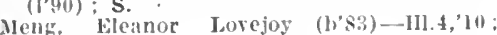
$(1,18)$

Meng, Wim. Jurlus (b'80)- Ill.4, 10 : (1'12)

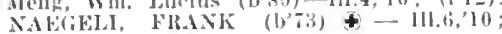
(l'12); 0b.

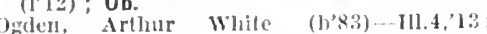
(1'allologist); Fergus Falls state IIospitil.

Patterson, Wm. Jeslie (h'82) Mass.n, 09 Fermus Jallo State Hospital for Iusane: $N$

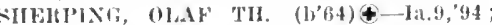
(1'01) ; $\mathrm{S}$.

Smith. Olive Ealla (b'so)-Mass.j, 09 ; (l'0st)

VIGFS, JOHGEN (i. (1)'64) $4-$-Minu.4, 94 (I'94)

Welch, Geo. 0.-II-JIass.5,'87; (l'93).

FERTILE, 614, POLK

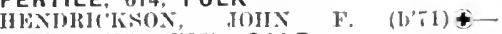
Uinn.4, $0.5 ;\left(I^{\prime} 05\right) ;$ OALR.

RIs.101R, I(bllX X. (b'63)-lat.9,98; (1'98) $0 p$.

\section{FISHER, 328, POLK}

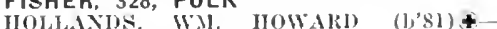
Mimm.n., 0 ; ; (lib).

FLOODWOOD, 48I, ST. LOUIS

Muirhead, llalter seott (1'85)-Ill.11,09;

( ).

Triplett, Martin $\mathrm{Y}-\mathrm{KY}, 2,95 ;\left(\mathrm{I}^{\prime} 9 \mathrm{~s}\right)$

FOLEY, 710, BENTON

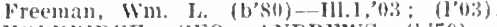

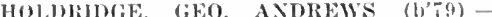
X.Y.19, $01 ;$ (1'1)2)

FORESTLAIKE, 540, WASHINGTON

Joirler, Jos. Alex. (b'80) - Mimm, is, 0 ; (l'(1)3).

FOSSTON, 1,075, POLK

sither, Allen (b'81)-Ia.3, 08 ; (1'09).

Turnbull, Robt. (b'72)-Ont.3,01; (1'01).

FOXHOME, 206, WILKIN

Ripperton, Sherman (b'65) - Ja.10,05: (1'11): Member la state ved. Soc"

Ripperton, Iustin Edgar (b'68)-Ia.6,'10 (स).

FRANKLIN, 439, RENVILLE

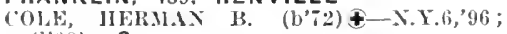
(l’as); 0 p.

FRAZEE, I,645, BECKER

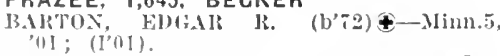

IBIHTENBACH, OSCAR CART (b'78)ङIlirh. 1,03; (Y'l!)

Tones, saml. \&. (b'49)-III.1,81; (I'S3).

FREEBORN, 275, FREEBORN

Butturt?, Carl R.--Iinn.5,'06; (I'06).
FREEPORT, 450, STEARNS

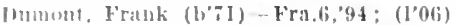

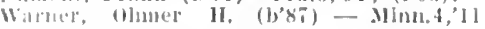
(1 [ [:3)

FT. SNELLING, 800, HENNEPIN

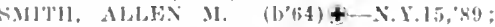

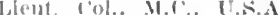

FULDA, 743, MURRAY

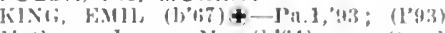

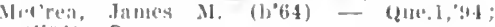
(l'!4); Op.

GARFIELD, 160, DOUGLAS

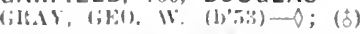

GARY, 25I, NORMAN

HROLL, SAML, FIWIS $\left(b^{\prime}-4\right)-I 11.15$ (in, Ill.11,0s; (1'10); Nember Ill. Slitle

lat. sioc.

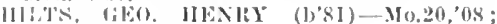
(I'II).

GAYLORD, 610, SIBLEY

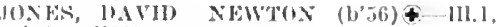
3): (1'83).

PFTEItSEN, THORVAID (b'R2)-III.II, ,II; (l,il); $\mathrm{S}$.

GIBBON, 533, SIBLEY

Fl, WVlit, WARD ZEl'ION (b'6I) \&-III.II, $8 \% ;(1,87)$.

stadtherr, inthony Jouls (1)90)-..Mo.34 13: ().

Thauwald, ("has. (asper (b'82)-Mnnn.5, 06; (1'06) ; OpA.

GILBERT, I,700, ST. LOUIS

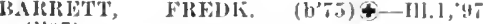
$(1,0,7)$

(ONXER, WM. HFXKY (b'(I"lo) : Member III. State lled. Soc. sTHATHERN, JOSES LANE (b, Ninn.4,07; (1'07).

GLENCOE, 1,788, MCLEOD

J.AIIIE'TT, ELAIER ELLSWORTII - N.JI.1, si: (l’91).

Greaves, Jay J.-Minn.4,09; not in practiee.

Dorsey, J. IIoratlo-NI.1,8.5; (1'85).

HOVORKA, TIIOS. W, $\left(b^{\prime}, 4\right) 4-$ WInn.5, , 02 : ( $\left(\mathrm{l}^{\prime} 02\right)$

WIEELAR, MERITTT WHHTACRE $\left(\mathrm{b}^{*} 86\right) \notin$ - IIInn.4,'10; (l'10).

GLENVILLE, 368, FREEBORN

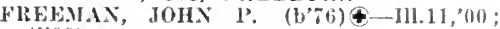
(l'00).

GLENWOOD, 2,16I, POPE

EBERIN, EDW. A. (b'7i) \&-Minn.4,01; (I'01).

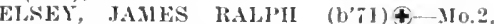
, $2 \mathrm{~A} ;(1,01)$.

FJELSTAl), CARL A. (b'72) \$-Minut,

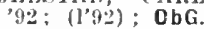

GLYNDON, 295, CLAY

LOWE, IFW MOLGGAN (b'75)--111.11,02: (1) 06 ).

GONVICK, 100 CLEARWATER

Sterens, John-Mimn.4,97; (1’97).

GOODHUE, 408, GOODHUE

GATES, (HESTER E. $\left(b^{\prime} 79\right)+$ Minn 4, 04 : (I.04)

SAITER, JIERBERT P. (b'70) \&-Minn.4, $95 ;$; (I'95).

GOOD THUNDER, 419, BLUE EARTH

SCHLESSEIMAN, J. TUIEODORE $\left(b^{\prime}, 6\right)-$ $0.7 .97 ;(1999)$

GRACEVILLE, 987, BIG STONE

OIIVER, CLIFFORD IRWIN (b'7

$11 ! .11,01 ;\left(\mathrm{I}^{\prime} 01\right) ; \mathrm{S}$.

RANDALL, BENJAMIN M. (b'58) $\$-111.1$, 83; (I'83).

GRANADA, 333, MARTIN

GA I'TH, W'M. H. (b'59) \&-M I0.22,'84; (I'92)

GRAND MEADOW, 552, MOWER

NIT'CHELI, RAIPH SIDNEY (b'74)

VIIII. 5,03 ; (I'03)

GRAND PORTAGE, 24, COOK

HICKS, FRINK B. (b'61)-IlI.1,99; (I'07) (Indian Service); Grand Portage Scbool.

GRAND RAPIDS, 2,230, ITASCA

Gendron, Jules-.Minn.5,'96; (I'96).

Hoeper, George E. (b'67)-IIl.8,06; (l'06)

Kussell, Thomas-Ont.1,'90 : (l'92)

storch, Chas. 21. (b'70)-Mlich.1,91; (l'91).

GRANGER, 111 , FILLMORE

Tierney, Chas. M. (b'81)-Ia.3,'96; (1'06).
GRANITE FALLS, 1.454, YELLOW MEDICINE

Bellh, SIgurd A, (12,80)-III.I,05: ().

Jlelfuss, Walter Franklln (b'86)-11.6,'12.

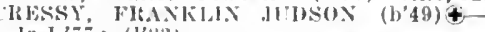
lil.1, $76:(1,8: 3)$

KLliNs, Howdit) (b76)\$-Md.1,09: (l'10)

TIIATTON, WM. M.-III.6,'T0; (I'83)

GRASSTON, 189, KANABEC

thein, John lidnmet (b'86) - Ill.6,'10 (Asslatant I'luy'sician).

GREENBUSH, 274, ROSEAU

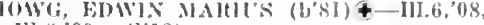
Ill.6,'09; (1'12).

GREY EAGLE, 378, TODD

Storey, Fruest I'otler-folo.1,01; (1'02).

GROVE GITY, 35I, MEEKER

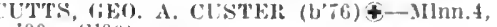
00 : (l'00).

GRYGLA, 30, MARSHALL

AIRINS, CIIAS. MARION (b'72) Io.20, 08 ; (I'09).

GULLY, 120, POLK
JOWEIS, JOILY T. (b'82) £-111.6, 08 (I'0!)).

HACKENSACK, 84, CASS

Button, Artlnur J. (b'69)-Mimn,4,06; ( ).

HALLOCK, 910, KITTSON

Fingson, Erlek-D; (t)

Itees, llawold (b'69)-III.1,96; (1'00)

shalcen, Arthur W. (b'78)-IIinn.4, 02 $\left(1^{\prime}\left(y^{2}\right)\right.$.

TOOH, JOHN RAYMOND (b'8i)-IL.4,'11; (1'12).

HALSTAD, 494, NORMAN

Ofterial, dine (b'79)-Minn.5,01; (l'01).

HAMEL, 150 , HENNEPIN

Aubln, Alexander (b'T2)-Qne.3,02; (I'03).

HAMMOND, 24I, WABASHA

Kyllo, l'ercy E. (b'88)-liy.z,'11; (*).

HAMPTON, 190, DAKOTA

llanmes, Ernest Wolfgang (b’o4)-Ill.1. 82; (I'83).

HANCOCK, 524, STEVENS

ANSOMI MATTHIS L $\left(b^{\prime}-73\right) \&-P a 2$, 02; (l'02).

HANLEY FALLS, 275, YELLOW MEDIGINE

Faulkner, Lloyd Anson (b'62)-IlI.8,85: (1'85).

HANSKA, 310, BROWN

SINIT, MATHIAS (b'82)€-Minn.4, 09 ; (1'09).

HARDWICK, 292, ROCK

Whyte, Peter H. (b'T4)-Ill.11,02; (I'05)

HARMONY, 655, FILLMORE

INDERSOX, NORMAN EDGAR $\left(b^{2} 81\right) \mp-$ Ill.1I, 03; (l'06).

KIEKIAND, PETER E. (b'7s)£-IIl.1,02;

HARRIS, 673, CHISAGO

IIITON, ALBERT J. (b'63)థ-Il1.11,90 (1.90).

HARTLAND, 227, FREEBORN

Yelson, llary E. Hood (b'76)-III.1,04; $\left(l^{2} 05\right)$

Schaaf, Fritz Hans honrad (I'89)-Mo.34 '12: (I'13).

HASTINGS, 3.983, DAKOTA

ADSIT, ALFRED M. (b'5i) - 0.14,'81 (1'8.5)

Prady, J'hilip J. (b's2)-Pa.2,09; (l'10) Dockstader, Alex. C. (b'54) H-Ill.4,'80: (1'84)

Fitch, Julius C. (1,'41)-JIl.1,66: (1'95)

PECK, LEWEILIN(TTON D. (b'7)-MInn.t,

$02:\left(l^{\prime} 02\right)$

WALD, RIDOHPH H. (b'/3)థ-Mass.1 $04 ;(1 ' 06) ; \mathrm{S}$

HAWLEY, 800, CLAY

HFIMAKK, JACOB I. (b'T) \&-Minn.5,

SIMINON, CIIAS. WADE (b'78)-Mo.3,07

HAYFIELD, 586, DODGE

Baker. Harry R. (l,'82)-Minn. 5,07 ; (I'07) Refsdahl, olaf I. (b'78)-Ill.6,'10; (I'11).

HECTOR, 866, RENVILLE

'Armes, Harry Lee-- $\checkmark$; $\left(l^{\prime} 92\right)$

McKibben, IIarry E. (b'80)-Minn.4,04; (l'04) 
HENDERSON. 733. SIBLEY

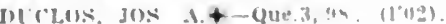

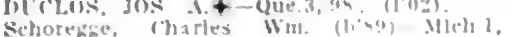

11: (1"12).

HENDRICKS, 406. LINCOLN

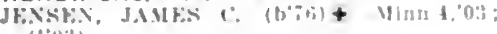

(1) (03)

HENDRUM, 355, NORMAN

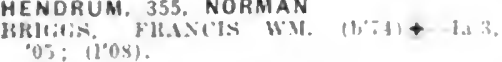

HENNING, 603, OTTERTAIL

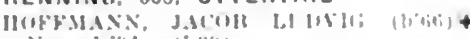

Surw. 1, "1) 1 ; $10: 01$

I.arsun, Anders [1. (166:2)-Minn \&." (1"93).

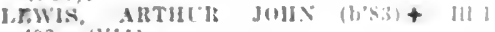
(19: (1'11).

Macdionald T. S - : : $1:)$

HERMAN, 604, GRANT

I.EIAXI), JUIIX T. (b"it) + [11.1.?!

(I'0!).

Thayer, Thus, M. (1,"ti) II X.l.

HERON LAKE, 803. JACKSON

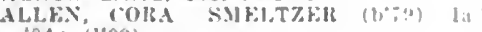

of: $(1009)$.

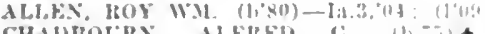

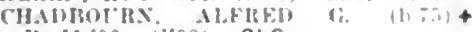

Pa. 11,$00 ;\left(l^{\circ} 00\right)$ : ObG.

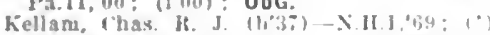

MUE. ANTOX JOIISAOX (1) (ix)+-111 $97:$ (l, 02$): S$.

HEWITT, 322, T000

T'arnow, Chrlstine $)$; (2).

HIBBING, 8.832, ST. LOUIS

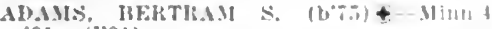
01: (1.01)

BASKETT, LINISAY MTLSON (h's3) +

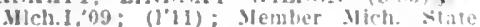
Med. Sinc.

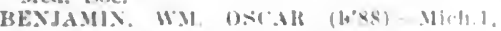
11: (): Member Miels. Shate Meri. Sin BHACKLOCK. SAML SCOT'S +-111.1. "111 (l'03). S.

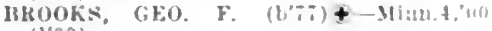
$(100)$.

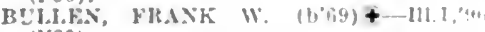
$\left(1^{\circ} 00\right)$.

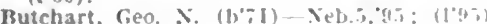

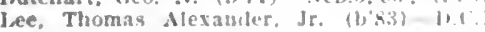
08; (1'12)

Morrian, Chas. Frank $(1,80)$-Xeb.5, 10 : (1.06).

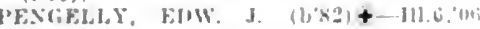
(l"09).

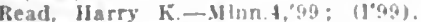

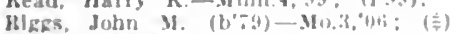

ROOD, UASI :

(See Dulull.)

saylur, G. 1., $-8 ;(1 ' s ;)$

SIINKS, ROBT, Eolli, (b'RI) - Vich. ' 'He (1'14).

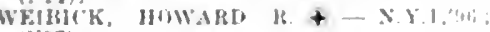
(1.9i).

HILL CITY, 220, AITKIN

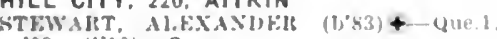
09: $(1.10) ; \mathrm{S}$

HILLS, 398, ROCK

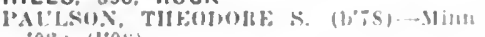
OQ: $(f \circ 0)$ S

HINCKLEY, 673, PINE

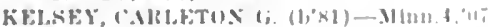
(I'0i)

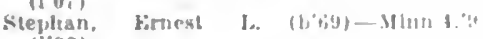
(1'93).

HOFFMAN, 39I, GRANT

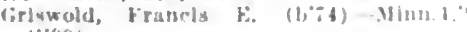
(1.99).

HOLDINGFORD, 350, STEARNS

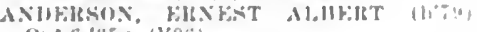

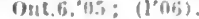

HOLLOWAY, 213, SWIFY

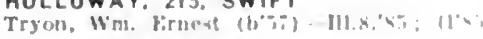

HOLT, 15. MARSHALL

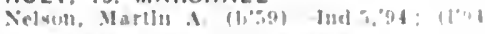

HOPKINS, 3.000, HENNEPIN

H.AKE, J.MH:A $11,521+.11111+11]$ (1)111): OALR.

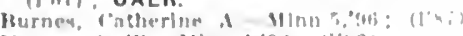

Momre, 6. If Mlam 4.92; (1) 21

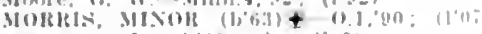

Swoet, i. J. $(1,49)-0 ;(1,40)$
HOUSTON, 700, HOUSTON

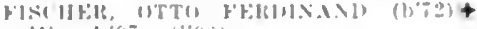

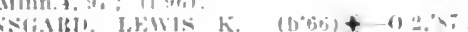
(lis?t)

HOWARD LAKE, 626, WRIGHT

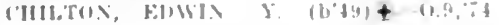
(1's:i).

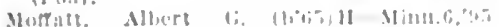
$\left(l^{\prime}(4, \pi)\right.$.

HUGO, 264. WASHINGTON

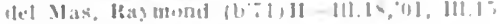
103: (1')1)

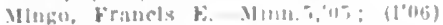

HUNTLEY, 25. FARIBAULT

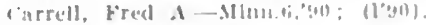

HUTCHINSON, 2.368, MCLEOD

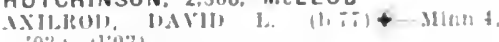

0:3: 11031).

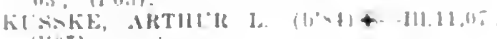
$\left(l^{*}()^{-}\right)$.

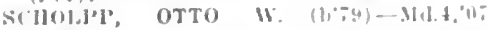
(1).

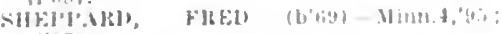
$11, y+3)$

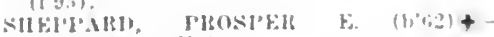
IIimn.t."ul: $(10 ! 1)$

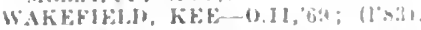

INTERNATIONAL FALLS, $1,487, \mathrm{KOOCHI.}$ CHING

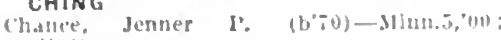
$\left(l^{\prime}(1) \geq 0\right)$

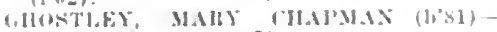

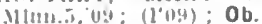

Monahan, Elizabeth Reil Stevens-Mhnn.j, "ilfi: $\left(j^{\prime}(0 i j):\right.$

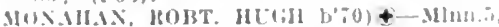
ini; $\left(10^{\circ}\right)$.

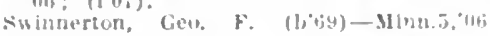
1]'vil)

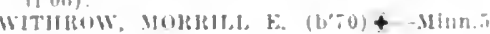
Cy: $\left\{l^{\prime}(1)\right\} ; U$.

IONA, 300, MURRAY

IIIher, Jis: II (11\%:)-111.11,"03; (104).

IRONTON, - CROW WING

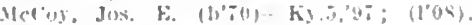

ISANTI, 3I6, ISANTI

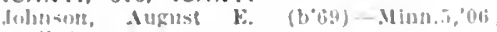
(1'0):3).

IVANHOE, 484, LINCOLN

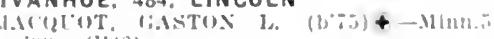
iIs: (1०i18).

JACKSON, 1.907, JACKSON

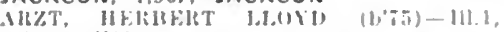

(1): (1.01)

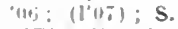

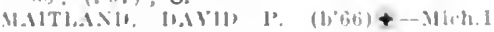
(1) $(1,10: 3)$.

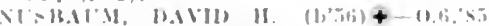

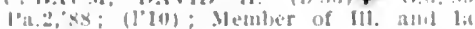
vinte lledeson.

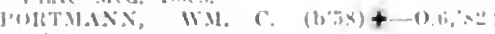
(1'sii).

IANESVILLE, I.173, WASECA

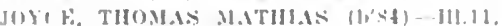
(1): $(1,12)$.

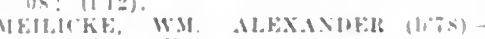

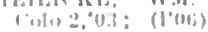

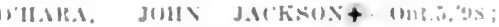
(1).

JASPER, 704. PIPESTONE

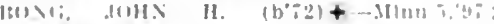
11? $491: 0 \mathrm{OA}$

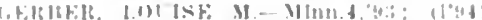

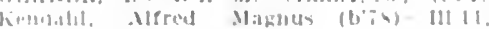
(1):? (1) (1):U).

JEFFERS. 227. COTTONWOOD

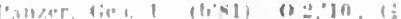

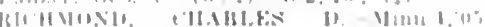
11 (194)

JENKINS, 130, CROW WING

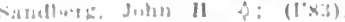

JORDAN. 1.151, SCOTT

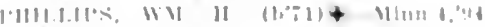

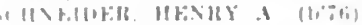

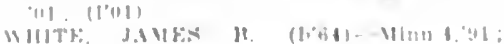
(1):1
KARLSTAD. 400, KITTSON

Turnlmil, Jwhe " : I bh

KASOTA, 700. LESUEUP

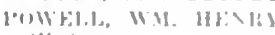

(1. $\times 1)$.

KASSON 932, DODGE

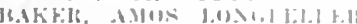

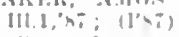

IRecllonlt, Jilogner Mana

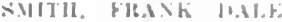

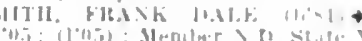

KEEWATIN, 695. ITASCA

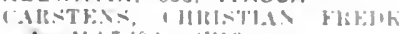

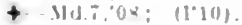

KELLIHER, 475, BELTRAMI

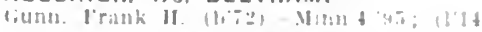

KELLOGG, 372. WABASHA

IIEUI"SEl, HUMINI I".

KENNEOY, 232, KITTSON

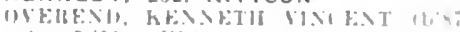

(191,5.11:1113)

KENSINGTON 244. DOUGLAS

Welzer, simon Minml (li, (I'Ii).

KENYON, 1,237, GOOOHUE

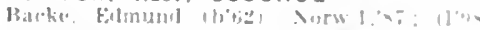

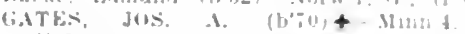

$11 \cdot 4.7)$

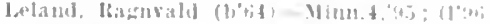

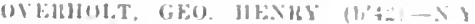

: (IS)

KERKHOVEN, 432, SWIFT

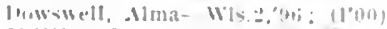

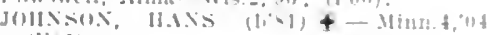
(l'0i).

KIESTER. 258, FARIBAULT

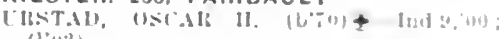
(1 (1)i) .

KILKENNY, 208. LESUEUR

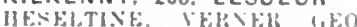

Em $11,1,04: 11331$.

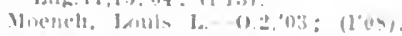

KIMBALL. 364. STEARNS

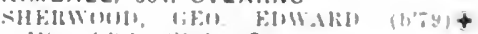
MInn.:?4; (1"?-1); Op.

KNIFE RIVER, 49I, LAKE

rurtin. Niam l.ete.

(re't l)uiul?

LAC QUI PARLE (R.F.D.. DAWSON), 100 LAC QUI PARLE

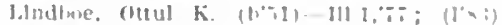

LAFAYETTE, 195. NICOLLET

(1).NB. WU. HAL (lib) - Man A un (1) $11,191$.

LAKE BENTON. 844, LINCOLN

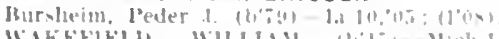

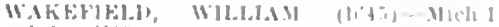
'x:?: (1's3).

LAKE CITY, 3.142. WABASHA

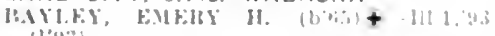
$11+4: 31$

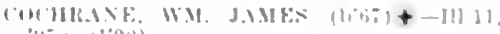
in: $\left.10^{\circ} 01\right)$

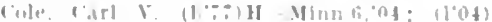

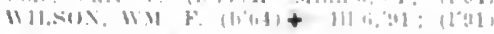

LAKE CRYSTAL, 1.055. BLUE EARTH.

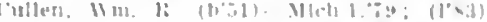

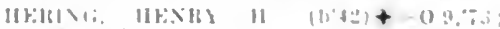

$(1 \times 4) ; G$.

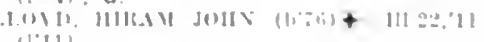
11.111

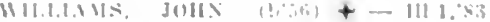

LAKE ELMO. 75. WASHINGTON

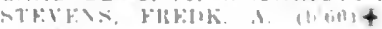

(I'-i)

LAKEFIELD. 921. JACKSON

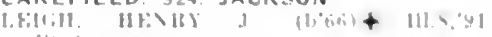
[1 $[1+9]$.

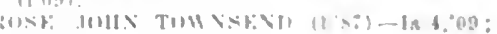
$111 ; 1$

(Filli, (1'!iil)

LAKE LILLIAN (R.F.D., OLIVIA). 30 KANDIYOH

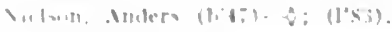


LAKE PARK, 740, BECKER

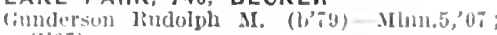
(1'0\%)

SUITII, MLI.VIJLE B. (b'68)-0nt.I,'95; (1'99)

Winberf, Oes1en K. (b'tit) - Mlnud, (1'93)

LAKEVILLE, 385, DAKOTA

Galprey, Thomas J. (l'69)-Minn.4, (I'9s).

Mllliams, J, P. (1'46)-Ill.6, i6; (1'84)

LAKE WILSON, 219. MURRAY

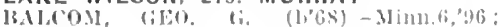
(l'46)

LAMBERTON, 652, REDWOOD

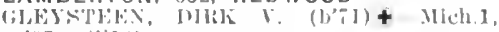

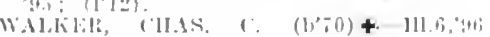

LANCASTER, 201, KITTSON

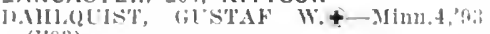
(1'P3).

LANESBORO, 987, FILLMORE

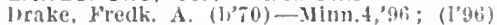

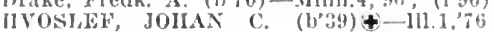
(l'83).

Lommen, Andreas P.-Minn.4,95; (1'45)

LE ROY, 702, MOWER

IIAIT', MIIAN I. (b'bi) 4 -IIMm., ,

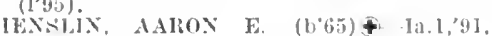
Wls.3,'05; (l'95).

LESTER PRAIRIE, 420, MCLEOD

('LWMENT, JOHN R. (1)'T)-O; (1'00).

LE SUEUR, 1,755. LESUEUR

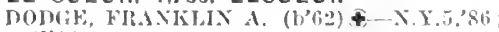
(isos)

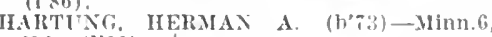
00: (I'00)

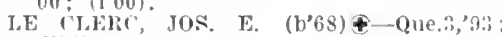
(l'93).

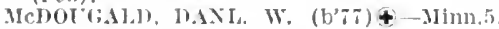
02; (1'02)

LESUEUR CENTER, 741, LESUEUR

ATTINS, IIERBERT B. (b'67)†-Minn.4 $93:$ (1'93).

WOONWORTH, LEONARD FORTEST (b'80) $\uparrow$-Ja.3,os; (l’08).

LEWISTON, 473, WINONA

Morrison, Wm. Schaw-0; (d)

NETMANX, C'ONIILD A.' (b'S2)-Ill.6, ,09; $(1 * 09)$

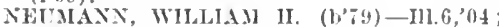
(1'04); 0 p.

LEWISVILLE, 218, WATONWAN

Blssell, Clias. P. (b, 92$)$-Ia.1,75;

LINDSTRON, 522, CHISAGO

Lagerstrom. Francis Gustave (b' 65 )-Kan.3, $99 ;(1,10) ; 0$.

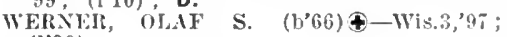
$\left(1^{\prime} 99\right)$.

LISMORE, 268, NOBLES

LEEBFNS, JOHY H. (b'82) $\$$-III.11, 07 ; (l'0s).

LITCHFIELD, 2,333, MEEKER

('IIAI'MAX, WILL E. (b'57) †-Vt.2,'79: (1'84).

DANIELSOS, KARL A. (b'T5)\&-Ill.I, 00 ;

IONOEIX, JOHX JOSEPH\&-MINn.4, 01 ; (l'01): $\mathrm{s}$.

ROBEITSON, ARCHIBALD WRIGHT (b'81)

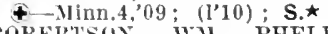

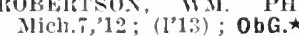

LITTLE FALLS, 6.078, MORRISON

Brown, Otis I. (b'56)-0.6,'82; (1'86)

Chance, Nolman W. (b*ay)-Ill.1,'s8; (l'9s).

Dumont, Noe (b'62) -Ont.4.'s7; (1'87).

Forlier, Edw. Louis (b'34)-Minn.4,08;

Fortler, Geo. M. A. (b'5̃) - Ont.4,'81; (l's2).

H.H.L, ELMER E. (b'72) $4-M d .4,02$; (l'02); S.

(l'01).

ILUI,S'P, J. BITTON (b'71)-Minn.4,95:

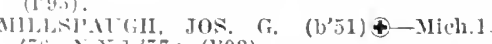

lEOERTA LEMTEL NIARTIN (b'62)\&l'at: $;$ (1's); LR.
LONG PRAIRIE, I,250, TODD

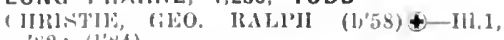
S2; (1'\$3).

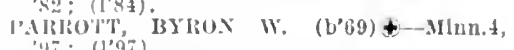
1.

$+\quad$ IIUII, 1,$93 ;$ (l',

LONSDALE, 27I, RICE

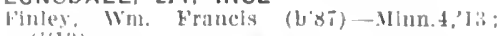
(l'itis)

1.EXA WIRINK IOS. \&-111.11,06; (l'06) OALR.

LOWRY, 252, POPE

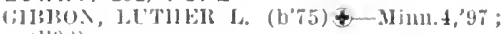
(l'mo).

LUVERNE, 2.540, ROCK

SIIERMAN, CHAS JEWIS $\left(b^{\prime}, 6\right) \&-M 0.28$ (00) (1'0.1) ; OALR.

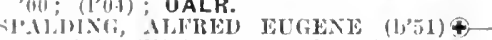
l'at.7.1; (1's3); I'res. Mlinn. Silate Med. Issil.; $\mathrm{S}$.

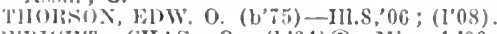
WRIGIIT, CHAS. o, (b'64) $4-11$ ini.4,'90; (l'9I).

LYLE, 552, MOWER

(0)13, WILl]S T. (b'47) \&-111.6,'74; (l'Si) lritzer, wm, A. (b'51) - Ml o.20,86; (1'87). I'ORKELSON, I'ETEIR THLODORE (b'81) + - H1.22,08; (1'09).

MABEL, 549, FILLMORE

('ady, chas. W. (b'46)-Ill.8, 7\%; (1'9s).

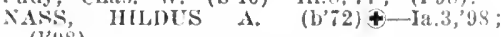
(I'ys).

MADELIA, 1,273, WATONWAN

(IIIMLS, IIENIIY B. $\left(b^{\prime 7} 7\right)$ \&-Mich.I, 03 ; $\left(l^{\prime} 04\right)$.

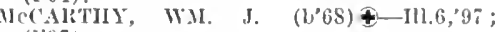
(192).

MADISON, I,8II, LAC QUI PARLE

Benolt, Frank T. (b'81)-Minn.4,05; (I'09).

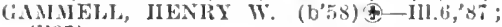

(1'87). Elis o. (b'68)£-Minn.4,92; (1'92).

OHNSON, ANDERS EINAR (b'71)\&-

Minn.4, 03 (I'03); OALR.
KOIBES, FINN (b't3)-Nlimn, ,01; (1'01).

MADISON LAKE, 335, BLUE EARTH

BIGELOW, CHAS. SUMNEI-NICh.1, '̃u; (l's3)

furina. Geo. Romeo (b'85)-II1.11,08; (1'10).

MAHNOMEN, 796, MAHNOMEN

Archibald, Frank M. (b'65)-Ill.11,'93; $\left(1^{2} 93\right)$.

RIMREICH, ERHARD ANTHONY (b'87)Ilun.411; (1'13); Nember N. D. State IIcd. Assil.

MALLARD, 78, CLEARWATER

Jrettyman, Francis M. (h'i9) $\rightarrow$; (

MANKATO, 10,365 , BLUE EARTH

ANIREWS, JOHN WESLEY (b'\$9) \&-Ill.1,

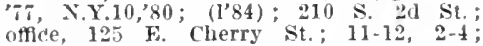
(Ai); $\mathrm{S}$.

ANDREWS, ROY NEWBERY (b'84) Mimn.4,08; (I’08); 510 S. $2 \mathrm{~d}$ St.; offlee, 125 E. Cherry St.; II-I2, 2-4; Pu.

Beach, Wm. A. (b'68)-Minn.4,93; (1'93); 420 Warrent St. ; office, Coughlan-Hickey Jidg.

BWNIIM, EDWARD W. (b'67) 4-Minn.4, '95; (I'96); 428 S. 5th St.; office, 305 S. Frout St. ; 9-12, $1: 30-5$; (B3I) ; OALR.* BRANDIUUP, IIAKY P. HOPJINS (b'\% 0 ) 4-Minn.4,01; (l'0I); not in practice;

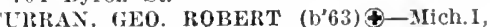
92; (1'92) ; 103 Parsons St.; office, National Citizens Bank BIdg.; S. $\star$

DAIIL, GEIHAARD A. (b, 72$)-I 11.4,97$; (1'97); 216 Fulton St. ; offlce, I20 $\mathbf{E}$. Jacksón St. ; $10-12,2-4: 30$.

ILarrington, Zina G. (b'30)-N.Y.3.'5 ; ; (1'84); not in practice; 526 S. $2 \mathrm{~d}$ St.

llielscher, Helen Hughes (b'64)-Minn.4,'96; (l'96) ; 309 Washington Park; office, National Citizens Bank Bldg. $9-12,2-4$. IIELSCHFR, JILIAN A. (b'64) \&-Minn.4, '91: (1':1); ; not is practice.

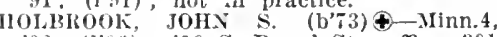
96 ; (1'96) ; 479 S. Broad St. ; office, 301 S. Front st.; 11-12, 2-4.
11OJMAX, CARL J. (b'69)\$-Ill.I,'99; (I'99); 135 Llncoln St.; oftlee, National

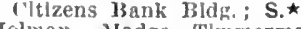

IIolman, Madge TImnerman (b'76)-1ll.9, $98 ;\left(I^{\prime} 98\right) ; 133$ lincoln St.

JAML, IOIIN II. $(1,46) \uparrow-$ N.Y.5,75; (1's: : $720 \mathrm{~s}$. 2l st, ofnce, Natl. Citizens KELLY, TIOS, COININ (b;1)-Minn,4, '04; (l'04): 114 Vin Brunt St. : oflce,

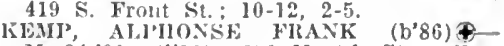
Mo.34,09; (1'10)；316 X. 4th St.; office, $401 \times$. Front St. $10-11,2-4$.

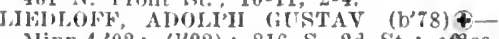
Minn.4,02; (l'02); 816 S. 2d St.; offce, 222 s. Front St: $1-5$.

LUCK, HILDA (b'84) †-Mo.28,05; (1'12) ; 216 Clark St.

Neredith, S. I',-II-III,4,'82; (t); not in practlce; 420 S. 5 th St.

MILLIR, VICTOI I. (b'75) †-Minn.5.'00; Citizens lbank I3ldg.; 10-12, 2-4; (B31): (l'00): 212 liberty 'st.; offlce, Natlonal OALR. *

OSגUIR, LIDA (b'75) $\oplus-\operatorname{Minn} .4,00$; (l'00); 5 I5 S. 4lh St.; oflec, $329 \mathrm{~S}$. Front St. ; 10-12, 2-4.

PIATT, CIIEISFA C. (b'77) \$-MInn, 4,06; (l'06); Je llillier St. : oflice, Immanuel IIospital; 9-12, I :30-5; (F6); LD.*

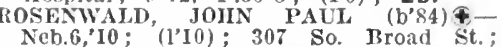
office, 223 N. Front St.; $10-12,2-4 ; S^{\prime}$.

SCIIMITT, AAION FRANKIAN (b'70) \&111.1,02; (1'02); 645 S. 4th St,; oftice. Itichards Block; I0-I2, 2-4; S.

SOHMLR, ALPHONSE EDW. JOHN $\left(b^{\prime} 79\right) \&$ -N.Y.8,99; (1'10); 214 N. Broad St.; offle, 329 S. Front St.: 1-4:S.

SUILIVAN, JANE CATHERINE HUGHES $\left(b^{\prime} 76\right)-M i c h .1,02 ;\left(I^{\prime} 02\right) ; 424$ S. Broad St.; office, National Citlzens Bank Bldg. ; $10-12,2-4$

YALIN, HONORE D.†-Vt.2,79; (1'98); 111 'herry St.; oflice, 301 S. Front St.; 8-6); (FG); LD.`

MANTORVILLE, 4I0, DODGE

ADAMS, ROLIIN T.-Minn.4,'93; (l'02).

MAPLE LAKE, 522, WRIGHT

IROUSSEAU, VICTOR-MINn.4,'05: (I'05).

MAPLETON, 809, BLUE EARTH

Blshop, Ira-Ill.1, 6 ; (I'84)

BOMBERGEI, FRANKLIN J. (b'66) Minn.4,02; (l'02)

KRUEGER, LOUIS W. (b'68) †-Minn.4,'96; ('’9\%).

MARBLE, 887, ITASCA

(iilbert, Geo. C.-MIO.7,'83; (1'93).

MARIETTA, 338, LAC QUI PARLE

1) I'NCAN, HENRY (b'6Z)-IIl.1,00; (l'02).

MARINE MILLS, 49I, WASHINGTON

Ifolcomb, Joel 'T. (b'82)—Pa.2,09; (1'09) ; G.

MARSHALL, 2,152, LYON

AKESTER, WARD D. (b'80) \&-Ind.8,'02; (1'10).

BACON, CHAS. GUSTAVE (b'67)థ-Que.3, '94; (1'94).

GRAY, FRANK D. (b';0)Ф-Ill.6,'99;

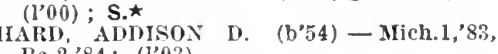

Pa.2,84; (I'03). '7\%; (1'84).

MAYER, I6I, CARVER

Emmerson, Wm. Stanford (b'78)-Mlnu.4, '04; (1'04).

MAYNARD, 386, CHIPPEWA

HELLAND, JOHN W. (b'78) -M-Minn.4, 05 ; (l'05).

MAZEPPA, 471, WABASHA HEAGERTY, WM. BROWN (b'76) $\oplus-$
Scot.9.12,14,00; (1,01).

MEGREGOR, 126, AITKIN

TANNER, ALVIS CHARLES $\left(b^{\prime} 75\right) \oplus-\Pi 1.1$, '10; (i'10).

MCINTOSH, 634, POLK

Amundsen, Albert Ldwin (b'88)-Minn.4, H.AIEL, CLARENCE E. (b'73) $\$-I l l .11$, $06 ;(1 ' 06)$.

MCKINLEY, 4II, ST. LOUIS FARMER, JOHS C. (b'il)\&-Minn.4,'95;
(1'95). 
MELROSE, 2,591, STEARNS

Camplell, Jos. Fi.- $\rightarrow$; (5):

GOEHRS, HENAY W: (b'ï) \& Mlun 4,05; (I'05): OALR.

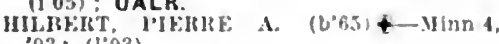
"93: (1"93).

05: (1"015).

MENAHGA, 3\$6, WADENA

Trlmbo, Jos. 11. (b'33)-1a.10.01: (l'0i).

MENDOTA, 245, DAKOTA

Lanoue, Alplonse (l'big)-QLie 4,02; (l'0ti).

MESABA, 84, ST. LOUIS

Eppersm, I'aul Slemersun (b'85)-Y"a f, 07 ; (III)

MIDDLE RIVER, I\$9, MARSHALL

Juliar, IIIchard Otio $\left(b^{\circ}+6^{\circ}\right)$ - Minn.1,03; (1'03).

MILACA, 1,102, MILLELACS

BACUN, HAlli: ${ }^{\prime}$. $\left(b^{\prime} ; 0\right)+$ MInn. (1'9:).

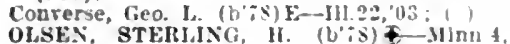
01: (1'01).

Phelps, Alvah Glibert (b\%0)-Mlun.4,96; (1'9i).

MILAN. 468. CHIPPEWA

Ianson. H. Horrick (1).9) - Minn.5, (I'0ij).

\section{MILLVILLE, I56, WABASHA}

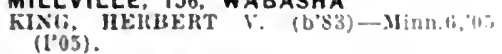

MILROY, 137. REDWOOD

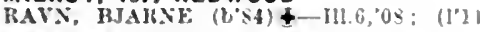

MINNEAPOLIS, 301,408, HENNEPIN NLMUE OF PHYSICIIN

ABBOTT, AMOS WILSON (b'A) \& X.I.I 69; (1'S4); $1710,3 d$ Ave., $S . ;$ oflec, 17i: 1st" Are., S.: 3-5: Einer. 'P'rof. Gyn. Minn.4; $A$ i, I, Fti; $S_{*}$

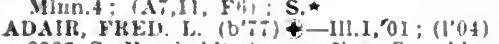
$3225 \mathrm{~S}$. Huntoldt Ave.: oflice, Donaldsum Blds.: $-3: 30$; Asst. I'rof. Obst., MInn.t (Fb): ObG

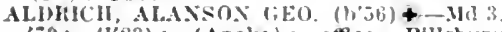
9: (1'83); (Anoka) : office, Pllisbury Bldg. : 1-6; (B29) : OALR «

Aldr!ch Henry $1:$ (b'5i) H-F'a.9,'81: (1'8i) 2209 Pleasant Are. : ofice, Donaldson Bldg. : 12-3; S.

Alger, Edmund Whitney (b"7)-MInn.4,02 (1'02); I219 Unlrersits Are., S.E.; Oflice.

105 lield Corner; 2-4.
Alger, Isaac D.-Wass.I.'64: (l'83); 1219 Unlversity Aie., S.E.; ottice, $10 \%$ Held Corner.

Corner. (l'01): $25 * 2$ Folk st.; office, Donaldson Bldg.: $10.12,2-5$.

Allen, Benson T. (b'J3) $\mathrm{F}-0.2 .85 ;(1 ' 85)$; 2142. Ist Are., s. ; offle, 60.3 'Nicollet Are.: $10-12,2-5,7-8$.

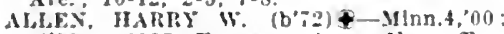
(l'00): 2135 Emerson Ave., N.; oftee, 903 , 20th Ave.. $X .11]-12,3.5$.

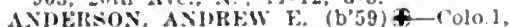
86: (l'97) ; $24+2$ killiot Are.; oflec, Syn dleate Rids, $9-12,2-4$.

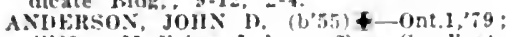
(I'83); Medlcine lake: offce, Syndicate IBldg.: $10-12,3-5$.

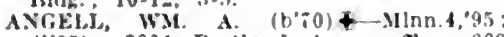
(1'95); 2804 Port!anil Are.; oflec, 602 Nicollet Are. : $10-12: 30,2-5$

AXNIS, HoMrit BURXHAM (b*32) t

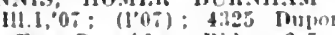
ome. Ponaldson Mde.; 2 -5.

Aruoli. Firaslus Y. (b'46)-111.1, $79 ;(1 ' 83)$ 3319, Ith lve., s. : ?-12, 2-6

AUNE, MAKTIX (1) î) \& - Minn.5,0z (l'0x): $254 i$ Fmerson $A$ re

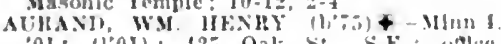
01: 1101): t25 Oak st, st: oml"c 800 Washlngton Are. st: 11 ig. 800 Washlngt
$7-8:\left(r_{i}\right):$ s.

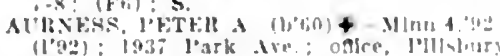
(1'92): ig3i l'ark

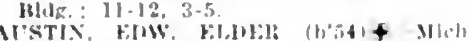

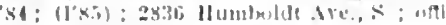
Andrua Halg.: : $10-11,=-1$

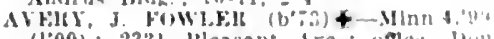

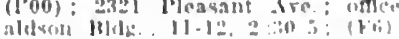

IILMEI, AKTIIUR L. (b'z3) \&-que, I, 99 (l'00); 515,9 th Are., S.R.: oftce, 325 Centrai Are.: 2-4, i-8.

Babcock, Fager Meirin (b'86)-Mlnn.4,13: (1'l:a); st larmahas Ifuspltal.

Bacharach, Harvey $\left(b^{\prime}(5) 5\right)-111.1 \%: 99$ : not in practlee: 2315 Cllnton are.

MAIEF, FLOLENCE $r\left(b^{\prime} 54\right)$-Minn.5 '97: (1'97) : 29l1 Bloumlneton Avo, ; 4 Balley, Ierbert Iturr (U'A)-Minn.1, 13; (l'i3); Mnneapolis cleg" Hospltal.

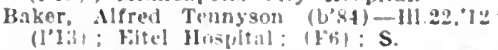

I'AKFIR, EAIINEST IAVFIRSE (b'80) Mlnu.4,09: (l'09): $13: 34$ ('ome Ave. of
fee, Donaldson Bidg.; 10-11, $2: 30-5: 30$

li.JKER, LOOE (b'\$4) +-11! 1,09; (1'10) ant3 rolfax dve.. $S$.; ontce, syndicate 13!lk. : 11-12, 2-5.

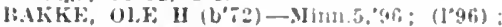
1sil. 13t1 Are., s.: offre, 5is vicollet ire: : -5 OALR.

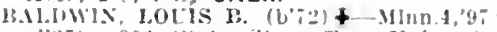
(190): 01 state st.: whece, Lnfversity llwilltal: $1-12,3-5 ;($ (Fit)

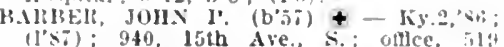
Nicullet Are.

Biss, GLo. WILLIS (b'5s)t re.2, (l'sis); Ioli byant Ave., N.: ottlee, 423 soth ire., $x$; 11-12, 2-4, $7-8$

BAXTER, STEPIIEX II. (bii) + Minn.A 02 ; (1'02); 2000 Henuepin Arc.: 1-3 (Fii) ; ObG

Bayley, Thos. Arthur ( $\left.b^{\prime} 78\right)-K a n .4,01$ (1'01); 213 , 9th st., S. ; otnce, $19 w_{a+1}$

Beard, kichard olding $\left(b^{\prime} 56\right)$ - III.6, 8 ; (1's3); 1755 Hennepln Are.; otuce, Jon. aldsun Bltg.; 2-5; S'cc. and Assoc. Prof. l'hyiol.. Minn.4; (F'(i).

beck, clement lillon (b'65)-111.14,04:

not in pructice: 1212 Mary I $^{3}$

Beeler, Margaret ilofer (b'i 6 ) $11-C o l o .1,99:$ (I'12); Saternity IIospltal; ObG.

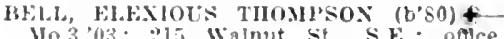
Iniversity of Minnesota; Asst. Prof path., Minnt: $(\mathbf{F} 1,2): P$.

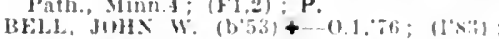

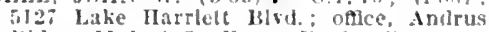
HIdg. 11-1,3-5; Emer. J'rof. Clin. Med. and I'hys. Dlaz., MInn.t.

Br.XEDHC, FIUE FDSON $\left(b^{\prime} \pi\right)+-$ aftec, 309 Cenlral Ire.; $11-12,2-4$

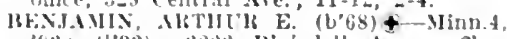

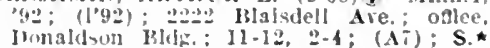

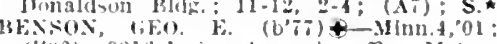
(I'v0); 3316 irvin Are., s. omce, Metro. polltan life Hugh: $9-12,2-0$

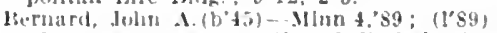
31 a siterens die, oflce, I b. Lake sit. $10-12,2-4$.

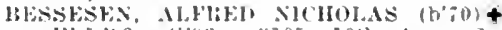
J11.1,43; 11.93): 305,10 th Are., s.

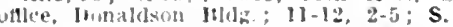

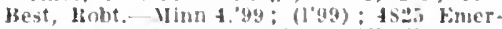

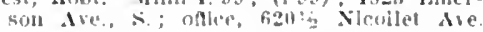

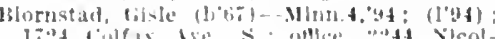

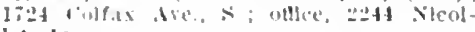
let Ise.

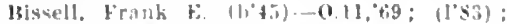

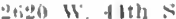

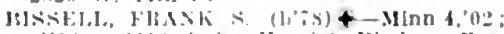

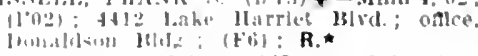

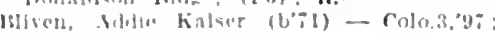

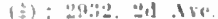

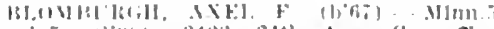

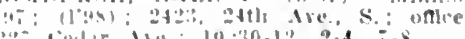

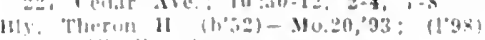

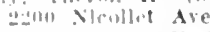

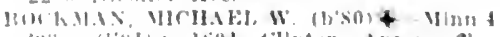

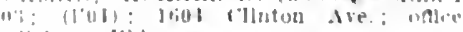

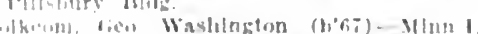

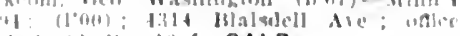
1 \& 31 if : fi 1: OALR

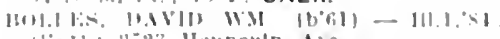

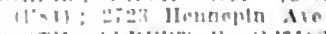

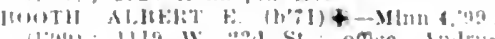

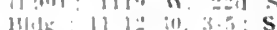

Borth, Chas. E. $(6+40)-111.1 ; 72 ;(3): 3003$

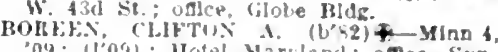
"09; 11'091): II otel Marslancl

dicate lilds: in $10-12$ rersant Ave; odce, Ave, s

Boteler, IVm. C. (b's)-Md1, 273. Park Ave: : unce, I619 "lulcaso

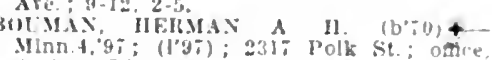
Andrus IBdy.

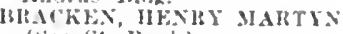

(siee st. l'aul.)

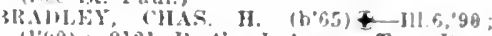
11'901; 2121 l'ortland Ave, offer, Don-

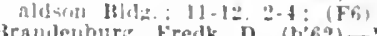

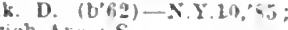
Trat

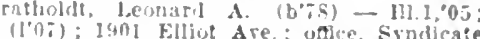
(Thi) ; 1901 Elliot Are.; udse. Syndicate Hll: OALR.

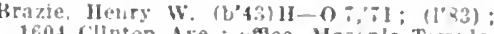
1604 rllaton Are; oflce, Mascnle Temule.

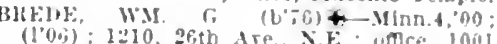
Main St, NE. 10-1:3-5, N

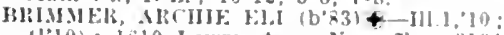

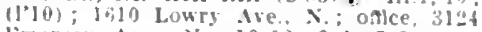

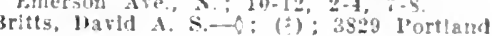
Are.

BROOKS, CH.LS, NOYFS (b'83)Ғ-MInn 4 09; (1'09) : 2209 \&. Lyndale Are, odlce. Donaldson Bldg. : $10: 30-2: 30$

BROWN, HUGAI D. (b'by) $¥-0.6,02$; not In iractice: also Menter 0 . Slate Mel. Assn. 3525 . $3 d$ Ave. s. oftee, IntIllnn 4

BROWX, ENWARN JOSIAH (b'5I) X.II.I,78: (J'83): 3027 l'leasant Ale. oftee, syndleate HIdf.; 10-I, 3.5; (BI, 2?) OALR.

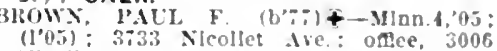
Neollet Are. : 11-12, 3-5: S

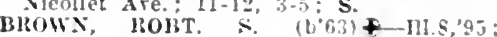

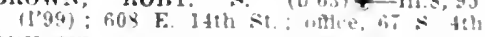

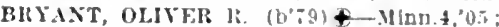
(1'05) : 3160 Chleago Are; ofice, $802 \mathrm{~L}$

Burgan. James Hinmer (b $; 3)$-Minn 4,90; (1P!y): Hotel Jlasungs.

Burns. Herhert Arthur (b'st)-Minnt, (0e (I'0s); 1;0: S.E. Rrook Are.

Burtun, Frank (b'53)-N.'s's2: (I's3): 1400 Willow st.; ofte, 60 s Nicollet Are 11-12, 2-t: S.

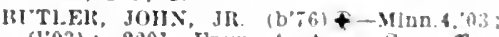
(l'03): 2201 Fremunt lie.. 5 : oflce, Pillslury Bldg: 10-12, 3-5; D.

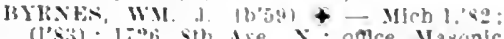

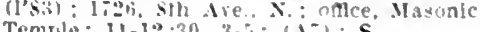
( $\left.x_{i}\right): \mathbf{S}$

(I'13): Clty llospital

MMIBEIL. RUBT. I (b'ts)\& Minn A,

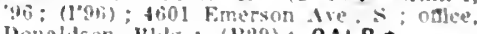
bonaldson Hldge: (1329): OALR

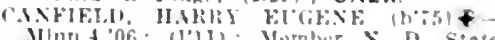
Mhnm.,06: (I'II): Vomber $\mathrm{N} n$. State Ved. issi : 2515 Rlakiell Are : ontre. Tonaldsun IHIdz: $10-12: 30,3$ : OALR. $91:(1: 01):$ anl: ltiafalell Are. once.

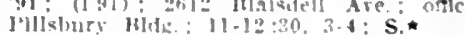

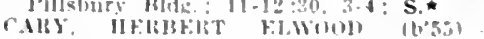

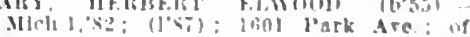
nce. Masonle Temple: $9.11 .2-4$

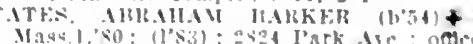

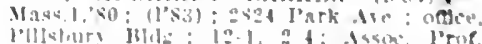

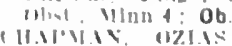

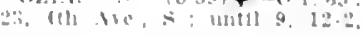

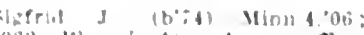

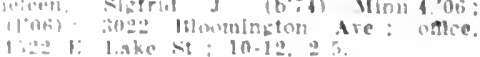
lian 1: l.ake st : 1A-12.

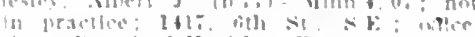

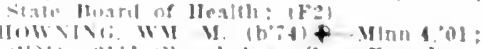

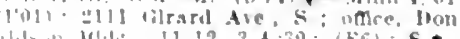




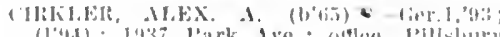

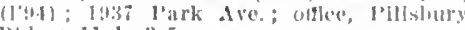
B1d15: : 11-1, 3-5.

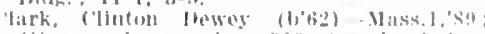

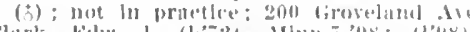

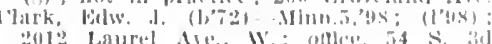

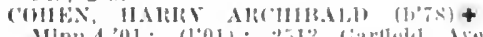

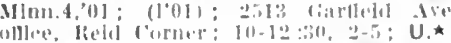

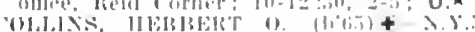

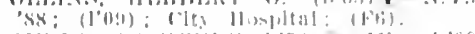

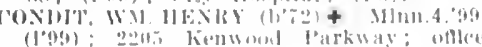

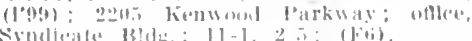

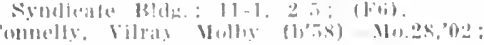

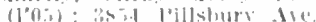

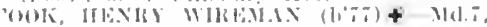

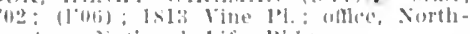
westerth Vatimal lite Blok

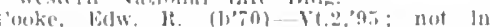
fraclice: ith Walnut st.; onlece, int Hennepin lise.

Cooke. lomtis los. (b'ts) - vt.2.94: not in practlen: 809, fitls St., S.l.: oflece, I"niverslly of Minnesolit.

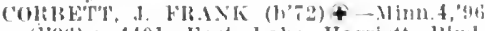
(1096); 4401 East lake Harrett lisul.

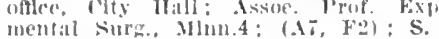

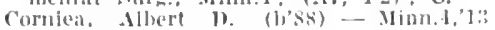
(1'I3): T"uiversily of Minmesota llwyilat].

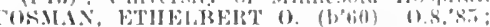

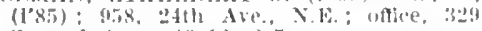
Centril Ave $117-12,2-2$

OWIES, MAXFORTII $r\left(1 r^{2} 33\right)+$ MIm.I, 01: (1,01): 2.54 Girard Ave., s. : offlece, Andrus Blde. : $2-6$.

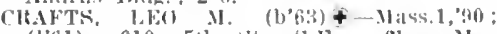

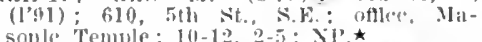

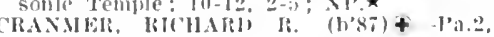
,05: (109) : 4433 Zenith Are.. S.; oftlee, Sindieate Midr.; $11-1,2-5 ;$ s.

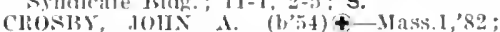
(1'83): 4724 Emersm Ave, s.; ufflce. 3018 Lymdale Ave. : 2-5.

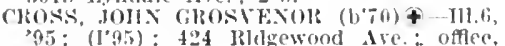

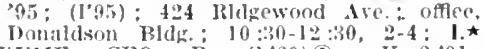
CHTME, CEO F. (b'60)+-ky,29i: (1'00); 1003 lark Ave.: oftlee, 519 Sirollet Ire.; $10-12: 30,2: 30-5 ; 0 . \star$

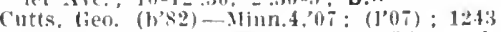
logan ire., $\mathrm{X}$; office, $928 \mathrm{x}$. Plymouth Ave.

Dady, FImer F. (1's.7)-Wis.3,10; (1'11)

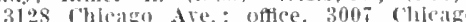
Are: $11-12,2-4$, $-9: \mathrm{S}$.

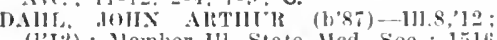
(1'12) : Nember Itl. State Ned. Soe. : 1516 S. J1th St. offce, 1525 E. Franklin Are. $1-12,2-4,7-8$.

Darby, II W-O: $\left(l^{\prime} 98\right): 307 \mathrm{~W}$. 15 th st. office, Andrus [i]dr.

Dart, l,eslle 0. (b'68)-Minn.4,n1; (1'01) rurtis ct.; offle, Dasonio Temple; 10-11. $3-5 ; \mathbf{P d}$.

de la Tsarre, W'm., Jr. (b't2)-Minn.4, (19.5) : 8122 James Are., s.; offlee, All drus ridg.; $11: 30-3: 30$.

Dempsey, Heo. P. (b'88)-Wis.6,'13; Intern, St Miry's Hospital.

DEMAR, JOHN EVANT-Qne.1,96: (1'96)

2735, 15 ih Ave.,

Deyell. Garl R. (b'83)-11inn.5,08; (1'11)

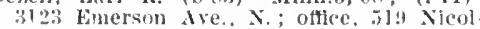
let Are.: 12-1.

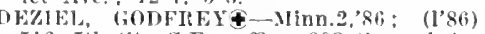
516,5 th st., S.E.; office, 303 (central Are Dickey, Itoht. Jaudolph (b'82) - 11 imm.5, 09 (1'11); 3016 Snelling Are.; office, I26

bight, ('las. F.-Nich.1,79: (1'89); 4818, $390 \mathrm{~h}$ Ave., s.; office, Unjuersity of Mlinnesota.

MISEX, CILAS. FREDK. (h'61)—-111.1,'86; (1'si) $; 2600$ E. 22d st.; $10-12,3-5$

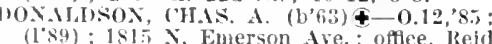
Comer ; $10-12,2-4$; (G1)

Doran. John Edumund (b'i2)-Ninn...998: (1's) ; Leamington Ilotel; office, Boston Bluck: $10-12,2-5$

Dorre. Bichard Irving (b'8i)-Minn.4,'13: Elliot Hospital.

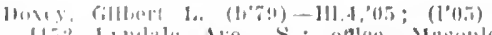

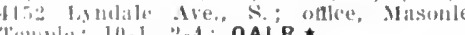

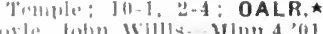

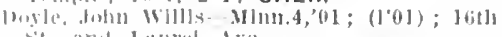
Sit. and laturel Are.

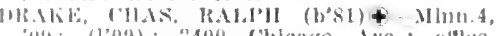

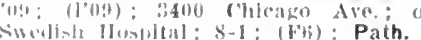

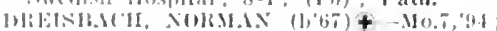

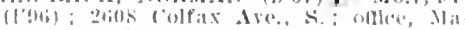
semle pemple: 11-1.3-30:30; U.

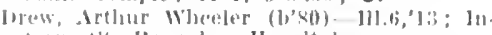
terin, si. Barmallats Hospltill.

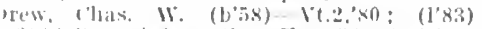

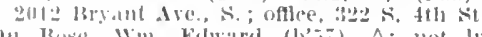

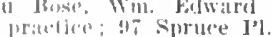

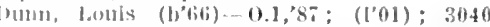
Landiale Are., s.; ; 3-5; S

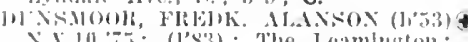

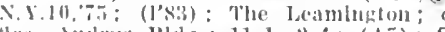

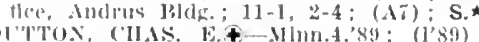

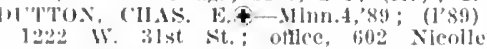
AKe; 11-12:30, 2-4.

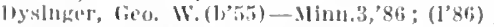
1321 Wishington Are. $x$

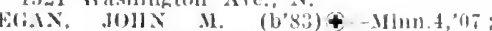

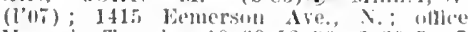
Masonic Temple; $10: 30-12: 30,2: 30-5: \mathrm{S}$

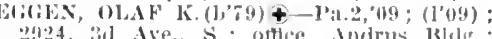

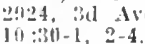

EIILIT, FUWIX II. (1) not in practice; Nember state Med. Sioe Whs, 1 sas bupont Ave, X.; olflece, 244 lst ire. $\mathrm{N}$.

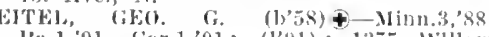

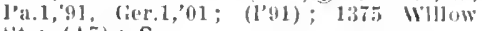

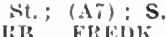

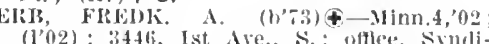
eate 13ldg.: $11-12,2-4$.

Erdmitun, l'bas. Andrew (b'66)-Minn.4, 93 $(1993) ; 612,9$ th Are, S.E.; office, Unlversity of Jlinnesuta; 3-5; Assoc. Prof. sersily of Minnesota; $3-5 ;$ Anat., Minn.4; (F1).

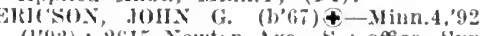

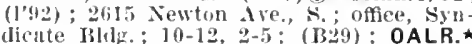
sstabrook, Edw. L. (b'46) - Y.Y.S, '(1:2) ; Iraryland IIotel.

EVAXK, OWEN J. (b'40)世-N.Y.3,62 (1'8:3); not in practice; 1726 Inpont

RAGEISTRON, AIBERT HARRY (0'8 Wis.3,12; (1'12); 45,5 1Iarriet Ave. office, syndicate Mldg.

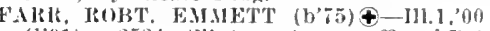
(1'01); 2524 (Yinton Ave.; office," lieid Corner ; $: 3-\overline{5} ;(\mathbf{F} 6) ; \mathbf{S}^{\star} \star$

Faulkner, Coryel]-Kan.3,99; (1'02); 5000 vicollet Are.

FEIDT, WILSON WELLINGTON (b'a 1'a.1,?9; (1'11); Member Med. soc. of the

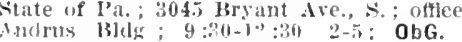

FIFIEL, EMLIY WALWORTH \&-MI.5 "84; (1'9s) : 481: Emerson Av.

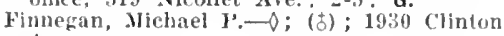
ive.

Fisclier, Gustav (b'60)-1'a.2,'96; (1'96); 1:28 Natin st., N.E.

Fisher, Amna H.-H-Mich.3,'73; (1'83); 3153 Columbus Ave.

FITZGEIALD, DON F. $\left(b^{\prime} 67\right)-M i n n .4,03$; (l'03) ; 2300 Portland Ave.; offlee, Lincoln 13]dg. ; 11-12:30, 2-4; S. *

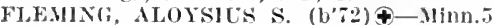
47; (195); 3344 Jrring $A$ re., S.; oftee, Nicollet Ave. and 9th St.; $10-11: 30,1-3$.

Flom, Andrew Olans (b's6)-NIinn.4,'12 (l'13) ; $230 \bar{i}, 2 \bar{t}$ th Ave., S. ; office, Donald son IBldtr.

Flymn, Tos. P. (b'i4)-I11.1, 00 ; (1'0I) ; 1i11 Emerson Ave., N.; office, 826, 20th Ave. N.; $9-12,2-5$.

F'oote, Lucius Field ( $\left.b^{\prime} 52\right)-111.6,75$; $\left(1{ }^{\prime} 00\right)$; 125 W. Lake St.; office, Mlasonic Temple; $10-12,2-4 ; N P$.

Foster, Lysander P.-H-11l.4,'82; (1'83); 755 Monroe St.

FOX, JOHX MARCLS (b'75)థ-Minn.5,'0I (1'01); 3601 Grand Ale., S.; office, 1940 Hennepin A ve. ; $1-5$.
Hranels. 'Thomas 13. (1)'66)-111.1,79; (184); 4100 L. lake sit

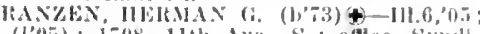
(1'05) ; 1708. 11th Ave, s.; ofltee, syndicote lif dg.; $-5-5 ; \mathrm{s}$.

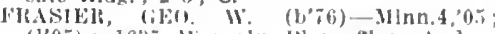
(1'0.5); 1635 Waverly 1'1.; ontec, Andrus likig.

Frlek, I.ewls (b'70)-III.ג,'97; retlred; 114 s. ith st.

Frisbee, N'in.-YY.5.60); (I'84); Soldlers' IIome.

Frost, fadw. S. (b'43)-l'a.1,68; (l'83); this fotom are, s.

Plipkenciter, wis.

(1'85) : Andrus lidig. llimnt, in; (1'12); $1011 \mathrm{k}$. Itirer Jid. oflce, Andrus rolckg; ; 10-11, $3: 30-i)$

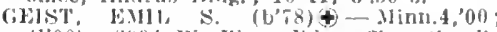
(l'00); $2904 \mathrm{~W}$. Jther Itd.; oftsed, ssudi-

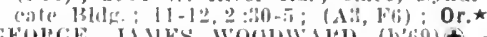

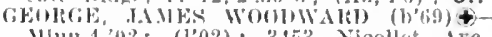

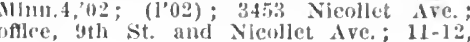
offle, 9 th

(ilbsolt, Fredk. M.-II-Mich.5,81; (1'85) 3315, stith Ave., s.; oftce, 60: Ncollet Are.; $10-12,2-5 ; 0 p A$

Goldlere, Marlin Luther (b'76)-Minn. 5,01 (1'01): 3217 Bryant Ave., S.; office, 3444 thl Are., s.

(ioldhlum, (ien. J. (b':9)-111.17, 02; (1'03) 24.2 Lartield Ave, office, Medical Block: $10-12: 30,2: 30-30$

Golden, Anson a. (b'47)-Vt.2,'73; (1'98); 609 if. 34th st.; $; 0013$

Golluox, GEO. JACOB $(b,-4) \mp-P_{11.2,00}$ $\left(1^{\prime}(00) ; 171 \%\right.$ I'ortland Are. ; offlee, Hatsonic Temple; $11-12,3-5 ; 0$ b.

G0ILI), JAMES BBNANTT $\left(\mathrm{b}^{\prime} 60\right) £-\mathrm{I}^{2} \mathrm{a}, 2$, '86: (1'86); 3217 Nicollet Are.; onice, pillshury 16jdg.: $11<12,2-5$.

GILEN, RTULNE K. (b'T0) \&-Minn.4, 113 (1'113) ; 1419 Emerson Arc., N.: office, iteid forner; 11-12:34), 3-4:30; (1F6); S.

GRPEXE, WILIARD PARKEIt (b'TI) Mliclt 1,04: (1): Nember Med, soc of ll. $52 \pi$ oak st. s.e. offlce, public Ilealth and I'athology BIdg.

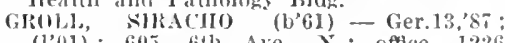
(l'01); 605, 6ith Ave., $X_{\text {. }}$; oftice, 1220 Wa'hngton Are. N.; 10-12, 2-4.

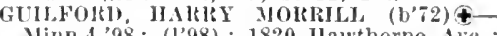
olfice, l'illsbury Bidg.; $4-6$.

GUNDEISON, HARLEY IAMES $\left(b^{\prime} 88\right)$ \& 11.6., 11; (1'12); 1422 W. Lake St. ; office, Lake St. and IIennepin Ave, ; $2-5,7-8$.

Haberman, Euil (b'78)-111,11,04; ( ): Aludrus Bldg.

IIAClINF, FRANK HENRY (b'r2) tIMAGEN, GILART I. (b'58)†-Minn.5, 04 ; (1'04); 3245 13100mington Are.; office, 1519 F. Frinklin Ave.; $10-12,2-4,7-8$.

IAGGARD, GEO, DELANEY (b'5i) llinn.4,93; (l'93) ; 2400 Chicago Ave.

11:11, Jos. Moffett (b'87) -Minn.4,13; (1'13) ; Ninneapolis City Hospital.

Hall, Levi (b'33)11-1!1.4,82; (1'82); 207 E.

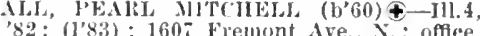
Pillsbury Bldg. ; $12-12: 30,2-3: 30$.

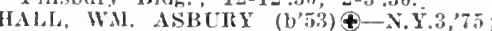
(1'8i); 1767 Colfax Ave., S.; offlce, Masonic Temple; 11-1: $\mathrm{s}$.

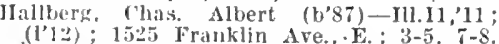

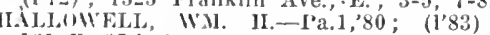
1ii E. 2ith'st.

IIAMHTON, ARTHLR S. $\left(\mathrm{b}^{\prime} 72\right) €-P a .1$, 97; (1'01); 328, 10th Are., S.E.; office, 1'illsilury Bldy.; 3-5: Assoe. I'rof. Yerv. and Ment. IDis., Ninn.4; (Et,13, F 6$)$;

Iamlin, Cen. B. (b'71) H-Minn.6,96; (1'96); 4422 Colfax Are., S.; office, Donaldson Blds. ; $3-5$.

Hammond, Asa J. II. (b'69) H-Minn.6,"96 ; (1'96); 2556 Aldrich Ave., S.; office, Masonic Temple; $1-4$.

IIASCOME, WALTEIR C. (b'55)-II1.1,84; (1'84); 3321 Jarriet Are.

HAXsox, JOS. - IJ].23,05: () ; Member III. State Ved. Soc.; 1802 , IIth Ave., s. 


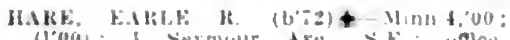

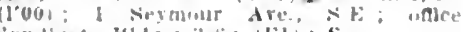

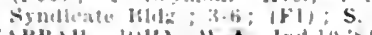

HAkRII, JUII,

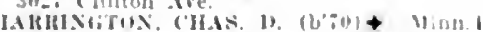

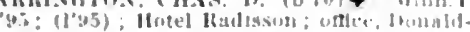
ax) $13 \|_{2}: 11-12,3-3 ; \mathbf{S}$

Harris, lorno Willorme $\mid 1,7 \mathrm{a})$

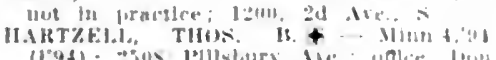

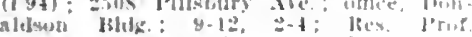

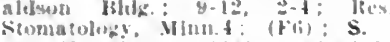

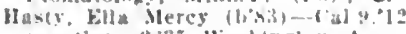

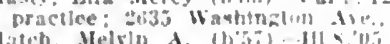

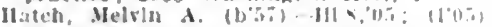

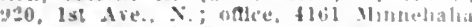
Are.: 11-1:, 2-s, i-4

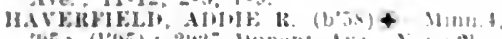

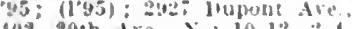

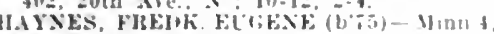

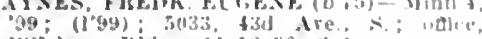
l’llsbury Mldx. ; 11-1:2:30,:-4

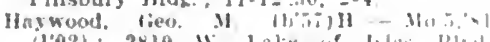
(1.02): 2810 W lake of Inke lind

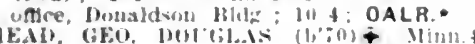

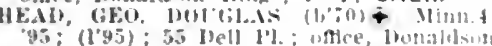
Mlig: 10-1; Assice. Irof. Meel. Minut

HEDBACK, AXEL, F. $(1,7 t)+-11$ Inn, 1,4

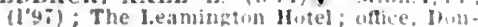

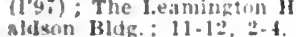

Aldson Bldg.: 11-1:, "-f. (1'06): Member X.L. Stale Men. Asnn.

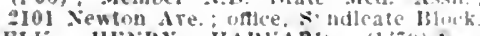

HELK, HENkY HAIIIR! $(1,-9)+$ Minn.5,02: (100) 3101 kmersull Ire ntnce, Ironaldson bldg; $11-1: 3 n, 2-1: \mathrm{s}$

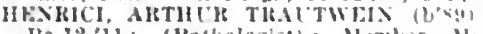
Fa.12,11: (Hathologla!); Meniler Med sore of the siate of loil.; "Lniversity of Yinnesota.

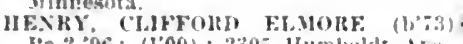
"a.2,96: (1"no): 2305 lfumboldt Are.,

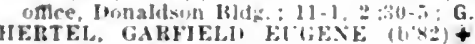

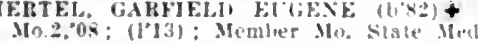
Asan. : 353s, an Ale.

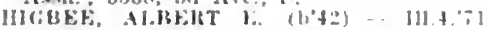

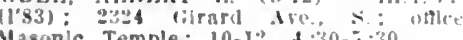
Masonlc Temple; 10-1:- 4:30-3:30.

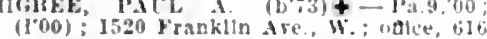
(I"00): 1520 Franklin Are. W.

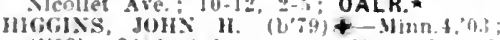
(1'03); 320z iedar ire; rifice. lakk St: $11-12,2: 30, \overline{7}, 7-8$

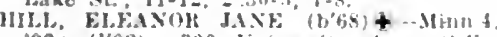
$02:(102): 306$ lniversity ite. s.t.

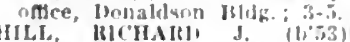

(1'83): 1910 sterus are. Block: 11-12, 3-4.

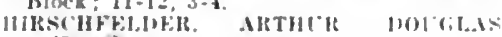

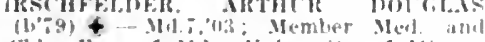

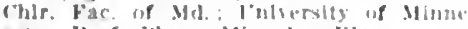
sota: Irof, lhat Minnt: 1Fl1

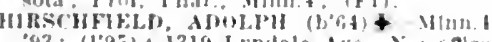

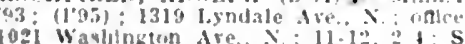
logl Wawlungton Are, Ni 11-10, 2 is (1'1:): :635 rollatury Ave : unlue, Nivollet Are. and ath tit

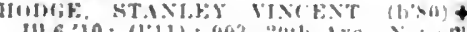

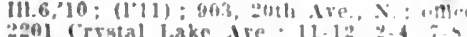

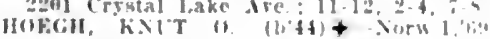
(8): 1620, 211 Are. Temple

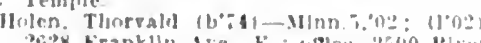

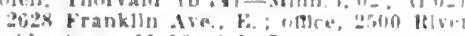
whe Ire: 11.12, 1.; ;

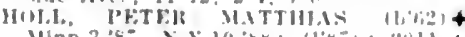

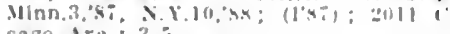
cago Are: $3-3$

Holmen, llensy k. (libi) - Mavi,

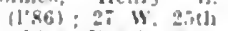

It,pkink, Fredk. Win. (1, bil) Ire.3,s): 6904 34th Nie \&: $10-1 \pm=2.1$

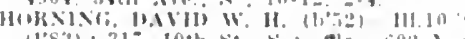

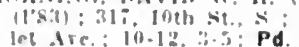

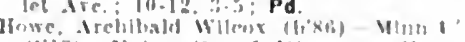

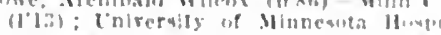

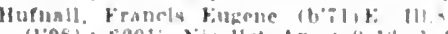

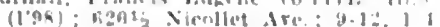

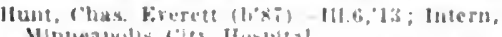
Mlinueaphlis fies Ifospltat

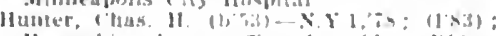

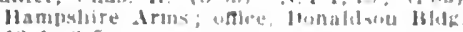
$1: 2-1,2-3$.

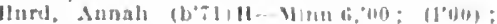

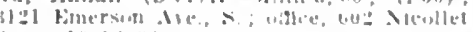
Ale ; 10.12 ; 30 .

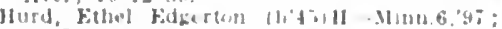

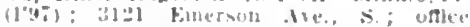
jellslume likle

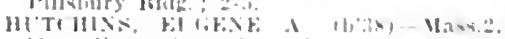

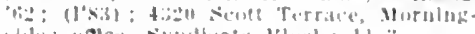

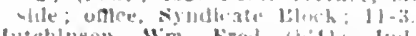

Hutehinson, Wm. Fred $(b+1$, Int.24, s.j:

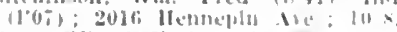

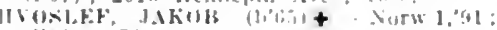

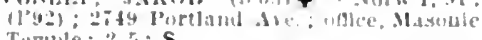
Termule; $2-5: \mathrm{S}$.

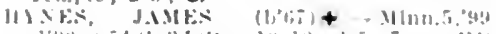

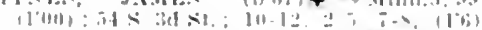

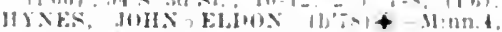
of: (104); 3349 Cniversity ire., st.

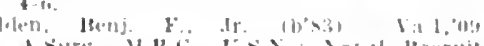

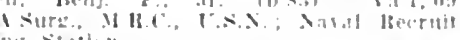
[12 statilun.

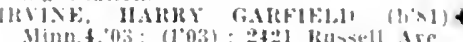

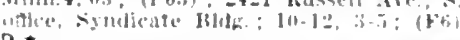
D.*

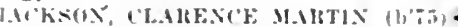

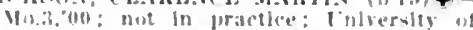
Ulunesota: l'rof. Mnat. Minn $4:$ : $(F)$

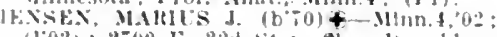

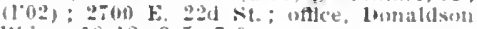
$161 d 2 ; 10-12,3-5,7-9$

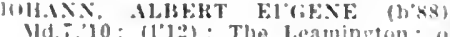

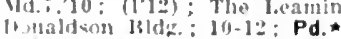

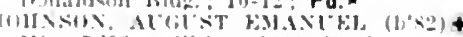

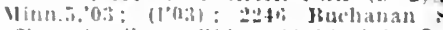

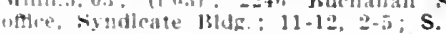

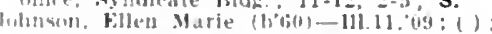
it Lilke st. ObG.

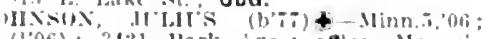
(1'06): 3f:1 l'ark Are; riftce. Masinte Te+uple: $11-1: 2,3-5: N P$.

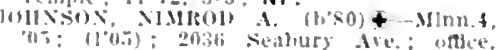

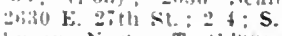

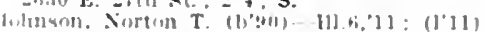

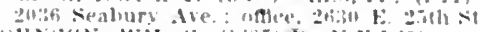

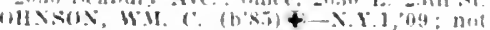
in practice: 31: 8th Are. s. lonfrersity if Mnmevital ifio.

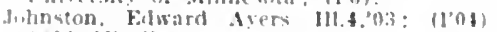

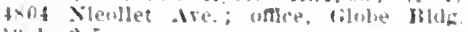
$111.1,=-$

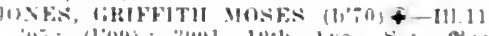

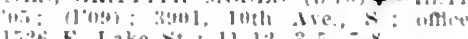

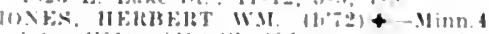

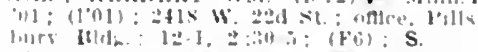

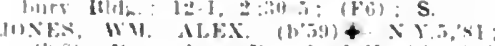

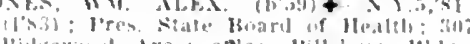

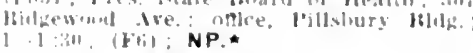

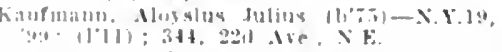

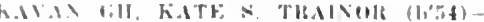

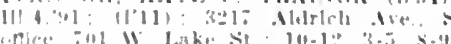

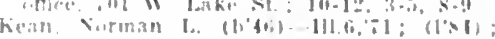
bill lowpme Iw"

lif.l:

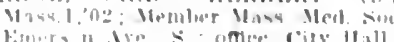

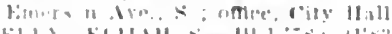

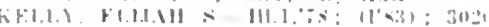

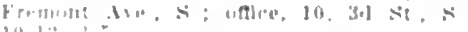

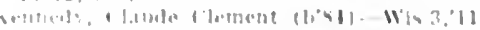

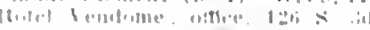

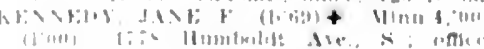

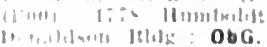
(1) $181,1 \mathrm{k}: 0 \mathrm{Obg}$

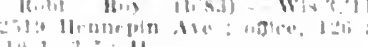

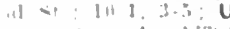

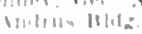

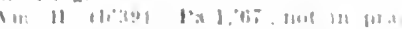

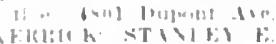

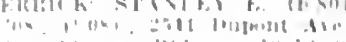

U1: $O A$, OALP.

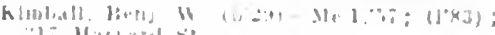

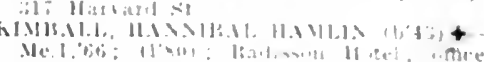

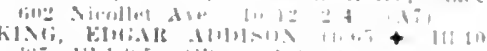

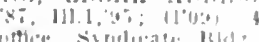

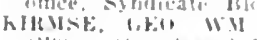

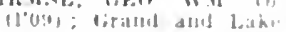

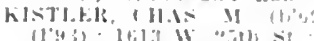

lidaz: :-6; $\mathrm{S}$

hIST.KR JUNAS

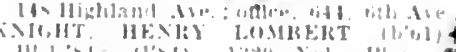

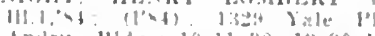

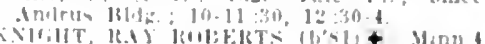

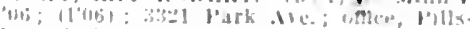

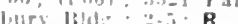

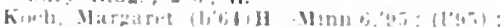

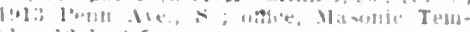
we: $1:-1,:-2$

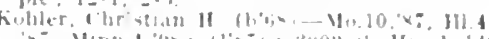

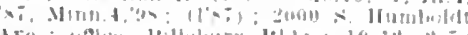

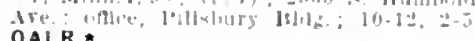
OALR. *

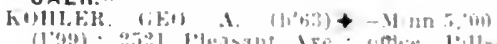

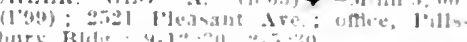
hill.t. Jolls lilis

$(90)+-119: 1$

Kerner, Waber Jahn (bis)-Minnt,11

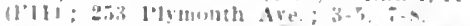

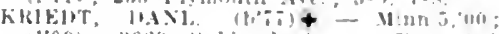

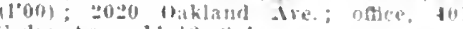
Colat Are. : 11-1:-

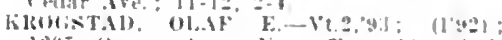

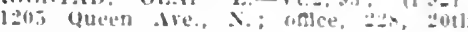
die.. N.

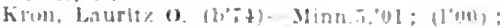
lanil entral are.

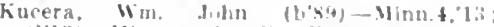

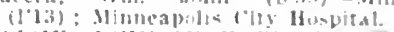

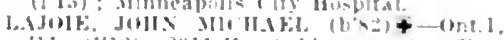

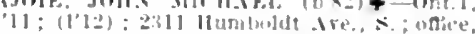
homaldsen bigl; : 10-1:; 1.

balliberte, Ifrom It (tho - Que 3, of

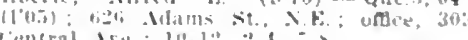
fencral Ire: $111.12,04:$

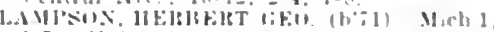

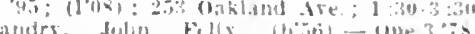
(1)

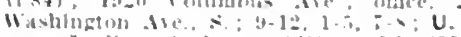

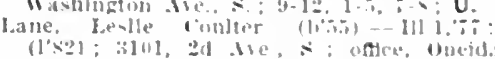

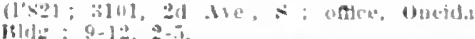

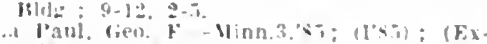

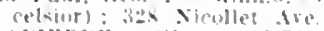

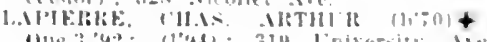
(3)

-.s. Ave. SE: Aste l'rof liacs. Monnt:

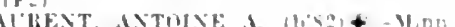

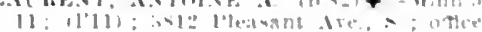

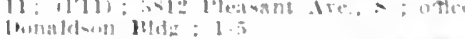

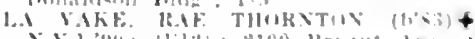

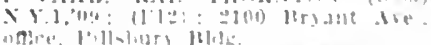

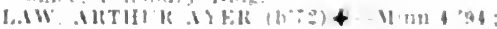

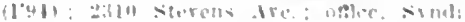

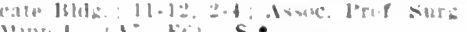

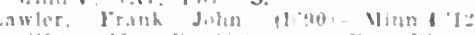

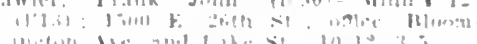

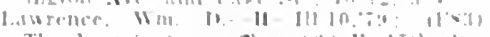

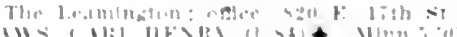

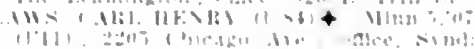

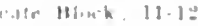

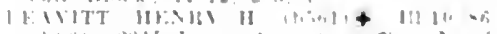

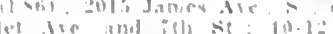

II: O, OALA.

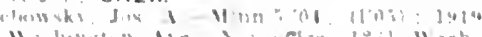

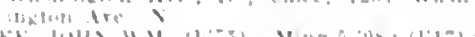

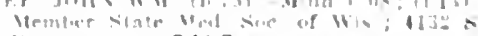
Itr) ane he OALR:

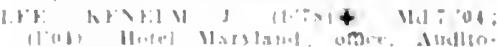
T'um 111:- 


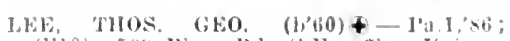
(1'10); 509 kiver lod. S.E; oftlee, I niverslty op Mlnnesota; l'rof. Combratilue Anat., Mhon. ; (F1)

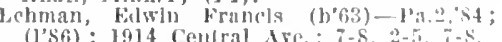

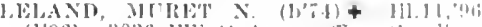

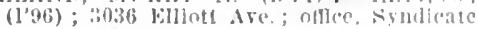
Pililg.: 1 -:

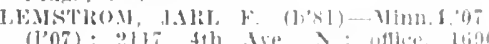
(1'07); 2117, 4th

leonarl, Wm, Eitwin (bos) II-Pa.4, ty

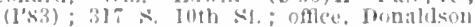

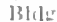

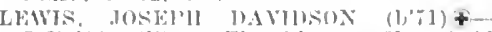

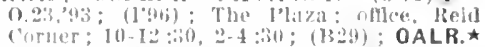

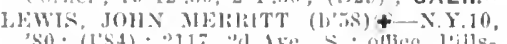

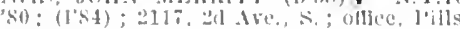
bury Midg.

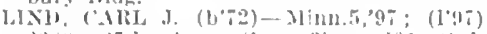
20010.

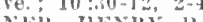

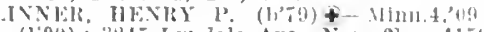

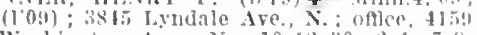

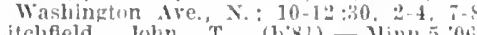
(1'06); 1520 W. WIst St, aflice, Andrus 13]dg. ; $11-1,3-5$

LITTLE, JOIIN HARIREN $\left(b^{\prime} 59\right)+$ l'a.2 $^{2}$ 83; (1'83); 2540 Pnitland Are.; ufflce

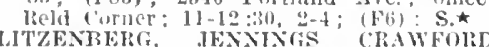
$\left(b^{\prime} 70\right)+$ Minn.t, $09 ; \quad\left(1^{\circ} 00\right) ; 3137$ Park Are.; ollee, Dnnaldson Bldg. : 3-5; I'rof.

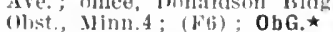

IORERG, AHOI.PH E. $\left(\mathrm{b}^{\prime} 66\right) \neq-$ Minn.4,01 ; (1'99); 1909 Wailington Are., S.; offlee, 221 Cédar ire., s.: $9: 30-11,2-4$

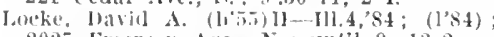
2027 Emerson Ave.. N.; mill 9, $12-2$.

Loekwood, s. O.-Minn.5,94; $(1,00) ; 4141$ Washlugton Ave. $\times$; $1-4$.

Lolller, Chas. 1. (b'7i)-Mo.2s.00; (1’05); 809 Douglas ire.; offlce, Anchus Bldg.

LONG. JESSE E. (b'58)†-Ill.1,'82; (1'85) 1208, 4 th St., S.E.; offlee, 228 Filymouth Ave., N., 11-12, 2-3.

Lore, Fred Andrew (b'88)-Minn.4,'13 (I'I3) : Asbury Methodist Deaconess Hospltal.

LUTHER, CLARA M. (b'59)-Minn.5.'01; (1'01); 1775 Hennepin Ave; offlee, Donaldson Blilg.; 10-5.

LYNCI, MATTHEW JOHN (b'7)థ-III.1 05; (1'06); 2416 Nicollet Are.; offlee, Masonie Temple; $11-1,3-5$.

Lynch. Rout. Fulton (b'5i)-0.2,'s2 ; (1'83) ; Bradley IIotel; office, 1'jllsbury Blde. $9-12: 30,2-6$

LYON, JOHN DEXTER (b'75)\$-Ill.6, 04 (1'04); Jember Iowa State Ned. Soc. 3617 Pleasant Ave.; offlce, sindieate Bldg. ; $10-1,3-6,7-8$.

Lysne, Henry (b'83)-Minn.4,'10; (l'10) ; 700,20 th AFe., N.

MACDOXILD, DANI.A. (b'86) §-Minn.5 09; (1'10); 2020 Elllott Are. ; offee, 1211 E. Franklin Ave.; $11-12,2-4,7-8$.

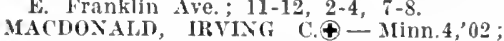
(1'02) ; 727, 2d St., N.E. ; oftee, Syndicaté BIdg. ; $10-12,3-5 ; 0$ bG. Mackeen, Ida A.-Minn.6,04; $\left(l^{\prime} 04\right) ; 1208$
Franklin Ire., W.; office, Masonlc Temple.

MACNIE, JOHN SILILMAN $\left(b^{*} 74\right) \oplus-N . Y .1$ 96 ; (1'98); 2113 Bryant Ave., S. ; offlee Donaldson Bldg.; 10-12:30, 3-5; Asst. Prof. Dis, Eye, Ear, Nose and 'Throat, Minn.4,; (B29) ; OAĹR.ネ

Magnusson, Gustát Alfred (b'80)-Mlnn.4, '08; (1'08); 320 Walnut St.; offee, Uni versity of Minnesota.

MAGUIRE. MARTIN FRANCIS (b'72) Mo.34,0S; 2339 Central Ave.; $11-12$.

MALAND, CLARENCE O. (b'81) -Minn.4, '07; (1'07) ; 3728 Colfax Ave., S.; offle, Reid Corner: $11-12,2-4,7-8$

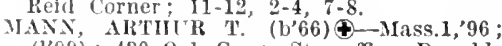
(l'99) ; 430 Oak Grove St. ; office, Donaldson Bidg. ; 1-12, 3-4; Asst. Prof. Surg., Minn.4,; $(\Lambda 7, \mathrm{~F} 6) ; \mathrm{S}$.

Mann, Wm. A.-D.C.3,'So; (1's7) ; 3109 Fremont Are, S ; offece, 608 Nlcollet Are.

WAIRLEY, WALTER J. (b'67) థ-Mass.5, (iftlce, Reid Corner; $2: 30-5$.
MARK, DANL, BENJ ( $\left.{ }^{\prime} 80\right)$ - Mo.28,09; (l'lis): M(m) IIl. Slate Med. Soc.

Jirk, Jos $\left(11^{\prime}-2\right) \rightarrow 0 ;(1 ' 33) ; 2433$ Finerson Ale., S.; oftice, 108 llennejuln Ave.; 9-12,

Matchan, Glemn H. (1,76) II-Mlnu,6,99; (I'!!1): 43:5 Xerxes Ave., S.; offlee, . 1a surnis: Temple; 11-3.

Malchitn. Robt. J. (b'54) $11-1$ 'at, 95

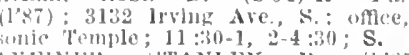

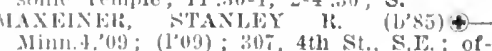
Nimn. 09 ; $(109) ; 307,4$ th St., S.I.; of flee, lieid Corner; 12-1,3-5.

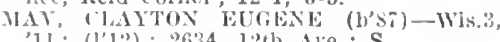

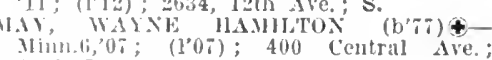

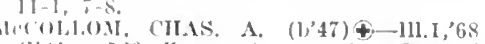
(1's1); 520 Forest Ave; Whice, Masonic remple ; $11-12: 30,2-5$

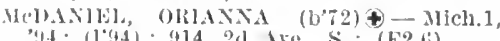

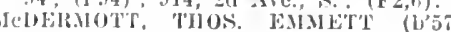
I11.6, $\times 3$; (1'07); s01 Irvlug Are offle, bomaldson bldg. ; $2-4: 30$.

MeDonald, Clás. A. (b'85)-111.22,'13 Intern, sit. Barnabas' Ifospital.

MeDONALI, IIUGII N. (b'63) \&-Que.1,' 89 $\left(l^{\prime} 90\right)$; 40 I, 4th St., S.E. ; oftice, 329 Central ile.; $2-4$

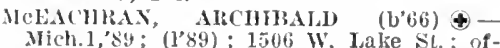
Mich.1,'s9; (Y89); 1506 W. Lake SL. ; of -
flee, syndieate Bldg.; 10-12:30,2-5; S. MeIntyre, Geo. (b'63) Mich.1,'87; (1'07)
80 Orlin Are. S.E.; OALR.

MeIAUGHLJ, JAMES A. (b'70)Ð-Que.1 'y. (I'y4); 3241 Stevens Are.; offlee, MLAD, HARION A.†-N.Y.14,'95; (1'99); IIampshire Arms.

Meligan, David [). (b’91)-Wis.6,'13; Intern, St. Mary's Ifospital.

Meland, Orville Newton ( $\left.b^{\prime} 89\right)$-Minn.4,'13; (1'13); Iniversity of Minnesota Hospital. Meleck, Hertz N. (b'7y)-Minn.5,03; (1'03) $928,2 d$ St. N.E.; office, 1001 Main St. N.E. ; $10-1 \%, 2-4,7-8$.

MEYER, ETTE LAWRENCE (b's2) \&Minn.4,05; (1'05); 3844 Lyndale Ave., S.; office, 3006 Nlcollet Ave.; $10: 30-12,2: 30-5$. Miller, IIenrietta Puthor ( $\left.b^{\prime} 67\right)-0.20 ; y$; (1'01) ; 1300, 20th Ave., N.; 8-9, 3-5.

MILLER, HLGO H. (b'66) †-Minn.5,'92 (Y92); 2744 Bryant Ire., S.; office, Syndieate BIdg.

Miller, Troy S. (b'81) -Mrinn.5,'08; (l'09) 3128 Chieago Are.; offlee, Medical Block; $2-4,7-8$.

Mills, Geo. E. (b'7 $) \rightarrow$; (\$); The Leamington; offee, Hulet Bloek.

(b'76) 4 -Minn.5 $00 ;(100)$; 2001 Girald Ave., S. ; office Pillsbury Bldg; 10-12, 2-5.

Mitehell, Wn. Hobart - N.Y.19, 08; $14_{22} \mathrm{~W}$. Lake St. Moats, Virgil H. (b'72)-Minn.5,'08;
3605,3 d Ave., S.

Ioeller, Maximilian W. (b'90)-Wis.6,'13; Intern, Norweglan Veaconess Ilospital.

Moen, Johannes K. (b'67) - Jinn.4,'93; (1'93) ; 3147 Cedar Are.; offee, 2629 E. Lake St.; $10-12,3-5$.

Moersch, Fred Iaul (1,90) - Minn.4,'13; (1'13); University of Minnesota Hospltal. Isyndale Ave. S. ; office, 2 ; $\left(l^{\prime} 06\right) ; 3444$ 11-12, 3-5; Path.

MONAIIAN, JOIIN A.\&-Minn.5,02; (l'02) 2549 Dupont Are., S.; office, Rejd Corner. Montgomery, Iohn Roe (b'75)-Ill.11,'02; (1'09); 241 Bloomington Are.; 9-11,2-5. MOORE, JAMES EDWARD ( $\left.\mathrm{b}^{\prime} 2\right)-$ N.Y.10,73; (1'S3) ; 1788 Fremont Are., S. : offce, Syndlcate Bldg.; 2-4; Prof. Surg., Minn.4; $A 5,6,7, F 6) ;$

(1,05):014, Moorhead, Arthur C.-Ill.10,02; 2540 Humboldt Are., $\mathrm{S}$.

MOREN, EDWARD (b'76) - Minn.4,'06 (1'06); Donaldson Bldg.; 2-5; (F6); S. MORRISON, ANGUS WASHBURN (b'83)థ $3-4: 30 ;(\mathbf{F} 6) ; \mathbf{N}$.
Morse, JoH: 11.Nolidiy (b'75) +
Mass.1,01; (l'0s); 2511 Washburn Ave

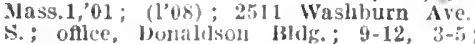
(I:; oftlce, bu

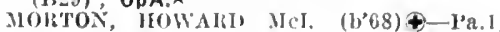
'91; (1'91); :110 ('llifion Are.; oftlee, An clrus H]de; $9: 30-12$, :30-5; (J329) OALR.

loulton, kacluel J-Whun, 502 ; (1'02) IT79 Dipent Are., S.; vfllce, Pllsbur. Bldg.

Mroulton, shuhel I. - kiy,2,92, Ill.6,'03 (l'93); 177 it Dupont Ale., s.; offlce, Plllsbury Bldg.

Mneller, I'Hill - N.Y.5,88; (1'87); 2443 Blalsdell Abo; oftce, $8271 / 2$ Nieollet Ave.

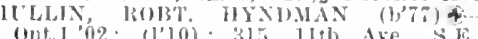
oftlee, siate Hoard of llealh Jaboratorles, tiniverslty of Minnesota: $9-5$ Assoc. J'rof. l’ublic Heallh, Mlnn.4; $\left(\mathrm{F}_{2}\right)$; LD. $\star$

MURDOCK, ALBERT J. (b'47) क-K.Y.1, "70; (1'83); 319 W. 25 th St.; olflee, Ma sonie Temple $1 \mathrm{I}-12,2-4$.

HURI'HY, WA, RERNAIRD $(1,71)+-$ Mirn.5.97; (1'97); 2652 Bloomington Are.; offlce, 1527 E. Lake St. ; $2-4,7-8$.

lurray, Wm. I3.-Minn.5,90; $\left(1^{2} 30\right) ; 3440$

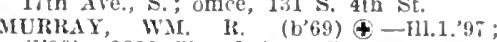
(1'99) ; 2320 Grand Ave., S.; oflee, Syndieate Lloek; 10-12:30, 3-5;' Assoe. I'rof. Dis. Eye, Ear. Nose and Throat, Minn.4; (Jiers, IIm ; OALR,

1509 2d Are S.0-5-D.C.1,61; (1'83)

Nalley, Thos. J. (b'80)-Mo.2,'05; not In practice; 3025 Garfleld Ave., S.

Neal, Homer Herbert (b'85)-. Ho.34, 0 ; $\left(1^{\prime} 10\right) ; 1392$ W. Minnehaha St.

Neill, Chas. II. (b'70) II-Ill.4,, $92 ; \quad\left(l^{\prime} 92\right)$; 2724 Ilumboldt Ave., S.; office, Syndicate Bldg.; $11-1,3: 30-5: 30$.

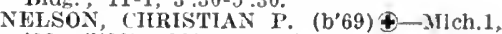
"96; (1'99); 3231 Lyndale Are., N.; offlce, Reid Corner; $2-4$; S.

NELSON, HEYRY S. (b'64)థ-Yinn.4,'93 ; (1'93); 2220 Irving Ave., S.; office, Andrus Bldg. ; 10-1, 3-5; U.

NEWHART, HORACE (b'72) $\oplus$-Mich.1.98; (l'00); 2 I 2 W. $22 \mathrm{~d}$ St.; offlee, Donaldson

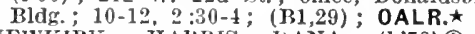

NEWKIRK, IIAHRTS DANA $\left(b^{*} 78\right) €$ Minn.6,'03; (1'03) ; 3241 Dupont
offlee, Donaldson Bldg. ; 1-4; Pd.

NICKERSON, MARGARET LEWIS $\left(b^{\prime} 70\right) \oplus$ -Minn.4,'04; (1'04); 517 Essex St.

IIPPERT, LOLIS A. $\left(b^{\prime} 60\right) \oplus-0.9,83$; (l'85); 1521 Dupont Are., N.; office, Reid Corner; $2-4 ; 1 . \star$
NISSEN, HEXRIK E. (b'64) $\oplus-$ Jorw.I,

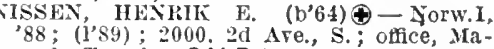
sonlc Temple; OALR.

Noe, I'hilip 1. (b'84)-Wis.3,'12; Intern, St. Mary's Ilospital.

TOONAN, DANI. FRANCIS (b'84)-Minn.4, '13; (1'13); 1618 Bryant Ave., N. Pd. NoOTNAGEI, CHAS. F., YR. (b'63)†N.Y.10,'87; (1'87) ; 2429 Girard Ave., S.
offiee, Andrus Bldg. ; $11-12,3-5$; (F6).

Nordland, Martin (b'89) -Minn.4,'13; (1'13); Minneapolis City Hospital.

Nordley, Harry Richard (b'88)-Minn.4,'12; (1'13); 2013 s. 4th St.

NORRED, CHAS. II. (b'42) \-Pa.2:86 ; (1'86) ; Rogers Hotel; offlce, Andrus Bldg. orrls, Julia Anna-IIl.9,00; not in prae

No'TH, IIENRY Wu. (b'7\%) क-Minn.4, 03 ; (l'03) ; 601 Elwood Are. ; 3-5, 7-8.

NYE, wM. F. (b'57)\$-I1l.6; 78 ; (1'85); 2117 Isyndale Ave., N.; 11-12, 2-4.

OBERG, CARL MAGNÚS $\left(b^{\prime} 76\right) \biguplus$ Minn.5, '99; (1'99); 2519 Grand Are. ; offlee, Syn

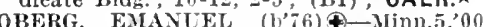

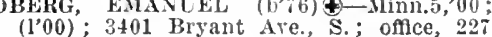
(l'00) ; 3401
Cedar Are.

o'Brien, Richard P. C. (b'63)-Ill.6,'85; (1'85); 1511 Emerson Are., N.; offlce, 608 Nícollet Ave ; $10-12,2-4$

O'Donnell, Dennls 'fichael (b'86)-Ill.I1, '10; (l'13); 1502, 20th Are., N. (l'07); 1801 Portland Are. ; offee, Donaldson Bldg. ; $12-1: 30,4-5: 30$; S. 


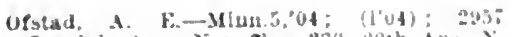
Lyndale Are., $\mathrm{x}$. oalce, 230 , 20th tre.,.

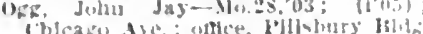

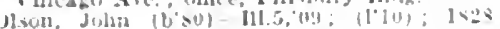
ieniral Aie

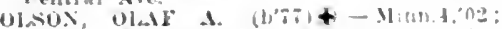
(1002): 9500 (hicalo ire; uale, $2 \pm 1$ cedar lie ; $11-12,2-t, 7-x ; s$;

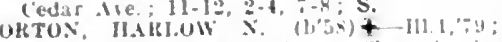
(l's3): 2101 ploanant Ale; ot crate lidk2: $11-1 \%, 3-5$

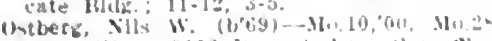

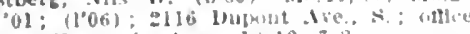
301 llenncpin Ale, : 10-12, i-8.

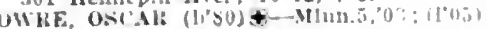

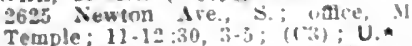

Temple: $11-12$ :30, $3-5 ;((3) ; 0.11 \%$

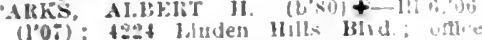
(bonaldicon Bld: : 12-3: $\mathbf{S}$.

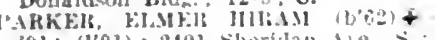

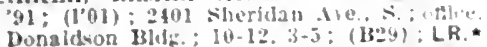

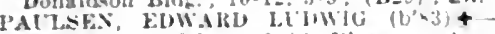

Mlantiog; (100!); 3103 learant s. offce, 3 k. Lake St.

learsall, thetwe I. (L's3) - Mimn.4, 1 \% (1'13): University hospital.

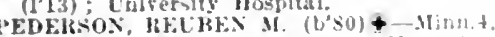
'00; $\left(l^{\prime} 06\right) ; 2610$ Fremolit Aie., $X$; unle,

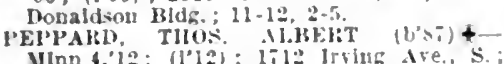
ofice, syodicate ridg ; 3-6.

l'ETERs, RALll H. (b',2) \&-111,1,94;

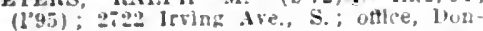
aldson bidg. : $12-1$, $f-5$

IETERSEX, JOII HCHALD $(, \% 2)+$

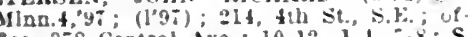
fce, 378 central ive: $10-12,1-4, ;-8 ; s$

petersoa, Clarence Melin (b's6)-1a.b, 13 Intern. Swedlsh Hospltal.

letit, Leon Julien (b'85) - Minu.s.' In

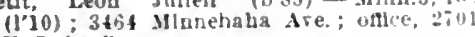

E. Lake St.
['ETTIT, CHAS. W. (6'7) \&-yina.t, 0 : (1'03): 3228 chleago Are, oflec, lieis Cortuer; 11-12:30,2:30-5; $\mathbf{0 b}$.

Phelan, HJchard J. $(b, 6)-M \ln n .4,03$ (l'03) : 1435 Idams st. ; offle, $72 x$ ito tral Are. : $2-4 ; 5$.

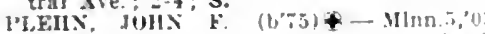

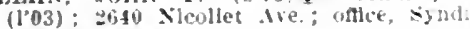
cate Bidg. ; $2-4$.

PHILLER. IILGO (b*38)-0; not in prir Uce; Meinber state Med. Soc of Wil. Hinnesota Soldiers' Home.

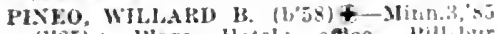
(1'85); 1'laza botel: otlee, l'illobur H1dg.: $9: 30-1: 2,2: 30-5 ;(13: 9) ;$ OLR.

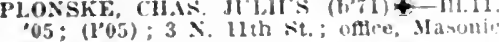
Temple; $9: 30-12,1: 30-5$.

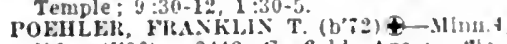
$96 ;$ (I'06): 2443 Garfleld Are.; uttice Reld Corner; $10:: 30-12,2: 30-4$.

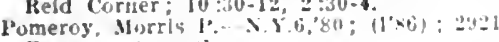
Emerson Are.. s.:

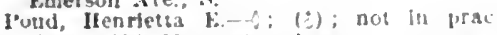
tlce; 12l2 Marquette Sie.

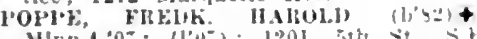

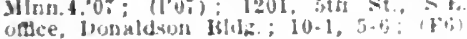
S.

Purteous, Wm. N. (b.56)-Que $1, x+$

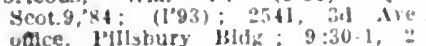
uflce,

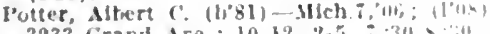
3233 Grand Are ; 10-12, 2-5, 30,01

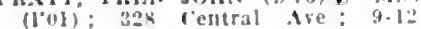
(B1,29); OALR.*

prelne frime Arthur (1,55) ...Mann + le

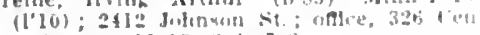
tral Ave; $11-12,2-7, i-1$.

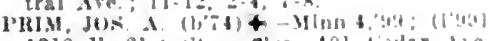
1216 b. $213 t$ st.; inlee, 401 indar sie $10-12,2-4,7-3$.

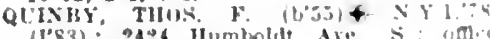
Innaldent Hdg.: $11-12,2: 30-4: 30^{\circ}$

Innaldent Hdg. $11-12,2: 30-4 ; 30$.

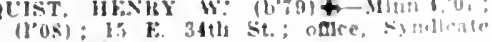
Hlde: : $\mathbf{s .}$

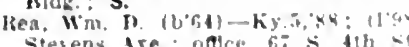

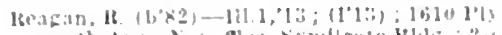

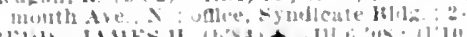

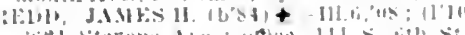

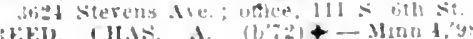

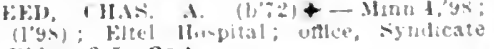
Hd: ; $2-5$; Or.

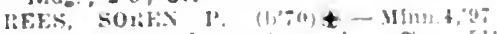

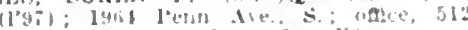

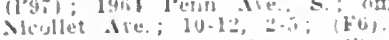

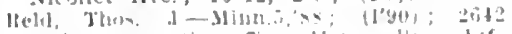

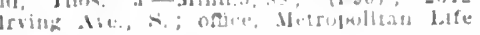
HId

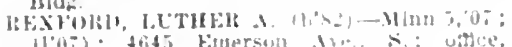
(100): teiti Einerson

symelicale Math.

(100) : 3104 timerson

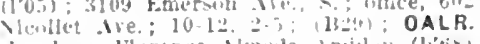

Iinnt, 45

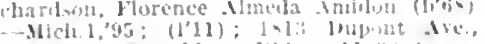

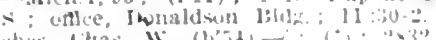

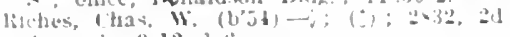
lie., $5: 9-12,2-6$.

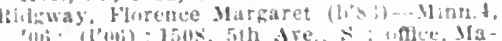
sonic Teurle ; 10.12,

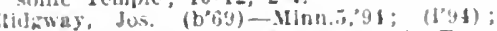

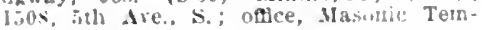
ple: $10-12,2-4$.

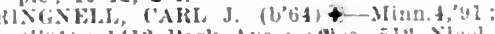

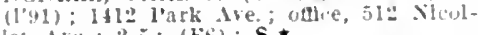
lei Ark;

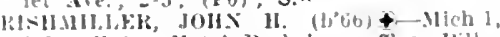
91; (1'y1); llotel Berkeley; oftce, l'ills: liury lidg; $10-12,2-4: 39 ; \mathrm{s}$.

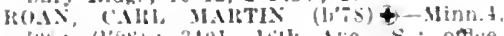
"11); (l'os): 3401, lith tre. S.;

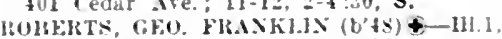
$\because 2, \times 1,9,81$; (l'st); Hampshlre Arms: Hice, lollsbury Hldg, 10-1.

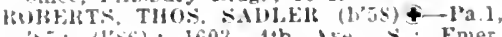
stof. I"sed. Minn.1; Pd.

HOBEITS WM k. $(1,75)+-1, a, 01$

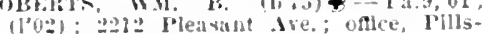

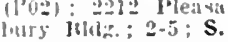

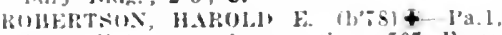
"15: 11'10); nut in praptice; $50 \overrightarrow{7}$ kssex St., S.E; w wtee, Lnlrersity of MInnesota

hulilliard, chas. iforton (b'st)-Minnt. 'l:; (1'13); st. Barnabas Hospltal.

'll,; (l'l3); st. Barnabas Hosnltal. Inon.t 03: (1.03)": 1913 mupont are., s.; oflce lillstiury Bldg: 11-4: $\mathrm{S}$

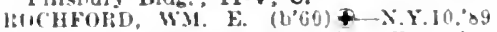
$(1048) ; 1640$ James Are., s.; office, syndlente Fidg.; (Ai); $\mathbf{S}$.

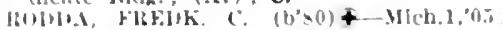

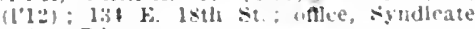
liliti: Pd.

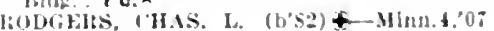

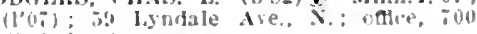
II lake sit.

ROSEN, SAML. (b'SO) - Minnt,0t

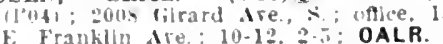

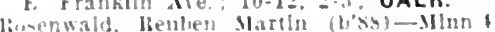
'lit: (l'I3) : 1'ity Hospltal.

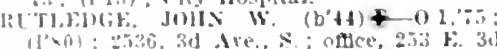
I1 1 , s. ; $10-12,3-5$.

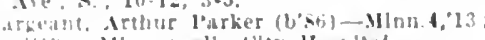

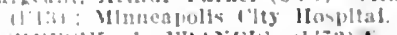

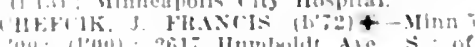
He. Maring Temple; 10-12, I:30 :

OALR. *

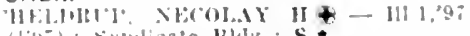

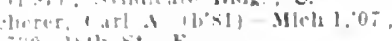

?in. inll $=$ it.

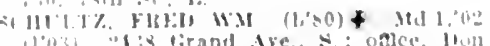

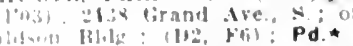

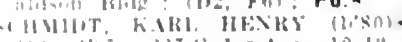
hames

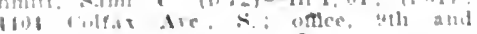
Vewllet Ires: $11-1,2-5: 5$.

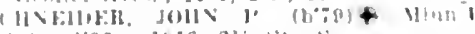

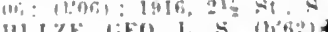

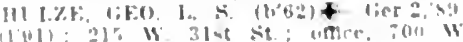
t.ahe sie : $3-5$
SI IIWYZEI?

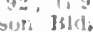

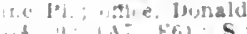

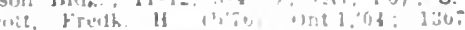

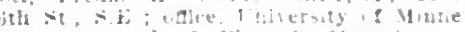

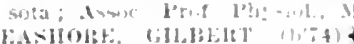

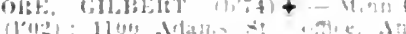

drus b!dz: $11-12,+1+1$.

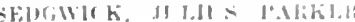

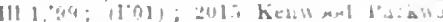

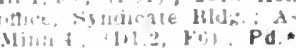

SEECIK, STANLEY JOS.

(1'l.i, , b. thabloten bld

"all, mante slaney (b kn

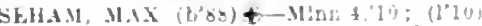

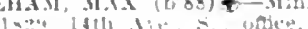

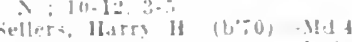

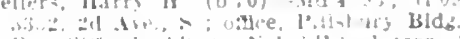

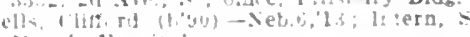

Marys lloplital

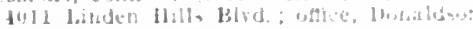
l,! 11, ; $11-12,3-3$.

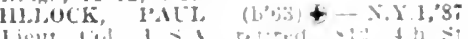

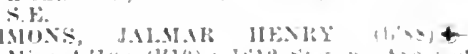
Itintat, lo: (l'10); lólz stebern die. of Blde.

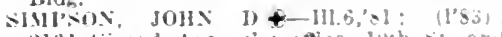

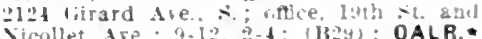
Nicollet Are.; $9-12,2-1 ;(B 2 y) ;$ OALR. nelair, Irthur

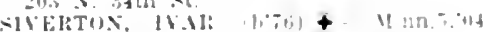
(l'ot): sio0, lith Aie., 5 ; once, synd!

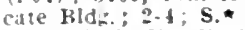

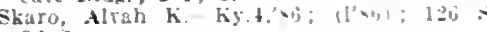
$3 \mathrm{~d}$ St.

SLOCLMB, M.11UE, STHIHE.S (b\$1) 111.11,05; (l'00i); sisos kremont Are., 5

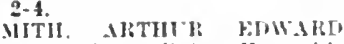

Ilna.1,05; (100): Hamphire Irma uf fle, Dunaldion klds.; 11-1, 3-6; OALR.*

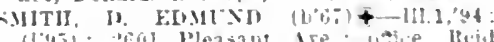
1.451; 2nol pleasant

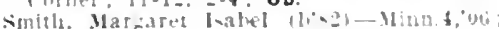
(I.06); $19 \pm 0$ Emerson Ave.

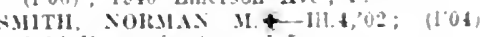
3014 Hennepin dve: $1-5$.

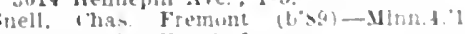
(l'13): city llowpltal.

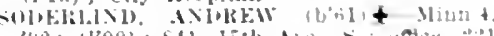

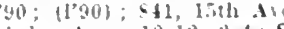

Cular $11,2,10-12,2-4: 5$.

speler, Ilua (boo)-bium.t. Itilt. ith st. $5 \mathbf{E}$.

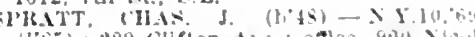

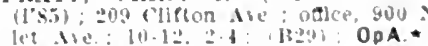

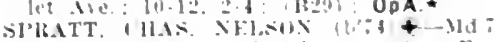

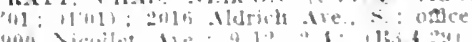
OALR.

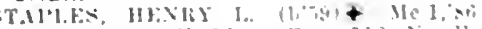

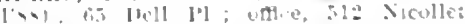
Ire: $10-12.2 \cdot t$

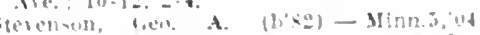

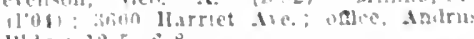
k112: $1=5,6-8$.

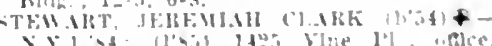

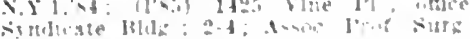
vilum t: (1:): S.

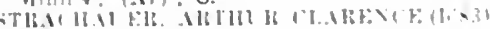

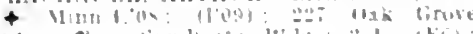
S.

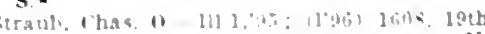

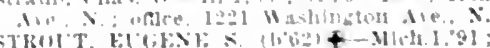

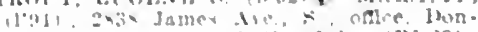

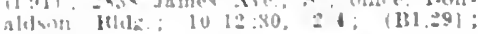
OALR.*

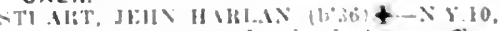

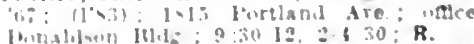

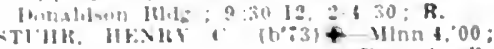

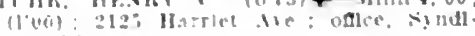
infe It\}t 


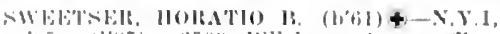

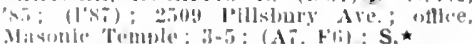

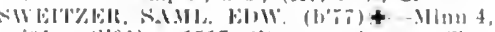

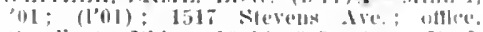

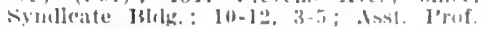

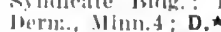

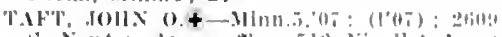

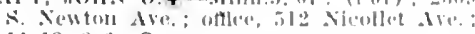
$11-12,2-6 ; S$.

Taft, Walter 1,oremon (bess) Wivel,

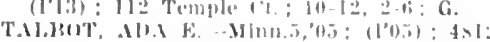

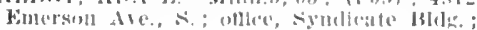

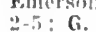

T:10lo

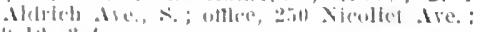
1.-1:2. $2-4$

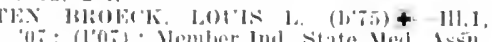

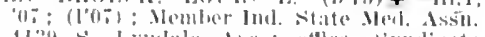

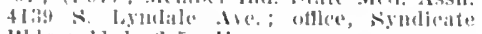
IBldin. ; 11-i, 2-7; U.

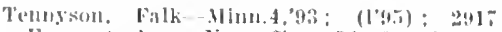
Fremont Are., $\mathrm{N}$.: offlce, $54 \mathrm{~s}$. id st. also 1:13] Waslulugton Ave.

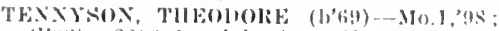
(l'4s) ; 2000 lyndiale Ave., $x$; otllee, il. 31 St. ; $11-1 ; \mathbf{S}$.

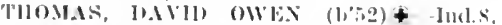

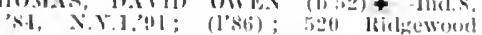
ive. : oflec, Misonle Temule: $2-1$.

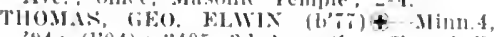
04: (1'04): 3405,31 Are., $s$; offlec, 1 F lake sit.; $10-12,2-4 ; G$.

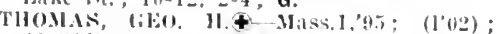
86 W'llow st. : otflce, Plllshury Bldg. TIROMPSOX, HFIBEl'T HENR (h'si) 'ra.2, 09 ; (1'13); (1667 )ayton Are. ['aul); offle, Reld corner: 11-1, $3-5$.

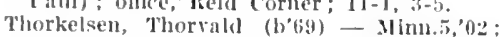

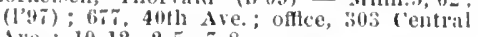
Ale, $10-12,2-5,7-8$

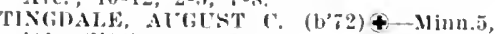
02; (l'02) ; 2951 Jark Ave.; offle, syndicate Bldip.

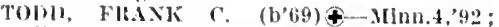
(l'y2); 2d Vice-lires. Amerlcan Medical tssn. 4ll Groveland American Bedical Assh.; 4ll Grovelatirl Are.; offlce, 1)onaldson bldg. : 10-1; l'pof. Ils. lye, Ear,
Nose and Throat, Minn.4; (B1,s,29); OALR. *

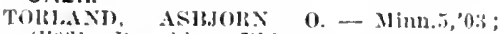
(li):b); Inomallson bldg.

TOWEItS, FllANK E.-N.Y.5, 75; (1'83) ; 4825 Vincent dre., $s . ;$ offlce, Jillsinry Bldg.; 1 11-12, 2-4; U.

Tuwers, Mary' E-Wllnn.4,98; (1'98); 4825 Vhrent die., s

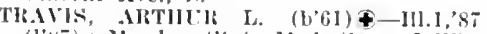
$(1 \times 5)$; Member state Meol. Soc of Wis. 506. listh Are., s.5.; oftce, cedar Ave and lake st.; $10-12,2-4,7-8 ; U$.

Tuke, llarry C. (b'63)-Minn.5,?6; (1’02); 4024 snellng Ave, oftlce, soldlers' IIome.

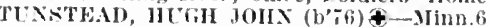
01: (1'01): 1524 x. Bryant Ave. office, lillisbury rikle.; $2-5: 30 ; 0$ b.

'Tupper, im. G. W. (b'65)-Mich.1,'84: $(1,86)$; ils, ith Are., s.E.; offlee, 30 central Are.

TYIIIELL, CIINTON C. $\left(b^{\prime} 76\right)-M i n n .4,06$ (1'ofi); 2422 Johnson st.; offece, $242 \mathrm{~s}$ central Ave: 4-6, $\%-8$.

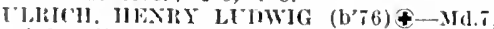
'0I ; (1'0z); 1718 Oliver Ave., S.; office. syndicate Bldg.; 10-12, after $5 ;($ F6) I. *

CIRICH, MABEL SIMIS (b'-6) $\$-M d .7$ 01; (1.03): 1708 Ollver Are., S.; offee,

valiely, lase Y. (b'76)-Minn.4,01; (1'01) llampshire Arms; office, Andrus Bldg. ; 10-12:30, $2-1 ; 0$

Y.I. THBOGE'T, I.EWIS $\left(b^{\prime}-4\right) \notin-M i n n .5$ (19); (1'09) : Hotel Warerly; office, $126 \mathrm{~S}$. $3 e 1$ st. ; 10-12, $2-5$.

insitka, Joln (b’54)- 0 ; (む); 3356 Chicago tre., $s$.

Celine. Olaf J. (b’66)-Minn.5,97; (1'9s); (2257 $\mathrm{N}$. Langford St., St. l'aul); oftice, 1.sin remple $r$ t.

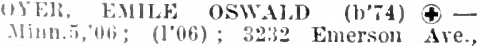
s. : vflice, Hasmic Temple; $11-12,1-3 ; \mathrm{S}$. Wianer, (has. H. (b'53)-0.7,73; (1'83);

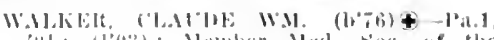

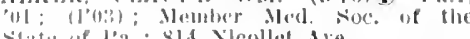
sliste of l'a.; sla Neollet dre.

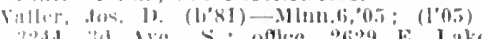

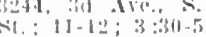

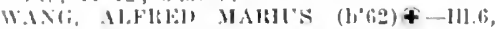

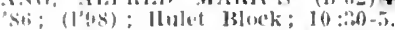

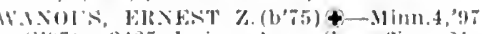
(I'!1) : 2425 Irving Ave., S.; othice, Mit scmli" ireminle: 11-1, 3-5; s.

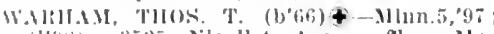

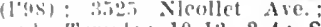

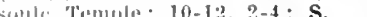

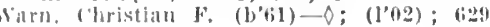
cellar Are.

Warwiek, Mary Margaret (b'8ti) - Mimn.4, 1:3: (1'l:3): 1516, ith St, S.E.: offlere luiversify of Minnesota.

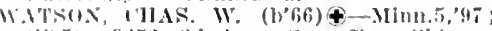

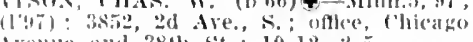

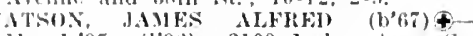
llan. 950 (1996), 2100 Irvlng Ave s.

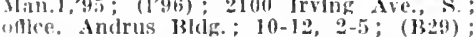
OALR. *

Willes, Henry Journeay (b’-6) -Mhnn.4, 01 ; (l'01); 19i6 Park Ave.; office, IIasonle Temple : OALR.

Wescott, (iuy ll. (1,25)-l'a.19,'70; not In pritefle; ig0s Jawthorne Are.

WHTON, ('IIAS. G. (b'58)థ-Mass.1.'82; (l'S9); 2107 Colfax Ave. S. ; offlee. Hed Corner; $11: 30-12: 30,3-5 ;(F 6) ; 0 b G$.

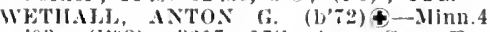
0.3; (1'03); 321\%, 17th live., s.; offle 3:5ं Cedar Are.

WIEAT, FILIKK. C. (b'69) \&-I11,11,01; (l'i1); 3325 Irving ive., S.; ofllce, Syndicate Iblag.: 10-12, 2-5.

WHETSTOAE, MAli I. S. (b'43) HETSTONE, MAlRY
Mleh.1,81: (I'83); 608 Nicollet Are.; Ileh.1,81: ('83);
$11: 30-12,2-4 ; 0$ bG.

WHPPIE, (LAREXCE D.†-MInn.4,03; (l'03) ; $273 \%$ Chlcago Are.; offee, Pillsbury Blilg.

WIITE, SOLOX MARX (b'73)£-Ill.6,97; (1'99); 424 Walnut St., S.F.; office, Donalclson Bldg.: 10-12; Assoc.' I'rof. Med. aldinn.4; (1.6): $1, \star$

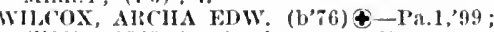
$\left(l^{\prime} 00\right) ; 2833$ Portland Ave.: oftlee, lon aldson 11dg.; $11-1,2-4 ;(\mathrm{F} 6)$.

Wilcox, Asi S.-H-I'a.9,85; (1'85); 116 Oak Grove St.

WHCOX, M, RLSSELL (b'69) -M-Mnn.4, 97; (1'97): 3343 Calhoun Blrd.: offlce, Norwegian Jutheran Deaconess Hospital $10-12,2-6$; Asst. I'rof. Physiol., Ilinu.1; (1329, F6)

W1], $\mathrm{VAx}$ H. (b'71)-Minn.4,02; (l'02); 3023 Dupont Are., s. ; offlee, Syndicate Bldg.: $10: 30-1: 30$

WIJACITT, (IARENCE ELVT (b'84) \&la.3,09; (1'11); Nember Ja. Slate Yred. Sor.; 4441 rpton Are., S.; offlee, 4306 Vutón Are., S.; $2-5$.

WILLAMS, BOỸ THONPSON (b'76)O.8,01; (\#); 2900 Euiversity Ave., S.E. ; $2-4$.

WHLIAMS, CHAS. WINTIROP (b'63) III.6,99; (1'91) ; 3301, 1st Ave., S. ; offlee, Reid Corner; 11-12, 2-4

WILLIAMS, HENRY L. (1,69)@-Pa.1,95; (l'01) ; 1313, 5th St., S.E.; offlee, Donaldson Bldg.; ( 1010$)$; $\mathrm{S}$.

Williams, John Walter (b'85)-Minn.5, 07 ; (l'0i) ; 1810, 11th Ave., s.; offlce, 1211 Franklin Ave, E.; 10-12, 2-4.

WILIAMS, ROBT. (b'73) $\oplus-$ Jll.1,00 (l'00) ; 3436 Chicago Ave.; office, $743 \mathbf{E}$. lake St. ; $10-11,2-4$.

WHMJAM, ULYSEES G. (b'64)€-Minn.4, s9: (1.89): 3128 Portland Ave. $;$ offlee, syndicate kidg.: $11-12: 30,3-5 ; \dot{S}$.

wilsox, HCGII SJAILDIXg (b' Minn.4,04; (1'04); Nember x.J. State Yled. Assil.; Hotel Leamington; office. 900 Nicollet Ave. : $3-5 ; 1, \star$

WITHAM, CARL ALBION (b'82)థ-Minn.4, 06: (1'06): 3036, 10th Are., S.: office 1522 lake si., E.; $10-12,2-5,7-8$.

Wohlrabe, Arthur Albert (b'88)-Minn.4,'13; (l'13); City Hosputal.

Wolski, Robt. A. (b’ '5)-Minn.4, 00 ; (1'00) 132s N.E. 4th St.; 10-12, 3-5, $\mathbf{i}-8$.
Woltmann, II'nry Wm. Fredk. (b'89) Ilnu.4,1:3: (1'13): I'niversity Hospital.

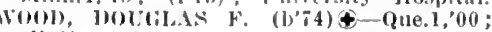
$\left(l^{\prime} 00\right) ; 4601$ I'pton Are., s, ollice, Donaldson 18ldg,; y.I2:30, 2-5; (B1,29); OALR.

Woul, Hiram D., .1r. (1) 71$)$ II - Jl.4,97. $(190) ; 2704,3$ d A ve., s.; ollice, Jlllsbury Hidg. : 11-12, $2-4$.

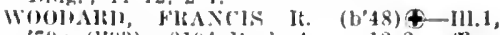
79: (1'83) : 2104 ]'ark Are.; 12-2; otflee, l'illsburs lshig.: 4-6.

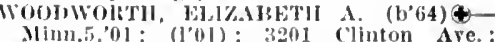

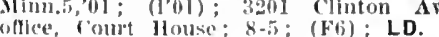

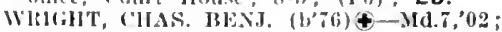
(l'04); 2119 Aldrlch Are., S.; offlce, Synilleate' lilug, ; $11-1,4-5: 30$.

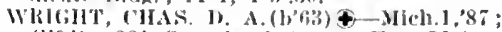
(I'94); 221 Groveland Ave.; offlee, Metronolitan I.lfe 13ldg.; 10-12, $1: 30-5$,

WIIGIT, FHANKIIX R. (b'66) $\mathbf{c}-M i n n .4$, 94; (l'94); 1806 J'ark Are.; ollice, Donaldson lbldg.; 2 :30-5; Asst. Prof.' Gen.[rin. I)ls., Minn.4; (C3.F6); U.ネ

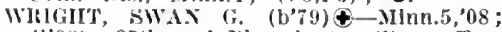
(1'08); 35 th and Bloomington sts.; offlee,
i1) Nicollet Ave.; I0-12, 2-5; OALR.

Wyat, John Higby (b'45)-; (d); not in pratedle: 2440 portiand Ave.

FOELG, OTTO WM. (b'86)థ-MInn.4,'10 (1'10); 409 Franklin Ave., W.; office, Syndicate IHIdg. ; 3-5; S.

Zatworskl, Hdw. Antliony (b'85) - Neb.6,11 ; (I'12) ; 829 Universily Are., N.E. ; offlee, 1700, 4 th st., N.E.

ZISKIX, TIOS. (b'88)-MInn.4,11; (1'11) ; 3 Highland Are.; office, 542 Aldrich Ave., న.; $10-12,2-4,7-8$.

MINNEISKA, 395, WABASHA

×AUTH, WALTER W. (b'83)థ-W1s.2,07 ; (1'10).

MINNEOTA, 819 , LYON

SANDLRSOX, EDWAIT T. $\left(\mathrm{b}^{\prime} 75\right) \oplus-111.8$, THOltodlesos, THEO. (b'65)థ-H1.11,'97 ; (1'9T).

MINNESOTA LAKE, 445, FARIBAULT

Hickford, Harley G. (b'6) II-Mlnn,6,01; (l'01).

MIZPAH, 149, KOOCHICHING

Shalett, ISenj. Jos. (b'87)-Ill.6,'11; (l'12). MONTEREY, 177, MARTIN

JUTZ, JOS. AAROS-III.8,'02; (l'02).

MONTEVIDEO, 3,056, CHIPPEWA

PATON, RISSELL S'TEWART (b'59)థ$111.1,85 ;(1 ' 85)$.

BFIRGH, LUTHAItD $\mathrm{x} . \quad\left(\mathrm{b}^{\prime} 80\right) థ-M m n .4$, BERSs, FLOYD W. (b'76)-111.11,02; PIINS, S. ALPIIEUS (b'74)థ-Minn.4, , $96 ;(1,96) ; \mathrm{S}$.

JUINSON, CalliL M. (b'82)-Minn.4,'10; $\left(l^{\prime} 10\right)$.

JINA, LCDWJG (b'6 )-.IInn.5,03; (1'03) ; Irurihy, Lea (b'49)-Ill.1,'74; (1'83).

SIITII, J.LON GRANT (b'S7)-Minn.4,'10; (l'11).

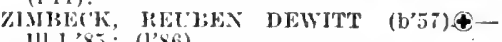
III.1,'85; (l'86).

MONTGOMERY, 1,267, LESUEUR

MeKEOX, J.MEA $\left(-b^{\prime} 61\right) \oplus-N . Y .10,{ }^{\prime} 89$, Minn, 90 ; $(190)$; $S$.

WHSTEMAS, FRED CHAS. (b'8T) $\oplus-$

Wis.3,'10; (1'10).

MONTICELLO, 858, WRIGHT

(iib)s, Elam S.--0.11,69; (l'83).

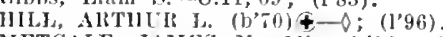

METCAIF, JAMES N.-Minn.4,06; (l'06).

MONTROSE, 284, WRIGHT

HAWKINS, EIW. I. (b'63)థ-Mich.1,97; (1'9i).

MOORHEAD, 4,840, CLAY

AlWTY, WXI. J. (b'62) \&-Ont.3,'91 ; (l'92). Brendenmuehl, Fredk. (b'38) H-Ill.4,65;

DiRirow, DANL. C. (b'50)Ð- Ill.1,'84; (1'84).

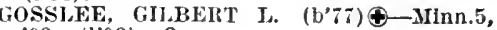
03; (1'03); S. 


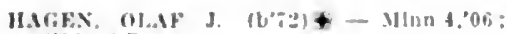
$\left(10^{\circ} 06\right)$ LR.

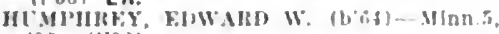
og: (1'02)

VERSE VICTOR k. (b'83)+-Minn d"af: (1"nij).

MOOSE LAKE, 526. CARLTON

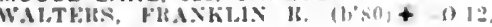
"05: $\left(\eta^{\circ} \cap G\right): S$

MORA 892, KANABEC

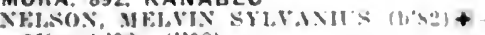
MInn.4, os: $(108)$.

WHITTEL. KAYMONI WMIHT (ban)

MInn.,'12: $(1,1 \pm 1$.

MORGAN, 553. REDWOOD

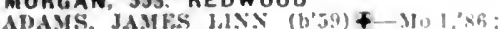
(1'93).

MORRIS, 1,685, STEVENS

CAISF, CHAS, F, (bos) - Mimt, (1'96)

HTZGEIRALD, KHW, THOS, $(2 \% 5)$ Neb.6,0i: (1'11).

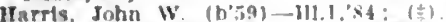
IIVISLRD HEHIERT $33:(1.83)$

Frity ayios $\left(b^{\prime}(8)+-\right.$ J 6 , ns: (10n:) OALR.

MORRISTOWN, 592. RICE

Dargarel John-ont 1.92: 11'92)

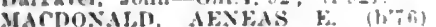
Ont.3.;01: (1001).

MORTON, 761, RENVILLE

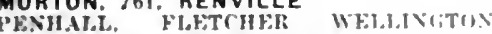
(1,69-1-Ont.3.89. NY 10:91; $(10 ! 1)$

MOTLEY, 428, MORRISON

MeCullakh. (ieo. (b'66) - MInn.5, n.; (l'nt)

MOUND, 300, HENNEPIN

Mikins, John I'-I11.4,"05; (1'0\%): Pr.

MOUNTAIN IRON, I.343, ST. LOUIS

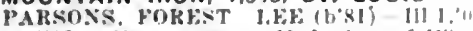

(1'13): Member state Med. Soe of Wis.

MOUNTAIN LAKE, I,08I, COTTONWOOD

COIITFER, HEHER WILSON (b'is)-OUI.: 03: 11 '10).

MURDOCK, 288, SWIFT

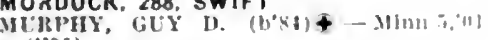
(1"0])。

NASHWAUK, 2,080. ITASCA

Hayea Mllebael b. (b'83) - Mlnnfint (1), Mehae

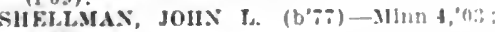
(1'03).

NEVIS, 238, HUBBARD

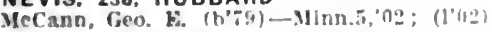

NEW DULUTH. 800 , ST. LOUIS

Spurherk. It,S' fieu. (1,8,

NEWFOLDEN, 200, MARSHALL

IOIINSON, GBO. LETHER (b'-6)-WIS 10: (1')1)

NEW LONDON, 418, KANDIYOHI

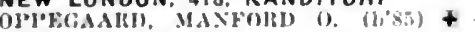
MInn.4.10: (1'10): S

NEWMARKET, 901, SCOTT

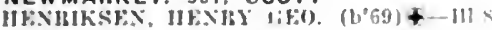
9 : : 11,10$)$

NEWPORT, 370, WASHINGTON

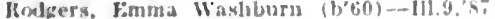
(1'98).

NEW PRAgUe. 1.554. LESUEUR

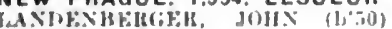
(1'83).

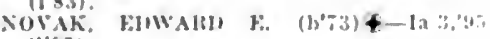
(1'

NEW RICHLAND, 685, WASECA

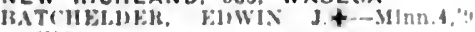

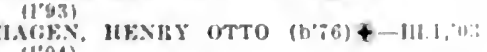
(1'04).

\section{NEW ULM, 5.648, BROWN}

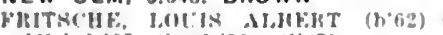

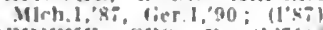

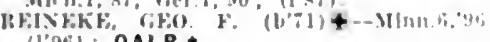
(I'Di): OALR.

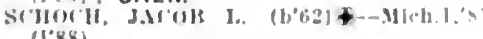

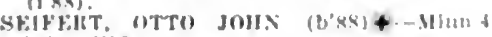

'19: 11 '121.

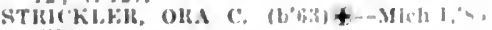
(1.83)

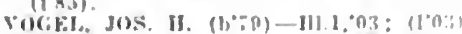

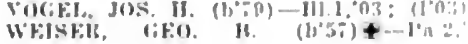
(1'09).
NEW YORK MILLS, 474, OTTERTAIL

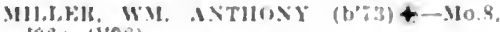
96: $\left(1^{\prime} 98\right)$.

NICOLLET, 338. NICOLLET

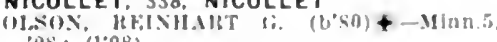
OS: (1"คQ)

NOPEMING - ST. LOUIS

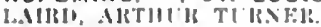

(See juluth.

Marleble, kirnest sidney (h'SR)-Minn A, $1 \%$ 11.131.

NORTH BRANCH, 6\$2, CHISAGO

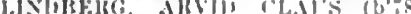

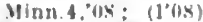

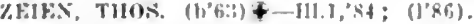

NORTHFIELD, 3,265 , RICE

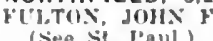

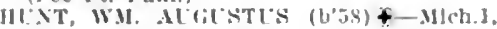
$82 ;(1283)$.

LEF, WY. I'. (b'72)+-MIMn 4, $44 ;(194)$; OALR.

Miller. fred ('hrlstopher (h'Sh)--111.11,2:; (1'13)

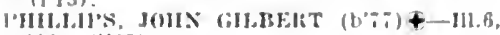

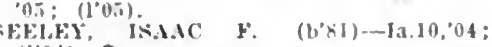
$(1004): \mathrm{s}$.

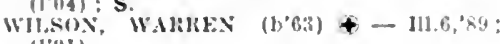
(1.Di).

NORTHOME, 206, KOOCHICHING

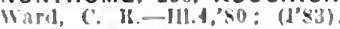

NORTH ST. PAUL. 1.404, RAMSEY

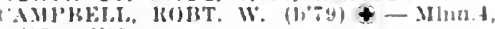
0.5: \{lo:i).

(')wern, Fornest W.(b*71)-N.11.1,02; (1'03) NORWOOD, 522, CARVER

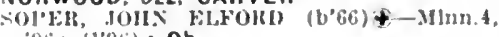
"Oti; $\left(1{ }^{\prime} 96\right) ; 0$;

ODIN, 139, WATONWAN

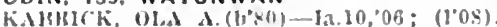

OGILVIE, 270, KANABEC

Sour. Sileples D. - I'a.2,"91, Mlnn.5,96; (l"in).

OKLEE, 100, RED LAKE

'Tessier, Wifrid o. (b'62) - Minn.5,8z; Torgerion, Win, B. (b'a)-MInu,6,9z; (1'y); nol in prafice.

OLIVIA, 960, RENVILLE

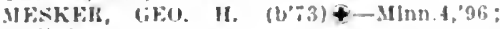
$\left(I^{\prime} y 6\right)$

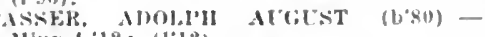
IIInn. 4, 12: $\left(1^{\prime} 1: 3\right)$

ONAMIA, 3I4, MILLELACS

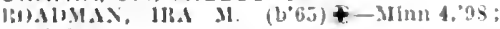
(I,IS)

ONIGUM, - CASS

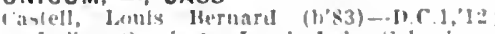
Ifudian stervlce): Leteh latke schowl.

llouge, Zacharlah bugene $(1,75)-1), 0^{\circ}, 1,03$ : 1'03); (lodlan Servfles); Iseall Latke subul.

ORTONVILLE, 1.774, BIGSTONE

kaker, Willard Bemington (b\%) -Mnnt, '1:-: (1'1:2)

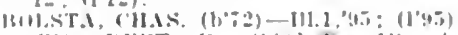

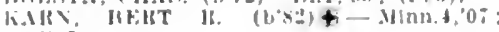
(loi).

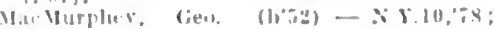
II $\times 3): 0 p$.

OSAKIS, I,013. DOUGLAS

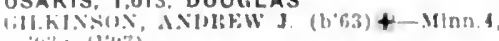
(10:?; 11,93$)$

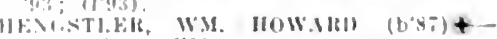
IIIn t.11: (1'11)

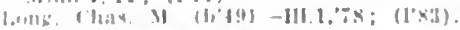

DSLO, 34, MIARSHALL

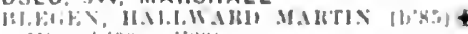

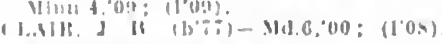

OSSE0,390, HENNEPIN

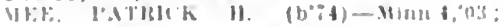

OSTRANDER, 175, TILLMORE

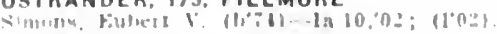

OTIERTAIL, 176, OTTERTAIL

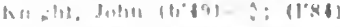

OWATONNA. 3,658, STEELE

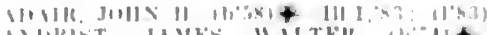

(II) (II) (1) inli)

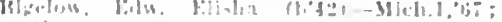

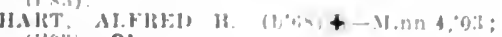
(1'0): $\mathrm{Ob}$.

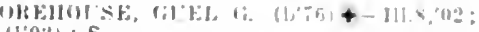
(1'0?): $\mathbf{S}$

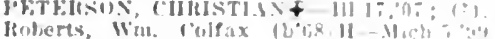
(I?g!n); ob.

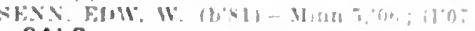
OALR.

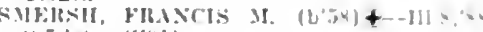
(1) : $: 4 ! n:(1.91)$.

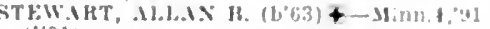
(1'91).

PALISADE, - AITKIN

(ATIA. TIECDDU]? JFFFHSON $(2+4)+$ - $111.1 .74 ;([\times \%)$

PARKERS PRAIRIE, 383, OTTERTAIL

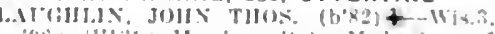
"fs: (1013); Member siate Med. sine, if

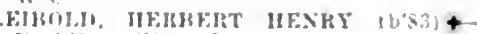

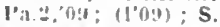

PARK RAPIOS, 1,80I, HUBBARD

(U) B.i; $\left(12 x^{2}\right)$.

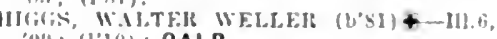
(1)!! ; (1'1(1); OALR.

Huluston. ('has. N.-Mnn.4.01; (101).

Fise. (ieo. $\rightarrow$; (1'8:3).

Walling, I'lympton A. (b'50)-X.5.76; (I's(1)i) : retired.

W'Inshlp, l'earl D. (b'41)-Ia.1,78; (1'si).

PAYNESVILLE, 901, STEARNS

IKXITT, IIAKIB IV.M. (b'RS) \&-11!,6,12: (1'13)

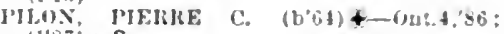

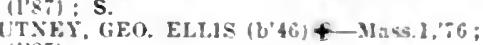

IITSE:

MUr. GEO. I. (b's0)-Minn.4,03; (I'03).

PELICAN RAPIDS, I,0I9, OTTERTAIL

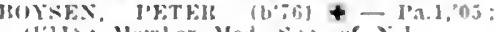

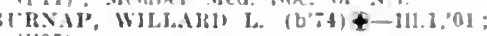

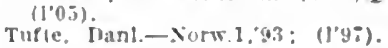

PEQUOT, 260, CROW WING

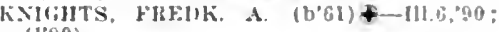
$(1000)$

PERHAM, 1,376, OTTERTAIL

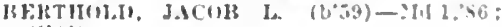
(sib)

Urabec Frank J. (1,69)-Minn 4.93: (1'03).

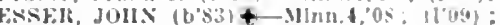
$\mathrm{S}$.

PETERSON, 266, FILLMORE

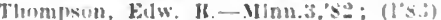

PIERZ, 545, MORRISON

Ilealy, Hasmond T. (b's3)-MInna. 09 ; (1'0? 0 ?).

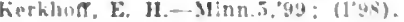

PINE CITY, 1.258. PINE

TOFTF. JUSFIHINE IHNIIIAU-A : (InA)

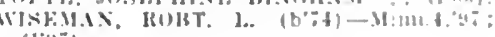
$(1: 17)$.

PINE ISLAND, 83\%. GOODHUE

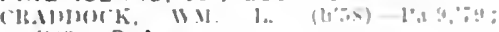
11 $831,0 D A$.

1111.. r.11.

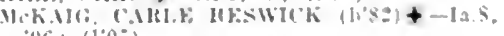

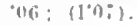

PINE RIVER, 329, CASS

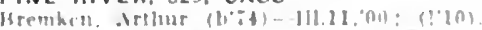

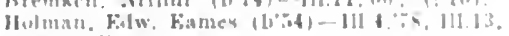
'toi: (I'Ali)

PIPESTONE, 2.475, PIPESTONE

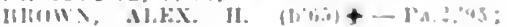
$\left.\left(l^{\circ},\right)_{3}\right)$

arr. Firra $\mathbf{Y} \rightarrow: 1$

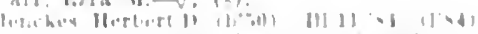

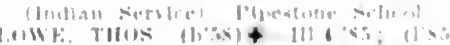

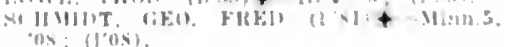

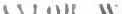

PLAINVIEW. I,I:3. WABASHA

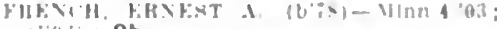

(I'li) i): $\mathbf{0 b}$

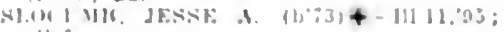


POKEGAMA, - PINE

WITTERSON, WALTER II. (b'15) + IH.6 "01: (1'01): Member 111. Stale Med. Sure $T$

\section{PONSFORD 75, BECKER}

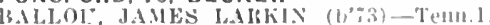

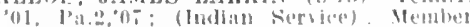

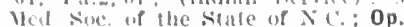

PORTER, 253, YELLOW MEDICINE

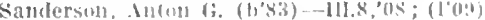

PRESTON, I,193, FILLMORE

(irimel. Wentell 18,-111.11, w0): (1"001

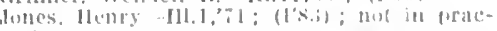
LotE fibo. MLLAN (10.51) + III.8,74

Love, fien, Robt. (b'S1) - Minu. 5,'10; (1'11) PRINCETON, 1.555 , MILLELACS

Armitage, Tlios. L. F. (b'60)-I'a.11, 93 (l'99)

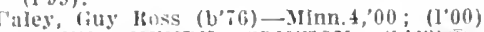
COONEY, IIESIY CLINTON (b'63) +

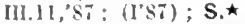

PRIOR LAKE, 162, SCOTT

CANNADY, EARL ENIORY (b'85)థ-III.6, '09; (1'10).

PROCTOR, 936, ST. LOUIS

MrHLGH, IBODERICK lREHK. (b'89) †W'Is.3,'12: (I'I3). '97; (1'02).

RANDALL, 195, MORRISON

Kinlght, Samuel Grahan (b'i0)-0nt.1,08 ; (1'10).

RAYMOND, 334, KANDIYOHI

MCM.IIOS, IVEIS J.-Ia.1,94; (I'\$6)

REDLAKE, 100, BELTRAMI

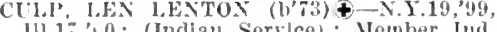
Milli, 0; (Indian servec) slember Ind.

Linton Edmund Cainlle (b'si)-N.Y.I9, 06 ; (Indiun serrice); Hedlake school.

RED LAKE FALLS, 1,757, RED LAKE

I.EMIKUX, ISIRALI-QUE.5,74; (1'83).

WATSON, NEIL1.M. (b'52)\$-Que.1,91; (1,

WHALSON, JOHN CLINTON (b'T2)థ1a.3, 96 ; $\left(1^{\prime} 01\right)$

RED WING, 9,048, GOODHUE

AANES, ALIER M. (b's6)-1'a.9, 09 ; (1'10)

ANOERSON, JOIN VICTOR (b'62) §-III.1, \&6: $(1,86)$.

CLAYDON, LEONARD E. (b'68) -MInn.4, $4.5 ;(1,95) ; s$.

TIIAS HUBERT (b'66) Ky.1,'91, Ill.I,'93; (I'95); S. JELINTA11, CII? I

INGIRAM, LAWIENCE C. (b'73)Ð-Ia.10,

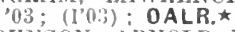

JoINSON, ARNOLD E. (b'76)--Ill.1,02; $\left(I^{\circ} 02\right)$

JONES, .LYAH W. (b'63)£-D.C.2,'91; Meriflidx, IIENIR THOS. (b'75) Vinn.4:0I; (1'0I); S

smith, Grace Gatrdiner (b'73) H-Mass.5, 45 ;

(1'4:1); Pd

MTII, MYTON W. (b'71) —-Mass.5,95;

Sweney, Wm. Montgomery-N.Y.10, 26 ; (*)

WELLNER, GEO. C. (b'49) (†-III.1, "73;

WERNER, NELS IAWRENCE (b'77) - III.11, $03 ;\left(10^{\prime} 03\right) ; G$.

REDWO0D FALLS, I,666, REOWOOD

lBRAN, WILLIAM A. (b'76) \&-Minn.4,04; FLINN, THOS. EDWIN (b's4)-Ill.1,09; Gibson, Christopher P. (b'41)-111.6,'73; $\left(1^{\prime} 84\right)$.

PEASE, GILES R. (b'68) - Mich.1,'S5; (1'S5).

\section{RENVILLE, I, $\mid 82$, RENVILLE}

CLAY, EWW. 11.4-Minn.5'93; (l'93); Op. Francis. Lewis T. (b'55)-InI0,'84; (I'86). Pressinger, Jos. W.-Minn.4,04; (1'04)

PICE, 262, BENTON

RATIULN, IDIHSON M.-III.1,78; (I'98).

RICHMOND, 563, STEARNS

GELZ. JUII JAMES (b'S3)-MInn.5,09;
ROBBINSDALE, 765, HENNEPIN

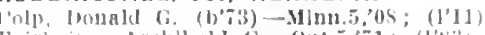

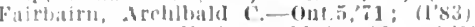
IInward, selh Evelyn (1,63)-Minn.4,93 $\left(I^{\circ}(3 ;)\right.$

ROCHESTER, 7,844, OLMSTED

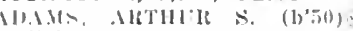
(1'หis)

Alen, Whyon A. (b'34)11-111.4,79); (1'84)

Archibald, Alexamder (b,86) - sent.3,10 (1'13) ; Malyo CIInle; LD.

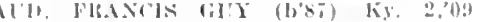
(Asslstant Plhgslolitn); si. Nary's llos

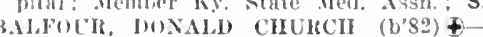
int.1,06; (1'03).

BE'TMAN, EMII, IIESSEL (b'T2) †MInu.4,01; (l’01)

Bertimin, Pavid diayo (b'86) - Ill.1,'I2 $\left(1^{\prime} \mid 2\right)$; St. Mary's fiospltal.

Blackford, John Miror (b's)-Tia.1.10 : (l'illhologlst)

BRA.ACCI, WM. F. (b't8)૯-Minn.4,'03 (1'(1):3); ( $(1,3, F 6)$ BRODERS, ALBERT COMPTON (b's5) +
Va.4,I0; (I'alhologist); st. Mary's IIOS inital.

CMIIAN, RUSSELL DANL $\left(b^{\prime} 75\right) \downarrow-$ Io 27,01 ; Member Mo. State Med. Assn. Blaye Clinie: (6iL, 4): R.

Carroll. Wm. Conaford (b'89) - Hinn. 4,12 ; (1'12): S.*

CBENSIIAW, JOIN LEW'IS (b'82)-Va.1, "06; Nember Med. Soc. of Va.; Mayo rlinie.

CIEWE, JOIIN E. (b'72)†-Minn.4,'96 (1'96).

('rumley, Win. Gregg (b'85)-Ga.11,12: (籴) EUSTERMAN, GEO. BYSSHE (b'82) †Minn.4, '118: (I'08); (F6): 1.*

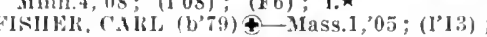

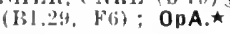

GIFFIN, HERBELT ZIEGLER ( (ค'T8)๑IId. $T, 04 ;(1,0 \pi)$.

GR.AIIAM, CIIRISTOPHER $\quad\left(\mathrm{b}^{\prime} 56\right) \uparrow-P a .1$ GAYGER (I'92).

GRAYGER, GERTIRUE BOOKER (b'il)-

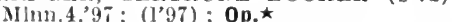
IALLENBECK, DORR FOSTER (b'82)III.6, 08 : (1'10)

IIENDERSON, MELVIN S. (b'83) \$-Ont.1

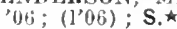

Henry, Michael Jos. (b'89)—Ky.2,'12; In. tern, St. Mary's Hospital.

IIEYER1)AIE, OSCAR C. (b'73)-III.6,'98 $\left(I^{\prime} \otimes 8\right) ; N P . \star$

10Y('E, (;LOC, T.-III.1I,'(04; (l'04).

Jnyce, Thos. Mlartin (b,85)-Mich.1,10.

JUDD, RDWARD STARR (b'78) \&-Minn.4, $02 ;\left(1^{\prime} 02\right) ;\left(A \bar{T}, F_{6}\right)$.

KHLBOLRNF, ARTHUR F. (b'58)£-N.Y.5 $83:(1,8 \pi)$.

kirseh. Ralph Louls (b'86)-Minn.4,'12,

Lewis, Wim. Howard (b'81)-0.9,06; (1'13); LD.*

LINTON, LAURA A. (b'53) †-Minn.4, 00 ; NTON, WILLIAY B. $\left(\mathrm{b}^{\prime} 55\right) \oplus-\mathrm{Pa} .2,86$; (1'8 7 ). Archibald Ilodge (b'7 7 )-I'a.1, $0 \pi$ : ogan, (1'11)

MaCCARTY, WM. CARPENTERT-Md.7, 04; (F2); Path.ネ

Iasson, James Carruthers (b'81)-0nt.1,06 Intern. St. Mary's Hospital.

MATTHEWS, JUSTUS $\left(b^{2} 77\right)$ (

(1)

IAYO, CHAS, MORACE (b' MAYO, WM. JAMES '(b'61)£-Mich.1,'83:

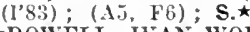

ICDOWELL, IYAN WODROW, JR. (b'85) Ya.4,08; (1'athologist); Member Med. Soe. of Va.; $723 \mathrm{~W}$. Zumbro St

ICGRATH, BERNARD FRANCIS - -D.C.2, '95, Mass.1,06: (Pathologist) M Member

Mass. Mea. Soc. st. Mary shospital; (F6) CKENNA, HENRY IOS. (b'S5) †-Ky.2 10 ; Nember $\mathrm{K}$

Mary's Ilospital.

c.Hahon, Francis Bartholomew (b'8i)-

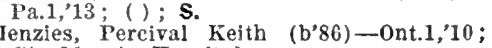
st. Mary's Hospital.
Meyerdlng, Henry W'm. (b'84)-MInn.4,09;

lewre, Alexander iberkeley (1,83)-Va.1,00; (Asslstant Plyystelan) ; Mayo Clinle; R.

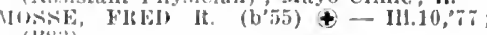
(I'X:3)

MUSSEY, IEOBT. DANL. (b'84) -0.1,08; (I'l1); 0 b.

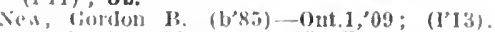

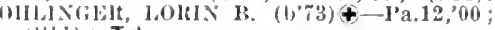

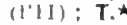

l'emberton, John deJarnette (b'87)-Pa.1,

'11; Intern, St. Mary's Hospltal.
I'LUMME, IIENRY S. (b'74)屯-11.6, 98 ; (I'98); (F6).

Pllmmer, Win. A (b'83)-Ill.6,'10; (1'13). Iflce, Ilarold. Waiter (b'88)-Cal.2,12; Intern, st. Nary's Hospltal.

SANYOLI), AITTHUI IIAWLEY (b'82) \& IH.6, "U7; (Bacteriologfst); Member State Ned. Sive of Wis.; Mayo Clinic; $\left(\mathbf{F}^{2} 6\right)$; LD.

SHELDFN, WALTEIS DE WITT $\left(b^{\prime} \% 0\right) \oplus-$ III.1,'yz̃; (I'03); Clin. I'ro?. Med., Mlnn.4

Simpson, Ellery DeWltt (1'87)-MId.7,12; (Pathologlst).

Sjolas, Amly Severne (b'87)-Minn.4,13: (['ahologist); Rochester State IIospital. SNITI, EITEST v. (b'80) - Minn.4, 07 ; (I'07).

STACY, LEDA J.†-IIl.1, 05; (1'05)

Stinchfield, Augustus W. (b'42)-11e.1,'68; (1'84).

CHOMAS, GILBERT JOSIUA (b'84) 111.6.,08; (1'13); U.

TOLAND, CLARENCE J. (b'75)†-110.20, 01 ; (); Nember Med. Soc. of the state

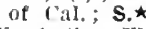

Ward, (ieo. Fletcher (b'84)-N.T.15,'13; () WILSON, LOUIS BLANCHARD $\left(b^{\prime} 66\right)$ Minn.4,96; (1'96); Asst. Prof. Clin. Path. Minn.4, (1) Ast. Pro

WITIERS'TINE, IORACE II. (b'52)‡III. 1,86 ; (1'86).

WOOD, HARRY GARDNER (b'83) £-Que.1 04 ; (I'05).

ROCKFORD, 287, WRIGHT

KIESIING, IIVING HENRY (b'80)कMass.5,"64; (l'04).

ROOSEVELT, 252, ROSEAU

Davls, Alvin N. (b'51)-0.9,'74; (1'83).

ROSEAU, 644, ROSEAU

DELMIOHE, JOHN LEO (b'86) §-MInn.4 $09 ;\left(I^{\prime} 09\right)$.

Leech, W. Stuart (b'68)-Ky.4,'90; (1'95).

IUIR, JAMES BLRNS (b30)థ-III.8,' 85 (I'95).

Forin, Frans L. (b'58)-Mlinn.2,'86; (1'86)

ROSE CREEK, 202, MOWER

lynde, C. V. (b'58)-IH.4, 83 ; (1'86).

ROSEMOUNT, 238, DAKOTA

SCILATZ, FRANCIS J. (b'82)థ-Pa.2, 09 (1'11).

ROTHSAY, 343, WILIKIN

SEllilalND, JOHN C. (b'72)-Minn,1,00; $(100)$

ROUND LAKE, 237, NOBLES

IIART, HHUCE D. (b'J8) \&-Ind.18,'06; (l'09).

ROYALTON, 6776, MORRISON

WATSON, ALEXANDIS M. (b'\$1)-Ont.6, $05 ;(105)$.

RUSH CITY, 964, CHISAGO

ANDERSON, CHISISTOPHER 'A. (b'67) $€$ Minn.4,'92; (1'92).

GRAY, CLYDE EDW. (b'T9)-Minn.4,04

(1'03). ALVAII J. (b'61)†-N.Y.5,87; (1'87)

RUSHFORD, I,011, FILLMORE

Boyum, Peter A. (b'80)-Minn.4,07; (I'07). Magelssen, Jacob W. (b'43)-III.1, ${ }^{\prime} 66 ;\left(I^{\prime} 83\right)$. ONFGARD, CHIISTEN K. $0.2,87 ;\left(l^{\prime} 87\right)$

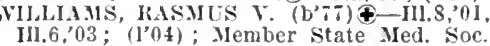
of Wis.; OALR.

RUSHMORE, 237, NOBLES

WATSON, FREDK. G.4-IIinn.5,'03; (1'03). RUSSELL, 262, LYON

Hall, Earl X,-H-llinn.6,02; (l'02).

RUTHTON, 290, PIPESTONE

Solsem, Fredk. N. (b’79)-Ill.8, 06 ; (1'08). 
SACRED HEART, 587, RENVILLE

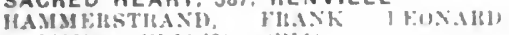
$\left(b^{\prime} \$ 1\right)+11111,0^{\prime}:\left(11^{\prime} 11\right)$.

SANBORN, 462. REDWOOD

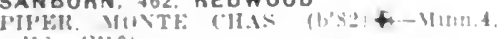
'10; (1)10)

SANOSTONE, 1.818, PINE

Bohline, Mernand stangur (b) (I'lli)

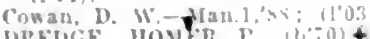

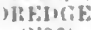

AUK CENTER, 2.154 STEARN

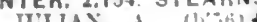

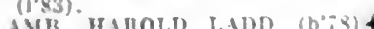

$02:(1302)$

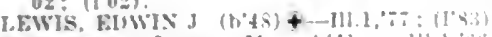

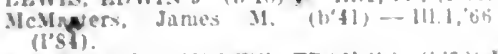

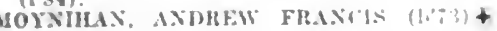
-Minn.5, 03: (1'03).

SAUK RAPIOS, 1.745, BENTON

FHESLEBEX, WU, $(1-8)+-01, n 6$

I.0NSTiLF, JAMES $\left(b^{\circ} 46\right)+$

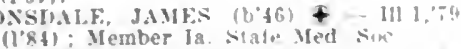

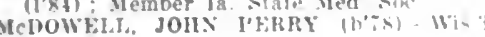
11: (1'11).

SEBEKA, 428. WADENA

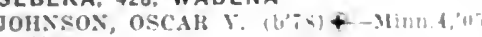
(l'05).

SHAKOPEE, 2,302, SCOTT

BUCK, FREDK. HEIBEPT (0'92) - Ont 1, '10: (1'11:

FISCHEL, HFNRY ID. (bo 70$)+M / C h .894$ (1'95).

FISCHER, PETER 31. $(1079)+$ - Jich Z, :0: : (109).

REITER, HEVRY II, (b'B) -Minn 1.93 (1'93).

SHELLY, 195, NORMAN

VIstaunet, Peder $5 .\left(b^{\prime} 58\right)-M \mid m n .4,06$ $\left(I^{n} \cap 6\right)$.

\section{SHERBURN 814, MARTIN}

Farrlsh, Malcolm J. (hibt) - Ont.3,"91: $\left(1^{\prime} 00\right)$.

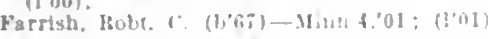

SILVER LAKE, 382. MCLEOD

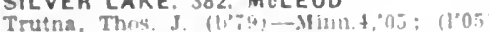

SLAYTON. 850, MURRAY

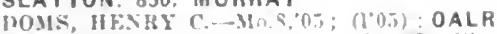

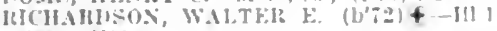
'96: (1'99).

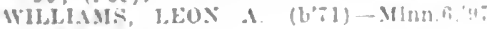
(l'9i).

SLEEPY EYE, 2,247. BROWN

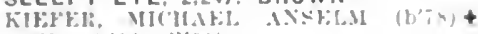
Slinn t, 04 : (1'04).

schuldes?

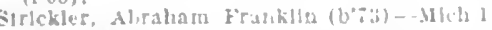

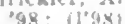

Strickler, Mars Ilanw)1 (l',-3) -Mun 4, ? $(1,9 x)$.

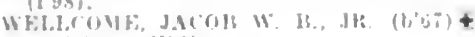
D(0.7,40; $\left.111^{2} 92\right)$

SOUDAN, 20. ST. LOUIS

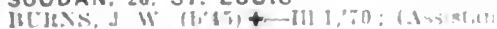
Jhysiclass; Memblier state Mat

IIts.

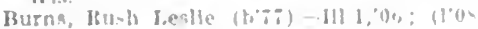
s.

SOUTH HAVEN, 287, WRIGHT

WB:M, THIHSTOS WM (b') +

os: (1,09); s

SOUTH ST. PAUL, 9.5I0, DAKOTA

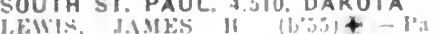

(1'S5)

SPICER, 228, KANDIYOHI

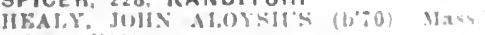

, $96 ;$; $(101)$

SPOONEA, 668, BELTRAM!

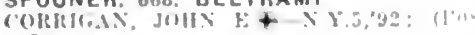

\section{SPRINGFIELD, 1,482, BROWN}

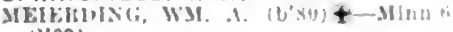$$
(1008)
$$

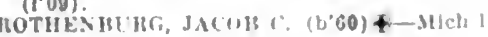
. $83 ;(1281)$

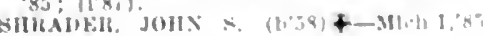
(1'si): S.
SPRING GROVE. 620, HOUSTON

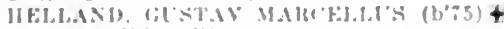

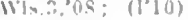

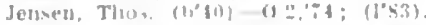

SPRING VALLEY. 1.81\%. FILLMORE

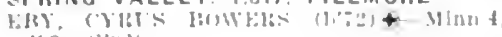
4.3: $(1+0 \%)$.

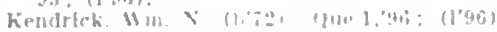

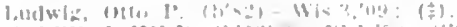

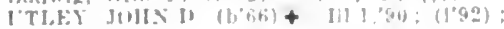

$\mathrm{S}$.

ST. BONIFACIUS. 275. HENNEPIN

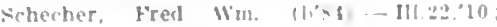

(I'10)

ST. CHARLES, I,159, WINONA

Bear, HIram $r$-III I?Z?; (1'Q4)

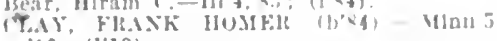
$10 ;(1,12)$

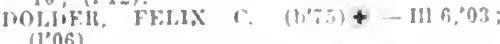

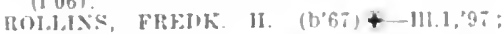
(I'9S).

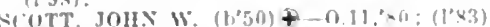

ST. CLAIR, 323. BLUE EARTH

WACIBFTH, JESSF; I. + -Ind.111,0.

ST. CLOUD, 10.600, STEARNS

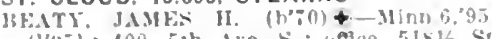

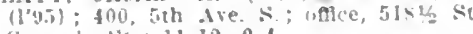
(iermaln st. ; 11-12. 2-4

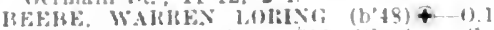

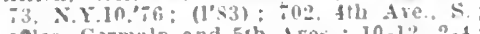
onlce, Germath and 5 th Ares.; $10-12,2-4$ (F6)

IBUFIIM. JOHN C. (b'60) - Mllint,93: (19.93); 345, 5th ire. s. ; oftce. 519 st Ciermaln st. $11-12: 30,2-4,7-8 ; R$.

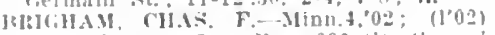
426. 3t Ne. S: attce, 601 st. (iermaisi St: $9-12,2-5$

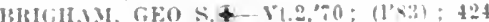
al Are. s.; ontice, 601 st. Germaln st. $1-18,2=0$

[nums, Johln Js. D. (b'59)-114.1,83: (l'\$3);

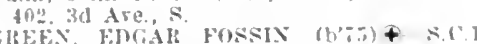

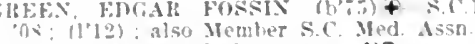
Minnecuta sinte beformatory; NP.

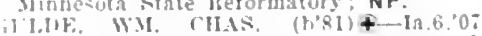
(I'09): 405, sth Are. s.; nffce, laht 13k kack: 1-12, I-T: OALR.*

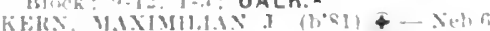

(1) : $(104): 411,-$ th ave, $s:$ offlce, 101 .

it1 ale.

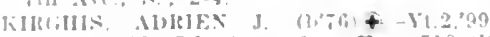

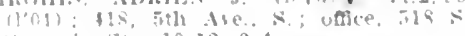
lewmin st: $10-12,2.1$

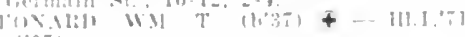

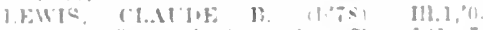

"10 ilo th Are \& aftere lol, ith

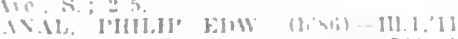

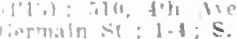

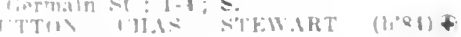

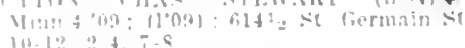

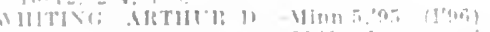

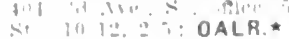

ET. FRANCIS 3HI ANOKA

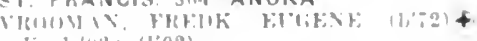

T. HILAIRE. 468. PENNINGTON

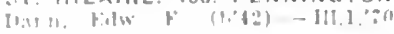

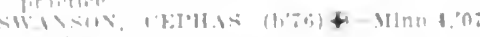

ST. JAMES. 2.102. WATONWAN

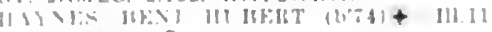
"1. $11+1,1 ; 00$.

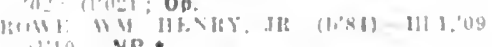
in in $\mathrm{NP}$.

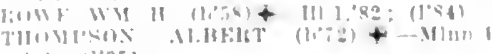

ST. JOSEPH, 706, STEARNS

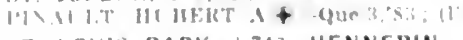

ST. LOUIS PARK 174.3. HENNEPIN

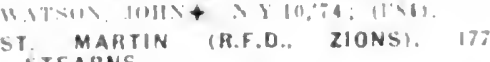
STEARNS

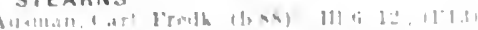

ST. MICHAEL, \$50, WRIGHT

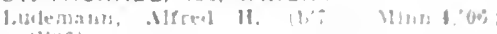
(1'106).

ST. PAUL, 214.744 RAMSEY

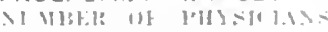

MHsuTr, livklatos J 11,19

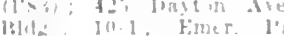

IIting

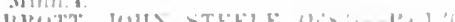

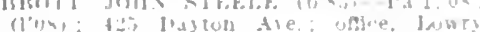

IIII:

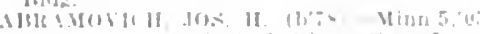

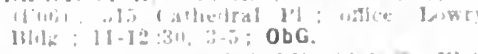

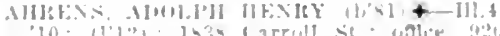

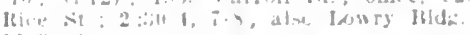

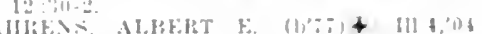

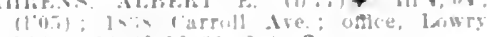
HIt, $111: 0-12: 30,21 ; \mathrm{S}$.

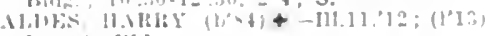
betroit [BIde

MLEXIVIEIR. FRINK 11 (b'bs) +-MInn I "9i (1'a) : twe Rlce st.

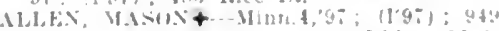
War-lall Are; oflee, Loury Bldz.; II l. $3-5: 30$.

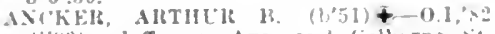
(l'v3): Jefferon Are and (inllwerne st cince, 337 Watianh st.

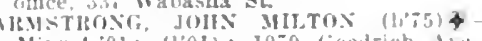

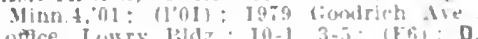

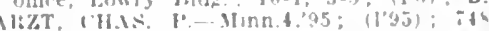
loyton Ave; nflce, Imilsburab trlde $10-12,2-1$

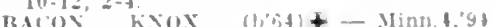
(1?:4): 111s summir dve, oflce, Lowry lildz. S.

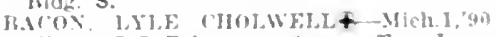

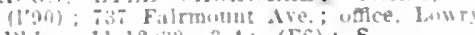

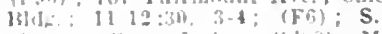

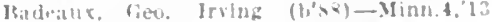
(1'lin): city and county llosptal

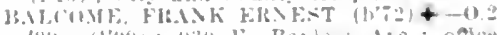

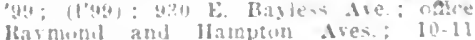

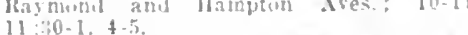

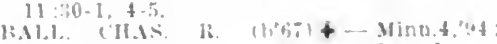

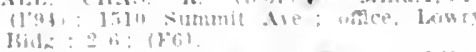

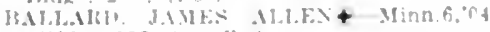

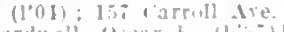

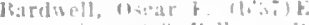

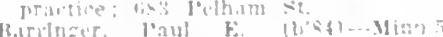

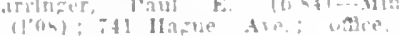

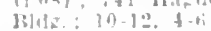

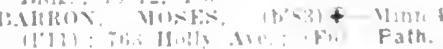

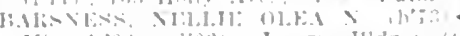

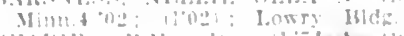

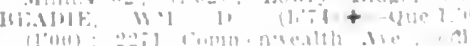

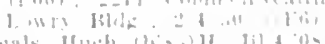

Marillatl die : ance

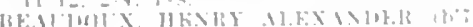

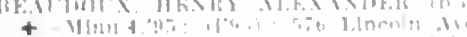

OALR.

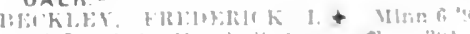

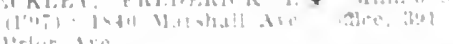

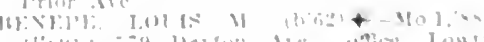

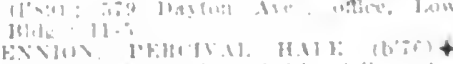

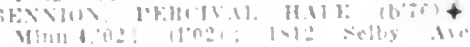

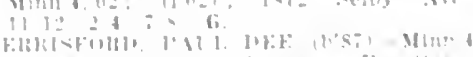

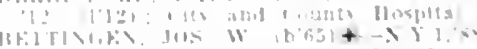

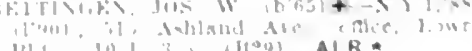

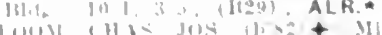

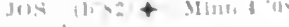

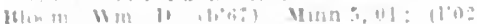

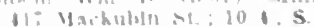

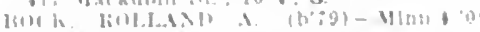
(1) 12 a 4. II folwedes die

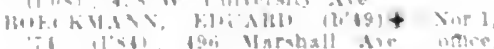

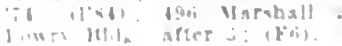




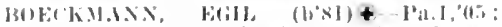

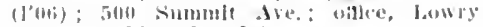

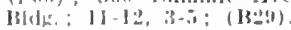

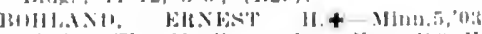

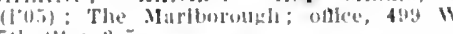

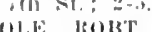

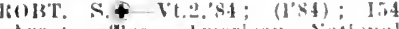
Bima Nith

Bitlik litith

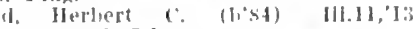

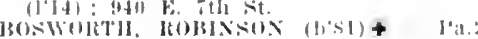

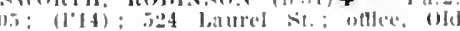
Citpitul Bldg, : $4-1+2,2-5 ; \quad T$.

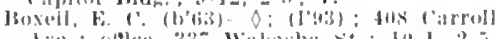

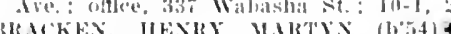
$x+1,7$ cond

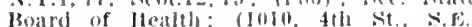

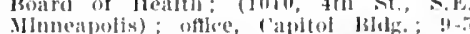

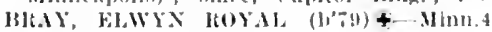

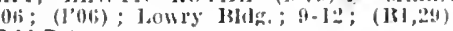
OALR.*

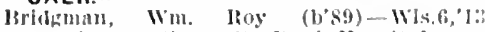
not in proctice; St. l'anl Hospltil

Briges, Warrens, (b'.4) II-III.4,69; (1'97)

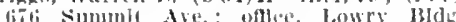
$8 \cdot 311-10,-4,5$

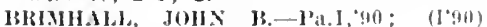
sos Goulrich We. oftle, Lowry Hats

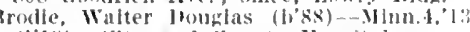
(1'I:i) : City and County Hospital.

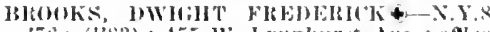

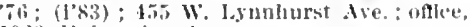

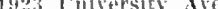

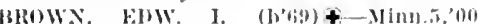
(l'0I): 9til Filrmunt Ale.; oflce, Balt more Hinek; $10-1,3-6$.

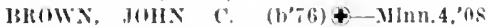
(l'08); 2080 ('ommonwenth Are.; onlle, lowry BIdg: : 9-1; OALR.

HROWY LEItOY (b'55)-Vich.1,85; (l's6) 934 (Vark St, oflee Lowry Bidg' 10-1.' 3-6; OALR

HROWX, SIIAAS E.\$-X.Y.5.83; (I'0S) $4: 30$ lortland Ave.; Offle, jowry Bldif. 10) $-12,2-5 ; \mathrm{S}$.

Bruntes, bicderich Geo. (1)'85) - 111.4,10 : (l'I1); 1921 kondo st.: offlee, stip rifor Ave. $11-12,2-4,7-8 ; U$

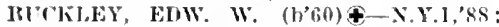
(I'00); 873 Faimount Ave, office, Lowry Bllk: : $11-1,2: 30-4$

BIlich, FRANK EARL (b'76)f-Mim.4.

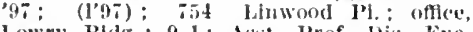
lowry Bldge : 9-1; Asst. I'rof. Wis. Eye, Ear, Cose and Throat, Mimn.4; (B1.29) : A. BlRSS, IROBT. M.\&-Mnn.4, $0 \%$ : $67 ! 1$ F. 3d St. ; offlee. Lowry bldit.

(ALDWELL, DAVID FNOX (b'78)\&Ylimn.5, 03 ; (1903); 1569 w. Minncliaha st.

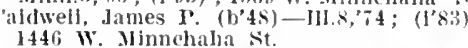

CAMEHO . TOHN ARCHIE $(\mathrm{h} 69)$ offlee. Lowry jifle: $11-1,3-5 ; \mathrm{S}$.

CAMPKLL, AlRERT A. (b'67) + S. Mimn.4

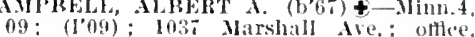
09: (lo9); 1037 Marshall Av

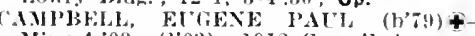
Minn.4,03; (1'03) ; 1912 ('arroll Are.; of flce. Lowry IHIdr. $10-12,2-4$.

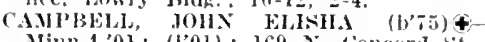
Minn.4,0l; (1'01); 169 x. Concord st.

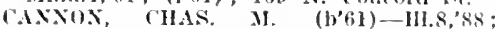
(14) ; 2275 farter Ave.; offre. Hampden and Raymond Ares, : 10-12. $2-5$

Cannon, Clild R. (h'91)-Wis.6,'is; Intern, St. Joseyh's IInspital.

A.YOX HARRY (b'72)丹- Mo.2,04 (1'0.7); 822 E. 7th St.; 11-12, 2-5.

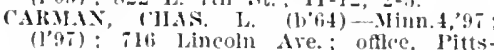
burgh Bldy.

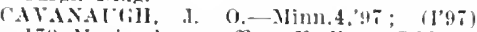
ITs II ria tre. office. Endicott Bldg.

CHAMBERIAN, IEHIEL WESTON (b;5) + I11.1, 40 : (1'84): 581 Portland Ave office, lowry Bldit.; 9-12, 2-4; (BI, 8, 29)

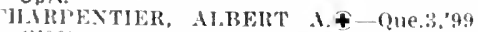
(l'00): Jonre Block: office. Pittsburgh

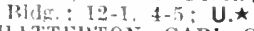

'HATTERTOX, CIRL, CHATOX (h's, :-

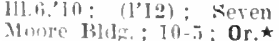

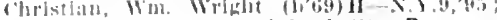

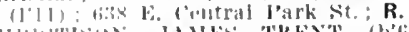

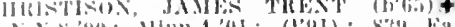

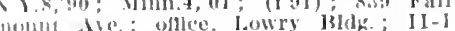

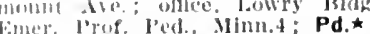

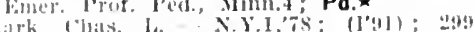

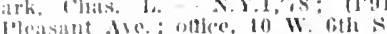

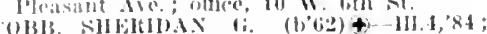

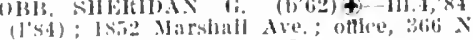
l'rinr Ave: 11-12, 2-4; $\mathrm{S}$.

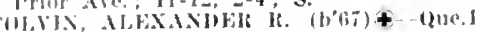

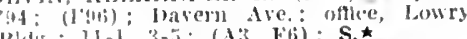

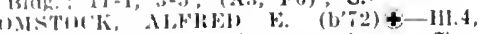
(t): (lom) : 639) Falrmount Ave.; oflce,

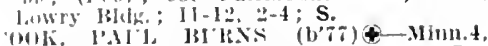

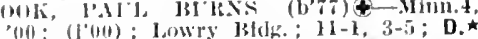

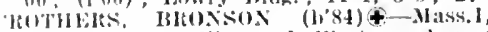
111: (l'1:3) : scllin and Western Ares.

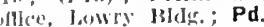

(1"FF, wM. S. Minn.4, labled st.; oflue, $428 \mathrm{~s}$. Wabasha si 'ummines, ('las. (i. -111.11,'85; (1'85) (Wilte bear laske); office, Baltmort bik

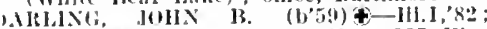
(l's) ; 442 summit st.; offlee, 337 Wa basha are.; I $10: 30-12: 30,: 3-5$.

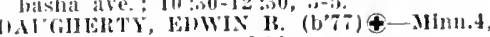
04: (1'04) : lowry lslig.

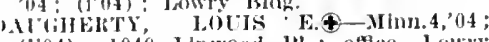
(1'04); 1049 Linwood 11.; offlce, howry 13ldg. : $2-5 ; \mathrm{S}$

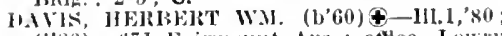
(I'86); 66I Faimount Ave.; ottlee, Lowry

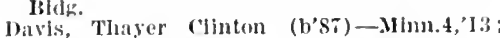
(1'13): City and County Hospital.

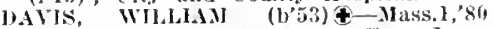
(l'S4) ; 409 Laurel Ave.; office, Lowry lildr.; $11-1,3-5$.

DEIOLPI, KAKL (b'87)†-Minn.4.'11 (1'11); 812 Ashland Are,; office, 170 N snelling tre.; $10-12,2-5$

1)ENNIS, WARHEN A. (b'f9) \$-NMn.4 '96; (1'96); T40 binwood Pl.; office, howry Bldg.; 3-5;

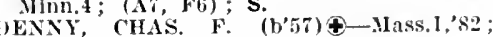

(l'83); Selby and western Ares.; oflice. lowry' Bldg. ; $10-12,2: 30-4 ; G$.

DEWAK, JOHN EVAN.

(See Minneapolls.)

llewey, J. J. - III.1,78; (t) : 315 somerset si UICKSON, THOS, HINTER, JK, (b'84) 4 Mim. 40; (1'10); 12l Cambridge Ave

inwoodle, Wm.-Pa.2, 7 ; (1'83); 71 E.

ith St.; offee, $798 \mathrm{~F}$. Fih St.

DITTSA GEo. CLACDEA-Minn.4,04; (l'04); 515 Ashand Ave. ; offee, Lowr (lo4); 515 Ashland Ave.;

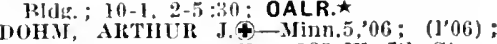
786 Hague Ave.; office, 133 w. Fin $\mathrm{st}$

Dolly, CHAS, L. (b'75) \&-Minn.4,'95

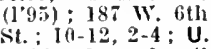

ponald, Alexander (b'46) H-111.4,'80 ; (1'83) ; 821 Fairmount Ave.; office. Endicott Bld r.

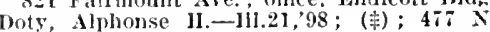
snelling Are.

bowner, Mary Alice (b'69) I-III.4,02, H1.9, '06: ( ) : sot selby dre

DRAKE, $\because R$, BILELOW (b's6) \&-Minn.4, '12: (1'12); 43., Portland Are.

prechisler, llerman A.-Minn.4,02; (l'02) Amerlean National Bank Bidg.

DIXNING, ARTIIR W. (b'60)థ-111.11,85 (I'S8); $807^{-}$Ashland Ave.; office, Lowry Blig. : $\mathbf{N}$.

ENRL GEO (b'84) - Minn 4,09: (I'09) 4:5 Hastings Ave, office, Endicott Bidg. $2-4 ;(F(j): S$.

EAII. ROH'T. (1'-2) †-Mlinn.4,96; (1'96)

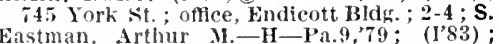
I\$6 Summit Ave.; office, Fndicott Bidg Endress. John K.-Minn.4,99; (I'99); 699 Iit. Ifope Ave.; nffice, 190 Concord st.

Engherg, Edward Joln (b'87)-Minn.4,'13; (1'13); Mounds Park Sanitarjum.

EKNENT. GEO. C.-Kan.2,'06; (l'12) ; 889 Portland Are.; office, pittsburgh Bldg.

ESHELBY, EZRA C. $\oplus-0 n t .4,86$; (1'86) ; Shubert Bldg.

FEMGLSON, JAMES B. (b'40)థ-Pa.2,66; (1'95); not in practice; 931 Portland Ave.

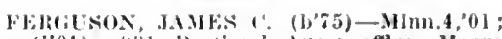
(I'01); \$31 Joriand lve.; offle, Hoore BHdr.; $10: 30-12: 30,3-4: 30 ;$ (F' 6 ).

Nitzsmmons, Waller - Minn.3,'83; (1'83); 548 Ohio st.

Flditi, silll b) (b'38) - 12a.2,50

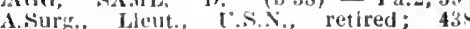
liture]" Are.; offle', chimuber of Commeree blilg

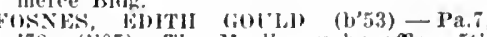
is; (loz); The Marlburough; offlec, 5th and st. Peier sits.; I $1-1,2-4$.

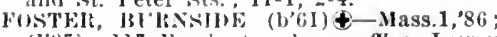
(1'87); 117 Furrington Ave.; offlee, Lowry H\}d ; 10-12, $2-4: 30 ;(12) ; D . \star$

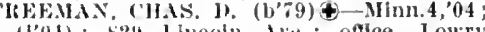

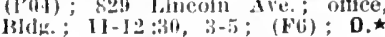

Freligh, Whfred P'rotaclo (b'85)-Mlimn.4, 13; (1'13); City and County Hospital.

Fry, christian (b'51)-Ky.2,74; not ispractice: I0sis summit Ave.

FllLERTON, WM. S. (b'57) -N.Y.10,82 (1'st); sog' Marshall Ave.; offle, 5th and st. Peter Sts.; 9-1, 2-5; R. ^

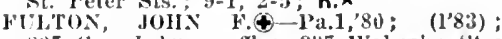
827 fraud Ne; offlce, 337 Wabasisa st. (138.29); OpA, *

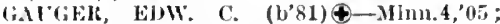
(1'05); 1183 Como Blvd.; oftlee, American National Bank Bldge; $11-12,2-4$.

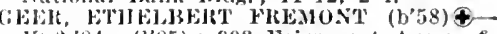
't.2, $84 ;\left(1^{\prime} 85\right)$; 993 Fairmount Ale.; of fice, Findicott Bldg,; 10-12, 3-5.

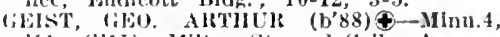
'Il: (l'1I); Wilton st. and Selby Ave.

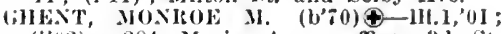
(1'(12); 284 Maria Ave; offlce, 3d St and harion Ave.; 11-12, 2-4.

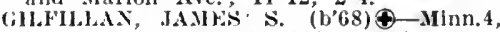
97. Pa.1,'98; (1'97); 820 lincoln Ave. office, Lowry Indg; ; $11: 30-1,3-5 ;$ Asst. l'rof. Med., Minn.4,; $(\mathbf{F} 6) ; 1 . \star$

GIII.WT'W, AR'TIUK J. (b'63)--Minn.2, '86, Minn.4,03; (1'87); St. Paul Hotel;
office, Moore Jsidg. ; 10-4; Prop. Ortho-

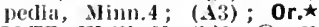

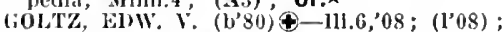
1084 bayton Ave, office, Lowry Bldg. $11-1,3-5$.

Goodrich, Isa F. (b'65) IF-Pa.9,'89; (1'89) 256 Nelson Are.; oflice, Lowry Bldg. $10: 311-12: 30,2: 30-4: 30 ; 0$ b.

GorilAM, CHAS. LEWIS. (b'66) $)$ Ill, 11; (1'12); 624 Como Are. ; offlee, Como

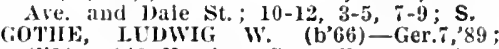
(1'I0); 942 Hastings St.; offlce, Americau Nationil Bank Bldg.; 10-12,3-5.

Grallam, David M. (b'43)-Pa.2,70; (l's3) ; 1668 Lincoln Ave.

liritzek, Thomas (b'85)-111.11,11;' (1'13); 101!s Nreade st.

GiAVELLE, I. M. ARTHUR $\left(\mathrm{b}^{\prime} 68\right) \oplus$ 27 E. 7 th st. ; $12-1,3-5 ; \mathbf{G}$.

GIHENE, CHAS. LYMAN' (b'62)థ-Minn.4, 90: (1'90); 324 Summit Ave.; office lowry Blolg.; 9-12; Prof. Med., Minn.4;

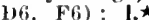

Jlats, (has. A.-Mlnn.4,94; $\left(1^{\prime} 94\right) ; 895$ E. 7 th St.

H.Ith, AlFAANIER R. (b'74)\&-Que.1, Lowry Bldg.; (F6)

llalloran, Edw. Nichael (b'75)-Ill.5,'09;

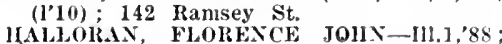
(1'93); 2053 Lincoin Ave.; ofllee, Lowry

HAMMES, ERNEST M. (b'S4)£-Minn.4, $66 ;(1 ' 07) ; 603$ Lincoln Ave; office, Endicott Arcade; $-5 ;(F 6) ; N P$;

HAMMON1), JAYES FELTON (b'82) Que.1,06; (1'10); 897 Iglehart Ave: of Hanley, (ieo. J.-X.Y.10,87; (1'8\%); 423 Robert St.

Hanser, Marius (b'ii)-Minn.4,94; (1’95); not in practice: 821 Selby Áre.

HARDING, JOHN C. (b'73) \-Ill.1,95: (l'99): Minnesota CIub; offlee, American National Iank Blde; $10-3 ;$ Op.‡

HAWKINS, VINCENT JOHN (b'55) \&-Il1.1 '81; (1'84); 127 E. Isabel St.; offlce, 428 S. Wabasha St.; 2-4; Pd.

Hayes, Edwin P. (b's6)-Wis.6,'13; Intern, Juther Hospital. 


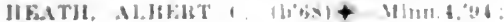

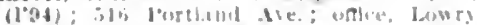

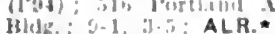

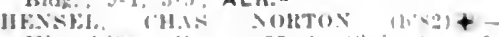

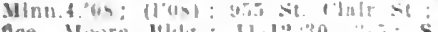

Ace, Minre llat: $11.12: 30,325$.

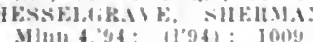
Jifrodis ine omre, Lowry H!ds. : 11-1, 3-t.

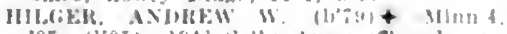

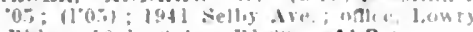

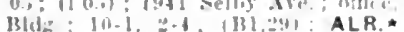

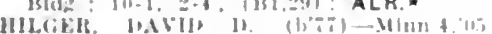

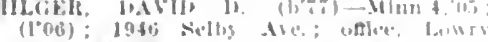
lildig.: ALR.

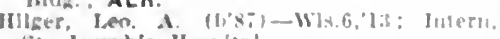
S2. Joseph's Huspltal.

IIJlebrand. Christlan II (lite)-lior l, fic

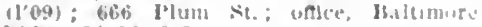
HIde. ; 10-1:. 3-3

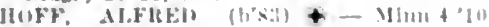

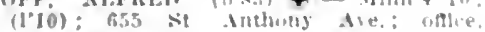
lowry Blels: $11-1,3-5$.

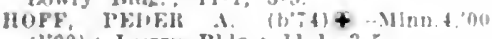
(1'no): Lowry Blela: : $11-1,3-5$.

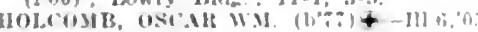

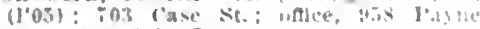
live.:-4, 7-8:5

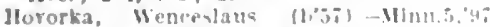

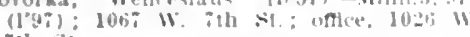
ith Sit.

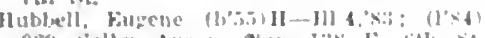

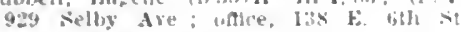
$10-1,3-5$.

HIBHT, ROHEJT MIXITIT: (libti) Minn.4'9s: (1'4s); 93 linlehart Are., "

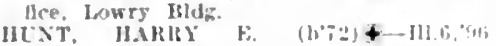

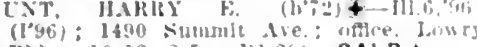
Rlel: $10-12,2-7 ;(131,26) ;$ OALR.*

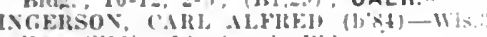
10: (1'11); I'iltutrurgli lildik.

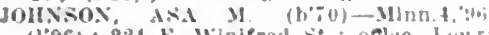
(l'96): 224 k. Winifred st, oflce, l.uwrs Hldg. : $10: 30-12: 30$.

Jollde: $10: 30-12: 30$.

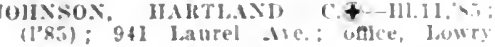
BIds.

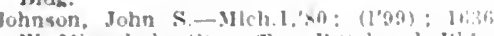

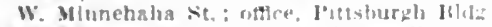

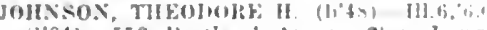

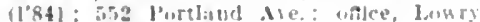
Hldp: $10.12,2 ;:$ LR.

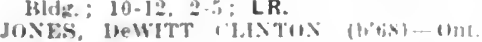

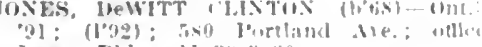
l.owrs Mldg. : $11: 301-31: 30$.

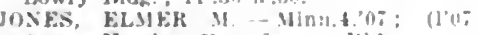

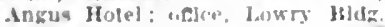

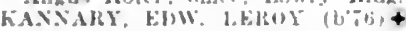

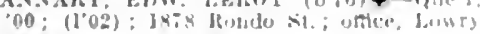

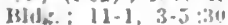

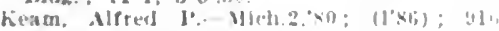
Marshall Ire, ; uftice, Jiswry Mld

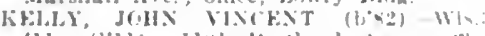
11: (1'11): 11:1 turtland Jie. :191. th aml Wabsalia sts.: 10-1::30,

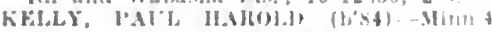
11: (1'11): s95 kraml Are; uflu, lw trolt Itldz: ; 12+1, 2-1.

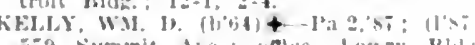

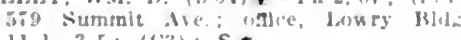

$11-1,3-5 ;(13) ;$ S. *

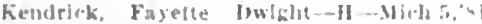

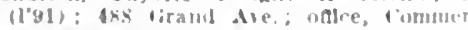
clal lilolk: g.l:"

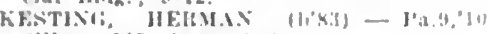
(1'lo): 115 (ntirotel st.

kIRkWriol, sAML MAKLE + Min

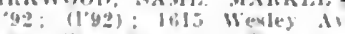

hIstaklk, ARTIIJ

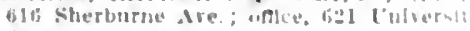
tie.

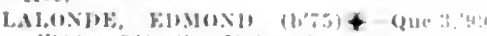

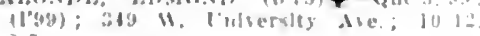
$3 \cdot 3$,

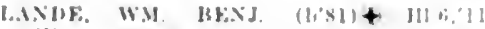

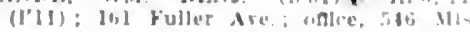

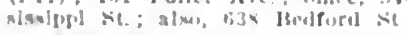

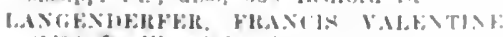

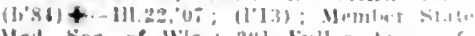
Med. Ane of Wis.; :ul bullet lis. Are, Aki lblce sh.

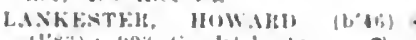
(I'x;3): Hidg: i 11.12, 3-.

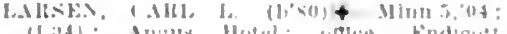

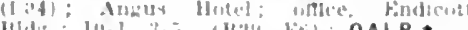

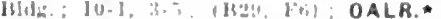

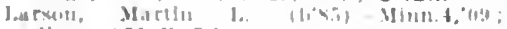

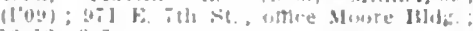
$10-12,2-6$

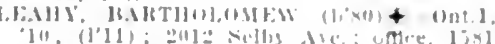

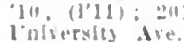

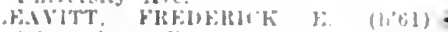

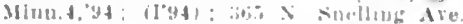

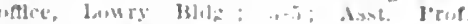
(1) Mt. MIm i: ObG.

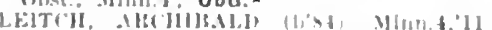

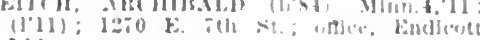
isldis.

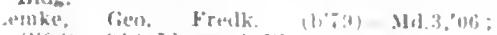
(1'0s): Ges blumeral 1 .

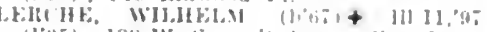

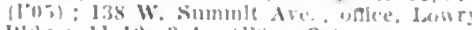

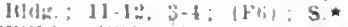

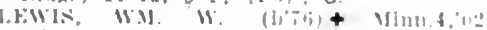

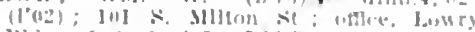
Bluli: 9:3u-i, 2-5; OALR:

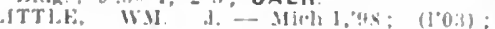

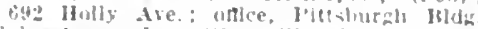
dringstons, Jos. Wm,-111.11,"0.5; (1'0i)

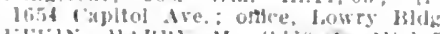

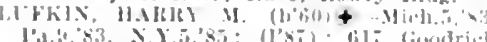

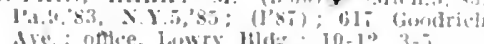

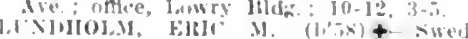

"था); (1'xa) ;

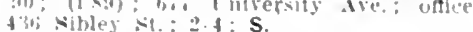

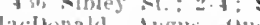

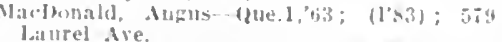
laturel Ave.

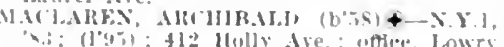

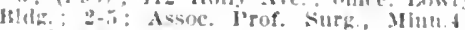
$(1+\cdots, F(b): S$.

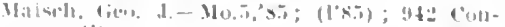

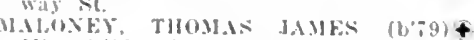

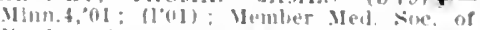

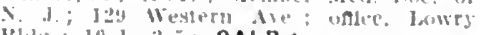
PHII : 10$)-1,3-\pi:$ OALR.

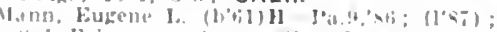

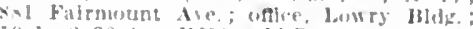
I0-1, 2:30-4: (18:9)": ALR.

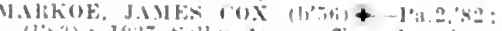

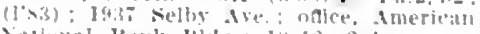

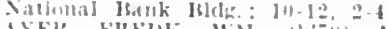

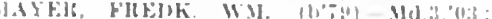
(1'10); Member Med. Sur. uf X.d. ; sigu

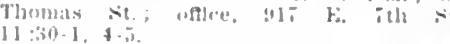

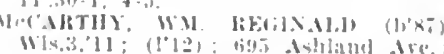

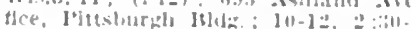

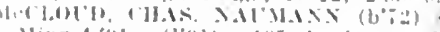
Minn.4:(1), (lol); 135 lexlugtun

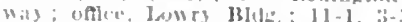

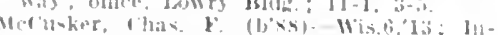
[urte. st. Juseph's llosiplat.

$111117 T$, T1101.

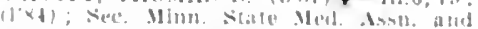

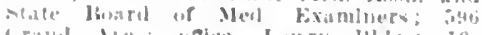

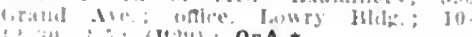

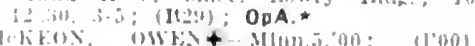

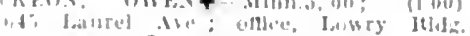
11, lis $\mathrm{s}$.

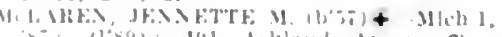

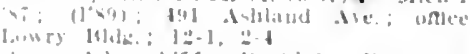

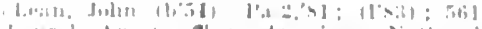

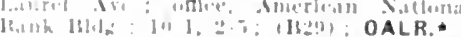

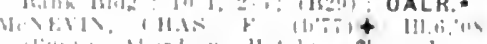

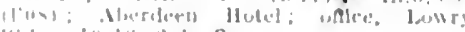

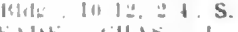

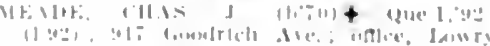

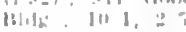

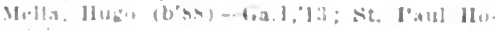

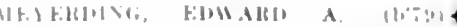

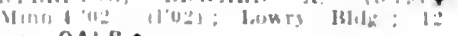
OALR.*

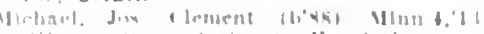

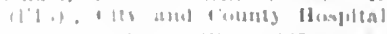

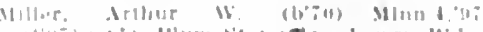

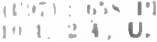

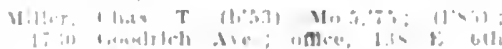

MTIIEI.I. FHElR Joll

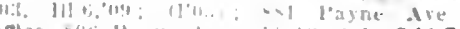

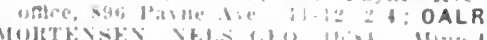

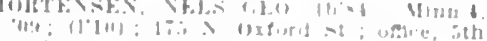

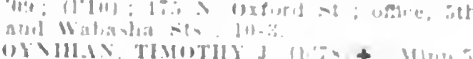

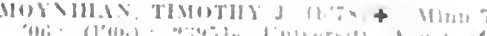

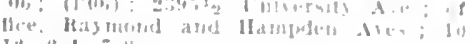
$1 x^{2}+1, z$

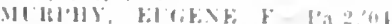

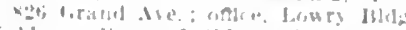

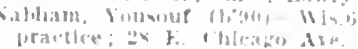

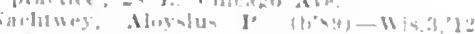

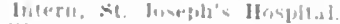

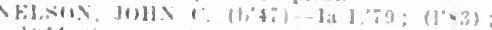

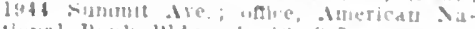

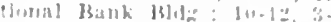

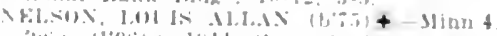

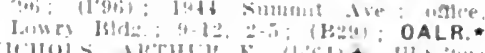

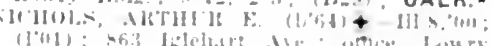

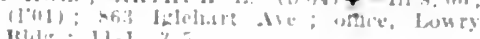
111] : : $11-1$.

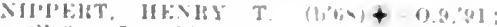

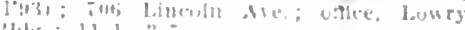
Hillis: : 11-1, :

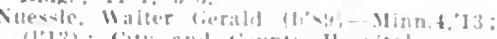
(l'13); ('ity and linunt Henpital

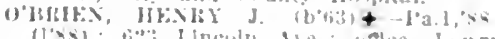

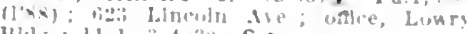
HId ; ; 11-1, ;-4:30; S.

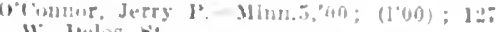
M. lletos st.

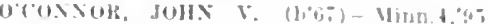

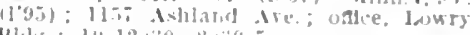

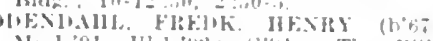

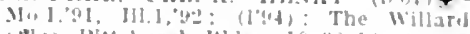

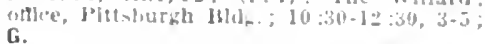

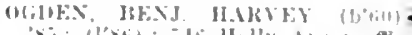
1.3.?

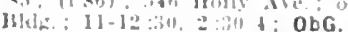

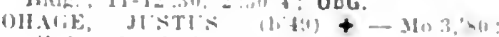

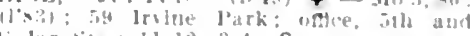
ledlat ris ; $11-12,3-t ; \mathbf{S}$.

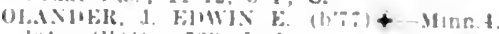

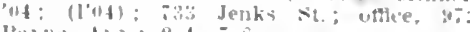

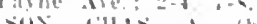

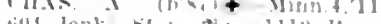

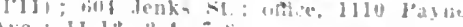

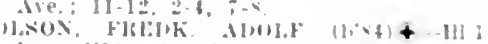

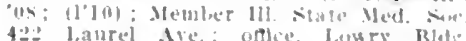

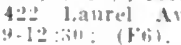

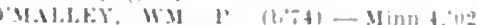

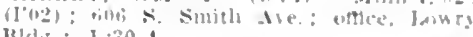

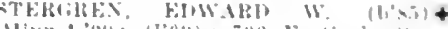

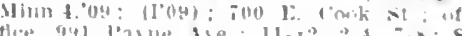

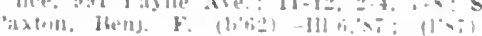

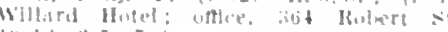
$11+-12,2-;=$

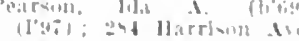

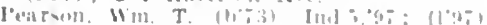

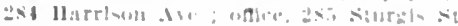

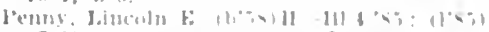

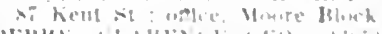

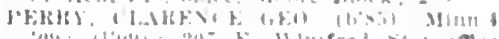

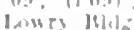

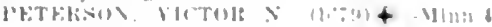

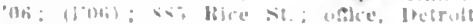

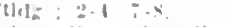

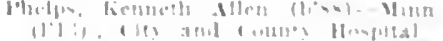

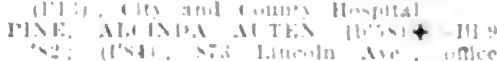

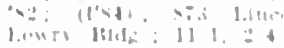

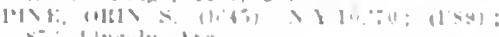

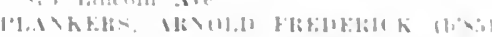

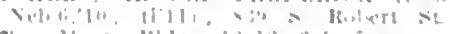

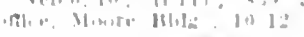

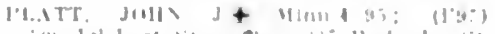

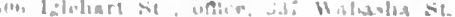

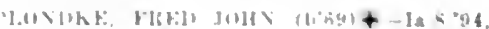

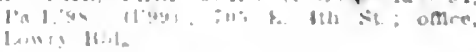


l'o(1), DANI。 (b'60)\$-Ont.1,8.5; (I's6); 75 Holly Ave; ofllce, Lowry IBhth. $10: 30-1,3-5 ; \mathbf{G}$.

QU1NN, JAMES A.†-N.Y.I, 80: (1'84) Snelling and Larpenteur Aves.; ollce, littsburgh litdg.

Qulnuell, Warle Douglass (b'88) - Minn.4, 13; (1'13); City and rounty lospital.

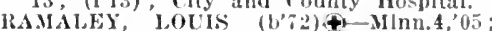
(l'06) ; 277 sherbnrne Ale, afllce, lowry lildg, ; $10-12,4-5: 30 ; R$.

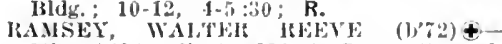
Mlnn.4,96; (1'96); 214 s. Grotto st. ; of

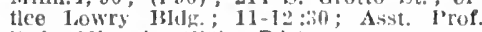

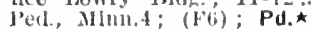

lemlek, Ionis 13,-Mlimn.5,95; $(195) ; 1219$ Como Blvd.; oftlee, Cllamber of commerce rilig.

liFu\%, (IUSTAV A.-1'a.1, $84 ;(1,84) ; 672$ summit Ave.; oflice, lowry bidit.

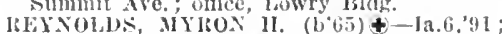
not In practlec; $21 \% 5$ Kuapp st.; oflice, I'nlversity Farm.

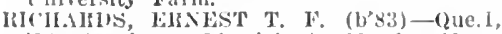
'05; (Assistant Ihysiclan); Hember Ilass. Meil. Soe. : Unirersity Club) ; ofllce, Lowry Ildg.; $9-1 ;(\mathbf{F}:) ; 1 . \star$

kicheson, William- $0.1,63 ; \quad(1 ' 81)$

Iaturel Are, ; ollec, lis lis. bith sit.

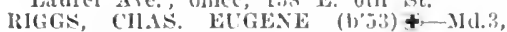
'30;' (1'83); 10 Croeus Hill; ofllee, 350 liokert st.; 2-5; Emer. I'rof. Nerv. ant

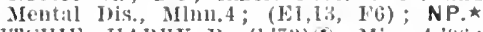
RT'CHIL, IIARIR I'. (b'73)\&-Minm.4, $(46$

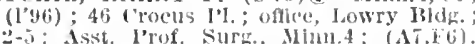

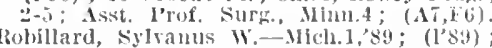
50 central Terrace; uttice, $2-1 \%$ ith st. BOHINSON, IOITA SYINEY BASHFORD $\left(b^{7} \cdot 3\right)+-M a s s .1,01 ;\left(10^{\prime} 05\right) ; 1430$ Grand (b73) t-Mass.1,01; (105) ; 1430

Ro(iERs, flitu 1). - Minn.6,02; (1'04) 1015 st. ('iair st. ; offee, Moore 13ldg.

ROGHRs, JOIIN T' (b'6i) \&-Minn.4,91; (l’1); 284 S. Exehange st. ; offlee, lowry lildg.; 12-1, 3-5; Asst. Prof. Surg., llinn.4; $\mathrm{S}$.

Roman, Henry-Ont.4,'s:; (l's3) Grand Are, offlee, I'ioneer Bldg.

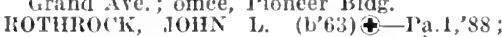
(l'90); 4.$)$ w. 4 th St. ; offlce, Lowry Bldg.; 10-12, 3-5: Asst. 1'rof. Gyn., Minn.4:

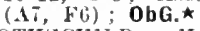

ROTHSCHILD, 11 MROLD J. (b'84) $4-$ Minn.4,05; (1'05); 948 IIague Ave.;

flce, Baltimore Block; 11-1, 3-5; Pd.
Routh, Geo. E. (b'47) II-0.9,74; (l'83) ;

537 Holly Are. ; offlce, Chamber of Commerce Bldg. : 10-12, 2-5.

ROY, PIILENION†-Ia.6,96; (1’97); 1042 Lincoln Are. ; oflee, Grand Opera House Bincoln Are. ; oflice,

RETHEKFORD, 2-4; S. (b'85)-Wls.3,'11; (1'11); 1764 Selby Are.; offee, Lowry Bldg.; 10-12, 2-5.

Ryan, Jobn J. (b'87) - Wis.6,'13; Intern, st. Joseph's Hospital.

Rydell, Chas. Birger (b'91)-Minn.4,'13; (l'13) ; Bethesda Hospital.

satterlund, Victor I. (b'87)-Wis.3,'12; (l'13); S26 Payne Are.; 11-12, 2-4, T-8.

SAYAGE, FRANCIS J. (b'75) - Minn.4, 01; (l’01); 530 110lly Are.; offlce, Lowry Bldg. ; $11-1,3-5 ;$ S.

Schier, Anton Robt. (b'72)-Colo.3,93; A.A. Surg., U.S.N.; Marine Recruiting Statlon; offlce, Ryan Bldg.

Schifrmanin, Rudolph (b'45) - Mo.2,'67; (l'98); 495 Summit Are.; offlee, 208 W. 6tlost.

SCHNACKE, ROY ALVIN (b'86)@-Minn.5, 09; (I'13); 361 Irlehart Ave.; office 133 w. 7 th St. ; $1-3,7-8 ; \mathrm{S}$

SCIIOCH, ROBT.' B. J. (b'83) †-Ill.6, 08 ; (1'0s); 206 Aurora Are.; offlce, Lowry Bldg. ; 11-1, 3-5.

sc1I0X, EDW. (b'84) $\oplus-$ Minn.5, 08 ; (1'09); 941 Selby Are,; office, 394 Selby Are. ; $11-12,3-5,7-8$.

SCHLLDT FRED C (b'75)థ-Mlinn.4, 03 ; (1'03) ; 55 X. Lexington Are.; office, 133 W. ith St. ; $2-4 ; \mathbf{S}$.

CHWYZER, ARNOLD (b'64) \$-Switz.7, 'SS; (1'02); \& Crocus Ilill; office, $123 \mathrm{~W}$. ith St.; $3-5 ;(A T, F 6) ;$ S. * Fa.1,93: (l’93); 649 Goodrich Are. fice, I.owry Bldg.
SIIFHI'HR, MYRON (b'so) - Ill.11,07; (1'07): 270 Kent St. ; oflee, Lowry Bldg. SHIMONBK. ANTON (1,55) \&-I11,', 9 ; (l'84) ; 458 Ianurel Are.; offlee, Lowry I3ldg.; $10-12,2-4$

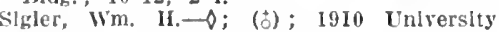
Ave.

SIMON, BENJ. FRANKLIN (1)70)-Ill.1 00; (l'00); 511 Capltol JHsd.; offlce, Lowry 13ldg.; $11-12,2-4$

SKIXNER, IIAHVEY OGIIEN (h's1)-Ill.4 (1) 4 ; (l'04); I072 Goodrleh Ave.; offlce, 1.0wry Jlelg.; $10: 30-12,2: 30-4: 30 ;$ Pd.

Smlth, ('has, lastwiek (1,4:3)-Pa.1,65; (liv3) : not in praetlee; 400 Marshall Ave. SMITI, CHAS. BASTWICK, JR. (b'83)I:a.1.08; (I08); The Angus; offlce, Lowry Blide.

SXYVW, IALDOR (b'65) †-0.1.'87; (1'87) 1.12 Mlssissippl Rlver IBlyd.; oflee, Lowry

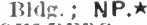

SOHLBERG, OI,ON (b'59) $€-M \ln n .3,84$; (1'84): 7s, Filrmount Ave; offee, $329 \mathrm{~F}$ th st.; $10-12,2-5$

Sipates, Finley C. (b'5 5)Il-Ill.4,'83; (I'86) $9+2$ Renney St. ; $3-5$

STALEY, JOHN CLARENCE (b'75) Minn.4.03; (1'10); I212 Laurel Are. offle, Lowry Bldg.; 3-5; S.

STERYNI, ERTEST G. (b'82) ()-MInn.5. 60: (1'(16) ; 679 Eniler Ave; offlce, 782 Wibaslua St. : 2-4.

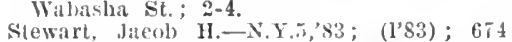
st. Peter sit.

STIBILE, ADOLIII, JR. (1,67) क-Minn.4, 01; (l'01) ; 954 Hastlugs Ave.; ofllce, Jittslourgh Bldg. ; 11-12, 3-5.

STOIPLSTAD, IIAROLO L. $\left(\mathrm{b}^{\prime} 79\right) \uparrow$ Minnt.4,01; (l'01); 734 E. 5tls St. ; of fice, $T$ th and Hope Sts.

STYMM, THOS. WESLEY (b'T1)-111.1 01; (1'01); Angus Hotel; ollice, Lowry Bldg. : 11-I, 3-5; (F fi) ; 1.ћ

SWEENEY, ARTHTR AMBROSE (b'58)థ Mass. I, 86 ; (1'88); 1525 Summit Ave omce, Lowry Bldg.; 10-12, 3-5; NP, *

SWTNEY, CLARENCE F. (b'57)-IIl.1,81; (187) ; 346 Goodrleh Are.; offlce, $133 \mathrm{~W}$. th st.

TAYLOR, HENRY LONGSTREET (b'5 -0.1,'82; (1'93); 748 hinwood Pl.; office, Lowry Bldg.; 9-12, 2-4; T.

TEISBERG, CARL BENJ (b'79)-Minn.4, 06; (l'06); 904 Fairmount Ave; offlee Lowry BIdr. ; 11-1, 3-5; S.

THOMPSON, HERBERT HENRY.

(See Minneapolis.)

Towle, Geo. E. (b'88)-Wis.6,'13; Intern, St. Iuke's IIospital.

TURNACLIFF, DALE D. (b'88) \&-Minn.4, '11; (l'11) ; I478 Cajtitol Ave.

University Ave.; 10-12, 2-5.

Turner, Val Jo '(col.) (b'66)-Tenn.7,'94; (1'00); 386 N. St. Albans St. ; offlce, 27 F. Tth St.; 10-11, 3-5.

VAN SLYKE, CHAS. A. (b'65) †-Minn.4, 91; (191); 911 Iglehart Ave. ; office, Veline, Olaf $\mathrm{J}$.

(See Minneapolls.)

Wilker, John Godfrey (b'51) - Ill.1,'73; (l'83) ; 210 E. 9th St. ; offlce, 390 Wabasha St. : $9-12,2-4 ;$ OpA. $\star$

WALSH, EDW. FREEMAN $\oplus-$ N.Y.1,'85; (1'91); Aberdeen Hotel; offlee, Lowry Bldg.

Walther, Edward-H-Mo.6,'71; (I'83) ; 443 Dayton Are.

Warne, Edwin Geo. (b'70) - Minn.5,97; (l'01) ; 405 Ig] ehart Are.; offlce, $138 \mathrm{E}$

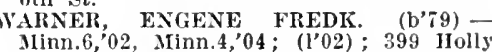
Ave. : offece, Lowry Bldg.; $10: 30-12$ $2: 30-4: 30$.

WARREN, JAMES WALTER (b'81) - Va.1, 06; (l'07): 1665 Selby Are.

WELCH, MICIIAEL CHARLES $\left(b^{\prime} / 4\right)-I I I .8$, 02, 1ll.11,05; (1'06); 176 Concord st.; offee, Lowry Bldg.

Wentwortl, Albert Johnson (b'91)-Minn.4, '13; (l'13) ; Bethesda Hospital.

Wharton, Alf-Pa.1,'57; (l'83); 923 summit Are. ; offlee, 208 W. $3 d$ St.

Wheaton, Chas. A. (b'53) - Mass.1,75 (1'83); not in practice; General Delivery.
WHITATLE, JOHX ClAFORD (b'76) $€-$ Mlun.4,0I; (1'0I); 622 Lincoln Ave.; oftec, I i 6 s. Hobert St.; I0-2; S.

WHITCOMB. EINW. 11. (b'0I) $4-0.14,84$; $(1 ' 84) ; 513$ W. Contral Ave.; offlee, Lowry Bidg.

HITE, JONAS SAML. (b'7I) 4-Pa.2,'93; (1'05) ; 14i A Ashland Ave. office, Jowr Bldg. ; 9-I, 2-4; ( 129, F6) ; ALR. *

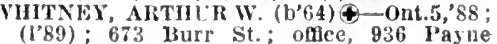
Ave, ; $2-4: 30$.

WILLAMS, CORNELIUS (b'48)-N.Y.1,'T4; (l'83); Lowry IBldg. ; 10-1, 3-6; (BS) ;

WNNICK, JOS, BERNARI) (b'82)\&-III.1. ; $(106)$; 226 Nelson St. ; oftlce, Low

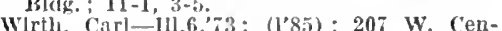
tral Ave, offlee, I'sttsburgh Bldg.; 11-1,

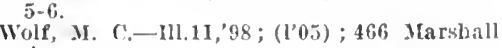
Ave.

ZANDER, CHAS, II. (1,'80)-Minn.4,09; (l'09); 1105 W. 7 th st. ; 10-12, $2-4,7-8$. 869 Dayton $A$ re.; office, 712 Selby Are.; $11-12: 30,3-3$

ZIMHWLMAN, II.ARRY B. (b'85) \&-N.Y.I, 09; (l'09); 246 I'leasant Are.; once, I.ONTy lidg.; (F6).

ST. PAUL PARI, 832, WASHINGTON

IIunger, Perry II. (b'6I)-Mlld.1,'S9; (1'9I)

ST. PETER, 4,176, NICOLLET

BASKETT, GEO. TERREIL (b'82) \& Mich.1,08; (1'09); NP *

BASKL'T' OLIVE' THORNE (b'81)-0.9, $06 ;(1,09)$.

BLAKELY, CLFMENT C. $\left(\mathrm{b}^{2} 76\right) €$-MInn.4, (2)

Que.1,07; (I'12)

ANIFIS. JARED W. (b'67) $\mathrm{f}-\mathrm{Ill} 1,189$, N.Y.1,90: (1'92).

EIRLEY, CI.ARA $\therefore$ (b'6i) $\mp-M d .5,92$; Memher Med. and Chir. Fac. of Md.

State IIospital: $\mathbf{P}$

GROUND, HOIIAND T. (b'8?)-I11.11, 07 ; (1).

ICINTYRE, (FO. WESLEY (b’33) Minn.3,'83, N.Y.5,91; (1'83).

IERRITT, GEO. F. (b'46) $\oplus-111.1,72$; (1'S3).

(l'87).

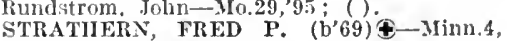
$99 ;\left(l^{\prime} 99\right) ; \mathbf{S}$.

ST. VINCENT, 328, KITTSON

Campbell, Alexander - E - 0.2,'8I; (l'84); not in practice.

STACY, 250, CHISAGO

tone, Wm. T. (b'55)-Ill.4,'82, Ill.11,'98; (l's:i).

STAPLES, 2,558, TODD

ALLEN, FRANK HARVEY (b'71)థ-Ill.1 94; (1'94); Member State Mied. Soc. of Wis.

Fowler, Fdw. S.-Que.1,94: (l'94).

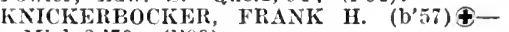
IIlch.2,'79; (l'89).

STARBUCK, 497, POPE

CAMPBELI, CLAUDE MEIVILLE (b'84) -Ill.6.']0: (l'11).

(b6) 1 - Alinn.4,

Ekrem, Johan' M. (b'66)-Minn.5,'03; (1'12).

STATE SANATORIUM, 25, CASS

BEACH, GEO. W'I. (b'67) $\oplus-$ Fra.6,'94

(l'13); Nember Med. Soc. of the State of N. Y.; T.

06 (1'06) Wis.

STEPHEN, 618, MARSHALL

GUILFOYLE, JOHN PETER (b'82)-111.6, 04; (1'13).

\section{STEVENSUN, 125, ST. LOUIS}

ROWE, ARTHLR NELSON (b'81)-I11.1,'13; ( ).

STEWART, 412, MCLEOD

Kohler, Fredk. G. (b'76) - Mlnn.5,'97;

TINKER, CHAS. W.-Pa.2,78; (1'87) 
STEWARTVILLE, 794, OLMSTED FAWTFT, IIIAS r. $\left(\mathrm{b}^{\circ} 69\right)+111.6,93$ : 110031.

RLSSEIL, IIETMIN K. $\left(\mathrm{b}^{\prime} 1\right)+-$ III.11, ?9: (1०Dis)

STILLWATER, 10,198, WASHINGTON

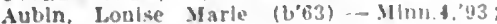
(1'y4); Pltmar) House; oflee, Turlnus Mide: $9: 30.11: 30,2-5,7-8$.

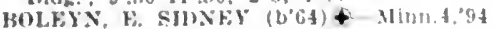
(1'94): Mower Hinck.

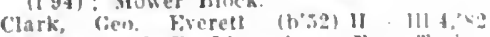

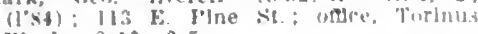
luok: s-10, 2-5.

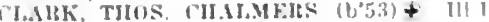

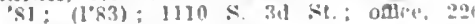
F. ilestnut St: $10-12.2-3$.

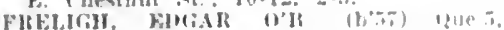

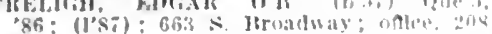
ह. Chesinui st. : 9-11. 2.4

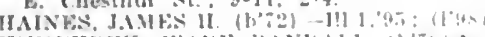

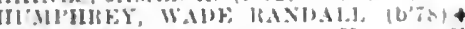

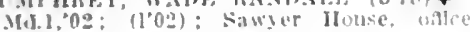
Torluus Blig. : 10-12, 2-5.

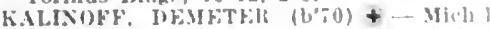

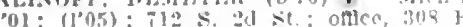
Chéstnut si: $\mathrm{s}$

LANDEEN, FirA (1'94).

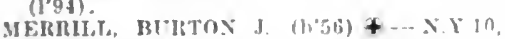

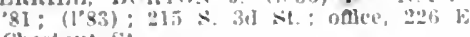
(hestnut si.

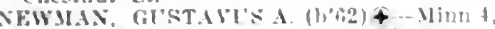

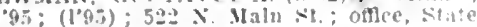
Prison Huspltal: 8-T.

Van Cuppellen, (has, $\left.(1)^{\circ}, 3\right)-$ Helf 1,8, ; (I'sej).

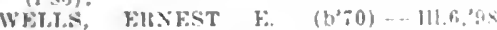
(1'01): 206 s. omen st.: oflee, lom : Maln Sit.; $10-12.2-5$

SWANVILLE, 397, MORRISON

WITTHOET. IIVING (:Ro) (b'SG) \&-WIS.2. II; (l'lid): Member State Med. soc. of W'ls.

TAYLORS FALLS, \$54, CHISAGO

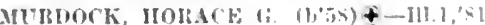
(I'B3)

TERRACE, 50, POPE

Skinner, John F-F-IIl.s,'sl: (l'83)

THIEF RIVER FALLS, 3,7I4, PENNINGTON

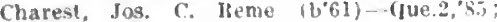
$(1 / 85): \mathrm{G}$

DOLFILASS, JFSSE FLI.SWOLTII (b'S9) + -Miun.4,12: 11'12).

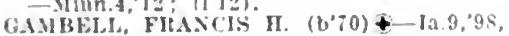
III.11,04: (1'98)

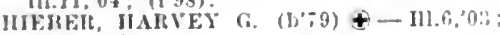
(100i): 0p.

MELLISY, OSCAI: $r$. (b?-6)-MInn.5,"01 (l'02).

Oftedal, siverre (b's3)-Ill. , I1 ; (1'12)

Vlstaunet, l'eter Lorent\% $\left(b^{\prime} i l\right)$ - Mlnnt, $02:(1,02)$.

TINTAH, 217, TRAVERSE

Doleman, Nathan $F$, (b'7i) II - Mass.5,"01 (l'02).

TOWER, I,III, ST. LOUIS

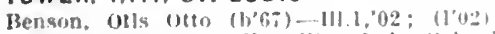
(Indlan servlce); Vermallion lake seluned

Hynes, E.lward Jus. (b'89)-W'ls.3,'J2;

TRACY, 1,876, LYON

HOHDAL, ANUIKW D. (U'T) - MIIII $04:(1,0+)$.

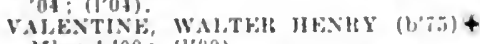
MInn.t, 00 : (1, (10)

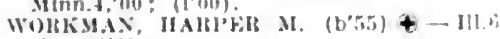
$\because 8:(1,83)$

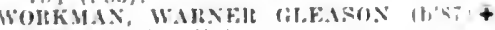
-MInn.4,12; (1'12)

TRUMAN, 45I, MARTIN

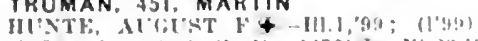

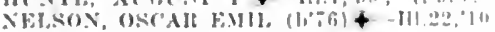
11011): Member III. Silate Meol Simo

TWIN VALLEY, 513. NORMAN

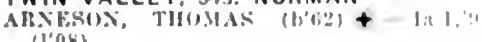
(1,0s).

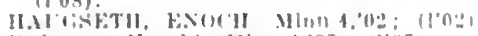

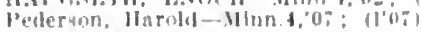

TWO HARBORS, 4.990. LAKE

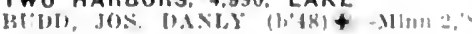
(1"Xí).

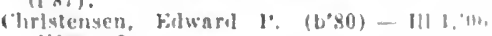
$(10 \mathrm{~s}) ; \mathrm{S}$.
KNAFF, MIHIFNBEHG K. $(1,69)-$ Jimn.4.95; $(1,(16)$.

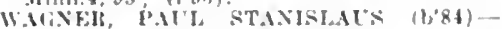
III 1, II; (1'11).

TYLER, 61\%, LINCOLN

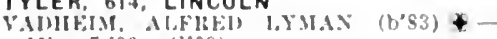
MInn.T, 09$) ;(1.09)$.

ULEN. 438, CLAY

Bolhne, Firliug Mlred 111.11,02: (1'02).

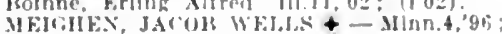
(1'86).

UNDERWOOD, 425, OTTERTAIL

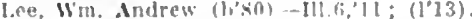

VERGAS, 237 , OTTERTAIL

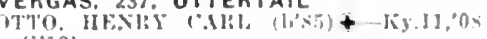
(1'12).

VERNDALE, 338, WADENA

'orae, Clins. I-MInn 4.97: (1.3i).

UOHEII, WIIKIJ $\mathrm{X}+$ S: (ISS3).

VERNON CENTER, 289, BLLIE EARTH

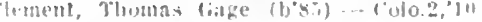

(1'11): $\mathbf{O b G}$.

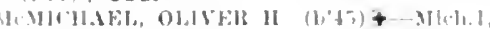
$\because$ I: $(1,4)$.

VESTA, 243, REDWOOD

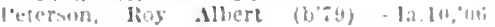

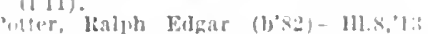

VILLARD, 260. POPE

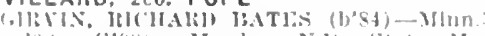
"IX: (l'0s); Member N.1. State Mes

VIRGINIA, 10.473, ST. LOUIS

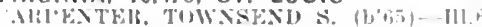

42: 11'45): Member Ia. Stale Hed. Soe

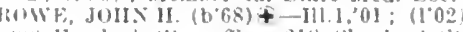
inl llemlock st. offlce, $21 \mathrm{~s}$ (hestnut st $\ddot{\sim}-4$

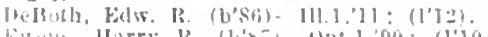

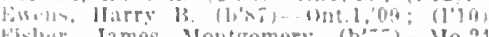

Hisher, James Montgomery (b'75)-Mo.24 (1'1i) : Lenunt Ilospital.

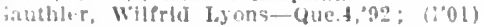

(1)hlabulnut

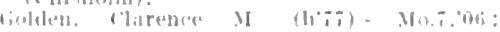

(1'i 10$)$.

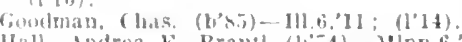

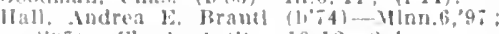

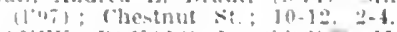

ANFY, IR(NALI) L. $(1,52)+-110.22,06$; 110!1); S.

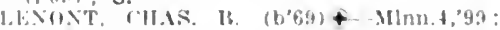

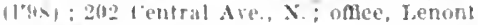
Ilumbltal: 1-3: S

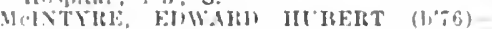
I11.1, (62:; (1002): MeIntyre IIospital; 8-4,

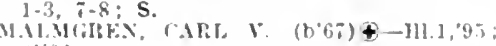
(1) 1$\left.)^{2}\right)$.

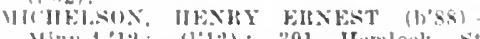

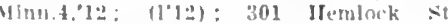

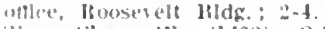

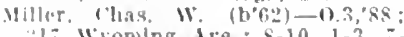

Ai Wyoming Are,

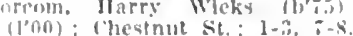

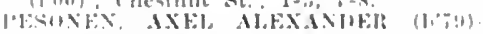

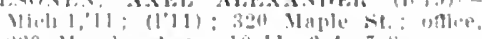

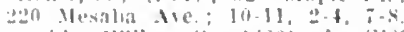

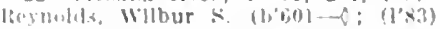

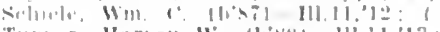

Tumiter, Hartey Wo

WABASHA, 2.622, WABASHA

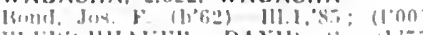

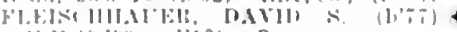

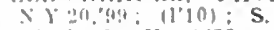

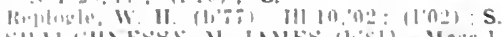

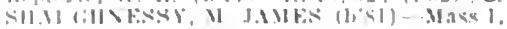

WABASSO, 343, REDWOOD

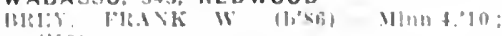
11.101

WACONIA, BI7, CARVER

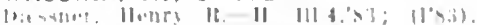

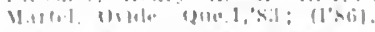

WADENA. 1.820. WADENA

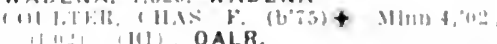

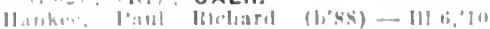

hlins, 10.11, 1: (bos) \& 111 n,

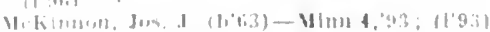

WAHKON, 450. MILLECLACS

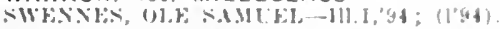

WALKER, 917. CASS

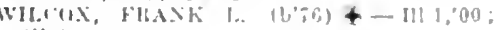
(I,III)

WALNUT GROVE, 366, REDWOOD

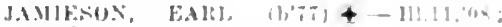
(100)

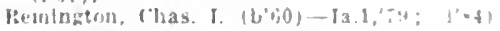

WALTHAM, I70, MOWER

Haker tilenn Iolewells

(1'ii).

WANAMINGO, 120, GOODHUE

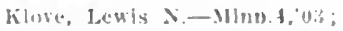

WARREN, 1.613, MARSHALL

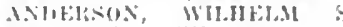

VInnt, $\left.0: 3 ; 11^{\prime} 03\right)$.

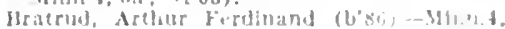
1:" : 11:121.

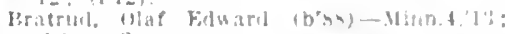

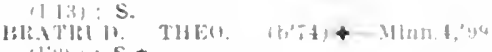

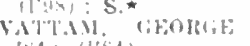

'xt; (I'SH).

WARROAD, 927, ROSEAU

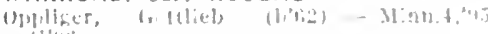

WASECA, 3,05t, WASECA

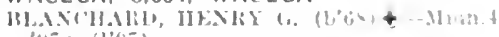
, 4 : $\left(\mathrm{J}^{2}, 3\right)$

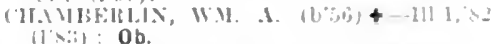

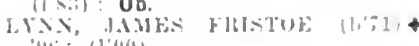
(1); : (1) (1)

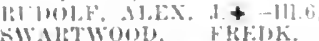

IIicli.1, >xi; ; (1'Mi).

WATERTOWN, 465, CARVER

lial-oren Jarry I Yinn 4,0 -

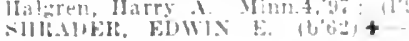
(1'y3); S.

WATERVILLE, 1,273, LESUEUR

lily, WHlli- Ill 1, $\$ 0 ;(1 ' 3)$.

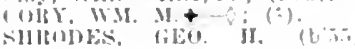
(1'titi).

WATKINS, 366. MEEKER

HIMIIAM, Flid.K T. $(190)+$ Minn (1):; (105)

WATSON, 152, CHIPPEWA

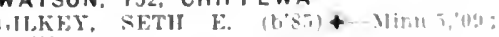
(I'0!)

WAUBUN, 230, MAHNONEN

(OMIIIFI, OMAR F. (1, (l'lf): Member III. Srate Mel. Sice.

WAVERLY, 460, WRIGHT

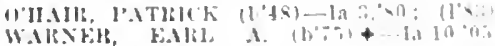
W.1B.Nith

\section{WAYZATA, 492, HENNEPIN}

WAYZATA. J92, HENNEPIN

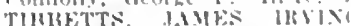

Indl.:s: (1'A); $S$.

WELCOME. 343. MARTIN

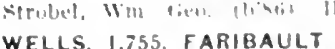

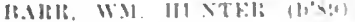

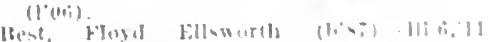

(1'13): OALR.

Wury Arme's Jane Ilotiar

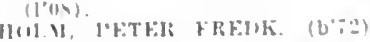

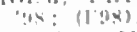

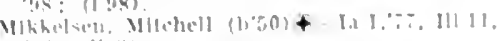

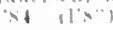

WENDELL, 173, GRANT

UITIIIEII, TIIUIIS

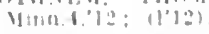

WESTBROOK, 429. COTTONWOOD

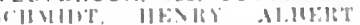

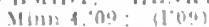

WEST CONCORD. 384 DODGE

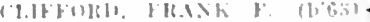

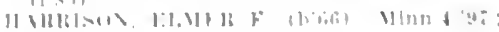
$11: ;, 1$ 
WEST DULUTH (IND. STA., DULUTH), - ST. LOUIS

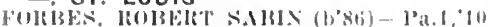
(I'13); : : 11 N. ('entral Are.

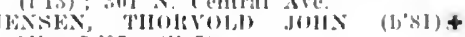

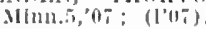

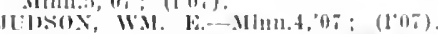

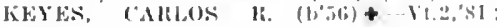
(1.83).

Olsen olliver \& (b's:3)-111.11,12: (1'13)

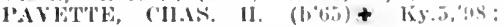
$(1,00)$.

WEST ST. PAUL (ST. PAUL P.0.), 2,660. DAKOTA

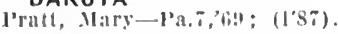

WHEATON । 300 . TRAVERSE

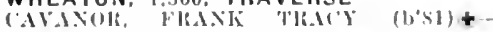

Mim, $4,10:(1,10)$.

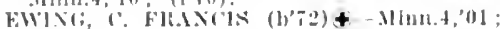
(1'01)

Joltun, 'lluodore (1)'83) - Wls.3.'ll; (1'12)

WHITE BEAR (WHITE BEAR LAKE P.0.), - RAMSEY

FRAXCIS, NIMHOX OTIIO (1)'(10)\&-

yinn:3ist: (I's.1)

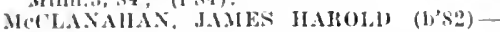
111,6, , $^{2} 9 \%$; (1'10)

WHITE BEAR LAKE, 1,505, RAMSEY

Commings, ('las. (i.

(Sue st. l'atul.)

1.FIs, WM. W.

(See st. l'alul.)

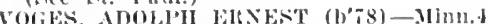
0.); (l'04); OALR.

WHITE EARTH, 350. BECKER

Ascher Alfued (b'Si) Mo.34,'l'; (Indian service); White farth selion

Gultlad, Virgll 1). - 0.25, 07 ; (Lndian ser-

vice); Whlte Earib sehool.

Tannes, James fiartheld $(1,82)-1$ Jo.2., 10 (Inclian service); White Eath selnool.

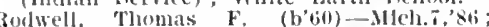
(1"43); (Indian service); White Eallh (1's)

WILLMAR, 4,135. KANDIYOHI

1BRAXTON, HERTON J. (b'B3)૯-Minn.4 0,$5 ;(105) ; \mathrm{S}$.

COLWMAN, FllED Is. (b'74)-Mimm.4, 09 (l'09) .

Foshager, Henry Theodore (1,81)-iImn.4 : $199 ;(1)(0 y)$.

FREFMAX, GEOH(:E H. (b'S4) + Minn.4 (1): (I'05).

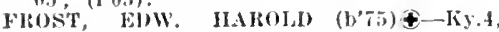
39 ; (L'99).

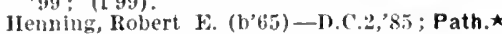
JACOBS, JOHANXEs C: (b'is)屯-Mim.t $05 ;(1,05)$.

JOHNSOX, CHRISTIAN (b'53)屯-Ma.2, $72 ;(1 ' 33)$

RAINS, JOHN M. (b.50) 4 -Ont.4.70 $(1,89): P d$

Thompson, vietor Cecil (b'85)-Minn,4,12 (1'12).
WILLOW. RIVER, 2I2, PINE

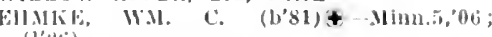
(1'(i)i)

WILMONT, 258, NOBLES

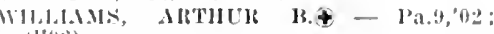

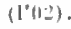

WINDOM, 1.749, COTTONWOOD

le roster, Wm. T. (b) $(1: 17) ; S$

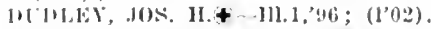

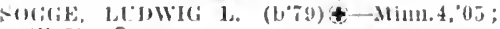
(l'o.i); $\mathbf{S}$

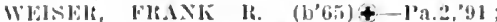
(lat): I'res, Mlum state Board of Med. Eximiners; OpA.

WINNEBAGO, 1.554, FARIBAULT

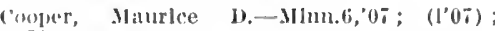
0 b.

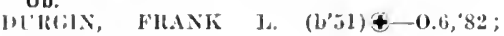
(lio(i).

YAlliti., diko. F. (b'64)-111.11,95; (I'95); ALR.

WINONA, 18.583 , WINONA

DI'(iAN, HOLLO $C$ (b'bi) \&-Minn.4,"90 $(1 \cdot 30)$; Choate Jiloek

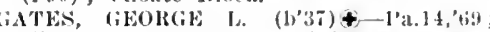
(1'8.i); 52 W. 30 st. ; 11-12, 2-5.

HEISE, WM. FREHK. ('All, $\left(b^{\prime}, 4\right)+$ I11.I,96; (1'97) ; 259 F. Broadway; oftice, 3] and Franklin sts.; $2-4,7-10 ; \mathbf{S}$.

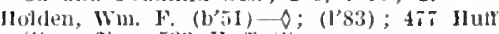
St. ; oftle, 523 Ilut st.

KFYES, LIWARI, D. (b'59) —-III.1, (I'85) ; 250 Center st. ; office, 216 c'enter St. : $9-12,2-4,7-8 ; S$.

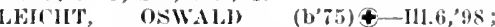
$\left(l^{\prime}, 98\right) ; 266$ Winona st.; olthere, ibl and

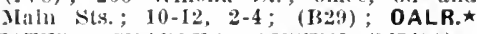
I.ESTER, CHAJLES ALSTIN (b'T4)\& Ky.5,97; $\left(I^{\prime} 02\right) ; 408$ Winona st.; oftice 72 W, 3d st.; 9-12, $1: 30-4 ;$ OALR *

LICHTENSTEIN, IIANS II. (b'66)-Ger.19 90 ; (1'91); 221 iे. 5th St.; oftice, 61 W. 4 th $\mathrm{si}$.

LINDSAY, WM. V. (b'73)థ-No.1,98; $\left(1^{\prime} 98\right) ; 113 \mathrm{~W}$. King St.; oftlee, $50 \mathrm{~W}$. 3(l st.; $10-12,2-4$.

LYNCH, ELIZABETH AHLEN (b'84)llis.3,'10; (1'11); 202 W. 11 th st.; office, is F. 3i St. ; $10-12,2-5$.

J. YNCH, MAMES L. (b'65) \&-Mich.1,00 : $\left(l^{\prime} 00\right) ; 74$ E. 5 th St.; offlec, 78 E. :il St.

MeGA[GHEY, IIUGH F. (b'T3)థ-X.Y.1, "yt; (1'96); 52 li. 5 th st.; office, 210 (enter st.; 1-4.

MclALGHIIX, ENMLND M. (b'7) Que.1,03: $\left(l^{\prime} 05\right) ; 479$ W. Broadway. offlee, $78 \mathrm{~W}$. $3 \mathrm{~d}$ Sı. ; $9-12,2-5,7-8$.

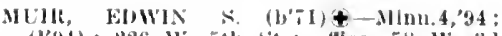
(l'94): 226 W. 5th st.; ollice, 58 W. $3 d$ Sit. ; II - 12, 2-5, $\tilde{i}-8 ; \mathrm{S}$.

Olsen, ot1o li. (1,79)-111.1,01; (l'02); Isfi L. Howard sit.

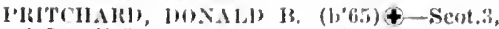

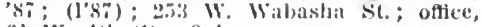
(i) W. 4 th st. : $2-4$

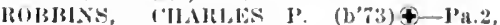
,94; (1,96): 7: W. Broadway; oftlee, 159 Center st, ; $11-12,2-5,7-8$.

Scliafer, Sianl.-11-Iich.5,04; (1'06); clioale Mlock.

STEWART, DALW1X А. (1) 45$)-N . Y .1,69$; (1'84) ; $78 \mathrm{~W}, 3 \mathrm{~d}$ st. ; $9-12,2-4,7-8$.

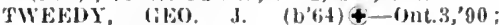
(I'85); 352 Maln St.; office, 78 E. $3 \mathrm{~d}$ St. ; $2-5$.

Whberton, Lawrence C. (b'53) 1J-I'a.9,80; (l's3); 103 E. Jih st.; oftec, Mfodel block.

\section{WINTHROP 1,043, SIBLEY}

JOINSON, OTTO F.\&-Minn.5,02; (1'03).

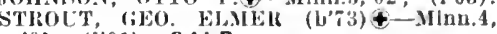
01; (1'01); OALR.

WINTON, 390. ST. LOUIS

METCALF, FIANK WOOUWAII) (b'75)屯 -III.1,06; (1'08).

WOODLAKE, 292, YELLOW MEDICINE

IIOORE, WII. J.†-III.8,93; (I'94).

WOODSTOCK, 226, PIPESTONE

l)oms, Win. $\rightarrow$; (む).

WORTHINGTON, 2,385, NOBLES

IOIAN, (HAS. P. (b'57)屯-1a.3,'s0 : (1'84)

MAXsox FlisxK M. $\left(b^{\prime}, 2\right) \oplus-$ Mimn.4, 39: $(199): \mathrm{S}$.

MOHK, BYRON O.t-Minn.5,07; $\left(1^{\prime} 07\right) ; \mathrm{S}$.

SHALLWOOH), JLSTI T. (b'82)-Mlinn.6, ,08; (1,08)

WHHOW, HENRY (b'72)-1a.3,02; (l'02) ; S.

WYKOFF, 456, FILLMORE

Walker, James Douglas (b'80)-Minn.4,09; (I'09).

YOUNG AMERICA, 303, CARVER

Eklund, Elmer J. (b'84)-Minn.4,,$^{\prime}$; $\left(l^{\prime} 0 \bar{t}\right)$.

GINELLI, CARL T, $D$; (I'96).

ZUMBRO FALLS, 208, WABASHA

RANKIN, ARTILK $A$. (b'i1) $\$$ - Minn.4, $00 ;(1,00)$.

ZUMBROTA, I,I38, GOODHUE

Fortuey, Gerhard olaus (b'79)-H1l.1,06; (1'08); OALR.

Gryttenliolm, Karl E. (b'62)-Norw.1,'91; (1'95); $\mathbf{S}$.

Kittleson, Olaf Lee (b'8T)-Minn.4,'12; (1'12).

IORSS, CLAREXCE IREPERT $\left(b^{\prime} 80\right) థ-$ P'il.1,08; (1'10).

FOR KEY TO SPECIALTIES, ABBREVIATIONS, SYMBOLS, ETC., SEE PAGE 77I

Information concerning state institutions, hospitals and sannforiums will be foumd in the introductory matter of each state. 


\section{ISS I S S I P P I}

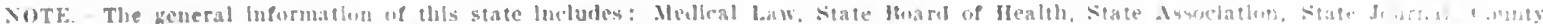

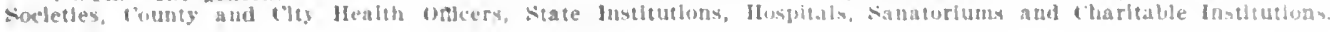

\section{MISSISSIPPI}

Population (1910 census)

Number of Countles...

1.797 .114

Number of Physicians.

0.047

Members State Association Dec. 31. 1913

Area of Siate in Square Miles.

MEOICAL PRACTICE LAW OF MISSISSIPPI

TIF: LAI

Itegulating the Iractlce of Nelicine in the state of Mlssisslupl. (bajter 110 Annotated Code, Iyoti.

3681. (3243.) 1.ICEXEF: VIOLATION Every person who deslres to practlce mediclne mist flest ubtaln a llcense to do sn from the state loard of Health; but this sectlon shall not anply to plyyslclans now holdlng bermanent license, the same having holding fernanent ficense, the sime haver lieen recorced as resulred by law (For venalty see sectlon I334: If any person shall practlce as a physlclan or surgeon obtulned a llcense as renulred by law, he shall, on convtetion, be fined not less than $\$ 20$ nor more than $\$ 200$ or be Imprisoned in the county fall not exceellug thirty days.)

36x2. (3244.) F.x.MINATIOXs; SIISECTS: Erery persion who deslres to obtaln a llcense to jratelle medicline must apply therefor, in writing, to the state Itwart of llealth, at least ten days before the date of examinatlon, and must be examined by sald bond towehing hla learnling on the following branches of mediclue only, viz: Anatomy, chenlstry, obstetrles, iniTeria Anatomy, chemistry, obstetrles, maand hyglese, and it the applleant be found by the bond, on examination, to fusvess
sutdelent learning in sald hranches ane] low of gool moral cliaracter. the board shail at umre lasue to litm a license to practloe medlclne. whlch shall be slgmed hy all of the nembers of the board jiresent at sali] meeting: brorlded. that no ibjlirant shall the granted a lifense unleas salll nuplicant shall hold a diplonat prons as routable medi

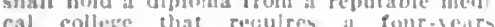
cal college that reciulres a four boars conrse

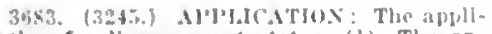
callon for license must state: (3) The applleant's name in full: (2) hls place of resulence and postonce address: (3) hls restatence and postinfce Aduress: (3) his natlrity and age: (t) the the suent ly him In medlcal stulles: (b) the hame and bost. meelical studies were purvucel; (ib) courses of medieal leetures attended; (i) name of medles! schors atconded; (S) if at hraduat. of a needlical colleke. name thereof: $\{9\}$ timo suent in a hosultal: (I0) time sprent in tlo practire of modlletne, if any: (11) schuol or system of pracllee chosen. and (1:) rofur. ehases as to hals liersonal iharmeter.

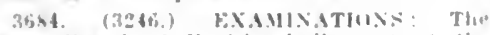

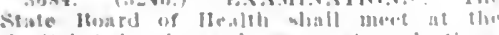
inultal twice in each sear, at suels thmes as may tre designated lig the hoarel. for the

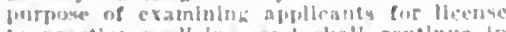
in foractliee melleine, and sliali continue in

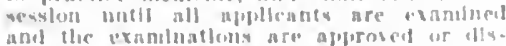
and the cxamiluatlons are ableroved or elise

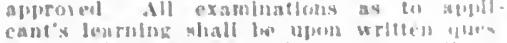

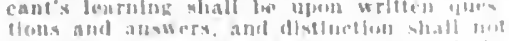

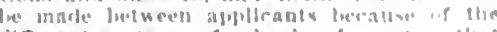
different as whems of schoels of prarlice lliat maty be chusen. 3rss. (324:) FkEs: Hory person who shall apply fur llecuse to pratice medlelue shall. tuefore he wlll be entilled to be exant. Ined. pay a fee of \$10.25, wi whll \$10 are ti) be arlded enually teitweol those niembers of the hoard whes attend aldel conduct the exnmination of the apjlleant. and 25 cents (i) be pald to the secretary of the board for flling and jresersing the application for llevise.

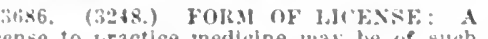
Ileense to practlee medleine may he of such furm as the state Hoard of Heallh may preserlbe, but It shall contain a statement thowing the place of resldence, postofice address and nualifications of the applleant,

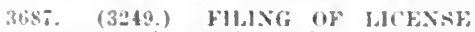
Fivery person who recelves a lleense to practic" medlelue must Hle it in the oftce of the clerk of the Clrcult court of the county in whlch he resldes witlin slxty dars from the date of its issuance: otherwlse it shall date of its issuance; otherwlse it shall be'come vold. When the lleense is filed the tionte of the flllug thereto attaclsed, In a sultable book to the kept in hls oflce for that purpose; upon the parntent by the licensee of the fee prorided hy las, and, when recorcled, he shall deller the oriflnal, on demand, to the llcensee. Whenerer the lliensee shall change the county of hls resldence aud of usual practlce he must, under like penalty, fle the orlginal or a certifled copy of the ilcense. or of the record thereof. copy of the linetnse, or of the record thereof. which he shall muse and practice, withln sixty days of the time of such remoral. to the there recorded in like manner and under like penalty.

iviss. (3250) loss on NoN-REcolb1)ANCE (OF I.ICF.NSE: If a license to praclice mallelne be fisued and to lost or if the lolder of a license fall to bare the same recordel within sixty days as requlreal lis haw the state buaril of liealth may. In its discretion, lasue a new lleense.

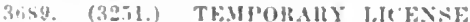
The secretary of the state lloard of Jieralti may lswe under his slinature a temporary

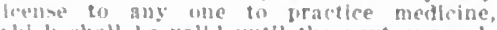
"hlill shall be vallal untl the next succeed. Int meeting of the lwarl for examlntug apfilionts, and such license shall show the alate of lis lisuance. otherwe lo shall tre

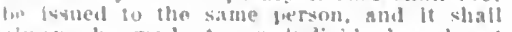
aluass he made to an thdividual nod not i) a parturrstsly. The secretary shall le culpled to 2:- cenls fur such a license, and

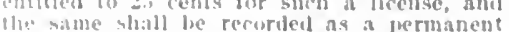
llonge is rejulret io bo, under llke penalty fir fallurio.

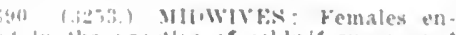

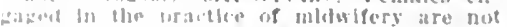

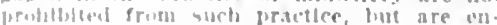

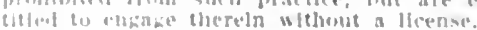

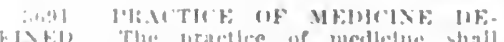

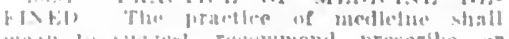

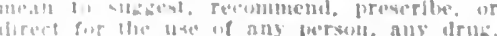

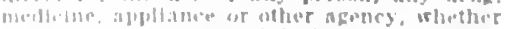
mitertal, or not underlal, fur the cure, re-

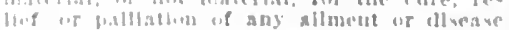

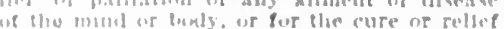

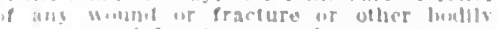

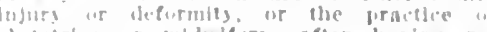

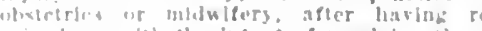

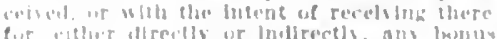

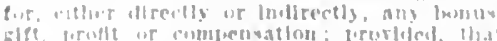

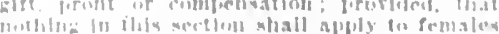

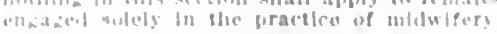

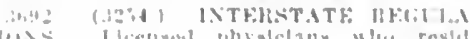

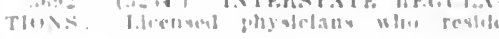

wlthout this state and bhowe Iractice "f

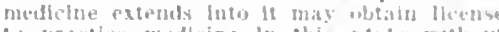
bil practire medteine ln this state willout luelug examineal as to their loarulug. by preanling a written applleation for lirenue. in the furm jirescribed. to the state joard if Heath. Wherengma the secretary of the In the name of the poard. for whlcls the sec. retary shall be entipled io recefre a fee of ar cents, and the ltecnse shall be recorded

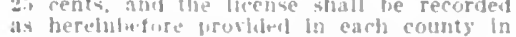
which the llocen-e wall wractire, wall like

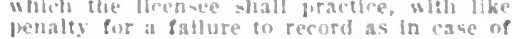
a resident phrslian. The non-resident jhy slclan not holdlug license from the stato shall mot he permited to practice medicln under any ciroumstances after remalning in the state fre dass, except when called in on this stase.

3694 (32T, STATIUNFI:Y SIPILJES: The lioard of Inblic controte's shall fur nish to the state looard of Health surl books. blanks and statlonery as may he neevled lw it in earrylly out the provislons of this chagter: and. at the request of the state Buarl of Health. shall dellre: to the secretary of state such record books as the clerk of the clrouit court may need, in whleh to revort llcenses to practlce mediclne, to be hy hin jromptly and safels tranamlites at the cost of the state to such of said clerks as the Board of llealth may designale.

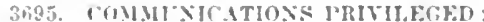
Ill ronmunicatlone male it a nhyslelan or curgeon low a palfent under his charge or lig one sceking profewinnal advice, are hereby declarel to the privllezed. and such physt. rian or surgeon shall not the recsulred th viept at the Instance of the patlent.

\section{STATE BOARO OF HEALTH}

II. . Nevander, I'reshlent, Tunica: 1 . S IIt T K. Hess. Hattieslurz: F. I. theek. Irosta: 1. W. cinoper. Newgon: Theorlore

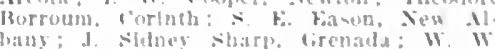

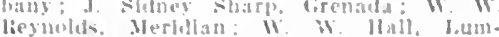

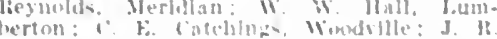

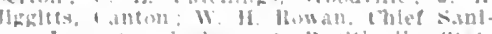
tary Inspector. Jachmob: i li. stinglly. State

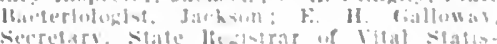

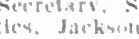

\section{MISSISSIPPI STATE MEDICAL} ASSOCIATION ()Aners 1013-14

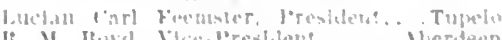

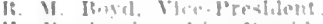

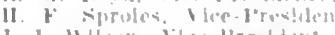

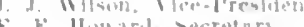

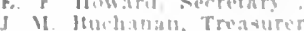
Nlierileen (i)liluater rliknolute onclal Publication

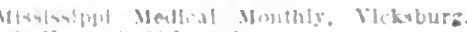
f: Howarit. It 10 . colit.

Counchlor Oistricts and omcers

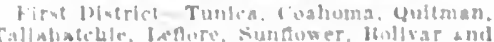

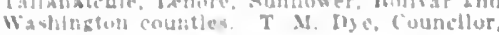
1 1) arhatale.

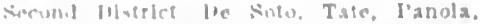
Valuluwla lirenala joaforeile, Marshali and lolhisun countios. I. J. Eromerson. iouncllor. llernando. 
Thbrd Intrict-Renton, Tiplah, Mrorn, Tishomkzo, I'rentiss, Lee, Union, l'ontotoc and Itawamba countles. S. F. Fason, foun cilor, New Albany.

Fourth District-Chlckasaw, Monroe, Clay Lowndes, Oktibbeha and choctaw countles. F. I. Underwood, Neflleton.

vifth bist rlet-carroll. Ifontgomery, it tala, IIadison, Itolmes, Webster and Va\%oo tata, Matison, Nolmes, Wetster mith conntes, C. M. Coker, Comblor, Eden.

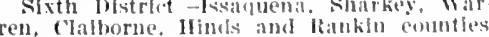
ren, claborne, Hinds and liallkfn eol

Seventin listrict-Nosuber Winston, Seventis Histrict-Noxuber. Winston, and Sewton comntles. s. A. Majure, coum cllor, Ilxom.

bifhth bistrlet-1awrence, simpsou, Covfugton, smlth. Jones, lasper. Wayne amil clarke counties. H. F. Garrison, Councllor, semllnary.

vinti pistret-unle Adams, coplah. Nraukliu, Jefferson. Lincoln, pike and Wil

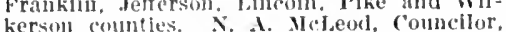
kersoul combli

rookhaven.

Tenth Ifistrict-Greene, Ifancork, Harrfson, Jacksol, Marion, I'erry ant l'earl Itiver countles. s.. L. Reese, (ounchlor, Jurrts.

\section{Component County Societies of the Missis-} sippi State Medical Association ADAMS (O)INTY

J. S. Tllman, l'resident......... Xittchez Ii reus Beekman, secretary......... Xatehez Al, CORX COLNTY

C. M. Taylor, Jresklent.. ...... Corinth

W. A. Johns, secretary............ rorinth INITE COLNTY

IV. R. Brumfletd l'resfdent.......... Nloster

1. II. Butler, secretary............ Liberty ATTALA COUNTY

1. F. Turnage, I'resident....... Kosciusko

J. W. Allen, Secretary......... Kosciusko BOLIVAR COUNTY

(Included in ('larksdale and six Counties.) CALHOLX COUNTY

G. G. Armstrong, President...... Vardaman C. IV. Patterson, secretary......... I'ittsboro CAIROLI, COLNTI

(Included in Winona District, M. C. W:

G., Medieal Soclety.) CHICKASAW COLNTY

(Included in East Mississippi Four Countles.) CHOCTAIF COUNTY

w. 1. Arnold, President..........Ackerman

J. M. Kellum, secretary.............. Reform CLAIBORNE COUNTY

k. D. Barroll, President..........Pattison i. W. Acker, seeretary ............. Gibson CLARKSDALE IND SIX COLNTIES-

COAIOMA-QUITMAN-SLNFLOWER

TALLAHATCHIE-TUNICA-BOLIVAK COUNTIES

J. A. Harris, President............Weh Thonas I. Iye, secretary........... Ciarksdale CLARK-WAYNE COUNTIES

B. P. Frans, President...........Qultman

A. P. Hand, secretary. . . . . . . . . Shubuta CLAY-LOWNDES-OKTIBBEIA COUNTIES s. s. Thomas, President.............Maten CoAHoNA COUNTy

(Included in (larksdale and Six Counties.) COPIAH cOUSTY

(Included in Tri-County, P. I. C. Medieal Society.) COFINGTON COLNTY

II. F. Garrison, I'resident ......... Seminary 1. B. Wallace, Secretary............. DE soTo COUNTY

A. J. Weissinger, President........Hernando J. If. Wright, Secrelary..........Hernando EANT MISSISSIPI FOUR COUNTIESIIONIROE-LEE-ITAWAIBA-CHICKASAW COUNTIES

E. K. Guinn, President............McCondy

F. J. Underwood, Secretary. FORREST rOLNTY

May F. Jones, President........Hattiesburg Wilham R. Bethea, Seeretary...Hattiesburg
GEOLEE-I'ELIT-GREENE COENTIES

F. A. Wenson, I'rosklent ........... Arrloula s. i.ewls knight, fecretary.............. GRERNE COUNT

(Included in fieorge-Perry-firene comu-

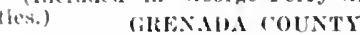

(sice Winona listrlet Medleal soclety.) IIITISION COUNTY

II. A. Weaman. I'resident...... Long Beald Winlel J. Willians, secretary...... diulfuolt IINMS-RANKIN (OONTY, M.S. (IINUS (OUNTY)

It. S. Curry, President...........jackson lintes Jerman Fox, secretary.......Asylum HOLMES COUNTY F. C. Jucas, l'reshlent......... Hibenezr ISAMQUWXA COUNTY

T. A. Heath, President............... initoh ITAWAMBB coliNeY

(Ineluded in East Mississippl Four rounties.) JACKsON COUNT:

Jos. A. Tabor, Presldent. ....... Trascagoula J. $\mathrm{X}$. Rape, Secretary............. Ihoss I'ofint JASPER COLNTY

Ioseph W. Stringer, President.......Stringer Charles H. Burnham, Seeretary. . Bay springs IEFFELSON COLNTY I. R. Harrison, President........... Fayette
sherrod le. Towns, seeretary... Union Chiurch JEFFEISSON DAVIS COUNTY

(Included in Iawrence-Jefferson Darls connties.) JoNES COUNTY

J. It. Kittrell, P'lesident........... Laurel

13. C. Clark, Secretary ...............aurel KEMIER COUNTY

W. Halliday, l'resident.... ....oak Grove

LAFAYETE COUNTY

S. D. Newell, President................. Eug. S. Bramlet, Secretary......... oxford LAJAR-MARION-PEARI, RIVEIT COUNTIES R. F. Nimoeks, Presldent........ Poplarville D. B. Stevenson, secretary........ Lumberton LAUDERDALE COUNTY

T. D. Baurdeax, President........ Meridian G. F. Douglas, seeretary.............. Ieridian IAWRENCE-JEFFELSON DAVIS COCXTIES

I. R. Harrison, President.......... Fayette s. R. Towns, seeretary....... Union Clureh I.EAKE COUNTY

J. L. Parks, President........... Cirthage W. S. Martín, Secretary........................ LEE COUNTY

(Included in Last Mississippi Four Com ties.) LEFLORE COUNTY

IV. Hunter, President......... Greenwood

II. B. Dickins, Seeretary..........Greenwood LINCOLN COUNTY

(Included in Trl-County, P. J. C. Medical Society.) LOWNDES CoUNTY

(Included in Clay-Lowndes-Oktibbeha counties.)

\section{MADISON COLNTY}

V. S. MeLellan, President......... Canton

James R. Jiggetts, Seeretary............. Canton MAKSHALL COUNTY

A. II. MeAuley, President......... Marianna W. C. Elliott, Seeretary.......Holly Springs MONROE COUNTY

(Included in East Mississlppi Four Counties.) MONTGOMERY COUNTY

(lncluded in Winona Distriet, M. C. W. G., Medical Society.) NESHOBA COUNTY

(Included in Tri-County, N. N. W., Medical Society.)

(Included in Tri-County, N. N. W., Medical Society.)

OKTIBBEHA COUNTY

(Included in Clay-Lowndes-Oktibbeha counties.)
- M vol a corvery

Ilbert I'rentisx Ilexander, l'resident..Como

J. M. Nulerson, Secretary............ Sardis P'EAIt, ItIVER COUNTY

Included in Lamar-Marion-Pearl Rlver counties.) l'bitty counTy

(Included In lieorge-1'erry-Greene countles.) viki corNTy

(Included lin 'Tri-County, I'. I. C., Medical socletys.) DONTOTOC COLXTY

Zorus A. Dorsey, Presldent...........Troy John Jarvin Furr, secretary........... Pontotoc IDIENTISA COLNTY

Haniel Thomas l'rtee, l'restdent. Boonevilte

It. I3. Caldwell, Secretary........... Baldwy QUITMAN COUNTY

([ncluded in (larkstale and Six Counties.) RANKIX COUNTY

(Included in llinds-Rankln M. S.) SCOT'T COUNTY

B. W" Sharp, I'resident........ Harpersille J. J. Haraison, secretary............... Forest SIIAIKEX COUNTY

Lewis li. Martin, I'resident

Abert is. Barrier, Secretary... . Roliling Fork SIMPSON COUNTY

A. F. Kyger, I'resident............Jiuol

J. I. White, secretary............... In SIITH COUNTY

N. E. Tullos, President.......... Raleigh SUNFLOWER COUNTY

(Included in clarksdale and Six Counties.) TALLAHATCHE COUNTY

(Ineluded in Clarksdale and 'Six Coun-

ties.) TATE COUNTY

J. I. Bucey, J'resident............Senatobli J. Sidney Eason, Secretary............. TIPPAII-UNION COUNTIES

II. N. Mayes, l'resident........ New Albauy Hugh Priddy Boswell, Sceretary..

............. WITYTONEWTON-NES COUNTES

D. J. Itush, President.........Phlladelphia

S. I. Majure, Secretary........... Dixon TRI-COVNTY-IIKE-LINCOLNCOPIAH COUNTIES

W. L. Lfttle, President........... Wesson

I. W. Jones, Secretary .........Brookhaven TRI-COUNTY-TATE-PANOLA-DE SOTO COUNTIES

II. C. Ellis, I'resident...........Senatobia TUNICA COLNTY

(Included in Clarksdale and SIx counties.) WARREN COUNTY

J. S. Ewing, President......... Vicksburg S. Ifyers, Seeretary............. Vheksburg WASHINGTON COUSTY

U. S. Wasson, President..........Moorhead Paui Gaston Gamble, Secretary...Greenville WAYNE COUNTY

(Included in Clarke-Wayne counties.) WEBSTER COUNTY

(Included in Winona District, M. C. W. G., IIedical Society.) WILKINSON COUNTY

Columbus Leonidus Field, President.

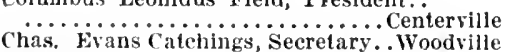

WINONA DISTRICT MEDICAL SOCIETYHONTGOMERY-CARROLI-IVEBSTERGRENADA COUNTIES

J. W. Young, Iresident..........Grenada S. S. Caruthers, Seeretary......Duek Hill WINSTON COUNTY

(Included in Tri-County, N. N. W., Medieal Soclety.)

YALOBUSHA COLNTY

Tohn I. Jandreth, Iresident.......Air Mont Frank Pulliam Smith, Secretary... Coffeeville YAZOO COUNTY

W. E. Noblin, President....... Yazoo City S. w. Purifoy, Seeretary........ Eazoo City 


\section{COUNTY HEALTH OFFICERS}

county

Adams-W. II Nikman........... Natchez

Alcorn-J. I lirewer............. Iorinth

Anlte-1:. M. Isutter............. Ifluerty

Attala-J. H. I'tirtwood......... Kistlu-ko

Benton-3. k. (1akley........ Mflehizan rity

Bollvar-II. L. Sutherlanil......... Itenolt

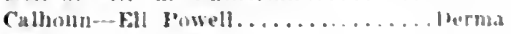

Carroll-J. o. lilugold............ Vialilen

Chlekasais-W. (i. Alermatlig . . . Woumllatul

Choctaw-W. I). Irnold.........herman

Clatborne-1. I. Chapman..... Hermanvllle

flarke-n. ('. Watkins......... (futmatn

Clay-1. It. Brown.......... Wust Polnt

foahoma-T. M. Jye........... riarksdale

Coplah-J. M. Iatchings....... Ilazlehurst

Corington-11. F. Garrison..........minary

DeSoto-T. I. Jones...........J6rnand,

Forrest-Robert Ionald......... Hattienturt

Franklin-1. Costles............... Iteadwllle

George-w. w. kley.............ucedale

Greene-3J. Is. Batson...........eakessllle

Cirenada-J. W. Young........... Rirenada

Hancock-J. W. Mooty.............. Kiln

Harrison-15. s. IJond............... Jund

HInds-J. 1. Villeyten............ Iatcksou

Holmes-C. C. Phlllins........... Lexington

Issartuena-W. II. Siudder....... Magersille

Itawamba -J. II. Stone........... Fremon:

Jackson-II. M. Huruhain. ....... Moss l'uint

Jasper-G. W. bant. ............ Louin

Jefferson-L. R. Harrisen............Faytle Jefferson Darly-JI. I3. Cowart. New Hehron Jones-H. $\&$ Tucker............ rillistlle Kemper-Dudley stenuls........... lloscow Lafayelte - E. S. Bramlette.......... Oxford Lamar-s. E. Reese............. lurvis Iauderdale-.I. J. I. IIoye.......... Meridlin Lawrence-T. F. Coun............ Vontleellu Leake-J. L. Parks............. Iarthate Lee-Jno. 0. Gurney............. Tupelo, Leflore-W. T. Matthews........ Greenwoml Lincoln-1). W. Jones.......... Brook!niven Lowndes-W. C. Brewer.......... Columbus Madlson-C. . Prlestley............ Cintum Marion-I. A. Shelbs............ Columbia Marshall-W. ('. Elllott.......Wolly springs Sonroe-F. J. Inderwood.......... .ettleton Montzomery-T. R. Trotter........Winona Seshoba-I). J. Kush......... Phlladelphla Sexton-A. I. Harrelson........... Ven ton

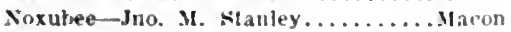

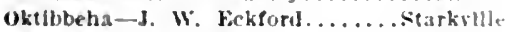
l'anola-G. H. Wood............ Batesville Pearl Itrer-W. I. Arledge...... I*olarville Perry-WIhls Walley............Bh.hton Ilke-W. D, Beacham.........Mclonb lity l'ontotoc-J. .I. Furr............ Jintotive l'rentiks- H. Jt. Smlth............kurthns Qultman-s. J. Stephenson..........Marks Rankln-A. F. McLaurln......... Mrinulon Scott-J. J. Haralvon............... Forest Sharkey-A. K. Barrler....... Rolllng Furn Slmpson-J. 1. White............ Jinuld Smlth-D. J. Inrr.................. Sunfloker-L. .. Wasson...... . Nooreduend Tallahatchle-11. G. Mardivell.... Marleston Tate-J. S. Fason............ . ivleluater Tippah-C. M. Murry..............Mplly Tishomingo-Itobt. A. Iirown.......... tuki Tunlea-l). W: Coker............. Turlcil Inlon-H. I'. Buswell......... New Nhany Warren-C. Y. Hleks........... Vilekuburk Washlugton-0. W. Sitone........firecenblllo" Wayne-J. C. Rush.......... Wis nesterro Webater-F. F. Arnold........ Mellifuntalne Wlikluson-1. W. Magruler......Winmlille Whiston-W. W. Hlekman......... Xus apalet Yalobusha-J. S. Sanders........titterfllo Yazoo-0. H. Swayze........ Ynzom ths

\section{CITY HEALTH OFFICERS}

Aluerelenn................ H. Sims

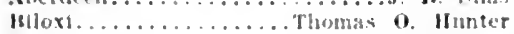
Jrookhaver................J. T. Hutler Clarkstale............... T. 1;. IJ fuhes Columbus. . . . . . . . . . . W. Je. Mekintery rorinth................. s. Voyles tireenville................ $C$. singthe direenwood................ Y. Barrier (iulfport...

Hattlesburg. il. S. 8num

Jarkwen....

[aure].

Meconth...

Meridian..

Mosspoint.

thert lonial

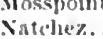

Tupelo...

Water Valles.

J. S. Ciatlln

1. F. Stenuls

II. F. Talum

west Polut.

F. I. Fulder
i1. Sexslens

llest Polut.
rayo City'.

Inh O. Ciurney

(i. II. sisler

J. IL. I'aslay

\section{STATE INSTITUTIONS}

Asylum

State Jnsane Jospltal, Asylum, Miss Kistablisled 18.51 ; public; insane: 1,600 beds; W. W. Smlthson. M.D., superintendent.

\section{Beauvoir}

Mlsslsslpul confederate state soldler: IJome, Beauvolr, Mlss. (Gulfport '.O.)

\section{Jackson}

IItssisslpp! Institute for the Klind. Jack

son, Ifjs. Hsiablished 1s48: 60 beds

It s. Curry, phy'siclan in charge.

Mississippl Institute for the lleaf and mimb, Jackson, Nlss. Estahlished 1854: 200 beds: J. R. Bobyns, superintendent.

Mississippi state Charlty IIosplial. Jachion. Mlss. Established 1910; general; 100 heds: Simut Ifoskins Jiclean, surgeou In charge.

\section{Meridian}

Fast Mississippl Insane Hospltal. Merid lan, Mlss. Kstablished lsst; publje; ner rous and mental: viso beds; J. M. Juchanan, superintendent

\section{Vicksbure}

Confederate Veterans" Jusultal Ammex. Vlekburg, Mlss. Establlslied 1900; put lle: 14 beds: B. M. Martu, physleian in charce.

Mlaslisipgl State Charlty Jlospital. vleksburg, Mlss. Fistablished Is:R: nubIIc; 1.00 beds: $\$$. W. Johnstoll, surgeon

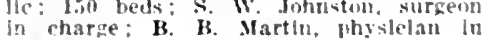
in rharke.

\section{HOSPITALS, SANATORIUMS AND CHARI.} Biloxi TABLE INSTITUTIONS

Charlty Iospltal, Mlloxl, Mlss Estah llshol lo0s: general: 16 beds: 1I. II Fulkes, medical illrector.

liule inast Jlealth ltevort. Mlloxl, Mlsu Establimleet $1902: 35$ beds: 16. H. White medlcal superintendent.

\section{Brookhaven}

brombaren Saultarlun, Brooklaven. Mls. Fistabllwhel 1909: prisate: general s Lieda: I1. W. Jenes aurd John II. John Columbus

columbus llowpltal, columbers, Mtso

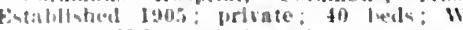
il I'ryer. M 11 . siperinterbileste

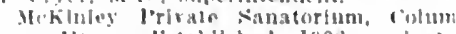

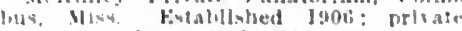

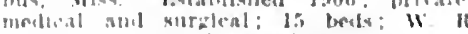
Ir.kinloy, mafleal superfutendent.

\section{Corinth}

forinth Sinulertun, Certath, Mis

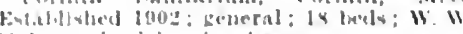

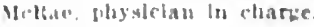

Greenville.

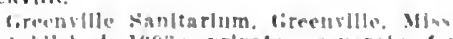

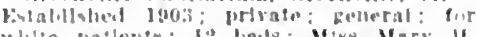
whlie pallents: i2 heals: Miss Mary it Tribis, superintendent.

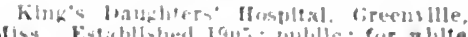

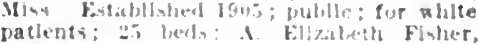

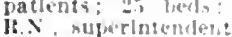

king's leatuhters" Hoaplat, lirecenvflle

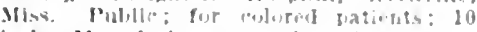

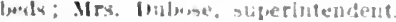

\section{Greenwood}

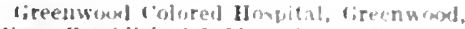
Mlsy. Lastabllshed Jill: prisare: I' heols F. I. Sandifer, owrer and surgeron in charke.

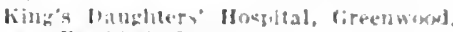

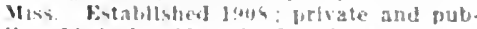
lic: It leeda: Mrs. H. H. Shackouls. superintendent.

Gulfport

K'nges Hauphters IInspltal. Bilfport. Laura Barron, superintendent.

\section{Halties bure}

Haltlesturg Hospltal, Hattlesturg. Mlsis. Evalillshed 1960; teneral: 4 is berls: Jenne. M. tgutnn, R.X., superintendent.

South Whisippl Infmary, Hatles. hurg, Mss. Fistablishel 1961: prirate so leads; W. W. Craw ford, abystelan In olarie.

\section{Hully Springs}

Holly Sprlngs sanatorlum. Holly Sprlnge. Miss. Fotablished 1:401: prlsate: \& bedi W. C. Elliot, whyslciau lu charge.

Jackson

Baptint Howpital. Tackron. Miss. Katitbllshed 1909: 20 leeds: J. F. Hunter and J. K. Sllituds, plassicolans in eharze.

Jackson Sinalorium, Jarkson, Mlss. Kstablished 1902, reorganized 1910: prlsate to lieds; Julias irister. bligsician in charke.

Oid Ladles' Hone, Jackan, Mlss, Kitablisbed 1908; public; ¿j leds; Mlsa llttie liuty. matron.

Sunshine Intirmary, Jackion, Mick, E: tablished 1911; private: 10 beds; Mary Prnctor, nurse in charge.

\section{Long Beach}

fiule Coast Sanatorium, Jong Beach, Miss. Established 1913: nerrous and

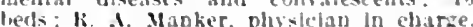

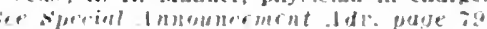

\section{Meridian}

Margaret Flynt samatorlum, Merldian, lls: Fitublished igus; privare: If beds. $\therefore$ H. Fynt, physician in charye.

Masomie Widuws" and Orpluan" Home Merdian, Miss. Fotablisherd 1908: 100 Leds: F. I. Marth, superlntendent.

Matty llerse Ilosgltal. Meridlan, Mlis. Established Is:40: publle: general: 61 thess: K. T Klein, house surbeva: Mrs. Frances Hogge. Superintendeut.

Meridian sanltarlum, Merldian. Mlso. Fotalillsbed lall: privafen: Hedlloal ano

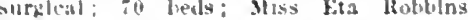
superintendent.

Turner IIospital, Merlalian, Mlas. Es

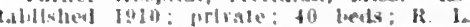
rurmer, phistan la charge: Mlxs il I. lirenes. sugerlntemetent.

\section{Natitic}

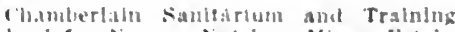
Scherl fur Nurses, Xatoluez. Mline Eivtab-

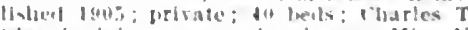

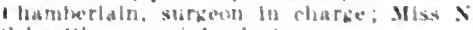
schoefton, suguerinferselent.

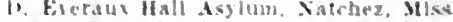

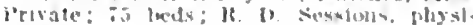
rlay

Natchez Charliy IInsutal, Dasclez

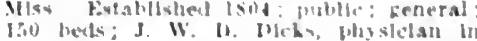
iharge.

Natchez. Sanaforium, Natchez, Mlses

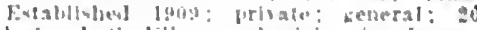

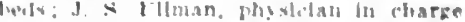

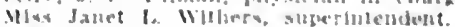

se. Mary's Orvian tolum, Natcher.

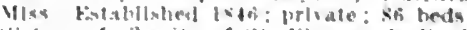
sisters of tharity of sit. Yheent do l'aul. in iharge 
Newton

Newlom santtarlum, Newton, MIss. Estal) 1909 ; private; general: 20 beds: W. (: cill and I. W. ('ooper, physlelang in charge. Oxjord

Bramletts Inflemary, oxford, Mliss. lis tablished 1913; private: surgleal; is beds lirs. Isramlett and I3ramlett, owners. Rosedale

King's loughters' llome, Kosedale, Miss. Established 1900: publin: 10 beds; Mrs. losabel slolby, superintendent. liosedale Hospiral, Itosedale, Miss. Fstabllstied 1903; surgteal; for colored ferole; 8 beds; L. 13. Austin, physteian ln cliarine.

University

Lniverslty of Mlsslssippl Ilospital, Untrepsity, MIss.

Vicksburg

Emergency Hospltal, Vicksburg, Mlss. Inblle; H. H. Wllson, physlctam In vlatre.
Vlcksburg Infirmary, Vlchsburg, Mlss. Established 1903 ; private; 40 beds; I3. I3. Astablished $1903 ;$ private; 40 beds; 13. B. Martin, physlefan in whar

Vleksburg saniturium, Vleksburg, Miss. Establlsbed 1901: private ; general; 100 beds; D. 1'. street, physiclan In charge. Yazoo City

Suruleal Inflrmary, Iazoo City, Miss. Estalllshed 1898; private; surglcal; 12 leds; John Darrington, surgeon in charge; Jiss Mury leeves, superintendent.

\section{PHYSICIANS OF MISSISSIPPI} KEY TO ABBREVIATIONS, SYMBOLS, ETC.

Nomes lu capitals slpnify membership in tlie County Soctety and Stale Association. (1)OE, JOHN).

Indlcates Fellowshlp in the Amerlean Med. Assn. (DOE, JOIIN $\oplus$ ).

(b'75) Year of virth.

[medic. (b) 75) lear of birth. H, homeopath; E, eclectic; P.M, litysiograduation. Information recelved docs not show grad. ualion.

S.-Surgeon.

Ob.-Oisletrielan.

ObG.-Obstetrician, Gynecologist.

G.- Gynecologlst.

Or.-Orthopedist.

Pr.-Proctolocist.

Op.-Ophthalmologist.

A.-Aurlst.

LR.-Iaryugologist, Rlinologist. (l'89) Year of license,

(む) In practice before passage of present law and licensed by filing diploma or by years of practice.

(li) liccnsed but year not known.

(击) Intormatlon recelved does not show lleense.

U.S. United States Army.

II.I.C., U.S.A., Medical Reserve Corps.

SPECIALTIES ARE INDICATED AS FOLLOWS:

ALR.-Aurtst, Laryngologist, Rhlnologist.

OALR.-Ophthalmologist, Aurlst, Laryngologist, Rhinologist.

U.-- Trologist.

D. Nermatologist.

Pd.-Pediatrist.

N.- Yeurologist.

P.-isychiatrlst.
U.S.X., Enited States Nary.

M.IR.C., U.S.N., Medlcal heserve Corps.

U.S.I.II.S., Unlted States Publlc IIealth Service.

College positions held are Indlcated by abbrevlated title of position, followed by key number of college. For key to colleges sce inslde iront cover page.

(AI,3, B6, C4) Membership In special Socicties. (See Key Table, page 122.)

WHEN THE ABBREVIATION REPRESENTING A SPECIALTY IS FOLLOWED BY AN ASTERISK ( THE PHYSICIAN CLAIMS HIS PRACTICE IS LIMITED TO THAT PARTICULAR BRANCH OF MEDICINE; WITHOUT THE ASTERISK, THAT HE IS ESPECIALLY INTERESTED IN, BUT DOES NOT LIMIT HIS PRACTICE TO, THAT BRANCH. THIS INFORMATION CONCERNING SPECIALTY IS BASED ON PERSONAL DATA FURNISHED BY THE PHYSICIAN AND IS NOT VERIFIABLE.

\section{MISSISSIPPI}

ABBEVILLE, 243, LAFAYETTE

Banks, Vacle $S$ (b'38)-Tenn,'s1; (1'8I). (ireer, Audrim T. (b'60)-Tenn.8, $92 ;(1922)$

АВBOTT, 30, CLAY

NACGli, ANIREW KINCANNON (b’\%) \&

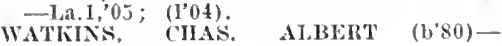

Teun. 8,06; (1'06)

ABERDEEN, 3,708, MONROE

ACKLI, JAMLS MILTON, JR. (b'86)-Ta.1, '10: (1'10).

Boxl, RICHARU M. (b'T6)-Tenn.8,'02; (1'00).

Broomficld, Wm. II. (col.) (b'83)-Tenn.i, 02 : (102).

Bryan, Wm. Wiley (b'sI)-Tenn.s,09; (109); R.F.D.2

COLEMAN, WM. MAHES (b'83)\&-1'a.2 09 : $\left(\mathrm{l}^{\circ} 09\right)$

Darracott, George F. (b'79)-Tenn.s, 06 ; (1'04) ; R.F.D. 4

DILWORT1, JAILs A. (b'61)€-Ja.1,9I (1'91).

DIRLE;, BEXIAMIX HOWARD (b'76)\&111.1,'10; (1'09) Ewing. Chas. Carter (b,52)-N.Y.10,75;

KINNEY, HORACE H. (b'77)\&-৩; (l'04); R.F.1) 7 .

Lee, Fletcher E. (b’75)-Tenn.6,'04; (l’01); SIMS, JAMES BEALFORT (b'61)\&-Ky.4, sis; (l, 90$)$

Tl“13R, G. T. (b'70)-Tenn.8,99; (l'99); R.F.D. 2.

Word. James C.-IA.2,'60; (lî̀) ; R.F.D. 1. ACKERMAN, I,398, CHOCTAW

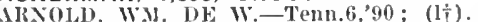
MALs, JTDGE (b'81)-Tenn.8,04; (1'05)

PREviT, R. K (b'44)-Ky.1, $82 ;\left(l^{\prime} 79\right)$.

Weeks, James D. (b'59)-Tem.6,'s2; (l's2)

ACONA (R.F.D., LEXINGTON), 150, HOLMES

SEWMAX, ANDREW J. (b'69)-Ky,2,97 $\left(l^{\prime} 97\right)$.
AGRICULTURAL COLLEGE, 200, OKTIB-

\section{BETA}

IIoward, S. II.-Tenn.8,'90; (1'89); not in practice.

AIR MOUNT, 56, YALOBUSHA

l.ANDRETH, JOHN .T. (b'68)\&-Tenn.8, '98: (1'98).

ALCORN, 512, CLAIBORNE

Cordon, R. A.-Tenn.7,'03; (1'06).

ALGOMA, 152, PONTOTCC

Abernethy, Edward (i.- $0 ;(1 ' 03)$.

l'hilpot, Van Buren (b'88) - Tenn.8,'12; (I'II) ; S.

ALLIGATOR, 200, BOLIVAR

ICCRACKEX, WM. HALBERT (b'67)†Tonn.6,'88; (1'88).

WELLS, SANH. TILDEX (b"i6)†-Tenn.1j, '08; (1'08).

ALVA (R.F.D., SWEATMAN), 10, WEB STER

James, Wm. A. De IV.-Tenn.I,'万o; (1'I3).

Olives', Iloward Booth (b'85)-Tenn.8,'II; (l'11).

AMORY, 2,122, MONROE

Boozer, Albert I. (b'73)-0; (1'06) ; R.F.D. 1. Boyd. Claude E. (b'81)-Ala.4,11; (l'10); IR.F.D. 1.

Brown, Wm. A. (b'38)-0.

BRYAN, GILAS SANFOKD (b'63) Tenn. 8,'88; (1's8).

Bryan, Guy sanford (b'85)-Tenn.8,09; (1'09่).

BURDINE, IIRA PRICE (b'65)-La.1,92; (1'92).

GRADY, WM. JACKSON (b'7 -Tenn.8, $00 ;(1,00) ; 0 \mathbf{b G}$.

Kirk, Robt. S. $\longrightarrow ;(1 \div)$.

Kirk, Wm. H. (b'86)-Tenn.8,'04; (1'05).

May, J. T. $\rightarrow$; (1\%).

REED, WOODIE N. (b'7 ) - Tenn.8,"0I; (l'01).

sloan, Wm. A. (b'84) $\rightarrow ;\left(l^{\prime} 06\right)$.

Walden, Ira Green (b'i5)-Temn, I, 06 ; (1'05); R.F.D. I.
ANGUILLA, 500, SHARIKEY

BARNARD, WM. II. $(6,49)-K y .5,77$; (l'82).

Hall, Joel Barnard (b'69)-Ky.4,94; (1†). HAIL, JOEL CLIAEN (b'38) ↔-X.Y. 8,67 ; (1'S2).

IARTIN, LEWIS ERNEST (b'80)-Ia.1, '05; (1'04); Ob.

STEWART, VIDA ODESSA (b'8:)-La.1, .07; (1'05).

ARBO, 200, COVINGTON

WAITACE, IIOBERT BILUCE (b'85)‡La.1,'10; (1'I2); S.

ARCOLA, 512, WASHINGTON

CHEEK, ELPERT A. (b'67)-Ja.1,89; WILASOX, 'THOMAS F. (b'79)屯-Va.6, '99: (1'030).

ARKABUTLA, 217, TATE

BREVARD, SIDNEY ADAIR (b'86)Tenm. 15,'07; (1'09).

IURPHY, HEGH LEWFRS (b'82)-Ky.4, '05: (1'04).

ARM, 50, LAWRENCE

Armstrong, Matthew Carnon $\left(b^{\prime} 80\right)=K y .4$, 04; (1'03).

ARTESIA, 535, LOWNDES

Guerry, Newton D.-Nla.2,89; (1'89).

LEIIMBER, EDW. (b'79)-Tenn.8,04; (1'05).

ASHLAND, 146, BENTON

FEIREELL, FRANK (b'69)-Ia.1,'98; (1'99). Honnoll, Robt. Edwin (b'86)-Tenn.8,'12; (1'II); R.F.D. 1.

ASHLEY (R.F.D., GEORGETOWN), 20, COPIAH

IJaynie, James F. (b'78)-Tenn.8,'05; Hays, George wilmer (b'75)-Tenn.1,05; (l’03).

ASYLUM, 75, HINDS

FOX, JAMES HERIIAN (b'80)-Tenn.8, '03; NP.

IIERRINGTON, JOHN CORNELIUS (b’־) $\oplus$ -Miss.1,I0; (1'08). 


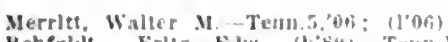

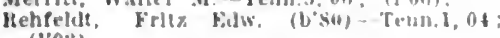
$(1,0: 0)$

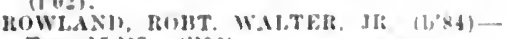
Tenn.15, $00^{\circ}$ : (1"0is).

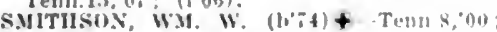
(I'98).

ATLANTA (R.F.D., WOODLAND), 100, CHICKASAW

MeCleskey, Ben J.-O; (IA).

AUBURN, 45, LINCOLN

liatclln, Marlon lukalb (b,ij) Teuns, 06 ; (1'06).

AUSTIN, 105, TUNICA

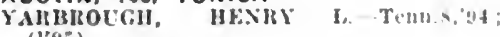
(1'95).

AUTER, 75, SHARKEY

Bommer, John $\left(\mathrm{b}^{\prime}+2\right)$-Tenlr.i, $: 6$.

AVALON, 25, CARROLL

(i)les, Bdgar (b'32)-Tenn. 1, 0s: (1'0i).

BAILEY. 56. LAUDERDALE

Franklli, Wm. Darld-Mllss. 2, $07 ;\left(10^{*}\right)$

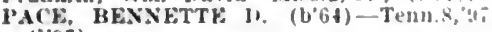
(1'9i).

WILSON, RALEIGH JACK (b's2) +

Tenn.1,0I: (l"0y); R.F.H. I.

BAIRD, 200, SUNFLOWER

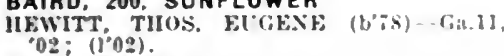

Mlller, Weeden C. $\left(\mathrm{b}^{\circ} 56\right)-\mathrm{Ky} \mathrm{y}^{\circ}, 5,83 ;(1, \$ 4)$.

BALDWYN, 787, LEE

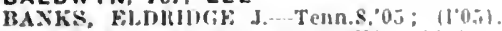

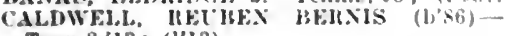

Tenn. 8, 13; (1'13).

Cox, J. I. $\rightarrow$; $(15)$.

Cox, Wm. M. R. (b'-8)-Tec. 8,$04 ;\left(l^{\prime} 03\right)$

not in practlce.

HEGILS, JOHS AXsIF (b's \&-Tenns:

KIRK, ROBT, IAIIIC- $\left.-\mathbb{1}_{t}^{t}\right)$; not in prac-

KIRK,
Ilce.

MICTOS. IESSE HOW.

Tenn.8,03; (I'08).

BALTZER, - SUNFLOWER

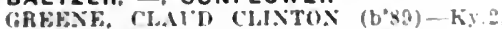

12: (1'12)

BANNER, 116. CALHOUN

Golng, llobt. (b'i5)-Tenn.s.'0s; $1 \mathrm{~b}^{\prime} 02$

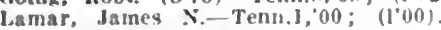

BARLOW, ITI. COPIAH

Furr, Francls I.ee (b's2) - Tenn.2."0t (1'06).

BASSFIELD, 34\%, JEFFERSON DAVIS

A'I'EWHTH, W. A.-Tenn.8,'88; (I'SS)

BIOLXT, FSTES $\rightarrow$ (b'it)-Tenn.J,ot (1"04).

BATESVILLE, 774, PANOLA

COLEHAX, GLI.]F GOHDON (b'S?)

Tenn.1, 06 ; $\left(1^{\prime} 06\right)$.

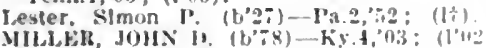

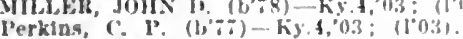

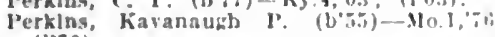
$(1 ; 6)$.

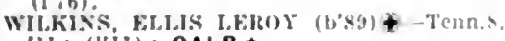
"Il: (l'II): OALR.*

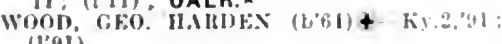
(I'9I).

\section{BATTLEFIELD, 30, NEWTON}

Hand, Wm. Ilols?. (b'o?)-Terun.s, 119 : $11^{\prime}(1 \mathrm{~s}$

l'rult, Geo, Thentas (b'it)-T(nu, (I'II).

BAY SPRINGS, 836, JASPER

IITIXIAM, (IIIS, EHNYY "A0: (1'93): OALR.

II:NSiON, J. O.-Ky.4, 89; (1)

sireel, W. T. $\rightarrow$; (

BAY ST, LOUIS, 3.388. HANCOCK

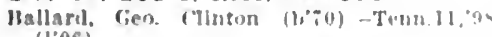
$(1,06)$.

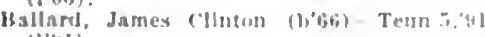
(1' 4 I).

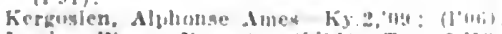

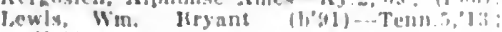
(1'13).

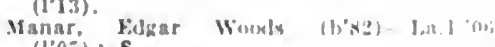
(l'0ii) : S

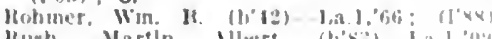

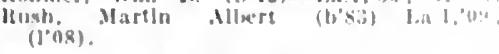

BEACH, 125, SCOTT

L.ee, Harry Otho $\left(60^{\circ}(0)-\right.$ Tenn $8 . " 1.3$
BEATRICE, 25, HARRISON

seaje. Thos. Jestersoll (1,8.t)

BEAUMONT, 250. PERRY

Wathls, Fetdin Jumes (b'tit) Ma.2,90; $\left(l^{\prime}, 90\right)$.

BEAUREGARD, 240, COPIAH

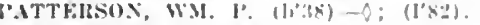

BEECHSPRINGS (R.F.D., UNION), 20, NESHOBA

llenderson, Il. C...-Temm.s, $0:$

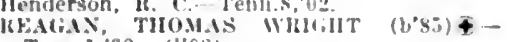
TeNIn.1,08; (1'08).

BELDEN, 400, LEE

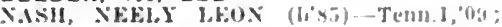
(I'0.*).

BELEN, 193, QUITMAN

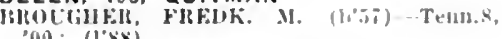
(0i) (1's8)

$01 ;(1+)$

BELLEFONTAINE, 160 , WEBSTER

IKXO!I), EIWIS $\mathrm{K}$ ( (l'91).

BELMONT, 367, TISHOMINGO

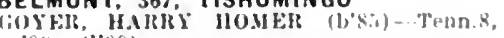
, 04 . (l.09).

Greene, Lewls S. (b':-)-Tenn.s, 01 ; (l'0l). Wontgumery, Jubers Lee (b-70)-Tenu.s, 03: (1'05).

BELZONI, I,059. WASHINGTON

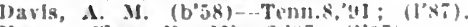

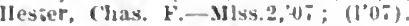

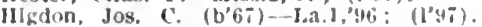

JAKSON, JMIES S. (b'64)-Tenn.8,93; (l'93).

MOHFITSON, FD. IAFAYGTE $(6,75)+$

Tenn.1,"99; (1'98).

Wadington, James Augustus (1,ij)--ba.1. 11; (1'10).

BENOIT, 4I2, BOLIVAR

MARTIS, F. (G.-No.2X, 98 ; (1'9s)

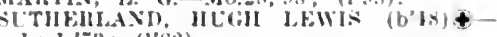
lan.1, -3:3; (1'82).

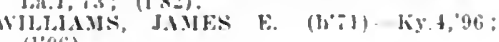
(1'96).

\section{BENTON, 200, YAZOO}

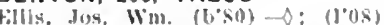

Juruan, saml. I. $(1,3 s)$ La. $1,=00(1) \div 0)$

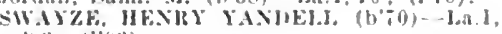
:38: $(1+33)$.

BENTONIA, 167, YAZ00

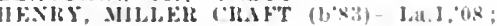
$(1,06)$.

Jumson, Perrln J', (b'0)-

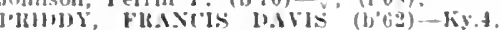
in:? (1.39).

BERCLAIR, I50, LEFLORE

(liarlton, Jlten Fenton (b'81) Temn.5, 09 ; (1)]0).

BETHANY, 50, LEE

Itriblukn, J. F. -

II Hdrup. HenryG. (1985) TUn S.'12; (1'13)

BETHEDEN (R.F.D., LOUISVILLE), 25, WINSTON

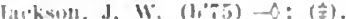

BEULAH. 369, BOLIVAR

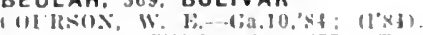

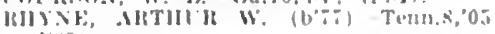
(1'(1):

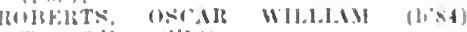

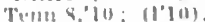

BEXLEY, - GEORGE

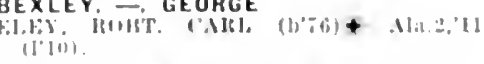

BIG CAEEK, 62, CALHOUN

IUU)

Tron

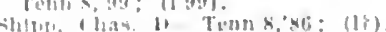

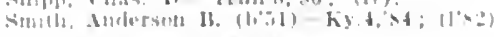

BILOXI, 8,049. HARAISON

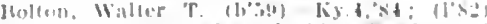

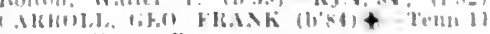

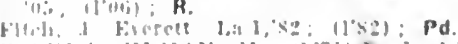

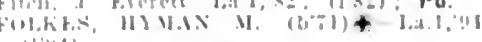
11:?1

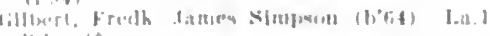

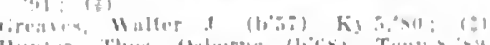

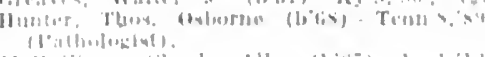

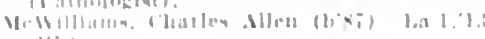

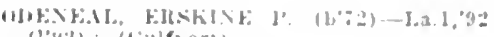
(low) (1)iulfumr:

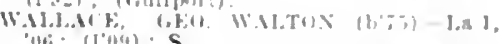
:110: (I"vy): S.

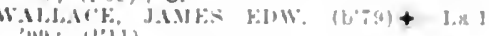
(1)!) : (1'11)

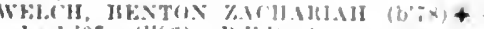

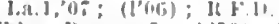

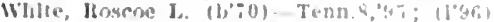

BLACK HAWK, 79, CARROLL

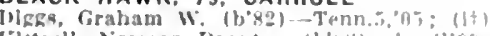

Klttrell, Norman Draytoll $\left(L^{\prime} \times S^{\prime}\right)-$; ; (l'0o)

BLACKMONTON. 54, CARROLL

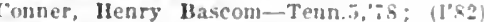

BLANTON, 30. SHARKEY

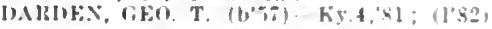

BLUE MOUNTAIN, 650. TIPPAH

F.I.I.ZEY, F.J.J.AII S. $\left(b^{\prime}+8\right)-K y .1,70 ;$ (1?:2).

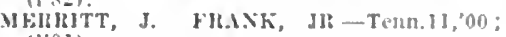
(1,0]).

Merrits, J. F. Sr.-A: (1†)

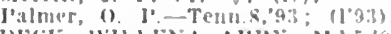

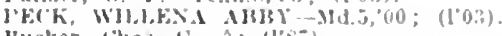

lucker, "has. (1)- (I'si).

BLUE SPRINGS, 167, UNION

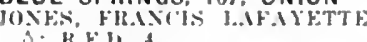

Silk K.l, 4 .

S'ER'

Willer, Iuke (b'-9) $\rightarrow$; (l'0:)

BOBO, 75, СОАНОМА

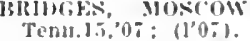

Tenu.J.1.07: (1'0:).

BOGUE CHITTO, 841. LINCOLN

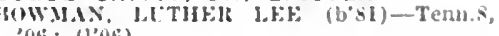
(1)

lisholin.

(106)

TIONIPios, FELIX II.-1.a.1, 36 ; (I'si)

BOLTON, 632, HINDS

Asliford. James A. $\rightarrow$ : (17).

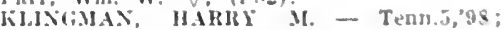
(1'is).

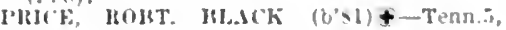
(1) : (1'0):

BOND, 536. HARRISON

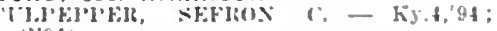

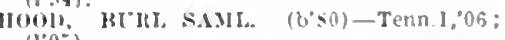
( ( 05$)$.

BOON (R.F.D., LOUISVILLE), 23, WINS. TON

Klrk, Walla M. (boti)-.? (lon)

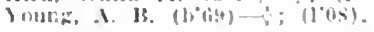

BOONEVILLE, 1.337, PRENTISS

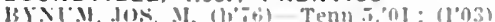

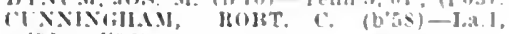
,

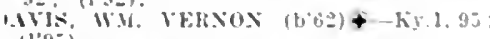
$(1,9 \overline{4})$.

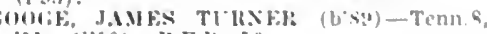

'11: (1'10): H.F.D. I0.

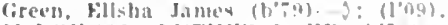

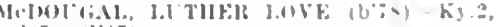
$11 \%:(10 \%)$.

silmer. dohn It. $(6,00)-(6,5,94 ; 1194)$.

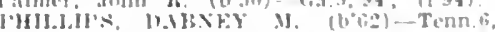

s.t. (?'si) : It.F.n.

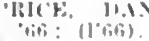

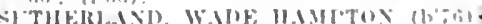
Tell, s, 04: (I04): OALR.

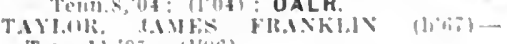

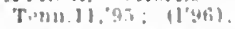

BOVINA, 40, WARREN

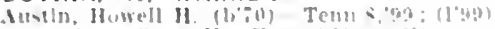

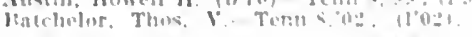

BOWLING GREEN (R.F.D., OURANT), 50 HOLMES

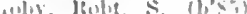

ROYLE, H\$, BOLIVAR

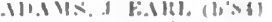

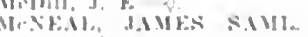

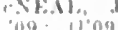

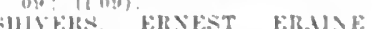

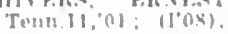

BRANDON, 720, RANKIN

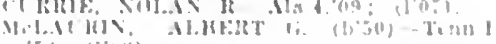




\section{BRANDYWINE (R.F.D., BARLOW), 26} CLAIBORNE

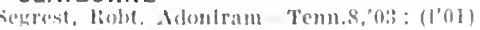
IR.l.1. I

BRAXTON, 286, SIMPSON

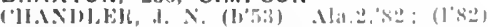

Farmer. s. 18. D; $(106)$

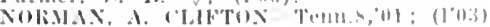

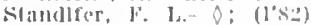

BREWER (R.F.D.. DE SOTO), 25, CLARKE

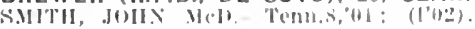

BROOKHAVEN, 5.293. LINCOLN

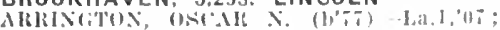
(1'(i)i)

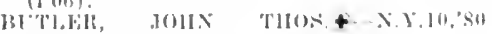
$(1 ' * 0)$.

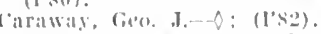

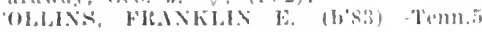

0 ;

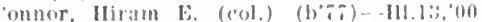
(l'00)

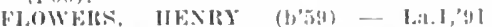
(1'\$?): OALR ^

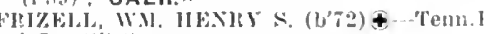

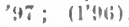

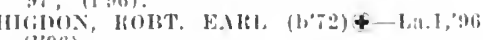
$\left(1^{9} 96\right)$.

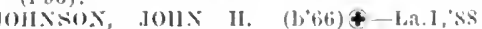
(1'88).

IONES DPULE WATHON-LAI, O0 (1,0) $:$ Pd

Litndls, Wm. 11. (b'.8)-0.3,85; not in practlee.

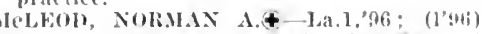

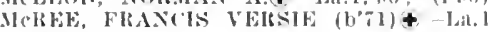
'94; (1'94).

Parsons, Ira To-laa, 1, sis; (l'98).

Weathersbs, Walter W. (1, tis) Tex.', 06 (I'MI) : R.F.D.

BROOKLYN, 200, FORREST

Gillls, Chas. Lyman (b'79)-Miss.2,10; (\$)

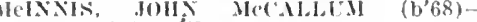
Tenu.II,98; (l'09)

roung, Rolert Newlon siplre (b'so)Tenn.11,0i: (1'06).

BROOKVILLE, 850, NOXUBEE

(IREEN, JOIIN D. +-0 : (I'0:3)

HEMMAN, GY LASLIE (b'88) - Tenn.6. 12: (1'T) : R.F. :

Jamison, Robt. S-Ky.2,79: (4)

Stanley Jos s $\left(b^{\prime}+6\right)-0$. (1)

BRUNSWICK, 50, WARREN

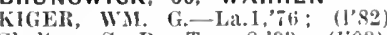

Shelton, S. I.-Tenu. \&,03; (I'03)

BRYANTVILLE (R.F.D., WINONA), 10 CARROLL

Gillesple, Wm. J.-La.1,'92; (1'89)

BUCATUNNA, 421, WAYNE

MLELINAIN, STOVA B. (1,8T) †-MHS.2. '11; (1'11).

BUDE, - FRANKLIN

GRAY, ROBT. E-Tenn.1,07: (1'06)

Magee, Jareus M.-Tenn.S,03; (1005)

Ilchehee, Jimes rlaude (b'88)-Tenn.8'T2: (t)

WARREN, GEO. TORKEY (b'85)\&-La.I, ,OL. (I08).

BUENA VISTA, 23I, CHICASAW

Albott, James. L. $\rightarrow$; $\left(1^{\dagger}\right)$.

Brand, Indrew J. (b'bi)-Temn.8,01: (1'99).

BURGESS, 50, LAFAYETTE

Loek, John S. (b'i2)-Tenn. 8,97: (199) : not in practice.

P'rice, saml. Orr (b'84)-Temn.s,'12; (1'12)

BURNS, 50, SMITH

MeWHORTER, W. It.-D; (1'0i).

BURNSVILLE, 336, TISHOMINGO

Montgomery, Aarlander Ifouston-Tem.8, $11 ;\left(\mathrm{l}_{1} 12\right)$.

BURTONS (R.F.D., BOONEVILLE), 50, PRENTISS

SIIITH, BOLIY.AR R. (b'Jl) $\rightarrow$; R.F.D.

BYHALIA, 5II, MARSHALL

PBILEY, JoS. B. (b'78)-Tenn.8,03; (I'OS).

Boyce, lames Druery-Temm. 万, 55 ; (l’03)

Fite, i. La ravette-Tenn.8,01; (1'0I).

sigmon, John H.-Tenn.1,'sl; (1̧े).

CAESAR, 12, HANCOCK

spence, Wu. F. - ; (1'S2); not in prac-

White, John Ierry (b'80)-la.1,09; (l'0r).
CALEDONIA, I37, LOWNDES

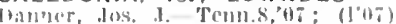

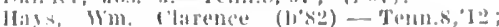
(l'i:is)

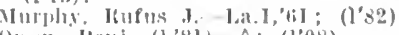

Owen, Benj. (b'81) - $0 ;(198)$.

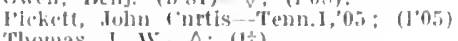

Thomas, 1. W: 0 ; $(1 \%)$.

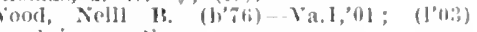

nol in foritellie.

CALHOUN CITY, 477, CALHOUN

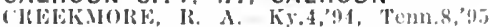
(1ث)

Fex, (i. L. - Ky. I, 85 ; (17).

Jation, Wm. Harrey-Tonn.6,94; (li)

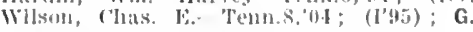

CAMDEN, 161 , MADISON

llooper, stam Jones $\left(b^{2} s(i)-\right.$ Temm.s,'In

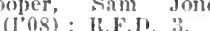

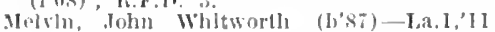

SHelhy, John M. (b'66)--Ia.1,'89; (I'8

CANTON, 3.929, MADISON

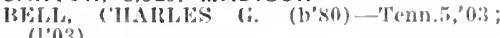

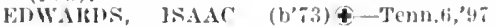

Howell. Wohn Blanch (h'81)-Tenn...,0.' (I'0i)

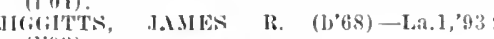
$(10: 3)$.

MeLELLAX, VAllMMAN \&. (b'70)-ky,l

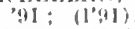

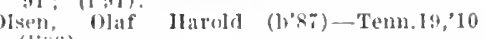
(]. (19)

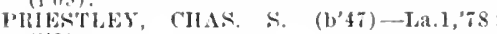
(l'82).

lihye, Vernon Thomas (b'74)-Tenn.8, yine, (1) rernon

Roly, John H. (col.) (b'72)-Tenn.7,06

waker, s. s. $\left(b^{\prime} 32\right)-0 ;\left(l^{\prime} 82\right)$; not in practice.

CARPENTER, 150, COPIAH

Green, E. I.-Ga.5, 95 : (1'95).

CARRIERE, 200, PEARL RIVER

Horne. Fredk. (b'te) Tenn.6, 07 ; (l'06) OCKE, WELLINGTON (b'十2)-La.I, 09 (1'0?).

\section{CARROLLTON, 608, CARROLL}

lddell, Wn W - La.1,89: (1\%)

Linder, D. E. Tenn.s, $94 ;\left(1^{\prime} 92\right)$.

Mabry, Ldwin Jewis (b'78)- $0 ;(107)$ B. $\mathrm{F}, \mathrm{l}, 3$.

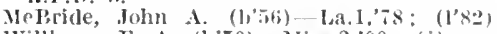

Willams, F. A. (b'70)-Miss.2, 09 : (

CARSON, 150, JEFFERSON DAVIS

NTCHOLA, TIRGH, (h'76)-Tenn.8,04; (l'04)

CARTER, 25, YAZOO

Stubblefleld, Darid F.-.Mo.34,04; (1'04).

CARTHAGE, 3I5, LEAKE

Barnett, Arden iI. $\left(b^{\prime} 68\right)-(1,90)$

('AIOWELL, SAML. 13. (b'42) $\left.-0 ;(1)^{\prime} 82\right)$

Chadwiek, Isaac A.-Tenn.11,02: (1'02).

fOLDEX, I. M. (b'71)-Tenn.8,91; (1'11)

lloward, Hector Haldbrook (b'73)-Tenn.8,

10 : (1'69).

MLARTix, W. S. (h'-1)£-Tenn.8,99

TARKES, TAMES LOVELACE (b'81)-Ky.2, 06; (I'05) ; R.F.D. 3.

WILLIMS. SIDNET II, (b'53)-Ala.2,'89 (l'83).

CARY, 64, SHARKEY

Goodman, Burleigh (b'46) - Ya.1,68; (l'82) 700DMAN, H. SAMPSON (b'75)-La.1,97 (l'95).

CASCILLA, 85, TALLAHATCHIE

IBibby, L. H.-Tenn.8,'91; (I广).

CASEYVILLE (R.F.D, WESSON), 25, LIN-

COLN.
MAGEF, DAVID WARD-Tenn.l,0T; (l’08).

Thompson, Fred Edgar-Tenn.8,03; (1\%).

CAYCE (R.F.D., COLLIERVILLE, TENN.),

36. MARSHALL

PEAIRCE, LEE 1'. (b'83) - Tenn.8,'04; (1'04)

CEDARBLUFF, 216 , CLAY

ELLIS, JOHN' EDW. (b'85)-Tenn.8,08 (I'0s).

CENTERVILLE, 865, WILKINSON

FIELD, COLUMBUS LEONIDUS (b'89) La.1,'11; (l'10).

MARSALIS, WM. I. (b’3)-Ky,4,93; (I'93) losewh ('lark-Tenn, 1,68; (1 i) ; not whe'rllee. wIIT'F,

(1.07). E

CHALYBER.

TIPPAH IYy.2,'82; (I'82).

1,11.1\%, J. II, - 834. TALLAHATCHIE

CHARLESTON ') JII'SON - Tenn.I,01;

AXIlisSiON, Tr.

$\left(\mathrm{l}^{\circ} 0 \mathrm{x}\right)$.

BAIIWHLL, DAVH)

(l'05).

(I'78)

Crow, James 1i.-Ky.2, 'tsemn.8.07; (1'06).

Wroman, Wu. E. (1,81)- - Tenn.8,99;

II

(l'94). Amenn,8,92 ;

Harrisull, landy Bartow (l, 62 ,

leigh, irmistead Macon-Ky.5,8i).

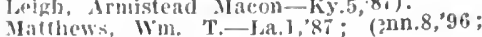

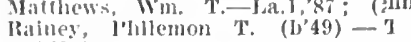
(I'91).

CHATHAM, 15, WASHINGTON

(1’04).

MALEN, KO'T' $\left(b^{\prime} 74\right)$-Tenn.8.'0I:

CHESTER, 62, CHOCTAW

STILONR, BEN.1. \$-I'a.L,'91; (1'91). I2,

CHESTERVILLE, (R.F.D., TUPELO),

PONTOTOC

CAIELTH, LEANIDER OIR ('7i)-Tenn.

CARIET'H, IROY WATIIEN (b'88) - Ky.2, 'll; (I'I1).

\section{CHICORA, 225, WAYNE}

Gordon, Yancey E. (b'62)-Ky, 1,90; (l'12),

Jolnson, Lowam S. (b'74)-Pa.1,07; (l'09).

MeMHLAN, AMON K. (b'83) †-Mla.2,09: (I'09).

CHULAHOMA (R.F.D., HOLLY SPRINGS), 100. MARSHALL

BAITNETT, LEVI AUBREY (b'86)-Tenn.8, 'I0; (I'IO).

CHUNKY, 280, NEWTON

I3OINIS, GHo. WM. (b'83)-Tenn.1,'06;

Martin, Chas. A. (b'80)-Mlss.2,10; (l'07).

I'ARTIN, ENIVIN B. (b'54) $\longrightarrow$; (1'83).

CLARA (R.F.D., WAYNESBORO), 12

WAYNE

Mason, James N. (1)'86)-Tenn.6,'09; (1'10)

CLARISSDALE, 4,079, COAHOMA

BIAA.MLETT, JAMES E. (b'54)-Tenn.5,87 ;

CliSILER, IBEN C-Tenn.15,07; (1'06)

DYE. THONAS MELYHLLE (b'74)థ-La.1,

GRAY, JAMES WM. (b'65) $\oplus-\mathrm{Ky} .1,90$;

HARRISON, IUTHER DENISON (b'54)$0.1,75 ;(1,80)$

11CriHEs, T. G. '(b'80)-Ky.9,'05; (l'05)

JA(i)E, ABRAHAM J. (1)'3L) - Ky.1,76; $(1,76)$.

Nichols, H. W. (eol.)-Tenn.,${ }^{\prime} 01$; (l'02).

Prisikose, jols W. (b'80)-Tenn.8, 02 ; (1'03).

Raines, claude W. (col.) (b'80)-Tenn.13, $01 ;(1.01)$

STUART, WM. W. (b'35) \&-0.2,58; (1'58)

CLARIKSON, I00, WEBSTER

Crowder, Jos. K. (b'78) - Tenn.8,'12; (1'12).

CLEVELAND, I,001, BOLIVAR

IIOWELL, JOHN JAMES $\left(\mathrm{b}^{\prime} 76\right)-$ Tenn.8, $06 ;$; (1'06).

M'IEAN, EPIIRAIM R. (b'78) $\oplus$-Tenn.s, ,02: (1'04).

SIARKWAN, ARTIIUR ALPHONZO (b'88) -Tenn.15, 10; (l’10).

SIARM.AN, LEVI B. (b'J1)-Tenn.6,'85; (1'8.T).

FTRER, FRANKIIN P. (b'79)-Tenn.8 01; (l,01)

CLIFTONVILLE, 100, NOXUBEE

Lusk, Wm. Jelferson (b'\$8)-Tenn.15,'10 ; (l'09).

CLINTON, 767, HINDS

IJ ALL, ROLAND W. (b'75)థ-Tenn.1, 01 ;

willer, Robt. D. (b'48)-Ky.1,79; (1'93).

POTTER, WH. DANL. (b'69) $\oplus$-Tenn.8, '92; (1'92).

Watkins, Chas. B. (b'6i) - Kiy.4,06; (lî).

CLYDE, 100, LAMAR

ROBERTSON, FIRANKLIN HUBERT (b'8T) -Tenn.8,'11; (1'12). 


\section{COAHOMA, 2II COAHOMA}

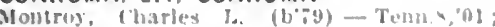

COCKRUM, I50, DE SOTO

Funderlunke, benter C. (b'sk) - Tum s, 13 (1"I3).

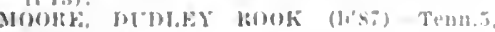
$12:(1 \cdot 12)$.

COFFEEVILLE, \$21. YALOBUSHA

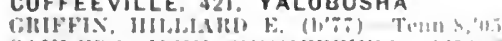

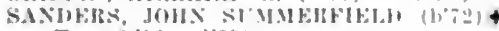
-Tenn.s, $(100 ; 11991$.

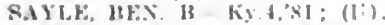

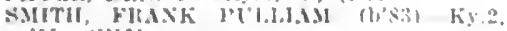
11: (1'11).

Smlh, J, Melville (b'43)-Mo. I, :0: (1'2)

COILA, 200, CARROLL

llolman. Chas. Hlluds.

(See Hemlugway.)

sanders, H. I. $\rightarrow$ : $\left(I^{*} 04\right)$.

COLDWATER, 774, TATE

Bowdon. Janes T. I. (h':0)-kyt.'y: ; ? Crawford, James W. (10"52) - Tenn, $(10 \div)$

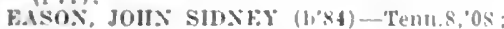

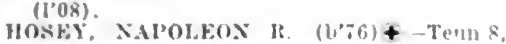
(69:- (loos).

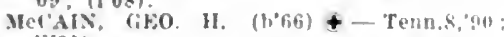
(1*91).

WH, SOS, JOS. JAMES, JR. (b's, + -La.J $0 \%$ : $(1,0 B)$

COLEMAN (R.F.D., HOLLY SPRINGS), 22, MARSHALL

SCHEGGS, M. F,-KY.2, R2: (I'S2)

COLLEGEHII.L (R.F.D., OXFORD), 150 LAFAYETTE

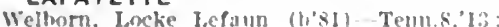
(I'13).

COLLINS, 2.581, COVINGTON

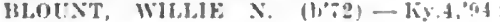

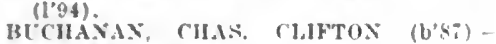

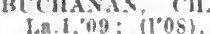

HOOD, LEWIS WADE (b'84)-Mles., II (I'Ii) : H.F.D. 3.

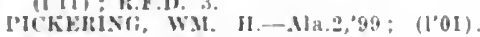

RAMSAY, ('HAS. HURM, (b'58)-lá. Sti: (1's6).

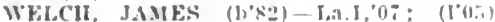

Welch. Timothy Wunlel (b'Ti)-Tenn.1, 115 (l'06).

Willson. Ixman W: $(1 \times 80)$ - Tenu.8,06: ( $\left.l^{\prime} 0 r^{\circ}\right)$.

COLUMBIA, 2,029, MARION

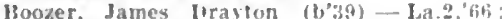
(I'82).

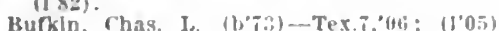

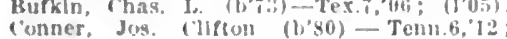
(I'II).

benson, firover cteveland (b'st)-Tenu.? 07 : $(1,0-1)$.

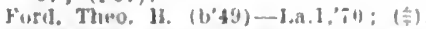

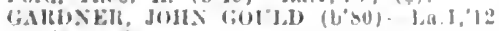
$\left(l^{\prime} 0 i\right): \mathrm{S}$.

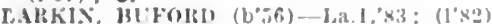

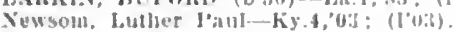

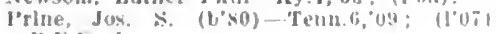
Ii. F.I. 1.

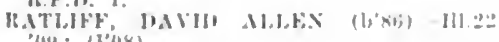
(1): $\left(\mathrm{H}^{\prime}(1) \mathrm{s}\right)$.

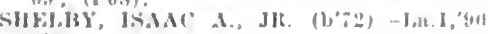
$(1+199)$

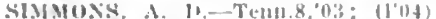

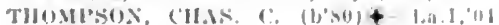
(I'03).

COLUMBUS, 8.988, LOWNDES

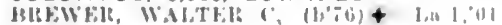
$\left.(1)^{\circ} 01\right)$.

lerown, Jolun a $\theta$; (1)

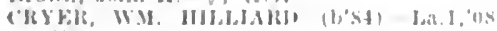
(1,0s)

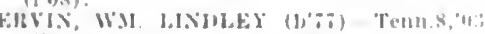
(1,06i); It.k.li. I.

Hinry, Taylur H.-Tenu.8,9g; (l'0i)

James. Theodorle $r$, (col.) - Tenn. i, (1'99)

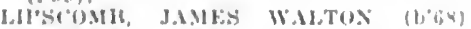
remin.j, 0 ;

Mctlaln, J. W. (1, :

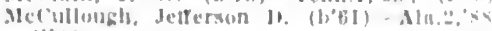
(lisiv).

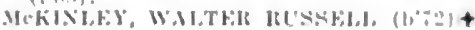
Nn:.? $(1000): S$

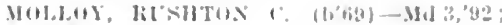
(1.4\%).

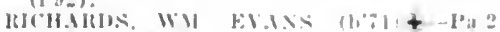
?:5: (1) O OAR

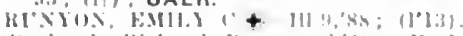

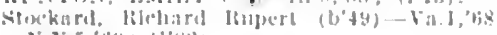

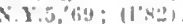

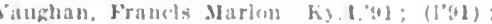
IR.F.H. 4.

COMO. Y05, PANOLA

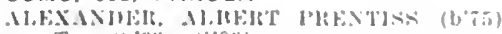

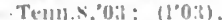

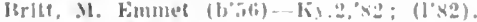

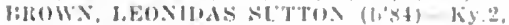
os: (l'0s).

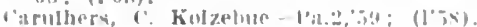

W is ril, Hend. $x,-1,3,1,97$

Iarlirough, A. S.-D; (1).

CONEHATTA, I52, NEWTON

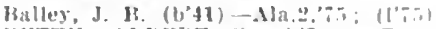

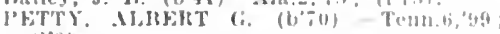
$\left(I^{\prime}(2), 3\right)$.

CONWAY, 54, LEAKE

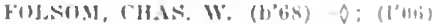

COOKSVILLE, 75, NOXUBEE

Ilolladiay, IRolst. 1. $\rightarrow$; (It)

CORINTH, 5,020, ALCORN

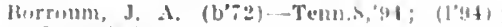
(IIrigghlst).

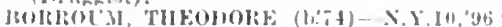
(I'9)(i).

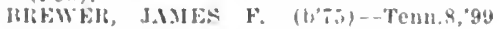

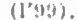

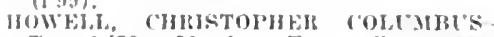
Tenu. 1, 2 : Menher Tenu. Stale Ved Aistl. ; H.1. 5.

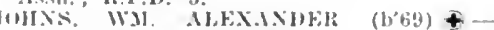

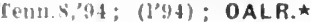

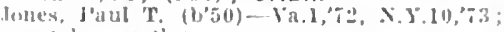
nut In practlee.

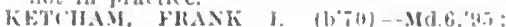
$(1+46)$.

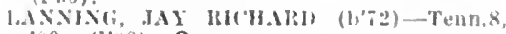
$00 ;(108) ; \mathbf{S}$.

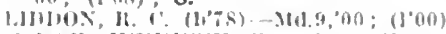

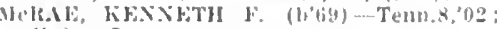
(1'(12); $\mathbf{S}$.

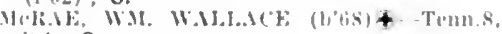
$\because 4 ;$ S.

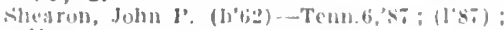
U.

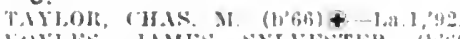

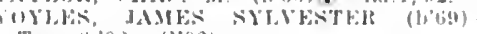
'THMII.8.92; (1'92).

CORNERSVILLE (R.F.O., POTTS CAMP), 70, MARSHALL

Montzumers, W: K. $\rightarrow$; (I'B:3).

COTTON PLANT. J03. TIPPAH

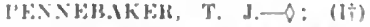

COURTLAND, 304, PANOLA

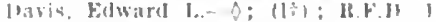

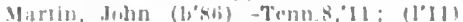

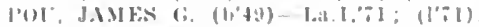

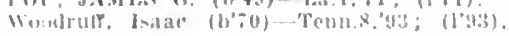

CRAIG, 500, YAZOO

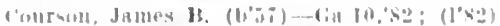

CRAWFORD, 396, LOWNDES

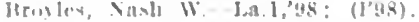

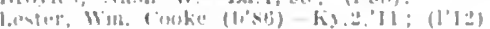
it.r.II

CRENSHAW, 358, PANOLA

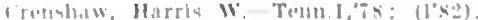

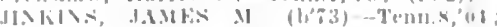
(1'ui).

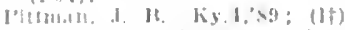

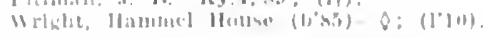

CHOCKETT (R.F.D., SENATOBIA), 25. TATE

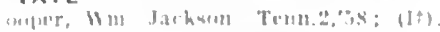

CHOTTSTOWN, I!, JONES

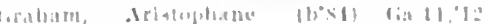
(I)11).

CRUGEH, 535, HOLMES

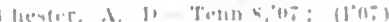

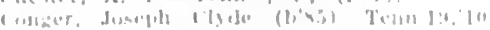

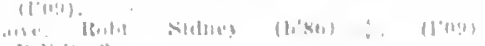

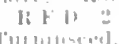

(1) 011
CRYSTAL SPRINGS, I313, COPIAH

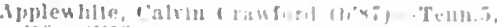
1:3; (1, $1: 3)$

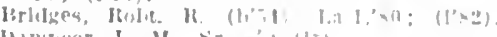

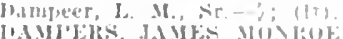

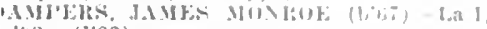
:!2: (l'92)

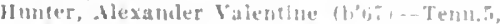
(3); $(1092)$

(os: (risis

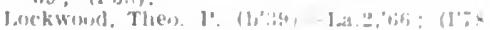

lansey, Juhn W.- Ky, an: (15).

CULLUM, 25, IKEMPER

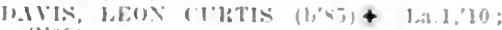
(l’0?).

DANCY. 143. WEBSTER

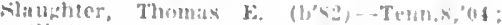
(I'(1);3).

DANIEL (R.F.D., PUCKETT), 75, SMITH

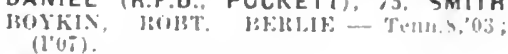

DARBUN, 25, PIKE

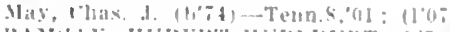

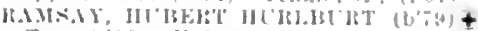

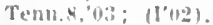

DARDEN (R.F.D., MYRTLE), 200, UNION

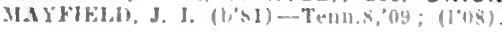

DAYS (R.F.D., LAKE), 100, CORMORANT

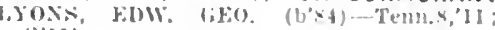
(l'11).

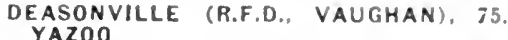

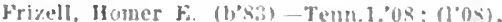

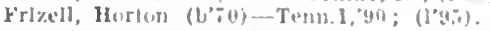

DECATUR, 283, NEWTON

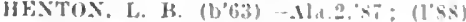

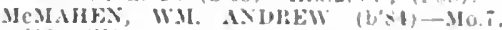
$08 ;(1$; 08$)$.

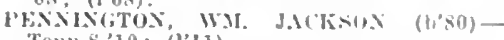
Temus,'10; (l'11).

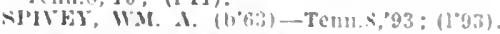

DEEMER. - NESHOBA

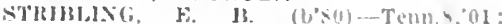
(1'U1).

DEERBROOK. 25. NOXUBEE

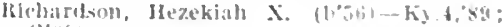
(1'00).

DEESON, I10, BOLIVAR

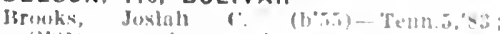
(1'. 1$)$; not in practlce

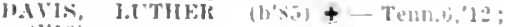
(I'I0).

DE KALB, 240, KEMPER

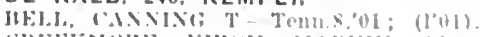

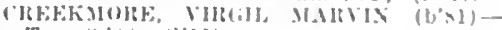
Tem.s.'0s: (1'11).

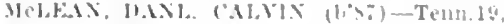
IU: (lo)!

DE LISLE, 76. HARRISON

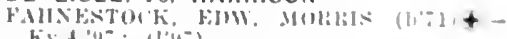

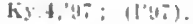

DERMA. 383. CALHOUN

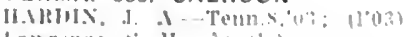

1.amrence, $\therefore$ : $11-0 ;$; (1)

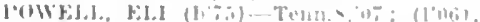

DE SOTO, 236, CLARKE

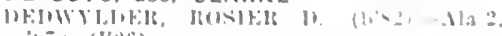

"10": (1'0(i).

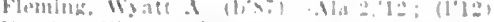

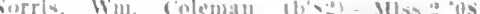
ITOS!

DEWEY (R.F.D., PRESTON). 15. KEMPER

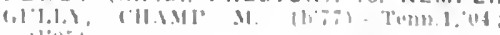
\{lo:il.

DEXTER (R.F.D., TYLERTOWN)。 50. MARION

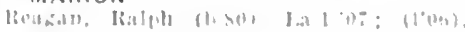

DILLON. 36. PIKE

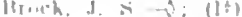

HVIOE (R.F.D.. MONTICELLO), 50. LAWRENCE

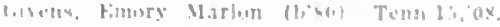

1) $X X O N, 100 . N E S H O B A$

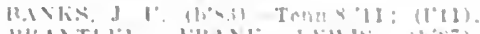

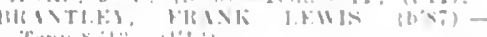
Tinen \& $1: 3,11, t$ is

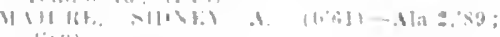
$(1,2)$ 
DLO, 400, SIMPSON

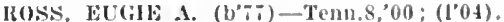
DOBSON (R.F.D., BRANDON), 66, RANKIN IJyers, Iran T. (b'SO)-O; (1'07).

DOCKERY, 39, SUNFLOWER

IIAVIS, JAMES A. (bo6s)-KY,4,

DODDSVILLE, 200, SUNFLOWER

CHALNAN, WHLALI JESSE (b'79)'Tenu.1,01 ; (l'01).

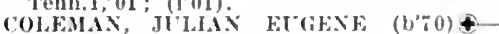
'Tenn.s,o1; (1'01)

LHONARl), HENIt o. (b'-s)-Tenn.s,o3. $\left(l^{\prime}(0,2)\right.$.

Weeks, Jumes Thomas Teum.8,12; (l'08).

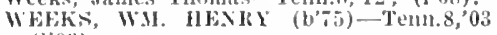
(l'0;).

wheeler, James Win. (b's2)-Tenn.6,'13: (1'13)

DOSSVILLE, 375, LEAKE

DOHSON, JAMES RILEY (b'83)- $\bullet$; (l'(13)

DOWSON, JOEI ('AlL (1,81)-Tenil.9, 05 ( 130 ).

Hodson, Willan J. (b'53)-0; (L'82).

DREW. 278, SUNFLOWER

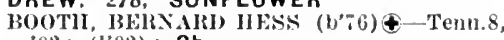
02: (l'02) ; 0 b.

Green, Janj. F. (1,75)-Tenn.6,99; (1'04).

(iRFES, BOLEY JOHX (b'T0)-Tenı.8,08; (l'05)

SAFLEY, TIIOS. JEXRY lints, Wm. (herrey-Tenn.11,90; ('97) DUBBS, 375, TUNICA HTT, J.MFs I'. (b'60)屯-Tem,8,96;

Leake, Vim. I._-Tenn.8,03; (1'03).

DUBLIN, I60, COAHOMA

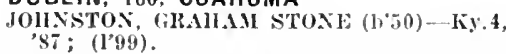

IHWDELL, TOKE MILDKED (b'84)--Tenn.8,

11: (1'12).

DUCK HILL, 499, MONTGOMERY

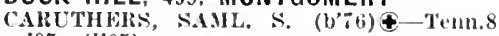
'05; (l'05).

GILLkSIIE, GEO. Y. (1, 55$) \oplus-T e n n .8,83$; (I'\$3).

DUKE (R.F.D., UTICA), 5, HINDS

Red, Geo. J. (b,51) - Pa.2,';3; (1†).

DUMAS. 175, TIPPAH

MURKY, WM. M.-La.1,75; (1'75)

kandolph, Thos. Lee (b'67)-Tenn.s, '9:3 (l'93)

Tlgret, Russell (b'87)-Tenn.15,'10; (l'10).

DUNCAN, 284, BOLIVAR

BHOWN, GEO. LEAI-La.I, 07 ; (1'06).

booley, F. M.-Tenn.8,90; (1'90).

HOLT, BERNAII SHIPP '(b'st)-Ky,2,'I0; $\left(\mathrm{l}^{\prime} 0 \overline{\mathrm{T}}\right)$.

Jackson, Lovelace Foster (b'83)-Tenn.8, 04; ( $\left.L^{x} 05\right)$.

Lipscoun, Edwin Jones (b's1)-Tenn.ð,'09; (l'10).

DUNDEE, I50. TUNICA

('arter, James Martin.-Tenn.11,01; (l'03) OHXSON, HAL GLENN (b'89)-Tenn.5, '11; (Y'II).

DURANT, 1.831 , HOLMES

Byrd, Jos. House (b'T4)-Tenu.8,'00; (l'00)

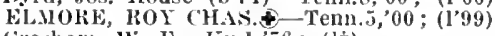
Gresham, W. F.-Ky.1,56; (1+).

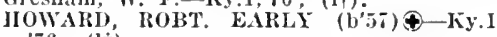
$76 ;(1 \div)$.

DWIGGINS, 10, SUNFLOWER

SHITI, RICHALD CURTIS $\left(b^{\prime}, 6\right)(-$ Tenn.8,02; (1'02).

EASTMAN, 150, ITAWAMBA

Collum, Wm. T. (b'-5)-Tenn.s, 05 ; (1'05)

Graham, Allison Travis (b'91)-Temu.8, 13 ; (1'13).

Graham, Chas. $\longrightarrow$; $\left(1 \frac{1}{\dagger}\right)$.

EBENEZER, 130, HOLMES

LICAS, EARLY C. -0 ; (1广)

ROBFITS, II. II.-Tenn.8,0I ; (1亡).

ECRU, 475, PONTOTOC

Teel, Jesse D. $\rightarrow$; (l'91).

Vewman, Leo L. $\mathrm{O}$; (1广)

spight, W. B. (b'41)-0; (1'82). Windliam, James Herhert (b; 65$)$-Tenn. 8 ,

EDDICETON, 350, FRANIKLIN

DODDS, AARON II.-La.1,'T3; (l'82)
EDEN, 176, YAZOO

(')KEL, ('H.A. MARTELLA (b'68) 4 'Ten11.8, 96 ; (1'01).

SEMARI, IOOYLE (b's2)-I'a.2,04; (I'03).

Walker, E, II,-0; (

EDINBURG, 425, LEAKE

Lowe, James Theodore (b'85)-Tenu.6,'12;

Russell, I'resley B. (b'T3)-Tenu.8,01; (l'0I).

Sluarl, IIenry Newton (b'6i)-Ky,4,'92; (声) ,

EDWARDS, 589, HINDS

lasurer, Jolin W'. (b'50)-Ky.I,'84; (I'84),

Juster, Cieo. W.-Tenn.8,'83; (1'83).

J'oole, Franklln Ionroe (b'51)-0; (1'82).

Ragat, Ashland IIeAfee (b'84)-Tenn.s, 07 ; (I'0(i); I.F.D.

EGYPT, 100, CHICKASAW

Hallsell, Jehl DeVan (b'87)-Tenn.I5,'11;

Ilearl, Jos. Marion.-X.Y.s,'89; (1'90).

ELECTRIC MILLS, - KEMPER

('HAMIENOIS, CECIL (b'74)-La.I,99: (I'98). CALARD (R.F.D., PINE VALLEY), 50,

Watson, Wm. Thos. (b'82)-Tenn.8,09; (l'08).

ELLIOTT, 161, GRENADA

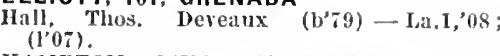

IIMMTON, WILBERN EDGAR (b'88)liy.2,'I0; (1'10).

ELLISVILLE, 2,446, JONES

CARTER, ILCES J.MIES (b'82)-Ia.1,'11; (l'I0).

Cranford, Whley Slıarp, Jr. $\rightarrow ;\left(l^{\prime} 07\right)$

S.MITI, SIHNEY 0.-La.I, 82 ; (1'82).

'IC'KEK, II. S.-La.1,'87'; (1'82).

ENID, I9I, TALLAHATCHIE

M('Lendon, Edwin F. (b'66) - Ky.4,'88 (l'88).

THOMISON, WM. GIRALD (b'72)-Ky.5,

Toolé, James A. (b'83)-Tenn.8, 07 ; (1'07).

ENTERPRISE, 877, CLARKE

Ferrlll, Saml. J. (b'63) $\longrightarrow ;$ (I's

HOSEY, JOHN THOS. (b'i9)@-Tenn. 8 , 03 (l'03)'

IlRBY, JOS. T. (b'79)-Tenn. I, 05 ; $\left(\mathrm{I}^{\prime} 05\right)$; G.

ENZOR, 50, LAUDERDALE

Foster, John B. (b'39)-O; (1'80)

ESCATAWPA, 50, JACKSON

BI'RNHAM, HENIRY HeCAIBE (b'7t)-La.I

ESSEX, 100, QUITMAN

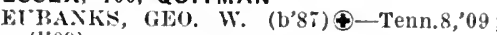
(l'09)

ESTABUTCHIE, 63!, JONES

(ialdner, Geo. L.-Md.4, 07 ; $\left(l^{\prime} 05\right)$.

ETHEL, 400, ATTALA

('laitor, W. S.-Temn.S,'II; (I'II) ; R.F.D. 3.

lleall, J. T. $-0 ;\left(1_{\dagger}^{+}\right)$

I'OI'E, WM. I.-Tenn. I, 00 ; (1'9s)

Wasson, Perry leaves (b'86)-Tenn.8,'08 (1'09).

ETTA, 50, UNION

WAIT, IIERBERT C. (b'75)థ-Tenı.8,"03 $\left(l^{\prime} 03\right)$

EUCUTTA (HEIDELBERG P.O.), 100 WAYNE

McNeill, Walfer 0.-La.1,87 (\$).

EUDORA, 150, DE SOTO

BREVAIR, LEON H. (b'81)-Tem.15,'07 (l'08)

HCILIOND, DANL. S. (b'37) $\rightarrow$; (1'82).

EULOGY (R.F.D., LEXINGTON), 37,

Phillys, Albert M. (b'65)-Tenn.6,'87; (ま).

EUPORA, 896, WEBSTER

BElRYIHLL, W'ILL A. (b'59)-Tex. ',0 ; ;

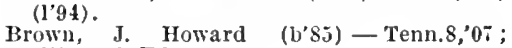
(I'06) ; K.F.D.

Donglass, Thos. 0. $\downarrow$; $\left(l^{*} 90\right)$; not in prac-

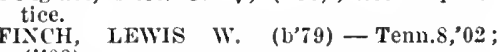
(1’03).

TABB, WM. GRANVILLE (b'88)-Tenn.8,

wiggins, James Purry-Tenn.8,'08; (1'08).
EVANSVILLE, 100, TUNICA

I'hilllps, Joln M. (b)'59)-T'enn.5.'82 ; (l'82). WHLLMS, WENIHAL IIOLMLS (b'85)TeUII.8,'I0; (1'10).

EVERGREEN (R.F.D., DORSEY), 75, ITAWAMBA

NABEISS, SAIIL. L.-Tenu.8,'03; (1'03).

EZRA (SWIFTOWN P.O.), LEFLORE

MeNeal, Benj. F. (b'71)-Tenn.1,04; (l'03).

FAIR RIVER (R.F.D., BROOKHAVEN), 100, LINCOLN

Robertson, Geo. 16. (b'44)-O; (1'82).

FALKNER, 148, TIPPAH

I'carce, James H. M. (b'T2)-Tenn.8,'04; (1'91).

I'FAK('E, LAWREXCE S. (b'ti)-Ky.2,'万: (1'82).

FANNIN, 150, RANKIN

Noble, John Edw. (I, 47$)-1$ 'a.2,70; (I'70).

FARRELL, 250, COAHOMA

Carson, J. G, $-0 ;\left(l^{\prime} 03\right)$; not in practlce.

CAHSON, WM. MONTGOHERY -N.Y.9,93; (l'89).

MeGOVJRN, JOS. DUNN (b'86)\&-Tenn.19, '10; (1'09).

FAYETTE, 775, JEFFERSON

Carradine, J. II.-Ia.I,'90; (I'89).

IIARILSON, ILON R.-Ky.1,'94; (1'64).

I.EWIS, W', H. II.-Ia.I,'89; (1'89)

ICNAIR, JOHN CLEMENT $\left(\mathrm{b}^{\prime}, 2\right)$-La.1, $98 ;(1,98)$.

FEARNS SPRINGS, 129, WINSTON

I'arks, Luther T. (b'i6)-Tenn.8,0I ; $\left(\mathrm{l}^{\prime} 0 \mathrm{I}\right)$.

Tabor, Hugh Il. (b'8I)-Miss.2,'10; (1'10).

FERNWOOD, 65, PIKE

MA(;EE, THOS. KIIIBY (b'64)-La.1,90; (1'89).

FITLER, 75, ISSAQUENA

Scott, Stanford Watson-J.a.1,03; (I'03).

FLORA, 747, MADISON

Fore, Oliver 1. (b'75)-Ga.I1,'02; (l'03).

ROWLAND, ROBT. W. (b'55) - Ky.5;77;

(1'82).

SI(iREST, ERNEST A.-La.1,04; (1'03).

FLORENCE, 260, RANKIN

WATSON, WHLLIE HARVEY (b'84)-La.I,

WHITL, Exoch Kxox (b'57)-Tenn.5,91 (l'90)

WITFIELA, RICHAIL NOBLE (b'テ9)Temu. 1,05: (1'03)

FLOYD (R.F.D., ASHLAND), 26, BENTON

Luna, Thos. L." (b'55) $\longrightarrow$; (1'82).

FOOTE, 75, WASHINGTON

I.EE, A. S.-Tenn. $\delta, 00 ;\left(l^{\prime} 00\right)$.

Worthington, Thompson F.-La.I, 02 ; (1'02).

FOREST, 1,136, SCOTT

ANIEEKSON, WM. C. (b*t)-Tenn.8,00; HAlALSON, JAMES J. (b’ร7)є-Ǩy.4,'86; (1*86).

PEVEI, WADE HAMPTON (b'69)థ-La.1, 01; (1'01).

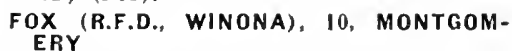

Taylor, John 1'-Tenn.5,81; (1'9I).

FOXWORTH, 75, MARION

Barkley, Claud Douglas (b'92)-Ga.I2,'13 ; (1'13); S.

FRANKLIN (R.F.D., DURANT), 80 , HOLMES

FRENCH CAMPS, 220, CHOCTAW

HOWELL, JOEL 'WALTER (b'83)-Tenn.8, 09; (l'09).

Robinson, Joe W.-Ky.4,72; (1'72).

SMITII, FRANKLIN F. (b'82)-Tenn.8, 06 ; (1'06)

YOUNG, FRANCIS SAML. (b'59)-Tenn.9. 92; (1'92); (See Hunisville).

FRIARPOINT, 875, COAHOMA

BECK, HENRY C. (b'48) $\longrightarrow$; (1'82).

Cooper, John Alehinson-Pa.2,'60; (l'81): not in pracilce.

EVERETT, AARON G. (b'74)-Tenn.8,00 ;

SLACK, JAMES AYLMER (b'82)-La.1,'05; (l'05).

SIACK, JANES JUNIUS (b'48)-Ky.1,'82; (l'82).

WEHMAR, HENIY WX. $\odot-$ Tenn.8,01 $(1 ' 06) ; U$. 
FULTON 194, ITAWAMBA

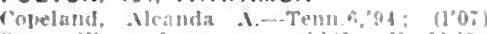
Orr. Wm. Jasurence (b's) ky $11.0 \mathrm{~m}$ $(1,0 ;)$

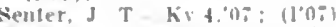

Walker, J. M. Mu, : : (l"S:3) GALILEE (R.F.D., MENDENHALL), 25.

Warren. J. I..-A: $\left(1^{\frac{1}{4}}\right)$ : (1)riggist

GARLANDVILLE, I00, JASPER

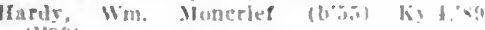
(1) 99

GATTMAN, 155. MONROE

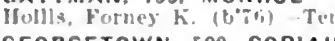

GEORGETOWN, 300, COPIAH

CHAHMA, H.KHEL, IIIIKL

Tenn. I, 0 : : (I'll)

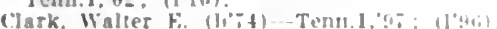

lipson. Jolun Harrlsin- $\vec{v}:\left(1^{\circ} 0 b^{\circ}\right)$.

GILLSBURG, 200, AMITE

STEWAIRT, Cl.MTUILS W, (b) no) Test $05 ;(1.05)$.

GLADING, 25. AMITE

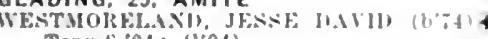
-Tent. $8,04:\left(1^{\circ} 04\right)$.

GLANCY, 35, CAPIAH

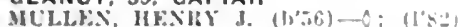

GLENDORA. 207, TALLAHATCHIE

Freeland, CIarence Furman (b's3) - Ten:1.

og: (l'09)

Holunson, s. W., Jr.-Tenu, s,0I: (1'n!

snith, rhesler W:- Tenn.s, 06 ; $(100.1)$

GLOSTER, 1.486, AMITE

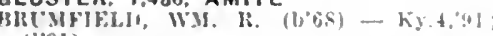
(1'91).

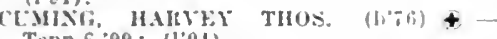
Tenn.6, 99 ; (1.04).

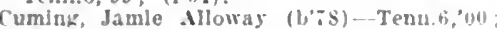
(I.04)

lamkIn, Wm. J.-I+a.1,68: (1'82)

JeGehee, Thos, Wren-1, $2,66:$ (1's:)

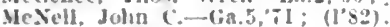

GOLOEN, 209. TISHOMINGO

Bostlck. Alonko F.-Tenn.s.'11:; (1'06)

GOOOMAN, 603, HOLMES

YABRY W 0 - Tenn.

Terry, lial Wabrey (b'k) - Cin.11.02:(l'04)

Wlllisms, sidnoy (colton (b'sis)-Tenn.t. 13: (1'13).

GOSHEN SPRINGS, 100, RANKIN

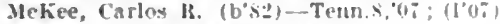

GRACE, 350, ISSAQUENA

F'tulay, Hobt. Conuay (b's) L La.J, "00 (1.08).

GRAFTON (R.F.D. RICHTON), 10, GREENE

llamond, Wrlihe Wiley (b)-

GRAYSPORT, 1.409, GRENAOA

Clanton, Rotut. Algeon (b'\$3)-Temr.8.'12. (I'II).

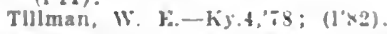

GREENVILLE, $\subseteq, 610$, WASHINGTON

Altaway, Wh. Alesander (col.)-Tenn. i, "un; (I'02)

Hrown. Howard I'. (col.)-Tenn. Zssf: (

Canuplell, Malcolm (b'a)-Va.4,01; ( 1.

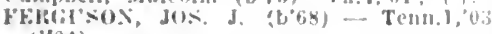
$\left.11^{\circ} 04\right)$.

Fulton, IS. F. (col.)-Tenn., $001 ;\left(l^{\circ} 01\right)$

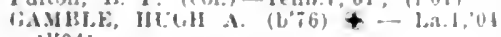
[1.04].

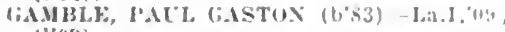
(1.09).

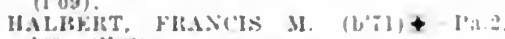
so: $(1 \times 2)$.

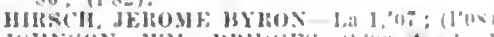

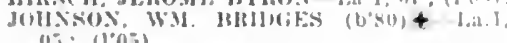
(i): $\left(j^{\circ} 0, j\right)$.

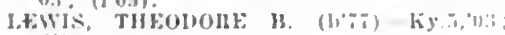
$1 l^{\circ} 04$

MIIJer. Jamea H, - Ill.1\%,00; (1'00)

Montgomery, banl. (amerón (6⿳亠口冋) . Ia:19: 11 13:

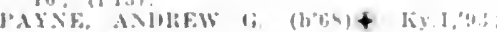
(1)93): $\mathrm{s}$.

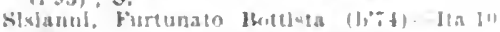
, $25 ;(1,1: i)$

sM

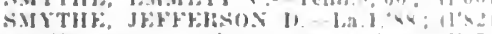

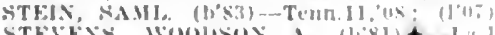

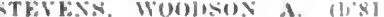

"6: (I'Uf): OALR*

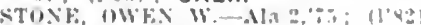

W.Kk. А.
GREENWOOD, 5.863 , LEFLORE

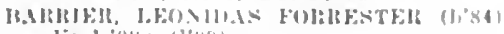
- ky, 1, os: $(10,0)$

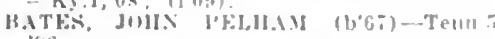
(ati.

Itwoth. Mark \& (cul.) (lisi)-Tern :,l? (1'1:3)

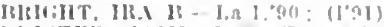

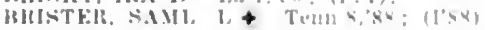

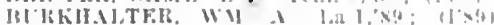

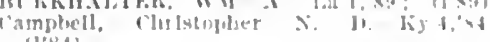

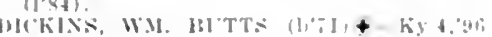
(1, 913$)$

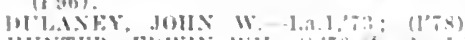

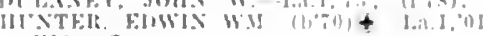
(1) $051 ; s$.

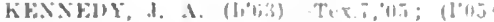

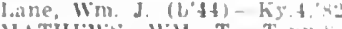

M.ATIE:Ws, W.H. T. Trun \&4: (1"96i).

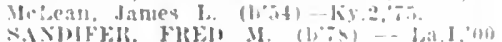
(I") (19)

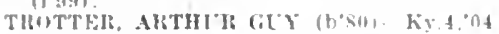
(In (0) : S.

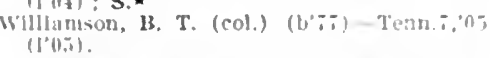

GREENWOOD SPRINGS, 300, MONROE

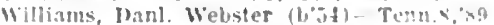
(卷).

GRENADA, 2.814. GRENADA

Buys Mlful H.- Ila.2:59: (1'79).

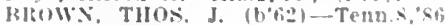

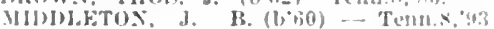
(l.

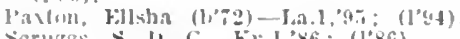

seruggs, s. II. G.-Ky.1,86 (1'R6)

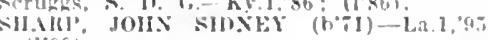
$(1,9(1)$

ślarp, John W. (1,39)-1.a.2,66; (l's2)

Whltaker, Wm. Henry-Kr.I,91; (INkii)

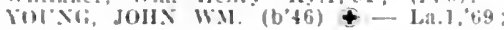
11 's:

GULF (RICHTON P.O.), PERRY

NIVEKT, EKNEST A. + - XY.3,00: I'A singr. 1's.l'II.s., quarantine station.

GULFPORT, 6,386, HARRISON

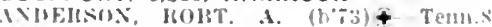
(1)

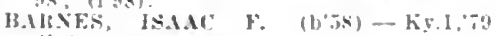
$1 / \times 3=1$.

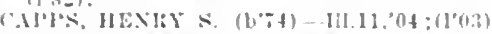

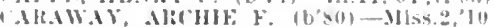
$(1,(),)^{2}$.

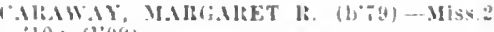
10: $(1,096)$

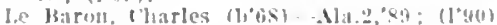

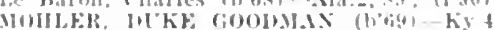
4.11: $\left(I^{\prime} 9 t\right)$.

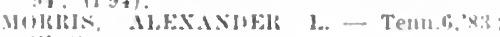
(I) 83,

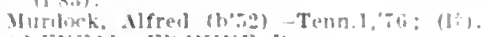

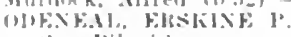

(ser hiloxi.)

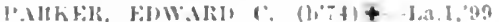
(10) 11$)$

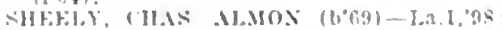
$\left(1^{\circ}+4\right): P d$

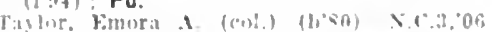

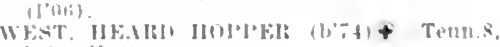
(1):3; 1100,6$)$

W:Ik!nson, J. I

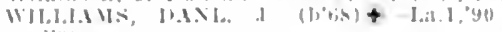
(1)!(1).

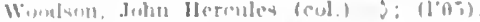

GUNNISON, 5I5. BOLIVAR

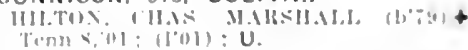

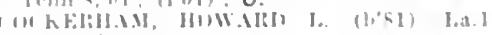
$($ J'in)

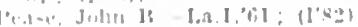

GUNTOWN. 330, LEE

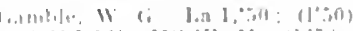

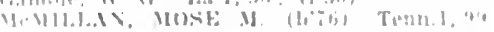

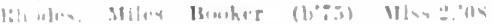

HAMBURG, 234, FRANKLIN

AAMILTUN. 5G, MONROE

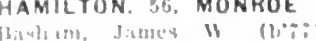

II FI"

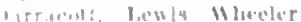

$(1,0)$
HAMPTON, 200, WASHINGTON

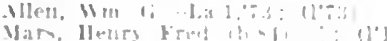

HANDLE (R.F.D., GHOLSON) 35 STON

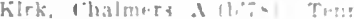

HANDSBORO, 90\%, HARRISON

Ilarty, Jelin \&.

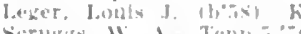

HARDY STATION, I66, GRENADA

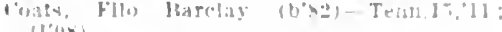

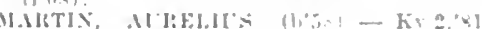

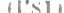

HARPERVILLE, 179, SCOTT

SHIII" HTHI?! WIJUE

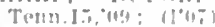

HARRISVILLE, 75, SIMPSON

H.MIII.11, 1; W KI: W

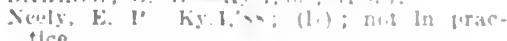

NFFH,Y, WII,KJE: K:- TH:M

HATHORN, ISO, MARION

Polk. Winfurd scott (b's - Tenta.10: (I०A:;).

HATTIESBURG, 11,733, FORPEST

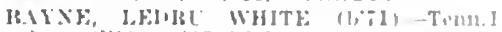

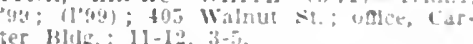
ter Blelg.: $11-12,3-$

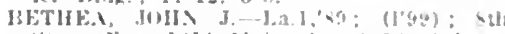

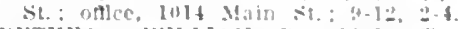

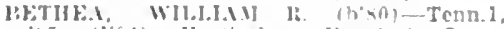

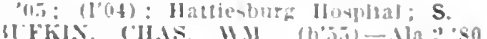

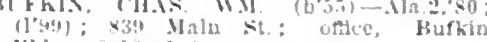
litrlg.: s-1:2, $1-4$.

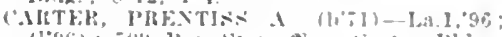

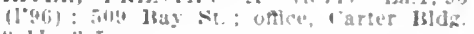
$4-11,3-5$

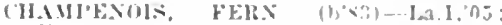

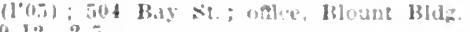

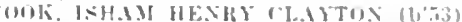

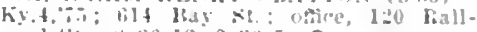
road st. $8: 30-1: 2,231,5: \mathbf{G}$.

(R.IWFORI, W.LTEK WV (b-2)+-Ta2 44: (194): Walnut 5 : unce Carter

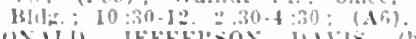

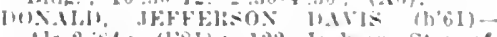
Ma.2.4; (IRI); 12u Jackion St.; of

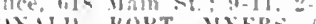

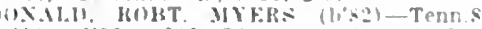
1): (1.03); 202,3 , Ile.; Oflce, Bufkin Hithe

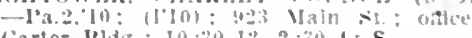
carter Hldg. $10: 30-1: 2,30-4: 5$.

Howard, Wesley f (wol.) (6\%) III.17.0? (1'02) : $205 \mathrm{~F}$. 5th st.

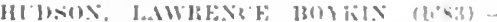

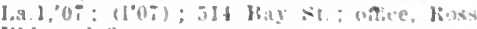
HIlle: : 1.:1

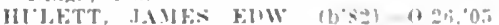
(loli); 304 William st.; oalce, koss Mlolz:; II -1:2, :-1

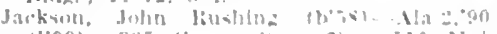

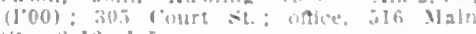
sit $5-1: 1$. 1 .

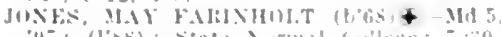

leve. "Wishliapton

It $r$ l?

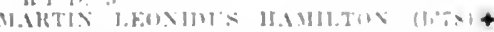
I.n. I. "111: $110:$

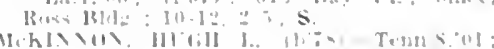

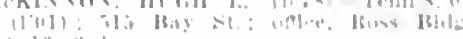

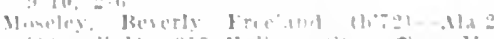

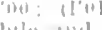

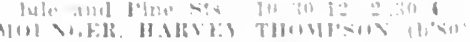

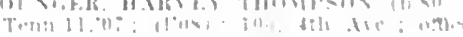

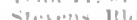

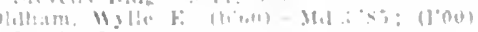
It 1 ! I 1

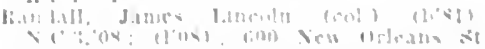

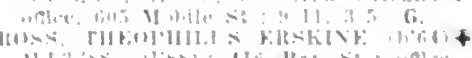

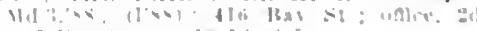
atid frome sts ; $1011: 0$ 


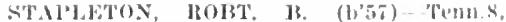
S.1; (1"90); :309 Baty sit.; oflle, Bufkin Bl, $x-10 ; 0$

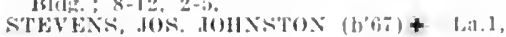
$90 ;(190)$; 117 colleze st.; offlew, sier ens 13dg.

SUMMEMS, ESTTS LEON (b'81) - Trmm.

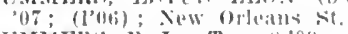

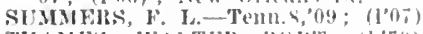

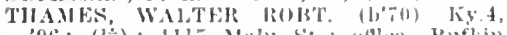

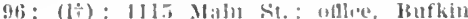
Bldg.; 9-11, 3-.5.

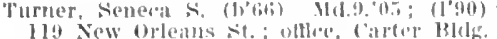

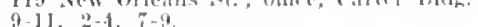

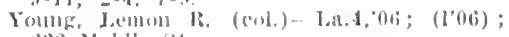

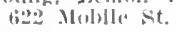

HAWKES, 25, JONES

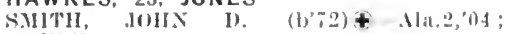
(1'04).

HAZLEHURST, 2,056, COPIAH

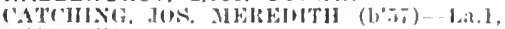
$83:(1,82)$.

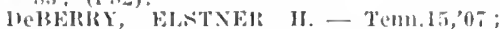
(l'm9).

Erwin. Frank Lewis (L'90) -. Tenn.5,13;

(1'13).

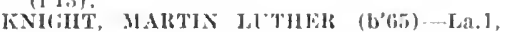
$95 ;(1,92)$.

Watson, Joseph I'rlce- Tenn.5,03; (1'02).

WHTE, IOHY CALHOLY (L'85) + -H11.2., $12 ;(1 ' 12) ; s$.

HEATHMAN, 35, SUNFLOWER

CAMPBL1, BULKE IILLI-Tenn.1, 04: (1'04).

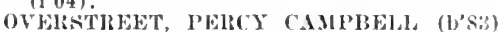
-Tem.1,08; (1'0s)

HEIDELEERG, 477, JASPER

Clayton, (i. W. O; (1) ; R.F.D. 1

Clayton, (ico. W. Ir. (b'

Dantzler, Frederiek A. (tris)-Ky.1,'s1; (1'91).

Eudy, Gillert E. (b'83)-1la.2,07; (1'06).

HEMINGWAY (R.F.D., COILA), 150, CAR.

ROLL
Holman, Chas. Ininds (b's0)-Temn.8,03 ; (1,03); (Colla).

HEMPHILL, 25, PERRY

SLAY, IRIS ,IOE (b'ST)-Tem. $8,{ }^{\prime} 13$; (l'13).

HERMANVILLE, 300 , CLAIBORNE

CHAPMAN, ALVAN LOTHAM (b'6) -

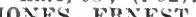

HERNANDO, 660, DE SOTO

RMERSON, INGL'S L. (b'65) —-Tem.8, $93 ;$; $\left(1^{2} 93\right)$

IONES, THIOS. MT. (b,46)-ILd.2,69; $(1,82)$

POWELL, WH. A. (b'52)-Md.3,'86;(1'87)

WEISSINGEI, ALEX. J. (b'60)屯-Tent.

94: (1'94).

WFISSINGER, WM. S. (b'46)-La.1,']

VRICHT, JOHX MARJON (b'\&2)-Ky.9,05; (1'05).

HESTERVILLE, 125, ATTALA

l'ender, Chas. A. (b'81)-Tenn. 8 , 08 ; (I'08). HICKORY, 600, NEWTON

iandy, John I. (b'68)-Tenn.6.,93; (1) ).

GILNORE, CLARENCE Y-KY.4,93; (I'00)

KING, JAMES ANIBEW (b't)\&-La.I, '11; (l'11).

I'TLMMER, IAMES ROBT. (b'84) $4-0$; (1'10)

Semmes, Frank G.-Ky.4,'82; (1'82).

HICKORY FLAT, 26I, BENTON

ABSTON, JOHN THOMLS (b'59)-Tenn.6, '82; $(1,82)$.

Holcombe, Robt. A. -0 ; $(1 \div)$.

HIGHLANOALE, 75, LEFLORE Berry, Marens Lafayette (b'84)-O; (l'11);
R.F.D.

HIGHPOINT, 104, WINSTON

RICHARDSON, ELBERT LEECH - Tenn.1, $\left.00^{-} ;\left(1^{\prime} 0\right)^{\circ}\right)$.

HILLHOUSE, 75, COAHOMA

NITHOLS, JAMES LLTELLC'S (b'86) Ten11.5,11; (1'11).

HILLMAN (R.F.D., LEAKESVILLE), -

MreLeod, Dan (b'S8)—Ga.12,'13; (1'13).

HILLSBORO, 175, SCOTT

ROWE, ELLIS J. (1'61)-111.11,'93; (1'01).
HILLSDALE, 40, PEARL RIVER

COLSOALE, WO, PEARL RI

lí.4, ?04; (1'03).

HINILE (R.F.D., BIENZI), 20. ALCORN

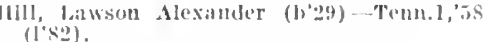

HINTONVILLE, I00, PERRY

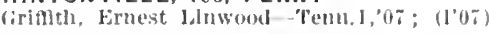

HOHENLINDEN, 50. WEBSTER

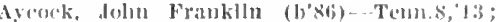

(ili:3).

$($ 'rumily

HOLCOMB, 152, GRENADA

13oll. Jimes Edgar (b'63) - Tenn.1,97; (1'US): R.F.M. 3.

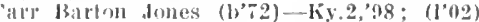

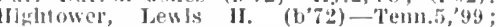
$(1,28)$.

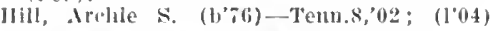

HOLLANDALE, 481, WASHINGTON

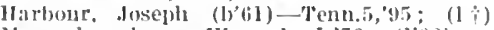
Maspruder, Jiules W'm.-La.1,76; (1'82).

SPIVEY, (IEORGE HOWARD (b'83)-KY.2. II; (1'T).

HOLLY BLUFF, 100, YAZOO

(Wen, H. (. (1';8)-Tenn.8.02; (1'02)

HOLLY SPRINGS, 2,192, MARSHALL

DANIEL, CHESLEY (l,49) - LAL, ', 2 ; (1'82).

HLLOT"1, WM. C. (b'58)-Nich.1,'s9; (l'ons).

GIJULAN, NORMAN GLASGOW (b'T⿰亻) E.TE: No1$$
\text { (l'08). }
$$

(108).

Tenn, 7,$04 ;(1 \circ 04) ; \mathbf{G}$.

SEALE, IKA BOLTON (b'80)-Tenn.8,'10; (I'0i); Pd.

Seale, Robt. A. (b'71)-Tenn.8,96; (1'89).

HOLLYWOOD, 500, TUNICA

MIXOR, JANCELO'T L. (b'76)-Tenn. ,'99;

TURNAGE, WM. M. (b'73)-Tenn.8,99; (I'98).

HOLMESVILLE, 200, PIKE

Busby, Ely Everett (b'86)-Mliss.2,09 ; $\left(l^{\prime} 09\right)$.

GEIALi), JAMES HOWARD (b'85)-Fenu.8, '09; (1'09).

HOMEWOOD, 100 , SCOTT

BARNES, WM. 11. (b'45) $\rightarrow$; (1'T9)

HORN LAKE, 200, DE SOTO

lihodes, I. A. (b'i2) - Tenn.8,'11; (I'11).

HOULKA, 389, CHICKASAW

Mitcliell, J. Bonner (b'78)-Tenn.8,'v2; (l'02).

WALKEK, JOIIN CHILDRESS (b'85) -

Tenn. 8, $09 ;$; (l'09)

Walker, Wm. C. (b'59) $\rightarrow$; (丰).

HOUSTON, 1,400, CHICKASAW

Davis, Chas. D. (b'72) - Tenn.6,'93; (l'93) ;

Evans, J. Augustus-Ky.1,'85; (1 $\dot{\dagger})$.

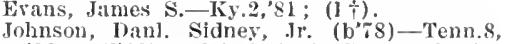
'12; (I'12); Mississippl State Charity

Knox, Hall-D; (1⿱亠䒑十).

WILLIAMS, J. RICE (b'67) - Tenn.6,94, Tenn.1,96; (1'93).

WILSON, E. PRYOR (b'T6)£-Tenn. 8,02; (1'02).

HUB, I00, MARION

INDERSON, STEVE HARMON-Miss.2,07 ; $\left(1^{\circ} 07\right)$.

HUDSONVILLE, 43, MARSHALL

JOHNSON, GEO. EDDIF (b'82)†-Tenn.1, 06; (1'09).

HUNTSVILLE (R.F.D., FRENCH CAMPS),

50, MONTGOMERY

Fair, A. S.-Tex.i,'07; (l'01).

YOLTG, F. S

(See French Camps.)

HUEHPUCKENA, 200, BOLIVAR

BROOKSHIER, JAMIES LELAND $\left(b^{\prime} 84\right) €$

Tem.1, 07 ; $(1,06)$

Jackson, Walter E. (b'78)-Tenn. 8,$03 ;\left(l^{\prime} 01\right)$.

INA (R.F.D., PINOLA), 15, SIMPSON

Farmer, Eslus-o; (京).
INCREASE, 100, LAUDERDALE

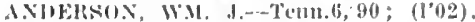

INDEPENDENCE。 106, TATE

POWELA, MINOR MERHITI - Ky.2,'11; (1'11)

THOMUSON, .T. WADE (b'T5)-D; (1†).

INDIANOLA, I,098, Sunflower

Alexinder, James A. (b'66)-11a.2,'88: (1'\$6).

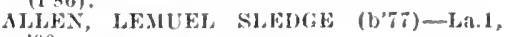

(iray, Wm. K. (b'55)-Ky,2,81; (1'81).

Kent, Henry ८: (b'i1)-Tenn.5,'93; (1'93); Pd.

Klmbriel, Albert carter (b'86)-Tenn.8,'11; (1'11).

MARTIN, WM. B. (b'at)-Lat 1,86; (1'86).

Walker, Jos. Edlsom (col.) (b'î) - Temn.7. , $06:$ : (l, 06$)$

INGLESIDE, 16, CLAIBORNE

(ivice, Nathaniel A.-D; (1'82).

INGOMAR, 234, UNION

'iriffln, Dale Jlutehison (b'84)-Teun.8,'13; (1'13).

(Auyton, Wm. Sylvester (b'84) - Va.1,'13; ().

Knox, W. J. (b'66)-1: (1'87).

INSMORE, 10, CLAIBORNE

Hecaleb, J. F.-la.I, 'y1; (1iे).

INVERNESS, 22I, SUNFLOWER

Anderson, kobt. L. (b'75)-Tenn.8,03; (l'03).

Irart, (ieo. F.-Ky.5, 04; (1'04).

Mayfield, Lee Kelly-Miss.1,'10; $\left(\mathrm{l}^{\prime} 0 \mathrm{i}\right)$.

ISOLA, 478, WASHINGTON

RARXES, JOIIN A. (b'60) $\rightarrow$; (1'82).

BYRD, W. GEO. (b'75) \&-Tenn.5, 03; $\left(1^{\prime} 03\right)$.

Harper, Byron $\mathrm{R}-0$; (1'08).

ISSAQUENA. - SHARKEY

Eggleston, W'm. M. (b'56)-O; (1'82).

ITTABENA, I,427, LEFLORE

BHOOKE, W. Cl.ACl)E-Tenn.6,91; (l'91).

DAVIS, CLEVELAND-Ga,11, 06: (1'06).

Holloman, Frank N1.-Tenn.8, 03 ; (1'02).

HOLLONAN, THOS. BASCON, JR. (b'74)Tenn.8,98; (1'98).

Kelrn, Walter L. (b'59)-Ky.1,'88; (l'90); not in practice.

IOORE, CHLISTOPHER C. (b'80)-Ga.1, $02 ;(1,02)$.

SIIANXON, H. L. (b'80)-Ky.4, 03 ; (1'02).

IUKA, 1,221, TISHOMINGO

Brown, Robt. Jackson (b'i2)-Tenn.8,07; $\left(\mathrm{l}^{\prime} 05\right)$.

Carmack, Frank T. (b'56)-Tenn.5, 80 $\left(1^{\prime} 80\right)$.

Ilaney, Taswen P. (b'68)-Tenn. 8,07; (l'07)

Hodges, Walter A. (b'5i) - Tenn.5,'80 (1'80).

Walker, James Thos. (b'62)—-4d.3,'86; (1'87).

Whitehurst, Alfred F. (b'68)-Tenn.11,98; (l'99) ; Pr.

JACK (UTICA P.0.), 60, COPIAH

kobertson, John L.-Tenn.8,'93; (1'93).

JACKSON, 21,262, HINDS

Adkins, Geo. Eli (b'81)-Ky.2,08; ( $\left.1^{\prime} 07\right)$; 810 N. President St.; offlee, W. Capilol St. ; $10-3 ;$ OALR. $\star$

Anderson, Lomax (b'46)-Ala.2,'79; (l'82); not in practice; President and Fortification Sts.

APPLEWHITE, ALBERT S. - Ga.12, 08 . (106) ; 124 k. Capitol St.

ASH, GEO. GLENDORE (b'80)-LA.1,'13: (l'11); 459 North st.; offiee, 431 E. Capi-

BAUER, HENRY LOUIS (b'66)-Ga.5.95, La. 1,'98; (l'94); Merchants Bavk Bldg.; $9-11,-1$, OALR. $\star$

Berry, John Pleasant (b’66)-Tenn.5,'90: (1'90); 616 West St.; offtee, 228 W. Capitol St. ; $2-3$.

BERRY, JOS. THOS. BELL (b'59)€-La.1, '83; (1'83); 1359 Nortl West St.; office Pithian Castle: 10-1, 2-4; S.

Berry, Wm. G. (b's1)-Tenn.8,03; (1\%).

BOSWELL, ILENRY, JR. (b'82) - Tenn.1, 08 ; (1'09)

Brandon, John Wm., Jr. (b'89)-La.1,'13: (1'13); Mississippi State Charity Hospital BRITT, WALLACE LESLIE (b'72) 4 -Ga.11 $02 ;\left(10^{\prime} 02\right) ; 933$ North St.; offlee, Millsops Bldg.; 9-1, 3-4:30; U.ネ 


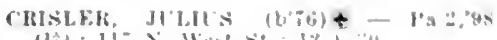

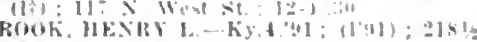

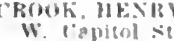

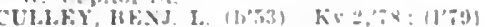
67 North st.; unlee, 131 k: inlutul st. $12-1,3-4$.

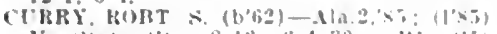
S. state st.; 8.1:2, $-4: 30)$ (111, 1il) OALR.

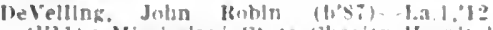
(l'11): Miswlislpul stare charitg llowpltat

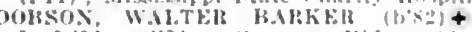

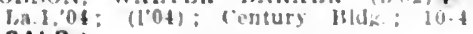

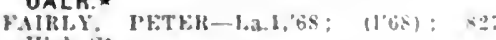
HIgh St.

1:AJLOWAY, ETHEI.HKRT HIXK (b") - Tenn.s, 03 ; (1002): See State Moard of Health; $304 \mathrm{x}$. Congress st. ; onlce, sentler Hd: : 12-1,3-4: S.

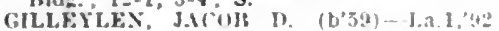
(I'91): Caplot and Mill St.

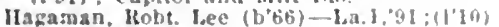
lis firime st.

Uerbert, Chrlstopher H.-1.a.l,1)i: (104) 515 Yazoo St.; ottce, Herberis Lrü store.

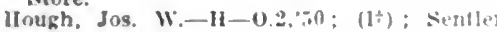
Blde.

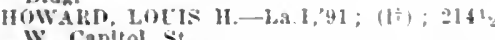
IT.)

MOLON BOBINSON (b'vi)

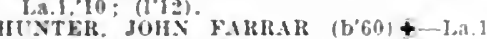
'82; (1'82): 199 N. State st; ottlee, ('en. tury Bldg.: $10-1,3: 30-4: 30$.

Jobnson. Robt. L. (col.) (b':i)-Tesn. : (h)

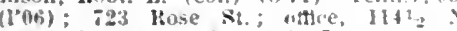
Furlsh's: : $8-10,12-1,5-7: S$.

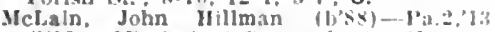
(1'13): Mlssisslppl State Clarity IIspital. MCLEAX. SAMT. HOSKISS $\left(b^{\prime}-1\right)+$ I.a.1 miner, Luclie $5 .(\mathrm{col}).(\mathrm{b}, 0)-\mathrm{Tenn}, \mathrm{*}, 00$ (l'00).

Miller, Saml. Albert (col) (b':5)-Lat4.0u (1.99)

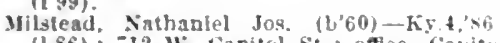
(1 86$)$ : $: 12 \mathrm{~W}$. Capitol St. : oftee, ("auitu and Hill sits, $9-11,1-4,6: 30-9$

Moore, Edw. W. (b'Gi)-La.4.98: (1'98,

l'lunkett, Randolph s. (b'i5)-Tenn.s, 10 (l'0t).

OLF, FUGFNE B. (b'53)-\$la.2.85 (1'85) : 509 E. Pearl St.

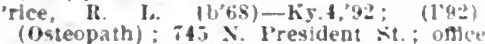
(Osteopath); i45 N. President st.; offoce
state and Capitol sts.

llead, Jos. Irotson (htt)-Fa.2, it: $t 14$ : Congress sit.

Itedmond, sidney I). (col.) (b'i1)-lll.Ii, (l'98); 229 Church St.: offec, 126 il Capltol st. : 8-10,3-4, i-8.

RFMBERT, (;EO. WM, FIR.INIS, JR. (b':! -La.1,03; (l'05); 633 ¿. State sit.

ROWAN, WALTER HAWTHOKSF $(1,25)+$ -Tenn. 8,"02; (1'1)2) : 104 Wells :

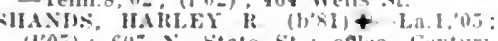

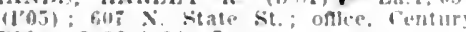

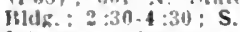

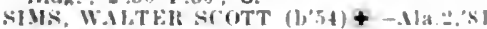

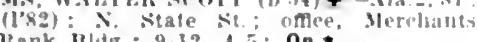
liank Mlig. : 9-12,4-5: 0p.

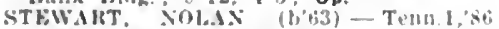

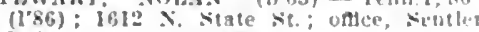
Ifldg.: $1 \%-1,4-5 ;$ NP.

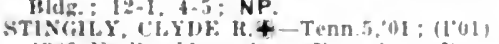
l:an. $x$. I'resldent st. : ontee, sitate liots of Heallh: 12-1, 3-4: L.D.*

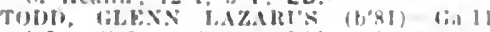

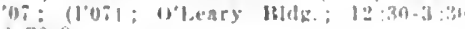
(1) :3i) -8 .

Turner. Dulley Wentwrotll (col.) (liso)

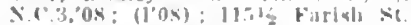

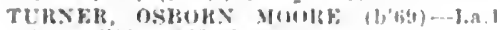

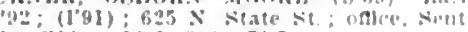
ler Hhig.: $12-1,3-4: 0$ :

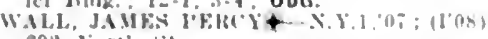
202 Ninth st

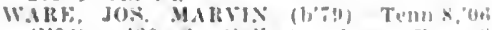
$(100 i)=4 \geq 9 \therefore$ liallatlu st.; unten, :(a)itu) St.: 2.4: G.

WATKIS, FRAXK J. (1979)+0.2." (1) not in pracllee: Mornugalde .lve; unler state lluard of hlealth.

welb, Circerd l. (1,82)-Cia.12,0s; (100) 1303 bailoy ire.

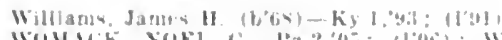

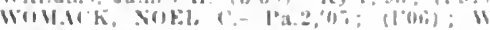
('ajultol SI

JAMESTOWN, 50, MARION

Iontgotuery, labin Waller (b'81)-Tenas $\left.0 \%: 1 l^{\prime} 0 B\right)$

JAVA (R.F.O. UNION), 75, NESHOBA

Sperd. S. 1.- : : $(1,1)$

JEANNETTE, 27, ADAMS

llontgomery, W. k., Jr. $(1, \cdots)-K s, t^{\prime} 0$ $\left(10^{\circ}\left({ }^{\circ}\right)\right.$

JEFFERSON (R.F.D., HOLCOMB), 50 CARROLL

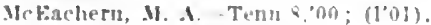

JEFFRIES, 25. TUNICA

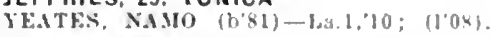

JOHNS, I00, RANKIN

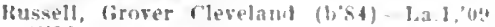
(I.08)

JOHNSTONS STATION, 170, PIKE

Wils, Ilollis Alex (b'S6) - Tenu. \&, I0; (1'10).

JONESTOWN, 367, COAHOMA

Inderson. (C. M. Tenus.'03: (l"03) : not u practice.

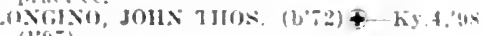
(1, 0 i)

hovisio, ROBT. E. (b-s)-Tenn.1.01: (1"0I).

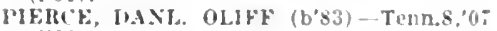
I'0s). (1): $\left(1^{\circ} 04\right)$.

KELLIS STORE, 27, KEMPER

Mcli.Ak, WM. M.-Tenn.8,03; (1'05).

KELLUM (R.F.D., RIENZI), 25, ALCORN

Hickson, D. F. $\left(b^{\prime}: 3\right)=0 ;(1 ' 8:)$,

KENAGO (R.F.D., WEIR), 75, CHOCTAW

direr, Thos. Calvin (b'si)-Miss.'? (1'1:2).

KENDRICK, I00, ALCORN

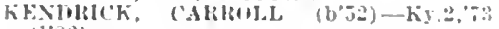
(1'sin).

KEOWNVILLE (R.F.D.. COTTON PLANT). 50. UNION

WHTTEN, W. A. (b'it)-D; (l'\&:3).

KILMICHAEL, 380, MONTGOMERY

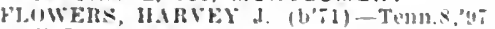

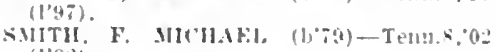
$(1,02)$

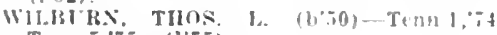

Telln.j, $7:$ : $(1,75)$.

KILN, 150, HANCOCK

llled, Wm. Wallace (b's1)-Tetme, 11 (h'1il.

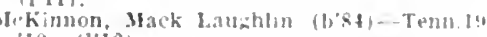
I0: (1,io).

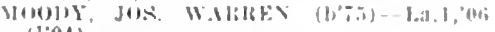
$\left(1^{\circ} 0 t\right)$.

KINCAID, 50, GRENADA

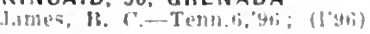

KING (R.F.D., FLORENCE), 42, RANKIN

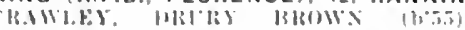
T'm $5, \therefore:$ : $11 x+1)$

KIRKVILLE (R.F.D. BALDWYN), 30 , ITAWAMBA

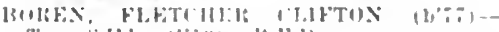

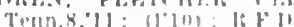

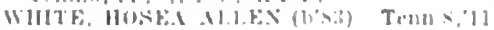
(1.1.3); not in pirateticts

KNOX0,500, PIKE

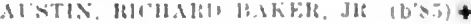
Laid. I, J0; (1,11)

KODOL (R.F.D., DEKALB), \$0, KEMPER

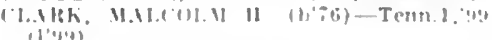

KOKOMO, SO, MARION

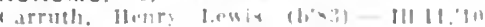
(I'B?

KOLA. IOO, COVINGTON

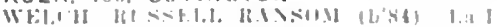

KOSCIUSKO, 2.385. ATTALA

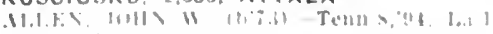

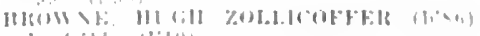
$1,1,11: 11.111$

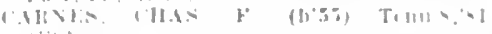

(1).

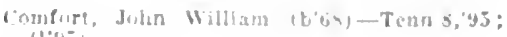

frawley, James T (1, : : 11:001.

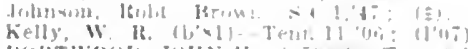

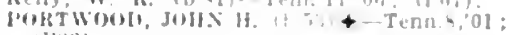
(1'x)

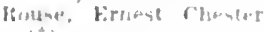

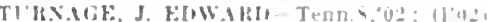
KOSSUTH, 193. ALCORN

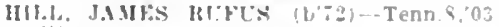
(1?03)

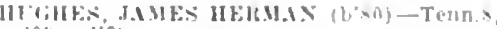

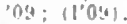

LAFAYETTE SPRINGS, 140, LAFAYETTE Burry. T. John $(1060)-2:(1,50)$.

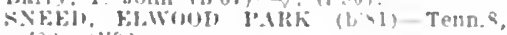
(1) $(36)$

LAINE, - JACKSON

SHIRI, WM. EDWAHI (bPa) +-MISS.2. $1\left(10^{6} ;\left(10^{\circ} \mathrm{OC}\right)\right.$.

LAKE, 429, SCOTT

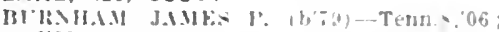
11'01).

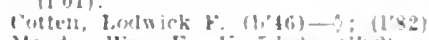

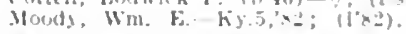

LAKE CARRIER, 200, PANOLA

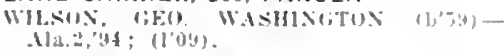

LAKE COMO, 150, JASPER

THIII'E.N. JUS. IS. (b':2). La.1,05; (1'0̈)

LAKE CORMORANT, 50, DE SOTO

Burress. Win. Hunt (b'5)-Tenns, 02

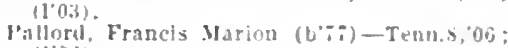
(1'06)

RCHMONI, AlRELT VELSON (b'sij)Tenn.s, 019; (1'09\%.

LAMAR, 75, BENTON

MURSEY, HLBEHT COMITOS (LSZ) $\longrightarrow$ (I'11).

LAMBERT. 573 , QUITMAN

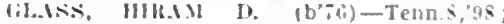
(1)its)

Hamilon, llubert lee (b'il)-Ky.5,3; : (1'0I).

Walker. Jos. Coleman $\left(b^{\circ} 90\right)$ - (Fal.11,13: 11 1:3j.

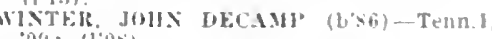
OI: (100)

LAMONT. 50, 80LIVAR

Ballwin, Jolin IR.-O) (l'ot)

MIILE:H, HCLH H. (b'T)

LAUDERDALE, 327, LAUDERDALE

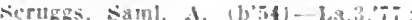

Sleverisin, Win. J.-Ala.z, si: (1'i)

LAUREL, 8.\$65. JONES

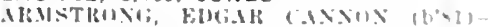
Teln 1, 11: $(1,06)$.

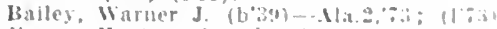

Itrown. H. $\leqslant$ (col, $1-3:$ (

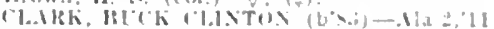
(I'1)

l. Illks:, 111.1.5

(1' 1191$) ; \mathrm{G}$.

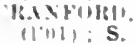

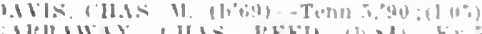
$11 \%$ ilinis

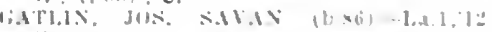
$11 " \| 10 \mid$

II. Ulirik

OALR.

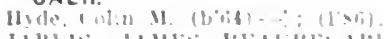

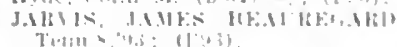

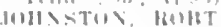

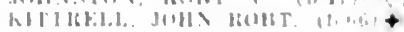

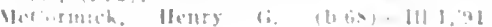

(6)

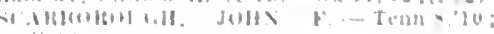
(?) $119 !$

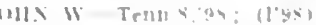

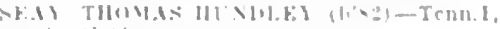

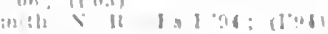

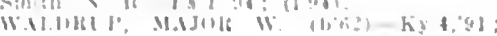


LAWRENCE, 200, NEWTON

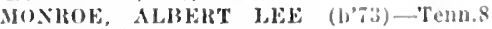
UIS; (I"US).

LEAKESVILLE, 466, GREENE

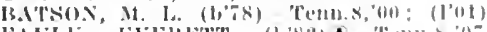

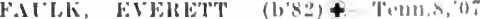
(1) 06$)^{2}$

loole, saml, $\rightarrow$; $\left(l^{\prime} 01\right)$

LEARNED, 134, HINDS

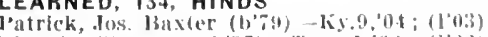

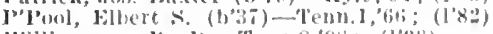
W'lllamison, lí. 11. T'enn.8, 98 ; (1'98).

LEEDO. 50, JEFFERSON

Bule, Xelll И. l,a.1, "30): (当).

LELAND, I.547, WASHINGTON

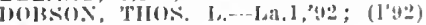

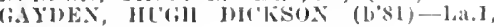

Iong, John A. $\rightarrow$; (l's3).

Jurner, li, Frank- Mo. I, 80 : (1's:)

Witty, W. H. $\rightarrow$; ( $( \pm)$.

LENA, 200, LEAKE

FELGLSON, JLON FESTI'S - Ky.2,05 (l'0is).

LINDSA GL10X ALTOX (1)'78)-Tenn.s $02 ;(1,02)$

WIJKEl\}, HEXJ, NEWTON (b'S6) - $\oslash ;\left(I^{\prime} 11\right)$ LERMA (R.F.D., EMBRY), 45, WEBSTER fiore, W. W.- 0 ; (1\%).

LEXIE, 125, PIKE

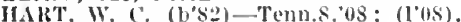

LEXINGTON, 2,428, HOLMES

BAKER, K. II. (t)'-1) Temn.s.'011: (1'00)

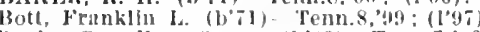

buck, camellus oscar (1)"69)- renn.s, (夆) : 1H. F.1).

IITY, A. M.-Tenn.s, 99; (1;)

H(iLESTON, STEPIIEX ARTILR $\left(b^{\prime}-1 t\right)-$ Tenn.8, 97 : (1,98)

IIOOKEL, OTHO DOLGLAS (b'8s)-La.1 '12; (1'11).

JORIAX, J, WALTEK (b'57)-Ky.2,'s1 (1.8:)

McBee, John II. (b'83)-lan.1,03; (l'03) not in practlec.

viller, Clayborne 13. (eol.) $\rightarrow$; (1'04).

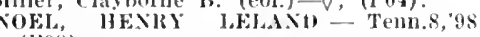
(I'9s)

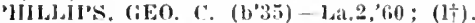
SHEIILIR, BAvlis A. (b'5)-Ten.5 $77 ;(1,82)$

Watson, James R. (b'48)-La.1,70; not in practice.

LIBERTY, 556, AMITE

Bates, Mirshail I'.-La.1,'86; (1'96)

Jutler, Fmmett loil (b's:')-ian.l,13; (l'18) BLTLEIR, ROBT. MORRIS-Ky.5,94; (1'94) Kennedy. Wm. R. (1,73)-Tenn.5,00; (1'95) Ouim, Julray ID-KY,4,97; (1'97) ; R.F.II LIGHT (R.F.D., PELAHATCHEE), 10

Carter, I. E. $-O$; (I'S2) ; R.F.D. 2.

LILIAN (R.F.D., HILLSBORO), 50, SCOTT Stubbs, Thos. II. (b'48)-liy.4,86; (l'87). LIZELIA (R.F.D., LAUDERDALE), 57, LAUDERDALE

Mc.Irthur, Benj. T.-Teun.8,03; (1'08).

LOAKFOMA, 75, WINSTON

Sanders, Arthur kaymond (b'si)-Tenn.8, '1:; (1'12).

LODI, 29, MONTGOMERY

synnott, J. I'--Tenn.8,94; (1'94).

LOGTOWN, 650, HANCOCK

Fountajn, James Q. (b'bi)-Ja.1.'93; (1'91) MeGOW

LOMBARDY, 50, SUNFLOWER

IIar'OWAN, JOS. JOHNSTOX-Tenn.8,'90; (l'11).

LONG BEACH, I,026, HARRISON

Carraway, Wyatt C. (b’57)-Ky.4,'s3; (1'82)

DEARMAN, WM, ALBERT (b'78) \&-La.1, $06 ;\left(\mathrm{l}^{\prime} 04\right)$; LD.

MANKER, HIVES ANDREW (b'82)(Tenn.8, $08 ;(113)$; NP.

LONGTOWN (R.F.D., SARAH), 250, PAN OLA

Diniel, F. E. P.-Tenn.8,94; (lí).

LONGVIEW, 190, OKTIBBEHA

(illis. M, I.- KY.4, $8 *$; ()

JIINET, MLLLREW PRICHARD (b'80)‡ MANCILI, (ivo. JEFFERSON (b'88)Temns,'il; (l'09).
LOOXAHOMA, 87, TATE

KISNER, ANDlBWW JAKSON (1,85)'C'In.S,10; (1'I0)

LORMAN, 50, JEFFERSON

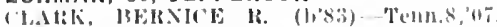
LOUIN, 523, JASPER

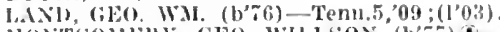
MONT(;OMEIS, GEO. WILASON (b'\%) M14:1,'10; (1'06).

LOUISE, 69, YAZOO

Ilecklin, IIervey II. (1)'85)-'l'enn.6,09; (10\%).

Meckliu, Janes Naylor (b'76)-Tenm,6,00. ( I'00).

LOUISVILLE, I,181, WINSTON

litvis, llenrs" I. (b'52)-Ky.4,7t); (l'82).

I,ENI'SEY, WALTEH G. (L'84)-Mld,9,05:

Hithuard, Rolbt. Arlhur (b'83)-(ia.12,'12; (1'12); 1R.F.D. 5

lirk, A. S. $-0 ;(1+)$

MONTCOMERY, MARION LEXTER (b'82) -Miss.2,10; (1'09).

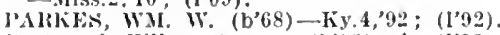
l'urtwood. IIllary Armour (b's3)-0; (l'13). SIIVA, WALTER-Ky.1,05; (1'02)。

suttle. Tlos. Cleveland (b'SJ)-Tem.s,'11: (l'11).

Woodward, (i. J'-MId.3,'7s; (1\%).

LOVE STATION, I08, DE SOTO

kinight, 'I'. A.- $)$; (1t).

LUCEDALE, 797, GEORGE

JORSE'T'T JAMES A.-Ga,11,02; (l'01).

ELEY, Wi. W. (b'75)-la.1, (0I; (I'01)

RATLIFF, R. FORD (b 78$)-$ La. 1, 01 ; (1'01)

IA'TLIFF, W. l. 4 -La.1,93; (l'9I).

LUCIEN, I53, FRANILIN

lludson, I'erey (b'82)-Ky.4,06; (1'09).

LUDLOW, (R.F.D., BEACH), 100, SCOTT

Lee, H. O. (b'82)-Miss, 2,07; (1'13).

LULA, I60, COAHOMA

J31tOOKS, JOHN S.-Tenn.8,'95; (1'92)

C.IIREER, THOS. A. (b'67) 4 -Tenn.8,'s8; (1'88).

\section{LUMBERTON, 2,122, LAMAR}

EDWAILDS, BRCCE F. (b'T4)-Tenn.8,01 (1'02).

HALL, W: W., IR.-Tenn.11,'99; (1'99)

I'igford, cora llyrtle Bass (b's1)-1'a.7, 04 (艺).

STEYESON, HANL. B. (b'75)-Ja.1,04 (1'03).

TllOMISON, ROBT. W.\&-Tenn.5,'95; (1'91).

LYMAN, I00, HARRISON

COX, WINFIELD WARDJOW (b'80)Tenn.8,'04; (1'03).

Harper, Stephen F. (b'84)--Tenn.19,'10 (1'11)

Terry, Wm. E. (b’0)-Ky.1,97; (l'98).

LYNWOOD (R.F.D., PUCKETT), 75, RAN. KIN

l'atrick, Robt. E.-Ky,4,'89; (1'89).

LYON, 223, COAHOMA

(HAl'MAN, ARTHUR L.-0.8,7T; $\left(1^{\prime} 02\right)$

DAVIs, ORVIJLE A. (b's2) “T́enn.8,08; (I'11); R.F.D.

GLASs. S. WADE (b'73)@-Tenn.8,99;

HWNDERSOX, JAMES WM. (b'it)-Tenn.8, '02 ; (1'01); R.F.'.

MABEN, 539, OKTIBBEHA

FONIREN, i.NL. H. (b'69)-Tenn.S,'93 (1"93)

HARPOLE, WAMAN BELTON (b'79)Tenn.8,09; (1'09)

IcGowen, General W. (b'75)-Tenn.9,09 (1'09) ; R.F.T. 1

NASON, ALBERT I. (b'70)-Tenn.9,0.5;

THOMAs, S. S.-Ky.4,'89; (l'89).

MACON, 2,024, NOXUBEE

Bush, Chas. R. (b'72)-La.1,94; (1)

HExDRICKS. O.

Hubbard, Jolin H.-Tenn.6, 92 ; (1'02)

Minor, Henry A. (b'36)-Va.1,37; (l'82).

Murphey, Eugene M. (b'69) - Ky.2,9l (l'91).

Stanley, John M. (b'87)-Ky.4,06; (1'06).

Taylor, Sylvanus Leroy (b'78) $-0 ;\left(l^{\prime} 06\right)$.

MADISON STATION, 323, MADISON

Dorroh, Wm. G. (b'70)-Tenn.S,93; (l'93).

Jones, Lewis C.-Ky.4,86; (l'86).
MAGEE, 685, SIMPSON

KENNEDY, A, E. (b'79)-Tenu.6,02; (1'03).

ROBßNSOS, J. J.- 'l'tnn.8,99: (l'99).

WAlkLk, EltAs'T's L. (b'i3)-Tenn.l, (60); (l'y9).

MAGNOLIA, I,823, PIKE

IBRIMFINI, JLSSE E. (b'7T)-La.1,01 ; (I'01) ; IR.F.I).

FELIE K, A. 1).-Ky.4,'85; (['85).

lloolk E J S -Tenn.8, $02:\left(l^{\prime} 02\right)$

IHOBEITSON, (;EO. WASHINGTON (b'72) Teun.5, $69 ;\left(1^{3} 97\right)$

Smith, John' May (b'86)-I,a.1,07; (1'08).

Wroten, Willam M, (b'4 7$)-\mathrm{liy} 4,7^{\prime} 2 ;\left(l^{\prime} 72\right)$.

MALVINA, I75, BOLIVAR

JOIISSON, ISAAC RAFORI), JR. (b*88)Tenn.8,'12; (I'11).

MANTACHIE (R.F.D., DORSEY), I6I, ITAWAMBA

Nanney, Jewman $1 \%$.-Tenn.8,04; (l'06).

MANTEE, 222, WEBSTER

Curry, Wm. Hugh $\left(b^{\prime} 81\right)$ - Tenn.8,'11; (I'10) ; Ob.

MARIANNA (R.F.D., HOLLY SPRINGS), 100, MARSHALL

ICAULEY, ANGUS M. (b'78)-Tenn, 8,04; (l'04).

MARIETTA, I46, PRENTISS

IIIARR, S'TANLEY IIVINGSTON (b'82) -Teuil.8,'11; (1'10).

MARION, 50, LAUDERDALE

fowler, Robt. E. L.-Ky.4,06; (1'02).

I Iarmon, Robt. W.-Ala.2,99; (l'99).

MARIS, 670, QUITMAN

Jamison, Alfred (b'81)-Tenn.8,'08; (l'08).

NEAL, SAML. FUL'TOX (b'82)-La.1,'13; (l'09)

STEPIIENSON, SAMIL. LOGAN (b'80)Tenn.8,'09; (1'09); $\mathrm{S}$.

MARYDELL, I0, LEAKE

MeGee, James L. (b'30)- 0 ; (l'09).

MATHERVILLE, I00, WAYNE

IIathers, Thaddeus Leander $\left(b^{*} 57\right)-A l a .2$, 04; $(1,06)$.

MATHISTON, 576, WEBSTER

Clegg, Claude (b'88) $\rightarrow$; (I'I1).

Lamb, I. Rube-Tenn.8,04; (l'05).

Mcclain, James Robt. (b; 74$)-$ Tenn.1,03; (1'09); R.F.D.

Ramsey, Shelton Alvin (b'89)- 0 ; (1'09).

steunis, James H.-Ky.4, 84 ; (l'84).

MATTSON, 375, COAHOMA

HARRISON, WM. BARNETT (b'83)-D.C.2, MONTGOMERY, THADDEUS R. $\left(b^{\prime} 79\right) €-$ Tenn. 8,04.

MAYERSVILLE, 185, ISSAQUENA

CROTHERS, VICTOR M. (b'86) †-Ky.2,'10; (l'10).

CLUDER, WALTER IIOWARD (b'6I)KY.4,87; (1'87).

MAYHEW, 180, LOWNDES

RAINEY, SAML. MILTON (b'49)-Tenn.1, $\% 1$.

MAYTON (R.F.D., PUCKETT), 60, RANKIN

Edwards, Luther $\Lambda$,-Tenn.8,'04; (1'04).

MeBRIDE, 40, JEFFERSON

SIMNONS, COLON L. (b'76)-Tenn. 8, 00 : (I'00).

MeCALL CREEK, 150, FRANIKLIN

Butler, D. P'-Ky.4,97; (1) .

Cain, J. J.-Tenri.8,07; (\$).

MeCARLEY, 70, CARROLL

TAYLOR, WM. S.-Tenn.8,'12; (1'08).

MссомB, 6,237, PIKE

BEACHAI, W. D.-La.1,'99; (l'98).

DICKERSON, LoUIS D. (b'69) 4-N.Y.10, '94; (1'94)'; S

GORDON, EUGENE R. (b'78)€-Tenn.11. 01 : (1,01):

Greer, L. L.-Miss.2,0T; (l'07) ; R.F.D. 1.

HEWITT, BRYANT JEFFERSON (b'86)Tenn.8,'11; $\left(1^{\prime} 10\right)$.

KJOTZ, S. PAUL (b'80)-La.1,'03; (l'05); $\mathrm{S}$.

rampton, W. S.-La.1,'00 ; (l'01).

NEVILLE, WM. (b'79)-La.1,01; (1'01).

PURSER, THOS. (b'72)-La.1,'97; (1'97)

Quin, ollver B. (b'57)-La.1,79; (l'79).

ROBERTSON, WM. W. (b'64) - Tenn.5, 86 ; $(1,86)$. 
Spurlock, Thos. 1. (b30)-0.2,"ati; (1"3i) not in practloe.

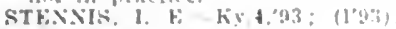

Webh, John $k \rightarrow$; 110.1$)$

licbb, saml. il - o. (ह).

MECONDY. 50, CHICKASAW

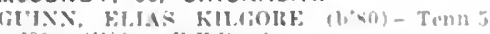
09: (1.09); H. F.1). "-

MCCOOL, \$22, ATTALA

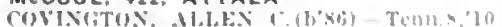
(1'11).

Turnlpseed. Maxy Leander (ben!) Tenn I. $00:(1,00)$

MCDONALD, - NESHOBA

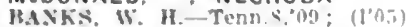

MCHENRY, 627, HARRISON

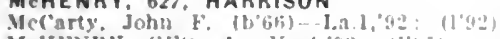

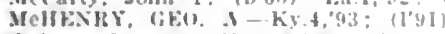

Siwltzer, lloss A.-TeIn Y, "0:"; (l'(12)

MCLAIN, 275, GREENE

Coleman, Jhobt. Heury (b'b2)-Alat: s lins

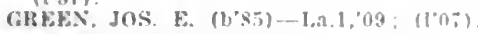

MELAURIN, 300, FORREST

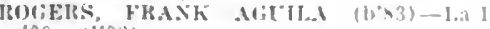

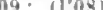

MENEILL, 300, PEARL RIVER

Ashe, Wm. 1 : $(1 \div)$.

MEADVILLE, 260. FRANKLIN

Costley, Jutnfleld-Teun.s, (01: (l'O1)

Walker, Lewls Winston (b'I) - Hiss 2, n! (1'09).

MEEHAN JUNCTION, I00, LAUDERDALE CARAITHAN, WM. (GKO. (b'Ya) - Ma:2, $(l, 05)$

DAVIS, W. I- I- $(1.98)$

MELIS (TYLERTOWN P.0.), 75, PIKE

BOSd, D. S $-0 ;(1+)$

MENDENHALL, 606, SIMPSON

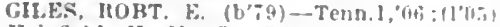

Holyfleld, II. X-Ter.

HITSOX, WM. JEFFEROS $11,-1$

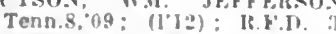

Rolmssox, THOs. T. $\rightarrow:(1 \% 9)$

Walker, Thos. M.-IA.1, 91 ; (I'si).

MERIDIAN, 23.285, LAUDERDALE

Akin, Chas, V"lvan, Jr. (b'90) - 1.al.1,'1l (1"11): 8th sit. and 2ith Ave.: offlce Mazza-Woods Bldg.; $9-11,2-4 ; U$.

ANUERSOX, WM. JKFFERSOX-1.n 1, "1 (1t): 1019, 29th ive.; oflce, tth st. and 22d Ave, : 11-12, 3-5: $\mathbf{S}$.

BAILEY JULIN THOMPSON (1,'s)

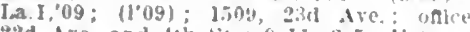
gad Are. and th si.: 9-II, a-5: U.*

BAKBFIR, TIIOS ALKXIXIBE, (ho, Tenn.5,"7: (1.82): I11\%, 24th Ave, omle 22d Are and th si: $9-12,2-5$.

BENNBTT, JAME (b\%2)-Ky.J,"01;(1"(1) 1205, Isth lie.

Bot'RIFALE, TIOS, DEVIXt-Ma 2, "H: (1.03).

HC'IIANAN, JAMLS MCQ. (b'5i) \&-Via.]

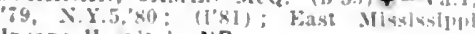
Insane llonisal; NP.

Card, Wm. If. (b'it)-Ky, $403:$ (1'tis)

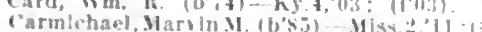

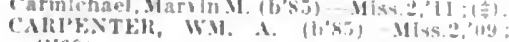
(1)03).

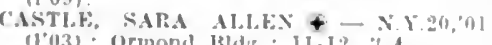
(Y)

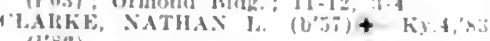
$(1, x=)$.

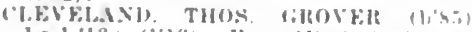

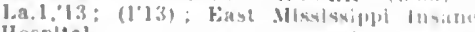
IIospltal.

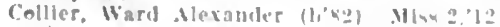

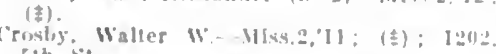

HAMEisox, JAMFin II. (1,ath) Ky $11,0 \mathrm{~m}$

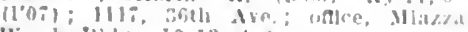

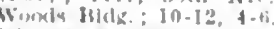

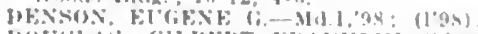

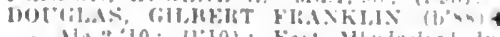

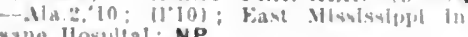

Flake, llenry Ledbelfer (b'bi) ky.l, "y (l'R9).

Fynl, $\therefore$. It Tenn.s."gs; (los).

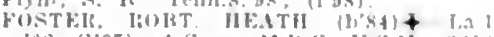

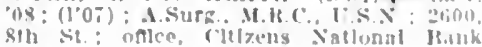

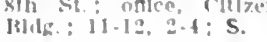

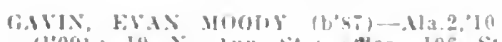

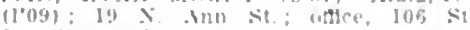
Josevili st. : 11-1, 6- -

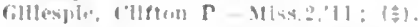

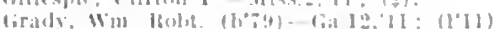

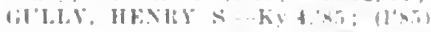

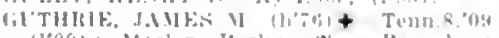

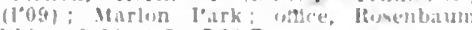
lild: : 12, 1 ; OALR.

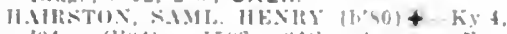

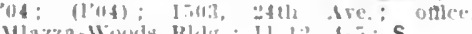

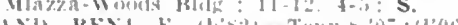

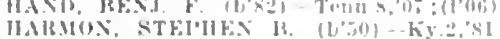

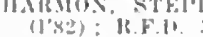

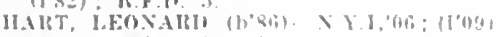

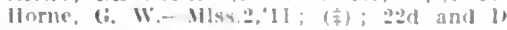

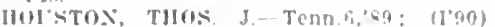

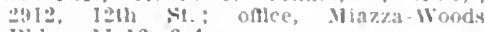
19.5

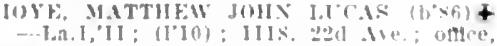

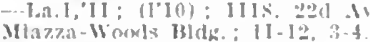

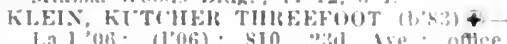

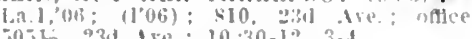
;0); 231 tre.; $10: 30-12,3-4$

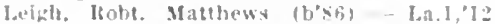

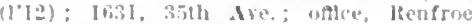
131dz; $10-12,3-5 ;$ ObG.

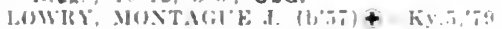

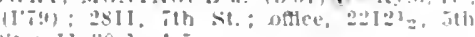
ㄴ. : $11: 30-1,1-5$.

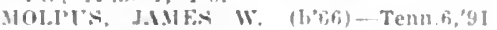
(I*:4]); K. F. [1

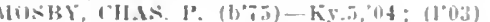
g.y dre. and the si ; s-12, 2-5.

linine, Frank [...

I'eflules, Tsaac locklari (b'5.5)-Miss.2,11 (ま); 1.220, 1321, Ne.

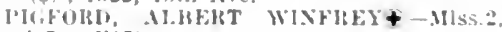

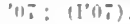

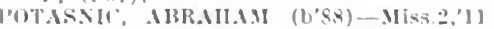

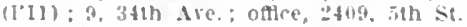

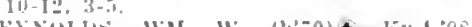

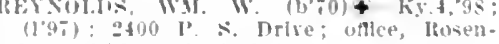
la um Bldk. : $11-12,3-4$.

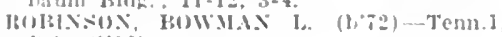
'11:; (1'n:2)

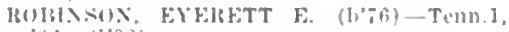

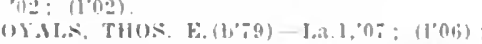
11(12, gind Ave, once, th and abl Are.

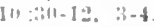

IBI

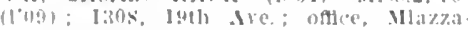
IVomis IHIs: 11-12, 3-1: S

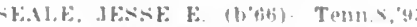

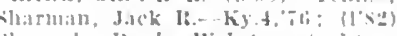

sherrul, hanl. Wehsler (col.) (bra9)

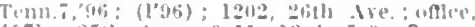

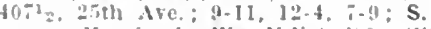
homers, llarriet 1). W. X.Y.20, 00 ; $(1004)$ llerillan Woman's Colleg

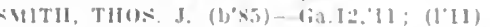
H Ho, zist ire.

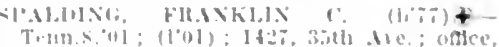

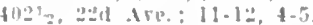

TAKFTt Jull li (bis) … la 189

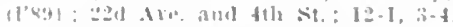

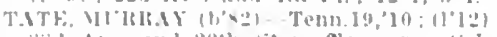

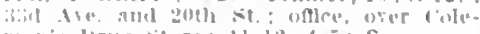

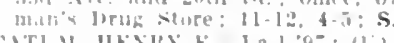

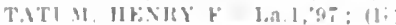

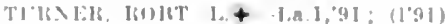

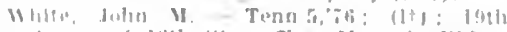

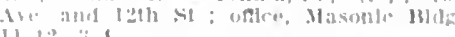
11 1:- : : i.t

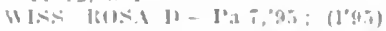

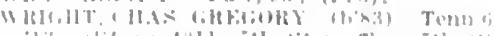

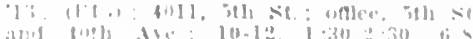

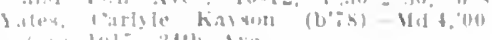

MERIGOLD. 241. BOLIVAR

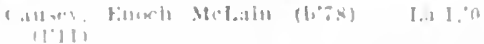

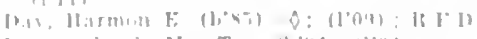

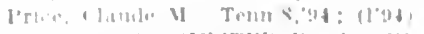

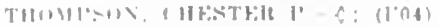

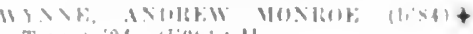

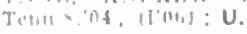

MERRILL. 328. GEORGE

KNIt.HT, SIIII. 1.HWIS

Tenn.1,

MICHIGAN CITY, 54, BENTON

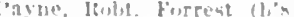

MIDNIGHT, 200, YAZOO

Slatighter.

MILLVILLE, I25. MADISON

औIJ1).

MINERVA

GOMERY

MINTER CITY, 725, LEFLORE

Fleming, Tucker buing (b'si)-Tengs, II (I'Iil)

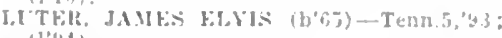
(1)!+1)

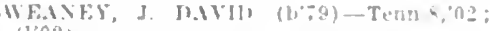
(1)

MISSISSIPPI CITY, 300, HARRISON

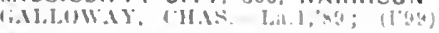

MIZE, 321, SMITH

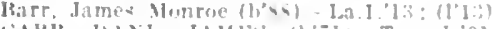

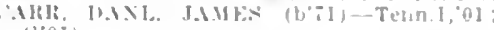
(1,0I)

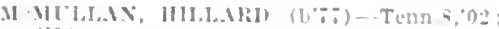
(a)

MIZPAH, 20, COPIAH

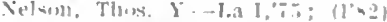

MOGUL (GLAOHURST P.O.), 3. PIKE

S.LB) IIfer. 11. W:...

MONEY. 75. LEFLORE

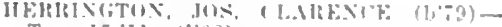

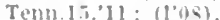

Kirly, larlos David (b's])-La I, I : (1'12).

kirby lirober fleveland (b'93)-Ian, 1:0 $(10 \overline{0})$.

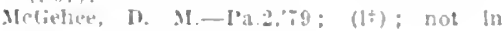
practloe.

MONROE, I50, FRANKLIN

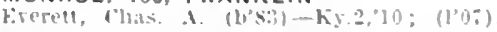

MONTICELLO. 450. LAWRENCE

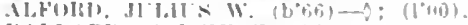

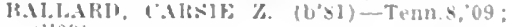
(1,0 04$\}$.

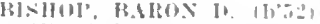

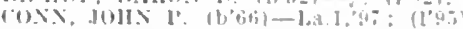

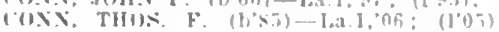

THI NIs: (1,TiO).

MONTPELIER, 121. CLAY

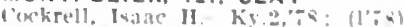

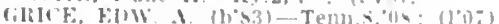

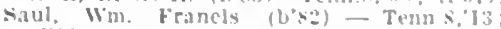
$(1,0) 0$.

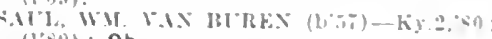
(I):Di); Ob.

MONTROSE, $\$ 27$, JASPER

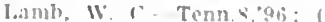

Vciaurin, Dunkin l'iere (1, in

MOORHEAD, 506, SUNFLOWER

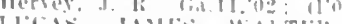

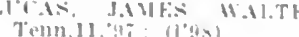

IV.

(['0):?].

MORGAN CITY, 50. LEFLORE

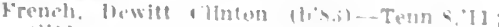
11 111

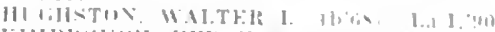

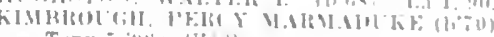
Tenn ; ys; $\left(l^{*}, \infty\right)$

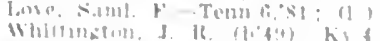

MORGANTOWN (CLAUDE P.O.), -, MAR. ION

loring Juhn liotrlom

MORTON, 374, SCOTT

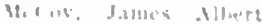

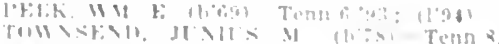

MOSCOW 125, KEMPEA

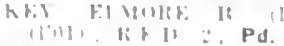

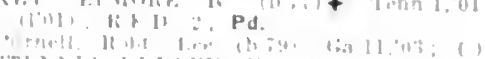

r. 
MOSELLE, 2.11, JONES

Butler, I. ('-Tenn.s.'04: (1'09).

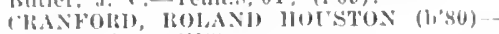

T('mn.8, 06 ; (l'05).

MOSS, - JASPER

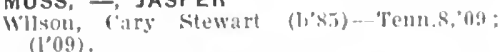

MOSSPOINT, 3.054, JACKSON

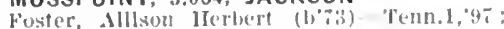

(l'9si).

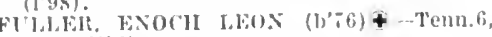
$09 ;(1.06)$.

May, James M. (col.) (b'68) - Tenn. б, (42: (末)

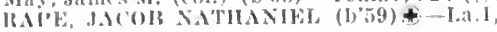
?!) I: (l’90).

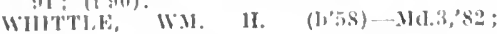
$(1,50)$.

MOSSVILLE (MOSS P.O.), - JASPER

Thigpen. II. A.-IISs.2,11; (†).

MOUND BAYOU, 537, BOLIVAR

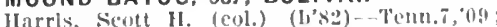
(I'10).

liyle, W. 1'. (col.)-Tenn.j, ,03; (l'05).

MT. CARMEL (R.F.D., PRENTISS), 200 , JEFFERSON DAVIS

Ilartlu syclney leanter (col.) (b*1) N.C.3, 0 : : (l'08).

MT. NEBO (R.F.D., DE KALB), 45, KEM PER

STFNNIS, S. D. $\rightarrow$; (1†).

MT. OLIVE, 1,077, COVINGTON

(Aillot:, NIRCIIE \&. (b'\$4)-1a.l,'11; (I'11).

('herry, Jumes G.-Ky.4,?3; (li).

HLYNT, MALTIN L. (b'so) —-Tenn.s, 0 . (l'06).

ICINTOSII, J011x s. $\left(\mathrm{b}^{\prime}, 6\right)-1,1,04$ (1'02).

Winclham, tarret $\mathrm{C}-\mathrm{O}$; (1'92)

MT PLEASANT, 130 , MARSHALL

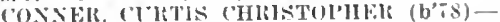
Tenn.s,"09; (l'08).

MULDON, 300, MONROE

川TIAI, JAMES ENTEILE (b'8\%) Tenn.8,'12; (1'12).

MULLET, 20, GEORGE

HOR., JOIIN WY. (b's0) \&-Miss. 2,09 (l०0S).

MULLONVILLE (R.F.D., CAMDEN), 150 MADISON

IBalley, Junes $11 \mathrm{~m} . \quad\left(\mathrm{b}^{\prime} 71\right)-\mathrm{Tenn} .15,11$; (1'09).

MURPHY, I00, WASHINGTON

Ferrell, Lee Thaddeus (D'T9)-Tenn.19,11; (1'09).

MYRICK (R.F.D., LAUREL), 50, JONES

IIL.NT, D. IROY (b'69)๑-Tenn.8, 04 ; (1'04).

MYRTLE, 255, UNION

MALI)EN, SAMI. JAMES TILDON (b'76)Tenn.8, 09 ; (l'09).

Goode, John S. (b'55) - 0 ; (l'S2)

l'CliNiLL, JAMES D. (b'68)-Tenn.6,'92; $(1 \cdot 92)$.

sineer, E. A. (b'52)-0; (1†); R.F.D. 3 .

NATCHEZ, 11,791 , ADAMS

All.MAX, WII. H. $\left(\mathrm{b}^{2} 5 \mathrm{~S}\right) \oplus$ - La.l, 85 ; (l'st); (609 Main St.; $\$: 30-9: 30,1-3 ; R$. BEEKILA, MARCUS' (b'81)—-La.1,11; (I'I1); 501 Monrue st.; uffice, Natchez Sanatorlun; 9-11, 4-6; ĹD.

Santorluin; 9-11, $\left.{ }^{4-6 ;}, 65\right)+510,88$ (l'ss) ; 301 N. Commerce st.; office, Natchez Sanatorium; 10-12.

Bhown, Fdward Floyd (b'68) - 1a.1,'96; (I'yti); not in practice.

chamberlain, chas. T. (b'80) - La.1,02; (l'(12): I is N. Pearl st.; office, 308 Franklin st.

(hamberlain, John Fleming (b'Ti)-La.1, '06; (1'05); Main St.; 9-11, 1-3.

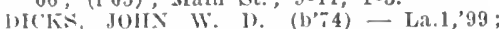

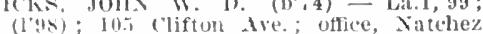

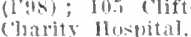

Dumas, Albert W. (col.) (b'76)-111.17,00; (1'99); 623 N. Pine st. ; office, 70T Franklin st.: $: 3-11,2-5$.

FTEXCH, EUGENE BREIVSTER, JR. (b'85) Lal.1,11; (1'09); 306 Franklin st. ; 9-11,

FRFXCII, RORT, CIENENT (b'ส Main si. ; $9-4 ;$ OALR.*

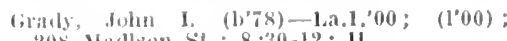
20.5 Madlson sit.; $8: 30-12 ; U$.

Ilall, Indrew J. X.Y.10,79; (I'82); 709 Maln sit.

Himiley, Latelus Lamar (b'90)-Ia.1,13; Intern, Natchez IIospital.

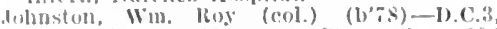
(10.) (1'10): 210 state St.: oftee $60 \times$ Franklln $10-12,3: 30-5$.

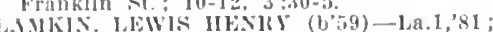

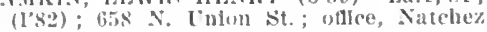
sinatorium.

Mazlune, fames C. (col.) (b'r0)-1).4.3. 347; (l'18); 121 N. Inlon st. ; $9-11,3-5$.

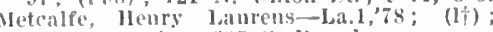
unf in practice: 30.5 s. Broadway

Yullens, rlarence Fimond (b'89)-x.Y.3. '12; Inlern. Natche\% rharlty llospltal.

volbi: WM. DAVIs (b'90) - La.1,12. (lii): Natele\% llospltal.

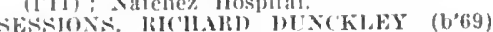

+ lat.1,92; (192); 313 cllfton Ave.

uthloe, 113 s. commerce st. ; $10-1,3-4 ; \mathrm{S}$

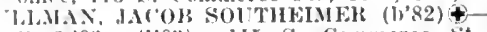
l'a.2,03; (l'03); 115 \&. Commerce st.

Watklns. Jebonald (I)'-4)-Ia. 1,00;(1'00) 700 Wain st.; oflece, 702 Maln St. ; 8-10,

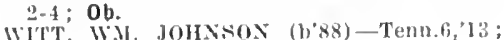
(1'13); Charly Hospltal.

NESBITT, 122, DE SOTO

Jirrintt, Asbury I. (b'35)-La.1,61; (l'82) (1'S2).

NESHOBA, 200, NESHOBA

JALVIS, TIIOS. E. (b'8?) - T'enn.1,08; (1'08).

NETTLETON, 733, LEE

Chastlan, Sldney $\left(b^{\prime} 6 \bar{C}\right)-0 ;\left(l^{\prime} 06\right)$.

DARBS, JOIIN T.-Ta.11,06; (1'05)

FARKAK, CIIAS. O. (b'72) - Tenn.s,oL; (l'01).

Feemster, Wm. O.-Tenn.1,73; (I'82).

Francis, G. I. $-\diamond ;(1 \dagger)$

IICOWN, C. B.†-Tenn. 8, 03 .

sloan. Win. Alfred $\left(b^{\prime} 83\right)-T e n n .1,07$; $\left(l^{\prime}(0)\right.$ i )

TXI) Filivoon, FEIIX JOEL (b'82)Tenn.8,08; 1R.F.D. 3.

NEW ALBANY, 2,032, UNION

130SWELL, HTGII I'RIDDY (b'8T) - LAI.1

"12; (l'lo). C.

(iassaway, Saml, A. (b'38) $\rightarrow$; $\left(l^{\prime} 82\right)$

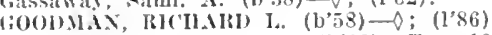
Gondelock, Joln Clifton (b'83)-Tenn.19 10 ; $\left(1{ }^{\prime} 09\right) ;$ R.F.D. 3.

Henry, M. I.' (b'41)- 0 ; (l'06) ; R.F.D.

MAYES, IIIGIIES N.t-Tenn. 8, 01 ; (1'01) I'urnell, J. 13. (b'29)-0; (1

WESSON, EGBERT HAYES (b'89) Tenn.15,'11; (1'11).

NEW AUGUSTA, 400, PERRY

IOOBINSON, BEXI. T. (b’8) - La.1, 06

(l'04).

MHTH, HEXRY I'. (b־6) - Miss.2, 0 ; ; (1'06)

Young, $11 \mathrm{~m}$. Allen $\left.(1)^{\circ} 82\right) \rightarrow 0 ;\left(1^{\prime} 08\right)$.

NEWHEBRON, I91, LAWRENCE

IZAlil), SAMUKS, E. (b'-70)-Tenu.1,00; (1'99).

NEW SITE, 20, PRENTISS

VITSON, WM. ARTHUR (b'80)-Tenn.8, '11; (1'10).

NEWTON, 1,878, NEWTON

COOPER, INMAN W. (b'82)๑-Tenn.6,'03; (l'03).

Gallaspy, Jesse B. (b'82)-Tenn. 1,07: (1'0T)

611.L, W.M. GREGG (b's1) - La. I,'10.

HARRELSON, AUGUSTUS M. (b'65)Tenn.6,'92; (1'92).

MeNEHL, GEO. H. (b’50)-Ky.1, 7 7 ; (

Tatum, James J. (b'59)-Ky. L, 86 ; (1'86).

NITTA YUMA, 50, SHARKEY

('rump, Rolit. 1'. ('b'65)-Ky.2,'90, Ky.1,'95; (I’90).

NORFIELD, 889, LINCOLN

Bowman, John Willis Conley-Miss.2,07; (l'0 0 ) ; R.F.D

MONTGOMERY, W. ERNEST (b'78)Tenn.8,00: (I’99)

TYNES, CLIFTON EDGAR (b'84) - La.1, $10 ;(10 \%)$.
NORTHCARROLLTON, 302, CARROLL

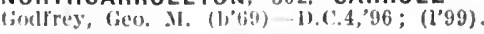

NOXAPATER, 3I, WINSTON

IIIKMAX, JOHI S.III. (b'84)-MIss.2, 'I1; (1'11). HIllMAX, WM. WATTER (b'79)-Tenn.8, (1): $\left.; 1^{\prime} 02\right)$.

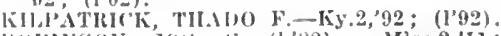
Itomisso., sos. C. (b'82) - Miss.2,'11; (l'11); $\mathrm{S}$.

OAK GROVE, 50, KEMPER

HOLLADAY, WAITLK W. (b'56)\&-D; (I'B3).

OAKLAND, 35I, YALOBUSHA

'ROFFOLII, 'IIUS. JEEFERSON, JR. (b'84) - Tenu.8, 06 ; $\left(1^{\prime} 06\right)^{\circ}$

JONAIISON, JOH, S.-Tenn.8,01; (1'01). fordon, T. Il.-Nla.2, 75 ; (1’95).

'I'ENENT, CHAS. II. II.' (b'7T)-Tex.7,04; (l'08).

OAK RIDGE, 25, WARREN

Austin, James S.-KY.1,78; (l’78)

OAK VALE, 298, LAWRENCE

LANGSTON, IEWIT' TAMMAGE (b'85) Jà.1,10; ( $\left.1^{\prime} 07\right)$.

l'olk, l'hllip IR. (b't9)-Tenn.9,01; (l'01).

STIRYGER, JESSE J. (b'71)-Tenn.9,00 (L'05).

OCEAN SPRINGS, I,472, JACKSON

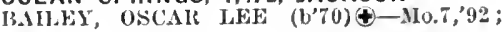

'OWELL, JENIRY B. (b'65)๑-Ont.4,'92; (l'05).

OFAHOMA, I06, LEAKE

I3armette, James M. (b'76) - Temn.8,03; (l'06).

OKOLONA, 2,584, CHICKASAW

Beaty, Thos. H.-Gia.10,'82 ; (1'82).

Collongh, Wm. Atlas (col.) (b'71)-Tenn. $\pi$, 02 ; (柊).

DONALISON, JAMES A. (b'7)-Tenn.8, $98 ;(1,98)$

Dottery, Wm. L. (b'42)-0; (l'02); R.F.D.

Iriller, Win. Howard-N.Y.10,73; (1'82).

MORGAN, DE WITT F. (b'68) 4 -La.1,'99; (1'99).

Sadler, Robt. M.-Ky.4,75; (l'82).

WICKS, ARMOND F, (b'81)-Tenn.15,'11; (I'05).

OLD SALEM (R.F.D., VAIDEN), 35, CAR ROLL

Wallace, Victor Vinnette-Tenn.8,08; (1'08). OLIO, 100, AMITE

linabrew, Wn. B. (b'26)-Ky.2,49; (1'82)

OLIVE BRANCH, 22I, DE SOTO

MAPLES, C. L. (b'66)థ-Md.3,'88; (l'88).

HCXEILL, J. HARVEY (b'83)-Tehn. 8, 05 ; $\left.(1)^{\prime} 05\right) ; S$.

STUAli, H. A. (b'68)-Ky.4,'94; (l'95)

WILKINS, WII. 'T. (b'59)-Tenn.8,'82 ; (1'83).

OMA, 100, LAWRENCE

Hennington, Benj. D. (b'43) - La.2,66 (1'82).

ORA, 462, COVINGTON

DAVIS, WINSTON W. (b'71) - La.1,98, (l'9s)

OSYKA, 824, PIKE

Barron, Oliver B. (b'82)-Tenn.8,'10; (1'10)

Bates, C. H.-Ky.1,71; (l'82).

Bates, Wm. Harbert (b'77)-La.1,01; (I'01)

Jesnith, Geo. C.-Ky.4,'85; (1'86).

liallace, J. C.-La. I,'99; (l'02).

OVETT, 383 , JONES

Foshee, Alex Mckowan (b'90)-Ala.2,'11 (l'10)

Melvin, John Leomard.-Tenn.1,01; (1'04).

OXFORD, 2,014, LAFAYETTE

Andrews, Clarence Ladelle (b'81)-Md.7,'l2, Prof. Anat., Miss.1.

BRAMLETT, AIIBROSE C. (b'51) - Ky.5 '87; (1'82).

BRAMLETT, EUGENE SHERMAN (b'80) -Ky.9, $05 ;\left(1^{\prime} 04\right) ; \mathrm{S}$.

Chandler, J. T.-Pa.1,'61; (l甬) ; not ln prac-

tlce.
CULLEY, JOHN CLIFTON (b'86)-Tenn.5, 09; (1,08); S.

HUNT, ARTHUR G.\&-Tenn. 8,04; (1'08).

LEATHERS, WALLER SMITH.

(See University.) 


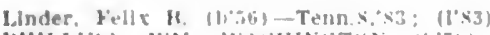

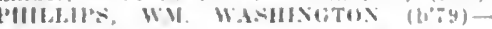
N. $1.06:\left(1^{1} 06\right)$

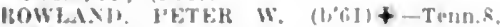

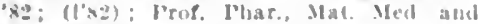
Hyg., Mlixwi

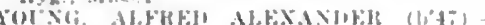

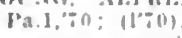

PACE, 50, BOLIVAR

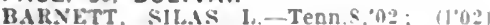

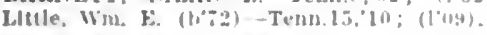

PACHUTA, 187, CLARKE

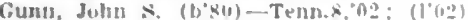

PADEN, 186, TISHOMINGO

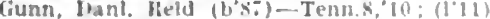

PANTHER BURN, 25. SHARKEY

SIIACKLFFOHI. WM. I., JH. (b'Bi)

KY, : $n s ;\left(l^{\prime} 0 s\right)$.

PARCHMAN, 23, SUNFLOWER

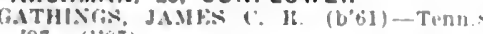
'8:-: (1+3i).

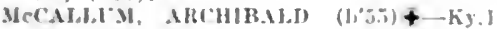
$79 ;(132)$

PARIS, 137, LAFAYETTE

XEWELL. SAML. WWAK (bSE) - Tenn. 09: (1'0S).

PASCAGOULA, 3.379, JACKSON

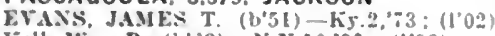

Kell, Wm. R. (6'63)-N.Y.10,90: (1'90)

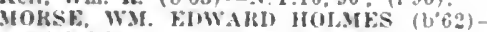
Slich.l:sj: (); Member la. Siate Med

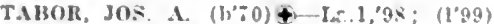

PASS CHRISTIAN. 2,458. HMRRISON

l'Inault. $X$. Jose (b't6)-Que.3,'it; (1)

kalnold, M. W:- -Tenn.11,96: (1.0\%)

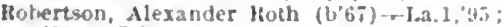
(I'95): Pd.

STEOXG, HOHT AILXANBEH (b'SA) + La.1,0 : (l'us): Memler la. State Med. Soc.; rTulane tulversity, Sew orleans, 1.at.): Pd.

PATTISON, 15I, CLAIBORNE

BARKON, ELMUNI) 1). (1,'tis)-Ky.t,'ss: (l'89).

PAYNES, 225, TALLAHATCHIE

IHENMAN, THOS. J.-Tenn.s.94; (1'94).

PEA RIDGE (R.F.D., DE KALB), 25, KEM PER

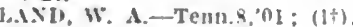

PEARL, 50, SIMPSON

Alusworth, John IB. (18:84) - Mlis.8.'1" (1'10).

PELAHATCHEE, 943, RANKIN

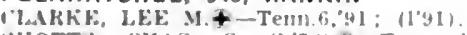

sliotTs, CHAS. C (b's) - -Tenn.s, 12 (1'0\%).

PERCY, 200, WASHINGTON

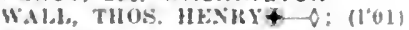

PERKINSTON, 350, HARRISON

llarrlson, James MeConnell (b'uti)-lia.5. "80: (1'02).

PHEBA, 282, CLAY

HUISPFTH, HENEST JACKSON (U82)--

Tenn. 1, 06 : $\left(1{ }^{\circ} D 0\right)$.

PHILADELPHIA, 1,209, NESHOBA

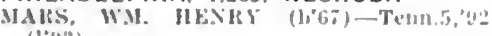
$(1+y 2)$.

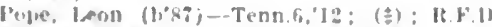

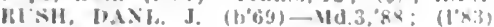
Strituling. Wim. J.-Tenn.8.00: $\left.(1)^{\prime} 93\right)$

Terry, Mllion W. $\left(10^{2} 3\right)-5:\left(10^{3}\right)$.

Wwekins, W. L. (1, 09$)$ - Tenn 8,02 ; (1'03)

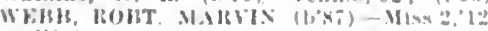
(1'12).

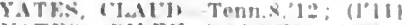

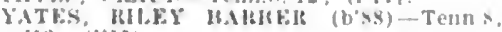
"li:: (1.11).

PHILIPP, 200, TALLAHATCHIE

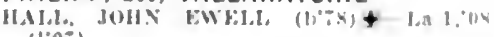
$(1,0 i)$.

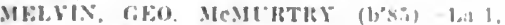
"ll: (1'I0).

PICAYUNE, BH6, PEARL RIVER

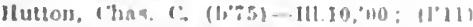

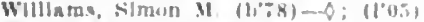

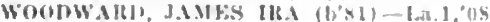
$\left(10^{\circ} 06\right)$.
PICKENS, 619, HOLMES

Anlersm, This. M -Tenn.1,'03; (104) II.P'I1.

Barnette, It J. (bot) Tenn.s.tur; (1003) restrots

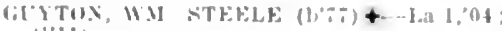
$11 \cdot 11$

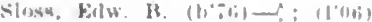

PINCKNEYVILLE, 23, WILKINSON

Brandun, J. W- La.1.!n; (1'11).

PINEBUR, 25, MARION

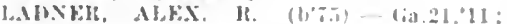
(1"II).

PINE RIDGE (SYKES P.0.), 100, CLARKE

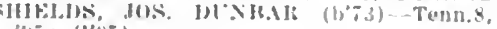

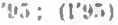

PINE VALLEY, 325, YALOBUSHA

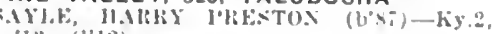
'I:-: (1'12)

PINEVILLE, I0, SMITH

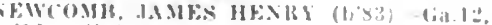
12: (1'1:)

PINOLA, 2\$1, SIMPSON

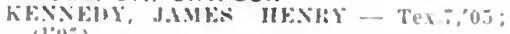
Gitik ARTHLR FRANK (1)"Z1) - Tenu 01) 4 : (1'0.5).

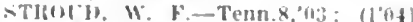

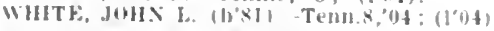

PITTSBORO. 249, CALHOUN

I'ATTKROX, IHAS. WALTEK (b'G3-

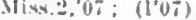

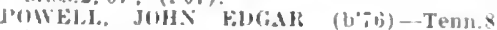
I1: (l'(1):4)

PLANTERSVILLE, 163, LEE

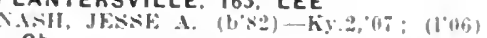
$0 \mathrm{~b}$

Stone, (ialusha rlyde-Tenns.'12: (106).

PLATTSBURG, 75, WINSTON

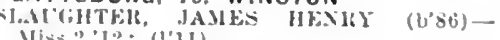
Niss.2,12: (1'11)

Watkins, Homer B. (b'a2)-b; (1'0t).

PLEASANTGROVE, 100, PANOLA

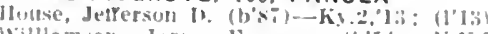
Villamson, James reeman $(1,56)-x .25$ 'ix: $(1 \times 1)$,

FLEASANT HILL, 182, DE SOTO

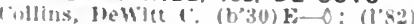

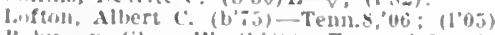

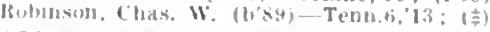

POCAHONTAS, 250. HINDS

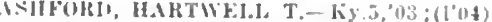

POLKVILLE, 175, SMITH

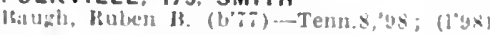

PONTOTOC, 1.277 , PONTOTOC

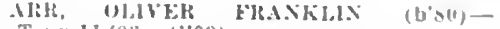

Te'Hก.11,03; (1'03).

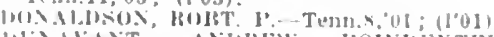

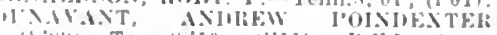

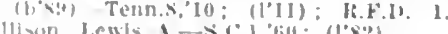

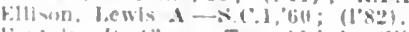

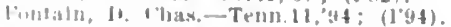

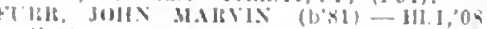
$\left(10()^{2}\right)$

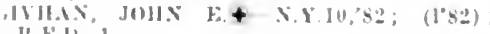
II $F$. 1 .

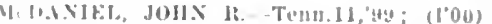
illin.

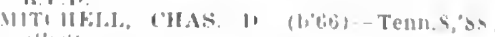
(l's:

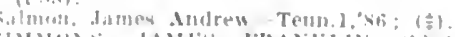

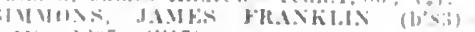

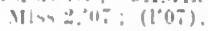

POPE. Ifi3, PANOLA

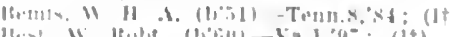

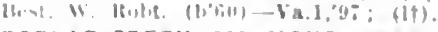

POPLAR CREEK. 225. MONTGOMERY

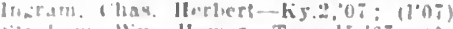

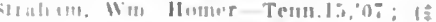

POPLARVILLE, 1.272 , PEARL RIVER

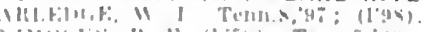

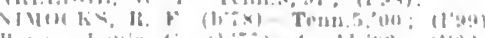

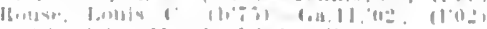

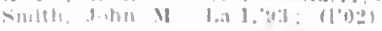

PORTERVILLE. 75, KEMPER

POTTS CAMP, 312, MARSHALL

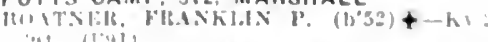

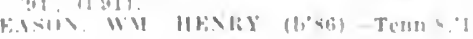

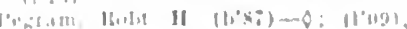

PRAIRIE, 160, MONROE

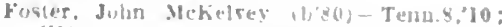
(I'T)!

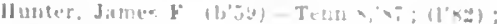

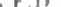

PRAIRIE POINT, 250. NOXUBEE

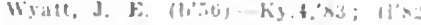

PRENTISS, 640, JEFFERSON DAVIS

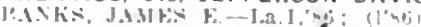

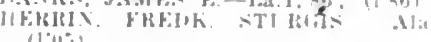

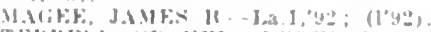

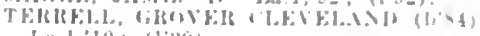

T.1.1.'10; 11"11!)

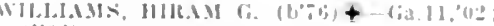
(1,0:)

PRICHARD, I00, TUNICA

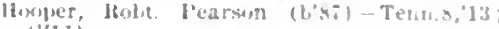
(l'il).

PT. GIBSON, 2.252, CLAIBORNE

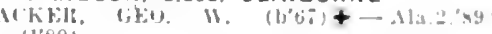
(1'8?).

Halley, Thos. T-Ia.1.292: (1'\$3),

M.1Y 1.1MK V-ky 1,$03 ;(1 \times 2)$

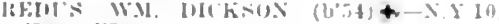

: $\left(\Gamma_{4}\right)$

PULASKI, 280, SCOTT

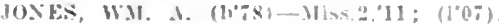

FURVIS, 724, LAMAR

'arawily, kidwin H. (b'bs) - Tenn.t. (1'03).

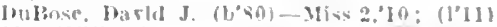

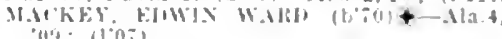

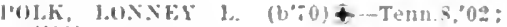
(l’01).

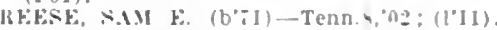

QUINCY. 275, MONROE

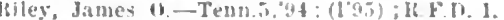

QUITMAN, 950, CLARKE

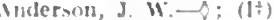

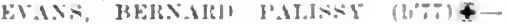

1.a.1,10: $(1,10)$.

liavin, 11, H- hy+.98; (1'02)

MARTIX, (illitios MICAJAIt (b\%)Misiz, os: $(1,10)$

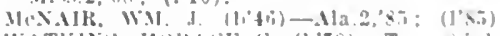

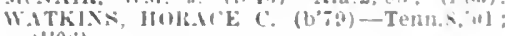
(1, $\left.00^{\circ}\right)$.

QUITO, 50, LEFLORE

IIII, Wobt. Nckachem-3; (l'0s).

RALEIGH, 200, SMITH

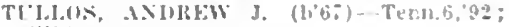
$(1+2)$

TILLOS $\therefore$. Fo $\rightarrow(1,05)$

RANDOLPH, I62, PONTOTOC

Vedireger, dduley Harrtson $(13 \% 5)$-Tenns. (1) : (1001).

$\rightarrow$ (1"

RARA AVIS, I00. ITAWAMBA

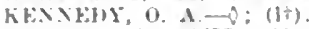

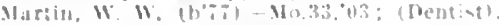

RATLIFF, 70, ITAWAMBA

clerelami, Hn. Henrs (b'ss) Tenm, ?.13: (1'13).

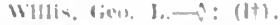

RAYMOND. 579, HINDS

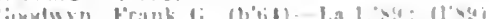

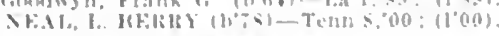
RED BANKS, 79, MARSHALL

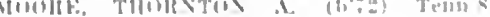

REDBONE (CEDARS P.O.). - WARREN

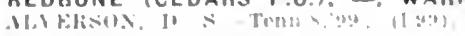

REDOING. 73. CALHOUN

"lepman, firgl| I - his.".:

RED LICK, 23. JEFFERSON

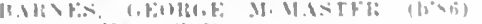

, ns: (liosi

REDMONVILLE (R.F.D., BENTONIA), 50 , $Y$ A 200

llwe? Thom 11 and (6)

REFORM, II, CHOCTAW

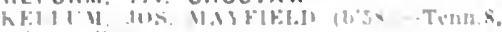

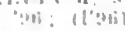

REIO. 17, CALHOUN

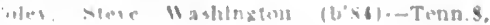


RENALARA, I00, COAHOMA

I.IHI)ELI, SA.HL. IIOI'STOX (b'89) $\rightarrow$; (1'11).

REUBEN, 25, SUNFLOWER

Wlgglns, Wm. Fidley (1,'K6)- T(1m,1!, 10 (1'10).

REYNOLDS (R.F.D., WATER VALLEY)。 25. PANOLA

liavls, Ned $(1,45)-0$; (t).

Knox, Nlilulas (aluin-Tenn.1, :4; (1'82).

RICH, 50, COAHOMA

('AMMACK, ABSEIR SAM - Tenn.S, 99 ; (I, 39$)$

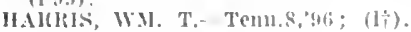

RICHTON, 1,250, PERRY

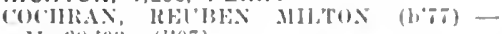
II0.25,03; (I.03)

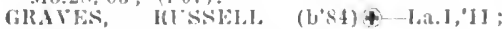
(l'lo)

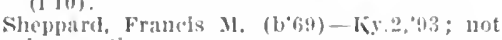
In practice.

Shurley, liugene Rerlnall (b's)-Mlss:1:2; (1, I:3)

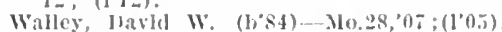
WALIFY, WILLLS (b'TS) + - (ial.11, 02 ; (I'0I): OALR.

RIDGELAND. I58, MADISON

('olpl, lsabel le. (1,

Shaw, Alberf Morion (b'65)-0.1,90; (l'13); not in practlee.

W'lllams, Wu, Orln (b'si) - - 4.1.1,12;(1'11)

RIENZI, 434, ALCORN

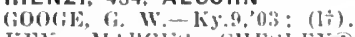

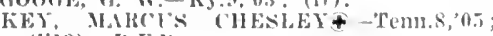
(l'i;): R.F.li,

Perry, Thos. J. (b'5fi)-Tenn. 5, 'so; (l's2).

Wllson, 'Illos. (b'si)-Tenn.s,'lis; (ま).

RIO, 50, KEMPER

Wood, James O. (b'4i)-Ala.2,'S2; (1's2).

RIPLEY, 767, TIPPAH

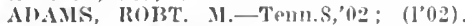

MUIRY, (HAS. M. (1'68)-1'a.2,90;(1'90)

Ilurry, Jolm Y.- Pa.2, 55 ; $(1,5.5)$; not in pracllee.

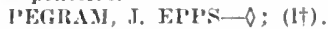

ROBINSONVILLE, 300, TUNICA

IONALDSON, HENHY ('LAY (b'SI)૯Tenn.s,os; (1"07).

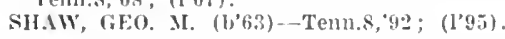
RODNEY, 338, JEFFERSON

Gray, Albert Sidney (b'i3)-Tenn.s,01; (1'02).

ROLLING FORK, 800, SHARIKEY

B.ARRIER, AIBERT K. (b'60)-Ky.1, 85 ; (l'82).

Chaney, wm. I. (b'28)-X.Y.5.55; (I'82).

ORFNDORF, RELI, TAYLOL (b'84)\& Ky. I, OT: (l'06).

Perry, Ioe Reid (b'79)-Ian.1,04; (l'03).

ROME, 148, SUNFLOWER

BIGGS, WALTEK M. (b'81) \&-Temn.15, 08 ; (I'07)

Harris, Win. O. (b'45)-Ky.2,'74; (174),

ROSEDALE, I, 103, BOLIVAR

AT'S'TIN, IEONHI.AS BIRDSONG (b'83)l.a.1,08; (1'06).

Nobles, Eugene R. (b'88)-Tenn.15,11; ('11).

PATTERSON, CIIAS. WHEELESA $\left(b^{\prime} 84\right) t$ -la.1, 08 ; (1'0-).

ROSE HILL, 300, JASPER

IICcune, A. M. (b'70)-Tenn.8,'99; (I'99) ROXIE, 294, FRANIKLIN

Marsalis, Tin II.-Ky.4.'Z2; (I) .

Wood, Joln H. (b'70)-Tenn.8, 04; (l'02).

RULEVILLE, 451, SUNFLOWER

CLARK, J.MIES A. (b'76)-Tenn.8, 03 ; $\left(l^{\prime} 02\right)$.

Elgin. Wm. Roy (b's?)-KY.5,04; (l'09).

IICNEAl, AR(IIBAll) W. (b'74) Tenn.8.'12; (1'118).

PITTMAX, CIIFFOLD JAMES (b'ss) Tenn.8.' I1; (l'09).

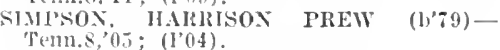

RURAL HILL, 250, WINSTON

Blanton, Wn. T.-Tenn.6,91; (1'91).

RUSIK (R.F.D., PLANTERSVILLE), I3, LEE Ilurris, T. C. $\rightarrow$.
RUSSELL, 75, LAUDERDALE

Wills, l'ressley N. (1)'64)-Tenn.6,90;

RUSSUM, 120, CLAIBORNE

IIoll, NIfreal-ky.2,'si); (I†).

RUTH, 25. LINCOLN

Jowmin, Wim. Leroy (1, 49$)-0 ;(1)$

Brewer, (oslas (c. (b's $\theta)$-lak.1, 10; (1'10).

SABOUGLA, 150, CALHOUN

Slici, S.MIL. ('0OKl: (b'85) \&-Tenn.8, 'I0; (108).

SALEM (R.F.D., HUDSONVILLE), 50 , BENTON

Hlelierson, Florence L.-Mlo.13,"82; (1'82).

SALLIS, 247, ATTALA

I.0N(i, JOIIN WI. (b'85)-Ky.l,08; (1'07).

smlih, salls F....Tenn.8, 02 ; (1'02).

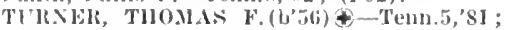
$(1 * 8,2)$.

SALTILLO, 306, LEE

Areller, reter $\mathrm{F},-0$

GHECORY, ARCHIE JEE (b'89)-Tenn.6, 'I2; (1'I2) : R.F.D. 1 .

II()LIAXI), W. 13.-Tenn.8,93; (去)

I'Y1.E. ('. ('...'Tenn.8,00; (I'00).

SANDERSVILLE, 604, JONES

Carter, Ciec. T. (h'72) - Miss.2,07; (1'07).

Mellwaln, $\therefore$. T. (b'ss)—Miss.2,'lo; (I'l0).

SANDY HOOK, IIJ, MARION

Wells, ('lus. Cllfton (b'80)-Temu.8, '08; (l'08).

SANFORD, 300, COVINGTON

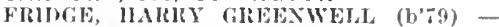
Ja.1,04; (l'04).

SARAH, 100, TATE

GARHETT, LUTHER PINKNEY (b'76)-

McCALLEI, JosIIIA J. (b'80)-0; (l'09).

SARDIS, 1,406, PANOLA

ANI) EllsON, JA('0B HOON (b'69)-Tenn.8, "9s; (1'98).

Echles, Julia C. Barrow-Pa.,${ }^{\prime} 0 \bar{\tau}$; (\$),

Henderson, (. M.-Ky.2,83; (1 lै ).

Storall, Jos. l'endleton (b'57)-Tenn.8,'\$3 ; $(1 \div)$.

WALTON, IOHX H. (b'53)-Ky.2,'82; (1'99).

WHIGH'T, EDWIN (1,62)-La.1,86; (1'86).

SAREPTA, I62, CALHOUN

Burke, Juther 13. (b'85) 0 ; (I'II); IR.F.U.

Jolnson, ('. A.-Tem.8, 94; (1+).

l'owell, M. A.-Ma.1, 55 ; (1'82)

REH), WAleRFy IL.Ky,4,06; (I'06).

somter, J. B.-Tenn., $94 ;(1 \div)$.

SATARTIA, 187, YAZOO

BONNEY, CALEB WHDY $\left(b^{\prime}, 0\right)-K y, 2$, (9): $(1,92)$.

Crisler, Robt. B. (b'75)-Tenn.8,99; (1'99),

TELFY, V. MLLTON (b'67)-Ky.1, 92 ; (1'93).

SAUCIER, 25.5, HARRISON

Cowart, Newlt Walter (b'78)-Tenn.8,'08; HOPPER, HEXRY P. (b'73) - Ky.1,04; (I'0I).

SCHAMBERVILLE, - , LAUDERDALE

Mehonald, S.-Mliss.2,'09; (ま)

SCHLATER, 250, LEFLORE

Birdsong, Kobt. Edw. (b'75) $\longrightarrow$; ( (l'01)

Holland, Martin Luther (b'85)-Tenn.8, 11 ; (1'11).

Whson, Walter Javis (b'67)-Tenn.6,'93; (1'93).

SCOBEY, 165, YALOBUSHA

Jinkins, Wm. F. (b't6)-Ky.4,'87; (1'87); NP.

\section{SCOOBA, 322, KEMPER}

Gilbert, Edward J. (b'75) - Tenn.8,92; (l'01).

Mlooney, J. B.-Ky.4,90; (I'90)

Rencher, Ilenry Warren (b'66)-Tenn.8, 00 ; (I'00)

SEBASTOPOL, 43, SCOTT

IOIJNSON, WM. F. $\rightarrow ;\left(l^{\prime} 0 \pi\right)$

Lnderwood, 'Thos. L. (b'60)-Tenn.8,'89; (1*89).

SELDEN (POCAHONTAS, TENN., P.O.), 14, TIPPAH

IcIntyre, John W:-0.1,'万1; (l'\$2).
SEMINARY, 526, COVINGTON

('ICANF()It), GFO, T. (1'T6)-Tenn.8, 98.

GAIRISON, IHARVEY FIRNKIIN-Tenn,8, 01: (l'01).

TEMI'LE, JAMES JALRIEIT (b'66)-Ky.4, '90; (1'90).

SENATOBIA, 1,275, TATE

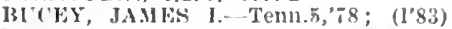

BYELS, IIOWAll, FALCONEL-Tenn.8, 06 ; (l'06).

Cooper, J. W. -0 ; (1\%).

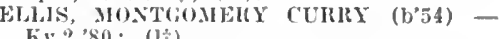

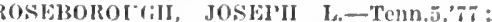
(l'82).

SMITH, Wy. WOLGLAS $($ b' 3$) \notin-T e n n .5$, 94; (1'04).

WILLIMIS, R. I).-Tenn.8,'98; (l'98).

SHANNON, 564, LEE

COWIIEN, IARVIN A. (b'79)-Tenn.8,04; (1'04).

Dabbs, Kome Grafton (b'76)-Tenn.8,'01; (1'0l).

SPFACER, SHFLI3Y C. $\left(\mathrm{b}^{\prime} S 6\right) €-A l \mathrm{a} .2,09$; (I'08); S.

SHARPSBURG, 30, MADISON

Turnipseed, Dellitt Talnage (b'86) Tenn. 19,'11; (I'12).

\section{SHAW, 871, BOLIVAR}

AILEX, TIIOMAS D. $\left(b^{\prime} 74\right)-0 ;\left(l^{\prime} 03\right)$

ASHIEX, W. F. (b'66)-La.1,01; (15).

I3erry, Thompson Nitchel (b'i 9 )-La.1,0s; (1"0i).

Ilihhouse, Wm. Lyle (b'56)-Tenn.8,94: (1'94).

Lowry, Roht. Clarence (b'80)- $\triangle$; $\cdot\left(\mathrm{l}^{\prime} 07\right)$.

Seruggs, Marlon Kirkland (b'58)-S.C.1, '81; (1'81).

SHELBY, 645, BOLIVAR

MAYELS, TIIOMAS J. (b'39)-M0.2,59; (1'82).

MERCER, RORERT L. (b'68)£-Ky.5, 04 ;

MIRNAN, JAMES R. (b'6ี)-Tenn.1,'89; (1\%).

Robinson, Sylvanous Wheeler-Tenn.8,01; (1'01).

SIIELRY, FLED. P. $\left(b^{\prime}, 6\right)-$ La.1,00; (l'00).

SHELLMOUND, 75, LEFLORE

11ANILTON, EMBREE GALLAND-Va.4, 04: (1'06).

SHERARD, I25, COAHOMA

LOCKIHAR'T, JAMES ROB'T. (b'-2)-Tenn.1, '99; (1'98).

SHERMAN, 353, PONTOTOC

GHLLESIIE, JOHN WOODSON (b';4)Tenn.8,03; (l'03).

PHILIIIS, WALTER B. $\left(b^{\prime} 54\right)-11 a .2,7 ;$ : (I'82).

SHILOH, I00, ISSAQUENA

HEATH, TIIOS. ADOLI'II (b'54)-Ky.5,'81 ; (1'82).

SHUBUTA, I,I68, CLARKE

IAN1), AlBERT P(JWE $\left(\mathrm{b}^{*} 86\right) \Phi-\mathrm{La} .1,09$; (l'0s).

HAND, ROBT. M. (b'52)-Ky.4, 74 ; (l'82).

MCIEVITT, JAMES A. (b'-4) 4-Nla.2,06; (I'05).

Reynolds, Juhlus M. (b॰92)-Ga.12,19; (1'13); R.F.D. 1.

SHUFORD, I5, PANOLA

Elliott, Iliram R. (b'74)-Tenn.8, 00 ; $\left(l^{\prime} 00\right)$.

SHUQUALAK, 636, NOXUBEE

Jones, Bolivar Thomas (b't2)-Ala.2,' 86 ; N.Y.10,'89; (l'90).

Kellis, John $3 .-\mathrm{Ky} .5,82$; (声).

Kirk, Cola D. Rienzi (b'41)-Ala.1,61; (1'82).

Perry, Jos. Angustus (b'62) - Ky.4,'86; (l'02).

SIDON, 39I, LEFLORE

ARMISTEAD, J. W. (l, 78$) £-T e n n .8,02$;

BARR, FRANK ELLIS (b'85)-Va.1,08; (l'09).

Sanders, W. S.-Ǩy.4,'94; (\$) 
SILVER CITY. 34I, YAZOO

HOI.MKS, CIIAILLS H. (6.6.3)-K.4.'\$5 (I'8.5).

SILVER CREEK, 54\%, LAWRENCE

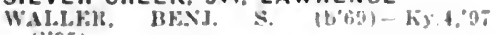

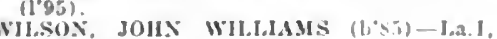
09; (

SIMMONSVILLE (R.F.O., MAGNOLIA), 75 , PIKE

Applewhile, liufus kildrlge (bosi) . Temn. 13 ; (1'13).

SITKA (R.F.D., SEMINARY), I5, COVINC. TON

Jenton, Zachariah Welch (bisl).... : (lilli)

SIWEL (R.F.O., JACKSON), 75, HINDS

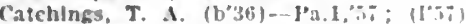

SLATE SPRING, 175, CALHOUN

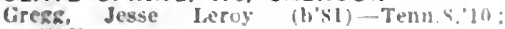
(1'0s).

SHAW, BRYANT J. (13"79)-Tenns, nt (]'Bes)

Smlth, (: E.-Ky. : 4 : (l'01)

SLAYDEN (R.F.D., HUDSONVILLE), 100, MARSHALL

I'ower, Jos. V. (b'-2)-Mo.7,09: (†).

SLEDGE, 73, QUITMAN

Slone, Fred 6 , $\left(b^{\circ}: 0\right)-T e n n .90^{\circ} 0$; : $\left(l^{\prime} 00^{\circ}\right)$.

SMITHDALE, 3I, AMITE

Huller, Class. Ilerbert $\left(b^{\circ}, 6\right)-0$ : $\left(1^{\prime} 11\right)$

Hewlti, James lirnest (b's?)

SMITHS MILLS (LE FLORE P.0.) 15. CARROLL

Mattox, C. C. - Tenn.8."03: (:\%)

SMITHVILLE, 179, MONROE

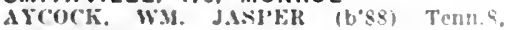
"I2: (1'11).

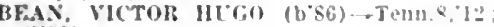

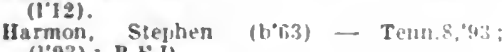
(1.93): R.t.1).

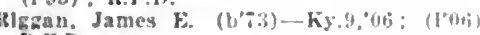
I.F. D

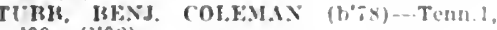
".

SONTAG, 100, LAWRENCE

Wood, Karanaugh Pagne-Tenn.8.09:11'0\%).

SOSO, 162, JONES

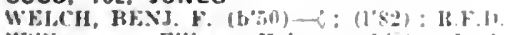
Willamson, Ellison Holmes (b's())-Lat. 09: (1.08).

SOUTH PASCAGOULA, 708. JACKSON

('OX, WM. A. $\left(b^{\prime}, 55\right)-6:(1 \%)$

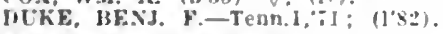

SPLUNGE, 75, MONROE

Boozer, Elljah lbavid (b's3) - Tenn.15."lu. (1'10).

Boozer, $\mathrm{Wm}$. Berley $\left(\mathrm{b}^{\circ} \mathrm{t}\right)$-Tes.i.6: $\left.\left(I_{0} 0\right)^{2}\right)$

SPRINGHILL (R.F.D., MICHIGAN CITY),

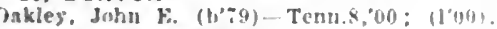

STALLO, 225, NESHOBA

lDarls, R. T. (b',

STANDARO, 50, HANCOCK

lioss, forest \%.-1A.1, (05; (1'0.)

STARKVILLE。 2,698, OKTIBBEHA

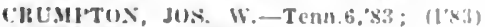

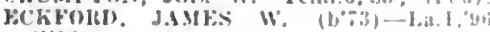
$(1966)$.

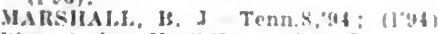

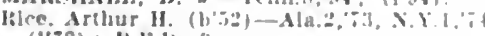

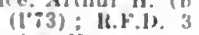

Scales, Hunter Jeelbetter (b'8.5) - Tenn ., "1): (1'06).

Scales, Saml. Welb $\left(b^{\circ} 80\right)-T e n n .5,0 \%$; (1'0).

silles, Wm. C. (b'52)-Ky.d.'8:; (1'53)

STATE LINE, 363, WAYNE

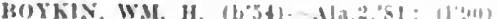

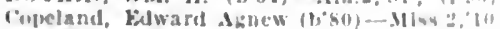
(1'10).

STEENS, 25, LOWNDES

Fennlngtur, Alexander ('ubb (b'sn) - Trus? or: $(100)$

Seay, J, T, O : (s).

STEWART, 188, MONTGOMERY

HAIIRIS, J, B, (b'G0)-Tent, Gs, : (1)

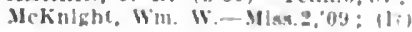

STOKES, 50, MADISON

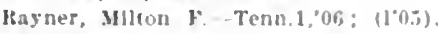

STONEWALL, 1,000 , CLARKE

H.IRI'KIL, IDAN LC'THKIl (b'81)-Ala.2,06 (l"06).

STOVALL, 25, COAHOMA

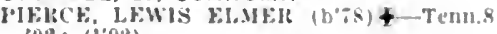
0.: (1,0s)

STRATTON, 25, NEWTON

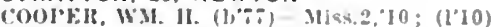

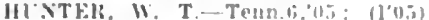

STRAYHORN, 137, TATE

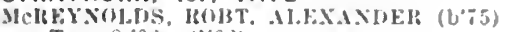
-Terin.8.06: $\left(1^{\prime} 06\right)$.

STREET, 50, AMITE

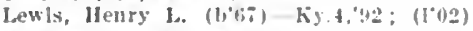

STRINGER, 267, JASPER

STRINIFIR, JUS, WM. (U'80) - MLs.2.'09 (1"03).

STURGIS, 321, OKTIBBEHA

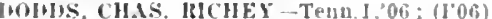

riday, Walter Clarence (b०91)-Tenn.s,'13; (1"II)

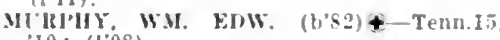
10: (1'08).

SUMMERLAND, 100, SMITH

CARR, JOS. T. (b'it)-Ky.9,'04; (1'0(i).

SUMMIT, 1,\$71, PIKE

आGYT, JOHA TIILMAN LAMKIN (b'82) + -La.1,09; (l'07).

CHISHOI, ROB T. R.-Ia.1, 03 ; (1'03).

('urtls, Jacob M. (b'+9)-Ky.2, so; (I'*0).

sample, J. 1t.-La.2,'(6t); (1\%).

SUMNER, 364, TALLAHATCHIE

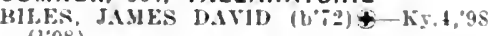
$\left(l^{\circ} 98\right)$.

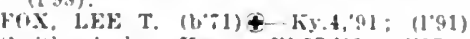

smith, Arthur Jenry-lll.1\%,09; $(106)$.

SUMRALL. 2,046, LAMAR

A.IUERSON, JOS. $\mathrm{k}$. (b"\%6)-Tenn.8, $0=$ (I'02).

BIOWS, ANDREW J. (b\%5)†-111.22,09

Isalah (b's) $\rightarrow:(1 " 02): U$

Ilikt, Jos. M. (b"i) + -Tenn.J,06: (l'03).

Tlsolale, Wm. A. (6.65)-La,1,90; (14).

SUNFLOWER, 200, SUNFLOWER

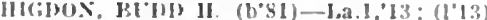

s'aton, Danl. FH (b's6)-Ja.J.09: (1'09)

sliti, WM. IMIJH (b'to)-Tenn.s.10 (l’09).

SUNNY SIDE, 50, LEFLORE

luke, Wm. Mddleton (b'80)-Tenns, 01 : (1 101$)$

Ilardlng. W. 1.-La.1:sto; (I's6)

SWAN LAKE, 20, TALLAHATCHIE

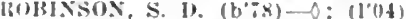

SWEATMAN, 150, MONTGOMERY

II K.MI'IIILI, C. B.-KY.t.SA: (1)

SWIFTOWN, 300, LEFLORE

llall. Marrin Montomery (b's2)-Tenn.s, "(1): II'0)!)

SYLVARENA, 200, SMITH

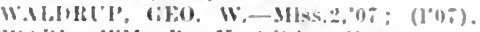

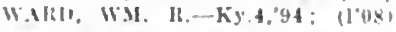

TAYLOR, 147, LAFAYETTE

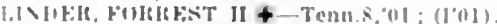

MATHS, WM, WASHISCTON (b'.53)

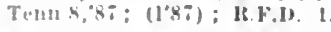

TAYLORSVILLE, 623, SMITH

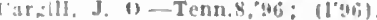

Huft, Juhn IR. $\left(10^{\circ} 65\right)-0$ : $(1 \circ 9)$.

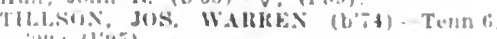
(2): 11.551

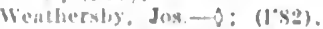

TCHULA, \$78, HOLMES

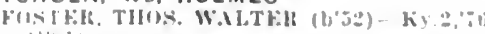
(1) 41$)$

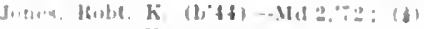

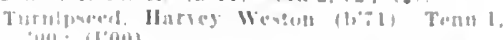

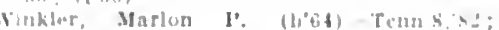
EOC (R.F.O., CARROLLTON), 10, CAR. HOLL

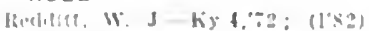

TERRY, 350, HINDS

Henlmbon, frank W. (1)

(I'04).

TERZA (R.F.D., SARDIS), I00, PANOLA

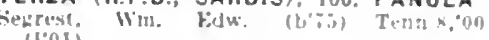

THAXTON, 1+3, PONTOTOC

White. fied, 1:- 0 ; $11 " 40)$.

THEADVILLE, 27. CLARKE

Melkae, Benj. Jeferson $(6: 79)-$ Mis, $: 0$ : (1'10)

THOMASTOWN (R.F.D., BOLATUSHA), 54。 LEAKE

fiowan. Wm. Nex (b\%9) - Tenn.15,09. (l'ses)

THORNTON, 64, HOLMES

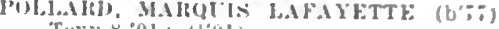

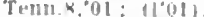

THOLNTON, (11.S, C. (b37) - La.2.60 $(196):$,$G .$

THYATIRA, 30, TATE

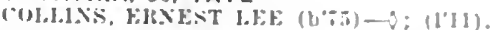

TIBBEE STATION, I50, CLAY

latiox. Fills Dearlih (1)'6y)-Tenn.s.13 (1'13).

TIE PLANT, 50, GRENADA

$155^{\circ}$ Walls Sterling (b'\$5)-Tenn.5,10

TILDEN (R.F.D., FULTON), 100, ITA lleed. M. I.-O; (1t)

TILLATOBA, I63, YALOBUSHA

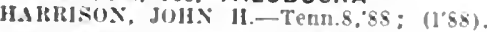

TISHOMINGO, 212, TISHOMINGO

WIIDHEL, NEWNUY TARE

Ky. I, $01 ;(1,0) 2$

WHEkLEK, IOSIAII $\therefore$ (b.6.) $-\mathrm{ky}, 5.98$ $\left(1 y^{\prime} y\right):$ li.F.D. :

TOCCOPOLA, 233, PONTOTOC

liathrlght. John M.-Tem.8.9s; (1'01).

White, Zenas X-Tenns."48; (I"6s).

Wlingo, Tlios. J. (b"56)-Tenn.j.so; (1"s0).

TOMNOLEN. 198, WEBSTER

IASUX, ALLF:S IBICHARD (b'80)-Tenn.9. oti; (1.06).

TOOMSUBA, 300, LAUDERDALE

Melourln, John R.-Ky.t.8.; (1:st)

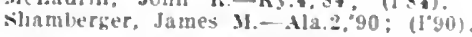

TORRANCE, 32, YALOBUSHA

SAlli, D. T. TOW:S (b'85)-Ky.2,0S: ['041).

TREMONT (R.F.D., RARA AVIS), ITA. WAMBA

Stone, Juhn Ilenry, Jr.-Tenn.5,99: (1*).

TRENTON, 200, SMITH

Jatton, Walter I._-(ia.5, 'S9: (1t).

TROY, 85, PONTOTOC

InISkE. ZURE'S A. (b69) - - (ia.5."95. (1) 011

WILLIAMS. THOS A (bot)-Tenn.G'st;

(1'S2) : K.F. II, 1 .

TULA, I5I, LAFAYETTE

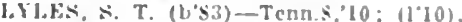

TUNICA, 555, TUNICA

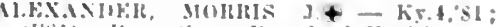
(I'sl): l're's. Sifate lioard of Health

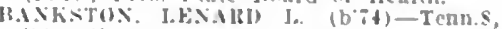
it: $11^{\prime} 01$

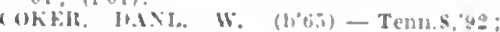
$(1+9: 2$

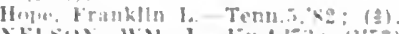

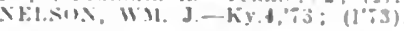

TUPEL $0,3,881$, LEE

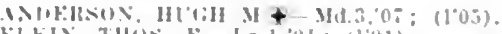

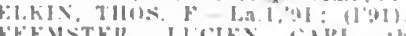

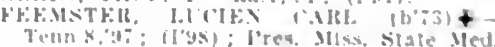
Tivn KAT: OOALR.

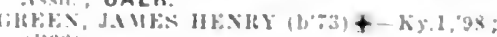
(1) (1):

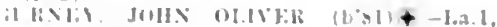
"pi: : 11 thil.

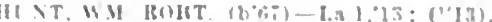

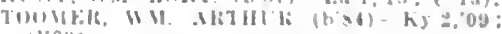

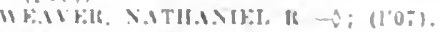

TURNBULL, 10 , WILKINSON

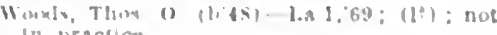
in piractice. 
TUTWILER, 4I0, TALLAHATCHIE BACKSTROM, JOHS GARSER (b'T1)Ky.4,98; (1'98).

ClAY, THOS. FIKANKIX (b'85) \&-Tem.5 $08 ;\left(P^{\circ} 07\right)$

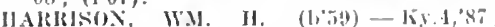
(I'ST); G.

TYLERTOWN, 795, PIKE

('ausey, Zack (1)'i!n) -dla.2,'05; (I'0i).

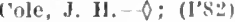

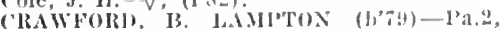
04 . (1'03)

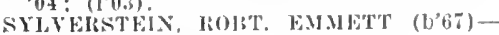
lal.1,98: (1985).

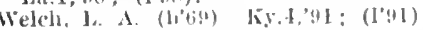

TYNES (NEW SITE P.O.), -, TISHO-

MINGO

Tylles, II. I. -0 ; (1\%).

TYRO, IIO, TATE

3owell, I. It. $\rightarrow$; (1'82)

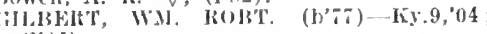
(1'i).

UNION, 693, NEWTON

Box. W'm. Edtgar (b's 6$)-0$; (I'11) ; R.P.D. I l3uckwalter, John cassel (b,73)-0.9,00 (ま) : $0 p$.

HACAX, Z. CARL (b'7a)-Mo.7,05: (1'05) Henderson, thas. Trissle-Tex.7,06; (l'07) LAIII). JOHN S. (b'82)-Ky.4, 04 ; (1'03) R.F.i)

Parlridge, ollver F-lir.2,92; ( $\left.H_{\dagger}^{\dagger}\right)$.

UNION CHURCH, 150, JEFFERSON

TOWXs, SHElkiton it. (b'-6)-Tenn.5, 04 (I'02); Ob.

WARUEX, DANL. C.-La.1,76; $\left(\mathrm{l}^{\prime} 76\right)$.

UNIVERSITY, - LAFAYETTE

Crlder, Jos. Otterbein (b'81) - Va.1,12 not in practice; Assoc. P'rof. Pliysiol. Miss. 1.

LEATHERS, WALLER $\therefore$ (b'\%2) \&-Va.1 '94; (1'0s); (Oxford); Dean and I'rof Biology and I'hysiol., Miss.1.

Lowe, E. N.-Ia.1,92; not in practlce.

UTICA, 572, HINDS

Burnett, E. Jake (b'55)-Ky, 1,76; (1'76)

Ellis, Geo. F. (b'56)-La.1,80; (I’80).

GIJ, AMERiCL' MACK (b'76)-La.1,09 $\left(I^{\prime} 0 \pi\right)$.

GREEN, CLIFTON L. $\left(b^{\prime} 76\right) \oplus$ Tenn. 8,99 (l'99)'

Ilaley, Herman M. $\left(b^{2} 57\right) \rightarrow 0$; $\left(1^{\prime} 82\right)$.

Ialey, Herman M. UACUS LAFAYETTE, JR. (b'80) -La.1,05; (1'03).

VAIDEN, 7I3, CARROLL

ALEXANDEI? C D-Tem 8,00; $(1,00)$

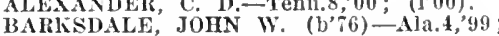
(I'99).

RIXGOLD, J. O.-Tenn.11,'97; (l'98).

Stephens, James J'. T.--La.1,'00; (l'(i)

VALLEY PARK, 25, ISSAQUENA

BENTON, JOIN FORD BURNET (b'69) La.1,0 0 ; (1'06).

VANCE, I80, TALLAHATCHIE

JFNNBERG, MALCOLM B. (b'8T)-Ky.2, '11; (1'12).

PRINCE, WiI. A. (b'80)-Tenn.8,'04; (l'04)

VANCLEAVE, 275 , JACKSON

Kennedy, John l'reston $\left(b^{\prime} 90\right) \rightarrow$; (1'11).

Yurply, Robt. N. (b'43) $-0 ;(1 \dagger)$.

RATLIFF, S. R.-La.1,01; (I'02)

VAN VLEET, 75, CHICKASAW

reden. Thos. White (b'73)-Tenn.8,01; (I'01)

Priest, James R.-Tenn.8,03; (l’03)

VARDAMAN, - CALHOUN

ARMSTRONG, GEO. G. $\left(b^{\prime}, 9\right) \oplus-T e n n .8,03$ (l'02).

Foung, Edmond Brooks (b'83)-Tenn.1,06 (1'05).

VAUGHAN, 125, YAZOO

IHENDERSON, CHRIS. R. (b'38)-Pa.2,'60 (1'60); R.F.D. 1 .

JoNES, GEO. CAMERON (b'76)-0; (l'09) $\mathrm{U}$.

STEEN, JOIN H. (b'81) - Tenn.1,0i; (1.07).

\section{VERONA, 558, LEE}

Lowry, Geo. W. (b'5i)-Ky.1,'80; (1'82).

SPENCER, CHAS. EDWIN (b'84)-Tenn.5,
VICKSBURG, 20.814, WARREN

1BEI.L, MA('l: II. (h'79) - Tenn.8,00; (1'03) : 3.ios Washington St. ; offre, First N (lomal bituk IBldr: i-1, 3-6; OALR.

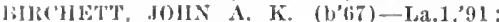
(P's) ; 1315 ('lay St. offlce, 12221 IIislington sit. : : : :30-10,12-1, 5-6.

JONEI,I, TINCLNT (b'79)\$-Que.1, 06 ; (I'0ti); 81.5 IBelmont St.; offle, 1401 Watohington si!. : Pd.

'itrr, lsaac I'rlce (h'87)-La.1,'13; (l'11): slate (hari(y Hospltal.

C'ook, Wdw. Iteese (b,56)-Mo.2,77; (1'77): National l'ark Addition; oflee, Helta 'Trust and IBanking ('o. Bldg.; untll 8, $10-12,1-3,5-7$.

('rock, (ieo. W. (L'67) H-l'a.9,'89; (1'89): 1214 (irove st. ; 10-12, $3: 30-5$.

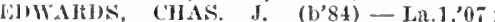
(l'0 $)$; 101 7 , 3d North St.; office, Trans fer Station; $9-12,2: 30-5 ;$ OALR.

EWING, JOHN SIIARI' (b'80)థ-La.1,04 (I'03); \$14 Crawford St.; office, FIrs Nallional Bank Bldg.; 9-10, 12-1, 5-6.

IIARALSOX, HIGII II. (b'54) - La.1, 83 (1'83) ; 1415 Baum St.; offee, 12221/2 Waslington St.

Ifardensteln, $\boldsymbol{\Lambda}$. Otto-H-Pa.9,'81; (I'89); 1813 ('herry st.; offlce, Wahut and Clay Clay Sts.

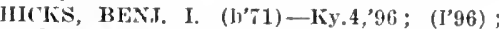
1625 Monroe St.; office, First National Bank FIdg.; 10-1.

HICKS, GEO. Y. (1,68)-Ky.4,93; (1'93); 2213 Cherry St.; office, South and WashIngton Sts. ; 10-12, 4-6.

HOWAR1, EWING FOX (b'74)€-La.1,97; (I'9T) ; Sec. Miss. State Med. Assn.; Confederate Are.; offlce, First National Bank Bldg.

Iames, Wm. Adam Dewitt, Jr. (b'88)-La.1 '13; (I'13); State Ifospital.

JOHNSTON, SYIONEY W. (b'78)-La.1,99 (1'99); 1320 Baum St.; office, Veto and Washington Sts.; 8-9, 12-1, 5-7.

Kemp, Enmett I). (b'82)-Tenn. 8, 11 ; (l'11)

KNOX, ISAAC CECII (b'87) 4 -Tenn.5,'11 (l'10); 2119 Cherry St.; offee, 12041/2 Washington St. ; $9-1,3-6 ; \mathrm{S}$. Lynn, John Harrison (b'si) - 111.11,'12 ;
(temporary permit,'12); Vicksburg Infirmary.

MARTIN, BWNSON BIAKE (b'76)†-La.1 '98; (1'98); 1918 Washington St.; office, Vicksburg Infirmary; $S$.

Miller, John Arthur (col.) (b'71)-Mich.1 '00; (1'00); 923, 1st North st. ; offee $11131 / 2$ Washington St. ; 9-11,3-5, $7-9$

MYLis, SYlWAN (b'73)-1'a.1,94; (1'97) 1335 Baum st.; office, Hardaway Bldg.; $1 \cdot-1,5-6$.

O'Jeary, John Perse-Ia.1,95; (1'94) ; 806 Crawford st.; office, First National Bank Bldg: ; 12-1, 3-5.

O'Leary, Richard - N.Y.5,61; (1'61) ; 806 Crawford St. ; offlee, First National Bank Bldg. ; 12-1, 3-5.

l'roctor, Georgia Ann (col.) (b'72)-Tenn.7, 02; (l'02) ; 700 Loeust St.

Proctor, Henry H. (col.)-Tenn. 7,02 ; (1'02) 700 Locust St.; office, 1105 Washington St. QUIN, ROBT. ARNOT $\left(\mathrm{b}^{\prime} 4 \overline{7}\right) \boldsymbol{\Psi}-\boldsymbol{N}$.Y.1, 70 (l'70); 1216 S. Cherry St.; office, Nirst Vational Bank Bldg. ; 8-12.

Smith, Clifford Talbot (b'90)-Tenn.5,'i3; (1'13); Yicksburg Sanitarium.

SPROLES, NENRY F., JR. (b'rs)-Ky.4, 04; (l'04) ; 814 Crawford St. ; offlee, First National Bank Bldg. ; 9-10, 12-1, $5-6$.

STREET, AIGLSTUS (b'91) - N.Y.I,'13; (I'13); Vieksburg Sanitarium; 9-10, 12-1,

STREET, DONALD P. (b'73) - -N.Y.19,'99 (1’99); Vicksburg Sanitarium; 9-10, 12-1, $6-7 ; \mathrm{s}$.

STREET, GEO. McQUEEN (b'8T)-N.Y.1 13; (l'13); Yicksburg Sanitarium; 9-10, $12-1,6-7$

Teat, Pinkney Alex. $\left(b^{\prime} 78\right)-\diamond ; \quad\left(l^{\prime} 06\right)$ 1100 Crawford St.; offlee, 12221/2 Washington St.

WILSON, HOLLIE B. (b'59)-N.Y.10,'88; (l'98); 1313 Monroe St.; offlee, Nationa Park Hotel.
VIMVILLE, 23, LAUDERDALE

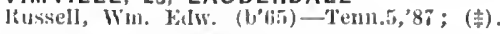
VOSBURG, 200, JASPER

Statlord, Thos. Edlward-Iat.1,01; (1t).

Walker, Dryden Litllar $\left(b^{\prime}, 6\right)-A l a .2,08$ : (I'08).

VOWELL, 75 , WINSTON

P'olve, Jolin biwarl (b'si) -Tenn.8,'13; ( )

WAHALAK, 107 , KEMPER

l'hlles, T. T. - Ali.2,'s6; (I'S6)

WALLERVILLE, 75, UN1ON

('ullens, l'. IN, (1'36)-('a, 1,57; (1'57).

CULLANS, fi, F。 (1'71)-Tem.8,'92; (1'92).

WALLS, 200, DE SOTO

Casey, Wm. Dermott (L'80) - Tenn.8, 08 : $(108)$.

1)IVIS, JULIIS A. (1)56) - Tenn.1,79; (1'82).

HIIOI)ES, WM. FlRANK-Tenn.8,07; (I'07).

WALNUT GROVE, 199, LEAKE

(Golden, lovett-Tenn.8,'l1; (I'11).

Goldin, Jolu F. $\left(b^{5} 50\right)-K y, 2,74 ;\left(I^{\prime}, 4\right)$

Kelly, Wn. A. (b'61)-La.1,'85; (1'34).

WALTHALL, 171 , WEBSTER

(iore, 16. Austin- - ; (l'90).

WANILLA, 225, LAWRENCE

HAR'T\%OG; (ARSIE MAICHOCS (b't6)La. $1,{ }^{\prime} 07 ;\left(1^{\prime} 06\right)$.

Johnston, Orauge Inderson (b'75)-Tenn.8, 00; (1'00).

WATERFORD, 128, MARSHALL

WILLER, JAMES FILDHED (b'82)-Tenn.8, 11 ; (1'11)

WATER VALLEY, 4,275, YALOBUSHA

MIMSTIROXY, JOS. CREATII $\left(b^{\prime} 73\right) \oplus-$ T'enn.5,'93; (l'93).

CAJR, IILTON RJCE (b'86)-Tenn.8,09; $\left(l^{\prime} 09\right)$.

COOPEi, SAML. FMERSOx\$-Tenn.1,97; (I†). SHELBY L. $\left(b^{\prime}, 6\right) \oplus-$ Tenn.8,01; (I'01)

ELLAKD, WM. F. (b'52)-Ky,4,82; (1'82) JACKSOX, II. WIXTER (b'64)-La.I, 00 ; (1'91); Pd.

Porter, Montie.-Ark.1,'06; (\$).

Shoffner, J. I1. (1'37)-Tenn.1,62; (l'62).

Sisler, Geo. W. $\left(b^{\prime} 70\right)-0$; $\left(l^{\prime} 04\right)$.

Whitson, John 31. (b'46)-Tenn.1, ‘3; (ł).

\section{WAYNESBORO, 652, WAYNE}

IRAY, WALTER P'ETWA Y-I,a.1,05; (1'03).

LOMAX, OLIVER A.-Ala.2,'98; (1'06).

Mason, Geo. David (b'88) - Tenn.19,'10 (l'09).

Mauldin, Roy Earl (b'87) - Miss.2,'12; (1'12).

Fitts, James R. S. (b'53)- 0 ; (1'78)

I'OF, JAMES FRANCIS, JK. (b' 78 )-La.1, ,05; ( (1'05).

Pou, James Francis, Sr. $\rightarrow$; (1'82).

RUSII, JAMES C.-Ky.2,92; (1\%).

WAYSIDE, 20, WASHINGTON

Russell, Franklin Iloward (b'S7)-Tenn.8, '12; (1'12).

WEATHERSBY, 175, SIMPSON

GANDY, TILLIS (b'85) $\longrightarrow$; (l'11).

MeCallum, Dodridge (b'32)-S.C.1,67; (1\%).

WEBB, 292, TALLAHATCHIE

HARISI, JOHN AARON (b'73)๑-Tenn.1,

'04: (l'03). ROBI. ROBN (b'88)-Tenn.5,'11; (l'13).

HIGHTOWER, GEO. D. (b'z̃) $\oplus$-Tenn.8, '03; (l'02).

WEIR, 220, CHOCTAW

HOLLOWAY, T. M.-Tenn.6,"94; (l'94).

lineh, Wm. C.-Ky.4,'83; (l'83).

Reed, Alvin Everett (b'- -9$)$ - Tenn.1,05; (l'04).

TerrelI, Geo. L. (b'32)-Pa.1,53; (1'82); R.F.D. 4.

WESSON, 2,024, COPIAH

Beavers, John II. (b'71)-La.1.95; (1'95). Beavers, John L. (h'39) - Ja.1,'68; (l'82). Dampeer, Jos. Hughston (b'86) -0 ; (1'09) LITTLE, W'M. L. (b'68)-La.1,'89; (1'82). Rea, Robt. Wiley (b'44)-Ta.1,'68; (1'82). ROWAN, IAMI

ROWAN, SAXIL. LAMB (b'79)-Tenn.5,04; (I’03).

Williamson, Plummer B. (b’ö5)-Tenn.1,01 (l'99) ; R.F.D. 3 


\section{WEST, 276. HOLMES}

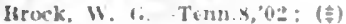

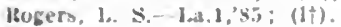

lRosamond, Juhn sitrlbling - Tenu.s,0 0 : (1'01).

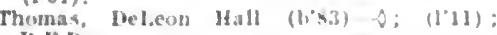
K. K.D.

WEST COLUMBIA (FOXWORTH P.O.) 50. MARION

Robertson. J. K. $\rightarrow$ : ( I'0N).

WEST POINT, 4.864, CLAY

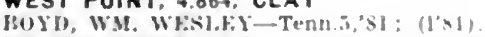

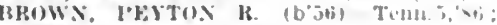
$\left(l^{\prime} \mathrm{S}^{2}\right)$.

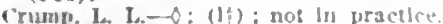

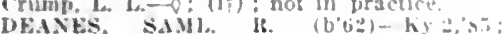
$\left(1^{\prime} 85\right)$.

Iross, Washlngton La.-Tenn.1,90: (1†): 11,4 In practlee.

DOTxON, LON W. (b's:) 40 ; $\left(l^{\circ}\left(b^{\prime}\right)\right.$ : OALR:

Holmes, James. W. (cul.) - Tenu. :4:; (It).

1VY, FRANK 1'HICE-Tenn.8,04: (1'03)

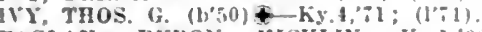

PASLAY, BYHON HICKLIS-K5.1,06; (1105).

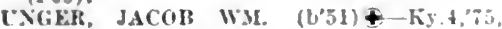

X.Y.10,82; (1'82).

WESTSIDE, 12, CLAIBORNE

Beck. James X.-la.1.'Js; (1†).

WHEELER, 181, PRENTISS

VANOIVER, JAMES COX (b's3)-Tenn.S, :08: (l'0s).
WIGGINS, 980, HARRISON

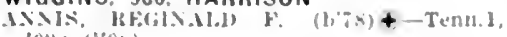
(0): (1.08)

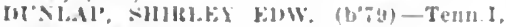
(40;) $\left(10^{\prime} 06\right)$.

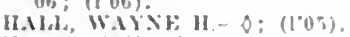

Hones, W. H.- 0 : (I01).

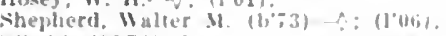

WILLIAMSBURG (R.F.D., COLLINS), 124 , COVINGTON

(IISNON. T. A. - -

WINONA, 2.512, MONTGOMERY

Apulewhice, Jue liavls $(1,91)$-Tenn, 5, 13; (l'13).

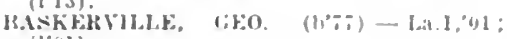
(l'01).

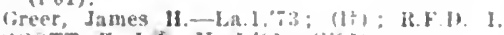
ivoTr, \%. J. + -Ky.1."91: (1'91).

SMaLAL, II. J.-Tenu.l,

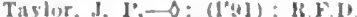

THOTTFL, TILLMAN HICHAHD-Tenn.l,

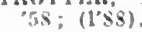

Ward, IBen). F-Ga.5\%?9; (J59)

WINTERVILLE, 100, WASHINGTON

Brashear, Horace C.-Tennt, $x 2$; (l'82).

Etherly, w. 16. - Ky, 2,91; (1'41)

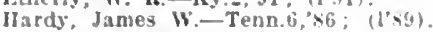

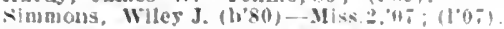

WOODLAND, 156. CHICKASAW

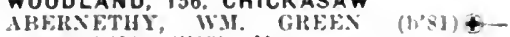

TEMn.S, 03; (1'05); U.

WOODVILLE, I,233, WILKINSON

(nsey, John 1', $\rightarrow$ : (l'83).

CATCHISG, (HAS. EVANS (b'69) -

Tenn.s.'94; (1'9t)

MARRLER, HEV W. (4'3)-Tenn.11,99; (1'00).
YALE (R.F.D., CLAY), 21, ITAWAMBA

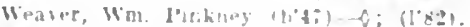

YAZOO CITY, 6.796, YAZOO

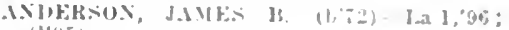
(I'i) .

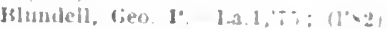

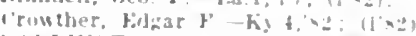

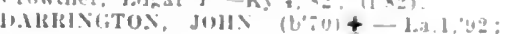
$(1+(1,2) ; \mathbf{S}$.

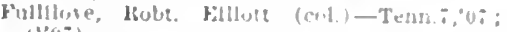
$\left(I^{\prime}\left(i^{2}\right)\right.$.

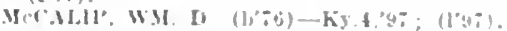

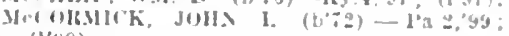
$\left(I^{\prime}, 3\right)$.

Miller, Losyes T. (col.)-Tenn.7,

Monre, J. I'atrlck, Jr.-N.Y.1,91; (1t)

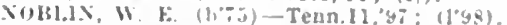

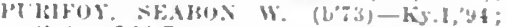
(l'yl): OALR.

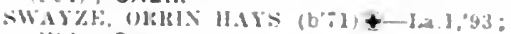
$(1,5+2) ; \mathrm{S}$.

Taylur, Juhn H. (1,56)-Ky 2; :S; (1\%).

YOKENA, 52, WARREN

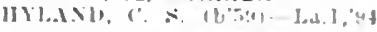

YOUNGS, 21, GRENADA

(MISA, h.ALHH J.-Tenn.1,04; (1.03).

ZEIGLERVILLE, 200, YAZ00

Smith, Warren Clifton-Tenn.s.06; (1'0i).

2ION (R.F.D., MADDEN), 200. LEAKE

Austin, K. 13. (b'st)-i; (1'N2).

ZION HILL. 77, AMITE

Butler, Hiram K. (b'si) - Jait 2,69; (全) ; It.r.II. :3.

FOR KEY TO SPECIALTIES, ABBREVIATIONS, SYMBOLS, ETC.. SEE PAGE 796

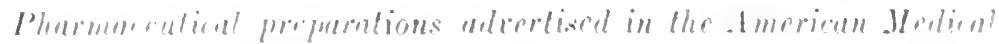

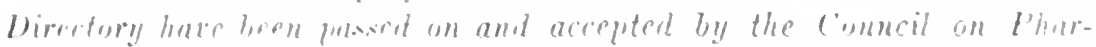

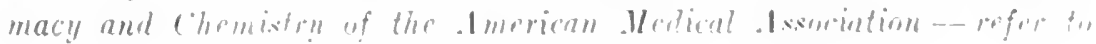

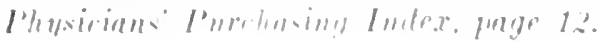




\section{ISSOUR I}

NotF. The general Information of this state Includes: Medlal Law, State Board uf Health, State Associatlon and Ionrnal, Oflleers

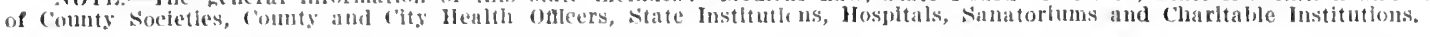

\section{MisSOUR!}

Population (1910 census) .......... $3,293,335$

Number of Counties.

115
6,224

Number of Physicians.

6,224

Members State Association, Dec. $3 i$,

1913

3,143

Area of State in Square Miles.... 60,420

\section{MEDICAL PRACTICE LAWS OF MISSOURI}

\section{('HAI'TER 53, R. S. 1909}

\section{ARTICLE I}

Section 665I. BOAIRD, HOW AI'POINTED : The governor, by and with the advlee and consent of the senate, shall appoint seven persons, who sliall constitute a hoard, whleh shall be styled The state Board of Health of thssotric The mer All vacancies occurring in the board shall he flited be flled hy the gorernor of the not in seswhen made. when the sion, will be subject of the senate. (R. S. next ensuing session

Sec. 6652. QUALIFICATIONS: At least five of said board shall be physteians in good standing, and of reeognized professional and sclentiftc knowledge, and graduates of reputable medical schools, and they shall have been residents of the state for at least five years next preceding thelr appointment: rrovided, that in the appointments made there slall be no discrimination made against the different systems of medicines that are reeognized as reputable by the laws of this state (It. S. 1899, Section 7519 .)

Sec. 6653. ITS PoWEItS ANI DETIES: The State Bonrd of Health shall have general supervision over the health and sanltary interests of the citizens of the state. It shall be their duty to recommend to the general assembly of the state such laws advanee the sanitary condition of the state. to recommend to the munieipal authorities of ally city, or to the county courts of any county, the adoption of any rules that they county, the adoption of any rules that they may deem wise or expedient for the prothe citizens thereof. (R. S. 1899 , Section $\div 520$.)

Sec. 6654. MAY QUARANTINE, WHEN : Whenever the state Board of Health shall be satisfled that any malignant, contagious or satisfed that any malignant, contagious or infectious disease exists in any city, district or part of the country to such an exhabltants of any part of the state of Missouri having direet communieation with such infeeted city. district or part of the country, said board shall have power by a majority vote, to establish quarantine regutrict, and may determine and regulate to what extent and by whom any communicawhat extent and by whom any communication or business transaction with such intablish such rules and regulations as may he deemed necessary to prevent the introduction and spread of such disease; and said board is hereby empowered to call upon ally executive officer of the state to enforce such rules and regulations, and it shall be the dity of all public offeers, sheriffs and constables and other executive offeers of the state to assist the State Board of Ilealth to carry out the prorisions of this article. (R. S. 1899, Section 7521.)

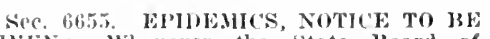
Gilis: Whenever the state Board of Ilealti shall deelare that any malignant, Infectlous or contagious disease Is eptdemic in any portion of the commtry or the state of Missouri, they shall Immediately, or as soon thereafter as possible, give nostate, and also glve public notice of the rules and regulations adopted by them for the enforcement of quarantine in infected the enforcement of quarantine in infected adopt such measures as they may deem adopt sted measures as they may deem necessary to prevent the introduction of
sud disease. (It. S. 1899, Sectlon 7522.) Sec. 6656. I'ENALTY FOR NONCONPLI ANIE WITH QUARANTINE REGLAATitis: Any perscn or persons falling, after notice, or refusing to comply with the after notice, or refusing to comply with the quarantine rules and regulations of the
state of Nissouri, as established by the state of IIissourl, as established by the
State Board of Ilealth, or any person or State Board of Ilealth, or any person or
persons resisting by force the enforcement of the quarantine regulations of the state of Missouri, established and approved as iforesaid, shall be deemed guilty of a misdemeanor, and on conviction thereof shall be fined not less than $\$ 10$ nor more than $\$ 500$ for each offense. (R. S. 1899, Secion

sec. 665\%. MEFTIxas of BoAItI: The meetings of the board shall be in January and Juty of each year, and at such other times as the board shall deem expedient. The meeting in Jannary of each year shall be held in the city of Jefferson, and four members shall constitute a quorum. They shall choose from their number a president, vice-president and a seeretary, and dent, vice-president and a seeretary, and
they may adopt rules and by-laws for their government. subject to the provisions of this government. subject to the provisions
irticle. (R. S. 1899, Section $\mathbf{7 5 2 4}$.)

Sec. 66:8. DUTIES OF SECRETARY: COAPRASATION OF BOARD: The secrepreseribed by the board and this article; he shall recelve a salary, which shall be fixed by the board; he shall also receive his fixed by the board; he shall also receive his trareling and other expenses in the per-
formance of his offleial duties. The other members of the board shatl recelve no compensation for their services, but their traveling and other expenses while employed on the business of the board shall be paid. The president of the board shall certify the amount to the secretary, and the traveling and other expenses of members, and on presentation of his certificate the auditor of the state shall draw his warrant on the state treasurer for the amount. (R. S. 1899, Section 7525.$)$

Sec 6659 BOARD TO TAKE COGNIZAXCE OF DISEASES AIONG DOMESTIC ANIMALS: The said Board of Health shall take cognizance of any fatal disease which may he prevalent among the domestic animals of the state, and ascertain the nature and causes of such disease, and shall, from time to time, publish the result of their investigations, with suggestions for the proper treatment of such animals as may be affected, and the remedy or remedies therefor. (R. S. 1899 , Section $\mathbf{7 5 2 6}$.)

Sec, 6660. BOARD TO ORGANIZE, ETC The State Board of Health shall organize within thirty days after the appointment of the members thereof. The president of the board shall have authority to administer oaths, and the board to take testimony in all matters relating to their duties and powers. In selecting places to hold their meetings, they shall, as far as is reasonable, accommodate the different sections of the state, and due notice shall be published of their stated meetings. All certificates issued by them shall be signed by at least five members of the board. (H. S. I899, Sectlon 7527.)

Sec. 6601 ANNIA REPOltT CON fling it shatl be the duty of the board fis in annul report, through the gecremory of otherwise, in writing, to first day of January of each year, and sucl first day of January of each year, and such
report sliall include so much of the proreport shall include so much of the proconcerning vitul and mortuary statistics, such knowledge respecting diseases, and such instruetlons on the subject of hygiene, as may be thought useful by the loard for dissemination among the people, with such sugrestions as to leglslatlve action as it may deem necessary. (R. S. 1899, Section 7528.)

Sec 6662. RYLES OF BOARD NOT IINIING, WHEN : No rule or regulation binding whicl shall conflict with legal or of the state, or any ordinance of ans munlcipality or town in the state. (k. S. 1899 Section 7529 .)

Sec. 6663. COUNTY BOARDs of
HEALTI: For the purpose of further carryling out the provisions of this article there is hereby created a county board of health, to be composed of the judges of the county court of each county, and a leputable physician to be appointed by them. said county board of health shall have the same powers and authority as are given to same powers and authority as are given to the State Board of lleaith by sections 6654 , 6655 and 6656 of this article within thelr
respective counties outside of incorporated respective counties outside of incorporated cities and towns respecting quarantine regulations and the prevention and spreading of malignant, contaglous and infectious diseases therein; the judges of the county court shall draw such per diem as is now allowed them by law while holding court while attending the duties required by this article: Provided, that the judges of said article: Provided, that the judges of said court shall not receive any per diem for is in session for the transaction of other business; they may pay the physician appointed a reasonable compensation, as wel as all other reasonable expenses incurred thereby, out of the county treasury. Said county board of health shall report their proceedings to the state board, and shall be a subsidiary board to said state board, and shall enforce such regulations as the state board may prescribe: Provided, however, that said county board of health shall have no power to raise a quarantine established by the State Board of IIealth. (Laws 1901 , p. 180. )

\section{CHAPTER T8}

Section 8:11 PRACTITIONER SHALI BE REGISTERED l'HYSICIAN : It shall be unlawful for any person not now a registered physician within the meaning of the law to practice. medicine or. surgery in any of its departments, or to profess to cure and attempt to treat the sick and other aly!ieted with hodily or mental infirmities, or engage in the practice of midwifery in provided (Laws 1901, p. 207 )

Sec. 8312. STATE BOARD OF HEALTH To HAVE SUPERVISION OF REGISTRATION: The State Board of Health shall have general supervision over the registration of all practitioners of medicine, sur1901. p. 207.)

Sec. 8313 EXAMINATIONS ; SUBJECTS TO BE PASSED : GRADE : All persons desiring to practice medicine or surgery in this state, or to treat the sick or afflicted, as provided in section 8311 of this article,
shall appear before the State Board of 
llealth ut such the aud place as the board mat dirett und shail there be examined as to their fluess we engage in such practice. All persons appearing for ex:mbation shal make appliestion, In writing. th the secre tary of said board thirty dags before the meeting. of their prellulluary ifualitleations. to wit: A certiffeste of grailuation from an nectedised high sethool or state mermal

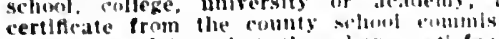
sioner, certifying that they have sitidenc torily passed an examination equivalent to terily passed an exardited high schoul or state normal sihool. colleke, unisersity or state norm:

They shall also furnlsh satisfactory erdence of having received a diploma from requirements at the tine of gridtition Provlded, that the time of aradination his been since March 12. 1901, and two years requtrements, if the date of Eraduition is prior to March 12. 1901, and shall alsi furnlsh evidence of good nural character. The niedleal examination mas be marle in The niedleai examinate or in part. In writing. und shall lo whole or in part, in writing. and shat bir of elementary and practleal etmrileter.
sumelently sirice to test the qualifleations
of the candidate as a practifloner, and shail of the candidate as a practitloner, and shail phislology, therapeutics, obstetries, gyne cology, surgery, practle of medlctive, hac teriology, medieal jurisprudence and hyglelle and such other branclies as the state buard may direet: Provided, that each applicalt for llcense shall have two hours, if necesfor llcense shall halve two hours, if necessary, during whlch to arswer the ustual number of questlons asked on each braneh examined upon. The candidate shall be required to answer 75 per cent. of such granted a certifleate: I'rorided, however. that the exumination of any applicant in therapeutles shall be conducted by the member or members of said board who repre. sent the system of mediclne of which such applicant has heen n student.

if there shall be no representatlre of the If there shall be 13 represellatire of the scliool or system of which the applicant has been a student, the examination in therapeupolnted for that purpose by the governor of lissourl, but nll cxaminations other than that in therapeutics shall be conducted as heretofore provided in this article. The as they shall find ufon examination to pos sess the requistie qualifications a license to practlce medlelne and surgery in accordpractlce medicine and of this article, and the state Board of llealth shall not he perthe state Board of lleath shall not he permitted to favir any particular school or system of medicine, but all nuplliants shall the same degree of proflciency shall he repulred of all. Tlie bost shall examine persons apulying for a license, althoukh such persons cunnot speak the Finglish language the applicant in all such cases in pay the expenses of an linterpreter satisfactory tu
the board (Iaws 1901, p. 207 ; ameinded the board (Iaws

LaW I907, o. 353.) p. $21:$ :

"And it is further provlded. that the sald State Board of Health may, at their discrelion, admit, wlihout examinatlon, leqaily fualithed pract!tioners of mediche who holi certitleates to irmetle medieine In ans bistrlet of columbia, with einal renilire ments to the state of ylissturl atus that

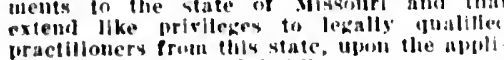
bractilloners frum tliks stat

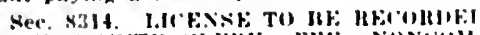

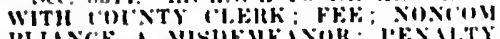

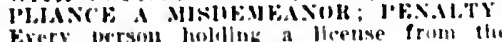
state lowars of llealth sliall hase it te. corifes lis the omece of the county clerk if

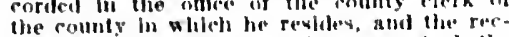

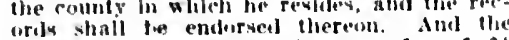
clerk is authoriacel to rluaras a tep of $\$$

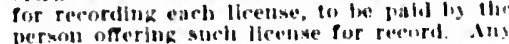
jerson remuring to aluther comnty bu practice medleine or surgery shall hase hi renoves, and the holder we sald licenve shatl nay sald relerk of said connty the usual fee fur making the reonral. The connty plerk shall kreplo "line of the licenses rece orted hi. hill, with the ditte if lissue. Any persun uchlectiog (i) record his ficense as in linls section providenl hefore enterjug upon the practice shall ine Luilty of a mistemear. be thed uot less thin \$sin. and on fallure to record said lieense for thirty days after such courfetion, such porson shall be linble
to if fine of not less than $\$ 100$. (Laws 1901,

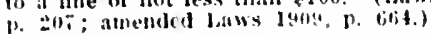

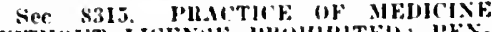

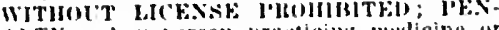
AITY: Ally person prateteing melieine or surjery in thls state atud iny jursul atcempting to treat the slek or ciflets attlicted person revesenting or advertising hituself by any means or through any medium whatso-

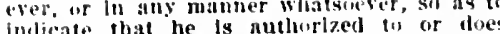
fractice miediclne or surgery in this state. or that he is authorized to or does treat the sick or others aflicted with bodily or mental sick or others anted lonse from the state Buard of Health, us prorlded in this article. or after the revocation of such license by the tate Board of Henth, as privlded in this article. shall be deenied gullty of a misilemeinor. and punished by a tine of not less than sio nor more than sion, or by impris mument in the county fail for a perted of got less or by both such fine and mprlsomment year, or by both such fine and ming treating for each and every onfense; and treating each patlent shall be regarded as a separate
offensc. Any lierson fling, or attempting to offensi. Any lierson fling, or atteinpting to Hle, as his own a license of another, or a wuilty of a felony, and, upon conviction thereof. whall be sibject to such fine and imprisonment as are made and provided by statutes of this state for the crime of forgery in the second degree. Sald fines to be turned bitu the state treasury when collected: I'rovlded, that physicians registered on or prior to Nareh 12, 1901, sliall be reLarded for every jurjose herein as licentiprovisions of this article. (Jaws 1901, p. 20\%: amended laws 190\%, p. 358.)

Sic 8316, FEES; JISIOSITION OF SAMt: In orler to provide the means to carrs ont and inamtalu the provislons of this artlele, the sald board shall charge each
persom applying to and nppearing before it for examinatlon for a license to practlce unedioine and surgery a fee of $\$ 15$, and should such exanination prove unsatisfactury ind the state boand refuse to issile a bicense thereon, the apslicant fatling to pastint within tlie next twolve months thereafter amel he examined wlthout extra charge, hut ino gupurary liceuse shall be issued to such un douprary license shall be lssued to such perwin. Ali foes so recelred from appli-

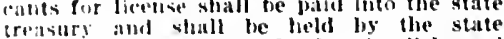
treisury and shall be field by the state ciliy itl payment of expenses of malutaining we aterepriated for said purpose, and no intuer lunney stabll pe patil out of the state treisury for the provislons of this article The state alulitor shall lesue his warrant on the state trotsuret por payment otte of sate fund on the certilleate of the president ant

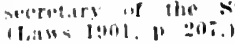

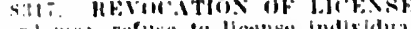

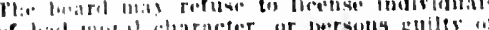

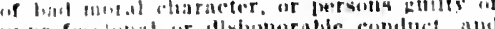

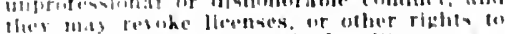

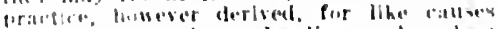

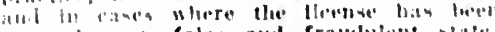

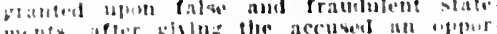

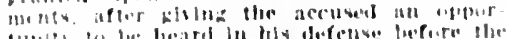

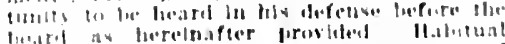

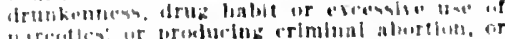

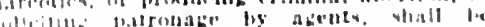

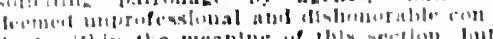

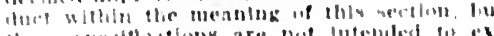

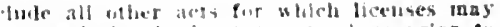

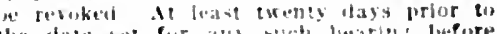

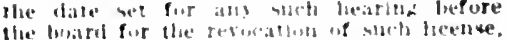
the secretars of the lward shall catuse writ-

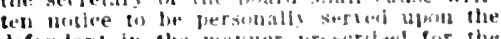
defendant in the naturer prosertbet for the

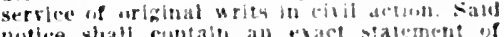

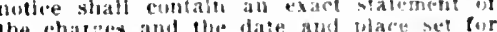
the beariug before the bonate. If life party thus nopifled falls to anpeas, ritler in per. son or loy cuutivel, at the thene and place desfenated in sidel notice, thes Imard shali. ifter receiving sallinfactury evidente of the truth of the cliarges and the fropler insuance ind serviec of notice, revoke sald llectise. liy counscl. the board shalt proceed with the hearing is herein prosided. The board may redetve and entusider degmsituns aud oral statcments, and shat rause stencraphic re. transerllied, which. logether with all other papers jertaining thareto, shall be preserved for two years. If a mujority of the board are satisfled that the lirentiate is fullty of any of the untenses eliarged. the license shall be reboked for such period of time as may

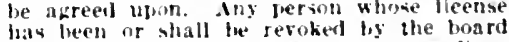
shall have the right to have the proceding. of salil board revoking his llcense and all the evidence therein reviened, or a writ of certiorari, by the cireuit court of the county in "lith suid board hited sald writ shall issue upon the petition of the person whose licellse sllall have been revoked to sald cours or to the clerk thereof in vacation at any time withln ninety days after such revocathon, and shall command the said board and the secretary thereof to certify to sald court the record and proceedings of said board. the erflence therein pertaining to the rerocation of sald license. The petitioner for the writ of certiorari shall set forth the rights of the petitioner and the injurles complatued of by hin and shall le rerifled by him. If the proceedisgs of the brard shail him. If the proceedisgs of the brard stail be sustalued or upheld by the cireuit court,
its orders. decisions or judgments revokjng sild license shail remain and continue in full force and efrect. And ally sueh license so revoked by tho hoard shall. pending sald review on certiorari, stand revoked and so relating thereto shall he quashed or otherwise annulled by the circult court on sald writ of certlorari. Testimuny may he takell by deposition. to le used in evidence on the trial of suchl charges before the loand in the same minner aud under the same rules and practice as is now provided for the taking of depositions in einl edses. (Law:

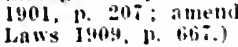

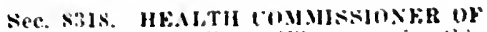

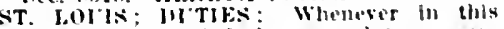
article it is prorided that any lusy or servee shall be performed ly any county clerk. such duty " te service in the city of st. lauis shall be performed by the health commis-

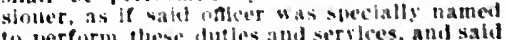
to perform these dutles and servlces, and sald

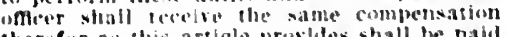
therefor as this article provldes shall the padd

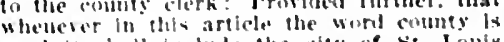

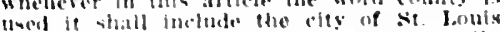

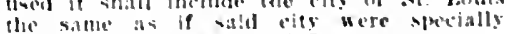

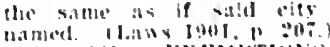

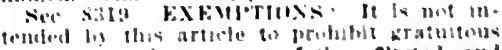

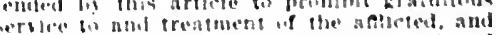

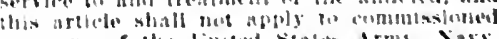

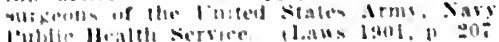

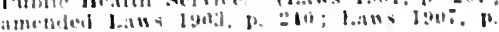

\section{Alti'J.F II}

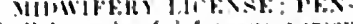
(1.T) It hlall lin unlawful to. any person (1) Dractles mbluifery fu this state befort devirlus (1) practice milwifers as a prefes.

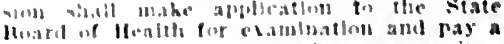

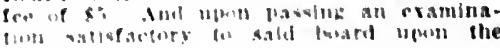


subject of olntetrics, shall receive a license to practice as above provided. It shall be IIIIawful for aul bersonl licensed as a mldwife only to engaged in any other branch of utedieal practice or to advertise herself as doctor, dinctress or phrsiclau. or to use any lefters before or after her liane on at sima or otherwise, incilenture that she is ather

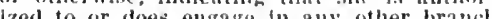
ized to or does ellegage in any other brand of medical practice. And any person price tieing midwifery als a profession or adver

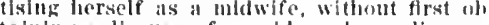
talning a licellse aforesald, and any licensed midwife who shall do any acts in this sectom probibited. slatl he deemed guilty of a mistemenuor, and upon coltrletion, shall he punished by a the of not less than slo nos more than sing. or hy Imprisonment in the cound jull not more than two mouths nor less than ten days. Actiug In each case shalt be deemed a separate utfense. Yinthing in thls sectlon slual be so in this secton shall he so eonstrited as to requite whmen practieing midwifery to obdo not practlee midwifery as a profession, and do not make any cliar
(Laws 190I, p. 207.)

Approved March 12, lo0l. Amended and approved April, $1900^{\circ}$.

STATE BOARD OF HEALTH OF MISSOURI (i. I3. Schultz, President, Cape Girardeau : F. II. Matthews, Vice-Iresident, Llberty : F. O. Cuppaidge, Moberly; R. L. Wilis, Wilcoxen, Bowing tireen; J. A. R. Atleock. secretary, Jefferson City.

\section{MISSOURI STATE MEDICAL ASSO.}

offleers 1913-T4

Enoch II. Miller, President.......... Liberty C. H. Nellson, Ist Vice-President...St. Lonis T. J. Downing, 2d Y.-President. New London Ir. I3. Austin. 3d Vice-President.Brunswick i. D. Allee, 4th vice-President.......Lamar A. E. Hertzler, 5th V.-Presiclent. Kansas City A. F. Hertzler, 5th V.-President. Kansas City J. Franklin Welch, Treasurer........... Lalisbury

\section{State Journal}

Journal of Missouri State Medical Association, st. Louis, F. J. Goodwin, II.D., editor.

\section{Councilor District and Officers}

F. J. Lutz, Clatirman, St. Louis; E. J. Goodwin, Secretary, St. I.ouls.

First Distriet-Holt, Atehison and Nodaway connties. C. L. Evans, Couneilor, Oregon.

Second District - Buchanan and Andrew counties. I.uther A. Todd, councilor, st. Joseph.

Third Distrlet-Harrison, Worth, Gentry and bekalb counties. (i. W. Whiteley, Councilor, Albany.

Fourth District-Grundy, Sullivan. Yercer and Putnam counties. J. B. Wright, Councilor, Trenton.

Fifth District - Clark, Scotland and Schuyler counties. E. E. Parrísh, Councilor, llemplis.

Sixth Distriet-Adair, Knox and Lewis counties. Alexander C. Crank, Cantor.

Seventh District - Sbelby, slarion and Ralls counties. Jacob D. Snith, Councilor, Shelbini.

Eighth District-Lincoln, St. Charles, St. Lonis and Pike counties. Leander W. Cape, Councilor, Mapiewood.

Ninth Distriet - Audirain, Boone, Howard, Callaway, Warren and Iontgomery counties.

A. Ii. IIcConias, Councilor, Sturgeon.

Tentl District-Macon, Randolph and Monroe counties. C. H. Dixon, Councilor, Holliday.

Eleventh Distriet - Chariton, Carroll, LJFingston and Linn counties. J. D. Brummall, Couneilor, Salisbury.

Twelfth District - Platte, Clay, Ray, Clinton, Caldwell and Daviess counties. Clar ence II. McConkey, Councilor, Lathrop.
Thirteenth Mistriet-Jackson County. F

F. Murphy, Coumcilor, Kinsas City.

Fourteenth District-Lafayette, Sialine and cooper counties. C. T. Kyland, councllor, l.exingteris.

Fifteenth Distriet-Cass and Johnson omuties. James 1. Anderson, Counclior, Wiareusburg.

Sixteenth Distrlit Bates, Veruon, Bar tots, tedar and bitle combtes. E. N. Chas tain, conncilor, Butler.

Seventeenth District-Pettis. IIenry, Ben toll st. Clalr and Ilickory counties. Saml. : Kelly, Councilor, Sellalia.

Figlitenth Istriet - Miller, Moniteat, Morgan and Camilen eounties. Frank DeVilbiss, Coumellor. Tipton.

Finctenth District-Cole, Osage, Maries and Fasconade counties. W. A. Clark, Councllor, Jefferson City.

Twentietl, Distriet-Franklin County and St. Jouls ('ity. F. J. Lutz, Councilor, st lonis.

Twenty-First District-Jefferson, ste Genevieve and lerry countles. G. M. Rutlektge, Councilor, ste. Genevlere.

Twenty-Secona District-Scott, Madison, Cape Girardeat, Mississippi and Bollinger counties. Garnett S. Cannon, Councilor, Fornfelt

Twenty-Tuird Distriet--Stoddard, DunkTin, Pemiseot and New Madrid

Twenty-Fourth District - Wayne, Ripley, Butler and Carter counties. W. Wotton, 'ouncllor, Van Buren.

Twenty-Flfth Distriet - Washington, Reynolds. Iron and $\mathbf{S t}$. Francois counties. $\mathrm{T}$. $\mathrm{T}$. O'Dell, Couneilor, Ellington.

Twenty-Sixth District-Crawford, Phelps, Pulaski, Laclede, Dent and Dallas counties. W. H. Prener, Comncilor, St. James.

Twenty-Serenth District-IIowell, Shannon. Czark, Oregon, Texas. Wright and Donglas counties. James Henry Elliott. Councilor, West Plains.

Twenty-Eighth District - (ireene, Law rence, Barry, Stone, Christian, lebster, Polk and Taney counties. T. O. Klingner, Councilor. Springfield.

Twenty-Ninth Districl-McDonald, New ton and Jasper counties. R. I. Neff, inm cilor, Joplin.

Component County Societies of the Missouri State Medical Association

\section{ADAIR COUNTY}

F. ('. Callison, I'resident ........ Kirksville

J. W. Martin, Secretary...........Kirksville ANDREW COUNTY

(Included in St. Joseph-Buchanan-Andrew counties.) ATCHISON COUNTY

James A. Hunter, President........Fairfax AIDRAIN COUNTY

Fred (iriffin, President............. Harry W. Gibbs, Secretary.............. BARRY COUNTY S. A. Newman, Iresident. . . . . . Tassville BARTON COUNTY

(;. D. Allee, President.............. Lamar

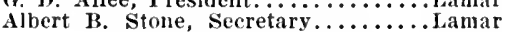
BATES COUNTY

T. C. Bulware, President.......... Butler Alva E. Lyle, Secretary ............Butle BENTON COUNTY

E. II. Gist. rresident............ Fristoe John R. Smith, Seeretary........... Wharsaw BOONE COUNTY

R. R. Hobinson, President........Hallsville A. W. Kampschmidt, Secretary..... Columbia BUCHANAN COUNTY

(Included in St. Joseph-Buchanan-Andrew counties.) BUTIER COUNTY

B. Lee Ellis, President........Poplar Bluff Wm. Spaulding, Secretary...... Poplar Bluff CALDWELL COUNTY

Tinsley Brown, President.........Hamilton J. A. Waterman, Secretary.......... Brekenridge
CALLAWAY COUNTY If rmon s. Major, Jresident......... Fuiton CAMDEN COENTY

1. II. Moore, l'resillent........ Linn Creek

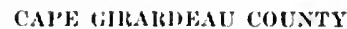

W. K. Statler, President........ Oak Ibidge w. E. Fonnt, Secretary.......... Cupe (iirardeau CAItRo].J، ('OTNT

Ik. F. Cook, I'resident.......... Carrollton Eithain b. Brumer, Secretary...... Carrollton CARTER-SHANNON COUNTIES

A. 1k. MeNeill, l'resident......... Winon: J. A. Chilton, Seeretary.......... Van Buren CASS COUNTY

Edgar M. Grifftli, I'resldent ..... Creighton II. S. Crawforl, Secretary.....Harrisonville CEDAR COUNTY

Kiniball IIIll, President....Eldorado Sprlngs Elisha II. Liston, Secretary...Cedar Springs CIIAITHON COUNTY

A. M. Zillman, President....... Keytesville CHRISTIAY COUNTY

W. B. Wasson, President............... Wixa lired H. J Jown, Secretary................ Billings CLARK COUNTY

l. 1). Mcliee, I'resident..........Wayland

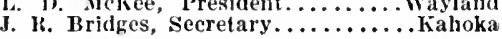
CIAY COUNTY

Burton Malthy, President..........Liberty F. II. Matthews, Secretary.............. Liberty CLINTON COUNTY

J. T. Iimsey, President........................ COLE COUNTY J. S. Summers, President..... Jefferson rity COOPER COUNTY Porter Williams, President.........Bunceton
C. S. Roberts, Secretary.........Boonvil]e CRAWFORD COUNTY

T, Coffee, President............ Steelville

E. L. Hume, Secretary ............ Bourboit DAVIESS COUNTY

N. M. Wetzel, President............ Jameson DE KALB COUNTY

H. P. Yeater, Presldent.........Maysville w. S. Gale, Secretary............ Osborn DENT COUNTY

Thos. F. Miller, President............. Salem w. E. Iiudd, Secretary ........................ DUNKIIN COUNTY

F. W. H. Presnell, President........ Kiennet

Thomas J. Rigdon, Secretary......... Kiennett FRANKLIN COUNTY

Otto L. Muench, President..... Washington H. A. May, Secretary.........Washington GASCONADE-MARIES-OSAGE COUNTIES F. Aufderheide, President........... Jrake

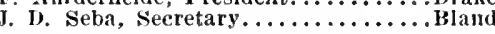
GENTRY COUNTY

W. T. Wartin, President................ Whiteley, Seeretary GREENE COUNTY

G. B. Lemnion, President......... Springfield

Thomas 0 . Klingner, Secretary. . Springfleld GRUNDY COUNTY

J. II. Stone, I'resident.............Laredo

o. Ir. Irooke, Secretary............ Trenton HAISRISON COUNTY

Chas. H. Robertson, President.....Eagleville Wm. Worth Vandivert, Seeretary....Bethany HENRY COUNTY

Sammel A. Poague, President.........Clinton irn. II. Shankland, Seeretary............ Clinton HICKOKY COUNTY

H. C. Brookshire, President.......Hermitage

R. C. Nevins, Secretary.........Wheatland HOLT COUNTY

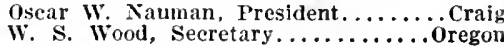
HOWARD COUNTY

Thos. J. Payne, President......... Fayette C. W. Watt, Secretary............Fayette 
Howkile $1012 \mathrm{TS}$

James if Eillowt. I'resflent. West Plalus Altert 11. Thorninghi, seeretary. We'st Plains IRON COUXTY

(i. W. Farrar, Presldent.......... Irtuton Boger w. Gay, secretary............. Irumton Jokson COLxt

Mchard t. Satton, President. Kallady lity H. lewwls Iless, secretary...... kitnsits l'tly JASPER COLNTY llobt. 1. Netr. P'resident........ Jupllin JEFELATSON COLXT:

v. B. Donnell, l'resldent.... Herculaneun b. E. Hensley, Secretary........... I'evely JoInsox colxty

Heney Park. Ireslient.........knolunnster o. H. Hall, secretary........Warrendurb KNOX COUNT

Henry J. Jurgens. President......... tillinil F. E. Luman, secretary............ karlnt LACLFDE, COLNTI

Jos. II. II. Iteser, Iresident. ...... ('innms J. A. McConb, Secretary............ I.ebanon LAFAYETTE COLNT

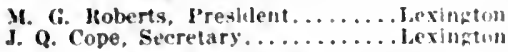
LAWHFNCE-STONF, COINTIES

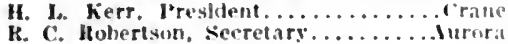
I.EWIS COLNT

B. B. Schofielil, Presitlent........ l.pwistown

11. L Ellery secretary.......... Ia tirantre LIN COEST:

C. E. Jenkins, J'resideut......... Brookfteld

Foster W. Burke, Secretiry.............aclede LWINASTON COCNTY

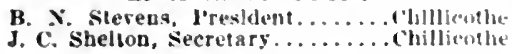
Macos cotots

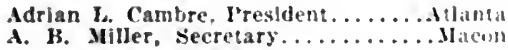
MADISOS COINT

F. IR. Newberry, Presldent...Frederiekstown Wim. Nifonz, secretary......trederlckstown ManiEs Colvery

(Included In Gasconde - Marles - Usage countles.) MARION corNTr

b. k. Hill, President............llannibal James J. Earrell, secretary.......... Ilannibal MEH'R COT'STY

G. M. Brlstow, Presilest.........Princeton Chas. It. Buren, secretary......... I'thecton MILLKH 10IXTY

E. C. Shelton. I'resildent........... Fildun

J. $\therefore$. kichardson, secretary........... blean mississiply rotext

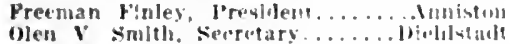
MONITEAT CONT

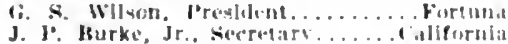
MOXIRE COI XT

Harry 6 Pnyne, President......... Piurls

Fred II. Carver, secretary........... MONT(;)MEL (UL:NT

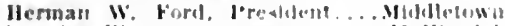

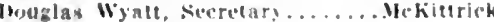
monthis rolext

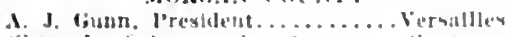

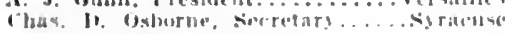
NFW M.SHEII 1 $111 \times 1 \%$

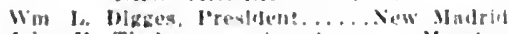

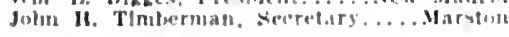
VHWTON $101 \mathrm{XT}$

kirbeat M. Mencherry, I'restelent.

IIorace s. Howers, sedretary.

Niveshon

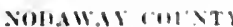

Wim. M. Wallis, Jr, IPresldente. Marnsille

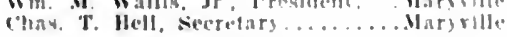
osstit: (o)

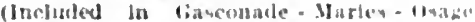
(ountles.)

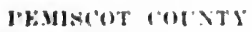

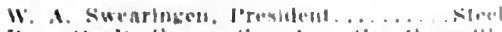

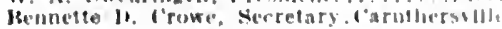

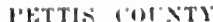

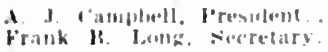
PHERT' FOLNT Louls J. Matlock, l'rewitemt.......... James

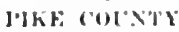

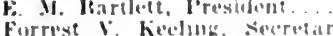
PlatTE: (WINT)

Ala Naylur, P'resldent........ Platte cits IDOL ININT Y

It. I.eo Itussell, Previltent..... Inmanssllle J. F. Robert.s. Seretary............. Bullivar PRLASKI COINTY

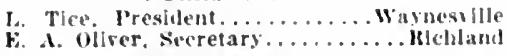

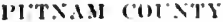

c II. Carryet, Prestalent........ Inionville J. II. Carryet. Presidemt......... Sunionville IIAJLS Col"NTY

Wim. T. Walers, J'sesldent........ Vew London

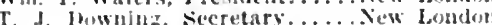

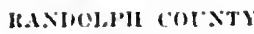

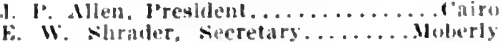

Ihohert sevier, l'resldent..........llichmond James F. Ball, secretary........... Bichmond RF.NOLIS COLNTY

Thomas W. Chlltru, President..... Ellington

T. H. sly, secretary.............enterville shist colats

Flosd W. Tuttle, Prevident.......MI. Teonard (ieel. A. Iiken, Secretary..........Malta Besd SOIIYLER IOLNTY

Wim. H. Zieber, Iresident...... queen clty J. B. Itridges, secretary........... buwning

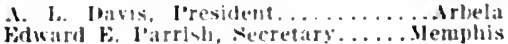
SOTT COINT

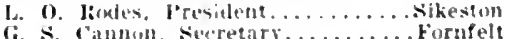
SIMTNox (O) XTY

(Iucluded in (arter-shanon countles.) SIIELAL COINT

A. Ib. Ferzusth, 1'resident...... Ihunew onl Adulph M. Woul. secretary......... Leutner ST. CHALLES COLNT)

Joseuh II. Juskins, I'resident. ........t. Jeters r. L. Marklin, secretary.............. Charles ST. FHINCOIS COLNTY

C. P'. P'oston, I'resiulent........ Bombe Terre is. J. Bobluson, secretary....... Fiarmingzon STE. CFINEYIFE COLNTY

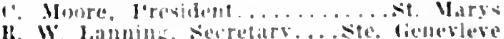

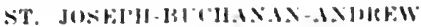
corretits

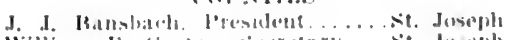

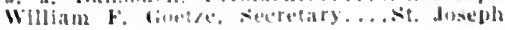
ST. I.1IIS (IT)

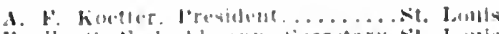
Fredk. C. huhlmann. Secretary.st. houls ST. LOHIS (OI'ST)

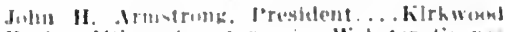

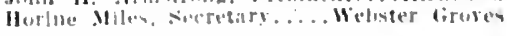

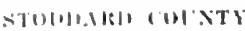

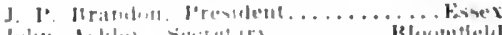

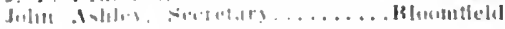
STOSt A IISTS

Incluted all l.anrencesestone combles.)

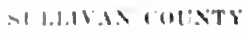

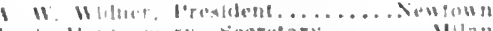

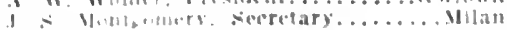
INH (WIST)

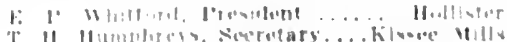
TENAS IOITS

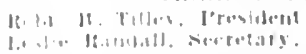

I FHAT I I IT

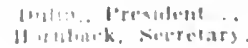

Surala RAL COLNT seotiono (o)

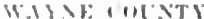

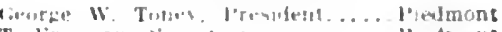

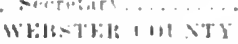

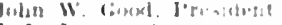

riurlianil WRIOHT A W NT

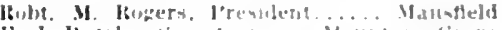

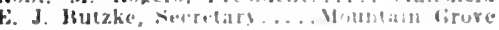

\section{COUNTY HEALTH OFFICERS}

Cominty

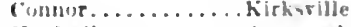

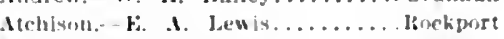

Aulrain Itohert 1. strinde.......... Vex]co

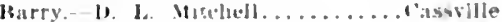

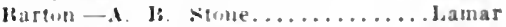

Bates. $T$. Bumlware............. Butler

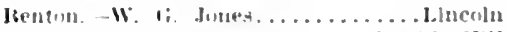

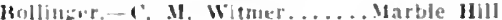

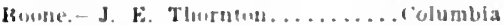

Buchanan. J. K. Cirdlatm.......... Jaseph

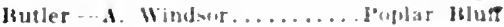
Calduell...James k. diartslde......Kingiton

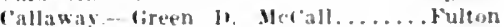
Caunderr.- J. S. Foril. .......... linn ('reek Gage birardean. W. W. Vingard...Jackson Cartoll-1 $\therefore$. Aistin.......... darrollton Carser. T. W. Cinton.......... Van buren Cass - H. U. May............. Harrisunville Cedar.-F. s. sunith............sinchion

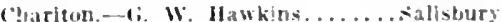
Christian.-W. B. Wasson............. Nixa Clark J. C. Buss................kibliohat Clay_-William II. Combon......... Liberty

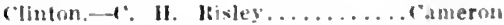

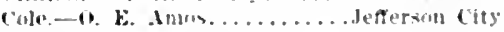

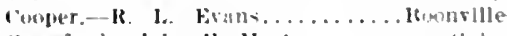

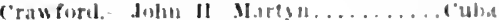

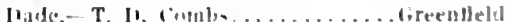
Wallas-Irvin I'hillin............. Muralo

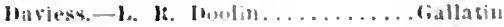
Dekalb.-W. d. Clark............ Wityntlle

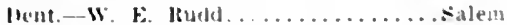
pouklas d. 1. liemtry................ Disnklin.... s Ilarriom.........kennetg

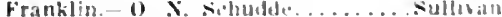
liasconade, W. I. Wesind........Hernam dientry lipo it. smith............hasmy

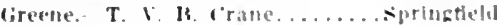

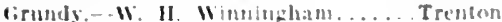

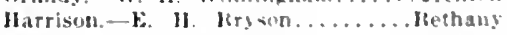

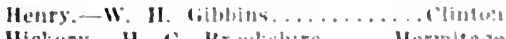

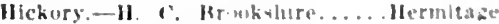

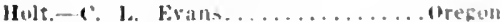

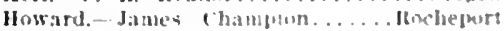

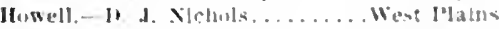
Iron-C: W. Farrar.

Jacksan. - J. II. Iirecen

Jasper - K. k. Rahor

Jolensor. Joln: Poners

knox. If $f$ alomnot.

Laclesle. T J rampledi.

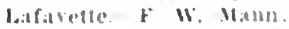

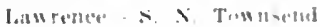

lowis. I vratme"

latuenth \&: I Heks

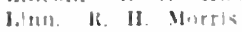

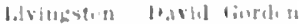

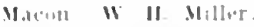

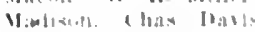

Vartes $16 \mathrm{~m}$ k Forrall

Natint I 18 stump.

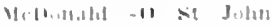

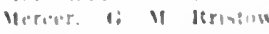

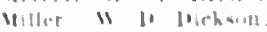

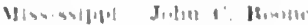

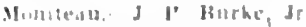

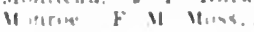

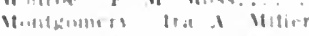

Nurgann if I J.utmant.

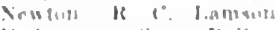

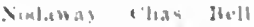

ilongon \& I fitilen.

Mrevoll al. betilem,
Warrembur: karimo ...tidina

Willongen Iuror. Fin 1 in: ...Troy

Lingers

Intllycothe Yacull

Fromertokiewn vernna loumea pinerille irinceten Tucirmtula inarlesient alifornia i..? Videllecounn lerallles virsulle ....entianz 


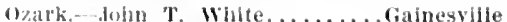
Perry.-T. . I. Hutson. . . . . . . . . I Ierryville Peltis.C. B. Trader.............. Sedalla linclps. C, H. Fulbright........... James

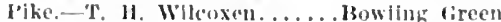

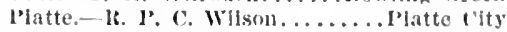
lolk. - W. D. Irake.............. IBolivar l'uinski,-I, Tice ..........W Wayesville Italis. - T, d. bowning, .......... New hondon

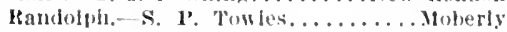
lay-.I, k. Ball............. . Rideimond Reynokls, -T. H. shy............ Tentervilio Itipley..... A. Iroctor.......... Inoniphan Saline, $r, .$. llariin............... Schusler- W. . I. Potter.......... Laneaster Scotiand-W. s. I'etty......... Itutledge Scott-Criel P. Haw...............Benton Shannon.-I'. I). Gum..........Birch Tree

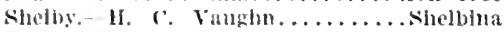
st. Charles.Cart Bitter........ St. Charles St. Franeols. - Ben 1t. Downing. Farmington ste. Gonerlere-F. E. IInch..ste. (ienevieve St. Louls. - II. II. II anson......... kirkwood stoddart. Eldon pliblips......... Bioomfleld stone.-L. Henson .............. tratena

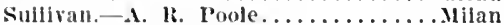
Taney-Guy B. Mitchell..........Branson Texas.I. I. Wamack............Ifouston Vernon.-G. W. l'etty ............... Nevada Warlen.-E. H. Brandt...........Warrenton

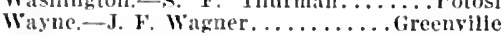
Veloster - W: It Beatile...... Mtarshfleld

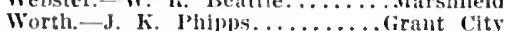
Wright.-13. E. Latimer. ............ Hartville

\section{HEALTH OFFICERS IN CITIES OF 5,000} POPULATION AND OVER

Brookflell................ F. Howard Cape Girardeat................ $\mathbf{c}$. F. Stone Carthage.............Wallace E. Steele Chillicothe ................ Jimpson Cofumbia ............. Woodson Moss II innibii................... Heavenridge Independenee........................ Jefferson City................... P. P'orth Joptin......................... it. Gregg s. Wheeler Kirksville $\ldots \ldots \ldots \ldots \ldots \ldots \ldots \ldots$, L. $_{\text {, }}$ J. $_{\text {T. }}^{\text {Conner }}$ Mexieo...................... T. Gibbs

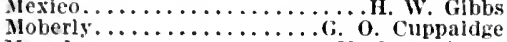
Nevadi.................. 0 . Whilams Poplar Bluft.................... B. L. Ellis Sedalia......Wm. Wheeler and F. B. Long St. Charles............... Whos. L. IIardin

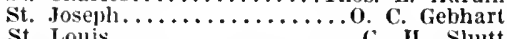
Trenton................... Winningham

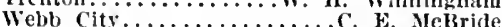
Webster Groves................ Frank it. Meclelland

\section{Chiilicothe}

\section{STATE INSTITUTIONS}

State Industrial Home for Girls, Chillicothe, Mo. Established 1888; reformatory; 200 beds; $W^{\prime}$. Girdner and $R$. Barney, visiting physieians; Mrs. A. MI. Clay, superintendent.

\section{Farmington}

State Hospital No. 4, Farmington, Mo. Established 1903; for the insane; nerrous and mentai; 600 beds; G. E. Serutehfleld, medical superintendent.

\section{Fuiton}

II adley Hospital (Tubereulosis branel of Stite Hospital No. 1), Fulton, Mo.

Mlissouri scinool for Deaf, Fulton. Mo. Established 185I; 50 beds; C. H. Christian, physician in eharge; J. S. Morrison, superintendent.

State Hospital xo. 1, Fulton, Mo. Establisined 1s4:; for the insane; 1,250 leds; 1 . 0 . Biggs, medical superinten(ient.

Higginsville

Confederate Home, Higginsville, Mo. Established I8!I; for ex-Confederate soldiers and wires: 30 beds in hospital
deparment: W. C. Webb, physieian in charge; J. C. Pace, superintendent.

\section{Jeffersen City}

Mlsionrl State Penitentiary Ilospital, Jefrerson dity, Mo. Established 1876 . fencral; so beds; (ieo. I McCutchan, physichan in charge.

\section{Kansas City}

Missouri State Sanitarlum, 1203-05 [aseo St. Kansas Clty, Mo. Established

1908: Folumbus D. Severe, medical supt. Marshall

Missouri Colony for Feeble Minded and Epileptles, Marshalt, Mo. Estabilshed Ist4, ; 500 beds; Horace D. Quigg, pliysiclais In charge.

\section{Mt. Vernon}

Missouri State Sanatorlum for the Treatment of Inciplent Tubereulosis. Iti. Vermon, No. Fstablisied 1607; 150 hedis; for theiplent tubercuiosls cases; dent.

\section{Nevada}

State Ilospltal No. 3, Neralla, Mo. Jstablished 1887. for the insane: 1250 leds; Wiil I. Bradiey, medical superintendent.

\section{St. James}

Ferleral Soldiers' Home of Missouri, St. James, No. Wstablished 1897; 260 beds in barracks: 35 beds in hospital ; general: IV. II. Breuer, medicai superintendent

\section{St. Joseph}

State IIospital No. 2, St. Joseph, Mo. Established 1874 ; for the insane; 1,550 beds; Abra C. I'ttijolin, medical supt.

\section{St. Louis}

Missourl Sehool for the Blind, 3815 Magnolia Ave., St. Louis. Estabilished 1851 ; 130 beds; J. F. Falle, medieal staff; S. M. Green, superintendent.

\section{HOSPITALS, SANATORIUMS AND CHARI- TABLE INSTITUTIONS}

Bethany

Heilbron Sanitarium, Bethany, Mo. Established 1896; mental and nervous diseases; 5t) beds; Jerome $A$. Kintuer, superintendent.

\section{Bonne Terre}

Bomne Terre Hospital, Bonne Terre, Mo. Established 1911; Lenerai; 30 beds; H. P. l'oston, chief surgeon.

\section{Boonville}

Boonville General Iospital, Boonville, Mo. Established 1912; general; 10 beds : Geo. J. Weitz, medical superintendent. St. Joseph's Sanatorium, Boonville, Mo. Established 1905; 44 beds; C. H. Van Rarensway, physician in charge; conducted by Benedictine Sisters.

\section{Burlington Junction}

Mineral Spring Sanitarium, Burlington Junction, 110. Established $1883 ; 40$ beds

II. A. Gaugh, physician in attendance

O. A. Harbison, manager.

\section{Cape Girardeau}

St. Francis Hospital, Cape Girardeau

Mo. Established $1882 ; 40$ beds; Sisters of St. Francis, in eharge.

\section{Carroliton}

Carroll County General Hospital, Car rollton. Mo. Established 1911; 35 beds F. E. Brumer, president of medical staft Miss Anna Belle Adams, superintendent. South Side IIospital, Carrollton, Mo. Established 1911; private; 10 beds; Robert Mavin Benson and Wm. G. Atwood physieians.

\section{Carthage} Carthage Hospital, Carthage, Mo. Es-
tablished 1903; 18 beds; Eila A. H. Goetsch, superintendent.

Taylor Sanatorium, Carthage, Mo. Established $1905 ; 12$ beds; C. B. Taylor medical superintendent.

Chillicothe

St. Mary's Hospital, Chillicothe, $\mathrm{Me}$ Established 1885; general; 40 beds; Sis ters of St. Mary, in ebarge.

\section{Clayton}

Methodist Orplians' Home for Boys, Clayton, IIo. Established 1900; eduea tional; 75 beds; J. L. Boogher (St. Louis) physician in charge; James Ashbrooke superintendent.

\section{Columbia}

Boone County Infirmary, Columbla, Mo. Established 1897; for paupers; 45 beds J. F. Thornton, pinsician in charge Chas. L. Edwards, superintendent.

Parker Memorlai Hospltil, Columbla, Mo. Estabilshed 1901; general; 30 beds Guy l. Noyes, medieai superintendent.

\section{Excelsior Springs}

Exeelsior Niprings Sanitarium, Excelsior Surings, Ho. Estabilshed 1909; 30 beds. Harriet Indsey, superintendent

\section{Gallatin}

Willow Bark Sanitarium, Gallatin, Mo. Establlshed 1897; 50 beds; for alcohol and drug aditietion eases; F. M. Helphinstine, superintendent.

\section{Georgetown}

Pettis County Ilospital, Georgetown, Mo. 35 beds; H. W. Harris, physlelan in cilitre.

Hannibal

levering IIospital, 1734 Market St. Itamilat, Ho. Established 1903; genin charge; Naude Landis, superintendent. Holden

Oxford Sanitarium, Holden, Mo. Estabished $1906 \cdot 10$ beds; W. G. Thompsolr, superintendent.

\section{Independence}

Independence Sanltarlum, Independence, Mo. Fstablished 1909 ; general; 45 beds Joseph Luff, physieian in charge.

loor Farin and Hospital, Independence, Mo. A. M. Harrison, superintendent.

alle Sanitarium, Independence, No. stiblisiled 1903; nervous and mental diseases, nareotic and alcoholic addiction 25 beds.

\section{Jefferson City}

Milton Hospital and Old Folks' Home, Jefferson City, Mo. Established 1911 ; colored people; 7 rooms; Mrs. A. E. Milton Murray, president of board and superintendent.

St. Joseph's Hospltal, Jefferson Clty Io. Establisined 1907; for small-pox cases: 24 beds; Sisters from St. Mary's Hospital, in charge.

St. Mary's Hospital, St. Mary's Bolivar Jefferson City, Mo. Established 1904 general; 75 berls.

Joplin

St. John's Hospital, Joplin, Mo. Established 1900 ; general; 100 beds; Sisters in eharge; Miss Cora A. Horine, R.N. superintendent.

\section{Kansas City}

Haptist Hospital, 620 Bennington Are., Kansas City, IIo. Established 1908; general: maternity : 35 beds: Noah Adams, physician in charge: Bessie Colvin, supt. Burnett Private Sanitarium 3100 Fuclid Ave., Kansas City, Mo. Established 1902; nerrous, mental, drug and aleoholic; 58 beds; S. Grover Burnett, nedical superintendent.

Catholic Orphan Home for Boys, 922 westport Ave., Lansas City, Mo.

Cliff View Sanatorium, Kansas City,

Dr. Coe's Sanitarium, 2548 Wyandotte St Kansas City, Mo. Establlshed 1888. 30 ' Kansas City, Mo. Hstablshed 1888; Douglas Hospital, 312 Washington Ave. Kansas city. No.

Elliott Sanitarium and Hospital, 501 Highland Ave., Kansas City, Mo. Established 1908; nervous and mental diseases, wareotie and aleoholie addiction; 22 beds. Emergency Hospital, City Hall, Kansas City, Mo. Established 1907 ; general ; 4 beds; W. S. Wheeler, physician in charge. Fenale Orphan Jiome, 31st and Jefferson Sts., Kansas City, Mo.

Fiorence Crittenton Home, 3035 Wood land Ave., Kansas City, Mo. Established 1896 ; maternity for single women; 18 beds; H. L. Hess, physician in charge 
6:IHIs" Orvhans Home, Tracy Ire and $22 d$ St. Kankas city, Mo. Fintabllshed 1875: 100 beds: Women's Chrigtian Kssosecretary: Mrs. II. Lantmin, suprin tendent.

Girls Induatrial llome, 2940 llighland Are., Kansas CIty, Mo. Jennle F. Mar tin. matron

Hahnemann Hoswtal, 91: Tracy st.

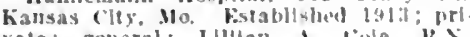
rate: genteral: Llllian I. Pvie, K.S. superintendent.

Home for the Afed, 3lst and loreust Sts Kansas clity. Mo, Litule Slisters of the loor. in cliarge.

Hosplial for Contaglous Irieases, hau sas City, Mo. Established 1590: small pox cases; tieo. I'. l'pkin, physiclan in charge.

House of the Fonl shepherd, 20th St. and Clereland Are., hansas (city, Mo. Fisfabllshed Iss: : lono beds: Sisters of the Good shepherd. In charge.

Joseph Walter Home. 2610 Cleveland Are Kansas City Yo. Fistablistied 1903. jeds; $\mathbf{F}$. J. llatch, jhystclan in charge. Kansas City tieneral Mospltal, zist to 24th and Jocust sits., Kausas (city, II Fotablished 1908; ceneral; 500 beds; ! E. Castelaw, medical superintendent.

Kansas Cliy Postgraduatc Hospital, 915 Independence Are., Kansas City", Mo, Kstablished 190: to beds: Albert $E$. Jones, house sungeon: Ellzaberli Cantleld, superhouse surse

Kansas City skin and Cancer Hosultal, 1205 Mchlgan Are. Kansals Clty, Mo. Fistablished 1913: prisate: 10 treds: IIal. sey $M$. Lole. physlcian in charge.

Kansas Cly Tuherculosis I'avillon, 2ad and Cherry sies. Kansas Cily, Mo. Ks. tabllshed $1909 ; 22$ beds; E. W'. Schaunler, medlcal director.

Ialuel Fo Cammage Itemorial Hoviltal, $\$ 800 \mathrm{E}$ ath St. Kansas clity. Ito Eistul. lished 1912: public: generil: : beds: I IR. Gammaie, physiclan jn charqe

Margaret hlock Irmuur Memnriat In me for Aged Couples, Tracy Are. and z21 $\mathrm{s} 1$. Kansas City. Mo. Fistabllshed I!Uu: $3:$ rooms; Women's forlstlan Issoctation. managers: Mrs. A. $\therefore$ If Ilnes, secretary: Man. W T Mays, superintendene.

MeCall Vospltai, 1424 Holues sit, Kan. saty, Mo.

Mchanna Sanltarlum, 10:9 summit st. Kansas Clty, Mo. J. J. MCKanna, physiclan In charge.

Mercy Hospltal, 414 Hlgliand Are. Kansas Clty, Mo. Fotabllshed $149 ;$; io beds; Mlss Virginla Forter, superinten. dent.

Missourl Ilospital for Women. Kansav Cisy. Mo. Fistablisled louk: I tienls; B. L. bastman, physirlan in charge.

Mismonrl pacific llallway Ifosplital. ino ilo W. Ioth St, Kungas fles, Wr. Kis

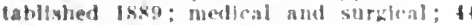
bedv: s. I. Fox, surgeon in warge.

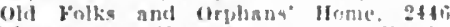
Mlchlean lre Kansis ("lo Mo kistil).

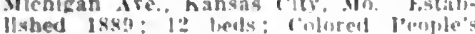
christian (harity Axsochation, in clasce Filia Jackson, matron.

lerry Sanitarlum, 1214 Vine st., kan

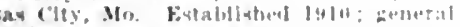

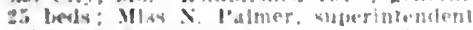

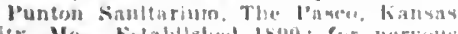

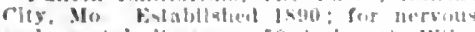

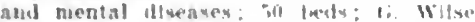
ltoblnsol, phystelan in char"e"

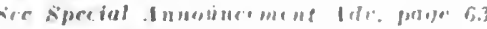

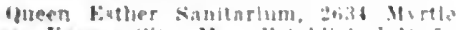

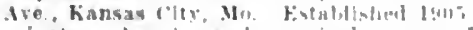
prisate: chroule and surgiral romes: herle: bilmer $T$ [ labh santiarlum.

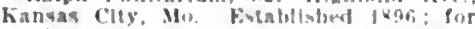
alcohol and ilewe aldletlon easry: 30 bivls: V. I. Smalt, physicion In rlarge.

Ited Crese II ospllal. Esies lherey se.

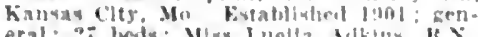
eral: 27 lowds: Mlas luclla dolkms, K. sulverintendent.

liest fottagn Hescue llome, 2033

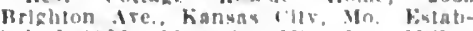
llaburl 1901: 10 beds: Mas latu Mllier. matron.
Somb side Ilospltal, 3007 Maln sit. Kansas f'lly, Mo. Histablished 1905 : zell eral: til beils

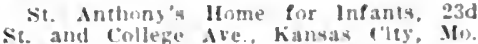

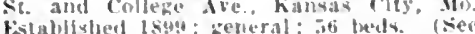
st. Vincomts Hospltal

st. lienrfe's l'est llouse, fout of cleve land st., Kansas loty, Mt.

st. Juseph's Ilospital, ilo Penn st. Kansas tity. Mo. Fistathlshed Ixif pri vale and charlialile:

St. Joseph's Orphan tilrts' IIome, 3lst St. Joseph's orphan lifrs Irome, 31st and lefterson sto. Kansat rity, Mo. Fos tal superintendent; sisters of st. Joseph. in charie.

st. Luke's IInspltal, 2011 f. IIth st, hansas city. Io. Fistabllshed 1902 : general: bolsonal: be heds: llerman t.

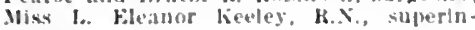
tendent.

si. Mary's Hospital, 2sth and Maln Sts Kansas Cies, Mo. Estathlished lyou: 170 bets: sisters of st. Mary. in charge. St. Incent's Hospital, College Ire. anil 23d St. Kansas clty. M.

Swetlsh Hospltal 30 th and wy andotte Sis. Kansas City, Io, Fstablished 1906 : in Harrelson, physl. general: 5 foeds: N. M. Harrelson, physlr clan in charge:

inirersity Hospital, 1005 (amphell st. Kansas Cly, Mo. Fistablished 18.1: hij beds: F. 13. Titany, physician in charke

Wesley Hospltal, 11th and Harrlson sts. Kansas City, Mo. Fistablished Is07: 85 beds: J. Arehte Bobertson, phislelan in charge: Miss Cora Churcli, $\mathbf{5}$. superintendent.

Willows Maternity Sanitarium. The, 2929 Main St., Kansas CIty, Mo, Fistabilshed 1905: muternity; 50 heds; John $W$. Kepner, house ohstetrlcian; Hodin 1". Haworth, sliperintendent.

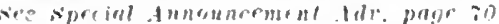

Keota

Voman's keformatory, hansas City, Mo.

Kenta Hospital, Kecuta, Mn. Establlstipel

1365: emercency cases: 3 beds: J. II Belyea, physlcian in charge.

\section{Kirksville}

IIr. B. B. Harrish, Unspital, Klrksulle. In. Fitablished $1:+10$ : prlvale: surgical only ; ti lueds: Gertruele Ilensley, suluetintendent.

\section{Kirkwood}

Itkins Home for Mental and Nersuls Miseases, Kirkwond, Mn. 31 bets: II. S Itkins, (st. louls), phys!eian in chutre. Koch

Mobert Koch Hospital, Korh, Mn. Fiatall. lished 1910: tulverculusis: 1 ith beds; M. J. jower, jhystelan in charpe.

\section{Liberty}

chal Follows Home Hospipal ldherty.

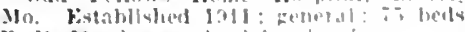

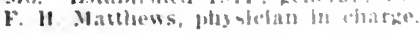

\section{Little Blue}

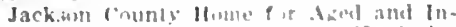

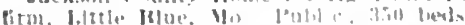

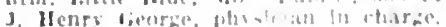

\section{Marthasville}

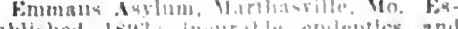

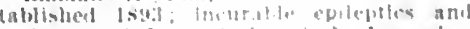

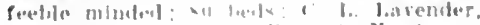

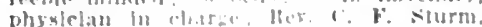
superinlentents.

\section{Marsville}

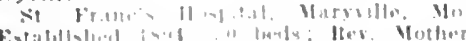
Augurtinte. at,

\section{Mexico}

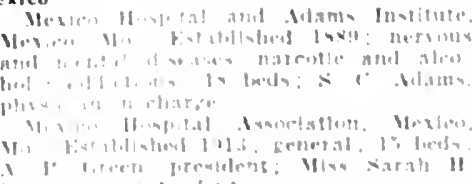

Moberly

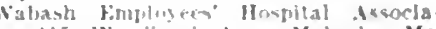
fon, t15 Worllatul IV" Mulwerly, Mo

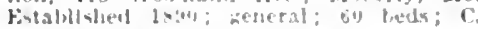

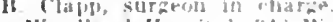

Wondland Ilospital, 3to Wrmblard tre.

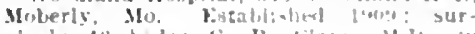

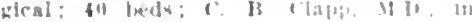
charine.

Nevada

Ferada Medleal and surgalmal sabl

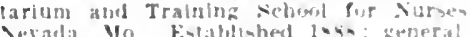

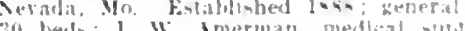
6t hels: 1. W. Anerman, medpeal stgpt fablfohod 19fl: mild nerwos and mental

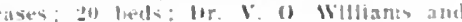
I II Yater, physlalans ln charge

\section{Pattonsille}

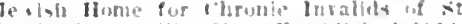

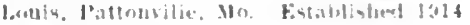
culvercutionis: 1the lieds.

\section{Poplar Bluff}

loplar Hlut Hospital, Poplar Blud, Mo. Established 1901: 8 ineds; Victur ladwell. physician in clarge.

\section{Queen City}

Hight Hospital, jupen r"ty, Mo, Litablisturl 1909; 15 beds; IIrs, iN, B. HItht. superinfendent.

\section{Rich Hill}

Jelamater Hospital. Heh Hill, Mo. Fs. tablished 1900]: general surgery: Hento

Richland

lichland Hospital, Richland, Mn. Es tabllshed 1906; aeneral; 5 Herlo; Foret Oliver, physlclau in charge.

\section{Sedalia}

Maywoml Hospltal, sedalla, Mo, Ko tablished 1905: general: 45 bed: : r. i

Wond, plysician in charze.

Misouri, Kansas a Teras kailmal

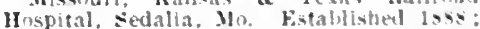
1.50 theds; r. F. Iances, chlef surgeom. sedalia Hospleal soctets, sewdalia, Mo Established I843; 20 beds; 5 . R. Morle? surgeon; Mrs. R. H. Wrlpht, treasurer.

\section{Springfield}

burge Theaconess Hospilal, sjringllebl. yu. Finablisled 1:406: Feneral: :30 heds: yliss Firma H. Bechtel, superlngendent. Frisen timployees" Iluoplal, sirtueflets.

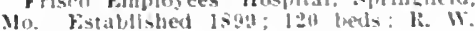
Jugetrom. surgenn in charge

Johnsen sanlfarium, sul $x$. Jetersin

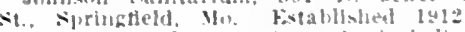
nervous, mental, marcothe and afcoliethe

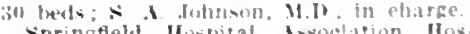

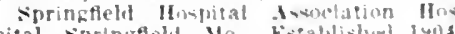

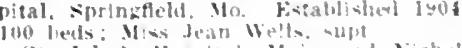

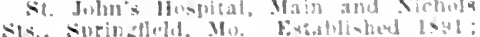
i. inuls.

\section{St. Charles}

count Ashlum St Charles. Vu Es

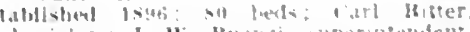

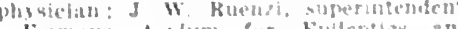

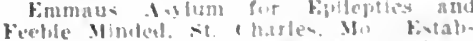

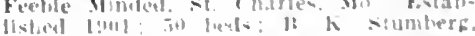

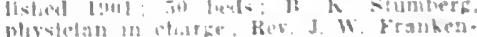

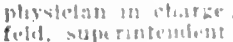

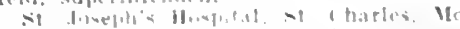

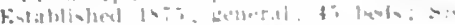
ters of st Vtart in chabize

St. Jaseph

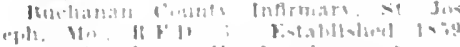

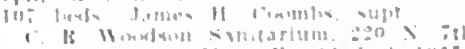

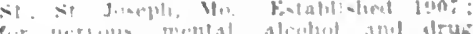

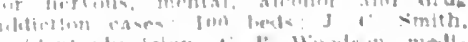

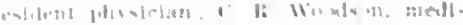

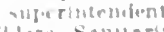

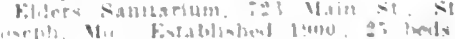

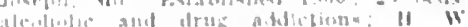

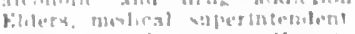

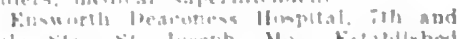

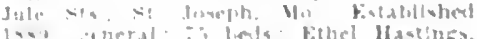

$$
\begin{aligned}
& \text { wher nite bulen }
\end{aligned}
$$

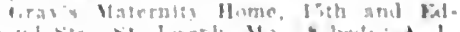

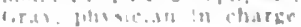


Inme for Littie Wanderers. 801 N. 28th it., Nt. Josepil, Mo. Estabilshed 1894: tio heds; Mrs. A. M. Curtis, superintendent.

Riverside Home, Louis and l'rospeet Ares St Joseph, Jlo Estabilshed 1910

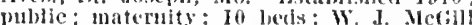
and I'. I. Leonard, eonsulting physiclans. St. Joseflits IIospltal, 1230 Powell st. si. Josepll, Mo. Fstablished listig; 101 beds; sisters of Charity, in rharge.

St. Joseph Sehoul and Ilospital, $402 \mathrm{~s}$ Sth St., St. Jusepin, Mo. Estallished 1869 branch, St. ofseph's Sanitarium; 37 beds; J. French, plusician in charge.

Thompsoll sanitarium and lest llome

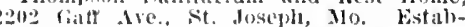
fisied loug: mentid aud nerrous diseases. uareotic and alcoholic: 20 bedis ; Geo. Ii Thompson, medienl sujerintendent.

Whittugton's I'rivate Santarimm, 2222 sacramento st., St. Joseph, Mo. Estal)lished 1910 ; nervous and mental diseases, nareotic and aleoholic addletion; 15 beds: W. 1. Whittington, pluysieian in charge. IV. J. Ieil's Sanitarim, 721 Franeis beds; W. I. lieil, plysician in charge.

\section{St. Louis}

Alexian Brothers' Hospital, $3933 \mathrm{~S}$. Broadway, St. Louls. Wiablished 1870 general; 250 heds; C. I. Nellson, chief of medical staff.

A. II. Jones Nemorial IIome, Newstead and Margaretta sts., St. Louls. Estabjished 1891; 75 beds; Rev. C. C. Stalimann superintendent.

Barnard Free skin and Cancer Hospital, Theresa and Washington Aves., St. Louis. Established 1905; charitable; skin and eancer; 44 beds; Yerna Cleveland, superintendent.

Bames Ilospital. King's Highway and Forest Park, st. Iouis.

Bethesda, 3649 Vista Ave., St. Louis. Established 1859 ; charity; 69 beds; E. W. Saunders, physician in charge.

Bethesda Foundlings' Asylum and Maternity Hospital, 3651 Yista Ave., St

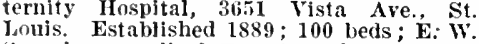
Saunders, medical superintendent

Bethesda Old Ladies' Home, 3660 Rutger St., St. Louis. Established 1889 ; benerolent; 41 beds; Mrs. F. Meclintock, supt.

Blind Girls' Industrial Home, 5235 l'age

Blyd., St. Louis. Established 1878; 40 beds; Mrs. P. L. Peiton, president.

Bridge Hospital, 731 South Broadway, St. Louis. Established 1910; general : 10 beds; C. L. Munson, medical superintendent.

Chouteau Maternity IIome, 1515 Chouteau Ave., St. Louls. Established 1909; 10 beds; Tos. Mills, house physician;

Christian Hospital, 2945 Lawton Ave. St. Louis. Established 1900; general; 5 beds; Weltha N. Mathews, superintendent. Christian Orphans' Home, 2951
Euclid Ave., St. Louis. Elizabeth Euciid Ave.,

City Infectious Disease Hospital, 560 Arsenal St., St. Louis. 150 beds (See st. Louis City Hospital, St. Louis.)

City Infirmary. 5800 Arsenal St., St. Louis. Established 1848 ; for indigent. 1.600 beds ; C. A. Rosebrough, resident phrsieian; Wm. Anderson, superintendent. physian; Wm. Anderson, superintendent. Chestnut St., St. Louis.

Deaf Nute Institution, 901 w. Garrison S1.. St. Louis. Established $1885 ; 65$ beds. Eilen Osborn Hospital, 2800 N. Taylor heds; Eilen M. Osborn, medieal superintendent.

Emergency Home and Hospital, 3108 line Sts., st. Louis. Mrs. II. E. Otto, superintendent.

Episeopal Orphans' IIome, 1701 S. Grand vie., St. Louis.

Erangelieal heaeoness Home and Hospital. 4125 W. Belle li., St. Louis. Establishel 1889 ; charitable; general; 100 beds: W\%. I3. Dorsett, ehief of medical F' Fospital Association 1 ตn ; gentera ; 120 beds; G. W. Cale, Jr., chief surgeon.
Girls' Industrial Home, 5501 Von Versen Are., st. Louls, Established 1854; 90 inels: IIrs. Anma Hitch, matron.

10r. Cioldstein's I'rivate Hospitai, 3858 Westminster 1'l., st. Louis, Fistublished la0.i; car, nose and throat; M. A. Goldteil. physician in charge.

Cood Sinmaritan Hospital, $1217 \mathrm{~N}$. Jefforson Ave., St. Louls. Estabilished 1859 ; 5it heds.

Ifephzihah lescue Home, 3014 Morgan St.. St. Lonis. Fstablished $1893 ; 43$ beds little E. Norman, superintendent.

llome for Aged and Infirm Israelites, $365^{2}$ s. Jefrerson Are., st. Louls. Established $1852 ; 30$ beds; M. R. IIorwit\% consuiting lhysielan: Joseph Gokenhem, uperintendent.

Home for Convalescent Women, $100 \mathrm{~N}$. Leffingwell Are., St. Lonis. Established 1893 ; 32 beds; Mrs. Martha Cooper, superintendent.

Home for the Aged, 2209 Hebert St., St.

Louls. Established 1880: 220 beds: branch at $3400 \mathrm{~S}$. Frand $A$ re., 150 heds: Edw. Evers, physieian in attendanee Little Sisters of the Poor, in eharge.

Louis. Establisied 1900; 15 beds; Waldo Briggs, physician in charge.

Jewish IIome for Cinronic Invalids of St. Louis, st. Louis. Estabjislied 1914. public; tuberculosis: 100 beds.

Jewish Hospital of St. Louis, 5415 Del. mar Ave., St. Louis. Established 1901; general; 90 beds; II. Tnholske, chief of medical staff; Margaret Rogers, superintendent.

Jewlsh Shelter IIome, 1722 Missouri Ive., S1. Louis. Pauline Kohn, matron. Josephine Hospital. Grand and Henrietta Aves., St. Louis. Established 1906:30 beds; F. J. Lutz, plysician in charge ; beds; F. J. Lutz, plysician in e

Lutheran Altenheim, 1906 Lafayette Are., St. Louis. Established 1907; home for old people; 40 beds; Albert H. Kanning, superintendent.

Gutheran Hospital, Ohio Ave. and Potomac St., St. Louis. Established 1858; general; 100 beds; Itev. Francis M. Rudi, superintendent.

Martha I'arsons Free Hospital for Children, St. Louis. Ender management of St. Louis ChiJdren's Hospital.

Masonic IIospital of Missourl; 5351 Delmar Ave., St. Louis. Established 1912; medical and surgical; 146 beds; A. C. Robinson and A. C. Leggat, physiclans in charge.

Matilda Mospital, 6\$15 Michigan Are. St. Louis, Established 1913; public: beds; Matilda Luke Tibe, physician in charge.

Mayfleld Sanitarium, $920 \mathrm{~N}$. Taylor Ave,, St. Louls. Established 1896; 75 beds; W. H. Mayfield, surgeon in charge: W. G. Tyzzer, house physician.

Memorial Home, 2609 S. Grand Ave. St. Louis. Established $1882 ; 115$ beds: Irs. Anna Howard, superintendent.

Mrs. Anna Howard, superintendent. Home Nethodist Episcopal Emergency Home for Girls, 3410 Morgan St., St. Louis.
Established $1909 ; \quad 16$ beds; Miss Ida Bentiey, superintendent.

Nethodist Orphans' Home, 4385 Maryland Ave., St. Louis. Established $1867^{\circ}$; 200 beds; Miss M. A. Sleith, matron.

Missouri Baptist Sanitarium, $919 \mathrm{~N}$. Taylor Are., St. Louis. Established 1890 ; general; 150 beds; I. H. Cadwallader, physician in charge; HIrs. I. H Cadwallader, superintendent.

see sipecial Annowncoment Ade. page $\mathrm{i}_{2}$

Missouri Pacifle Hospital, California and Eads Ares., St. Louis. Established 1854; general; 200 beds; Paul F. Vaster1854 ; General ; 200

Nothers and Babies' Home, $304 i \mathrm{~N}$. Taylor Ave., St. Louis. Established 1899; 100 beds; L. C. MeElwee, W. John Harris and T. R. Ayars, surgeons in eharge.

It. St. Rose Hospital, 9201 S. Broadway, St. Louis. Established 1902 ; for
tuberculosis eases; 75 beds; 1. C. Boisliniere, medical director; David R. Lamb, resident physician.

Mullanphy Orphan Asylum, Taylor and Maryland Aves., St. Louis. lasteur Institute of st. Jouis, $803 \mathrm{~W}$. Garrison Are, st Louis Fstablished 1913; private; rables; R. B. H. Gradwohl. medical director.

l'rovident Hospital, 2824 Iawton Ave., St. Louis. Wstallished 1895; 15 beds; E. S. Williams, superintendent.

Rebekah IIospital, 3564 Caroline St.. St. Louls. Establisined 1894 ; general ; 50 beds; Miss Fdith Mllster, li.N., superintenclent.

Robt. Koch IIospilal.

(see Koch, Mo.)

Russell Home for old Ladies, 3217 Washington Ave., St. Louis. Established 1908; 18 beds; Mrs. Itiser, superintendent.

Salvation Army lying-in llospital, $\mathbf{3 7 4 0}$ Marine Ave., St. Louls. Established 1897 ; maternity ; 30 beds; II. C. Kloepper, physician in charke.

Sanjtarinm, St. Iouis. Established 1869 ; Insane patients; 2,000 beds; Geo. A. Johns, medical superintendent.

Sliloh Rescule IIome, 2316 Morgan St.. St. Lonis. Established 1904; Fannje Mi. Oliver, superintendent

St. Ann's Maternity Hospitai, 5301 rage Hlvd., St. Louis. Established 1853; i5 beds; $P$. II. Swahlen, physleian in charge.

St. Anthony's IIospital, 3520 Chippewa St., St. Louis. Established 1886; 100 beds.

St. John's Hospital, Euclid Are. and rark View 1'l., St. Louis. Established 1871; 80 beds; Sisters of Mrercy, in charge.

St. Joseph's Male Orphan Asylum, 470I S. Grand Ave., St. Louis.

St. Louis Altenheim, 5408 s. Bróadway, St. Louis. Established 1902; general; 70 eds; Edwin Sehisler, physician in charge.

St. Louis Baptist Hospital, 2945 Frank-

lin Ave., St. Louis. Established 1893; 48 beds; C. C. Morris, medical superinendent.

St. Louis Children's Hospital, $400 \mathrm{~S}$. Jefferson Are., St. Louls. Established 1880 ; general; 104 beds; Mlss Candice Montfort, superintendent. Country branch, Ridge Farm, Mo.

St. Louis City Hospital, 14th and Lafayette Sts., St. Louis. Established 1853; 950 beds: F, E Chapman, superintendent.

St. Louis Colored Orphans' Home, 4316 National Branch Road, St. Louís. Elizabeth B. Thornton, matron.

St. Louis Maternity Hospital, 4518

Washington Blva, St. Louís. Established physician in charge; Mrs. S. Hausmann, superintendent.

St. Louis Mullanphy Hospital, Bacon and Montgomery Sts., St. Louls. Established $1829 ; 175$ beds.

St. Luke's Iospital, Delmar Blvd. and Belt Are., St. Louis. Organized 1866 ; medical and surgical; 175 beds; Miss Franees Chappell, superintendent.

St. Mary's Female Orphan Asylum, Emerson and Harney Ares., St. Louis.

St. Mary's Infirmary, 1536 Papin St., St. Lonis. Established 1877; general; 160 beds.

St. Vineent German Orphan Asylum, 1421 Ilogan St., St. Louis. Established . John 0. Guhman, physiian in charge.

St. Vincent's Institution, St. Charles Itation, St Iuuis I. W. Hermann, physielan in charge.

United states Marine Hospital, 3640 Marine Are., St. Louis. Fstablished 1835; general; 100 beds; Surgeon P. M. Carrington, U.S.P.H.S

Tanderbeck's Maternity Hospital, 2007 Park Ave., St. Louis. Established 1908; 15 beds; C. C. Vanderbeck, medical superintendent.

Washington Unirersity Hospltal, 611 N. Jefferson Are., St. Louis. Established 1904; general; 101 beds; Chas. E. Baur, ireal superintendent.

Wellston Hospital, 6200 Ella Ave., St. Louis. Estabilished $1910 ; 20$ beds; E. A. Scharff, physician in charge. 
Trenton

Winninclean's Sianlearlum. Trenton. Mo

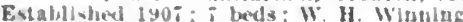
ham. physleian in charge.

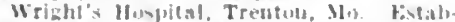

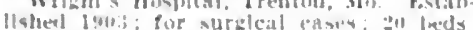
3. It. Wright, physlclas in chaphe

Villa Ridge

Villa sanflarium, Villa Hidge, Ma, Fo Iablisherl [903: 10 lieds, $r$ leunkin. medlcal sujerintelodent.

\section{Warrensburg}

(lak Hill sanltarluan, Warrofoluzr, Mo.

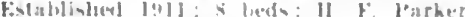

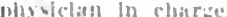

Webb city

Jane Chinn Jovpital Iswelajlon. Hose and Austin sis.. Weble (irs. Mo. kivgls Ilahed 1910; general: 30 beds; Mr llouser, superlufoulens

salvathn Irny, Webl, (ois, Wo, Kxtabllahed lyot: 10 bed
Webster Groves

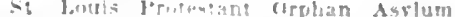

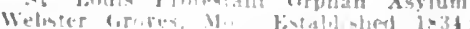

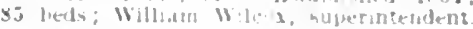
West Eminence

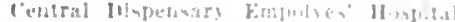

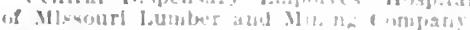

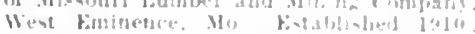

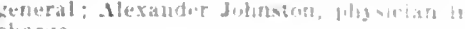
chisize.

\section{PHYSICIANS OF MISSOLRI}

Xatoes In capltals signlfy nembersbip in the County Suclety ard State Arrucia tlon. (DOE, JOHX)

Indlcates Fellowshlp in the American Med. Assn. (DOF, JoH:it)

$\left(b^{\prime}, 75\right)$ Year of birth. Imedic. II, homeopath; E, eclectlc: P.M, physin Md :,09, College and year of graduation.

o Information received does not show grail uation.

S.-Surgeon.

Ob.-Obstetriclan.

ObG.-Obsteirlclan, Gyuecologist.

G.-Gynecologist.

Or.-Orthopedlst.

Pr.-Iroctologist.

Op. - Ophthalmologist.

A.-Aurist.

LR.-Iaryngologlst, Rhinologlst.
KEY TO ABBREVIATIONS, SYMBOLS, ETC.

(1'89) Year of llcense.

(3) In practlce lefore passage of uresent law and lleensed by fillng diploma of by yesry of practleu.

(1t) latrensed but year not known.

(ڤ) Information recelved does not show lleense.

I's - l.. I'ulted States Army.

Il KC., L'.A.A., Medical Keserve Corps.

\section{SPECIALTIES ARE INDICATED AS FOLLOWS:}

ALR,- - IurJst, Laryngologist, Rhlnologlst.

OALR.-Ophthalmologist, Aurlst, Laryngulogist, Rhinologlst.

U.- C'rologlst.

D. - Dermatnloglst.

Pd.-Pediatrlst.

N.-Neurolnglst.

P. pirchlatrlst.
1.2 quled siares Jary

I. H. I. I. X. Medical lieserve fortus.

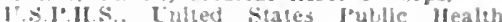
Serrlce.

College postlons held are Indicated by abbrevlated itle of insition, followed by key numlier of colle:se. For bey to collezes ste Inside front cover toare.

(A1,3, 156, (1) Membershlp in special Socleties. (see key Table, Dage ["as]

NP.-Neurologist, Psychlatrlst.

I.-Interalst.

T.-Tubereulotheraplst.

Anes, - Anesthelist.

LD.-Laboratory Jlagnostleian, Iglst. R.-Actinologist, Radlologist, RoentgenoloPath.-I'athologist.

Bact-Bacteriologlst.

WHEN THE ABBREVIATION REPRESENTING A SPECIALTY IS FOLLOWED BY AN ASTERISK ( THE PHYSICIAN CLAIMS HIS PRACTICE IS LIMITED TO THAT PARTICULAR BRANCH OF MEDICINE: WITHOUT THE ASTERISK. THAT HE IS ESPECIALLY INTERESTED IN, BUT DOES NOT LIMIT HIS PRACTICE TO, THAT BRANCH. THIS INFORMATION CONCERNING SPECIALTY IS BASED ON PERSONAL DATA FURNISHED BY THE PHYSICIAN AND IS NOT VERIFIABLE.

\section{MISSOURI}

ACASTO (R.F.D., FARMINGTON, IA.). 25. CLARK

Beuchler, Conde A-Ia.9,94; (1'9i)

ADAIR (R.F.D. BRASHEAR), 57, ADAIR HII.F: FILINK. PATHCK (b'S) KY 'ID: (1).

ADRIAN, 929, BATES

BATES, SMITH I. (b'51)+-0.1, $\left.78:\left(l^{\prime} \times\right)^{-}\right)$

l'ope, Allert llamond (b'iti)-Mo.99,06 $(1,00)$.

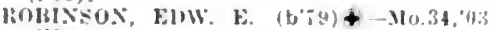
(1+0弓).

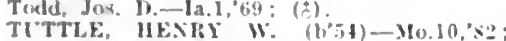
(IPA): Pd.

ADVANCE, 621, STODDARD

(iook, Jolin L. (b'fS) - Ia 9,92; (l'nl).

Hinduan, dames $91 .-110,-002: 10^{\circ}(1)$

It ausey, Holue. L. (b't5)-Jlo.24,92; (1'92)

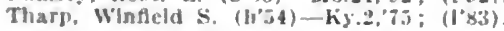

AFFTON, 725, ST, LOUIS

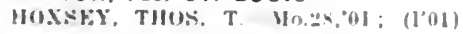

AGENCY, 429, BUCHANAN

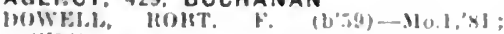
$(1 \mathrm{~S} 4)$.

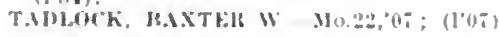

ALBA, 1.296, JASPER

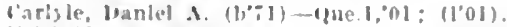

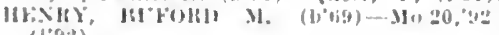
$(1,9: 2)$

ALBANY, 1,922. GENTRY

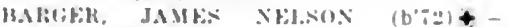
Ino.

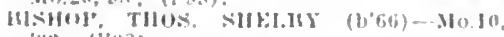

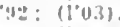

Cmmpishl, Malcolm Munroe - Michl, il: (1)

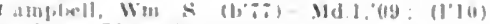

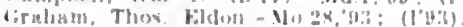

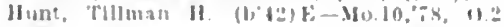
A; $(1+6: 3)$.

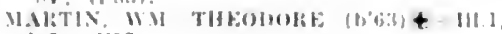

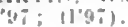

SMIII, (;F). W- Mo.29:97: (1997)

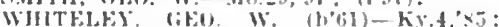
(1'u); OALR.

\section{ALDRICH, 225, POLK}

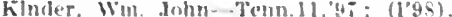

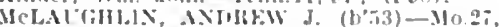
98: $(1,02)$

MVElis, Wi. T. (b76)‡-Mo.24,04; (104)

ALEXANORIA, 650, CLARK

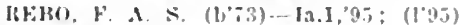

ALLENDALE, 2.13, WORTH

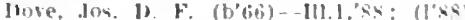

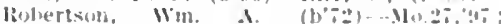
(1'9:)

ALLENVILLE, 257, CAPE GIRARDEAU

HIGIHOX, EIWW. E. $(6,70)+-.10 .28,03$ : (1) (1);

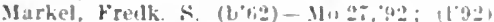

ALLEY. 50, SHANNON

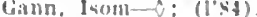

ALMA, 319, LAFAYETTE

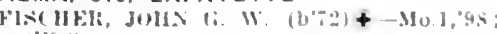
(1'gs).

ALMARTHA, 25, OZARK

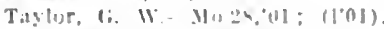

ALTAMONT, 270, DAVIESS

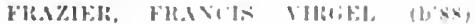

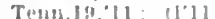

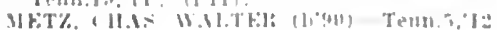
$(1 \% 1: i)$

ALTENBURG, 274, PERRY

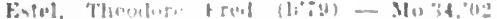

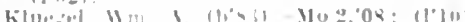

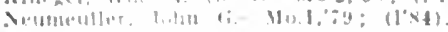

ALTON, \$4, OREGON

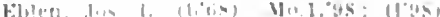

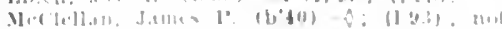

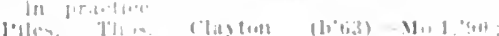

AMAZUNIA \$5T, ANDREW

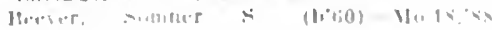

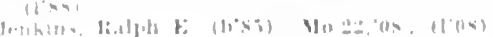

AMERICUS, 100, MONTGOMERY

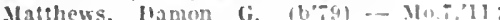
(I’11).

AMITY, 173, DEKALB

Amold, Zachary Tastor-Mich l, st: (1'st). llerren, Carl (hamplon (1)<i)-Ky z,0s: (I'11)

AMORET, 307, BATES

Curn, John A. $(1,-2)$ - In 3.2, 00 : (1'00)

Mnore. Fidwin Forrest (bugil - Mox.sio $(1 ; 9+i)$

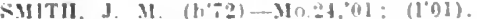

AMSTERDAM, 162, BATES

Anyx. John swiney (b'bt)-Mo.s,96;(1"96) Ob.

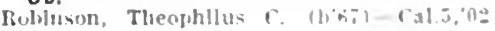
(引).

ANABEL, 60, MACON

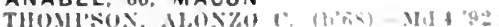
$\left(1^{\circ} a^{\prime \prime 2}\right):$ R.Y.J.

ANDERSON, 721, MCDONALD

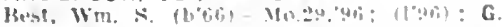

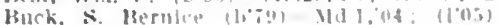

woT: (1'id)

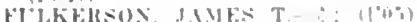

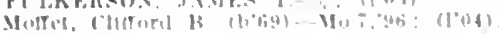

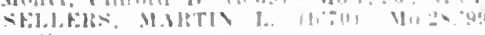
$(1, y+4)$

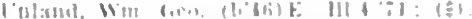

ANNISTON. 364. MISSISSIPPI

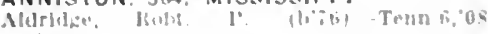

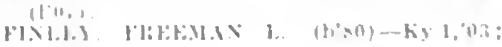

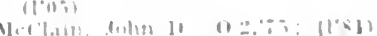

APPLETON, 98, CAPE GIRARDEAU

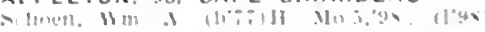

APPLETON CITY, 1,018. ST, CLAIR

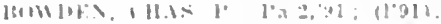

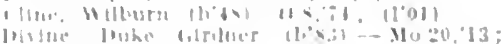

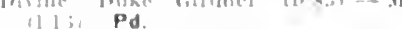

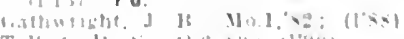

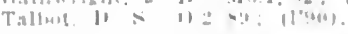

ARBELA, 131. SCOTLAND

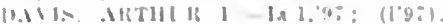


ARCHIE, 246, CASS

AlMAR, THOMAS W. (b"36) $千-$ Mo.R, Si (1'so)

TOL'T, BLisJ. B. (b'6ti)-Mo.4l, 01 ; (1'bl) $\mathrm{S}$.

ARCOLA, 300, DADE

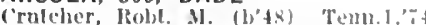

lilgklns, Abner-Tenn.11, 4 ; ; (1'00).

AROMORE, 500, MACON

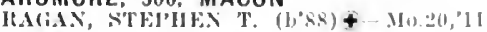
(l'II)

ARGYLE, 176, OSAGE

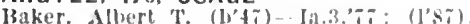

shirley, (ivo, H. (b'ss) Mo.Ii, II (1'il)

ARKOE, 87, NODAWAY

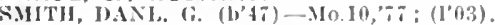

ARMSTRONG, 579, HOWARD

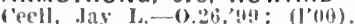

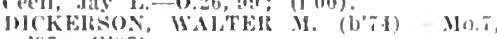
$97 ;(1,3 i)$.

THOMISON, WAITER SCOTT ( h'(G.T) Mo.1, $90 ;$; (I, 90$)$

ARROW ROCK, 336, SALINE

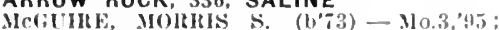
(I'9ī).

ASBURY, 250, JASPER

ALBFIRT, OMER LEROY (b'5) - Mo.', OI (l'0l)

ASHERVILLE, 100, STODDARD

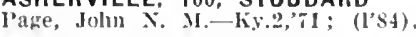

ASH GROVE, 1.075 , GREENE

COWEX, HOW'Al[) KELR (b'68)—-Mo.20, $01 ;\left(l^{\prime} 01\right)$.

DOOLIN, TIIOMAS (b'3 3$)-\mathrm{Ky}^{*}, 79 ;\left(\mathrm{l}^{\prime} 90\right)$

boolin. Thos. (C. (b'st)-Mo.2,11 ; (l'H).

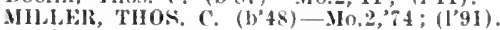

Smlth, Onas (b'83)-Mo.7, 04; (I'05).

ASHLAND, 341, BOONE

Christlan, $\mathrm{P}$. F.-D; (ठ)

Lamaster, W. L.-Ky.2,'83: (1'84)

Nlehols, Arlee Isbell-Mo.3, 04 ; (1'04)

smith, W. I.-Mo.I, 78 ; (l'S4)

SU(igint, FINIS (CLFFoRI) (b'8I)-Mo.2, 08: $(1$ 0 08$)$.

ASHLEY, 480, PIKE

P'hipps, W. C. (b'כs)-Ky.I,'s4; ()

ASHTON, 200, CLARK

Leedom, John MIIton-Ia.1,'81; (1'S4).

ATLANTA, 523, MACON

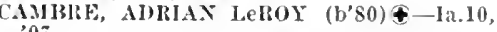
07

Halliburton, James M.-Jlo. 7,92 ; $(1,92)$

I.YIA, (IIUEON C.-Ky.1,'88; (l'93).

AUD, 25, OSAGE

LeFevre, IIarry M.-KIy.5,'98; (l'98).

AUGUSTA, 267, ST. CHARLES

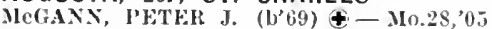
$(1 ' 05) ; \mathbf{G}$.

Schnittker, Kuward ('. $(1, ; 4)$ - Mo.1,98 (1'9s).

AULLVILLE, I66, LAFAYETTE

Aber, llm. H-IIO.D4, (17\%)

AURORA, 4,148, LAWRENCE

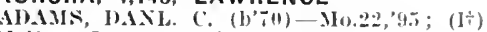

Melton, James A.-0; (l'8:3)

IHLLER, THOS. D. (b'66) - Mo.1,'9s: (1'99).

MOORE, CHAS. ANDREW (b'(ij) - Mo.t,

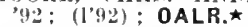

ROBERTSON, ROB'T. CLAHENCE (b'S3)

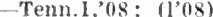

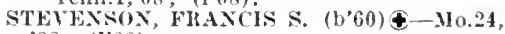
'S8; (I's8).

Townsend, Siml. N. (b'70)-Mo.5,00; (1'00),

AURORA SPRINGS (R.F.D., ELDON), I35,

MILLER
Bliss, S. D. $\rightarrow$; (1'S5).

AUSTIN, 300, CASS

Small, James F.-Mo.22,'92; (192); OALR.

AUXVASSE, 4II, CALLAWAY

Emmons, Franeis Iloward (b'7 8$)-30.28,08$; (l'og)

GLEASON, ROY T. (b'80) $\oplus-M o .34,08$; (l'08).

HLME, JOEL Y. \&-Mo.2,79; (I'84).

MacFARLANE, WU. W. (b'34)-IOo.2,'66; (I'84).

AVA, 713 , DOUGLAS

BIRDETT, CIIAS. W. (b'-2)-Tenn.8,94;

Gentry, .T. 1.-Tenn.8,94, Mo.28.99: (1'0I)

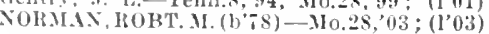

AVALON, 500, LIVINGSTON

("()]ALIEll, ALFItEII (1,86) - KY.2,'10

IIIME, JAMES II. (b'5:)-Ia.I, 80 ,

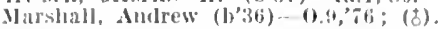

AVENUE CITY (R.F.D., ST, JOSEPH), 50, ANDREW

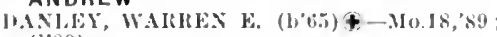
(1'89).

AVILLA, 150, JASPER

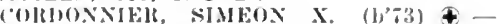
TeIn,5,'(3); (1'01)

BACHELOR, 35, CALLAWAY

H]1, IIALBEH'T IOOWLANI) (b'80)-Mo.2, $08 ;(\mathrm{I}, 0 \mathrm{~S})$.

BACON (R.F.D., JAMESTOWN), I5, MONITEAU

Inglish, Jolin E. (b'43)-O; (l'84)

BAD0, 15, TEXAS

(imurley, Osear k\&.- $D$; $\left(l^{\prime}, 90\right)$.

BAKERSFIELD, 270, OZARK

IJoggatl, Isiac B. (b'46)-0; (1'84).

WHEs, WM. T. (b'-4) 4 Tenn.s, 02 ; (I'0:3).

BALLWIN, 300. ST. LOUIS

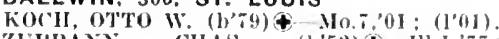

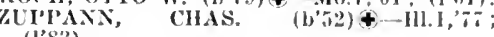
(I'83).

BARING, 379, KNOX

LUMAN, FHANK L. (b'74)-\$lo.34,04; (lo5)

O'Connor, Wm. F. (b'68)-Ia.I,'98; (l'94),

BARNARD, 338, NODAWAY

LAIIIABLi, JAIES A.†-Ia.t,'SI; N.Y.10, '91; (1'84).

Pollard David A (b'66)-110,18:89; (I'89). POLIARD, M. M.-Mo.1S,'93; (1'93)

BARNETT, 118 , MORGAN

HATLEl, W. I. (L'Jl)-Tem. 6 ,'82 ; (1'81)

WHFAT, W. J. (b'70)-IIo.1,98; (1'98).

BARRY (R.F.D., GASHLAND), 50, CLAY

ALTON, GROVEIK P.-HO.8,'9\&; (l'99).

BATES CITY, 74 , LAFAYETTE

Galıs, Jdgar F.-Mlo.8,'9S; (l'9S)

BAY, 130, GASCONADE

HAY,OE, JOHS S. (b'58)-Ky.5,'s ; (1'88).

BELGRADE, 250, WASHINGTON

H:rown, Hartwell H.-No.24,87; (1'9.1)

ROBLSEOX, JOHA 1) (b'82) - Mo.28, 06 ; (l'06).

BELL CITY, 3I6, STODDARD

Bennett, (has. O.-Mo.28,98; (l'90).

BELLE, 600, MARIES

BUR(IFSS, JOHX W. (b'Tl)-Wo.28, 03 ; $\left(l^{\prime} 03\right)$.

J0HNSOS, WI, E.-Mo.28,01; (1'01).

Nieweg, fieo. A. (l'9(i)-111.8,'13: (1'13).

Terrell, Saml. J. (b'i6)-Mo.28, 01 ; (1'01).

BELLEFONTAINE (R.F.D., CHESTERFIELD), 150, ST. LOUIS

De Foe, James L.

(see Chesterfleld.)

BELLEVIEW，100, IRON

Al'IJEIBEIRY, DALFY-Mo.2s, $06 ;\left(l^{\prime} 06\right)$; LD

RATES, CONWAY (b'56)-Mo.2,'83; (l's3). MEADOR, ADOLPH A. (b'75)-Mo.28, 05 ; (l'05).

BELLFLOWER, 500, MONTGOMERY

Bellamy, John A. (1)'86)-Mo.1,'90; (宩)

Iarman, Wm. R. (b'67) E-Jo.10, 03 ; (I'to3).

l'ierce, koscoe P. (b'Tl)-Ky.2, 95 ; (1.00).

BELMONT, 200, MISSISSIPPI

TARR, GOLGII H. (b'-1)£-Ky.2,92; (1994)

BELTON, 922, CASS

FAIR, SHIELDS W. (b'J3)థ-M0.20,00; (l'98).

MILLER, ROBT, II. (b'80)屯-Mo.34,05;

Moad, Ewing S. (b'60)-Mo.1,'82; (1's4)

WALKER, RICHARD P. (b'60)-Mo.8, 8 ;, Pa.2,'85; (l'83).

BENTON, 320, SCOTT

HAll, LRIEL, P. (b'九2)\&-Tenn. (l'98)

Henderson, Alex.-Mo.2,'万1; (l'84).

WADE, SHDNEY J.\&-Mo.1,94; (1'94).

BENTON CITY, 235, AUDRAIA:

DOUGLASS, WH. H.๑-Ho.28,'98; (l'98)
BERLIN (R.F.D., KING CITY), 60, GENTRY Irlce, James Viesley (b'83) - No.22,'In; (1'12); Pd.

BERNIE, 742, STODDARD

ALIEN, THOMAS $\left(: \quad\left(b^{\prime}+2\right)-M 0.28,01\right.$; (l'01).

Kenjamln, Allen M.-Ky.1,94: ( ).

Goad, Wim. II.-IIo.I0,48; (1’01)

ltuy, Davkl H.-Tenn.6,'8; (I'84); R.F.b. Itidde, John F-Tenn.6,'93; (1'96).

Ity an, Dansey-Mo.7,04; (1'05).

BERRYMAN, 35, CRAWFORD

'AIIKEIt, JAMLS IIAHOLL) (b'86)\$-Ky,2, 10: (l'11).

PARKER, WAJLEIR J, $\left(b^{\prime} 60\right)-0$; (1'85).

BERTRAND, 346, MISSISSIPPI

IIamner, Marsliall Dayton (b"56)-X.Y.J. ,7 7 ; $(1,78)$.

I.OVF, WX. SPENCER (b'83) -Tenn.5,

WALiACF, GEO. R. $\left(b^{\prime} / 2\right) \leftarrow-T e n m .8,98$; (1'00).

BETHANY, 1,931, HARRISON

BHOYLFS, FHAXKLIX II. (b'59)屯-Mo. 8 , '87; $\left(1^{\prime} 00\right)$.

BRYSON, F. JI. (b'72)†-Mo.20,98; (l’98).

Burgess, Frances E, ltutledge (b'59)-111.9,

02; ( ); It.F.I. 1.

Kavanaugh, J. W: (1) 68 - Mo. 18,86; (1'86).

Marth, Danl. W.-No.10,75; (1'85)

Jollison, Josepli Allen (b'60)-IIo.8,04; (l'04).

l'hillebaum, lohn C. (b'81)-Mo.22, 06 ; ( ). Seigenthaler, Geo. iI.-Mo.10,77; (1'94).

Stewart, 13. Sanford (b'60) - Mo.18,93; (l'03).

TANIIVERT, ASIIIAX IIENRY $\left(\mathrm{b}^{\prime} 53\right) \uparrow$ Mich.1,77; (1'83); Prop. P'rin. and Prac.

VANDIVEIT, WILLIAM WORTHINGTON (1)'89)-MI0.20,'13: (I’13).

WALKER, JACKSON (b'36)-Mlleh.1,6r; (1'83).

WFBI, IESIJE RICHARD (b'83)£-Ia.6, 09; (1'I0); S.

BETHEL, 235, SHELBY

S.IITH, LAWRENCE LETTON $\left(\mathrm{b}^{\circ} 6 \mathrm{i}\right)+$ 28,$99 ;(199)$

Smoot, lames J, (b'47)-Ia.1,75: (t).

BETHPAGE (R.F.D., ROCKY COMFORT), 50, MCDONALD

Bowers, Jos. Nanil.-Mo.28,07; (1'07).

BEULAH, 50, PHELPS

IT FED, IHENR Y L.-Mo.28,'04; (l'08)

BEVIER, I,900, MACON

BIREWINGTON, GEO. F. (b'63)-II0.22,'92;

GHONOWAY, TERREXCE P. (b'87)థMo.2, I0; (1,10).

MASOX, LEE O. (b'78) \$-Ala.4,04; (1'04).

lkowland, D. D.-No.2, 84 ; (l'84). loWLAXID, W..1. P. (b'61)-M0.2,'88; $\left(1^{\prime} 88\right) ; 0$ p.

Warsox, THOMAS S. (b'58)-Mo.,'s2: (l'84).

BIGELOW, I56, HOLT

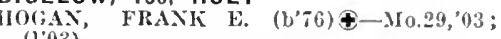
(l’03)

BILLINGS, 760, CHRISTIAN

BIROWN, Eld B. (b'45)-Ia.1,76; (l'83)

BROWN, FREDK. H. (b'i6)†-Mo.28, 99 ; (l'99).

NAGLE, PATRICK E. (b'52)£-Mieh.1, '80; (1'05)

shafer, Waiter Wm. (b'65)-Mo.2.,92, Mo.28,93; (1'01).

Wilson, J. A. (b'37)-Tenn.6,'s5; (I's5).

York, James W. (b'49)-Ia.1,74; (1'8:).

BIRCH TREE, 497, SHANNON

C'ourtney, John I. (b'45)-0.S,' 81 ; (b)

beatherage, Wm. N. (b; 78$)$-Ark.1,12;

(I)ruggist)

GUM, POSEX D. (b'72)-Ky,4,'94; (l'97).

BIRMINGHAM, I36, CLAY

WARD, THOS. J. (b'64)-IIo.\$,'96; (l'97).

BISMARCK, 848 , ST. FRANCOIS

Faton, Jesse I. (b'63)-Mo.1,'84; (1'84).

Kerlagon, C. C. (b'55)-Mo.2,'83; (l'83).

BIXBY, 5U, IRON

Henderson, W'm. ('. (b'81)-Ky.2,'12; (1'12).

BLACKBURN, 389, SALINE

IRICHART, GRANYLLE A. (b'60)-Ky.2, '86; (1'04). 
BLACKWATER, 371, COOPER

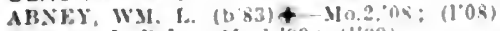

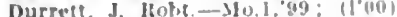

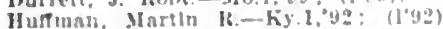

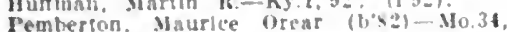

12: (1'12)

BLACKWELL, 73. ST. FRANCOIS

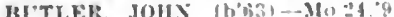

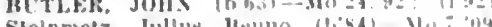
(l'09): Pd.

\section{BLAIRSTOWN, 288. HENRY}

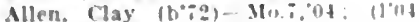

rarnes, Ira (b.66)-Mo.5.91: (191)

BLAND. 359. GASCONADE

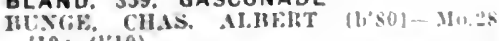
10: $(1,10)$.

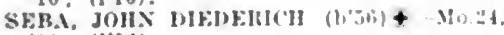
'92: (1.04).

\section{BLOOGETT, 422. SCOTT}

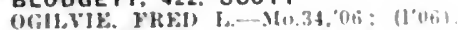

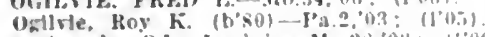

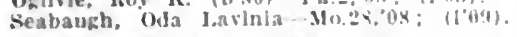

BLOODLAND, 100. PULASKI

MALIFTTE, CYLLS (6.82)+-ky.9.09: (109).

BLOOMFIELD, 1.147, STODDARD

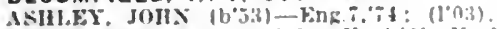

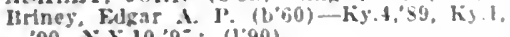
90 X.1.10.9': (1'90)

Faxs, SAMI'E, II. (b'it)-Ky.l, (1'99).

Phlillos, Eldon -Mo.2.'\&3: (1'st).

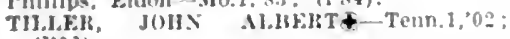
(1'กะ).

Trlbule, John W.-Tenn.6,'s0; (1'sfi)

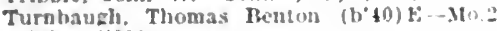
$60: 11011$.

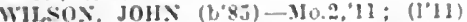

BLOOMSOALE. 100. STE. GENEVIEVE

JARVIS. TORVHL WM. (b'SO) - Mo.3t. '04: (1'05).

BLUE EYE, 25. STONE

Miller, Chas. k. (b'(ii)-Tenn. 11,01 : (1'i)!

BLUERIDGE (R.F.D., GILMAN CITY), 67. HARRISON

Stowers, Guy 1.-1/n.8,00: (1'00).

BLUE SPRINGS, 361, JACKSON

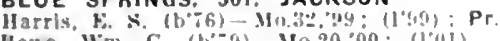

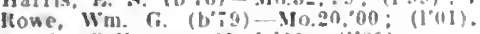

smilh, Zollcopes- No.1, SQ: (1'QSi).

BLYTHEDALE, 345, HARRISON

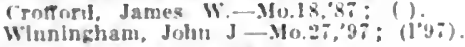

WImningham, Johis J-Mo,
BOGARD, 316, CARROLL

HAIISI, WM. C. (1,391)-111.1.65: (1.93)

Exell, s. W. $\left(h^{2}, i\right)-k y, 2,42:(191)$

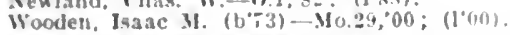

BOIS DARC, 200, GREENE

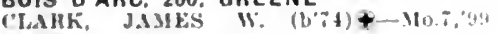
(1.02).

BOLCKOW, 376. ANDREW

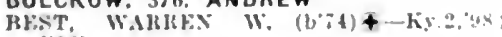
(1'98).

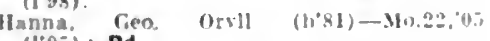
(I'0,j); Pd.

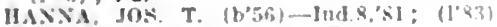

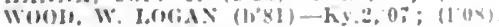
BOLIVAR. 1,973, POLK

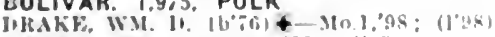

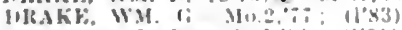

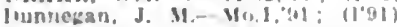

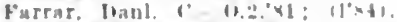

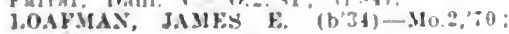
(I.8.is)

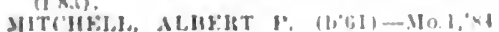
(1) $x+1$ ).

Odor, w. S. (b'31)- $10.10,81$ : $(1 \times 83)$

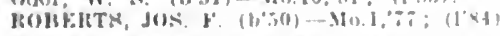

BONNE TERRE, 5.500 , ST. FRANCOIS

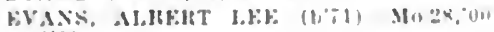
(1'0n)

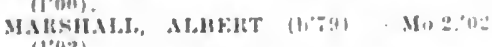
$(1,0) 21$

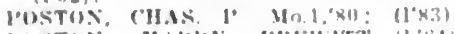

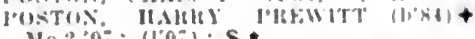
$\left.310.2,07 ; 10^{\prime 0}\right)$ : S.

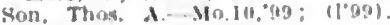

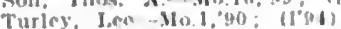

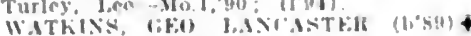

W.

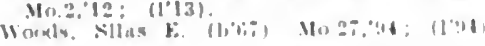

BONNOTS MILL, 175, OSAGE

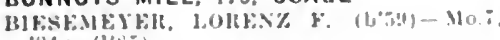
$84:(1,8,5)$

BOONESBORO, 47, HOWARD

Finn, Thos. (bitbi)-l'it.14;it; (1'st).

BOONVILLE, 4.232, COOPER

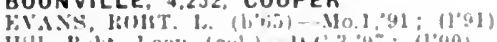

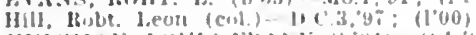

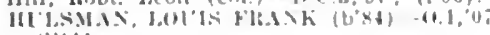
(1)ill)

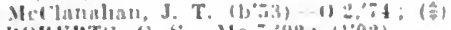

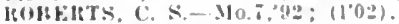

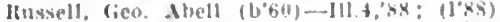

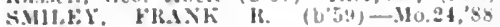

(1'ss): s.

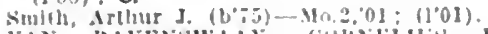

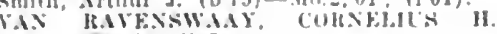

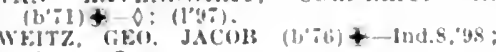
(1'11): $\mathrm{s}$.

BOSWORTH, 767, CARROLL

BHOWX, ARTHUK GRANISON BOES (1)'05) IIo. 34,$113 ;$; (1'0:3).

Brown. Hetary G.-Mo.10,'s3: (1'83).

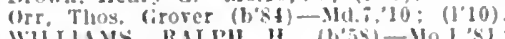

WHLLISWS, RALPH H. (b'55)-Mo.1,'s1

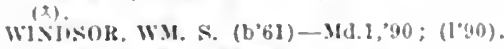

BOURBON, 382, CRAWFORD

HTME, LDWIS L. (b'64) t-110.28,05: (I0).

BOWER MILLS, 82, LAWRENCE

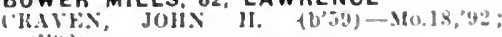
(1'!n:

Jasper. W'm. Cloyd (b'62)-0.1,89: (1).

BOWLING, GREEN, 1.385. PIKE

Blg:z, James Bzown (6.90)-\$10.2.'13; (1'13).

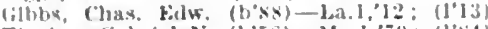

Tinsley, fabriel X. (b'58)-Mo, 19 ; 1184$)$ W.M.TEKS YLOYH ERSEST (160)-Mo.28,

Wilcuxen, T. H. (1, 6.5) H-Mo.5.00: (1'10)

BOYER (LORING P.0.), 10, WRIGHT

smith, rasld 11. (b'35)- 0 ; (1'st).

BRADLEYVILLE, 6I, TANEY

IIuminel. I.011s ( 6 . (b'63)-M0.27.95; (1'96).

BRAGGADOCIA (DUDLEY P.0.), PEMISCOT

Cirainger, Ciustavlus A.-Tenn.5.04; (1'05).

BRANDSVILLE, 500, HOWELL

iullic. James Franklin-Tenn.s, 03; (100t).

BRANSON, 700, TANEY

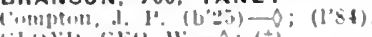

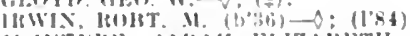

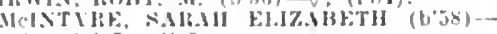

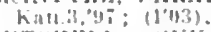

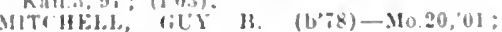
(I'01).

BRASHEAR, 458, ADAIR

Barnes Frumb If (1,5i)-110.10,85: (1'si)

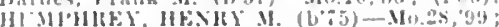
(10? (19).

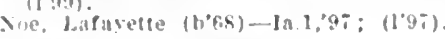

BRAWLEY, 30, OREGON

Le'nlite. WIIT, (i. $\rightarrow$; (I'S4).

BRAYMER, 1.027, CALDWELL

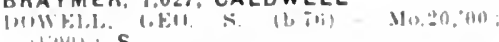

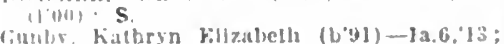

(1) 13)

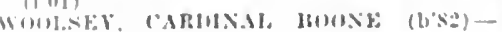
H.

BRECKENRIDGE, 1,025. CALDWELL

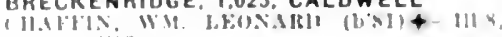

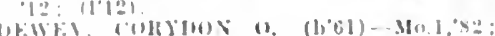

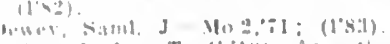

Mond

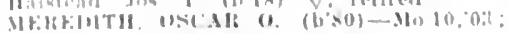

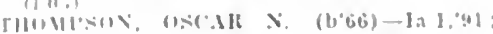

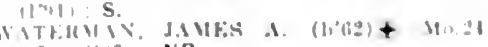

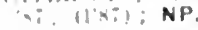

BRIOGETON, I29, ST, LOUIS

IIt,

BRIGHTON, 150, POLK

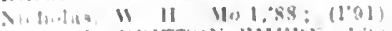

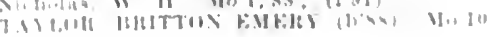

BRIMSON, I04, GRUNDY

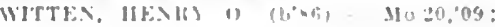

BRINKTOWN, - MARIES

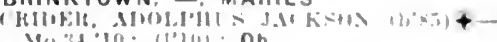

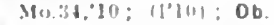

BRISCOE, 66, LINCOLN

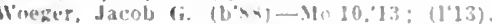

BRONAUGH, 263, VERNON

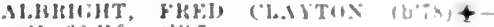

Mo. 20,10: (10),

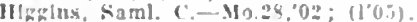

BROOKFIELD, 3.749 , LINN

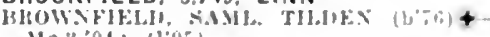
Mo.:0.01: 110,0$)$

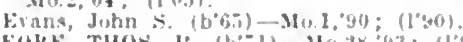

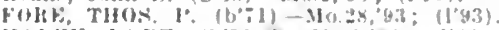

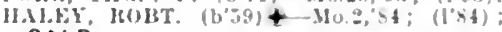
OALR.

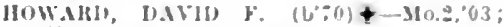
$(1 \% 3)$

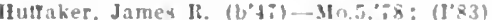

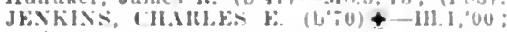

$(1 \cdot 0+1)$.

peugh, kiluin lew: (15:33)--1104,95;

(I'yi).

I'R.ITT, HONER II (b'45)-111. 1, :2: (1'83)

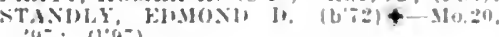
(4); $(1.57)$.

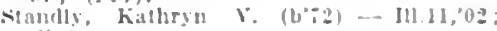

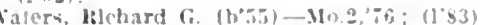

BROOKLINE STATION, 300, GREENE

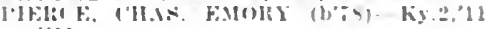
1!०11!

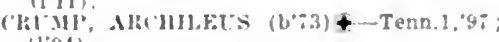
(1'94)

BROWNING, 629, LINN

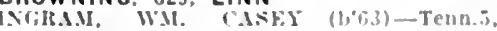
93: (1'93).

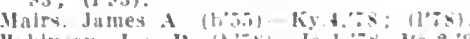

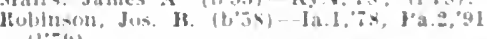
$(1 \div \div+4)$

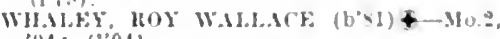
?I: (I,04)

BROWNINGTON, 348, HENRY

llogers, James Roberl (b'SJ)-Mo.20,09: (1' $(100)$.

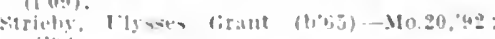

$110+101$

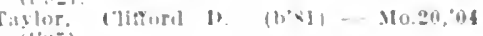

aslor, Martin Haker-0):31,"3x; (1'8:3) Hoi In practlete.

BRUMLEY, 200, MILLER

Cunner, Juhll l. (1) BRUNOT, 80, WAYNE

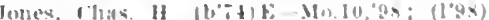
BRUNSWICK, 1.606, CHARITON

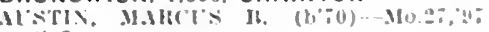
$(1,46)$.

buwell, Cyrus W. Mo.33."0n: not lin prac Mrea l'rut l'harmars, Mo 38

(1)

(10) (1,8,i)

BUCKLIN. 790. LINN

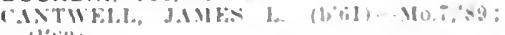
(1)

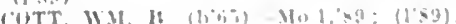

BUCKNER, 410, JACKSON

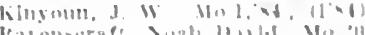

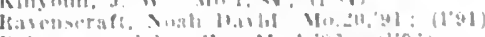

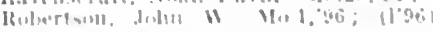

BUFFALO, B?0. DALLAS

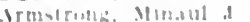

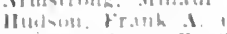

lalingen, lians, p

I.1 1 ind 1

BUNCETON, 78.8 , COOPER

BII IUPT. WV. HH:II

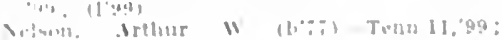

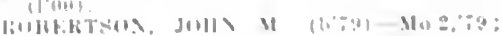

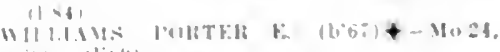

DUNKER, 606, REYNOLDS

li(b)

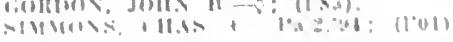


BURFORDVILLE, II4, CAFE GIRARDEAU

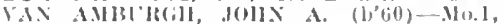
'86; ; $\left(l^{*} 96^{3}\right)$.

BURLINGTON JUNCTION, 942, NODAWAY

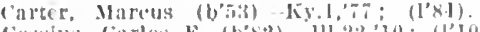

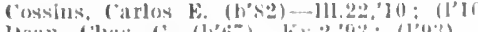

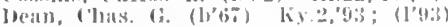

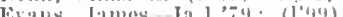

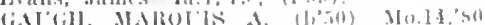
(l'84).

BURTON, 100, HOWARD

WIILIA.US, W. F. (1,? i) - Mo.28,98; (I')S).

BUTLER, 2,894, BATES

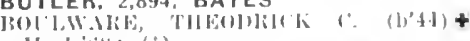

Mo.1, is: (:).

(1). $1, \mathrm{si}$

'II.1.

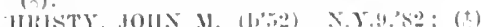

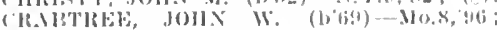
(1.96i)

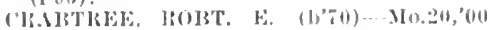
(1'(1)1).

fosteliti, IPIOS. W. $(1,60)+.110 .27,9 \mathrm{I}$ (l'9I); G.

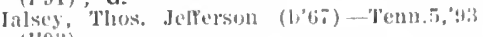
(I'98)

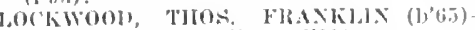

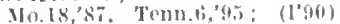

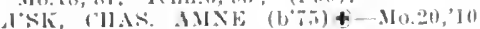

(I'11) : K.F.

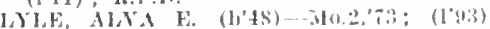

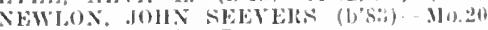

os: (1"0 08$)$ : OALR.

Norrls, James M. (b'42)-Ia.10,65; (l'83)

WHIIPl,E, XITIISIIEL, 1. (b"3t)-Mo.2,

(65); (8) LR.

BUTTERFIELD, 200, BARRY

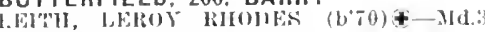
?i:?; (l')(i)

BYNUMVILLE, 100, CHARITON

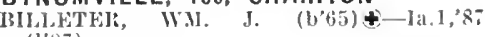
(1'8i).

\section{CABO0L, 789, TEXAS}

Brooks, 'Thomas (b'71)-Mo.20,'92; not in practice.

Coats, I. M.-Mo.10,99; (l'a9)

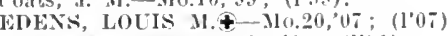

PATTOX, 1. WM.-Yd.1, 81; ; (1':11).

ROBERTSOX. TOHN T.-110.8,94; (1'97).

CAINESVILLE, 887, HARRISON

Doolittle, Fmmett Warren (b'si)-1a.3,75

(1'12).

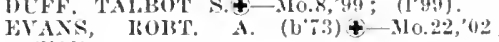
$(1,02)$

foodrich, Richard Johnson - Ky.l,'y3; (ling)

(T93) saml. D. (b'44)-Ia.1,74; (1'83)

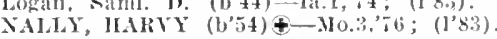

CAIRO, 220, RANDOLPH

Al.LEN, JOHN l'EARl, (b'Ti)-110.28,'0f (l'05).

ORR, CHAS. ALGLSTL's (b'a) - Mo.10, '13; (I'13).

CALEDONIA. I28, WASHINGTON

Duckworth, Walter I'. (b'TS)-ML.10,'04; (1'05).

Eversole, (ieo. II.-IIo.I,'S6; (1'86)

(ioodykoontz, Wm. K. (b'4 $)-$ IIo.1,66; (1'90).

\section{CALHOUN, 684, HENRY}

lBronaugh, James H. (b'39) - Io. 1,'71: (1'84). (iray, Alfred A. (boti)-Mo.7, 996 ; (196i)

IIusick, J. I1.-No.10,07; (I'06).

CALIFORNIA, 2,154, MONITEAU

BURKE, JOHN P. (b'57)-M0.2,78; (1'83).

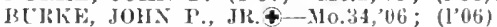
hatusman, Fred-Mo. 7 ; $\left(08 ;\left(1^{\prime} 99\right)\right.$.

(iRAY, LASHLEY M. (1,58)-Mo.2,'s2 (['s3).

Houser, Fredk. Wm. (b'y4) - Mo.1,'80; (I'84).

KI, ABER, HLGO C.-Ger.20,'64: ( ) 1'OPEJOY, II. R. (b',5)-JU., II; (1'91).

CALLAO, 526, MACON

AILEX, FRANCIS WITHERS $\left(b^{\prime}, 3\right) \oplus$ Mo.3,98: (l’39)

WELCH, WM. ALEX.INDER (1);2)€-MO.2, '(0;); (1'03).
CALUMET (R.F.D., EOLIA), 10, PIKE

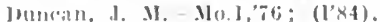

CALWOOD, I00, CALLAWAY

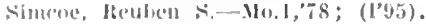

CAMDEN, 477. RAY

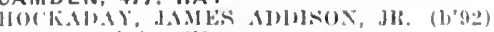
No.20, $13 ; 3 ;(1,13)$

CAMDEN POINT, 169, PLATTE

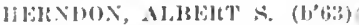

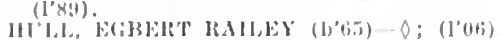

CAMERON, 2.980, CLINTON

Iruold, Orlon T-E-0.2,98* (1'98).

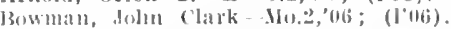

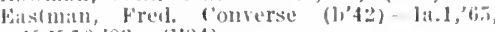
X.Y.10,'8:3; (1'84).

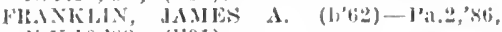
N.Y.10.'8R: (1'01).

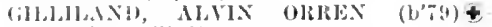

Io. 8,$03 ; ;\left(l^{\prime} 03\right)$

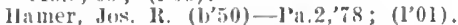

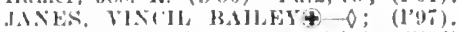

Mcloonald, Edwh s.-No.18,'s: : (1's4).

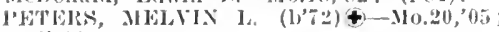
(1'05).

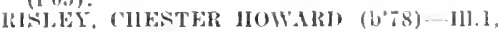
(1) ( [?]1)

Shaw, Elwin Everelt $(1,74)-0.7,88$; (3'89).

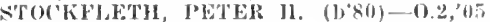

II0.28, 06 ; $\left(1^{1} 06\right)$

stungliton, Elgin I. (b'81)-J11.11, 03 ; (1'02).

CAMPBELL, 1.781, DUNKLIN

Brown, (has. W. (h'65) - Mo.7, 9y0; (l'91)

Jrown, Johl - No.7, 90 ; (1'91).

Cone, Mareus 1.-110.27,99; (1’99)

Ilammersley, (ieo. O.-Tem.8,00; (l'00).

Kesling, Perey J. (b'is) Mo.28,'Il (l'il)

Hay, Chas. $A$. (1, 51)-0.6,7\%; (1,04).

Pollock, D. C. $O$; (1'84).

CANALON, 296, NEW MADRID

S'Tl'Pl, ABRAILAM LINCOLN (1,83)IIo.28,'11; (1'1]).

STOKJE, CIIATCEx M. (b'80)-Mo.10, 1\%; (1'12).

CANE HILL. 60, CEDAR

All.DER, IOHNE. (b'43)- Ky. I, '76; (l'84)

CANTON, 2.218, LEWIS

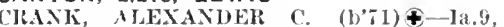
95; (1'97); S.

DYNLOP, HALIY HOWARJ) (b'64)\& N.Y.5, $86 ;(1,97)$.

FERRALh, (1HAs. (b"58)-Mo.22,'83, x.Y.10, $84 ;(1 ' 84)$.

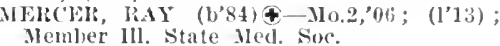

Nichols, Frank J. (b'73)-Mo.28,'05; (l'05) ; not in practice.

Relo, Wm. A. (1,69)-Ia.10, 01 ; (1'01)

sllANS, (HAS, OZIUS (b'71)-Mo.1,95; (1'95).

CAPE GIRARDEAU, 8,475, CAPE GIRAR-

\section{DEAU}

IBERIRY, JOHN W. (b'71)-】[0.28,96; (1'96) Blomeser, Adam b. (1,65)-Mo.24,yI; (l'91)

Blount, Danl. I. (b’58)-Mo.2,79; (1'84); R.F.D. 1 .

COPP, WALTER FIANK (b'83)-N.Y.1,'1 I (l'13).

CENSISGHAM, HARVEX L. (b'66)-Ma.1, '89; (l'89) ; OALR.

MALTON, ROBERT P. (b'68)-Mo.28, 94 (1'05).

HOPE, DANL. HOWARD $\left(\mathrm{b}^{\prime}, 9\right) \oplus-110.2$ 04; (l'04)

IIOWARD, WILLIAM N. (b'62) †-M0.2,'90 ; (1'90).

NETTLES, FRANK H. (b'72)-MI0.2.'05; (l’05).

Odell, Isail Hugh (b'79)-Mo.34,05; (l'05) J'aton. Warren C. (b'.5)-Ia.1,82; (l'93). Peirounet, $A . \longrightarrow$; not in practice

PORTERFIELD, JOHN D. (b'41)-Mo.1,'S4; $\left(1^{\prime} 30\right)$

Rolston, Wm. T. (b'54) H-Ill.4,76; (l's3). Rosenthal, Moses (b'5\%)-Mo.1,'80; (1'03) SCHYLZ, GTSTAV BERNHARD $\left(b^{\prime} ; 0\right)+$ Mo.24,92; (1'92); I'res. State Board T. (1'08).
TARLTON, GLOHGL W. (b'50)-Mo.2,'81; (1'84)

IORRBCK, Jos. C.-Mo.10,"49; (l’99).

Vorleck, Markaret A.-Mo.10,"92; (1'92).

llALKR, lido. W. (b'76)-110.2,03; (l'03).

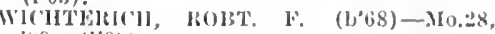
$39 ;(1,8,3)$

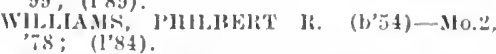

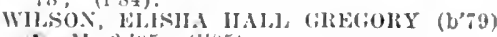
$+-M 0.2,40,\left(I^{\prime}(1.5)\right.$

FOUNT, WM. k. (b'53) †-Temm.5,98:

CAPLINGER MILLS (R.F.D., STOCKTON), 100, CEDAR

llackelmail, C. 'T, -0 ; (1'84)

CARDWELL, 874, DUNKLIN

liack, fll (b'76)-Ky.1,04; (1'05).

13lrchett, John (: (1,bi)-Ky.4,"84; (1'01).

l'arker, 1). A.-Tenm.9,"(1); (1'01).

CARL JUNCTION, I,II5. JASPER

Bruton, besse ' $\mathrm{T}$. (b'32) $\mathrm{E}-\mathrm{O}$; (l'65).

Gilson, Hawin it. (b'72)-110.J0, 06 ; (1'06)

sherwood, Ilortense 1. (1,50)-I1l.1,78; ( I $\left.^{5} 84\right)$.

CARROLLTON, 3,452, CARROLL

ATWO()I), WM. (i. (b'84) \& - Mo.2,'11; (I'11).

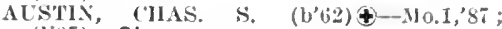
(1'87); 0b. Benson, Iobt. Mavin (b'82)-Mo.20,'05; (l'05); S.

BIRUNER, ETHAN E.-Me.3,'04; (1'05).

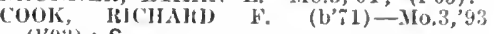

(1'93) ; S.

('ooper, John C. (b'32)-Pa,1,56; (l'84).

Cralon, Marshal W.-N.Y.5,'82: (1's6).

(ratlin, Wm. II. (col.)-Tenm.7,97; (1’37).

IIarris, Roland 0 . (b'51) II-O.8, 3 ; (l'90)

SAMLHis, LYXN (16'52)-Ia.1, 81 ; (l's3);

F.D. 6.

TILL, HARHY W.—-N10.1,'91; (1'91)

Williams, Chas. S. (b'58)-Ky.2,'80; (c).

CARTERVILLE, 4,539, JASPER

Barry, Jesse K. (b'70)-Mo.10,'y9; (l'99).

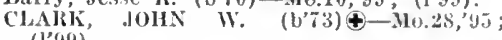

DUMBAILD, BUNN ALLEN (b'73) Ky. 9,$203 ;(1,03)$; S.

Dumbauld, Wm. A. (b'47)-0.8,75; (1'87).

Haile, Enoch (-Mo.20,07; $\left(1^{\prime} 07\right)$.

STORMONT, RILEY NCIIJINN (b'T4)\&Ky.1,'9s; (1'12); Op.

CARTHAGE, 9,483 , JASPER

IBaker, Karl E. (b'79) -No.3,03; (l'03).

I3ROWN, WM. I). (b'61)-Mo.1,'84; (1'84).

Burch, Edw. Judson (b'66) II-Mo.1,87; (l'01); S.

Chambliss, Joseph J. (b'57)-Ky,4,'78: (l'95).

COTTINGHAM, IRA A. (b'60)-0.2,'85, Mo.7,"90; (1'\$5)

Flower, Frank W.-II-Ill.4,76; (l'85)

GENTRY, WILLIAM H. (b'i3) - Mo.1,'96; (1'96); $\mathrm{S}$.

HALL, 'ELIZABETH L. (b'68)-Pa.7,92; (1'93).

Ilewitt, D. E.-No.1,'81; (1'84)

Johnson, Geo. W. (b'56) E-Pa.17,78; (1'84).

KETCHAI, CASSILS M. $\oplus-$ D.C.1,'93; (1'94).

Korn, Adolf L. (b'75)-Ger.19,'02; (l'05). McMurtry, Thomas Arthur (b'70)- 10.20 , 95; $\left(\mathrm{l}^{3} 03\right)$.

POST, WINFRED BRYANT (b'71)£-Mo.1, $97 ;(197) ;$ OALR. *

POWERS, EVERETT $\left(b^{\prime}, 69\right) థ-0.2,{ }^{\prime} 92$,

STEELF, WALIACE E. (b'58)†-Ia.10,01 (l'01).

TAYLOK, CALVIN B. (b'63) - Mo.1,'85; (1'85).

Webster, ltoger Williams (b’ (1'02).

Wise, David-Mo.7,'92, Mo.24,'93; (I'94).

CARUTH, (R.F.D., KENNETT), 75, DUNK-

\section{LIN} Brotherton, James Ionroe (b'i1)-MIo.2s,
,00; (l'00).

CARUTHERSVILLE, 3,655, PEMISCOT

BYARS, HENRT T. (b'59)థ-Pa.2,'S6: (1'87).

Conrad, Albert IR.-Tenn.6,'89; (1'89); Pd. Crafton, James A. (b’59)-Tenn.1,97; (ま). 


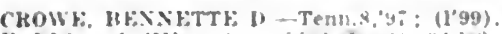

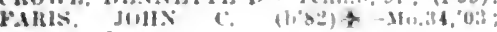
(I'03) ODA.*

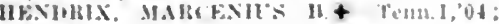
(1? 0.5$)$

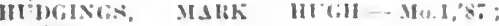
(I, 88 ).

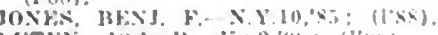

L'TrD. Jos 16-ky

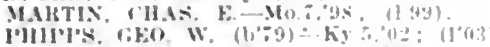

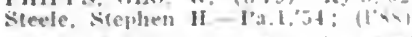

CASH (R.F.D. CALLAO), 23, MACON

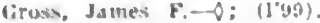

CASSVILLE, 781, BARRY

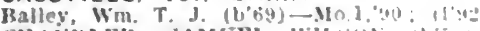

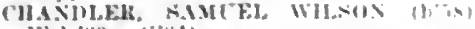
III.1: $\times 9$ : (19:3)

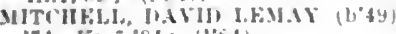

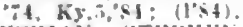

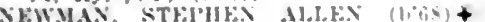

Y10.97,92: (I'94).

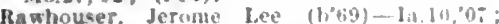
(1'09).

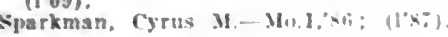

CATAWISSA, 100, FRANKLIN

HEMKR:H, WII. H.ABRISOI Mo.31,04; (I'0).

CAVE SPRING (R.F.D.. WILLARD)。 50. GREENE

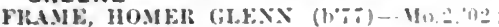
(1'01).

CEOAR CITY, 208. CALLAWAY

BHley, Chas. A.-Mo.1,'T: (1'?1)

CEDAR HILL (R.F.D., HILLSBORO), 25, JEFFERSON

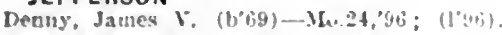

CEDAR SPRINGS, I50, CEDAR

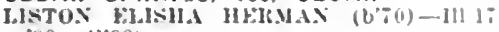
'98: (l'98).

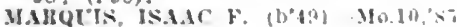

CENTAUR STATION. 150, ST. LOUIS

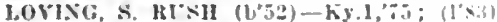

CENTER. 340, RALLS

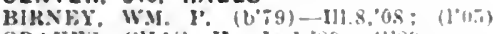

GRAVES, CHAS. H.-la.1,89; (1'89)

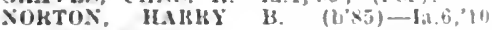
$\left(I^{\prime} 10\right)$; OALR.

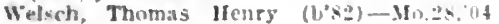
(In: $n$ i).

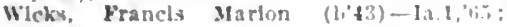
(ITOi).

CENTERTOWN. 285. COLE

BACIBY, HFAJ. IIONEH $\left.\left(6^{\prime} 66\right)+-16,20\right)$. 's9; (1'90).

Latimer, Marion A, (l, $\$ 3)-M+1,192$; not In practlce.

CENTERVIEW, 400, JOHNSON

kozarth, John Hicha rif--1l1.1,"91; (1"!:2)

KIng, Hobt. Mclice MU.24,2:; $(1,92)$.

CENTERVILLE, 500, REYNOLOS

SHY. THOS. IIISTUX (b.a.) - hy : (IOOT).

CENTRALIA, 2.116, BOONE

A'STENE, CHAS. W. $(1,76)+-M 0,3,111$$$
\text { (1) } 01)
$$

(1)01)

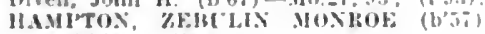

Mo. $27.91:(1,91)$.

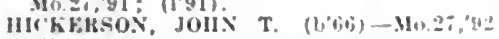
(1092).

llulen, J. Calrin (f, $4 \$$ )-Mo.1,7 $x ;(1, s, 3)$

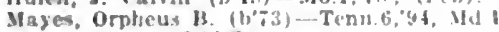
'y5: (1'y:) : OALR.

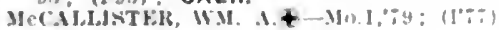

CHADWICK, 150. CHRISTIAN

liensley, H. W, $\rightarrow$ : (1'S4).

CHAFFEE, 2.082, SCOTT

('urdres, Henry I. (1'6.5)-T(n).9,"11) (1'00).

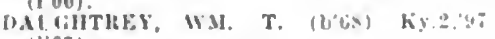
(lio 0 ).

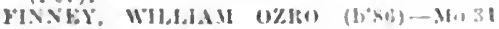
(II): $(1 \times 10)$

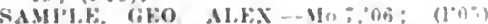

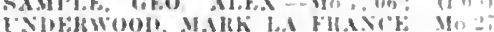
DSR: (I,DK)

CHAMOIS, 649, OSAGE

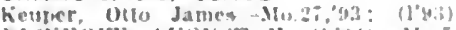

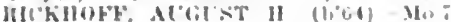
(1.93).

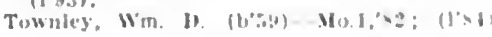

CHAPEL HILL (R.F.D.. BATES CITY), LAFAYETTE

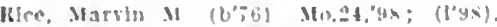
CHARITON (R.F.D., MENDOTA), 17, PUTNAM

Hart, Has. II. M.-MIa.10,02; (1'0I)

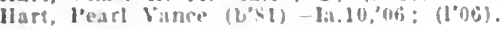

CHARITY, I00, DALLAS

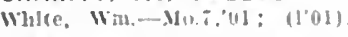

CHARLESTON, 3.144. MISSISSIPPI

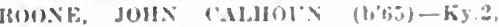

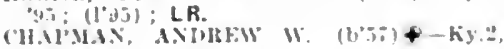
:

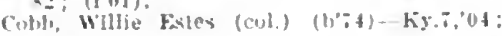
(1'09)

Fubley, Byron firnest-Ky, 1, 40; $\left(1^{\circ} 00\right)$; not in juactlee.

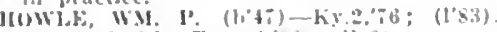

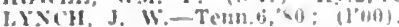

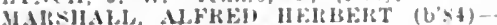
Vo.3t,0i: (108): OALR.

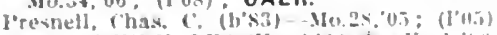

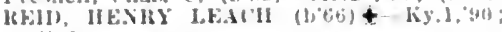
$\left.\left(\mathrm{t}^{n} \geq\right)^{2}\right)$.

hulve, Join M.-Tenn. 1, '09; (1'01); not la practlee.

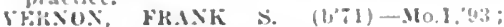
(1'93).

CHERRY BOX. 30. SHELBY

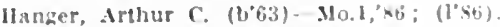

CHESAPEAKE, 30. LAWRENCE

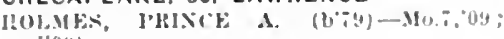
(I'09).

CHESTERFIELD, 125, ST. LOUIS

loe Foe, Iames L. (b64)-Mu.1, 91 ; (1/0) : (Jillefuntalne)

\section{CHILHOWEE, 425, JOHNSON}

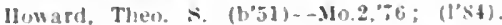

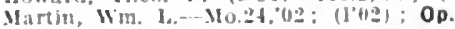

CHILLICOTHE, 6.265. LIVINGSTON

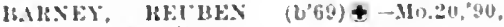

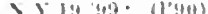

Haketey, Thomas Joln (bos)-Mo."2s.99:;

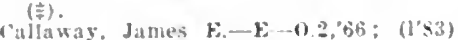

lowell, itobt. 1.-No. 20,$93 ;$ (1)

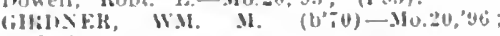
(I'yos).

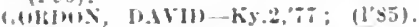

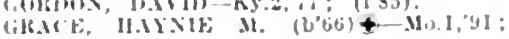

(I'(4)); Pr.

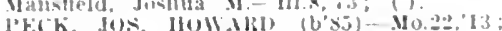
(I'1:i): $\mathbf{P d}$

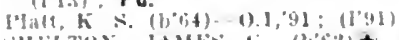

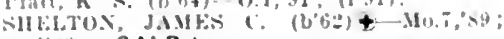
(1) $\$$ ! : OALR.

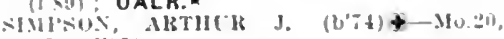
3,$5 ;(1.95)$

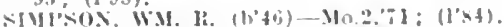

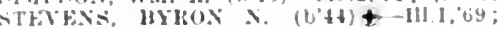
(:) ALR.

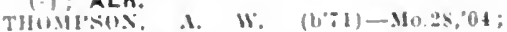
(1'11) ; OALR.

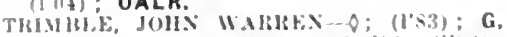

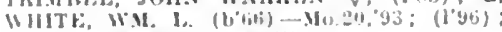

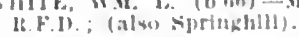

CHULA, 384, LIVINGSTON

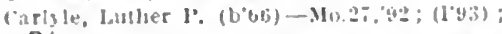
Pd.

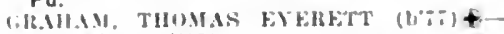
Ifo :- ot: (1.03)

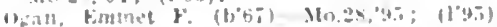

CIVILBEND (R.F.D., PATTONSBURG), 78. DAVIESS

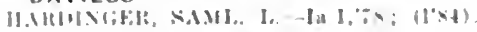

CLARENCE, I.322, SHELBY

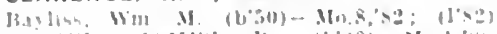

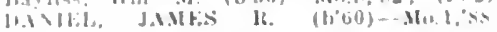

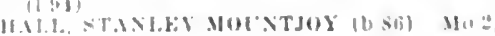

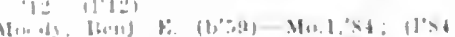

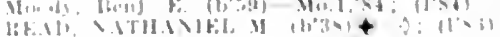

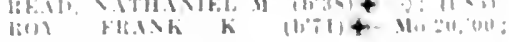

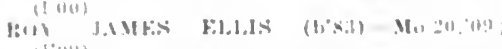

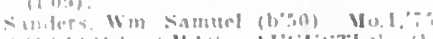

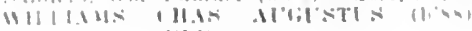
$31, \ldots(12,11: 2)$
CLARK. 300. RANDOLPH

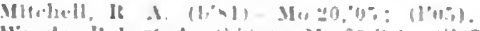

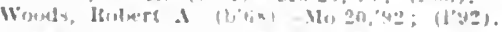

CLARKSBURG。399. MONITEAU

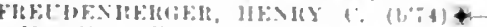
M10.3, 0)?; $11^{\prime} 0 \div 3$.

CLARKSDALE, H16, DEKALB

KIILIOTTT.

(1) 31

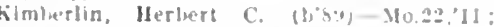
(1'1:-1.

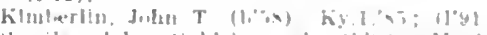

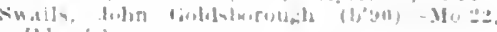
"11.

CLARKS FORK (R.F.D., BOONVILLE), 50. COOPER

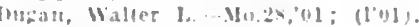

CLARKSVILLE, 918. PIKE

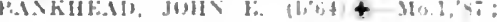

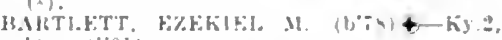

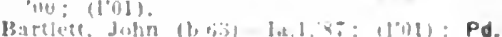

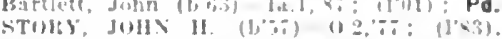

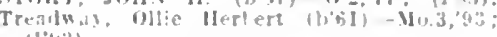

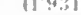

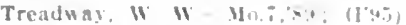

CLARKTON, 682, DUNKLIN

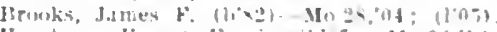

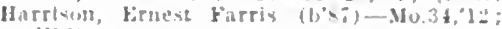
(I, $1: 2)$.

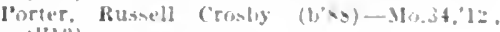
(I)13).

CLAYTON, 1.500, ST. LOUIS

larnard, Albert L.

(Nee Ne. Louik.)

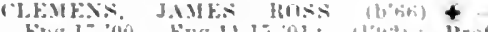

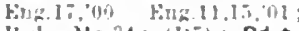

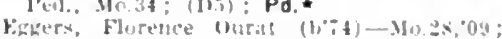
(1'09).

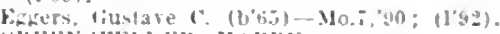

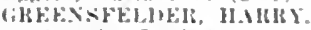

(sie si. Louls.)

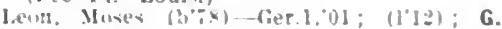

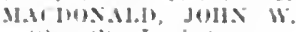

(see st. Louls.)

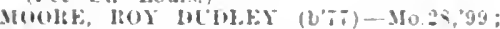
(1999).

SIUPTI, J.MES BOSXEL-Mo.28,04: (t'0 $(0,1)$.

CLEARMONT, 263, NODAWAY

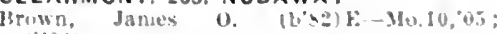
(l'opi).

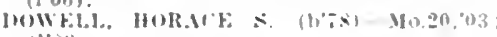
(1'i):il.

CLEVELAND, 170, CASS

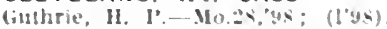

CLEVER, 248, CHRISTIAN

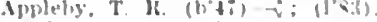

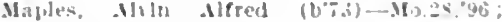
$\left(1^{2} y 6\right)$

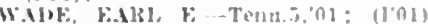

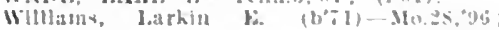
$(1+4+i)$.

CLIFTON CITY, 175, COOPER

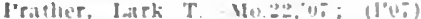

CLIFTON HILL. \$00, RANDOLPH

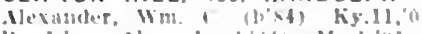

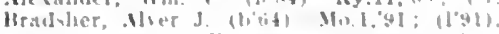

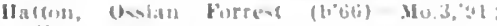
$(1,9)$

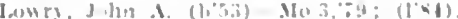

CLIMAX SPRINGS, 250, CAMDEN

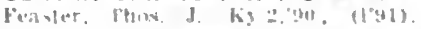

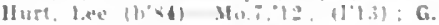

CLINTON 4.992. HENRY

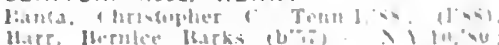

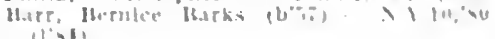

is is is

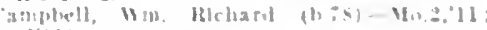
(1)111)

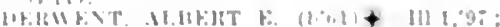
$(1, b !)$, OALR.

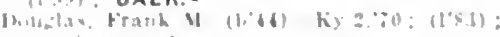

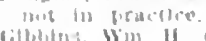

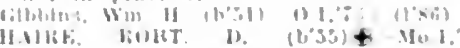

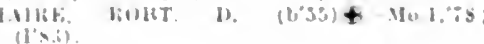




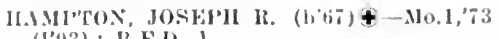
(P93) ; 1R.F.D. 1 .

Jennings, Williston T. $($ ( 653$)-M o .20,92$; $\left(I^{\circ} 9: 2\right)$.

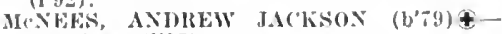
Ky.5,02; (l'07).

vellierion, rredk. F. (b'6i) 11-111.1,91: (1'91)

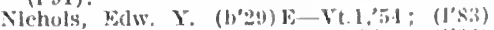

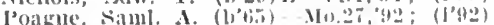

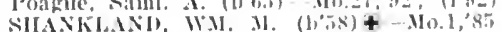

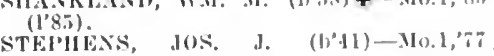

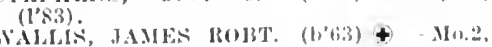

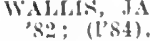

CLYDE, 360. NODAWAY

Hohls, (ieo. W.-la.1,'80; (t)

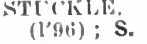

COAL (R.F.D., CLINTON), 75, HENRY

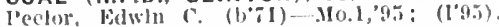
COFFEY, 390. DAVIESS

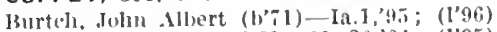
HOSTEL, TILODORE X.-Mo.20,04; (l'05). COFFMAN, 20, STE. GENEVIEVE

J'opp. Edw. Martla (b'79)-Mo.34, 0 T TIUNER, JAMES A. (b', SB) $\rightarrow$; (I'\$3).

COLDWATER, 60, WAYNE

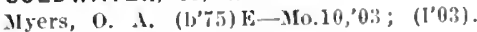

COLE CAMP, 910, BENTON

BAY, JALITYA-MO,28,04; (1.05).

DICK. M.ACHICE (1,60)-MO.1,83; (1'83)

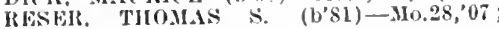

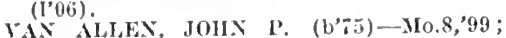
(1'01).

COLLEGE MOUND. 230. MACON

TTRIPPEER, FIANK L. (b'6T)-Mo.28,'96; (1'96).

COLLINS, 259, ST. CLAIR

Follin, Eilijah 1). (b'45) $\rightarrow$; (t)

IANDAKER, CHESTER L. (b'68)థ-Mo.28, ,00; (l'00).

Sitton, Wo. Ir $\left(b^{\prime} 49\right) \mathbf{E}-0$; $\left(l^{\prime} 84\right)$.

sitton, Wm, II. (b'81)-Mo.33,'02; (1'03)

COLONY (R.F.D., RUTLEDGE), 89, KNOX Wright, Moses Frank (b'40)-IId.1,90 ; (1'8:3).

COLUMBIA, 9,662, BOONE

BELDEN, WM. E. (b'69)€-Ky.1,93; (l'93); OALR. $\star$

Bradford, (ieo. A. (b'65)-MIo.7,'ss; (1'88).

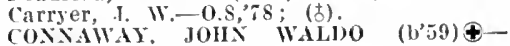
IIo.3,91; (i’9L).

Itavidson, Chas. Oliver (b'56) E-N10.10,92; (1'92); Op.

DeJarnett, Win. B.-MIo.2,';I; (t).

DOLLEY, 1.JWI1) HUGH-IId.7,02; Prof. I'atlli. and Baet., Mo.3: (F2)

Dysart, Wm. P. (b'65)-Io.1.87; (1'87).

GORDOX, JAMES (1'?8)—-Mo.3,'81; (1'83)

IIopper. Robert L. (b'64)-Mo.1,'si; (1'8i); OALR.*

Hume. W. A.-Mo. 7,89 ; (1'90)

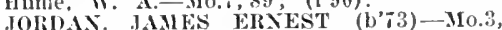
, $90:(1,95)$.

KAMPS(HMINT ATGLST WM. (b'75)\&Mo.3, $06 ;\left(\mathbf{l}^{\prime} 06\right) ; \mathbf{S}$.

Lawrie. Wm. H. (col.) (b'71)-Neb.5,96; $(1,97)$.

LENTS, MALCOLMI DIANE-NO.3,'75; (古).

long, Osear 11 - Kv.2,92: (l'92)

MCALESTER, ANDREW WALKER (b'41)110.2, 66 ; (5); Fmer. Prof. Surg., 210.3 ; S.

Mikel, Henry F.-Mo.3, 00 ; (l'01).

Miller, James A-Mo.10,01; (1'01).

MIILER, WILTER IICNAB (b'59) (- Cal.1,95; (F1,2).

MITCHELL, OLIYER WEXDELL HOLMES (b'86) \&-Mo.3,08; (1'08); Assoe. Prof Path and Bact. YIo 3; (F2) : LD.

Mitchell, Porter J--No.1,'s0; (f); not in practice.

Noore, Otis Andrew (col.) (b's8)-Ill.11, '10; (1'11)

Moss. WOODSON (b'52)-Mo.3,74; (b); Troe. Med., Mo,3.

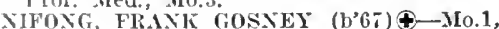
89; (l'89); (Maplewood) ; S.ネ
NOMBIS, WHLFORL A. (b'58)-N10.3,'83:

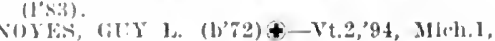
(1)1; (1'02); Acting Dean, Mo.3; (131); OALR. *

Shitefer, Wm. 1t.-M6.3,97; (1'97)

Simpson, Floyit-Mo.2,'93: (1'93).

Thylor, John Alhert (col.) (b'il)-Tenn. $94:(1960)$.

THOHNTON, Jos. E, $(1,66)+-.10 .3,93$;

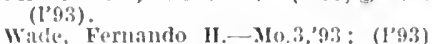

Watson, Berry A.-N.io, 61 ; (5)

COLUMBUS, 150 , JOHNSON

Kiurt\%, lanl, Webster Boone, Ir. (b'7t)I(0.3.,9.5; (1'95).

COMMERCE, 544, SCOTT

MIAI'KLELGE, IIUGIII T. (b'63)\&-No.2, $88 ;\left(I^{\prime} !(4)\right.$.

Frazer, Theodore k. (b'4t) - Tenn.5,"82; (1's2).

FKA\%EL, THOS. ROYDEN $\oplus$ - Tenn.1,00; (I'(0)

COMPETITION, 35, LACLEDE

TINAI, EY, JAMES' HI-MO.22,'87; (I'85).

Wrlght, Edw. 13.-Mo.10,'76; (1'85).

CONCORD (R.F.D., AUXVASSE),

\section{CALLAWAY}

Fllis, Wm. 13.-II0.5,'88; (1'93).

CONCORDIA, 931, LAFAYETTE

LEISER, FREDK. D. (b'54) - MI0.2L, 85 , Ky $2,96:\left(l^{\prime} 97\right)$

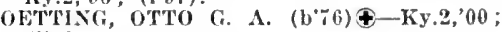
(l'00).

SCIINEIIER, JACOB A. (b'56)-310.20,94; (1'95); OALR.

SCIIREIMAN, FERDINAND (b'67)-Mo.24, $96 ;\left(1^{\prime} 96\right)$.

Welnberg, Herman (b'52)-Mo.10,'92; (l'92). CONNELSVILLE, 652, ADAIR

Lewis, Chas. W. (b'64)-Ky.5.95; (1'95).

CONWAY, 394, LACLEDE

BENA(XE, OT'TO CLARENCE (b'75)-Mo.7, '01: (l'0I).

Marsh, Stephen R. (b'56)-0.2,'84; not in practice.

RESER, JOS. H. I1. (b'59)-II0.22,'93; (1'9i). COOTER, 300, PEMISCOT

COOPER, THOS. S. (b'66)-Tenn.5,'91; (1'91).

CORDER, 649, LAFAYETTE

CARTIIRAE, LEIVIS, JR.-Mo. 8,'04; (l'05).

CARTHRAE, I.EWIS E. $+-N 10.1,74 ;(1,83)$.

MARTIN, EDW. F. (b'5î) $₫$-Mo.1,'84;

$\left(11^{\prime} 84\right)$

(l'06),

CORNING, 253, HOLT

Long, Louis II.-Mo.22,03; (1'03).

CORRIDON, 50, REYNOLDS

BUGG, ANDREW E. (b'7 6 ) $-210.28,93$; (I’03).

CORSICANA (R.F.D., PURDY), 75, BARRY Overton, Abuon Alexander (b'30)-La.1, 37 ; (I'83).

OVERTOA, OSCAR SAML. - Tenn.1,87; (1'01); l'rof. Clin. Mled., MIo. $\tilde{t}$.

COSBY, 170, ANDREW

ALLEN, CHAS. L. (b'73) $†-M 0.29,98$; (I'98)'

COTTLEVILLE, 225, ST. CHARLES

BALTZER, HERMAX F. W. (b'51) $€-$ Ger.20,75; (1'75).

Currier, Marion L.-Pa.1, 75 ; $\left(1^{\prime} 02\right)$.

COTTONPLANT (R.F.D., HORNERSVILLE), 300 , DUNIKLIN

BOND, VAN H. (b'68)-Mo.1,93; (1'93).

COTTONWOOD POINT (R.F.D., CARUTHERSVILLE), I70, PEMISCOT

SHARP, ISAIC FLOYD (b'79)-Tenn.1, 08 ; (1'08).

COUCH, 40, OREGON Brooks, Andrew J. - No.1,78; (1's3);
H.F.D 1.

Rhea, Calvin (b'61)-Mlo.1,'82; (l'84).

COWGILL, 363, CALDWELL

COWLEY, GEO. B. (b'61)-Mo.1,'82; (1'82).

PARRISH, ISAAC N. ( (b'76) $\rightarrow$; (1'01).

Pollard, Dow S. (b'5.5)-Ia.1, it; (I'83).

SMITH, STEPHEN DECATUR '(b'6i) $₫-$ IIo.2,'96; (I'96).
CRAIG, 62I, HOLT

DAYIS, JOHN MORGAN (b'62)థ-Mo.3,85; (1'93).

NAUMAN, O. W. (b'T)£-I11.6, 03 ; (l'09). Ottman, John Carl (b'87)-Mo.20,'10; (1'11). CRANE, 1,002, STONE

IOC:(iE'T', JOS. C. R. (b'82)-NLo.28, 05 ; (l'0.5)

KERIT, HOMER L.-MO.T.01: (1'0I).

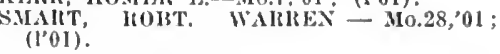

CREIGHTON, 400, CASS

(iRIFFITH, WATHi, ll, $\rightarrow$ : (l'84).

GIRFFIT, FOCAAR MCDONELA Mo.20,'11: (l'11).

LEVENS, IT. I3. (b'65)-NI0.28,93; (1'93).

TANDY, ILONIDAS W. (b'30)-0.2,85: $\left(1^{\prime} 87\right)^{\prime}$.

CRESCENT, 100, ST. LOUIS

Fraser, Samuel 1I.-NI0.24,'01; (1'01).

CREVE COEUR, 400, ST. LOUIS

DENNY, IROBT. B. (b'-0)-Mo.28, 03; (1'03).

Ham, Wrin. J. (b'67)—No. i,'98; (l'99).

CROCKER, 500, PULASKI

OHIICK, GEO. WRIGHT (b'T5)-Mo.1,'98;

RAYL, JOIIN EDW. (L'78)-MLo.3,o4; (1’05).

CROSS TIMBERS, 500, HICKORY

Clark, Johın W. (b'62)-110.7,'92: (1'96).

CROSSTOWN, 75, PERRY

Carner, Kirby C. (b'78)-NI0.24,'01; (I'01).

CRYSTAL CITY, I,800, JEFFERSON

COMIERFORD, JAMES JOS. (b'81) $\oplus-$

Io.34,09; (1'09).

DONNELL, JESSE F.૯-Mo.24,91; (1'91).

CUBA, 619, CRAWFORD

('OX, WALTER S.\&-ML.1,'89; (1'93).

FINLEY, ROBT. II.-1I0.1,'81; (1'94)

HEIRZOG, (ILSTAY G. ADAH-No.24,'95; (1 95$)$

MARTYX, JOIIN H. (b'69)-Mo.1,'90; (1'91).

CURRYVILLE, 238, PIKE

Gibbs, Henry C.-IIo.2,'84; (l'85).

SHOTWELL, JOHN H.-ML.7,'95; (1'95).

DADEVILLE, 401, DADE

Drisdell, Theodore J.-110.34,05; (1'05).

llembree, Owen Y.-Ky.4,95; (1'95).

Kirby, Ben R. (b'66)-Ní.1,'94; (l'94).

DALTON, 26I, CHARLTON

KIMBALL, GALIEN FORREST (b'81)IIO.22,'I0; (1'I0).

DARLINGTON, 352, GENTRY

Ganaway, Alfred M. (b'66) - Mo.18,'92; (1'92).

WOOLIS, ASA L. (b'74)-Mo.20,00; (क).

DAWN, 400, LIVINGSTON

YATES, DAYID D. (b'77)-Mo.22, '03 ; (1'93).

DAYTON, 60, CASS

DODD, CASPER SWART (b'69)-II 20,201 ; (l’0I).

DEARBORN, 499, PLATTE

HALE, JOS. M. (b'64)-MO.22,'91; (l'91).

IOORE, NILTON H. (b'i0) \&-MIO.22,'96; (1'96).

SMITH. ALBERT S. J. (b'i1)-Mo.22, 05 ;

DE CAMP, 75, PHELPS

Livingston, A. A.-MIO., 00 ; (\$).

DECATURVILLE. 25, CAMDEN

CLAIBORN, EDW. G.-MO.1,96; (1'96).

DEEPWATER, I,398, HENRY

Howard, ('orwin F'. (b'56)-IJo.10,'83; (l'84).

RLSSELI, JOHN'J. (b'61) £-Mo.20,'89;

( (1's9).

Wilson, John S. (b'48) $\rightarrow$; (1'83).

DEERFIELD, 129, VERNON

PRIMM, NINIAN B. (b'78) - Ia.10,04; $\left(l_{0} 0 J\right)$.

DEERING, 500, PEMISCOT

LCTEX, DREW WM. (b'8I) - MId.T,'11; (I'I 2 ).

DEFIANCE. 168, ST. CHARLES

Snycer, Osear L.-Mo.T,'09; (夆).

DE KALB, 391, BUCHANAN

McAdaw, Ernest B. $\left(b^{\prime} 73\right)-M o .22,97$; (1'97). McAdow, James Wm. (b'83)-Mo.20,08; $(1,08)$

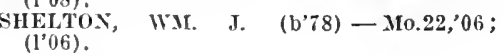


DENLOW, 30, DOUGLAS

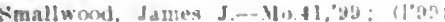

OENVER, 250, WORTH

Antrobus $j$ \&

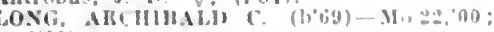
$(1,00)$.

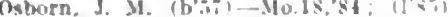

DES ARC, 287, IRON

Farr, Pred F-Mo.2S,98: (1.03)

Park, valotion a (bol)

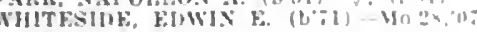

$\left(I^{\circ} 0 i\right)$

DESLOGE, 2.500, ST. FRANCOIS

HETEL ROLLO REIRTEL (h"-

Q1: (1.05)

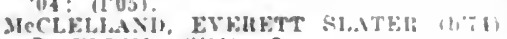

4-I11.I, (03: (1)11): 6 .

T(RLF:, JOH: 6. (i)"7t

DE SOTO, 4.721. JEFFERSON

BHYAN, GRFGOKY, G. (b"69) + Mo.2:44:

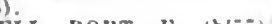

DONNELL, ROHT. K. $\left(\mathrm{b}^{\prime}:\right)+-M a .2$, on

$(1,00)$

PARRAR, W. H. (b'56)-MO2,75: (I'st)

gibson. Waller $\mathbf{E}$. (b 633$)-Y 0.1,91$ : (l'ii)

Keaney. James-II-Mo.5., "1: II's.

sklnner, Frltz F.-Mo.23,99: (1'99)

DE WITT, 423, CARROLL

logan. John P. (b'54)-0: (1'83)

THOMPSOX. FRASK E. $\left(b^{\circ}=0\right)+-1112,94$

(1)13): Member Oblo State Med. Isist.

OEXTER, 2,322, STODDARD

Dleckman, Wm. C.Mo.T, 01 : (I'0l): S

pouglas. John Howard (h',0) - Ky,9.03 $(1004)$.

migan. Wm. Jay (b:73)-Mo1:99: (

IA RLE, FRANK (b'89)-Mo.34,'0: (I'10)

LA RIE. UARRY (b'6̈)-Ky.2,9z; (1'01)

SLAYDH. JOHX I. (b.5) - Ky.2, (1'34).

VEKSol, GFo. W. (b'56) - Ind.8." 56

WALTERS, CHAS, B.-MO.28,07; (1'05).

DIAMOND, 500, NEWTON

(HAYMAX, TH,ISEFS SIDNFY (b'63) -

Mo.24, $92:$ : (1'92).

DIEHLSTADT, I60, SCOTT

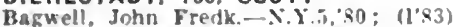

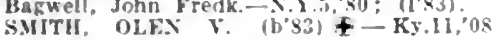
(l'09)

DITTMER. 29, JEFFERSON

Roeser, John Prancls $\left(b^{\circ}, 0\right)-M o .28,10$; $(1 \cdot 10)$.

DIXON, 7IS, PULASK

MeClLLY, JAMES (b'hs) $4-$ kan 2,06 (1.07).

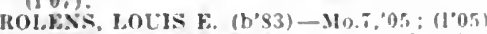

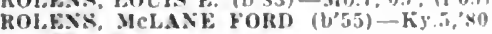
(1'89); $0 \mathrm{p}$.

VOX GREMl, HEXRY J. (b'63)-Mo.1, 87 ; (1'8:): G.

DONIPHAN, 1,225, RIPLEY

Hanlels, John Joseph-K5.5.'96: (1'47)

IIUMF, JOHX R. (b'62)-Mo.2s,97: (l'97)

PHOCTOR, SAMEb. A (b'bi)-Ky.4, (1) 84$):$ s.

ROBINSON, JRAIBLRY NORTOX, JI.(b'84) -MO.34, 0 \&: (l'08)

DORA. 35, OZARK

fiordon. Timothy Daul.-B: (1'81)

Morzan, Walter $c \rightarrow 0$ : 11921 .

DOVER, 214, LAFAYETTE

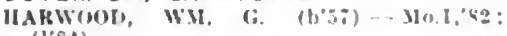
(1'84).

DOWNING, 513. SCHUYLER

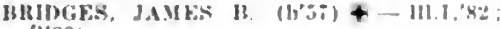

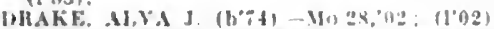

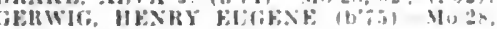
$02:(1 ' 01)$.

DRAKE, 85. GASCONADE

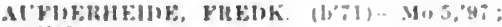
$(1,9 i)$.

DRESDEN. 175. PETTIS

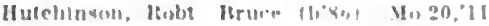
(I"II).

DREXEL. 512, CASS

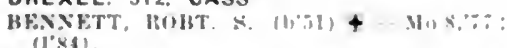

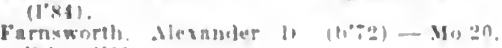
is: 1100 :

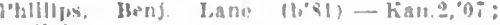
(1) 11 (1)

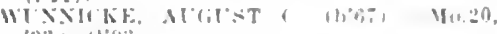
31: 1193

DRYGLAIZE (R.F.D.. SLEEPER), I3, LACLEDE

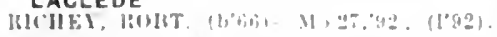

ORYNOB, 45. LACLEDE

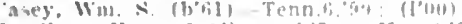

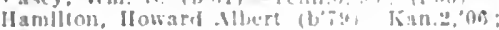
(I'06).

DUDLEY, I50, STODDARD

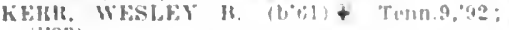
(1.93)

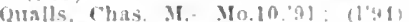

DUENWEG, 2,500, JASPER

Irrookshire, W. II. IIn.tI, no: 1$)^{\circ} 01$

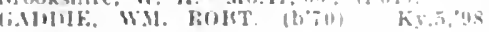
(I'D?)

DUNCANS BRIDGE, 150, MONROE

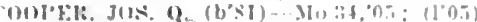

DUNKSBURG (R.F.D., KNOBNOSTER), 75 JOHNSON

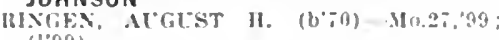
(loger

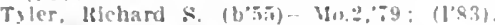
DUNLAP, 150, GRUNDY

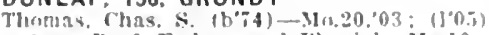

IN-1 Prof. Embry, and Illysiol., Mo.10.

DUNNEGAN, 250, POLK

II.IIX, CHAS, NEWTOY

12: (1'12).

villingarorth inderson Tenn.s.01; (1’01).

DURHAM. 200, LEWIS

(1uster, Jant. M. (b'6t)-Mo.19,"92: (1"92)。

liangerfleld, Firzll slont (b'it)-ill.14,04; (1. I 2$)$

DUTCHTOWN, 46, CAPE GIRARDEAU

NHONTXER, NOE: $F$. (b'T9) - MU.i,": (1'05).

DYKES, 240, TEXAS

JUIRSTUN, REX I.-MO.IS,94: 11'9S1

EAGLEVILLE, 330, HARRISON

lOWWISF, JAMES L.4-Mo.20,96: (1"96)

ROIERTYOS, (HAS, H-W0.22,93; (1'93).

EAST LYNNE, 277, CASS

FOSTEL, FriIK W. (b;2) - Ky.4,'94: $(1,95)$

Ilanan, J. W. (b'33)-Ja.1,'81; (1*92).

EASTON, 225. BUCHANAN

Jubham. D. F" (1,72)-Mo.22."03; (1.02)

lalvert, Iloward Allen (b'\$9) - Neb.6,12 (1'12).

\section{EAST PRAIRIE, 1,243, MISSISSIPPI}

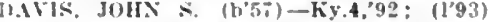

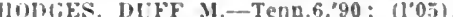

MAKTIX, ALBELT J. $\left(b^{\circ} 70\right)$ - Mo.24, $96:$

MAITIX, S.IMH, I. (b'\%)-Mo.2,06: (1.06)

EBENEZER (R.F.D., SPRINGFIELO), 100 GREENE

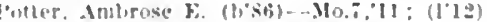

EDGAR SPRINGS. 75. PHELPS

(1)

EDGERTON, 534, PLATTE

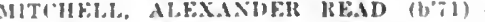

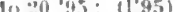

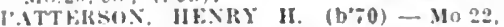
int $(1004)$.

Shafier, \&. Atraham-Mo.1,:6; (s)

EDINA, 1,562, KNOX

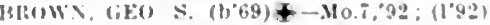

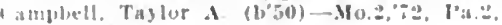

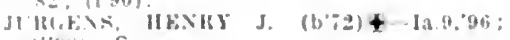
(l'sx): S. $\left.11^{\prime} 01\right)$

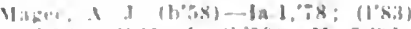

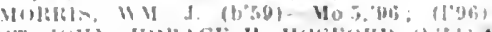

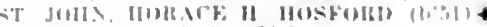

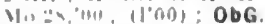

EDMONSON, 125, BENTON

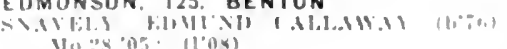

EDWARDS 6\%. BENTON

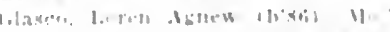

EGYYPT MILLS, DO, CAPE GIRARDEAU

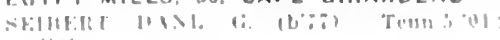

ELDON, 1,999, MILLER

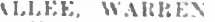

$(1+(1 i)$

Rurkuiat, ('llnton

$(10+4)$

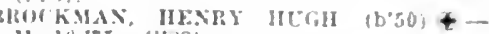

all.t.

00 : $(100)$.

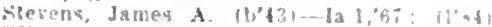

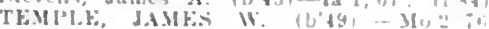
(l'8:i).

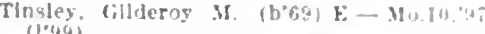

II. Il hibils.

$(1 \circ 90): G$

ELDORADO SPRINGS, 2.503. CEDAR

Bolllnger, John M. $\rightarrow$ : (1"00)

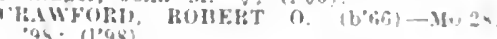

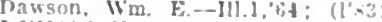

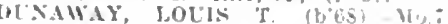
(1.91)

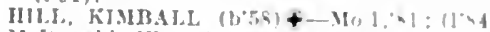

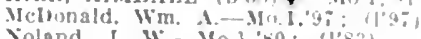

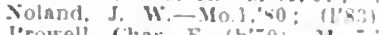

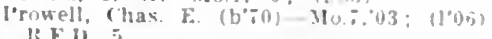
li. F. II.

IROYSTOX. W. P. (h'6l) - Mo.2."\$3; 1":"

Scholl. Jesse IH $\left(b^{\circ}+1\right)-M 0.1, \cdots:$ (l)

ELDRIDGE, 75, LACLEDE

FOY.TTER, COLEMAN I. (b'30) $\rightarrow$ : (l'st)

ELK CAEEK, 35, TEXAS

Harmon. Geo. W. (b'j0)- ; (103).

ELKLAND, 50, WEBSTER

HAHEY, EZEKJHT, II (b'-3)-MO - 20.49 $(1.99)$

ELIKTON. 125, HICKORY

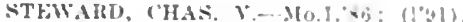

ELLINGTON, 500, REYNOLDS

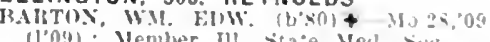

(1'0!) : Menber In. Siate Med sive

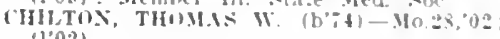
$(1,02)$.

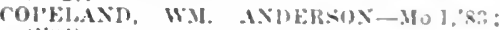
(1'st)

Moure. John IIenry-Mo. 1.,2n: (").

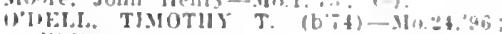
$1]^{\prime 2} 3\left(6^{\circ}\right)$

ELLSINORE. 350, CARTER

Mcllierson. I). ¿ (

Sheets, folumbus I'- Mo.10,49; (I'?R)

ELM (R.F.D., KINGSVILLE), 20, JOHNSON

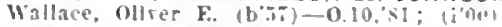

ELMER, 512, MACON

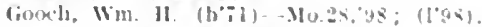

ELMO, 3\$2, NODAWAY

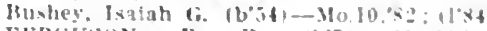

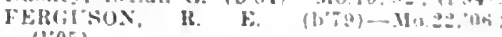
(1.05).

Cieley, James Filjah-Mo:s, 04: (1004)

ELMWOOD (R.F.D., BLACKBURN), 59 SALINE

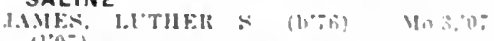
(1)0\%)

ELSBERRY, 1,018. LINCOLN

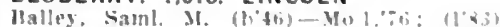

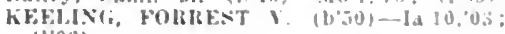
(1.03)

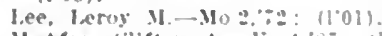

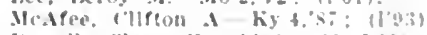

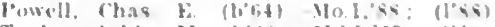

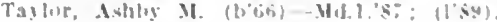

ELSEY, 125, STONE

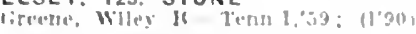

ELSTON, 108. COLE

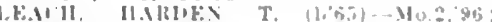

ELVINS, 2.071, ST, FRANCOIS

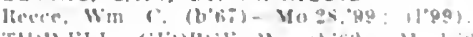

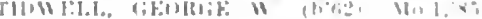

ELWOOD, 30, GREENE

Hanllus, killiers I II

EMUEN, 100, SHELGY

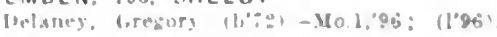

EMINENCE, 200 . SHANNON

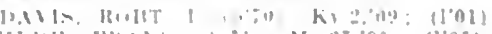

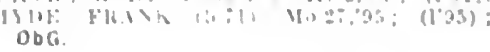


EOLIA, 343, PIKE

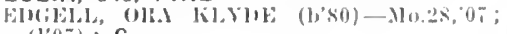
$\left(10^{\prime \prime}\right): G$.

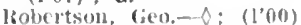

ESSEX, 548, STODDARD

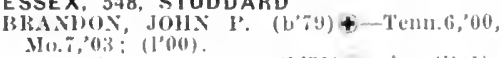

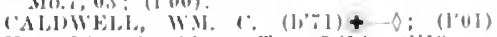

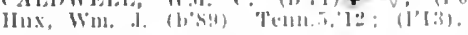

ETHEL, 423, MACON

B.IIVING, NEII II.VIN $(1,96)+-M 0.31$, $12 ;($ I'l:2) OALR.

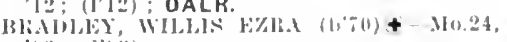
, $03 ;$; (l'b3)

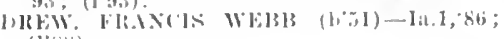
(I"SS).

EUGENE, 195, COLE

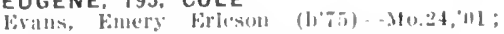

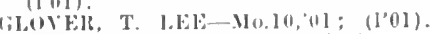

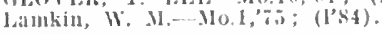

EUREKA, 500, ST. LOUIS

Monrue, lace billsworth (b85)-110.2,07; (1) 10 -

Ioncoe, Ite E.-Wo.2,81; (1'84)

EVERSONVILLE (R.F.D., WHEELING), 5I, LINN

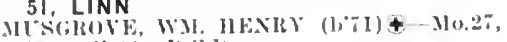
sug; (l'39); li.r.1).

Tharp, J. I1.-IIO.2,65; (1'84).

EVERTON, 522, DADE

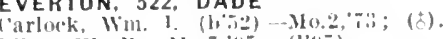

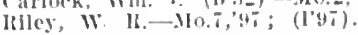

EWING, 327, LEWIS

colts, l'ill.

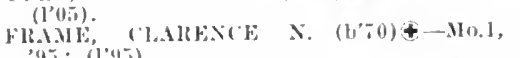
; $45 ;(1,1,5)$

frime, I. I?: (b'35)-0; (1'83)

EXCELLO, 150, MACON

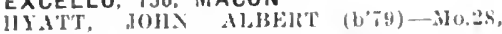
'Il: (l'l1). Whell b. (b'T) \&-Mo.34, 04 ;

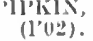

EXCELSIOR, 125. MORGAN

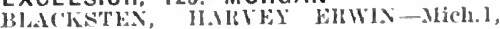
'84; (1'85).

EXCELSIOR SPRINGS, 3,900. CLAY

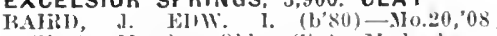
(l'0sy; Memier Okla. State Med. Assur.

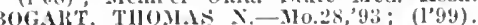

CHAK, HHAM JA(KSON (b'6i) \&-Mo.2, $07 ;(1,08)$

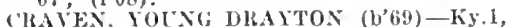
$96 ;$; $129-$ -

Fraker, Geo. Wm. (b'58)-.110.20,91; (I'05). JOHN J. (b'62)-Mo.20,93; (1'94).

IACE, JOHX F-MIL.32,03; (1'03)

(irace, Thos. A. (b; I) - Io.32, 03 ; (1,03); U. Greason, Woodayd B. (b'73)-Mo.20,'97. $(1,97)$

Henry, James K.-H-Mo.35, 07 ; $\left(\mathrm{l}^{\prime} 07\right)$.

llenry, Saml. 1). (6.54) H-Mo.26,'94; (1'y4).

llughes, Jolun Henry (b; 5 -Jio.8, 95

(l'0I). Jolm Henry (b'sa) yis,

Isley, Cluas. Forest (b's0)-N10.32,04

sley, Lafayette (b'64)-Mo.33, $01 ;\left(1^{\prime} 01\right)$

IAIFs, WhBLR J.4-0.2,94; (1'05).

Keith, Sampson R. (b'51)-Tenn.6,'83; (l'83).

KEITH, WHLLIS F1MER (b'82)-I11.11,07;

(l'12): OALR. *

LAWRESCE, JAIIES M.-No.18,'82; $\left(1^{\circ} 84\right)$

LAMHTFOOT, FRANK (b'50)- Il.1, 76 ;

LOWREX, ERNEST (b'70)-.110.2\%, 92 ; (1'92) ; Prof. Gyn., Mo.33.

Maxwell, Isalain M. (b'68)-Ia.1,'89; (1'89)

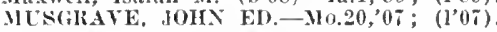

NELSON, HCGO E.\&-Neb.6,02; (1†).

O'KFLL, OTIE C.- IIo.18,'93; (1'93); $\mathrm{Adj}$

Prof. Gyn., No.33

IARKER, ELMER L.屯-M0.20,05; (l'05) NP.

Polk, D. T.-Mo.33,05; not in practice.

1KICE, JAMES T. (b'61)-No.20, 89 ; (1'90). IROBICHATX, EL('ENE CHAS, (b'84) La.1,06; (1’09).

WALIACE, WH, S. (b'67)£-Pa,2,93; $\left(I^{\prime} 0.3\right)$

Wurrall, Benj. W. J. (b'79)-Kan.2,06;
EXETER; 375, BARRY

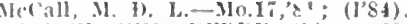

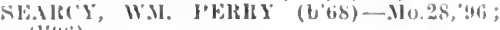
$\left(1^{\prime}, 4()^{2}\right)$

FAIRDEALING, 35, RIPLEY

WIITE, HOMEli b. (b'8) - Ǩy.2,09: (I') 9 ).

FAIRFAX, 666, ATCHISON

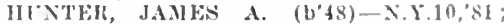

111'NTER, OWEN A. (b'75)-.110.2\%, 48 ; (l'a!) $(1258)$

Templeton, Ollver 1'. (b'54)-0.4,78; (1).

FAIRFIELD, 150, BENTON

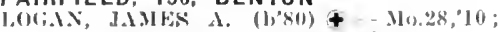
(1.13); Menber lil. State Megl. Soc.

valmes, Nilught w. (b'4s)-8; (1'84); not in practice.

FAIR GROVE, 150, GREENE

Fidmondson, Moses T. (b'74)-Mlo.7, 03 ; (l'03).

EWHLL, W: D. - $110.10,82$.

FAIR PLAY, 421, POLK

Hrewer, M. W.-la.1, 80: (去)

Brewer, Wn. I,-Mo.8,92: (1'92)

Buow, chas. 11. (b, 75$)-110.31,03$; (1'0.3)

coy, JOII W.-Mo.7,93; (1'9;3)

Griltin, Geo. W. (b'44)-Mo.1, '7 ; (l'84)

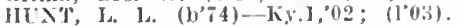

FAIRPORT, 250, DEKALB

RICHEY, I.ATHEN('F A. (1,\%8)--110.2?, $04 ;(1,04) ; \mathrm{S}$

FAIRVIEW, 300, NEWTON

MCCAII, TECUMSEII J. S. (h'66)-Mo. '88; (I'S8).

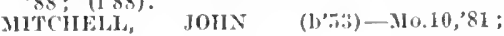
(1'8I).

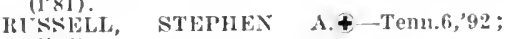
(1'?2).

FARBER, 305, AUDRAIN

May, W'm. -Ia.1, 80 ; (1'84).

Ilecollum, Kobt. Wesley (b'48)-0.3, 85 ; (1'90); ObG.

FARLEY, 96, PLATTE

Willis, John B. (b'74)-Mo.28,'97; (l’97).

FARMERSVILLE (R.F.D., CHULA), 50 , LIVINGSTON

BATIORF, FRANKIIN I'lER('E (b'49)†Pa.1,74; (1'85).

FARMINGTON, 2,6I3, ST. FRANCOIS

Braning, Fredk. M. (b,74)-110.28,00 (l'00); ObG.

DOWNING, BEA.l. R.--110.27,96; (1'97).

WNGLISII, JAMES H.-Mo.1, $90 ;(1,90)$.

ELGAS, IUGCST F. (b'66) - Mo.28, 04 (1'04).

Graves, John B.-Mo.2,9 ; (

IIerwig, Emll il-Pa.11,'s3; $\left(l^{\prime} 96\right)$

LONG, FRANK I. (1'05).

MeCormick, Emmett C.-Mo.2,8J; (I'97).

McEwen, Geo. A. (b'64)-Mo.28,97; (1'97) PATTON
(l'10)

ROPLSOX, BRADBURY J. (b'66)-Mo.2T. $92 ;\left(l^{\prime} 92\right)$.

SCRTTCHFIELD, GUTHRIF E. (b'70)Mo.1,94; (194). SMITH, OWEN A. (b'68)£-Mo.2,92;

WEBER, FRANK SCHLLTE (b'81)-Mo,34 , $08:$ : (1'07).

FATE, - LACLEDE

Scott, John C. (b'67) - Ind.24,'88; ( )

FAUCETT. 125, BUCHANAN

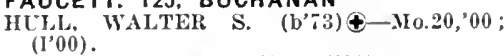

Isaacs, Geo. W.-Mfo., ,'93; (1'93).

FAYETTE, 2,586, HOWARD

BONHAN, VAUGHAN Q. (b'56)-Tenn.1,

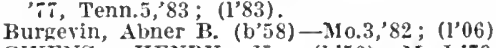
GIVENS, HENRY K. (b’56)-No.1,79; (l'83)

HOBSON, ABRAIIAII DANA (b'82)-ML.2, 08; (1'08); Member Kan. Med. Soc

Lawrence, (has. B. (b'66)-Ky.2,'90; ( $\left.1^{\prime} 00\right)$.

LEE, CHAS. H. (b'-1)-Mo.28,93; (l'96).

LEWIS, CHARLES 0.-0.2,79; ( 1,83$)$.

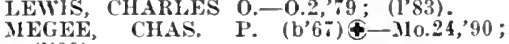
(l's9),

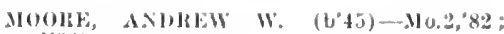
(1'83).

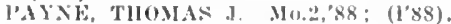

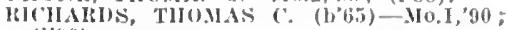
(l'(90).

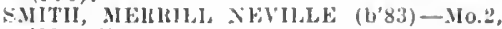
"I2: (1'13)

s.ulTir, NiwTox b. (b'80)+-110.2,03:

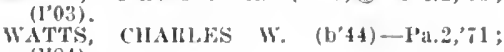
(1'84).

WIIGIIT,

FAYETTEVILLE, 100, J0HNSON

Flshback, M. I, - liy.2, 80 ; (1'94).

FENTON, 172, ST. LOUIS

DAITON, IIALT1N (b'69)-Mo.25,96:

FERGUSON, I,658, ST. LOUIS

ATWOOI, ieGll

Breler, (has. A. (b'7)-Mo.27,98: (199)

DOUGIAS, JAIIES T. (b'35)-II $0.2,59$; (l's4).

Fllnn, fico. W. -Mo.34, $(16 \%$; (1'07).

l'erry, kilw. I. (b'74) HI-M10.5, $0 \mathrm{l}$; (l'01).

FESTUS, 2,556, JEFFERSON

HARIRIS, ('HAS. GIRANT (b'68)\$-Mo.34,

$04 ;(1,02)$

LICKFY, FRANK SEYMOL'K (b'8:) - Mo,2, HTLETHE, (1'97).

FEUERSVILLE, 65, OSAGE

LEA 'H, CHAS. T. (b'69)-KY, 5, 98; (1'98)

FILLEY, 50, CEDAR

MAKR, IS LSSLLLL I3. (b'48)-Mo.2.'T5; (l'90).

FILLMORE, 232, ANDREW

MHLAS, BLLCE L. (b'T6)-110.22,02:

Parks, Danl. C. (b'56)-Mo.18,92; (1'92).

FISI, 800, BUTLER

GREATHOUSE, $\quad$ v. L.-Ky,4,98; (I'99)

MCALSTEK, JOHX MOGA' - Mo.28,04: (I'0.5).

FLAGSPRINGS (R.F.D., UNION STAR), II0, ANDREW

Kirk, Benj. H.—O; (l'84).

FLAT RIVER, 5, II2, ST. FRANCOIS

BARBEK, JOSES BUKETTE (b'69)£-

Mo.28,99; (1'99).

HANEY, THOMAS LEE (b'70)-MO.24, 01 ; (1.01).

KEITH, FKANK LEE (b'60)£-Mo.1,'81;

(1'85)

F'RINT, LOU'S EDW. (b'88)-Mo.34,'11;

Rohrbach, Edw. C. (b'75)-Mo.10,08; ( $\left.{ }^{3} 08\right)$.

TOPIING, MOSES H.-Ky.4,96; $\left(1^{\prime} 96\right)$.

WHLLIANS, GEO. B. (b'64)-Mo.24,93; (1'95).

FLEMINGTON, 250, POLK

Hedrick, Warren A. (b'59)-Mo.28,'93; (\$).

FLORENCE, 57, MORGAN

GIBBS, TIIOS. J.- $110.24,90$; (I'90).

FLORIDA, 200, MONROE

Shroat, Loren Gerald (b'86)-Mo.28,'11; (l'I1).

FLORISSANT, 765, ST. LOUIS

JENSEN, NICHOIAS N. (b'63)-Mo.t,'91; (1'91).

MeNearvey, simon (b'62)-Mo.24,'98; (4)

Mlillmann, John J. (b'72)-XI0.24, ${ }^{\prime} 00$; (1'00).

FOLEY, 227, LINCOLN

Dunbar, D. D.—110.27,'91; (1’91).

FORBES, 300, HOLT

HOGAN, JOS. HEVI (b'84)\&-Mo.22,09: $\left(l^{\circ} 09\right)$.

FORD CITY, 85, GENTRY

Ruhl, Jordan E. (b'78)-Mo.29, 03 , Mo.28, 04; (1'05).

FORDLAND, 250, WEBSTER

GOOD, JOHN W. (b'61)-NI0.7,'97; (l'99).

RABENAU, WM. J. (b'57) 4-ÍL.1,85; (I'85).

Williams, S. O. H. (b'62)--Mo.i,'93; (l'93).

FOREST CITY, 534, HOLT

BULLOCK, FRANK E. (b'58) €-M10.14, '81; (1'84); S. 89 ; (1'89). 
FOREST GREEN 75, CHARITON

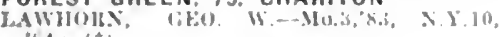
"84: (专).

FORISTELL, 250, ST. CHARLES

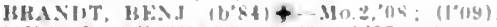

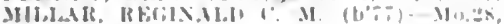
"01: (10).

FORNFELT, 1,209, SCOTT

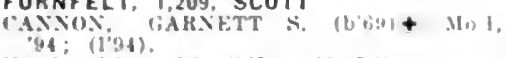

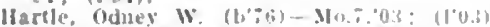
HITTON, WM. SHELLEL $\left(b^{2}+4\right)+$ THUL (00; $\left(l^{\prime} 00\right)$.

Maypeld, stephen A. (b'ati) lyo.a, of (1'01).

FORSYTH, 187, TANEY

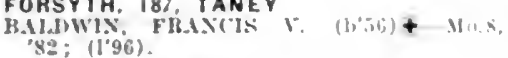

FORTESCUE, 65. HOLT

Minton, Isase M.-MO.1, $\times 3 ; \quad 11,83)$

Jilnton. J. Laafayelte Mo.1,80; $(:)$

Schar, Guldo-0: (1.98)

FORTUNA, 203, MONITEAU

WHLON, GFNERAI, SHFHMAN-MU 2N, 464 (1000).

FOSTER, 318, BATES

Mason. Isaac HI. (b'50)-Mo.:,93; (I'93). RHOALFS, HERBERT A. (b'tix) Mns,

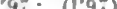

witson, Wesley R. (b't?)-Mn.10, is: (1'84).

FRANKCLAY, 350, ST. FRANCOIS

Aubuchou, Wm. F. (1, (1) (U9)

FRANKFORD, 793, PIKE

KHNNRDY, JACOB J. (b'65) - MO 1, 4, : (1.02).

Pryor, Channly: 8. (b'5.5)-Mo.24, 4 ,

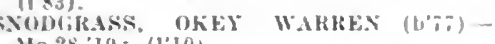
Mo.28, '10; (1'10).

FREDERICKTOWN, 2,632, MADISON

ANTISONY, ('AIBLTIIEKS A. (b" Mo.1, $82 \vdots$ : (1'83).

DAVIS, CHAS. I: (b'-2) - Mo.24, (1'98).

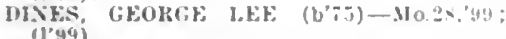

(IREENWOON, (iEO HFAR $(1, i j 1)$

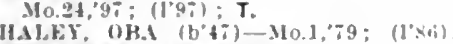

NEWBEKRY FRANKUIS HOBT. (b'.,

N.Y.5, 75, Mo.I,91: (1,91)

sirow, wM. Mo.866; (1'33).

Kenfroe, Jaln if $(6 \circ 2)-M 0,1, ; 8$; (1'st)

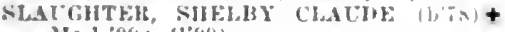

- Ilo.1.99: (1'40).

FREEBURG，33I， OSAGE

HEBCWLEII, JOS. I. A. (b'73)-Mo 24,433 : (1'93).

FREEDOM，20. OSAGE

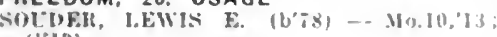
(1'13).

FREEMAN, 25I, CASS

KELLEIR, HOHEKT (i. (b'Bi) MO,8,94: (100).

FREISTATT, 250, LAWRENCE

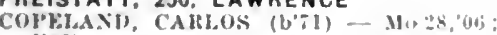
(1'0i).

\section{FREMONT. 150, CARTER}

Anson, Gordun C.-MO.5,00; (1'00).

FRIEDHEIM, 50, CAPE GIRARDEAU

1)ALTOS, ALEXANDEL E. (b'BA)-NOT, . 96 ; $(1.96)$.

FRISTOE, 100, BENTON

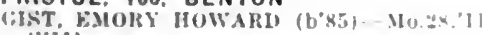
(1'11).

\section{FROHNA, 150, PERRY}

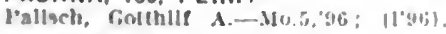

FULTON, 3,228, CALLAWAY

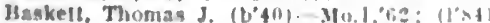

Bricis, MARION OLKY (1)

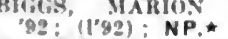

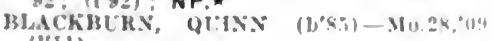
(I'II).

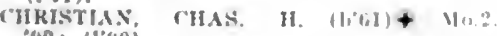
$.90:(1$ : 90$)$.

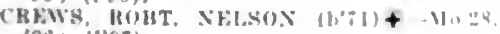
38: (1'9i).

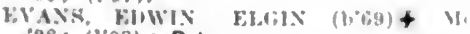

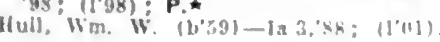

Kulght, 2. T, la in? 0 :

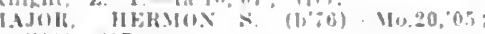
(1'(1).): NP.* Mot

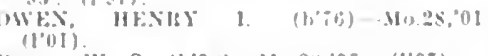

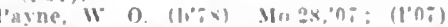

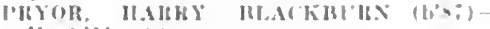

ky.2, I1: 11.

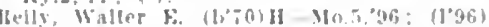

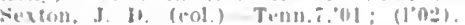

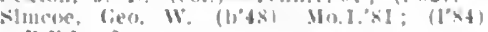
is ' is. -

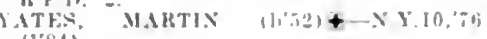
(1's+1).

(I)

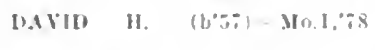

GAINESVILLE, 195. OZARK

Whlte. .luhn T. - 110.2X.99: (1"98)

GALENA, 353. STONE

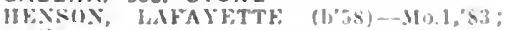
(i) 81 ).

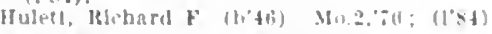

GALLATIN, 1.825, DAVIESS

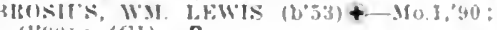

(1'b0): (GI): 8 .

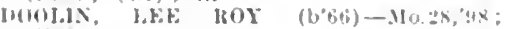
(1'9s),

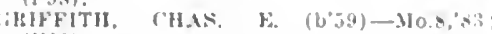
$(1 \times 3)$.

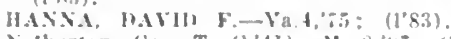

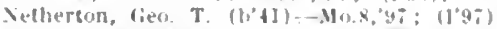

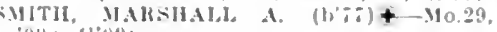

(II) (ii)

GALLOWAY, 16, GREENE

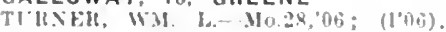

GALT, 583, GRUNOY

îricklind, Wm. Medman (b'it)-Ma.lo, '12: (1'12).

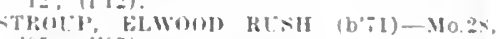

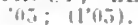

GAMMA。35, MONTGOMERY

Filhins, Caleb F.- Mo.10.01: (1'01).

GARDEN GITY, 7I3, GASS

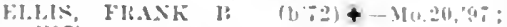

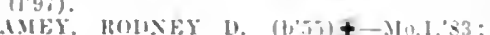
(I.II

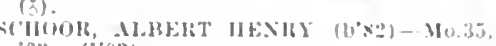
03 ; (103)

GARRISON, 35, CHRISTIAN

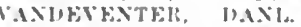

MO.1\%:82; (1'U): OD.

GARWOOD, - REYNOLDS

Mearlor, Hartey lapayette $\left(b^{\circ}: 2\right)$ - Mo.10, 'I3; (1.13).

GATEWOOD, 110 , RIPLEY

SCree, Nathan 1"- Tenus,"93: (1'93).

GENTRY, 226, GENTRY

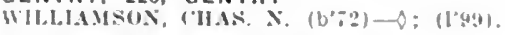

GEORGETOWN, 275, PETTIS

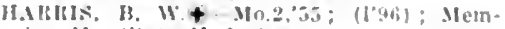
ber Mo. State Metl. Assil.

GERALD，225, FRANKLIN

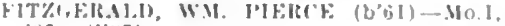
$8: ;(1,80)$.

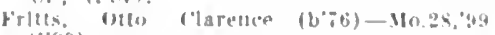

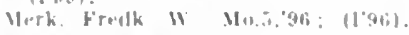

GIBBS, 266, ADAIR

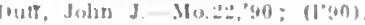

GIBSON, 143, DUNKLIN

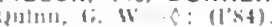

GIDEON, 702, NEW MADRID

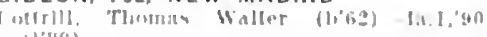
$11^{\prime}$ (191)

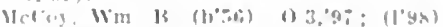

GILLIAM, 299, SALINE

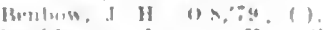

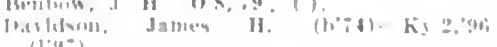
(11:19:

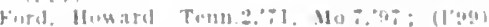

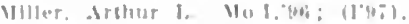

GIILMAN CITY, 537, HARRISON

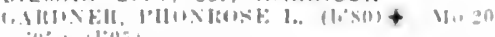

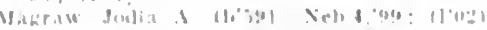

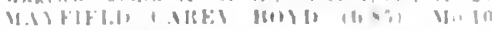

GLASGOW, 1,507, HOWARD

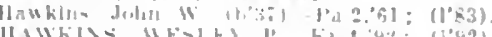

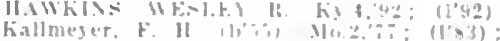
hallmeger, f. It

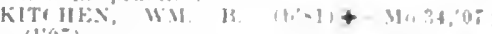
(1'0\%).

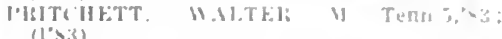

TH:MII.t:

(1)

GLENALLEN, I06. BOLLINGER

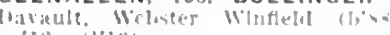

1\%: (1:12)

GLENSTED, 150, MORGAN

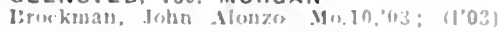

GLENWOOD, 375, SCHUYLER

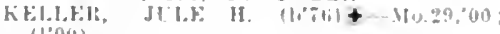

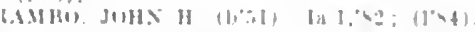

GOLOEN, I50, BARRY

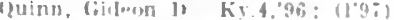

GOLOEN CITY, 882, BARTON

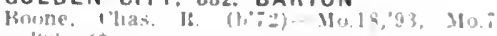
?il: i

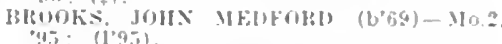

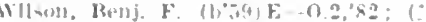

GOLOSBERRY, 25, MACON

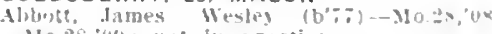

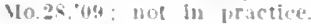

GOOCH MILL (R.F.D., OVERTON). 100. COOPER

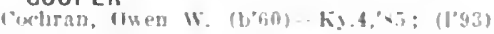

GOOD HOPE, 75, DOUGLAS

"ermuson, John 11. (b"it)-Mo.10,'13: (1'13).

GOODLAND, 23, IRON

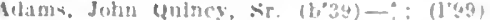

GOODMAN, I00, MCDONALD

Friblet, Worlh! W. Neb.t.

GORDONVILLE, I70, CAPE GIRAROEAU

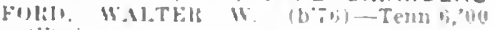

(1)

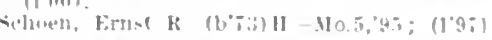

GORIN, 84, SCOTLAND

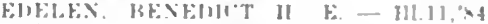
11 का

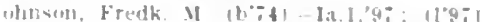

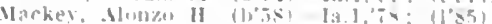

GOWER. 370, CLIN TON

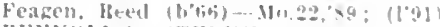

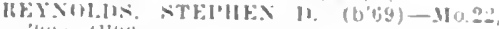

STAIRS, JUHA (IIAH,K (b\%t)-Mo.

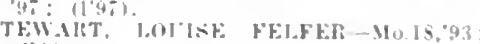
(1"Sit).

GRAHAM, 365. NODAWAY

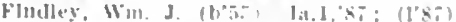

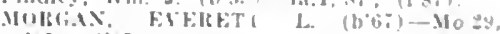
$45 ;(1,0,5)$.

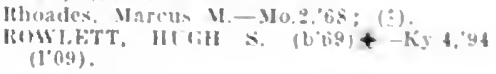

GRAIN VALLEY, I33, IACKSON

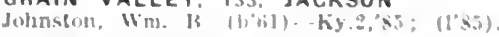

GRANBY, $2,4+2$, NEWTON

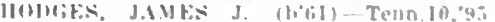
(1'0l)

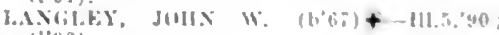

(l's01.

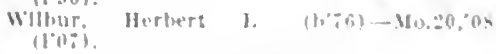

GRANDIN, I,500, CARTER

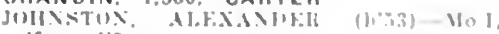

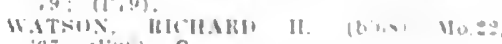

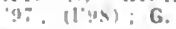

GRAND PASS, 200, SALINE

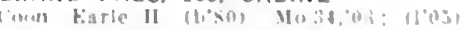

CHANDVIEW, 523, JACKSON

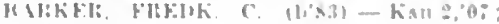
तासरा

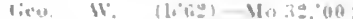

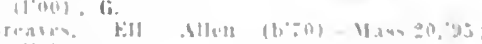
$11^{\circ}: 0 \%$

GRANGER, 230, SCOTLAND

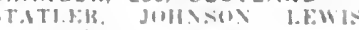

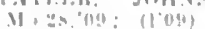


GRANT CITY, I.207, WORTH

Allen, Jonas 6.-Mn.14."82: (1"42)

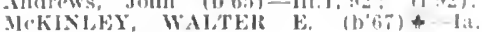
'87; (1'87); OALR.

Mllls, ollver I". II (1) 63$)-M 0.27,42$. (1.92).

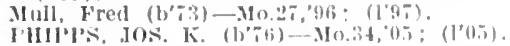

GRAVELTON, 80, WAYNE

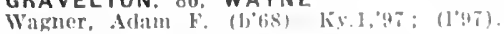

GRAVOIS MILLS. 40, MORGAN

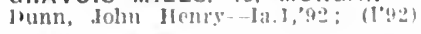

GRAY SUMMIT, 200, FRANIKLIN

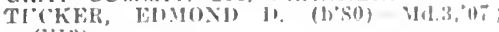
(1'I3).

GREEN CASTLE, 454, SULLIVAN

Parions. Wm, (1,62) F-Mo.I0, 90 : (1'00).

Schoolfig, Thos. II. J. (b' 40$)$ - Ia.1, "it (I'99).

Taylor, WH. I. (b*3)-MO.10,76: (l'sk)

GREEN CITY, 844, SULLIVAN

HEIIXVTON, WAliNER $(1,-1)+$-Mo.34.

03: (1'02).

Iane, lillas F. (b'43)- (l'84);

Magee, looht. Scott (b'54)-Ia.1,82: (1's4)

Righlns, Ibavld M. (b"il)-.INo.33,'04, Mo.7. ofo: $(1,07)$

Shibley, John-111.1,'S6; (1'86).

GREENFIELD, 1,434, DADE

Combs, Thaddeus I.-Mo.7,04; (1'0.5)

Combs, Thaddeus N-M M.',

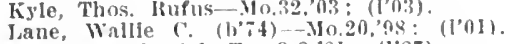

Martin. Zacharlah T.-O.8,'sI; (1'87).

Thomas. Robt. C. (b'io)-Tem.io,'94:

(1'05).

Welr, Geo. Lafayette (h'69)-..110.24.93: (I'93).

GREEN RIDGE, 436. PETTIS

CIAHFGI OMER WHLFER N.Y.10,93.

Ifte, Ieniy dohby (b'7)-Mo.34,02; (1'01).

GREENTOP. 275. SCHUYLER

FARRINGTOX, FIRANK B. (b'T5)-ML.34,

,05; (1'05).

Wilson, James Arthur (b'4s)-N.Y.10,68: (I'85).

GREENVILLE, 914, WAYNE

WAliNER, JOHN F. (b'82) - Mo.10,06; (I'06).

Ward. i. A.-Mo.1.91; (1'93)

WHITESIDE, EDGAR HESEBIUS $\left(b^{\prime} / 6\right)-$ Yo.2,'12: !!'12)

Wilson, N. G. (b'64)-Mo.10,89; (1'89).

GREENWOOD, 300 , JACKSON

Conrad, Carl I. (b'8l)-Mo.20,07 ; (l'07).

GROVESPRING, 65, WRIGHT

Iott, James R. (b',

GUILFORD, 207, NODAWAY

BARNET, AIBERT DEANS (b'66)థ-0nt.1, $87 ;(1,91)$.

MC'LANAHAX, JOHX M. (b'59)£-Mo.1, '86; (l'86').

GUMBO (R.F.D., CHESTERFIELD), 25 , ST. LOUIS

Terry, Robt., Ir.-Mo.28,'98; (1'99).

GUNN CITY, 143, CASS

BIRIERLY, JOHN B.-MO.1,'88; (I'88).

HALE, 587, CARROLL

Dill, James P. $\rightarrow$; (ち)

Ilerrington. s. B. $-\left(l^{\prime} 95\right)$.

Shawhan, Rezin C. (b'71)-Mo.20,97; (1'99).

HALFROCK (R.F.D., SPICKARD), I30, MERCER

MeClanahan, Cecil L.-Ia.1,98; (t'98).

HALF WAY, 89, POLK

Hammontree, Danjel E.-Mo.32,'03; (1'03). Higginbotham, W. W.-Mo.1.'89; (1'90).

HALLSVILLE, 195, BOONE

Austin, Robert S. (b'60)-M0.27,'92; (1'93) ROBINSON, ROBT. ROY (b'-8) $4-M 13$. OI: (1'01).

HALLTOWN, 63, LAWRENCE

Clark, Saml. M. (b'78)-Mo.7, 03 ; (l'03).

HAMILTON, 1,761, CALDWELL

Bradley, Chas, E. (b'65) Mo.20.95: (1'95):
BRowy, TISSLEY (b'49) \&-Mo.1, 66 ;

U['FFIE, W.IRREX M. (b'60)€-Ia.10,06 $(106)$.

EADS, IEE J. (b'67)-Ky.2,'89; (t'01).
Epperson, Harry E. (b'5I)-Ky.t,94: (1'84)

Johnson, Neill Watrles (b'53) 11-111.10,03:

(I'12). W.If. T. $(656) \leftarrow-M 0.1,81$; (1'83) : G.

TIfPn, Clayton (1,3i) .110.2,59; (1833)

HAMMOND, 25, OZARK

ligle, Ernest Haskell (b'79) - I1.11,'10; (1'10).

HANNIBAL, 18,341 , MARION

Ayres, Alturt R. (b'4I)-Mfo.7,70; (I'S3) ; not in practice; 8II Jird St.; ofllee, IIs Broarlway.

BANKS, HENRY L. $\left(\mathrm{b}^{y} 64\right)+-. M 0.2,90$; (1'90); 20s s. 5th st.;8-10, $1-3,7-s ; s$.

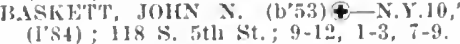
BL.E, ARTIIVI I3. (b'79) - Mo.29, 04

ROINDS, EDWNRD HFNRY (b'73) Mo.28,98; (I'98); 1012 ('enter st.; offlee, 524 Broadway ; $10-12,3-5,7-8 ; \mathrm{G}$.

BOURX. JOIIN J. (b'70)+-II.1,96; (1'98); 1 I 0 N. $6 \mathrm{th}$ St.

laush, Franklin Worthlngton $(1,50)-M o .1$,

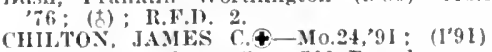
1003 Center St.: office, 500 Rroadway.

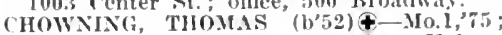
(l'90): 1103 Center St. ; office, Ilolmes

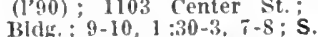

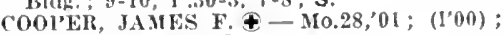
231 Market St.; $\mathbf{S}$.

DETWEHLER, ANDREW JACKSON $\left(b^{\prime}-3\right)$ - Ijch.l,00; (l'00); 504 Broadway : offlee, 522 Broadway ; 8-8:30, $1-3,7-8: 30$.

FARRFLL, JOHN JOS. (b'79) - Mo.2,'0l ; (1'01): 208 S. 6th St.; offlee, Main and Broadway: $8-10,2-4,8-9$.

Fisher, L. L.-Mo.1,'95; (1'95) ; 225 Broadway.

GLES, WM. CLOYD (b'67) $\oplus-$ Mo.1,99: (1'03) ; $21 \mathrm{~L} x$. 7 th $\mathrm{st}$; offle, 503 Proadway; 11-12, 1-3, 7-8:30; Pd.

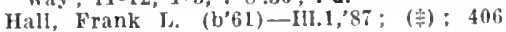
Center st.

IIAYS, WM. II. (b'75)-Mo.2,98; (1'9s) ; 609 Church St.

Heavenrldge, Robt. J.-Mo.29,97; (1'97); 2015 Chestnut St.; offlce, 1912 Market st. $8-10,2-5,7-9$.

IILL, ISAAC E. $\left(b^{\prime} 78\right) \mp-C o l o .2,06$; $\left(l^{\prime} 06\right)$; 207 N. Maple Ave. ; office, Trust Company Bldg. ; 9-11, 2-4.

HOR.JBACK, EDWARD T. (b'64) †-Mo.1, 91; (1'91) : 919 Center st.; office, 500 Broadisay : 9-12, 1-4; OALR,

HOWELL. JOHN \&. \-Mo.1,'80; (1'01) ; Hannibal Trust Bldg.

MALLET, JOIN A.BERT $\left(\mathrm{b}^{2} 8 \mathrm{~T}\right) \notin-$ Mo.7, '11: (l'11); 510 chureh St.

McCoLL, NÉTTE IONA (b'80)-H1.8, 09 ; (l'10) ; 609 Broadway.

Mclfechen, Harry Blaine (b'86) - Tenn.7, 11: (l'i1): 1230 Broadway.

PAXON, CHÁS. EVAN (b'73)૯-Pa.9,99; (1'03); 511 Broadway.

Primm, John Newton (b'54) - Il1.4,'81; (l'84); 111 N. 6th St.; 9-11, 2-4.

Queen, oceola C. (col.) - Tenn.7,91; (1'92); 1325 Lyon St.

roSS, MARY SOPHIA (b'6i) $\uparrow-$ Ill.1,'08; (l'09); 302 N. ;th St.; offlce, 500 Broadway; G.

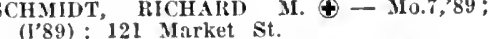
SHANKS, ARCHIE L. (b'75) - Mo.2,0l; $\left(l^{\circ} 01\right): 313,5$ th $\mathrm{St}$.

Shepherd, Chas. Thomas (b'84)-Mo.34,06; (1'06); 210 Cypress St.

Smith, Stephen G.-0.14,'78; (l'83) ; 507 Broadway.

SMITH, ULYSSES SCOTT (b'73)థ-Mo.2 $98 ;(1 \times 9) ; 116 \times$. 9 th St. ; office, $3 d$ and Broadway; $9-12,2-4$; OALR.

Sparrow, J. I.-Ia.l,81; (1'92); $124 \mathrm{~N}$ 3d st.

Tutt, Lewis Hiram-X.Y.10,88; (1'90); Hannibal Trust Bldg.

WALIDO, ELMER E. (b'62) - 111.10,'94: (1'94): 1130 Broadway.

Welsch, John Albert (b'74)-Ia.1,96, Mo.28, 01 ; (l'00); 3021/2 Broadway; 8-4, 6-8.

WINX, RICHARD MARVIN (b'it)-Mo.2 03; (1'03) ; 1203 Broadway; $i-8,11-12$. $1-4,7-8$.
HARDIN, 635, RAY

l)earing, Wm. A. (b'ci3)-MIo.24,93; (l'93).

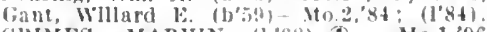
riRIMES, MARVIN (b"68) - Mo.1,96 (l'pti)

MCGHEF, HOMEK PI.BEIT (b'84)-MO.20, I2; $(1,12) ;$ OALR.

smlth, James $Y$. (1,'7.5)-la.10, 02 ; $\left(1^{\prime} 02\right)$. STAN', IOS. II. (b'76)+-IIo.8,99; (1'93). HARRIS, 395, SULLIVAN IBradtey, Ulysses S. (1)'68) …Ia.1,'96; (1'9ï) lioon. Guy Alton (1)'8: -Mo.34,'13: (1'13. SHRIVR, CALkI F. (1)'si) - Ky.4.91 (1'91).

HARRISBURG, 146, BOONE

Frakes, Eugene X. (1,83)-Mo.20,07; (100(i) WOOD, JOIIN T. (1)'46) \&-0.8, $70 ;(1 \% 84)$

HARRISONVILLE, I,947, CASS

CRAWlOR1, HAIRTY S. (b'64) £-Mo.8, 02 ; (1'05).

ELDER, A.RON IR. (1,53)-M10.1,84; (1'84). Georce, Wm. Francls (b'65) - Mo.2,'89, Mo.20, 04: $\left(1^{\prime} 11\right)$

LoNe, DAVI) S. (b'84)-Mo.20,10; (l'10). MAY, IIARVEY G. (b'64) $4-\mathrm{M} 0.27,96$; $\left(l^{\prime} 96\right)$.

YYRHOI.SFR, MILTON P. (b'59) †-ML.8, '84; (1'89)

SCOTT, IAMES U.t-Mo.1,"94; (1'94)

TRIPLETT, JACOR S. (b'65) $₫$ Mlch.1, 91 ;

$\left(1^{\prime} 92\right)$; S.

HARTSBURG, 175, BOONE

l'armer, ('has. C. (b'72)-Mo.3,'98; (1'98).

HARTVILLE, 507, WRIGHT

Farmer, Andrew. J. (b'63)-la.9,'91 ; (1'91).

Hanson, Richard H. (b'42)-0: (1'83).

Latimer, Benj. F. (b'83)-Ito.28, 05 ; (1'05).

HARVIELL, 20I, BUTLER

Turner, Robt. I. (b'68)-Tenn.6,'94; (1'94).

HARWOOD, 208, VERNON

WALKER, GEO. SHEL.BY (b'84)-Mo.20, $07 ;(1,07)$.

HATFIELD, I50, HARRISON

DUNKESON, EDW. B. (b'68) - Mo.8.'93 ; (1'93).

HAWKINS, 14, PULASK!

HOWLETT, ROBT. ELGENE - Mo.2T,91; (1'91).

HAWK POINT, 299, LINCOLN

DeVereaux, John Jos.-Mo.28, $0 \vec{i} ;\left(\mathbf{l}^{\prime} 0 \vec{i}\right)$.

Diggs, Jos. $(\mathrm{b}+40)-M o .1, ; 4 ;(1,74)$.

HAYTI, I,057, PEMISCOT

Crider, Jos. (ireen (b'72)-Ga,1,94; (1'97). JOHNSON, JOHN w. (b't2)屯-Mo.28,03 ; (1'03).

Mayes, F. A. - : (丰)

PHLPP, JOHN औ. (b'66)-Ky.5,99: (1'11). TRACTMANN, THEODORE JOHN, $\left(b^{\prime}, 4\right)$ \& - Io.27,99; (1'99); G.

HEBRON, 50, DOUGLAS

Lovan, John W. $\rightarrow$; (l'99).

HELENA, 200, ANDREW

CARPEN'TER, ERNEST HENRY (b'7s)థIfo.34, 03 ; (1'03).

HEMATITE, 300, JEFFERSON

EIders, Geo. W. X. (b'42)-No.1, 73 ; (1'8:).

HENDERSON (R.F.D., ROGERSVILLE), 150 , WEBSTER

Delzell, W. D.-Mo.2,75; (1'83); - not in practice.

HENDRICKSON, 200, BUTLER

HARWELL, J. TEE (b'T4) - Mo.10,06: (l'01).

HENRIETTA, 443, RAY

SMITH, GEO. W. (b'68)-Mo.28,93; (1'93).

HERCULANEUM, 300, JEFFERSON

DONXELL, NEWMAN R. (b'て2)屯-Mo.24, 01: (l.0I) ; 0p.

IILIEK, CHAS. WACGH (b'8i) - Mo.34. '12; (l'12).

HERMANN, 1,592, GASCONADE

IIAFFNEK, ERNEST 1. (b'i1) - Mo.7,'95; $\left(l^{\prime} 95\right): S$.

RICKHOFF, HERMA. J. (b'78)-Mo.đ,'04 (l'04).

SMITH, ACGIST ARXACD (b'74)-Mo.i. $98 ;\left(I^{\prime} 98\right)$.

Wessel, Wm. C. $\left(b^{\prime}-6\right)-M 0.27,99 ;\left(1^{3} 02\right)$; $\mathrm{S}$. 
HERMITAGE, 300, HICKDRY

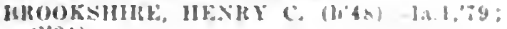
[1'84)

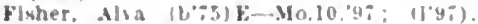

HERNDON (R.F.D., MARSHALL), 50,

SALINE

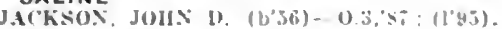

HICKMAN MILLS, 200, JACKSON

Siraney, loren (b'49)-MU.s, 3 ; ; (1'x+1).

HICKORY. SO, GRUNOY

POHTKHYELS, DAXL. REWIA (10":9) Mo.2.06; (1.05).

HIGBEE, 1,215, RANDOLPH

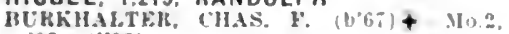

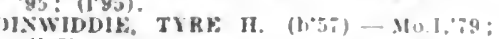
(1's3).

Nichols, George M. (b'b0)--Ia.l, sti: (l bib),

Winn. Jatues W.-M0.1.95: (1"4, )

HIGGINSVILLE, 2,628, LAFAYETTE

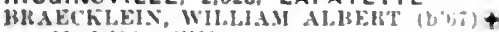

- $10.1 .88:$ : (1's8).

(irimes, John A-Ky.2, $\$ 2:(1.91)$; 209 (0) linsille Are.

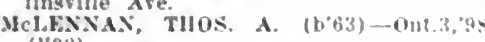
(l'9s).

OTT, CIIAS. W. (b*Ts) MU 26,$99 ;(100)$

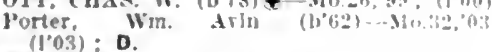

WVBB, WM. C. $(1,63)-0.1,86 ;(1 \% 1)$.

HIGH GATE, 10, MARIES

UNIIERWOOD, JOIIN B.-IIO.28,01: (I'01),

HIGH HILL, 325, MONTGOMERY

IBest, John-Mo.2×.

Leslle. James T.Mo.28,04; 1luiv

HILLOALE (R.F.D., ROCHEFORT), 30. HOWARD

CHAMHION, JAMES R-P; (I'OB)

HILLSBORO, 26!, JEFFERSON

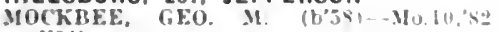
(I'34).

HINTON (R.F.D., BROWNS STATION), 175. BOONE

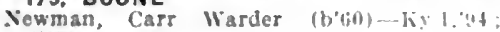
$(1,00)$.

HOBSON, 13, DENT

LENOX, WILSON M. (b'+3)

(1'83).

HOLCOMB, 279, OUNKLIN

Drace, Chas. C ( $\left.b^{\prime}, i_{i}\right)-M(1) 2 t^{\prime} 00:$ (l'wit)

HFSS, JOHN D. (b.7) -Mo.2,00: (100)

Horue, G. A. - .

HOGUE, JOHI A., JIt. (b'33)-Ki, 1.'0; (1'0:).

POWELL, ISAAC W. (b'53)-Ky, (1900): not in practice.

HOLDEN, 2,007, JOHNSON

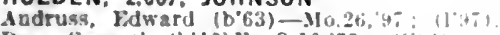

Day, Samuel $\left(6^{\circ}+6\right) \&-0,10,-5 ;(1+14$

Ilarrls, Geo. W,-la.1,82; (1'91).

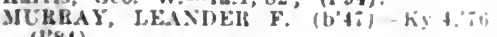
$(1 / 84)$.

MUßKA), SAMI. A. (b'83)—-Ma.31,01:

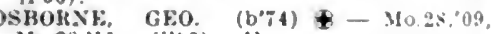

Mo.28, 1I: (1'10); U.

Slmpson, James T-Tenn 8.80 (1.24

THompsos, wM. G. (b'70) Mn l, (1'90).

HOLLAND, 273. PEMISCOT

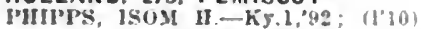

HOLLIOAY, 262, MONROE

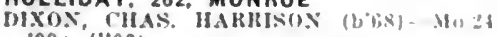
99 " (J'00).

Nol.ND, MOSs ItAMONI (b'he) Yo.34,08: (J'08).

HOLLISTER, 75, TANEY

WHITHRE, ELWIS $0.2,: 88:(1.93)$ : Op.

\section{HOLLYWOOD, 36, DUNKLIN}

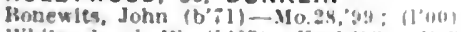

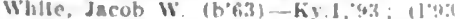

HOLSTEIN, 400. WARREN

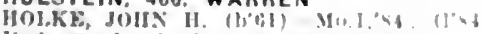

Inderwond, Abrabin ol M11

HOLT, 336, CLAY

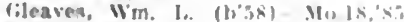

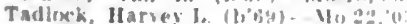

HOPKINS. 909. NODAWAY

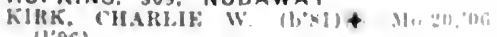
$(1.06)$.

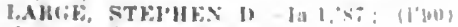

sarsent, llana i la los. l'y l,
HORNERSVILLE, 390, DUNKLIN

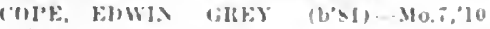$$
\text { (1'10). }
$$

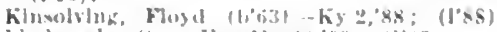

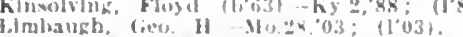

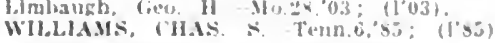

HOUSE SPRINGS, 60, JEFFERSON

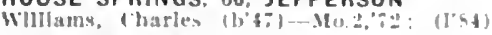

HOUSTON, 644, TEXAS

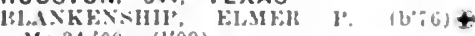

M $0.34,0, \quad(1 \circ 09)$

COVEHT, WM. I (1062)--160.25.02: (103)

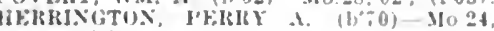
il: (1,01).

'IHMISTE, JOHx W. (b'65)-Mo.i,"90 (1'90).

WOMAlK, JAMES R. I, (b'bs) . Mo.18,98 (1'93).

HOUSTONIA, 349, PETTIS

Brown, Jos. T. (to'32)-Mo,3,'5t; (1'\$t); 180t In practlce.

Mcconnell, ibarles T. (b'i $\ldots$ )..110.2t,"49 $\left(1^{\circ}(9 y)\right.$.

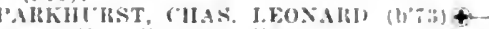

Iก,3,01, IH. 6,02; (1001)

smith, Thos. t.-Ky.5, s1; (19.5)

HOWELL, 100, ST. CHARLES

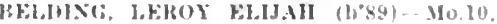
"12: (l'12).

HUGHESVILLE, 200, PETTIS

HISHOL", WM. THOMAS $(1,05)+-110.3,01$; (1'01).

AITWRIGHT, CIARENCE I'. (b'bs)Mn.7,91; (1'94); R.F.D. 1.

Witchell, IIenry ("lay-Mo.1,98; (1'98)

MTCUEL, J) (1'9s).

HUMANSVILLE, 9I3, POLK

IHI.L, RICIIAIII) IV. (1,'st)-Mo.7,09: (1'ili).

ISESEEII, IHCHABI) LEF ( 05: (l'05)

STIFIALHAM

II0.:, $98 ;$ (I'9S)

HUME, 514 BATES

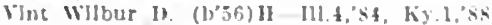
(111) ; K.F.D.

WILLAMS, JAMks H (b'bin)-Mo.7,"9:3; (1.93).

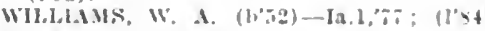

HUMPHREYS, 292, SULLIVAN

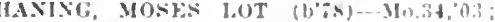
(l'03).

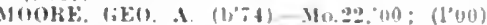

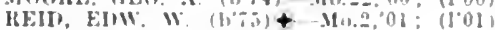

HUNNEWELL, 406. SHELBY

barts, fill ('. (b'3(t) Ial, is: (1's3); not in practice.

bilisies

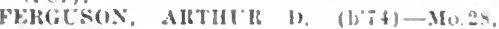

06 ; (100).

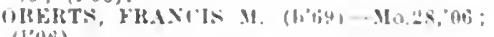
(1"06).

HUNTSVILLE, 2,247, RANDOLPH

IIUU, SIMEON 1 . (1,:11)-Mn.28,"(12. (l'01).

HARNHART, IUON I-MU.2:45; (195)

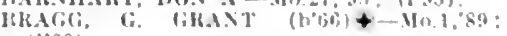
11.89).

Miliee John K. - Ky 2.9: $\left(1^{*} 96\right)$.

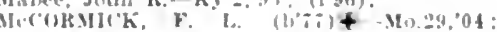
(I'05).

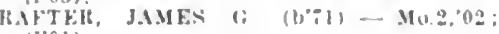
(I.0)

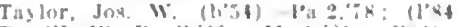

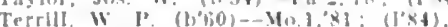

HURDLAND. 322, KNOX

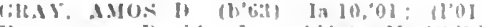

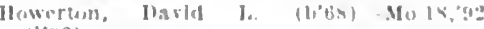
$(1+32)$

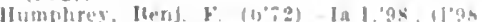

HURLEY, 100, STONE

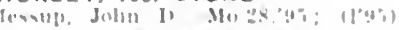

HUZZAH I8, CRAWFORD

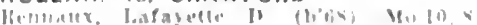
(1'+4).

IANTHA. 250. BARTON

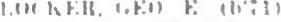

IRERIA. \$28, MILLER

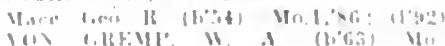

ICONIUM, 75. ST. CLAIR

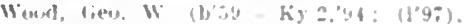

IDALIA, 200, STODDARD

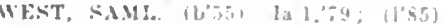

ILLMO, 976, SCOTT

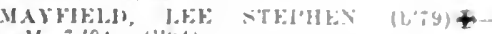

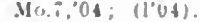

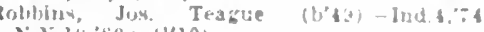

X.Y 16,$\left.80 ; 11^{\prime} 10\right)$

INDEPENDENCE. 9,859, JACKSON

Alrams. Lant. Orvllle-Ill.l, st; not in practice.

ITKINS, IALVIX-\$10 20,"90; (1"y0).

Mraun, Harry bidgar (U's(0)-\$10.20,11.

(1'11) ; 16.5,1). 6.

Bryant, John-No.2.'65, Pa.2, és: (4)

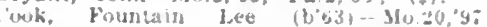

$(1.9 ;): G$

lammatr. ihrintian Ausustus (b'to)-I'a.1, $72 ;(1033)$

luzaly, Ilarrs Wu. (b'ss)-Mo.20,"13:

(l'13)

Green, Jos. Wh- Mo.20,0 : (l'05)

Grinln, saml. H. (col.) (b':-T)-Tenn.7.05:

II (I'99).

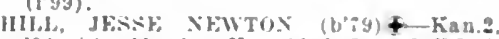

"00; ( ); Member Kan. Med. Sox.; K. W. D.

keown, (bas. (b'su)-111.15;'?3; (1'13).

KIIMIINitit, rIIAs. \&-M0..20,03; (1'03).

li.k. b. 6 .

Luf, Jos. (1,52)H-390.35,03: (l'01).

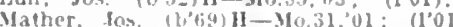

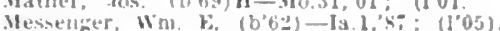

ihenlx, bis. M. (col.)-Tenn.13,03: (1'03): U

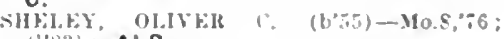
(1'83): ALR.

STIAIT, FHANCIS MANTILS (b'85)II. viate yed issn.

TIYMAN, EMMkik D.IVIS (b'St) \$-III.6. $07:(108): S$.

WOOI) NIMKOI) IPOLK (b'59) \&-Mo.2.\$1; (1/33)

INDIANCREEK (R.F.D., MONROE CITY), 3I, MONROE

Corley, Jos. R.-MO. I, 'SE; (I'SS).

IONIA, 100, BENTON

Windle, Benj. Franklin (boi)-Mo.2s,'9:; $(1,9 i)$

IRONDALE, 338, WASHINGTON

lonmell, saml. $\rightarrow$; (l'93).

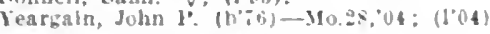

IRONTON. 721, IRON

Marnhouse, Edw. 1. G. (b'67)-Mo.10,98. Mo. 25,$93 ;$;

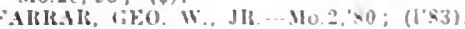

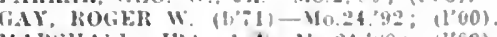

MARSHAtal, IHA I+-110.21, $s 9 ;$ (l'sg)

JACKSON, 2,103. CAPE GIRARDEAU

ATKINS, PK.INK IT. (b'is)-MU.I, B3; (I'siti).

Hrase, Ferdlnand-II-Mo.5,"92; (1'92).

H.IY, likRAARI W. (libi) - Ky.2,94.

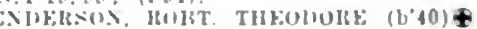

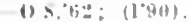

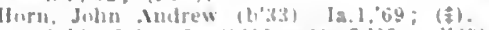

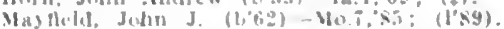

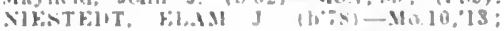
$(1,|j|$

III. II

JACKSONVILLE, 275, RANDOLPH

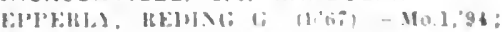
(I")\$)

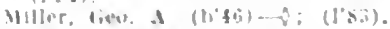

JAMESON. 358, DAVIESS

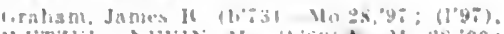

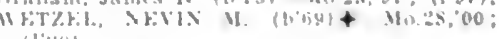
(I')U)

IAMESPORT, GII. DAVIESS

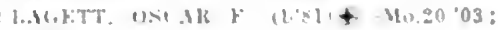

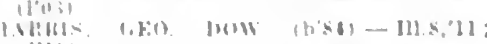
(1'il).

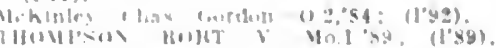


JAMESTOWN, 305, MONITEAU

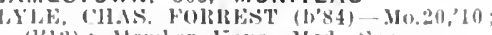

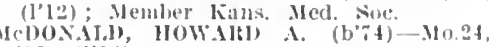
$98 ;(1,98)$.

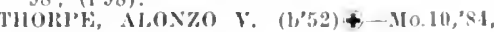
II $0.24,90 ;$; (1'84).

\section{JANE, 200, MCDONALD}

Webstero, James (i. (1,54)…Mo.10,'s0: (1's9)

JAPAN (R.F.D., SULLIVAN), 50, FRANKLIN

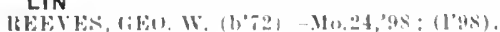

JASPER, 664, JASPER

Hendricks, Virgl] H.-Mo. 8,97; (197).

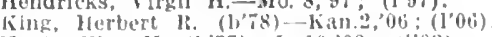

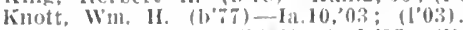

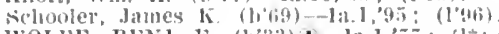

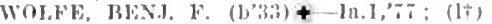
R.F.1)

JEFFERSON BARRACKS (ST. LOUIS BRANCH P.0.), 800, ST, LOUIS

FOSTEl, (1iss. l. (b'71)£-1). C.1,02:

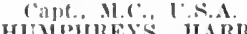

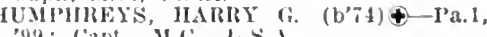

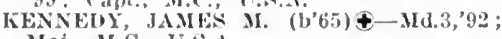
Maj., M.C., U.S.A.

'ILASBUIY, HENTY CHLRCH (b'S1)\$-

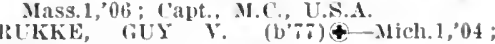
Capt., M.C., I.S.I

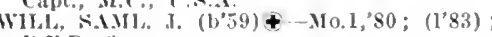
K.F.D. \&.

JEFFERSON CITY, 11,850, COLE

MICOCK, JOHX ALFKED B. (b'sl) -0.2 of Health of Mo.; 325 E. High St.

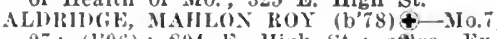
07 : (1'06): sof k. lligh st.; oftee, $\mathrm{Ex}$ clainge Bank Blog.

Amos, 0. E.-M0.10,01; (1'05); 3021; E. High St.

BEIFOH11, STEI'HEN V. (b'81)-Mo.3, 03 (l'05) ; $230 \mathrm{~W}$. High; offlee, $103 \mathrm{~W}$. High.

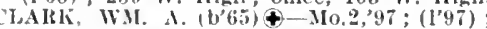
213 Adams St. ; offlee, 101 W. High St. ; $1-3,7-s ; s$.

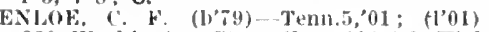
320 Washington st.; offlce, $104 \mathrm{~W}$. Hlgh. ENIOE, ISAAC N. (b'60) 1 -No.1,'s: (1'95); 319 E. High st.

ENLOF, LAWRENCE DAVII) (b.91)-Mo.2 13 ; 319 F. High St.

(l, 99$)$, FRANK W. (b'76) \-No.5,99 High St. ; $10-12,2-4,7-8$

HIILL, JAMES A. $\left(b^{\prime} 70\right)+-M 0.22,05$ $(105) ; 208$ Monroe St.; office, $1281 / 2$ F. (ligh : 208 Monroe St.;

HOLGII, CHAS. PINCKNEY (b'5) $4-M O .1$ "75; $(1,00): 400$ E. Maln st.

JONES, GEO 11. (b'34)-No.20,'13 ; ( ) 210 F. McCarty st.; offlce, 236 E. Hlgh Mt.; s-5. Edw Earl (b'85)-Mo.34'12 (l'12); 1225 W. Maln St.; offce, Madison and IJigh Sts.; $9-12,1-4$

McCutchan, Geo. L. (b'76)-Mo.2,02 (l'01); 1010 Jackson st. ; offlee, Missourl State Penitentlary.

Miller, B. T, (b'31) $\rightarrow$ : $\left(1^{\prime} 90\right)$; not in practice: 410 F. High St

Moore, Osborn L. (b'63)-Mo.20,91; (1'91) 103 Madison st.

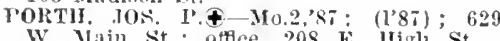
W. Jian St.; othee, 20s E. Higl 'St. (l'99): 109 W. Iigh St.; office, $300 \mathrm{E}$ High st.

SUMIERS, JOS. S. (b'77) †-Mo.3,'08 (los); 114 k. IreCory St.: offlee, $126 \mathrm{E}$. HIgh S.t.; $S-11,2-5,7-s ;$ OALR.

JENNINGS (ST, LOUIS P.0.), 800, ST. LOUIS

Thomas, Harry M.-MIo.24,'96; (l'96).

JERICO SPRINGS, 395, CEDAR

Holmes. Andrew T. Mo.8,90; (1'90)

Mynatt, Abmer J.-Mo.20,98; (1'98).

JOHNSON CITY (R.F.D., APPLETON CITY), 20, ST, CLAIR

smith, Rollin J.-MIO.1,'Si; (1'92).

JONESBURG, 456, MONTGOMERY

Ball, Enoch A. (b'54) $\rightarrow$; (1'85).

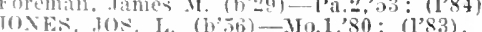

Menefee, Buell F.-Mo.7,07; (1'07).

\section{JOPLIN, 32.073, JASPER}

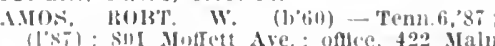
sit. Wm, 1. (bosi)-Mo.1,74: (1'01): (i2) Maln st.

Balsley, Martin T.-Ind.8,'81; (l'91); 210 W. ill st.

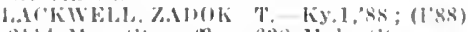

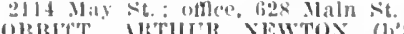

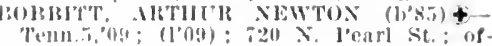
flco, Frisco Bldg. ; 8-11, 12:30-5; OALR.

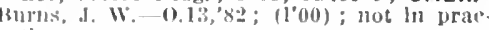
Hliee.

(amp, Lew is M. (b'53) b-O.2,7s; (1'83).

in refenter. Alonzo I. (b'hs)-Mo.20,97 $\left(I^{*}, y^{-}\right) ; 2013$ Emplre St. ; office, 506 Main

(1.AlkK, MHAF BENSON (b'6.5)-0.14, '00:

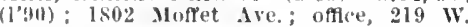
th sit 1 - 4

'ommls. Miller Oliver (b'86)--Ill.4,'12 (l'13): 320 Noffet St.; offlec, Niners Bank Bluk. : $10: 30-12,2-4$

IMMINGS, CMIS. C. (b'66) +-111.1,97 (1'99) ; 315 , Joplin st. : $8-10,2-4,7-8$

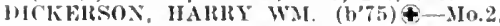
01: (1'05); 601 X. Mofret St.; offuce, 530 Main st. 10-12, $2-5:$ Pd.

wrake, rester M. (h?8)-Mo.33,04; (1'04): 609 Main St.

Dreshach. IIarry V. (b'6i) - D.c.2.94: $(105)$ : 11 W 31 st. : offlee, 621 Main st. 1humit. Munford (b'85)-Ky 2, 09 ; (1'09)

Eills, C. I- - : (l'98): 1451 Perkins St.

Fills, James M-Ky,5,'94; (1'94); 2118 II ain sit.

Erans, Mllton II.-Jll.1491; (l'00) ; 2305

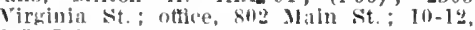

FHLFMAN. ARTHIR B. (h'79)-KY.2,86: (1'89); $432 \mathrm{~N}$. Wall St. ; 10-12, 2-4.

GRANTILM, SAMI. A.MIO27,92; (1'92) $414 \mathrm{~N}$. Wall St.; offle, 424 Byers St. $2-4$,

Cray, John X. (b’74)-Mo.7.'99; (l’01) ; 316 Parkvlew : office, 323 Parkview.

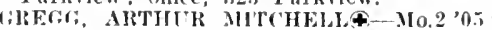
$\left(l^{\prime} 05\right)$; 1901 Plcher St.; offlce, $513 \frac{1}{2}$ Maln St.

IIIA, KARL, HERBERT (b'7 T)-Ga.11,01 (1'12): also Member Med. Assn. of Ga. IIardman, IIenry B. (b'75) - Neb.4,'98 (l'us) ; 111 W. sth St.

Ilarutum, Joses B. (1)66)-X.Y.5.96 (l'99) ; $402 \mathrm{~N}$. Pearl St. ; offlee, 634 Maln $2-4: U$

Haskins, Fredk. (b'62)-Mo.22,03; (I'03) : 1216 Main St. (b'5) - Mo.22,93; (l'00) Main St.

Main st.

Member Kan. Ired. Soc.; Keystone Bldg.

Hurwltz, Leon (b'is)-MIo.28, 01 ; (1’01) 510 Wall St. $:$ s-10, 2-4, 6-8

JAMES, ROBERT M. (b'79) \&-M0.34,04; (l'04) ; 725 May St.; offle. 513 Main St. ohnson, Joel E. ( (b'64)-Tenn.5,95: (]'95) : 1831 Jearl St. : offce, 2004 Wall St. KINUELOF. MOSES B. (b'45)\&-Ky. '74, Ill.11,'s7; (l’83) ; Modet Bldg. ; $9-11$. $2-5$.

ANYON, WIHIIAM IIEXRY (1)'52) \& LFAIIG, HARRY A. (b'80)-Mo.20, 05 (1'05); Member Kan. Med. Soc.; Worth Bldg.

LFAS, IIAROLD ROY (b'76) †-III.11, 04 $\left(l^{\prime} 05\right) ; \quad 12 \neq$ Pearl St. Offlce Hiners Bank Bldg. : $10: 30-12,2-4: 30: 0$ bG.

MACK, MAlY LATIMEK (b;8)\$-Pa.í, ' W. 4 th st.; $9-11,2-5,7-8$.

MAYIOKS, WM. H. (b'-9) - Mo.32,05 (l’05) ; 2001 Brers Ave, office, 418 Main St.; 2-5, 7-8. (l'9ews, Luther I. (b'39)-Mich.1,66;

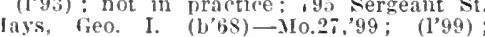
21st and Empire Sts. ; $8-9,1-2,6-7$

ICALISTER, XATHAN E. (b'68)-Mo.20, 97 ; (1’98); 714 N. Pearl St.; offlce, IIcrinley Bldg. : $9-11,2-4,7-8$.

MILIER, GEO. W. (b'45)థ-N.Y.10,80; (1'91); 111 Byers Are.; office, $214 \mathrm{~W}$ 4th St. ; $9-11,2-4$.
MJLER, SAMULI, H. $(b, 62)+-M 0,1,9 !$; (I'99) 219 W. Ith st. $11-12,2-4: 30 ; S$. $81 ;\left(l^{\prime} 12\right) ; 407$ W. 4 th St.

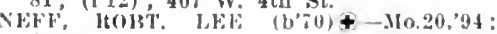

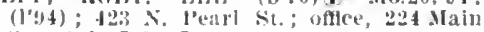
St. $2-4,7-8 ; 5$.

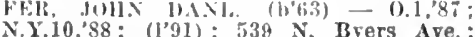
offle, Frlsio lith:; $10-1$. Byers Ave;

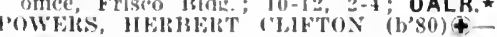
I10.29,03; (l'113); 52y N. l'earl st. ; offlee,

ROGHRS, ALFRED H.-NO.32,'99; (1'99); Member lian. Med. Soc.; 621 Maín St.

loohn, Francls H.-Mo.1, it; (I'93); 2201 I'ear] st.; olthe, lirlseo Bldy.

Scarborough, othello C. (b":50)-La.1,7t; (1'95) ; (610 Broatlwat

Searies, Orren 1. $\left(b^{\prime} 53\right)$-I11,4,86: $\left.\left(1^{\prime} 0\right)^{\prime}\right)$ : 2101 kyers st. ; oflle, 620 Main St. ; $10-12,2$

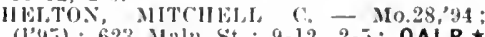
$\left(l^{\prime} 45\right)$; 623 Maln Sit. ; 9-12, 2-5; OALR. *
loan, Humer I. (b'69)-Mo.28,07; (l'06) ; 810 Byers St.; offlee, 530 Main St.; $9-11$, $2-4,7-8$.

SNYLER, ANLHEW R. (1,.64)-N.Y.10,85: (l'si) : Ollvla Ayts.; offlce, MLodel Bldg. TATHLEE, JA'KSON B. $\left(h^{\prime} 58\right) \&-M 0.15$, '81; (1'07) ; 311 Wall St. ; 1-3; S.ネ

Thornton, Rolut. A.-Mo.24,'93; (1'93) ; 819 Moffet St.; office, 820 Main st.

Tlsdale, clarence S.-Ill.4,'09; (1'12).

TIREEX, JAMKS L. (1'62)-Mo.8,91; (1'94) ; Tyler, Maln St. 22 .

914 Noln. B. (b'54)-Mo.17,82; (1'83); Walter, Otto $\left(\mathrm{b}^{\prime} \mathrm{i} 0\right)-\mathrm{Ky} 4,97 ;\left(1^{\prime} 12\right) ; 214^{\prime 2}$ W. 4th St.

WELCOME, EART, IIOWAIRJ) (b'82) Mo.22,'03: (l'11); 1831 B1rd St.; offlee, 219 , W. 4th St.; $10-12,2-4 ; \mathrm{s}$.

Wier, F. A.-Mo.22,04:(1'05): 522 Main St. Whllim, Whlliam J. (b'53)-Ia.1,'82; (1'87); 326 N. Wall St, : 10-12, 2-4; OALR.

, 1 ; (1'97): $50 \%$ sergeant A Main St.; $8-10,2-4,7-9$.

KAHOKA, 1,758, CLARK

Bridges, Mvah C. (b'69)-Mo.7,'99; (l'99).

BRIDGES, JAMIES R. (b'63)€-Ia.1,'88; (l'88).

MARTIX, WM. H. (b'37) +-Ia.1,'68; (l'83). Perry, Arnold A.-Mo.28,'00; (l'05)

IiOSS, JESSE CLIFFORD $\left(b^{\prime} 85\right) \uparrow-$ Mo., ,

SISSÓN, WM. B. (b'59) \&-M0.1,'90; (1'90).

KANSAS CITY, 248,381 , JACKSON

(See also: Kansas Clty, Kan.)

NLMBER OF PHYSICIANS, 903.

Ibeles, Edw.-Mass.1,78; (l'88); Altman

Bldig. : 11-1, 2-4.

Abramopoulos, Christos A. (b'87)-Mo.20 '13; (1'13) ; 1303 Penn. Ave.; offce, 338 W. 5ih st.; $9-6$

DAMS, NOAH (b'i4)-No.28,'99: (l’03) 620 Benningt on Are.; offlce, Rialto Blyg.; $9-5 ;$ OALR.

dams, Win. W. (b'58)-Mo.35,'06; (l'06) 3005 Glllham Blvd.; offlce, 1021 Grand Ave. ; 10-12, 2-5; OALR.

Adkins, James M.-Mo.8,'80: $\left(1^{\prime} 80\right) ; 100$ ś. ('ypress Are.; ottice, 404 Wyandotte.st.

Agin, Burroughs-1lo.32, $00 ;\left(10^{\prime} 00\right) ; 2420$ chestmut Ave.

Alexander. Date R. (b'85)-Kan.i,'10;.2814 I'asen St.; Sec., Mo.33.

llexander, Mary'J.-E-Mo.33,'05; (1'05) ; New Sllukert Bldg.; 2-5.

Alexander, Saml. (b'45)-Ill.6,69; (1'33) : 2008 E. 14th St. : Pd.

ALLBRITAIN, JAMES WII. (b'68)-Mo.2n, 96; (1'96) ; 3243 Pennsylrania Are.; of fice, 622 Southwest Blvd, ; 10-12, 2-4.

Allcutt, Carrie Ilckens (b'66) H-Mo.26,96 ; (1'96) ; $3200^{7}$ Harrison St.

$\left(l^{\prime} 96\right)$; 3207 Harrison St.
Allen, Clias. Fdw. (b'76) H-Mo.35, 04 :

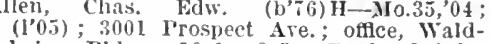
hein Bldg.; 10-1, 3-5; Prof. Ophth., otol, and Laryn., IIo.35; OALR.

Allen, Chas. Harry (b'85)-MLo.34,'13; (1'13); General Hospital.

Inderson, Axel Isadore (b's0)-Mo.20,09; (l’09); Rialto Bldg.

Anderson, Chas. I.-Mo.1,'96; (l’01) ; 3435 Michigan Are. ; office, Long Bros. Bilds. 


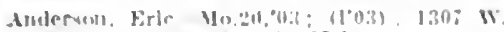

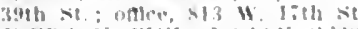

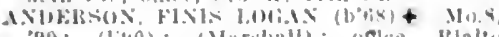

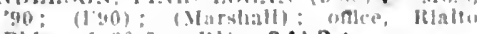
Bide. $1: 30.5:(131) ; 0 A L R$.

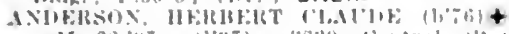

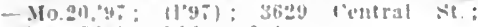
oglce Riatto Mluly: $2-4$

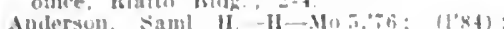

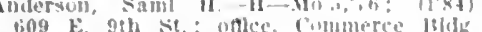
10.12 . $4 . \mathrm{h}$. Or.

Anderson, Wim. Connelly (b"it) - Vt, $20 . n_{i}$

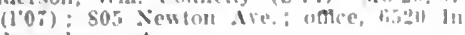
dependence ive.

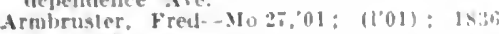
ร. 911 Sit,

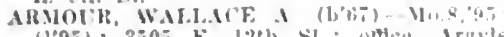
$(19.5) ; 3.10$

Mlile: : $2-5$.

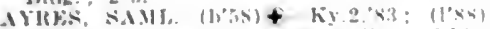
3729 Kahlume tre ; once, sharp Bhag.

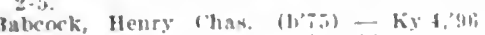
(1"yi): Bith st and Brooklyn Ar". oftice. L125 firand Ive. : $2-1$

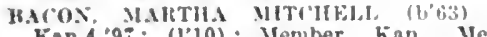
Kan.4,97; (170); Menter han. Med soc.

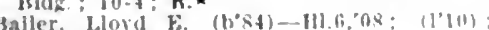

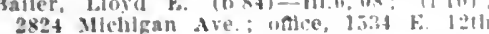

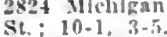

MAlliv, WM. MOTCHKISS (b's) \& l*a b

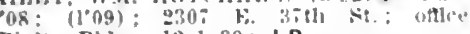
Rialen Mlele: : 1:2-1:30: Lo.

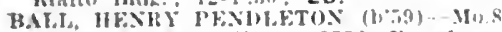
83. X.1.5.84; (1'84): 355.2 Broadway ofice, 921 Walmut st: $1-3$

Barber. Arch lamont (b'is)-110.32, 03 (104): $\$ 19$ Marlsom tre.

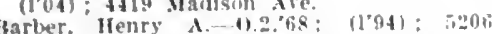

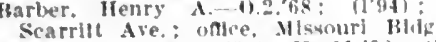

Barker, John E. (b"-5)-Ky.11, ns: (1'll): Member W.Ya. Siate Med. Assil.; t3010 Rell St

HEATTIF. THOMAS IFFFEMSOX (1, $(2,3)+$ - $110.8,85.8 .5,8 h^{\circ}(1 ' 85): 1201$ 1.1nwond Blvd. : once, Waldhein Bldg. : 1-4:
l'rof, Fyn. Wo.til: G.

Bechdoldt, Feo. F,-Mo.1,99; (1'99); .0020 F. ith st

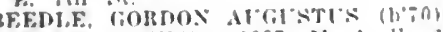
Mo.8.94: (1"94): 4007 Monstall offce, Bryant Blig.: 12-1. 2-1: S*

BEII. JOHI WATIACl: $(1,75)+.110 .20$,

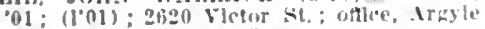
Blule: : 9.1, 2-t; CALR.*

BFILLOW. GEO, k. $\left(b^{\prime} b 1\right)+$ N.Y.1, (l'8i): 3239 Fuellel Are.: oflece, litals.

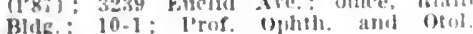
Blde. : 10-1:

Mo.f1: OPA. $(1880)-M 0.20,04:\left(10^{\prime} 0\right)$

1417 Forest ire: often. Shukert Mlly $4: 30.6: 0 \mathrm{r}$.

Berry. Benj. \&. Ky.2, kn: (1"92); 711; J'row

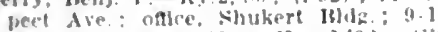

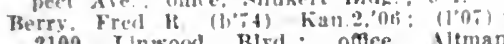
ilidg.: $11-1$.

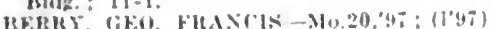

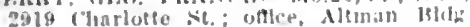
2919 r liarlo

Herry, Jullan (b':fi) -Teun.8,82; (1'm2) 1225 Forest Are: $8-12,1-8$.

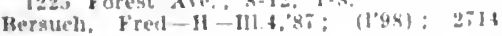
lister Ile.

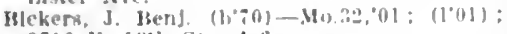
: 16 F. 1 \& $1 \mathrm{~h}$ St. : 4.13

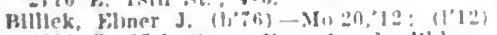
4.21 F. lith si ante. Argyle julz.

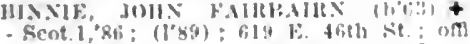

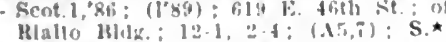

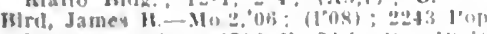

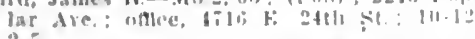
$2+\%$.

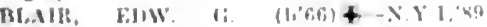

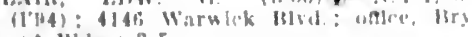
ant Hels.: $3-:$

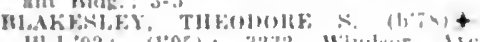

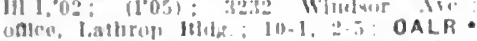

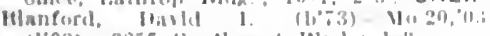

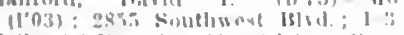

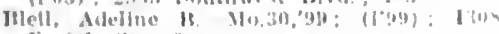
b. जth sit. : 2.1

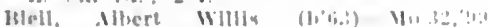

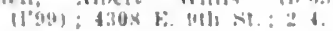

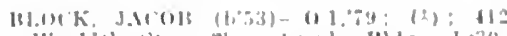

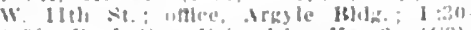

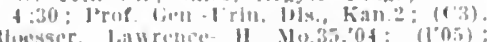

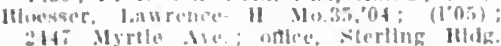
boarman, Jeroma inguse (b'bl) Mo.20,

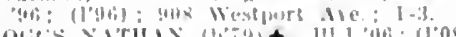

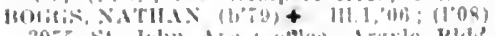

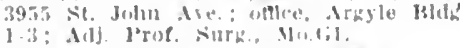

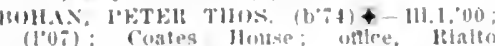
(lou): Cospes

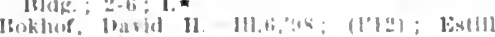

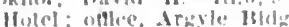

Holand, John Thos. (li'ali) - Mo.26."63: $(1993): 4043$ Furest Ire : obllee, Mlssour Hilg.: 11-4:30; l'rof. I'rth, and l'rac, rif Mhlag. : 110.35

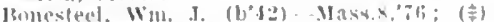

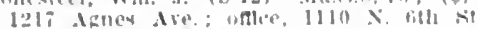

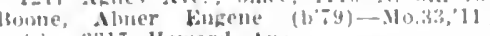
( ) ; 3:31\% llowarl Aro

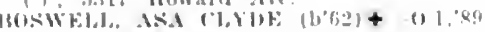

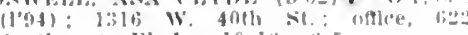

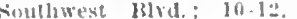

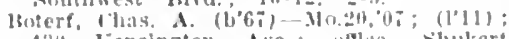
$4: 30$ Kensington Ave: olllee, sluukert lilds.: $10-12$, : $2-t i$ : D

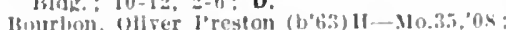
(1.08): 2703 Harrison tit.; oftlce, Argyle IBIdy.: $9-12,3-5 ;$ OALR. *

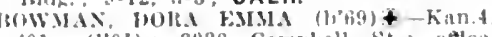
01: (101); 3936 Camjuell st.; oftleo, Argyle Kidg. : $1-4: 5$.

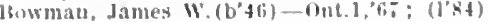
atiol Wabash Air.; oflce, 2.ts Itrosuect ive : $10-12,3-5$

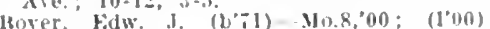

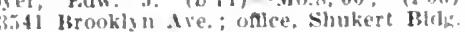
$1-4$.

Itrilliury, Anderson D. $\left(b^{\prime} i t\right)$-Tenn., $0^{-}$; (1'0? : 60:3 Ilarrlson si.

Branaman, L. (b)ot) No.s.44: (1"0!9) 1020 Pemalyanla Are $7-4,1-8: G$.

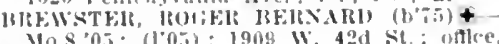
Iraglo lidis.

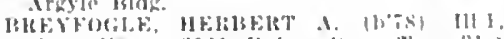

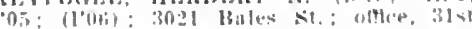

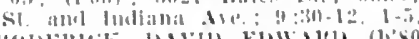

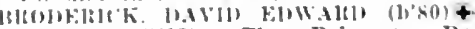
111.1,01; (1'08): The Belmont; Prot Ined, Inotit.

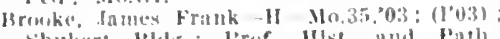

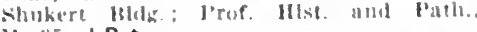
V110.35: L D.*

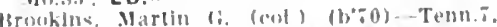
99: (101): 2315 Hghland Are; offlee.

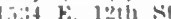

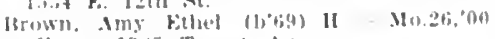
(1"1)ii): 13115 Troost Are.

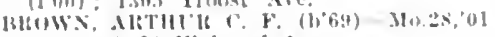
(101): 500t walruma Are.

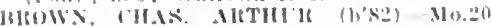

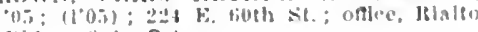
Hhig: $2-1: 5 *$

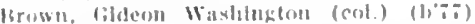

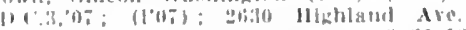

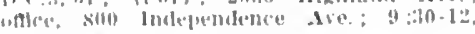

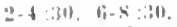

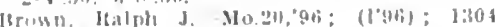
t. I I th sit

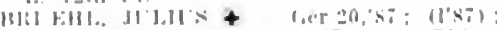
3516 loseo St: oflce, Bryant Bldg: II- - : T.

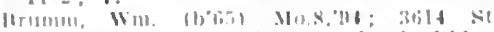

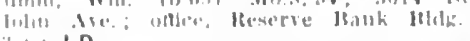

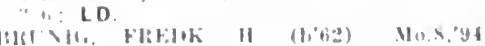

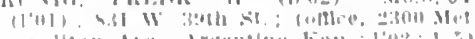

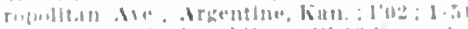

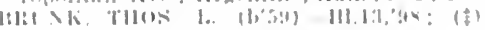

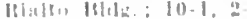

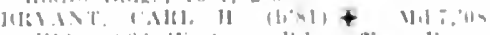

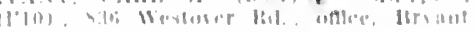
$161,1 \%=1$

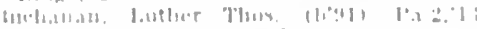

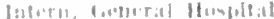

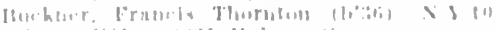

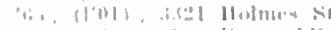

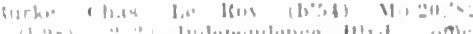

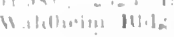

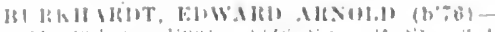
oh

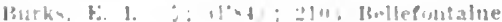

liurnich, Juster il sit.

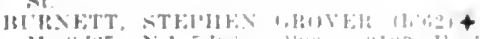

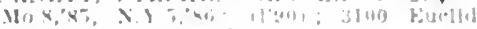
$110^{2}: 11,-1 \%$ NP.

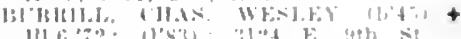

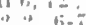

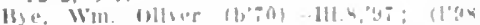
31:1 Varrknu $\leqslant 1: 10,:-4$

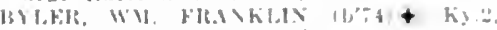

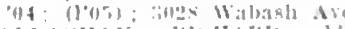

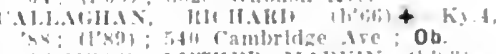

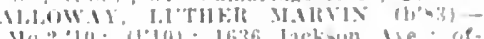

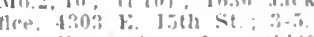

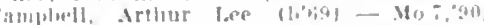

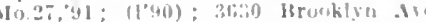

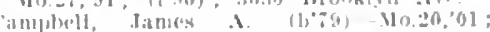
(10)1): 2314 Wabails Ire: $3-$

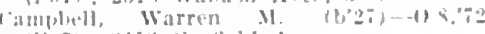

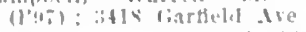

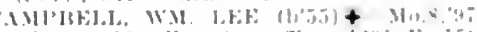

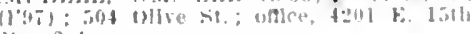
st. : 24 .

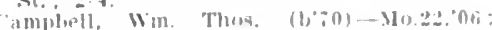

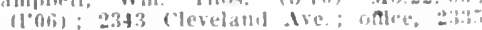
Jickion ire.

lammon Jelferson 8 . $(1,54)$ - Teun 4,42 .110.24:14: ( ) : 402 k 31st st

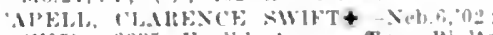

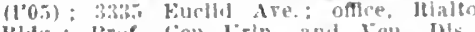

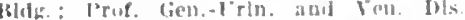
Io. lil: U.

(口il (1999): 30t6 suarl lie, uffee, sharg Blig.: 1-6.

cart, siml. Thos. (h'tu)-ky.s,91; (1000) B.:22 Wanut st.; Ob.

farmahan, Jox. Y.ynn $\left(b^{\prime} t+\right)-310.9 .92$ (19.9); $30: 3: 6$ firand lve.

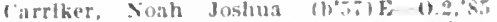

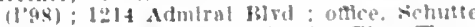
llikg.; 10-12. 2-tj; I'rof. Filec-Ther. 110.33

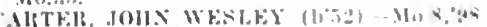
(1'a9): 2407 Iackson Are: :-5. (AlTE: A

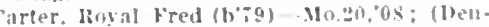
(list) : thist k. sth St.: 9.t

(artilch Jesse $16 .(6+45) 11-0.13,{ }^{\circ} 83$ : (1'St) 311fi Flora dre: oftce, sliukers lildg. $12-3$

arver, Henry x. (het)-Mo.1,:81; (1901) office, zson Fo. loth st

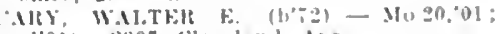

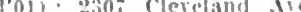

ase, Wm, llenry-1).12.83; (100.2); 2020 Penter ile.

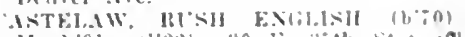

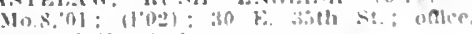
lieneral llosplial.

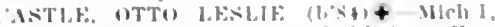
(1): (1'w4): $2+1,0$ 1.111

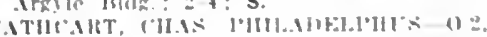

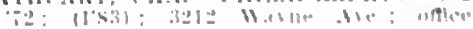
Wablhom lolit

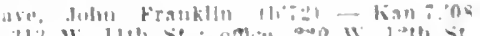

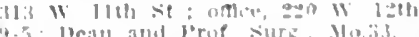

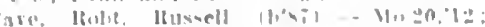
(lia): vi Maryes Humpllal

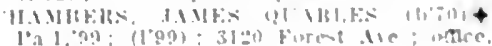

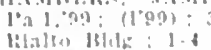

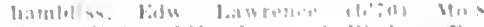

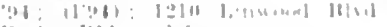

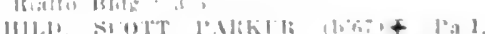

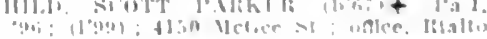

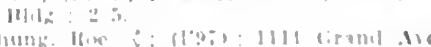

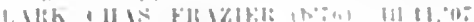

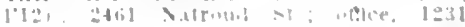
, rant] $\mathrm{sin}$

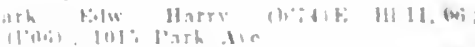

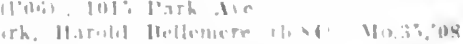

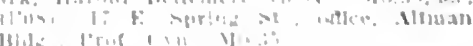




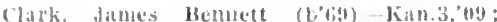
(111) : 121:3 E. Isth st. (1) (l'13) (ieneral llospltal.

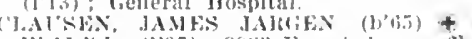

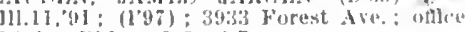
ltialto IBldg. : 2-5; LD.

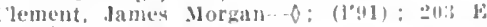
12 th st.

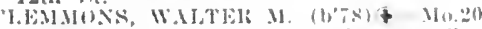
(1); (l'01); itit4 swoje l'arkway: oflow.

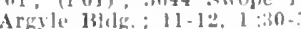

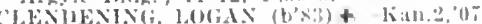

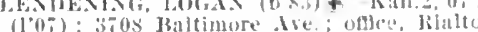
1311. : $11-1$

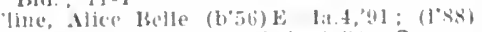

1704 l'rosplect Ave. $1: 30-4: 30:$ G.

Cline. Jarmella $d$.

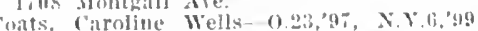
$\left(l^{\prime} 06\right) ; 2 \pi 23$ Ilarrlson st.; oflce, Yew

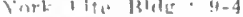

COCIIRAX, SOIHIA LEE (b'68)-Mo.35,

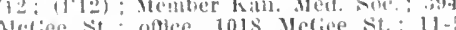
Heliee st.; onter 1018 Mefice st. $11-5$ (1's9): 2544 Wyandotte st.; offce. Wranut sit.; 8-6.

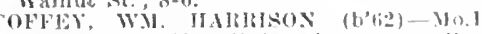
'86; (190); 500 Helletontaine Are. : ollice Waiklhein Ridg.: : $-6:$ : $\mathrm{S}$.

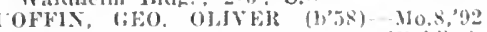
(1)42); 11: Isocust st.: offlee, Waldheim Bldg. : $2-5$.

("ole, Ilugh II-Mo.8,05; (1005); not in practice : a.2. cleveland dve

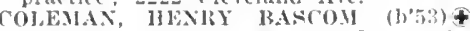

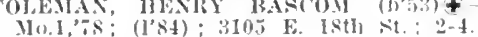

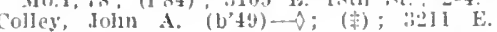

2lith Terlace.

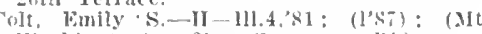

Wishington); offlee, Commere bld

Combs, Wm. Cliffori (b'bi) - .'Tenn.t, 89 (1.89) ; 3110 E. 25 th st.

Conley, (Geo. d. (1'\%1)-Mo.33, '(12: (1'03) 2640 Cleveland st, ; oflce, shukert IBldg. $10-12,2-4$

Comnell, Evan shelly (b'90) - La.1,13; (1'13); 3301 Flrginla Ave, ; OALR.

(113); 350 B (b'56) Are,; OALR,

zon Troost ive.; office. Commerce B'y connell, Wm. Adams (b'64) II-Mo.2f, 00 (1'00); 3301 Virginla Are.; offle, Con merce Pldg. : 11-12, 2-5

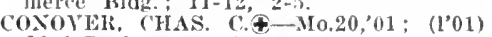
2636 Park Ave.; office, Argyle 13ldr. ; 2-4 Prof. Med., Mo.g1.

Cooper, Calrin L. $\left(b^{\prime}, 1\right)-M 0.20,98 ;\left(1^{\prime} 99\right)$. 4509 St. John Are.; offlce, New Lathrop Blig. : 1-4: S.

cope, Paul Francis (b'78)-Tex.3,06; 3945 Troost Are.: LD.

CORDIER, AIBERT IIAWES $\left(b^{\prime} 59\right)$ - Ky.2, 's1, N.Y.10,84; (1.93); 415 Benton Blvd. office, Conmerce Bldg.; $2-4$; S.

coldiry, Ilarold Vincent (b'79)-Mo.34, 0 $\left(1^{\prime} 03\right) ; 4130$ E. 9 th st. (ounsel1, Chester M. (b'83)-Mo.z,07: Ave. Temple; $U$.

('OWHERI, IOS. RIRD (b'85)-N.Y.1.09: (1'12): Member Ky. State Med. Assn. (1'12) Member Ky. Stafe Med. Assn.

3027 Camphell St.; office, Rialto Bldy.
Cowhick. Rehece Anna - H - Mo.31,02; $\left(1^{\prime} 02\right) ; 81 \%$ Forest Are. ; 2-5.

Cowles, John V. (b'71) H-Mo.26,98; (l'01); 1524 Grand Ave.; 9-12.

Cramer. Wm. Emlle (b'65)-Ill.4,'88; (l'96) 912 Tracy Ave; offlee, Bryant Bldg. lrof. Gin., Mo.35.

Crooks, orson R. (b'70)-Mo.8,97; (l'97) ; 6235 E. 15 th St. ; offce, 7206 E. I5th St.; I $2: 30-2: 30$.

Croskey, llenry (b'48)H-Pa.9, 78 : (1'92) : 3223 Prospect Are.; offlce, Altman Bldg. 11-3:30.

Cross. Roht. Orr (h'b5)-Mo.8,89: (1'93) 1701 E. 8th st. : offlee. United states and Mexican Trust Bldg. ; $2-5$

('Ross, 120Y (b'st) - Mo.20,'08: (1'08) 4415 Harrison st.: office, 1013 Grand Ave: LD. *

CROS, W.MTEM MAlTIN (b'TS) \&-Mo.20, 02: (102); 1415 Harrison St.; office City Hall.

lowiler, Wm. Henry (b'T) - Mo.20,03; (1710:3) : 63\% Woodland Are.; offlee, 1002 Walmet st. ; $11-1,2-5$.

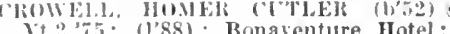
Yt.2,75; (1'88); Bonaventure Hotel; of Hea. Lilond Blilg.: 11-3.

rume dun llus Dei liarlleld are.

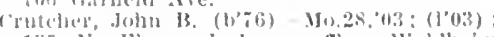
1:35 N. Elmwool Are, oftres. Wallhein $13 \mathrm{dg}$

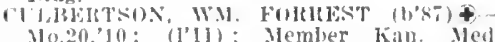
110.20,'10; (1'11); Member kan. Wed Soe : Mlssourl laclfe kallway Hospital.

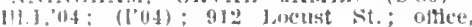
Italio Bidg. : 2.5

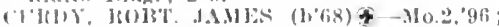

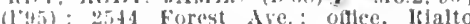
1:11. ; $-12,2-4 ;(1: 4) ; 0$. *

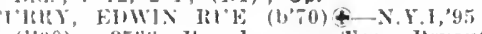
(l'00); 35:3 lisoadway ollee, Bryant lildg. : $2-5$.

inrlis. Homer lutrton - II - .110.28,01: (l’01); 2200 Indlana Ave.; offlee, 913 Main st. : $9-3$.

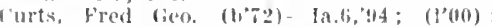
1603 Iinwood Hivol; offlce. diumiel Bldg. 'yrene. Chas, lidw. (b'71)-Mo.20,95 (l'99) : 1700 W. $391 \mathrm{~h}$ St. : $2-5$

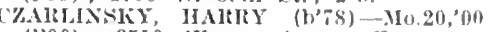
(1'00); 3510 Wayne Ave.; offre, ion merce Bldg. ; I-3.

Dailey, Forrest W. (b'75)-Mo.8,'96: (1'96) : 3322 Flora Ave.

l)argatz, (f. Emil (b'60)-ML.1,83: (1'89) 500 Bennington Ave. $1-5$.

DAVIS, ALJBRT WLLILNGTON (b'63) No.8,02; (1'02); 3306 Prospeet Are.; of fice, 3ist St. and Troost Ave.; 10-1 I, 3-5

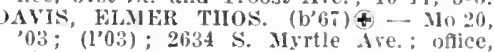
sliukert Blig.

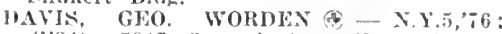
(1'84) ; 5817 Central st.; offle, shuker lilder ; $9-11,1-3 ; U_{*} \star$

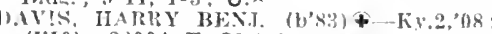
(I'10) ; $2200 \mathrm{~A}$ E. 31 st St. ; offlce, 3Ist and Brookiyn Ave.; $2-4,7-8: \mathbf{S}$.

Datis, James T.-Mo.35, 06 ; (1'06); 1712 F. sth st. ; offlec, Missouri Hilg.

Datis, John Jume (b'87)-Mo.20,'11; (1'11) 3850 Brooklyn Ave.; offle, lialto Blalg.

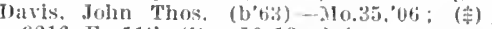
0216 E. 11th st. : 10-12, $2-4$

DAVIS, SAMI. IVXES THLDEN (b'76)\$ Mo.20,'05; (1'05): 3625 Mlehigan Ave. office, Waldheim Iildz.; $10-1,4-6$.

Davis, Virgil Allen (b'80)-Mo.20,10 (1'10) ; $309 \mathrm{E}$. I0th Sit.

awson, Benj. Lilisha (b'52)-(1.1,75; (19i1) ; 322t) Gak st. : 9-12, 1-4; I'rof. surg., Mo.33.

IIONFT, FRANKLIN IR.-Mo.j,'04 $\left(l^{\prime} 05\right)$; 2626 Askew Are.; offlee, $3401 \mathrm{E}$ 2 th St.; $2-4,7-8 ; S$

I E LAMTER, HASBPOUCK (b'70)- - la.2,
01: (l'96); 3939 Troost Ave. office, Waterworks Bldg.; Pd.

bela1, Darwin (1'82)-Ill.1,09; (1'n9): 275 Giarfield Ave; office, Argyle Bldg. $2: 30-4: 30$.

llelap, Silas Cllarles-H-Ia.4,80, Mo.33, 03: (j’90) : 2219 Brooklyn Are.; offlce, Argyle Bldg. ; 9-12, 2-4; OALR.ネ

Denman, Joel Isham (b'76)-Mo.2, 00 (1'00); Argyle Bldg.

Dennie, Chas. Clayton (b's4)-Kan.2,'12: Intern, (ieneral Hospital.

DENSLOW, FRANK MCDONALD (b'7T)థ -Kan.2,06; (1'05); 3015 (irand Ave. offee, Rialto Hldg.: 2-6; U.*

DeVILAIS, EDGAl FRANK (b'82)థ Mo.34,'05: (1'05) ; 3001 Paseo St.

DLWEY, MARTIX (h'81)Ð-Associate Fel low-ia.10,04; (Dentist); 1016 Armour Bird. : $10-4$.

Diblle, Jos. Edgar (col.) (b'72)-Tenn. 97: (1'00): 1729 Michigan Ave.; offce 1832 Vine st.; 8-11, 3-5, $7-9$.

Diblule. Martha rleveland-111.9, 85 : not in practice; $1304 \mathrm{~S}$. Paseo Pl.

OOI, FliLDK. 1. $\left(b^{\prime}: 8\right)-110.20,04 ;\left(1^{\prime} 05\right)$ 4646 Troost Aie.; $9-12$.

Donaldson, Andrew-0.11, 'Tt; (1'8i); 2621 Ignes Are.

DONALDNON, CLIDE OWEN (b'8)-
110.20,00: (I'00); 642 Schaefer Are. ; office, 4050 Broadway; $2-5: 30 ; R$.
JONALDSON, JAMES EARLE (b'74)oflce, Wheeler Hilg.: 10-12

vorsey, John , Ios (1,'s, 10-12. 1323 L. 31st st.; once, Bryant Bldg. $12-1,3-5$

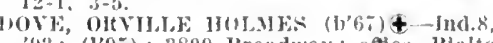

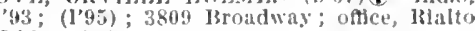
IBldig. ; $3-5$.

boyle, Theodore $\left(b^{\prime} 46\right) \mathbf{F}-\mathbf{M 0 . 1 0 , 7 6 ; ( 1 ' 8 7 )}$ 1001 E. 15 th St. ; I-4.

I)roll, lico. Amos (b'bis)-CaI.I, 00 ; (l'05):

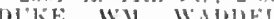

(1) (1) 82$)+-11 \mathrm{~d} .7$

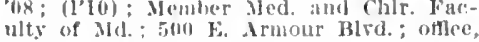
ltialto liddg.: $1 . \star$

bunham, Stephen Alanson (b'51)-X.Y.jo, 65; (1'86); 6024 Swope Park Blvd.; of flce, Shukert Bldg.

bum, Ell Hamlin (1,58)-111.1,85: (1999) 3820 Wain st. ; offlce, l'ennock Blde.

purrett, IIarry s. (1, 52$)-\mathrm{Ky}, 4,79$;

Eastman, Burt Leander (h'0)-Ill.6,92: (1'97): 2244 Woodland Ave.; offlce, $\mathrm{Ar}$ gyle Blag.; 2-5.

Eter, Fredk. M. (b't1)-Mo.2S,0I; (l'01) 1120 Main S1.; U.

Edgerton, Nark (b'54) I-1'a.9,'79; (1'89) 3029 (harlotfe St.; offlce, Shukert Bldg. ; $11-1,3-5$.

Edmonson, Milton Marion $\left(b^{\prime}\right.$ io) $\rightarrow$ N.Y.10, (91; (1'91); 3516 Harrison I3lvd.; 9-12

Edwards, Gustavus W. (b'50)-Mo.1,7: (ま); 436 II. I5th St

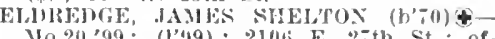
Mo.20,99: (1'49); 2106 E. 27th st.: of

Elliott. Frank-11- -llo.35,05; (1'94); 2812 Forrest Ave ; oftce; Missouri Bldg. ; II-4. Prof. Gyn. and Obst., Jio. 35

Elmere, Johannes Alfred (b'66)-Kan.3.'94; (1'10); Young Men's Christian Associatlon; oftce, Braley Bldg.

Elston, Geo, B.-Mo.20, 07 ; ( ) :
Monroe Ave.; offlce, Argvle 13ld

Enz, Elizaveth E.-11-Mo.26, $96 ;$; $\left(1^{\prime} 96\right)$ 1307 Locust St.; Prof. Mat. Med., Mo.35.

Enz, Helena Eleanor $\left(b^{\prime} 86\right)$ - Mo.;j,'I2; ( ) : 1307 Locust St

Esmond, John Jackson (b'52)-0nt.1,'7T; (1'84); 1049 E. 5th St.; office, 500 Troost Ave.

Esmond, Marle E.( (b'83)-Mo.35,'05: (1'05) : 3533 Troost Ave.

EUBANK, AMBROSE EASTIN (b' 6 ) Mo.20, 01 ; (1'01); 1600 W. 39 th St.; offlee, lieserve Bank Bldg. I-2. at

EVANS, ELIJAH JOHN EDWIX (b'so)Mo.20,08; (l'08); 4200 Washington st. office, Wheeler Bldg. ; $3-5$.

EVANS, FREDK. HARRY (b'iz)-Kan.4, '01: (1'01); 100 Chelsea Ave.; offlce, Argyle Bldg.; 2-4.

FAIRES, OLIVEL PERIKY (b'65)£-Mo.8, 05; (1'05); 3031 E. $2 \%$ th St.; offlce, 10 th and Walnut Sts.; 1-3; Prof. Anes., Io.GI; Anes.

Falconer, Alexander-Mo.28,'89; (l'89); 526 Independence Are.

FARKOIV, GEO. W. (b'42)£-III.I; 75 ; (ठ) ; 6620 E. 15 th St. ; $3-10,3-8$.

Federinan, Chas. Adam (b'i0)-0.1,91; E. 40 th St.; offce, Shukert Bldg. ; $2-5$ Prof. Surg. and Anat., Mo.35; S.

Feild, Albert C. (b'80)-Mo.20,08; (1'08); i26 1: 15th St.; office, 214 E. 12 th St. $9-11: 30,2-4$

Ferster, Wm. Rollie (b'is) - Mo.20,08; (l'07) : 5108 E. I5th St.; office, 4318 E. Itsth St: : $2-5$.

FIEI.1), WM. STANTON (b'65)-Mo.20,'96; (1'tc) ; Walle Hall Apts.; office, Shukert Bldg. ; $1-4: 30$.

FIELDS, THOS. (b'67) †-Mo.8,'94; (1'95) ; 2023 Benton Blvd.; office, $2600 \mathrm{a}$ E. $15 \mathrm{tb}$ St. ; $1-4 ;$ S.

Flanders, Francis L. (b'48)-Ill.6,68; (১); 3215 E. 9 th St.

Fleteher, 'Thos. Augustus (b'86)--D.C.3,'12 ; (l'13); 1114 Vine St.; (office, 1512 X. 5th st., Kansas City, Kan.; $9-11,2-6,8-9)$. 


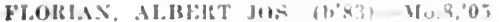

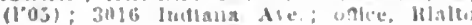
Bldig.

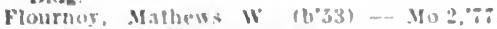

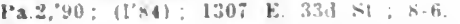

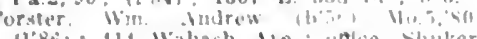

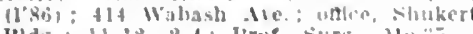
Illds. : 11-12. (1'1:i): 514 Jachson Ive.

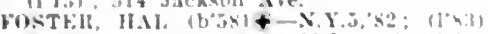

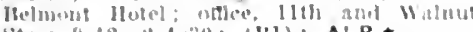

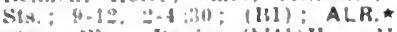

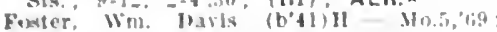
(l's4): il:s Warwlok llwu. omce. A

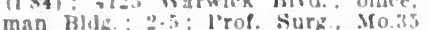

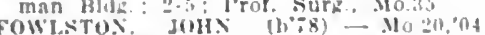

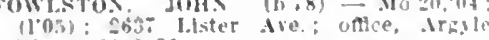
Hldk. $12-2: 30$.

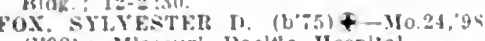
(l'98): Missourl Pacltic II opplat.

FR.ACCISCO, CFARFACE B. (b's0) Kan.2.07: (l"09): Washington

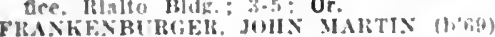
+ once. Rlalto Bldg.: 2-5; Prof. Rectal oftce, Rlalto Bldg. ; $2-5$

'razler. Claude Eugene (b';6)-Mo.33,04 (1005): 2704 F. :bill st.; unce, Cirand Are Teniple: 12-2

PREYMAX AMOE ABROHAM (h',2)O.8.74: (1'83): Sth and Truost Sts. : $2-5$ (I'\$3): 508 Montgall Are.; ottce, $1101 \mathrm{~F}$

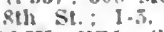

Fick, WM. (b'57)\&-Mo.2.84; $\left(1{ }^{\prime} 84\right)$ nol: Wornall Id.; once, Halto Blds. 10-3; D.

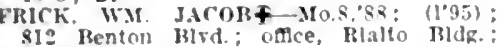

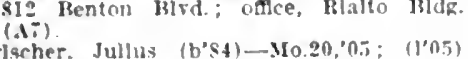

Frlscher. Jullus (b's4)-Mo.20,0.5; (l'0.5) 5.5 I'ros

Frizell. Iloyd $\mathrm{x}$ ( ( Cosbr Hotel.

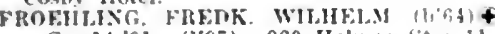
-Ger.14.?1; (1007); 920 Holnes S: : 11 12. $2-7$

Frye Ininn from. (b'62)-rier.10,84:(1.03) 2933 (Tharlotte $\mathrm{St}$; offec, $702 \mathrm{~F}$, 31 at st. $1-5$

prre, Wim. (b"1)-Mn.7.93; (1'93); 1616 E. Jeth st.: nfflee, Missouri bldg. $1=5: 30$.

Fullet iouia (c-Mich.1,79: (I'83): 1313 E. 1 sth $8 \mathrm{t}$

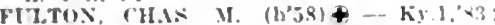
(I88); :t92 forest Are.; unlce, Arigyl Bldg. : $1-1 ; \mathrm{S}$

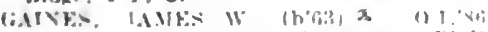
(I'8i): Italtinior Ilotel: ontee, Itiallo BIds. : 9.2: ALR.*

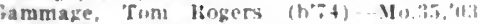
$4800 \mathrm{E}$. 2tth st. : I'rop. Surg. Mu, 33 Carlner, Joslah Sylvang Ind. 13, $85:\left(1^{* 4} 4\right.$

Ronaventure Hotel; 8-10, 1-2, 6-8.

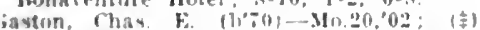

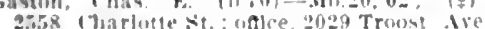

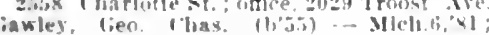
(1)83); 320 if Glllham lid.

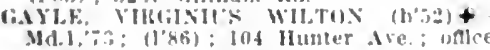
Kelth and l'erry |bld.

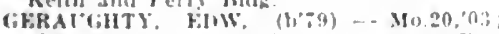

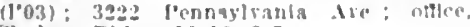
Shukert Mlrlz, : 10.12, 2-.

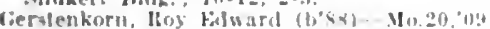
(1'09): 1402 Pernoslianla lie.

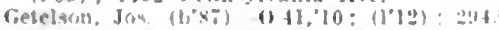

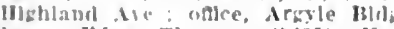

Glbson, balw. Thomas (b'8I) -Kan.2,12

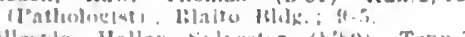

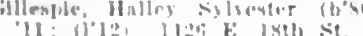

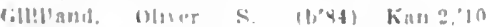

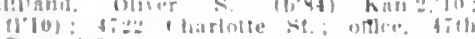
St. and Troost Are : $1-$ b.

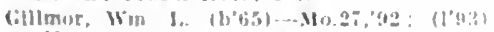

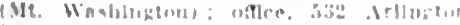
Ave.

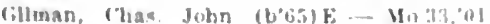

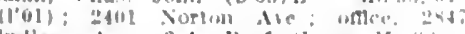

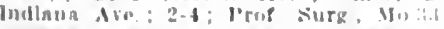

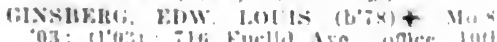

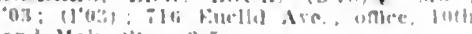

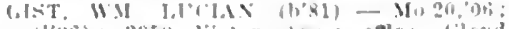

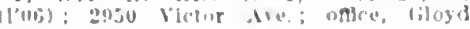

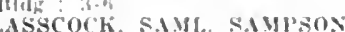

Isee kansas t lly, kin.!

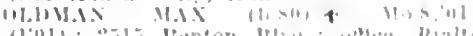

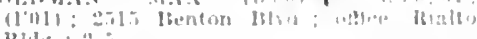
$13 \mathrm{H}_{\mathrm{i}} \mathrm{R}$

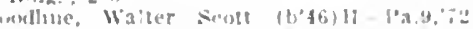

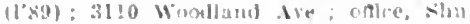
kitert Hli: : 111-12

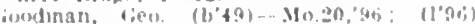

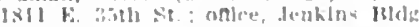

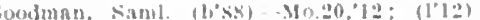

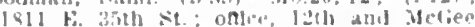
sts. : 10-3.

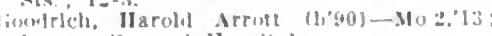
Intern. Cieneral Ilospltal.

Gorlson, Jesse X. (b'ti) Ia.1,75: (1'8.3)

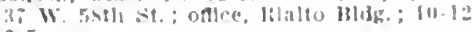
$2-5$.

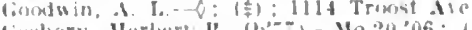
cushorn, llerlere It. (b'a)-No.20,06; (1) Seli and brooklyn sis.

Cioslln, dames A (1) 411$)-M 0.2,66$, X.5.10 $71 ;\left(l^{\prime} 03\right):-5 t h$ st. and Broadway.

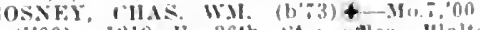
(1'00): 1:19 t. 36,th st.; villec, Halt BHly : 9-3) OALR.

GRAIIIU, GFO ALEXIXI) FR (b"60) Que.1,st: (1'85): $1+14$ Truost Ave.

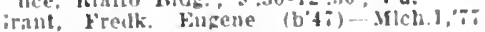
(1'94): liaynomd B!d

Gray, Fidward Benj. (b'8s)

lnsern. (ieneral llospital.

$118 \mathrm{w}$ 10th St: 0 mce, Waldhelm Bld $: 30-5 ;: \mathbf{S}$.

ireene. iynne I31rdsall (b'81) - Ia.4.'(44 (1'08) ; $4: 340$ Campbell St.: offle, Shukert Mag. $11-1,3-5$; Prof. Mental and Nerv Dlर., 110.37

GILEENE, MARIE A. (b'jt)Ғ-Kan.2,"(is (1) unle, 12th and NcGee sts. : 10-12: ObG.

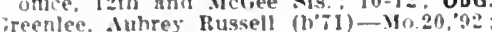

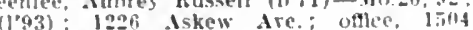
(1) 93 ) : 1220 ister

Griftin. John Morke (b'5) Mo:s, 119 : (1'99) : 1517 F. 10th st

Grifin. Theodore.

See Kansas city, Kan.

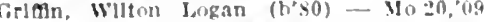
not In practice: 2412 F. $23 \mathrm{~d}$ St.

GIRIEFITII. ARRAM COMIXCO) (b's!

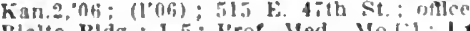
Rlalto Bldg.: 1-5: I'rof. Med. Mo lit

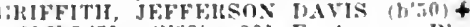
X.Y.5,"il; (l'S3): 201 E. Arinnur l3lvil. nfle, Rlalto Rlils. :

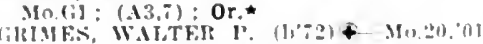
(lol): loth and Harrlson sts. :

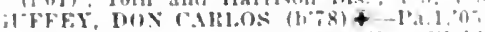
(lon) : 4129 (ambridge st: imce. Wald. heln Itldy. 11.1; J'rof. Obst amil dibn. Kan.2: ObG.

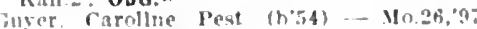
$(109): 1325$ s. Jaseo I'I.: G

IIAL. IRAWFORI I.ESTER (b' 4 ?

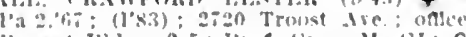
hryant bld : 2-5; J'rop firn. Isolil: G

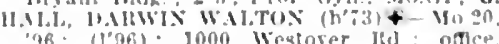
(aR: (1'B6): 1000 Westorer

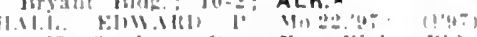

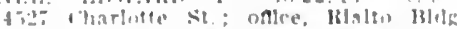
Asut l'rof. Ihln. and Larsn., Kan.2

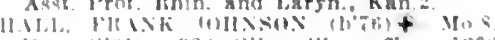

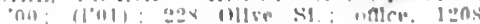

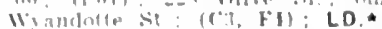

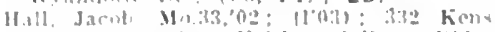

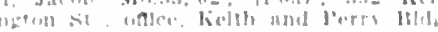

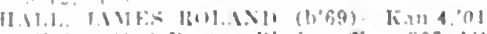

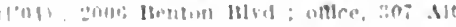

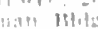

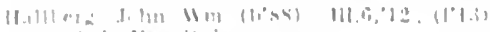

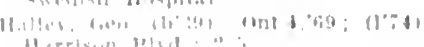

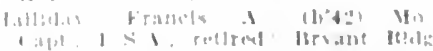

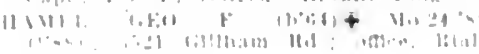

II:Imill rim:

IIAMII. soll

Ir.

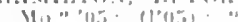

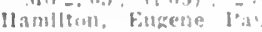

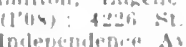

II.1111.T1)

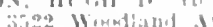

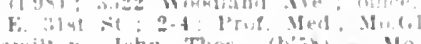

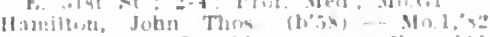

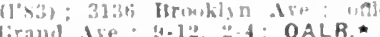

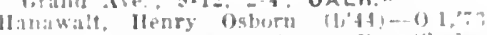

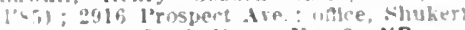

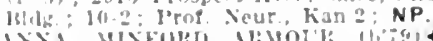

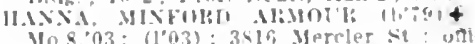
lob and Walnut sta: 3.: ObG.

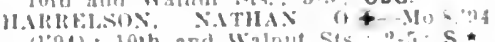

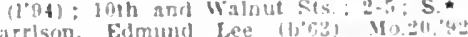

Itirrlson, Edmund Lee

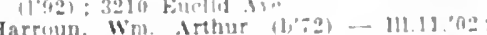

(145): (Nerriam, kan): utce. Wuld

belin Blilg.: 2

Jarman. Milo E. (b, Tal-kan 4,00) (1900) 1"0.0 firand Are

Hahinger, fieo. Ilenry (bofi) Io a, at lloti: 2820 E. 12ih st.: aftice. litate Hlak. : 30-12.

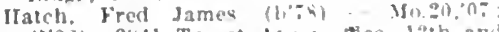

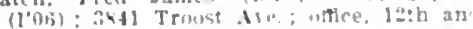
IreGee" sis. : $2.5 ;$ S.

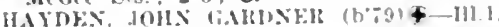
04: (108): 1104 benton BIra: oftce

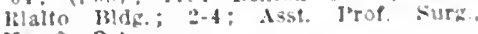
Kan.2: S. $*$

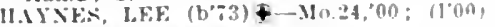
901 Westport Ire.

llaty. Ilenry Cornwell (bofi)-0 1, 92 g.95): (Bonner springs, Kan.

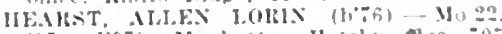

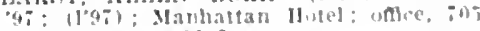
I'monect Ire.: $11-2$.

lleath, Folwin Buthren (h'39)II X Y.9."4.3 1]95); (1121 (iarfleld I10. Kancas $1 \mathrm{lg}$. Kan.: 1*1; oflee. Hall Hide

lledrlck, Harold Hert (b'on) - Mo. 90,13 ; (1'13): 1005 Camptell St.: oftice, Rialto Hide: 1.3: Anes.

lleinzelmann. Irthur $\left(b^{2}-s\right)$ - Kan :07

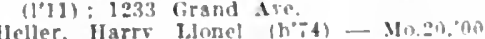
(I’ni) : 3821 Warwlck HIrJ.; ontce, Hialu Blig.: $2-4$.

IIenderson, Ilbert I (b)-2) - Mo 20.90 $(197): 2120$

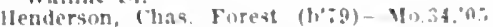
(liti) 1441 Independence ire: iale

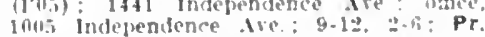

llemdersun, (jenerous leander $(b+4)-111$ :

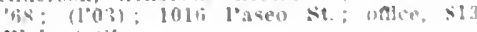
Walnut $\leqslant 1$

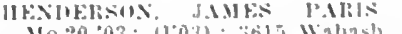
tlce loth and Molion sto:

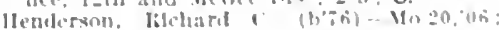

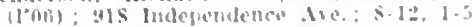

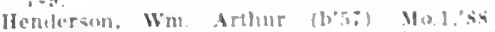

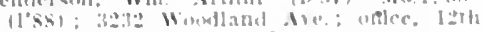

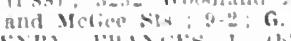

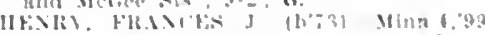

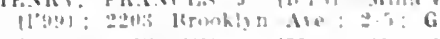

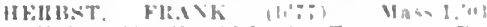

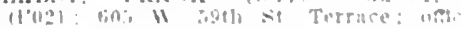

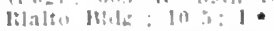

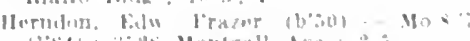
(l'st): Hes Momenall Are

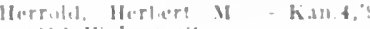

(i) 1.011 ilnut $>$ it.

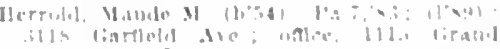
Ne: a : G.

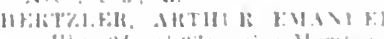

Jif

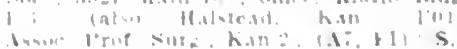

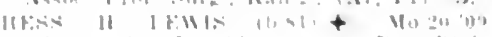

Iilit: 


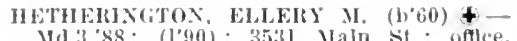
MId.3, \&8: (1'90); 35331

njbbard, Sherman Hlaine (1,88)-111.1,12 (1'12); 1738 Troost Are.

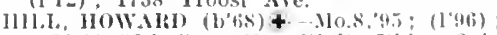

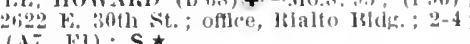

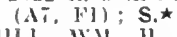

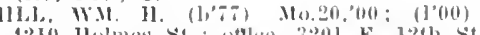

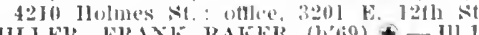
(9): $(1,91)$; Westover klug.

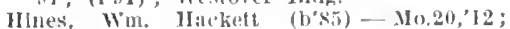
(1'12); 430.5 Independence Are.; onlee, RIalto' nulle.; $10-1$

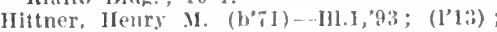
4019 forest st.

Jloagland, Wm. Lewis (b'72) - Mo.20,98 (1'45) : 3t32 I'rospeet Are; oftlee, Rialto Bldg. : 11-1; Pd.

Hobbs, Arthur A. (1, P i ) -110.8,96; (196); 3317 k. 30 th st.; $12-3$.

Hodre, Jussell lowe (1,88) - Ill.22,'12; (1'12); (icneral Ilospltal.

llodges, Wm. Henry-No.8,'89; (1'91) ; 527 Woodland Ave.

IIofmann, ottokar, Jr. (1'“9) - Jo.2,0I ; (1'01); 24:33A Benton 131va.; offlee, litalto 13ldtr.: $3-5$.

II)HBROOK, RALI'II WALDO (b'80)-Mo.8, , 1 ; $(10.0) ; 14$ E. 56 th st. Terrace; office, Arryle Bhlg.: $2: 30-6$

IIOH,AS, LETIIER TALMADGE $(6,62) \notin$ $\mathrm{N} \cap 20,{ }^{\prime} 96 \mathbf{6} ;\left(\mathrm{l}^{\prime} 96\right) ; 281 \mathrm{~T}$

HOLISTER WUBER L. (1, 75)-1a.10,03: (1'04): 1009 Admiral Blvd.; oftec, rlalto 13ldg. ; $3-5$.

Holly, Luclus Johnson (col.) (b'61) - D.C.3, $90 ;\left(I^{\circ} 94\right)$ : 1117 campbell St.; 8-11.

Io Ly Ynen- 0 : $\left(1^{\prime} 99\right)$; 1210 dlain St.

Hook, Fredk. It. (b'89)-1lo.20,'13; Intern, (ieneral Hospltal.

HOl'KINS, CIIAS. B. $\left(\mathrm{b}^{\prime} 76\right)-\mathrm{H} .1,00$; (l'00);3212 011ve St.; offlee, 2600 E. 31st st. ; $1-5$.

Hord, W. S -Kan., 08 ; 1535 Prospect Are. offtee, 1021 irand Are, ; l'rof. Anat., Mo.33 HORIGAN, JOS. ASCHWANDEN (b'64)

D.C.1,'88; (l'88) ; 1107 E. 53d St.

Howard, Chas. (b'52) - Mo.32,'03; (1’03) ; 2711 Jaekson Ave.; offlee, 1415 Grand Are.; 9-12, 2-6

IIOWARD, JOS. WM.థ-Mo.20,'03; (1'03) ; 2810 Olive St.; offlee, Mlalto Bldg.; $10-12$, 3-5; (B1) ; OALR. *

HOXIE, liEO. IIOWALD (b'T2)\&-Switz. 7 , 01 : (1'05): 3719 Pemsylvania St.; office, Rialto Blas. : 1-4; 1,

IIudson, Thomas Howard (b'4i) H-Ky.2,'7i, $0.2,79 ;(1,94) ; 1001$ Prospect Are.; office, slukert 13ldg.; 10-12, 2-5; Prof. Mat. Med. and IIomeo. Philos., Mo.35.

Hueyette, Hurel Perrie - Mlo.8,'99; (1'99); 611 E. 14th St.

Hughes, Ulysses S. Grant ( $\left.\mathrm{b}^{\prime} 64\right)-\mathrm{M} 0.41,00$; (l'01); 4602 I'ennsylvanla Ave.; offce, 1211 Grand Ave. ; $9: 30-6: 30$.

Hulen, Wm. Ambrolse (b'62) - IIo.1,90; (1'01) : 3024 ollve St.

HULL, ALBERT GREGORY (b'6⿰)£-Ia.3, '90; (1'01); 214 E. Armour Blva.; offee, Rlalto Bldg.; 1-3.

Hulme, Laura P.-Pa.7,86; not in practice; 3411 Broallway.

Hummer, Fredk. Antonio (b'r1) -Kan.2,'06 (1'06); 900 Admiral Blvd. ; $2-4$.

HUNT, JESSE E. ( $\left.b^{\prime} 78\right)-0.6,02$; (1'07); 3734 Walrut st.; offlee, 12th and lefee Sts.; 3-5; Asst. P'rof. T'ed., Kan1.2; Pd.` Irunter, James Seat on-Pa.12,95; (\$); 3045 Wyoming St.; offce, 1201 Mulberry St.
urles, Thomas Dreux (b'90) - Art.1,i1

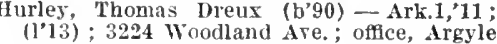
Bldy.; 2-5; s.

Hurwitt, Frank (b'84)-Mo.10,09; (l'09); 15 th St. and Euclid Ave.

Hutt, Jaekson Xf. - Ia.1,'79; (l'84) ; 2649 Loekridge St.

HYNE, BENNETT CLARK (b’ Hynds, Andrew Jackson (b'46) - Ill. $1,{ }^{\prime}, 73$ (t); 3403 Woodland Ave.; office, 3300 Woodland Are.

BRLANE. BOBERT D. (b'79) - Kan.2.'09; (1)09): IIs E. 43d St.; office, Rialto HHWIN, CHAS. BHICE (b'81)+-Md.1,04; IBldg.; $11-1$.

HUN, MUANK JOHN $\left(b^{\prime} 63\right)+-0.1,87$ (1'si) : 3310 l'emsylvanla ive.; offec. 1332 (irand Are.: 11-1,5-6.

Whis, WH. CHRISTIAN (b;59)-0.1,83 (irand Ave.; 11-1, 5-6.

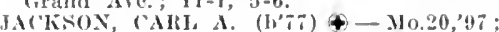
$\left.(1)^{\prime}\right) ; 4154$ Troost St. $^{2}$ olfice, 10 th and Walnut sts. ; $1-4$.

JA'KSOX, JAIBE\% NOHTH (1)'68) +-No.20 91 (1'9I) : 3531 Walum st.; offlce, 12th and Neriee Sts.; $2-4 ;(A, i, i) ;$ S.*

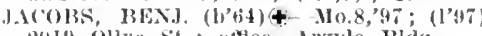
2!!1!) Ollve st.; ontlee, Arryle Bldg.

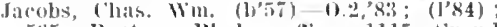
535, Benton Blvd.; ottice, $111 . \overline{\text { cirand }}$ Ave. ; $10-4$.

Jalcols, Maurlec (,-一0.2.66; (1'84); 1624 Paseo sit.

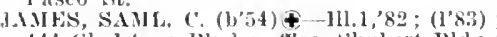
44 Glidstone Blva.; offlee, sluukert Bldg. enuct, Harry Nielson (l,'69) - Mo.20, 00 $\left(l^{\prime} 00\right) ; 4603$ H. 9 th st.; oftlee, 4521 Independence Ave.; $2-4$.

MEROW1T\%, HEKMAN DAYI) (b'69) No.20,91; (l'91); 2330 l'irk Are.; office,

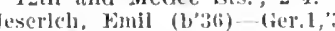
E. 12th st.; 8-10,1-3.

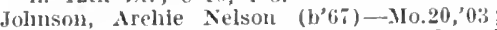
(l'03) : 3102 E, eith st.; office, 10t1 and Nlain Sts.; 2-5; G.

Johnson, Chas. Ransom (b'63)-Mo.20,05: $\left(10^{05}\right)$ : 3611 victor st.; offlec, 10 th and Walnut sts.; $10-2 ; \mathrm{s}$.

Johnson, Edgar W. (1)'s6) Mo.3.t.10; (1'10) \$20 Clinton 1'l.; oftlee, Shukert Blik Jolnson, Edith W. (1, 85$)$ Mlo.35, I2; (1'12) 404 l'aseo St.; offlee, 1020 Mrciee st. 10-1,3-5; Adj. P'rof. Inat., $310.35 ; G$.

JOHNSTON, J'AUL ALEXANDER (b'6

IIo.20, $03 ;\left(l^{\prime} 05\right) ; 3340$ Olive st. 10.20 Nos: (1.08): 3531 Hain st.; office, Bryant Bldg. ; $2-5 ; \mathrm{S}$.

Jones, Brummell (b'4t)-3ro.2,68; (1'83) lickseeker Bldg.

Jones, Harry Lander ( $\mathrm{b}^{\prime} \mathrm{i}$ ) - Mo.2, 04 ; (l'05); 4005 Holly Ave.; office, 800 W. 39 th

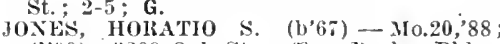
(l'40) ; 3209 Oak St.; oftee, Braley Bldg. $10-12,2-4$

Jones, John Hugh (col.) (b'65)-Tenn.7,93 (1'99); 1326 Highland Ave.; 9-11, 1-3.

JONES, KNEWLAND l'ARR (b'61)-N.Y.10,
'85; (1'85); 6033 Swope Parkway; office, rommeree Bldg.; 11-12:30, 3-5.

Jones, Oliver F.' $\left(b^{\prime} 56\right)$-Md.1,'80; (1'89); IIanluattan Hotel; offlee, 812 Grand Are. $2-4$

Jones; Thomas Amos - D.C.3,06; (1'10); 1503 E. 18th st.

Jones, Zacharlah G. $\left(b^{\prime} 84\right)-110.8,05 ;\left(l^{\prime} 0 i\right)$; 716 W. 10 th St.; offlce, Grand Ave. Temple : $9-12,2-5 ; \mathbf{R}$

('See Kansas City, Kan.)

Kane, Cyril A. N1. (b'76)-1).C.3,07; (1'10) 18 th and Paseo Sts.; 8-10, 2-5, $7-9$.

RANOKY, JOHN PHLLIP (b'59)€-Mo.8, '81; (1'94); Fairland Heights; office, 10th and Walnut Sts.; D. $\star$

KELLEY, EUGENE HENRY (b'69)-Mo.8, '99 (l'99) ; 2018 I'rospect Are.; office, Rialto Bldg.; $11-2$

KEPNER, JOHN WALTER (b'74)-Mo.20, '02; (I'02); 1336 E. 9th St.; office, 15 th and olive Sts.; $12-3 ; \mathbf{O b}$

Kerley, Granville Lessen (b'87)-Mo.34,'10; (l'10); 2220 E. 12 th St.; office, Argyle Bldg.

Key, Geo. Bernard, Jr. (b'85)-D.C.3,12; Intern, General IIospital, Colored Dirision. Key, Morris Howard (b'73)-N.Y.8,'99; (191): 2526 Michigan Ave.; office, 716 E. 12th St.; $8-9,2-4,7-8$.

Kimberiin, Jos. W. (b' 73$)-\mathrm{I}$ Io. 20,00 ; (1'00); 3643 Baltimore Ave.; office, Rialto Bldg.; 10-12, 1-3; Op. $\star$

King, Geo. Andrew (b'7)-1ll.1,04; (1'05) : 3340 Jichigan Are.; office, Gloyd Bldg.

King, Walter x. (b'78)-N10.20,'12; (); St. Mary's Hospital.

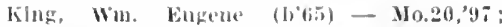
(1'47); 4400 troost are, ; oftee, Commerce Blidg.: $1-4$.

kilnyoun, James Vauce (1)'63)-Mo.7,92; (1'92); 608 F. 9/h st. ; offlec, Rialto Bldg.; $2-5$.

klusey, Frank Mllan (b'To) - Mo.1, 98 (198) : 1:300 Paseo Blvil.; offle, sliukert 13lilg.; $111-12,20-7$

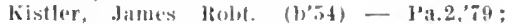
(1'03) : 1218 Benton 131val.; offlce, 1120 ilelu win Mlember Med. Soe of the state of Cal,; KlEPINGEH, JOIN CALVIN (b'70)-Mi.11, '97; (1'12); Member Kan. Med Soc.; KNERR, ELL, 07; (l'06) ; 3338 Broadway; offlee, 920 llolimes st.; $11-5 ; \mathbf{R}$

KNOX, AXIHEW (IIIISTY (b'at)廿-Mo.8 99 ; (l'99); 3535 Campbell St.; office. Illalto Blug.; II-J, 2-4. (1'06); 2904 L. 31st St.; 2-5, 7-8; Ob.

Koestering, Herman Fred ( $\left.b^{\prime} 64\right)-110.35,07$

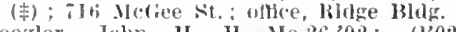

lioogler, John II-W-Mo.26,02; (1'02) 3320 Virginia Ave, offlee, 2026 VIne St. I'rof. Mled. Juris., Mo.35.

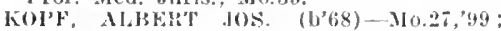
(1'99) ; (i22 So Soutliwest J3lyd.

Kowertz, fieo, $\left(b^{\prime} 80\right)-210.28,0 \vec{\prime} ; \quad\left(l^{2} 02\right)$ 4552 irrospect ive

Krueger, Ernest A.-MI0.8,'95; (1'95) ; 3523 St. John Are.; office, 262 W. 4 th St.

KlUUEGER, OWEN (b'65) - Mo.8,90; $\left(1^{\prime} 90\right)$; 62.5 Benton Rlvd.; office, 1115 Grand Ave. : $2-5 ; \mathrm{S}$.

Kryder, John L. '(b'33)-Ia.I,' 8 ; ' not in practice: 1428 1'rospeet Ave.

KUHX, HAROLI PHILI'P (b's1)£-Kan.2, 06; (1'06); 12 E. 58 th st. ; offlee, kialto Bldg.; $1-4 ; \mathbf{S} \star \star$

liUHN, WM. FREDK. (h'49)€-Pa.2,'84; (1'88); 4239 Harrison st.; office, Rialto l3ldg.; 10-12, 2-5; 1'rof. Neur., Kan.2; NP.

KYGER, TRED T. (b'86) - - $110.20,08$ $\left(l^{\prime} 07\right)$; 3130 (liarlotte st.; office, $700 \mathrm{E}$ ist st. ; $2-4$.

Laffoon, France leslie $\left(b^{\prime} 87\right)-110.20,13$; (1'13) ; 4300 I3ell st.

LAKE, NOEL ERNEST (b'-6)—Io.20,04; (1'05) ; 1204 Broadway ; $2-4,7-8 ; \mathrm{s}$

Lamar, Fredk. C. (b'83)-Ky.4,0.7, Nd.s,'07; (l'09); 708 E. 34th St,; offlee, Argyle Bldg. ; $1-4$.

Lambright. Middleton Hughes (col.) (b'65) -Tenn.7,98; (1'98); 1717 Woodland Ave, ; office, 150 \& E. 18th St. ; 5-9.

Lameaster, Fnox K. (b'85)-Mo.33,'13; ( ) 1 \$103 Euelid $\mathrm{A}$.

lane, E. Alma (b'68)-110.30,'02; (l'02); 1404 Troost Ave.; offce, Missourl Bldg. $10-12,2-4$

I.ANE, HALLIE HIRAY (b'i4)థ-Mo.20, Waldheim Bidg.; $10: 30-12: 30,2-5 ;$ office

Lane. Harry Saml. (b'75) - Mo.20,08. (l'11): (Leeds); offlce, Rialto Bldg.

Langsdale, John Marion (b'56) - Mlo.1,78 : (1'83); 3001 E. 31st St. ; office, $1029 \mathrm{E}$ 12th St.; 10-2; U.

LANING, J. IHALCONBE (b'69)థ-Va.1,99; (1'01); 3819 Central St.; office, 10th and Walnut Sts.; 10-12, 3-5; ALR. *

Lantz, John Lee (b'64)-1Io.1,93; (1;93) ; 3241 Thompson St.; offlce, 10th and Main Sts. ; 2-5; OALR.

LAPP, JOHN G. (b'70) +-Mo.20,'97; (l'97) ; 203 Askew Ave.; office, Rialto Bldg.; 2-5; Anes.

La Rue, Harper Miles (b'76)-Mo.32,'04; (l'03); 1100 Paseo St.; office, 10th and Main Sts. ; 2-5.

IAURENZANA, DONATO ANTONIO (b'65) (4)-Ita.10,91; (1'01); 416 White Ave.; office, 527 E. 5th St. ; $9-12,1-7$.

LAURENZANA, LOUIS (b’0)థ-Ita.10,94 ; (1'99) ; 428 White Are.; offlee, $527 \mathrm{E}$. 5 th. lee, Riehard Henry (1, 76$)$ - Io.32, 00 ; $\left(1^{0} 00\right): 635$ W. 58 th st. Terrace; office, Bryant Bldg.

Lentz, Chas. Lester (D'85)-Mo.20,'08; St.; $9: 30-12,1: 30-6: 30 ; \mathrm{U}$. 
Leonarl, Arthur (has. (b'7) I1]19:96 (I'08): 3821 Harrlson Blrd: odce, Rialto Mlatg.; I0-1, 3-5; I'rof. Med., Mu.3

LEOXAHW, HWMER OLESSA (h:T3

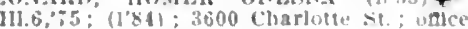
1115 lirand st: $2=-3 ; 0 b$.

I.eonard, llomer thlessa. Jr. (b'si) - Kand, "IIs: isj; stitlo tharlotte st

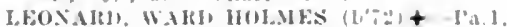

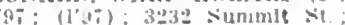

Southwes jlid: i:30-4; 0 bG.

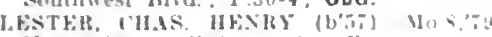

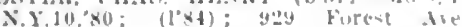
[1 $: 30-2: 30$

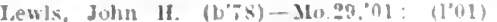

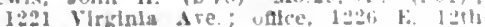
Sit: $9.1 \pm, 1-5$

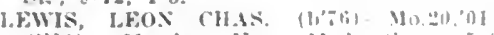

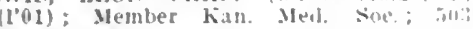
Kansas Ave.

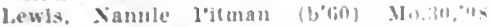
(1'98) ; $2 \times 14$ k. 31st st.

LEWIS, NED OFHIRTON (b'82)-JI0.20,05

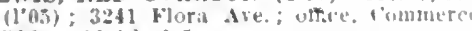
B]dg. : $10-1: 2,2.5$

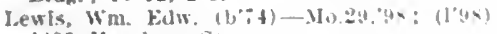
433 Harrlion st

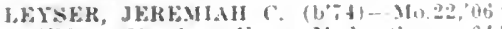
(li1): Menler kan Mell. Soe.: 6 t (III); Menuer kan. Meldheim ishlin. (also, Portsmoun lidg, Kansil t'ity. (also, Porth.

ICHTENBEIG JOS. STANIAY (b'tio)

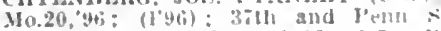

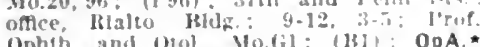
Ophth. and Otol. Mlodil: (161): OpA.

I.IELEZMMAX, 1S. MLRERT

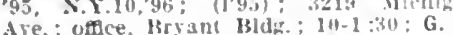

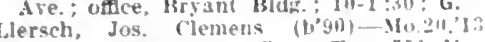

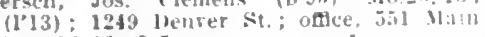
St. ; $10-1 \% 3-5$.

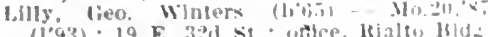
$(193) ; 19$ E. $32 \mathrm{~d}$ sit.; otice, Itialtw Ho $1-4$.

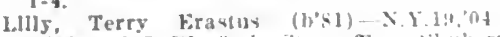

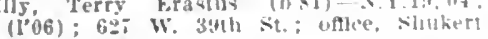
Bidg. ; $12-2$.

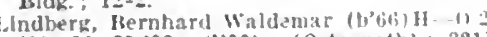
'90, Mo.31,'02; (1'90); (Osteopath): 321 E. 36 th St; ofice, 1115 Grand Ave. ; 12-5

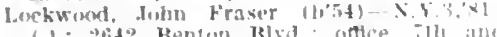
(1: 2:3t2 Bentur Blw

Wyandotte stw.; $9-5: 30$.

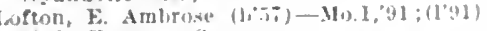

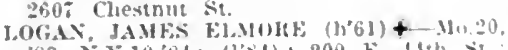

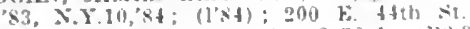
office, 1208 Wyandotte st.; $8: 30-1$; (15:2) j) : ÁLR。 *

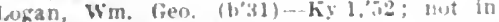
practlce; 115 t Warwick Blvd.

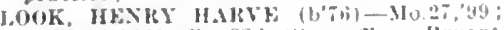
(1002): 3021 k. 32 d st. : vfllet, Bryant Bldg: : $10-12,3-5$

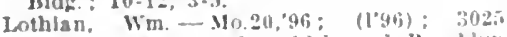
Brooklyn Are; oftre, 12th and Broohlyn Sis.

GOWE, FHEDK. MCKESIHE (b-1) Ill.J.03: (107): 2914 Tracy die.; olllo Arayle Hids. : 10-2:30.

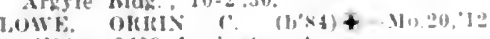
(1'1*1: 2203 Lexlngton dre

lowe, Rob E. $\left.\left(b^{\prime}(6)\right)-310.20,00\right)$; (I"0) 2143 k. 8 ih st.

LOWIEY, WATER JWKSON (libi)

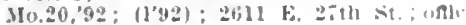
II $0.20,92 ;(1,92)$

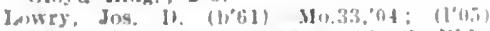

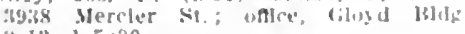
4. $1:-1-5: 30$

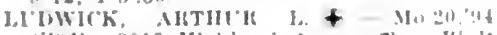

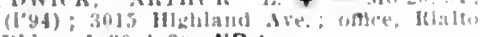
Hlds: : $1: 30-4: 30$, NP.*

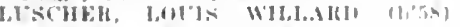

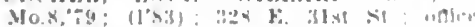
Argyle kidk.

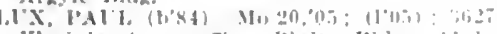

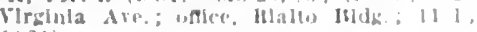
(A21).

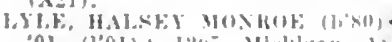

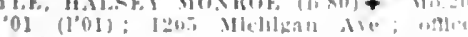

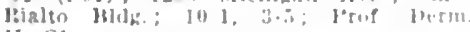
In. Cil.

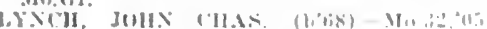
(lons): 1:Bis lirand An

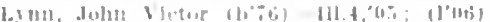
Sexpon Hotel: ontce, Aruble Bldir.; 11-3. $3-5$

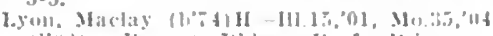

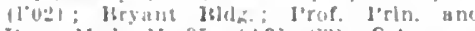

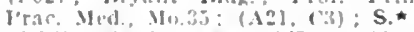

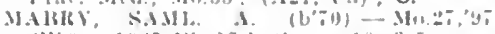

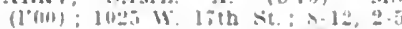

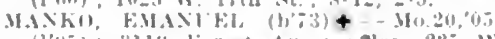

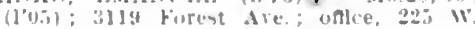
lith $\leqslant 1 .: 2-5$

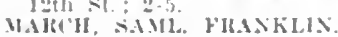

(Neo Kansas Clly, Kan.)

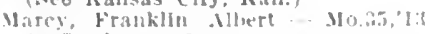
loii iherry st.

Matls, Mlliet James (biR)--Inds, 92

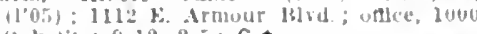
(ak sit.; 9.12, 2.5; G.*

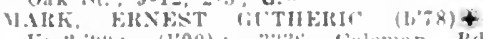

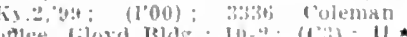
oftere, dilogd IBldg, : In-- : (1'3); U.

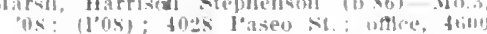
Tremst ire : $1=$

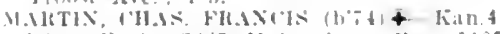

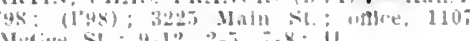

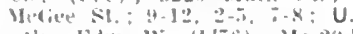

M.urth, Edw. W. (1, 16$)-M\left(20,01:\left(1^{\circ}(1)\right.\right.$ tisl:s Washington lark Blyd

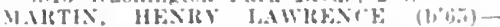

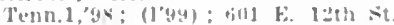

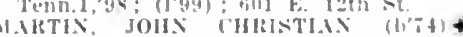

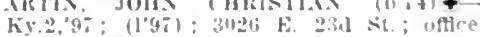
zonf Imblana Are, ; $2-4,7-8$.

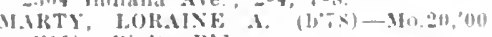
(1.11): Blallio Bldy.

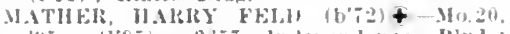

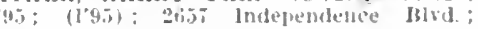

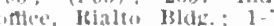

Mather, Valcolum Warsaw (b"ti)--1).13, $x 3$ :

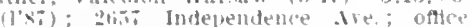
Rialto lalkg.: $3-5$

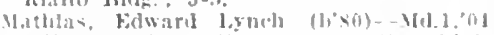

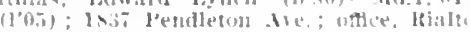
Mlutio.; P.*

Matllas. John swoge $(1,50)-M a 1,79$ (1) : 1s:37 lendleton Ife $402,3-3$

Mathis, (aleb bugene (his)-mllo st (l’si): Ifls Wyckham Wa!: ottice. Fen nock Bblat:

MOAJETEK, INIREW WMLKEM, JR

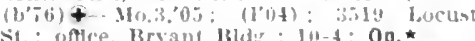
sit.; nftee, Bryant liddy : 111-4; Op.*

McARTHK, MRTII"K WM, (litit)

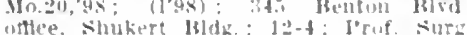
Molit: S

Welbeth, John waller $(1052)-$ Pa.3, (l'sin: 1+11 kenslngton Are.

McIBIIt, WM. LIN $\left(b^{\prime}(t)+-111,01\right.$ 110.1); $3 \times 15$ Walnut si.: oflce, IRialt Bllat: 10-3; Assoe. I'ruf. Lherm. : Kan?

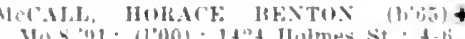

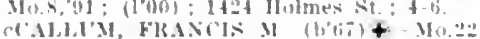

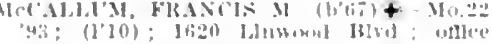

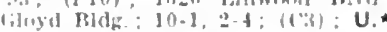

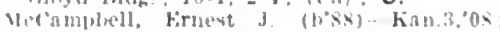

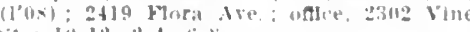
, li-s

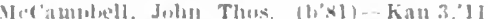

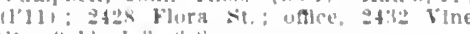

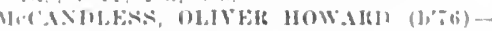

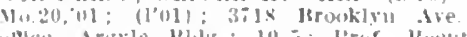

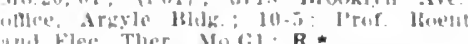
and biler Ther, Mo dil: R.

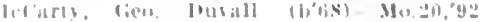

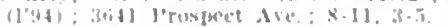

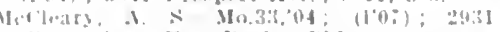

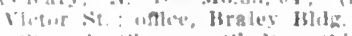

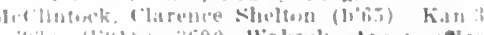

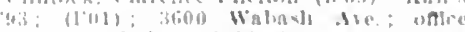

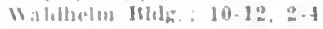

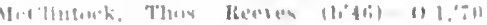

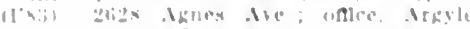

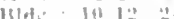

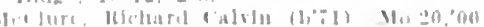

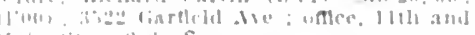

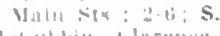

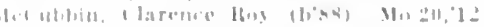

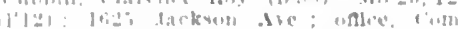
niel11. Hids: : 11 -

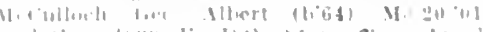

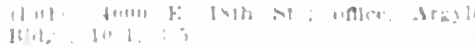

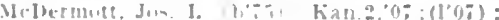

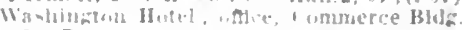
$\mathbf{R} *$

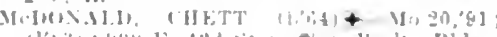

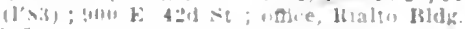
I-3.

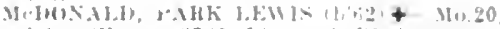

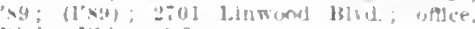
Rialer klato

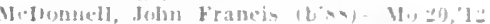
(1"1:), 3111 Harrinu $\mathrm{x}$

Metilros, thester A. (col) (t'As)-Trun. $13 ;$ ild ling Honplal; U.

McElvaiu, ["lbsed firant $(5,70)-\$ 10.10,1]$

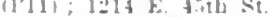

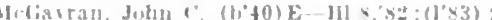

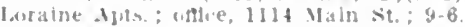

Midaurau, Maly If. (b6t)-0; (1'St); 1114 Malz sit.

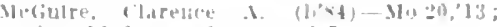

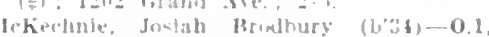

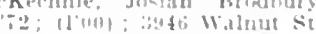

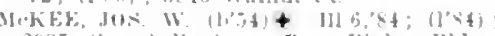

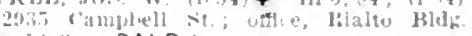
-I: :3n: OALR."

Hehoetuan, Lyman I'rentice $\left(\mathrm{U}^{\prime}\right.$ ts) -Kan.2, 0 : (l’0 i) : 2411 Walnut st

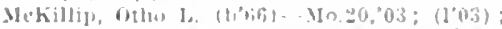

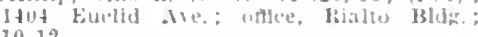
10-12.

Meloaphlin, I'hilen W

(See Kansas f'lty, Kan.)

Mrlau,blin, James Arthur II0.29, o4:

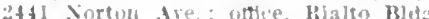

W. Laughlin. Jwah (andur (l'tit)-Kant

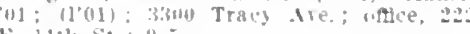
k. $111 \mathrm{l}$ st. : $9-5$.

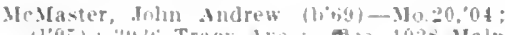

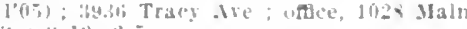

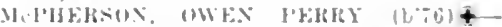

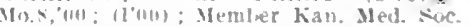

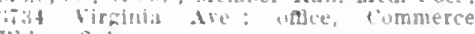
Haldy: : $2-4$.

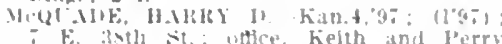
Blils.

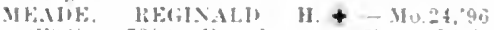

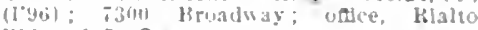

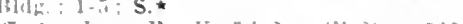
lormaners aive.

MHKHIMAN ITIY SHEMMAS (1'bl) +

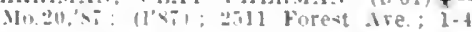

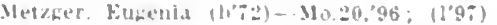

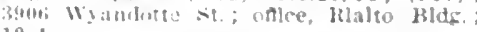
$10 .+$

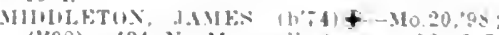
$(1 \times 95) ; 424 x$ Monfall ire, $y-1=, 1-5$ $i-S$.

Mles, filward 1)- M11, 9i: (1'si); 2535

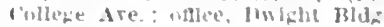

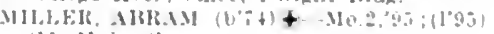
ill Maln si.

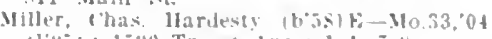
(1'uli) 15010 Traks wre, 1-1. $7-8$.

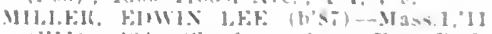

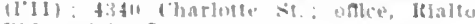

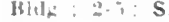

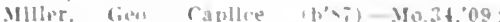

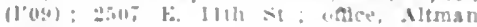
Mlats ; a.t

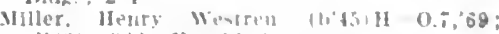

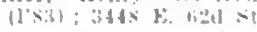

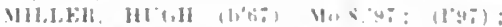

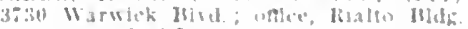
1. 12. 1: OALR.

Vliller, Isis:

Mlswour Blate.

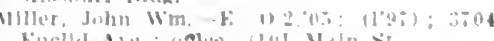

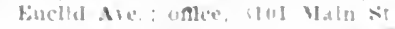

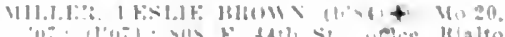
1110: $1.3:<0$

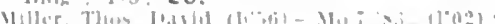

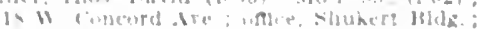
the

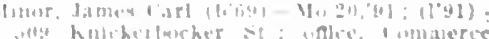
HIII)

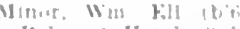
Helenuth Holel: : 1: 12

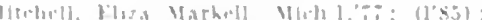

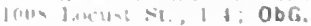


Mlchell, (ivo. 13. (b'17)-Mo.1,79; (l'83): (2312 N. 12th st., Kunsus Clty, Kan. l'01) ; onlee, Hall Hldg.

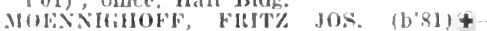

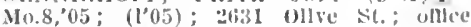
Gloyd Bli. ; $2-5$; S.

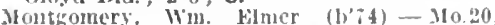

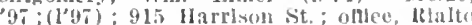
13ldy. $11-4$.

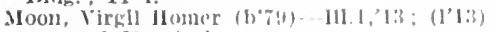
General IIospltal.

Mooney, Belle sill (1,70)-Mo, 20,01 ; (l'01); s1:3 k. 16th sit.; $2-5$

MORIS, WM. ('IAIY (b'52)

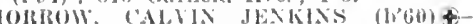
I0.1,84; (1'84); $311 \%$ I'ark Are, ofllce, Itl and frand tre: $11-1, \cdots-5$

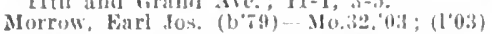
Maryland Apts.; oflled, lieserve domh 13lelg.; I11-12, 2-3.

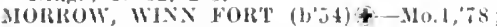
$\left(l^{\prime} 01\right): 2629$ k. Huth st.; offle, 11 th and Wuluut sts.; $10-12,2-5, ; \mathrm{S}$.

Morse, Saml. Smlth (b'7t)-Ill.1, $\left(0: 2 ;\left(l^{\prime} 05\right)\right.$ 3938 Woodland Are, oflice, 3701 Woodland Are.

Morlon, David kilght (b'41)-Mo.8,'75; (l'84); 817 Glen Aliry 1"l.; onlee, MIssomr IBlig.; $y \cdot 5$

Moses, James Edmund $(6,52)-10.20,85$ (1'84) ; 3739 Genesce st.; 2-4.

MOSHER, (IEO. CLARK (b'5s)†-Ky.1,'8z (1'47); 3612 locust st, ; oflee, Bryant likg.; 1-4; ob.

Moss, Harvey lidw. (b'ts) - Ky.4, '93: (1'93) ; 322 I Olive st.; offlec, Rialto Bldg.; 9-1, 2-5.

MOTT, IOIN SABEKT (b'4t)†-Mich.I 67; (1'83) ; 4025 0ak st.; Offlce, Rialto Bldg. ; 10-1; (BI) ; OpA. *

Nulvany, Nlra Ilake $\left(b^{*} 8(t)-\mathrm{M} 0.20,04\right.$ (l'05); 727 Bennington Ave.; offlce, 6800 Independence Are.; $2-5$.

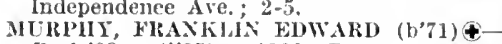
Pa.1,93; (l'95); 1100 Prospect Are. office, Waldheim Bldg.; 11-1, 3-5; 1'rof Clln. Med., Kan.2; i. $\star$

Murphy, G. T. $-0 ;\left(l^{\prime} 9\right) ; 220$ Troost Ave Murphy, James H. (b'62)-Ill.1,'85; (l'10) $3: 07$ Summit St. offlce, 904 Southwest Blyd. : 1-10; S.

Murphy, John Redfleld (b'50)-111.1, '8 (l'84); 429 W. $11 \mathrm{th}$ St. ; 1-4, $7-8$

MURPHY, WALTER WAUGH' (b'84)-111.6 I1; ( ) : Nember Ill. State Mcd. Soe. 25 E. $53 d^{2}$ Nt.:

Murray, Darid J. (b'6I)-No.8, 00 ; (l'00) 1315 Troost Ave.

Murray, Elmore W. (b'60)-IIl.4,'85, Ill.17 95 ; $\left(\mathrm{I}^{\prime} 97\right)$; 2814 Tracy Are.; office, Commerce Bldg. ; $7-5$. Myers, Edw. W. (b'3 5$)-M d .1,52 ;\left(1^{\prime} 84\right)$
701 w. 38in St. ; 9-12.

Neal, James Park (b'74)-Mo.20,07; (l'06) Buckingham IIotel; office, 12th and HcGee Sts. ; $3-5 ; \mathrm{S}$

NEFF, FRANK C. (b'72))థ-110.20,'97 (l'01) ; 3609 Baltimore Ave.; office, Rialto Bldg. ; 3-4:30; Pd.

NEWHOL'SE, STANLEY (b'7 7$) \oplus-M o .20$, 98; (1'98); 3505 Harrlson Bird.; office, Commerce Bldg. ; 11-1; S.

NEWLON, CHAS. S. $\left(b^{\prime} 58\right) \oplus-1 \mathrm{a} .1,81$ (1'88); 3007 Independence Blvd.; office, Waldheim Bldg.; 2-5.

NICKSON, CHARLES EDW, (b'73)థ Mo.32,'04; (1'05); (Mt. Washingtou! oflle, 570 Arlington Ave.

Nixon, John Wesley (b'71) - Mo.27,'96 (1'99); 25 th and Harrison Sts.; offlee, 1115 Grand Ave, ; 10-12, 4-6; G.

NoRBERG, GEO. BENJ. (b'72)థ-110.20, '97; (1'97) ; 205 W. $53 \mathrm{~d}$ St. Terrace; office, Rialto Bldg.; 11-2; Prof. Gyn., IIo.Gl S. $\star$

Sorris, Emma Leora (b'48)-No.26,90 (1'90) ; 2416 Wabash Are.

Yutz. Joseph Franeis (b; 79 - Ifo.20,09 (l'09) ; 3448 Brooklyn Are.; offiee, Com meree Bldg. ; 12-3, 5-6:30; ób.

Nyland, Carl A. (b'78)-Mo.20,00; (1'01); $1 \$ 02$ Holly st. ; office, 4012 Main St.

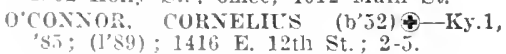

O'Fluherly, Mloyslus $\left.\mathrm{k}, \quad\left(\mathrm{b}^{\prime}, 2\right)-\mathbf{2}\right)-8,98$; (I'js); 12s Montigill Ave.; Op.

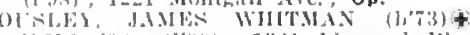
‥1‥

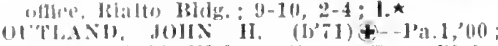
(l'04); 3621 Walnut st.; offlee, Rialto blalg.; $2-4:$ S. $\star$

Overali, 'Thes. Wilson (b's9)-Mo.8, 94 (l'94): 340. l"aseo it.; offee, Argyle Hillg: : $10-1$

Owch, folnh I'ant (b'89)-Mo.:34,13; (1'13); liencral Hospltal.

Owens, los. landis $\left(b^{\prime} 81\right)-M 0.20,04$ (l'04); liensmore llotel; offle, Halto

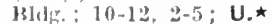

OWES MH (11: (105) ; 430.5 Walunt st. ; oftce, Wald helm lille; ; $2-5 ;$ S.

Wias, Myrtlo Mary Mo.28,09: (7) : 34.6 Trowst Are, : atlece, Irmar Jrrin Isldg. $4-12,5-8$

l'atmer, Ihilip collman (b:5l) H1.1,'84; (l's7); 3001 E. 9lh St.; office, Alman IB!(lg. : $10-12,2-\% ; G^{\star} \star$

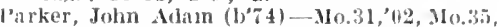
06 ; $\left(l^{\prime} 03\right)$; 1233 framd Ave. ; $2-5$

Parmenter, (Thas. Guy (b'83)--No.20,12 (l'12): 3747 Euelid Ave.; offle, 3701 Woodland Are.

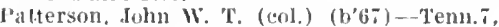
$92 ;$ (市) : 1400 F. 18 ith sit.

Pallerson, Jos, M. (b'65) 11-0.13,'87 ; (1'98) 104 Hunter Are.: offiee, Bryant BIdr. 10-1.3-5; l'rof. Ophth., itol. and Jiryin. Mo.35; OALR,

Peak. John Robl. (1'69)-IIo.27,'97; (I’03); $9 \mathrm{~L} 2$ Oak St,

Pearl, Frank Adrian (b'86)-D.C.3,12; Intern, old General Hospital.

PHARSE, HERMAN ELWYN (b'59) + Io.7, 88; (l'88) ; 4515 Wornall lid. ; offee, Rlalto Bidg.; 2-5; (A7)

Peet, Antoinette B.-H-Mo.26,95; (l'95) not in practlee; 3327 Euclid Ave.

lect, 1'utnam F. (b'47) H-Mo.26.92 ; (l'92) 3327 Euclid Are.; oftlce, New Ridge Bldg. 10-8; Prof. Ven. Dis., Mo.35; D.

Perdue, Edw. M. - H - No.35, 04: 3920 Ianhem Rd. ; Prof. Bact. and Embry. N10.33.

PERKINS, JOHN WALTER (b'60)\$Jlass. 1, 86 ; (1'88) : 318 W. Armour Blvd. offlce, Altman Bldg.; 2-4; 1'rof. Surgica Jlag.. Kan.2; $\mathrm{S}$.

Perkins, P'hllip M. (b'65)-Mo.27,98; (1'98) 3827 E. 9 th St.; offlce, Braley Bldg.

lerry, J. E. (col.) (b'to) - Tenn 70 (1'95): 1512 F. 18 th St.: 2-4, $7-8: 30 ; \mathrm{S}$. 'HILLIPS, EDWIN TAYLOR (b,60) †-Mo.8 Phlllips, Myrtle H.

(See Kansas City, Kan.)

PICKARD, MATTHEW W. $\left(\mathrm{b}^{\prime} ; 4\right)-M 0.8,98$. (l'98); 2700 Linwood Blyd. ; offee, 1036 Union Are. $10-12,2-5: S$.

l'ihblad, Arvid (b'5)-1it.1,99; (\$) : 1310 (iillham Rd.: offee, Gloyd Bldg.

PINCKART, CYRCS GIBSON (b'59)-111.1, 87; (1'01); The Paseo; offee, 907 E. 8th St.; $2-5$.

Pipkin, Chas. (b'47)-Mo,1,70; (l'83); 4027 Prospect Are.

PIPKIN, GEO. PHILLXS (1,73)-Mo.32, 02 ; $\left(1^{\prime} 02\right)$ : $22 \mathrm{~d}$ and Cherry Sis.

PITTAM. JESSE THOS. (h'75)థ-Mo.20 02; (I'02); 1318 W. 39 ih St.; office, 1211 Wyandotte 'st. ; $9-12,2-5$.

Planck, Fredk. Marshall (b'68) E-Mo.33, 04; (l'05): 3611 Walnut St.

Poindexter, J. M. (b'59)-Ky.2,'84; (l'91); 1204 W. 39th St.; offlee, 900 Main St. $8 \sim 8 \cdot \mathrm{U}$.

Pond, Eugene Adelbert (b'80)-Mo.20,'10 ; (l'10) : 3817 Baltimore Ave.: 9-3.

POORMLN, ALBERT ALLEX (b'Ts)థIfo.20,03; (J'03); 3137 Benton Blvd. : offee, Atman Bldg. ; $3-5 ; \mathbf{S}$.

PORTER, ALLEN L. (b'7 7$)-M o .20,00$; (l'00): 3601 Central St.; offee, Rialto Bldg. ; 2-5; (C3).

PORTER, DATID RITTENHOLSE (b'38) 一a.1,65, X.Y.10,72; (l'83) ; 430 W. 10th St.; 11-2; Emer. Prof. Inter. Med., Kan.2. Potterf, Albert A.-H-No.5,'88; (1'89); 3108 Garfleld Are.
Potterf, Fannit, L.- H - M0.26,95; (1'95) 3 los Gartield Ave

I'ratt, Fublan lee (b'88)-Tenn.5,'11; (1'12) 3317 l'aseo St. ; oftce, Rlalto I3ldg.

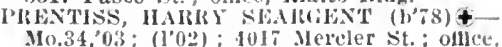
Rlalto Bldg. : $12-3$.

J'ICE, CLALIE ('HANDLER (b'8I)Mlo.20,08; (l'08); Avllon Hotel; oftlce, Commeree Isldir.; $2-5 ; \mathrm{S}$.

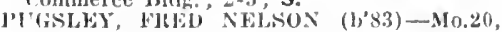

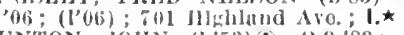

I'UNTON, IOHN (h's:3) \&-0.9,83; (I'88) ; 1329 linwood Itvd.; otllee, IRlalto IBldg.; $2-4 ;(1: 1,1: 3) ; \mathbf{N}$.

I'ulan, Carolyn E. (b57) II-Mo.26,97, No.35,06; (1\%); 525 \&. 10th st.; 2-5; I'rof. Mat. Mod., Mo.35.

l'yle, Chas, W'--11--lat.4,81; (1'88); 3127 Hu rrison st.; ufflece, 1320 Main st. ; $9-6$.

laab, F. Henry (1's6)- Pa.1,10; (1'12); 409 Wyandute st.; ofllce, 3838 Troost Are. : 2-4; 0bG.

MAlix, Monteis (:-Mo.32,03; (1'03); 503 W. Fith St.

liagan. Stephen . Hood (b'64)-Mo.8,94 (1'94) : 3034 Holmes St.; office, $621 \mathbf{k}$. 3Ist st. ; $2-4,7-9$,

Kalph, Benj. Burroughs (b'73)-Mo.8,97: (l'97) ; 529 Highland Ave. : $10: 30-5$.

Malston, dames llarry (b'íl)-Mo.32,04; (l't5); 3628 Bell St. ; oftce, 3908 Bell St. : $2-4$

liamsey, Ldw. Benj. (eol.) (b'- 8)-M.C.3,00; (1'00);1426 E. 18th St.

HANHBOXE, FRANCIS WAIT (b'56)థI'a.2,'83; (1'85) ; 3532 College Ave.; offce. Itlalto Bldg: $1-3$,

Rawlings. Janl. Westervelt - Mo.27,97: (l'01): 1200 E. 34 th St, offlce, 15 E. 12 th St. ; $9-6$.

Kay, James Edwin (b'80)-Mo.8, 05 ; $\left(l^{\prime} 05\right)$;

liy, Rlchard (b'61)-Mo.20,99:

$\left(l^{\prime} 99\right)$; 2201 Brooklyn Are.; 3-4

Ray, Wm. Iepoe (1'63) H-No.26,'91; (1'92); ditman Bldg.; 10-12, 3-6.

Rea, Chas. Lee-X.Y.20, 00 ; (丰); 3633 Broadway; office, 927 E. 15th st.

Reed, Elmer Elsworth (b'66)-Mo.31,'97; (l’11); Member Ia. State Med. Soc.; 5202 Wilburn Ct, ; office, Shukert Bldg.; Prof. Prin. and Frae. Med., Mo.35.

Reed, James F.-Mo.8,'98; (l’98) ; 2431 Park Are.; office, Kansas City Life Bldg.; $9: 30-12$.

REED, WM. MARTIN (b'66) - -Ky.4,96 (1'07) ; 2651 E. 29th St.; offlce, Rialto Bldg. ; $9-12,1-4$; OALR. $\star$

REESE, IIARVEY S. (b'56)-Ia.1,81;(1'83) ; 422 spruce Ave.

Reilly, Jos. A. $\longrightarrow$; (l’98) ; 2822 Troost Ave. office, 1016 Central St.

Remley, Geo. Carlos (b'84)-Mo.34,10 (l'10); 2122 E. 15th St.; offlee, 15th and Brooklyn Sts. ; 3-5, 7-8.

REVELLE, CLAREN' A AIBERT (b'80)Mo.34,02; (1'02); 3132 Euclid Are. offlee, Rialto Bldg. ; $1-4$ :

REYLING, FREDK. THOS, (b'62) $\uparrow-$ N.Y.5, 84; (1;95); 2530 Troost Ave.; office, Argyle Bldg. ; 10-12, 2-4; OpA. *

REYNOLDS, WM. TUN1S $\left(b^{\prime} 70\right) \oplus-M o .28$, 95: (1'06) ; 3866 Charlotte St. ; office 12 th and MicGee Sts.: 1-4; (A7) ; S.*

Rhoads, Mark Herbert (b'75)-Mo.32,02; (1'03) ; 3211 Loeust St.

Fice, Geo. Wesley (b'67)-Mo.20, 00 ; $\left(l^{\prime} 00\right)$ 2312 College Ave. : offlee, $3400 \mathrm{E}$. 27 th St. 2-5;0b.

RICE, WH. (b'71)\&-Mo.20,97; (l'97) ; 526 Quincy Are.; offiee, Gloyd Bldg. ; 11-2.

RICHARDSON, KATHERINE BERRY-Pa.T, '87; (1'94); $121 \mathrm{~N}$. Clinton Pl.; 2-5; G.

Richardson, Lucian Palmer (col.) (b'81) Tenn.7,10; (l'11); 2439 Walrond Are. $8-10,4-6, \pi-9$.

Richardson, Wm. C.-Mo.8,04; $\left(1^{\prime} 05\right) ; 427$ N. Wheeling Are.

Richmond, Spier ( $\left.{ }^{\prime} 6 \overline{1}\right)-M 0.22,91 ;\left(l^{\prime} 91\right)$; 2444 Benton Blvd.; 10-4

Ridge, Frank Isaae (b'85) - N.Y.1,10; (l'13) ; 3019 Highland Ave.; office, Rialto Bldg.

RIEGER, EARL C. (b'78)థ-MIo.20, 06 ; (l'06); 4218 Walnut St.; offlee, $805 \mathrm{~W}$ 17 th St. ; $2-4,7-S$. 
Heger, Joel Heury-X.Y. I, : 9 ; (l'st); not

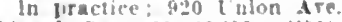

Illngel, Geo.-. Mo.:20,01; (1'01)

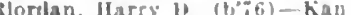

Hryans Iulde:

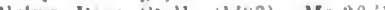

3918 si Juhn Are $: 3.5, i=8$

Kltchey, James Wealle (b'his) - Mn l gl 1'91): $35 \% 5$ Monfgall si. : 1-4.

Rlechey, Wm. Wood (b'62)-Mo.2(0.97, Mo: 96: (l'95): 2810 l'rospect die: itare. 2601 Prospect lve: $2-5$

ITTER, CALFB ANDEIRSO Ind 4, $7:$ : $(184)$; 3524 Wyandote: onlee Bryant Bhly.; 2-4; l'rof. Otost. Molit

Roberson. J. H.-Kan.4:9i; (1'9i): I32:A Troost Are.

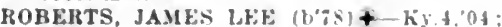
(1'07): $351 \%$ Central st.; untre. Jilalto Blds. 10:30-4: l'rof. Wis. Stomach and Intestines, Mo.Gl : I.

Roberts, Sam Fiarl (b's6)-Kan.2,11;(1"11) Waldheim BIds.; OALR.

ROHKRTSON, JAMEN ARCHY (b'BA Mo.7.99: (L'89): 3610 Giadstone Blid Mo.6.99: (L'99); 3610 (Bladsto
ontace, Rialto Bldg. : I-4; S.

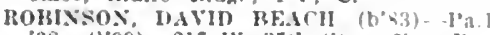
$08 ;\left(10^{\circ}\right): 217 \mathrm{~W}$. 37h st: onlce, Hry ant Bldg. ; ?-4.

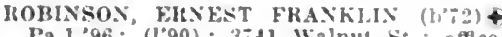
Pa.1.96: (l'90): 3i+1 Walnut St. : offlee. lbryant Hlde. : 1-4; $S$

ROBIXSON, G. WILE (b"il) + Mo.24," 96 ; (1'96): 3001 Pasce St.; once, Ibialto 1ldg. 9-4 I'ro? Xeur. and l'yeh. Mo.Gi: NP.

IOBISSOS, JOHS IISCOLS (1,6]1+ Mo.20, st: (1'st): 3426 St. Inlln Ire offec, 11 th and Walnut Sts. : 2.5

Robinson, Jos lIamilton (b'83) Y (l'04); I521 Central We. : offce. Natlonal Heserve Bldg.

ROGERS, FORN B. (us 1$)+-111,6,05$ : (1005): 3041 Park Are.; ottere. Irugle Bldg.

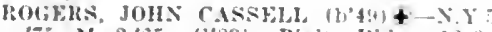
'75, Mo.2.65; (1'83); Rlaltu Bhlg. ; 12-3.

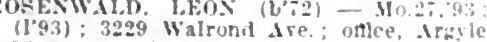

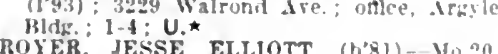
'0:: (1'06); Bryant Blug. ; 11.

luble, Elmer Lee (b'80) - Mo.20,0. 60I F. 15th St: $2-4$, $1: 30-8: 30$.

Ituhl. Irwin Earl $\left(\mathrm{b}^{\circ}, 6\right)-M(0,29,03$ 2015 Benton Blvd.; 9-12, 2-5, i-s.

Kummel, Luella z. (b'64) $11-111.150^{\prime} 1$ (l'03); 2317 E. 30th St.; onle, shutert Bldz. : I'rof. Mat. Med., Hyg., Sintt Sclence and Embry., Mo.35.

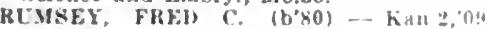
(1'08): 4145 Woodiand Ave

Itunnels, Moses Thurston (b'49) H- (1), ; 4 . Mo.35,05; $(1 \cdot 85)$; 3241 Bromklyn ive. once, Arryle Bidg.; $8: 30-10: 30, \because 4$; Dean and Prof Surg. Mo.35: s.

fuah, Geo. Alten (b'33)-Mo.20,"117; (1'07): 1902 F. 3th st. once, (irainl lie Temple: $2-5$.

Russell, banl. K. (b'80)-Mo $\left.20,0 s ;\left(l^{\prime} \cap\right)^{\prime}\right)$ 3231 E. 11 th St.: $1-4$

RUSSELL, FNWIX HACLARE (b'is) Mo.20,'01; (1'01); 23th and IIartiun sts.

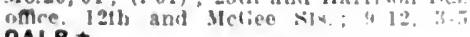

ltussell. Myron M. (b's8)-M[o. 20.'13: (I'1:3) 284B Benton St.

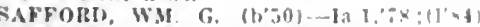
3229 victor se: : onjre, llalge lslitg

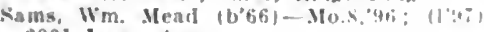
2001 lown A

SANDERS, FRAXK LISCOI.N (b'bin) Mo.20,"98: (1'98): Bonaventure Hotel

Ace, Rialio HIdR, $9.12,2-4$ : OALR. *

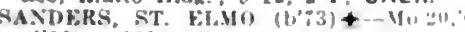
(1'00): 351 i fiarner st. ont. $111 \%$ Cirand Are, : 2-5i: S.

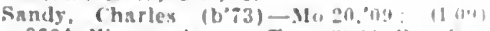

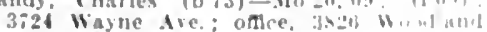
Are.: $12: 30-3$.

sandzen, farl John (b'be)-a; (l'as)

Warwick Blid.

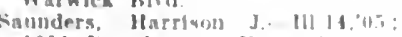

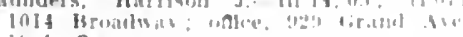
$111 .+1 ; \mathrm{S}$.

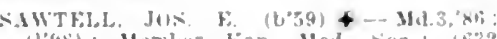

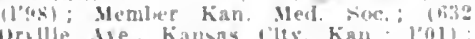

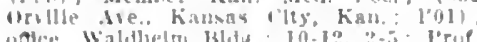

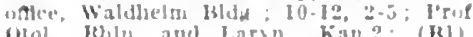
Minl., Mlu anl Laryn., Kan.2; (BB)
ALR,

AWYEK, JAMFS F.MO.S.9-

Ulle Si: once Argile blute.

Sawyer, Lewls Berdine (b'by)-Mo.8,92: (1)93): tot ln practlce: 1039 Waluut $\therefore$.

AIYKK, THOS. THEOHORE $\left(b^{-49}+\right.$ Mo.20,"0\%: (1'06); 1701 Jackson Atr.

flce, 4201 E. lith St.; 3-6; OALR.

schaefer, Edw. Ifenry (b'6i)-Mo.20, $y^{\prime \prime}$; (1'92): 3215 inderson Are.

Schaper Theolore Win. (b59)-Md.1, 80 . (l'sy): a0l Benton litrd.; oflce, Wald helm Bldg. : 2-4.

SCHALFI.HR, FDWARN WM. (b'39) Y. Y.1, $68:$ ( $): 353 \%$ wyandotte st.; oftlce, Arryle Blde; 12-4; $1 . \star$

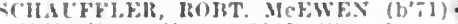

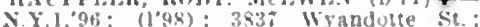
oftce, srale Hldg. ; $2-5$.

Schmlt, Georige I.ouls (b'75)-Mo.20,98 $\left(1^{\prime} 4,4\right)$ : 4309 Harrison $S t$ : $9.12,2-7$

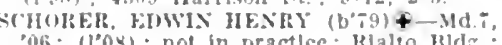
(06; (1'0s): not in practlec; Hialto Hidg. $(\mathrm{F}, 2)$.

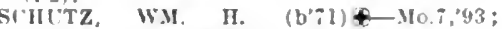
(1.93): 55 Janssen Pl.: Oftce, Bryant [Bldin.: 20-1, $2-4 ;$ OpA.

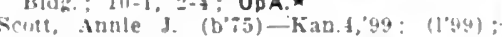
loensmore Hotel.

SIOTT, IOHX NESBIT $\left(b^{\prime} \cdot 1\right)+M O 20$, $97 ;(107)$; Cuates bouse; oftice, connmerce Hldg.; $2-5$; R.

cevere, Columbus $[1,-13.6,35$; (1092) ; 1321 Silmiral Rlvd.

Shanmon, James Flourney (col.) (b'i3)-

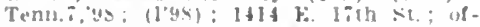
fice, 1 tros $F$. Isth st. i i i, $;=9$.

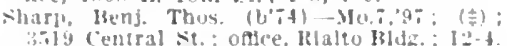

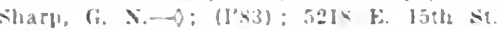
Sbary, Jus. (b'je)-Mo.s, 73; (1 01); 14:-

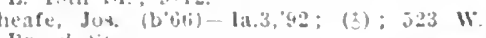
IBroind $\leq 1$

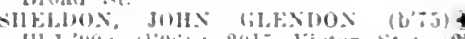

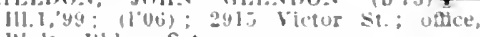
lalal:e Hor.; S.

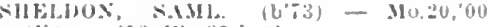
(l'00); 450 W. 35th sit.

SIELTIX, WM. DIBEMT $(6 \% 9)$ - MO Z (14: 110 i) : 3301 Wabash Are.; ofdce, As Fyle Hat ; 94. Pa.1,95; (1'9\%) 1122 E. Glllham

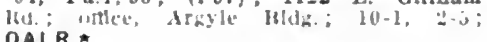
OALR. *

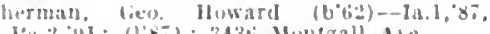

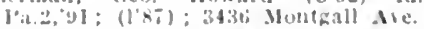

Sherriek, Sehembah l'a.l,7:; (l'sk); :3:2l

Maln sil.

Chras, Howard Hoy (bob)-\$lo.20,12;

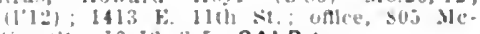
line st. : I0-I?, 3: OALR.

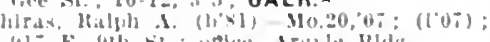

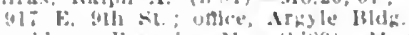

shomkl Francis it (6'89)-Mo.20,1:

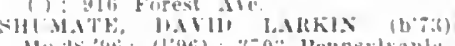

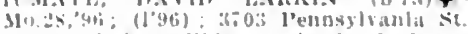

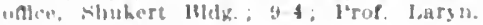
and Khlu., Mo.til.

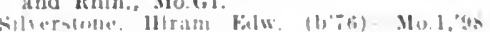

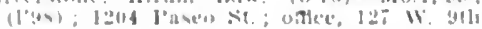
Ni., 1:2-1

(n)

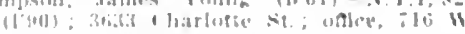
Ji1: I : N N *

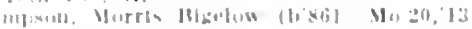
nueral Husphat.

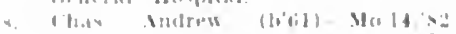

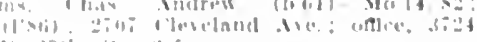

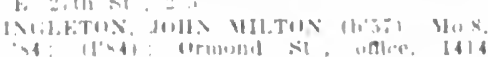

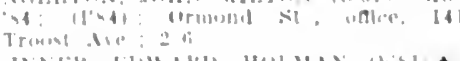

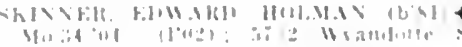

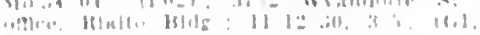

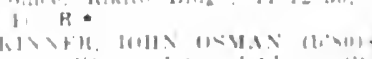

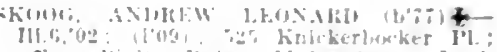

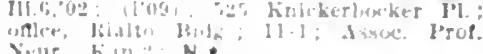
Neur, kitn $=\mathbf{N}$

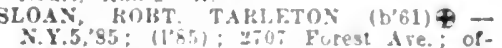

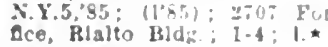

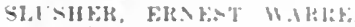

Mo.".,"9: (1'9:);

Klatto Bidg: ; $3-3$.

529 Hohland st.; ; $-12,2-5$.

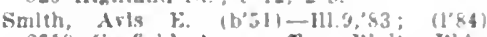

ail9 farfield Ave: once, Klalín Hldg.

Smith, Don La.Motte (b'ss)-Mo.20,13: (1'13): (5s freeman St., Kansas Cliy, kis.l; oflce, shukert Bidg.: 10-12, 2-5: OALR.

Smlth, Filmore Oscar $\left(b^{*} 50\right)-111.1,81$

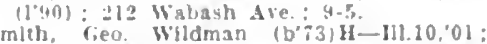

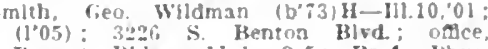

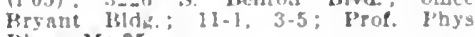
Dlag., Mo.35.

Smleh, Howard Mllton (b's0)-X.Y.s.05: (I"1I); "ti26 Woodland Are.; oace, 1509 SUITH, JAMES HFHHERT (b'os)-Mo.I.

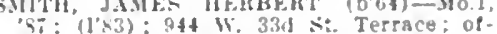
flce, Halto Bldg.; 2-5: Sec. and Prof. Gyn., Mo.Gl.

Smlih, 'Paul crews (b'71)-Pa.2,"94: (1'94): 3940 Camplell St.; oftlce, Comrnerce Bldg. ; $10-1,4-5$.

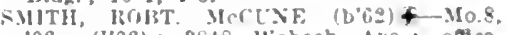
02; (1'02) ; 38ts Wabash dre.; otice. (irand Are. Temple ; $2-4$

smlth, Thomas Holland (b'60)-Mo.33,03: (1'05) : $17 \geq 1$ w. f"d sic

Smlth, Wm. H.

(Aee Kansas rity, Kan.)

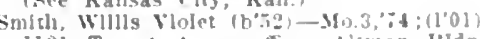
11:1 Troose Ave: uffice, lltmin HId 9-12, $1-5$.

Snell, John R. Mo. I, ' Il: (l'B3) : Rotel Ballimore; office, Argyle Iilds.

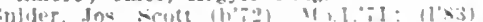
2615 Brooklyn Are : othice. Rlalto Blds. Snow, saml. H. $\left(b^{\circ} 72\right)-M 0.35,0$; : (1'0s): t2s iackon ive : nflce. 111 s (irat)d lie. 2-5: I'rup Olst., II 0.35 : ObG.

nden. Frank J.-Mos," lark Are: nthe, Mldpe Bidg

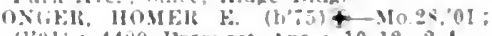
(1)1): 44119 I'rospect Are. 10-12. $2-4$

soule bleline findrich--11- 1114.90 (I'0l) ; 3009 E. 2ith St: : 10-4.

soule, loaac l'lark (h) bill-111 1.90;(1'99) 3009 b: 20 th 5 : unle shukert Bldg. 10-4; Prof Laryn., Rbin. Ophth and (1) ol.. Mo.3\%

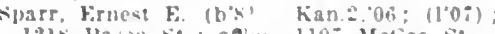
121 S Iraseo st. : oflue l10: Mrliee st. st. Nalr, IRobt. L. (b'it)-Mo.1,"2s; (1'9s): 11:5 S. Harlexty Are.; offee, 5014 s. John ive, ?-11, :-4.

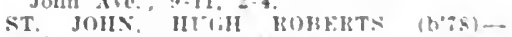
Kan.4.00: (1'00): 215 E. 35th st Terrace; office, Rialto Hldz.: 10-1.

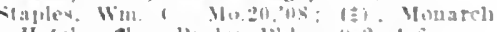
IIntel unle krales likdy

Starche, Mndre" HI (b" fill Matios: (1.95): 3605 (llire st; oftee, Sbukert

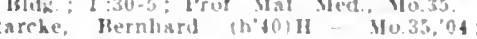
llosi: all kalev lien

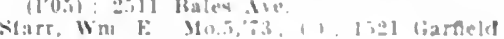
Aie

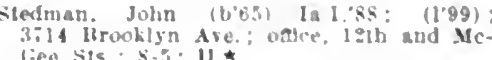

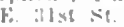

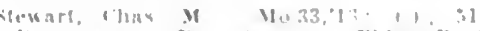

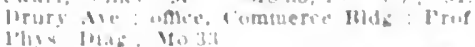

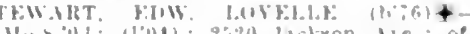

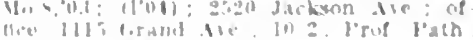

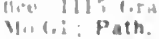

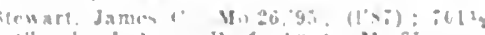

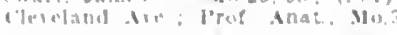

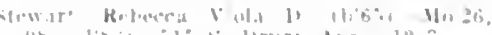

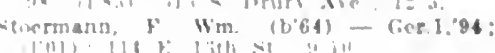


STOFFIR, EAR ST.1.TOX (b'86) -.110.20,'10) (1"10): TIS Kenslngton IVe.; oflce, 3620 )

sTotEe sid la

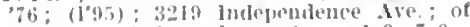

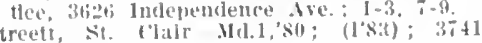
(illiham lid.

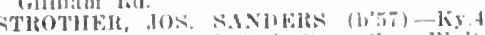

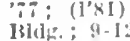

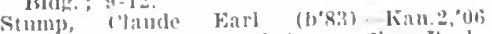

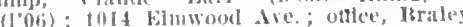
Bldg, : $2-6$.

Slutels y

Sulabacher l2runo louls $\left(\mathrm{b}^{\prime} i 4\right)-\mathbf{M} 0.20$ Sulzbacher, 13runo louls (b'it)-Mo.20,

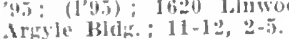

sulzbacher, farl 1. (b,76) - Mo.20,99 (1'99); 3930 Troost Ave.; $9-12,2-5$.

sutllu, John 1I. (h'35) H-Mo.5, 85 ; (1'8.3)

3320 Virrinla Avo, onlce, Kinsas ('Ity life Bldg: $9-12,2-9$

SUTTUN, HICIARD LIGHTBURN (b'78) + -Mo.20,01. 1).C.1.04; (1'01); A.surt. lieut., U.S.X., relled; 420 W. isth st. oftce, Commerce Bld

lerm, Kan.: D. D ${ }^{\star}$ (

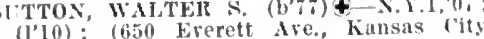
(1'10); (650 Ererett Are., Kansas City l'rof.' Surg., Kan.2; (A21); $\mathbf{S}$.

1ror. shre, Kheodore (h"79)-Kan.2, 0 (108): 27ll and ludlana Sts. ; oftice, ltialto Jildg. ; 11-1.

swarens. John F. (b'67)-0.18,'92, K.y.9,'99, warells, John F; (to60) Tracy ive

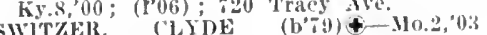
$\left(1^{*} 03\right) ; 31 \mathrm{st}$ St. and Troost Are.; oftlee, IEtis St. and Troost Ave.: 3-ti.

TAIBOT, A.MBROSE (b'60) \&-Mass. 1 , 8.5 (186); 3552 Broalway; oltice, ilialto istlg. : $10-5$.

Tappan, Franels A.-Mo.s, $\because 1$; not in practlee; 2805 Forest Are.

TAYLOR, IYNN GRIY (b'60)-0.6,'s:2 (1'85) ; 3738 Jarrlson helm Bldg.; $2-4$ :30.

FACHENOH, FRAN LANDALE (1)88) + -Kan.2,'I1; (1'11); 3230 Woodland

TESSON, NOAL ALBEIT GitiN' (b'63) Mo.8, 95 ; $(195)$; 3500 E. 12 th st.; oftice, Rlalto Bldg. ; $2-$

Theilnann, Fmll-Mo.26,97: (197); Nlt man Bldg: $10: 30-12: 30,3-6$.

Thomas, Jlollis sherman $\left(\mathrm{b}^{\prime} 91\right)-\mathbf{I}\left(0.35,{ }^{2} 12\right.$

( ): 4146 south Benton Blyd.
Thonis, Wh. Sherman (b'64)-Mo.8,92; (l'92): $4146 \mathrm{~s}$. Benton R!vi.; offec, 1131 (l'92); 4146 . Benton $\mathrm{B}$ !

THONASOX, HENRY E. (b'T)-Mo.24, 00 Mo.34,02; $(100) ; 3210$ Ollve st.; ofthce, Argyle Bldk: 10-12, 2-5; Alj. Prof. Ophth. and Otol., Mo.fi; (B1).

Thompkins, Wm. J. (b'78) - D.C.3,05; (1'06); 1509 E. 18 th st.; $9-12,2-5,7-9$.

THOMINOX, (iEO. BYRON (b'66)-1

00; (T00) ;ieo. C. (b'68) - Mo.20,'99: (1'99); 6002 Cherry st. ; 2-4.

Thompson, James Edw. (1)67)-0.6, 88 (1'90) ; 1109 McGee St. : 9-12, 1-5, i-8.

T1IOMPSON, JOHY HENRY (b'52)-N.Y.1, Bidg.; 10-12, 2-4; Op.»

Thompson, Pauline; A. (b'70)-Mo.28, 05 (l'08); 3007 Bales Are.: office. 305 Grand Are.; $1-5: 30 . ;$ G.

Thompson, win. (b'58)-Mo.1,81; (l'98) 3428 F. 6th St.; offlce, Rlalto Bidg. $9: 30-11: 30,3: 30-6$.

Thompson, Win. Anderson (b'52)-Ky.2,'83

(l'90): 220 W. 12 th St.; $9-6$. $90 ;(1,90)$ THRAIIKILL, EDW. II. Linwood Blvi.; offlce, Rialto Bldg. $11-1,3-5 ;$ Pr. $\star$

Thym, Herman H. (b'85)-MFo.35,'10;(1'10) 2947 Flora Are.; office, Aitman Bldg. Irof. Physlol. and Ped., Mo.3i.

TIEMANN, TIIEO. (f. (b'67)-Mo.20,'03 (1'03); 608 Southwest Blyd; 1-4, 7-9.

TIFFANT, FLATEL B. $\left(\mathrm{b}^{\prime} 46\right) \pm$-Mich. 1 $74 ;(1,84) ; 100$ Garfleld Are. :

Mefee St.; 10-12,3-5; OALR.* (105); 4042 Baltimore Are.; oftice, 1330 summit. st.; 2-4; ObG.

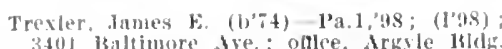

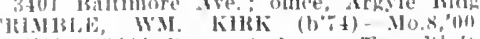

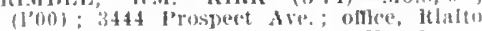

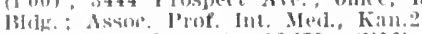

Trjpl-1ta 0 , liendetto-Ita.12,79; $\left(1{ }^{\prime} 06\right) ; 707$ pi-1tao, Rendetto-1ta.12, 79 ;

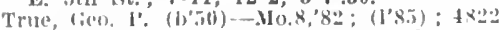

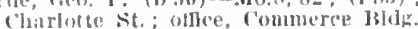

Pucker, liarrey' F.-IIo.33,0]; (1'01); 3333 Aines die.

Tucker, I. M.-Ky.4,9.5; (1'97) ; 4218 s Jonton Itwel.

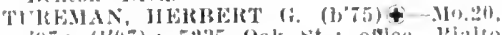

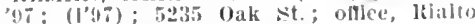
lida; $11-3$; ALR.

Turgeon, Leo 'V. (b'91)-Mo.20,'13; (1'I3) fieneral 1Iospltal.

Tuthll, II rerbert (b'81)-Kan.2,"1) ; (1'08) itlailto bldk.

inderwood, lioss IIolland (b'88)-Mo.20) $13 ;(1+3)$; 2800 Maln St.

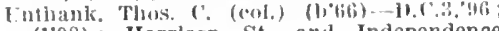
(1'98); Harrlson $S t$. and Independence

VINATTA, JOIN ROBT. (b'84)†-Kan.2, '11: (l'11); 3515 Prospect Ave.; office fieneral Hospital: 8-5: LD.

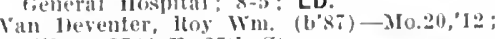
(1.12) : 3720 E. 27 til St.

SAN HMAN, FREDK. T. (b'70) क-Mo.8 97 ; (1'97)'; 3537 Fuclld Ave.; offlce, 12th and IIcGee Sts.; 2-5; ObG.

van Fossen, Joo' 13. (h'52) H-No.26,'9s (1'9S); I231 Troost Are, ; 9-I2, 5-7; G. (1) 3120 Troost dre.

Finorden, Herberi Francls (1) 84$)-N d .7$ 10; (10); 361 s Chestuut Are.; offlce, liaito Hidg.; $10-1$

Van Stavern, Devilt Clinton (b'5i)- Ill.12, '86; (1'98); 3411 Montgall Are.; office, laeserve Bank Bldg. ; $10-12,2-5$.

YILFY, LELAN1) I'EAK (b'83)-Mo.2,'08; (1'1) : 2838 Forest Ave; offlec, 31st

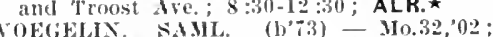
(1'02); 3236 Roberts st. ; oftlce, Bryant Bldg. ; 2-5.

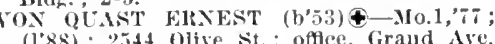
Temple : $2-5 ; \mathbf{S}$.

Valker, Callie S.-Mo.30,01; (t’01); 1414 Troost dre.

Walker, Elijil Alexander (col.) (i)' 7 ) -

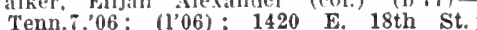
$9=11,2-4,7-9 ; \mathbf{G}$

Walker, Janes Chas. (1) 88)-La.1,13; ( ) 3930 'Troost Are.; offlce, 509 Grand Are Nalker, John Milton (b'91)-La.1,'13 (1'13) ; 3715 Wasbington Are.

Wall, Arthur Harvey (b'i i)-Mo.8, 95 (1'95); $301 \%$ Independence Blsd.; offlce, Rialto Bldg. ; $11-1$.

Wall, James Thomas (b'91)-Que.1,13; Intern, General Hospital

Waring, Robt. P. (b'48)-No.2,79; (I'83) 2100 IIontgall Are.

Watson, Benj. Frank (b'70) - Mo.8,95; $\left(1^{\prime} 95\right)$; 2401 Prospect Are.; offlee, Halto Bldg. ; $9-11$.

Watts, Darid S.-Mo.1,'85; (I'84); 3714

AY, FIANKLIN E. (b'67)૯-Mo.8,'95;

Nember Kan. Med. Soc.; 2301 F. 6th St. WEATER, JOHN SEBASTIAX (b'72) Ill.11,97; (l'01) ; 904 F. 43d St.; offlce, Rialto BIdg.; 10-12, 2-4; (B1); OALR.
vedding, Columbus (1'89); 2643 Benton Blvd.; $12: 30-4,6-8$; G.

WEDDING, EST11, VICTOR (b'74) Ky.4,95; (1'95); 2519 Linwood Blrd.; oftice, Ríalto Bldg. ; 12-4.

Weinberg, Abraham (b'88)-Mo.20.'10:

(l'10); 519 olive St.; oflice, Argyle Bldg.

WEICH, ALBERT JAMES (b'67) \&-0.3. $94 ;(1,95)$; 3732 Jefferson St. ; offlce, Rialto Bldg.; $11-3 ; \mathbf{S}$.

Wells, May Reynolds (b'T8) E-Mo.33,04; (ま); 900 Topping Ave. ; $1-4$

Wells, Sanford Edmonds (b'74)-Mo.20,'04; (l'05) ; 900 Topping Are.

Welsh, Luther Winfield (b'52)-Mo.35, 03 : (1'95) ; 3323 Summit St.; offlce, Bryant Bldg. : $9-6$.

West, Chas. A. (b'83)-Mo.34,05; (l'05); 1127 Forton Ave.
West, Wu. Chas. (b'79)-Mo.8,03: (l'03) ; 47 is Campbell St.; once, Rialto Bldg. I1 - 2

WIIEEIFR, BERTAN IIENIR (b'72)\&Hloe, 4050 Broaldway Jlvd. : $3-5$.

WIEFLLR, WAITHE SHWELI (b'59) \& 1'a.2,85; (1'85); 3316 Troost Ave.; of -

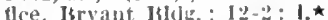

White, feo. W. (1, \%2) N.Y.I, $\left.94 ;(1)^{\prime} 11\right)$; 6508 E. 37th st.; offlec, 6.501 E. 3ith st. white, Thos. S.-F-Mo.10,79; (1'93) (kansas City, Kan.); oftlee, 1230 Unlon Ave.

Whittaker, John I1.-Wo.20,'01; (1'01) ; 3227 sit. Iohn Are.

Whittler, IIemain J. (b'56)-0.2,83: (1'83) 2326 Brooklyn Ave, offlce, $1 \mathrm{ith}$ and $\mathrm{Al}$ (iee Sts. ; $9-$, .

Wicker, Wm. F. (b'70)-Mo.35,10; (1'11) 1012 Troost Are. office, Shukert Bldg. Idj. P'rof. Obst. IIo.35

Wlles, l'has Kimball (b,54) II-Ill.4,'78 (1'96) ; 2617 k. ith st.; offlee, 1115 Grand Ave; 11-3; Prof. Ment. and Nerv. Dls., Mo.35; NP.

thelm, Bonls F. $\left(b^{\prime} 83\right)-M o .20,07 ;\left(l^{\prime} 05\right)$. ect Ave.

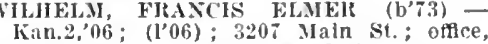
1208 Wyandotle St. ; $2-4 ; 0$ bG. $\star$

Wilhelm, Leland Paimer (b'88)-Mo.20,'10; (1'10); 3836 Prospect Ave. ; 9-11, 1-3.

WILLIAMS, DUDLEY B.-MO.2,03; (l'01) ; Argyle 1stug.

Willams, James II. (col.) (b'70)-Tenn.̄ 09; (l.09); 2203 Flora Ave.: offlce, 810 Independence Are.

Willams, lames lkex (b'91) - Mo.20,'13; $(1 ' 13)$; isth and Locust Sts.

Villiams, lRobt. Alvin $\left(b^{\prime} 71\right)-M 0.32,00$ (1'01): 5012 St. Joln Ave.; offlee, 3400 St. John Ave.

WILIITS, WILMOT CHAS. (b'66) \&-Mo.20, 01: (1'01); 3001 Park Are.; offce, Argyle

vilson, Albert Miller (b'54)-Mo.20.'91: (l'91) ; 3601 Montgall Are.: office, Waldheim Bldg.; $9-10,12-1,2-5 ;$ G.

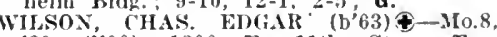
89; (1'90); 1200 F. 11 h St.; offlee Rialto Bldg. : $1-4$.
WIISON, DORA GREENE (b'64)€-Hll.9, 86; (1'86) 3042 Troost Ave.

WILSON, JOIIN-Mo.2,66; (1'84) ; 332 ; Wabash Ave: offlce, 1115 Grand Are. $11-12,2-4$.

MTSON, WU ANDREW (b'79) क-Mo.34 heim Bldg. ; 11-1, 3-5; U

weim Bldg. ; 11-1, 3-5; (b. 88$)-\mathbf{M o . 2 0 , 1 3}$ (l'13); 1512 Lawn Are.; offee, $4303 \mathrm{~F}$. 15th St. : 3-5.

winfrey, Caleb-Mo.2,47; (1'84); 907 E. 14th St.; offlee, Juncțlon Bldg.

Winfrey, Napoleon B.-Mo.8,'81; (1'83) 5630 Swope Parkway.

Wise, Jullus C.-H-Mo.26,'96; $\left(l^{\prime} 96\right)$; 1115 Wyandotte Ave.; Prof. Pharmacy, Mo.35. Witt, James Polk- ; (立); 3618 Troost Are. WOLF, ISADORE JULIUS (b'64)£-Ger.16, 87; (1'88) ; 3710 Tracy Ave.; offlce, 12th and IIcGee Sts.; 2-4; Prof.' Inter Med. Kan.2.

Wolfe, Clinton S. (b'83)-J11.8,'09: (1'10) 1409 E. 29 th St, ; offlee, 1107 MeGee St.
WOOD, DELBEIT LEROY (b'80)థ-Mo.32, 04; (1'05); 1116 TIaln St.; 9-5.

WOOD JAḾES FRANKLIX (b’37) \&Io.2,78; (1'84); 1327 E. 9th St.; offce, Rldge Bldg, ; 9-12, 1-4; 0pA *

Vood, John Borden-1ll.1,83; not in practice 4446 VIn $\mathrm{St}$

Wood, Wm. Alfred (b'59)-Mo.28,'94;(1'94) ; 1119 Troost Ave.

Woodruff, Chalmers P. (b'43)-Ia.1,'84; (1'85); 525 Knickerbocker Pl.

WOOLIEY, PALI VINCENT (b'81) कMFo.20,05; (l'05); 4146 Charlotte St. : offlee, Sharp Bldg. ; 1-5; U.

wright, Wm. Carver '(b'88)-Tex.2,'13; Intern, General Hospital.

wyatt, Thomas Eddy (b'テ̃)-Mo.20,00; (1'03) : 3216 ollre St.; offce, 1208 Wyandotte St.: $1: 30-5 ;$ OALR. $\star$

Wysong, Luther E-Mo.20,'00; (l'05); 1422 Forest Are.

Young, Cook Bar-Chlnas,'39; (106); 111 E. 12th St. 
Young, Herbert Farl (1,75) H-Mo.35, 03 :

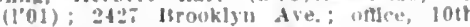

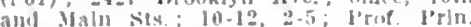
and P'rae. Met.. Mo.35; S.

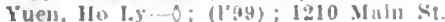

Zelter, Henry J. Mo.20,00: $(1,00):$ :2929 flora tie.

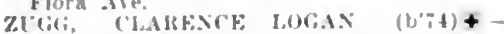

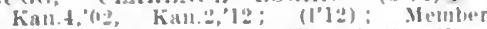

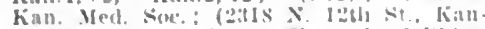

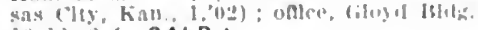
111. 1:-4; OALR.

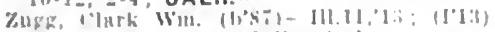
kinsas fley lieneral Huspltat

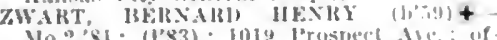

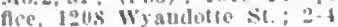

KEARNEY, 63I, CLAY

DAILFY, HLOYI R. (b'S2)\&-Kan. $(1,0 \%)$.

IbAVIS, WM. I.-M10,20,"99: (]'99).

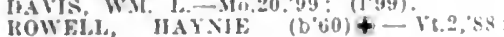
$(1,28)$.

KELSO, 190, SCOTT

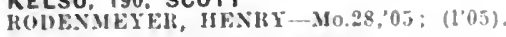

KENNETT, 3,033, DUNKLIN

BALISWI, PAU1, (b'SO) — - Mo.2,04 $(10 \%)$.

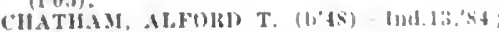

(1'88): G.MES J. (b'69) \-Mo.24,93; (1'93).

Egbert. Thomas Ittram (b'70)-Ky.2,98; $\left(f^{\prime} 00\right)$.

FIXXE:, wM. B. ( (b'5R)-Mn, i, $90 ;\left(I^{\prime}(4)\right)$ GOSSAGE, WM. L. (b'65) \&-Mo.i.'(15) (1'05).

Ilarrlson, irthurs, (b"bfi)-Mo.1, \&8; (I's,

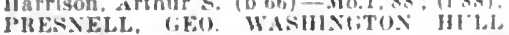
$\left(b^{\circ}, 3\right) \&-M 0.28,9 ; ;(1,9 ;)$

JRESNELI, CRAT, ALMEIT VKST (1, SO) + - Mlo.28,04; (1'04)

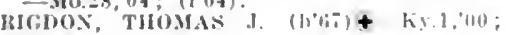
$(1,00)$.

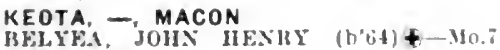
89; (1'90).

KEYTESVILLE, 963, CHARITON

Dewey, James T. -Mo.1,'88; (1'88)

Garnet, H. T.-Ky.2,62; (1'83).

SIXGIETON, 1)ENIS" 05: (l'05).

ZIJIMAX, AUGUST W. (b'59) \-III.I,'\$6; (1'86).

KIDDER, 306, CALDWELL

Cannon, J. M. W. (b'51) ll--1'a.9,'is: (1'83).

MeMUITREY, CHAS. T. (b"ï)-Mo.18, 94: (1.98).

KIMMSWICK, 235, JEFFERSON

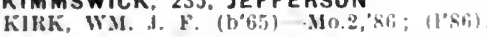

KING CITY, 966, GENTRY

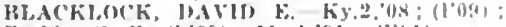

Forbls. ( F. (1, $699-M 11.1,91 ;(1,91)$

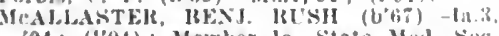

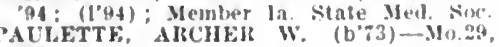
(96:) (1,97)

spence. Wm. E.-Mo.22,87; (1'88)

KINGSTON, 535, CALDWELL

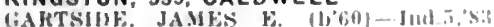
(I'85).

Jones, Chas. K-Mo.1,'86; (1'80)

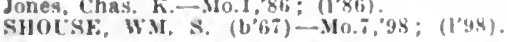

KINGSVILLE, 238, JOHNSON

Angell, J. L. (b"57)-Mo.42,"43; (I'96i).

KINLOCH, 300. ST. LOUIS

Jorrls. Indrew B. (b):50)-1a.1, iti; (1pibl

KIRBYVILLE, 91, TANEY

Anderson, KH T.-Ind.6,'T?; (I'84).

KIRKSVILLE, 6.347, ADAIR

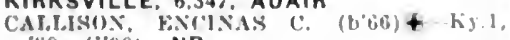
' $\mathrm{Sg}$ : (1'00); NP.

Comor, lemnltas J. (1,0.3)-Mr.27,92; (l'03).

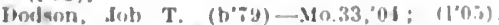

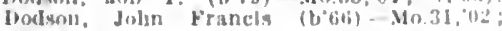

oxisming

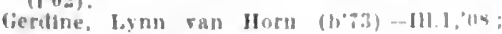

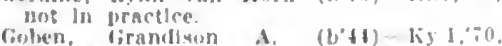

×. $1.10,84 ;\left(t^{\prime} 92\right)$

firlm, Vidw. I. (b'bi)-Mo. I, "uu, J'a 1,40 $(1 \cdot 90)$.

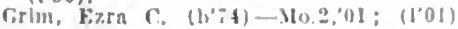

M.IRTIN, JMMES W. (6,.) - M19.1,79; Martis. Wilfurel W. (1,7i)-.110.33,03 (1'(1);3)

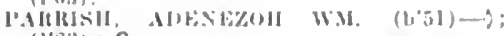

(1.53): G

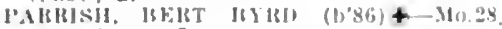

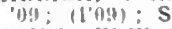

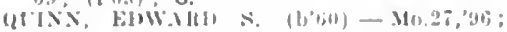

([2).

sparting.

(1'81)

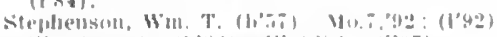

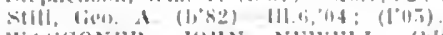

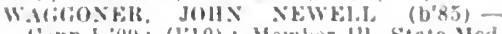
loun. 1,04; (1'10); Memler 111. State Med. Asste.

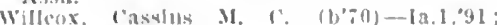
(I"U) ; OALR. *

KIRKWOOD, 4,17I, ST, LOUIS

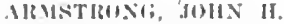

(Niee Ni. Jollils.)

Hruderlek. John K.-Mlo.2t, $00 ;(100) ; n n t$ In practice.

[Mlongstus. Henry J. (b'57) Mo..3.80; (1'8t)

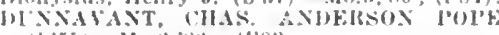

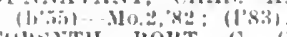

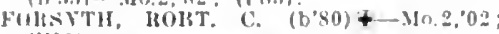
(1,01)

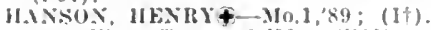

Mars, Win. T. - Ifo, $5,\left(00 ;\left(10^{\prime} 00\right)\right.$; not in practlce.

Purker I M. Mo." I

l'ickel, John W. (b,5i5)--M(1.3,'st; (1'90): not in practice.

WYIHF, CHARLES

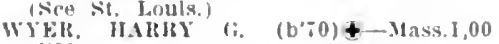
(1001).

KISSEE MILLS, 66, TANEY

III:MIIIIFYS, 'TIOMAS HAZEN (b"63) † 1a.6.'84: (1'95).

KNOBLICK, 209. ST. FRANCOIS

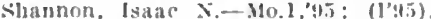

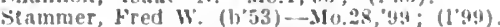

KNOBNOSTER, 670, JOHNSON.

Mlller, L. ( $\rightarrow$ : (l'Bt).

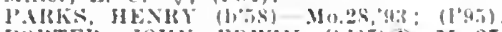

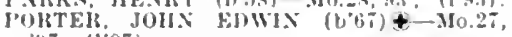
$37 \cdot(1,97)$.

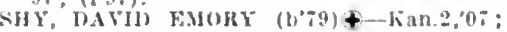
(I'07)

stauley, dames $\mathrm{T},-\mathbf{H}-\mathbf{k} y .1,93$, Mo.28, 99 ; $(1,94)$.

KNOX CITY, 395, KNOX

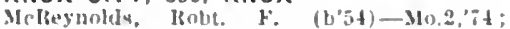
(l'ul).

Mckeyuolds, Lrlal IR. (b'81)-Mo.3t,0t: (I'0弓)

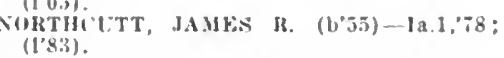

KNOXVILLE (R.F.D., POLO), 81, RAY

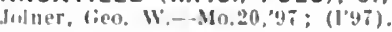

КОСН, - ST. LOUIS

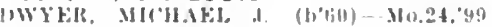
[एक:

KOELTZTOWN, 200, OSAGE

Verhoff, ('onsad s. (b'81)-Mo.10,'12: (1'1:)

KOENIG, 27, OSAGE

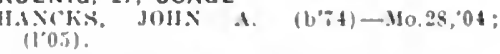

KOSHKONONG, 452, OREGON

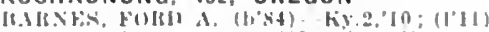

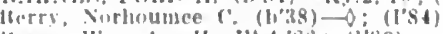

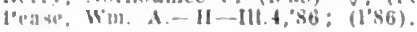

LABADDIE. 69, FRANKLIN

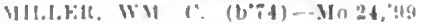

LA BELLE, 1,017, LEWIS

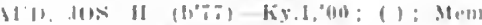
luer ki sifale lted sioc.

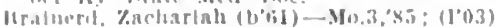

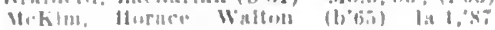
(1) $x=1$

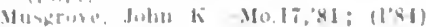

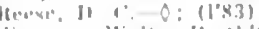

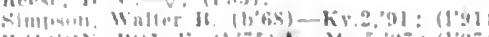

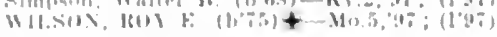

LACLEDE, 7\$0, LINN

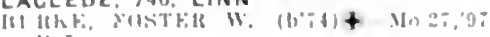

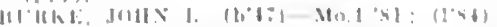

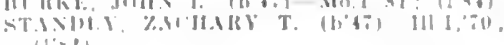

LA CROSSE. - MACON

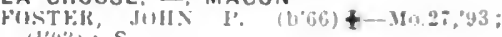
$\left(l^{\prime}(3,3) ; \mathrm{S}\right.$.

LADDONIA, 6I4, AUDRAIN

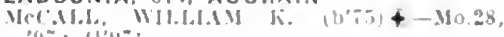

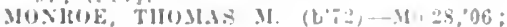
(l'ul) ).

LA DUE, 235, HENRY

firaham, Anthom! W. (b'51) Mo.3,'ic: H:S

LAFLIN, - BOLLINGER

rinney, Johin Marsehell, Jr. Min.9s,"03 (1'03); K.F.J).

LA GRANGE, 1,360, LEWIS

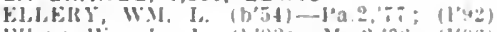

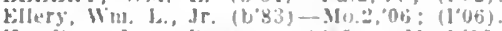

Hamlin. Jos. Reagah (b's) - Mo.2,10 (1) 10$)$.

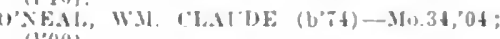
(1"00)

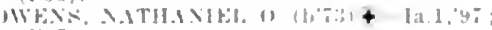
(1'y?).

LAKENAN, 137, SHEL8Y

WIITE, ALEAXIVER T. ( (1"1)!); N.

LAMAR, 2,316, BARTON

ALLFE, GiAlL DARWIS (b'6) \&-MO.24 '98; (1'98).

COJE JUS, KENYETT (6'51) $\rightarrow$ : (1'84).

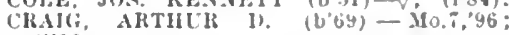
(1'96)

Cromley, Jolun F. (b'jt)-Jnd.16,94; (1'95).

Fletcher, Robt. 1. (b'3t)-1a.3,57; (1'93).

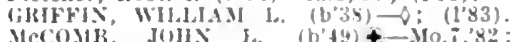

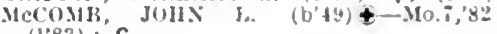
STOVE:

$(1,90)$.

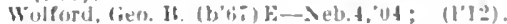

LA MINE, -, COOPER

Boberts, Waller-N.1.10,"93; (1"43).

LAMONTE, 684, PETTIS

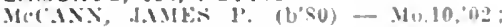
(I, ili:i)

Walker, John I'-Mo.2,:5; (1'84)

WALKEK, WM. K. (b'-2) II 25,$03 ;\left(10^{\prime} 03\right)$.

LANCASTER, 964, SCHUYLER

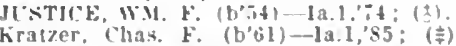

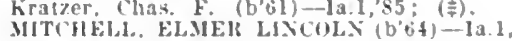
$44 ;(1,44)$.

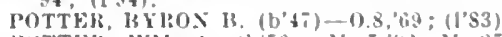

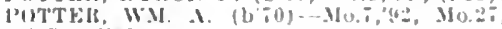

$09.5 ;(1,42)$.

LANTON, 32, HOWELL

HOMPSON, HFNKL ALFKEL (b'68)Tenn.8.95; (1'9S).

LA PLATA, 1,605, MACON

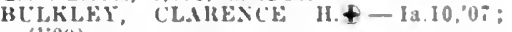
(1.09)

BULKLEY, JAMFS F'RANKLIX (b'54)Mo.18, 'MI: (1'91)

Camplell, Juhn F. (1, 40$)-0$ : (1's3)

cunnlngham, Jeury $k$. (b'3is) - la.1, :t (I'st).

EHIs. sylvester 1.-1a.1.80; (['33).

Ciarrison, 1,awsun W. (1, 34$)-9 ;(1,89)$; not in practice.

(iates, Joslalı-0.2, $19 ;(1+34)$

(iultey, Hen], $\rightarrow$; (1'it)

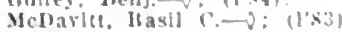

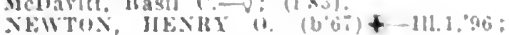
(1)

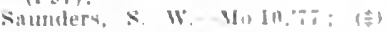

LAQUEY, - PULASKI

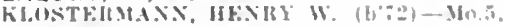
$02 ;\left(\left[0^{\circ} 02\right)\right.$

LAREDO, 758, GRUNDY

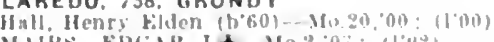

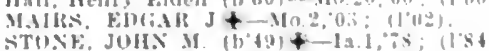

LATHAM, I50, MONITEAU

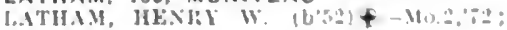
IIsit.

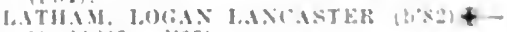
M1,:3.0\%: 110051

LATHROP, I,038, CLINTON

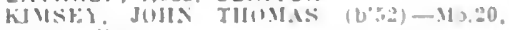

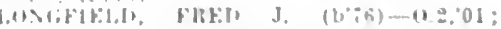
II 111

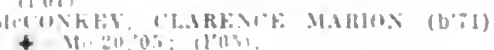


Porter, (Geo, 13. $-110.20,00$ : (1'00)

liobertson, Arthbald W. (b'ti)-Mo.2,"7l (I'8:i)

IUUSI, GLO, B.†-Tenn.5,82; (1'92).

LATOUR, I00, JOHNSON

SHEFHEH, JAMFS T.-liY.A,"9I: (19I)

LAWRENCEBURG, 300, LAWRENCE

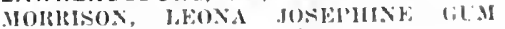
(b'69)-Mo.28, $05 ;$; (1'05)

Willkerson, W. Deek-Mo.7,02; (1'03).

LAWSON, 604, RAY

FSTILL, WMI. G. (b'60)—-Mu.I, 'B3; (l'83) Janes, Wiu. Arthur (b'75)-.110.20,97

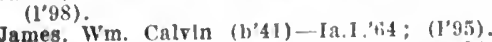

James, Wm.

08; (1'08).

Roney, John H. (b'(0)-N.1.10,88; (1'95).

LEAD MINE, I00, DALLAS

Eilmondson, Hantort-Ind.4, if: (I's3)

l'hlllps, Irrin (b'58)-No.24,'s7; (1'88).

LEADWOOD, 250, ST. FRANCOIS

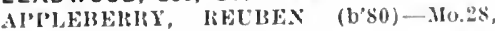
03; (1'03).

H'F'MAX, JAMES WM.- Ind.8,05; (113) Menter lnd stots yed tssu.

MeKENZIE, DAVII) IIENRY (b'63)-L'Y.I 96; (1'97).

LEASBURG, 79, CRAWFORD

IRWIX, W.I. F. (b'i4)-MI0.27,97; (1'9i)

LEBANON, 2,430, LACLEDE

ITCHLEY, JOILX H. (b'54)-MO.I0,'8';

(1'83).

Barker, Joln C: -0 ; (1'84)

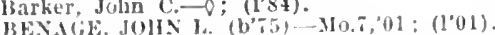

IBILLING JAMES M. (b'44)-0.4,73:

(l'83).

AlWWHA, THOMAS (b'45)-v

CAEx, SHEDELIC A. (b's6)-Tenn.6, 07 $(1 * 0 \pi)$.

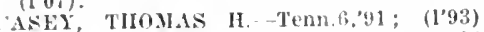
lenson, Lafayette Leonard (bois) -Mo.28.

IIEIRERT, THOMAS B. (b'Gs) \&-Mo.I, , $90 ;(1,30) ;$ OALR

Yeromb, James (b'32)-Pa.2,65; (1's3); not In prillice.

Meco.M3, JAMES ALBRRT (b'63) †-Mo.24, 'S.; (101).

LEEDS, 一, JACKSON

Lunte. Hirry saml.

(Seo Kansas City.)

LEEPER, 400, WAYNE

B.ILEY, WI. SIMPSON (b'66) 4 Mo.T, "48; (1"98).

LEES SUMMIT, 1,455, JACKSON

Ellis, Samuel-0.1,66; $\left(1^{\prime} 66\right)$; not In prac-

H.MLL, GROVER C.-Mo.20, $07 ;(1 \cdot 07) ; 0 p$ HARISOX, AUDISON M. (b'6) \$-Mo.24, "yz; ( 1 ;'yz)

RAGSDAL, THOS. J.-Mo.27,95; (1'95) SIIASEY, IDDISON (i. (b's1) \&-Mo.20,

THokstos, THOS. R. (b'43)-Mo.2, 68 ; (1'83).

LEESVILLE, 124, HENRY

Finley, Thomas A. (b'45) F-O; (l'8:3); G.

LEETON, 420, JOHNSON

YALE, ELIJAII Y. (b'‘2)-Mo.28,98; (l'98)

LEMONVILLE, I15, PUTNAM

Cobb, Benj. Eldon (b'80)-Mo.34,'12; (1'12).

LENTNER, 4I, SHELBY

WOOD, ADOLPII M. (b'78)\&-IIo.1,99; (l'00).

Wood, Adolphus G. (b’31)-la.1,'59; (1'84) ; not in practice.

LEONARD, II0, SHELBY

lierard, Edw. 3 . (b'69)-Mo.20,95; (1'95).

LEORA, 70, STODDARD

FORI, EUW. (b'-0)せ-IL.28, $05 ;$ (l'05).

LESLIE, 325, FRANKLIN

(WENS, ISAIAH II. (b'67)\&-MO.28,97; (1'3\%).

LESTERVILLE, 170 , REYNOLDS

Fitepatrick, chas. Ml. (b'79) - Mo.10,07

MIXUR, RICIMOND TERRILL $\left(b^{\prime} 4 t\right) \notin-$ ia.1, 6 ; $; 1,5)$.
LEWIS STATION, 300, HENRY

Allen, James Thomas (b'64)-MIo.24,92: (1'83).

LEWISTOWN, 405, LEWIS

HROWN, JOFL CARLTON (b'62) - -l11.1,

siti; (l'sis)

aris $(1,92)$

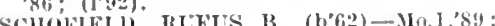
(1'8:) ; G.

LEXINGTON, 5,242, LAFAYETTE

Ball, Jolun D. (col.) (b'60)-Tenn. i,'92; (1'93)

CIALKLEY, A. JUISON (b’78)-Mo.2,05;

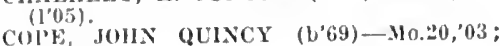

(l'03); S. IREDLND

FULKEISSON, JACOB J. (b'49)-Mo.2,75; (l'84).

Payne, Pryan Temple-Mo.5,'06; (l'05).

Payne, N. B. - Ky.2,76; (1'03)

MOHFIRT, McCORD G. (b'61)-Mo.7,91 (l'93); G.

IR ILIX, CAIUS TACITUS (b'74) \&-Mo.24,

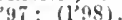

Weedin, Wm. B. (b'72)-Tenn.5,'93; (l'y3).

LIBERAL, 800, BARTON

(iish, James S.-Mo.1,'81; (1'83).

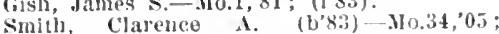
(l’05).

LIBERTY, 2,980, CLAY

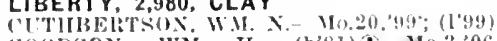
GOODSON, WM. H. (b'81) (1'06).

MALTBY, BURTON (b'85)థ-Mo.20,08; (1'0S).

MATTIEWS, FRANCIS H. (b'66)†-Mo.20, $00:\left(l^{\prime} 00\right)$

MHLER, ENOCH H. (b'51)\&-Mo.1.'T4; (1'83); Pres. Mo. State Med. Assn.; ALR. Robinson, John M. (b'4 $\left.)-M 0.2,69 ;(1)^{\prime} 68\right)$ IROTHWELL, JOHX IIUGIIES (b'58)\&N.X.10,'83; (1'83).

EVIER, ROBT. E. (b'60)\&-Mo.20,90; (1'90).

LICKING, 35I, TEXAS

IITCHELL, SHEHRILI l. $\quad\left(\mathrm{b}^{\prime} 62\right) \oplus-0$ : (1'84); Op.

RANDALL, LFSLIE CORNEALOUS (b'81) 4-No.28, 08 ; (1'09).

LILBOURN, 484, NEW MADRID

llowe, Pearl P.-0.1',93; (1'01).

J0NES, EDW. E. (b'80)-M0.10,06; (l'06).

LINCOLN, 336, BENTON

CUDDY, ORA L.-NO.28,03; (1'03).

JONES, WILLIS G. (b'73) $4-110.24,97$; $\left(1^{\circ} 92\right)$.

RHOUES, E. L. (b'54)-Mo.19,79; (1'84)

STRATTON, SAM. O. (b'70)-Ky.4, 93 (l'8:1).

LINKVILLE (R.F.D., PLATTE CITY), 75, PLATTE
OFFEY, GRUNUI C. (b'7T)-.Iu.20, 01 ; COFFEY, GR

Swaney, Wm. D.-Mo.32,03; (1'03).

LINN, 482, OSAGE

Ahrens, Vineent Geo. (1) 833$)-.110 .34,08$; (l'08).

GOVE, HERMAN SAML. (b'79)\$-Mo.27,

Jett, James F. (b'56)-Ky.5,'y1: (1'y1).

LINN CREEK, 435, CAMDEN

Ford, J. S.-Mo.1,'il; (l'83).

MOORE, GEO. M. Ky.2, 92 ; (1'92).

MOULDER, GEO. A.MO.20,0I; (1'01)

Moulder, John I.-Mo.20,0I; (1'01).

LINNEUS, 882 , LINN

ADAMS, WILSOX ROY (b'S1)-Mo.20,'04: (1'04).

Home, Louis 0.-Mo.1, 84: (1'84)

MORRIS, ROB'T. HAKOLD (b'75) \&-Mo.28 $96 ;(1,96)$

LITTLE BLUE, - JACKSON

GEOLGE, JOHN HENRY (b'6 ï)-Mo.8,'96: (l'96).

LITTLE ROCK (R.F.D., SLATER), 65 , SALINE

SHARP, WM. LOWERY (b'78)-No.,,$^{\prime} 04$; (1'05).

LIVELY (P.O. DUROC), - BENTON

Xoblit, Wu. I'. (1)'14)-0; (1'85).
LIVONIA, 45, PUTNAM

NULTON, IDA MAY (b'66)\&-Ia.9,'98;

(1'98); Pd.

LOCK SPRING, 255, DAVIESS

MINNK, ASIMEW (;. (b'T0)-\$0.20, 00 ; (l'00).

LOCKW00D, 96I, DADE

Massey, Thos. J.-Wo.18,91; (1'91).

Melermot, John-Mo.28,95: (1'95).

Middlecon, Marjon C. (b'55) E-Mo.10,'85; $\left(l^{\prime} 85\right)$.

liussel, Decatur-II-Mo.2,'82; (1'\$4).

LOHMAN, 65, COLE

Feller, Chas. Ernest (b'84)-Mo.10,'10: (l'10).

LONEJACK, 900, JACKSON

Kreeger, Geo. G. (b'72)-Mo.8,'95; (l'95).

LONG BRANCH (R.F.D., MOLINO), 23 , MONROE

Duncan, Edw. $\rightarrow$; (ठ゚).

LONG LANE, I06, DALLAS

liandle, Franklln W. $\rightarrow$ : (1'98)

Talbot, Lucien IIale $\left(b^{\prime} 59\right)-.110 .1,89$; $\left(1^{\prime} 90\right)$.

LONGTOWN, I58, PERRY

Bowman, Chas. B. (b'59)-Mo.28, 02 ; (1'02).

Russell, James Wm. (b'65)-Mo.2,'87'; (1'8i).

LONGWOOD, - PETTIS

P'LOWELI, JOIIN DAWSON (b'63)-MO.I, $89 ;(1,90)$.

LOOSE CREEK, 100, OSAGE

Nolte, Jolin II.-Mo.10,'88; (1'88).

LOUISBURG, - DALLAS

(ianmon, Wm. Edw. (b'72)-Mo.8, 01 ; (1'0I)

LOUISIANA, 4,454, PIKE

Crewdson, J. W.-Ky.2,80; (1'97).

DAVIS, JANIES D. (o'39)-Pa.1,61, Mo.5, $78 ;(1 ' 84)$.

DKEYFUS, JAMES W. (b'51)\&-Mo.2,7\%; (l'83).

Golnes, Ioln Berkeley (col.) - Tenn.:,'95

$\left(1^{\prime} 96\right)$.

HARDIX, WA. REFUS (b'75)-Mo.2,99; (1'99)

IIETHEILL, T. GUY (b'69) - 310.1,'93;

(l'02); Ob. CHWELLEN, CHAS. P. (b'\%8) - Ky.9,04; (1'06).

Lonergan, Albert C.-Mo.2,73; (I'34).

Miller, Ira II. (b'7T)-Mo.1,99; (1'99)

I'EARSOS, DONNELl, M. (b'il)-Mo.2,'9I ; (1'91).

Unsell, Ios. B. (b'80)-Mo.28,'05; (l'0.').

LOUISVILLE (R.F.D., CYRENE), 65, LINCOLN

Iotley, Janles Darid $\left(b^{\prime} 62\right)$ - Мo.27,93: (1'93).

LOWNDES, 100, WAYNE

BURTOX, PHILLIP PATRICK (b' 6 ) $)-110.7$ '90; (l'90)

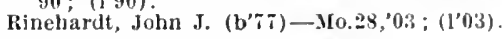

LOWRY CITY, 462, ST. CLAIR

Hice, Wm. H-Mo.10,'76: (I'84): Pd

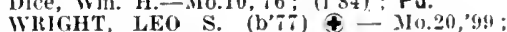
(I'99).

LUCERNE, 264, PUTNAM

Corbett, Jiltcliell Saml. (b'84)-111.16,'11; (I'I2).

kice, Franels I). (b'

steele, Geo. Mlbert (b'63) E- Mo.10,'89 : (I'89).

LUDLOW, 300, LIVINGSTON

Broyles, otls (b'60)-Mo.1,92; (l'92) ; Pr.

Morse, Geo.-0.2,02; (1'01) ; 0p.

MURRAY, RALPI W. (b'68) - Mo.18,'92 ; (1'92); $\mathrm{G}$.

LUPUS, I64, MONITEAU

Lopp, John H. (b'i4)-Mo.28,'98; (1’97); S.

LURAY, 163, CLARK

CALLIHAN, RICHARD G. (b'69)\&-Ia.I,'91; (1'91).

GEESLIN, PRESTUN A. (b'68)-Mo.T,06; (1'05).

LUTESVILLE, 55I, BOLLINGER

CHANDLER, JOHN J. (b'64)\&-Mo.7,92 ; (l'92).

Farrar, Chas. B. (col.)-Mo.28, 0 T; $\left(1^{\prime} 06\right)$.

Lages, Wm. (b'62)-110.1,91; (1'91).

MACKS CREEK, 150, CAMDEN

MILLS, SHERMIAT (b' 71$) \rightarrow M 0.7,03 ;\left(l^{\prime} 00\right)$

IYEKS, GEO. THOMAS (b'7) -Temn.II, (98; (1'99) 
MACON. 3.584. MACON

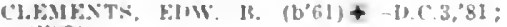
(I's $\$ 3$ )

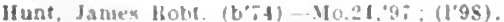

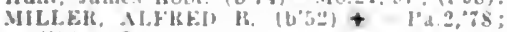
$(1.83): 5$.

MILLFil, WM. II $\left(b^{\prime} 60\right)+$ Mo.3.4. Mo.2. 89: $(1.85)$

Halnes Alpheus M. (bo:a)-Mo.24,00: $(1,00)$.

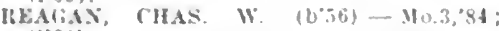
(1'St).

Rubey Wm. C-0.J6,79: not in pracelese

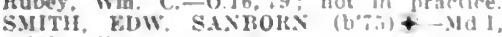
(1.00)

Smith, J, bidgar (col.) (b':9)-Tenn :,0 :

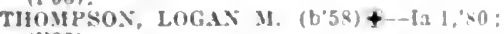
(1'83).

WEBB, WM, F. (b'55)-0.1.79; (1'S5); G.*

MADISON, 638, MONROE

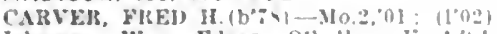

Juhnson. Wm. Fdgar othello-. Ky t.st: (1's4).

MAGNOLIA, 44, JOHNSON

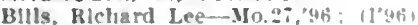

MAITLAND, 736, MOLT

DAVIS, THOMAS ORVILIL $\left(b^{6} 60\right)+-M(18$, 89: $(1 \times 9)$.

WILLIAMS, IRA (b'73)+-Mo.1,96; (1"96);

Wyman, Chas. W:-Mo.2.204; $(1,03)$

MALDEN, 2,1 16 , DUNKLIN

Heall, IIomer (b'\&2)-M(n.2,04: ( I'0.5)

DALTON, GEO. W: (b'53)-Mo.1,89; (1'91) OALR.

MTCHEL, SAMLEL, F. $\left(b^{\prime} \cdot 2\right)+-10,34$, $06:(1,00)$

Morris, John W--M1. I4,96; $(1 \% 79)$

Price, Wm. A-Mo.28, 04: (['05)

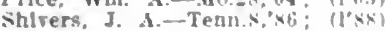

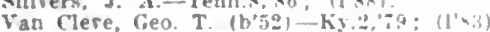

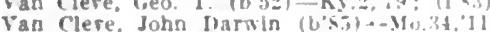
(1'11).

MALTA BEND, 399. SALINE

AKLN, GKO. ALFIRED (b"\&S) + MU.20,'ll;

(l'II): S. (l,04)

RROWX, JAMES R. (b'56)-MU,1,"is: (").

MANCHESTER, 500, ST. LOUIS

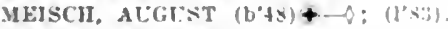

MANES, 102. WRIGHT

EVANS, EIRASTLS LAFAYETTE (b'bI)Mo.28, 95 : (1'95)

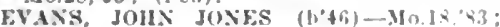
(1'85).

MANSFIELD, 477, WRIGHT

YUSON, JOHS ALVA (b'75) \& MU.2n, 05 (1'05).

Hamilton, Wm M. (b'54)-Mo.34, 0 : ROGFRS, BOHT, M. (b'62) YI, 291 (1'91).

MAPLEWOOD, 4,976, ST, LOUIS

HROSSARD, I'IERRE; MAYYIIIE $\left(\mathrm{b}^{\prime}, 9\right)+$ Mo.2, 45 ; (1'05)

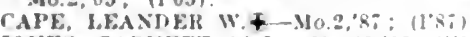

JONES, GARXETT (6.0\%)-110.29, $00^{\circ}$; $(100)$ NIYONG, FHANK (.

(see (olumbla.)

Napplngton, Wallace $\mathbf{L}, \mathbf{M}$ - 2,'s2;: (1'93).

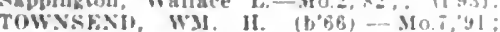
(1'93).

MARBLE HILL, 313 BOLLINGER

Presnell, Chas. E.-Mo: $: 84:(1 \cdot 8 y)$

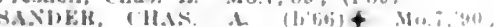
$(1.90)$.

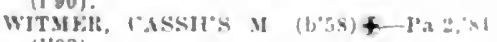
(1'83).

MARCELINE, 3.920, LINN

Asbury, Jevl M. Ia.8,84; (1'94)

Caler, John X...M(1.10,'s3; $11^{\prime} 431$.

Pater, Wm. A. Mn.10\%: $(10 x)$

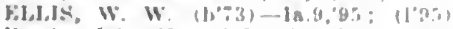

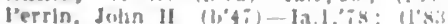

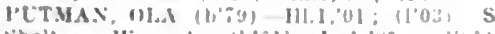

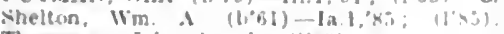

Thompsion. John at 0 : (1"M8).

MARION, 35. COLE

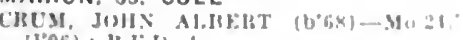
(1?96): Is औ 11.
MARIONVILLE, 1.272, LAWRENCE

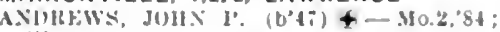
$(1.84)$

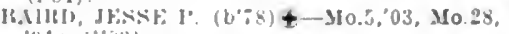

HULMK: WY M-MO.:93; (1'93)

MARQUANO, 339. MAOISON

larr, (ieo. M (b'3i) Mo.1,:79: (1'84)

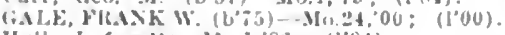

II ull, Lalfayelfe-Mo.1, 86 : (t'S4).

MARSHALL, 4.869 , SALINE

AXIItRSON, FISIS LUGAS.

(Fee Kansas ("lty.)

Rell, Danl. F.-Mu.l; 6i; (1'st)

Hradkhaw, Beaj. C. $\left(b^{\prime}, 3\right)-M 0.28,95 ;$ $(1 \cdot 95)$.

BLTISK, THOMAS ITIIIAHD (b'b2)X.1.10:8.': (1'm) : OALR

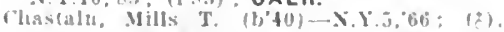

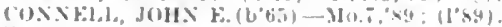

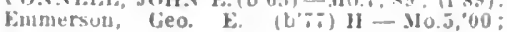
(1)ov).

CORL, ABNER EILLIS (b'S2) - Mo.34,06: $\left(1^{\prime} 06\right)$

(iols: i).WII) C. (b.52)+-Mo.1:70; $(176)$

H.ULI., JU11. H. (b+19)+-Mo.1, 73 ; (ह).

H.M., THUS, H. $(658)-M 0 ., 11 ;(1.84)$ 13.F.in.

Harlln, George S. (b'bit)-Mu.'sy: (1'so).

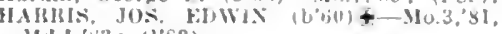
M11.1, $83:(1,83)$.

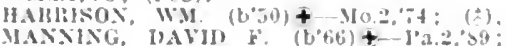
(1'59),

l'helan. John Thoma (bije) - Mo.27,9

I'utnam, Arthur C. (b';6) 11 - Mo.n, 00 (1'(ui),

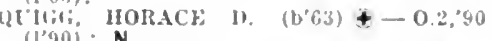
N.

Smlth, Thomas A. (b*58)-Mo.2., 50 : (l"8t) not in praclles.

SI'OTTS, BAYLOH M. (b'66) - Mo.!'9I: (I)BI).

MARSHFIELD, 1,193, WEBSTER

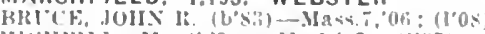

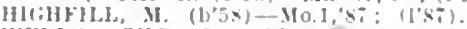

WELLS. GEO. H. (b'S5)+-Mads.11: (I"I1).

MARSTON, 258, NEW MADRID

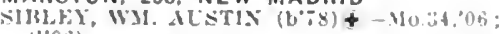
(l'06).

TIMBERMAX, JOHS HARRISUN $\left(b^{\prime}\right.$ in +

II $0.34,06$; (I"0i); Op.

MARTHASVILLE, 300, WARREN

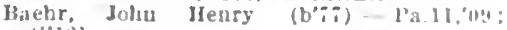

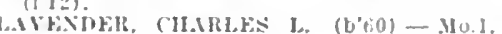

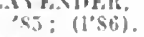

MARTIN CITY, 68, JACKSON

HCIIXNHD, KKXJ. F, (b'6t) +-111.11, $\$ 6$.

Kan+4,04: (I'Si).

MARTINSBURG, 436, AUDRAIN

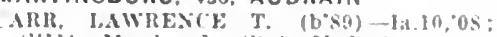

(l'Ii): Member la. Siale Merl. Sur.

MARTINSVILLE, 88, HARRISON

Reynolds, Alfred Card (b.54)- Jal. (I'ing).

MARYVILLE, 4,762, NODAWAY

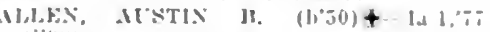

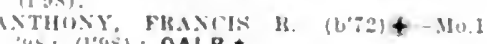

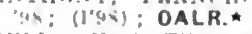

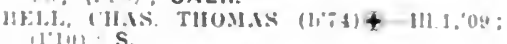

i1112:

$(1,9 \div 2)$

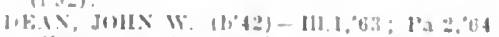
(1'm(i): mul ln vracllce

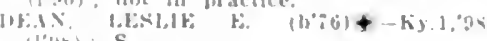
$(1, a, n): S$.

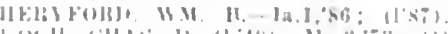

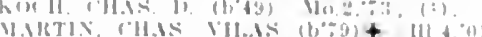

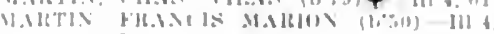

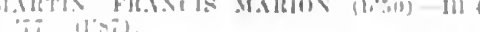

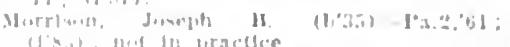

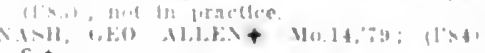

S.

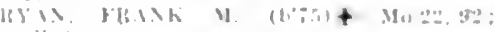

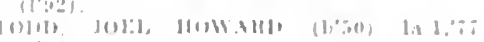

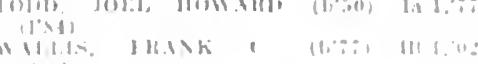

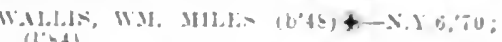
$\left(l^{2}+4\right)$.

M.MUIS, WM. M. JK. -Mn.24,0\%; (1003).

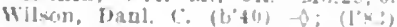

MATTHEWS, 237. NEW MADRID

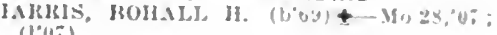
(1"0)

Wluchesler, iester Carl-Ky f."

MAUD (R.F.D., CLARENCE), 60, SHELBY

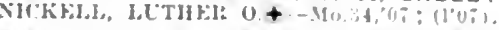
MAY (R.F.D., GOODMAN), 3, MODONALD IUKlns, W. J. $\rightarrow$ : (昘).

MAYESBURG (R.F.D.. URICH), 43, HENRY

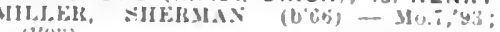
(1'y3).

MAYSVILLE, 1,051. DEKALB

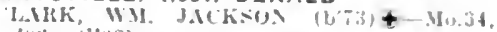
(1):- $(102)$.

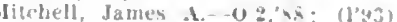

E.ITKK, HOMEIS J". (1) (2)

MAYVIEW, 308, LAFAYETTE

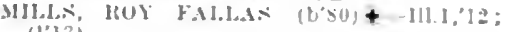
(l'13).

ICKELL (19.9.

MAYWOOD, 250. LEWIS

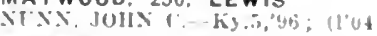

MCBAINE, 80, BOONE

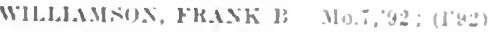

MODOWELL. 75. BARRY

DOHEHTSUN, S.MI'SUN J. - MU.\%,93: $\left(1^{\circ} 93\right)$.

M.FALL, 385, GENTRY

Inulon, IJugh J.-.Y.Y.10,"yz; (1'92)

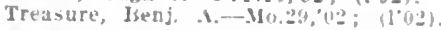

MEADVILLE. 380, LINN

CHAT, MUIBGIX 1. (U'S1) —-MU.3,'US; (1.0.0.

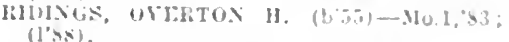

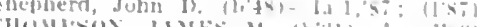
THUMI:SUN, J.MES W. (b'31)-8; (1'm3) MEDILL, 125, CLARK

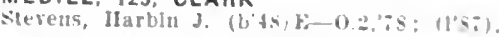
MEHLVILLE (R.F.D., ST. LOUIS), 300. ST. LOUIS

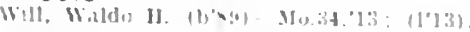

MEMPHIS, 1.984, SCOTLAND

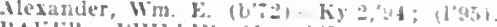

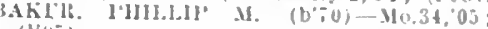
(T0i).

Botulurant, Wm, k. H. (boj)-Mo.1, sj (I's s).

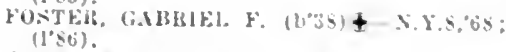

Gliens, Frank-1a.1,:3; (l's:

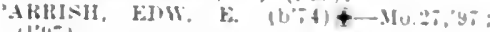
$(197)$.

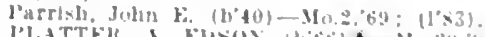

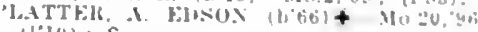
(1०10); $\mathbf{S}$

(1THKT, IIKMMN (b\%5) - U.9, $\left(l^{\prime} y_{i}\right)$ : Nemler III. Siare Ved. Ninc.

Skidmore, Jemse 1) (b"36)-Mu. 1, st: (j'ss).

Vinger, Ios. 11. (19:36)-125:93; (1'95).

MENDON, 408. CHARITON

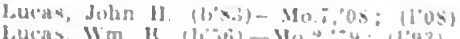

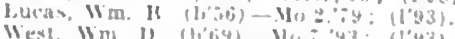

MENDOTA. 400 , PUTNAM

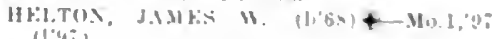
(1"yi).

MENFRO. - PERRY

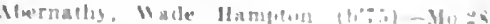

"U:i: (1'13).

MERCER, 533. MERCER

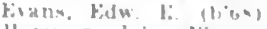

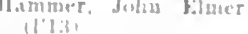

MERWIN. 195. BATES

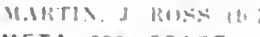

META. 399. OSAGE

J6IIUIIHIR JUI?

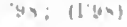

METZ. 240. VERNON

M.THIAU, I (, (1:?')

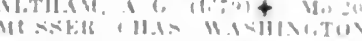

$u_{11}+1+11021$. 
MEXICO, 5.939, AUDRAIN

Aams, Simpon l'. (b'52)-Ky t's0; (l'sio)

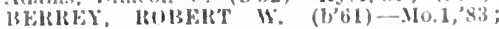

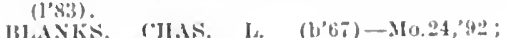
(1':2): OALR

Brldeford, Fumett Itel), (1,65)-Mo., :s: ; (1'\$9).

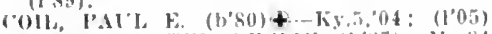

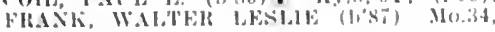
12: (1'1, 2$)$

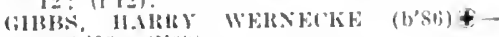

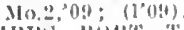

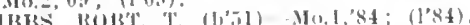

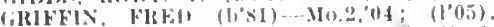

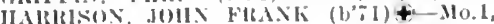
:48; (1,98)

Ilawkilus, Jos, ls (6'38) - o: (I'83)

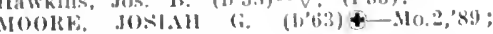
$\left(I^{*} 8.2\right) ; \mathrm{S} . *$

taehels, diames Jiarrlson (col.) (b’a)T(1)11. $,, 08:\left(l^{\prime} 08\right)$

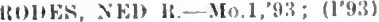

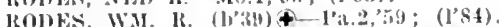
(b'b6)-Mo.1 (4) (1.91)

STRONF, ROHST. C-Mo.2, 05 ; (1'05)

TAYIAll. W.M. F. (b'48)-Mo.1,7\%; (1'84) TOAIAON, GEORGE F. (b'65) $4-M 0.1,88$;

(l's8). Theodore 11. (b'53) If-111,10,'88;
Whans, The (l'x8).

WREN, JAMES A. (1,"76)-Mo.?8,01; (1'0J).

MIAMI, 43I, SALINE

Cirady, JIenry D. (b"56)-IFo.3,80, X.X.10, $81 ;(1.83)$

sullivau, Jigermon H. IE. (b'84)-DEo.34,04 $\left(l^{0} 05\right)$.

Sullivan, Amos 11. W. (b' 41$)-1 a .1,71$, II0.27,97; (1'84); S.

Sulllvan, Francls $k$. If. $(6,72)-\$ 10.27,98$

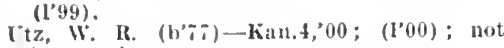
ii urictice.

Wheeler, Imos A. (h'42)-N.Y.10,'68; (む)

MIDDLETOWN, 323, MONTGOMERY

FORE, IERMAN W.-NO.28,07; (1'07)

Miller, Ira A. (1)'78)-Mo.28,0.; (1'05).

Higg, Chas, II (h'51)-Mo.10,78, Mo.7,'88 (I'83).

MILAN. 2,191, SULLIVAN

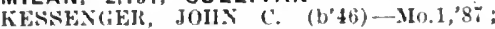
(l'8\%)

Mackey, ('has. A (b'fs)-Mo.28,02; (1'02)

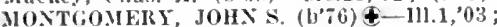
(1'03).

POOLE, ALFIED R. (1,78)†-Ky.1,04; (1'05)

PORTER, EMEIROA 95: (1'98) ; S.

WITTER, WI. L. M. $\oplus-$ Mo.1,'86; (1'83).

MILFORD, I25, BARTON

DI'('KETT, CIAIDDE F. (b'8li)-Mo.20, 09 ; (l'09).

DICKFTT, TIIOMAS I1. (b'54)-3I0.8, 89 ; (l'89)

MILLER. 343, LAWRENCE

Burney, Wallace S. (b'78)-Mo.28,03;

(I'03). Leinuel 1. (b'82) - Ky.2.'10

Holmes,

powley, (harles l'. (b'o9) - Ark.1,'81

(1'84)

MILLERSBURG, 87, CALLAWAY

Ours, B. F. I'.-0.2,'82; (l'84).

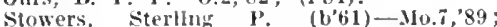
(1'03).

MILLERSVILLE, 99, CAPE GIRARDEAU

MEABALGIF, 1)ATON I. L. (b'82)-\$O.28,

0.5 : $\left(\mathrm{l}^{\prime} 05\right)$

MILL GROVE, 252, MERCER

ILLIAXAX, CIAI ELI (b'89)\&-Mo.28, '11; (1'11).

oyler, Harry W. (b'78)-Ia.10,0:?: (l'01). l'addock, Edw, k. (b'65)-Mo.8,95; (1'95)

MILL SPRING, 225, WAYNE

OWFAs, IIIC1I.1RI) J. (b"52) \&-Tenn.6,'90 (1'bii).

MILLVILLE (R.F.D.. RICHMOND), I10, RAY

Etherton. Wm, (c. (h'ti )-Pa.2.90; (1'86)

koherts, rames I. Mo.s, 02 ; (192)
MILO, 128, VERNON

MEITIIL, FIILES JASTER (b'73) $\mathbf{t}$ II $(2,2,1) ; ;(1,05)$.

MINDENMINES, 59I, BARTON

liish. lieu. J. l'. (b'iti)-MI).28, 01 ; (l'01).

MINE LAMOTTE, 400, MADISON

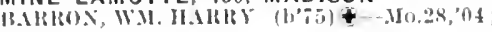
(l')l).

MINEOLA, 128, MONTGOMERY

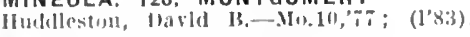

MIRABILE, 250, CALDWELL

I'rescion, dirian 1i, (b'4i)-0.2,'Ts; (1'83)

MISSOURI CITY, 559, CLAY

Hrenthuger, Leland Groty Mo.8."04:

llenshaw, saml. J.-Mo.30,05; (I00)

WYSON(x, WI. 1. (b'71)-Mo.20,9s; (l'01).

MOBERLY, 10,923, RANDOLPH

ASH, DT"PIS ORIILLE (b'15\%)-Mo.24,"92, .1o.2,'93; (1'92) ; 816 s. WHllams st. ; oflloe, $2032 / 2$ Iteed st.; 9-12, 3-4.

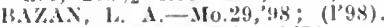

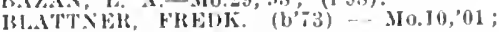
(101); 827 s. Whlllams st. ; ottlce, Ratzer 13lak.; $8-3: 30, \quad 1-3,7-8 ; \mathbf{S}$

Blatner Loulsa Eastham (b'b1)-Mo.10. 34; (3) ; $511 \mathrm{~W}$. Hollins st. ; offlce, $323 \frac{1}{2}$ lieed St.; ; $3-5$

Campbell, koscoe C. (b's0)-Neb.5,04; (1'12); 1225 Buchanim St.; offlee, $4001 \frac{1}{2}$ keel st. ; $10-1.2,2-4,7-8$

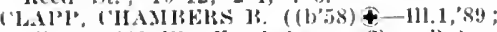
(l'91); 3 if Woolland Ive.; oftlee, Ratzer Bld $5 . ; 2-5 ;$ S. $\star$

Cotthgham, Thomas A. (1'5I)-MIo.1,80 ; (I'84); 613 II. Coates st.; offlee, 3191/2 Reed st.; $10-12,2-5,7-8$.

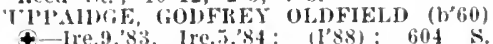

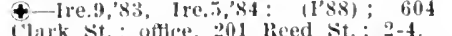

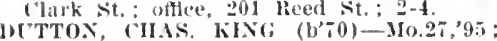

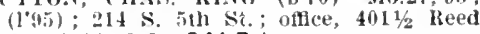
Sit. ; 9-12, 2-5; OALR, *

Enulk, Wm, L. lí.1, '70; (1'92); $2031 / 2$ Reed st.

Ficklin, Frauk Baker $\left(b^{\prime} 87\right)-M o .34,13$ : (l'13); f08 $\mathrm{s}$. 4 th $\mathrm{st}$.

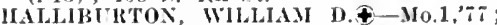
(1'84) ; $625 \mathrm{~s}$. Willlams St.; offlee, $109 \mathrm{E}$. contes st. : $1-3,7-8 ;$ Pd.

Ilarlan, Ira Finley (b'71)-Mo.28,'97; $(199) ; 409$ Rollins St.; office, 401 Beed St. : $8-5$.

HCKERSON, EDWIS R. (bo2)థ-M0.2, '85; (1'85); $315 \mathrm{~s}$. Williams St.; offlee, $2181 / 2$ Reed St. ; 2-4, $7-8$.

Irwln, Thomas (b'45)-Mo.2,73; (1'33) : 319 Grand Ave, : offlce, Reed and Clark Sts. $9-12,1-4, \quad ;-9$

Jenkins, Wm. J. (b'78)-Ill.38,'91; not in practice; $213 \frac{1}{2}$ W. Reed St.

kelly, sidney 'T-H-Ill.4,91; (l'91) ; 413 Reed St.; $8-9,1-3,7-8$.

Levlck, Geo. G.-Mo.24,87; (1'8i). LYTER, I. CLITIS (b's2)\$-11o.34,07;

Maddox, Jesse (b'78)-Mo.20,07; (1'06): 529 Taylor St.; offee, $2031 / 2$ Reed St. $9-11,2-4,7-8$.

Magulre, Mlchael los. (b'83)-Mo.34,'13; (1'13); Wabash Hospital.

Mangus, Chas. W. (b'(00)-Mo. T,'91; (l'91) 801 Reed St.; offlee, $419 \frac{1 / 2}{2}$ Reed St. $10-12,2: 30-5,7-8$.

Mangus, Taylor 0.-XIo.27,'96; (1'96).

MEGEE, W. K.-Mo.2,'84; (1'89); $3121 / 2$ Reed St.

Paey, James S. (eol.)-Tenn.7.'93; (1'93).

Selby, Wm. H. (1)'4)-Mo.1,99; (1'99)

SHRADER, FUCENE WESLEY (b',3)

Io.1,95; (1'95) ; 318 Epperson St. ; offee $3121 / 2$ Reed St. : I0-12, 2-4, $7-8$.

Sireetor, Roderiek Dhu (b'82)-IIo.34,'10 (l'10); Wabash Railroad Hospital.

TOWLES, STOKIX P. (b'it)-Ia.1,'98; (l'98); $2201 / 2$ Reed St.

MODENA (R.F.D., MILL GROVE), III, MERCER (1)39).

\section{MOKANE, 646, CALLAWAY}

NICHOLS, CHAS. B. (b'69)-Mo.28,'06; (1'06).

Parmer, .Tohn Elrin (b'69)-310.3,'94; (1'95)

WILLIAISON, WM. HARVEY (b'-6)-Ky.1 $33 ;(1,00)$
MOLINO, 35, AUDRAIN

Flynt, Jos. F. (b'68)-Mo.27,'92, Mo.1,99; (1':2).

MONETT, 4,177, BARRY

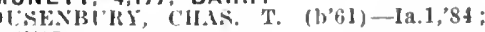
$(1,85)$.

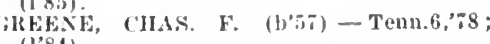
(I'84)

MWKINS, ALFX.NDEK STEIHEXS (b'51) $+-11 \mathrm{~d} .3,79 ;(1,84)$

Jones, Ara (1,6i)-Ky.1,92; (1"01).

MIILEI, JAVII) ELLIS (b'66)-Ky.1,97:

RI'NARIL, MAMES M. $(1,67) \oplus-0.3,92$; (1'92).

RIULHBWEK, MHTON R. $\left(b^{\prime} 50\right)+-0$ :

WEST, WM. MOORE (b'73) \$-Mo.24,98; (1'98) ; S.

MONPOE CITY, 1,949, MONROE

(i)ODIEK, ROBT. H. (b'61)£-\$IO.1,83; (1'83).

GYILFORD, EDGAR WM. (b'2) †-I'a.12, $00 ;(1.09) ; \mathrm{Pr}$

IIarwood, W: S. $\rightarrow$; (1'83)

Maddox, Shelvy-0.2,'S1; (1'83).

McNUTT, WM. B. A. (b'50)-Mo.2,75; (1'83).

Iloore, Francls Marion-Ill.1,'76, Mo.8,79; (l'84).

Southern, John N. (b'71) - Mo.20,'95; (1'6.5).

Turner, Geo. L.-III.1,80; (1'83).

MONTEER, 125, SHANNON

Wriglit, Clias. A. (b'69)-Mo.1.'99; (l'99)

MONTEVALLO, 146, VERNON

MOOLE, WI. A. (b':2)-MI0.41, 00 ; (1'00).

MONTGOMERY CITY, I.789, MONTGOM-

ERY
IIUDSON, DAYID 0.-Mo.1,79: (1'84)

MLNS, (IEO. E. (1, 56$)-$ Mo.3, ; 80 ; (1'84)

NoWlix, IDAVIl $(1,66) \notin-30.2,90$ : (1'90).

Stephens, dieo. W'-Mo.7,'83: (1'84).

TINSLEY, ELISHA WIITTES (b'66) Ку. 5,'89; (1'89).

MONTICELLO, 283, LEWIS

KNIGHT, GEO. P. (b'53)-Ia.1,76; (1'84).

lllliard, Arehie H. (b'76)-Ga.9,11; ( ).

Marehand, John B. (b'42)-Ia.1,'82; (1'83).

MONTREAL, 75, CAMDEN

C'larke, W:n. J. (b'56)-Mo.20,'90; (1'90).

MONTROSE, 667, HENRY

l3EIR1KY, GEO. W. (b'69) $\odot-$ Mo.32,'03;

FEWEL, RJCHARD B. (b'5i) \-Mo.1,81; (1'84).

MILLER, JAMES M. (b'63) A-Mo.8,'86; (I'86).

MDORESVILLE, 205, LIVINGSTON

PATTON, CHAS. W.-IIO.8,'88; (l'88)

MOREHOUSE, 1,636, NEW MADRID

Bell, Janadius Baker (b'66) - Ify.1,98; $\left(1^{\prime} 00\right)$.

DUNCAN, BURWELL A. $\left(b^{\prime} 35\right) \oplus-$ S.C.1. 57 ; (l'05).

MeKInney, Jos. Jefferson (b'-1)-Mo.7.09; (1.09).

MORLEY, 494, SCOTT

Harris, Clarence D.-Mo.1,'95; (]'95).

Moulder, Thos. Y. (b'73)-Mo.20,98; (I'98).

TATE PRENTISS $S . \quad\left(b^{\prime} T i\right)-M 0.34,02$; (1'0i).

TOMLINSON, THOS. E. (b'57)-Tenn.6,78; ''84)

Tomlinson, Wm. David-Mo.28,'93; (1'9?).

Trisler, J. W. (b'61)-Pa.2,'84; (1'07).

MORRISON, 257, GASCONADE

CAUGIIELL, FRANK H. (b'€l)-Mo.20,'83 ; $\left(1^{\prime} 85\right)$.

Cook, Isaac Gladstone (b'-3) - Mo.7,11; (1'11).

MORRISVILLE, 360 , POLK

viller, I. W. 0 ; (1'83)

MILLER, WM. FLEXY (b'83)-Mo.28,09;

PARIS, RICHARD WESLEY - M0.7,'85; ('s3) 
MOSCOW MILLS, 395, LINCOLN

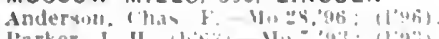

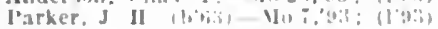

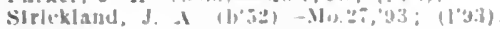

MOSELLE, I 48 , FRANKLIN

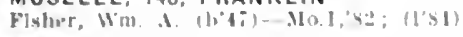

MOUNO CITY, 1.575. HOLT

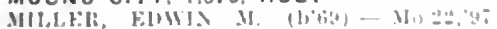
$\left(l^{\prime}, 4, x\right)$.

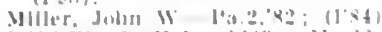

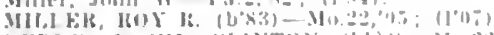

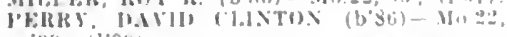
'04: (1.09).

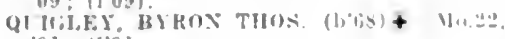
Q1: (1)

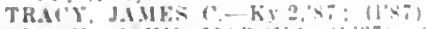

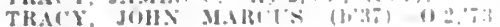
(1'si): $0 p$

MOUNDVILLE, 247, VERNON

FARIRINGTUS, U)WE. I". (b'tin)--.16).27., Pa.2,"95; (1'02).

MOUNTAIN GROVE, 1,722, WRIGHT

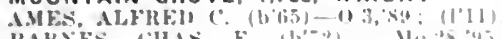

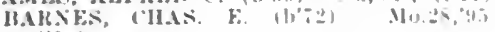
(1 95$)$

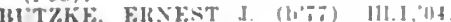

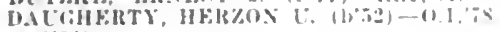

(1) 81 .

England, Cornellus II. (1, t2) $\mathbf{k}-0$. not in practice.

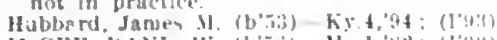

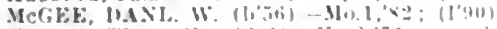

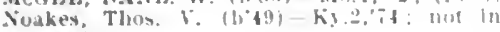
practice.

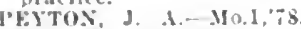

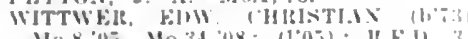

MOUNTAIN VIEW, 552, HOWELL

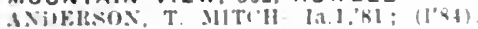

Bickel, James T. (b'2)-Mo.20,01: (1'01)

Ferguson. A. Marion III.1,10; 1196).

Fergusen Ellobell -1119.90. ()

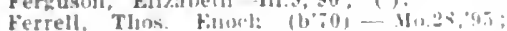
(1'95) : ALR

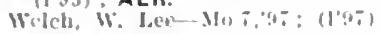

MT. AIRY (R.F.D., CLIFTON HILL), 30. RANDOLPH

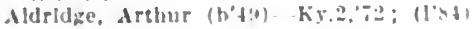

MT, LEONARD, 200, SALINE

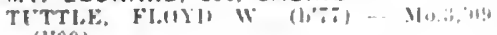
(1009).

\section{MT, MORIAH, 350, HARRISON}

Mnne. Albert A. (b'it) Yo.22,

P'RICE, J. T. - IO.10,'05; (1'05)

Sellers, Chas, J. (b'if)-Mo.10:9.5; (1"95).

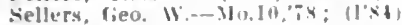

MT, VERNON, I, $16 !$, LAWRENCE

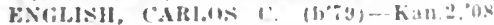
$\left(I^{\prime}(08)\right.$.

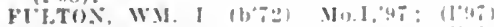

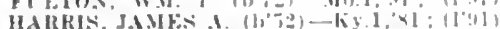

HAlRIS: II,

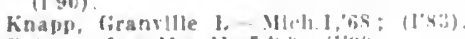

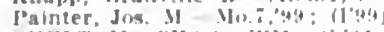

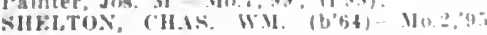
(1.95).

\section{MT, WASHINGTON, 150, JACKSON}

("uil. Emily :

(Sice Kunsay Clty)

rillinor. Win. I.

lave Kanvas (IRy.)

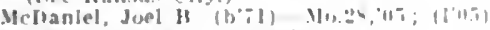

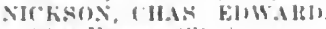

URRY (R.F.D., COLUMBIA), 56, BOONE

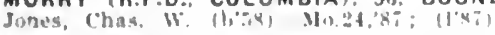

MYSTIC (R.F.D., GREEN CITY), 13, SUL

LIVAN

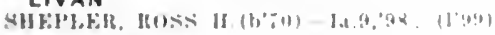

NAPOLEON, 146. LAFAYETTE

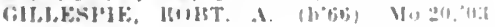
(1) (cit)

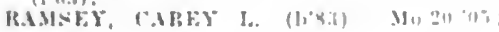
(I,0j).

NAPTON, I30, SALINE

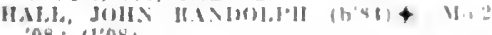

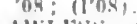

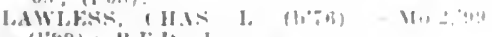

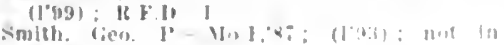
pravilice.
NASHUA, 25, CLAY

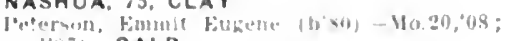
(I'11); OALR.

NAUVOO, 50, STONE

I.aW Pello", T It

NAYLOR, 406, RIPLEY

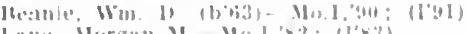

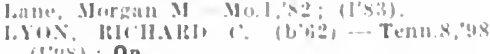

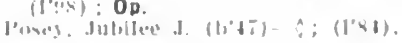

NEBO, 25, LACLEDE

Harlley, Lorenzo lhow (b'63)-.110.1,'85; $\mid 1 \times 3)$

NECK, 528, JASPER

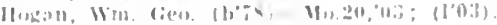

NEELYVILLE, 241, BUTLER

l'owell, Lyon H. (b'65)-Ky,2,30; (1'93),

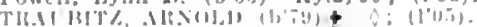

NE_SON, 480, SALINE

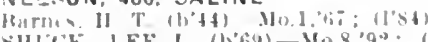

SIITK, LEK I. (1,69)-Mo.8,92: (l'92).

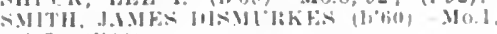
ini: (l'si)

\section{NELSONVILLE, 21, MARION}

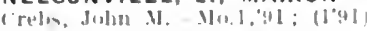

NEOSHO, 3.66I, NEWTON

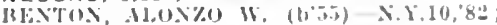
(I'84).

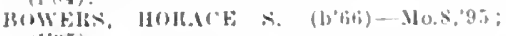
$(1,9.5)$

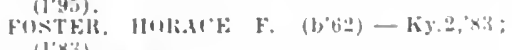
(1'x3')

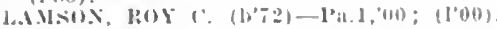

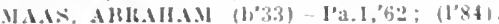

M!lls, Ellza If. Burch $\left(b^{\prime} 49\right)-1 \mathrm{a}, 1,81$; not in practice: 11 F́.J1.

Mlis, fieo, Mortlmer $(1,4 x)-111.1,83$; not in practive; R.J.J.

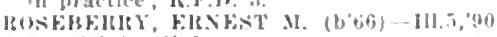
in: 26,04; (1'01).

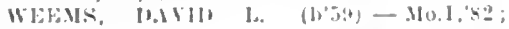

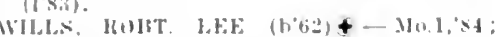
(1') i).

NEVADA, 7,176, VERNON

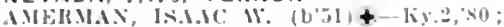

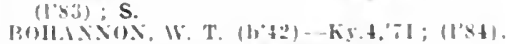

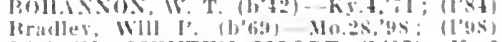

BROWX, QLINTEX MOORE (b'si)-Ky.2. ,11; (1'll); Member Ky stare Mell. Assu.

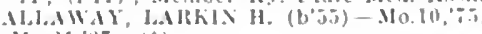

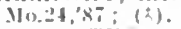

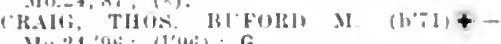
M1..2t.?ni ; (1"m(i); G.

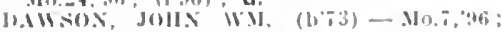
(1) (1)(i).

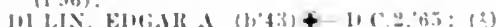

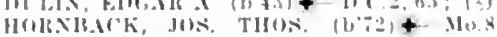
"4ti; (1'9(i)) : OALR.

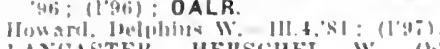

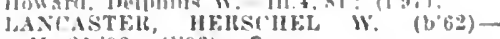
Ilo.21,92: (1'92);G.

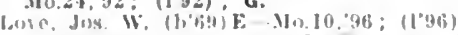

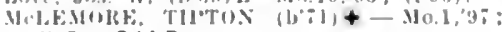
$(1+4)$ : OALR.

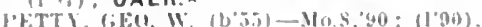

130131.

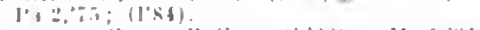

Simache ("has. Balley (b'bil) - Mo.1.'St: (1'st).

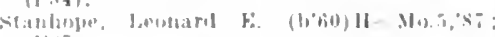
$(1 \div \div)$

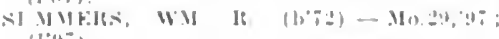
$(1,4)+2$

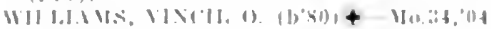
11 'n 1

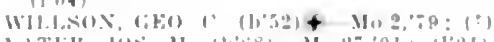

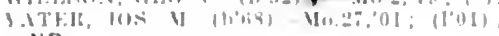
NP.

NEWARK, 217, KNOX

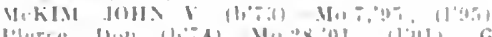

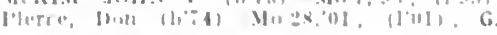

NEW BLOOMFIELO, 300, CALLAWAY

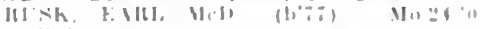

(1) in 10

II ik. Jull

$(1,7,+1)+$

$11, \ldots=2,3$

NEW HOSTON, 100, LINN

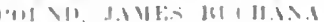

NEWBURG, 932, PHELPS

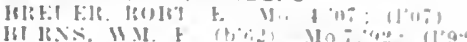

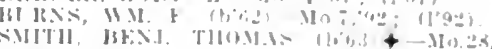

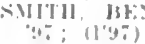

NEW CAMBRIA, 387, MACON

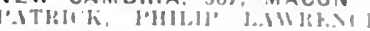

Y.) $2102:$, 1111

WH.ST, IIIN,

NEW FLORENCE, \$24, MONTGOMERY

IIn)

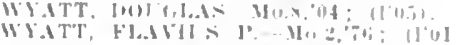

NEW FRANKLIN, 794, HOWARD

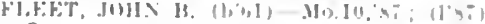

G

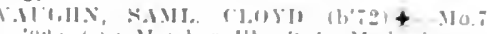

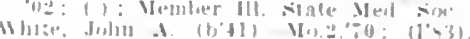

NEW HAMBURG, 120, SCOTT

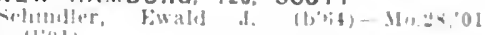
(1")1).

NEW HAMPTON, 456, HARRISON

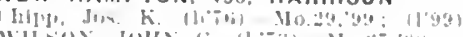

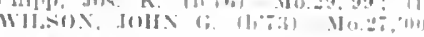

NEW HARTFORO, 75. PIKE

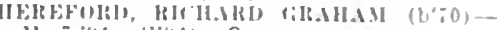

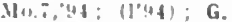

NEW HAVEN, 855, FRANKLIN

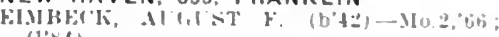
$(1, x i)$.

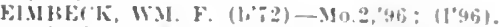

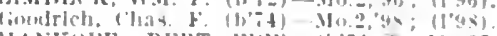

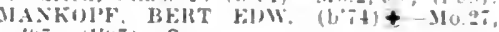

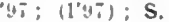

NEW LONDON, 942, RALLS

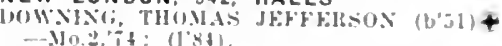
Hendrlx, John llbitley (6\%3)-116.25

IIFIIKIX, WHITLE GKAY (b't?)-1a.1, i1: $(1,5: 3)$.

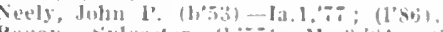

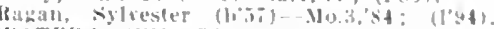

ITElis, WM. THU.MIS(I.) (b'bs)-I11.1. "96; ; (1'Y7)

NEW MADRID, 1,882, NEW MADRID

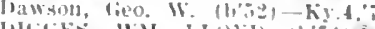

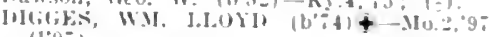
$(1,1)$

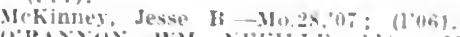

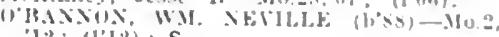
12: 11 12): $\mathrm{S}$.

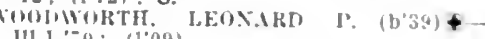
I11.1,70: (1009).

NEW MELLE, 250, ST, CHARLES

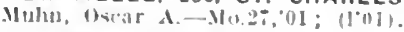

NEW POINT, 100. HOLT

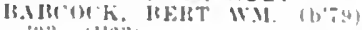

arion (1) sistant lohystelan.

NEWTONIA, 293. NEWTON

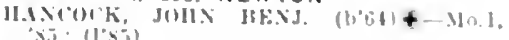

NEWTOWN, 261, SULLIVAN

Yalrs, Wm. J ky t, in: (l000)

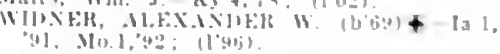

NIANGUA, 250, WEBSTER

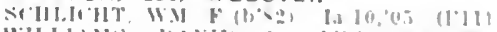

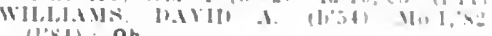
(1):H): 0 b.

NICKELLTON, 37, MACON

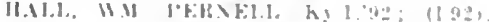

NIXA, 276, CHRISTIAN

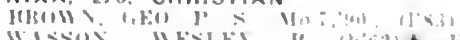

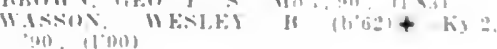

NOIILE, 30, OZARK

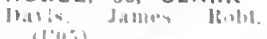

NOEL. 300. MIDONALD

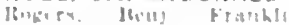

NORBORNE. 1.241, CARROLL

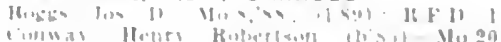

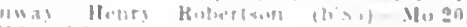

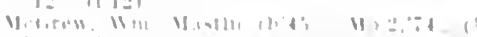

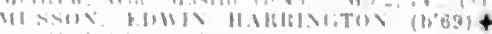


STIRONG, BENJ. F. $\left(b^{\prime} 61\right)-111.1, ?$ : 6 ; (1"03): OALR.

Tluompson, linbl. J. (b'4j)-Ky,1,70: (l'st) NORTH KANSAS CITY, —, CLAY

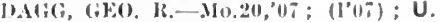

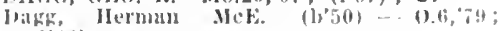

$$
\text { (I'R8). }
$$

NORTH SALEM, 100 , LINN

Nevlus, ,ames $A$. (b'64) Mn.2S, NORTHVIEW, 78, WEBSTER

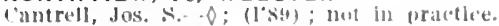
NORWOOD, 250, WRIGHT

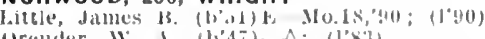

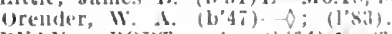

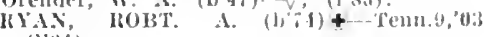
(1'(14).

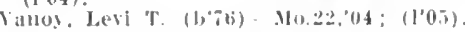

NOVELTY, 232, KNOX

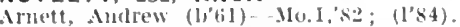

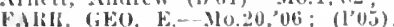

Mellillams, Join A.-Ja.l,'sL; (1's:i).

NOVINGER, 1.711, ADAIR

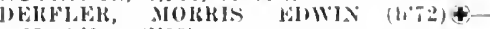

II $0.2,{ }^{\prime} 0 y^{\prime} ;\left(l^{\prime} 09\right)$.

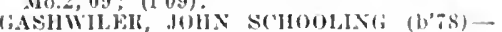
Mo.32,00; $(1,00)$.

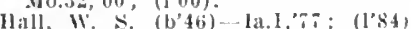

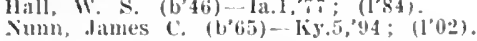

OAK GROVE, 641, JACKSON

MAN, NBXEl W. (b.52)-MU.1,8:" (1'83)

Perry, Elmer k.- Mo.s, 'y2: (l'44)

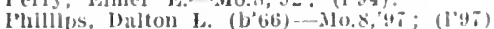

OAK HILL, I00, CRAWFORD

Tiebster, Darld P. (b'48) E-Mo.10,'80; (1's $O$ )

OAK RIDGE, 256, CAPE GIRARDEAU

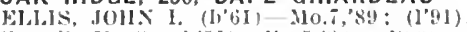

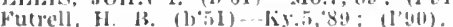

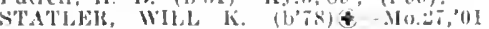
(I'0I).

OAKWOOD, 450, MARION

liuy, Luke l'axton (b's0) - Ial. 10, '0: ; (I'04) ODESSA, 1,531, LAFAYETTE

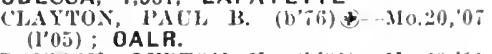

DAWSOX, LERTON $Y$. (b'S1)-N10.20,'11

(I'II); Pr

Goodwln, Wm. C.-Pa.2,33; (l's(i).

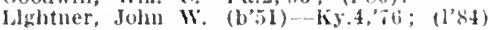
MACKEY, JUHN F. (b*6) (l, 05$)$.

Milllams, Henry (b'55)-Mo.1,'84; (l's4).

OERMANN, 50, JEFFERSON

Torbit\%ky, Joln E. (b'67)-Mo.2,'40; (l'90)

O'FALLON, 475, ST. CHARLES

Whrels, Leo C: (b's0)-Mo.34,0s; (l'0s).

fidwards, Jolin (C. (b'32) - Va.1, 53

(l'84).

Cilosemeyer, Louls II. (b'72)-Mo:\$4,"97 (1'97).

OHIO, 20, ST. CLAIR

Taylor, Vim. Edw.-Mo.27,94; (1'94)

OLD MONROE, 25I, LINCOLN

('ampbell, Danl. 13.-Mo.2,'73; (1'8:)

lidwards, Brice-Mo.1,'83; (l'91).

OLD ORCHARD (ST. LOUIS P.O.), - ST,

LOUIS

MOSBY, (H.AS. $V$

(see st. Jouis.)

OLEAN, 2I4. MILLER

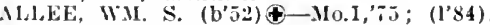

OLNEY, I30, LINCOLN

Iosely, ('has. G.-Mo.I,'86; (l'86).

Nortlicutt, w. L. $\rightarrow$; (I'83).

ORAN, I,023, SCOTT

Baker, Elliert (b's!)-Mo.34,'12; (1'12). CLINE, JESSE ANDREW'S (b'81)-Ky.9,

IIarrls, Wm. E. (b,54)-Tenn.6,82; (1'84).

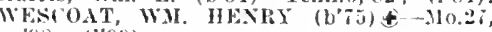

Winters, Hiram s.-...10.7,"49; (1'94)

OREGON, I,002, HOLT

EYASE, (IIESTER 1. (b'T)-110.18, 82 : ( 1.84 )

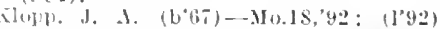

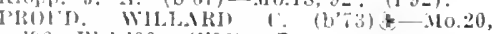
THATCHER, JOHN ; T. (b'50)-Jich,3,

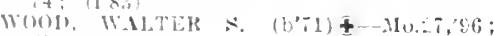

ORLA, 15, LACLEDE

ORLA, 15, LACLEOE W. (b,75)-M11,34,05 $\left(l^{\prime} 05\right)$.

ORONOGO, 1,912, JASPER

Jarson, John Willam (b'62)-Ky.2,"198 (I'9s) ; S.

lilrkham, Archloald-Mo.32,04; (l'05).

o'Brleu, Jumes J-Ia.J0, 00 : (l'00).

ORRICK, 435, RAY

Ashley, Thos. I. (b'65)-Ky.I.92; (l'y2)

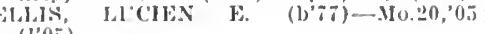
(l'05)

SIIETY, ROIST, C.\$-Mo.7,90; (1'90).

OSAGE CITY, 220, COLE

SON, EIDWIN HOIST. (b'6i)-Mo.24, 94 (1'94)

OSBORN, 360, DEKALB

(ALE, WM. S. (b'73) \& Mo.2S,05; (3'05)

Metealf, W. A.-ky,1,76; (l's4).

shafer, Frank M. (b'76)-Mo.20,0I; (l’0I)

OSCAR, 7, TEXAS

MIJBRIDE, 0. C (b'73)-Mo.28,99; (l'99)

OSCEOLA, I,II4, SAINT CLAIR

Rell. Wm. W. (b'4i)-MIO.I, 80 : (l'84)

Dalgliesh, Geo. D. (b'65) -Mo.20,'90; (l'90)

severs, kuth (b's3) - No.3,06; (1'06)

s.IITI, ('IAs. A. (b'74) $\$$ ' Mo.7,99 (1"(99)

Sullivan, F. Watson $\left(b^{\prime} 72\right)-k y .2,95$;

Vard, Alonzo clinton (b'56)- $\rightarrow$; (

OSGOOD, 204, SULLIVAN

Bowers, IIarrey E. (b'76)-Mo.20,00

Veston, I'rsa C. (b'85)-No.20, "I0; (1'10)

OTTERVILLE，453， COOPER

FOGLE, ROBT. L. (b' (1003).

FIION, ABRAHAM MINCOLN (b'6t) Mo.24,'93; (1'95).

OVERLAND, 800 , ST, LOUIS

Holden, Wm. A.-E-Mo.10,99; (1'99); not

Merwin, (ieo. Mittlin Dillits (b'44)-Mo.21, PUाती (1) (I'9I).

OWENSVILLE, 677, GASCONADE

Bridges, Jolnn H. (b'tii)-Mo.7, 05 ; (l'05)

FERRELL, JOHL J (b'6.5)-Mo.', (l'\&9)

JOSE, JAMES E. (b'73)-Mo.24,96; (196)

Natthews, $N$,,$-\infty ;\left(l^{\prime} 84\right)$.

Mellies, Edw. (b'十)-Mo.5."93; (l'93).

OXLY, 200, RIPLEY

Hasslen, C. R. (b'4l)- 0 ; (1'99).

OZARIK, 8I3, CHRISTIAN

BRUTON, J.MIES WM. (b'69)-Mo.28,'93 (1'93); OALR.

Hedrpeth, I). F-Mo.I,'s8; (I'89;

ROBERTSON, JAMES ANTHONY (b'76) MIO.1,98: (I'98).

PACIFIC, 1,418 , FRANKLIN

BOOTH, BOOTH, H ALLEN (b'57) - Mo.1,'86, Le Saulnler, Fdward Baumlott $\left(b^{*}, 5\right)-$ Mo.28,'I0; (羊).

MCNAY, ALBERT I.A-Mo.2s.'97: (1'97). Sargent, Jesse $\$$. (b'67)-Mo.5,94; (1'94)

Smith, Wm. E.-Wo.10,'92; (1'92).

WILLIAMS, DAVID EGAK (b'64)-Mo.28,

04: (l'04) : Pd.

PALMYRA, 2,168, MARION

Coons, James $N$.' (b'29)-Ia.1,'57, Mo.2.'68; (l'84); not in practlee.

GIAHN, CIIRISTIAN $1 . \quad\left(b^{\prime} 74\right) \notin-I I o .2$, 02; (l'01).

Jaudon, Benj. Yeager (b'74)-N.Y.1,96;

Luckenbaugh, James E-Mo.20,01: (l'0l) RONELLE, THOMAS A. $\left(\mathrm{b}^{\prime} 76\right) \uparrow-\mathrm{Ky} .5,03$;

(l'03).
SANFORD, SILAS $\left(\mathrm{b}^{\prime} 59\right)-\mathrm{N} . \mathrm{Y}^{\prime} 10,{ }^{\prime} \mathrm{S} 6$; NFOR

Stone, Archibald Rcdd (b'8\%)-Mo.2,09; (l'09).

WOON. MALCOLM LATIMER (b'61)-Ky.I, 92; (1'92).

PALOPINTO (R.F.D., LINCOLN), 20, BENTON

Greeson, Geo. A. (b'sl) - Mo.1,\$2, Pa.2 89 ; (1'8.1).

PARADISE (R.F.D., SMITHVILLE), 100 , CLAY

Rupe, James F.-Mo.22,'S6; (l'92).
PARIS, 1.474, MONROE

LELSLEY, MAIRIN EUGENE (b'74)IIo.2,0I; (1'0I).

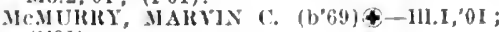
$\left(1^{\prime} 01\right)$.

MOSS, FRED M. (- -hy,1,81; (す).

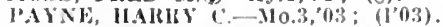

HAGSDALF, GEO. MOSS (b'85)-Ky.5,07; $\left(l^{\prime} 07\right)$.

PARKVILLE, 765, PLATTE

FOIRD, SAII I'.-Ind.5, 00 ; $\left(1^{\prime} 0{ }^{\circ}\right)$

UNDEKWOOD, JOHSSON (b'64)-Mo.8, '91: (1'95).

WINTER, JAMES II. (b'-1) \&-111.10,96 ; (1'96); Op.

PARMA, 905, NEW MADRID

BI.ACKMAN, CHAS. S. (b'69) $₫-M 0.27,97$; (l'05).

Llenhardt, Howard Orville (b’8i)--Mo.34, 12; (1'13).

MALLETTE, LESTER TAYLOR AJLEN (b'86) - KY.2,'10; (I'I0).

PARNELL, 438, NODAWAY CROWSON, EGBEIT (b'71)-Mo.29, 03 ;

DAY, IIIRAM-Mo.22,92; (1'92).

PASCOLA, 128, PEMISCOT

Johnson, Urlah Ifenry (b'48)-Mo.7,'91 (1'91)

wells, Chas. A.-Mo.27,'99; (1'99).

PATTON, 152, BOLLINGER

O'Kelley, Henry Thomas (b'85)-Mo.28,'I0 ; (l'10).

Thos. K. $\rightarrow$ : (t)

PATTONSBURG, 1,044, DAVIESS

DUNHAI, J. D, (b'55)-Ja.1,75; (l'83),

HED(iEs, FliNK (b'72)-Mo.22,'97, (1'97).

MCCLUNG, ANNA MAE HENRY (b;8)Minn.4.'99: (l’99).

Nigh, John Wesley (b'84) - Mo.22,'09; (1'11).

['arker, John Z. (b'79)-Mo.20,'04; (1'05).

WAGGOXEK, ELLERY IIARYEY (b'4 $\stackrel{\longrightarrow}{\longrightarrow} ;(1,84)$.

PATTONVILLE, 61, ST, LOUIS

COLENAN, HENRY T.-Mo. 2,95

PAYNESVILLE, 300, PIKE

BANKHEAJ, CHARLES L. (b'68)-Mo.2, 95 ; $(1295)$.

GUY, ROBIN JEFFERSON (b'87)-Mo.7, '10; (I'II); not in practice.

PECULIAR, 205, CASS

BHIERIY, HEX'RY A. (b'6s) - Mo.20,'95; (l'95)

Dawes, Gustave A. (b'41)—Ia.1,70; (1'83).

PEIRCE CITY, 2,043, LAWRENCE

HYNES, JOS. CHAS. (-W-No.28, 07 ; $\left(l^{\prime} 06\right)$; OALR.

Richardson, I1'm. F.-Mo.10;\%1; (1'S4).

RODMAN, WM. W. (b'54) $4-1 \mathrm{a} . \mathrm{i}, \overline{5}$;

TOOLEY, GEO. E. (b'75)-Mo.27,0I; (1'0I) ;

Nember Kan. Med. Soc

PERRIN, I 25, CLINTON

KAY, JOHN (b'69)-Mo.I8,'93; (I'93).

STLKGIS, JOHN (b'42)-Mo.8,'82; (l’85)

PERRY, 895, RALLS

BIROWN, JOHN E. (b'66)థ-Ky.5,'95; (1'97)

MENEFE, CHAS. D.- Mo.27,98; (l'98)

Suter, Robt. F.-Mo.I,'96; (1'96).

WALTER, FREDK. (b'62)Ð- Mo.1,'88; (I'88).

PERRYVILLE, 1,708, PERRY

Barks, Wm. H. '(b'76)-Mo.28,03; (l'03).

BLAYLOCK, GEO. A. (b'79)థ-Mo.28;03; (1'03).

Clark, John I.-Mo.2,'81; (1'83)

Feltz, Lawrence L. H-IIl.15;03; (1'03).

Hudson, Thos. M. (b'65)-Mo.2,'94; (1'94); Ob.

Morton, David $\mathrm{H}_{\text {. }}$ (b'58)-Mo.I,'83; (1'83).

Simpson, Henry C.-Mo.2, $74 ;\left(y^{\prime} 02\right)$

ESSELLS, FRANCIS M. $\left(b^{\prime} 74\right) \Phi-M o .1$,

PEVEL

IBARON, JLLESF-MIO.2,'81; (1'85)

Moxsl, O. E. (b'4)-Mo.34,03; (1'03) 66: (1'83)

PHELPS, 97, LAWRENCE

Dlckerson, Wm. T. $\left(\mathrm{b}^{\prime} 64\right)-M 0.27,92 ;\left(\mathrm{l}^{\prime} 92\right)$. 
PHILADELPHIA, 199. MARION

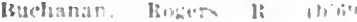

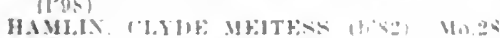
11: 180is

Rhodes, Henry $r$ (bos)-I'al

TIpton, E. F-Mo.2, M3: (1005)

PHILLIPSBURG, 100, LACLEDE

GOI'KLEL, TIIOS, I'. Ib'S'

Il'84!

PICKERING, 264, NODAWAY

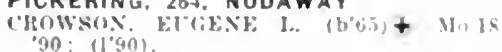

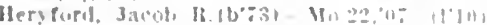

PIEDMONT, 1,15\%, WAYNE

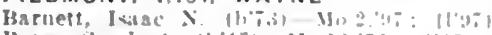

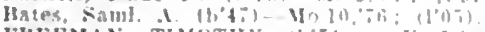

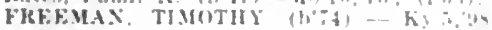

(l'9.8)

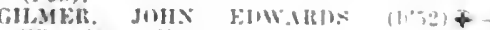

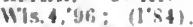

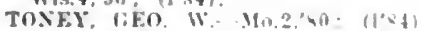

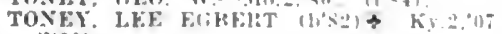
(I.09).

PILOT GROVE, 65\%, COOPER

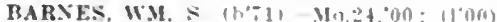

PENDIETOS, TIIOS a (1) (I'01).

TOMD, THOM.IE H. $(1,7)+-110.20,00$ (l,00).

PILOT KNOB, 445, IRON

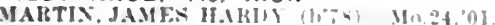

PINE, 25, RIPLEY

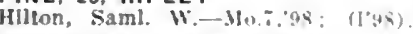

PINEVILLE, 500, MCDONALD

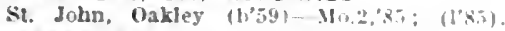

PITTSBURG, 100, HICKORY

WR1NKLE, THOS. II. (b), - M, 2:-2,: $(1 / 87)$.

PITTSVILle, 50, JOHNSON

Turabow, W: B. (h'b2)-0.2.4I: (I'In)

PLATO, 73. TEXAS

LYNCH, RAISOM B-MO.,?: (I'st)

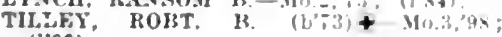

(l'99)

PLATTE CITY, 763, PLATTE

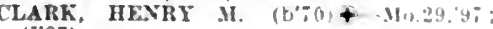
(I'97).

Hammond, Thos. C.-Pa.2,69: (1'24)

MERRAY, WILSOX-M0.20,94; 1 1.

AYLOR, IIYA-Mo.20, (15; ('n)

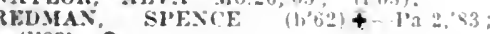
(1'83): $\mathrm{S}$.

WTISOX, HORT. I. (9. $\left.(1)^{\circ}, 76\right)-M(1,22,00$ (1'00).

PLATTSBURG, 1.650 , CLINTON

Bennett, Frank W*. (b'in) (1'0,5): OALR.

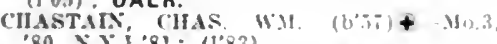
80, N.1,81: (1'93).

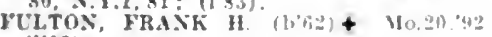
$\left(1^{\prime} 92\right)$

RE.A. ROBT. W. $\left(h^{\circ} 60\right)+M 1.80:(1 \% 5)$

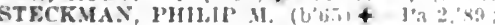
(l'89)

PLEASANT GAP, 75, BATES

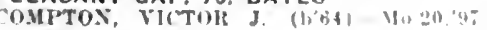
$(1,9 i)$.

PLEASANT GREEN, 68, COOPER

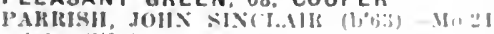
'D1: (I'BD).

PLEASANT HILL, 2.065, CASS

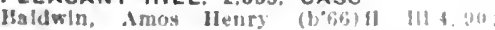
(l'90).

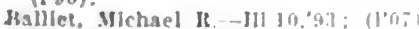

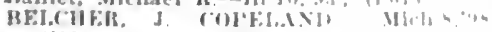
(1.01).

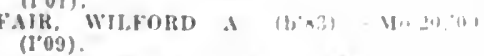

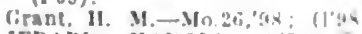

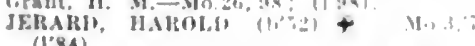

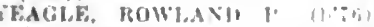

$0.5:(100)$

PLEASANT HOPE, 300. POLK

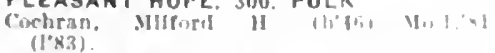

i.

PLEVNA, So, KNOX

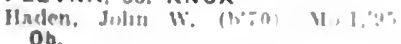

POCAHONTAS, 239, CAPE GIRARDEAU

IHLAY.OCK, MII IIALL D. - MO.24, 0 '

(I.1)3,

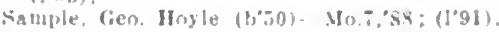

POINT PLEASANT, 99. NEW MADRID

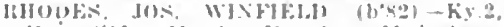

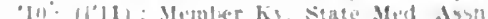

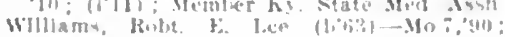
$(1 \times 90)$

POLK. 52, POLK

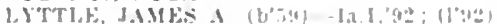

POLLOCK, 200. SULLIVAN

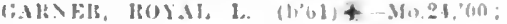
(1'0).

POLO. 526, CALOWELL

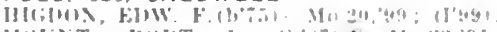

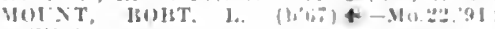
(I"9I)

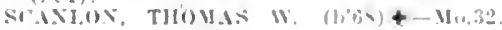
; $(1,0,5)$

POMONA, 200, HOWELL.

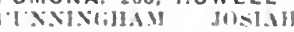

Mo.24,01; (1'01).

Falmer, (has,-Mo.28,99; (l'9;).

PONCE DE LEON, 250, STONE

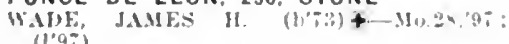

PONO (R.F.D., ST. LOUIS), 75, ST. LOUIS

Dean. Jos. Wilson-Mo.:, 97 : (1"98).

PONDER, 60, RIPLEY

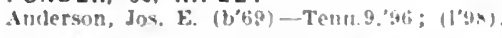

POPLAR BLUFF, 6.916. BUTLER

Bisselt, Joln A. (b51)-(0.11, 72: (1406): OALR.

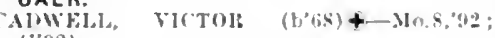

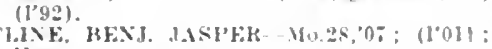
U.

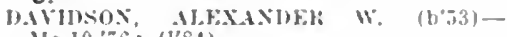
IIo. In:" is: (1'8\$).

FI.J.I, HERRHF I.FE (b'Gi) Mo.28,0I: [1"0]): $\mathbf{G}$.

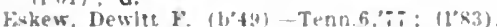

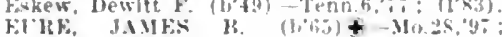

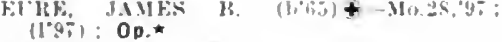

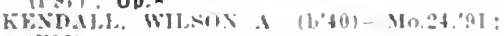

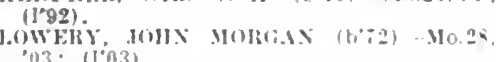
(0.3: $(103)$

MOTT. A.MES w. (1063) - Ky. 2.8ni: (1991)

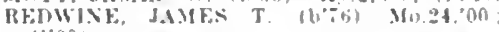

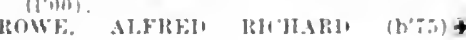

In. 34, 03 ; (1003).

ETBOLI. IRA W. $\left(10^{\prime} 69\right)+-M 14.93:$ (1.93): OALR.

smlti. James M. T. - I:a.9:s0: (1'93)

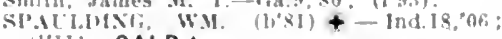
(I'II): OALR.

T.AYluk. WM. F. S $\left.(1)^{\circ}(i)\right)+-T e n n s, 92$; Militivis.

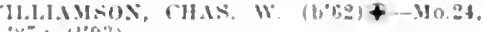

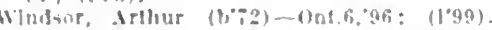

PORTAGE DES SIOUX, 218, ST. CHARLES

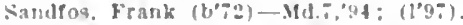

PORTAGEVILLE, 98\%, NEW MADRID

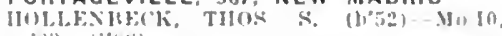

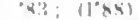

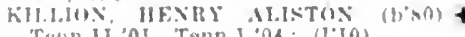

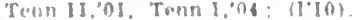

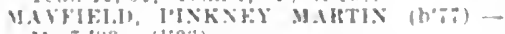
$110.7113:(1,03)$

Whills, llarry II Vuzsem: (loun)

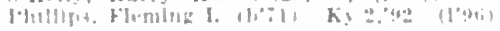

PORTLAND, 275, CALLAWAY

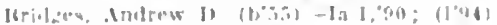

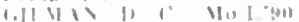

POTOSI, 772, WASHINGTON

Illonit II

$$
\mathrm{Pd} \text {. }
$$

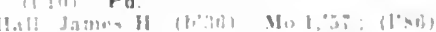

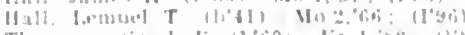

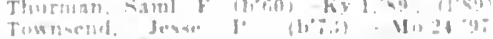
ilavi i op

POTSDAM: 2n. GIASCONADE

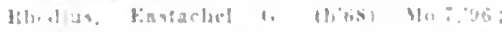

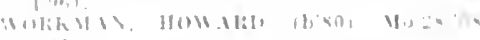

POTTERSVILLE. 3G. HOWELL

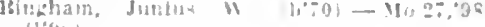
(1) $3 \times$,

n. 1 It

(1'u价

PDWERSVILLE, 500, PUTNAM

l'obad. Franelis b. (1) t'

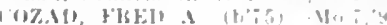

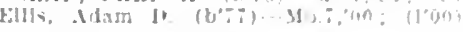

POYNOR. 75. RIPLEY

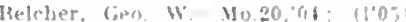

PRAIRIE CITY (R.F.D.. ROCKVILLE), 50 , BATES

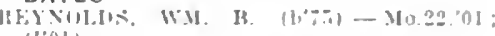
(I)(I).

PRAIRIE HILL, II3, CHARITON

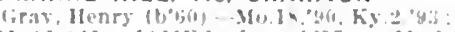

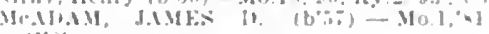
(I) $\rightarrow 4)$.

PRAIRIE HOME, 184 . COOPER

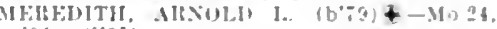
ol: $(1,0)$

folndexter, Joln wast (bjl) - Vat, 11.84).

PRINCETON, 1.385, MERCER

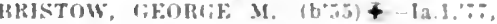

Ky.4,81: $(1,83)$

BITFX, CHIS TR (bo-2)

$(1.96):$ Pd.

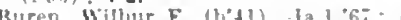

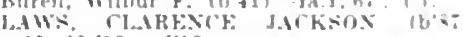

In in: 13; (I"13)

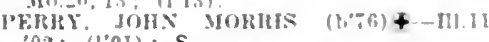
'02: (1,0I); $\mathrm{s}$.

POWFI, R. S (1075) Kant $113:(1010)$

STAFE, EMMFTT W. (b'TS (1'05).

PROSPERITY, 1.200, JASPER

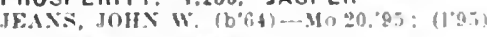

PROTEM. 150. TANEY

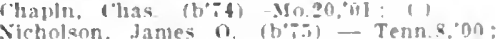

Sicholan
(I'0I).

PURCELL, 994, JASPER

Short, Leland $\mathbb{I}_{A .}-$ Mo 10.'04; (]"n.i)

PURDIN, 337. LINN

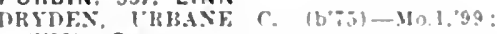
(1"9.9): 0 o.

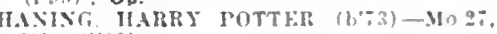
$89:(1,99)$.

PURDY, 459. BARRY

Freeland, pleasant 1 .

$11(00)$.

IIorton. Mm. Henry-30.28.97: (199)

Kelly, Benj. H. (b.69)-Tenn fi,90; 1190$)$

PUREAIR (R.F.D., NOVINGER), 20, ADAIR

Uunn, Wm. F. (b:-6)-1a.10,05; (1'0)

PUXICO, 814. STODOARD

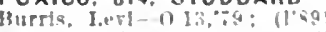

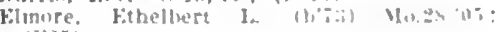
(I'i)j).

Pace, Juhn M (b's)- In i.,ng: (l'09)

PYLE (R.F.D., DEXTER), I6, STODDARD

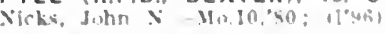

QUEEN CITY, T01. SCHUYLER

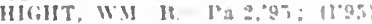

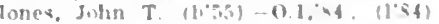

kim= dien

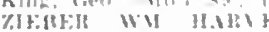

[ISS]: OALR.

QUINCY, 150. HICKORY

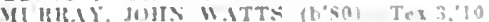
$11.1 \%$

QUITMAN, 23\%, NODAWAY

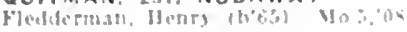

QULIN 375, BUTLER

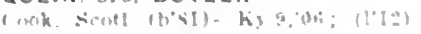

RAVANNA, 251, MERCER

LA1) TZFYHISF:R MU11)

Simifl, Sirts

RAVENWOOD, 3H, NODAWAY

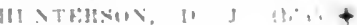

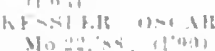

RAYMONOVILLE, 100, TEXAS

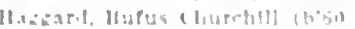


RAYMORE, 218, CASS

('HAFFIX, WEIJMAN F. (b'66)-Ia.3,90; $(1,00)$

Dean, Carler B.-0.2,'92; (1'00).

RAYTOWN (R.F.D., INDEPENDENCE), 175, JACKSON

IIORIBS, WM, WOOH (1,S1) MI).20,04 (I'05).

RAYVILLE, 239, RAY

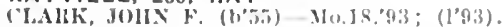

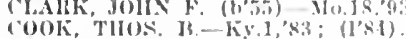

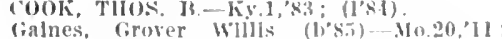
(1"11): 1R.F.I). 1.

REA, 200, ANDREW

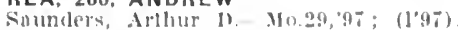

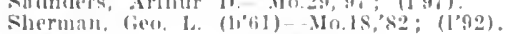

READSVILLE, 65, CALLAWAY

()berkrom. I.W. MU.'.'01: (1'01).

RED BIRD, I00, GASCONADE

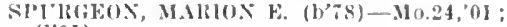
(l'0I).

REDFORD, 25. REYNOLDS

MOFFITT, JAMES IIENIUEISSON (1,4i) $\rightarrow$; (む).

REDMAN, 40, MACON

Stark, Fibin B.-O.1,'s!) (1',91)

REEDS, 298, JASPER

Boyd. Johm , Iay-Mllo.26, 01 ; (I'01)

BHAFDOS, GEO. IJEILERT (b'75) \& Tex.7,06: (1'05).

REEDS SPRING, 300, STONE

SHIMATE, L. STT. ("IAHR (1) T.9)-Mo.28, 02: (1"02).

REGAL (R.F.D., RICHMOND), I0, RAY

Cramer, Wm. H.-Mo.I,90; (1'9I).

REGER, 250, SULLIVAN

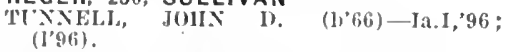

RENICK, 213, RANDOLPH

J3yam, limer ('larence (b'82)-Mo.10,'12: (1'12).

Terrlll, Wm. Robt. (I'b9)-Mo.1,96; (1'96); Pd.

REPUBLIC, 884, GREENE

Beal. Jolward l. (1)'64)-I'a.2,'88; (1'88).

CARTER, OSCAR XEWTON $\left(\mathrm{b}^{3} 74\right)$

Tenu.I 1, 99: ( I'02)

(arler, Wm. C. (b'si) -Ma.3,88; (1'94).

French, Tiysses S. (b'69)- Mo.28, 00 . (1'00).

Merlwether, Chas. W.-Mo.7,'98; ().

REVERE, 196, CLARK

ICCONXELL, JOHX L. (b'72)-Ia.1, 'G; (1'9\%).

RHINELAND, 190, MONTGOMERY

Bureh, Sidney J. (b'55) Mo.2.7\%; (1'84). Kauschelbach, Oscar R. (b'ti)-Ky.1,96; $\left(I^{\prime} 37\right)$.

RICHARDS, 303, VERNON

I'ITMF, RALPII OLIVEI (b'8:3)-Mo.20,

RICH FOUNTAIN, 125, OSAGE

Wiell, Louls-110.2\%, $96 ;$; (1'96).

RICH HILL, 2,755, BATES

ALLEN, CLAUNE JULIAN (b'86)-N10.20, , 09 ; (1'09); $\mathrm{S}$.

ALIFX, WH. H-Ky.4, ' I ; (d).

IDELANATER, GEO. A. (b'65)-I11.10,'93; $(1,96)$.

INSIEY, HERBERT WELIAXGTON (b'81) -Mo.20,13; (1'13)

J.ANE, ('EO. GARFIELD (b'SI)-Mo.2,05;

SHAFEH, ROY lR. (175)-M0.28, 02 ; (1'03). smalley, ravid E.-Mo.5, 73 ; (1'83).

RICHLAND, 884, PULASKI

II'RI'1IY, IIEXRY C. (b'53) - Ky,4,8I; (1'83)

OLIVER, EVERTT A. (b'63) \&-Mo.34,02; (1'01).

RAliA: WILSON J.Mo.M,74; (1'84).

TITTERINI;TON. JAMES L. (b'65)-MO.I, 'S6; (1'83); (Dentist).

RICHMOND, 3,664, RAY

B.ILL, JAMES EDIII, JR. (b'82)-MU.2, '04: (l'04).

BI'HAX.X, JA.HES M. (b'80)-Mo.2,03; (1'v2) claude C. (b'-6) - Ky.1,98; (1.40

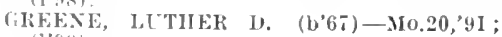
(1'g(i).

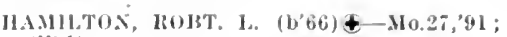

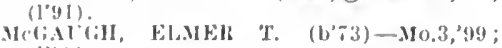
(l'm)

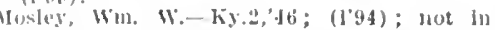
SEVIER, ROBERT (b'09)\$-Mo.1,95; (1) (1,i): ALR.

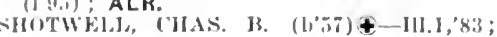
(I'84); OpA.

SMITI, IA.MES W. (10,51)-M0.2, “4:(1'84). RICHWOODS, I80, WASHINGTON

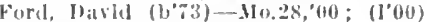

RIDGEWAY, 841. HARRISON

BIREWLR, IAAKE (b'82) \&-Mo.3,08; (1'08).

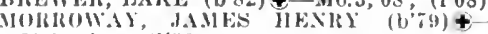

Nelo.ti, (0); (1'00).

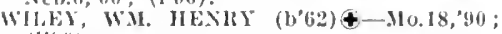
(1'9(1).

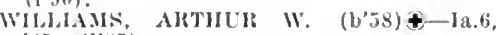
'85; (1'85).

RIPPEE, 35, DOUGLAS

IAMES, HIRAM (IAKMETT (b'b9)-Mo.7, 'J0: (I'10).

RITCHEY, 250, NEWTON

inell, Lewls C.-Mo.20,'00; (1'00).

ROADS (R.F.D.. NORBORNE), 30, CARROLL

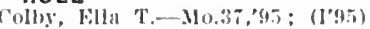

Colby, Wm. D.-MIo.I,90; $(1 ' 90)$.

ROANOKE, I10, HOWARD

HAWKINSOX, W. O. (L'63)-MU.I,84; (1'84).

ROBINS (R.F.D., FAYETTEVILLE), 28 , JOHNSON

STIIOOLEX, liENITK (ALVIN (b'2)IIO.24, 44 ; ; (1'46).

ROCHEPORT, 434, BOONE

ANGELL, WM. L. (b'73) \&-Mo.1,'55; (l'95).

Chinu, Elhannon 1I. (b'59)-..110.2, $80 ;\left(l^{\prime} 80\right)$ Gose, Everett Rush-Mo.28,07; (l'05).

ROCKPORT, 1,053, ATCHISON

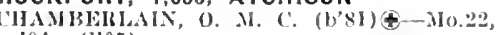
,04: (1'05).

Hedgpeth, James H. (b'55)-Mo.15, 82 ; (1'89).

LEWIS, EDGAR A. (b'7T) \&-Mo.20,05; (l'05)

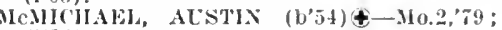

$\left(1^{*} 84\right)$.

SETTLE. ('IIAS. THONAS $($ b' 69$) €-110.20$, 'OI; (1'0I).

STRI('KLANI), W:H. R. (b'69)屯-Mo.27,98; (1'98)

\section{ROCKVILLE, 5£6, BATES}

GitY. THOMAS W. (b'62) - Mo.7,'95;

(I'y.j).

POWERS, CHAS. E. (b'75)-Mo.29,97;

Short, Chas. 1). (b'7)-Mo.10,02; (1'02).

ROCKY COMFORT, 400, MCDONALD

Jablos, llarid N-CTent, 40 ; $\left(l^{\prime} 00\right)$.

Me(all, M. S. (b'70)-Mo.28,95; (1'y5).

ROGERSVILLE, G50, WEBSTER

ATKINS, WI. ARTHIR (b'78)-.110.34, 05; (I'05) : Op.

MCHAFF1E,

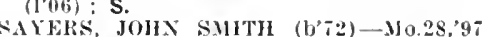
(1'97): ALR.

ROLLA, 2,261, PHELPS

Arthur, Saml. F. (b'50)-Mo.1,'74; (1'84).

BAYSINGER, STCART LEE (b'69) \&-Mo.1, '40: (1'90).

Cooper, Christopher C. (b'52)-Ia.1,'82, No.1, 84; (1+).

IOWE, SAMI. BRIDIEMAN (b'44)-Mo.1, '81: (1'83).

SHORT, МARTHA-Mo.22,'92; (1'92).

SMITH, WH. S. (b'78)-M10.1,99; (1'99).

ROMBAUER, 125, BUTLER

BRYANT, JEWEL ALBLRN (b79)\&-

Yo.7,11; (J'12).

ROME, 45, DOUGLAS

Bailey, D. J. $\rightarrow$.

ROSCOE, 182, ST, CLAIR

Green, John P.- IIo.I0,'89; (1'89).

Stration, Chas. Stewart (b'69)-Mo.28,'99 (1'99).

ROSEBUD, 200, GASCONADE

DONXELL, JOHX WY. (b'i3) $\oplus-\mathrm{J}_{0.20}$,
ROSENDALE, 359, ANDREW

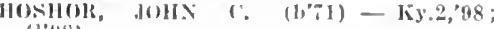
(1'i) 8 ).

KEILEY, AITIIL'R 11. (b'84)-Mo.22,07: (l'0i)

ROTHVILLE, 245, CHARITON

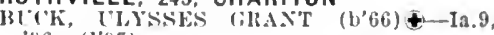
(96; (1'97).

'THATTON, (HAS. I) (b'58) †-Mo.1, 83 .

(1'8.3); S.

ROVER, I6, OREGON

IIall, James II. (1,5i)--liy.4,'89; (1'90).

RUSH HILL, 168, AUDRAIN

Cormatt, Will. Edlyill-Mo.7,"100; (1'89).

RUSH TOWER, 27, JEFFERSON

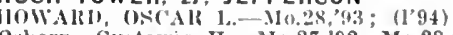

Osborn, fustarus H.-Mo.27,'92, Mo.28, 93 ; $\left.\left(10^{\prime}\right) 2\right)$.

RUSHVILLE, 566, BUCHANAN

Cardner, E. I. (b'82)-Mo.29,03; ('03)

RUSSELLVILLE, 335 , COLE

Glover, Clark S,-Mo.10,'01; (1'01); G.

LESLIE, WALTEIR J.-Mo.2, 06 ; (1'06)

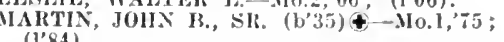
(1'84).

RUTLEDGE, 418, SCOTLAND

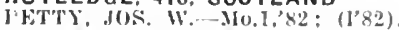

I'ETTY, WALLACE S. (b'86)-Ia.10,08 (1) $(18)$.

likk, Jos. 11m,-Mo.:28,10: (1)

SHACKLETT, JAMES AITHUR-Ia.1,'98; (1'98).

SALEM, 1,796, DENT

dkers, Eugene ( 1 -..llich.3,75; ( )

HI'NT, THOS, Ii. (6'68)-Mo.10,'0I; (1'01) MAIIJTIY, AJEX. T.\&-0.2,81; (1'84) MILILET, THOS. F (b'78)-Mo,1,96; (1'99) RLDD, WM. F. (b; 0$)-M 0.28,97 ;(197)$.

WELCH, JAMES C. (b'61)‡-0.1, 89 ; (1'89).

SALINE, 67, MERCER

DEIONG, WARD J3.-Mo.22,'06; (1'06).

SALISBURY, 1.834 , CHARITON

JIR L MMALI, JEFFERSON D. (b'61) Mo.I, 82; (l'83) ; 0p.

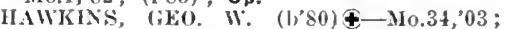
(l’05).

JENXIGG, CLEMENT A. (b'38)-Pa.1, 57 ;

MOHEY, OTIS T. (b'75)-Ia.1,98; (1'9s).

'VELCII, J. FRANKLIN (b'56) 4-MO.1,80; (1'84).

SANTA FE, 200, MONROE

Botts, Il Dowell-Mo.1,99; (l'99).

Jrake, John S.-0.9; 71 ; (1'93).

SARCOXIE, I,311, JASPER

lioyd, John W. (b'-1)-JIo.28,'96; (1'96)

In umbauld, David F.-0.14,'83; (1'09).

Roper, W'm. H. (b'33)-Mo.10,81: (1'83).

Simmons, Leroy (b'82)-Mo.20,06; (J'05).

Stark, Alexander J. (b'63)-IFo.I,8\%; (I’87).

SAVANNAH, 1,583, ANDREW

Balley, Wm. Henry (b'74) H-Ill,4, 05 ;

EFFERIES, CLARENCE O. (b'53)‡-

II0.20,'88: (1'88).

Kelly, Kalph-Mo.29, 03 ; ( $\left.Y^{\prime} 03\right)$.

Kerr, W'm. II (b'40)-O.9, 68 ; (l'83)

MARTIN, WOODFORD (b'43)-Ky.4,76:

(1'84).

MYRS, WALTER C. (b'76)-Mo.29,97; (l'97).

SCHALLS, 35, PERRY

Selall, Ot to Moritz-110.28,04

SCHELL CITY, 562, VERNON

COL SOX, IOHA R. (b'64)-MO.20;'90; (1'90). CLRL, ARLANDO COLLMBLS (b'52)\&Mo.1,'88; (1'83).

JARVIS, HENRY C. (b'49)--I11.8,'82, Mo.20 0I ; (1'83); OALR.

Potter, Wm. II.-Mo.10,79; (I'83)

Ross. Geo. II. (b'61)-IIo.1,'83; (1'83).

SCHOLTEN, 25, BARRY

Wheeler, G. P.- ; (1'88)

SEDALIA, 17,822, PETTIS

Abell, Danl. 'T.-P'a.6,'60; (1'-4)

ALBER, EDWAPD A 'GCSTUS (b'76)Mo.8,03; (1,03); 914 W. 3d St.; offlee, 115 E. 4th St

ALDERMAX, MASON C. (b'TI)—-Mo.20 03: (1'03); II2 W. 41h St.: 9-12, 2-4.

Bandy, Wm. A. (b'5i) E-Mo.10,'84; (1'99); 911 S. Ohio st.; $9-10,12-2,5-8$. 


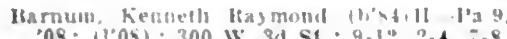

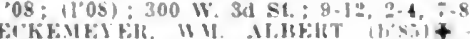

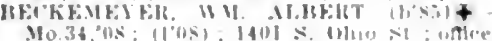

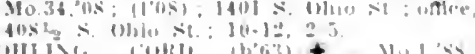

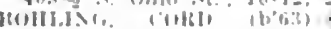
(I.A9): Masuma! Hosplth!

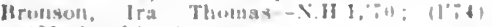
$301 \leqslant$ ohlon $\leqslant$

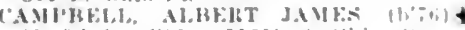

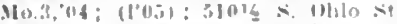

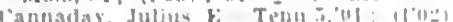

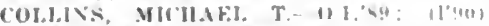
422 W. 6th St.; oflce, Ilgenbritiz IBldg

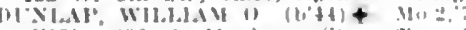
$(1095):=36$ S. Ilubltean st. : witlce, lou IV. Maln st

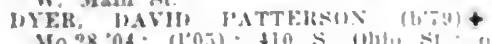
Ace. in w th $10.1 \%, 0$

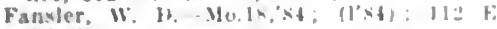
ans

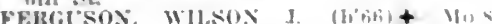

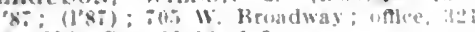
s. Ohlo St: $10.12,1.0$

Fowler, Jos. J. (b'bif) H Wleh, sti: (1's)

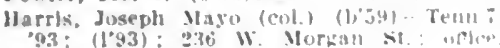
Ilf w. Naln st.; $10-11,4 ; 30-7$

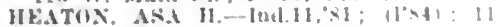
E. 4 tli si.

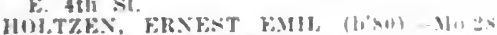
OL: (1.01): $706 \mathrm{~W}$. Broadway; unce

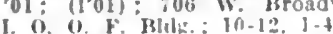

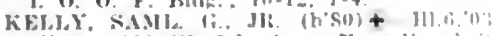

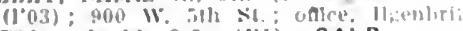
Bldy: : I1-12, :-5; (111); OALR.

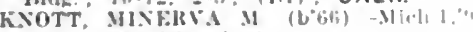
$(1 * 95) ; 210$ W. tith sit.

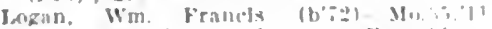

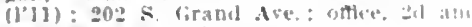
thlo sts: :

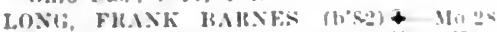
09: (109): 303 W. 4th St.; offee, Kaly Bldh.: $11-12,1-4$

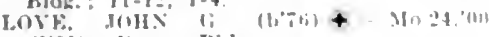
$(1 \circ 00):$ lester Blito

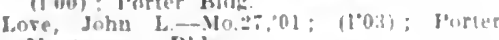
Yontromery

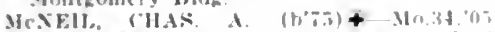
(1005); $221 \mathrm{~S}$. Grand Are.; office, I. 0. O f. Hldg. ; 10-12, $2-5$

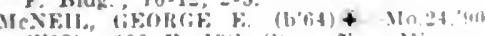

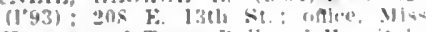
Kansas and Toxas Kallrond lisidital

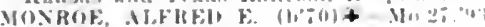
(1'93); $1316 \mathrm{w}$, $4 \mathrm{th} \mathrm{st}$; oflce, I0.0. lildg: $10-12,2$

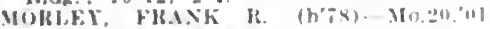

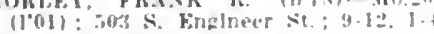

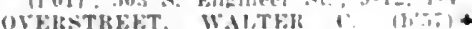
Mo.1,78, X.Y.10:82; 106 W, 5th s1. $8-10,1-3,7-9 ; G$.

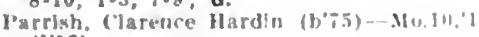
(1'13).

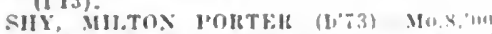
(100): Mlsenurl, Kansas and Toxar linil

roal llowpltal: S.

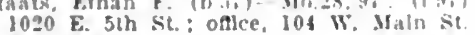

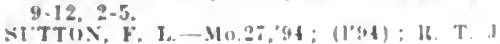
Iitis.

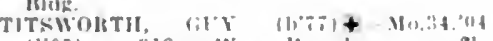

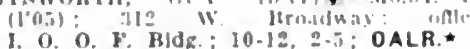

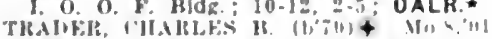

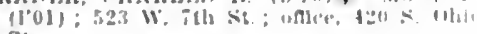
Se.

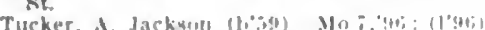

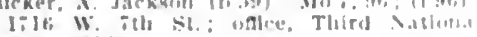
liank Mlus:.

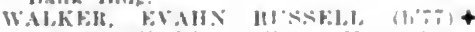

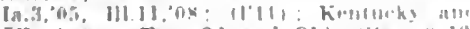

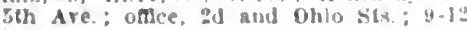
1. 4.

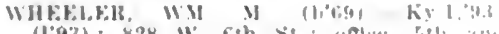

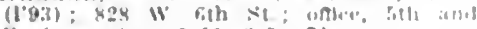
tinglneer sis.: $5-11,2-5: O b$

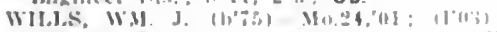

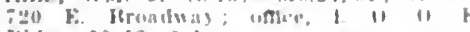
IBlis.: : 10.12.

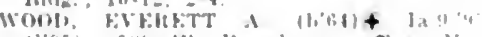

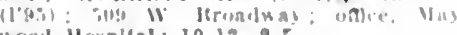
work] jlospltal: 10-12, 2-5.

IAXCE. FHWT F + $110,1,82 ;(1.83)$

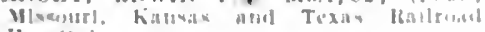
Humplal.
SEDGEWICKVILLE, 100, BOLLINGER

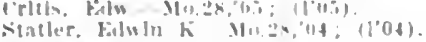

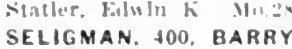

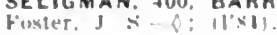

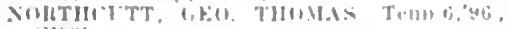
(l'gs).

SENATH, 1.029. DUNKLIN

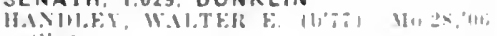
(l'(lip).

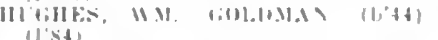

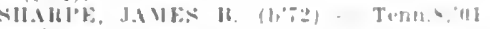

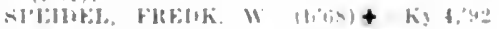

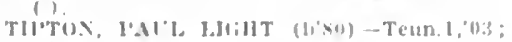
(10:8).

SENECA, 981, NEWTON

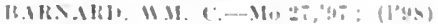

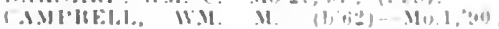
$(1,4(4)$

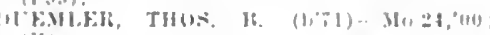
llo(1)

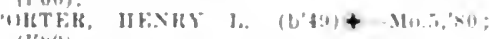
(l’sil).

\section{SEYMOUR. 590. WEBSTER}

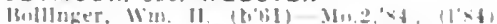

HFETOS, TLRREL $S$. (b'08)-110.28,00; (l'(i0)

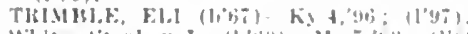

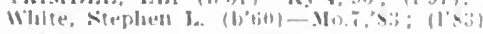

SHACKELFORD, 50, SALINE

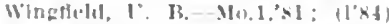

SHAMROCK, 35, CALLAWAY

HIlWH, II.KEHT (b.MU)

SHANNONDALE, 80, CHARITON

WIITE, MELVIX $\rightarrow$ (b'Gi) - Ia.1,97: $(1,4 \%)$.

SHAWNEETOWN, IIC. CAPE GIRARDEAU

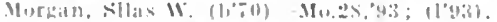
SHEFFIELD (KANSAS CITY P.0.), 300. JACKSON

Brown. Win. Wallace $(1,70)-T(n) 11,00$,

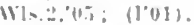

SHELBINA, 2,174, SHELBY

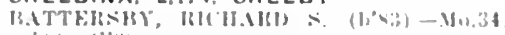
(1)

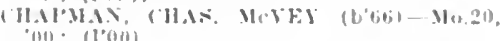

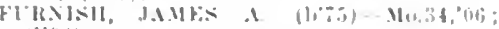
(l'(iti)

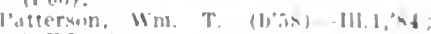

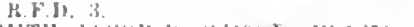

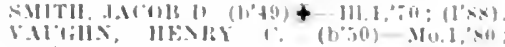
(100.7).

SHELBY (R.F.D.. PUROIN),50, LINN

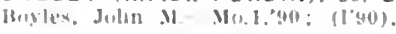

SHELBYVILLE, 685, SHELBY

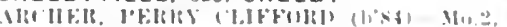
(i) ; $11^{\prime}(1 \mathrm{~m})$

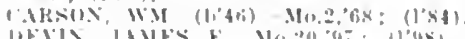

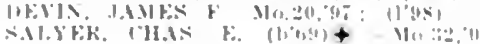

MIVHK. "I

\section{SHELDON, 528, VERNON}

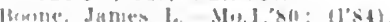

JULA, FHAXK (b's3)-Ky.2,10; (1'10)

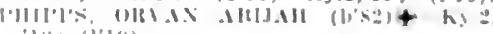
(111: (1'1(1)

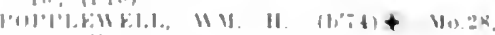

SHELL KNOB, 52 BARRY

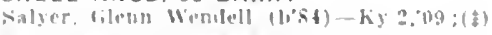

SHERIDAN H09, WORTH

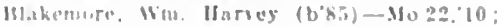

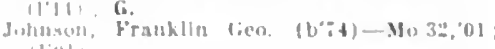

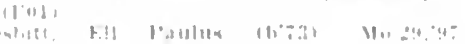

\section{SIKESTON 3,327. SCJTT}

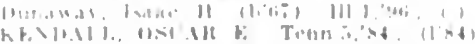

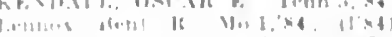

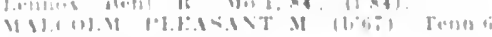

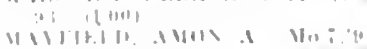

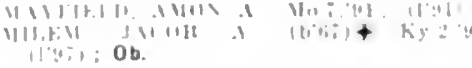

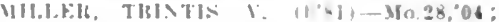

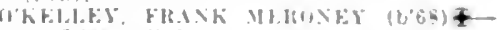
II... $: 4 ? ;\left(l^{\prime} 40\right)$

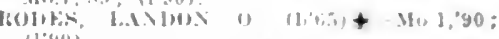
(1):(1))

Simili. Warren- 110 $7,46:\left(10^{*}\right)$.

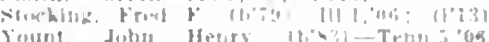
1105

SILEX, 276, LINCOLN

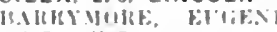

w": $(10 \%)$

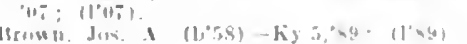

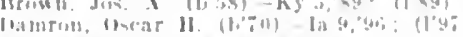

SILOAM SPRINGS, 86, HOWELL

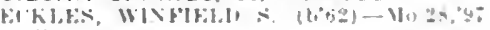
(1"11:3).

SILVER LAKE, 50. PERRY

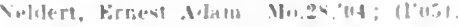

SKIDMORE, 56L, NODAWAY

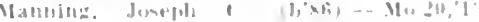

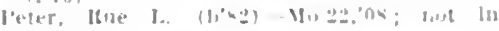
puratiofice

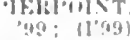

SLATER, 3,238, SALINE

I.HIHWFI.I. IHIS U

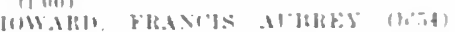

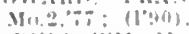

I.IH

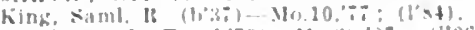

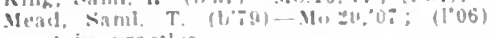

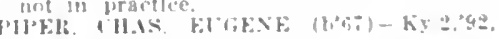

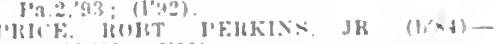

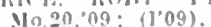

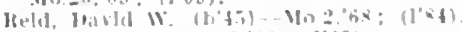

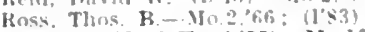

Snoddy, Alfred H. (b'55)-Mo.10,82: (1'85). SLIGO, 300. DENT

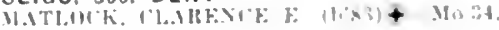
i) 1 ; (1'(15).

SMILEYVILLE (R.F.D., PALMYRA), I3,

\section{MARION}

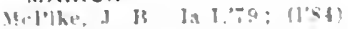

SMITHTON. 346, PETTIS

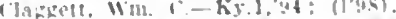

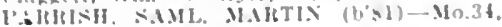
i: $\left(b^{\circ} 0 i\right)$.

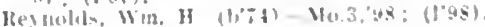

SMITHVILLE, 680. CLAY

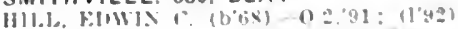

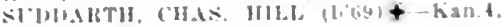

यर: (10)

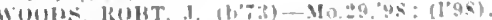

SOUTH FORK. 30. HOWELL

A-lawurth, Janes-in: (1's3)

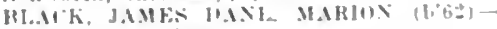

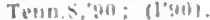

SOUTH GIFFORD. 148. MACON

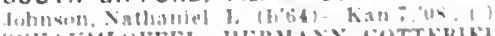

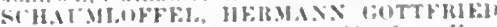

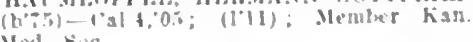

SOUTH GREENFIELD, 274, DADE

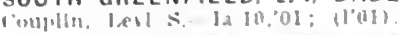

SOUTH ST, JOSEPH. - BUCHANAN (Seo St. Josenh.)

SOUTH WEST CITY, 483, MEDONALD

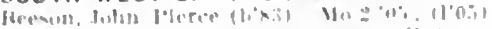

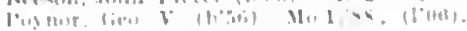

SPARTA, 27I, CHRISTIAN

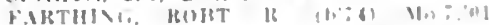

(110:-1

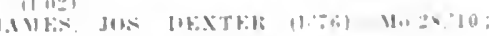
(I'liti)

SPEED. 100. COOPER

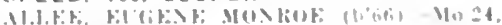

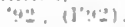

SPICKARD. 638. GRUNDY

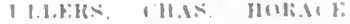

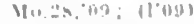

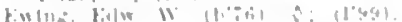

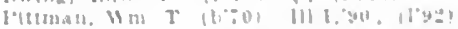

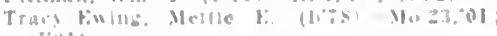
11011.

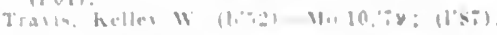


SPRINGFIELD, 35.201, GREENE

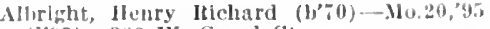
(1'95); 200 W. Canal St.

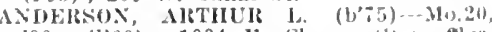
$00 . \quad\left(l^{\prime} \theta 0\right)$ : $1004 \mathrm{k}$. Cherry st. ofthe. 3 I8' College St, $2-5: 1 . \star$

AIMSTItoxi, AIRTHCIR (b'65)-M1). I, (l'06); 6It HHllugs st.; oftlce, Campliell st.

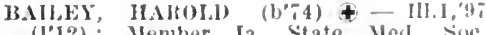
(l'12) : Hember Ia. Niate

Baker llerschel Delog (b'jey) - Vlch I's. (l'03) 509 \&. Milu st: ontice, Baker

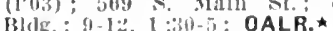

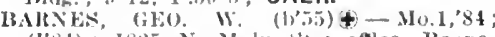
(l'8t); I $825 \mathrm{x}$. Maln st. ; oftee, Boonevile and commercial sts.; 8-9, 2-4, 7-8.

H.IRTLET'T IAMES IR. (h'bl) \&-N.Y.5, 83 (1'st); 1417 Washlngton Nre

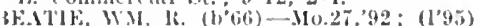
$573>0$. 3 trd.

I3lair. Saml. T.-Tenn.1,67; (1'83); Jlckwitck I'l.

Box, Warnest M.-.Mo.7.98; (I'98); 410 South st.: offlee, $3222_{12}$ Soutl st. $8-12$, $1: 30-5 ;$ OALR. *

BOYD, JOLN REZIN (b'54)-Ky.2,'86 $\left(I^{\prime} y 6\right)$; WondrufY IBId

Hrown. WM. M('F. (h'til)-Mo.I.85; (1'84); Commercial and Boonerlle sts.

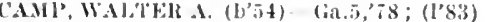

is 18 . What st.; offlee, $3281 / 2$ south St. $9-12,3-3$

Clark, Herbert Ross (b'77)-Mo.24,01; (I'01) ; $3221 / 2$ South st.

COFFELT, TIIEO. ALBINLS (b'55)-Mo.1, '86; (l'91); 1240 Benton Ave. : office. WoodrufY Blidg.; 8-1:2 2-5; OAR *

Cooll, James W. (b'64)-lnd.5,'91, Ill.5, 04 ; (1'91) ; 1120 Boberson Ave.; office, 228 E. Commerclal St.; $8: 30-11: 30,2-5 ; \mathrm{s}$.

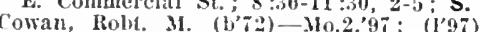

448 S. Grant st.; oftice, 924 N. Miln st. ; $10-12,2-4$.

COWDEN, W. H.-ML.1,80; (1'87); 1376 N. Jefferson St.; offlee, 500 E. Cómmercial St. $; 9-11,2-4$.

Cox, f. J,Mo.1,81; (l'92) ; 2281/2 W. Corul.

COX, LEE (b'61) \$-Mo.1,91; (1'91); 923 Booneville St.; offlee, 301 South St.; $10-12,2-4$

Coy, Win. A. (b'59)-Mo.7,92; (1,97) 832 Washlngton Ave.; offlce, 306 S. Campbell St. ; untll 11, 2-5.

CRANE, THOS, Y. B. (b'69)-Mo.28,03; (l'03); 961 IRoberson Ave; offee, 3181, College sit. ; $9-12,2-5,7-8$.

Darby, IBoht. E. (b'64)-Mo.20,'93; (1'95); (Dentist) ; $1139 \mathrm{~N}$. Jefferson St. ; offlee, Garlick Bldim. ; 8-12, $1: 30-5: 30$

Daris, Geo. K. A.-(o) ; $3281 / 2$ South st.

DELZELL, WM. ANDREW (b'S6)-ilo.34 '12; (I'12); $1491 / 2$ square st.

DEWEY, JAYES E. (b'79)-IIl.1, 03; (1'06) ; $961 \mathrm{~S}$. Jefferson St.; offlee, Woodrulf Bldg. ; $2-5$; S. $\star$.

Diemer, Frank W.-Mo.1,91; (1'91).

DORRELL. GREEN B. (b'62)-N.'.10,'89; (l'89) ; Woodruft Bldr.

ELKINS, C. BRYANT (b'62)-Mo.1,85: (1'85); 712 E. EIm St. ; office, $3181 \%$ College st.; $y-11,2-4$.

EVANS, EZRA L. (b 67$) 4-M 0.27,95$; (1'95); 512 Harket St.; oftice, 318 College St. ; 9-12, 2-5; ALR.

Evans, Harry Troy (b'8 - ...ILo,2,12; (1'12) 1023 St. Louis St.; offlce, Landers Theatre Bldg. ; $9-12,2-5$; ALR.

Erans, John F-31o.10,98; (1'98); 1437 Washington Are, office, 22.2 E. Commercial $\mathbf{S}$.

FARNSWORTI, IUETEK BOYISTOX (b'49)

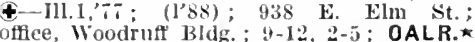

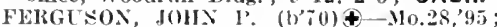
(l'95) ; 604 E. Elm St.; office, $328 \frac{1}{2}$ soutl St.; $9-12,2-5$.

Freeman, saml. F. (1)'si)-Mo.10,09; (l'09); crank Blds.

FlLIBRIGIT, IAMES IIARVEY (b'6T)C. $1+90 ;(1+4) ; 609$ s. Jetferson st. ; ottice, 21: 2. South st.; $10-12,2-5$.

Fl.TON, (IIEATER E. (b'61)-1a.3,'88;

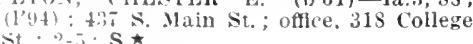

FISON, FItANK I3, (b'59) +-Mo.1, 86

(l'84) - 1124 E. Elm St.; oflice, Woodruff 13lit. ; $10-12,2-5$.

litrord, Inson H. (b'54) II - Ill.10,'89;

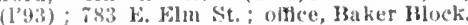

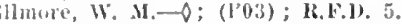

HINKINS, CHAS, ('-Mo.10,st: (l'01) ist F. Wlin St, oftce, llaker Hlock.

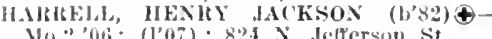
Mo.2,06; (1'07); 82. N. Jelferson St.

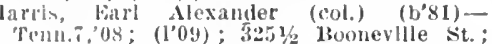
$4-12,2-6$

H11., IHEKHERT S. (b'43) - Ill.1,'69; (l'88) $1431 \mathrm{~N}$. lefterson $s t$; offlce, $4+51 / 2 \quad \mathrm{~B}$ commerclal st. : $10-11,4-6$.

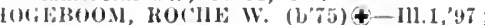
(l'a:3); Frlseo Hospltal.

Hol'kINS, WELLINGTON s. $\left(b^{3} 62\right)-M o . I$ st; $\left(t^{\prime} 87\right) ; 470$ s. Maln St.; oftlec, Landers Theatre Bldg. ; 9-12, 2-5.

HOKST, OT'TU CALL (b'86)-Mo.2, 09 (I'09) ; Friseo Hospital; S.

IIFFHAN, D.VII, M, (b'61)-Tem.6,'92 (1'y2); 2147 Missourl Ave.; offlce, Wood lufl Bldg. ; 9-12, 2-4.

JAMES, EWWIN F, (b'70)-Mo.24,95; (1'95); 1251 Summit Ave, aftlce, $4451 / 2$ Commercial st. ; $2-4$

Johuson, Frank il.-IIl. I,'32; (I'01) ; 1102 N. Girant sit.

JOHNSON, SAML. A. (b'63) -Ky.1,'89; (I'90); Ali N. leflerson St.; N. (l'0(i) ; 544 W. Center st. offlee, 318 Col$(1>00) ;$

Kizer, Wibid T-C0.3,'88; (l'93); $1115 \mathrm{E}$ Elin St.

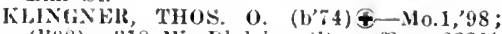
(1'9s); 3is W. Dlvlsion St. ; offlee, 2221/2 W. Comnercial st.; $9-12,2-5$; OALR.

liNABls, ENOC11 (b'67)屯-1a.9,'95; (l'02) 1538 Washlngton Ave.; offlee, $5001 \% \mathrm{E}$ Commercial st. : 9-11, 2-4, 7-8

kinighten, John A.-I,a.t, 00 ; (I'89); 303

LEMMOS, GEO. MRLCE (b'80)\$-Mo.2, $07 ;(1,07) ; 451$ Harket St. ; office, Woodrulf Bldg. ; $10-12,2-5$.

LOVE, JOS. WOODINGE-N.Y.1,90; ( ) ;

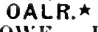

HoRA('E A. (b'85)-Mo.34'10 $\left(I^{\prime} 10\right) ; 240 \mathrm{~W}$. Stales st.; Offlee, Hoodruts Bldle.; $10-12,1-3,7-8$.

Lunsford, Isalac Newton (b'59)-Ia. I,'80 (l'83); S. Caupbell st.; office, :3281/ South St. ; $9-12,2-5$.

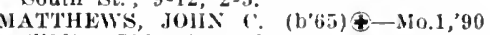
(1'90); $706 \mathrm{~W}$. Walnut st.; office, $21 \%$ South st. ; $9-11,3-5$.

Meclain, corydon $s .(1,43)-1 a .1,70$; (l's5); R.F.D. 8.

Ioore, J. Omar-1io.7.96; (1'90) ; 93.j porter Ave.; office, 8io Booncville 'st

MORGAN, JAMES T.-1a.1,T7:

$300 \frac{1 / 2}{2}$. Commercial St.; OALR.

ORISBEE. 1A.MES I. (b'6T)-Mo.1,'91 (1'91); 1862 National Blvd.; 9-12, 2-5.

PATTERSON, WM. 1'. (b'61) \$-T'Tn.5,'85 (I's6) ; 621 ('ollege st.: office, 149 Sorth Side Square; 10-12, 2-5.

I'EAK, OSCAR L. (b'49)-0.8,'78; (l'93) 1525 Tational Blyd.; offlee, $4101 \%$ F. Commereial St. ; 9-11,2-t.

Pingry, Wm. B. $\rightarrow$; (l'83)

PII'KIN, IROBT. L. (b'69)-ML.1,'94; (1’94) 705 Cherry st.; offlec, $2231 / 2$ South St. $10-12,2-4: 0 \mathrm{Ob}$

POTTS, JAIES MADISON (b'T3)-Mo.34, 10 ; (1'10); 528 State St. ; office, Woodruft Bldg. ; $11-12,3-5$.

P'HSSELLEY, WAITER L (b'66)-MIo.1, 47; (1907); 300 S. Campbell St. ; 9-12, ALSTON, JOHN P. (b’51)-Mo.10,'80; (I’91); 433 E. Elm st.; offlce, Woodruff bldg.

RIENILOFF, WM. (b'58)๑-Ger.20,83; (1'87); 564 St. Louls St.; offlce, Baker Block; 9-12, 2-5.

Rogers, Isaac X.-Mo.2,'72; (I'83); 108 Public square.

ROSEBERRY, EUGENE C.-Ill.1,'95; (1'98) ; 629 Clierry St.; office, Woodruff Bldg. $11-12,2-5 ; \mathrm{S}$.

Ross, J. E.-Mo.2,'02; (1'02) ; 444 St. Louis St.
Rosis, LEONIDAs

(b'60)-Io.I,'91;

('95). (1) 03): (1'12): Member Colo. State Med. soe. ; 4:2 s. Jufferson st. ; office, Woodruty ibldit: $10-12,2-5 ; \mathrm{S}$.

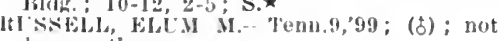
lin practice.

IRTYLE, HLXI:Y J. (b'70)£-Ky.1,'93; (1'93); Hatier Hlock.

Scales, Wim. C. (col.)-Tenu.7,91; (1'92). sIIEIMAN, INYID U. (b'71)-Mo.24,98 (1'01) ;

Scquare. (l'01); 1.302 N. defferson St.; offle, Publlc square: $11-2,3-5 ;$ S.

\$MITH, W.M. M. (b'42)-Ill.1,70; (1'82) $12 \% 2 \mathrm{~N}$. Jelferson st. ; offleo, $200 \frac{1}{2} \mathrm{~F}$. Cominerclal St. ; 9-12, 2-5.

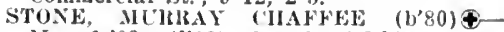
Mass.1,03; (I'12) ; Woodruff Bldg.

THOMAS, ARTHUR W:-M0.20,'95; (1'97) : Frlseo Hospltal.

TICKLE, SOLOMON WINCHESTER (b'60) -Mo.1,"90; (1'90); 1847 Douglas Are.; offce, $224 \frac{1}{2}$ W. Commerclal St. ; $9-11,2-4$ T-8; Anes.

Tlllery, Jesse S.-Mo.7,'93; (l'03) ; 135 N. Jefferson St.; offlce, $500 \frac{1}{2}$ H. Commerclal St, ; $9-12,1-4,7-8$.

E Flm Se: Tucker, Camplell St. 1920 Curts A. (b'72)-Mo.10,'03; (l'02) 1929 N. Ramsey Are.; office, $200 \frac{1 / 2}{\text { W }}$ Commercial St, $10-11$; $\mathrm{S}$.

Turner, Dwlght M. (b'48) H-0.7, 7 ; ; $\left(l^{\prime} 00\right)$ yndall. Martin V.-Mo.28,96; (1'00); Dale and Boulevard sts.

HAlKER, EDW: $x$ (1)'72)-Kan.4,'99 (1'97); $3221 / 2$ South St.

Well, IJenry Adam (b'65)-Mo.28,'98; (1'98) 958 W. Walnut St.; offlce, 330 South St. ; 9-12, 1-5.

Wilkerson, James M.-Mo.10,78; (l’88) ; 226 E. Commerclal St.

WILLIAMS, J. WM. (b'52) $\oplus-\mathrm{Ga} .5 ; 77$ (l'93); $3181 / 2$ College St. (l'01): 225 Sate C. (b'60)-Mo.28,94 St.; $9-12$

W'llliams, Robt. F. (b'79)-Ky.4,'04; (l'05): 527 New St.; office, Baker Block; 10-12, $2-4$; Pd.

Wlllams, Wm. J.-Mo.1,78, Ia.2,'82; (l'87)

WILLIER, AIBERT FRANC'S (b'80) Mo.3,"04; (l'04); 1437 Summit Ave.; office. $538 \%$ E. Commerclal St. ; 9-11, 2-4, 7-8.

Woodward, John H. (b'48) E-0.2, ' 55 ; $\left(1{ }^{\prime} 84\right)$ 1611 Roberson Ave.; $9-12,2-6$.

WOODY, CHAS. ELB́BRT $\left(\mathrm{b}^{\prime} 60\right) \uparrow-K y .1$, "93; (1'93); 907 State St.; office, 318 College $\mathrm{St}$.

WRIGHT, JAMES P. (b'44) - Ky.2,'74 $\left(1^{\prime} 94\right) ; 791$ W. Walnut St. ; offlee, $3181 / 2$ College St.; $9-12,2-5$.

SPRINGHILL (R.F.D., CHILLICOTHE, 75,

Everett (b'68)-Mo.20,'99; (l'99).

WHITE, WM. L.

isee Chillicothe.)

SPROTT, 150, STE. GENEVIEVE

Perkins, Geo. Ben-Mo.1,'93; (l'93).

SPRUCE, 60, BATES

FLETCHER, JAMES HENRY (b'81) 4 Ho.20,09; (l'09).

SPURGEON (R.F.D., NEOSHO), 250, NEWTON

Sution, John Roland-Ia.1,'84; (l'84).

ST. CHARLES, 9,437, ST. CHARLES

Arnold, U. S. Grant (b'64)-Mo.2,96; (1’96). BITTER, CARL. II. (b'67)-Mo.2,94; (1'94). Castlio, Mitchell (b'53)-Mo.2,'83; (1'84).

Freeman, Win. L. (b'(69)-Colo.1,93; (l'97). GOSSOW, AUGCST ANTON F. (b'65) Mo.24,'92, Ger.1,'97; $\left(1^{\prime} 94\right)$; OALR.

HARDIN. 'THOS. LEEY-Mo.28,96; (1'96). Ilch, Otto B. (b'68)-Mo.27,98; (1'98).

Jackson, Thos. J. (col.) (b'82)-Tenn.t,05; (l'05).

JOHNSON, SAML. R. (b'64)-Mo.20,'84; (l's4).

MORR, SCHULZ, A. P. ERICH (b'81)-Mo.2,'12 (1'13). 


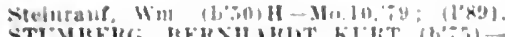

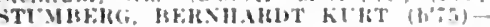
Mld.9,00; (100s)

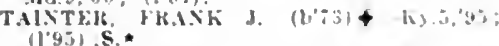

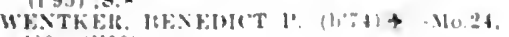
$00:(1,00)$.

ST. CLAIR, 397. FRANKLIN

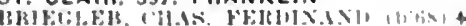

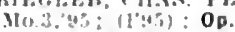

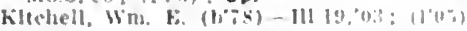

STE, GENEVIEVE, 1,967, STE. GENEVIEVE

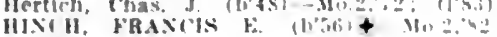

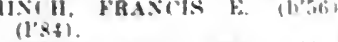

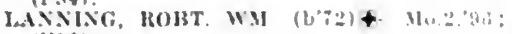
(1"96).

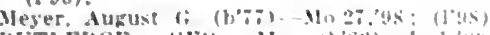

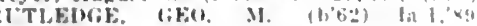
(I'90).

ST. ELIZABETH. 150. MILLER

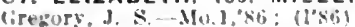

ET. JAMES, 1,100, PHELPS

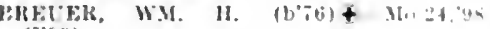
(1'99)

F'I.PRIGIT, CHAS. H (1) (1'sis)

MATLOCK. LOI'IS JOHS (1)'(it) - Mn.28, (105)

ST, JOHN (R.F.D., POWERSVILLE). I 49. PUTNAM

firay, Lorin L. (b.51)-MO 18,84: (1.34).

ST. JOSEPH, 77,403, BUCHANAN NTMREI OF IIISIUIAS. liti.

Atchlson, (ad If. (h'-3) - Mn.22.01: (1.01) 512 \&. 15 th St.; office, 705 koblidesux $\leqslant 1$. $0.19,3-6,7-8$

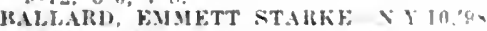

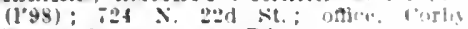
Forsee Bidr.: 1I-4: Pd

Bandel. Osear i. (b'81)-Mn.34, $(0)$ : $\left(f^{\prime}(9)\right.$ $1224 \times 3 \mathrm{~d} \leq 1$

Hanes, A. V.-Fa.2,6s; (1) : 502 Jile tit

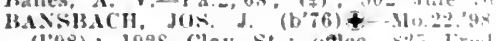
(198): 1925 Clay st.: watle erick Are.: 10-1:2, 2-4:U.

ALMAX, LOLIS C. $\left(b^{\prime}, 5\right)+11,20,04$ $(104): 402$ s. 15th st, offlet. 4 th ant Ednond sis.: 10.t; U.

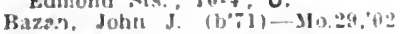
500 Messante sit.

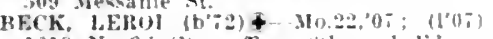
1618 S. 3d si. ance. sth am bilmumi

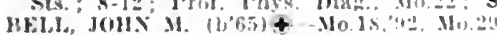

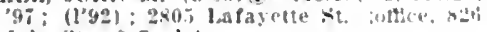
Jule st.; $9.5 ; 1$.

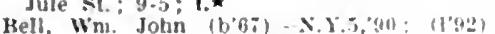

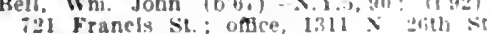

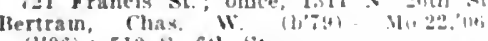

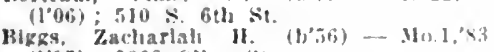
(1'97): 2802 ollre st.

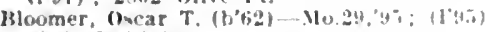
$1220 \mathrm{~N}$. 3d st.

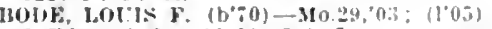
bi Finond st. : $10-12,2-4$.

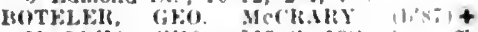
Mo.22,10: $(1+10) ; 115$ \&. 1311 st. : onlo" $716 \frac{1}{2}$ bellx st.; 10-12, 2-4: U.

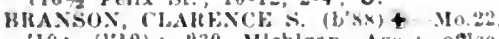
10: $(1.10): 230$ Mlehigan Ire.; ontece. 324 is llunols Aie, ; 4-6, 7-8.

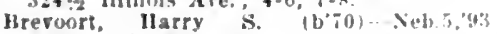
(l'gi): i20 Fell si

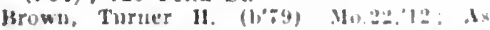

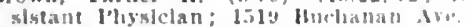

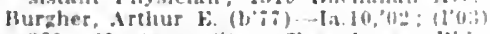

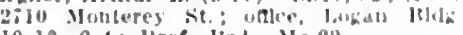
10-12, 2-4: I'rof. J'tu. No.22

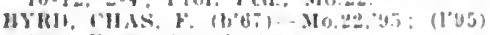
2004 I. St. Josewh die.

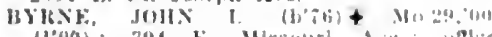

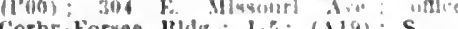

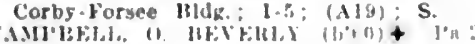

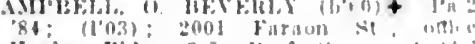

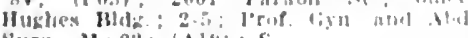
Surg, Mu, 2: : (Aty): S

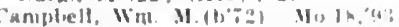

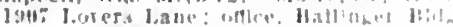
10.5

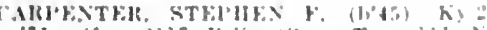

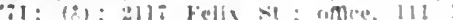
sth st: : $9.6 \mathrm{i}: 30$. artlon. Wm. S (col) - Tenn 7.948: 11"99);

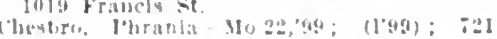
Francis st

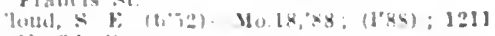
a 31

Co.tTs, (RAS, CIINTOS (b'i)-Mo.22, "11!: (l'u!n). Cintuerclal ltank blelg.

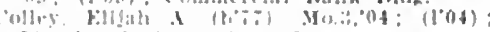

fox.161. J011 11 (1,62) 1 -19.9.95:

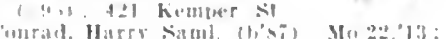

onimi, Harsy tam

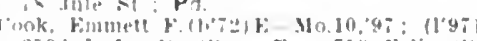

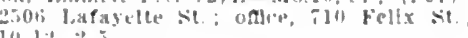
$111-1: 2,-1,0$

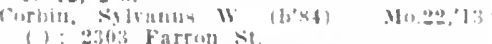
cwan. Sam. 1) (b)sal Mo.2,,11: ( 1501 Faraon -1 .

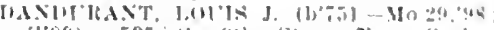

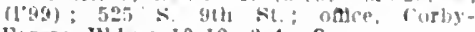
Forsee Blag. : 10-12, 2-4: S.

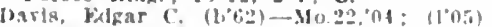

$1309 \times 11$ th st. ; uftce, commercial bink Blik. : $10-5$.

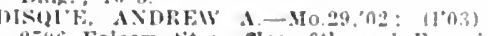
27106 Folsom st. onice, fith and rrancis its.: 8-12.2.4; OALR.

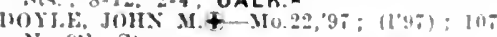
$\therefore$ gth st

01NSMORE, IOHX MCAITITR

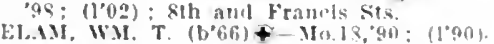

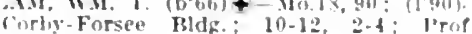
len.-Irlt. Surg. and Gyn., Mo.ze: (AI!) ('3) ; S.

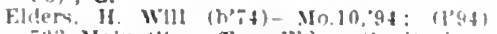

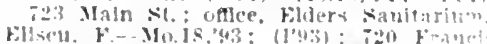

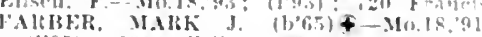

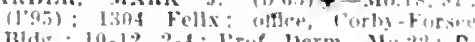

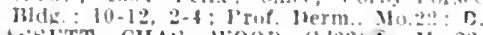

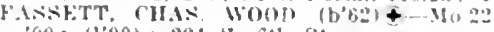
(1in: $(1,0) 0): 204$ s. fith st.

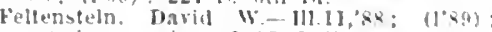
not in uractire: lais liell st.

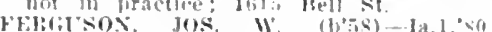

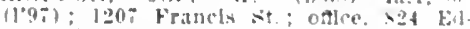
mond St.: $2-1$

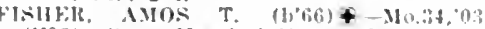
(1)03): State Irosplat No. $=00$.

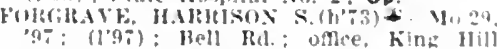
bilig.: $1-5:($ (A) $: \mathbf{S}$

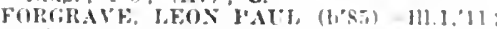
(1'JI): a Francls sit.: J'rof Opbet Laryn. and Rhln., Mo.2.

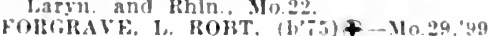
(1'99): i11 jule S1: utlee, logan Bldi: 10-12,2-4: OALR.

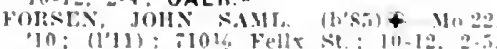

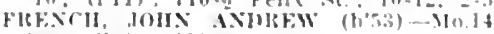
"(ix. (l'st); 402 s. sith st.

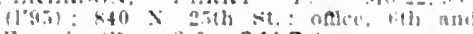
Pranely sto: g-1: OALR.

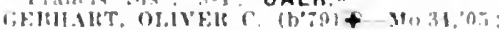

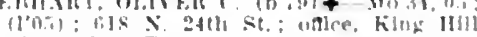
Mluk: :-4: $\mathbf{T}$

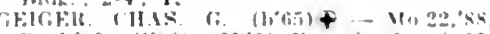

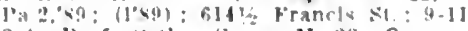
2-1: Prof Wrthe Nurz. Mose: S.

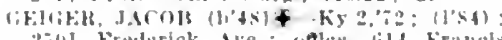

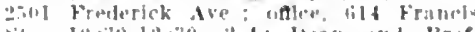

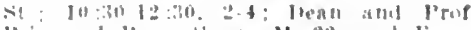

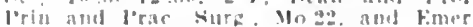
l'rof suro, Vo 34: (17.19): S

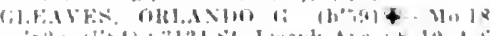

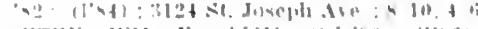

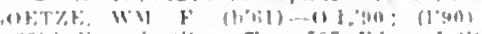

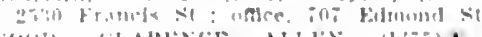

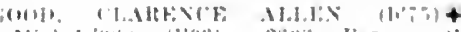

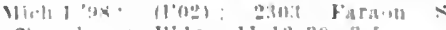

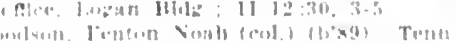

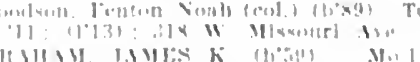

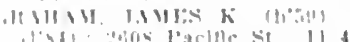

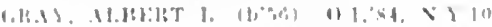

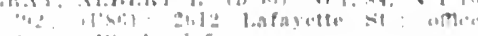

ikit W11,Tin

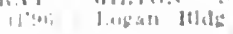

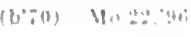

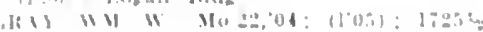
1.mmoritial th

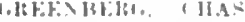

(1):2a) - ky.2,11:

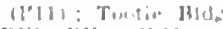

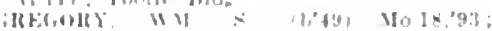

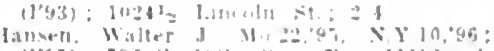

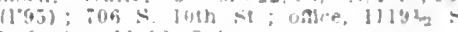
loth : $1: 11 \cdot 12.34$

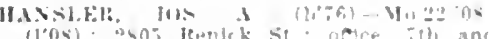
Fellr sts.: : : $\mathbf{S}$

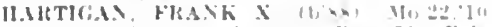

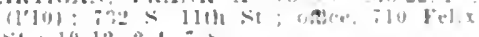

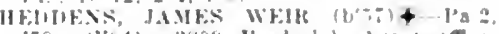

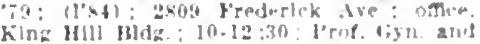
Alyl Sirre. Mo 20: (A19): S

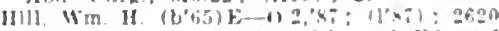

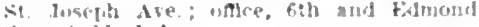
its: : $1-11,1.4$

nillyard. l.1da-110 29,05: (105); ;16 5

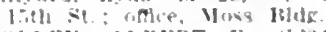

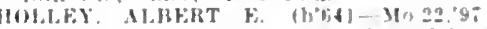

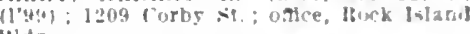
Itide.

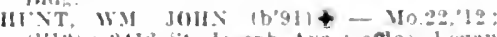

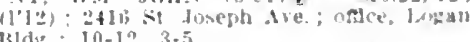
और2, $10-12,3-5$

Si joren we

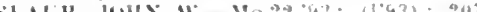
$\therefore 1$ th $\leqslant$ it.

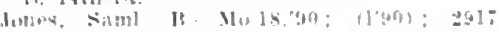
Mesiante st

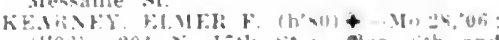

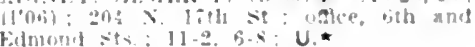

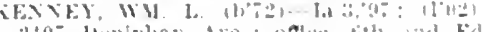

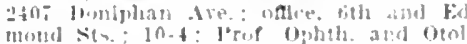
IIIstid 20.25 .

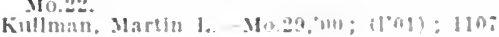
Frederick Are

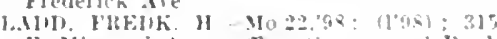

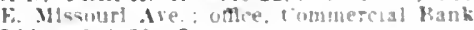
lllly.: : $1-4: 00 ; 5$.

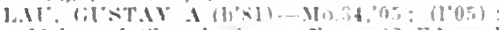

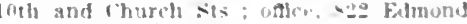
Si. $10-100-4=0$

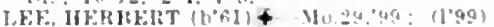

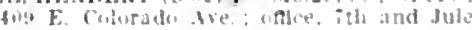

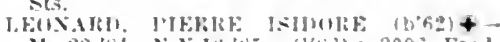

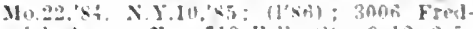
erlck lie : once, ilo bellr st: $9-12,2-3$ OALR.

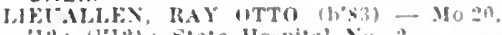

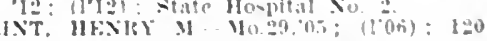
Ilidama

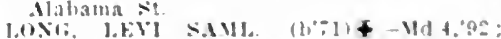

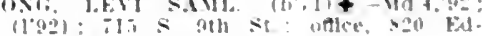
motil st lit.1:-t. Pr.

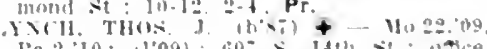

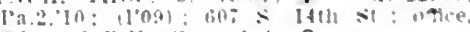
wh ind fill ste: 1-t: Or.

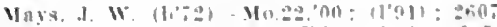

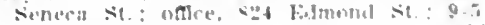

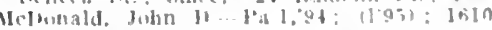

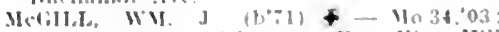

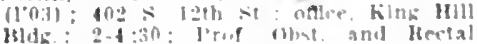

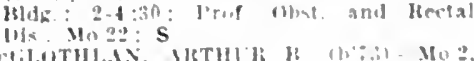

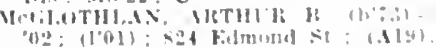

Volnery, Jus. II (h:3) Min. It as: (1'ys):

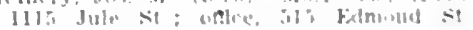

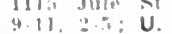

Vemlenil. Hilulis fimnorelat llide

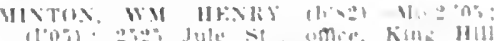
Wal: la li:

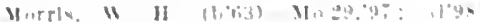

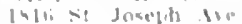

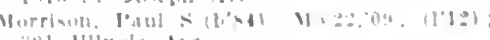
[al 1111 neik .160

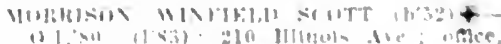
(ill lll1mola lie : Pd.

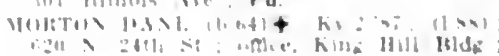
$\because 1:$ s.

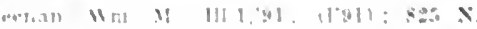

ti. $\therefore$ : 


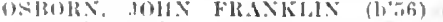

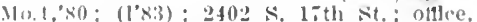

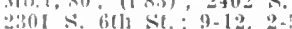

mWlis, JMME r. $(1,70)-110,18,92$;

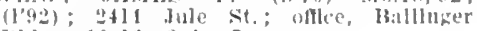
13litg.; $10-12,2-4$; G.

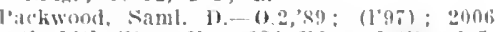
‥ Ith st.: oftce, sot Edmond sit. i t

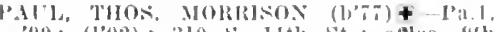

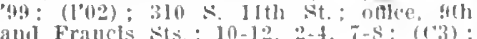
U.

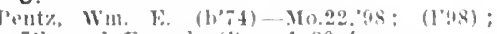
th and Francls ste. ; $1: 30-4$.

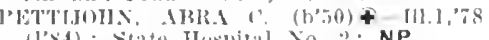
(l's4): state Inaspital No. 2: NP.

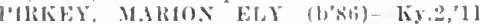
(1): Member lir. State Med dswim.

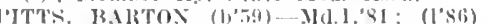
if $x$. ith st. oflloe, sth and franci sits. ; $9-5 ; 0$ pA.

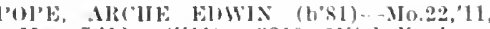

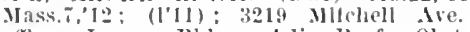
offlee, Logan

I'O'T'TER, CARYL ASHBY (b'86)-MId.7,'11 (1,13): 130s $x$ ith st. oftice Ftls and Edmond sts.: $11-12: 30,3-5: 30 ; 1$ rof Prac. Med., Mo.22, ; $\mathrm{S}$

Po'T'ER, THOMPSON F. $\left(\mathrm{b}^{\prime} 49\right) \notin-\mathrm{Pa} 2$

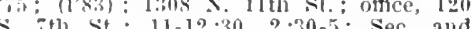
Frof Prin. and Prac. Surt. Mo.22; (A19).

Ravold, Irenry . Facques (h'64)H-Mo.n, $(1: 90): 401 \times$ X. 6th St. : $10-4$

REDMOND, TIIOS. (b'73)-H1.1, $06 ;\left(l^{\prime} 07\right)$ 2222 Frederlck Ave.; oftice, Corby-Forsee Bldig. : $10-12,3-6$.

Rellud, EdwIn C.-La.1,96: (k’97); 8031/2 Frincls St.

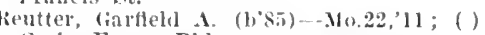
Corby-Forsee Bldg.

REVNOLDS, IOIIN B. (b'58) \&-.110.1.82 (184); 383 x. $22 d$ st. ; oflce, $4131 / 2$ Frin cts st. ; s-12, $1: 30-5,7-8$

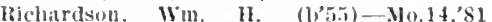
(1'90); 1108 bouglas St.; oftice, IIoss Bldir.

Ricketts, Matthew O. (col.) - Neb.5,'84 $\left(l^{\prime} 86\right)$; $3081 / 6$ Edmond St.

Riemer, Henry lR. (b'46)-Mo.22.'97; (1'97); 906 Dewey Are. offlce, 3221; Francis St. $9-12,2-5$.

Riemer, Milton F-Mo.22,04; (l'03) ; 2606 Lafayette St.: office, Ballinger Bldg.; $10=$ $12 \cdot 30,1: 30-5$

RILEY, IOS. B.-Mo.19,'88; (l'89); Ballinger Bldg.

sampson. Christopher M. (b'80)-Mo.22, '05; (1'05); 3022 Messanie St.; office, Corby Bldg. ; $11-5$

SAMPSON, JOHN If. $\left(b^{\prime} 57\right) \oplus-M o .1 .81$ (l'84); 2606 Lafayette St.: oflce, Corby Bldg. ; 9-12, 1:30-5, $7-8: 30$; Prof Prac. Med., Mo.2.

S('HMID, OTTO A. (b'82)-Mo.34, 08 (l'09); Stl and Francis Sts.; offlce, Pitts BIdg.: 10-12, 2-4, 7-8.

SCHMID, WM. F. (b'73) \&- Мo.22,95 H1.6,'08: (1'95): sth and Francis sts. offle, Pltts Bldg.: 11-12, 2-4.

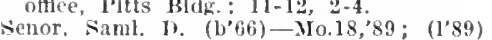
2323 Jule st.

Hhorow. Henry W-Mo.29,99; (l'99); 190 Jule St.

Siemens, Claus A. $(1,28)$ - Ger., 53 ; not in iractice; $730 \mathrm{~s}$. 14 th $\mathrm{St}$

SHMONS, B. B.\&-Mo.29,99; $\left(l^{\prime 99}\right) ; 6$ th and Francis Sts.; $10-12,2-4$; S.

Skimmer, l'hineas - Mo.18,'93; (l'93); 43 Hyde rark Ave.

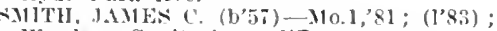

Woodson Santarium; NP.

SPEXCER, FLOYI II.ક-Mo.29.'00: $\left(l^{\prime} 00\right)$ : tiot Bonton St.; office, Ballinzer Bldg. $-5: S$.

STAM1: JAMEA THOS. (b'72)-Mo.29,97 $(1.97) ; 2624$ st. loseph Ave. : office, Corby Forsee Aldir.; $11: 30-4 ;$ G.

STEYEYSOX. GEO. ROY (h's6)-Mo.22,'0s; (lin); \{30:; Witchell Are.; offlce, Logan l3low; l'rof. T'ler., No.

bank Bldg.
Stury. John C. (b'ti3) $\mathrm{F}-0.2,89 ; \quad\left(1^{\prime} 89\right)$;

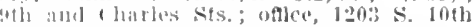
st. : $11-11,: 3-1 ;$

(b). (bol) - 111.10,9s; I"THERIANi). J. (". (b'34)-110.14, 69 (1'8:3); $509 \leqslant$. 15 th $\leqslant t$

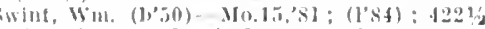

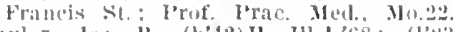

faylor, Jos. R. (b't2) Jl- lll.t, (fis: (I'x3) 70! S. loth st.; ofllee, Commerciall Islock; 1.5: G.

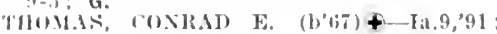

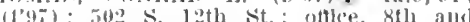
loduond sils.; $8: 30-11: 30,1: 30-5: 30$.

Thmmpson, Frolk. (iregg (b'fis)-0nt.3,'8s:

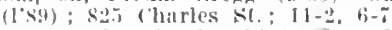

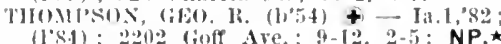

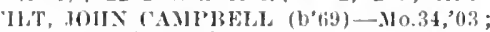
(1'03) ; 214 s. sth st.

TIVEMMA, ARTIIR k. (1,72)-Ky.4,"94 $\left(P^{\prime} 05\right): 215$ Massachusets Ave.; olfle the and Francls Sts.; $9-11,2-4: 30,7: 30-$ $8:: 30 ; \mathrm{S}$.

'TOlib, IUTHER ANSON (b'T4) Z-NY.I, (00: $\left(1^{\prime} 02\right) ; 2515$ Francis st.; offle TOOTIAKER, JFYJ IY (1, (1.02): 1506 N. 11 th st. oftice, 7201 \% Francis st. : $10-12,2-4 ; P d$.

Tonnsend, Alfred N. - Mo.22,93; (194) 1307 Dewey Are.

Tucker, Win. Peyton (b'69) - Mo.22,'93 (l'll) ; 624 N. fith st.

Walker, Frank 1'. (b'75)-Mo.22, $08 ;(108)$ 180.5 Faraon St.; offlce, Ballinger Bldg.; (1-12, 2-5.

WATEEK, HEXKY L.\$-M0.22,01; (1'01) logan lildg.

WALACE, CHAS. HODGE (b'58) \#N.Y.10,'s3; (1'84); 605 N. 8th St. ; offle,
301 N. 8th St.; Prof. Prac Surg., Mo.22 $(A 7,19) ; \mathbf{S} . \star$

Veary Franklin G. (b'62) E-Ili.8, 83 (l’93) ; 5401 Swift Ave.; oflce, Klng FHl and Colorado Ares.; $9-12$.

Wenzel, Richard J. (b'68) - Mo.18,93 (1’93) : 1712 Lafayette st.; offlce, Moss Bldg. ; $2-4 ; 0$

Wertenberger, Wm. W. (b'61)-Mich.1,'92 (l'92); Corby-Forsee Bldg. ; 9-5.

Westfall, F. Kemper (b'80) - Ill.4, 03 (l'08) : 5905 King Hilt Are.: offlce, $58371 \%$ King Hill Ave, ; $10-11: 30,1-5,7-8$

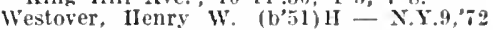
(1'84); 1401 Felix St.; oftlce, Logan Block: 8-10, 1-3, LR.

WHITSELT, JOHN C. (b'75) - Mo.22,'03: (l'03); Ricket Rd.: offlce, 6th and Edmond 'Sts. ; 9-12, 1-5; OALR.

WIITTLNGTON, WI. L. (b'64)-Pa.2,'88 (l'89) ; State Hospital No. 2; NP.*

WITLMAN, REINHOLD (b'55)-Mo.22, 02 (I'02); 1103 Jule St.; offece, 301 N. $11 \mathrm{fh}$ St. ; 2-4, 7-8.

WISAER, JOHN J.-MO.29,95 : (1'95) ; 1501 Penn St.; offlce, $109 \frac{1 / 2}{2}$. 8th St.

WOONSON, CHAS. R. $(h, 48) \notin-\lambda$ - 1,72 ; (1'34); 19th and Felix Sts.; offce, 220 N. ith St.; 10-12, 2-4; Prof. Neur. and liseh ith 10.

WOOLSEX, CALVEN LEE - Mo.34, 06 (1'05): State Hospital No, 2.

WRHGHT, GORDON D. (b'zi)-Mo.20,'98 (1'99); 1909 olive St.

FOKOM, GUICFORD D. (b'48)-1ll.10,79; $1505 \mathrm{~N}$. 17 th St.

ST. LOUIS, 687,029, ST. LOUIS CITY NUMBER OF THYSIINS, 1,720

$\triangle 13 \mathrm{EKEN}$, FIEIIK. W.-IIo.1,76; (f); 914 Ctah St.

Abel, Rudolph X.-Mo.í,'06; (l'06); 5081 Wells Ave.; offlce, 2605. Franklin Ave.; $9-12,1-3, \tau-8 ; 0 \mathrm{bG}$.

chenbach, Johin Ii. (b'81) - Ill.22, 06 (l'08): 3806 Washington Btwd.; offece, .0. Crand Ave.

Idcox, Reuben (b'62)-Mo.10,10; (l'10) 3329 Lucas St.; office, 3445 Pine St.

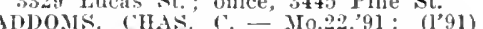
4265 Faston Are.; oftce, 11 S. Broadway. shlbrandt, Chas. G.-IIo.1,'95; (I'95) $3213 \mathrm{~A}$ Greer Are.; offle, 2548A' St. Louis Are.

Albin, Edw. R.-Mo.1,86 ; (1'86) ; 4255 Finney Are.

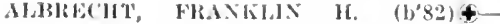
Mo.2,"12; (I'01); Humboldt Bldg.; (D5); Or.

Sleh, lieo, Harrls-M[o,8,9); (未) ; 4546 (cook Ave; wftce, r110 Witshington'st. Illenderfer, "larence Elbert (h'76)-Mo.2s, 07 ; (107); 23 ti3 (illnure Ave; office, 2107 W Wren Are.; 8-10, 1-2, 6-8.

Alexander, Frank is. (bot) (1'0:3) : 21st aud Market sls. ; $9-11,2-5,7-9$. 1] HX.INDER, ROBT, WUBOSE (b'75) $\$$

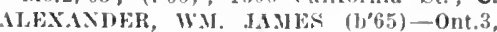
'90; (1'40); 2909 Cuton I3]rd.; 8-9, 1-2, 6-7:30.

Alford, Jeland Barton (1,85)-ML.2,'12; (I'12) : 4700 MeTherson Are; LD.

Allen, claude II. (b'80)-Mo.7., $04 ;\left(l^{\prime} 06\right)$; $2338 \mathrm{~A}$ st. Louls Ave, ; offce, $2212 \mathrm{x}$. 15 th St. ; $8-10,1-3,7-8$

Aben, I. 'dwin-Ifo.1,96; (l'01); 3680 lilahe Ave.

Allen, Jos. W. (b'70)-Mo.27,96; (1'96) (Wellston, R.F.D. 29) ; offlee, 1216 Franklln Ive, ; $10-12,2-4 ; U$.

Allen, Thos. E. (b'42) IJ-0.7,'67; (l'99); 3334 Washington Are.; 11-8.

Aileı, Wm. Franklin $\left(b^{\prime} 70\right)-M o .7,97$;

Allison, Ira-No.6,03; (l’03); $\$ 321$ Jucas

LIISOS, NATHAXIFI (b'76) \&-Mass.1.

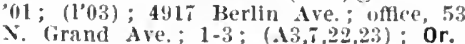

Ainerotl, Edw. (b'68)-Mo.7,91; (1'91) ; 2119 A Ollre St.

AIAYX, ASA 13.-Mo.27,'92; (1'93) ; 5004 Arsenal St

1LT, ADOLF (b,51)\&-Ger.10,75: (l'83) 3819 W. Pine Bird.; office, 50s $\mathrm{N}$. Grand Are. : 10-12, 2-3; Prof. Clin. Ophth. Io. 2; (B1, 4,5,27);0p.

ATTHAXS, ('ARL (b'81) \&-Mo.2, $03 ;\left(I^{\prime} 03\right)$; 3668 Tafayette $\mathrm{A}$ ve; office, 3248 Lafayette Ave. ; 9-10, 2-3, 7-8.

1ltheide, Chas. If. (b'7t)-Mo.28, 04 ; (1'06) : 3723 N. 25th St.; F'rof. Proct., Mo.7. A.JBROSE, OINEY ALPHONSO (b'5) -110.28,98; (1’98); 932 Beach Ave. office, hister Bldg.; 9-1; Jrof. Dis. Stomach., Mo.10; S.

AMEISS, FREDK, C. (b'59) - Mo.1,'82; (1’83); 4908 Euclid Terrace.

ANERLAND, JOHN HENLY $(1,55) \varphi$ Mich.1,'83; (I'86) : 3501 California Ave.; $8-9,2-3,7-8$

Ammann, Edgar Wm. (b'80)-Mo.34,04 $\left(\mathrm{l}^{\prime} 05\right) ; 4475$ Gibson Are.; offlce, $2900 \mathrm{~A}$ ollve

AMOS, NEWTON W. (b'67)-Mo.2,97; $(197) ; 5744$ 11cPherson Ave.; office, 4500 Olive $\mathrm{St}$.

AMYX, ROBT. FLEMING (b'65)๑-ML.27 $97 ;\left(1{ }^{\prime} 97\right) ; 1943$ N. 11th St.; 8-9:30

$1-2: 30,7-8$; (A22).
Anderson, Chas. k. (b'58) - Mo.10,'91 ; (1'91) ; $3105 \mathrm{~S}$. Jefferson $\mathrm{St}$

Andrus, Duane I'. (b'50)-Mo.10,83; (1'84); 107 N. 9th St.; 1-6 ARCHMALD, JAMES STEWART (b'83)-
Mo.34, $08 ;$ ( ); Member Ill. State Med. Soc. : 3865 Utah I'l.

Mrgus, Francis (b's6)-IIn.34,'13; ( ) 3933 S. Broadway.

Armet, Leon T. (b’85) H-MIo.5.n8; (ros) not in practice: 5143 Cote Brlifiante Ave. office, 4721 Easton Ave.; 2-4, 6-7:30.

ARMSTRONG. JOHN H. (b,76) \&-Mo.24, (00); (l'00); (kilkwood); office, 700 Kingshighway 131vd.; 1-3.

Arzt, Franz J-Mo.4,'b8; (l'83); 12th and Lami Sts. ; $i-9,3-4$.

ATKINS, HENRY \&. (h'67)-MIo.24,8 7 ; (1'99); Grant and Big Bend Sts.

ATKINSON, ROBT. C. (b'41)-La.1,67; (l'84); 3002 lafayette Are.; $8-9,1-2,7-8$. 1518 E. Grand Are.; $8-9,1-2,6-7: 30$

Aufderheide, otto F.-110.5, $00 ;\left(10^{\prime} 0\right) ; 2206$ F. Fair Ave.; oftice, $151 \mathrm{~s}$ E. Grand Ave. $8-9,1-2,6-7.30$

ALFUERHEINE, WM. DIETRLCH (b'75)థ110.27,98; (1'98); 3456 Magnolia Are.

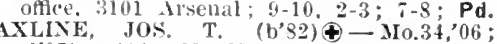
$\left(l^{\prime} 0 \bar{i}\right) ; 4141 \mathrm{x}$. Newstead Are.; offlec 4143 N. Newstead Are.; 2-4, 6-8; S. 


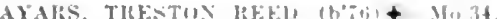

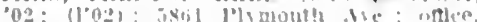

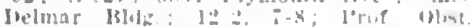
Min:: (.120) ObG

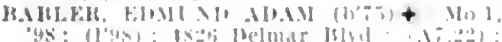

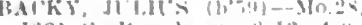

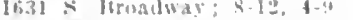

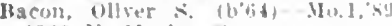

4303 X. Markes st.

Bade, Wim. John Proilk.
2023 SIdney st.; LD.

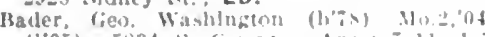

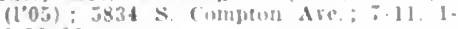
$6-10: 30$.

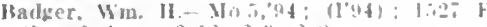

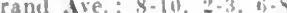

Baerens, Oscur Frank (1, (1'92): 5ilsa Eizel Ave. untere, If $x$ bu st. : 1:310-5:30; OALR.*

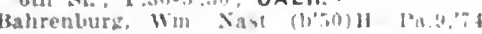

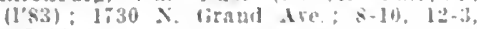
$5-: 30$

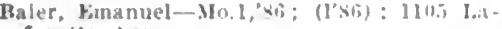
Paselte Are.

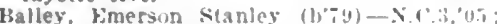
(1'i1): $811 x$. Jeftersion Ave.

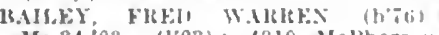
Mo.34,03; (1"03): 4310 Mclhersent ofice, Metropoldtan Midg.; 1-3; As. Prof. Surg. II0.34; (122): S. *

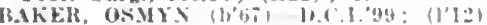

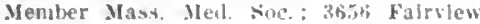
Are.

HAKER, WM. MONROE (b'十1)†-Mo.24,02:

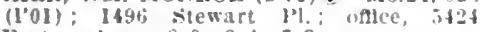
Easton Are.; 8-9, 3-4, 7-9.

BAIDWIN, FBEDK. AMOS (b'Ti)-Mlch.1,

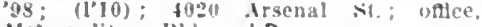
Metropolitan IBdg.: LD.

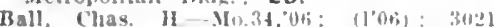
$\therefore$ Yewstead Are; oflce, Metropolltan Blde

BALI, JAMES MOOJES, JH. $(1,1,2)+-13.3$, 'S4: (1'05); +37t Wastington Mbd.; oftce, Idster Bldg.; 9-12, $4-6$; Dearr and I'rof. Ophth. Mo.10; (18:-) Op.

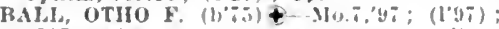
5337 Cabanne Are.; oftce, Metropnlitan

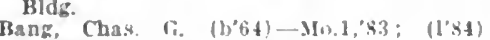
4000 sto Louls lre, $8-9,2-3,-s$

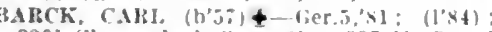
3301 shenandoals st. ogle, , Are. 9-12, f-ti: Prop, Opluth, Mo.:

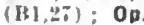

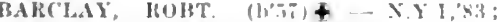

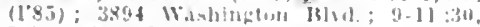

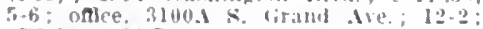
(B5,33) : ALR.*

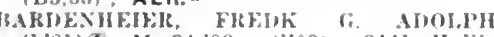
(1, 81) — No.34,03; (1'03); 3411 Hall1day Ave,: office, Friacr 1blelg.: I0-1 (B1,33) :) ALR.

HABKFB. WM. SHIR.MER (b'b3) - -110.1, 90; (l'90); 3855 Delmar Rlvil.; uffice,

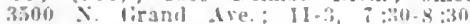

(115); Pd.

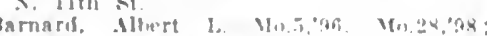

(1'96); (Claston); oflec, iog X. Kings: highway B1rit: : 9-10, 2-3.

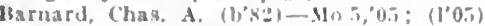

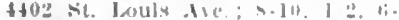

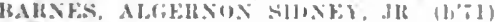

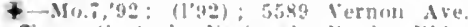

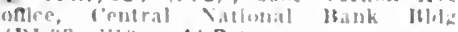

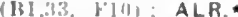

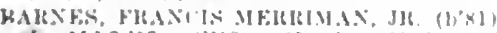

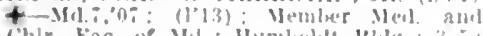

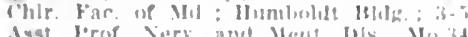
( $\mathrm{H}, \mathrm{i})$ : NP.*

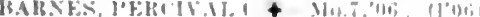

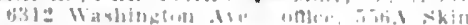
kencing

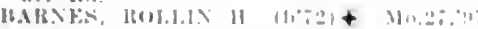

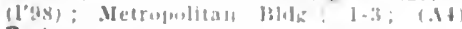
Prok

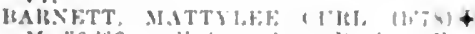

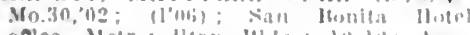

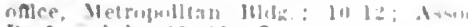

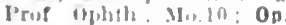

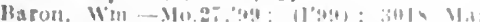

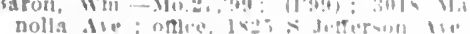

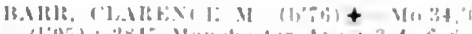

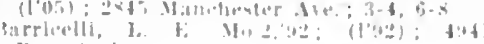
Bentanteal An

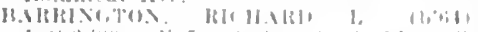

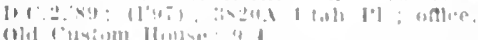

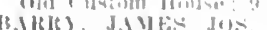

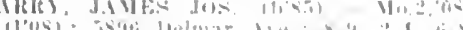

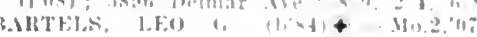

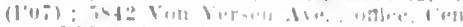
tury Blug : 1-3: U.

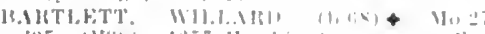

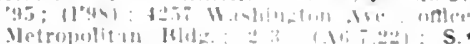

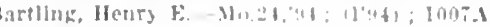
rass ive.

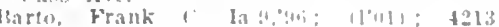
Natural Brldge kn!

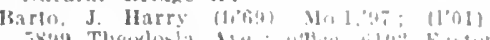

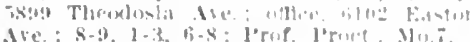

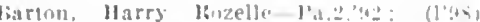

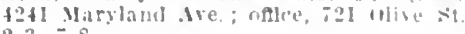

BASSETT, CHAS WALACE (b)

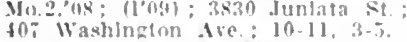

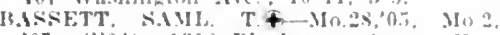
05: (1'0t): 130s Blackatonte ire, offer

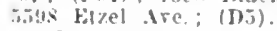

BAIER, PHAS F. (1,:59)

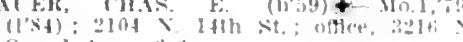

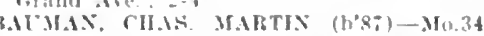
'11: (l'11): 3649 slumandnah st.

B.IIMGAKTEX, WAITFR $(1,73) \mp-$ Mo. "96; (1.00): 4310 Mnryland Ave.; uffee. Humlioldt Bliz.: : :-1: 1.*

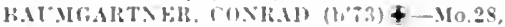
0.5: (109); 2108 lkussell Are

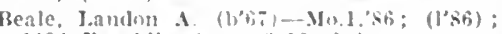
1432 Franklin Ave : $-10,2-4$

Beall, Gen. T. (l'30)-0; Cajit. I's.A, retred; ista Page Are

Beall. Katn W-. Mo.seng: (1) Delimar Blsod : 8-10, i-3.

Reall, Mary F. $(1,-6)$ Mn 5,95, IN 28.02 ;

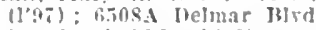

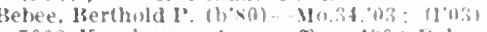
5000 Kensington Ire, office, fink Delmar Blvd. : 1-3, :-8; G.

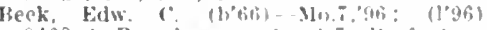

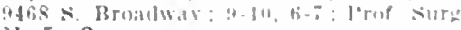
ฟ1) $\bar{i}: \mathrm{S}$

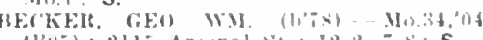

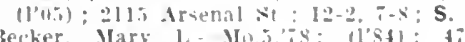

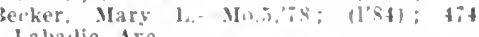
Labalie Are

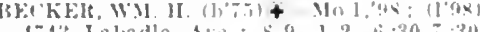

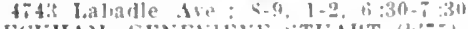

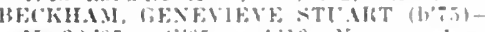

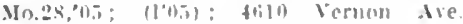

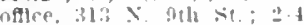

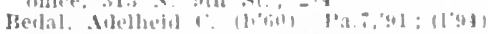
not in rractire: 345 lataspte

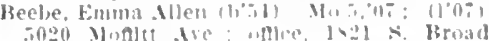
way: $3-\overline{0}, 7-8: G$.

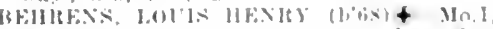

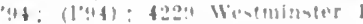

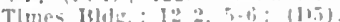

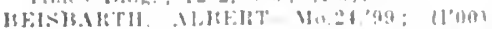

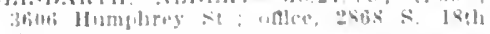
st.

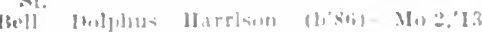
(1) l"1: rits Hompltal

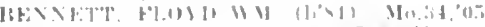

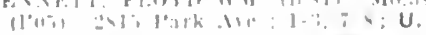

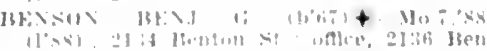

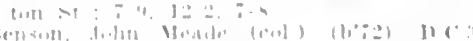

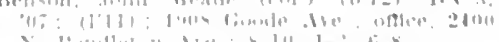
Ith low

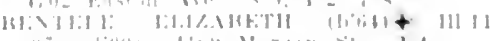
In

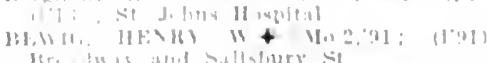

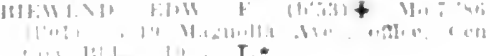

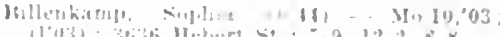

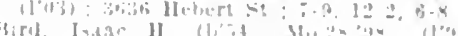

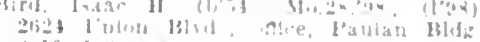
Qin,

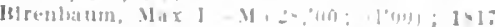
Wianlingent is

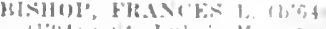

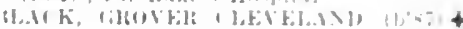

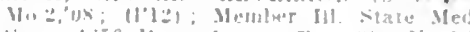

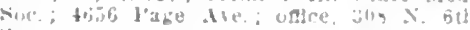

H..W K, WM. DAVIS (1,

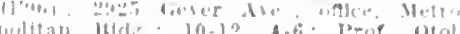

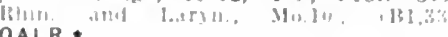

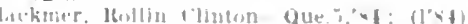

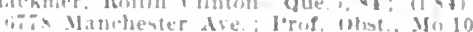

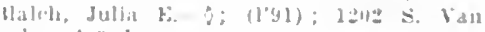
thentar atre.

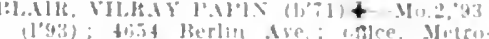

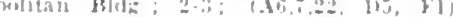
S.*

Blitkemore. Jumeph Marean - Vo.10.20 $\left(1^{\circ} 9 t^{\circ}\right): 5023$ Von Versen Are : 10.12, 6-

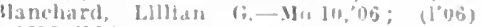
2 IIhittemore st.

Blank, Chats. F, Ile.2.4; (1'8\%); 365

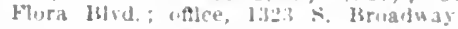

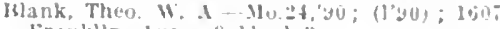

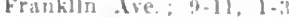

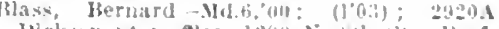

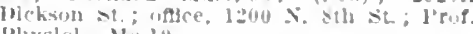

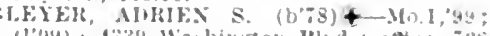

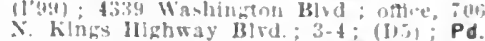

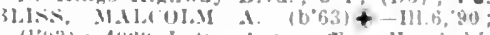

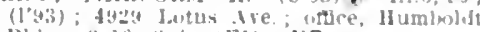

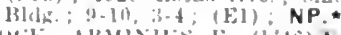

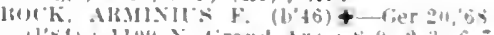

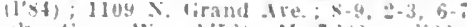

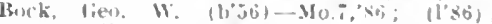

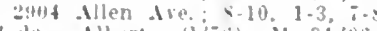

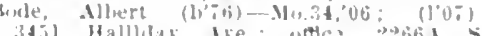
341 Hallhay Are, uttc

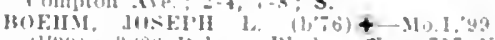

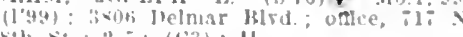

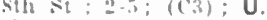

mevite litokrt (1)+1) - Moll'su

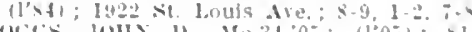
m

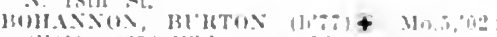

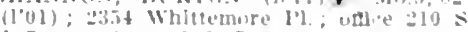

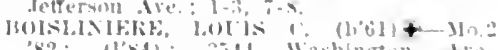

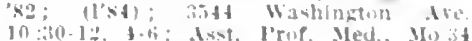

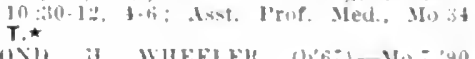
(1990); it Vanderenter Pl.; oflce, jos lizand are

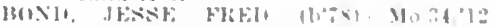

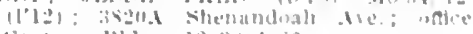

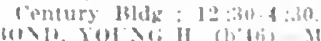

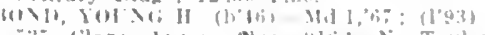

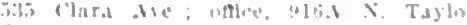

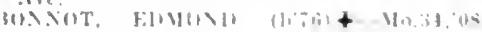

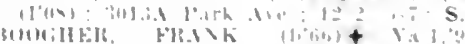

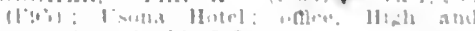

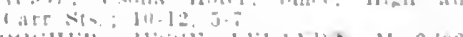

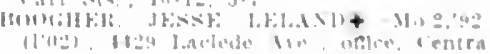

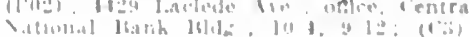
U.

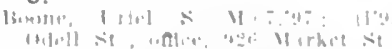

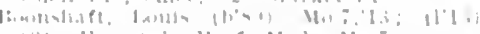

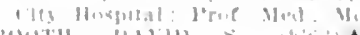

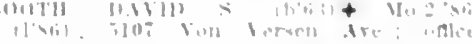

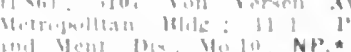

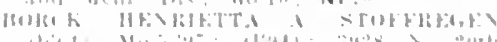
(1) G. G obci.

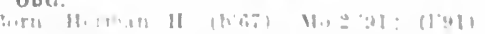


HOSSE, FIWIX H. (Litis) $\$-110.2,86^{\circ}$ (I's(3); 32I0 lireer Ale.: offlce, $1023 \mathrm{X}$ lirand Are. : y-1; (B:7); OpA.

BUSTICK, WIIL (b'76)+-Mo.8,98: (1'02) Marquelle llotel.

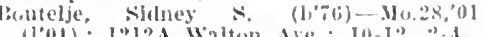
(1) $1212 \mathrm{~d}$ alton $\mathrm{AlC}, 10-1,2,-1$

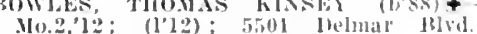

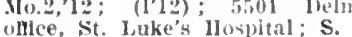

loyne, Walter Wm. (b's4) M(1.34,'13; Interu, st. Mary's Inflrmary

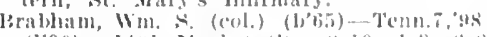
(1'00); Itul Mitrket

Bhil', ROLLIE 1.+ Mo.28,94: (10,5) (Wellston); oftece, til:o listston Ale.

BLAM,Fy, MTHIIt IIENIt (b)

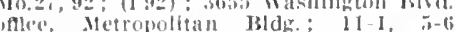
ALR.

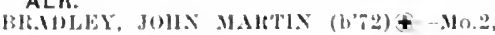
01: (I.01) : Washlngton Blvd. and sinral St. : $1-3, i-8 ;$ NP

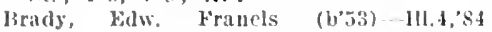
(l’5) : $917 \mathrm{~N}$. Cliannlug tre.; oftle,

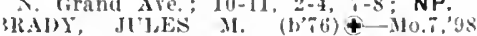

(1'9s); 14tir 'nlon Are.; 1-2; Asst. I'rop I'pd., No.34; (I).i); Pd.

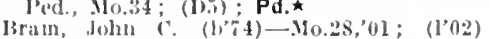

ratu, John (C. (h'it) -Mo.28,

Branul. ('harles- 0 ; (1'sis); St. Cyr Are.

IIANIt, ELI THOMAS (b's3) \& Mo.2, 08 (l'0s); I201 Tower lirove Ave.; Prot Anat Vo.t

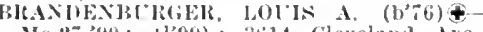
Mo 27,99; (1'99); 3614 (levelund Are. r-g $,-3,7-8 ;$ H'rof. Hist., Ho.7; Assoc l'rur. Med. dio. 10; ObG.

Brande, Ilerman I). (1064)-Mo.2,91; (l'tl) 2829 . lirand Are

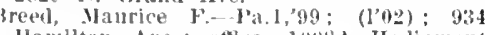
Ifamilton Ave.; office, loos I Hodiamont Are.

Breedlove, fames Thomas (col.) (b'7s)'Jenn. $, 12:$ (l'12) : 2038 Market st.

13remser, Wm. Liw. (1,76)-Mo.7,04. (l'0, ): New firand ("entral Theatre Blilg. ; $10-12,7-8$.

BREXNAN, JOII WM. 1. (b'81)-MU.T '06; (l'06i); 3113 Lacust st.; oflee, 284i

Brezany, Eugene (b'il)-\$us.3,97; (l'00); 1625 Cass, Are.; 9-I0, 3-4, T-8,

Bribach, Eugene-Mo.24,90; (1’90); 3648 S. Cirand Are, ; 9-I0, 3-4, 8-7.

3147 s. Jefferson Ave.

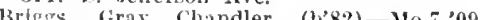
(J'li) ; 3518 ('lay Ave. offlee, Wall Bldg. ;

BIITCS, GLI IOLYG (b'T)-Mo.2,08; (1'08); 3101 s. firand lve: $8-9: 30,1-2$ $6: 30-7: 30 ; \mathbf{S}$.

rkkits, WALDo (b'55) - Tenn.1,76: (l'st); 579s Berlin Ave.; offee, Marina lidg. ; 10-11, 1-2; l'rof. Surg. IIo 7 . S Brin, Jacob-Ger.20,92; (l'94);3100A Lu(as Are. ; 9-10, 4-7; ObG.

Brinkman, Edw. W.-Io.2,'85; (l'85) ; 26.51 Olive St.

Broadhead, Wm. Carr (1,84)-Mo.34,08: (1'08); 4707 Virginia Ave.; offlee, 5600 Virminia Ave.; $10-1 \mathrm{I}, 3-4,7-8 ; \mathbf{G}$.

Broeker, Eugene Jeo (b'81)-Mo.34,11; (l'1I); 2202 North Warket St.; 9-1I, 1-3,

PROOKES, HEXKY S. (b'58) †--Mo.2,84; (1'84) ; $355 \%$ Lafayetie Are. ; $8-9,2-3,7-8$. BROOKES, THWOIURE JREWITT (b'8T)No.2, 09 ; (1'09); 3612 Lafayette Ave.

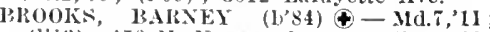
(1'1:3); $456 \mathrm{X}$. Newstead Ave.; offlee, $1806^{\circ}$ locust St. ; S. $\star$

BROOKA, FREDK, C.-\$10.24,00: (1'00)

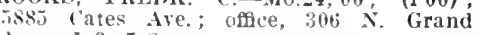
Ave; I $-3,7-8$.

ROONE, (i. WILET - Mo.1,72; (1'84) soos Delmar Blrd.

BHOWX, JOHN YOLNG (b'65) \&-X.Y.10 s.; (1'45); 5089 Walerman Ave.; office Vetropolitan Pildg.; $2-4$; Prof.' Surg. M(N, , $(A, 6,1,22) ; S . \star$

MI, WW, OLVILLE HARRY (b'-5)థffice. Humbolat Bldg.; 111-12; Asst. 1'rof.
Bruegel, Fillialieth snilth $\left(b^{\prime} 65\right) \mathbf{E}-\mathbf{M} 0.10$,

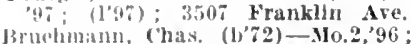
I:s06s. 5 tl st. : $1-3,6-8$

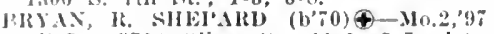

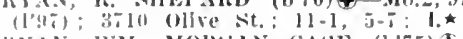
HIYA, WM. MORtiAN CASF $(b, 75) \$$

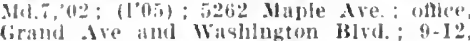
Grand Ave and Willilugton Blid. ; 9-12

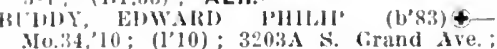
Io.34,10; (1'10); $3203 \mathrm{~A}$ s. Crand Ave.

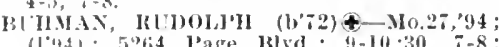
(I'4): 5264 l'age 13lvd.: $4-10: 30,7-8$; LD.

kulls, Florence Howard $\left(b^{\prime}, 7\right)-M o .10,12$; (1'12) : 3514 Morgan St.; $9-11,2-4$.

Bunter, Louls Fdw,-1I-Mo.5,'98; (l'98). i.0. Sullivan dre

Buntln, tirover ('leveland (1'84)-Mo.34, 13; (1'13); Lnited States Marlne Hospital.

Burllok, chas. llenry (b'8i)-Mo,2,'I2; (I'I2); St. Jouls Clity JIospital.

M'IUICK, JESSE JFROME (b'85)\&-Mo.2, os: (los) ; 2104 E. Grand Ave. ; office. Carleton blidg: 12:30-3.

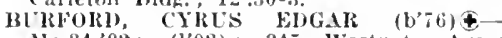
Mo.34,02; (1'02); 345 Westgate Ave.
offle, Century Bldg.; 10-1, 2-3; Asst. Prof. Gen.-Urh. Dis., Mo.34; (C3) ; U.ネ Burger, Floyd Ansler (b'89)-.Ho.2,'13; (l'13); st. Louls Cily 11 ospital.

Burgherr, Emll llenry (b'78)-11o.s4,"09; $\left(l^{0} 09\right) ; 4300$ N. 20 th St. ; $9-10,2-3,7-8$.

Burke, Wm. lidgar (b'i2) - Mo.28, 04 (l'01) ; 33i3 Market st.; $3-4,7-8 ; 0 p$.

Burleigh, W'm. J.-.llo.1,'83; (1'84); 4352 belmir Blid.

Burnett, Edwin Clark (b'54) - Mo.2,'83; (1'84); IRacquet Club: office, Century Bldg, : $12-2,5: 30-6: 31)$

BCRNS, IROBT., IR. (b'79) A-Mo.2,01 (I'0I); 4953 Mclherson Ave.; offlee, 4500 Olive St. ; $2-4 ; S . \star$

BURNS, STANEEX SHERMAN (b'89)Io.2,10; (1,10); 3534 Washington Ave. office. Grand and Washington Aves.; I0-I ALR. *

Burst, Emil Andrew (b'85)-Mo.34, 09 (I'09) ; 190:3 Cherokeo St.; office, 1901 Cherokee st.; $9-11,2-3,6-8$.

Bush, Wn. Bert (b'7)-110.28,'11; (l'11) ; $4893 \mathrm{~A}$ Bartmer Are.; office, 508 $\mathrm{S}$ Frand Are.

Bussard, Clifford Frank (b'86)-NIo.34,'13 (l'I3); Alexlan Brothers' liospilai.

BITLER, LOUIF P. (b'66) †-Mo.2,'88 $\left(1^{\prime} 38\right) ; 4475$ laclede Are.; oftice, 4661 llaryind Ave: $3-5 ; 0$ b.

Butler, Thomas Bernard (b'85)-Mo.34,11 (l'I1) ; 3606 Delmar Ave; offlee, Metropolitan Bldg.; 9-11, 1-4, 6-8.

Button, Wm. I.-Mo.24,92; (1'93); 430 Manchester Are.

13yrd, Ritchie Lilburne-Mo.24,99: (l'00) 1000 Pittner st.; offlee, $8321 \mathrm{~N}$. Broad-

BYRNS, ROBT, EMMETT (b'86)-Ma.28, $11 ; 3619 \mathrm{~N}$. I1th St.; osice, Itobert Koch IIospital; T.*

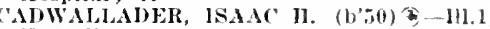
75 : $\left(1^{\prime} 78\right) ; 919$ N. Taylor Are. ; $9-11$.

CALE, GEO W., JR. (b'66)\&-Mo.T, 85 Ave.; Prof. Surg., iIo.34; (A22); S.ネ

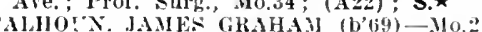
96: (1,97): I3I9 (lara Ave.: offee,

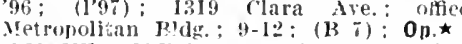

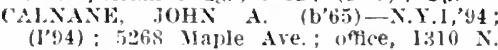
Grand Ave. ; 1-2, 4-5, 7-8; ObG.

('MMEHON, SOI.ON (b' 69$) \&-M o .28,03$. (1'0.3) ; 45.52 Ashland Are.; offee, Odd Fellows Rldg. ; 11-2

CAMPBELL, ARTIUR VINCENT $\left(b^{\prime} 54\right) \notin$ -Mo.2,'75; (1'86); 6137 Westminster Pl. offlee, Globe-Democrat Bldg.; 9-1, 2-5 Op. $\star$

CAMPBELL, GIVEN, JR. (b'66)థ-Mo.2 89: (1'92); 5165 Washington Are.

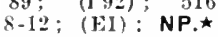

Campbell, James A. (b*4j) H-Mo.5,'69; (1'84); 5097 Washington Ave.; offlee Mermod-Jaceard Bldg. ; 9-1, 4-5.
CAMIHELL, OLJER II. (b'71)\&-Mo.1, '99: (l'(4t); 354: Washlugton Ave.; 1-3; Cannon, Chas. W. (b'5i)-D.C.1, 88 ; (\$) ; 4217 Washington Ave, office, 222 N. 3d sit.

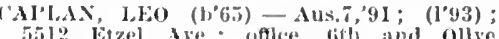
5512 Etzel Mre; oftce, fih and ollve Sts.; 10-1; (131,33); ALR.

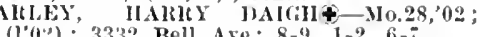
currlere, Chas louls (b'39) II-Ma.5,

(l'84); 2 I2s st. Iouls Ave, 8-10, $1-3$.

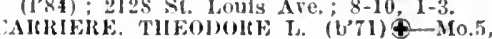
95; (1'95); 2128 St. Louls Are.; 10-12, 6-8.

(AIRIEIE, VICTOK ALVIN (b'70)कMo.5,'96; (1'96): Menber Ill. State Med. Soc.: 2203 bodler St. : 9-10, 1-3, 6-8.
Carruthers, Wm. Jj. (b'7I) 11-Mo.5,00; (1'00) ; 3339 Iaclede Ave.

CAItSOX, (IIRBOX w. (b'54)-Mo.1, $\% 8$; (1'83); 4104 W. Plne Blvd.; offlee, Cen tury lildg.; 12-2; 0b.

CAlusox, NoRMAX 13, (b'44) - -Mo.2,68; (l'S4) ; 4379 Westminster Pl, office, Humboldt Bldg.'; ( $45,22,23$, C1).

Case, Calvin M. (b'5 '̈)-Mo.2,'80; (1'80); (Osteopath); 5 i28 Etzel Ave.; offlee, Carleton Bldg.; 10-4.

Cataldl, (iuglielmo (b'il) - Ita.12,97; (l'06): 5719 Delmar Blvd.; office, 917 N. Fth St. : $9-11,5-8$.

('AULK, JOHN ROBERTS (b'81)€-Md.7, "06: (l'10); 5511 Cabanne Ave.; office,

Humboldt Bldg.; 10-1; (A23, C1); S.

'awood, John 11.-Mo.28,'95; (I'95); 4768 llammett Pl.; office, 2009 E. Grand Ave. ; 1) $-12,2-5,6-9$.

CHAWUOK, CIIARLES GILBERT (b'61) $\}$ -.Mlch.1,85; 3705 Delmar Blrd.; 3-5; Prof. Nerv and Ment. Dis, Mo.34; N.‡ (l'95), Fmllie J. (b'i3) H-Mo.5,95; Chambers, Jos. E.-IIo.18,81; (1'86); 4967 Page Blvd.; Prof. Fyn., Mo.7.

Chamblin, Baylis-H-ḾLo.5,'86; (1'86) ; 2427 N. Grand Aye.

Chancellor, Eustathius (b'54) - Va.1,76, IId.I,77; (183); office, 316 N. 6th St.; $11-3,6-7$

CHAPMAN, HENRY NORMANTON (b'66) - Mo.1,'93; (1'93); 3814 Washington Ave. : 1-3, 7-8; (D5); Pd.
ClIARLES, JoS. W. (b'68)@-Mo.2,'91 (1'91); 3640 Waslington Are.; offlce, Humboldt Bldg.; 8-1; (B4,27); Óp.

Chase, Frank E, (b'66)-Ill.12,'90; (1'91);
4328 Chouteau Ave,; office, 4234 Arco 4328 Chouteau Ave.;
Ave. : $9-11,2-4,7-9$.

Chattle, Wm. II. K. (b'i9) - Mo.i,'05 (l'05); 74I6 Gravois Are.; office, 407 N. Broadway

Cheatham, Anderson Wm. (b'81)-Ill.6,09; (1'10); $100 \mathrm{~A} \mathrm{~N}$. Jefferson Ave.

Cherry, W. W. E.-Mo.10,'91; (1'91) ; $44: 6$ Washington Blvd; offlce, olívla Bldg.

Chiles, John S. $\left(\mathrm{b}^{\prime} 7 \mathrm{~T}\right)-110.34,07 ;\left(\mathrm{I}^{\prime} 07\right)$; I744 Chouteau Ave, 11-2, 4-6; OALR.

Chiles, Joseph H. (b'75)-Mo.34,03; (1'03) ; 1744 Chouteau Ave.

Chopin, Geo. F.-Jo.1,96; (1'9i); 8548 Chureh Rd.; office, 8111 S. Broadway.

Chureh, Harry L.-Mo.7,94; (1'94); 924 Brooklyn St

C1ANCY, JAMES FRANCIS (b'88)-Mo.34, '12; (1'12); St. Mary's Inflrmary. (I'04) : Washington Hotel; office, Delnar Bldg. ; $1-2,7-8 ; \mathrm{S}$.

Clarenbach, Wm. A. $\left(b^{\prime} 75\right)-M o .28,08$; (1'09) ; 2803 locust $\mathrm{St}$.

CLARK, IIA ROSS (b't5)£-.Ho.2,09; (1'04); 1211 Clara St.; offlee, Metropolitan Bldg. ; $1-2$ :30, $7-8$; S.

Clark, Jolm Franklin (b'si) -.110.7,'04: $\left(1^{*} 03\right) ; 1715 \mathrm{~N}$. Jefferson Ave.; offiee, $1717 \stackrel{5}{*}$. Jefferson Ave.; $9-10,1-2,6-8$.

CLARKE, BOONE WM. (b'74)@-Mo.2,97; $\left(l^{\prime} 07\right)$; 3431 Morgan st.; vince, veiropolitan Bidg. : $2-4$

CLAI'S, OTTO F-NO.27,'97; (1'97); 3513 Hebert St.; office, 1406 st. Jouls Are.; $8: 30-10,1: 30-3,6: 30-8$

Clausen, Henry W.-No.28,'94; (l'94) ; 2812 Ileramee st.

(IEVELAND, ANIIEW HAVEN (b'83)\&Iass.5,'10; St. Inthony's Hospital. 
Clithero. Wm. IIarvey (b' $\forall t)$ - Mo.'12: (I"12): Ni. Inthony's Hoyplat

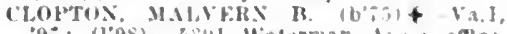

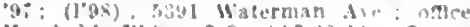

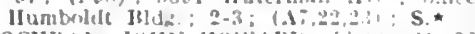

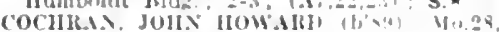

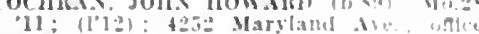
Me:rounllean Hid : $3-\bar{a}$

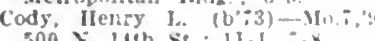

$300 \times 1+$ th st.; $11-1$,

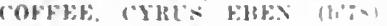

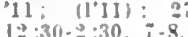

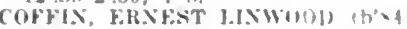

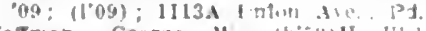

(1.05); 6i01 Mlchlgan Are.; 8-10, 1-3, $7-8$.

Cogan, Ithllp-110.1,90: (1'011; fils.

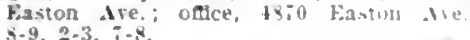

COLLASOWITY

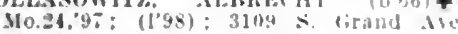

$10-12,2-4,-8 ;(B=11: 0 p$.

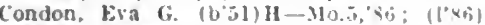

5018 A Helmar hird. : $4-2$.

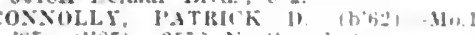
\$5: (1'85): 25510 X. (irand are.

Conrad. Adolph II. $(6,84)-310.34,13+$

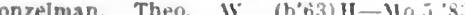

(1'84): 5043 Vernon are: $8-9,1-2,-0$

coOK GEO EDW Are.

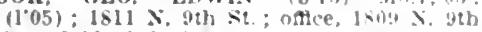

St. : 8.10, $1-3,6-8$.

COOK, JEROME F. $(1,84)+\ldots .10 .205$

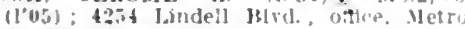
polltan Rlulg: 2.

I. 4 -Ky,1,92: (I'94): 937 Hamllion Ale.; offlce, 4500 Olive Si.

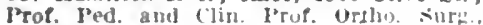
Mo.10; Or.

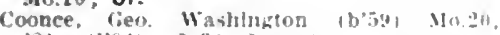
84: 11 's4); 2930 Cass Are.

COOPER, JAMES OSTAR (b'at) II as

07: (1'07): 1111 $x$. (irand lie

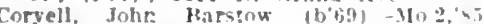
$\left(1^{2} \times 5\right) ; 30.98$ Brondway: $8: 311-94.60,2-4$

Cotsell, Walter 1.-Mo.10,78; (1'84); 1141

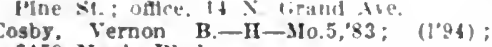
i459 Maple Bird.

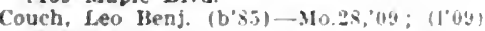
5942 Maple Are

COUGHLA, WH. THOMAS $\left(\mathrm{b}^{\prime}-3\right)+-110$ ? 01: (1'01); 2613 Washington Are: nitce Metroplitan Bidg, ; 2-3; Asst. I'rop. surp Mo.34: (A.2)

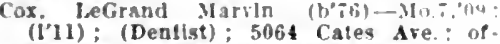
ace, Central Natlonal Bank Bidg.; 10-12,

raddock. Azzore W (col.) (1, -2a - Tenn . 02: 110021: 4183 11. Belle st.; oftce 16ut $x$. Leftingwell cte.; $8-10,1-3,6-8 ; T$

Crapp, Lererette H. (b'i4)-Mn.;in: (1100); 4000 freer Ave.: once. 30.31 Warne Are. : $8: 30-9: 30, \quad 1-3,6: 30-7: 30$ CREVELING HANLEY CLAY (b'-3) Mo.1, 95 ; $(1 \cdot 93)$ : (Webster Grores) : offled firand Are. and olive St:; 10-1, ;-1 (131,33): AL. *

Crooks, Amor A.-IIo 23,98: (1998); 322033 laclede Are.: offlice, Holland Blugin: 10.4 ALR* *

CHOSSEx, HAIEY STIRCEON (b'ba) Mo.2,"92: 1 (1'92) ; 54:3 hartmer Ave.: nce, Metropolltan Hug.; 1.3 ; 1.11.2.7, G.

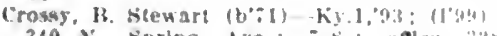

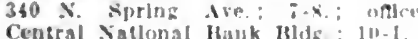

cowles, thos 5 (1):59)-0.8. 2311 x. I'ninh Hud : $11-1,5.8$

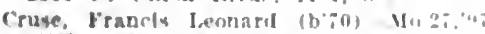
(1'95) : 5601 Ciartelid Are : $9-12,3-5$

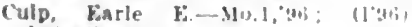
latuadle Ave

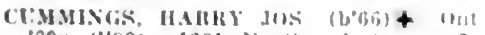

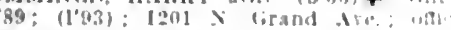
Metropolitan Hude: : $2-3$.

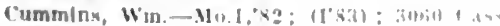
Are.

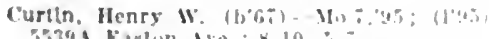

CRTIS ARTHER NICHOLA (bét)

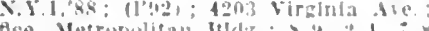

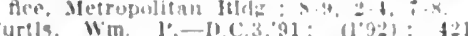
roluey are.

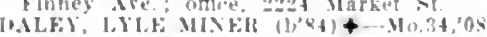

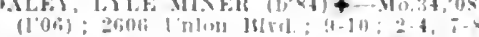

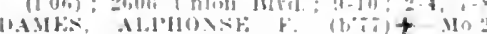

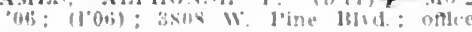

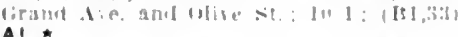
Al. *

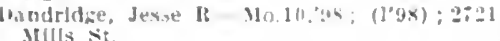

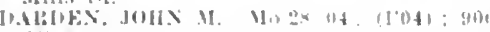
Ollie sit.

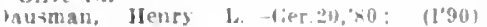

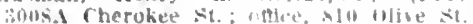
$11+3: 319 ; \mathbf{G}$.

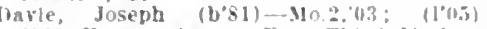
iiles kaston Are. ; whre, Third vatheral Bank 1slde.: 9-11, 1-2, 4

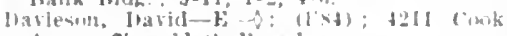

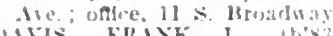

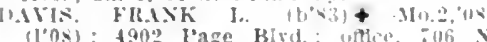
Kingshlyzliway Rled.

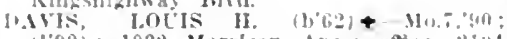

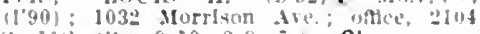
$\therefore 11$ th st. $9010,0-3,7-2 ; 0$ ob

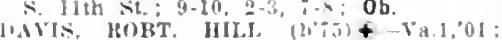

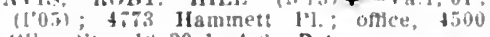
ollse st.; 111:30-1, 4-11: D.*

IDAVIS, THOMAS MILLER (b'8i)

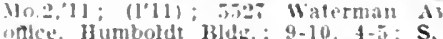

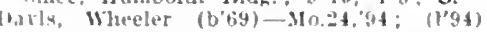

5.5. Mcl'berson are; office, ins $x$ hingulghway Mird.

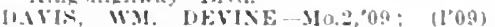
ingid s. Grand Are.; offlce, toll Chouteitu die.

Tharis, Wm. Jortian (b't5) Ma.34.'06

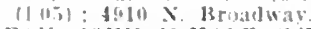

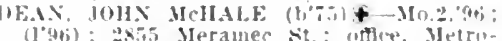
monliean Bldg.: J-3; Asst. l'rof. Surg. (I) $34:(1 \geq 2): \mathbf{s}$

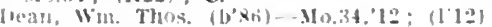
(iit) lluipltal.

theatherage. Wn. W--Mo.28,94; (195)

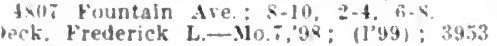

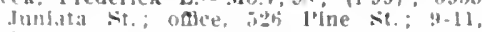
$\because-4$

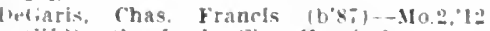
(1'l0y); St. Louls CIty IInspital.

letirest, (has 1t. (b'a) Mo 2 - 4 (1)

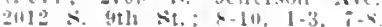

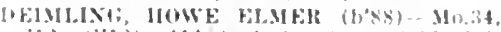

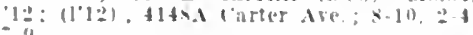

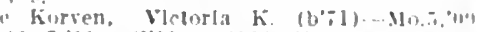

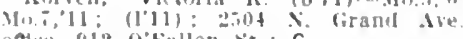

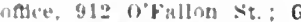

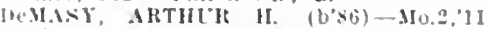
(1'11) : 100\% X. "toth st.

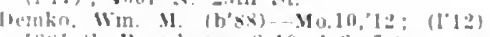
$1321 \leq$ Mroadway $;-10,1-1,=-10$

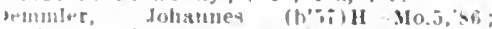
(1' $(6)$; 140 s 1'ark Are.: $8-9: 31), 2 \cdot 3,6-7$ :

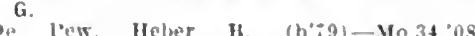

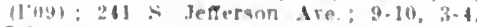

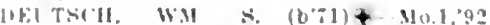

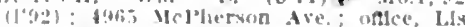

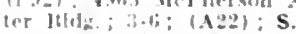

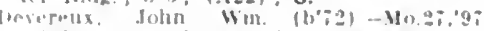
(1'97): 12:5 Tuwer firole Ale.; 10-1

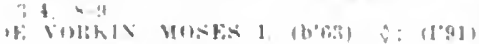

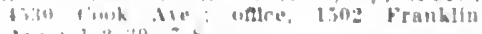

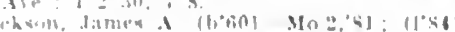

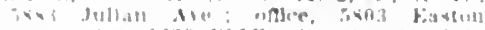

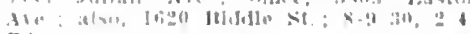
Po

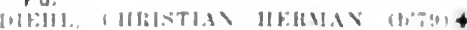

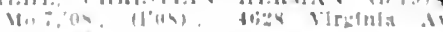
$\because 4$. is

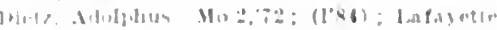
it.uk Hits:

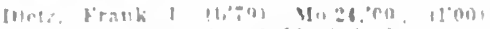

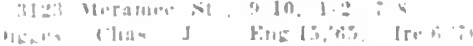

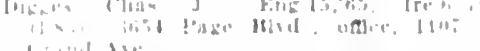

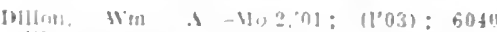

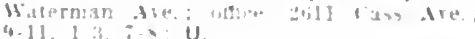

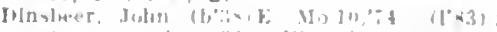
not th luratce I. Herbert $\rightarrow 1$

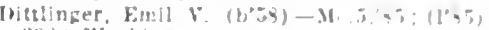
292" Washington Are.

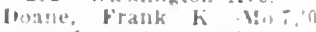

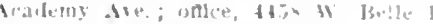

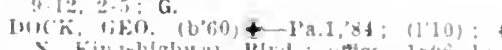

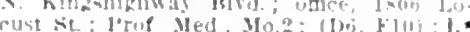

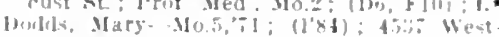

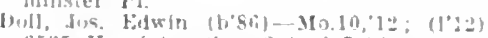

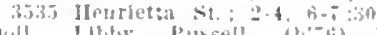

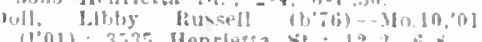
11'01): 35.35 Henrlets st: 19-2 b-t.

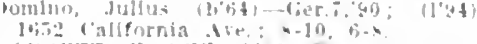

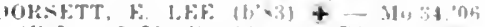

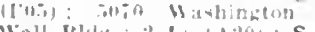

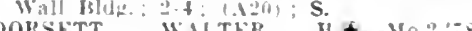

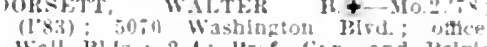

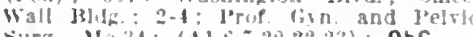

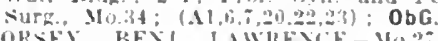

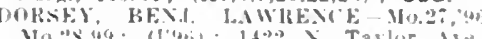

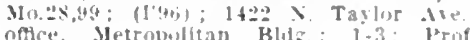
(i)

bougherty, James 10.- M10.24,01: (1001) 1900 Belt ire.

D) unes, Mlchael-Mo.1.91; (1'y1); $1: 11$

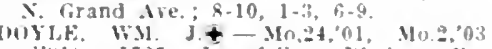

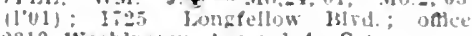
.2313 Washlngton Ave.; $1-4 ; \mathbf{S}$ *

1)rake, Francls 0. (b'40)-Mo.2,66; (I'33) lei24A (11) re St.: 8-12, 2-5.

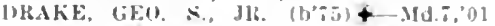
(I"11); \$\$00 l.indel] Hird, linlel milli.

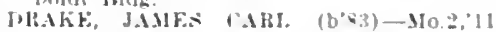
(1'11): St. louls (7ty Hospltal

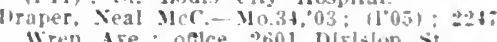
Wren Are: oflce, otsol Dirliton st.

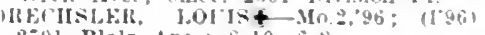
$2: 01$ Blalt Are.: $8-10,6-8$

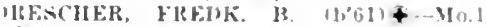
st: (l's4); 2134 Stansbury st.: s'-1t (Mrlygs, hoy C. (b'9n) - WII. 5,13 ; (1'13) amod North Market st: $010,3-30$ Wuck, lonts A. - I10.0

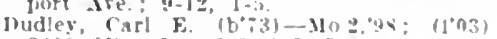
3 tion olle st.: $8-9,1 \cdot 3,-$

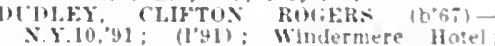
othe, themlcal Illd

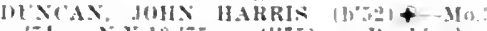

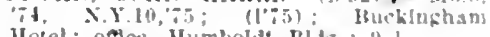

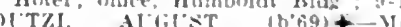

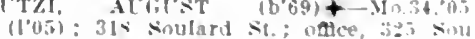

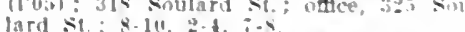

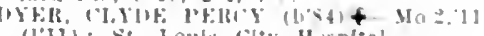
(l'H1): st. Jouls rity Hespltal.

oyer, Darid A-Mo.1.81: (1'93); 4036.1 Lerington Ave.

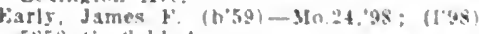
$5 x$ is ciartleld Alve

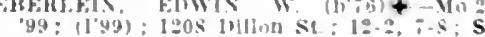

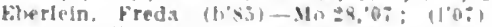
logs follun st

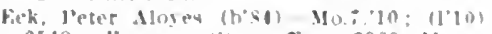

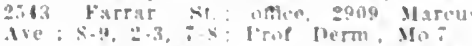

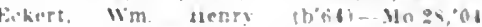

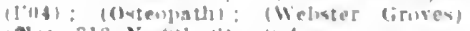
sth st: $: 4$.

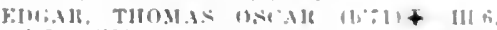

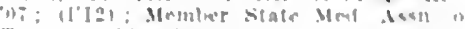
TLL.

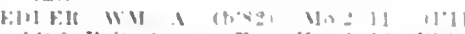

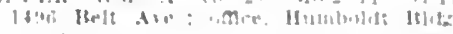
Fin

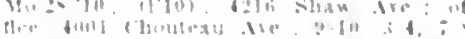

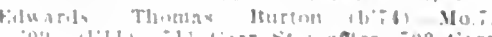




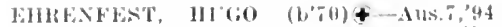

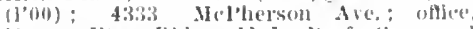
Metrofolitall Bklk.; 11-1; J'rof. (iym, and (13)st., No..34; $(.12,20)$; ObG.

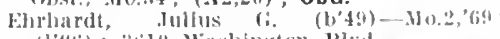
(1'4ti): 3tisto Wishingt on 13lod.

EIIRIRIPT, RTIOLIPH T. (b'65) + Ho.2

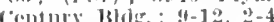

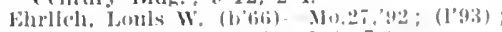
18028 sith st: $8-10,10$

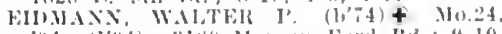
104: (1'4) ; 31till \$organ Ford Ral.; :-10

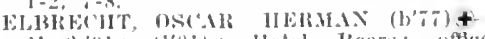
N10.2, (11: (1'01): I10tel Iscers: oftice.

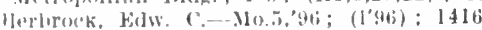
Hedert st.

ELIEMSIECK, ATGIST (b't4) \&-Mo.10, 1:2; (I'12); 2548 University sit.; 10-12,

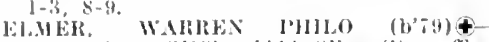

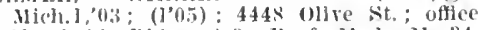

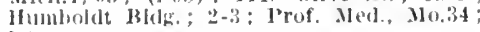
I.`

Emerson, Chas. (C-Mo.5, $(0) ;\left(1^{\prime} 03\right) ; 3870$ Eastont Are.

Fmitr, Charles 11.-No.7.49; (I'99); 5378 Flurlssant Ave

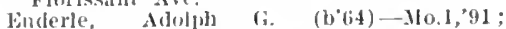
(1'M1); 524 ('hestnul st.

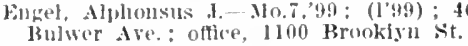

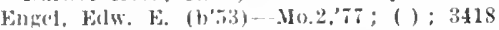

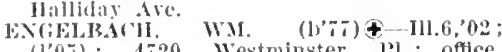
Hlumboldt Rlda. ; 2-3; Prof. Med., No.34; I. $\star$ mboldt Bldg.; 2-3; Prof. Med., 110.34

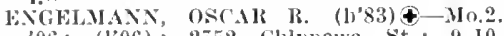

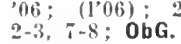

EAMUAN, MARTIN FEENEY (b'68)૯X.Y. Bird.; office, llumboldt Bldg.; 10-1 Clin. I'rof. Derm.. MIo.2, ; (C2) : D.*

Epperson, Ernest i. -Ia.1,"83; (\$); 4124 thephersen ave.

Epstein. Jarob M.-Mlo.2,93; (1'93) : 1323.1 Bayard Ave; office, 4103 Easton Are.

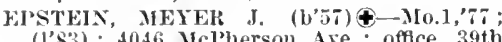
(l'83) : 4046 Ifcl'herson Are.; offlce, 39th and olive Sts.; $10: 30-1,5-6: 30$.

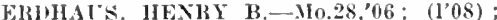
-222 Oakjand Ave.; oftice, 1204 Tanner

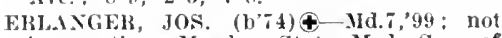
In practice; Nember State Ned. Soc. of Wis.; 4248 W. Pine Blvd. ; Prof. I'hysiol. IIo.2

Erust, Edw. I.-Mo.27,00; (I'00) ; 4129 Cleveland Are.; office, 4000 Clouteau Ave. : $9-11,7-8$.

Ernst, Edwin (Chas. (b'85)-Mo.2,'12 (1'12) ; 2522 I'nlversity St. ; offlee, Mnllanphy Hospital.

FSSELBRUEGGE, FREDERICK C (b'83) 8-9, 1-2:30, 6-7:30; $($ A20); G.
(A20)

Ftherton, Monte $C$ (b'86́)-Mo.34,'12 ; (l'13) ; 3323 Pine St. Mo.28,'05; (l'05) ;

5i14 Page Ave, ; offee, Chemical Bldg. ; 10-12, $5-7: 30$.

EYERETT, ALFRED EDW. (b'T3)↔-MO.7, 02: $\left(1^{\prime} 01\right)$; $2150 \mathrm{E}$. Harris Ave.; offlec, Metropolitan Bldg, : $10-1,2-3,6-8$ : U.

Evers, Edward (b'49)-110.2,'72; (1'84) 1861 North Narket St. ; 2-3, $7-8$

EYERS, EMLE T $\left(\mathrm{L}^{\prime} 80\right)-\mathbf{M} 0.2,06 ;\left(1^{\prime} 06\right)$; 1238 Hodiamont Ave.: $2-4, \tau-8$

Fwerhardt, Paul Jacob (b'90)-Mo.2,'12; (1'12); Missouri Paeific Hospital.

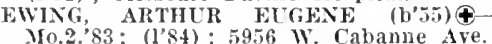
office, Ietropolitan Bldg.: 9-12; Clin

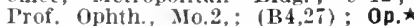

WWING, FAYETTE CLAY (b'62)-Pa.2,'84 (1'ss): (Webster (iroves); office, Centur

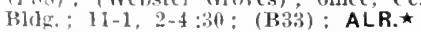

EYERMAN, CHAS. HFRMAN (b'89)Ylo.34;11; (1'11); 1722 S. Jefferson Ave.

Eyermann, Christian Herm (b'56)-Mo.5, 's: : (1'\$1) ; 1122 \$. Jefferson Are. ; 9-12,

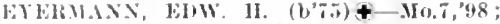

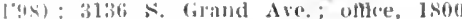

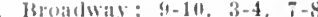

bermann, huby 1 -.Mo.s, 05 ; not ln

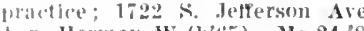

Faluer. Herman W. (b'tis)-Mo.24,'88; (1'88) ;

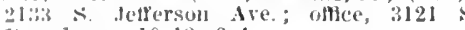
lkruldway: 10-12, 2-4.

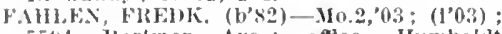
rint bartmer Are, oftce, IHumboidt Blige: : 10-11.

FAIRCHIL, EMHA STATELA FITEA-

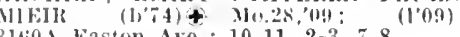
3160.1 Easton Ave: $10-11,2-3,7-8$

FALK, 1011N C. (bo3)—-110.2,90; (1'90) $4 . t$ is page 131 vil. ; $8-9,2-4,7-8$.

FAlMER, 1'ERCY 木. (b'is) $4-\mathrm{M} 0.2,99$; (1'09); 5329 Vernon Are.; offlee, Metropolltan Mldy. ; $1-3 ; \mathbf{N}$.

Fitrar, John (1'fallon-Mo.28.96: (1'96)

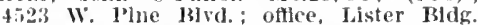

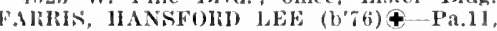
00; (1'11): Menther 'T'enn. State Med. Assn.; 4960 Laclede Are, office, Frlseo Employees' Hospital ; s.

Fatultaum, Adolph W.-Mo.2,03;

(l’03) ; 3212 T. $92 \mathrm{~d} \mathrm{St}$.

FAY, HAROLD WY. (b'86) + - Yo.2,'10 (l'10): 3904 Hartford st.; oftice, $2320 \mathrm{~s}$ Grand St. ; $9-10,1-3,7-8$

Fethrenbacher, Harves Iel (b'85)-Mo.34, '13: Intern, st. Louis city Hospital.

Feigenbaum, Gerson-1Id.6,00; (1'00) ; 2910 Itickson St.

FHINATEIN, LEON A. (b'87) †-Mo.34, 09 ; (l'09) : 5886 Easton Ave.; $2-4,7-8$.

Feld, Willard Carl-Pa.1,92; (1'92); 510 Pine $s t$.

Ferguson, Roy Harrison (b'86)-Mo.34,13; (ity lospital.

Fernander, Julius Baymond (b'90)-Lat.1, 13; lntern, St. Louls Clty Hospital. FICHENKAI, HARRY L. (b'48)-Mass.1 69; (1'84) ; 1933 Lynch St.; 8-10, 2-4.

Field, Henry I. (b'60)-Mo.27,'91: (1'91); 6825 Scanlan Are. $7-10,2-4,7-8$

Finkelstein, Ignaz H. (b'63)-Mo.7,'07 ; (b) ; 200I Washington St.

Finley, Alice B.-110.37,'94; (1'94); 3402 P'ark Are,

FISCHEL, ELLIS $\left(b^{\prime} 83\right) \uparrow-N 10.2,08$; $\left(l^{\prime} 08\right)$; 5284 Westminster $\mathrm{Pl}$.; office, Iletropolitan Bldg. : 2-4; $\mathrm{S}$.

FISCHEL, WALTER (b'81)↔-M0.2,05. $\left(l^{\prime} 05\right)$; 5284 Westminster Pl. ; office, Ilumboldt Bldg.; $8: 30-9: 30,3-4$

FISCHEL, WASHINGTON EMIL $\left(\mathrm{b}^{\prime} 50\right) \biguplus-$ No.2,'־1; (1'84); 5284 Westminster 1'l.; office, Humboldt Bldg. ; 2-5; Clin. Prof. Med., Mo.2; (D6).

Fischer, Jos. A. (b'42)-Mo.2,' 74 ; (Assistant Physician).; 3634 Connecticut st. ; 10-12, $2-4$

Fischer, O. H. (b'76)-Mo.2,99; (1'99); 4562 Cook Are.; offlce, Carleton Bldg. ; 11-4.

FISCHER, OTTO F. (b'î1) $€$ - M10.1,'95; (1'95); 3728 Arsenal St.; office, 2315 Pestalozzi St.; $9-10,2-3,7-8$.

FISCHER, WALDEMAR E.† - Mo.27,98; (1'98) ; $3634 \mathrm{~A}$ Connecticut St.; office, Wall Bldy. ; 9-12, 4-6; (B27); 0p.*

FISIIER, ARTHUR OSCAR (b'84)థ-MA.7 ,09; (1'12); Washington University Hospital: $\mathbf{S . \star}$

FISHER, JUNIATTUS A. (b'73)-Mo.7,'99; $\left(1^{\prime} 10\right) ; 5924$ Easton Are.; $9-1,6-8 ; R^{\star} \star$ FISHER, ROLAND FREDK.' (b'86) $€$-Md.7, 12; (1'13); 611 N. Jefferson Ave, ; office,

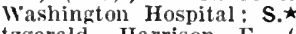

Fitzcerald, Harrison F, (b'6i)-Mo.i,'92; (1'02) ; 3131 Washington Are.

Fitzpatrick, Jos. P.-Mo.1,'89; (1'89) ; 1472A Clara Are.

Fitzporter, Alonzo Leo (b'84)-Mo.34,'10 ; $\left(l^{\prime} 10\right) ; 4604$ MIcPherson Ave.; offlee, 3549 Olive St.; $9-12,3-5,7-8$.

Fitzporter, John L.-MIo.2; $; 1$; (お) ; 1516 Chestnut St.

Flader, Otto F,-Mo.î,'04: (১) : 5149 Delmar St.; office, $1102 \%$. Vanderenter Ave. $9-11,2-4,6-8$.

Flader, Robt. H.-Mfo.1,97; (1'99) ; 3457 Shenandoah Ave. ; office, Manchester Bank Bldg.

Flanders, Jesse P. (b'55)-Mo.2,'75; (1'84); 1402 Aubert Ave.; office, 800 olive St.; $10-1,2-5$.
Fieck, dohn Lewis (b'73)-No.34,03; (1'03); 2500 S. 12ll St a ollice, 2614 S. Broadway $10-12,2-4, i-9$

Flelschman, Jerome $\left(\because-0 ;\left(1^{\prime} 0 J\right) ; 1626 \mathrm{~N}\right.$. $14 t h$ st.

FLEISIIER, MOYER S $\$$-Associate Fellow-rat.1,0t; $282 x$. Taylor Ave.; office, liarnard skin and Cancer llospital; $\left(\mathrm{F}_{2}\right)$;

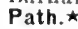

FLEMING, ALBERT W. (b'59)†-Mo.1,87: (l'8i); 4262 Flura Blvd.; office, 922 Vandeventer Are.

Flemlng, Thomas Simpson (b'87)-Mo.3t, 13; (1'13): City Hospital.

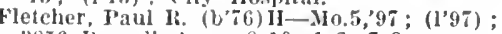
3856 Russell Are, ; 8-10, 1-3, $7-8$.

Floyd, Frank M. (b'66)-MI0.27,'97; (1'97): 4400 Forest 1'ark Blyd.; 10-12; S. $\star$

FLURY, JOHA ALBERT (b'86)-Mo.2,12; (1'12); 3726 W'ashington Bivd.; offlee, Metropolitan Bldg.; $9-5$; Op.*

FLNN, (:EO. WI. (b'85)థ-Mo.34,'10 ; (1'10): 3653 Folsoin Are.; offlee, Grand and Park Ares. ; $1-3, i-8$.

Forder, Wm. Carver (b'78)-Mo.2,'01; $\left(1^{\prime} 01\right)$; not in practice; $735 \mathrm{~S}$. 4 th $\mathrm{St}$;

FOLSTER, OTTO E. (b'59)-Mo.2,81; (1'85); 4954 lindell B1rd.; office, $318 \mathrm{~N}$. 6th St.; $9: 30-2$.

Fortner, $A \operatorname{mos}$ Hall, Jr. (b's3)-La.1,'13; () : City llospital.

OSTER, WM. HEARY (b'69)-Mo.34,'08: (1'08);3553 Caroline St.

FOSTER, WM. HENRY (b'76)\&-M0.34, 05 ; (1'05) ; 4139 ('houteau Ave.; offlee, 4065A ("houtean Are.

Foy, llaud, If. (h'68)-N.Y.6,91; (1'91); 5062 Delmar Blvd.; 11-3; G.

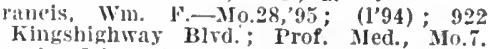
lrank, John N. (b'48)-No.2,69; (1'83): 1723 Waverly Blrd.; offlee, 1321 Ś. Broadway : $7-10,1-2,6-7$.

FRANK, KONRAD-N.Y.8,00; (1'00); 5954 Kingsbury Ave, office, 501 whittier St. FMANT, WALTER EMIL $\left(b^{\prime} 86\right) \notin-M o .2$, '10; (1'10); 2024 S. Jefferson Ave.; office, 1321 \&. Broadway; $8-10,1-3,7-9 ; \mathrm{T}$.

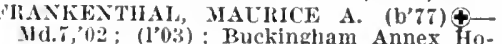
tel; office, 4500 olive St.; 11-1: S

Franz, H. Kurt A.-H-No.5,'84; (1'84) ; 2932 Barrett $\mathrm{St}$.

FRAZEI, HAL S. (b'Tz)-N10.7,98; (l'03): 2110 Lafayette Are.; offlce, 1111 Chouteau Ave, ; $10-12,1: 30-3,7-8 ; \mathbf{S}$.

Freitag, otto W. (b'64)-Mo.10,04; $\left(1^{\prime} 05\right)$; 5554 Terry Are.; 8-10, 1.3

French, Benj. F. (b'35)-1'a.8,'80 ; (\$) ; 5053 Delmar Blid.; office, 810 ollre st.

FREULENSTEIN, WM. H. (b'74)-3Ho.24, 99; (l’t3) ; 4.564 Chouteau A re. ; offlce, 4583A Gibson Are. : 11-12, 3-4.

Freund, Julius Theo. (b'80) - Mo.34, 04: $\left(l^{\prime} 05\right) ; 5.307$ shaw Are, ; 8-10, 2-4, 6-8. 'REUND, NEWTON M. (b'83) \&-M0.2,04: $\left(l^{\prime} 05\right) ; 1440 \mathrm{~s}, 18 \mathrm{~h}$ St, ; office, $1224 \mathrm{~S}$. Broadway ; $8-10,1-3 ; \mathrm{S}$.

FIREDMAN, JACOB (b'56) $\uparrow-M o .2,78$; (1'84) ; 4653 Berlin Are.; office, Carleton Bldg.; $12: 30-2$; I'rof. Ther., Mlo.34.

FRIELINGSDORF, EWALD H. (b'65)థMo.24, $89 ;\left(l^{\prime} 99\right)$; 3322 Humphrey Ave.;
offee, 2202 s. Rroadway; $9-10: 30,3-4: 30$, $7=8$.

FRIES, WM. AUGLST (b'61)థ-Mo.2,83 (1'85); 3209 shenandoal Ave; offlce, 1544 S. Broadway; 9-10, 3-4, 7-8.

Froelich, Edwin Jacob (b'86)-Mo.10,12: (1'12); 12th St. and St. Louis Are.; 8-10, $1-3,7-8$. 2301 s. Grand Ave.; after $8: 20,2-4$. Frumson, llerman (b'53)-Mo.2,89; (1'92); 3060 Hawthorne Blyd.; $2-4$.

Fruth, Otto I. (b'74)-Mo.2,'98; (l'98); (Dentist) ; 3060 Hawthorne Blrd.

FRY, FRAXCIS RHODES $\left(b^{\prime} 53\right) \oplus-M 0.2$, 79; (1'79) ; 4609 MrcPherson Are.; office, (E1,13).

Fry, Walter F. (b'5 - No.27,01; (1'01) 1495 Arlingt on Ave.; $9-10,2-3,7-9 ; \mathbf{P d}$ FtCHS, WALTER H. (b'69)ॄ-N10.24,91; $6: 30-\tau: 30 ;($ A 20$) ; 0$ bG. 


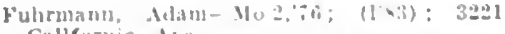
Callfornia dre.

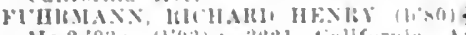

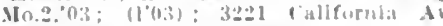
onice, Metrogultian IBlak : :-4

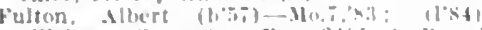
(Webster firoves): onsce, ?fil \& Hroad

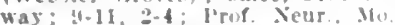

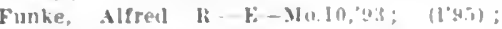
titi spalding Ale.

fำKIH)

furlong, Jos. Alphonse (h'se) - Mo it: i"

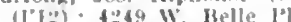

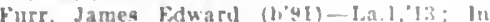

tern. sit. Inula City Hospltal.

Ciaehler, Idolph X.Mo.In:60; (1'00) Cabanne lie; once. 14 al ollue st

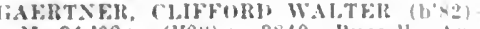
Mo.34.0s: (los): 3840 Ituriell Are offce, $60 \mathrm{f}$ Mloblgan st, $2-3, ;-s:$ G

IAJ.L.I(IHER, JOHX F (b)

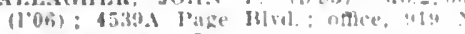
sarah st. : 3-ti, :-

Galloway, Wn. L. (b'60) H - Mass,., (1'8s) : $1232 \times$ Taylor Ave ; 2-4, h.8

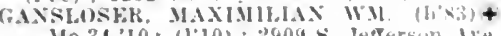

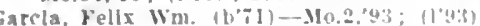
3165 \& Grand Are: $2-4$

ciarlltz, Arnold (b';)-Mn.10,13; (I'Lo! senlor Assistant Ihyslclan, Clty sault. rium.

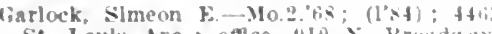

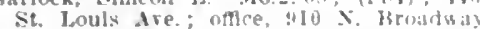

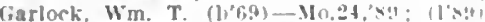

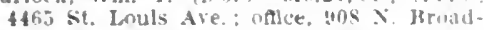
way: $8=10: 30,3: 30-5: 30$.

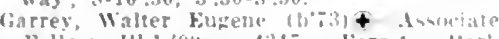
Fellow-111.1.0!: 4:34: Forest loith Blrd.; Assoc. I'rof. I'hrsiul. Mn.:

liarrison. Ilarvey W. Mu.2s, (lli Salonat linfrerilts.

Garst, Yirgll Paul (b'so) - Mo.39.13; (l'l3) 3534 Ilenrletta st.; oftce, St, Iouis rity Ilasiltal.

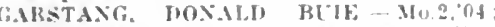

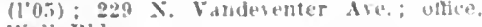
wall Hidg.

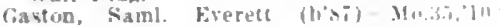
(I'I0): 2729 ('ass lie.; ofuce. ill $x$ Grand ire

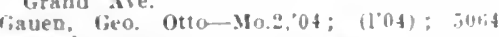
Maple Are

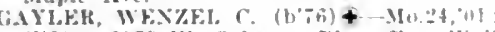
(l'01); 6058 16. Cahanne H. ; oftlee, Will Bldg. : 3-4; ObG.

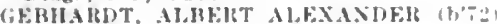
-Mo.7.09: (l'11); 2920 chippend sit. $8-10,1-3,7-8 ; \mathrm{S}$

GFHILUNG, FUGFE ('HAS. $\left(\mathrm{b}^{\prime}+0\right)+$ Mo.7,70: (1.01): 385\% Westmluster I'l. (A2); $\mathrm{G}$.

FHLLIOUS, (IFO) $(1,70)+-$ Ger 20,94 (1"00): 436fi Mcloherson Are.: oftion. Metropultan Bldh: 2-4; (A2,20); ObG

GrTTYs, IIF:NKY B. (b'5)+-310.34,0: (1'03): 3.25 Washington A

(ETTYS, SE:NTER L. - Mo.1,95; (1\%95)

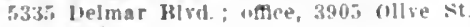
$11-1,4-6$.

Ghlo, Jos. I'. $(6,74)-M o .27,97 ; \quad(1,03)$ fige Washington Ale, offee, $1300 \mathrm{~A}$ 0llre St. : $9-12,2-4$

Gibbs, Fred le liranule (b'8I) - Mo.2.'1: (I"13): st. Anthony"s Huspltal.

Cibson, Ilayld M. - I - Mo.5,90; (1'?0) 43:" Washlngton 13|rd.

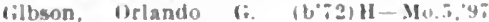
(1'9i): \$14i Vernun Are: onfe, 1310 I Jefrerson Are : $11 \cdot 10,:-3,:-8$

dilbson. Itobt. If (b'b6)-Ky 5,90; (1'11) 4600 Westminster sit.

lillbert. W. Wallace - II-Mo.n,"98: (1'9k) 2934 Sulliran Ave : oflee, 2400 (ass Ate

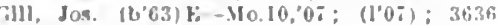
Nehert St.

Giss5, Custarns Anoluhue $\left(h^{\prime} 66\right)-$ Mo 24 97; $(1.97): 250 \%$ s. Jefferwon Ave

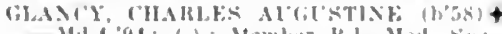

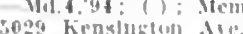

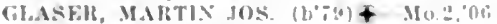

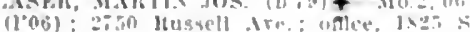

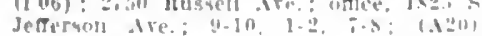

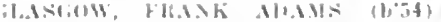
Non"

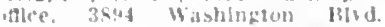
$(10,23) ; \mathrm{ObG} *$

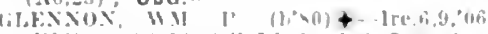

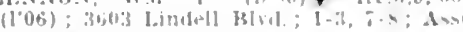
l'rot. Inat., Mn.34: S.

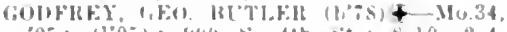

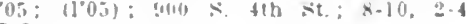

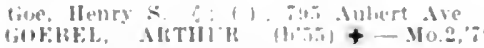

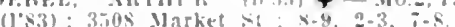

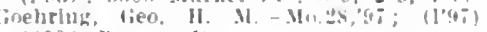
1400 A Iutger st

oessilug. Mahel banHorn (biti)-Mo.I0, 'Su: (l'03): 1209 Virtolk Ave

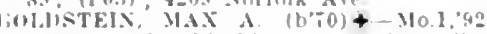

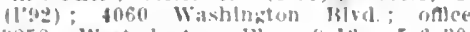

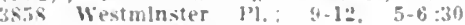
$(|B|, 2,3,5,33):$ ALR.

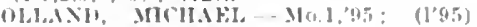

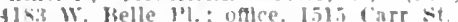

chlman, Chas. H. (h+4) H-l'a.6.69; (2) Rucklupham Hotel: aftce, Hister Bldg S-10. $2-1$.

GOOINWIX, FDWARIJ J. (l, fit) + Mo.2,94

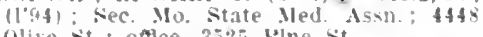
ORIOS. FItAK XEWTON (b"

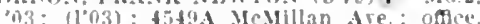
l.later lidg.: 8-0:30, $2-4 ;(\mathrm{D} ;):$ ob.

lORHAM. FR.NK DeVOKE (h'ss) +-Mo.2.

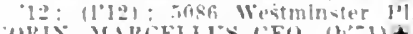

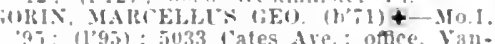
deventer and ollve Nis.: 11-1:

iottichall, Imos WIIson (1,"SS)-Pa.2,'I3; Intern, st. Louls (ity Ilospltal.

cowans, Charles W. (b'i5) - Mo.2,99: (l"y?): fio13 (ates ive.

(iR.MUWOHL. BLTIERFORD B. H. (bT:)

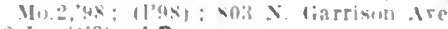
$10-1:(1: 3):$ LD

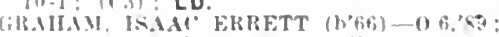

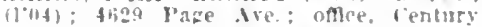
Bllg: $12: 30-2: 0$.

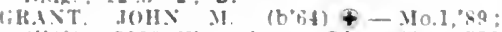
(1's9): 5053 Westminster PI.: nffer. 536 x. Tayler Are. : 11-1. i-s: (122): S.

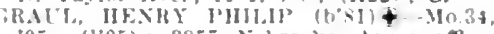

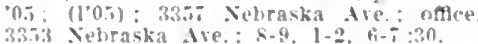

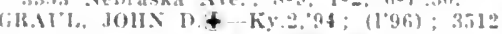
crltenden st : nftlce, 3 uos ollre st.

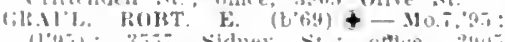

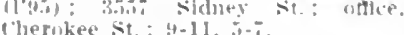

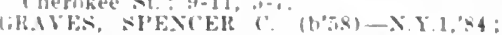
(1.85); Huckingham Hotel: unlee, Lister HIdp: $: 5-4, I-4$

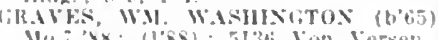

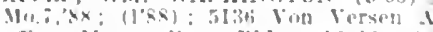

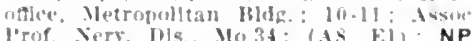

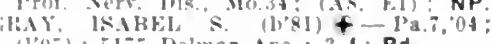
(lon:

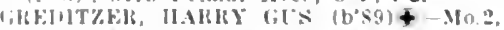
"12 (l'la) : 43ris.l Maryland Are

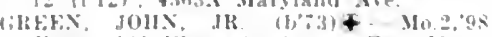

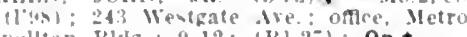

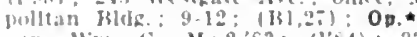

reen, Wm. in-Mo:2, $33:$ (1's): $337 \mathrm{x}$

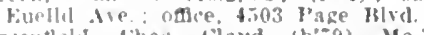

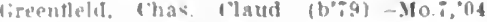

(1): 411 ! Wablington [H]d, U

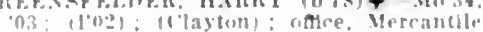
Truat llds: $U$.

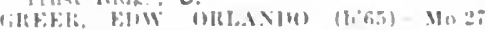

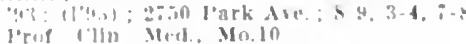

lostrishl lie

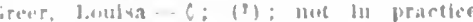

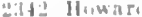

reer Vark (1,09) - Mo.34:13; (I'1:i) liolinetale lluspleal.

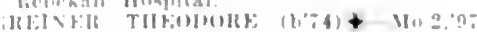

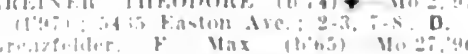

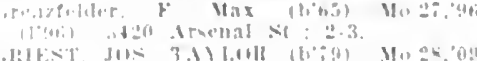

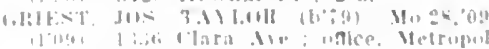

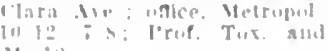

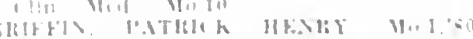

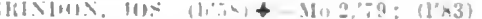

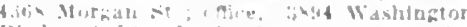

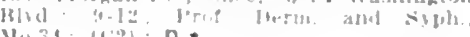
arlot, libert Jacol Indg.; $:-1: 5$.

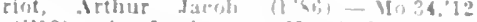

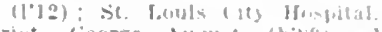

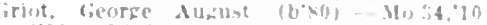

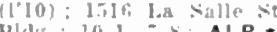

Mrly: 10-1, ;-s ALR. *

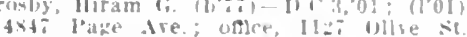
$12-2,-1 ;$ Or.

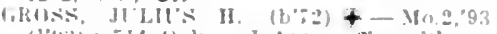

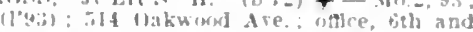

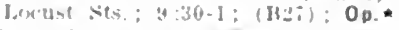

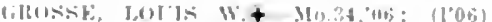
Bhim Juniata st.; oftee, fou s. 14th st

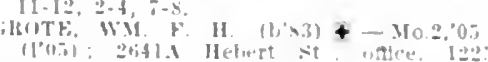
Sillivia Ire.: $4-111,7-8: 30$

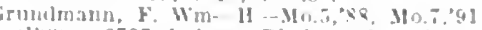

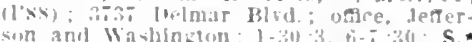

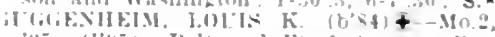

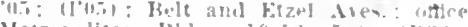

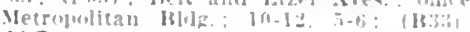
ALR *

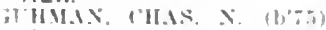
(1)113); Is:3 rabanne Ive

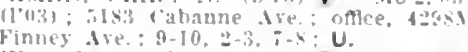

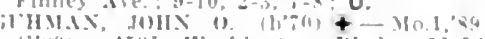
(1) 4 ; thil Washlngton J15d: II-12.

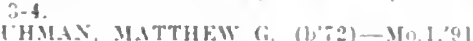
(I'?I) ; $3505 \times$ Jefterson Ave; $: 2,2-3$

G] NIFIACH, CHAS IRMIN (bos) \&

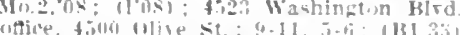
AL."

AL. NIFIAACH. WM.

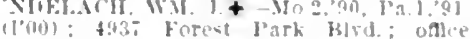
llelmar Haldz.

Gil NII.ACII, ARTHIR (1, -

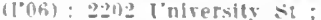

molitan IMI; : $2-4 ;$ S.

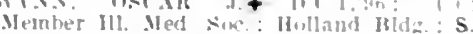

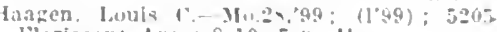
Florisant Are : $8-10,-4 ; U$.

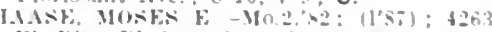

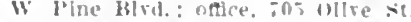

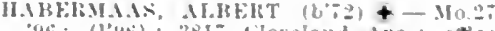

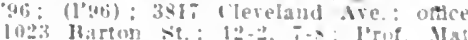
Med. Ther

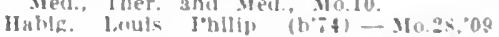
(1'09); 2914 $x$. Newsteal Ave: : :30Ji) $: 30,1: 30-3: 30$, $: 30-5: 30$

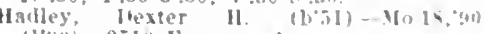

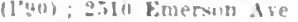

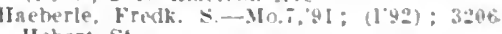
Hehert St.

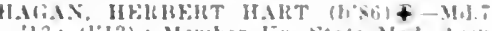
$13:\{13)$ : Nember hy. Ntate

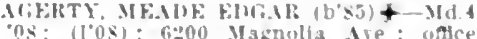

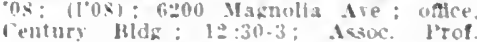
lien,-I rm. Suro, Mo.10: U.*

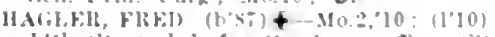
lth st. and
Huspliti:

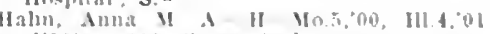
(100): 3832 shenamosh tre

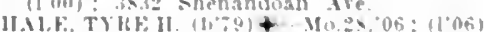

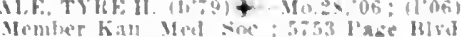

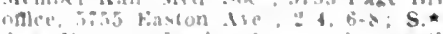

IIaley. Sayoma J. of $1: 1$; not in practlet 4a:- Wiarne Are.

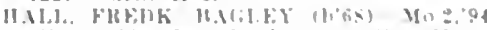

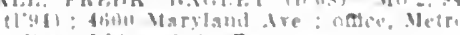
fmilltan Mlige: 1 \&: R.

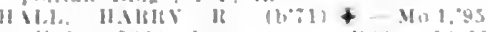
(1'4ai) : ised fater

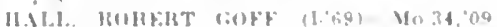

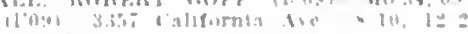

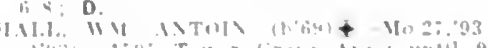

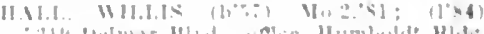

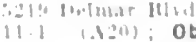


HALLAM, JHIN C. $\left(b^{\prime} 76\right)+M 0.27,99$; (I'9:9); Mermod-Jaccard Bldg; 11- 1 , 2-5. Halsted, Fredk. Snlth (b'88)-Mo.34,'I3
(I'13): Barnard Free skin and cance IIospital.

HAMEL, ALBERT II. (1)67) \&-Mo.2,990 (1'90); 3519 Arsenal st.; $8-10,1=2: 30$, $6-8$

HAYILTON, JMMES W

(Nee Mi. Vernon. III

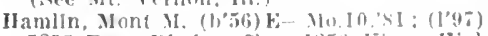
525.5 Page Blcil: offlce, Itsil king lligh way Blvil.

Hancock, Clifford Alphomzo (col.) (h's90)Tenn. :, 1: : (1'12); 40ti3 Finney Are.; of flee, 26,0

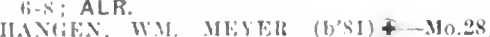
IANGF, IIM. MESFil (i)'SI) +-110.28

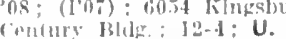

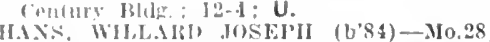

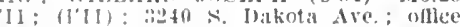
4532 Virmlnia Ave ; $8-9,2-4,7-8 ; \mathbf{G}$.

IIASERR. IIERMAN A.†-MO.l,98; (1'98); 36 I Delmar Blefl. $(120)$ : $\mathbf{G}$.

Hanson, Wn. Lulwig (b'92)-Mo.2,'13; (1'13): City Hospital.

HAPl'EL, HORACE E. (b'84)-Pa.2,10; (1'12): 5038 Washington Blvd.; oftice Olive St. and Vanderenter Are; $1-3 ; \mathrm{S}$.

HARBOIT. SCHIYLER C. (b'68) Mo.34 03: (I\%33); 1520 Marcus Are, ; $7-9,1-2$,

HRUAWA WM A -Mo,7,70; (l'95) 4527 Maryiand ire, oftle, Lister Blog. $10-1,4-6$.

Harder, Flidela (b'46)-Mo.1,78; (I'84) 8015 Florissant $A$ re.

Hardesty, Toel Wise (b'85)-Mo.34,'12 ; (I'12) : sit. Louis City Hospltal.

IIARIV; JOS, (b'61) - Mo.2,"92; (1'92) 6.511 illchigan Ave, offlce, 7602 S. Broadway ; $9-11,2-4,7-9 . ; 0$ bG.

HARDY, WM. FRED. (b'75) $\odot-M 0.2,01$ (l'01); 234: Alblon PI.; ofllce, Metropoll

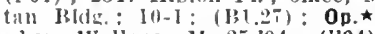

Harker, Wallace-Mo.25,94; (I'94); not In practice: 5661 Cabanne Are.

Harkins, Hugh C.-Mo.20,'S4; (1'87); 4600 Cook Ave.

HARLAN, WARREN E. $\left(b^{\prime} 76\right) \uparrow-M o .28,02$ (]'02) ; 3403 Bell Are. ; offce, 1719 Market St. $10-1,2-4,6-8$

HARMAXN, MARTIN F. (b'82) †-Mo.7,'03 (1'03) ; 3441 N. 9 th St.; $8-10,2-4,7-9$ Iarmann, 1'eter if. (b'76)-Mo, 7,98 , Mo.2s '00; (l'98); 3938 I'age Blrd.; offlce, 2343 olive St. : 2-4, $7-8$; Prof. Gín., Mo. 7 .

Harnagel, Fredk. Henry (b'86)-Mo.34'12; (1'12) : 5005 Delmar Are.

HARXISCH, HFNRY I. (b'58) (-Mo.2,'81 (l'84) : 2407 S. 18th St.; 11-1, 6-7:30. HARRAL WALTER E. (b'i7) †-Mo.28,03; (1'03); 6.201 Etzel Ave.

Harrell, Chas.-Mo.5,04; (ち); 1310 Montgomery St.

HARRIS, DOWNEY L. (b'75) -M-Mich.1, '99: (l'00): 4946 Park V'lew Pl.: offlce. Mctropolitan BIdg.; Prof. Hy. and Prev. Ved. Vo.34; (F⿻) Bart.

Harris, Irwin 'J.-Mo.2,01; (1'02)； 4935 Fountain Are.: offlce, 1105 Carr St.

Harris. Mae sherer (b'68) E-Mo.33,'01 (l’01): 3528 Olire St. : 1-3, 7-8: G.

Harris, I'earl Q.-Mo.28,'03; (1'03); $2151 / 2$ N. 13th st.

HARRIS, RUFLS CHAS. (b'76) †-Mo.1,'98 ; (l'98): 5747 McPherson Ave.; office, Lls ter Bidg. : 9-10, 1-3, $7-8$; Prof. Phys. Diag., Mo.i Harris, William Iohn (b'52) H-Mo.5,75
(I'84) ; 3514 Lucas Ave.; at 10, 2-4;'S.

Hartmann, Henry C.-Mo.2,'82; (l'89) ; 1815 Lafayette Are.

HARTMANX, JACOR ARRAHAM (b'69)థIo.2,96: (I96): $930 \mathrm{X}$. Kingshighwa Blrd.; office, 1224 S. Broadway; $10-12$,

IIartwell, Harold Willis (b'58) H-Mich.1, 83. N. Y.9,84; (1'89); 6015 Clemens Arc.

HARTWIA, OTTO A. (b'43)-Mo.1, 80 ; (1's4); 3908 Clereland Are.; offlce, 219 X. Ith St. ; $10-12,2-4$.

larres, Thos. I.-Io.1,76; (1883); 5439
II iskell, Hosese ('hester (b'81)-Tenn. i, II I'11) ; $4915 \mathrm{x}$. (compton Ale ; oftice, 3500 Lawion Ave. $9-10: 30,1-3,7-8$

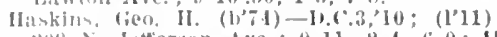

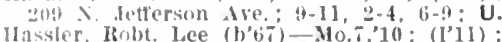
2.).33 Arlington Ave.

Jitlen, James 0.-Tenn.8.94: (I'97) : (19steopath); 616A $x$. Taylor Ave.

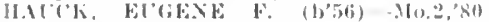

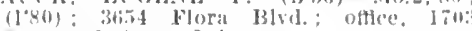
A. Girand Ave.: 2-4.

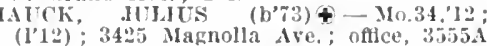

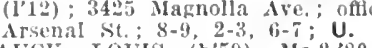

IIACCK, LoU'IS (b'59)-Mn.2, 80 ; (I'85) 3658 Commectleur St.; oftice, $3555 \mathrm{~A}$ Ar senal St. : 8-9, 2-3,6-7

llauck, siml. Walter (1)'81)-M10.34,04 (l'05); 1702 A Market $\mathrm{st} ; 5-8: 30:$ D.

(l'y5); 4259 Marvland Ave.; oflice, liet (195) ; 4259 Maryla

HAWKEI, CHAS. IROSS (b'81)-Mo.34,'l2

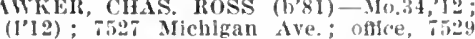
Michigan Are.; 8-10, 1-3, $7-8$.

HAWKER, WM. DAVIS (b'73) 11 ; (1'id) : 930 Hamilton Ave 40.34 IAWLEY, NELSON J. (b'72)థ-Mo.2,'95 $(1,95) ; 3864$ Cleveland Ave, offlce, Grand Are and ollire St.: 1-3; 0 bG.

HAWLEY, THOMAS S. (b'37)-Mo.2,61 (1'84); 3065 Easton Are.; $7-9, \quad 12-2$, $6-7: 30$

Hayman, Arlsta F. (b'74)-Mo.28,03; (I'03) 5923 Horton Pl.; office, Mermod-Jaccard BIdg. ; I0-1, 2-5.

Haylies, Frank W. (b'74)-Mo.34,'11; (1'11) ; $1416 . i$ Arlington Ave; office, Easton Ave and I'nion Blvd. ; 8-11, 1-4, ij-8.

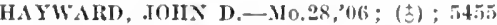
l'age Ave.; Prof. Anat., Mo.10.

Hearn, Nifred Gilliam (b'74)-Mo, 24,'48; ( ) Missouri l'acifte Hospilal.

Heaton, Wm. Danl. (b'89)-II.
tern, St. Louis City IIosiptal.

tern, St. Louis City Irosiptal. ECKER, CHAS. IHENRY (b'75)-Mo.2,'11; (1'11); 1924 St. Louls Ave.; offlee, City Sanitarium; $\mathbf{P}$.

Heeley, Danl. C. (b'45)-Mo.1,67; (l'00) 1805 N. Sarah St. : 9-11.

lleideman, Christian (b'71) - Mo.27,92; (l'92); 3221 N. 20th Nt; ; $8.9,1-3,6-8$ Mary Ave.

Ifeinrichs, Julius $\mathrm{Clay}^{\circ}\left(\mathrm{b}^{\prime} 76\right)-$ Mo.1.99 ; (l'93); 4056 McPherson Ave.; office, Marina Bldy.; 9:30-12; Prof. Ophtir. Io. 7 ; 0 p.

IEITHAUS, ALOYSIUS SEVERNE (b'90)Mo.34,11; (l'11) : 2919 Accomac St. : D. Von Versen Are.

Helbing, II. H. (b'69) E-Mo.10,'95; (I'96) $1208 \%$. Klngshighway ; until $9,3-5 ; \mathrm{S}$.

HELWIG, HENRY J.-Mo.2, 92 ; (1'92) 4538 Washington Blvd.; offee, 2804 Mar ket $\mathrm{St}$.

Hempel, Ellzabeth Robenla - Mo.28,'09 (l'09); 5412 Florissant Ave.; 8-9:30 $1-2: 30,6-7: 30$

HEMPERMANN, LOUIS H. (b'73) \&-Mo.2, 96; (l'96); 3508 Russell Are; office, EMPELMANN, THEODORE C. (b'85) Mo.'08: (l'0s); 1653 S. Spring Ave. office, Grand Ave. and ollve St. ; 1-2, office, Grand Ave. and

HENCKLER, EMIL H. (b'76)-Mo.34,00 (100); 3500 N. 14th St. ; $8: 30-9: 30,6: 30$ $7: 30$.

HENDERSON, FRANK L. (b'65)€-Mo.1, ' 8 ; (l'94); Humboldt Bldg.; 9-1; B1,27); Op.ћ

Hendricks, Chas. (b'75)-Kan.3,99; (\$) 1379 Temple Pl.; offlce, 222 N. 3d St. $9-4: 30$.

HENKE, IUGCST FREDK. (b'73) 96; (l'96); 3201A St. Louis Are,; offlce, $1637 \mathrm{~N}$. 19th St.; $9-10,2-3,7-8$.

HENKE, CHAS. F. (b'84)-Mo.34,05; (l'05) ; 1823 Menard St. ; 8-10, 2-4, $7-8$.

Ifennerich, Jos. Paul, Jr. (b'83)-Mo.2,'13 ; (l'13); 3603 Utah PI.; office, 2921 s Broadiray ; $10-11 ; \mathrm{S}$.

HENNERICH, JOS. P. (1)'59) \&-Mo.2,'87 (l'87) ; 3603 Ctall I'l.; office, 2921 S Broadway ; 8 -9.
HENRY, ROI3T. Y. (b68)†-Mo.5,91; (1'96); 2838 S. Cirnud Ave.

MENRY, ROLLA IIARRISON $\left(b^{\prime} 85\right) \downarrow$ Mo.34,08; (1'07) ; $2757 \mathrm{~A}$ Accomac st.

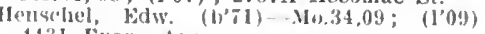
$443 \mathrm{I}$ Evany dre

IKNSKF, ANDIRE ADOLFIIUS (b'52) Mo.2,75, X.Y.5,75; (I'84); 1504 St. Jouis $8-9,1-3,6-8$.

NASKE, ANUREW' C. (b'83) +-Mo.2,06 $(106) ; 4133$ kirans Are.; offlec, 4103A HERCILNROEISER, LOLIS CHAS. (b'72) +-M0.5, $96, M 0,7,02 ;$ (l'96); Grand and Lafayctte Aves. : 9-10, 2-3, 7-8.

IEIRANN, GUSTAV J-MÓ1, $85 ;$ (1'85); 3204 Hawllorne BIrd.; onlce, 802 Morgan Sit.

IERMANN, IIENRT W. (1)'55) †-Pa.2,78; (1'\$3) ; 3654 Delmar BIrd. ; 2-4; N.ネ

IEIRICK, HAROLD COLTUN (h'80) \& In.28,04; (1'05); 1414 Blackstone Ave.; office, $\mathbf{s}$.

Hertel. Aibert Lafayette (b's1)-Mo.34,0 $\vec{i}$; (1’07); 3618 Connecticut $s t$; office, 3155 S. Grand Ave ; $9-11,7-8$

HELEK, PHILI' JAMESON, JR. (b'71)No.2,95; (l'95); 3520 Vletor St.; offle,

Heter, Scott (b'9i)-Mo.2,'i2; (1'12); 3520 Victor st.

HEUKRMAXN, IIENRY WM. (b'81) Mo.34,04; (Y'05); 3106 Chippewa. St. ; of -

fice, 1637 S. Broadway; $9-10,2-3,7-8$.
IEUMAN, GEo. W. (b'82) 4-Mo.34,03 (l'03); 6104 N. Broadway; office, Frlsco Bldg. ; 1-2.

HEWITT, WALTER ROY (b'85) - Mo.2, '08; (l'08); 5212 Delmar Ave.; offlce,

Heyenga, I'. Harren' (b'71)-Mo.10,'10 (1'11); 4919 Loughborough st.

HEYEI, CHAS. (b'39) $\$$ Ger.6,'63; (1'83) 910 N. 10 th St.; $8-9,2-3,7-8$

HOBEE, FDW. H. JR. (b'75) - Mo.1, 97 . $\left(l^{\prime} 97\right) ; 4952$ Park View Pl.; offlce, Metropolitan Bldg. ; 9-1; (B2i); Op.

Higgins, James Rálph (b'87)-Mo.34, 13 ; (1'13); St. Louls City Hospital.

IIlgson, John W. (b'61)-Mo.5,02; (l'01) ; 4149 Cleveland Are.

HILD, RELNHART I. (b'69)-Mo.5,'09; (1'09); 4053 Cook Ave.; 1-3, 6-8; Assoc. Prof. Clin. Med. Mo.10: S.

Hill, Alice Laura Scott-Ia.4,00; (l'10) ; 4001 Shenandoah Are.

HILL, ROLAND (b'68)థ-Ont.3,'90; (l'91) ; 535 Clara Are.; office, Lister Bldg.; 1-3; $(A \tau, 22) ; \mathrm{S}$.

HIll, Russell S.-H-Mo.5;00 ; (1'01) ; 7 SunAre.

HYCHEY, FRANK (b'67)Ф-Mo.1,94; (1'94); ( $F_{.} 19$ Yale Are, Unirerslty); offlce, Hunboldt Bidg. ; 1-3; (A20); ObG.* IIRSCHI, W.M. T. (b'72) $4-M 0.27,99$ (1'99) ; 2306 St. Louls Are. ; 8-9, 1-2, 7-8. Hitchcock, Sarah Josephlne J. (b'42) H-
Mo.5,75; (ち); 6265 Columbla Ave.; 8-12. HOBFRECHT, CARL ALBERT BECK (b'83) -No. 2,09; $\left(11^{\prime} 09\right) ; 2603$ Cherokee St.

HOCHDOERFER, DANL. F.๑-Mo.24,'89 ; (l'89) ; 3100 S. Grand Are.

HOEFFER, JOHN PAUL (b'67)-MO.2, $92 ;(1 ' 92) ; 2120$ S. Grand Ave.; $9-10$,

Hoelscher, Wm. A. (b'65)-Mo.7,'93; (1'93); $4103 \mathrm{St}$. Louis Ave.; offlce, 1501 ' $\mathrm{N}$. Jef ferson Are. ; 8-10, 7 -8.

Hoffman, John J. (b'60)-Mo.27,95; (1'95) ; 1917 Virginia Ave; offlce, 705 Olive

HOFFMANN, PHILIP (b'70)-Mo.1,92 ; (1'92) ; 3657 Helmar Blvd.; 10-12; (A3,22, D5) : $0 \mathrm{r}$.

Hogan, Edw. James. (b'65) E-Mo.10,'94; (l’94); 2018 Olive st. ; $9-5$.

HOGAN, ROBERT EDW. (b'87)-Mo.2,09; (l’09); 346 N. Boyle Are.; offee, City Infirmary.

HOGE, MOSES W. (h'61)@-Mo.2,'8?; (l'97) ; 3693 W. Pine St.; offlee, Metropolitan BIdg. ; $1: 30-3$; NP.`

HOLDENRIED, WM. FDW. (b'73) - Mo.34, '08; (1'08); 4504 iIrginia Ave. ; 8-9, $12-2$. 
Holley, claude Dlckerson ( ( 81$)-M 0.34$. $10 ;(10) ; 3520$ Washlngton Are

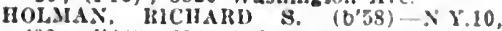
32: (1'84): 3931 Delmar misu.

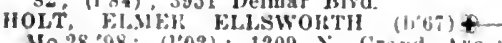
Mo.28,95; (1'02); 1209 ×. Grand . Me. : 8-9.1-3.

OLTGREWE, FREDK. W. $\left(b^{\circ} 65\right)+$ Mo.2 HoMis Gibot llalr Are: : 1-3, (b-7: LR. Find Hotel; once. 8ib cillre st.; $9-10$. $12-1,+5$

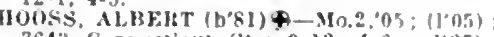
3643 Cunnectleut st.; 9-12, 4-8: (1t27) : 0o.

Hupklns, Blatuche k. Conserse (b'oi)111.11,03: (I'04): 1055 lfamllen Are: $10-2$.

HOPKINS, MLTON J-M0.1:96: (1'96)

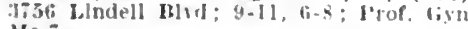

Hol'klxs, hoss (b'is) - Nd t, 03: (1'03) Hopkis, THamllon Are: $8-10,12-2 ; 0 b$. Al94): Belcher Hotel: onles, century Bldg.: 10-1, 3-4; l'rof. Gen.-U'rin. Surg. Mo.10: (C3): U.*

Iforst, Walter lim. (b'85)-YIC,2,'13: (1'13) City Hosplial.

H(OHWITZ, ALEXAXIER E. (b'78)—Mo.2, 04: (1'05): 955 Maple Pl.; office, Humboldt Bldg.; 11-1; Asst. "P'ruf. Wrtho. surg., Mo.34: Or.

HoRWITZ. MAXIMILIAN R. (b'î)-Mo.1 93: (1'93): 3224 Delmat B1rd.: onfe, Century Hag.; 12-1.

HOUR, GFo. EDWIN (b'78)-Mo.2, 13 ; (1'13): 2338 Holly Ave.; rfice. St. Louis Clty Hospltal.

HOIWINK, JOSEPI J. (b'68) 9-Neth.? 00, Mo.34,03: (l'03): (Webster Groves): offce, Delmar Bldg. 10-12, 4-6: Pro?.

Derm. and ssph.. Mo.10: D.

How, James Lads (b'68)-M0.7,08: (1'10):

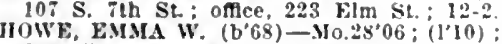
2610 Tennessee Are; $9-11,7-9$

Howell, W'm. Llewellyn (b'87)-Wls.6,13: (1'13): 3226 N. Nerslead Are.: ottice,

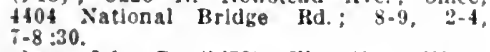

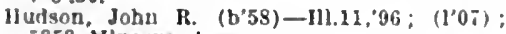
5353 Ninerva Are.

HCELSMANN, LEO CHRISTIAN (b'81) Io.2,05: (1'05): 2424 5 . Grand Are. $8: 30-9: 30,2: 30-4,6: 30-8$

Ilughes, Andrew J. $\left(b^{\prime} 76\right)-110.28,04:\left(l^{\prime} 05\right)$ 3902 Morgan St. ; $9-11,2-4,7-9$.

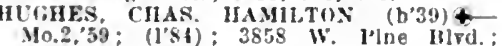
$3: 30-10: 30:$ NP.
M

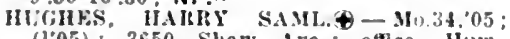
(1'05): 3650 Shaw Ave.: offlce, lium boldt illdg. : 9-1; (B25): Op.

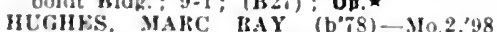

(1'01), 3858 W. IPIne Rlvi.: once. Il nollian Bldg.: 9.12 ; NP.»

Hughes, Roberl Edward tee (b'72)-No.2 10; (1"10) : 5819 De Giverville Ave.: of flee, velmar Bldg.; $9-10,3-5$; l'rof. Veur Mo.i

HUMPERT, GEO, A. (h'61)†-Vo.g.84 2406 kingshlghway, N. E

C.MPIRE JOS. 11AlHISONt-Mo.2,01 (1'01) : 3867 Greer Ave.: once, 6th and Chesinus Sts.: 12-1, 4-f

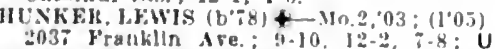

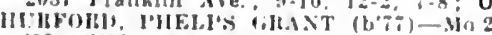
08 : (1'08): $346 \mathrm{~N}$. Iswyle are. $1.3, i=8$ (Di): $\mathrm{Pd}$.

Hutter. Chas. lipo. (10.85)--Ill.6.'13: Intern. st. Ionts colty Hosplal

ni-TTON, JOS. l.KWIS (b',

(1'11); 2752 Cheroke st

H) Ninge

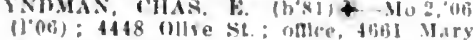
land Ale.; 3.4, i-8.

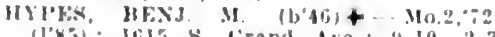

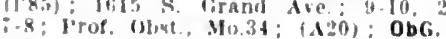

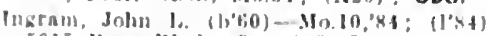

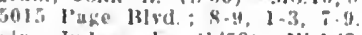

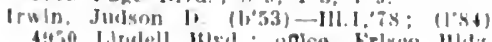

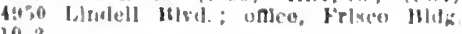
10.2

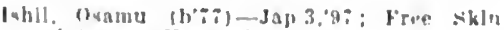
and rancer Hospltal.
Iterman, fieo Fidwarl (b'88)-Mo.34:13 Intern, St. Youts ('ity llospltal.

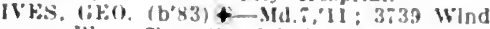
sor l'l.; oflee, St. Juhn's Ilousltal; 2.4 Asst. l'rop, l'ath., Mo.34: LD. *

Jackson, Honnls timersob $\left(b^{\prime}-8\right)-111,1,13$ :

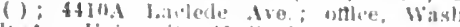
Ington I'niserilty Medleal schom

Jackson, tiet). B (col.) (b'6) - Tenn. i, 83 $\left(1^{\prime} 93\right) ; 809 x$ Jelfersul Are.; $x .10,1.3$ 6-8.

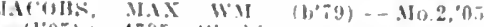
(l"05): tiss Wislimaton Ale.: offer

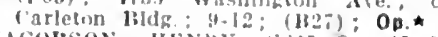

JArOHSON, If

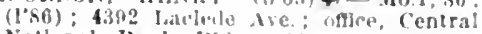
Natlonal Batrk 13ldt: : 11.1:30, 2:30-4

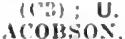

ACOBSOE, JACOH (1, 159) - Mo.1,992 Cass Are. : 9-10, $:-8:$ also 1 of 9 in 18. $12-3$.

lacoly. Aar

Thekla Ale. D. (1) JOHN A. JAMFS (b66) + Mo.24. carleton midg.: 11-1: (1,1,33): ALR. Jamleson, boy bos (bosi)- I11.6,'13 Intern, st. louls ('ity llospltal.

Jeans, Phlilp rhay (b'83)- Md : :09 (1'13); 6158 Washingt on Ave.; Pd.

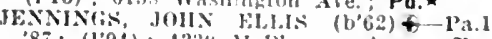
'87: (1'94): 433:4 II"l'berson Are.; once Carleton Mldg.: 9.2: 1"rof. Ophth., Mo.10 (BI, 27): OALR.

ENNINGS, M. IIWY;IT (b,60) - Mo 's8; (1'88); flol Washlngton Rled.; $9-10$

lessup. Chas A (b'51)-110.1, it; (1'97) nngwell Are. : 8. 10 . 2-1,

leude, Jullus John $\left(b^{\prime}, 6\right)-30.1,98:(199)$ 936 Morrlson Are.: offlce, $2521 \mathrm{~A}$

Broadway; $9-10,2-3$,

1OHNS, GEO. A.M0.34:05; (1'05):540n Arsenal St.

HNSOS ENW HORACE $(1,-26)+$ Mo. 28,99: (1'97): a 433 N. Grand Ave. $2-3,6-8 ; G$.

TOHNSON, FRANK PIFRCE - O.6. (l'83):3744 Flnney Ase ; at 9, 6-7:30 -1.a.1,90: (1'01); 5.to Waterman live. oftece, Wall Bldy.: (r), 3): U.

Jolinson, Horeph- Mo.2.68; (t) ; 33 ; caluanne Are

IOINSON, WILTEK I.FE $(1,69)+-$ - IO I

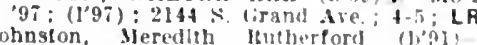
Mo.2,'13: interm, Wishimgton iniversit. llospltal.

Jolley, James Frank (b'\& $\ldots$ - I11.2.13 Intern, st. Lonls Cley lluspital.

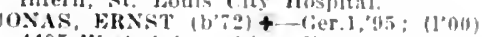

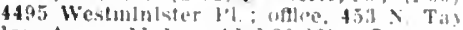
lot Ave.; 11-1: (A1,0,20.22): S

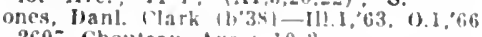
260; Chouteau Are. $10-:$

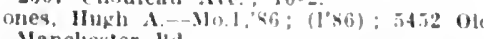
Manclester lid

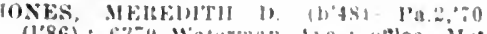

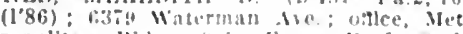
ropolltin

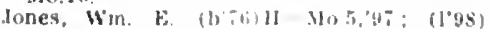

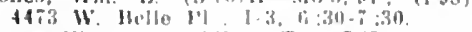
Jones, Wh. 10 T (1, Tena 79: (1'st)

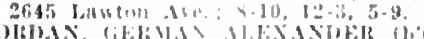

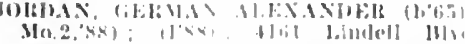

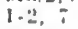

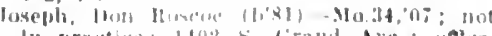

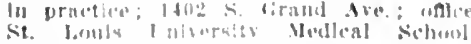
St.

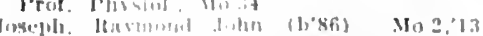

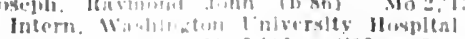

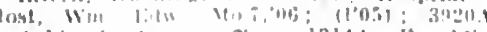
Ashlan! lu, Mtre, 1314A brankiln

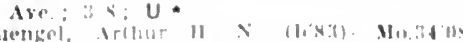

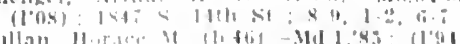

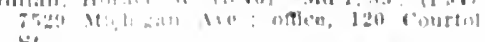

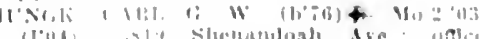

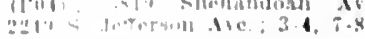

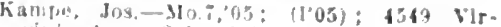

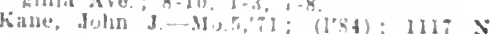
Cirand dro.

KANE, H. E.MIFT 11, \% - 11,2.93 (1'09) : $1117 \mathrm{~s}$ Cirand lice once, IIUm boldt Bldg. 2-4; 11,3$)$; S.

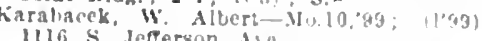
1116 s. Jefterson As

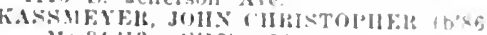

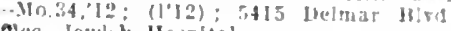
once, lestsh llospltal.

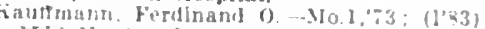
I.j6: $x$ liraml Ale.

kityler, orsille keuneth (6,-3,-110,28,03

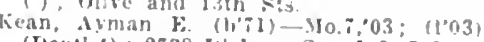

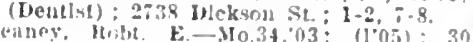
keaney, lwh. E.-Mo.34,03: (1005): 30 $x \sin$ st.

(0) thithe st ; oflce, bot the chestnut st 11-1. $3-4, i-8$

KEERLE, IEOHT, R. (b'it) Mo.2=29t. (1'94): 3012 lafayette Ave : $8-9$

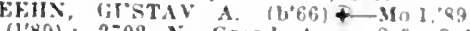
(1'89): 2702 X. Grand Are.; 8-9, 3.4 Kehoe, Juhn Jus. (b'82)-30.34,05; (1'09) 4061 St. I Inuls atre

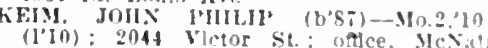
and Lynch Sts.

(on. Mon 1 , 1 ,

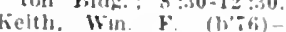

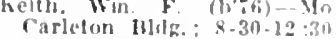

hell, Fredk. (b's)-No.34,13; (1'13); st louls rity IInspltal.

kelly, Chas. A (b'SI)-Mo.:'0 : ll'ns 3904 Folsom Are. ; oflce, 705 ollve st TLIY iS ALR.

(1'08): 4166 II.. JR. (6.85)-Mo.34.'08 (108) 4166 Washington Are, O office.

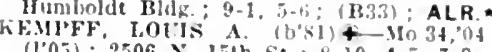
(1'0.5) $2506 \times 1$, 1 th 5 t $8-10,4-5,-8$

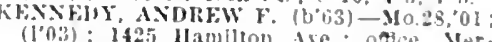
(1'0:3) : 1425 Ilamilton Are, oftwe, Mer (1)

जo.28,98. (1,49) omee, 1121 Cass Are.: 10-11, 2-3, $=-8$ l'rof. Sury yo ane.

hennel. Archllald $\therefore-M \circ 1.9: ; \quad(18 \pi)$ 1315 s. Crand Are: omber 2605 Iark ine

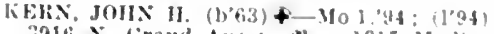
$.916 x$. Crand Ave omce, 131 ; Madion s.: $9-10,2-3,7-8$

Nern, Nophia 1. (b'56) II-1/0.5.'00; (1'00) .Mvaterman Are

$34 ? 1$ Washlngton Are.; nglce, 4h: Broaduay

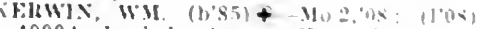
$1900 \mathrm{~A}$ laclede Are? once, finclid and laclede Airs : t: 1.1201 : ObG.

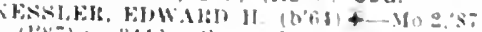

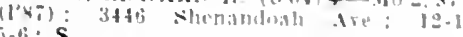

(1'13) Fred cise:

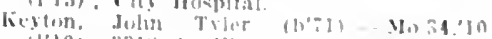

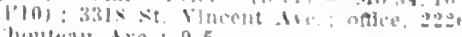
Thompents Aro: 9-5.

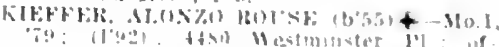

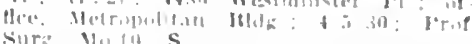

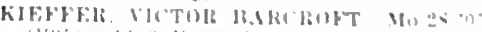

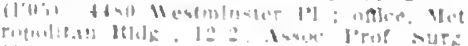

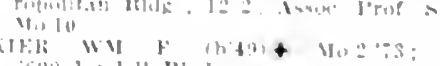
inith 1..mblell Buis

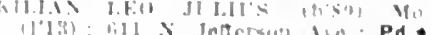

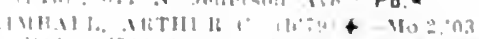

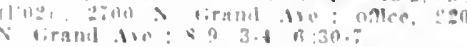

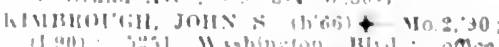
1) 401 :

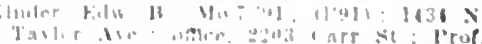

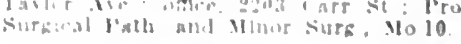


K'ng, John I. (b'42) 7036 Lindenwood Pl.; 11-1.

Klng. Saml. J. (b'S0)-Md.1,03: 5606 Etzel Ave.

KIN(i, W.II. RLFIS (1, 8,5$)-M o .34,09$ $(109) ; 4646$ Yirginia Ave, ; 8-9, 1-2, $6: 30-$ $7: 30$.

Finner, Helmuth M.-Mo.1,93; (I'44); 2134

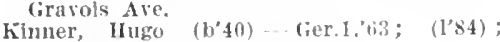
(10?

Klnselia, Rilph Iloysins (h'sh)-Mo.34,'11 (I'11): . 't. Louls i'ity II (1spltal.

KIRCHIER, W.ALFER C. Ii. (b'T) + Mo.2

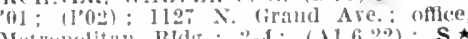
Morrenoulitan BIdg.: 2-1; (11,6,22); S.* KIRKI'ATIR, IIIRIY E. (b'1)-Mo.34, 03: (1'03); 611:5 01t] . Minchester Ri. ; 8-9

lirsell, F. Wm. Jr. (b's4)-Mo.5,05; (l'05) 2860 Lnlon IBHel. : $8-11,2-4$, (i-8: S. Kittredge. Idit F, Mo.I0,03: (1'03); 2806 prof. livn. Mo.10.

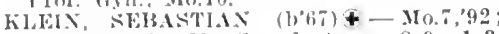
(1.12); $2025 \mathrm{~N}$. Cirnd Ale.; $8-9,1-3$ i: $: 30-7: 30$

Kileinecke, Arlolph-Mo.2.82; (1'84); 1724 Choutean Ave, : oflce, 1657 S. Grand Are.

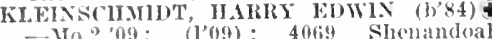
- I (1.2.09; (1'09);

KLENK, (HAS. LEONARI (b'82) 4-Mo.2, of. (1'05) : 3509 Utall St.; offlce, Metropolitan Bldig.; Bact.

kleykimp. Irthur F. (b'so) - Mo.2,"02 (l'0I) : 3834 st. 1,ouis Are.; office, $711 \mathrm{~A}$ N. bitl st. : $10-12,2-4,5-7$.

Kleykamp. Angust-Mo.1,'88; (1'88); 2313 Iniversily st.

THE CONSTANTIN M. T.-Mo.2,03; (l०03): 2328 wren Ave. : $8-10,6-9$

KLIF, GEO HENRT CIAS. (b'45)థ Yo.1,95; (1'45); $5100 \mathrm{~N}$. Broadway ; $10-12,1-3,7-9$.

KAINEFELTER, MARION, I. (b'73)థ$12: 30-2: 30,7-8$.

klippel, Benj. W. N. (b'91) - Mo.2,'12; (1'12); 4012A Shenandoah Ave

Kllppel, Edw. Theodore (b'S4)-Mo.T,'10 (1’10); 617 Chouteau Are. ; 9-11, 7-9.

klocke, Frank W'm. (b'69) - Mo.2,08; $\left(l^{\prime} 0 s\right) ; 2304$ Cass Ave. ; $10-12$. 6-8

KLOEPIER, IIENRY (: L. (b'S1)-MIo.34 07 ; (1'06) : 3607 S. Jefferson Ave. ; ofllee, 3801 S. Broadway; $9-10,3-4.7-8 ; 0$.

KLOKKE, WM. FMIL $\left(\mathrm{b}^{\prime} 76\right)-111.11,99$; (1'99): 4112 Flad Are.: offlee, Century

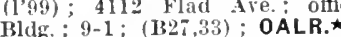

kinabl, Arthur Dolphie (b'89)-Mo.34,'13; (1'13) : Alexian Brothers' Hospital.

Knalp, Harry J.-No.7,'01; (1'01); $3155 \mathrm{~S}$. Grand Are.

Knapp, Perey T.-Io.28, $02 ;$ (I'01) ; 2614 Olice St.; $2-4,6-8$.

hnarf, Robt. A-d; not in practice; 1624 Pine st. $9-12,3-5$.

Kneale, Earle Ellsworth (b'90) -Mo.34,'12 ; (I'12); St. Louis City Hospital.

K.ECHT, LOI'L BERNARD (b'87)-Mo.2, 10; (1'10); 506 Park Ave.; City Infrmary. (1'02); (Webster

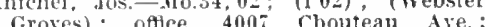
iroves); oftee, 400 (Choutean Are. $10-11,2-4,7-8: 30$.

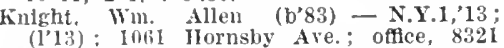
N. Broadway ; 11-12, 2-4. $7-8 ; \mathrm{S}$.

Knox, Franklin'T. (b'47)-Mo.5, 73 ; (1'84) 535 CIara Ave; offlee, 627 Mermod-Jac card Bldg. : $30-5$

KOENIG, (iEORGE W. (b'T2)థ-No.2,04 $\left(1^{3} 05\right) ; 2626$ Lowisiana Ave.; offlce, $\mathbf{7 4 0}$ S. 4 th st.: $9-10,2-3.7-8$.

KOEXIG, OTTO MARTIN (b'74) - Mo.34, '13; (1'13): 3515 Park Are.; 1-2, 4-6, 7-8. KOETTER. ALBERT F. (b'-1) † Mo.1,'92: (1'97) ; 5226 Waterman Ave.; oftice 1023 KohrumeI, Wm. J. A.-Mo.27,99; (1'99); $401 \times$ Broadway.

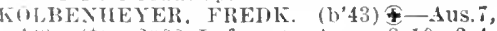
ObG.

COLLIE, (ITTO (b., $2,+4$ Park itre, \&-9, $2-3$, i-8
KONZELMAN, JOHN ALBERT-111.11,06 (1'06); 1730 Franklin Are.; office, 5342 I'age Ave.

KONZYIMANN, PAUE R. (b'71)-Mo.28, 99: (1'99); 2500A S. Jefferson Ave. $9-10,2-3, i-8$

KOONT\%, CARL JESSE (b'75) - Mo.27,'99; (199); 5560 Etzel Are.

Kopelowit\%, Jomas clarence $\left(\mathrm{b}^{\prime} 92\right)$ - Mo.2 '13; (1'13); 4350 Cook Ave. ; Pd.

Koppenbrink, Walter Edwh (b'90)-Mo.2. '13: (I'13); $400 \mathrm{~N}$, Jefferson Ave.; Washington Iniversily IIospltal.

FO'll, MARTIN F. (b'8I) - Mo.2,06 (1'06) ; 4046 Russell Ave; offlee, Navarre Hider.; 1-3, 6-7:30; (D5); Pd.

Kraft, Albert J. (b'74)-Mo.28,01; (l'01); 2709 Whittier st.

KRAMOIOWSKY, IIELMUTI JENRY (1)'89) †-Mo.34,11; (1'11); 5785 Waterman Are.; offlce, Century Bldg.; 1-2. Inan $\mathrm{U}$.

Krape, (ico. E.-Mo.10,03; (1'03); 2318 lafayette Ave.; I'rof. Med., Gy'n. and CIn. Obst., Mo.10.

KREBS, FlRANZ J. V. (b'75)థ-Mo.27,'97 (l'0); 1906 St. Louls Are.; 8-9, 12-2, $6-7: 30 ; \mathbf{I} . \star$

KREBS, GEO. A. (b'68) † - Mo.7, 88 ; $(188) ; 3622$ Hum

Kremar, Victor (b'73)-N10.27,98; (l'98) $14^{2} t$, Salisbury st.; oftice, 2007 Destrehail Si. ; $9-12,2-5,6-7 ; 30$.

KRENNINi, WM. GEO. (b'75)-Mo.2,01 (1'01) ; $4041 \mathrm{~A}$ St. Louls Ave.; Anes.

Kriege, IIenry W. (b'59) II - Mo.5,'88; (1'85) ; 2201 E. Athlone Ave.; office, 150 St. Louis Are.

Fring, Elbert Vletor (b'85) - Mo.28,09 (l'09) : $809 \mathrm{~N}$. 18th St.; offlce, 1801 IIorgan St. ; $10-12,3-5,7-9$.

kring, Richard (b'63)-Mo.1,'91; (1'91) 2732 s. 13 th St.

KROEGER, GEO. BALDWIN†-Mo.2,04 (l'05); 3622 Garfleld Are.; office, 3620 Garfleld Are. ; $8-9,2-4,7-8$.

KRUG, FREDK. H. (b'69)†-Mo.34, 05 (l’04) ; 2249 St. Louis Ave. ; 8-9, I-2,6-8 Irof. Wiet, Clim. Chem, and Mlleros. Mo.10.

Krug, Henry Stuart-Ont.3,'95; (1'98) ; 5072 kaymond Ave.; offlee, 915 Aubert Ave. Kruse, Henry J.-Mo.7,99; (I'99); 2801
Dayton St.; I-4, 7-8; Prof. Mat. Med., Mo.i.

KUHLMANN, FREDK C. E. (b'71) (4) Mo.2,96; $(196) ; 2135$ St. Louis

KUHN, DANL. (b'37) ๔-Mo.2, 65 ; (1'84) 4583 Forest Park Blvd.; office, 1746 Chouteau Ave.; $8-9,2-3,7-8$.

Kultgen, Edward (b'84)-Mo.34,'10; (1'10) 5978 Easton Are.; 8-10, 7-8.

KUPER, GEO. HENRY (b'74) ४-Mo. 7,96 , IIo.28,11; (1'96); 5222 N. 20th St.; 8-9, $3-4,6-8 ; \mathrm{Pd}$

KURTZEBORN, EUWIN F. (b'72)థ-Mo.27 $99 ;(1 ' 99) ; 3626$ W. Pine Blvd.; offlce, 4900 MIcPherson Ave.; 9-10, 2-3, $7-8$; Asst. $\mathbf{P}$

Kusmo, P. H. (b'66)-Tenn.11,00; (l'01) ; $1600 \mathrm{~N}$. Jelferson Are, $10-12,2-4,7-8$.

LaBarge, Chas. L.-No.2,'T4; (1'85); $253 \vec{\imath}$ Bernays Ave.

Lamb, David iR. (b'85)-Mo.34,'10; (1'10) 3640 Arsenal st.; office, 9101 S. Broadway ; 4-6.

LAMB, HARVEY DENSMORE (b'83) Mo.2,10; (1'10); 3647 Hartford St.

LANDREE, IANES CLIFFORD $\left(b^{\prime} 86\right) \notin-$ IIo.2,09: (I'09): 5890A Delmar Blvd.

Jangan, Wm. Jos. (b'86)-Mo.34,'09; (1'10) ; 5803 Plymouth Ave ; $8-10,1-3,7-8: 30$. (1'84); 5803 Plymouth Ave.; offlce, 1444 N. $23 \mathrm{~d}$ St. ; $9-10,3-4$.

Launhear, Emory (b'59)-Mo.1,81; (1'34); 3447 Pine St.; 2-4.

LARE. HARRY' S. P. (b'61)థ-Mo.1,'81; (1'84); 4226 Botanical Are.

LAREW; JOHN T. (b'51)థ-N.Y.10,'75 1'87); Cates and Academy Ares.; 8-9 1-3.

LARIMOKE, JOS. WM. (b'87)-Mo.2,'13;
Jarsen, Geo. I. C. $\left(h^{\prime} 67\right)-310.27,92 ;\left(l^{\prime} 92\right)$;

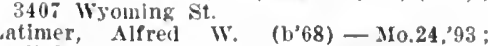
(l'93); 4132 Flora BlFd.; office, $1004 \mathrm{~s}$ Vanderenter Ale, $9-10,3-4,7-8$.

Lausch. John--Cier.14,'92; (1’98); 5830 Cote Brillante Ave.; offlee, $1000 \mathrm{~N}$. Grand Ave. Lavat, S. Ella-Mo.5,84; (l'84); 4422 W. Thelle Pl.

LAWRENTE, WM. SCOTT (b'7) £-Mo.24 OI; (l'0I) ; 3503 st. Louls Ave.; offlee, Jlealli Department.

Leavell. Nincy M. (h'32)-Pa.7,'65; (1'83) 5712 Calianne Are.

LEAVY, CHAS. ALFONZO (b'73)థ-Mo.34 03; (l'03); IIotel Beers; offlce, Metropolitan Bldg.; 10-12; (Bi,33).

LEIBRECIIT, JOLIIN C. (b'59) \&-Mo,2,'82 : (1'84) : 1737 S. Grand Ave.; office, 1509 ('louteall Ave.; 2-4, $7-9 ; \mathrm{G}$.

LEE, FLIBRT JOHNSON, IR (b'73)Mlo.28,'98; (1'98); Member Ill. State Med. Sor.: Melrouolitan Bldg. : S.

IEGGAT, IRRAM C. (b'73) - Mo.2,'95; (l'95); 5076 McI'herson Ave.; offlce Metropolitan BIdg.; 11-2, 5-6.

IEICHTON, WM. E. (b'72)†-Mass.1, 0 . (1'05); 5891 Washington Are.; offlce, IIumboldt Bldg.; Asst. Prof. Surg., Mo.34 (A22); $\mathrm{S}$.

Lemolne, Leo. L. C. - Mo.24,'91 ; (1'91): 3850 Delmar Blid.

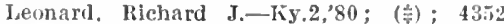
Maryland Are.; offlce, Chemleal Bldg. ; $11-2$

Lester. Franklin W. (b'68) H Mo.5,00: (I'00) ; 3455 Shenandoah Ave. ; $7: 30-8: 30$, $1-3,7-8$.

LEVY, AARON (b'76)థ-Mo.1,95; (l'97) : 4757 Westmlnster Pl.; offlce, Llster Bldg. (D5) ; Pd.

Lery, Molse Dreyfus (b'89) - Tex.2,13. Intern, St. Iouls City Hospital.

EWALI, JAMES (b'88)-M0.2,'11; (1'11) $5130 \mathrm{~A}$ Wells Ave, offlee, City Sanltarlum

Lewin, Wm. A. (b'62)-Ill.1,92; (l'93); $10-12,2-4$.

LEWIS, BRANSFORD (b'62) †-Mo.1,84: (l'84) ; 4.54 Lindell Blvd.; offlee, Century Bldg. ; 10-1; Prof. Gen.-Urin. Dis., Mlo.34 (C1,3); U.»

LEWIS, CHAS. + -Mo.7,91 ; (1'91); 1312 llonroe st.

LEWIS, EUGENE W. - Mo.,,$^{\prime} 00$; (l'01); 5987 Page Blvd.

Lewis, Robt. - Tenn.1,62; (l'93) ; 4759 Washington - Blvd.

Lewis, Walter C.-Mlo.1,75; (1'83); 5004 Florissant Ave.; offlce, 5230 N. Broadway.

Lewis, Walter Scott (b'83) - Mo.34,13: (l'13) ; 4002 S. (irand Are.; offee, Grand

Ave. and Lindell Blvd.; $1-3$.
Licklider, Thos. E. (b'66)- Io.34,05 ; (1'05); not in practice; 4029 Kennerly Ave.

LIGH'TNER, CALVIN R. $\oplus-N . Y .10,80$; (1'84) : Washington Hotel; office, Iretro-

(1)

Cherokee St.

LINK, J. JOS. (b'63)థ-Ill.6,'90 : (l'91) : 3550 Russell Ave, offlee, 2102 S. Grand Ave.; 2-4; Prof. Surg. and Clin. Surg., II $0.10 ; \mathrm{S}$.

Lionberger, John Robt. (b,75)-Mo.2,01; (1'01); 6011 Kingsbury St.

HPPE, MEYER J.\&- Mo.1,95; (1'95); 5349 Iaple Are.; office, Century Bldg.; $12: 30-2,3: 30-5$.

IIPPIIAN, GUSTAVE (b'68) (-Ger.2,'92 ; (1'94) ; 4668 Berlin Ave. ; 3-4; Asst. Prot.

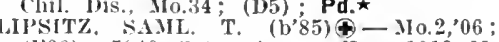
(I'06) ; 5040 Cates Ave; offle, 1019 X. 14 th sit.; $9-10,3-5,7-8$.

Livingstone, Ilenry Erhardt - Mo.i,03: (I'03); 3400 Neramec St.; 8-10, 1-3.

loyd, Henry-MFo.7,90; (1'90) ; 3031 Easto’1

Lloyd, H. Chas.-Mo.20,95; (l'95); 1214 Olive St.

LOEB, CLARENCE (b'76)థ-Mo.27,99; (1'99) ; 4207 Westminster Pl.; offlce, 537 ․ Frand Ave, ; $9-12$; Asst. Prof. Ophth. iio.34; (B27); OpA.ऋ 
LOFB, HAXAl W. (b'6.3) - Mo.22, $8:$ X.1.88: $(140) ; 5154$ Wextmlnste Bird: offlee, $33 \%$ i. lirand Me, $10.1 \%$ 5-6: lean and prof kar, Nose and Thrnat II\%., Mo.34; (I1, 2.3,5.7,33, F1)

\section{ALR. *}

"98: nos in practice: Karnard free skin and fancer Hospltal: (I) $\left.6, F_{1}, 2,10\right)$.

IOEIt, IIRGII (b's3) f Mo.34,06; (1'07) (llentlst); 5535 Waternan Are. (oftce $537 \mathrm{~N}$. lirand IYe.: $\$: 30-11: 30$.

Loew, Fdw, C. - Mo.27,98: (1'99) ; 2050 Lafayeste Ave ; oftce, $1411 \mathrm{~S}$. Rrouduas

I.OFWFISTHX, HARRY Y (n? Mo.2,09; (1'01): 5943 rlemens Ire fce, I.Inmar Bldg.: 11-1.

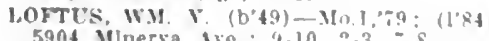

Loler, Wm. J.-.110.29:99; (1'93); 1241.1 Fuclid Are.

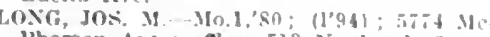
lherson Ave : oflce, $513 \times$. Sarah se

Lotz, John A. No 34,06: $(106) ; 2323$ Enlon Ave.

I.uce, Townsend M- $\rightarrow$; (IS:); 4626 kaston

Lucke, Euzene Muton (b'an) - Mn.2.12 (1'12): St. Louls rlty Hospital.

Iuckey. Inrace I.eslle (b'85) - Mo.2.'1n (1'10); :2bs Sarah st.

Ludwlg, Benellet J. - Mo.27,96: (1.96) 426: Holly Are: offce, 1601 (Che unut st

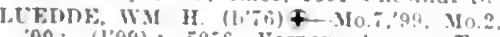
Mo: (l'99): 50 is Vernon ire : nflice

Luhn. Walter n. (hos)-Mo.10, 0 f : (l'n6)

4111 Grasola Ave: $8.0,1-3,6.30-8$

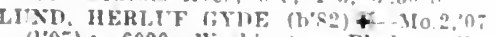
(1.0\%): 6020 Wablugton Blru: offce Carleton HIde; in-12:30, 5-7: U.

LITON, IIONFI, SINCIAIR $(\mathrm{b}-5)+$ - III I oI: $(197) ; 3739$ windsor ly : nftre. 102 ? V. Grand ire.: 2-4, i-S: (1,

I.LTZ. ANTHONY LEO (b'7)-MO.'10 (1'12); $333 \%$ Jafayette Ire.: offre, Ib3o s. Frand Are: $9-12$.

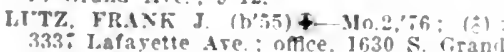
$333:$ Lafagette Are : offce. I $630 \mathrm{~S}$. Cirand Are 9-12: Prof Clln. Sura. Mo? (A5,22,23) : S.

LTTTIES, (ARL J. (b'60) \&-MOI."44 P2.9,85; (1'85); 2100 Iafayette Arp

LYMAX, IHARY w. (b':3) ₹-Mo.7,95: (1'85); 3657 Vernon Are. ; offlee, Carletn Blds. : $10-1,4-5 ;$ (B33) : ALR. *

Lunch, Fdward Jos. (H's5)-Mo.34,13 (l'13) : 9101 \$. Broalway.

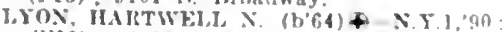
(1'93): t4:6 Washington Blvi. : ont.e Fumboldt Blak.; $3-6$; ( 33 ) : S.

l.yttle, Farnet $\mathrm{C}$. (b's5)-Mn.34:07: (I'ti) 9612 S. Cirand Are.; once, 309 \& Jiroad way; $10-1, \$-6$.

MacDONALI, JOHX w. $\left(b^{\prime} 78\right) \mp$ Vo 34 05: (l'05i; (Clayton); ofire. nlivla

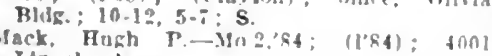
Ifncoln Are

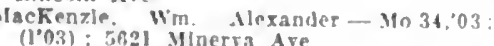

MACKLIN, I,IRIN JATRICK (h'sfi In. 3.5: (1009): 5943 I'lymouth Ale: 10.12

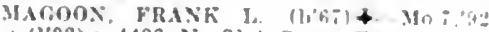

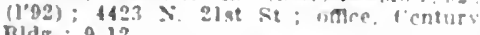
Midr. : $9-12$

Mahon, Wm. T. (1):32)- Va $1,80:(1 \times 3)$

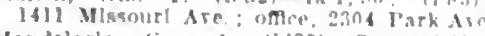
Mandelarls, lien. A. $(1,80)$ - Treece 1,04 :

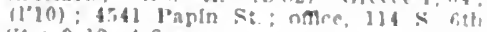
Si: $0.72,4-8$

Manderbach, cyruv IASan - I'a 2.83 (1'95) ; 3121. S. Jefrepsin Nir

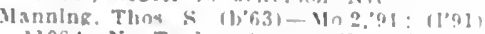
IIOAA $x$ Tavior ive; omee, $1050 \mathrm{x}$ Taylur iro: $11.1,4-f$.

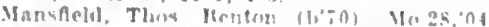
(l'0i); 3014 l'age luel; omer, thenileal HId : $12-3$.

Mansifer, Wim II (libit) III 10:Ra, III II

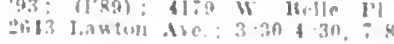

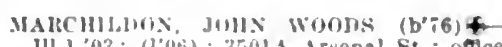
Ill.1,03; (1'06); 3501A Arenal St. otice. Il umbolus Mldg.; 11-12; Asut Prof. Hact. No.34: U.

MARDEis, JUIR L.FE $(1,71)+-1 a .10,01$ (l'0l): Ashland and Vanderenter Ares. $3-10,+-5$.

MAIRDOHF, WM. IH.L. (b'67) +-Mo.2,88 $(1,88)$; 2136 S lirand Are.; $8-6,2-3$ $6: 30-7: 30$.

Marculls, Alirahan A $\left(b^{\prime}(8 b)-M 0.2,09\right.$ $\left(l^{\circ} 09\right) ; 1714$ ('arr sit.

MAthis, HEIXE (b'5!) + 0 5:78; (1'84) 393: l"ige Jivd.; ottice, Marina Blug $11-12.6-7$.

Ilarksoll, liavld Edmund (1,86)-IIl.6,12 (l'1:); St. Louls C'Itg Hosiltal.

M.IIKWORT, HEHIRHT F. Mo.,.,03 (1'03); 4109 Junlata Nit, oftlee, $165 \%$ S Cirand Ale.; $10-11: 30,7.450$.

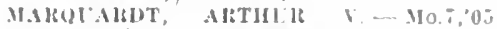
$(1+0.5) ; 3658$ rlark Ire.; untec, lentur: lslels, $9-11,2-4$

Marrlot, Wm. Mcklm (b'a) X.Y 20, l) McMillan Hall; uflee, Wdshingtim initersity Medical sihool.

Marten, Win. frealrich-111.4,"03; (1'b: (1) $42 x$. 11 th $x-1$.

Martens, Edw. J. (b'69)-Mo.27,9-; (l'9i) 4.07 Ilammeti Pl.; oflce, "yus' Marcuire. : $1-2,7-8$

MAKTIX, CIIAS. I'. (b'80) + Mo.34, "Il (10.3); 3603.1 Lee Are; 8-9, 1.3, ; (11i); Pd.

Martin, Clarence (b*7)-Mo.28, 48 ; (l'mu) 504 Kenslngton Are, oftce, 3rou Morgan st.; $11-1,3-5$.

Martin, lobt. E, (b's)-Mo.2s,11: (l'd1) $430 ;$ Manchester Are.

Martin, Solomon Clallorne, Jr. (boil) Mu.28.433; (1"y3); 5049 Kensluzion Are.

mince, 3roo Motgan st.; 10-2; U.»

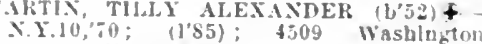
Ave; oflce, Metropolitan Bldg.; 1:30 $4: 30:(A 20)$

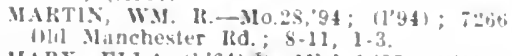

IARX, EI.I.A (b'64) t-Mlch.1, $87 ;\left(1^{\prime} 91\right)$

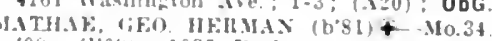

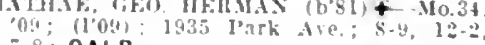
i-8: OALR. Mathews, Myra Inn-Mo. :,4l: (1"05): 151.4
Mllre si.

MAX CLARENCE OSCAL PHISTIAN (674) +.Mo.2.99; (1.99); 35.55 l.ong bldew Hid.; oftee, IRallway kixchange Bide

MAY, MLBERT (b\%5)+ Mo.2, 10 .

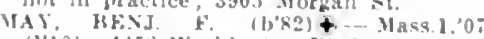
(lio); the washlngton Hid. ; nflce. 53 N lirand itre.

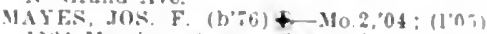
112t Morrisun Are.; oftce. I vol Ollye si

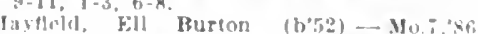

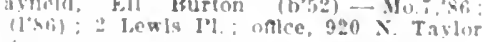

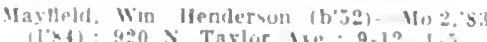

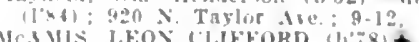

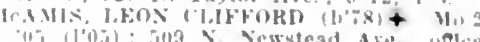
Ilumblit Islda: ; 1 - 8

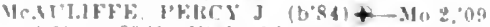

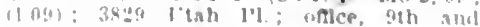
(1)

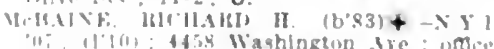

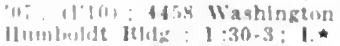

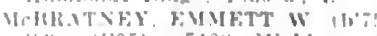

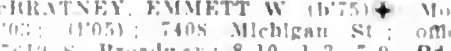

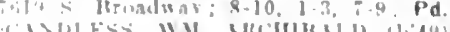

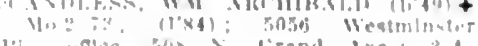

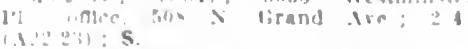

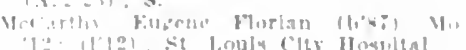

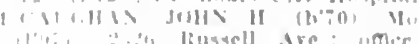

$$
\text { obs. }
$$

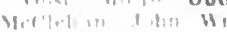

MeCOY, (ITHAL a (b'81)+Mo.2,08; (l'08): polltan Ho: ; 11-12; S.

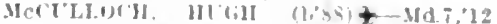
(I"13); Washington I uisermley Ifoupliad Mcklraln, Mube. 'thlders Ib's:1-111.11.'10

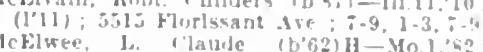

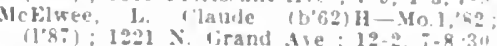
Nckinan, saml. Wilorn $\left(b^{2} 85\right)-31$ inntin A.I surg. I's. N: Nary Recruling Sta

YCFA[I,EX, JAMES FREUK, (b'sa) - Mo.34. 13; (1'13); 3433 S. Broadway.

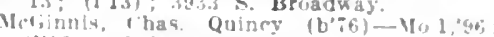
11(0.3): 425: Meramec st.

Mctinnis, krasmus (b'72) - Mo. 27,9 $(1960 ; 2430 \leqslant$ Broaduay; $10-11,6,7$

Mrlisath, Edw. J-Mo.10:00; 11001; 730 llawh ire.

M(KII, HAMVEY S \& Mo.24,01: 11001 3x:bi lavileman Are: oftce, Meropolipan

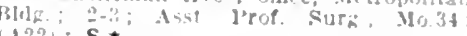
$(.12.) ; \mathrm{S}$.

Mekelvey, sami. Wheeles $\left(b^{\circ} 90\right)-$ Mon'13: (l'13); St louls clty Hostial.

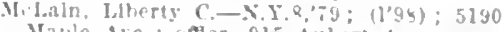
Manle Are ; oflec, 91: Aubert Are.

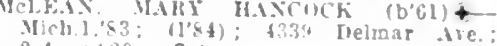
$2.4: 1.1201 ;$ G.* $^{2}$

McMahan, claude 11 (6'74) - Mo.1.99

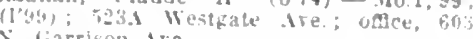
X. Giarrison Are.

(1)90) - Mu 34,13: (1'13)

termary: $S *$

chernolds. l'alph (b'a) - I11.1,13; Intera. st. Louis rity 110sultal.

Meacham, (owan (aderon (b'bs)-Tenol.

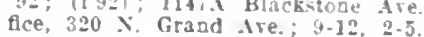

MFINHLARD, J0S. +-M0.87,97; (107); 2800 Chinnewa st.

MEISEXPACII AIRERT EIW (b"il)

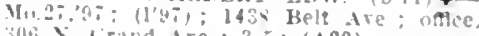
IFISESI? ICII ALBEIT H (A22).

$\because 6$ (1'xt) ALBERT H. (b"52)-Mo. 2ase $\leqslant$. I3roadwar; $\mathbf{S}$.

Mellies, rhas (lo59)-Mo.5, "it: (l's9) $38.25 \times$. 20th $\leq 1: 8-10,1-3,6-8$

Mellies, lieo $1-11-M 0.5,95:(195): 991$ : St. Lonls the ; $\$-10,1-2,6-k ; \mathrm{S}$.

Melvin. Janies M.-Mo I, $91 ;(1,91) ; 1000$ Arsenal st.

MENG, EIWWI II'TIVEN (b'49) + MoI, 76: (1'93); bis.3 Mclherson Are.: ofle,

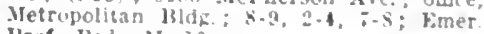
Prof. I'êt. Mo. Mo.

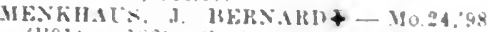

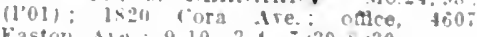
Easton Ale: $9-10,3-4, ;: 30-3: 30$

2356 Ceraldine Are. : $\$ .9,1,03$;

Meredlth, Thas Arthur (b'bsi-Mos:, Me (1.93) : 3903.1 l.ee Ire.

MEll:Ditu, Jos. J. Mo.1.93; (1'n3)

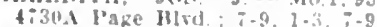

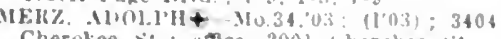
Cherokee st.; once, zool i herolice st.

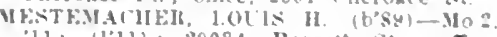
11: IIII): 290SA Barrett st; once. 1704 l'nfuz It!rd.

Meyer. Alfrml II lb's:) Mo.:06: Ilenti)

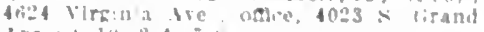

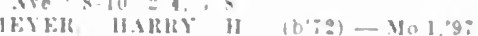

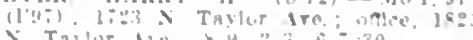

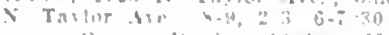

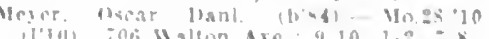
Ieser. IIm Frank $(b, 0)-V 0$ is 05

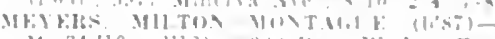

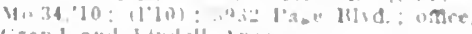
lipand and letudoil lies

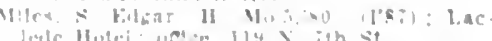

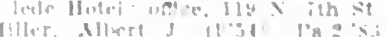

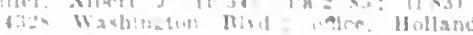
111.i:

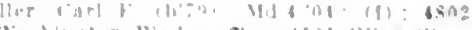

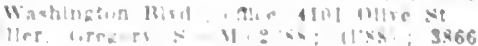


Miller, Harry fancourt (b'is)-Mo.34,'13; (I'13); 8219.1 ('luurch lki.; offlee, 8212 WV. Itroadway: $9-11,4-5,5-8$

MILLE], IIEHMAN IBEN. (b'79)-Mo.2, 0I: (l'01); 4004 Westmisister Blvd. oflle, Metropolitan I3lig.; $9-12,5-6$; ALR. *

MILLER, II, EDVIAIR) ( (I'01); $2017 \mathrm{~S}$. Grand Ave; onde, Metropolltań Bldr.; (B333); 9-1; ALR.*

MILI.ER, JOHA J. $\left(b^{\prime} 42\right)+-M 0.2,64$ (1'S1)； 4439 Morgin st.; oflee, Taylor Ave, and Suburban Tracks; $8-10,3-5$ ALR.

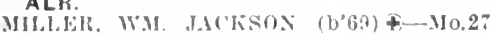

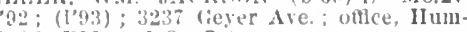
boldt 13 ld : $1-3 ; \mathbf{S} \star$ J Miller, Wm. J. - Mu.10,'82; (1'62); 4852

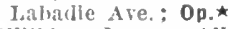

Millikin, l,ester Allen (b'89)-Mo.34,'10 (1'10); 5127 Shaw iro.; $8-10,3-5,6-8$. Mills, Josepll Walter (b'82)-Mo.10,'13; (1'13); 1515 Clionteau Are.

MILLS, RAMl'I WALTER (b'7T) $\oplus-M o .34$ 02; (1'02); (Welster Grores) ; offlce, 3905 Olive St.; $10-12 ; 1 . \star$

Mhigos, Geo. W.-IIl.4,80; (1’97); $1141 \mathrm{~S}$ ith st.

MISSIMORE, IEWIS L. (b'77)థ-Mo.34 04; (104); 4869 Page Bird. 8-9, i-3, 6-7:30; l'rof. Olst., Mo.7; Ób.

Mitchell, Chas.-Mo.t,06; (年); 2609 N. Taylor Ave.

MICHLLL, ERNEST (b'88)-Mo.2,'12; (1'12); St. Louls Clty Hospital.

IIZE, EDW, LINISAY (b'82)-No.28,'11 (I'11); $2821 \mathrm{~A} \mathrm{~N}$. Vandeventer Ave.; 9-11, $2-4,7-8$.

MOLILER, CARL E. (b'79)-Mo.2,03; (l'03) ; 3537 Jetierson Ave.; 8-10, 1-3,

Moeser, Phllip (b'60) E-Mo.10,'82 $3417^{\circ}$ Vlsta Ale. $9-12,2-5 ; 1, \star$

MONTAGUE, HERBERT L. (b'70) i-Ho.2 96 ; (1'96) ; 6140 Washington Are.; of fice, 4503 Page Ave.; $11-1,7-8 ; \mathrm{S}$.

Montgomery, Alexander-Mo.2,'56; (1'99); $420 \mathrm{~W}$. Kansas $\mathrm{St}$.

MOOK, WM. II. $\oplus-M o .24,{ }^{\prime} 00 ;\left(I^{\prime} 00\right) ; 4458$ Washington Are, offlce, 537 N. Grand

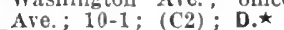

Aoore, Clarence Dalzell-0.2,03; (1'03) ;

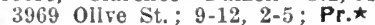

Moore, Fountain S. (b,75)-Mo.24,97; $\left(l^{\prime} 97\right) ; 1635$ Franklin Ave.

MOORE, HAHRY M. (b'74) $\uparrow-M 0.2,98$. (1'98); 5614 Waterman Ave.; offlee, Wall Bldg. ; $11-1$; S. $\star$

Moore, John W. (b'58)-Mo.1,83; (1'83):

not ln practice (bon - Mo.1,83:

Moore Neil Sewell (b'87)-Mo,34,13. (1'13) ; St. Louis City Hospital.

MOORE, WM. GIANT (b'53)\&-Pa.2,75; (1'84); $86^{\circ}$ Vanderenter PI.; 1-3, 7-S I'rof. Med., Mlo.34.

Hoore, Wm. Laban (b'74) - Mo.28,'99; (1'03); 1616 Haniliton Are.; offee, 375 ; s. Broadway; $9-11,8-9$.

MOLFLT, JOHY CAMIBELL (b;4) Ild.3,95; (1'97); 3534 Washington dve. (A2.2); S. *

Iorguer, Kossuth (b'49)-Mo.10,78; (1'83) 3509 Easton Are.: $9-12,1-5,6-8$.

Mornino, Adriana Pasetti (b'S0)-Mo.10. '12; (I'12); 1117 Franklin Ave. ; 1-3, 6-8; ObĞ.

Morrell, Michael 1'inckney (b’50) - Va.1 73 ; (5):320 skinker Rd.; offlee, 14th and Market Sts.

Morrill, Geo. H.-0.7,'61; (1'8i); 2713 Washington Are.

MORRIS, CHRISTOPHER C. $\$$-Mo.3,'84; Louis Baptist Hospital; 9-12, 3-5; Prof. Surg., Mo.10.

Morrish, Edward-Mo.24,00; (1'00) ; 1005 Glascow St. offlee, Metropolitan Bldg. $11-12,3: 30-5$; Prof. Ped., Mo.7.

Morse, Frank L. (b'76)-Mo.24,00; (I'01) 3504 St. Louis Are. ; offlee, 2105 N. 11
St. ; 8-9, 1-3, 7-8; Prof. Gyn., Mo.7.

Mortland, Chittick B.-110.2,884; (专); 3649 Vista Ave.

MOSBY, CILAS. V. (b'75)థ-Mo.i, 00 $\left(I^{\prime} \cup 0\right)$ (Old Orchaid); offle, Metropolltan Bldg; $9-1,2-5$.
MOSKOP, l'F'EIR GEOHGE (b'87) \-Mo.2, 'I0; (1'10); 2730 s. 13th St.; 8-9, 2-3, MiDi), IIAVEY GILAEK (b'5i)Ð-Mo.2, ' I: (I'84); 47 Vanderenter Pl.; oftlce, llumbolelt Bldg.; $1: 30-3$; Cin. I'rof. surg., Mo.2; (A5,7,22,23, C1): $\mathbf{S}$.

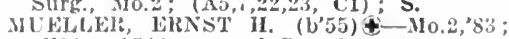
(1'84); 3548 Arsenal St.; $9-10,2-3,7-8$; N.

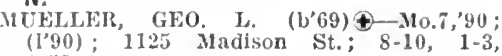

MUELLEH, VINCENT J.-Mo.2i,'96; (I'96) ; 1426 Belt Ave.; $9-10,2-3: 30,7-8: 30$.

MUETZE, IIENITY (b'63)-Mo.1,91; (I'91) 3201 Shenandoah Ave.; oflice, $1703 \mathrm{~S}$

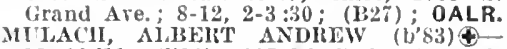
Ito.10,'11; (1'11); 117 W. Steins St.; of tice, $335 t$ Califurnla Are.; $9-11,2-4$, $6: 30-8$.

Mulford, Roy Thomas (b'83)-Mo.34,'06 (I'06); 3901 Easton Ave; 8-10, 1-3.

MULLEK, CARL J. (b,86)-Mo.2,'10; (1'10); Vanderenter and Evans Ares. $2-4,6-8$.

Mruller, John D. (b'54)-MIo.1,90; (1'00) 3903 Erans Ave. ; Prop. Ther., Mo.7. IINSCH, AUGUSTIN $\Gamma^{\prime}$ (b'79)↔-Pa.2, 03; (1'05) ; 5133 Page Biva.; offlee, 125 N. Kingshighway Blvd.; 9-10, 3-4, 7-8. MUNSON, CIIARIASS LUCIUS (b'69) $4-$
Mo.34,03; (I'03); 731 S. Broadway $8-10,1-2,6-8 ; \mathrm{U}$.

Murphy, Arthur John (b'S6)-Mo.10,'12; (1'12); 6931 Gravols Ave.

Murphy, Edward Sarsfleld (b'86)-Mo.34 '10; (1'12); 3670 W. I'ine Blvd.; oflce 4004 Chouteau Ave.

MURPIIY, FIRED TOWSLEY (b'72)థMass. 1,01; (l'11); Member Mass. Med. St.; 'Prof. Surg., Mo.2; (Á5,7,22, D3);

MURPHY, JOHN C. (b'72) †-Neb.6,95; (1*96); 4916 McPherson Are.; 2-4; G. 12: (I'is): 919 N. Taylor ATe. 1-3, $7-8$

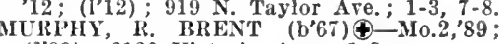
(1'39); 6120 Victoria Ave.; 1-3

Murrell, Chas. P. (b'67)-Mo.24, 00 ; $\left(1^{\prime} 00\right)$; 1407 Market St. ; 9-11, 2-4.

Musick, Catherine A. (b'50)-Mo.10,'99 (1'99); 1419 Franklin Are.; 8-12, 4-7.

llustard, Harry James (b'85)-111.1,'13

Intern, City Hospital.

MYER, MAX W. (b"is) \&-Mo.27,'99 (I'00); The Washington; office, Wail Bldg.; 2-3; Asst. Prof. Surg., Mo.34; (A22); S.`; Asst. Prof. Surg., Mo.34; MIYRDICK, ALBERT H. (b'74) \&-Mo.i, '99, Mo.2,'03; (1'98

MYERS, EUGENE LEE (b'80)†-Mo.7,'09; (1'09); 3904 Laclede Ave.; 9-11, 2-4 -8; Prof. Phys. Chem., Mo.10.

NAPIER, AMALIE MARIE (b'67) \$-Mo.28, '08; (10); 3158 Ohio Are.

1SH, WADE HAMPTON (b'77)-Mo.7,03

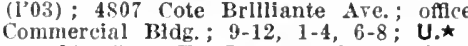
Nawrocki, Jos. F. J.-Ho.34,'06; (1'06) 1438 N. 9 th St. ; 8-10, 2-4, 7-8; Pd.

Nity, Albert (b'48)-Mo.10,'\$4; (l'89); 4248 Morgan St.; office, Frisco Bldg.

Nehl, Charles W.-Mo.10,03; (1'03) ; 4139

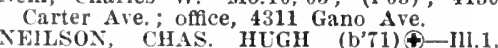
0.5; (l'07); 4353 Forest Park Blrd.; office, Humboldt Bldg.; Prof. Mled., MIo.34; 1. $\star$

NELAN, WM. IAURENCE (b' $\tau 9)-M o .2$, 01; (1'01); 1483 Union Bivd.; 2-4, $\mathbf{T}-8$; N.

Semours, Paul (b'62)-Mo.7,'89; (1'89) 3852 Crreer Ave; offlce, 3142 Franklin Are. ; 8-10, 1-3, 8-9; ObG.

Neubert, Adolph (b'43)-N1o.4,69; (1'84); Broadway and Wainut; $8-10,2-4$.

NEUHOFF, FRITZ (b'63) $\oplus-\mathrm{M}_{0} .2,8 \%$ (1'87); 3206 Lafayette Ave. ; 3-4, 7-8

NEVILLE, EUGENE J. (b'67) -Mo.2,'92; (I’92): 5891 Washington Blvd.; offlce,

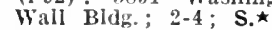

Sewcomb, Carman A., Jr.-Mo.2,'94; (1'91) American Hotel; office, Carleton Bldg. $10-12,4: 30-6$.
Newell, John 11.-Ho.2,'70; (1'91)； 5063 Delmar Blvd.

NEWELL, QUITMAN UNDEILWOD (b'86)

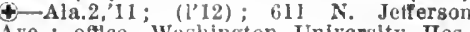
Are.; oftlce, Washington Unirersity Hos pital; ObG. $\star$

NEWMAN, LOVIS L. (b'61) - - Pa.2, 83 (1'85) ; 5381 Waterman Ave.; ofllce, Humboldt Bldg. ; 2-4; ( 11 ) ; ObG.

NEWMAN, I'WHC' - Mo.2,'07; 4364A W. I'lne Blid.; ofllee, Wall Bldg.; 9-10, $1-2 ; 0 \mathrm{bG}$.

NEWIAN, SAMUEI, F. (b'78) -0.9,02 ; (1'03); 4900 J3erlin Ave, offlee, Metropolltan 13ldg.; 11-12; $\mathrm{S}$.

Nichols, Andrew Bascome (b'52)-Mo.1,73 ; (1'81); 3877 Washington Ave.; 1-3, 5-8. Nichols, David-Ho.1,90; (1'00); 922 High St. ; $10-2,5-7$

ICHOLSON, CILARENCL M. (b'68) Mo.1,91; (I'91); 727 Lnion Blvd.; office, lister Bldg.; 2-4; Prof. surg., Mo.34 (A 7,22$) ; \mathrm{S} . *$

Ničś, HÁRLY G. (b'61)-Mo.22,90; (I'94);

933A Goodfellow Ave; $2-4,7-8 ; 0$ og. 00; (1'00); 2000A Salisbury St.; 8-10,

Niederst, Pichard Henry (b'72)-Mo.7,98: (1'98); 1409 McCausland St. ; 11-12, 2-4

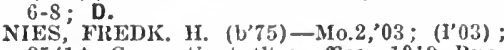
$3541 \mathrm{~A}$ Connecticut st.; offlce, 1019 Rus sell Ave. : $9-10,2-3,7-8$.

NIETERT, HERMAN L. (b'66)థ-Mo.2,'89; (1'89); 3614 kussell Are.; offce, Century Bldg. ; 11-2.

Nitzschmann, Emil J-Mo.1,'90; (1'90) ; 6203 Man Ave

OBBE, WILHELM (b'69)-Ger.14,'95; (l'03); 4234 Page Blrd.; offlee, Frisco Bldg. : $10-1,3-5 ;$ Op.

Folan, Bartholomew J.-Mo.7,'13 ; ( ) ; 1223 5. 6th $\mathrm{St}$

FoRRIS, EDW. J. (b'66)-Mo.22,'88, Mo.27, '91; (1'03); 4223 Russell Ave.; office Mo.7.

Norrls, Saml. Relly (b'85)-Mo.2,'12 (1'12) St. Louls City Hospital.

NORTH, EMMETT P. (b'Ti)-Mo.24, 00 ; (I'01); 212 \& $\mathrm{S}$. Grand Ave.; offlee, Grand Ave. and Olive St. ; $9-1 ;(B 2 \pi) ; 0 p . \star$

Nufer, Frederick M. - Mo.10,01; (1'01) ; $18160^{\prime}$ Fallon St.

OATMAN, LOUIS JAMES $\left(b^{\prime} 71\right)-M 0.27$, 93, Mo.28, 00; (I’94); 4214 MePherson

Are. ; offce, Metropolitan Bldg.; 1-3. Hebert St. ; oflce, 3500 N. Grand Are. ; Hebert St. ; ofl

o'Brien, Cornelius (b'32)-H1.1,63; (l'94); 1404 Union Ave.; offlce, 3041 . Easton Ave. ; $9-3$.

O'BRIEX, LEO. F. $\left(b^{\prime} 77\right) \oplus-M 0.7,(1)$ (1'02); 5401 Gravois Ave.

o'Brien, Stephen Leo (b'89)-Mo.34,'13; (1'13); City Hospital.

OBKOCK, LOUIS C. $4-M 0.10,01$; (I'01) : 779 Lemay Ferry Rd.; $8-10,1-2,7-9$.

0 'Connor, Chrlstopher 'Sebastian (b' 76$)$ Mo.34,0i; (1'0i); Grand and Easton Aves.; $10-12,2-4,7-8$

odeneal, Thomas Helm (b'89)-La.1,10; () ; 4530 A Laclede Ave. ; 2-4; ALR. $\star$

OFHLEP, EMANUEL F. (b'77) $\uparrow-M 0.34$, oelfcken, Firnest W. (b'70)-Mo.1, 96 (1’96); 3148 Olive St. ; $9-10,1-3,6-8$; $\mathbf{S}$. $0^{\star}$ Gallaher, James-Mo.2,'78; $\left(1^{\prime} 78\right) ; 1355$ Eucild Ave. ; 9-11, 3-5.

OCLE, OLIVER L.-Wo.2,97; (1'97); 3126

v. Grand Ave

O'Gorman, Danl. D.-Ont.3,'88; (1'95) ; 2839 Park Ave.

O’Hara, James F.-Mo.2,'65; (1'94); 3925

'Hara, Mary F.-Mo.10,'95: (1'95) ; 3850

Texas Ave.

Ohmann-Dumesnil, Amant H. (b'57)-Mo.2, '80; (1'83); 3966 Lincoln Ave.; ofllce, Tlmes Bldg.; 11-2, 5-6; Prof.' Derm., Ho.7.

O'KEEFE, JAMES J.†-Mo.7,03; (1'03) ; 4298A Page Blvd.; offlce, 3221 Lucas Are. : 8-10, $2-4$

olunsted, Him. Harwood (b'87)_MId.7,'13; Intern, Washington UnIversity Hospital. 


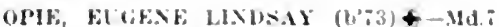
97 ; not la practce: Member ltcil and chir. Faculty of Mid. "tit Washlugton Bird. ; whice, 1 for leneust st.; Hean and Prot. 1'ath., M10.2: (1D6, Fe)

O'HEHLLY JAMES AlRCHEM $(1,79)+$ oflce, Huzblolat Bidr. (13)

O'REHAY, HOHT, J.-MOE'to

9: Wiashington Terrace; omce

firand tre.: 11-1, 5-7.

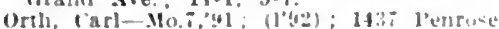

st.

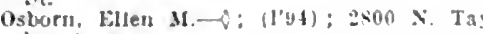

lor Ave.

Otlersbach, Carl $\therefore \quad(1,56)-141.11,02$

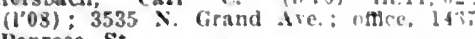
Venrose $\mathbf{S t}$.

Ottofy, Ladlslaus M. $\left(63^{\prime} 65\right)-M(1), \infty$ (1's8); New Grand Central Theatre 1hi: 1.3; D. *

Orerman, Davld R. (1,51) H-O $1: 3,8$ (1992); 4948 Maple Ave.; untll !), $3-4$ $i-8 ; \mathrm{N}$.

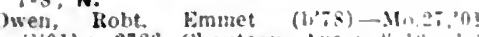
(1'01): 2726 Chonteau die.; $k-111$. 6-8: 0 p.

OWEN, WM. CORNWAIAS (b'65) - Mo 89: (I'95): 3833 Folson Are. : th Metropolitan Bldg.; $9-12$; (B27); Op.

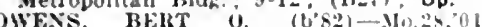
(I'04); 3903A raston Are.; 1 - 3

l'ADBEHG, LOC'S 1t. (b'78) - Mo.24, $(100) ; 3624$ Callfornla Ave; oflece, 260 . Lyach St.: $8-9,3-4, i-8$.

l'allou, Emile K. (b'bí) ll-1'a.9,93; (1'43) 4003 Bolanlca! Ave.; oftlce, $119 \times$ ith St.: Op.

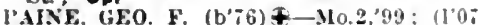
1109 Walton Are, oftce, Carleton 13!ds $8-12 ;(132 \pi)$

PAPACHAKALAMBOs, KOSMOS (t'75) Greece 1.01; (1.11); Navarre Bldr.

Paquin, Ozlas (t'6t)-Mo.t.9s: (I'96) i001 Waterman Ave.; office, Victorial Bldg. : 9-10, 12-1, 3-4.

PARK, GEORGE MATTHEW \&-MU.D. (l'05): 5893 Cabanne Ave. : offlce, Ri Hamilion Are. $1.2,6.8, S$.

Papker, Chas. Weakley-1Io.20,91) (1'91) 2349 Hebert St

PARKEI, FREDK. PHLLIP (h'6y) Mo.27,93: (1'93); 1518 x. Euclid Ar office, Times Bldg. : $9-12: 30, \quad+-5: 311$ (B2i) : Op.*

Larker. Wm. Garfleld (b'si)-310.28,1 (1'0); St. Mary's Inflrmary; $\mathrm{s}$.

PARMAN, DAVID 16OBT, (b'T6) Mo.34 03; (l'03); 5206 Kensington Are.; once 4503 H'aje Are.; 11-1, ;-8; 0bg.

arrish, John (i. - Mo.1, 'i2: (1'b4); 4th

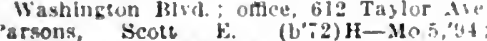
$\left(1^{\prime} 96\right)$; 4052 Washington Ave.; 8-10, 1.3 Passler, ReInhold-110.27,92; (1'92); 1 lli N. $15 \mathrm{th}$ St. $; 9-11, i-8$

Patlerson, Arthur B. (1,83)-Tenn.7,'lo (10):6900 s. Broadway. (b55)-0y,

I'ATTON, FHEUK WM. (t55)-0.9, 11'99) : $5372 A$ Vermon A tre.

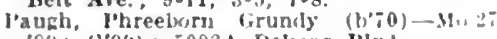

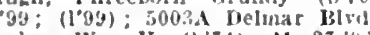

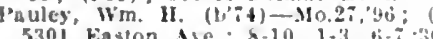

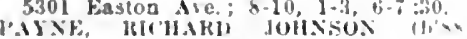

Mo.34, 13: (1'13) : 4125 W. Helle 1 I

reake, sami. A - $10.22,45 ;(1205) ; 705 \times$ KIngshlghway Blod,; oflice, commetclal BIdg: : 11-1.

l'eart. Allert botward-Mo.i,10: (1'll

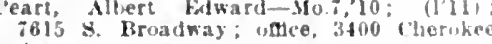
Ale.

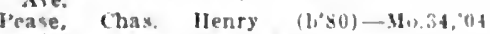
(1'05): 10 s. Girand Ave : 12-1, ; 8 .

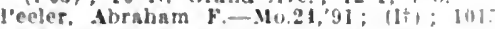
Marlon St. offce, If:lt Menaril st

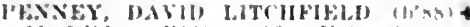
Mo.2.11: (1'11): 192ti Veliranka dre onlce, Vaubreuter die and obls.

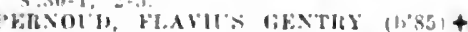

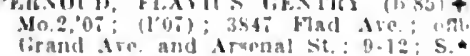
lirand Aro and Arwonal st. 9.12: S. (1.13): Fred Lelly

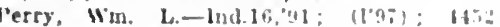
kenuerly ire. l'eters. Ausustus 11 . $(1,81)-110.2,06$

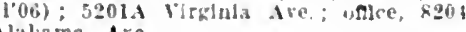
Alablims Are.

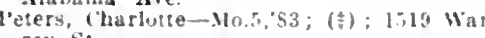
rell st.

Peteron, Cyrus Aslury-Mo.1,7s (3)

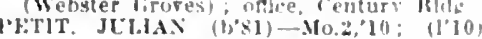
1003 S. EwIng Aie.: 6:30-7::36): ince "entury t3lde. 11-1:

Perlt Jultus (1) practce: 3519 Palm st. : omee, 3isto :Cirand Are.

letl: Willan 1) (1)'83)-110.2,11; (1'11) limin Callformia Nie.

P'efter, Chas, Aukust (b'90) - Mo.31'12

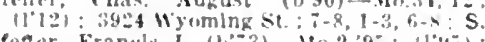

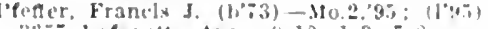

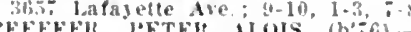
os: (1'09) ; 3940 shaw ive, ; offce. lith

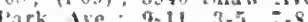

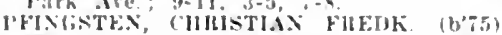
+-160.7.98; (1'98); 2918 Dodier st. oflice, Hetropolltan Bldte; 10-1. in(1:2:3); ALR.*

Phelan, Emma (b’08)-No,:,09; (1'11 $612 \pi$ A Easton Are.

Phelan, Mchard A. (b'i2)-M(1.;, (1): : (100); 6531 Bartmer Are., Enlversiby

Phillips, Chas. Henry, Jr. (col.) (b'82)-

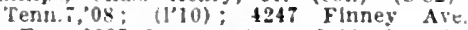
offce, $260 \%$ Lawton Are.: 9-12, 2-4, 6I'IlLLIIS: (ikO MARQLeT (b'62) fice, Commercial Blug.; 10.12, 3-4; (C3). U.

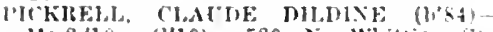
to.2.10; (1'10): $520 \mathrm{~N}$. Whittier st. nttce, Century Bldg.; 11-12, $1: 30-3$; U.* lieper. Henty G. $(1, \% 9)-M 0.34,03$; (1'03). the Shesiandoah Ave; once, $1911 \mathrm{~S}$ lath st. i $10-12,+-5, i-8$.

Pierce, Win.-Mo.2, 03 ; ( ven Are, ; offce, 1 it Broadway.

Pim, Lonis T. (b'i)-Mo.1, 93 ; (l'93) kide.; $9-10: 30, t-5: 30 ; \mathbf{S}$.

Winkitafr, James T-In $29,97:(1005) \cdot 134^{\circ}$ Blackstone lve: : mce, Mermod-saccard [3] de: : 9-ti.

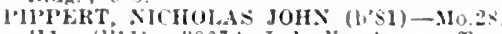
'll: (11); 396i. Labarte Are, oftice

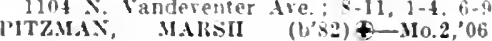
(106i); 6 kingsbury Jl.: oftice, Vanderemter Ire. and ollre st. $1-3 ;$ S.

l'ne, Arthur (b'87) $\rightarrow$; (1); 2619 Nadlson

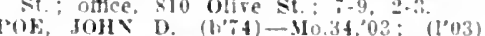

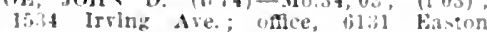
Ave: $8-3,1-2,7-8$.

bokll, GEo WM. (bsi) Mo.34, 12 (1'] '

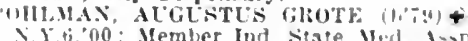
s. Louls Endversity; jrop. Anat., No.s6 (ril)

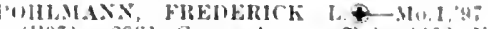

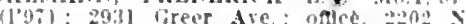
Varket st.

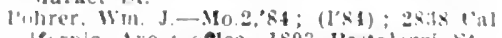
Iforma Are calce, 1803 l'estalwzic st.

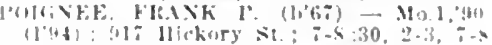

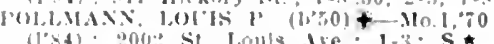

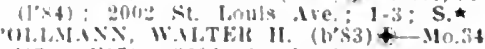

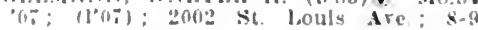
12.1: S. Maswoll a (1),90)-Mn 10:12

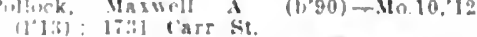

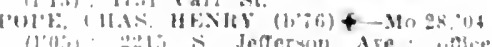

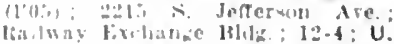

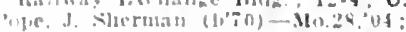

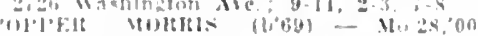

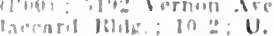

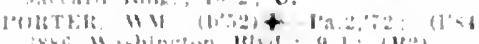

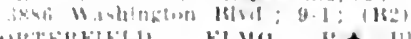

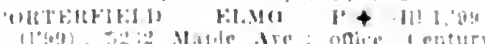
Nis?
l'OST, MAlTTIN HAIWAH, JR. (b/6)-

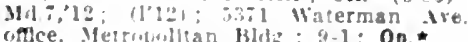

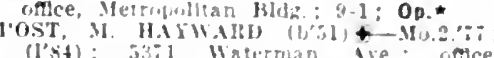
(I'sit); $33 \%$ Waterman

lote, Thomas 13. (1) 6 i) - in

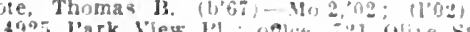

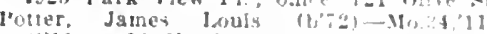

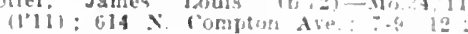

rotter. Nelson-Mo.20,"00 Jefierson Aro.

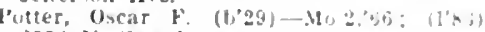
2956 N rirand Ave.

Potte, (bas 1 -No.7, 92

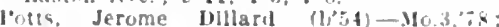

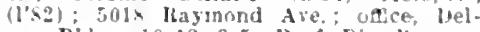
mar Bidg.; 10-12, 3-5; Pro\&. Dlg. Mectum. Mo. $10: \mathrm{Pr}$.

I'otts, Jerome Fredk (b'sh)-M!o.2Q:09: Blde: $8-10,1-3,7=8$

Iowell, carl Arthur (b'as)-Mo.3t,13; In. tern, st. Imuis rley Howltal.

POWFLL, JGSATIS WALTHLL + -

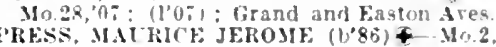
09: (1.09): 2837 Dekion St.; 9-11, 2-4.

Prewitt, Robt. Conk, Jr. (b';6) - Mo.25, 00 ; (100ii); $521 \mathrm{X}$. Yewstead Are.

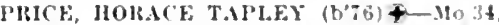
12: (l'12); \$200A Ifartford

rrice, John l.en $(6,84)-110.34,10$; (1'10); $1642 \times 19$ th St.; $9: 30-11: 30,2: 15-4$ $6: 30-5$.

I'rlce, John M-No.5, $02:$ (l'03); 1246 Purcell Are.

P'RICHALD, JAMES BICHANAX (b.60)Mo.1,85; (1's5): 2017 l'ark ire: offee. 2007 Park Are.; 8-10, 2-4, 6-8; ObG.

Pringle, Jolun A (b'sx)-Mo.s'11; (1'11): (Pittsfeld, Ml,); St. Louls Clty Hospltal. Proctor, Carter itwater (b'ss)-
(1'12): St. Louls Cyr Hospital.

PROETZ, IRTHCR WALTEK (b'S)-Mo.2. 12 ; 1121 ; 4\$6 Hamniett Pl.; 7-9, 2-3,

l'rueti. Danl. Slmpson (b,5) E-180.10,43: (1.02) : 455 Dower Pl: affle, 60ne $\mathrm{Vir}$

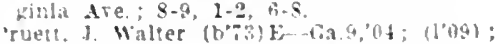
nocet Virginia Are

I'CKETT, CHAS L - No.:04; (1'04) $+X$. 21st st.: office, 2001 olise st

PrCKETT, CORUELIA AXN (h'T-Mo 10 12; (1'12); 356's Cottace Are.; 8-10, 1-2, P'IIJAM, MADISOX JAMkS (b'SO)110.34,12; (1'12); 1011 Biddle $s t$.

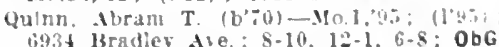

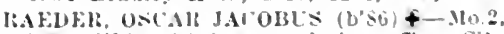

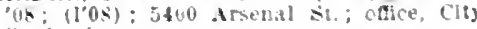
Santarlum.

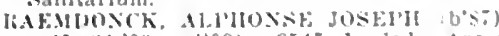

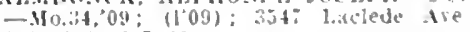
S-9, $1-2,6-3: 30$

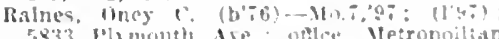

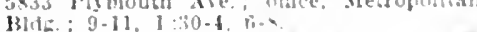

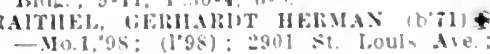

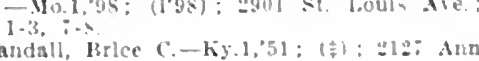

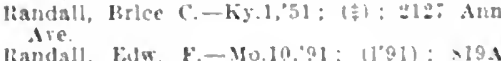

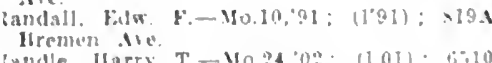
liandle, llarry T. Mo 24 : tho

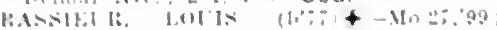

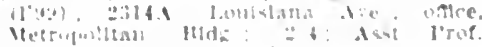

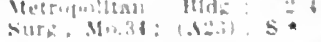

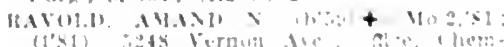

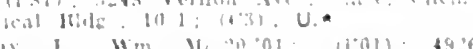

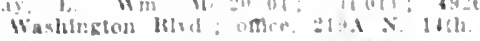

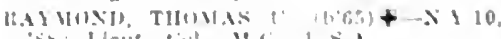

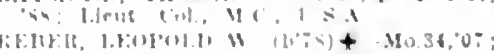

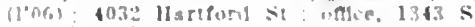


lieber, Lyman S.-I'a.1;70; (I’90); $6925 \mathrm{~S}$. Broadway.

RFBER, HOBT. L. (b'5) \-Mo.34, 06 : (l'06): 18:35 S. 11 th St. $i$ oflec, 1837 ,

REDER, FRANCIS LE SIRELIE (1,64) + Mo.2,'84; (l'S4); 6346 Berlln Are.; of fle, Delmar Bidg.; 1-3; (A1.6,20,22) S. $\star$

REHD, ELIZARETII BSAS $(3)^{\prime}(64)+-1$ 'a 91; (l'05); 4500 Olive st.; $2-4$ Reel, Jesse (b's2)-Mo.28,11 ; (I'i1) ; 2527 N. Taylor Ave.; once, ran High st. $8-10,1-$

REHFELIT, (HIS. SIXTLS $\left(\mathrm{b}^{\prime}-3\right) \uparrow-110.2$, 96; (l’96); 2302 \&. Jefferson Ave.; $8-10$. $2-4,7-8$; irot. Thys. Dlag., Mo.10.

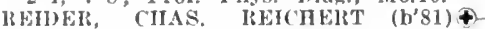
Yo.28,07; $\left(1^{\prime} 06\right) ; 1605 \mathrm{~A}$ s. 9th St.; 8-10, $2-4, \tilde{i}-8$

REILIX, JOS, JOIIN (b'85)-Mo.34,'12 (1'12); 4220 Loulsiana Are.

REIM, WM. HUOO (b'83) -M- Mo.2R, 04 ; (l'04); 202

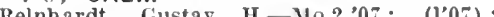
2003 E, Frand H.-Mo.2,07; $\left(l^{\prime} 07\right)$; Graud Are, : 8-12, 1-5, 6-10

Reitz, Matthias Winfleld WaslingtonMo.28,'06: (I'05): 1101 l'ark Are.

Reuter, John F.-IIo.2 $i, 01 ;\left(l^{\prime} 01\right) ; 4100$ Lee Are.

REYNOLDS, SAML. II.-Mo.28,97; (l'97); 7370 Manchester Ave.; 9-10, 1-4, 6-8; U. Rhodes, Thomas Fzra (b'it)-Mo.28,'10: (l'10) ; $807 \mathrm{~N}$. Garrison Ave.; offlce, 721

RICE, DELI FRANK (b'63) †-Ky.5,'92; (1'93): 5145. Cabanne Are.; office, Delmar Bldg.; 1-4; Prof. Clin. Obst. and Gyn., Mo.10; (A20); ObG.

Rice, Geo. Henry (b'55)-Ky.2,79; (l'01) ; 3139 Scliool St.; offlce, 3509 Page Blrd. $2-4 ; G$.

RIch. Harry (b'85)-Mo.2,08; (l'08); 1849 Biddle St.; $8-10,1-3,7-8$. OALR.

RICHMAN, W. C. (b'60)-Ill.10,'88; (l'90) ; Member Ill. State Nled. Assn.; 3011-Easton Are. ; 3-4, 7-8.

97: (l'97): 7310 M (b'68) †-IIo.24, $1-3,7-9$.

Richter, Geo.- $\rightarrow$ (1'84); 3538 Humphrey St. ; office, Metropolltan Bldg. : 12-2

RICHTER, GEO. (b'52) $\oplus$-Ger. 6,74 ; (1'81) ; 3538 Humphrey St.: offlce, Metropolltan Bldg. : 1-3; Prof. Med., Mo.10; I.

Rlgler, Robt. I. (b'72) E-Mo.10,'02 ;

4152 N. Newstead Ave.; 8-9, 7-8.
RILEY, CASSIUS II. (b'4 4)

(1'84) ; Member Hil. State Med. Soc.; 3945 iragnolia Ave.

RILEY RALPH D.-Mo.2,'02; (l'02); 4641 Washington Blvd.; S.*

RING, FRANK (b'55)థ-Mo.7,'92; (1'92); 6218 Wagner Ave.; offlee, Chemical Bldg. Rlnkel, Jacob 1.-Mo.2,81; (1’91); 4526 Page Blvd.

RITCHIE, FRANCES RANKIN (b'80)Pa.7,08; (1'10); 4348 Delmar Ave.

RIVES, THOS. L. (b'63) - Mo.1,'85; (l'85); 5717 Vernon Ave.; offlee, 934 Goodfellow Are.

Robards, Younger Potts ( $\left.b^{3} 73\right)-$ Mo.28, 0 ? (1'01); 4234 Arco Ave. ; 7-9, 1-3, 7-9. ROBERTSON, WM. M. (b'66)-Va.1,89; (I'S1); Humboldt Bldg. ; 11-1; (A22); U.*

ROB1NSON, ANSLEM C. (b'51) \&-Mo.1, 74 ; ( 174 ) ; 5083 Westminster Pl.; office, Delmar Bldg. ; 8-10, 4-6.

ROBINSON, GEO. CANBY (b;8)€-Md.7, 03: Hember Med. Soc. of the State of N.Y.; 4914 Forest Fark Blvd.; office, Wishington University Medical School Assoc. Prof. Med., Mo.2; (F10) ; 1.ћ
Robiuson, Guy Frank (b'84)-Mo.7,05; $\left(l^{\prime} 05\right) ; 4154$ Shaw Are.

Rodenheĺser, Edwin Win. (b'91)-Mo.2,'13; (l'13): St. Luke's Hospital.

ROHLFING, ARTHUR HERMANN†-Mo.2, 04; (1'05) ; 2600 Market St.

ROHLFING, CHAS. G. (b'43) †-Mo.4, 67 : (1'83): 3803 Russell Ave.; office, 1827 Cass Are, ; $9-10: 30,2-3,7-9$

ROHLFING, HENRY'A. L. (b'61) \&-Mo.1, 'S3; (1'84); 3665 Humphrey St.; offlce, 2602 Narket st.; $9-10,2-4$.
ROHLFING, LOUIS C. (b'66)-Mo.1,8
(l'02); 3521 Dodter sit.; untll $\mathbf{9 ,} \mathbf{1 - 3 .}$

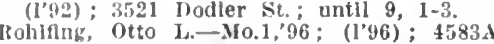
Easton Ave.

hohifing, Waiter Alfred (b'S9)-M10.2,'11; (I'11); 5020 Gravols Ave.

lolling. Fredk. W.-MI0.27,'94; $\left(l^{\prime} 94\right)$; 212 Sidney St.; $10-11,7-8 ; U$.

lose, lose Minnle-Mo.28,'07; (1'05) ; 5606 Easton Ave.

16OSERHOUGII, CIIAS. ASCHER (b'86)Mo.7,10; (1'11); City Intlrmary.

ROSERROUGH, FRANKLIN II. $\left(\mathrm{b}^{\prime} 78\right) \oplus$ Mo.34,'04; (I'05) ; 4961 Mcl'lierson Ave.; offlce, 928 N. Grand Ave. : 9-12, 2-4; 0pA.

Lothman, IIenry leo (h'89) - Mo.34,13; (I'13) ; 1446 X. 11th st.

ROTIMAN, PAIL MOLRIS (b'63)-Mo.2, 02; (1'01) ; 1446 N. 11th st.; $9-11,4-5$,

ROTISTE1N, HUGO (b'38) - Mo.1,77

(l'92); 3309 S. 13th St.; (A20); ObG.

ROTTECK, JULIUS (b'81) 4 Mo.5, 04

3830 Conneetlcut St.; office, 2623 Park Are.; 2-3, 7-8; Prof. Clln. Ped., Mo.10

\section{Pd.}

O'TTEK, CHAS. FRANK (b'61)-Mo.27,

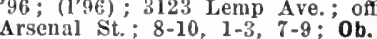

ROYSTON, GRANDISON DELANEYQ Mo.2,07; (1'07); 201 N. Taylor Ave.; offlce, Delmar Bldg. ; 9-12; (A20).

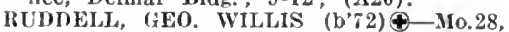
04: (1'04) ; 1201 N. Taylor Ave.; offlce, velmar Bldg.; 9-12; Prof. Oper. Surg. IIo.10; $\mathrm{S}$.

IULE, JOHN B. (b'63)-Mo.24,'92; (l'94) Melrose Apts. ; office, 1023 N. Grand Ave. RUMBOLD, FRANK MEEKER (b'62)Mo.2,'84; (1'S4); not in practice; Buck Ingham Hotel.

Runde, Fredk. Wm. (b'74)-Mo.27,'98; $\left(l^{\prime} 98\right) ; 3203$ Dodler st.; offlce, $3024 \mathbf{N}$. Grand'Ave.; 9-12, 5-6; 'Prof. Ear, Nose and Throat, Mo.7; Assoc. Prof. Ophth., Mo.10; 0pA

RUSK, ELIZABETH ETTA†-Mo.28, 04; (1'05); 4215 Delmar Blvd.

Russell, Llbby-Mo.10,01; (l'01)； 3535 Henrietta St.

Russell, Thomas J.-Mo.1,'93; (l'93) ; 3658 Page Blvd.; offec, 1308 N. Grand Ave. $9-11,2-4,7-8 ; 0$ b

RUSSLER, JACÓB J. (b'75) - -Mo.34, 03 ; (l’03);2620 S. Jefferson Ave.

RUTHERFORD, ORRA LEROY (b'84) Mo.10,'13; (1'13); 5817 Gravois Ave.

Ryan, Lawrence Áugustus (b'84)-Mo.34, 11; (1'11); 3536 Sldney St.; offlce, 2320 S. Grand Ave.

SACHS, ERNEST (b'79)థ-NI.7,04; (1'11); 5557 Berlin Ave.; office, 1806

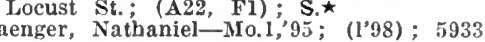
Page Blvd.; offlee, 9 th and Olive Sts. $10: 30-1$; AĹR.

SAHLENDER, OTTO L. (b'il) SALE, LLEWELLYN (b'81)థ-Mo.2,'07 $\left(l^{\prime} 07\right)$; Westmoreland Hotel; offlce, Wal Bldg. ; 1-3; Asst. Prof. Med., Mo.34; I. Bldg.; 1-3; Asst. Prof. Med., Mo.34; $1, \star$
SALTER, JOHN CLEVELAND sId.7,01; $\left(l^{2} 04\right) ; 4398$ Olive St. ; offlce,

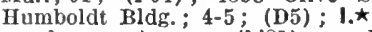

samuelson, Aaron (b'81) - N.Y.8,'05; (1'12) ; 1719 Carr St.

Sanborn, Jos. Henry (b'34)-N.H.1,'5i ; $\left(l^{\prime} 98\right)$; 2615 Lafayette Ave.

SANDERS. CLIFFORD E. - Mo.28,'09; (1'09); 2510 Emerson Are.

SANDPERL, HARRY (b'84)థ-Mo.2,'08; (1'08); 5636 Cabanne Ave.; offlce, Del-

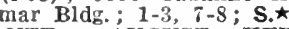

SANTE, ALGUS'T HERMAN (b'64)Mo.10,92, Mo.28,94; (1'93); $1115 \mathrm{~S}$. Grand Ave.; untll 9, after 6.

Sante, LeRoy (b'90)-Mo.2,'13; (1'13); $1115 \mathrm{~S}$. Grand Ave.; office, City Hospltal.

Sargent, Mary U. (b'65)-Mo.5,'88; (l'88); 1623 Semple Ave. ; 8-10.

Sattler, Georgía Belle (b'79) - 0.2,'13; $\left(1^{\prime} 13\right)$; 4139 A Lee Ave.; 8-10, 2-3, 7-8;

SAUER, IVHLLIAM E. $\left(\mathrm{b}^{*} 75\right)(-\mathrm{M} 0.2,96$; (l'9i); 4965 Maryland Ave.; office, Humboldt Bldg. ; 10-1; (B1,3,33); ALR. $\star$ Savermanu, IIans II-Mo.1,88; (1'88) ;
1910 VIrginla Ave.; oftlce, 1708 Market St.

Sauls, Joseplı A.-Ky.4,'84; (l'05); 2008 Obear Ave; ottlee, 2009 b. Grand Ave. $8-12,2-9$.

SAUNDERS, ElW. WATTS $\left(\mathrm{b}^{\prime} 54\right) \uparrow-V a .1$ 75 ; (5) ; 154I s. (irand Ave, offlce, Lister Bldg. ; Finier. Prof. Dis. of Chll.

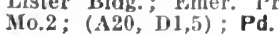

Sauter, (A20, D1,5); Pd. $\quad$ (l'83); 4120 A Shenandoah Are.

Sauter, Kdwln (b'72)-N10.27,97; (l'97) $\$ 120 \mathrm{~A}$ Shenandoah Ave; offlee, $1331 \mathrm{~N}$. 7 th St. ; $10-12,3-4,7-9$.

AXI, ElRFS'Tt-Aus.5,'93; (1'93): IIotel Beers; otflce, Mietropolitan Bldg. $9-1 ;\left(\mathrm{B}_{27} 7\right) ; 0 \mathrm{p}$.

Say, Wm. J.-Mo.1,95; (1'95); 14 'Thornby SCHAAF, KATHERINE $\left(b^{\prime} 75\right) \oplus-M 0.28,05$; (1'05); 5237 Cates Ave.

Schafer, Jos, Chas, (b'84)-Mo.34,'13 (1'13) ; 3861 Botanical Ave. ; offlce, Fldelity Bldg. ; $2-5,7-9 ; S_{\text {. }}$

Scharf, Jos. H. (b'77)-Md.9,'00; (1'00): 3134 Bell Are. ; 9-1, 6-8.

Scharti, Eugene A. (b'77)-Mo.1,'98; (1'98) : 4967 W. Pine Blvd.; 10-2, 5-6:30

SCIIAUB, CHAS. W. (b'67) - Mo.1,'94: (l'94); 2300 Sallsbury St.; offlee, 2302 Salisbury St. ; 8-10, 2-4, 7-8.

SCHEELE, MLATTHIAS HWNRY (b'84) † Mo.34,09; (l'09); 3135 Meramec St.; $8-9,2-4,7-8 ; \mathbf{S}$

(b'74)-Ill.22,'11; ( ) ; 3110 SCHERCK

'89; (1'89) ; 4561 Mel'herson Ave, ofli, Century Bldg. ; 9-12:30; Asst. Prof. Gen. Urin. Dls., Mo.34; (C3); U.ћ

Schermann, Louls Wm. '(b'78)-Mo.5, 00 . $\left(l^{\prime} 00\right) ; 5438$ old Manchester Kd.; 8-10, $1-3,7-8$.

SCHERY, CHAS. WMI. (b'76)(-M0.7,04 ; (l’05) ; 917 Allen Ave.; 9-10, 2-3, 7-8.

SCHISLER, EDWIN (b'74) $\rightarrow-M 0.24,96$ (l'96); 2600 S. Grand Ave.; $2-3 ; 1, \star$
Schlagenhauf, Henry J. (b'65)-M (l'00); 2651 Shenandoah Ave.; offlee, 816 Soulard St. ; $9-10,3-5,7-8 ;$ ObG.

Schleeter, Chas. Edw. (b'72)-Mo.34,'10 ; (l'10) ; 1939 Montgomery St.; offlce, 1502 St. Louls Are. ; 9-10, 1-3, 7-8.

'89; (1'89); 3618 Connectlcut St.; 8-10,

chlelffarth, Edgar L.-Mo.2,'81; (1'83); 2804 Eads Ave.

CHLENKER, LAIWRENCE (b’74) †-Mo.34 '10; (1'10); 4206 Humphrey St.; office, 7623 S. Broadway.

SCHLOSSSTEN, ADOLPH GEORGE '(b'72) (4-Mo.2,94; (l'94); 3153 Longfellow BClu.

L. $\left(b^{\prime} 72\right) \odot-M 0.1$

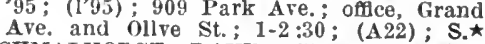
CHMALHORST, DAVID EDW. (b'74) Mo.24,"00; (1’94); 808 MeIaran Ave. offlee, Metropolitan Bldg.; 12-1; Assoc.

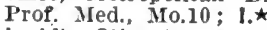

Schmidt, Otto A.-Mo.34,'08; (l'09) ; 3820 Humplurey St.; office, 439 Bates S't.

Schmidt, william Carl (b'74) - Mo.7,98: (1’98); 2417 S. Broadway ; 9-10, 2-3, T-8. SCHMITZ, EDGAR FERDINAND (b'88)Pa.1,12; (l'12); 5385 Waterman Ave.

Schoemaker, Danl. M. (b'67)-Ill.1,04; (1'05); $1402 \mathrm{~S}$. Frand Ave.; 9-12, 2-5: Prof. Anat., Mo.34; (F1)

SCHOLZ, PAUT, C.-Mo.28, 02 ; $\left(\mathrm{l}^{\prime} 02\right) ; 846$ N. Kingshighway; offlce, $809 \mathrm{~N}$. Grand SCHOJZ, ROY PIILIP (b'79) $4-M 0.2,04$; (l’05); 1110 Ferry St. : office, Metropolí$\tan$ Bldg.; 9-11, 4-6; (B1,33)

SCHOLZ, SAML. B., JR. $\left(b^{\prime} 78\right) \oplus-C o l o .5$ 05: () : Member Colo. State Med. Soc. 5926 McPherson Are, ; office, Equitable Bldg. ; 1. $\star$

chott, August H.-Mo.5,'79; (l'84) ; $406 \dot{6}$ Westminster Pl.; until 10, 4-7.

Schrelner, Jos. Géo.-Mo.10,'78; (籴) ; 4512 Tower Grove Pl.; offlce, $816 \frac{1 / 2}{2}$ Chestnut St.

Schroeder, Robt. C.-Mo.1,'\$4; (†) ; 3849 W. Pine Blvd. 


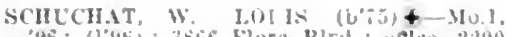

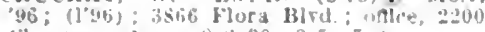

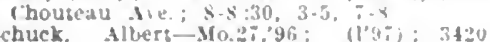

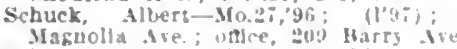

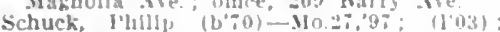
1133 Ruthet st.; utice, 14295 lirwad-

Schuhardt, frnst-Ger.t,o: (E); ly2t S ith $58 \cdot(1-11,2-1,7-8,2$,

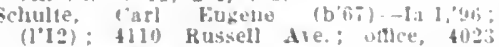
(1'12): (110)
Chouteau lie.

Schuliz, W: F. A. (b'\%1)-Mo.1.'96: (1'06)

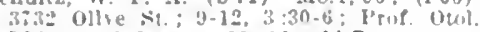
Ithin. aud Iaryn. Mo.10; ALR.

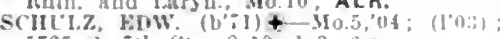
1725 s. ith st. $8-10,1-3$, ii-

SCHILZ, IEXKY H. (b'bs)-Wu.2.' (l'93): $3343 \mathrm{~S}$. Jefterson we.: tatle $\$ 603$ Cherokee St; $8: 30-10,2-3, ;-8$.

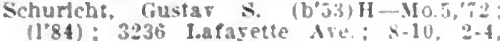
(1) 8

SCHW IR SINDEY ISAMC $(b ; 1)+$ Mass.1.96; (I'99); 5859 Clements Ive otace, Humboldt kids.: 2-5; (F:1)

Schwalbe, Samuel (b'5S)-IId.1,85; (I's6) ('entury Bldg.: 1-4: OpA.

SCHWAHTZ, FREUERICK OSCAR (b'si) + -Mo.2,10; (1'10): 3524 Humphrey si. once, $2 ; 35$ s. Broadway ; 4-5, $;-8$; also

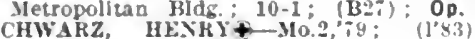

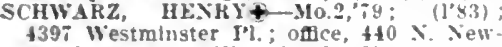
$\$ 397$ Westminster I'l.; office, $\mathbf{4 1 0} \mathrm{N}$. Vew
stead Are: Clin. Yrof. Obst. Mo.z (A1,20)

SCHWARZ, OTTO IIEXRY (b'\$8)-.IO.2, $13 ;\left(l^{\prime} 13\right) ; 440$ N. Newstead Ave.

2yel $S$. Jefferson Are.; $;-9: 30,2-4,6: 30$ $8: 30$

SCHWENINGER, KIWARD A. $\left(b^{\circ} ; s\right) \mp$ Mo.2,07: (l'08); 2727 Elllot Are, ; 8-10, 12-2, $:-9 ; U$.

Schwer, Otto James $(\mathrm{b} ; 0)$ - Mo.2s, 0 ; (1'07): 2105 S. Broadway; $1-$

SCOTT, CLIVE D. Mo.2,03; (1'03) ; 442. Fountain Are.; offlee, Islset Bld

Scolt, Iranld W:-D.C.3,'s2 : (1'93)

Plne st. : offlee, 222t Market st

SCOTT, E.IJAH A. (b'80)-Jlo.2n, 't) Broadiay: $8-10: 30,1-3$.

scott, Electa A.-u; (1'03); not in prar.

Scott, Electa A.mb; (l'0.

SCOTT, JAJES II.Mo.2,53; (1'\$4): 5109 Palrmount ire.

SFABOLI, JOII ALBRT (b'84)+ 10. 09 ; (lo9); fillo Klngshury Bivd. ; oftle Times Blug. : 9-11, 2-4.

SFELIG, MIJOH GIBRIFI, (b\% x.1.1,"00; 1105$)$; 5059 A Waterman Ate oflice, Wall Blde.; l'rof. Surf., Mo... (A:, Fl) : $\mathbf{S}$ *

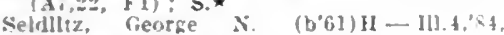

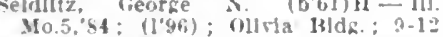

Sellers. Claude L. (b'84)-Mo.34,'10 (l'I1): 3903 Easton Are.

SFXENEY EDCIA MORF-MO.'si Bldg: $9-1$ ? $5-\beta$

SFISFIFI, FIGENE T. (b'SO) + MU.2

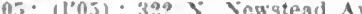

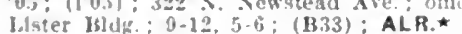
Llster Isldk: : 9-12,5-6; (B33): ALR. (I'13): Washlngton loulterslty Howplial.

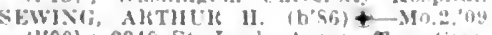
(1'09): 234 S St Louls Ire, ofle, liraml and Sulliran Ares.; $1-3,7-8,9-10 ; \mathrm{S}$

Shaffer, Mayuoni C.

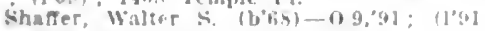

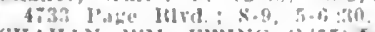

SHAHAN, WM. EWIX( (1)

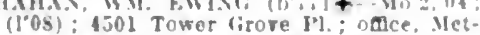
ropolitan lillg: :1-12; (B27); OD. shank, Wu. l. (b'tä)-0 rlark Ave.

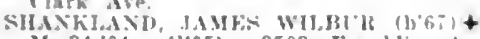
Mo.34,04; $(105): 3503$ Yrankiln IVe $3-4,7.8 ; 5$.

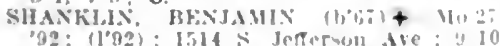
2.3, i-8; 1rop. l'rac. Med. Mo,10

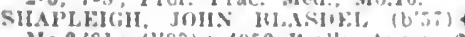

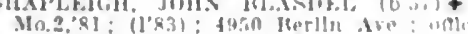

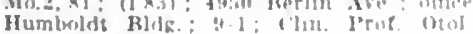
Io.2: (B3,3:3)

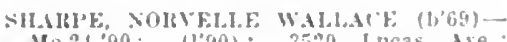
Mo.24,90; $(190) ; 3500$ Lucas Ire. 11-1; (A21) ; S. *

SHATTIStits, (IIAS. (b'b5)-Mo.2,'86 $1186) ; 2421$ s. (irand Are.: $9-11,6: 30$ -

SHAW. SFESE M.SIINGTON $(1,84)+$ Mo.t,0s: (1'0s); :415 $\mathrm{x}$. Jetterson Are

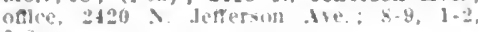

Shat silis 1 .

Shar kilbridge A $\left(b^{\circ} 49\right)-(9.7 .83:(1 ' 85)$ : $121 ;$ Himanont Ave: $8-10,2-5 ;$ Frot. Ines. Mo.7

SHFAHAS, EDWIX L. (b's2)+-Mo.2,05; (1005) : $363 \%$ Finney Are.; oftice, s21 (1)

sheets, John s. (b's3)-Mo.2,08; (1'0s); 1049.1: Tomer Grove Ate.

SHEETS, MARTIX E. (b' 76$) \mp-M 0.24,01$; (1'01); 4.til lithon Ire.: antee, 4361 thouteau tre. 8.9, $2-3, i-8$

shellman, Arthur P. (b'69)-N.Y.5.9t: (lo5): 2119 A E. Obear Are.: oftlce, 2009 E rirand Are. $8-12,1-5, i-8$

sherman. Wm. Mark-Mo.34,04; (1'05): 4916 Berthold ire, once, $\$ 258$ Manches: ter Ave.

SHIELIS, WILLIAM B. (b'63)-Tenn.8, 89; (1.99); 305 Westgate Are.; offle, wail bldg. :9-12. 4-6.

SHOEMAKFK, JUHX F. (b'b8)-Pa.11,93; (l’05); 1498 Lindell Blrd.; office, CarleIon Bidg: 9-1; (BH,27).

SHOEMAKLR, WM. ALFRHI $\left(\mathrm{b}^{\prime} 59\right) \mp-$ Id.1.85; (1'95); 4386 Westmlnster Pl. $\mathrm{Op}$,

Shore, Harry (b'81)-Mn.7,09; (1’11); 1931 Hiddle St.

SHORT, LI.YSAFS S.-Mn.34,03; (I'05) Memlier Ill. State Iled. Soc.: 3603 Humphrey Sit.

Shumaker, Chas. Henry (b'90)-Mo.2,'12 (1'12); Clty Sanjtarlum.

S111TT, CLEVELAND H. (b'81) \&-Mo.i, 04: (1’05): 3953 Delmat Blod.; oflice. Metropolitan Rlalg: : $\mathbf{S}$.

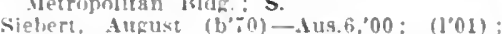

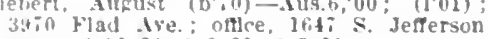
Ive. ; $9-10: 30,1-2: 30,6-7: 30$.

fiesing, fiustar W. (b'72)-Mo.27,98; $\left(l^{*}, 15\right): 3455.1$ firace ire.

ilrerwom. Wllliam r. (h'3i)-Mich.1, 1 ; (1'st); not in practice, $733 \mathrm{x}$. Barard

IMMS, WM. W. (b'73)-M[0.10,12: (1'12) 3971 Chouteau Are. $8-11 \cdot 30 \% 30$

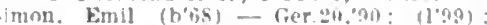
2623 Lemp Ire. s.9, 1.2, ; : l pot Hyce and led. Mio. io: Pd

MUN, FHEDK. C. (b'Ts) + Mo.1, 99 (1'99): 3515 lomliet st.: ofter. Metropolitan Hidg: 1 12:30: (B.33): ALR.

IVOS, JUHX H.-Min.100: (1.90): 1201 Iefausland Are; oflice, fono chouteau IIfer

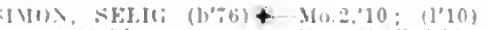

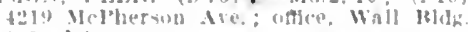
$1-3 ; 1 .+11$

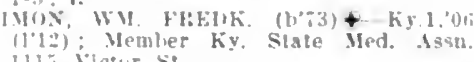

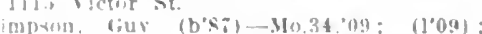

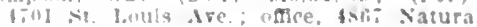
istilige $\operatorname{lin}_{1} \mid$

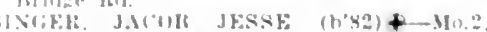
(1) 4 : (105): 3437.1 shenandual st : of

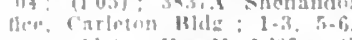

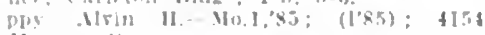
Vurgath sit.

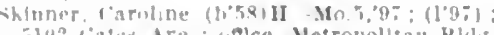

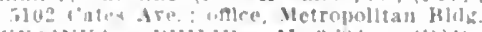

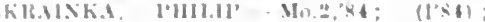
lizo Marjland Ave ; oftlee. Méropolital [1] I ] ; : : - I

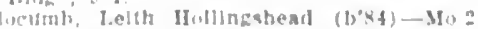
1.5: 11'131: 1 16y Ilusplea]

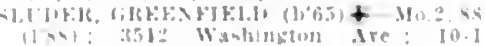

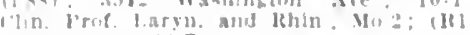
\#) H1! ALR.

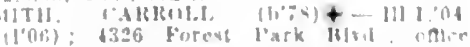

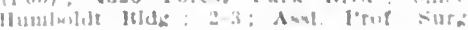

Smitli, Clarence bermin $(b, 5)-$ III $11,1:$ II'ls) : City llosjitat

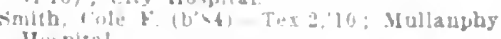
SMITII, El.

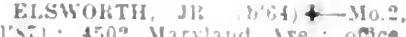

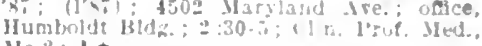
Mo: : I.

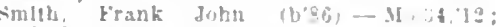
(1'12); ("ty" Hospital.

MITH, liEO MILT(I)

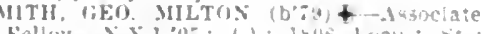
(1) ; Path.

sinlth, Henry A-Mo.10,05: (1'05) ; 5914 Minerva Ire: ollice, $40: x$ Brodilway. $10.2 ; U$.

smith, James Niklninn (J)'81) -110.29,05:

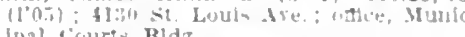

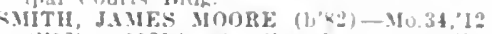

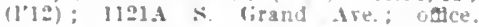
Metrolmlitan IS]; :

SMITH, JOHX CAMISEL, (b'b0)-Md.1,

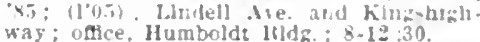

imltl. Jarshall Vey $\left(b^{\prime} 60\right)$ F-III,

(1'8.8); 5530 Etzel Are; oflce, 302 . 12 th St. ; $9-12$. 1-5:30.

smith, Orrick E.-Mo.2:,91; (I'01); $\$ 109$ Mancherter Are

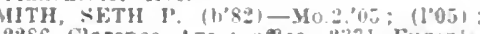
2256 Clarence Are, once, 331 Eugenla

mith. Thos. H-Mo.28, 0 ; : ( ) : $563:$ Fernon Ave. uthce, Cirand and Franklin Ares, $9-11,2-4,7-8 ; N$
MITH, WM. ALEXAXER (I.) W W

Alhert Edw. (b'0)-Jo.10,93. (19.3); 351 Pine St: ; $11-1.4$

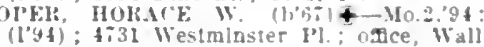
Illdig. : 1.*

Sorachan, Jnhn T.-Ino.1,91; (J'92); 1503 1.. Jefferson Are ; oflce, 411: Greer Are.
$8-10,1-3,6-8$.

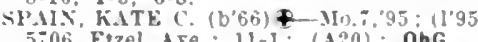

5706 Ezel Are. 11-1; (A20); ObG.

spangler. John b. (b.5)-Ky.2, ...

SHAlHAWK. WM J. (h's0)-Mo. 98.03 : (1'03); 6821A Manchester Are.; $8.9=30$. spector, isaac (b'it)-Md.4:05:

1815 Carr St: $\$-10,2-3,6-8$

speer. Relnhold (b'6i) -Mo.34,04: $(104)$ itos Mlchigan Are; $5-10.2-4 \div-9$

SPENCEK, IORATIO NELSON (b'12) NY.1,69; (2): 283 Washington Ire.

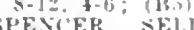

E.NCER, \$FI.IEXI Mn.1.99: (1.99) 4332. McPherson Are, natce. $0:-3$ Wash-

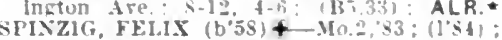
937 Iark Are.; $9-10,2-1$.

SPIVI LAYMón MLLO

intit Itymuth ive

sponner, Frnest II. (hot)-MIn.: :94; $(1994)$ 4397 Forest Inapk Hlid: s-1n

stafrord. saml. I" teol. (b'a)-Pa.1,9:

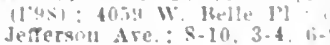

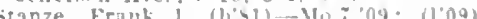

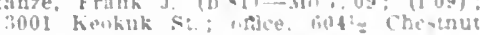
st : I'rot. Mtaur surg. Mo.?

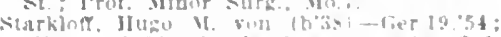

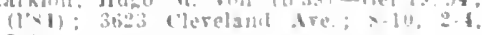

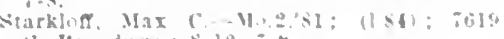

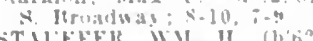

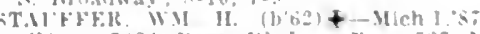

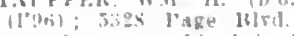

Cormal Wh ?-10, 1.h Pro is

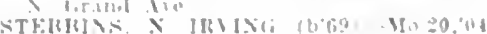

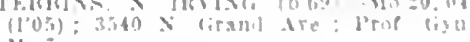

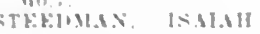

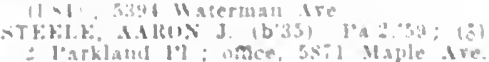

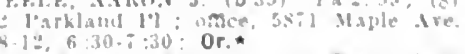

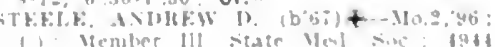

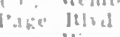

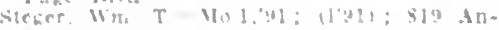
incliea is 
STEIN, ARTHUR WM. (b'81)-Mo.34,11; $(1+11)$
$7-8$.

Stein, Johu Phillp (b'81)-Mo.T',0s; (1'08); Stit4 Goodfellow St.; $8-9,12-1,6-8 ;$ G. STEINER ILRERT' S. (b'is) + 10.34 03; (1'03); 1507 Destrehan St.; oflee. Commercial Bldg.: 9-11, $\$-6$; OALR. ${ }^{\star}$

STEINMANX, WHLAM A. H. (b'Ss) + Ito.2,'10; (1'10); 5428 A Magnolla Ave stelzlenl, dieo. M-ML.2,so; (I'84); 1215 x. Grand Are, : 10-12,6-8.

Stephens, Albert F.-0.2.85; (1'01); 2831 N. $23 \mathrm{~d}$ st.

TERNFELS, ART!ILR FRANCIS (b'86)$10.34,10 ;\left(1^{\prime} 10\right) ; 2270$ Falr Ave.; offlce Itth and surelrodt sts.

STEVEN CHAS. HILLON (b'52)-110.2 Stivis vernon Ave.

III.'10: (1'11); 4148 Olive st.; oftlee 4201 olire St.; $2-4$

STrYEASON. WALTER DAVIS (b'83) Mll.4,06: Memler Ill. State Med. Soc.; 6024 Kingshury Hlvd.; (offlee, Metropoliran Bldg. ; East St. Louis, 111.; (111) ; OALR. *

STEWART, FLOYl (1, 73) $\$$ - Mo.2,96 Bldg.; 12-3: Prof. Gen.-Urin. Surg., Bldg.; 12-3; Prof. ten.-Urin. Surg., Mo.10; U.

(1'95): 6053 McP'lerson Ave.

STEWART, WM. CYRUS (b'84)-Mo.34,'12 (1'12); 26031, Washington Ave.

STOCKING, LYMAN C. (b'72)\&-Pa.11,99; (1'99); 5890 Jullan Ave.; offlee, Delmar Bhy. : $1: 30-2: 30,7: 30-8: 30$

STOCKWELI, BEXJ. F. (b'63)థ-Mo.28 04: (1'99); $2345 \mathrm{~S}$. Broadway; 9-11, 2-4,

Stoffel, Remy J.-IIn.2,'80; (1'84): 3868 Cleveland Are.; offlee, 2868 Lemp Ave.: $10-11,2-3$.

STONE, CIIAS. ALLEN (b'83) - Mo.2,'08; (1'08); 2230 College Are.; offce, College and Florlssant Aves.; $8-9,1-2,7-8 ; 0$. (1'09) : $5084 \mathrm{~A}$ Easton A ve. : 8-10,2-4, 7-8.

Storm, (ieo. Randolph (b'89)-Pa.2,13; In. tern, St. Louis City llospital.

STORRS, HENRI JOHN (b'i $\tilde{i}) \oplus-M d . \overline{7}$, 04; (1'09); 4518 Washington A re.; office, 346 . Boyle Are ; $2-4$.

STRECTKER, CHAS. E. F. (b'73)థMo.1, $2-3,7-8$.

Stubblefield. James Preston (b'55)-Ky.5, 06 : not in practice : 4217 Russell Are.

STURHAHN FERDINAND O. (b'65)-Mo.i. 91; (1'91) ; 3519 Hebert St.; 10-11, 2-4,

Suffrin. Clement (1'85)-Wis.6,13; ( ); 2741 Dayton St.

SUGGETT, OHMH, Le GRAND (b'T3)€Mo.2S,'93: (1'93) : 3655 Washington Ave. office, Metropolitan Bldg; ; 11-2, $7-8$; Prof

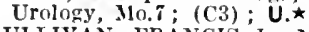

SULIVAN, FRANCIS J.-M10.2.06; (1'06) . 517 Ternon Are.; offlee. Wali Bldg. SUMLA, HENRY H. (b'53) \&-110.3, (l'84); 5703 Florissant Ave.; 5- $\tilde{7}$; office 3707 N. IIth St. ; $8-9,2-3$; $\mathrm{S}$

SUMMA, HUGO (b'59) §-Ger.16,84; (1'85) 4253 Washington Blrd.; office, Netropol

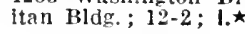

SUTTER, JOHN H. (See Unirersity.)

SUTTER, OTTO (b'64) $\oplus-\mathrm{M} 0.24,{ }^{\prime} 92$; (1'92); 6360 Washington Are.; office, Frisco Bldg.; $1-4$; Clin. Prof. Abd. Surg., . $10.10 ; \mathbf{S . \star}$

SWAHLEN, PERCY HYPES (b'7 $) \oplus$ Mo.34,'03: (1'03) ; 5301 Page Blrd.; office. Metropolitan Bldg.; 12-2: Asst. Prot. SWARTS, JOS. LOUIS (b'85)-Mo.34 (1'11); Regis Apts.; office, City Hospital.

TALPOTT, HUDSON (b'74) $\oplus-M 0.27,98$; (1.99); 4229 Washlngton Are.; office, Netropiolitan Blidg.: 1-3; $\mathbf{S}$.

TANQUARY, JAMES HIRAM (b'56)Ð111.11,'S3; (1'92); 930 Belt Are.; until 9, I-6; Prof. Ortho. Surg., Mo.10; Or.

Tanquary, Renel James (b'87)-Mich.1,'11; (1'11): 950 Belt Ave

Tate, B. Frank-1I0.5,04; (l'04); $9427 \mathrm{~S}$ Broadway ; 12-2, 6-8.
TAUSSIG, ALBERT ERNST (b'71)@-MIO.2, 94: (l'94); 4336 Delmar Ave.; office, Metropolltan Bldg. : $3-4 ; 1, \star$

TAI'SSIG, FREDK, J. (b'72) $\left(1^{9} 98\right)$; 4506 Maryland Ave. ; offlce, Metropolltan Bldg. ; $11: 30-1$; $(A 2,11,20,22, \mathrm{FL})$ obG.

Taylor, Herbert Isaac (b'80) - Mo.7, '08, Mlo.34,'13; (1'07); 1502 Wagoner PI!: office, Taylor and Faston Ares.: 9-10, $1-3,6-8$.

TAYLOR, THOS. B. (b'49) - Мo.2, T6; (1'83) ; 4595 West Belle Terrace.

TAYLOK. THOMAS WHFIHI (b's0) $\$-$ N10.2,09; (1'09); 3513 Morkan St.

Teum, Francis $\Lambda$. ( $\left(\mathrm{b}^{\prime} 66\right)-M 0.1,90 ;\left(\mathrm{l}^{\prime} 90\right)$; 5115 lage Blrd. : 8-9, $12: 30-2: 30,6-7$.

T'emm, louls $x$. (b'74)-Mo.1,'96: (l'96) Market st.; 10-12, 5-6.

THRKY, LORT. JANES (b'71)€-Mo.1,95. (1'45) ; 5241 Waterman $A$ re.; office, isof locust St.; Sec. and Prof. Anat., Mo.2: (F'1).

THAJLR, WM. HARVEY (b'86)-Mo.2,09 (I'09) ; 3945 Connectlcut St. ; oftice, 1825 ('arr St.; $9-10,3-4,7-8$.

TIIE, OTTO WM. (b'74) $€-M 0.34,12$; (1'12) ; 1536 I'apln St.

THERIY CHAS. W., JR. $\left(b^{\prime} 75\right) €-M 0.2$, 98: (1'98); 6113 Berlin Are.; offlce, Vetropolitan Bldg.

Thomas, Chas. Sylvian (b'82) -Mo.34,09 (l'09) : 4643 Tower tirove $P 1$, office ino $\therefore$. Jefferson Ave.; $9-11,2-4, i-8$.

Thomas, James Henry (col.) (b'89)-Mo,10, '12; (I'12); (Lovejoy, 111.); offlce, 2928 Market st

Thompson, (ieo, 1)-Mlo.2,'79: (5) ; $4109 \mathrm{~N}$. Grand Are.; 10-12, 2-4, 6-8.

Thompson, Gen. Howard (b'66)-Mo.1,'88, N.Y.10,'89: (1'88) ; 2341 Olire St.; office, 2343 Olive St.; $9-10,2-4,7-8 ; u$.

Thompson, J. Mauriee - Mo.5, 07 ; (1'06) : 6240 Maple Are.

Thompson, Nathan P. (b'67)-Mo.1,'88 (1'03) ; 3108 Cass Are. ; 8-10, 1-3, 6-8.

Thompson, Preston (b'89)-M0.2,'13; (l'13) St. Louls City Hospital.

THOMPSON, RALPH LEROY (b'73) 1402 S. Grand Are.; Prof. Path., Mo.34 (F2) ; Path:^

Thomson, David A. (b'75)-No.7, 03 ; (1'03): 3119 N. Grand Are.; $10-12,2-4,6-8 ; U$ TIIORPE, BURTON LEE (b'71) $\oplus$-ASSOciate Fellow-110.28,05; (Dentlst) ; 3605 lindell BIrd.; 9-4.

THMEADGLL, JESSE MERCER (b'T3)Mo.7,98); (l'98); 6236 Ollve st.; offce, 6401 Maple Are.; $8-9,2-4,7-8$.

Throckmorton, Chas. M1.-Pa.2,'85:

1721 Cora Ave.; 7-9, 3-5; G.

THUMSER, LAWRENCE $\left(b^{\prime} 66\right) \oplus-$ Aus.5, '91; (1'91); 180 S Vletor St.; 9-10, 2-3, 6-8.

THURMAN, ELISHA J. (b'40) - Mo.2,73; (1'80); 2805 S. Kingshlghway; $7-8,1-2$,

Thurnian, Josiah D. - Mo.28,'04;

6753 Page Blvd.

Tibe, Natilda Luke (b’79) -Mo.7,09; (J’09); 6815 Michlgan Are.; 9-11, 2-4, 6-8.

TIEDEMANN, ERNST FRED (b'61) $€-$ Mo.2,80; (5) ; 3615 Cleveland Are.; Assoc. Prof. Bact., Mo.2

TIERNON, L.UKE BBART (b'82)-Mo.7,'09; (1'09); 6200 National Bridge Rd.; until 10,

TILLES, RANDALL SOLON (b'83)\&-Mo.2, 08; (l'08) ; 5217 Delmar Blvd.; office, Metropolitan Bldg. 2-4: (A20): ObG TITTERINGTON, NILES B. (b'i0) †-No.í, 96; (l'12); 4318 Ollve St.: (G1); R.ћ Toalson, Noah I
Compton Ave.

TOBEY, EDW. NELSON (b 71 -MIass.1,'01 () ; Member Mlass. Mled. Soc.; 3634 Shendoah Are.

Todd, Charles A.-N.Y.1,69; (l'S4) ; 3723 Delmar Blrd.

TODD, DAYID CLAY (b'75) $\uparrow-M 0.34,02$ (l'02) ; 4523 Page Blvd.; office, 4503 Page Blvd.; 1-3, i-8; Prof. Anat. and Surg., II0.10; S.

Toeppen, IIugo - Ont.1,'92; (1'92); 1813 Lami 'St.; office, 3114'S. 'ith St.
Tontz, Geo. W. $(1,74)-M 0.34,04 ; \quad$ (1'05) 2906 (ireer Are.; offlce, 3009 N. 23d St. : $8-10,1-3,7-8$.

TOoktil, CIIAS. W., JR. (b'81)-Mo.2,04 (1'05) ; 4326 W. p'ine Blvd.; offce, Het ropolitan Bldk.; $3-6 ;$; (1)5); $0 p, \star$

Tracewell, Geo. (b'72)-Mo.10,05; (l'11) 1.212A Easton Ave.

Tremain, Feo. W. (b'i3) $\rightarrow$; (1'02); 264i Ollve st.; $12-2 ; 6-8$

TRIGG, IOS. MILTON $\left(b^{\circ} 70\right) Ð-$ Ia.1,93; Bartmer Are, : 10-12, 2-4, 6-8: 1'ros. Surg., Mo.7; $\mathrm{S}$

Trlmble, Wilbourne Frank (b'88)-La.1,'13 Intern, st. Jouis city Hospltal.

THOTMAN, CILAS. A.4-Mo.2,01: $\left(1^{\prime} 02\right)$ 5193 Von Versen Ave.; office, 812 Clarendon Ave.

Trumpour, Roswell H. (b'70)-Mo.7, 01 ; (1'00) ; 8100 Gravols Ave.; 8-10, 2-4, 6-8. Tucker, Mary Emlly (b'39) Mo.5, 90 ; TLHOISKE, MLMMAN $\left(b^{\prime} 48\right) \oplus-M 0.1 ; 0$ (1'\$4) ; 4495 Westmlnster Pl.; offlce, 453

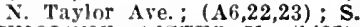

TUHOLSKE, LISTER H, (b'8i)-Mo.2, 09 (1'09); 4525 . McPherson Are.; offlee, 453 N. Taylor Ave. ; 11-1, 2-4.

UP'PER, FAUL YOER (b'58)థ-Ky.5.'80 (1'81); 4629 Berlin Ave.; office, Wall 13ldg.; 1-3; Clln. Prof. Surg., Mo.2; (A22, 23, Fi) : S. $\star$

TUREK, ALOIS EDW. (b'86)-Mo.34,'11; (11); 3015 Wisconsin Ave.

, Prof. Clin.'Ped., No.2; (D5); Pd.

Tyler, Wendell II'olmes ( $\left.\mathrm{b}^{\prime} 88\right)$ - D.C. 3,12 ; (l'12) ; 4279 Cote Brlllante Are.; $8: 30$ $10: 30,2-4,6-8$

Tyzzer, Robt. Neal (b'8s) - Mo.10,'12 (1'12); $4486 \mathrm{~W}$. Belle Pl.; office. $920 \mathrm{~N}$ Taylor Ave. ; 8-12, 4-6, 7-8; $\mathrm{S}$.

Tyzzer, Walter G. (b'63)-Mo.28, 03 ; (l'01); 920 N. Taylor Ave., 9-12, 1-2, $6-10$
Assoc. Prof. Clin. Obst., Mo.10; G.

CDE, WALDEMAR (b' 71 - M M.27,'92; (1'92); 3544 Victor St.; $2-4,6-8$

Uhlemeyer, II. Adolph (b'78) H-ifo.5, 00 (1'00); 1511 E. Grand Ave.; 8-10, 3-4 $6-7: 30: \mathrm{Pd}$

UNTERBERG, HILLEI-Mo.34,'02; (1'02); 1401 Temple Pl.; office, Frisco Bldg.; ; $2-5$. pshaw, Harry Anderson (b'it) -Mo.2i,'98 (1'03); 3166 Morganford Rd.

Upshaw, Ira W. (b'77)-Mo.10,'89; (l'92); 5015 Shaw Ave.

Upshaw, Orin .Thomas-Mo.10,'94; (1'94) 3422 Gravols Ave.

Upshaw, Platt Welch (b'70) - Mo.10.'92; (I'92): 6831A Manchester Ave.

Upshaw, Thos. Jefferson (b'44)-Mo.10,90 (l'92); 4247 Neramec St.

URBAN, EMANUEL T. (b'78) E-Mo.2,02: (l'01): 1458 S. Grand Are.; 1-2, 7-8 see. and Prof.

Urquhart. Wilford H.-Mllch 7'93; (1'98) 4347 Cork Ave.

VALLE, JULES F. (b'59) $€-M 0.2, ' 85$ (l'85); 4955 Maryland Ave.; $8-10,2-3$ (A20)

Vanderbeek, Cornelius C. (b`52) - $\mathrm{Pa}_{2}, 2,72$; (1'95) ; 2007 Park Are, ; 1-4, 6-8; Ob.

VANDOVER, SAML. T. (b'70)-MO.24, 01 . (l'02) ; 3728 Arsenal St.

Vangsness, Ingmar Unius (b'88) - Ill:6,'13, Intern. St. Iouls City Hospital.

VAN HOEFEN, SAML. (b'49)£-Ger.16, 73 (1'02) ; 8313 Halls Ferry Rd.; 9-10, 3-4; $7-8$

VAN HOEFEX, SIEGFRIED A. ( $9-10,3-4,7-8 ; A L R$

Van Honk, Forest Clyde (b'87)-111.6,13 Intern, St. Louis City Ilospital.

Van Raalte, Martln (b'88)-Mo.2,'12; (1'12)) $2827 \mathrm{~A}$ Whittier St.

Varney, Yranklin Thomas (b'64) - Mo.27, 96; (\$) : 568 De Baliviere Are.

VASTERLING, PAUL F. (b'62) §-Mo.2,'83 (1'83); 2125 Nebraska Are.; offlce, 1600 California Ave. : 9-1.

raughan, Iohn Russell (b'88)-Mo.2,'10 ; (1'10); Delmar BIvd. and Skinner Rd. $8-9,1-3,7-8 ; 0 b G$

VALGHAN, IOHN W. (b'5i) क-AF. 7,84 (1's4); 4900 Washington Ave. 
Vaugban, Walter W. - Mo.7,90; (1'90): 1913 Page Hive, once, 1.59 $\mathrm{X}$. Kings higbway.

Vaughn, Rufus -Tenn.1,'72; (J's3) ; $51: 4$ Kensinglan die : once, 313 x. tht: $11-4$.

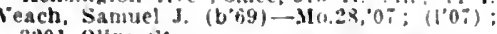
:301 Ollve st

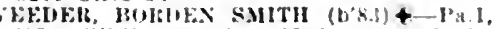
07 (1'12); Member Mad. Foc of the omce, st. louls chlldren's Huspltal: (Dl, Elo) : Pd.

Venlnga, Fredk. Wm. (b'it) - Mo,10,0ti enlnga, Fredk. Wm. (b-it)-M.10,0ti vickrey, Aden Cobbs (1,sib)- Mo.2.11 (l'li): llth and Marhet sits.

IELT, FIDW. J. (5.64)-Mo. I, 93: (1.103): $5600^{\circ}$ Mllhlgan Ave.; $4.12,2-4$

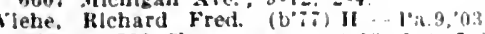

(1'05); 1738 Choteau ire ; $8-10,1-3 ;-8$

Terllnt, otto (b'75) - $11,24,17 \%:(1.06)$

4555 Adkins dre.; $8 \cdot 10,5-\overline{0}$

VIXYARD. IAUI, (b'a) \& - MO.207 (1'06); 2566 Delmas Bird.; iftec, buule renler Are and Olive St.; $1-3,7-8 ; \mathrm{S}$

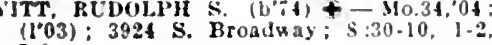
$7-8$.

Voerster, Engelbert, Jr. (b'65)-Mo.24,'97 $\left(19^{\prime}\right): 3401$ Fads Are., offce, 405 Wal nut St.: 9.1, 2-5.

FOGLER, NIFREH TIFODORE (b'82) Mo.34,04; (l'05): 5711 Fhorlssant Ave: offce, 1523 Penrose St. : $9-10,3-4,7-8$

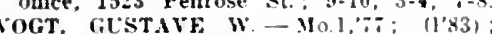

497- Lotus Ave: offce, it5i Rials Ave

vogt. WM. HANS $\left(b^{\prime}, 6\right) \$-M 0.1,97$ (1'97): 4953 Lotus Are.; once. Wetropolltan Bldg. : 2-1; (A20); OBG.

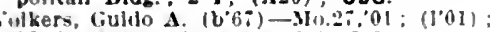
3 it5A Wisconsin Are. : $8-9,7-8$

von Achen. John ludolph (b'9i)-\$o.3t, "I3: (1'13); 3702 Cook Ave.; $\mathrm{S}$.

von Clossman, August - 0.25,7\%; (1'96); 6828 Salzburger Are.

FON IER AU. OTTO L. (b'69) \&-Mo.24.92 (194): 3134 llinols Ave ; once.

Jerterson Ive:: 10-12: OALR.

Vordick, August H. $\left(b^{\prime} 49\right)-M o .10,34$
(1'8t): $2329 \mathrm{~A}$ Hebert $5 ! . ;$ offe, 102: (1'81) 3294 Hebert 5 !. $;$

VOSBLRGII, CIIAS. AĆGLSTLS (b'is) + Mo.28,04; (1.05); Hucklnghan Clut Mo.28, 04; (los) ; Bucklnghan $12: 3 \mathrm{j}$ $2: 30$, i-8; Prof. Clin. Surg., Mn.10:S vosburgh, Ilatthew 1). (b'62)- Mo.26."99 (1.85): $202 \times$. 9 th $54 . ; 10-2$.

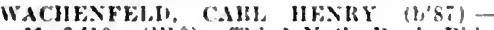
Mo.2,10; (l’10): Thled Natl. Hank Blde. Wazenbach, Wn. F. (b'89) - Mo.2,13 Wazentach, Wm. F. Th'

Wagner, Matthlas Imbrose (b'88)-Mn 34 12: (1'12) 5294 I'age Blid.

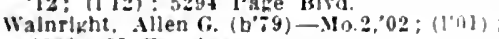
126isd Maftit Are.

Wakeflelil. Harry ic - Mn.24,92; 11.92)

Marlne II ospltal.

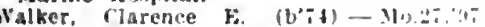

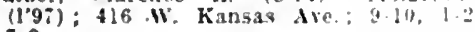

WÄ.KER, JACOB J. (b'62) - Mo.24,99

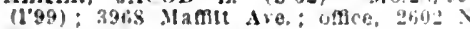
UnIon Blsd. : \$.10, 2-t.

Walker, lester I. -310.707 ; $(106)$ : 1396. Natural Brldge $\mathrm{Rd}$

WALKER, WCHARI ASIERY $(1, T+\rangle$ Phar and clin ther Ilo

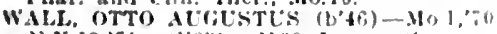

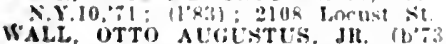
Alo.I,9s; $(1,98)$; 3122 s. Grand Ave ; if Ace. Ciramol Are. and Ilarfford St. ; 1.2. $-78 ; \mathbf{S}$

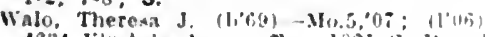

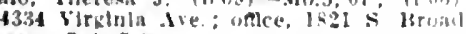
say : $3.4, \div 5$

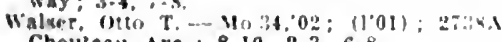
Choutcall Are.; 8-10, 2-3, 6.8.

Walton, luclus A. - Mo.2,"63: (2): 12: Cook Are.

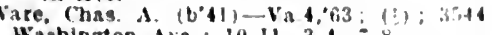

Washington Ave, : $10-11,3-4$;

Warner. Jamea Albert $\left(b^{\prime} 69\right)$-Tenn $1,0.1$ (1'01): 3417 Mckean Are: onlce. 10s: Ith sit.

Washlngton. Jancaster lieb. $(1,98)-1$, It II: (I'II) : 2025 Hebert St.
Washington, Nicliolson C.-Mo 2.667; (1'55) asert $x$

Washiniton, onls (i. (b'ss) - Tenn.:.11 Waterhouse, Eigene $\mathrm{l}$. $(450) \mathrm{K}$ - o.2.8t,

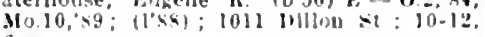

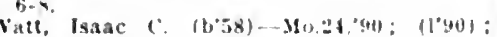

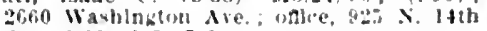
st. ; s-11, 2-5, ;-9.

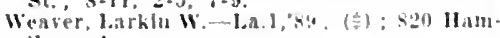
liturl die.

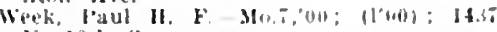

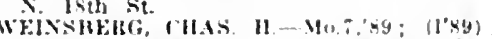

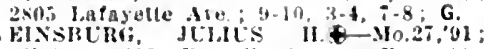

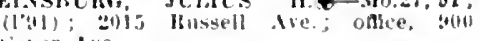
liever Ale.

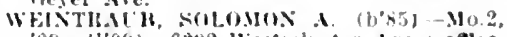

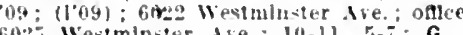

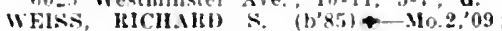

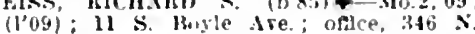
(l'og) : 11 S. Hoyle Are.

WEISs Wi. Ih. $(1,82)+-M o .2,06$; (l'06); 312s Arsenal St. oflce, 1946 Gravols Ave : $9-10,2-3$, i $: 30-3: 50$ Pd WEITERkR, Himis L. (b'68)4 Mo.7 N. 11th St.; $,-10,1-3,7-8$.

Weller, Clarence Wm. (b'83)-Tex.2,"13; In-

wern, St. Louls City Hospltal. 1828 vletor st.: oflue. $2002 \mathrm{~s}$. Broadway: $10-11$. WFAGER, OLISER CIAKENCE (b'st)Mo.34,0s; (1.08); 18:8 victor st.; $9-10$. 4. $5,7-8$

Wentzel, Fmma C. t. (b65)-Mo.j,"92: (142): 2100 F. Obear Are.

Werner, (has. F. $\rightarrow$; (E) ; 2703 Virginia

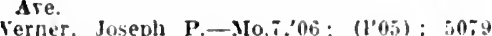
Hidge Ave. : 10-12, 2-4, $7-9 ;$ G.

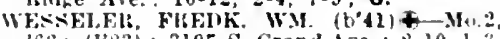
66 : (1'83); $3195 \mathrm{~S}$. Grand Are.: $8-10,1.3$

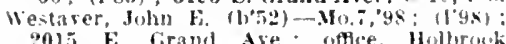
2015 E Crand Ave.: offle.

Wothruok, Geo. W. Mo.10,97 sisla Faston Are.

WESTFRMAN, (H.WENCE MANSLR (b'S4 + Mo.28,0n (1'06) 6134 Washlncton

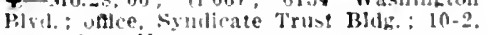
: (C3): U.

wheler, Elhiti Hiheary (b'-9)-Mo.10,'11 (1'11); 1327 (hestmit st.; 11-2, 5-7.

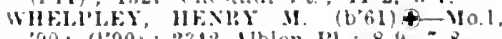

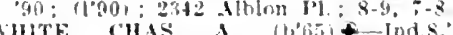

(1)60); $1+40$ insicilupl Ire.; once, sos

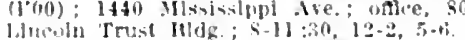

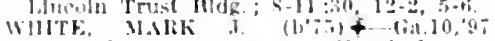
surz. 1.s.1'll $\leq$ Marine Hosplial

WHTE $T$ WISAl-Va.1, Sty Washing:on Ave, (D.i).

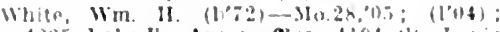

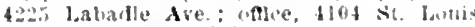
4) $y-11,2-4,7-s$

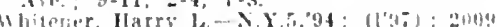

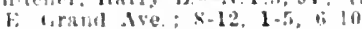

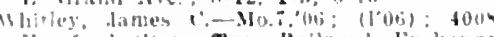

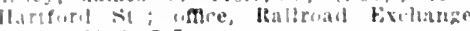
$161,2,8,11.2,3-7$

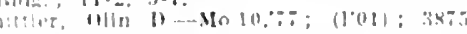
lwatata st

Wlatlleney, lirangllle k.-Mo.J0,01; (l'0l)

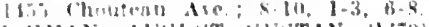

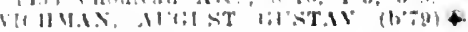

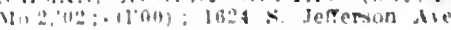
10.10

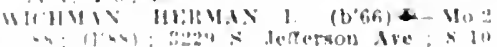

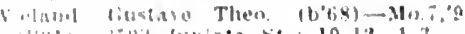

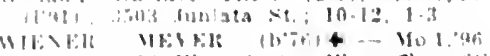

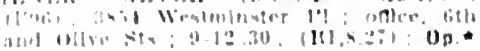

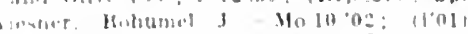

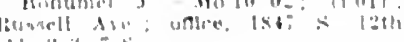

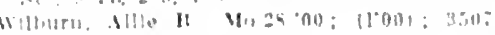

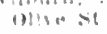

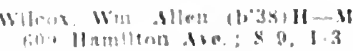

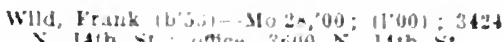

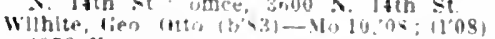
\$358 Ritation . 1

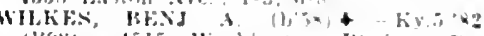

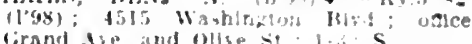

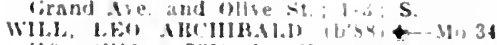

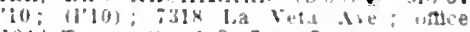
124- Tamat st: 1 -3, 7-h; $\mathbf{S}$.

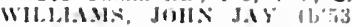

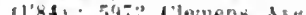

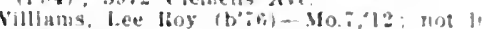
practice; 143\% l3lackstone ire, l'rut Inat., Mo. 7 ; LD.

WIISON, ALIFE - Mo 1.79; $11+31 ; 171$ Wagoner I'l.

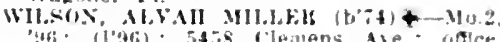

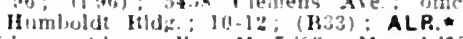

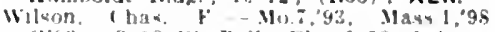

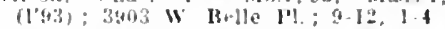

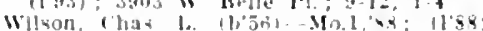

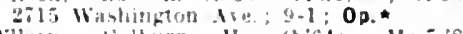

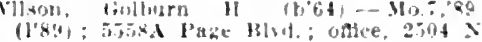
Ith $S$ t. ; 8-9, 1-2, 7-8

WISOS, HARRY H.LI. (b') 37; not in practice: Memier Met. Som l3ank Blelg. : $9-5$.

WILSON, ROBT EDWALD $\left.\left(\mathrm{b}^{\prime}, 0\right)+-\right)_{0}:$ $96 ;(196) ; \mathbf{4 2 5 9}$ Lindell Bird. ; oftce, 50 olve st: $2-5 ; \mathrm{S}$.

Wiluckl, Leo Earl (b'81)-Mo.36, (19: (1'09 4331 Elchelberzer Are.; $9-10,3-4,8-8$

Windanr. Forman $31-30.28 .00 ; 1100$ 6131 Etzel Are.

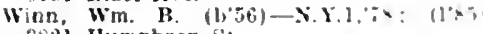
$3 \times 21$ II mphrey Sit.

WINTER. WM. OTTO (b'69) - Mo.27:97

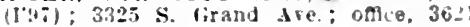
L Rroadway; 9-10,3-4.7-8. (l'04); $3510 \times$ lirand tie. oflce. 420 S. Jroadway

WOBLS. HEIYHARI E. $(1,79)+M 0.20 \%$ (1'05): 35 X. 11 th st oftce, 110.

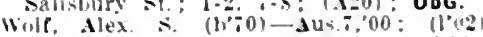
1360 Rurd ive; offce, century Blds. $10-12$, t-15; $11-3) ; 0$.

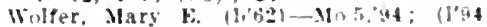
34,18 cirand die $7-9,3-4.7-8$

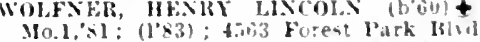

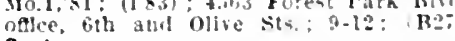
Op. *

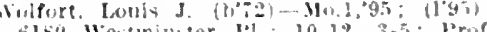

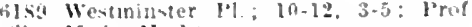
1'lin. Biesl., Mull,

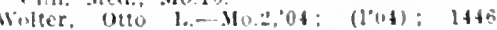

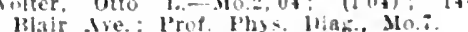

Wulters, Hertert Fredk (posi-Mo.34."1: (1+12): st. Lauls clty Hewpital

Vorml ihas Alyere (1)\%11-3]

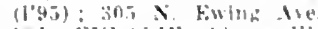

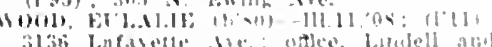
liramel tien: $12+1$

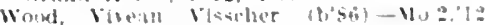

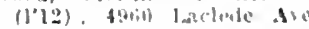

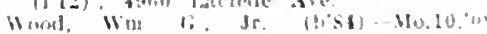

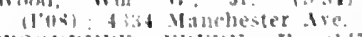

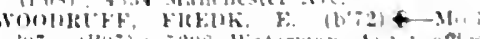

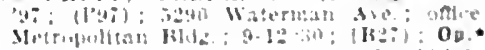

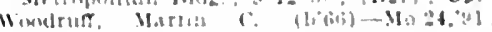
$114011 ; 300 ; 11$ ymlnt st : $9-12$

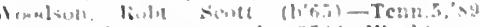

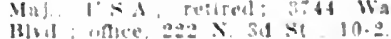

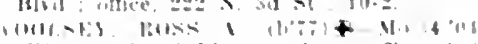

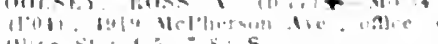

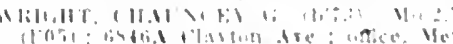

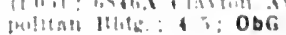

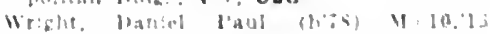

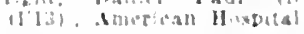

Writhe prancis 11 mare-111.1,

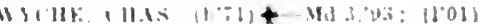

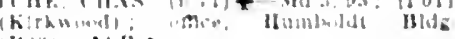
11.33). ALH.

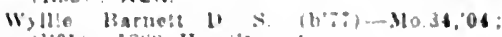

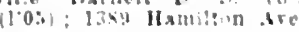


YAHLEM, NATHANIEL N. (b'81)-Mo.j, 04; (l'04); 1816 Franklin Ave.; 9-10, $1-3,7-8$.

Yaley, Clins. $11-M 1.28,06$; (I'06); 2830 Frink!lu Ave.

leek, S. E. $\left(b^{\prime} ; 6\right)-M o .7,03 ;\left(l^{\prime} 01\right) ; 5416$ Florlssant Ave.; $9-12,2-4,6-9$

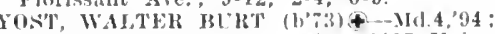
(1'98): 950 Belt Are.; ottlce, 1115 V'nlon Are. ; $1-3,7-8$.

Young, Anthony Obedial $\left(b^{\prime} 6 s\right)$ - 7 to. 24, 93 ; (l'93); SI36 l'age Are; oflice, Vanderenter ive and (ollse st.; $1-3,7-8 ; S$.

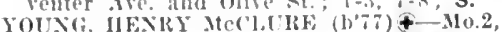
os. (1'0s). Rucklugham ILotel Munx: offece, rarlton BSIdg.; I-3: U.

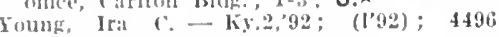
Laclede ire.

Young, Leo l'aul (b'S5) - M10.34,09; (1'09); 3134 Illlnols tre.; oftlee, Mucller bros. B)(lh. $9-10: 30,2-3,7-8$.

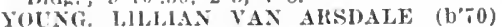
+ -M0.28, 09 ; $(109) ; 4511$ N. 20 th St.; $8-10,2-3,7=9$

YOUNG, LOUISE SANFORD - Ky.2,05; Member 11l. State Med. Assn.; 4496 Laclede Are.

YOLNG, WLLISS IBROCK $\left(b^{\prime} 68\right)+-M 0.5$, 9I; (l'91) ; 3620 Blalne Are; oftlce, Met-

ropolitan Bldg; 3-4. GEO (b'80)-Mo.34, '1:; (1'12): 3433 (iravols Ave; oftlec, 12; (122); 3433 Ciraols Are,

YOUX(;)A , JACOB ANDLEW' (b'7i) Mo.7,05; (1'05); 5817 Grarols Are.; 8-9, $1-2,6-8$

ZAHOLRKY, JOIN (b'71) - Mo.I,95; (1'95) ; $1460 \mathrm{~s}$. Grand Ave.; offlec, Lister IBldg.; $12: 30-2$, F-8; I'rof. Ped., Mo.34; (D5) : Pd. $\star$.

Zatlin, Anna-110.28,05; (l’05); 3145 Easton Are.

Zelnert, ollver Bernard (b'85) H-Milch.5, 07 ; (1'09): 1600 Callformia Ave.; $\mathbf{S . \star}$

ZELIE. FREDK. F. (b'79) - Mo.2,06; $\left(1^{\prime} 06^{6}\right) ; 2843 \mathrm{~N}$. Grand Ave. ; $8-10,2-4,7-8$.

Zeller, Francls F.-Mo.24,'88; (I'88); 7204 Pennsylrania Ave.; oftlce, 7119 S. Broadway.

Zenor, Edw. H.-Mo.10,04; (l'05) ; 2844 Belt Ave.

ZUERCHER, JOHN CHAS. (b'85)-MO.31, '12; (1'12) ; 3606 DeImar Blvd

Zwarts, Jobu H., Jr.-Mo.5,97; (1'97) ; 920 Lami St.; oflice, 208 N. 4 th 'St.

ST. MARYS, 702, STE. GENEVIEVE

DAYIS, GEO. W. (b'40)-MO.I,68; (I'1I) MOOKE, ('RYSANTHUS (b'54)-Mo.I, 85 ; (l'85)

SHIRLEY, JOHN M. (b':1)-Mo.7,90; (l'90)

WILKENS, JOHN ALBERT (b'74)-\$10.7, 02, Mo.34, 05 ; (l'01).

ST. PAUL, 200, ST. CHARLES

CORLEY, HENRY NORBERT (b'68) \$ Mo.27,'96; (1'96).

ST. PETERS, 269, ST. CHARLES

JENKINS, JOS. i1. (b'82)\&-Mo.34, 08 ; (l'08).

ST. THOMAS, I25, COLE

Werner, H. C.-Mo.1,94; (1'94).

STANBERRY, 2,121, GENTRY

BROOKS, W. W. (b'48) - Mo.22,73; (l'84) -Ia.6,97; ( ); Member Mo. State Med. Assu.

CHAFFI, ROBT, ELIEI $\left(b^{\prime} 59\right) \uparrow-0.9,93$; (1'93).

CROCKETT, JAUES A. (b'76)థ-Mo.3, 03 ; $\left(l^{\prime} 0 \tilde{)}\right)$

Grantham, Clinton B. Fisk (b'69)-Mo.22, $90 ;(1,10)$

HINKLEY, FREDK. J. (b'79)-M0.28,0I ; (l'0I).

LINDLEY, EMMETT R. (b'T3)-Mo.28,'96; ('963)

MCAALIN, C. H. (b'52)-Ky.I,'8I; (I'8I)

WELLS, JAMES HARLAM (b'59)-Ia.3, 02 ; (1'99); $\mathrm{S}$.

STEELE, 333, PEMISCOT

ROBAHS, JESSE W. (b'82) - Mo.̌,os (1)io).

SWEARINGEN, WM. A.-Mo.28, 00 ; $\left(l^{\prime} 00\right)$ TURTEY, OTTO 0.-110.2s,9s; (l'9́s) ; Pr.
STEELVILLE, 773, CRAWFORD

lsarnard, Siarali 1.-Ito.5,'99; (l'99).

('OFFEF, IOEL T. (b'42)- 0 ; (l'83).

HORX, AIBSER 11.-Mo.28,03; (I'03) ; LD.

veteale, Wm. A. (b'51)-Pa.2,84; (1'81);

not in practle.

IURGAN, WIJLIS BUITON (b'53)-Mo.5, is; (I'S4).

STEFFENVILLE, I20, LEWIS

O)en, Wul. W. (b'i4)-Mo.13,'81, Mo.10, 'A3; (1'83).

\section{STELLA, 175, NEWTON}

Cullers, I)anl. F.-Ia.I,'96; (l'97)

Edmondson, John Leonard (b'83)-Mo.20, 1)!; (I'11).

IIolmes, Iames K.-Mo.28,95; (l'95).

I'lumlec, D. Carus (b'80)-ML.28,11; (\$),

STEPHENS, I50, CALLAWAY

('ox, Albert H. (b'59)-Mo.1,'82; (1'8: $b)$.

STEWARTSVILLE, 543, DEKALB

SAUNDERS, LOUIS F. $\$$ - Mo.18,'88; (l'83).

\section{STOCKTON, 590, CEDAR}

Brown Frank A.-Mo.28,03; (l'03).

Brown, Robt. A.-Mo.1,76; (1'84)

Emerson, Burr Hamilton-Mo.8,99; (l'99).

SMITII, ELTON S. (b'73)-Mo.1,'97; (1'97)

STONE HILL, 36, DENT

CONAWAY, ROBT. H. (b'52) $\longrightarrow$; (l'92).

Crandall, Edw. D.- $\rightarrow$; (1'84).

STONY HILL, 36, GASCONADE

EN(;ELBRECHT, JOHN (b'67)-MO.5,'93; (l'94).

STOTESBURY, I59, VARNON

Leisure, EImer A. (b'82)-Ill.22,'13; (l'I3).

Steel, Chas. L.-Md.I,'82; (t).

STOTTS CITY, 548, LAWRENCE

KIN(;, CLARENCE R. (b'63)-Mo.T,'98; (l'9s).

Rlce, Marlon (b'45)-Ky.2,74; (l'90).

STOUTLAND, 250, CAMDEN

CARLTON, CHAS. E. (b'76) - Mo.8, 01 ; (l'01).

Monday, Lewis Robert (b'z2)-Mo.2,04; (l'04).

POOL, WM. 0.-Mo.24,'98; (1'98).

STOUTSVILLE, 315, MONROE

BELL, WM. T. (b'58) $₫$-Mo.1,'86; $\left(1^{\prime} 86\right)$

Gilpin, Geo. Seeley (b'87)-Mo.2,'12; (l'12)

Griffith, Arrllls (b'43)-Ky.I,'sI; (1'89).

STOVER, 386, MORGAN

NEWTON, SAML. NASON (b"T5)-MO.I0, $07 ;(1 ' 08)$.

WIEST, CHAS. A. (b'73)-Md.I.'97; (l'97).

STRAFFORD, 300, GREENE

SUNINER, WESTON COLUNBUS (b'76) Ky.2,'09; (l'09)

STRASBURG, 180, CASS

BECKMAN, WM. (b'77)-Mo.20, 04; (l'05).

STURGEON, 663, BOONE

GENTRY, ENOCII N.-Ky.2,79; (I'84).

Kelth, Janes F. (b'49)-Mo.1,71; (ठ).

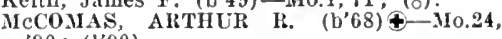
'90; (l'90).

Robinson, W. A.-No.28,'98; (I'00).

SUE CITY (R.F.D., LA PLATA), 100, Mitcliell, Robt. C. (b'49)-Mo.1,'78; (1'84).

SULLIVAN, 934, FRANKLIN

DUNIGAN. JAMES P. (b'59)-Mo.1,'85; (I'91).

LANE, A. $\rightarrow:\left(I^{\prime} 84\right)$.

MATTOX, WALTEK P. (b'70)-Mo.24,97; (l'98).

RUTHERFOIRD, WALTER S. $-;\left(1^{\prime} 96\right)$

SCHUDDE, OTTO N. (b'68)-Mo.28,98; (1.98).

SULPHUR SPRINGS, 200, JEFFERSON

IIUIL, WALLACE W. (b'54) - Mo.1,'75; (I'76).

SUMMERSVILLE, 236, TEXAS

TERRILL, CARLOS REUBIN (b'so)-Mo.7, '10; (1'10).

WALLEN, LUTHER H.-Mo.28,'05; (l'05).

SUMNER, 394, CHARITON

HARDY, JOHX WALTER (b'63) @-0.9,'9I; (I'96)'

LEIVIS, ANDREW I. $\left(b^{\prime} 66\right)(-110.27,98$; (l'98).
SWEET SPRINGS, I,I22, SALINE

IIARIISON, J. S.-MIO.20,05; (I'05); R.F.D. JAlTIS, JAMES F. (b'56)-Ky.2,79, I'a.2. $91 ;(1 \% 9)$.

Noel, James A.-Mo.27,96; (l'96) ; Pd.

(OWENS, JOLN 1I, (b'58)-KY.5,'97'; (|'97).

SWINTON, 35, STODDARD

Tarpley, Robt. F.-Tenn.II, 00 ; (I'01).

SYRACUSE, 193, MORGAN

FRY, CIIAS, (b'67)-Mo.28, 3

OSIBOIRNE, CHARLES I)[NI.IP (b'97) Mo.20,'09; (l'09) ; OALR. $\star$

Schulte, Francis A. (b'64)-Mo.34, 04 ; (1'05)

TABERVILLE, 120, ST, CLAIR

Davidson, A. C.- - ; $\left(1^{*} 84\right)$.

TANEYVILLE, 100 , TANEY

DIAMOND, WM. N. (b'65)-MLCh.7,'9l; (I'00).

TARKIO, I,966, ATCHISON

Andis, Saml. 1R. (b'45)-Mo.15,'80; (l'84).

BWNHAM, CHAS, E. (b'66) $€-M 0.20,00$ (l'00); LR.

Haskell. ('laude D: (b'7T)-Ia.10,04; (l'10). HOLLIIIA, JOIIN WESLEY (b'52)-Ia.I, '79, I’a.2,'92; (l'93).

ICBRIDE, GEO. E. (b'80)-Mo.20,'06;

POSTLFWAIT, JOIIN A. (b'50)£-I'a.?. 78 : (l’83).

WAUGH, CLIFTON M. (b'T6)£-Ill.1,'02 (1'05).

TEBBETTS, 200, CALLAWAY

ROOTES, GEORGE F. (b'57) \$-Mo.1,'8I (I'84).

THAYER, I,6I3, OREGON

Cantrell, A. C.-Mo.7, 05; (\$).

Cantrell, James K. P.' (b'50)-MIo.7,'80;

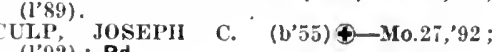
(1'92) ; Pd.

(l'99).

THOMASVILLE, I00, OREGON

Bugg, Robt. M. (b'69)-Ky.4,'91; (l'93).

Darls, Jos. 11.-Ky.4,'94; (l'01).

Plummer, Grover Cleveland (b'85) - Va.6.

HOMPSON

40, AUDRAIN

TODD, WM. T. (b'73)-Kan.4,01; (l'0I).

TIFF CITY, 57, MODONALD

Chase, Abraham U. (b'67)-.\0.27,'92; (I'93). TILMAN (R.F.D., ADVANCE), 20, STOD.

Reynolds, oltver R.-Mo.28,05; (1'05).

TILSIT (R.F.D., JACKSON), 75, CAPE GIRARDEAU

Ramsey, John Walter-Mo.24,'89; (1'89).

TINA, 304, CARROLL

EDMONDS, OLIVER R. (b'64)‡-Mo.27, $96 ;\left(l^{\prime} 36\right)$.

TINDALL, 100, GRUNDY

OWRY, IHEARY L. (b'68)-M0.28,'04; (l’05).

TIPTON, 1,273, MONITEAU

DE VIIJISS, FRANK (b'59)(-Mo.I,'83;

MARSI, JOIIN WELLINGTON (b'60) Mo.I,81; (l'84); OALR. NoRMAN, Jos. B. (b'64)-Ky.5,'94; ( ).
Redmon, Squire H. (b'54)-Mo.2,80; (l'80). (1'80).

TRENTON, 5,656, GRUNDY

ASHER, JOHN A. (b'54)-N.I.5,'81; (1'81). BEISHE, GEO. W. (b'81) - Mo.20, 04 ; (l'04).

Bickel, Chas.-Mo.32,02 ; (l'05).

DOAN, DEBORAH (b'88)-Ill.11,'09; (1'I2): Member Ill. State Med. Assn.

DUFFY, EDGAR ALLEN \&-Mo.27,'99;

FA1R, IESSE F. (b'58) \&-M0.5.85; (l'S5) : G.

FULKERSON, W.I. D. (b'62)-Mo.1,93;

(l'95).
MOORE, THORNTON E. $\left(b^{\prime} 78\right) \bigoplus-M o .3,03$; (l'05); $\mathrm{s}$.

PICKETT, CLARENCE P. (b'78)\&-Mo.22, 05: (I'05); Pd.

ROOKS, OLA' R. (b'87) $\rightarrow$ Mo. 20, 09 ; (l'09). SHEETZ, BERTHA E. SUTTON $\left(\mathrm{b}^{5} 79\right)$ Kan.4,01; (l'01). 


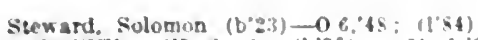
WRKSTEH, CHAS. 1. (b'70) - Mo.1,24

Wrot, WALTEK FRXEST (b'80)-Ia.3, 08 : (l'13): Member Ia. Siste Mled Soc.; Op.

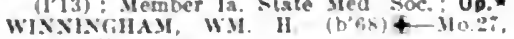
$93:(1 ' 93)$.

WRIInT JiMEs B. $\left(b^{6} 60\right)+-11018,22$ : (I's3).

TRIMBLE, 222, CLINTON

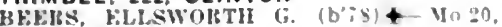
01: (1"01).

TRIPLETT. 473, CHARITON

Brown. bim. Gurdun (b'ti)-Mo.18, 8 ? (1'89).

Collins. Chas, T.-Mo.1.90; (1.96)

vlemer, Frederlc Earl (b'st)-110.00.0s (I'0s).

TROY, I,120. LINCOLN

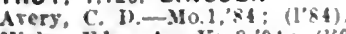

Hicks, Ldw. A-Ky.9, Ot: (l'0t)

Mckay, S. R.-Mo.2:75; (1'85).

Vorton, Harley S.-Mo.3t,04: (l'05).

Pendleton. Lafayetto (b'61) - Mo.1, 82 (1'84).

Smlth, Wm. P. (b':0)-Mo.24,93; (1'93),

TRUXTON, 275, LINCOLN

Drunert. Nathanlel L (b'62)-Mo.;,"s9: (l'89).

Gunn, Burwell W.-Mo.97,'92: (1'92)

Turner, Herbert H. (b'81) - Mo.10,'13: (1'13).

TULIP (R.F.D., CENTRALIA), 25, MONROE NEGENT, JESSE THOMAS (b'S4) IIOL. ०9: (I009): IT.F.1).2.

TURNEY, 212, CLINTON

Ashley, Wm. A. (b'53)-Mo.1, st; 1

PORT\&R, WOOL K.-Mo.2.94; (1'94)

TUSCUMBIA, 283, MILLER

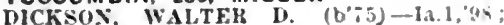
(l'98).

KOUNS, DOCGLAS If.-Ky.1.'83: 11'831

Nixdorf, Perry Tecumseb-Mo.1,85; (1'85)

TYLER, 175. PEMISCOT

Hichle, Thomas Adolphus $(b ; 0)-T e n n .8$, $25:$ (l'03).

TYRONE, 100. TEXAS

JOHXSTON, BEN 1..-Mo.18,94; $(1.98)$

ULMAN, I20, MILLER

DLNCAX, GEO W (B'79) - 10.2 .08 . (l'08).

UNION, 934, FRANKLIN

STIERBHHG:R, EDW. A. $\left(b^{\circ} .5\right)+110:-5$ -97: (1'97).

UNION STAR, 388. DEKALB

Ankrum, Fred Leslle (b'85)-Ia.3,'0s; (1'08).

F'erklns, Oscar I.-Mo.18,'62; (l'38)

Rernolds, Elda M. (b'it)-Mat:, 01 (l'ol).

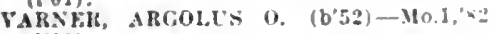
(I'01).

UNIONVILLE, 2,000, PUTNAM

BEKRY, ALBSERT $\left(\because \quad\left(b^{\circ} 52\right)-0.1 \%\right.$ (1"83)

CAKRYLH, C.IRL II $\left(\mathrm{b}^{\circ} 90\right)-\mathrm{H}_{0.28,(02}$

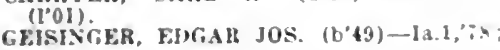

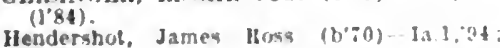

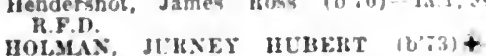

Mo.3,9s: (1'96).
McFihinney, Johin S. (b'66) E-Mo.33,06 (1'06); $\mathbf{R}$.

MONTGOMERX, FAOCH A (b'7) - Mo.2x 99: (1'92).

St. John, Rutus 1. (b'39)-D: (1*83)

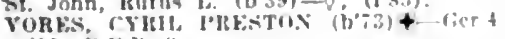
96 : I..K.II. $X$.

UNIVERSITY (ST, LOUIS P.0.), 2.417, ST. LOUIS

Innchey, Frank

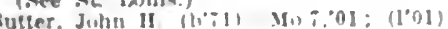

URBANA, I50, DALLAS

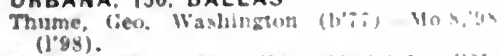

Vaughad, Rend. W. $(1,6)-M 0.3,01 ;(1 \% 01)$

URICH, 484. HENRY

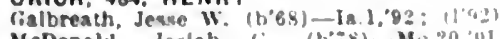

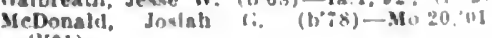
(Iro1).
Powers, John-Mo.1,x1: (l'34): not In practlce.

Sinth, Ienlle L. (1)'it)-IHd 8,92: (1'9i). Wolizen, saml. W (6\%70)-Mo.27,93; (1"93).

UTICA, 500, LIVINGSTON

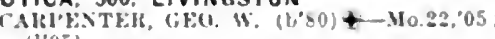
(1'05).

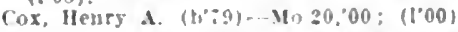

VALLEY CITY (R.F.D., KNOBNOSTER), 54. JOHNSON

SaUlis. 11arluw A-Mo.34, 03 ; (1'02).

VALLEY PARK, 2,500, ST. LOUIS

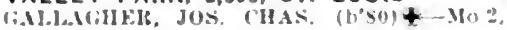
(0): (l'01).

Ganuly, Juhn A.-Fra.6.'63: (1'84).

I

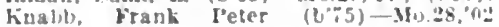
$(1,0: 2)$.

VAN, 37, POLK

IIaralson, J. Malt-M(0.1,85: (1'35)

VAN BUREN, \$00, CARTER

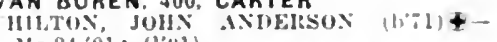

110.24:01; (l"11)

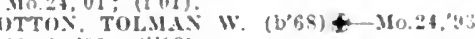

MU: $2 \times, 93 ;(1093)$.

VANCLEVE, 50, MARIES

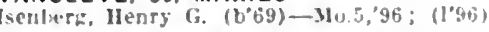

VANDALIA, 1.595, AUDRAIN

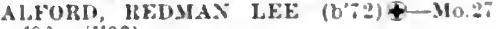

96 ; (1'96).

Mland, Warren W. (b'75)-Mo.2,99: (I'94)

llollngsworth, Jobn E.-Ky.5,90; (1'86).

'ARHISII, JOHS C. -Mo.27'91; (l'91).

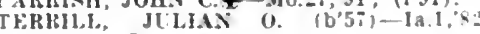

(I'B3); LR.

VANDUSER, 388, SCOTT

Haurilion, Gen. Mcclellan (b'70)-Mo I0,"Il; (1'11): ObG.

VANZANT, 10 , DOUGLAS

True, $\therefore$. M. $\rightarrow:$ (1'S3).

VERDELLA (R.F.D.. LIBERAL)。 55, BAR -

TON
MILIKK El.1JAH r. (b'56)-MO.10,'80, No. $20,400^{\circ} ;\left(1^{\circ} 86^{\circ}\right)$

\section{VERONA, 446, LAWRENCE}

lirigir. E. 1). $\rightarrow$; (l'St

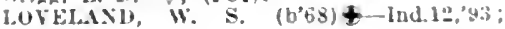
(l'95).

SUITI, JAMES WH.L (6';8)-Ind.5,01 (l'0l).

Tlterington, Jesse M. (b'55)-Tenn.6,7s (l'AS).

VERSAILLES, 1,598, MORGAN

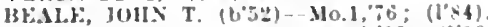

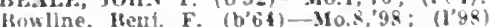

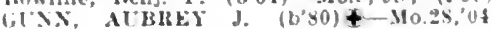

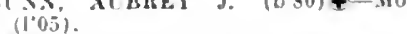

KFl.1.; ILOHT. Q. - K5.1,93; 1'93).

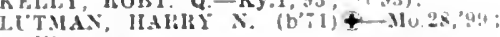
$(1.99)$.

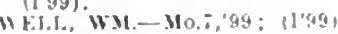

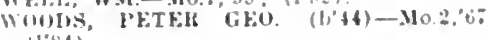
(1:\$4).

VIBBARD, IIO, RAY

M.Comt; J. A. $\rightarrow$; (l'01).

VICHY, 200, MARIES

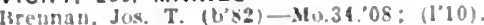

VIENNA. 300. MARIES

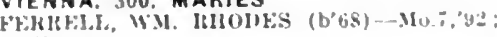
(1'yi).

VILLA RIDGE, 150. FRANKLIN

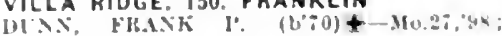

(l'ys). Janes s. $(6: 9)-110.601$ (1.01).

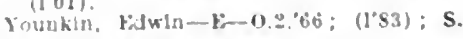

WAKENDA, 279, CARROLL

Tuble, James Dllart (inture (b'B̈) - Mo a "G!?: (1'U0)

WALDRON, 160. PLATTE

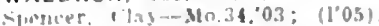

WALKER, 364, VERNON

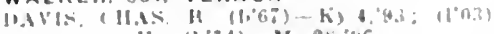

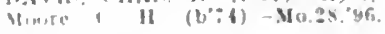

WALLACE, $15 \%$, BUCHANAN

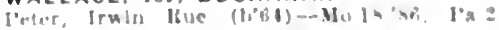
DI, $\left.11^{\circ}: B\right]$

WALNUT CROVE, 600. GREENE

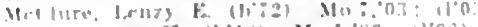

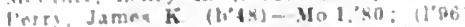

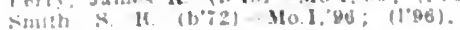

WARDSVILLE, 51. COLE

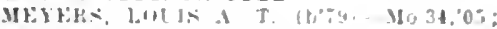
(1'0.5).

WARE (R.F.D. HILLSBORO), 25, JEFFER. SON

Elders, (jeo. W. (1,:-2)-Mo.10.933; (1"33).

WARREN, 100, MARION

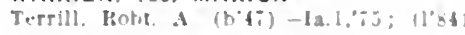

WARRENSBURG, 4.689 , JOHNSON

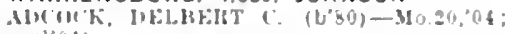
(l) $(0+1)$

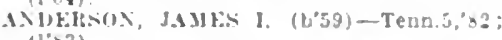
(1'm3).

AMIBESIIX, JOHX T. (6.07) +-MO 1,89: (1'a! ) ; K है।

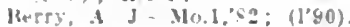

BKAILEY, THUS i. $(0 \% 0)-110.2,96$;

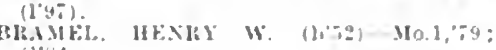
(1'*4).

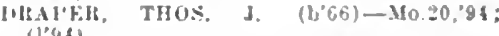

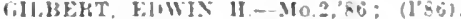

illkeson, Hucll I'-III 4,$82 ;(1)^{\circ}$ i)

IIALL, OSTAL BLIX (b'68)-Mo.20,98:

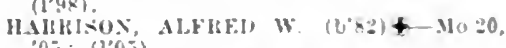
$0,8: 11,0 j)$

JoHXSON, w3. E. Mo.2x.90; (1's7).

WZIAE VIHAE (1) (b)

'WhKEK, HARKY FIELD (b'st)-Mo.?, 06: $(1205)$.

Y'ATTERSON, WM. R. $\left(b^{\prime} 65\right)+-M 0.24 .91$ (1'91).

lowers, John Alexander ( $b^{\prime}\left(b_{3}\right)-310.20,05$ : $11,0 x)$

Powers, Jos. M. (b'52) E-0.2.:5; (1's8).

Roblnson, leomard Hughes (b's5)-3lo.2,07; (l'0 $)$; not In practlce.

SCHOHLLD, LIXI J.t-Ky.2.87; (1'37).

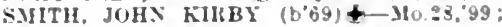
(l'99).

WARRENTON. 795. WARREN

Hrandt, Ernest H.-Mo.2,'s: : (I'ST)

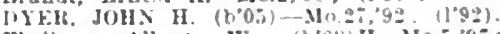

Ebellng, Albert 15 . (b'58)11-Mo.5, 97 $(1,4)$

FUKLMA, CHAS, O. (L+1)-Mo.1,75: (1'91): S.

WARSAW, 824, BENTON

DILLON, JAMLS MARION $\left(b^{\circ}: 4\right) \leftarrow$ MU. AY.F, EIWARD F. (b'55)-Mo:"91: (I'91).

POMEROY, LORT. I. $(6,60)-M$ M. ., 87 : (1'90).

SANIUS, MARTLP LITHER $\left(6^{\circ} 55\right)+-M 0.1$, $83 ;(1,90)$

AVICF, HOHAE GR.IIIM (b'6s) + Ky:4, 43, Y Y.10,'95; (1.93); OALR.

MITH, JOH. ICLSERLL (b'64)-Mo.\&, S8: (I'SS); $\mathbf{6}$.

WASHBURN, 219, BARRY

CORTHILTT LEUN RLCM (U'69)Tenn. 6.,91; (l'9l).

WASHINGTON. 3.670 , FRANKLIN

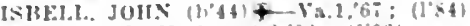

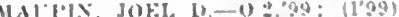

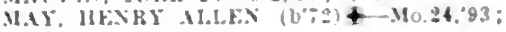

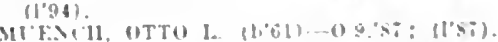

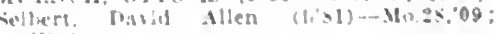

WATSON 245. ATCHISON

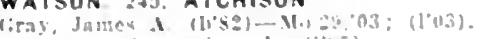

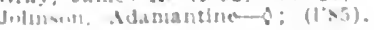

WAVERLY, 777, LAFAYETTE

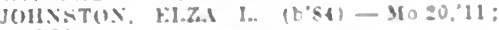
(I) 11 .

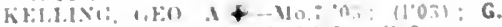

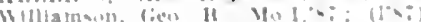

WAYLAND, 384. CLARK

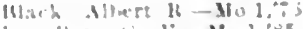

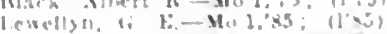

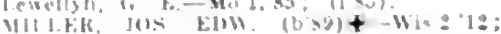
(i") :

WAYNESVILLE, 23\%. PULASKI

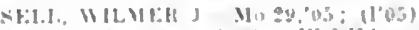

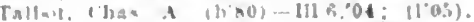

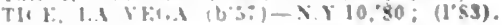


WEATHERBY, 171 , DEKALB

lledrick, James Frankllu (b'-2)--.10.25,04; $\left(l^{\prime} 00\right)$.

WEAUBLEAU, 347, HICKORY

Gentry. W'm. C.-Mo.14,'82; (1'34)

IHODGFs, WM. U. (b'61)-Tenn.9, 01 (I'07).

WEBB CITY, 11,817 , JASPER

Balrd, Earnest H. (b'79) H-Mo.5, '03; (1'03).

CHENOWETII, I.INCOLN (. (b'62) -Mo.1 '86; (1'86); Webl City Bank Bldr.; 9-i2, $2-5$; $\mathrm{s}$.

COOK, JAIRHACE C. (b'81)-Mo.8, 05 ; (l'05); $512 x$. Lang St.; offlee, Cnlty Blde. ; 9-1:2-5, 7-8.

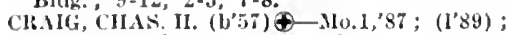
-11 ir. Joplln st.; oftce, $110 \mathrm{~W}$. Dough erty st.

Eilelen, Johnson E. (b'48)-Ky.2, 70 ; (l'86); 220 S. Penn Ave.; offce, 220 N. Allen St. ; $2-4,8-10$

Gentry, Colby C. (b'50)-Mo.1,'s3; (1'83) 314 N. Liberty St.; offlce, Allen and Dorr Sts. ; 8-11, 1-5, 6-8.

Growdon, Artliur S. (b'80)-Ky.2,06; (l'06) : 521 W. Dougherty St. ; ofllce, 14 S. Allen St. ; $9-11,2-4,7-8$.

Joyee, Wm. J.-Mo.28,'98; (l'00); 1007 Crow St. ; offlce, $830 \mathrm{~W}$. Dougherty St.

Locke, John E. (b'60) E-0.2,94; (l'94) $120 \mathrm{~N}$. Penn Are.; offce, $29 \mathrm{~S}$. Állen St.

Melsride, Chas. E. (b'58)-Mo.1,80; (1'83) ; 711 W. 3d St. : offlce, Main and Allen Sts. ; $8-9,1-3,5-6,7-8$.

RATLFF, IIARRY L. (b' 7$) \oplus-M o .20,03$; (I'13); Member Mo. State Med. Assu.; Unity Bldg.

Sanz, Geo. (b'66)-0.1,'97; (1'04); Unity Bldg. ; 8-9, $1-3,7-8$.

Waggoner, Wm. W. (b'62)-0.8,92; (1'99) Lakeslde; olfice, II Immphrey Bldg.; U.

WIIFLEY, OTA S. (b'T2)-No.28, 95 $\left(l^{\prime} 94\right) ; 113 N$. Roane St. ; 10-12, 3-5,

WEBSTER GROVES, 7,080, ST. LOUIS (See St. Louls.)

ARMSTRONG, CLAUDE L. (b'68) †-Mo.27, $96 ;\left(l^{\prime} 96\right)$.

BAKER, MARSHALL (b'45)๑-Mo.2,79 ; (I'83); 0b.

BENRY, JOHN MARSHALL (b'55) -Mo.2, $78 ;($ ('84).

BROENSEI, MILTON AUGLSTUS (b'89) -Mo.2,11: (l'11).

CARTER, HOWALD (b'58) - Mo.24,93; (l'93).

Cockrell, Eugene P. (b's0)-Mo.2,06; (l'05).

Conway, Arthur (b'61)-Mo.2, 83 ; (1'83).

CREVELING, HANLEY CLAY.

(See St. Louis.)

Eckert, Wm. Henry.

(See St. Louis.)

EWING, FAYETTE CLAY.

(See St. Louls.)

Fulton, libert.

(See st. Louls.)

HOLWINK, JOS. J.

(See St. Louls.)

Kinlchel, Jos.

(See St. Louis.)

MIJES, HORINE (b'64)-Mo.1,'86; (l'89)

MILLS, RALPH WALTER.

(see St. Louls.)

NoRTH, WM. R. (b'75)Ð-Mo.24,'00; (1'00). Peterson, Cyrus Asbury.

(See St. Louls.)

TOWNSEND, JAMES ARTHUR (b'76)థMo.24,00, Mo.28,01; (1'00) ; Prof. Bact. Mo.7.

Westrup, Arthur Wm. (b'84) $\rightarrow$; $\left(l^{\prime} 10\right)$

WEINGARTEN, 85, STE. GENEVIEVE

MORGANSTEIN, HERMAN J. (b'58)-MU.1,

WELLINGTON, 558, LAFAYETTE

'85; (l'03).

IANN, JoHx A. (b'51)-Mo.2,76; (l’83).

NASSE, HDMUND (b'58)-Mo.2,' 1 ; (1'83).

Watts, Robt. (b'63)-Mo.8,'94; (1'95).

WELLSTON, 7,3I2, ST. LOUIS

Allen, Jos. W.

(See St. Louis.)

BRACT, ROLIIE I

(see Sit. Louis.)
WELLSVILLE, 1.194 MONTGOMERY

(OX. S. S. -Mo.1,94; (1'92)

Dallas, Ilugh G. (b'82)-IIo.7,'08; (l'08) DIY'L, THOS. II. (b'71)-Mo.27,95; (1'95) G.

MeCully, Alexander (b'78)-Mo.2,02; (1'02)

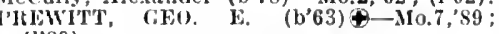
(I'89).

WENTWORTH, 154, NEWTON

Lazenly, Benj. F.-Mo.10,87; (l'87).

WENTZVILLE, 539, ST. CHARLES

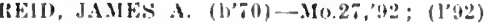

WESCO, 100, CRAWFORD

VALGHAN, IRUBLN FIANL-O; (I'S3)

WEST ALTON, $300, S T$. CHARLES

l'ennington, Geo. IR. (b'67)-.Mo.34, 02 ; (l'02)

WESTBORO, 333, ATCHISON

Goltry, Clias. F. (b'63)-IIl.8, 08; (l'09)

LOTT, GFO. W. (b'58)-Ia.3,'89; (I'89).

WEST EMINENCE, 30, SHANNON

EUDY, WH. THOS. (b'75)-Ky.2,'09; (l'09) :

Pd.

E COMPTE, ELMO M. (b'sz)๑-Ky.2,'10; (1'10).

WEST LINE, I20, CASS

loore, Watson Alex. (b'78) - Mo.32,04; (l'05).

WESTON, 1,019, PLATTE

CALYEHT, LEWIS CASS (b'84)-I'a.2,08 (1'11); Anes.

CHASTAIN, CHAS. H. (b'75) \$-ATk.1,00 ; (l'00).

Doran, Thos. (b'49)-Ky.2,89; (l'89)

JOHNON, GEO. A.-IIO.1;86; (1.87)

IIULTZ, JOIIN W. (b'38)-110.20,02;

WESTPHALIA, 321, OSAGE

BOWLES, SAMI. A. (b'52)-Ky.1,'83; (l'83).

REICHMANN, PHILIP JAMES (b'79)-

Mo.7,'11; (I'11).

WESTPLAINS, 2,914, HOWELL

BESS, WM. EDDIE (b'83) $9-\mathrm{K}^{\circ}, 2,10 ;$ ( )
EIIIOTT, JAMES HENRY ELIIOTT, JAMES HEN

JOHNSON, J. MeBRIDE (b'62) $-\mathrm{K} y .1,99$; (l'97); OALR.

LOTTMANN, WM. AUGUST (b'71)-Mo. 02; (1'02); Nember State Med. Assn. of

(l'95)

(l'95). (1'81); OALR
(1)

Sparks, Kichard A.-Tenn.6,'91; (1'91).

SPEAKS, ROB'T. SMITH (b'66)-Ga.5, 90

$\left(l^{\prime} 97\right)$; Member N.M. Med. Soc.

THORNBUKGII, ALBERT H. $\left(\mathrm{b}^{\prime}, 0\right)-\mathrm{Mo.1}$, 95; (l'95).

Woodford, Wm. S.-\$10.8,'01; (1'06)

WUESTHOFF, LEOPOLD W. $\left(\mathrm{b}^{2} 72\right)$ - 4 -Ia.8,

03; (l'11) : Ob.

WET GLAIZE, 20, CAMDEN

Carlton, John M.-O.

WHEATLAND, 400, HICKORY

Fisher, Arthur Is. (b'49) E-0.2,'82 ; (l'84)

Johnston, Albert Sldney (b'72) E-Mo.10,97 (1'97).

EVINS, ROSCOE C. (b'86)--Mo.20,'11; (l'11).

WHEATON, I0, Barry

Sheldon, Thos, J.-Ky.2,'82; (1'83)

WHEELING, 381 , LIVINGSTON

SWOPE, WM. A.-Ky.2,'85; (1'85)

WHITE CHURCH, 53, HOWELL

Ilendrix, John F.-Md.3,'83; (l'S3).

WHITEOAK, 250, DUNKIN

I cHaney, H. A.-Ky.2,'90; not in practice.

WHITESIDE, 129 , LINCOLN

K.'OX, JOS. IZEL (b'39)-No.2,'65; ()

Stuckert, otto (b'62)-Ia.1 '90; (l'90).

WHITESVILLE, 225, ANDREW

Jefferies, Elmor C. (b'58)-Mo.22,'88; (1'88)

Peter, Alex. (b'70)-Mo.18,'91; (I'92).

WHITEWATER, 250, CAPE GIRARDEAU

ILRPHY, AMOS M.-MO.7,04; (I'05).

WHITHAM, 250, CHARITON

Crawford, David P. (b'72)-Ky.2,02; (l'10) : Pd.

WILLARD, I25, GREENE

PIKE, COLUMBLS J.-Mo.8,'92; (I'92).
WILLIAMSBURG, I05, CALLAWAY

Bolton, James J. (b'31)-0.2,60; (l'84).

Glover, Leslle (1'80)-Mo.35,'11; (l'11).

WILLIAMSTOWN, 204, LEWIS

FORD, JOHN-Ore.1,'71; (I'83).

IIo.2,08; (1'08).

WILLIAMSVILLE, 477, WAYNE

Horn, J. L.-Mo.1,'85 ; (I'03)

McGhee, J. L. $\rightarrow$ Mo. 1,'89; ( $\left.\mathbf{l}^{\prime} 89\right)$

P'RICE, J. I'. (b'64)-Mío.10,97); $\left(1^{\prime} 00\right)$

SEBISTIAN, JOHN l'. (b48)-Mo.2,'i1; (1'83).

WILLOW SPRINGS, 1,401, HOWELL

Bowlin, Wm. 'T. (b'67)-Mo.10,94; (I'94).

D.IVIS, JAMLS C. B.9-Mo.28, 03 : (I'03).

ROWE, HLLIARD JAMES (b'59) $86 ;(1 ' 84)$.

WINCHESTER (R.F.D., GREGORY LAND-

ING), II8, CLARK

HAlitis, H. W. W-Mo.1,'88; (1'88)

WINDSOR, 2,241, HENRY

AGNIEL, MAUDE I. (b'75)-Mo.30,98; (1'98).

Blacknore, Thos. Albert (b'73)-Mo.1,9s; (1'98); OALR.

Feaster, James Fowler-Mo.3,70; (1'83)

Gray, Jos. W. $\left(b^{\prime} 42\right)-0 ;\left(l^{\prime} 83\right)$; not in practice; R.F.D. 17

Head, Chas. W. (b'55)-Mo. 1,7 : (1'86).

Jennings, Robt. J. (b'7)-Mo.28, 03 ; (l'03).

Shadburn, Robt. I. (b'54)-Ky.2,68 ; (t).

WALL, HARVEY MONROE (b'84) \$-Mo.2, 08 ; (1'08); Pd.

WALTON, JOSIAH H. (b'74)๑-Mo.28, 02 ; (I'01).

\section{WINFIELD, 422, LINCOLN}

WHIT'T, WAYNE A.\$-Mo.34,'04; '(l'07).

WINIGAN, 134, SULLIVAN

Baker, Edw. (G.-Mo.28,'97; (l'98).

WINONA, 444, SHANNON

Jamleson, A. J.-Mo.10,'80 ; (l'83).

MCNEILL, ADOLPIIUS' RÚDOLPH (b'\$5) Mo.7,'10; $(1,10)$.

WINSTON, 257, DAVIESS

Clagett, Dudley M.-Mo.2,72; (l'83).

COX, JOHN LAWRENCE' (b'78)-Mo.22, 03 ; (l'05).

WISHART, 100 , POLK

Davles, Chas. E. (b'75)-Ill.6,'98; (l'83).

WOODLANDVILLE, 20, BOONE

Trimble, 0. S.-Ia.I,77; (1'83).

WOODLAWN (R.F.D., MADISON), 50, MONROE

Pickett, Ambris C.-No.24,'95; (1'95).

WORTH, 150, WORTH

Andrews, Albert (b'81)-Mo.22,05; (l'05).

WORTHINGTON, 200, PUTNAM

Jackson, John C. (b'53) H-Ia.3,'86 ; (l'93)

Thomas, Cullen 0. (b'7t) - Mo.29, 03 ; $\left(\mathrm{l}^{\prime} 03\right)$.

WRIGHT CITY, 377, WARREN

Fluesmeier, Elihu Ashby $\left(b^{\prime} 71\right)-M o .3,91$; (1'91); Ob.

SHEPHERD, HORACE A. (b'74)@-Tenn.11, Tho; $\left(\mathbf{P}^{\prime} 00\right) ; \mathbf{P d}$

Thompson, Fannie M. $\rightarrow$; (1'92)

Thompson, Robt. Avery' (b'90)-Mo. ', '13 ( ).

WYACONDA, 480, CLARK

CRUMII, ASA CLAYTON (b'61)@- 0 ; DOSS, SYLVESTER E. (b' $(2)$-Ia.1, 88 ; (l'88).

MCREYNOLDS, WH. C.-Ta.1,'71; (1'83)

Pechstein, J. W.-Ia.1, $86 ;\left(1^{\prime} 90\right)$.

ROBEHTS, ISAAC M. (b'50)-Ia.1,75. (l’90).

Swearingen, Jobn A.-la.1,'92; (l'92).

WYATT, 50, MISSISSIPPI

MARSHALL, ALVIS TAYLOR-Mo.34,03; (I’03).

RAIVLS, FRVIN J. (b'43) (l'00).

ZALMA, 197, BOLLINGER

Doggett, Sylvester (b'89)-Mo.10,'12; (l'12) U.

Klrkpatríck, Arza T.-Mo.28,'05; (1'05).

Speer, Asler J. (b'74)-Mo.7,'03; (l'03) ; OALR. 


\section{MONTANA}

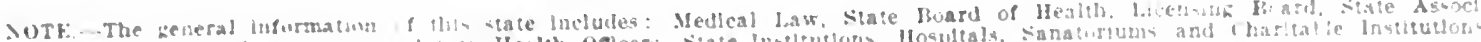

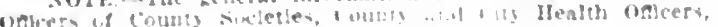

\section{MONTANA}

Population (1910 census) . . .

376,053

Number of Countles.

Number of Physicians........... 378

Members State Association, Dec. 31,

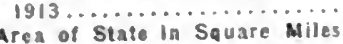

MEDICAL PRACTICE LAW OF MONTANA Aricle XVJ, Julltieal ("nde of Mnutana Sec I5S3. IBOAKI (1F EX.MUNELS; Al.

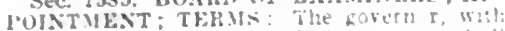

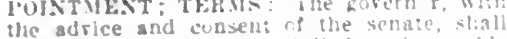
the adrice and consen: nf the semate, stanl physcians, who shall have becn reverter? uf the state of Moratas for not lew thas is years preceding thelr appoivtment. than two uf whom shall be froni the ant count and who have allestled $t^{t}$.

cot lectures and who are ofadu credited culleges of medicing wh crediled cuileces or modicino, wr tha par posen of this dit. The lihysicials is a

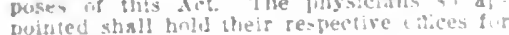
buinted shall hill their restertive taces to

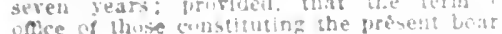
once of thise constituting the present bet this lct: and the terms if their wall te so arranged It is alleceed ?h y u ent iscumbellis as ther terms exp

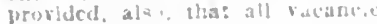

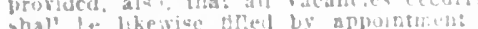

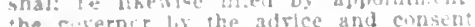
the sumate the semale semate is nut in sosing shall lake so

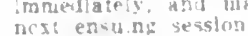

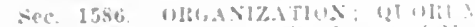

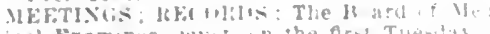

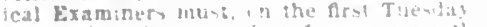

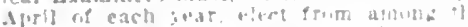
number a provident, secreary and ire,

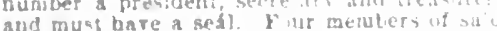
and mul bare a sedite a our run. The p:e fent and secresary hare the power sir aulm

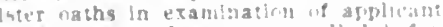
cersidiaies, and witnecies ralleal befir Pward in the iranartins of trasnes is

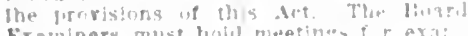
Fxaminers must hill meeting二, if exat

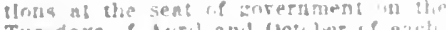

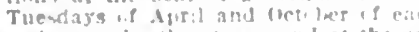
and at such other tines and at the

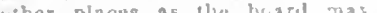

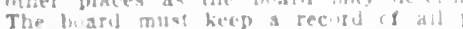

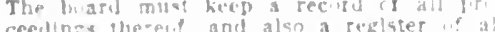

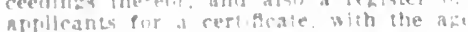

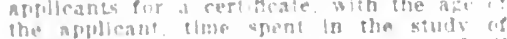
the andicant the enept in tha studs all

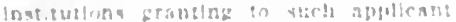
greey it cortallcatos ap lentures attendest inndicane os surdery "Tho reglver muat

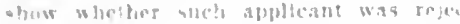

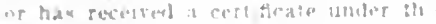
wich reclater is prima firce esulence twatters there!n hest?

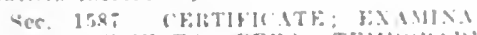

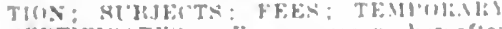

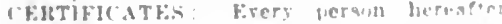
withing to jractice mallotice or surgery anz of the derarimetis of this state shall

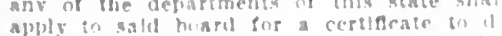
wr. Fibers perwen allulying shall pre erl:

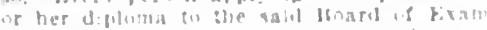

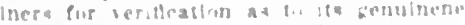

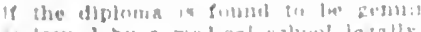

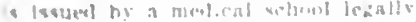

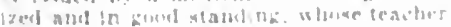

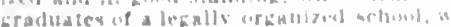

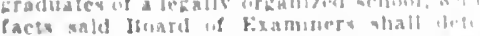

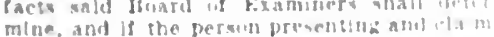
iag said dlufoma slasll bo the perain to whom
The same was oritinally granted, at a time of toy sald torit. ne st a repular meeting of sald buad, sand appllnulu shall subnit to an examination in the wluwne branches, to-wit: anatom, phystligy. inaterin medlea. Iherapeutics prac.

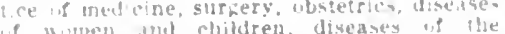
$f$ women and chituren, diveasey it? the

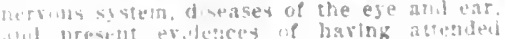

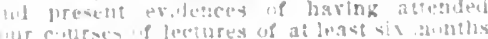

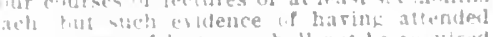

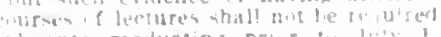

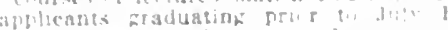

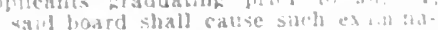
in both scientiac and pratical ind -umetent thurmolneas atul wresiy :he candidate's lltness in practice me. he and vurgery; when devired such exa:" then may be conducied in the presenec thent of any medical ancie!y if tha bite ifter examination such rist. is il:

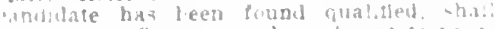
unt a certilieate to such apslicant t.1 brat nued cone ind surfery in the state it I malda. whicla sald certilicate cas be the cunsens of net lese that

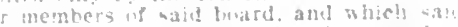

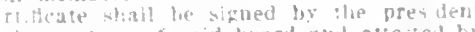

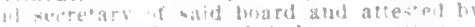

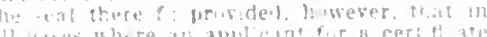
ase where an amblicant for a retid? at

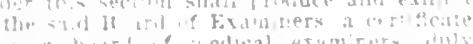
(1) ind and es -ing under the las: of an

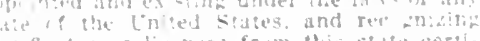

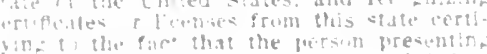

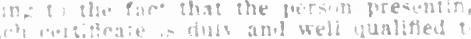
a.t fe nuli, no am? surger in the state

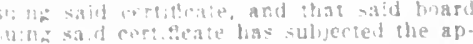

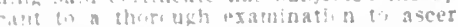
n this fast. o certifynt to the fact that

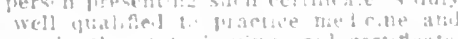

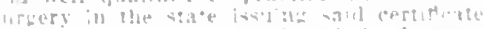

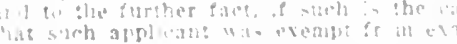

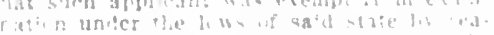

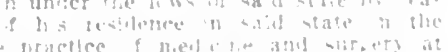

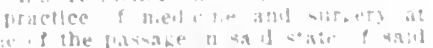

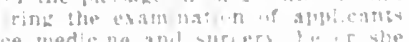
re mediene and sarbers ?." r whe

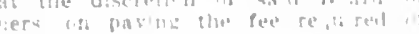

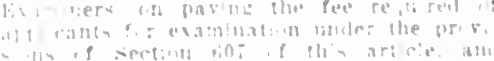

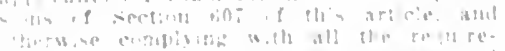

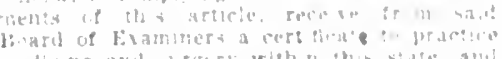

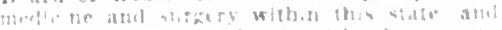

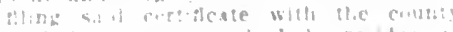

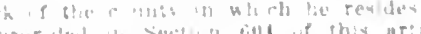

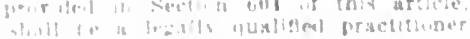
alut sibaery in thls state; pro

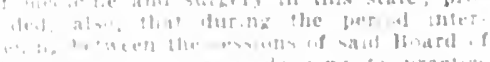

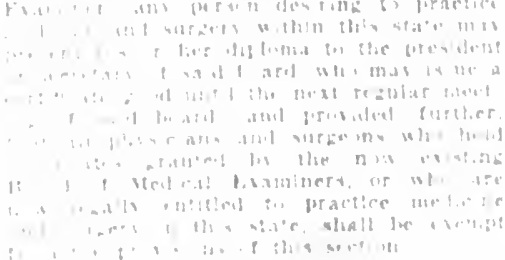

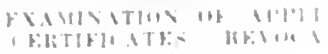

TION OF TEKTIHICATE- AI'EAIS FHWW

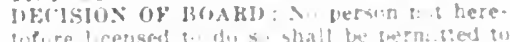

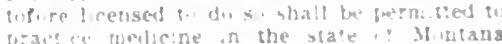
whlew he - hall hare ilst becu -ubecied to it ritubly examination as tw hls yual. Alca. toll , iearnong and rofessional shill by the

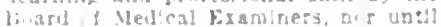
de haw bers aned a certilicate by such 6) ar.! after such examinat. in adm! .ag h:D

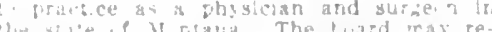
fache of W ritala. The luard male re

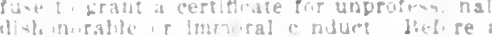

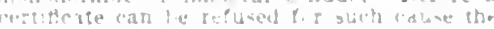

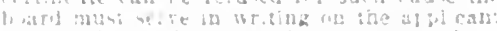

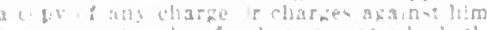

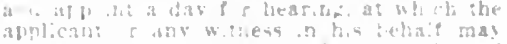

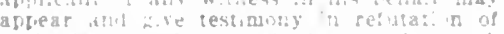

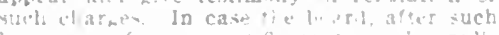

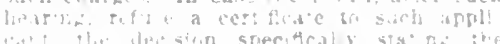

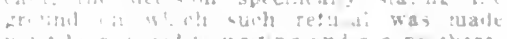

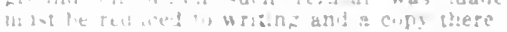

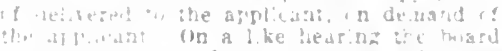

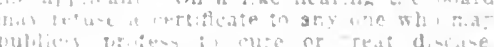

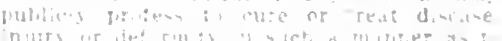

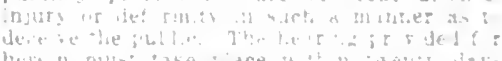
here n nuta tathe ace

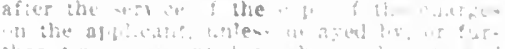

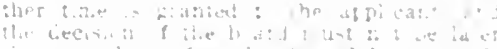

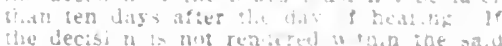

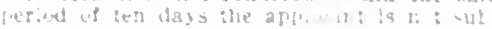
pet to any venaities $l$ r pas.

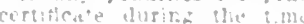

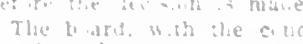

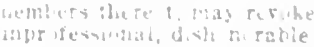

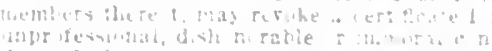

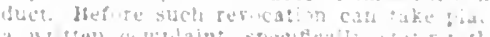

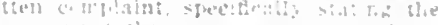

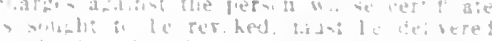

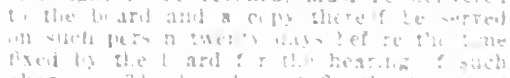

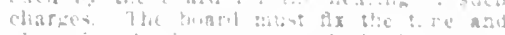

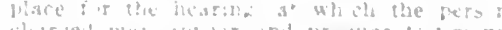

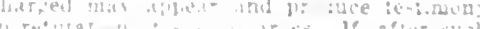

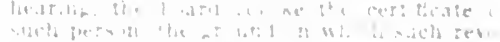

idiket b.

py there

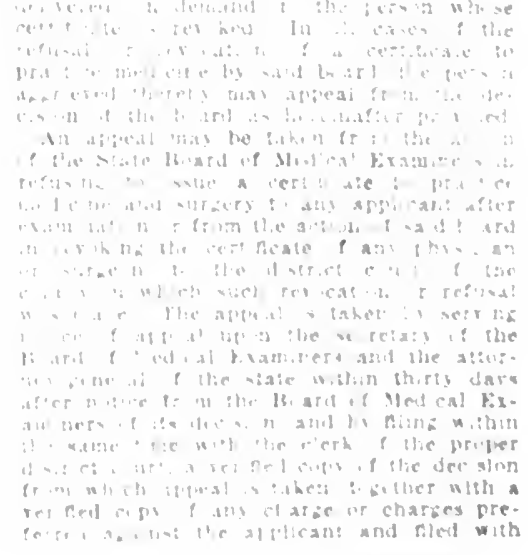


the Board of Medleal Examiners. The appellant is required at the time of flling sueh appeal, to furnish and file with the clerk of the court a good and suntelent bond to bo approved lyy the clerk of the court. With $t$ wo good and sutfielent surelles, in tlle sum of ment uf all costs of the anpent shumbl the

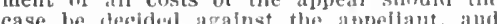
the costs shall cunsist of the sheriff"'s fees for servine jurors jurors fees and the fees of the clerk of the court. such appeal slull therearter be tried loy the district court bethereafter be tried lig the district court betwo of whom shitll be of the same school of medicine as the ippellant--iml in ease sueh jury camot be obtalined in the county where the case is trled. the jurge of such court any adjoining poenas shall be served by the sherifp of such adjolnlng clerk of the crint where the subpona is clerk of the conrt where the simpona is such subpoena to sueh sheriff. Bias or such subpoena to steh sherif. Mias or prejudice or fixed opinion shall constitute in ground of challenge to a juror for cause, and the appellant and the medical board shall each have the right to peremintorly challenge not more thall liave boen selectel and sworn to try the cause, they constitute a hlwhering of the be aflrined or overruled upon the issues presented to such board, and such jury inay make such examination of the appellant as they nay deem necessary or desirable. It diet, and no niember of the medical board is qualified to act as a juror. The attorneygeneral is hereby made the attorney for said board. Jurymen subpoenaed under this Act shall be entitled to mlleage at the rate of I0 cents per mile for each and every mile by them actually traveled in attending upon the court, and of $\$ 3$ per lay for their services. (Act approred March 5, 190\%) (10th Sess. (halp. I00.)

Sec. 1589. CERTIFICATE TO BE KECORDED : REPORT CIANGES: PENALTIES: Erery person obtaining a certificate from the board must, within sixty days from the date thereof, have the same recorded in the offlce of the county clerk of the county wherein he resides; if he renoves from one county to another to practice medicine or surgery, his certificate must be immediately recorded in the county to which he removes. The county clerk milst endorse on the certo eliarge and receive his usual fee for such to eliarge and receive his usual fee for such serrices, the fee to be paid by the applicant.
Until the certifleate be recorded, as provided bs this section, the physician practicing under it is subject to the penalties jrescribed in the penal colle for practicing without a certificate. (Section 604. Ict approved Mlareh 13,1895 .)

Sec. 1590. TO WHOM NOT APTLIEL: This Act sliall not apply to midwires of skill and experience, comnissioned surgeons of the United States Army and Nary in the discharge of their official duties, nor to phssicians and surgeons in actual consultation from other states and territories.

See. 1591. PRACTICING MEUICINE WITHOLT CERTIFICATE; PEXALTIES : Any person practicing medicine or surgery within this state without flrst having ohby law, and after his certificate to practice has been revoked, or contrary to the provisions of this Act, slall for each violation of the provisions of this code, or any act relating to the practice of medicine and surgery in this state, be guilty of a misdemeanor and upon conviction shall be punished by a fine of not more than $\$ 1,000$ nnor less than $\$ 250$, or by imprisonment in the enunty jail not exceeding one year, nor less than ninety days, or by botl such fine and imprisonthent, as the court may determine. withy person shall be regarded as practieing append or atfix the letters M.B. or AI.D., or the title of Dr. or Doctor, or any other sign or appellation in a medical sense to hls or her name, who shali publlely profess to be a physlctam or a surgeon, who shall publiely profess cither on hls own behalf, In his own iny other person, corporation, association, bartnershlip, efther ats manager, bookkeeper, sollicitor or other agent, to cure, treat, relieve, or palliate any allment, disease or hhrminty of the mind or body of another by surgical treatment, or who shall recommend, preseribe or direct for the use of any perfou iny drug, mediclne, applianee, appason, this drug, nediclne, apor wee, appanot material, for the eure. relief or palliathon of any anment or disease of the mind or body, or for the eure or relief of any wound, fracture or bodily injury or other deformity after having receired, or with the intent of receiving therefor eitler directly or indirectly, any bonus, gift, or compensathon; provided, huwerer, that nothing in this section shall he construed to restrain or restrict any legally licensed osteopathic practitloner practlelng under the laws of
this state. Nothing in this Act sluall prolifiblt any legally licensed pharmaclst or mercantlle dealer from sellng any druts or mercantlle dealer from selling any druips or
medicines which are now allowed to be sold under the laws of the state of Montana or the United States. (Act approred March 5 , 1907.) (10th Sess. Chap. 101.)

Sec. 1592. FEES: Candidates for examination shal pay in advance to the secretary of the Board of Medical Examiners a fee of $\$ 25$, which fee shall defray the entire expense of said candidates for examluation hefore the aforesaid Board of Examiners Any one failing to pass the required examination within six months, without fee. And the moneys so received shall be turned over to the state treasurer, to be by him deposited in the medical board fund, as bereinafter provided.

Sec. 1593, CONPENSATION OF BOARD; ANNUAL REPORT TO GOVERNOR: Each member of the board ls allowed the sum of $\$ 5$ per day and mileage while in the actire and necessary dlscharge of his duties. And there is hereby established a fund to be known as the medical board fund. And a sum of $\$ I, 500$ is hereby annually appropriated out of any moneys in the state treasury not otherwise appropriated, to meet the expenses incurred in carrying out the provisions of this Act. The state treasurer is hereby directed and required to set such sum apart to the credit of such fund, subject to the orders and disbursements as herein provided for. The moneys in such fund shall vidy be paid out by warrant on said fund on only be paid out by warrant on said fund on an order drawn by the secretary of said rate of mileage and attendance before said board shall be the same as is now allowed in justice of the peace courts. And the board must report annually on the first Ionday in November to the gorernor, which report must show all the transactlons of the board, giving the number of applications received and from whon received, the number of certificates granted and rejected, and the names of those receiving certificates and those rejected, giving the reasons therefor, the amount of money received, the expenses, the fees and mileage paid, and by whom ing in said fund.

\section{STATE BOARD OF HEALTH}

D. Jonohue, President, Glendive; 1. Butler, Vice-President, Helena; Gov. Kelly, Helena; C. E. K. Vidal, Great Falls; E. F. Maginn, Butte; W. F. Cogswell, Secretary, Helena.

\section{STATE BOARD OF MEDICAL EXAMINERS}

P. H. McCarthy, President, Butte; F. J. Adams. Great Falls; W. W. Andrus, Miles
City: S. A. Coones, Helena; W. L. Renick, City : S.A. Coones, Helena; W. L. Renick,
Butte; W. P. Mills, Missoula; Wm. C. Riddell, Secretary, Helena.

\section{MONTANA STATE MEDICAL ASSOCIATION}

Oficers 1913-1914

II. I'. Mllis, President............. Mtssoula

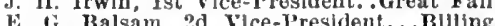
sidney Cooney, 3d Vice-Iresldent....Helena

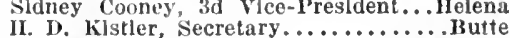
II. D. Kistler, Secretary................. Wutte

Councilar Districts and Officers

First District-Silverbow County. J. A. Donovan, Councilor, Butte.

Second bistric1-Missoula County. (i. M. Jennings, Councilor, Missoula.

Third Distrlet.-Deer Lodge and Fergus countles. E. D. O'Neil, Councilor, Kallspell. Fourth Dlstrlet-Cascade County. LeRoy Southmayd, Councilor, Great Falls.

Fif th Dlstrlet.-Chouteau and Valley countics. M. D. Iloyt, Councllor, Glascow.

Sixth District-Beaverhead County, E. I. Sutherland, Councllor, Sheridan.

Serenth District-Lewls and Clark coun es. B. C. Brooke, Councilor, Helena

Eight District-Flathead County. iv. II Buskirk, Councllor, Mlles City,

Ninth Dlstrlet-Park County. B. I. Pampel, Councilor, Llvingston.

Tenth District-Gallatin County. C. W. Jump, Counellor, Bozeman.

Component County and District Societies of the Mentana State Medical Association

CASCADE COUNTY

R. B. Durnln, President........Great Falls Aloysius Dolan, Secretary........ Great Falls CHOTEAU COUNTY

F. Atkinson, President.............. Benton
P. H. O'Malley, Secretary......... Chinook DEER LODGE COUNTY

C. R. Bancroft, President.........Anaconda FERGUS COUNTY

A. C. Biddle, President......... Lewlstown FLATHEAD COÜNTY

W. S. Little, Presldent..........Kalispel L. G. Griffl, Secretary........... Kalispell GALLATIN COUNTY

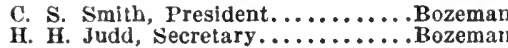
HILI COUNTY

W. F. Hamilton, President............ Havre LEWIS AND CLARK COUNTIES

W. C. Riddell, President.......... Helena MADISON COUNTY

H. F. Smith, President.................... Pony MISSOULA COUNTY

Sanford H. IIcCall, President..... Missoula Alien G. Fuller, Secretary........... Missouli MUSSELSHELL COUNTY MEDICAL SOCIETY

w. H. Brissenden, President....... Roundup
C. T. Pigot, Secretary ........... Roundup PARK COUNTY

K. D. Alton, President.......... Livingston

P. L. Greene, Secretary............. Livingston POWELL COUNTY (Included in Silver Bow County Medical

SILVER BOW COUNTY

Mac C. Snlelters, President.......................... YELLOWSTONE VALLEY MEDICAL SOCIETY

J. D. Barrett, President............Bllings E. G. Balsam, Secretary................. Billings

\section{COUNTY HEALTH OFFICERS}

County Address Bearerhead.-R. H. Ryburn.......Bannack Big Horn. - o. S. Haverfield.......... Hardin Blaine.-C. E. Foss.............. Harlem
Broadwater, - C. W. Smith...... Townsend Carbon.-Gaylord MeCoy............. Jollet 
Cascade.-1. M. Macaulay..... fireat Valls Chouteau. -J F. Murphy......... Ft. Benton Custer.W. W Andrus............lles City Dawson. - Rajdwin Consler........ Glendive Deer Iodfe. - J. F. Spelman. ...... Inaconda Ferzus.-A. W. Deal............ l.ewistown Mathead.-IV, H. Campbell....... Kallspell Gallatin.-Jus, Pledalue......... Bozeman Granlte.-W. E. Casey........... Hhillpsburg IIIU. $\checkmark$. \$. Almas................ Harre Jetrerson.-1. A. Lelghton.......... Boulder Lewls and Clarke-S. A. Coones....llelena Llncoln. - P. Baxter ............. Libby Madison.-D. Clancy..........Virginla Clty Meagher. - IL. B. Tice........... Tiro Dot MIssoula. -J. J. Fynn...........Misvouta Musselshell. - C. T. I'igot......... Roundup Park.-Jos. C. Denney.......... lyde l'ark Iowell.G. L. Marquetse....... beer Lndge Rarall..-T. H. Hanbldge.......... Victor Kosebud.-J. G. Oosterbeek......... Hssham Sanders.-E. D. Peek...........Thomnson Sheridan. J. H. Drake............Mondak Sliver Bow.-P. H. McCarths......... Butte

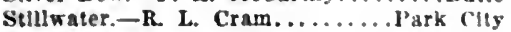
Sweet lirass.-A. Clalborn.......Big Timber Teton.-H. W. Bateman........... Choutesu Valles. - T. L. Cockrell............ Hinsdale Vellowstone.-M. H. Arnold......... Billings

\section{CITY HEALTH OFFICERS}

Anaconda................. IR. Hancrops Bullings..................... G. Balsam Bozeman.................. F. Jump Bulte.................... H. Horst Glendire ................... F. Consler Great Falls.............. T. E. Murray Hamilton............... Fritz E. Buchen Helena............'Prof. Albert J. Roberts Kaltspell.................. D. O'Nell Lewiston................. C. Jiddle Livingston.................. E. Leard

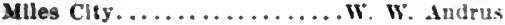
Missoula................... I fease Walkerrille................ Jno. Virogan

\section{STATE INSTITUTIONS}

\section{Boulder}

Jontana School for the Deal and Blind and Tralning School for lackward children. Roulder. Mont. Hstab. lished 1893; public: educational; I50 beds; A. L. Ward, surgeou; H. J. Meu. zemer, superintendent.

Montana Tralning School for Backward Children: Houlder Mont. kistablfsherl 1894: Reneral: so beds; H. k. Menzeiner, $1894:$ Reneral:
superintendent.

\section{Columbia Falis}

Jontana Soldiers' Hone, 'olumbia

Falls, Mont. Establlshed 189: : tio heds

in barracks, 35 beds in hostital; John $T$ Roblason, physiclan and surgeon, in charge; J. K. Sprague, commander.

\section{Deer Lodge}

Slate lisison Hospital, lleer lombe Mont.

Galen

Jontana state Tuberculosis Saritartum,

Galen, Jont. (Warm Sprins, I'I')

Fistabllated 1913: publle. 2ti treds: Thu

11. Tuttle, medical suberintondent.

\section{miles City}

Montana state Vleform schoul. Nilen

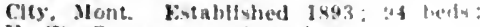
H. IV. Georgo, suberintendens.

\section{Twin Bridges}

Home for Orohans. Fonndlings ant Ilestlute chlldren. Twin Brlatgey. Womt fatablished 1894; 17 : beds: controllod

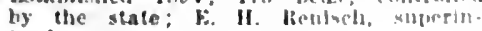
tendent.

\section{Warm Springs}

Montana stale llospltal for she Inabue Warm springs, Mont. Kalabllated ivi: pulvilc: ingane: 1.000 beds: $A$. Kulpht. M.L. subcrintendent.

\section{HOSPITALS. SANATORIUMS AND CHARI. TABLE INSTITUTIONS}

\section{Alnambra}

Athambra llot Siprings IIotel and Sint tarfum, Hot springs, Allombra, Yont ristablished 1904: Leneral: 65 beds Charles sconeld, physiclan in charge.

\section{An acond}

St. Ann's IIospltal, Anaconda, Mont. Fistablshed 1989; prirate; general; 100 beds.

\section{Bear Creek}

Rear Creek Hospltal, Near Creek, llont Eistabllshel 1911: Irtiate: Renphyselan in charge.

\section{Belgrade}

Heltrade IIrospltal. Belgrade, Mont. Fa tablished 1309; prliate: 12 bels; Mrs Foll Ftan, superintendent.

\section{Billings}

st. Vincent's Iluspltal. Ist Are and Witiston st., Hillings. Mont. Fotablished 1892: pliblic: cencral: 50 beds: sister of Charity, in charge.

\section{Boulde}

Boulder Hot Springs, Boulder, Mont Fstablished 1855 : 125 heds: I. A. lelgh con, resident physicinn: J. f. IncCormick, in charge.

Lelghton's collage llospital, Boulder. $\Pi$ ont. Established 1895 ; 5 beds; I. I l.eizhton, physlclan in charke.

Ward'3 Ifospital, Boulder, Mont. Establlshed 1909: prirate: 10 beds: Ward. physlcian in charge.

\section{Bozeman}

Bozeman Deaconess Hospltal, Bozeman. Mont. Fistablished 1898; private; 30 beds: Mlss Eilzabeth Bjork]und, superintendent.

\section{Bridger}

Brilger Ilonultal, Bridger, Mont. Fs tallished 1906: ceneral: 20 beds: I I

Butte

Cly Emergency llospital, Butte llont Fistabllshed 1910: C. II llorst, phystan in charge: Matida schenkelberger, na tron.

Murray Hospltal, Butte, Mont. Estab lished 1890: prlvate: ceneral: 100 beds: T. J. Murray, medical superintendent. Sllrerbow County Hospital, south Butte statlon, liute llont Established les? nublle: 150 beds: J. A. Tremblay, physt clan in charge: Mrs. Velle bennson surerintendent.

st. James Hospltal, Rutte, Mont. bi tablished 1851; prirate: 250 beds.

Chouleau

Teton County Hospital. Phouteau, Mont Fistabllshed 3 Ho2: Fenseral: 10 beds: IIar mon $T$. lthoads, physiclan in charge.

Conrad

Conral Henevotent Hospital, Conraf. Vont. Fostablistied 1905 : prfvate: general

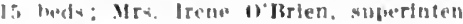
dent.

Deer Lodge

St. Joseph's Ilosplith], Jeer Lodse, Mout.

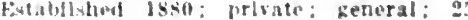
perly: slsters of charity, in charge.

Dillan

[seaverhead Connty Ilowpltal, Dhion,

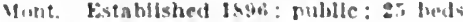
coldual (". Barnett, yuperinteldene

Emigran

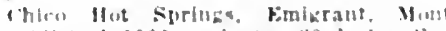

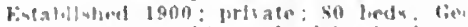

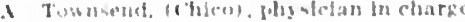
Fi Benton

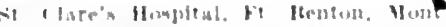

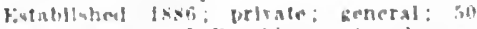
Pedv: Sisters of Prouldellece It chathe

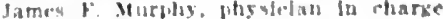

Gill Edob

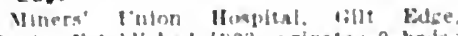

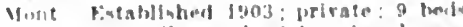

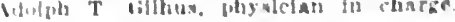

\section{Giasgow}

ientral Hospltal, Claszow, Mont. Es tablsbed 1911; frtiate: reneral: 20 beds: Giny Stone, surgeon: Kathicen Wiatson. superintendent.

\section{Glendive}

Dawson County Ilospla!. Glendire, Mont. Establisherl 1911: wrivate: zeneral: 20 beds: Baldwin 'onsler, physlclan in charge.

Grace Hospital, Glendive, Mont Es tablished 1305 ; vrivate: ieneral: 10 beds. Robert t: Hathaxay, ihjolelan in charge Northeru pacitle Ilospltal, Glendive Ifont. Fatalished 1913: wubllr: fur emDloyeers: 50 bedr: K. H. Beach, medical suverintendent.

Great Falls

rascade rount Hospltal. Cireat Falls,

Mout bistabllshed Is4:; 40 beds.

Columbur lloapltal. Great kalis Vont Fistablihed 1892: prliate: 140 beds Sisters of charits in charzo.

Montana Deaconess Hospllat Great Falls, Iont Fstablished 1902; General: :5 beds; E. Augusta Ariss, suberiutend-

\section{Hamilton}

Ilamiton Hospital, Hamllton, Mont. Ftabllshed 1912; general; 1: beds; Mls liose Cusserly, superintendent.

\section{Helena}

Florence Crittenton Ifome. Kenwood Ielena, Mont. Established 1900: surglal: for homeless girls and bables: Mas W. Barbour, attending physiclan: C. $\mathbf{~}$. letra Cullum. matron.

Lewis and Clark County . Ilospltal. Ifelena, Jont. Establlshed 159s: zen'ral: luo heth: Max Barbour, physlclan in charge: Win. IIoftorogk, superintendent.

st. John's Ilospltal. Catholic Hill. Hel. (na, Jont. Kitablished 18:2: General: (.) beds.

it Josezh's Orphan Home, Helena. Mont. Fistablished 18.1; prlvate; 230 jeds.

St. I'eter's Hospltal. Helena, Mont. Es tablished 1s:o; prirate: general: 50 treds: Mlss Hanna II. Dellees, superlntendent.

\section{Hunter's Hot Springs}

Hunter's IJut springs S.anitarium, IIunter's Ilot springs, Ilont Estubllshed 18:0: private: 200 belto: Geo. Mccahn. superintendent.

\section{Kallspell}

Flathead County Hospltal, Kalispell. Mont. Established $190 \%^{\circ}$ : public general 3.5 theds: Joluyd A. Buwer, R.X. superln cendent.

Kalispell General Hospital. Kallspell. Mont. Established 1911; public: general to bed4: Sisters of Merey, In charge

Macdonald Hospltal, Kalinnell. Mont Fistalllihed 19t0: prirate: 10 beds: Mllse B. Hysn, superintendent.

Kendall

Miners Iilon Hupltal, Kendall, Mont Fistaflufed 1903: prlvate: ceneral:

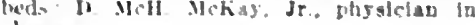
charge.

Lewiston

St Joseph's Hospltal, Lewfotown, Mant Fistahlished 1905: prlvate: Eeperal: so ibby

loldy Howpital. Holly, Mont, Fatab

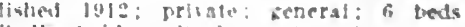

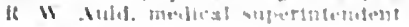
cuingston

I.Irfnevton Ilosplta\}, I.Jbleston. Mont.

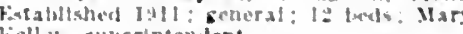
lielles. alyertntendent

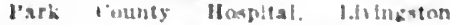
Iont. Fostablishel 15:99: 30 heds: count plasstcian, In clarge.

l'ath IIospltal. I.tringston. Mont Es.

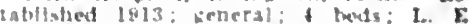
saltes, phistrian in charice

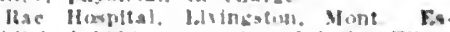

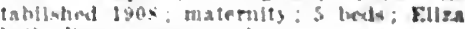
lweth itao. supwringmedent. 
Miles City

Custer County Hospital, Mlles city, Mont. Establlshed 1907 ; publle; 42 beds ; I'resentation Slsters, In charge.

Missoula

McCall's Maternity Hospltal, Mlssoula, Mont. Establlshed 1909: private: 12 beds: Sanford H. McCall, physlclan in charge.

Northern Paclfle Beneflelal Assoclation Hospltal, Mlssoula, Mont. Listabllshed 1890 ; for rallway employees and their dependent famllies only; general; 85 beds: ieorge M. Jemings, chlef surgeon.

st. Patrick's llospltal, Mlssoula. Mont.

Established is 33 ; general; 137 beds: sisters of Charlty, In charge.
Trinlty Hospital, Missoula, Mont. Establishel 1912; public; general; 10 beds; Mrs. W. F. Wardle, superintendent.

Red Lodge

Carbon county Ilospltal and Saultarlun. Red Lodge, lont. Established 1903 ; prlrate; general; 25 beds; S. M. Souders, plysiclan in charge.

\section{Sheridan}

Sutherland's IIospltal, Sheridan, Mont Estublished 1904; prlvate; 8 beds; $E$. I. Sutherland, physician in charge.

Stockett

Stockett llospital, Stockett, Mont.

\section{Twin Bridges}

Jordan's IIospltal, Twin Brldges, Mont. Fstablished 1006; private; 6 beds ; Arthur Jordan, physlclan in charge.

Virginia City

Vlrginla City Hospltal, Virginla city Molit. Fstablished 1906; private; general; 6 beds; D. F. Clancy, physlclan In charge.

Whitefish

Whitefls] Hospllal, Whiteflsh, Mont. Establlshed 1903; jubllc: 24 beds; Mrs. P. II. Gutensohn, in charge.

Whitehall

I'ackard's Prlrate Hospltal, Whitehall, Mont. Establlshed 1901 : prlvate: 10 beds; L. R. l'ackard, physiclan in charge.

\section{PHYSICIANS OF MONTANA}

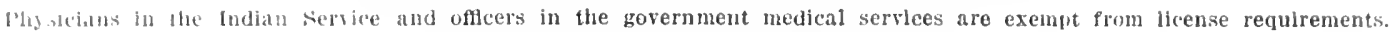

KEY TO ABBREVIATIONS, SYMBOLS, ETC.

Names In caplals stgnify membershl] in the County Sordety and State Assocla tion. (DOE, . DIIN).

() Indlcates Fellowshlp in the American Med. Assn. (DOE, JOHNE).

(b'75) Year of birth. H, homeopath; E, eclectle; P-M, physioMid, , 09 , college and $y^{2} i r$ of graduation.

o Information recelved dues not show grad uatlon.

\section{S.-Surgeon.}

Ob.-Obstetrlcian.

ObG.-Obstetrician, liverenturist.

G.-iynecolngist

Or.-Orthopedist.

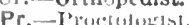

Op. - Ophthalmologrist.

A.-Aurlst.

LR.-Larygologist, Rhinologist. (l'89) Year of Hcense.

(d) in practlce before passage of present faw and licensed by flling diploma or by years of practlee.

(l†) licensed but yeal not known.

(卖) Information recelved does not show license.

U.S.A., United States Army.

M.lic., U.S.A., Nedical Reserve corps.

SPECIALTIES ARE INDICATED AS FOLLOWS:

ALR.-Aurist, Laryngologist, Rhlnologist.

OALR.-Ointialmologist, Aurist, Iaryngolorrist, Rhinologlst.

U.-Urologist.

D.-Dermatologist.

Pd.-Pediatrist.

N.-Neurolorist.

P.-I'sychlatrist.
C.S.X., Unlted States Nary.

M.R.C., U.S.N., Medical Reserve Corps.

U.S.I.IIS, United States Publle Health Service.

College positions held are Indicated by abbrevlated tltle of posltion, followed hy key number of college. For key to colleges see linslde front cover nage.

$(A 1,3, \quad B 6, \quad C 4)$ Membershly in speela Societies. (See Key Trble, ping 122)

NP.-Neurologist, Psychlatrist.

I.- Internist.

T.-Tuberculotheraplst.

Anes،-Anesthetist.

LD.-Laboratory Diagnostlcian.

Path.-Pathologyst.

Bact.-Bacterlologist.

WHEN THE ABBREVIATION REPRESENTING A SPECIALTY IS FOLLOWED BY AN ASTERISK (*) IT INDICATES THAT THE PHYSICIAN CLAINS HIS PRACTICE. IS LIMITED TO THAT PARTICULAR BRANCH OF MEDICINE; WITHOUT THE ASTERISK. THAT HE IS ESPECIALLY INTERESTED IN, BUT DOES NOT LIMIT HIS PRACTICE TO, THAT BRANCH. THIS. INFORMATION CONCERNING SPECIALTY IS BASED ON PERSONAL DATA FURNISHED GY THE PHYSICIAN AND IS NOT VERIFIABLE.

\section{MONTANA}

ABSAROKEE, 70, STILLWATER

Blackstone, Alfred Varney (b'S0)-Mass.I, 0 ; ; (l'09).

ALBERTON, 100, MISSOULA

WIITING, SI'ENCER DRAPER (b'79)Milss.5,'05; (1'05).

ALHAMBRA, - JEFFERSON

Scotield, Chas. (b'55)-l'a.12,'11; (1'12)

ANACONDA, 10,134, DEERLODGE

ALBRIGH', CLIFTUN C. (b'78)-Mo.3, ${ }^{\circ} 05$

(1'05); 508 hain st.; office, Durston

Block; $9-12,2-5,7-8 ;$ OALR.

BANCROFT, CARKOLI ROLLIN (b'79)

Md.3,0s; (1'09); Montana Hotel; ofllee.

Wily bank Bldk.; $11-12,2-4,7-8$

EVANS, OWEN C. (1) 69$)-11.10,93 ;(194)$

fli Oak st.; oflice, Daly Bank Bldg. ; $2-4$,

j(14 Oak st.; onfice, Daly Bank Bldg. ; $2-4$

Pet

baly Bank Pldg. ; 11-12, 2-4. 7-8.

LEAlY, MKHAEL M. (1'40)-I'a.2, $8:$ $(1,4 i)$.

LINEBACK, PALL ELGENE (b 11; (l'13); Member lit. State Yod. Soc. lurston Blig.; 9-12, 5-8.

Mckenzie, Thos. J. (b'67)-Ky.4,'89; (1'8y)

If itil and Commercial Ave

slim, James M. (b'45)-Mich.2,'80; (l'89).

ST. JEAN, FELIX 1. SERRES MTT (b (it) Ont.4,'s9; (l'92): 420 W. l'ark Ave. ottice, 206 F. Park Are.; $1: 30-5,6: 30-8$.

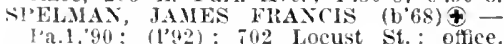
Pa.1,90; $(1+2) ; 702$
Fitectric P1d : $2-4 ; \mathrm{S}$

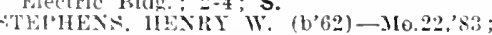
(l's9): Bank Bldg. ; $11-12,2-4,7-s$

WILLITS, ALFRED JOY (b'i4)-I11.6,'00 f I: Menher Ill. State Med. Soc.; 510
ANTELOPE, - SHERIDAN

KEATS, JULIA M. IACOBSON (1)58) Mlnn.3,'87; ( ) ; Nember N.1. State Hed. Assn.

AUGUSTA, 265, LEWIS AND CLARIK

Fonts, Edwin Rolander (b'69)-Mo.24,'92; (1'09).

BAKER, :50. FALLON

Young. William $\mathrm{H}$. (b'7R)-H1.11, 04 ; $\left(\mathrm{l}^{\prime} 10\right)$.

BALLANTINE, 125, YELLOWSTONE

Malone, Saml. 1. (b'60)-Mo.20,'s2; (l'11)

BANNACK, I50, BEAVERHEAD

R.tburn, liobt. II. (b'72)-Mo.20,96; (1'00)

BASIN, 650, JEFFERSON

Kainvile, 1). Fuclide (b'65) - Que.3,88: $\left(1^{\prime}(93)\right.$.

BEAFCREEK, 302, CARBON

Holmgren, Knut Darid (b'7i) - III.6,'10: (1'11).

Siegfriedl, f. C. F. (b'78)-Ill.11,02; (1'03)

BELFRY, 150, CARBON

Chileott, Wm. L. (b'76)-Kan.2,'09: (l'10); G.

BELGRADE, 56I, GALLATIN

Graybeal, Jame; M. (b'78) - Tenn.6,01; (105).

Mccoz, COLCMBus L. (b'71) †-Tenn.5, 9 ; (['99) ; S. Noonan, John Henry (b'81) - HI.6,'0s; ('13)

Tewey, Danl. Edw. (b'83)--111.6,08; (1'09)

BELT, 1,158, CASCADE

Chamberlain, Arthur E. (b'60) - 0.7,91; (l'93).

Hayes, Richard (b'75)-I11.6,06; (l'13).

MeCurdy, Lauson L. $\left(b^{\prime} 66\right)-$ Hl.1, 90 ; not in practice.
BENCHLAND, 100, FERGUS

Wilder, Curtls Warde (b'8i)-Wis.?,'Il: (I'I2).

BIG ARM, 100, FLATHEAD

Trekell, John H. (b'58) H-Ill.4,83; (l'93). BIGFORI, 300 , FLATHEAD

HENDERLITE, PHII S. (b'62)-M0.28,'05 ; $\left(1^{\prime} 05\right)$.

BIGHORN, 10, ROSEBUD

Owens, Francis C.-Mo.22,00; (항.

BIG SANDY, 100, CHOUTEAU

ACKLEY, NEW"TON B. (b'73) - 1a.1,'98; (1'13); Member 111. State Med. Soc.

Mclellan, Gordon Lawrence (b's9)-IH.11, 13; (l'13)

Worstell, Gaylord (b'63)-D.C.1, $\$$ : (l'11)

BIGTIMBER, I,022, SIVEET GRASS

CLAIBORN, DRURA R. (b, 65$)-119.1,98$; $\left(I^{\prime} 05\right) ; 0$.

O'LEARY, ALBERT 1'. (b'71)-Mich.1,98; (1'00); (Mcleod); $\mathrm{S}$.

Reed, Stanley Goorlich (b's4)-IIl.6,'11; (1'13); $S$.

BILLINGS, 10,031, YELLOWSTONE

ARMSTRONG, IIENRY EDWARD (b'6i) FOnt.3,'94; (1'98); 122 N. 30th St.; office, Stapleton Bldg. ; 3-5; S.

ARNCLD, MOTT H. (b'83)†- Ill.11,07: (1'09); $313 \mathrm{~N}$. 33d St.; offlce, Chicago Bldg. : $10-12,2-4,7-8: S$

BALSAI, ELMER GOODMAN (b'84) Mich.1,06; (1'08); 122 Yellowstone Ire. office, Stapleton Bidg.; $9-11,1-4$.

BARRETT, JAMES I\%. (b'80) - III.6, 06 ; (I'09); 39 Wyoming Are.; office, Stapleton Bídg. : 10-12, 2-4, $1-8$.

Bishop, Win. Lee (b'73) - Pa.1,94; (l’06): 33.; ("lark Are.; offlee, Stapleton Bldg.; 2-4. 
Brown, Marcus Francis (b'\$1)-III.J1,0s: (1'10); 319 N. $33 d$ st, ; offle, stapleton HId $: 0.12,2.5,7-8$

CHAI'LE, JAMES $\left(b^{\prime} \div 0\right)$ \& Ont 3,00 $\left(1^{\prime} 00\right): 114$ N. 29 th st.: omre, lelknap Block: $11-12,2-4,: 30-8: 30$.

clark, Andrew (L'65)-Mlich.7.?5: (l'98) Iff Divislon st; otlce, Firvi valional Ilt Dirlslon st; ott

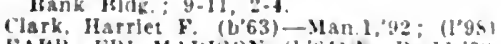

FAlth, E.LI MAIHSON (b'st)+-Pa.11,04 1): Member Med. Soc of the slate of ra.: 301 vellowstone si.; S

Free, James F-Md.3.'s; diot in practles

lierhart, Fdwin A. (b'3)-1'a.9.01: il'05) 611 N. 28th Si, onlce, 23 Helknap block

in practice.

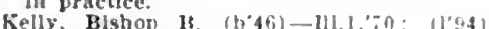

Cirotto Springs.

Crotto Springs.
L.Indsey, Cilf (b'on)-111.1.9: : (1.93); 15 $x$ sth st. vilice, Ist die. and $2 \times t h$ it. : $11-12,2-4$.

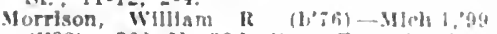

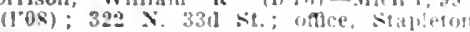
1Hdg.

MOVIf: IRTIITR J. (b's) +-Minn 4,04:

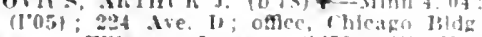

Perry, Willson James (b'A (l"09): 2 ith $\mathrm{st}$. Anel Montana A re

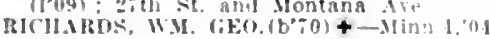
(1'0): Chleagen R!dg.: 10-1:2, 2-4

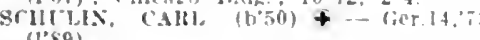
$(1 ; x)$

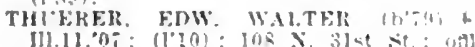

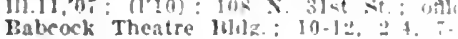
S

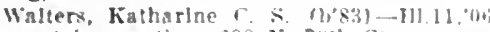
nut in practlce; $\operatorname{lin} 8 \mathrm{x}, 2 ! 4 \mathrm{~h} S t$

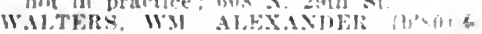

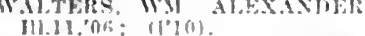

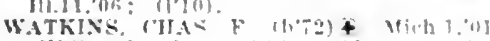

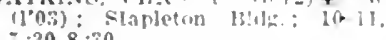

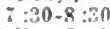

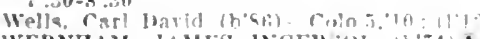

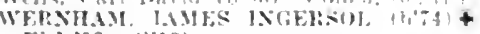

III.1,02; (1"13)

BOULOER, 955, JEFFERSON

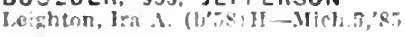

BOX ELDER, - HILL

Warkenzle, dohn Win. (h"; 6 ) -In(is, " 00 :

BOZEMAN, 5.107. GALLATIN

BI.AIR, JAMES FRAXK (b'b) F-V1.2, 99 (1)(1): $\mathrm{S}$.

HOL.E, WM. SYMINGTOS (b's2) Ma : I0 (1'10).

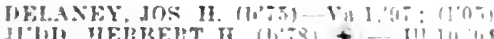
I'] inE

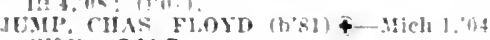
(1)(06): OALR,

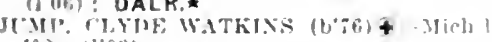

"0\%

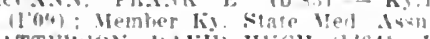

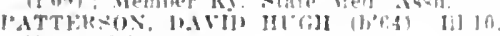
(0), 111.193: (1'01).

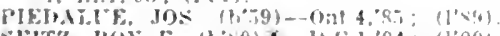

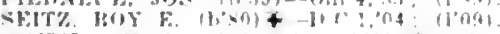

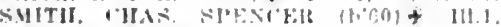
"84, X.Y.10,:4; 1100\%).

BRADY. 150. TETON

Marulte. les M. (l)

ERIOGER, S14, CARBON

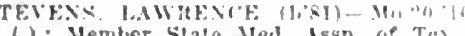
(1): Member stafe Ved desn. of T"

BROADVIEW, 200. YELLOWSTONE

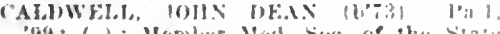
of : ( ) : N(In)

Iof I"R : ALR.

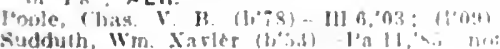
Sudduth. Win.

BROWNING, 500. TETON

thilllps, Or!yn sirgent (1)

(Indian serslce); Itlackfeel schomil

BUTTE, 39,165, SILVERBOW

Allan, Arthur (ierrlis $\left(b^{\prime}, 56\right)-1$ in 1 . (1"0 l): lhoentr HIJ

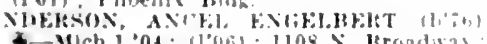

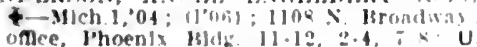

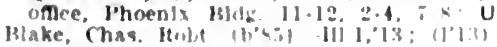
Vurray liopiltal
Mankenhorn, Chas. Edward $\left(b^{\prime}(8)-1 W \cdot 6\right.$, "13; (1'13): Murray liospltal.

Campana, Eugene Geo. $\left(b^{\prime} 84\right)-111.11,04$; (1"04).

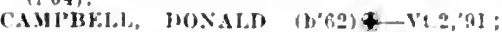
(1)92): $30 \%$ W. Broadway; oftce, Murray llospltal: $1-3.7-8$

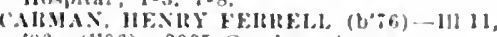
(06): $(1,06)$; 200.; Ciarrison Are

Cowperthwale, Jos. Fiwh (b'-2) H 11110 , "6t: (1.96); 522 w. Mereury st.

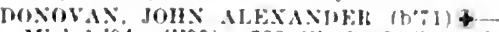
Ileh.l,"94; (l'99); :23 W. I'ark St. of -

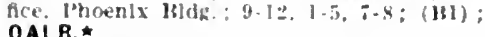
OALR. *

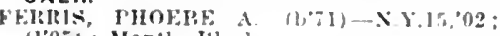
(l'05); Mantlo Ihlork.

Freund, Isadore D. (b'46)-Mlch.1,:2; (194): $403 \mathrm{~W}$. Broalway; ottce, lhornlx I:|dg.; $1-3,7-8$

Freund, Jerl 1!. (b'74) - I! ] l, 1,$00 ;(100)$ :

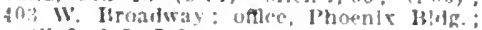

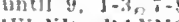

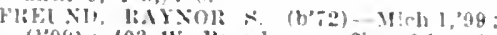

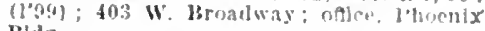
Birla

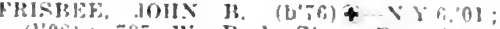
l'os): 73\% W. Park St. ontre. Stalé Salnge Bank Blde: $3-4,7-8: 1$.

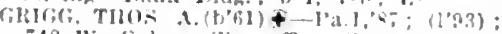

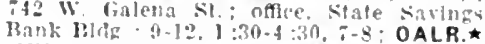

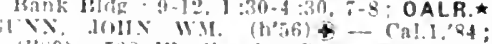

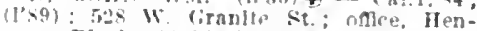
re-cy B]ork: 10-32, $2-4, i-9$.

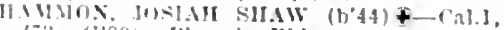

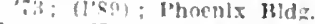

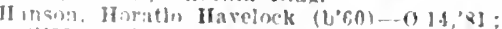
$11 \times 9 j: 40 \% 5$ Idaho st. : oflce, Sitver Bim klwk: 11-12, 2-4, $7-8: 30$

Invlland, Wills H.-II-X.Y.9,81: (190); Ils $x$ Washlngton: offec, Shodair Bhok.

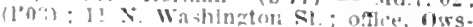
le'v licick: $11-12,2-4,7-8$

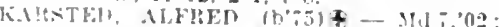

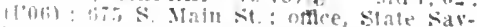

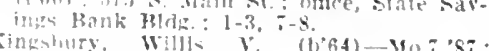
(1) Whillis $V$. (b'64)-Mo.7.87 :

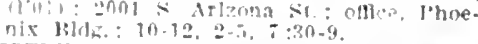

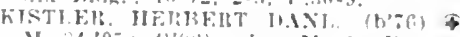

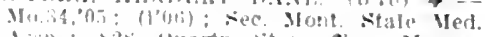

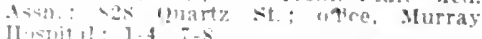

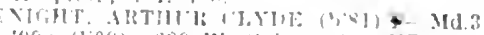

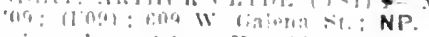

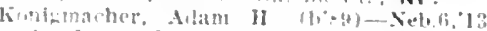
sit. lanes Huppltal.

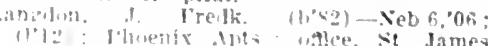

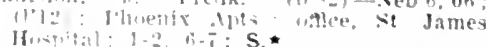

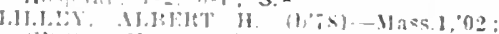

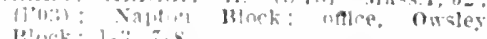

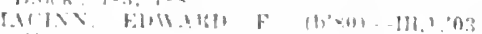

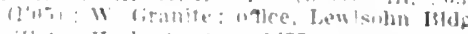

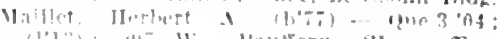

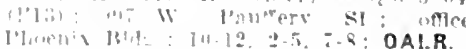

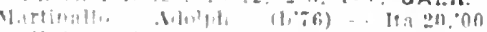
(!'ul): S:Tver bus blinck.

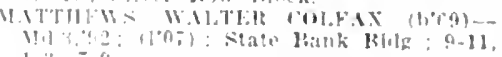

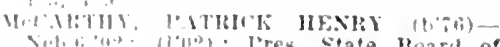
Yol

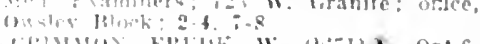

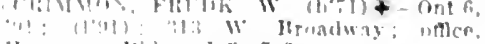

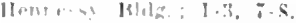

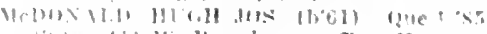

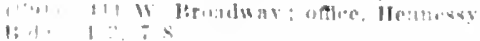

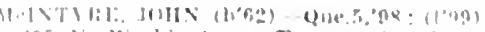

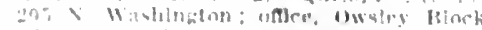

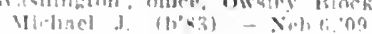

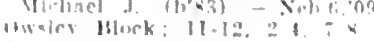

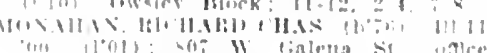

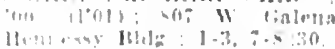

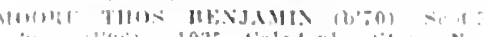
10:35 t'tedenta

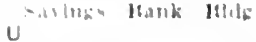

Moore, This verner, Jr. (b'83)-Neb.6,'[1: (1'11): 732 W. 13roadway; odce, Jewisohn

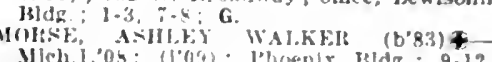

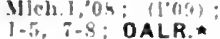

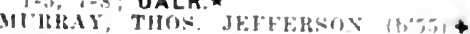

1'a.2,79; (1'59); 5. W1. Quartz st: colde.

Murray Hospltal; S.

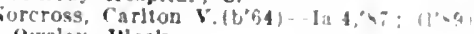

O)wley Hlock.

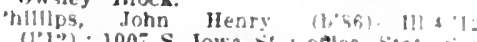

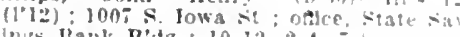
ling liank Bitg : 10.12, 2

"ITKANEX, GCSTAF (b'f,4) - lius 1, (gio

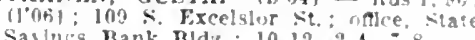

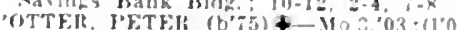

Namton Blook: oflce, Hennessy Bldg i. : (F)): OALR.

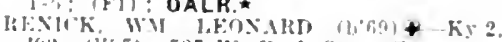
(42) $(1,47):-27$ W. Park st: oftce, lew. Goln lidg: 9-10,1-3, i-s

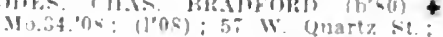

lice. "Turray IIosplta! : 1 -

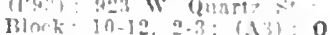

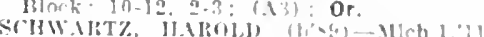

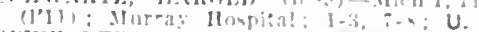

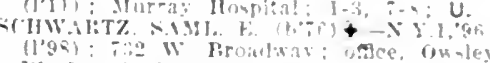

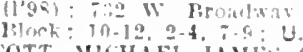

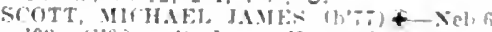

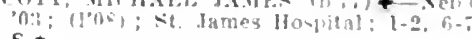
S.

Shanloy, Thos y H. (1) $1,1,1$

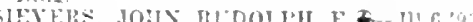

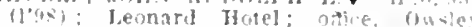
linek : 5 .

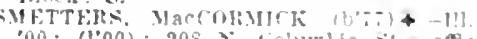

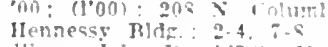

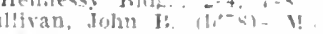

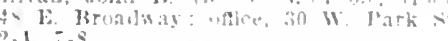

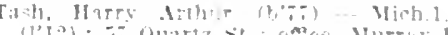

pital: $\mathrm{s}$.

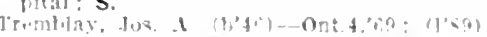

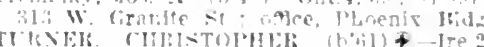

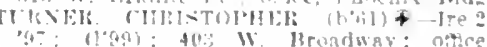

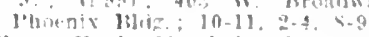

Ware, Hugh Mardan,

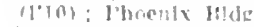

Whitfori, o'Ilflon Is

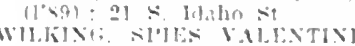

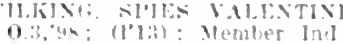

Ason: I'lonenis Bloch

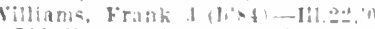

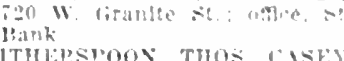

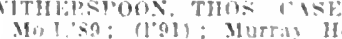

(ni, fl): $\mathrm{S} *$

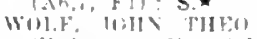

(1'0)

MHII:

CAMAS, 30, SANDERS

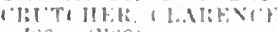

II

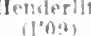

CASCADE, $\because 00$. CASCADE

HItrohl twh W Wlith

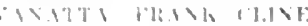

$$
\text { R. 100. H!LL }
$$

CMESTER, I00, M!LL

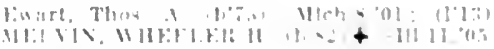

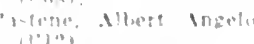

Mas; :01

CHICO, 43, PARK

CHINOOK, T80. BLAINE

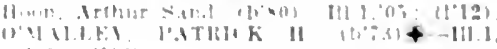


CHOUTEAU, 400, TETON

BATFMAY, IIOWARD WM. (b'79)-Ia.3.'07 $\left(l^{\prime} 07\right)$

IIcregor, Ilarry Jos. (b'36)-Ia.3,'10 (1'11); $\mathrm{S}$.

IIOA]S, IIARMON TALIFI (b'80) + IO.20;10; (I'12); OALR.

CIRCLE, 75, DAWSON

KOEII,ER, IIIRAM I.AWRENCE†-III. '12; (I'13); Member III. State Med. Soc

CLYDE PARK, 400, PARK

DENNEY, JOS. CIIANIII.FA (b'85) — Lian 300 (1,

MARQU1S, 'THOS' MA11.E (b'69)-Mo.20 '9S; (1'98).

COLUMBIA FALLS, 601, FLATHEAD

PURDY, ROLLO C. (b'85) $\oplus$ - III.22,'08 (1'10) ; Pd.

Robluson, Jolin T. (b'70)-0nt.3,93; (1'97)

COLUMBUS, 521, STILLWATER

('raig, James (b'50)-Me.1, 76; (l'92).

Line, Iemuel II. (b'6I)-VI.3, 84 ; (]'96). I.SIONE, TBRIGID ELIZA1BETII-Ind.9,'98 not in practlee; Member Ind. State Med.

SMITII. WM. POISON (b'80) $\rightarrow-I 1.11,09$ (1'10)

\section{CONRAD, 888, TETON}

DuBols, W. Lynn (b'S0)-111,6,06: (l'10) PATERSON. WM. FlRDK. $\left(\mathrm{b}^{\prime} 76\right) \notin-q u e .1$

Powers, Henry W. (b'79)-IIl.6,03; (1'03).

CORVALLIS, 50, RAVALLI

Coughenour, J. T.- ; (1'89). 1 . 19, 05; (1'06).

Thornton, Chas. R. (b'a)

Carrer, R. T. (b*47)-0.1,72; (1*9S)

CROW AGENCY, 100, BIG HORN

Ellis, Frank G.-Mo.28,06; (Indian Servlce); Crow School.

Lieurance, Edw. (b'79)-Wo.32,03; (1'10) (Indlan Service); Crow School.

oberlander, Hartman I.-N.Y.15,'87; (Indian Service); Crow School.

CULBERTSON, 528, SHERIDAN

Collinson Thos. W. (b'7 7 ) -Ont.1,05: (l'0S). Herbert David (b'75)-Mo.34,04:

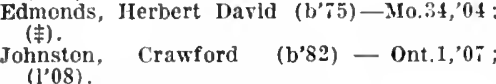

\section{CUT BANK, 250, TETON}

HULBUSH, WM. ALBERT (b'84)Ð-Ind.20 ros; $\left(l^{\prime} 08\right)$.

Neraal, I'aul o. (b'70)-1a.3,'97

Strain, John Edwin (b'72) - Mich.7,'06 (1'12).

DARBY, 50, RAVALLI

DAY, LESTER W. (b'71) $€-M d .4,98$ (l'12); Member Minn. State Med. Assn. ALR.
Hayward, Herbert (b'82)-Wis.3,'08; (1'09).

DAYTON, 150, FLATHEAD

Dixon, Edw. F. (b'81)-Pa.2,'06; (1'10).

DEER LODGE, 2,570, POWELL

CRABB, GEO. MELVILLE (b'82) \&-111.1 10 ; (1'12).

DYF, WIILOUGHBY G. (b'73) —-111.6, 01 ; (1'03); S.

Marquette, Geo. John (b'82) - N1.1,07:

Willard, Harry Gaylord (b'75)-111.1,04; (l'09).

DENTON, - FERGUS

Jenson. Tames Lloyd (b'86)-Pa.2,'12 ; (I'I3).

DEVON, - HILL

uson, Alonzo Allen (b'83) - Mo.34,'12 (1'13).

DILLON, I,835, BEAVERHEAD

BOND, HARRY A. (b'59) ₹-1a.1,'89: (1'91) ILacMillan, Hugh Allan (h's2)-Mid.3,'10 (l'I0)

Poindexter, Fredk. II. (b'75) - Ill.6,02; (1'03): Pd.

WALKER. JAURICE A. (b'6i) -Colo.1 89, Mass.1,91; (I'99); R.

DIXON, 50, SANDERS

Sweet. Edw. A. (b’T)-1HI.10,02; (1'02).

DODSON, 200, BLAINE

Hamilton. İosciusko $\left(\right.$ b' $\left.^{\prime} 3\right)-$ D.C.1,06 $(10 \mathrm{~s}) ; \mathbf{0 b}$
DRUMMOND，350, GRANITE

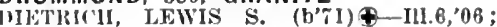
(I'12).

\section{DUPUYER, 300, TETON}

Maynard, Ernest B. (b'72) II - Mich.5,'98 (1'13)

EAST HELENA, 1,200, LEWIS AND GLARK Dent, John II. (b'62)-Mlch.1,'92; (1'97). EKALAKA, 175, FALLON

Baker, lieo. A. (1),79)-1a.10,08; (

Colvin. Hdwin Osear (b'55)-Mlch.1,95; (1’09)

Wendell, W. G. (b'59)-Pa.1,94; (1'09).

ELGIN, - FALLON

Sandy, Benj. Brooks (b'\%0)11-1a.4,03; not In practlce.

ENNIS, I50, MADISON

IIOLMSEN, HOLN (b'73) $\oplus-111.1,06$; (I'06).

EUREKA, 603, LINCOLN

BOGARDUS, T1RED. $13 .\left(b^{\prime}, 8\right)+-111.10,01$ III.11,06; (1'03)

Stone, Solon 13. (b'55)-D.C.1,79; (1'99)

Waller, Geo. II. (b'45)-11.1, 69 ; not In practice.

FAIRVIEW, 1,000, DAWSON

Frankl, Jullus (b'72)-Aus.7,'97; (l'09)

Frankl, Julius (b'iNs, J. ROBT. (b'84) - Wls.3,10

Member N.D. State Med. Assu.

FAMILY, 125, TETON

Clarke, E. Ray (b'75)-Colo.4, 09 ; (s).

FORSYTH, 1,398, ROSEBUD

Nexander, Wm. Archlbald (b'82)-Pa.2, 06 . (1'07).

Huene, Harry J. (b'80)-111.6,'04; (1'05).

wisó, ARTHUR C. (b'62)-ont.5,91; (1'92).

FOX LAKE, - DAWSON

Armour, Geo. E. (b'80)-Ia.8,'05.

FROID, I00, SHERIDAN

Fleischmann, Chas. B. (b'88)-Wis.3,'11; (I'13).

FROMBERG, 300, CARBON

Beuson, Theo. J. (b'73)-MInn. 4,04; (I'07) FT. BENTON, 1,004, CHOUTEAU

Carroll, John V. (b'54)-N.Y.5,86; (1'89) loutz, Chas. S. (b'82)-Ind.8, 05 ; (1'12) Iurphy. James Francis Mlchael (b'i5)Pa.2,09; ( $\left.\mathrm{I}^{\prime} 09\right)$.

Porter, Enoch N. (b'77)-Mo.20, 02 ; (I’08). FT. MISSOULA, - MISSOULA

HEA, WM. EDW. (b'80)@ - D.C.1,05; (I'06) ; 1st Lleut., M.R.C., U.S.A.; S.

GALATA (SUMMER P.0.), 475, HILL

Curtiss, Fred Decker $\left(b^{\prime} 76\right) \mathrm{H}$ - Ill.10,'01 ; ( ).

GARDINER, 600, PARK

Smith, Erle F. (b'89)-Colo.2,'12; ().

GARNEILL. 150, FERGUS

BETTEN, IIERMAN JOHN (b'70)-III.1,00 (I'03).

GEYSER, 200, CASCADE

BRANT, HEZEKIAH W. (b'56)-I11.4, 88 ; (1'10)'

GILDFORD, 350, HILL

HOPKINS, MILES (b'74) $\oplus-$ Pa.9,'07 (I'13); Member Wash. State Med. Ássn. GILMAN, - LEWIS AND CLARK

Dice, Harland Everett (b'83) H-Ia.4, 08 ; ( ).

GILTEDGE, 300, FERGUS

IILHCS, ADOLPH T. (b'79) - II1.16,02 Ill.11,03; (1'08).

GLASGOW, 1,158 , VALLEY

Iloyt, Mark D. (b'68)-Pa.1,91; (1'92); S. Veedles, Arthur Stone (b'85)-Mich.1,'11:

PEASE, CHESTER I. (b'65) \&-II1.1,'89 not in practice; Menber Ia. State Med. Soc.

Simpkins, Justin C. (b'55)-Ind.8,'96; (l'11)

Stone, Guy (b'77) - 1H.14, 05 , Ill.11,'10 (1'11); $\mathbf{S}$.

GLENDIVE, 2,428, DAWSON

BEACH, ROBT, H. (b'79) \$-Mich.1, 06 ; (I'08); Member N.D. State Med. Assn.

Consler, Baldwin F. (b'⿳5)-0nt.3, 03 (1'04).

Danskin, Melville Geo. (b'83) - Ill.6,09; (l'12)

Donohue, Danl. James (b'74)-Minn.5,'99 $\left(I^{\prime} 00\right)$; Pres. State Board of Health.
Ifanmerel, Ambrose I. (b'81)-Minn.4,05; (107)

liathawny, Robt. E. (b'74)-Ill.11,02; (l'03); S. Bolmes, Harry Stark (b'90)-Tenn.6,'13;
Bacferlologlst, Northern Paclfc Hospltal. IIunt, John II. (1,'62)-Mich.1,'90; (1'91). TARSONS, IIOUSTON HADDON (b'85) Va.1,07; (1'08); OALR.

Swarthout, Hils Frank (b'78)-Ill.11,'03; ( )

GOLDEN (BRIDGER P.O.), I0, CARBON Johnson, John IIumphrey (b'51) - N.Y.5,79
(1'92).

GRASSRANGE, 100, FERGUS

Brown, Pearl Hubert (b'70)-Ill.1,'96, Pa.2, '00: (Indlan Serrlce).

BRUGGE, IIENIRY JAMES $\left(h^{\prime}, 0\right)-111.1,97$ (l'10).

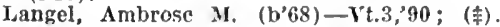

GREAT FALLS, 13.948, CASCADE

ADAMS, FRANClS JOS. (1)'59)-D.C.2,'81; $(1.89) ; 1008,3 \mathrm{~d}$ Ave., $\mathrm{N}_{8}$; offlce, Conrad Bank Bldg.; 11-12, 3-5, 7-8:30.

Dodge, Albert A. (b'68)-Minn.4,94; (1'05)

DOLAN, ALOYSIUS N. J. (b'71) G-I1.11, '98: (1'13); 1524, 4th Ave., N.; offles, I. O. O. F. Bldg.; 10-2; OALR.^

DURNIN, RICHARD BROWN (b'82)థOnt.1,'0s; (1'10)

FAIRFIE1.D, JOHN H. (b'56) ๑-Pa.1,80 ; (l'89); 715, 4th Ave., N.; offlce, Phelps Block; $10-12,2-4$.

FERGUSON, GOWAN (b'66) -Ont.1,'88 ; (1'91) ; 500, 1st Ave., N. ; 2-4; S.

FRIZZELL, JOHN IV. (b'54) $-0.7,84$ (1'91); not in practlce; 601 Central Ave. FRIKZEL, IREX RUSSELL (b'85) @-III.1, '11, III.4,'12; (I'12); $3171 / 2$ Central Ave. ; $11-12: 30,2-4, \quad 7-8$.

GREEI, EDWIN JAMES (b'75)-N1.11,08; (1'09); Great Falls Dam.

IRIVIN, IAMES H. (b'76) - IIl.1,99. (I'01) ; 1416, 3d Ave., N.; offlce, Conrad Bank Bldg.; $\mathbf{s .}$

KEARNEY, PERCY F. (b'78) $\oplus$ - Minn.4, 04; (l'10): $711,2 d$ Are., S.; office, Conrad Bank Bldg. ; 11-12, 2-4.

Ladd, Alfred Greeley-Me.1,78; (1'89).

LAKEY, WM. I. (b'75) $\oplus-$ Mich.1, 00 ; (1'02); 101\%, 6th Ave., N.; offlce, Thisted Bldg. : $10-11,3-4,7-8$

IARSON, EDW. MARTIN (b' 79$) \oplus-\mathrm{Pa} 2$ 04: (l'09) ; Grand Hotel ; offlce, Conrad Bank Plig. ; $11-12,2-4,7-8$.

LOBB, JONATHAN G. '(b'63) - nl.1,'97 (l'98) ; 1108, 3d Ave., N.; offlce, Ted Bldg. : $10-12,2-4$.

LONGEWAY, ALBERT F. $\left(b^{\prime} 65\right)(-$ - Que.5, '86: (1'89)'; 505 3d Ave., N.; offlce, McKnight Block; 10-11, 2-3, 7-8.

MACALLEY. ALEX. M. (b'76)-Man.1,07; (l'07) ; 1417, 2d Ave., N.; offlee, Thisted 13ldg.: 10-12, 2-4, 7-8.

MADDEX, WII. DUNN (b'77)-Ml.11, 03 : (l'08); Member Ia. State Med. Soc.

IcBurney, Lee Roy-Ill.8,'11; (1'13) ; Smelter Hill.

ICCARTEN, ROBT. EMMETT (b'84)-Pa.2, '10; (I'11); 514, 3d Ave., N. ; offlce, Vaughn Bldg.; 11-12, 2-4, 7-8.

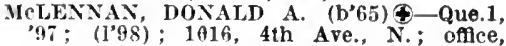
First National Bank Bldg. : OALL.;

IURRAY, THOS. E. (b'82)-Pa.2,08; (l'08); 418, 5th Ave., N.; offlee, Tod Block; 11-12, 2-4, $7-8$.

PATTON, AMBLER BAXTER (b'85) $\odot$ I11.6,'11; (I'13);-619, 3d Ave., S.IV.; offlce, Thisted Bldg.; 11-12, 3-5, 7:30-8:30; G.

PIACE, BEFONI AUSTIN (b'i8)- Ill.1 10; (1'13): Member N.D. State Med Assn.: $317 \%$ Central Ave.

REYNOIDS, JAMES BENJ. (b'98) \&Mo.20,'13; (l'13) ; First National Bank Bldg.

Roberts. Helen C. (b'60)-IIl.9,'87; (l'94); 313. 1st Ave., N. : 11-12, 2-4.

SOUTHMAYD, ISEROY (b'69) 4 - Mich.1 92 ; (1'92) ; $220,3 d$ Ave., N.; offlce, Tod Bldg. ; 11-12, 2-4; G.

STRAIY, EARLE (b'68)-Pa.1,'90; (1'92) : 317 , 1st Are.

SWEAT, JOHN AIKEN (b'56)-Me.1,'80;

Ten Brook, Glen John $\left(b^{\prime}, 7\right)-N . Y .1,08$ (I'10). 
TITUS, Chas. I. $\left(b^{*} 76\right)+$-Colo.5, 05 (1'11); Nember N.b. State Hed. Aswa. 1416, 3th Ave., x.; once, Thlsted Hudg. 2-4. i-s: 5 .

VIDAL, (IIAS. EMERIC K. $\left(b^{\prime} \sigma_{0}\right)-O n t .1$ 90 : $(1.41) ; 811$, th Ale., $x$; ontce, Mc Kingh Hock; I1-12, 2-3, :-8.

HAMILTON, 2.240. RAVALLI

Browning, Harry D. (b'Bs)-111.1.92; not In mractice.

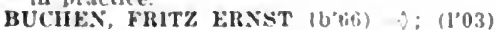

Casserly, Micbael Jos. (b's2) - Unt.1.08 (1'09).

Getty, Robe. W. (b'6s) $\rightarrow l^{\prime} a 1,41 ;\left(t^{\prime} 93\right)$,

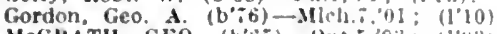

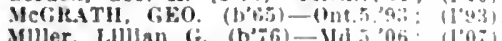

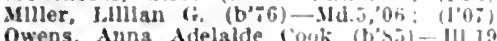
Owens, Auna ddelalde couk (b'sj)- III.1.

$\mathrm{S}$.

HARDIN, 250, BIG HORN

Haverfleld. Orrllle sinell (b'si)-Mo.7,'] I (1'12): S.

HARLEM, 383, BLAINE

FOSS, CARL ELMEK (b'si) +-1'a.,'10; (l'11). ARTIUR 1'. (b'69) \&-111.6, (l'03).

Sproule, Wm. Johnston Denltt (b's2)-Ont.I. $06 ;\left(l^{\prime} 13\right) ; \mathbf{S}$.

whllams, Wm. Iarlus-0.9, 85 ; not in practlce.

HARLOWTON, 770, MEAGHER

C.AMPBELL, SAML, h. $\left(\mathrm{b}^{\prime} 80\right)+-M 0.34$

05: (l'06). Frank (b'65) - Vt.2.95. Ross, E

HAVRE, 3.624, HILL

AIUS JOS SS (b.6t) F Ont "gI : (1"g)

BASSOW CARL FKELK (b'33) - Pa.2 12; (1'12)

Camperu, Baslle (b'51)-Ont.4,76: (1'02)

vuncan, John Alex. (b'78)-ont.1,04; (I'13)

HAMIITS, WM, FRANCIS (b'80)廿-11.2, $03 ;(1.05) ; S$.

Lringstone, John I. (b'54)-Mich.ti, , $^{\prime}$

MACKkxzIE, D. STLART (b'i9) \&-ll.1. I : (l'0I)

Meldell, Kolf (b'69)-Nor.1,95; (1'11)

WARL, AISTIN I.EROY $\left(b^{\prime}, 3\right)$ - Minn i, 00 ; (I'OI).

WILLAMS, ARCHE ELTOS (b':2) •

MInn.4,00; (1'03); D.

HECLA, - BEAVERHEAD

McComb, Thos. T. (b'i)-Ia.t, "

HEDGESVILLE, 250, MEAGHER

HAGiK, JOHN CHAS. EDWALU $\left(\mathrm{b}^{\prime} 3\right)+$ III. $8,00^{\circ} ;(1,10): 0$ b.

HELENA, 12,515. LEWIS AND CLARK

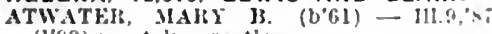
(l'93): not in practlce.

B.AIBOLR. GEO II. $\left(6^{\circ} 63\right)+-0.1$ ' $^{\circ}$ (I's9) : puwer iblig.

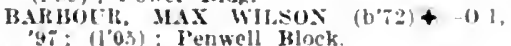

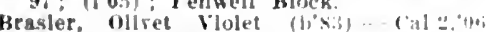
(l'08): The Itelen.

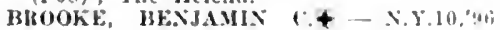

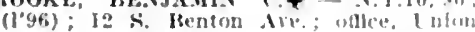
Bank Hock; $2: 30-4: S$.

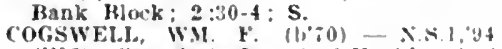
$\left(l^{\circ} 96\right)$ : sec. State lioard of Heallh; iagl tol Hils.

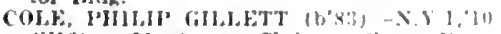
(1'12); Jontana Club: onlec, powet

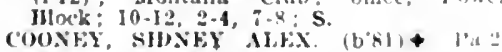
05: (1005); 110 [rearborn Ale. Who Penwill lliek.

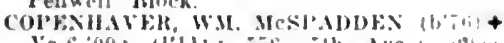

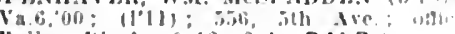
Balley llink 9-12 2-4 DALR.

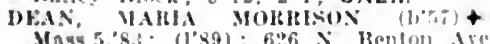
ofles, Power Hile: $10: 30-12,2-4$.

logke, Alfred $C$. (b:2)-X.Y.10,93; (1.93)

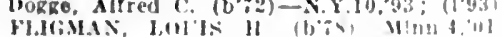

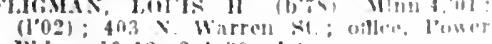
H1d2: $10.12,2.4: 30 ; 1 . *$

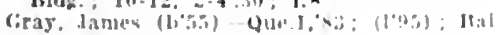
ley Hlık'.
HIllyer, Frank M-X.Y.10,'s7; (1'9s) ; Pellwell B!nck

Holden, Katherlue Q. (b*56)-Mich.1.89; (1's9) : Isalley $\mathrm{hlock}$

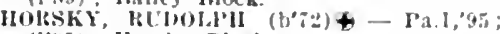
(1.95): Horsky Rlock.

Johuston, Eills A. ( (b'7)-I11.6.'04: (1'08) Allas Block: $10: 30-12,2-4,6: 20-7: 30$

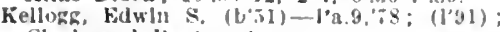
Clark and kenton Ales.

LAXSTR LM, OAf AK M. (1)'69)-JII.11,'94

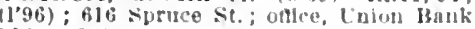

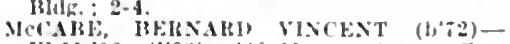
Ill.11,0s; (1.08): $\$ \neq 0$ Monroe Are, ; oflec $13 \%$. Maln st. $2-4,7-8$.

reek. Wh. I. (bos)-Mo.5, $98 ;(1,03) ; 1413$ Roberts St. $10-12,1-4,6-8 ; U$.

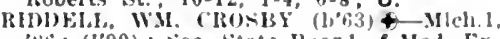
'si: (1'90): sec. State Boart uf Med. Fxumliter: 504 Vearborn Ale, otlee, ruwer Hidg.: $10-12,2-4, ;-3$

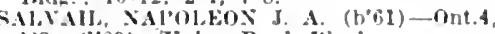
83: (l's9); 'Uulon Rank Hlock.

shelby, Fred L. (b'it)-111.17,0\%; (l'09),

Thompison, Chas. S. W-I'a.8,"so; (1'89)

Thompson, John Ciodfrey (b'so)-111.6,0ij (1'07): Cnion Bank HIdg, $10-12,2-4$.

TREACY, JOHN IEAK (b'S4) \$-III.I, 10 (l'10); 454 Lawrence st. ; oftice, IIs rulIer Ire.; $10-12,2-4$.

TIRINITI, THOS. H. (b'76)-Wls.3, 0 I (I'I0); lowers Bldg.; 10-12, 2-4, 7-\$.

HELMVILLE, 100, POWELL

Rennlck, Percy Shelley (b'80)-Ky.9,'04; (1'04).

HILGER, - FERGUS

cotton. Frank Webster (b's0)-Pa.2,04: (1'09).

HINGHAM, 300, HILL

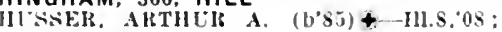
$\left(l^{\prime} 12\right) ;$ Member N.D. State Med. Assn.; Pd.

HINSDALE, 173, VALLEY

Cockrell, Thomas Lytlleton (b'84)-III.11, i) 8: (I'09).

HOBSON, 200, FERGUS

Keenan, Francls fdurard (b'83)--ra.2,10; (1'10)

POAkA, ABRAIIAM (b'79) $-111.1,99$; (lioz).

HUNTERS HOT SPRINGS, 54, PARK

Toney, Wlimer biverut (b'st)-Mllch.1,'II (l'B2).

HUNTLEY, 250, YELLLOWSTONE

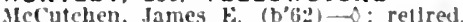

liussell. Wilson .1. (b'i2)-111.10,9:; (1'10).

HYSHAM, 150, ROSEBUD

lemberton. CHIvin W.-Mo,34,03; (

ISMAY, 300, CUSTER

Heluman, Marcus H. (b73)-Tenn.l.'6t; (1'1I).

JOCKO. 50, MISSOULA

HELUEIM.X. ,OHX H. (b'b6) +-0.8,91 (Indjan Fervice): Flatlead school.

JOLIET, 389, CARBON

Nlen, Wm. 11. (b'5ti)-X.Y.6, 80 : $\left.11^{\prime} \$ 9\right)$.

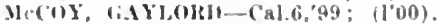

JORDAN, 46, DAWSON

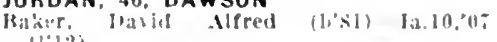
1112

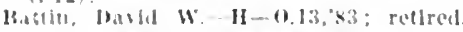

JUDITH GAP. 575. MEAGHER

li.1. ENII .I. (lif(i)\&-MInU.4,05

lemaly, Mhas. Haw. (bo

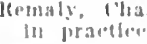

KALISPELL, 5.5\%9, FLATHEAD

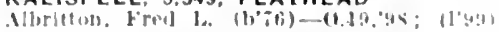

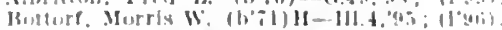

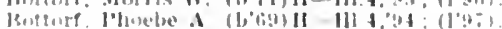

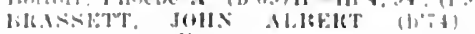

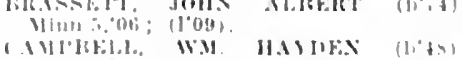

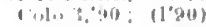

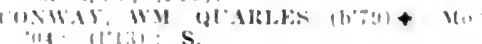

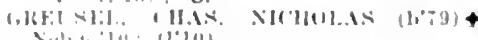

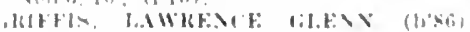

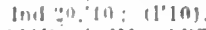

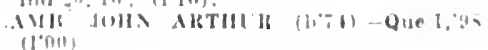

H.TTLF, WM. STAKLING (b'8I)-KY,2, 06 ; $\left(1^{\circ} 10\right) ; \mathrm{S}$.

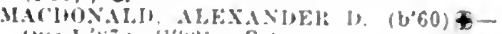
Que, 1,$8 ;$; $\left(1^{\prime} 42\right):$ S.*

Holshow, AlThil (b'b4)-Sco:3, 86 ; (1'93).

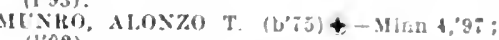
(1'02)

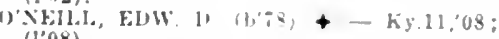
(l,08)

KFYXOLLS, ROIST. IAWRENCE (b'S5)HI.1.'11; (1'12): S

SIITI, CIAHKL SHELWOOD $1 \mathrm{~b}^{\circ} 81$

Tifnet, 0s: $\left(I^{\prime} 0 \mathrm{~s}\right)$

ALOK, WM. W. (6*2)+-Mlnn.4.00 WISFY,

OALR.

KENDALL, 500, FERGUS

Mckay, llanl. Mell., Jr. (toj)-\$1,2:,yz: (1'Us).

LAME DEER, - ROSEBUD

('amphell. (inln Nexander (b'i4) - Ont.3, 7,0 "

Morrow, Wn, Boyd-La. 2,91; (1t); Indian Service): Tongue River School.

LAUREL, 806, YELLOWSTONE

Lrougliton, Joscoe (b'81) - Mlch.;.04 (1'bi). Albert Edw. (boz)-.Mlch 1,0t; (1'0S).

LAVINA, 100, MUSSELSHELL

Appelman, Koger $11 \mathrm{~m}$. (b'78)-Ia.10,08. (1'1:2).

LEWISTOWN, 2,992, FERGUS

ATTIX, FREI) F. $\left(\mathrm{b}^{\prime}, \mathrm{s}\right)+\mathrm{Pa}, 1,00$; (I'01) :

HUDLE, ASHER C. $\left(b^{\prime} \cdot 3\right) € M d .3,04$;

HRICE, JOS. THEOBOLD $\left(b^{\prime} 66^{\circ}\right)+-G a .5$. 't1; $(1,95) ; S$.

IFAL, ARTER W. (b'sz)-IId.3,03; (1'07) Dunn, John C. $\left(b^{+73}\right)-111.6,02 ;$ (1'11)

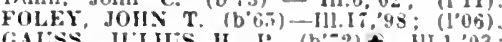

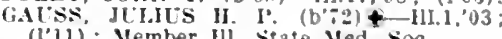
(1)

Newell, Sharon $C$. (1, $84 ;(1.07)$; S.

PLEASANTS, THOS HICKS $\left(b^{\prime} 50\right)+$ Va.4.7; (1.89); OALR.

WII,I,Y, CIIAS. C. (b; $; 6)$ \&-Mlch.1,02; (1'05)

WIJLIARD, JOHS HEXRY (b'ti)-0.1,69; (1's!3).

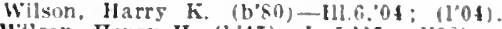
Wilson, Henry H. (b'4i)-Ia.I, 6 i: (l'9s)

Woolcock, George a rnold $\left.\left.\left(b^{\prime}, 0\right)-I\right], 1\right], 94$ :

not In practice.

LIBBY, 630, LINCOLN

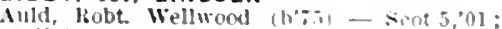
(1'10)

Baxter, Portus-N.:10.42: (10.2)

I'lllllps, Bert L. (b'it)-Mul, 03 ; (1'12).

LIMA, 385. BEAVERHEAD

Ford, Lewls C. (b'52)-Ia 1,"ib; (1'\$8).

LINDSAY, 25, DAWSON

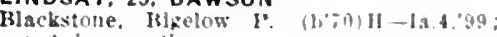
not In prantice.

LIVINGSTON. 5.359. PARK

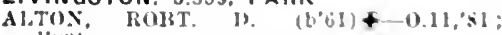

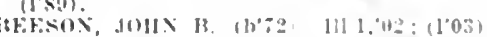

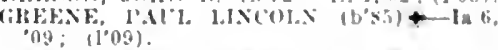

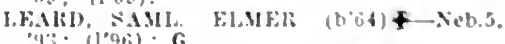

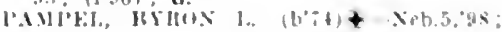
(1.99)

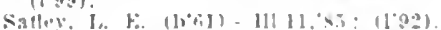

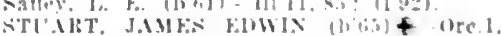

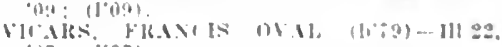
$0 \%$ : $110 \%)$

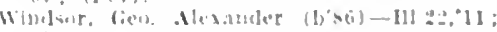
(1.11)

LOGAN, 150, GALLATIN

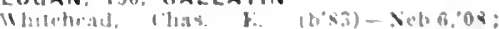
UTHER. - CARBON

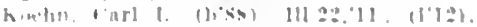

MALTA. 433, VALLEY

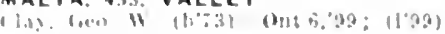


MANHATTAN, 400, GALLATIN

HOLGATE, IIALI'I CAILTON $\left(b^{\prime} 77\right)+$ [1].6,'10; $\left(1^{\prime} 10\right)$

I'EAfCL, WM. MADDEN (b'88)\&-Tenn.s

'10: (l'11). CIFA CLIFFOIII (b'80) +

III.6,08; (1'11).

MCLEOD, 22, SWEET GRASS

G'LEAITY, ALBEHLT $P$.

(See Blgtlmber.)

MEDICINE LAKE, 250, SHERIDAN

Morrow, Thomas M. (b'SS) -NiL.ti, 11 (I'13); OALR.

MELROSE, 200, SILVERBOW

Molleur, louls l'. (b'65)-(mit.4, 60 ; (1'4s)

MELSTONE, 200, MUSSELSHELL

lleaton, II uch (b'a3)-0.'26.'0s; (l'10)

IJeclges, Ralph s. (b'67)-N.Y.19,'y9; (1'99).

MILDRED, 50, CUSTER

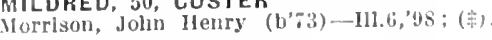

MILES CITY, 4,697, CUSTER

IN1)I? (1'93).

kerry, lient $w,(1), 87) \rightarrow 0$; not in practice

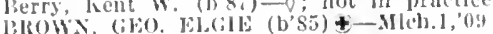
(1'11)

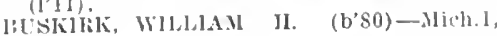

cat; $\left.\left(1^{\prime} 06\right)^{3}\right)$ John Joward (b'83)-111.6, '07;

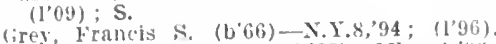
Jlycle, Marle Merrill (b'65)-Mnn.4,'!(i (1'09).

Sadle B, (b'84)-Mleh.l, 0 ndeber

Malienzle, Thomas A. (b'77)-S $\cot , 3,03 ;$

$(105)$. Dlbert baymond (b'S])-MInn.4, 0 ; ;

(1'08).

MISSOULA, 12,869, MISSOULA

ANDERSOA, DDWIN CLARK (b'-2:)

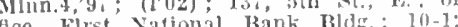

flee, Flrst

2*-4, 00 (l'10); 542 s. 5th St., $\mathrm{x}$.; ottlee, Montana Ijock; $9-12,2-5$

BHYNT, GUY DeVERE (b'68)-0.1,'94 (1'95); Jlgrins Block; 10-12, I-3:30.

BTCKLEY, JOIIN J. (b'53) †-N.Y.L'Ts; (1's0) ; Gerald Are. ; offlec, lirst National Bank Ildf. ; 11-12, 2-5.

noI) (1'00); 241 Unlversity Are.; offlec, First National Fank Bldg.; 11-12, 2-4:30

FAlRSWORTII, ILARRY B. (b, 75$)+-111.19$ $00 ;(1$ '04); $120 \mathrm{~S}$. 5 th St., W.; onlee, Montana 13ldg., I0-12, 2-5.

I'ITZGELAID, THOMAS ALIEN (b'bs)Ont.3,SS: (192); 201 S. 5 th St., W.; of tce, Tirat Sational Jank Bidr.; $11-\frac{1}{2}$

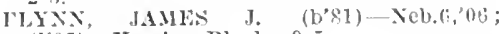
(1'07); Higgins Block; 9-5.

FIREERE, EDWIN H. (b'7s) - Que.I, 03: (l'0s); 330 Gerald Ave.; office, Hlggins Block; $10-12,2-5,7-8$.

FCLLER, ALLEN GARFIELD (b'so) क Bo.2, 4 ; $10-12,2-5$

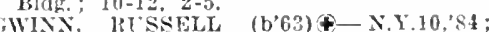
(1.89); 507 S. 3d st., W.; oftice, first Tational Bank Bldg.; 9-12, i:30-5 OALR. *

Ileilman. Adam feorge (b'S6) - Pa.1,'13; not in practice; Tniversity of Montana. MXNIVis, (iEo, M. (b'80) s-yinu, $y^{\prime} 07$ (108); Northern Pacific IJospital.

MeCAll, SANFORD H. (b'63)-Wis.2,00; $\left(10^{3}\right) ; 221$ E. Cedar St. : $2-4$

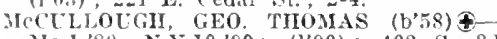
Io.1.'s!), N.Y.10,'90; (1'90); 402 S. 30 st., W.; offce, Higgins Block; 10:30$11:=0,2-4.7-9$

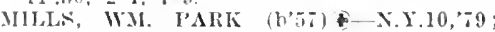
(1'89) ; Pres. Mont. State Med. Assn.: 410 Sterens Are.: office, First National Bank Fldg. ; 9-I0, 2-5: S.

Barsone, W. Buchanan (b'5I)-N.Y.10,70 (1.91); 2.5 S. 5th st., E. ; offee. Roberts Block

PEASE, FRANK D. (b’:2)-Pa.2,?3; (1'05) Hiring Block.

PIXIEY, CHAS. (b'65)-III.1,0I; (l'01)
RANNDAI,L, JOHX G. $\left(b^{\prime} 73\right)+-111.4,98$ (l'05): 402 Beckurelte St.; oftce, HIg glns Block; $2-5,7-8 ; G$.

Itemington, Paul Archibald (b'88)-Wls.3, '11; (I'12); 515 N. 4 th St. ; oftce, North. crn'Paclfle Hospltal ; $8-12,1-5,7-8$.

SMITII, IIATIRY C. (b'-2) \&-N.Y.10,04: (l’04); IIIgglns Block: S.

srotTsWood, JDW. W. (b'66) $\bullet-M I n n .4$, 93 ; (1'95); 1006 Cierald Ave. ; offlce First Nallonal Bank Bldg. ; $8-[2,3-6$.

T1 IIIAN, GEO. FUGETT $\left(b^{\prime} \& 3\right) \notin$ Va.6, 05 (1'06); Montana Block; 11-12, 2-5, 7-8.
Yalters, Ilavld N. (b'99)-Wls.6, 13; in-

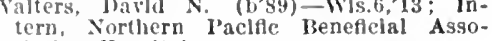
clation IIospital.

whitty, John Thos. (1)'87) Wls.6,"13; Intern, Northern Paclfic Beneffelal Assoclatlon Iospltal.

\section{MONDAK, 350, SHERIDAN}

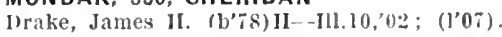
MONOTA (DAGMAR P.O.), -, SHERIDAN Cowlng. I'. (i. $\left(b^{\prime} ; 2\right)-0$; not in practlec MOORE, 573, FERGUS

bavld, Osear F. (b'60)-Mllnn.5,'95; (l'93) Owen, solomon s. (h'6s)-Kan.4,04; (l'04). 09; (I'10).

Stutzman, T. Benton (b'50) - Ill.8,"79; (1'09). OPHEIM, - VALLEY

SHERRAItD, MILTON B. \&-Kan.2,00; (l'06).

PARK CITY, 400, STILLWATER

Cram, Itobt. Lee (1)'79)-Colo.2,06; (1'08).

PHILIPSBURG, I,109, GRANITE

Casey. Wm. E.-Mo.24,01, H1.I1,'05; (l'07)

CONYNCHAM, E. F. Minm.5,86: (1'90). $\left(l^{\circ} 90\right) ; G$.

PINIELE, - FALLON

RAIG, JAMES W. (b'\%)-0n1.6,0I: ( ); Member Neb. State Med. Assill.

PLAINS, 48I, SANDERS

Billmeyer, I). II, (b'63)-1'a.2.'84; (1'89).

Coats, Edw. S. (b'70)-110.35, 09 ; (1'10).

Fuhrer, John Farl (b'81)-Ky.2, 09 ; (1'10)

PLENTYWOOD, 300, SHERIDAN

Cooper, Denton J.-MInn.5,03; ( )

STEELE, FUGENE GILLIS (b'81)-N.Y.3, 06; (l'10); Member N.D. State Med Assn. POLSON, 300, FLATHEAD

Bobb, Earl Vletor (b'74)-Ill.6,'98; (\$).

MARSHALL, WM. J. (b'75) $\$$-Mich.1, 09 ; (1'09).

Owen, Geo. B. (b'78)-Minn.4,00; (1'00).

Powell, Thos. Milfreal (b'(i.i) II-IIl.18,'98 (1'13).

Redeker, Fredk. Wm. (b'58)-Pa.2,78; not in practice.

HOMAS, ALBERT AFNEW (h'S?) Assn.

PONY, 369, MADISON

SMITH, HAJVLY F. (b'64)-Cal.2,94;

Stafford, I. S. $\rightarrow$; (1's9)

POPLAR, 200, SHERIDAN

Atkinson, James L. (b'56) - Mo.1,79; (1†); (Indian Service); Ft. Peck School.

Huber, Levi Houston (b'71)-D.C.I, 06 ; (l'09); (Indian Service); Ft. Peck School.

Underwood, Frank (b' 78$)$ - Ill.11,05; (Druggist).

PRAIRIE CITY, -, CHOUTEAU

Rudin, John J. (b'-9)-Mo.28, 05; not in practice.

RADERSBURG, 300, BROADWATER

Hewins, IIenry A. (b'T5)-I1l.11,03; (l'13).

RED LODGE, 4,860 , CARBON

Adams. Edwin Myron (b'82)-0.1,09; (I'10)

I,utz, Ernest T. (b'73) H-Mo.20,'96; (l'98)

Makkyla, Johannes Benj. (b'64)-Rus.1,'94;

Palm, Walter Gilbert (b'84)-111.22,'10; (守). Souders, Saml. Mott (b'73)-0.1,00; (l'01) G.

\section{RONAN, 20, MISSOULA}

Hall, Illton Weston (b'is) - 111.11,03; (l'07).

Putney. Geo. H. (b'73)-Mich.I,97; (I'9s); OALR.

RESNER, ANDREW K. (b'65) (-Ia.3,'95; (1'I2); G.
ROSEBUD, I80, ROSEBUD Seymour, Wm. Augustus (b'80)-I11.6,'10;
(1'11).

ROUNDUP, 1.513 , MUSSELSHELL

BAIRD, DAVID EIWIN $\left(b^{\prime} 76\right)-M d .4,06$;

BHISSENDEN, W. II. (b'76)-II1.22, 05 ; (l'08).

JACKNER, FRANK (b'71)-111.4,00; (1'12); Member State Med. Soc. of Whis.

LEWIS, GEO. ALDEN (b'79) 9 -Wls.2,05; (1'09).

PIGOT, CIESWELL T. (b'79) -Ont.6,00; $(1 ' 02)$.

Welsh, Thomas W. (b'78)-IIl.6,03; (1'08); OALR.

RUBY, 200, MADISON

Townshend II. II arlan (b'68)-Neb.6,96; (1'97).

RYEGATE, 50, MUSSELLSHELL

LUBLIEY, LUDWIG FISANCIS (b'85) Neb.6,'10; (1'10).

SACO, 200, VALLEY

Minnlek, Itobt. P. (b'79)-Va.4, 04; (1'05).

SANDCOULEE, 900, CASCADE

Snyder, Karl Avery' (b'88)-111.6,'10; (1'I3).

SAND SPRINGS, - DAWSON

BIEWLI?, ALREIIT THVII (b';4)\&Mass. 1, 01; (1'05).

SAVAGE, 10, DAWSON

Flres, Walter Irvln (b'81)-Ill.I1,'10; (I'12). Jolunston, Wn. Walter (b'75)-Mlmn.4,02; (1'10).

SHELBY, 350, TETON

Rldle, Milles D. (b'74)-Ill.11, $0 t^{\prime}$; (l'I0).

SHERIDAN, 399, MADISON

DYER, IIOY HOMLR (b'82)-.IIO.34, 0 - ; (l'Ii); Member Mo. State Med. Soe

SUTHEILAND, ELMEL: I. (1'93) (, 73$)$ \&Que.5, 99 ; (l'00).

SIDNEY, 345, DAWSON

Bealgle, Joln S. (b'72)-Ill.4,96; (1'09).

coWUY, FHANCIS AIHLBERT (b'71) \&IIed. Assn.; 5 .

Morrili, Robt. A. (b'74)-Minn.4,'05; (J'06).

SIMMS, - CASCADE

SMITIF, CIYUE LIVINGSTONE (b'\%9)I11.11,02; (1'09).

SOMERS, 750, FLATHEAD

Fuson, Geo. A. (b'71)-Mo.28,'99; (1'10)

MILLER, CHAS. B. (b'43) $\mp$ - $0.1,67$

(1'89); not in practice.

ST. IGNATIUS, 80, MISSOULA

MATTHEW', THOMAS A. (b'82)-Mich.1, '10; (1'12).

ST. REGIS, 350, MISSOULA

FESSLER, ELMER (b'73)-I11.1,00; (l'06). STANFORD, 200, FERGUS

Igel, Richard L. (b'71)-Mo.20,01; (l'0S).

Myrick, Arthur Eugene (b'69)-Iil.10,96; (1'10).

Willians, John 1I. (b’33)-Ger.15, \%6; not in praetice.

STEVENSVILLE, 796, RAVALLI

FALTS, LOUIS HENIRY (b'69) $4-111.1,97$; (1'12); Nember State Med. Soe. of Wis. Kelloge, Karl 11. (b'81)-Mich.7,'04; (1004).
Marshall, James Fredk. Stewart (b'87)Ont.1,08; (1'10).

PORTER, JOHN E. (b'67)-Ill.1,95; (ま) ; Nember Ill. State Med. Sce.

PRINCE, FRANK JOSEPII (b'73)-0.1; ${ }^{\circ} ;$; (1'13); Member Ohlo State Med. Assn; THORNTON, WM. T. (b'7) + -Ill.19,03; $\left(10^{\prime}\right) ; 5$.

STOCKETT, 1,400, CASCADE

Chipman, lilehard Leverett DeV. (b'đI)Que.I,08; (1'09)

MACDONALD, WILIIAM GEORGE (b'80)-Scot.1,0S; (1'12); Path.

SWEETGRASS, 200, TETON

Lovell, John Fredk. (b'86) - Mass.5,'08; A.A.Surg., U.S.P.H.S.

IERRITT, CHAS. H. (b' 6 (6) $)-111.8,01$; (1'I2).

TERRY, 700, CUSTER

Brindjone, Eugene Franeois (b'81)-La.1, 08; (I'09) ; U.

Shaw, Arthur 13. (b'\&6)-X.H.I,'11; (1'I3). 
THOMPSON FALLS. 325. SANDERS

Gates, Lemont Addison $\left(b^{\prime} \cdot 3\right)-$ 13.1,98: (1'00): $\mathbf{S}$.

Lewers, Yredk. K. (b'68)-Mos.'11: (1'09).

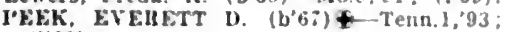
(1'03).

stixrud, Thos. Thomasen (U's8)-x.C.4. 13: not in practlce.

THREE FORKS, 674. GALLATIN

GAFRTAEl, LFo PAUL (b'S9) \&-Nub.t. 11: (1'11).

HoY, CLITOS JUMAN (b*i) \&-HI.L. .06': (1'09): Ob.

Young, Wm. Fo (b'55)-Mlch 1, '8:; (1'12): not in practlee.

TOWNSEND. 759, BROADWATER

GILHAM, GEO. W. (b'60)-Cal 2, $\vee 1:(1 ' 90)$.

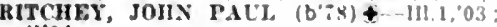
(1'04).

SMITI, CHAS, w: (b'b)-0 1,04: (106): 8.

TROY, - LAS ANIMAS

ENGLISH, IVINTER II. (b'60)-Ind.11,91: (1'91).

TWIN BRIDGES, 491, MADISON

BAKER, FMORY DODGE (b'so)-Mo.35 10 ; (1'10)

Jordan, Arthur (b'69)-Ja.3,'95: (1'96).

Wllson, Fdwin N. (b'69)-Neb.5.95; (1997).

TWODOT, 200, MEAGHER

Tice, Harry B. (b'55)-X.Y.19,99: (l'00).
VALIER, 750, TETON

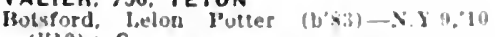
(l'13): G.

P'THELI. CI.AIEENCE IHAY (b's0)-III.11. $05:(1010)$.

TIIYM.1., riA: r. (b':2)\&-111.6,00: (1'02).

VICTOR. 374. RAVALLI

Ilanliblge, Thomas IIenry (b'34)-Xi.10. b0: (1i91).

VIRGINIA CITY, 467, MADISON

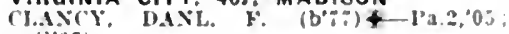
(l'0).

WARMSPRINGS, 100, DEERLODGE

bickerls. Mlonzo IBurton (6,36)-MU.3,11 (1'13).

RAGSDAI, JAMES F. (b'63)-M0.27,96;

(I'02)

ścanland, John Jltiton $\left(\mathrm{b}^{\circ} ; 4\right)-\mathrm{Md} .3,97$; (1.95): (E13): P

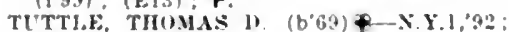
(1'9S).

WASHOE, 15, CARBON

Beltzer, Chas. bugent (b's0)--111.11, 09 : (l'] 10$)$.

WASON. - DAWSON

Maclntyre, Donald (b':2)-Mlch $8.9 ;$; not in practice.

WHITEFISH I,479, FLATHEAD

Hot'STON, if L'CII E. (b'ti) \&-MInn.5, 00 .

LFFis. AIFREN TENNYSON $\left(b^{\prime}, 5\right) \notin-111.1$. 01 : (1'02).
WHITEHALL, HI7, JEFFERSON

Jobyna. I.e lloy (b'43)-0.3,65: (1'45).

Packard, Lawrenre K. $(4 ; 7)-J 11.6,00$ : (l'02).

Tralnot, Elmer W. $\left(b^{\prime}=0\right)-K y \cdot 1,02:\left(10^{\prime} 02\right)$

WHITE SULPHUR SPRINGS, 417, MEA. GHER

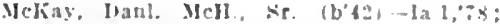
(1'xis).

Rogers, Weaver Burnslde $\left(b^{\prime} 80\right)-M a A^{\circ} 0$; $1111 \%$.

s(HAl'sHZICK, CHAs. F. (t;9)-11111. of: not In vractlce: Yember Siato Mmi. soe. of Wis.

WIBAUX, 487, DAWSON

Ashlez, raul L. (b'SO)-MInz.4,06: (I'1n).

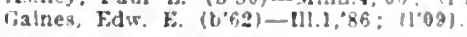

WILSALL, 100. PARK

'arson, I.loyd R.M Mo.8.05; ( ).

schpader. Llerman Fredk. (1,80)-1'a 2,10: (l'13).

HHEIRI, I'ETEI? J. (b.6.9) - Vt.2.'4 ; (l'95).

WISDOM, 250, BEAVERHEAD

BOLTOX. HAIRIS A. $\left(b^{\circ} \times 3\right)+$ Md.3.'10, (1'11).

WORDEN, 25, YELLOWSTONE

Graham, John Ilenry (b's 4 )-MInn.5.,06: (1.07).

ZORTMAN, 350, BLAINE

Smoot. John D. (b"-4)-.110.27.99: (1'021.

FOR KEY TO SPECIALTIES, ABBREVIATIONS, SYMBOLS, ETC., SEE PAGE 872

You an place confidence in the reliabilit! of the sanatorinm. and hospital. that are allertised in the American Wedical Diportury. For classifind list refer to the l'hysicians" I'urchasing Inder. 


\section{NEBRASKA}

NoTk:- The general luformation of thls state includes: Nedical Law, State Board of llealth, State Assoclation, State Jour-

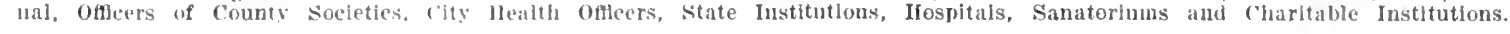

\section{NEBRASKA}

Population ( 1910 census).

$1,192,214$

Number of Counties.

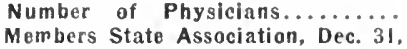
1913.

Area of State in Square Miles....

\section{MEDICAL PRACTICE LAW OF NEBRASKA}

From the Compilat statutes of Nicbraska. Annotated. 1905. Chapter 55. Hedicme.

4315. Section 1. BOAlRD OF HEALTH :

There shall be established in the state of Nebraska a board to be styled the State Board of Health. Said board shall consist of the Governor, Attorney-General and Superintendent of Public Instruction, and the Governor shall be ex-offlcio chairman of sald board.

4316. Sec. 2. MEETINGS: Said board shall meet on the call of the Governor and within thirty days after the approval of this Act, and shall meet thereafter as often and at such times as the Governor may from at such times as the

4317. Sec. 3. SECRETARIES : SaId Governor shall withln sixty days after the approval of this Act appoint four secretaries, who shall be graduated physicians of at least seven years consecutive practice, who shall be at the time of their appointment actually encaged in practice in the state of Nebraska; one of whom shall be appointed for the term of one year, one for the term of two years, one for the term of three years, and one for the term of four years, and thereafter it shall be the duty of said board to appoint or reappoint one secretary erery year as the term of those theretofore appointed shall expire, but each secretary shall have been appointed. Said appointments shall be made so that of said secrements shall he made so that of said secre-
taries two shall be physicians of the socalled regular school, one of the so-called eclectic school, and one of the so-called homeopathle school.

4318. Sec. 4. SAME : POWERS, DUTIES : Sald secretaries shall have power, and it shall be their duty to assist and advise sajd board in the performance of its duties as prescribed by this Act, to summon witnesses and take testimony in the same manner as wituesses are summoned and testimony taken under the Code of Civil Procedure, and to report said testimony to the board, together with their findings of fact and recommendations on all matters coming before said board requiring evidence for their determination except as hereinafter provided.

4319. Sec. 5. SAIIE: CERTIFICATES It shall be the duty of said board to see that all the provisions of this Act are strictly enforced, to grant certificates as herein provided, and to cause to be prosecuted all violations of this Act. Said board shall have and use a common seal and may make and adopt all necessary rules, regulations and by-laws not inconsistent with the constitution and law of this state or of the United tSates to cuable it to perform its duties and transact its business under the provisions of this Act.

4320. Sec. 6. QUORUMI: A majority of said board shall constitute a quorum for the transaction of business.

4321. Sec. 7. WIIO MAY PRACTICE : EXAIINATION: It shall be unlawful for any person to practice medicine, surgery or obstetrics, or any of the branches thereof, in this state without first having applied for and obtained from the State Board of Health a Hecuse to do so. Application therefor shall bo in writing, and shall be accompanled hy the examination fee hereinafter spectlled and with proof that the applicant is of good moral character. Appilcations from candklates who desire to practice medleine and surgery in any or all their lranclies shall be accompanied by proof that the apjlicant is a graduate of a medical school or collecre in rood standing, as detiued in section 8 of this article. When the the board and found to comply with the foregoing provisions the board sliall llotify the applicant to appear before it for examithe applicant to appear before it for examination at th

Examinations may be made wholly or in part in writing by the board and shall be of a character sufficiently strict to test the qualifications of the candidate as a practitioner. The examination of those who desire to practice medlcine and surgery in any or all their branches shall embrace those subjects and toples, a knowledge of which is commonly and generally required of candi. dates for the degree of doctor of medicine, dates for the degree of doctor of medicine, by reputable medical colleges in the United
states. All examinations provided for in this Act shall be conducted under rules and regulations prescribed by the board, which shall provide for a fair and wholly impartial method of examination. It is also provided that examinations on practice of medicine and therapeutics shall be conducted by the nember or members of the board of secretaries who are of the same school of medicine as that of the applicant. And it is cine as that of the applicant. And it is of Health may, at their discretion, admit, without examination, legally qualified medwithout examination, legally qualified med-
lcal practitioners who hold certifleates to practice medicine in any state with equal
requirements to those of the state of Nebraska.

4322. Sec. 8. MEDICAL SCHOOL DEFINED : The term medical school or college in good standing shall be defined as follow's, to-wit: A medical school or college requiring a preliminary examination for admission to its course of study in all common branches and in Latin and the higher mathematics, which requirements shall be regularly published in all the advertisements and in each prospectus or catalogue issued by said school, which medical school or college shall also require as a requlsite for lege shall also require as a requisite for least four courses of lectures of six months each, no two of said courses to be beld within one year, and having a full faculty of capable professors in all the different inatomy, physiology, education, to-wit : pathology, hygiene, materia medica, therapeutics, obstetries, bacteriology, medical jurisprudence, gynecology, principles and practice of medicine and surgery, and spepractice of medicine and surgery, and spetwo last named of not less than four hours per week in each during the last two courses of lectures. Provided, That this four year clause shall not apply to degrees granted, or to be granted, prior to August, 1898.

4323. Sec. 10. LICENSE; CERTIFICATE; REGISTER: If on inrestigation of the proofs sumbitted to the board, and after the applicant shall be found entitled to practice, there shall be issued to said applicant the certificate of said board under its seal and signed by its secretaries stating such fact, and it shall be the duty of the applicant before practicing to file such certifleate or a copy thereof in the offlee of the she resides or in which he or she intends to practice: such certifleate or eopy shall be flled by the rounty clerk and by him recordesl in a hook kept for that purpose, broperiy indexed, to be culled the "Physiclans" lReglster," and for sucl serrices the county clerk sliall recelve from the applicant the same fees as are allowed to the register of decds for the recording of conveyances.

4324. Sec. I1. EXCEPTION' TO ACT: All physicians who shall be engared in practice at the time of the passage of thls Act shall within six montls thereafter jresent to sald board their hiplomas and affidarits as hereinbefore provided, or in the case of persons liot graduates who were entitled to registration and practice under the provlsions of the Act entitled "An Act to regulate the practice of medicine in the State of Nebraska," approved March 3, 1881, an to so register and practice and a certifled to so register and practice and a certified transcript of their registration under satd to the certificate herein provided, which they shall flle with the county clerk as herein provided. Provided, That no one having the qualifleations required in and haring complied with said Act of March 3,1881 , shall be liable to prosecution for fallure to comply with this Act until

4325. Sec. I2. SECRETARIES ; RECORDS; CERTIFICATES: It shall be the duites of said secretaries to keep a full record of all the acts and proceedings of sald board and of all certificates granted thereby, together with the proof on which certificates are granted, but when said proof in any case shall have been on file in the office of said board for ten days said certiflcate may be issued by sald secrecertiflcate may be issued by sald secretaries without a rote of the board, if no
protest has been fled and if in their opinion said proof complies with the prorisions of this Act.

4326. Sec. 13. REMOVAL FROM COUNTY: Any person who shall bave obtained a certifleate provided by this det and shall remove to another county shall before entering on the practice of his profession in such other county cause said certlficate to be filed and recorded in the office of the
county clerk of the county to which he has county clert
removed.

4327. Sec 14. CERTIFICATE: RFFUSAL; REVOCATION: The board nay refuse to issue a certificate, or may reroke one already issued for any of the causes defined in this section, to-wit: The employment of fraud or deception in applying for
llcense or diploma or in passing the examination provided for in this Act; conviction of crime involving moral turpitude; habitual intemperance in the use of ardent spirits, narcoties or stimulants; unprofessional or dishonorable conduct. The words "unprofessional or dishonorable conduct" as professional or dishonorable "conduct" as
used herein are declared to mean: First, the procuring, or aiding or abetting in procuring a criminal abortion; second, the obtaining of a fee on the assurance that a manifestly incurable disease can be permanently cured; third, betrayal of a professlonal secret to the detriment of a patient; fourth, causing the publication and circulation of advertisements of any medicine or means whereby the monthly periods of women can be regulated or the menses can be established, if suppressed; flfth, causing the publication and circulation of adrertisements of any kind relative to diseases of the sexual organs tending to injure the morals of the public.

4328. Sec. 15. EFFECT OF ACT ON SUITors: Yo person shall recover in any court in this state any sum of money what- 
ever for any mealical, surgical or otstetrical services unless he shall hare complled with the provlsions of this Act and Is one of the persons authorized by this $A$ ct to be registered as a physician.

\$329. Sec. I6. UNI AWFII. PISACTIC. ING: I'KAITY: Any jerson not possessing the qualitications for the practlce of mediclue, surgery or obstetrles refulred by medine, surgers or obstetrics relulred by who has not complied with the provistons of this Act, who shall engage in the practice of nedicine, surgery or olistetrics, or any of the brauches thereof in this state, shall be deemed gullty of a mistemeanor, and on conrictloa thereof stiall be tineil in any sum not Jess than $\$ 50$ nor more than $\$ 300$, and costs of prosecution for esch offense. and shall stand commitled until such tine and costs are pald.

4330. Sec. I7. PRACTITIONkIt DEFINED: EXCEITIOXs: Any person ahall be regarded as practicing medicine within the meaning of tils Act who shall onerate or profess to beal or prescribe for or otherwise treat any physical or mental allment of another. But nothing in this Act shali be construed to prohibil gratuitous serrices in cases of emergency, and tlifs Ait shall in cases of emergency, and this Al't shall not apply to commissioned surgeons in the Uniled tSates Army and Navy, nor to nurses
in their leallimate occupations, nor to the administration of ordinary houseliold remedies.

4331. Sec. I8. ITINEILANT VENDORS ; PBNALT: Any junerant vendor of any drug, nostrum, ointment or appllance of any drug, nostrum, ointment or appliance of any kind Inlended for the treatment of any dis-
ease or injury, or who shall by writing. printing, or any other method, publicly proress to cure or treat diseases or injury or deformlty, by any drug, nostrum, manipula tlon or other expedite, shall be deemed gullty of a misdemeanor, and on conviction thereof shall be flned in any sum not less than $\$ 50$ nor more than $\$ 100$ or be impris oned in the county jall for a pertod of not less than thirty days nor nore than three less than thirty days nor more than three months, or both, in the
court, for each offense.

4332. Sec. 19. FEFS : Every holder of a diploma from a recognized medical college within the state of Nebraska, making appll. cation for an examination and a certificate under the prorlsions of thls Act, shall pay under the prorisions of thls Act, shall pay to the board of secretarles prior to his
examination the sum of $\$ 10$. All other perexamination the sum of \$10. Alt other persald board the sum of \$25. All such fees shall be equally dirided among the four secretaries of the board as full compensation for their services and expenses. For the taking of any testimony each of the secre taries sball be entitled to charge and receire auch fees as are provided for notarles putilic for similar services. No part of putilic for simllar serrices. No part of
such fees shall be pald out of the state such tees

STATE BOARD OF HEALTH

E. A. Carr, Prestdent, Iincoln : $I^{2} \mathbf{k}^{\circ}$ Dodson, Vice-P'resldent, Wiber: H, B. Cum mins, Secretary, Seward; C. T. Burchard Treasurer, Falla city.

\section{NEBRASKA STATE MEDICAL ASSOCIA- TION}

Ofacers $1913-14$

D. C. Bryant, I'resident,......... Omaha D. Martyn, Jr., lst Vico-1'resldent. . Columbus W. E. Shook, 2d Vice-I'resident.... . Shuthert Joneph M. Aikln. Secretary......... Omaha Alex. s. Von Mansfelde, Treasurer...Ashland

\section{Omcial Publication}

Western Medical Rerlew, Omaha. A. I. Stuirhead, M.L., editor.

\section{Counellor Districts and officer}

First Distrlct.-Douglas and sarps cuun. ties. If. H. Iemere, Councllor, Umaha Second Instrlet.-1"uss, laneaver and Otoe countles. H. W' Howe, lunnellor. Lincoln. Third District-Gage, Johnson, Pawnee, Nemaha and Richardson counti
Waggoner, Councllor. Humboldt.

Fourth District.-intelope, Knox, Cedar, Madjson, Wayne, Stanton, Dixon, Dakota, Thurston, plerce and Cuming countles. II. I. Welts, Councllor, West I'olut.

Fifth Iistrict.-Boone, Inurt, colfax, Dodge, Merrick, Nance, I'latte and Washington counties. A. P. Overgaard, councllor, Fremont.

Sixth Islstrlet.-Siaunders, Butler, Seward, rolk lork and Hanliton countles. J. C. Malster, counclior, stronsburg.

seventh District,-Clay, Fllmore, Thaser, jefferson, Nisckolls and sillne counties. J. A. Trowbrldge, Councllor, Superior.

Elghth District.-Wheeler, Cherry, Brown,

kock, Holl, keyapaha, llosd, Grant, Hooker,

Thomas, Bialne, Loup and Garfleld countles.

J. P. Gilligan, Councllor, O'Netll.

Sinth Istrict-Dawson, Buffalo, Hall, Custer, Howard, Greeley, Valley and Sherman countles. S. II. Moore, ('ouncllor, (iothenburk.

Tenth District.-Adams, Webster, Kearney, Franklin, Thelps, Harlan, fosper and Furnas countles. F. A. Crelghton, Councilor, Red Cloud.

Fieventh District.-Chase, Dundy, Hayes, Hitchcock, Kelth, Lokan, IIcPherson, Perkins, Lincoln, Frontler, Arthur and Red WHIow counties. G. B. Dent, Councilor, Sorth Platte.

Tirelfth Distrfct.-Sherldan, Deuel, Dawes, Boxbutte, Cbeyenne, Sloux, Scotts Bluff, Banner and Kimball countles. II. H. Bellwood, Councilor, Alliance.

\section{Component County Societles of the Nebraska} State Medical Associatlon ADAMS COUNTY

Frank Schauffelberger President... Hastings Alma J. Chapman, Secretary...... Ingleside BOONE COUNT

Frnest Thelen, Presideut...... Cedar Raplds

i. W. Sulliran, Secretary.......st. Edwards BOXBUTTE COUNTY

II. H. Bellwood, Presldent..........Alllance BOYD COUNTY

H. A. Skelton, President.......... Spencer BHOWX COLNT

(Included In Rock-Brown-Keyapaha Countles.) BUFFalo CoUNTY

11. S. Bell, President............ Kearney

I. S. Blanchard, Sccretary............ Kearney BUHT COLNTX

II. Wood, I'resident............ Tekamah on, secretary............kland BUTLER COUNTY

I. 1. Marron. President............ Bralnard Cass counTy

W. M. Butler l'resident.... Weephng Water

o. H. Iston, secretars........... Filmwood ('kill CotNT:

included in Dlxon-Cedar-Thurston-liakuta-Wagne l'uunty Hedical soclety.)

CHANF-I'NUY-HAYKS-HITCHCOCK COUNTIES

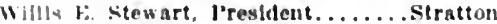

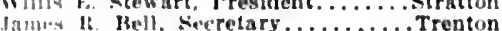
- IIFH Coust

1. I lompton. Ires. and sec.... . Valentue

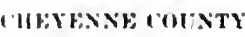

11 t. Mantur, l'resident............. Sldney

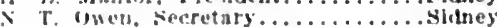
1.1.13 101\%T1

lampliler, f'reslifent.

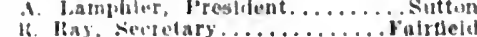

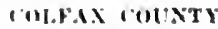

charlon 1) kily, l'reshlent.... CTMAi int:NT

II W. rancls, I'rewflent
CESTEIt COLNT

John II. Marrow, J'resltent.

H. B. Jandls, secretary......... Jiroken Bow DAKOTA COLNTY

(Included in Dixon-redar-Thurstion-Dakota-Wayne county Medical soclety.) DAWES COLNT:

A. V. Stephenson, Presilent..... r rastord fionge W. Deemer, sectetary........ Chaldron IAWSON COENT

J. H. Quinn, I'restdent......... Gothenburs i. J. Bartholomew, Secretary ... . rothenburk

DIXON-CFI,AR-THURSTON-DAKOT. WATYE COUNTES

J. A. Maronde, I'resident.......... Emerson

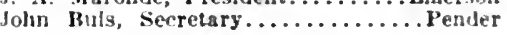
Dolnik COLTT

1. F. Buchanan, Jresident........ Fremont ․ A. Preston, Secretary.............Fremant DOLGIAS COUNTY

(Included in Omaha-Douglas county Itedical Soclety.)

FIIISURE COTXTY

Gen. Mozee, President............Geneva F. I. Beck, Seeretary............... Genera FHANLIN COUNTY

wm. F. Dugan. l'reslclent....... Camplell IIal Clarke sinith, Secretary......... Franklı FLRNAS COUNT

F. F. Cone, Secretary............ oxford GAGE COLNTY

J. I. McGirr, Prestdent............ Beatrice L. F. Penner, Secretary ...................... GARLIELD COUNTY

(Membership in Valley County Medical Soclety.) HALL COUNTY

J. L. Southerland, I'resldent. . . Grand Island W. T. Engleman, Secretary....Grand Island HAMILTOS COLXTY

k. A. Steenburg, President..........Aurora J. M. Woodard. Secretary ................ Aurora IIARLAX COLNT:

W. I. Sucba, l'restdent ............ Orleans Samuel II. Baker, Secretary............. HOLT COLNTY

F. Tr wilson, presldent............ J. I. Gilligan, secretary.................. Nell Howall COLNTY

J. F. Ilart, l'resluent ................ Elba I. i. l'ederson, secretary....... Taminobrog JEFFERON COLTT

W. I. Curtis, l'reshlent.........Falrtury

A. J. Coats, secretary ............Falrbury JOHNSOX COLXTY

B. F. Fay reseldent........... Tecumsels

libert $P$. Fltzsimmons, Secretary. Tecumseh KHARNEY COTSTY

A. I. Marsteller, President.........Wlicox hEYATHII COIXTY

(Included in llock-Hrown-kejapaha 1 munties.) kNix rolst

A. O. Carmack, lresldent........... Center l. i. Helck. Secretary.............. Blowngla

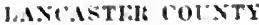

II ] B.chuhury. J'rosident.

I. uncoln

II. F. Fanslurg. Secretary

I.Inivin I.INCOH COINT

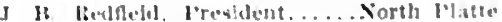

T. J Kerr, Sectelary........... Sorth I'latto $1.011 .1001 \mathrm{NTY}$

Membershlp in Valley county Medlcal

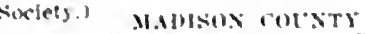

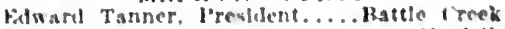
F. I. lirush. Serretary............. Sorfolk Mfittick rOLNTY

$\therefore$. MInnich, Iresflent.......... l'alumer J. H. Itenton, secretary......... ientra] clty NANit: (1) NT

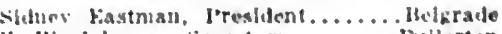
* W. Juhnsou, secretary........... Fullerton VENAHA COLNTY

llenfamin F. Lorance, l'resldent....Auluurn r: If Tyler. secretary.............. Anturn 
NITKOLLS TUUNTY

W. A. 'ate, Vice-I'resldent............. w. $r$. Mitcheli, Secretary............ Superlor OMAHA-DOUGIAAS COUNTIES

F. s. Owen, I'resident........... Omaha Iiobert R. IIollister, Secretary...... Omalıa OTOE COUNTY

1. 1'. GInn, Iresident........ Nebraska City iin. Fimonds, Secretary..... Nebraska City PAWNEE COUNTY

4. B. Brooks, l'resident........ Pawnee lity I. C. Waddeli, Secretary......... Pawnee r'ity I'IlkI,IIIS COUNTY

W. D. Slijelits. I'resident......... Holdrege

P. I. Sundbury, Secretary......... Holdrege IIERCE COUNTY

(i. 13. Iresuarols. Presldent.......... Pierce

F. II. Nye, secretary.............. Plainview I'LATTE COUNTY

B. Tiesing, l'resident............ Columbus W. R. Neumarker, Secretary........ Columbus I'OIK COINTY

L. M. Shaw, Secretary............ Osceola RED WHLOW COUNTY

7. Kay, President.............cCook

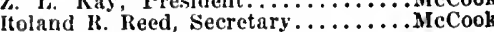
RICHARDSON COUNTY

I. L. Wilson, President........ Falls City

C. L. Ifustead, Secretary......... Falls city IROCK-BROWN-KEYAPAIIA COUNTIES

i. o. Remy, President..........Ainsworth

I. C. Tucker, Secretary........... Iong Pine SALINE COUNTY

Win. H. Pallett, President.......... Crete SAUNDERS COUNTY

F. o. Weber. President...........Wahoo

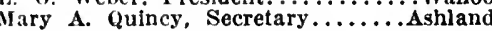
SCOTTS BIUEF COUNTY

C. A. Boyd, President.......... Scotts Biuf

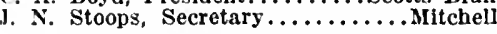
SEWARD COUNTY

C. W. Doty Presldent... Beaver Crossin

Charles o. Petty, Secretary... Beaver Crossing SHERMAN COUNTY

L. E. Dickinson. President........Rockville

L. E. Dickinson, President........................ Whanton STANTON COUNTY

o. C. Ilopper, President.............Stanto

Fmil C. Underberg, Secretary.......... Stanton THAYER COUNTY

R. F. Decker, President.............. Byron

Chas. Henry, Secretary ............... Hebron THURSTON COUNTY

(Included in Dixon-Cedar-Thurstonlakota-Wayne Counties Medical Soclety.) VALLEY COUNTY

II. M. Newbecker, President........... ord

C. J. Sliller, Secretary ............... Ord (Including membership from Loup and Garfleld Countles.)

WASHINGTON COUNTY

J. V. Hinchman, Presldent............ Blair WAYNE COUNTY

(Inciuded in Dixon-Cedar-Thurston-Dakota-Wayne County Medical Society.) WEBSTER COUNTY

Robert Damerell, President.......Red Cloud H. S. Reed, Secretary............Gulde Rock IORK COUNTY

E. B. Hanna. President........... York

J. N. Plumb, Secretary............ York

\section{HEALTH OFFICERS IN CITIES OF 3,000 POPULATION AND OVER}

Alliance............... W. Boman

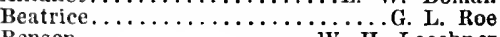
Benson............... H. Loechner Columbus.............. Samuel Ross Fairbury................ J. Coats Falls City . . . . . . . . . . . J. M. Greene Fremont . Grand Island................. Phelan
IJastings. . . . . . . . . . . B. Calbreath

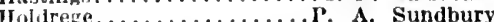

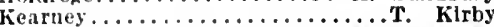

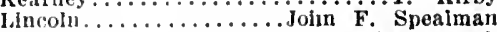
Ilerook............... L. Fahnestock Nibristia (citr................. L. Koser Norfolk................ 13. Tashjean North I'latte............. Vorhees lucas Omaha ................ W. Conneil Plattsmouth............... B. Martin South omahit.............. Ir. Ed. Hurson Unfversity 1'lace................. Th. Taylor

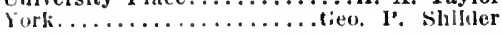

\section{Beatrice}

\section{STATE INSTITUTIONS}

Nebraska Institution for Feebie Minded, 13eatrice, Neb. Established 1886; feoble ulluded; 480 beds; Wm. S. Fast, physlcian ln charge.

Geneva

Girls' Industrlal School, Geneva, Neb. Established 1891 ; reformatory ; public ; 89 beds; Lydla J. McMahon, matron.

\section{Grand Island}

Nebraska Soldier's and Sallors' Home, Frand Istand Neb Estabilished $1888^{\text {. }}$ generai; 600 beds in barracks; 250 beds in hospital; Claude P. Fordyce, physician; F. Tímmerer, commander.

\section{Ingleside}

Nebraska State Hospltal, Ingieside, Neb Established 1888; for nerrous and mental dlseases; 1,300 beds; M. W. Baxter, medical superintendent.

\section{Kearney}

Nebrask State Tuberculosis Hospital, Kearney, Neb. Wstablished 1912; public: 40 beds: $\mathrm{L}$. M. Stearns, attendIng physieian; lirs. P. F. Barker, R.N., superinendent.

State Industrial School for Boys, Kearney, Neb. Established 1880 ; reformatory ; Manuel, superintendent.

Lincoin

Nebraska Hospital for the Insane, Lincoin. Neb. Established 1869; 540 beds B. F. Williams, physician.

Nebraska Orthopedic Hospital, Lincoln, Nel. Established 1905 ; for crippled and ruptured children; orthopedic: surgical 109 bedis J. I'. Lord, (Omaha), chief surgeon, H. W. Orr, medical superintendent. Milford

Nebraska Industrial Home, Milford, Neb. Establlshed $1890 ; 24$ beds; Lena E. Vard, superintendent.

Soldiers and Sailors' Home, Milford. Neb. Established 1896; for disabled volunteer soldlers and sailors, thelr wires widows and mothers; 26 beds in hospita department; J. G. Muir, surgeon in charge: Henry Howard, commandment : Rena Walsh, matron.

\section{Nebraska City}

Nebraska School for the Blind, Nebraska City, Neb. Established I875 school oniy; 50 beds; Claud Watson, physiclan in charge; N. C. Abbott, superinterident.

Norfolk

Hospital for the Insane of Nebraska Norfolk, Neb. Fstablished 1885; for the insane; 450 beds; Wm. David Guttery, medical superintendent.

Omaha

Nebraska School for the Deaf, Omaha Neb. Established 1869 ; public; 190 beds F. W. Booth, superintendent.

\section{HOSPITALS, SANATORIUMS AND CHARI-} TABLE INSTITUTIONS

Aurora

Hamilton County Poor Farm, Aurora

Neb. Public ; 12 beds; J. M. Woodard, physiclan in charge.

\section{Beatrice}

Beatrice Sanitarium, Beatrice, Neb. Established 1900 ; private; 25 beds; C. P Fall. pbysician in charge; Mrs. E. A Fall, pbysician in charge;
Memonite IJoaconess Home and Hosyitai, Beatrice, Neb. Estabilshed 1911; gelleral; $4 \theta$ beds.

United Bretheri IIospital, Beatrice. Neb. Established 1909; pubilc; surgery : 50 beds; H. M. Hepperien, physician in charge.

Beaver City

Lr. F. A Brewster's l'rivate Hospital. Beaver City, Neb. 15 beds; F. A. Brewster, physlclan in charge.

\section{Beaver Crossing}

Beaver Crossing IIospital, Beaver CrossIng, Nel. Surgleal; 4 beds; C. W. Doty and $\mathbf{F}$. L. Stone, phissiclans in charge.

Petty Hospltal, Beaver Crossing, Neb. Surglcal; 10 bedis; Chas. 0 . Petty, physjclan in charge.

\section{Beemer} Beemer Sanitarium, Beemer, Neb. Es-
tablished $190 \%$; private; 7 beds; Wm. L. Crosby, physlcian in charge.

Blair

Hiair Hospitai Beneft Association, Blair, Neb. Fstablished 1906 ; public; II

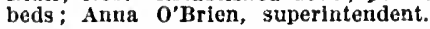

\section{Bloomfleld}

Bloomfleid General Hospitai, Bioomfleld. Neb. Fstahilshed 19I1; public ; 12 beds: L. C. Biejck, J. H. Mettien, S. B. Kalar. medicai staff; Kate M. Duncan, superintendent.

Cody

Cherry County Hospital, Cody, Neb. Estabilshed 1905; private; general; 8 beds; Meyer H. Newman, physlclar. in charge.

Collegeview

Coliege Vlew Sanitarium, Collegeriew, Neb. Established 1394; public; general : 50 beds: Seventh Day Adventists in charge: J. D. Shirely, medical superintendent; Ida Johnson, matron.

\section{Columbus}

Columbus Hospltal, Columbus, Neb. Fstabiished 1911; private; 15 beds; Carroll D. Evans, physician in eharge.

St. Mary's Hospital, Columbus, Neb. Established 1880; private: 160 beds: Franciscan Sisters, in charge.

Crote

Crete Hospital and Sanitarium, Cretè.

$\mathrm{Neb}$. Establisheed 1902; prirate; general

24 beds; Il. W. Quirk, physician in charge.

\section{David City}

David City Hospital, David City, Neb. Established 1901; public; 30 beds; S. C. Beede, pbysician in charge; Emma Mohler, matron.

\section{Dunbar}

Otoe County Infirmary, Dunbar, Neb Established 1885;25 beds: Geo. llolmes, superintendent.

Fremont

Dodge County Poor Farm, Fremont, Neb. Fstablished 1883; public: 15 beds: John W. Sexson, superintendent.

Fremont Hosuital, Fremont, Neb. Fsrablished 1900 ; public ; 40 beds: Ifanor T. Kelly, manager.

\section{Grand Islanld}

Grand Island General IIospital, Grand Island, Neb. Established 1913; public; general; 50 beds; B. R. McGrath, physiclan; P. C. Kelly, surgeon; Mrs. Juli: Barnes Adams, R. Superintendent.

St. Francis Hospltal, Grand Island, Neb. Established 188.; general; 140 beds; C A. Roeder, surgeon.

\section{Hastings}

Nebraska Sanitarium, Hastings, Neb. Established 1908; private: general : 3 . beds: Osear H. Halun, physician in charge. St. Anthony's Hospital Hastlngs, Neb. Established I912; general; 14 beds; conducted by Hisses $E$. Horsey and $C$ Krouturck.

\section{Hebron}

Blue Valiey Hospital, Hebron, Neb. Establlshed 1905 ; private; 20 beds; J. H. Boyes, surgeon in charge.

\section{Holbrook}

Repubilcan Valley Hospltal, Holbrook. Neb. Established 1908; private : 8 beds C. W. Lyon, medical superintendent: 


\section{Kearney}

St. Luke's IIospltal, Kearney, Neb. H: tablished 191:: general: 23 becls: L. It Whistan, H.N.. superintendent.

Women's Chrtstian Teinverance Lnion Hospltal, Kearney, Neb. Estalllshed 1883: public: general: 23 beds: Mrs Alma Lehnhárd, auperintendent.

\section{Lincels}

(see Iniversity Place.)

Andrus lluspital. 3259 Holdredge st Lucoin. Neb. Established 1910: private 16 beds: 5 . II. Andrus, physilian in charge; intolnette V. Merselis, R.N., suverintendent.

bisther's Iluspltal. $609 \mathrm{~S}$. 1:th st. IInculn. Neb. Estab. isox: private : 26 bed.

Frank L. Wilnseth, physician in charge" Green tiables, Dr. Benj. F. Balley Sanatorium. Lncoln. Neb. Fistablished ign: general; nervous and mental : anjex, liest Cottage; 90 beds; Benj. r. Balley, physiclan in charge.

see spectal Announcement Itlt. page 75 Isolation Hospltal, Ilncoln, teb Jub. lle: 10 beds.

Iincoln Hospltal $315 \times$. 14th st., I.In. coln, Neb. Established 1904: T,rirate general: 23 beds: W. N. Mamej, medical superintendent.

Lincoln Santarlum, Ilncoln. Neb. Es. tablished 1893: pritate: generil: ino teds: 0 . W. biverett, medical suiverin. tendent.

Shoemaker's P'rtiate IJospital. Ifincoln. Neb. Established 1898 ; feneral; 12 leeds

C. A. Shoemaker, phrsictan in charre. St. Fllzabeth's Hospital, Lincoln. Neb. Establlshed 1889: public; 103 beds.

St Thomas' Orphanage, Inncoln. Yeb Sistablished 190:; publtc: is0 beds; $w^{-11}$ Slattery, phystcian in charge.

Tabitis Home and Lutheran Hospital, Lincoln, Neb. Established $190 \%$; home for the aged, orphanage: H. R. Mlller, surgeon in chter; $C$, W. Thomas, physi: clan in chlep.

\section{Mocook}

MeCook General Hospltal, McCook, Neh Establlshed 1912; zeneral, except no contaglous or mental cases: 10 beds: David J. Reld, medical superintendent.

\section{silford}

PInes, Mrllford. Neb. Fstabllshed 1910: prirate: general: 8 beds; Paul A. DeOfny physician in charge

\section{Minatare}

Minatare Ilospital, Minatare, Neb. Established 1912: pritate: zeneral and maternity: 6 heds: C. E. Vandirer, medical superintendent.

\section{Minden}

Keamey County IIospltal, Minden, Net Establlshed 1909: prirate: 10 beds: Chas B. Abbott, phrsletan in charge.

\section{Nebraska City}

General Hospital, Nehraska Clty. Neb, Established 1912: keneral: 80 beds: Iflsa Rose Graham, R.X., superintendent.

\section{Norfolk}

Norfolk Cenera! Ifospltal, Norfolk, Net. 25 heds: P. H. Salter, E. I. Brush, A. X 25 heds: P. Il. Salter.
Howley. medical start.
North Platte

North Platte Hosplal. North Matte Neb. Fstablished 1910: 15 beds: IIrs. E. P'ulver, superintendent.

J'hysiclans and surgeons' Hospltal. North Flatte. Neb. Establistied 1910: 1 beds: J. B. Hedtleid and W. J. Redfeld physlclans.

St. Luke's Iloupltal, Notth Platte. Neb. Established 1910: gereral: 10 beds: (ieo. B. Dent and Daniel $T$ quigley, physiclans in charge.

Omaha

Hishoy Clarkson Meniortal Hospital, 2100 Howard St. Omaha, Neb. Kutab lished 18:9: publle: general: 80 beds Fllen stewart. R.N. superintendent.

Chlid Saring institute. 12d and Jackson

sts., Onaha, Neb. Established 1597: pub.

IIC: 104 beds: II. M. MeClanahan, physlcic: 104 bedz: II, M. MeClanahan, phys! chan in

City Metention Hosnital, W. Center st. Omaha. Neb. Established 1901; for con tagious diseases: small-pox onty: 85 beds H. C. Strouse, physlelan in charge.

Crelghton Heinorial St. Joseph's Hos.

pltal. 10th and Castellar Sts., Ornaha.

Neb. Fstablished 1880; publle: medical and surgical: 100 beds.

Douglas County Detention Home 310 Bancroft St. Omaha, Neb. Estabilshed 1905: 50 beds: Dexter Bryn, superin tendent.

Douglas County Hospltal. 40th and Poppleton Sts. Omaha, Neb. Establlshed 1.88S ; general: 123 beds: Edw. M. Robln. son, superintendent.

House of Hope, $958 \mathrm{~N}$, 2ith Are. Omaha, Neb. Established 1906: publlc: for aged jeople: 0 beds: Rev Chas. IV savidze, superintendent.

Immanuel Deaconess Instltution, 34 th st. and Meredith Are., Omaha, Neb. Established 1889 : general: 65 beds: $R$. B. Daris, surgeon-in-chler: Rev. P. M. Lindbers, superintendent.

Immanue! Orphans' Home. 34th St. and Fowler Ave., Omaba, Neb. Established 1900: Irlrate : 25 beds: Ker. F. M. LInd. bers, superintendent.

Nebraska Methodist Iosnlta! and Dea. coness Home, 36 th and Cuming St. coness Home, 36th and Cuming St, Omatha, Neb, Established 140 beds; Mrs. Alle $1^{*}$. Mclaughlin, superintendent.

Ntcholas Senn Hospital, Park and Dewey Ares., Omaha, Jeb. Establlahe: 1912: private: 40 beds; $A$. I. Condor. phystelan in charge.

Omaha (ieneral Ijospital, ifth $\mathrm{st}$, and Capitol Ave., Omaha. Neb. Fstablishel 1906: publlc: 100 beds: Chas. F, Robel. 1906 ; publlc:

superintendent.

Presbiterian Hospltal, $1240 \leqslant 10 t h \leqslant$ Omaha, Neb. Fstabllshed Is92: vilsate 50 heds: J. E. Graham, sufierintendent Salration Army Rescue Hone. 3824 . ith st., Omaha, Neb. Establlshed 1896: private: maternity : 30 beds: Mary strong. physleian in charge: Filizabeth raldwell, stuperlutendent.

St. Katherin's llospital, sla Forest Are Omaha, Yeb, kstablished 1910 : ceneral: 40 heis: : sisters of Meres, in charge.
Sirodish Misston Huspltal, 3:06 x. 24th St.. Omaha Neb. Eistallatied 1903; gen. etal: oo hedi: Rev. 3 II Westlund, hujerIntendent.

Wise Nemorlal Ilospltal. 2th Ave and llarney st. Omaha, Teb. Fstabliahed

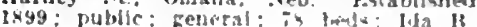
llulette. It $\mathbf{x}$, superintendent

Ord

Ibllings Hospital, Ord. Neb. His:al. lished 1907: private: ceneral: i lieds llobert $A$. Hlllings, uhysiclan in charge

Pender

Dr. ISuls" Ilospltal, Pender, Neb. Es tabllahed 1912: prirate: zeneral: 10 treds fohn Buls, medlcal superintendent.

\section{Plattsmouth}

Nebraska Maronte Home. Platisnouth Teb. Histablisher 1894: General. for de vendent masons, their widows and or Dhans: 50 leds: Wm. S. Askwlth, super. intendent.

\section{Scottsbluff}

MA-West Ilospltal. Scutisblutt. Net. Established 1912; prirate: 10 beds: A M Faugh and C. I. More, thyslctans.

\section{Seward}

Morrow Hompllal, Senard, Neb. Surzlcal and chronle cases: 10 beds: Juseph Murrow, vhysician in charge

\section{South Omaha}

South Omaha Ilospital, 25th and $f$ : sts South Omaha, Neb. Fstalllshed 1894 general: 30 beds; Miss Myrile Dean, $\mathrm{h} \times$ superintendent.

\section{Spence}

Spencer Hospltal, spencer, Neh, lieneral: It beds: H. A. Skelton and $k$ : $B$ Bradley, physlclans and proprietors: Mrs. $X$. Tifany, superiviendent.

\section{Springfleld}

Springfleld Itospltal, Springteld. Neh Establlshed 1596: private: 12 beds: 1 . veters, surzeon-tri-chlet.

St. Paul

it. Iatal Ilospital, St. Paul, Neb, Establlshed 1894: prirate: general: theds Frank $\therefore$ Nicholson, physlclan in charge

\section{Stration}

Stewart-Rell Hospltal, Strattuln Neb Established 1907: titrate: : beds: W E Stewart, physician in charke.

\section{Stromsbure}

Maywood, Stronshurs, Neb. EstabIlshed I90S: general: 1: beils: Ceorte I Fliprin. physician in charce.

Sutton

Sutton IIospltal, Sutton, Neb. FotabIlshed 1904: Reneral: 15 heds: Bruno J F. Getrlat, medical director and surzem. in-chtef.

\section{York}

Randa!l Memorlal Hospltal, lork. Net Established 1907 : urirate: 10 heds: Mis laura kellows, matron.

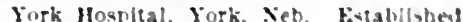
1910: prliate; io helk: Jaura M. Itkknsnu, silperintendent. 


\section{PHYSICIANS OF NEBRASKA}

\section{KEY TO ABBREVIATIONS, SYMBOLS, ETC.}

Names in capitals signify membership in the County Soclety and State Association. (DOE, JOHN).

- Indicates Fellowship in the American Med. Assn. (DOE, JOIIN + )

(b'75) lear of birth. I, homeopath; E, eclectic; P-M, physloMd. 7,09, College and year of graduation.

$\checkmark$ Information recelved does not show grad uation.

S.-Surgeon.

Ob.-Obstetriclan.

ObG.-Obstetrician, Gynecologist.

G.-Gynecologist.

Or.-Orthopedist.

Pr.-Proctologist.

Op. - Ophthaimologist.

A.-Aurist.

LR.-Laryngologist, Rhinologist.
(I'89) Year of license.

(5) In practice before passage of present law and licensed by flling diploma or by years of practice.

(1) Licensed but year not known.

(\$) Information recelved does not show license.

U.S.A., United States Army.

I.R.C., U.S.A., Medical Reserve Corps.

U.S.N., United States Navy.

SPECIALTIES ARE INDICATED AS FOLLOWS:

ALR.-Aurist, Laryngologist, Rhinologist. OALR.-Ophthalmologist, Aurist, Laryngologist, Rhinologist.

U. - Urologlst.

D.-Dermatologist.

Pd.-Pediatrist.

N.-Neurologist.

P.-Psychiatrist.
M.R.C., U.S.N., Medical Reserre Corps.

U.S.P.H.S., United States Public Health Service.

College positions held are lindlcated by abbrevlated title of position, followed by key number of college. For key to colleres see inside front cover page.

(AI,3, B6, C4) Membership in special Socletles. (Sce Key Table, page 122.)

NP.-Neurologlst, Psychlatrlst.

I.-Internist.

T.-Tuberculotherapist.

Anes.-Anesthetist.

LD.-Laboratory Diagnostician.

Path.-Pathologist.

Bact.-Bacterlologist.

WHEN THE ABBREVIATION REPRESENTING A SPECIALTY IS FOLLOWED BY AN ASTERISK ( ) IT INDICATES THAT THE PHYSICIAN CLAIMS HIS PRACTICE IS LIMITED TO THAT PARTICULAR BRANCH OF MEDICINE; WITHOUT THE ASTERISK, THAT HE IS ESPECIALLY INTERESTED IN, BUT DOES NOT LIMIT HIS PRACTICE TO, THAT BRANCH. THIS INFORMATION CONCERNING SPECIALTY IS BASED ON PERSONAL DATA FURNISHED BY THE PHYSICIAN AND IS NOT VERIFIABLE.

\section{NEBRASKA}

ADAMS, 647, GAGE

LAMB, JOS. A. (b'75)-IIo.20,04; (I'I3) Member Kan. Med. Soc.

ICKIBBIX, JAUES W. (b'52)-ILl.6,78; (1'91).

Simpson, Bryant Robt. (b'87)-Neb.5,'10 (1'10).

AINSWORTH, 1,045, BROWN

CARTER, JOHN ROBT. CALVIN†-Ont.3, 02: (1'06); 0b.

Ely, Wm. B. (b'42)-Mich.1,78; (l'91).

Evans, Jonathan J. (b'54)-0.2,'80, 0.14 '83; (1'91).

JONES, TYRE K. E.-Neb.4,'05; (l'05)

Lambley, Geo. W.-Ia.1,'83; (1'91).

REMY, CHAS. EDWARD (b'8I)£-Neb.5, '10; $\left(1{ }^{\prime} 10\right)$.

REMY, GEO. 0. (b'51)-0.1,7\%; (1'91)

WHITE, HOSEA J.-Ia.1;'85: (1'91).

ALBION, I,584, BOONE

HOWARD, HARVEY (b'TI) - Ill.1,94:

(1'12). FINLEY J. (b'7T)-Ont.6,'02;

SMITH, JAMES W. B. (b'77)-Neb.5,03; (1'03)

SMITH, JOS. II. (b'42)థ-Mlch.2,70; (l'9I)

Stoakes, Wm. H. (b'55)H-Ia.4,0I; (1'01)

THOMPSON, JOS. H. (b'59)๑-Que.1,'88 (1'9I).

ALDA, 150, HALL

Pitts, Sollis 0. (b’69) H-Colo.4, 02 ; (I’03).

ALEXANDRIA, 447, THAYER

BIRDSALL, GEO. A. (b'65) $4-111.1,86$; (1'91).

NEWELL, HARRY J. (b'72) †-Neb.6,03 : (l'03)

ALLEN, 37I, DIXON

GRAHAM, JAMES R. (b';9) - Neb.5, 03 ; (l'03).

Hoskins, John B. (b'76)-1a.4, $00 ;\left(l^{\prime \prime} 07\right)$

IcDonald, James L. (b'45)-Mí.8,'80;(l'91).

ALLIANCE, 3,105, BOXBUTTE

BELLWOOD, HARVEY II. (b'48) \&-IIl.I, '87; (1'95); S

BOWMAx, LUTHER W. (b'58)థ-Ia.3,'86 ; (i'91).

COPSEI, H. A. $\oplus-$ Neb.4,'06; (1'06)

HAND, GEO. J. (b'75)—-Ia.4,04; (1'04).

IIFRAMAN, CHAS. EDWARD '(b'85) Ill.22,'0s: (1'12).

Jackman, Chas. Bernard (b'85)-Ill.11,'11; (‡)

Slagle, Chas. E. (b'70)-Ia.10,03, Mo.34, $06 ;(1$; 03$)$
ALMA, 1.066, HARLAN

BAKER, SAMI. M. (b'65)-0.2,'92 ; (1'92) ob.

BARTLETT, WU. C. (b'78)థ-Mo.29,'04 (1'04); Pd.

Dodge, Burton J.-Ia.9,'98; (1'98).

ALVO, 225, CASS

Muir, Lconard (b'74)-Neb.4,97; (1'97).

AMHERST, 256, BUFFALO

Ilart, Raymond L. (b'i2)-Ia.3,'97; (1'98).

ANSELMO, 351 , CUSTER

SPIVEY, CLARK DIVIGHT $\left(\mathrm{b}^{\prime} 85\right) \oplus$ Mich.1,09; (1'10).

WILLS, CLAUDE L. (b'78)甲-Neb.5,'06 (1'06).

ANSLEY, 700, CUSTER

HANNA, EDGAR A.-M0.22,'95; (1'95).

Higglns, Ralph Philip (b'88) - Neb.5,'12 (1'12); S.

Ilousel, Chas. Lawson-Neb.4,'07, IIl.17,'08; (1'07).

YOUNG, WM. R. (b'68) -Ia.3,'93; (1'97)

ARAPAHOE, 901, FURNAS

IIUDSON, EIWARD A. (b'67) †-Mo.I,'90 (1'11).

Muldoon, John Kennedy (b'S4) - Neb.6,'08; (1'08); S.

ARBORVILLE, 45, YORK

Ensign, Lucien P. (b'51)-N.Y.5,'72; (1’9I)

ARCADIA, 618, VALLEY

CROMIVELL, PHILIP I. (b'48)-N.Y.3,'T0 not in practice; Member III. State Ned. Soc.

LANGRALL, C. D. D. M. M. S.థ-Mo.22, OI ; (1'03); U.

JEE, DANL. R. (b'56) —-1a.3,90; (1'91) Scudder, Royal (b'80)-Ill.14,'09; (1'12); Ob.

ARCHER, 75, MERRICK

PAXTON, CHARLES C. (b'69) $4-$ Kan.3 '99, Neb.6,'00; (1'00).

ARLINGTON, 645, WASHINGTON

DAVIES, RUPERT A. (b'75) $\oplus$ - III.1,00 $\left(l^{\prime} 00\right)$.

ARNOLD, 231, CUSTER

BURNHAI, FRANK ASABEL (b'77)Neb.5,'11; (1'11)

Logan, Johanna Eisie (b’59) E-Neb.4,04; (1'04).

ASHLAND, 1,379, SAUNDERS

(lark, Bennett Hillsman-Mo.3,'80; (l'96). KIRKPATRICK, CHAS. F. $\oplus-0.14, ' \mathrm{\prime} 2$; (l'9I); Pd

Mereditb, Earnest Louis (b'84)-Mo.28,'09; (1'09).

IEREDITH, GEO. W. (b'51) $€$-Ind.4, 73 ; l’91)
QUINCY, MARY A. (b’57) $\oplus-$ Neb.5,'96; $\left(1^{\prime} 96\right)$.

On MANSFELDE, ALEXANDER S. (b'45) $(£-111.1,72 ;(1 ' 91) ; \mathrm{G}$.

ASHTON, 404, SHERMAN

WANEK, ANTON E. $\left(b^{\prime} 70\right) \oplus-N e b .6,05$; (1'05).

ATKINSON, 8I0, HOLT

DOUGLAS, WM. J. (b'78) $\oplus-$ Neb.5, 00 ; (I'00).

STURDEVANT, CHAS. L. (b'58)-0.2,'80 ; (1'9I).

TOWNSFND, (:UY WALTER (b'84) $\oplus$ Neb.6,'10; $(1 ' 10)$.

AUBURN, 2,729, NEMAHA

BOAL, VARRO M.-Ia.I,'8I ; (1'9I)

Cline, Edgar (b'90)-Neb.6,'13; (1'13).

DILION, IRA IIUGH (b'73) $\oplus$ - III.11,'98:

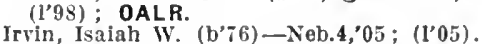

LORANCE, BENJ. FRANKLIN (b'58) Ia.3,'87; (1'92).

1.utgen, Clifford Athenus (b'72)-Neb.4,'01; (1'11); Prof. Rectal Dis., Neb.4; S.

Shull, Harrison I.-E-Mo.10,'83; (1'91).

TYLER, EUGENE M. (b'63)-Tenn.6,' 85 ; (1'91).

AURORA, 2,630, HAMILTON

COOPER, SUSAN RACHEL MERRILI, ${ }_{3}\left(b^{\prime} 76\right)$ †-0.2,02, Ill.11,'06; (1'09)

HAUGHEY, ISAIAH WM. (b'68) §-Ia.3,'89 (1'9I) ; Op.

HUSTEAD, CHAS. D.-KY.2,'9I ; (1'9I)

Jones, Cora White Carpenter (b'68) - Ill.11, 0I ; (1'12).

Marvel, Geo. H. (b'73)-Neb.4,'05; (1'05).

Marvel, Perry o. (h'81)-Neb.4,09; (1'09)

STEENBURG, FDILND A. (b'65) $€-I 11.1$ 87; (1'91).

Thomas, Fred A.-F-Neb.4,05; (1'05)

WOODARD, DANL. S. (b'48)థ-Mo.15,'82 ; (I'9I).

VOODARD, JAMES IIADISON (b'8I) $\oplus-$ Neb.5,0i; (I'07).

AVOCA, 249, CASS

Breñdell, J. W.-Neb.4,'01; (1701).

AXTELL, 394, KEARNEY

ENGLAND, JOHN D. (b'58) - N.Y.10,'87; (1'91).

Spannare, Chas. Irar (b'81) - IIl.8,'10 (l'10).

Wells, Francis A. (b'76)-Neb.5,'01; (1'01). AYR, 142, ADAMS

Gray, Oscar Sylvester $\left(b^{\prime} 80\right)-\mathrm{Ta} .3,^{\prime} 04$; (I'09).

BANCROFT, 742, CUMING

FRANCIS, HARRY W. (b'66) 4-Neb.5,'96; (1'96).

KIEFER, JOHN" J. (b'69)-MO.7,97; (1'97). Pratt, Geo. Gale (b'53)-Ia.I,'89; (1'91). 
BARAOA, II8. RICHARDSON

Slong. Jesse Franklin $\left(b^{*}, i f\right)-1 a .10,00$ : $\left(l^{\circ} 01\right)$.

Woorls, Fred J-Nebt.97; (1'9i)

BARNSTON, 228, GAGE

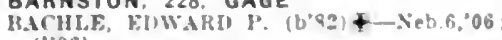
(1"06).

BARTLETT, II2, WHEELER

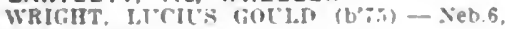
'10; 1110

BARTLEY, 5II. REO WILLOW

Hathorn, Jobn bi, (h'4) - Ill. l, it: (['91).

I'HIIIII'S, WARRLI II (b'st) \&-AIK.2, 11; (1'18).

BASSETT, 383. ROCK

barqubar, Elwood Mlller (lo'ts)-111.11, (1'09).

BATTLE CREEK. 597, MADISON

TANNEK, ETWARD (b'55) D- X.Y.5,:9 (I'9l).

BAYARO, 26I, MORRILL

Deputy, Jos. F. (b'-7) - Ky.5,"03; (l'0s)

Faught, A M.-E-Neb.4,05; (1'05)

vranklin. Wm. S.-Yeb.6,06; (I'06)

OLSOX, EVALD $\left(b^{\prime}(0 b)+-K a n .3,0 \%\right.$

Member Kan. Med. soc.

BEATRICE, 9.356, GAGE

BRADLEY, C. A.-la.1,'80: (1'91)

BRASH, GEO. HENRI (b'-0)†-MIcb.1,'92 , (1'93).

Brother, Ferdinand (b'33)-Mo.1,'62, I'3.2, $66 ;(1.91)$.

BUCKLEI, FRED W. (b'31)+-111.6,0i (l'09).

Claussed, Jullus Edward-Ill.1,83; (1'91)

CURRY, CHAS. S, $\left(b^{\circ}, 3\right)-\Pi 1.1,00 ;\left(l^{\prime} 00\right)$

Dlers. Harry Edward (b'd4) - Pa.2, 0 "

(1'L1): S.
ALL, CLIFFORD P. (b'63) -111.11,'88;

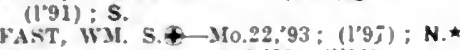

Feleh, Albert H.-Pa.9,'76; (l'91)

Fultoo, John B. $\rightarrow$; (1'9l).

UEPPERLEN, HARRY MICHAEL $\left(b^{\circ} 6 S\right) \mp$

Ia.9,91, P..2,96; (1'91).

Kennedy, Chas. F. (b'61)-Ill.6,'8; ; (1'92).

Lore, C. A-Mo.I0,90; (l'0I).

MCGIRR, JOHX 1. $\left(b^{\circ} \% 3\right)+-$ Neb.5,'97

Aus. :0I: (1'97): OALR.*

NONTGOMYRY: WIILIAM P. (b'65)-Neb.5. 9-: (1'98); OALR. *

PENYER, LOUTS EDW.ARD - Neb.5, 04 ; (1'04); S.

Peaplngton, James Lewis (b'68)-Mo.28,'93; (1'94).

PLATZ, ADA (b'82) - Neb.5,09; (1'09); G.

Pice, Allen T-Ia.1.'8I: (['92).

ROBINSON, AIICK VAS Z.NDT-N.I.IO '\$1: (1'92).

ROE, G. L.-Ky.4,"79; (1.91)

Starr, Calvin (b'22) II-0.7.51; (l'91).

Starr. Julla C. -0 ; (1t).

THIILETT, THOMAS M-Mo.5, T8: (1'93).

Walden, clinord W.-Neb.6,"96; (1'9i).

Walden, I). A-III.1, 0 ; (1'91)

Webb, Jos. Lewls-111.8,05; (1'06)

BEAVER CITY, 975, FURNAS

BREWSTEK, YHANK A. (b'a) $\$-$ Yeb.5, 00 ; $(1,00) ; \mathrm{S}$.

Copelaad, Cecll C. (b'68)-Ill.1,94; (1'05)

Green, Clarence C.-I'a.n.'ss; (1'92).

BEAVER CROSSING, 542, SEWARD

DOTF. CHAS. WILI.ARI) (b'b1) - III.1,88, I11.10,'95: (I'11).

DETTY CHAS (1) $\left(b^{\prime}, i\right)+-1010.3,00$ (I'01): OALR.

STONF, FR.NK I.ER (b'85) \&-I11.11,10 ;

(l'Is): Member III. Staie Med. Soc.; ObG.

BEE, I55, SEWARO

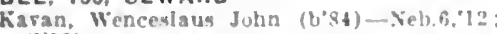
(1'12).

BEEMER, 494, CUMING

CROSBY, WM. I. $\left(b^{\circ} 66\right)+-111.1 .95 ;(1.96)$

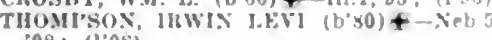
.08: (l.0S).

BENNINGTON, 276, DOUGLAS

Heley. Chas. W.-Nieb.6,03; (1'03)

BELOEN, 247, CEOAR

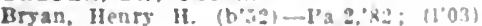

BELGRADE, 400, NANCE

A.NTHEWS, HENRY SELIEY (U'BO) Mo.20,09; 1[091

EASTMAX, SVIINY (b"i2) - Xob.6.0? (1'09); Pd.

BELLEVUE, 596, SARPY

IVT\%, WM, IIFAK I

(siee south Omahn.)

BELLWOOD, 397, BUTLER

MCNAILY, JAMEA M. (1)'85)-Nel, b,"12 (1'12)

MIRIVEIR, MICHAE, E $\left(b^{\circ} i t\right)+-$ Neb $A$, 0i: (l'i0)

BELVIOERE, 475, THAYER

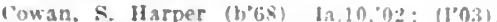

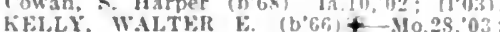
(1'03): Ob.

BENEDICT, 336, YORK

Karter, Fred W. (b'-S)-Yeb.j,04; (1'04).

BENKELMAN, 538, DUNDY

F'CQLA. EL.MEIS F.-Mo.29,'03; (I'03).

I'ICKESS. EDGSR ALIKN (1) 84$)+-M 0.22$, 08: (1'09): Pd.

Walthall, John 6. (b.54) -Ind.8,8.5; (1"92)

BENNET, \$57, LANCASTER

('ameron, Jos, R. (b'-8)-lll.11,05: (l"0 0 ).

Chariton, Chas. Percy-111.22,13) (1'13).

beck, Mllton B.-IId.I, :9; (1'91)

IreWolf. W'm. W. (b'zt)-Neb.4,98; (l'9s)

Torbltt, Wm. F.-Md.1,03; (1'03).

BENSON, 3.170, DOUGLAS

HALl, RYRON W. (b'-5)- Neb.5, 01 ; (l'01).

Heumann. John Martla Frledrlch (b;8) [11.1,12: (1'12)

I.INULEST, ADOLPII IB.

(See Omaha.)

Loechner, Wm. Ileury (b'76)-Neb.5,01; (l'0I).

V'arsons, John Wesley (b'67) - Ia.I,9I; (1'91)

HYMAN, FUGEXE MILES (b'65)-Neb.6. 10; $(1 ' 10)$.

BERLIN, 196, OTOE

schall, Davld Horace (b'35) - -3a.2,01: (1'01).

BERTRAND, 643, PHELPS

RII):R, ELGENE E. (b'S1) +-Mo.20,'03: (1'03).

HREK, WM. A. (b'64)+- Ky.2,9r: (1'96).

BERWYN, I30, CUSTER

VIcbols, Itarry Carl (b'si) - Neb.6,"1l (I'II); G.

BETHANY, 948, LANCASTER

(2)REIITS, DU[CILAS H.-Neb.4,96; (l'96)

BINGHAM, 15, SHERIDAN

Emerson, Irthur G-Neb.5,01; (I"01).

BLADEN, 49\$, WEBSTER

Keller. Chas. I' ( $\left.b^{\prime} 3 t\right)-13.1,80 ;(1.91)$

Wirman, Wm. M.-Mo.31,01; (1,01)

BLAIR, 2.584, WASHINGTON

HIRTIES LUIIS LATIE (WRB) IAG ilk: (1'i2) : $u$.

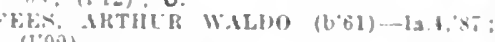
(1'00).

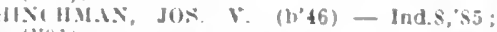
(1) 0,1$)$

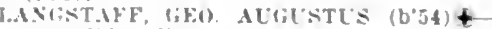
(int $1,7 i:(1,9 i)$

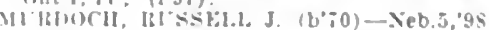
$(1,9 x)$

Vlelsen, Marle thua $(6,75)-$ Neb.5,05; 11.0:3): (traveling)

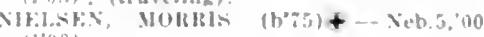
(1'00)

falmer. Wm. II (b'39)-111. I, 30; (1'91)

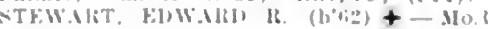

BLOOMFIELD, 1,264, KNOX

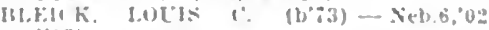
(1'02)

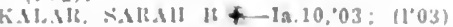

WHTTLEN, J.MHE HAHVEY (b'GS) - IA 3

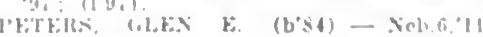
11.11\}; S.

BLOOMINGTON 55\&, FRANKLIN

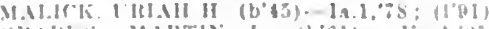

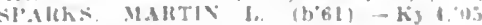

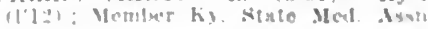

SLMMH.H, FI.LA l'. (b'(n) - Neb.5,"95: (l'95)

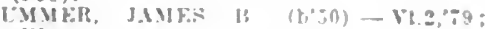
(I'3)

BLUE HILL, 761, WEBSTER

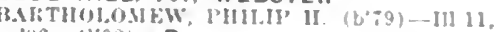
$02 ;(102) ;$

Ialrd, Claude ltons (b's!) - Seb, fo, 1?; 12131 .

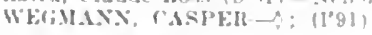

BLUE SPRINGS, 712, GAGE

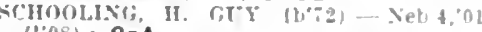
(1'0s): ODA.

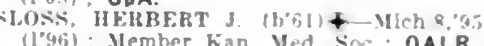

BOELUS. 183. HOWARD

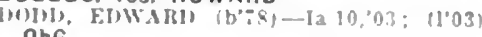
ObG.

BOSTWICK, 100, NUCKOLLS

l'inkerton. Wm. Janes (b'60)-Neb.5, 98 (lop).

BRADISH, 53, BOONE

Young. Husaell M. (1,\%)-111.1,00; not in praciloe.

BRADSHAW, 359, YORK

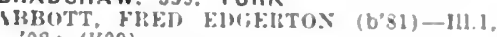
08: (I'09).

MOMISOS, (;F, A. (b'-8) - Neb.5,05: (I'05).

BRADY, 308. LINCOLN

('art. F. Fred (b'81)-Ill.9.06; (I'06)

YETTER, FARL W. (b'85) — Neb.6, 09 : (l'09).

BRAINARD, 465. BUTLER

M.MROS, JAMES G.-NY.10, 8 : (1.92)

BREWSTER, 225, BLAINE

Wlillams, HIchard J. Ont.6,'95: (1'05).

BRIOGEPORT, 54I, MORRILL

Inderson. Fictor $\left(\mathrm{b}^{\prime} 66\right)-\mathrm{M} \cap 20, \mathrm{BZ}$ (1'92)

I'almer, Claud (b'72)-Neb.5, $0 b^{\circ} ;\left(10^{\prime} 06\right)$

BRISTOW, 175, BOYD

Blak, Finar $Y$. (b'86)-Yeb.6.'13; (1'13)

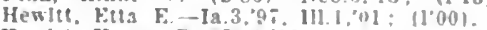

Hewitt. Henty F.-Ia.3,"97; $(1 ' 00)$

BROCK, 434, NEMAHA

lutgen. S. R.S: $(1 \% 91)$

MOFII. 30SEPII FRANKLIX (b"is) + -

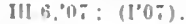

BROKEN BOW, 2.260. CUSTER

(OMHOS, GEO. O. (b'is)-Jeb.4,'11: (1'11). liurst, Warreo Thomas (b;s)- I11.22,"12; (1'12): OALR.

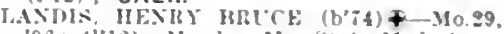

"96: (1'12): Member Mo. Siale Med. Assn. MELIAS, CIAS. I. (b'6i) \& leb.5.9!: (T)

Yullins, R. R.-Neb.5,9s; (l'9s)

PENAINGTON, GEO. E. (b'75)-MO.93,02:

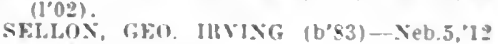

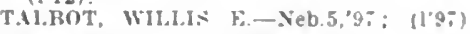

BROWNVILLE, 457 , NEMAHA

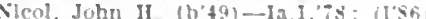

BRUNING, 353, THAYER

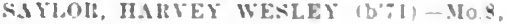
$97:(1,00)$

Sitratlot, bex B. (b'si) - Neb.6, 09: (1'09)

BRUNO, 245, BUTLER

JELISEK, JOIIS A (b' $\left(1^{\circ} 0 \mathrm{~s}\right)$.

BRUNSWICK, 278, ANTELOPE

Melerlan. Henry (b'0) III 1.96: (1'9:)

BURCHARD, 315. PAWNEE

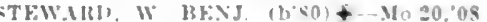

(1'li3): Memper has. Vel.

BURR, II3, OTOE

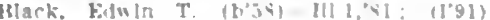

BURTON, 95, KEYAPAHA

Hoops. Marcus (bog) Yeb f.0e: (1'us).

BURWELL, 915, GARFIELD

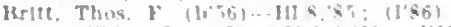

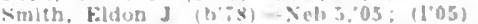

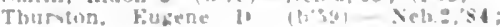
(1,:0:).

BUTTE, 550, BOYO

MFITTV, JoHI K (b'is) - Xieb 3.99 (1)

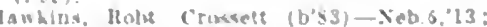
(1'13): Ob.

Warner, Kmua i Ia 8.93: (1'93). 
BYRON, 184, THAYER

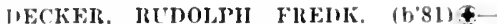
I'a.2,'06; (1'08).

CADAMS, 100, NUCHOLLS

JOIINSON, JASI'ER l1AN. (b'75)-Kan.4 02: (1'01); not In practice; Member Kan. Mled. Soc.

\section{CAIRO, 364, HALL}

liuegle, Fredk. II. (b'78)-Neb.6,05; (l’06) l'IEISOL, MARCLS R.Neb.4,01; (1"01). CALLAWAY, 765, CUSTER

BRYSON, lROY DOUGI.AS (b'83)-Neb.4, 0 ; : (l'11).

Davles, James Franklin (b'70)-Neb.5,'93: (l’97).

IATILES, ALEXANI)EIK I. (b'49)-0.2 '82; (1'91)

STORKAN, LOLIS JOHN (b'85)-Neb.6,'13 (I'13) ; Ob.

CAMBRIDGE, 1,029 , FURNAS

Aiken, saml. Armstrong (b'60)-N.Y.5,'87 ; (1'91).

IeCABE, FORDYCE H. (b'75)\$-Ia.4,99; (l'01).

\section{CAMPBELL, 573, FRANKLIN}

CUTLER, MORGAN GEO. (b'83)-Ill.4,'07 ; (I'11).

DUGAN, WM. F. (b'81)-I11.17,03, Neb.4.

'04; (1'04); CHRISTIAN V. (b'74) $₫$ Me.1,'10; $(1 ' 12)$.

CARLETON, 393, THAYER

Westerhoff, John G. W. (b'72)-Neb.5,'99 (1'99).

CARROLL, 382, WAYNE

Heeren, Edna Susanne (b'87)-Mo.28,'11; (1'11).

Phillips, Wm. H. (b'70)-Ia.8,99; (l'99).

Texley, Audrew-Mo.26, 00, Mo.28, 05 ; (1'00)

CEDAR BLUFFS, 500, SAUNDERS

BIAS, MARINE S.-Ky,2,'87; (1'98).

Hadley James E (b'60)-Neb.5,82; (l'93)

STUART, ANDREW E. (b'62)-Mleh. 7,86 (1'9I).

CEDAR CREEK, 175, CASS

Duff, John B.-Ia.1,'84; (1'91).

CEDAR RAPIDS, 576, BOONE

Burgess, Frank D. (b'66)-Neb.5,'88; (1'9I)

Hazle, Ilnor M. (b'48)-0.8,78; (l'91).

THELEN, ERNEST-Neb.6,07; (1'07).

CENTER, 119 , KNOX

CARMACK, ALBER'T ORTON (b'73)-Ill.I1, 04; (I'IO).

CENTRAL CITY, 2,428, MERRICK

BENTON, JOS. E. (b'76)-Neb.5,97; (1'97) Boyd, Earl Eugene (b'73) E- Neb.4,'06 $\left(10^{\prime}\right)$; Prof. Ped., Neb.4.

BROWN, ANDREW 'DOBBIE (b'86)-Neb.5 '12; (l'12).

FOUTS, FREDK (b'7) -Neb.6,02; (l'02)

Gawne, Wm. Y. R. (b'52)-N.Y.8, 80 ; (l'91)

Gawne, Wm. Y. R. (b'52) - N.Y.8,80; (l'91)
(ilatfelter, II arvey F. (b'69) - Id.I,'91 (l'98).

Hull, Solomon L. (b'53)-Ill.1,'89; (1'91)

CERESCO, 296, SAUNDERS

WOEPPEI, FREDK. W. 4 Neb.6,'05; (I'05) Wright, Frank Taylor (b'75) E-Neb.4, 07 ; (1'07); Prof. Jat. Med and Ther., Neb.4.

CHADRON, 2,687, DAWES

DEEMER, GEO. WM. (b'65) 4 - Ill.6,'94; (1'08).

FLMIS, BXRON C. H. (b'53)-Ill.10,'80; (1'03); T.

Gibson, IIenry C. (b'67)-Mo.29,00; (1'08).

MeDOWELL, MILTON BERLIN (b'75)Neb.5.02; $\left(1^{\prime} 02\right) ; S$.

VERNON, EARL LEON (b'83)-Ta.6,09; (1'10); OALR.

CHANBERS, 300, HOLT

(FILL, JAMES W. (b'80)-Neb.4,'12; (1'12).

OXFORD, EDWIX J. (b'80) - Neb.6, 05 : (l'05); Ob.

CHAPMAN, 266, MERRICK

TRIPLETT, JOHN M. (b'67) - Neb.4,09; (I'09).

CHAPPELL, 329, DEUEL

Patty, Marion B. (b'il)-Ia.10,01; (1'01).

\section{CHESTER; 560 , THAYER}

Spohn, Marlon W:-la.3,91: (l'97)

STIRTTON, IARRY H. (b'67)-Neb.4,95 (1'95).

Youngman. John W. $\left(b^{\prime} 54\right)-$ Mo.10,8.3 (1'91); G.

CLARKS, 605, MERRICK

('Irlstle. Ralph Conklln (b'83)-Neb.5.'0?:

DOUGLAS, ROB'T. RAYMOND, JR. (b'89)Neb.6.'1I: (1'11).

IITTIE, I.OWELL (b'79)-III.10,0I; (1'01)

CLARIKSON, 647, COLFAX

AISEN, SILAS GILBER'T (b'73) -Neb. $01 ;(1,02)$.

ZOERR, EDWARD FRANKIIN (b'77)\& III.1,10; (1'10).

CLATONIA, 233, GAGE

Deardorf, Benj. M,-1'a. 2,'96; (1'99).

CLAY CENTER, 1,065, CLAY

ARCIIERI), JOHN W. (b'57) - Neb.5,'91: (I'91)

IATTA, J. OSCAR (b'T7)-Neb.4,'02; (l'02).

CLEARWATER, 4i4, ANTELOPE

Bennle. James Walker (1)'82) - Mllch. I,'10: (l'12).

IIldebrand, Guy H. (b’52)--Ia.7,89; (1’91).

CODY, 185, CHERRY

Cornelius, Wm. R. (b'78)-Md.3,01; (1'01).

NEWMAN, MEYER HARRIS (b's0)৫-

Neb.5,'10; (l'10); $S$.

COLERIDGE, 535, CEDAR

BRAVCITT. FREDK. E. (b'68)థ-III,I,'94 (1'02): $S$.

DEWEY, FRED GIRARD (b'80)@-M1.11, 06; (1'09).

COLLEGEVIEW, I,508, LANCASTER

Jespersson, Sven (b'64)-III.11,'13

Shirely, Eva MeGee (b'70)-Ia.6,05: (1,13) OALR.

Shively, Jay Dow (b'69)-Ill.19,'00; (1'12)

COLON, I60, SAUNDERS

MeCAW, FRED WARREN (b'81)\$-Neb.6. $07 ;(1,07)$.

COLUMBUS, 5.014, PLATTE

ALLENBURGER, CHRISTIAN A.9-III.I, '95; (1'95).

CAMPBELL, CIIS. HARVEY - Ia.3,'98; (1'98).

EVANS, CARROLL, D. (b'56) ९-Md.3,'82 ; (l'93) ; S.

EVANS;WM. S. (b'63)-Md.3,'03; (1'03); S MARTYN, DAVID T., SR. (b'45) $†-I 11.6$ 69 ; (1'93).

MARTYN, DAVID T., JR. $\oplus-$ Neb.6,'01;

(l'01).
MORROW, FRANK HENRY (b's0) - Heb.5, 08 ; (1'08); S.

NEUMARKER, WM. RICHARD $\left(b^{\prime} / 8\right) \oplus$ II $0.29,00 ;(1,09) ; 1 . \star$

Ross, Saml. Boyd (b'84)-Md.4,'12; (Assis tant Physlclan): OpA

TIESING, BERTHOID CHAS. F. $\left(b^{\prime} 72\right) \oplus$ Ger.11,'95; (1'97)

Tímmons, Clifton K. (b'83) - Ill.22,'10 (1'13).

Voss, Lorenzo C.-Mo.5,'88; (l'91)

COMSTOCK, 323 , CUSTER

DRASKY, BRETILAV WM. $\oplus-$ N.Y.10,'01 ; (I'0I).

PREST, JOHN ELRY (b'78) - Neb.5,'04: (l'04).

\section{COOK, 387, JOHNSON}

Blumer, Fredk. Wm. (b'81) E - Neb.4,'08;

TOWNIEY, FRANK NEWCOMER (b'82)థ -Neb.4,'10; (1'10).

CORDOVA, 20I, SEWARD

DOUGLAS, GEO. G. (b'63) - Mo.1,'9I; (1'9I).

CORTLAND, 364, GAGE

Sawyer, Roy H. (b'73)-Neb.4,02; (1'02)

Sawyer, Roy H. (b'73)-Neb.4,02; $\left.11^{\prime} 02\right),{ }^{\prime}$ (1'12).

COTESFIELD, 300, HOWARD

JONES, HOB'T. T. $\left(b^{\prime}, 7\right)-N e b .6,11$; (1'11). COWLES, 190, WEBSTER

BOREN, ALBERT J. (b'82) - Mo.2,06 ; (I'09).
COZAD, 1,096, DAWSON

Dunn, John Erman(b'89) - Neb.6,'12; (1'13). FOC'HTMAN, JOHN H. (b'62) Md.3,'83;

MUNGER, IRVIA c. (b'75)థ-I11.17,00 ;

TAYMAN, ERNEST II. (b'78) $\$$-Colo.5, 08 ; (I'08).

CRAB ORCHARD, 274, JOHNSON

DOUGIAS, VOINEY D.-Neb.4,0T; (l'08)

CRAIG, 339, BURT

COOPER, IIFRBERT (b'67) - Neb.,,$^{\prime} 0 \tau$ (1'07).

Harvey, Andrew (b'84)-Neb.5,'13; (1'13)

Paddleford, ,Iames F. (b'\%0) - Ky.9,04; (l'04).

CRAWFORD, 1,323, DAWES

CROSS, ANNA M. $\left(b^{\prime} 55\right)-\$ N . Y .13,{ }^{\prime} 96$; (1'96) : Member Med. Soc. of N.J.; Ob.

HARTWELL, JANES E. (b'51) 9 -Mád,'91: (1'93).

IVINS, RICIIARD LXNOEUS (b'86)-Neb.6. (1I)

CIIATDS, BENI. FRANKLIN (b'74)STEPIIENSON. ANDREW VICTOR (b'69) Neb.5,96; (1'03).

CREIGHTON, 1,373, KNOX

BRIT'T, WM. H.-Ia.3,'84; (1'91).

BURRELL, RAMON HADDOCK (b'74)Mlch.1,00; (1'00).

CAMPBEL, WM. C.-1a.1'81; (1'91)

FLEMIING, THOS. N. (b'80) - Neb.6,'13 ; (1'13).

Hazen, iWm. $\rightarrow$; (1’9I). JOHNSON, CZAR C. (b'81) 9-Neb.6,07:

CRESTON, 338, PLATTE

MOLRIS, GEO. H. (b'78)-Neb.5,'05; (l'05)

CRETE, 2,404, SALINE

BYRNES, M. ROBT (b'70) -M-Mtch.10, $0 \pi$; $\left(l^{\prime} 07\right)$.

Hartman, Jesse (b’72)-Neb.7,09; (1'09).

PALLET', WM. H. (b'71)-Mo.8, $98 ;\left(1^{\prime} 98\right)$.

QUIRK, HOWARD W. (b'58)థ-0.6,'82;

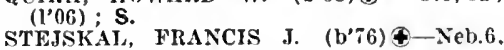
$06:\left(l^{\prime} 06\right)$

WARD. NARY WINIFRED TUCKER (b'8I) -Neb.5,'11; (1'II); G.

CROFTON, 6IO, KNOX

SWIF', CHAS. HENRY (b'77)-Ia.3,04: (1'10)

TALCO'T'T, DON LEROY-Ia.3,'04; (1'05).

Talcott, James M.-Ia.3,'96; (1'97).

CROOKSTON, 100, CHERRY

Beebe, Addison James (b'48) - Ia.6,'89; (l'12).

Vanden, Walter H. (b'72)-0.1,'95; (l'08).

CULBERTSON, 580, HITCHCOCK

FUNK, MARLEY E. (b'81) - Mo.22,'09 ; (1'09); $\mathbf{O b}$.

Miller, Alexander H. (b'49) - Mo.2,78; (1'92).

CURLEW, 5, CHERRY

Roth, Rollin G. (b'72)-Ill.16,'00; (1'08).

CURTIS, 6I3, FRONTIER

ANDREW'S, JAMES A.-111.1,93; (I'94).

Minnick, Clarence (b'79)-Ill.6,05; (1'05).

Rayee, S. R.- $\diamond$; (1'91)

Wilson, ivillis M.-Ia.9,'91; (1'91)

CUSHING, 125 , HOWARD

Raynor, Wlllis 'J. (b'56)-0.1,'80; (l*9I).

DAKOTA, 474, DAKOTA

MAXWELL, CHAS. H. (b'60) - Ill, I, 83 ; (1'92)

DALTON, 207, CHEYENNE

HEDLUND, AXEL EMANUEL $\left(b^{\prime} 79\right) \$$ Neb.6,08; (l'08).

DANBURY, 268, RED WILLOW

De May, Wm. Alonzo (b'57)-Mo.8,91; (''91).

DANNEBROG, 380, HOWARD

PEDERSEN, 1'ETER M. (b'71) $9-\mathrm{Neb.5}$ '04; (1'04).

DAVENPORT, 484, THAYER

Du Vall, Geo. R. (b'S0)-Mo.29,'04; (l'08) Du Vall, Grace it. Bliss (b'80)-Mo.29, 02 ; $\left(l^{\prime} 08\right) ; G$.

MILBOÚRNE, PERCY ELMORE (b'74)Mo.22,'10; $(1 ' 10)$.

SNOWDEN, CHAS. C.-Pa.2,'82; (1'91). 
DAVIO CITY, 2,177, BUTLER

UEEIPE, SIMOX C. (b'64) + Ja $3 .^{\circ} 91$ (1'91): (Ai): S.

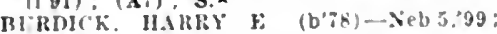

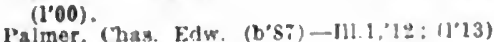

Palmer, (has. Edw. (b's )-T11.,

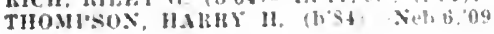
(l'03).

DAWSON, 340, RICHARDSON

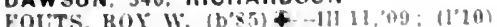

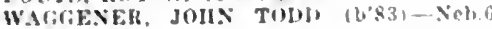
"11: 11,111 .

DAYKIN, 220, JEFFERSON

BIBW: HARLI RICHABDE-MO 36,00 $(1,0:)$

Humphrey, Hall II (b's) - Neb4,"13 (I'J3).

OECATUR, 782, BURT

GREGG, WY. B-1)

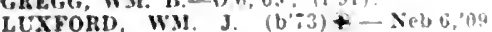
(1'09).

SEARS, EDGAR A.-Ia.ti,ss; (1'9l)

STEPHENSON, WM. J. $\left\{h^{2}, 2\right)$-I I I. 8,36 (1'91).

DESHLER, 609, THAYER

HFKNEY, ADAM-MO.:2,93; (1'9;

JOHNSOS, AIFRED (b'-9) +- Mo. 6,07 (1'07); Member Kan. Med. Soc.

DEWEESE, 250, CLAY

Baker, Frank Lawrence (b'S5)-Xieh.'10

(hamberlain. Andrew J.-Mo.18.'s3; (1'91)

DE WITT, 675, SALINE

Cross, Guy B. (b'T)-Neb.6.04; (1'0t).

Cross, Leroy J. $\left.\left(b^{\prime} 40\right)-a_{i} ; l^{\prime} 91\right)$.

Maharfay, Andrew De Wits (b'65)-Mo.3 02: (l'03).

SLOSS, GEO. A-MIch.8,99: (1'99)

DILLER, 506, JEFFERSON

Banguess, Harrs (b'73)-Xeb.5.99: (1'?4) DIEIII. OLIN CARL (b'i2)-Neb.fo' (1'02).

DIXON, 217, DIXON

FYYNS FRAXK BITI.ER (b'8I)†-111.6 04: $(1,0 \%)$.

PIILLLII'S, CI.ARK I.. (b'85)-Neb.5,'12 (1'12).

DODGE, 66I, DDDGE

Capek Ennest Jos, (b.70)-Aus. $7.95 ;\left(1^{\prime} 02\right)$

Capek, Ernest Jos. (b'70)-Aus, i, 95 ; (1 02$)$ oi: (1,0 :

Patterson, Fredk. B. (b'83)-0nt.6,04: (1'06).

DONIPHAN, 399, HALL

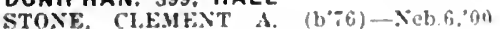
(1'00).

DORCHESTER, 6I0, SALINE

('ase, Jarues D. (b':4) L-Neb.4,01: (1'02)

Holbrook (has 1 (b'+9) k-III \& (1'91)

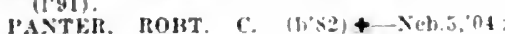
(1.04)

Waller. Jos, b. (b'sz) E-Nel 4,'96: $(1,96)$

DOUGLAS, 305, OTOE

Hosteller, Allen II. (b's.8)-Ill,1, 86 ; (1'91) DUBOIS. 339, PAWNEE

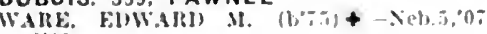
(l'0i).

DUNBAR, 216. OTOE

riluton. Wm. Marles $(1,2+1)-$ I in 5,95 (l'03).

DUNCAN, I50, PLATTE

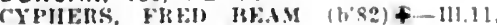
O:: (1.0i): OALR.

DUNNING, 120 , BLAINE

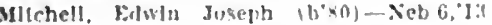
(1'13).

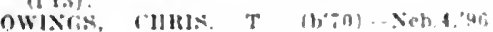
$\left(l^{\circ} 05\right)$

DWIGHT, 184. BUTLER

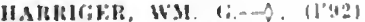

EAGLE, 360, CASS

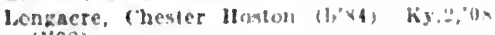
(1'08).

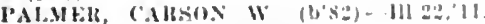
EDDYVILLE, 254, OAWSON

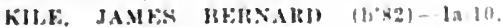
oti: $(1,10)$.
EDGAR, 1,080, CLAY

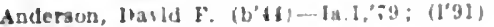

S.

asterline, latph W. F. $\left(b^{\prime} ; 0\right)$-Neb.6.'95 $\left(1^{\circ} 95\right)$.

GHMM, IETER c. (b' $\left(1^{\prime} 93\right)$

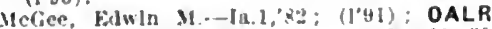

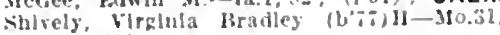
$07-(1,00)$

W'laston, John S- - la.l, du: (t'91).

EDISON, 334, FURNAS

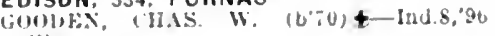
(1'yu).

ELBA, 302, HOWARD

HAHT. JUIIN (1.04)

ELGIN, 606, ANTELOPE

Cunwell, baul Larsh (b*9)-Xet.j,0: (I'07); ObG

basidson, Carnel 1. . Man.b,9e: (1'00) PALR.

leallan, lillbert A. (b'til)-que.1,"90) (1.91)

Peterson, Wm. A. (b'59)-111.1,86; (1'91).

ELK CREEK, 240, JOHNSON

HOWAll1, S(1.1.WAX (b'65)-('olo.1,92 (l'92).

ELKHORN, 29I, DOUGLAS

burke, Thos. $\therefore$. (b'5)-Neb,6,04: 11'0\$1.

IIall, Gllbert II.-X.r.19,01; (l'vì)

ELM CREEK, 620, BUFFALO

Frank, J. W.-Ia.l, $70 ;\left(l^{\circ} 91\right)$.

Laughlin, Joseph Wilson (b'35)-Neb.5,' L' (1'13); Ob.

conkr cilas a (b'75)-Nebt,02; (l'vol

ELMWOOD, 635, CASS

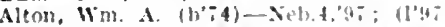

LISTON, OSCAR EARL (b'83)-Mo.20,10; (1'10). (1'96):

ELWOOD, 464, GOSPER

CLARK, (IUY W. (b'i3)-Xieb.6, $04 ;(1.04$

EMERSON, 838, DIXON

FYANS, IIORHIS H. (b'56) \$-0.14, 84 (1'91).

MAROXDE, JOHX A. (b'i4) $4-1 \mathrm{a}, 8,04$ (I'O1).

ERICSON, I50, WHEELER

keen, Edwin Rudewln (b'tal) - Ind $260^{\circ} 9$ (1'08).

EUSTIS, 403, FRONTIÉR

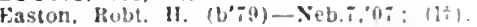

IIale, Norman Toti (b'tit)-Ill.l, eti: (l'lo

EWING, 440, HOLT

HRIGGS, WALTH:1? II (b"t) +-1a.3, (1'03).

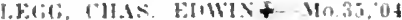

EXETER, 916. FILLMORE

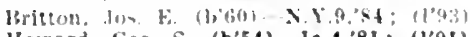

Howatd, Geo. S. (b'54)-1a.4, 81 ; (1'91).

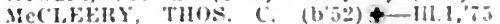
(1) 101$)$

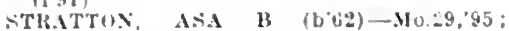

(l'00). Wm \&-MIch 8,$95 ;\left(I^{\prime} 9 \pi\right)$

Whgens, Win s $(1 \div)$.

FAIRBURY, 5.294, JEFFERSON

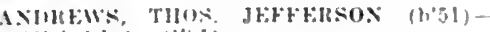
Illels $1.2,2 ; 11^{0} \$ 11$.

Clarke. Ilariay hlewellsn (b'58)H-MJch.b (N): $(1,91)$

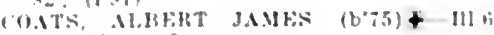

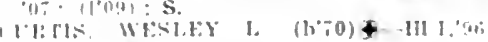
OALR*

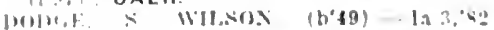

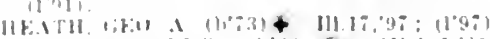

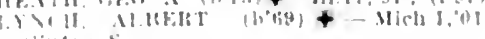

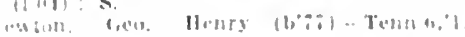

(1)

P.litis

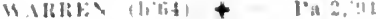

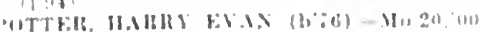

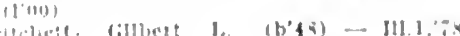

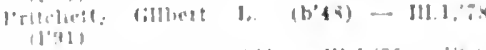

FAIRFIELO, 1.054, CLAY

BENT\%, GLO. H. (b'il)-MO8,02; (1'0:3\}

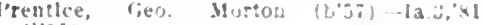
(1.01)

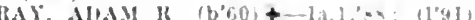

Reves, Alfred $k$. (b'sl) Mo

S.

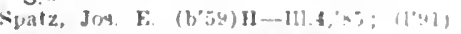

FAIRMONT, 921, FILLMORE

Ashby, sherman $F^{*}$. (b'66) $11-1 ! 14$ (In,

CAIRI, JESSE MYHON-III S,05: 11005

FALLS CITY. 3,255, RICHARDSON

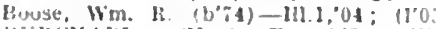

LELCHARI, (HAS, T, (t'5tj)-111.1, :5; (1) 61$)$.

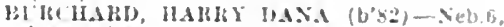
(1): (1'0)

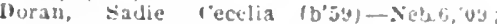

(1'! (0).

Grene, Joln Morton (b'7t)-K):2, w2

$(110): \mathrm{S} *$

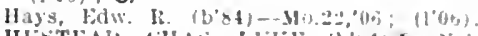

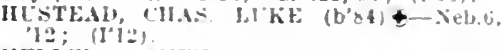

KELLEL, ANTHANY (b'51) - Pu2, 83 (1'92).

Keller, Fredk. A. (b'a) - W0.22, (102; 1102$)$ Lang, Oscar Fredk. (b's) - 111.6,05; ("1:)

Lakrence, Emma d. (b'60)-Mo.29,05; (1'06)

Mtner, Heury R. (b'69) II-III.10,'91: (1'y

Reneker, Geo. Wlrt (b't)-Mo.ls, Mo.19,99; (l'00); OALR.

WIISOS, MLLAHI LEWIS $\left(b^{\prime} 6 b^{\circ}\right)-X e b 4$ 96 ; (l'09).

FARNAM, 462, DAWSON

LIGGITT, JOHX M. (b':2)-0.3,"5i; (109:)

FARWELL, 246, HOWARO

Pedersen, Hans C. (b'S3) - Neb."B.'05; (1'0:)

FILLEY, 194, GAGE

Loggs, Chas. S.-Neb.1,84; (1'01)

FIRTH, 343, LANCASTER

Claybaugh, Wrn. W.-111.1,83; (1'81)

FLORENCE, 1.526, DOUGLAS

AIAMS, ARTHEH B.-Neb.6,05; (1'0.i)

forton, Warren H. (b'+3) II-Mo.26, (1'97)

OSS, WM. LYTLE

(See Onaha.

Teal. F'r

FORDYCE, 150, CEDAR

NAGELMANS, CH.MIESS 16.81) + Néb.6, 09 ; (1'09).

FOSTER, 122, PIERCE

CRAFT, WM. T. (b'69)-Neb.5,'02: (1'02). FRANKLIN, 949, FRANKLIN

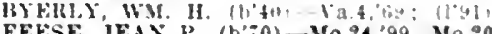
FELSE, JEAN R. (b'70)-Mo.24,'99, Mo.20. 01: (1'01).

S.ITH. $11 \mathrm{Al}$

FREMONT, 8.718, DODGE

Rell, Xellle (6 102$)-11,26,95 ;(1995)$

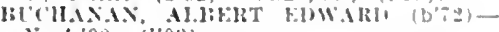

Vit +001$):(1,03)$

chlixis, flet: (1'49).

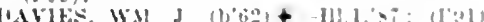

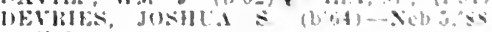
(1"91):

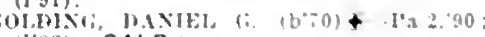
(1'92): OALR.

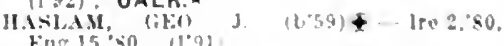

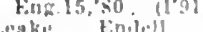

MIITIN.

(1) 911

(He)

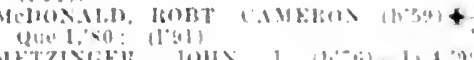
(1) 0101 OALR.

(1) Jeim 111.1,01: 11.011

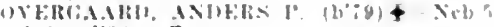

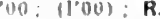

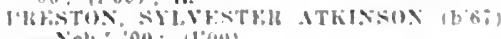

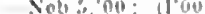

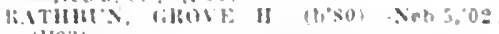

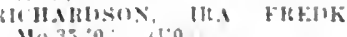

$11, \div 31-$ 


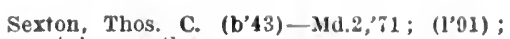
not In practice.

SMIITI, IIERBEITT HOMEIS (b'69) † N.Y.10,96; (l'96); Member Mo. State Med. Assn, : OALR. *

SMITH, LEANDER B. (b'10) †-Ia.I,'is (1'91); not in practlce.

VAN METRE, RICHAIRD TIOMPSON (b'70)-1a.3,05; (1'12).

Welland, Johann F. E.' (b,62)-Colo.2,04 (1'05); OALR.

FRIEND, 1,261, SALINE

FARIVELI, FLETCHER J, $(\mathrm{b} \% 0)+-110.22$, 09; (1'09).

Gerblg, IIerman A. ( $\left.\mathrm{b}^{\prime} 78\right)-111.22,08$; (1'13) HAMILTON, FRANK T. (b'76) \-I11.4,04 $\left(l^{\prime} 08\right)$

HoY'T, ANDIROS W. (b'56)-Ia.6,'92; (1'92) I'LAT', IRICIIALE BELT' (L'S4) +)-111.16, 09 ; $\left(l^{\prime} 10\right)$.

FT. CALHOUN, 324, WASHINGTON

CUR'TIS, JOS. NI. (b'66) \&-Neb.5,94 (1'94).

I'ETTLNGILL, SOMELS T.-Ia.3,'79; (1'91). FT. CROOK, 203, SARPY

DELANNEY, EMIILY I.

(See South Omaha.)

FT. OMAHA (OMAHA P.0.), - DOUGLAS

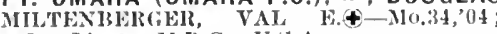
Ist Lieut., M.R.C., U.S.A.

FT. ROBINSON, 200. DAWES

HARNETT, EUGENE HOWE (b'70)థN.Y.1,94; Maj., M.C., U.S.A.

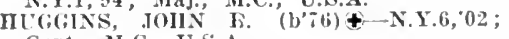
Cnut., II.C., U.S.A.

FULLERTON, 1,638, NANCE

BATES, llENRY Y.-E-0.2, 'T6; (1'93)

JOIISON, FITANK WARIBEN $\left(b^{\prime} 67\right) \oplus$ Neb.5,94; (1'94).

JOIINSON, IOIIN F. (b't1)-0; (l'91).

O'HAVER, PAIL C.-Ia.10,04; (1'04).

GARRISON, 177, BUTLER

IROH, CARL F. (b'64)-Mo.20,92; (1'92).

GENEVA, 1,741, FILLMORE

BECK, FREDK. L. (b'71)૯-Neb.5,'03; (1'03). Jos $\left(\mathrm{b}^{\prime} 75\right)+-150.20,00$; (l'00). RIAKELEY, NATHAN II. (b'69)-Neb.6. $10 ;\left(l^{\prime} 10\right)$

MOZEE, GEO (b'45)-0.8,66; (l'91).

MOZEE, GEO, (b'45)-0.8,'66;

Mozee, Wm. T. - O,8,75; (1'12); (l'91)

Wallnngsford, Chas. Curtis (b'7)-Neb.4, '11; (1'12)

WOODS, ROYAL (b'64)€-Ta.1,'89; (l'91).

GENOA, 1,376, NANCE

GAVIS, IIONER (b'68)-Neb.5,00; (1'09) (Indian Service): Genoa Sehool

KING, H. EUGENE (b'75) $₫$-Neb.6,03 ; (1'03)

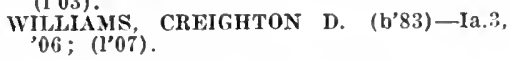

GERING, 627, SCOTTS BLUFF

Flx, Georgia A.-Neb.3,'85; (l'91).

KNODE, ROBT. C.-Neb.5,'98; (1'98):

Ilember Wyo. State ISed. Soc.

GERMANTOWN, 275, SEWARD

Atha, J. Frank-Neb.4,07; (l'0 $\left.{ }^{i}\right)$

GIBBON, 718, BUFFALO

Melean, Robt. F. (b'83)-Ont.6,06; (1'07)

MILLER, JAS. W.-11l.1,'84; (1'91)

GILEAD, I81, THAYER

IIAGILI, J. L. (b'T8)-Mo.20,'00; (l'00).

GILTNER, 300, HAMILTON

Browne, Chas. F. (b'53)-NIo.18,'81; (1'91).

Wainwright, J. S. ( $\left.b^{\prime} 78\right)$-Neb.5,'01; ( $\left(1^{\prime} 01\right)$

wulsteln, Wm. J. (b'70)-Ill.4, 03 ; not in practice.

GLENVILLE, 304, CLAY

Bailey, Hugh I. (b'57)-0.8,91; (1'91).

MARTIY ROY DAVID (b'85) - Neb. 5 , '11; (1'11).

GOEHNER, 350, SEWARD

HAMIBLE, VIRGIL ROSS (b'84)థ-Mo.22, 10; (1'10).

GORDON, 920, SHERIDAN

Dwyer, Edw. H. (b'72) -Mo.28,98; (l'03). Elmore, John Q. (b'51)-Tenn.6,'S8; (1'91). GOTHENBURG, 1,730, DAWSON

BARTHOL(MEN, WM. J. (b'5T)-M0.18,

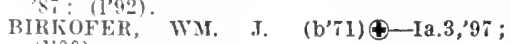
$\left(l^{\prime} 00\right)$.
MOORE, MILES STANDISH (b'73) QU1NN, J011 11. (b'57)๑-Ill.1,80; (1'91). GRAFTON, 353, FILLMORE

SWEENEY, EDWARD E. (b'73)@-Mo.20, '08; (1'08); G.

GRAND ISLAND, 10,326, HALL

BAKEIR, ANDIEW J. (b'59)-Neb.5,'92 (1'y2); 1303 W. 1st St.; offlce, Hedde Bldg. : $10-12,2-5$.

BOYLEN, IIENIR Y BIAKESLEE (b'89) 111.1 ,'ll; (1'I2); 122 k. $2 \mathrm{~d}$ St.; oftice, $3 \mathrm{~d}$ and PIne Sts.; $2-5$; $\mathbf{S}$

CIBSON, DAY'1D H. '(b'66) - Neb.6,05 (1'05); Dolan 13ldg.

Defenbaugh, Martin II. (b8)-Neb.4,04 (1'04); $505 \mathrm{~W}, 10 \mathrm{th}$ St.; office, $121 \frac{1 / 2}{\mathrm{WW}}$ d St.; $10-12,2-5 ; T$.

Dungan, Fdward stacey-Pa.9,'00; (1'02) ENGLEMLAN, WM. T. (b'79) †-Neb.6,09 (1'09); 110 West 8th St.; offlee, Hedde Bldg. ; 10-12, 2-5; R.

FARSSWORTH, ALBEITT HENRY (b'75) \& -111.10.00; (1'00) : Hedde Bldg. ; S.

FAlRASWOR'II, EARLE EDIVIN (b'81)IIass.1,'12; (1'12); i15 W. 2d St.; office,

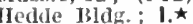

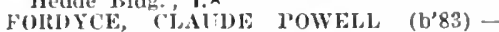
IIo.2,'10; (l'10); Soldiers' and Sailors'

Hetien, Wm. Jos. (b'58)-Ia.9,'95; (l'10) ; Dolan Bldg.

IIGGINS, JOS. E. (b'78)-Neb.6,04; $\left(l^{\prime} 04\right)$

Iloge, Wilmer Brown (t'62)-Mlch.1,'86; (1'91) ; 512 W. 2d St.; office, $3 \mathrm{~d}$ and locust sts. : $10-12,2-4$.

KELLEY, PETER C. (b'T0)-No.28,'98; $\left(l^{\prime} 00\right)$.

LINGENFELDER, JULIUS $\left(b^{\prime} 64\right) \oplus$-Ger.I0, 89 ; (1'93); Member of Mo. State Med. Assn.; 1015 w. 2d St.; offee, Hedde Bldg.; Or.

MeGRATII, BENJ. R. (b'73)థ-Ill.11.'02 ; (1'02); 1018 W. $10 \mathrm{th}$ St. ; offiee, $1111 / 2 \mathrm{~W}$. 3d St.; $10-12,2-5$; $S$.

Pells, Edna Smith-; (l'09); 2151/2 W. 3d

PHEL 9-12, 2-5. (1'07); 1109 Koenig St.; office, 117 W. 3d St. ; $9-12,2-5$.

Rleh, Max L.-Neb.5,'93; (1'95).

ROEDER, CLYDE AUGUSTUS (b'83) $\oplus$ Conn.1,07; (1'08); 616 W. $2 d$ St. ; office,

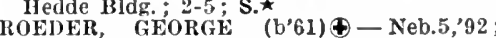
(1'92); 616 W. $2 d$ St.; offlee, 115 W. 3d St. ; $2-5 ;$ S. $\star ~$

Spence, Edith H. Saunders $\left(b^{\prime} 78\right)$-Neb.6, '01; (1'01); 1316 W. $2 d$ St.; office, MeAllister Bldg.: 10-12, 2-5.

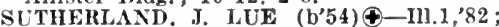
C1.91) (1'91); 212 W. ith St: ${ }^{2}$.

Weeter 'G. Washington (b'4i) -0.6,76; (1'91) ; $121 \mathrm{~W}$. 81 st St.; offlee, W. $3 \mathrm{~d}$ St. ; $10-12,2-5$.

GRANT, 358, PERKINS

Bell, Flrman Merrill (b'i3)-Mo.29'04; (l'04).

GREELEY, 845, GREELEY

Bowen, Geo. Sanford (b'60)-N.Y.8,'83;

(l'91).
Brannen, James L. (b'69) - Neb.6,'01 ; (l'01).

LONG, JOHN H.૯-Mlnn.3,'88; (1'92).

GREENWO0D, 387, CASS

Jones, Agnes Houston (b'76)-Neb.4,'06; (l'06).

JONES, EDW. I. (b'64)-Neb.4,05; (1'05) Member State Med. Ass. of Tex.; Prof. Mat. Med. and Ther., Neb.4.

TALCOTT, NORRIS 'D. (b'T0)-Ta.8,'96; (1'97).

GRESHAM, 344, YORK

IARRIS, SQUIRE OLIVER (b'79)ÐNeb.6,'10; $\left(l^{\prime} 10\right)$.
YLTON, WH. NATHANIEL (b'62)-Neb.1, HYLTON, WM. NATHANIEL (b'62)-Neb.1,
'86; (l'91)
JOHNSON, AMOS FRANK (b'74)థ-Neb.6, '04; (1'04).

GRETNA, 484, SARPY

Hilsabeck, Lester Clyde (b'83)-Neb.6,'10 ; (1'10).

Keyes, Edw. C. (b'7n-Neb.5,02; (1'02);

not in practice.

Murphy, Wm. M.-Mo.18,'88; (l’91).
GUIDE ROCK, 690, WEBSTER

AMBROSE, ADDISON LEE (b'54) Mlch.5, 82 ; (1'10).

P'ACE, IRA A.- Vt.2,'91; (1'98).

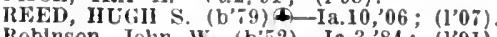
Robinson, John W. (b'52)-Ia.3,'84; (1'91).

HAIGLER, 205, DUNOY

PItEMER, JA IIES FIREIK. (b'81)†-Neb.5, (

ELCII, MORTON GIFTORD (b'88)-Neb.4, '12; (1'12).

HALLAM, I68, LANCASTER

TEMILE, ('LAUDE: II.-Neb.4,94; No.7, $95 ;\left(l^{\prime} 94\right)$.

HAMPTON, 500, HAMILTON

Gelow, John E. (b'?9)-Ill.6,05; (1'05) Neb.5,'11; (1'11); S.

HARDY, 496, NUCKOLLS

Anderson, W'm. Meredlth (b'78)-Mo.20,08; (1'12).

fiauffman, Enamuel-Pa.2,89; (1'92).

HARRISBURG, 186, BANNER

l'ackard, W'm. Harlan (b'79) - Neb.6,'05; (1'05); not in practlce.

PAGE, CLIFFORD S. (b'75) $\$-C o n n .1,96$; $\left(l^{\prime} 05\right)$.

HARRISON, 186, SIOUX

CRAMER, LLOYD L. (b'86)-Neb.6,'11 ; (1'12).

Priest, Wendell II. (b'\$3)-Neb.6,'10; (1'10). HARTINGTON, I.413, CEDAR

DORSEY, FRANCIS P. $\left(b^{\prime} 67\right) \oplus-K y .2,95$; (l'96).

King, John Wm. (b'63)-Mleh. 7,86 ; (l'91). Paden, Frank A-11l.4,07; (1'08).

Stark, Lucien (b'82)-Neb.6,'03; $\left(1^{\prime} 03\right)$; not in practice.

HARVARD, 1,102, CLAY

BUTLIR, FLETCIER ASBURY (b'54)†Ky.4,79; Ia.1,82; $(1,91)$; $\mathrm{s}$.

Howard, Isaae D. (b'40)-Pa.17,70; (1'91).

JENISON, ANDREW J. (b'62)-Ia.3,95; (1'95).

SEELY, HENRY HAMBLIN (b'72)-Vt.2, '98; (1'10); Member Vt. State Med. Soc. Skinner, Leander $\mathrm{Z}$, (b'66)-Md.4,'94; $\left(\mathrm{l}^{\prime} 07\right)$.

HASTINGS, 9,338, ADAMS

ARTZ, CHAS. V. (b'58)-Ia.3,'82; (1'09). Bamford, Saml. E. (b'59)-Ia.1,89; (l'06): (1'91).

Blackman, Jullan Raymond (b'78)-Md.7, '06; (1'12); G.

CALBREATH, ClAUDE BERNARD ( $(;, 8)$ (- Ia.9,98; (1'10)

EGBERT, CHAS. LLOYD (b'78)థ-111.11, 03: (1'03); S.ネ

FOOTE, EU'GENE C. (b'79)-Neb.6,05; (1'05); OALR.*

HAHN, OSCAR HERMAN (b'85)†-Mo.22, '08; (1'10); s.

HA.MEL, EI

Harper, Glenn Carl (b'85)-Ill.4,'13; (l'13).

OPKINS, SAML. R. (b'76)థ-Ill.1,00; $\left(1^{\prime} 07\right)$; S.*

JONES, SHERMAN J. (b'̃8)@-Ia.1, 91 ,

IIl.1,'98; (1'91).

KEITH, WELLINGTON W. (b'65)-Neb.4, 02; (1'02).

Lightner, Theodore-MId.3,'80; (1'92).

Marble, Russel Ross (b'71)-Mich.1, 02 ; $\left(l^{\prime} 02\right) ; R . \star$

Naulteus, Francis-Ky.2,'94; (1'92).

O'HARA, WARREN JOS. (b'67)థ-Ill.1,91; (1'10).

Putt, Wm. T. (b'51) E-0.2,74; (l'92):

RIDDILE, JOS. P. (b'59)-0.1,'85; (1'91);

OALR. $\star$

Robinson, Amy R.-Mfich.10,01; Neb.4,02 ; (1'01) Prof. Med. Gyn., Neb.4.

SCHAUFELBERGER, FRANKLIN (b'67)Pa.2,'94; (l'94); 0 b.

CHAUFELBERGER, FREDK. J. $\left(b^{2} 50\right) \oplus$ Pa.2,'84; (1'91); Ob.

Schunk, Clara IIargaret (b'82)-Ill.11,'10; (1'13).

STEELE, JOS. TURNER-IIl.1,'83; (1'91) ;

STRAIGHT, JOHN W. (b'68)-Neb.5,91; (1'91); OALR. 
HAVELOCK, 2.680, LANCASTER

BAI.LA HI), (HARI.ES $r^{\prime} \cdot\left(b^{\prime} 56\right)+-I n d .8$, $\because 9:(1.91)$.

LI.TON, HAKl? A. $\left(b^{\circ} 68\right)+$-Neb.5,98: (1.98).

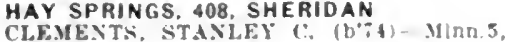
$04:(1,13)$

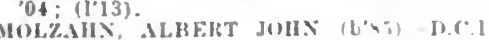

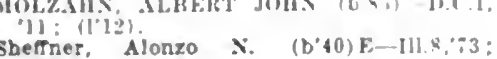
Sheffner.
(l'92).

\section{HEARTWELL. 100, KEARNEY}

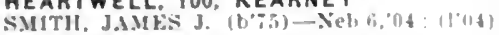

HEBRON, 1.778, THAYER

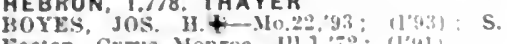

Faston, Cyrus Moarue-lili, 72 (I"ul)

HENRY, CHAS. (b's9)+-ia3:86: (1':1).

squires, U. II.-0.7, $\mathrm{s}:$ : (1'01).

TAYLOR, GUL 1 , -

HEMINGFORD, 272, BOXBUTTE

BOLAND

(l'08).

Kunz, T. O. $\rightarrow$ : (

Ilttle, Thomas wm. Whlte (b':5)-Ja 1,00 (1'01).

McEuen, ollver (b'6h)-Mo., : 89 : (1'0!b)

Moranvilie, Calvin $L^{\circ}\left(b^{\circ}, 0\right)-0:\left(l^{\prime} c_{1}\right)$

HENDERSON, 39I. YORK

H'ETEKSON; WILLIAM
"09; (I'09).

(lis $s$ ii) - vel: bis

HERMAN, 345. WASHINGTON

CAMEROX, ALI.A. J.- OmT.3, nn: (l'01)

CLARK, PERRY JACOB (b) - Uiml

'83; ( 1 '91).

HERSHEY, 332, LINGOLN

Jystrom, John Oscap-h-111.8,00; $1 \mathrm{H}^{\prime} \mathrm{l}$

SADLER, WM. W. (b'75) -I I.. 10, 02 ; 1102

HICKMAN, 388, LANCASTER

Strough, Geo. W. (b'70)-Yeb.5,'96; $11^{\prime 4}$ :

ALR.

HILDRETH, 450, FRANKLIN

LYON, JOHN L. (b'St)-KY.1, $0 ;$; (1'12)

Yember $\mathrm{hy}$. State Med. Assn.

NE1TLLE, DENXTS (b' 61 ) - $111.17,00: 11^{\circ} 01$

HOLBROOK, 4I4, FURNAS

Lyon. Chas. Walter (b'-5)-Mo.27. (1'98.)

HOLDREGE, 3.030, PHELPS

ANDFRSON, JAMKS C. (b'S8) + Vel. 6 , (10"

Palmer, Danlel s.-E-0.2,90; (l'9I)

SANDERS, SAML, F. (b'45)-Mo.1.;2

(II'91), WM. DAYTON (b'5i) \&-Ind.s 86: (I'91); OALR.

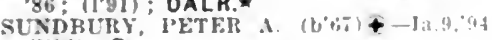
(1'94); $S$.

Warrick, James E. (b'6t)-Md.3,'ss; (1':1)

OALR.

Whilter, Geo. X-II-III.4,88; (1'91)

HOLMESVILLE, 168, GAGE

WOBLE, LLCIAX I.-\$O.18,94; (1.44

HOLSTEIN, 323, ADAMS

CAKSON, WY. T. ('b'67) -Ia.3,'89; (1'9!

HOMER, 397, DAKOTA

Smlth. Nina Ream (D'63)-Ia.8,00; (1'01)

Sildworthy, Danl. B. (b'64)-Ia.8,"94; (1'yt)

HOOPER, 741, DODGE

HAUSER, IBYHON H. (b'71)—-Md.3,98

MFINE; w. HOWARI $\left(\mathrm{b}^{\prime} 77\right)+$-Neb. 5,05

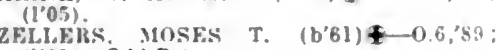
(1'91): OALR.*

HORDVILLE, 125, HAMILTON

Jarmin. Firnest Geo. (b'86) k-Neb.4,08: (]'08).

HORSEFOOT, 7, ROCK

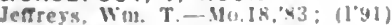

HOSKINS. 262, WAYNE

Parchen, Ilenry W.-Mo.18;'\$2; (l'92)

HOWELL, 800, COLFAX

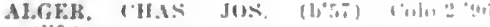

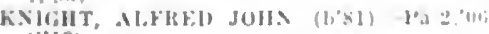
(10 13$)$

MYKS, HEDI WFY

$\left(l^{\prime} 00\right): \mathrm{S}$.

HUBBELL, 295, THAYER

(l'13).

whon. Fredk-X $4.6 .83:(1.99)$
HUMBOLDT, I 176, RICHARDSON

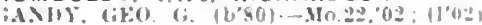

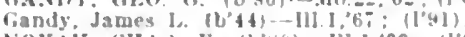

NOVAK, (HAS, F. (b's0)-III.1,03; (I'03)

WAGGEDER, JOIIN 1 . (b'52)-K5.4, (I.0I).

WArGisk, WM. H. (b's1)-Neb.6,05 $\left(l^{\circ} 05\right)$

HUMPHREY, 868, PLATTE

'auley. Anthuny- Neb.6,'04; (1'05)

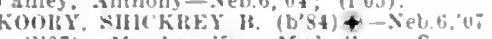

(1'07): Munler Kan. Med. Soc.: S.

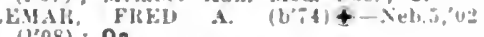
(l'08): OD.

HUNTLEY. 185, HARLAN

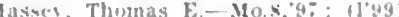

HYANNIS, 262, GRANT

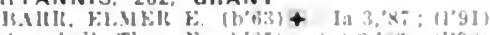

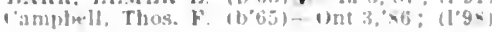

MPERIAL, 402. CHASE

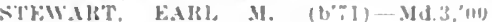
(I'UI): $\mathrm{G}$.

INAVALE, 250, WEBSTER

Ilatiln, irthur 1b. (h65)-Ja.9,96; (bou)

Ililllips, Alford I:-0.5;83; (1'04)

INDIANOLA, 68I, REDWILLOW

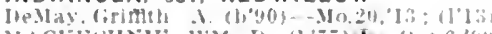

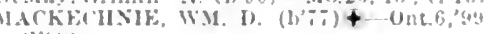
(1.9.3)

INGLESIDE, 500, ADAMS

BAXTER, NAKK WM. (b'62) \-Smith inlf., Jeterboruugh, Fing.'s, lat.", (1) 633 ;

H.tilis

(j) 97$)$

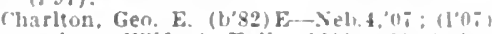

'rutcher, Wilford Hall (b's:)-Mo:zs, (0. (l'0s): U.

Ilayden, rlara May (b'S0)-Ia.3,07; (l'1:a)

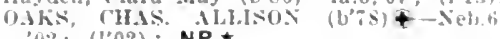

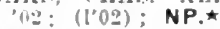

INMAN, 225. HO! T

(1)EE WIILIAM WALIACE (b'S2)-

NiEb. 0 : : (1'08).

ITHACA, IZI, SAUNDERS

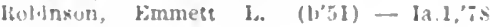
(1'01)

JANSEN, 308, JEFFERSON

IBISIIOI", JOILN I'. (b'T(i) - 0.1,'(1); (l'11)

Member Ky. State Med. Assn.

JOHNSON, 273, NEMAHA

ian Osdel, saml. Irthur (b'76)-Mo.2\% $02 ;(110) ; \mathbf{G}$.

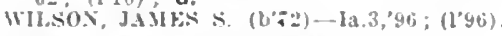

JOHNSTOWN, 200, BROWN

'ameron, Hugh ('ampbell-Ont.1,'00; (l'02)

JULIAN, 168, NEMAHA

'KLLI", SETH J.-Md.4,'90: (1'93).

JUNIATA, 471. ADAMS

('KLEY, GI'Y WISFRFI) (U'S6)-Tenn.LL, (09; 素).

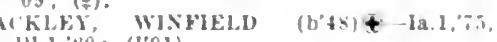
III. 1. $\$ 0$; (J'91).

KEARNEY, 6,202, BUFFALO

BASTEX, C. YAN DYCK-la 4, 83 ; (l'9l)

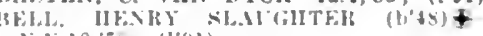
V. 1. $10, \because 5 ;(1 \circ 91)$

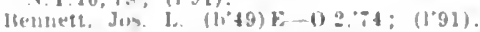

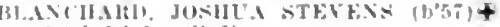
Hich. l, sl: (l'02).

('ammern, Alex I1. (b'62)-Ont.5, s'2: (l'41)

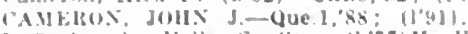

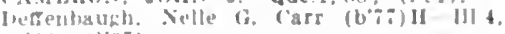
"(ni; : $(1007)$.

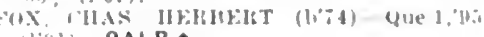
(I')1): OALR.*

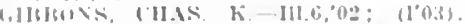

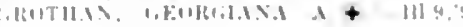

Il hierd, Induert Is. (b'st)-Neb.6.1\%

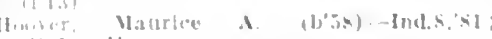
U.

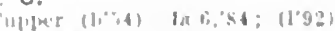

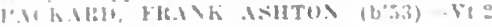
(1) 31$)$

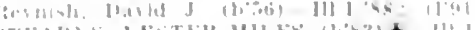

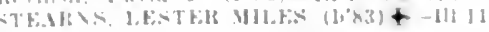

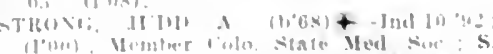

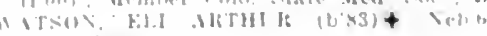

KENESAW, 657, ADAMS

Iatta, Eiltert Jolunkton

(l'94); I'rol. Med. Sieb.

Mouers Walter V. (lin I) - Xeh bi, (us: (1'09)

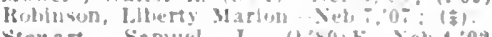

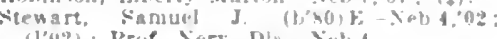

(l'uz): Prof. Verv. DIa., Deb a

KENNARD, 319. WASHINGTON

ANIDEREON, JAMES HIJAS

Neb.6,10; (1'10).

I. (1'9I).

KILGORE, 200, CHERRY

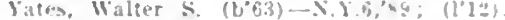

KIMBALL, 454, KIMBALL

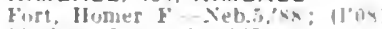

Jockest, Fercy C. (b'-i)-Colo. 1,01: (1'02),

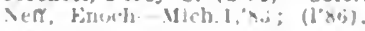

LAUREL, 3I4, CEDAR

IIAY JAS. ( $\left(1,{ }^{\circ}(1)+\right.$ Man 1,$\left.4 ;(1)^{2}\right)$ Ia.3, 'YS; (1'0A).

LAWRENCE, 475, NUCKOLLS

Barrelte, Juth F.-IT-Ia.t?

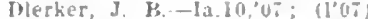

LEBANON, 197, REDWILLOW

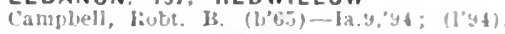

LEIGH, 567, COLFAX

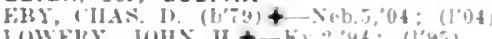

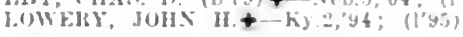

LEWELLEN. II5. GARDEN

MUIRIS, LUS FR.INK (b'5b) t

(l'yl)

LEWISTON. 127. PAWNEE

Houglas, Jokn Wesles (b'85) E-Neb.t, 0s (1.0.)

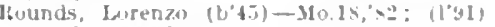
Dot ln practice.

LEXINGTON, 2,059, DAWSON

B.IKER. MIITOS B.-MU.'Bt; (1'Y1)

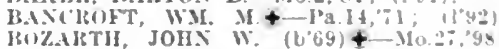
(l'09).

OLASON, JUETI'S LUGAK (b'St)-Neb. 'IU; (1'L)

I'I'RI0X, ITRILt-Kan.3.93; (l'03)

IROSHNBFRG, FHANK J. (b'J0) +0.23

WALE。 ARTHL'R F. (b's0)‡-IA.s,05 (1'06)

LIBERTY. 394, GAGE

I'KOIITFOOT CLIS

"98: (1.98).

LINGOLN, 43.973, LANCASTER

SIMIBER OF JHYSICIAYS, IVU

ADAMS, ROY BEXSETT (LSO)-III I,

(100s); 207: 0 st.; once, Funke Hidg.

liamson, Wm. J.-F-Neb.t.03; (1'03)

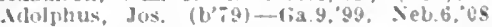

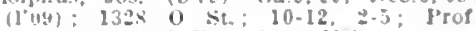

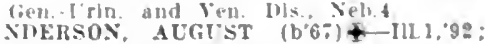
$(1,9: 3)$ : fos s. Isth st.

Antrus, Fredk. Menre-k-Xeht, 10 (I'(10): $325 y$ Ifoldrege st attce. Iit) 13 th St: $9-12,2-5$; I'rot. Surn., Debt S.

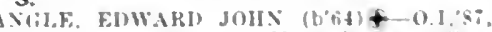

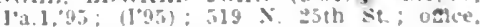

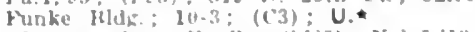

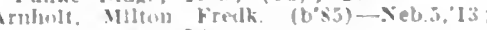
11'13): Walsh Wh

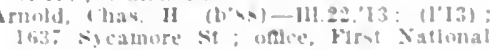
ltaitk jilde

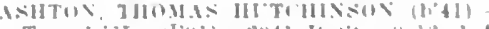

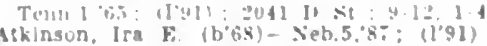

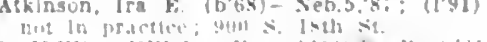

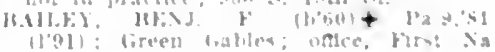
11'01): Cireen l.alle.

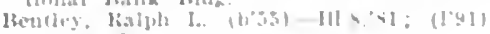
211ti (1) $\mathrm{st}$

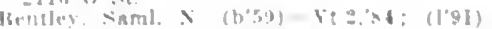
Eluli is lith st : 10-3.

Uirhises John lartin (tisj) Mal,

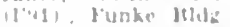

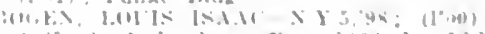

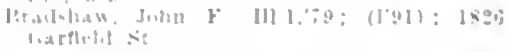


I3rown, Laura J. (b'65) II-111.4,03 ; (1'03) ; $1520 \mathrm{D}$.t. ; oftee, $31 \%$ llttle Btock ; 9-12 $1-5$.

Bucluanan, Rea (b'79)-Neb.4,'11

(l'11) ; Burnet, Anuo-111.9,85; not in practlce R.F.1). 3 ; (E13).

Canlne, Thos. Clay (b'53)-Neb.1,'86 (l'y1) ; 1924 1'rospect St

Carr, E. Arthur (b'72)H-IH.4,'96; (1'97) P'res. Sitate Roari of llealth; $1144 \mathrm{~F} \mathrm{st}$; ofllice, $141 \leqslant 12 \mathrm{th} \leqslant \mathrm{s}$.

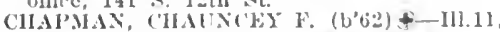
92; (1'11) : Nember 111. Med. Soc. 164: II St. ; offee, luttle Bldg; $1-4 ;(\mathrm{F} t)$.

LAI', RAIMOND GUSTAVUS $\left(\mathrm{h}^{\prime} 75\right) \$$ a.10, 02 ; (l'03); 2017 Washington St, $: 30-3 ;(\mathrm{F} 6) ; \mathrm{S}$.

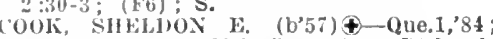
(1'93) ; 1400 S. 20 th st.; ollice, Richards Block; $9: 30-12,2-5$; OALR.

collcill, WAHWHCK M. (b'57) t-Ky.2, 83: (l'03); 1331 S. 21 st St.; offlee, l'res. Bldir.; $9-12,1-5 ;$ OALR. *

Davls, Thomas V. (b'66)-Neb.4.'02 ; (l'02) ; $5.25 \times$. 26th st

Darls, Fallace Clydo (b'66)-Nieb.4,98; (1'98)

DAYTOX, WM. LINSLEX (b'57) \&-I11.6, S1; (1’91); 1201 I St. ; offlce, Funke Des Jardlell llphonse Rerist $\left(b^{\prime} 73\right)-N e b .4$ 10; (l'11) ; 1637 B St. ; offlce, 11050 St. 3-5; Prof. Path. and Minor Surs. Neb. 4 ; 5 ;

louncan, ('arrie G.-Neb.4.10; not in practhe : 13190 st.

WWIGGIS, FHANK PIERRE (b'S6)111.8,12; (1,12); 2630 o St. ; offlce, 1329 0 St. ; $1-3 ; \mathbf{G}$.

IICHE, FLEDK. - -Ill.6,'03; (1'03); 1541 A St. : offlce, 1205 o St.

EMERSON, CIAREXCE (b'86) †-Ill.1,'11 (1'12); Sebraska Ilospital for Insane

Ervin, Chas. W'm. (b'77)-1ll.1,04; (1'04) $1110 \mathrm{E}$ St. ; oflce, First Natlonal Bank Ildg. : 2-5.

EVERETT, HARRY HARDING (b'75)-Ill.6, $00 ; \quad\left(l^{\prime} 01\right)$; 2024 D St.; offlce, Lincoln Sanitarium;2-4; (F6); $\mathrm{S}, \star$

EVERETT, MIITTON H, $\left(b^{\prime} 47\right) \oplus-I I .1,70$, Pa.2,'85; (l'91); 620 S. 17th St.; offlce,
14 th and II Sts. : $9-11,3-5 ;$ (F6); S.

EVEliETT, OLIVEL W. (b'81) 4 - Neb.5, '05; (1'05) ; 2224 A St.; offlce, Iincoln Sanitarium; 2.4; Pd.*

Ewing, Halle Laura-Mich.1,99; (l'99) Nebraska Ilospital for Insane; NP.

FARNHAII, GEO, 0. W.-Vt.2,'84; (1'91); 1430 s. 2uil st.; ofllee, Funke Bldg.; 10 Wilson-Pa.7,'07; (\$); 2410 Field, Susan Wilson-Pa.7,07; (\$); 2410

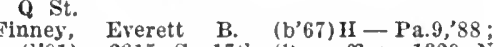
(l'91); 2315 S. 17th St.; offlce, 1329 N St. : $2-4 ; \mathrm{S}$

Flanagan, May Loulse-H-Ill.4,'00; (l'02); Green Gables; offlee, First National Bank Bldg. ; $3: 30-5: 30$.

FTANABERG IIARRT ERVEST (b'85) III.1,09; (1'11); 1645 A St. ; offlce, Banker's Life 13!dg. : $10-12,2-5$.

Folsom, Arte (b'68)-la.3,91; (l'99); 2640

K St. ; OALR.
Frankel,
Leopold (b'69) - Iung.1,93; (1'11); Delaware Hotel; offlce, Banker's Life Bldg.

URGAS, ALLEN P. (b'67) †-Mo.18, '89; (l'91) ; R.F.D. 8; Prof. Ophtl.

Ganoung, Bloom Warren (b'59)-X.Y.6,85; (l'91); 1211 M St.; offlee IIth and 0 Sts. ; $10-12,2-6$.

Giffen, Robt. Emmett (b'59)-N.Y.10,80 $\left(1^{\prime} 91\right) ; 1125$ S. 11th St.; offlee, 1317 N St. ; $3-5 ; \mathbf{S}$.

GRAIAM, ALICE W1N1FRED GOLDSBERRY-M0.28,05; (1'06); 1701 S. 24th St. ; offlee, $F$ and MI Bldg.

GRAIIAN, FRANCIS A. (b'62)- Neb.5 89; (l’91); 1701 S. 24 th St.; offlce, Yebraska State Bldg.; 10-12, 3-5.

Gray, (has. W. (b’0)- 0 ; (ま); 349 N. 28th st.; office, $1209 \mathrm{~N}$. St. ; $9-5$.

rifliths, Danl. Gurney (b'75)-Yeb.5,02 $\left(1^{\prime} 02\right)$; llospital for insane.
Grimes, lilehard S. (b'53) E-III.8, 78 (l'y1) ; $1414 \mathrm{C}$ St.; oftlce, Lltile Bldg.

IIAIL, I'IIIIIP LOUIS-III.1,'83; not in prictlce; Central Natlonal Bank.

IIASEN, DAISY MAY (b'75)-Ill.1,06; (l'0i) ; 1637 R St.; offlee, Rlchards Block $10-12,2.5$.

Hanson, Geo. Ilerbert (b'75) F-Ill.8,, 06 (l'06) : 1635 IR St.

IIYMAN, LDWARD CIAPMAN (h'83) क Nol.5,08; (1'08); Y.M.C.A. ; oflee, Flrst National Bank Bldg.; 1-5; (B1,18) OALR. *

Iledlund, Ward Wlllard (b'88)-Neb.4, 1. $\left(1^{\prime} 12\right): 2012$ Q St.

Howit, Hamllton W. (b'50) - Ill.1,77; (1’91) ; 1029 C St.

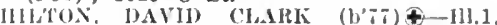
03: (1'03); 2832 o St.; oftice, Hlchards Block; (F6) ; S

HOLAM, JOS. A. (b'72)-Mo.2,02; (1'02) : $2 \pi 01$ P. St.; ofllce, 140 N. 27 th St. ; $2-5$. 1011LEN, KARL SIEGFIRIED J. (b'S6)First National Bánk Bldg.; 10-12, 1-5; S. IOLLENBECK, FRANK B.' (b'68) $€$-Ill. 1 . 98 ; (1'00); 1212 S. 20th St.; offlee, Richards Block; 12-1, 5-6; S.

Ilolyoke, Edgar Loomis-Ill.1,'85; (l'91):

1515 if St.; offce, 128 N. IIth St.

IOMI'ES, JOSEPH JUSIAH (b'83)-Neb.5, '0S; (l'0S); 2128 VIne St.; offlce, 12th and o Sts.; $9-12,2-5$; OALR.

IIUMMEL, RAY O. (b'80)\$-Ill.6,05: (l'07); 3229 R. St. ; offlce, Funke Bldg. $10-12,2-5$.

Jester, Clras. Wm. (b'65) $\mathbf{E}$ - Neb.4'04 (l'04) ; R.F.D. 7 ; 1'rof. I'hysjol. and Ped. Neb.4.

Keith, Chas. W. (b'79)-Neb.6,'12; (l'12) ; 894 N. 27 th St.; offlce, Chapln Bldg. $9-12,1-5$.

linipht, Ralph Thomas (b'86)-Minn.4,'12; (1'13): City Hall.

Kraft, F. E. (b'74)-Neb.5,'97; (1'97) ; 1220 Wood St.

Krieg, Frank W.-Mo.22,'93; (l'93)； 2132 S. 16 th St.

kurtz, Harriet G.-Ill.8,'07; (1†) ; $1136 \quad 0$ St.; offlee, Securlty Iutual Life Bldg.

L.ee, Vera Mae (b'i4)-Neb.4,09; (l’09) 1309 O St.

LEHNIIOFF, HENRY JOHN (b'72)\&-111.6, '01; (l'03) ; 940 S. 20 th St.; offlce, rittle H]dig. : 2-5: (F6).

l.eonhardt, John $\mathrm{s}$. (b'5s)-Ia.1, $79 ;\left(\mathrm{L}^{3} 91\right)$; $17 \pm 0$ N st. ; $2-5 ; 1 . \star$

lockwood, Ira 11. '(b'84)-111.4, 09 ; (1'11); Nember Ia. State Med. Soc.; Green Gables Sanatorium; 9-5.

long, Louls C. (b'57)-Mo.18,'82; (1'91); 250 S St.; offlec, Northwestern St.

Longdon, Harrison A. (b's'z)-Tenn. ',08; (l'08) ; $33 \pi$ S. 21 st St.; offlce, 145 S. 11 th St. ; $10-12,2-5 ; \mathrm{G}$

LOWRY, HAMIT'ON BERNARDA-0.8, 6 . (l'91); 843 s. 10 th St.; offec, 1136 o St.

IYHAN, RUFUS ASHLEY (b'75)థ-Neb.5, 03; (l'03) ; 1641 5. 21st St. ; 2-5; (F6) Macdonald, Louisa 13. S.-Pa.7,'89; (1'91) Salsbury Block.

MacliNNON, ARTEMAS I. (b'6z)甲 Que.1,92; (1'92); 1406 C St.; offlce, First National Bank Bldg.; 2-4; (Ai) S. $\star$

MANTOR, HARRY L. (b'82)థ-Neb.5,'09; (1'09): Richards Block.
IAYHEiv, JOHN M. (b'70)๑-IL.11,'95; (1'01); $1521 \mathrm{D}$ St. ; offlce, lunke Bldg. ; (F6).

McCARTHY, TINOTHY FRANCIS (b'80)Neb.6.10; (l'10); 1416 S. 14th St.; offlce, 13th and $N$ Sts.; $10-12,2-5,6: 30-8$.

Icleal, Fredk. Leon (b'78)-Neb.4,01, o St. : $10-12,2: 30-5: 30 ; \mathrm{G}$.

ICLEOD JULIUS MARTix (b'65)-Neb.4, 95; (1'10); 1700 Washington St.; offlce, 13010 St.; $2-5$

Wetheny, Saml.-E-Neb.4,02; (1'02); 640 N. 16 th St.; oftlce, 1548 o St.

MILLER, HÁROLD' B. (b'61)-Pa.2,'90; (1'02); 1610 A St.; offlce, Security Mu tual Life Bldg. $8: 30-10,2-4,6-7: 30$.

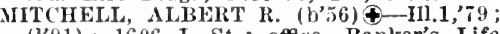
Bldg. ; $2-5: 30 ;(\mathrm{F} 6) ; \mathrm{S}$.
MORRILL, RALI'II AI. (b'74)-111.8, 00 ; (l'02); Little Bldg.; 2-5; I'rof. Mled., Neb.

MOSLEY, ELMER W: (1)'83) †-III.11,'11; Nember Ill. State Icd. Soc.; 124 j. 27th

Loss, Arthur Bryant (col.) (b's3)-Ill.16 '08; (1'09); I634 P' St.; offce, 1136 o

Iosshart, Jos. C. (h'50)-Ia.1,'81; (1'12) 1800 S. $22 \mathrm{~d}$ St.

OYFR, C'IAS. CALVN (b'66)థ-Md.6. 93 ; (1'99): $1954 \mathrm{~B}$ st.; ofllce, first $\mathrm{Na}$ tlonal Hank Bldg.; $2-5$.

IIulr, Danl. II. (b'43)-incli.1,71; (1'91) 302 N. 2 Fth St.; 1-6; G.

ifyers, Wm. Alfred (b'71)-Neb.4,'11; (l’11) ; 1740 I'ruspeet St.; offlee, 14170 St. ; 9-12, 2-5; 1'rof. Anat., Neb.4.

OlsON, OLE (1'7 7$)-\mathrm{Nel} .7,09 ; \quad\left(1^{\prime} 09\right)$; 2040 S. 18 th St.; offlce, Flrst National liank lildg.: 10-12, 2-5.

OIRR, IIIRA.I " WVINNETT (b'7 '99; (I'99); Nebraska Orthopedlc Hos:pltal; offlce, First Natlonal bank Bldg.; $1-3$;

Palne, Bartlett L.-II-0.1,75, 1'a.9,77 ; (l'91) ; 1238 i St.

'arks, Chas. W'm. (b'88) - Ill.6,'12 ; (l'12) 321 S. 12 th St. ; offlce, $12050 \mathrm{St}$.

'HILBRICK, INEZ C. (b'66)థ-1'a.7,'91; (l'93); 1023 H St. ; 2-4.

Colo.3,99, N.Y.19,03; (1'03) : Nebraska Hospltal for Insane; (F6).

Ramey, Walter Newman -E - 0.2,03 ; (1'93) ; 315 N. 14th St.; Prof. Obst. and Gyn., Neb.4

REYNOLDS, CRANDALL A. (b'80)-Neb.7, '08; (l'0s) ; 2819 Q St.; offlce, Security Mutual Life BIdg: $9-12,3-5$.

liEYTOLDS, NA'IHAN O. (b'89)-Neb.6, '12; (1'12) ; 2530 Q St. ; offlce, Security' Mutual Life Bldg.; $3-5$.

1.FYNOLDS, ROBT. WAYNE (b'82)Neb.4,06; (l'06); 1620 N St. ; D.

RICKAHD, WESLEY GRANT ('b'69)- 111.8 , 05; (1'05) ; 1122 Pine St. ; offlce, Chapln Block; $10-12,2-5$.

RIghter, Fredk. B.-H-Ill.4,'71; (l’91) ; 1547 II St.

Rosat, Lina M. (b'60)H-Mo.5,'91; (1'03) ; 1227 II St.; offlce, Bankers LIfe Bldg.; 9-5; Prof. Elec. Ther., Neb.4.

ROWE, TDWARD W. (b'80)£-1ll.6,05; (l'05); 1260 S. $22 d$ St.; office, First National Bank Bldg.; 2-5; (F6).

tiush, Chas. H.-Neb.4,94; (1'94); $195 \%$ Washlngton St. ; offlce, Bankers Life Bldg. lyerson, Edwin Ramah (b'78)-Neb.4,'11; (1'11); 2011 S. 19th St. ; offlce, Bankers Life Bldg.; Prof. Hist., Neb.4.

Sabin, Margaret L. (b'35)-Ill.10,79r; (l'91); not in practice; $1305 \mathrm{G} \mathrm{St}$.

searles, Frank I. (b'52)-Ill.1,81; (l’91): 1309 o St. : 9-4; U.

seng, Geo. E. (b'82)-Neb.4,'08; (l'08); 418 S. 25 th St.; offlee, 0 St.; 9-11:30, 2-5.

shoemaker, Chas. Alonzo (b'61) H-Neb.3, '86: (1'10) ; 1117 L St. ; $12: 30-3 ;$ S.

SLATTERY, WMI. H.-No. 7,02 ; $\left(1^{\prime} 02\right) ; 116$ N. 13 th St.

MITH, ARTHUR ANDREW (b'84)-III.1, "12; (l'12); 1401 M St.

SMITH, ROSCOE L. (b'84)-Neb.6,08; (1'0s) ; 1632 Locust St. ; offlce, Fịrst $\mathrm{Na}$ tlonal Bank Bldg.

SIPES, JAMES JOIINSTON (b'80)-La.1, '03: (l'10) ; Melick Court; offlce, Funke Bldg. ; $9-5$.

snyder, Frank A. (b'58)-Ill.6,'81; (1'91) ; 1555 S. 20 th St.; offlce, Funke Bldg.

spenlman, John Franklin-E-Neb.4,03 ; (l'03) ; 2740 Holdrege St.; offlce, City 11all; Prof. Hyg. and Public Health, Neb.4; $\mathrm{S}$.

Spear, Geo. E. (b’3)-Neb.5,'03; (l’03); 847 South St.; NP.

spradling, Richard Hargrave $\left(b^{\prime} 63\right)-$ Neb.4, 04; (l'04) ; 1645 Maple St. ; offlce, $141 \mathrm{~S}$. 12 th St.; $10-12,2-5 ;$ Dean and Prof. Prac. Med., Neb.4; D.

Sitauhoje, liedington-0.6,'80; (1'91); 920 H St. 
STEVFAS, JAMES FIBANLAX $\left(6^{\circ} 39\right)$ + -

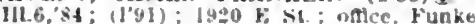
IHlock: 3-6: i'rof. Introductory Med. Nicb.5; $\left(\boldsymbol{r}^{3}\right)$;

stivers, Chas. C. (b'65)-la.1.92: (l'03): 12130 st.

STCHDEVANT, LAZELLL: MHANTY (b०9)-Neb.5.09: (1'09): 2857 Huldrege St. : $12-2$.

Sward, yrnest d. C. (b*3)-Xeb.5.96. (1'96) : Praternlty kldg.

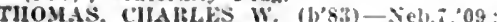

(1'09): Securlty Mutual Life lsidr.

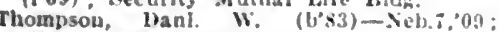
(1'09): 1234 o st.

Tourelle, Albert R.-0.1:8:; (1092)：1226 D st. once, Litle Bldg.

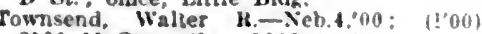

3100 II St.: offce, $12050 \mathrm{st}$

Tucker, Frank W.-W-M, 10,'s?

(1'9)

$1 \% 2 \%$ S.

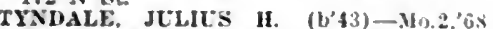
(l'91): Free Preas Bldz.; ontce, Iblhardy

Hlock: $10-12,2-5$.

WAITE. HERBEITT HAROLD (b'68) Mlch. 1;01: (1'02); 2144 B St.: (F'o)

WALKEK, GEO. HEMMAN (b'S2) - - eb. 08: (1'08): Orlo Flats; once, Ganter 13lock: 10-12, 1-4; (F6)

WEKESSER, HENKY PETKR (b'so)Neb.5.0S; (1'08); 004 E. St.; oflce, rirst National Bank bildg.; 2-5: (Fi)

WELCI, J. STANIES (b'-3)-IIL. 03 (1'03): 1938 Washington st.; oflce, First Natlonal Bank Bldg.; (F6).

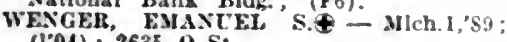
(1'04) $26350 \mathrm{st}$.

WILLIASI, BENJ. F. (b'5) -Nebt,99 (1'99): Nebraska Hospltal for Insane

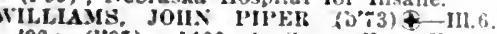
96: (I'9): 1 100 i St: ofnce, Funke Iแส. : $9: 30-12$, $1: 30-5:$ OPA.

wimeth, Frank Lncoln -E;- Neb.t,94 (1'94); 609 S. 1ith St: Prof. Surg. veb.t: $\mathrm{S}$.

WIIsos, WM. 11. (b'56) -II1.11,84; (1'09): 1901 Washlngton St.: offee, statc House.

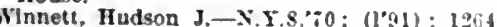
S. 20 th $\mathrm{St}$.

Witte, Wra. E.-Neb.4,03; (1'03); 12th and

OLCOTT, ROBT. HENRY (b'6S) 4

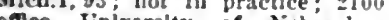
once, Unlverslty of Nebraska: (F!) Dean, Neb.5.

WOODWARD, FRLE B. (b'i5) - -Mich '99: (1'99): 2044 C St.; oftee, nichardi Block: 9-5.

Woodward, Thaddeus II. - Tenn.ti,'s? (1'91): 1441 M St.; oqce, Bchardy Bloct.

LINDSAY, 465, PLATTE

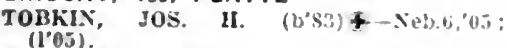

WALKER, DANL, (;) (b'69) f -la lach $\left(1^{\circ} 98\right)$.

LINWOOD, 329, BUTLER

KOLOUCII, FREDK. (IEU. (b'3i)-Neb.6, '12; (1'12); $\mathrm{S}$.

UITCHFIELD, 403. SHERMAN

Gorf, John L. $\rightarrow$; (l'91).

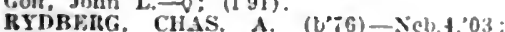
(I'03).

LODGEPOLE, 245. CHEYENNE

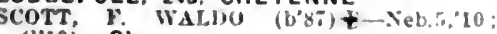
(I.10): Ob.

LONG PINE. 781, BROWN

LAWSON THOMAS JAMES (b, 6.3)-NEU.D. "96: (1'09).

TUCKEK, JiMks CYLL' (b's6)-Nef, 12; (1'12); OALR.

LOUISVILLE, 778, CASS

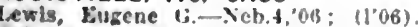

Polk, Lurion F. (b'58)-ind : s0: (1'91)

Worihman, Edward II. (b'5)-.ieb.6,00: (1'00).

LOUP CITY, 1.128, SHERMAN

Rowman, Carrle luella $(1,84)$-Neb.4, 12 (l'12).

Bowman, Joln kiw, (1,09)-Neb.4,12 (1'12).

Chase, Warren T.-III.4,'s2; (1'91); not In practice.

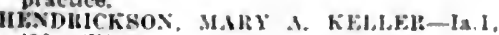
'90: (1'93).
Jones, J. W. $\rightarrow$ : (1'9!)

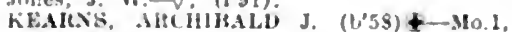
S6; $\left.11^{9} 91\right)$.

LONGACHE. OTTO EARLE (U.'9) \&-Md.4 06: (1'06): $\mathrm{S}$

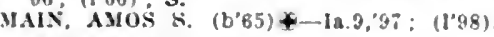

LUSHTON, 205. YORK

DEAIING. WM. IIE.YIT (b'59)-la.3,'s2 (l'91).

LYNCH, 583, BOYO

IRA, GFO. W. (h't?)-Mo.

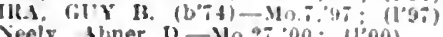

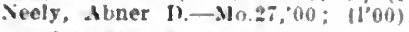

LYONS. 865, BURT

HILDERTI, MOILTIMER I. (650) - -IIIL 30: (1'91)

IMI, Allen T, -12.3,83; (l'91)

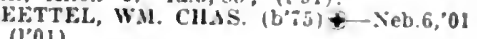
(l'01).

MADISON, 1.708. MADISON

i.ADBOIS, AHTILYK E. (b'-t)t-Neb.6. 03: (1'03).

OXio FraxcIs A. (b"59) \&-13.3.82: (1.91); 5 .

Shlke, Wm. Earle (b'84)-Neh.4'11: (1'11)

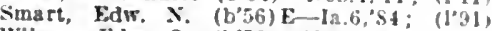
Wilson, Edw. 0. (1)'9)-Neli,6,09; (1'09)

MALCOLM, 80, LANCASTER

I'rotzman, Chas. E.-Neb.4,02; (1'03).

MALMO, 214, SAUNDERS

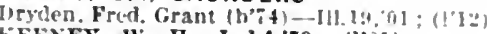

KEENEY, W. IL-Ind.4; 73 ; (1'S1).

MANLEY, 175, CASS

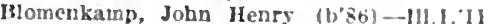
(走)

MARION, 250, RED WILLOW

Bartholotuew, Wm. S.-Neb.t,0i: (l'0:

MARQUETTE, 290, HAMILTON

IIntchison, Jos. W. (b'7i)-Ncb.6;11; (l'11)

LINE, THOS. H. (b'58)£-Ill.1.'S1; (1'91)

MARSLAND, 150, DAWES

IIANEEX CHAS. AVER (b'T2) -III.19, 06: (1'10)

WIIIIS, JAMES M. $\left(b^{\circ} 81\right)-.10 .299^{\prime}(03$; (1'03).

MARTINSBURG, 29I, DIXON

Kiray, Robt. Ellis (b'35)-Neb.6,'11; (l'11)

MASON CITY, 480, CUSTER

'arothers, l'aul Henry Jacob (b'sI) -Neb.4, '10: $(1 ' 10)$.

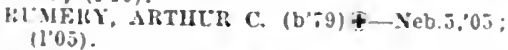

MAXWELL, 289, LINCOLN

KENNOS, CLIDE K. (b'79) - Neb,6,06 (l'ati)

MAYWOOD, 443, FRONTIER

Bills. Rernard I. (b'st) t'- Nebt.0s: (loos) stuckey, lloyal scott (b'73)- Teb.j, 03 (1'03): OALR.

MCCOOK, 3,765, RED WILLOW

FASTHRIY, FMMA MEINHALDT (b'ti2) - $1114.85 ;(1.95)$.

F.MINHSTOCK, CHAS. L. (b'it)-Mo.2.96: (l'01): $\mathbf{s}$.

Johes, Win. Francis (b'it)-0.9,00; not in

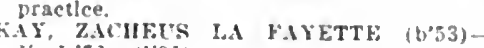
Kiv.1, it: : (1'91)

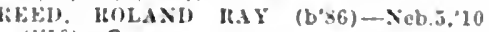
(1'10): S.

IเEIL, INAVID J. (b':0) - Neb.5.02 $(1,12): \mathbf{S}$.

जitu, "INivin F-111.22,06: (l006)

Wocklruf, Ware (b's2)-Colo.5,05: (1'12).

MOCOOL JUNCTION. 369, YORK

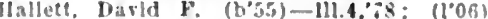

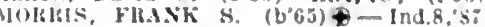
(I')! ! )

MEAD, 330, SAUNDERS

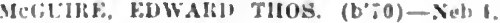
S: 1108$\}$.

MEADOW GROVE, 388. MADISON

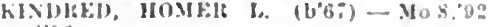
(11.921.

MEMPHIS, 162, SAUNDERS

XYF., MAIK Al.YA (l,'?2)-Neb.3,04: 1['04

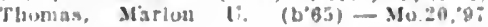
$(1+i)$.
MERNA, 459, CUSTER

HOWNING, ALABHT R. (461)-14.12,86: (1'9!)

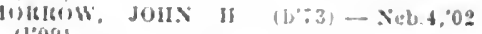
(1.09).

Iread, francls T. (b'so)--116.8, I:

MERRIMAN, 254, CHERRY

Maldw!n, Francls J.- Ind. P, 0I: (1'02).

MILFORD, 7I6, SEWARD

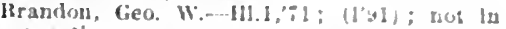

De Ogny, l'aul A. (6⿳八人口)-0.209; (1'09).

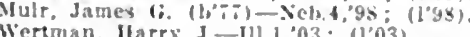

MILLARD, 260, DOUGLAS

rossler, John Jacob (b'it) - Neb.not:

(1'06): Member ligo. State Jed. Soc.

MILLER, 330, BUFFALO

Yorthrod, Eric W. (b'4t)-Pa.13, :5: (1'91)

Watson, Claude 1. (b'84)-Ky.1,06; (1'08).

MILLIGAN, 336, FILLMORE

MMRUA, v. V. (b'78) †-Neb.6,05: (1'05)

MINATARE, 338, SCOTTS BLUFF

Cole, Anna A. (b'65)-Neb4.04; (1'04)

YNDIVER, C. E-Mo.22:'s; ( 1921$)$

MINDEN, 1.559, KEARNEY

Ibbott, Chas. K. (b'76)-Ont.6,02: (1'03)

OALR.

TRART, EFYE A. (b'3)-1nd.8,0!: (l'09)。

iansen. Nlels r. (b';2)-M0.20,00: (l'03).

MAPMAN, HARK (b'53)-MI,'82: (l’91): $\mathbf{S}$.

YARTIX JAMES A-Mo.10.84; (1'91)

'owell, ward Ilughes (b'82) - Neb.5.'13; (1'13)

MITCHELL, 640, SCOTTS BLUFF

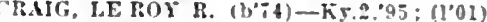

raulk, Andrew J. (b'5s)-ras,01: (1'03).

TTEWART, ALFRFD JESSE (b'68) —-III. 96. Ill.11,06; $(1996)$; $\mathbf{S}$

toops, Eunlce R. (b'07)-M11.12,02; not in practlec.

TOOP'S JAMES NORVAL (b's1)-Tex.3. $06:$ (l'II).

stonps, Roy P. (b'7i)-Ill.11,03: (l'13).

roblas, Jolin Mutton $\left(\mathrm{b}^{\prime}+0\right)-0.2, \mathrm{i}^{2}$; $\left(\mathrm{I}^{\prime} 06\right)$

MONOWI, 109, BOYD

'aughn, Frank Wesles (b'8i) - Ia.4'12: (1'12)

MONROE, 282, PLATTE

Webb, Waterman Thos_-IH.1.'1; (1'12).

MOOREFIELD, 175, FRONTIER

Sklnner, Almeron 0 . (b'\$1)-Neb.t,0;: $\left(\mathrm{l}^{\circ} \mathrm{O}^{\circ}\right)$

MORRILL, 346, SCOTTS BLUFF

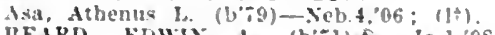

BEARD, EDWIX A. (b't1)- Ia.1,'s: (1'04)

Fox, Clarence P. (b'i6) 11-116.10,0 : 110a).

Nichols, Edwin (b'tis)-0.3,

MORSE BLUFF, 196, SAUNDERS

armienter, John A. (b's3) - Ncb.6,'0s: $\left(l^{\prime} 0 s\right)$.

MT. CLARE, 125, NUCKOLLS

sayles, Dasld Jiccos (b"i5) - III.8.1: (1'I:).

MULLEN, 175, HOOKER

Adamis, Jobn Qulney. Jr, $\left(b^{\circ}, 6\right)-k^{\circ} y .5 .98$ (1'08).

MURDOCK, 222, CASS

Jones, Isaac friller (

MURRAY, I30, CASS

Brendel, Benj F-1'-M-Ind 5.'s3: (1'91),

Iirendel. Jacob il - Neb 4,03

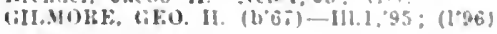

NAPER, 300, BOYD

Frazlet, Cico. J. (h;6)-Colo 4,03: (1'03). SEASONGOOD, EDWIRD REMSON (D'S5) -.'cb.6."10; (1'10).

NAPONEE, 195, FRANKLIN

Iloylman, Marcus IR.-Neb.t.04: (104).

NEBRASKA CITY, 3,488, OTOE

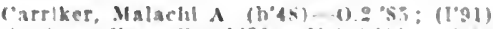

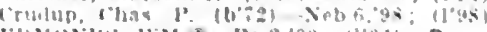
killuslls, Wy + In

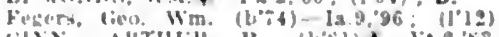

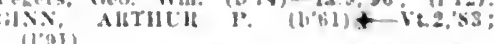

Haltaway, Thos. Wllbur-kixa's? 


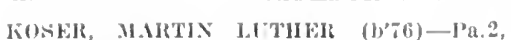
$03 ;\left(1^{\prime} 10\right)$.

MaclEax, i. MARTIA Culo.3.'98; (l'08) OALR. $\star$

Mclinney, Edward (1, 60 (6) - III.18,01 (103).

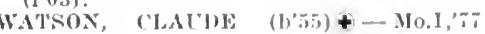
(1)

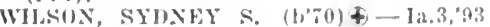
(l'43)

Yager, irm. S. (1, 68) LE IIIS, 94 ; (1'97)

NEHAWKA, I50, CASS

Thornas, James W. (1)'Bn) - N(w,6,'10; (1'10).

NELIGH, I,566, ANTELOPE

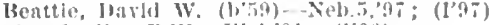

Chamberlin, IR.W.-Ill.4,01; (l'06).

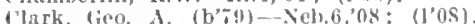

conters, Arthur F-E- 0 : (1'01).

CONWELL, WM. E, N.Y.10,86; (1'91).

IIait, M. Freeman-Mo.22,01; (I'03).

Johnson, lev! ('. (b'52)-0.9, 08 : (1'05).

Johtuson, Ihhoda I3. (b'56) -Ind.8,91; (1'05).

NELSON, 978, NUCKOLLS

l3uftlngton, I. R. (b'40)—Ia.I,'55; (1'81).

CATE, W. A.-JH.10,?2; (192)

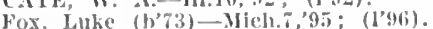

Thomas, Yalorous A.-P'a.2,97; (1'97).

NEMAHA, 325, NEMAHA

Andrews, 13. BCll-Mo.2;,96; (1'96)

Kay, James $\triangle$; (1')I).

Keeling, Wm. Wesley (1'31)-E-0.2,64; (1'91)

KELIX, JERRY D. (b'70)-Mo.22,93 (I'10); Nember Mo. state Afeil. Assn.

NEWCASTLE, 436, DIXON

HEALY IBENTS BARTHOLONEW (b'80) क -Ky.I,01; (I'08); Nember la. State Med.

RICHARDS, ROY CHARITON (b; $:$ T) + 111.6, 05: (l'11); Nember 111. State yed. Soc: ; ob.

TAIBOY, WM. R. (h'65)-Ia.8,93; (I'93).

NEWMAN GROVE, 850. MADISON

Frink, Frank L. (b'b5)-Ky.4,'91; (1'91).

JENSEN, FRANK (b'SO) †-Neb.5,03; (Y'03).

WELLS, NELSON DREW-Ia.3.07; not in practice; Member Colo. State Nied. Soc.

\section{NEWPORT, 268, ROCK} Dodd, Clinton Quincy (b'88)-Neb.6,'10 ;
(I'I0).

NICKERSON, 135, DODGE

BYERS, ROBT. CHAS. (b'78)-Ont,6,03; (1'09).

NIOBRARA, 633, KNOX

BERGGILE, ANDREW LEON (b'78)Neb.6,06; (1'13).

CHARK, WILlARD K. (b'66)‡-Neb.5,97; $\left.\left(I^{\prime} 9\right)^{\circ}\right)$.

\section{NORFOLK, 6025, MADISON}

BRI'SII, EDWARD 1. (b'78)-Neb.5.'06; $\left(I^{\prime} 06\right)$.

Carson, Harry Raymond (b'74)-Neb.5,'10; (1'10).

Foster, ROBT. H. (b'81) - Neb.6,'06;

Guttery, Wm. Darid (b':2) E - Neb.4,01;

(I'01): Trof. Ners and Mental Dis., Neb. $;$ NP.

llowley, Ambrose N. - Neb.4,07; (1'07); OALR.ネ

Nacomber, Acastus L. (b'44) II-N.Y.9,72 $\left(I^{\prime}, 91\right)$.

MILLOAG. CHAS. ROBT. (b'84)£-la.8, ,09: (1'11): S.

Pllger. Walter Ilerman (b'79)-Neb.6,05;

RoOT, CHAS. H. (b'75)-Neb.5, 03 ; (1'03).

SALTER, I. HAROLD (b'62) \&-Scot.9,12, 14,'85; (1'91); $\mathrm{S}$

Sonneland. Arthur M. (b'88) - Neb.6,'12 (1'12).

T.SHJEAX, ARMENAG B.-Ill.8,'84, Ill.1, $29 \overline{2} ;(1,91)$

Verges, Carl J. (b'84)-111.15,08; (1'08),

WATERS, THEODORE H. (b'is)-III.4; 01 ; (I'11).

NORMAL, -, LANCASTER

Aukes, Ehme E. (b'52)-Ger.7,;7; (1'91).

NORMAN, 125, KEARNEY

Hill, James Stanley-0.25,'97; (1'00).
MORTH BEND, I,105, DODGE

WOANE, WM. WHIEN (b'T8)\&-Mo.34, 96

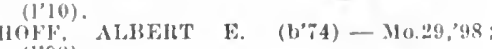
(1'9s).

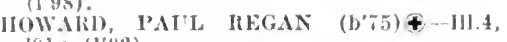
$01 ;(1,02)$.

NORTH LOUP, 519, VALLEY

Hemplill, Wn, J. (b'45) II-III,4,02: (1'02)

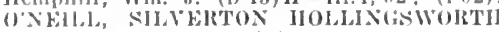
(b'7) -Md.3,07; (I'11).

NORTH PLATTE, 4,793, LINCOLN

IMES, MARIL A.-Neb.6,"0I; (I'0I) ; U.

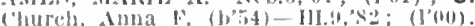

WENT, GEO. 13. (b'68)-Md.6,'98; (1'98)

lisms, J. li.-I11.10, 79 ; (1'03)

KERk, TJkonork Jós. (1,89)-Neb.5, 08 (l'0s).

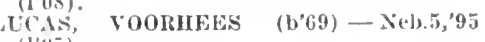
$(1,4.3)$

H('SIRE, NIC'HOLAST-N.Y.6,86; (I'9I). QCItiLY, $1 \mathrm{ANI}$. T. $\left(\mathrm{b}^{\circ}, 6\right)+-11.1,02$ $\left(I^{\prime}(1)^{\prime}\right) ; \mathrm{S}$. $*$

ITELIEI, JOSIAII IBECKLEY (b'82)Nels..5.,08; (l'08)

REIHIEIA, WILIS JAY (b'76)\$-Neb.6 100 ; (1'00); $\mathbf{S}$.

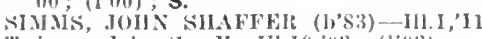

'lwinem, Jom s.-II-III. 10,03; (1'03). 'YITELF, FHEJK
X.Y.I!, (1) ; (13).

OAK, 237, NUCKOLLS

NEINON, WM. IIAHKY (b' 60$) \notin-111.11,10$ (1'I0).

OAKDALE, 63I, ANTELOPE

MINTON, EDWAITD WILLISON (b'53)£III.1,76; (1'41); 0 p.

ielson, laloyd J.' (b'86)-Nulb,15,'10; (1'10)

OAKLAND, 1,073, BURT

IBENSON, HARTY WM. (b'76) +-Neb.5, 03 (l'03); Member Ia. State Med. Soc.

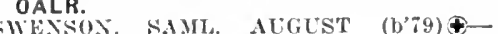
Neb.5,10; (I'10).

OCONTO, 245, CUSTER

Wade, John C. (b'70)-Ia.8,97; (1'99).

OCTAVIA, I50, BUTLER

MAISELES, If. IE. (b'80)-111.2z,'04; (1'04)

ODELL, 427, GAGE

(I'm. J. (b'88)—Neb.6,'13; (l'13); LD.

PICKETT, 11:A N. (b'52)\&-Ind.4,'7s (l'9I).

OGALLALA, 643, KEITH

Hollingsworth, A. (b'51)-1a.1,'8I; (1'91) LIKENS, Wis

\section{OHIOWA, 373, FILLMORE}

lanter, Saml. Goodall (b'52) - Neb.5,'86 310.7,'88, Mo.1,'91; (1'91).

PANTER, SAML. GOODALL, JR. (b'84)థ$111.6,09 ;\left(I^{\prime} 09\right)$.

OMAHA, 124,096, DOUGLAS NCMBER OF THYSICIANS, 322.

Abbott, Edw. Carson (b'76)-1a.4,'99; (1'03) ; 3618 Mason St.; office, Brown Block: 10-12, 2-5; OALR. *

ADCOCK, LEE CAIIPBELL - Pa.2,03 ; (1'13); Karbach Block.

AIKIN, JOS. MELANCHTON (b'57) \&Ia.3, 87 ; (1'91) ; Sec. Neb. State Med Assn.; 322 N. 4lst St.; offlce, Brandeis Bldg. ; 10-12, 2-5; Prof. Nerv. and Ment. Dis., Neb.5; NP. *

(b'74) $\$$-Neb.6, 02 (102) ; 1621 Emmet St.; offlce, Neville Bldg. ; $11-1,5-7$. 01: (1'01): 1028 S. 31st St.; offlce, City '01; (1'01); 1028 S. 31st St.; offlce, City and Clin Med., Neb.6; (F9); 1.

Alexander, Ernest L.' (b’58) H-Ill.4,'82 $\left(I^{\prime} 91\right) ; 614$ N. $22 d$ St. ; offlce, 207 S. 16 th St. ; 10-12, 2-4.

Alexander, Jeremiah S. - II - Ill.10, 00 ; (l'01) ; 107 N. 41st St. ; offlce, Paxton Block; 10-12, 2-4; 0 b.

ALLEN, WILIIAM ELSWORTH (b'84) III.22,'10; (1'13); 521 N. 16th St.; Member Wis. State Med. Soc.

ALLISON, CHAS. C. (b'65)€-Ky.1,'88; (I'91): 410 S. $39 t^{\prime}$ St. ; offlee, 15th and Douglas Sts.; 2-8; Prof. Prin and Prac. Surg. and Clin. Surg., Neb.6; G.

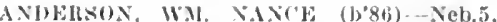
'I0; (l'10); 3212 ('umlug St. ; ofllce, Contlnental Block: 11-12, 2-4; (Fo) Anglln, Robt. \& (b'59)-Ont.5,82: (l'91) $10 \mathrm{I}$ s. 39 th St.; offlce, W.o.w. Bldg. (3-12, 2-5; ALR. $\star$

Angus, Geo. Angustus (b'70)-Colo.4, 06 : (I'10) ; 3520 IIamllton St.; offlce, Wouglass lilock.

ARYOLD, HARIX L (b'69)-111.11,'97 : (1'98); 434 N. 38th Are.; offlce, Clty Nathonal Bank

Arrasmlth, wm. (b's8)-Neb.6,'13; (l'13) $40 \mathrm{ll}$ St. and I'oppleton Ave.

ARTHCK, MATTIE L. (b'58) \&-Ia.3,'86 (I'91): 1333 S. 331 St, ; onlee, Paxtor Block; 1-4; S.

Jacon, Fred. (b'57)-Ia.J,79; (1’91); 201 S. Central Blvd. ; offlec, Irandels Theatre l31dg. ; $11-12,4-5$

BAILARI, CARL HARDIN (b'77)कllch.I,00; (l'04); 3905 N. 24th St.; ot flce, Brandels Bldg. ; 11-12, 2-5; R.

BANISTEL, JOHN MONRO (b'54)€-Va.I, '78; Col., U.S.A., retlred; Brandels Theatre B]dg.; 9-12, 2-5; (1318); OALR. *

Baptist, John (b'76)-Ind.9,05; (主); Barker 13lock; 10-12, 2-4, 7-8.

Barnes, Erskine y. (b'76)-Neb.4,'03 : $\left(1^{\prime} 03\right)$; Brandels Bldg.

BAKNHART, EDGAR GEOFFREY (b'84)థ -Neb.6,10; (1'10); 13221 N. 24th St.; Barns, Frank M.-Neb.5,02; (I’02); 1810 Grace St.; office, Brown Block.

B1SHOI', JAMES C. (b'68)-Neb.6,99: $\left(1^{\prime} 99\right)$ : 1624 Binney St.: offlce, 2828 Sherman Are.; 10-12, 2-4.

Sherman Are; $10-12,2-4$. 04: (1'06): 3606 Lincoln Blvd.: office, Brandels Theatre Bldg.; 3-5; Adj. Prof Clin. IIed. and Fhys. Dlag., Neb.5; (F9) BOLER, 'HIOMAS 1HANL. (b'85)-111.6,08; (1'10) ; 913 S. 36 th St.; office, City $\mathrm{Na}$ tIonal Bauk Bldg.; 2-5.

Bonaviez, Katherine Filza Kinsey (b'76)Neb.6,'11: (l'11); 834 S. 24th St.

Borghoff, Jos. F (b'86)-Neb.6,'13; (1'13): 135 S. 35th St.; offlce, Bishop Clarkson Memorial Hospital for Chlldren: LD.

Bowser, William Wolfe (b'66)-Mo.20,'11 (l'11) ; 113 S. 25 th St.; offlce, 1502 Far nam St. ; $10=5$

BRIDGES, EDSON L. (b'74)థ-Neb.5,'96 (1'97); 144 S. 38th St.; offlce, Brandeis Theatre Bldg.; $10: 30-12,3-5 ;$ (F9); 1.

BIRIDGES, WILLSON ORTON (b'56)ङY.Y 579 ; (1, I) : 2002 Douglas St. : of fice, Brandeis Theatre Bldg.; $9-10,3-5$ Dean and Prof. Prin. and 'Prac. Med. and Clin. Med., Neb.5.

Britt, Leonard F. (col.) (b'78)-Ky.7,09: (l'09) ; 2010 Lake St. ; office, 108 S. 14 th St. ; $10-12,3-5$.

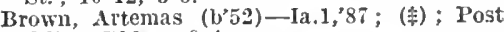
Offlee BIdy. ; 9-4.

Brown, Chas. P. (b'67)-310.20,00; (1'12); not in practice: $563 \mathrm{~S}$. 26th Ave.; $9-5$ not in practice; 563 S. 26th Ave.; $9-5$; 3405 Farnam St.; offlee, Brandeis Bldg. $2-4 ; \mathbf{O} \mathbf{b G}$.

BRYANT, DE WITT C. $\left(\mathrm{b}^{\prime} 49\right) \oplus-0.11$, 75; (1'91); Pres. Neb. State Med. Assn.; Bldg. ; 9-1, 3-5; (131S); OALR.

BUCE ARTHUR (" (b'65) - Neb.6, ${ }^{3} 06$ (1'06); 2610 Bristol St.; 11-5; ObG.

BURKARD, ADRIAN F. (b'78)-Neb.6,02 (1?02): 1902 S. 17th St.; $3-4: 30,7-9$; Anes.

Burke, Wm. A. (b'58)-Ia.6,'91; (1'9I) 4612 N. 28th Are.; office, Bushman Block ; $9-5$.

BUSHMAN, LOUIS B. (b' 76$) \oplus-\mathrm{Neb} .6$ 03: (I'03) ; 3004 Farnam St. ; offlce, City National Bank Bldg.; 9-12, 3-5; (B18).

CALLFAS, WM. F. (b'68) 4 -Ont.5,98; (1'08); 1920 S. $32 d$ Ave.; offlee

dels Bldg. ; 8-4; (B18) ; OALR.`
Campbell, Sam1. (1'91) : 1804 Farnam St.; $10-12,3-5,7-8$ Capell, western L.-Mo.28,'94; (1'94) ; $245 \mathrm{I}$ S. 201h St.; offlce, Range Bldg.; 10-12, $2-4 ; \mathrm{D}$.

Chedeck, Benj. H. (b'79)--Yiun.5,03; (l'03); 2417 Charles St. ; office, $220 \mathrm{~S}$ 15th St.; $11-12,2-4,7-8 ; 0$ bG. 
(HRISTH, H[HTU. WHITHA) (b"0:)

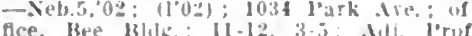
flce, the lild :
l'ed., Neb.5: (10).

Clark, Chis. F-Ill.1, 81 ; $\left(1^{\prime} 91\right)$; rrandels Theatre lildg

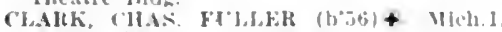

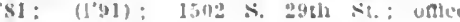
Brown Block: 1-t

Clark. Martha F. (b:56) 11-111.4,

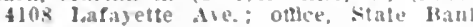
Hil. $11.30-1,3$

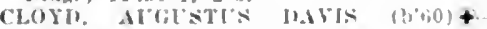

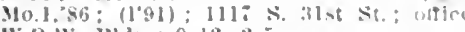
W.0.W. Hldg.: :-12, :-

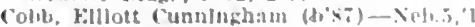
(1'13): Vehraska Mebhodlst Jospital and Jiearonevs llome.

Cochran, Francls It. (10's0)-30.22,0:" ; (1'11) t sure

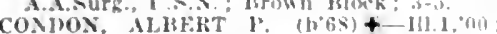

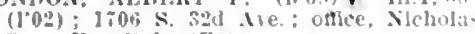
Senn IJospltal: ( $\left.F^{*}:\right)$

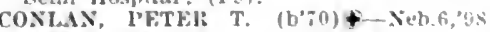

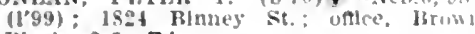
Hock: $2-5 ; P d$.

CONLIX, FHANK MATTIEW (b'S3)+ 111.1,07: (1'09); The Flatron: "Hflce

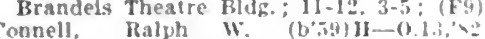

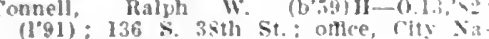
(1.91): 136 \&. 35th St: : Om
tlonal Rank I3]dg.: 2-4: Pr

Col"LTER. FR.

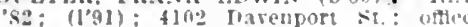
("liy Natlonal Hank 1Hluk.: 2-5; $N$.

Criss, Clalr r. (b, 79$)$ - Neb, 6,$10 ;$ (I'1:) 906 S. 3Sth st.: offle, City Nattonal Bank Bldg.; 10-12.2-4.

CRISS, NFII"L. (b's6)-Neb.6.'12; (I'12) 909 \& 35 th st.: offlee. City Nationa Bank Bldg. ; 10-12. 2-4.

Croll. Mercer R. (b':5)-Pa.1, Ts: (1':1) 302 S. 2ath St. : oftice, Brandels Rldr.

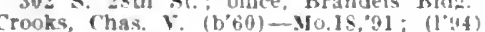
$1+14$ Chlergo St.

Cross, Clara Glines (b'81)-I11.8,'1s: (1'13) 1460 Douglas st.

Crowiey, Chas. F.-Neb.6,01: not in practlce: 331 i Burt St, 'Prop. (hem. ame Tox., Neb.6.

CILMIIEK, LEROY $\left(\mathrm{b}^{\circ}-2\right)+111.6,96$ (109); The Beaton; ontee, Contine?ba Block; 11-12, 2-4; Clln. Prof. Med. Nieb. 5

Curry, wllllam (b'6s)-111.1,97; (1'97) 2865 Manderson st. : 4-8.

CUSCADEN, GERTHI) (b'\$9)-Mleh.l it: (1*91); 3202 Webster St.; oflce, Be Bldg.

CITTER, IRVIX; SAITLL (b:5) Neb.5,10: $\left(1^{\prime} 10\right)$; not In practlce: so 5 . 39 th 5 : oflce, $42 d$ and lowey ives. Sec. and $A d j$. Jor. Chem., Neb.is: (Fit)

Dally, Fleanor S.-Ill.9, 75 ; (1'91); 251s Woolworth Ave.

DALLAI, JOS. JOIIN (b'69) +-X゙eb.6.'01 (1'01): Member Kan. Med. Soc.; :2: llason $\mathrm{st}, 10=2,2-4$

MVIS. BYROF BEXNETT (1053) MInn.3,84: (I.91): 1502 \&. 32d Ire.: of nce. Hee Itldg.: 3-5: Irot. I'rln. Surt and Clln. Surg., leb.5: $(A ;): S$.

Darls. Delmer J. (b'76)H-III t,02; (l'11) Strehlow Apts.: onlce, City National Bank Blde: $3-5:$ S.

DAVIS, JoHN (? (b'5.5) \& Ia.1, '83; (1'91) @114 Cumlng st. : 12-2, 5-s.

DAVIS. WILIJAM WINII,E (b'st)-Neh.ti

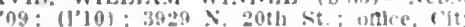
Natjonal lank 13lde ; $11-12030,2-5: 5$

Delfs Claus lillbert (b.92)-Nebiti:1 (i): swejlish Misulon Ilospltal.

lermody, leo A. (b'st)-Xeb.8, os; (1'0s)

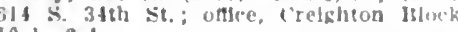
$10-1,2-4$

Dermody, louls Arthur (b'S6)-Nets fo'lo (l'11): 2103 Douklus st.: untee, Irefigh ton IHork: $9-11,3-5,7-2$,

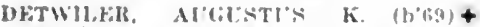

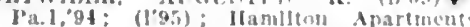
Pa.1,94: (1'95); Iramllton Apart

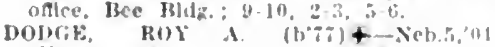
1101): 1420 Jothrop st.: anlie, Ihran dels riklg.; :-t, i.s; ob.

Duncan, John W. (b'sy)-Nob.6,12: (1'1:) ('retahton 13lock.
Dunlam, Frank s. (6'6s)-0.2, 43 ; (1033)

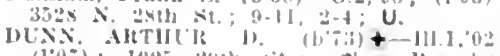

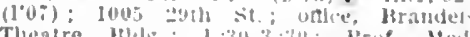

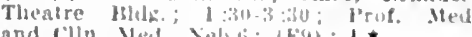
and clln. Med., Veli, is; (Fy); 1.

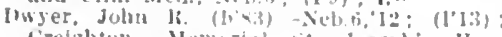
Crefghton Memorial st. Josephli's llus pltal.

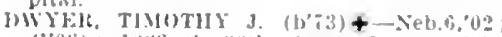
(10:6): 10:3 s. guth st.; under, Creinh ton lifuck

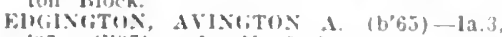

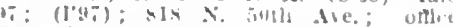
Kitrbach lifock: li-

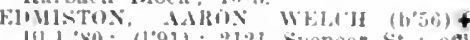
III.1.80; (1.91); 212t spencer st.; once Mranders Theare Hag.

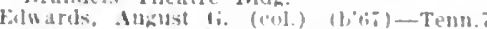

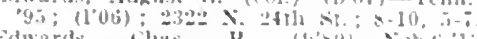

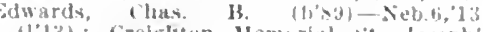
(1.13); Crelpliton Memurial st. Joseph IImpltal.

Ellwardi. Fredk. Arthur (b'74)-0nt.3,01 (1"ilz) : $2106^{\circ}$ (irace st. : ostlee, Bec bidr.

Folwarils, Lee W.-Neb.5,93; (1'94); 2.238 Fisnam St.

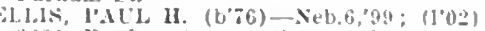
23at Fouler Ave. ontice, 24 th sit. and Ames Ire, ; $3-5 ;$ (Fy); $\mathbf{S}$.

kilnure, ('has, G. (b'58)-Tenn.6, ss: (1.91) zon! tapltol Are

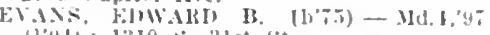

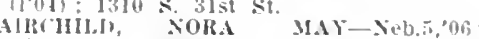

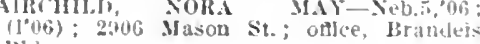

Femner, Harry B.-H-H110,84: (1's9)

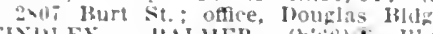

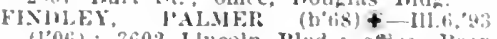
(1'06i); 3602 IAncoln Blsd.; oftce, Brandels Mldr.; 1-3: I'rof. Gyn., Nob,5; (AI 2,11, F9);ObG. *

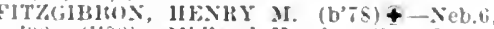
'us; (1'0s); Midland Hotel; Oftice, Hran deis lldg: $9-11,1-3,5-i$.

PITALMUS, ALEXANDER W. (b'7) -

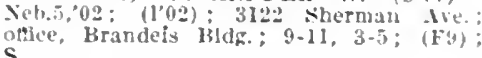
S.

Flanagan, 1,ibble l. Fltch Miller (b60)-

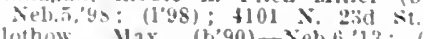

Gruirhton slemorlat st. Joseph sejuly IIos Jital.

orte, Dellizon A. (b'60)-111.10, s; ; $\left(1^{\prime} ? 1\right)$ $1 \pm$ Park Ave, oftice, I'axton Hluck $1:-1,3-5: 30: \mathrm{S}$

FonTE JAMES \& $\left(b^{\prime} 31\right)+-x Y 1,1$ Creigliton IIcallal College; I'rof. Hist.

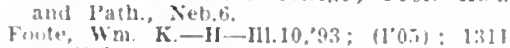

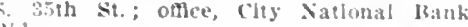
$1: 1,1,2$

MII. IICHAEL JOS. $\left(b^{\prime} \div 1\right)+$ - Xel.

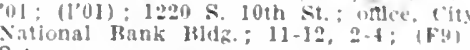
S.*

liarlner, (has Alven (b'st)-Ill.15, 10: (l'10): 38 sis seward st.: unlese sita liank Jidir.: 11-12:30, 2-4.

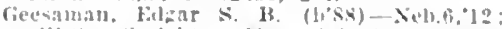
(1:1:): ('reluhton Memorlal st. dusepli llmultal

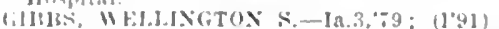

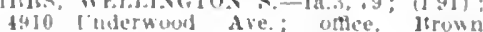
litork.

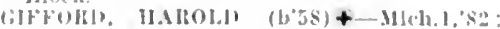

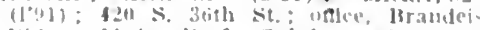
Hita: 11t: l'rup. Ophth. and otol. Velo (II, I ) : OALR.*

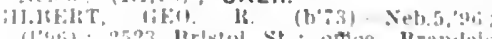

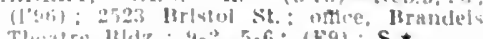

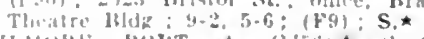

illallit: liont A. (i)

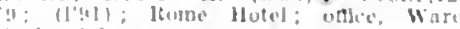

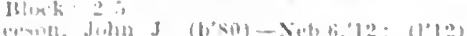

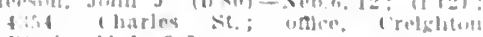
Mlowk $11-1,3-5$, T. $(1+40)+111,6$ 11,51201010 मू

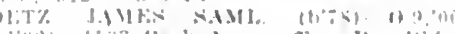

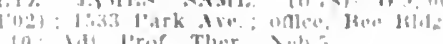

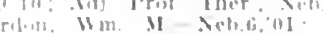

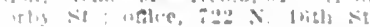

lirlan, klmer J-Vieb.totit; (l'04); 2001 l.ake sit.

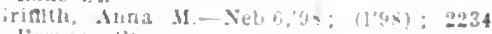
Fornam st.

HAHN, IINTAV $(6,63)+\mathrm{Neb.6,03}$

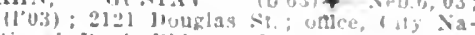
thoul kank lild:

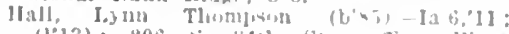

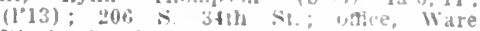

Illock: 10-12, :-5. Siprlug st. oftlce, liee likig.

hy.

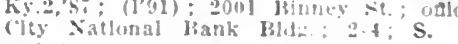

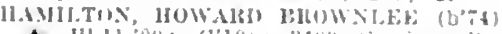
+ I11.11,00: (1'10): Pd.

1.MMUXI), JFIRI CHADW] $K(b+1)+$

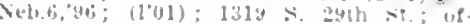

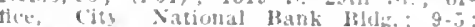
(His) ; OALR.*

llarrix, Ibolitey lougllsun-Mo.:, so: (191) 240 sinmes st

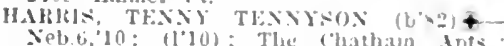

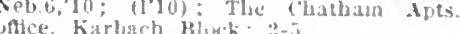

IIALSLIN, HAS MHHEL-111, 00 ; (l'ibi) : 2530 ('ajplol die.

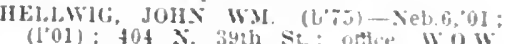
lildi. ; y-5: $0 . \star$

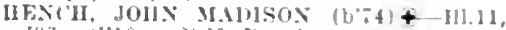

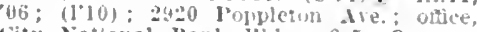
City Natlonal Bank Mids: $2-5 ; \dot{S}$.

IIF.NFY, EDHIX C. $\left(\mathrm{b}^{\circ} 70\right)+$ Neb.6.95, I'a.11,'96: (1'y5) ; 554 \& 35 th Are: of: fice, Brandels Theare bldf.: 11.1; ( 19$)$; S. *

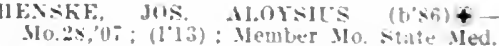
Ass. Missueri imacitio lia ilroad.

HIRE HIIXX, HEKHAX (b'

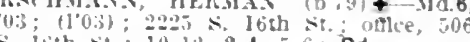
S. loth st.; $10-12,2-4,5-6 ; \mathrm{Pd}$

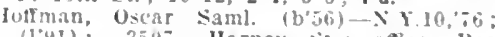
(1.41): $35 n$ il Haruey st.; oftce, Hee libldit: $9-10,5-6$.

HOLISTER, HOBT. RISEFIL (b'73) IIass.1, 02 : (1706); $490 \%$ Davenport st. offlce, State Bank IBldz: :-5; Adi. I'rof.

Holmes, Abbey b.-H-H1.4,"99: (l'99)

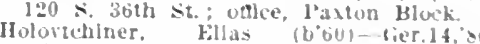
(191); 2401 SI Ith Si.; utice, liamge Hlock: 10-I: 2-1

IIolst, John, Jr. (b's5)-Neh.6.'13; (1'13) ; 1308 X. 4 al st.: once, Braudejs Bldg.; (1-12, 1-5: OALR. *

Holtman, Amadeus Andrews (1):3) - 116, 07 ; City National Batuk $13 \mathrm{dg}$. (1\%95): sos s. 20th st.: $10-12,2-4$.

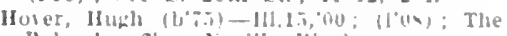
Roland; oflee, Dewlle lthoh

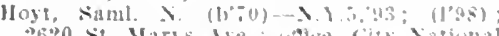
bank Halk.

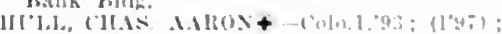

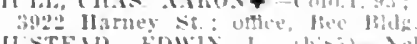

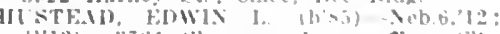

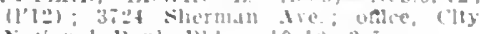

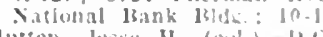

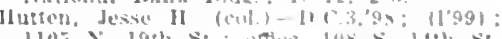

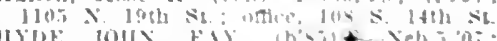

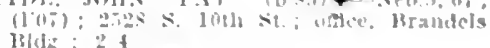

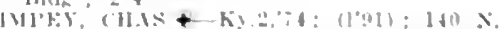

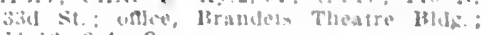

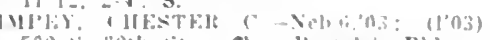

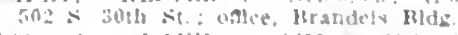

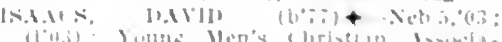

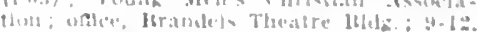

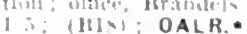

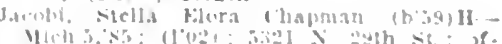

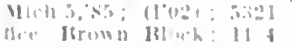

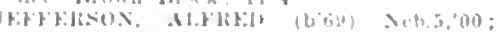

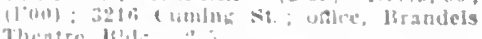
schand loulis

lice liti: 
JOINSON, ALDIS ADLLHLIT (b'S0)$0.6,{ }^{\prime} 1 \% ;(1)$; Member bhio stato Med Assn. 4"d st. and Dewey Ave.

JOINSON, ANDlRE (b'60) —-Neb.5,90 (1'91); 2003 Wirt st.; offlce, Brown Block; 9-11, 4-6; NP.

JONAS, ALGi's'T FREIR. (b'58) + - 111.8 , '7t, Ger.16,'84; (1.91); 106 s. 31st Ave.; office, Brandels Bldg.; 2-4; I'rof. I'race.

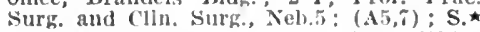
JONES, NEWLLL (b'81)-111.17,05; (1'05) : 2154 S. 33d St.; oftice, ("ity Nitlonal Bank IBldg.; Assoc. I'rof. l'ed., Neb.6.

Kalal, Frank J. B. (b'72)-Neb.6,01 (l'01) ; 2808 Clilcago St.; offlce, City National Bank Bldg.; 10-12, 2-4; G.

KAN1, M. ALACE MANTZ (1) 79$)+-111.19$ 03; (l'08); 2808 13urt st.; oftlce, old Boston store 1ildr.; ObG,

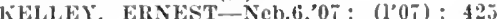
Manderson St.; offlce, Clty National Bank Blilg.

KENAEDY, CHAS. RHX (b'82) +-Neb. '05: (1'05); 707 Webster St,; oflce, Neb.5; (F9).

Kenner, Chas. Andrew (b'61)-Ill.1,83; (l'91) ; 1552 N. 19th St.

Keys, Jerome M. (b'50) E-0.2,'82; (I'9I) 923 N. 38th St.; ollece, W.O.W. HIdg.;

9-12, 2-5. N. Pauline (b'69)-Neb.6,03;

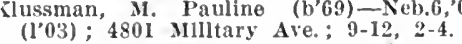

KNODE, ARCIIBALD R. (b'82)\&-Neb.5, '04: (1'04); 3130 Masen St.; office, knode, Robt. \&. (b'42)-0.9,'67; (1'9I); 3126 Mason St.: offlce, Omaha National Bank IBldg.; I I -3.

lioenle, Margaret $W$. Rhode (b'75)-Neb, 6, '03: (1'03); 814 X. 49th Ave.; $2-4$.

IAKE, FREDK. W. (b'76) $\oplus-\mathrm{Pa}, 1,0 \mathrm{I}$; (1'01); 220T Dodge St.; offlee, Brown 13loek : $3-5: 1 . \star$

LANGFELD, MLLARD (b'72)—-Md.7,'98; (1'99) ; 4205 Dodge St.; office, Brandeis Theatre Bld ; II-I2, 3-5; Prof. Med. and Clin. M!ed., Neb.6.

LAVENDHR, WM. It. $4-\mathrm{Neb}, 5,90 ;(191)$; 2208 Burt St.; offlce, Brandeis Bídg.

Leary, Wm. J.-Yel.6.05; (1'06); 181 i Ontario St.; offlce, Brown Block.

LEE, DANL. FRANCIS $\left(b^{\prime} 78\right)$-Neb.5,02; (l'03); 2702 S. 19th St.; offlec, City Natlonal bank Bidg. ; $11-1,4-6$; G.

LEUERE, HENRY BASSETT (b'T2)థNeb.5,98; (l'9s); Brandeis Theatre Bldy.; 9-12, 2-4; (B18) ; OALR.t

Lerey, Philip (b'88)-Neb.6,'13; (1'13); St. Joseph's Hospital.

Lichtenwallner, Jolin B. (b'59)-1'a.1,'82 ; (1'91) ; 1136 Park Ave.

LIEBER, CHAS. (b'8̈) $₫-N e b .5,08$; (I'08); 4117 N. 20th St.; office, $2524 \mathrm{~N}$. 24th st. 3-5, $;-8 ;($ F9) ; s.

LINDQUEST, ADOLPH B. (b'75)-Neb.5, "01; (1'02); (Benson); offce, Brandels Theatre 13ldg.; $9-4$; (B18); OALR. $\star$

Lindt, Harriet L. (b' 78$)-$ Neb.6,00; (1'00); The Flatiron; offlce, Paxton Block; 9-11, $2-4$.

LONEY, JAIIES S. (b'86)-Neb.6,'1I; (1'11): 1326 S 8th St.; offece, Karbach BIdg. ; $1-5,7-8$

LOOMIS, MILO MASON (b'74)థ-Ill.I,'97; (1’0J); 2117 Lothrop St.; offlce, Brown Block; $1-4$.

LORD, JOHN PRENTISS $\left(b^{\prime} 60\right) \oplus$ - Ill.I, 82 (1'91) ; 3421 Farnam St. ; office, City National bank Blat

LOUGHRIDGE " WILLIAM K. (b'74) Neb.4,94; $\left(1^{\prime} 10\right) ; 4819$ Underwood Ave.; office, Brandeis Theatre Bldg.; 2-5; S.

Lucke, Robt. S.-Ill.I,'84; (1'9I); 3839 Seward St.; office, Creighton Block.

Ludington, Horace (b'32)-Pa.1,'55; (1'91); not in practice; 3232 Harney St.

LUDINGTON, PAUL HAGANS-Pa.1,97; (l'97); 3232 Harney St.; oflice, Brandeis Bldg.

Lurvey, Homer D. (b'83)-Neb.6,'12 ; (1'12); 2215 N. 29th St.; office, Brandels Bldg.; $10-12,1-5 ; \mathrm{Pd}$.

Lyman, C. Elizabeth-Neb.6,'03 ;

$\left(1^{\prime} 03\right)$;
IXNCII, DELIA AIELINE (b'74)€-Nel, 6 , '09: (1'09); 1717 lodge St.; offlce, W.0.W. Bldg.; $9-12,2-5$.

Macl)larmld, Stuart B. (b'81)-Neb.6,04 (1'01) ; Y'axton Ifotel; offlce, Bee lildg. 9-11, I-3, 5-0.

MACK, ALONZO E. (b'69)థ-Neb.6,96 $\left(l^{\prime} 96\right)$; 5.66 P'ark Ave. ; oftice, Brandel Theatre IBldg.; II-12, 2-4; Prof. Obst. Neb. 6 ; 0 b.

Nobt. F. (b'85)-Neb.6,'13 ; Intern, Crelghton Memorlal St. Joseph'a Hospltal. MANNING, EILEST T. (b'77) $)$-Ill.I, 04 $\left(l^{\prime} 08\right)$; Member IH. State Med. Soc. ; 510 Underwood Ave.; office, Paxton Bldg. II- $12,1: 30-3: 30 ;$ (F9) ; 1.*

Harble, Robert E. (b'82) II-III.15,06; (1'06) 2220 Erans St.; office, Clty Nati. Bank Bldk.; ; $10-12,2-4$

Iarcotte, Abner It. (b'79)-Kan1.3,02; (末); Bachelors Hotel

Mares, Anna M. (b'69)-Neb.6,03; (1'03): 3502 s. 49 th St. : $2-4$.

Zellmond E-Ia.9,'94,

Helen Apts. ; offlce, Bee Hidg.

Mathews, John 'T. $\left(b^{\prime} 53\right)-110.2,81$; (1'91) 2552 IIarney St.; offtce, Brown Block; $10-12,2-4$.

Mattson, Alfred S. (b'59) IJ - Pa.9,80; $\left(\mathrm{I}^{\prime} 02\right)$; 1050 S. $32 \mathrm{~d}$ St.; offlce, Bee Bldg. $2-4$.

Maxwell, Wm. Creighton $\left(b^{\prime} 54\right)-N . X_{1} 10,74$ (1'9I); Yaxton Ilotel; offlce, Onaha $\mathrm{Na}$ tional Bank Bldg.

McAvin, James (b'89)-Neb.6,'13; (l'13). Creighton Atemorial St. Joseph's Hospital. McCauley, Paul B. (b'86)-Neb.6,'12; (1'I2); 2609 wirt St.

MeCaw, Hugh E. (b'55)-Ill.1,79; (1'91); $25 i 1$ Pinkney st.

CCLANAHAN, IIATRY MONROE $\left(b^{\prime} 56\right)$ (\$-Pa.2,78; (1'91); 1312 N. 40th St.; Neb.5; (DI) ; Pd.^

MCCLENEGIIAX, SAML, (b'80) -Neb.6, '07; (1'07) ; 1321 N. 29th St.; office, 1514 N. 24 th St.; $2-4,7-8 ; 0$ b

IcCrann, Wm. J, (b'55)-Ky 4,83; (1'91): 3003 California st.; offce, 17th and Farnam Sts. ; 8-10, 3-5.

MCCRANN, WM. JOS., JR. (b'88)-Ky.2,'12. ICDERMOTT, BERNARD A. (b'80)@-IIl.6, 03; (1'03); 3826 Webster St. ; office,

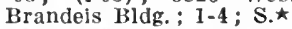

MCMARTIN, CHAS. (b'80) (-IIl.1,06; (1'07); 5102 Webster Are.; office, Brandeis Bldg. : 9-5; Prof. Derm. and Gen. Urin Dis., Neb.6; D.

MePIILRSON, JOS. B. (b'78) - Neb.6,'05 (1'0\%); 481 , Douglas St.; offce, City Na-

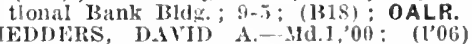
1318 N. 40th St.; office, Brandeis Bldg. 11-3.

MERRIAM, LALRESTON A. (b'43)-Nich.1, '73; (1'9I) ; Bee Bldg.; 8-5.

MICK, WM. H. (b'7t) 211 S. 36th St.; oflice, Brandeis Bldg. 8-12, 1-5; ( (i1); P. *

lillen, Sarah C.-Ia.1,'82; (1'93)； 1511 Leavenworth St.

MLROY, WM. FORSYTI (b'55) $4-N . Y .1$, '83; (1'91); The Colonial; office, Bran lled. and Phys. Diag., Neb.5.

Ioon, Louls Edwin (b'88)-Mlich.1,'12 (1'13); 4002 Hamilton St.; $2-4, i-8$.

MOORE, JOHN CLYDE (b'85) †-Neb.5, 08 ; (l'08): 3722 N. 29th St. ; office, Brandeis Bldg.; $11-12,2$ :30-5; (F9); Pd.

HOORE, JOSEPII C. (b'51) - Mo.T,'82; (1’91); 2107 Lathrop St.; offce, Brandeis Bldg. ; 11-12, 3-5.

MOORE, RICHARD CHANNING (b'41)@Emer, Prof Dis. Mind, Neb. 5 .

Iorian Clarence Herbert (b'74)-Pa.2, 12 (l'13); Nebraska Methodist Episcopal Hospital.

MORIARTY, PIERRE COLON (b'66)†N.Y.9,'s8; (l'93); Old Hamilten Apts. MORISON, CHAS. CAMPBELL $\left(b^{\prime} 75\right) \oplus-$ Neb.5'03 - (1'03); 1608 Locust St.; office Neb.5,'03; (l'03) ; 1608 Locust St.
Brandeis Theatre Bldg. ; $3-5 ; \mathbf{S}$.

Morsman, Leslie W.-Neb.5,'06 ; (1'06) ; 3215 Creighton Ave.; offlce, Omáha National Bank Bldg.
MUIIIILAD, AltCHIBALD $\mathbf{l}_{2}$ (b'65)Mlch.1,93; (1'94); 5306 N. 25th St.; Dean and Prof. Phar. and Physlol., Neb.6.

IULLEN, THOS. IR. (b'68) 1 -Neb.6,'96; (1’97) ; Member Ill. State Med. Soc. ; $1830^{\circ}$ l'Inkney St.; onlee, Brown Block; 9-12, I-5; (B18); OpA.

MUNiRo, HENItY S. (b'69) †-Md.1,91. $\left(\mathrm{l}^{\prime}(09) ; 614\right.$ s. 29 th $\mathrm{St}$; ; offlce, 13randels Theatre Bldg.; $9-12,2-5$.

Needhain, Chas. T.-Neb.6,'12; (1'12) ; 3526 IBurt St.; oftice, Barker Block.

fielson, Fred A.-Neb.6,04; (1'04); 1018 N. 40 th St. ; offce, 3023 Cuming St.

Nelson, Mary Ellzabeth Rosenberh-Neb.5, 97 ; (1'97) ; 1626 Burdette $\mathrm{st}$.

FEMEC. CHARLLS' J. (b'84)థ-Neb.6,'08; (l'08); 1316 Willlam st. ; $2-4: 30 ; \mathbf{S}$.

NEWELL, CIIAS. HAROLD (b'82)-Neb.6 '08: (l'08); 2028 Maple St.; office, City

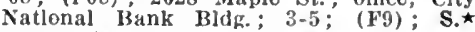

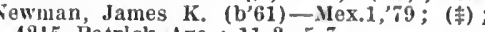
4215 Patrlck Ave. $11-2,5-7$.

IILSSON, JOHN R. (b'78) †-Neb.5,01. (1'01); 1403 N. 33d St.; oftice, W.o.W Bldg. : 2 -4; (F9) ; S.

O'CONAOR, II. KATHLEEN $4-N e b .6,{ }^{\prime} 03$; (l'03) ; 2201 Locust St.

O'Reilly, Robt. Henry-0nt.3,'00 ; (1'03) 15 th and Dodge Sts.

OWEN, FIANK STYLES $\left(b^{\prime} 56\right) \oplus-M I c h .1$ '85; (1'92); 2111 Emmet St.; offlce, 13 ranRhin., Neb.5; (BI,18); OALR.

PARKS, ALBERT L. (b'71)(t-IIl.1,97 ; $\left(l^{\prime} 04\right)$; 1331 S. 10 th St.; offlce, Burlington Station: Member Ill.' State Mled. Soc. PATTON, JAMES MIDOWELL (b'76) $\nrightarrow$ Neb.5,04; (1’04); 915 N. 4Ist St. ; effice,

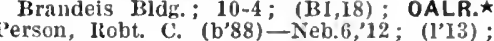
2708 N. 56th St.; office, Brandeis Bldg. OALR. $\star$

PETERSEN, LEROY T. (b'85)-Neb.6,'12 ; (l'I2); 2305 Douglas St. ; office, City Natlonal Bank Bldg.; I0-12, 2-4. PETERSON, ALFRED OLAF (b'i3) (\$)
Neb.5,99; (1'99); 3313 Cuming St.; of flee, Ramge Bldg.; 10-12, 3-5.

Petr, Francls J.-Neb.5,04; (l'04); 1516 Lincoln Ave.; offlce, State Bank Bldg. Pierce, Albert S.-D.C.2,'67; (1'91); 320 N. 23d St.; office, Brandels Bldg.

PINTO, ALVA SIIERMAN€-Neb.6,'98; (1'98); 2510 Charles Sts.; office, 1605 Dodge St. ; I1-12, 2-5.

POLLARD, CHAS. WHITNEY $\left(b^{\prime} \tilde{i} 1\right) \oplus$ N.Y.1,99; (1'99); 2962 Pacific St.; offlce, State Bank Bldg. ; $2-4$; Adj. Prof.' Obst.; Neb.5,; ObG.

PORTER, ELMIER R. (b'71)థ-Neb.5,'98 : (1'98); 4112 N. 51 th St.; office, Brandeis Theatre Bldg.; $9-$ II, I- $3,5-7$.

PORTER, IRA W.-Ala.2,92; (1'02); 422 N. 31st St.; office, W. O. W. Mldg.

POTTS, JOHN BEEKMAN (b;6) \&-Neb.5. deis 13ldg.; 8-5; (131,18); OALR.

POWELL, ERNEST WLLARD (l'98); 1814 Laird St. ; oftice, Paxton

POYNTER, CHAS. WM. MCCORKLE (b'75) $\Psi-$ Neb.5, 02 ; $\left(1{ }^{\prime} 02\right) ; 42 \mathrm{~d}$ and Dewey Sts. Prof. Human Anat., Neb.5; (F6).

Prince, Norman Call - Colo.5, 07 ; (1'15); 2407 Chicago St.; office, Paxton Block 5322 N. 24 th' St.; offlce, Contlnental Block.

Pugsley, Geo. 'Wm. (b'80)-Neb.6,07; PUVER, JOHN E. (b'84) $\oplus-N \times$ Neb.6,'08. (1'08); 3312 Hamilton St.; offlee, Brandels Theatre Bldg.; $2-4 ; 1 . \star$

Race, Wm. F. (b'57)-N.Y.5,'84; (l'91): I039 Park Ave.

Ralph, John B.-Ill.I,'69; (l'91); 2545 Capltol Are.

Rice, Raymond (b'85)-Neb.6,09; (1'09); 16 th and Farnam Sts.; office, Paxton Block ; 10-12, I :30-5:30, i-8; Or.ネ

RICH, CHAS. O'NEILL (b'75)€-Pa.11,'98 (1'99) ; 33 I9 Dodge St.; office, Brandels Theatre Bldg. ; 2-4; (F9); S.

Richardison, Chas. T. (b'38)-Va.4,'63; (1'01) ; 124 S. 3ist Ave.; 10-12, 3-5. 
KILEY, HIYAX M. $\left(b^{\prime}: 4\right)+-$ Neb.6,00 (1'00): 3364 l'opuleton ive: oftlce, C'tty Vatlonal llank Itlds.; 2-is; Pror, Med. and clin. Merl., Neb.

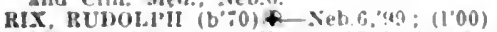
$3304 \mathrm{~S}$. 24th St ; oflce, 1605 thelpe st $11-12,2-4:$ l'rop. fyn. and "lln. diyn. Iieb, $6, \mathbf{G}$

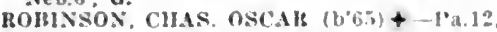

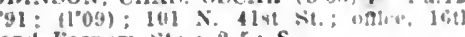
and Farnam st. : 2-5: $\mathrm{S}$.

Roeder, Jullus A.-Neb. N. Ifth st : office, 3302 Parker st

tomm, Abraham-Md.0,02; (I'03) : „y00s Iluri si.

ROSEWATER, CHAS. (b'59)†-Ger.20,79: (I'9l): 3424 Farnam sit: offlce, lhee (1'91): 3424 Farnam :- : oflee, Re Rldg.; I1+12, 2-f.

Obst., Neb.6; ObG.
Ross, Collin (110): 1512 $\mathrm{x}$. $27 \mathrm{th}$ st

Ross. WM. I.YTl.t (b'59) +-111.1. X.Y.10:8\%: (1'91): (Horence): othee Clty Xatlonal Bank Mldz: 10-11, 2-4: S

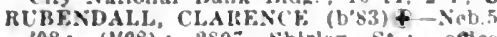
08: (t'08); 2S07 Shlrley St: ottice Brandels Bldg.: \$-12, 2-5:" (1318) Brandels

SACIS, ADOLPH -Neb. 6,07 ; $\left(1{ }^{\prime} 07\right)$; Ma Jestle Flats; odice, City National Rauk BIdg. : (Fy)

SCHALEK ALFRED (b'65) \&-AUS.5, ? 0 (lo0); jool tienrgla Are.: unlee. Mran.

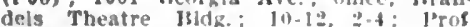
berm. and Gen.-lini, Jis. Veb. 0.

SCHLEIER, FRANK J. (b'08) +-Neb.6,04 (l'0t); Virginia Apts, : onlce, state bank HIdg. ; $2-5$

SCHULTZ, OSCAR TIFOHUHE (b"i) Id.7,03; not in practlce: Hember ()hic State Med. Assn.: I'nlrersity of Nob.

Prof. Bac. and Iath., Neb.5; (F2).

SEDLACEK, FREDK. ILOIL $\left(b^{\prime}(0.5)+\right.$ III.11,97; (I'10); Member S. lak, Stat Med. Assn.; 1453 s. Ilth st.; valce, 1270 S. 13 th st: $1.5:$ S

shepard. Carlton S.-III.1,81; $\left(1\right.$ I. $\left.^{\prime} 1\right)$; 2004

SIIER, PHILIP\$-NA.6,02 ; (I'03) ; 1613 Burt St.

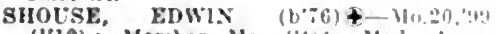
(1'12): Member Mo. State Med. Asst. 2507 Cass St. : N.*

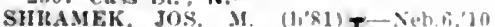

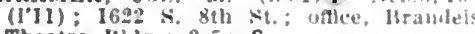
Theatre Ibldg.: 2-: : S

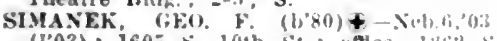
(I'03): $1605 \mathrm{~s}$. 10th St.; oftlee, 1202 : 13 h st.: $2-4,60: 30=: 30: \mathbf{S}$.

SIMON, FRANK (b'62)-Id.3.84; $11^{\prime 41)}$ 1809 Emmet St. : :-

SIMISON, JoHs है (b'il) Xeb.t.os

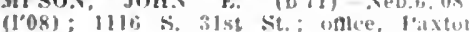
Hock: 11.1.

Smersh, olto (: (b'80)-Neb.5, 03 ; (1'0;) 1126 $\times$. ath st.

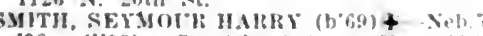
98: (1'9s): Cornisli Auts.: ontere, 10. S. 10th sit. : 11-12,2-4, i-s.

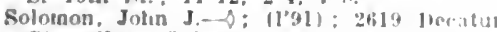
St. (

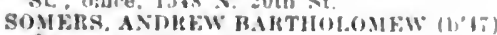

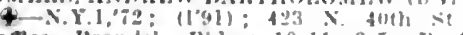
omee, Jrandein Iblds: $10-1 \hat{i}, 3-5:$ i'rof Obst. : Neh.5; Ob.

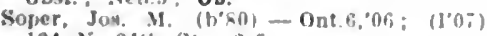

$124 \times$. 34 st: 2 :

Spalellne. Saml. K. (fii) la lit y y lo 82: (1*91) ; 2.04 (Tharles st.; ontre, I fiv. nowige Sit. : $11-12,3-5$

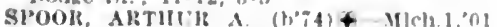
not in practlce: Mromier Mich. Nite Med. Soc: 1723 liats st.: onlec, irelgliton Vinlverstly: LD.

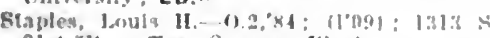
3 int Nit. : omee, Crounse Itloxk.

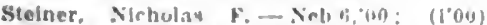
The foland Apts.; umce, liranilois lslil.

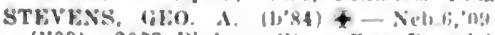
(I'09); 2023 linkney st.; once, Brambel Theatro Itlis

STOKL: A

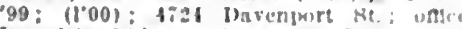
Irrandela Hidg.: $3-h_{0}$ : Aww. I'rof lient tirln. Surk and fixper. surg. Xrb (Ii, (3, F9): S.
STRONG, MARY (b.T4) + Michl.R8: $(101) ; 24 t h$ and binney sits. : $10-12,2-5$ Ob.

strouse, llenry St fieurec-l'a $3,8 \beta ;$ (1'96) Omaha finergency [10opltas.

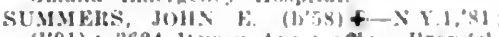
(1'91): 3624 lewey Ira ; onlee, Hrandel. Theatre Hlde.

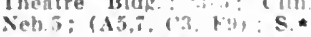

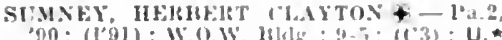

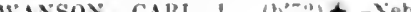
(198): 3312 l'arker st.; unje, Mrandely Isidg.; $11-12,3-5$

Swartzlander, Fred (1,4i)-1'al, 2,72: $(1091)$ 2601 Capltol Ave.

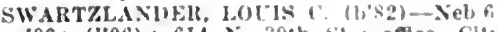

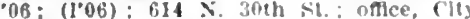
Natlonal Bank Bidg. ; $2-5$

Swetland, Agnes V.-Ia.4,91; (1'91); 1;tl and vodge sit.s.; 2.4 .

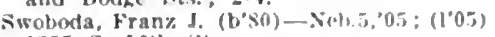
1255 s. $160 \mathrm{~h}$ sit.

SWOBODA, 1.0U1S (b'49) + - Nob.5,"9t) (1'96) : 1237 s. 16th st.; oflce, paxtor Hlock: $11-12.3-4$

TAYLOR, WHIJIA IIALYEY (b'86)-Neh.5 11: (1'12): 3212 Cuming st.: offlce. Brandels Bldg.: 10-12, 3-it: $(59) ; 0$.

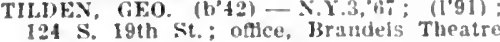
Bldg.

TOWNE, SOLON RODSEL (b'ti)-N.H.I 75: (l'91); 5302 ('harles st. ; offler and State Mlded; $11-12$

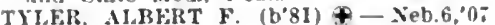
(I'07): $3 i^{2} 6$ Charles St. : oftce, Brandels Theatre Bldg. : $1: 30-3: 30: \mathbf{R}$.

U1DEGRAFF, BLMER J. (b'5i) \$-Neb.5. 99 ; (I'99) ; 829 I'tne St.; offlce, Brandel Bldg.; 2-4, $\mathrm{S}$.

CRHA, CLALDF, TIIOMAS (b'87)-Mllch. '10: (l'12): 132: S. 30th Are.: offlce, State Bank Blug.: 9-1, 2-5: (BI8) : ALR.*

VIN BUREN, FRENK. ARTHUR $(b ; 6) \neq$. IIl.6,04: (1'12); 2552 Ames Ave.: offlee. Brandels Theatre 131dg; 11-12, 3-5; S. WAX CAMP, LEE B. $\left(b^{\prime} ; 6\right)+$ Neb.5,'9s $(1998) ; 2301$ s. 32 .

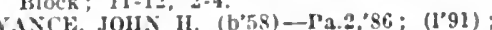
2002 Emmet St. : oflice, Brandels Theatre ßdd. : 11-12, 2:30-4:30.

VA. FLEET, HWIRD A. (b'69) $\uparrow-$ Veb.5 02: (l'0 0 ) : 1112 s. IIth st.: office MeCague lildg.: 11-12, 3-5.

WAGENkR, IIFWITT A (b'79) \&-Neh.6 04: (1'04): $31 \mathrm{st}$ and Dewes" Are.; oftice, Hrandels IBIdg.: $11-1,3-5 ; \mathrm{S}$.

W.I.KVil, WM. H.-\$eb.6,01; (1'01); $295 \%$ Harney st.; office, Barker Block.

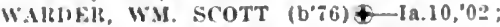
(1009): 1919 Cass St.

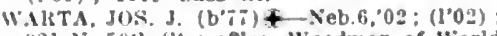
921 .5. 5oth st. : offlce, Woodman of World Hdr: : $y=$; OALR. *

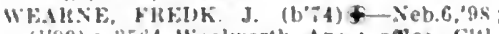
(l'99); 3itts Woolworth Ire; oflce, CItlze"lis Xatl. Jank Iulds.: 2-5.

tived, John Will am (1, 7 - Neb.6, 04

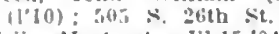

Wellw, Iyrta i -111.15:04; $(104) ; 1116 \mathrm{~s}$

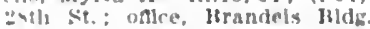

Wastervelt, Alfreal kilward $\left(b^{\prime} S s\right)-$ Neb.5. '1:b: (1'13); llshop Clarkson llospllal fur (hildren.

WHFABY, WM. I'ENAIAXA $(b 50)+$ Sinb.s, 03 ; (1003): 2143 Manderson :

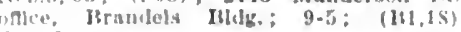
OALK.

Wightman, lirace S.-III.8,06: (1'13): \$ls l'ark Ave.

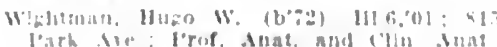
lourh lif l'rof, Anat and llin ind Sist bi : $\left(p^{2}\right): \mathbf{S}$.

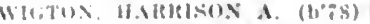
(1'(i) $1 x^{\circ} 00$ Vinton SL: $2-4$

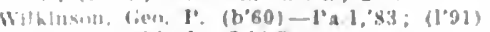
(relahtons lluek; OALR.*

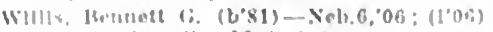
culnluk st. : 13-\%, 6-8.

Hilmon, Arthur 3 -Veb.6,95: (1997): The

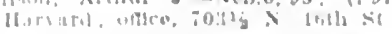

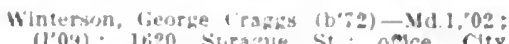
$\left(l^{\prime} 09\right)$; ligo sipazue st: onlce, Clty

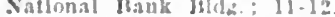

Wood. Orlando s. (b:52)11-1'a.6,6.8; (1'91); 2531 I'arker sit.; ontee, 1srandels Theatre Blde : $8.10,1.4$

Wray, frank Jorace (b'+9) - la l, 87 :

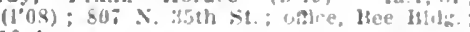
10-4

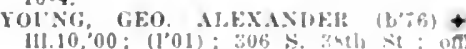
Hrandels theatre Hldg. : : 1 ru? Ment. and Nert. Ins., Sels.0; NP.

O'NEILL, 2.089, HOLT

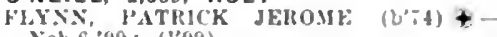
Neh.6,"99; (1'99).

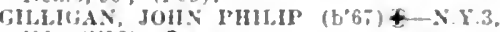
$90 ;(1.92) ; 0$ D.

WILSON, EIREHTON T. "(b66)-Mlch." (43); ( 1005$)$

ONG, 285, CLAY

ASA, OHAN C. (b'71)-.Neb.4,08; (l'0x). Martin, Jos. W. (b'b:)-X'Neb.5,"03; (103).

ORCHARD, 532, ANTELOPE

Fleicher, 1). L, - lit.s, 08 ; (娄)

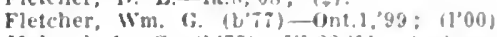

Mahood, 1). G. (1,75)-I11.20,'11; Asintant lhyslclan.

ORD, 1,960 , VALLEY

B.IITA, FRANK A.BELT (h's5) $\&$ - Ia.3 10 ; $\left(1^{\prime} 10\right)$.

blllnes, Irout. A. (b'61) 11-\$10.219,93; (1.96).

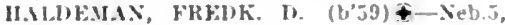
S.2: (1.91): D.

MILLER, CIISTON JAMES (b'Sl) +-Neb.5 05: (1'05): $\mathbf{S}$.

THWHEKRI, MINEKLA M. (b:51) III.9,93; (1'94).

Shepard, Chas. Carter (b'.59) H-Pa.9,01: (I'03)

ORLEANS, 942, HARLAN

CIARIEL, ALBE:LT JACKSON $\left(\mathrm{b}^{\circ} 73\right)+$ MO.:,01; (1'03).

HOFFMA, JAOO OLIVER $(6,54) \$-$ Mch..., 53 : (1'91)

Bundle, Wolter (: (b'a6)-Ill.1,06; (1'13).

SLCCIIA, WM. I. (b'3t)-Neb.6,08; (1'08).

OSCEOLA, I.105. POLK

IE MAK, CLAIR L. (b;:) - Neb.5, (l'03).

Ucthesney, M. Josephine - H-lat, st: (1.91).

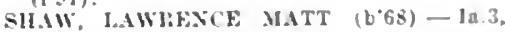
s9: (l.01).

S.ITH, DAVin J. (b'64)-Neb.5,'9s; (199s),

OSHKOSH, 175. GARDEN

Hough, llarry 11. (b'ri9) lI-Mo.26,93; (1093),

OSMOND, 567, PIERCE

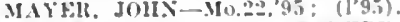

WHITHIIEAl, FHLAS MFHBR.RT (b'bs)1a.3, 04 ; (1'12).

OVERTON, 574 , DAWSON

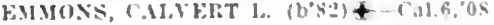
(1'0)

Whingitis

OXFORD, 593. FURNAS

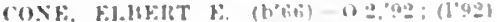

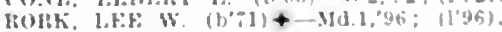

PAGE, 300, HOLT

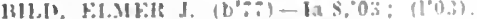

PALISADE, 380, HITCHCOCK

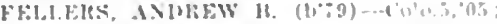

(1) 0.1$)$

PALMER, 373. MERRICK

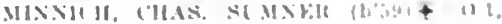

(1): (1?) ; 0 p.

PALMYRA, 334, OTOE

iamerut, WHItam I

$(1, y)$

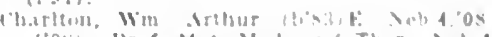

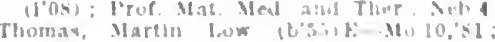
(I'0!)

PANAMA, 230, LANCASTER

lHslor. William Cirast (b) (i) t: Sebt.03:

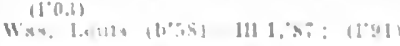


PAPILLION, 624, SARPY

AlMNTIONG, ROM'T. B.-Neb.5,94: (1'98).

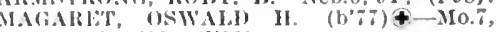
' 99 , Neb.5, 00 ; (1'00).

PAULINE. I50, ADAMS

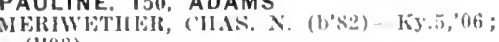
(I'0S).

PAWNEE CITY, 1,610, PAWNEE

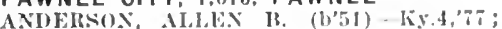
(l'9l).

130YYli, WII. 16. (1)'71) III.4,94; (1'03).

BROOKS. HAlRI HKISIBS $(1,30)+-$ II.6, 05 ; $(1006)$; OALR.

Collins, Geo, Wm, $\rightarrow:(1 \cdot 91)$

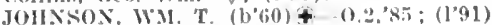

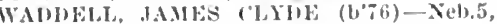
10 ; (1'10)

PAXTON, 179, KEITH

Paxton, W. F.-No.22, 00 ; $\left(\mathrm{I}^{\circ} 00\right)$.

PENDER, 804, THURSTON

BUIS, JOHN (b'70) \$-Neb.5.07: (l'07)

IILRRox, Wy. F. (b'-8) \pm -Neb.5, 01 ; (I'01).

\section{PERU, 950, NEMAHA}

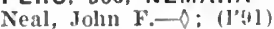

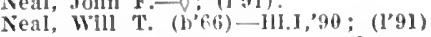

REED, ELEANOR (. (b'62) $4-I 11.9,85$; (l'Bi).

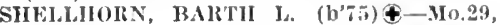
95. Ill.1,00: (l'00).

VANCE, V. VERNE-Neb.5.'03; (1'03).

PETERSBURG, 533, BOONE

BYKLS, SAMIH, JOHN (b'70)—-0n1.6,99; (I'99).

DAVIS, JOS. EDWAIRD-Jo.20,'00: (l'00)

Mogan, Wm. F. (b'87)-Neb.6,'12; (1'13); S.

PHILLIPS, 274, HAMILTON

Conaway, Henry ollver (b'48)-0.2,75; (l'03).

PICKRELL, 120, GAGE

LFE, NMFSBURY (b'8I) $\uparrow-$ Neb.6,'10; (l'10).

PIERCE, I,200, PIERCE

DESPAROIS, GUY B. (b'82)-III.6, ${ }^{\circ} 07$; (1'08).

Lllledahl, Frank E.-Neb.5,'96; (l'96).

MARTIN, ARTHUR ALVIN (b'79)£-que.1,

'0s ; (1'10).

SALTER, FRAXKK GEO.-Ont.3,'89; (l'91).

PILGER, 47I, STANTON

REID, JOHN D. $\left(\mathrm{b}^{\prime} \mathrm{i} 4\right) \Theta-\mathrm{\Theta}$ - No.5, 02 ; (l'02)

PLAINVIEW, 941, PIERCE

COE, CHAS. BENJ. (b'81) - Neb.6,'12 ;

JENSEN, JENS PETER-Neb.5,03; (l'03)

NYE, FRANK H. (b'66) \&-Ia.1,'91; (l'91)

Platte CEnTER, 388, Platte

BALI, ARNO ALBERT (b'86)-Neb.5,'11; (l'1i).

Benthack, Peter I.-H-Ilo.26.'99; (I'00). SEASONGOOD, ROBT. R. (b'83)-Neb.6,'08;

PLATTSMOUTH, 4,287, CASS

COOK, EDWIN W. (b'57) $4-1 \mathrm{a} .3,{ }^{\prime} 84$; (1'91).

Cummins, Edgar D. (b'64)-Neb.5,'89; (l'91).

Hall, Jos. II.-Ill.1,'78, N.Y.10,'82; (1'91).

LlvIngston, John Stuart (b'71)-Neb.5,'98; (1'98).

Livingston, Theodore P. (b'64)-Neb.5,'88: (1'91).

Martin, Joslah B.-E-111.8,'77; (1'02).

PLEASANT DALE, 257, SEWARD

Sandusky, Wm. (b'81)-Neb.6.'10; (1'10).

PLEASANTON, 252, BUFFALO

Randall, Andrew La Roy-Ill.6.'03; (1'03).

PLYMOUTH, 438, JEFFERSON

Meisenbach, Geo. W. (b'76)-Ill.1,00; $\left(1^{\prime} 00\right)$.

PENNEL, HENRY G. (b'72) - Neb.5,04; (I'04).

POLK, 396, POLK

Ayers, Clinton L. (b'T) E - Neb.4,06;

(I'06); OALR.

SLISSER, FRANK B. (b'6s) - Ill.1,95; (1'95).

WESTFALI, DAVIS H. (b'74)-Neb.6,02; ('03).
PONCA, 1,000, DIXON

HAYEY, JOHX MC'IIAEL (b'82)-Ia.8,05 (l'0ii)

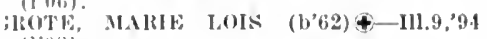

$(1,98)$

Mallison, (ieo., Jr. (1,87)- Neb,6, 13

O'(ONNELL, IAMES II. (b'53) \&-III.I,'91 (l'y $]$ ) : Pd.

Young, (iyuchon Angus-II--Ia.4,00; (1'00). POTTER, 200, CHEYENNE A.Mrs, NIBI:O J. (b'52) $4-$ Neb.6,'01
(I'0I).

PRAGUE，39., SAUNDERS

KASIMI, J(OS, FRANCIS $(1,76)+-N . Y .19$, $30 ;(1,00)$

PRIMROSE, I58, BOONE

llewey, (ieo. J. (b'62)-la.1,'00; (l'01).

PROSSER, 163, ADAMS

COI.MAN, A. ( $.(1,83)+$-Neb.4, $07 ;\left(1^{\prime} 07\right)$ S.

Morrow, Chas. Dudley-E-Neb.4,95; (1'97).

RAGAN, 214, HARLAN

ROGERS, DANI. lR. (b'55) -1'il.2,'80; (I'91).

RALSTON, 400, DOUGLAS

Barnes, Cyrenius $\$$. $\left.\left(b^{\prime} 42\right)-0 ;\left(l^{\prime} y\right]\right)$.

RANDOLPH, 1,137, CEDAR

'OOK, ARTHUI? E. $\left(\mathrm{b}^{\prime}, 0\right)+-1 \mathrm{a} 0.8,98$;

GLEASON, BERT F. $\left(b^{\prime}, 79\right) \notin-111,6,07$ (1'09).

KEMLEY, QUILLEX A. (1,72)-Mo.28, 00 $\left(l^{\prime} 00\right)$.

Kiennedy, Sallie F-Ia.8,'97; (l'9i)

RAVENNA, 1,359 , BUFFALO

Buol, Geo. (b'86)-Neb.5,'10; (I'I0)

HALE, CHAS. A.-Neb.I,'86; (I'91).

Inmpal, Jos. J. (b'85)-Neb.6,'11 ; (l'11).

I'EN J, JOIIN H.-Mo.22,'93; (1'93).

Walker, Davld A. (b'74)-la.10,02; (l'02)

RAYMOND, 236, LANCASTER

Bowman, Delhert J. - Neb.4,'11; (1'11) Prof. Obst., Neb.4.

IIILIAPSEN, JOIIN ALRERT $\left(b^{\prime} / 1\right) \notin-$

Io. I8,94; (1'94).

RED CLOUD, 1,686, WEBSTER

Caldwell, James C. (b'83)-MI0.20,'12; (l'12)

COOI, HENRY (b'49)\&-b; (1'99).

CREIGHTON, ERNEST A. (b'71) - Ont.6, '98; (1'99).

DAMERELL, ROBT.-Ill.1,'82; (1'91).

Hoxsey, Robt. P. (b'70)-IH.11,'01 ; (1'06)

IITCHELL, ROBT. S. (b'7i) \&-IIl.6, 04 (l'06)

MORANVILLE, J. W. (b'45) - ; (l'91).

SANIERSON, DAVID DOCGLÁS (b'85) IIo.28,'11; (1'11).

STOCKAMN, JAMLS WM. (b'73)-Ill.4,'03 (l'03); 0 p.

REPUBLICAN CITY, 476, HARLAN

VALIICOTT, OSCAR J. (b'67)-Neb.4,'99 (1'99).

\section{REYNOLDS, 246, JEFFERSON}

Ammerman, Ulysses S.-Ia.9,'98; (l'98).

Caulk. Wm. H. (b'55)-la.1,'81; (l'91).

RICE, - ARTHUR

kice, Chilton S. (b'55)-0.16,'93; (ま)

RISING CITY, 456, BUTLER

Downing, Ios. Henry (b'56)-Ill.1,'82; (1'10)

ANDEHHOOF, THOS. J. (b'84) $4-N e b .4$

'0S; (1'08).

RIVERTON, 369, FRANKLIN

TAII, FRAYK E. (b'S0)-M0.22.07; (1'08)

PACKWOOD, W. E.-Ill.8,'06; (1'07).

ROCA, 129, LANCASTER

Demaree, Emma W. (b'51)-IIl.9,'95; (l'95) Demaree, IIenry C. (b'49)-Ky.1,'79; (1'91). ROCKVILLE, 201 , SHERMAN

OICKINSON, LOUIS E. (b'78) \&-Ia.8,04; (l'04).

ROSALIE, 147, THURSTON

IIcCarl, J. Jay (b'80)-Neb.6,'07; (1'07).

ROSELAND, 249, ADAMS

MACE, JOHN L. (b'79) $€$-Tenn.6,'09: (1'09).

ROYAL, 125, ANTELOPE

Curtis, Elmer E. (b'88)-Neb.6,']1 ; (1'11)

RULO, 66I, RICHARDSON

Henderson, R. G. (b'72)-Mo.8, 00 ; $\left(1^{\prime} 00\right)$.

Shepherd, John C. (b'54)-Ky.2,76; (l'92)
RUSHVILLE, 633, SHERIDAN

11.NIEL. 'TAHOK T. (b'S9) + N.Y. 10,70 (I'04);0p.

Vilson, Osear 1. (b'57)-Ind.8,79; (1'95).

RUSKIN, 339, NUCKOLLS

Savlle, Frank N. (b'75)-.'Yeb.7,'09; (l'09)

LR.

SALEM, 391, RICHARDSON

l'ollard, Jullan $\mathrm{A}$. (b'52)-Vt.2,'82; (I'91).

S.IITI, ANIIEW JACKSON (b'85)-Mo.22,

10 ; (1'10).

SANTEE, 20, KNOX

Hart, Edw, S. (b,50)-0.6,'73; (Indian Servlce); Santee śchool.

SARGENT, 65I, CUSTER

Fenstermacher, Clark H. (b'73)-Ky.2,00 ; (1'00).

Taylor, Clas. F.Ẍeb.4,'06; (l'06).

SARONVILLE, I30, CLAY

Belrne, Chas. J.....Mo.7,'02; (1'02).

SCHUYLER, 2,152, COLFAX

HART, RALI'H S'TACY (b'80)-Neb.6, 07 ; (1'07); OALR.

MOORE, CI.ELAND G. (b'82) \&-Md.1, 09 ; (1'09).

SIXTA, YEWIS 11. (b'67) †-111.6,89; (1'97) WOODS, JAMES $\left(\mathrm{b}^{\prime} 44\right)+-0.6,70 ;(1,91)$.

Woodward, James Claude $-\mathrm{E}-\mathrm{Feb.4,00}$ (1'05); S.

SCOTIA, 328, GREELEY

Weekes, Chas. W. (b'82)-Neb.6,'04; (1'04). SCOTTSBLUFF, 1,746 , SCOTTS BLUFF BOYD, CHAS. ALBERT (b'54)-IIl.1,81; (1'10).

CRAWFORD, ANDREW (b'51)-Neb.5,88; (1'9I).

GRIGSBY, RAB AARON (b'82)†-Ia.1,05;

JONES, LE ROY R. (b'76) - Neb.4,'10

(l'10). Clyde Newton (b'82)-Neb.4,'11

Moore,

(1'I1). PLEHN, FRANK W. (b'65) - Mo.20,98;
(1'98); S.

Schrock, Josef B. (b'73)-N'eb.4,'10; (1'10). SCRIBNER, 89I, DODGE

BARTLETT, GROVE W. (b'78)-Neb.5,'00 (1'00).

INCHES, CHAS. (b'44)-N.Y.5,'68; (l'91).

SENECA, 150, THOMAS

Pass, M. D.-0.23,'96, Ky.9,99: (I'00)

Phillips, Isaac H. (b'78)-0.25, 00 ; (1'02).

SEWARD, 2,106, SEWARD

Cummins, Hersehell B. - E. - Neb.2,'85 ; (1'91); Sec. State Board of Health.

Diers, Louis H.E-Neb.4,97: (1'98).

IIlrsch, Robt. S. (b'48) E- 0 ; (1'91).

Morrow, Bert E. (b'81) E-Neb.4, 05; (l'05)

Morrow, Jos.-0.2,'92; (l'92) ; Prof. Gyn., Neb.4; S.

Morrow, Milton-Neb.4,98; (1'98) ; Prof. Mat. Med., Neb.4.

NEISON, CARL DAVII (b'79)-Neb.5,09; (1'09).

Ragan, Seth Ellsworth (b'72)-Mo.28,97 ;

Stoekert, Chas. Fredk. (b'69) - Ill.I,'93; (1'93).

SHELBY, 503, POLK

Fulliam, Edmon B. (b'y1)-Ill. 8,13; (1'13).

INKS, JOHN A.-Ill.1,'80; (['9I)'

Porter, Epaphroditus J, (b'54) - Ill.1,'־8:' (1'98)

POT'TER, GEO. B. $\left(b^{\prime} \div\right) \oplus-N e b .5,05$; (1'05).

SHELTON, I,005, BUFFALO

KANZLER, REINHOLD (b'83) - Ill.6,'10 ; (l'12).

LUCAS, CHAS. (b'66)-D.C.2,'93; (l'95).

SHICKLEY, 429, FILLMORE

Reeves, Geo. I. (b'60)-Mo.22,'02; (l'02); G.

Wilson, Evert A. (b'77)-Uo.28, $04 ;$ (1'07)

SHUBERT, 3II, RICHARDSON

SHOOK, WAI. E. (b'72)\&-Ill.11, 01 ; (l'01)

SIDNEY, I,I85, CHEYENNE

MANTOR, HUGII E. $\left(b^{\prime} T 4\right)-N e b .5,02$; (1'02); $\mathrm{S}$. (l, 12$)$

Simon, Lincoln G.-Pa.2,'95; (1'95).

Swatslander, John C. (b'il) - Mo.20,97; (I’04)

Woitishèk, Frank J. (b'64)-Ill.6,'90; (1'91). 


\section{SILVER CREEK, 379, MERRICK}

(illesple, Liduard J. (b'83)-Neb.6,11: (1'11).

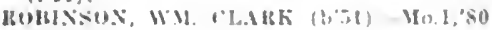
$\left(l^{\prime} 91\right)$

SIOUX. 1,200, DAKOTA

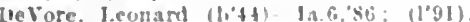

SMITHFIELD, 190, GOSPER

Vander-silce, Augustus .M. (L'bs)--Neb. z. $09 ;(1,0,4)$

SNYDER, 314, DODGE

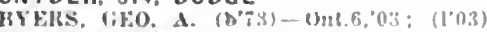

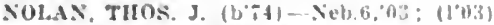

SOUTH AUBURN. 800, NEMAHA

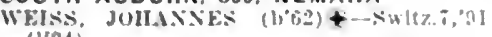
(1.04)

SOUTH OMAHA, 26,259, DOUGLAS

Aberly, Uenry J. (b'45)-Tenn.4.'Y1; (1.92): 2418 N St.: $9 \cdot 10,7=8: 0$.

Allngham, Henry T. (b'80)-Neb.6.'12 (1012): 2318 A St.: ondce. $405 \%$. 242 St.; 9-10, 4-6.

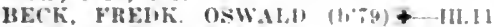
(05: (1'10): 1519 N. $254 t_{2}$ st.: ontce, 425 X. 2th St: $11-12,2-4,7-8$, S.

HEIKKX, WM. $\left(b^{\circ} 62\right)+-8.3,54:(195)$ IHI x $29 t h$ sto once, 514 .

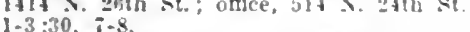

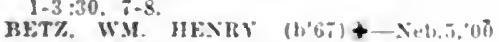
(1'Do) : (Bellevue): omce, $410 \mathrm{x}$. 2 (h) st. $1-6 ; 5$.

Chaloupla, Foward (b'-9) - Neth, po: $(10.5): 260$ S. 22d st.; catce, 443 X. 24th St. : $2.5 ; \mathbf{G}$.

Chaluupka, Ifuso R. (b.si) - Nebs,11 (1"11): $260 \mathrm{~s} .22 \mathrm{~d}$ st. : offee, $433 \times 24 t$

Darls. Wm. M. (b*56)-Mo.1,8t; (1'97) $1+24$ N. 2tih St.; ontice, Llve stock Na tlonal kank Bidg.

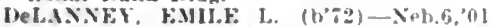
(I'0i); Ist Lleut., II R.C. V.S.A.; (Ft) Crook): offce, $402 \mathrm{x}$. 24th St.; 1-3, $7-8 ; \mathbf{S}$.

Ensor. Thos. II. (b'58)-Mo.2,'80; (1'91) $1604 \times$ 23d st.; ontre, $503 \times$. 2tth st. $9-11,2-5$.

FA ULK, FHED W. (b'65)-Tenn.9.4\% (1'99); 1302 Jackson st; iflce, ty2. St.

FRICKF, ALHERT NBOLPH (b'T + Neb, 5,08: (1'08); 2301 F'st.; offce, 40. N. 24th St, : 10-12, 2-4; $\left\{\mathrm{F}^{2} 9\right\}$

Fuester, Blchard (b'46)-Ger.9,02; (I'08) 1902 Jackison S?.

Koenig, Albert Henry (b'8(t) - Neb.6,04 (I'04): 2401 : st. : $2-4, i-8$

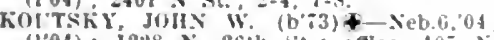

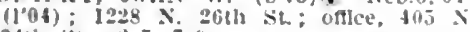
2 th st. $:-5, \div-9$.

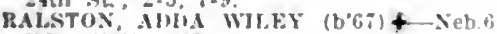
99; (1'99); 1608 X. 204th 58 ; 2-4.

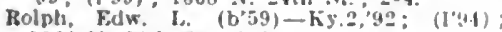
$1124 \times 24$ ih St ; $9-4$.

SCUINEL, CIIAS. M. (b'63) - N Y.in's:

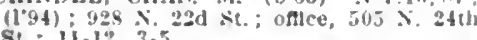

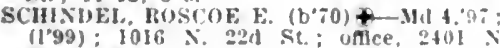
St: 8.9, 1-4, 7-8: Prot, Dis of the stomach, Neb,

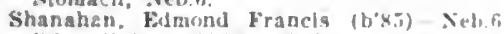

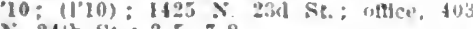
S. 24 th 8 St. $3-5,7-8$

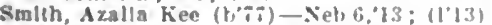
$734 \times 24 i t s$ st.; onlee. 2fth and $J$ sits $10-5: G$.

\section{SPALDING, 637, GREELEY}

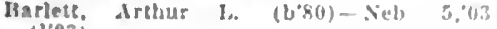
(1?03).

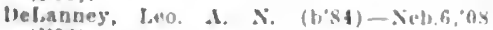
(1'08)

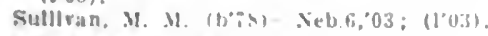

SPENCER, 671, BOYD

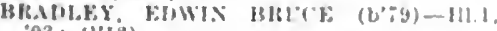
03; (1'19)

Keep, Frank F. (b'75)-6).23, (bi: (1'ys)

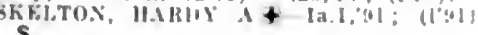

\section{SPRAGUE, 130, LANCASTER}

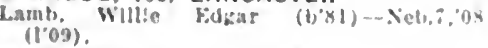

SPRINGFIELD, \$63, SARPY

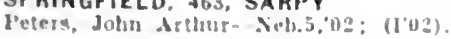

ST. EDWARD, 814, BOONE

Flory, "Wrollle II . Mo.8."yL: (1'91).

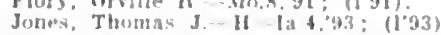

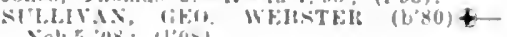

Neh.s.os: $11^{2}(0) 1$

ST, LIBORY, 125, HOWARD

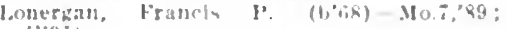
(10)

ST. PAUL. 1.336. HOWARD

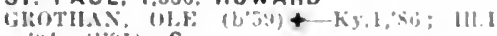
(4): $(1,91) ; \mathrm{S}$.

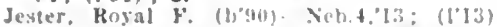

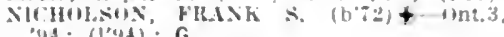

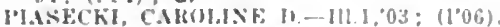
STAMFORD, 301, HARLAN

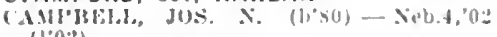
$\left(10^{\circ}: 0\right)$.

Waggoner, Dlckson II. (b.tt,-11,1,il (1)03).

STANTON, 1,342, STANTON

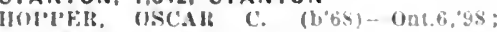
$(1,98)$.

Kalar, James Rldey-Ia.10,03; (l'03)

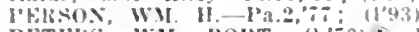

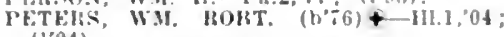
(1'04).

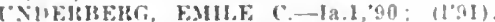
STAPLEHURST, 228, SEWARD

Melsentrach, Jacob H. (b'T(t)-...Neb.J,0: (1004).

STAPLETON, - LOGAN

Mcheay, Hugh L.-Unt.6.'GS; (I'G9); OALR.

STEELE CITY, 300, JEFFERSON

Rarton, Thomas Edwln-Seb.5,92; (1'92).

TAYLOR, J. S. (b'ib)-Ky.4'SS; (1'92),

STEINAUER, 2\$8, PAWNEE

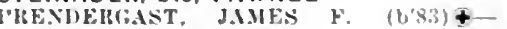
Neb.6, 08 ; $\left(10^{\circ} 08\right)$.

STELLA, 430, RICHARDSON

MONT(i)MEKL, AS.I W:. (b'72) - II1.1,96: (1)98)

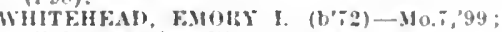
(1'10); Nember HII. State Med. Soc.

STERLING, 714, JOHNSON

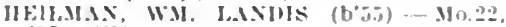

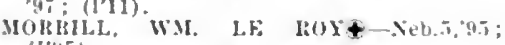
TIKSEIR, JAMES W:-0.2993; (1'93).

STOCKHAM, 189, HAMILTON

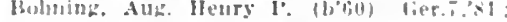

WrL, JI, JOS. M. (b'7s) - -111.1,02: (1'04).

STOCKVILLE, 232, FRONTIER

lase. Hrnest spencer $\left(\mathrm{b}^{\circ} ; 2\right)$-Neb.5,97;

STRANG。 238, FILLMORE

HICKNAY, JUEL CLYHE (b'S̈)-Neb.t (0): $(1,05)$.

STRASBURGER, - SHERIDAN

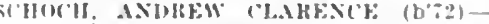

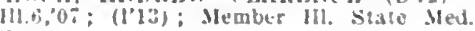

STRATTON, 367, HITCHCOCK

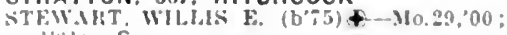
11,01): $\mathrm{S}$.

STROMSBURG. 1.355, POLK

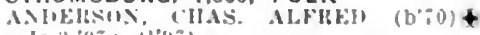

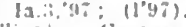

Flibstn, Cieorke Altert (botis)- $111.16,00$

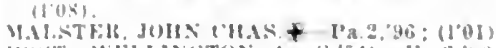

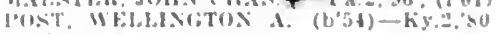
("0:).

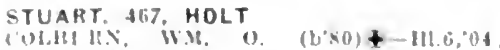
(I"in), ALR.

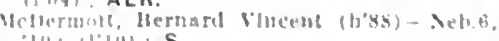
10: 11?11): S.

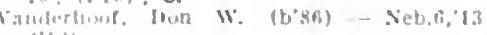

SUMNER, 321, DAWSON

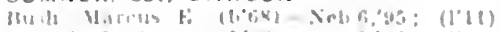

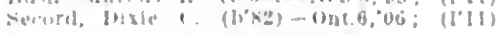

SUPERIOK, 2.106. NUCKOLLS

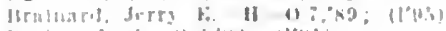

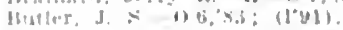

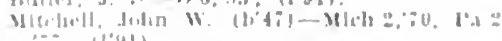

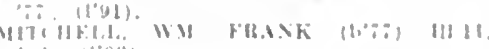

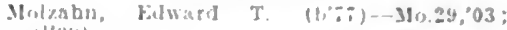
(1'0y).

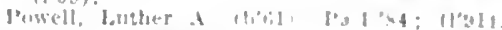

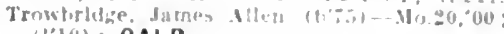
(I'B(1); OALR.

SURPRISE, 323, BUTLER

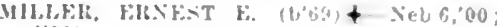
$1100)$.

MHLFi, Justill H (b'tis)- Yet,5,88 (lofi): nor la juactlo.

SUTHERLAND, $\$ 17$. LINCOLN

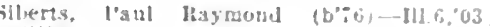
$\left(l^{\circ} 09\right)$

SUTTON, 1.702. CLAY

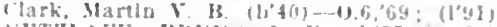

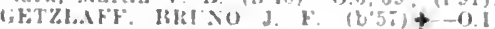
(y2: 1101, ;

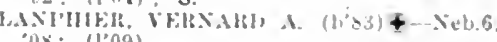
os: (I'09).

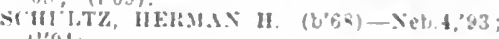
(1'04,

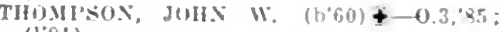
(1.91).

SWANTON. 285, SALINE

Hoschrner, lieo. Hexier (b's3)-Nebt,10. (l'10).

Silmerek, Joxceh-III.1,34; (1'94).

SYRACUSE, 8.2. OTOE

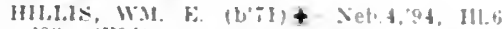
03 ; (l'94).

Kruse, Fredk. W: (b'63)-Neb.5,02: (I'02).

LISICK, HEXIY MAX (b'63) +-110 (03; $(1 \cdot 12) ; 00 A$.

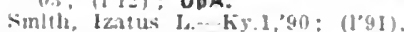

Thomson, John (b'il)-Oni.3, pa: (l'02).

TABLE ROCK, 814, PAWNEE

CHEHIY, WALEK S. (b'yb)-Neb.5.05 $(105)$.

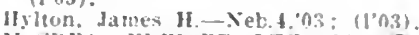

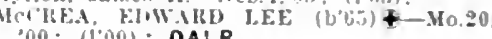
00: (100); OALR.

TALMAGE, 46I, OTDE

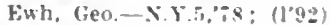

Gritzk, Chrintlin T.-Neb.5,"u1; (1001).

TAMORA, 205, SEWARD

("larke, Harry I. (6'S5)-Neb.i,'l=; (1'12).

TAYLOR. 197. LOUP

ICNulty, J. k-111.11,93; (1.93).

TECUMSEH, 1.748, JOHNSON

IBARXKE, (HFATEIR D. $\rightarrow:(1 ' 98):$ ObG.

cochran, John W.-Tenus,90; (191).

DAVIEs, IHAS, HOWAKL (bsi) - HA: "11: : (1'06) : S.

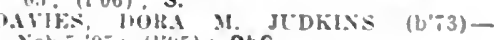
Neb.5.95; (1" 45$) ; 0$ bG.

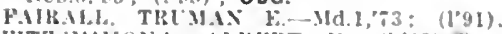

FITZSIMMONE, MLIBRT

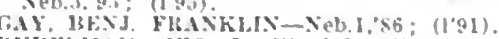

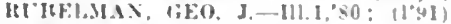

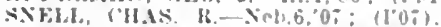

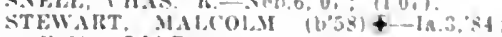

(I'UI) ; OALR.

TEKAMAH. 1,524, BURT

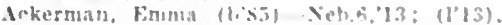

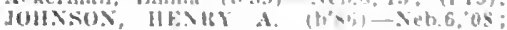

$\left(1^{\circ} 0 \mathrm{~s}\right)$.

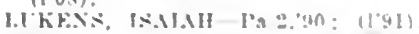

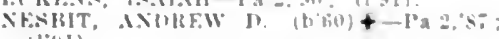
$(1 * \pm 1)$.

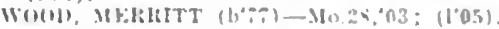

THEDFORD, 150, THOMAS

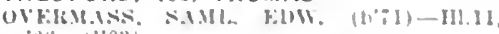
(1):-; $(100))$

THURSTON, 112, THURSTON

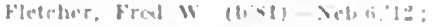

TILDEN.901, MADISON

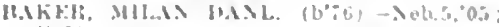

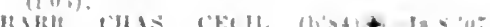

(1)istive

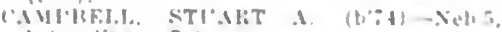
Bun $(1+3, a) ; \mathrm{S}$.

TOBIAS. HS. SALINE

Mascaporer. Armolut (harles (bst)-lll 6 .

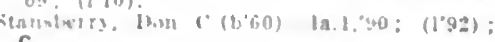

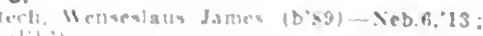


TRENTON, 497, HITCHCOCK

BLILI, JAMHS li. $(1,72) \notin-M o .22,07$; (l'0s) ; OALR.

TIOMAS, AKFlKLI) II. (b'59)-Ia.4,'84; (l'91).

TRUMBULL, 175, CLAY

Blalr, Geo. Alliert (h'5s)-Md.3,'80; (l'08). Stone, Jamies (i. (h'82)-Neb.6,06; (l'06). TRYON, 100. MCPHERSON

CARTEI: I.EW ARTILIL (b'T5) - Mo.35, 03: (l'0s).

UEHLING, 228, DODGE

Parsong Antuny (b'T5)-Neb.6.10; (1'10). Perlee, Byron I.-Xieb.5,01; (l'04).

ULYSSES, 551, BUTLER

Avery, W'm. A.-N.Y.1,'68; (l’91)

(OLNMAN, CIIAS, IB.-0.3,8: (I'91)

Stanard, John Turner (b'87)-X'Neb.4,09; (l'09); OALR.

UNADILLA. 209, OTOE

IcIniyre, Wm.-E-Ia.6, 87 ; (l’91)

Wlllams, Biljalı C. (b'81)-Mo.22,09; (l'11)

UN $10 N, 302$, CASS

IBAIRITTT, WV. M. $\oplus-0.1,83 ;$ (1'91).

Huston, Danlel Farrel (b'S3) - Neb.6,'13; (l'13)

UNIVERSITY PLACE (BRANCH P.O. LIN. COLN), 3,200, LANCASTER

AIBIN, WALTER JWONARD (b'76) $\oplus$ -

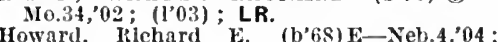

(1'04); Prop. Bact. and Path., Neb.4; Pr.

Iufman, Irobt: Wlllard (b'59) - Ill.15, 03 ; (l'03),

TAYLOR, HARRY ALIEN (b'83)థ-Neb.5, 08; (1'08).

Walker. Arthur B. (b'78)-Neb.6, ${ }^{\prime} 06 ;\left(1^{\prime} 06\right)$; OALR.

WILLIAUS, GEO. E.-Ia.3,97; (l'03).

UPLAND, 390, FRANKLIN

JOHNSTON, NORMAN T. (b'-8)-Ont.6, 02 ; (l'02); OALR.

UTICA, 520, SEWARD

Houchen, H. IR.-E-Neb.4,05: (1'05)

Kenner, Wm. Clinton (b'68) - Neb.5,94;

(l'94). Wm. Clinton (b'68) - Neb.5,'94

IcConaughby, Freeman E.-II-N.Y.9,'90 ; (1'02).

VALENTINE, 1.098, CHERRY

COMPTON, MliTIUR N. (b'72) \&-Mo.7,'98; (1'98).

Hynes, Wm. P. (1)'87)-Neb.6,'12: (1'13)

IEWIS AIFRED (b'58)

LYNCII, EDWARI C.-Feb.6, 06 ; (l'06); S. $\star$

VALLEY, 810 , DOUGLAS

Agee, James Clarence $\left(b^{\prime} ; 6\right)-N e b .5,03$; (1'03)

Reed, Wilson H. (b'71)-Ia.9,'98; (1'98).

VALPARAISO, 560, SAUNDERS

Guttery, Jesse D. (b'63)-Ky.1,91 ; (1'92).

Spradling, Frank L. (b'89) - Neb.4,'12

(1'12); Prof. l'ath., Neb.4.

VERDEL, I62, KNOX

Plumb, Darley Garfield (b'83) - Ia.4,'12; (1'12).

Slssakian, Avedls II. (b'66)-Ill.6,'9i ; (l'02)

VERDIGRE, 403 , KNOX

Bates, John B. (b'60)-Ia.1,'90; (1'91).

Kucera, Frank H. (b'79)-Neb.6,04; (1'04).

VERDON, 406, RICHARDSON

Hurka, Robt. (b'st)-Ill.11,'12 ; (1'12).

VESTA, 140, JOHNSON

ZHEGLER, CHARLES H. (b'70)థ-0.3,94; (l'94).

VIRGINIA, I54, GAGE

Thornton, Lorenzo R. (b'41) $\rightarrow$; (l'91)

WACO, 293, YORK

Foster, Wm. L., Jr. (b'73)-Mo.28,'98; (l'98)

Gairdner, Thomas M. (b'63) - Que.1,'s6; (l'92).

WAHOO, 2,168 , SAUNDERS

LAUVETZ, J. F.-Neb.6,05; (1'05)

Rupp, Benj. D.-N.Y.10,'s1: (1'91).

SHITH, JOHN G.-110.22,'91: (l'97)

TORNHOLA, FRANK (b"70) $€-N e b .5,02$ :

WAY, FRANK E. (b'68) $\oplus-$ Mass.5,'90;

WEBER; ERNEST o. $\left(\mathrm{b}^{\prime}, 6\right) \oplus-\mathrm{Ill}, 1,02$ $\left(1^{\prime} 0^{2}\right)$; NP.
WAKEFIELD, 861, DIXON

VLEETWOOL, EINWARL J. (b' 62$) \&-N e b .5$ 0): $\left(10^{\prime} 02\right)$

irabln, Clas. S. (b'68)-Neb.4, $02 ;\left(l^{\prime} 02\right)$

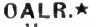

Tomllnson, Chas. Crelghton (b'84)-Nieb.5, '0S; (1'08).

WALLACE, 175, LINCOLN

FAIRELLL, IIENRY (b'77) $\oplus-\mathrm{Md} .4,07$ (l'0i).

WALTHILL, 810, THURSTON

HAIR'T, GEO. ENMIT (b'T6)\$-Ia.10,06 $\left(l^{\prime} 0 i\right) ; \mathbf{G}$

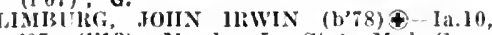
'07; (1'13); Menber Ia. State Med. Soc.;

Moodle, Walter Chafey (b'82)-Neb.5, I2; (l'I3).

PICOTTE, SUSAN LA ILJSCIE-Pa.7,'89; (1'91)

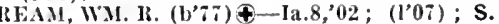

WATERBURY, 199, DIXON

Munson, Ellzabeth 13. King (b'45) E-Ia.6, '91, Mo.5,'93; (1'91).

WATERLOO, 402, DOUGLAS

Kelly, Harry D. (b'79)-Neb.6,'03; (l'03)

Nason, William Chrlstopher (b'79)-Neb.6, 08; (1'09).

Richardson, Louls-Neb.5,'90; (1'00).

WAUNETA, 327, CHASE

BAIIEY, BYRON G. (b'84) - Mo.22,'08; (1'08).

Grosbach, Ifarry II. (b'64) E-0.2,'85 ; (l'93)

WAUSA, 604, KNOX

GFNUNG, FRANK C.-Ill.11,'91; (l'92).

HANSEN, OTTO TIIEODORE' (b'75) Ill.8,'01; ( (l'03)

FEUMANN, ERXST V. (b'79) \$-Neb.6,'13; (1'13).

WAVERLY, 297, LANCASTER

Emery, Alpheus Iewellyn (b'79)-Mo.34, $02 ;\left(l^{\prime} 02\right)$.

McCándless, George A.-Ky.4,77; (1'03).

WAYNE, 2,140, WAYNE

BIAIR, EDWART) S. (b'5i)-Mich. 1,87 ; (l'94); G.

Hess, Geo. J. (b'68)-Mlch.7,'94; (l'99).

INGHAM, CHAS. T. (b'69)-Ia.8,93; (l'98) Lutgen, Anson S. (b'78)-Neb.4,04; (1'04)

WIILIAIIS. JOHN J. (b'50)థ-Ia.3,'80 ;

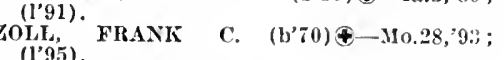

WEEPING WATER, 1,067, CASS

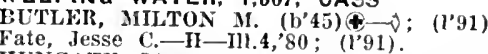

HUNGATE, JAMES BLCHAXAN (b'56) Ind.8,'81; (l'91).

REED, FREDK. P. (b'70) - Mo.20,'99; (l'13).

WELCH, ALBERT C. (b'54)-Nंcb.4,'08; (1'08).

WEISSERT, 15, CUSTER

McArthur, Andrew J. (b'62)-Mo.1,'91; (l'02).

WELLFLEET, 100, LINCOLN

Rundstrom, David A. (b'78)-Neb.5,'02; ( $\left.l^{\prime} 03\right)$.

WESTERN, 499, SALINE

BRENN, CHAS. P. $9-I 11.22,06$; (l'07).

Chidester, T. J. (b'4T)-0.8,'73; (l'91).

Lewellen, Chester Elmer (b's8)-Ill.8,'12; $\left(l^{\prime} 12\right) ; \mathrm{G}$

Smith, Levi N. (b'54)-Ky.1,'81; (1'91).

WESTPOINT, 1.776, CUMING

SUMMERS, HENRY S. $\left(\mathrm{b}^{\prime} 56\right) €-0.6,{ }^{\prime} 82$; (l'91).

THOMPSON, KIMBALL EDW. (b'Să)Neb.6,'08: (l'0s).

THOMPSON, THOS. D. (b'49) (-Pa.1,73; (l'91).

WERLS, HARRY LEE (b'68)-Neb.6,02 ; (1'02).

WHITMAN, 50, GRANT

MeClelland, Elmer E. E.-Ia.6,'87 ; (l'91).

WILBER, I,219, SALINE

CERNY, JOS. (b'66)థ-Ill.16,'99; (l'99).

DODSON, POrTER F. (b'66) 4 -Md.6, 89 ; (l'91).

HEIN, HENRY (b'T) + -Neb.6,03; (l'03). Love, Wm. S. (b'50)- (1'92).
WILCOX, 382, KEARNEY

BURFORD, JAMES A. (b'66)-Neb.4,95; (1'95)

MAISTELLER, ARLIL 1. (b'82) + IIo. 28,'06.

WILSONVILLE, 385, FURNAS

JOIINSON, FRANK BHUCE (b'64)-Ia.9 94; (1'94).

WINNEBAGO, 399, THURSTON

Jolunson, IIomer H. (b'76) E-Neb.4,04 ; (1'04).

YOUNG, CIIFTON E. (b'81)థ-D.C.1,'10.

(Indlan Servlce); Member Mled. Soc. of D.C.: Winnebago 'School.

WINNETOON, 220, KNOX

CROOK, ROY (b'80)-Neb.6,05; (1'05)

WINSIDE, 450, WAYNE

Cherry, Allan Bernard (b'63)-Ia.3,'90.

lansing, Levinus A.- N.Y.6,97; $\left(1^{\prime} 00\right)$.

MeIntyre, Backus M. (b'71)-Neb.6,'05: (l'03).

Neely, Jobn G. (b'65)-Ia.3,'93; (1'93).

WISNER, 1,081 , CUMING

Morse, Marle Hansen (b'79) - Neb.6,02 (l'02); $\mathbf{G}$.

MORSE, RUSSEL H. (b'74) $\$-N e b .6,02$; (1'02).

RIEEY, IINCOLN (b'67)-Ia.3,'88; (1'91).

Thompson, Edgar S. (b'82) $\rightarrow$ Neb.6,'11 ; (1'12).

WOLBACH, 563, GREELEY

Adams, Howard C. (b'73)-Ill.1,98; (1'02)

Holm, Adolph Hjalmas $\left(b^{\prime} 74\right)-$ Neb.5, 05 (l'05).

WOOD LAKE, 198, CHERRY

Tlsche, James Matthews-Ky.1,'98; (1'98).

WOOD RIVER, 796, HALL

HUBBELI, ABRAHAM TURNER (b'7i) $\odot$ Ill.10,'03, Ill.6,'05; (1'03)

Starkey, Harvey L.-Mo.28,'99; (1'09).

WYMORE, 2,613, GAGE

EIIAS, FRANCIS LEANDER (b'83)-Kan.2, '10; (1'11).

GAFFORD, CHAS. C.(4-Ia.1,'8I ; (l'91)

GILLESPIE, PETER L. (b'5)-Neb.6, 01 ; (]'02)

Willis, Chas. Menry (b'79) - Neb.5,'07 ; Winter, Fredk. Wm. (b'52)-Ia.4,'80; (l'91) : Ob.
YODER, SAMIL. E.-Mieh.1,'89; (1'92).

WYNOT, 258, CEDAR

JONES. WM. Y. (b'68)-Neb.5,'02; (l'02).

TELLESEN, CHAS. CIYDE (b'76)-Ill.1, 09; (1'11)

YORK, 6,235, YORK

BANGHART, EDGAR DAVID $\left(b^{\prime}, 0\right) \oplus-$ Neb.5,07; (1'07)

CONAWAY, JOHN B. $\left(b^{\prime} 40\right)-111.1,88$; (l'91).

Eckles, Dora B. (b'73)-Ia.1,98; (1'00); not in practlce.

ECKLES, WARREN F. (b'74)-Ia.1,98; (1'00); OALR.

FARLEY, BENJ. F. $\left(\mathrm{b}^{\prime} 43\right) \uparrow-I 11.1,70$; (1'92).

HANNA, EDWIN B. (b'-1)-Ill.10,00; $\left(l^{\prime} 00\right)$

Knapp, Wm. R. (b'56)-Neb.1,'84; (1'93).

MeCONAUGHY, ROBT. (b'52) @-Pa.2,75 ; (l'91).

MeKINLEY, JEROME C. (b'61) (4-Ky.4,'91 ; (1'91); S.

ORVILLE H. (b'59) - 0.2,84; (1'91).

PLUMB, JAMES NORRIS (b'68) $\rightarrow$-Ill.1, '91; (1'91); OALR.

Root, Benj. A. (b'75) E-Neb.4,'05; (1'05).

SHIDLER, GEO. P. (b'82)-Ill.6, 0 T; (1'08)

SNYDER, FRANK GRAY (b', (1'97).

VRADENBURG, HARRY L. (b'53)-Ill.4,'86 ; (1'91).

WATKINS, RACHEL A. (b'-8) (4-Ill.11,'06; (l'11)

ZIMMERER, EDMUND GEO. (b'89)-Neb.6, '11; (1'11); 0p.

YUTAN, 353, SAUNDERS

Hullhorst, Fredk. (b'37) H-Ia.4,'82; (1'91). KOERBER, PAUL ERNEST (b'74)-Neb.5, ' 96 ; (l'96). 


\section{NEVADA}

NoTE.-The general Information of this stato Incluiles: Medlcal Iaw. State Board of Health, Jofensing Board, State Associatlon.

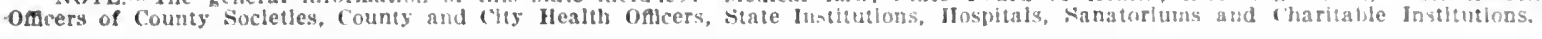

\section{NEVADA}

Population (1910 census).

81,875

Number of Counties...

Number of Physleians.

Members State Association, Dec. 31,

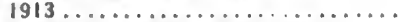

Area of State in Square Miles.......110.690

MEDICAL PRACTICE LAW OF NEVADA

An Act

Vegulating the Practice of Mediclne, Surgery and Obstetrics in the state of Nevaclit

providing for the appointment of a State Board of Medical Fxamlners and
definlng thelr dutles; provlding for the issuing of llceuses to prnctice medlclne: definlng the practice of mediche: definimg certaln mlademeanors and provld-

ing penalties, and rcpealIng all other Acts, or
parts of Acts, In. parts of Acts, in

[Approved March 4, 1905.]

The People of the state of Nerada, represented in senate and assembly, do enact as follows :

Section 1. I.ICExSE: That it shall hereafter be unlawful for any person or in this state without first obtaln'ng a II cense so to do as hereinafter provided.

Sec, 2. BOARD OF EXAMIFIS; APPOINTMENT: TERM: Whlth thirty days after this law goes into effect it shall be the duty of the gorernor of the state of of flve members, which shall be known as the Board of Medleal Fxamliers of the State of Nevada, and shall be reputablo practiclng physlcians, duly llcensed as such by some legally chartered medical instituton in the United States, and who shall Ion in the Unlted Stales, and who shall haro been actually engazed in the bractice
of mediclne in the state of Nevada, three of whom shall be selected from the schowl of mediclne known as the regular, one from the school hnown as, the eclectic, anis one from the school known as the huniousithle. Thls board shall be selected whthme rekaril to thelr Indirldual political heliefs, and they shall hold offce for the time fur which the'y were anpolnted, riz., two for four years. che for three years, one for two years, and on for one year; from the date of their altumt. ment, and shall serve vutll their successuts are appointed and quallfed. Ifereafter one term of four years. In the event of acancy occurring in sald board, ir abcence from the state for a perlow of six munths without Derafssion, the governor shall npmolnt a person duly ifualifieit under this Act to mil the unexplied term.

sec 3. O.ATII: kinch memaer of siall buard shall, before entertng on the dutles oflce. and shall, in aldition, make uatl that be is a graduate in medlcine nut in legally quallfed praclltoner of medielne in this state.

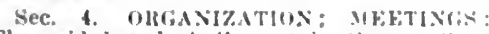
The wald board shall meot in tonrson (ity, and shall organlze by elcellng from lis num. ber prealdent, vice-preslitent, serretary and treasurer, who shall listl their restrec tive positlons during the pleasure of the board. Sald board shall hold lts regular mectings on the frst. Munday of May aud the Brst Mn the frat of Novenday of May and at nuch time and place as shall be most conrenlent to sald bonrd, and due notice of all speclal meetings of the huard sball be giren by publlcatlon twice a week for each given by publication twice a week for each ing in three papers pullished In the state of Nerada. Speclal meetings of the board may be held at the call of the president, as in the case of regular meetings.

Sec. 5. RLLEs: Sald bonrd may, from time to Ilme, adopt such rules as may be necessnry to enable it to carry into effect the provlslons of thls Act. Any member of sald hoard may administer oathy in all matters pertaining to the dutles of said board, and the board shall have the authority to take cridence as to any matter cofnizable by it. Such board shall procure a seal, and shall recelre through lts secretary applications for the cerlific

Sec. 6. QUORUM; RECIPROCITY : majority of said board shall constlute a yuorum to transact all business. All certifcates Issued by sald board shall bear lis seal and the signatures of lis president and secretary, and shall authorlze the person to whom it is issued to practice nedpeine in to whom it is issued to practice nedeine in all Its branches in thls state, on complying with the requirements of this Aet. Sait register, on payment of the reglstration fee, and without examlnation of the applicant. any certifleate which shall hare been issted to him by the Medical Examining Hoard of the Nistrict of Columbla of of any state or territory of the Unifed States: provlted, however, that the legal requirements of such medical examining board shall have been, at the time of issulng such certifleate, in at the time of issulng such certiflcate, in no degree or partlcular less than those of shall be presented for reglstration to the board created by this Act; and provided, further, that the provisions in this paracraph contained shall be held to apnly only to such of said medical examlning board as accept and reglster the certifleates granted of the ones holding such cerliacates.

Sec. 7. CERTIFICATE; AFFIUAVTT: tifer thls law goes into effect any person desiring to practice medlcine, surkery or colstetrics or any of the rarious branches of medicine in this state shall, bcfore beste lhurd ne Medical bxaminers a certlibate that such morson is entitled to practice medl. that such merson is entitled in practce medfincer suraery or olistetrles in this state. In "riler th procure such certifleate the alphlilior difloma, issued by some legally abar. torewl modlleal school, the renulrements of whicle medical schoul wall have leen at the fime of geanting suclo dislioma in no particutar lesg than those prestribed hy the Issiochilon of And he muat necompany snid

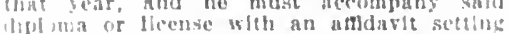
list mat or lleense sheh an attdarte sething forly the number and ritratem of terms the and that he is tha lawful possessor of the ande, that lie is the perang therein named. the flat the eliphema or license was broialy kim. Such appllication shall lie :

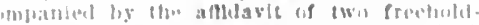
$\checkmark$ rentilent if the same coundy in whel

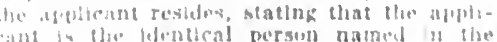

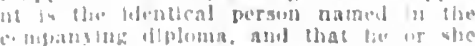

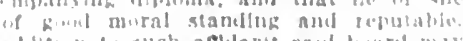

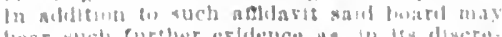
lion, ie may lecen orofer na to any of tho

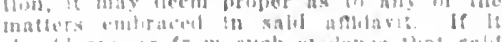

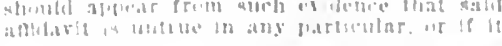

should ablutar that the ayplicant is not must be rejected sald bort shall retaln such diploma such time ai is necessary, but in no case shall sald brim retain such ill no case shall sald brard retaln such diplomas and amlarits shall be addressed to the secretary of the board.

Sec. 8. AP'LICATI(INS F̈OR LICENSES: diulicants for certificates to practlce medicine, surgery or nbsterries in the state of diploma from a lezally recognlated clleze, diploma from a lezally recognlzed cilleze, and to bass a satisfactry eximination beas to his or her qualificatlons. The appllcant must appear persinally pefore the board, and the examination shall be concheted in the English language, and shall ve, In whole or in part in wrttlog, and in each branch shall obtain 75 per cent., and shall he on the plthwing subjerts, to-ntt: thatomy, physlology, maleria nedica and therapentics, chemistry, bacterlology, pathclogy, toxicology, obsietrles, surgery, gencral medicine, diseases of the skin, ege, ear. nose, throat, braln, genito-urinary system. tial and the questions of sucli character as will determine the fliness of the applicant to practice his or her profession. When applicant applles for examination in materia medica and therapeutics and theory and practice of medlcine, he shall desimate in which school of medicine he desires to pracwhich school of medicine he desires io practice, and only the member or members of the board who belong to the schoul so the examination.

Examinations shall be practical in character, and designed to discover the appllcant's thness to practlce medicine and surgery. If an appllcant fail in his first exmonths, he reeramlned, without addittonal fee If he fait In a second examinathon, he shall not thereafter he entisled to another shall not thereafter he entifled to another examination in less than one year after the
late of second examination. and shall be required to pay for such examination the full fce. The examination papers shall form a part of the record of sald hoard, and shall be kept on file by the secretary. and said records shall be open in mublic inspection whonever requestel after the examInation; provided that any persun who is n regular graduate from a regularly chartered collece of the bractlce th the sisiem of what college of the practice tif the sysem of what drugless syctem. may present themselres fur eramlnation under the rejulations hereinbefore specifled. nnd shall he reguired in pass an examinatorn in all the subjects and liserapeutles. und upon the gasing satIsfactorlly of sa!d cxaminatinn by the bonat, shall liare Isqued to thema a lleense to brac-

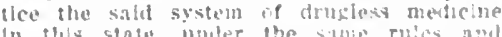
reculations prescrthed and recputred if the

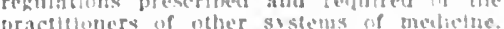
biach opglleant, on making ayblication. ahall may to the secretary if the buard a

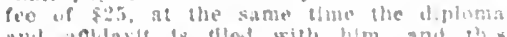
amb anlinvit is tlles with hlm, and t? Pee shall not he repurned in the swnt if cramination. Any jersin why may leceafer be gramicd a license to machlee medt. let, upon the grounds of recintitely with

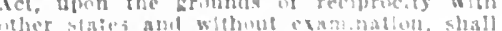
bat is fee of $\$ 25$ for such license.

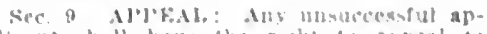
blente shall hare the riall th alperal to

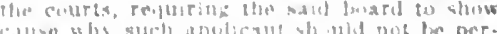

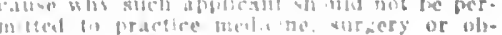

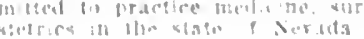


Sec 10. IRECOIH OF CEIRTIRICATE Sald board shall broeure a book for the purpose of recording the nimes of all persons to whom is issued certiflcates. In this book shall be entered the names of the alp plicunts, together with the name of the seloool granting the dipfomat, the date of the diploma the number of terms the applicant attended school, residence of applicant, and the dlate of issuance of rertifleate. This book shall be retalted by the secretary, who shall note the unsuccessful appificants, furnishing the same information as is given above. The secretiry shall furnisl each above. The secretiry shall furnish cate county clerk in this state a complete list sued, after each meetlug of the boirul. Suci sued after each meetho retinged and fled by the county clerk, and it shall show the name, age anc location of the holder of cach certitleate together with the name of the institution conferring the degree and the date of the issuance of certifleate.

Sec. 11. Expexses of ROAleJ): The members of the board shall serve without compensation, except that their actual expenses incurred while attending a repular or special meeting of the board shafl be refunded; provided, that the secretary shall receive a semi-ammual salitry of $\$ 150$ for lils services. All moneys receired by the board shall be paid out on Its oriter for its expenses and the traveling expenses of the members, and if the moness received are nembers, and if the moness received are not board shall certify to the Board of $\mathrm{Ex}$ aminers, with accompanying vouchers, over it.s seal and the signatures of its president and secretary, the amount actually necessary to meet the remainder of its expenses, and on the approval of said claim by the Board of Examiners the state controller shall draw his warrant on any moneys in the general fund not otherwise appropriated, and the state treasurer shall pay the same.

Sec. 12. RECORDING OF CERTIFICATE; REFUSAL; REYOCATION: Every person to whom the board shall issue a certificate shall present the same to the county recorder of the county in which he clesires to practice and have the same recorded, and shall pay the fee usually paid for recording such papers. The board may refuse a certiflcate to any applicant cuilty of ungrofessional conduct, and may revoke any certificate for a like cause. In all cases of tificate for a like cause. In all cases of
refusal or revocation the party aggrieved refusal or revocation the party aggrieved
may appeal to the courts. The words "unprofessional conduct," as used in this Act, are hereby declared to mean

First-The procuring or aiding or abetting in procuring a criminal abortion.

second-The obtalning of any fee on the assurance that a manifestly incurable disease can be permanently cured.

Third-The wilfully betraying a profesinnal secret.

Fourth-All adrertising of medical business in which grossly improbable statements are made.

Fifth-All advertisements of any medicines, or of any means whereby the monthly periods of women can be regulated, or the menses reestablished if suppressed.

Sixth-Conviction of any offense involving moral turpitude.

Seventh-Habitual intemperance.

Sec. 13. PRACTICE OF MEDICINE DEFINED: For the purposes of this Act the words "practice of medicine, surgery and ohstetrics" shall mean to open an office for such purpose, or to announce to the public or to any individual in any way a desire or willingness or readiness to treat the sick or afflicted in any county in the state of Nerada, or to investigate or diagnosticate or to offer to inrestigate or diagnosticate any physical or mental ailment, or clisease of any person, or to give surgical assistance or to suggest, recommend, prescribe or direct for the use of any person any drug, medicine, appliance or other ageney, whether material or not material, for the cure, relief or palliation of any ailment or disease of the mind or body, or for the cure or relief of any wound, fracture or bodily injury or deformity, after having therefor, olther alrectly or indirectly, any molies, gift or any other form of compen-

It sliall also he regarded as praetielng medreine whinin the meaning of this Act if anyule shall use hn connection with bis or her "lane the words or letters "Inr," "Doctor," "Professor," “Mt.l).," or "llealer," or nation Intencled to inply or designate him or her as a practitioner of medicine or surfery or obstetries in any of its branches provict, that nothing in this Aet shant be iruggists or other persons in cases of enerfency, or the domestic administration of family remedies, and this Act shall not apply to commissioned surgeons of the inited States Army or Nary in the discharge of their official duties, nor shall it apply to professional or other nurses in the discharge of their duties as nurses, nor to physlcians who are called into this state fied to practice in the state where he or she resides. In charging any person in an she resides. In charging any person in an affidarit, information or indictment with a surgery or obstetrics without a license, it shall be sufficient to charge that lie or she did. on a certain day, and in a certain county of this state, engage in the practice of medicine, he or she not laring a license to do so, without averring any further or more particular facts concerning the same.

Sec. 14. VIOLATION; PENALTIES: Any person who shall practice medicine, surgery or obstetrics in this state without first complying with the provisions of this Act shall be deemed guilty of a misdemeanor, and on conviction thereof shall be punished by a fine of not less than $\$ 100$ nor more than $\$ 200$, or by imprisonment in the county jail for not less than fifty days nor more than 180 days or by both such fine and imprisonment for each and every such offense. Any person may institute proceedings at law provided for in this Act.

Sec. 15. FALSE CLAIMS; PUNISHMENT : Every person filing for record, or attempting to file for record, the certificate issued to another, falsely claiming hinself to be the person entitled to the same, shall be guilty of felony, and, on convlction in the state prison not less than one year nor exceeding fire years.

Sec. 16. FALSE CLAIM TO BOARD ME.MBERSHIP; PENALTY: Any person assuming to act as a member of a State
Board of Medjcal Examiners, or who shall sign or subscribe or issue or cause to be issued, or seal or cause to be sealed, a certificate authorizing any person to practlce medicine or surgery in this state, except the person so acting and doing shall have been appointed a member of said Board of Medical Examiners as in this Act provided shall be guilty of a misdemeanor, and shall be punished by a fine of not less than $\$ 100$ nor more than $\$ 500$, or by imprisonment in nor more than $\$ 500$, or by imprisonment in sixty nor more than 180 days, or by botl such fine and imprisonment.

Sec. I7. FEES; RECIPROCITY : Every person practicing medicine, surgery or obstetrics in the state of Nevada on the first Monday of May, 1905, shall submit to the said board his or her diploma for registration, and a fee of $\$ 25$ shall accompany such diploma; provided, that the owner of such diploma shall, if he or she was practicing medicine, surgery or obstetrics prior to the passage of the Act approved March 15,1899 and has not complied with said Act of March 15,1899 , pay a fee of $\$ 5$ for such registration, but such person shall subnit to the board said diploma on the first Monday of May, 1905 ; provided, further, that all persons who have complied with the Act of registration by the said Board of Medical Examiners, and nothing in this Act shall Examiners, and nothing in this Act shall be construed to prevent such registration, free of all charge on a record book of sald board the names of all persons who have complied with the Act of March I5, 1899. cate of registration or licenso issued by the proper examinjug boarl of any stute, whlch agrees on reciprocal registration witls this state, may be accepted as evidence of quall. flcation for reciprocal registration in this stato; provided, that the holder of such certificate was at the time of such reglstration the legal possessor of a diploma Issued ly a medical college in good standing In prior to tise passage of this Act.

STATE BOARD OF HEALTH

W. II. ILood, I'resident, Reno; O. P. Jolnstone, Reno; S. I. I.ee, Secretary, Carson City.

STATE BOARD OF MEDICAL EXAMINERS

Joln A. Lewis, President, Reno; J. J. Sullivan, Virginia City; E. A. Whecler, Goldficid: Sidney k. Morrison, Reno; Slmeon (it):

NEVADA STATE MEDICAL ASSOCIATION Officers 19I3-I4

A. I'. Lewis, I'resident..............Reno

P. .Y. Mangan, Ist V.-P'esident.. Wimnemucca i. A. Robison, Secretary-Treasurer... Reno

Councilors

A. C. Olmsteit $\ldots \ldots \ldots \ldots \ldots \ldots \ldots \ldots$ Wells

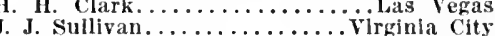

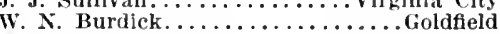
Wm. T. Gleason................... Ely J. R. Cunningham............. Tonopah .

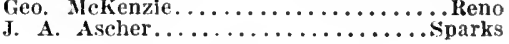

Component County Societies of the Nevada State Medical Association CHURCHILL COUNTY

James C. Ferrell, President..........Fallon

F. E. Nichols, Secretary............Fallon ESMERALDA COUNTY

Edgar J. Howland, President and SecreHUMBOLDT COUNTY

ratrlck J. Mangan, President.. Winnemucca Chas. E. Swezy, Secretary..... Winnemucea NYE COUNTY C. I. Richards, Iresident......... Tonopah
J. R. IIasterson, Secretary...... Tonopah WASHOE COUNTY

J. L. Robiuson, President. . . . . . . . Reno WHITE PINE COUNTY

C. E. Early, President........... East Ely

COUNTY HEALTH OFFICERS

County Address

Churchill.-G. M. Gardner...........Fallop

Clark-Roy W. Martin.................. Vas Vegas

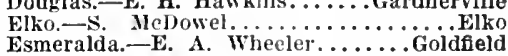
Eureka._G. I. Roberts............... Eureka Humboldt. $-\mathrm{P}$. J. J angan . . . . . . i innemucea Lincoln. -J. Wesley smith......... Caliente Lyon.-G. E. Leavitt.......... Yerington Mineral.-F. C. Pache..................

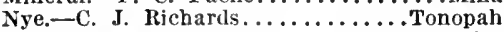
Ormsby.-W. J. Circe................ Tarson Clty Storev.-F. W. Hodøins. ....... Virginia City

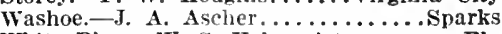
White Pine.-w. S. Holmquist............ Ely

\section{HEALTH OFFICERS IN CITIES OF 2,000} POPULATION AND OVER

Carson City..............W. J. Circe Ely $\ldots \ldots \ldots \ldots \ldots \ldots \ldots \ldots \ldots \ldots \ldots \ldots$ s. Holmquist Goldfleld................ A. Wheeler

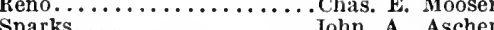
Spar............John A. Ascher

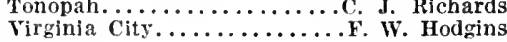




\section{AUIATE INSTITUTIONS}

lander founty Hospltal. Austhn, Nev. Eataflished 1850 ; public and prlvato; zen. eral; s bels: (i. I. Belanger, M.L., physl. clan in charge.

Carson City

State Urphans' Home, larson ('lt5. Ner. kstabllshed 186i3; publle: orphany nud neglected chlldren; 100 beds; lice. IV, Cowing. superintendent.

State Pententary Hosnltal, Corsin lity, Reno

Ser. Honald yacleallo physiclan in cliarpe.

Nerada Hospltal Pur Mental Miseases. Reno, Ner. Jublic; 300 beds: nerrous and mental; John A. Lewls, physiclan and sisperintendent.

\section{HOSPITALS. SANATORIUMS AND CHARI. TABLE INSTITUTIONS}

\section{Callente}

Caliente Hosultal, Caliente, Nev. Wstablished 1911; public; general: 15 beds J. Wesley smith physlobal in clatre: iyrtle M. Furd, matron.

Elko

Eilko County Hospltal, Elko, Nev, Fostabllshed 1871; publlc; general; 40 beds: A. J. Wood and i: IV. West, county whyslclans in charge: J. M. Taber, supt.
Goldneid

bineraldir county Hospital, Coldelfelel. Nev. Fistabllsted 1:05; public : 30 beds E. A. Wheeler. Dliystelan in charg" st. Ilary's llospiful, Goldfield, Ner. E⿱s calilished 190: : public ( b. I. Whecler, surgeni in charge.

Hawthorne

llineral lounts Hospleal llawthorne.

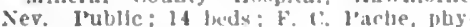
sician In charge.

Las Vegas

Las Vegas Hospltal, Lay Vegas, Jer. Fotabllshed 1911; Jrlvate; 12 heds: Henry H. Clark and H. W. Martin, physlelans in charge,

\section{Manhattan}

Miners Linton IIospltal. Manhatan, Ner. Extathlished 1905; I0 beds: Alexander Mclntyre, physiclan in charge.

Mason

Walker Rircr Hospital, Yason, Nor Fivtablished 1111: prirate: Ecneral; 10 beds: (i. Knox, physlclan in charge: Mrs. F. loykin, matron and hoad nurse.

Pioche

Duckworth Hospltal, Pioche, Sev, rstablished 1997; prlrate; 25 lieds; T. () buckworth, physiclan in charge.
Reno

St. Nary's llospital, kenc, Ney kstab[ished 1808: prifule: lit beds: sister Fiballa, superintendent.

St George's llosultal, Heno Ver Es. tablistuet 1907: prisate: -0 1,eds: Mtss

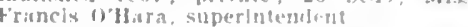
Wasboe County II onpital, hotro, ver.

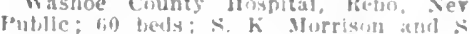

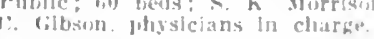

\section{Sparks}

Suthern Prcifle Company's Emargency Ilospital, Sparks, Nev. Establislied 1905: private; 3 beds; ins cmplosees only; J.A. Ascher, visiting physlclan.

\section{Tenopah}

IIners" Enlon Ilospltal, Tonoyah, Nev. Fostabllshel 1903; private: teneral; 24 beds; Jusephine Warmer. matron.

Sye County Hospltal. Tonopal. Nev. Established 190\%; pullis": 2f beds; C. J. lichards. physiclan in charke.

Virginia City

Storey Cunnty Hosfital, Virginia rity. Ner. Iubllic; 50 veds; $F$. W. Ifexlgins, pliysiclan in charge.

Winnemueca

Humboldt County Hosplial, Winnemucca. Nev. Fistablished 1908; pubilic: 20 beds: E. D. Groux, pbysician in charge; W. L. Wilkinson. superintendent.

\section{PHYSICIANS OF NEVADA}

\section{KEY TO ABBREVIATIONS, SYMBOLS, ETC.}

Names in capitals slgnify membershy in the County Soclety and state Assoelatlon. (DOE, JOHN).

I Indicates Fellowshly In the American Med. Assn. (DOE, JonN + ).

(b'ij) Year of birth.

II homeopath [medic. If homeopath; L, eclectle; P-M, physio - Information received does not show urad uation.

\section{S. - Surgeon.}

bstetrician.

ObG-Obstetrlclan, Gynecologlst.

G.-Gynecologlst.

Or.-Orthopedist.

Pr.-Proctologist.

Op.-Ophthalmologist.

A.-Aurist.

LR.-Laryagologlst, bhinologist. (l's9) Year of license.

(\$) In practice before passage of present law and licensed by fling diploma or by years of practice.

(1†) Licensed but sear not known.

(t) Information recelved does not show license.

I.S.A., United States Army.

M.H.C., U.S.A., Medical ISeserve Corps.

\section{SPECIALTIES ARE INDICATED AS FOLLOWS:}

ALR.-Aurist, Larsngologist, Rhinologlst. OALR.-Ophthalmologlst, Aurlst, Laryngologfst, Rhinologlst.

U.- Vrologlst.

D.-Dermatologist.

Pd.-I'edlatrist.

N.- Veurologist

P.-P'sychiatrist.
IS. Lnited States Nayy.

I.R.C., C.S.N., Medical Heserve Corps.

U.S.P.iI.S., Unised States Iublic Health Service.

College positions held are indicated by abureviated tlte of position. followed by key number of college. For key to colleges see Inslde front corer page.

(A1,3, B6, C4) Membership in special Socletles. (See Key Table, page 1:o.)

NP.-Neurologlst, P'sychiatrist.

I.- Internist.

T.-Tuberculotheraplst.

Anes.-Anesthetlst.

LD.-Laboratory Iiagnostician. Path - Patholorist.

Bact. - Bacterlologist.

WHEN THE ABBREVIATION REPRESENTING A SPECIALTY IS FOLLOWED BY AN ASTERISK (*) IT INDICATES THAT THE PHYSICIAN CLAIMS HIS PRACTICE IS LIMITED TO THAT PARTICULAR BRANCH OF MEDICINE: WITHOUT THE ASTERISK. THAT HE IS ESPECIALLY INTERESTED IN. BUT DOES NOT LIMIT HIS PRACTICE TO. THAT BRANCH. THIS INFORMATION CONCERNING SPECIALTY IS BASED ON PERSONAL DATA FURNISHED BY THE PHYSICIAN AND IS NOT VERIFIABLE.

\section{NEVADA}

\section{AURORA, 75, MINERAL}

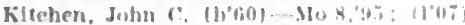

WOODS, CHAS, W.X.13,82; (1'07)

AUSTIN, 1,215, LANDER

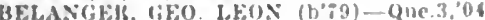
(I'0i): G.

BATTLE MOUNTAIN, 360, LANDER

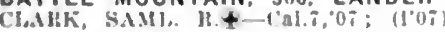

BAUVARD (MONTELLO P.O.), 75. ELKO Jaradis, Ilenry A.-Md.6.,01: (1'04).

BLAIR, 200, ESMERALDA

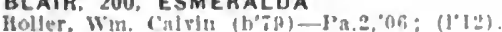

BUCKHORN, 125. EUREKA

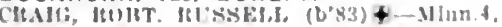
11: (1"1:3).

CALIENTE, 5. LINCOLN

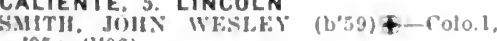
"95: (1'0 is).

Tuges, Frank-foln:"04: ( ) : S.

CARLIN, 4I3, ELKO

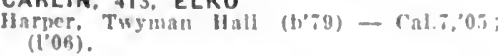

CARSON CITY, 2.466, ORMSBY

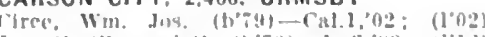

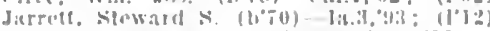

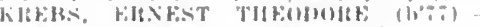

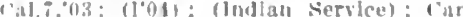
sul Suchol.

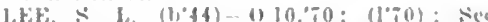

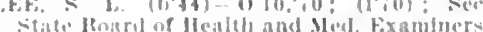

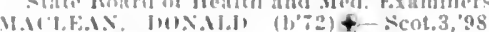
$\left(10\left(0 q_{i}\right): S\right.$.

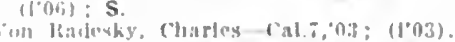

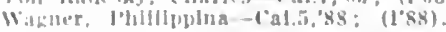

CHERRYCREEK, 350, WHITE PINE

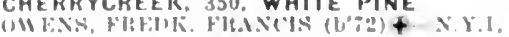

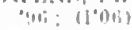

DAYTON 458, LYON

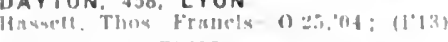

DEETH, 200, ELKO

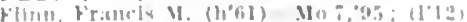

EAST ELY, 175, WHITE PINE

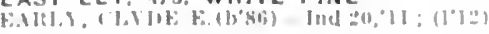

ELKD, 1,650, ELKO

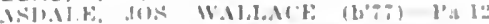

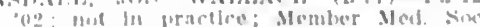
of tho sitate us l'a.

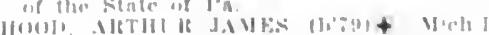

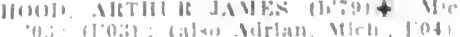

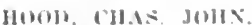

(see Nurian, Mledi)

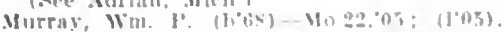

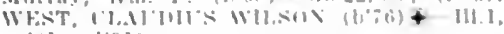
111: (1) 011 .

Wordoll, John kdw. (605)-111 h,99: (1008). ELY, 2.053. WHITE PINE

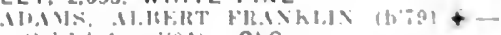

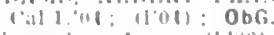

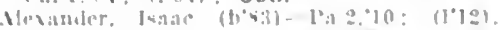

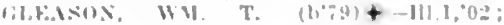
(1)

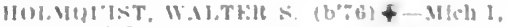

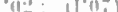

(B) $\left(I^{\circ} 0 \pi\right)$.

EUREKA, 1,609. EUREKA

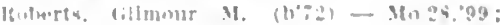

FAIRVIEW, \$0, CHURCHILL

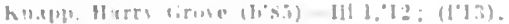

FALLON. IH, CHURCHILL

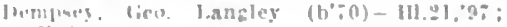
(I) 10 ,

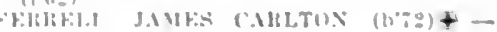
]II $2 ., 10$ : 11,11$).$ 
fardner, lieo. M. (b'74)-Cal.1,96; (1'05); (Indlan Service): Fallon School. Ilascall, C. A. (b'51)-Cal.4,04; (1'06) Hascall, Nelle 13. (b'69)-Cal.4,05; (i'05). uciners, Carl lIernan-Cal. 03 ; (1'05).

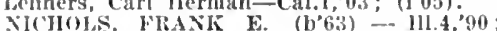
XI(I)

Sulth, Virginla I'alne-Cal.5,01; (l'02).

FERNLEY, 10, LYON

Joslin, Saml. Lees $\left(b^{\prime} 70\right)$ - Mass.1, $00 ;\left(l^{\prime} 08\right)$ IEEES, JOHN TIIOS. (b'66) $€-$ Mo.s,'94 $\left(l^{\prime} 00\right)$.

GARDNERVILLE, 210, DOUGLAS

Hawklns, Ermest 11.-Colo.3,00; (l'01)

Marotz, Frelk. W'm. (b'59) - N.Y.8,'s5; (1'06)

SElitoss, GEO. I. (b'67) $\oplus$ - Ind.8,'94 (l'0(i).

GOLCONDA, 800, HUMBOLDT

'ettingell, lanl. II. (b'73) -Mo.34,06; (1'06)

GOLDFIELD, 4,838, ESMERALDA

RURDICK, WM. Y.-Nich.I, T3; (l'05)

Tavis, Jacob W. (b'63) - Ind.5,'89; (l'13) Junliam, ora I3. (b'-9)-111.11,00; (1'05)

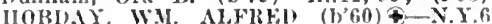

81: $\left(\mathrm{l}^{\prime} 07\right)$; also Menber Ind. State Med.

IOWLAND, EDGAR JOS. (b'60)\&-Mass. 7 , $97:\left(10^{\prime} 4\right):$ OALR

McCarthy, J. J. (b; ;i)-Neb.6,00; (l'07) TURNER, DELOS ASILEY $\left(b^{\prime} 78\right)+$-Ill.1 $01 ;(1 ; 04)$.

WIFELER, EUGENE A. $\left(\mathrm{b}^{\prime} 66\right) \oplus-$ Colo.1, '93; (1'06); S,

HAWTHORNE, 1,000, MINERAL

PACHE, FIANCIS CHARIJER (b'76)屯Cal.I, $02 ;\left(l^{\prime} 06\right) ;$ (IIIna).

IMLAY, 100, HUMBOLDT

('olby, Herbert E. (b'69)-Il1.14,'98; (1'11) Viebster, John M. S. (b'83)-Ky.2,'08; (l'I3).

KIMBERLY, 25, WHITE PINE

BEDINGER, DA VID WADE $\left(\mathrm{b}^{\prime}\right.$ ' 9$) \oplus-0.9$ 02 ; (1'10)

HIDY, KLORE WM. (b'89) $₹-$ Ind.20,'11 : ( ) Member Incl. State Med. Assn.

LAHONTAN, -, CHURCHILL

Williamson, Norman F. (b'i5)-Ill.1,04; (l'I3).

\section{LAMOILLE, 50, ELKO}

RAND MARITT J (b'78) - Minn $60^{\prime} 0$; (l'13) ; Menber Mllnn. State Med. Assn. LAS VEGAS, 1.500 , CLARK

CLARK, HENRY II. $\left(b^{\prime} 64\right) \oplus-I l l .11,,^{\prime} 93$; (l'10); S.

Fuller, John Andre, Jr. (b*83)-Neb.5,'06 ; (1'10).

Hewetson, Halle I. (b'64)-Pa.1,'86; (l'05). Martin, Royse Wood (b'T4) - Mo.20,03: (l'05): S.

LIDA, 224, ESMERALDA

Allen, Eleazer D. (b'53)-1a.1,'89; (l'05),

LOVELOCKS, 1,204, HUMBOLDT

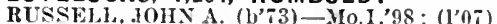

WEST, FRANCIS MYRON (b'72)甲-Cal.

WFST, FRA

Wittke, August R. (b'64)-Wis.3,'98; ().

LUDWIG, 50, LYON

SMENIEY, ROBT. CLEMENS (b'i1)कColo.1,'00; not in practice.

MANHATTAN, 750, NYE

McINTYRE, ALEXANDER (b'71)€-Jich.7, $96:(1 ' 02)$.

MASON. 150, LYON
EDWARDS, JOHN B. (b'48) $4-\mathrm{Pa} .2,81$;

( ): (EI3). Turner (b'64) - Wis.3,'01; (l'09): not in practlce.

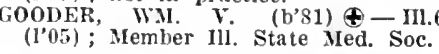

MCGILL, I,000, WHITE PINE

Millington, Wm. Arthur (b'87)-Ind.20,'10; (l'13); $\mathbf{S}$.

Wallace, Lew E.-Ind.8,02; (l'07).

MIDAS, 100, ELKO

Cloutier. Saul A.-Oue.3,01: (1'12)

Dunscomb, Edw. (b'38)-N.Y.5,63; (1'05).

MINA, 325, MINERAL

PACHE, FRANCIS CHARLIER.

(See Hawthorne.)

MOAPA. 160, CLARK

Murtangh, Edw. G. (b'68)-Mo.20,98; (Indian Servlce); Moapa River School.
NATIONAL, 50, HUMBOLDT

('lianey, Only J. (b'87)-0.41,'I1; ()

NIXON, -, WASHOE

CAP'P, PAUL GILIBEIR (1'84)-.110.28,'08 (Indian Servlce); Novada School; Op.

OVERTON, 47, CLARIS

Beal, Davld O. (b'87)-Md.3,'12; (l'13).

PARADISE VALLEY, 600, HUMBOLDT

KNORR, IAWRFNCE R. (b'76) - $\mathrm{I}^{\prime} \mathrm{a} .12$,

01: (1'13); Nember IIed. Soc. of the State of Pa.

PIOCHE, I,000, LINCOLN

Camplell, John D. (b'53)-Nllch.1,78; Duckworth, Theophlus o. (b'74) E-Mo.10, '05; (1'07).

RENO, 10,867 , WASHOE

IILERS, GEO. T.OUIS - N.Y.6,'03 ; ( ) Nember Med. Soc. of the State of I'a. Colonial Ilotel.

13ERGSTEIN, HENRY (b'47) - Cal.1,72; (l'05); 23S N. Virglnia St.; 11-12, 2-4. $7-8$.

BROWN, HENRY ALEXANDER (b'67) Pa.11, 00 ; (l'09): I2S W. Llberty St. office, Washoe County Bank Bldg.; 10-12, -4: OALR. *

CUNNINGIIAH, BENJ. FRAZIER (b'69)థMass. 1,94; (l'07); 441 (heney st.; oftice, Washoe County Bank Bldg.; 10-11, 2-4, $7-8 ; S$.

Gerow, James Wiggins (b'79)-Cal.4,02; (l'05) ; 538 N. Virginla St.; offlee, 2d and Virginia Sts.; $2-4$.

Glbson, Saml. C. (b'57)-No.1,79; (ち) ; Thoma-Bigelow Bldg.

Gregory, Ernest B. (b'64)-Cal.7,'02 ; (l'05) 225 Court St.; offee, Gazette Bldg.; 10$12,2-4,7-8 ; \mathbf{G}$.

IIANILTON, GORDON BATTELLE (b'T) (-Tenn.I1,05, Mass.6,06; (l'06); Page Apts.; office, Masonic Temple; $10-12,2-4$,

ardy, Jos. Bryant (b'78)-Mo.34,02; $\left(l^{\prime} 10\right) ; 158$ N. Virginla St. ; 9-12, 2-4

Iargrave, IIenry G. (b'72) - Ont.1, 99 ; (1'13): 56 Lake St

HARTZELL, KEIN KEELOR (b'76) (-Pa.2 02; (l'I0); Riverside Hotel; office, Masonic Temple Bldg.; 10-II, 2-4; S.

Hershier, Anthony E. - 0.9,'80, Pa.2,'84; (1'99); $214 \mathrm{~N}$. Virginla St.

IITCH, VICTOR E. (b'72)-Pa.2,'96; (1'0ï) ; IIotel Grand.

IIOOD, WY. HENRY (b'62) -Mlch.1, 86 . (l'99) ; Pres. State Board of Health: 5 MIll St. ; office, Gazette BIdg. ; $10-12,2-4$. Ingalls, Eiliza A. Shaw (b'37)-Mich.1,'75; (1'02); I44 Slerra St.; 9-12, 2-4.

JOHNSTONE, OSCAR PERCY (b'il) Ill.1,'05: (1'10); Masonic Temple.

LEWIS, ARTHUR PARKER (b'74)@-Cal.7, 00 ; (I'06); Pres. Nev. State Med. Assn. II 1 Ralston St.; office, Masonic Temple; II $-12,2-4,7-7: 30 ; S$

EWIS, JOHN A. (b'57) (-N.Y.8,77; (1'7) ; Pres. State Board of Med. Examiners; Nevada Hospital for Mental Diseases.

MARTIN, JOHN PERRY (b'72)@-Cal.4,

HCKENZIE, GEO. (b'71) \&-Ill.1,93; ( $\left.{ }^{\prime} 07\right)$; Colonial IIotel; offce, Thoma-Bigelow Bldg.; 11-12, 2-4, 7-8; S.

Niniggio, $A .\left(b^{\prime}, \bar{c}\right)$ - Ita.20,04; (1'07); Phoenix Bldg.

MOOSER, CHAS. EDW. (b'65) \&-Cal.1, 01 ; (I'02); 104 Sierra St. : $2-4, i-8$.

IORRISON, SIDNEY KING (b,79) $\odot-C a l .1$, 02: (l'02) ; 325 Flint St. ; office, Gazette Bldg. : 10-12, 2-4, 7-8.

OSTROFF, HENRY (b'63)థ-Ind.9,'97 ; $\left(l^{\prime} 08\right)$; also Nember Ind. State lied. Assn. ; 145 Pidge St. ; office, Odd Fellows Bldg. : $2-4,7-8 ; 5$

JICKARD, JOHN EVERITT (b'56) \&-Ont.4, '85; (1'07); 231 Granite St.; 11-12, 1-4, $7-8$

ROBINSON, JOHN IAA RUE (b'72) (4)-Ia.9, $98 ;\left(l^{\prime} 04\right) ; 3$ Washington St. ; office, Masonic Temple; 2-4; OALR. $\star$

ROBISON, MARTIN A. (b'63) (-Colo.2,'96; (I'06); Sec. Nev. State Med. Assn.; 510 S. Virginia St.; office, 25 E. $2 \mathrm{~d}$ St.; $2-4$ $7-8 ;(A 21)$
SAMUELS, WM. I. $\left(b^{\prime} 74\right) \oplus-K y .2,97$; (l'02) ; 29 Court st. ; offlce, Masonlc Temple 13ldg: $1-4,7-8$.

ST. CIAIR, RAYMOND (b'70)-Ia.1,96; (I'07) : 1119 Wells St.; oflce, Odd Fellows Pldg. : 2-4, 7-8; $S$.

WALKER, M. RÓLILN (b'62) -Cal.7,01 ; (l'01) ; 103 Mlll St.; oftlee, Odd Fellows Bldg.; $11-12,2-4 ; \mathrm{R}$.

Wullschleger, A. IV. II. (b'78)-Swltz.7,02 ; (1'08); Virginla St.

RHYOLITE, 800, NYE

BUT,FTTE, CLARENCE E. (b'68)-Colo.3, 97 ; (l'05).

ROCHESTER, - , HUMBOLDT

Wilson, John Byron (b'69)-Cal.4,'03 ; $\left(1^{\prime} 04\right)$

ROUNO MOUNTAIN, 600, NYE

NESMITH, FRANCIS M. (b'57)-D.C.1,'93; (1'05).

RUBY VALLEY, 52 , ELKO

Hagar, Henry-Ia.I, 75 ; $\left(l^{\prime} 00\right)$.

RUTH, 175, WHITE PINE

Hershman, Fredk. (b'86)-Ind.20,'10; (l'10).

SCHURZ, 50, MINERAL

IIallman, Hubert Victor-D.C.I,'07 ; (Indian

Service); Walker Itiver School.

SHERIDAN, IIO, DOUGLAS

Cook, Ellza (b'56)-Cal.1,'84; (l'99).

SPARKS, 2,500, WASHOE

ASCHER, JOHN A. $\left(b^{\prime} 74\right) \oplus-I 11.11,97$; $(1,97)$

Blce, Barrett D. (b'78)-Pa.2,'02 ; (l'03)

KISTLER, WASHINGTON L. (b'65)-N.Y.6,
(l'96).

TONOPAH, 3,900, NYE

Cal10, JOHN CLEMENT (b'64)-

Cal.10,00; $\left(1^{\prime} 05\right)$.

Crane, F. J.-lll.6,79; (l'13). CUNNINGHAM, JOHN R. (b'65)๑-I1l.1,

Pa.9,'94; (1'05).

Llggett, Wilbur 'T (b'52) -Ia I,87; (l'04).

MASTERSON, JOHN RICHARD (b'74) $\oplus$

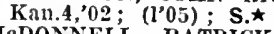

McDONNELL, PATRICK J. (b'79)-NId.7, '08: (l'10)

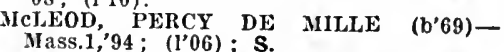

Cal.7,04; (l'05); Member Med. Soc. of the State of Cal.

RICHARDS, CHAS. JOHN (b'70)@-Cal.7,

Robinson, Benj.-N.Y.5,72; (l'00).

TUSCARORA, 450, ELKO

SECOR, CHAS. E.-WIS. 2,'05; (l'08).

VERDI, 500, WASHOE WILCOX, WM. SHELDON (b'72)-III.I,'00 ;
(l'08).

VIRGINIA CITY, 2,244, STOREY

Hodgins, Fredk. WV. (b' $\left.\mathrm{b}^{\prime} 4\right)$-Ont.1,'96; ULIJIVAN, JOHN J. (b'77)థ-N.Y.I,'02 (1'02).

WADSWORTH, 800, WASHOE

Jackman, Enoch A.-Vt.2,'86; (†)

REES, JOHN THOS. (b'66) $\odot-M o .8,94$; (l'00).

WELLS, 254, ELKO

OLMSTED, $\triangle M O S$ C. (b'71) ()-Cal.1,'95; (1'95).

WINNEMUCCA, 1,275, HUMBOLDT

BOYLAN, WM. FRANKLIN\$ - $0.2,91$; (l'05); $\mathrm{S}$.

Giroux, Edw. David (b'75)-Cal.2,'98; (l'00). Hall, Geo. Uriel $\left(b^{\prime}, 6\right)-M n .22,99 ;\left(1{ }^{\prime} 04\right)$.

MANGAN, PATRICK J. (b'65)థ-Cal.1, 96 : (l'03).

Pope, Geo. F. (b'68)-N.Y.1,'92 ; (I'08).

SWEZY, CHAS. EDISON (b'7) 9 Cal.7,

'06; (1'06); Member Med. Soc. of N.J.

WONDER, 50, CHURCHILL

Smith, David Angus-Ia.9,'92; (l'06).

YERINGTON, 682, LYON

BROWN, BEAUMONT (b'77) G-Cal.7,04; (I'05).

Knox, Geo. A.-Cal.6,'06; (l'06). (l'03). 


\section{NEW HAMPSHIRE}

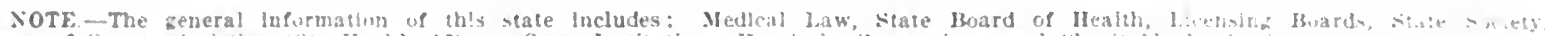
otleers of County socletles, tity Heabh vaters, State Institutions, Hisfitals, Saratwiums and (haritable lintitutions.

\section{NEW HAMPSHIRE}

Population (1910 census).

$\$ 30,572$

Number of Counties.

Number of Physicians........... 705

Members State Society, Dec. 31, 191 j 503

Area of State In Square Mlles...... 9.341

\section{MEDICAL PRACTICE LAW OF NEW} HAMPSHIRE

\section{An Act}

To regulate the Idcensfuz and lezistration of Physlclans and surpeon

Be is enacted by the sennte and Hown of Representatives In tieneral fouri conrened:

Sectlon 1. IRACTITIONHLA MTST IHF ISTER: No persun shall hold himself wht to the publle as a bhysiclan and surkewn, or adrertise as such, or use the iltie of $\mathrm{II}$ l'. or ghow that the person using the same is practituner of any of the tranches of incel

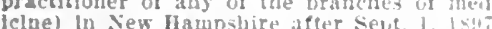
unless prevlousiy repistered and authurizted. or unless licensed and resistered as repuired by thls chapter; nor shall any frersun practce mediclne and surwery whose authurit to pracilce is suspended or revoked by the regent of a state toosu.

Sec. 2. HOARD Or WXIMINERs: Within alxty days after the passage of this $\Lambda(t$ the governor and council thall arg int three separate State Boards of Medlcal Framiners, of flre members each, so appointesl that the term of oathe of wre member sluall explare each jear, and the members thereafter ab potnted shall bold oftice the years, or until their successurs are appolnted aud quallied. One board shall reprosent be Jew Hamb shire Medlcal soclety, urg the New Ilamp-

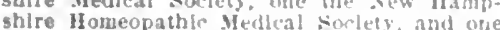
shire Itomeopathic Medlal Sorlegy, and one the New Hamplire belectic simety balch
of these three socletles shall nominate, annually, twice the number of examiners tis be appotnied in that jear on the bxard renre sentlng it. The names of stols numbirew by the presldent and ernor and councli, who shall alujolnt from such llsty the examlners ruulreis (i) ? rm the boards and to ell any bacanes thit mas occur from explratlon of oftice ur vitherwlite Fach nomlnee, before alyolutment, sliall

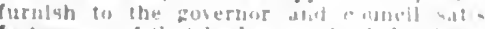
factory prouf that he has revefved the dugree of ductor of medilelise from some rebl-tere medical school, and that be bas leatly practsced medlcine in thls state por it least

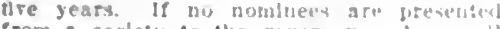
from a moclety to the governor ant? crounchl they may abjolat from membing in cows standing in such sorelete without rivtrblien The governor a mes councll, shl recommeralia thon of the boart. may remove any tabn iner for misconduct, Imotiparits of duty

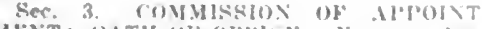

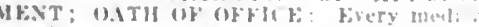

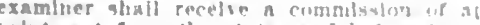
polntment from the state. Mul hegire lie.ti

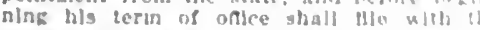
secretary of state the comaliutlonal cush

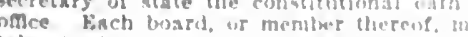
sake testlmony and broms concernlub matters wlthln lty furlsilfutlon. Eash luars may make any by-laws ant rules, not lncips. ststent with ian, necessary bn jerformatse its dutles.

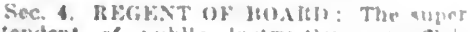
shall be the regent of the sitate forarts
Medical Examtners and slatl verform such duties as are hereln spreitled.

sec. 5. No cuMll.s.ston: from the fees provtded by thls $\mathrm{A} c \mathrm{ct}$ the retent may thay all proper expenses incurred by the uro. vlslons, excent compensation 10 medlcal examiners; and any surplus at the end of may year shall be apporthoned endually among the three boards: and the state shail not pay the expenses of said buarus, or either of them, or compensale then, or elther of them, for servlces rendered umier their commls. słuns.

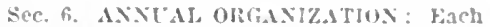
board shall annually elect from its members a presldent and $n$ secretary for the year, and shall holl one or more mettings each year, bursuant to the call of the rogent, who may also call foint meetings of the three boards or of thelr ollleers. Al any meeting a majorlty shall constiture a quirum, but questions prepared by the maris may be troujed and edited, or inswer papers of candidates may be examined and marked by commlrees only auhorized by the twards.

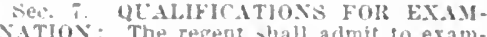

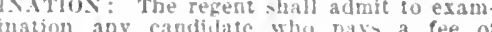
$\$ 10$ and submits satiffactury evidence, vertded by oath, if reinired, that he

1. Is more than 21 years of are.

2 . Is of food moral character.

3. Has graduated from a registered col leze; or satisfactorily combleted a rul comrse in a registered academy or hiph choul : or had a preliminary education considered and actepted by the recent as fully equilvalent.

4. Has stulled medlelne not less than four full school years, of at least nine month each, including fuur satlsfactory courses, of at least six months wach, in futr ditferent calcudar yesrs, In a medical college regis. lererl as malntaluing at the tIme a satisfac (ury standard. The regent stall acrept. as the cilulvalent for any nart of the third and fourth reaulrements, evluence of yors reputable practice, problted that sus sorars reputable practioe, problded that

llas elther recelfed the dewrev of bache inr ur doctor of mediclue from some regtsterisl medleal school, or a diplona or llcense

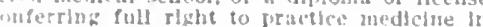
me furetin coumtry.

siutenis who matrieulate in a New llamphifre medleal school hefore la!. 1. I sys. un the frowerleed stuily of medlefine. shall be

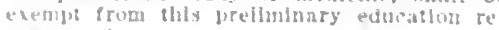
rent.

FAMINATION QIFSTINS: Fiach hoard shall subnlt to the rezent. ay

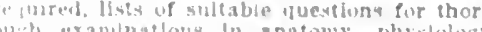
mich exantmatfous In anatomy, bhyslology

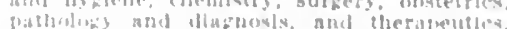

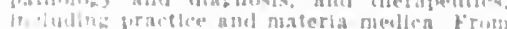

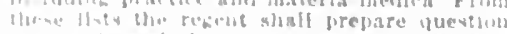

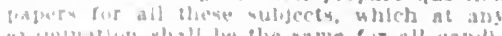

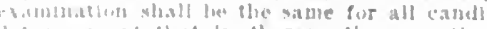

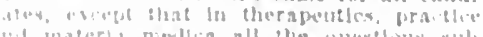

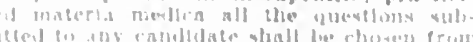

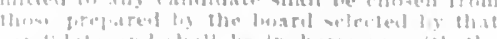

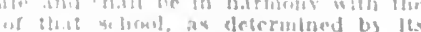

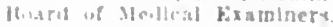

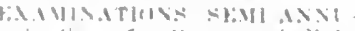

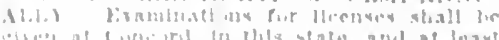

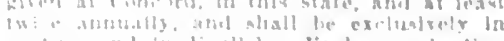

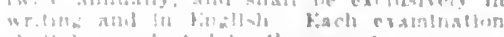

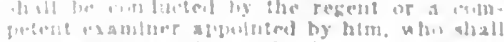

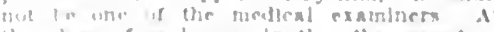

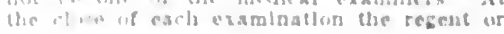

eximiner in charice shall leliber tho yuestions and answer vayers to the board

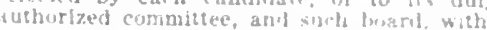
out unnecesiary delay, strall exambine and wark ariswers and transmit to the regent an whllal repors, qinned by tos frealderst and scretary, stating the slanding of each canlidate in eacll branch hls zencral areraze. and whother the board recotimends ithat license tie granted. Fuch rejmith ill in. clude the gnestons and answers mu shall he tlled in the public records of the resent. If a candidate fails on first eramluating he inay, after not less than six munthi further study, have a secons examitustion without

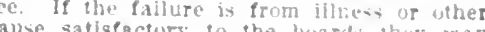

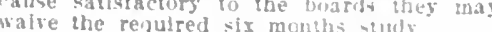
sec. IO. I.ICWNE; HECHPIUITY PEE : LITEXSE: TO BE RECURIEI): On recelving from a state boarl an otlial rejort llat an applicant has successfully passech the examinatiuns and Is recommended for llcersie. the repent shall lisule $20 \mathrm{~h} / \mathrm{m}$ a lirense to bractice medicine. Firery lleenso shall be issued loy the regent under seal and shall be minned by eath acthit medical

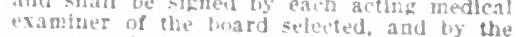
rejent, and thall state thit the llownee has fiven sulfisfordory eridence of flress as to afe, charauter, prellminars and medical education, and all wher matters rejulred by law, and that after full examination he has been found yroweriy unalified to practlce. Applicants eramined and licensed by other state examinlug boaris rezistered ly the rezent as maintainlng stablards not lower than thuse provided hy this chinter. and shire medical statricul hefore Jan. Hampand who recefie the degree Min. Jan. 1903. may, without further exanination, on payment of sit to the rement and on submisting such evilence as may he requlred, reretie an endursement of thelr heenses or dipiomns conferriat all rights and yrdileges a regent license lssued after ezamination. ounbered and reetrofed in aled it shalt be rerent's onlec and lts number shall he noted refents oftce and lis number hall be noted
ln the llcense. This recurd sball tee coen to public Inspection, and in alf lecral procedInzs shall have the same welpht as erifence that is then to a record of conveyance of
land.

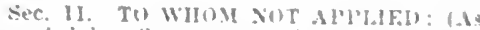
anculed by rhapter I uf the sension lasts

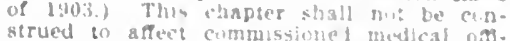

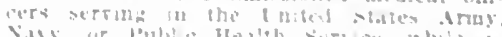

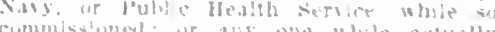
serring on whe or ang mes while actually lically lneorgerafed hospleal; or any legally renistered deablet exclusively engated in

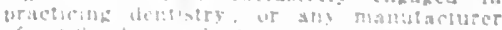

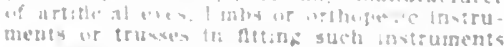

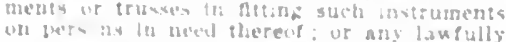
on bors ny lu need thereof: or any lasufully

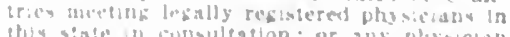

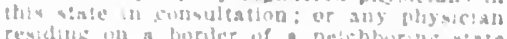
and duig authursed under the laws besect

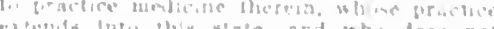

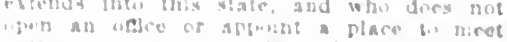

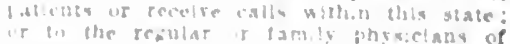

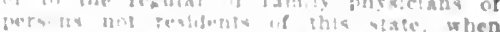

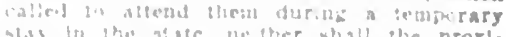

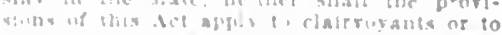

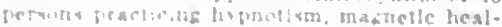

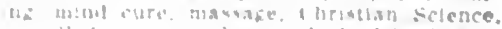

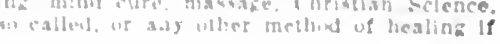


no drugs are employed or surgleal operathons are performed : provided, such bersons do not violate any of the provislons of thls Act in relation to the use of $11 . \mathrm{H}$. or the title of doctor or pliysiclan.

Sec. 12. JALSE ('LAIMS; FIHAIDITISNT IEPIESESTATON: J'NISHIFNT: AHY person who, not being then lawenly suthor ized to practice medlelue within this state und so registered according to law, shall hold himself out to the publie as a phystelun and surgeon, or adrertlse as stuch, wlthin this stute, without lawful reglstrution or in vlolation of any provisions of this chinter. violaten of any provisions of this chiater and any person who shall bus sem or fraudrecord or reglstration, or who shall ald or record or reglstration, or who shall aid or
abet sueh buying, selling or fraudulently obtainting, or who shall practice medicine under cover of any medical diploma, license, record or registration illegally ohtilined or signed or issued unlawfully, or under fraut ulent representations or mistake of fact in a material resard; and any person who shal append the letters MI. I) to his or her name apend the lette or shall assume or atrertise the title of doctor (or any title wherh sliall show or tend to show that the person assuming or advertlsing the same ls antioner of an of the branches of medicine) in such a manner as to convey the impression that he or she is a legal practitioner of mediclne, or of any of its branches. without having legally recelred the medical degree, or without havIng recelved a license which constituted at the time an authority to practice medicine under the laws of this state then in force, shall be gullty of a misdemeanor, and on shantion thereof shall be punished by a flne of not more than $\$ 100$ or inprisoment for three months for the first offense; and on conriction of any subsequent oflense, by a fine of not nore than $\$ 250$ or imprisonment for not less than six months, or by both fine aud imprisonment.

Sec. 13. REGISTRATION OF CERTIFICATE; FEE: Every person who is a practitioner of medicine and surgery in this state prior to the passage of this Act shall be, on satisfactory pronf thercof to the regent and on the payment of a fee of $\$ 1$, entitled to registration; and the said regent shall issue to him a certifleate signed by himself and the chairman and secretary of -such Board of stedical Examiners as the applicant may elect; and said certiflcate shall state the facts and the cause of said registration, and shall entitle the said person to practice medicine legally in the state of New Ilampshire.

Sec. 14. MEETINGS OF BOARD; RECIPROCITY: The first meeting of the board may be called by any one of its members by a notice in writhn. stating the time and place of meeting, sent by mail to each of the other members at least one week prior thereto. Any legal practitioner of medicine and surgery in any other state or territory, which will grant to physicians and surgeons registered in this state slmilar privileges shall be admitted to practice medicine and surgery in this state by paying the usual fee of $\$ 10$ and presenting to the boards of medical examiners a satisfactory díploma from some medical school, a certificate of registration, or license to practice medicine, from the state or territory from which he comes, and evidence satisfactury to said boards of examiners of his professional standing.

Act effectire Sept. 1, I89i.

\section{STATE BOARD OF HEALTH}

Robert Fleteher, C.E., President, Hanover Irring A. Watson. Secretary, Concord; F. E hittrefge, Nashua; Gor. Samuel D. Felker, Rochester; 1). E. Sullivan, Concord.

\section{REGULAR BOARD OF MEDICAL EXAM- INERS}

Arthur C. Heffinger, President, Ports mouth: George II. Shedd, North Conway; John F. Robinson, Nanchester; Iloward $\mathbf{N}$ Concord.

\section{HOMEOPATHIC BOARD OF MEDICAL}

ricorge 1R. Sinth, President, Dover; C. W Idams Franklin: IIenry I. Wiggin, Whitetheld; Channhr Blshop, Brlstol; It. V. Sweet, secetary, lochester.

\section{ECLECTIC BOARD OF MEDICAL EXAM-}

I. J Marston, l'resident, Nymouth: Walter Il. 'frue, Laconla: Lester k. Brown. secretary, Jaconia.

\section{NEW HAMPSHIRE MEDICAL SOCIETY} Offleers 1913-14

Abram W. Mtchell, President......Epung Herbert k. Faulkwer, Vice-Iresident... Feene

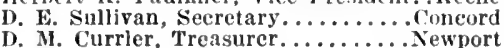

\section{Councilors}

Belknap County.-A. II. IIarrinan, Councllor, Laconia.

Carroll County.-S. 1'. Getchell, Councilor Wolfeboro.

Cheshire County.-H. K. Faulkner, Councilor, Keene.

Coos County.-Joseph J. Cobb, Councilor, Berlin.

Grafton County.-Fredk. ron Tobel, Counclior, Lebanon.

Hillsboro County.-Ella B. Atherton, Councilor, Nashua.

Merrimack County.-1'. T. Haskell, Counilor, Concord.

Rockingham County. - walter Tuttle, Councilor, Excter.

Stafford County.-Louis W. Flanders Councilor, Dover.

Sullivan County.-E. M. Fitch, Councilor, Claremont.

Component County and District Societies of

the New Hampshire Medical Society BELKNAP COUNTY

B. W. Baker, Presldent............. Laconia

C. S. Abbott, SARRoLL CoUNTy

B. F. Horne, President............ Conway N. II. Scott, Secretary........... Wolfeboro

CENTRE DISTRICT-MERRIMACK COUNTY

S. G. Morrill, President........... Coneord P. T. Haskell, Secretary ............. Concord CHESHIRE COUNTY

Edward A. Tracy, President.......... Keene
E. C. Haviland, Secretary............ Keene coos counTy

E. F. Brown, President..........Groveton J. B. Warden, Secretary........... Whitefield GRAFTON COUNTY

Howard N. Kingsford, President.... Hanover

G. A. Weaver, Secretary.......... Warren HILLSBORO COUNTY

W. II. Lyons, President..........Manchester G. S. Foster, Secretary....................... MERRIMACK COUNTY

(Inclnded in Centre District-Merrlmack County.) ROCKINGHAM COUNTY

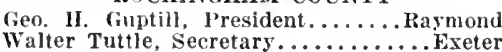
STRAFFORD COUNTY

J. J. Buckley, President............. Milton SULLIVAN COUNTI

John E. Toye, President........ Charlestown E. II. Fiteh, Secretary............. Claremont

\section{SECRETARIES OF HEALTH BOARDS IN CITIES OF 2,500 POPULATION} AND OVER

Berlin................ James B. Heald Claremont...................... Rowell

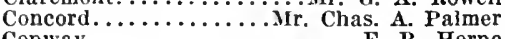

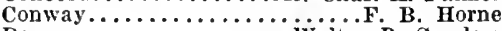

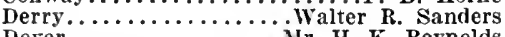
Dover................... $\mathbf{k}$. Reynolds Exeter................ William H. Nute
Franklin................ Goffstown............... Mr. A. P. Seeton Keene................ 1). Worcester I.aconla................ Walter II. True

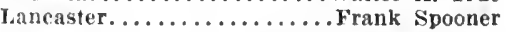
J.cbanon............... Frederic Von Tobel bittleton.............. Gr. George W. Smlth Manchester........... Wr. Whllam K. Itobbins Milford................. Br. F. Foster Nasluua.................. J. MeLaughlin Nexmarket............. Chas. A. Morse Newport................... L. Cain Pembroke.............. Fred W. Saltmarsh Pittsfield............. Samuel F. Jenkins

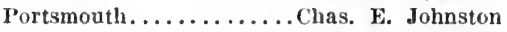

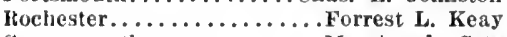

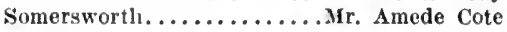
Walpole................W. P. Craig

\section{Concord}

\section{STATE INSTITUTIONS}

New Hampshlre State Hospital, Concord, N. H. Establlshed 1843; for the Insane; 1,100 beds; Cbas. P. Bancroft, medical superintendent.

New Irampshlre State Prison, Concord, H. Established 1812 ; public; 268 beds: Charles H. Cook, physician in charge.

Glencliff

New Hampshire State Sanatorium (for the treatment of tubcrculosis), Glencliff, i. Wise, inedical superintendent.

Laconia

New II ampshire School for the FeebleMinded, Laconia, N. H. Established 1903; educational; 180 beds; Benj. W. Baker, medlcal superintendent.

\section{Manchester}

Industrial School, Manchester, N. H. Established 1858; general; 175 beds; Wm. C. Morton, superintendent.

\section{Tilton}

New Hampshire Soldiers' Home, Tllton, N. F. Established 1890; general; 125 beds; J. B. Frskine, plysician and surgeon in eharge.

\section{HOSPITALS, SANATORIUMS AND CHARI- TABLE INSTITUTIONS}

\section{Berlin}

St. Louis Hospital, Berlin, N. H. Established 1905; general; 50 beds.

Claremont

Claremont General Hospital, Claremont, N. If. Established 1893; 25 beds; Niss N. A. Steeves, superintendent.

\section{Colehrook}

White Mountain Health Resort, Colebrook, N. H. Established 1911; public and private; liealth resort; 9 beds; H. H. Nadig, physician in charge and superintendent.

\section{Concord}

Margaret I'illsbury General Hospital, Concord, N. H. Established 1884; gen-
eral; 60 beds; Nina A. Smitb, R.N., superintendent.

New Hampshire Memorial Hospital for Women and Children, Concord, N. H. Established 1896; general; 25 beds; M. L. Bugbee, physician in charge; $R$. O'Donoghue, superintendent.

Orphans' Home, Concord, N. H. Established 1866; private; 45 beds; Mrs. Mary H. Bartlett, superintendent.

Pembroke Sanatorium, Concord, N. H. Established 1901; tuberculosis; 40 beds; Robt. B. Kerr, physician in charge; Anna MeDerby, R.N., superintendent.

Rolfe and Rumford Asylum, Concord, N. H. Established 1880 ; for destitute children; 21 beds; Emma Dupee, superintendent.

Dover

Hayes Hospltal, 45 Summer St., Dover, N. H. Established 1900; general; 1

Wentworth tablisbed 1906; general; 50 beds; Grace P. Haskell, R.N., superintendent. 
Exeter

Exeter Ilospital. Irospect IIIl, Exeter N. II. Eistablished 1SuT: general : 35 Intendent.

Franklin

Franklln Hospltal, Franklin, X, H, Fs tablished 1910: zeneral; 20 bets; Itiss Ida A. Sutter, It. $\mathbf{X}$. superintendent.

New II ampohire Orphans" II ome, FrankIIn. $\mathrm{X}$. Establlshed is:1 : educational 200 beds: E. T. Drake, surfeun in charge: Rufus P. Gardner, superintendent.

\section{Grasmere}

Hillsboro County Hospital, Cirasmere x. II. Fstabllshel 190\%: 90 lueds; to ieds in tuberculosls pavilion: C. I Yolsom (Manchester), physiclan in charge.

\section{Hanover}

Mary Hitcheoch Memorlal Hospltal, Hanover, X. II. Fistablished 1593; teneral; 65 beds: Ida F. Shepard, R.N. superintelident.

Keene

Elllot City Hospltal, 305 Main St Keene, $\mathbf{X}$. II. Establlshed 1892; general Koene, $\mathrm{X}$. II. Establlshed 1892 ; Reneral: to beds; Geo. W. say Boston, J, Wh. am. Mass. medleal staff; Ella McCobb superintendent.

Whitebrook Tarern. Hurricane Rd. Keene, $\$. H. Established 1912; prirate nerrous and mental cases; 12 beds; $11 \mathrm{~m}$ W. Coles, consulting pisslclan: Ruth Barker Coles, medlcal superintendent.

\section{Laconia}

Laconla Hospital, Iaconla. N. H. Es tabllshed 1898 ; prlvate; general : 25 beds Anna C. Lockerby, R.N., superintendent.

\section{Lin coln}

Lincoln Hospltal, Llncoln, N. H. Establlshed 1900: general; 24 beds; F. D. Burt, physlcian In charge.

\section{Littleton}

Littleton Hospital. Littleton, X. H. Establlshed 1907: general: 22 beds: Kitherine II. Kurgs, K.X., superintendent.

\section{Manchester}

Amoskeag Emerzency Iospital, Man chester. H. Establlshed 1911: emergency work only; Walter A. Bartlett, phy slelan In charfe.

Asylum of Our Lady of Perpetual Help. Manchester, $\mathbf{X}$. H. Established 1902; for Infants: 50 beds; Wm. II. I.yons, rlsitin physlclan.

Beacon HIll Hospltal, Manchester, Xi. II Fstabllshed 1908; general: 25 beds: John 11. Gleason, medlcal director; Mlss Jenuie B. Messer, superlntendent.

Fillot Hospltal, Manchester, N, II. Fatabllshed 1888: ceneral: 44 bets; Vellie tablished 18s8, general 4 bets

M. Haruing. R.X., superintendent. Establlshed 1895: prirate: for aced and destltute women: 40 beils: 1 . F Wheat, at tute women: 4 beds: 1. F. Wheat, at tenden

Hosplce St. VIncent de Paul, Lake Are., Ianchester. $X$. H. Established IS92; orphanage: 100 bers.
IIospinal of Notre Dame de Lourdes, Wauchester, $>$ H. Established 1892 nublic; 60 hetls; sisters of Charlty, in charge.

Manchester Chlldren's Home, Webster

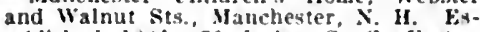

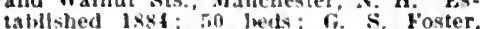
vlslting phrslclan: Mrs. Joslah Carpenier. susting phrsician

Notre bame Orphanage, Manchester. N. II. Established 1885; 130 beds.

Sacred Heart IIospltal, Manchester N. II. Established 1892; general; :0 beds: sisters of blerey, in charge.

St. John's Ilome for Ired Iten, hiberty and Clarke sts. Manchexter. II by tablished 1908; 25 beds: Sisters of Mercy. In charre.

St. Joseph's Orphanage for Boys, Pine and Hanorer Sts., Manchester, N. H. Established 1888; i30 beds.

st. Patrlck's Home for sged Women 22 Hanorer St. Vanchester, $Y$. H. tablished 1879 ; private: 33 heds.

St. Patrlck's Orphanage for Cirls, Ilanorer St. Manchester. $\mathbf{H}$. Establlshed 1873 ; private: 135 beds.

St. Peter's Orphanage for Boys. Man. chester, $N$. H. Fistabllshed $1902 ; 125$ beds.

Woman's Christian Temperance Unlon Merey Home, 86 Mammoth Kd., Manches ter. X. II. Establlshed 1890 ; for girls: 25 beds: Ella C. Hurd matron.

Nashua

IIIghland Sprlng Sanatorlum. Bellerue Are., Nashua, $\mathbf{N}$. H. Establlshed 1900 for nerrous cases; 15 beds; A. E. Brown rlgh. physlcian In charge.

Home for Aged Women, Nashua, N. H. Established 187\%; prirate; for residents of Sashua only; 18 beds: Mrs. M. Heed superlntendent.

Isolation Hospltal, Taylor Rd. Nashua r. II. Establlshed 1894: smali-pox; 1 beds: controlled by Board of Health.

John M. Junt Home for Aged Couples, Nashua. $\boldsymbol{X}$. H. Established 1876; private Fred Wright. superintendent.

Nasliua Memorial Ilospltal, Nasbua. x. H. Establlshed 1892; feneral: 25 heds: Harriette E. Behrens, I.N., superintendent.

Xashua Protestant Orphanage Associatlon, 16 Burrett St.. Nashua, X. H. Bs cablished 1903; 30 beds; $A$. S. Wallace phrsician in charge.

St. Joseph's IIospital, Nashua, N. II. Established 1908; puthle; general; 85 beds; Itontreal fires Nuns, in charge.

st. Juseph's Orpbanage. Maln St. Nashua, X. II. Fstabllsheil 1900; 180 beds.

Newoort

I:arrle F. Wright Memurlal Insphtal. Nowport, N. 11. Establlshed 1910 : putille "peneral; 18 heds: Julia B. Suinney, B. superlnteluleut.

North Conway

Meruorlal Hospltal, North Conway, N, II Eistallished 1911: general: 25 bels; Lill inan Fraser, superintendent.

\section{North Haverhill}

firafton County farm Hosplial, North if II F.11. Fistabllshed 18 i $0: 15$ heds; H. C. l'hillips, sutht

Wordstlle lolleze II ospisal, Sorth Ilaverbill, $x$. II. (It F.II) Established 1901: Ceneral: 20 beds: Hist Annle Talsey, matron.

\section{Ossipee}

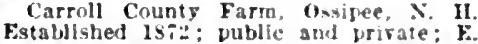
B. Indrews, uhysician; Frank Jelion. superintendent.

\section{Pembroke}

Pemiroke Sinatorlum, Pembroke, X. H Established 1901: tuberculosis: 40 bed. It. I3. herr (concord), Ihyslelan in charge.

Pittsfield

Sargent IIail, Plttsfleld, $x$. H. EstabJished 1404; prirate; narcotic and alcoholle addiction: 10 beds; Frank H. Sargent, Jhyslcian in charge.

Plymouth

Bmily Balch Cottage Haspital, Hymouth, N. H. Extablished 1849: general; 1 s beds; Margaret l.uckward, It.X. superintendent.

\section{Portsmouth}

Ellward S. Cowles Isychotheropeutl Sanitarium. Portsmouth. $X$. H. FitabJished 1912; nervous and mental; 25 veds Edward 5 . Cowies, physiclan in charze.

Home for Aged Women. Fortsmouth. X. H. Established 157\%; pr/rate ; 12 beds; C. W. Hannaford, physictan in charge F. J. Philbrick, superintendent.

Portsmouth Hospital. Portsmouth, $\mathbf{X}$. H. Established 1587 ; Reneral, maternity ; 35 beds; Miss Mary F. Hamsey. P...., supt. Unlted States Nars! Hospltal. Nary Yard, Portsmouth, N. H. Established 1834 general; for members of the Yary and Marine corps: 38 beds: B. L. Wright. C.S.X., surgeon in command.

Ward Il. Wentworth lleme for Chronic luvallds. 340 Pleasint st., l'ortsmouth. N.H. Fstablished 141:2: public: penersl except contagious : if beds: Iliss Jessle McFarlan. R.X., superintendent.

\section{West Ossipee}

Dr. Lord's Sanstorium, Mt. Whitller Sta. West Oss!pet, $X$. If. Established 1906: general; 6 beds; L. W. leard, physician in charge.

\section{Whitefield}

Iorrlson IIospital, Whitefleld. N. H. Establlshed 1902: nrivate; general: 25 heds fieo. H. Morrison, physiclan In cliarge.

\section{Wolfeboro}

Hurgins IInspitil. Woifelanro. $X$ H. Fs tablisled 1908: general: 15 beds: S. 1' Getcliell. president of medical and suretical staft; Ulss Thurza B. Jackson, K.X., superintendeut.

Woodsville

Womlsrille Cottage IIospital. Woodsrille $x$ 11. Fistabilished 1:43; ceneral: So hels; k. M. Mtiller, physciau in charge Innle bantle Talsey, superinteudent. 


\section{PHYSICIANS OF NEW HAMPSHIRE}

Names in capltals signlfy membershlp in the County Soclety and State Associathe County Soclety a

- Indicates Fellowship in the American Med. Assu. (DOE, JOHNњ).

(b'75) Year of birth. [medle. If, homeopath; $\mathrm{L}$, eclectle; I'-M, physioMat 7,09 . College and year of graduatlon.

O Information recelved does not show grad uation.

\section{S.-Surgeon.}

ob.-Obstetrician.

ObG._Obstetrician, Gynecologlst.

G.-Gynecologist.

Or.-Orthopedlst.

Pr.-Proctologist.

Op.-Ophthalmologist

A.-Aurist.

LR.-Laryngologist, Rhinologist.
KEY TO ABBREVIATIONS, SYMBOLS, ETC.

(I'89) Year of license.

(d) In practice before passage of present law and lleensed by fling diploma or by years of practlce.

(li) Lleensed but year not known.

(末) Information recelved does not show Itcense.

U.S.A., United States Army.

M.R.C., U.S.A., Medical Reserve Corps.

SPECIALTIES ARE INDICATED AS FOLLOWS:

ALR.-Auríst, Laryngologist, Rhinologist.

OALR.-Ophthalmologist, Aurist, Laryngologist, Rhinologist.

U.-Ürologist.

D.-Dermatologlst.

Pd.-Pedlatrlst.

N.-Neurologist.

P.-I'sychlatrist.
U.S.N., United States Nary.

M.R.C., U.S.N., Medleal Reserve Corps.

U.S.P.II.S., United States Public Ilealt Service.

College positlons held are indicated by abbrevlated title of position, followed by key number of college. For key to colleges see inside front cover page.

(A1,3, B6, C4) Membership in speeia Socleties. (See Key Table, page 122.)

NP.-Neurologist, 1'syehlatrist.

I.-Internlst.

T.-Tubereulotherapist.

Anes.-Anesthetist.

LD.-Laboratory Dlagnosticlan.

[gist.

R.-Aetinologist, Radiologist, RoentgenoloPath.-Pathologist.

Bact.-Bacteriologist.

WHEN THE ABBREVIATION REPRESENTING A SPECIALTY IS FOLLOWED BY AN ASTERISK ( ) IT INDICATES THAT THE PHYSICIAN CLAIMS HIS PRACTICE IS LIMITED TO THAT PARTICULAR BRANCH OF MEDICINE; WITHOUT THE ASTERISK, THAT HE IS ESPECIALLY INTERESTED IN, BUT DOES NOT LIMIT HIS PRACTICE TO, THAT BRANCH. THIS INFORMATION CONCERNING SPECIALTY IS BASED ON PERSONAL DATA FURNISHED BY THE PHYSICIAN AND IS NOT VERIFIABLE.

\section{NEW HAMPSHIRE}

ACWORTH. 200, SULLIVAN

WOODBURY, CHAS. EDWARD -N.Y.5,'73 Nember R.1. Med. Soc.

ALLENSTOWN (R.F.D., SUNCOOK), 1,457, MERRIMACK

BUTTERFIELD, CLARENCE E. $\left(b^{\prime} 75\right) \oplus-$ N.H.I,'03; $(1,03)$; S.

ALSTEAD, 412, CHESHIRE

Mousley, Bayard T'. (b'79)-Md.4,'05; (l'06). STEVENS. PARKER BENTON (b'69) N.Y.9,'94; (I'0I).

ALTON, I,348, BELKNAP

ELLISON, DANL. JAMES (b'S6)@-Mass. $\tilde{z}$ 08; (1'08).

MelaUghLiN, FRANK W. - Md.6,'94 (1'97)

Wrighi, Elam R. (b'66)-N.H.I,96; (l'97)

AMHERST, 1,060, HILLSBORO

Chandler, Fredk. (b'52)-Me.1,77 ; (l'97)

Felt, Paul Revere (b'82)-N.H.I,'I0; (I'11)

Garland, Geo. Franklin (b'67)-Md.4,'98; not in practice.

ANDOVER, I,20I, MERRIMACK

ROWE, WAITER C. (b'73)-N.H.1,'99; (l'99).

ANTRIM, 1,235, HILLSBORO

Chesnutt, Arthur Allen (b'69) H-Mass.5, 96 ; (1'97).

DEARBORN, EDMUND G. (b'79)-Mass.I, 04 ; (l'04).

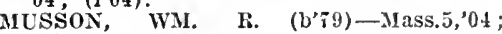
(l'05).

WARNER, FRANKILIN GEO, (b'63)-N.T.3, 92 ; $(1 ' 97)$.

ASHLAND, 1,412, GRAFTON

CHENHY, JONATHAN M. (b'63)-Vt.2,'87

HUCKINS, JOHN CALVIN (b'7 6$)-M d$, 04: (l'04)

ORTON, LEON MARTIN (b'87)-Vt.2,'II (1'12)

Spaulding, Melville $\operatorname{Cox},\left(b^{\prime} 42\right)-V t .2,65$; (1'9T).

WORTHEN, EUGENE MARK $\left(b^{*}, 2\right) 8-$ N.H.I,OI; (I'0I).

ASHUELOT, 382, CHESHIRE

Basch, W. A. - ; (I'02).

AUBURN, 637, ROCKINGHAM

Crowell, Geo. M. (b'72)-Mass! 1,'99;(1'04).

PITMAN, ARTHUR J. (b'68) -N.H.l,'91 (l'97).

BARTLETT, I,I97, CARROLL

MULLIN, SETH SMITH $\left(\mathrm{b}^{\prime} 83\right) \oplus-$ Me.I,'08; (l'09).

BATH, 978, GRAFTON

DeGross, John Henry (b'62)-N.H.I,'99;
BELMONT, 1,350, BELKNAP

BLANCHARD, WATTFR

N.H.1,84; (1'98); Member Me. Med. Assn. BERLIN, 11,780 , COOS

COBB, JOS. J.\&-Me.I,'SI; (I’97) ; $20 \mathrm{High}$ St.

LAVALLEE, ARSENE (b'62) - Que.3,'86 (l'97) ; Church and Pleasant Sts.

MARCOU, LOUIS BENJ. (b'64)-Vt.2, 99 (1'99) ; 277 School St.; office, 275 Schoul St. ; II-2, T-8; S.

MARKS, HOMER HOPKINSON (b'76) Me.I,'06; $\left(I^{\prime} 10\right)$; 211 Emery St. ; I-3, $7-8$ CeGEE, EDW R. B. (b'79) - ' $\left(l^{\prime} 04\right)$; 16 Main St.

PROVOST, AZARIE M. J. (b'69) (8-N.H.I 98 ; (1'00); 12 Church St. ; $9-11,2-4,7-9$ Pulsifer, Tappan Chase (b'70)-N.Y.I,'99 (l'00) ; I5 Main St.

Rodier, Chas. S. (b'64)-0nt.4, 87 : (l'97).

Sasseville. H. M. Nicholas (b'69) - Que.3, '90; (l'97).

BETHLEHEM, 1,201 , GRAFTON

BLAIR, ALEX. MCNIEL.

(See Southern Pines, N.C.)

THOMPSON, HOWARD EDW. (b'84)థN.H.1,07; $\left(1^{\prime} 07\right) ;$ S.

BOW (R.F.D., CONCORD), 676, MERPI MACK

Colby, Frank Edgar-N.H.I,'87 ; (I'97).

BRADFORD, 695, MERRIMACK

HOWLAND, CLIFFORD $\left(b^{\prime} ; 8\right)-$ N.H.1, 08 ; (1'I0).

Richards, Paschal B. (b'29)-N.Y.4,'52; (1'97).

BRENTWOOD, 759, ROCKINGHAM

Pike, Ezra Barker (b'33)-Me.I,'57; (l'04).

BRISTOL, I,478, GRAFTON

Bishop, Channing (b'64)H - Mass.5,'89 ; (1'97)

Calley, George H. (b'54)-N.Y.I,'80; (1'97).

Dowd, Arthur V. (b'67)-Mich.I,'96; (1'97).

Robertson, Fredk. McNaughton (b'77) Mass.1,'01; (I'06).

BROOKLINE, 50I, HILLSBORO

HOLCOMBE, CHAS. HENRY (b'59) Mass. I,'86; (I'87).

CAMPTON, 845, GRAFTON

Cheney, Harry A. (b'70)-Vt.2,'94; (1'97).

CANAAN, I,408, GRAFTON

BOGARDUS, FRANK A. (b'69)-MI.4,'94; $\left(I^{\prime} 97\right)$.

Newcomb, Chas. E.-Vt.2,'80; (l'99).

WING, PERSONS WALTON (b'7)-N.Y.8, $02 ;(1$ '03).

CANDIA, 993, ROCKINGHAM

FOSTER AVERY MOULTON (b'5I)-Me.1, 75 ; (I'02).

Robinson, Herbert Winslow (b'57)-Me.1, '92; (l'99).
CENTER, BARNSTEAD, 500, BELKNAP

HAWLEX, GEO. H. (b'58) - N.H.I,'78; (1'97).

Tuttle, Ralph W. (b'8I)-Mass.1,'09; (l'11). CENTER EFFINGHAM, 100, CARROLL Gould, Albert N. (b'47)-N.H.1,73; (l'97). CENTER HARBOR, 420, BELKNAP

MORRILL, LEONARD B. (b'65)-Vt.2,'88 (1'97).

CENTER SANDWICH, 400, CARROLL

HOAG, ALBERT B. (b'72)-N.H.1, 00 ; (l'00).

White, Chas. Henry (b'38)-Mass.1,62; Med. Dir., Rear Adumlral, U.S.N., retired. CHARLESTOWN, I,496, SULLIVAN

Brooks, Natbaniel G. (b'38)-N.Y.3,'61 (1’97)

TOXE, JOHN E. (b'76)甲-N.H.1,0I ; (l'01). YOUNG, OSCAR CUMMINGS (b'69)-Vt.2, '94; (1'97).

CHESTER, 818, ROCKINGHAM

ROBERTS, JAMES STANTON (b"72)Mass.I,'93; (l'97).

CLAREMONT, 7.529, SULLIVAN

BROOKS, ROBT. HARTLET (b'78) (-) Mass. I, 05 ; $\left(\mathrm{l}^{\prime} 06\right)$.

COUTU, JOS. EDWARD (b'63)-Que.4,'94 (l'97).

CUSHMAN, EARL PERCY (b'73)-Vt.2,'00

DOW, JESSIE ANDERSON $\left(b^{\prime} 72\right) \oplus$ Mass.7,'09; (1'09).

WWL, (1'97)

TTCH EMEPY MOORE (b'76) $05 ;\left(l^{\prime} 05\right) ; \mathrm{S}$.

GEORGE, HENRY PAUL (b'85)\&-MId.4, 'I2; (1'12) ; ALR.

Holt, James P.-N.H.I, 78 ; (1'97).

JARVIS, LEONARD (b'52)(4-Mass.I,'82 ; ('97).

MORGAN, FIELD CHILSON (b'67) S-Vt.2,

SANDERS, HENRY CLAY, JR. (b'71) (Pa.I,'99; (1'99)

TOLLES, CLARENCE IVESTON (b'45) N.X.10,'68; (I'97).

UPHAM, SAML. RICE (b'62)-Vt.2,'88; (1'97).

WAY, OSMON B. (b'40)-N.H.1,'66;(1'97).

COLEBROOK, 1,905 , cOOS

Dight, Mary Alice Glidden Crawford (b'60) -Mich.1,'84; (l'09).

JONES, EDWIN E. $\quad\left(b^{\prime} 70\right) \oplus-N . H .1,94$; (I'98); $\mathrm{S}$.

Nadlg, Henry H. (b'76) H-IIl.30.'98: (I'II).

Noyes, Waiter Fredk. (b'85)-V't.2,08; (I'12).

TWOMBLY, EDW. E. (b'59)-Me.2,'85; (1’97). 
CONCORD, 21 497 MERRIMACK

ADANS, CILNCFY (b'61)+-Me.1,9I (1'y7): 44 Merrimack St.; onlce, $11 \mathrm{~s}$ Maln St. ; $1-3, \quad-8 ; S$.

AMSDEN, HESIT IILBBAIII $\left(b^{\circ}, 2\right)$ t Mass.s."96: $\left(1^{\prime \prime} 06\right) ; 46$ \%. State St.; 1-3. i-8; ALR.

AXXABI.E, ELWIS GLIJAOIt) (b'\$0) Vt.2, 80 ; (1"97); 2.2 South st.: 1 -2, 7.9

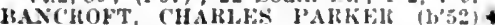
- Mass. 178: (1'97): New Hampshiro State Hospltal: $(\mathbf{1}, 13): \mathrm{NP}$

BFALCLFRK, WM. PRESTOS (b"3)Vt.2,96; (1'97): 2 s. State St. $1-3$ $6: 30-8$.

BCGBEF, MARION L. (b'i1) - Y Y I I (1'07); 11 Court st.; offle, 20 l'teasan: St. : 1-4; Pd.

CIARK, EDFAR A. (b'58)-N.1I.1, 84 (l'97): 35 I'leasant st. $12-2,6-8$.

ClARKE, GEO. IIAVW (b'59) ,02: (1.05): 102 Pleasant St: ${ }^{3}-3,-3$

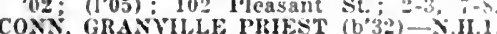
56; (I'97); retlred; Pres. State Inuard o? fiealth: $17 \mathrm{~s} \mathrm{~N}$. Maln St.; otthce, $130 \mathrm{X}$ Maln st.: Fmer. I'ro?. Hyg. XII.

COOK, CHAS, HENRY, JR. (b'i4)-N.H.I

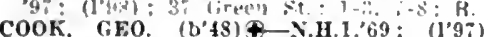
Sec. Reg. Board of Med. Fxaminers; 16 centre St. $1-3,6-5$ : 0 .

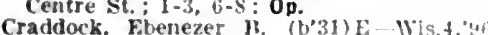
(1'97); 50 Monroe St.; $9-10,2-4,7-3$

Cummings, Fredlk. Fben (b'ss) $\left(l^{\prime} 97\right) ; 17$ Merrimack st. ; 1-3.

DAY, ARTHUR KEHEW (b'62)-Mass $89 ;\left(1^{\prime} 97\right) ; 11$ South st.; untll $9,2-3$ aftér $i$.

Delaney, Edwarl J. $\left(b^{\prime}-1 x\right)-M d .4,0$ (I'03); 15 Centre St.; 2-4, ;-9.

DOLIOFF, CHAS. HALi, (b'a)-X.11.2, 03 (1.04): New Hamphire Stato Hospital: $P$

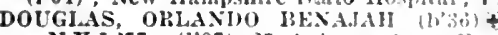
20 Pleasant St.; 8-12, 2-5; ALR.»

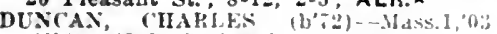
(104); $43 \mathrm{~S}$. Sprlng St.

Ereleth, Fred Shaller (b'75) H-Mass.5,99; (1'12): I88 N. Main st 1000-30,

Gallinger, Jacob H. (b37) II-X.1.9, $6 !$ (1,97)

GKAFTON, FRANK WHLARD (1)69) \&N.II.I.'9

GRAVES, ROBT. JOHN (b; 7 ) -Mass. I 03: (l'04) $3 \mathbf{S}$. State st.: oftce, $4 \mathrm{~S}$ State St, $2-3 ; \mathbf{S}$.

HASKELI, PEARI, TENNEY (bos) $€$ Me.1,93; (l'97); New Ilampshlre state Hospital; NP.*

Herrin, Herbert Fllot (b's3)-Mass.7, 10 Intern, New Hampshire State Hospital; $P$.

HLL, I.AWRESCE RIC'HIHLDSON (b" Soc.: Pleasant st. : $9-10,2-3, j-s$

Howard, Arthur Blckford (b'si)

New Iranpshlre State Ilosultal.

KERR, ROBT. BROWN (b'87)-MIass, 7,10 ; (1'I2); pembroke sanatoriun: (also offlce, Manchester) ; $T$.

KIMBALL, GEORGE' MORRIL, (v'.j) Jass.1,84; $\left(1^{*} 97\right) ; 2: 6$ N. Mast Nit.

IEET, GEO' E. (b'51)-N.H, M, ' (1'9i) 31 \&. Spring St. ; $7-8,12-2,5=7$.

MACMILLAN, ANIBREW IOULA, Jl, (b'82) -Mass.1,09; (1"13); 52 Pleitsant st offce, $29 \mathrm{~s}$. Maln St.; $9-12,2-4 ;$ (B1.5) OALR. *

MFTCALF, CARI,TON RAY (b'80)-Mast. I, 06 : (l'12): 4 N. State St.; Or.

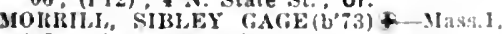
$97:(1,98) ; 65$ School St.; onled, 11 Main st. : $1: 30-3,7-8$.

NEWTOX, HTHF., \&, MTCHEL, (b) -Mass.7:03; (1'04): $50 \mathrm{~N}$. Spring St. :

NEGKNT, ARTHLl J. (1) 80$)-$ Ma! 9 (1'11): New Jampshlre state l[uciflal.

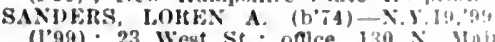
(l'99): 23 West st.: onlce, $130 \mathrm{~N}$. IInt St. $2 \cdot 2 ; \mathbf{S}$.

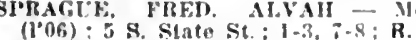

STANLYY, OMAMEL, HENKY (b'Si)-M, I. 12: 11 (3); $11 \leqslant$. State Si.

STEVENS, JANE ELIZABFTI HOIT (b'60) OBG.
STILIICS, FEItDIXANI, A. (b't9) 4

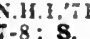

SULIFAX, DENNIS ELWAHI) (b'63) N.1.10,55; $\left(1^{\prime} 97\right)$; see. X.II. Med. Suc. $7 \mathrm{~N}$. State $\mathrm{St} ; 1-3,7-x$.

TAYLOL, FREO' BOWEIS (b'SI)-Mass. $T$ 09 ; (1'10); 14 s. State st. ; $1-3,7-8$

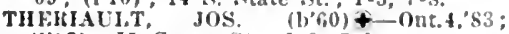
(1'9i): II Green sit. : 1-3, 7-8

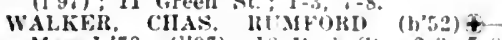
Mass.1,78; (1'9i) : is l'ar' St. ; 2-3. ;-8

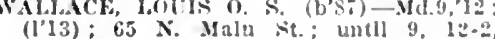
6.8 .

WATSON, IRVING MIIISON $\left(b^{2} 49\right)+$ Vt.2,'il; (1'97); sec. State Hourd of Ilealth; State House : $9-12, *-5$.

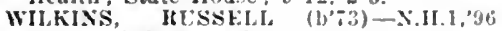
(l'97) : $149 \mathrm{X}$. Maln St.: I:30-4, $i-x$

CONTOOCOOK, 952, MERRIMACIK

IHLAISDELI, GEOITGK ('LAIKK (b'A) FMARBEIL, WALLACE HENRY (b'/l) lit.2, "0?; (1'03)

CONWAY, 3.413, CARROLL

HOKNE, H. FHANK (b'64)‡-JJ.3,93 ; (1'97); OpLR.

WIgrlu, Chester Mclean (b'\$1)-Vt.2, 06 ; (1'08).

coos, 450, coos

FYANS, FRANK WEBSTER (b'GS)-N.U.1. 98; (1'98).

DANEURY, 592, MERRIMACK

KNAP?, LEE; VIC'TOR (b'66)-JI.4, 9 : (1'96)"

\section{DEERFIELD, 917, ROCKINGHAM}

TOWLF, GEO. IIEXKY (b'39)-Me.1,'65: (l'00)

DERRY, 5,123, ROCKINGHAM

Barker, Blanche Hayes (b'-if)-Mass.;, 01

BAIKEK, KALPH HIGGIS (b'

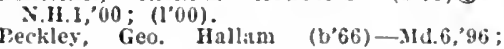
(1'9i)'.

CHAHEST, JOS CHAS, HENONI (b'63)Que.2,'90; (1'97).

COLSWFLL, SAII, JOHXSON (b'/s)Vt. 2,'97; (1"97)

DEAKBOR'N, I.UTHFR GOILD, JR. $\left(b^{\prime}, 6\right) \mp$ -Mass.i, 04; (I'05) ; OALR

PEIKINS, FHANK is (b'56)-X.H.I, 77 (1'97).

\section{DERRY VILLAGE}

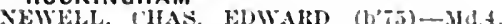
06: (1,06).

Sanders, Waiter R. (b'62) F-lll.s,'st; (l'97).

DOVER, 13,247, STRAFFORD

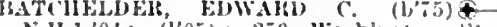
N.HI.1,04; (l'05); 250 Washlugton st. ostce, Irasonie Temple: $2-4,7-8$.

bennet, louland Jos. (b'89)-Me.1,12 ; (1'12): 31 Belknap st

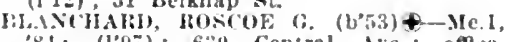
' 4 ; (1.97); $6 \% 0$ Central Ave; oflle, Masonic Temple: $2-4, i-5$.

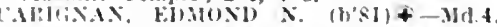
10; (1'10); 31 Atk!nson St.; oftice, I1

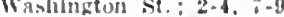

'HAPMAN, EVEHETT LEON (b'B)-Y?.2 10: (l'12): i2 Ilack kiver sit: onlee. Masonle Temple: untl] $4,2-4,7-3 ; \mathrm{S}$.

('IESLEY, IIAH OSCAIt (b:71)-X.H.1. "as; (I'9s) : 23. thh sto; unlce, 505 Ceniral Ave.: $1: 30-4,7-8$

Clmill. Fien. 11. $\rightarrow:(1+97)$.

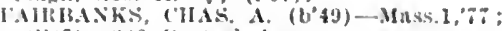
(l":i) : $\quad$ bin Central Ire

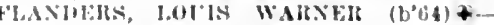
V.2, $85 ;(196)$ : 14 llamllton St. omce, Mil inulc" Temule: 9.1:-2-4; OpA.

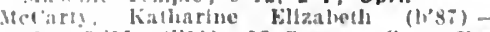
Mlas, 5, 11; (1'11): 15 summer st.: onlee, Masulle Tenuple: $9 \cdot 11,2-4,7-8$

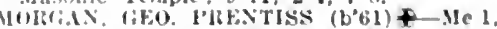

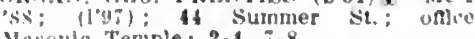

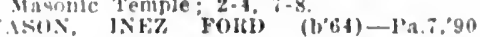
(I)i): 9 lliemllom st.; onlec. Maruble Templo: : $9.10,2 \cdot 4$

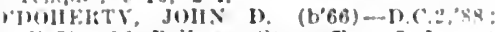
(1*07): It Relknay st. ; omce, 5 borust
I'ATTEK, JOII SALPH (L'60)-0.2,'83; (1'97)

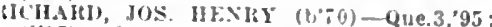
(1'97): 25,20 St. : offce, 372 C'entral HCH.MONI, AH.E. I'. (b,61) - N.Y.10

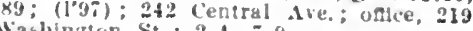

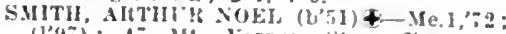
$\left(l^{\prime} y_{i}\right) ;$ ti Mt. Vernon st.; odtce, 430 Central A ve. : 2-4, $7-9$

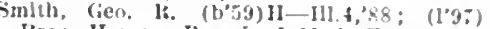
I'res. IInmen, Intard of Med. Framiners. LIAIVAN, MIAII I3. (1,3i) + N.Y.5.,80 oflce, $\$ 30$ central Ave, $2-4, i-9$.

Ont.5,08; (l'0S); $63 \mathrm{Maln}$ St.; offle Bracemell Iidg.: 2-4. $i=8$.

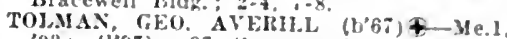
93; $\left(1^{* 97}\right)$ : 37 summer St; office, 7 Washlngton Sit; 8-9, 2-4, i-9.

DUBLIN, 57I, CHESHIRE

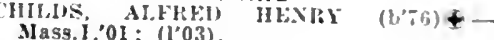
(1)

Mellus, Edward Lindon.

(STee Bronkline, Mass.)

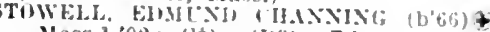
To

92: (I'03); Ob.

DURHAM, 823. STRAFFORD GIRANT, ALBERT ERNEST (b;, 3$)-$ X.H.I,

EAST ALSTEAD, 120. CHESHIRE

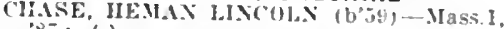

EAST ANDOVER, 350, MERRIMACK

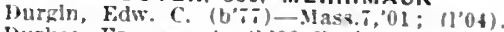

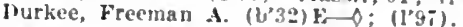

EAST JAFFREY, 1,7\$1, CHESHIRE

Hatch, I.awrence B. (1)'- 8$)-$ N.II.I, 01 (l'03)

Sweeney, Fredk. C. (1272)-15t.2.95; (1'97).

EAST ROCHESTER, 1,000, STRAFFORD

B.ATES, JOHN H. (b'\%)-Me.1.'49; (1'01)

EAST WEARE, 325 , HILLSBORO

HATON, FRAXK (b'5i)-X.H.1, '

EFFINGHAM 558, CARROLL

Lenvit, James M. (b'ì)-Me.1;is; (1'9s)

ENFIELD, I,448, GRAFTON

GISTIX, WILTFIR SEBHE (b't) - Vt.2. Iamb, Zenan F Member Vt. State Med. Soc

ENFIELD CENTER, 6I8. GRAFTON

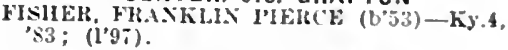

EPPING, 1,649. ROCKINGHAM

BESWELI, M.BEITT CLRRIER (b'J3)-

MTCHELL, ABRAM WHTTEMOIE (b'62)

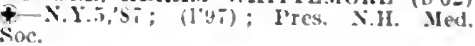

EPSOM. 725. MERRIMACK

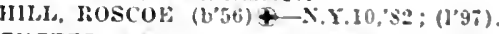

EXETER. 4.897. ROCKINGHAM

CHFSLYY, ALI'E, MAL'W MAliY (b'61) \&

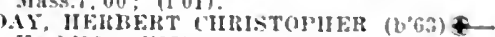
hy $\left.2.96:\left(1^{\prime} 9\right)^{\circ}\right)$

Krisistox, Wir. 13. $(6,70)+-M e .1,95$; (l'01)

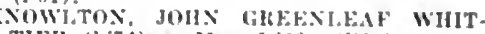
TIEI $\left(b^{\prime} 64\right)+$ Mass $10^{\circ}(00)\left(10^{\circ} 04\right)$

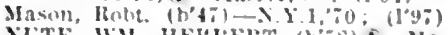

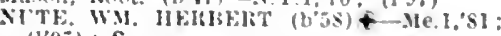
$(197) ; \mathrm{S}$.

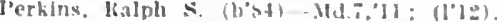

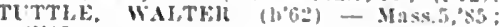
(l:0i).

FARMINGTON, 2.62I, STRAFFORD

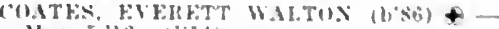

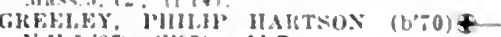
N.11.1,9\%: (1.61\%): ALR.

Huntress. Fucone $(1,99)-9 ;(1,97)$

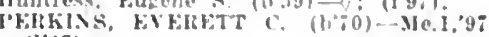
(1'9\%).

logilits
(l'no)

FITZWILLIAM, J,I48, CHESHIRE

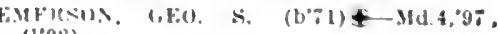
$\left(1^{*} 08\right)$. 
FRANCESTOWN, 602, HILLSBORO

siterens, Edwh learborn (1,65) $11-.1$ ass. 5 , , $95 ;$; ( ( 9297$)$

FRANCONIA, 504, GRAFTON

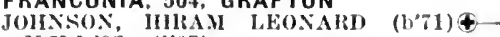
Y.H.1,'97; (1'97).

FRANKLIN, 6,132, MERRIMACK

Adans, Chas. W1. (b'63)II-Mass.5,' 84 ; (I'97).

BAKEMAN, FRAXCIS ALBERT (b'65)N.11.1,01; (1'02)

Barney, Jenule Saruh (b'6I)-Mass.5,96; (l'97)'

BEATON, MLXANUIE AXGUS $(1,72) \oplus-$ N.II.I, $98 ;\left(1^{*} 97\right)$.

CIIII), IIOWAL1, TENSYSON (b'84) \&I'a.z, 09 ; (1'12) : NP

DRAKE, WKVIN TIIIYKR (b57)-N.Y.5, 84; (1'97).

IONES, SETII w (l'6.1)-IId.1.94: (l’97)

Lataci, Alphonse (b'82)-Que.3,'09; (l'11)

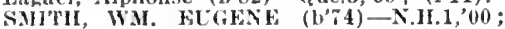
(l'01).

WOODMAN, JAMFS B. (b'79)-X.Ir.1,03; (l'03).

FREEDOM, 542, CARROLL

Iarmon, Melvin A. (b'54)-Me.1, 79 ; (1'13)

FREMONT, 622, ROCKINGHAM

LOWE, ERNES'T WIITTIER (b'75) -M-Md.4, $98 ;(1,98)$.

FT. CONSTITUTION (NEWCASTLE P.O.), CULILN, CIIAS. IV. $\left(b^{\prime}, 6\right) \Theta-0.1,00$; Ist Lleut., M.R.C., U.S.A.

GILMANTON, 968, BELKNAP

Iackenzle, Nicholas loung Bradford-N.H.1, 01; (1'04).

GILMANTON IRON WORKS, 560, BELKNAP

BAIIARD, CIARENCE PRESSEY (b' $\tau)-$

N.II.1,00; (1'00).

GILSUM, 470, CHESHIRE

HUBBARD, OSMON HUNTLEX (b'62)Que.1,88; (I'88); Member Mass. Med.

Williams, Harry Geo. (b'84)-Vt.2,'06; (l'08). GLEN, 130, CARROLL

Sweetland, Genevieve Gustin (b'79)-r'a.7, 03; (1'12).

GLENCLIFF, 50, GRAFTON

WISE, JOII MAGEL (b'i6) - X.Y.6,0耳;

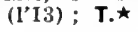

GOFFSTOWN, 2.579 , HILLSBORO

BLAISDELL, FRANK (b'52)@-N.H.1, 7 ;

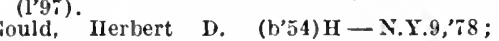

Gould, Herbert D. (b'54) H - N.Y.9, 78 ;

Marden, Albert Lewis (b'49)-N.H.1,74; (l'97)'

MILLIKEN, CLARENCE W. (b'66)-X.H.1 95 ; (l'03)

STARK, MAVRICE ALRERT (b'74)†N.I1.1,97; $(1 ' 98)$.

GORHAM, 2,155, COOS

Bryant, Hamnibal IIamlin, Jr. (b'83)-Me.1

MARBLE, II INRY (b'48)-MIe.1,70; (l’97).

IICHARDSON, BERT LEOX (b'78)-Yt.2 02 ; (1'03).

GRAFTON, 641, GRAFTON

Manchester, Frank Constant- N.H.1,'85 (1'99).

GRASMERE, 400, HILLSBORO

SWE'T, EDDY BENJ. (b'6i)-MISS.1,'89 (l'97).

GREENFIELD, 574, HILLSBORO

CHEEVER, NA'THANIEL F. $\left(b^{\prime} 56\right) £-V^{\prime} .2$ $83 ;(1 ' 97)$.

GREENLAND, 575, ROCKINGHAM

MCLACHLAN, DONALD CATTANACH $\left(b^{\prime} 78\right)$ Que.I,'04; (1'05).

GREENVILLE, 1,374, HILLSBORO

PEASE, BYRON DOCGLAS' (b'61) †-Vt.2 '87; (1'97).

Potvin, Victor F. (b'85)-Que.3,09; (l'10). Roy. Jos. Edmund Egide (b'53)-Ont.4,80; (1'97).

GROVETON, 1.880, COOS

BROWN, ELAIER F. (b'68)屯-MI.4,'97 : (1'97).

HIGH'T, CLARENCE ELGENE (b'T4)-Me.1 O'BRION, CHAS. CARROLL (b'49)-Me.1, '81; (1'9T)
HAMPSTEAD. 796, ROCKINGHAM

Al,LE, WALTEL ALGENO $\left(b^{\prime} 69\right) \oplus-$ N.I1.1,93; (1'97)

IAKE, EIAIEI GLSWORTI (b'64)-YK.2, ?): (l'00).

HAMPTON, 1,215, ROCKINGHAM

Iack, Wm. B. (b'52)-N.II.1,78; (l'si). Sinlth, Marril Fisher (b'52)-N.Il.1,83; $\left(\mathrm{l}^{2} \mathrm{9}\right)$.

TIIOMISON, EDWAR1) HENIRY (b'62)Y.11.1,96; (1.97)

Ward, Stauley ir. (b'59)-1'a.2,82; (1'97).

HANCOCK, 6+2, HILLSBORO

IRICHARIS, CAROLINE MARIA-Mass.6, 93 ; Nember Mass. Med. Soc.

HANOVEP, 2,075, GRAFTON

IBartlett, Hdwlu Julius (b'51)-111.1,79; not In practice; I'rof. Chem., N.II.I

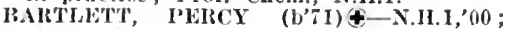
(1'04); S.

Blood, Robt. Oscar (b'87)-N.11.1,'13; (l'13).

BOWLEL, JOIIN WH. (b'65)థ-N.H.1, 06 ; (l'07)

CARLETON, ELMER IIOWARD (b'68) N.II.1,97; $(1,97)$; (1315); ALR. $\star$

'leasby, Ifoward Wiffred (b'92)-N.H.1,'13;

Mary Hitcheoek Hospltal; $\mathbf{S}$.

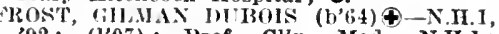
92 ; (1'07); I'rof. Clin. Med., N.H.I (Fi) ; $\mathbf{O b}$.

(l,07) IOHN MAR'TIN (b'04) - N.H.1,91; (1'97); Dean and Prof. Clin. Surg.

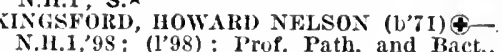
N.H.1.; (12) ; LD. $\star$

Lord, Fred. Pomeroy (b'76)-N.H.1, 03 not In practice; Prof. Allat., N.H.I.

Medlar, Edgar Matthias (b'87)-Mass. I,'I3; ( ).

Sterens, Saml. E. (b'59)-ra.1,70; (l'00) Virlan, W'm. James (b'84)-N.H.1,'12; (1'12)

HAVERHILL, 3.498 , GRAFTON

STEARNS, HENR $X$ C. $\left(b^{\prime} 66\right) \oplus-N .11 .1,96$; $\left(l^{\prime} 97\right)$.

HEN NIKER, 1,395, MERRIMACIK

COLE, CHENEY ISAAC (b'65)-MI.4,'96 (1'97) SANBOKN, GEO. HOITT $\left(\mathrm{b}^{\prime} 54\right) \Theta-M e .1$,

HILL, 556, MERRIMACK

Fowler, Fred A. (b'69)-Vt.2,'99; $\left(l^{\prime} 00\right)$

HILLSBORO, 2,168, HILLSBORO

Abboti, Chas. Benj.-N.H.1,'02; (l'02)

BAIIEY, FEO. SAML. (b'68)థ-ilass.6, 99 ; (1'06).

Goodell, John (b'29)-N.Y.1,59: (l'97)

KEISO, WALTER LAMSON (b'72) -Vt. 05; (1'06).

easlee, Benj. D. (b'57)-0.13,'85; (I'97); OpA.

HILLSBORO BRIDGE (HILLSBORO P.O.), I,500 HILLSBORO

GRINES, WARREN

PARKER (b'68) -

HINSDALE, I,673, CHESHIRE

BROWX, HUBERT LESLIE $\left(b^{\prime} 75\right) \oplus-M d .4$ 03 ; (l'03).

GRAY, CHAS. A. (b'46)-N.Y.10,69; (l'08) LACHAINE, EDMOND (b'7) $€$ Que.3, 04 (l'0T).

HOLLIS, 935, HILLSBORO

HAZARD, GEO. S. (b'66)-Md.3,'90; (l'97).

HOOKSET, I,528, MERRIMACK

TOGLS, LEOPOLD THEODORE $\left(b^{\prime} 80\right) \oplus$ Yt.2,'09; (l'09)

HOPKINTON, I,578, MERRIMACK

FLANDEKS, MARIETTA E. M. (b'60)Mass. 6,'94; (l'97).

HUDSON, I,344, HILLSBORO

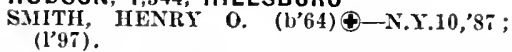

JEFFERSON，1,06I, COOS

ALDRICH, LEWIS CLARENCE (b'79)థMd.9,'02; (1'04)

KEARSARGE, 100, CARROLL

Smith, Ella G.-MIass.5,'s4; not in practice.

KEENE, 10,068, CHESHIRE

Coles, Ruth B. (b'80)-Mass.5,'04; (1'13)

Coles, Wm. Wharton (b'76)-Mass.5, 04 ; (1'13); NP.A

Davey, Harry E. (b'84)-Mass.5,'13 ; (I'14) ; 75 ivinter $\mathrm{St}$.

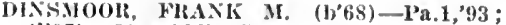
(1'97); 29 Mllddle St. ; 1-3, 6-8.

DLNSMOOK, SILAS M.' (b'36) --D.C.1,60; (l'95) ; 21 Summer $s t$; $2-4,6-8$

AULKN WR, HEHBERT KIMHALL (b'59) Mass. 1,'85; (1'97); 78 West St. : 1-3, 7-8. Flagg, Geo. W. (b'48) H-N.Y.9,74; (1'97); not in practlce: 31 West $\mathrm{St}$.

II SYIAND, EVERAL C. $\left(b^{\prime} T T\right) \oplus-N . Y .3$, HILI, GAIRDNER C. (b'29)৫-Vt.1,56; (1'97); 17 Winter St. ; untll 9, 12-3.

HOLMES, ROB'T. WARD (b'82)-D.C.1,'07 (1'12)

LOVELAND, ISRAEL ALBERT (b'50) $\theta-$ N.H.1, $75 ;\left(1^{\prime} 97\right) ; 49$ Central Sq.

Massicotte, L. C. I'hlllye $\left(b^{\prime}, 58\right)-111.8,90$ : (1’97) : 22 Roxbury St. ; $12-3,6-9$

OSTERIIOUT, JOIIN JA('OB (b'76)-N.Y.3 $98 ;\left(l^{\prime} 00\right)$; 52 Washington St.

'R.AT'TE, ARTHUR A. (b'69) $₫$-Que.3,'93

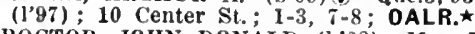

PROCTOR, JOHN DONALD (b'68) - Mass.7, 97 ; (1'98); 61 Winter St.; I-3, $i-8$.

PROU'TY, HRA JOSLIN (b'57)€-N.Y.5,'82 ; (l'97) ; 81 Court St. ; 1-3.

Robb, Wm. Mattluews (b'71) - Md ${ }^{\prime} \cdot 9 \tau$ (1'97); 573 West St.; offlce, 17 Central $S_{\text {II. } ; ~} 9-9: 30,2-4,7-8$

TAFT, ALBER'T A'THERTON (b'67)-N.H.1, 95: (1'97); Menller Mass. Med. Soc.; 56 Court St. ; 2-4, 7-8.

TIGIIE, ELEANOR MARIE (b'84)-Mass.7. 07: (1'11): I08 IIoward St: offlee, 51 Iain St. ; 2-4, 7-8; Pd.

TRACY, EDW. ANDREW (b'76)-Que.1, 02 ; (1’03) ; 54 School St. ; 1-3, 7-8:30.

WAlKER, (HAS. SIDNEY (b'70) $4-$ N.H.1 '01 : (]'01) : 39 Yernon St. ; ]-3, 7-8:30.

WESTON, ARTHUR FRANCIS (b'72) Mass.5,03; (l’06); 53 summer st.; 2-4

Worcester, Frank J. (b'52) H-H1.4,'87 (l'97); 75 Winter St.

\section{KINGSTON, I,0I5, ROCKINGHAM}

Joyce, Chas. P. F. (b'66)-N.H.1,'93; (1'98).

SWRENY, HENRY L. (b'58) 4-Mass.1,82; (1'97).

LACONIA, 10,183, BELKNAP

ABBOTT, ALFRED WELLS (b'42)-N.H.1, '08; (l'97).

ABBÓT'T, CLIFTON SMFTH (b'71)\$N.H.1,'94; (l'97); 8 Academy St.; offce. 538 Maln St.; $11-2,7-8 ; S$.

BAKER, BENJ. WARD (b'74)-N.H.1,98; (l’98); New Hampshire School for FeebleMinded.

BECKFORD, HENRY SHEDD $\left(b^{\prime} 74\right)-$ N.H.1,99; (1'99); 102 Church St.; until 9 , $12-2,5: 30-7: 30$.

BROWN, LESTER RUPERT (b'74) Ecec. Board Med. Examiners; 420 Main St. ; 12-2, $6: 30-7: 30$ 04; (l'04); 75 Franklin St.; office, 106 Beacon St. ; $1-2,7-8$.

IBRRIMAN, ALPHA HAVEN (b57)థMe.1,83; (1'97); 778 Main St.; office, 440 Main St.; $1-2 ; \mathrm{S}$.

HOYT, PARK ROWE (b'81)€-N.H.1,'06 ; (l'08) ; 16 Lyman St. ; (offlce, Lakeport). LA FRANCF, ALBERT JOS. ( $\left.b^{\prime}, 2\right) \ddagger-M e .1$, 96 ; (1'00); 63 Church St.; 8-9, 1-3, $7-8$;

Normandin, Alphonse-Md.6,95; (l'12).

NORMANDIN, ARMAND-Que.3,'11; (I'12)

POWELL, MAUD AGATII (b'74)-Pa.7, 06; (1'08); Member Mass. Med. Soc.; 127 Union Áre.

TRUE, WAL'TER H. $\left(b^{\prime} 66\right) \oplus-0.2,91$; (l'97) ; 642 Main St.

Wley, Maurice G. (b'70)-NId.8,'94; (1'97); 1 Is Court St. ; 8-9, 1-3, 7-8

Wiley, Rebecea W. (b'48) H-Mass.5,'82 : (I'97).

LAKEPORT, 3,185, BELKNAP

HODGDON, EDWIN P. (b'67) ९-Vt.2,'91;

HOY'T, PARK ROWE.

(See Laconia.)

UIMBY, JOHN GRANT (b'62)-Me.1,'88; (1'97).

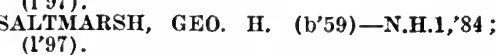

Wrisley, John A. (b’ร6)-Pa.9,'81; (1’97). 
LANCASTER, 3,054, COOS

CAMPENTEL, HALKY B. (b'zl)-N.Y.10, "4s: : I 4 ): OALR. *

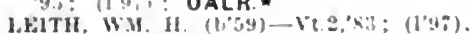

l'RATT, HAKlil s. (b't)-X.11, (1'99).

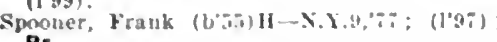
Pr.

Snith, llomer lirandel (b'ä)-Miss.1.03

Stockwell, Emmonx Franklln ( $\because 0:(197)$

TOWX, Frixcls L. $\left(b^{\prime} 36\right)+-X .11 .1,60$

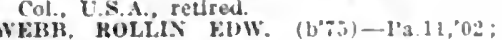
(I'03).

LEBANON, 5,718, GRAFTON

Brockwas, Dsul. G. (b'ti) - X.Y.5, i? Brockwas,

CHASE, DANI, KOKT. (1):9)\$-X.II.1,05;

DEAN, ELMER ELLSWORTII $\left(b^{\prime} 61\right) \uparrow$ Vi..,'88; ( I'97).

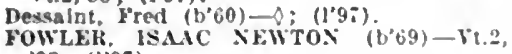
$93 ;(1,97)$.

IIazelton, Robt. H. (b'68)11- I11.4, 9.5 (1'98).

Powers. James Jos. (b'88) - N.II.1,'13

SMITH, FRANK A. (b'55) \&-N.Y.1,'81;

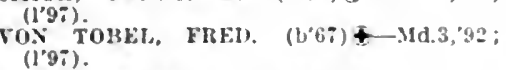

LEMPSTER, 383, SULLIVAN

CLAKK, WH. E. (b',

LINCOLN, 1,278. GRAFTON

BUITT, EDW: DANL. (b'71)£-Md., 00 ; (l'00).

LISBON, 2,460, GRAFTON

BOINTOS, HAHE HOLLISTER (b'9)Md.4,93: (1'97).

CROSSMAX, EDGidR o. (b'64) +-Vh2,5: (1'97).

Shattuck, fieo. W: (b'61) - V't.2,'S8; (1'97).

SIEAR, FRANKLIX E. - VI.2,03; (1'06).

LITTLETON, \$.069, GRAFTON

Brown, winfred Oren (b'80)-Colo.3,02 ; (I'12):

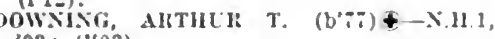
03: ( 1 '03).

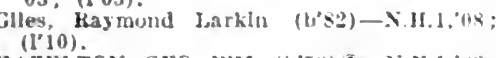

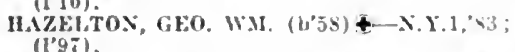

McFREGOR, REFO WHLITI $(6,53) \pm$ X.11.1,78; $(1997)$.

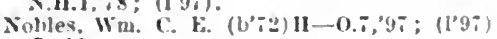
OpAL.

Page, lkenj. F. (b'43)-Vi.2, $6 i$ : (1'0i).

HAGF, JOII, MARSHAIL (b'i i) - Vt:? $(1,97): 5$,

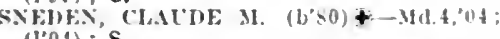
(1'0t); S.

LONDONDERRY, 1.533, ROCKINGHAM

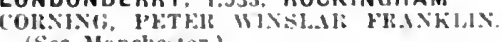
(See Janchester.)

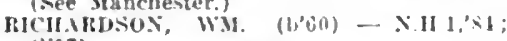
(1'9\%).

\section{LONG ISLAND, 30. CARROLL}

Greene, Jared Alonzo

(See Hoston, Ways.

LOUDON, 838, MERRIMACK

MITHKIL, WM. H.IIVE) (b'GS)-XIII, "93. (1"yi)

LYME, 1,007, GRAFTON

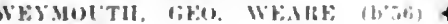
X.1I.1, $\mathrm{X}:$; (I'9:)

MADISON, 507. CARROLL

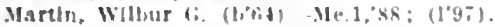

MANCHESTER, 70,063, HILLSBORO

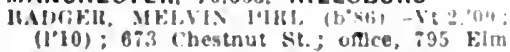
St. 2-4. i-s.311: ObG.

(1.04) ; 449 leech St. ; 2-4, i-9.

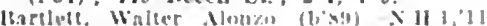

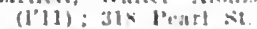

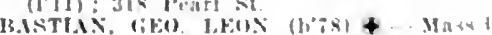

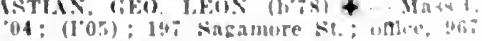
Eimi st. : 2-4:30, -19: S.

Hemett, Honry Wells Xewell (b":i) -

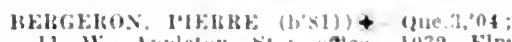
11. W. Mppletun

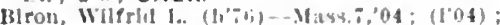

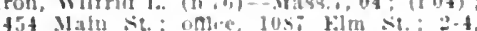
\pm .4
7.9.

Hlack, [tennis I. (b's?)-X.H.1,'10); (1"10) $96.3 \mathrm{k} / \mathrm{m}=\mathrm{t}$.

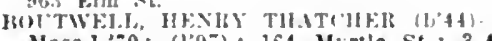
Mass. 1,70; (1"97); 164 Mgrte st.; $3-4$

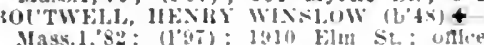
Mass.1,82; (1"5i) ; 13]0

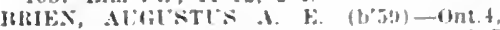

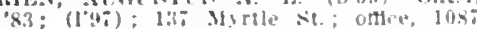
Fini

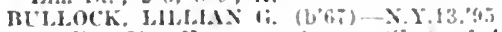

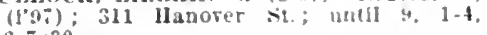
$6=1: 30$

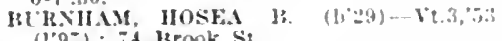
(1) 1 (1)

196 Belmont St: offce, 1037 Eim St 2.4 i. 9

CARI'ENTEK, IRVINC; J. (1, (ib)-Mass.1. 90; (1'97); 1458 Elm St.; unlce, 9 is Hiln St. $2-4,-8$.

IRVHILE, HFERY DE WOIFE (1'52)

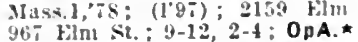

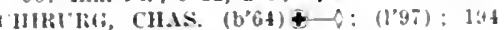
Relt St.; offce, 2\$1 Central sit.; 10-11,

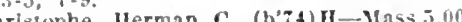
Christophe, Herman $C$. $\left(b^{\prime}+\mathbf{f}\right) \mathbf{H} \rightarrow$ Mass.o, (100); 106 Jiodset

ite st.: 2-4, ;-s.

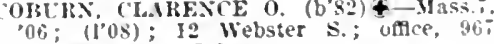
Film st.; $2-4 ; \quad i-9$

(cllity, dames Yi. (b'55) - X.1.10,79; (1'9-) -11 Pine St. : office, $970 \mathrm{kim}$ St.

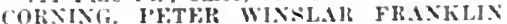
(b'72)-Md.4,06; (1'07); (Londonderry); ontue, liofts ralls.

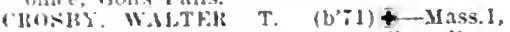

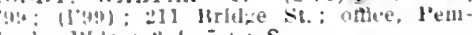
broke lindg, :-6, :-5: S.

CLIHIER, EDWARI HERYEY (b'47) X.11.1;:1; (1,4); tto Ifanchester St.:

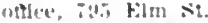

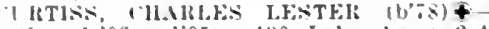
(conn.J, 03 ; (1"05); $\$ 30$ Lake die.; $2-4$,

WINFORTH, MAIY SHEFHEIRD $(1 \% 40)-$ l'il. $75: 1$ stichool st.

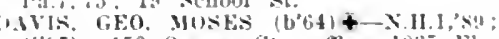
(l'yi); 156 Orange st.; ottlee, $10: 5$ rim billon. Richard Hastings (bos)-I11.11, $\left(I^{\prime} 98\right)$; offce, 913 Elm st.

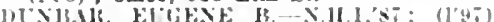

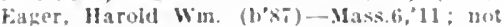
in priarlee; 911 Cnton st

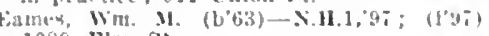
$1089 \mathrm{EIm}$ St.

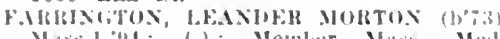
Mavis, 1, ; (); Metuler Mass. Mell.

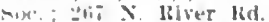

fersuson, John 11.-Ifd.t,"96; (1'97).

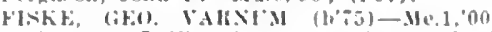

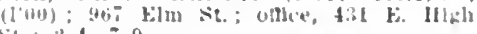
. $1 . ;=7,7-9$.

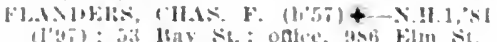

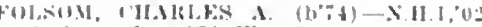

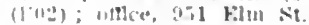

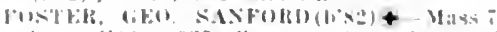

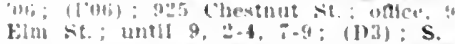

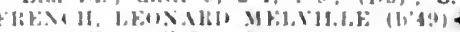

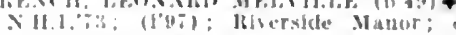

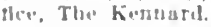

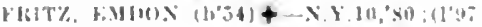

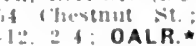

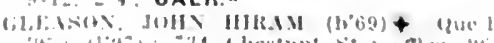

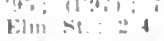

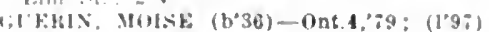

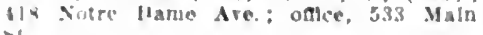

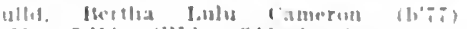

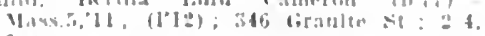

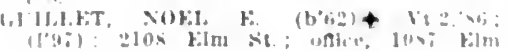

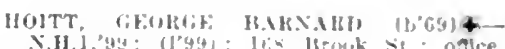

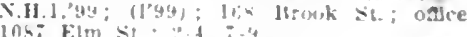

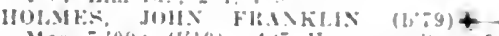

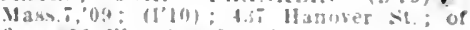

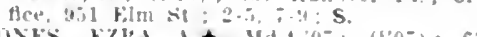

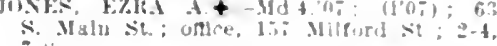

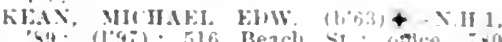

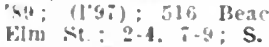

hFIIR, Briso' is

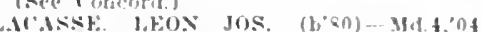
(104); 196 F. Spruce St; offce, 6.1 Elm (1.:-4, $: 5: 30 ; 0 b$

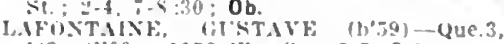

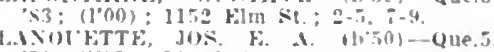
72: (195); The Helmont; 2-1. :-9: 0 b.

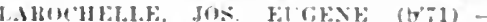
Que. 3,$347 ;\left(13^{\circ}\right) ; 412$ Sutre Dame Are.

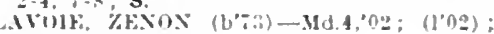
$156^{\circ}$ Hanwer $\leq 1$

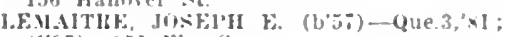

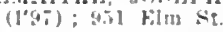

Liphthody. Win. Musvell (b'R2) -Mass.1,10 (1.12) ; $14: 0$ Film 5 .

4rox:, WM. H. A. $\left(b^{\prime} 60\right)+-M a 5 s, 1,90$ (l'y;); 200 Laured st.; oflce, ins kilo st. ; $2-4, \quad 7-9$

MACLFAY, AIFREI A. (b'6:)-Que 1,95 (1'43); $913 \mathrm{kim}$ s:

Mangurian, Armen Stevens-N.11.1,0 $(1+10): 9 \leqslant 6 \mathrm{kHm}: \mathrm{t}$

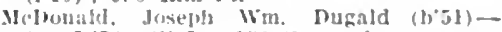
Que, $7,7 k:(1,4): 150$ loneord st.

Michon, Nicholai demetrls $(6,5)$-fireece 1.

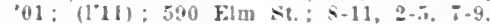

Mivlle, Enile bugal (1,85)-it.2.11 (I'11): 41 Hlodger st.; ottce, 535 Maln

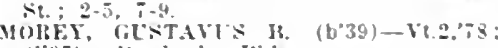
$(195)$; lembroke Ibla:

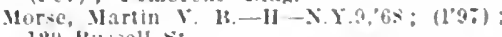
1.

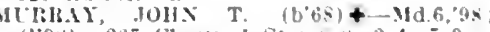
St. $-4,2-4,7-9$.

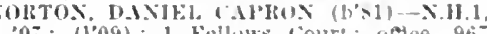
07 ; (1'09); 1 Fellows 'ourt; oftce, $90^{\circ}$ Elin st. $9-1: 2: 4: 30 ;$ OALR.

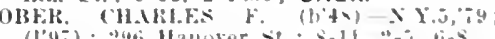

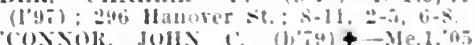
(1'03); 324 Amlierst St; otce, 1037 Elm Si. : $=4, \quad ;=4 ; s$

I'Al'ATHIPII.OS, MICHUJAS l', (b'so)t

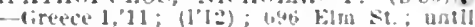
4., $-3-5,6,: 50-4 ; U$.

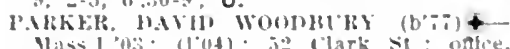

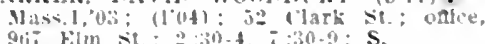

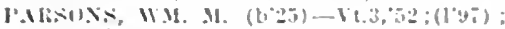
1037 kin si

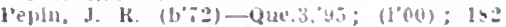
Wilsul sit: $1-4, Z-4$

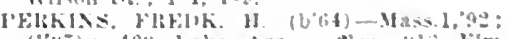

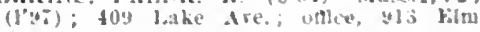

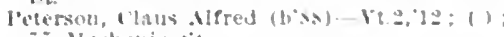

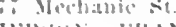

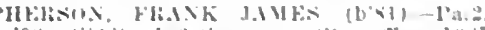

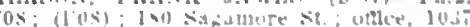
film Sit. : $-4, \quad i-4$

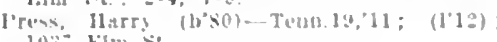
1030- Film is

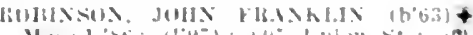

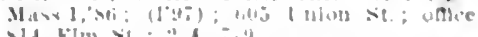

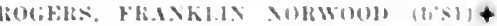
-Mass.; 05 ; $(106) ; 101 \mathrm{~N}$. Rirer Hd. unlee, 103; Film st

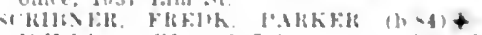

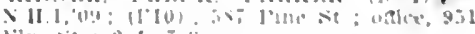
kiln :it: :-t.

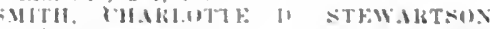
(bibi) Iaxk

i ' r.

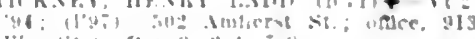

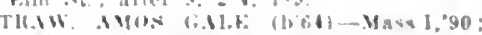

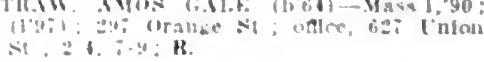


STRAW, ZATAE LONGSDORF (b'66)-l'a.7, (40): (1'97); 297 orange st. ; utflce, 627 Inion St.

Sturtevant, Chas Alton (b'75) H-Mass.5,"99 (l’04) : 176 Walnut st.; oftlec, Amosien Bank Bldg. ; 2-4.

STUR'TEVANT, CHAS B. (b'50)-N.II.1 $75 ;\left(1^{\prime} 97\right)$; 605 Belnont St.; offlec, 852 Fim St. ; 3-5.

SYLVAIN, WMIL A. (b'60)-Que.3,'83; (1'97); 70 lBlodgett st.; oltlee, 891 lin st. : $2-5,7-8$.

TAYIOI?, JONEPII $(\mathrm{l}, 60)$ \&-N.II.1, '93; (l'97): 313 franite St. TIOMISON, WLLLINGTON $\Lambda$. (b'79) $\$$ ['a. 1,03; (l'05); Member Mass. Med. Soc. 264 Milford st.; olflee, 6 X. Main St.
$2-1,7-9 ; S_{.} \star$ Todll, Arthur J.

96 i Fim St.

TOWLE, MLIRAY HANSON (b'84)-N.II.1 $09 ; \bullet(1 ' 10) ; 33$ Asll St. ; offlce, 967 Elı St $: 2-4,7=9$

TREMBLAY EVARISTE C. (b'59)-0ut.4

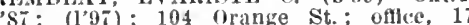
Prldge St. : $2-4.7-9$

VARICK, WM. REMSEN (b',0) $\oplus-\mathrm{N} . \mathbf{Y} .1$

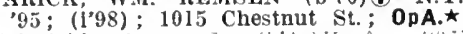

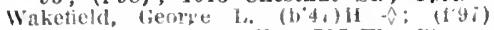
582 Chestnut St.; omce, $795 \mathrm{Elm}$ St.

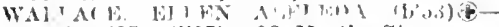
N.Y.14,85; (1'97); 93 Myrtle St.

WATSON, GEORGE M. (b'68) †-Md.4,'93 $\left(1^{\prime} 9\right)^{2} ; 17$ Oak st.; office, 10.5 Lim st. $2-4,7-9$.

WATSON, MAUIRICE (b'T4)-N.H.1, 01 $\left(l^{\prime} 01\right)$; 193 Massabesic St. ; offlce, 103 Elm st. ; 2-4, $;-9$.

WERBER, NORMAN B. (h'75)-Vt.2,03; (l'03) : 52 Nelson St, office, $961 \mathrm{Elm}$ St. after $10,2-4,7-9$

WEEIS RUFCs, WM (b'71)-Mass.5,98, Mass.6,04; (1'98); 422 Lake Ave.

WHEAT, ARTHUli F. (b'71) \$-Mass.1,'93 $\left(1^{\prime} 97\right): 1837$ Elm St. ; office, The Dunlap $2-4:$ R.

WILKINS, GEORGE C. (b'76) - -Mass.1 $99 ;\left(l^{\prime} 03\right) ; 174$ N. kirer Rd.; offlce, The Penibroke; 2-4; $S$.

MARLBORO, 1,478, CHESHIRE

AlDLICII, WAITON IIEKMAN (b'54)(N.Y.5, 80 ; (1'97).

HILDRETII, LOUIS G. (b'68)-Ky.1,'92 (1’97)

MELVIN VILLAGE, 263, CARROLL

Berry, Nathaniel Leander (b'81)-Mass.1 Berry, Nathan

Copp, Geo. W. (b'54) H- $\longrightarrow$; (l'97).

MEREDITH, I,638, BELKNAP

Borland Alexander (b'75)-Ky.2,05: (l'11) HAWKINS. FREDK. LEWIS $\left(\mathrm{b}^{\prime}(61)+\mathrm{Pa}_{2}\right.$, '86; (1'97)

Nutting, Mary A. (b'62)-Mass.6,'90; (l'97) G.

Nutting, Newell Curtls (b'59) - N.Y.8,'82 (1'97); T.

MERIDEN, 600, SULLIVAN

Huse, Ernest L.-N.H.1,'07; (l'0s)

MERRIMAGK, 1,039, HILLSBORO

GRFELEY, GUY IIAS'INGS (b'66)-Md.4 91; (1'97) ; (offlce, Thorntons Ferry).

MILAN, 924, COOS

Doughty, Horace Everett (b'73)-Md.4,'09 ; (寄).

MILFORD, 3,939, HILLSBORO

DEARBORN, DARIUS S. (b'34)-N.Y.5,'75 $(1,9 \vec{i})$.

FINER'TY, JOS. W. (b'66)-N.Y.9,'89 ; (1'97).

Hinds, Wm. H. W., Jr. (b'67)-Mass.5,95;

HUTCHINSON, HERBERT S. (b'49)N.Y.10,'S0; (1'97); G.

LOYEJOY, FRANK' H. (b'75)-N.II.1,'97; (1'9i); OALR.

PROCTOR, JOHN HARVEY $\oplus-$ N.II.1, 01 ; (l'01).

Smith, Albert Wellington (b'53) - N.H.1, $76 ;\left(1^{\prime} 97\right)$.

TAFT, EDWARD HARVEY (b'69)-N.H.1, WASON, EUGENE (b'44) - N.H.1,73 (1'97); Prof. Obst., Mass.6; 0 bG.

MILL VILLAGE, 100, SULLIVAN

JONES, FREDK. PERLEY (b'53)-N.Y.5, '78; (1'97).
MILTON, I,542, STRAFFORD

BUCKLEY, JAMES J. (b'77) - N.H.1,'00 (l'00).

IIART, MALCOLM A. II. (b'61)-N.X.5,'88 $\left(1^{2} 97\right)$

MILTON MILLS, 760, STRAFFORD

Anderson, Harry E. (h'87)-Me.1,10 ; (\$)

Weeks, Frauk S. $\left(b^{\prime} 71\right)-M d .4,96 ;\left(1^{\prime} 97\right)$.

MONT VERNON, 4I3, HILLSBORO

Corllss, Oscar Luzerne $\left(b^{\prime} 54\right)-V^{\prime} t .2,81$; (l'03).

MOULTONBORO, 783, CARROLL

LOV ERING, FILANK S. (b'61)-N.I1.1,84; (1'97).

MOUNTAINVIEW, 300, CARROLL

HOISDON, FIRVIN WILBUR (b'63) (4) 110.1,'84; (1'97).

NASHUA, 26,005, HILLSBORO

ALT.EN, IBRDFORD (b'57)థ-Mass.1,'83 (1’97); 12 Auburn St. ; offlce, 9 Main St. $2-4,7-9$.

ANTIIOINE, ISAIAII GILMAN (b"46) Masonic Temple; $2-4 ; 7-8: 30$.

ATIELTON, ELLA BLAYLOCK $\left(b^{\prime} 60\right)+$ Ont.5,'87; (1'97) ; 31 Fairmount St. ; office, 148 Maln' St. ; 2-4, $i-8 ; G$.

BAIBBI'TT, CHAS. HOLTON (b'69) $\oplus$ Tenn.11,01; (1'09); 277 Main St.; 1-3; OALR. *

Benmosche, Moses (b'82)-Va.4,04; (I'12) : 260 Main St.; LD.

BIACK, JAMES STANISLAUS (b'74)N.H.1,01; (I’01) ; 24 Lake St. ; $2-4,7-9$

BROWNRIGG, ALBERT EDWARI ( $\left.b^{\prime} 72\right)$ (E:2,13): $\mathbf{N}$.

CAIN, WiL. GEO. (b'59) $\oplus$ - N.H.1,'84 (1'00); Member Mass. Med. Soc.; 33 Maln St.; office, 77 Maln St.; $2-4,7-8$.

Charest, Jos, Amidee (b'67)-Mass.7,'96 ; (1’97); 39 Kinsley St. ; 2-4, 7-9.

COYGDON, CHAS. EVERETT (b'72) N.Y.8,'96; (1'97); 30 Concord st.; office, 7 Main St. ; 2-4, 7-8

Currier, Geo. Washington-N.Y.1,'64; (l'97) not in practice.

Dansereau, Pierre E. (b'46) - Ont.4,'71; (1'97) ; 46 W. Hollis St.

Daudelin, Alfred (b'78)-MId.4,08; (l'09) : 148 Main St. ; 2-4, 7-9.

DAVIS, STILLMAN GEO. (b'86) - N.H.1, 11; (l'12); 6 Locust St. ; office, Main St. $8-9,7-8 ; \mathbf{S}$.

Dearborn, Frank Alonzo (b'57)-Mo.1,'84; (1'97) ; 2 Manchester St.

DEARBORN, SAM STARRETT $\left(\mathrm{b}^{\prime} 72\right) \oplus$ Irass.1,98; (1’98) : 6 Concord St. ; offlce, 3 Abbott St. ; $1: 30-3: 30,7-8: 30$; 's.

GRELLEY, JAIES THORNTON (b'62)(9) Id.4,91; (1'97); 2 Thayer Court; 2-4 $7-8: 30 ; 5$.

Guertin, Auguste (b'66)-Que.3,'92; (l'97) 44 Kinsley St. ; office, 135 Main St. ; 2-4, $7-9$.

Jewell, Henry Hiram (b'57) H - Ill.4,'82; (l'97) ; The Dunbarton; office, Masonic Temple; 2-4, 7-8:30.

KITTREDGE, FRANK EVERETT (b'62) Pa.1,'85; (l'97) ; 11 Concord St. ; offlce, Masonic Temple; 2-4, 7-8:30; (B3,15) ALR.

Lagace, Jos. Alfred (b'60)-Vt.2,'87; $\left(\mathrm{l}^{\prime} 97\right)$; 30 Chestnut St. ; 8-9, 2-4, 6-8.

LOCKE, EVA MAY (b'74) $4-$ Mich.1, 00 ; $\left(1^{\prime} 00\right) ; 11$ Amherst St.; 2-4, 7-8; G.

Maynard, Oswald (b'74)-Que.3,00; (l'00) ; 295 Main St.; office, 148 Main St.; 2-4,

ICLAUGHLIN, PATRICK JAMES $\left(b^{\prime} 78\right)-$ Md.4,06; (1'06); 7 Crescent St.; offlce, 115 Main St.; $2-4,7-8: 30$.

MORAN, BENJ. GEO. (b'70)-N.Y.5,'91; (1’97) ; 29 Kinsley St. ; offlce, 165 Main St. ; 2-4, 7-9; S

MULVANITY, ALBERT FRANCIS-D.C.2, 06; (1'08); 148 Main St.; 2-4, 7-9.

NUTTER, CHAS. FRANCIS (b'70)థ-Me.1, 92; (1'97); 16 Amberst St. ; 2-4, 7-8; Op.

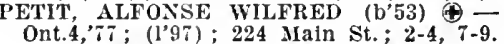
IREED, WM. EDWARD (b'77)-Mass.1,01; (l'04) : 171 Main St. ; 2-4.
ROBIINS, ELWIN DE WITT (b'59)Mich.8,'96; (1'97) ; 142 Main St.; 10-12 2-4, $7-8: 30$

ROCK, TINOTIIY FRANCIS (b'84)-Mass.7, 07 ; (1'08); 5 Spruce St.; office, 92 Main St. : 2-4, 7-9.

SIILA, AUGUSTUS WASHINGTON (b'65) †-Vt.2,'87; (1'97) ; 248 Maln St.; 2-4, Shea, Dennl

217 Maln St.

SIKORSKY, VIADIMIR N. (b'67)†-0: (197); 40 Glllis St.; offle, 148 Main St. $9-11,2-4,7-8: 30$

SMITII, IIERBERT LLEWEIIIY (b'62) Mass.I,'87; (1’97); 9 Auburn st.; offle, Goodrlch Block.

SWEENEY, MARY A. (b'83) $\$$-Mass.7,'06 (l'07) : 91 Ash St.; office, 183 Maln St.

Valcour, Chas. S. (b'72)-Md.4,'95; (l'97) ; 211 Maln St.; $2-4,7-8: 30$

WALIACE, AIONZO STEWART (b'47)ゆN.II.1,74; (1,97); 35 Orange St.; office, Masonic Temple; $2-4,7-8: 30$.

WALLACE, ARTIIUR LOWELL (b'7 7$)(\boldsymbol{\theta}$ office, Masonic Temple ; $2-4,7-8: 30$.

NEW BOSTON, 982, HILLSBORO

Dunbar, Clarence Eugene (b'88) - N.H.1,'12; (l'13).

WEAVER, CHAS. A. (b'65) $\oplus-$ Vt.2,'81; (1'97).

NEWFIELDS, 503, ROCKINGHAM

VARNEY, ALBERT H. (b'36) †-Md.4,'92 ; (1'97).

NEW HAMPTON, 821, BELKNAP

DOJLOFF, ALBERT SIMEON (b'62)థN.H.1,'91; (l'01).

NEW IPSWICH, 927, HILLSBORO

JONES, FRED. WM. (b'48)థ-N.Y.5,'81; (1'97).

NEW LONDON, 805, MERRIMACK Gardner, Guy H. (b'56)-Mass.1,'79; $\left(l^{\prime} 00\right)$. Conn. 1,00; (1'03) ; LR.

LAMSON, CHAS. AILEN (b'65)-N.H.1,'91; (1'97).

LITTLEFIELD, ANNA M. (b'59)@-Pa.7, '95; (1'97)

NEW MARKET, 3,348, ROCKINGHAM

Beaudet, Louis Phillipe $\left(\mathrm{b}^{\prime} 54\right) \longrightarrow$; (l'97).

Monge, Jos. A. (b'66)-Que.3,'97; (1'97).

MORSE, CHAS. ALFRED (b'57)-N.H.1,'82

TOWLE, GEO. H., JR. $\left(b^{*} 72\right)-V t .2,00$; (1'00).

NEWPORT, 3,765, SULLIVAN

CAIN, JOHN LEAVITT (b'58)-N.H.1,'84; (1'97).

CLAGGETT, FRED P. $\left(b^{\prime} 69\right) \oplus-$ N.H.1, 97 : (l'97).

CURRIER, DAVID M. (b'40) - N.H.1,67; (1'97) ; T.

HANAFORD, HOWARD A. (b'75) (-Md.4

LIBBY, MARY GORDON-Mass. $7, ' 98$; (1'98) not in practlce; Member Mass. Med. Soc. MARDEN, ALBION S. (b'52)-N.H.1,'83; (1'97).

Thorpe, Burton Durrell (b'86)-X.Y.1,'11 (l'12).

NEWTON, 962, ROCKINGHAM

AXTEIJ, JOHN F. (b'56) $\oplus-v \mathrm{t} .2,{ }^{\prime} 81$; (1'9T).

Gale, Walter C. (b'47)-Mass.1, 72 ; not in practice.

NORTH CONWAY, I,500, CARROLL

SHEDD, GEO. HAROLD (b'82)(-Mass.1, $10 ;(1 ' 10)$.

SHEDD, GEO. HORSLEY (b'53)@-Me.1,

SHEDD, JOHN Z. (b'61) †-Me.1,'91; (1'97) ; LR.

Snow, Saml. Dryden (b'73) - N.H.1,97 ;

(1'97)

NORTH HAMPTON, 783, ROCKINGHAM

Crosby, Wm. Pierce (b'74) - N.H.1,'98; (l'00).

NORTH HAVERHILL, 60, GRAFTON

LAWRENCE, WM. E. (b'71)థ-Md.4,'96; (1'03). 
NORTH WALPOLE (BELLOWS FALLS, VT.,P.0.), C, CHESHIRE

LEXAHA., JOHS I'. $\left(b^{\circ} 6 S\right)-V t .2,02$ : (l'03).

Ialston, Arthur Clas. -MId.t,0n: (1'07)

NORTH WEARE, 500, HILLSBORO

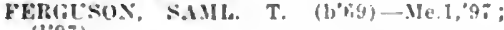
(1'97).

NORTHWOOD NARROWS, 200. ROCKING HAM

MERRH, JOHN FRANKI.IN (hos)

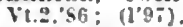

NORTHWOOD RIDGE, I30. ROCKINGHAM

HAXSON, CALEB W. (b'3:)-N.II.1,"53; (1.9i) : not in practlce.

WIITSEY, HARLAN HONEHI (D'SJ)‡ Ye. I.0S: (1'0s).

NORTH WOODSTOCK, 750. GRAFTON

MYGAT, HARIE EDWIS (b'iz)-XHI $96:(1997)$.

NOTTINGHAM, 607, ROCKINGHAM

FERSALD, FREI) (b'it) \& MI 4,00 ; ([001).

ORFORD, 799, GRAFTON

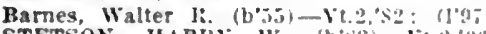

STETSOS, IIARiy w. (b (1'08).

OSSIPEE, I,354, CARROLL

ANDREWS, FZEKIEL, BF.SNLTT (1,61) Mass. 1,$\left.89 ;\left(19^{\circ}\right)^{\prime}\right)$.

PELHAM, 826, HILLSBORO

Hsde, Edward (b'46)-N.11.1,'̈s: (I'y

PENACOOK (IND. STA., CONCORD), 3,000, MERRIMACK

(See Concord.

Alexander, Anson C. (b'55) $11-$ ' (1.9i)

FARNUM, MARY 1. It. (b'0)-Mass.5,00 ; (l'01): Slember I.I. Med. Sioc.

GRAVES, ELI EDWIX $\left(0^{4}+1\right)+-1: 2,45$; $(1 \cdot 97)$.

HOLBROOK, IIENRY CAIBROLL (b':9) Y.H.1,'85; $\left(1{ }^{\prime} 97\right)$.

Rowe, Arthur James (b'68) - N.II.1,99: (l'99).

Sargent, Kilmer Ulysses (b'il)-XiJl.1,00: (i'00).

PETERBORO, 2.277, HILLSBORO

CLTLER, CIIAS, H. (b'ti)-Vt.9.92: (1.97)

Foster, Frank Brooks - H - Iass.5,'99: (l'09).

IIARRINGTON, CHAS. WOOHBLRY (bot) f N.Y.5,9: : (1'98)

Talbot, Bertell L. (b'62)-Mass.1,'96; (['9:).

PITTSFIELD, 2,222, MERRIMACK

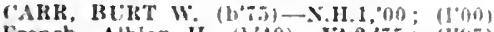

French, Albion II (b'49)-Vh.2,75; (1'95)

SAll:FNT, FR.A.N

PLAISTOW, 1,173, ROCKINGHAM

LAXDMA., EI,BEITT A. (b'i) - N H.I, 94 ; $\left(l^{\prime} 00\right)$.

PLYMOUTH, 2.200, GRAFTON

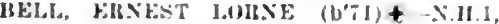
$\because 4:(1797)$

BOWLES, GFo. HALL (b'60) 一 Mass. I,93; not In practlce: Member Mass. Mel Soc

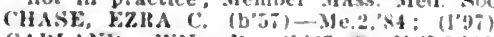

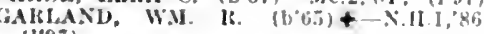
$(1.97)$.

Marston, Albert J. (b'52) E 0.2.76: (1'111) l'res. Fclectle Buard of Meal. Kiaulu.r. Muchmore, Alonzo It. $\left(b^{\prime}+0\right) \boldsymbol{k}-$ We. 2, (1,9.)

llogers. Trlstram (b*33) - Mass f

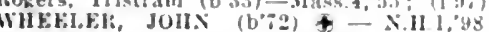
(1.28).

PORTSMOUTH, 11.269, ROCKINGHAM

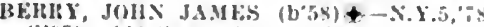

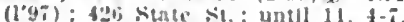

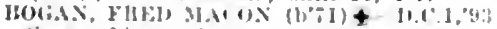

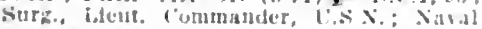
llo:jultal: $\mathrm{S}$

coules, bilw. spencer (b'79) - Va.6.07; (1'H): I: Mlddle st.: onlee. Santtarlum NP,

Dlxon, Jamca Henry (b"it) - Mo.1.98: (I'03): 173 Court st.; untli $10,2-4,6-8$

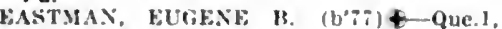
02: (1'02): 37 State sit. omlee, 47 Con gress st.; $11-12,3-1, \div 3: 30$.
MAXXAFOKI), RHAS. WM. (b'7t) -

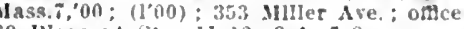
39 J'leasant st. : 11-12, 3-4, $7-8$.

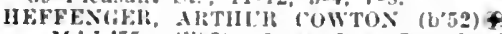
-Md.1, is; (I'0); J'res. Heg. Bonal of Med. Examlners: I'A.S., ].leut., I.s.S.: retlred: 53 Austin St.: once, 46 Congress S6. : 11-12, 3-4, 7-8: $S$.

Hlchina, Martlu Andrew (b's3) - Md.4,07 (1007): 16 I'leasant st: $11-12,2-1,7-8: 30$

Johnston, (lias. Edward (bef) -

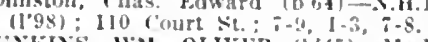

JLXKIXS, WM. OIIVER (b't5)-Me.l,'00: $\left(19^{\circ}\right): 438$ state st.: offle, 32 Congress st.: $11-12,3-4,7-9$

LAID, SAML. TII.DF $\left(b^{\prime} T\right)+-$ - .H.1,00 $\left(1^{0} 00\right) ; 49$ rongress; uneil Ii) $: 30,2-4, ;-8$.

LANCE, ARTHLR J, $\left(b^{\prime}, 0\right)+-\mathbf{v}_{t}, 2,93$; (1'08); 208 Hlghand St: ottee 15 Concress st: : $8: 30-12, \geq-4:$ OALR.

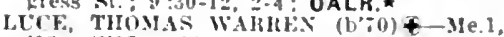
$95 ;$ (1'?:) ; 82 Court st.; 2-t.

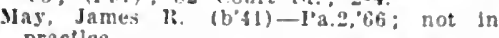
practlee.

NEAL, JOIIN HERBERT (h'ต2) $₹$ N.Y.S, $86 ;(139) ; 452$ state St.; $2-4.7-8$

PEXDER, GEO. FDWAHD $\left(\mathrm{b}^{\circ} \div 2\right)+-\mathrm{X} . \mathrm{Y} .5$ 97: (l'os); 85 Merrlinac St.; offle, Iarket St, $11-1,3-6,7-4: 30$

IIKE. FORILST WILFY (b'62)-Vt.2.90 : (1997); Member Mass. Med. Soc.; 16 Ileasaint Nt.: 9-10, I-3, †-8:30.

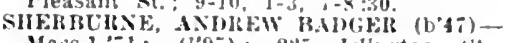
Mass.1, $1 ;$; $(19 \%) ; 2.5$ Isliugton st. ; office, $i 3$ iongress st.

SIDIs, BöIs.

(See loston.)

SOLTEl. W.I. SORWOOD (b'61)£-Md.1,

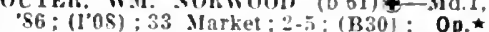

TAITOK, HERBEIT t. $\left(b^{\prime}, 6\right) \mp-1,2,02$; $\left(1^{\prime} 02\right) ; 63$ State St.; oflee, 16 I'leasant St. : $11-12,2-4,7-8: 30$

THOMAS, GIIFFITH EDWAMDS (b's2) Yard.

TOWLE, FRED S. (b'63) \&-DC 1.93 . $\left(I^{\prime} 9\right)^{\prime}$ : 350 State st.; unt]1 $9,2-4, i=8$.

WALKER, WAIIIS NTNLAl" (b'J) 4 IIass.1,01: (l'03); 349 stale St. : 3-4. $7-9 \cdot \mathrm{Pd}$

WHEELFK, LEWIS H. $\left(\mathrm{b}^{\prime}-6\right) \uparrow-$ Conn.1,97; Member Conn. State IIed. Soc.; P.A.S. Hleut., I.S.X.; Naral llospital.

Woodbury, Benj. Collins (b'82)-Mass.5, 0 i

(l'0.8); 10-1, 2-4, i-s.

WRIGHT, BAHTOX L. $\left(\mathrm{b}^{\circ} 0\right)+$-Pa.1.9: Surg., Lleut. Commander, C.s.N.: Xary

RANOOLPH, 137, COOS

'ross, Ernest Siml.

(See Alken, S.c.)

RAYMOND, 1,203, ROCKINCHAM

(i) PIJI, GEO. IIERBEHT (1'ti)-MLI '88: (1'97).

REEDS FERRY, 350, HILLSBORO

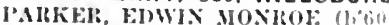
"y2: (): Member Masi Mpl.

ROCHESTER, 8.868, STRAFFORD

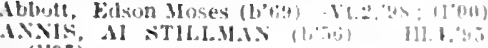
(1.97)

Blazo, ('has, (b'42) - Me 1, :1; (["4:)

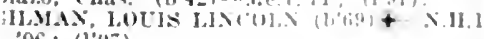
"จ6: $(1,10)$.

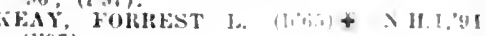
$(193)$.

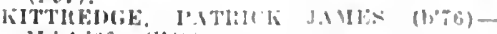

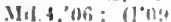

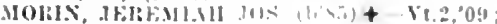
(I'I (i)

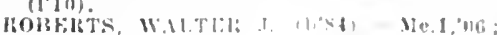
(10ख).

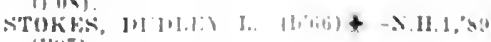
$\left.(1,4)^{2}\right)$.

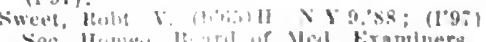

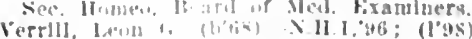

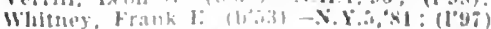

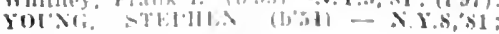
$(109)$

RUMNEY, 850, GRAFTON

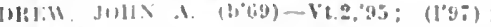
OALR.

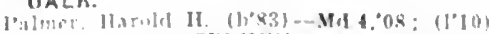

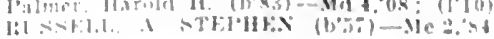

RYE, I,0I4. ROCKINGHAM

White, Herlert Augusiu (bos) -N.11.1,01: (I'01).

SALEM, 2.117, ROCKIHGHAM

1.ATON, CFO. I'F:A'Y (h'=1)+-N.C.1,09: (J'09); Jember Mash. Med

SALEM DEPOT, 650, ROCKINGHAM

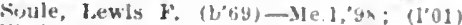

Wade, Edrlc A. (1'51)-Mas.1,ig; (1'bi)

SALMON FALLS, 1,836, STRAFFORO

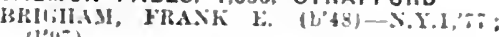
$\left(1, y_{i}\right)$.

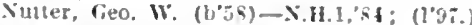

SANBORNVILLE, \$75, CARROLL

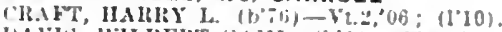
UAls, WILIBELT S.MI. (b'ti)-Me.1,"91: (l'05).

SEABROOK, 1,425, ROCKINCHAM

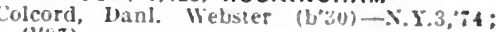
$(19 i)$.

Drurs, Forrest Jay (b'55) - Mass.5,12:

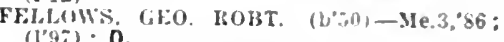

(1'9i); 0.

SNOWVILLE, 150. CARROLL

Stanley, Clas. Maurice $\left(b^{\prime} b^{\circ} b^{\circ}\right)$-Mass.6:12; retired.

SOMERSWORTH, 6.704, STRAFFORD

lherube, Ilavid Telespluore (b'si) -Md.y, I: Dot (IHEIRTY, THOs. J. (b'os) \-Md.4:94;

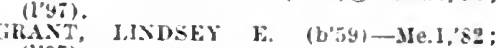
$\left.(1,9)^{\circ}\right)$.

AFI', NAPOLEON (b'ct) Que.3,90:

Mayo, Dana Bartlett (b'82)-Ma*s.5,06: (1'11).

MOHIRISON. THOS. Jos. (b's2) \&-V3,2,09: (l'10).

Situens, Chas. X. (b'49)II-IIl.4,'s0; (I'9;). SPOFFORD, 300. CHESHIRE

I3unler. John F. (b'31)-Mass. 1.jt: (1'93).

SUNAPEE. 1.071, SULLIVAN

FINIIII, EDWIX C. (b':2)-X.H.1,'s2; (1"9:).

SUNCOOK, 2.880, MERRIMACK

HII, FIDMISI EMLISON (b'ES)

Wass. 1,93: (1'97)

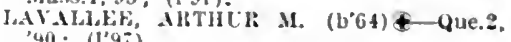

MLYSEY, GEO. F. (b०55)-X.H.1,:9; (1†).

SURRY, 213, CHESHIRE

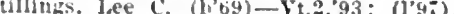

SUTTON. 698. MERRIMACK

(lougl, Wm. l'lummer $\left(b^{\circ}, 9\right)-$ X.11.1,11 (1'14)

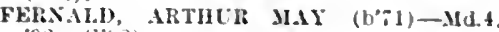

$98 ;(1,48)$.

SWANZEY, 275, CHESHIRE

B.I.COM, GEO WHANKLIS - \$.11.1,\%0: not In practee; Member Mass. Med. Soc 11OLBHOOK, tiko. (b'tit)-Vt.2,94; not in

practice; Member Vt. State Med. Sin.

TAMWORTH, 993. CARROLL

Itemlck, Fidwln (b'66)-V't.2,94; (1'9;).

THORNTONS FERRY, 184, HILLSBORO

THELFY, GLY IISTISLS.

(See Mertmack.)

TILTON, 1,866, BELKNAP

ERSKISF, JAMES BLHIINUTON (W"iJ)-

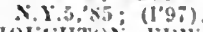

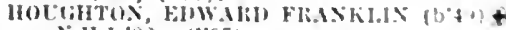
- O.11.1.'s: (1998)

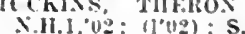

TROY, 1,331, CHESHIRE

Ilatts, llarry \&. $\left(b^{\prime}-6\right)-\times 11$ I.

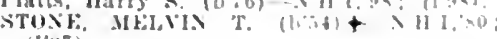
(1"10).

UNION, 375, CARROLL

Stevens, Juln . Mulrew

(I'U3)

WAKEFIELD, 1.543, CARROLL

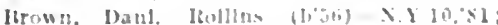
(客).

WALPOLE. 2.663. CHESHIRE

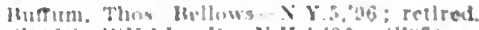

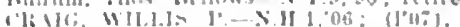

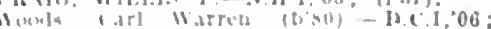




\section{WARNER, I,226, MERRIMACK}

ABBOTT, WALTER IIAKIY N.11.1,92: (1'97).

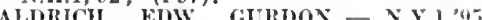
not in practlce; Member Med. Soc. of the State of N.Y.: IR.F.D. 1

Cogswell, John iR. (b'40)-X.II.1,65; 1196). COGSWELL, LLOYI HHJIRHTI (b'7y)\$-N.Y.19,'01; (l'03); Pd.

OLIVER, ROBT. F. (1,62)-Vt.2,90; (1907). WARREN, 701, GRAFTON

GEIRAIL, FHANCIS I. (b'3s)-0.2,73; (I'97); not in practlce.

WEAVHK, GEO. ALBERT $\left(\mathrm{b}^{\prime} 68\right)+-$ Conn.I, '97; (1'98).

WEBSTER (R.F.D., CONCORD), 44j, MERRIMACK

Dodge, Henry (b'63)-Vt.2,'si; (1'9:)

WENTWORTH, 595, GRAFTON

FIASER, SAML. (b'6) \&-Que.1,04; (1'04).

WEST CONCORD, - MERRIMACK

QUINN, CHAS. II. (b'73)-N.H.1,'Y8; (1'97).

WEST LEBANON, 700, GRAFTON

IRAKE, ('HAS. ISYRON (b'48)\$-N.II.I, '83; ( 1 '07).

WESTMORELAND, 275, CHESHIRE

CRAIG, JA.IIS A.-Yt.2,'85.

WEST OSSIPEE, 250, CARROLL

IOLD, IASTER WINSLOW (b'74)-MId.4, '97: (1'97).
WEST STEWARTSTOWN, 1,000, COOS

larbour, Guy Wm. (b'83)-Ky.1,'08; (l'08). Ilodrett, Joln Moody (b's0)-Ild.1,10; (\$). COOLIDGE, JOHN WESIAY (b'64)

N.H.1,OI; (l'0I); S.

WEST SWANZEY, 700, CHESHIRE

Byrues, Ambrose (i. (b'69)-Vt.2,'95; (l'9i) HORKLS, AITIUUI WARIEN (b'7)N.II.I,'03; (1'03).

WHITEFACE, 100, CARROLL

BIRYAIR, FIRED W. (b'71)-N.II.I,'94; (l'97).

WHITEFIELD, 1,635, COOS

MOKRISON, GEO. H. (b'54)屯-Pa.9,'81; (l'98).

Bondinella, Annina-Pa.7,99: (l'07).

Walker, Gertrude A.-1'a.7,92; (ま).

WARIEEN, JOIIN B. (b'7s)-N.H1.1,03; (l'03).

WIG(iIN, HENRY M. (b'67)-Mass.5,95; (1'97).

WILDER, IRICHARD F. (b'70)-N.Y.10,94; $\left(l^{\prime} 97\right)$.

WILTON, 1.490, HILLSBORO

HATCH, GEO. WINDSOR (b'55)-N.H.I,'S0 : (1'97)

IIIGGINS, CLIFFORD E. (b'57)-N.H.1,'84; (1'97).

Hice, Carrie Elizabeth-Mass.5,'00; (l'04).
WINCHESTER, 2,282, CHESHIRE KENNEY, JOIIN CLEMENT (b'59) $\$$
N.H.I,'92; (I'1I); Member Vt. State lled. Soc.

IOBDEILI, ALRAX JUDSOA (b'68)-N.Y.9, $93 ;(1,97)$

Pelree, Geo. W. (b'33)-Mass.2,'ว5 ; (l'97). WOLFEBORO, 2,224, CARROLL

BIADEORD, HKNRY WITHINGTON (b'52) †-IIass. I, 75; (l'94); Member Mass. Mted. Soc.; $(134,14) ; 0 p$.

CIOW, Frí, F. '(b'81) - Mass.I,'04.

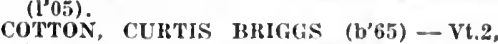
'88; (l'97); Prof. Anat., Mass.6.

GFTCIELL, STILLMAN is. (b'42)-Mass.2 65: (1'98).

SCOTT, NATIIANIEI, IIARVFY (b'51)कMe.I,'74; $\left(1^{\prime} 97\right)$.

TOBEY, FRED. CHAMBERLAIN (b'78)Mle.1,01; (l'03)

\section{WOODSVILLE, 1,750 , GRAFTON}

Dearborn, Selwyn Kenson (b'79)-N.II.1, 05;

EASTMAN, OLIVER D. (b'58) $\rightarrow-$ N.H.1,'83 ; (l'97).

GIBSON, CHAS. R. (b'53)Ð-Me.I, 75 ;

MILLER, EIMER M. (b'73)థ-Md.4,'98; (l'98); OALR.

FOR KEY TO SPECIALTIES, ABBREVIATIONS, SYMBOLS, ETC., SEE PAGE 904

Wuch more information has been incorporated herein than in any previous edition, and to save space, symbols and abbreviations have been used; it is imporlant that the reader thoroughly familiarize himself with these, as well as with the various departments of the directory.

The information is here, but much of it is available only through the use of the keys. Have yon become familiar with them? See pages 55-56. 


\section{NEW JERSEY}

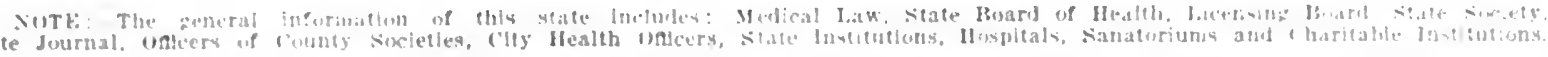

\section{NEW JERSEY}

Population (1910 census).

Number of Counties.

Number of Physicians.

Members State Sociely. Dec. 31. 1913.

Area of State in Square Miles

2.537 .167

21

3,012

1.516

8.224

\section{MEDICAL PRACTICE LAW OF NEW} JERSEY

\section{An Act}

To reculate the iractice of mediche and surgery. "w license phyilelans and surgenns. and to munish mersons ri

[Aprored May 2:2. 15:4. Thapter 306.] Anembel as bo the thlod, forurth and ninth sections, and apjrovel sprll \&, 1903. Chapter $2: 38$

Sectlon 1. APIOINTaET OF BOARD: TER3S: Be if cnicted by the senate and ceneral assembly of the state of sen Jersey, That the goreruor shall angoint, by and with the adrice and consens of the sernate. siate Board of Medical Examiners, said board to conslst of nine members. who shall be persons of recounlzed brofessional ability and honos: the terms of ufice of said hoard and honot: the terms of unce of sald that shall be three jears, or uneil thror successoss are appointed: provlded, humeser, that shall be divided lrito three clitsises. each class to constst of three persons; the thrst class shall holil offlce under sald apmint. ment for one year, the sevond for (wo sears and the thlrd for three years frum the date of their appointment, and thereafter each member shall be appolated for a term of thrce years: and yrovlded, further, that sald board shall consist of tive old-schoul ahyslclans. three fomeripathlc and one physiclans, threesinters hill, withln thirty eclectlc; said spountees thall, within thirty
days after the recospt of the rexpecture commisslons. take, subscrife and tlle in the once of the secretary of state, the wath or aftrmatlon prescribed ho law.

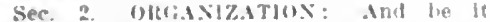
enacted, That kalil prard shall clect it president a secretary aul a treiturer from lts membership: It shalt hare a comush seal. and les presldegs whall te composered to Issue subirenas ant! to alIminluter watlis in taklno testimons in any matter iertalnIng to the dutles of salil buard: it shatl lations and by-lawy isus inrobsintert nith the laus of this atale or of the l'niferl to tranvact the husinese fedulted under the to tranvact the hustote
uroviatons of thly int

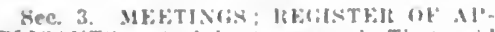
I.ICAXTs: Anit low it cracted. That sads board shall hold meetsige for cramilnations at the caplest fuilding of the state on the third Tueway of June and hetutier be each rear, and at such witur thmes and placed as

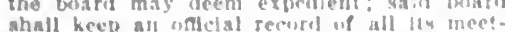
ahall kecp all "medal secorel of all tis mees:-

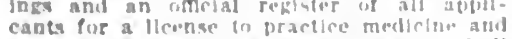
sursery in thls state: sald regituter shall nhow the nane. ace. Nitivity, last and In teniled place of rieviderice. of cacts camiluate. the IIme he or slse hite siacht in whitulne

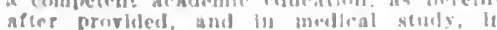
or out of melienl schroul, anil the namer and forntlon of all melleal sebuels i, examln. Ing and lerensing learde whirle hare
Granted said abslicant any degree or certlflente of attumines "n lectures on mediciue and surgery ir state elaminations: said reglster shall alse show whether sald alphliunder this act, and hul reglster shall be wrima facle eridence of all mattery theredn (ontained.

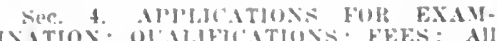

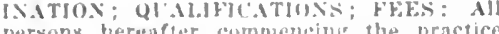
gerson. hereafter commencing the practice in this stite sloall apjly to saul forar for IIcenise so to do sajo hord yhall, except llcesise so to do. said horard uliall, except as herein otherwise profited, examino ati puallifed applicants for license on practice medicine or surkery in accurdance with the vrorlsions of this Act. Fvery asplicant for examination shall present to the secretary of sald hoard, at least ten days before thi commencement of the esamination at whlch he or she desires to be examlned, a writien appllcation for almissirn to sucti examina tlon on a form or forms lirurided by sald hoard, together with bittisaciors profof thas

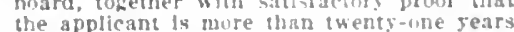
of age and of goms moral chariater. Such applicant shall also present is shill board a certifleate from the ermmisionuer of education of thly state, showing that before entering a wedical college he or ble had obtalned an academic educition conninting of a four years' course of rends in ath atbproted putilic or

Frery apolicant for addmissing for cramInation for a license to practice medicise "1r surcers shall, in addition to the above reculrenents prore to sald luarel that lo has received a diploma conferrillg the derree of doctor of medicine $\mathrm{rom}$ sume lezally in corporated medical colleze of tho lobled States, which college. In itwe arinien of hid hoard, was In good standing itt the time of the issuance of sald dimlamil, or a diblomit or license conferring the full right to prate ice all of the hratuches of molicino and surgery in some foreign countr. and fursurgery in some foreign comery. and filtdiploma from any sucll fllolical collyowe of

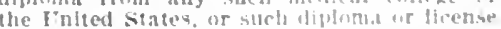
conferring the right io pratctioe metheme and surgery. as aforestid. he hizl vinlied medt. rine not leqs than funt fu!l soluowl beare.

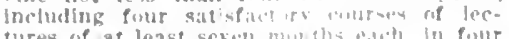

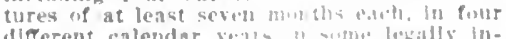
different calendar yoll m " wtme lowally in-

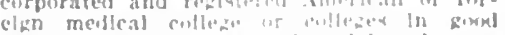

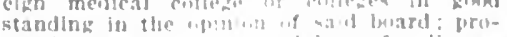

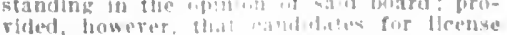

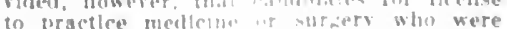

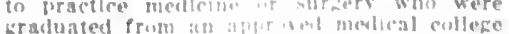

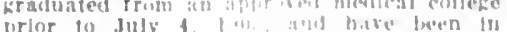

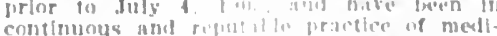
continuous and remint il le practier of medi-

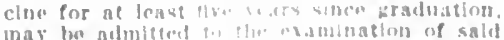

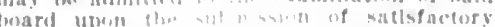
erldence of the fact that three enusat. threen fontson. dat rears. academlo ard at thit of non by the statio:

Phe In

sturle t

this

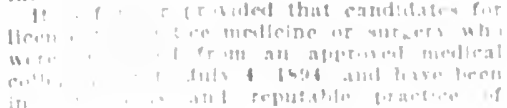

medicine since chraduatcon, nay le almulted (1) suih exanunation of this busol uimes the

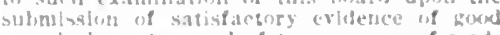
mural character, and if iwo proves of mest. Ical lectures in an aunrored medical rollece

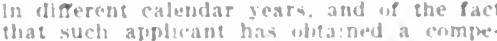
ent acadonsce exlucation aceroling to the standars at shat time as determinerl in the

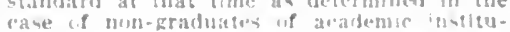

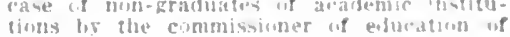

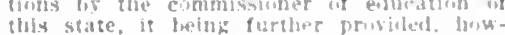
ever, that the recurts of such loitril and such licence shall state that any ituch atwlicant was licenved under the second anption cuntained in thla sectlon.

Ipon the approral of the alpulication for examinatlon. steh applleant hall depust with the treasurer rif sidd board the sum of $\$ 2.5$ as an examination foe, and shall thereupon be entitled $t)$ admission to such examination. In case sald apolleant fixils to pars the examinatlon, he mas to reexamined at the next regular examination lield ly said board without the pasment of an aldipional tee. Fach applicant stall sign h!s or her name opposite a number in a brok kept for that purpose by the secretary of said fwarl and shall nark bls or her examination paper with sald number, and shall the known number untl his or her lapers have been examinel and narked. Iny applicant for license to practice metlicine bit surqery, upon prening to the satisfaction of situ berat proring to the satisfaction of sold betart that he ls of fond moral character. amd that examluing and licensing buad if another state of the lonited stateq, and that the standarl of requirements for licenses to practice mediclne or surgary In the state where such llcense wat Eranted were at the tantialls the same as tho standard of reguirements for said licesses in force in this state at the time of sail applicaton, and state st the time of sad application, and urmen fllng wh the serretary of satd inard a coly of his llicense ar certlficate rerifed

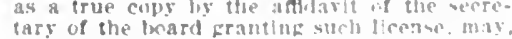
In the discretion of the sald hoard if lied. ical Examiners of thly state. he frampla a lirense to bractice medterine and suraery whout further examination upwn the lav-

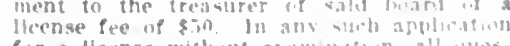

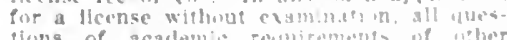

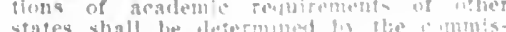

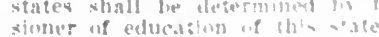

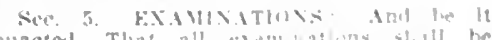

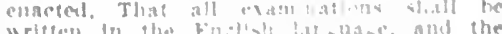

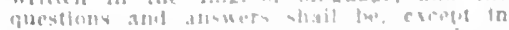

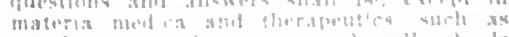

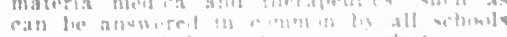
if pract:ce of the alt te ant ntends p. prace

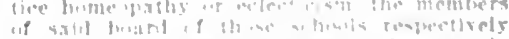

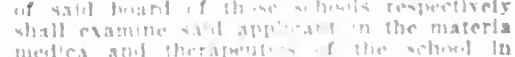

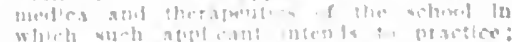

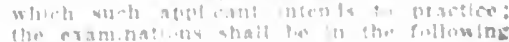

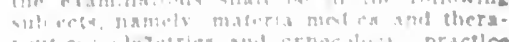

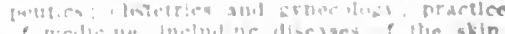

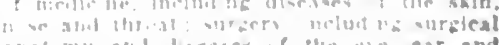

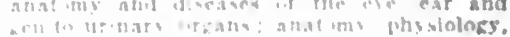

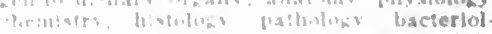

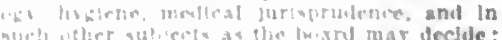

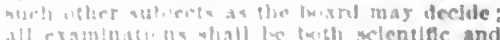

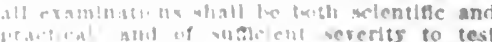

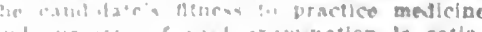

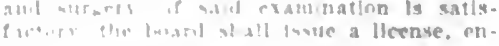




\section{AMERICAN MEDICAL DIRECTORY}

titling the abplicant to practice medicine and surgery in this state; the votes of all examiners sliall be yes or no, and written with their slgnatures upon the backs of the ex amination papers of each candlate; said application and examination papers shall be depesited in the state library, in the capitol building, and they shall be prima facle evidence of all matters therein contilined all licenses shall be signed by the presflent and secretary of the board, nnd shall be attested secretary of the boar
by the seal thereof.

Sec. 6. REFLSAl; REVOCATION: That the board may refuse to graut or may revoke a llcense for the following causes, to-wit chronle and persistent inebriety, the practice of crininal abortion, conviction of crim involving moral turpitude or for publicly ndrertising speclal ability to treat or cure chronic or incurable diseases; or where any person shall present to this board any diploma, license or certiflcate that shail have been illegally obtained, or that shall have been signed or issued unlawfully or under feen signed or issued unlawfully or under fradulent representations; in complaint for vlolating the provislons of this section a copy of the complaint, and glven a hearing before said board in person or by attorney, and any person, after such refusal or revocation of license, who shall attempt or continue the practlce of medicine, siatil be subject to the penalties hereinafter preseribed.

Sec. ‘. LICENSES FILED; FEES; $A N$ NUAL LIST: And be it enacted, That the person so receiving said license shall flle the same, or a certified copy thereof, with the clerk of the county in which he or she resides, and said clerk shall file said certificate or copy thereof and enter a memorandum thereof, giving the date of said license, with the name of the person to whom the same is issued, and the date of whom the same is issued, and the date of board and to be kept for that purpose, and for which registry the said county clerk shal be entitled to demand and reeeive from each person reglstering the sum of $\$ 1$; in case the person so licensed shall move into another county of this state, he or she shall procure from the sald clerk a certifled copy of such registration and then file the same with the clerk of the county to which he or she shall remore, and the said clerk shall fle and enter the same with like effect as if the same was an original license, and for which regstry the said clerk shall be entitled to deniand and receive the sum of $\$ 1$, and each county clerk in the counties of this state shall, upon the last day of November of each year, furnish to the secretary of said board a list of all the certificates of this board fled in his office during the previous year, and upon notice to him of the change of location or death of the person so licensed, or of the revocation of said license censed, or of the revocation of said license, said county clerk shall enter at the appropriate place in the records so kept by him a memorandum of said fact, and said memorandum shall be furnished to the secretary required.

Sec. 8. PRACIICE OF MEDICINE DEFINED : And be it enacted, That any person shall be regarded as practicing medicine or surgery within the meaning of this Act who shall use the words or letters "Dr." "Doctor," "Professor," "M.D.," or "M.B." in connection with his or her name, or any other title intending to imply or designate him or her as a practitioner of medicine surgery in any of its branches, and who in connection with such title or titles or without the use of such titles, shall prescribe direct, recommend, advise, apply, gire or sell, for the use of any person or persons, any drug or medicine or other agency or application for the treatment, cure or relief of any bodily injury, infirmity or disease; and it is further prorided, that the use of any one of the aforementioned titles or the exposure of a sign, circular, adrertisement or any other device or information, indicating thereby the occupation of the person or persons, shall be considered prima facie evi- dence: and it is further provided, that the provisions of this act shall apply to all persons professing and attempting to cure discases by means of the so-called systems of "futh-curism," "mind-healing," "layingon-of-hands" and other similar systems.

sec. 9. To WHOM NOT APl'lliso: And be it enacted, That this Act shall not apply to the commissioned surgeons of the United States Army, Navy or Public Health Service while so commissioned, or to lawfully qualifled physiefans or surgeons residing in other states meeting registered physicians and surreons of this state in consultation, or to any legally qualitled physician or surgeon of another state taking charge of the practice of a legilly qualltled physician or surgeon of this state tempormrily during the latter's absence therefrom and upon the written requests to sald board therefor, or to any bhysician or surgeon of another state, and physict practice medicine and surgery therein; provided, that such practltioner shall not open all offlce or a place for the practice of his profession withln the borders of thls state or to anyone whlle actually serving as a member of the resldent medical stafr of any legally incorporated charitable or municipal hospital or asylum, or to any legally qualifled and registered dentist exclusively engaged in practicing the art of dentistry, or to any person claining the right to practice medicine and surgery in this state who has been practicing therein sfuce before the fourth day of July, 1890; provided, said right or tltle was obtained upon a duly recistered diploma, of which the holder and applicant was the lawful possessor, issued by a legally chartered inedical institution which. in the opinion of said board, was in good standing at the time said diploma was issued; or to any person resident of tbis state who has been continuously engaged In giving treatment by electricity herein during the past fourteen years; provided, that said person has graduated trom a legally incorporated electrotherapeutic school in good standing, or to any legally licensed and registered pharmacist of this state actually engaged in the practice of his profession, but this exception shall not be extended so as to gire said licensed pharmacist the right and authority to carry on the business of a dispensary, unless said dispensary shall be in charge of a legally licensed and registered physician and surgeon of this state; or to any legally licensed and registered veterinary physician, surgeon or dentist of this state engaged in the practice of veterinary medicine, surgery or dentistry in any of its branches; or to any professional nurse, masseur or electrician, operating in each particular case under the specific direction of a regularly licensed physician or surgeon; or to any person or persons giving aid, assistance or relief in emergency or accident cases pending the arrival of a regularly licensed physician and surgeon.

Sec. 10. VIOLATION; PENALTIES : And be it enacted, That any person hereafter commencing or continuing the practice of medicine and surgery in any of its branches in this state without first haring obtained and filed the license herein provided for or contrary to the provisions of this Act, shall be deemed guilty of a misdemeanor, and upon conviction thereof shall be punished for the first offense by a fine of not less than $\$ 100$ or by imprisonment in the county jail for a period of not less than thirty days or by both such fine and imprisonment, and for each subsequent offense the punishment shall be double that of the preceding one; and it shall be the duty of the respective district attorneys of the counties of this state to prosecute violations of the provisions of this Act.

Sec. 11. EXPENSES; COMPENSATION : And be it enacted, That the expenses of said board and of the examination shall be paid from the license fees above provided for ant if any surplus remain, the same may be distributed among the members of said beard as a compensation for their service as nembers, but otherwise they shall receive no compensation whatever.

Sec. 12. And be it enacted, That all acts or parts of acts, general or special, now exlsting, not In accordance with thie provisions of this act, or inconsistent therewith, are hereby repealed.

Approved May 22, 1894.

Amended as to Sections 3, 4 and 9 and approved Aprll 8, 1903.

Anended as to Sections 4 and 6 and approved March 21 and 25, 1912.

STATE BOARD OF HEALTH

John II. Capstick, I'resldent, Montvilie ; Jacob C. Prlce, M.D., Secretary, Branchvllle; lichard C. Newton, M.D., Montclair ; Wm. donfleld; Oliver Kelly, Oak Tree.

\section{STATE BOARD OF MEDICAL EXAMINERS} OF NEW JERSEY

Edw. Hill Baldwln, President, Newark; Davis P. Borden, 'Paterson; Alexander Iic.Alister; Canden; F. Wilbur Cornwell,
llanfineld; John J. Mooney, Jersey Clty; Alex Marcy, Jr., Riverton; W'm. Perry Watson, Jersey City; Armin Ĺebelacker, Morristown; D. Webb Granberry, D.0., Orange ; Horace G. Norton, Secretary, Trenton.

\section{MEDICAL SOCIETY OF NEW JERSEY} Offlcers 1913-14

Enoch IIollingshend, President...Pemberton lrank D. Gray, 1st V.-Presiclent.Jersey City l'bllip. Chandler, 2d V.-Pres...South Orange Harry A. Stout, Cor.-Secretary.... Wenonah Thos. N. Gray, Kec-Secretary. East Orange Archibald Mercer, Treasurer....... Newark

\section{State Journal}

Journal of the Medical Society of New Jersey, Orange, D. C. English, M.D., editor.

\section{Councilor Districts and Officers}

First Distrlct.-Sussex, Warren, Morris and Essex counties. Christopher C. Beling, Councilor, Newark.

Second District.-Union, Bergen, Hudson nnd Passaic counties. Robert is. Curts, Councilor, Paterson.

Third Distriet.-Mercer, Middlesex, Somerset and Hunterdon counties. W. A. Clark, Councilor, Trenton.

Fourth District. - Camden, Burlington, Ocean and Moninouth coun

Fifth District.-Cape May, Cumberland, Atlantic, Gloucester and Salem countles. James Hunter, Jr., Councilor, Westville.

Component County Societies of the Medical Soclety of Now Jersey ATLANTIC COUNTY

Walter P. Conaway, President Atlantic Clty

Edward Guion, Secretary.......Atlantic Clty BERGEN COUNTY

Edwin Holmes, President.........Englewood

Frederick S. Hallett, Secretary...Hackensack BURLINGTON COUNTY

Clint on D. Mendenhall, President.Bordentown George T. 'Tracy, Secretary..........Beverly CAMDEN COUNTY

Joseph L. Nicholson, President. . . Camden Daniel Strock, Secretary.............. Camden CAPE MAY COUNTY Clarence W. Way, President..... Dennisvllle
Eugene way, Secretary......... Dennlsville CUMBERLAND COUNTY

Leslie W. Cornwell, President.....Bridgeton

H. Garrett Miller, Secretary...........Millville ESSEX COUNTY

E. Zen. Hawkes, President.......... Newark

R. II. Rogers, secretary............. Newark GLOUCESTER COUNTY

B. Trank Orien, President......... Clayton George E. Reading, Secretary..... Woodbury 
HIHSON COLIT:

F. T. Stesitmun, Precistent. Charles 11. rinke, secretary......jersey clis HUXTERHON COLNT Floyd A. Thomas, I'revldent..... Flemington
o. II. Sproul, Secretary........ Flemington MERCEI COIXTY

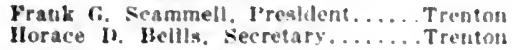
MIDDLEE COITY

I1. C. Voorhees, P'resldens... New ltrunswick Frelk. Lo Hrown. Secrefiary........ Jirunswick MONMOUTI COL'NTY

Reginalds. Benuct, l'tesldent... whurw l'ark

Lester D. Wise, Secretary.........ont krancl Mormis cotsTy

James B. Grlswold, I'resideti..... Morristuwn
II. W. Kice, Secretary...........Whartun OCEAN COLNTY

F. G. Herbener, Iresident........ halkewound PASSAIC COLNTY Andrew $\boldsymbol{F}$. Mclbide, Presldent..... Paaterson SALEX COLNTY

Bichand Mller Davis, I'restdent...... Salum

John $\mathbf{F}$. Smith, Secretary.................. SOMERSET COENT:

Wm. II. Merrill. Prestdent........ somerville

Lancelot Ely, Secretary.......... Somervllle SUSSEX COUNT:

Hlase Cole. Presldent............... F. P. Wibur, Secretary....Frankliii Furnace ENION COUNTY John If. Conorer, Jresldent...... Ellzalueth
Geo. L. Orton, Secretary.......... lialuway WARREY COLSTY

F. S. Gordon, President.......... Blalrstown willam J. Burd, Secretary..........Belvidcre

\section{PRESIDENTS OF BOARDS OF HEALTH IN CITIES OF 4,000 POPULATION AND OVER}

Asbury Park........Mr. Theodne II. Meringer Bloomfeld.............. Jir James J. Thompsion Bridgeton........... Ir. Frank $S$. Mckee, Jr.

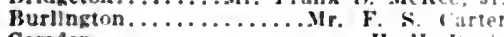

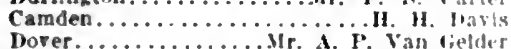
Dover................. A. P. Van lielder Ellzabeth............... John W. Whetasz

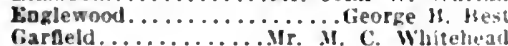

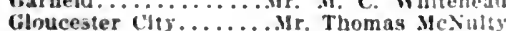
Gutienberg............... Phillp Martip Hackensack................... F. H. Walden

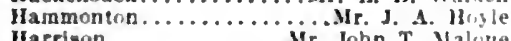
Harrison................. John T. Maline Irvington.............. Jonah Harclgrove Jeraey Clty.............. John J. Wroulertek

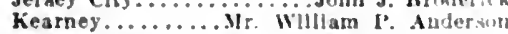

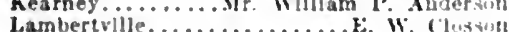
Lambertville................. W. Wheph T, Welch long Bratuch............. Joseph T, Welch Mllville........................ Wide

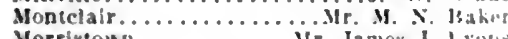
Morristow in............... James J. loyus Newark................. (I. II. lgerold New Brunswich.............. Fred is Kllmer

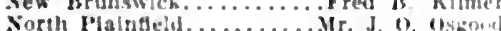
Nutles..................... J. i. Miller Orange..................... Hi Isiclaped Passalc City................. trank 11 . vleh Patersun................. Jolan lo. leal Perth Ambry............!r. Justus Kaletsch Phlllipsturz.............tr. Josemb d'feino Halndeld...............Wm, Mt. Murra

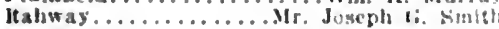

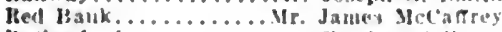
Rutherford................ Charles C'alhwan. Salen...................... M. A liar somerville..............Aaron L. Sibllwelt South Amboy................ II. Fulnc south orange............... Me mord isutayot summit........... ivin it lawrence Jr.

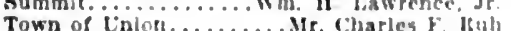

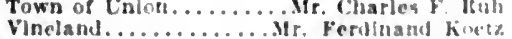

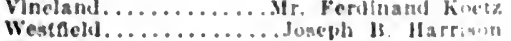

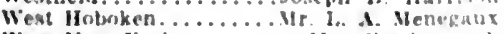
West Now York.............Mr. Gharles urth Weat Grange.............Mr. Gharles Jolm
HEALTH OFFICERS IN CITIES OF 13,000 POPULATION AND OVER

Arllngton..............Walter R. Rleck Atlantle Clty............... Edward Gulon Hayonne................John $r$, Connelly

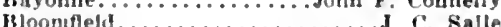

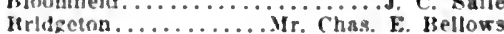

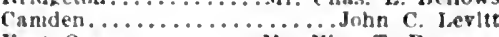
kinst orange........... Wr. W. T. Bowman Ellyabeth............Mr. Irouls J. Michards Hackensack............kJurd F. Essertler Harrlson. ................John T. Mcclure IIoboken................. T. Kudll Jersey city................ James J. Hagan Kearney................. A A. Mutter long Brancli............ Edr. Edn F. Taber Montelalr............Mr. Chester II. Wells Newark............... It. Vavld It. Chandler New Brunswlck.................. I. Cronk Urange................. Frank J. Osborne Passalc.................... John s. Jyan

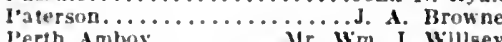
phlllpsburg.......... ir. jtoward i cares plalnfe!d........... J. Jtandolph Chandler Town of Enlot1.............. P. Curts Trenton......................... Fell West Hoboken.......... ir. F. A. Frederick West New York...........r. Itudolph Kunze

\section{Glen Gardner}

\section{STATE INSTITUTIONS}

Ves Jersey Sanatorium for Tuberculou. Disesses, Glen Gardner, $x$. J. Establlshed 1907: tuberculosls: 225 beds: Sam uel B. English, medlcal superintendent

\section{Jamesburg}

State llome for Hoys, Jamesburg, x. . Establlshed 1866: educational: 500 bets 11. I. Zendt, physlctan in charge: J. ( Kallem, superintendent.

\section{Kearney}

Yew Jersey Home for Disabled Soldiery hearney, ‥ J. (A pllugton J'U.). Estailished 1668: getueral: 200 beds lit ho. jhal: E. H. tioldberh, surzeon in charge.

\section{Morris Plaln}

New Jersey State Hospltal at Yorr Plains, Greystono l'ark, j. J. kistab Ilshed 1sit: for the insane: 2.385 berls B. II. Evans (Greystone l'ark), medic:il direcior.

\section{Rahway}

New Jerscy Iteformatory IIospital, Itah way, N. J. Establlshed 1901; Leneral 2 ibeds; G. L. Orton, physlelan In charge.

\section{Skillman}

New Jersey State Vlllage for Eplleptle at Sklltman, Skillman, $x$. J. Establlshed Is9s: Relleral : 600 beds: Irarh Falrchlla Weeks, medlcal superituendent.

\section{Trenton}

New Jeruev state llome for bilels, Tren on, x. J. Establlshed is:a: peformatory 235 beds: 1i. If. larker. vislthe physt ctan: Mrs. F. V. H. Mansell, superin temlent.

New Jersey state llospltal, Trenton, X Estatnlatied lsäl: for the Insano

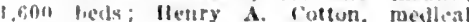
ilireterts

Vew Jersey state frison Howpleal Tren

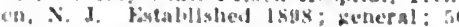
liets: Mtartin W. Jecdder, prison physi lat

state Srhool for the leaf. Trenton. N solati in chatire.

Vineland

Now Jerney llome pur lbsabled Soldlerw saltors dortnes and thelr Wlves. Vine

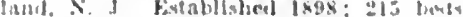

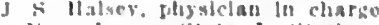

New Jerwy state Institutlow for the

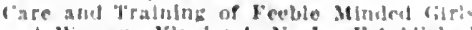

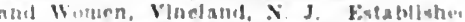

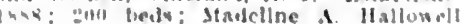

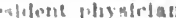

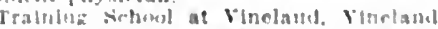

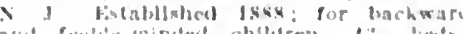

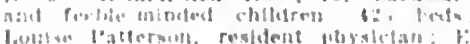
it Jetunntulne, sugerintendert
HOSPITALS. SANATORIUMS AND CHARI. TABLE INSTITUTIONS

\section{Asbury Park}

Asbury Park Murlelpal Hospltal. As. beds Park. N. J. Fistablished 1903; 30 charge.

\section{Atlantio City}

Atlantle Cley IIospltal, 2h s. Ghlo Ave., Atlantle Clty, $x$. J. Eitabllothed 1497: genteral; 130 beds; Nannette L. Murkhard. superintendent.

Chlldren's Seashore Ilouse for Invalld Chlldren, Atlantle clty, $x^{\circ}$ J. Fistabllshed 19:3: bonte tuberculosls; 425 beds: Wh. II Hennett, Mhysleian la charze.

Buerency Heach llospltal, Atlantle Clty, X. J. Fistabllshed 1906 ; t buls: Chas. L. Hosqert, tnedleal sumerintendent. Galen Hall, l'actfle and Couer Are. Nilantlc City, $N$ J. Eistabllsher 1893: general marcotle and nerrous: 300 heds: E. T. Wraht, M.D., superintendent

llahnemann llall Sanatorium, Atlantle Clty, N. J. Fstabllshed 1909: 25 berts: A. W. Bally, medlcal superlntendent.

House tor Private Patlents, Is01 racifle Ave., Mtlantle Clty 5. J. Kastabilshed 1903: Zeneral; 14 beds; Fimery J/arrel, sturgeon; Mlss Ilannah h. Sichroth. superIntendent.

Leonard's Sanltarlum. 2842 Atlantlc Are. Atlantle City. X. J. Nlcohol and drug addlctlon cases: 25 beds: I. E. Leonard, medleal subrerintendent.

Munlelpal IIospltal, Virinla and Adriallc Ares. Atlantle CIty. $\aleph_{0}$. Estst. beds; Eilw, fulon, medical superintendent Seaside House for Invalld Women. At tantic CIty. J. J. Establlshed 1878: 140 beds: Vim. II. Bennett, phystelan in charge.

Bayonne

kayonne Iosultal and IIspensary. Hay. onne, $N$. J. Fistabllshed 1889: 45 bed D. M. Fletcher, superiutendent.

\section{Belle Mead}

Belle Head Farm Colonito and sant tarlun, Belle Mead, X. J. Estallished 1911: hersous and mental dlseases. nar. cotic and alcoholic addictlon: is beds: Wir. E. Viesregen, shysiclan in charge: J. J. Kindred, consulting physician.

\section{Belleville}

Eissex County Isolation Hospltal, Belleville. N. J. Fistalullstled 1903; 225 berls: Ilenry $\boldsymbol{E}$. Ricketts, niedleal superintendent: lias tuberculasls branch.

Tulerculosls Irranch of Easer County Isolatlon IIospltal, Rellerille, $x$. J. Kistabllshed 1911: tutierculosls: 91 betr: Win. J. Douglas, medleal sugerintendem?

\section{Beveriy}

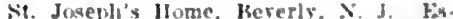

balllshed 1ssi: fur agerd mers and wonen: is beds; (i. Tracy, blaysledan la charze.

\section{Blackwood}

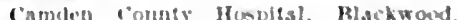
X. J. Fotibhtihed 1s:1: is heds: Jos. E. Hurn, attendig physletisn: lestid Poyn. tor. sureertntchdent.

Camuse Counts flespltal for the In-

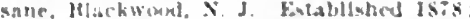
2io tredv: J. Ansou smlth, attenting bhy. slelau: J. A. Sitarkes, sugerlutendent.

Bloomneld

llone of the fioud Samaritan. Bloum. fluls. $x, j$ for briendiess and crrbe numen: Velumsects of Anerlea. In classo: c. Mhimblu, matron.

Boonton

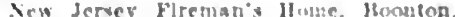

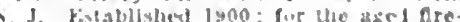
mey of Seir Jessey: 53 teds: cuthitert

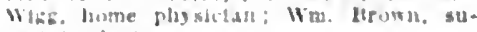
wetintelident.

Bridgeton

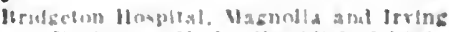

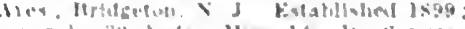

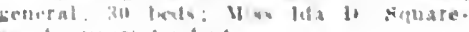

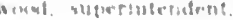

